DOE/RL-2009-35

Revision 0

\title{
Treatability Test Report on Mending the In Situ Redox Manipulation Barrier Using Nano-Size Zero Valent Iron
}

Prepared for the U.S. Department of Energy

Assistant Secretary for Environmental Management

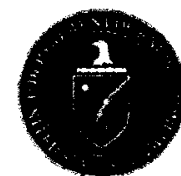

U.S. DEPARTMENT OF

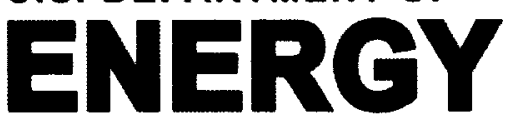

Richland Operations

Office

P.O. Box 550

Richland, Washington 99352

Approved for Public Réease;

Further Dissemination Untimited 
DOE/RL-2009-35

Revision 0

\section{Treatability Test Report on Mending the In Situ Redox Manipulation Barrier Using Nano-Size Zero Valent Iron}

Date Published

October 2009

Prepared for the U.S. Department of Energy

Assistant Secretary for Environmental Management

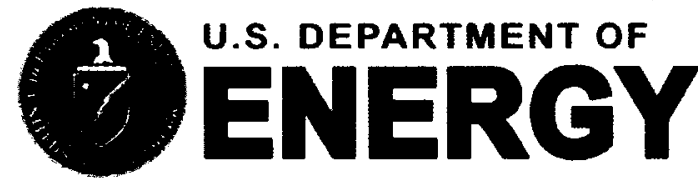

Richland Operations Office

P.O. Box 550

Richland, Washington 99352

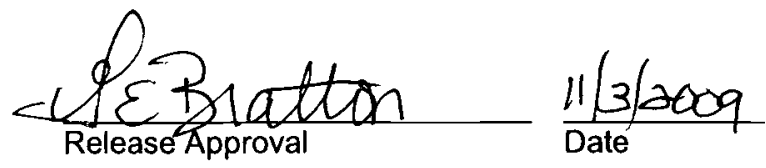

Approved for Public Relecese;

Further Dissernination Unlimited 
TRADEMARK DISCLAIMER

Reference herein to any specific commercial product, process, or service by trade name, trademark, manufacturer, or otherwise, does not necessarily constitute or imply its endorsement, recommendation, or favoring by the United

States Government or any agency thereof or its contractors or subcontractors.

This report has been reproduced from the best available copy. 


\section{Executive Summary}

An In Situ Redox Manipulation (ISRM) barrier was completed in 2002 to intercept hexavalent chromium contamination in the unconfined aquifer at the Hanford Site's 100-D Area and chemically reduce it to trivalent chromium using sodium dithionite as a reductant. Although field and laboratory tests indicated that the innovative ISRM technology would be effective for up to 20 years, some barrier wells began showing signs of breakthrough as quickly as 18 months after injection. In 2004, a Technical Assistance Panel recommended that an alternative technology consisting of the injection of micronsized zero-valent iron (mZVI) be tested and possibly deployed to mend the barrier, which should extend the barrier life for many years.

Seven zero-valent iron (ZVI) materials were evaluated during this treatability test for their ability to chemically reduce groundwater and be injected into the aquifer at least $7 \mathrm{~m}$ (23 ft) from the injection point. This document presents the methods, results, and conclusions based on laboratory testing, computer modeling, and field testing activities associated with the selection and subsequent injection of ZVI into the subsurface at the 100-D Area. Some of the most significant tasks completed and conclusions reached during this effort are as follows:

- MicroPowder ${ }^{1}$ S-3700 was identified in an independent study as an appropriate $\mathrm{mZVI}$ candidate, but was determined to be unsuitable because of poor distribution in flow cells, poor reduction of hexavalent chromium, and slow reaction rates when applied in a slurry containing a shear-thinning polymer.

- A literature search identified six additional ZVI compounds that appeared to have appropriate injection and geochemical properties. Initial geochemical and injection screening tests showed that two nano-sized ZVI (nZVI) compounds (PolyMetallix ${ }^{\mathrm{TM}}$ and RNIP-M2 ${ }^{\mathrm{TM}}$ ) were best suited for field testing.

- Advanced geochemical and injection testing of these two compounds showed that the nZVI compound RNIP-M2 was superior in terms of its ability to effectively reduce hexavalent chromium without significantly impacting hydraulic conductivity.

1 MicroPowder $^{\top \mathrm{M}}$ S-3700 is a product of International Special Products, Wayne, New Jersey.

PolyMetallix ${ }^{\mathrm{TM}}$ is a trademark of Crane Polyflon, Norwalk, Connecticut.

RNIP-M2 $^{\mathrm{TM}}$ is a trademark of Toda Kogyo Corporation, Hiroshima, Japan. 
- Flow and solute transport computer modeling was performed to optimize field injection activities, and it was determined that an injection rate of $53 \mathrm{~L} / \mathrm{min}$ (14 gallons per minute [gpm]) would be adequate to provide optimum injection distance and ZVI deposition within the target area.

- A field test was performed, where approximately $370,970 \mathrm{~L}(98,000 \mathrm{gal})$ of RNIP-M2 slurry were injected into a well located within the ISRM barrier. Significant elements of this test included the following:

- Modest increases in hydraulic conductivity were similar to those predicted by computer modeling.

- Visual observations showed that nZVI was present in a well located $3 \mathrm{~m}(9.8 \mathrm{ft})$ downgradient of the injection well 16 hours after injection began and 35 hours after injection was begun in a well located $3 \mathrm{~m}(9.8 \mathrm{ft})$ upgradient.

- The effects of ZVI injection on oxidation-reduction potential and dissolved

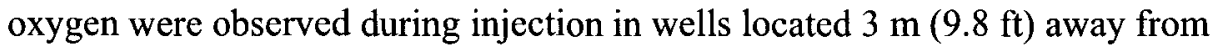
the injection well but were not observed in a well at a distance of $12.8 \mathrm{~m}(42 \mathrm{ft})$.

Borehole and surface geophysical surveys were performed to characterize subsurface changes after injection. The techniques included borehole electrical conductivity, electrical resistivity, and induced polarization. The latter two were the most successful surface geophysical methods for estimating the lateral extent of the injected ZVI, largely because these two methods were capable of direct detection of the iron compound. Interpretation of these data estimated the radial extent of nZVI injection to be greater than the target minimum of $7 \mathrm{~m}(23 \mathrm{ft})$.

A borehole drilled $7 \mathrm{~m}$ from the injection well collected aquifer material containing approximately $4 \mathrm{wt} . \% \mathrm{nZVI}$ in the targeted permeable layer near the bottom of the aquifer. This verified that the goal of emplacing $\mathrm{nZVI}$ at least $7 \mathrm{~m}$ into the aquifer was successfully accomplished.

Groundwater in the injection well and nearby monitoring wells showed that $\mathrm{C}^{+6}$ and total chromium values decreased to near detection limits after the test, as did dissolved oxygen and nitrate. Iron and manganese increased significantly in the vicinity of the injection well; slight increases were observed $60 \mathrm{~m}(197 \mathrm{ft})$ downgradient of the injection well in the few months following the injection. 
DOE/RL-2009-35, REV. 0

The combined cost for the treatability study (including laboratory testing, modeling, and field injection) was approximately $\$ 1,640,000$. Approximately $\$ 760,000$ of this was expended on laboratory testing and modeling, and approximately $\$ 880,000$ was spent on the field injection phase of the treatability study. A significant fraction of the field injection expenditures was the purchase of the RNIP-M2, which cost nearly $\$ 320,000$. 
DOE/RL-2009-35, REV. 0

This page intentionally left blank. 


\section{Contents}

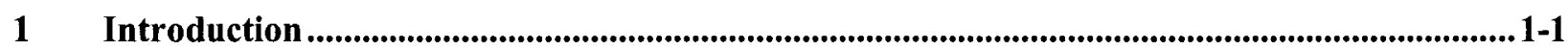

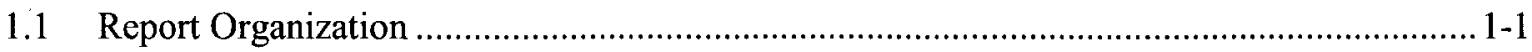

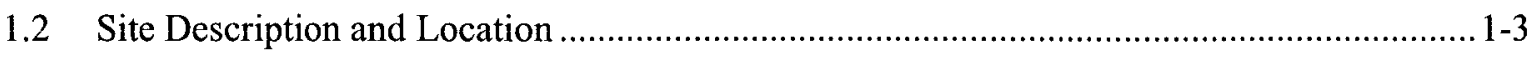

1.3 History of Operations and Release Summary …........................................................... 1-4

1.3.1 Site Contaminant Summary ............................................................................ 1-4

1.3.2 In Situ Redox Manipulation Barrier .............................................................. 1-4

1.4 ISRM Treatment Technology ................................................................................ $1-4$

1.4.1 In Situ Redox Manipulation Barrier Status ................................................... 1-7

1.4.2 ZVI Technology Summary ....................................................................... 1-7

1.5 Treatment Process and Scale .............................................................................. 1-10

1.6 Objectives of the Test ....................................................................................... 1-10

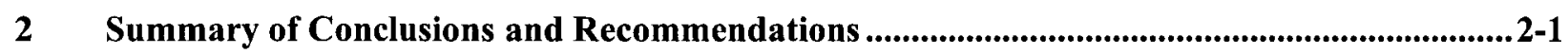

2.1 Laboratory Testing, Modeling, and Field Test ............................................................ 2-1

2.1.1 Initial Micron-Sized Zero-Valent Iron Testing ..................................................2-1

2.1.2 Evaluation and Selectin of Zero-Valent Iron for Field Test...................................2-2

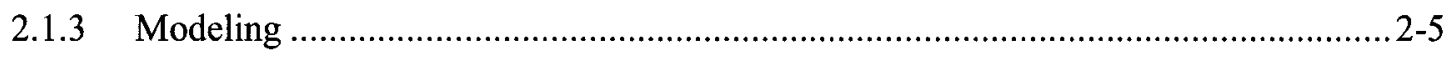

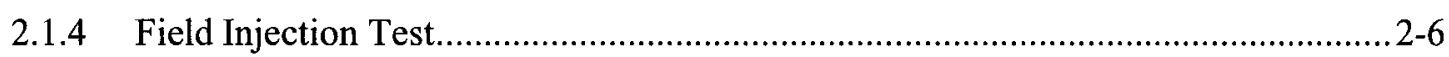

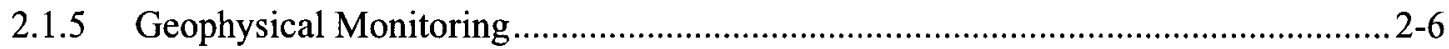

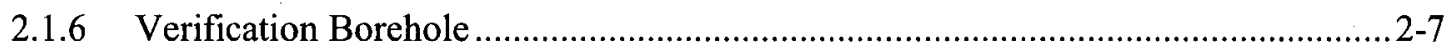

2.1.7 Post-testing Groundwater Monitoring ............................................................ 2-7

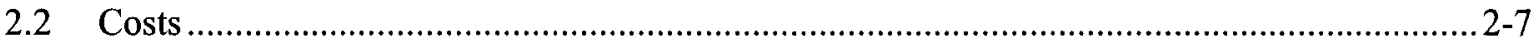

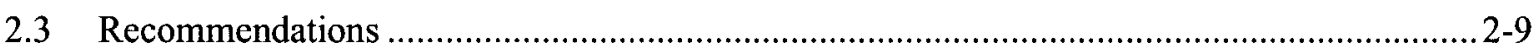

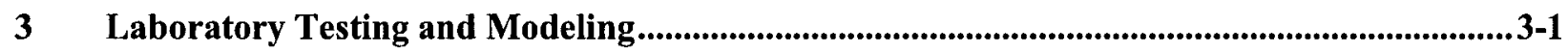

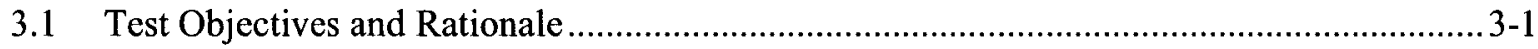

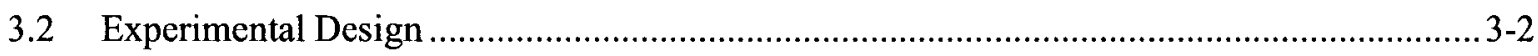

3.2.1 Micron-Sized Zero-Valent Iron Testing (Original Scope) .......................................3-3

3.2.2 Nanometer-Size Zero Valent Iron Testing .......................................................... 3-4

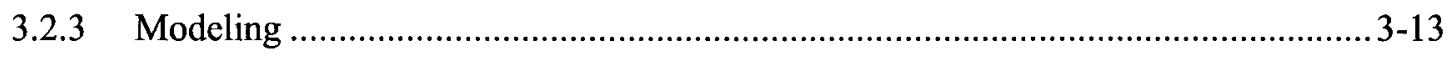

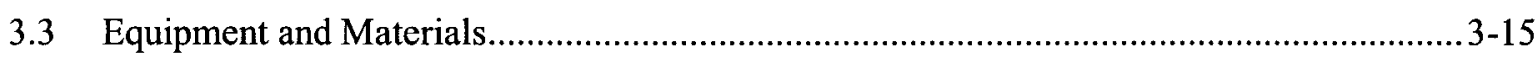

3.3.1 Micron-Sized Zero-Valent Iron Testing (Original Scope) ...................................... 3-15

3.3.2 Batch Screening Test................................................................................

3.3.3 Injection Screening Test............................................................................. 3-16

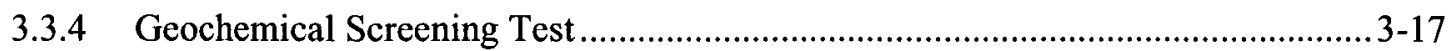

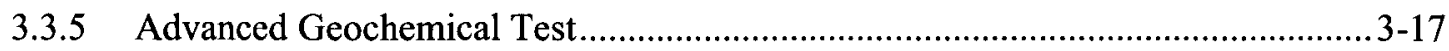

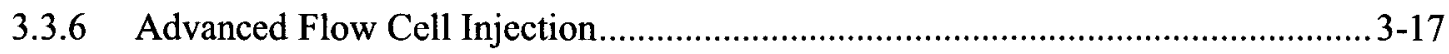




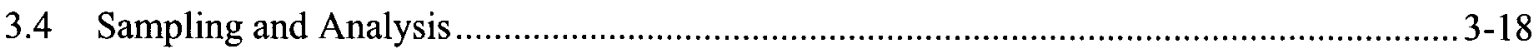

3.4.1 Micron-Size Zero-Valent Iron Testing (Original Scope) .................................... 3-18

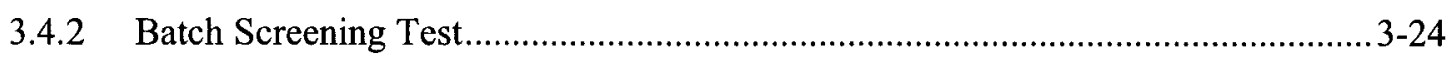

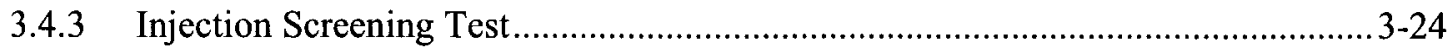

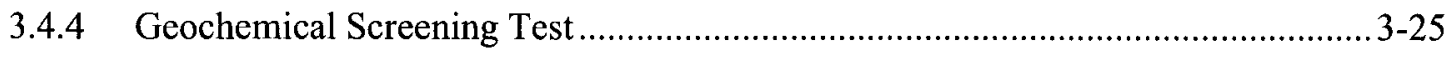

3.4.5 Advanced Geochemical Test.............................................................................. 31

3.4.6 Advanced Flow Cell Injection.................................................................... 3-34

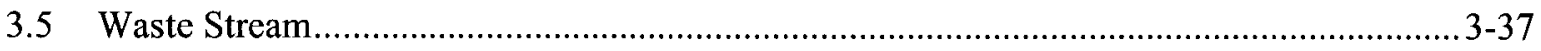

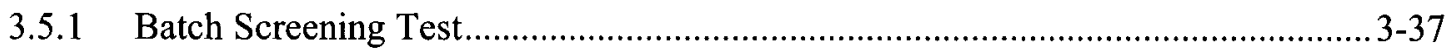

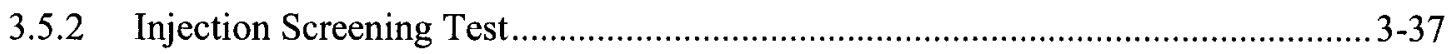

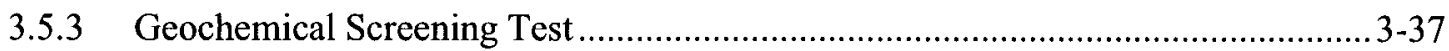

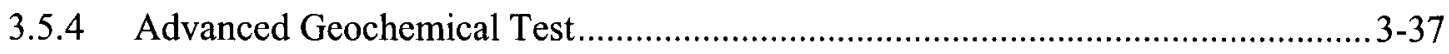

3.5.5 Advanced Flow Cell Injection....................................................................... 3-38

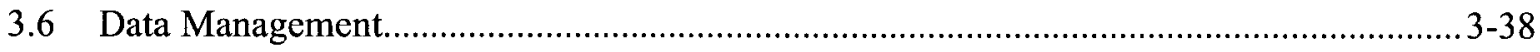

3.6.1 Micron-Sized Zero-Valent Iron Testing (Original Scope) .................................. 3-38

3.6.2 Batch Screening Testing, Injection Screening Testing, and Geochemical Testing .................................................................................................. 3-38

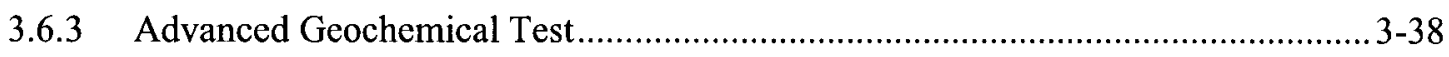

3.6.4 Advanced Flow Cell Injection................................................................... 3-38

3.7 Deviations from the Treatability Test Plan ......................................................................3-39

3.7.1 Micron-Sized Zero-Valent Iron Testing (Original Scope) .....................................3-39

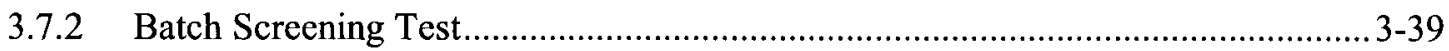

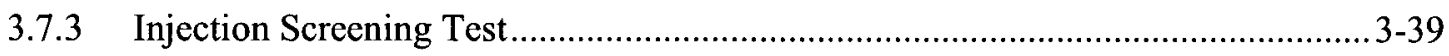

3.7.4 Geochemical Screening Test ........................................................................ 3-40

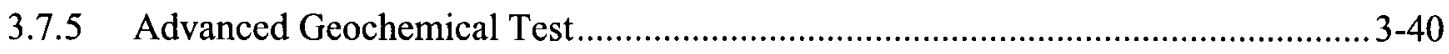

3.7.6 Advanced Flow Cell Injection..................................................................... 3-40

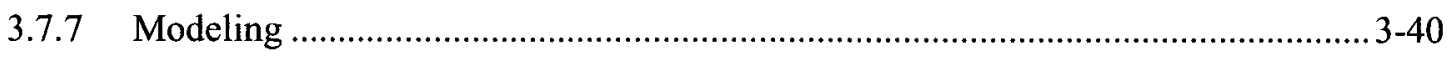

4 Results and Discussion - Laboratory Testing and Modeling ..................................................4-1

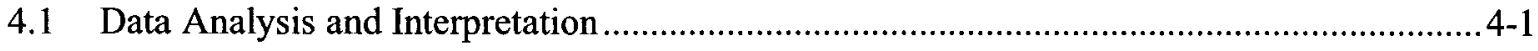

4.1.1 Micron-Sized Zero-Valent Iron History ........................................................... 4-1

4.1.2 Micron-Sized Zero-Valent Iron Testing (Original Scope) ..................................... 4-1

4.1.3 Batch Screening Test.................................................................................... 4 -

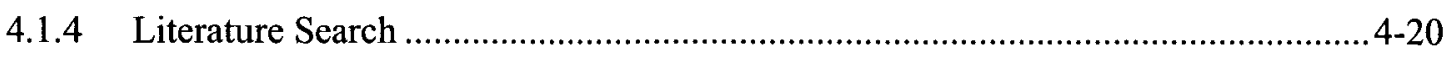

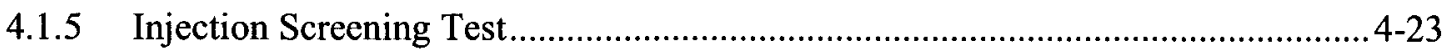

4.1.6 Screening Geochemical Test .........................................................................28

4.1.7 Advanced Geochemical Test....................................................................... 4-33

4.1.8 Advanced Flow Cell Injection......................................................................... 41

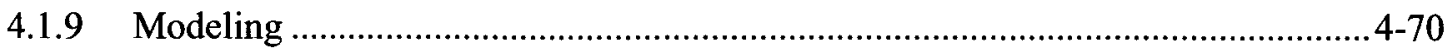




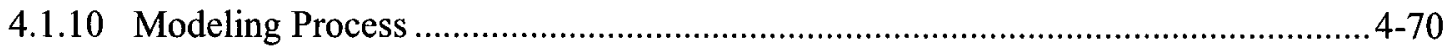

4.2 Comparison to Test Objectives ................................................................................ 4-79

4.2.1 Micron-Sized Zero-Valent Iron Testing (Original Scope) ...................................4-79

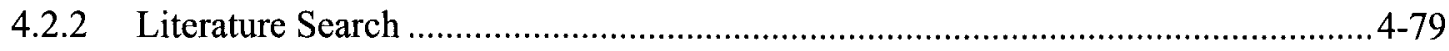

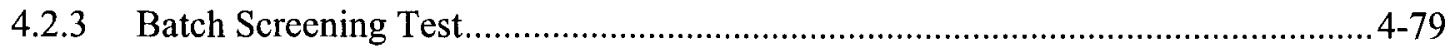

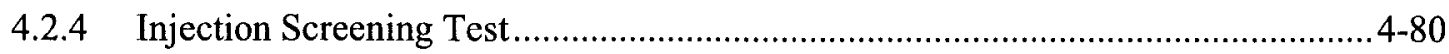

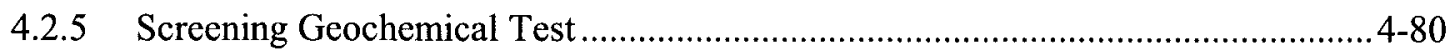

4.2.6 Advanced Geochemical Test.......................................................................... 4-80

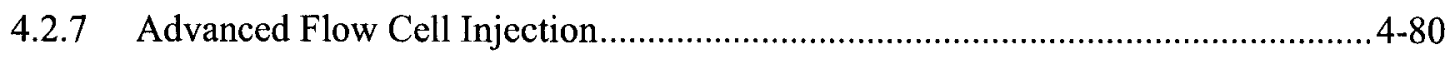

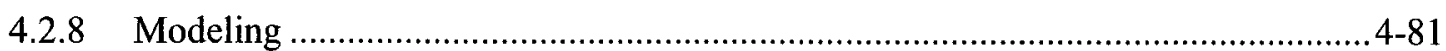

4.3 Conclusions and Recommendations from Laboratory Testing and Modeling ....................4-81

4.3.1 Micron-Sized Zero-Valent Iron Testing (Original Scope) ................................... 4-81

4.3.2 Literature Search ............................................................................. $4-82$

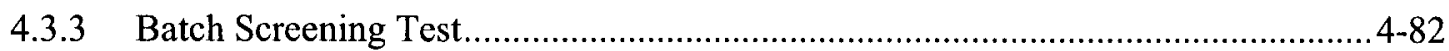

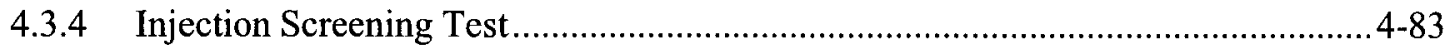

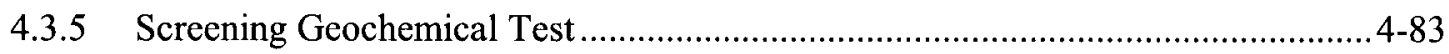

4.3.6 Advanced Geochemical Test.......................................................................... 4-84

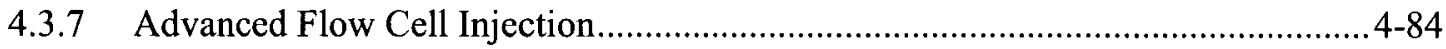

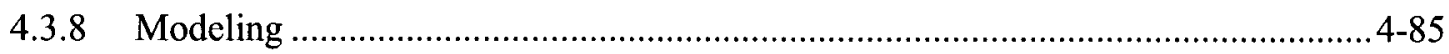

4.4 Quality Assurance/Quality Control .......................................................................... 4-86

4.4.1 Micron-Sized Zero-Valent Iron Testing (Original Scope) ...................................4-86

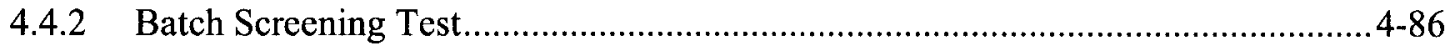

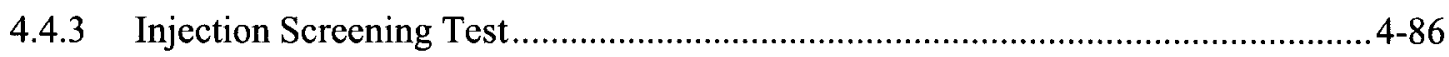

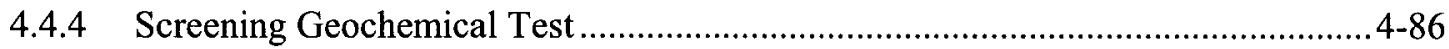

4.4.5 Advanced Geochemical Test........................................................................... 4-86

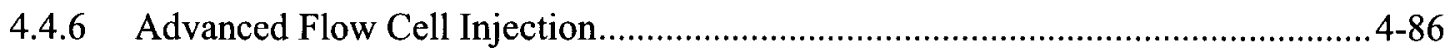

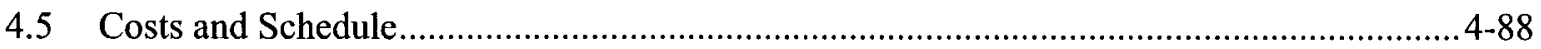

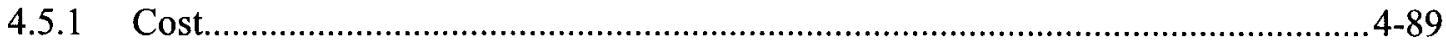

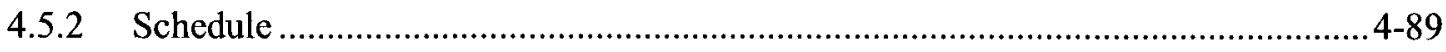

4.6 Key Contacts - Treatability Test (Laboratory Testing and Modeling) ..............................4-89

$5 \quad$ Treatability Study Approach, Field Injection ...............................................................................5

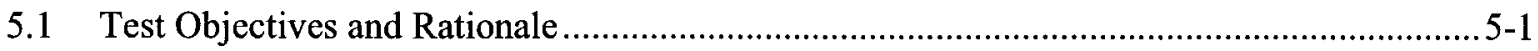

5.1.1 Estimated Zero-Valent Iron Required to Achieve Test Objective ...........................5-1

5.1.2 Technology Performance Criteria .................................................................... 5-1

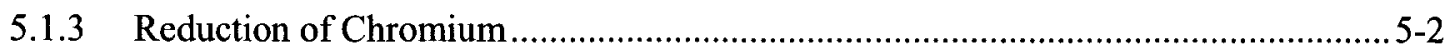

5.1.4 Reduction of Nitrate to Nitrite and Ammonia .................................................... 5-2

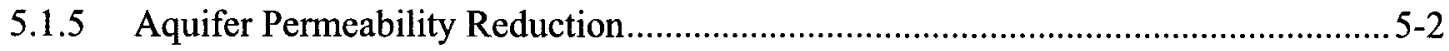

5.1.6 Data Assessment and Treatability Test Evaluation ................................................5-2 


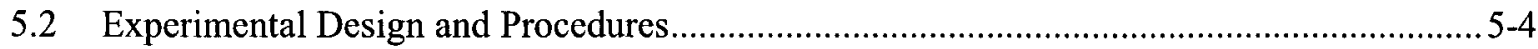

5.2.1 Description of Injection Schemes...................................................................

5.2.2 Nano-Sized Zero-Valent Iron Slurry to Be Tested................................................. 5-5

5.2.3 Methods Used to Prepare and Inject the Iron Slurry ........................................... 5-7

5.2.4 Conceptual Design for the Injection............................................................ 5

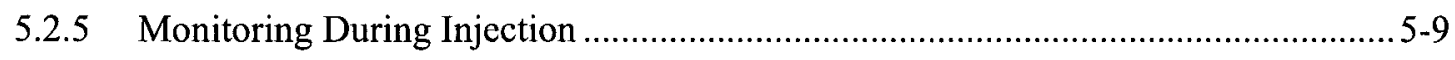

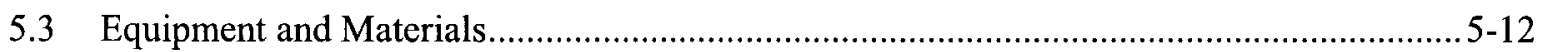

5.3.1 RNIP-M2 Slurry (Nano-Sized Zero-Valent Iron) …..................................... 5-12

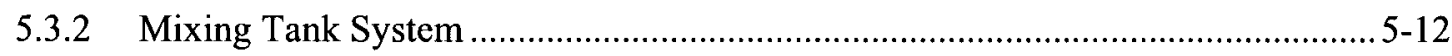

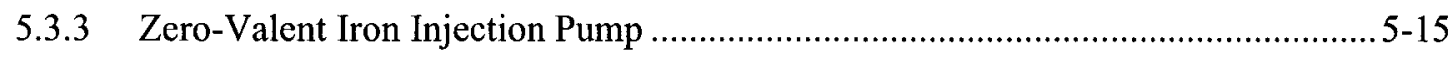

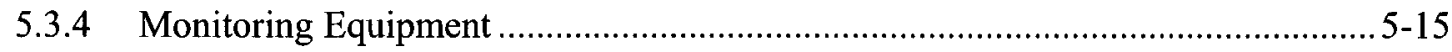

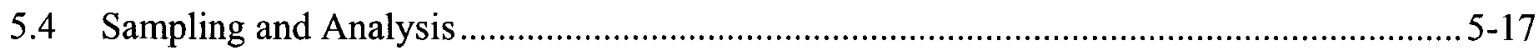

5.4.1 Nano-Sized Zero-Valent Iron Quality Control and Assurance Samples

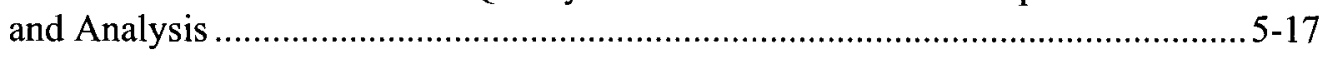

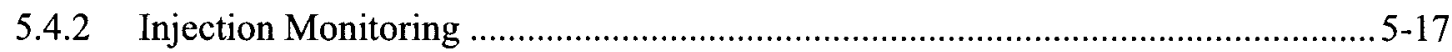

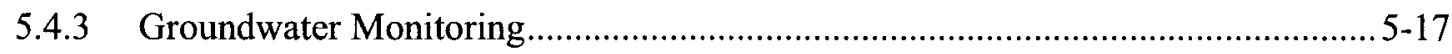

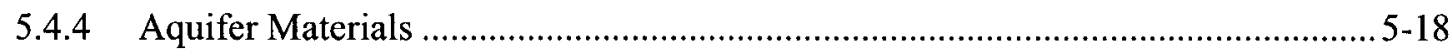

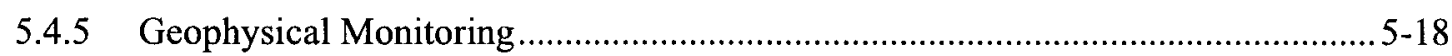

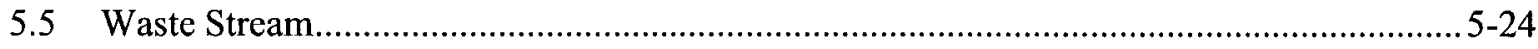

5.5.1 Disposal of Unused Nano-Sized Zero-Valent Iron ...........................................5-24

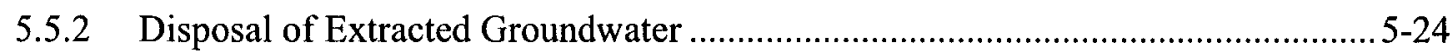

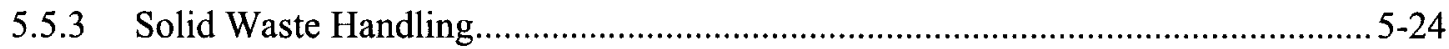

5.6 Data Management............................................................................................... 5-24

5.6.1 nZVI Quality Control and Assurance Data Analysis ..........................................5-24

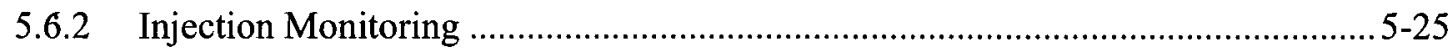

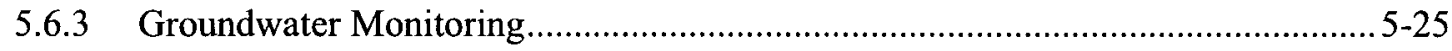

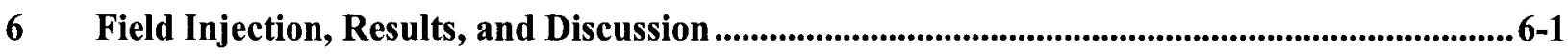

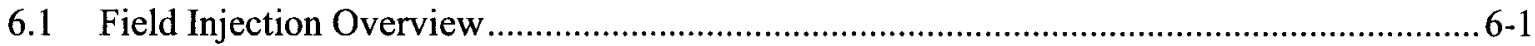

6.1.1 Site Preparation and Construction ..................................................................... 6-1

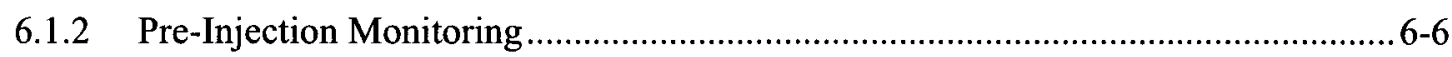

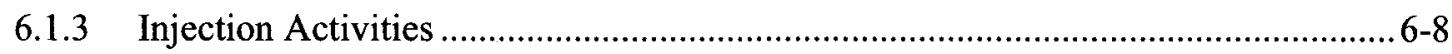

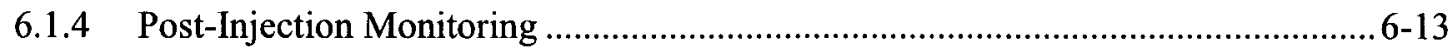

6.1.5 Site Tear Down and Cleanup.........................................................................6-13

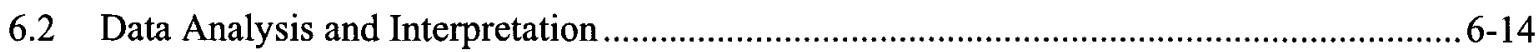

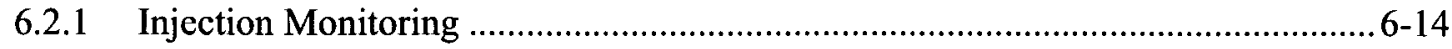

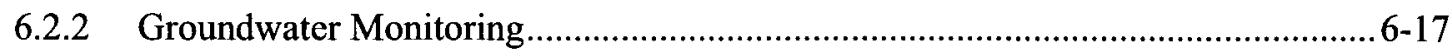

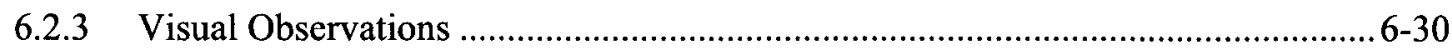

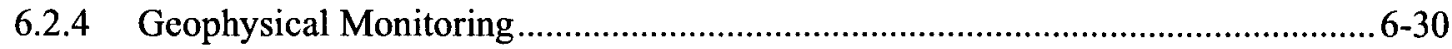


6.2.5 Well 199-D4-26 Vacuum Slug Test Results ....................................................6-56

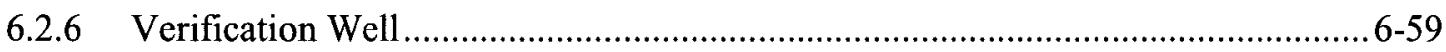

6.2.7 Post-Injection Groundwater Monitoring .......................................................6-60

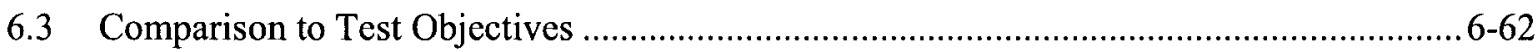

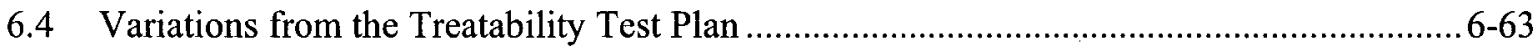

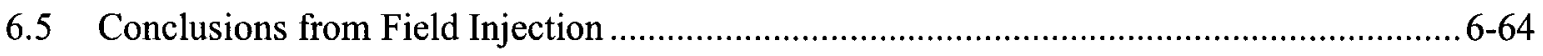

6.6 Quality Assurance/Quality Control ...............................................................................6-66

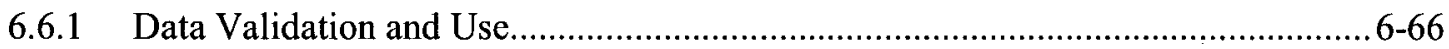

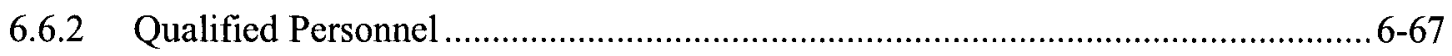

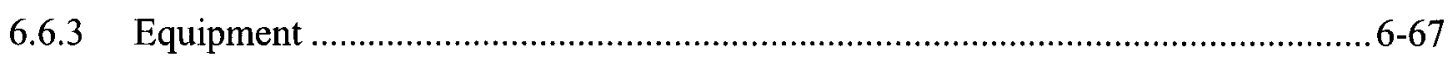

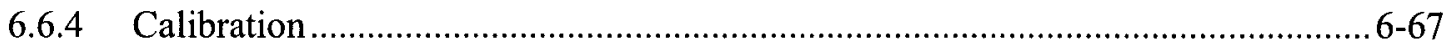

6.6.5 Nano-Size Zero-Valent Iron Slurry Preparation..............................................6-67

6.7 Costs/Schedule - Field Injection .......................................................................6-67

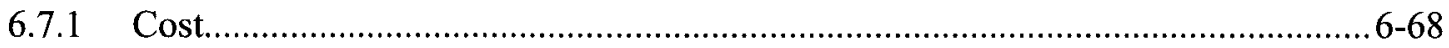

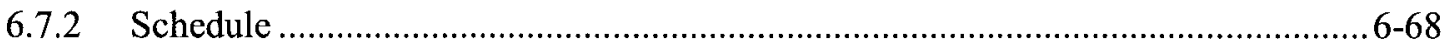

6.8 Key Contacts - Treatability Test (Field Injection) ..................................................6-68

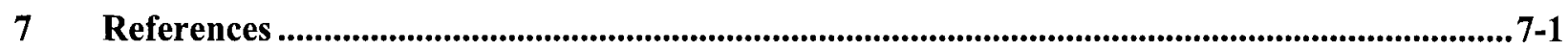

\section{Appendices}

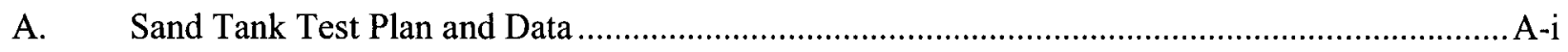

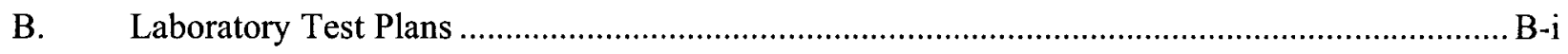

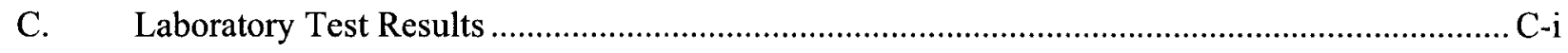

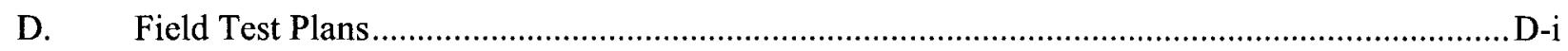

E. Iron Injection Verification Well....................................................................................... E-i 
DOE/RL-2009-35, REV. 0

This page intentionally left blank. 


\section{Figures}

Figure 1-1. 100-D Area and Location of the In Situ Redox Manipulation Barrier ............................... 1-2

Figure 1-2. Hydrogeologic Cross-Section at the 100-D Area ........................................................ 1-3

Figure 1-3. 100-D Area Hexavalent Chromium Plume Map, Third Quarter Fiscal Year 2008 .............. 1-5

Figure 3-1. Flow Cell Schematic Diagram ................................................................................ 3-11

Figure 4-1. Micron-Sized Zero-Valent Iron/Polymer Injection Laboratory Parameters Specific Conductance ........................................................................................ 4-2

Figure 4-2. Micron-Sized Zero-Valent Iron/Polymer Injection Laboratory Parameters Dissolved Oxygen.

Figure 4-3. Micron-Sized Zero-Valent Iron/Polymer Injection Laboratory Parameters - pH ............... 4-3

Figure 4-4. Micron-Sized Zero-Valent Iron/Polymer Injection Laboratory Parameters Oxidation-Reduction Potential

Figure 4-5. Micron-Sized Zero-Valent Iron/Polymer Injection Analytical Results - Total Chromium

Figure 4-6. Micron-Sized Zero-Valent Iron/Polymer injection Analytical Results - Hexavalent Chromium

Figure 4-7. Micron-Sized Zero-Valent Iron/Polymer Injection Analytical Results - NitrateNitrate/Ammonia

Figure 4-8. Description of Permeability Flow Cell \#1P After Micron-Sized Zero-Valent Iron Injection .

Figure 4-9. Description of Permeability Flow Cell \#2P After Micron-Sized Zero-Valent Iron Injection .

Figure 4-10. Oxidation-Reduction Potential Trend During Simple Batch Testing 4-15

Figure 4-11. Dissolved Oxygen Trend During Simple Batch Testing .....

Figure 4-12. pH Trend During Simple Batch Testing.

Figure 4-13. Batch Screening Test Dissolved Chromium Results 4-19

Figure 4-14. Batch Screening Test Nitrate Results

Figure 4-15. Change in Hydraulic Conductivity After Zero-Valent Iron Injection and Surrogate Groundwater Flush .

Figure 4-16. Average Soil Core Total Iron Concentration After Injection

Figure 4-17. Average Soil Core Total Iron Concentration After Surrogate Groundwater Flush 4-28

Figure 4-18. Screening Geochemical Test Dissolved Oxygen... 4-29

Figure 4-19. Screening Geochemical Test $\mathrm{pH}$.. 4-29

Figure 4-20. Screening Geochemical Test Oxidation-Reduction Potential. 4-30

Figure 4-21. Screening Geochemical Columns Hexavalent Chromium Reduction 4-31

Figure 4-22. Screening Geochemical Columns Total Organic Carbon 4-31

Figure 4-23. Screening Geochemical Columns Phosphorous 4-32

Figure 4-24. Screening Geochemical Columns Ammonia Results 4-32

Figure 4-25. Oxidation-Reduction Potential Trend - High-Concentration (1.5 Percent) Columns 
Figure 4-26. Oxidation-Reduction Trend - Mid-Concentration (0.15 Percent) Columns..... 4-34

Figure 4-27. Oxidation-Reduction Potential Trend - Low-Concentration ( 0.015 Percent) Columns 4-35

Figure 4-28. pH Trend - High-Concentration (1.5 Percent) Columns ...............................................4-36

Figure 4-29. pH Trend - Mid-Concentration (0.15 Percent) Columns ..................................................4-37

Figure 4-30. pH Trend - Low-Concentration (0.015 Percent) Columns...............................................4-37

Figure 4-31. Chromium Removal Trend - High-Concentration (1.5 wt \%) Columns ............................4-38

Figure 4-32. Chromium Removal Trend - Mid-Concentration (0.15 Percent) Columns...................... 4-39

Figure 4-33. Chromium Removal Trend - Low-Concentration (0.015 Percent) Columns .................... 4-39

Figure 4-34. Nitrate Trend - High-Concentration (1.5 Percent) Columns ............................................ 4-41

Figure 4-35. Nitrate Trend - Mid-Concentration (0.15 wt\%) Columns............................................... 4-41

Figure 4-36. Nitrate Trend - Low-Concentration (0.015 wt \%) Column............................................... 4-42

Figure 4-37. Nitrite Trend - High-Concentration (1.5 wt\%) Columns ................................................4-43

Figure 4-38. Nitrite Trend - Mid-Concentration $(0.15$ wt \%) Columns ..............................................4-43

Figure 4-39. Nitrite Trend - Low-Concentration (0.015 wt\%) Columns.............................................4-44

Figure 4-40. Ammonia Trend - High-Concentration (1.5 wt\%) Columns............................................4-44

Figure 4-41. Ammonia Trend - Mid-Concentration (0.15 wt\%) Columns ............................................4-45

Figure 4-42. Ammonia Trend - Low-Concentration (0.015 wt \%) Columns .......................................4-45

Figure 4-43. Alkalinity Trend - High-Concentration (1.5 wt \%) Columns .......................................... 4-46

Figure 4-44. Alkalinity Trend - Mid-Concentration (0.15 wt \%) Columns.......................................... 4-46

Figure 4-45. Alkalinity Trend - Low-Concentration (0.015 wt\%) Columns ........................................4-47

Figure 4-46. Mineral Liberation Analysis for High-Concentration (1.5 wt\%) PolyMetallix

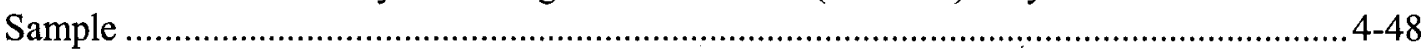

Figure 4-47. Mineral Liberation Analysis for High-Concentration (1.5 wt\%) RNIP-M2 Sample.........4-49

Figure 4-48. Overall Flow Cell Hydraulic Head Loss (PolyMetallix Runs) ........................................4-52

Figure 4-49. Overall Flow Cell Hydraulic Head Loss (RNIP-M2 Runs) ............................................. 4-52

Figure 4-50. Final Flow Cell Hydraulic Head Distribution (PolyMetallix Runs) .................................. 4-53

Figure 4-51. Final Flow Cell Hydraulic Head Distribution (RNIP-M2 Runs) ...................................4-54

Figure 4-52. Calculated Hydraulic Conductivity Variation Over Elapsed Time for PolyMetallix

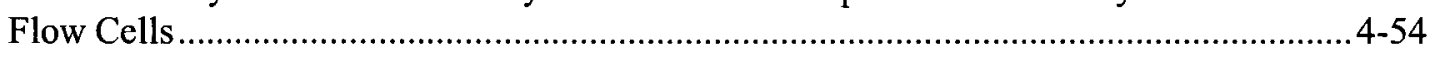

Figure 4-53. Calculated Hydraulic Conductivity Variation Over Elapsed Time for RNIP-M2

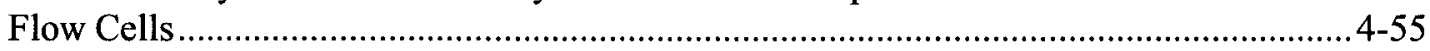

Figure 4-54. PolyMetallix Flow Cell Flow Rates.........................................................................5-56

Figure 4-55. RNIP-M2 Flow Cell Flow Rates ........................................................................ 4-56

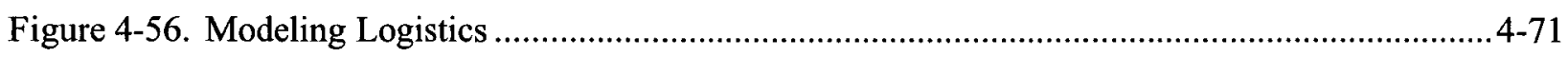

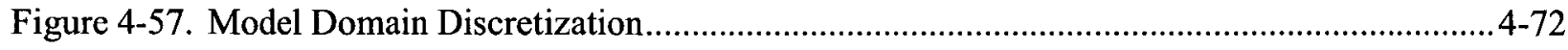

Figure 4-58. Flow Field for 14-gpm Injection Rate .....................................................................4-74

Figure 4-59. Flow Field for 22-gpm Injection Rate .................................................................... $4-75$

Figure 4-60. Deposition of Iron at $7 \mathrm{~m}$ from Injection Well ......................................................... 4-75

Figure 4-61. Details of Iron Deposition for 14-gpm Injection Rate ...............................................4-76 
Figure 4-62. Details of Iron Deposition for 17-gpm Injection Rate . 4-77

Figure 4-63. Maximum Travel Distance of Iron for 14-gpm Injection Rate.......................................4-77

Figure 4-64. Maximum Travel Distance of Iron for 17-gpm Injection Rate........................................4-78

Figure 4-65. Laboratory Testing Cumulative Cost and Schedule ....................................................4-90

Figure 5-1. Hydraulic Conductivity Profile for Well 199-D4-26 ....................................................5-6

Figure 5-2. Hydraulic Conductivity Profile for Well 199-D4-37 ........................................................5-6

Figure 5-3. Well Location Map ................................................................................................. 5-11

Figure 5-4. Conceptual Drawing Depicting Nano-Sized Zero-Valent Iron Mixing and

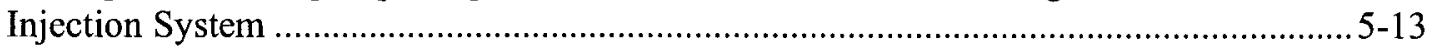

Figure 5-5. Pole-Dipole Electrode Configuration ...........................................................................

Figure 5-6. Data Coverage for Pole-Dipole Electrical Surveys ...................................................5-20

Figure 5-7. Measurement Points for Magnetic and Mise a la Masse Surveys ....................................5-22

Figure 6-1. Injection Well Packer System..................................................................................... 6-5

Figure 6-2. Injection Well (D4-26) Pressure Mounding During Zero-Valent Iron Injection................6-14

Figure 6-3. Injection Well (199-D4-26) Temperature During Injection ............................................6-15

Figure 6-4. Zero-Valent Iron Mixing Tank Oxygen Monitoring …................................................6-17

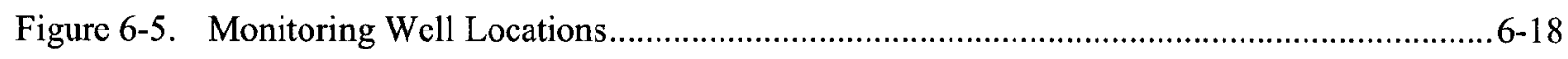

Figure 6-6. Monitoring Well Pressure-Down-Hole Measurement .......................................................6-19

Figure 6-7. Monitoring Well Temperature-Down-Hole Measurement .............................................6-19

Figure 6-8. Monitoring Well Specific Conductivity-Down-Hole Measurement..................................6-20

Figure 6-9. Monitoring Well Field Parameters - Temperature (Surface Measurement)...................... 6-27

Figure 6-10. Monitoring Well Field Parameters - Dissolved Oxygen (Surface Measurement) ............. 6-28

Figure 6-11. Monitoring Well Field Parameters - pH (Surface Measurement) .....................................6-28

Figure 6-12. Monitoring Well Field Parameters - Specific Conductivity (Surface Measurement)

Figure 6-13. Monitoring Well Field Parameters - Oxidation-Reduction Potential (Surface Measurement)

Figure 6-14. Pre-Injection Apparent Resistivity Data for Forward Pole-Dipole Survey ....................... 6-32

Figure 6-15. Pre-Injection Apparent Resistivity Data for Reverse Pole-Dipole Survey ........................6-32

Figure 6-16. Pre-Injection Reverse Pole-Dipole Induced Polarization Data........................................6-33

Figure 6-17. Observed Magnetic Field Data from Lower Sensor Pre-Injection .................................. 6-34

Figure 6-18. Observed Magnetic Field Data from Upper Sensor Pre-Injection....................................6-35

Figure 6-19. Pre-Injection Apparent Resistivity Calculated from Mise a la Masse Data ......................6-36

Figure 6-20. Relative Phase Shift Observed in Pre-Injection Mise a la Masse Data ............................6-37

Figure 6-21. Post-Injection Data for Forward Pole-Dipole Survey................................................6-38

Figure 6-22. Post-Injection Data for Reverse Pole-Dipole Survey .......................................................6-38

Figure 6-23. Resistivity Models Constructed by Separate Inversion of Pre- and Post-Injection Data.

Figure 6-24. Resistivity Models Constructed by Smoothness-Constrained Time-Lapse Inversion of Pre- and Post-Injection Data 
Figure 6-25. Region of Data Influent Index Calculated Using Post-Injection 1-Hz Resistivity Data......

Figure 6-26. Analysis of Depth of Investigation for Resistivity Data 6-43

Figure 6-27. Post-Injection Reverse Pole-Dipole Induced Polarization Data

Figure 6-28. Induced Polarization Models Constructed by Separate Inversion of Pre- and PostInjection Data.

Figure 6-29. Comparison of Pre- and Post-Injection Borehole Conductivity Data $.6-46$

Figure 6-30. Comparison of Modeling Results with EM-39 Borehole Conductivity Logging Results $.6-48$

Figure 6-31. Comparison of Pre- and Post-Injection Apparent Resistivity Computed from Time-Domain Electromagnetic Data

Figure 6-32. Observed Magnetic Field Data from Lower Sensor Post-Injection. 6-50

Figure 6-33. Observed Magnetic Field Data from Upper Sensor Post-Injection 6-50

Figure 6-34. Raw Difference (Post- Minus Pre-Injection) in Magnetic Field for Lower Sensor $6-51$

Figure 6-35. Raw Difference (Post- Minus Pre-Injection) in Magnetic Field for Upper Sensor 6-51

Figure 6-36. Post-Injection Apparent Resistivity Calculated from Mise a la Masse Data $6-52$

Figure 6-37. Percent Difference Between the Pre- and Post-Injection Apparent Resistivity Calculated from Mise a la Masse Data 6-52

Figure 6-38. Relative Phase Shift Observed in Post-Injection Mise a la Masse Data $6-53$

Figure 6-39. Raw Phase Shift Difference from Mise a la Masse Data 6-54

Figure 6-40. Pre-Injection Vacuum Slug Test Analytical Plots . $6-57$

Figure 6-41. Post-Injection Vacuum Slug Test Analytical Plots. 6-58

Figure 6-42. Location of New Well 199-D4-99 and Surrounding Wells 6-59

Figure 6-43. Plot of Unfiltered Iron and Turbidity in Groundwater from Well 199-D4-38. .6-63 


\section{Photographs}

Photograph 4-1. Experimental Control Flow Cell \#1 1 .................................................................. 4-8

Photograph 4-2. Injection Flow Cell \#3 (Injected with Micron-Sized Zero-Valent Iron Polymer and Surrogate Groundwater)................................................................................ 4-8

Photograph 4-3. Injection Flow Cell \#8 (Injected with Micron-Sized Zero-Valent Iron/ Polymer and Surrogate Groundwater .............................................................................

Photograph 4-4. Permeability Flow Cell \#1P After Micron-Sized Zero-Valent Iron/Polymer Injection

Photograph 4-5. Permeability Flow Cell \#2P After Micron-Sized Zero-Valent Iron/Polymer Injection.

Photograph 4-6. Simple Batch Tests After Completion 4-17

Photograph 4-7. Simple Batch Tests 8 Months After Completion 4-17

Photograph 6-1. Poly-Tanks in Position and Secured.................................................................... 6-2

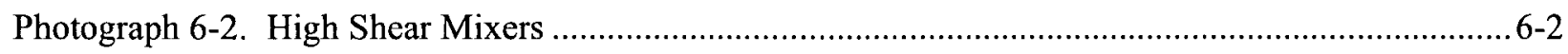

Photograph 6-3. Zero-Valent Iron Batch Mixing Pump ................................................................ 6-3

Photograph 6-4. High Shear Mixer Feed Pump ..............................................................................6-4

Photograph 6-5. Installation of the Injection Well Packer System ....................................................6-4

Photograph 6-6. Zero-Valent Iron Transfer Station .....................................................................6-10

Photograph 6-7. Nitrogen Sparging of Water in Injection Tank ....................................................... 6-11

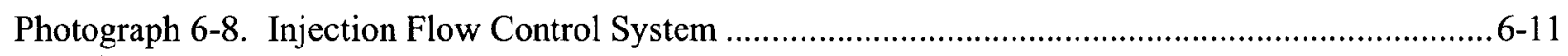


DOE/RL-2009-35, REV. 0

This page intentionally left blank. 


\section{Tables}

Table 1-1. Potential Amendments for Mending the ISRM Barrier................................................. 1-8

Table 2-1. Top Zero-Valent Iron Materials from Literature Search ..............................................2-2

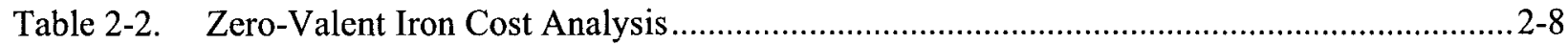

Table 3-1 Batch Screening Test Surrogate Groundwater Formulation ............................................ 3-5

Table 3-2. Advanced Geochemical Testing Zero-Valent Iron Materials .............................................3-7

Table 3-3. Advanced Geochemical Column Configuration .............................................................. 3-8

Table 3-4. Groundwater Chemistry of Hanford 100-D Area ............................................................ 3-9

Table 3-5. Zero-Valent Iron Selected for Advanced Flow Cell Injection Testing.............................. 3-11

Table 3-6. Advanced Flow Cell Injection Testing Zero-Valent Iron Fluid Flow Velocity and

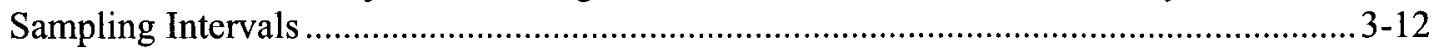

Table 3-7. Injection Screening Test Zero-Valent Iron Materials and Dispersant .............................. 3-16

Table 3-8. Micron-Size Zero-Valent Iron Primary Measurements and Analyses................................3-18

Table 3-9. Micron-Size Zero-Valent Iron Secondary Measurements and Analyses...........................3-19

Table 3-10. Micron-Sized Zero-Valent Iron Sampling, Analysis, and Measurement Schedule............ 3-21

Table 3-11. Injection Screening Test Primary Measurements and Analyses..................................... 3-24

Table 3-12. Injection Screening Test Sampling and Analysis Schedule ............................................3-26

Table 3-13. Injection Screening Test Secondary Measurements and Analyses .................................. 3-28

Table 3-14. Geochemical Screening Tests Primary Analyses ........................................................ 3-28

Table 3-15. Geochemical Screening Tests Secondary Analyses .................................................... 3-28

Table 3-16. Geochemical Screening Test Sampling Schedule......................................................... 3-29

Table 3-17. Advanced Geochemical Testing Sampling Schedule and Measurements .......................3-31

Table 3-18. Advanced Geochemical Testing Chemical-Based Measurements and Analyses .............. 3-32

Table 3-19. Advanced Geochemical Testing Physical Measurements and Analyses ...........................3-33

Table 3-20. Advanced Flow Cell Injection Testing Sampling and Measurements Location.................3-34

Table 3-21. Advanced Flow Cell Injection Testing Nominal Sampling and Measuring Time

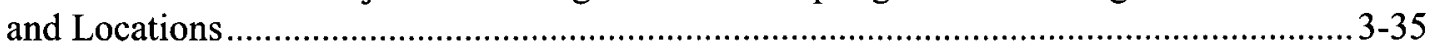

Table 3-22. Advanced Flow Cell Injection Testing Physical Measurements .....................................3-36

Table 3-23. Advanced Flow Cell Injection Testing Aqueous Samples ............................................3-37

Table 3-24. Modifications to Micron-Sized Zero-Valent Iron Proposed Test Plan............................. 3-39

Table 3-25. Modifications to Injection Screening Proposed Test Plan .............................................. 3-40

Table 3-26. Modifications to the Proposed Advanced Injection Test Plan ..........................................3-40

Table 4-1. Analytical Analyses of Iron Along Selected Flow Cells ................................................4-9

Table 4-2. Summary of Batch Test Mixtures ................................................................................ 4-13

Table 4-3. R-12 Sponge Iron Powder Physical Properties .............................................................. 4-14

Table 4-4. Total Chromium and Hexavalent Chromium Analytical Results .................................... 4-16

Table 4-5. Batch Screening Test Average Parameters ................................................................... 4-18

Table 4-6. Zero-Valent Iron Materials and Manufacturers ............................................................ 4-20 


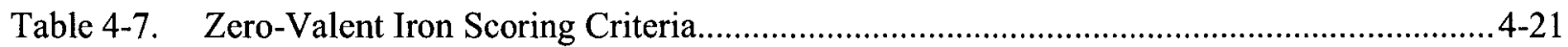

Table 4-8. Zero-Valent Iron Materials and Associated Score.........................................................4-24

Table 4-9. Extra Analytical Column Data - RNIP-M2 Columns .......................................................4-49

Table 4-10. Extra Analytical Column Data - PolyMetallix Columns ................................................4-50

Table 4-11. Extra Analytical Column Data - Control Columns ....................................................... 4-51

Table 4-12. RNIP-M2 Flow Cell Laboratory Analysis Results ......................................................4-58

Table 4-13. RNIP-M2 Flow Cell Laboratory Analysis Results ........................................................ 4-61

Table 4-14. PolyMetallix Flow Cells - Zero-Valent Iron Front Measurements ................................... 4-65

Table 4-15. RNIP-M2 Flow Cells Zero-Valent Iron Front Measurements ........................................... 4-66

Table 4-16. Zones of Hydraulic Conductivity Within the Model Domain ....................................... 4-73

Table 4-17. Summary of Key Results of Nano-Sized Zero-Valent Iron Deposition Modeling .............4-78

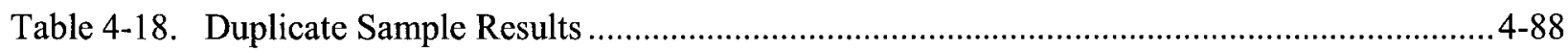

Table 4-19. Nano-Sized Zero-Valent Iron Injection Project Personnel .............................................. 4-91

Table 5-1. Components Required for Each Batch....................................................................... 5-7

Table 5-2. Reporting Ranges, Resolutions, and Accuracies for Monitoring Equipment in

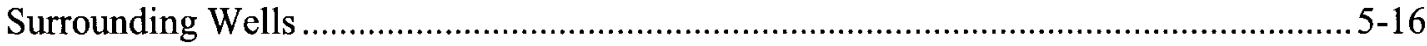

Table 6-1. Down-Hole Transducer Locations .................................................................................... 6-6

Table 6-2. Pre-Injection Timetable for Geophysical Data Acquisition............................................6-8

Table 6-3. Post-Injection Timetable for Geophysical Data Acquisition ............................................6-8

Table 6-4. Quality Assurance/Quality Control Measurements for Zero-Valent Iron Injection

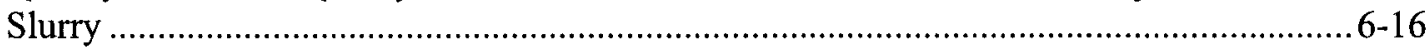

Table 6-5. 199-D4-25 Field Parameters (Surface Measurement) ...................................................6-21

Table 6-6. 199-D4-27 Field Parameters (Surface Measurement) ...................................................... 6-22

Table 6-7. 199-D4-92 Field Parameters (Surface Measurement) .......................................................6-24

Table 6-8. 199-D4-93 Field Parameters (Surface Measurement) .....................................................6-25

Table 6-9. Electrical and Electromagnetic Units and Symbols....................................................6-31

Table 6-10. Time-Domain Electromagnetic Receiver Loop Distance and Direction from

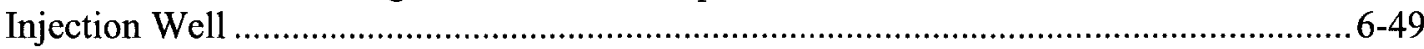

Table 6-11. Vacuum Slug Test Results for Injection Well 199-D4-26 ..............................................6-58

Table 6-12. Modifications and Additions to the Treatability Test Plan ............................................6-63

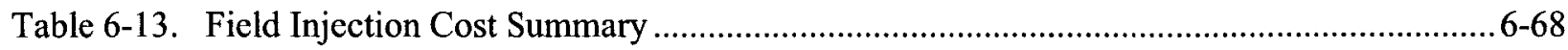

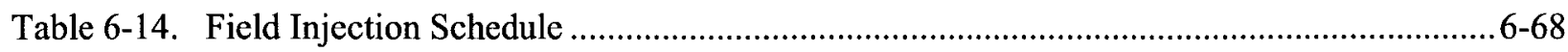




\section{Terms}

ARAR

ASTM

DO

DOE

EBF

EPA

gpm

IP

ISRM

MCL

MLA

MSDS

mZVI

$\mathrm{nZVI}$

ORP

$\mathrm{OU}$

PNNL

$\mathrm{ppb}$

psi

PV

PVC

QA

QC

RAO

RDI

ROD

RPD

RSD

SAP

TAP applicable or relevant and appropriate requirement

American Society for Testing and Materials

dissolved oxygen

U.S. Department of Energy

electromagnetic borehole flow meter

U.S. Environmental Protection Agency

gallons per minute

induced polarization

In Situ Redox Manipulation

maximum contaminant level

mineral liberation analysis

material safety data sheet

micron-sized zero-valent iron

nano-sized zero-valent iron

oxidation-reduction potential

operable unit

Pacific Northwest National Laboratory

parts per billion

pounds per square inch

pore volume

polyvinyl chloride

quality assurance

quality control

remedial action objective

region of data influence

Record of Decision

relative percent difference

relative standard deviation

sampling and analysis plan

Technical Assistance Panel 
DOE/RL-2009-35, REV. 0

TEM

WAC

$w t \%$

ZVI time-domain electromagnetic

Washington Administrative Code

weight percent

zero-valent iron 


\section{Introduction}

This document provides details on an effort to increase the effectiveness of a groundwater remediation system to treat hexavalent chromium at the 100-D Area of the Hanford Site. The technology tested was the injection of zero-valent iron (ZVI) into the groundwater where a permeable reactive barrier is installed. This barrier has become less effective in some portions over the last few years. This test was performed in an effort to augment the less-effective portions of the In Situ Redox Manipulation (ISRM) barrier and produce a sustaining remediation solution for this area. This work included laboratory testing of different ZVI materials, numerical modeling, and injection of a suitable material into the subsurface.

From 1997 to 2002, a permeable reactive barrier was installed in the 100-D Area (Figure 1-1) to remediate a hexavalent chromium groundwater plume by reducing hexavalent chromium to trivalent chromium by injecting sodium dithionite into the aquifer, thereby creating persistent reducing conditions by converting native iron from ferric iron $\left(\mathrm{Fe}^{+3}\right)$ to ferrous iron $\left(\mathrm{Fe}^{+2}\right)$. Although laboratory and field tests indicated that this innovative technology, known as the ISRM barrier, would effectively treat hexavalent chromium for nearly 20 years ("Creation of a Subsurface Permeable Treatment Zone for Aqueous Chromate Contamination Using In Situ Redox Manipulation" [Fruchter et al. 2000]), a few of the barrier wells exhibited signs of breakthrough 18 months after treatment. The most probable cause of the premature barrier breakdown was determined to be heterogeneities in the aquifer where laterally discontinuous units with high permeability and lower inherent reductive capacity (because of lower iron content) were re-oxidized faster than the less permeable layers. A Technical Assistance Panel (TAP) (DOE 2004, U.S. Department of Energy Hanford Site - Evaluation of Amendments for Mending the ISRM Barrier, Technical Assistance Project \#33, Final Technical Solutions Report) recommended that an alternative technology consisting of the injection of micron-sized zero-valent iron (mZVI) be tested and possibly deployed to mend the barrier. This would reduce or eliminate the need of periodically reinjecting the ISRM wells with sodium dithionite.

The TAP recommended that if this technology were to be tested, the following should be considered:

- Reduction potential of co-contaminants and any impacts these would have on the aquifer and groundwater quality

- Generation of byproducts

- Potential for the mZVI to convert nitrate to ammonia

- Formation of carbonate due to the generation of high $\mathrm{pH}$ conditions in the groundwater.

\subsection{Report Organization}

This document consists of nine chapters. Chapter 1 contains the introduction, and Chapter 2 provides conclusions and recommendations for the treatability study. Chapter 3 presents the treatability test plan as it pertains to laboratory testing and modeling, and Chapter 4 provides the results and a discussion of the laboratory testing. The treatability test plan, as it pertains to field injection tests, is included in Chapter 5. The results and discussion of the field injection are provided in Chapter 6, and Chapter 7 lists the references cited in this document. Appendix A provides the sand tank test plan and data. The test plan for the $\mathrm{mZVI}$ injection project is included as Appendix B. Appendix C contains the complete laboratory test results, and Appendix D contains field test data. Appendix E contains results and discussion of the verification borehole. 

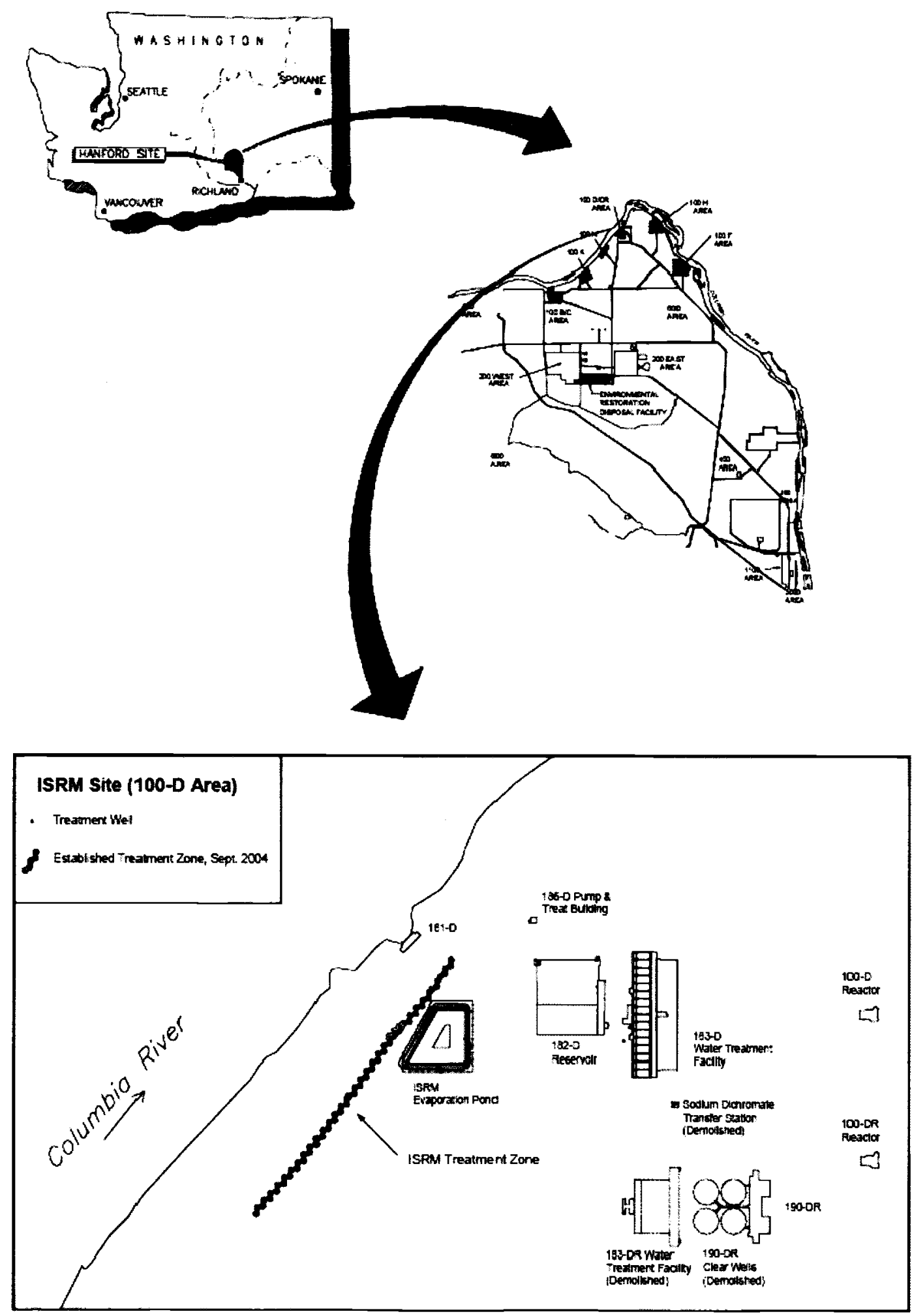

Figure 1-1. 100-D Area and Location of the In Situ Redox Manipulation Barrier 


\subsection{Site Description and Location}

The ISRM barrier is located in the 100-D Area at the U.S. Department of Energy (DOE) Hanford Site in Washington State. As defined in PNNL-16424, Treatability Test Plan for an In Situ Biostimulation Reducing Barrier, the unsaturated (vadose) zone in the 100-D Area lies in the Hanford formation and the upper portion of the Ringold Formation. The unconfined aquifer is composed of sandy gravel to siltysandy gravel, approximately 3 to $9 \mathrm{~m}$ (9.8 to $29.5 \mathrm{ft}$ ) thick, which corresponds to Ringold Unit E. Depth to the water table ranges from $<1 \mathrm{~m}(3.3 \mathrm{ft})$ near the river to approximately $25 \mathrm{~m}(82 \mathrm{ft})$ farther inland. The base of the unconfined aquifer is a fine-grained silty sand to clay overbank interval, designated the Ringold Upper Mud Unit, which is about $15 \mathrm{~m}$ (49.2 ft) thick and generally dips to the west. Based on interpolations between wells elsewhere in the 100 Areas (PNNL-12086, Hanford Site Groundwater Monitoring for Fiscal Year 1998), the deeper Ringold Formation is believed to be comprised of more layers of clay, silt, and sand. In the 100-D Area, hexavalent chromium is the major contaminant of concern in groundwater.

Groundwater in the unconfined aquifer in the area of the ISRM barrier generally flows toward the northwest, transporting dissolved hexavalent chromium from source areas toward the Columbia River. The estimated groundwater flow velocity is approximately $0.3 \mathrm{~m} /$ day $(0.98 \mathrm{ft} /$ day $)$ based on measured hydraulic gradients (PNNL-15499, Effect of Geochemical and Physical Heterogeneity on the Hanford 100-D Area In Situ Redox Manipulation Barrier Longevity), and an average hydraulic conductivity of $16.5 \mathrm{~m} /$ day $(53.1 \mathrm{ft} /$ day) was obtained from hydraulic tests conducted at the ISRM test site. Figure 1-2 shows a generalized hydrogeologic cross-section from the Columbia River to the area upgradient of the ISRM barrier (in this figure, well 199-D4-1 is located within the ISRM barrier).

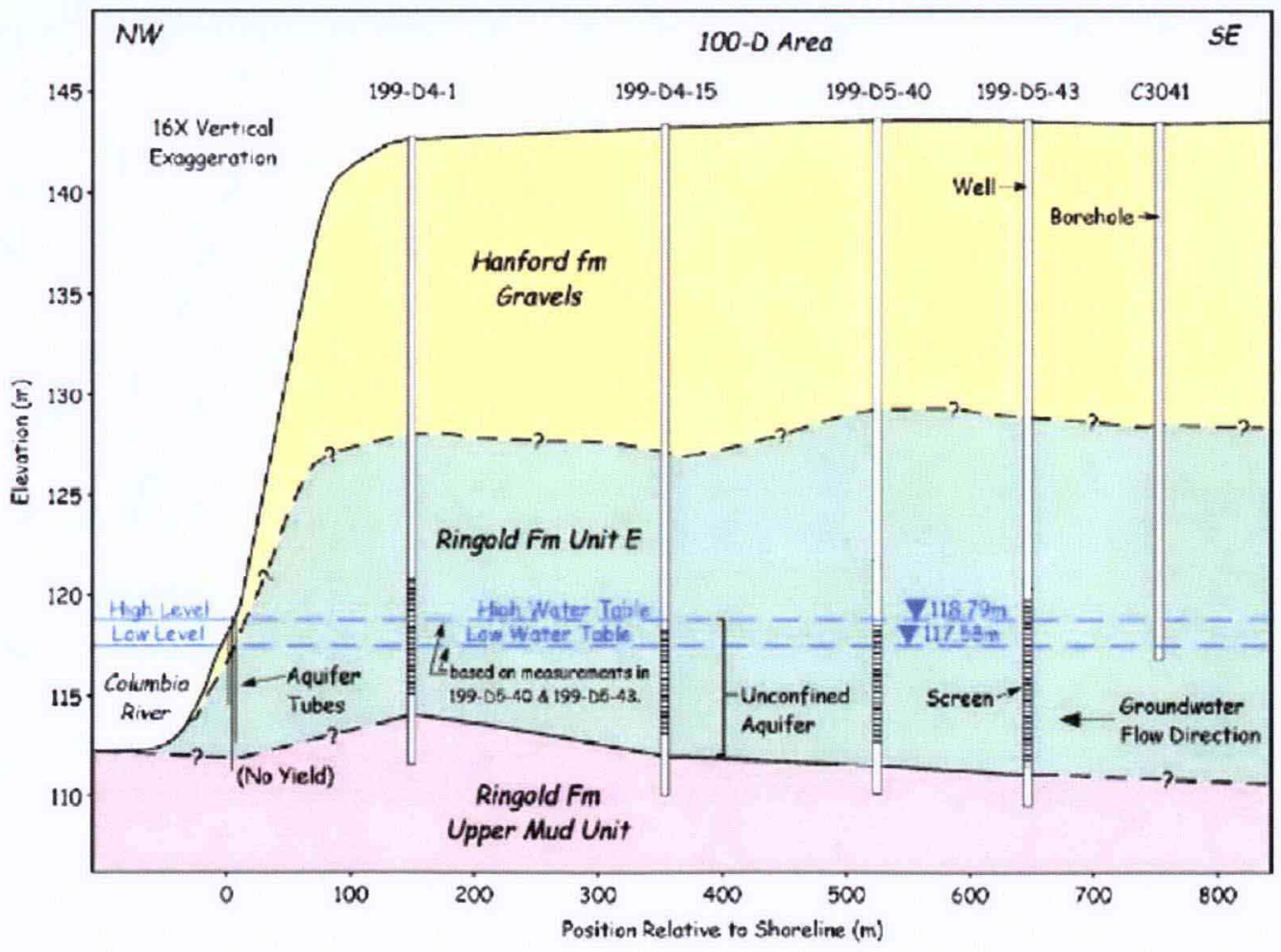

NOTE: Modified from PNNL-16424, Treatability Test Plan for an In Situ Biostimulation Reducing Barrier.

Figure 1-2. Hydrogeologic Cross-Section at the 100-D Area 


\subsection{History of Operations and Release Summary}

\subsubsection{Site Contaminant Summary}

The 100-HR 3 Operable Unit (OU) is located in the northern portion of the Hanford Site, along the Columbia River. This OU includes the groundwater underlying the source OUs associated with the $\mathrm{D} / \mathrm{DR}$ and $\mathrm{H}$ Reactor areas, as well as the property between the two areas. During operation of the D/DR Reactors between 1944 and 1967, large volumes of water were pumped from the Columbia River for use as reactor coolant. Sodium dichromate was added to the cooling water to inhibit corrosion of the reactor piping and subsequently leaked into the soil, contaminating the groundwater.

\subsubsection{In Situ Redox Manipulation Barrier}

Following discovery of hexavalent chromium contamination in groundwater beneath the western portion of the 100-D Area in 1995, an ISRM treatability test was conducted. The first ISRM treatment was applied in well 199-D-47 in September 1997, and four additional wells were treated between May and July 1998. The five treated wells created a reducing zone in the unconfined aquifer that was approximately $46 \mathrm{~m}(151 \mathrm{ft})$ long by $15 \mathrm{~m}(49 \mathrm{ft})$ wide.

During the fall of 1999, the treatment zone was extended by treatment of well 199-D4-21, resulting in hexavalent chromium concentrations being reduced from $1,050 \mu \mathrm{g} / \mathrm{L}$ to less than detection in that well. The success of these six treatment wells provided sufficient additional data to support advancing from treatability testing to emplacement of a large-scale treatment zone. The barrier was completed to its total length of $680 \mathrm{~m}(2,230 \mathrm{ft})$ in 2002.

\subsection{ISRM Treatment Technology}

The ISRM technology creates a chemically reduced, permeable treatment zone that changes hexavalent chromium in groundwater to trivalent chromium, which is less mobile and less toxic than the hexavalent form. Sodium dithionite is a strong reducing agent that scavenges unbound dissolved oxygen (DO) from the aquifer and reduces several metallic elements and oxy ions present in the aquifer in an oxidized state.

A number of reduction reactions occur in the groundwater system during ISRM emplacement, after which numerous oxidation reactions occur on a continuous basis. The principal reaction providing the residual reduction capacity to treat chromate ions flowing through the treatment zone is the reduction of ferric iron to ferrous iron. After the reduction treatment, ferrous iron is present in two forms: (1) dissolved ferrous iron in solution in the groundwater, and (2) structural ferrous iron associated with the geologic material forming the aquifer matrix. Some dissolved ferrous iron may migrate slowly downgradient with the groundwater flow, while structural ferrous iron provides residual reduction capacity that can react with the hexavalent chromium in incoming groundwater. Hexavalent chromium in aqueous solution flows into and through the treatment zone at the natural groundwater velocity. When dissolved hexavalent chromium (in the form of the water-soluble chromate ion) in the aquifer enters the reducing environment, it reacts with ferrous iron in the treatment zone and is reduced to trivalent, or chromic, chromium (Equation 1-1). The resulting trivalent chromium ultimately precipitates from the groundwater as chromic hydroxide or a chromic-ferric hydroxide complex. Both of these compounds have very low solubility in water and are less toxic and mobile than dissolved hexavalent chromium at typical groundwater $\mathrm{pH}$ and $\mathrm{Eh}$ conditions.

$$
\mathrm{Cr}(\mathrm{VI})+3 \mathrm{Fe}(I I) \rightarrow \mathrm{Cr}(I I I)+3 \mathrm{Fe}(I I I)
$$

Figure 1-3 shows the configuration of the hexavalent chromium groundwater contaminant plume during the third quarter of fiscal year 2008 . 


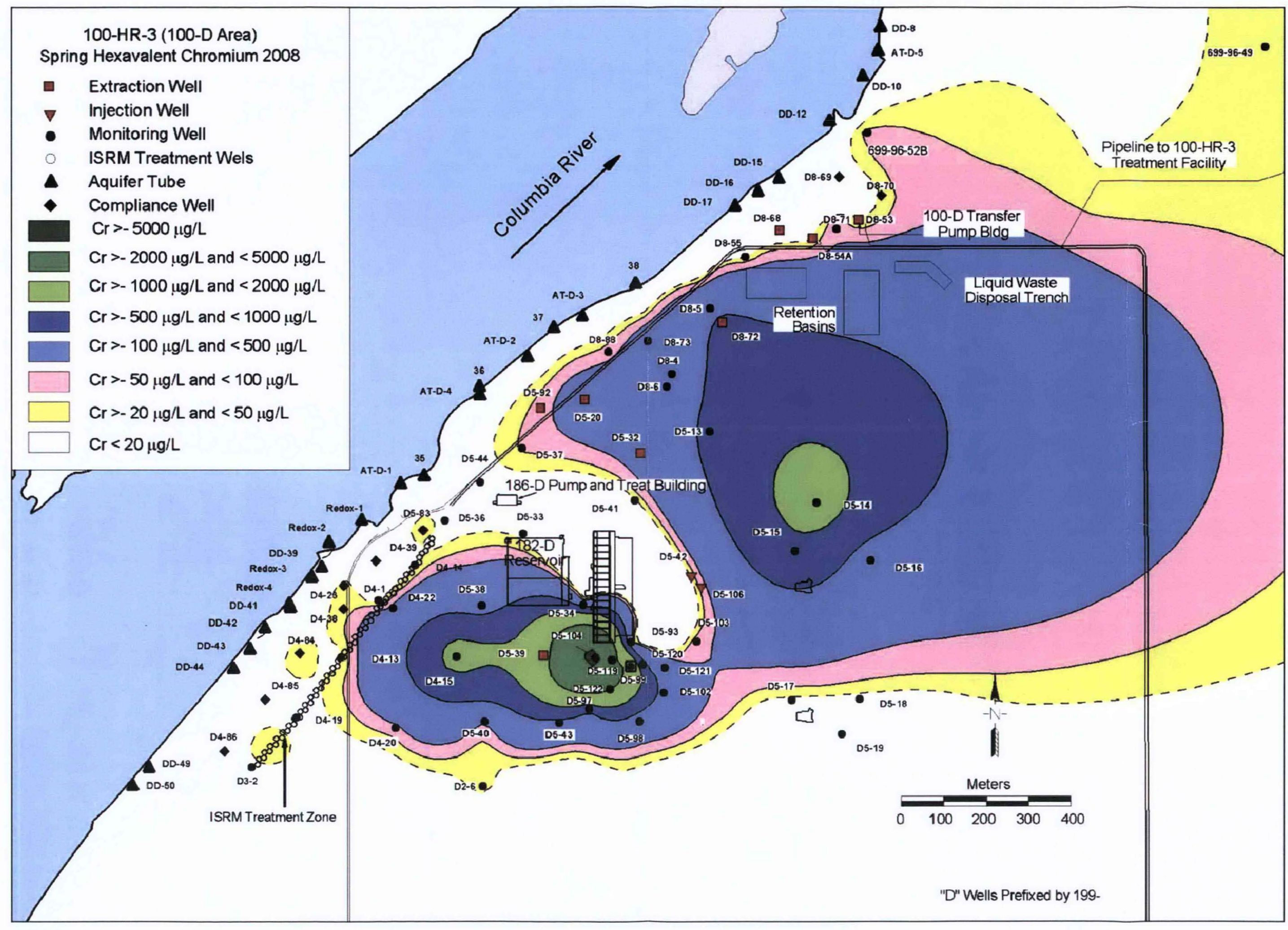

SOURCE: SGW-38942, Calendar Year 2008 Semi-Annual Technical Memorandum for the 100-HR-3, 100-KR-4, and 100-NR-2 Pump-and-Treat Operations.

Figure 1-3. 100-D Area Hexavalent Chromium Plume Map, Third Quarter Fiscal Year 2008 
DOE/RL-2009-35, REV. 0

This page intentionally left blank. 


\subsubsection{In Situ Redox Manipulation Barrier Status}

Over the past several years, it has become evident that performance of the barrier is not uniform. The southwestern portion of the barrier generally appears to be mitigating hexavalent chromium contamination. Some areas in the northeastern portion of the barrier are losing reductive capacity, evidenced by increasing hexavalent chromium concentrations in the ISRM treatment wells. On an annual average, 36 percent of the barrier wells exceeded the remedial action objective [RAO] of $20 \mu \mathrm{g} / \mathrm{L}$ hexavalent chromium in fiscal year 2008. This RAO is defined in EPA et al. 1999, County, Washington, Amended Record of Decision Summary and Responsiveness Summary (100-HR-3 Operable Unit). Seven compliance monitoring wells located between the barrier and the Columbia River shoreline are sampled quarterly to assess the performance of the ISRM treatment zone in reducing chromium concentrations and protecting aquatic receptors. During fiscal year 2008, the annual average hexavalent chromium concentrations in five of the seven compliance wells exceeded $20 \mu \mathrm{g} / \mathrm{L}$. The highest average hexavalent chromium concentration in fiscal year 2008 in compliance wells was $391 \mu \mathrm{g} / \mathrm{L}$ in well 199-D4-39, which is downgradient from the portion of the plume with the highest concentrations.

This documented reduction in barrier performance led to the realization that the barrier needed to be mended to maintain optimal performance. A study of alternative technologies that could be used to mend the ISRM barrier (DOE 2004) determined that injection of ZVI into the aquifer had the potential to create a long-lasting zone of reduction. Table 1-1 presents a summary of ZVI and other amendments that could be employed to mend the barrier. The ZVI technology is one of these options and is further described below.

\subsubsection{ZVI Technology Summary}

The process using ZVI has been used to remediate groundwater contaminated with a wide range of chlorinated compounds ("Enhanced Degradation of Halogenated Aliphatics by Zero-Valent Iron" [Gillham and O'Hannisin 1994]) because it is an extremely strong chemical reductant. For the ISRM barrier, a particularly attractive feature of ZVI is the potential to produce three electrons for reduction, compared to the single electron produced during ferrous iron oxidation. Thus, one mole of ZVI could potentially reduce one mole of hexavalent chromium, whereas three moles of naturally occurring ferrous iron are needed to reduce one mole of hexavalent chromium to trivalent chromium. The ZVI also has the ability to reduce hexavalent chromium. The reduction of hexavalent chromium and co-precipitation of trivalent chromium occur according to the following net reactions ("Use of Waste Iron Metal for Removal of Cr[VI] from Water" [Lee et al. 2003]) (Equations 1-2 and 1-3):

$$
\begin{gathered}
\mathrm{Cr} 042-+\mathrm{FeO}+8 \mathrm{H}+\rightarrow \mathrm{Fe} 3++\mathrm{Cr} 3++4 \mathrm{H} 2 \mathrm{O} \\
(1-x) \mathrm{Fe} 3++(x) \mathrm{Cr} 3++2 \mathrm{H} 2 \mathrm{O} \rightarrow \mathrm{Fe}(1-x) \mathrm{Cr} x \mathrm{OOH}(s)+3 \mathrm{H}^{+}
\end{gathered}
$$


Table 1-1. Potential Amendments for Mending the ISRM Barrier

\begin{tabular}{|c|c|c|c|c|c|c|}
\hline \multirow[b]{2}{*}{ Amendment } & \multicolumn{6}{|c|}{ Evaluation Criteria } \\
\hline & Effectiveness & Implementability & Safety & Regulatory & Longevity & Chemical Cost \\
\hline $\begin{array}{l}\text { Calcium } \\
\text { polysulfide and } \\
\text { organic } \\
\text { substrate }\end{array}$ & $\begin{array}{l}\text { EXCELLENT: } \\
\text { Proven in field tests to } \\
\text { quickly reduce aquifer; } \\
\text { presence of carbon } \\
\text { substrate provides } \\
\text { additional capacity. }\end{array}$ & $\begin{array}{l}\text { EXCELLENT: } \\
\text { Proven at multiple field } \\
\text { sites for source-zone } \\
\text { treatment; liquid } \\
\text { injection similar to } \\
\text { dithionite. }\end{array}$ & $\begin{array}{l}\text { GOOD: } \\
\text { Stock solution is } \\
\text { corrosive; requires } \\
\text { proper handling during } \\
\text { mixing. }\end{array}$ & $\begin{array}{l}\text { EXCELLENT: } \\
\text { Accepted by multiple } \\
\text { state and EPA. }\end{array}$ & $\begin{array}{l}\text { GOOD: } \\
\text { Comparable to or better } \\
\text { than dithionite; multiple } \\
\text { injections could be } \\
\text { necessary to maintain } \\
\text { reducing oxidations. }\end{array}$ & $\begin{array}{l}\text { LOW }^{\text {a }} \\
\$ 800 \text { to } 1,200 / \mathrm{kg} \\
\text { hexavalent chromium } \\
\text { reduced; } \$ 1 \text { to } \$ 2 \text { per } \\
1,000 \mathrm{~L} \text { of water } \\
\text { treated. }\end{array}$ \\
\hline $\begin{array}{l}\text { Micron-scale } \\
\text { iron }\end{array}$ & $\begin{array}{l}\text { EXCELLENT: } \\
\text { ZVI is proven to } \\
\text { reduce hexavalent } \\
\text { chromium in the } \\
\text { laboratory and field } \\
\text { PRBs. }\end{array}$ & $\begin{array}{l}\text { GOOD: } \\
\text { Concern regarding } \\
\text { delivery; laboratory } \\
\text { injection with shear- } \\
\text { thinning fluids } \\
\text { demonstrated. }\end{array}$ & $\begin{array}{l}\text { EXCELLENT: } \\
\text { Potential explosive and } \\
\text { inhalation hazard for } \\
\text { powdered form. }\end{array}$ & $\begin{array}{l}\text { EXCELLENT: } \\
\text { ZVI proven in PRBs at } \\
\text { multiple sites; concern } \\
\text { regarding generation } \\
\text { of ammonia from } \\
\text { nitrate. }\end{array}$ & $\begin{array}{l}\text { EXCELLENT: } \\
\text { Expected to last for } \\
\text { decades. }\end{array}$ & $\begin{array}{l}\text { MEDIUM } \\
\$ 1,650 / \mathrm{kg}^{\mathrm{b}} \text { hexavalent } \\
\text { chromium reduced, } \\
\$ 2 \text { per } 1,000 \mathrm{~L} \text { of } \\
\text { water treated; } \\
\$ 5,000 / \mathrm{m} \text { barrier. }\end{array}$ \\
\hline Nano-scale iron & $\begin{array}{l}\text { EXCELLENT: } \\
\text { Nano-scale ZVI proven } \\
\text { to reduce hexavalent } \\
\text { chromium in the field; } \\
\text { higher chromate } \\
\text { reduction capacity per } \\
\text { gram of iron. }\end{array}$ & $\begin{array}{l}\text { GOOD: } \\
\text { Potential delivery as } \\
\text { a slurry; in situ delivery } \\
\text { demonstrated at field } \\
\text { pilot scale; radius of } \\
\text { influence uncertain. }\end{array}$ & $\begin{array}{l}\text { EXCELLENT: } \\
\text { Stable slurry; requires } \\
\text { proper handling. }\end{array}$ & $\begin{array}{l}\text { EXCELLENT: } \\
\text { ZVI proven in PRBs at } \\
\text { multiple sites; concern } \\
\text { regarding generation } \\
\text { of ammonia from } \\
\text { nitrate. }\end{array}$ & $\begin{array}{l}\text { EXCELLENT: } \\
\text { Expected to last for } \\
\text { decades. }\end{array}$ & $\begin{array}{l}\text { HIGH': } \\
\$ 2,750 \text { to } \$ 5,500 / \mathrm{kg} \\
\text { hexavalent chromium } \\
\text { reduced, } \$ 3.5 \text { to } \$ 7 \\
\text { per } 1,000 \mathrm{~L} \text { of water } \\
\text { treated; } \$ 9,000 \text { to } \\
\$ 18,000 / \mathrm{m} \text { barrier. }\end{array}$ \\
\hline $\begin{array}{l}\text { Biological } \\
\text { substrate }\end{array}$ & $\begin{array}{l}\text { GOOD: } \\
\text { Effective in field and } \\
\text { laboratory for reducing } \\
\text { metals; long-term } \\
\text { effectiveness uncertain } \\
\text { as stand-alone } \\
\text { reductant. }\end{array}$ & $\begin{array}{l}\text { EXCELLENT: } \\
\text { Potential delivery as } \\
\text { a liquid, similar to } \\
\text { polysulfide. }\end{array}$ & $\begin{array}{l}\text { EXCELLENT: } \\
\text { Benign, biodegradable } \\
\text { and non-toxic. }\end{array}$ & $\begin{array}{l}\text { EXCELLENT: } \\
\text { High acceptability. }\end{array}$ & $\begin{array}{l}\text { POOR: } \\
\text { Continuous or multiple } \\
\text { injections necessary; } \\
\text { recirculation possible; } \\
\text { biofouling potential } \\
\text { problem. }\end{array}$ & $\begin{array}{l}\text { LOW }^{c} \text { : } \\
\text { Insignificant relative } \\
\text { to CaSx or iron; } \$ 0.04 \\
\text { to } \$ 0.35 \text { per } 1.000 \mathrm{~L} \\
\text { of water treated. }\end{array}$ \\
\hline
\end{tabular}

SOURCE: DOE 2004, U.S. Department of Energy Hanford Site - Evaluation of Amendments for Mending the ISRM Barrier, Technical Assistance Project \#33, Final Technical Solutions Report

a. Assumes that hexavalent chromium reduction occurs via Equation 1-1, S0 has no residual reduction capacity, $8.4 \mathrm{mg} / \mathrm{L} \mathrm{DO}, 1.29 \mathrm{mg} / \mathrm{L} \mathrm{hexavalent} \mathrm{chromium,}$ and $58.8 \mathrm{mg} / \mathrm{L} \mathrm{NO} \mathrm{N}_{3}$ - converted to $\mathrm{N}_{2}$ gas, and a cost of $\$ 2$ to $\$ 3 / \mathrm{gal}$ for CaS5.

b. Assumes that hexavalent chromium reduction occurs via Equation $1-3, \mathrm{H}_{2}$ evolved cannot reduce hexavalent chromium. It is assumed that micron-scale iron and nano-scale iron can reduce the same mass of hexavalent chromium. In all cases, it is assumed that all the reductant is fully used to reduce all oxidants present in Hanford groundwater (assuming $\mathrm{NO}_{3} \rightarrow \mathrm{NH} 4+$ );

c. Assumes $8.4 \mathrm{mg} / \mathrm{L} \mathrm{DO}, 1.29 \mathrm{mg} / \mathrm{L}$ hexavalent chromium, $58.8 \mathrm{mg} / \mathrm{L} \mathrm{NO}{ }_{3}$ converted to $\mathrm{N}_{2}$ gas, 75 percent of total electrons available are used for reduction of oxidants, and 25 percent go into biomass production.

$\mathrm{DO}=$ dissolved oxygen 
Areas of the ISRM barrier that have undergone some loss of reductive capability could potentially be mended by the addition of ZVI. However, to apply the technology at the ISRM barrier, the ZVI must be delivered to a distance of $7 \mathrm{~m}(23 \mathrm{ft})$ in sufficient quantities to replenish the barrier. Previous studies ("Retention of Zero-Valent Iron Colloids by Sand Columns: Application to Chemical Barrier Formation" [Kaplan et al. 1996]) have investigated the potential of injecting colloidal-size ZVI (micron-sized ZVI [mZVI]; 1 to 3 micron particle diameter) as a suspension into porous media. Due to the high density of the $\mathrm{mZVI}$ particles $\left(7.6 \mathrm{~g} / \mathrm{cm}^{3}\right)$, the research found that it was difficult to force the particles at significant concentrations very far into porous media. Flow rates much greater than that of typical groundwater were required to move the mZVI colloids through the sand columns, and the iron particles quickly settled out of suspension due to gravitational effects. In "Injection of Colloidal $\mathrm{Fe}^{0}$ Particles in Sand with ShearThinning Fluids" (Cantrell et al. 1997), column studies were conducted with several shear-thinning fluids to enhance mZVI colloid emplacement. The studies indicated that the viscosity of these fluids decreases with increasing shear rate, resulting in a relatively high-solution viscosity near the iron particles in the interstitial fluid between the porous media where the shear stress is low, relative to locations near the surfaces of porous media where the shear stress is relatively high. The primary reason to use these additives was to create a fluid that is viscous enough to keep the $\mathrm{mZVI}$ in suspension for extended periods to improve colloid mobilization into the porous media, while not causing a detrimental decrease in hydraulic conductivity.

Cantrell et al. (1997) used three non-toxic polymers at different concentrations in $1 \mathrm{~m}$ (3.3-ft)-long columns containing laboratory sands. This showed that the use of shear-thinning fluids greatly improved the injectability and mobility of the iron suspensions in porous media. It was clearly demonstrated that the mZVI MicroPowder ${ }^{\mathrm{TM}}$ S-3700, combined with the polymer SlurryPro ${ }^{\circledR}$ CDPTM, performed the best overall, producing iron enhancement of up to 1 weight percent (wt\%) when 30 pore volumes (PVs) of a $1 \mathrm{wt} \%$ iron solution were injected. In a longer column $(3 \mathrm{~m}[9.8 \mathrm{ft}])$, the iron concentrations ranged from $0.27 \mathrm{wt} \%$ at the inlet to $0.1 \mathrm{wt} \%$ near the outlet. The experimental results showed that effective $\mathrm{mZVI}$ injection could be obtained at much lower velocities with the addition of the polymers than those needed to inject iron into porous media without added polymers (Kaplan et al. 1996). Later work focusing on the injection of these suspensions into Hanford Site sediments showed results that were quite promising: the iron was fairly evenly distributed throughout $1 \mathrm{~m}(3.3-\mathrm{ft})-$ long columns and the polymer material did not adsorb onto the aquifer materials (WMP-28119, Mending the In Situ Redox Manipulation Barrier).

These studies with polymer additions were conducted with homogeneous porous media in onedimensional columns. Experience has shown that the heterogeneities at the 100-D Area heavily influence the chemical and hydrologic behavior of the aquifer, so experiments were designed and performed to investigate the behavior of micron-size iron and shear-thinning fluids in heterogeneous systems using multi-dimensional flow cells (PNNL-15573, An Experimental Study of Micron-Size Zero-Valent Iron Emplacement in Permeable Porous Media Using Polymer-Enhanced Fluids). The objective of this study was to evaluate the efficacy of injecting ZVI into highly permeable Hanford sediments (specifically Ringold Unit E gravels) using shear-thinning polymers. At a minimum, the emplaced iron should provide the average reductive capacity currently provided by ferrous iron, estimated to be approximately $11.0( \pm 3) \mu \mathrm{mol}$ of ferrous iron per gram of sediment (PNNL-15499). Because ZVI can theoretically provide three times more electrons than ferrous iron, an amendment of at least $5 \mu \mathrm{mol}$ of ZVI per gram of sediment would be considered a satisfactory result. This minimum amended concentration equals approximately $0.03 \mathrm{wt} \%$. These flow-cell experiments indicated that iron concentration enhancements of

MicroPowder ${ }^{\mathrm{TM}}$ S-3700 is a trademark of International Special Products, Wayne, New Jersey. SlurryPro ${ }^{\circledR}$ CDP is a registered trademark of KB International LLC, Chattanooga, Tennessee. 
at least $0.6 \mathrm{wt} \%$ could be obtained using moderate flow rates and injection of $30 \mathrm{PVs}$ of the polymer and iron. Even though the aqueous pressure increased by up to 25 kilopascal $(\mathrm{KPa})$ (approximately 3.5 pounds per square inch [psi]) during infiltration, detrimental effects to the hydraulic conductivity were not observed.

The calculations presented in PNNL-15573 show that the longevity of a $0.6 \mathrm{wt} \%$ amended ZVI zone will provide 2,640 PVs of treatment before breakthrough is observed, assuming that groundwater flowing through the treatment zone contains $8 \mathrm{mg} / \mathrm{L}$ oxygen, $60 \mathrm{mg} / \mathrm{L}$ nitrate, and $2 \mathrm{mg} / \mathrm{L}$ chromate, and assuming that a complete reduction of these oxidation-reduction reactive species takes place. The $0.6 \mathrm{wt} \%$ amended ZVI concentration would provide approximately 20 times the average reductive capacity provided by the sodium dithionite-reduced ferrous iron in the ISRM barrier. For effective supplemental

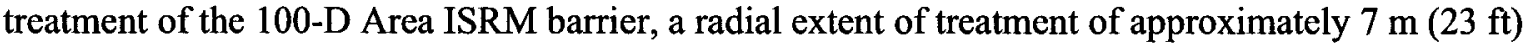
would be required.

Additional laboratory testing of MicroPowder S-3700 mZVI indicated the assumption that the material was effective at reducing the hexavalent chromium was invalid. In fact, the $\mathrm{mZVI}$ was very slow to react in the presence of simulated Hanford groundwater and aquifer materials. Due to this finding, testing was stopped on MicroPowder S-3700 and an investigation of other ZVI materials (including nano-sized materials [nZVI]) was initiated. The additional laboratory testing presented in the following sections indicates that a sufficient quantity $(0.10 \mathrm{wt} \%)$ of $\mathrm{nZVI}$ can be delivered to the high-permeability areas of the ISRM barrier in need of repair. Controlled geochemical tests have also shown that the injectable quantities are capable of reducing hexavalent chromium for at least 40 PVs.

Remediation of contaminated groundwater using nZVI has become an emerging technology in recent years with many promising benefits; primarily due to the improved mobility and higher surface area (and, thus, higher reactivity) of the $\mathrm{nZVI}$ in comparison to the much larger, less reactive and less mobile mZVI particles. However, like many emerging technologies, there are uncertainties associated with using nano-scale reactive iron particles for remediation purposes. Two of these uncertainties include the injectability and the long-term reactivity of the nZVI. To address these uncertainties, a broad range of geochemical and injection tests were conducted in the laboratory using various forms of $\mathrm{nZVI}$ and $\mathrm{mZVI}$ (i.e., discussed in this report). These tests ultimately identified a particular nZVI, RNIP-M2 ${ }^{\mathrm{TM}}$, for a field injection demonstration at the 100-D Area.

\subsection{Treatment Process and Scale}

Several ZVI materials were tested in the laboratory through a series of batch tests, geochemical column tests, flow cell injection tests, and finally a $1.5 \mathrm{~m}$ (5-ft)-diameter radial sand tank injection (Appendix A). The results of the laboratory testing suggested that it was feasible to inject $\mathrm{nZVI}$ into the aquifer to repair portions of the ISRM barrier. A pilot field injection proceeded for one of the areas in need of repair around barrier well 199-D4-26. During the pilot injection, approximately $370,970 \mathrm{~L}$ (98,000 gal) of $1 \mathrm{wt} \%$ iron injection slurry were emplaced in the subsurface over a period of 126 hours (i.e., 5.25 days).

\subsection{Objectives of the Test}

The following were the objectives of the treatability study.

- Test and select a ZVI compound that can be injected into the unconfined aquifer and create a persistent reduction zone that will reduce hexavalent chromium.

RNIP-M2 $^{\mathrm{TM}}$ is a trademark of Toda Kogyo Corporation, Hiroshima, Japan. 
- Demonstrate that a sufficient amount of nZVI can be injected into zones within the ISRM barrier that have prematurely lost some of their treatment capacity to re-establish reducing conditions.

- Demonstrate that $\mathrm{nZVI}$ can be communicated into the aquifer up to $7 \mathrm{~m}(23 \mathrm{ft})$ away from the injection well.

- Demonstrate that nZVI injection will not adversely affect groundwater in downgradient compliance wells or the Columbia River.

The technology performance criteria include the following:

- Presence of $\mathrm{nZVI}$ at a concentration of up to $0.10 \mathrm{wt} \%$ at a $7 \mathrm{~m}(23-\mathrm{ft})$ radius around the injection point

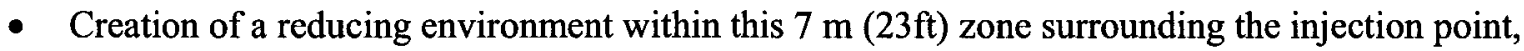
especially within the high permeability region

- Reduction of hexavalent chromium within the influence of the iron injection

- No adverse groundwater quality effects as the result of the nZVI injection that would impact human or environmental receptors

- No significant loss of permeability in the aquifer. 
DOE/RL-2009-35, REV. 0

This page intentionally left blank. 


\section{Summary of Conclusions and Recommendations}

This chapter presents a summary of the conclusions and lessons learned for the laboratory testing, modeling, and field injection activities associated with the selection and subsequent injection of a ZVI product into the subsurface at the 100-D Area at the Hanford Site.

The purpose of this project was to demonstrate the feasibility of using ZVI to repair portions of the ISRM barrier that was installed to intercept a hexavalent chromium plume in the groundwater moving toward the Columbia River. An investigation of ZVI products was conducted, including an evaluation of materials properties as provided by vendors and laboratory tests to evaluate their geochemical and injectability properties. These efforts were performed to select an appropriate ZVI product for mending the ISRM barrier. Two nZVI compounds, PolyMetallix ${ }^{\mathrm{TM}}$ and RNIP-M2, were determined to be suitable for more detailed testing in the laboratory and the field. After completion of laboratory testing, RNIP-M2 was identified as the superior material. Computer modeling was employed to optimize field injection activities. After completing laboratory testing and modeling, a field injection test was performed at injection well 199-D4-26, located within the ISRM barrier. Approximately 370,970 L (98,000 gal) of a RNIP-M2 slurry were injected successfully into the well during five days in August 2008. Post-injection groundwater monitoring and sampling of aquifer materials was performed to evaluate the success of the field test.

\subsection{Laboratory Testing, Modeling, and Field Test}

\subsubsection{Initial Micron-Sized Zero-Valent Iron Testing}

A series of laboratory tests were performed on MicroPowder S-3700 (a micron-sized zero-valent iron compound [mZVI]) in order to evaluate the chemical effects of this compound on simulated Hanford groundwater. MicroPowder S-3700 had previously been evaluated by Pacific Northwest National Laboratory (PNNL) (PNNL-15573) and was found to have favorable properties for injection when combined with a shear-thinning polymer. The laboratory tests consisted of flow cell injection of mZVI to address potential reductions in permeability, followed by a synthesized Hanford groundwater flush to address the geochemical effects of the injection. The results of the initial $\mathrm{mZVI} /$ polymer injection and geochemical testing indicated the following:

- The mZVI distribution in the flow cells after injection was less uniform than desired.

- The ZVI may reduce a portion of the nitrates in the surrogate groundwater to ammonia.

- Reduction of hexavalent chromium to trivalent chromium was less than expected.

After these test revealed that S-3700 would not strongly reduce the synthetic groundwater system, a set of simple batch tests were performed to investigate the interaction between the mZVI and a surrogate groundwater containing hexavalent chromium. The tests were designed to assess the reaction rate of $\mathrm{mZVI}$ and the effects that additives (e.g., surfactant and polymer) have on reaction rates. The results of the laboratory testing led to the following conclusions:

- The reduction of hexavalent chromium to trivalent chromium by the $\mathrm{mZVI} /$ polymer slurry was less than initially anticipated, reducing less than one-half the hexavalent chromium to trivalent chromium.

PolyMetallix $^{\mathrm{m}}$ is a trademark of Crane Polyflon, Norwalk, Connecticut. 
- The reaction rate of the $\mathrm{mZVI}$ appeared to be inhibited by the addition of the polymer.

- Insufficient rate of reduction of hexavalent chromium indicated that the $\mathrm{mZVI} /$ polymer slurry was not suitable for mending the ISRM barrier.

- Other ZVI materials should be identified and tested to select a suitable candidate for field testing.

\subsubsection{Evaluation and Selecting of Zero-Valent Iron for Field Test}

Based on the poor performance of S-3700, the decision was made to investigate other ZVI compounds to find a material that would effectively reduce hexavalent chromium present in the groundwater and would also be injectable into the Ringold Unit E soils at the 100-D Area. A literature search was performed to investigate available ZVI products. The most promising ZVI materials were then evaluated in batch, injection, and geochemical screening tests.

Complete descriptions of the screening tests are provided in Chapter 3, and the results are presented in Chapter 4.

\subsubsection{Literature Search}

The literature search resulted in a database that contained 30 separate ZVI materials. Each material was rated using a scoring system developed to evaluate the materials on their injectability, geochemical properties, cost, and availability. The literature search resulted in the following conclusions:

- There are a wide variety of available ZVI products. These vary in their physical properties, chemical compositions, and costs. The availability of the materials also depends on their stage of development. Many of the materials are "researched-based" and, as a result, are only available in small quantities.

- The top six materials from the literature search were advanced to further screening testing. Table 2-1 presents the top six materials and their manufacturers.

Table 2-1. Top Zero-Valent Iron Materials from Literature Search

\begin{tabular}{ll}
\hline \multicolumn{1}{c}{ ZVI Material Name } & \multicolumn{1}{c}{ Manufacturer } \\
\hline EZVI & Toxicological and Environmental Associates Inc. \\
PolyMetallix & Crane Polyflon \\
NanoFe Slurry II & Lehigh Nanotech \\
NanoFe Slurry I & Lehigh Nanotech \\
Z-loy & OnMaterials LLC \\
RNIP-M2 & Toda Kogyo Corporation \\
\hline NOTES: & \\
EZVI is a product of Toxicological and Environmental Associates, Inc., Baton Rouge, Louisiana. \\
NanoFe Slurry I and NanoFe Slurry II are products of Lehigh Nanotech, Bethlehem, Pennsylvania. \\
PolyMetallix is a trademark of Crane Polyflon, Norwalk, Connecticut. \\
RNIP-M2 is a trademark of Toda Kogyo Corporation, Hiroshima, Japan. \\
Z-loy is a product of OnMaterials LLC, San Diego, California. \\
ZVI = zero-valent iron
\end{tabular}




\subsubsection{Batch Screening Test}

Batch screening tests were performed on the top six materials identified in the literature search to evaluate the ability of each material to create a reducing environment and to reduce hexavalent chromium. The experiments consisted of a 4-hour batch test performed on a mixture of the ZVI material, clean silica sand, and surrogate groundwater containing hexavalent chromium. The results of these tests indicated that all six materials successfully reduced the dissolved chromium; therefore, all six of the materials were recommended for additional testing to evaluate injectability.

\subsubsection{Injection Screening Test}

Injection screening tests were performed to evaluate the ability of the six ZVI materials to permeate and deposit throughout the entire cross-section of horizontally placed flow cells, as well as to quantify any effects on hydraulic conductivity as a result of injection. Slurries of each material were injected through two flow cells packed with a blend of silica sand. Samples of solid cores and flow cell effluent were analyzed for iron to evaluate the depositional characteristics of each ZVI material. The data gathered from the injection screening tests led to the following conclusions:

- PolyMetallix and RNIP-M2 demonstrated superior uniformity of distribution throughout the flow cells.

- NanoFe Slurry I and NanoFe Slurry $\mathrm{II}^{2}, \mathrm{EZVI}^{3}$, and Z-loy ${ }^{4}$ did not distribute sufficient amounts of iron to the flow cells.

- NanoFe II and EZVI did not distribute the iron uniformly throughout the flow cells.

- Z-loy and NanoFe I resulted in large reductions in hydraulic conductivity during and after injection.

- PolyMetallix and RNIP-M2 were advanced to a screening geochemical test.

- MicroPowder S-3700 was also advanced for further testing because of previous favorable testing of this material (PNNL-15573).

\subsubsection{Geochemical Screening}

Geochemical column screening tests were conducted on PolyMetallix, RNIP-M2, and MicroPowder S-3700. Surrogate groundwater containing 572 parts per billion ( $\mathrm{ppb}$ ) hexavalent chromium was injected through vertical columns for approximately $20 \mathrm{PVs}$. The columns were filled with sand containing two concentrations of ZVI: $1.5 \mathrm{wt} \%$ (high) and $0.075 \mathrm{wt} \%$ (low). The materials were evaluated on their ability to reduce hexavalent chromium without producing unwanted byproducts (e.g., ammonia). The following conclusions were reached based on the geochemical screening tests:

- At $1.5 \mathrm{wt} \%$, both RNIP-M2 and PolyMetallix successfully reduced hexavalent chromium for the length of the test.

- At $0.075 w t \%$ the PolyMetallix showed chromium breakthrough while RNIP-M2 still reduced the hexavalent chromium for the length of the test.

- MicroPowder S-3700 showed insufficient reduction of hexavalent chromium at both concentrations and, thus, did not adequately address the needs of the project;

2 NanoFe I and NanoFe II are products of Lehigh Nanotech, Bethlehem, Pennsylvania.

3 EZVI is a product of Toxicological and Environmental Associates, Inc., Baton Rouge, Louisiana.

4 Z-loy is a product of OnMaterials LLC, San Diego, California. 
- Further advanced testing was recommended for PolyMetallix and RNIP-M2.

\subsubsection{Advanced Geochemical Test}

The primary objective of geochemical testing was to evaluate the reactive lifetime of the nZVI materials. The experiments used vertical columns that were packed with nZVI material and Ringold Formation sediment. Approximately 40 PVs of surrogate groundwater were passed through each column, and effluent samples were taken at six different times during testing. The following conclusions were made based on the results from these tests.

- At the high concentration ( $1.5 \mathrm{wt} \% \mathrm{nZVI}$ ), both $\mathrm{nZVI}$ materials were able to reduce hexavalent chromium to levels below detection for the duration of the test.

- At the medium concentration $(0.15 \mathrm{wt} \% \mathrm{nZVI})$, the following results were observed:

- RNIP-M2 almost completely eliminated hexavalent chromium throughout the duration of testing (i.e., hexavalent chromium was below detection each time it was measured).

- PolyMetallix reduced 20 to 25 percent of the hexavalent chromium by the end of testing.

- At the low concentration $(0.015 \mathrm{wt} \% \mathrm{nZVI})$, the following results were observed:

- RNIP-M2 reduced approximately 75 percent of the hexavalent chromium during the initial stages of testing and about 15 percent at the end of testing.

- PolyMetallix was not able to reduce an appreciable amount of hexavalent chromium.

- Physical examination of the high-concentration (1.5 wt\%) columns indicated the following:

- The RNIP-M2 column was very dark in color with only a very thin band of oxidized material extending approximately $0.6 \mathrm{~cm}(0.25 \mathrm{in}$.) from the influent screen.

- The PolyMetallix column contained a visibly oxidized zone extending approximately $15.2 \mathrm{~cm}$ (6 in.) from the influent screen

- Physical examination of the medium-concentration (0.15 wt\%) columns indicated the following:

- The RNIP-M2 column was very dark colored, but with an irregular zone of visible oxidation extending from 15.2 to $20.3 \mathrm{~cm}$ (6 to 8 in.) from the influent screen.

- The PolyMetallix column appeared to be nearly completely oxidized.

- Both PolyMetallix and RNIP-M2 were recommended for injectability testing.

\subsubsection{Advanced Flow Cell Injection}

Advanced injectability tests were performed on PolyMetallix and RNIP-M2 to evaluate hydraulic head losses caused by their injection into sand and to develop a mathematical expression for nZVI deposited as a function of injection time, distance from the injection point, and nZVI fluid velocity. Testing was performed using $3 \mathrm{~m}$ (10-ft)-long, $7.8 \mathrm{~cm}$ (3.1-in.) inside-diameter transparent pipes packed with very coarse sand and configured for horizontal flow.

The following conclusions resulted from the advanced injectability testing: 
- For experiments where a high number of PVs were injected (i.e., more than 11 PVs for PolyMetallix and more than 26 PVs for RNIP-M2), both nZVI materials were successfully transported through the entire length of flow cells.

- Hydraulic head increases on the injection side of the flow cells were encountered in both PolyMetallix and RNIP-M2 runs:

- Hydraulic head increases were directly proportional to flow rate, thus were accompanied by corresponding decreases in hydraulic conductivity,

- Hydraulic head increases for PolyMetallix runs were much greater than those for RNIP-M2 runs at equivalent flow rates.

- The mathematical expression for deposited nZVI as a function of injection time, distance from the injection point, and seepage velocity was developed for RNIP-M2 using a statistical application of multiple linear regression applied (Equation 2-1):

$$
\begin{aligned}
\text { Mass Deposition }= & 0.0322+3.77 E-7 \times \text { Time }-0.0192 \times \text { Distance } \\
& +8.44 \times \text { Seepage Velocity }
\end{aligned}
$$

(Equation 2-1)

Amassing of $\mathrm{nZVI}$ particles, defined as an increase in the iron concentration of suspended particles (nZVIs) above the influent nZVI concentration, was observed during flow cell testing.

\subsubsection{Sand Tank Test}

A $1.5 \mathrm{~m}$ (5-ft)-diameter, cylindrical steel tank filled with sand was used to conduct an intermediate-scale injection test using RNIP-M2 to simulate injection under radial flow conditions and to refine the injection procedures before field injection. After the test, the sand was excavated as necessary to visually verify the extent of injection. The results from this test were used to validate the injection model determined from batch and column testing. The testing procedure and results are described in Appendix A.

\subsubsection{Modeling}

The objective of the modeling effort was to predict the behavior of nZVI fluid injected into highconductivity sediments in the ISRM barrier. The goals of this task were to (1) predict the concentration

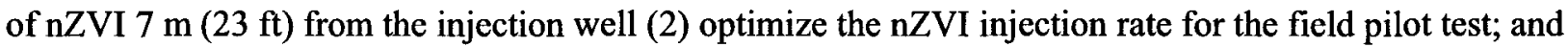
(3) approximate the maximum distance nZVI could be emplaced in the aquifer by injecting it through a single well.

The modeling results indicated the following:

- The target concentration for deposition of $1 \mathrm{~g}$ of $\mathrm{nZVI}$ per $1 \mathrm{~kg}$ of soil is achievable.

- The results predicted a $3.545 \mathrm{~g} / \mathrm{kg}$ maximum deposition of $\mathrm{nZVI} 7 \mathrm{~m}$ (23 ft) from the injection well for a $64 \mathrm{~L} / \mathrm{min}$ (17-gallons per minute [gpm]) injection rate.

- The recommended injection rate for the pilot field injection test was determined to be $53 \mathrm{~L} / \mathrm{min}$ (14 gpm). This rate resulted in a 10 percent larger extent of the deposited nZVI while depositing only 3.3 percent less $\mathrm{nZVI}$ at the $7 \mathrm{~m}(23 \mathrm{ft})$ distance, in comparison to results from the $64 \mathrm{~L} / \mathrm{min}(17-\mathrm{gpm})$ injection rate. 


\subsubsection{Field Injection Test}

The field injection test was conducted in August 2008 at the 100-D Area in well 199-D4-26. The goal of the field injection test was to place sufficient $\mathrm{nZVI}$ into the more permeable portions of the barrier to a

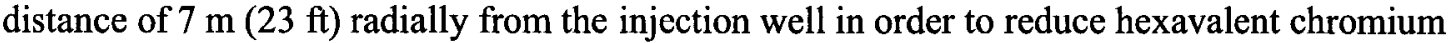
concentrations in the groundwater. Over a period of 5.25 days, approximately $370,970 \mathrm{~L}(98,000 \mathrm{gal})$ of a $1 \mathrm{wt} \%$ RNIP-M2 nZVI solution was injected into the Ringold Formation aquifer at a rate of $53 \mathrm{~L} / \mathrm{min}$ (14 gpm). Based on the data that were gathered before and during the test, the following observations were made:

- The injection activities experienced no major equipment problems during the injection, thus validating the design.

- The hydraulic head increase resulting from the injection of RNIP-M2 into the aquifer at the 100-D Area was similar to the increases observed in laboratory flow cell tests and sand tank test.

- A minor amount of pressure increase (i.e., increase in head) was necessary to maintain a constant

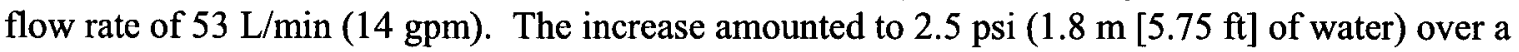
5-day period.

- Slug testing performed on the injection well before and after the injection determined that the nZVI mixture caused a decrease in hydraulic conductivity of the aquifer material immediately around the well by a factor of 2.7 .

- The $\mathrm{nZVI}$ material was observed in a well located $3 \mathrm{~m}(9.8 \mathrm{ft})$ downgradient 16 hours after injection started, and 35 hours after injection started in a well located $3 \mathrm{~m}(9.8 \mathrm{ft})$ upgradient.

- Monitoring data were consistent with the visual observations made during the injection. Temperature and $\mathrm{pH}$ increased in three wells (199-D4-92, 199-D4-93, and 199-D4-25). The oxidation-reduction potential (ORP) and DO measurements showed significant decreases in the two closest monitoring wells, indicating that $\mathrm{nZVI}$ was influencing the geochemistry in the immediate area around the wells. No significant changes in ORP or DO were observed in the outer two monitoring wells, indicating that the iron depositional front had not advanced as far as $12.8 \mathrm{~m} \mathrm{(42} \mathrm{ft})$ away.

- The use of an injection well packer is not necessary for future injection projects in similar hydrogeologic settings using the same injection material.

\subsubsection{Geophysical Monitoring}

Geophysical monitoring of the nZVI injection at Hanford included electrical resistivity, multi-frequency induced polarization (IP), time-domain electromagnetics (TEMs), surface magnetics, and mise a la masse electrical potential mapping. A time-lapse methodology was used to acquire the geophysical data. A background survey was completed prior to the injection, followed by an identical survey performed post-injection. Observed differences between the pre- and post-injection surveys were attributed to subsurface changes resulting from the ZVI injection. The following conclusions were made based on geophysical monitoring:

- The borehole induction logs from the polyvinyl chloride (PVC)-cased monitoring well, located $3 \mathrm{~m}$ $(9.8 \mathrm{ft})$ from the injection well, showed a significant response to the $\mathrm{nZVI}$ injection. The in-phase response (magnetic susceptibility) is most likely due to the iron component, whereas the quad-phase response (electrical conductivity) is most likely due to the polymer component. 
- The IP data were useful for constraining the lateral extents of the injected nZVI. A conservative estimate by the IP modeling results is that the radial extent of the nZVI injection exceeded the target minimum of $7 \mathrm{~m}(23 \mathrm{ft})$.

- For this particular injection, the total field magnetic data were of limited use in determining the extent of the injection, which resulted from a combination of factors (including a thick vadose zone and numerous proximal steel-cased wells).

\subsubsection{Verification Borehole}

A new borehole was drilled $7 \mathrm{~m}(23 \mathrm{ft})$ from the injection well to evaluate the extent of $\mathrm{nZVI}$ injection. Eleven split-spoon samples were collected and analyzed for iron and other constituents. This borehole was completed as a groundwater monitoring well. Results from this effort led to the following conclusions.

- $\mathrm{nZVI}$ was successfully deposited in a high-hydraulic conductivity layer at least $7 \mathrm{~m}$ from the point of injection, as evidenced by the above-background iron concentrations in the characterization well soils from the 95.5 to 97.7 interval.

- Hexavalent chromium is being reduced/immobilized in the aquifer, as shown by the increase in total chromium at the intervals that contain the most nZVI.

\subsubsection{Post-testing Groundwater Monitoring}

The injection well and nearby monitoring wells were sampled and analyzed after the field test. The data lead to the following observations.

- Hexavalent chromium and total chromium plummeted after the injection.

- Total chromium fell from $490 \mathrm{ppb}$ to $18 \mathrm{ppb}$.

- Hexavalent chromium analyses were affected by coloration of groundwater from dissolved iron; splits analyzed by ion chromatography indicated values $<10 \mathrm{ppb}$.

- Dissolved oxygen fell from about 5,000 ppb to 0 after the injection.

- Nitrate decreased over an order of magnitude, from about 50,000 ppb to about 1,500 ppb.

- Nitrite did not appear to change significantly.

- There was no apparent effect on arsenic concentrations.

- Manganese rose from near 0 to $273 \mathrm{ppb}$.

- $\mathrm{pH}$ rose by 2 to 3 units.

- Uranium decreased from approximately $2 \mathrm{ppb}$ before injection to $0.1 \mathrm{ppb}$ after injection.

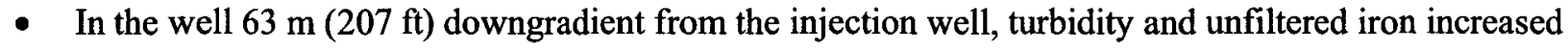
approximately one year after the injection.

\subsection{Costs}

The combined costs for ZVI laboratory testing and field injection totaled approximately $\$ 1,640,000$. Table 2-2 presents the costs associated with the development and injection of ZVI. 
DOE/RL-2009-35, REV. 0

Table 2-2. Zero-Valent Iron Cost Analysis

\begin{tabular}{|c|c|c|}
\hline Task/Subtask & Task Type & Cost (\$) \\
\hline Task 1 - Laboratory Testing Plan & Fixed price & $22,809.00$ \\
\hline \multicolumn{3}{|l|}{ Task 2 - Laboratory Testing } \\
\hline Task 2a - Mid-Point & Fixed price & $33,373.00$ \\
\hline Task $2 \mathrm{~b}$ - Complete & Fixed price & $33,373.00$ \\
\hline Task 3 - Modeling & Fixed price & $44,073.00$ \\
\hline Task 4 - Treatability Test Plan & Fixed price & $28,306.00$ \\
\hline Task 5 - Pre-injection Characterization & Fixed price & $23,860.00$ \\
\hline \multicolumn{3}{|l|}{ Task 6 - Design and Construct Injection System } \\
\hline Task 6a - Submit 50\% Design & Fixed price & $73,065.14$ \\
\hline Task $6 b-$ Submit $100 \%$ Design & Fixed price & $73,065.14$ \\
\hline Task 7 - Field Injection & Fixed price & $596,024.96$ \\
\hline Task 8 - Monitoring & Fixed price & $59,767.69$ \\
\hline Task 9 - Treatability Test Report & Fixed price & $76,606.70$ \\
\hline Task 10a - Define Study/Test Objectives & Time and materials & $40,426.35$ \\
\hline Task $10 b$ - Investigate alternative forms of $Z \mathrm{VI}$ & Time and materials & $59,553.19$ \\
\hline Task 10c-Geochemical Testing Selected ZVI & Time and materials & $222,338.04$ \\
\hline Task 10d - ZVI Material Injectability Testing & Time and materials & $201,691.98$ \\
\hline Task $10 \mathrm{e}$ - Numerical Modeling of ZVI Injection & Time and materials & $48,167.13$ \\
\hline \multirow[t]{2}{*}{ Task $10 f-$ Go/No-Go Decision Point } & Time and materials & $3,113.23$ \\
\hline & \multicolumn{2}{|r|}{$\$ 1,639,613.55$} \\
\hline
\end{tabular}

$\mathrm{ZVI}=$ zero-valent iron

Based on the cost analysis, the following conclusions were made.

- Approximately 46 percent of the total cost was expended on ZVI screening, selection, modeling, and testing.

- Approximately 54 percent of the total was expended on design, equipment procurement, monitoring, and field injection activities.

- The cost of the RNIP-M2 material represented substantial portions of the field injection and total project costs (approximately 36 percent and 19 percent, respectively).

- The potential exists that larger procurements of RNIP-M2 may significantly lower the cost per unit of the material.

- Another effective method to reduce overall costs is to identify a less expensive ZVI material. 


\subsection{Recommendations}

The laboratory tests, numerical modeling, and field injection demonstrated that RNIP-M2 can be

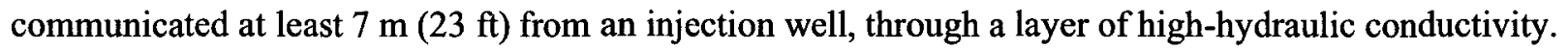
A strongly reducing zone (established by the injection) released excess electrons, which reduced hexavalent chromium to trivalent chromium and depleted oxygen and nitrate in the aquifer. The lessons learned during the course of testing and post-test monitoring lead to the following recommendations.

- The carrier fluid (i.e., dispersant) should be optimized for the specific ZVI material used.

- Column tests to evaluate reactivity and longevity of ZVI compounds should be conducted until breakthrough occurs.

- Computer modeling using data obtained from flow cell experiments should be used, because the model appeared to accurately predict the radius of influence and concentration of ZVI materials in the field test.

- Geophysical surveys should be conducted during injection in an attempt to track the iron front as it moves through the aquifer.

- Injection equipment (e.g., in-line mixing) should be designed to eliminate dilution and mixing of ZVI in a separate tank, which is a time- and labor-intensive process.

- Monitoring of groundwater near and downgradient of injection wells should be conducted at least quarterly to evaluate the persistence of the reducing zone created by ZVI.

- A less expensive ZVI material with chemical and hydrological properties similar to RNIP-M2 should be identified and tested to make this technology more cost-effective.

These recommendations should be considered for any future testing or deployment of ZVI injection. They do not endorse this technology for mending the ISRM barrier. Any future deployment of this technology will be decided through consideration of all options currently being evaluated for the 100-HR-3 OU through a remediation process optimization assessment. 
DOE/RL-2009-35, REV. 0

This page intentionally left blank. 


\section{$3 \quad$ Laboratory Testing and Modeling}

A series of laboratory tests were performed on MicroPowder S-3700 (a mZVI compound) to evaluate the chemical effects of the compound on simulated Hanford groundwater. The tests consisted of flow cell injection of mZVI to address potential reductions in permeability, followed by a synthesized Hanford groundwater flush to address the geochemical effects of the injection. After concluding that the performance of MicroPowder S-3700 was inadequate due to poor mZVI distribution in flow cells, less-than-anticipated reduction of hexavalent chromium to trivalent chromium, and slow reaction rates when used in a polymer slurry, it was determined that investigation would continue with other ZVI compounds that could effectively reduce hexavalent chromium present in the groundwater that could be injected into Ringold Unit E soils in the 100-D Area.

\subsection{Test Objectives and Rationale}

The laboratory testing objectives for the original mZVI candidate, MicroPowder S-3700, included the following:

- Evaluate changes in water chemistry when groundwater of similar composition to that of the 100-D Area reacts with mZVI emplaced in the aquifer, with emphasis on the following:

- $\mathrm{pH}$ changes

- Influence of strongly reducing conditions on nitrate (e.g., does it reduce all the way to ammonia?)

- Changes in carbonate concentration due to high $\mathrm{pH}$ (high carbonate concentrations may decrease the aquifer permeability).

- Evaluate the passivation (i.e., formation of an inert coating layer of oxide or other material) of the mZVI under field conditions (e.g., high groundwater carbonate conditions).

After tests on MicroPowder S-3700 were cancelled, a number of alternative ZVI materials were evaluated. These were tens to hundreds of nanometers in size. Batch screening tests were designed to determine the ability of the ZVI materials, without the addition of any dispersants, to remove dissolved hexavalent chromium from a surrogate groundwater at a dilute iron concentration after 4 hours of iron/surrogate contact time.

Laboratory injectability testing was performed on the remaining ZVI materials to determine their injectability, assess the changes in the permeability of the soils (possibly due to the precipitation of carbonates, iron oxy-hydroxides or other inhibiting byproducts), and attempt to select the best-performing ZVI materials for further laboratory geochemical and injectability testing.

The potential reduction of nitrate to ammonia is of some concern because ammonia is known to be toxic to aquatic species, including juvenile salmonids (e.g., EPA 440/5-85-001, Ambient Water Quality Criteria for Ammonia - 1984). The stoichiometric conversion of nitrate to ammonia by ZVI is well documented (e.g., "Reduction of Nitrate, Bromate, and Chlorate by Zero Valent Iron [Fe0]" [Westerhoff 2003]).

Geochemical screening tests were performed as an initial screening of potential ZVI materials based on their reduction of hexavalent chromium over a moderate time in a field simulation using small columns. The geochemical screening test served as the final elimination process before advancing two selected iron materials for advanced geochemical testing. 
Advanced geochemical laboratory testing was performed to evaluate the geochemical changes in a simulated aquifer environment after injection of ZVI, including those changes that may adversely affect groundwater quality. The geochemical testing objectives included the following:

- Evaluate changes in water chemistry when surrogate groundwater of similar composition to that at the 100-D Area reacts with ZVI emplaced in the aquifer, with emphasis on the following:

- $\mathrm{pH}$ changes

- Effect of ZVI-induced reducing conditions on nitrate (e.g., conversion to ammonia)

- Changes in carbonate concentration due to high $\mathrm{pH}$ (high carbonate concentrations may decrease the aquifer permeability)

- Ability of ZVI impregnated Ringold soil to remove/reduce hexavalent chromium.

- Assess passivation by the formation of iron hydroxy-oxides or other secondary minerals on the ZVI material.

Advanced flow cell injection was performed to determine the distribution of ZVI removed from the $\mathrm{ZVI} /$ dispersant/polymer/water mix (ZVI fluid) and deposited in the clean sand in columns during injection of the ZVI fluid. It is considered that the amount of ZVI deposited in the sand represents the ZVI that was adsorbed to sand grains and/or precipitated due to gravity. The results from this test are required to formulate a mathematical expression to evaluate ZVI deposition as a function of distance, time of injection, and ZVI fluid velocity. This type of functional relationship is necessary for computer modeling of the field injection process. It is anticipated that the developed function may need to be extrapolated beyond the original data set.

Numerical modeling was applied twice during laboratory testing: first, as part of testing of the original mZVI compound (MicroPowder S-3700), and then as part of testing of the nZVI compound (RNIP-M2) identified for possible injection. The objective of the proposed modeling efforts for the original $\mathrm{mZVI}$ compound was to use a numerical model to predict the behavior of the $\mathrm{mZVI} /$ polymer injection into a high-conductivity channel in the ISRM barrier. The modeling was to consider transport of two substances within the model domain (the $\mathrm{mZVI}$ laden polymer, and the $\mathrm{mZVI}$ itself) and would be created for wells 199-D4-26 and 199-D4-37. The goals of this task were to approximate the maximum distance that iron can be injected from a single point, the concentration of iron at $7 \mathrm{~m}(23 \mathrm{ft})$ from the injection point (assuming it can be communicated to that distance), and the dilution of the polymer under field hydrologic conditions. The objective of the numerical modeling effort for the nZVI compound was to use the functional relationship determined in the advanced flow cell injection and to develop a model to simulate and optimize a pilot ZVI injection of RNIP-M2 in well 199-D4-26 at the ISRM. The numerical model would predict the behavior of ZVI fluid injected into the high-conductivity strata in the ISRM barrier. The goals of this task were to approximate the maximum distance that iron can be injected from a

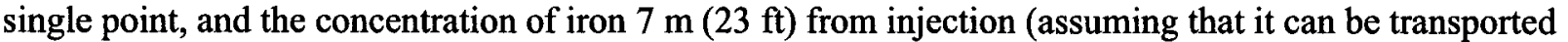
that distance). A flow and solute transport model (PORFLOW 5 Version 6, Revision 3) was used to accomplish these objectives.

\subsection{Experimental Design}

Experimental designs for the various elements of the laboratory testing are described in this section.

5 PORFLOW is a trademark of Analytic and Computational Research, Inc. (ACRi), Bel Air, California. 


\subsubsection{Micron-Sized Zero-Valent Iron Testing (Original Scope)}

The laboratory testing for the mZVI compound built upon previous injection experiments completed by PNNL (PNNL-15573). The results of PNNL's experiments, along with follow-up flow cell experiments, identified an $\mathrm{mZVI} /$ polymer mixture as having a high probability for success. The mixture identified was comprised of the colloidal iron MicroPowder S-3700 with a $1 \mathrm{wt} \%$ iron concentration, $0.001 \mathrm{wt} \%$ Aerosol $22^{\mathrm{TM}}$, and the polymer SlurryPro ${ }^{\circledR} \mathrm{CDP}$ at a $0.02 \mathrm{wt} \%$ concentration. The laboratory testing described below used this $\mathrm{mZVI} /$ polymer mixture. The formulas for preparing the polymer-enhanced $\mathrm{mZVI}$ and for synthesizing 100-D Area groundwater are from PNNL-15573.

Laboratory testing was designed to simulate the entire injection process, from pre-injection through postinjection, using small-scale flow cells. A flow cell is essentially a column maintained in a horizontal position during testing. One set of flow cells for the geochemical portion of the laboratory testing (herein referred to as the injection testing and experimental control cells) was packed with Ringold Unit $E$ soils from the 100-D Area. These cells had only surrogate groundwater flowing through them during the testing process. A second set of flow cells designed for permeability testing (herein referred to as the permeability testing cells) was packed with $12 / 20$ Accusand $^{\circledR}$. Flexible membranes (consisting of black rubber tire tubing) were placed on the inside of all but one of the flow cells. The purpose of the membranes was to reduce the effects of channeling, which was anticipated on the outside edges of the flow cells. The one flow cell without a membrane was included to provide visual observation of the $\mathrm{mZVI} /$ polymer front and potential visual changes in chemistry during testing. Prior to injection, the soils in all of the flow cells were saturated with water of a similar composition as the groundwater from the 100-D Area and then allowed to reach a geochemical equilibrium. Following geochemical equilibrium, $20 \mathrm{PVs}$ of a $\mathrm{mZVI}$ and polymer mixture in the prescribed ratio was then injected into the injection testing and permeability testing cells. An injection rate of $0.02 \mathrm{~cm} / \mathrm{sec}$ was used, based on the injection rate used in the PNNL injection experiments, which was determined to be most effective for distributing the $\mathrm{mZVI}$ (PNNL-15573). Following completion of the mZVI/polymer injections, an additional $20 \mathrm{PVs}$ of surrogate groundwater were injected through the injection testing and permeability testing cells.

To assess changes in the geochemistry as a function of the PVs of $\mathrm{mZVI} /$ polymer and surrogate groundwater injected, $\mathrm{pH}, \mathrm{ORP}$, specific conductance, $\mathrm{DO}$, and temperature of the effluent from the injection testing and experimental control flow cells were measured at regular intervals throughout the testing. Samples of the effluent were also analyzed for nitrogen as ammonia, nitrogen as nitrate and nitrite, alkalinity, iron speciation, and total and hexavalent chromium. In addition to effluent sampling, selected injection testing and experimental control flow cells were removed from the test setup periodically during injection testing to collect and analyze the soils from the cells for deposited iron concentration (using laboratory analytical methods presented in Section 3.4.1.1). This required multiple flow cells in the test setup to ensure that an adequate number of cells were available for soil sampling and effluent sampling for the entire testing period.

It was anticipated that if passivation of the $\mathrm{mZVI}$ occurred during injection testing, it would be primarily due to the formation of iron oxy-hydroxides (Yarmoff and Amrhein 1999, Fundamental Studies of the Removal of Contaminants from Ground and Wastewaters via Reductions by Zero-Valent Metals). Therefore, the "amount of iron passivation" would be based on the amount of iron oxy-hydroxide that formed in the flow cells, which may be observed through a number of microscopic techniques (e.g., optical microscopy, scanning capacitance microscopy). If formation of a significant amount of iron

Aerosol $22^{\mathrm{TM}}$ is a trademark of Sigma Chemical Company, St. Louis, Missouri.

SlurryPro ${ }^{\circledR}$ is a registered trademark of KB International, LLC, Chattanooga, Tennessee.

Accusand ${ }^{\circledR}$ is a registered trademark of Unimin Corporation, New Canaan, Connecticut. 
oxy-hydroxides was observed, it was then assumed that there is an increased potential for passivation of iron. A decrease in the rate of hexavalent chromium reduction with increasing volume of groundwater flushed through the system could also be an indication of iron passivation. A positive correlation between the formation of the iron oxy-hydroxides and a decrease in the rate of reduction of hexavalent chromium would further support the assumption that iron passivation is related to iron oxy-hydroxide formation. Optical microscopy was planned to be used to qualitatively estimate the amount of iron oxy-hydroxides that formed in the soil samples; however, the original scope of $\mathrm{mZVI} /$ polymer injection testing was stopped in May 2007 and the optical microscopy was not performed.

To assess changes in the permeability of the soils (possibly due to the precipitation of carbonates or other inhibiting byproducts), permeability testing was conducted in the permeability testing cells prior to, during, and following the injection of $\mathrm{mZVI} /$ polymer by measuring head differentials across the flow cells during testing. (It should be noted that the head differentials measured when only water is flowing through the flow cells cannot be directly compared to head differentials obtained when the $\mathrm{mZVI} /$ polymer was flowing through the cells due to distinctly different fluid properties.) In addition, effluent from the permeability testing cells was analyzed for $\mathrm{pH}, \mathrm{ORP}$, specific conductance, $\mathrm{DO}$, and temperature according to the sampling schedule for the $\mathrm{mZVI} /$ polymer injection flow cells.

\subsubsection{Nanometer-Size Zero Valent Iron Testing}

Each material was evaluated on its ability to reduce hexavalent chromium contained in surrogate groundwater over a period of 4 hours. For each ZVI material, $0.73 \mathrm{~g}$ of solid iron were added to a flask containing $50 \mathrm{~g}$ of 100 -mesh silica sand and $200 \mathrm{~g}$ of surrogate groundwater. The flasks were then sealed and placed on a rotary shaker for 4 hours. After the test was complete, each material was evaluated to determine its ability to create a reducing environment and reduce hexavalent chromium without producing any negative byproducts.

\subsubsection{Surrogate Groundwater}

The surrogate ground water was prepared to match the site conditions at the 100-D Area. The surrogate groundwater was prepared in a $10 \mathrm{~L}(2.6-\mathrm{gal})$ batch in accordance as specified in Table 3-1, and the batch was then allowed to equilibrate for approximately 18 hours before use.

\subsubsection{Injection Screening Test}

The injectability tests consisted of two phases: (1) injection of ZVI/carrier fluid, and (2) flushing with Hanford surrogate groundwater. During each phase, head loss along each of the injectability flow cells and turbidity of the effluent were measured prior to, during, and after the $\mathrm{ZVI} /$ carrier fluid injections using manometers and a portable turbidity meter, respectively. After completing the $\mathrm{ZVI} /$ carrier fluid injections, each of the injectability flow cells was visually inspected and photographed. Soil samples were removed from the upgradient and downgradient ends of the flow cells and analyzed for total iron concentration. The effluent was also analyzed for total iron after injection of approximately 20 PVs of $\mathrm{ZVI} /$ carrier fluid.

The ZVI/carrier fluid was injected at a rate within the range that would be created during the field injection. In a radial injection, the flow rate will decrease logarithmically with the distance from the injection well. An injection rate of $55 \mathrm{~mL} / \mathrm{min}$ was selected for the testing. The injection rate produced a seepage velocity that was expected to be representative of the field injection $3.5 \mathrm{~m}(11.5 \mathrm{ft})$ from the

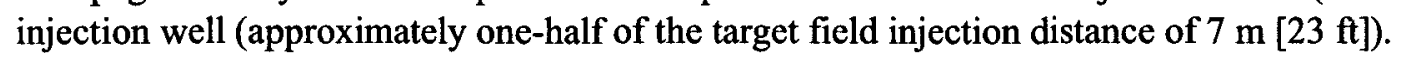


DOE/RL-2009-35, REV. 0

Table 3-1 Batch Screening Test Surrogate Groundwater Formulation

\begin{tabular}{lccc}
\hline \multicolumn{1}{c}{ Constituent } & $\begin{array}{c}\text { Hanford Water } \\
\text { Concentration }\end{array}$ & Units & $\begin{array}{c}\text { Calculated Surrogate } \\
\text { Groundwater Concentration }\end{array}$ \\
\hline Alkalinity (as HCO3-) & 97.13 & $\mathrm{mg} / \mathrm{L}$ & 100.2 \\
Calcium & 90 & $\mathrm{mg} / \mathrm{L}$ & 94.2 \\
Chloride & 33.96 & $\mathrm{mg} / \mathrm{L}$ & 30.7 \\
Chromium & 100 & $\mu \mathrm{g} / \mathrm{L}$ & 553 \\
Magnesium & 20.77 & $\mathrm{mg} / \mathrm{L}$ & 21.1 \\
Nitrate (as NO3-) & 23.6 & $\mathrm{mg} / \mathrm{L}$ & 61.0 \\
Potassium & 4.82 & $\mathrm{mg} / \mathrm{L}$ & 0.00 \\
Sodium & 9.89 & $\mathrm{mg} / \mathrm{L}$ & 17.6 \\
Sulfate & 135.35 & $\mathrm{mg} / \mathrm{L}$ & 135 \\
\hline
\end{tabular}

Following completion of the ZVI/carrier fluid injections, Hanford surrogate groundwater was flushed through the flow cells. Head loss and turbidity continued to be measured during the groundwater flush. After the groundwater flush, each of the flow cells was visually inspected and photographed, and effluent and soil samples were removed and analyzed for iron.

The flow rate for the Hanford surrogate water flushing was comparable to the $1.4 \mathrm{~m} /$ day $(4.5 \mathrm{ft} /$ day) rate of groundwater flowing through the high-permeability zone of the Ringold sediments under natural average regional hydraulic gradient. This value was estimated based on information from electromagnetic borehole flow meter (EBF) testing, which indicated that the hydraulic conductivity (and, thus, the flow velocity) in wells 199-D5-26 and 199-D5-37 is 4 to 5 times greater than the average hydraulic conductivity. Conservatively, the flow rate for the flow cells was $2.7 \mathrm{~m} /$ day ( $9 \mathrm{ft} /$ day).

\section{Surrogate Groundwater Preparation}

Approximately $757 \mathrm{~L}$ ( $200 \mathrm{gal})$ of surrogate groundwater were prepared for the flush cycle used in testing. As with the batch screening tests, the surrogate groundwater was prepared to match 100-D Area site conditions. The surrogate groundwater was prepared as specified in Table 3-1 and was allowed to equilibrate for approximately 18 hours after preparation and before use.

\section{Injectability Flow Cells}

Laboratory testing was conducted using injectability flow cells packed with saturated Accusand, having a customized particle size range similar to the zones of highly permeable Ringold Unit $E$ soils from the 100-D Area. A series of prototype flow cells were constructed to develop a surrogate sand mixture having the proper hydraulic permeability prior to preparing the flow cells for injection testing. The flow cells were connected to a series of peristaltic pumps to provide controlled injection of the $\mathrm{ZVI} /$ carrier fluid mixture and Hanford surrogate groundwater.

The flow cells were maintained in a horizontal position during the injection simulations to representatively simulate the injection process and any settling of ZVI out of suspension due to gravity. 


\section{Preparation of ZVI/Carrier Fluid Mixture}

The $\mathrm{ZVI} /$ carrier fluid preparation was prepared with a $1 \mathrm{wt} \%$ iron concentration. All ZVI materials that did not have a vendor-preferred carrier fluid or that did not come pre-packaged with a carrier fluid were suspended in water using a $0.001 \mathrm{wt} \%$ concentration of Aerosol 22 surfactant prior to injection.

\subsubsection{Geochemical Screening Test}

For each ZVI material (RNIP-M2, PolyMetallix, and MicroPowder S-3700), two $75 \mathrm{~mm}$ (3-in.) by $500 \mathrm{~mm}$ (20-in.), clear PVC columns were used to test the ability of each ZVI material to reduce hexavalent chromium under flow conditions. The columns were arranged in a vertical array and fed a continuous solution of Hanford surrogate groundwater at a rate of approximately $3 \mathrm{~mL} / \mathrm{min}$ to achieve a column seepage velocity approaching $3.3 \mathrm{~m} /$ day ( $11 \mathrm{ft} /$ day), which is close to the maximum flow velocity of $10 \mathrm{ft} /$ day noted in PNNL-15499. Laboratory equipment considerations resulted in a slightly higher flow rate of $3.3 \mathrm{~m} /$ day $(11 \mathrm{ft} /$ day $)$. The surrogate groundwater simulated the aquifer conditions at the 100-D Area site and contained a hexavalent chromium concentration of approximately $550 \mathrm{ppb}$. Each column was filled with a mixture of surrogate groundwater, saturated, highly permeable (particle size not to exceed $7.5 \mathrm{~mm}$ ) Ringold K soil, and ZVI material. Two different concentrations of each iron sample ( $1.5 \mathrm{wt} \%$ and $0.75 \mathrm{wt} \%)$ were mixed into the column packing material. The iron concentration was a functional representation of the deliverable iron for each individual ZVI material, as determined by the injection results obtained in the injection screening tests. The concentrations mixed in the column were consistent with the high-end and low-end concentrations for each injected iron source. Before packing, the iron was mixed with the selected dispersant and the Ringold Unit E soils as a saturated paste to ensure an even distribution of ZVI material throughout the column. The iron materials were tested over an injection of $20 \mathrm{PVs}$ of surrogate groundwater.

\section{Preparation of Hanford Surrogate Groundwater}

The surrogate groundwater was formulated to contain the major components present in 100-D Area groundwater and possess the characteristics responsible for its geochemical behavior. Sufficient hexavalent chromium was added, resulting in a concentration of $523 \mu \mathrm{g} / \mathrm{L}$ in order to test the ability of the ZVI ability to remove (or reduce) chromium. The nitrate concentration was set at $60 \mathrm{~m} \mathrm{NO}{ }_{3}^{-} / \mathrm{L}$ to indicate the ZVI effect on (1) the reduction of nitrate to nitrite and ammonia, and (2) high nitrate on the removal of hexavalent chromium. A complete description of the components present in the Hanford surrogate groundwater is presented in Table 3-1. The reagents were mixed and allowed to dissolve in $200 \mathrm{~L}$ ( $52.8 \mathrm{gal})$ of de-ionized water. Because the barrel would be open to ambient air and calcium was added in excess, the equilibrium calcium concentration was likely to be approximately 60 to $75 \mathrm{mg} \mathrm{Ca} / \mathrm{L}$. The surrogate groundwater was equilibrated in ambient air for at least 24 hours to reach saturation with calcium and to stabilize the ORP.

\subsubsection{Advanced Geochemical Test}

The laboratory work for advanced geochemical testing focused on only the reactivity of the two chosen ZVI compounds: RNIP-M2 and PolyMetallix.

Table 3-2 describes the two chosen ZVI compounds and their composition, dispersant, and some of the physical characteristics. 
DOE/RL-2009-35, REV. 0

Table 3-2. Advanced Geochemical Testing Zero-Valent Iron Materials

\begin{tabular}{|c|c|c|c|c|c|c|}
\hline ZVI & Manufacturer & $\begin{array}{l}\text { Particle-Size } \\
\text { Distribution }\end{array}$ & Dispersant & $\begin{array}{l}\text { Shipped } \\
\text { Form of } \\
\text { Material }\end{array}$ & Coating & $\begin{array}{l}\% \text { Iron in } \\
\text { Material }\end{array}$ \\
\hline RNIP - M2 & $\begin{array}{l}\text { Toda Kogyo } \\
\text { Corporation }\end{array}$ & $\begin{array}{l}\text { Average size } \\
=70 \\
\text { nanometers }\end{array}$ & $\begin{array}{l}\text { Olefin malic } \\
\text { copolymer }\end{array}$ & $\begin{array}{l}\text { Water-based } \\
\text { slurry: } 80 \mathrm{wt} \% \\
\text { water, } 17 \mathrm{wt} \% \\
\text { solids, and } \\
3 \mathrm{wt} \% \\
\text { polymeric } \\
\text { additive }\end{array}$ & $\begin{array}{l}\text { Magnetite } \\
\text { coating } \\
\text { surrounding } \\
\text { alpha-iron } \\
\text { core }\end{array}$ & $\begin{array}{l}65 \% \mathrm{ZVI} \\
\text { (per vendor } \\
\text { information) }\end{array}$ \\
\hline PolyMetallix & $\begin{array}{l}\text { Crane - } \\
\text { Polyflon }\end{array}$ & $\begin{array}{l}100 \text { to } 200 \\
\text { nanometers }\end{array}$ & $\begin{array}{l}\text { Vendor } \\
\text { recommendation: } \\
5 \% \text { to } 10 \% \\
\text { sodium } \\
\text { hexameta- } \\
\text { phosphate }\end{array}$ & Slurry & None & $>99 w t \%$ \\
\hline
\end{tabular}

Table 3-3 summarizes the test setup and rationale. The experiments used vertical columns packed with ZVI and Ringold sediment, which were flushed with surrogate groundwater at a specified flow rate of $2.2 \mathrm{~mL} / \mathrm{min}$. The flow rate was set to mimic twice the linear velocity (approximately $2.7 \mathrm{~m} /$ day [9 $\mathrm{ft} /$ day]) of the high-permeability zones in the Ringold Formation under the natural regional gradient.

The laboratory test set up was based on the geochemical screening studies previously conducted. The columns were designed to simulate the aquifer conditions after ZVI emplacement. Choice of the column length was arbitrary but yielded a residence time within the column of approximately 300 minutes. This time was more than sufficient for nZVI particles to reduce hexavalent chromium to trivalent chromium, as the reduction process has shown to be an exceedingly rapid ("Surface Chemistry and Electrochemistry of Supported Zero Valent Iron Nanoparticles in the Remediation of Aqueous Metal Contaminants" [Ponder et al. 2001]). The columns were packed with Ringold Unit E soils, and surrogate water was pumped through each of the columns. The surrogate water chemical composition was designed to be similar to the 100-D Area groundwater.

The column testing commenced with the ZVI and dispersant/carrier being manually mixed with the Ringold soil and packed into the column. Effluent samples from the geochemical columns at prescribed PVs were acquired during the study to identify changes in the groundwater chemistry as a function of the effluent volume. In addition to the effluent sampling, one column for each ZVI being tested was submitted for mineralogical examination at the end of testing. One control column containing only Ringold Unit E soil was also set up for the test. Effluent from the control column was analyzed in parallel with the samples from the experimental columns.

The column effluent $\mathrm{pH}, \mathrm{ORP}$, specific conductance, DO, and temperature were measured at prescribed PV intervals as discussed in Section 3.4.4.3. Samples of the effluent were analyzed for nitrogen as ammonia, nitrate, and nitrite; alkalinity; sulfate; iron speciation; and total and hexavalent chromium 
Table 3-3. Advanced Geochemical Column Configuration

\begin{tabular}{|c|c|c|c|c|c|c|c|c|c|}
\hline & & & Colun & Con & atic & & & & \\
\hline$\sum_{\mathbf{N}}$ & $\begin{array}{l}\stackrel{0}{z} \\
\frac{2}{\varepsilon} \\
\frac{5}{0}\end{array}$ & ह & 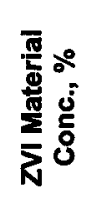 & $\frac{\stackrel{8}{8}}{\frac{8}{0}}$ & 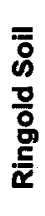 & $\sum_{\mathbf{N}}$ & $\begin{array}{l}\text { 范 } \\
\frac{2}{0} \\
\frac{0}{0} \\
\frac{0}{0}\end{array}$ & 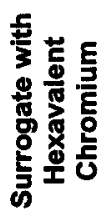 & 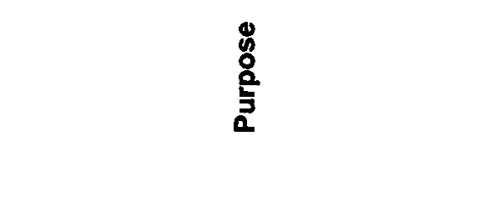 \\
\hline \multirow{9}{*}{ 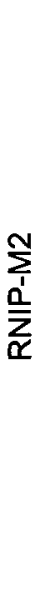 } & 1 & 1 & 1.5 & $A$ & $\sqrt{ }$ & $\sqrt{ }$ & $\sqrt{ }$ & $\sqrt{ }$ & \multirow{9}{*}{$\begin{array}{l}\text { Determine } Z V I \text { hexavalent } \\
\text { chromium removal capacity at } \\
\text { three different } Z \mathrm{VI} \text { concentrations. } \\
\text { Also, determine rate of nitrate } \\
\text { reduction to ammonia. }\end{array}$} \\
\hline & 2 & 1 & 1.5 & B & $\sqrt{ }$ & $\sqrt{ }$ & $\sqrt{ }$ & $\sqrt{ }$ & \\
\hline & 3 & 1 & 1.5 & C & $\sqrt{ }$ & $\sqrt{ }$ & $\sqrt{ }$ & $\sqrt{ }$ & \\
\hline & 4 & 1 & 0.15 & A & $\sqrt{ }$ & $\sqrt{ }$ & $\sqrt{ }$ & $\sqrt{ }$ & \\
\hline & 5 & 1 & 0.15 & B & $\sqrt{ }$ & $\sqrt{ }$ & $\sqrt{ }$ & $\sqrt{ }$ & \\
\hline & 6 & 1 & 0.15 & C & $\sqrt{ }$ & $\sqrt{ }$ & $\sqrt{ }$ & $\sqrt{ }$ & \\
\hline & 7 & 1 & 0.015 & A & $\sqrt{ }$ & $\sqrt{ }$ & $\sqrt{ }$ & $\sqrt{ }$ & \\
\hline & 8 & 1 & 0.015 & B & $\sqrt{ }$ & $\sqrt{ }$ & $\sqrt{ }$ & $\sqrt{ }$ & \\
\hline & 9 & 1 & 0.015 & C & $\sqrt{ }$ & $\sqrt{ }$ & $\sqrt{ }$ & $\sqrt{ }$ & \\
\hline \multirow{9}{*}{ 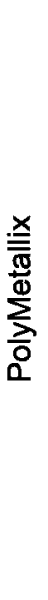 } & 1 & 1 & 1.5 & A & $\sqrt{ }$ & $\sqrt{ }$ & $\sqrt{ }$ & $\sqrt{ }$ & \multirow{9}{*}{$\begin{array}{l}\text { Determine } Z V I \text { hexavalent } \\
\text { chromium removal capacity at } \\
\text { three different } Z \mathrm{VI} \text { concentrations. } \\
\text { Also, determine rate of nitrate } \\
\text { reduction to ammonia. }\end{array}$} \\
\hline & 2 & 1 & 1.5 & B & $\sqrt{ }$ & $\sqrt{ }$ & $\sqrt{ }$ & $\sqrt{ }$ & \\
\hline & 3 & 1 & 1.5 & C & $\sqrt{ }$ & $\sqrt{ }$ & $\sqrt{ }$ & $\sqrt{ }$ & \\
\hline & 4 & 1 & 0.15 & A & $\sqrt{ }$ & $\sqrt{ }$ & $\sqrt{ }$ & $\sqrt{ }$ & \\
\hline & 5 & 1 & 0.15 & B & $\sqrt{ }$ & $\sqrt{ }$ & $\sqrt{ }$ & $\sqrt{ }$ & \\
\hline & 6 & 1 & 0.15 & C & $\sqrt{ }$ & $\sqrt{ }$ & $\sqrt{ }$ & $\sqrt{ }$ & \\
\hline & 7 & 1 & 0.015 & A & $\sqrt{ }$ & $\sqrt{ }$ & $\sqrt{ }$ & $\sqrt{ }$ & \\
\hline & 8 & 1 & 0.015 & B & $\sqrt{ }$ & $\sqrt{ }$ & $\sqrt{ }$ & $\sqrt{ }$ & \\
\hline & 9 & 1 & 0.015 & C & $\sqrt{ }$ & $\sqrt{ }$ & $\sqrt{ }$ & $\sqrt{ }$ & \\
\hline o & 1 & 3 & N/A & A & $\sqrt{ }$ & -- & -- & $\sqrt{ }$ & $\begin{array}{l}\text { Determine baseline conditions } \\
\text { and chromium sorption by } \\
\text { Ringold soil. }\end{array}$ \\
\hline
\end{tabular}

NOTES:

PolyMetallix is a trademark of Crane Polyflon, Norwalk, Connecticut.

RNIP-M2 is a trademark of Toda Kogyo Corporation, Hiroshima, Japan.

N/A = not applicable

ZVI = zero-valent iron 
Mineralogical analysis using mineral liberation analysis (MLA), which incorporated additional hardware interfaced to the scanning electron microscope, was used to evaluate the column materials after the completion of the test. MLA uses the ability of the scanning electron microscope to provide consistent grey levels for each mineral in a "back-scattered electron" image of the sample. Minerals produce different grey levels that are proportional to their average molecular weight. The X-rays produced by the electron beam impact are used to confirm the mineral phases in the sample. MLA was used to qualitatively estimate mineral phases, including the amount of iron oxy-hydroxides that formed during the reaction of the ZVI with hexavalent chromium. It was anticipated that if passivation of the ZVI did occur, it would be primarily due to the formation of iron oxy-hydroxides (Yarmoff and Amrhein 1999).

Therefore, the amount of iron passivation was based on the amount of iron oxy-hydroxide that formed in the columns, which may be observed through MLA. If formation of a significant amount of iron oxy-hydroxide was observed, then the assumption that there is an increased potential for passivation of iron could be made. Furthermore, a decrease in the amount of hexavalent chromium reduction with increasing volume of groundwater flushed through the system could also be an indication of iron passivation. If there was a positive correlation between the formation of the iron oxy-hydroxides and a decrease in the amount of reduction of hexavalent chromium, this would further support the assumption that iron passivation is related to the iron oxy-hydroxide formation.

Head differentials across the columns were also monitored. Changes in hydraulic head could indicate fouling of the columns, which could be due to a reduction in the permeability from iron chromium oxy-hydroxide formation as the test progresses.

\section{Groundwater Chemistry Formulation}

The average groundwater chemistry is presented in Table 3-4. The data were used to formulate the surrogate groundwater and helped to establish the detection limits required for the analytical methods used in the geochemical testing.

Table 3-4. Groundwater Chemistry of Hanford 100-D Area

\begin{tabular}{l|c|c}
\hline \multicolumn{1}{c|}{ Analytes } & Average Value & Units \\
\hline Alkalinity & 97.13 & $\mathrm{mg} / \mathrm{L}$ \\
\hline Aluminum & 38.96 & $\mathrm{\mu g} / \mathrm{L}$ \\
\hline Calcium & 90.00 & $\mathrm{mg} / \mathrm{L}$ \\
\hline Chloride & 33.96 & $\mathrm{mg} / \mathrm{L}$ \\
\hline Chromium* & 100 & $\mu \mathrm{g} / \mathrm{L}$ \\
\hline Dissolved oxygen & 9.59 & $\mathrm{mg} / \mathrm{L}$ \\
\hline Iron (total) & 136.53 & $\mu \mathrm{g} / \mathrm{L}$ \\
\hline Magnesium & 20.77 & $\mathrm{mg} / \mathrm{L}$ \\
\hline Nitrate & 23.60 & $\mathrm{mg} / \mathrm{L}$ \\
\hline Oxidation-reduction potential & 156.63 & $\mathrm{mV}$ \\
\hline pH & 7.80 & $\mathrm{Standard} \mathrm{units}$ \\
\hline Phosphate & 0.33 & $\mathrm{mg} / \mathrm{L}$ \\
\hline Potassium & 4.82 & $\mathrm{mg} / \mathrm{L}$ \\
\hline
\end{tabular}


DOE/RL-2009-35, REV. 0

Table 3-4. Groundwater Chemistry of Hanford 100-D Area

\begin{tabular}{l|c|c}
\multicolumn{1}{c|}{ Analytes } & Average Value & Units \\
\hline Sodium & 9.89 & $\mathrm{mg} / \mathrm{L}$ \\
\hline Specific conductance & 675.13 & $\mu \mathrm{S} / \mathrm{cm}$ \\
\hline Sulfate & 135.35 & $\mathrm{mg} / \mathrm{L}$ \\
\hline
\end{tabular}

* Total chromium value from DOE/RL-2005-97, Fiscal Year 2005 Annual Summary Report for the In Situ Redox Manipulation Operations.

\section{Test Setup}

The laboratory testing was conducted using ZVI, dispersant(s), and Ringold Unit E soils packed into the experimental columns. The control column was packed with Ringold Unit E soil with no ZVI. Surrogate groundwater was pumped from the bottom to the top, through each column, using a peristaltic pump.

Column effluent was collected and the volume was recorded to determine the number of PVs that had passed through the test material. The estimated PV of each column was determined using a prototype column that was packed with dry Ringold Unit E soils and then filled with water. However, the PV of each of the test columns would vary due to inherent differences in the material contained within the columns and small procedural differences caused by different individuals packing different columns; however, these differences should be small in comparison to the amount of water pumped through any one column for the duration of the test. As such, any error produced by using a single value for the PV of all the columns should be negligible.

\section{Column Preparation}

The columns were prepared using $7.6 \mathrm{~cm}$ (3-in.) nominal-diameter by $60 \mathrm{~cm}$ (23.6-in.)-long, clear PVC pipe. The column diameter was chosen so it would be10 times greater than the diameter of the largest particles in the sieved Ringold soil. The ends of each column were fitted with threaded couplings that were connected to a drainage system at the outlets. The columns were also fitted with manometers at each end for monitoring differential heads and, thus, pressure in the columns.

\subsubsection{Advanced Flow Cell Injection}

The test objectives were achieved by conducting laboratory experiments using numerous flow cells, filled with grade 10/20 Colorado silica sand and injected with a ZVI fluid. The flow cells (Figure 3-1) (built as approximately $3 \mathrm{~m}$ [9.8-ft] long and $75 \mathrm{~mm}$ [3-in.] nominal-diameter, transparent pipes) were configured for horizontal flow.

Each flow cell had sampling ports to collect fluid samples for total iron concentration analysis. The sampling ports were installed every $0.61 \mathrm{~m}$ ( $24 \mathrm{in}$.) along the flow cells. The mass of ZVI deposited in the sand was determined from the time-integrated difference between the mass of ZVI present in the fluid at the given sampling location and the ZVI remaining in the ZVI fluid at the next sampling location. The data provided information regarding the ZVI mass deposited as a function of distance from the injection point. 


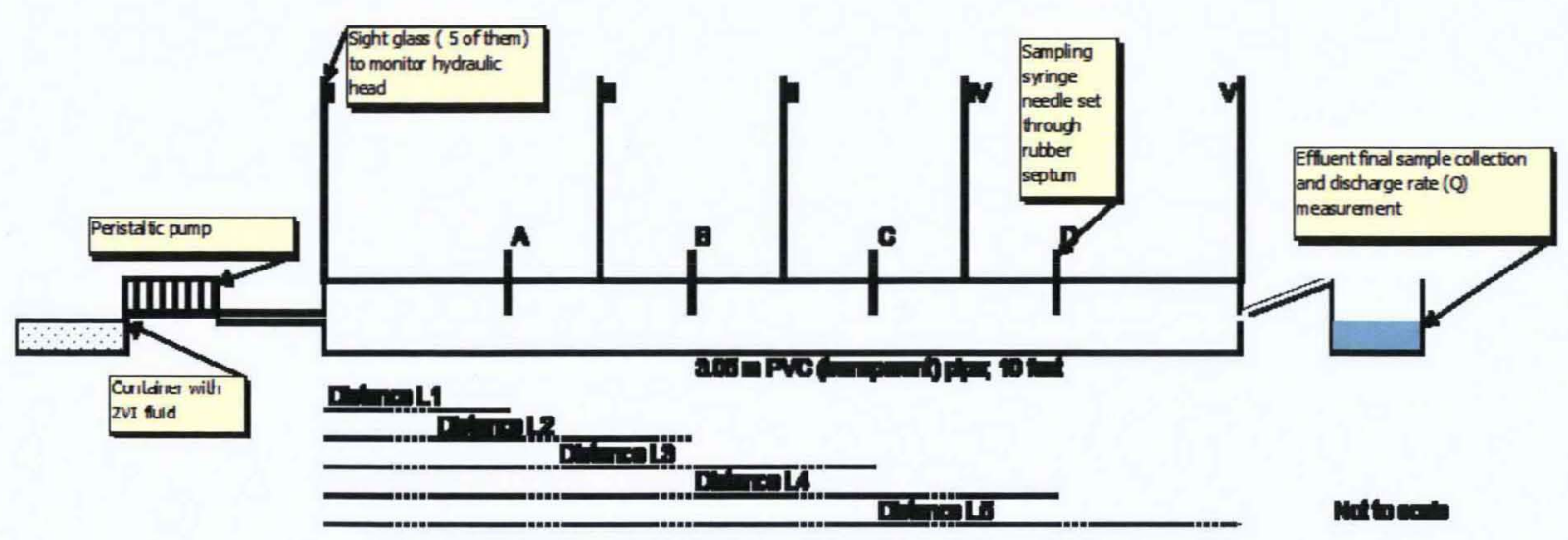

Figure 3-1. Flow Cell Schematic Diagram

Because ZVI would ultimately be emplaced in the aquifer using injection wells (which, by definition, create a radial flow pattern in which the volumetric flow rate of injected fluids decreases with distance from the well), it was important to evaluate the relationship between ZVI deposition and ZVI fluid velocity. This was accomplished by using four different volumetric flow rates (i.e., ZVI fluid velocities) through the flow cells.

The ZVI fluid was injected into the flow cells for a time period equal to the duration needed to inject five PVs into flow cells flowing at the lowest flow rate. Five PVs coincided with the maximum number of PVs expected during the field injection. The number of PVs injected into the flow cells flowing at a greater flow rate than the lowest velocity differed by the ratio of their respective flow velocities. Fluid samples were collected after injection of each of the first five PVs and then at the time interval coinciding with the sampling time at the lowest flow rate. These data provided information relating the mass of deposited ZVI with time expressed as both dimension-less time (PV) and actual time.

Two nZVI fluid formulations were tested (Table 3-5) (i.e., one for RNIP-M2 and one for PolyMetallix). The testing of two nZVI fluid formulations at four volumetric flow rates or fluid velocities required a total of eight flow cell experimental runs.

Table 3-5. Zero-Valent Iron Selected for Advanced Flow Cell Injection Testing

\begin{tabular}{|c|c|c|c|c|c|c|}
\hline ZVI & Manufacturer & $\begin{array}{l}\text { Particle-Size } \\
\text { Distribution }\end{array}$ & Dispersant & $\begin{array}{l}\text { Shipped } \\
\text { Form of } \\
\text { Material }\end{array}$ & Coating & $\begin{array}{l}\% \text { Iron in } \\
\text { Material }\end{array}$ \\
\hline RNIP-M2 & Toda America & $\begin{array}{l}\text { Average }=70 \\
\text { nanometers }\end{array}$ & $\begin{array}{l}\text { Olefin maleic } \\
\text { co-polymer }\end{array}$ & $\begin{array}{l}80 \% \text { water, } \\
17 \% \text { to } 18 \% \\
\text { solids, and } \\
2 \% \text { to } 3 \% \\
\text { polymer }\end{array}$ & $\begin{array}{l}\text { Magnetite } \\
\text { coating } \\
\text { surrounding } \\
\text { alpha-iron } \\
\text { core }\end{array}$ & $\begin{array}{l}65 \% \text { ZVI } \\
\text { (per vendor } \\
\text { information) }\end{array}$ \\
\hline PolyMetallix & $\begin{array}{l}\text { Crane - } \\
\text { Polyflon }\end{array}$ & $\begin{array}{l}100 \text { to } 200 \\
\text { nanometers }\end{array}$ & $\begin{array}{l}\text { Vendor } \\
\text { recommendation } \\
5 \% \text { to } 10 \% \\
\text { sodium } \\
\text { hexameta- } \\
\text { phosphate }\end{array}$ & $\begin{array}{l}\text { Water-based } \\
\text { paste, } 54 \% \\
\text { solids }\end{array}$ & None & $>99 \%$ \\
\hline
\end{tabular}

ZVI = zero-valent iron 
The possibility exists in laboratory testing that an experimental run will fail for unforeseen reasons. To limit the potential for data loss and to provide to check on data quality, flow cell experimental conditions were run in duplicate, which required a total of 16 experimental runs. In addition, one control flow cell was injected with de-ionized water. The fluid velocity in that cell was at an intermediate level " $b$ " (Table 3-6).

Table 3-6. Advanced Flow Cell Injection Testing Zero-Valent Iron Fluid Flow Velocity and Sampling Intervals

\begin{tabular}{|c|c|c|c|c|c|c|}
\hline \multicolumn{3}{|c|}{ ZVI Fluid Velocity } & \multirow{2}{*}{$\begin{array}{l}\text { Flow rate for } \\
\text { 3-in. Diameter } \\
\text { Flow Cell at } \\
0.35 \text { Effective } \\
\text { Porosity, } \\
\mathrm{mL} / \mathrm{min}\end{array}$} & \multirow[b]{2}{*}{$\begin{array}{c}\text { Expected } \\
\text { Hydraulic } \\
\text { Head } \\
\text { Differential, } \\
\text { cm }\end{array}$} & \multirow[b]{2}{*}{$\begin{array}{c}\text { Expected } \\
\text { Hydraulic } \\
\text { Gradient } \\
\text { (-) }\end{array}$} & \multirow[b]{2}{*}{$\begin{array}{l}\text { Elapsed Time for } \\
\text { Sampling, min }\end{array}$} \\
\hline $\begin{array}{l}\text { Flow Rate } \\
\text { Designation }\end{array}$ & $\begin{array}{c}\text { Seepage } \\
\text { Velocity, } \\
\text { ft/day }\end{array}$ & $\begin{array}{l}\text { Darcy } \\
\text { Flux, } \\
\text { ft/day }\end{array}$ & & & & \\
\hline a & 43 & 15 & 14 & 2 & 0.007 & $\begin{array}{c}328,656,984,1312 \\
\text { and } 1641\end{array}$ \\
\hline b & 99 & 35 & 32 & 4.6 & 0.015 & $\begin{array}{c}143,285,428,571,714 \\
984,1312, \text { and } 1641\end{array}$ \\
\hline c & 228 & 80 & 75 & 10.6 & 0.035 & $\begin{array}{c}62,124,186,248,310 \\
656,984,1312 \text {, and } 1641\end{array}$ \\
\hline d & 525 & 184 & 172 & 24 & 0.081 & $\begin{array}{l}27,54,81,108,135,328 \\
656,984,1312, \text { and } 1641\end{array}$ \\
\hline
\end{tabular}

$\mathrm{ZVI}=$ zero-valent iron

It was anticipated that data acquired from the test described above would be suitable to determine functional relationships for the following independent variables: (1) distance from the injection point, (2) volumetric flow rate or ZVI fluid velocity, and (3) time or dimension-less time (expressed as PVs injected). Functional relationships were assessed using multivariate regression analysis.

Finally, head differentials along the flow cells were monitored during each experimental run. This provided information indicating whether not ZVI deposition and resulting iron oxy-hydroxide formation increased (as the test progressed) to a level sufficient to cause fouling of the sand matrix in the flow cells, which would result in measurable reduction in hydraulic conductivity.

\section{Flow Cells}

The flow cells were prepared using $7.6 \mathrm{~cm}$ (3-in.) nominal-diameter by $3 \mathrm{~m}$ (10-ft)-long, clear PVC pipe. The ends of each flow cell were fitted with female threaded adapters. The inlet couplings were connected to an injection tube, while the outlet coupling was connected to a drainage system. The flow cells were also fitted with four sampling ports located at $61.1 \mathrm{~cm}(24-\mathrm{in}$.) intervals along the flow cell, and six manometers located midway between sampling ports and at each end of a flow cell.

Each sampling port was constructed of a plastic fitting, which accommodates an $11 \mathrm{~mm}$-diameter rubber septum of the type usually used for gas chromatography analyses. A $10.2 \mathrm{~cm}$ (4-in.)-long syringe needle was installed in the septum to allow for drawing ZVI fluid samples. 


\section{Zero-Valent Iron Fluid}

The injectability of two ZVI fluids (RNIP-M2 and PolyMetallix) was tested, with each ZVI fluid laden with the same $1 \mathrm{wt} \%$ ZVI. The ZVI fluids were prepared in a manner that mimics the procedure that would be used during the field injection. For PolyMetallix, dispersant was mixed with water and then the PolyMetallix slurry was added. For RNIP-M2, which is supplied as slurry already mixed with dispersant, the slurry was added to water for dilution and subsequent mixing.

\section{Zero-Valent Iron Fluid Flow Rates}

The flow velocities of ZVI fluid flowing through each of four flow cells were determined based on expected seepage velocity during the field injection at the rate not exceeding $56.8 \mathrm{~L} / \mathrm{min}(15 \mathrm{gpm})$. The lowest velocity (marked as "a" in Table 3-6) was related to the expected seepage velocity $3.3 \mathrm{~m} \mathrm{(10.8 \textrm {ft } )}$ from the well. Similarly, the highest velocity (marked as "d" in Table 3-6) was related to the expected seepage velocity $0.24 \mathrm{~m}(0.8 \mathrm{ft})$ from the center of the injection well. The value for highest velocity was checked with regard to the upper limit applicability for Darcy's Law and was found acceptable. The Reynold's number for these flow conditions was calculated as 0.76 , which is significantly lower than the value of 10 given in Bowen 1986, Groundwater as the upper limit for which the divergence from Darcy's Law is still acceptable. Intermediate velocities (designated as " $b$ " and "c" in Table 3-6) were set as approximately 2.3 and 9 times higher, respectively than the lowest velocity. The ZVI flow velocities and related values are provided in Table 3-6.

\subsubsection{Modeling}

The modeling effort using PORFLOW focused on simulating the groundwater flow field and emplacement of ZVI into the aquifer (saturated medium) by injecting ZVI fluid through injection well 199-D4-26.

At the time, there was no modeling procedure that could be followed or software that had been identified to determine the transport of ZVI in an aquifer. Therefore, the modeling approach described in this plan was experimental in its nature but was sound with respect to the input data that were developed through laboratory testing.

\subsubsection{PORFLOW Synopsis}

PORFLOW is general purpose software developed for simulating transient or steady-state multiphase fluid flow, heat, salinity, and mass transport in multiphase, variably saturated, porous or fractured media with dynamic phase change. The geometry of the modeled domain may be structured or unstructured, two-dimensional, three-dimensional, Cartesian, or cylindrical. The media modeled may be heterogeneous and anisotropic. Injection or pumping sources may be present, and chemical reactions or radioactive decay may take place. From the numerical point of view, PORFLOW is a hybrid of a finite volume with a finite element mesh code written in FORTRAN.

PORFLOW has a graphical user interface; a pre-processor for entering geometry, boundary conditions, and flow; transport; and dynamic-phase change relationships. A post-processor, ARCPLOT ${ }^{\circledR}$, generates charts, flow vectors, contours, grids, three-dimensional surface plots, and X-Y cross-sections at any direction.

ARCPLOT ${ }^{\circledR}$ is a registered trademark of Environmental Systems Research Institute, Inc. (ESRI), Redlands, California. 


\subsubsection{Modeling Domain}

The model encompassed a block of the unconfined aquifer around the injection well. This domain was discretized in the vertical direction in the manner that reflects geological and hydrogeologic stratification, as recorded in the borehole log of the injection well and the results of subsequent investigations reported in Waldrop and Waldrop 2004, Electromagnetic Borehole Flowmeter Test of the Wells of 100-D Area In Situ Redox Manipulation (ISRM) Barrier Site, Hanford Site, State of Washington with modifications provided in PNNL-18218, Electromagnetic Borehole Flowmeter Surveys at Selected In Situ Redox Manipulation Barrier Wells, Zero-Valent Iron Site, Hanford, Washington. Other available documents and publications were examined to assign appropriate hydraulic parameter values for each stratum, including an anisotropy ratio for horizontal to vertical hydraulic conductivity values. In case of a lack of site-specific information, well-documented values for similar sites were used. All strata were horizontal and assumed to be continuous throughout the domain (i.e., uniform thickness within the horizontal extent of the modeling domain).

The horizontal extent of the domain was set $30.5 \mathrm{~m}(100 \mathrm{ft})$ away from the injection well so the domain boundaries would not interfere with the cone of impression created by injection activities. Discretization of the model domain in the horizontal plane was dictated by hydraulic parameters of strata and numerical requirements of PORFLOW to converge to the defensible solution using appropriate tolerance criteria.

\subsubsection{Flow Field}

Modeling work involved simulating the flow of ZVI fluid in groundwater through an injection well. The ZVI fluid contained ZVI in the form of reactive, nano-sized iron particles (RNIP-M2). The selection of ZVI fluid for the modeling and then field injection was made based on the laboratory study. The ZVI fluid is water-based, with olefin maleic copolymer as an additive. Because the concentration of the additive in the injection fluid is approximately $0.2 \mathrm{wt} \%$, it was reasonable to assume that the physical properties of the fluid (density and viscosity) were those for pure water. Presence and gradual separation (deposition) of ZVI particles originally suspended in the fluid were addressed through transport mechanisms.

To minimize undesired spreading of the ZVI fluid in the aquifer due to the regional groundwater flow system, the actual field injection activities were originally scheduled for the month of July when, due to high water stages in the Columbia River, the groundwater table is relatively flat. The timing of the field implementation allowed modeling of the injection processes to be set in a flow field that was affected only by the injection itself. Such modeling is most efficiently conducted using a radially symmetric flow set within a cylindrical coordinates system. Modeling using cylindrical coordinates provides a threedimensional flow field (i.e., the feature especially important for simulating injection processes through a well) using significantly less central processing unit time. Consequently, within the same period, more alternative injection scenarios could be simulated for a model that uses cylindrical coordinates than for those models that use three-dimensional Cartesian coordinate systems.

\subsubsection{Zero-Valent Iron Transport}

PORFLOW was used to calculate the concentration of ZVI in the injection fluid (and the concentration of iron that fell out of the fluid) using a pseudo-solute-transport approach. This is because nano-size particles of iron behave in the fluid more like solids than dissolved constituents. Nevertheless, a pseudoisotherm approach was used to quantify the relationship of the rate that iron particles fell out of the fluid. The isotherm equation, as defined through the laboratory study, included the relationship between ZVI deposition as a function of distance, time of injection, and ZVI fluid velocity. This functional relationship was incorporated in the PORFLOW simulation algorithm using its unique ability to accommodate userdefined functions. 


\subsubsection{Modeled Scenarios}

The model was run for several injection scenarios. The number of scenarios depended largely on the complexity of the user-defined function used to simulate deposition of the ZVI in the aquifer. The more complex the function, the greater the computational time required to converge to the acceptable solution. The overall plan was to model the injection setup of a single well injection over a range of injection rates and hydraulic parameters of the aquifer. The basic hydraulic parameters used for modeling were those listed in PNNL-15499 and PNNL-15573.

\subsubsection{Model Description}

Output options used to present the modeling results included concentration iso-lines, flow lines (i.e., flow vectors), and time-versus-concentration X-Y plots.

\subsubsection{Limitations}

All of the models developed were quantitative, although conceptual in their nature because there are no field data that could be used to calibrate the models. Nevertheless, the model was essential for setting injection parameters and selecting equipment to be used. It should be possible to calibrate the model after the injection is completed. However, these efforts are not included in the scope of work for this project. Due to the lack of calibration data, the appropriateness of the model is based on the professional judgment of the modeler and the assistance of reasonable and competent reviewers.

\subsection{Equipment and Materials}

The equipment and materials used for the various elements of the laboratory testing are described in this section.

\subsubsection{Micron-Sized Zero-Valent Iron Testing (Original Scope)}

The injection testing and experimental control flow cells were constructed using $5.1 \mathrm{~cm}(2.0$-in.) nominaldiameter by $60 \mathrm{~cm}$ (23.6-in.)-long, clear PVC pipe. The permeability testing cells were constructed using $7.6 \mathrm{~cm}$ (3-in.) nominal-diameter by $1 \mathrm{~m}$ (39.4-in.)-long, clear PVC pipe. The flow cells were fitted with manometers at each end for monitoring head loss across the flow cells. The injection testing and experimental control flow cells were filled with Ringold Unit E, soils sieved to eliminate particles greater than $25.4 \mathrm{~mm}$ (1-in.) and less than $200 \mathrm{mesh}(0.074 \mathrm{~mm}$ [0.0024-in.]). The permeability testing cells were filled with $12 / 20$ Accusand. Additional materials used to construct the flow cells are outlined in the experimental test plan (see Appendix B).

The $\mathrm{mZVI}$ injection and geochemical testing were conducted with a $1 \mathrm{wt} \%$ iron-concentration colloidsuspension containing a 0.001 percent aerosol surfactant and 0.02 percent polymer. The ZVI particles were dispersed in the surfactant before the polymer was added. For quality assurance (QA)/quality control (QC) purposes, specific gravity measurements were performed on the injection solution to determine if the appropriate mixture was obtained. Based on previous laboratory work using a mixture with similar proportions as the proposed mixture (PNNL-15573) and based on discussions with technical personnel at K.B. International LLP (the manufacturer of SlurryPro CDP polymer), incompatibilities were not anticipated between the S-3700 MVZI and SlurryPro CDP polymer or between chlorinated tap water and the SlurryPro CDP polymer. However, according to manufacturer's technical personnel, if the SlurryPro polymer were mixed with a centrifugal mixer (as originally planned), the vigorous shearing forces produced by the centrifugal mixer might prematurely degrade the viscous properties of the polymer. Based on these discussions, a large paddle mixer was designed and built to replace the more turbulent vane mixer head originally intended to be used, and the $\mathrm{mZVI} /$ polymer was mixed at a low speed to reduce degradation of the polymer prior to injection. 
The materials required for preparation of the $\mathrm{mZVI} /$ polymer mixture included the following:

- MicroPowder S-3700 (10 g/L of mZVI/polymer mixture)

- Aerosol $22(0.01 \mathrm{~g} / \mathrm{L}$ of $\mathrm{mZVI} /$ polymer mixture)

- SlurryPro CDP (0.2 g/L of mZVI/polymer mixture)

- Fresh/tap water (amount of water equaled the number of liters of mZVI/polymer mixture).

\subsubsection{Batch Screening Test}

Each test was completed in a $250 \mathrm{~mL}$ Erlenmeyer flask containing the following:

- $50 \mathrm{~g}$ of 100 -mesh silica sand

- $0.73 \mathrm{~g}$ of solid iron

- $200 \mathrm{~g}$ of surrogate ground water.

The batch tests were used to evaluate the top six ranked materials from the literature search. The ZVI materials and their manufacturers are listed in Table 3-7. Additional materials used this laboratory testing are discussed in the experimental test plan (Appendix B).

Table 3-7. Injection Screening Test Zero-Valent Iron Materials and Dispersant

\begin{tabular}{lll}
\hline \multicolumn{1}{c}{ ZVI Material } & \multicolumn{1}{c}{ Manufacturer } & \multicolumn{1}{c}{ Dispersant } \\
\hline EZVI & $\begin{array}{l}\text { Toxicological \& Environmental Associates, Inc. } \\
\text { (Baton Rouge, Louisiana) }\end{array}$ & Aerosol 22 (by default) \\
PolyMetallix & Crane Polyflon (Norwalk, Connecticut) & Sodium hexametaphosphate \\
NanoFe I & LeHigh Nanotech (Bethlehem, Pennsylvania) & Poly(acylic acid) \\
NanoFe II & LeHigh Nanotech (Bethlehem, Pennsylvania) & Poly(acylic acid) \\
Z-loy & OnMaterials, LLC (San Diego, California) & Proprietary ingredient \\
RNIP-M2 & $\begin{array}{l}\text { Toda Kogyo Corporation (Toda Kogyo Corporation, } \\
\text { Hiroshima, Japan) }\end{array}$ & Olefin malic co-polymer \\
\hline
\end{tabular}

$\mathrm{ZVI}=$ zero-valent iron

\subsubsection{Injection Screening Test}

The injection screening tests were performed in clear PVC pipe measuring approximately $7.6 \mathrm{~cm}$ (3-in.)diameter by $100 \mathrm{~cm}(39.4-i n$.) in length. The flow cells were fitted with manometers at each end to monitor head loss across the flow cells. The outlet of each flow cell was elevated above the top of the flow cell to maintain complete saturation of the cell during the entire test. A series of peristaltic pumps were connected to the flow cells to provide controlled injection of the $\mathrm{ZVI} /$ carrier fluid mixture and Hanford surrogate groundwater.

For each ZVI material tested, the vendors were asked to provide a dispersant that would provide the best results for their product. The ZVI materials tested, their manufacturer, and the dispersant are listed in Table 3-7. Additional materials used to construct the flow cells are discussed in the experimental test plan (Appendix B). 


\subsubsection{Geochemical Screening Test}

The geochemical screening tests were completed using the following main components:

- $7.6 \mathrm{~cm}$ (3-in.) nominal-diameter by $60 \mathrm{~cm}$ (23.6-in.)-long, clear PVC pipe

- Ringold Unit E soils sieved to eliminate all particles greater than $7.6 \mathrm{~mm}(0.3 \mathrm{in}$.) and less than 200 mesh (0.074 mm [0.0024 in.])

- PolyMetallix

- $\quad$ RNIP-M2

- MicroPowder S-3700

- Surrogate groundwater

- Surrogate groundwater distribution system consisting of peristaltic pumps, silicon tubing, and pipe fittings.

Additional materials used to construct the flow cells are discussed in the experimental test plan (Appendix B).

\subsubsection{Advanced Geochemical Test}

Completion of the advanced geochemical columns required the following materials.

- $7.6 \mathrm{~cm}$ (3-in.) nominal-diameter by $60 \mathrm{~cm}$ (23.6-in.)-long, clear PVC pipe

- Ringold Unit E soils sieved to eliminate all particles greater than $7.6 \mathrm{~mm}(0.3 \mathrm{in}$.) and less than 200 mesh (0.074 mm [0.0024 in.])

- PolyMetallix

- RNIP-M2

- MicroPowder S-3700

- Surrogate groundwater

- Surrogate groundwater distribution system consisting of peristaltic pumps, silicon tubing, and pipe fittings.

Additional materials used to construct the geochemical columns are discussed in the experimental test plan (Appendix B).

\subsubsection{Advanced Flow Cell Injection}

The advanced flow cell injection tests required the following materials:

- $\quad 7.6 \mathrm{~cm}$ (3-in.) nominal-diameter by $305 \mathrm{~cm}$ (10-ft)-long, clear PVC pipe

- $10 \times 20$ silica sand

- PolyMetallix

- RNIP-M2. 
The following supporting equipment was used during the advanced flow cell injection testing:

- High shear mixer (HSM)

- $1,136 \mathrm{~L}$ (300-gal) ZVI mixing tank

- ZVI injection distribution system.

Additional materials used to construct the flow cells and testing are discussed in the experimental test plan (Appendix B).

\subsection{Sampling and Analysis}

\subsubsection{Micron-Size Zero-Valent Iron Testing (Original Scope)}

The measurements and analyses were divided into primary and secondary classifications depending on the data use. The primary data were used to support the laboratory testing objectives listed in Section 3.1. The secondary data were used for laboratory QC purposes and to provide data for numerical modeling and injection design, if necessary. All laboratory analyses and measurements were carried out by MSE Technology Applications, Inc., of Butte, Montana.

\subsubsection{Primary Measurements and Analyses}

Table 3-8 lists the analyses, sample matrix, analytical methods, and required detection limits for the primary measurements and analyses.

Table 3-8. Micron-Size Zero-Valent Iron Primary Measurements and Analyses

\begin{tabular}{|c|c|c|c|}
\hline $\begin{array}{l}\text { Measurement/ } \\
\text { Analysis }\end{array}$ & Matrix & $\begin{array}{c}\text { Analytical/Measurement } \\
\text { Method }\end{array}$ & $\begin{array}{l}\text { Detection } \\
\text { Limit }\end{array}$ \\
\hline $\mathrm{pH}$ & Pore fluid & EPA Method $150.1^{a}$ & $0.1 \mathrm{SU}$ \\
\hline Oxidation-reduction potential & Pore fluid & Standard method $2580^{b}$ & $1 \mathrm{mV}$ \\
\hline Nitrogen as ammonia & Pore fluid & EPA Method $350.2^{\mathrm{a}}$ & $0.05 \mathrm{mg} / \mathrm{L}$ \\
\hline Nitrogen as nitrate and nitrite & Pore fluid & EPA Method $353.2^{c}$ & $0.05 \mathrm{mg} / \mathrm{L}$ \\
\hline Alkalinity & Pore fluid & EPA Method $310.1^{d}$ & $5 \mathrm{mg} \mathrm{CaCO} \mathrm{CO}_{3} / \mathrm{L}$ \\
\hline Iron speciation & Pore fluid & Standard method $3500-F e D^{b}$ & $0.05 \mathrm{mg} / \mathrm{L}$ \\
\hline $\begin{array}{l}\text { Total and hexavalent } \\
\text { chromium }\end{array}$ & Pore fluid & $\begin{array}{c}\text { Total (EPA Method 200.9) / } \\
\text { Hex (SW 7196A) }\end{array}$ & $0.001 / 0.005 \mathrm{mg} / \mathrm{L}$ \\
\hline Iron speciation & Soils & $\begin{array}{c}\text { As described in PNNL-15499, } \\
\text { Section } 3.5\end{array}$ & TBD \\
\hline $\begin{array}{l}\text { Alkalinity (acid-neutralization } \\
\text { method) }\end{array}$ & Soils & ASA (1965) $91-4^{f}$ & $1 \mathrm{mg} / \mathrm{kg}$ as $\mathrm{CaCO}_{3}$ \\
\hline Permeability testing & Soils & $\begin{array}{l}\text { ASTM D-2434, Standard Test } \\
\text { Method for Permeability of } \\
\text { Granular Soils (Constant Head) }\end{array}$ & $\begin{array}{l}\text { 2.5-mm pore fluid head } \\
\text { differential over } 1 \mathrm{~m}\end{array}$ \\
\hline Iron oxy-hydroxides & Soils & Microscopy techniques & Qualitative assessment \\
\hline
\end{tabular}


Table 3-8. Micron-Size Zero-Valent Iron Primary Measurements and Analyses

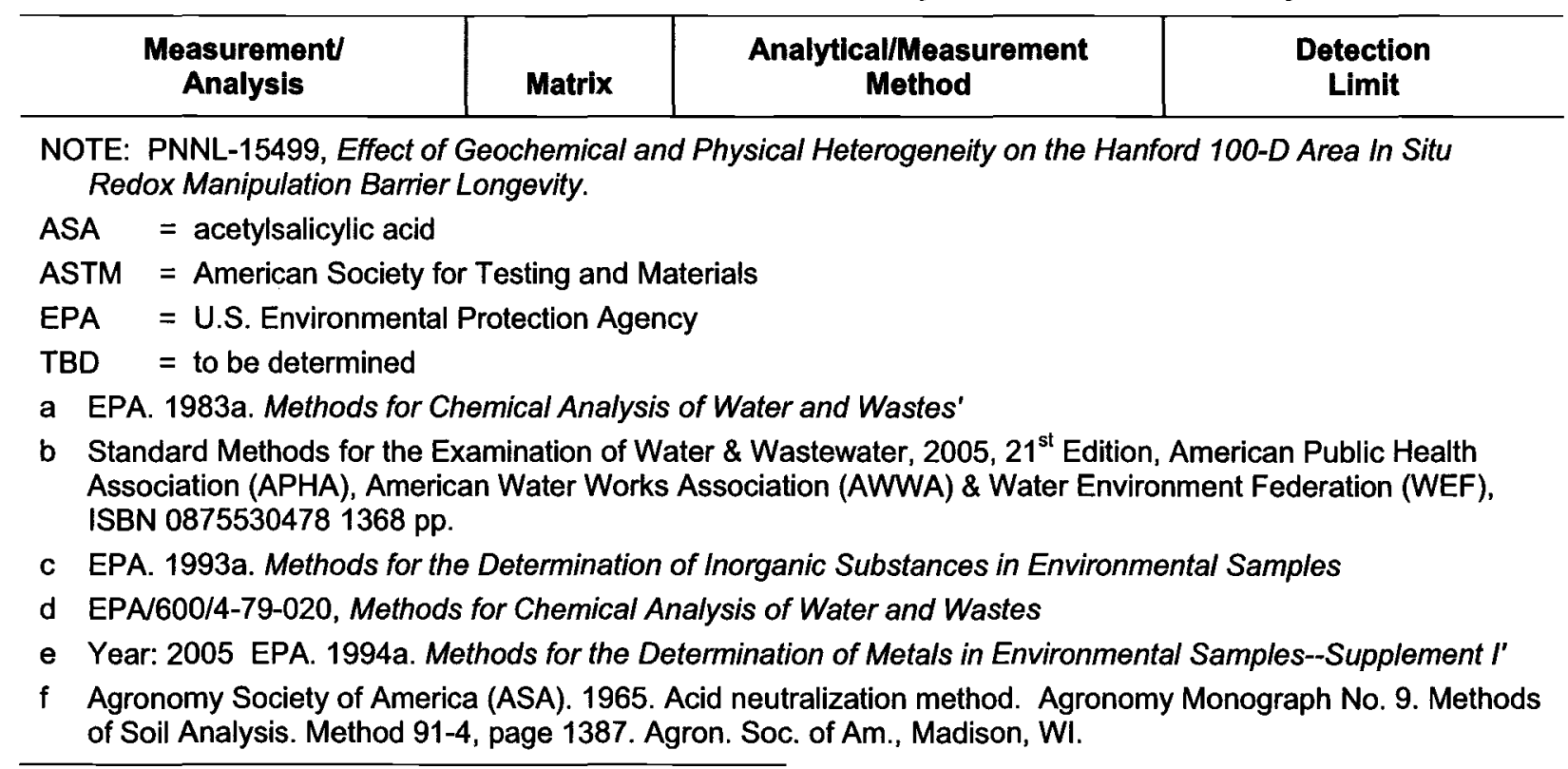

\subsubsection{Secondary Measurements and Analyses}

Table 3-9 lists the secondary measurements and analyses with associated sample matrix, analytical methods, and required detection limits. These are primarily laboratory parameters that were measured in the experimental laboratory during injection testing.

Table 3-9. Micron-Size Zero-Valent Iron Secondary Measurements and Analyses

\begin{tabular}{l|l|l|c}
\hline \multicolumn{1}{c|}{$\begin{array}{c}\text { Measurement/ } \\
\text { Analysis }\end{array}$} & \multicolumn{1}{c|}{ Matrix } & \multicolumn{1}{c}{$\begin{array}{c}\text { Analytical/Measurement } \\
\text { Method }\end{array}$} & \multicolumn{1}{c}{$\begin{array}{c}\text { Detection } \\
\text { Limit }\end{array}$} \\
\hline Specific conductance & Pore fluid & Laboratory meter & $\begin{array}{c}0.001-0.1 \mathrm{~ms} / \mathrm{cm} \\
\text { (range-dependent) }\end{array}$ \\
\hline Dissolved oxygen & Pore fluid & Laboratory meter & $0.1 \%$ air saturation $0.01 \mathrm{mg} / \mathrm{L}$ \\
\hline Viscosity & Pore fluid & Laboratory methods (viscometer) & $1 \mathrm{cP}$ \\
\hline Density & Pore fluid & Laboratory methods & $0.1 \mathrm{mg} / \mathrm{L}$ \\
\hline Temperature & Pore fluid & Laboratory meter & $0.01{ }^{\circ} \mathrm{C}$ \\
\hline Injection flow rate & Pore fluid & $\begin{array}{l}\text { Setting positive displacement } \\
\text { pump pumping rate }\end{array}$ & $1 \mathrm{~mL} / \mathrm{min}$ \\
\hline Injection pressure & Pore fluid & Manometer & $2.5-\mathrm{mm} \mathrm{pore} \mathrm{fluid} \mathrm{head}$ \\
\hline
\end{tabular}

The $\mathrm{pH}, \mathrm{ORP}$, specific conductance, and DO data were initially used to determine when the flow cells and groundwater reached a geochemical equilibrium. The viscosity and density data were used for QC and numerical modeling. The temperature data were required to support the $\mathrm{pH}$ measurement and the other parameters listed in Tables 3-8 and 3-9. 
The parameters listed in Table 3-9 and the ORP and $\mathrm{pH}$ were analyzed and recorded regularly in the $\mathrm{mZVI} /$ polymer mixture prior to injection to ensure that the mixture was uniform throughout laboratory testing.

Injection pressure and flow rate were monitored to provide input for the geochemical model and field injection design. The data were used to ensure that the tests were completed under uniform injection conditions.

\subsubsection{Geochemical Sampling and Measurement Schedule}

Samples were drawn from the effluents of the injection testing and experimental control flow cells for analysis according to the sampling schedule shown in Table 3-10. The sampling schedule was based on the number of PVs injected for both the $\mathrm{mZVI} /$ polymer mixture and groundwater following the injection period. Two sets of flow cells are shown in Table 3-10: $\mathrm{mZVI} /$ polymer injection flow cells, and a set of experimental control flow cells. The experimental control flow cells included in laboratory testing only had surrogate water flowing through them. Once a flow cell was taken off-line and the soil was sampled, and the cell would not be available for additional effluent or soil sampling.

A total of 12 flow cells (11 with flexible membranes and one without a flexible membrane, not shown in Table 3-10) were used for geochemical sampling and measurements to ensure that primary samples and duplicates (for QA purposes) were available for both effluent and soil samples during testing.

The pore fluid samples would be analyzed for the full suite of analytes listed in Table 3-8 for each sampling event. The soil samples obtained from the flow cells would be analyzed for iron, alkalinity, permeability, and oxy-hydroxides as specified in Table 3-8. Due to a change in the original scope of $\mathrm{mZVI} /$ polymer injection testing in May 2007, some of the analyses described above were not performed. Laboratory parameters (e.g., $\mathrm{pH}$, specific conductance, DO, temperature, etc.) listed in Tables 3-8 and 3-9 were monitored on a regular basis (as shown in Table 3-10).

Fluid density and viscosity measurements of the mZVI/polymer mixture were made when the mixture was initially prepared, daily during the injection testing, and following preparation of any additional $\mathrm{mZVI}$ polymer mixtures.

Equilibrium conditions were determined by monitoring the $\mathrm{pH}, \mathrm{DO}$, temperature, $\mathrm{ORP}$, and conductivity of the effluent. When the effluent values were equal to the influent values for at least five consecutive measurements, the system was considered to be in equilibrium. Values were considered equal when the relative percent differences (RPDs) between all of the influent and effluent parameters were less than 10 percent.

\subsubsection{Permeability Testing}

An additional set of three permeability testing cells (not shown in Table 3-8) were also included in laboratory testing. Testing was performed on each of the permeability testing cells by measuring head differentials of manometers installed on the flow cells prior to, during, and after $\mathrm{mZVI} /$ polymer injection.

Effluent from the permeability testing cells was analyzed for $\mathrm{pH}, \mathrm{ORP}$, specific conductance, $\mathrm{DO}$, and temperature according to the sampling schedule for the $\mathrm{mZVI} /$ polymer injection flow cells (Table 3-8). The data were used to establish a correlation between the permeability testing cells and the mZVI/ polymer injection flow cells so any results obtained from one set of flow cells could be related to the other set of flow cells. 
Table 3-10. Micron-Sized Zero-Valent Iron Sampling, Analysis, and Measurement Schedule

\begin{tabular}{|c|c|c|c|c|c|c|c|c|c|c|c|}
\hline \multirow{2}{*}{$\begin{array}{l}\text { Sampling } \\
\text { Schedule }\end{array}$} & \multicolumn{8}{|c|}{ mZVI Injection Flow Cells } & \multicolumn{3}{|c|}{ Experimental Control Flow Cells } \\
\hline & 1 & 2 & 3 & 4 & 5 & 6 & 7 & 8 & 9 & 10 & 11 \\
\hline Pre-injection & $\begin{array}{c}\text { Lab } \\
\text { parameters } \\
\text { Pore fluid } \\
\text { Soil }^{*}\end{array}$ & $\begin{array}{c}\text { Lab } \\
\text { parameters } \\
\text { Pore fluid }\end{array}$ & $\begin{array}{c}\text { Lab } \\
\text { parameters } \\
\text { Pore fluid }\end{array}$ & $\begin{array}{c}\text { Lab } \\
\text { parameters }\end{array}$ & $\begin{array}{c}\text { Lab } \\
\text { parameters }\end{array}$ & $\begin{array}{c}\text { Lab } \\
\text { parameters }\end{array}$ & $\begin{array}{c}\text { Lab } \\
\text { parameters }\end{array}$ & $\begin{array}{c}\text { Lab } \\
\text { parameters }\end{array}$ & $\begin{array}{l}\text { Lab } \\
\text { parameters } \\
\text { Pore fluid }\end{array}$ & $\begin{array}{c}\text { Lab } \\
\text { parameters }\end{array}$ & $\begin{array}{c}\text { Lab } \\
\text { parameters }\end{array}$ \\
\hline $1 / 2$ PV mZVI & - & $\begin{array}{c}\text { Lab } \\
\text { parameters }\end{array}$ & $\begin{array}{c}\text { Lab } \\
\text { parameters }\end{array}$ & $\begin{array}{c}\text { Lab } \\
\text { parameters }\end{array}$ & $\begin{array}{c}\text { Lab } \\
\text { parameters }\end{array}$ & $\begin{array}{c}\text { Lab } \\
\text { parameters }\end{array}$ & $\begin{array}{c}\text { Lab } \\
\text { parameters }\end{array}$ & $\begin{array}{c}\text { Lab } \\
\text { parameters }\end{array}$ & $\begin{array}{c}\text { Lab } \\
\text { parameters }\end{array}$ & $\begin{array}{c}\text { Lab } \\
\text { parameters }\end{array}$ & $\begin{array}{c}\text { Lab } \\
\text { parameters }\end{array}$ \\
\hline $3 \mathrm{PV} m \mathrm{mZl}$ & - & $\begin{array}{c}\text { Lab } \\
\text { parameters } \\
\text { Pore fluid } \\
\text { Soil }\end{array}$ & $\begin{array}{c}\text { Lab } \\
\text { parameters } \\
\text { Pore fluid }\end{array}$ & $\begin{array}{c}\text { Lab } \\
\text { parameters } \\
\text { Pore fluid }\end{array}$ & $\begin{array}{c}\text { Lab } \\
\text { parameters }\end{array}$ & $\begin{array}{c}\text { Lab } \\
\text { parameters }\end{array}$ & $\begin{array}{c}\text { Lab } \\
\text { parameters }\end{array}$ & $\begin{array}{c}\text { Lab } \\
\text { parameters }\end{array}$ & $\begin{array}{c}\text { Lab } \\
\text { parameters } \\
\text { Pore fluid }\end{array}$ & $\begin{array}{c}\text { Lab } \\
\text { parameters }\end{array}$ & $\begin{array}{c}\text { Lab } \\
\text { parameters }\end{array}$ \\
\hline $6 \mathrm{PV} \mathrm{mZVI}$ & - & -- & $\begin{array}{c}\text { Lab } \\
\text { parameters }\end{array}$ & $\begin{array}{c}\text { Lab } \\
\text { parameters }\end{array}$ & $\begin{array}{c}\text { Lab } \\
\text { parameters }\end{array}$ & $\begin{array}{c}\text { Lab } \\
\text { parameters }\end{array}$ & $\begin{array}{c}\text { Lab } \\
\text { parameters }\end{array}$ & $\begin{array}{c}\text { Lab } \\
\text { parameters }\end{array}$ & $\begin{array}{c}\text { Lab } \\
\text { parameters }\end{array}$ & $\begin{array}{c}\text { Lab } \\
\text { parameters }\end{array}$ & $\begin{array}{c}\text { Lab } \\
\text { parameters }\end{array}$ \\
\hline $9 \mathrm{PV} \mathrm{mZVI}$ & - & -- & $\begin{array}{c}\text { Lab } \\
\text { parameters } \\
\text { Pore fluid } \\
\text { Soil }^{\star}\end{array}$ & $\begin{array}{c}\text { Lab } \\
\text { parameters } \\
\text { Pore fluid }\end{array}$ & $\begin{array}{c}\text { Lab } \\
\text { parameters } \\
\text { Pore fluid }\end{array}$ & $\begin{array}{c}\text { Lab } \\
\text { parameters }\end{array}$ & $\begin{array}{c}\text { Lab } \\
\text { parameters }\end{array}$ & $\begin{array}{c}\text { Lab } \\
\text { parameters }\end{array}$ & $\begin{array}{c}\text { Lab } \\
\text { parameters } \\
\text { Pore fluid } \\
\text { Soil }^{*}\end{array}$ & $\begin{array}{c}\text { Lab } \\
\text { parameters } \\
\text { Pore fluid }\end{array}$ & $\begin{array}{c}\text { Lab } \\
\text { parameters }\end{array}$ \\
\hline 12 PV mZVI & - & - & - & $\begin{array}{c}\text { Lab } \\
\text { parameters }\end{array}$ & $\begin{array}{c}\text { Lab } \\
\text { parameters }\end{array}$ & $\begin{array}{c}\text { Lab } \\
\text { parameters }\end{array}$ & $\begin{array}{c}\text { Lab } \\
\text { parameters }\end{array}$ & $\begin{array}{c}\text { Lab } \\
\text { parameters }\end{array}$ & -- & $\begin{array}{c}\text { Lab } \\
\text { parameters }\end{array}$ & $\begin{array}{c}\text { Lab } \\
\text { parameters }\end{array}$ \\
\hline $15 \mathrm{PV} \mathrm{mZVI}$ & - & - & - & $\begin{array}{c}\text { Lab } \\
\text { parameters } \\
\text { Pore fluid } \\
\text { Soil }\end{array}$ & $\begin{array}{c}\text { Lab } \\
\text { parameters } \\
\text { Pore fluid }\end{array}$ & $\begin{array}{c}\text { Lab } \\
\text { parameters } \\
\text { Pore fluid }\end{array}$ & $\begin{array}{c}\text { Lab } \\
\text { parameters }\end{array}$ & $\begin{array}{c}\text { Lab } \\
\text { parameters }\end{array}$ & -- & $\begin{array}{c}\text { Lab } \\
\text { parameters } \\
\text { Pore fluid }\end{array}$ & $\begin{array}{c}\text { Lab } \\
\text { parameters } \\
\text { Pore fluid }\end{array}$ \\
\hline $20 \mathrm{PV}$ mZVI & - & -- & - & -- & $\begin{array}{c}\text { Lab } \\
\text { parameters }\end{array}$ & $\begin{array}{c}\text { Lab } \\
\text { parameters }\end{array}$ & $\begin{array}{c}\text { Lab } \\
\text { parameters }\end{array}$ & $\begin{array}{c}\text { Lab } \\
\text { parameters }\end{array}$ & -- & $\begin{array}{c}\text { Lab } \\
\text { parameters }\end{array}$ & $\begin{array}{c}\text { Lab } \\
\text { parameters }\end{array}$ \\
\hline
\end{tabular}


Table 3-10. Micron-Sized Zero-Valent Iron Sampling, Analysis, and Measurement Schedule

\begin{tabular}{|c|c|c|c|c|c|c|c|c|c|c|c|}
\hline \multirow{2}{*}{$\begin{array}{l}\text { Sampling } \\
\text { Schedule }\end{array}$} & \multicolumn{8}{|c|}{ mZVI Injection Flow Cells } & \multicolumn{3}{|c|}{ Experimental Control Flow Cells } \\
\hline & 1 & 2 & 3 & 4 & 5 & 6 & 7 & 8 & 9 & 10 & 11 \\
\hline $30 \mathrm{PV} \mathrm{mZVl}$ & - & - & - & -- & $\begin{array}{c}\text { Lab } \\
\text { parameters } \\
\text { Pore fluid } \\
\text { Soil }^{*}\end{array}$ & $\begin{array}{c}\text { Lab } \\
\text { parameters } \\
\text { Pore fluid }\end{array}$ & $\begin{array}{c}\text { Lab } \\
\text { parameters } \\
\text { Pore fluid }\end{array}$ & $\begin{array}{c}\text { Lab } \\
\text { parameters }\end{array}$ & - & $\begin{array}{c}\text { Lab } \\
\text { parameters } \\
\text { Pore fluid } \\
\text { Soil }\end{array}$ & $\begin{array}{c}\text { Lab } \\
\text { parameters } \\
\text { Pore fluid }\end{array}$ \\
\hline 1 PV GW & - & - & - & - & - & $\begin{array}{c}\text { Lab } \\
\text { parameters } \\
\text { Pore fluid } \\
\text { Soil }\end{array}$ & $\begin{array}{c}\text { Lab } \\
\text { parameters } \\
\text { Pore fluid }\end{array}$ & $\begin{array}{c}\text { Lab } \\
\text { parameters } \\
\text { Pore fluid }\end{array}$ & - & - & $\begin{array}{c}\text { Lab } \\
\text { parameters }\end{array}$ \\
\hline 5 PV GW & - & - & - & -- & - & -- & $\begin{array}{c}\text { Lab } \\
\text { parameters }\end{array}$ & $\begin{array}{c}\text { Lab } \\
\text { parameters }\end{array}$ & - & - & $\begin{array}{c}\text { Lab } \\
\text { parameters }\end{array}$ \\
\hline $10 \mathrm{PV} \mathrm{GW}$ & - & - & - & - & - & -- & $\begin{array}{c}\text { Lab } \\
\text { parameters } \\
\text { Pore fluid } \\
\text { Soil* }^{*}\end{array}$ & $\begin{array}{c}\text { Lab } \\
\text { parameters } \\
\text { Pore fluid }\end{array}$ & - & - & $\begin{array}{c}\text { Lab } \\
\text { parameters } \\
\text { Pore fluid }\end{array}$ \\
\hline 15 PV GW & - & - & - & - & - & - & - & $\begin{array}{c}\text { Lab } \\
\text { parameters }\end{array}$ & -- & - & $\begin{array}{c}\text { Lab } \\
\text { parameters }\end{array}$ \\
\hline $20 \mathrm{PV}$ GW & - & - & - & -- & - & - & - & $\begin{array}{l}\text { Lab } \\
\text { parameters } \\
\text { Pore fluid } \\
\text { Soil }\end{array}$ & - & - & $\begin{array}{c}\text { Lab } \\
\text { parameters } \\
\text { Pore fluid } \\
\text { Soil }^{*}\end{array}$ \\
\hline \multicolumn{4}{|c|}{ Total laboratory parameter measurements } & \multicolumn{5}{|c|}{61} & \multicolumn{3}{|c|}{25} \\
\hline \multicolumn{4}{|c|}{ Total pore fluid sample analyses } & \multicolumn{5}{|c|}{21} & \multicolumn{3}{|c|}{10} \\
\hline \multicolumn{4}{|c|}{ Total soil sample analyses } & \multicolumn{5}{|c|}{12} & \multicolumn{3}{|c|}{5} \\
\hline
\end{tabular}


Table 3-10. Micron-Sized Zero-Valent Iron Sampling, Analysis, and Measurement Schedule

\begin{tabular}{|c|c|c|c|c|c|c|c|c|c|c|c|}
\hline \multirow{2}{*}{$\begin{array}{l}\text { Sampling } \\
\text { Schedule }\end{array}$} & \multicolumn{8}{|c|}{ mZVI Injection Flow Cells } & \multicolumn{3}{|c|}{ Experimental Control Flow Cells } \\
\hline & 1 & 2 & 3 & 4 & 5 & 6 & 7 & 8 & 9 & 10 & 11 \\
\hline
\end{tabular}

NOTE: Laboratory parameters include $\mathrm{pH}$, oxidation-reduction potential, conductivity, dissolved oxygen, and temperature.

* Duplicate samples will be collected for these soil samples for quality assurance purposes.

- $\quad$ = flow cell used for soil sample, no longer available for effluent sampling

$\mathrm{PV}=$ pore volume

$\mathrm{GW}=$ groundwater

$\mathrm{mZVI}=$ micron-sized zero-valent iron 


\subsubsection{Batch Screening Test}

A single set of samples were collected from each batch test. The sample results were used to evaluate the materials on their ability to reduce hexavalent chromium and create a reducing environment.

\subsubsection{Primary Analysis}

Samples were collected to evaluate the materials on their ability to reduce hexavalent chromium and to monitor their effects on nitrogen. Dissolved chromium and nitrate samples were collected from each test. Along with the analytical data, laboratory parameters were also collected, which included solution conductivity, $\mathrm{pH}, \mathrm{ORP}$, and temperature.

\subsubsection{Sampling and Measurement Schedule}

Prior to beginning the initial series of tests, the baseline parameters were collected for the surrogate groundwater. These measurements included solution conductivity, $\mathrm{pH}, \mathrm{ORP}$, and temperature. Samples for dissolved chromium and nitrate were also collected from the surrogate groundwater. A single set of samples and parameters were collected for each material after a period of 4 hours on the rotary shaker table.

\subsubsection{Injection Screening Test}

Sampling of the effluent pore fluid and constant measurements were performed by properly trained personnel, as outlined in the following sections. Samples of the effluent for laboratory testing were obtained from the effluent sampling ports included in the test apparatus.

\subsubsection{Primary Measurements and Analyses}

Table 3-11 lists the analyses, analytical methods, and required detection limits for the primary measurements and analyses performed during injectability testing.

Table 3-11. Injection Screening Test Primary Measurements and Analyses

\begin{tabular}{|c|c|c|c|}
\hline $\begin{array}{l}\text { Measurement } \\
\text { Analysis }\end{array}$ & Matrix & $\begin{array}{l}\text { Analytical/Measurement } \\
\text { Method }\end{array}$ & $\begin{array}{l}\text { Detection } \\
\text { Limit }\end{array}$ \\
\hline Total iron & Pore fluid & $\begin{array}{l}\text { ICP-AES, Methods SW-3050B and } \\
\text { SW-6010* }\end{array}$ & $0.015 \mathrm{mg} / \mathrm{L}$ \\
\hline Head loss & Pore fluid & $\begin{array}{l}\text { ASTM D-2434, Standard Test } \\
\text { Method for Permeability of Granular } \\
\text { Soils (Constant Head) }\end{array}$ & $\begin{array}{l}\text { 2.5-mm pore fluid head } \\
\text { differential over } 1 \mathrm{~m}\end{array}$ \\
\hline Total iron & Soil & $\begin{array}{l}\text { ICP-AES, Methods SW-3050B and } \\
\text { SW-6010a }\end{array}$ & $3.0 \mathrm{mg} / \mathrm{kg}$ \\
\hline Iron emplacement & Pore fluid & Gravimetric samples & N/A \\
\hline Iron emplacement & Soils & Visual methods & Qualitative assessment \\
\hline \multicolumn{4}{|c|}{ * SW-846, Test Methods for Evaluating Solid Waste Physical/Chemical Methods } \\
\hline \multicolumn{4}{|c|}{$=$ atomic emission spectrophotometry } \\
\hline \multicolumn{4}{|c|}{$=$ American Society for Testing and Materials } \\
\hline \multicolumn{4}{|c|}{$=$ inductively coupled plasma } \\
\hline \multicolumn{3}{|c|}{$=$ not applicable } & \\
\hline
\end{tabular}


Primary measurements were performed during injection testing based on the sampling schedule shown in Table 3-12. The sampling schedule was based on the number of PVs of ZVI/carrier fluid or Hanford surrogate groundwater injected.

\subsubsection{Secondary Measurements and Analyses}

Secondary measurements and analyses were collected as shown in Table 3-13. Injection rate measurements were made at the same time that effluent samples were collected. Additional measurements were performed as needed, but not less than twice per day. The head differential data obtained during the ZVI/carrier fluid injection provided important insight into the injectability of the ZVI materials and information for the numerical modeling and design of the field injection system.

\subsubsection{Geochemical Screening Test}

Sampling of the effluent pore fluid and constant measurements were performed as outlined in the following sections. Samples of the effluent for laboratory testing were obtained from the effluent sampling ports included in the test apparatus.

\subsubsection{Primary Measurements and Analyses}

The main constituents of concern in the geochemical screening tests were dissolved chromium and nitrate. A critical characteristic of the ZVI material is its ability to reduce a continuous supply of chromate over an extended period of time. Total organic carbon was analyzed to evaluate the mobility and longevity of the dispersant in the column. In the field, the dispersant is used to increase the mobility of the ZVI material during the injection and then wash out, leaving the emplaced ZVI material adsorbed to the aquifer matrix. Table 3-14 presents the analyses, sample matrix, analytical methods, and detection limits for the primary measurements and analyses.

\subsubsection{Secondary Measurements and Analyses}

A reducing environment is required for trivalent chromium precipitates to form. The parameters of DO and ORP were measured to quantify the extent of the reducing environment produced by a particular ZVI material. Total organic carbon was of interest to determine when the dispersant was flushed out of the system. Other parameters (e.g., temperature and $\mathrm{pH}$ ) were also measured at each sampling interval, while pressure head differential and test cell flow rate were measured on an as-needed basis with no less than two measurements per day. A summary of each analysis is provided in Table 3-15.

\subsubsection{Sampling and Measurement Schedule}

Samples were drawn from the effluent for analysis based on the sampling schedule shown in Table 3-16. The sampling schedule was based on the number of PVs injected. The pore fluid samples were analyzed for the full suite of analytes listed in Table 3-14 for each sampling event. The sampling events occurred after 1, 5, 10, and 20 PVs of surrogate groundwater had passed through the columns. Laboratory parameters (i.e., $\mathrm{pH}, \mathrm{ORP}, \mathrm{DO}$, and temperature) were sampled in conjunction with the fluid samples, as well as an additional of samples set taken after 15 PVs of surrogate groundwater had passed through the columns. For QC purposes, a control cell was tested along with a duplicate column for each ZVI source. The control cell did not contain ZVI but was packed with Ringold Unit E soils and flushed with the surrogate groundwater solution. 
Table 3-12. Injection Screening Test Sampling and Analysis Schedule

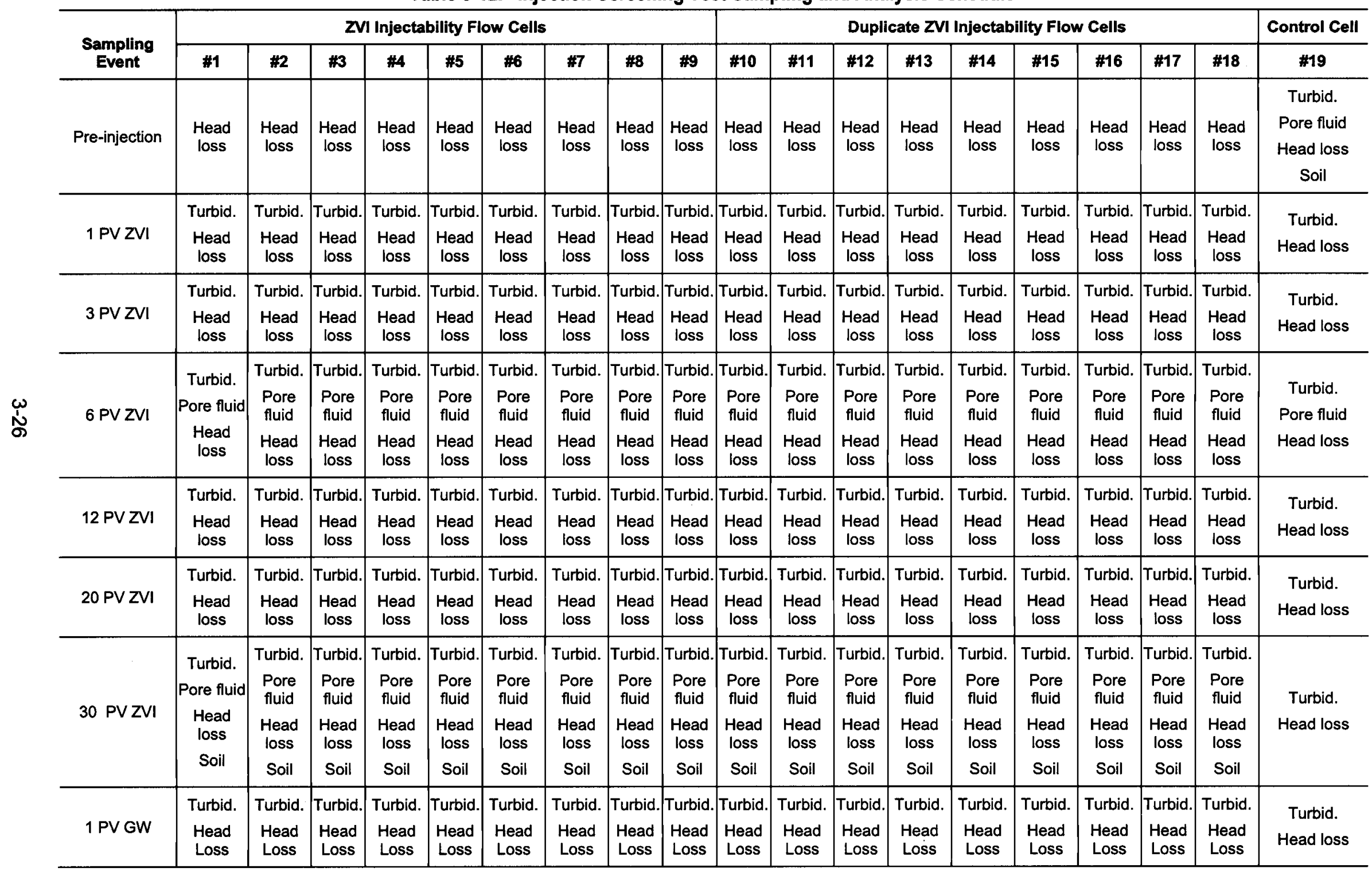


Table 3-12. Injection Screening Test Sampling and Analysis Schedule

\begin{tabular}{|c|c|c|c|c|c|c|c|c|c|c|c|c|c|c|c|c|c|c|c|}
\hline \multirow{2}{*}{$\begin{array}{c}\text { Sampling } \\
\text { Event }\end{array}$} & \multicolumn{9}{|c|}{ ZVI Injectability Flow Cells } & \multicolumn{9}{|c|}{ Duplicate ZVI Injectability Flow Cells } & \multirow{2}{*}{$\frac{\text { Control Cell }}{\# 19}$} \\
\hline & \#1 & \#2 & \#3 & \#4 & $\# 5$ & $\# 6$ & $\# 7$ & \#8 & $\# 9$ & $\# 10$ & $\# 11$ & $\# 12$ & $\# 13$ & \#14 & \#15 & $\# 16$ & $\# 17$ & \#18 & \\
\hline 5 PV GW & $\begin{array}{c}\text { Turbid. } \\
\text { Head } \\
\text { loss }\end{array}$ & $\begin{array}{c}\text { Turbid. } \\
\text { Head } \\
\text { loss }\end{array}$ & $\begin{array}{c}\text { Turbid. } \\
\text { Head } \\
\text { loss }\end{array}$ & $\begin{array}{c}\text { Turbid. } \\
\text { Head } \\
\text { loss }\end{array}$ & $\begin{array}{c}\text { Turbid. } \\
\text { Head } \\
\text { loss }\end{array}$ & $\begin{array}{c}\text { Turbid. } \\
\text { Head } \\
\text { loss }\end{array}$ & $\begin{array}{l}\text { Turbid. } \\
\text { Head } \\
\text { loss }\end{array}$ & $\begin{array}{c}\text { Turbid. } \\
\text { Head } \\
\text { loss }\end{array}$ & $\begin{array}{l}\text { Turbid. } \\
\text { Head } \\
\text { loss }\end{array}$ & $\begin{array}{l}\text { Turbid. } \\
\text { Head } \\
\text { loss }\end{array}$ & $\begin{array}{c}\text { Turbid. } \\
\text { Head } \\
\text { loss }\end{array}$ & $\begin{array}{c}\text { Turbid. } \\
\text { Head } \\
\text { loss }\end{array}$ & $\begin{array}{c}\text { Turbid. } \\
\text { Head } \\
\text { loss }\end{array}$ & $\begin{array}{c}\text { Turbid. } \\
\text { Head } \\
\text { loss }\end{array}$ & $\begin{array}{c}\text { Turbid. } \\
\text { Head } \\
\text { loss }\end{array}$ & $\begin{array}{c}\text { Turbid. } \\
\text { Head } \\
\text { loss }\end{array}$ & $\begin{array}{c}\text { Turbid. } \\
\text { Head } \\
\text { loss }\end{array}$ & $\begin{array}{c}\text { Turbid. } \\
\text { Head } \\
\text { loss }\end{array}$ & $\begin{array}{l}\text { Turbid. } \\
\text { Head loss }\end{array}$ \\
\hline 10 PV GW & $\begin{array}{c}\text { Turbid. } \\
\text { Head } \\
\text { loss }\end{array}$ & $\begin{array}{c}\text { Turbid. } \\
\text { Head } \\
\text { loss }\end{array}$ & $\begin{array}{c}\text { Turbid. } \\
\text { Head } \\
\text { loss }\end{array}$ & $\begin{array}{c}\text { Turbid. } \\
\text { Head } \\
\text { loss }\end{array}$ & $\begin{array}{c}\text { Turbid. } \\
\text { Head } \\
\text { loss }\end{array}$ & $\begin{array}{c}\text { Turbid. } \\
\text { Head } \\
\text { loss }\end{array}$ & $\begin{array}{l}\text { Turbid. } \\
\text { Head } \\
\text { loss }\end{array}$ & $\begin{array}{l}\text { Turbid. } \\
\text { Head } \\
\text { loss }\end{array}$ & $\begin{array}{l}\text { Turbid. } \\
\text { Head } \\
\text { loss }\end{array}$ & $\begin{array}{l}\text { Turbid. } \\
\text { Head } \\
\text { loss }\end{array}$ & $\begin{array}{c}\text { Turbid. } \\
\text { Head } \\
\text { loss }\end{array}$ & $\begin{array}{c}\text { Turbid. } \\
\text { Head } \\
\text { loss }\end{array}$ & $\begin{array}{c}\text { Turbid. } \\
\text { Head } \\
\text { loss }\end{array}$ & $\begin{array}{l}\text { Turbid. } \\
\text { Head } \\
\text { loss }\end{array}$ & $\begin{array}{c}\text { Turbid. } \\
\text { Head } \\
\text { loss }\end{array}$ & $\begin{array}{l}\text { Turbid. } \\
\text { Head } \\
\text { loss }\end{array}$ & $\begin{array}{c}\text { Turbid. } \\
\text { Head } \\
\text { loss }\end{array}$ & $\begin{array}{c}\text { Turbid. } \\
\text { Head } \\
\text { loss }\end{array}$ & $\begin{array}{l}\text { Turbid. } \\
\text { Head loss }\end{array}$ \\
\hline $20 \mathrm{PV} \mathrm{GW}$ & $\begin{array}{c}\text { Turbid. } \\
\text { Pore fluid } \\
\text { Head } \\
\text { loss } \\
\text { Soil }\end{array}$ & $\begin{array}{c}\text { Turbid. } \\
\text { Pore } \\
\text { fluid } \\
\text { Head } \\
\text { loss } \\
\text { Soil }\end{array}$ & \begin{tabular}{|} 
Turbid. \\
Pore \\
fluid \\
Head \\
loss \\
Soil
\end{tabular} & $\begin{array}{c}\text { Turbid. } \\
\text { Pore } \\
\text { fluid } \\
\text { Head } \\
\text { loss } \\
\text { Soil }\end{array}$ & $\begin{array}{c}\text { Turbid. } \\
\text { Pore } \\
\text { fluid } \\
\text { Head } \\
\text { loss } \\
\text { Soil }\end{array}$ & $\begin{array}{c}\text { Turbid. } \\
\text { Pore } \\
\text { fluid } \\
\text { Head } \\
\text { loss } \\
\text { Soil }\end{array}$ & $\begin{array}{c}\text { Turbid. } \\
\text { Pore } \\
\text { fluid } \\
\text { Head } \\
\text { loss } \\
\text { Soil }\end{array}$ & \begin{tabular}{|c} 
Turbid. \\
Pore \\
fluid \\
Head \\
loss \\
Soil
\end{tabular} & $\begin{array}{c}\text { Turbid. } \\
\text { Pore } \\
\text { fluid } \\
\text { Head } \\
\text { loss } \\
\text { Soil }\end{array}$ & $\begin{array}{c}\text { Turbid. } \\
\text { Pore } \\
\text { fluid } \\
\text { Head } \\
\text { loss } \\
\text { Soil }\end{array}$ & $\begin{array}{c}\text { Turbid. } \\
\text { Pore } \\
\text { fluid } \\
\text { Head } \\
\text { loss } \\
\text { Soil }\end{array}$ & $\mid \begin{array}{c}\text { Turbid. } \\
\text { Pore } \\
\text { fluid } \\
\text { Head } \\
\text { loss } \\
\text { Soil }\end{array}$ & $\begin{array}{c}\text { Turbid. } \\
\text { Pore } \\
\text { fluid } \\
\text { Head } \\
\text { loss } \\
\text { Soil }\end{array}$ & $\begin{array}{l}\text { Turbid. } \\
\text { Pore } \\
\text { fluid } \\
\text { Head } \\
\text { loss } \\
\text { Soil }\end{array}$ & $\begin{array}{c}\text { Turbid. } \\
\text { Pore } \\
\text { fluid } \\
\text { Head } \\
\text { loss } \\
\text { Soil }\end{array}$ & $\begin{array}{c}\text { Turbid. } \\
\text { Pore } \\
\text { fluid } \\
\text { Head } \\
\text { loss } \\
\text { Soil }\end{array}$ & \begin{tabular}{|c|} 
Turbid. \\
Pore \\
fluid \\
Head \\
loss \\
Soil
\end{tabular} & $\begin{array}{c}\text { Turbid. } \\
\text { Pore } \\
\text { fluid } \\
\text { Head } \\
\text { loss } \\
\text { Soil }\end{array}$ & $\begin{array}{l}\text { Turbid. } \\
\text { Head loss }\end{array}$ \\
\hline
\end{tabular}

\section{$\mathrm{PV}=$ pore volume}

GW = groundwater (Hanford surrogate)

Turbid. $=$ turbidity

ZVI = zero-valent iron 
DOE/RL-2009-35, REV. 0

Table 3-13. Injection Screening Test Secondary Measurements and Analyses

\begin{tabular}{lccc}
\hline \multicolumn{1}{c}{$\begin{array}{c}\text { Measurement/ } \\
\text { Analysis }\end{array}$} & Matrix & $\begin{array}{c}\text { Analytical/Measurement } \\
\text { Method }\end{array}$ & $\begin{array}{c}\text { Detection } \\
\text { Limit }\end{array}$ \\
\hline Flow rate & Effluent & Effluent collection & $1 \mathrm{~mL} / \mathrm{min}$ \\
Differential pressure & Porewater & Manometer & $\begin{array}{c}0.5-\mathrm{cm} \text { pore fluid head } \\
\text { differential over } 60 \mathrm{~cm}\end{array}$ \\
\hline
\end{tabular}

Table 3-14. Geochemical Screening Tests Primary Analyses

\begin{tabular}{llcc}
\hline \multicolumn{1}{c}{$\begin{array}{c}\text { Measurement/ } \\
\text { Analysis }\end{array}$} & Matrix & \multicolumn{1}{c}{$\begin{array}{c}\text { Analytical } \\
\text { Method }\end{array}$} & $\begin{array}{c}\text { Detection } \\
\text { Limit }\end{array}$ \\
\hline Chromium $^{\mathrm{a}}$ & Pore fluid & ICP-AES SW-6010 & $20 \mu \mathrm{g} / \mathrm{L}$ \\
Nitrogen as ammonia & Pore fluid & EPA Method 350.2 & $0.05 \mathrm{mg} / \mathrm{L}$ \\
Nitrogen as nitrate and nitrite & Pore fluid & EPA Method $353.2^{\mathrm{c}}$ & $0.05 \mathrm{mg} / \mathrm{L}$ \\
Total organic carbon & Pore fluid & EPA Method $415.1^{\mathrm{d}}$ & $0.10 \mathrm{mg} / \mathrm{L}$ \\
\hline
\end{tabular}

a. Dissolved chromium will be measured; it is assumed that this measurement will represent hexavalent chromium.

b. SW-846, Test Methods for Evaluating Solid Waste Physical/Chemical Methods

c. EPA. 1993a. Methods for the Determination of Inorganic Substances in Environmental Samples

d. EPA/600/4-79-020, Methods for Chemical Analysis of Water and Wastes'
AES = atomic emission spectrophotometry
$E P A=U . S$. Environmental Protection Agency
$\mathrm{ICP} \quad=$ inductively coupled plasma

Table 3-15. Geochemical Screening Tests Secondary Analyses

\begin{tabular}{lcccc}
\hline \multicolumn{1}{c}{$\begin{array}{c}\text { Measurement } \\
\text { Analysis }\end{array}$} & Matrix & \multicolumn{1}{c}{$\begin{array}{c}\text { Analytical } \\
\text { Method }\end{array}$} & $\begin{array}{c}\text { Detection } \\
\text { Limit }\end{array}$ & Precision \\
\hline $\begin{array}{l}\text { Dissolved oxygen } \\
\begin{array}{l}\text { Oxidation-reduction } \\
\text { potential }\end{array}\end{array}$ & Pore fluid & YSI 556 MPS probe & $0.1 \mathrm{mg} / \mathrm{L}$ & $20 \% \mathrm{RPD}$ \\
$\mathrm{pH}$ & Pore fluid & YSI $556 \mathrm{MPS}$ probe & $10 \mathrm{mV}$ & $20 \% \mathrm{RPD}$ \\
Temperature & Pore fluid & YSI $556 \mathrm{MPS}$ probe & $0.1 \mathrm{SU}$ & $0.2 \mathrm{SU}$ \\
Pressure head differential & Pore fluid & YSI 556 MPS probe & $0.05^{\circ} \mathrm{C}$ & $0.5^{\circ} \mathrm{C}$ \\
& Pore fluid & Manometer & $\begin{array}{c}2.5-\mathrm{mm} \text { pore fluid over } \\
1-\mathrm{m} \text { manometer }\end{array}$ & $5 \mathrm{~mm}$ \\
Test cell flow rate & Pore fluid & Volume elapsed time & $0.1 \mathrm{~mL} / \mathrm{min}$ & $0.2 \mathrm{~mL} / \mathrm{min}$ \\
\hline
\end{tabular}

NOTE: $Y S I^{\circledast}$ is a registered trademark of YSI Incorporated, Yellow Springs, Ohio.

$\mathrm{RPD}=$ relative percent difference 
Table 3-16. Geochemical Screening Test Sampling Schedule

\begin{tabular}{|c|c|c|c|c|c|c|c|c|c|c|c|c|c|c|c|c|c|c|c|}
\hline \multicolumn{20}{|c|}{ High Iron Concentration } \\
\hline \multirow{2}{*}{$\begin{array}{l}\text { Sampling } \\
\text { Schedule }\end{array}$} & \multicolumn{9}{|c|}{ ZVI Geochemical Test Cells } & \multicolumn{9}{|c|}{ ZVI Geochemical Test Cells (QC Cells) } & \multirow{2}{*}{\begin{tabular}{|c|}
$\begin{array}{c}\text { Control } \\
\text { Cell }\end{array}$ \\
19
\end{tabular}} \\
\hline & 1 & 2 & 3 & 4 & 5 & 6 & 7 & 8 & 9 & 10 & 11 & 12 & 13 & 14 & 15 & 16 & 17 & 18 & \\
\hline 1 PV GW & $\begin{array}{c}\text { Lab } \\
\text { param.. } \\
\text { Fluid } \\
\text { sample }\end{array}$ & $\begin{array}{c}\text { Lab } \\
\text { param.. } \\
\text { Fluid } \\
\text { sample }\end{array}$ & $\begin{array}{c}\text { Lab } \\
\text { param.. } \\
\text { Fluid } \\
\text { sample }\end{array}$ & $\begin{array}{c}\text { Lab } \\
\text { param. } \\
\cdot \\
\text { Fluid } \\
\text { sample }\end{array}$ & $\begin{array}{c}\text { Lab } \\
\text { param. } \\
\cdot \\
\text { Fluid } \\
\text { sample }\end{array}$ & $\begin{array}{c}\text { Lab } \\
\text { param.. } \\
\text { Fluid } \\
\text { sample }\end{array}$ & $\begin{array}{c}\text { Lab } \\
\text { param.. } \\
\text { Fluid } \\
\text { sample }\end{array}$ & $\begin{array}{c}\text { Lab } \\
\text { param.. } \\
\text { Fluid } \\
\text { sample }\end{array}$ & $\begin{array}{c}\text { Lab } \\
\text { param.. } \\
\text { Fluid } \\
\text { sample }\end{array}$ & $\begin{array}{c}\text { Lab } \\
\text { param.. } \\
\text { Fluid } \\
\text { sample }\end{array}$ & $\begin{array}{c}\text { Lab } \\
\text { param.. } \\
\text { Fluid } \\
\text { sample }\end{array}$ & $\begin{array}{c}\text { Lab } \\
\text { param.. } \\
\text { Fluid } \\
\text { sample }\end{array}$ & $\begin{array}{c}\text { Lab } \\
\text { param.. } \\
\text { Fluid } \\
\text { sample }\end{array}$ & $\begin{array}{c}\text { Lab } \\
\text { param.. } \\
\text { Fluid } \\
\text { sample }\end{array}$ & $\begin{array}{c}\text { Lab } \\
\text { param.. } \\
\text { Fluid } \\
\text { sample }\end{array}$ & $\begin{array}{c}\text { Lab } \\
\text { param.. } \\
\text { Fluid } \\
\text { sample }\end{array}$ & $\begin{array}{c}\text { Lab } \\
\text { param.. } \\
\text { Fluid } \\
\text { sample }\end{array}$ & $\begin{array}{c}\text { Lab } \\
\text { param.. } \\
\text { Fluid } \\
\text { sample }\end{array}$ & $\begin{array}{c}\text { Lab } \\
\text { param.. } \\
\text { Fluid } \\
\text { sample }\end{array}$ \\
\hline 5 PV GW & $\begin{array}{c}\text { Lab } \\
\text { param.. } \\
\text { Fluid } \\
\text { sample }\end{array}$ & $\begin{array}{c}\text { Lab } \\
\text { param.. } \\
\text { Fluid } \\
\text { sample }\end{array}$ & $\begin{array}{c}\text { Lab } \\
\text { param.. } \\
\text { Fluid } \\
\text { sample }\end{array}$ & $\begin{array}{c}\text { Lab } \\
\text { param. } \\
\cdot \\
\text { Fluid } \\
\text { sample }\end{array}$ & $\begin{array}{c}\text { Lab } \\
\text { param. } \\
\cdot \\
\text { Fluid } \\
\text { sample }\end{array}$ & $\begin{array}{c}\text { Lab } \\
\text { param.. } \\
\text { Fluid } \\
\text { sample }\end{array}$ & $\begin{array}{c}\text { Lab } \\
\text { param.. } \\
\text { Fluid } \\
\text { sample }\end{array}$ & $\begin{array}{c}\text { Lab } \\
\text { param.. } \\
\text { Fluid } \\
\text { sample }\end{array}$ & $\begin{array}{c}\text { Lab } \\
\text { param.. } \\
\text { Fluid } \\
\text { sample }\end{array}$ & \begin{tabular}{|c|} 
Lab \\
param.. \\
Fluid \\
sample
\end{tabular} & $\begin{array}{c}\text { Lab } \\
\text { param.. } \\
\text { Fluid } \\
\text { sample }\end{array}$ & $\begin{array}{c}\text { Lab } \\
\text { param.. } \\
\text { Fluid } \\
\text { sample }\end{array}$ & $\begin{array}{c}\text { Lab } \\
\text { param.. } \\
\text { Fluid } \\
\text { sample }\end{array}$ & $\begin{array}{c}\text { Lab } \\
\text { param.. } \\
\text { Fluid } \\
\text { sample }\end{array}$ & $\begin{array}{c}\text { Lab } \\
\text { param.. } \\
\text { Fluid } \\
\text { sample }\end{array}$ & $\begin{array}{c}\text { Lab } \\
\text { param.. } \\
\text { Fluid } \\
\text { sample }\end{array}$ & $\begin{array}{c}\text { Lab } \\
\text { param.. } \\
\text { Fluid } \\
\text { sample }\end{array}$ & $\begin{array}{c}\text { Lab } \\
\text { param.. } \\
\text { Fluid } \\
\text { sample }\end{array}$ & $\begin{array}{c}\text { Lab } \\
\text { param.. } \\
\text { Fluid } \\
\text { sample }\end{array}$ \\
\hline 10 PV GW & $\begin{array}{c}\text { Lab } \\
\text { param.. } \\
\text { Fluid } \\
\text { sample }\end{array}$ & $\begin{array}{c}\text { Lab } \\
\text { param.. } \\
\text { Fluid } \\
\text { sample }\end{array}$ & $\begin{array}{c}\text { Lab } \\
\text { param.. } \\
\text { Fluid } \\
\text { sample }\end{array}$ & $\begin{array}{c}\text { Lab } \\
\text { param. } \\
\cdot \\
\text { Fluid } \\
\text { sample }\end{array}$ & $\begin{array}{c}\text { Lab } \\
\text { param. } \\
\cdot \\
\text { Fluid } \\
\text { sample }\end{array}$ & $\begin{array}{c}\text { Lab } \\
\text { param.. } \\
\text { Fluid } \\
\text { sample }\end{array}$ & $\begin{array}{c}\text { Lab } \\
\text { param.. } \\
\text { Fluid } \\
\text { sample }\end{array}$ & $\begin{array}{c}\text { Lab } \\
\text { param.. } \\
\text { Fluid } \\
\text { sample }\end{array}$ & $\begin{array}{c}\text { Lab } \\
\text { param.. } \\
\text { Fluid } \\
\text { sample }\end{array}$ & $\begin{array}{c}\text { Lab } \\
\text { param.. } \\
\text { Fluid } \\
\text { sample }\end{array}$ & $\begin{array}{c}\text { Lab } \\
\text { param.. } \\
\text { Fluid } \\
\text { sample }\end{array}$ & $\begin{array}{c}\text { Lab } \\
\text { param.. } \\
\text { Fluid } \\
\text { sample }\end{array}$ & $\begin{array}{c}\text { Lab } \\
\text { param.. } \\
\text { Fluid } \\
\text { sample }\end{array}$ & $\begin{array}{c}\text { Lab } \\
\text { param.. } \\
\text { Fluid } \\
\text { sample }\end{array}$ & $\begin{array}{c}\text { Lab } \\
\text { param.. } \\
\text { Fluid } \\
\text { sample }\end{array}$ & $\begin{array}{c}\text { Lab } \\
\text { param.. } \\
\text { Fluid } \\
\text { sample }\end{array}$ & $\begin{array}{c}\text { Lab } \\
\text { param.. } \\
\text { Fluid } \\
\text { sample }\end{array}$ & $\begin{array}{c}\text { Lab } \\
\text { param.. } \\
\text { Fluid } \\
\text { sample }\end{array}$ & $\begin{array}{c}\text { Lab } \\
\text { param.. } \\
\text { Fluid } \\
\text { sample }\end{array}$ \\
\hline 15 PV GW & $\begin{array}{c}\text { Lab } \\
\text { param.. }\end{array}$ & $\begin{array}{c}\text { Lab } \\
\text { param.. }\end{array}$ & $\begin{array}{c}\text { Lab } \\
\text { param.. }\end{array}$ & $\begin{array}{c}\text { Lab } \\
\text { param. }\end{array}$ & $\begin{array}{c}\text { Lab } \\
\text { param. }\end{array}$ & $\begin{array}{c}\text { Lab } \\
\text { param.. }\end{array}$ & $\begin{array}{c}\text { Lab } \\
\text { param.. }\end{array}$ & $\begin{array}{c}\text { Lab } \\
\text { param.. }\end{array}$ & $\begin{array}{c}\text { Lab } \\
\text { param. }\end{array}$ & $\begin{array}{c}\text { Lab } \\
\text { param... }\end{array}$ & $\begin{array}{c}\text { Lab } \\
\text { param.. }\end{array}$ & $\begin{array}{c}\text { Lab } \\
\text { param.. }\end{array}$ & $\begin{array}{c}\text { Lab } \\
\text { param.. }\end{array}$ & $\begin{array}{c}\text { Lab } \\
\text { param.. }\end{array}$ & $\begin{array}{c}\text { Lab } \\
\text { param.. }\end{array}$ & $\begin{array}{c}\text { Lab } \\
\text { param.. }\end{array}$ & $\begin{array}{c}\text { Lab } \\
\text { param.. }\end{array}$ & $\begin{array}{c}\text { Lab } \\
\text { param.. }\end{array}$ & $\begin{array}{c}\text { Lab } \\
\text { param.. }\end{array}$ \\
\hline 20 PV GW & $\begin{array}{c}\text { Lab } \\
\text { param.. } \\
\text { Fluid } \\
\text { sample }\end{array}$ & $\begin{array}{c}\text { Lab } \\
\text { param.. } \\
\text { Fluid } \\
\text { sample }\end{array}$ & $\begin{array}{c}\text { Lab } \\
\text { param.. } \\
\text { Fluid } \\
\text { sample }\end{array}$ & $\begin{array}{c}\text { Lab } \\
\text { param. } \\
\cdot \\
\text { Fluid } \\
\text { sample }\end{array}$ & $\begin{array}{c}\text { Lab } \\
\text { param. } \\
\cdot \\
\text { Fluid } \\
\text { sample }\end{array}$ & $\begin{array}{c}\text { Lab } \\
\text { param.. } \\
\text { Fluid } \\
\text { sample }\end{array}$ & $\begin{array}{c}\text { Lab } \\
\text { param.. } \\
\text { Fluid } \\
\text { sample }\end{array}$ & $\begin{array}{c}\text { Lab } \\
\text { param.. } \\
\text { Fluid } \\
\text { sample }\end{array}$ & $\begin{array}{c}\text { Lab } \\
\text { param.. } \\
\text { Fluid } \\
\text { sample }\end{array}$ & \begin{tabular}{|c|} 
Lab \\
param.. \\
Fluid \\
sample
\end{tabular} & $\begin{array}{c}\text { Lab } \\
\text { param.. } \\
\text { Fluid } \\
\text { sample }\end{array}$ & $\begin{array}{c}\text { Lab } \\
\text { param.. } \\
\text { Fluid } \\
\text { sample }\end{array}$ & $\begin{array}{c}\text { Lab } \\
\text { param.. } \\
\text { Fluid } \\
\text { sample }\end{array}$ & $\begin{array}{c}\text { Lab } \\
\text { param.. } \\
\text { Fluid } \\
\text { sample }\end{array}$ & $\begin{array}{c}\text { Lab } \\
\text { param.. } \\
\text { Fluid } \\
\text { sample }\end{array}$ & $\begin{array}{c}\text { Lab } \\
\text { param.. } \\
\text { Fluid } \\
\text { sample }\end{array}$ & $\begin{array}{c}\text { Lab } \\
\text { param.. } \\
\text { Fluid } \\
\text { sample }\end{array}$ & $\begin{array}{c}\text { Lab } \\
\text { param.. } \\
\text { Fluid } \\
\text { sample }\end{array}$ & $\begin{array}{c}\text { Lab } \\
\text { param.. } \\
\text { Fluid } \\
\text { sample }\end{array}$ \\
\hline
\end{tabular}


Table 3-16. Geochemical Screening Test Sampling Schedule

\begin{tabular}{|c|c|c|c|c|c|c|c|c|c|c|c|c|c|c|c|c|c|c|c|}
\hline \multicolumn{20}{|c|}{ Low Iron Concentration } \\
\hline \multirow{2}{*}{$\begin{array}{l}\text { Sampling } \\
\text { Schedule }\end{array}$} & \multicolumn{9}{|c|}{ ZVI Geochemical Test Cells } & \multicolumn{9}{|c|}{ ZVI Geochemical Test Cells (QC Cells) } & \multirow{2}{*}{$\begin{array}{c}\begin{array}{c}\text { Contro } \\
\text { Cell }\end{array} \\
19\end{array}$} \\
\hline & 1 & 2 & 3 & 4 & 5 & 6 & 7 & 8 & 9 & 10 & 11 & 12 & 13 & 14 & 15 & 16 & 17 & 18 & \\
\hline \multirow[t]{2}{*}{1 PV GW } & $\begin{array}{c}\text { Lab } \\
\text { param.. }\end{array}$ & $\begin{array}{c}\text { Lab } \\
\text { param.. }\end{array}$ & $\begin{array}{c}\text { Lab } \\
\text { param.. }\end{array}$ & $\begin{array}{c}\text { Lab } \\
\text { param.. }\end{array}$ & $\begin{array}{c}\text { Lab } \\
\text { param. }\end{array}$ & $\begin{array}{c}\text { Lab } \\
\text { param.. }\end{array}$ & $\begin{array}{c}\text { Lab } \\
\text { param.. }\end{array}$ & $\begin{array}{c}\text { Lab } \\
\text { param.. }\end{array}$ & $\begin{array}{c}\text { Lab } \\
\text { param.. }\end{array}$ & $\begin{array}{c}\text { Lab } \\
\text { param.. }\end{array}$ & $\begin{array}{c}\text { Lab } \\
\text { param.. }\end{array}$ & $\begin{array}{c}\text { Lab } \\
\text { param.. }\end{array}$ & $\begin{array}{c}\text { Lab } \\
\text { param.. }\end{array}$ & $\begin{array}{l}\text { Lab } \\
\text { param.. }\end{array}$ & $\begin{array}{c}\text { Lab } \\
\text { param.. }\end{array}$ & $\begin{array}{c}\text { Lab } \\
\text { param.. }\end{array}$ & $\begin{array}{c}\text { Lab } \\
\text { param.. }\end{array}$ & $\begin{array}{c}\text { Lab } \\
\text { param.. }\end{array}$ & $\begin{array}{l}\text { Lab } \\
\text { param.. }\end{array}$ \\
\hline & $\begin{array}{l}\text { Fluid } \\
\text { sample }\end{array}$ & $\begin{array}{c}\text { Fluid } \\
\text { sample }\end{array}$ & \begin{tabular}{|c|} 
Fluid \\
sample
\end{tabular} & $\begin{array}{c}\text { Fluid } \\
\text { sample }\end{array}$ & $\begin{array}{c}\text { Fluid } \\
\text { sample }\end{array}$ & $\begin{array}{c}\text { Fluid } \\
\text { sample }\end{array}$ & \begin{tabular}{|c|} 
Fluid \\
sample
\end{tabular} & $\begin{array}{c}\text { Fluid } \\
\text { sample }\end{array}$ & $\begin{array}{c}\text { Fluid } \\
\text { sample }\end{array}$ & $\begin{array}{c}\text { Fluid } \\
\text { sample }\end{array}$ & $\begin{array}{c}\text { Fluid } \\
\text { sample }\end{array}$ & $\begin{array}{l}\text { Fluid } \\
\text { sample }\end{array}$ & $\begin{array}{c}\text { Fluid } \\
\text { sample }\end{array}$ & $\begin{array}{l}\text { Fluid } \\
\text { sample }\end{array}$ & $\begin{array}{c}\text { Fluid } \\
\text { sample }\end{array}$ & $\begin{array}{c}\text { Fluid } \\
\text { sample }\end{array}$ & $\begin{array}{l}\text { Fluid } \\
\text { sample }\end{array}$ & $\begin{array}{c}\text { Fluid } \\
\text { sample }\end{array}$ & $\begin{array}{c}\text { Fluid } \\
\text { sample }\end{array}$ \\
\hline \multirow[t]{2}{*}{5 PV GW } & $\begin{array}{c}\text { Lab } \\
\text { param.. }\end{array}$ & $\begin{array}{c}\text { Lab } \\
\text { param.. }\end{array}$ & $\begin{array}{c}\text { Lab } \\
\text { param.. }\end{array}$ & $\begin{array}{c}\text { Lab } \\
\text { param.. }\end{array}$ & $\begin{array}{c}\text { Lab } \\
\text { param. }\end{array}$ & $\begin{array}{c}\text { Lab } \\
\text { param.. }\end{array}$ & $\begin{array}{c}\text { Lab } \\
\text { param.. }\end{array}$ & $\begin{array}{c}\text { Lab } \\
\text { param.. }\end{array}$ & $\begin{array}{c}\text { Lab } \\
\text { param.. }\end{array}$ & $\begin{array}{c}\text { Lab } \\
\text { param... }\end{array}$ & $\begin{array}{c}\text { Lab } \\
\text { param.. }\end{array}$ & $\begin{array}{c}\text { Lab } \\
\text { param.. }\end{array}$ & $\begin{array}{c}\text { Lab } \\
\text { param.. }\end{array}$ & $\begin{array}{l}\text { Lab } \\
\text { param.. }\end{array}$ & $\begin{array}{c}\text { Lab } \\
\text { param.. }\end{array}$ & $\begin{array}{c}\text { Lab } \\
\text { param.. }\end{array}$ & $\begin{array}{c}\text { Lab } \\
\text { param.. }\end{array}$ & $\begin{array}{c}\text { Lab } \\
\text { param.. }\end{array}$ & $\begin{array}{l}\text { Lab } \\
\text { param.. }\end{array}$ \\
\hline & $\begin{array}{c}\text { Fluid } \\
\text { sample }\end{array}$ & $\begin{array}{c}\text { Fluid } \\
\text { sample }\end{array}$ & $\begin{array}{c}\text { Fluid } \\
\text { sample }\end{array}$ & \begin{tabular}{|} 
Fluid \\
sample
\end{tabular} & $\begin{array}{c}\text { Fluid } \\
\text { sample }\end{array}$ & $\begin{array}{c}\text { Fluid } \\
\text { sample }\end{array}$ & \begin{tabular}{|} 
Fluid \\
sample
\end{tabular} & $\begin{array}{c}\text { Fluid } \\
\text { sample }\end{array}$ & $\begin{array}{c}\text { Fluid } \\
\text { sample }\end{array}$ & \begin{tabular}{|c|} 
Fluid \\
sample
\end{tabular} & $\begin{array}{c}\text { Fluid } \\
\text { sample }\end{array}$ & $\begin{array}{l}\text { Fluid } \\
\text { sample }\end{array}$ & $\begin{array}{c}\text { Fluid } \\
\text { sample }\end{array}$ & $\begin{array}{l}\text { Fluid } \\
\text { sample }\end{array}$ & $\begin{array}{c}\text { Fluid } \\
\text { sample }\end{array}$ & $\begin{array}{c}\text { Fluid } \\
\text { sample }\end{array}$ & $\begin{array}{l}\text { Fluid } \\
\text { sample }\end{array}$ & $\begin{array}{c}\text { Fluid } \\
\text { sample }\end{array}$ & $\begin{array}{l}\text { Fluid } \\
\text { sample }\end{array}$ \\
\hline \multirow[t]{2}{*}{10 PV GW } & $\begin{array}{c}\text { Lab } \\
\text { param.. }\end{array}$ & $\begin{array}{c}\text { Lab } \\
\text { param.. }\end{array}$ & $\begin{array}{c}\text { Lab } \\
\text { param.. }\end{array}$ & $\begin{array}{c}\text { Lab } \\
\text { param.. }\end{array}$ & $\begin{array}{c}\text { Lab } \\
\text { param. }\end{array}$ & $\begin{array}{c}\text { Lab } \\
\text { param.. }\end{array}$ & $\begin{array}{c}\text { Lab } \\
\text { param.. }\end{array}$ & $\begin{array}{c}\text { Lab } \\
\text { param.. }\end{array}$ & $\begin{array}{c}\text { Lab } \\
\text { param.. }\end{array}$ & $\begin{array}{c}\text { Lab } \\
\text { param.. }\end{array}$ & $\begin{array}{c}\text { Lab } \\
\text { param.. }\end{array}$ & $\begin{array}{c}\text { Lab } \\
\text { param.. }\end{array}$ & \multirow{2}{*}{$\begin{array}{c}\text { Lab } \\
\text { param.. } \\
\text { Fluid } \\
\text { sample }\end{array}$} & $\begin{array}{c}\text { Lab } \\
\text { param.. }\end{array}$ & $\begin{array}{c}\text { Lab } \\
\text { param.. }\end{array}$ & $\begin{array}{c}\text { Lab } \\
\text { param.. }\end{array}$ & $\begin{array}{c}\text { Lab } \\
\text { param.. }\end{array}$ & $\begin{array}{c}\text { Lab } \\
\text { param.. }\end{array}$ & $\begin{array}{l}\text { Lab } \\
\text { param.. }\end{array}$ \\
\hline & $\begin{array}{c}\text { Fluid } \\
\text { sample }\end{array}$ & $\begin{array}{c}\text { Fluid } \\
\text { sample }\end{array}$ & $\begin{array}{c}\text { Fluid } \\
\text { sample }\end{array}$ & $\begin{array}{c}\text { Fluid } \\
\text { sample }\end{array}$ & $\begin{array}{c}\text { Fluid } \\
\text { sample }\end{array}$ & $\begin{array}{c}\text { Fluid } \\
\text { sample }\end{array}$ & $\begin{array}{c}\text { Fluid } \\
\text { sample }\end{array}$ & $\begin{array}{c}\text { Fluid } \\
\text { sample }\end{array}$ & \begin{tabular}{|c|} 
Fluid \\
sample
\end{tabular} & $\begin{array}{c}\text { Fluid } \\
\text { sample }\end{array}$ & $\begin{array}{c}\text { Fluid } \\
\text { sample }\end{array}$ & $\begin{array}{c}\text { Fluid } \\
\text { sample }\end{array}$ & & $\begin{array}{l}\text { Fluid } \\
\text { sample }\end{array}$ & $\begin{array}{c}\text { Fluid } \\
\text { sample }\end{array}$ & $\begin{array}{c}\text { Fluid } \\
\text { sample }\end{array}$ & $\begin{array}{l}\text { Fluid } \\
\text { sample }\end{array}$ & $\begin{array}{c}\text { Fluid } \\
\text { sample }\end{array}$ & $\begin{array}{l}\text { Fluid } \\
\text { sample }\end{array}$ \\
\hline 15 PV GW & $\begin{array}{c}\text { Lab } \\
\text { param.. }\end{array}$ & $\begin{array}{c}\text { Lab } \\
\text { param.. }\end{array}$ & $\begin{array}{c}\text { Lab } \\
\text { param.. }\end{array}$ & $\begin{array}{c}\text { Lab } \\
\text { param.. }\end{array}$ & $\begin{array}{c}\text { Lab } \\
\text { param. } \\
.\end{array}$ & $\begin{array}{c}\text { Lab } \\
\text { param.. }\end{array}$ & $\begin{array}{c}\text { Lab } \\
\text { param.. }\end{array}$ & $\begin{array}{c}\text { Lab } \\
\text { param.. }\end{array}$ & $\begin{array}{c}\text { Lab } \\
\text { param... }\end{array}$ & \begin{tabular}{|c|} 
Lab \\
param..
\end{tabular} & $\begin{array}{c}\text { Lab } \\
\text { param.. }\end{array}$ & $\begin{array}{c}\text { Lab } \\
\text { param.. }\end{array}$ & $\begin{array}{c}\text { Lab } \\
\text { param.. }\end{array}$ & $\begin{array}{c}\text { Lab } \\
\text { param.. }\end{array}$ & $\begin{array}{l}\text { Lab } \\
\text { param.. }\end{array}$ & $\begin{array}{c}\text { Lab } \\
\text { param.. }\end{array}$ & $\begin{array}{c}\text { Lab } \\
\text { param.. }\end{array}$ & $\begin{array}{c}\text { Lab } \\
\text { param.. }\end{array}$ & $\begin{array}{c}\text { Lab } \\
\text { param.. }\end{array}$ \\
\hline \multirow[t]{2}{*}{$20 \mathrm{PV} \mathrm{GW}$} & $\begin{array}{c}\text { Lab } \\
\text { param.. }\end{array}$ & $\begin{array}{c}\text { Lab } \\
\text { param.. }\end{array}$ & $\begin{array}{c}\text { Lab } \\
\text { param. }\end{array}$ & $\begin{array}{c}\text { Lab } \\
\text { param.. }\end{array}$ & $\begin{array}{c}\text { Lab } \\
\text { param. }\end{array}$ & $\begin{array}{c}\text { Lab } \\
\text { param.. }\end{array}$ & $\begin{array}{c}\text { Lab } \\
\text { param.. }\end{array}$ & $\begin{array}{c}\text { Lab } \\
\text { param.. }\end{array}$ & $\begin{array}{c}\text { Lab } \\
\text { param.. }\end{array}$ & $\begin{array}{c}\text { Lab } \\
\text { param... }\end{array}$ & $\begin{array}{c}\text { Lab } \\
\text { param.. }\end{array}$ & $\begin{array}{c}\text { Lab } \\
\text { param.. }\end{array}$ & \multirow{2}{*}{$\begin{array}{c}\text { Lab } \\
\text { param.. } \\
\text { Fluid } \\
\text { sample }\end{array}$} & $\begin{array}{c}\text { Lab } \\
\text { param.. }\end{array}$ & $\begin{array}{c}\text { Lab } \\
\text { param.. }\end{array}$ & $\begin{array}{c}\text { Lab } \\
\text { param.. }\end{array}$ & $\begin{array}{c}\text { Lab } \\
\text { param.. }\end{array}$ & $\begin{array}{c}\text { Lab } \\
\text { param.. }\end{array}$ & $\begin{array}{l}\text { Lab } \\
\text { param.. }\end{array}$ \\
\hline & $\begin{array}{c}\text { Fluid } \\
\text { sample }\end{array}$ & $\begin{array}{c}\text { Fluid } \\
\text { sample }\end{array}$ & $\begin{array}{l}\text { Fluid } \\
\text { sample }\end{array}$ & \begin{tabular}{|} 
Fluid \\
sample
\end{tabular} & $\begin{array}{c}\text { Fluid } \\
\text { sample }\end{array}$ & $\begin{array}{c}\text { Fluid } \\
\text { sample }\end{array}$ & \begin{tabular}{|} 
Fluid \\
sample
\end{tabular} & \begin{tabular}{|} 
Fluid \\
sample
\end{tabular} & $\begin{array}{c}\text { Fluid } \\
\text { sample }\end{array}$ & $\begin{array}{c}\text { Fluid } \\
\text { sample }\end{array}$ & $\begin{array}{c}\text { Fluid } \\
\text { sample }\end{array}$ & $\begin{array}{l}\text { Fluid } \\
\text { sample }\end{array}$ & & $\begin{array}{c}\text { Fluid } \\
\text { sample }\end{array}$ & $\begin{array}{l}\text { Fluid } \\
\text { sample }\end{array}$ & $\begin{array}{c}\text { Fluid } \\
\text { sample }\end{array}$ & $\begin{array}{l}\text { Fluid } \\
\text { sample }\end{array}$ & $\begin{array}{l}\text { Fluid } \\
\text { sample }\end{array}$ & $\begin{array}{l}\text { Fluid } \\
\text { sample }\end{array}$ \\
\hline \multicolumn{13}{|c|}{ Total laboratory parameter measurements } & \multicolumn{6}{|c|}{190} & \\
\hline \multicolumn{13}{|c|}{ Total pore fluid sample analyses } & \multicolumn{6}{|c|}{152} & \\
\hline PV & \multicolumn{18}{|c|}{$=$ pore volume } & \\
\hline GW & \multicolumn{18}{|c|}{$=$ groundwater (surrogate) } & \\
\hline \multicolumn{20}{|c|}{ Lab param. = laboratory parameters (including $\mathrm{pH}$, oxidation-reduction potential, dissolved oxygen, and temperature) } \\
\hline QC & \multicolumn{19}{|c|}{$=$ quality control } \\
\hline $\mathrm{ZVI}$ & \multicolumn{19}{|c|}{$=$ zero-valent iron } \\
\hline
\end{tabular}




\subsubsection{Advanced Geochemical Test}

The effluent was collected for field measurements (i.e., temperature, $\mathrm{pH}, \mathrm{ORP}$, specific conductivity, and DO) and laboratory samples from each of the experimental columns based on the sampling schedule shown in Table 3-17.

Table 3-17. Advanced Geochemical Testing Sampling Schedule and Measurements

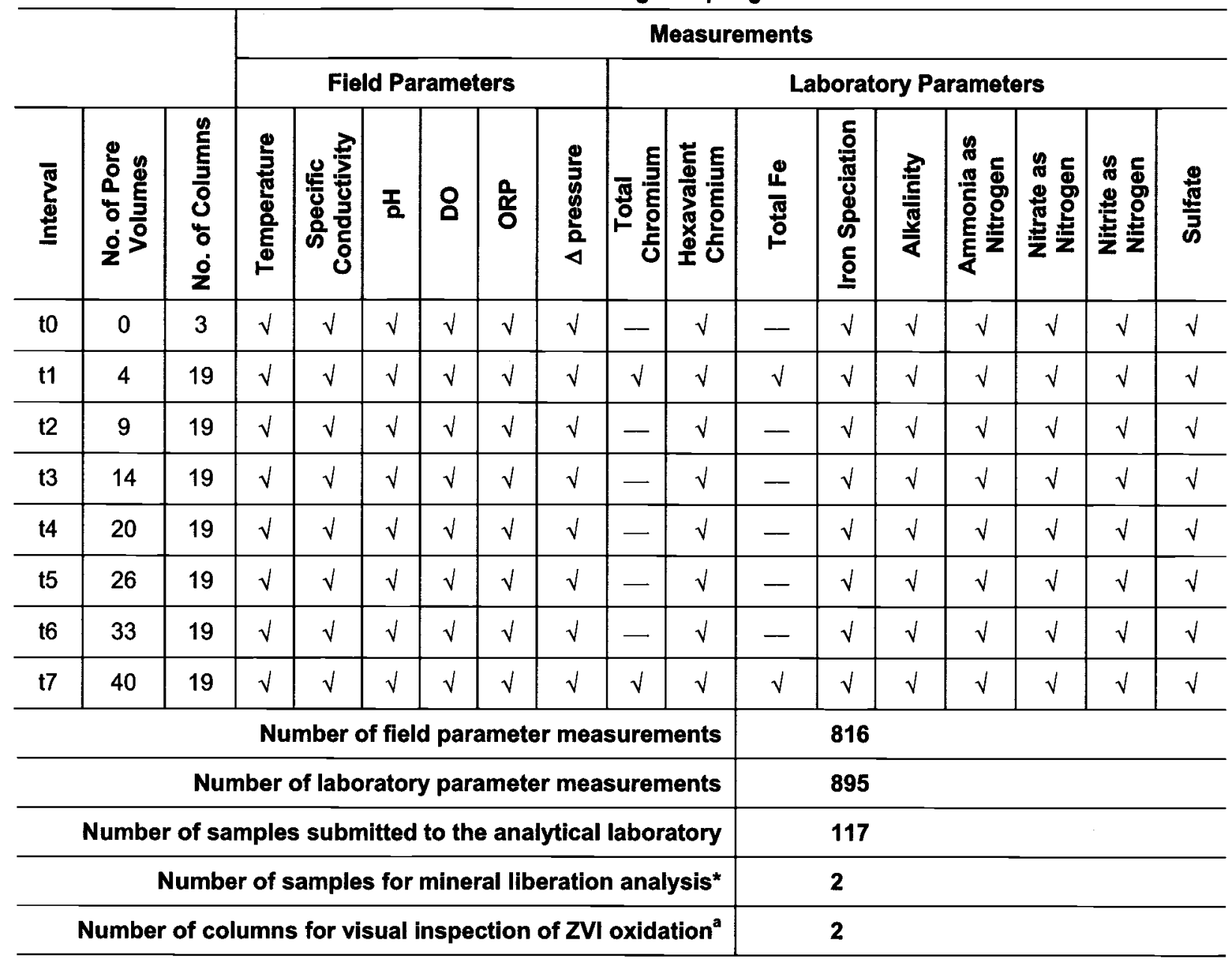

* High ZVI concentration columns will be used for these analyses.

$\mathrm{DO}=$ dissolved oxygen

ORP = oxidation-reduction potential

$\mathrm{ZVI}=$ zero-valent iron

The sampling schedule was based on the number of PVs of effluent. The sampling schedule was extended to $40 \mathrm{PVs}$ based on the preliminary chromium results from the geochemical screening tests. In those tests, the RNIP-M2 and PolyMetallix products at the ZVI concentration of $1.5 \mathrm{wt} \%$ showed no sign of breakthrough of hexavalent chromium at 20 PVs. Consequently, the columns were operated until 40 PVs had been passed through each column to ensure that breakthrough would occur in the columns and/or passivation of the ZVI would occur to a measurable extent. 
The effluent analyses are shown in Table 3-18. There were nine experimental columns for each ZVI. One control column, containing only Ringold soil was set up to monitor baseline conditions. Each $\mathrm{ZVI} /$ soil mixture was run in triplicate (for QA purposes) to determine experimental and analytical variability. The ZVI concentrations (high, mid-, and low) in the soil mixture were determined from the concentration of ZVI remaining in the flow cells after surrogate groundwater flushing during the injection screening tests, as well as the concentration of ZVI placed in the columns for the geochemical screening tests. The ZVI concentration in the injection screening test flow cells after flushing was calculated from the iron analyses after emplacement and subtracting solids removed during flushing. The average amount of RNIP-M2 and PolyMetallix remaining in the flow cells after flushing was calculated to be $1.7 \mathrm{wt} \%$ and $2.0 \mathrm{wt} \%$, respectively. However, it was discovered during the screening geochemical tests that it is only possible to load the RNIP-M2 ZVI at $1.5 \mathrm{wt} \%$ because the product is shipped with $17 \mathrm{wt} \%$ water. For comparability between products, the high ZVI material concentration was set at $1.5 \mathrm{wt} \%$ (high concentration) for both RNIP-M2 and PolyMetallix. The mid-concentration $(0.15 \mathrm{wt} \%)$ was at one-tenth of the high concentration, and the low concentration $(0.015 \mathrm{wt} \%)$ was at one-hundredth of the high concentration.

Table 3-18. Advanced Geochemical Testing Chemical-Based Measurements and Analyses

\begin{tabular}{llcc}
\hline \multicolumn{1}{c}{$\begin{array}{c}\text { Measurement/ } \\
\text { Analysis }\end{array}$} & Matrix & $\begin{array}{c}\text { Analytical/Measurement } \\
\text { Method }\end{array}$ & $\begin{array}{c}\text { Detection } \\
\text { Limit }\end{array}$ \\
\hline $\mathrm{pH}$ & Effluent & EPA Method 150.1 & 0.1 standard unit \\
$\begin{array}{l}\text { Oxidation-reduction } \\
\text { potential }\end{array}$ & Effluent & Standard method 2580 & $1 \mathrm{mV}$ \\
Nitrogen as ammonia & Effluent & EPA Method 350.2 & $0.05 \mathrm{mg} / \mathrm{L}$ \\
Dissolved oxygen & Effluent & YSI 556 MPS probe & $0.1 \%$ air saturation \\
Nitrogen as nitrate & Effluent & EPA Method 300.0 & $0.01 \mathrm{mg} / \mathrm{L}$ \\
Nitrogen as nitrite & Effluent & EPA Method 300.0 & $0.05 \mathrm{mg} / \mathrm{L}$ \\
Alkalinity & Effluent & EPA Method 310.1 & $0.05 \mathrm{mg} / \mathrm{L}$ \\
Iron speciation & Effluent & Standard method $3500-\mathrm{Fe} \mathrm{D}$ & $5 \mathrm{mg} \mathrm{CaCO} / \mathrm{L}$ \\
Total chromium & Effluent & EPA Method 200.9 & $0.05 \mathrm{mg} / \mathrm{L}$ \\
Hexavalent chromium & Effluent & SW-7196A & $0.001 \mathrm{mg} / \mathrm{L}$ \\
\hline
\end{tabular}

NOTE: $\mathrm{YSI}^{\oplus}$ is a registered trademark of YSI Incorporated, Yellow Springs, Ohio.

$\mathrm{EPA}=$ U.S. Environmental Protection Agency

\subsubsection{Planned Measurements and Analyses}

Column effluents were analyzed for the full suite of analytes listed in Table 3-18 for each ZVI and Ringold Unit E soil combination. One column for each ZVI at high concentration was dedicated for MLA analysis for iron chromium oxy-hydroxides at the completion of the column testing. It was recommended that a column from each ZVI at high concentration be cut open and visually examined for the presence of ferrous and ferric compounds, as visual examination may provide insight regarding if the 
ZVI oxidized completely to ferric iron $\left(\mathrm{Fe}^{+3}\right)$ or may exist as ferrous iron $\left(\mathrm{Fe}^{+2}\right)$, as indicated by green staining or secondary mineral formation. The kinetics of the reaction between ZVI and hexavalent chromium are faster than for the reaction between ferrous iron and hexavalent chromium ("The Reduction of Chromium [VI] by Iron [II] in Aqueous Solutions" [Pettine et al. 1998] and "Reduction of Aqueous Chromate by $\mathrm{Fe}(\mathrm{II}) / \mathrm{Fe}$ (III) Carbonate Green Rust Kinetic and Mechanistic Studies" [Legrand et al. 2004]), although ferrous iron maintains some additional reductive capacity. Therefore, if the reaction between ZVI and the components in the surrogate water produce ferrous iron, this could have implications on the longevity for ZVI injected into the Ringold Formation.

Table 3-19 lists the physical measurements with associated sample matrix, analytical methods, and required detection limits performed during the advanced geochemical testing.

Table 3-19. Advanced Geochemical Testing Physical Measurements and Analyses

\begin{tabular}{lccc}
\hline $\begin{array}{c}\text { Measurement/ } \\
\text { Analysis }\end{array}$ & Matrix & $\begin{array}{c}\text { Analytical/Measurement } \\
\text { Method }\end{array}$ & $\begin{array}{c}\text { Detection } \\
\text { Limit }\end{array}$ \\
\hline Specific conductance & Effluent & YSI 556 MPS probe & $\begin{array}{c}0.001 \text { to } 0.1 \mathrm{~ms} / \mathrm{cm} \\
\text { (range dependent) }\end{array}$ \\
Iron oxy-hydroxides & Column material & MLA & Qualitative assessment \\
Temperature & Effluent & YSI 556 MPS probe & $0.01^{\circ} \mathrm{C}$ \\
Flow rate & Effluent & Effluent collection & $1 \mathrm{~mL} / \mathrm{min}$ \\
Differential pressure & Porewater & Manometer & $\begin{array}{l}0.5 \mathrm{~cm} \text { pore fluid head } \\
\text { differential over } 60 \mathrm{~cm}\end{array}$ \\
\hline
\end{tabular}

NOTE: $\mathrm{YSI}^{\circledast}$ is a registered trademark of $\mathrm{YSI}$ Incorporated, Yellow Springs, Ohio.

$M L A=$ mineral liberation analysis

The $\mathrm{pH}, \mathrm{ORP}$, specific conductance, and DO data were used to monitor the geochemical conditions in the columns. The temperature data were required to support $\mathrm{pH}$ measurement and the other parameters listed in Tables 3-16 and 3-17.

Differential pressure was monitored by visually inspecting the manometers, and the flow rate was periodically measured by timing the filling of a known volume. Both of these parameters were used to indicate column fouling.

Column material samples were obtained from the high-concentration ZVI column at the conclusion of the experiment. After the column was removed, the influent end plug was unscrewed and the material from the first $5.1 \mathrm{~cm}(2 \mathrm{in}$.) of the column was emptied into a clean plastic container. The sample was then placed into a labeled sample container. The sample was taken to the Metallurgy Department at the University of Montana (Butte, Montana) for MLA.

One column from each ZVI at the high-concentration ZVI columns for both RNIP-M2 and PolyMetallix materials were cut open for visual examination following advanced geochemical testing. The visual examination looked for indications of the oxidation state of reacted ZVI, which most likely be present in the high-concentration ZVI columns. The presence of ferrous iron may be observed by the presence of green staining on the Ringold soil and/or green secondary mineral formation, whereas ferric iron may leave a reddish-brown stain on the Ringold soil and/or secondary mineral formation. 


\subsubsection{Advanced Flow Cell Injection}

For each ZVI fluid, aqueous samples for chemical analyses of total iron concentration were collected from sampling ports A, B, C and D located along the flow cells, from the influent tank, and from the effluent of each flow cell (Table 3-20). The samples were analyzed using U.S. Environmental Protection Agency (EPA) Methods 3005A and 6010C, respectively, for sample digestion and analysis. Because suspended nZVI material is refractory to digestion, standard EPA analytical methods for iron (including sample preservation and preparation 0 are inappropriate.

Nominal flow rates (a, b, c, and d [from lowest to highest] in Table 3-20) were set on peristaltic pumps that were used to inject ZVI fluid to the given pair of flow cells. The flow rates were checked by measuring the flow rate of the effluent from each flow cell using a graduated cylinder and a stopwatch. If any discrepancy was found, measurements of effluent flow rate were considered correct and used for further data interpretation and related calculations.

Table 3-20. Advanced Flow Cell Injection Testing Sampling and Measurements Location

\begin{tabular}{|c|c|c|c|c|c|c|c|c|c|c|c|c|c|c|c|}
\hline \multirow[b]{2}{*}{ Fluid } & \multirow{2}{*}{ 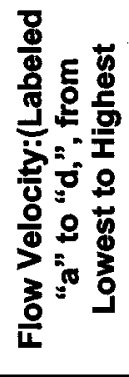 } & \multirow[b]{2}{*}{$\begin{array}{l}\text { Cell } \\
\text { ID }\end{array}$} & \multicolumn{6}{|c|}{$\begin{array}{l}\text { Location of Aqueous } \\
\text { Sample for Total Iron }\end{array}$} & \multicolumn{5}{|c|}{$\begin{array}{c}\text { Location of Hydraulic } \\
\text { Head Measurements, } \\
\text { mm }\end{array}$} & \multirow[b]{2}{*}{ 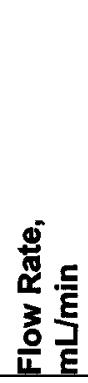 } & \multirow[b]{2}{*}{ Comment } \\
\hline & & & 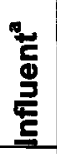 & A & B & C & D & 蒙 & $\mathbf{I}$ & II & III & IV & $\mathbf{v}$ & & \\
\hline Water & b & 0 & $x$ & & & & & $x$ & $x$ & $x$ & $x$ & $x$ & $x$ & $x$ & Control cell \\
\hline \multirow{8}{*}{ RNIP -M2 } & \multirow{2}{*}{ a } & 1 & \multirow{2}{*}{$x$} & $x$ & $x$ & $x$ & $x$ & $x$ & $x$ & $x$ & $x$ & $x$ & $x$ & $x$ & \\
\hline & & 2 & & $x$ & $x$ & $x$ & $x$ & $x$ & $x$ & $x$ & $x$ & $x$ & $x$ & $x$ & \\
\hline & \multirow{2}{*}{ b } & 3 & \multirow{2}{*}{$x$} & $x$ & $x$ & $x$ & $x$ & $x$ & $x$ & $x$ & $x$ & $x$ & $x$ & $x$ & \\
\hline & & 4 & & $x$ & $x$ & $x$ & $x$ & $x$ & $x$ & $x$ & $x$ & $x$ & $x$ & $x$ & \\
\hline & \multirow{2}{*}{ c } & 5 & \multirow{2}{*}{$x$} & $x$ & $x$ & $x$ & $x$ & $x$ & $x$ & $x$ & $x$ & $x$ & $x$ & $x$ & \\
\hline & & 6 & & $x$ & $x$ & $x$ & $x$ & $x$ & $x$ & $x$ & $x$ & $x$ & $x$ & $x$ & \\
\hline & \multirow{2}{*}{ d } & 7 & \multirow{2}{*}{$x$} & $x$ & $x$ & $x$ & $x$ & $x$ & $\mathrm{x}$ & $x$ & $x$ & $x$ & $x$ & $x$ & \\
\hline & & 8 & & $x$ & $x$ & $x$ & $x$ & $x$ & $x$ & $x$ & $x$ & $x$ & $x$ & $x$ & \\
\hline \multirow{7}{*}{ PolyMetallix } & \multirow{2}{*}{ a } & 9 & \multirow{2}{*}{$x$} & $x$ & $x$ & $x$ & $x$ & $x$ & $x$ & $x$ & $x$ & $x$ & $x$ & $x$ & \\
\hline & & 10 & & $x$ & $x$ & $x$ & $x$ & $x$ & $x$ & $x$ & $x$ & $x$ & $x$ & $x$ & \\
\hline & \multirow{3}{*}{ b } & 11 & \multirow{3}{*}{$x$} & $x$ & $x$ & $x$ & $x$ & $x$ & $x$ & $x$ & $x$ & $x$ & $x$ & $x$ & \\
\hline & & 12 & & $x$ & $x$ & $x$ & $x$ & $x$ & $x$ & $x$ & $x$ & $x$ & $x$ & $x$ & \\
\hline & & 14 & & $x$ & $x$ & $x$ & $x$ & $x$ & $x$ & $x$ & $x$ & $x$ & $x$ & $x$ & \\
\hline & \multirow{2}{*}{ d } & 15 & \multirow{2}{*}{$x$} & $x$ & $x$ & $x$ & $x$ & $x$ & $x$ & $x$ & $x$ & $x$ & $x$ & $x$ & \\
\hline & & 16 & & $x$ & $x$ & $x$ & $x$ & $x$ & $x$ & $x$ & $x$ & $\mathrm{x}$ & $x$ & $x$ & \\
\hline
\end{tabular}


Table 3-20. Advanced Flow Cell Injection Testing Sampling and Measurements Location

\begin{tabular}{|c|c|c|c|c|c|c|c|c|c|c|c|c|c|c|c|}
\hline \multirow[b]{2}{*}{ Fluid } & \multirow{2}{*}{ 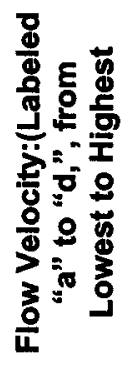 } & \multirow[b]{2}{*}{$\begin{array}{l}\text { Cell } \\
\text { ID }\end{array}$} & \multicolumn{6}{|c|}{$\begin{array}{l}\text { Location of Aqueous } \\
\text { Sample for Total Iron }\end{array}$} & \multicolumn{5}{|c|}{$\begin{array}{c}\text { Location of Hydraulic } \\
\text { Head Measurements, } \\
\text { mm }\end{array}$} & \multirow[b]{2}{*}{ 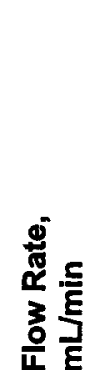 } & \multirow[b]{2}{*}{ Comment } \\
\hline & & & 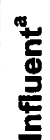 & A & B & C & D & 蒙 & I & II & III & IV & v & & \\
\hline
\end{tabular}

NOTES:

PolyMetallix is a trademark of Crane Polyflon, Norwalk, Connecticut.

RNIP-M2 is a trademark of Toda Kogyo Corporation, Hiroshima, Japan.

a. For flow cells 1 through 16 , one sample of influent will be taken if fed by the same influent.

b. Indicates manometers I, II, III, IV, and V.

ID = identification

Measurements of hydraulic heads were taken using manometers located along the flow cells. Each flow cell was equipped with five manometers (I, II, III, IV, and V). The sixth data point for the hydraulic head measurements was constant for each flow cell as it was the height of the effluent outlet. All hydraulic head measurements were taken with respect to the upper surface of the flow cell placed horizontally on a level bench. Aqueous samples and field measurements were obtained as listed in Table 3-21.

Table 3-21. Advanced Flow Cell Injection Testing Nominal Sampling and Measuring Time and Locations

\begin{tabular}{|c|c|c|c|c|c|c|}
\hline \multicolumn{2}{|c|}{$\begin{array}{l}\text { Nominal Time Elapsed } \\
\text { for Sampling } \\
\text { or Measuring Point }\end{array}$} & \multicolumn{4}{|c|}{$\begin{array}{l}\text { Sample collection: } \\
\text { Sampling ports A, B, C, D and effluent. } \\
\text { Influent - one sample per set of flow cells that run } \\
\text { simultaneously. } \\
\text { Measurements: } \\
\text { Hydraulic head at manometers I, II, III, IV, and V. } \\
\text { Flow rate at effluent. }\end{array}$} & \multirow[b]{2}{*}{$\begin{array}{c}\text { Sample o } \\
\text { Influent } \\
\text { Only }\end{array}$} \\
\hline Minutes & $\begin{array}{l}\text { Hours and } \\
\text { Min. }\end{array}$ & $\stackrel{a}{14 \mathrm{~mL} / \mathrm{min}}$ & $\begin{array}{c}b \\
32 \mathrm{~mL} / \min \end{array}$ & $\begin{array}{c}\text { c } \\
75 \mathrm{~mL} / \mathrm{min}\end{array}$ & $\frac{d}{172 \mathrm{~mL} / \mathrm{min}}$ & \\
\hline 0 & $0: 00$ & - & -- & -- & -- & $x$ \\
\hline 27 & $0: 27$ & -- & - & - & $x$ & - \\
\hline 54 & $0: 54$ & -- & -- & - & $x$ & -- \\
\hline 62 & $1: 03$ & - & -- & $x$ & - & - \\
\hline 81 & $1: 21$ & - & - & -- & $x$ & -- \\
\hline 108 & $1: 48$ & -- & -- & -- & $x$ & -- \\
\hline 124 & 2:04 & -- & -- & $x$ & -- & -- \\
\hline
\end{tabular}


Table 3-21. Advanced Flow Cell Injection Testing Nominal Sampling and Measuring Time and Locations

\begin{tabular}{|c|c|c|c|c|c|c|}
\hline \multicolumn{2}{|c|}{$\begin{array}{c}\text { Nominal Time Elapsed } \\
\text { for Sampling } \\
\text { or Measuring Point }\end{array}$} & \multicolumn{4}{|c|}{$\begin{array}{l}\text { Sample collection: } \\
\text { Sampling ports A, B, C, D and effluent. } \\
\text { Influent - one sample per set of flow cells that run } \\
\text { simultaneously. } \\
\text { Measurements: } \\
\text { Hydraulic head at manometers I, II, III, IV, and V. } \\
\text { Flow rate at effluent. }\end{array}$} & \multirow[b]{2}{*}{$\begin{array}{l}\text { Sample of } \\
\text { Influent } \\
\text { Only }\end{array}$} \\
\hline Minutes & $\begin{array}{c}\text { Hours and } \\
\text { Min. }\end{array}$ & $\begin{array}{c}a \\
14 \mathrm{~mL} / \mathrm{min}\end{array}$ & $\begin{array}{c}\text { b } \\
32 \mathrm{~mL} / \mathrm{min}\end{array}$ & $\begin{array}{c}c \\
75 \mathrm{~mL} / \mathrm{min}\end{array}$ & $\begin{array}{c}\text { d } \\
172 \mathrm{~mL} / \mathrm{min}\end{array}$ & \\
\hline 135 & $2: 15$ & -- & - & - & $x$ & - \\
\hline 143 & $2: 23$ & - & $x$ & - & -- & - \\
\hline 186 & 3:06 & - & -- & $x$ & -- & - \\
\hline 248 & $4: 08$ & -- & -- & $x$ & -- & -- \\
\hline 285 & $4: 45$ & - & $x$ & -- & -- & -- \\
\hline 310 & $5: 10$ & -- & -- & $x$ & -- & - \\
\hline 328 & $5: 28$ & $x$ & -- & -- & $x$ & -- \\
\hline 571 & $9: 31$ & - & $x$ & - & -- & -- \\
\hline 656 & $10: 56$ & $x$ & -- & $x$ & $X$ & -- \\
\hline 714 & $11: 54$ & -- & $x$ & -- & -- & -- \\
\hline 984 & $16: 24$ & $x$ & $X$ & $x$ & $x$ & - \\
\hline 1312 & 21:52 & $x$ & $x$ & $x$ & $X$ & -- \\
\hline 1641 & $27: 31$ & $x$ & $x$ & $x$ & $x$ & -- \\
\hline
\end{tabular}

The physical measurements are specified in Table 3-22. Samples for chemical analysis collection and analysis are specified in Table 3-23.

Table 3-22. Advanced Flow Cell Injection Testing Physical Measurements

\begin{tabular}{lccc}
\hline Measurement & Method & Units & Accuracy \\
\hline Hydraulic head & Metric tape & $\mathrm{mm}$ & $\pm 1 \mathrm{~mm}$ \\
Flow rate & $\begin{array}{c}\text { Graduated cylinder over } \\
30 \text { seconds }\end{array}$ & $\mathrm{mL} / \mathrm{min}$ & $\begin{array}{c} \pm 0.5 \mathrm{~mL} \text { or } 1 \% \text { of the volume } \\
\text { collected (whichever is greater) } \\
\text { and } \pm 1 \text { second }\end{array}$ \\
Time & Stop watch & $\begin{array}{c}\text { Military time } \\
\text { (hours and minutes) }\end{array}$ & 1 minute \\
\hline
\end{tabular}




\subsection{Waste Stream}

For each element of laboratory testing, all wastes were handled in accordance with applicable federal, state, and local regulations, as well as the facility's waste-handling procedures. Specific elements of waste handling are noted in the following sections.

\subsubsection{Batch Screening Test}

All flasks were thoroughly cleaned and the solid material disposed into a labeled waste container dedicated to the project. The effluent was be less than $5 \mathrm{mg} / \mathrm{L}$ in concentration and, as such, was disposed to a publicly owned treatment facility.

Table 3-23. Advanced Flow Cell Injection Testing Aqueous Samples

\begin{tabular}{|c|c|c|c|c|c|c|c|}
\hline Matrix & $\begin{array}{l}\text { Method of } \\
\text { Collection }\end{array}$ & $\begin{array}{l}\text { Volume } \\
(\mathrm{mL})\end{array}$ & $\begin{array}{c}\text { Sample } \\
\text { Bottle }\end{array}$ & Preservation & Analyte & $\begin{array}{l}\text { Analytical } \\
\text { Method }\end{array}$ & $\begin{array}{l}\text { Detection } \\
\text { Limit }\end{array}$ \\
\hline \multirow[t]{2}{*}{ ZVI fluid } & $\begin{array}{l}\text { For ports } A \text { through } \\
D \text { : using a syringe } \\
\text { with needle set to } \\
\text { the center of the } \\
\text { flow cell through } \\
\text { a rubber stopper. }\end{array}$ & 25 & $\begin{array}{c}50 \mathrm{~mL} \\
\text { centrifuge } \\
\text { tube }\end{array}$ & $\mathrm{HNO}_{3}$ & $\begin{array}{l}\text { Total } \\
\text { iron }\end{array}$ & $\begin{array}{l}\text { EPA Methods } \\
\text { 3005A } 6010 \mathrm{C}\end{array}$ & $\begin{array}{l}0.015 \\
\mathrm{mg} / \mathrm{L}\end{array}$ \\
\hline & $\begin{array}{l}\text { Grab samples of } \\
\text { influent and } \\
\text { effluent. }\end{array}$ & 50 & $\begin{array}{c}50 \mathrm{~mL} \\
\text { centrifuge } \\
\text { tube }\end{array}$ & $\mathrm{HNO}_{3}$ & $\begin{array}{l}\text { Total } \\
\text { iron }\end{array}$ & $\begin{array}{l}\text { EPA Methods } \\
\text { 3005A } 6010 \mathrm{C}\end{array}$ & $\begin{array}{l}0.015 \\
\mathrm{mg} / \mathrm{L}\end{array}$ \\
\hline
\end{tabular}

$E P A=$ U.S. Environmental Protection Agency

$\mathrm{ZVI}=$ zero-valent iron

\subsubsection{Injection Screening Test}

Because the chromium concentrations were below hazardous concentrations, the effluent was discharged to a common waste tank and was handled in accordance with all applicable federal, state, and local regulations, as well as the facility's waste-handling procedures. The ZVI fluid waste was disposed by concentration and disposal to a landfill as a solid. Sand from the flow cells injected with ZVI fluid during testing was disposed at a municipal landfill.

\subsubsection{Geochemical Screening Test}

The ZVI fluid waste was collected in a common waste tank for subsequent disposal by concentration and disposal to a landfill as a solid waste. Sand from the flow cells injected with ZVI fluid during testing was disposed at a municipal landfill.

\subsubsection{Advanced Geochemical Test}

In general, ZVI fluid waste was collected in a common waste tank for concentration and subsequent disposal to a landfill as a solid. Sand from the advanced geochemical testing columns was disposed at a municipal landfill. 


\subsubsection{Advanced Flow Cell Injection}

After appropriate measurements and sampling, the waste was collected in a common waste tank before disposal. The wastewater was concentrated and disposed to a landfill as a solid. Sand from the flow cells with ZVI injected during the test was disposed at a municipal landfill.

\subsection{Data Management}

Data management is discussed in the following subsections.

\subsubsection{Micron-Sized Zero-Valent Iron Testing (Original Scope)}

Data from each sampling event were compiled into the project database. The database includes a record of all paper copies of sampling records, chain-of-custody sheets, and analytical laboratory reports. It also includes the project laboratory logbook and instrument calibration records. In addition to the paper copies of the data, all numerical values obtained from the testing were entered into an electronic spreadsheet for further analysis.

For each sampling event, an appropriate statistic describing the data (i.e., average with standard deviation) was calculated for each parameter. These values were plotted as functions of date and discharge volume. Additionally, data from the $\mathrm{mZVI} /$ polymer injection flow cells were compared to data from the experimental control flow cells to determine if significant changes to the geochemistry and permeability had occurred.

\subsubsection{Batch Screening Testing, Injection Screening Testing, and Geochemical Testing}

Data from each sampling event were compiled into the project database. The database includes a record of all paper copies of sampling records, chain-of-custody sheets, and analytical laboratory reports. It also includes the project laboratory logbook and instrument calibration records. In addition to paper copies of the data, all numerical values obtained from testing were entered into an electronic spreadsheet for further analysis. Additionally, data from each material (and test cells) were compared to data from the control to determine if a significant change had occurred.

\subsubsection{Advanced Geochemical Test}

Data from each sampling event for the advanced geochemical testing were compiled into a database. The database includes a record of all paper copies of sampling records, chain-of-custody sheets, and analytical laboratory reports. It also includes the project laboratory logbook and instrument calibration records. In addition to the paper copies of the data, all numerical values obtained from the testing were entered into an electronic spreadsheet for further analysis. For each sampling event, an appropriate statistic describing the data (i.e., average with standard deviation) was calculated for each parameter. These values were plotted as functions of PVs injected. Additionally, data from the test cells were compared to data from the control cell to determine if a significant change is occurring.

A detailed description of the QA/QC procedures can be found in Appendix B.

\subsubsection{Advanced Flow Cell Injection}

Data from each sampling event were compiled into a database. The database includes a record of all paper copies of sampling records, chain-of-custody sheets, and analytical laboratory reports. It also includes the project laboratory logbook and instrument calibration records. In addition to paper copies of the data, all numerical values obtained from testing were entered into an electronic spreadsheet for further analysis. 


\subsection{Deviations from the Treatability Test Plan}

Deviations from the treatability test plan are discussed in this section.

\subsubsection{Micron-Sized Zero-Valent Iron Testing (Original Scope)}

The initial testing of $\mathrm{mZVI}$ was stopped due to inadequate hexavalent chromium reduction. A series of simple batch tests were then designed and performed to evaluate the reactivity of the iron and investigate the effects of the polymer and surfactant on the reactivity (Section 4.1.2.3). The modifications to the proposed test plan procedure are shown in Table 3-24. A complete copy of the original mZVI test plan is provided in Appendix B.

Table 3-24. Modifications to Micron-Sized Zero-Valent Iron Proposed Test Plan

\begin{tabular}{|c|c|c|}
\hline $\begin{array}{l}\text { Proposed Test } \\
\text { Plan Procedure }\end{array}$ & $\begin{array}{l}\text { Procedure Used } \\
\text { in Testing }\end{array}$ & $\begin{array}{l}\text { Reason } \\
\text { for Change }\end{array}$ \\
\hline \multicolumn{3}{|l|}{ Modifications } \\
\hline $\begin{array}{l}\text { Planned to have eight geochemical } \\
\text { flow cells }\end{array}$ & $\begin{array}{l}\text { Added an additional geochemical } \\
\text { flow cell }\end{array}$ & $\begin{array}{l}\text { Needed a clear flow cell to observe } \\
\text { ZVI movements, oxidation, etc. }\end{array}$ \\
\hline $\begin{array}{l}\text { During the mixing of the } \mathrm{mZVI} \\
\text { polymer a nitrogen blanket was to } \\
\text { be used. }\end{array}$ & $\begin{array}{l}\text { A nitrogen blanket was not used, but } \\
\text { mZVI exposure to oxygen was } \\
\text { limited. }\end{array}$ & $\begin{array}{l}\text { A nitrogen blanket was deemed } \\
\text { unnecessary for the purposes of the } \\
\text { experiment. }\end{array}$ \\
\hline $\begin{array}{l}\text { Eliminate all particles greater than } \\
25.4 \mathrm{~mm}(1.0 \text { in.) from Ringold } \\
\text { Unit E soils prior to testing. }\end{array}$ & $\begin{array}{l}\text { Eliminated all particles greater than } \\
25.4 \mathrm{~mm}(1.0 \mathrm{in} .) \text { and less than } \\
0.074 \mathrm{~mm}(0.0024 \text { in.) from Ringold } \\
\text { Unit } E \text { soils prior to testing }\end{array}$ & $\begin{array}{l}\text { Reduce the presence of fines in the } \\
\text { flow cells and their effluent during } \\
\text { testing. }\end{array}$ \\
\hline $\begin{array}{l}\text { Pack the permeability test cells with } \\
12 / 20 \text { Accusand. }\end{array}$ & $\begin{array}{l}\text { Packed the permeability test cells } \\
\text { with } 10 / 20 \text { Colorado silica sand. }\end{array}$ & $\begin{array}{l}\text { Colorado silica was more cost } \\
\text { effective without any negative effect } \\
\text { on the test. }\end{array}$ \\
\hline
\end{tabular}

Additions

The flow cell material was packed inside a rubber sleeve within the flow cells to reduce channeling in the material during injection.

NOTE: Accusand is a registered trademark of Unimin Corporation, New Canaan, Connecticut.

$\mathrm{mZVI}=$ micron-sized zero-valent iron

\subsubsection{Batch Screening Test}

The batch screening tests were carried out as presented in the test plan, without any modifications or additions. The complete test plan for the batch screening is provided in Appendix B.

\subsubsection{Injection Screening Test}

Only one modification was made to the original injection screening test plan, which is presented in Table 3-25. 
Table 3-25. Modifications to Injection Screening Proposed Test Plan

\begin{tabular}{lll}
\multicolumn{1}{c}{$\begin{array}{c}\text { Proposed Test } \\
\text { Plan Procedure }\end{array}$} & \multicolumn{1}{c}{$\begin{array}{c}\text { Procedure Used } \\
\text { in Testing }\end{array}$} & \multicolumn{1}{c}{$\begin{array}{c}\text { Reason } \\
\text { for Change }\end{array}$} \\
\hline $\begin{array}{l}\text { Effluent analysis using turbidity } \\
\text { meter }\end{array}$ & $\begin{array}{l}\text { Effluent analysis using gravimetric } \\
\text { solids }\end{array}$ & $\begin{array}{l}\text { Turbidity too high at low ZVI } \\
\text { concentrations }\end{array}$ \\
\hline $\mathrm{ZVI}=$ zero-valent iron & & \\
\hline
\end{tabular}

\subsubsection{Geochemical Screening Test}

There were no significant modifications made from the original screening geochemical test plan. A detailed summary of the testing is provided in Appendix B.

\subsubsection{Advanced Geochemical Test}

No modifications were made to the original advanced geochemical test plan. A complete treatability test plan for the advanced geochemical tests is provided in Appendix B.

\subsubsection{Advanced Flow Cell Injection}

The modifications and changes to the proposed advanced injection test plan are shown in Table 3-26.

\subsubsection{Modeling}

There were no modifications made from the original modeling test plan. A complete summary of the testing can be found in Appendix B.

Table 3-26. Modifications to the Proposed Advanced Injection Test Plan

\begin{tabular}{|c|c|c|}
\hline $\begin{array}{l}\text { Proposed Test } \\
\text { Plan Procedure }\end{array}$ & $\begin{array}{l}\text { Procedure Used } \\
\text { in Testing }\end{array}$ & $\begin{array}{l}\text { Reason } \\
\text { for Change }\end{array}$ \\
\hline \multicolumn{3}{|l|}{ Modifications } \\
\hline $\begin{array}{l}\text { Planned to have four sampling ports } \\
\text { (A through D). }\end{array}$ & Added a fifth sampling port (E). & $\begin{array}{l}\text { To determine the iron content } \\
\text { deposited in the sand at the } \\
\text { outlet of the column. }\end{array}$ \\
\hline $\begin{array}{l}\text { Planned to preserve approximately } \\
25 \mathrm{~mL} \mathrm{ZVI} \mathrm{fluid} \mathrm{samples} \mathrm{by} \mathrm{adding} \\
0.5 \mathrm{~mL} \mathrm{HNO} \text { before delivering to } \\
\text { laboratory and to analyze } \mathrm{ZVI} \text { fluid } \\
\text { samples using EPA Methods } 3005 \mathrm{~A} \\
\text { (digestion) and } 6010 \mathrm{C} \text { (analysis). }\end{array}$ & $\begin{array}{l}\text { PolyMetallix ZVI fluid samples } \\
\text { preserved as proposed. RNIP-M2 ZVI } \\
\text { fluid samples preserved immediately } \\
\text { after collection using } 2 \mathrm{~mL} \mathrm{HCl} \text {. Added } \\
\text { another } 23 \mathrm{~mL} \text { when delivered to } \\
\text { laboratory. Digestion with } \mathrm{HCl} \text { only. } \\
\text { Analyzed using EPA Method } 6010 \mathrm{C} \text {. }\end{array}$ & $\begin{array}{l}\text { Preserved immediately to } \\
\text { eliminate sorption to the sample } \\
\text { container. A more rigorous } \\
\text { digestion process was } \\
\text { implemented to put the } \mathrm{ZVI} \\
\text { materials completely into } \\
\text { solution. }\end{array}$ \\
\hline $\begin{array}{l}\text { Planned to collect only one } \mathrm{ZVI} \\
\text { injection fluid sample per each flow } \\
\text { rate. }\end{array}$ & $\begin{array}{l}\text { Collected ZVI injection fluid samples } \\
\text { influent to each flow cell. }\end{array}$ & $\begin{array}{l}\text { Extra samples were collected to } \\
\text { evaluate consistency of the } \\
\text { injection solution. }\end{array}$ \\
\hline
\end{tabular}


Table 3-26. Modifications to the Proposed Advanced Injection Test Plan

\begin{tabular}{|c|c|c|}
\hline $\begin{array}{l}\text { Proposed Test } \\
\text { Plan Procedure }\end{array}$ & $\begin{array}{l}\text { Procedure Used } \\
\text { in Testing }\end{array}$ & $\begin{array}{l}\text { Reason } \\
\text { for Change }\end{array}$ \\
\hline $\begin{array}{l}\text { Planned to inject } \mathrm{ZVI} \text { fluid } \\
\text { concentration of } 10 \mathrm{~g} / \mathrm{L} \text { based on } \\
\text { ZVI. }\end{array}$ & $\begin{array}{l}\text { Injected ZVI fluid concentration based } \\
\text { on } 10 \mathrm{~g} / \mathrm{L} \text { solids (resultant total iron } \\
\text { concentrations were } 7,760 \mathrm{mg} / \mathrm{L} \text { for } \\
\text { PolyMetallix and } 9,030 \mathrm{mg} / \mathrm{L} \text { for } \\
\text { RNIP-M2). }\end{array}$ & $\begin{array}{l}\text { Injected on a solids basis for } \\
\text { consistency. }\end{array}$ \\
\hline $\begin{array}{l}\text { Planned to decontaminate sampling } \\
\text { port syringes between samples. }\end{array}$ & Used new syringes for each sample. & $\begin{array}{l}\text { Eliminated any possibility of } \\
\text { cross contamination. }\end{array}$ \\
\hline $\begin{array}{l}\text { Planned to collect ZVI fluid samples } \\
\text { in } 50 \mathrm{~mL} \text { centrifuge tubes. }\end{array}$ & $\begin{array}{l}\text { PolyMetallix ZVI fluid samples } \\
\text { collected as proposed. RNIP-M2 ZVI } \\
\text { fluid samples collected in } 250 \mathrm{~mL} \text {, } \\
\text { wide-mouth polyethylene containers. }\end{array}$ & $\begin{array}{l}\text { Provide room for foaming } \\
\text { generated during the } \\
\text { preservation process }\end{array}$ \\
\hline \multicolumn{3}{|l|}{ Additions } \\
\hline \multicolumn{3}{|c|}{$\begin{array}{l}\text { - Measured field water quality variables (i.e., conductivity, dissolved oxygen, oxidation-reduction potential, } \mathrm{pH} \text {, } \\
\text { and temperature) on a discretionary basis as time allowed. } \\
\text { - Used high shear IKA disperger to maintain ZVI particle size prior to injection. } \\
\text { - Mixed ZVI injection fluid in accordance with Polyflon recommendations and for } 1.4 \mathrm{~min} / \mathrm{gal} \text { of } 1 \text { percent solids. } \\
\text { - Kept PolyMetallix and RNIP-M2 ZVI injection fluids under a nitrogen blanket prior to injection. }\end{array}$} \\
\hline \multicolumn{3}{|c|}{ NOTES: } \\
\hline \multicolumn{3}{|c|}{ RNIP-M2 is a trademark of Toda Kogyo Corporation, Hiroshima, Japan. } \\
\hline \multicolumn{3}{|c|}{ EPA = U.S. Environmental Protection Agency } \\
\hline $\mathrm{ZVI}=$ zero-valent iron & & \\
\hline
\end{tabular}


DOE/RL-2009-35, REV. 0

This page intentionally left blank. 


\section{$4 \quad$ Results and Discussion - Laboratory Testing and Modeling}

This chapter provides an overview of the laboratory testing performed to identify the most promising ZVI material for subsurface injection into failing portions of the ISRM barrier. Complete descriptions of the planned testing can be found in the experimental test plan in Appendix B. Modifications and additions to the original test plans are presented at the end of each individual section. Complete data sets and analytical results are presented in Appendix C. A summary of the costs and schedule associated with the laboratory testing is presented in Section 4.5.

\subsection{Data Analysis and Interpretation}

\subsubsection{Micron-Sized Zero-Valent Iron History}

Injection and geochemical testing were performed to support a mZVI injection demonstration to mend the ISRM barrier in the 100-D Area. The testing was designed to answer the primary question of whether the $\mathrm{mZVI}$ would cause nitrates in the groundwater to be reduced to ammonia, which would adversely impact the aquifer. A secondary question was also evaluated regarding the effectiveness of the mZVI with respect to reducing hexavalent chromium to trivalent chromium. The reduction of hexavalent chromium to trivalent chromium is significant in the overall deployment of the technology; however, it was not the primary focus of laboratory testing conducted under the original scope.

The results of the $\mathrm{mZVL} /$ polymer injection and geochemical testing suggested that a portion of the nitrates in the surrogate groundwater might be reduced to ammonia. The results also suggested that there was some reduction of hexavalent chromium to trivalent chromium, but not as much of a reduction as had initially been anticipated.

\subsubsection{Micron-Sized Zero-Valent Iron Testing (Original Scope)}

Initial laboratory testing was designed to simulate the entire injection process, from pre-injection through post-injection, using small-scale flow cells packed with 100-D Area sediments from the Ringold Formation. The flow cells were injected with $\mathrm{mZVI} /$ polymer, followed by flushing with surrogate groundwater that matched the groundwater chemistry of the 100-D Area and had approximately $450 \mathrm{ppb}$ hexavalent chromium. However, the results observed during $\mathrm{mZVI} /$ polymer injection and geochemical testing indicated that the test results had not adequately addressed the project's concerns (production of ammonia and reduction of hexavalent chromium to trivalent chromium). A literature review was performed that also supported this conclusion. The analytical results and supporting data from the initial $\mathrm{mZVI} /$ polymer injection and geochemical studies are included in Appendix C, Section C1.

\subsubsection{Micron-Sized Zero Valent Iron Injection and Experimental Control Flow Cells}

The results discussed in this subsection include data from 12 horizontal injection flow cells that contained Ringold sediments. Nine flow cells were injected with $\mathrm{mZVI}$ using a carrier fluid consisting of a surfactant and organic polymer, followed by flushing with surrogate groundwater. Three control flow cells only had the surrogate groundwater injected as experimental control. Water quality parameters were measured during and following the injections for all flow cells. In addition, effluent samples were collected at periodic intervals during testing for total chromium, hexavalent chromium, nitrogen, and ammonia analyses. Water quality data from the testing suggest that the geochemistry from flow cells were comparable; therefore, the results from injection flow cell \#4 (injected with both $\mathrm{mZVI} /$ polymer and surrogate groundwater) and experimental control flow cell \#11 (injected with only surrogate groundwater) were used for comparison, as discussed below. As shown in the following figures, the flow cells can be called "columns" or "cells." 
The results shown in Figures 4-1 and 4-2 indicate a significant decrease in specific conductance and DO during the $\mathrm{mZVI} /$ polymer injection, which returned to the baseline conditions following the injection.

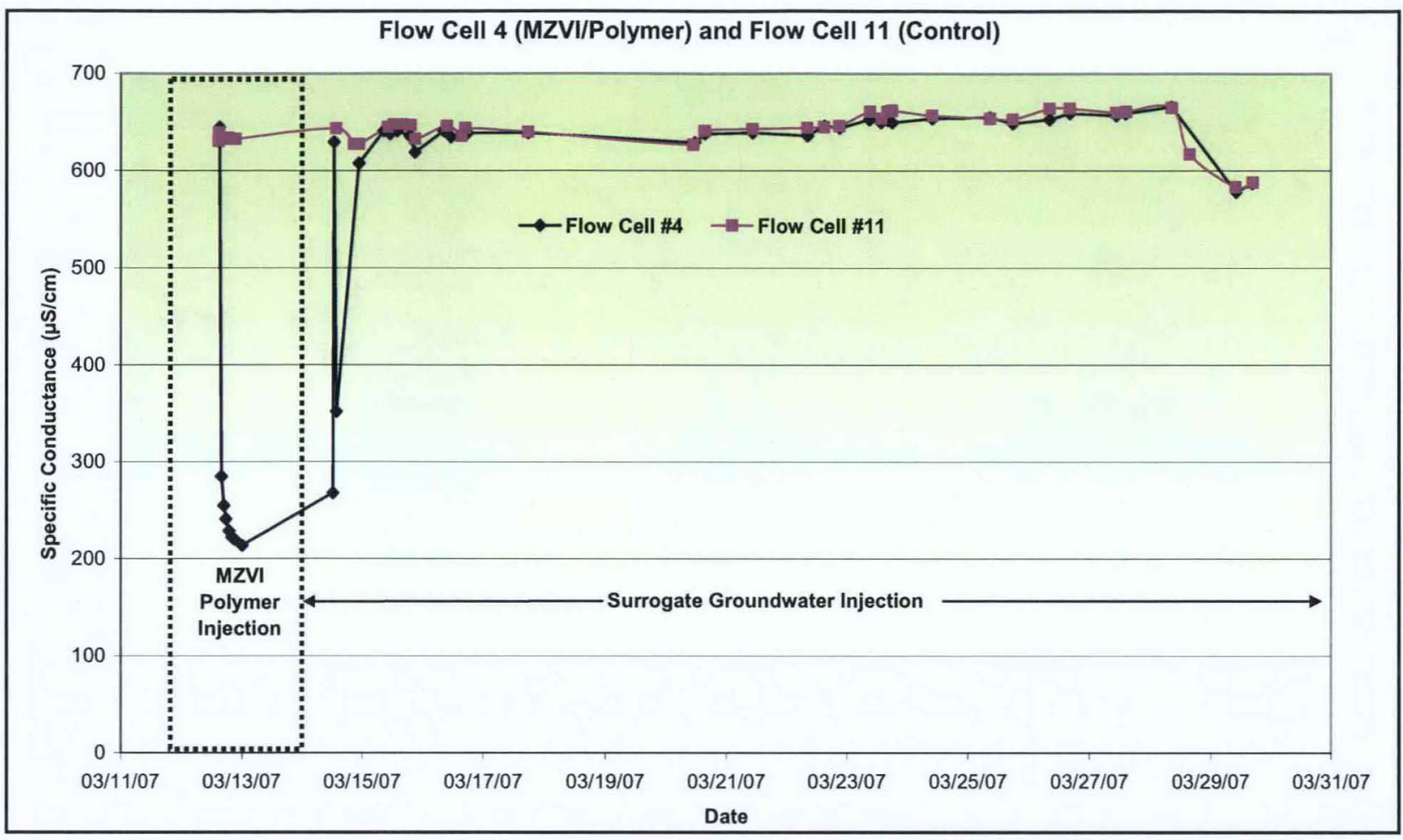

Figure 4-1. Micron-Sized Zero-Valent Iron/Polymer Injection Laboratory Parameters - Specific Conductance

Injection flow cell \#4 (injected with both $\mathrm{mZVI} /$ polymer and surrogate groundwater and represented by the blue line) showed a significant decrease in specific conductance during $\mathrm{mZVI} /$ polymer injection, followed by an increase to near the specific conductance observed in experimental control flow cell \#11 (injected with only surrogate groundwater and represented by the magenta line) during surrogate groundwater injection.

Injection flow cell \#4 (injected with both $\mathrm{mZVI} /$ polymer and surrogate groundwater and represented by the blue line) showed a significant decrease in DO during $\mathrm{mZVI} /$ polymer injection, followed by an increase to near the DO observed in experimental control flow cell \#11 (injected with only surrogate groundwater and represented by the magenta line) during surrogate groundwater injection.

Figure 4-3 presents the $\mathrm{pH}$ of the effluent during the $\mathrm{mZVI} /$ polymer injection. The $\mathrm{pH}$ increased slightly during the $\mathrm{mZVI} /$ polymer injection but returned to near the baseline conditions following the injection.

Injection flow cell \#4 (injected with both $\mathrm{mZVI} /$ polymer and surrogate groundwater and represented by the blue line) showed a slight increase in $\mathrm{pH}$ during $\mathrm{mZVI} /$ polymer injection, followed by a decrease to near the $\mathrm{pH}$ observed in experimental control flow cell \#11 (injected with only surrogate groundwater and represented by the magenta line) during surrogate groundwater injection. 
DOE/RL-2009-35, REV. 0

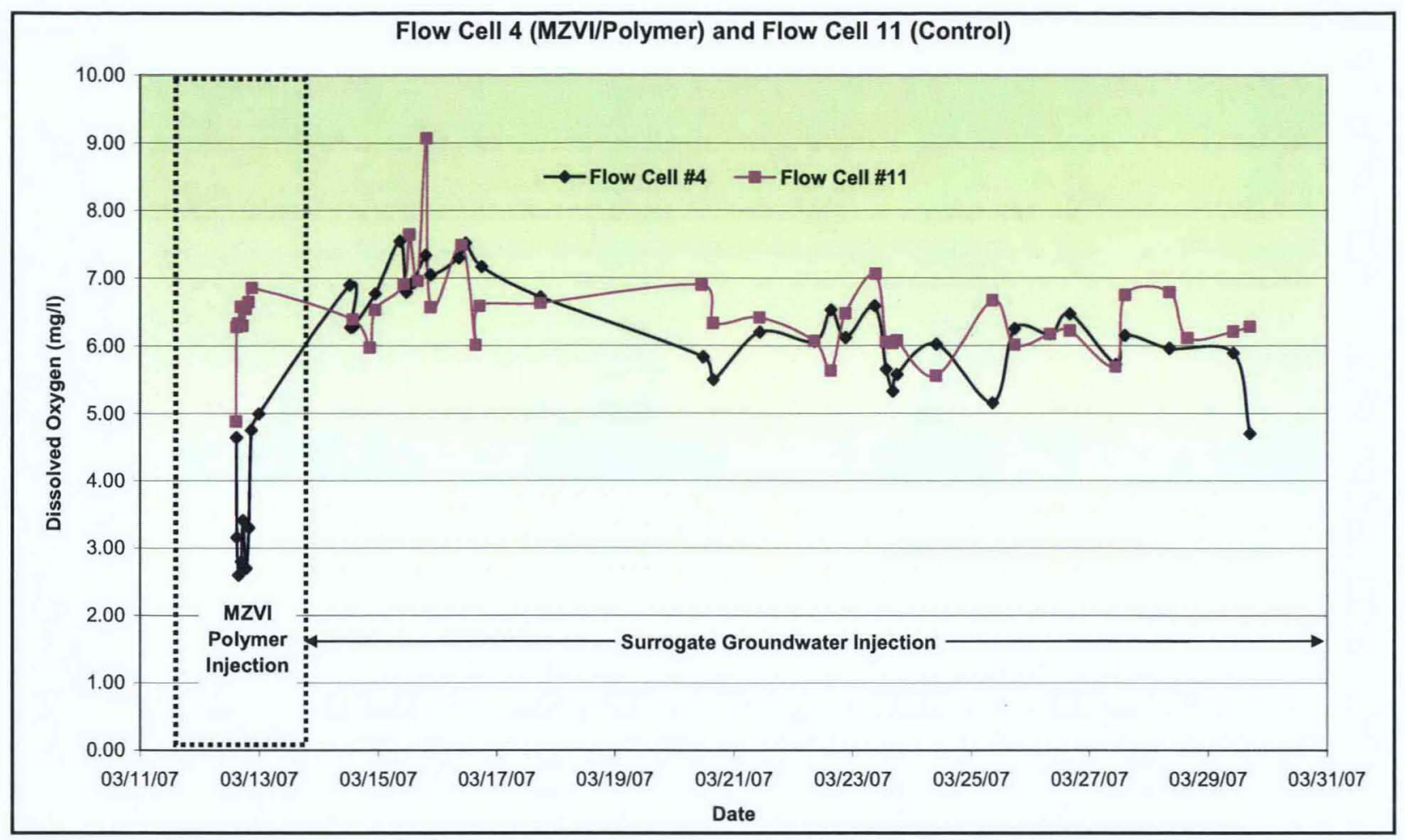

Figure 4-2. Micron-Sized Zero-Valent Iron/Polymer Injection Laboratory Parameters - Dissolved Oxygen

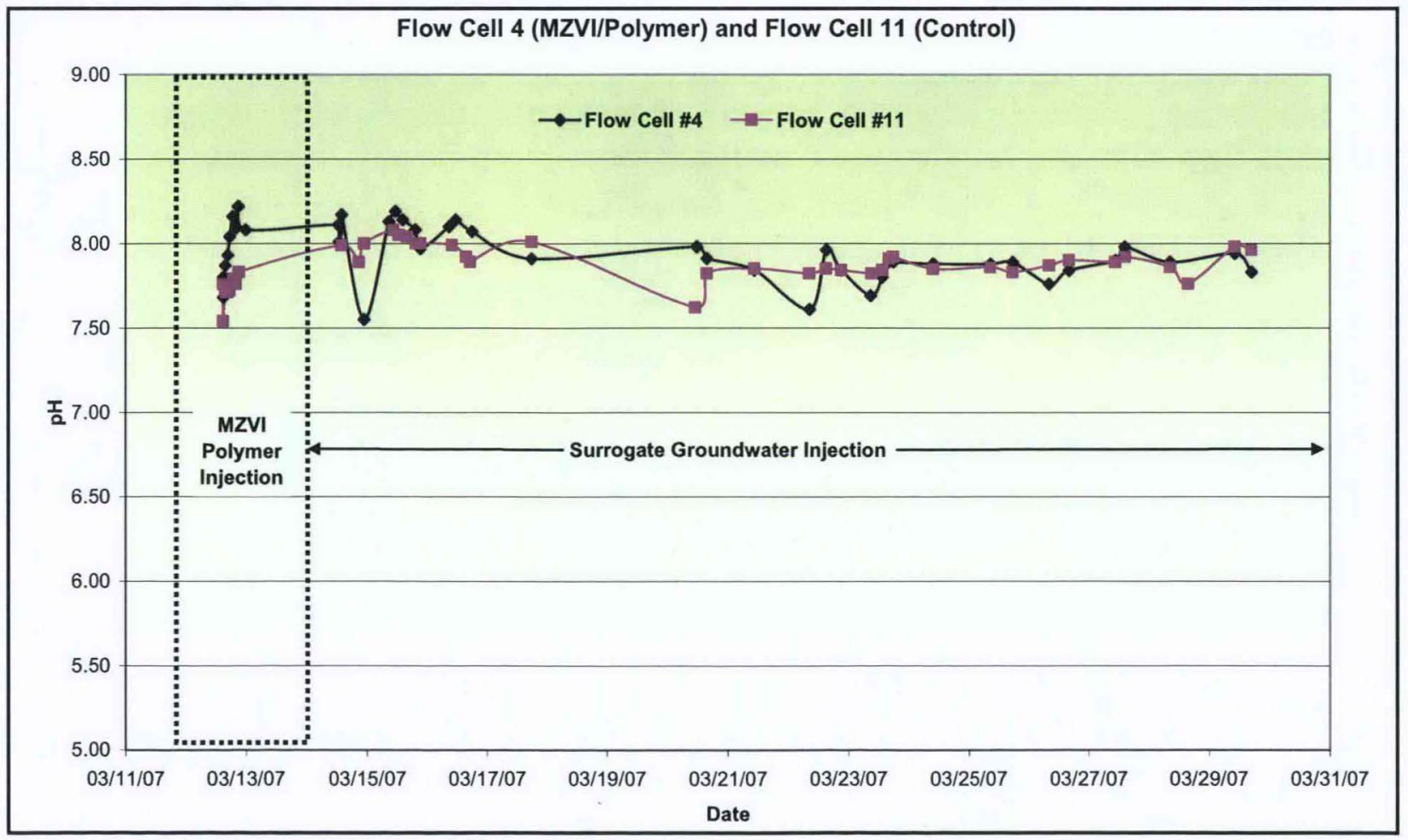

Figure 4-3. Micron-Sized Zero-Valent Iron/Polymer Injection Laboratory Parameters - pH 
Figure 4-4 presents the ORP during the $\mathrm{mZVI} /$ polymer injection. As noted in the figure, it is evident that the ORP of the effluent is not significantly influenced during the $\mathrm{mZVI} /$ polymer injection or during subsequent flushing with surrogate groundwater. The strong similarity between the analytical and control columns was likely due to probe bias from the sequence of analysis, therefore, causing the ORP measurement trends of the two columns to reflect one another. It is expected that the control column ORP values would remain relatively constant; however, this was not observed. Generally, the analytical flow cell (injection flow cell \#4) showed an initial decrease in ORP, followed by an overall increase in ORP with substantial variability.

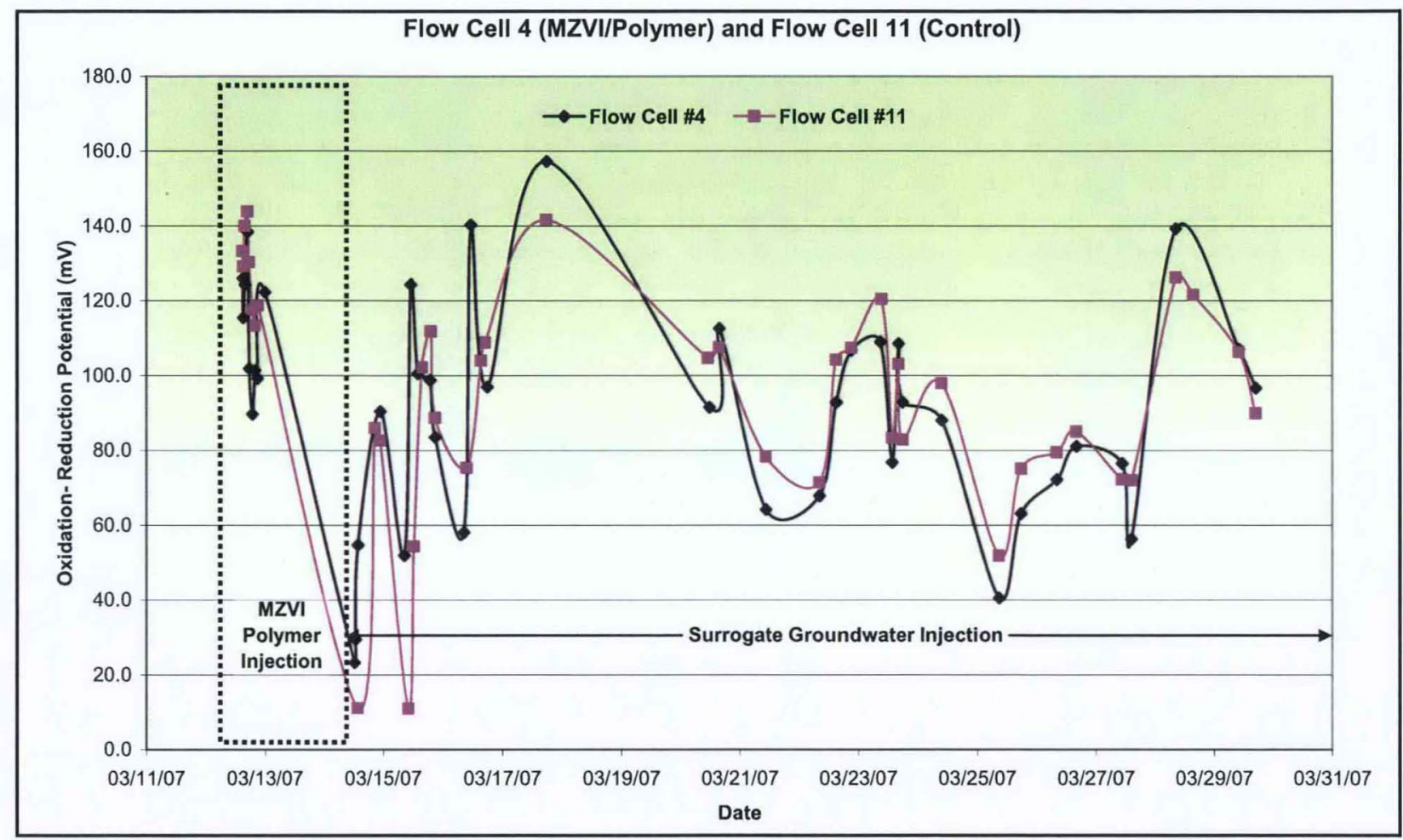

Figure 4-4. Micron-Sized Zero-Valent Iron/Polymer Injection Laboratory Parameters - Oxidation-Reduction Potential

Injection flow cell \#4 (injected with both $\mathrm{mZVI} /$ polymer and surrogate groundwater and represented by the blue line) and experimental control flow cell \#11 (injected with only surrogate groundwater and represented by the magenta line) are similar throughout the injection testing and generally show a slight reduction after $\mathrm{mZVI} /$ polymer injection, followed by some variability and a general increase back to initial conditions during surrogate groundwater injection.

In general, the results of the injection and geochemical testing indicated a slight change in fluid chemistry between the $\mathrm{mZVI} /$ polymer injection fluid and the surrogate groundwater; however, the ORP (which is an indicator of the flow cell reductive capacity) did not change significantly throughout the testing relative to the control column(s). The lack of variance between the control and test columns for the flow cell effluent parameters, $\mathrm{pH}, \mathrm{DO}$, and ORP indicated that the MicroPowder S-3700 (mZVI)/polymer solution may be ineffective at addressing the requirements and goals. However, a significant variance between the control and the test columns was observed for specific conductivity. The lower relative specific conductivity in the test column was likely caused by the presence of the organic carrier fluid. 
Total and hexavalent chromium analyses from the experimental and control flow cells generally indicated a reduction in chromium concentration during $\mathrm{mZVI} /$ polymer injection, but an immediate breakthrough in chromium concentration was noted following surrogate groundwater flushing. The results from the total chromium analyses (Figure 4-5) indicate a reduction in total chromium in injection flow cell \#4, followed by a steady increase in total chromium almost back to concentrations found in the experimental control flow cell \#11.

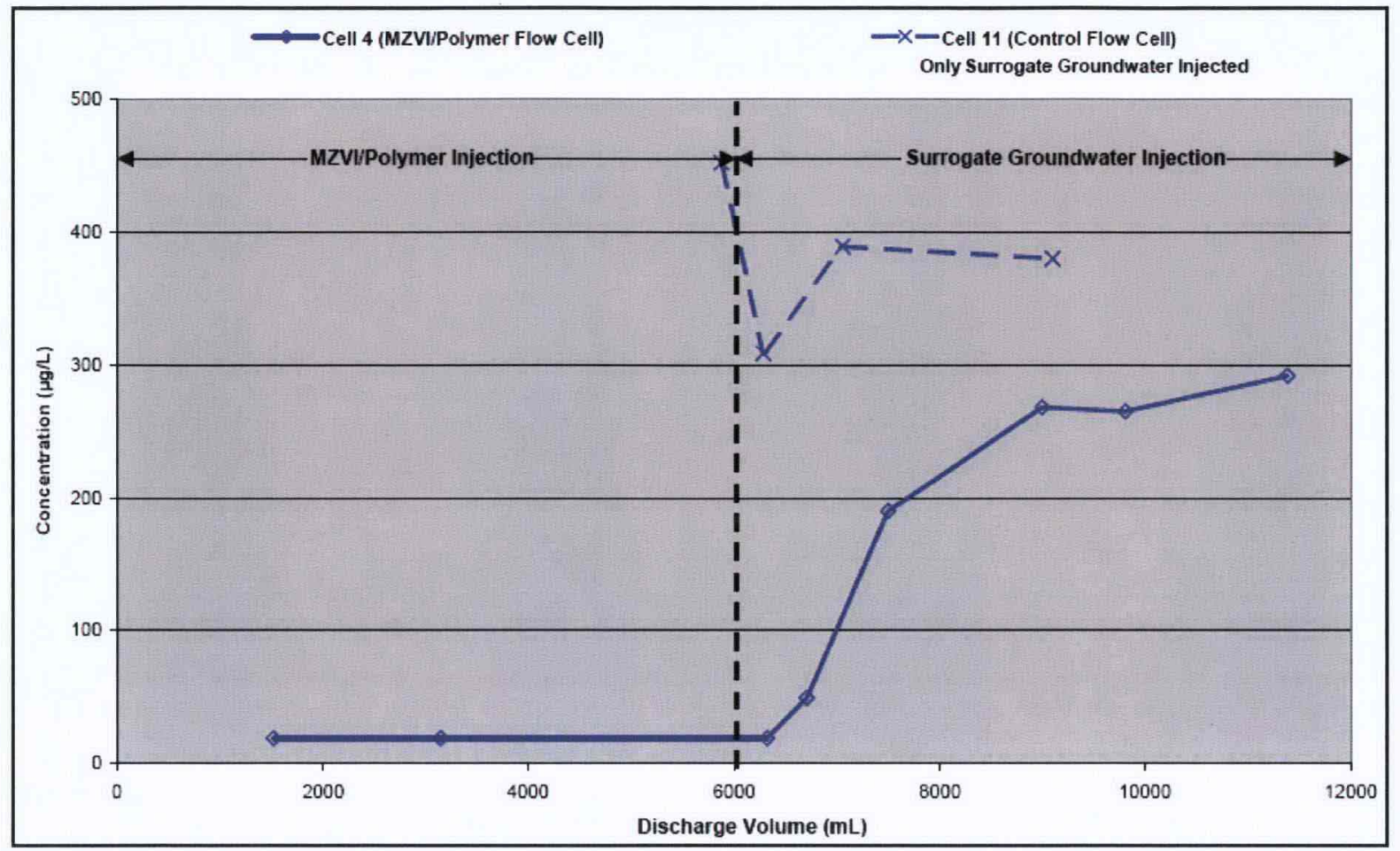

Figure 4-5. Micron-Sized Zero-Valent Iron/Polymer Injection Analytical Results - Total Chromium

Injection flow cell \#4 (injected with both $\mathrm{mZVI} /$ polymer and surrogate groundwater and represented by the solid blue line) showed negligible total chromium concentration during $\mathrm{mZVI} /$ polymer injection, followed by a return to near the concentration found in experimental control flow cell \#11 (injected with only surrogate groundwater and represented by the hatched blue line) during surrogate groundwater injection.

The results from the hexavalent chromium analyses show a subtle increase in the hexavalent chromium during $\mathrm{mZVI} /$ polymer injection, a sudden decrease immediately following surrogate groundwater injection, and then a steady increase in hexavalent chromium almost back to concentrations found in the control flow cell \#11. The results of the hexavalent chromium analyses are provided in Figure 4-6 


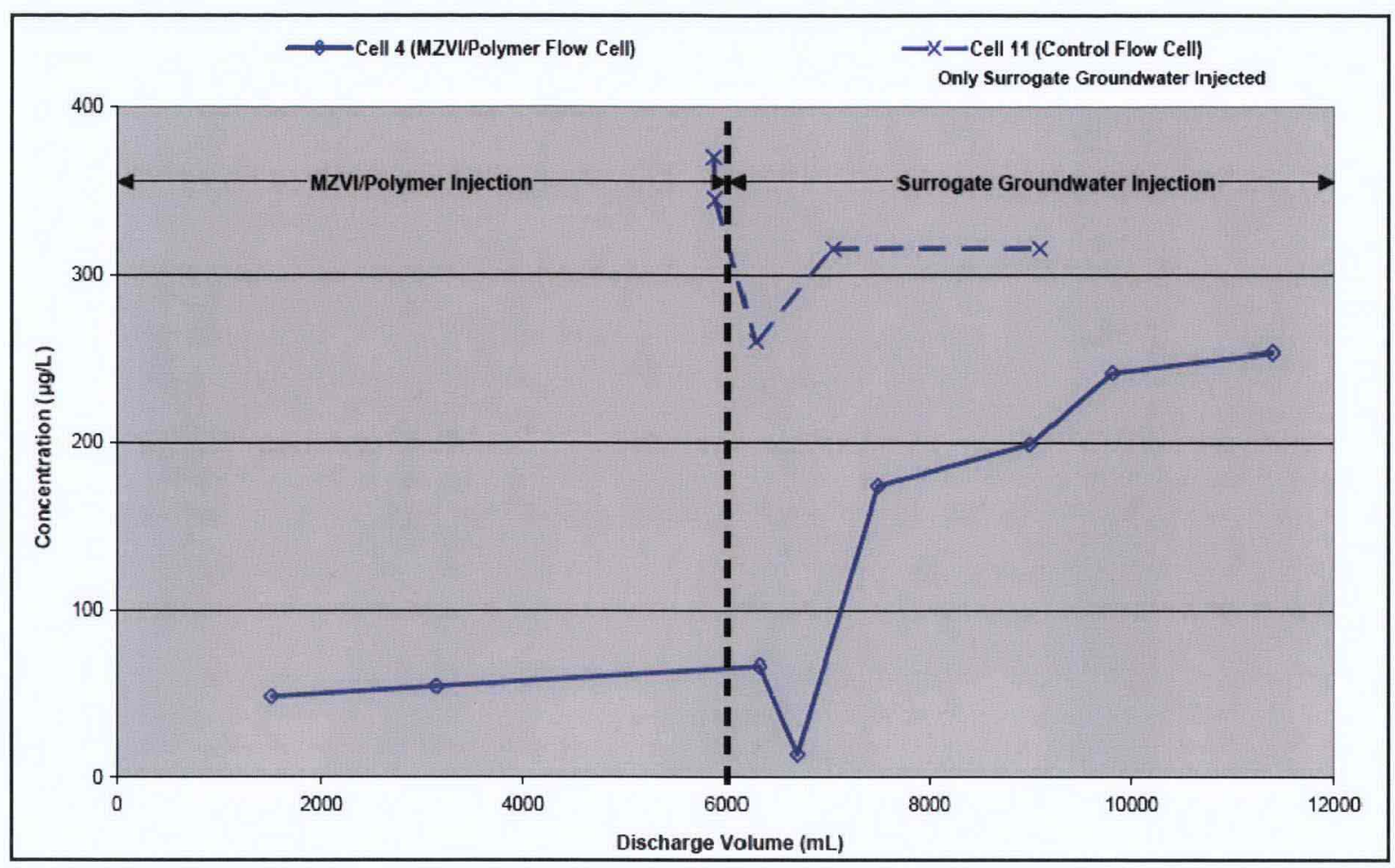

Figure 4-6. Micron-Sized Zero-Valent Iron/Polymer injection Analytical Results - Hexavalent Chromium

Injection flow cell \#4 (injected with both $\mathrm{mZVI} /$ polymer and surrogate groundwater and represented by the solid blue line) showed slightly increasing hexavalent concentration during $\mathrm{mZVI} /$ polymer injection, followed by a sudden decrease, and eventual return to near the concentration found in experimental control flow cell \#11 (injected with only surrogate groundwater and represented by the hatched blue line) during surrogate groundwater injection.

It is interesting to note in Figures 4-5 and 4-6 that the hexavalent chromium concentration is higher than the total chromium concentration throughout MVZI/polymer injection. This may be results of analytical interference due to the analytical technique that was used and/or the high concentrations of organic polymer present in those samples. This anomaly was observed in future analytical testing for chromium and is discussed further in later sections of this report. Another anomaly to note are the reductions in total and hexavalent chromium concentration observed in experimental control flow cell \#11, as well as the fluctuation in hexavalent chromium that was observed in injection flow cell \#4 immediately following surrogate groundwater injections. The fluctuation in chromium concentration was not as notable in control flow cells \#9 and \#10, although there were slight reductions in total and hexavalent chromium concentrations in all three control flow cells throughout the injection test. The reduction in chromium may be an indication of adsorption, other reduction processes, and/or analytical interference. The fluctuation in hexavalent chromium observed in injection flow cell \#4 immediately following surrogate groundwater injection may be a result of analytical interference due to sampling and/or analytical interference due to a high concentration of polymer that may have washed out during surrogate groundwater flushing.

The results from the nitrogen analyses show a negligible concentration of nitrate-nitrate during $\mathrm{mZVI}$ /polymer injection, followed by a return to concentrations found in the control flow cell \#11 (baseline conditions) following $\mathrm{mZVI} /$ polymer injection. The results from the ammonia analyses indicated a slight increase in concentration during $\mathrm{mZVI} /$ polymer injection above the concentration in 
control flow cell \#11 (baseline) and a maximum concentration of about $1.34 \mathrm{mg} / \mathrm{L}$, followed by a reduction during surrogate groundwater flushing to approximately one-third of the high concentration during injection (about $0.48 \mathrm{mg} / \mathrm{L}$ ). The highest ammonia concentration observed during testing was approximately $1.07 \mathrm{mg} / \mathrm{L}$ higher than the highest concentration of ammonia observed in the control column, indicating that the flow cells had the potential to produce approximately $1 \mathrm{mg} / \mathrm{L}$ of ammonia throughout the duration of the test. The nitrate/ammonia results are shown Figure 4-7.

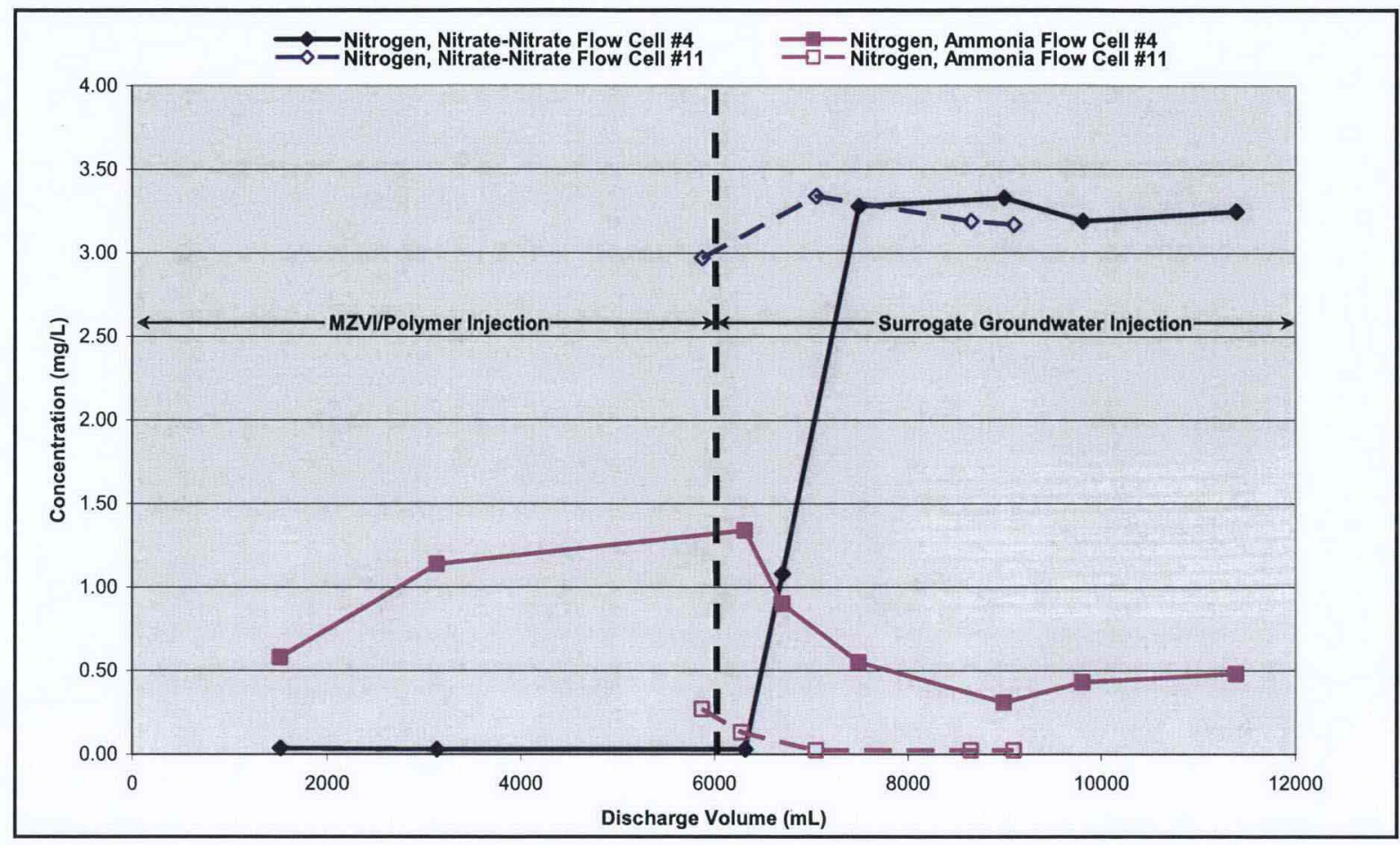

Figure 4-7. Micron-Sized Zero-Valent Iron/Polymer Injection Analytical Results - Nitrate-Nitrate/Ammonia

Injection flow cell \#4 (injected with both $\mathrm{mZVI} /$ polymer and surrogate groundwater and represented by the solid lines) showed a reduction in nitrate-nitrate and a slight increase in ammonia during $\mathrm{mZVI} /$ polymer injection, followed by a an eventual return to near the baseline concentrations found in experimental control flow cell \#11 (injected with only surrogate groundwater and represented by the hatched lines) during surrogate groundwater injection.

A destructive visual examination was performed on injection flow cells \#3, \#4, and \#8 and experimental control flow cell \#11 following the mZVI/polymer injections. Photograph 4-1 shows experimental control flow cell \#11 (which was injected with only surrogate groundwater) after injection testing and is presented as a baseline comparison for Photograph 4-2 (injection flow cell \#3) and Photograph 4-3 (injection flow cell \#8).

Photograph 4-2 shows injection flow cell \#3 (which was injected with $\mathrm{mZVI} /$ polymer) after injection testing, and Photograph 4-3 shows the inlet of injection flow cell \#8 (which was also injected with $\mathrm{mZVI}$ polymer) after injection testing. 
DOE/RL-2009-35, REV. 0

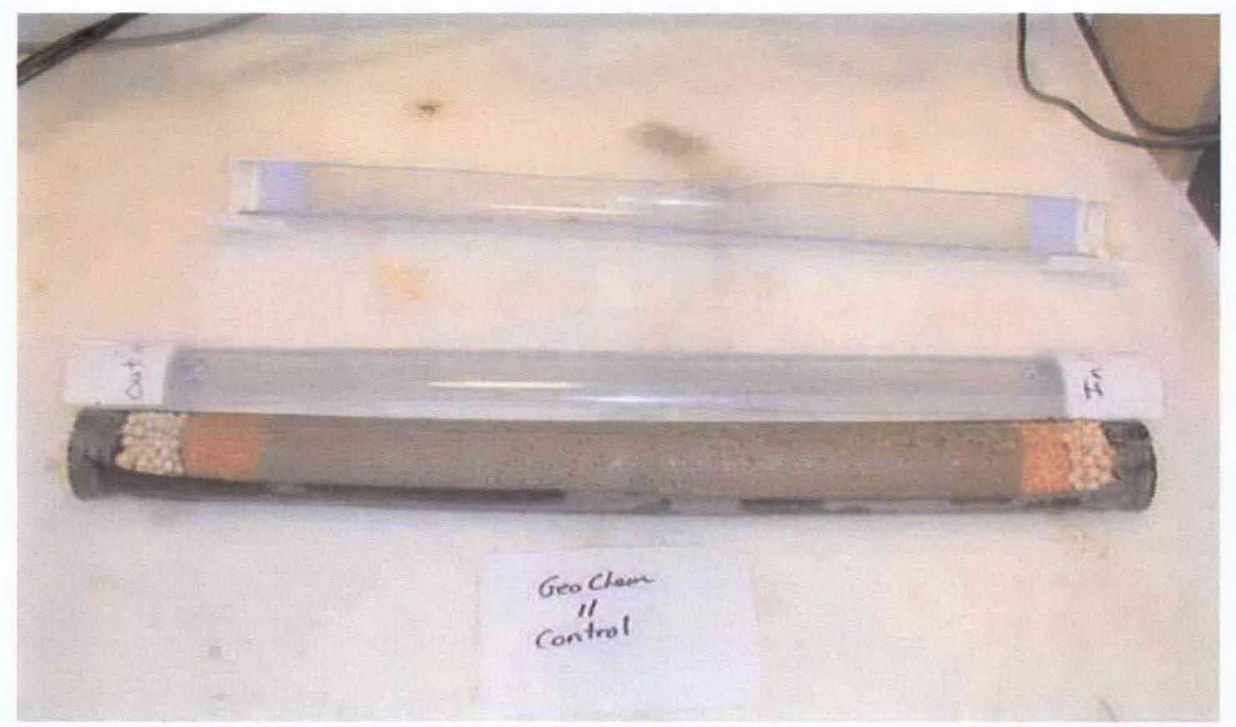

Control cell injected with only surrogate groundwater) after injection testing. The dense stone and silica sand at both ends of the flow cell are approximately 4 inches in length.

\section{Photograph 4-1. Experimental Control Flow Cell \#11}

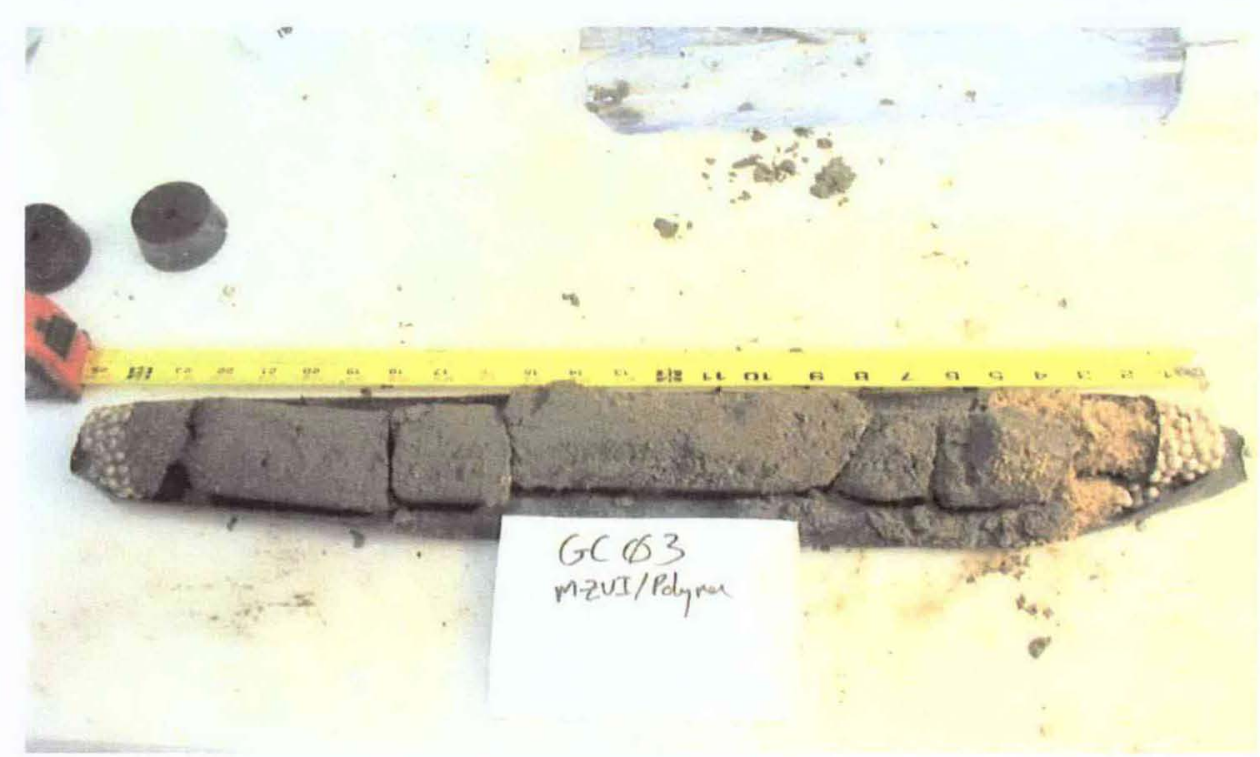

The dense stone and silica sand at both ends of the flow cell are approximately 4 inches in length. Note the difference in color of the silica sand at the inlet compared the outlet and the slight difference in color of the Ringold sediment along the length of the flow cell.

Photograph 4-2. Injection Flow Cell \#3 (Injected with Micron-Sized Zero-Valent Iron Polymer and Surrogate Groundwater) 


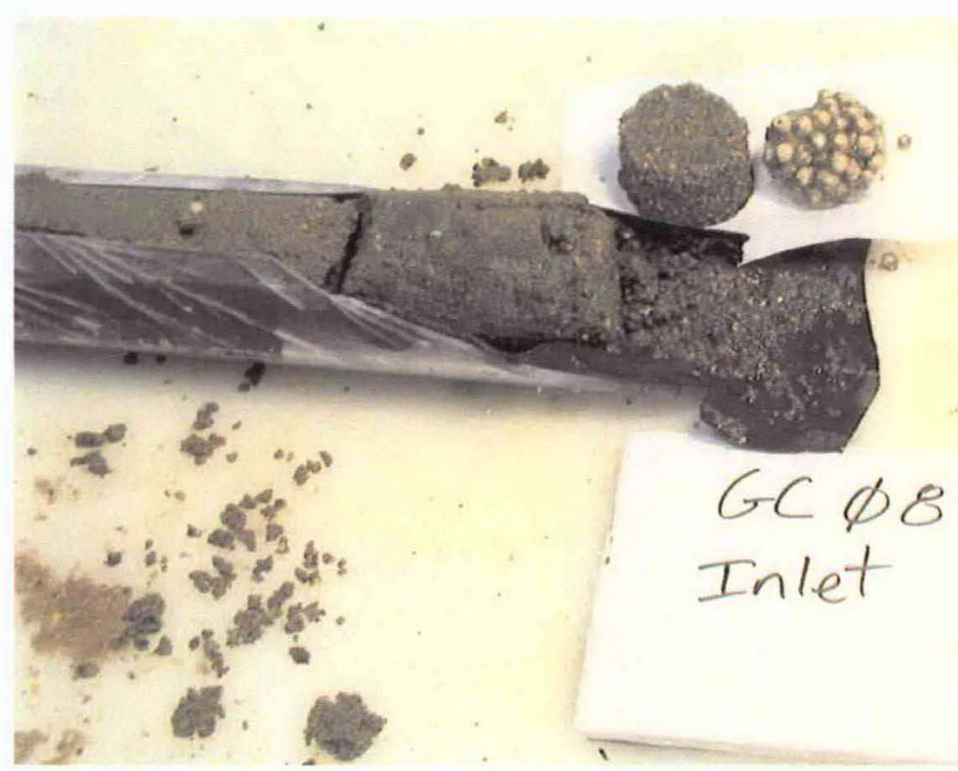

The dense stone and silica sand are placed above the flow cell and are approximately 4 inches in length. Note the darkening color of the Ringold sediment nearest to the inlet.

\section{Photograph 4-3. Injection Flow Cell \#8 (Injected with Micron-Sized Zero-Valent Iron/ Polymer and Surrogate Groundwater}

In addition to the visual examinations, a series of iron digestions of samples taken along the length of the flow cells showed that the bulk of the iron accumulated at the inlet end of the flow cell (Table 4-1). As the yellow-highlighted columns of the table indicate, the samples collected nearest to the inlets of injection flow cells \#3 and \#4 are substantially higher in total iron concentration than that of the experimental control flow cell \#11 (baseline), while the samples collected further from the inlets are near the baseline concentration. The mZVI concentrations near the inlets range from 0.29 to $0.99 \mathrm{wt} \%$.

Table 4-1. Analytical Analyses of Iron Along Selected Flow Cells

\begin{tabular}{|c|c|c|c|c|c|c|c|c|c|}
\hline \multirow[b]{2}{*}{$\begin{array}{l}\text { Flow } \\
\text { Cell \# }\end{array}$} & \multirow[b]{2}{*}{ Section } & \multirow{2}{*}{$\begin{array}{l}\text { Total } \\
\text { Iron, } \\
\mathrm{mg} / \mathrm{L}\end{array}$} & \multirow{2}{*}{$\begin{array}{c}\text { Estimated } \\
\mathrm{mZVI}, \\
\mathrm{mg} / \mathrm{L}\end{array}$} & \multirow{2}{*}{$\begin{array}{c}\text { Total } \\
\text { Volume of } \\
\text { Extraction, } \\
\mathrm{mL}\end{array}$} & \multicolumn{2}{|c|}{ Mass of: } & \multirow[b]{2}{*}{$\begin{array}{l}w t \% \\
m Z V I\end{array}$} & \multirow[b]{2}{*}{ Section } & \multirow[b]{2}{*}{$\begin{array}{l}\text { Lab } \\
\text { ID }\end{array}$} \\
\hline & & & & & $\begin{array}{c}\text { Sample, } \\
\mathbf{g}\end{array}$ & $\underset{\mathrm{g}}{\mathrm{mZVI}}$ & & & \\
\hline 3 & 0" - 4" & 690 & 192 & 200 & 10.034 & 0.04 & $0.38 \%$ & 0" - 4" & \multirow{4}{*}{ GC03 } \\
\hline $\begin{array}{c}3 \\
\text { Duplicate }\end{array}$ & 0" - 4" & 643 & 145 & 200 & 10.022 & 0.03 & $0.29 \%$ & 0" - 4" & \\
\hline 3 & 6" - 9" & 521 & 23 & 200 & 10.080 & 0.00 & $0.04 \%$ & 6" - 9" & \\
\hline 3 & $13 "$ - 17" & 530 & 32 & 200 & 10.018 & 0.01 & $0.06 \%$ & $13^{\prime \prime}-17^{\prime \prime}$ & \\
\hline 4 & $3^{\prime \prime}-6^{\prime \prime}$ & 993 & 495 & 200 & 10.009 & 0.10 & $0.99 \%$ & $3^{\prime \prime}-6^{\prime \prime}$ & \multirow{4}{*}{$\mathrm{GCO}$} \\
\hline $\begin{array}{c}4 \\
\text { Duplicate }\end{array}$ & 3" - 6" & 985 & 487 & 200 & 10.022 & 0.10 & $0.97 \%$ & $3^{\prime \prime}-6^{\prime \prime}$ & \\
\hline 4 & 9" - 12" & 488 & -10 & 200 & 10.059 & 0.00 & $-0.02 \%$ & 9" - 12" & \\
\hline 4 & $18 "-21 "$ & 577 & 79 & 200 & 10.012 & 0.02 & $0.16 \%$ & $18^{\prime \prime}-21^{\prime \prime}$ & \\
\hline
\end{tabular}


Table 4-1. Analytical Analyses of Iron Along Selected Flow Cells

\begin{tabular}{|c|c|c|c|c|c|c|c|c|c|c|}
\hline \multirow{2}{*}{\multicolumn{2}{|c|}{$\begin{array}{l}\text { Flow } \\
\text { Cell \# }\end{array}$}} & \multirow[b]{2}{*}{ Section } & \multirow{2}{*}{$\begin{array}{l}\text { Total } \\
\text { Iron, } \\
\text { mg/L }\end{array}$} & \multirow{2}{*}{$\begin{array}{c}\text { Estimated } \\
\text { mZVI, } \\
\text { mg/L }\end{array}$} & \multirow{2}{*}{$\begin{array}{c}\text { Total } \\
\text { Volume of } \\
\text { Extraction, } \\
\mathrm{mL}\end{array}$} & \multicolumn{2}{|c|}{ Mass of: } & \multirow[b]{2}{*}{$\begin{array}{l}\text { wt } \% \\
\mathrm{mZVI}\end{array}$} & \multirow[b]{2}{*}{ Section } & \multirow[b]{2}{*}{$\begin{array}{l}\text { Lab } \\
\text { ID }\end{array}$} \\
\hline & & & & & & $\begin{array}{c}\text { Sample, } \\
\mathbf{g}\end{array}$ & $\underset{\mathrm{g}}{\mathrm{mZVI}}$ & & & \\
\hline 11 & & 3" - 6" & 483 & N/A & N/A & N/A & N/A & N/A & N/A & N/A \\
\hline 11 & & 9" - 12" & 515 & N/A & N/A & N/A & N/A & N/A & N/A & N/A \\
\hline 11 & & $18^{\prime \prime}-21 "$ & 497 & N/A & N/A & N/A & N/A & N/A & N/A & N/A \\
\hline Blank & & N/A & 0.318 & -- & -- & -- & - & -- & - & -- \\
\hline \multicolumn{11}{|c|}{ ID = identification } \\
\hline \multicolumn{11}{|c|}{$=$ not applicable } \\
\hline \multicolumn{11}{|c|}{$\mathrm{mZVI}=$ micron-sized zero-valent iron } \\
\hline$w t \%$ & $=$ & weight perc & & & & & & & & \\
\hline
\end{tabular}

The poor iron distribution in the injection flow cells (displayed in Photographs 4-2 and 4-3 and Table 4-1) would likely result in a substantially lesser contact time between the chromium or nitrate and the $\mathrm{mZVI}$ impregnated sediments as compared to the contact time that would be expected had the $\mathrm{mZVI}$ been uniformly distributed along the length and cross-sectional area of the flow cells.

\subsubsection{Micron-Sized Zero-Valent Iron Permeability Testing Cells}

The results discussed in this subsection include data from four permeability Testing Cells that contained 10/20 Colorado silica sand, two of which had the mZVI injected in a carrier fluid consisting of a surfactant and organic polymer, followed by flushing with surrogate groundwater, and two control cells that only had the surrogate groundwater injected as experimental control. Water quality parameters were measured during the $\mathrm{mZVI} /$ polymer and surrogate groundwater injections and following the completion of the injections for all flow cells.

A destructive visual examination of the two flow cells injected with $\mathrm{mZVI} /$ polymer suggested that the $\mathrm{mZVI}$ was not distributed uniformly across the flow cells and that some preferential flow paths developed during the injection (Photographs 4-4 and 4-5).

Detailed notes were made in the laboratory logbook to summarize the visual observations made after $\mathrm{mZVI}$ /polymer injection testing on permeability flow cells \#1P and \#2P and are presented in Figures 4-8 and 4-9. As indicated in the figures, the $\mathrm{mZVI} /$ polymer flow in permeability flow cell \#1P appeared to be influenced by a contraction in the rubber membrane approximately $20 \mathrm{~cm}(8 \mathrm{in}$.) from the flow cell inlet. At the inlet side of the contraction, the mZVI appeared to be concentrated along the top half of the flow cell; at the outlet side of the contraction, the mZVI appeared to be heavily concentrated throughout the flow cell to approximately $3.8 \mathrm{~cm}(1.5 \mathrm{in}$.) from the contraction and then blended to lighter gray and became brown (with no apparent $\mathrm{mZVI}$ ) at approximately $61 \mathrm{~cm}(24 \mathrm{in}$.) from the inlet. 


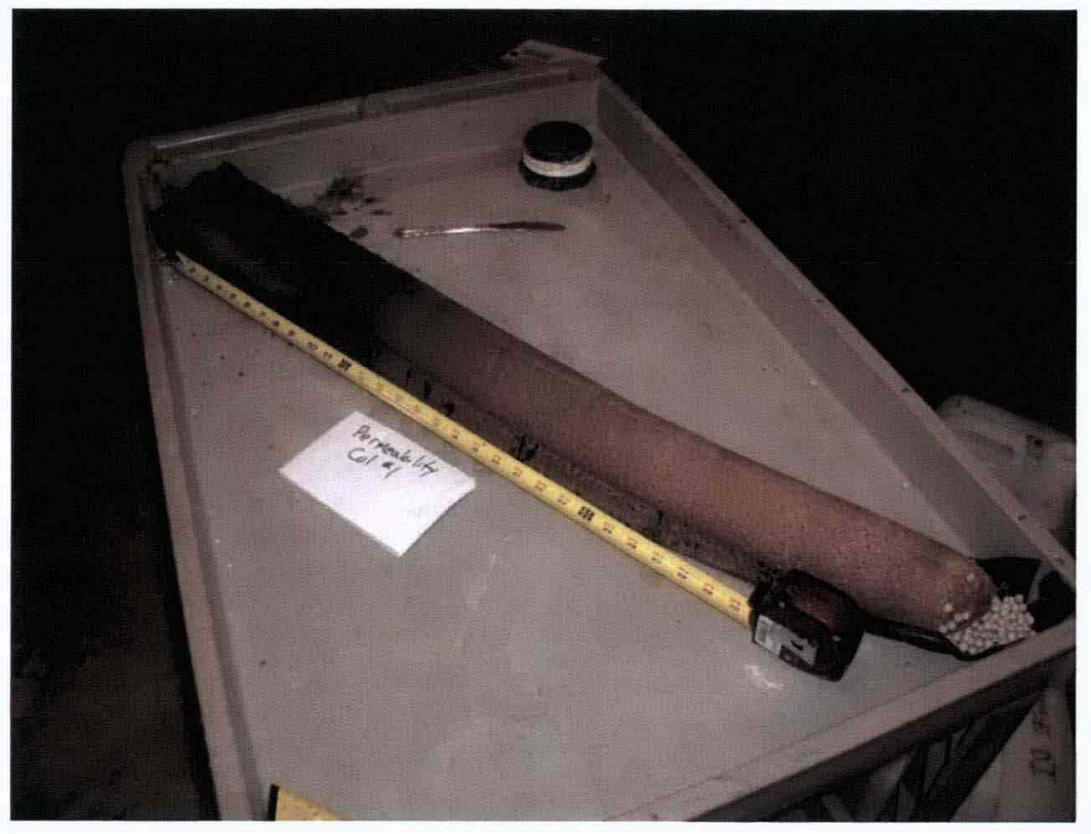

Photograph 4-4. Permeability Flow Cell \#1P After Micron-Sized Zero-Valent Iron/Polymer Injection

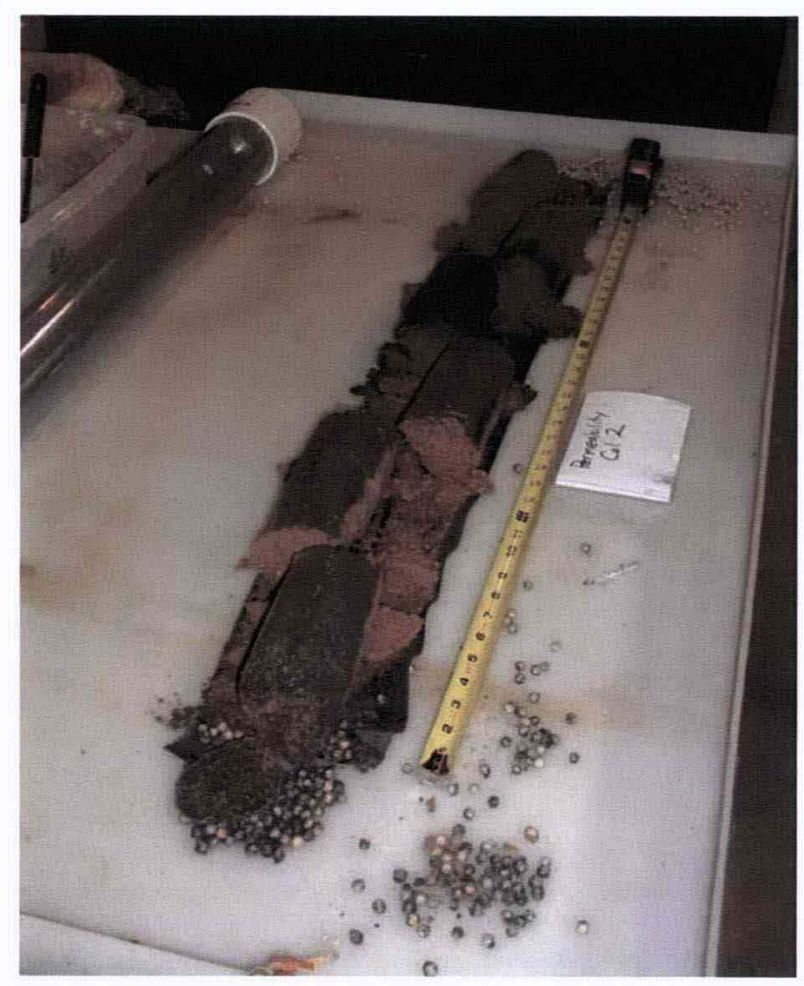

Photograph 4-5. Permeability Flow Cell \#2P After Micron-Sized Zero-Valent Iron/Polymer Injection 
In permeability flow cell \#2P, the $\mathrm{mZVI} /$ polymer movement appeared to be influenced by a contraction in the rubber membrane approximately $47 \mathrm{~cm}$ (18.5 in.) from the flow cell inlet. The mZVI appeared to be channeled along the top half of the flow cell at the inlet side of the contraction; at the outlet side of the contraction, the mZVI appeared to be concentrated along the top and bottom half of the flow cell and blended to lighter gray and became brown (with no apparent mZVI) at approximately $62.2 \mathrm{~cm}(24.5 \mathrm{in}$.) from the inlet. The visual observations made of permeability flow cell \#1P and permeability flow cell \#2P are summarized in Figures 4-8 and 4-9, respectively.

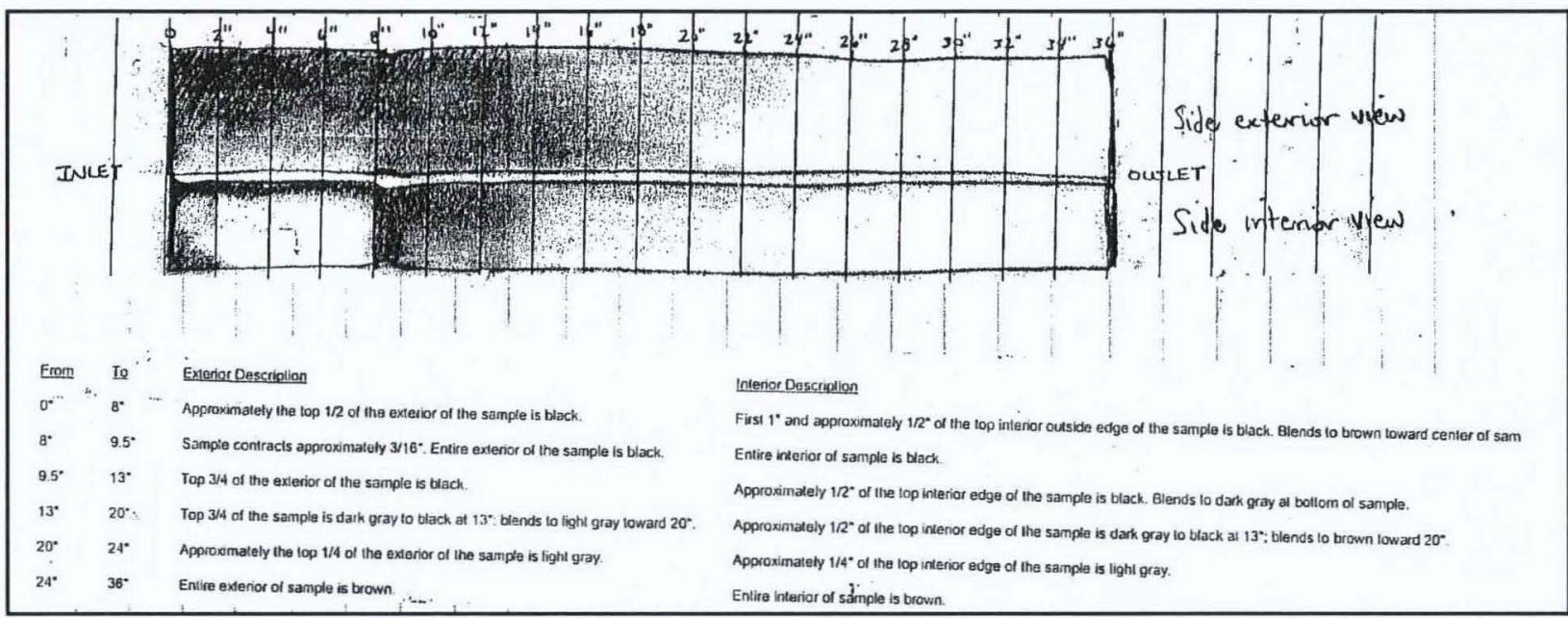

Figure 4-8. Description of Permeability Flow Cell \#1P After Micron-Sized Zero-Valent Iron Injection
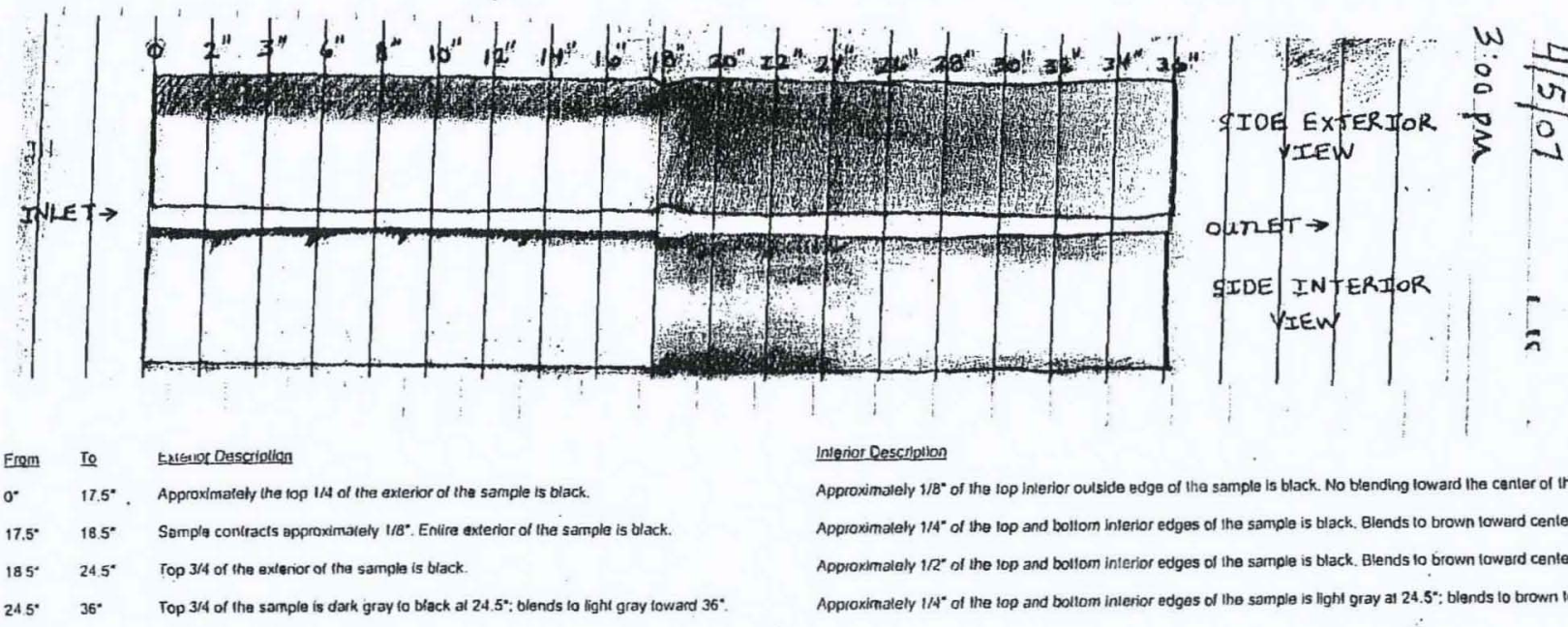

Figure 4-9. Description of Permeability Flow Cell \#2P After Micron-Sized Zero-Valent Iron Injection 


\subsubsection{Micron-Sized Zero-Valent Iron Simple Batch Tests}

Before testing began, it was assumed that hexavalent chromium would be reduced over the course of the injection and geochemical laboratory testing; however, analysis of the treated water suggested that very little reduction of hexavalent chromium was occurring. Upon further research, it was discovered that MicroPowder S-3700 zero-valent iron had much slower reaction rates as compared to ferrous iron. In addition, reaction of the $\mathrm{mZVI}$ could have further been impeded due to the addition of a surfactant and polymer during the mZVI injection. After considering the data, it was determined that additional information on the kinetics of the reduction reaction with $\mathrm{mZVI}$ was needed before this compound was tested in the field. In April 2007, a series of simple batch tests were completed to investigate the interactions between $\mathrm{mZVI}$ solution compounds and a surrogate groundwater containing hexavalent chromium. These tests and the results are summarized in this section.

The batch tests (a total of four) were designed to assess the reaction rate of the mZVI and the effects of additives (e.g., surfactant and polymer) on reaction rates. Table 4-2 summarizes the four mixtures tested in the simple batch tests.

Table 4-2. Summary of Batch Test Mixtures

\begin{tabular}{|c|c|c|c|c|}
\hline $\begin{array}{l}\text { Batch Test } \\
\text { Description }\end{array}$ & $\begin{array}{l}\text { mZVI (S-3700 } \\
\text { ZVI Colloids }\end{array}$ & $\begin{array}{c}\text { Aerosol } \\
\text { (Aerosol 22) }\end{array}$ & $\begin{array}{c}\text { Polymer } \\
\text { (SlurryPro } \\
\text { CDP) }\end{array}$ & $\begin{array}{l}\text { R-12 Sponge } \\
\text { Iron Powder }\end{array}$ \\
\hline mZVI & $\mathrm{x}$ & & & \\
\hline $\mathrm{mZVI}+$ aerosol & $\mathrm{X}$ & $\mathrm{x}$ & & \\
\hline $\mathrm{mZVI}+$ aerosol + polymer & $\mathrm{x}$ & $\mathrm{x}$ & $\mathrm{x}$ & \\
\hline Sponge iron powder & & & & $x$ \\
\hline \multicolumn{5}{|l|}{ NOTES: } \\
\hline \multicolumn{5}{|c|}{ Aerosol $22^{\mathrm{TM}}$ is a trademark of Sigma Chemical Company, St. Louis, Missouri. } \\
\hline \multicolumn{5}{|c|}{ R-12 Sponge iron powder is a product of North American Höganäs, Hollsoppie, Pennsylvania. } \\
\hline \multicolumn{5}{|c|}{ SlurryPro ${ }^{\circledR}$ is a registered trademark of KB International, LLC, Chattanooga, Tennessee. } \\
\hline \multicolumn{5}{|c|}{$\mathrm{mZVI}=$ micron-sized zero-valent iron } \\
\hline $\mathrm{ZVI}=$ zero-valent iron & & & & \\
\hline
\end{tabular}

The mZVI mixture was composed of MicroPowder S-3700 ZVI colloids, Aerosol 22, and SlurryPro CDP. This was determined by previous studies to be optimal for injecting into 100-D Area aquifer sediments (PNNL-15573). The R-12 sponge iron powder 6 is another form of powered iron that had been successfully used in previous remediation. The physical properties of the R-12 sponge powder are shown in Table 4-3.

${ }^{6}$ R-12 Sponge iron powder is a product of North American Höganäs, Hollsoppie, Pennsylvania. 
Table 4-3. R-12 Sponge Iron Powder Physical Properties

\begin{tabular}{ccccc}
\hline $\begin{array}{c}\text { D50, } \\
\boldsymbol{\mu m}\end{array}$ & $\begin{array}{c}\text { Percent by Weight } \\
<\# 200 \text { Sieve }\end{array}$ & $\begin{array}{c}\text { Surface Area, } \\
\mathbf{m}^{2} / \mathbf{g}\end{array}$ & $\begin{array}{c}\text { Percent Iron } \\
\text { by Weight }\end{array}$ & $\begin{array}{c}\text { Apparent Density, } \\
\mathbf{g} / \mathbf{c m}^{\mathbf{3}}\end{array}$ \\
\hline 260 & 5 & 0.23 & 97.3 & 1.34 \\
\hline
\end{tabular}

NOTE: R12 sponge iron powder is a product of North American Höganäs, Hollsoppie, Pennsylvania.

Each batch test was completed using $400 \mathrm{~g}$ (approximately $400 \mathrm{~mL}$ ) of the surrogate groundwater. Combinations of the remaining ingredients were then added to the groundwater. The amounts of S-3700 ZVI colloids, Aerosol 22, SlurryPro CDP, and R-12 sponge iron powder used were always $1 \mathrm{wt} \%$, $0.001 \mathrm{wt} \%, 0.02 \mathrm{wt} \%$, and $1 \mathrm{wt} \%$, respectively. These ratios had been optimized during prior laboratory work (PNNL-15573).

The batch tests were run for approximately 66 hours. Laboratory parameters (including temperature, specific conductivity, DO, $\mathrm{pH}$, and ORP) were monitored for each of the tests using a YSI ${ }^{\circledR}$ Model 556 MPS multi-parameter probe. Prior to mixing, a set of baseline laboratory parameters for the surrogate groundwater were acquired. After mixing (i.e., time zero), the laboratory parameters were acquired at 10-minute intervals for the 66-hour duration of the test. The ORP, DO, and the $\mathrm{pH}$ results, which are most indicative of the reducing conditions that were developed in the columns by the ZVI materials, are presented in Figures 4-10, 4-11, and 4-12, respectively.

As the figures below indicate, the ORP decreased for all samples; however, the ORP of the sponge iron sample varied widely during the latter half of the test but decreased more than in any of the other samples, and even became negative during the test. The DO of the mZVI samples decreased to about 4.0 to $4.75 \mathrm{mg} / \mathrm{L}$, while the DO of the sponge iron sample decreased the most and was at about $3.25 \mathrm{mg} / \mathrm{L}$ and dropping at the end of the test. The $\mathrm{pH}$ of the $\mathrm{mZVI}$ samples increased slightly to between 8.0 and 8.2 , while the $\mathrm{pH}$ in the sponge iron sample increased quickly, from about 7.7 to 8.6, during the first 20 hours of testing and then leveled off at about 8.7. Although not shown in the figures below, specific conductivity of the sponge iron test remained fairly constant (approximately $648 \mu \mathrm{S} / \mathrm{cm}$ ) throughout the duration of the test, then decreasing slightly toward the end of the test.

At the end of the test, the mZVI and sponge iron samples and a baseline surrogate groundwater sample were collected and analyzed for total chromium and hexavalent chromium analyses. The results from the total chromium and hexavalent chromium tests are summarized in Table 4-4. As the table indicates, the commercially available sponge iron powder was effective at completely reducing the hexavalent chromium, while the mZVI and mZVI + aerosol reduced only about one-half of the hexavalent chromium. The $\mathrm{mZVI}+$ aerosol + polymer (i.e., the prescribed recipe for $\mathrm{mZVI} /$ polymer injection) only reduced the hexavalent chromium by about one-third.

$\mathrm{YSI}^{\circledR}$ is a registered trademark of YSI Incorporated, Yellow Springs, Ohio. 


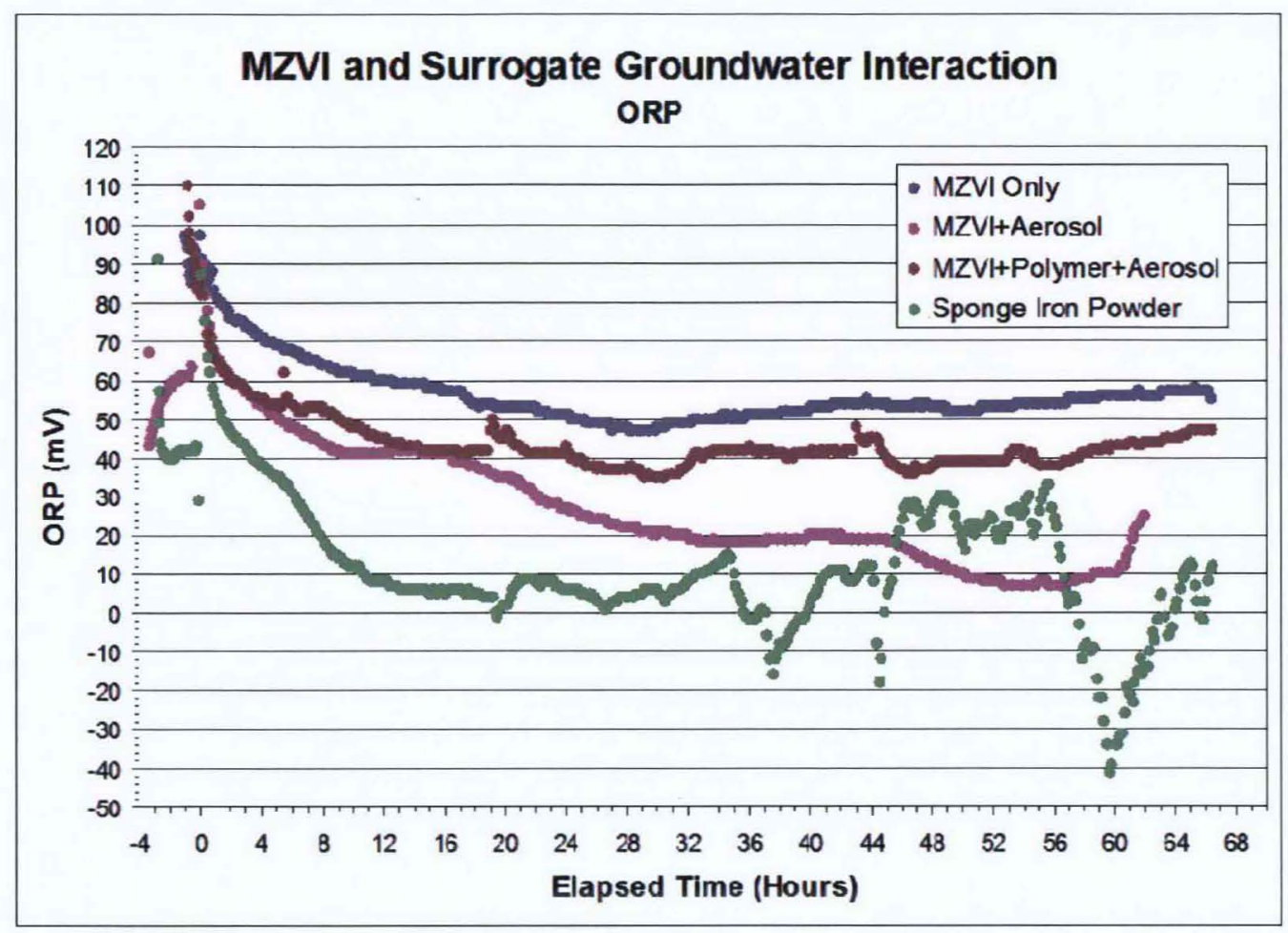

Figure 4-10. Oxidation-Reduction Potential Trend During Simple Batch Testing

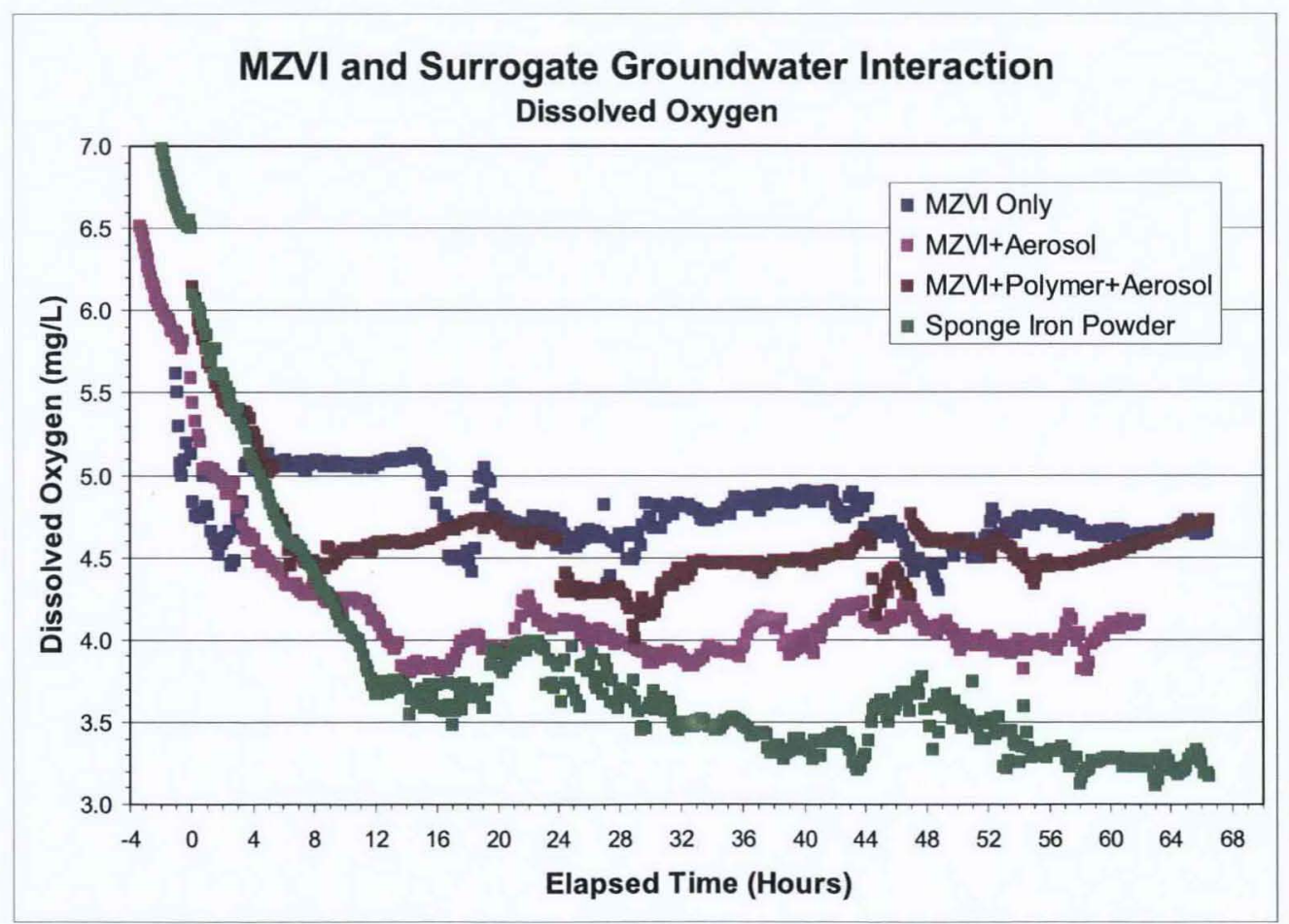

Figure 4-11. Dissolved Oxygen Trend During Simple Batch Testing 


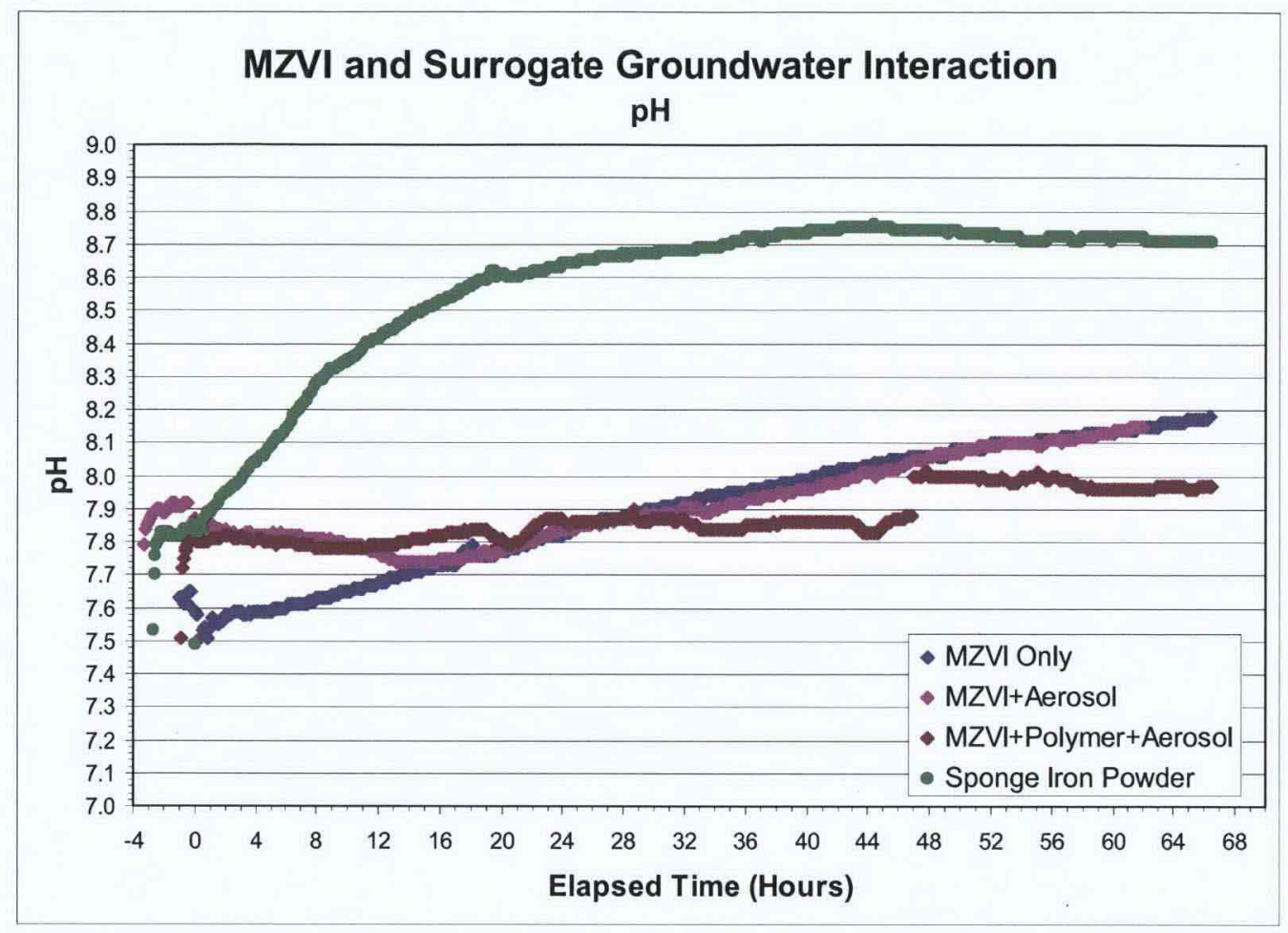

Figure 4-12. pH Trend During Simple Batch Testing

Table 4-4. Total Chromium and Hexavalent Chromium Analytical Results

\begin{tabular}{lccc}
\hline $\begin{array}{c}\text { Batch Test } \\
\text { Description }\end{array}$ & $\begin{array}{c}\text { Total Chromium, } \\
\text { ppb }\end{array}$ & $\begin{array}{c}\text { Hexavalent } \\
\text { Chromium, ppb }\end{array}$ & $\begin{array}{c}\text { \% Hexavalent } \\
\text { Chromium Reduced }\end{array}$ \\
\hline Surrogate groundwater & 303 & 245 & N/A \\
mZVI & 153 & 131 & $46.5 \%$ \\
mZVI + aerosol & 128 & 121 & $50.6 \%$ \\
mZVI + aerosol + polymer & 223 & 163 & $33.5 \%$ \\
Sponge iron powder & 11 & 0 & $100 \%$ \\
\hline
\end{tabular}

$\mathrm{mZVI}=$ micron-sized zero-valent iron

$\mathrm{N} / \mathrm{A}=$ not applicable

$\mathrm{ppb}=$ parts per billion

Photograph 4-6 shows the simple batch tests after the 66-hour test was completed. As indicated in the photograph, oxidation (i.e., reddish brown discoloration of the iron) was visible after the duration of the test in both the bare $\mathrm{mZVI}$ and sponge iron powder tests. However, no oxidation was visible in the mZVI + aerosol and $\mathrm{mZVI}+$ aerosol + polymer tests. 


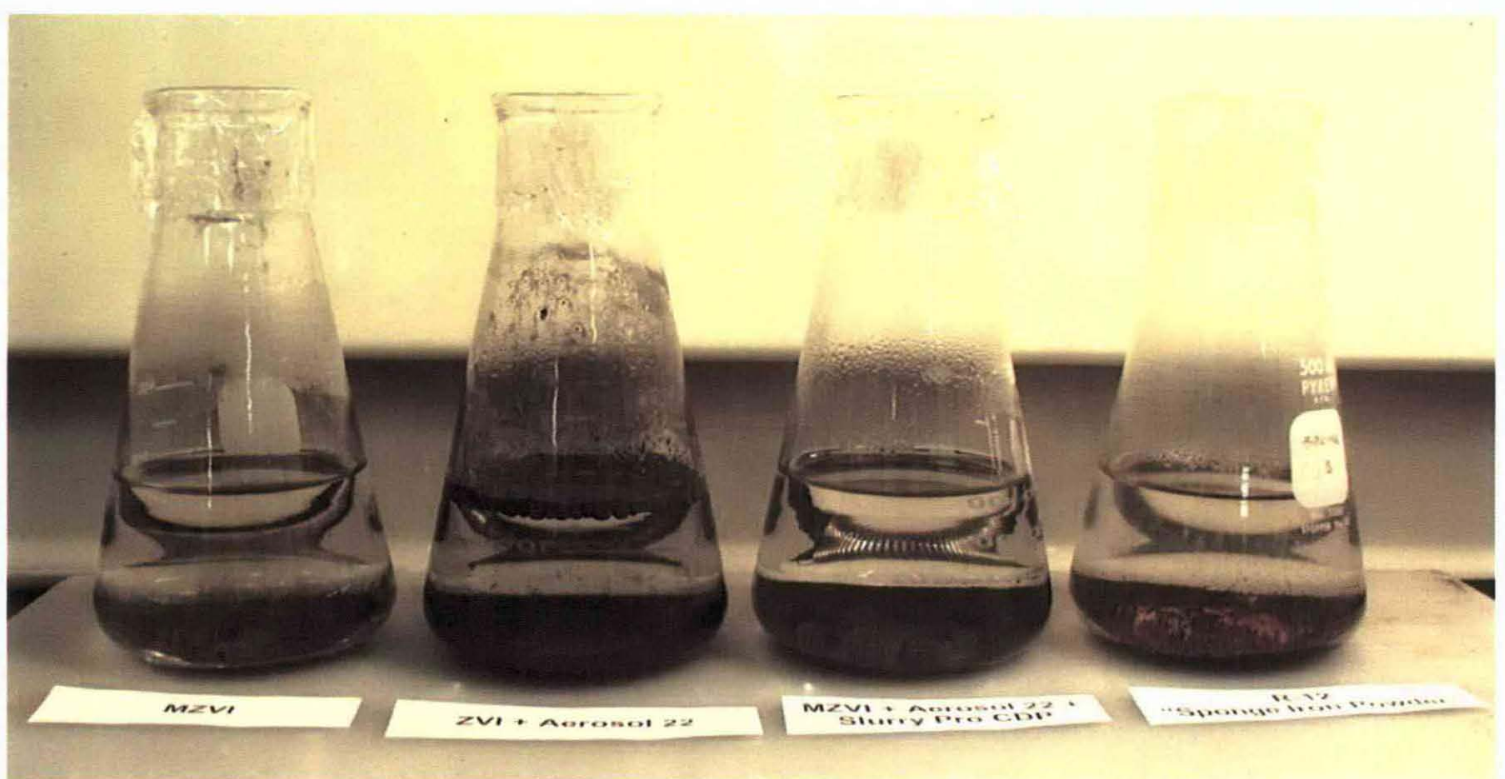

Left to right: $m Z V I, m Z V I+$ Aerosol, $m Z V I+$ Aerosol+Polymer, and sponge iron powder.

Photograph 4-6. Simple Batch Tests After Completion

Visual observation of the samples approximately 8 months after the simple batch tests indicated that the bare $\mathrm{mZVI}$ and R-12 sponge iron powder had an almost completely oxidized surface, and the $\mathrm{mZVI}+$ aerosol had some oxidation. However, the $\mathrm{mZVI}+$ aerosol + polymer showed no sign of oxidation (see Photograph 4-7).

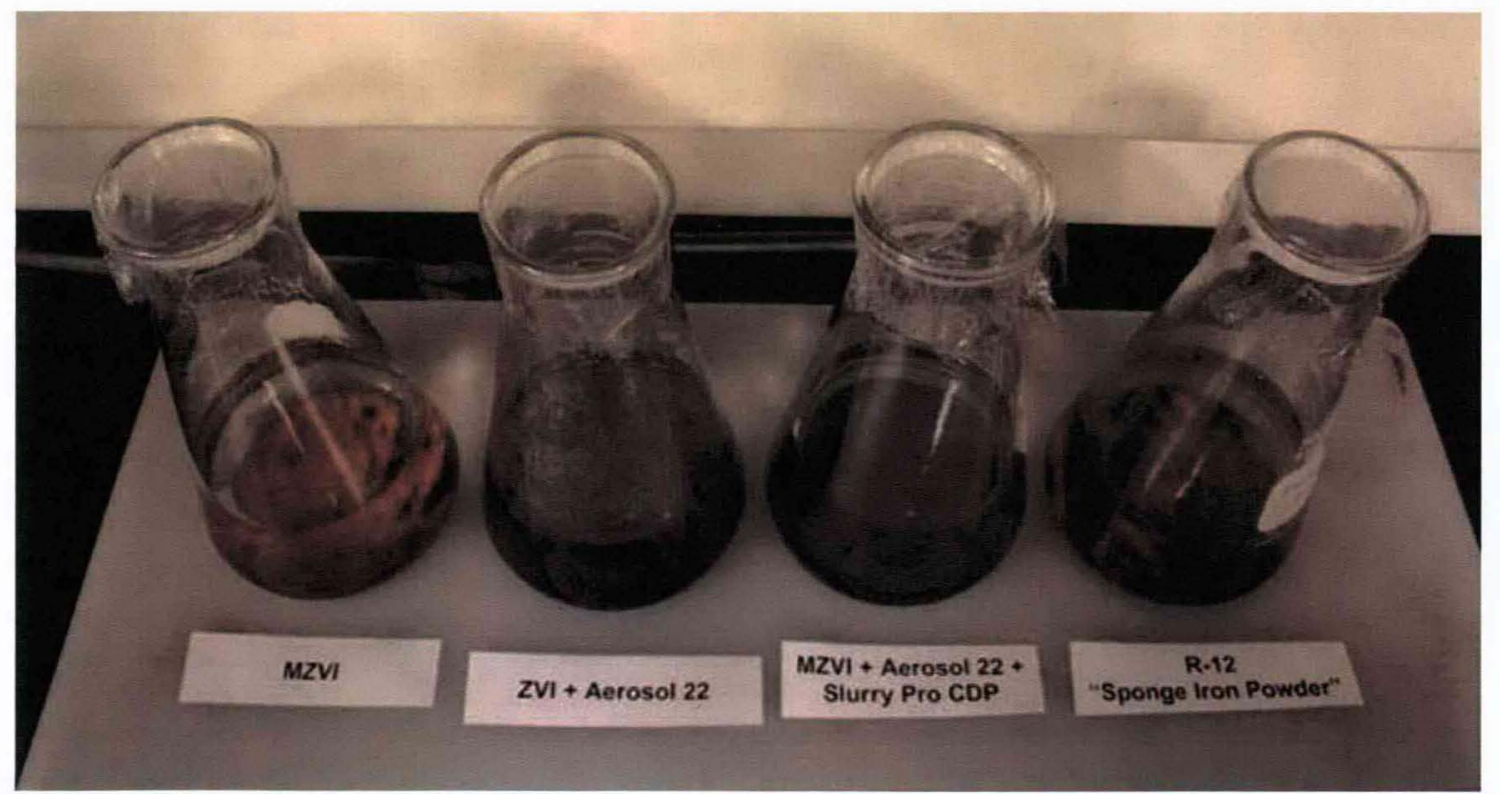

Left to right: $m Z V I, m Z V I+$ Aerosol, $m Z V I+$ Aerosol+polymer, and sponge iron powder.

Photograph 4-7. Simple Batch Tests 8 Months After Completion 


\subsubsection{Batch Screening Test}

Controlled batch tests were performed on the top six ranked materials in the database without polymer modification: EZVI, PolyMetallix, NanoFe I, NanoFe II, Z-loy, and RNIP-M2. Bare particles without polymer modification were used in the batch screening test, thus RNIP-10DS was used instead of RNIP-M2. The experiments evaluated the materials on their ability to create a reducing environment and to reduce hexavalent chromium. The following sections describe the findings of the batch screening tests. A complete description of the experimental test plan is provided in Appendix B. Data and analytical results from the testing are discussed in Appendix C, Section C2.

During the batch screening tests, $0.73 \mathrm{~g}$ of solid iron was added to a flask containing $200 \mathrm{~g}$ of surrogate groundwater and $50 \mathrm{~g}$ of 100-mesh silica sand. The amount of iron used was derived from the average value of total ferric iron of $0.059 \mathrm{wt} \%$ present in Hanford formation sediments (Fruchter et al. 2000). The flasks were then sealed and placed on a rotary shaker table for 4 hours, and then the solution conductivity, $\mathrm{pH}, \mathrm{ORP}$, and temperatures were recorded. Samples were analyzed for dissolved chromium and nitrates. A summary of the average field parameters is presented in Table 4-5.

Table 4-5. Batch Screening Test Average Parameters

\begin{tabular}{l|c|c|c|c|c|c|c|c}
\hline $\begin{array}{l}\text { Reactivity Part A - } \\
\text { Averages }\end{array}$ & $\begin{array}{c}\text { Surrogate } \\
\text { ZVI GW }^{\mathbf{a}}\end{array}$ & $\begin{array}{c}\text { RNIP- } \\
\text { 10DS }\end{array}$ & EZVI & NanoFe II & NanoFe I & PolyMetallix & Z-loy & Control $^{\mathbf{b}}$ \\
\hline Temp $\left({ }^{\circ} \mathrm{C}\right)$ & 18.67 & 22.46 & 22.49 & 22.26 & 22.62 & 22.55 & 22.53 & 22.28 \\
\hline $\begin{array}{l}\text { Specific conductivity } \\
(\mu \mathrm{S} / \mathrm{cm})\end{array}$ & 595 & 571 & 526 & 621 & 655 & 609 & 441 & 644 \\
\hline $\begin{array}{l}\text { Dissolved oxygen } \\
(\mathrm{mg} / \mathrm{L})\end{array}$ & 6.25 & 0.36 & 0.90 & 2.84 & 0.43 & 4.06 & 1.45 & 5.73 \\
\hline pH (standard units) & 7.33 & 8.91 & 9.38 & 8.56 & 9.08 & 7.84 & 9.28 & 7.57 \\
\hline ORP (mV) & 263.7 & 90.2 & 211.4 & 190.8 & 167.4 & 159.3 & 140.0 & 205.0 \\
\hline \hline
\end{tabular}

NOTES:

EZVI is a product of Toxicological and Environmental Associates, Inc., Baton Rouge, Louisiana.

NanoFe Slurry I and NanoFe Slurry II are products of Lehigh Nanotech, Bethlehem, Pennsylvania.

PolyMetallix is a trademark of Crane Polyflon, Norwalk, Connecticut.

RNIP-10DS is a trademark of Toda Kogyo Corporation, Hiroshima, Japan.

Z-loy is a product of OnMaterials LLC, San Diego, California.

a. Surrogate ZVI groundwater does not contain ZVI material or silica sand and was analyzed prior to each respective batch test.

b. Control sample contains surrogate groundwater, silica sand, but no $\mathrm{ZVI}$ and was analyzed at the end of the 4-hour batch test.

$\mathrm{GW}$ = groundwater

ORP $=$ oxygen reduction potential

$\mathrm{ZVI}=$ zero-valent iron 
The field parameters indicated a reduction in the $\mathrm{DO}$ and an increase in $\mathrm{pH}$ from the baseline conditions for all ZVI materials tested. The ORP was reduced from baseline conditions for all materials but EZVI and NanoFe II, with the largest reduction being observed from RNIP-10DS. Dissolved chromium results from the batch tests are presented in Figure 4-13. As indicated in Figure 4-13, dissolved hexavalent chromium was reduced completely by all the ZVI materials tested. In an effort to monitor potential side effects from the ZVI injection, total nitrate was monitored at the conclusion of the test. These results are presented in Figure 4-14.

ZVI Reactivity Testing

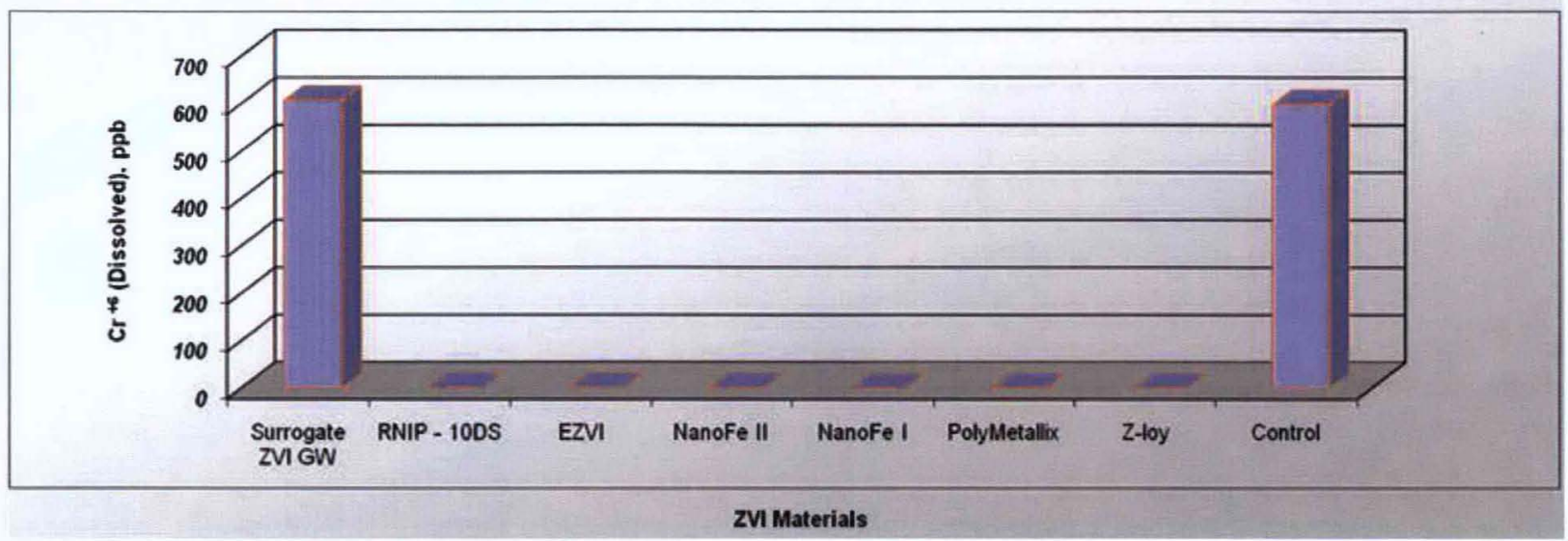

Figure 4-13. Batch Screening Test Dissolved Chromium Results

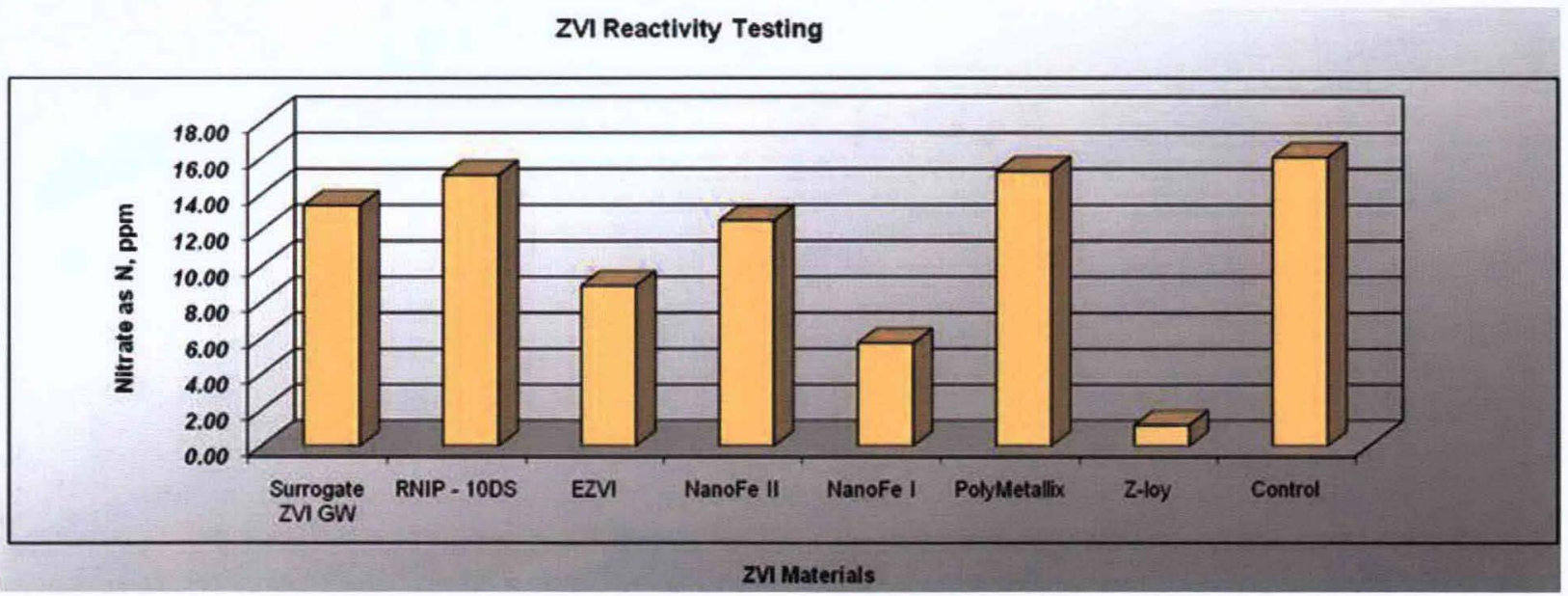

Figure 4-14. Batch Screening Test Nitrate Results

As indicated in Figure 4-14, RNIP-10DS, PolyMetallix, and NanoFe II showed relatively limited reduction in nitrates as compared to the control, while the remaining ZVI materials reduced nitrates by almost 50 percent to greater than 90 percent. The complete data from the batch screening tests is provided in Appendix C, Section C2. 


\subsubsection{Literature Search}

Based on extensive literature research, consultation with internal and external resources, and on-line searches, a database was developed that identified 30 separate ZVI materials. A list of these materials and their manufacturers is provided Table 4-6.

Table 4-6. Zero-Valent Iron Materials and Manufacturers

\begin{tabular}{|c|c|}
\hline ZVI Material Name & Manufacturer \\
\hline Cellulose stabilized nZVI & Auburn University \\
\hline CIP-EQ & BASF \\
\hline CIP-EW & BASF \\
\hline CIP-HQ & BASF \\
\hline CIP-HS & BASF \\
\hline Connelly CC-1200 & Connelly GPM Inc. \\
\hline EZVI & Toxicological and Environmental Associates Inc. \\
\hline EHC-M & Adventus Americas Inc. \\
\hline $\mathrm{H}-200$ & Hepure Technologies Inc. \\
\hline HC-5 & Hepure Technologies Inc. \\
\hline HC-15 & Hepure Technologies Inc. \\
\hline H2OMet-56 & Quebec Metal Powders Ltd. \\
\hline H2OMet-414 & Quebec Metal Powders Ltd. \\
\hline H2OMet-XT & Quebec Metal Powders Ltd. \\
\hline Iron Metal & CERAC \\
\hline LD-80 & North American Hoganas Inc. \\
\hline Metamateria A & Metamateria Partners \\
\hline Metamateria B & Metamateria Partners \\
\hline Metamateria C & Metamateria Partners \\
\hline MicroPowder S-3700 & International Specialty Products \\
\hline NanoFe & Lehigh Nanotech - distributed by PARS Environmental \\
\hline NanoFe Slurry I & Lehigh Nanotech \\
\hline NanoFe Slurry II & Lehigh Nanotech \\
\hline NF-325 & North American Hoganas Inc. \\
\hline Peerless Iron Powder & Peerless Metal Powders and Abrasives \\
\hline Polyflon Particles & Crane PolyMetallix - distributed by Nanitech LLC \\
\hline R-12 & North American Hoganas Inc. \\
\hline RNIP-10DS & Toda Corporation \\
\hline
\end{tabular}


Table 4-6. Zero-Valent Iron Materials and Manufacturers

\begin{tabular}{l|l}
\hline \multicolumn{1}{c|}{ ZVI Material Name } & \multicolumn{1}{c}{ Manufacturer } \\
\hline RNIP-M2 & Toda Corporation \\
\hline Z-loy & OnMaterials LLC \\
\hline
\end{tabular}

In addition, to the ZVI materials database, a scoring system was developed based on a number of selection criteria describing the material's injectability and capacity to reduce hexavalent chromium. The selection criteria were separated into five categories, each of which was assigned a multiplicative weighting factor based on the perceived importance of the contained factors. Additionally, two of the selection criteria (i.e., availability and particle size) were assigned as elimination criteria within the scoring system. The ZVI materials were eliminated from further consideration if they possessed either of the following conditions: (1) 5 tons of the material could not be available within 3 months, or (2) the majority of the material's particles are greater than 10 microns. The second elimination criterion was determined from the literature search, specifically work developed by Lehigh University ${ }^{7}$, as well as research from the paint and pigment industries. The scoring system is summarized in Table 4-7, and information from the ZVI materials database (with the associated scored rankings of each material) is provided in Table 4-8. Materials that were eliminated by the set elimination criterion are labeled as "eliminated" in the respective category.

Table 4-7. Zero-Valent Iron Scoring Criteria

\begin{tabular}{l|c}
\hline \multicolumn{1}{c|}{$\begin{array}{c}\text { Selection } \\
\text { Criteria }\end{array}$} & $\begin{array}{c}\text { Scoring } \\
\text { System }\end{array}$ \\
\hline \multicolumn{1}{c}{ Elimination Criteria } \\
\hline Particle Size & Retained \\
\hline$<10$ microns & Eliminated \\
\hline$>10$ microns & Retained \\
\hline \hline Availability & Eliminated \\
\hline$>=5$ tons in 3 months & \multicolumn{2}{c}{} \\
\hline$<5$ tons in 3 months & \\
\hline Weighting Factor 1 &
\end{tabular}

7 Zhang, W. 2005, Dispersed Zero-Valent Iron Colloids, United States Patent Application \#20050199556. 
Table 4-7. Zero-Valent Iron Scoring Criteria

\begin{tabular}{|c|c|}
\hline $\begin{array}{c}\text { Selection } \\
\text { Criteria }\end{array}$ & $\begin{array}{l}\text { Scoring } \\
\text { System }\end{array}$ \\
\hline \multicolumn{2}{|l|}{ Cost (per pound of solid iron) } \\
\hline$\$ 0.01$ to $\$ 1$ & 5 \\
\hline$\$ 1$ to $\$ 5$ & 4 \\
\hline$\$ 5$ to $\$ 15$ & 3 \\
\hline$\$ 15$ to $\$ 30$ & 2 \\
\hline$>\$ 30$ & 1 \\
\hline \multicolumn{2}{|l|}{ Weighting Factor 2} \\
\hline \multicolumn{2}{|l|}{ Surface Area $\left(\mathrm{m}^{2} / g\right)$} \\
\hline$>25$ & 3 \\
\hline 1 to 25 & 2 \\
\hline 0.1 to 1 & 1 \\
\hline \multicolumn{2}{|l|}{ \% Iron by Weight } \\
\hline$>90 \%$ & 2 \\
\hline$<90 \%$ & 1 \\
\hline \multicolumn{2}{|l|}{ Weighting Factor 3} \\
\hline \multicolumn{2}{|l|}{ Field Injection History } \\
\hline Yes & 1 \\
\hline No & 0 \\
\hline Unknown & 0 \\
\hline \multicolumn{2}{|l|}{ Metals Reduction History } \\
\hline Yes & 1 \\
\hline No & 0 \\
\hline Unknown & 0 \\
\hline \multicolumn{2}{|l|}{ Weighting Factor 5} \\
\hline \multicolumn{2}{|l|}{ \% Reduction of Chromium in 24 hours } \\
\hline$>95$ & 5 \\
\hline 86 to 95 & 4 \\
\hline 76 to 85 & 3 \\
\hline 66 to 75 & 2 \\
\hline 55 to 65 & 1 \\
\hline$<55$ & 0 \\
\hline
\end{tabular}


DOE/RL-2009-35, REV. 0

Table 4-7. Zero-Valent Iron Scoring Criteria

\begin{tabular}{l|c}
\hline \multicolumn{1}{c|}{$\begin{array}{c}\text { Selection } \\
\text { Criteria }\end{array}$} & $\begin{array}{c}\text { Scoring } \\
\text { System }\end{array}$ \\
\hline ORP Reduction Between 1 and 6 days & 0 \\
\hline Positive trend & 1 \\
\hline Negative trend & 2 \\
\hline Steep negative trend & \\
\hline ORP $\quad$ oxidation-reduction potential & \\
\hline
\end{tabular}

\subsubsection{Injection Screening Test}

A set of injection screening tests were developed to evaluate all six materials from the batch screening tests and MicroPowder S-3700 on their ability to distribute iron throughout the horizontally placed flow cells, as well as their effect on the hydraulic conductivity. The materials tested included EZVI, PolyMetallix, NanoFe I, NanoFe II, Z-loy, and RNIP-M2. RNIP-M2 is the same ZVI material as RNIP-10DS; however, its injectability is enhanced by the addition of a polymer. The following sections describe the results of the injection screening tests. A complete description of the experimental test plan is provided in Appendix B. Data and analytical results from the testing are provided in Appendix C, Section C3.

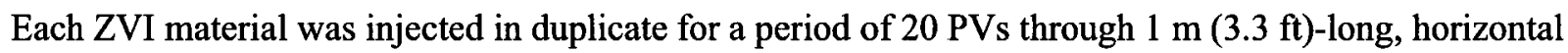
flow cells. The materials were injected at a concentration of $1 \mathrm{wt} \%$ of solids at a rate of $55 \mathrm{~mL} / \mathrm{min}$. During the injection, head measurements were taken to evaluate the material's effect on the hydraulic conductivity. The calculated hydraulic conductivity before injection, after ZVI injection, and after surrogate groundwater flushing are shown in Figure 4-15.

After injecting the ZVI materials, the flow cells were flushed with surrogate groundwater for an additional $20 \mathrm{PV}$ at a rate of $9 \mathrm{~mL} / \mathrm{min}$ for the first PV and $2 \mathrm{~mL} / \mathrm{min}$ for the remaining PVs. The flush was designed to examine the ability of the emplaced ZVI materials to remain emplaced under simulated natural aquifer conditions. Continued monitoring of the hydraulic head during the surrogate groundwater flush would also indicate any fouling of the flow cells by formation of iron oxy-hydroxides. The initial hydraulic conductivity before injection is compared to the hydraulic conductivity after injection and flushing in Figure 4-15. 
Table 4-8. Zero-Valent Iron Materials and Associated Score

\begin{tabular}{|c|c|c|c|c|c|c|c|c|c|c|}
\hline $\begin{array}{l}\text { ZVI Material } \\
\text { Name }\end{array}$ & $\begin{array}{l}\text { Weighted } \\
\text { Score }\end{array}$ & $\begin{array}{l}\text { D50, } \\
\text { pm }\end{array}$ & $\begin{array}{c}\text { Surface } \\
\text { Area, } \\
\mathrm{m}^{2} / \mathrm{g}\end{array}$ & $\begin{array}{l}\% \\
\text { Iron }\end{array}$ & $\begin{array}{l}\text { ORP } \\
\text { t to } 6 \\
\text { Days }\end{array}$ & $\begin{array}{c}\% \\
\text { Chromium } \\
\text { Reduction }\end{array}$ & Availability & $\begin{array}{c}\text { Cost } \\
\text { per } \\
\text { Pound }\end{array}$ & $\begin{array}{c}\text { Field } \\
\text { Injection }\end{array}$ & $\begin{array}{c}\text { Metal } \\
\text { Reduction }\end{array}$ \\
\hline EZVI & 41 & 1 & 10 & 98 & - & 99.2 & $\mathrm{Y}$ & $\$ 16.00$ & $\mathrm{Y}$ & $\mathrm{N}$ \\
\hline Polyflon particles & 40 & 0.15 & $37-58$ & $>99$ & Pos. & 99.2 & $\mathrm{Y}$ & $\$ 72.00$ & $Y$ & $Y$ \\
\hline NanoFe (Lehigh) & 40 & 0.1 & $10-45$ & $>99$ & - & 99.2 & $\mathrm{Y}$ & $\$ 50.00$ & $\mathrm{Y}$ & $Y$ \\
\hline NanoFe Slurry II & 40 & 0.15 & $10-45$ & $>99$ & - & 99.2 & $Y$ & $\$ 50.00$ & $Y$ & $Y$ \\
\hline NanoFe Slurry I & 39 & 0.075 & $10-45$ & $>99$ & - & 99.2 & $Y$ & $\$ 50.00$ & $\mathrm{Y}$ & $Y$ \\
\hline RNIP-10DS & 39 & 0.07 & 30 & 66 & - & 99.2 & $Y$ & $\$ 22.00$ & $Y$ & $Y$ \\
\hline Z-loy & 39 & 0.2 & 15 & 40 & -- & 99.2 & $Y$ & $\$ 20.00$ & $Y$ & $\mathrm{Y}$ \\
\hline H2OMet-XT & 32 & $\sim 10$ & - & 78 & Steep & 88.8 & $Y$ & $\$ 0.55$ & $N$ & $\mathbf{N}$ \\
\hline RNIP-M2 & 28 & 0.07 & 20.2 & 65 & Pos. & 78.8 & $Y$ & $\$ 32.35$ & $Y$ & $Y$ \\
\hline MicroPowder S-3700 & 19 & 2 & - & $>97$ & Neg. & 63.6 & $Y$ & $\$ 10.35$ & $\mathrm{~N}$ & $\mathbf{N}$ \\
\hline $\mathrm{HC}-5$ & 19 & 5 & -- & $>98$ & Neg. & 32.0 & $Y$ & $\$ 7.00$ & $N$ & $\mathbf{N}$ \\
\hline CIP-EQ & 12 & 3 & -- & $>97.7$ & -- & 4.3 & $Y$ & $\$ 4.25=$ & $\mathrm{Y}$ & $\mathbf{N}$ \\
\hline CIP-EW & 12 & 3.5 & - & $>97$ & - & - & $\mathrm{Y}$ & - & $Y$ & $\mathbf{N}$ \\
\hline $\mathrm{CIP}-\mathrm{HQ}$ & 12 & 2 & -- & $>97.8$ & - & -- & $Y$ & - & $\mathrm{Y}$ & $\mathrm{N}$ \\
\hline CIP-HS & 12 & 2.2 & -- & $>97.5$ & -- & 11.6 & $\mathrm{Y}$ & $\$ 5.30$ & $\mathrm{Y}$ & $\mathbf{N}$ \\
\hline Connelly CC-1200 & 0 & Eliminated & & & & & & & & \\
\hline $\begin{array}{l}\text { Cellulose stabilized } \\
\mathrm{nZVI}\end{array}$ & 0 & & & & & & Eliminate & & & \\
\hline EHC-M & 0 & Eliminated & & & & & & & & \\
\hline $\mathrm{HC}-15$ & 0 & Eliminated & & & & & & & & \\
\hline $\mathrm{H}-200$ & 0 & Eliminated & & & & & & & & \\
\hline
\end{tabular}


Table 4-8. Zero-Valent Iron Materials and Associated Score

\begin{tabular}{|c|c|c|c|c|c|c|c|c|c|c|}
\hline $\begin{array}{l}\text { ZVI Material } \\
\text { Name }\end{array}$ & $\begin{array}{l}\text { Weighted } \\
\text { Score }\end{array}$ & $\begin{array}{l}\text { D50, } \\
\text { pm }\end{array}$ & $\begin{array}{l}\text { Surface } \\
\text { Area, } \\
\mathrm{m}^{2} / \mathrm{g}\end{array}$ & $\begin{array}{l}\% \\
\text { Iron }\end{array}$ & $\begin{array}{l}\text { ORP } \\
1 \text { to } 6 \\
\text { Days }\end{array}$ & $\begin{array}{c}\% \\
\text { Chromium } \\
\text { Reduction }\end{array}$ & Availability & $\begin{array}{l}\text { Cost } \\
\text { per } \\
\text { Pound }\end{array}$ & $\begin{array}{c}\text { Field } \\
\text { Injection }\end{array}$ & $\begin{array}{c}\text { Metal } \\
\text { Reduction }\end{array}$ \\
\hline H2OMet-56 & 0 & Eliminated & & & & & & & & \\
\hline H2OMet-414 & 0 & Eliminated & & & & & & & & \\
\hline Iron metal & 0 & Eliminated & & & & & & & & \\
\hline LD-80 & 0 & Eliminated & & & & & & & & \\
\hline Metamateria A & 0 & Eliminated & & & & & & & & \\
\hline Metamateria B & 0 & Eliminated & & & & & & & & \\
\hline Metamateria C & 0 & Eliminated & & & & & & & & \\
\hline NF-325 & 0 & Eliminated & & & & & & & & \\
\hline Peerless iron powder & 0 & Eliminated & & & & & & & & \\
\hline R-12 & 0 & Eliminated & & & & & & & & \\
\hline
\end{tabular}




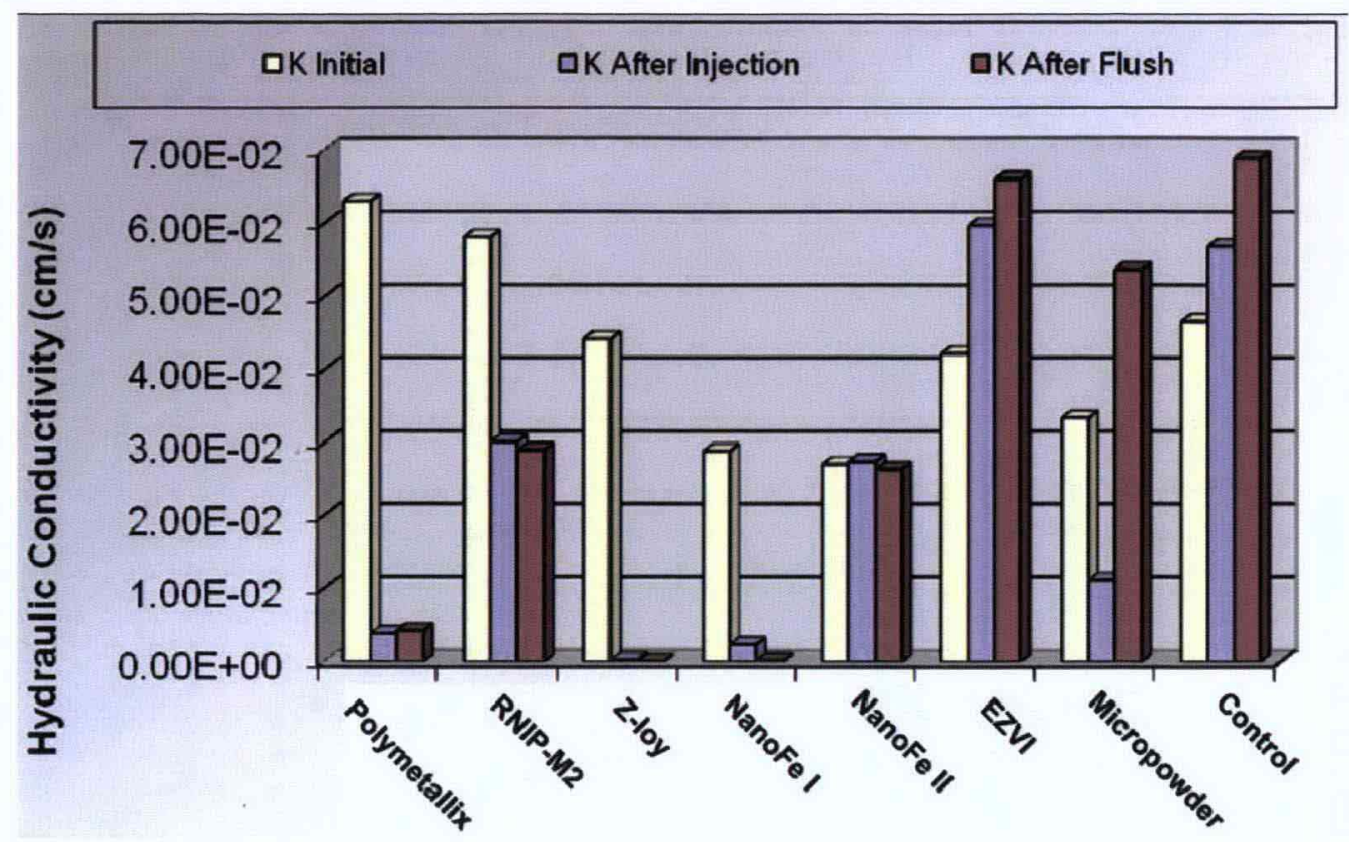

Figure 4-15. Change in Hydraulic Conductivity After Zero-Valent Iron Injection and Surrogate Groundwater Flush

Based on Figure 4-15, it appears that the hydraulic conductivity in the PolyMetallix, Z-loy, and NanoFe I flow cells decreased dramatically following ZVI injection. The RNIP-M2 and MicroPowder S-3700 flow cells showed a decrease in hydraulic conductivity during ZVI injection, although not as drastic as the PolyMetallix, Z-loy, and NanoFe I flow cells. Following surrogate groundwater flushing, PolyMetallix, RNIP-M2, NanoFe I and II, and Z-loy maintained relatively constant hydraulic conductivity, indicating that the flow cells retained the injected ZVI. Both EZVI and MicroPowder S-3700 showed an increase in hydraulic conductivity after the surrogate groundwater flush, which could indicate loss of injected ZVI.

Following ZVI injection, two soil cores were taken from each flow cell (one at the influent end of the flow cell, and one at the effluent end of the flow cell) for total iron analysis. The soil core voids were replaced with clean composite sand before beginning the flushing test. The results of the iron concentrations presented in Figure 4-16 were averaged for the test cell and the duplicate cell for each ZVI material injected.

Based on the iron core results, PolyMetallix and RNIP-M2 were the most effective at emplacing the iron throughout the length of the flow cell, and visual observations during the flow cell experiments correlated with this conclusion. Visual observation of the injection suggested an even distribution of the PolyMetallix injection solution throughout the flow cells and a fairly even distribution in the RNIP-M2 flow cells with some settling at the effluent end. The Z-loy and NanoFe I injection solutions appeared to distribute well through the flow cells; however, they were emplaced at less than $1 \mathrm{wt} \%$. Visual observation of the NanoFe II material indicated that the material did not distribute well through the top half of the flow cell, which is also reflected in low emplaced iron results. Visual and analytical results both indicate that EZVI was not emplaced in the flow cell. MicroPowder S-3700 ZVI was emplaced in the flow cells at greater than $1 \mathrm{wt} \%$ total iron at the influent but less than $1 \mathrm{wt} \%$ at the effluent. 


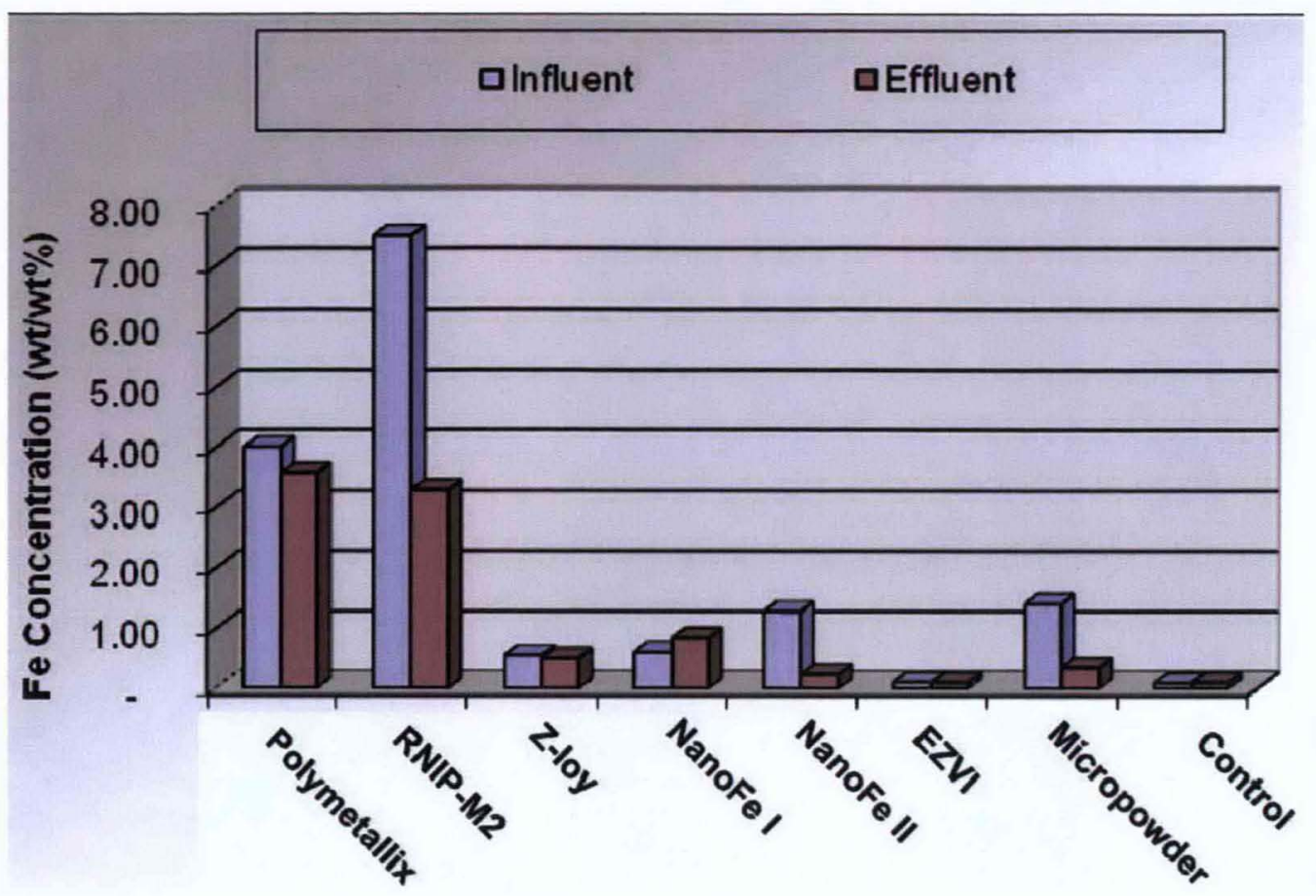

Figure 4-16. Average Soil Core Total Iron Concentration After Injection

Gas bubbles were observed in the stand pipes of the Z-loy and NanoFe I flow cells during injection of ZVI and during surrogate groundwater flushing. Analysis of the gas from one of the Z-loy flow cells concluded that it was primarily hydrogen.

After the flow cells were flushed with surrogate groundwater, soil cores were again collected and analyzed for total iron. Because the soil cores sample were theoretically clean prior to surrogate groundwater flushing, the total iron concentration from these sample should not be seen as an indication of the amount of iron in the flow cell after flushing, but it should be related to the mobility of the iron as a function of its ability to be flushed from the upgradient portions of the flow cells and into the core sample areas containing clean composite sand prior to flushing. The amount of iron available for transport into the clean soil cores would also be a function of how much iron was initially emplaced in the column. Figure 4-17 shows the average total iron results from the soil cores after the surrogate groundwater flush.

PolyMetallix and RNIP-M2 had significantly higher iron concentrations in the soil cores after flushing with surrogate groundwater; however, these two materials also emplaced the highest concentrations of iron during the injection. The high mobility of the materials is a positive indication that the ZVI can be effectively carried through the saturated aquifer at simulated field groundwater flow rates; however, there is also a concern that the high mobility of the ZVI may cause problems with retaining the ZVI at sufficient concentrations after injection. The complete data from the injection screening tests are provided in Appendix C, Section C3. 


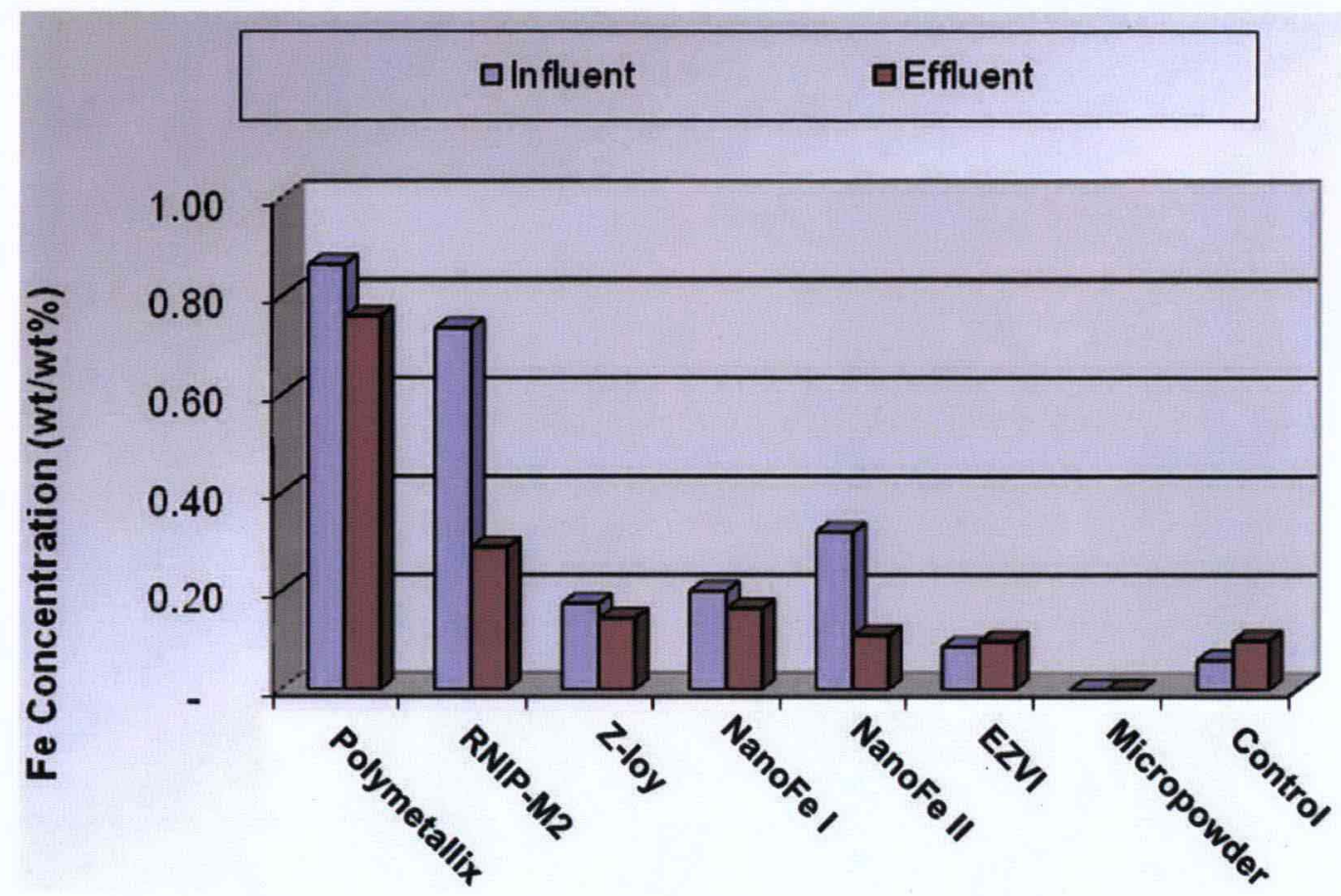

Figure 4-17. Average Soil Core Total Iron Concentration After Surrogate Groundwater Flush

\subsubsection{Screening Geochemical Test}

A set of screening geochemical tests were prepared to further evaluate the remaining three ZVI materials (RNIP-M2, PolyMetallix, and MicroPowder S-3700) on their ability to reduce hexavalent chromium and create a reducing environment under simulated natural aquifer conditions. This section describes the findings of the geochemical screening tests. Data and analytical results from the testing are presented in Appendix C, Section C4.

MicroPowder S-3700, RNIP-M2, and PolyMetallix were evaluated in the screening geochemical tests to evaluate the ability of the ZVI materials to reduce hexavalent chromium under simulated natural aquifer flow conditions flow. For each material, columns were tested containing Ringold Unit E soil and ZVI material at two concentrations ( $1.5 \mathrm{wt} \%$ and $0.75 \mathrm{wt} \%)$. The columns were fed synthesized Hanford groundwater at approximately $2.2 \mathrm{~mL} / \mathrm{min}$ to achieve a column seepage velocity close to $3.3 \mathrm{~m} /$ day $(11 \mathrm{ft} /$ day) for approximately $20 \mathrm{PVs}$. The synthesized groundwater simulated the aquifer conditions at the 100-D Area site and contained a hexavalent chromium concentration of approximately $500 \mathrm{ppb}$. Summaries of the laboratory parameters are presented in Figures 4-18 through 4-20, with complete results presented in Appendix C, Section C4.

The laboratory parameters serve as an indicator of the presence of reducing conditions in the columns. A reducing environment is indicated by reduced $\mathrm{DO}$, elevated $\mathrm{pH}$, and decreased ORP. At the high ZVI concentration of $1.5 \mathrm{wt} \%$, both PolyMetallix and RNIP-M2 both created reducing conditions; however, the low ZVI concentrations PolyMetallix and RNIP-M2 and both concentrations of MicroPowder S-3700 columns show little variation from the control column. 
DOE/RL-2009-35, REV. 0

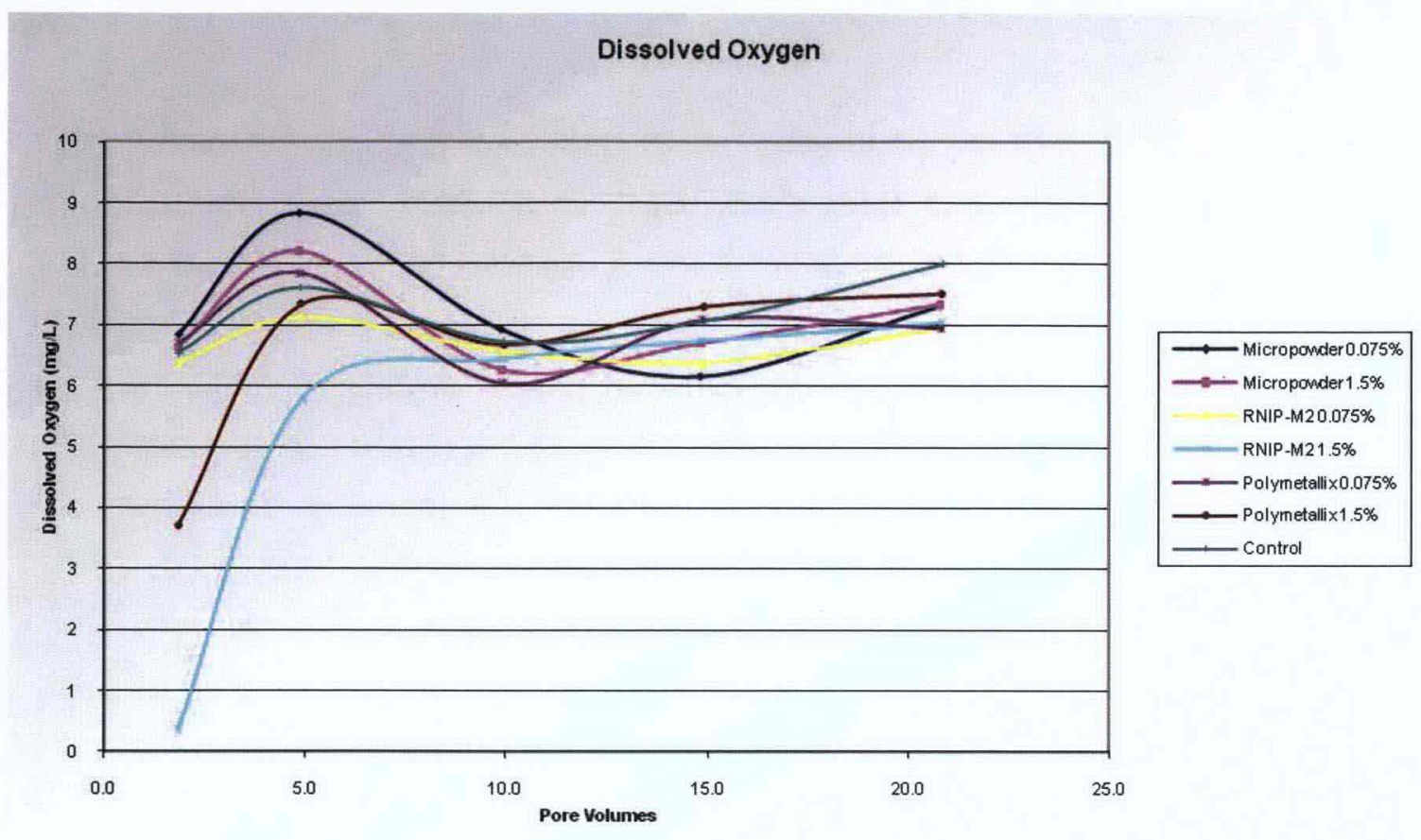

Figure 4-18. Screening Geochemical Test Dissolved Oxygen

$\mathrm{pH}$

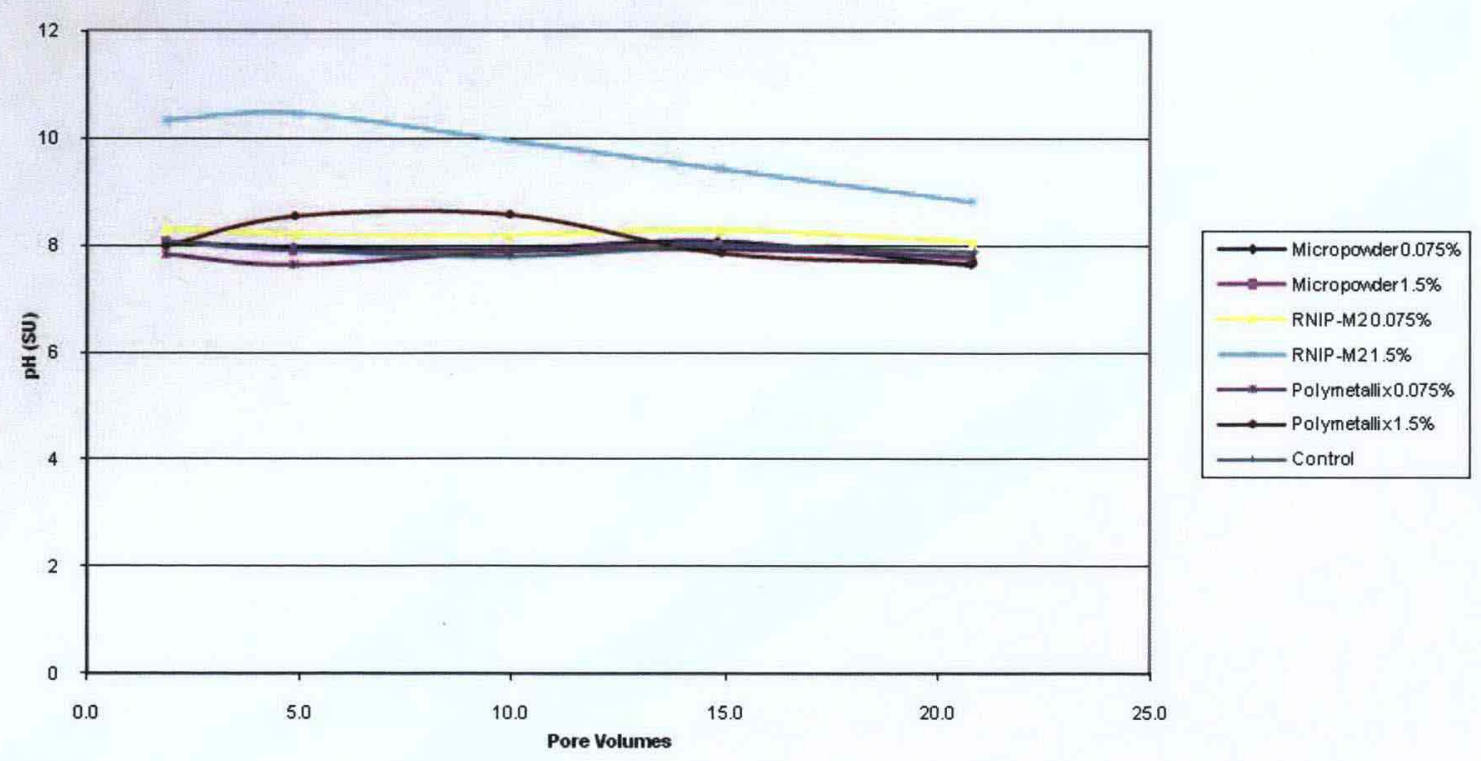

Figure 4-19. Screening Geochemical Test pH 


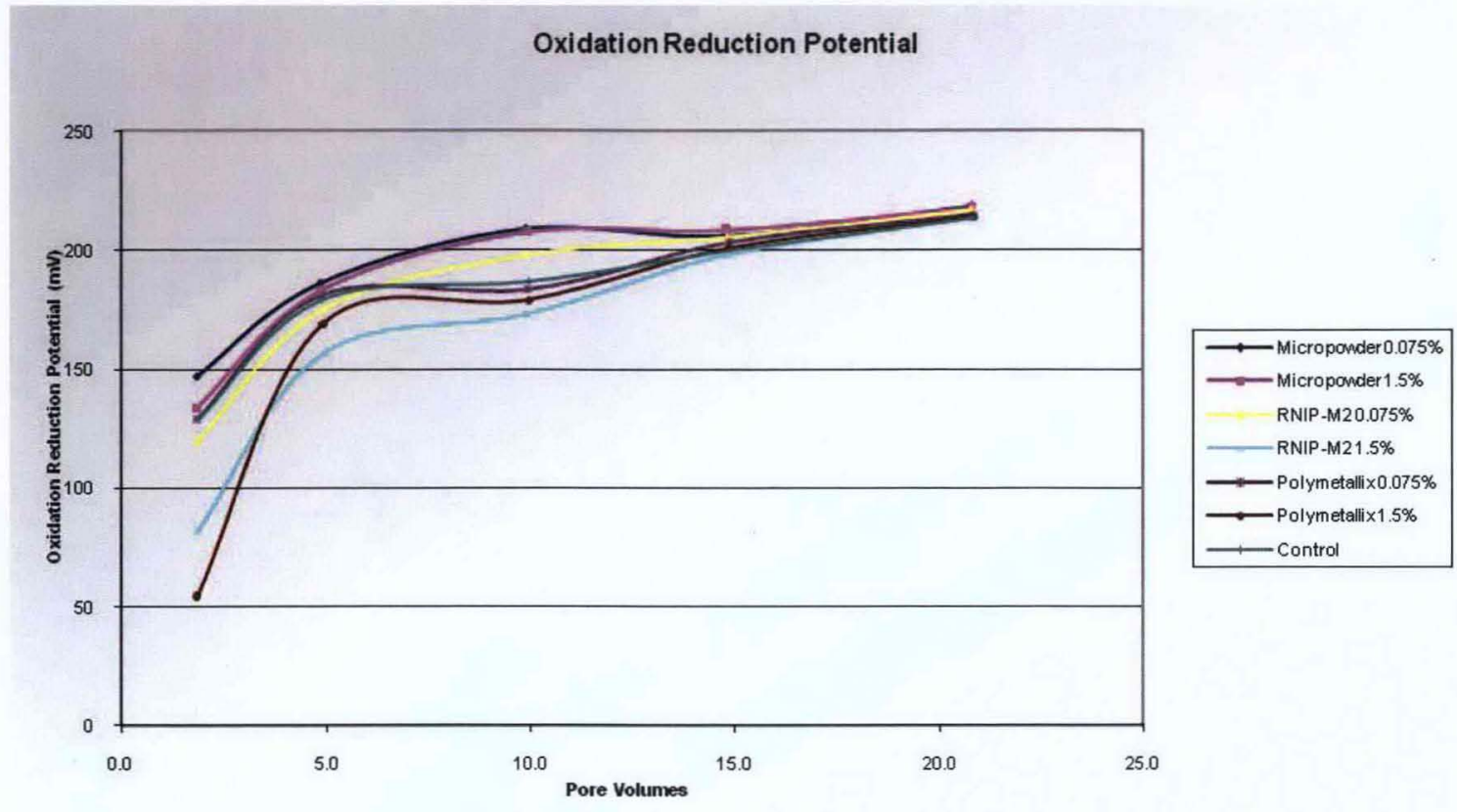

Figure 4-20. Screening Geochemical Test Oxidation-Reduction Potential

Figure 4-21 through Figure 4-24 show analytical results of the screening geochemical tests.

The results of the samples collected at approximately 1.8 PVs should be disregarded, because these anomalous results can be attributed to the fact that the columns were initially saturated with deionized water during the packing procedures and had not reached equilibrium when the initial samples were collected. Equilibrium was established in the columns by the second sampling event.

The results in Figure 4-21 show a breakthrough in hexavalent chromium in the MicroPowder S-3700 high and low concentrations, and in the low concentration PolyMetallix sample at the second sampling event, of approximately 5 PVs. The RNIP-M2 at both high and low concentrations showed no breakthrough throughout the duration of testing. The MicroPowder S-3700 columns showed increase in hexavalent chromium concentration greater than the control column between 5 and 10 PVs. This could be a function of desorption from the MicroPowder S-3700 material.

Figure 4-24 shows a general increase in the ammonia concentration in the RNIP-M2 and MicroPowder S-3700 high-concentration samples and a general downward trend in all other samples. Generally, the low ZVI concentration $(0.075 \mathrm{wt} \%)$ columns ammonia production decreased over time, while the higher ZVI concentration (1.5 wt \%) columns increased over time. The continuing production of ammonia suggests that the ZVI materials were still chemically active at the end of testing.

The complete set of data obtained from the geochemical screening tests is provided in Appendix C, Section C4. 
DOE/RL-2009-35, REV. 0

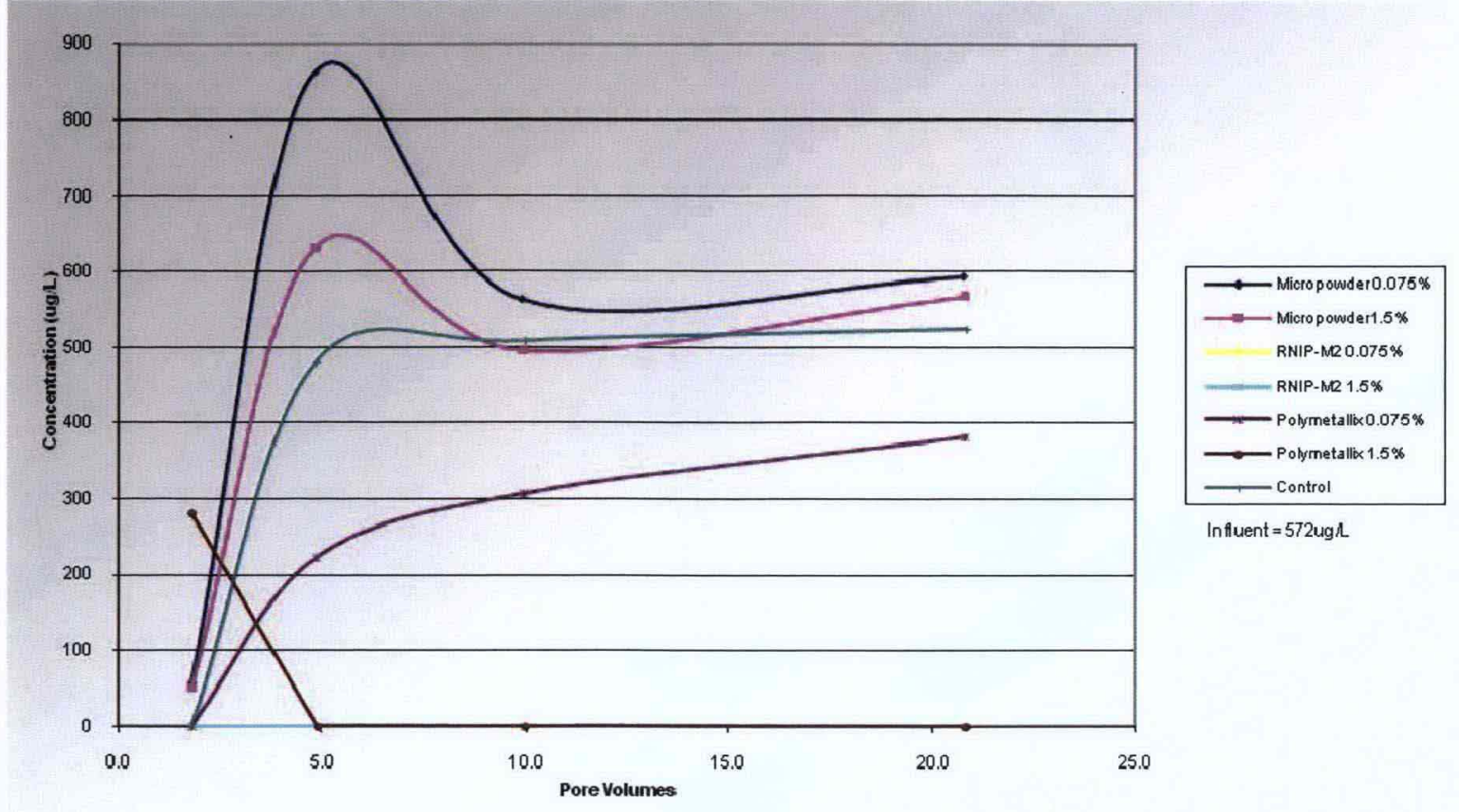

Figure 4-21. Screening Geochemical Columns Hexavalent Chromium Reduction

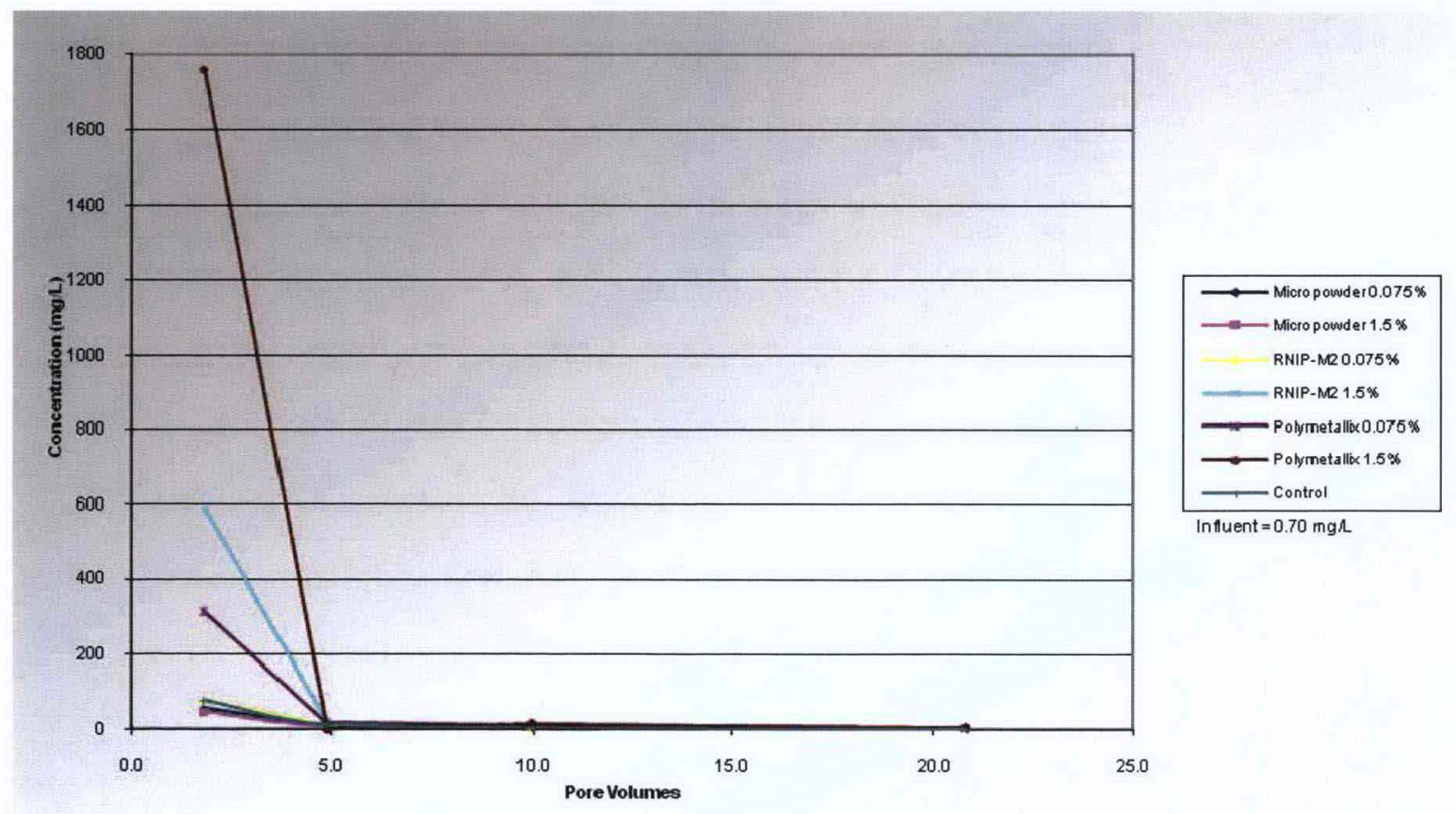

Figure 4-22. Screening Geochemical Columns Total Organic Carbon 
DOE/RL-2009-35, REV. 0

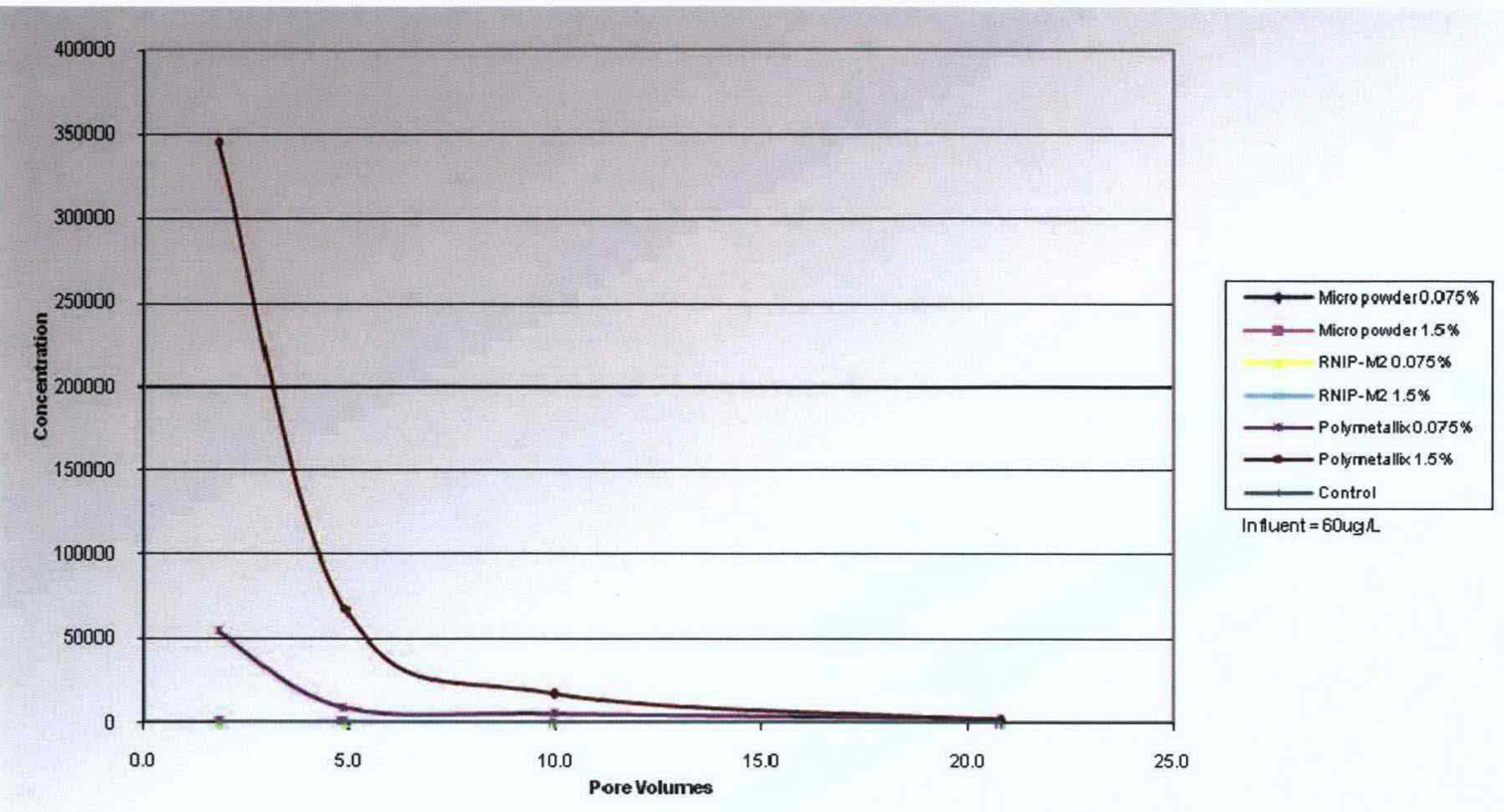

Figure 4-23. Screening Geochemical Columns Phosphorous

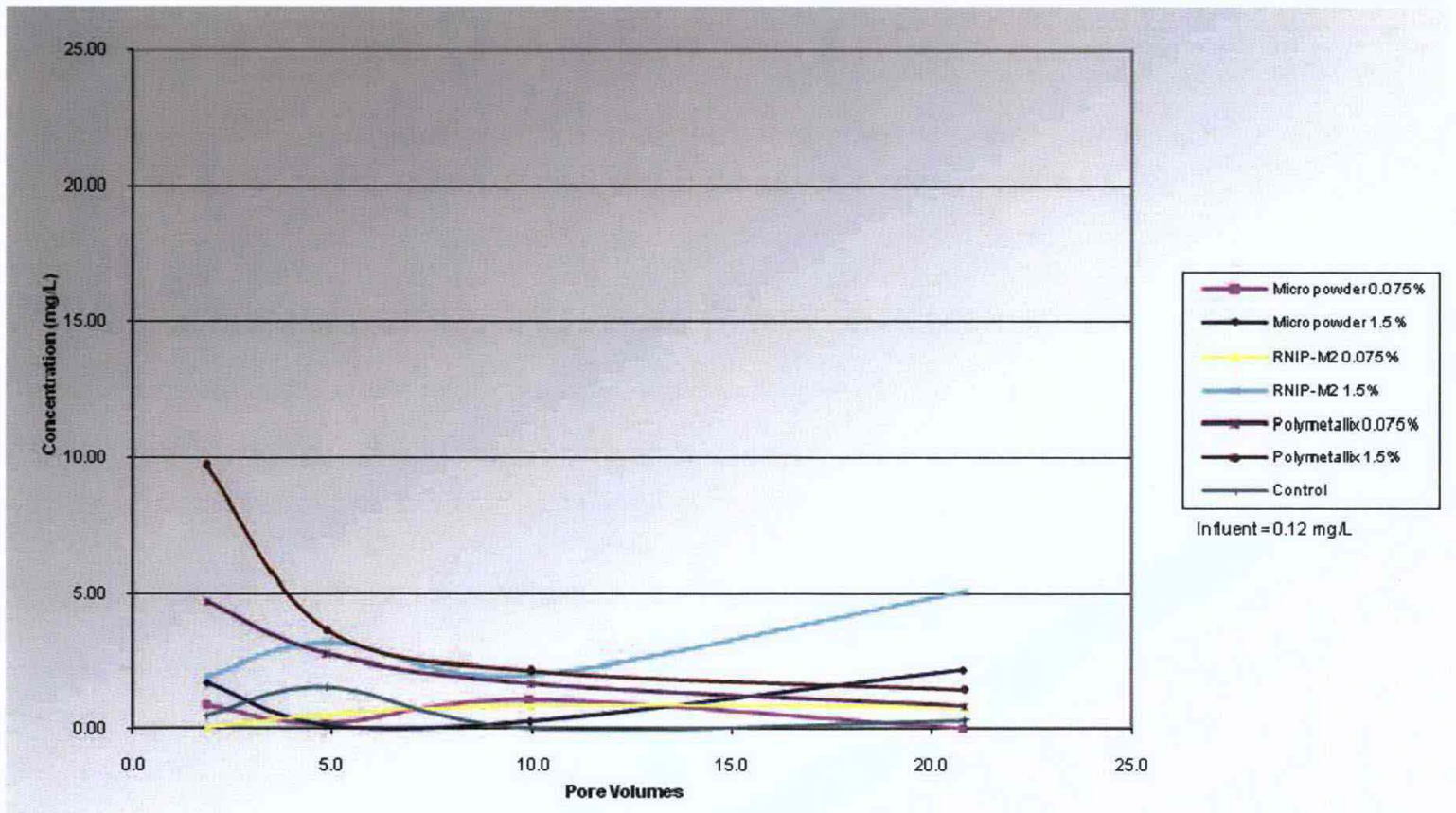

Figure 4-24. Screening Geochemical Columns Ammonia Results 


\subsubsection{Advanced Geochemical Test}

As a result of the screening tests, advanced geochemical testing of RNIP-M2 and PolyMetallix was recommended in order to evaluate geochemical changes in a simulated aquifer environment after injection of ZVI, including those that may adversely affect groundwater quality. The following sections describe the findings of the advanced geochemical tests. A complete description of the experimental test plan is provided in Appendix B, and analytical results from the testing are presented in Appendix C, Section C5.

Samples of the column effluent were collected throughout the vertical geochemical column experiment at each sample time for laboratory parameters and for laboratory analysis were collected. The physical parameters included $\mathrm{pH}, \mathrm{ORP}$, specific conductance, $\mathrm{DO}$, temperature, and the head differentials across the column. The summary of these results are presented in Figures 4-25 through 4-30. Laboratory analyses included dissolved hexavalent chromium, dissolved iron speciation, dissolved sulfate, alkalinity (reported as calcium carbonate), dissolved nitrate, nitrite, and ammonia (all three nitrogen species were reported as nitrogen).

\subsubsection{Ability to Create a Reducing Environment}

Physical parameter data were collected throughout the geochemical column experiment for each RNIP-M2 column, each PolyMetallix column, and for the control column at each of the sample times. The physical parameters were collected to evaluate the ability of the ZVI materials to create a reducing environment.

The ORP and the DO concentration of the effluent were monitored throughout testing, which are indicative of the reducing conditions developed in the columns by the ZVI materials. Both of these parameters can denote the reductive condition, which is believed to be the primary removal mechanism of hexavalent chromium by ZVI materials. Both RNIP-M2 and PolyMetallix were able to reduce the ORP of the high-concentration ( $1.5 \mathrm{wt} \%)$ column effluents during the initial stages of the test. However, at between 10 and 15 PVs, the ORP of the effluent from the high-concentration PolyMetallix columns began to match the ORP of the effluent from the control column. The ORP of the effluent from the highconcentration RNIP-M2 columns continued to be strongly reduced relative to the effluent from the control column throughout the remainder of the test.

Figure 4-25 shows the trends in the ORP of the column effluent throughout the duration of testing for the two ZVI materials compared to the control column at the high concentration.

The medium concentration ( 0.15 percent) of the two ZVI materials showed a distinct difference in the ability to lower the ORP of the column effluent. The RNIP-M2 material at the intermediate concentration was able to moderately reduce the ORP of the effluent, while the PolyMetallix material at the intermediate concentration was not able to show a significant effect on the ORP of the column effluent.

Figure 4-26 denotes the trends in the ORP of the column effluent throughout the duration of testing for the two ZVI materials compared to the control column at the medium concentration.

Neither of the two ZVI materials at the low concentration was able to significantly lower the ORP of the column effluents. Figure 4-27 denotes the trends in the ORP of the column effluent throughout the duration of testing for the two ZVI materials compared to the control column at the low concentration. 
DOE/RL-2009-35, REV. 0

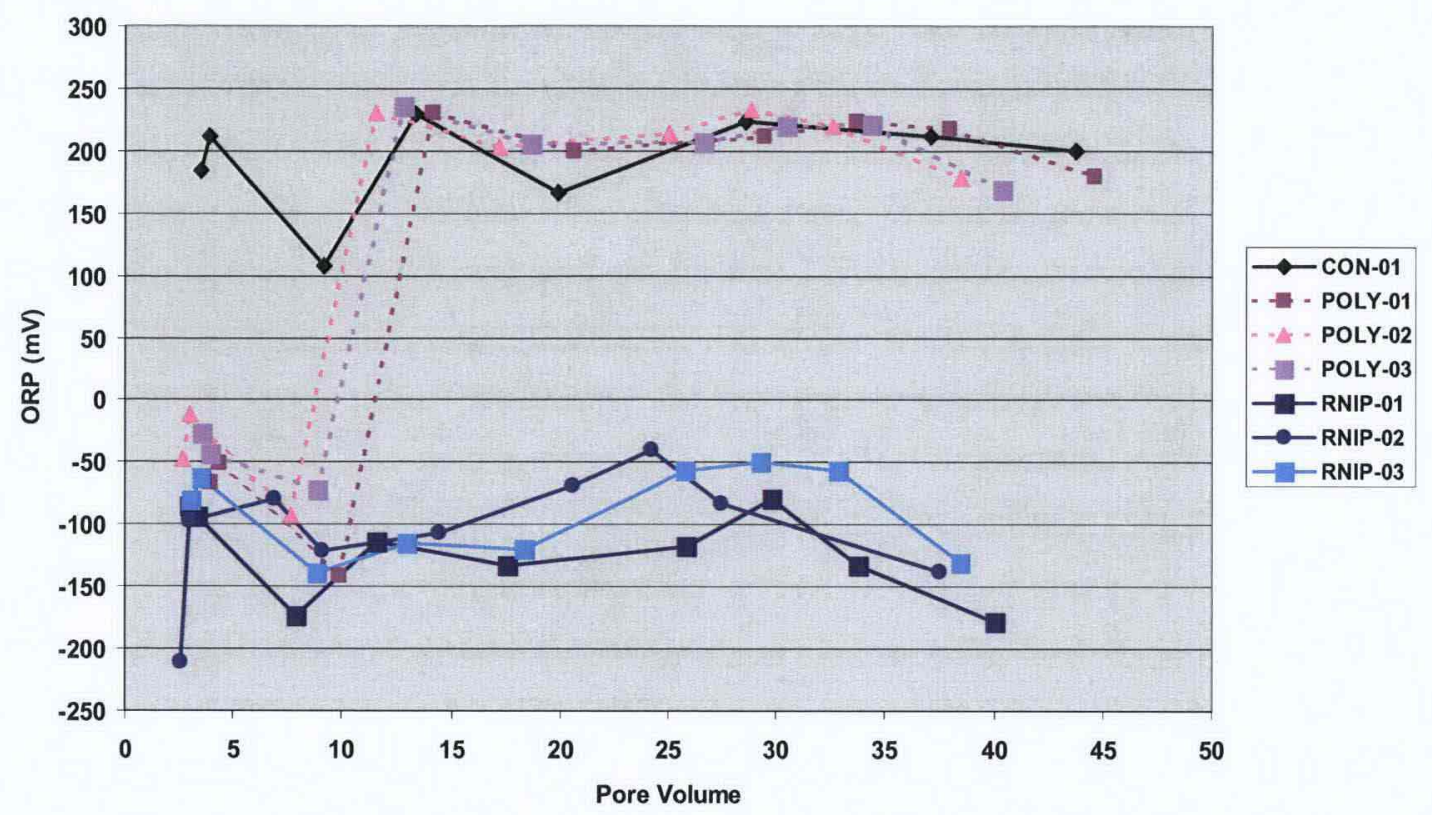

Figure 4-25. Oxidation-Reduction Potential Trend - High-Concentration (1.5 Percent) Columns

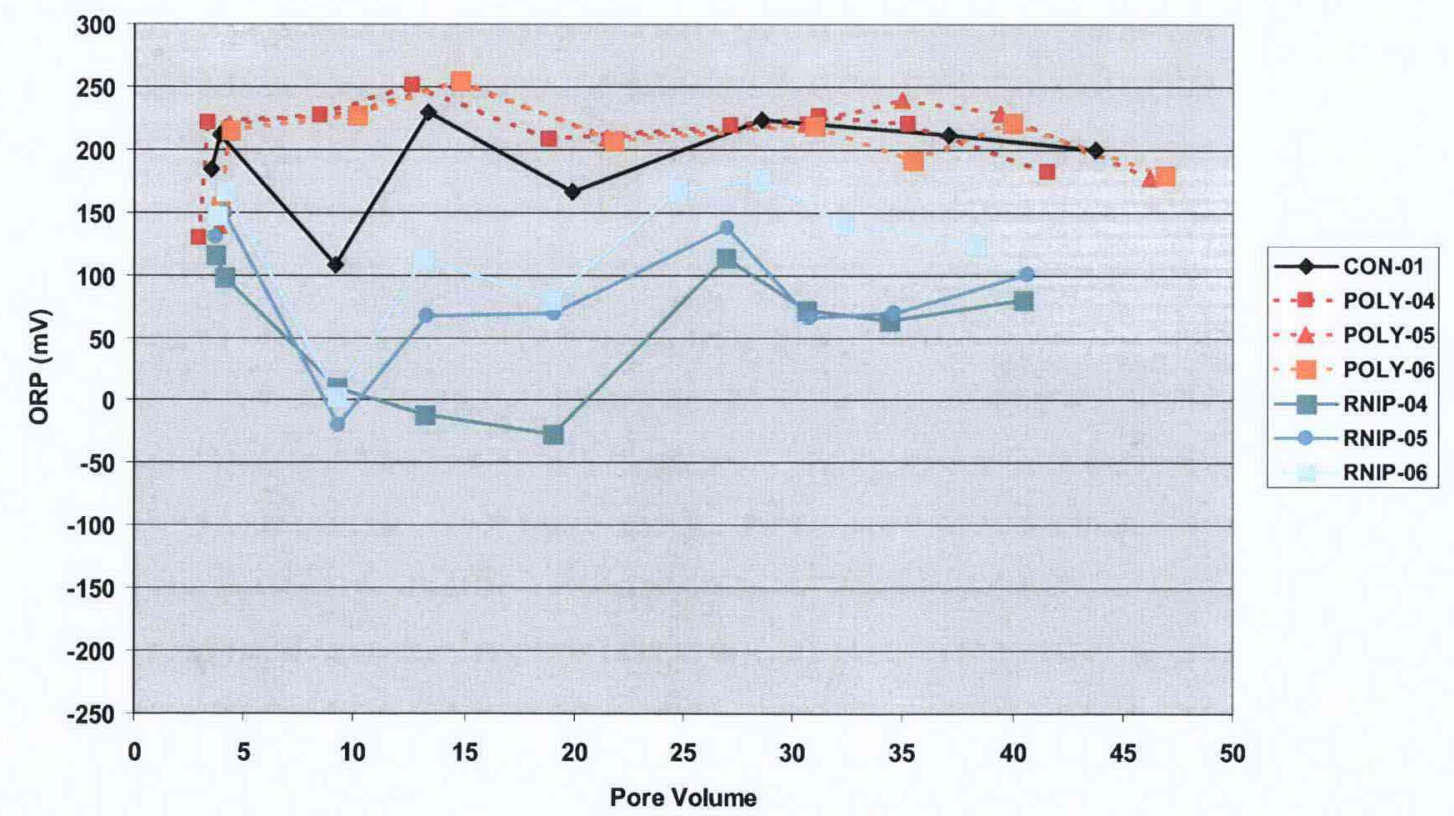

Figure 4-26. Oxidation-Reduction Trend - Mid-Concentration (0.15 Percent) Columns 


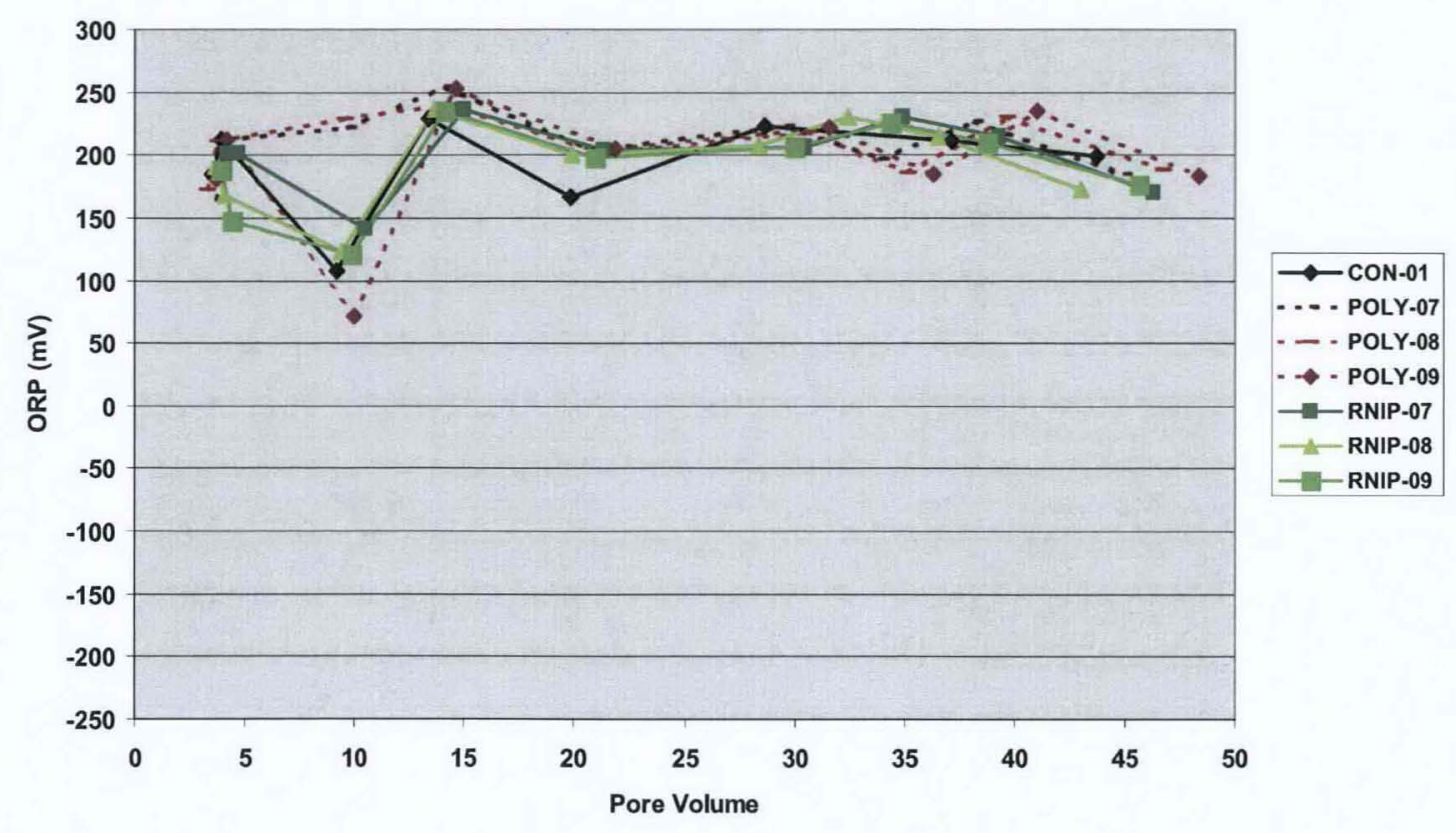

Figure 4-27. Oxidation-Reduction Potential Trend - Low-Concentration (0.015 Percent) Columns

The DO of the column effluents was sampled in two ways during each sample time. The first method of sampling was to collect a sample of several tens of milliliters and then measure the DO of that sample. Due to the extended length of time required to collect this sample at the low flow rate used throughout the experiment, there was concern that the DO values would have equilibrated with the atmosphere during sample collection. The second method of sampling was to collect a sample of a few milliliters and measure the DO of that sample, thus alleviating some of the equilibration potential. These results are denoted as "SDO." The small samples proved to be problematic operationally and provided erratic results. The DO results for the high-concentration (1.5 wt \%) RNIP-M2 columns were initially reduced but increased to values similar to the control column (between 5 and $10 \mathrm{PVs}$ ). The DO results for the medium- and low-concentration RNIP-M2 columns and all of the results from the PolyMetallix columns (at all concentrations) were quite similar to the DO results from the control column. The second DO results (SDO) for the high- and medium-concentration columns for both ZVI materials were lower than those of the control column, with the results of the RNIP-M2 columns being generally lower than the results of the PolyMetallix columns. The low-concentration column second DO (SDO) results for both materials were quite similar to the results of the control column. Complete DO results are presented in Appendix C, Section C5.

Another objective of the advanced geochemical testing was to evaluate the ability of ZVI-impregnated Ringold soil to change the $\mathrm{pH}$ of the groundwater. Changes in the $\mathrm{pH}$ of the column effluent that were different from those of the control column effluent are directly attributable to the reactivity of the two ZVI materials. Increases in effluent $\mathrm{pH}$ are due to the effects of the oxidation/reduction couple of iron and chromium, as shown in Equation 4-1:

$$
3 / 2 \mathrm{FeO}+\mathrm{CrO} 42-+5 \mathrm{H}+=3 / 2 \mathrm{Fe} 2++\mathrm{Cr}(\mathrm{OH})_{3}+\mathrm{H}_{2} \mathrm{O}
$$


As was the case with the ORP, the $\mathrm{pH}$ of the column effluent from the high-concentration $(1.5 \mathrm{wt} \%)$ RNIP-M2 columns were significantly higher than in the control column. In fact, the $\mathrm{pH}$ of the effluent from these columns was initially above a value of 10 and remained above a value of 9 throughout testing. The $\mathrm{pH}$ of the effluent from the high-concentration PolyMetallix columns was initially above the $\mathrm{pH}$ of the effluent from the control column, but this increase in $\mathrm{pH}$ attenuated after approximately $15 \mathrm{PVs}$ had passed through the column. The $\mathrm{pH}$ of the high-concentration PolyMetallix columns and the control column were very similar after 15 PVs had passed through the columns. Figure 4-28 denotes the trends in the $\mathrm{pH}$ of the column effluent throughout the duration of testing for the two ZVI materials compared to the control column at the high concentration.

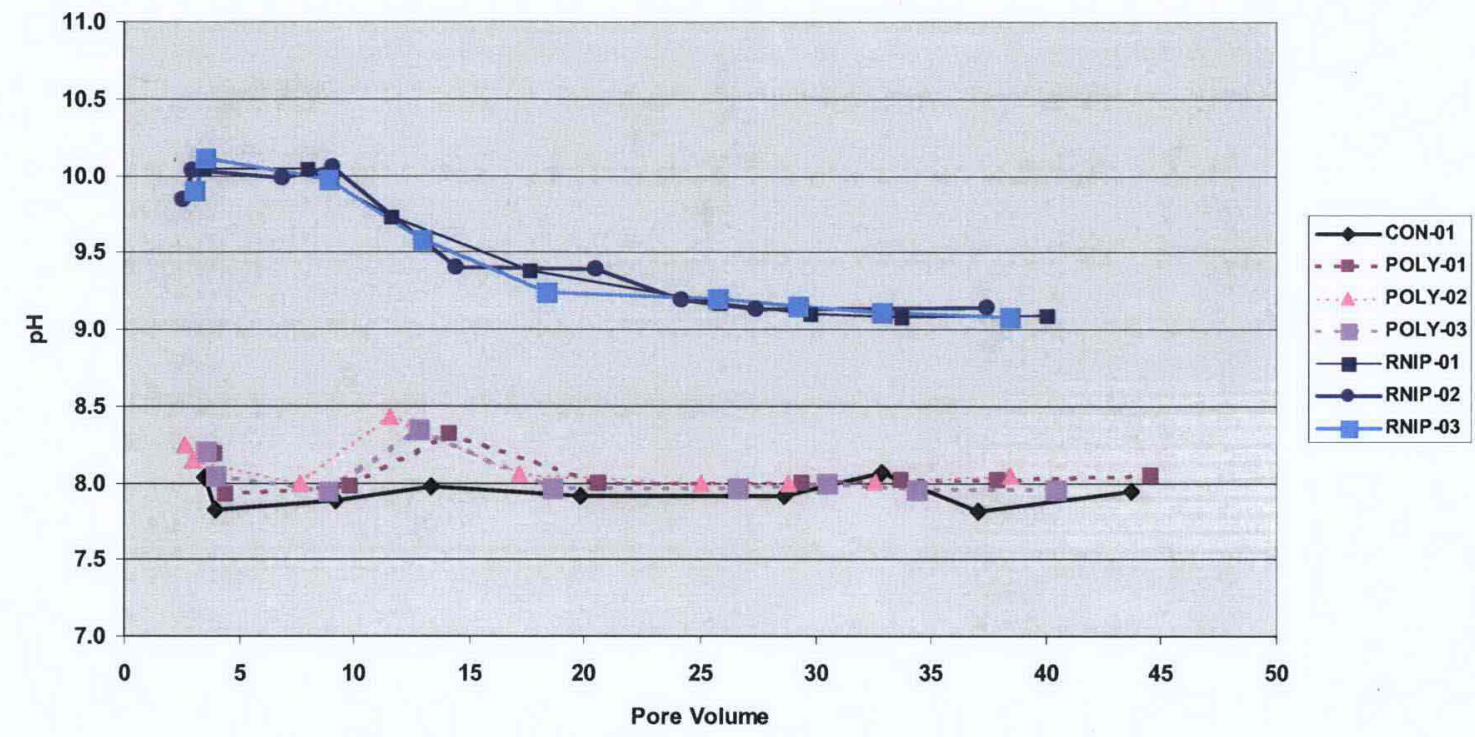

Figure 4-28. pH Trend - High-Concentration (1.5 Percent) Columns

The $\mathrm{pHs}$ of the medium-concentration $(0.15 \mathrm{wt} \%)$ RNIP-M2 columns were above that of the control column throughout testing by approximately 0.5 to $1.0 \mathrm{pH}$ units. The effluent from the mediumconcentration PolyMetallix columns, as well as from the low-concentration columns of both ZVI materials, did not exhibit $\mathrm{pH}$ values significantly above those of the control column effluent. Figures 4-29 and 4-30 denote the trends in the $\mathrm{pH}$ of the column effluent throughout the duration testing for the two ZVI materials compared to the control column at the medium and low concentrations, respectively. 


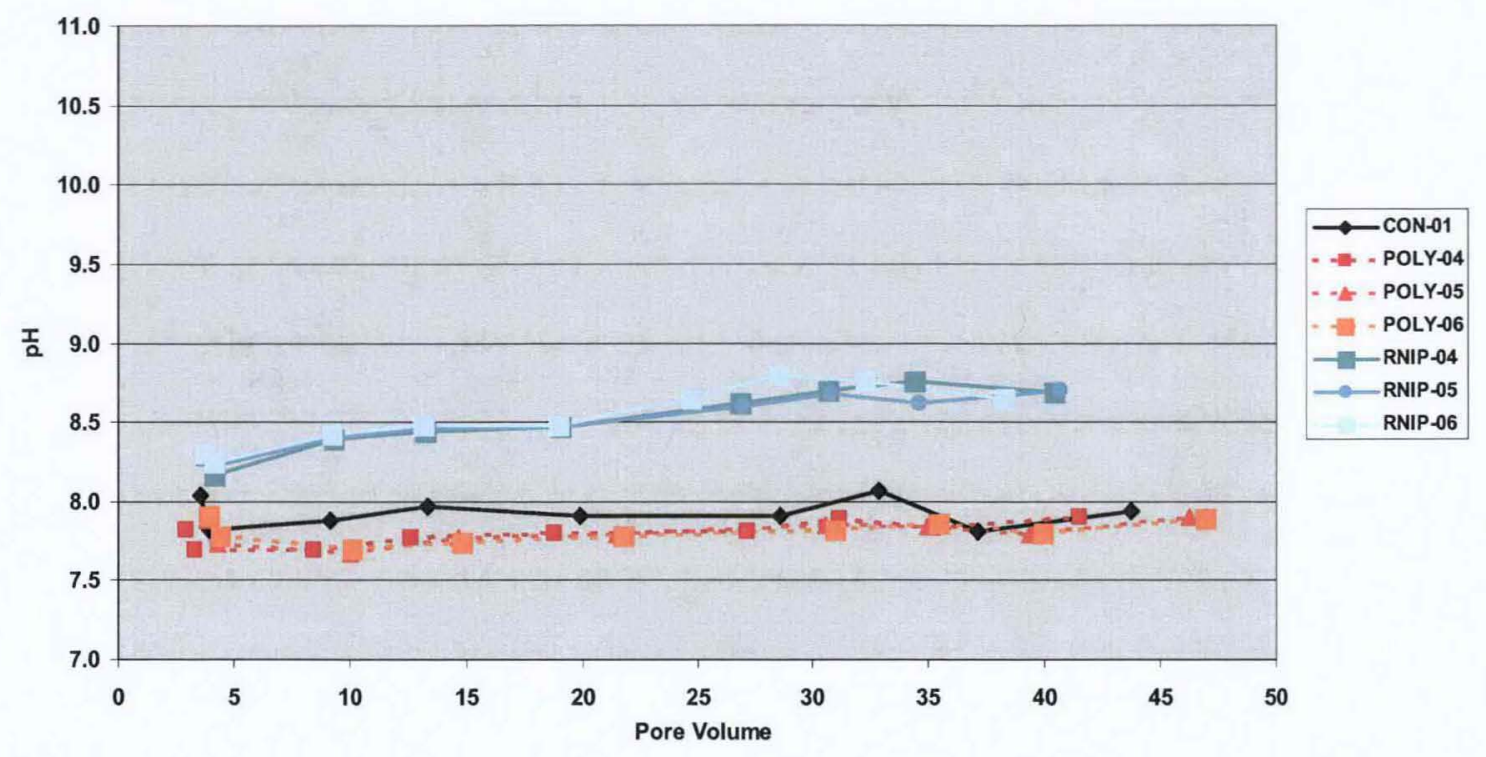

Figure 4-29. $\mathrm{pH}$ Trend - Mid-Concentration (0.15 Percent) Columns

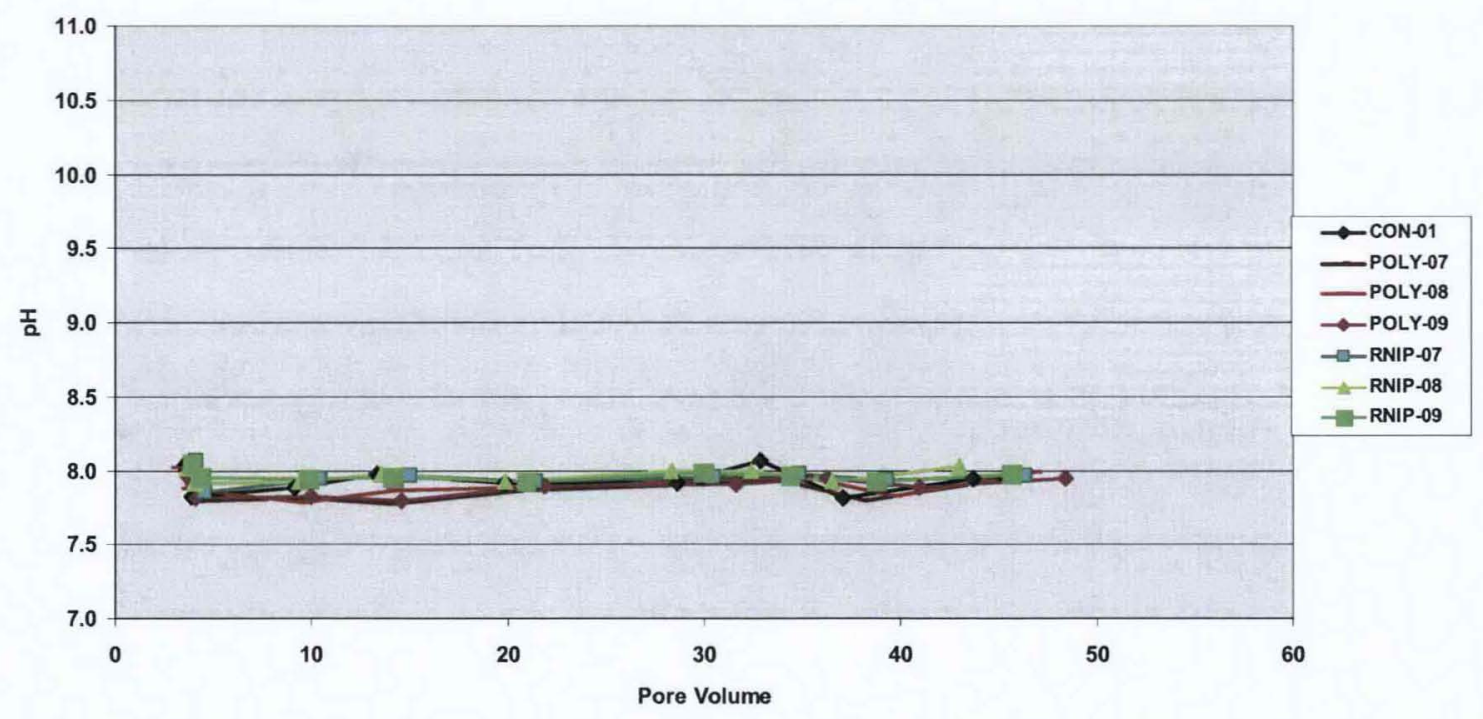

Figure 4-30. pH Trend - Low-Concentration (0.015 Percent) Columns

From the results of column effluent testing, it is apparent that RNIP-M2 is distinctly more reactive in the development of a chemical-reducing zone in the column test environment than PolyMetallix. The results of the physical examination of the columns following geochemical testing support this conclusion.

During the physical examination, four columns were cut open along the long axis of each column. The four columns consisted of one of each of the high-concentration (1.5 wt \%) columns and one of each of the medium-concentration $(0.15 \mathrm{wt} \%)$ columns. The high-concentration RNIP-M2 column was very dark in color, representing unoxidized ZVI, with only a very thin band (approximately $0.64 \mathrm{~cm}[0.25 \mathrm{in}$.$] ) of$ oxidized material located at the influent screen. The medium-concentration RNIP-M2 column was also very dark colored, but with an irregular zone of visible oxidation ranging from 15.2 to $20.3 \mathrm{~cm}$ (6 to $8 \mathrm{in}$.) 
from the influent screen. In addition, the material immediately downgradient from the oxidized zone showed a subtle green coloration on the surface of the light-colored Ringold sediment minerals. The high-concentration PolyMetallix column was very similar to the medium-range concentration RNIP-M2 column in that a visibly oxidized zone was present down range of the influent screen for a distance of approximately $15.2 \mathrm{~cm}$ (6 in.); as such, about 25 percent of the column filling was oxidized. No green color was discernable adjacent to the oxidized zone. The medium-concentration $(0.15 \mathrm{wt} \%)$ PolyMetallix column was nearly completely visibly oxidized.

\subsubsection{Hexavalent Chromium Removal}

One of the objectives of the advanced geochemical testing was to evaluate the ability of ZVI-impregnated Ringold soil to remove/reduce hexavalent chromium and to determine which of the two tested ZVI materials was better able to perform this process. As shown in Figures 4-31 through 4-33, there was a distinct difference in the performance of the two tested ZVI materials in regard to the ability to remove chromium from the column effluent. At the high concentration $(1.5 \mathrm{wt} \%)$, both of the tested ZVI materials removed hexavalent chromium from the surrogate groundwater to levels below the detection limits used by the analytical laboratory through the entire duration of testing. It should be noted that hexavalent chromium data for the first sample time for the columns containing the high concentration of the RNIP-M2 yielded values that were above the analytical detection limits. However, these chromium values are believed to be a function of interference to the analytical technique used for hexavalent chromium by the high concentrations of organic dispersant in those samples. This belief is supported by the total and dissolved chromium analysis data from the same sample time, the values of which are an order of magnitude lower than the hexavalent chromium values.

Figure 4-31 denotes the trends in the removal of hexavalent chromium throughout the duration of testing for the two ZVI materials compared to the control column at the high concentration.

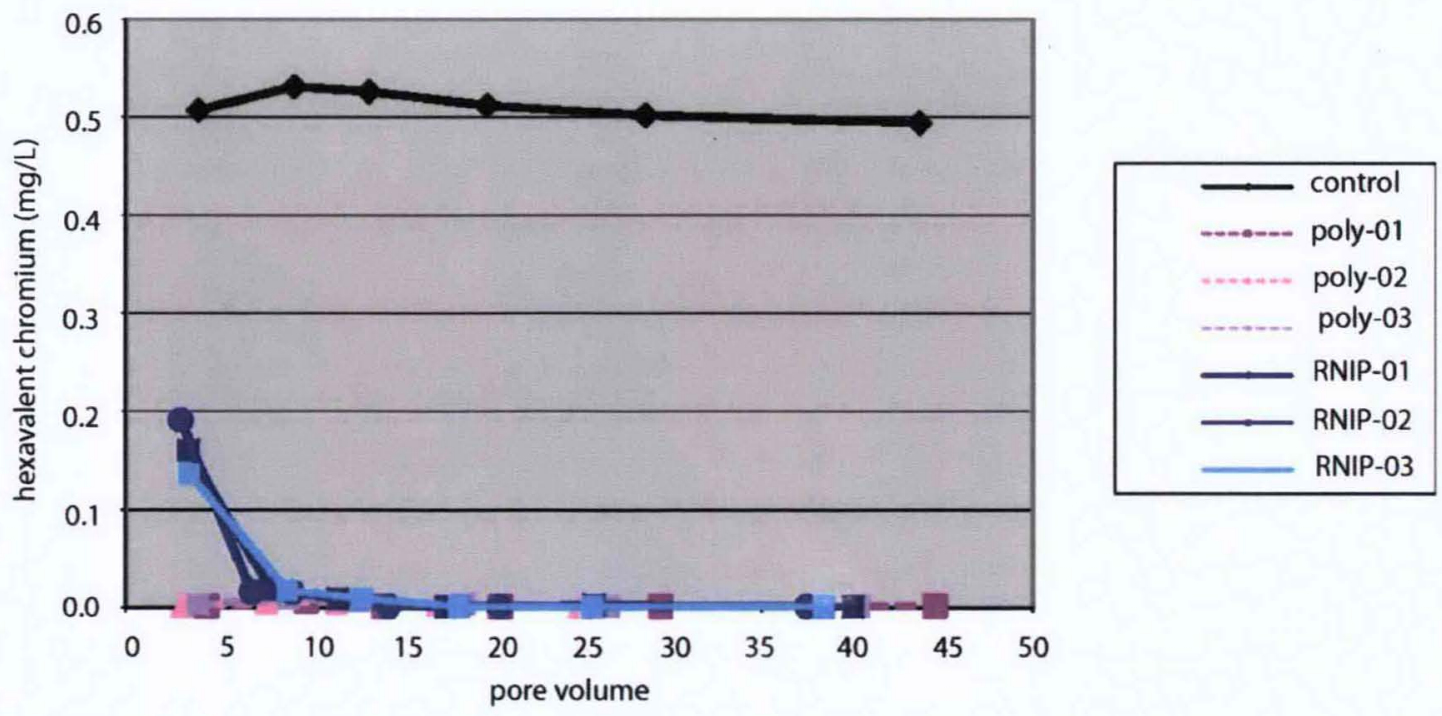

NOTE: Initial RNIP-M2 samples should be disregarded due to probable interference to analytical method from high organic dispersant concentration in the effluent.

Figure 4-31. Chromium Removal Trend - High-Concentration (1.5 wt\%) Columns 
DOE/RL-2009-35, REV. 0

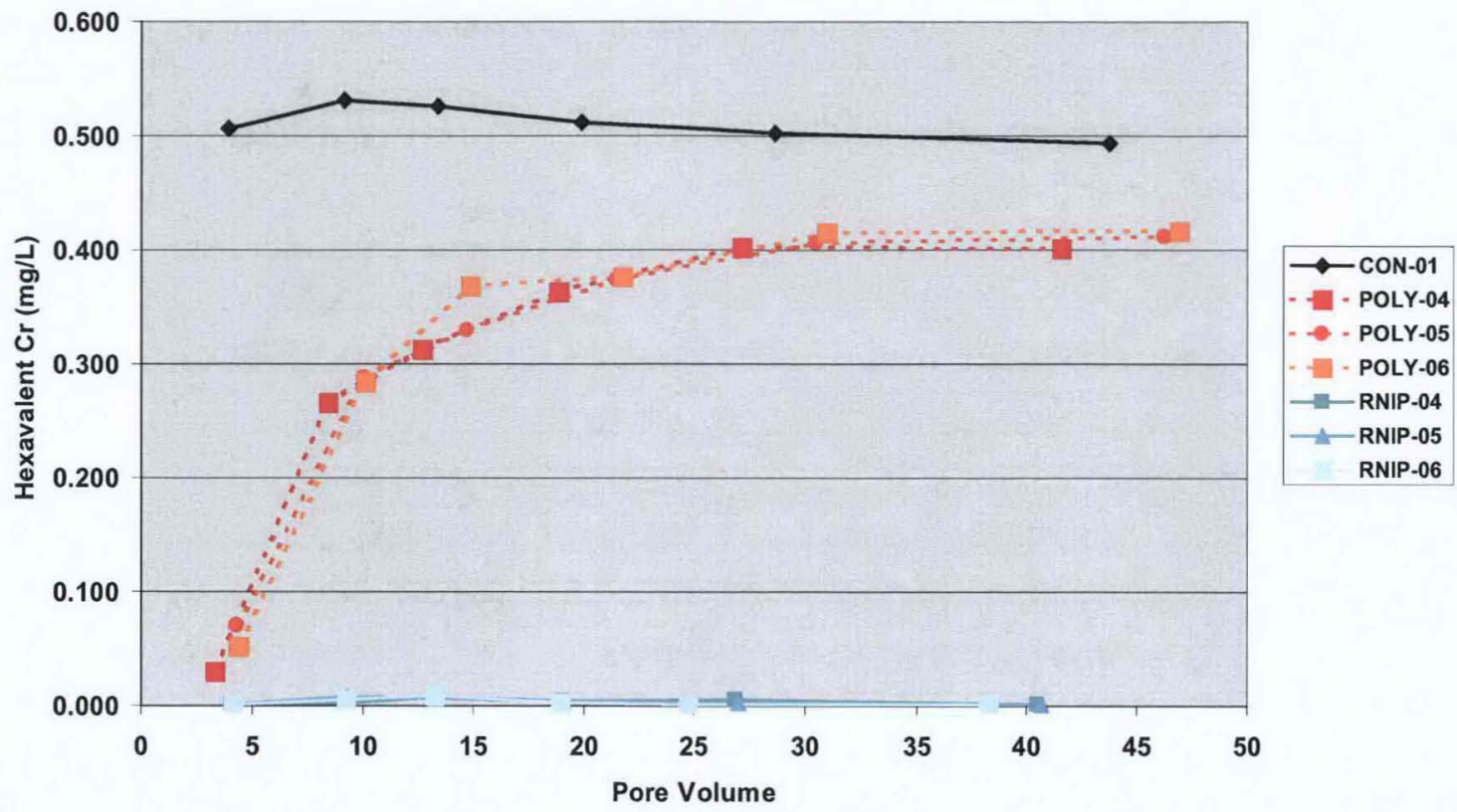

Figure 4-32. Chromium Removal Trend - Mid-Concentration (0.15 Percent) Columns

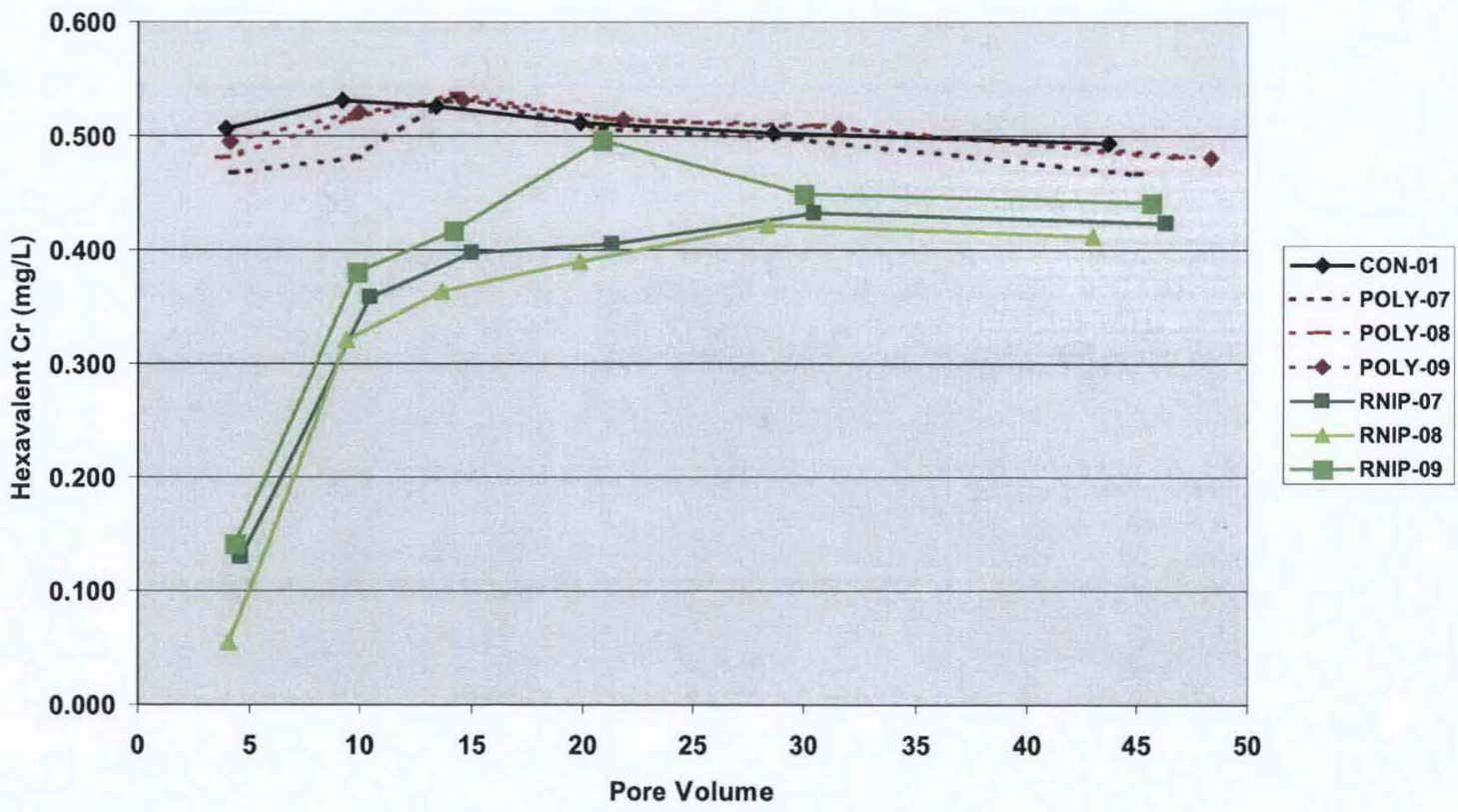

Figure 4-33. Chromium Removal Trend - Low-Concentration (0.015 Percent) Columns

The medium-concentration $(0.15 \mathrm{wt} \%)$ of the two ZVI materials showed a distinct difference in the ability to remove hexavalent chromium from the surrogate groundwater. The RNIP-M2 material at the intermediate concentration removed hexavalent chromium from the surrogate groundwater nearly completely through the entire duration of testing. No interference was detected during the intermediate analyses as a result of the lower concentrations of dispersant in the samples. The PolyMetallix ZVI 
material at the medium concentration was not able to remove the hexavalent chromium from the surrogate groundwater to a level below the detection limits used by the analytical laboratory at any point during testing. By the end of testing, the medium-concentration of the PolyMetallix ZVI material removed approximately 20 to 25 percent of the hexavalent chromium from the surrogate groundwater.

Figure 4-32 denotes the trends in the removal of hexavalent chromium throughout the duration of testing for the two ZVI materials compared to the control column at the medium concentration.

The low concentration ( $0.015 \mathrm{wt} \%)$ of RNIP-M2 material was able to remove approximately 75 percent of the hexavalent chromium from the surrogate groundwater during the initial stages of testing. During the latter stages of testing, the lower concentration of RNIP-M2 material removed lesser amounts of the hexavalent chromium, until approximately 15 percent removal was denoted after $40 \mathrm{PVs}$ had passed through the columns. The low-concentration PolyMetallix material was not able to remove any appreciable amount of hexavalent chromium from the surrogate groundwater. Figure 4-33 denotes the trends in the removal of hexavalent chromium throughout the duration of testing for the two ZVI materials compared to the control column at the low concentration.

\subsubsection{Effect on Nitrate}

An additional test objective of advanced geochemical testing was the effect of the ZVI-induced, chemical-reducing conditions on the conversion of nitrate to ammonia. It should be noted that the initial concentration of nitrate as nitrogen in the surrogate groundwater was approximately $14 \mathrm{mg} / \mathrm{L}$. It should also be noted that if the concentrations of nitrate, nitrite, and ammonia (the complete data are presented in Appendix C, Section C5) for the effluents from both the RNIP-M2 and PolyMetallix ZVI columns are summed, the total value is over $14 \mathrm{mg} / \mathrm{L}$ for a number of samples; in fact, in a number of the ammonia samples alone exceed $14 \mathrm{mg} / \mathrm{L}$. As such, these ammonia values have been removed from the data set. The ammonia graphs that are included in the report use the abridged data. However, the concentrations of nitrate and nitrite appear to be viable. The decrease in the nitrate concentration below the concentration of the surrogate groundwater can be construed as being converted to nitrite, nitrogen gas, and ammonia. Therefore, the differences between the control column effluent nitrate concentration minus the effluent nitrite concentration can be construed to be the potential concentration for the combined amount of ammonia and nitrogen gas.

In the initial portions of the test, the effluent from the high-concentration (1.5 wt $\%)$ columns of both ZVI materials were significantly lower in the concentration of nitrate than the effluent from the control column. In the latter stages of the test, this difference is distinctly reduced for the PolyMetallix column effluents but remain unchanged for the RNIP-M2 columns. Figure 4-34 denotes the trends in the nitrate concentration of the column effluents throughout the duration of the test for the two ZVI materials compared to the control column at the high concentration.

The effluents from the medium-concentration $(0.15 \mathrm{wt} \%)$ PolyMetallix columns are only slightly lower in concentration than the effluents from the control column throughout testing. The effluents from the medium-concentration RNIP-M2 columns are lower in nitrate concentration than either the control column or the PolyMetallix column and show a distinct reduction in concentration during the middle to later portions of the test. Figure 4-35 denotes the trends in the nitrate concentration of the column effluents throughout the duration of the test for the two ZVI materials compared to the control column at the medium concentration. 


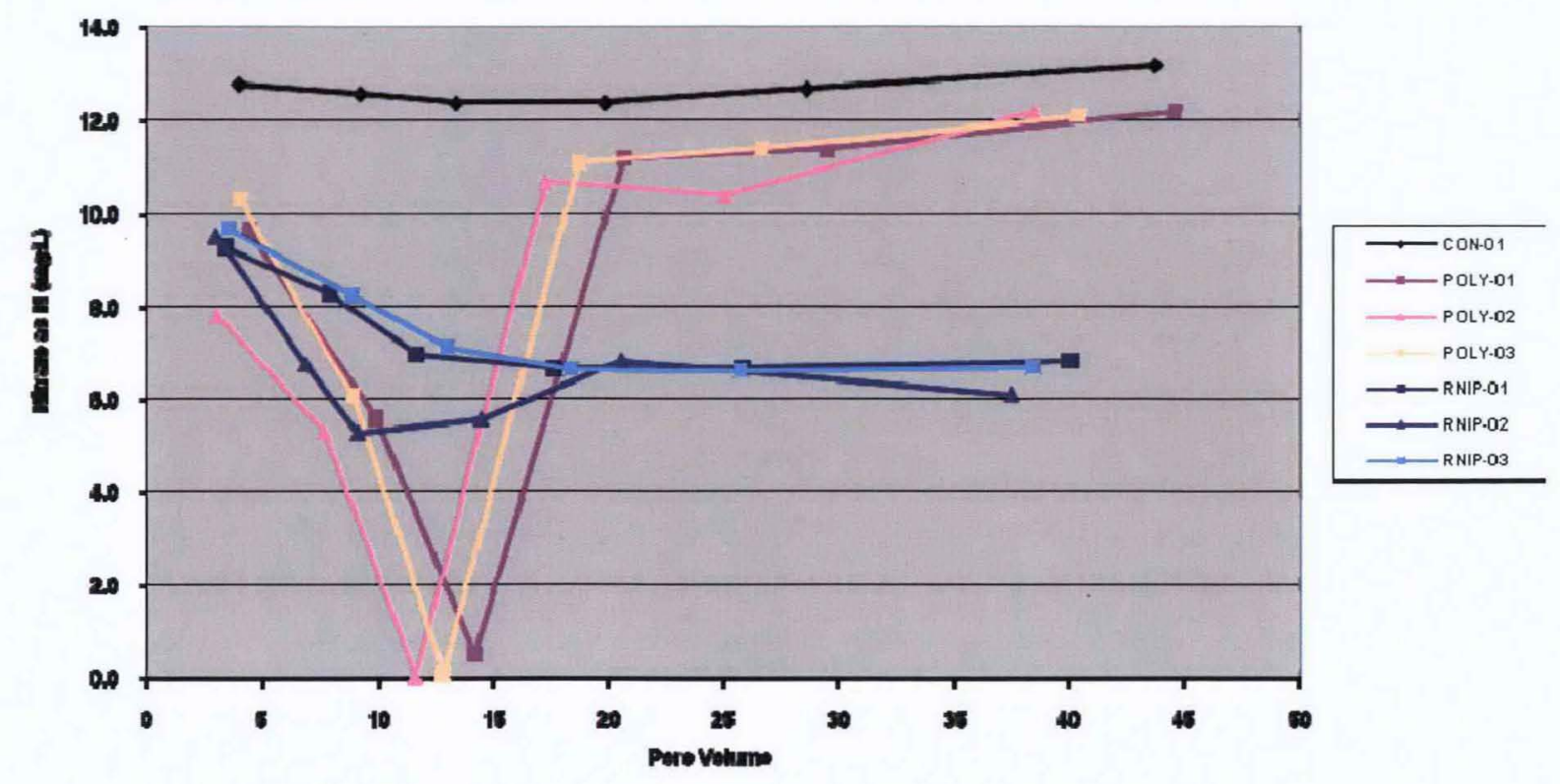

Figure 4-34. Nitrate Trend - High-Concentration (1.5 Percent) Columns

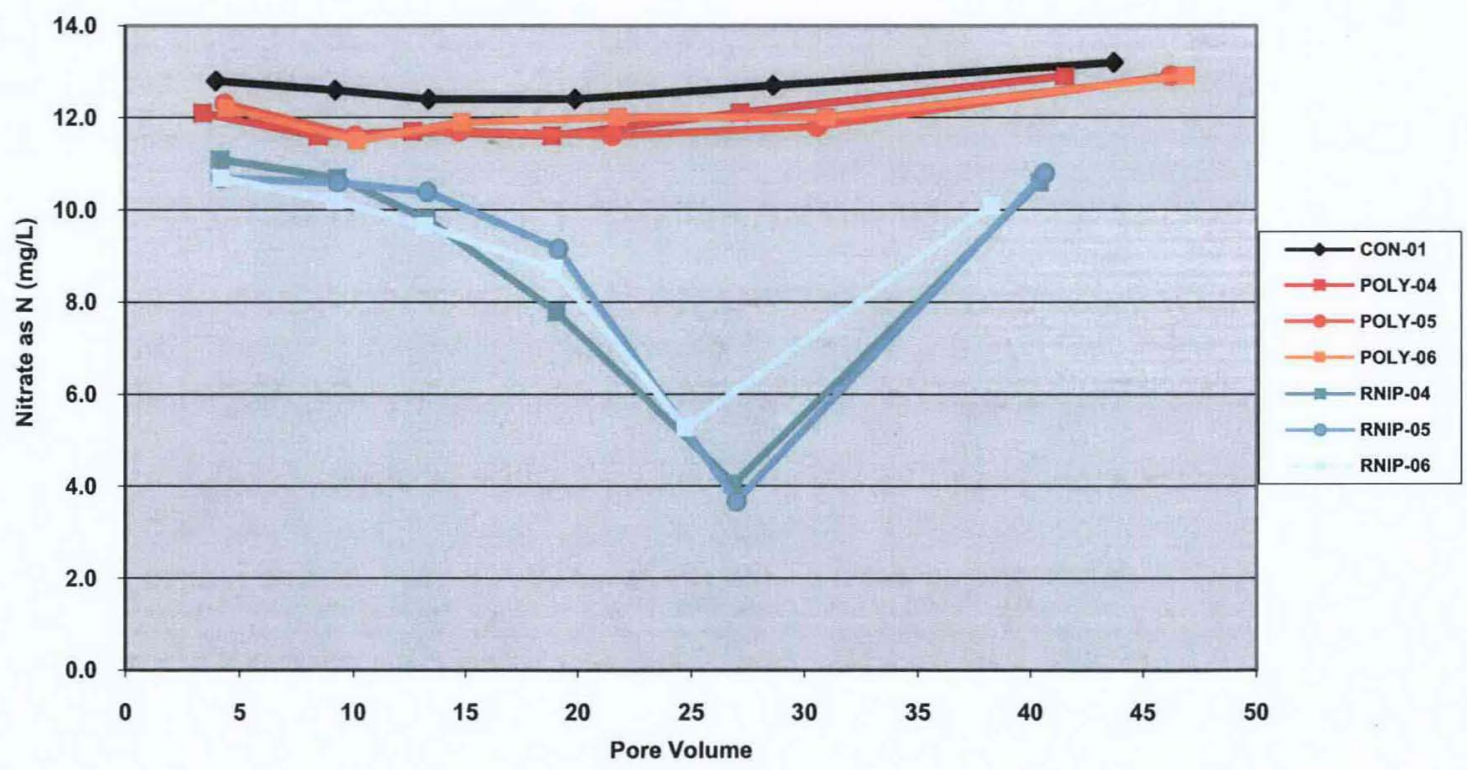

Figure 4-35. Nitrate Trend - Mid-Concentration (0.15 wt\%) Columns

The effluents from both sets of low-concentration ZVI columns are quite similar in nitrate concentration to the effluent from the control column. Figure 4-36 denotes the trends in the nitrate concentration of the column effluents throughout the duration of the test for the two ZVI materials compared to the control column at the low concentration. 


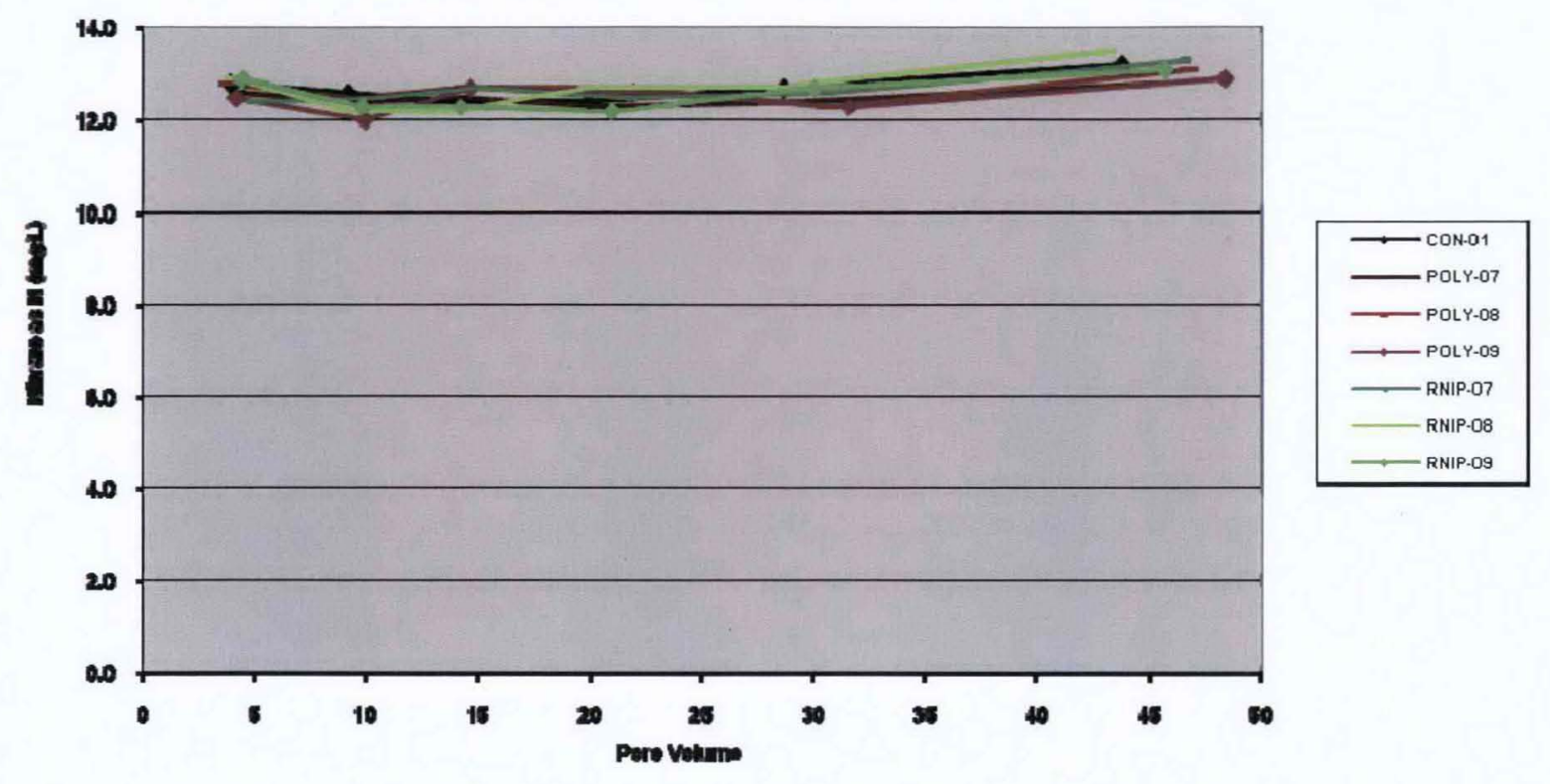

Figure 4-36. Nitrate Trend - Low-Concentration (0.015 wt\%) Column

The rapid decreases in nitrate concentration exhibited by both the high-concentration PolyMetallix columns and the medium-concentration RNIP-M2 columns at 12 and 28 PVs, respectively, occurred soon after the ORP of the effluents from those columns also increased. The chemical reduction of nitrate in the columns is, therefore, a direct result of the reactivity of the ZVI materials and the reactions produced by that reactivity. Changes in nitrite concentration are shown in Figures 4-37 through 4-39.

The ammonia production trends are shown in Figures 4-40 through 4-42. All columns show a slight increase in the effluent ammonia from approximately 7 to $20 \mathrm{PVs}$, and thereafter decreasing. It is important to note that this same trend was observed in the control column, suggesting that maybe the ammonia results may be due to constituents present in the column sediment.

\subsubsection{Effect on Carbonate}

Another objective of advanced geochemical testing was to distinguish changes in carbonate concentration during testing that could have been caused by high $\mathrm{pH}$, as high carbonate concentrations may decrease the aquifer permeability. The concentration of alkalinity in the effluents from all the test columns, with the exception of the high-concentration (1.5 wt \%) RNIP-M2 columns, was very similar to the concentration in the effluent from the control column. The effluent from the high-concentration RNIP-M2 columns were lower in alkalinity than the effluents from the control columns by 25 to $30 \mathrm{mg} / \mathrm{L}$ throughout the majority of the test; however, this value was only approximately $10 \mathrm{mg} / \mathrm{L}$ at the end of testing. The alkalinity trends are presented in Figures 4-43 through 4-45. 
DOE/RL-2009-35, REV. 0
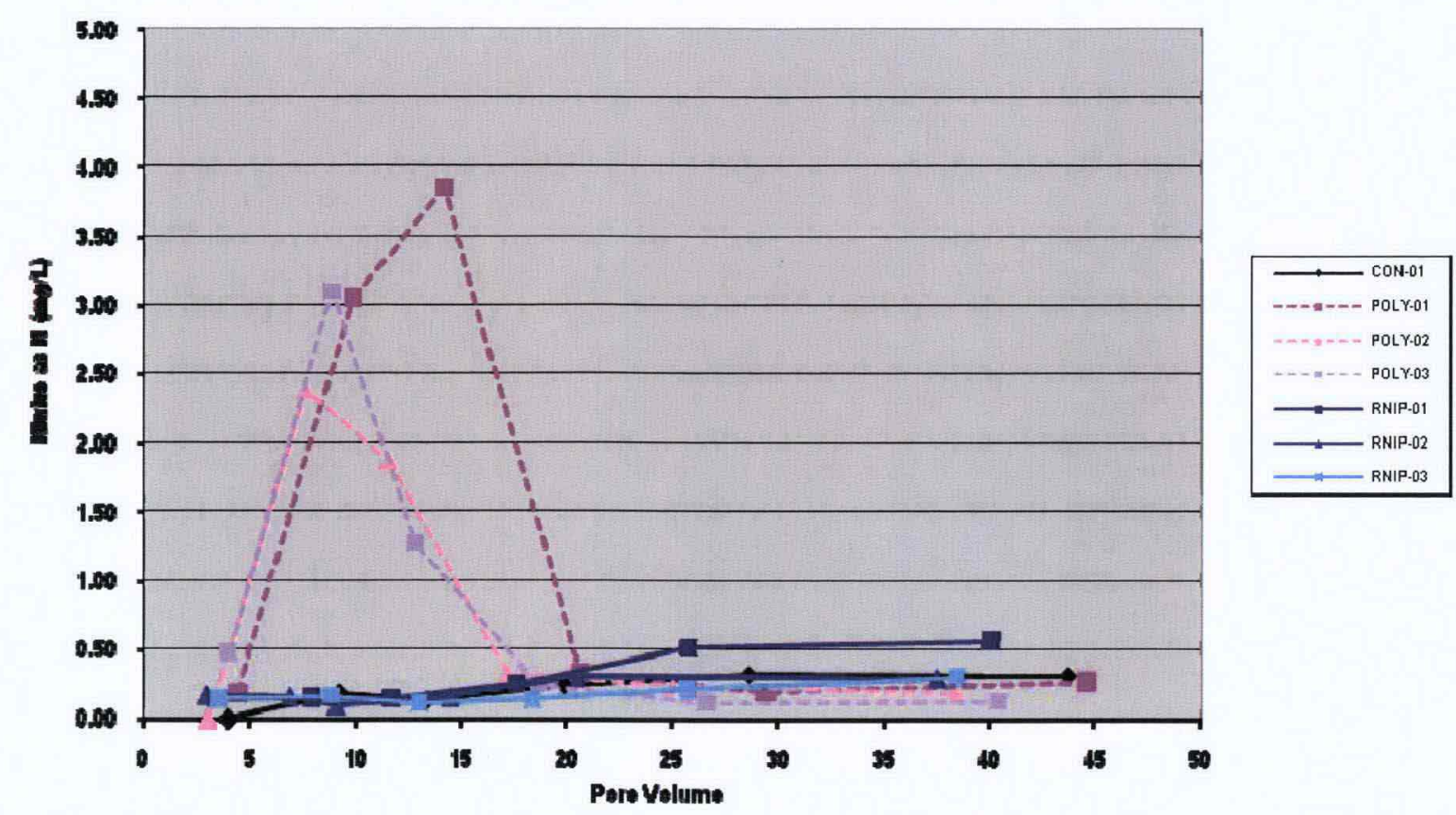

Figure 4-37. Nitrite Trend - High-Concentration (1.5 wt\%) Columns
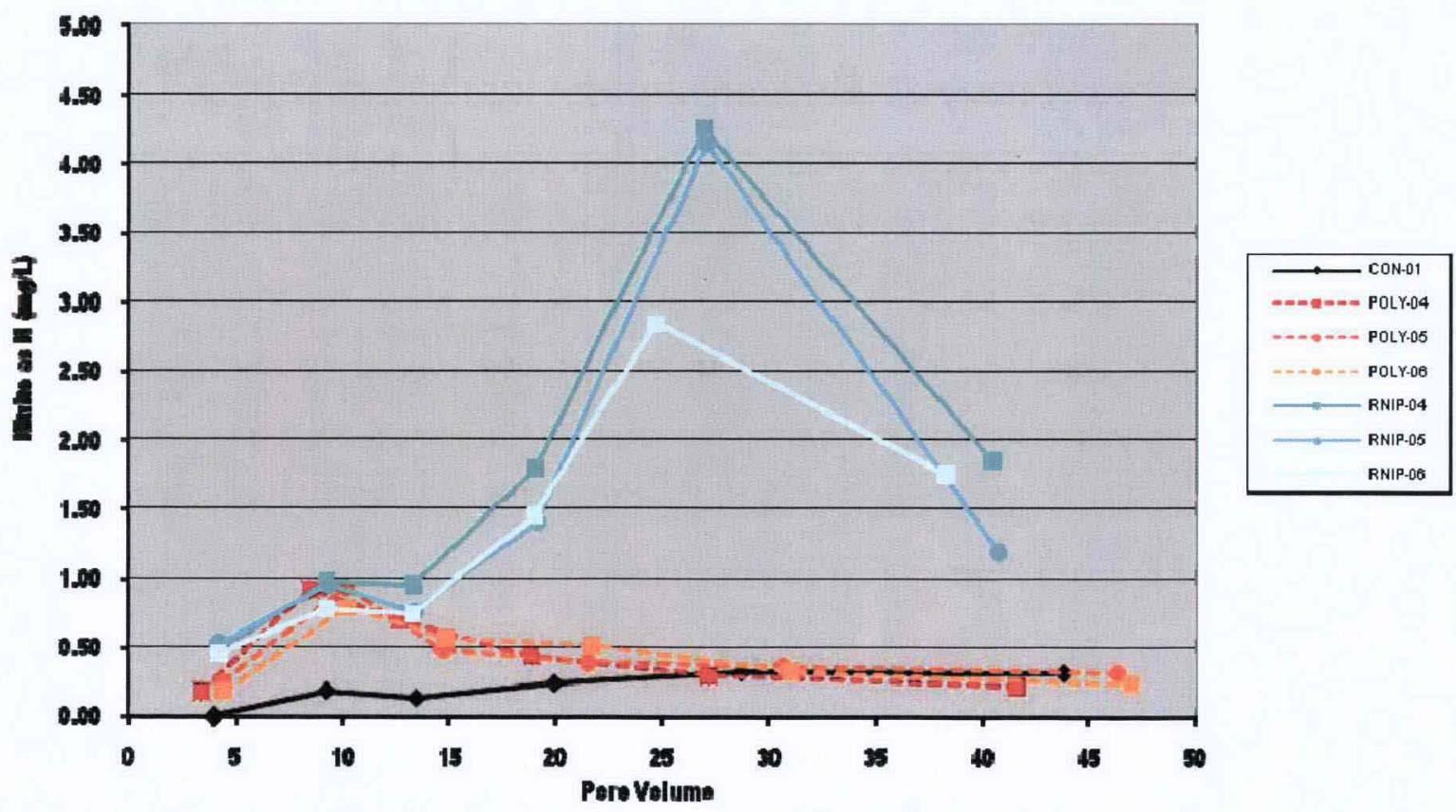

Figure 4-38. Nitrite Trend - Mid-Concentration (0.15 wt\%) Columns 
DOE/RL-2009-35, REV. 0

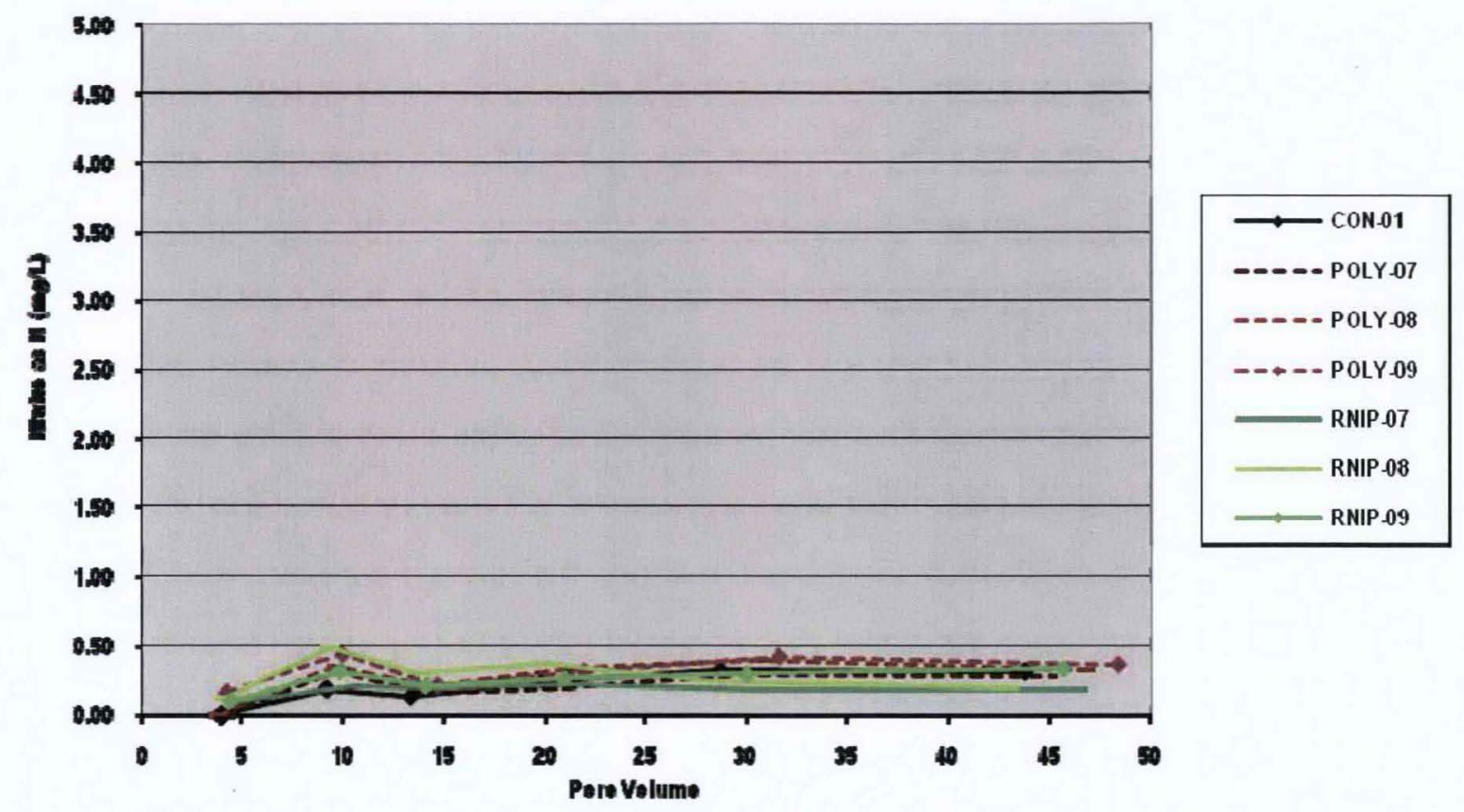

Figure 4-39. Nitrite Trend - Low-Concentration ( $0.015 w t \%)$ Columns

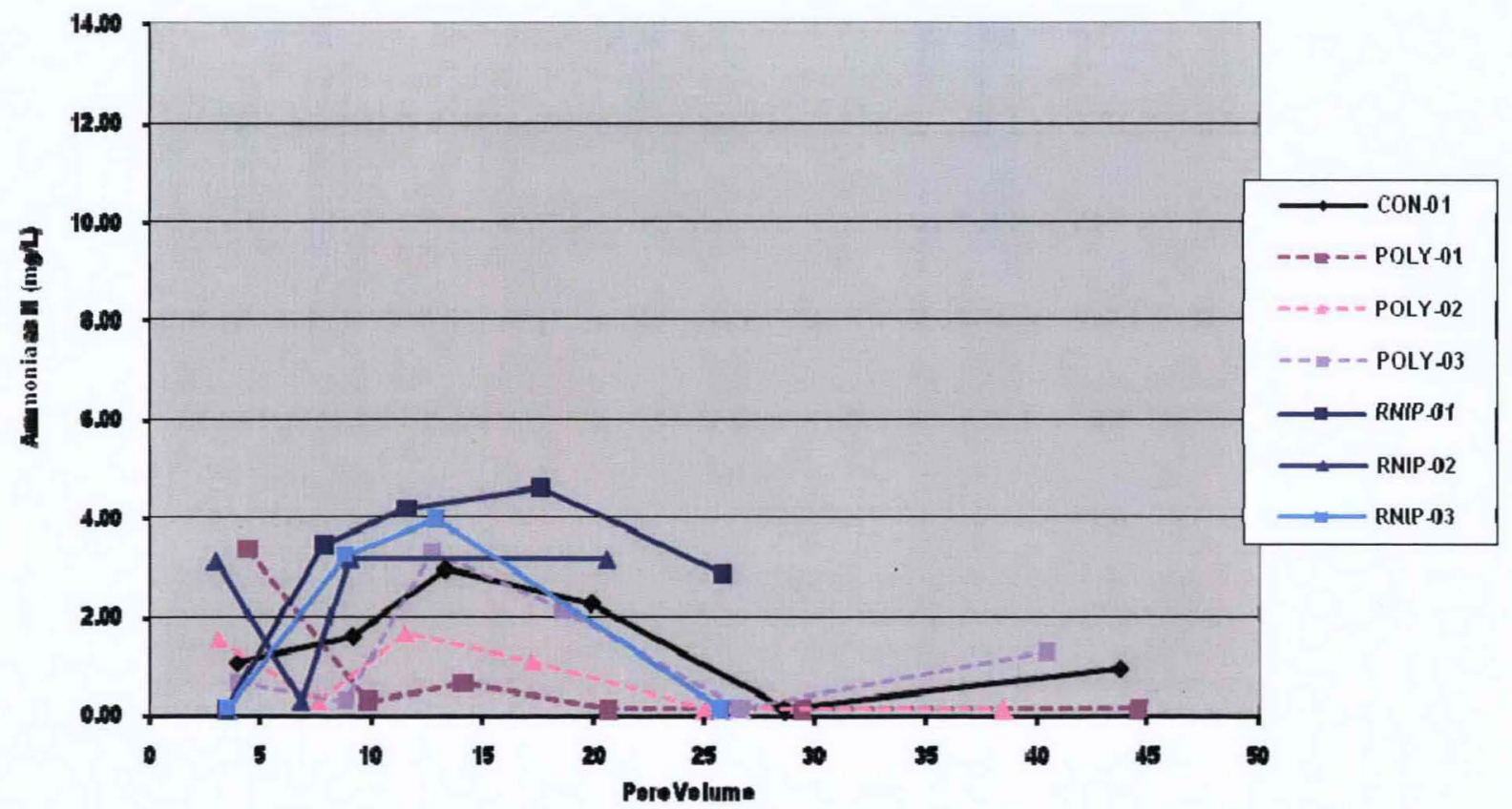

Figure 4-40. Ammonia Trend - High-Concentration (1.5 wt\%) Columns 
DOE/RL-2009-35, REV. 0

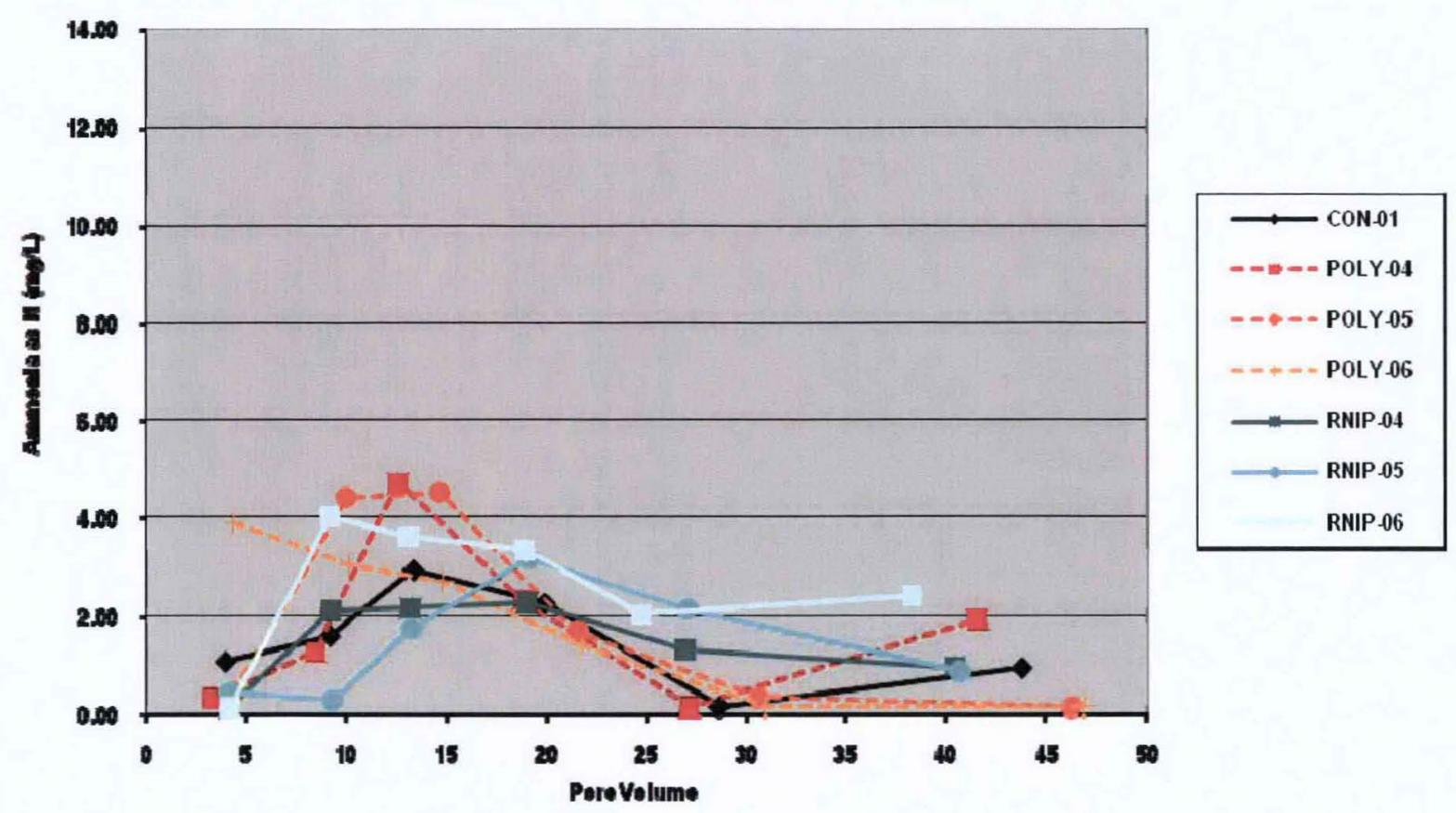

Figure 4-41. Ammonia Trend - Mid-Concentration (0.15 wt\%) Columns

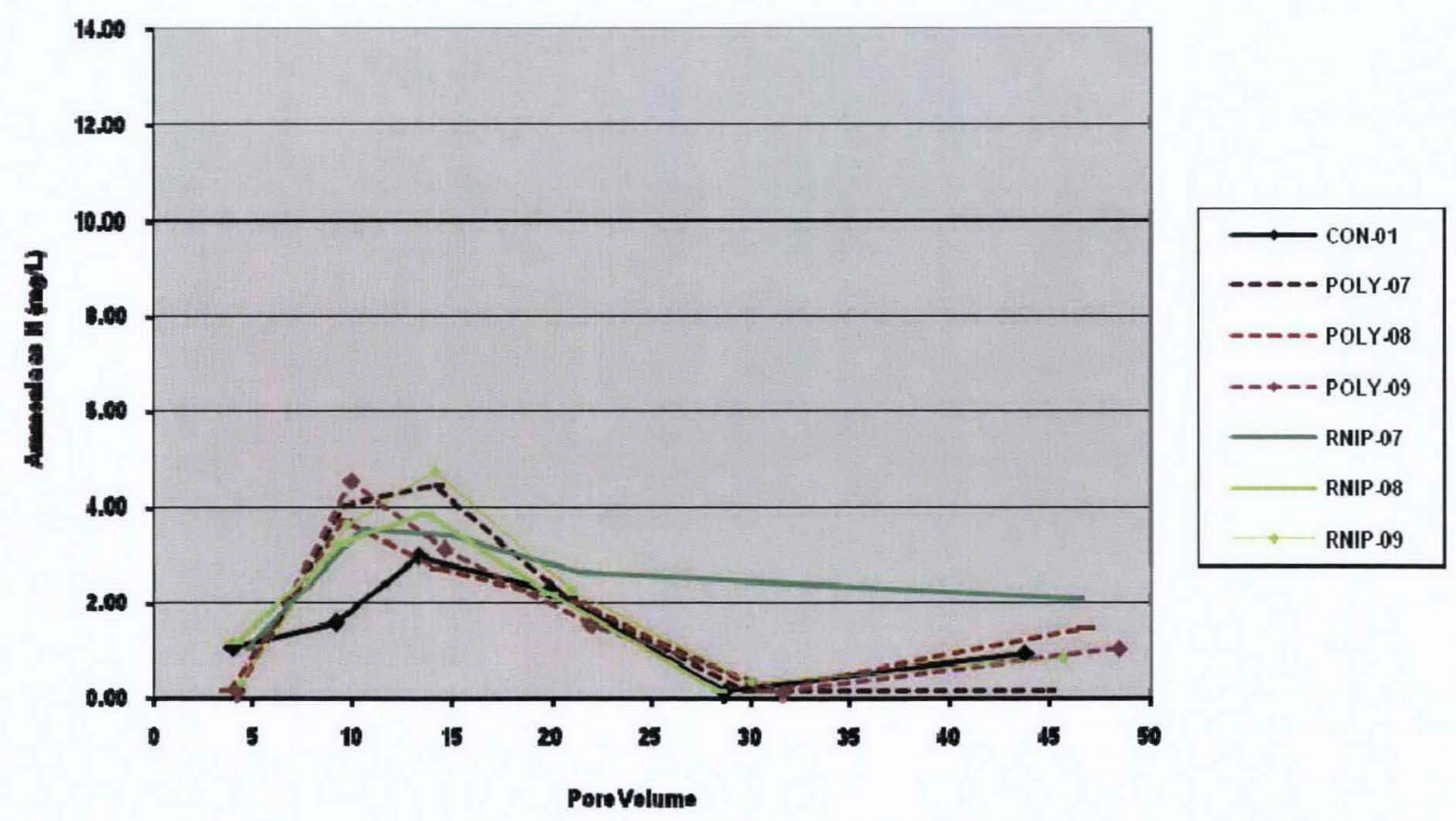

Figure 4-42. Ammonia Trend - Low-Concentration (0.015 wt\%) Columns 
DOE/RL-2009-35, REV. 0

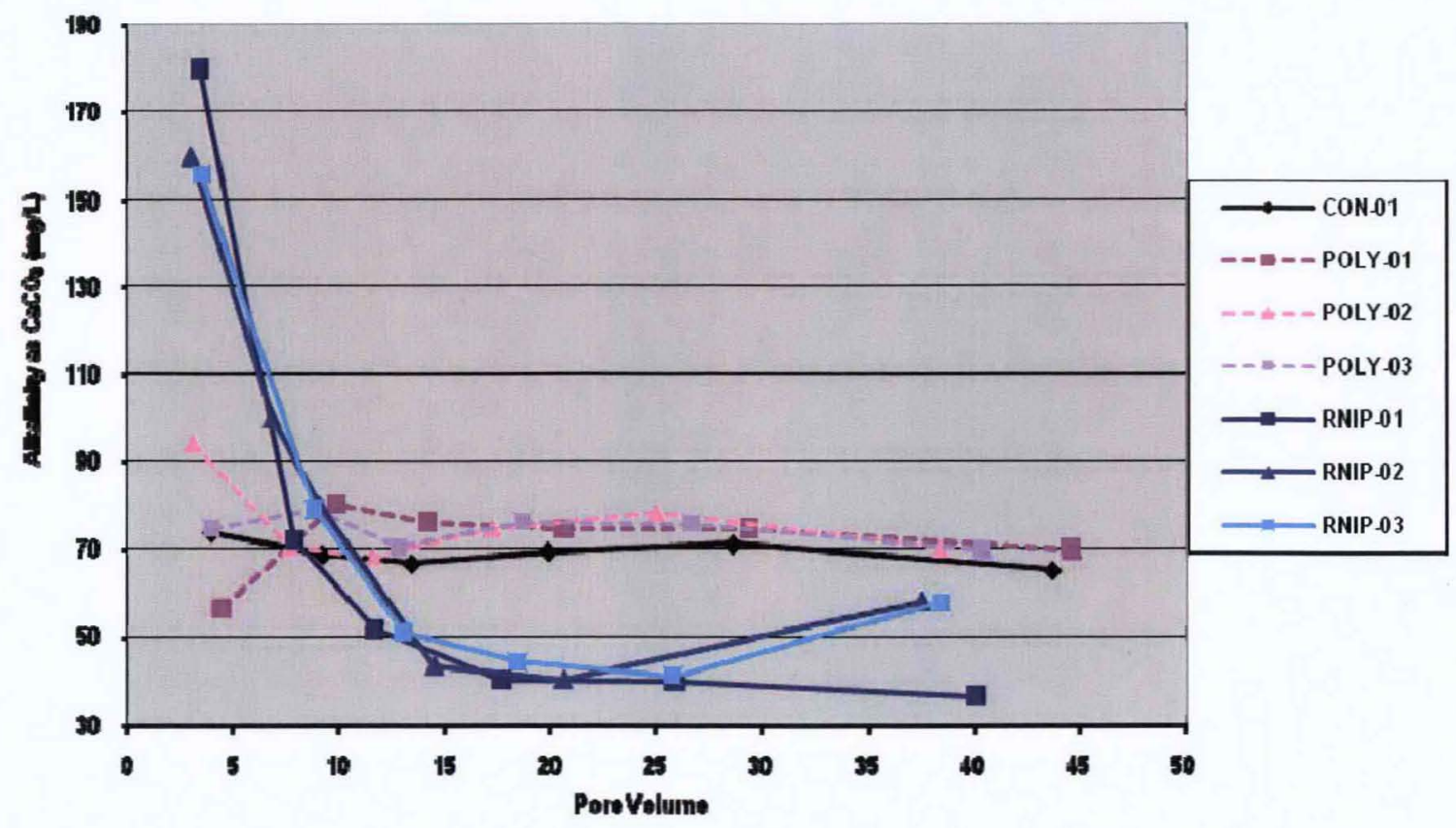

Figure 4-43. Alkalinity Trend - High-Concentration (1.5 wt\%) Columns

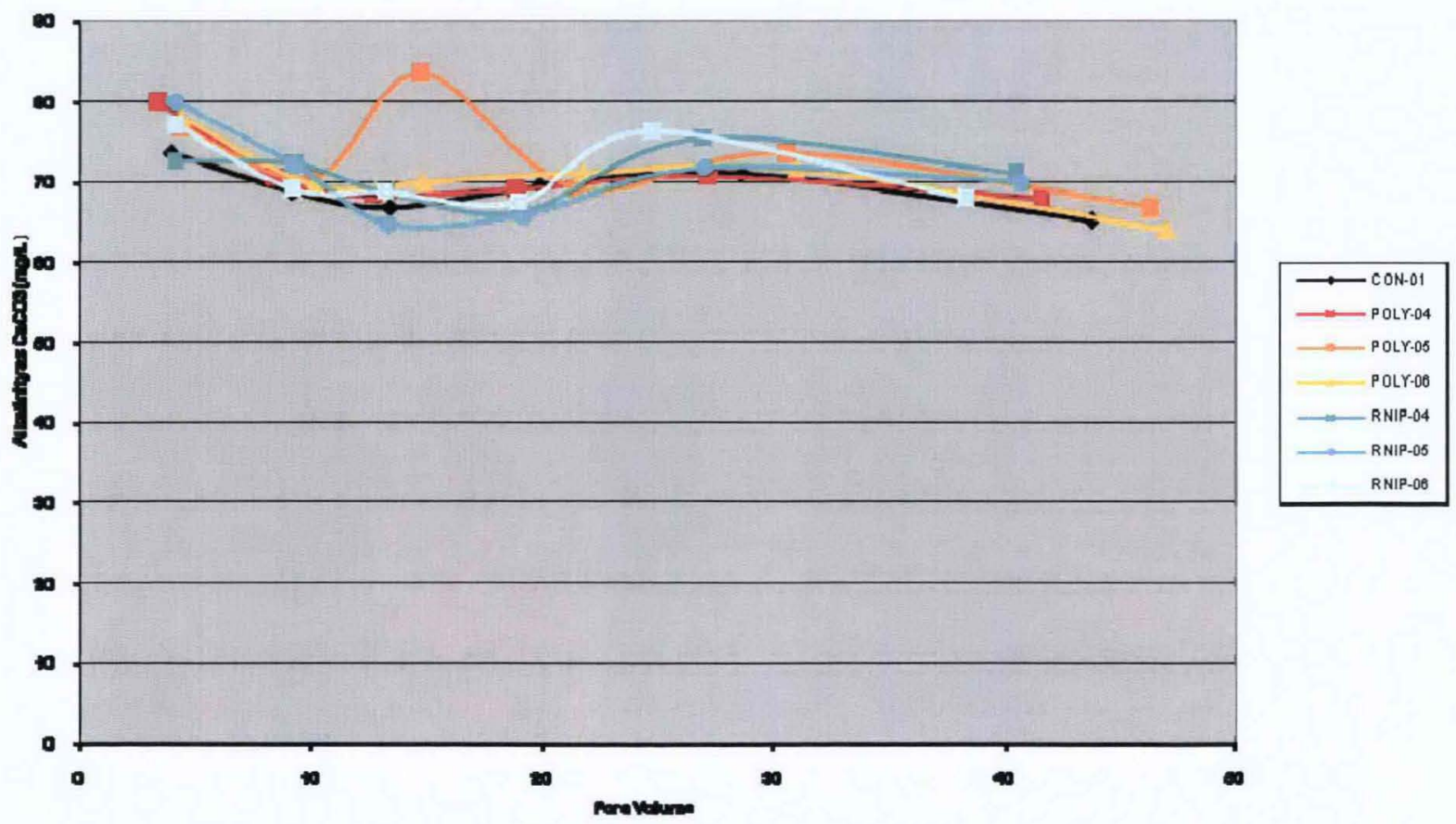

Figure 4-44. Alkalinity Trend - Mid-Concentration ( 0.15 wt\%) Columns 
DOE/RL-2009-35, REV. 0

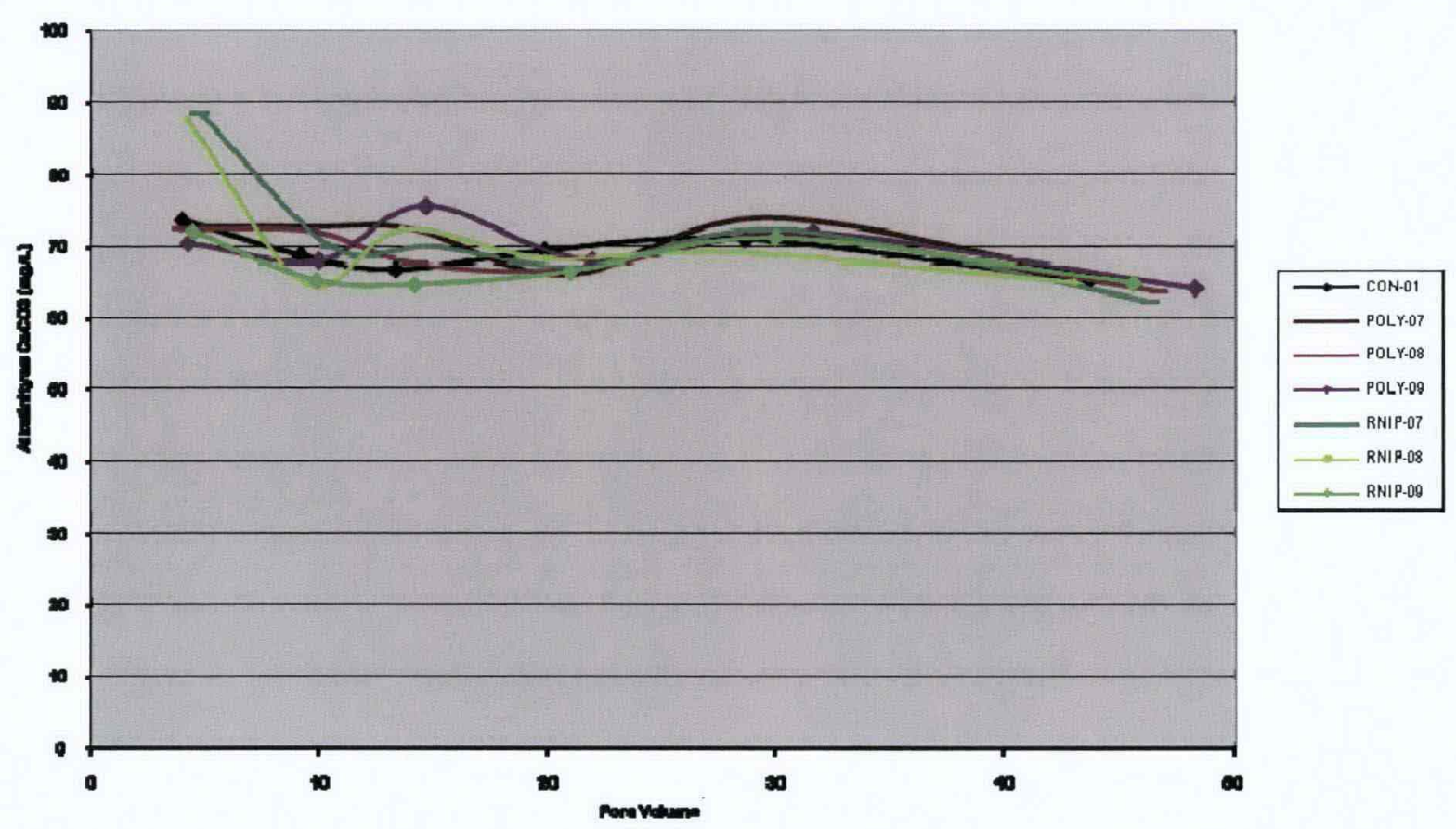

Figure 4-45. Alkalinity Trend - Low-Concentration (0.015 wt\%) Columns

The lowering of the alkalinity in the effluent from the high-concentration RNIP-M2 columns could have been due to the development of a secondary carbonate mineral in those columns. However, no buildup of secondary carbonate minerals was observed during the physical examination of the columns after the completion of the test. In addition, no increase in head differential was observed for the highconcentration RNIP-M2 columns during the testing. In fact, the head differential for the highconcentration RNIP-M2 columns decreased during testing. The lack of secondary carbonate formation is reasonable for the length of experiment. For example, assuming that $30 \mathrm{mg} / \mathrm{L}$ of calcite would be produced due to the reduction in the alkalinity, a column porosity of 24.5 percent, and a flow rate of $1 \mathrm{~mL} / \mathrm{min}$, in excess of 14 years would be required to completely plug the column.

\subsubsection{Passivation}

The final objective of advanced geochemical testing was to assess the passivation of the ZVI material by formation of iron hydroxy-oxides, or other secondary minerals, on the ZVI material. For that purpose, MLA was conducted on samples collected from the columns by the Center for Advanced Mineral Processing at Montana Tech. MLA was developed at the University of Queensland (Australia) and uses a modern scanning electron microscope that uses the technique of backscattered electron imaging combined with $\mathrm{x}$-ray options to determine the mineral phases. The MLA technique is discussed in more detail in "Automated Scanning Electron Microscope Based Mineral Liberation Analysis" (Gu 2003). The results of MLA did not show significant deposition of secondary mineral phases. No oxidized iron phases or chromium bearing phases were observed. Potentially, had the experiment been run for a longer period of time, such phases may have been formed to a size that could have been more readily observed by MLA. Figures 4-46 and 4-47 present the diagrams produced by the Center for Advanced Mineral Processing. 
The figures show very small grains of iron-rich materials clinging to the edges of minerals from the Ringold Formation sediments. The data developed during the experiment allude to possible passivation of the PolyMetallix material, specifically the sharp decrease in ORP after some 15 PVs had passed through the columns and the subsequent decrease in nitrate reduction at approximately the same time during the testing. However, the causes of these changes cannot be specifically determined from the generated data.

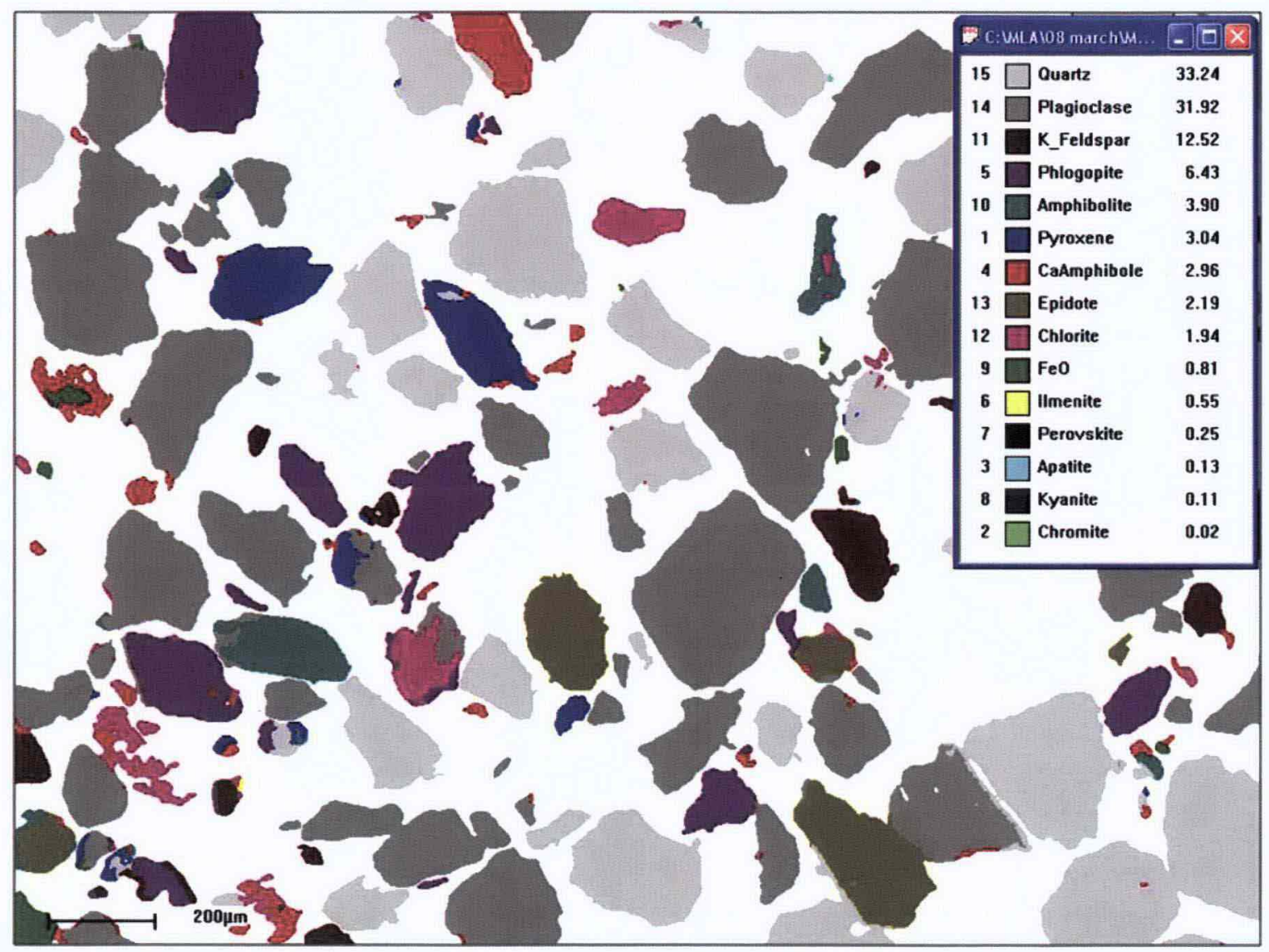

Figure 4-46. Mineral Liberation Analysis for High-Concentration (1.5 wt\%) PolyMetallix Sample

\subsubsection{Additional Information}

In addition to the analytical samples (which were taken from the column effluent at each of the sample times), a number of additional samples were also taken at specific sample times for specific analyses. The specific analyses included total chromium analysis of samples taken at the first and last sample times from each of the columns, hexavalent chromium analysis of samples taken at the first sampling time from each of the columns, total iron analysis of samples taken at the first and last sample times from each of the columns, and dissolved iron analysis of samples taken at the first sampling time from each of the columns. The analytical data generated from these samples are presented in Tables 4-9 through 4-11. 


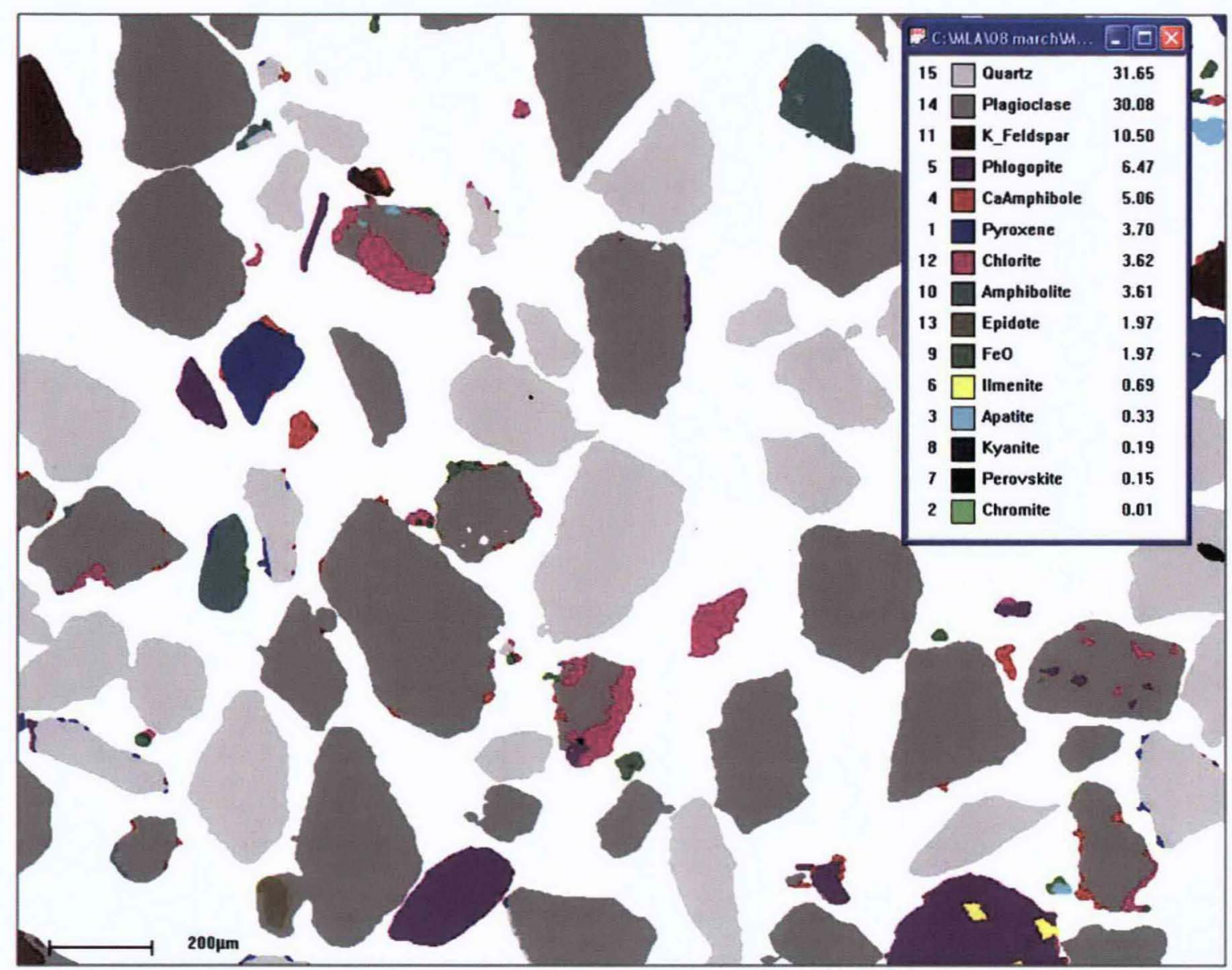

Figure 4-47. Mineral Liberation Analysis for High-Concentration (1.5 wt\%) RNIP-M2 Sample

Table 4-9. Extra Analytical Column Data - RNIP-M2 Columns

\begin{tabular}{l|c|c|c|c|c|c|c|c|c}
\hline Parameter & $\begin{array}{c}\text { Column } \\
\mathbf{1}\end{array}$ & $\begin{array}{c}\text { Column } \\
\mathbf{2}\end{array}$ & $\begin{array}{c}\text { Column } \\
\mathbf{3}\end{array}$ & $\begin{array}{c}\text { Column } \\
\mathbf{4}\end{array}$ & $\begin{array}{c}\text { Column } \\
\mathbf{5}\end{array}$ & $\begin{array}{c}\text { Column } \\
\mathbf{6}\end{array}$ & $\begin{array}{c}\text { Column } \\
\mathbf{7}\end{array}$ & $\begin{array}{c}\text { Column } \\
\mathbf{8}\end{array}$ & $\begin{array}{c}\text { Column } \\
\mathbf{9}\end{array}$ \\
\hline \hline Total $\mathbf{~ C r}$ & $\mathbf{m g} / \mathbf{L}$ & $\mathbf{m g} / \mathbf{L}$ & $\mathbf{m g} / \mathbf{L}$ & $\mathbf{m g} / \mathbf{L}$ & $\mathbf{m g} / \mathbf{L}$ & $\mathbf{m g} / \mathbf{L}$ & $\mathbf{m g} / \mathbf{L}$ & $\mathbf{m g} / \mathbf{L}$ & $\mathbf{m g} / \mathbf{L}$ \\
\hline $\begin{array}{l}\text { Sample } \\
\text { Time 1 }\end{array}$ & 0.052 & 0.055 & 0.058 & 0.016 & 0.016 & 0.016 & 0.144 & 0.050 & 0.133 \\
\hline $\begin{array}{l}\text { Sample } \\
\text { Time 6 }\end{array}$ & 0.016 & 0.016 & 0.016 & 0.016 & 0.016 & 0.016 & 0.509 & 0.499 & 0.496 \\
\hline $\begin{array}{c}\text { Dissolved } \\
\text { Cr }\end{array}$ & $\mathbf{m g / L}$ & $\mathbf{m g} / \mathbf{L}$ & $\mathbf{m g} / \mathbf{L}$ & $\mathbf{m g} / \mathbf{L}$ & $\mathbf{m g} / \mathbf{L}$ & $\mathbf{m g} / \mathbf{L}$ & $\mathbf{m g} / \mathbf{L}$ & $\mathbf{m g} / \mathbf{L}$ & $\mathbf{m g} / \mathbf{L}$ \\
\hline $\begin{array}{l}\text { Sample } \\
\text { Time 1 }\end{array}$ & 0.048 & 0.030 & 0.017 & 0.016 & 0.016 & 0.016 & 0.143 & 0.049 & 0.146 \\
\hline
\end{tabular}


DOE/RL-2009-35, REV. 0

Table 4-9. Extra Analytical Column Data - RNIP-M2 Columns

\begin{tabular}{|c|c|c|c|c|c|c|c|c|c|}
\hline Parameter & $\begin{array}{c}\text { Column } \\
1\end{array}$ & $\underset{2}{\text { Column }}$ & $\begin{array}{c}\text { Column } \\
3\end{array}$ & $\underset{4}{\text { Column }}$ & $\underset{5}{\text { Column }}$ & $\underset{6}{\text { Column }}$ & $\underset{7}{\text { Column }}$ & $\begin{array}{c}\text { Column } \\
8\end{array}$ & $\underset{9}{\text { Column }}$ \\
\hline Total Fe & $\mathrm{mg} / \mathrm{L}$ & $\mathrm{mg} / \mathrm{L}$ & $\mathrm{mg} / \mathrm{L}$ & $\mathrm{mg} / \mathrm{L}$ & mg/L & $\mathrm{mg} / \mathrm{L}$ & $\mathrm{mg} / \mathrm{L}$ & $\mathrm{mg} / \mathrm{L}$ & $\mathrm{mg} / \mathrm{L}$ \\
\hline $\begin{array}{l}\text { Sample } \\
\text { Time } 1\end{array}$ & 80.7 & 100.0 & 75.9 & 0.367 & 0.329 & 0.960 & 0.007 & 0.007 & 0.018 \\
\hline $\begin{array}{l}\text { Sample } \\
\text { Time } 6\end{array}$ & 0.673 & 1.24 & 0.780 & 0.161 & 0.176 & 0.203 & 0.007 & 0.007 & 0.007 \\
\hline $\begin{array}{c}\text { Dissolved } \\
\mathrm{Fe}\end{array}$ & $\mathrm{mg} / \mathrm{L}$ & $\mathrm{mg} / \mathrm{L}$ & $\mathrm{mg} / \mathrm{L}$ & $\mathrm{mg} / \mathrm{L}$ & $\mathrm{mg} / \mathrm{L}$ & $\mathrm{mg} / \mathrm{L}$ & $\mathrm{mg} / \mathrm{L}$ & $\mathrm{mg} / \mathrm{L}$ & $\mathrm{mg} / \mathrm{L}$ \\
\hline $\begin{array}{l}\text { Sample } \\
\text { Time } 1\end{array}$ & 25.8 & 30.7 & 24.1 & 0.052 & 0.043 & 0.060 & 0.007 & 0.007 & 0.007 \\
\hline
\end{tabular}

Table 4-10. Extra Analytical Column Data - PolyMetallix Columns

\begin{tabular}{|c|c|c|c|c|c|c|c|c|c|}
\hline Parameter & $\underset{1}{\text { Column }}$ & $\underset{2}{\text { Column }}$ & $\underset{3}{\text { Column }}$ & $\underset{4}{\text { Column }}$ & $\underset{5}{\text { Column }}$ & $\underset{6}{\text { Column }}$ & $\begin{array}{c}\text { Column } \\
7\end{array}$ & $\begin{array}{c}\text { Column } \\
8\end{array}$ & $\underset{9}{\text { Column }}$ \\
\hline Total $\mathbf{C r}$ & $\mathrm{mg} / \mathrm{L}$ & $\mathrm{mg} / \mathrm{L}$ & $\mathrm{mg} / \mathrm{L}$ & $\mathrm{mg} / \mathrm{L}$ & $\mathrm{mg} / \mathrm{L}$ & $\mathrm{mg} / \mathrm{L}$ & $\mathrm{mg} / \mathrm{L}$ & $\mathrm{mg} / \mathrm{L}$ & $\mathrm{mg} / \mathrm{L}$ \\
\hline $\begin{array}{l}\text { Sample } \\
\text { Time } 1\end{array}$ & 0.016 & 0.016 & 0.016 & 0.021 & 0.060 & 0.039 & 0.522 & 0.522 & 0.525 \\
\hline $\begin{array}{l}\text { Sample } \\
\text { Time } 6\end{array}$ & 0.016 & 0.016 & 0.016 & 0.467 & 0.481 & 0.491 & 0.543 & 0.535 & 0.529 \\
\hline $\begin{array}{c}\text { Dissolved } \\
\mathrm{Cr}\end{array}$ & $\mathrm{mg} / \mathrm{L}$ & $\mathrm{mg} / \mathrm{L}$ & $\mathrm{mg} / \mathrm{L}$ & $\mathrm{mg} / \mathrm{L}$ & $\mathrm{mg} / \mathrm{L}$ & $\mathrm{mg} / \mathrm{L}$ & $\mathrm{mg} / \mathrm{L}$ & $\mathrm{mg} / \mathrm{L}$ & $\mathrm{mg} / \mathrm{L}$ \\
\hline $\begin{array}{l}\text { Sample } \\
\text { Time } 1\end{array}$ & 0.016 & 0.016 & 0.016 & 0.018 & 0.068 & 0.45 & 0.501 & 0.519 & 0.511 \\
\hline Total Fe & $\mathrm{mg} / \mathrm{L}$ & $\mathrm{mg} / \mathrm{L}$ & mg/L & $\mathrm{mg} / \mathrm{L}$ & $\mathrm{mg} / \mathrm{L}$ & $\mathrm{mg} / \mathrm{L}$ & $\mathrm{mg} / \mathrm{L}$ & mg/L & $\mathrm{mg} / \mathrm{L}$ \\
\hline $\begin{array}{l}\text { Sample } \\
\text { Time } 1\end{array}$ & 0.250 & 0.525 & 0.180 & 0.007 & 0.007 & 0.007 & 0.007 & 0.007 & 0.007 \\
\hline $\begin{array}{l}\text { Sample } \\
\text { Time } 6\end{array}$ & 0.023 & 0.046 & 0.082 & 0.007 & 0.007 & 0.007 & 0.007 & 0.007 & 0.007 \\
\hline $\begin{array}{c}\text { Dissolved } \\
\text { Fe }\end{array}$ & $\mathrm{mg} / \mathrm{L}$ & $\mathrm{mg} / \mathrm{L}$ & $\mathrm{mg} / \mathrm{L}$ & $\mathrm{mg} / \mathrm{L}$ & $\mathrm{mg} / \mathrm{L}$ & $\mathrm{mg} / \mathrm{L}$ & $\mathrm{mg} / \mathrm{L}$ & $\mathrm{mg} / \mathrm{L}$ & $\mathrm{mg} / \mathrm{L}$ \\
\hline $\begin{array}{l}\text { Sample } \\
\text { Time } 1\end{array}$ & 0.007 & 0.031 & 0.007 & 0.007 & 0.007 & 0.007 & 0.007 & 0.007 & 0.007 \\
\hline
\end{tabular}

NOTE: PolyMetallix is a trademark of Crane Polyflon, Norwalk, Connecticut. 
Table 4-11. Extra Analytical Column Data - Control Columns

\begin{tabular}{lll}
\hline & Parameter & Column 1 \\
\hline \hline Total Cr & $\mathrm{mg} / \mathrm{L}$ & 0.536 \\
\hline Sample Time 1 & 0.569 \\
Sample Time 6 & $\mathrm{mg} / \mathrm{L}$ \\
\hline Dissolved Cr & 0.547 \\
\hline Sample Time 1 & $\mathrm{mg} / \mathrm{L}$ \\
\hline Total Fe & 0.007 \\
\hline Sample Time 1 & 0.007 \\
Sample Time 6 & $\mathrm{mg} / \mathrm{L}$ \\
\hline Dissolved Fe & 0.007
\end{tabular}

\subsubsection{Advanced Flow Cell Injection}

The purpose of the laboratory advanced flow cell injection testing was to determine the distribution of ZVI removed from the ZVI/dispersant/polymer/water mix (ZVI fluid) and deposited in the clean sand in flow cells during injection of the ZVI fluid. Results from this experiment are required to formulate a mathematical expression to evaluate ZVI deposition as a function of distance, time of injection, and ZVI fluid velocity. Such a functional relationship is needed for computer modeling of the field injection process. A complete description of the experimental test plan is provided in Appendix B, and analytical results from testing are included in Appendix C, Section C6.

The results consisted of all measurements and observations made during horizontal flow cell testing and laboratory analytical reports for samples.

\subsubsection{Flow Cell Hydraulic Head Measurements}

Flow cell hydraulic head measurements are listed in Appendix C, Section C6. Overall head loss (head at manometer I minus head at manometer $\mathrm{V}$ ) versus time for each flow cell is graphically presented in Figures 4-48 and 4-49 for PolyMetallix and RNIP-M2 flow cell runs, respectively. As shown in these plots, injection of PolyMetallix resulted in much greater head loss than was for RNIP-M2 (a maximum head differential of over 3,000 cm [1,181 in.] for PolyMetallix compared to values less than $100 \mathrm{~cm}$ [39.4 in.] for RNIP-M2). For all but the lowest flow rate PolyMetallix flow cells, it was necessary to replace manometers with higher range pressure gauges to be able to measure the large head increases occurring (see Appendix C, Section C6).

Head losses observed for the two intermediate flow rates (Figure 4-48) appear to be reversed in order (i.e., head losses were expected to increase with flow rate and ZVI flux, but head losses for flow cells \#13 and \#14 were less than those for flow cells \#11 and \#12 at a lower flow rate). A possible explanation may be greater initial oxygen concentrations in the atmosphere overlying ZVI fluid in the mixing tank for the second PolyMetallix flow cell run (see Appendix C, Section C6). 

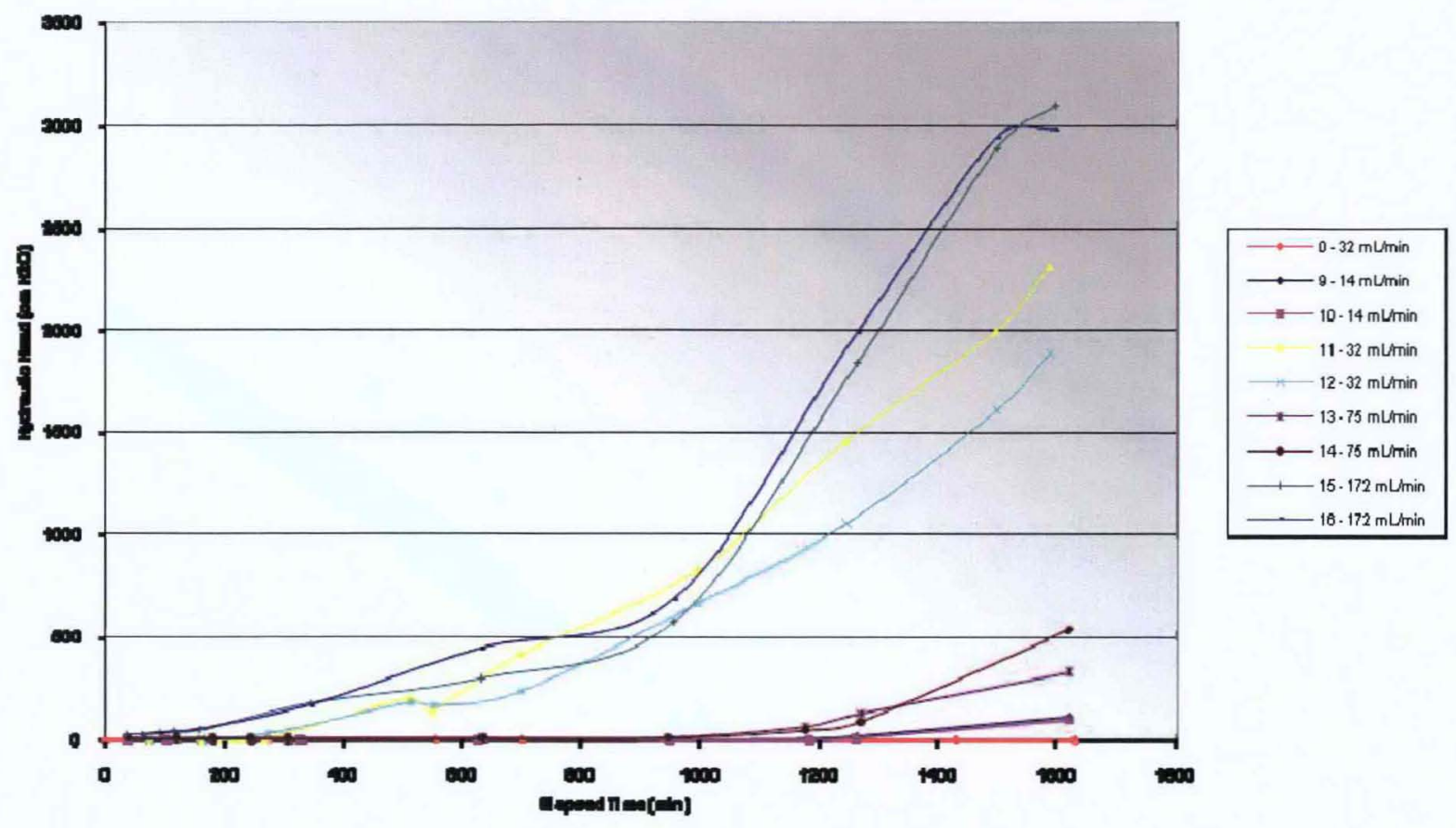

Figure 4-48. Overall Flow Cell Hydraulic Head Loss (PolyMetallix Runs)

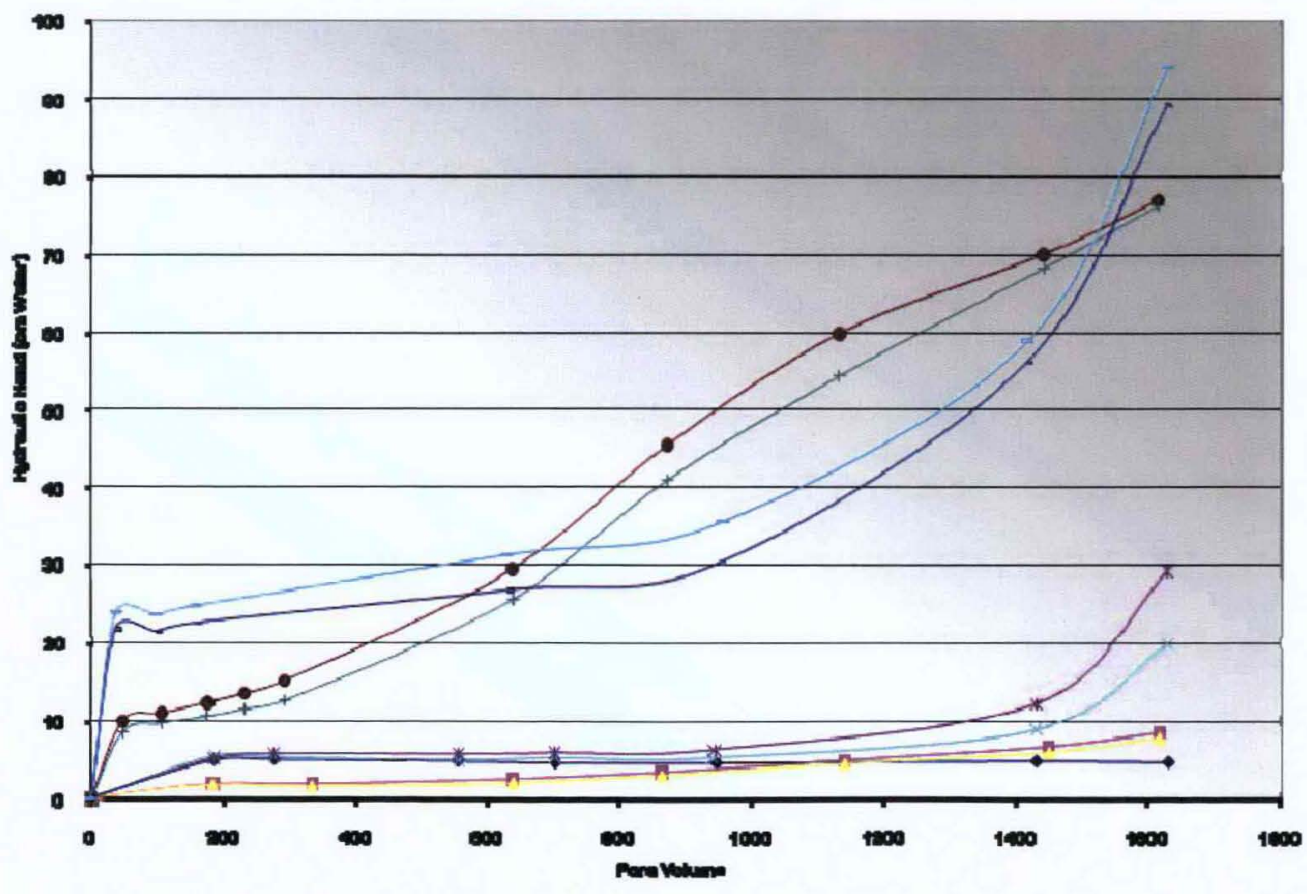

$$
\begin{aligned}
& \longrightarrow 0.32 \mathrm{~mL} \text { Limin } \\
& \longrightarrow-1.14 \mathrm{~mL} / \mathrm{min} \\
& 2.14 \text { mLumin } \\
& -3.32 \text { mLAmin } \\
& \longrightarrow-4.32 \mathrm{~mL} \text { Umin } \\
& \longrightarrow \quad-5.75 \mathrm{~mL} / \mathrm{min} \\
& \longrightarrow \quad 8.75 \mathrm{~mL} \text { Amin } \\
& \longrightarrow 7.172 \mathrm{~mL} / \mathrm{min} \\
& -8.171 \mathrm{~mL} / \min
\end{aligned}
$$

Figure 4-49. Overall Flow Cell Hydraulic Head Loss (RNIP-M2 Runs) 
Flow cell final head distributions are also plotted in Figures 4-50 and 4-51 for PolyMetallix and RNIP-M2 flow cells, respectively. There is a striking contrast in the impact of iron deposition in the flow cells for the two highest flow rates when reviewing data for PolyMetallix flow cell plots in Figure 4-50 (with heads plotted on a logarithmic scale because of the high values involved) and data for RNIP-M2 plots in Figure 4-51 or the control flow cell plot. The primary difference is that the impact on hydraulic head is spread along the entire length of the RNIP-M2 flow cells but is concentrated in the initial part of the flow cells for PolyMetallix. This reflects a significant difference in both movement and deposition between the two ZVI formulations with these flow cells.

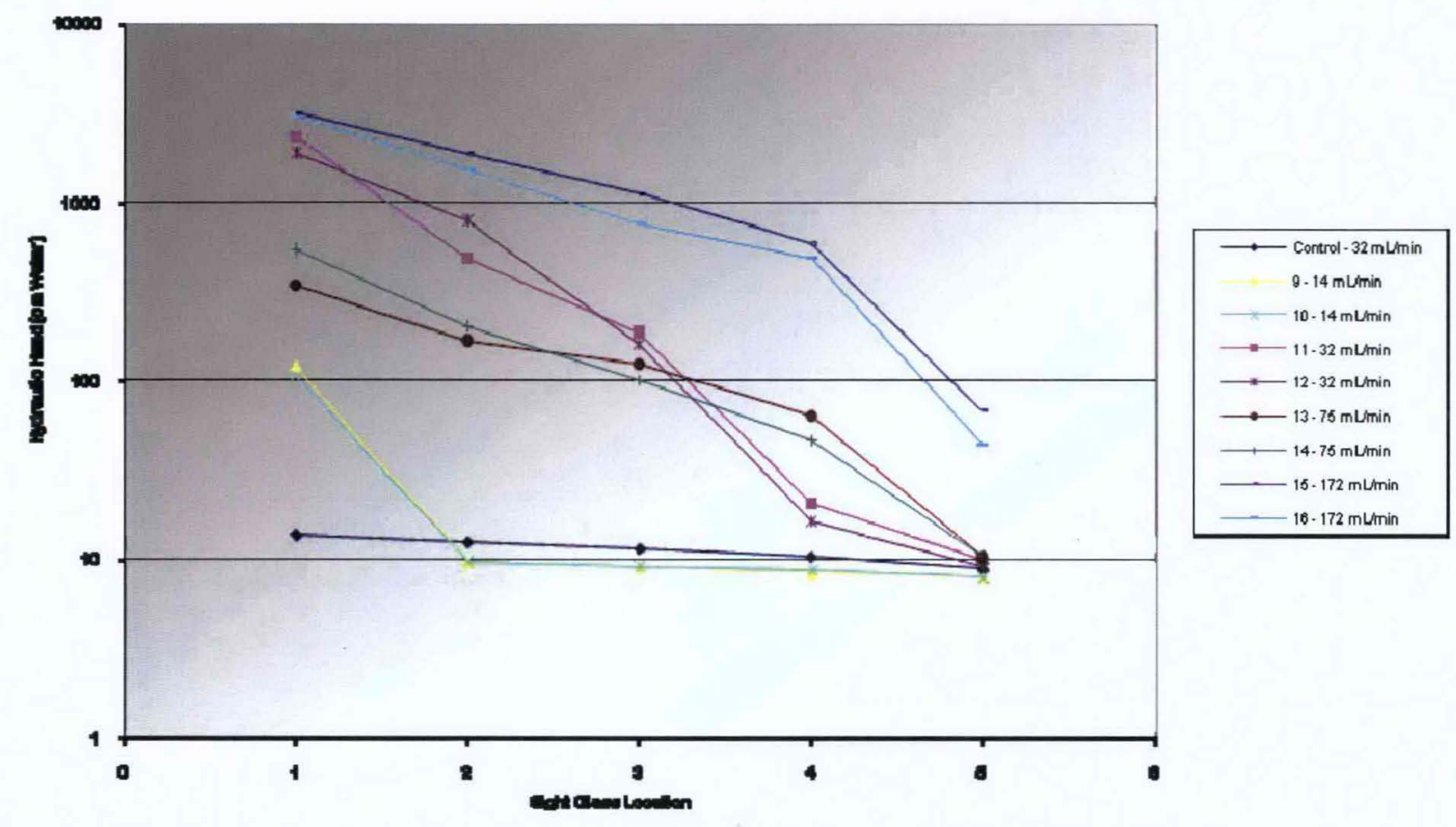

Figure 4-50. Final Flow Cell Hydraulic Head Distribution (PolyMetallix Runs)

Hydraulic head data were also used to calculate changes in hydraulic conductivity (K) for each segment of flow cells and overall across each flow cell using Darcy's Law. The preliminary estimate of K for the $10 / 20$ sand used in flow cells was about $0.8 \mathrm{~cm} / \mathrm{sec}(0.32 \mathrm{in} . / \mathrm{sec})$. The mean hydraulic conductivity value calculated for the overall control flow cell as a whole during its run (the hydraulic conductivity value was also calculated for individual segments of flow cells) was $0.72 \mathrm{~cm} / \mathrm{sec}(0.28 \mathrm{in} . / \mathrm{sec})$ and, as can be seen in Figures 4-52 and 4-53, the plot of hydraulic conductivity over elapsed run time is essentially flat with little change. In contrast, plots of overall hydraulic conductivity for both PolyMetallix and RNIP-M2 runs decline with time. The declines for the PolyMetallix runs are much greater than for the RNIP-M2 runs. For example, hydraulic conductivity declines more than two orders of magnitude for flow cell \#16 (at the highest flow rate for PolyMetallix) from $0.8 \mathrm{~cm} / \mathrm{sec}(0.32 \mathrm{in} . / \mathrm{sec})$ initially to $0.003 \mathrm{~cm} / \mathrm{sec}$ $(0.00118 \mathrm{ft} / \mathrm{sec})$ by the end of the run. In comparison, the decline in hydraulic conductivity for flow cell \#8 (at the highest flow rate for RNIP-M2) is relatively marginal at about a factor of four from $0.8 \mathrm{~cm} / \mathrm{sec}$ $(0.32 \mathrm{in} . / \mathrm{sec})$ to $0.2 \mathrm{~cm} / \mathrm{sec}(0.079 \mathrm{in} . / \mathrm{sec})$ by the end of the run. 


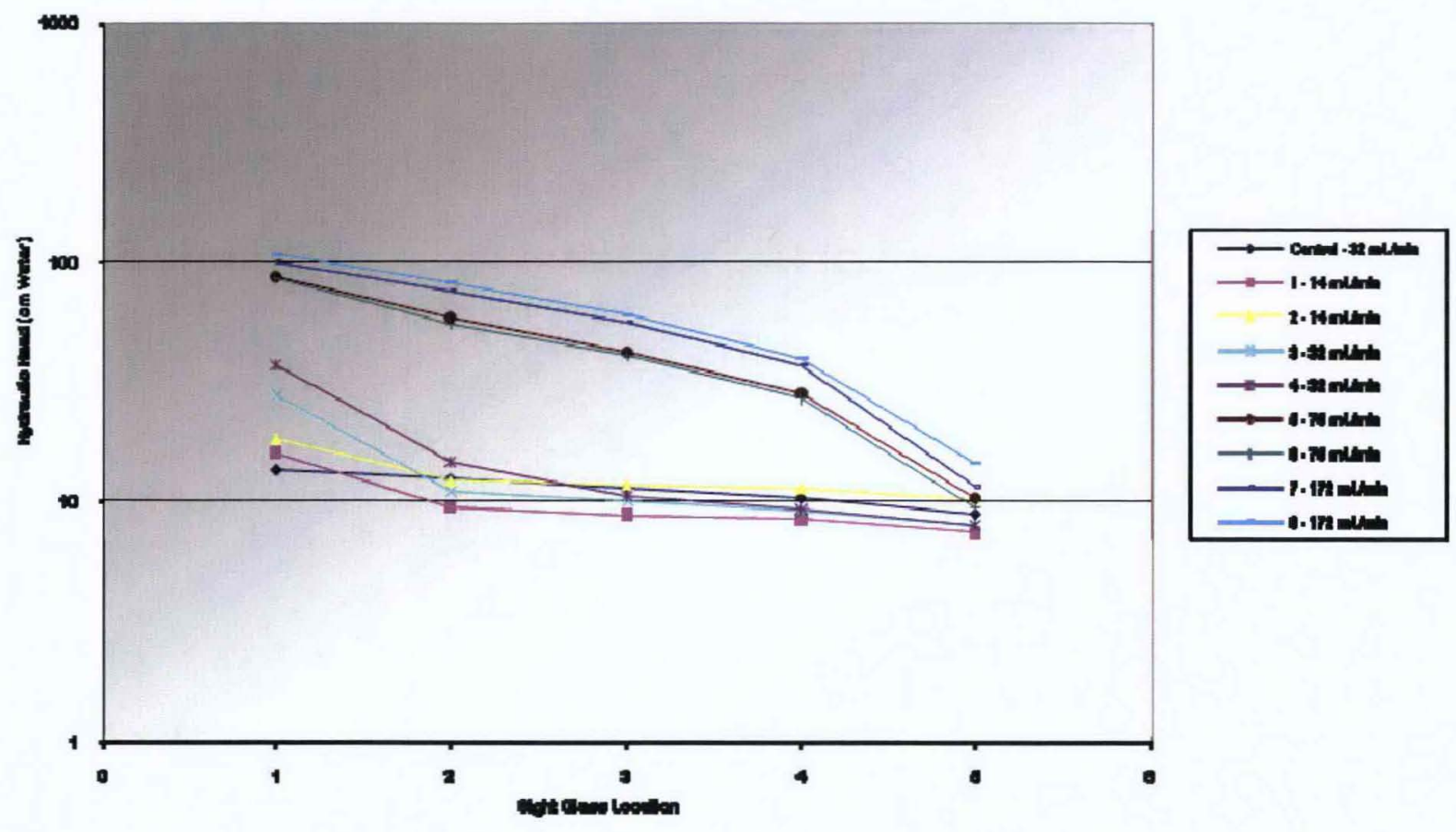

Figure 4-51. Final Flow Cell Hydraulic Head Distribution (RNIP-M2 Runs)

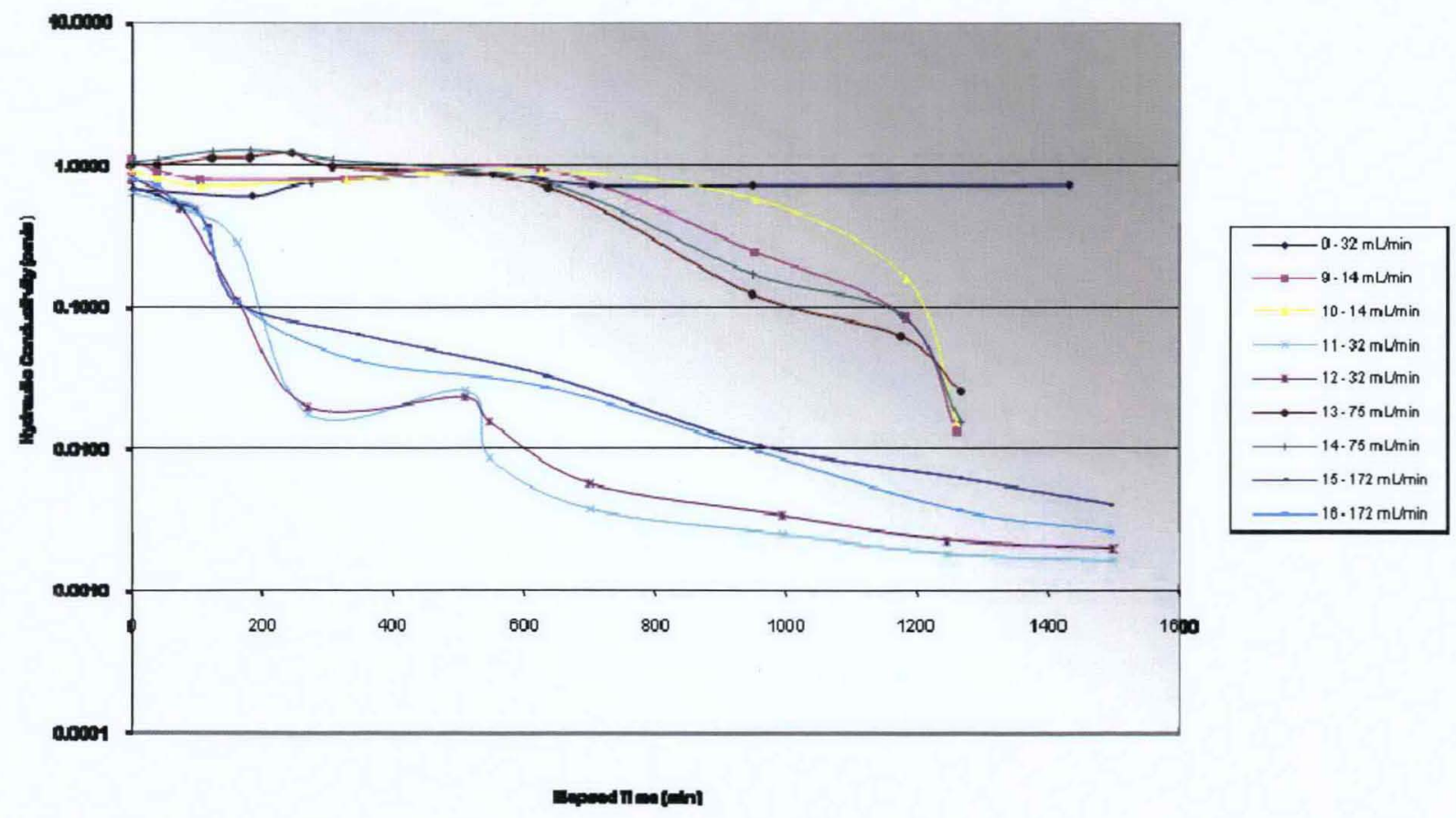

Figure 4-52. Calculated Hydraulic Conductivity Variation Over Elapsed Time for PolyMetallix Flow Cells 


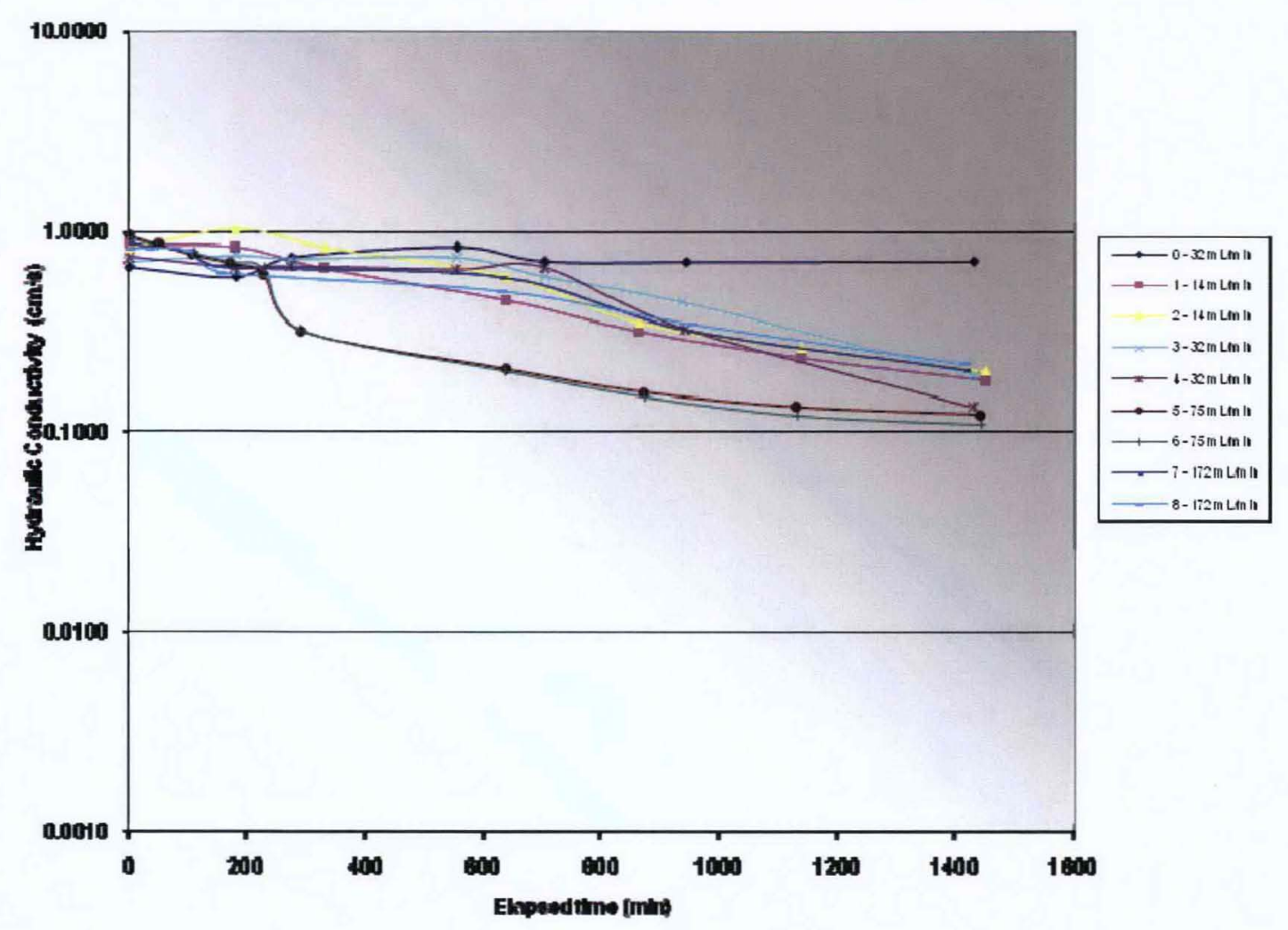

Figure 4-53. Calculated Hydraulic Conductivity Variation Over Elapsed Time for RNIP-M2 Flow Cells

\subsubsection{Flow Cell Flow Rate Measurements}

Flow cell effluent flow rate measurements are provided in Appendix C, Section C6. They indicate that marginal variation in flow rates occurred during flow cell runs but that, for the most part, flow rate objectives were achieved. For example, the flow rate for the control flow cell (i.e., flow cell \#0) varied between 28.0 and $36.4 \mathrm{~mL} / \mathrm{min}$ over the 1,630 minutes involved with the mean for all measurements of $31.9 \mathrm{~mL} / \mathrm{min}$ compared to the objective of $32 \mathrm{~mL} / \mathrm{min}$, and the standard deviation of flow rate measurements for this flow cell of $2.6 \mathrm{~mL} / \mathrm{min}$ was about 8 percent of the mean. With the exception of the highest flow rate for PolyMetallix (flow cells \#15 and \#16), the standard deviation was less than 10 percent of the mean and for most flow cells it was much less.

It can be noted in Figures 4-54 and 4-55 that, with the exception of the highest flow rate for PolyMetallix (flow cells \#15 and \#16), flow cell flow rates throughout runs were relatively steady regardless of the head increases that were occurring (see Figures 4-48 and 4-49). For flow cells \#15 and \#16, the large increase in head that had occurred by late in the run produced a substantial reduction in flow rate (on the order of 50 percent). This was most likely associated with the back pressure affecting the preset flow rate of the peristaltic pumps. 
DOE/RL-2009-35, REV. 0

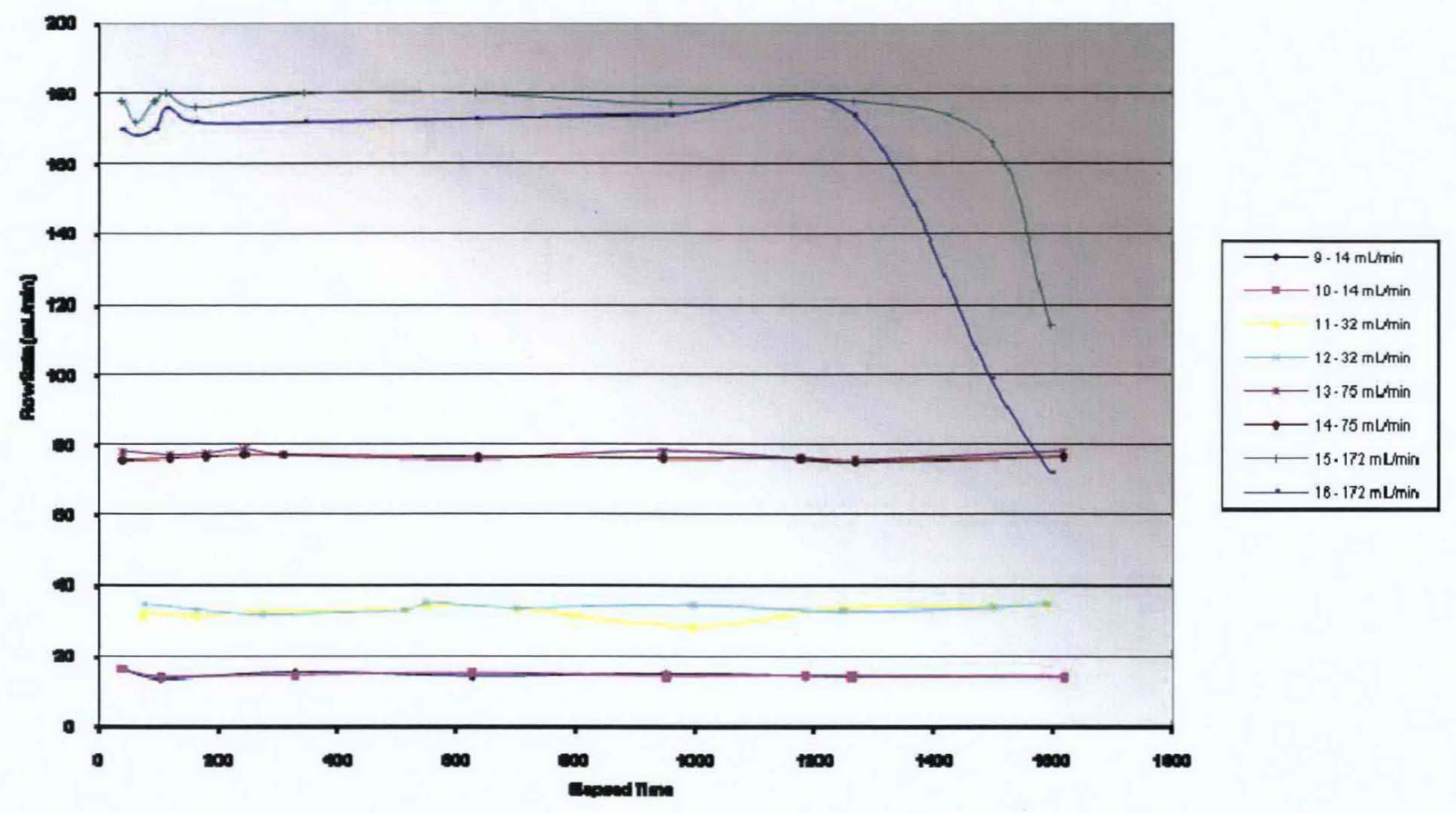

Figure 4-54. PolyMetallix Flow Cell Flow Rates

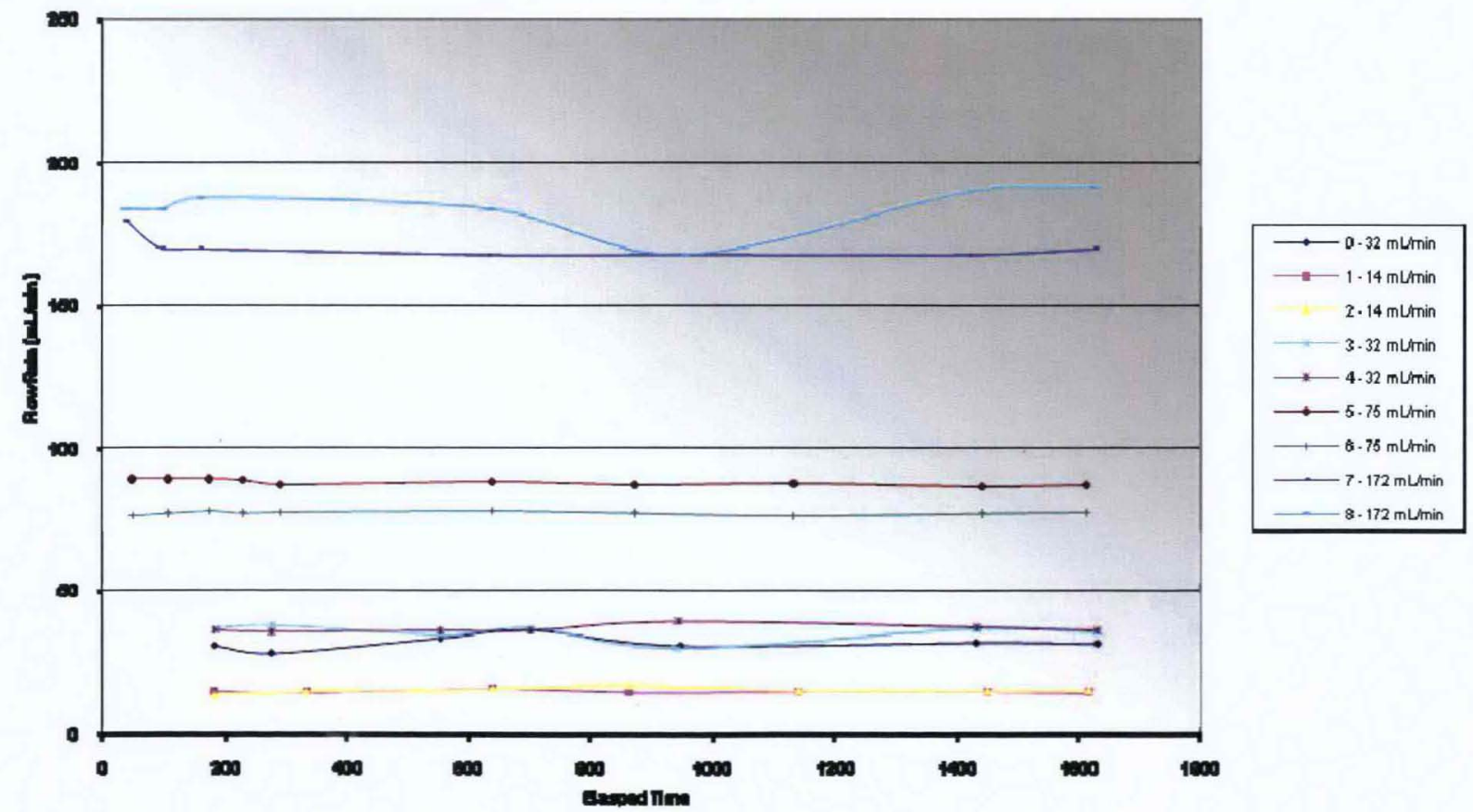

Figure 4-55. RNIP-M2 Flow Cell Flow Rates 


\subsubsection{Flow Cell Influent/Effluent Water Quality Measurements}

A limited number of water quality measurements were obtained on the flow cell ZVI fluid influent streams and effluent streams during both PolyMetallix and RNIP-M2 runs. The water quality measurements helped monitor the progress of the injection through the effluent's geochemical parameters; the results were later applied to the field injection. The complete water quality measurements are presented in Appendix C, Section C6. The measurements indicate that ZVI fluids are, as expected, characterized by relatively high conductivity, low DO concentration, low ORP, and high $\mathrm{pH}$, as well as being physically highly turbid and black in color.

Flow cells were filled with deionized water as they were packed with sand. However, after a period of time, the deionized water would have dissolved trace levels of constituents from the sand. As ZVI fluids were injected into flow cells, effluent from the flow cells at first would be expected reflect this quality. As the injection proceeded, effluent conductivity and $\mathrm{pH}$ began to increase while the effluent $\mathrm{DO}$ and ORP begin to decrease until, as the number of PVs injected increased, the DO and ORP approached influent ZVI levels. The presence of ZVI fluids in effluent was also reflected by high turbidity and black color.

Injected ZVI temperatures were sometimes relatively elevated (e.g., on the order or in excess of $30^{\circ} \mathrm{C}$ $\left.\left[86^{\circ} \mathrm{F}\right]\right)$ due to heating produced by the disperger. When influent-effluent sample pairs were measured, it was' found that the flow cells functioned to some degree as heat exchangers and that effluent temperatures decreased as much as 5 to $10^{\circ} \mathrm{C}\left(41\right.$ to $\left.50^{\circ} \mathrm{F}\right)$ below corresponding influent temperatures that were elevated above ambient.

\subsubsection{Analytical Laboratory Fluid Sample Results}

Laboratory data results are presented in Appendix C, SectionC6 and are summarized in Tables 4-12 and 4-13. The tables facilitate comparison of sample results for each flow cell over time. Results for samples collected after passage of the ZVI front (as indicated by a change in sand color from light brown to black) are shaded gray in the tables. Orange shading in the tables indicates influent or the first one or two segments of flow cells showed averages excluding the last value in column Due to analytical complications with some of the PolyMetallix samples (discussed in Section 4.1.8.6), only the RNIP-M2 data are presented in Tables 4-12 and 4-13.

\subsubsection{Other Observations}

Other observations made during flow cell runs included the concentration of oxygen in the nitrogen atmosphere overlying the ZVI fluid in the mixing tank prior to injection, observations of the position of the black "ZVI front" in flow cells over time, and the generation of gas bubbles in flow cells (assumed to be hydrogen gas). Measurements of oxygen concentrations were discussed in Section 4.1.8.1, and the data from those measurements are presented in Appendix C, Section C6. Observations of the position of the black ZVI front in each flow cell are presented in Tables 4-14 and 4-15.

The position of the black ZVI front correlates to the sharp increases seen in the total iron analytical results (Tables 4-14 and 4-15). A sharp decrease in hydraulic conductivity, particularly in the PolyMetallix flow cells, is also noted with the position of the ZVI front (Figures 4-50 and 4-51).

The generation of gas bubbles was also noted during the flow cell injection. Samples of gas produced during the injection screening test revealed that the generated gas was hydrogen. Gas bubbles, presumed to be hydrogen gas, were observed in all PolyMetallix flow cells to some extent. However, this circumstance was not observed in the RNIP-M2 flow cells. 
Table 4-12. RNIP-M2 Flow Cell Laboratory Analysis Results

\begin{tabular}{|c|c|c|c|c|c|c|c|c|c|}
\hline \multirow[b]{2}{*}{$\begin{array}{l}\text { Flow } \\
\text { Cell }\end{array}$} & \multirow[b]{2}{*}{$\begin{array}{c}\text { Elapsed } \\
\text { Time }\end{array}$} & \multicolumn{7}{|c|}{ Sample Location } & \multirow[b]{2}{*}{ Remarks } \\
\hline & & $\begin{array}{c}\text { Influent } \\
0\end{array}$ & $\begin{array}{c}\text { Port A* } \\
66\end{array}$ & $\begin{array}{l}\text { Port B } \\
127.25\end{array}$ & $\begin{array}{c}\text { Port C } \\
188.5\end{array}$ & $\begin{array}{l}\text { Port D } \\
249.25\end{array}$ & $\begin{array}{c}\text { Port E } \\
308\end{array}$ & $\begin{array}{c}\text { Effluent } \\
315.25\end{array}$ & \\
\hline \multirow[t]{7}{*}{0} & 143 & 4.42 & 4.6 & 1.2 & 6.3 & 2.7 & 1.6 & 6.2 & Control \\
\hline & 285 & 10.0 & $<0.1$ & 0.4 & 0.6 & 8.2 & 1.5 & 1.2 & \\
\hline & 571 & 4.5 & $<0.1$ & 0.3 & 0.5 & 3.1 & 0.6 & 1.9 & \\
\hline & 714 & 24.7 & 7.4 & 3.8 & 2.3 & 0.9 & 8.5 & 6.0 & \\
\hline & 984 & 0.4 & 0.3 & 0.8 & 0.4 & 0.3 & 0.4 & 0.6 & \\
\hline & 1,312 & 0.6 & 0.2 & 0.4 & 0.3 & 0.2 & 0.4 & 0.6 & \\
\hline & 1,641 & 0.9 & 0.5 & 0.5 & 0.5 & 0.2 & 0.6 & 0.8 & \\
\hline \multirow{6}{*}{$\begin{array}{c}\text { Mean } \\
1\end{array}$} & & 6.5 & 2.6 & 1.0 & 1.6 & 2.2 & 1.9 & 2.4 & \\
\hline & 328 & 4,630 & 129 & 147 & 125 & 99 & 56 & 53 & ZVI front did not reach Port $A$ \\
\hline & 656 & 15,900 & 121 & 104 & 154 & 192 & 191 & 172 & \\
\hline & 984 & 12,200 & 124 & 110 & 123 & 132 & 145 & 134 & \\
\hline & 1,312 & 13,000 & 117 & 108 & 112 & 105 & 118 & 102 & \\
\hline & 1,641 & 9,510 & 222 & 141 & 132 & 119 & 128 & 125 & $\mathrm{DL}=117$ \\
\hline \multirow{6}{*}{$\begin{array}{c}\text { Mean } \\
2\end{array}$} & & 11,048 & 123 & 122 & 129 & 129 & 128 & 117 & \\
\hline & 328 & 5,490 & 137 & 148 & 132 & 106 & 41 & 37 & ZVI front did not reach Port $A$ \\
\hline & 656 & 14,100 & 120 & 137 & 162 & 172 & 175 & 162 & \\
\hline & 984 & 11,900 & 117 & 112 & 116 & 125 & 149 & 121 & \\
\hline & 1,312 & 9,240 & 128 & 120 & 118 & 118 & 120 & 112 & \\
\hline & 1,641 & 10,900 & 218 & 148 & 126 & 139 & 116 & 117 & $\mathrm{DL}=125$ \\
\hline
\end{tabular}


Table 4-12. RNIP-M2 Flow Cell Laboratory Analysis Results

\begin{tabular}{|c|c|c|c|c|c|c|c|c|c|}
\hline \multirow[b]{2}{*}{$\begin{array}{l}\text { Flow } \\
\text { Cell }\end{array}$} & \multirow[b]{2}{*}{$\begin{array}{l}\text { Elapsed } \\
\text { Time }\end{array}$} & \multicolumn{7}{|c|}{ Sample Location } & \multirow[b]{2}{*}{ Remarks } \\
\hline & & $\begin{array}{c}\text { Influent } \\
0\end{array}$ & $\begin{array}{c}\text { Port } A^{*} \\
66\end{array}$ & $\begin{array}{l}\text { Port B } \\
127.25\end{array}$ & $\begin{array}{l}\text { Port C } \\
188.5\end{array}$ & $\begin{array}{l}\text { Port D } \\
249.25\end{array}$ & $\begin{array}{c}\text { Port E } \\
308\end{array}$ & $\begin{array}{c}\text { Effluent } \\
315.25\end{array}$ & \\
\hline \multirow{8}{*}{$\begin{array}{c}\text { Mean } \\
3\end{array}$} & & 10,326 & 126 & 133 & 131 & 132 & 120 & 110 & \\
\hline & 143 & 2,460 & 66 & 78 & 83 & 76 & 52 & 49 & \\
\hline & 285 & 2,970 & 45 & 60 & 67 & 76 & 76 & 69 & \\
\hline & 571 & 1,570 & 43 & 43 & 43 & 54 & 53 & 53 & \\
\hline & 714 & 17,800 & 53 & 46 & 48 & 52 & 52 & 51 & \\
\hline & 984 & 14,700 & 55 & 45 & 48 & 49 & 46 & 44 & \\
\hline & 1,312 & 22,300 & 64 & 57 & 54 & 54 & 54 & 49 & \\
\hline & 1,641 & 46,900 & 71,100 & 88 & 76 & 78 & 66 & 63 & $\begin{array}{l}\text { ZVI front max. approximately } 96 \mathrm{~cm} \\
\text { at } 1,706 \mathrm{~min}\end{array}$ \\
\hline \multirow{8}{*}{$\begin{array}{c}\text { Mean } \\
4\end{array}$} & & 10,300 & 54 & 60 & 60 & 63 & 57 & 54 & \\
\hline & 143 & 6,120 & 59 & 83 & 85 & 63 & 48 & 44 & \\
\hline & 285 & 3,680 & 45 & 58 & 72 & 78 & 81 & 72 & \\
\hline & 571 & 3,560 & 43 & 43 & 46 & 52 & 55 & 51 & \\
\hline & 714 & 17,500 & 50 & 46 & 47 & 50 & 48 & 49 & \\
\hline & 984 & 22,400 & 50 & 44 & 43 & 42 & 48 & 45 & \\
\hline & 1,312 & 10,400 & 73 & 59 & 53 & 54 & 50 & 49 & $\begin{array}{l}\text { ZVI front approximately } 99 \mathrm{~cm} \text { at } \\
1,610 \mathrm{~min}\end{array}$ \\
\hline & 1,641 & 45,700 & 44,400 & 37,700 & 91 & 74 & 71 & 67 & $\begin{array}{l}\text { ZVI front max. approximately } \\
127 \mathrm{~cm} \text { at } 1,706 \mathrm{~min}\end{array}$ \\
\hline
\end{tabular}


Table 4-12. RNIP-M2 Flow Cell Laboratory Analysis Results

\begin{tabular}{c|c|c|c|c|c|c|c|c|c|}
\hline & & \multicolumn{9}{c|}{ Sample Location } & \multicolumn{1}{c}{} \\
\cline { 3 - 10 } Flow & Elapsed & Influent & Port A* & Port B & Port C & Port D & Port E & Effluent \\
Cell & Time & 0 & 66 & 127.25 & 188.5 & 249.25 & 308 & 315.25 & 57 \\
\hline Mean & & 10,610 & 53 & 55 & 62 & 59 & 54 & \\
\hline
\end{tabular}

NOTES:

1. RNIP-M2 is a trademark of Toda Kogyo Corporation, Hiroshima, Japan.

2. Iron concentrations are reported in $\mathrm{mg} / \mathrm{L}$.

3. "Elapsed Time" is time in minutes since flow cell run commenced. Numbers below sampling locations are position along flow cell in cm. Gray-shaded cells indicate that the "ZVI front "had passed that sampling location when the sample was taken. Additional remarks about the location of the ZVI front are presented in the far right-hand column.

The location of the ZVI front was indicated by a change in color of the sand from a natural light brown to black. This was measured in centimeters from the downstream end of the flow cell end fitting. Because observations of the ZVI front were not recorded after time 1,101 minutes for flow cells \#5 and \#6 or

1,080 minutes for flow cells \#7 and \#8, it cannot be determined from observations whether the ZVI front had passed Ports D or E when those samples were taken at time 1,312 minutes. Therefore, lack of shading for those cells is not based on data.

4. Orange shading for influent or the first one or two segments of flow cells indicates average excludes last value in column.

a. Port A is located 24 in. from the inlet of the flow cell, Port B is located 48 in. from the inlet, Port C is located 72 in. from the inlet, Port D is located 96 in. from the inlet, and Port $E$ is located 120 in. (10 ft) from the inlet.

$\mathrm{DL}$ = field duplicate fluid sample

$\mathrm{ZVI}=$ zero-valent iron 
Table 4-13. RNIP-M2 Flow Cell Laboratory Analysis Results

\begin{tabular}{|c|c|c|c|c|c|c|c|c|c|}
\hline \multirow{3}{*}{$\begin{array}{l}\text { Flow } \\
\text { Cell }\end{array}$} & \multirow{3}{*}{$\begin{array}{c}\text { Elapsed } \\
\text { Time }\end{array}$} & \multicolumn{7}{|c|}{ Sample Location } & \multirow[b]{3}{*}{ Remarks } \\
\hline & & Influent & Port A & Port B & Port C & Port D & Port E & Effluent & \\
\hline & & 0 & 66 & 127.25 & 188.5 & 249.25 & 308 & 315.25 & \\
\hline \multirow{9}{*}{$\begin{array}{c}\text { Mean } \\
5\end{array}$} & 62 & 3,980 & 78 & 98 & 122 & 116 & 89 & 81 & \\
\hline & 124 & 4,380 & 78 & 83 & 97 & 107 & 98 & 101 & \\
\hline & 186 & 4,640 & 306 & 81 & 85 & 94 & 92 & 97 & \\
\hline & 248 & 3,000 & 1,540 & 91 & 79 & 84 & 93 & 84 & \\
\hline & 310 & 3,260 & 10,000 & 109 & 98 & 107 & 102 & 105 & $\begin{array}{l}\text { ZVI front approximately } 126 \mathrm{~cm} \text { at } \\
566 \mathrm{~min}\end{array}$ \\
\hline & 656 & 9,660 & 18,800 & 8,790 & 129 & 111 & 116 & 111 & \\
\hline & 984 & 11,500 & 11,200 & 16,800 & 18,500 & 3,090 & 117 & 113 & $D L=112$ \\
\hline & 1,312 & 9,710 & 12,900 & 15,100 & 27,800 & 27,700 & 15,000 & 4,590 & $\begin{array}{l}\text { ZVI front approximately } 269 \mathrm{~cm} \text { at } \\
1,101 \mathrm{~min}\end{array}$ \\
\hline & 1,641 & 6,840 & 20,700 & 10,400 & 19,300 & 13,200 & 9,300 & 935 & Observed May 6, 2008 \\
\hline \multirow{7}{*}{$\begin{array}{c}\text { Mean } \\
6\end{array}$} & & 6,330 & 8,400 & 5,728 & 7,357 & 4,957 & 2,779 & 691 & \\
\hline & 62 & 3,670 & 79 & 110 & 115 & 71 & 7 & 8 & \\
\hline & 124 & 3,480 & 77 & 83 & 100 & 109 & 115 & 113 & \\
\hline & 186 & 2,910 & 87 & 84 & 87 & 102 & 108 & 97 & \\
\hline & 248 & 3,070 & 128 & 92 & 85 & 90 & 98 & 97 & \\
\hline & 310 & 2,780 & 2,550 & 106 & 106 & 102 & 104 & 100 & $\begin{array}{l}\text { ZVI front approximately } 66 \mathrm{~cm} \text { at } \\
383 \mathrm{~min}\end{array}$ \\
\hline & 656 & 5,290 & 29,600 & 10,800 & 121 & 113 & 115 & 106 & $\begin{array}{l}\text { ZVI front approximately } 138 \mathrm{~cm} \text { at } \\
736 \mathrm{~min}\end{array}$ \\
\hline
\end{tabular}


Table 4-13. RNIP-M2 Flow Cell Laboratory Analysis Results

\begin{tabular}{|c|c|c|c|c|c|c|c|c|c|}
\hline \multirow{3}{*}{$\begin{array}{l}\text { Flow } \\
\text { Cell }\end{array}$} & \multirow{3}{*}{\begin{tabular}{|c} 
Elapsed \\
Time
\end{tabular}} & \multicolumn{7}{|c|}{ Sample Location } & \multirow[b]{3}{*}{ Remarks } \\
\hline & & Influent & Port A & Port B & Port C & Port D & Port E & Effluent & \\
\hline & & 0 & 66 & 127.25 & 188.5 & 249.25 & 308 & 315.25 & \\
\hline \multirow{14}{*}{$\begin{array}{c}\text { Mean } \\
7\end{array}$} & 984 & 10,100 & 34,700 & 20,600 & 27,800 & 134 & 105 & 100 & $\begin{array}{l}\text { ZVI front approximately } 181 \mathrm{~cm} \text { at } \\
924 \mathrm{~min}, \mathrm{DL}=108\end{array}$ \\
\hline & 1,312 & 7,600 & 26,200 & 29,400 & 34,900 & 43,600 & 131 & 119 & $\begin{array}{l}\text { ZVI front approximately } 227 \mathrm{~cm} \text { at } \\
1,101 \mathrm{~min}\end{array}$ \\
\hline & 1,641 & 8,210 & 31,000 & 16,900 & 26,000 & 40,000 & 33,500 & 6,470 & Observed May 6, 2008, DL = 8,470 \\
\hline & & 5,234 & 13,825 & 8,686 & 9,924 & 9,369 & 3,809 & 801 & \\
\hline & 27 & 3,500 & 467 & 148 & 47 & 7 & 5 & 9 & \\
\hline & 54 & 3,530 & 1,190 & 86 & 67 & 71 & 75 & 70 & \\
\hline & 81 & 3,910 & 1,482 & 113 & 58 & 65 & 72 & 63 & \\
\hline & 108 & 2,980 & 1,910 & 166 & 54 & 55 & 61 & 53 & \\
\hline & 135 & 2,950 & 2,180 & 264 & 52 & 52 & 53 & 55 & \\
\hline & 328 & 2,640 & 5,460 & 1,010 & 162 & 37 & 35 & 38 & $\begin{array}{l}\text { ZVI front approximately } 77 \mathrm{~cm} \text { at } \\
192 \mathrm{~min}\end{array}$ \\
\hline & 656 & 1,370 & 4,630 & 12,500 & 819 & 78 & 42 & 43 & $\begin{array}{l}\text { ZVI front approximately } 117 \mathrm{~cm} \text { at } \\
340 \mathrm{~min}\end{array}$ \\
\hline & 984 & 3,720 & 15,400 & 16,400 & 14,800 & 235 & 49 & 51 & \\
\hline & 1,312 & 6,190 & 13,200 & 20,000 & 22,700 & 19,700 & 1,300 & 668 & Last observation at 1,080 \\
\hline & 1,641 & 28,700 & 51,100 & 60,900 & 54,100 & 52,300 & 40,600 & 23,600 & Observed May6, 2008 \\
\hline \multirow{3}{*}{$\begin{array}{c}\text { Mean } \\
8\end{array}$} & & 3,421 & 9,702 & 11,159 & 9,286 & 7,260 & 4,229 & 2,465 & \\
\hline & 27 & 3,660 & 903 & 189 & 141 & 20 & 12 & 9 & \\
\hline & 54 & 3,590 & 1,850 & 174 & 76 & 71 & 78 & 76 & \\
\hline
\end{tabular}


Table 4-13. RNIP-M2 Flow Cell Laboratory Analysis Results

\begin{tabular}{|c|c|c|c|c|c|c|c|c|c|}
\hline \multirow{3}{*}{$\begin{array}{l}\text { Flow } \\
\text { Cell }\end{array}$} & \multirow{3}{*}{$\begin{array}{c}\text { Elapsed } \\
\text { Time }\end{array}$} & \multicolumn{7}{|c|}{ Sample Location } & \multirow[b]{3}{*}{ Remarks } \\
\hline & & Influent & Port A & Port B & Port C & Port D & Port E & Effluent & \\
\hline & & $\mathbf{0}$ & 66 & 127.25 & 188.5 & 249.25 & 308 & 315.25 & \\
\hline \multirow{8}{*}{$\vec{b}$} & 81 & 3,740 & 2,530 & 271 & 63 & 65 & 66 & 63 & \\
\hline & 108 & 3,380 & 3,320 & 414 & 75 & 57 & 59 & 55 & \\
\hline & 135 & 3,280 & 2,600 & 495 & 75 & 53 & 55 & 56 & \\
\hline & 328 & 2,430 & 5,080 & 3,800 & 313 & 63 & 38 & 33 & $\begin{array}{l}\text { ZVI front approximately } 86 \mathrm{~cm} \text { at } \\
192 \mathrm{~min}\end{array}$ \\
\hline & 656 & 1,100 & 3,790 & 3,620 & 3,160 & 191 & 46 & 47 & \\
\hline & 984 & 2,160 & 23,300 & 9,110 & 9,460 & 2,930 & 59 & 49 & \\
\hline & 1,312 & 5,230 & 10,600 & 16,400 & 20,000 & 22,200 & 15,700 & 3,280 & Last observation at 1,080 \\
\hline & 1,641 & 3,190 & 55,000 & 58,400 & 60,400 & 48,300 & 44,900 & 28,300 & Observed May 6, 2008 \\
\hline Mean & & 3,176 & 10,897 & 9,287 & 9,376 & 7,395 & 6,101 & 3,197 & \\
\hline
\end{tabular}


Table 4-13. RNIP-M2 Flow Cell Laboratory Analysis Results

\begin{tabular}{|c|c|c|c|c|c|c|c|c|c|}
\hline \multirow{3}{*}{$\begin{array}{c}\text { Flow } \\
\text { Cell }\end{array}$} & \multirow{3}{*}{$\begin{array}{c}\text { Elapsed } \\
\text { Time }\end{array}$} & \multicolumn{7}{|c|}{ Sample Location } & \multirow[b]{3}{*}{ Remarks } \\
\hline & & Influent & Port A & Port B & Port C & Port D & Port E & Effluent & \\
\hline & & 0 & 66 & 127.25 & 188.5 & 249.25 & 308 & 315.25 & \\
\hline
\end{tabular}

NOTES:

1. RNIP-M2 is a trademark of Toda Kogyo Corporation, Hiroshima, Japan.

2. Iron concentrations are reported in $\mathrm{mg} / \mathrm{L}$.

3. "Elapsed Time" is time in minutes since flow cell run commenced. Numbers below sampling locations are position along flow cell in cm. Gray-shaded cells indicate that the "ZVI front "had passed that sampling location when the sample was taken. Additional remarks about the location of the ZVI front are presented in the far right-hand column.

The location of the ZVI front was indicated by a change in color of the sand from a natural light brown to black. This was measured in centimeters from the downstream end of the flow cell end fitting. Because observations of the ZVI front were not recorded after time 1,101 minutes for flow cells \#5 and \#6 or

1,080 minutes for flow cells \#7 and \#8, it cannot be determined from observations whether the ZVI front had passed Ports D or E when those samples were taken at time 1,312 minutes. Therefore, lack of shading for those cells is not based on data.

4. Light brown shading for influent or the first one or two segments of flow cells indicates average excludes last value in column.

* Port A is located 24 in. from the inlet of the flow cell, Port B is located 48 in. from the inlet, Port C is located 72 in. from the inlet, Port D is located 96 in. from the inlet, and Port $E$ is located $120 \mathrm{in.}(10 \mathrm{ft})$ from the inlet.

DL = field duplicate fluid sample

$\mathrm{ZVI}=$ zero-valent iron 
DOE/RL-2009-35, REV. 0

Table 4-14. PolyMetallix Flow Cells - Zero-Valent Iron Front Measurements

\begin{tabular}{|c|c|c|c|c|c|}
\hline $\begin{array}{c}\text { Elapsed Time, } \\
\text { min }\end{array}$ & $\begin{array}{c}\text { Pore } \\
\text { Volume }\end{array}$ & $\begin{array}{l}\text { Flow } \\
\text { Coll }\end{array}$ & $\begin{array}{c}\text { Front } \\
\text { Distance, } \\
\text { cm }\end{array}$ & $\begin{array}{l}\text { Flow } \\
\text { Cell }\end{array}$ & $\begin{array}{c}\text { Front } \\
\text { Distance, }^{*} \\
\text { cm }\end{array}$ \\
\hline \multicolumn{6}{|l|}{$14 \mathrm{~mL} / \mathrm{min}$} \\
\hline 1,516 & 4.62 & 9 & 21.00 & 10 & 21.00 \\
\hline 1,676 & 5.11 & 9 & 33.00 & 10 & 34.00 \\
\hline \multicolumn{6}{|l|}{$32 \mathrm{~mL} / \mathrm{min}$} \\
\hline 295 & 2.06 & 11 & 13.50 & 12 & 13.60 \\
\hline 499 & 3.49 & 11 & 33.60 & 12 & 37.20 \\
\hline 673 & 4.71 & 11 & 64.00 & 12 & 64.00 \\
\hline 813 & 5.69 & 11 & 93.90 & 12 & 92.60 \\
\hline 1,034 & 7.23 & 11 & 145.10 & 12 & 139.00 \\
\hline 1,224 & 8.56 & 11 & 179.60 & 12 & 170.20 \\
\hline 1,345 & 9.41 & 11 & 199.10 & 12 & 194.00 \\
\hline \multirow[t]{2}{*}{1,513} & 10.58 & 11 & 243.30 & 12 & 233.20 \\
\hline & & 11 & Breakthrough & 12 & Breakthrough \\
\hline \multicolumn{6}{|l|}{$75 \mathrm{~mL} / \mathrm{min}$} \\
\hline 1,150 & 18.55 & 13 & 80.40 & 14 & 77.60 \\
\hline 1,371 & 22.11 & 13 & 182.00 & 14 & 163.90 \\
\hline 1,516 & 24.45 & 13 & 270.00 & 14 & 258.00 \\
\hline \multirow[t]{2}{*}{1,676} & 27.03 & 13 & 305.00 & 14 & 305.00 \\
\hline & & 13 & Breakthrough & 14 & Breakthrough \\
\hline \multicolumn{6}{|l|}{$172 \mathrm{~mL} / \mathrm{min}$} \\
\hline 297 & 11.00 & 15 & 187.90 & 16 & 172.50 \\
\hline \multirow[t]{2}{*}{347} & 12.85 & 15 & 226.90 & 16 & 225.70 \\
\hline & & 15 & Breakthrough & 16 & Breakthrough \\
\hline
\end{tabular}

* The ZVI "Front Distance" is defined as distance from downstream end of influent cap to extent of black discoloration of sand produced by ZVI fluid (in $\mathrm{cm}$ ).

$\mathrm{ZVI}=$ zero-valent iron 
DOE/RL-2009-35, REV. 0

Table 4-15. RNIP-M2 Flow Cells Zero-Valent Iron Front Measurements

\begin{tabular}{|c|c|c|c|c|c|}
\hline $\begin{array}{l}\text { Elapsed Time, } \\
\text { min }\end{array}$ & $\begin{array}{c}\text { Pore } \\
\text { Volume }\end{array}$ & $\begin{array}{l}\text { Flow } \\
\text { Cell }\end{array}$ & $\begin{array}{c}\text { Front } \\
\text { Distance, } \\
\text { cm }\end{array}$ & $\begin{array}{l}\text { Flow } \\
\text { Cell }\end{array}$ & $\begin{array}{c}\text { Front } \\
\text { Distance, } \\
\text { cm }\end{array}$ \\
\hline \multicolumn{6}{|l|}{$14 \mathrm{~mL} / \mathrm{min}$} \\
\hline 739 & 2.25 & 1 & 10.95 & 2 & 6.99 \\
\hline 1,103 & 3.36 & 1 & 20.32 & 2 & 22.07 \\
\hline 1,455 & 4.44 & 1 & 35.56 & 2 & 32.07 \\
\hline 1,674 & 5.10 & 1 & 43.82 & 2 & 41.59 \\
\hline \multicolumn{6}{|l|}{$32 \mathrm{~mL} / \mathrm{min}$} \\
\hline 192 & 1.34 & 3 & 10.80 & 4 & 9.37 \\
\hline 609 & 4.26 & 3 & 20.00 & 4 & 24.45 \\
\hline 789 & 5.52 & 3 & 22.23 & 4 & 25.72 \\
\hline 1,080 & 7.55 & 3 & 25.72 & 4 & 33.02 \\
\hline 1,532 & 10.71 & 3 & 50.17 & 4 & 72.39 \\
\hline 1,610 & 11.26 & 3 & 67.95 & 4 & 98.74 \\
\hline 1,706 & 11.93 & 3 & 95.89 & 4 & 127.64 \\
\hline \multicolumn{6}{|l|}{$75 \mathrm{~mL} / \mathrm{min}$} \\
\hline 166 & 2.68 & 5 & 39.37 & 6 & 29.21 \\
\hline 383 & 6.18 & 5 & 73.34 & 6 & 66.36 \\
\hline 566 & 9.13 & 5 & 126.37 & 6 & 100.49 \\
\hline 736 & 11.87 & 5 & 172.72 & 6 & 138.43 \\
\hline 924 & 14.90 & 5 & 218.60 & 6 & 180.98 \\
\hline \multirow[t]{2}{*}{1,101} & 17.76 & 5 & 268.92 & 6 & 227.33 \\
\hline & & 5 & Breakthrough & 6 & Breakthrough \\
\hline \multicolumn{6}{|l|}{$172 \mathrm{~mL} / \mathrm{min}$} \\
\hline 70 & 2.59 & 7 & 33.34 & 8 & 30.48 \\
\hline 192 & 7.11 & 7 & 77.47 & 8 & 85.73 \\
\hline 340 & 12.59 & 7 & 117.16 & 8 & 118.11 \\
\hline 687 & 25.44 & 7 & 142.88 & 8 & 150.50 \\
\hline \multirow[t]{2}{*}{1,080} & 40.00 & 7 & 180.98 & 8 & 181.29 \\
\hline & & 7 & Breakthrough & 8 & Breakthrough \\
\hline
\end{tabular}


Table 4-15. RNIP-M2 Flow Cells Zero-Valent Iron Front Measurements

\begin{tabular}{c|c|c|c|c|c}
\hline $\begin{array}{c}\text { Elapsed Time, } \\
\text { min }\end{array}$ & $\begin{array}{c}\text { Pore } \\
\text { Volume }\end{array}$ & $\begin{array}{c}\text { Flow } \\
\text { Cell }\end{array}$ & $\begin{array}{c}\text { Front } \\
\text { Distance, } \\
\text { cm }\end{array}$ & $\begin{array}{c}\text { Flow } \\
\text { Cell }\end{array}$ & $\begin{array}{c}\text { Front } \\
\text { Distance, } \\
\text { cm }\end{array}$ \\
\hline
\end{tabular}

NOTE: RNIP-M2 is a trademark of Toda Kogyo Corporation, Hiroshima, Japan.

* The ZVI "Front Distance" is defined as distance from downstream end of influent cap to extent of black discoloration of sand produced by ZVI fluid in centimeters.

$\mathrm{ZVI}=$ zero-valent iron

\subsubsection{Analytical Complications with Total Iron Analysis}

Initial efforts to analyze samples of ZVI fluid influent to each flow cell obtained from the eight PolyMetallix flow cell runs indicated very low recovery of total iron and erratic results. Reported results for influent samples appeared to represent on the order of 10 to 20 percent recovery of expected actual injection concentrations. Expected concentrations had been calculated based on information from the manufacturer on the concentration and form of iron present in the paste and how the material was diluted and mixed. An insoluble black residue was also found to have precipitated to the bottom of some of the sample containers. Fusion analysis determined that this residue was predominantly iron and that the mass involved was sufficient to account for most of the apparently missing iron not being reported in influent sample results. This indicated that the extreme digestion method developed for this project was not capable of fully solubilizing all of the iron present in PolyMetallix.

Because it appeared to be impractical to obtain satisfactory analysis for high-concentration samples from these flow cell runs under the circumstances, and because other available information supported RNIP-M2 as being a superior product for the intended purpose of ground water remediation, efforts to analyze samples from PolyMetallix flow cell runs were suspended.

\subsubsection{Influent Concentration Results}

Reported laboratory results from analysis of fluid samples taken of the influent are summarized in Section 4.1.8.4. The results indicated an unexpectedly high degree of variation and, in some cases, the total iron analytical results of the influent are much lower than the expected concentration.

It is pertinent to note that the lowest and second highest flow rates (flow cells \#1 and \#2, and flow cells \#5 and \#6) were run at the same time from the same tank of RNIP-M2 mix, and the second lowest and highest flow rates (flow cells \#3 and \#4, and flow cells \#7 and \#8) were also run at the same time from the a different tank of RNIP-M2 mix. However, both tanks of RNIP-M2 mixture were made from the same production lot provided by the manufacturer and the same ratio of dilution water was used with each to achieve a $1 \mathrm{wt} \%$ solids concentration (i.e., $9,030 \mathrm{mg} / \mathrm{L}$ total iron). Nevertheless, reported total iron values from influent samples were (as indicated in Appendix C, Section C6) somewhat at variance with theoretical based on the mixing ratio used:

1. First tank (flow cells \#1, \#2, \#5, and \#6):

a. For the lowest flow rate, flow cells \#1 and \#2, the mean total iron concentration from reported values in samples was approximately $10,300 \mathrm{mg} / \mathrm{L}$. This is about 14 percent higher than the target mixture level. 
b. Mean influent results reported for the second highest flow rate, flow cells \#5 and \#6, were more consistent with expectations for flow cell $\# 5$ at $6,330 \mathrm{mg} / \mathrm{L}$ (roughly 70 percent recovery of the target mixture level of $9,030 \mathrm{mg} / \mathrm{L}$ ) and appeared to be unexplainedly biased low $5,230 \mathrm{mg} / \mathrm{L}$ for flow cell 6 (roughly 58 percent recovery of the target mixture level of $9,030 \mathrm{mg} / \mathrm{L}$ ). Laboratory results on standards made from RNIP-M2 prior to flow cell runs for a wide range of concentrations (from $9,030 \mathrm{mg} / \mathrm{L}$ downward) indicated that recoveries on the order of 70 percent could be expected.

2. Second tank (flow cells \#3, \#4, \#7, and \#8):

a. If the final value is ignored (i.e., the value for time 1,641 minutes), the mean concentrations for the second lowest flow rate, flow cells $\# 3$ and \#4, are of a similar level to that for the lowest flow rate (i.e., approximately $10,000 \mathrm{mg} / \mathrm{L}$ ). There is no known reason the final reported influent value would be so inordinately high for both of these flow cells (i.e., at roughly $46,000 \mathrm{mg} / \mathrm{L}$, this value is over twice the next highest reported value of about $22,300 \mathrm{mg} / \mathrm{L}$ and five times the target mixture level of $9,030 \mathrm{mg} / \mathrm{L}$ ). It is possible there was some backflow under these low flow conditions from the high level of iron apparently being deposited in the first segment of the flow cells, but there is no way to confirm this possibility.

b. In the case of the highest flow rate (flow cells \#7 and \#8), the final value reported for the influent sample for flow cell \#7 (i.e., at time 1,641 minutes) is also inordinately high (i.e., at $28,700 \mathrm{mg} / \mathrm{L}$, over four times the next highest reported sample level and over three times the target mixture of $9,030 \mathrm{mg} / \mathrm{L}$ ). The reason for this is unknown. In the case of both of these flow cells (ignoring the inordinately high last value for flow cell \#7), the mean of reported influent samples is around $3,300 \mathrm{mg} / \mathrm{L}$ or roughly one-third the target mixture level of $9,030 \mathrm{mg} / \mathrm{L}$.

There is an apparent inverse relationship between reported influent concentration and flow rate. Preliminary reviews of initial data from a subsequent tank injection test provide an additional data point that is consistent with the indication of this relationship. The reason for this relationship is unknown, but it is hypothesized that it may be an artifact of the suspended particulate nature of ZVI fluid, rather than being a true solution, and the physical arrangement of sampling lines. Whatever the explanation may be, it is clear that reported influent sample results are unreliable to support flow cell mass deposition calculations.

\subsubsection{Mass Deposition Calculations}

The original testing plan was based on an assumption, taken directly from the principle of solute transport, that the concentration of a solute migrating through a porous media can never be greater than the solute concentration at its point of origin. Analytical results for total iron suspended in the flow cell experiment showed that concentrations of suspended particles traveling through porous media can increase above the influent concentration. Therefore, attempting to translate the above stated solute transport principle to the transport of suspended particles is not appropriate. Consequently, the method for determining the relationship of deposited ZVI as a function of injection time, distance, and flow velocity needed to be modified.

The following provides a description of the modified methodology used for calculating the ZVI mass deposited in the experimental flow cells.

In view of the nature and similarity of data for flow cell pairs, it was decided to use only one flow cell from each pair to calculate the functional relationship of the deposited ZVI. The flow cells used were \#1, $\# 3$, \#5, and \#8. 
1. The influent ZVI mass (MI) that entered the flow cell during the given elapsed time was determined as the product of ZVI concentration $(9,030 \mathrm{mg} / \mathrm{L})$, rate of injection $(\mathrm{mL} / \mathrm{min})$, and the time interval (min).

2. Flow cells were divided into five segments, with each segment being centered on a sampling port.

3. The ZVI mass suspended (MS) in the fluid present in each segment at the given elapsed time was estimated as a product of concentration of ZVI in fluid samples (Appendix C, Section C6) collected through the respective sampling port and the PV of fluid present in this segment.

4. The effluent ZVI mass (ME) that left a flow cell during the given elapsed time was determined as the product of ZVI concentration $(\mathrm{mg} / \mathrm{L})$ in a sample of the effluent, rate of injection $(\mathrm{mL} / \mathrm{min})$ and the time interval (min).

5. The ZVI mass deposition (MD) in the entire flow cell during the given elapsed time was calculated by the following mass balance (Equation 4-2):

$$
M D=M I-\Sigma M S-M E
$$

6. The ZVI mass deposited in each segment (MDS) during the given elapsed time was assumed proportional to the suspended mass and estimated as shown in Equation 4-3:

$$
M D S=(M S / \Sigma M S) \times M D
$$

(Equation 4-3)

7. For fluid sample with ZVI concentration values of approximately $200 \mathrm{mg} / \mathrm{L}$ or less, it was assumed that all ZVI was in suspension (i.e., no ZVI deposited in that segment).

8. To obtain finer discretization for flow cells \#1 and \#3 where the ZVI front did not reach first sampling port (due to the low flow rate), the cell was subdivided into sub-segments for which MS values were estimated based on visual observations of the ZVI front moving along the flow cell.

9. The MDS values (shown in Table 4-12) were converted to ZVI concentrations in sand (kilograms of ZVI per kilogram of sand) and used to calculate the relationship of the deposited ZVI as a function of injection time, distance, and fluid velocity. This was accomplished by statistical application of multiple linear regression (MLR).

The resulting MLR functional relationship obtained is shown in Equation 4-4:

$$
\begin{gathered}
\text { Mass Deposition }=0.0322+3.77 E-7 x \text { Time }-0.0192 \\
x \text { Distance }+8.44 \times \text { Velocity }
\end{gathered}
$$

(Equation 4-4)

The coefficient of determination (R2) for this relationship is 0.59 . This indicates the proportion of variability in the data set explained by the model (i.e., functional relationship equation). A value of 0.59 is not very high; therefore, although this functional relationship may be the best explanation available for the data, it is not particularly strong.

An example of MDS calculation for cell \#8 is given in Appendix C, Section C6. Two alterations were applied to the database prior to the MLR calculation and unit conversion took place. Spreadsheets with data used for calculating MDS values for the four selected flow cells $(1,3,5$, and 8) are provided in Appendix C, Section C6. A spreadsheet with combined MDS values for all four of these flow cells, the spreadsheet with input data for MLR, and MLR summary output are presented in Appendix C,

Section C6. The values shown for MLR input data are those after unit conversion and translation of MDS values in units of $\mathrm{mg}$ to total iron concentrations in units of kilograms of iron per kilogram of sand (kg-Fe/kg-sand). 
The complete set of data collected during advanced injectability testing is provided in Appendix C, Section C6.

\subsubsection{Modeling}

The advanced flow cell injection developed a functional relationship, formulating a mathematical expression to evaluate ZVI deposition (nZVId) as a function of distance, time of injection, and ZVI fluid velocity. This functional relationship (Equation 4-5) was used for computer modeling of the field injection process:

$$
\begin{aligned}
n Z V I d=0.0322 & +3.77 E-7 \times \text { Time }-0.0192 \times \text { Distance } \\
& +24.12 \times \text { Darcy Velocity }
\end{aligned}
$$

In this equation, $\mathrm{nZVId}$, time, distance, and Darcy velocity are expressed in kilograms of $\mathrm{nZVI}$ per kilogram of soil $(\mathrm{kg} / \mathrm{kg})$, seconds, meters, and meters per second, respectively. This function was then used for computer modeling of the post-injection nZVId in the aquifer.

\subsubsection{Modeling Process}

The modeling process is shown in Figure 4-56. Because PORFLOW is a highly flexible and modular software package, a special subroutine was developed to solve Equation 4-5 (unshaded shapes shown in Figure 4-56) based on the simulated flow field (which resulted from the injection of nZVI fluid) and the distribution of $\mathrm{K}$. When solving Equation 4-5 for a given element of the model domain, flow velocity, elapsed injection time, and distance of the given element from the injection point were used to calculate nZVIe (i.e., the concentration of nZVId for each element). These values were then normalized with respect to hydraulic conductivity to obtain nZVIKe (i.e., the concentration of nZVIe in each element). Finally, for mass conservation, ZVIK was calculated (i.e., concentration of deposited nZVI for each element) (Equation 4-6):

$$
Z V I K=n Z V I K e \times \Sigma(n Z V I K e) \times F / n Z V I i
$$

In this equation, nZVIi is the total mass of injected nZVI through the injection well at the given time, and $\mathrm{F}$ is a dimension-less laboratory-defined factor calculated as a ratio of $\mathrm{nZVId}$ to $\mathrm{nZVI}$ injected.

\subsubsection{Model Domain}

A simplified, three-dimensional approach was used (i.e., cylindrical coordinates with the injection well being the axis of the cylinder). This type of approach was used because at the August 2008 time of injection, it was anticipated that the regional hydraulic gradient would be small, thus justifying radial symmetry of the model domain. Because PORFLOW requires that the axis of a cylindrical domain be oriented along an X-axis well, well 199-D4-26 was oriented accordingly. The model domain encompasses a cylindrical block, $31.1 \mathrm{~m}$ (102 ft) high (X-axis) and $30 \mathrm{~m}(98.4 \mathrm{ft})$ radius, set along the Y-axis. The model simulates prescribed processes (e.g., flow, transport, etc.) within a 1-radian portion of the cylindrical domain, and can be visualized as two-dimensional picture. However, the depth of elements in the direction perpendicular to a two-dimensional projection of the domain increases with the distance from the axis of symmetry and has a length equal to the length of a 1-radian arc at the given radius. For example, any element located at the cylindrical boundary of the model domain has a depth of $30 \mathrm{~m}(98.4 \mathrm{ft})$ if measured along its outer side. 


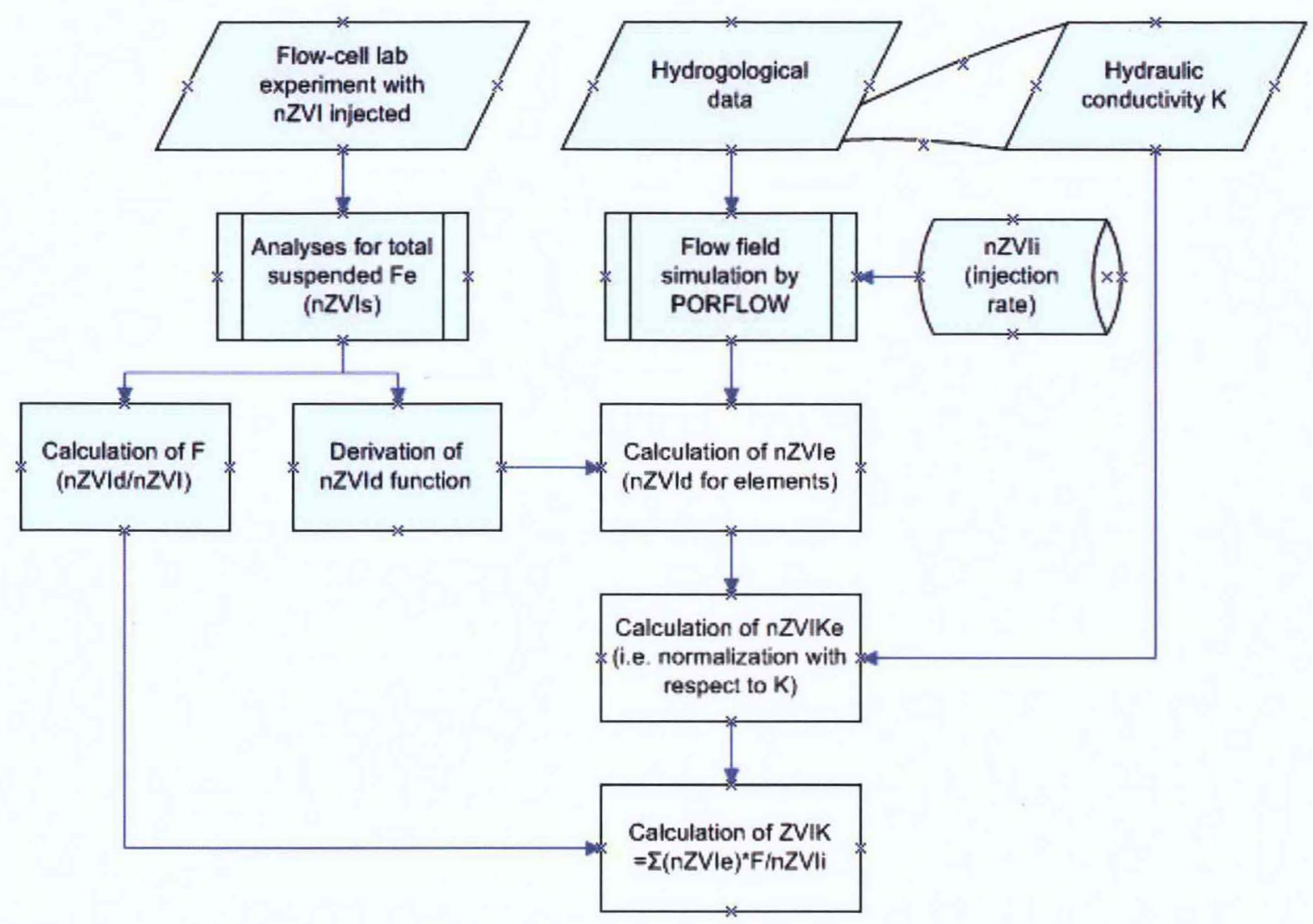

Figure 4-56. Modeling Logistics

The domain was discretized to 8,560 internal elements using a 109 by 82 structured grid in $\mathrm{X}$ and $\mathrm{Y}$ directions, respectively. Thus, there are 107 layers of elements in the model, each consisting of 80 elements with irregular (progressively larger) spacing along the $\mathrm{Y}$-axis. A side view of the model domain showing its discretization is presented in Figure 4-57. Because elements close to the symmetry axis are small in the Y direction, they blend with each other for this scale of the diagram.

\subsubsection{Boundary Conditions}

In PORFLOW, external boundaries of a cylindrical model domain are referred to as the following:

- "X-" indicates a surface perpendicular to X-axis at its lower end.

- " $\mathrm{X}+$ " indicates a surface perpendicular to $\mathrm{X}$-axis at its upper extension.

- "Y-" indicates a symmetry axis that is perpendicular to Y-axis at its lower end.

- "Y+" indicates a cylindrical surface that is perpendicular to $\mathrm{Y}$-axis at its upper extension. 


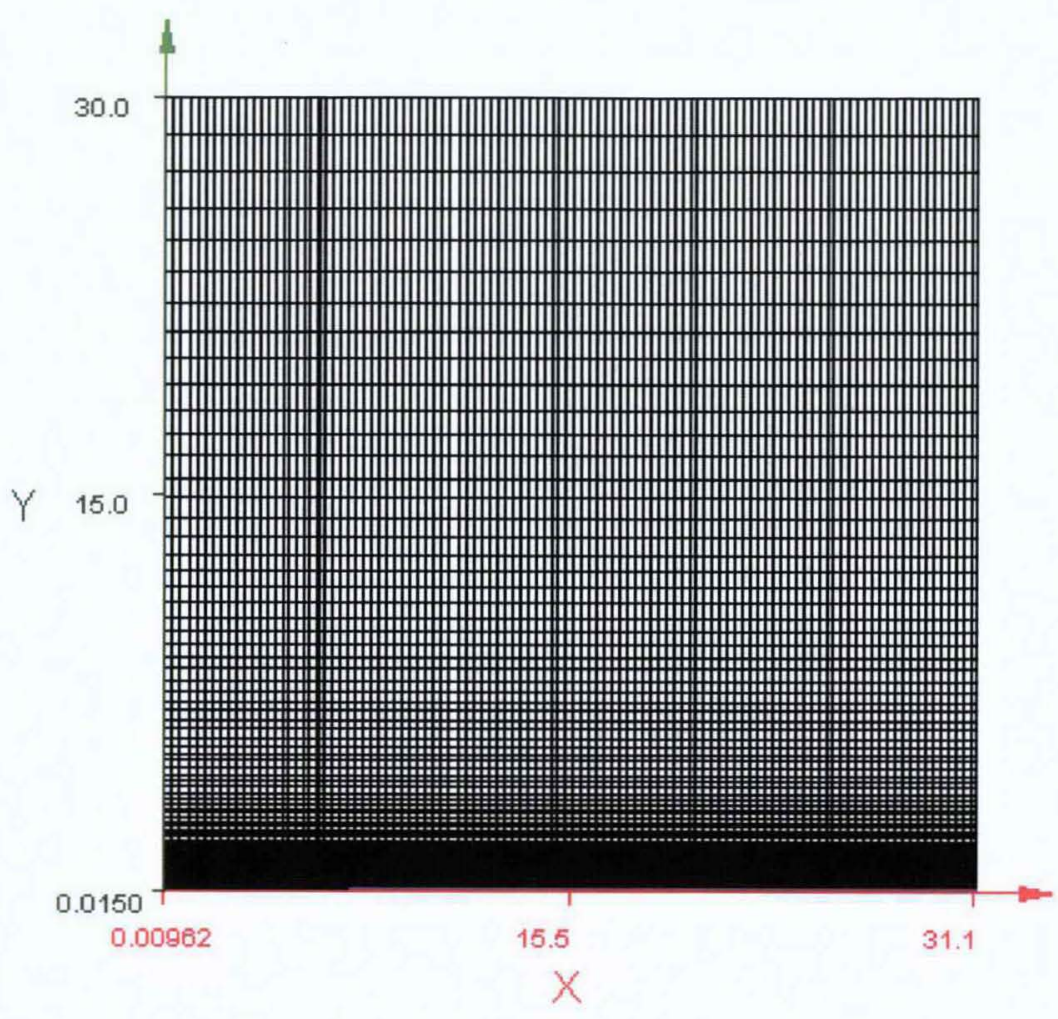

Figure 4-57. Model Domain Discretization

Boundary conditions for the simulated domain were set as follows:

- "X-" indicates a no flow boundary.

- "X+" indicates a no flow boundary.

- "Y-" indicates a no flow boundary (model default).

- "Y+" indicates a no flow boundary for the vadose zone.

- "Y+" indicates a constant head (5 m [16.4 ft]) for the saturated zone.

\subsubsection{Hydraulic Conductivity}

The model domain was divided into separate zones with respect to horizontal hydraulic conductivity, as described in Table 4-16. Within the saturated portion of the Ringold Formation, the vertical distribution of hydraulic conductivity is based on values presented in Figure 5-1 in Chapter 5. Hydraulic conductivity for the unsaturated portion of Ringold Formation was obtained from PNNL-13349, 100-D Area In Situ Redox Treatability Test for Chromate-Contaminated Groundwater. The hydraulic conductivity (K) value for the Hanford formation was assigned using a mid value reported in PNNL-14112, Groundwater Monitoring Plan for the 216-B-3 Trench on the Hanford Site for the 200 Areas, where a portion of the Hanford formation is saturated. Since the sand pack of well 199-D4-26 was installed using 10/20 silica sand, its hydraulic conductivity value was assigned as that measured for the control cell of the injectability test that was also packed with 10/20 mesh silica sand. The inside space of the screen is an injection chamber void of any solid matrix; therefore, it was simulated by assigning to this zone an extremely high hydraulic conductivity value. Above the screen, also directly adjacent to the X-symmetry axis, there is a grouted well casing that is considered inactive, and therefore it was modeled by assigning a very low hydraulic conductivity. 
Table 4-16. Zones of Hydraulic Conductivity Within the Model Domain

\begin{tabular}{|c|c|c|c|c|c|c|}
\hline \multirow[b]{2}{*}{ Zone } & \multicolumn{2}{|c|}{ Zone Bottom } & \multirow[b]{2}{*}{$\begin{array}{l}\text { Thickness, } \\
\text { m }\end{array}$} & \multicolumn{3}{|c|}{$\begin{array}{l}\text { Horizontal Hydraulic Conductivity } \\
\text { (Y Direction for the Model) }\end{array}$} \\
\hline & $\mathrm{ft}$ bgs & $\begin{array}{c}\text { Above } \\
\text { Bottom of } \\
\text { Borehole, m }\end{array}$ & & $\mathrm{m} / \mathrm{sec}$ & $\mathrm{m} /$ day & $\mathrm{ft} /$ day \\
\hline $\begin{array}{l}\text { Grouted well casing } \\
\text { (inactive zone) }\end{array}$ & & & & $1.0 \mathrm{E}-11$ & 8.6E-07 & $2.8 \mathrm{E}-06$ \\
\hline Sand pack & & & & 8.0E-03 & $6.9 \mathrm{E}+02$ & $2.3 \mathrm{E}+03$ \\
\hline $\begin{array}{l}\text { Inside screen (injection } \\
\text { zone) }\end{array}$ & & & & $1.2 \mathrm{E}+01$ & $1.0 \mathrm{E}+06$ & $3.3 \mathrm{E}+06$ \\
\hline Hanford formation & & 13.47 & & $1.4 \mathrm{E}-03$ & $1.3 E+02$ & 4.1E+02 \\
\hline $\begin{array}{l}\text { Ringold Formation above } \\
\text { saturation }\end{array}$ & 86 & 4.90 & & $1.9 \mathrm{E}-04$ & 1. $6 \mathrm{E}+01$ & $5.4 \mathrm{E}+01$ \\
\hline \multirow{8}{*}{$\begin{array}{l}\text { Saturated Ringold } \\
\text { Formation }\end{array}$} & 88 & 4.27 & 0.61 & $1.3 \mathrm{E}-04$ & $1.1 \mathrm{E}+01$ & $3.6 E+01$ \\
\hline & 89 & 3.96 & 0.30 & 4.6E-04 & $4.0 \mathrm{E}+01$ & 1.3E+02 \\
\hline & 91 & 3.35 & 0.61 & $8.6 E-05$ & $7.5 \mathrm{E}+00$ & $2.4 \mathrm{E}+01$ \\
\hline & 92 & 3.05 & 0.30 & 3.5E-04 & $3.0 \mathrm{E}+01$ & $1.0 \mathrm{E}+02$ \\
\hline & 94 & 2.44 & 0.61 & $1.0 \mathrm{E}-07$ & 8.6E-03 & $2.8 \mathrm{E}-02$ \\
\hline & 97 & 1.52 & 0.91 & $1.9 \mathrm{E}-04$ & $1.6 \mathrm{E}+01$ & $5.3 E+01$ \\
\hline & 101 & 0.30 & 1.22 & 7.3E-04 & $6.3 E+01$ & $2.1 \mathrm{E}+02$ \\
\hline & 102 & 0.00 & 0.30 & $2.3 \mathrm{E}-03$ & $2.0 \mathrm{E}+02$ & $6.5 E+02$ \\
\hline
\end{tabular}

bgs $=$ below ground surface

For all, but inactive, sand pack, and injection zones an anisotropy ratio 1:10 was assigned for hydraulic conductivity in the vertical direction ( $\mathrm{X}$ direction for the model).

\subsubsection{Simulations}

All simulations were run for transient flow conditions over the time period necessary to inject the $3,345 \mathrm{~kg}$ of total iron prescribed for the pilot field injection test. At the $9,033 \mathrm{mg} / \mathrm{L}$ or $9,033 \mathrm{~kg} / \mathrm{m}^{3}$ concentration of total iron this amount corresponds to $370 \mathrm{~m}^{3}$ (97,394 gal) of nZVI fluid. To determine an optimal injection rate for the pilot field injection test, multiple simulations were run with different injection rates ranging from 22.7 to $83.3 \mathrm{~L} / \mathrm{min}$ ( 6 to $22 \mathrm{gpm}$ ). The optimal injection rate was defined as that resulting in the highest concentration of deposited nZVI in the highest hydraulic conductivity strata at

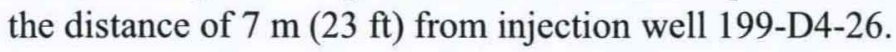

An example of a model input file for the injection rate of $53 \mathrm{~L} / \mathrm{min}(14 \mathrm{gpm})$ or $0.000887 \mathrm{~m}^{3} / \mathrm{sec}$ is included in Appendix C, Section C7. As required by PORFLOW, this file is written in consistent units (in this case, in meters, seconds and kilograms), with nZVI fluid injection rates divided by $2 \mathrm{~A}$ because the calculations are conducted for a volume subtended by a 1-radian arc. 


\subsubsection{Data Analysis and Interpretation}

During modeling, increasing injection rates resulted in individual flow fields with progressively higher velocities, but the cone of impression did not increase significantly (as documented in Figures 4-58 and 4-59) for injection rates $53 \mathrm{~L} / \mathrm{min}(14 \mathrm{gpm})$ and $22 \mathrm{gpm}$, respectively. This indicates that a buildup of pressure during the field injection would not be a concern.

However, deposition of iron within the model domain changes significantly for different injection rates. This is shown in Figure 4-60, where the maximum iron deposition value corresponds to a $64 \mathrm{~L} / \mathrm{min}$ (17-gpm) injection rate. Deposition of iron at an injection rate of $53 \mathrm{~L} / \mathrm{min}(14 \mathrm{gpm})$ is only slightly smaller.

The mathematical expression (Equation 4-5) for deposited nZVId (as total iron) as a function of injection time, distance from the injection point, and nZVI fluid velocity was developed based on analytical results for total iron concentrations. Therefore, this equation does not discriminate between iron in the form of $\mathrm{nZVI}$ and that contributed in the form of magnetite. By using Equation 4-5 in PORFLOW, modelobtained results for deposited iron are also expressed in terms of total iron. The actual deposition of iron as $\mathrm{nZVI}$ can be estimated from these modeled results, by multiplying by a factor of 0.72 . This factor was derived as a ratio of nZVI $(0.65)$ to the total iron (0.9033) present in a unit volume of the injected fluid. Such a calculation assumes no change from the initial ratio as provided by the manufacturer. This factor needs to be applied to all numerical values of deposited iron that are discussed below.

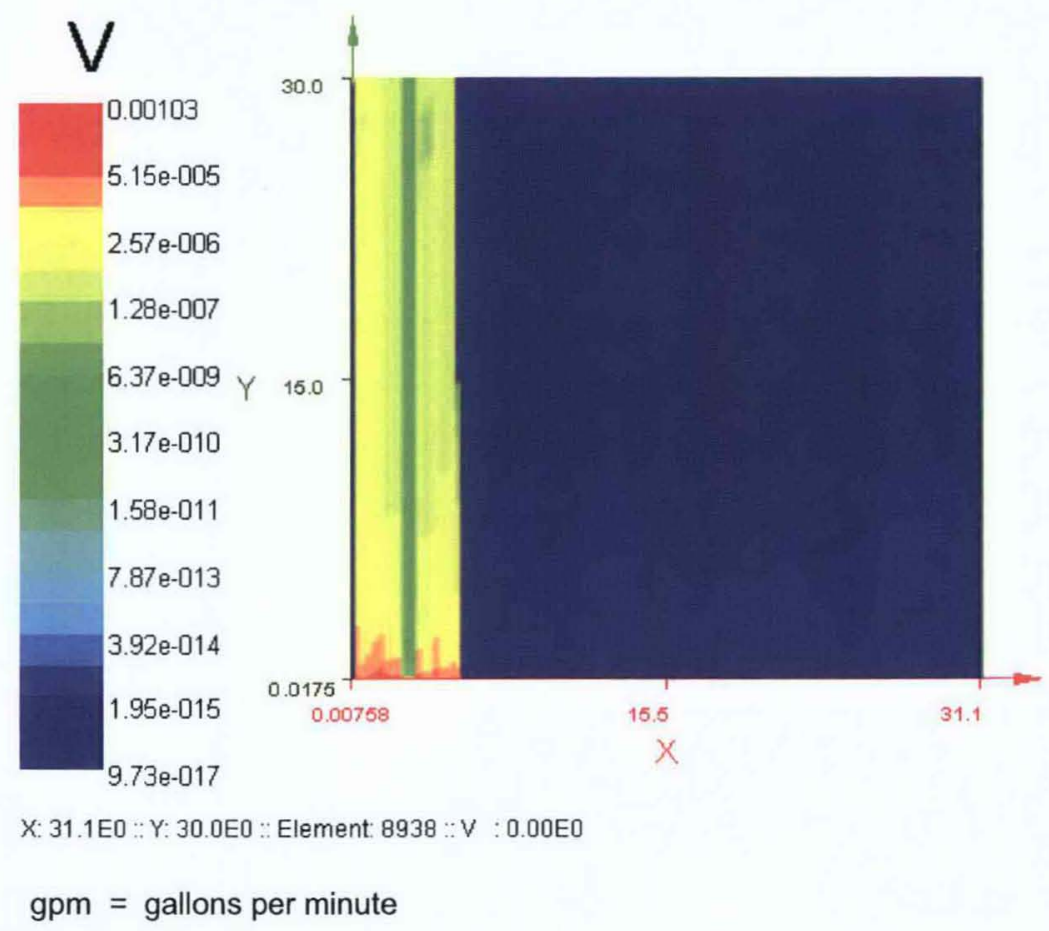

Figure 4-58. Flow Field for 14-gpm Injection Rate 
DOE/RL-2009-35, REV. 0

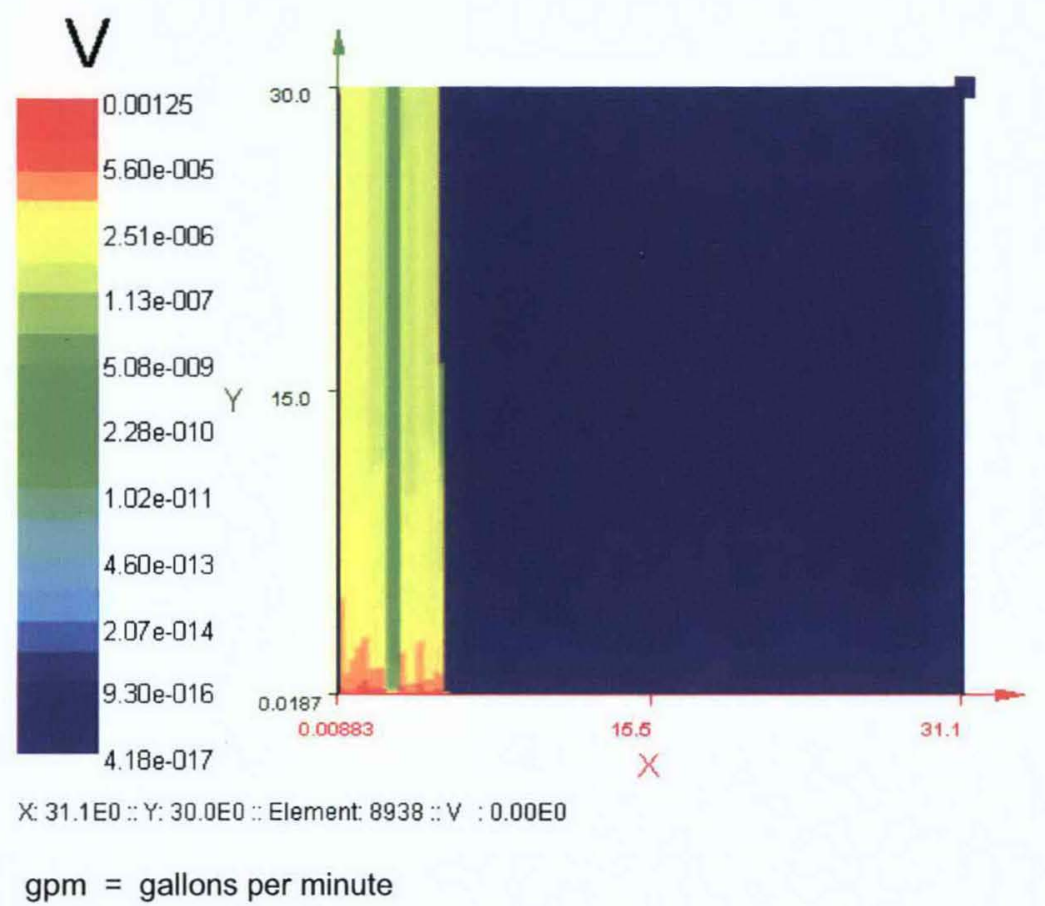

Figure 4-59. Flow Field for 22-gpm Injection Rate

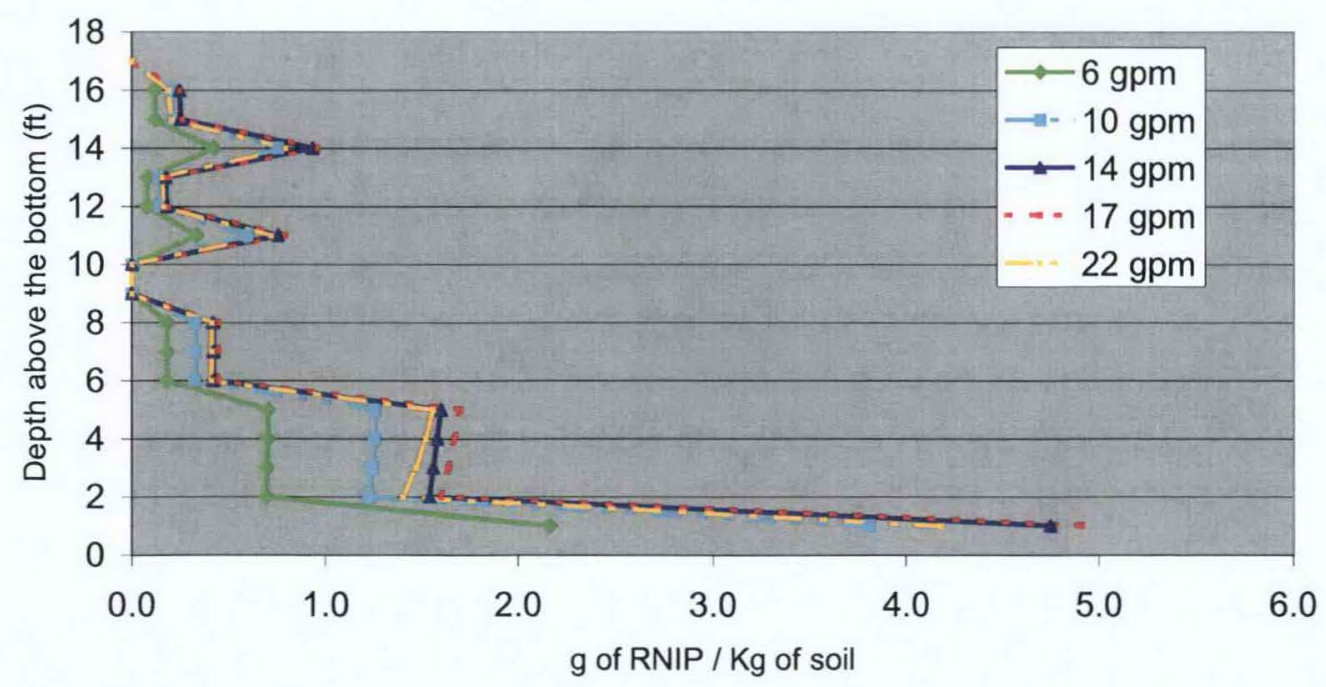

Figure 4-60. Deposition of Iron at $7 \mathrm{~m}$ from Injection Well 


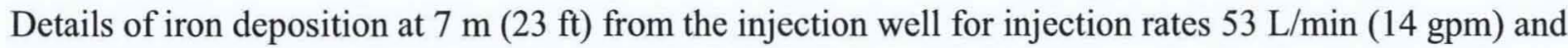
$64 \mathrm{~L} / \mathrm{min}$ (17 gpm) are shown in Figures 4-61 and 4-62, respectively. These show only slightly different (3.3 percent) values of $4.768 \mathrm{~g} / \mathrm{kg}$ and $4.924 \mathrm{~g} / \mathrm{kg}$ for injection rates of $53 \mathrm{~L} / \mathrm{min}(14 \mathrm{gpm}$ ) and $64 \mathrm{~L} / \mathrm{min}$ (17 gpm), respectively. However, the difference in the extent of deposited iron for the $53 \mathrm{~L} / \mathrm{min}(14 \mathrm{gpm})$ and $64 \mathrm{~L} / \mathrm{min}(17 \mathrm{gpm})$ injection rates is more substantial (10 percent). These distances are $11.17 \mathrm{~m}$ and $10.16 \mathrm{~m}$ (36.65 ft and $33.33 \mathrm{ft}$ ), as shown in Figures 4-63 and 4-64, respectively. Therefore, considering the uncertainty of modeling results, a $53 \mathrm{~L} / \mathrm{min}(14 \mathrm{gpm})$ injection rate was recommended for the pilot field injection test. A summary of the results is presented in Table 4-17.
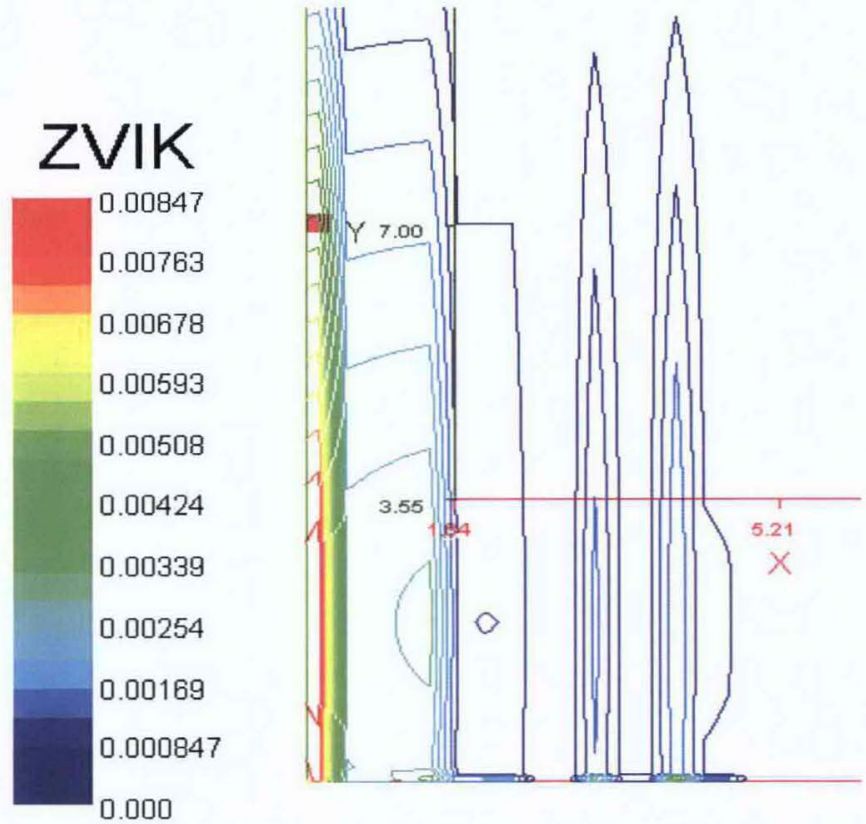

$\mathrm{X}: 157.32 \mathrm{E}-3: \because \mathrm{Y}: 7.0115 \mathrm{E} 0::$ Element: $5458::$ ZVIK: $4.768 \mathrm{E}-3$

gpm = gallons per minute

Figure 4-61. Details of Iron Deposition for 14-gpm Injection Rate 
DOE/RL-2009-35, REV. 0

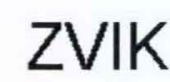

0.0105
0.00949
0.00844

0.00738

0.00633

0.00527

0.00422

0.00316

0.00211

0.00105 0.000

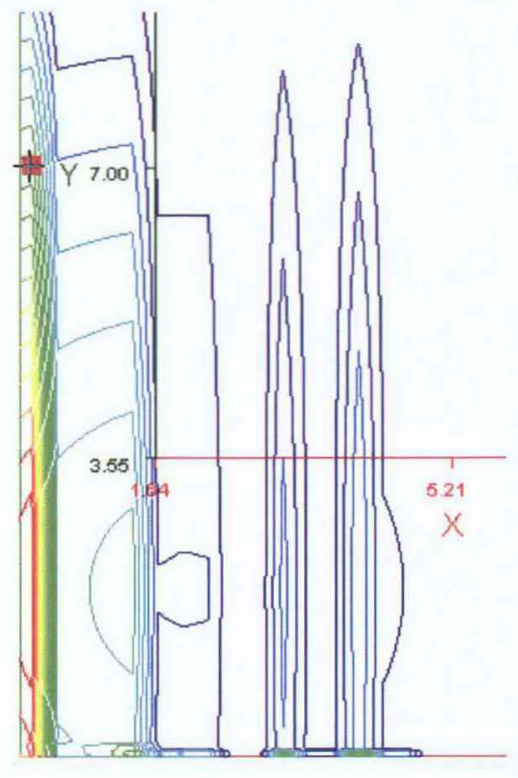

X: 154.25E-3 :* $Y: 6.9996 E 0 *:$ Element: $5458 *:$ ZVIK: $4.9239 E-3$

gpm $=$ gallons per minute

Figure 4-62. Details of Iron Deposition for 17-gpm Injection Rate

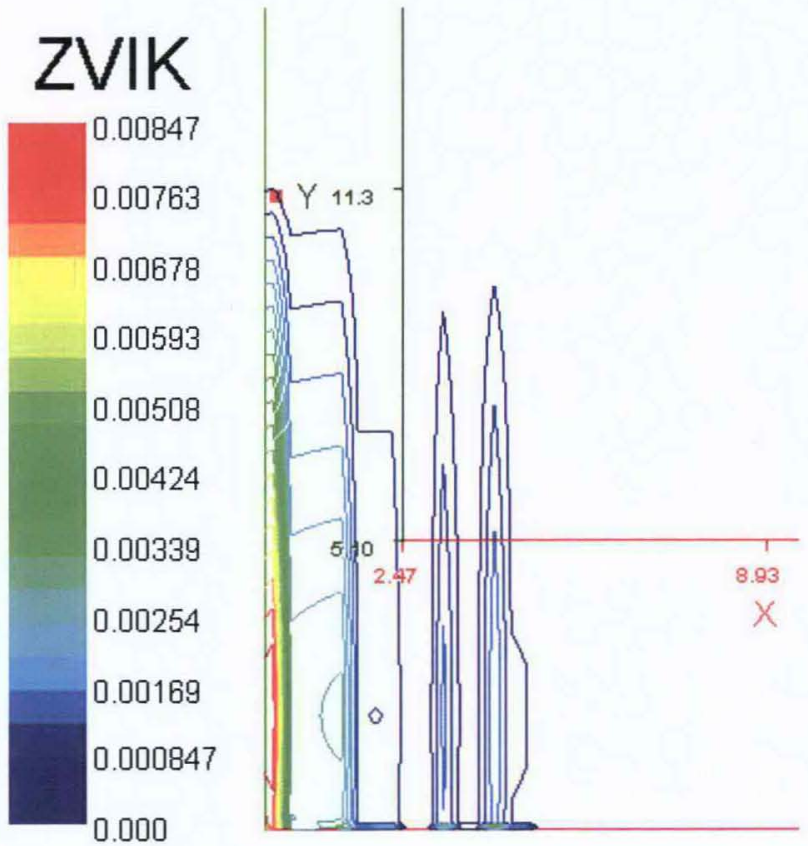

X: 206.48E-3 ::Y: 11.166E0 :: Element: $6421::$ ZVIK: 491.97E-6

gpm = gallons per minute

Figure 4-63. Maximum Travel Distance of Iron for 14-gpm Injection Rate 

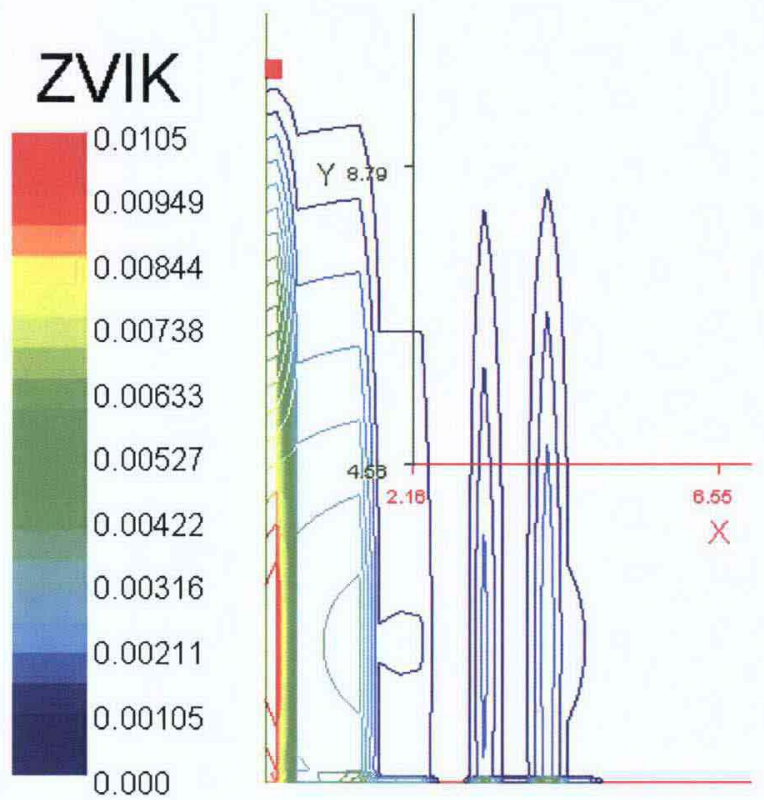

X: 121.16E-3 ::Y: 10.159E0 $\because:$ Element: $6207: \because$ ZIK: 154.97E-6

gpm = gallons per minute

Figure 4-64. Maximum Travel Distance of Iron for 17-gpm Injection Rate

Table 4-17. Summary of Key Results of Nano-Sized Zero-Valent Iron Deposition Modeling

\begin{tabular}{|c|c|c|c|c|c|c|}
\hline \multirow[b]{2}{*}{$\begin{array}{l}\text { Injection } \\
\text { Rate, } \\
\text { gpm }\end{array}$} & \multirow{2}{*}{$\begin{array}{c}\text { Concentration } \\
\text { of Iron } \\
\text { Deposited at } \\
7 \mathrm{~m} \text { from } \\
\text { Injection Well, } \\
\text { g/kg }\end{array}$} & \multirow{2}{*}{$\begin{array}{c}\text { Concentration } \\
\text { of } \mathrm{nZVI} \\
\text { Deposited at } \\
7 \mathrm{~m} \text { from } \\
\text { Injection Well, } \\
\mathrm{g} / \mathrm{kg}\end{array}$} & \multicolumn{2}{|c|}{$\begin{array}{l}\text { Extent of Deposited } \\
\text { Iron }\end{array}$} & \multirow{2}{*}{$\begin{array}{l}\text { Distance to } \\
\mathbf{0 ~ g / k g} \\
\text { Concentration } \\
\text { of Deposited } \\
\text { Iron, } \mathrm{m}\end{array}$} & \multirow{2}{*}{$\begin{array}{c}\text { Max. } \\
\text { Concentration } \\
\text { of Deposited } \\
\text { Iron in the } \\
\text { Domain, } \mathrm{g} / \mathrm{kg}\end{array}$} \\
\hline & & & $\begin{array}{c}\text { Distance, } \\
\mathrm{m}\end{array}$ & $\begin{array}{c}\text { Concentration, } \\
\text { g/kg }\end{array}$ & & \\
\hline 6 & 2.167 & 1.560 & 21.74 & 0.143 & 22.73 & 2.660 \\
\hline 10 & 3.825 & 2.754 & 14.61 & 0.257 & 15.21 & 5.547 \\
\hline 14 & 4.768 & 3.433 & 11.17 & 0.492 & 11.83 & 8.473 \\
\hline 17 & 4.924 & 3.545 & 10.16 & 0.155 & 10.67 & 10.548 \\
\hline 22 & 4.184 & 3.012 & 8.25 & 1.095 & 8.66 & 13.704 \\
\hline
\end{tabular}

$\mathrm{gpm}=$ gallons per minute

$\mathrm{nZVI}=$ nano-sized zero-valent iron 


\subsection{Comparison to Test Objectives}

Comparisons to test objective for specific elements of laboratory testing and modeling are in this section.

\subsubsection{Micron-Sized Zero-Valent Iron Testing (Original Scope)}

The test objectives for the initial injection and geochemical testing included the following:

- Evaluating changes in water chemistry when groundwater of similar composition to that at the 100-D Area reacts with $\mathrm{mZVI}$ emplaced in the aquifer with emphasis on:

- pH changes

- Influence of strongly reducing conditions on nitrate (e.g., does it reduce all the way to ammonia?)

- Changes in carbonate concentration due to high pH (high carbonate concentrations may decrease the aquifer permeability)

- Evaluating the passivation of the mZVI under field conditions (e.g., high groundwater carbonate).

The injection and geochemical laboratory testing performed in March 2007 was designed to address these test objectives. The results from the initial injection and geochemical testing indicated geochemical issues with MicroPowder S-3700 that needed to be addressed. Although not all of the original test objectives were completely explored, the results of the flow cell injection and geochemical testing, subsequent simple batch testing, and literature review provided valuable information about the reactivity of MicroPowder S-3700.

\subsubsection{Literature Search}

The test objectives of the literature search were as follows:

- Identify commercially available ZVI materials suitable for injection and hexavalent chromium reduction

- Investigate injection studies associated with identified ZVI materials

- Investigate geochemical studies addressing the reduction of metals by ZVI-particularly with respect to the kinetics of the reactions.

A thorough evaluation of the commercially available ZVI materials resulted in the development of a database listing materials with a wide range of composition, sizes, and surface-stabilizing enhancements. After researching the potential materials and the available literature, a well-informed recommendation on the most promising ZVI materials was made. A series of tests were then developed to evaluate the materials in several critical performance areas.

\subsubsection{Batch Screening Test}

The batch screening tests were designed to determine the ability of the bare (non-polymer-modified) ZVI materials to remove dissolved, hexavalent chromium from surrogate groundwater after 4 hours of iron/surrogate contact time. The batch screening tests successfully evaluated the ability of the selected ZVI materials to remove dissolved, hexavalent chromium from a surrogate groundwater, while also evaluating the potential for reduction of nitrates. This investigation also provided additional insight regarding the reductive capacity and reactivity of the materials, which was applied to further testing on the materials. 


\subsubsection{Injection Screening Test}

The objective of injectability screening tests was to determine the injectability of various ZVI materials, assess the changes in the permeability of the soils (possibly due to the precipitation of carbonates, iron oxy-hydroxides or other inhibiting byproducts), and select the best performing ZVI materials for further laboratory geochemical and injectability testing.

The injectability screening tests were successful in assessing the ability of the materials to inject and distribute through a porous media while assessing the changes in the permeability of the soils (possibly due to the precipitation of carbonates, iron oxy-hydroxides, or other inhibiting byproducts). The tests revealed significant differences in the characteristics of the materials in the following areas: (1) ability to transport the ZVI the length of the flow cell, (2) ability to distribute ZVI evenly throughout the flow cell, and (3) effect of the ZVI injection on the permeability of the porous media.

\subsubsection{Screening Geochemical Test}

The screening geochemical tests were successful in demonstrating the ability of the ZVI materials to reduce hexavalent chromium over a moderate time in a field simulated environment. However, not all of the ZVI materials were tested to their reactivity limits.

\subsubsection{Advanced Geochemical Test}

The advanced geochemical testing was successful for evaluating changes in water chemistry when surrogate groundwater (of similar composition to that at the 100-D Area) reacts with ZVI emplaced in the aquifer, with emphasis on the following:

- Ability of ZVI-impregnated Ringold soil to remove/reduce hexavalent chromium

- $\mathrm{pH}$ changes

- Effect of ZVI-induced reducing conditions on nitrate (e.g., conversion to ammonia)

- Changes in carbonate concentration due to high pH (high carbonate concentrations may decrease the aquifer permeability)

- Effect of ORP on interstitial water

- Establish specific geochemical differences between the two nZVI candidates

- Assess longevity of nZVI materials per the ability to reduce hexavalent chromium, as related to nZVI emplacement concentration.

The data obtained from advanced geochemical testing was used to evaluate and design a potential field injection.

\subsubsection{Advanced Flow Cell Injection}

The injection tests were able to evaluate injectability of the materials on larger scale and over a variety of flow rates. A functional relationship was developed for the distribution of RNIP-M2 from the results of the injection tests. This functional relationship was used to model and design a field injection. 


\subsubsection{Modeling}

The modeling effort was used to develop a numerical model to predict the behavior of ZVI fluid injected into high-conductivity strata in the ISRM barrier. With the numerical model, it was possible to (1) approximate the maximum distance that $\mathrm{nZVI}$ could be emplaced in the aquifer by injecting it through a single injection well, (2) predict the concentration of nZVI $7 \mathrm{~m}$ from injection well, and (3) optimize the nZVI injection rate for the field pilot test.

\subsection{Conclusions and Recommendations from Laboratory Testing and Modeling}

Conclusions and recommendations from specific elements of laboratory testing and modeling are presented in this section. In general, based on the extensive literature research and laboratory testing, it was concluded that RNIP-M2 was the best candidate for addressing the requirements listed for Task 10 of the project. Therefore, a field-scale injection of RNIP-M2 at the 100-D Area was recommended.

\subsubsection{Micron-Sized Zero-Valent Iron Testing (Original Scope)}

The results of the initial $\mathrm{mZVI} /$ polymer injection and geochemical testing indicated that (1) the $\mathrm{mZVI}$ accumulated near the inlet of the injection flow cells and was channeled along the exterior edges of the permeability flow cells, (2) a portion of the nitrates in the surrogate groundwater were reduced to ammonia, and (3) the reduction of hexavalent chromium to trivalent chromium was less than expected. Based on the initial testing, the following list of concerns was prepared regarding the effectiveness and rate of mZVI reducing hexavalent chromium. The concerns would be addressed through further laboratory testing prior to the field injection phase of the demonstration:

- Reaction rate for $\mathrm{mZVI} /$ surfactant/polymer/Ringold sediments with surrogate groundwater

- Effect additives have on reaction rates (e.g., surfactant or polymer)

- Effect iron quality has on reaction rates

- Effect aquifer materials have on reaction rates

- Parameter(s) that can be used as indicator of reaction rates (the literature suggests ORP and DO).

Following the initial $\mathrm{mZVI}$ testing, a set of simple batch tests were performed and a literature review was conducted to learn more about the geochemistry of the $\mathrm{mZVI} /$ polymer slurry. The results of the testing and research led to the conclusion that using $\mathrm{mZVI} /$ polymer slurry had not adequately addressed the project's goals and concerns. As a result, it was recommended that the original scope of work be modified and other ZVI materials (including nano-sized) be investigated. Some of the lessons learned from testing are as follows:

- Based on the difficulty encountered with viscosity measurements for QC of the mZVI/polymer slurry in the laboratory (due to the apparatus and auxiliary equipment required to perform the analyses, its dependence on temperature and less-than-desirable accuracy), it is believed that viscosity should not be used as a field QC parameter.

- ORP and $\mathrm{pH}$ have shown to be good indicators of $\mathrm{mZVI} /$ polymer reactivity and should be used for monitoring of future ZVI injections.

- Specific conductivity has been shown to be a good indicator of the presence of polymer and not necessarily $\mathrm{mZVI}$. This should be considered when evaluating future $\mathrm{mZVI} /$ polymer injections. 
- If $\mathrm{mZVI} /$ polymer is injected into low-permeability materials, it is important to account for increased inlet pressures.

\subsubsection{Literature Search}

The ranking of the available ZVI products listed in Table 4-6 indicates a distinct break between the top ranked materials and the remaining materials. Further testing of the materials with a score of 39 or greater was recommended. NanoFe and RNIP-DS were not advanced because they were bare particles without polymer modification and, therefore, were not suitable for injection. RNIP-M2 was advanced because it consisted of the same particle as RNIP-10DS, but it has adds a polymer to allow the solution to be injected. MicroPowder S-3700 was advanced for further testing as a benchmark because of its it had previously been used on the project. As a result of the literature search, a series of batch tests were developed to further evaluate the following materials: EZVI, PolyMetallix, NanoFe I, NanoFe II, Z-loy, and RNIP-M2. Some lessons learned from the literature search include:

- Subtle changes in material make significant changes in material behavior. The reactivity and injectability of the ZVI material is impacted by small changes in the material's physical and chemical properties.

- Simple laboratory testing with site-specific materials is essential to selecting the appropriate ZVI and optimizing injection parameters.

- A wide variety of potential dispersants are available. The search to find the optimum dispersant/ZVI pair should be performed. During testing, the ZVI vendors were asked to supply a dispersant with their product. Further research could be performed to evaluate the effect of different dispersants on the material's injectability.

\subsubsection{Batch Screening Test}

All six ZVI materials tested were successful in reducing the dissolved chromium and creating a reducing environment during the batch tests. RNIP-10DS, PolyMetallix, and NanoFe II did not indicate a detrimental reduction of nitrates, while the remaining ZVI materials showed a reduction in nitrates (up to 90 percent by Z-loy). The primary goal of testing was to determine the ability of the nZVI to rapidly reduce chromium. Reduction of nitrate was a secondary objective and, as such, only nitrate was analyzed. Because the reduction of nitrate can only produce nitrite, ammonia, and nitrogen gas, efforts were focused on total reduction of nitrate in the preliminary screening tests. Reaction time was only 4 hours, so it was not prudent to think that the reactions had reached pseudo-equilibrium, resembling what may be observed in more representative testing. As such, none of the materials were eliminated due to their effects on nitrate.

Based on the batch screening tests, it was suggested that all six ZVI materials be advanced to the injection screening test. Future geochemical testing would be needed to further define the reductive capacity of the materials. The future testing would also evaluate the materials over an extended period of time while continuing to monitor any detrimental effects that the materials might have on the aquifer. Lessons learned from the batch screening test include the following:

- Because all of the materials successfully reduced the available hexavalent chromium, chromium loading should be increased to stress the materials. A more demanding test would help separate the mediocre materials from the top-performing materials.

- The batch tests were very repeatable. The need to run in triplicate was unnecessary, and sufficient QC could be achieved with duplicates. 
- Expanded batch testing is recommended in the future because a large amount of information is gained from a relatively quick and cost-effective experiment. A wider variety of materials could easily be tested to obtain a better understanding of reactive capabilities.

\subsubsection{Injection Screening Test}

Based on the injection screening results, it was concluded that there was a distinct difference between the ZVI materials tested. PolyMetallix and RNIP-M2 clearly demonstrated a superior ability to emplace throughout the flow cells. Along with insufficient iron emplacement, several other flaws were associated with the eliminated materials. NanoFe II and EZVI were eliminated due to their inability to distribute evenly through the flow cell, while Z-loy and NanoFe I were eliminated due to their excessive reduction in hydraulic conductivity during ZVI injection. PolyMetallix and RNIP-M2 were advanced to a screening geochemical test. Based on its previous history with the project, MicroPowder S-3700 was also advanced for further testing. Lessons learned from the injection screening test include the following:

- Although the soil cores were successful in determining the total iron emplaced in the column, the method should be refined to improve ease of operation and repeatability.

- The results of the horizontal flow cells show the effects of gravity on ZVI transport, so horizontal flow cells are preferred over vertical flow configuration.

- The packing procedure is critical to the injection testing performance and even distribution of flow, in particular to ensure that there were no preferential flow paths. Using a shaker table to pack saturated sediments was the most effective means used for packing.

- The experiment could have been simplified by using 10/20 sand to fill the flow cells rather than the surrogate blend, as the difference in hydraulic conductivity was minor.

- Other variables could be evaluated in future testing, including the effect of the concentration of ZVI, different injection rates and methods, and the effect of different dispersants.

\subsubsection{Screening Geochemical Test}

Based on both the injection and geochemical screening tests, it was concluded that the MicroPowder S-3700 (mZVI) did not adequately address the needs of the project due to insufficient reduction of hexavalent chromium. At a concentration of $1.5 \mathrm{wt} \%$, both RNIP-M2 and PolyMetallix were successful at reducing hexavalent chromium for the length of the test; however, at a concentration of $0.75 \mathrm{wt} \%$, the PolyMetallix showed breakthrough while RNIP-M2 still removed hexavalent chromium. Therefore, it was recommended that further advanced geochemical testing be carried out for only PolyMetallix and RNIP-M2. Further testing was necessary to evaluate the reactive lifetime of both ZVI products and to monitor potentially harmful byproducts. Further testing would evaluate the materials at different ZVI concentrations over a longer period of time. Lessons learned from the screening geochemical test include the following:

- The column tests should be run for a longer period of time. During testing, both concentrations of RNIP-M2 reduced hexavalent chromium for the entire length of time. Extending the PVs of the experiment would help to determine the reactive lifetime of the material.

- Smaller diameter columns could be used for the experiment. Smaller diameter columns would still provide the desired information on the material's reductive capacity while using less material, which in some cases might be available in limited volume. 
- The first analytical sample results, collected at one PV, were inconclusive. This could be avoided by collecting the sample later, after the columns had adequate time to equilibrate.

\subsubsection{Advanced Geochemical Test}

Based on the data generated during advanced geochemical testing of the two ZVI materials, the overall conclusion can be drawn that RNIP-M2 is distinctly more reactive than PolyMetallix relative to the development of a zone of chemical reduction in the environment of the tested columns. This increased reactivity also enhances the longevity of RNIP-M2 relative to PolyMetallix.

The recommendation is that RNIP-M2 is the preferred material based on geochemistry. RNIP-M2 removed hexavalent chromium from the column for a longer period and at lower ZVI concentrations when compared to PolyMetallix. From the viable data, both materials produced similar quantities of ammonia. Lessons learned from the advanced geochemical test include the following:

- To better measure the reactive lifetime of the materials, experiments should be run on a time scale for as long as possible. A period of 2 months or longer would be preferable when attempting to establish the duration of reactivity.

- To save on the amount of column material required to run a number of tests, smaller diameter columns would have provided the information to establish hexavalent chromium removal of the nZVI materials tested.

- The DO measurements would have been more meaningful if the sensor had been mounted in-line with the effluent before coming into contact with ambient air.

\subsubsection{Advanced Flow Cell Injection}

The hydraulic head data indicates that PolyMetallix had a large impact on the hydraulic conductivity of the flow cell. However, RNIP-M2 was injected uniformly into the flow cell at significant concentrations without detrimental effects on the hydraulic conductivity. When taking into account the geochemical performance and the material's injectability, RNIP-M2 was recommended as the best candidate for mending the ISRM barrier. Lessons learned in advanced flow injection testing include the following:

- Long flow cell tests provide necessary proof that $\mathrm{nZVI}$ material can be injected at relatively long distance without unreasonable increase of the hydraulic head. Longer term flow tests will not, however, provide all of the information required to solve the model transport equation (Equation 4-5 in Section 4.1.9).

- Short flow cell experiments with varying hydraulic conductivities and several influent nZVI concentrations will be necessary to develop an isotherm for amassing of $\mathrm{nZVI}$.

- Because nZVI material is suspended in the sampled fluid, the location and alignment of the sampling port with respect to the flow stream is critical. During laboratory testing, the influent ZVI fluid sampling port was located perpendicular to flow, resulting in iron concentration data that were biased inversely proportional to flow rate. Modifications to the sampling method should be made in future testing to achieve representative ZVI concentrations.

- When analyzing nZVI fluid for total iron, it is critical to analyze known samples of the specific ZVI materials in order to develop sampling, preservation, and analytical methods to produce accurate and reliable data. 


\subsubsection{Modeling}

The following conclusions can be derived from the PORFLOW modeling of a post-injection nZVI distribution in the Ringold Formation aquifer:

- In the absence of available software packages for modeling the transport of colloidal iron, extensive laboratory experiments and significant adaptation of general purpose software are necessary to simulate a post-injection distribution of deposited iron.

- $\quad$ RNIP-M2 nZVI material appears to be well suited for mending the ISRM barrier.

- The objective of depositing $1 \mathrm{~g} / \mathrm{kg}$ of $\mathrm{nZVI}, 7 \mathrm{~m}$ (23 ft) from the 199-D4-26 injection well in the high-permeability zone, is achievable.

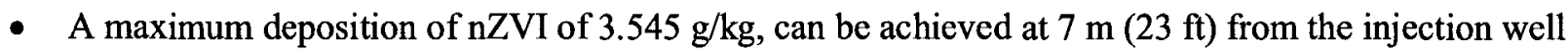
in the high-permeability zone, using a $64 \mathrm{~L} / \mathrm{min}(17 \mathrm{gpm})$ injection rate.

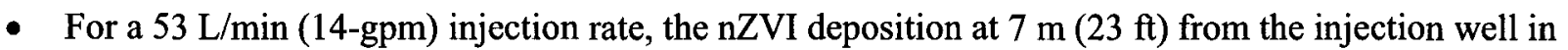
the high-permeability zone is $3.433 \mathrm{~g} / \mathrm{kg}$ (which is 3.3 percent less than that for a $64 \mathrm{~L} / \mathrm{min}$ [17-gpm] injection rate).

- A 10 percent reduction of deposited iron for the $64 \mathrm{~L} / \mathrm{min}$ (17 gpm) injection rate was observed, compared to the $53 \mathrm{~L} / \mathrm{min}(14-\mathrm{gpm})$ injection rate. The deposition was $11.17 \mathrm{~m}$ and $10.16 \mathrm{~m}(36.65 \mathrm{ft}$ and $33.33 \mathrm{ft})$ for the $53 \mathrm{~L} / \mathrm{min}(14-\mathrm{gpm})$ and $64 \mathrm{~L} / \mathrm{min}(17-\mathrm{gpm})$ injection rates, respectively.

- An injection rate of $53 \mathrm{~L} / \mathrm{min}(14 \mathrm{gpm})$ was recommended for the pilot field injection test because it had resulted in only 3.3 percent reduction of deposited iron at $7 \mathrm{~m}(23 \mathrm{ft})$, but it had provided a 10 percent increase in the extent of deposited iron.

The following considerations should be made regarding the results of the modeling efforts, as well as for identifying future research needs:

- To increase the reliability of modeled iron deposition results, flow cell experiments should be conducted using sand media of various hydraulic conductivities and nZVI injection fluids of various concentrations. This would allow the development of an isotherm for amassing of $n Z V I$. The amassing phenomenon (observed during flow cell testing) is an increase of the suspended $\mathrm{nZVI}$ concentration in the fluid above that injected. It would also allow for solving the nZVI transport equation internally in the model rather than using a deposition function in a post-processor manner.

- Results from the subroutine developed for solving a mathematical expression for deposited nZVI as a function of injection time, distance from the injection point, and flow velocity are sensitive to the location of the injection point. The subroutine currently allows listing only one element of the model domain as an injection point. For the reported simulations, this element was placed within the injection zone, just in front of the highest hydraulic conductivity layer. Modeling results slightly differ when the assigned injection point is moved to other locations within the injection zone.

Lessons learned from the modeling are presented below:

- To increase the reliability of modeled iron deposition results, flow cell experiments should be designed for better development of the parameters required to solve the model transport equation. This would allow for solving the nZVI transport equation internally in the model, rather than using a deposition function in a post-processor manner. 


\subsection{Quality Assurance/Quality Control}

Aspects of QA/QC that were addressed during the various elements of laboratory testing and modeling are described in this section.

\subsubsection{Micron-Sized Zero-Valent Iron Testing (Original Scope)}

Laboratory data quality was checked in three ways: (1) data were reviewed as a whole for consistency with reasonable expectations based on general theory, (2) unidentified field duplicates were taken, and (3) laboratory QC data were internally validated. When necessary, appropriate statistical analysis for confidence interval or bias was conducted. An experimental control was also implemented to measure the effects of testing and to monitor influence of the testing equipment.

\subsubsection{Batch Screening Test}

Laboratory data quality was checked as stated in Section 4.4.1.

\subsubsection{Injection Screening Test}

Quality assurance included a review of all relevant laboratory documentation to ensure that procedures were followed and that the results were within acceptable project quality limits. This included a review all planning documents, material specifications, test equipment designs and specifications, personnel qualifications, equipment calibration records, and QC sample results.

Laboratory data quality was checked as stated in Section 4.4.1.

\subsubsection{Screening Geochemical Test}

Quality assurance included a review of all relevant laboratory documentation to ensure that procedures were followed and that the results were within acceptable project quality limits. This included a review of all planning documents, material specifications, test equipment designs and specifications, personnel qualifications, equipment calibration records, and QC sample results.

Laboratory data quality was checked as stated in Section 4.4.1.

\subsubsection{Advanced Geochemical Test}

Laboratory data quality was checked as stated in Section 4.4.1. The field blank results are presented in Appendix C, Section C5.

\subsubsection{Advanced Flow Cell Injection}

Laboratory data quality was checked in three ways: (1) data were reviewed as a whole for consistency with reasonable expectations based on general theory, (2) unidentified field duplicates were taken, and (3) laboratory QC data were internally validated.

A number of anomalies occurred in the laboratory data:

- Influent sample data were not consistent with calculated values based on the manufacturer's data on the iron content of RNIP-M2 and the volume of dilution water used in mixing the influent solution. As shown in the sample data (Appendix C, Section C6), mean influent concentrations appear to be inversely proportional to flow rate. Mean influent sample total iron concentrations for the two lowest flow rates (flow cells \#1 through \#4) were in the 10,000 to $11,000 \mathrm{mg} / \mathrm{L}$ range, while mean concentrations for the next higher flow rate (flow cells \#5 and \#6) were in the 5,000 to $6,000 \mathrm{mg} / \mathrm{L}$ range, and the highest flow rate had a mean concentration of approximately $3,000 \mathrm{mg} / \mathrm{L}$. The cause 
of this apparent relationship is unknown but may reflect bias due to sampling methodology. Additionally, three influent values appear to be unexplained outliers (i.e., the final values for flow cells \#3, \#4, and \#7).

- The mean influent total iron concentration for the control flow cell was $6.5 \mathrm{mg} / \mathrm{L}$. This value and values for a number of samples from flow cell ports during the first four sampling events (times 143 through 714), while small in comparison to ZVI solution concentrations, indicates concentrations greater-than-anticipated background water supply levels. The reason for this circumstance and why it was not noted for the final three sampling events is unknown, but it may reflect bias due to the sample preservation equipment (e.g., the pipette used for nitric acid contained a metal component).

- Very high total iron concentrations were reported for late time samples from Port A in flow cells \#3 and \#4 and for all ports for the flow cells with the two highest flow rates, as well as effluent (particularly for the highest flow rate). The variation evident in these results was not always consistent (e.g., the sequence of results for the last three samples from Port A of flow cell \#8 of $23,300 \mathrm{mg} / \mathrm{L}$, to $10,600 \mathrm{mg} / \mathrm{L}$, to $55,000 \mathrm{mg} / \mathrm{L}$ ). Consequently, the ZVI results for flow cell \#8 for the 1,641-minute elapsed time were not used in MLR statistics to determine the ZVI mass deposition function.

With regard to field duplicate fluid samples (identified by the initials "DL" after the sample number), reported iron concentrations in the duplicates were, in most cases, reasonably close to those of the original samples. With two exceptions, RPDs were around 6 percent or less (Table 4-18), and these exceptions involved high-concentration effluent samples from flow cells \#6 and \#8 with RPDs of approximately 27 percent and 31 percent, respectively. The reason for such high RPDs when low RPDs were achieved for two other relatively high-concentration samples is unknown. It may be a function of the necessarily sequential nature of these duplicate samples and high variability in effluent quality under highconcentration conditions. In any case, it raises concern with regard to how representative highconcentration sample results may be in this case.

An internal validation of laboratory QC data was performed, which resulted in no flags or data qualifiers being specified. Copies of data validation review summary sheets for each laboratory work order number are provided in Appendix C, Section C6. A number of comments were noted on summary sheets, including elevated preparation blanks (still significantly above sample concentrations) and matrix spike/matrix spike duplicates that were often unusable because sample concentrations were much greater than the spike. For various reasons, some sample results were "J" coded to indicate that results should only be considered estimates because QC requirements were not met. In total, 71 of 483 samples (15 percent) were "J" coded:

- Work order \#0803223: Sample 001A was "J" coded because it was above the linear dynamic range. This test sample was run to check preservation and digestion procedures.

- Work order \#0804059:

- Sample 048A was "J" coded as "estimated low" because a low result outside control limits was obtained for a continuing calibration verification sample (sample 10D-5-E-186). However, the actual result reported for that sample is consistent with expectations based on data for that flow cell run and, in fact, is identical to the value for sample 10D-6-E-186 in the duplicate flow rate flow cell. 
- Samples 001A through 024A were "J" coded because the first serial dilution was out of limits. These 24 samples are early timeframe samples from flow cells \#5 and \#6 (times 62 and 124 minutes).

- Samples 073A through 096A were "J" coded because the third serial dilution was out of limits. These 24 samples are early time frame samples from flow cells \#1 and \#2 (times 328 and 656).

- Work order \#0804085: Samples 159A through 180A were "J" coded because serial dilution was out of limits at 13.0 percent. These 22 samples are mid-time frame samples from flow cells \#3, \#4, \#7, and \#8 (times 984).

Table 4-18. Duplicate Sample Results

\begin{tabular}{l|c|c|c|c}
\hline $\begin{array}{c}\text { Sample } \\
\text { ID }\end{array}$ & $\begin{array}{c}\text { Sample } \\
\text { Location }\end{array}$ & $\begin{array}{c}\text { Sample } \\
\text { Result }\end{array}$ & $\begin{array}{c}\text { Duplicate } \\
\text { Result }\end{array}$ & $\begin{array}{c}\% \\
\text { RPD }\end{array}$ \\
\hline $10 \mathrm{D}-0-\mathrm{F}-1641$ & Effluent & 0.78 & 0.833 & -6.57 \\
\hline $10 \mathrm{D}-1-\mathrm{F}-1641$ & Effluent & 125. & 117. & 6.61 \\
\hline $10 \mathrm{D}-2-\mathrm{F}-1641$ & Effluent & 117. & 125. & -6.61 \\
\hline $10 \mathrm{D}-3-\mathrm{F}-1641$ & Effluent & 62.9 & 62.7 & 0.32 \\
\hline $10 \mathrm{D}-4-\mathrm{F}-1641$ & Effluent & 67.3 & 67.1 & 0.30 \\
\hline $10 \mathrm{D}-5-\mathrm{F}-984$ & Effluent & 113. & 112 & 0.89 \\
\hline $10 \mathrm{D}-6-F-984$ & Effluent & 99.7 & 101 & -1.30 \\
\hline $10 \mathrm{D}-5-\mathrm{F}-1641$ & Effluent & 935. & 859 & 8.47 \\
\hline $10 \mathrm{D}-6-F-1641$ & Effluent & 6,470 & 8,470 & -26.77 \\
\hline $10 \mathrm{D}-7-F-1312$ & Effluent & 668 & 666 & 0.30 \\
\hline $10 \mathrm{D}-8-F-1312$ & Effluent & 3,280 & 3,320 & -1.21 \\
\hline $10 \mathrm{D}-7-F-1641$ & Effluent & 23,600 & 24,200 & -2.51 \\
\hline $10 \mathrm{D}-8-F-1641$ & Effluent & 28,300 & 20,700 & 31.02 \\
\hline
\end{tabular}

ID = identification

$\mathrm{RPD}=$ relative percent difference

With regard to analytical data quality, there was considerable variability in sample results, due in part to the complexity of the matrix and sampling methods, but also as a function of laboratory data quality. Nevertheless, analytical results are considered to be generally useful for their intended purpose.

However, considering all of these factors, there is uncertainty regarding the relatively high-concentration results. This has the most potential to impact results based on late run time data for flow cells \#5 through \#8.

\subsection{Costs and Schedule}

For the purposes of this report, the laboratory testing effort is considered to be workscope associated with Tasks 1 through 5 of the original contract and Task \#10 of the revised contract, subject to Change Order CTC-002, dated May 24, 2007. 


\subsubsection{Cost}

The original laboratory effort (Task 1 through Task 5) was planned at a fixed price cost of was $\$ 183,290$. Minor change orders eventually increased the cost to \$185,794. After determining that the MicroPowder S-3700 iron would not perform adequately, the screening, evaluation, and selection of an alternative iron were funded through a time-and-materials contract modification covered under the new Task 10 (see Table 2-2). The total cost for Task 10 activities as of October 30,2008 , was approximately $\$ 575,810$; therefore, the total cost assigned to laboratory testing is approximately $\$ 761,603$.

\subsubsection{Schedule}

The original schedule for Task 1 through Task 5 involved startup on December 5, 2006, and completion by May 18,2007 . Change orders and contract modifications eventually extended the schedule for Tasks 1 through 5 and Task 10 to October 15, 2008.

Figure 4-65 presents the cumulative costs and schedule for each of the tasks considered to be part of the laboratory testing.

\subsection{Key Contacts - Treatability Test (Laboratory Testing and Modeling)}

Key contacts involved with the nZVI project are listed in Table 4-19. 


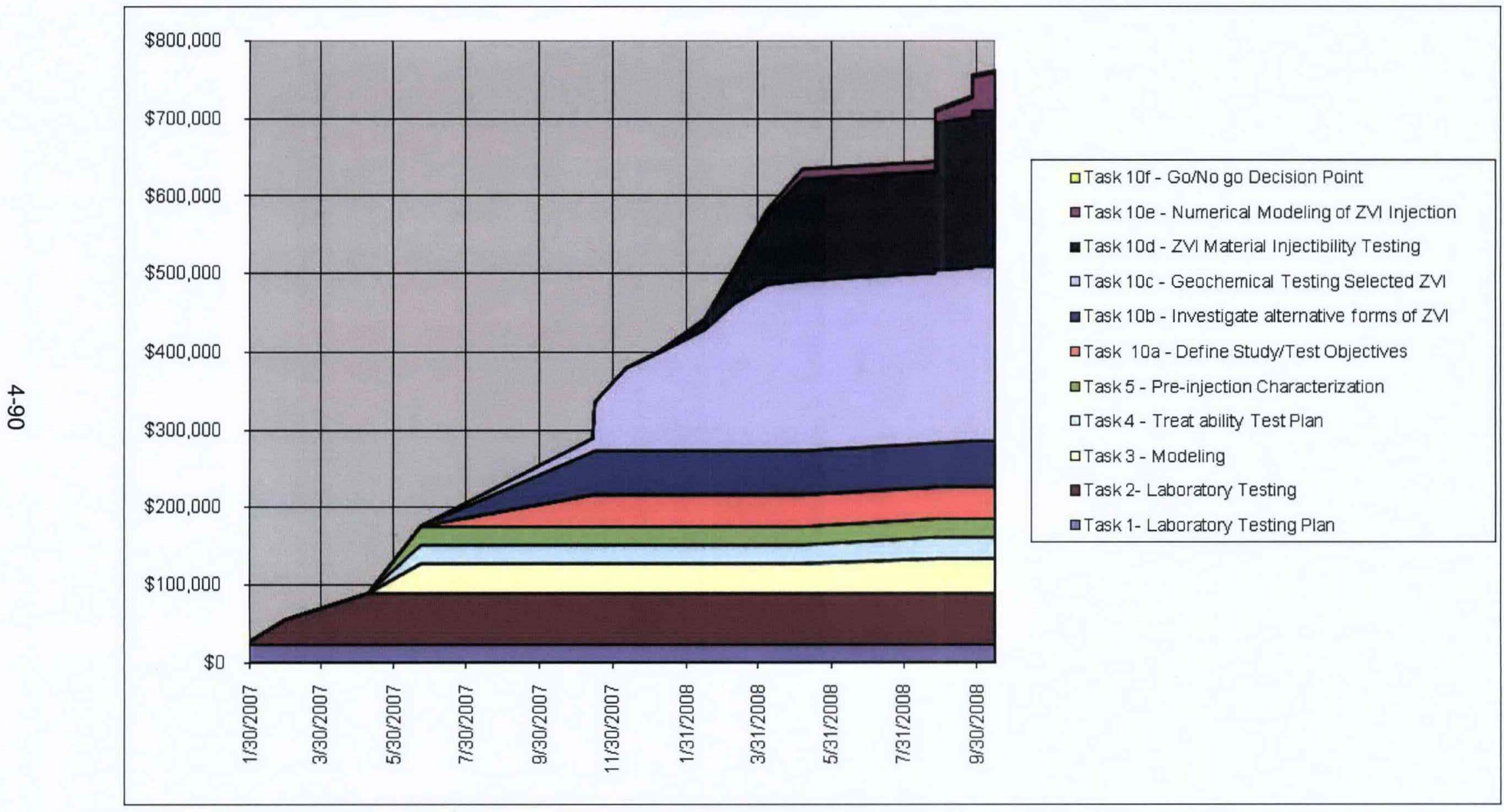

Figure 4-65. Laboratory Testing Cumulative Cost and Schedule 
DOE/RL-2009-35, REV. 0

Table 4-19. Nano-Sized Zero-Valent Iron Injection Project Personnel

\begin{tabular}{|c|c|c|c|}
\hline Name & Mail Address & Phone, Fax, Cell, and E-mail & $\begin{array}{c}\text { Roles/ } \\
\text { Responsibilities }\end{array}$ \\
\hline \multicolumn{4}{|c|}{ Hanford Site Management } \\
\hline \multirow[t]{2}{*}{ Scott Petersen } & \multirow{2}{*}{$\begin{array}{l}\text { P.O. Box } 1000 \\
\text { Richland, WA } 99352 \\
\text { Mail Stop E6-35 }\end{array}$} & Office: $509-372-9126$ & \multirow{2}{*}{$\begin{array}{l}\text { CH2MHILL Plateau } \\
\text { Remediation Company } \\
\text { Technical } \\
\text { Representative }\end{array}$} \\
\hline & & E-mail: Scott_W_Petersen@rl.gov & \\
\hline \multicolumn{4}{|c|}{ MSE Technology Applications, Inc. Management and Personnel } \\
\hline \multirow[t]{2}{*}{ Steve Antonioli } & \multirow[t]{2}{*}{$\begin{array}{l}200 \text { Technology Way } \\
\text { P.O. Box } 4078 \\
\text { Butte, MT } 59701\end{array}$} & \multirow{2}{*}{$\begin{array}{l}\text { Office: } 406-494-7343 \\
\text { Fax: 406-494-7230 } \\
\text { E-mail: steve.antonioli@mse-ta.com }\end{array}$} & \multirow{2}{*}{$\begin{array}{l}\text { MSE Project } \\
\text { Manager/Quality } \\
\text { Assurance Manager } \\
\text { Track schedule and } \\
\text { budget; ensure that } \\
\text { project documentation } \\
\text { (weekly/monthly } \\
\text { reports) is completed } \\
\text { and milestones are me }\end{array}$} \\
\hline & & & \\
\hline \multicolumn{4}{|c|}{ US Department of Energy } \\
\hline \multirow[t]{3}{*}{ Mike Thompson } & \multirow{3}{*}{$\begin{array}{l}825 \text { Jadwin Ave. } \\
\text { Richland, WA } 99352\end{array}$} & Office: $509-373-0735$ & \multirow{3}{*}{$\begin{array}{l}\text { DOE Project } \\
\text { Representative }\end{array}$} \\
\hline & & Fax: $509-372-1926$ & \\
\hline & & E-mail : k_m_mike_thompson@rl.gov & \\
\hline
\end{tabular}


DOE/RL-2009-35, REV. 0

This page intentionally left blank. 


\section{Treatability Study Approach, Field Injection}

The treatability study objective and the criteria used to determine if the objective was met are described in this chapter. A separate sampling and analysis plan (SAP), the DOE/RL-2008-49, Treatability Test Plan for Injecting Zero-Valent Iron Into an In Situ Redox Manipulation Well was prepared. The SAP includes the data quality objectives for the treatability study, as well as the samples and analytical methods for evaluating the performance criteria. A discussion of the test data evaluation is also included in this chapter.

\subsection{Test Objectives and Rationale}

The treatability study objectives are as follows:

- Demonstrate that a sufficient amount of nZVI can be injected into zones within the ISRM barrier that have prematurely lost some of their treatment capacity to re-establish reducing conditions.

- Demonstrate that $\mathrm{nZVI}$ can be communicated into the aquifer up to $7 \mathrm{~m}(23 \mathrm{ft})$ away from the injection well.

- Demonstrate that $\mathrm{nZVI}$ injection will not adversely affect groundwater in downgradient compliance wells or the Columbia River.

- Address the regulatory objectives, which are to aid in the implementation of the remedy selected in the interim Record of Decision (ROD) amendment and to aid in selecting a remedy for the final ROD.

\subsubsection{Estimated Zero-Valent Iron Required to Achieve Test Objective}

The estimated extent and volume of ZVI that must be injected into the aquifer is a $7 \mathrm{~m}(23-\mathrm{ft})$ injection radius of $0.10 \mathrm{wt} \%$ concentration of $Z \mathrm{VI}$ around the injection point. This estimate is taken from calculations presented in PNNL-15499 and the geochemical evaluation of RNIP-M2 performed by the subcontractor. In PNNL-15499, it is indicated that the average reductive capacity of $11.2 \mu \mathrm{mol} \mathrm{Fe} e^{2+} / \mathrm{g}$, or $0.06 \mathrm{wt} \%$, would have a reductive capacity of 9.6 years or $88 \mathrm{PVs}$, assuming a single homogenously reduced aquifer. In the geochemical evaluation of RNIP-M2, columns amended with $0.15 \mathrm{wt} \% \mathrm{RNIP}-\mathrm{M} 2$ effectively reduced surrogate groundwater for $40 \mathrm{PVs}$ without breakthrough. Therefore, the goal of this field injection test was to emplace ZVI at a concentration of $0.10 \mathrm{wt} \%$ into the formation at least $7 \mathrm{~m}$ $(23 \mathrm{ft})$ from the injection well.

\subsubsection{Technology Performance Criteria}

The technology performance criteria include the following:

- Presence of $\mathrm{nZVI}$ at a concentration of up to $0.10 \mathrm{wt} \%$ at a $7 \mathrm{~m}(23-\mathrm{ft})$ radius around the injection point

- Creation of a reducing environment within the $7 \mathrm{~m}(23-\mathrm{ft})$ zone surrounding the injection point, especially within the high-permeability region

- Reduction of hexavalent chromium within the influence of the iron injection

- No adverse groundwater quality effects as the result of the nZVI injection that would impact human or environmental receptors

- No significant loss of permeability in the aquifer. 


\subsubsection{Reduction of Chromium}

The principle performance criterion for reducing hexavalent chromium is to achieve the RAO of $20 \mu \mathrm{g} / \mathrm{L}$ or less in the four wells surrounding the injection well. A secondary criterion is to achieve the RAO in the nearest downgradient monitoring well outside the presumed radius of the influence of injection (well 199-D4-38). This well is $64 \mathrm{~m}(210 \mathrm{ft})$ to the northwest of the injection well, and groundwater from the barrier would take over a year to reach it under natural flow conditions, as shown by monitoring results after emplacement of the ISRM barrier. Therefore, well 199-D4-38 is not suitable for evaluating performance in the near term.

\subsubsection{Reduction of Nitrate to Nitrite and Ammonia}

The geochemical environment resulting from injection of nZVI into the aquifer might be expected to reduce some of the nitrate present in the groundwater to nitrite and ammonia. Nitrate reduction was observed during the geochemical column tests. The surrogate water used in the geochemical column tests contained $14 \mathrm{mg} / \mathrm{L}$ nitrate as nitrogen. The geochemical column tests using Ringold soil impregnated with $0.15 \mathrm{wt} \%$ RNIP (the RNIP-M2 concentration used in the treatability test) showed that nitrate was reduced approximately 25 percent, with the greatest reduction occurring around $25 \mathrm{PVs}$. At this point, about 70 percent of the nitrate was reduced, primarily to nitrite. Ammonia was present in the effluent at less than 14 percent of the influent nitrate for the majority of the test. The highest ammonia concentrations were seen early (prior to $20 \mathrm{PVs}$ ), with the peak conversion of about 25 percent of the nitrate occurring between 10 and 20 PVs.

The maximum contaminant level (MCL) for nitrite (as nitrogen) is $1 \mathrm{mg} / \mathrm{L}$; there is no MCL for ammonia. Nitrite (as nitrogen) concentrations obtained during column testing on $0.15 \mathrm{wt} \% \mathrm{RNIP}-\mathrm{M} 2$ rose to as high as $4.3 \mathrm{mg} / \mathrm{L}$ in the effluent at approximately $25 \mathrm{PVs}$, dropping to between 1 and $2 \mathrm{mg} / \mathrm{L}$ after 40 PVs. Ammonia (as nitrogen) increased in the same column to values similar to nitrate, but these data are questionable because of correspondingly high concentrations in the control columns. Based on the experimental results, the performance criterion for nitrite and ammonia will be $\leq 5 \mathrm{mg} / \mathrm{L}$.

\subsubsection{Aquifer Permeability Reduction}

Reduced permeability due to carbonate was monitored during laboratory geochemical testing by measuring alkalinity (as $\mathrm{CaCO}_{3}$ ), monitoring $\mathrm{pH}$, measuring hydraulic head and pressure, and visually inspecting the soil samples following injection. Alkalinity concentrations measured in the effluents from columns containing $0.15 \mathrm{wt} \% \mathrm{RNIP}-\mathrm{M} 2$ were similar to the control columns; $\mathrm{pH}$ increased approximately one unit over that measured from the control columns. Injection pressures increased only slightly at the beginning of injection testing and attenuated over time. Visual examination of the flow cell contents after testing did not identify calcium or other precipitants in the matrix. The experimental data indicated that any reduction in permeability due to the influence of $\mathrm{nZVI}$ injection would be minimal. The performance criterion will be $\leq 20$ percent reduction of hydraulic conductivity, as measured in the injection well by a pumping test after iron injection and compared to development data collected after the injection well was installed.

\subsubsection{Data Assessment and Treatability Test Evaluation}

At the conclusion of the treatability test, test data were compiled from electronic recordings, field operation logs, laboratory reports, and operator notes. The evaluation report discusses the results of treatability test against the following seven criteria identified in EPA/540/R-92/071a, Guidance for Conducting Treatability Studies Under CERCLA - Final: 
10. 1. Overall protection of human health and the environment.

11. 2. Compliance with applicable or relevant and appropriate requirements (ARARs).

12. 3. Long-term effectiveness and permanence.

13. 4. Reduction of toxicity, mobility, and volume through treatment.

14. 5. Short-term effectiveness.

15. 6. Implementability.

16. 7. Cost.

A brief description of each criterion in relation to this treatability study is presented in the following subsections.

\subsubsection{Overall Protection of Human Health and the Environment}

The results of this study will be evaluated to assess how injection of nZVI achieves overall protection of human health and environment. The focus will be on reducing or eliminating overall site risks, primarily the in situ reduction of hexavalent chromium concentrations in the groundwater and the evaluation of physical and/or chemical effects of the injection on groundwater and aquifer, as measured in the iron injection well and the surrounding area affected by nZVI injection. Successful implementation of the technology includes reducing hexavalent chromium in and immediately surrounding the injection well to less than the RAO of $20 \mu \mathrm{g} / \mathrm{L}$, as defined interim ROD (U.S. Environmental Protection Agency et al. 1999).

\subsubsection{Compliance with Applicable or Relevant and Appropriate Requirements}

This criterion focuses on the ability of iron injection to meet specific ARARs. The primary ARAR for this site will be the reduction of hexavalent chromium in and immediately surrounding the injection well to less than the RAO of $20 \mu \mathrm{g} / \mathrm{L}$, as defined by the interim ROD (U.S. Environmental Protection Agency et al. 1999).

\subsubsection{Long-Term Effectiveness and Permanence}

This criterion focuses on the long-term effectiveness and permanence of iron injection to meet the remediation objectives of reducing hexavalent chromium concentrations in groundwater. Laboratory tests indicate that a $0.5 \mathrm{~m}(1.6-\mathrm{ft})$ radius of $\mathrm{ZVI}$ in the aquifer will reduce chromium for more than 7 years. Thus, injecting a $7 \mathrm{~m}$ (23-ft) radius would equate to over 100 years of effectiveness in treating groundwater under natural aquifer flow conditions. Heterogeneities in the aquifer add a large margin of uncertainty to this estimate, as do scaling issues related to laboratory tests versus field deployment. The primary focus will be on the ability of this a portion of the iron-amended ISRM barrier to meet the RAO of $<20 \mu \mathrm{g} / \mathrm{L}$. This will be determined by monitoring well 199-D4-92 (located $5 \mathrm{~m}$ [16.4 ft] upgradient of

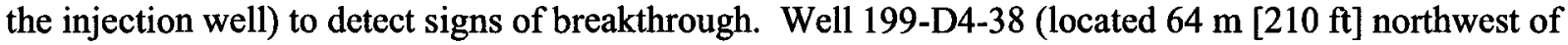
the injection well) and other nearby wells will also be monitored monthly to determine the effects of the injection. The ISRM barrier wells surrounding the injection well will continue to be monitored monthly in accordance with the DOE/RL-2003-63, Sampling and Analysis Plan for In Situ Redox Manipulation Project to evaluate longevity of the influenced area. 


\subsubsection{Reduction of Toxicity, Mobility, and Volume Through Treatment}

This criterion focuses on the ability of iron injection to meet the performance objective of reducing hexavalent chromium concentrations in the groundwater in the portion of the aquifer influenced by the injection, without adversely affecting groundwater chemistry.

\subsubsection{Short-Term Effectiveness}

Short-term effectiveness focuses on protection of the environment and workers during operation of the treatment system. The RNIP-M2 nZVI is not considered a hazardous waste and will be suspended in an aqueous solution; thus, it will not be a respiratory hazard.

\subsubsection{Implementability}

The implementability criterion focuses on the overall maturity and reliability of the remediation technology. Successful contact of nZVI at $7 \mathrm{~m}(23 \mathrm{ft}$ ) away from the injection well (which would form an overlapping treatment zone when the technology is deployed in neighboring wells) will be the key factor considered when evaluating this criterion. Another factor is the availability of large quantities of nZVI material.

\subsubsection{Cost}

Evaluation of costs will include discussion of capital and tests costs. Overall cost will be evaluated on a cost-per-well basis and will include a comparison with injection of a liquid reductant (e.g., sodium dithionite).

\subsection{Experimental Design and Procedures}

This section discusses the design and procedures for emplacing the nZVI into the high-permeability zone of the Ringold Formation.

\subsubsection{Description of Injection Schemes}

Emplacement of the nZVI into the Ringold Formation will be accomplished by injecting iron slurry into a single injection well and monitoring four nearby wells for water-quality parameters and fluid levels. Injection testing will be performed in well 199-D4-26. A single packer system will be lowered down the well and set approximately $1.5 \mathrm{~m}(5 \mathrm{ft})$ above the well screen to allow higher injection pressures, if required. The well construction (specifically the sand pack) precludes the use of a two-packer system because the nZVI slurry would move through the sand pack, effectively short-circuiting the interval between the packers.

The iron slurry injection system will be designed to accommodate a wide range of flow rates and pressures. Actual flow rates will depend on subsurface conditions and results from numeric modeling. Effective delivery of $\mathrm{nZVI}$ may be possible by gravity flow alone; however, a variable-rate pulsed pumping scheme may be necessary to effectively deliver $\mathrm{nZVI}$ a distance of $7 \mathrm{~m}(23 \mathrm{ft})$ from the injection well.

Monitoring in the four surrounding wells at each injection location will help indicate flow patterns in the subsurface. Monitoring will consist of measuring fluid levels and water quality parameters, which will be monitored throughout the injection period to provide feedback on the status and effectiveness of the injection. 


\subsubsection{Nano-Sized Zero-Valent Iron Slurry to Be Tested}

Based on laboratory geochemical and injection testing, RNIP-M2 was determined to be the best candidate for field-scale injection at the 100-D Area. RNIP-M2 is shipped as slurry containing approximately $18 \mathrm{wt} \%$ solids. Water is then added to slurry to dilute it to approximately $1 \mathrm{wt} \%$ solids, which is the preferred injection concentration. The rationale for determining the amount of nZVI required for the field injection is described in the following subsections.

\subsubsection{Basis of Estimated Volume of Nano-Sized Zero-Valent Iron}

The volume of $\mathrm{nZVI}$ slurry needed to complete an injection was estimated based on measurements obtained on well 199-D4-26 using an EBF. A summary of this technology and results from testing are discussed in this subsection.

The EBF measures the vertical distribution of the horizontal flow into or out of a well, and it provides a relative measure of vertical distribution in hydraulic conductivity. The EBF measures flow using Faraday's Law of Induction, which states that the voltage induced by a conductor moving at right angles through a magnetic field is directly proportional to the velocity of the conductor through the field. The conductor is the water flowing through the probe, which generates a magnetic field, inducing a voltage in electrodes within the probe, which are directly proportional to the velocity of the water flowing through the probe. This method of velocity measurement provides a virtually instantaneous gauge of flow rate changes.

When operating the EBF, ambient flow is usually recorded throughout the screened interval of the well first. This is typically performed with the flow meter at the bottom of the screen, where vertical flow rates should be zero. The probe is then raised one increment of depth. After any flow disturbance caused by the probe movement has subsided, the vertical flow at that depth increment is recorded. This process is repeated throughout the entire screened portion of the well. After the ambient flow profile is performed, flow is induced in the well by either pumping from or injecting into the well at a constant rate. When equilibrium is achieved (as evidenced by a steady water level in the well), the probe is then moved up the well at pre-determined depth intervals throughout the screened portion of the well. After the data are collected at the target depth intervals, the lateral inflow from each interval is calculated by successively subtracting the cumulative flow measured at each depth interval from the cumulative flow recorded at the level immediately below. These measurements allow for determining relative values of hydraulic conductivity for each strata.

The EBF testing to support this treatability test plan was performed in 2007 (PNNL-18218). Measurements were conducted at $0.3 \mathrm{~m}$ (1-ft) intervals in wells 199-D4-26 and 199-D4-37, which are $168 \mathrm{~m}(551.2 \mathrm{ft})$ apart. Figures 5-1 and 5-2 show that there are significant differences in the vertical profile of relative hydraulic conductivity between the wells. This would be expected based on the known heterogeneities in the aquifer at Hanford's 100 Areas. The maximum relative hydraulic conductivity in well 199-D4-26 is in the lower foot of the screened portion of the well, while the maximum relative

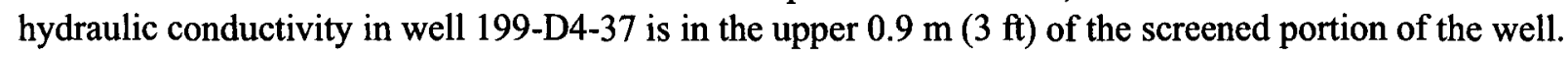
The amount of the ZVI injected into a given stratum during field testing should be proportional the hydraulic conductivity of that interval.

Because strata of high hydraulic conductivity in well 199-D4-37 are present just below the water table, there is the risk that injected ZVI could be "stranded" in an interval that becomes unsaturated during low groundwater stages. This would be expected to accelerate oxidation of the nZVI. Based on these data, well 199-D4-26 was chosen for the iron injection test to maximize the effect and longevity of the iron injection. 
DOE/RL-2009-35, REV. 0

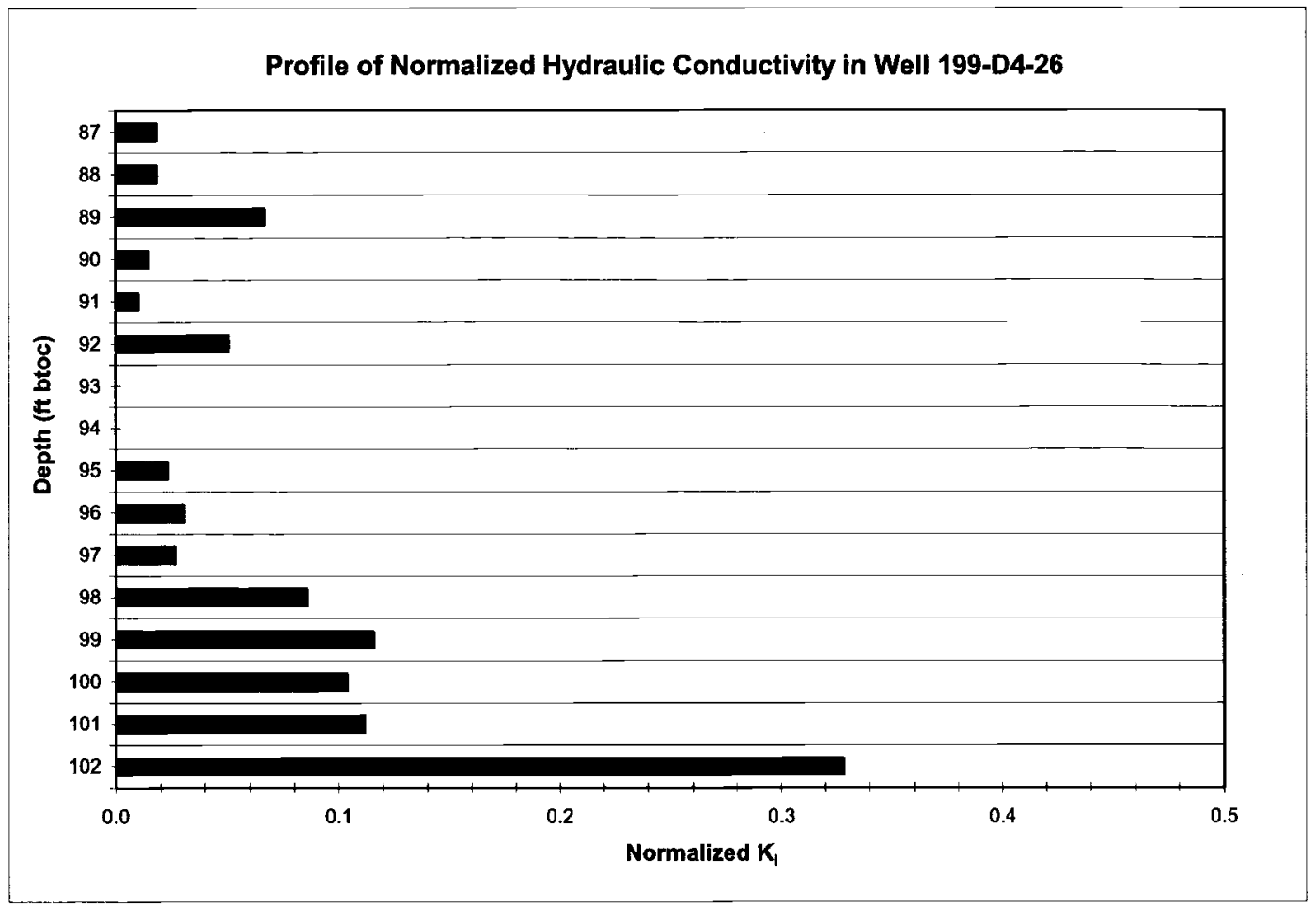

Figure 5-1. Hydraulic Conductivity Profile for Well 199-D4-26

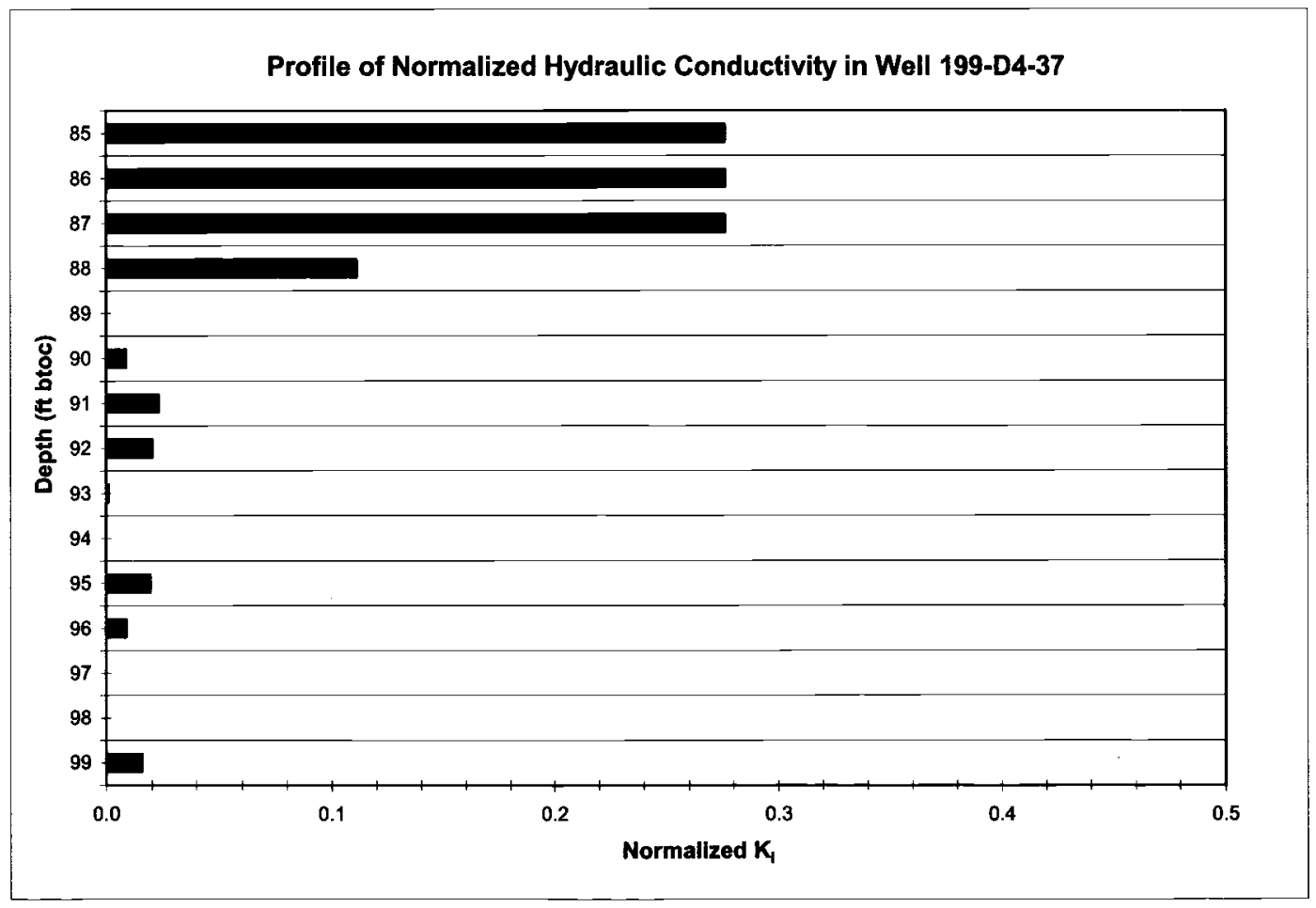

Figure 5-2. Hydraulic Conductivity Profile for Well 199-D4-37 


\subsubsection{Estimated Mass of Zero-Valent Iron to Be Injected for Treatability Test}

The mass of ZVI needed was calculated by targeting the bottom $1 \mathrm{~m}(3.3-\mathrm{ft})$ interval for injection. An estimate of aquifer mass was calculated based on a cylinder with a radius of $7 \mathrm{~m}(23 \mathrm{ft})$ and a height of $1 \mathrm{~m}(3.3 \mathrm{ft})$, and a bulk soil density estimate of $2,700 \mathrm{~kg} / \mathrm{m}^{3}$. The mass of iron required to create an effective treatment zone was estimated based on a required emplaced concentration of $0.7 \mathrm{wt} \%$ of the soil mass, resulting in $2,396 \mathrm{~kg}$ of ZVI required. The RNIP-M2 as delivered contains $18 \mathrm{wt} \%$ solids, of which 65 percent is $\mathrm{nZVI}$ (according to the manufacturer). Therefore, the mass of injected slurry required is determined to be $20,480 \mathrm{~kg}$. Furthermore, if the RNIP-M2 slurry is to be injected at a $1 \mathrm{wt} \%$ solids concentration, then $351,573 \mathrm{~kg}(352,077 \mathrm{~L}$ [93,009 gal]) of water is required to dilute RNIP-M2 slurry and treat the high-permeability zones in the ISRM aquifer around well 199-D4-26.

\subsubsection{Methods Used to Prepare and Inject the Iron Slurry}

Preparation of the iron slurry will follow a well-defined procedure to ensure that the liquid injected meets the proper design criteria. In addition, sufficient quantities of the iron slurry will be prepared beforehand, allowing uninterrupted injection of the slurry into the subsurface. An estimated 368,680 L (97,395 gal) of $1 \mathrm{wt} \%$ RNIP-M2 slurry will be required for injection. For the preparation and mixing of the iron slurry, two 24,600 L (6,500-gal) mixing tanks will be used. Once prepared, one batch of solution can be injected while the second batch recirculates in the tank using a dedicated pump. The formula for mixing a standard batch of injection solution is shown in Table 5-1; batches smaller than $22,712 \mathrm{~L}(6,000$ gal) may be prepared by mixing equal fractions of water and slurry.

Table 5-1. Components Required for Each Batch

\begin{tabular}{lccc}
\hline $\begin{array}{c}\text { Injection Slurry } \\
\text { Component }\end{array}$ & $\begin{array}{c}\text { Concentration } \\
\text { Delivered }\end{array}$ & $\begin{array}{c}\text { Mass } \\
\text { to Add }\end{array}$ \\
\hline Water & $100 \%$ & $21,658 \mathrm{~kg}^{*}$ \\
RNIP-M2 slurry & $18 \%$ & $1,261.7 \mathrm{~kg}$ \\
\hline
\end{tabular}

NOTE: RNIP-M2 is a trademark of Toda Kogyo Corporation, Hiroshima, Japan.

* Assuming density of water $=1 \mathrm{~kg} / \mathrm{L}$.

To avoid de-agglomeration of nano-sized particles, the iron slurry will be circulated through an HSM immediately before injection. Data sheets will be prepared for each batch of slurry, during both the mixing and injection phases. The procedure outlined below will be used when preparing a standard batch of injection solution, assuming that the density of water is $1 \mathrm{~kg} / \mathrm{L}$, the RNIP-M2 solution is delivered as $18 \mathrm{wt} \%$ solids, and the HSM flow rate is $340.7 \mathrm{~L} / \mathrm{min}(90 \mathrm{gpm})$ :

1. Displace the oxygen from the injection tank using nitrogen:

a. Monitor oxygen level through monitoring port and oxygen meter.

b. Displace oxygen level to below 5 percent oxygen.

2. Add 4,227.9 L (1,116.9 gal) of dilution water to injection tank:

a. Added from water supply line.

b. Quantified using totalizer assuming density of water $=1 \mathrm{~kg} / \mathrm{L}$. 
3. Start circulation pump:

a. Start circulation pump

b. Monitor oxygen level and adjust nitrogen flow as necessary.

4. Add $1,261.7 \mathrm{~kg}$ of RNIP-M2 slurry:

a. Record the weight of the shipping barrel containing RNIP-M2 slurry and the vendor-provided weight of material.

b. After the shipping container has been opened, mix the ZVI slurry with a hand-paddle mixer to resuspend any settled RNIP-M2 particles.

c. Pump the RNIP-M2 slurry from the shipping barrel into the ZVI mixing tank using the enginedriven transfer pump.

d. Re-weigh the shipping barrel to document the mass of RNIP-M2 slurry added to the ZVI mixture.

e. Continue to transfer RNIP-M2 slurry into the ZVI mixing tank until the desired mass of RNIP-M2 particles, using the vendor-specified percent solids for the slurry, has been transferred.

f. As a QA/QC check, the ZVI mixing tanks will be graduated to reference the volume of RNIP-M2 slurry added using the vendor-specified specific gravity of the slurry.

5. Maintain oxygen level in tank below 5 percent:

a. Monitor oxygen level through monitoring port and oxygen meter.

b. Use the regulator to adjust the nitrogen flow to the injection tank.

6. Let solution mix for 2.3 hours:

a. Recirculation pump running at a flow rate adequate to produce turbulence in the system.

7. 7. Add remaining $17,399.3 \mathrm{~L}(4,596.4 \mathrm{gal})$ of dilution water to bring the solution to 1 percent solids:

a. Added from water supply line.

b. Quantified using totalizer assuming density of water $=1 \mathrm{~kg} / \mathrm{L}$.

8. Let solution mix for 2 to 3 hours:

a. Recirculation pump running at a flow rate adequate to produce turbulence in the system.

\subsubsection{Water}

In order to ensure proper iron slurry mixing, the water directed to the mixing tanks will be metered using two calibrated flow meters/totalizers to measure the desired volume to within 1 percent of the target volume. The raw water supply is limited to a $5.1 \mathrm{~cm}(2-\mathrm{in}),. 189.3 \mathrm{~L} / \mathrm{min}(50-\mathrm{gpm})$ line; therefore, the flow meters will be capable of measuring flows from 0 to $189.3 \mathrm{~L} / \mathrm{min}(50 \mathrm{gpm})( \pm 1$ percent $)$ full-scale reading within a $2.5 \mathrm{~cm}$ (1-in.) pipe with a repeatability of \pm 0.25 percent. In the event that the readings from the two flow meters/totalizers are not identical, the average of the two readings will be used for the volumetric calculations. The volume of water will then be converted to a weight for calculating the amount of nZVI, taking into account the water temperature and adjusting for density. 


\subsubsection{Conceptual Design for the Injection}

Injection of the iron slurry will be accomplished by maintaining a constant supply of the slurry in mixing tanks, which will be passed through the HSM during the injection process. A separate auxiliary pump will be plumbed into the injection system in case higher injection pressures are required. A $15.2 \mathrm{~cm}$ (6-in.) packer system connected to a $3.8 \mathrm{~cm}(1.5$-in.) inside-diameter downcomer will be positioned in the well approximately $1.5 \mathrm{~m}(5 \mathrm{ft})$ above the well screen prior to the start of injection. The packer system will allow controlled pressure injection of the iron slurry into the formation through the downcomer passing through the center of the packer, allowing the iron slurry to be pumped under higher pressures into the screened portion of the well.

Controls and equipment for injecting the iron slurry into the wells will allow a wide range of flow rates and injection pressures. Injection strategies will be developed with input from the results of the computer modeling effort and EBF pre-injection characterization data. The injection equipment will be designed to pump up to $189.3 \mathrm{~L} / \mathrm{min}(50 \mathrm{gpm})$ at an injection pressure of $80 \mathrm{psi}$, allowing injection at relatively high rates if necessary. Hydrofracing is not expected to be a problem at these pressures based on a general relationship of $1 \mathrm{psi} / \mathrm{ft}$ of soil column, which suggests that pressures in excess of 85 psi would be required to hydrofrac the soil. Conversely, the delivery system will be capable of injecting at much slower rates and lower pressures as conditions warrant.

Once pumping of the iron slurry into the well begins, injection operations will not end until the design volume $(368,680.2 \mathrm{~L}$ [97,395 gal]) has been emplaced into the formation. Injection monitoring will consist of an in-line flow/totalizer to monitor flow rates and the total gallons injected. Pressure will be monitored by pressure gauges mounted on the line leading to the injection well and a pressure transducer placed down-hole below the packer. An in-line valve will be used to provide fine adjustment of the flow rate.

During the injection operation, a logbook will be maintained to document the flow rates, injection pressures, and pump settings. Readings will be recorded three times per hour, or as necessary during changing conditions or changes in flow rate.

\subsubsection{Monitoring During Injection}

Monitoring will be performed during ZVI injection activities to provide field personnel with data to ensure that the transmission and emplacement of ZVI are occurring as planned. The monitoring program will consist of both manual and automated measurements to support ongoing decisions that occur in the field and to provide documentation that injection is being performed in accordance with the plan. The following subsections detail the monitoring activities, QA checks, and procedures that will be used during the injection activities.

\subsubsection{RNIP-M2 Slurry Mixing}

To maintain the proper iron slurry mixture during mixing and injection, each batch of iron slurry will be periodically measured for specific conductivity and correlated to actual ZVI concentrations. During laboratory testing, measurements of specific conductivity were shown to provide good indication of the presence of the RNIP-M2 iron slurry. For example, plant tap water moving through the monitoring wells during the large-scale tank test had an specific conductivity of $175 \mu \mathrm{S} / \mathrm{cm}$ and increased to $959 \mu \mathrm{S} / \mathrm{cm}$ when the ZVI front passed through the well. Specific conductivity measurements during mixing will be compared to the laboratory standard readings (after corrections for differences in feedwater conductance), and will be recorded on data sheets. Deviation from the laboratory standard readings will indicate that the iron slurry mixture may not be correct, and the batching procedure for the mixture in question will be reviewed. Additional data will need to be gathered once in the field to measure the onsite water source 
for specific conductivity and the influence of adding various concentrations of RNIP-M2 slurry on the specific conductivity.

If, during the execution of any of above-referenced QA testing methods, a better procedure is discovered that is more efficient and/or cost effective, and produce the desired quality and results, the new procedure shall be documented, approved, and implemented.

\subsubsection{Injection Rates, Pressures, and Times}

Throughout injection operations, operations personnel will record injection flow rates, injection pressures, and the time that the readings were taken in the injection logbook. In addition, a pressure transducer will be installed with a 30-psi rating through the well packer to monitor injection pressures and temperatures in the screened section of the injection well. The transducer will be connected to a laptop computer to continuously monitor down-hole pressures and temperatures. Corrections of the pressure readings will be made, taking into account the specific gravity of the nZVI mixture being injected into the well. All instruments will be calibrated prior to injection and will be checked following completion of the injection. Based on a review of the ISRM injection and recovery records, the injection well will be monitored for a period of 24 hours after injection is completed.

\subsubsection{Water Levels, Specific Conductance, and Temperatures in Surrounding Wells}

To measure the effects of the injection on surrounding wells, automated down-hole sensors will be

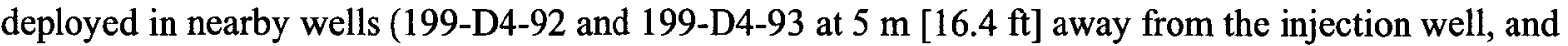
199-D4-25 and 199-D4-27 at $42.5 \mathrm{~m}$ [39.4 ft] away from the injection well) to measure water level (pressure), specific conductivity, total dissolved solids, and temperature during injection into well 199-D4-26 (see Figure 5-3 for well configurations). The automated down-hole sensors will collect data at least every 5 minutes for the duration of the injection operation and for 24 hours after injection is completed.

Along with the automated monitoring system, two electronic water-level indicators (i.e., e-tapes) will allow for manual readings to verify the readings from the in situ pressure transducers, and the electronic measurements will be available as backup for the automated monitoring system. Water levels in the surrounding wells will provide indication of the direction and magnitude of where the iron slurry may be moving. The temperature data will also be useful if there is a significant temperature contrast between the groundwater and the iron slurry. 


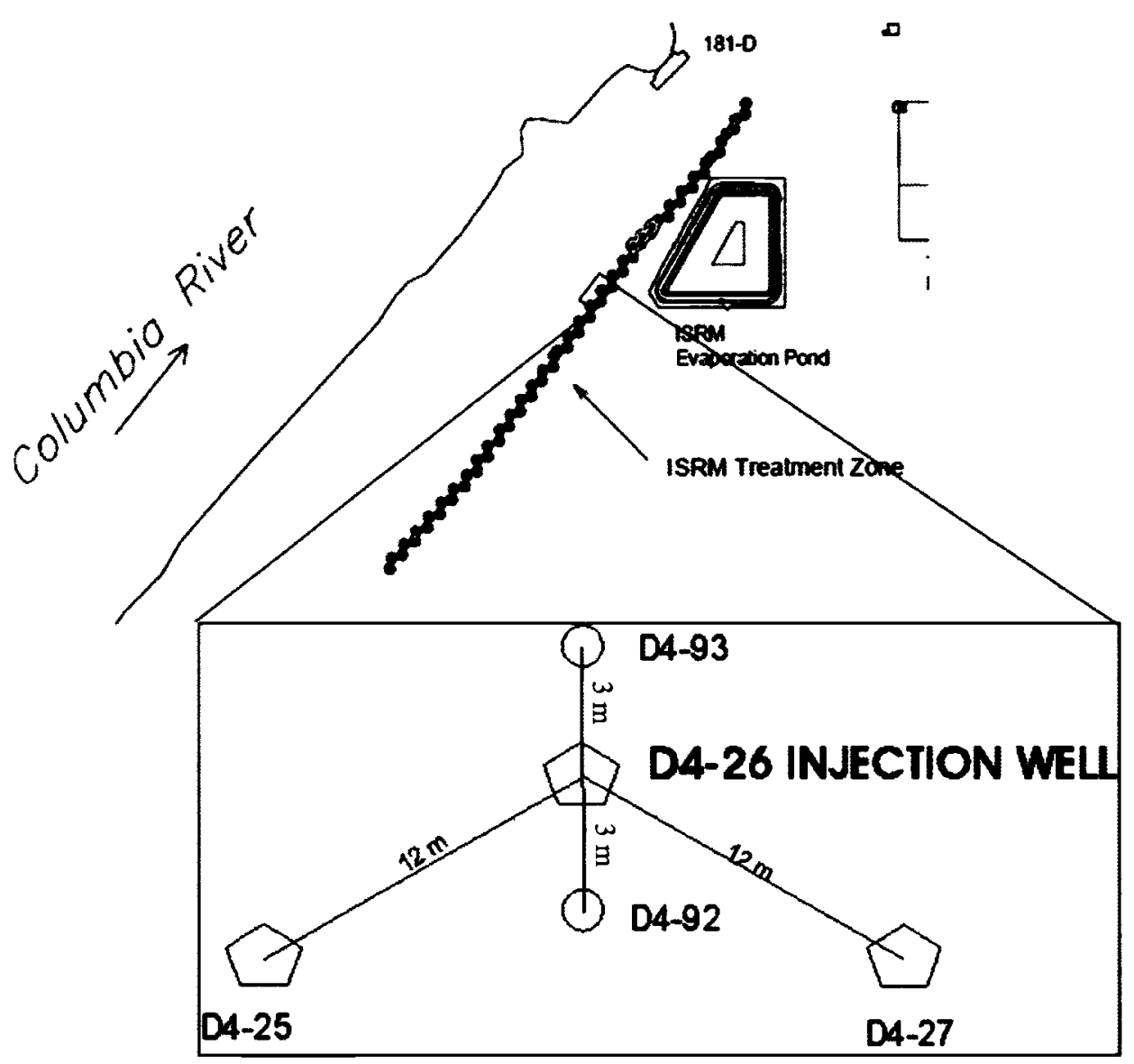

Figure 5-3. Well Location Map

\subsubsection{Water Quality in Surrounding Wells}

To gauge the progress of the iron slurry injection, field personnel will monitor the water quality in the four wells surrounding the injection well. Variable-flow submersible pumps will be lowered into the surrounding wells to pump water samples to the surface to measure water quality parameters, including temperature, $\mathrm{pH}$, specific conductivity, DO, and ORP. Flow from each well will be directed to a flow cell that contains a YSI 556 MPS multi-parameter probe. Water-quality parameters will be measured in each monitoring well immediately before the start of injection, every 4 hours during injection, and 24 hours after injection is completed.

Filtered and unfiltered groundwater samples will be collected from all wells before the injection starts, daily after arrival of the $\mathrm{nZVI}$ front, and 10 days after injection. All samples will be analyzed for anions (e.g., nitrates and nitrites), ammonia, and metals (e.g., iron, hexavalent chromium, and arsenic).

Baseline monitoring will be conducted in well 199-D4-38, which is $64 \mathrm{~m} \mathrm{(210} \mathrm{ft)} \mathrm{northwest} \mathrm{of} \mathrm{well}$ 199-D4-26 and is not part of the ISRM barrier. Well 199-D4-38 is currently sampled quarterly for hexavalent chromium and field parameters, and annually for anions. These data will be sufficient for baseline comparisons of the key groundwater parameters. 


\subsubsection{Geophysical Monitoring}

Injection of ZVI into the subsurface will alter the physical properties in the region of the injection, particularly the electrical and magnetic properties. Several geophysical methods are suitable for imaging the region of increased electrical conductivity and magnetic susceptibility. Data will be acquired using at least one of the following four geophysical methods: (1) borehole monitoring using borehole tools, (2) magnetic survey, (3) electrical resistivity, and (4) mise a la masse (electrical potential survey). These methods have been selected based on a combination of several factors, including simplicity of data acquisition, availability of equipment during the required timeframe, and likelihood of success. Pre-injection testing will determine which of these techniques will be used during and/or after the injection test. A more detailed discussion of the proposed geophysical monitoring is provided in Section 5.4.5.

\subsection{Equipment and Materials}

This section details the equipment and materials required to inject RNIP-M2 into the subsurface.

\subsubsection{RNIP-M2 Slurry (Nano-Sized Zero-Valent Iron)}

RNIP-M2 nZVI iron slurry has been selected for the field injection demonstration based on previous laboratory geochemical and injection testing results. RNIP-M2 is manufactured by high-temperature reduction of $\mathrm{FeOOH}$ using hydrogen gas. The result of this process is the creation of crystalline iron particles having an average particle size of 70 nanometers $(\mathrm{nm})$ and an average reactive surface area of $30 \mathrm{~m}^{2} / \mathrm{g}\left(9,155 \mathrm{ft}^{2} / \mathrm{oz}\right)$. The RNIP-M2 iron particle consists of an iron oxide (magnetite) shell $\left(\mathrm{Fe}_{3} \mathrm{O}_{4}\right)$ and an elemental iron core (ZVI). According to its material safety data sheet (MSDS) and certificate of authenticity, RNIP-M2 slurry contains approximately $18 \mathrm{wt} \%$ solids, $3 \mathrm{wt} \%$ water-soluble polymer, and $80 \mathrm{wt} \%$ water. Of the solids, approximately 65 percent are considered to be ZVI with the remainder being the mineral magnetite $\left(\mathrm{Fe}_{3} \mathrm{O}_{4}\right)$. Typically, due to its small particle size and self-ignition properties, RNIP-M2 is shipped as a slurry in $159.7 \mathrm{~kg}(352-\mathrm{lb})$ steel drums. The MSDS categorizes RNIP-M2 and the polymer as nonhazardous and noncarcinogenic. Before injection into the aquifer, RNIP-M2 will be diluted with water at a ratio of approximately 12:1 (water/RNIP-M2). Thus the concentration of ZVI in the injectant will be $0.1 \mathrm{wt} \%$ and the polymer will be $0.025 \mathrm{wt} \%$.

\subsubsection{Mixing Tank System}

The various components of the system used to mix the iron slurry include the holding tanks, transfer pumps, HSMs, and circulation pumps. Each component plays a crucial role in proper preparation of the iron slurry and is discussed in further detail in the following subsections. Figure 5-4 shows the conceptual layout for the slurry mixing and injection system.

Two $24,600 \mathrm{~L}(6,500$-gal) mixing tanks will be used. The tanks will be transported to the site by truck and used for the mixing and storing the iron slurry. The tanks will have domed tops and flat bottoms and

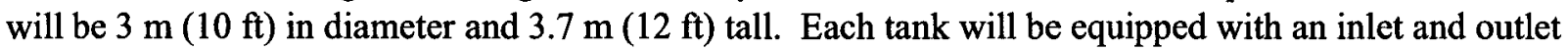
for a HSM, an inlet and outlet for a recirculation pump, a water supply inlet, and oxygen monitoring ports. The tanks will be fitted with the proper fittings once onsite. The tanks will be placed on the ground having a slight slope ( 1 to 2 degrees off-level) to facilitate tank drainage toward pump intake lines. Access the top of the tanks will be provided. 


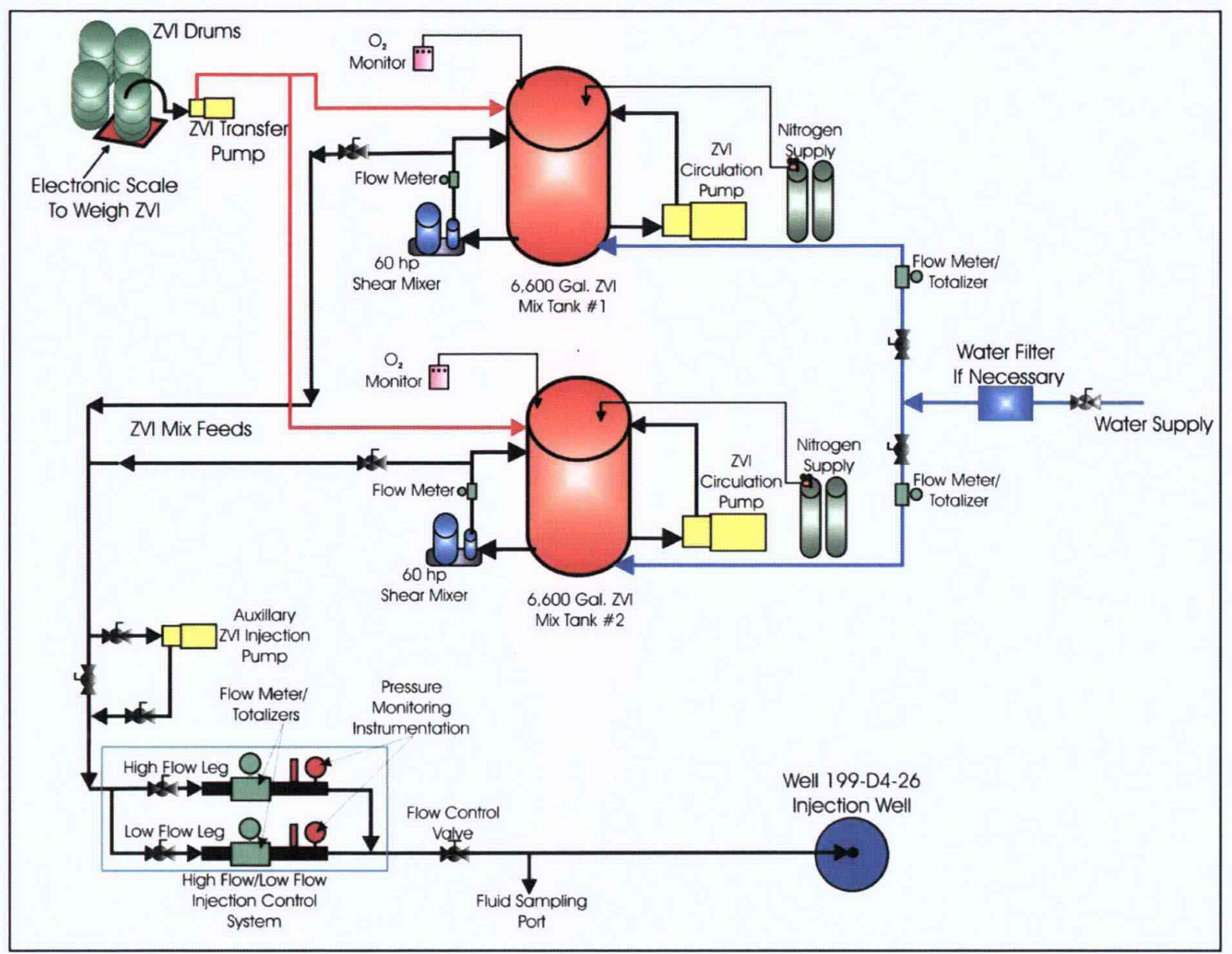

Figure 5-4. Conceptual Drawing Depicting Nano-Sized Zero-Valent Iron Mixing and Injection System

\subsubsection{Transfer Pumps}

An engine-driven transfer pump will be used to transfer the RNIP-M2 slurry from the shipping containers into the ZVI mixing tanks. The pump will be gasoline-powered and capable of delivering up to $832.8 \mathrm{~L} / \mathrm{min}(220 \mathrm{gpm})$. The suction end of the inlet hose for the transfer pump will be fitted with a screened canister to allow RNIP-M2 slurry to be removed from the bottom of the shipping barrels without interference from the plastic liner. The pump will have a fully automatic priming system (which enables the pump to self prime from completely dry conditions, even with extended suction lines) and will be capable of producing a water suction lift up to $7.9 \mathrm{~m}(26 \mathrm{ft})$. The pump will be able to accommodate thick slurries and solids up to $5.1 \mathrm{~cm}(2 \mathrm{in}$.) in diameter.

\subsubsection{High Shear Mixers}

Nanometer-size particles have a magnetic affinity toward each other, resulting in larger particle clusters due to agglomeration. The nZVI mixing system will use HSMs to break the particle agglomerations down to or close to the original particle-size distribution. The HSM is composed of an interlocking rotor and stationary stator combination. A very high shear force is created at the liquid interface between the rotor and stator, breaking apart any particle agglomerations. Incorporating the HSM will help to ensure a consistent injection solution throughout the injection process.

The mixer chosen for the process is a three-stage HSM supplied by IKA Works, Inc. (Wilmington, Delaware). The DR 2000/4 model was previously used in the flow cell and tank test, but the project will 
scale-up to the DR 2000/20 model for the field injection. Rebuild kits will be available onsite for pump maintenance, if required.

Two HSMs will be required for the field injection, each dedicated to one mixing tank. The injection feed will come off of a slipstream from the outlet of the HSM so the material is de-agglomerated immediately before injection.

\subsubsection{Circulation Pumps}

Even though the iron slurry contains a polymer to enhance suspension, it will be important to induce sufficient mixing to keep the particles in suspension, maintaining a homogenous injection solution. A diesel engine-powered circulation pump capable of delivering 3,028.3 L/min (800 gpm) will be provided for each mixing tank. The circulation pump will draw out of the bottom of the injection fluid tank and discharge back into the injection solution through appropriate-sized hoses. Based on the performance of a $37.9 \mathrm{~L} / \mathrm{min}$ (10-gpm) circulation pump (which was used to mix RNIP-M2 slurry in a 1,140 L [300-gal] tank during laboratory testing), this flow rate will create a turbulent environment inside the injection tank, which will be sufficient to keep the particles in a uniform suspension. The flow rate of the pumps will be controlled by either engine speed and/or a valve on the outlet side of the pump to provide optimum flows. Each pump will have a fully automatic priming system to enable the pump to self-prime from completely dry conditions and will be able to handle thick slurries and solids up to $5.7 \mathrm{~cm}$ (2.25 in.) in diameter.

\subsubsection{Supply Water Handling System}

Raw water from the 100-D Area water system will be used for formulating the nZVI mix. The water will travel through hoses from the source to the $24,600 \mathrm{~L}(6,500$-gal) mixing tanks. To ensure the proper iron slurry mix, the water directed to a mixing tank will be metered to accurately deliver the required volume of water. Two calibrated, appropriately sized Great Plains Industries, Inc. (Wichita, Kansas) turbine flow meters/totalizers will be used to measure the volume of water being delivered. Based on technical specifications provided by Great Plains Industries, the flow meters have an accuracy of \pm 1 percent. If readings on the two flow meters/totalizers are not identical, the average of the two meters for the volumetric calculations will be used. The volume of water will then be converted to a weight for calculating the amount of nZVI concentrate required, taking into account the water temperature, and adjusting for density. Data sheets will be used to document the mixing process.

\subsubsection{Nitrogen Supply System}

The nZVI is very reactive due to its large surface area. When a ZVI particle is exposed to the atmosphere, it will reduce the oxygen in the atmosphere, therefore reducing the particle's reactive lifetime. The mixing of the injection solution creates a turbulent environment inside the tank, bringing the ZVI particles in contact with the tank's atmosphere. To reduce the effects of oxygen on the reactive particles, field personnel will emplace a nitrogen blanket inside the tank during mixing and injection to minimize the effect of oxygen on the particles.

A local industrial gas supplier will provide the nitrogen gas for the mixing and injection operations. For large quantities, the gas will be supplied in a "gas pack," which consists of a single, insulated tank containing a total volume of $141.6 \mathrm{~m}^{3}\left(5,000 \mathrm{ft}^{3}\right)$. Each $24,600 \mathrm{~L}(6,500$-gal) poly mixing tank will connect to its own gas pack, with up to two extra gas packs in reserve. Regulators on the gas packs will control the nitrogen flow to the mixing tanks at rates up to $11.3 \mathrm{~m}^{3} / \mathrm{hr}\left(400 \mathrm{ft}^{3} / \mathrm{hr}\right)$. Field personnel will monitor and record the effectiveness of the nitrogen blanket in the tank with the use of a Model OX231 Industrial Scientific (Pittsburgh, Pennsylvania) hand-held oxygen meter. Ports will be installed on the sides of the injection tank so a sampling pump can draw gases out of the tanks at different levels. 
Nitrogen flow to the injection tanks will be adjustable to maintain an oxygen target level of approximately 5 percent of atmospheric oxygen in the injection tanks. Oxygen concentrations in the mixing tank atmosphere will be monitored throughout the duration of mixing and injection.

\subsubsection{Zero-Valent Iron Injection Pump}

Current data suggest that gravity feed will supply a sufficient flow rate to inject the ZVI solution. If numerical modeling indicates that optimal injection pressures need to be higher, an auxiliary pump will be used to boost injection pressures. The pump can supply flow rates and pressures of approximately $189.3 \mathrm{~L} / \mathrm{min}(50-\mathrm{gpm})$ at $80 \mathrm{psi}$. Maximum pressures for injection will be limited to around $80 \mathrm{psi}$ to avoid fracturing the soils.

\subsubsection{Monitoring Equipment}

The monitoring equipment to be used during this field demonstration can be separated into the following three categories:

- Iron slurry quality monitoring

- Injection monitoring

- Surrounding well monitoring.

The equipment to be used for each category of monitoring is discussed in the following subsections.

\subsubsection{Iron Slurry Monitoring Equipment}

The quality of the iron slurry will be monitored by measuring specific conductivity. Specific conductivity measurements will be taken hourly during mixing, compared to the laboratory standard readings (after corrections for differences in feedwater conductance), and recorded on data sheets. Deviation from the laboratory standard readings will indicate that the iron slurry mixture may not be correct, and the batching procedure for the mixture in question will be reviewed. Additional data will need to be gathered once in the field to measure the onsite water source for specific conductivity and the influence of adding various concentrations of RNIP-M2 slurry on the specific conductance.

\subsubsection{Injection Monitoring Equipment}

Monitoring during injection activities will include flow rates and injection pressures, both at the surface and within the screened zone below the well packer. The flow-injection control system will consist of a low-flow leg and a high-flow leg to account for the anticipated range of flow rates. Two flow rates are anticipated: 0 to $18.9 \mathrm{~L} / \mathrm{min}$ and 18.9 to $189.3 \mathrm{~L} / \mathrm{min}$ ( 0 to $5 \mathrm{gpm}$ and 5 to $50 \mathrm{gpm}$ ). Field personnel will use appropriately sized digital read-out Great Plains Industries, Inc. turbine flow meters/totalizers to accurately monitor real-time surface nZVI flow rates and volumes injected and will use dial read-out pressure gauges to monitor pressures. The Great Plains Industries' meters will have a flow range capacity of 3.8 to $37.9 \mathrm{~L} / \mathrm{min}$ ( 1 to $10 \mathrm{gpm}$ ) (at \pm 2 percent accuracy) in the low-flow leg and a flow range capacity of 18.9 to $189.3 \mathrm{~L} / \mathrm{min}$ ( 5 to $50 \mathrm{gpm}$ ) (at \pm 1 percent accuracy) in the high-flow leg and will be manually recorded in the project logbook approximately every 30 minutes. A flow control valve will be placed downstream of the two flow control legs, allowing the injection rate to be controlled throughout the project.

In addition to surface monitoring, a pressure transducer (Instrumentation Northwest P2X) (30-psi rating) will be installed through the well packer to monitor injection pressures and temperatures in the screen section of the injection well. The transducer will be connected to a laptop computer to continuously monitor down-hole pressures and temperatures. The data logger will be programmed to record the data every 5 minutes or less, depending on storage capacity of the data logger. Corrections of the pressure 
readings will be made taking into account the specific gravity of the $\mathrm{nZVI}$ mixture being injected into the well. The injection well will be monitored for a period of 24 hours after injection is completed.

\subsubsection{Monitoring Equipment in Surrounding Wells}

The groundwater in the four surrounding wells will be monitored for water levels and basic water quality parameters immediately before the start of injection, every 4 hours during injection, and 24 hours after completion of injection to provide data on the radius of influence of the nZVI from the injection well. In situ water levels, specific conductivity, total dissolved solids, and temperatures will be measured using Aquistar PT2X submersible pressure/temperature smart sensors (Instrumentation Northwest) installed in the four wells located near the injection well (wells 199-D4-92, 199-D4-93, 199-D4-25, and 199-D4-27). Each sensor will be suspended with a fixed cable allowing retrieval for real-time monitoring and periodic downloading of data.

Groundwater parameters including DO, specific conductivity, ORP, $\mathrm{pH}$, and temperature will be measured by using a YSI 556 MPS multi-parameter probe (or equivalent) having the reporting ranges, resolutions, and accuracies shown in Table 5-2.

Table 5-2. Reporting Ranges, Resolutions, and Accuracies for Monitoring Equipment in Surrounding Wells

\begin{tabular}{lccc}
\hline \multicolumn{1}{c}{$\begin{array}{c}\text { Measurement } \\
\text { Analysis }\end{array}$} & Range & Resolution & Accuracy \\
\hline Dissolved oxygen & 0 to $50 \mathrm{mg} / \mathrm{L}$ & $0.01 \mathrm{mg} / \mathrm{L}$ & $\begin{array}{c} \pm 2 \% \text { of reading, or } 0.2 \mathrm{mg} / \mathrm{L}, \\
\text { whichever is greater }\end{array}$ \\
Specific conductivity & 0 to $100 \mathrm{mS} / \mathrm{cm}$ & $\begin{array}{c}0.001 \mathrm{to} \\
0.1 \mathrm{mS} / \mathrm{cm}\end{array}$ & $\pm 0.5 \%$ of reading, $+0.001 \mathrm{mS} / \mathrm{cm}$ \\
$\begin{array}{l}\text { Oxidation-reduction } \\
\text { potential }\end{array}$ & -999 to $999 \mathrm{mV}$ & $0.1 \mathrm{mV}$ & $\pm 20 \mathrm{mV}$ \\
$\mathrm{pH}$ & 0 to $14 \mathrm{standard}$ & $\begin{array}{c}0.01 \text { standard } \\
\text { units }\end{array}$ & \pm 0.2 standard units \\
Temperature & $-5^{\circ} \mathrm{C}$ to $45^{\circ} \mathrm{C}$ & $0.1{ }^{\circ} \mathrm{C}$ & $\pm 0.15^{\circ} \mathrm{C}$ \\
\hline
\end{tabular}

Water from the monitoring wells will be pumped to the surface using a $5.1 \mathrm{~cm}$ (2-in.)-diameter Grundfos Redi Flo 2 variable-flow submersible pumps (Bjerringbro, Denmark), capable of pumping water from $30.5 \mathrm{~m}$ (100 ft) below ground level at approximately 3.8 to $15.1 \mathrm{~L} / \mathrm{min}$ ( 1 to $4 \mathrm{gpm}$ ), or a 12-volt Typhoon submersible pump (Wilden Pump and Engineering Company, Grand Terrace, California). Water will then be pumped into a flow cell for measurement with the YSI 556 MPS multi-parameter probe.

Solinst Model 101 water-level meters (Solinst of Georgetown, Ontario, Canada) (or equivalent) will also be used to measure water levels on a periodic basis to provide field team members with real-time waterlevel information and act as a backup for automated monitoring.

\subsubsection{Geophysical Monitoring Equipment}

The geophysical equipment that will be provided for this field demonstration project is listed below.

- ZVI injection well and the surrounding region, including the nearby PVC-cased well.

- Geophysical data processor/receiver (Zonge GDP-32, or equivalent) 
- Electrical transmitter for the electrical resistivity, IP, complex resistivity, and mise a la masse tests (Geotronics FT-20A, or similar)

- Electrical transmitter for the TEM tests (Zonge NT-20, or similar)

- Magnetometer (Geometrics G-858, or similar)

- Borehole induction conductivity tool (Geonics EM-39C, or similar)

- Generator (400 Hz) (Zonge GGT-3, or similar)

- Laptop computer for interfacing with instruments for data download and command upload

- Hand-held multi-meter for troubleshooting electrical connections

- Rebar stakes (approximately $60.1 \mathrm{~cm}$ [24 in.] in length)

- Plastic stakes (approximately $25.4 \mathrm{~cm}$ [10 in.] in length)

- Experimental logbook

- Surveying equipment (TOPCON GTS-2B, or similar; with tripod, roving rod, prism, etc.)

- Miscellaneous items including wire spools, batteries, chargers, electrical tape, survey flagging, tape measure, etc.

\subsection{Sampling and Analysis}

A summary of the sampling and analysis activities during and after injection is presented below. A detailed summary of the sampling activities is provided in the SAP (DOE/RL-2008-49).

\subsubsection{Nano-Sized Zero-Valent Iron Quality Control and Assurance Samples and Analysis}

After a new batch of slurry has been mixed, field measurements of specific conductance will be made hourly to ensure slurry quality and consistency. The samples will be obtained from a sample port at the effluent of the mixing tanks. Additionally, to ensure the quality of the slurry during injection, samples will also be obtained from a sampling port installed at the well head during the injection process and monitored using the same measurements as described above. The samples will be compared to the laboratory standards for QC.

\subsubsection{Injection Monitoring}

The nZVI flow rates, injection pressures, and measurement times will be recorded throughout injection operations at the surface. In addition, one pressure-monitoring location will be established under the well packer to monitor injection pressures in the screen section of the injection well. Data-logging equipment will be used to record the data. Manual readings will also be recorded as backup to the logging systems.

\subsubsection{Groundwater Monitoring}

Groundwater monitoring will follow the specified procedures. Water levels, specific conductance, total dissolved solids, and temperatures will be monitored in four nearby wells to measure the effects of the injection using down-hole sensors. These will be programmed to collect data at least every 5 minutes for the duration of the injection operation and 24 hours after injection is completed. 
In addition to the automated monitoring system, two electronic water-level indicators (i.e., e-tapes) will be used for manual readings, allowing for quick checks and as a backup for the automated monitoring system. The manual readings will be made at the same frequency as the water quality measurements.

The water quality in the four wells surrounding each injection well will be monitored as indicators of iron slurry injection progress. To monitor water quality, submersible pumps will be lowered into the wells to pump water samples to the surface for measuring water quality parameters. The parameters that will be measured include temperature, $\mathrm{pH}$, specific conductivity, DO, and ORP. Flow from each well will be directed to a flow cell in which the YSI 556 MPS multi-parameter probe will be installed. Water quality parameters will be measured in each monitoring well immediately before the start of injection, every 4 hours during injection, and 24 hours after completion of injection. Filtered and unfiltered groundwater samples will also be collected and analyzed from all of the surrounding wells before, during, and after injection.

\subsubsection{Aquifer Materials}

Post-injection soil samples will be collected after injection to evaluate the amount and distribution of $\mathrm{nZVI}$ deposited in the formation. Continuous split-spoon samples will be collected through the aquifer in one borehole by cable-tool drilling. The borehole location will be chosen after evaluation of groundwater data collected during injection and will be sited to intercept the outer portion of the injected aquifer. Samples from the continuous core will be homogenized on $0.3 \mathrm{~m}(1-\mathrm{ft})$ intervals (based upon analysis of previous sampling intervals, as reported in PNNL-15499) and analyzed for total iron, total chromium, and hexavalent chromium. A sieve analysis will also be performed on each of the samples to help establish geologic correlations with nearby wells. All aquifer material not used for laboratory analysis will be archived and appropriately stored for at least one year after collection. This boring will be converted into a groundwater monitoring well as described in the SAP (DOE/RL-2008-49) and according to WAC 173-160, "Minimum Standards for Construction and Maintenance of Wells."

\subsubsection{Geophysical Monitoring}

The ZVI material has unique physical properties (e.g., high magnetic susceptibility) that may be detectable using a number of geophysical techniques (described in more detail below). This workscope at the Hanford Site would provide a basis for designing and implementing similar data acquisition for other DOE sites. Geophysical monitoring of the ZVI injection at Hanford may include electrical resistivity, multi-frequency IP, TEM, surface magnetics, and mise a la masse electrical potential mapping. These methods were selected based on a combination of several factors including simplicity of data acquisition, availability of equipment during the required timeframe, and likelihood of success. Because injection of nano-scale materials into the subsurface is relatively rare at this time, this injection presents a unique opportunity for researching strategies for monitoring of these types of injections in the future.

\subsubsection{Site Preparation}

Preliminary locations for the geophysical data acquisition will be selected based on maps and site diagrams. These locations will be adjusted as necessary during a site visit/walkthrough. After the locations have been selected, non-metallic stakes will be used to mark out the survey grids and lines. The remote current electrodes and the roving current electrodes will be constructed with rebar. 


\subsubsection{Site Surveying}

The initial positioning of the site will be performed using a fiberglass tape measure and a compass. Once the positions have been established and the stakes driven into the ground, a total station instrument or differential global positioning system will be used to determine relative locations and elevations of all the stakes. Additionally, the location and elevation of several wells will be surveyed to provide a tie between the wells and the geophysical line locations.

\subsubsection{Geophysical Methods}

Time-lapse methodology will be used to acquire all of the geophysical data. Prior to injection, a background survey will be completed. This pre-injection survey will be used to screen out inappropriate methodologies and identify possible interferences. Post-injection, an identical (to the extent possible) survey will be completed. If each survey is completed using the same station locations and instrument orientations, the data differences between the surveys can then be attributed to subsurface changes induced by the ZVI injection. Non-metallic stakes placed in the ground will ensure that the same locations are reoccupied before and after injection. The same transmitter/receiver stations will be reoccupied for each survey and care will be taken to ensure comparable conditions during each survey. If timing allows and interferences can be adequately minimized, some of the geophysical data may also be acquired during the injection. The subsections below describe the individual geophysical surveys. Field modification to survey design may be necessary to achieve adequate resolution. The order in which the surveys are to be completed will be determined onsite. If, during the execution of any of these geophysical testing methods, a better procedure(s) is/are discovered, which are more efficient and/or cost effective and produce the desired quality and results, the new procedure(s) shall be documented, approved, and implemented.

\section{Electrical Resistivity}

In an electrical resistivity survey, low-frequency alternating current is injected into the ground via a grounded dipole, and the resulting electrical potential is measured at several locations, also using grounded dipoles. Electrical resistivity data are sensitive to the electrical conductivity/resistivity of the subsurface, and, thus, will be useful for imaging the increased conductivity resulting from the ZVI injection.

A pole-dipole electrode configuration will be used (illustrated in Figure 5-5) to acquire electrical resistivity data. The pole-dipole configuration, compared with other electrode arrangements, has the advantages of high signal strength and low electromagnetic coupling. This configuration requires that a remote current electrode be placed at a distance from the survey area. To reduce bias in the data, measurements will be made in both a forward and a reverse direction, thus requiring a second remote current electrode (Figure 5-5 [a and b]). Depth of investigation and lateral coverage for the pole-dipole survey are adjusted by changing the location of the roving current electrode (C1) and the potential dipole (P1-P2) and also by adjusting the spacing between P1 and P2 (referred to as the a-spacing).

Electrical resistivity data will be acquired along a single two-dimensional profile (possibly two profiles) centered near the injection well. The survey will include a-spacings of 9.1 and $18.3 \mathrm{~m} \mathrm{(30} \mathrm{and} 60 \mathrm{ft})$, with $\mathrm{n}=0.5$ to 8 . The depth and lateral coverage for the planned electrical resistivity survey is shown in Figure 5-6. The total distance between the two remote current electrode locations is approximately $853 \mathrm{~m}$ $(2,800 \mathrm{ft})$. The main region of data acquisition spans a distance of $121.9 \mathrm{~m}(400 \mathrm{ft})$. There are 16 depth levels in the proposed survey. 


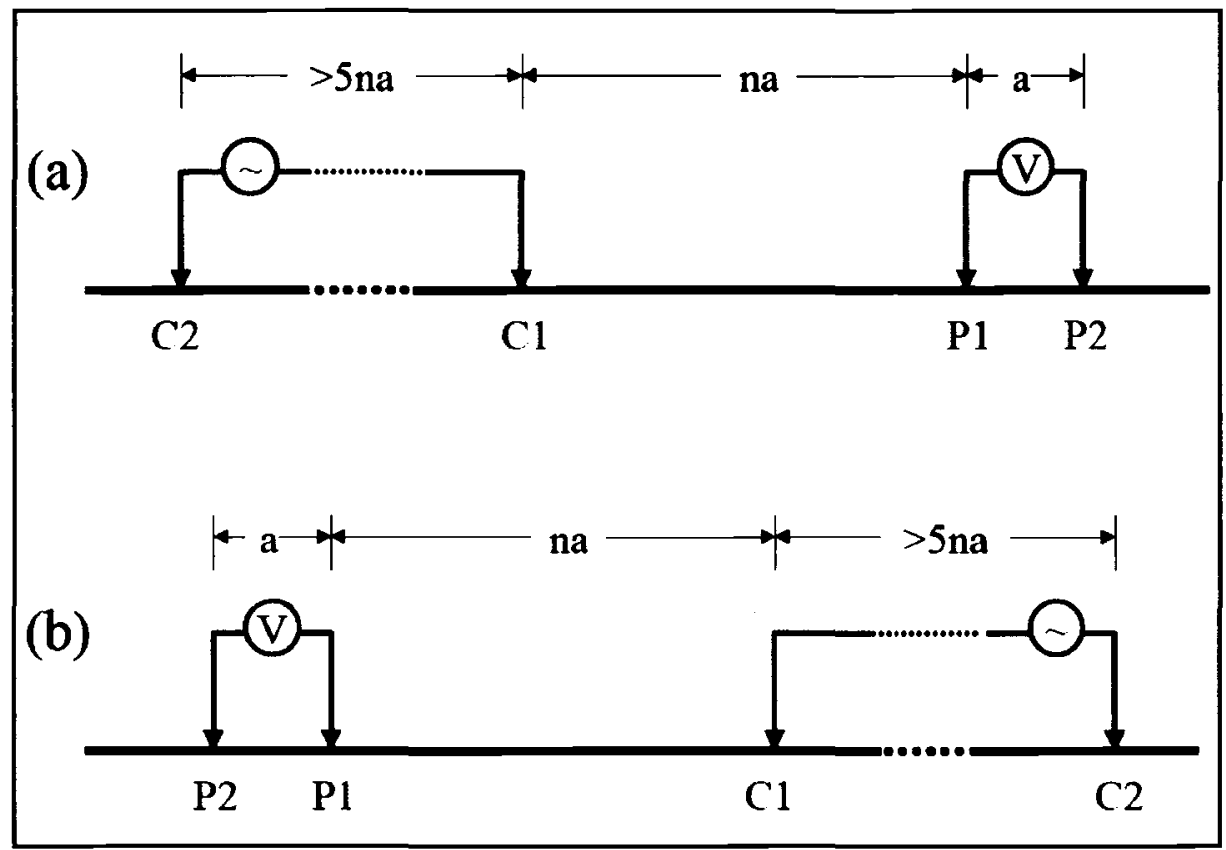

(a) Forward pole-dipole. (b) Reverse pole-dipole. Electrodes P1 and P2 are the potential electrodes, $\mathrm{C} 1$ is the roving current electrode, and $\mathrm{C} 2$ is the remote (stationary) current electrode.

Figure 5-5. Pole-Dipole Electrode Configuration

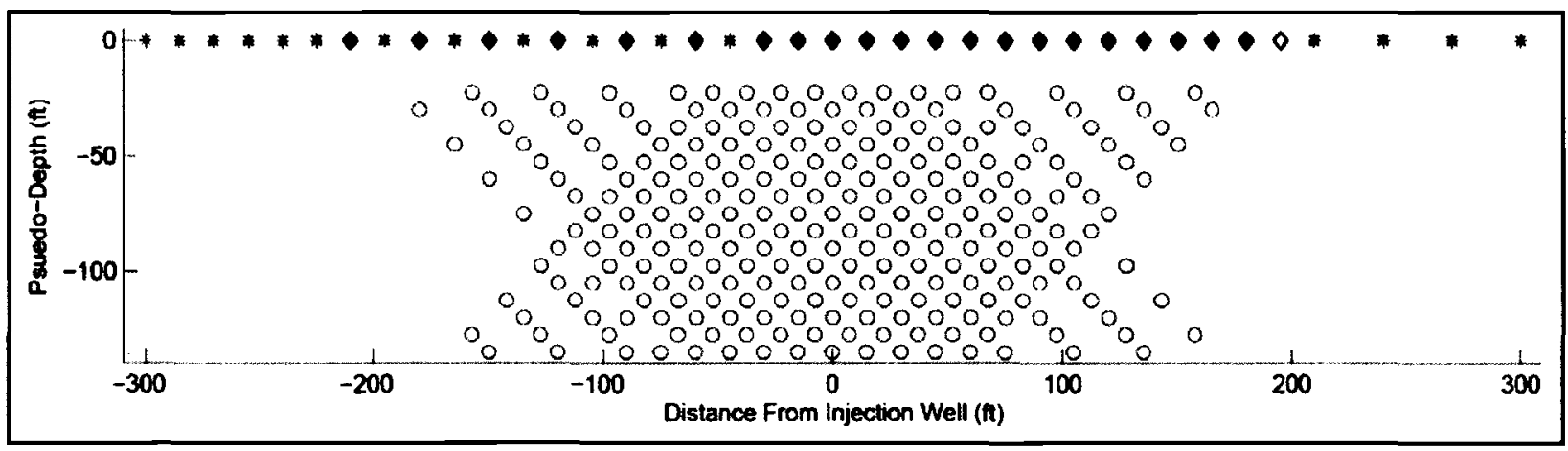

NOTE: The pseudo-depth plotted on the vertical axis is based on a projected data measurement point in the subsurface and generally exceeds the actual depth of investigation.

Figure 5-6. Data Coverage for Pole-Dipole Electrical Surveys

The remote electrodes will be constructed with 15 to 30 rebar stakes hammered into the ground to a depth of less than $30.5 \mathrm{~cm}$ (12 in.) in a radial pattern. The area surrounding these stakes will be saturated with $40 \mathrm{~L}$ (10.6 gal) of approximately $40 \mathrm{~g} / \mathrm{L}$ salt water (at least once daily). The roving current electrodes will be constructed by pounding three rebar stakes into the ground to a depth of less than $30.5 \mathrm{~cm}$ (12 in.), and then saturating the surrounding soil with $20 \mathrm{~L}$ (5.3 gal) of $40 \mathrm{~g} / \mathrm{L}$ salt water. This method provides the high surface area required to inject adequate current into the subsurface. Potential measurements will be made using non-polarizable electrodes that achieve ground contact through a porous surface.

In the IP method, as in the electrical resistivity method, current is injected into the ground via an electric dipole. When this current is shut off, the electrical potential in the subsurface does not immediately 
return to zero, but rather decays gradually. In the time domain IP method, this decay curve is sampled, providing information about the chargeability of the subsurface materials, which can then be related to material type and other physical properties. The IP effect can also be determined in the frequency domain, in which case the phase of the received signal is compared to that of the transmitted signal. The IP data are sensitive to interfaces between regions of contrasting resistivity, such as the interface between fluid and host rock. The physical property of interest in an IP survey is the chargeability (similar to capacitance) of the subsurface. IP is considered a very good method for the detection of disseminated metals (such as the ZVI injection at Hanford).

The field procedures for IP are very similar to electrical resistivity, so the IP data can be collected using the same source-receiver pairs and at the same time as the electrical resistivity data previously described. Non-polarizable electrodes will be used for the IP acquisition.

\section{Complex Resistivity}

The complex resistivity method is an extension of the IP method. Essentially, it is a multi-frequency IP survey. Recent research suggests that complex resistivity is capable of imaging permeability structure in the subsurface. Again, field procedures will be similar as for the electrical resistivity survey so the data can be acquired concurrently with the resistivity data. This acquisition plan includes of 256 individual source receiver pairs (Figure 5-6). Diamonds indicate roving current electrode locations, asterisks indicate potential electrode locations and circles indicate projected subsurface data measurement points. Note that the remote current electrodes are located several hundred feet to the left and the right of the region plotted here.

\section{Time-Domain Electromagnetics Survey}

In a TEM survey, the source and receiver are ungrounded wire loops. Current is transmitted through the source loop, which induces magnetic fields in the subsurface; these magnetic fields interact with subsurface materials. A second loop, the receiver loop, is used to measure the response due to interaction of the induced fields with the subsurface materials. An advantage of this method versus electrical methods is that large investigation depths can be achieved with a much smaller survey "footprint." A disadvantage is that it is time consuming to collect these data over large spatial extents.

A few one-dimensional TEM soundings in the vicinity of the injection well will be acquired.

A concentric loop arrangement will be used, where a large source loop will be laid out on the ground, and then a smaller receiver loop will be placed in the center of the source loop.

\section{Borehole Logging}

A borehole induction conductivity tool will provide high-resolution imaging of the subsurface conductivity versus the lower resolution of surface methods. Although the resolution of borehole methods is higher versus surface methods, the volume of subsurface materials measured by the borehole tools is confined to a small region surrounding the borehole.

The disadvantage of borehole methods at this particular site is that most of the boreholes are steel-cased and thus not useable for electrical/magnetic tools. The one available PVC-cased borehole, 199-D4-92, will be used to house an electromagnetic induction tool, thus allowing monitoring of the electrical conductivity of the formation surrounding the borehole. This borehole will be logged from top to bottom and then from bottom to top. 


\section{Magnetic Survey}

Iron has a far higher magnetic susceptibility than most naturally occurring earth materials (e.g., ground water has essentially zero magnetic susceptibility). A surface magnetic survey will be used to image the injection via the enhanced magnetic susceptibility. Data acquisition for this survey will be performed in a radial grid (Figure 5-7), with data spacing closest in the vicinity of the injection well and increasing with distance from the injection well. Measurements will be made with the magnetometer at a constant height and orientation to facilitate repeatability of the results. A magnetometer base station will be established distant from the injection site. This base station will be reoccupied periodically during the survey in order to quantify instrument drift, thus allowing for the removal of drift from the data.

Additional distant data points will be acquired in order to characterize the regional magnetic field, which will be useful when later analyzing the data.

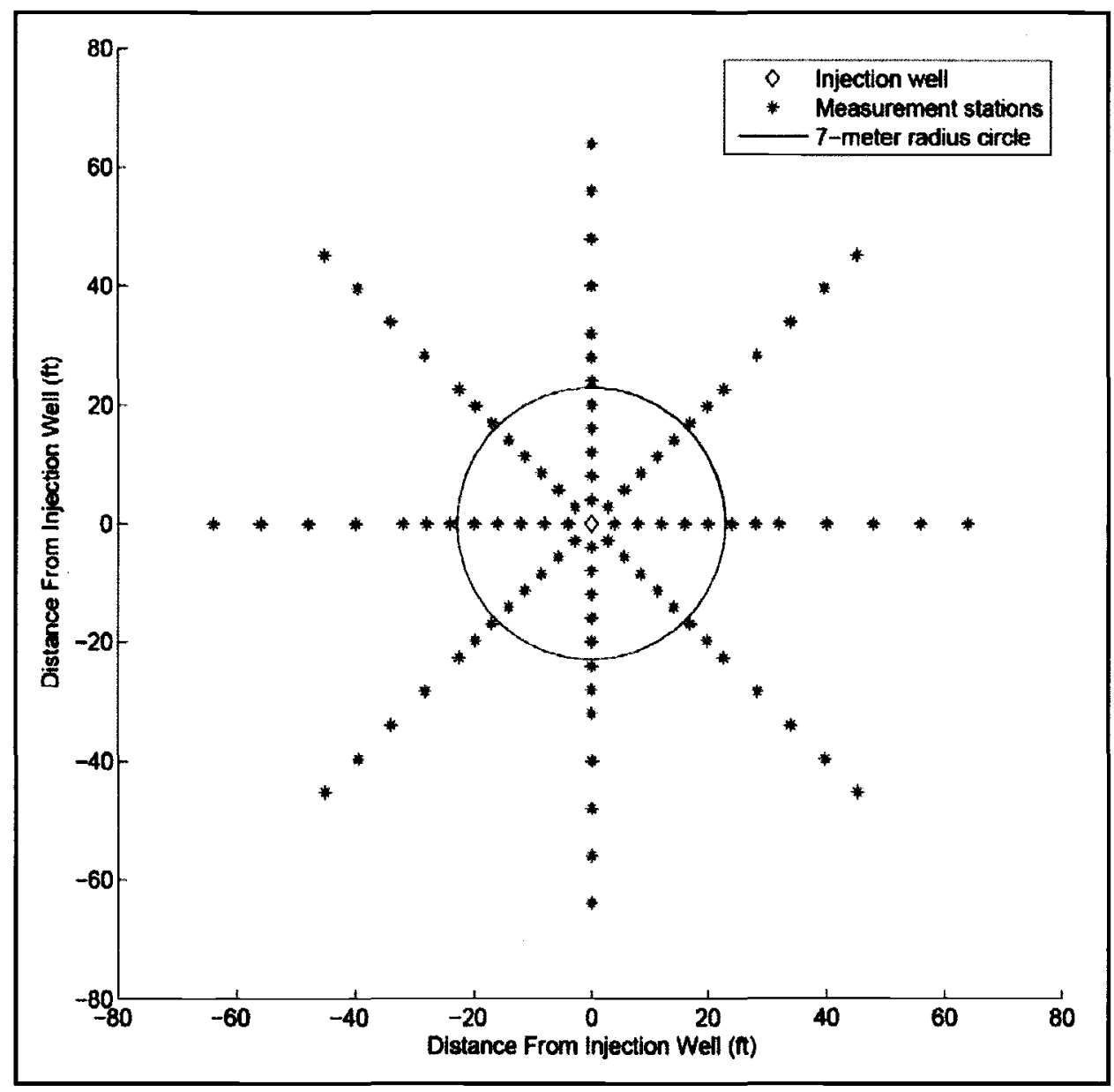

Figure 5-7. Measurement Points for Magnetic and Mise a la Masse Surveys

\section{Mise a la Masse (Electrical Potential Survey)}

In the mise a la masse, or "excitation of the mass" method, one current electrode is placed down a borehole (in this case into the region of the ZVI injection), and the second current electrode is placed at "infinity" (at least 5 times the expected extent of the conductive body). A potential electrode is then moved to several locations surrounding the current electrode, thus mapping the lateral extent of the conductor. In this case, the conductor is the injected fluid. Quantitative interpretation of these types of 
data is difficult, but this method may provide a quick and simple way to map the lateral extents of the ZVI injection.

This survey will be performed using the same set of radial measurement points as for the magnetics (Figure 5-7). The remote current electrodes from the electrical surveying will serve as the "infinity" electrodes for this survey.

\subsubsection{Geophysical Data Analysis and Interpretation}

This section describes the data analysis and interpretation procedures. Data analysis will include plots of the raw data, both pre- and post-injection. Where feasible, the inverse modeling results are also included. Interpretation will integrate the various data and models so the best possible image of the ZVI injection is reconstructed. Modeling interpretations will include the hydro/geochemical data from the injection monitoring as appropriate.

\section{Electrical Methods Data}

Most of the data acquired for this project fall under the category of electrical methods. These data will include measured electrical potential, current, and phase at each station and for each frequency. Where feasible, results from the various data sets will be compared/contrasted to form a complete picture of the subsurface changes induced by the ZVI injection.

\section{Electrical Resistivity}

To analyze the electrical resistivity data, the subsurface will be discretized into a rectangular grid, with grid spacing less than or equal to one-half the minimum electrode spacing. The electrical potentials and currents will be used to compute apparent resistivity values for each datum. These apparent resistivities will be used in a two-dimensional inverse modeling program (RES2DINV) ("Rapid Least-Squares Inversion of Apparent Resistivity Pseudosections by a Quasi-Newton Method" [Loke and Barker 2006]) to calculate the electrical conductivity of each cell in the rectangular grid.

It may be determined useful to complete some time-lapse inversion of the data either by model subtraction following individual inversion, conditioning of the post-injection data with the pre-injection data, or direct inversion of the data differences to recover the model differences.

- Induced polarization (IP): The IP data will also be inverted using RES2DINV, in this case with the goal of recovering the chargeability structure of the subsurface.

- Complex resistivity: Inversion of the complex resistivity data will also be completed using RES2DINV to provide information about the frequency dependence of the electrical conductivity, and to recover the chargeability structure.

- Mise a la masse: The mise a la masse data will be plotted in contour, for both the pre- and postinjection survey. A third contour plot will be prepared by comparing the two data sets. If possible, these data will also be inverted using RES2DINV, although the software has some limitations regarding inverting data with non-traditional geometry.

- Electromagnetic data: The electromagnetic data will be inverted in one-dimension to recover the layered earth conductivity structure beneath each data measurement station. These conductivity results will be compared with the conductivity models obtained from inversion of the electrical data.

- Magnetic data: The magnetic data (e.g., the mise a la masse data) will be plotted in contour maps for qualitative comparison. If data quality is adequate, three-dimensional inversion of the magnetic data may be attempted with a goal of recovering the subsurface magnetic susceptibility structure. 
- Borehole logging data: The borehole logging data will be compared pre- and post-injection to determine regions of increased formation electrical conductivity.

\subsection{Waste Stream}

All waste was handled in accordance with all applicable federal, state, and local regulations and facility waste handling procedures.

\subsubsection{Disposal of Unused Nano-Sized Zero-Valent Iron}

The $\mathrm{nZVI}$ formulation that is proposed for field injection is not considered hazardous waste. Therefore, unused and uncontaminated nZVI will be disposed in accordance with the MSDSs and all applicable regulations and procedures. If required, unused $\mathrm{nZVI}$ and empty drums will be disposed at an appropriate waste disposal facility.

\subsubsection{Disposal of Extracted Groundwater}

Injection and extraction groundwater will be properly collected and contained at the well head until transported to the Purgewater Storage and Treatment Facility or the Effluent Treatment Facility.

\subsubsection{Solid Waste Handling}

Project derived construction debris and refuse will be placed into an approved waste container and managed and stored in accordance with DOE/RL-97-01, Interim Action Waste Management Plan for the 100-HR 3 and 100-KR 4 Operable Units. In addition to the waste management plan, a supplemental waste packaging/labeling instruction sheet will be used for handling, packaging, and storage.

\subsection{Data Management}

Personnel conducting the experiments will record all pertinent test activities in bound logbooks with sequentially numbered pages. All data will be electronically logged or recorded on data collection sheets or logbooks. Each new test day shall be identified by the date at the top of the logbook page. Each new entry will be designated by a time-of-day entry and start on a new line; data of sufficient detail will be entered to fully describe the activity or data being logged. At the conclusion of each day's activities, the logger will provide his/her initials at the end of the log for that day and place a diagonal line across the remaining unused page for that day's activities. All entries will be recorded in the logbook or on data collection sheets using waterproof, non-smearable ink. Calibration data for monitoring/measuring equipment will be recorded in the logbooks. Photographs/digital/video images will be taken and noted in the logbook for reference and will then be cataloged and retained for future reference. Errors will have a line drawn through them, followed by the correction and initials of the person making the change. Data to be recorded include the measurements and observations identified in the previous sections and any other data necessary to reconstruct the experiments for a final report.

Data from each sampling event will be compiled into a database for this project. The database will include a record of all paper copies of sampling records, chain-of-custody sheets, and analytical laboratory reports. It will also include the project logbook and instrument calibration records. In addition to paper copies of the data, all numerical values obtained from the testing will be entered into an electronic spreadsheet for further analysis.

\subsection{1 nZVI Quality Control and Assurance Data Analysis}

The $\mathrm{nZVI} \mathrm{QC} \mathrm{data} \mathrm{from} \mathrm{the} \mathrm{samples} \mathrm{taken} \mathrm{directly} \mathrm{out} \mathrm{of} \mathrm{the} \mathrm{mixing} \mathrm{tank} \mathrm{effluent} \mathrm{sample} \mathrm{ports} \mathrm{will} \mathrm{be}$ temperature corrected and compared to the laboratory standards and the RPD between the sample, and the 
standard will be calculated as shown in Equation 5-1. This calculation will be made in the field prior to proceeding with the injection. The batch will be considered to be within the specifications if the RPD is less than \pm 15 percent for all measurements.

The nZVI data obtained at regular intervals from the well head will be compared to the laboratory standard by calculating the relative standard deviation (RSD) as shown in Equation 5-2. The nZVI at the well head will be considered within the specifications if the RSD is for all parameters is less than \pm 15 percent for all measurements.

$$
\begin{gathered}
R P D=\frac{X_{1}-X_{2}}{\bar{X}} \times 100 \% \\
R S D=\left(\sqrt{\frac{\sum\left(X_{i}-\bar{X}\right)^{2}}{n-1}}\right) \times \frac{1}{\bar{X}} \times 100 \%
\end{gathered}
$$

where:

$$
\begin{aligned}
& \mathrm{Xi}=\mathrm{i}^{\text {th }} \text { data value } \\
& \bar{X}=\text { average value of data } \\
& \mathrm{n} \quad=\text { number of samples. }
\end{aligned}
$$

\subsubsection{Injection Monitoring}

The injection monitoring data (i.e., flow rates, injection pressures, and time) will be reviewed in the field to identify optimal injection parameters and to ensure that the injection is proceeding according to plan and the design injection volumes of nZVI are being injected into the subsurface.

\subsubsection{Groundwater Monitoring}

Groundwater monitoring and aquifer material data collected during and after injection will be compiled and evaluated against the seven Comprehensive Environmental Response, Compensation, and Liability Act of 1980 treatability test criteria (see Section 5.1.6). A treatability test report will be prepared discussing the results of treatability test. A brief description of how each criterion will be evaluated is presented below.

\subsubsection{Overall Protection of Human Health and the Environment}

The results of this study will be evaluated to assess how iron injection achieves overall protection of human health and environment. The focus will be on reducing or eliminating overall sites risks, primarily reducing hexavalent chromium concentrations and evaluating the type and concentration of degradation products (e.g., nitrite).

\subsubsection{Compliance with Applicable or Relevant and Appropriate Requirements}

Groundwater chemical data will be used to compare statistical parameters (e.g., $90^{\text {th }}$ percentiles, maximum concentrations) of the groundwater chemistry data collected to MCLs and remedial action goals. 


\subsubsection{Long-Term Effectiveness and Permanence}

Long-term effectiveness and permanence of the treatment probably cannot be addressed in the treatability test report because of the anticipated persistence of reduction in the treated area.

\subsubsection{Reduction of Toxicity, Mobility, and Volume Through Treatment}

This criterion will be evaluated by using chemical data from groundwater and samples of aquifer material collected after the treatability test. The primary focus will be on the ability of nZVI injection to meet the $\mathrm{RAO}$ of $<20 \mu \mathrm{g} / \mathrm{L}$.

\subsubsection{Short-Term Effectiveness}

Hydrologic and chemical data will be used to assess short-term effectiveness by evaluating the success of moving the iron slurry to and beyond the surrounding wells.

\subsubsection{Implementability}

Hydrologic and chemical data will be used to assess implementability by evaluating the success of moving the iron slurry to and beyond the surrounding wells. Other operational information (e.g., availability of nZVI) will also be considered.

\subsubsection{Cost}

Evaluation of costs will include discussion of capital and implementation costs. Overall cost will include a comparison with emplacement of the ISRM. 


\section{Field Injection, Results, and Discussion}

In August 2008, RNIP-M2 was injected into the ISRM barrier to test the feasibility of using ZVI to repair portions of the barrier. This chapter discusses the field injection, results of the test, and verification of the test.

\subsection{Field Injection Overview}

The following sections present an overview and schedule of the field injection process. Chapter 5 presents the procedures for the field injection as they were to be completed. A summary of the modifications and additions to the treatability test plan is presented in Section 6.4. The complete data from the field injection is presented in Appendix D, SectionD1. Appendix D, Section D2 presents the complete geophysical data, including the raw field data sheets.

\subsubsection{Site Preparation and Construction}

A project safety meeting was held on June 25,2008 to discuss project safety issues and update all involved personnel on the schedule, equipment changes, and procedures. Immediately following the safety meeting a site walkdown was conducted to discuss equipment placement, utilities availability, and procedures to be used during the field injection activities.

Construction of the injection system began on July 8, 2008. Actual building of the system was performed by the various craft groups from the Hanford Site, including pipefitters, carpenters, electricians, teamsters, operators, and laborers. The first 24,600 L (6,500-gal) poly-tank was delivered to the site on July 8, 2008, which was uprighted, moved into its proper position, and secured with ecology blocks and tie-down cables (Photograph 6-1). Once secured, the pipefitters began installing the various bulkhead fittings required for the nZVI mixing and injection system. Additional equipment (including an office trailer, diesel generator, and material handling equipment) was delivered the same day. The office trailer was secured to tie-down rods driven into the ground to protect it from potential high winds. The second polytank was delivered and installed on July 9, 2008.

After preparing the poly-tanks, the two HSMs (Photograph 6-2) and the two $10.2 \mathrm{~cm}$ (4-in.) ZVI batch mixing pumps (Photograph 6-3) were moved into place around the poly-tanks. Measurements were then taken for the various hose lengths required to connect all of the pieces of injection equipment. The hoses were custom fabricated at a local hose supplier. Concurrent with the pipefitting operations, the site electricians began setting the HSM control panels and connecting them to a diesel generator through variable-frequency drive controllers. 
DOE/RL-2009-35, REV. 0

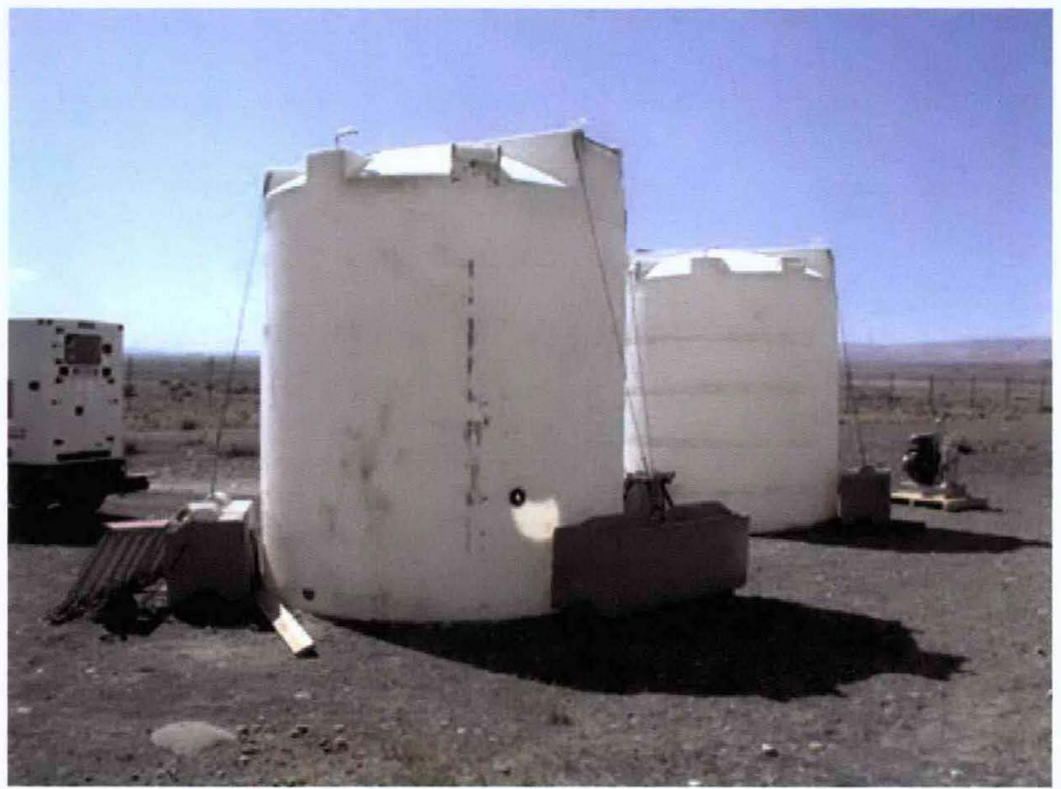

Photograph 6-1. Poly-Tanks in Position and Secured

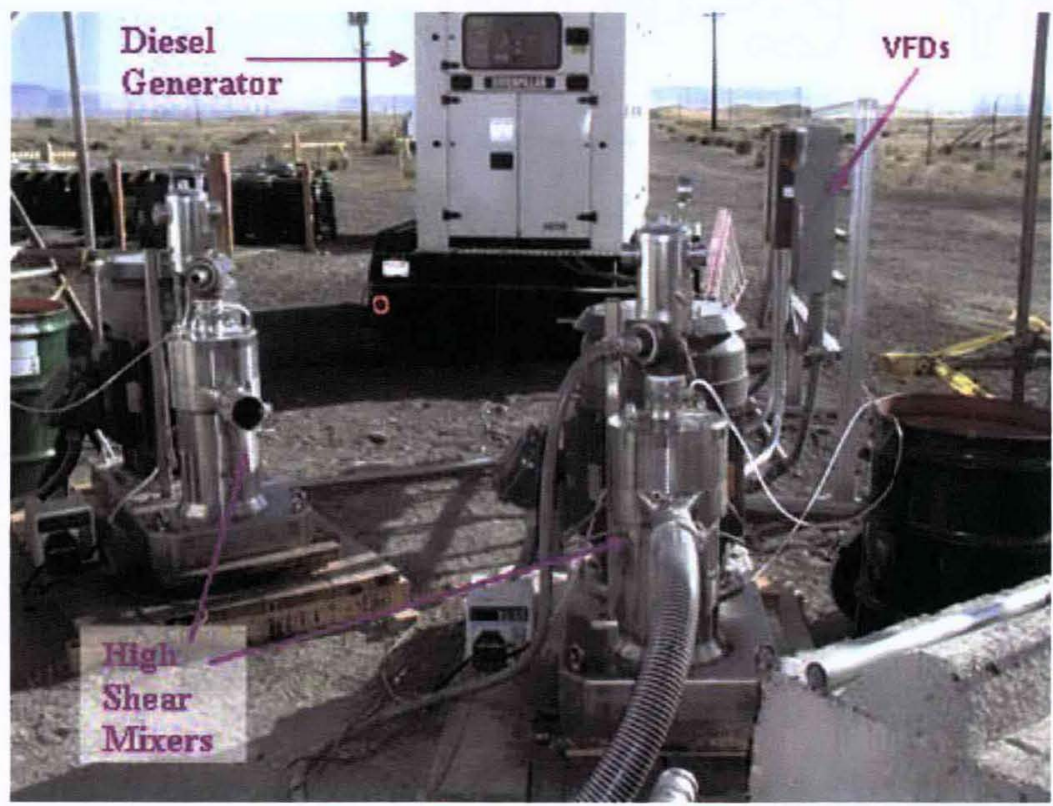

Photograph 6-2. High Shear Mixers 


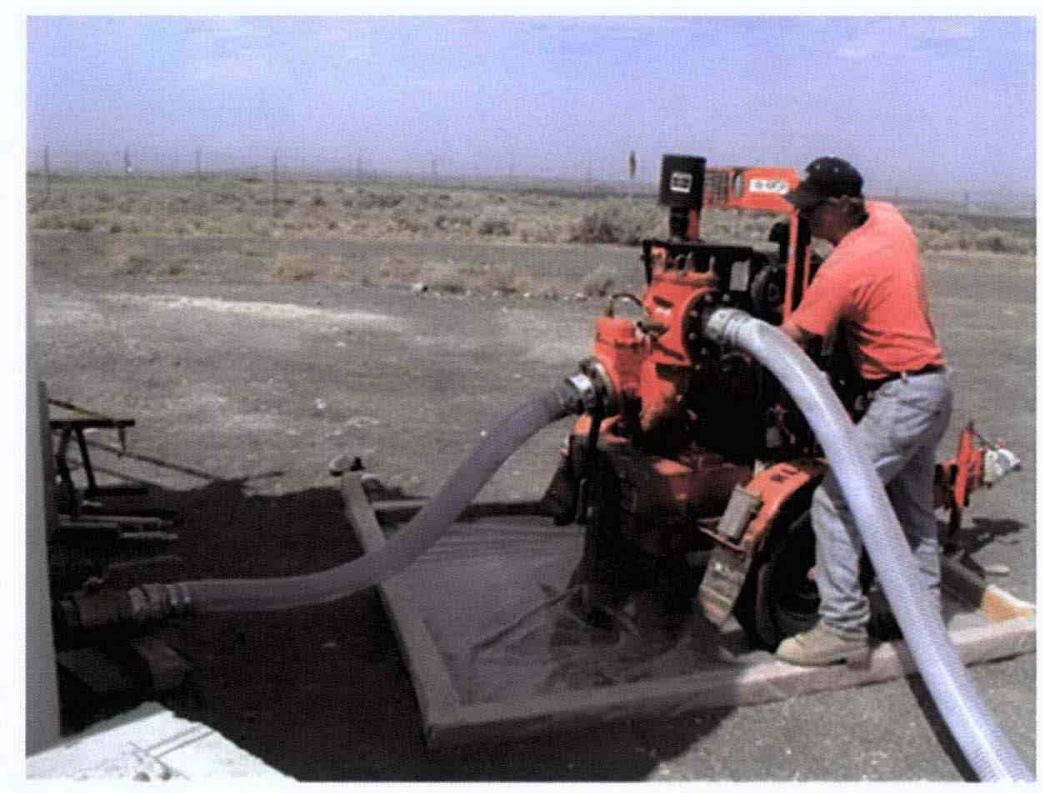

Photograph 6-3. Zero-Valent Iron Batch Mixing Pump

On July 10, 2008, notification was given that the injection of the ZVI would be delayed for approximately 3 weeks to finalize the regulatory documentation. Construction of the system resumed on August 5 , 2008 , with continued pipefitting work to fit and connect all hoses. Scaffolding was erected for each polytank to provide safe access to the entry port on the top of each tank, which would allow for placement of the nitrogen sparge lines on the tank bottoms and provide access to the injection solution for observation and QA/QC purposes. The electrical wiring and pipefitting was completed on August 7, after which a final leak check was performed on the tanks and piping system. During this check it was discovered that the HSMs did not develop sufficient suction to move the nZVI from the mixing tanks into the mixers. To remedy the problem, an HSM feed pump was installed to supply ZVI mix to the HSMs (Photograph 6-4).

The down-hole packer/pressure transducer system was lowered into the injection well on August 6, 2008, using a Hanford Site pump hoist truck (Photograph 6-5). The $0.9 \mathrm{~m}$ (3-ft)-long inflatable packer was set at the 22.7 to $23.7 \mathrm{~m}$ (74.6- to $77.6-\mathrm{ft})$ interval, which was approximately $0.73 \mathrm{~m}(2.4 \mathrm{ft})$ above the static groundwater level (Figure 6-1). A $1.5 \mathrm{~m}$ (5-ft) extension of pipe was attached to the bottom of the packer to extend the injection string below the static water level. An Instrumentation Northwest PT2X pressure transducer/ temperature data logger was installed below the packer and below the static water level to monitor down-hole pressures and temperatures. Once in position, the packer was inflated with compressed air to $111 \mathrm{psi}$ to form a positive well seal prior to startup of injection activities. 


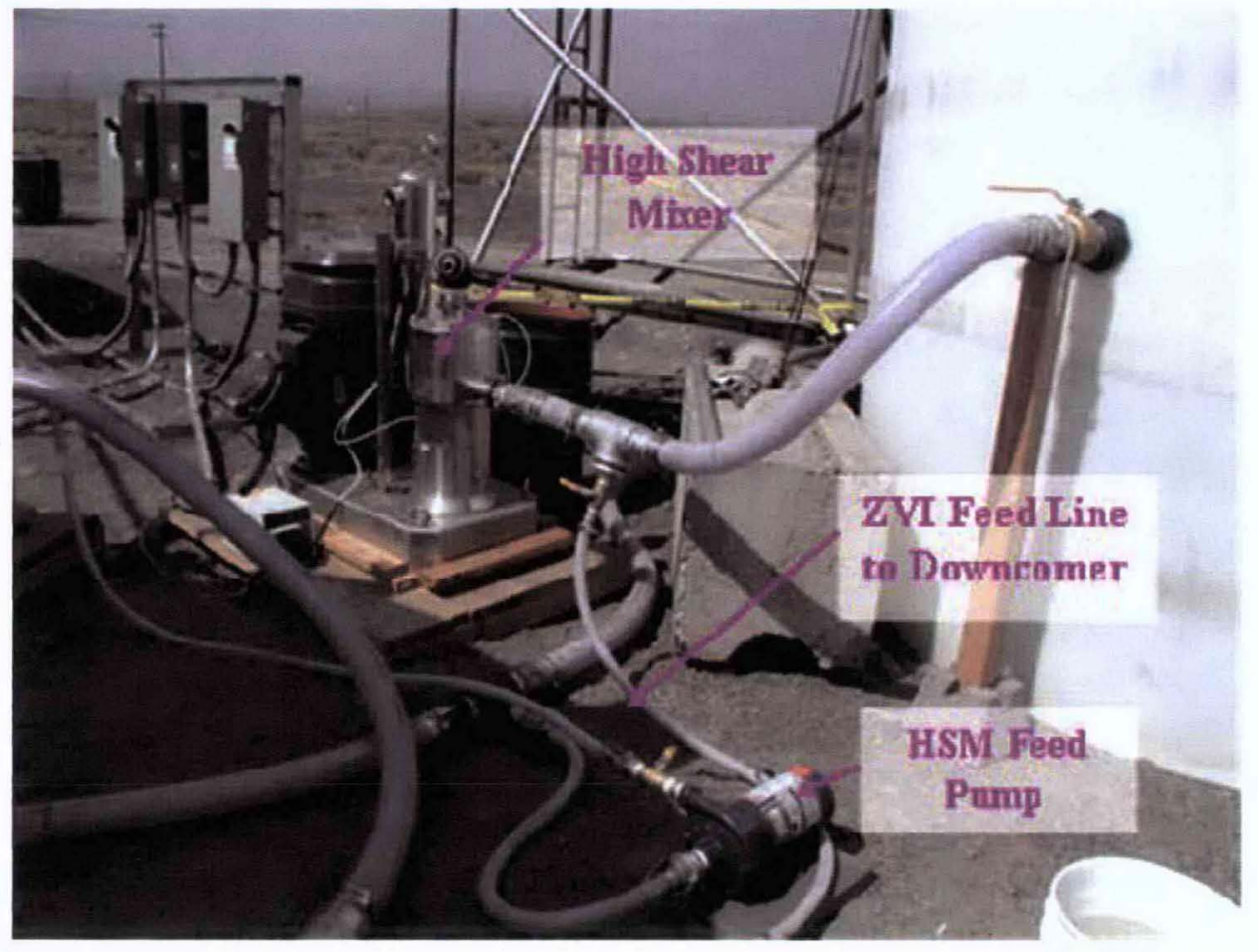

Photograph 6-4. High Shear Mixer Feed Pump

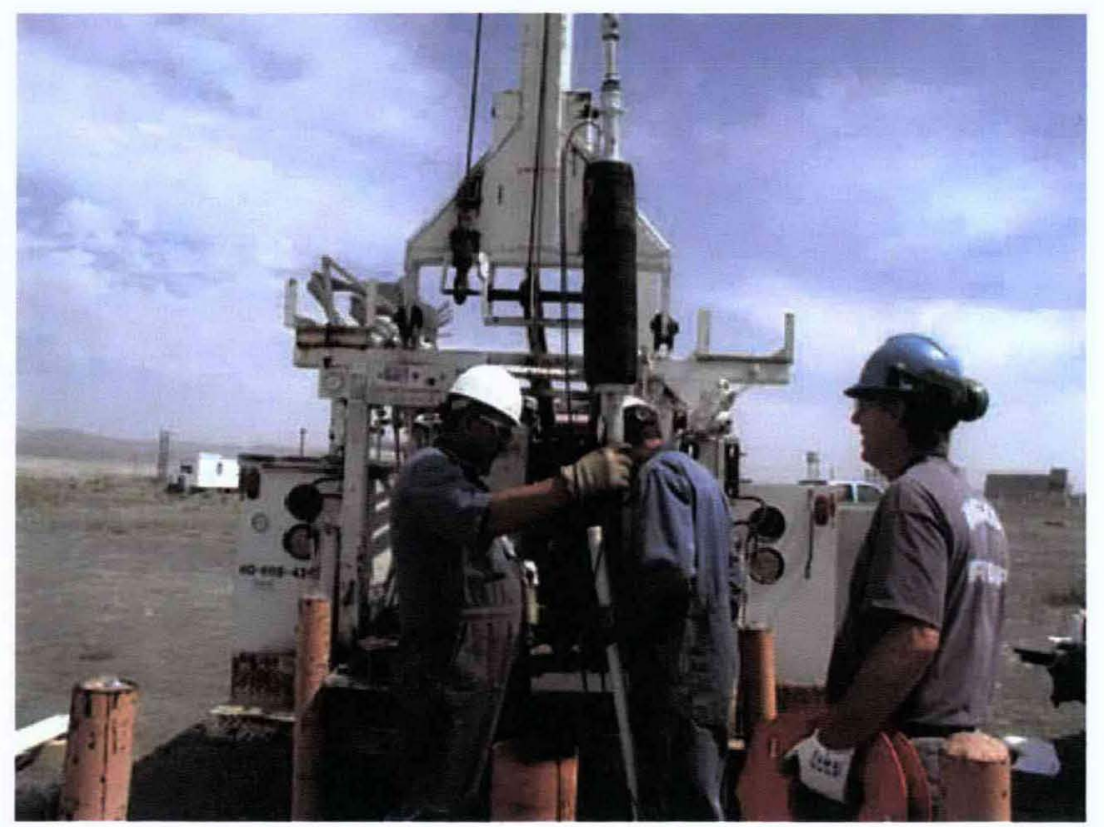

Photograph 6-5. Installation of the Injection Well Packer System 
DOE/RL-2009-35, REV. 0

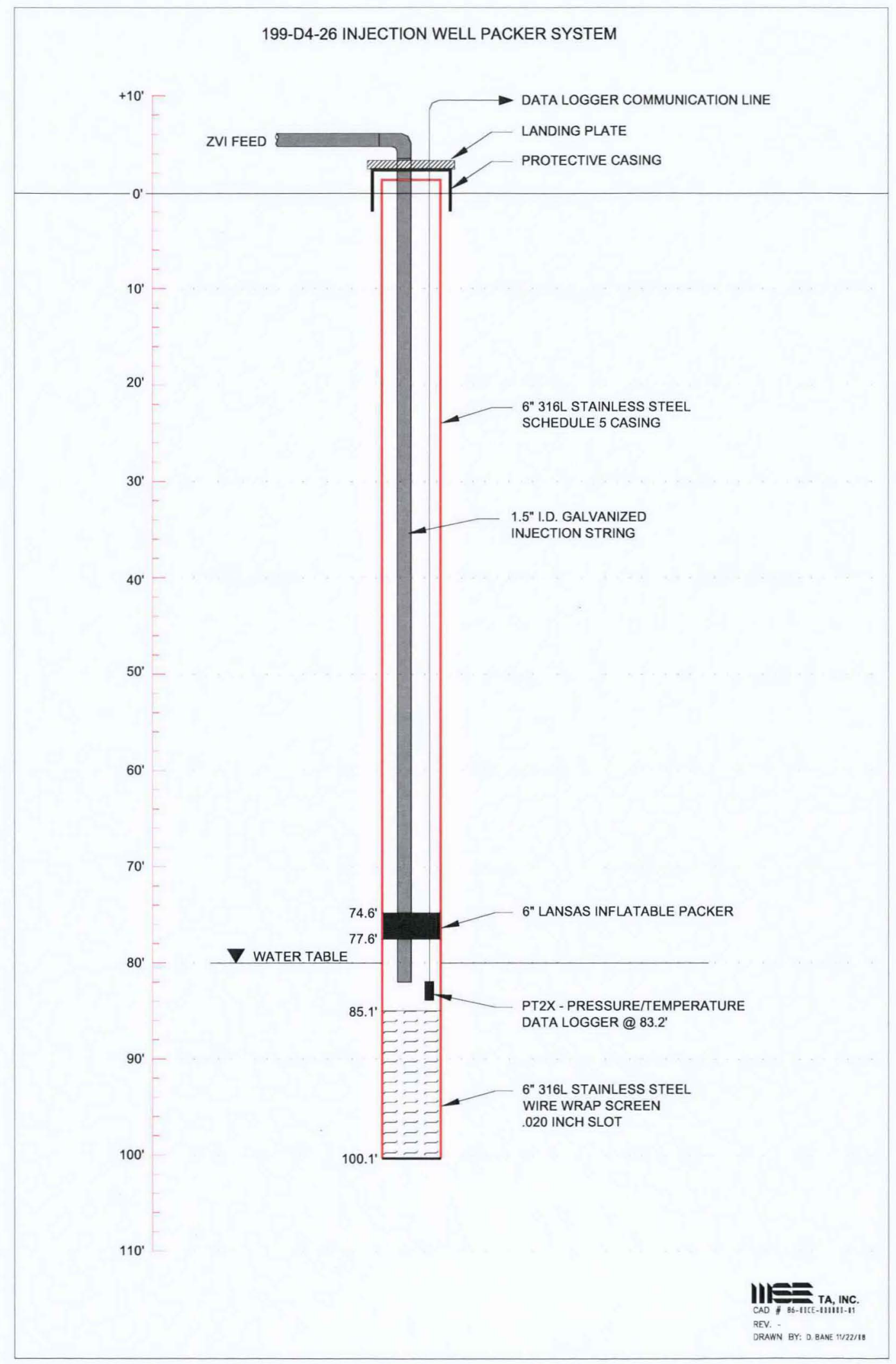

Figure 6-1. Injection Well Packer System 
During the last phase of construction, the field team began final preparations for mixing and injection. Flow meters were calibrated by pumping measured amounts of water through the instrument over a known period of time. The nitrogen supply was connected to the poly-tank sparging systems to create an inert atmosphere in the tanks. The injection system was completely operational by August 8, 2008.

\subsubsection{Pre-Injection Monitoring}

Monitoring data were collected before and after injection to determine the influence of the injected ZVI. Data were collected for groundwater monitoring, slug testing, and geophysical monitoring.

\subsubsection{Groundwater Monitoring}

Initial groundwater monitoring activities were conducted on August 6, 2008, at wells 199-D4-93, 199-D4-92, 199-D4-27, and 199-D4-25. From each monitoring well, groundwater was collected and sent to the onsite laboratory for analysis of arsenic, cadmium, fluoride, hexavalent chromium, iron, lead, manganese, molybdenum, nickel, nitrate, nitrite, phosphate, sulfate, and zinc. These samples were collected using submersible pumps. Initial field parameters were also measured at this time using the YSI 556 MPS multi-parameter probe. Down-hole transducers were installed in each of the monitoring wells on August 7, 2008. The transducers had the capability to monitor pressure, temperature, and specific conductivity. Table 6-1 shows the transducers that were installed and their distances from the injection well.

Table 6-1. Down-Hole Transducer Locations

\begin{tabular}{llcc}
\hline Well & $\begin{array}{c}\text { Transducer } \\
\text { Type }\end{array}$ & $\begin{array}{c}\text { Pressure Rating, } \\
\text { psi }\end{array}$ & $\begin{array}{c}\text { Distance from } \\
\text { Injection Well, } \mathbf{m}\end{array}$ \\
\hline $199-D 4-93$ & CT2X/PT2X & 30 & 3.2 \\
$199-D 4-92$ & CT2X/PT2X & 15 & 3.2 \\
$199-D 4-27$ & CT2X/PT2X & 15 & 13.0 \\
$199-D 4-25$ & CT2X/PT2X & 15 & 13.0 \\
$199-D 4-26$ & PT2X & 100 & - \\
\hline
\end{tabular}

psi $=$ pounds per square inch

Each transducer was programmed to collect data every 2 minutes, for a total of 15,000 data points. All of the CT2X sensors were calibrated for specific conductivity using a $1,413 \mu \mathrm{S} / \mathrm{cm}$ calibration solution. Pressure and temperature sensors were left at factory calibration. On August 7 at 09:00, all of the down-hole transducers were synchronized to the laptop computer clocks. During this synchronization, the transducers in monitoring wells 199-D4-92 and 199-D4-93 inadvertently changed to the default date of January 7, 2008, rather than the correct date of August 7. These dates have been adjusted appropriately for analysis.

\subsubsection{Pre-Injection Slug Tests}

In order to measure any permeability reduction in the aquifer due to the injection of nZVI, a series of vacuum slug tests were performed on injection well 199-D4-26 prior to installing the packer system initiating injection. The vacuum slug test technique is beneficial in testing wells completed in very permeable material. The technique can create large water-level displacements with little to no turbulence, making water-level measurements more accurate. A vacuum head attachment was placed on the $15.2 \mathrm{~cm}$ (6-in.) well casing, allowing a vacuum to be created inside the well, displacing the water level upward in 
the well. A pressure transducer/data logger system was placed in the well and connected to a laptop computer to record water levels during each test. A water-level indicator was also placed down the well to measure and confirm the initial water-level displacement caused by the vacuum.

On August 5, 2008, three slug tests were performed on the injection well where the water level was raised $3 \mathrm{~m}(10 \mathrm{ft})$. The water level displacement for each test was confirmed using a water-level indicator that was set $3 \mathrm{~m}(10 \mathrm{ft})$ above the static water level. When the water level was raised $3 \mathrm{~m}(10 \mathrm{ft})$, the water level indicator would activate and the vacuum adjusted as necessary to maintain the $3 \mathrm{~m}(10-\mathrm{ft})$ displacement. After water level stabilized, the data logger was set to record water levels at a rate of 10 times per second. The vacuum was then released using a $7.6 \mathrm{~cm}(3$-in.) ball valve, which created a falling head slug test within the well.

The data collected during each of the three vacuum slug tests were downloaded from the data logger and imported to a slug test software package to determine the permeability of the aquifer material.

\subsubsection{Geophysical Monitoring}

When using injected material to remediate a site, understanding the extent of the injection is important so additional treatments can be planned if necessary and to establish baseline conditions for long-term performance monitoring of the remedy. One option for determining the fate of an injected material is to monitor the injection using geophysical methods. This approach is potentially more cost effective and less invasive than.installing monitoring boreholes and also provides distributed measurements of subsurface properties.

Because injection of nano-scale materials into the subsurface is relatively rare, this injection presented a unique opportunity for researching strategies for monitoring of these types of injections in the future. The geophysical methods used in this test included electrical resistivity, IP, complex resistivity, mise a la masse electric potential field mapping, TEM, borehole electromagnetic induction, and total field and gradient magnetometry. Tables 6-2 and 6-3 provide a timeline for pre- and post-injection geophysical data acquisition, respectively. The results of this geophysical monitoring effort could provide a basis for designing and implementing similar data acquisitions at the Hanford Site and at other DOE sites as well. 
DOE/RL-2009-35, REV. 0

Table 6-2. Pre-Injection Timetable for Geophysical Data Acquisition

\begin{tabular}{c|c|l|l}
\hline $\begin{array}{c}\text { Date } \\
\text { Started }\end{array}$ & $\begin{array}{c}\text { Date } \\
\text { Completed }\end{array}$ & \multicolumn{1}{|c}{ Description } & \multicolumn{1}{c}{ Remarks } \\
\hline $6 / 29 / 08$ & $6 / 29 / 08$ & Magnetics & \\
\hline $6 / 30 / 08$ & $7 / 1 / 08$ & Resistivity/IP/complex resistivity & $\begin{array}{l}\text { Problems with transmitter encountered after } \\
\text { completing transmitter location 1-11 } \\
(41 \text { total). }\end{array}$ \\
\hline $7 / 11 / 08$ & $7 / 11 / 08$ & TEM & \\
\hline $8 / 1 / 08$ & $8 / 2 / 08$ & Resistivity/IP/complex resistivity & Transmitter locations 12-41. \\
\hline $8 / 3 / 08$ & $8 / 3 / 08$ & Mise a la masse & $\begin{array}{l}\text { Some stations were under the poly-tanks so } \\
\text { these were skipped. }\end{array}$ \\
\hline $8 / 6 / 08$ & $8 / 6 / 08$ & EM39 induction logging & \\
\hline $8 / 8 / 08$ & $8 / 14 / 08$ & ZVI injection & \\
\hline IP = induced polarization \\
TEM = time-domain electromagnetic \\
ZVI = zero-valent iron
\end{tabular}

Table 6-3. Post-Injection Timetable for Geophysical Data Acquisition

\begin{tabular}{c|c|l|l}
\hline $\begin{array}{c}\text { Date } \\
\text { Started }\end{array}$ & $\begin{array}{c}\text { Date } \\
\text { Completed }\end{array}$ & \multicolumn{1}{|c}{ Description } & \multicolumn{1}{c}{ Remarks } \\
\hline $8 / 8 / 08$ & $8 / 14 / 08$ & ZVI injection & \\
\hline $8 / 16 / 08$ & $8 / 16 / 08$ & EM39 induction logging & \\
\hline $8 / 16 / 08$ & $8 / 17 / 08$ & Resistivity/P/complex resistivity & \\
\hline $8 / 19 / 08$ & $8 / 19 / 08$ & Mise a la masse & $\begin{array}{l}\text { Same as previous; some stations were } \\
\text { skipped due to poly-tanks. }\end{array}$ \\
\hline $8 / 19 / 08$ & $8 / 19 / 08$ & TEM & \\
\hline $8 / 21 / 08$ & $8 / 21 / 08$ & Magnetics & \\
\hline IP $=$ & \\
TEM induced polarization $=$ time-domain electromagnetic \\
ZVI = zero-valent iron
\end{tabular}

\subsubsection{Injection Activities}

After the pre-injection inspection, the first batch of injection solution was prepared. All team members were onsite to observe and assist in preparing the initial batch. This allowed for final review of the injection scheme with all members while final issues were worked out of the system. Team members from the day and night crew were also able to standardize their respective practices and procedures during the initial batch. Injection of the first batch of RNIP-M2 began on August 8, 2008, at 16:09. After the injection started, two qualified crews, consisting of three personnel on each crew, operated the injection 
process 24 hours/day. The injection was successfully completed on August 13, 2008, at 22:01. Over a period of 5.25 days, a total of approximately $370,970 \mathrm{~L}(98,000 \mathrm{gal})$ of $1 \mathrm{wt} \%$ RNIP-M2 was injected into the high-permeability areas of the ISRM barrier.

During the injection process, a series of tasks were routinely performed to ensure successful operation of the process. These tasks can be summarized into five main areas:

- Injection solution preparation

- Tank change over procedure

- Injection performance monitoring

- Groundwater monitoring

- Equipment maintenance and site monitoring.

A general summary of each task as performed in the field is presented in the following subsections. The planned procedures were presented in Chapter 5; however, if a better procedure was developed during the injection it was documented and implemented. A complete summary of the variations from the treatability test plan is presented in Section 6.4.

\subsubsection{Injection Solution Preparation}

Two identical poly-tanks were used to inject the ZVI solution: one tank was used for injection, and the second tank was used to prepare the next batch of injection solution. The mixing process began shortly after each tank was emptied from an injection. The first step of the mixing process was to begin the addition of approximately 7,571 L (2,000 gal) of service water. The volume of water was measured by the two in-line flow meters installed in series. The water was fed into the injection tanks at a rate of approximately $170 \mathrm{~L} / \mathrm{min}(45 \mathrm{gpm})$. Before the water was added to the tanks, it passed through a 10-micron bag filter to remove any suspended solids that could have interfered with the mixing and injection process. After the initial volume of service water had been added to the tank and properly documented, the batch was ready for the addition of the concentrated RNIP-M2 solution. The RNIP-M2 was consolidated in an area surrounding the central transfer station, located between the barrels of RNIP-M2 and poly-tanks. Photograph 6-6 shows the transfer point during the mixing of a batch.

Each barrel of concentrated RNIP-M2 solution was mixed with a hand paddle after opening to resuspend any settled product. The concentrated ZVI solution was then pumped from the original barrel to a transfer barrel using a submersible pump. The product was weighed and recorded at the transfer station and then added to the mixing tank using an engine-driven centrifugal pump. The concentrated RNIP-M2 was added through a port in the side of the tank (located beneath the surface of the water to avoid any extra air exposure resulting from turbulence). Three barrels of concentrated RNIP-M2, containing approximately $475 \mathrm{~kg}$ of $18 \mathrm{wt} \%$ solids solution, were added to each batch of injection solution. After the addition of the concentrated ZVI solution, the transfer barrel was rinsed with service water to remove any excess iron remaining in the bottom of the barrel. Finally, the remaining amount of dilution water required to obtain the desired 1 percent solids RNIP-M2 injection solution was calculated and added to the mixing tank. 


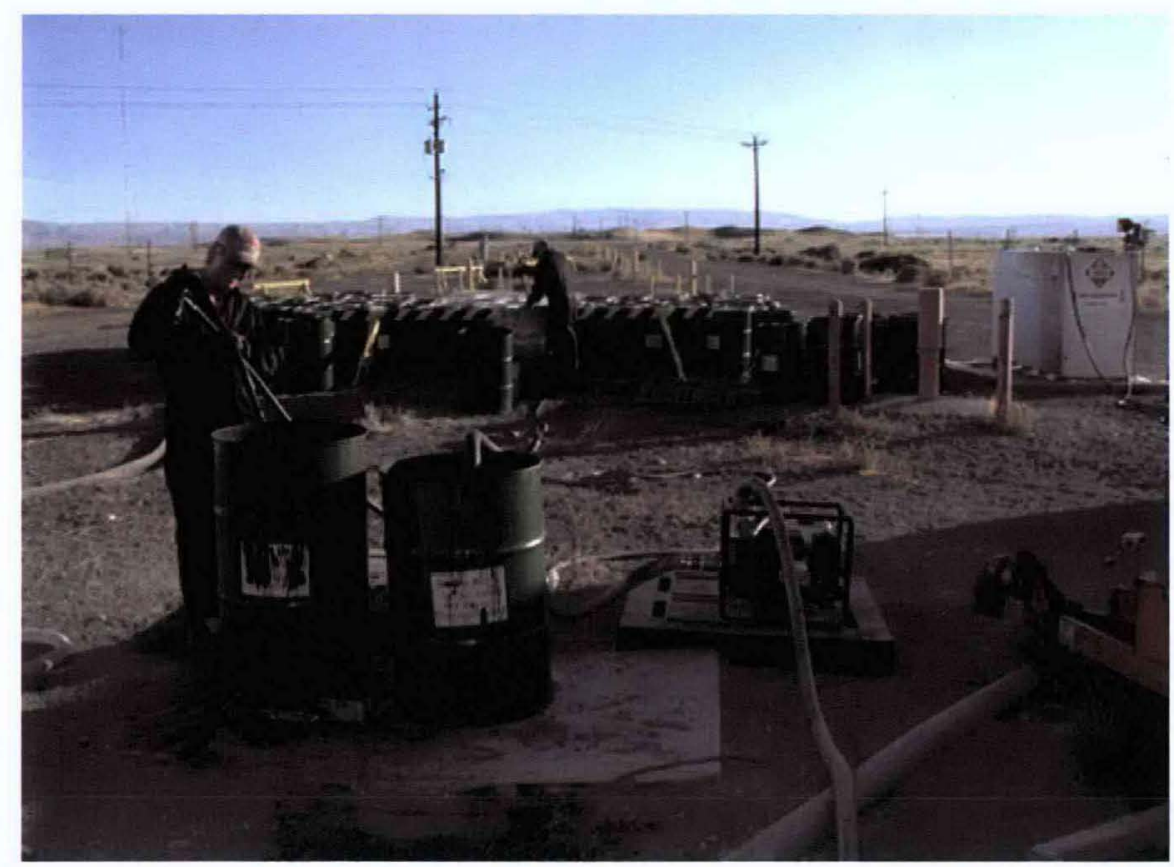

Photograph 6-6. Zero-Valent Iron Transfer Station

Each batch of injection solution was required to pass a QA/QC check before it was injected. The QA/QC check consisted of obtaining the specific conductivity of the injection solution through a sample port on the injection line or through an opening in the top of the tank and comparing it to the specific conductivity of a $1 \mathrm{wt} \%$ standard solution stored at ambient conditions. The batch was required to be within a RPD of 15 percent when compared to the standard solution for it to be acceptable to inject. The injection solution was kept in suspension within the poly-tanks through constant mixing from the nitrogen sparge points located in the bottom of the tanks. However, diesel-powered mixing pumps were also activated prior to injection and periodically during the injection to ensure that the ZVI solution was adequately suspended. Photograph 6-7 shows the nitrogen sparging of a tank containing only service water during the initial setup of the mixing process. The view is from the access port at the top of the tank.

At an injection rate of $53 \mathrm{~L} / \mathrm{min}$ (14 gpm), each batch of injection solution lasted roughly 3.5 hours, which provided sufficient time to prepare a batch before it was required for injection. This minimized the exposure time of the ZVI to the atmosphere.

\subsubsection{Tank Change-Over Procedure}

A change-over procedure was required to quickly transition from an empty injection tank to the tank containing a QA/QC-approved batch of injection solution. Once the injection tank ran dry, the HSM and HSM feed pump were shut down (see Photograph 6-4). The appropriate valves were closed to isolate the empty injection tank. The HSM was then connected to the full injection tank. Valves on the full injection tank were then opened and the injection solution was recirculated back into the tank through the HSM feed pump and HSM, which was set at $45 \mathrm{~Hz}$ using a variable-frequency drive. When everything was operational, the flow from the HSM was directed to the downcomer and adjusted to $53 \mathrm{~L} / \mathrm{min}$ (14 gpm). 


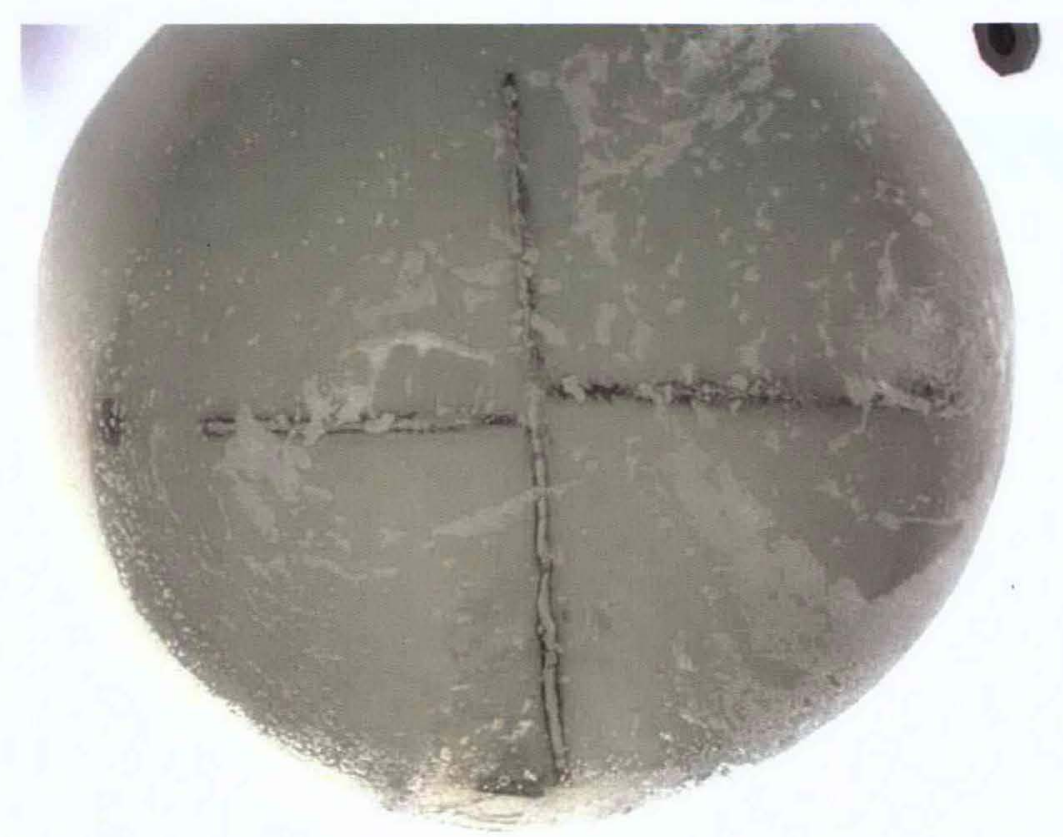

Photograph 6-7. Nitrogen Sparging of Water in Injection Tank

\subsubsection{Injection Monitoring}

A series of parameters were monitored to ensure proper operation of the injection system. The modeling of laboratory results determined that $53 \mathrm{~L} / \mathrm{min}(14 \mathrm{gpm})$ would be the optimum flow rate for the injection process. The flow rate was monitored and adjusted if found to vary using the flow control system pictured in Photograph 6-8. The flow control system measured the backpressure on the injection system, the total volume injected, and provided a port for sampling the injection solution. Manual recordings of the injection parameters were periodically recorded in the injection logbook.

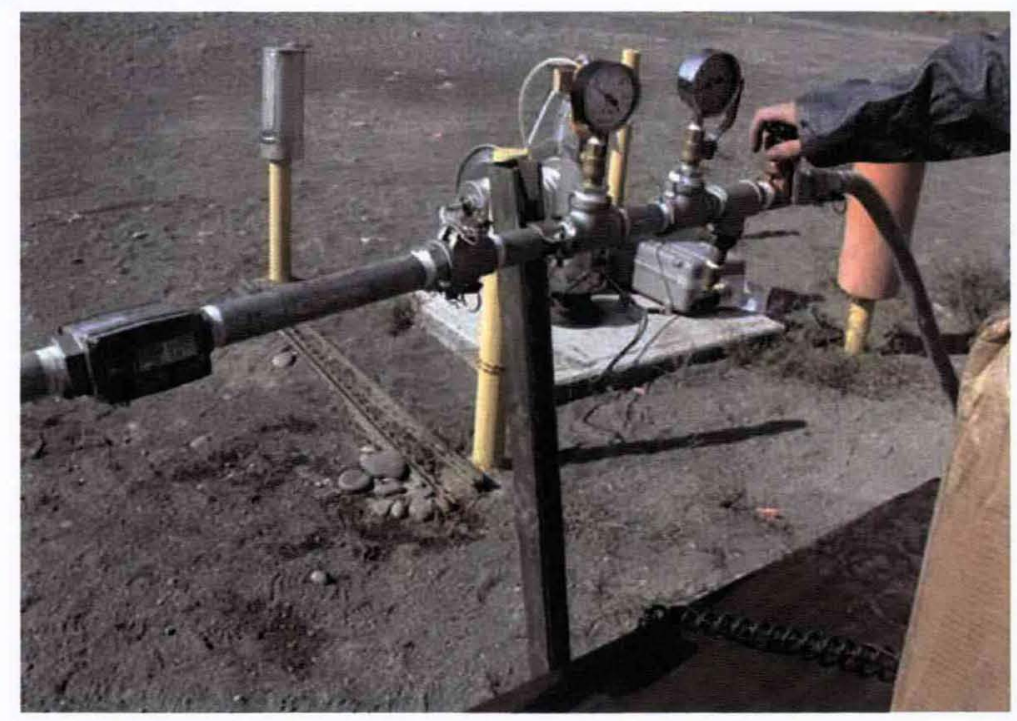

Photograph 6-8. Injection Flow Control System 
The down-hole pressure transducer in the injection well monitored pressure and temperature through a direct link to a computer, and served as an indicator of the formation's ability to accept the injection solution. Data from the transucer were downloaded to a laptop computer and transferred to a flash drive twice each day to create a backup of the data. Manual recordings of the down-hole data were also kept in the injection logbook.

To maintain the maximum reactivity of the ZVI, its contact with oxygen was limited by implementing a nitrogen blanket in both tanks. The oxygen levels inside the tanks were monitored by a series of three sampling ports installed at three levels on the sides of each tank. An oxygen meter was connected through silicon tubing to each port and the percent oxygen was measured at each level. The oxygen level was optimally maintained below 5 percent of atmospheric levels through the adjustment of nitrogen flow to the tank. Approximately 350 standard $\mathrm{ft}^{3} / \mathrm{hr}$ of nitrogen was supplied from the source to the two tanks. The rate of nitrogen consumption was tracked throughout the injection operation.

\subsubsection{Groundwater Monitoring}

During injection, four surrounding wells (199-D4-25, 199-D4-27, 199-D4-92, and 199-D4-93) were continuously monitored for pressure, temperature, and specific conductivity with down-hole transducers. These monitoring wells were also monitored with a surface YSI 556 MPS multi-parameter probe for $\mathrm{pH}$, DO, specific conductivity, ORP, and temperature approximately every 4 hours during injection. The YSI probe was calibrated every morning during the injection using water saturated air; $1,413 \mu \mathrm{S} / \mathrm{cm}$ solution; Zoebel's solution; and $\mathrm{pH}$ solutions of $4.01,7.00$, and 10.01 .

Groundwater samples for laboratory analysis were collected from the monitoring wells during injection after the influence of ZVI was apparent. The influence of ZVI was established by discoloration of the groundwater or a 50 percent increase in specific conductivity from baseline conditions. Once the influence of injection was observed, samples were collected twice each day from the effected monitoring well (i.e., once in the morning and once in the evening). Initially, water was drawn from the wells using a submersible pump, but due to pump failures, dedicated bailers were used the majority of the time for collection of both YSI probe parameters and samples for lab analyses.

\subsubsection{Geophysical Monitoring}

Geophysical monitoring during the injection was limited by the amount of equipment on the site and the efforts required in keeping the injection progressing smoothly. An attempt was made to log the PVCcased borehole using the EM-39 down-hole conductivity probe on the second day of the injection.

However, the tool could not be properly calibrated and no data were acquired. Later attempts to calibrate the tool led to the conclusion that it was temperature-sensitive and required a long time to equilibrate prior to calibration. Ideally, the tool would have been calibrated and then left suspended in the borehole above the water table to minimize temperature fluctuations. Unfortunately, this interfered with the requirement to take frequent fluid samples and water-level measurements from the borehole and, thus, was not feasible.

\subsubsection{Equipment Maintenance and System Monitoring}

Routine maintenance and site monitoring was required to maintain safe and proper operation of the ZVI injection process. These tasks were performed as needed, which included the following.

- Fueling of the light plants, generator, and engine driven pumps

- Maintaining pressure in the injection packer

- Maintaining the HSMs

- Maintaining proper drive belt tension 
- Greasing the motor bearings

- Maintaining adequate seal pot pressure

- Maintaining a safe and clean work area

- Securing of empty RNIP-M2 barrels and pallets

- Consolidating and disposing solid waste

- Inspecting the scaffolding.

\subsubsection{Post-Injection Monitoring}

Monitoring data were collected after injection to compare to the pre-injection data. Changes in the data from pre-to post-injection were determined to result from the injection. As in the pre-injection, data were collected in the three following areas: groundwater monitoring, slug testing, and geophysical monitoring.

\subsubsection{Groundwater Monitoring}

Groundwater samples and monitored water quality parameters were collected for 10 days following the completion of the injection. All post-injection samples were retrieved with dedicated bailers. Samples from wells 199-D4-92 and 199-D4-93 were collected every day, and samples from wells D4-25 and D427 were collected every other day during the 10-day period. The down-hole transducers continued to collect data for approximately 1.5 days after the injection was completed.

\subsubsection{Post-Injection Slug Tests}

The post-injection vacuum slug tests on injection well 199-D4-26 were completed on August 15, 2008. The same setup used for the pre-injection vacuum slug testing (described in Section 6.1.2.2) was used for post-injection testing. Two vacuum slug tests were performed on the well to obtain permeability data after injection of the ZVI material. The two post-injection slug tests attempted to re-create the $3 \mathrm{~m}$ ( 10 - $\mathrm{ft})$ water-level displacements created during pre-injection testing. However, the residual ZVI in the well interfered with the water-level indicator, causing it to sound continuously when ZVI material accumulated on the probe. To overcome the problem, a vacuum gauge was used to estimate the water level rise in the well. Reasonably good data were acquired from both tests, which were downloaded to a computer for analysis.

\subsubsection{Geophysical Monitoring}

The post-injection geophysical data were collected in the same manner as the pre-injection data (described in Appendix D). Post-injection data were collected as consistently as possible with the preinjection data to eliminate or reduce survey noise. A schedule of the post-injection data collection is presented in Table 6-3.

\subsubsection{Site Tear Down and Cleanup}

Tear down of the injection equipment and clean up of the site began immediately following completion of the ZVI injection. Actual decommissioning of the system components was performed by the various Hanford Site craft groups (including pipefitters, carpenters, electricians, teamsters, operators, and laborers) under the direction of subcontractor personnel. Site contractor personnel were responsible for the proper disposal of solid waste associated with the injection process. The subcontractor was responsible for removing and disposing the RNIP-M2 shipping drums and the ZVI mixing tanks. All of the equipment was removed offsite by August 21, 2008. 


\subsection{Data Analysis and Interpretation}

During the injection activities, data were collected to monitor the progress and success of the field injection. This information is presented and discussed below; complete data and results are presented in Appendix D. All work performed and data collected were by properly trained personnel.

\subsubsection{Injection Monitoring}

The pressure and temperature in the injection well were continuously monitored during the ZVI injection using a down-hole transducer. The transducer was installed to monitor buildup of pressure in the injection well, which would be an indicator of plugging of the formation. Figure 6-2 shows the logged pressure results for the injection well. The primary axis shows the pressure as recorded from the transducer (in psi), while the secondary axis presents the data in feet of water (corrected for the density of the injection solution).

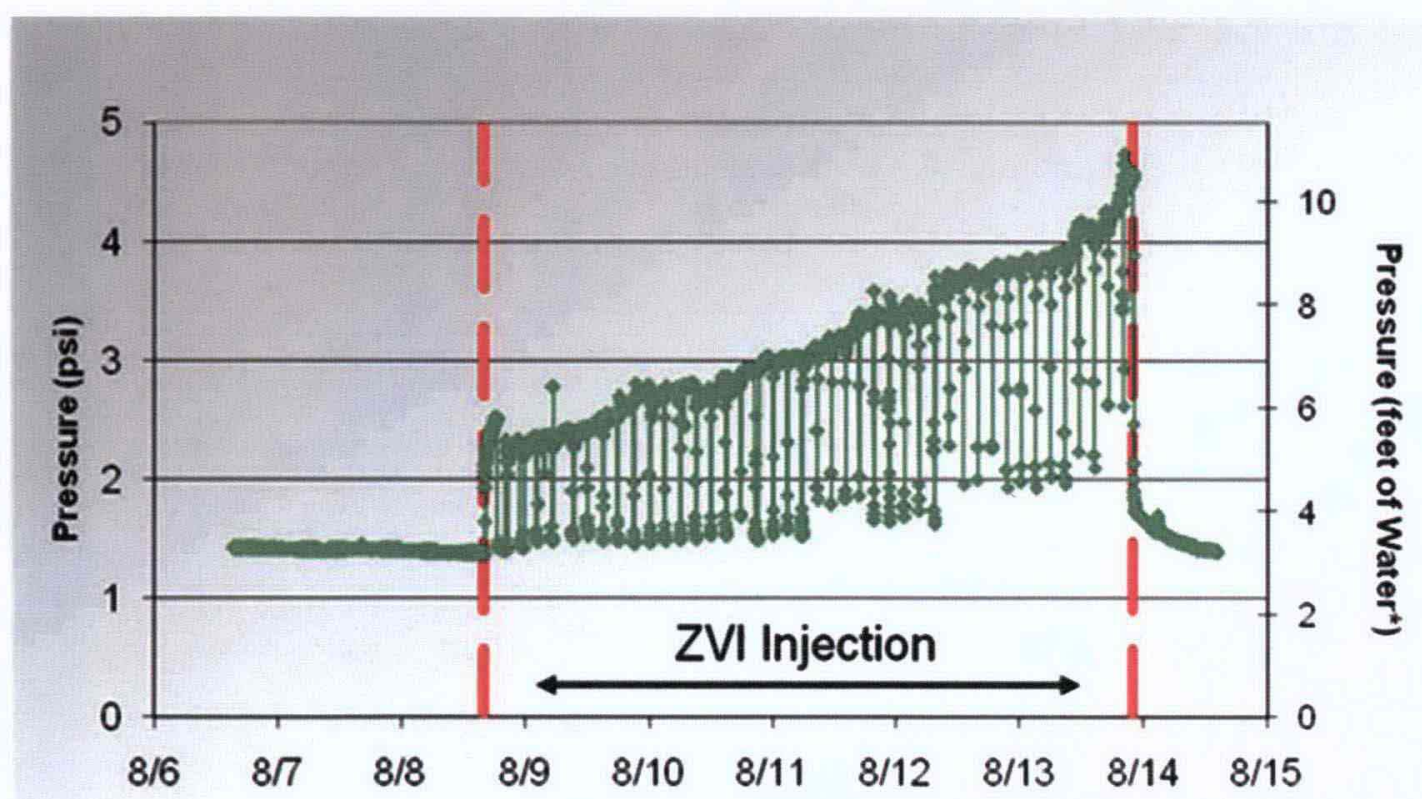

NOTE: Density of zero-valent iron corrected to that of water.

Figure 6-2. Injection Well (D4-26) Pressure Mounding During Zero-Valent Iron Injection

As shown in Figure 6-2, there was a steady increase in pressure throughout the injection. During the injection, the initial formation entry pressure was approximately $0.75 \mathrm{psi}$. By the end of the injection the pressure had risen to approximately 2.5 psi. Also shown in Figure 6-2 is a regular sudden decrease in pressure that was observed throughout the injection. This corresponds to the batch change over process during which the ZVI injection had to be paused for a short period of time while the change-over process was completed.

The temperature recorded by the down-hole probe in the injection well during the ZVI injection is presented in Figure 6-3. 


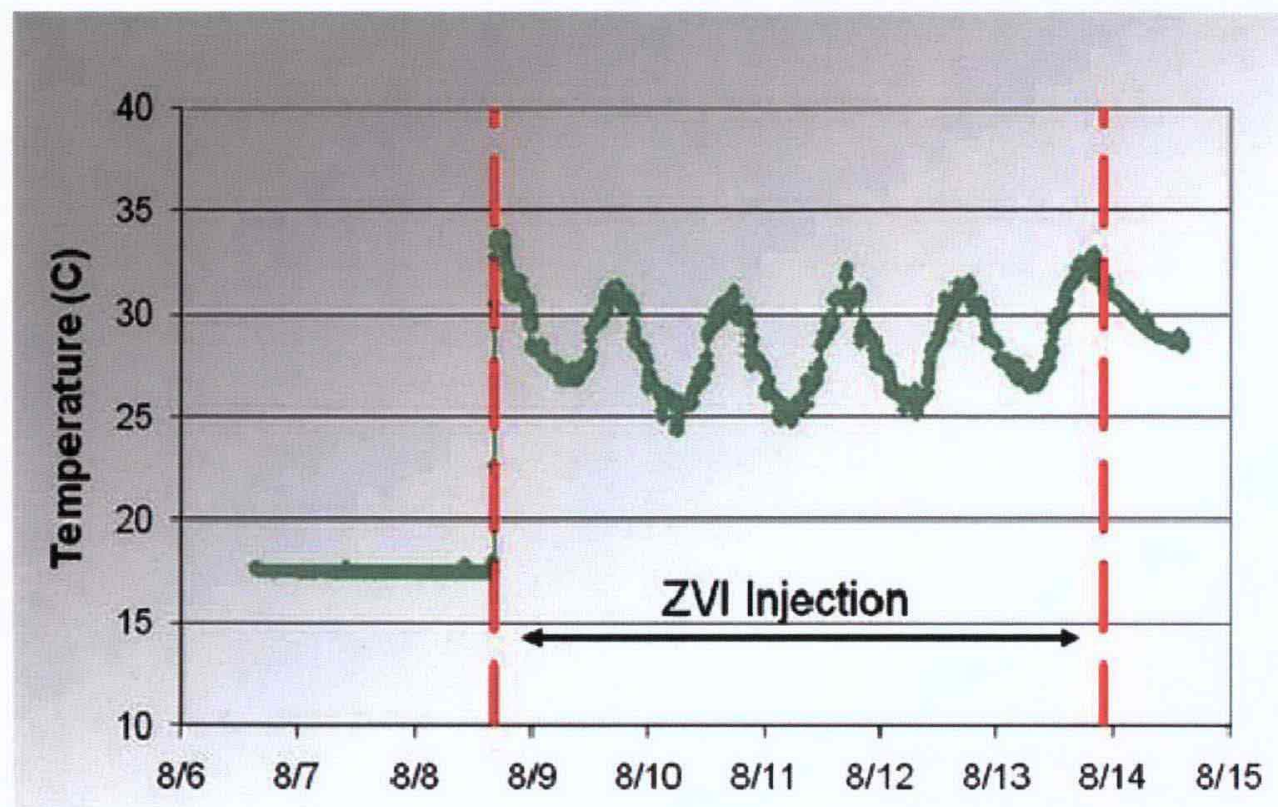

Figure 6-3. Injection Well (199-D4-26) Temperature During Injection

Groundwater temperatures were very stable; however, as shown in Figure 6-3, a distinct diurnal fluctuation in temperature of more than $5^{\circ} \mathrm{C}\left(41^{\circ} \mathrm{F}\right)$ is apparent during the ZVI injection. The injection well temperature fluctuation corresponds to the change in temperature of the injection solution (presented in Table 6-4), which was directly related to the surface ambient conditions (ranging from approximately 15 to $38^{\circ} \mathrm{C}\left(59\right.$ to $\left.100^{\circ} \mathrm{F}\right)$ at the time of injection

\subsubsection{Nano-Sized Zero-Valent Iron Quality Control and Quality Assurance Data and Analysis}

As part of the QA/QC process, the specific conductivity of the ZVI injection slurry and a 1 percent solid standard solution at ambient conditions were measured prior to injection. The injection slurry was required to be within a RPD range of 15 percent when compared to the $1 \mathrm{wt} \%$ solids standard. If the injection solution was found to be outside the allowable RPD range, additional dilution water or RNIPM2 would be added until the proper proportions were achieved. The RPD was calculated using Equation 5-3:

$$
R P D=\frac{X_{1}-X_{2}}{\bar{X}} \times 100 \%
$$


Table 6-4. Quality Assurance/Quality Control Measurements for Zero-Valent Iron Injection Slurry

\begin{tabular}{|c|c|c|c|c|c|c|c|c|c|c|c|}
\hline Batch & $\begin{array}{c}\mathrm{SC}, \\
\mu \mathrm{S} / \mathrm{cm}\end{array}$ & $\begin{array}{l}\mathrm{T}, \\
{ }^{\circ} \mathrm{C}\end{array}$ & $\begin{array}{l}\text { SC std } \\
\mu S / \mathrm{cm}\end{array}$ & $\begin{array}{c}\mathrm{T} \\
{ }^{\circ} \mathrm{C}\end{array}$ & $\begin{array}{c}\text { RPD } \\
\%\end{array}$ & Batch & $\begin{array}{c}\mathrm{SC} \\
\mu \mathrm{S} / \mathrm{cm}\end{array}$ & $\begin{array}{l}\mathrm{T} \\
{ }^{\circ} \mathrm{C}\end{array}$ & $\begin{array}{l}\text { SC std } \\
\mu S / \mathrm{cm}\end{array}$ & $\begin{array}{l}\mathrm{T} \\
{ }^{\circ} \mathrm{C}\end{array}$ & $\begin{array}{c}\text { RPD } \\
\%\end{array}$ \\
\hline 1 & 1065 & 35.3 & 1102 & 39.4 & $3.41 \%$ & 23 & 1048 & 26.3 & 1095 & 41.6 & $4.39 \%$ \\
\hline 2 & 1070 & 29.9 & 1062 & 26.9 & $0.75 \%$ & 24 & 1065 & 28.4 & 1086 & 38.5 & $1.95 \%$ \\
\hline 3 & 1046 & 25.3 & 1053 & 24.1 & $0.67 \%$ & 25 & 1056 & 28.2 & 1095 & 42.1 & $3.63 \%$ \\
\hline 4 & 1056 & 24.8 & 1031 & 19.6 & $2.40 \%$ & 26 & 1064 & 27.2 & 1074 & 34.9 & $0.94 \%$ \\
\hline 5 & 1053 & 23.8 & 1025 & 18.1 & $2.69 \%$ & 27 & 1068 & 25.1 & 1034 & 22.4 & $3.24 \%$ \\
\hline 6 & 1195 & 26.9 & 1059 & 24.8 & $12.07 \%$ & 28 & 998 & 24.1 & 1024 & 17.9 & $2.57 \%$ \\
\hline 7 & 1199 & 32.3 & 1069 & 30.3 & $11.46 \%$ & 29 & 984 & 23.3 & 1009 & 15.2 & $2.51 \%$ \\
\hline 8 & 1033 & 32.8 & 1083 & 36.2 & $4.73 \%$ & 30 & 1035 & 23.5 & 1010 & 16.1 & $2.44 \%$ \\
\hline 9 & 1018 & 30.2 & 1070 & 30.6 & $4.98 \%$ & 31 & 1066 & 26.1 & 1091 & 38.3 & $2.32 \%$ \\
\hline 10 & 1080 & 25.2 & 1043 & 23 & $3.49 \%$ & 32 & 1058 & 27.3 & 1101 & 45 & $3.98 \%$ \\
\hline 11 & 1057 & 21.8 & 1028 & 17.9 & $2.78 \%$ & 33 & 999 & 28.6 & 1055 & 29 & $5.45 \%$ \\
\hline 12 & 1045 & 22.3 & 1011 & 16.1 & $3.31 \%$ & 34 & 1047 & 28.2 & 1037 & 24.2 & $0.96 \%$ \\
\hline 13 & 1032 & 19 & 1055 & 15.2 & $2.20 \%$ & 35 & 1060 & 26.7 & 1035 & 23.7 & $2.39 \%$ \\
\hline 14 & 1061 & 26.2 & 1057 & & $0.38 \%$ & 36 & 1055 & 25.7 & 1048 & 23.2 & $0.67 \%$ \\
\hline 15 & 1061 & 29.1 & 1088 & 38.8 & $2.51 \%$ & 37 & 1022 & 25 & 1030 & 22.1 & $0.78 \%$ \\
\hline 16 & 1058 & 28 & 1052 & 31.3 & $0.57 \%$ & 38 & 1019 & 19.2 & 1035 & 24.5 & $1.56 \%$ \\
\hline 17 & 1063 & 27.7 & 1068 & 32.3 & $0.47 \%$ & 39 & 1030 & 24.8 & 1049 & 30.1 & $1.83 \%$ \\
\hline 18 & 1060 & 25.9 & 1031 & 21.2 & $2.77 \%$ & 40 & 1060 & 27.2 & 1066 & 32.4 & $0.56 \%$ \\
\hline 19 & 1050 & 24.3 & 1028 & 16.9 & $2.12 \%$ & 41 & 1070 & 28.8 & 1056 & 26.8 & $1.32 \%$ \\
\hline 20 & 1109 & 23.7 & 1017 & 15.4 & $8.65 \%$ & 42 & 1030 & 29.8 & 1040 & 25.2 & $0.97 \%$ \\
\hline 21 & 1031 & 23.1 & 1005 & 13.1 & $2.55 \%$ & 43 & 1010 & 29.6 & 1054 & 33.5 & $4.26 \%$ \\
\hline 22 & 1056 & 24.1 & 1067 & 28.2 & $1.04 \%$ & & & & & & \\
\hline RPD & \multicolumn{11}{|c|}{$=$ relative percent different } \\
\hline SC & \multicolumn{11}{|c|}{$\begin{array}{l}=\text { relative percent ditierent } \\
=\text { specific conductivity }\end{array}$} \\
\hline SC std & \multicolumn{11}{|c|}{$=$ specific conductivity (standard) } \\
\hline $\mathrm{T}$ & \multicolumn{11}{|c|}{$=$ temperature } \\
\hline
\end{tabular}


Specific conductivity measurements were taken with a dedicated specific conductivity meter. Table 6-4 lists QA/QC results for each injection solution batch. All of the batches were within the RPD requirement for specific conductivity and, therefore, did not need additional modification.

Complete mixing data are provided in Appendix D.

\subsubsection{Injection Tank Oxygen Monitoring}

To preserve the reactive life of the ZVI material, the oxygen was purged from the injection mixing tanks throughout testing using a nitrogen blanket. The initial oxygen was purged from the ZVI mixing tanks before the start of injection and was maintained below 4 percent atmospheric oxygen concentration for most of the testing. The spike in the oxygen level (labeled in Figure 6-4) is the result of a malfunction in the primary oxygen meter. When the primary oxygen meter failed, a backup meter was briefly used, which was not as accurate. The primary oxygen meter was reset and functioned properly for the remainder of testing.

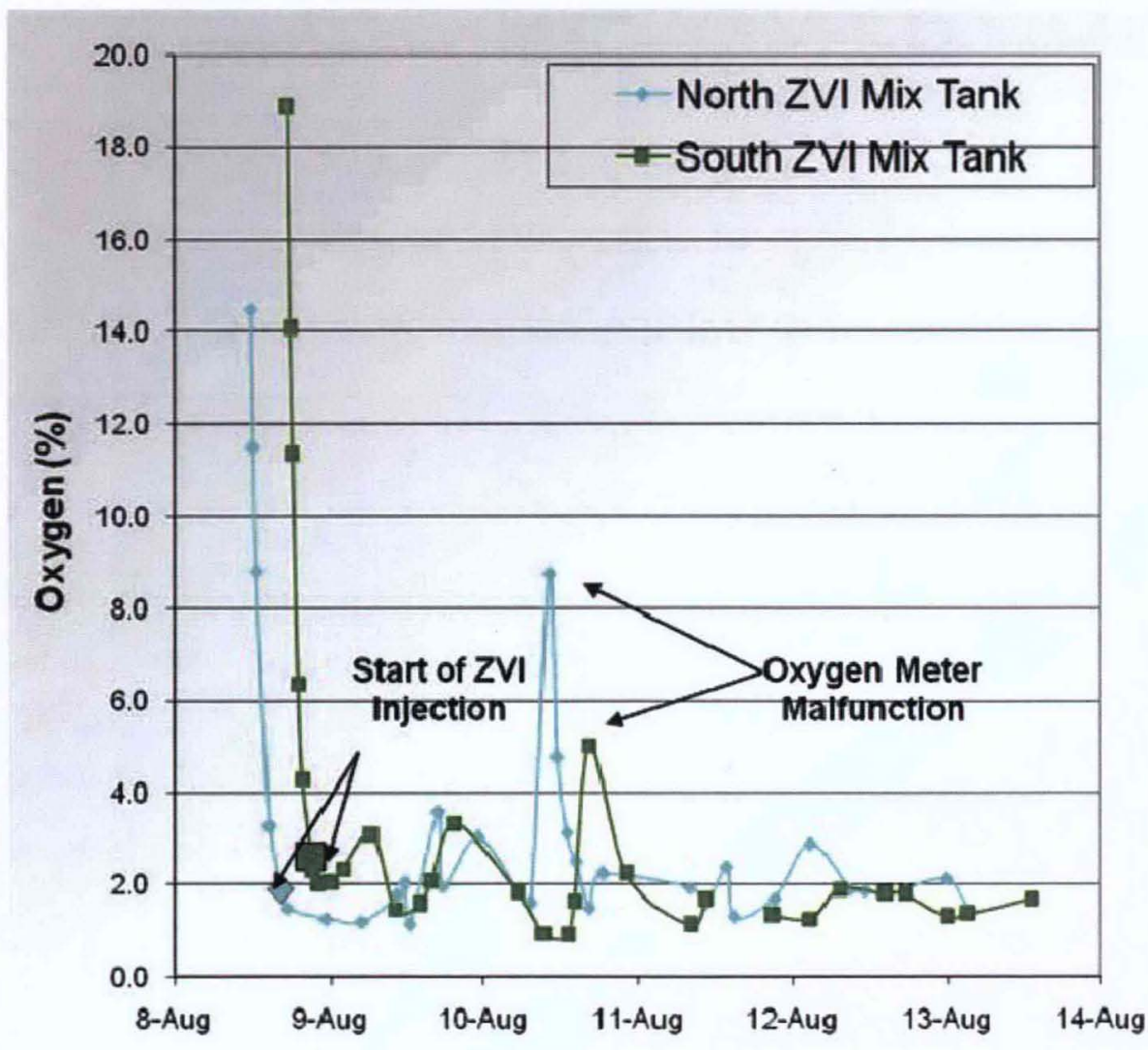

Figure 6-4. Zero-Valent Iron Mixing Tank Oxygen Monitoring

\subsubsection{Groundwater Monitoring}

The four surrounding wells (199-D4-25,199-D4-27, D4-92, and 199-D4-93) were continuously monitored for pressure, temperature, and specific conductivity using down-hole transducers. The monitoring wells and their relation to the injection well are shown in Figure 6-5. 


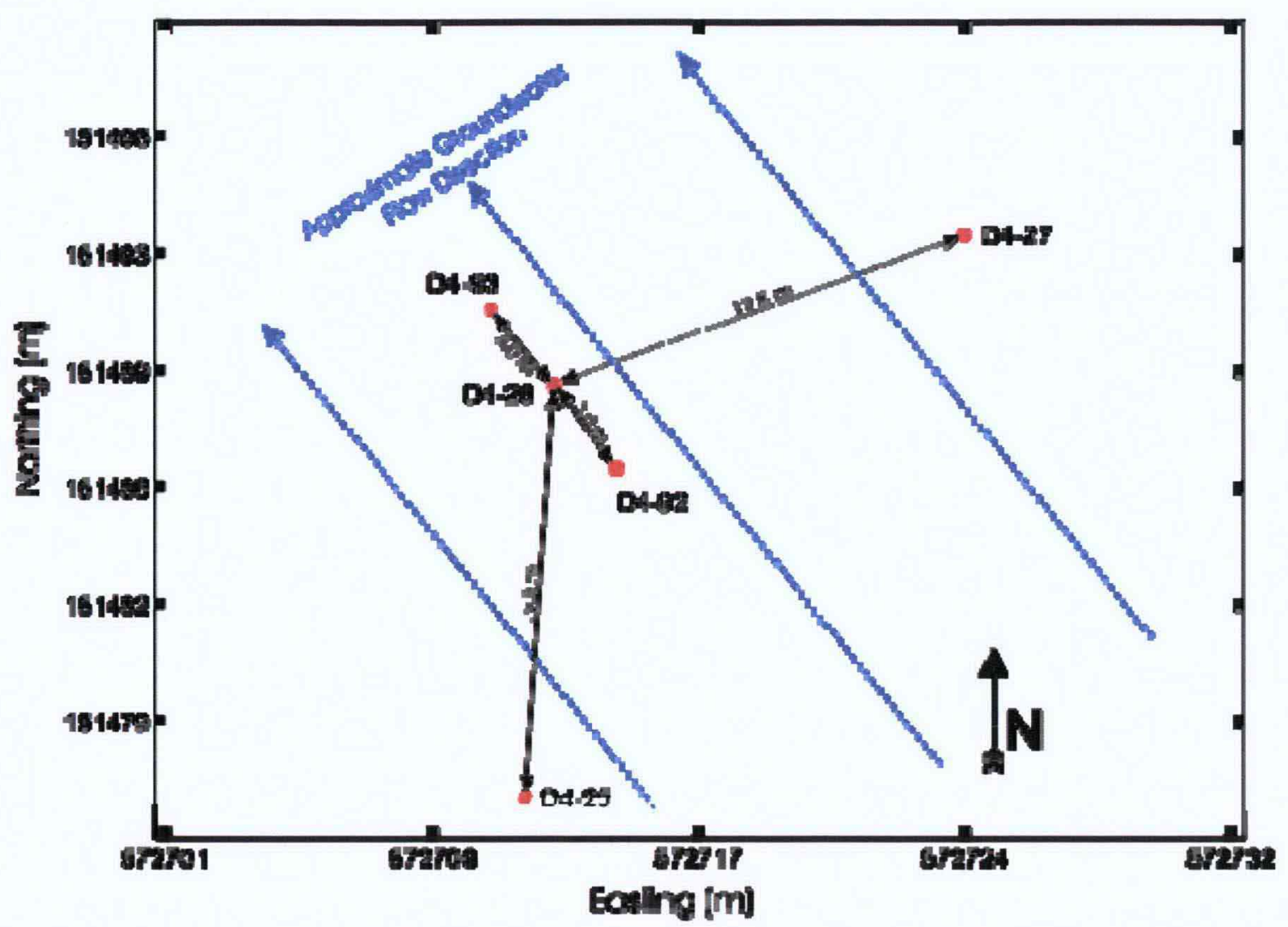

Figure 6-5. Monitoring Well Locations

Figure 6-6 shows the change in pressure (or mounding) during injection for each monitoring well. As expected, the downgradient injection well closest to the injection well (199-D4-93) was the first monitoring well to be influenced by the injection and showed the largest increase in pressure.

Well 199-D4-92 (upgradient of the injection well) was the next well to be influenced by the injection, showing a steady increase in pressure, with a steeper increase the final day of injection. The sudden drops in pressure during the injection period correspond to the batch change over process during which the ZVI injection had to be paused briefly while the change-over process was completed. The two farthest monitoring wells (199-D4-25 and 199-D4-27) showed only minor effects from the ZVI injection. These results are similar for each of the field parameters measured (Figures 6-7 and 6-8).

After injection was completed, all of the monitoring wells quickly returned to near-baseline conditions. The sudden decreases in pressure below baseline conditions can be attributed to the collection of samples for the surface measured field parameters. The decreases are more notable in well 199-D4-93, as a submersible pump was used for the collection of the samples, where as bailers were used in the other monitoring wells. 
DOE/RL-2009-35, REV. 0

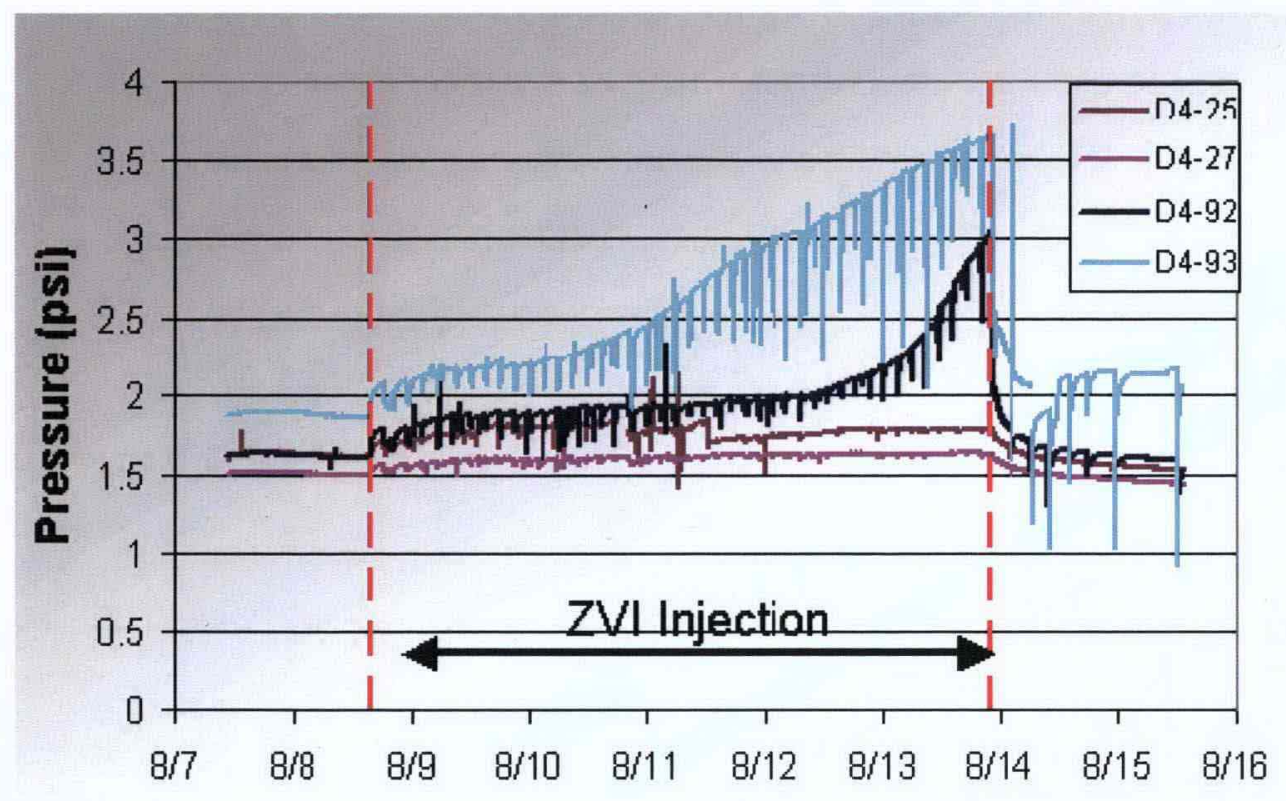

Figure 6-6. Monitoring Well Pressure-Down-Hole Measurement

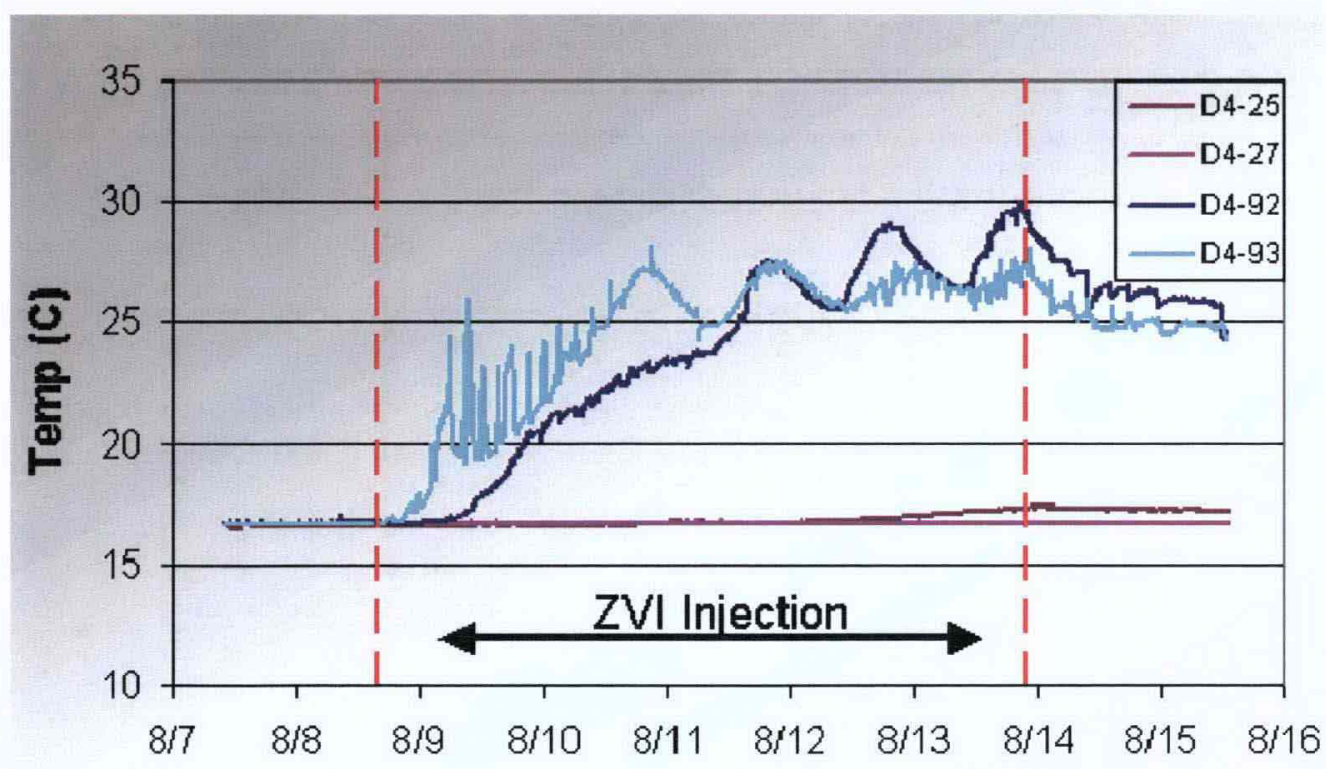

Figure 6-7. Monitoring Well Temperature-Down-Hole Measurement 


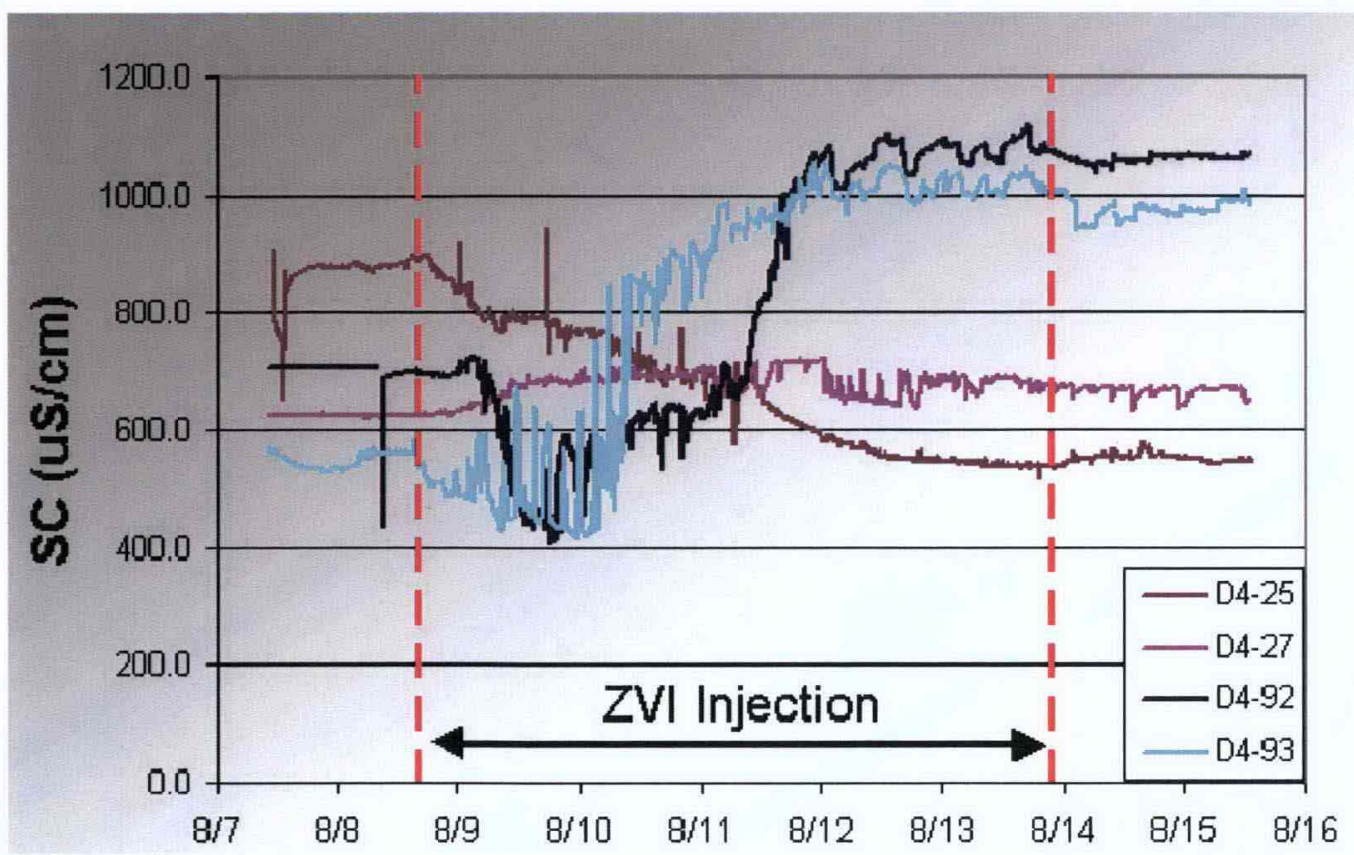

Figure 6-8. Monitoring Well Specific Conductivity-Down-Hole Measurement

The temperature difference between the injection solution and the groundwater provided an excellent indicator for the influence of the injection solution. As shown in Figure 6-7, monitoring well 199-D4-93 was the first well to be influenced by the injection solution, followed by monitoring well 199-D4-92. Visual observations of the color of the monitoring well samples indicated that monitoring well 199-D4-25 began to show some influence from the injection toward the end of injection while monitoring well 199-D4-27 visually showed no influence. This is clearly supported by the slight change in temperature in well 199-D4-25 and the lack of change in well 199-D4-27.

As shown in the laboratory testing (Section 4.3), the polymer associated with RNIP-M2 significantly increases the conductivity of the solution. The down-hole conductivity measurements generally follow the expected trend; monitoring wells 199-D4-93 and 199-D4-92 showed an early increase in specific conductivity while the specific conductivity in monitoring well 199-D4-27 remained relatively constant. However, the specific conductivity in monitoring well 199-D4-25 actually decreased over the injection period.

The four surrounding wells were monitored at the surface using a YSI 556 MPS multi-parameter probe for field parameters, including temperature, $\mathrm{DO}, \mathrm{pH}$, specific conductivity, and ORP. These field parameters were used to monitor the progress of injection. Initially, water was drawn from the wells using submersible pumps, but due to pump failure, hand bailers were used the majority of the time. Tables 6-5 through 6-8 present the field parameter for each well, and Figures 6-9 through 6-13 display the individual field parameters collected during injection. 
DOE/RL-2009-35, REV. 0

Table 6-5. 199-D4-25 Field Parameters (Surface Measurement)

\begin{tabular}{|c|c|c|c|c|c|c|c|c|}
\hline $\begin{array}{l}\text { Datel } \\
\text { Time }\end{array}$ & $\begin{array}{c}\text { Elapsed } \\
\text { Days }\end{array}$ & $\begin{array}{l}\text { Elapsed } \\
\text { Hours }\end{array}$ & $\begin{array}{l}\text { Sample } \\
\text { Collection } \\
\text { Method }\end{array}$ & $\underset{{ }^{\circ} \mathrm{C}}{\text { Temp., }}$ & $\begin{array}{l}\text { DO, } \\
\text { mg/L }\end{array}$ & $\begin{array}{l}\text { pH, } \\
\text { su }\end{array}$ & $\begin{array}{c}\mathrm{SC} \\
\mu \mathrm{S} / \mathrm{cm}\end{array}$ & $\begin{array}{c}\text { ORP, } \\
\text { mV }\end{array}$ \\
\hline 8/9/08 0:52 & 0.00 & 0.00 & Purged & 17.58 & 6.41 & 8.12 & 1022 & 110.2 \\
\hline 8/9/08 10:47 & 0.41 & 9.92 & Flow cell & 17.48 & 4.38 & 8.29 & 993 & -21.9 \\
\hline 8/9/08 13:27 & 0.52 & 12.58 & Flow cell & 17.68 & 3.97 & 8.35 & 963 & -4.8 \\
\hline 8/9/08 17:55 & 0.71 & 17.05 & Flow cell & 17.36 & - & 8.33 & 944 & -2.7 \\
\hline $8 / 9 / 0821: 43$ & 0.87 & 20.85 & Purged & 16.97 & 3.56 & 8.42 & 930 & 189.0 \\
\hline $8 / 10 / 082: 40$ & 1.07 & 25.80 & Purged & 16.50 & 4.18 & 7.90 & 852 & 63.0 \\
\hline $8 / 10 / 085: 32$ & 1.19 & 28.67 & Purged & 16.86 & 4.18 & 7.82 & 875 & 41.0 \\
\hline $8 / 10 / 08 \quad 11: 40$ & 1.45 & 34.80 & Purged & 18.65 & 3.00 & 8.63 & 767 & 92.9 \\
\hline $8 / 10 / 08$ 13:55 & 1.54 & 37.05 & Purged & 18.08 & 3.51 & 8.70 & 864 & 184.5 \\
\hline $8 / 10 / 08 \quad 17: 50$ & 1.71 & 40.97 & \multicolumn{6}{|c|}{ Pump stopped working } \\
\hline $8 / 10 / 0822: 10$ & 1.89 & 45.30 & Purged & 17.56 & 3.18 & 8.66 & 684 & 150.0 \\
\hline 8/11/08 3:02 & 2.09 & 50.17 & Purged & 17.01 & 3.55 & 8.34 & 765 & 73.5 \\
\hline $8 / 11 / 08$ 7:00 & 2.26 & 54.13 & Purged & 18.05 & 3.29 & 8.81 & 750 & 19.4 \\
\hline $8 / 11 / 0815: 45$ & 2.62 & 62.88 & Bailer & 20.10 & 3.08 & 8.50 & 791 & 158.2 \\
\hline $8 / 11 / 0820: 27$ & 2.82 & 67.58 & Bailer & 17.43 & 4.87 & 7.80 & 733 & 58.9 \\
\hline $8 / 11 / 0820: 44$ & 2.83 & 67.87 & Bailer & 20.06 & 3.26 & 8.39 & 735 & 151.8 \\
\hline 8/12/08 0:15 & 2.97 & 71.38 & Bailer & 16.83 & 2.18 & 8.49 & 725 & 97.4 \\
\hline 8/12/08 3:38 & 3.12 & 74.77 & Bailer & 16.88 & 2.22 & 8.30 & 719 & 80.8 \\
\hline $8 / 12 / 08$ 7:40 & 3.28 & 78.80 & Bailer & 17.31 & 2.62 & 8.55 & 703 & 54.0 \\
\hline $8 / 12 / 08$ 11:27 & 3.44 & 82.58 & Bailer & 18.87 & 3.36 & 8.27 & 719 & 163.6 \\
\hline $8 / 12 / 08$ 15:20 & 3.60 & 86.47 & Bailer & 18.53 & 3.11 & 8.01 & 704 & 119.5 \\
\hline $8 / 12 / 08$ 19:31 & 3.78 & 90.65 & Bailer & 18.64 & 2.75 & 8.30 & 695 & - \\
\hline $8 / 12 / 08$ 23:04 & 3.92 & 94.20 & Bailer & 18.05 & 3.03 & 8.42 & 679 & 64.8 \\
\hline 8/13/08 3:15 & 4.10 & 98.38 & Bailer & 17.61 & 3.20 & 8.70 & 670 & 79.3 \\
\hline $8 / 13 / 08$ 7:47 & 4.29 & 102.92 & Bailer & 19.19 & 2.85 & 8.79 & 672 & 53.8 \\
\hline $8 / 13 / 0811: 35$ & 4.45 & 106.72 & Bailer & 20.76 & 3.23 & 8.73 & 669 & 129.2 \\
\hline $8 / 13 / 08 \quad 15: 30$ & 4.61 & 110.63 & Bailer & 19.57 & 3.30 & 8.66 & 668 & 44.0 \\
\hline $8 / 13 / 08$ 19:21 & 4.77 & 114.48 & Bailer & 19.23 & 3.30 & 8.72 & 668 & 130.2 \\
\hline $8 / 13 / 08$ 22:04 & 4.88 & 117.20 & Bailer & 18.57 & 3.33 & 8.71 & 659 & 101.8 \\
\hline $8 / 14 / 08$ 1:53 & 5.04 & 121.02 & Bailer & 18.05 & 3.45 & 8.85 & 648 & 53.6 \\
\hline
\end{tabular}


Table 6-5. 199-D4-25 Field Parameters (Surface Measurement)

\begin{tabular}{c|c|c|c|c|c|c|c|c}
\hline $\begin{array}{c}\text { Datel } \\
\text { Time }\end{array}$ & $\begin{array}{c}\text { Elapsed } \\
\text { Days }\end{array}$ & $\begin{array}{c}\text { Elapsed } \\
\text { Hours }\end{array}$ & $\begin{array}{c}\text { Sample } \\
\text { Collection } \\
\text { Method }\end{array}$ & $\begin{array}{c}\text { Temp., } \\
{ }^{\circ} \mathbf{C}\end{array}$ & $\begin{array}{c}\text { DO, } \\
\mathbf{m g} / \mathbf{L}\end{array}$ & $\begin{array}{c}\mathbf{p H ,} \\
\mathbf{S U}\end{array}$ & $\begin{array}{c}\mathbf{S C}, \\
\boldsymbol{\mu S / \mathbf { c m }}\end{array}$ & $\begin{array}{c}\text { ORP, } \\
\mathbf{m V}\end{array}$ \\
\hline $8 / 14 / 085: 55$ & 5.21 & 125.05 & Bailer & 17.39 & 3.54 & 8.94 & 646 & 37.8 \\
\hline $8 / 14 / 089: 25$ & 5.36 & 128.55 & Bailer & 18.91 & - & 8.90 & 643 & -25.5 \\
\hline $8 / 14 / 0813: 30$ & 5.53 & 132.63 & Bailer & 19.68 & 3.64 & 8.94 & 649 & 41.2 \\
\hline $8 / 14 / 0817: 26$ & 5.69 & 136.57 & Bailer & 20.49 & 3.20 & 8.78 & 651 & -21.8 \\
\hline $8 / 14 / 0822: 40$ & 5.91 & 141.80 & Bailer & 19.86 & 3.35 & 8.85 & 633 & -58.2 \\
\hline $8 / 16 / 0810: 34$ & 7.40 & 177.70 & Bailer & 25.32 & 2.94 & 8.76 & 627 & -16.5 \\
\hline $8 / 18 / 0811: 00$ & 9.42 & 226.13 & Bailer & 31.25 & 2.89 & 8.68 & 611 & -45.3 \\
\hline $8 / 20 / 087: 33$ & 11.28 & 270.68 & Bailer & 18.13 & 2.94 & 8.74 & 626 & -25.2 \\
\hline $8 / 22 / 086: 45$ & 13.25 & 317.88 & Bailer & 16.80 & 3.95 & 8.81 & 677 & 103.0 \\
\hline
\end{tabular}

DO = dissolved oxygen

ORP = oxidation-reduction potential

SC = specific conductivity

Table 6-6. 199-D4-27 Field Parameters (Surface Measurement)

\begin{tabular}{|c|c|c|c|c|c|c|c|c|}
\hline $\begin{array}{l}\text { Date/ } \\
\text { Time }\end{array}$ & $\begin{array}{c}\text { Elapsed } \\
\text { Days }\end{array}$ & $\begin{array}{c}\text { Elapsed } \\
\text { Hours }\end{array}$ & $\begin{array}{l}\text { Sample } \\
\text { Collection } \\
\text { Method }\end{array}$ & $\begin{array}{l}\text { Temp., } \\
{ }^{\circ} \mathrm{C}\end{array}$ & $\begin{array}{l}\text { DO, } \\
\text { mg/L }\end{array}$ & $\begin{array}{l}\text { pH, } \\
\text { sU }\end{array}$ & $\begin{array}{c}\text { SC, } \\
\mu S / c m\end{array}$ & $\begin{array}{l}\text { ORP, } \\
\text { mV }\end{array}$ \\
\hline 8/9/08 2:58 & 0.09 & 2.10 & Purged & 17.29 & 4.52 & 7.70 & 647 & 112.0 \\
\hline 8/9/08 5:35 & 0.20 & 4.72 & Purged & 17.63 & 2.84 & 7.92 & 654 & 86.5 \\
\hline 8/9/08 9:19 & 0.35 & 8.45 & Purged & 18.28 & 2.15 & 8.16 & 658 & 26.5 \\
\hline $8 / 9 / 08$ 13:30 & 0.53 & 12.63 & Flow cell & 17.61 & 2.88 & 8.18 & 664 & -32.5 \\
\hline 8/9/08 17:33 & 0.70 & 16.68 & Flow cell & 17.79 & 3.00 & 8.15 & 665 & -4.8 \\
\hline 8/9/08 22:49 & 0.91 & 21.95 & Purged & 16.93 & 4.04 & 8.06 & 653 & 164.7 \\
\hline $8 / 10 / 08$ 1:40 & 1.03 & 24.80 & Purged & 17.00 & 3.71 & 7.69 & 662 & 33.8 \\
\hline 8/10/08 5:57 & 1.21 & 29.08 & Purged & 16.70 & 3.19 & 7.71 & 655 & 70.5 \\
\hline $8 / 10 / 08$ 10:16 & 1.39 & 33.40 & Purged & 17.86 & 3.44 & 7.84 & 674 & 251.4 \\
\hline $8 / 10 / 08$ 14:35 & 1.57 & 37.72 & Purged & 17.87 & 3.43 & 8.26 & 667 & 200.4 \\
\hline $8 / 10 / 08$ 17:30 & 1.69 & 40.63 & Purged & 17.68 & 4.17 & 8.22 & 656 & 163.4 \\
\hline 8/10/08 23:02 & 1.92 & 46.17 & Purged & 17.34 & 3.42 & 7.61 & 637 & 62.0 \\
\hline $8 / 11 / 080: 27$ & 1.98 & 47.58 & Purged & 16.96 & 3.55 & 7.90 & 636 & 61.0 \\
\hline $8 / 11 / 08$ 15:40 & 2.62 & 62.80 & Bailer & 20.08 & 2.66 & 8.23 & 713 & 138.0 \\
\hline
\end{tabular}


DOE/RL-2009-35, REV. 0

Table 6-6. 199-D4-27 Field Parameters (Surface Measurement)

\begin{tabular}{|c|c|c|c|c|c|c|c|c|c|}
\hline & $\begin{array}{l}\text { Datel } \\
\text { Time }\end{array}$ & $\begin{array}{l}\text { Elapsed } \\
\text { Days }\end{array}$ & $\begin{array}{c}\text { Elapsed } \\
\text { Hours }\end{array}$ & $\begin{array}{l}\text { Sample } \\
\text { Collection } \\
\text { Method }\end{array}$ & $\underset{{ }^{\circ} \mathrm{C}}{\text { Temp., }}$ & $\begin{array}{l}\text { DO, } \\
\text { mg/L }\end{array}$ & $\begin{array}{l}\text { pH, } \\
\text { SU }\end{array}$ & $\begin{array}{c}\text { SC, } \\
\mu \mathrm{S} / \mathrm{cm}\end{array}$ & $\begin{array}{l}\text { ORP, } \\
\text { mV }\end{array}$ \\
\hline & 8/11/08 21:00 & 2.84 & 68.13 & Bailer & 17.47 & 3.21 & 7.97 & 673 & 155.20 \\
\hline & $8 / 12 / 080: 38$ & 2.99 & 71.77 & Bailer & 16.52 & 2.85 & 8.26 & 637 & 134.10 \\
\hline & $8 / 12 / 083: 49$ & 3.12 & 74.95 & Bailer & 16.58 & 3.14 & 8.05 & 653 & 85.90 \\
\hline & $8 / 12 / 087: 55$ & 3.29 & 79.05 & Bailer & 18.16 & 3.43 & 8.26 & 680 & 87.50 \\
\hline & $8 / 12 / 08$ 11:40 & 3.45 & 82.80 & Bailer & 20.72 & 3.32 & 7.96 & 683 & 162.20 \\
\hline & $8 / 12 / 08$ 15:30 & 3.61 & 86.63 & Bailer & 18.96 & 3.51 & 7.99 & 678 & 144.90 \\
\hline & $8 / 12 / 08$ 19:42 & 3.78 & 90.83 & Bailer & 17.74 & 3.44 & 7.99 & 676 & 134.50 \\
\hline & $8 / 12 / 0823: 17$ & 3.93 & 94.42 & Bailer & 17.49 & 2.98 & 8.16 & 663 & 82.3 \\
\hline & 8/13/08 3:24 & 4.11 & 98.53 & Bailer & 17.04 & 3.00 & 8.18 & 666 & 101.3 \\
\hline & 8/13/08 8:00 & 4.30 & 103.13 & Bailer & 18.06 & 3.46 & 8.22 & 667 & 97.4 \\
\hline & $8 / 13 / 08$ 11:46 & 4.45 & 106.90 & Bailer & 19.62 & 3.22 & 8.28 & 663 & 149.1 \\
\hline & $8 / 13 / 08$ 15:42 & 4.62 & 110.83 & Bailer & 19.24 & 3.11 & 8.23 & 656 & 84.6 \\
\hline & $8 / 13 / 08$ 19:30 & 4.78 & 114.63 & Bailer & 17.70 & 3.19 & 8.30 & 660 & 130.1 \\
\hline & $8 / 13 / 0822: 16$ & 4.89 & 117.40 & Bailer & 17.82 & 3.50 & 8.34 & 656 & -2.7 \\
\hline & 8/14/08 2:09 & 5.05 & 121.28 & Bailer & 17.18 & 3.11 & 8.32 & 647 & 104.8 \\
\hline & 8/14/08 6:10 & 5.22 & 125.30 & Bailer & 16.52 & 3.73 & 8.19 & 654 & 77.4 \\
\hline & 8/14/08 9:37 & 5.36 & 128.75 & Bailer & 18.24 & 3.46 & 8.40 & 654 & 12.6 \\
\hline & $8 / 14 / 08$ 13:54 & 5.54 & 133.03 & Bailer & 18.72 & 3.49 & 8.36 & 659 & -12.9 \\
\hline & $8 / 14 / 08$ 17:35 & 5.70 & 136.72 & Bailer & 19.64 & 4.75 & 8.31 & 660 & -18.0 \\
\hline & $8 / 14 / 0820: 45$ & 5.83 & 139.88 & Bailer & 18.35 & 3.03 & 8.21 & 641 & -40.6 \\
\hline & $8 / 16 / 0810: 55$ & 7.42 & 178.05 & Bailer & 23.76 & 3.51 & 8.21 & 654 & -17.2 \\
\hline & $8 / 18 / 0811: 30$ & 9.44 & 226.63 & Bailer & 29.05 & 3.23 & 8.13 & 663 & -36.0 \\
\hline & $8 / 20 / 087: 55$ & 11.29 & 271.05 & Bailer & 17.30 & 3.00 & 8.07 & 651 & -18.5 \\
\hline & 8/22/08 7:05 & 13.26 & 318.22 & Bailer & 16.18 & 3.60 & 8.18 & 684 & 136.6 \\
\hline \multicolumn{10}{|c|}{$\mathrm{DO}=$ dissolved oxygen } \\
\hline \multicolumn{10}{|c|}{ ORP = oxidation-reduction potential } \\
\hline \multicolumn{10}{|c|}{$\mathrm{SC}=$ specific conductivity } \\
\hline
\end{tabular}


Table 6-7. 199-D4-92 Field Parameters (Surface Measurement)

\begin{tabular}{|c|c|c|c|c|c|c|c|c|}
\hline $\begin{array}{l}\text { Date/ } \\
\text { Time }\end{array}$ & $\begin{array}{c}\text { Elapsed } \\
\text { Days }\end{array}$ & $\begin{array}{l}\text { Elapsed } \\
\text { Hours }\end{array}$ & $\begin{array}{l}\text { Sample Collection } \\
\text { Method }\end{array}$ & $\underset{{ }^{\circ} \mathrm{C}}{\text { Temp., }}$ & $\begin{array}{l}\mathrm{DO} \\
\mathrm{mg} / \mathrm{L}\end{array}$ & $\begin{array}{l}\text { pH, } \\
\text { SU }\end{array}$ & $\begin{array}{c}S C \\
\mu S / c m\end{array}$ & $\begin{array}{l}\text { ORP, } \\
\text { mV }\end{array}$ \\
\hline $8 / 9 / 080: 30$ & -0.02 & -0.37 & Purged & 18.16 & 3.07 & 8.13 & 677 & -12.4 \\
\hline $8 / 9 / 085: 25$ & 0.19 & 4.55 & Purged & 17.28 & 5.84 & 7.65 & 638 & 64.0 \\
\hline $8 / 9 / 088: 25$ & 0.31 & 7.55 & Purged & 17.68 & 5.37 & 8.74 & 604 & 59.3 \\
\hline $8 / 9 / 08$ 10:21 & 0.40 & 9.48 & Flow cell & 18.37 & 3.65 & 8.83 & 553 & -94.3 \\
\hline $8 / 9 / 08$ 13:40 & 0.53 & 12.80 & Flow cell & 18.43 & 4.08 & 9.03 & 513 & -98.5 \\
\hline 8/9/08 18:08 & 0.72 & 17.27 & Flow cell & 18.55 & 2.69 & 9.17 & 497 & -126.5 \\
\hline 8/9/08 23:20 & 0.94 & 22.47 & Purged & 19.65 & 1.59 & 9.52 & 526 & -127.8 \\
\hline 8/10/08 3:03 & 1.09 & 26.18 & Purged & 18.59 & 0.55 & 10.08 & 539 & -380.0 \\
\hline 8/10/08 6:08 & 1.22 & 29.27 & Purged & 18.88 & 0.51 & 10.18 & 561 & -359.0 \\
\hline $8 / 10 / 08$ 10:26 & 1.40 & 33.57 & Purged & 20.98 & 0.06 & 10.26 & 583 & -388.2 \\
\hline $8 / 10 / 0813: 32$ & 1.53 & 36.67 & Purged & 21.56 & 0.25 & 10.33 & 605 & -427.1 \\
\hline $8 / 10 / 0817: 17$ & 1.68 & 40.42 & Purged & 21.58 & 0.14 & 10.43 & 640 & -417.0 \\
\hline $8 / 10 / 0820: 30$ & 1.82 & 43.63 & Purged & 21.71 & 0.51 & 10.47 & 635 & -427.0 \\
\hline $8 / 11 / 08$ 1:31 & 2.03 & 48.65 & Purged & 19.30 & 0.60 & 10.35 & 609 & -388.8 \\
\hline 8/11/08 3:50 & 2.12 & 50.97 & Purged & 21.17 & 0.63 & 10.22 & 597 & -356.0 \\
\hline $8 / 11 / 0814: 46$ & 2.58 & 61.90 & Bailer & 25.19 & 0.50 & 10.81 & 1462 & -436.0 \\
\hline $8 / 11 / 0818: 25$ & 2.73 & 65.55 & Bailer & 26.51 & 0.24 & 10.88 & 1662 & -491.6 \\
\hline $8 / 11 / 0820: 46$ & 2.83 & 67.90 & Bailer & 24.66 & 0.57 & & 871 & -427.00 \\
\hline $8 / 12 / 080: 27$ & 2.98 & 71.58 & Bailer & 24.42 & 0.61 & & 981 & -472.00 \\
\hline $8 / 12 / 08$ 4:15 & 3.14 & 75.38 & Bailer & 22.54 & 0.25 & 11.28 & 965 & -763.10 \\
\hline 8/12/08 8:10 & 3.30 & 79.30 & Bailer & 24.72 & 0.19 & 11.20 & 962 & -757.20 \\
\hline $8 / 12 / 0811: 45$ & 3.45 & 82.88 & Bailer & 26.48 & 0.19 & 11.21 & 990 & -582.00 \\
\hline $8 / 12 / 08$ 15:32 & 3.61 & 86.67 & Bailer & 27.06 & 0.33 & 11.14 & 1018 & -565.60 \\
\hline $8 / 12 / 0819: 52$ & 3.79 & 91.00 & Bailer & 22.48 & 0.20 & 11.16 & 1003 & -660.90 \\
\hline $8 / 12 / 08$ 23:58 & 3.96 & 95.10 & Bailer & 25.99 & 0.18 & 11.25 & 1016 & -644.0 \\
\hline $8 / 13 / 08$ 3:44 & 4.12 & 98.87 & Bailer & 25.08 & 0.23 & 11.22 & 1005 & -642.0 \\
\hline 8/13/08 8:36 & 4.32 & 103.73 & Bailer & 26.57 & 0.15 & 11.10 & 1027 & -650.3 \\
\hline $8 / 13 / 0811: 57$ & 4.46 & 107.08 & Bailer & 26.60 & 0.37 & 11.07 & 1014 & -415.7 \\
\hline $8 / 13 / 0816: 00$ & 4.63 & 111.13 & Bailer & 27.84 & 0.12 & 11.10 & 1032 & -354.5 \\
\hline $8 / 13 / 0819: 43$ & 4.79 & 114.85 & Bailer & 28.22 & 0.16 & 11.15 & 1053 & -519.7 \\
\hline
\end{tabular}


Table 6-7. 199-D4-92 Field Parameters (Surface Measurement)

\begin{tabular}{|c|c|c|c|c|c|c|c|c|}
\hline $\begin{array}{l}\text { Datel } \\
\text { Time }\end{array}$ & $\begin{array}{l}\text { Elapsed } \\
\text { Days }\end{array}$ & $\begin{array}{l}\text { Elapsed } \\
\text { Hours }\end{array}$ & $\begin{array}{l}\text { Sample Collection } \\
\text { Method }\end{array}$ & $\underset{{ }^{\circ} \mathrm{C}}{\text { Temp., }}$ & $\begin{array}{l}\text { DO, } \\
\text { mg/L }\end{array}$ & $\begin{array}{l}\text { pH, } \\
\text { su }\end{array}$ & $\begin{array}{c}S C \\
\mu S / c m\end{array}$ & $\begin{array}{l}\text { ORP, } \\
\mathbf{m V}\end{array}$ \\
\hline $8 / 13 / 0822: 25$ & 4.90 & 117.55 & Bailer & 27.50 & 0.23 & 11.20 & 1043 & -567.6 \\
\hline $8 / 14 / 082: 19$ & 5.06 & 121.45 & Bailer & 26.30 & 0.27 & 11.23 & 1016 & -621.4 \\
\hline $8 / 14 / 08$ 6:23 & 5.23 & 125.52 & Bailer & 23.23 & 0.31 & 11.35 & 1018 & -609.3 \\
\hline $8 / 14 / 089: 48$ & 5.37 & 128.93 & Bailer & 27.10 & 0.17 & 11.19 & 1032 & -504.9 \\
\hline $8 / 14 / 0814: 09$ & 5.55 & 133.28 & Bailer & 27.37 & 0.13 & 11.20 & 1039 & -621.8 \\
\hline $8 / 14 / 0817: 39$ & 5.70 & 136.78 & Bailer & 27.18 & 0.23 & 11.26 & 1047 & -545.0 \\
\hline $8 / 14 / 0822: 50$ & 5.92 & 141.97 & Bailer & 25.13 & 0.18 & 11.23 & 999 & -596.1 \\
\hline $8 / 15 / 0812: 00$ & 6.46 & 155.13 & Bailer & 26.77 & 0.21 & 11.23 & 1146 & -621.6 \\
\hline 8/16/08 11:17 & 7.43 & 178.42 & Bailer & 27.21 & 0.20 & 11.29 & 1051 & -625.3 \\
\hline 8/17/08 8:50 & 8.33 & 199.97 & Bailer & 25.08 & 0.28 & 11.31 & 1079 & -576.7 \\
\hline $8 / 18 / 08$ 16:30 & 9.65 & 231.63 & Bailer & 26.48 & 0.43 & 11.09 & 1074 & -431.8 \\
\hline 8/19/08 9:26 & 10.36 & 248.57 & Bailer & 21.89 & 0.26 & 11.29 & 1148 & -574.1 \\
\hline 8/20/08 8:00 & 11.30 & 271.13 & Bailer & 21.86 & 0.25 & 11.28 & 1081 & -526.7 \\
\hline $8 / 21 / 08$ 7:35 & 12.28 & 294.72 & Bailer & 20.30 & 0.33 & 11.40 & 1103 & -555.3 \\
\hline $8 / 22 / 08$ 7:21 & 13.27 & 318.48 & Bailer & 21.11 & 0.30 & 11.41 & 1134 & -655.2 \\
\hline $8 / 23 / 08$ 6:00 & 14.21 & 341.13 & Bailer & 19.20 & 0.39 & 11.45 & 1119 & -631.0 \\
\hline \multicolumn{9}{|c|}{$\mathrm{DO}=$ dissolved oxygen } \\
\hline \multicolumn{9}{|c|}{ ORP $=$ oxidation-reduction potential } \\
\hline \multicolumn{9}{|c|}{ SC $=$ specific conductivity } \\
\hline
\end{tabular}

Table 6-8. 199-D4-93 Field Parameters (Surface Measurement)

\begin{tabular}{c|c|c|c|c|c|c|c|c}
\hline $\begin{array}{c}\text { Datel } \\
\text { Time }\end{array}$ & $\begin{array}{c}\text { Elapsed } \\
\text { Days }\end{array}$ & $\begin{array}{c}\text { Elapsed } \\
\text { Hours }\end{array}$ & $\begin{array}{c}\text { Sample Collection } \\
\text { Method }\end{array}$ & $\begin{array}{c}\text { Temp., } \\
{ }^{\circ} \mathbf{C}\end{array}$ & $\begin{array}{c}\text { DO, } \\
\mathbf{m g} / \mathbf{L}\end{array}$ & $\begin{array}{c}\mathbf{p H ,} \\
\mathbf{S U}\end{array}$ & $\begin{array}{c}\mathbf{S C}, \\
\boldsymbol{\mu S / c m}\end{array}$ & $\begin{array}{c}\text { ORP, } \\
\mathbf{m V}\end{array}$ \\
\hline $8 / 9 / 088: 45$ & 0.33 & 7.88 & Purged & 29.15 & 0.64 & 10.34 & 556 & -332.5 \\
\hline $8 / 9 / 0811: 38$ & 0.45 & 10.77 & Flow cell & 25.72 & 0.85 & 10.42 & 706 & $\mathrm{Na}$ \\
\hline $8 / 9 / 0815: 30$ & 0.61 & 14.63 & Flow cell & 25.06 & 0.90 & 10.49 & 655 & -283.0 \\
\hline $8 / 9 / 0818: 25$ & 0.73 & 17.55 & Flow cell & 24.93 & 1.90 & 10.42 & 626 & -198.7 \\
\hline $8 / 9 / 0823: 45$ & 0.95 & 22.88 & Purged & 21.60 & 0.43 & 9.87 & 483 & -424.6 \\
\hline $8 / 10 / 083: 20$ & 1.10 & 26.47 & Purged & 20.46 & 0.64 & 10.25 & 541 & -422.0 \\
\hline $8 / 10 / 086: 29$ & 1.23 & 29.62 & Purged & 20.56 & 0.21 & 10.46 & 594 & -436.3 \\
\hline $8 / 10 / 089: 15$ & 1.35 & 32.38 & Purged & 23.51 & 0.20 & 10.94 & 742 & -478.3 \\
\hline
\end{tabular}


DOE/RL-2009-35, REV. 0

Table 6-8. 199-D4-93 Field Parameters (Surface Measurement)

\begin{tabular}{|c|c|c|c|c|c|c|c|c|}
\hline $\begin{array}{l}\text { Datel } \\
\text { Time }\end{array}$ & $\begin{array}{l}\text { Elapsed } \\
\text { Days }\end{array}$ & $\begin{array}{c}\text { Elapsed } \\
\text { Hours }\end{array}$ & $\begin{array}{l}\text { Sample Collection } \\
\text { Method }\end{array}$ & $\underset{{ }^{\circ} \mathrm{C}}{\text { Temp., }}$ & $\begin{array}{l}\mathrm{DO}, \\
\mathrm{mg} / \mathrm{L}\end{array}$ & $\begin{array}{l}\text { pH, } \\
\text { su }\end{array}$ & $\begin{array}{c}\text { SC, } \\
\mu S / c m\end{array}$ & $\begin{array}{l}\text { ORP, } \\
\text { mV }\end{array}$ \\
\hline $8 / 10 / 08$ 13:00 & 1.51 & 36.13 & Purged & 24.98 & 0.17 & 11.19 & 847 & -471.9 \\
\hline $8 / 10 / 0816: 55$ & 1.67 & 40.05 & Purged & 26.02 & 0.48 & 10.97 & 831 & -469.2 \\
\hline $8 / 10 / 0821: 01$ & 1.84 & 44.15 & Purged & 24.42 & 0.33 & 11.08 & 802 & -474.2 \\
\hline $8 / 11 / 08$ 2:05 & 2.05 & 49.22 & Purged & 22.79 & 0.45 & 11.24 & 844 & -483.8 \\
\hline $8 / 11 / 085: 35$ & 2.20 & 52.72 & Purged & 18.49 & 0.52 & 11.52 & 940 & -501.1 \\
\hline $8 / 11 / 08 \quad 17: 45$ & 2.70 & 64.88 & Purged & 30.13 & 0.78 & 10.94 & 1701 & -514.6 \\
\hline $8 / 11 / 0821: 41$ & 2.87 & 68.82 & Purged & 24.43 & 0.50 & & 1002 & -521.4 \\
\hline $8 / 12 / 08$ 1:18 & 3.02 & 72.43 & Purged & 22.92 & 0.27 & 11.42 & 1010 & -761.3 \\
\hline $8 / 12 / 084: 32$ & 3.15 & 75.67 & Purged & 22.20 & 0.24 & 11.33 & 979 & \\
\hline $8 / 12 / 088: 45$ & 3.33 & 79.88 & Purged & 23.56 & 0.20 & 11.30 & 998 & -789.0 \\
\hline $8 / 12 / 0812: 00$ & 3.46 & 83.13 & Purged & 26.25 & 0.16 & 11.31 & 1053 & -692.5 \\
\hline $8 / 12 / 08$ 15:50 & 3.62 & 86.97 & Purged & 26.57 & 0.16 & 11.29 & 1064 & -675.3 \\
\hline $8 / 12 / 0820: 22$ & 3.81 & 91.50 & Purged & 25.56 & 0.18 & 11.28 & 1020 & -728.6 \\
\hline $8 / 13 / 08$ 0:15 & 3.97 & 95.38 & Purged & 23.46 & 0.17 & 11.28 & 1015 & -717.2 \\
\hline $8 / 13 / 083: 58$ & 4.13 & 99.10 & Purged & 24.36 & 0.18 & 11.32 & 1029 & -710.3 \\
\hline 8/13/08 8:55 & 4.34 & 104.05 & Purged & 27.29 & 0.11 & 11.28 & 1029 & -730.9 \\
\hline $8 / 13 / 08$ 12:10 & 4.47 & 107.30 & Purged & 26.28 & 0.19 & 11.26 & 1030 & -672.9 \\
\hline $8 / 13 / 0816: 30$ & 4.65 & 111.63 & Purged & 27.53 & 0.11 & 11.26 & 1067 & -668.4 \\
\hline $8 / 13 / 0819: 53$ & 4.79 & 115.02 & Purged & 25.74 & 0.15 & 11.33 & 1031 & -630.7 \\
\hline $8 / 13 / 0822: 34$ & 4.90 & 117.70 & Purged & 23.69 & 0.21 & 11.36 & 1025 & -662.5 \\
\hline $8 / 14 / 082: 32$ & 5.07 & 121.67 & Purged & 21.72 & 0.28 & 11.41 & 1022 & -674.9 \\
\hline $8 / 14 / 085: 32$ & 5.19 & 124.67 & Purged & 21.66 & 0.20 & 11.29 & 971 & -683.4 \\
\hline $8 / 14 / 08$ 10:05 & 5.38 & 129.22 & Purged & 25.66 & 0.13 & 11.24 & 1021 & -700.0 \\
\hline $8 / 14 / 0814: 22$ & 5.56 & 133.50 & Purged & 25.34 & 0.08 & 11.25 & 1030 & -722.7 \\
\hline $8 / 14 / 0818: 00$ & 5.71 & 137.13 & Purged & 27.08 & 0.16 & 11.17 & 1050 & -626.5 \\
\hline 8/14/08 23:10 & 5.93 & 142.30 & Purged & 23.50 & 0.20 & 11.19 & 1029 & -641.0 \\
\hline $8 / 15 / 0812: 00$ & 6.46 & 155.13 & Purged & 27.31 & 0.27 & 11.14 & 1176 & -635.8 \\
\hline $8 / 16 / 0811: 30$ & 7.44 & 178.63 & Bailer & 28.30 & 0.13 & 11.17 & 1065 & -647.6 \\
\hline 8/17/08 8:50 & 8.33 & 199.97 & Bailer & 26.49 & 0.50 & 11.20 & 1053 & -607.3 \\
\hline $8 / 18 / 08$ 16:30 & 9.65 & 231.63 & Bailer & 25.05 & 0.32 & 10.96 & 1081 & -544.2 \\
\hline 8/19/08 9:00 & 10.34 & 248.13 & Bailer & 21.90 & 0.24 & 11.23 & 1143 & -528.2 \\
\hline
\end{tabular}


Table 6-8. 199-D4-93 Field Parameters (Surface Measurement)

\begin{tabular}{c|c|c|c|c|c|c|c|c}
\hline $\begin{array}{c}\text { Datel } \\
\text { Time }\end{array}$ & $\begin{array}{c}\text { Elapsed } \\
\text { Days }\end{array}$ & $\begin{array}{c}\text { Elapsed } \\
\text { Hours }\end{array}$ & $\begin{array}{c}\text { Sample Collection } \\
\text { Method }\end{array}$ & $\begin{array}{c}\text { Temp., } \\
{ }^{\circ} \mathbf{C}\end{array}$ & $\begin{array}{c}\text { DO, } \\
\mathbf{m g} / \mathbf{L}\end{array}$ & $\begin{array}{c}\mathbf{p H}, \\
\mathbf{S U}\end{array}$ & $\begin{array}{c}\mathbf{S C}, \mathbf{\mu S / \mathbf { c m }} \\
\mathbf{\text { ORP, }} \\
\mathbf{m V}\end{array}$ \\
\hline $8 / 20 / 088: 25$ & 11.31 & 271.55 & Bailer & 22.46 & 0.25 & 11.17 & 1066 & -600.8 \\
\hline $8 / 21 / 087: 47$ & 12.29 & 294.92 & Bailer & 21.15 & 0.31 & 11.31 & 1087 & -577.1 \\
\hline $8 / 22 / 087: 40$ & 13.28 & 318.80 & Bailer & 22.30 & 0.25 & 11.30 & 1126 & -653.5 \\
\hline $8 / 23 / 086: 10$ & 14.22 & 341.30 & Bailer & 20.72 & 0.29 & 11.35 & 1115 & -632.5 \\
\hline
\end{tabular}

DO = dissolved oxygen

ORP = oxidation-reduction potential

$\mathrm{SC} \quad=$ specific conductivity

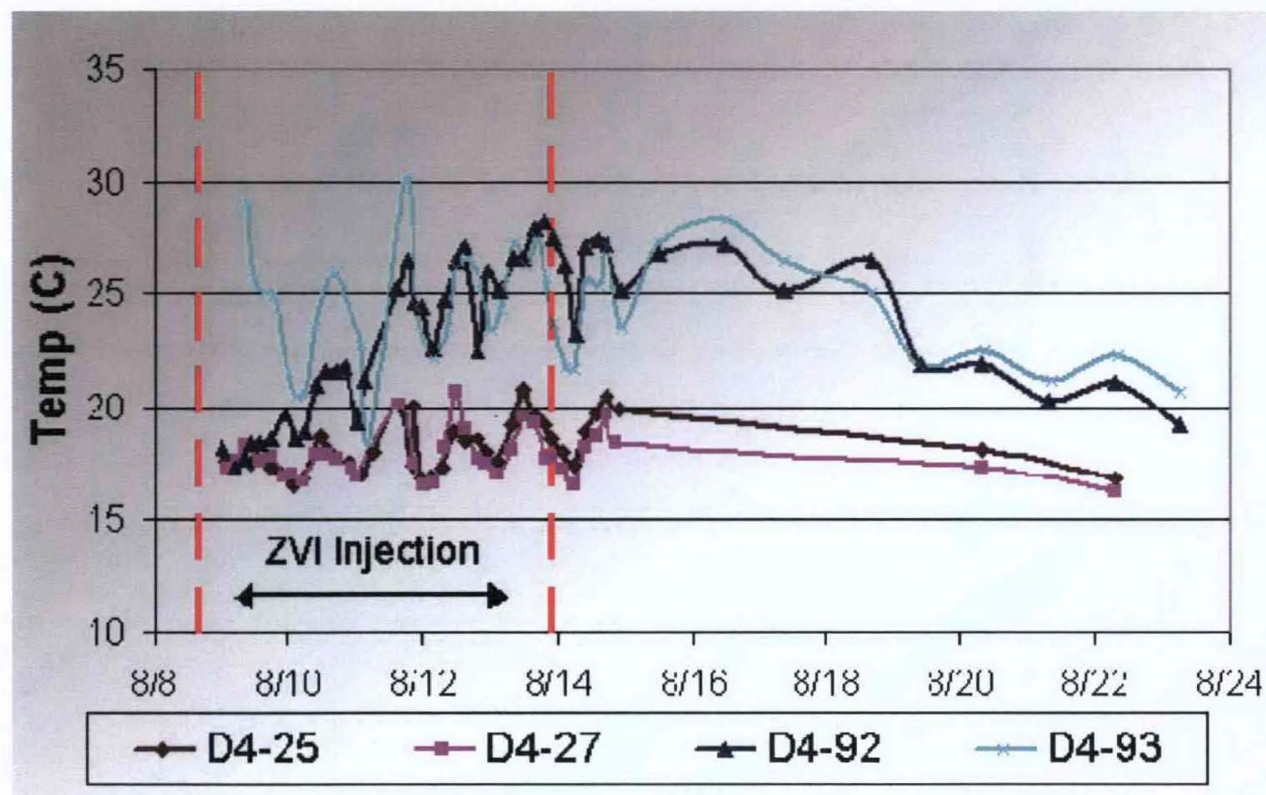

Figure 6-9. Monitoring Well Field Parameters - Temperature (Surface Measurement) 


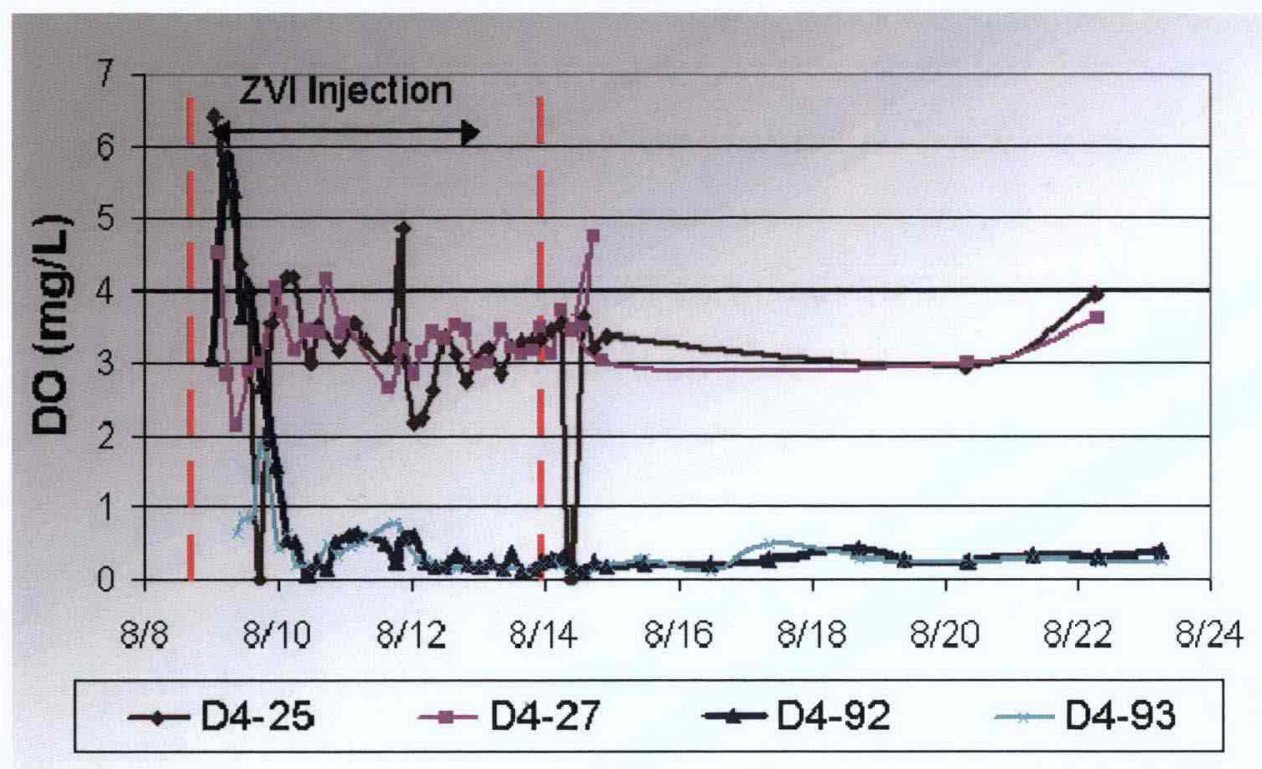

Figure 6-10. Monitoring Well Field Parameters - Dissolved Oxygen (Surface Measurement)

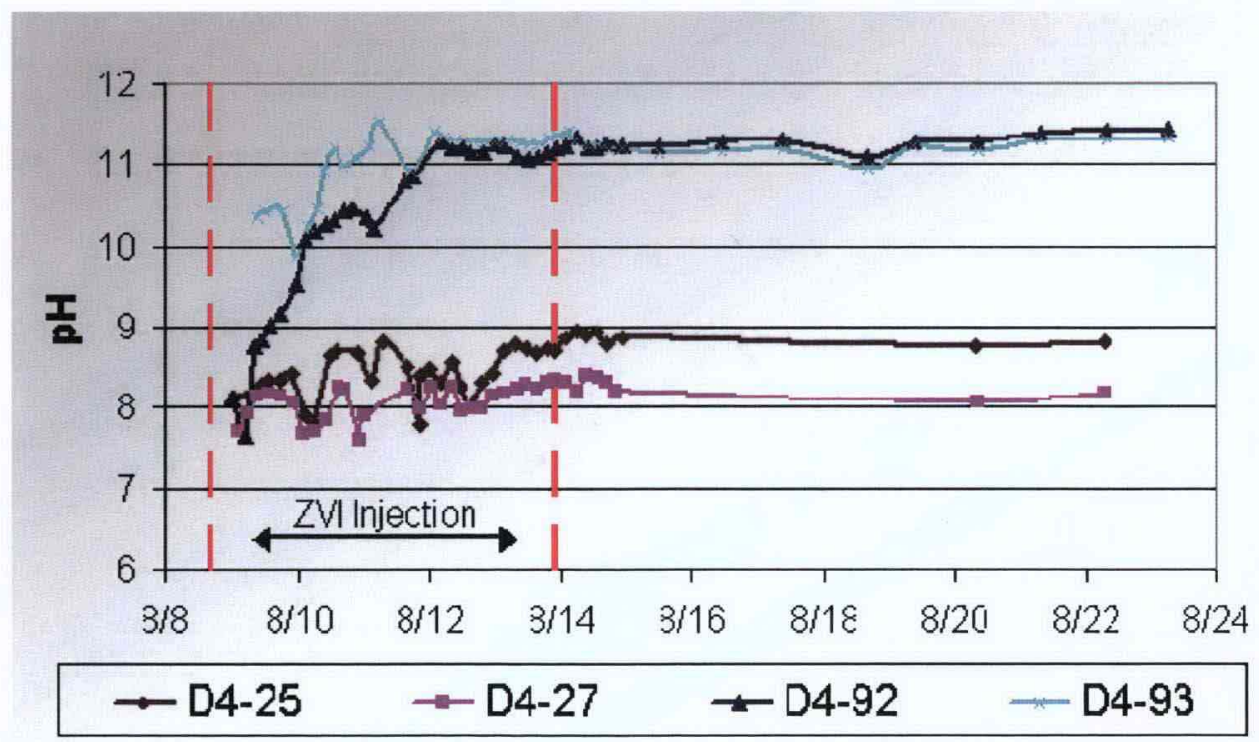

Figure 6-11. Monitoring Well Field Parameters - pH (Surface Measurement) 


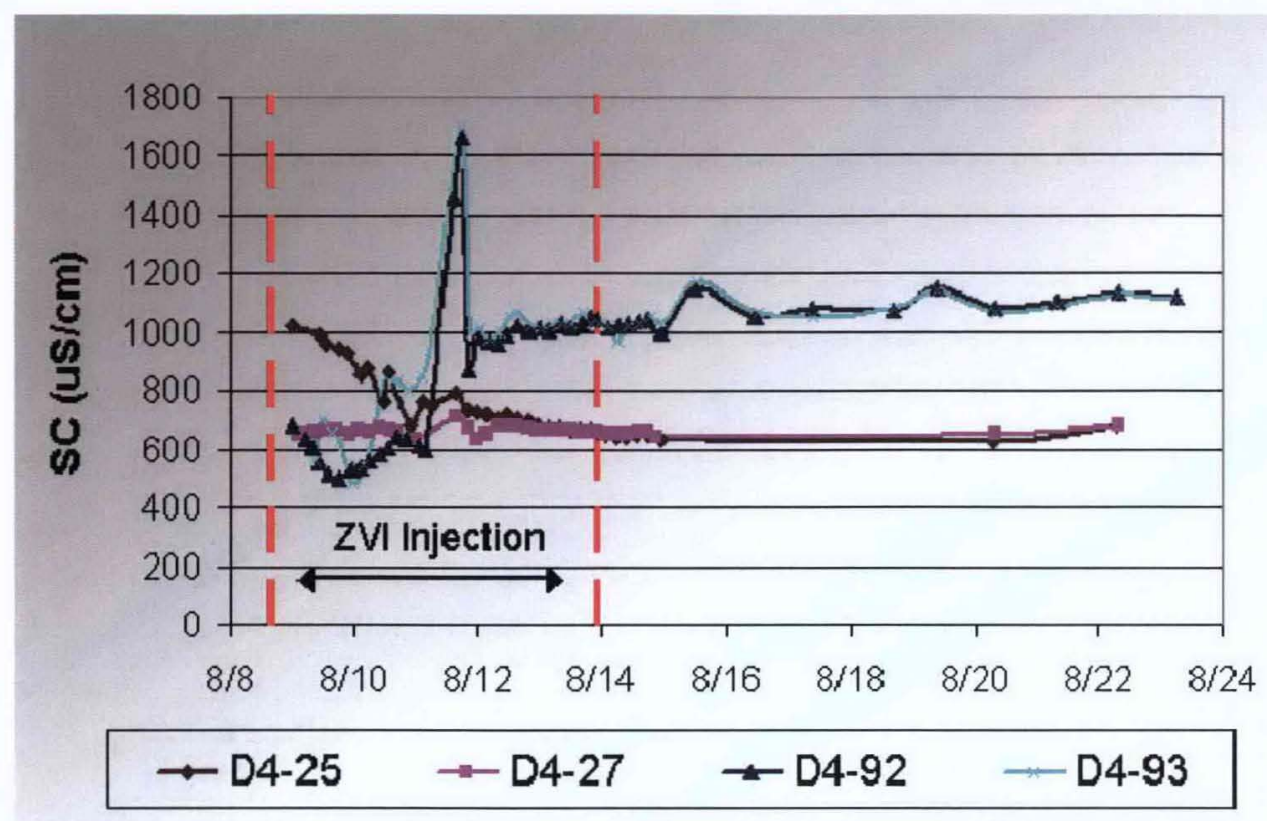

Figure 6-12. Monitoring Well Field Parameters - Specific Conductivity (Surface Measurement)

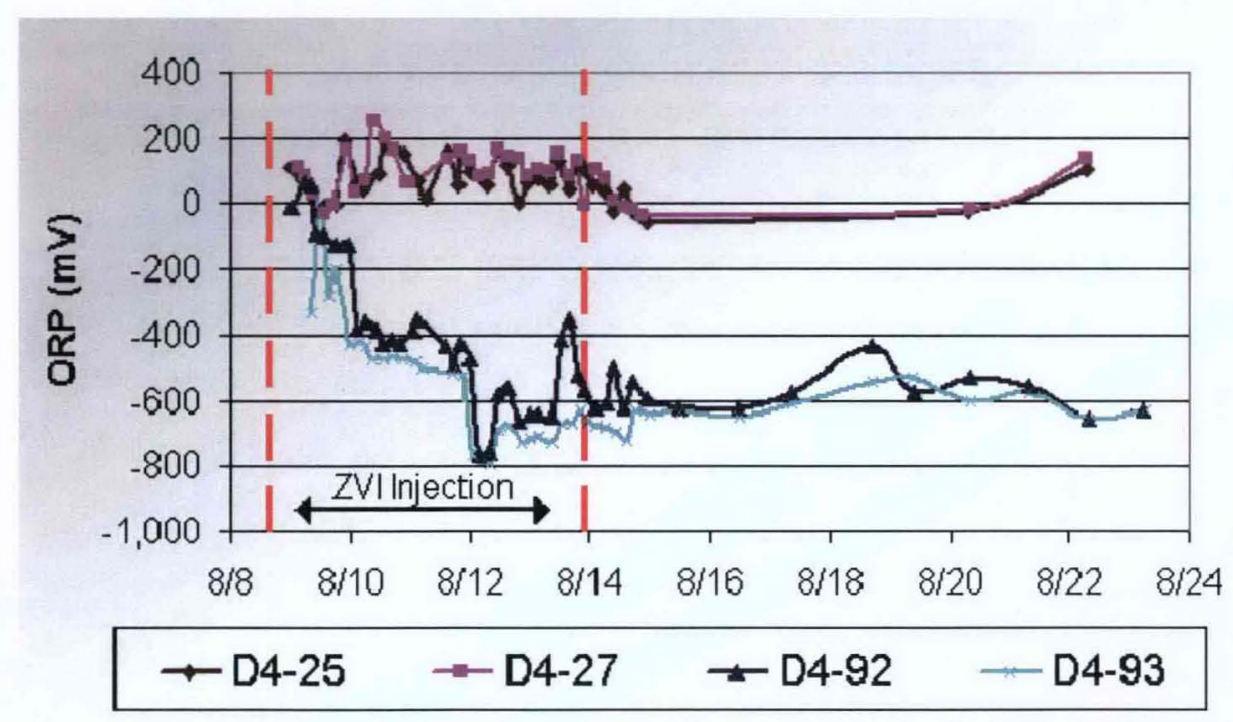

Figure 6-13. Monitoring Well Field Parameters - Oxidation-Reduction Potential (Surface Measurement)

The monitoring wells (199-D4-92 and 199-D4-93) closest to the injection well showed significant changes in water quality parameters. The monitoring well field parameters followed the same general trend as observed in the down-hole data. As expected, the $\mathrm{pH}$ and specific conductivity increased and the ORP and DO decreased in the two closest monitoring wells during the injection.

The changes in field parameters suggest that the ZVI injection affected well 199-D4-93 (approximately $3 \mathrm{~m}$ [9.8 $\mathrm{ft}]$ from the injection well) by the time the first sample was taken on August 9 at 08:45. 


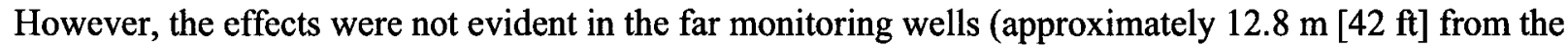
injection well). Appendix D contains the complete results for the field parameters and the down-hole data.

\subsubsection{Visual Observations}

Visual observations were made during field parameter sampling of the monitoring wells. Laboratory testing indicated that an observable color change would occur in the solution with the presence of the polymer and ZVI particles. The arrival of the polymer typically precedes the ZVI front and is indicated by a gradual change in the solution from clear to a light-yellow/brown color; along with a color change, the polymer also will create "soapy" bubbles when present. The arrival of the ZVI front is indicated by an abrupt change to a black solution.

The presence of ZVI was first indicated in monitoring well 199-D4-93 on August 9, 2008 at 08:45, which was just 16 hours into the ZVI injection. Monitoring well 199-D4-92 effluent began to turn a light-brown color on August 9 at 05:25, and it then turned black on August 10 at 03:03. The effluent of both wells 199-D4-93 and 199-D4-92 remained black for the remainder of the injection. A yellow/brown color and the presence of bubbles were noted in monitoring well 199-D4-25 on August 9 at 13:55; however, the presence of ZVI was never observed. Monitoring well 199-D4-27 did not visually show influence of the injection for the duration of the testing.

Visual observations of the monitoring well samples were concurrent with the field parameter and down-hole data presented in the previous section. Both suggest that the ZVI front quickly reached and surpassed the $3 \mathrm{~m}(9.8-\mathrm{ft})$ radial distance, however, it did not reach the distance of $12.8 \mathrm{~m}(42 \mathrm{ft})$. The slight color change in monitoring well 199-D4-25 at the end of injection also corresponds with the temperature monitoring data (Figure 6-7) in that the influence of injection had just begun to reach monitoring well 199-D4-25 by the end of the injection; however, the ZVI front had not reached the well.

\subsubsection{Geophysical Monitoring}

Data repeatability between the pre- and post-injection geophysical surveys was excellent in general, with the exception of a few data outliers that were readily identified and removed prior to data analysis. The site conditions limited the options for geophysical monitoring methods. For example, there is only one nonmetallic-cased borehole on the site. The electrical conductivity was logged in this borehole using an electromagnetic induction tool, and the induction logs showed a significant response to the ZVI injection. Having at least two nonmetallic-cased boreholes onsite would have allowed for high-resolution, crossborehole imaging techniques (e.g., ground-penetrating radar and electrical resistivity tomography).

Surface-based geophysical methods had mixed results in monitoring the ZVI injection. The electrical resistivity and IP data were the most useful in constraining the lateral extent of the injection.

A conservative estimate consistent with the interpretation of the electrical resistivity, IP, and TEM results is that the radial extent of the ZVI injection exceeded the target minimum of $7 \mathrm{~m}(23 \mathrm{ft})$. The total field magnetics and mise a la masse data were not as useful in determining the extent of the injection. This resulted from a combination of factors, including a thick vadose zone and several steel-cased wells that interfered with the geophysical signals. Total field magnetics and mise a la masse data acquisition required notably less field effort than two-dimensional electrical profiling and, thus, should not be ruled out for future studies if the site conditions are favorable (e.g., depth to target substantially less than this test site). The results of the monitoring effort will be useful as a basis for designing and implementing similar data acquisition efforts at the Hanford Site, as well as other DOE sites. 


\subsubsection{Pre-Injection Geophysical Monitoring}

This section discusses the pre-injection geophysical results. The post-injection data and differences between pre- and post-injection data are discussed in Section 6.2.4.2. Table 6-9 provides details of the units and symbols for the geophysical results.

Table 6-9. Electrical and Electromagnetic Units and Symbols

\begin{tabular}{lcc}
\hline \multicolumn{1}{c}{ Property } & $\begin{array}{c}\text { Typical } \\
\text { Units }\end{array}$ & $\begin{array}{c}\text { Symboll } \\
\text { Abbreviation }\end{array}$ \\
\hline Resistance & ohm & $\Omega$ \\
Resistivity & ohm-meter & $\Omega$-m \\
Phase angle & radians & rad \\
Electrical potential & volt & $\mathrm{V}$ \\
Magnetic field & tesla & $\mathrm{T}$ \\
Frequency & hertz & $\mathrm{Hz}$ \\
Power & watt & $\mathrm{W}$ \\
Current & ampere & $\mathrm{A}$ \\
\hline
\end{tabular}

NOTE: The following magnitude abbreviations are used as appropriate in conjunction with the above quantities:

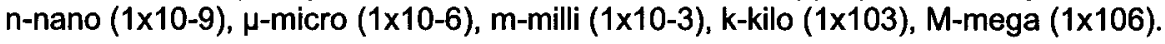

\section{Electrical Resistivity}

Electrical resistivity data were acquired at eight separate frequencies. There is some redundancy in these results; consequently, the results are presented from the $1-\mathrm{Hz}$ data only, as this frequency is in the middle of the range acquired, and the data obtained from this frequency exhibited consistently high repeatability. The electrical resistivity data were processed using two-dimensional electrical resistivity and IP inverse modeling software (RES2DINV Version 3.55 [Loke and Barker 2006]).

The pre- and post-injection data were first inverted separately using default settings for the modeling software. Plots of the pre-injection survey data are shown in Figure 6-14 (forward pole-dipole) and Figure 6-15 (reverse pole-dipole). Each of these figure includes two separate plots: one showing observed results, and one showing predicted results from the inverse modeling. In each case, the data were fit reasonably well with a root-mean-square error of 15 to 19 percent. These data fits can be observed visually by comparing the plots of observed and predicted data for each model (Figures 6-14 and 6-15). Each of these plots is presented with the same color scale to facilitate comparison. The quantity plotted here is the apparent resistivity (see Appendix D). The electrical resistivity models from these pre-injection data are discussed in Section 6.2.4.2, along with the post-injection models. 
DOE/RL-2009-35, REV. 0
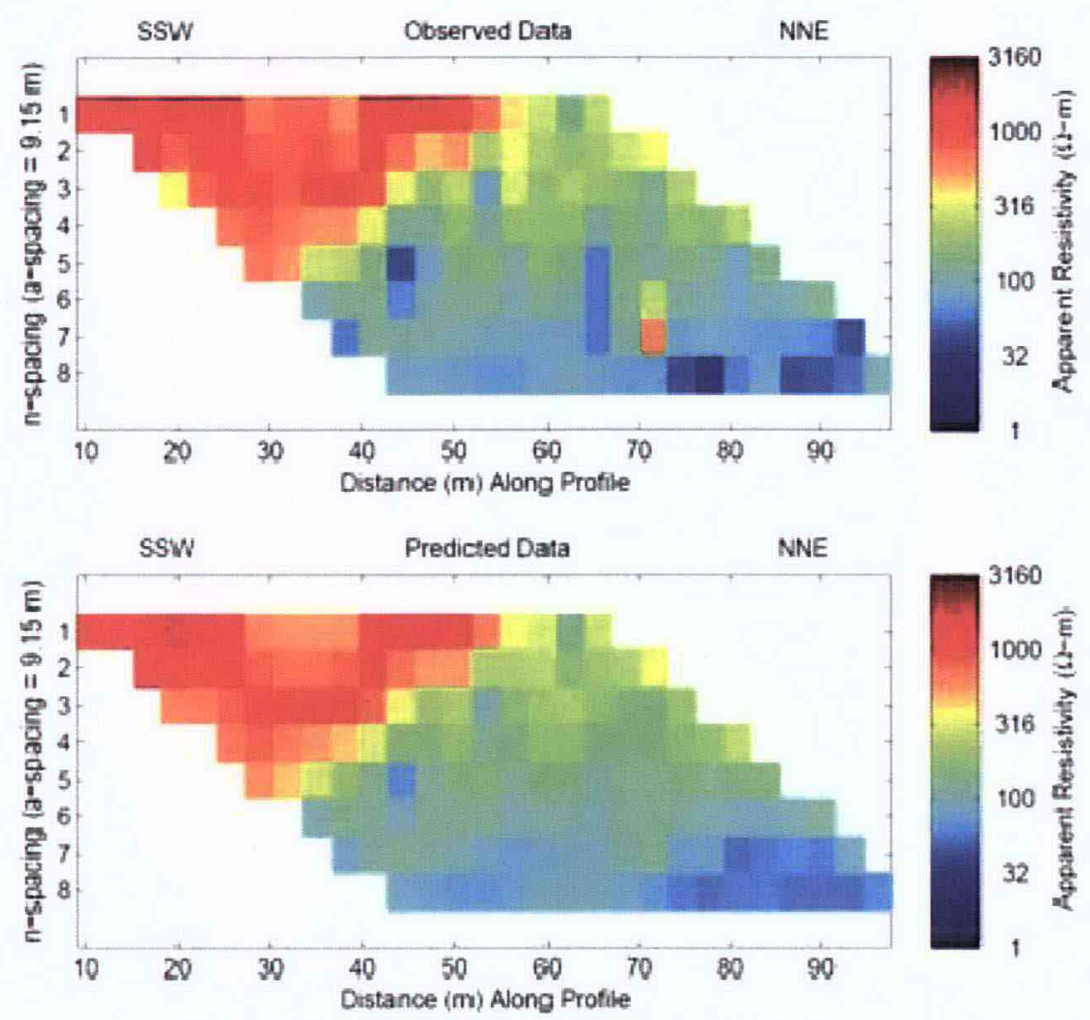

Figure 6-14. Pre-Injection Apparent Resistivity Data for Forward Pole-Dipole Survey
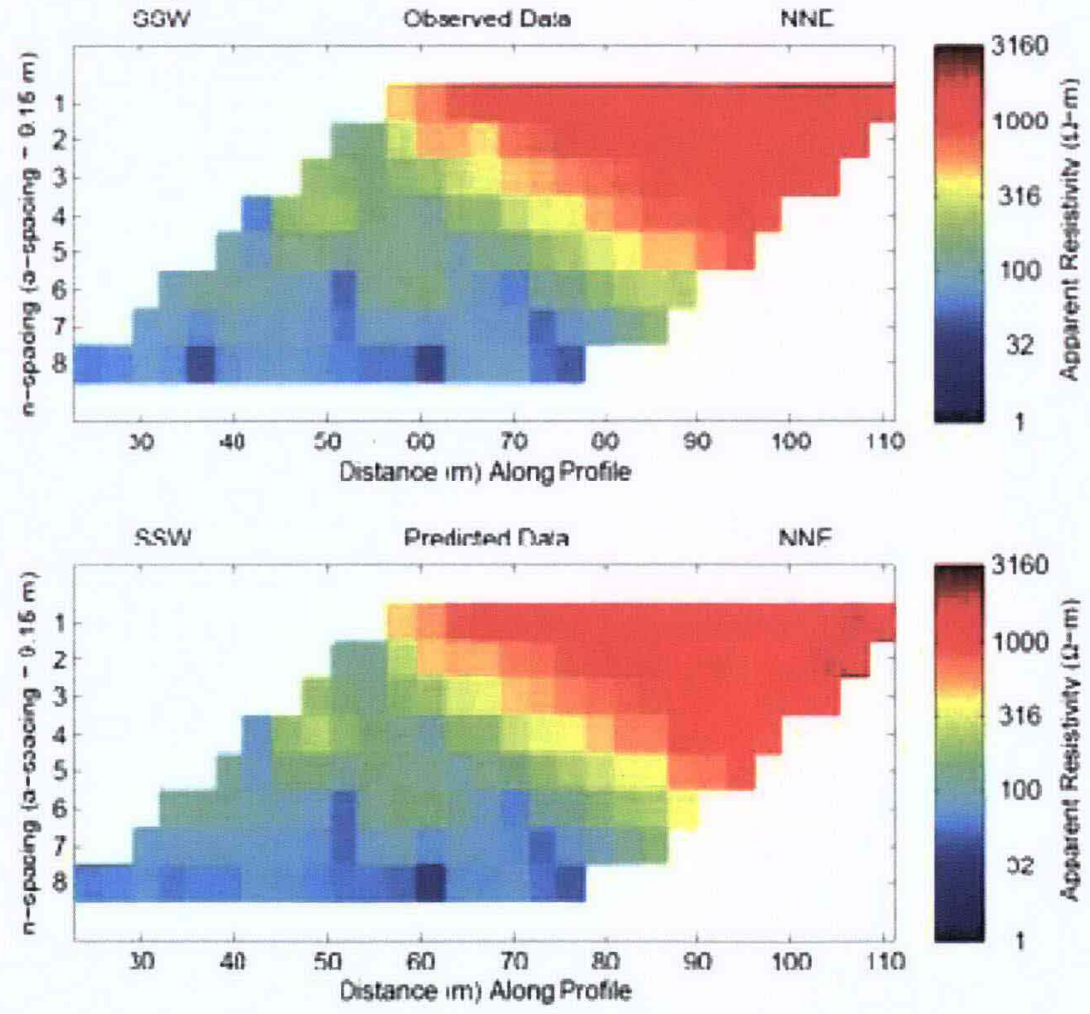

Figure 6-15. Pre-Injection Apparent Resistivity Data for Reverse Pole-Dipole Survey 


\section{Induced Polarization}

The IP data were acquired concurrently with the electrical resistivity data. During pre-injection data acquisition, problems with the phase-synchronization between the transmitter and the receiver were encountered, and a different transmitter had to be used to complete the survey. This led to some compatibility problems between the data sets; thus, only the reverse pole-dipole results are presented here. The results from only the 8-Hz IP data are presented; thus, the analysis and results of the complex resistivity will not be discussed. The IP response is frequency-dependent and thus is not expected to be the same at all frequencies. The $8-\mathrm{Hz}$ data were chosen because of good data repeatability.

Plots of the pre-injection IP data are shown in Figure 6-16, which includes two plots: one showing observed results, and one showing predicted results. The predicted results are calculated from the inverted models of the pre-injection IP response. As with the resistivity data, these data were inverted using the RES2DINV software. The results of the pre-injection IP modeling are discussed in Section 6.2.4.2, along with the post-injection results.
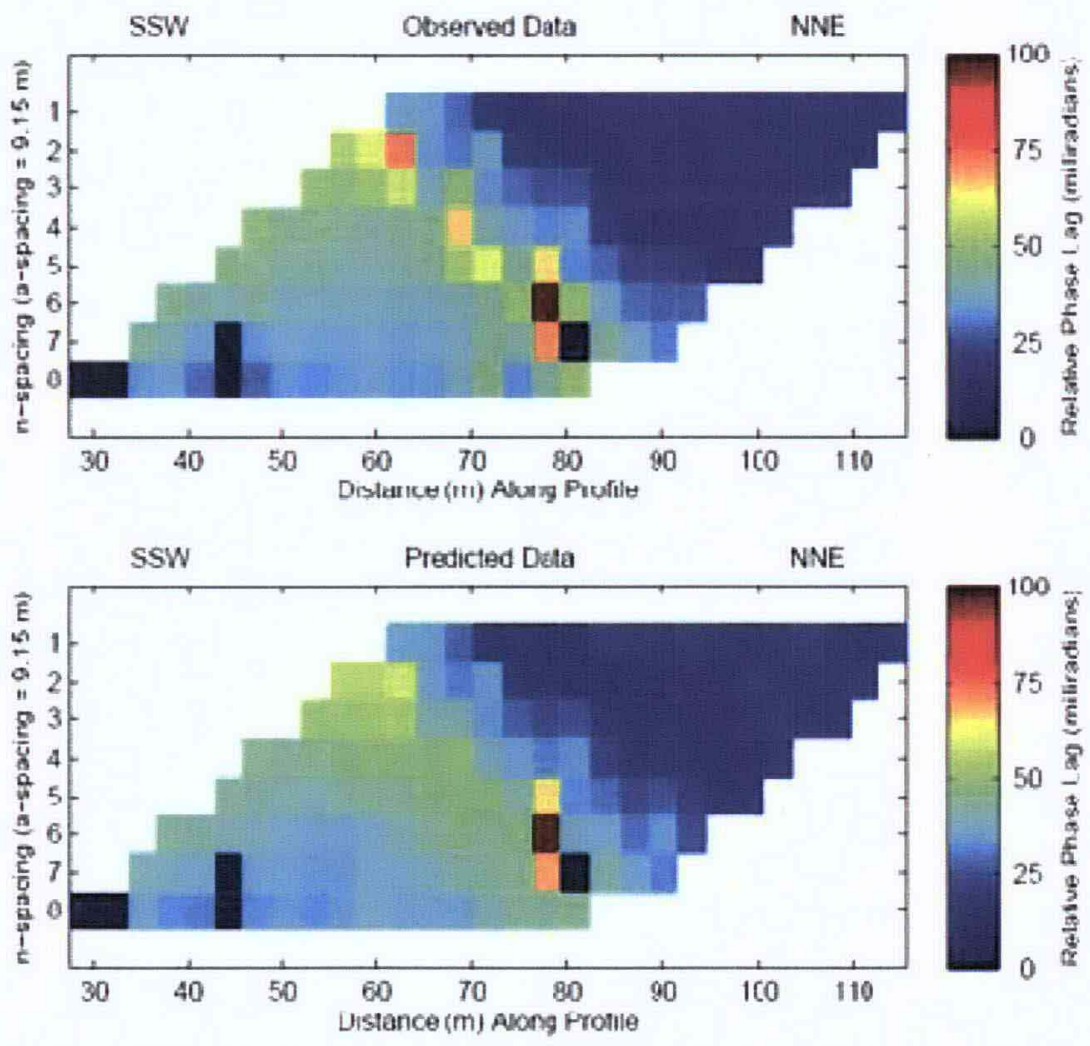

Figure 6-16. Pre-Injection Reverse Pole-Dipole Induced Polarization Data

\section{Borehole Conductivity Logging}

The results of the pre- and post-injection borehole conductivity logging have been combined for comparison purposes and are presented in Section 6.2.4.2. 


\section{Time-Domain Electromagnetics}

The results of the pre- and post-injection TEM surveying have been combined for comparison purposes and are presented in Section 6.2.4.2.

\section{Magnetics}

The pre-injection total field magnetics data are shown for the lower and the upper sensors in Figures 6-17 and 6-18, respectively. The lower sensor was located just above ground surface, and the upper sensor was located $1 \mathrm{~m}(3.3 \mathrm{ft})$ above the lower sensor (approximately $1 \mathrm{~m}[3.3 \mathrm{ft}]$ above ground surface). The data from the upper sensor were more stable (based on several repeated measurements at the base station), suggesting that the lower sensor data were more subject to influence by very near surface materials. The magnetic field data acquired adjacent to the wells were occasionally outside of the measurement range of the sensors due to the effect of the steel casings. These data points are not included in the data contour plots. Further discussion of these results can be found in Section 6.2.4.2, as well as post-injection magnetics data.

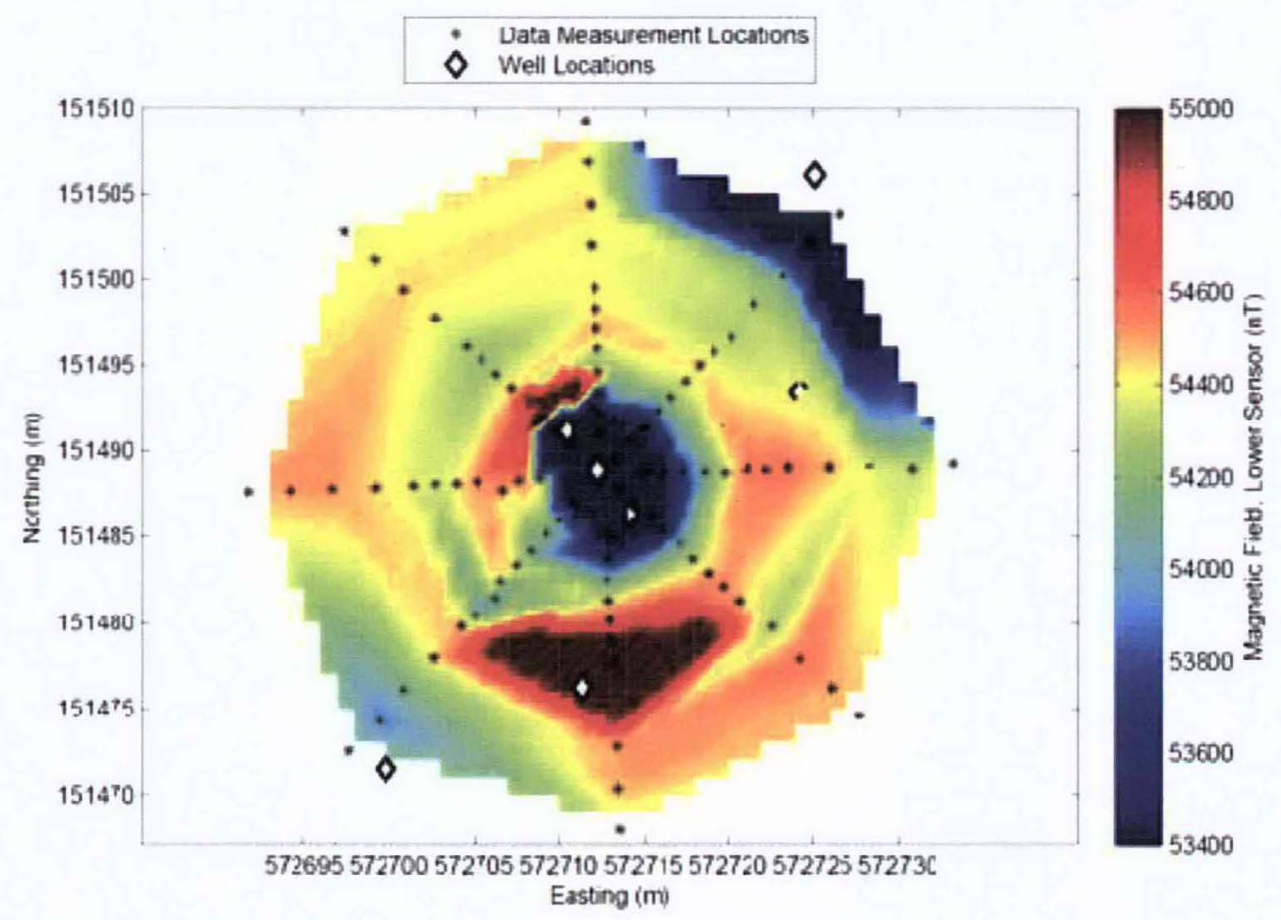

NOTE: The injection well is located at the center of the grid.

Figure 6-17. Observed Magnetic Field Data from Lower Sensor Pre-Injection 


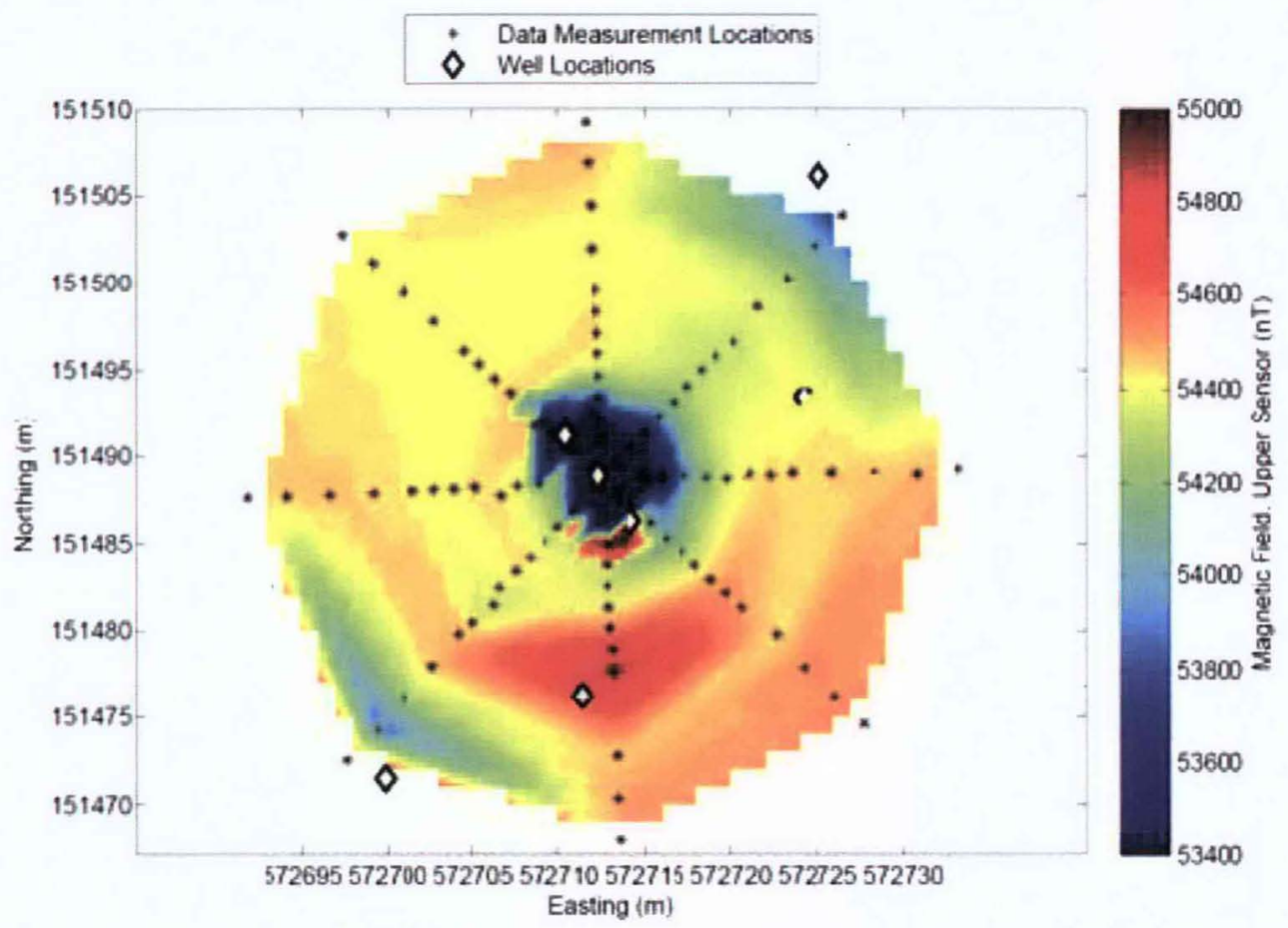

NOTE: the injection well is located at the center of the grid.

Figure 6-18. Observed Magnetic Field Data from Upper Sensor Pre-Injection

\section{Mise a la Masse}

The mise a la masse data were acquired by injecting an alternating current $(1 \mathrm{~Hz})$ into the ground via the injection well casing. The resulting electrical potentials were converted to apparent resistivities (see Appendix D) and then plotted (Figure 6-19).

The pre-injection data exhibit higher apparent resistivity in the northern portion of the survey grid and lower apparent resistivity in the southern portion. The low in resistivity observed near the center of the grid likely results from the steel casings of the injection well and well 199-D4-93 (to the northwest of the injection well).

The relative phase difference between the injected current and the received potentials is shown in Figure 6-20. Again, the data are not easily interpreted or analyzed due to the complexities of the current injection. The anomaly in the phase difference observed near the center of the grid correlates well with the location of well 199-D4-93, which has a steel casing. This anomaly can be attributed to noise due to disturbance from the casing. However, there is also a persistent anomaly in the phase lag data in an east-west trending region located south of the injection well. This larger phase lag may be indicative of a clay lens or other low-porosity material in this region. These results are discussed in further detail in Section 6.2.4.2, as well as the post-injection results. 


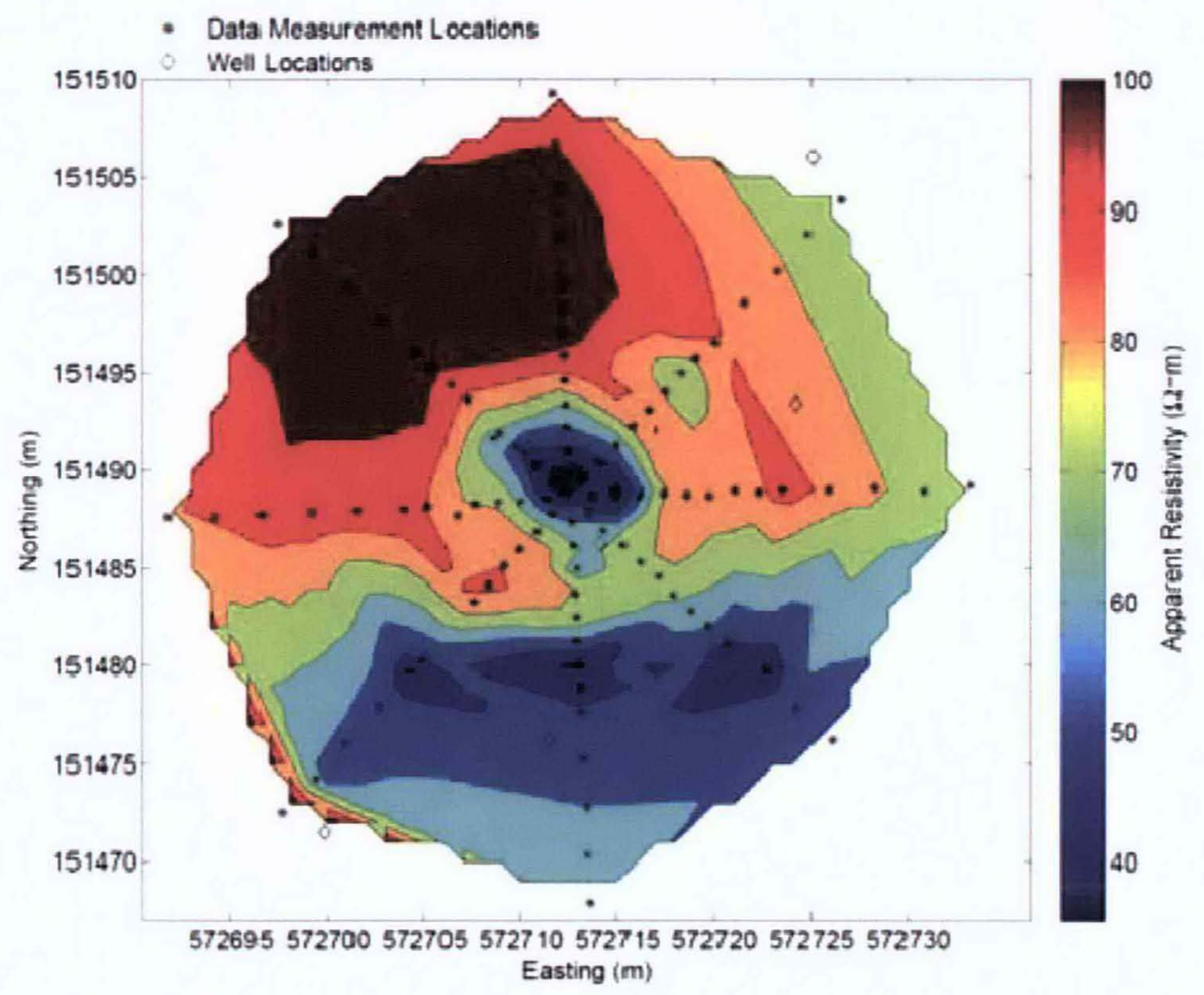

NOTE: Assumes a current injection at the ground surface elevation. The injection well is located at the center of the grid.

Figure 6-19. Pre-Injection Apparent Resistivity Calculated from Mise a la Masse Data

\subsubsection{Post-Injection Geophysical Monitoring}

This subsection discusses the post-injection geophysical results and compares them, as applicable, to the pre-injection results in an attempt to quantify the lateral extents of the ZVI injection.

\section{Electrical Resistivity}

Plots of the post-injection survey data are shown in Figure 6-21 (forward pole-dipole) and Figure 6-22 (reverse pole-dipole). The data fits can be observed visually by comparing the plots of observed and predicted data (plotted with the same color scale) for each model. In general, the data from the postinjection survey fit slightly better than the data from the pre-injection survey. An earlier iteration from the post-injection modeling (with a root-mean-square error of 16.8 percent) was used for comparison with the pre-injection modeling (a root-mean-square error of 18.3 percent) so a more direct comparison is facilitated. 


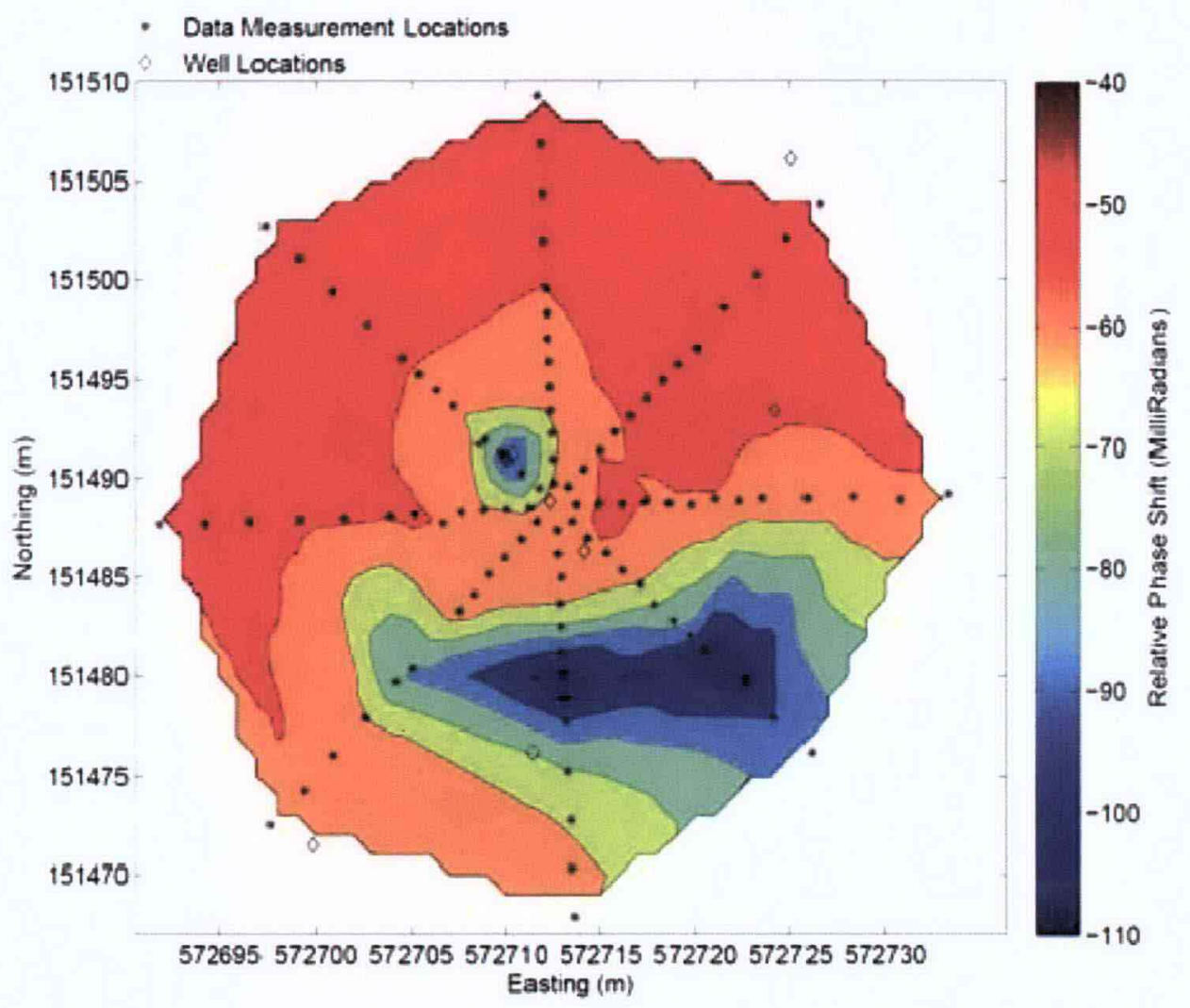

NOTE: The injection well is located at the center of the grid.

Figure 6-20. Relative Phase Shift Observed in Pre-Injection Mise a la Masse Data

Although the overall resistivity structure remains similar from pre-injection (Figure 6-23a) to postinjection (Figure 6-23b), there are noticeable differences in resistivity around the injection well and at depth. Figure 6-23c shows the RPD (see Equation 6-1) between the pre- and post-injection resistivity models. There are several localized anomalies in the range of 10 to 20 percent located within the vadose section of the model that are possibly due to differences in electrode contact resistance between the preand post-injection surveys (although these were minor) or due to added moisture in the vadose zone from a rainfall event that occurred during the injection. The apparent high relative changes in the model corners are likely artifacts from the modeling program. Note, however, there is a laterally extensive resistivity decrease ( 30 to 50 percent) located on each side of the injection well, near the bottom of the model. This resistivity decrease is likely due to the increased electrical conductivity resulting from the conductive polymer injected along with the ZVI.

The presence of iron alone did not significantly change the fluid conductivity in several batch tests; thus, these modeling results should be sensitive to the location of the electrically conductive polymer, which should (to some degree) be indicative of the location of the iron as they were injected together in solution.

Although choosing a specific contour is somewhat arbitrary, it appears that the influence of the injection

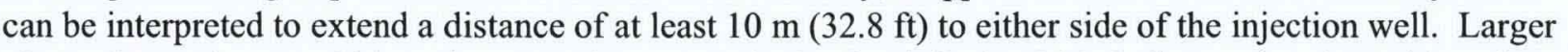
electrode spacings could have been used to constrain the depth limit of this influenced region, although this would have resulted in decreased lateral resolution (given an equal number of measurement stations). 
DOE/RL-2009-35, REV. 0
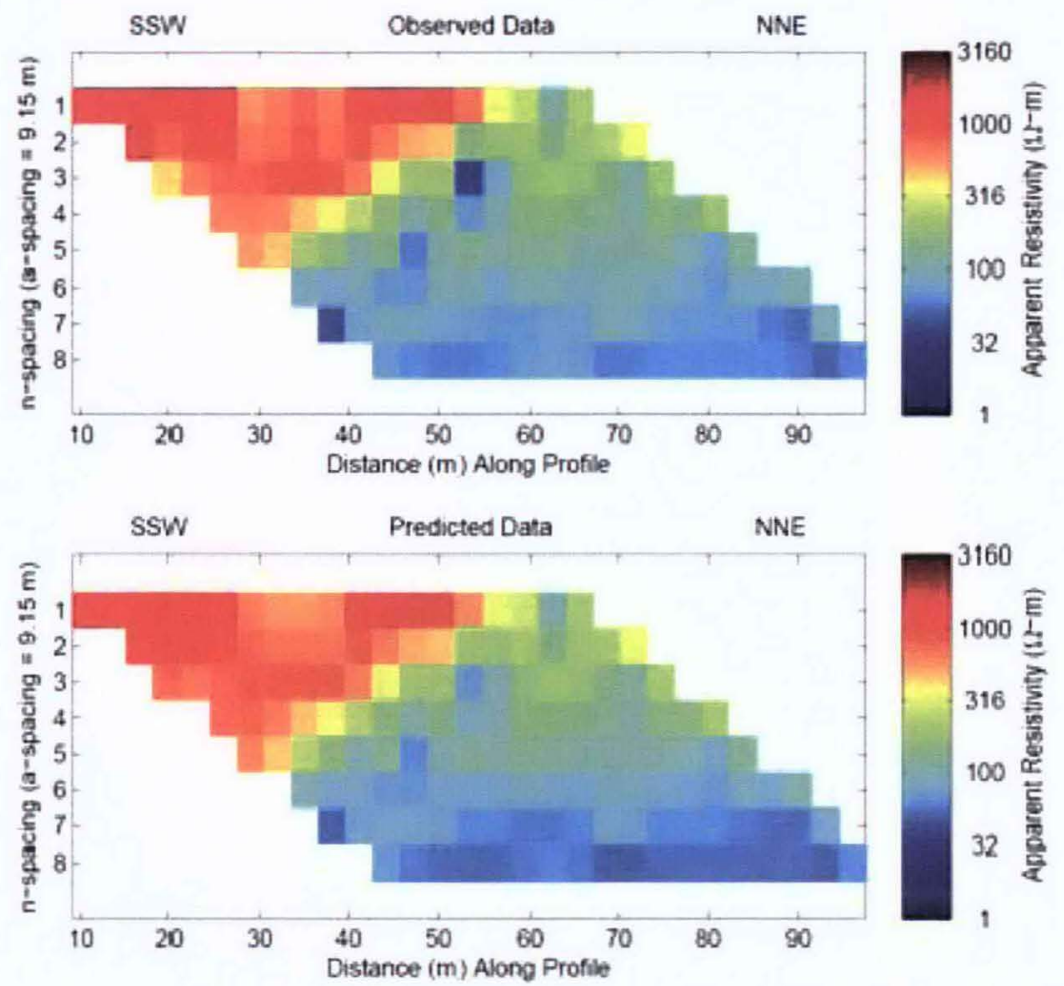

Figure 6-21. Post-Injection Data for Forward Pole-Dipole Survey
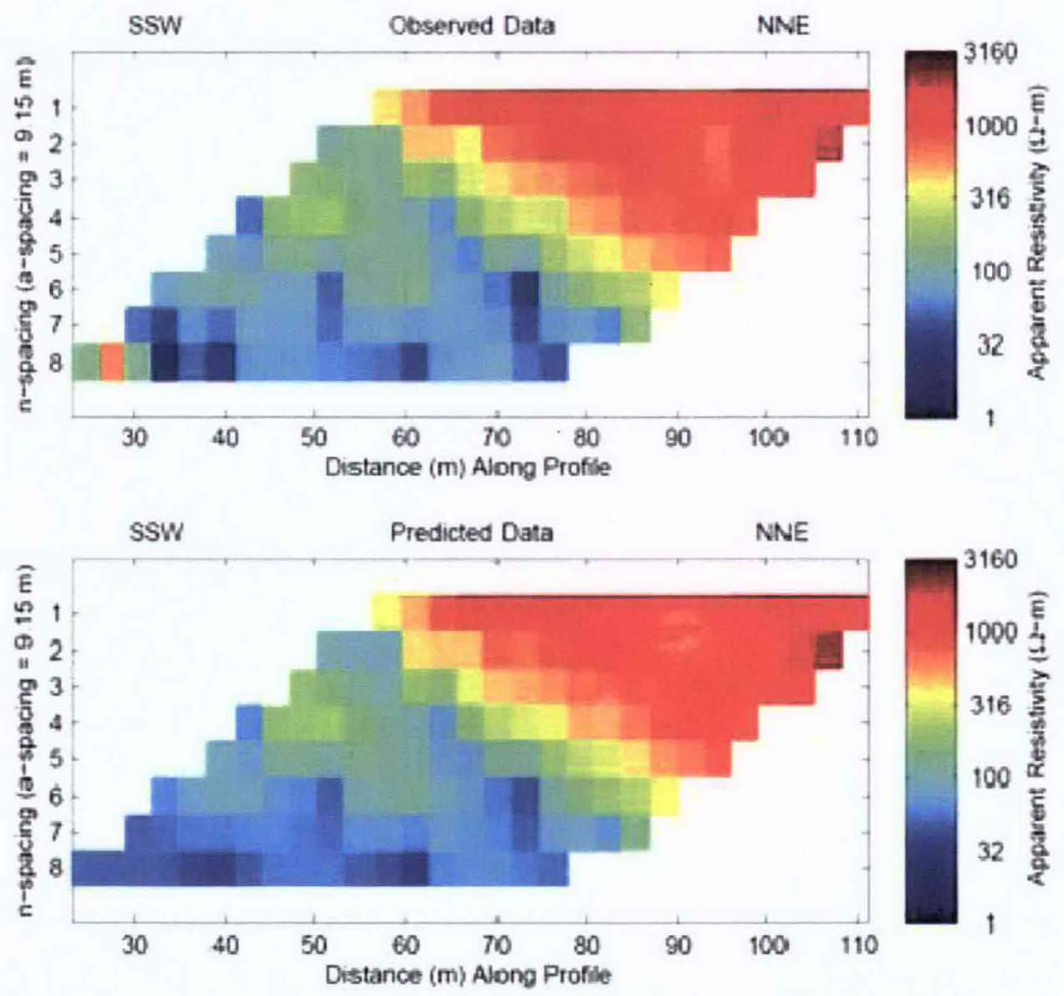

Figure 6-22. Post-Injection Data for Reverse Pole-Dipole Survey 

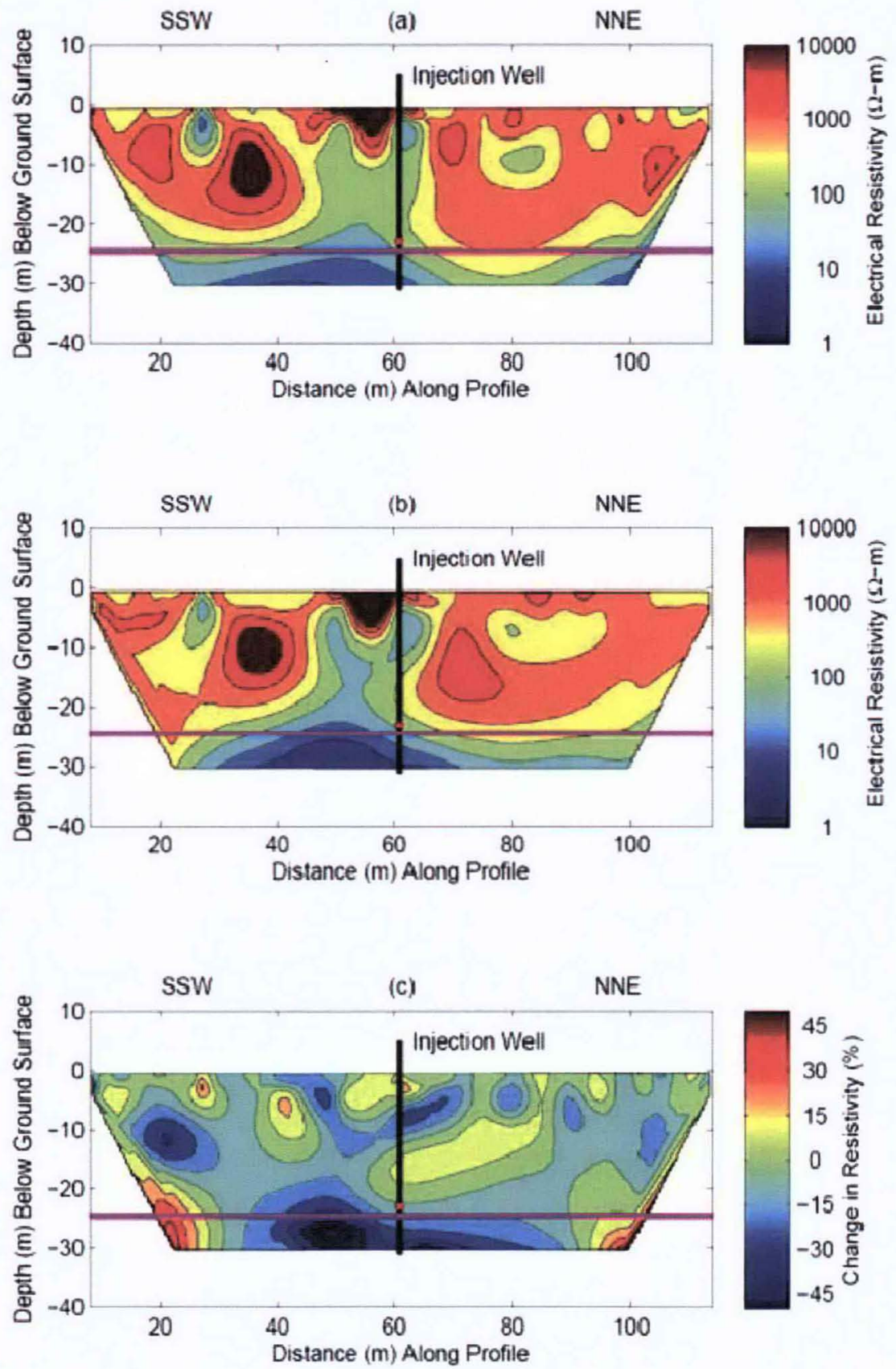

NOTE: (a) Pre-injection modeled electrical resistivity, root-mean-square misfit 18.3 percent after five iterations. (b) Post-injection modeled electrical resistivity, root-mean-square misfit 16.8 percent after three iterations. (c) Relative percent difference between preand post-injection modeled electrical resistivity. The red mark near $20 \mathrm{~m}$ depth indicates the location of the inflated packer and the horizontal magenta line indicates the average water table depth.

Figure 6-23. Resistivity Models Constructed by Separate Inversion of Pre- and Post-Injection Data 
A tradeoff between vertical and lateral resolution is often encountered when acquiring geophysical data. The RPD calculation is shown in Equation 6-1:

$$
R P D=100 \times \frac{m_{2}-m_{1}}{\left(\frac{m_{2}+m_{1}}{2}\right)}
$$

(Equation 6-1)

Where $\mathrm{m}_{2}$ is the post-injection electrical resistivity model and $\mathrm{m}_{1}$ is the pre-injection model.

Figure 6-24 ( $\mathrm{a}$ and $\mathrm{b}$ ) shows the pre-injection (a) and post-injection (b) electrical resistivity models, inverted using a smoothness constrained time-lapse inverse modeling procedure. In this case, the preinjection and post-injection data were inverted simultaneously in a manner that minimized the changes between the two models. This procedure tends to reduce the effects of noise on the modeling and takes advantage of the similarity of the two models. These two models are presented with the same color scale to facilitate comparison. Figure 6-24c shows the RPD between the pre- and post-injection resistivity models. The resistivity decreased approximately 10 to 20 percent in the region to both sides of the injection well near the bottom of the model and was relatively unchanged in the remainder of the model, except for a resistivity increase of approximately 15 percent indicated in both bottom corners of the model. This indicated increase appears to be an artifact of the data interpolation and is not interpreted as an actual resistivity increase.

\section{Electrical Resistivity Region of Data Influence}

The resolution of the resistivity models can be examined using the region of data influence (RDI) method, described in "Estimating Depth of Investigation in DC Resistivity and IP Surveys" (Oldenburg and Li 1999). In this method, the same data are inverted twice using two separate reference models while holding all other inversion parameters constant. In those model regions that are well constrained by the data, the model values should be independent of the reference model, at least to some extent. On the other hand, in those regions that are not well constrained by the data, the model values should revert to the respective reference model values. By differencing the two inverted models, then normalizing by the difference in the reference models, an RDI index can be constructed (Equation 6-2).

This index will approach unity in regions poorly resolved by the data and will approach zero in wellresolved regions. For these data, the first step taken to construct the RDI was to find the geometric mean of the observed apparent resistivity values $(185 \Omega-\mathrm{m})$. This value was then perturbed by plus and minus 33 percent to choose the two separate reference models for the inversions. Figures 6-25 and 6-26 show examples of the RDI index computed for these data using these two reference models. Figure 6-25 indicates that the resistive regions of the model are resolved poorly compared to the conductive regions (this result is expected as electrical currents will tend to follow the path of least resistance). Most of the modeled region is well resolved by the data, with the exception of some loss in resolution in the 25 to $30 \mathrm{~m}$ ( 80 to $98.4-\mathrm{ft}$ )-depth range on the right side of the model. It is possible to invert the same data with a grid extending to greater depth, which was done in order to construct the plots in Figure 6-26 and in turn to examine the depth of investigation limitations for these data. The depth of investigation appears to be approximately $30 \mathrm{~m}(98.4 \mathrm{ft})$. This is more than $5 \mathrm{~m}(16.4 \mathrm{ft})$ below the water table and should be sufficient for imaging the lateral extent of the ZVI injection. In order to capture the vertical extent of the injection, a model that extended several meters deeper (to at least $40 \mathrm{~m}$ [131.2 ft] in depth) would be required. Data constraint of a model to this depth is not possible given the electrode configuration used for this survey. 

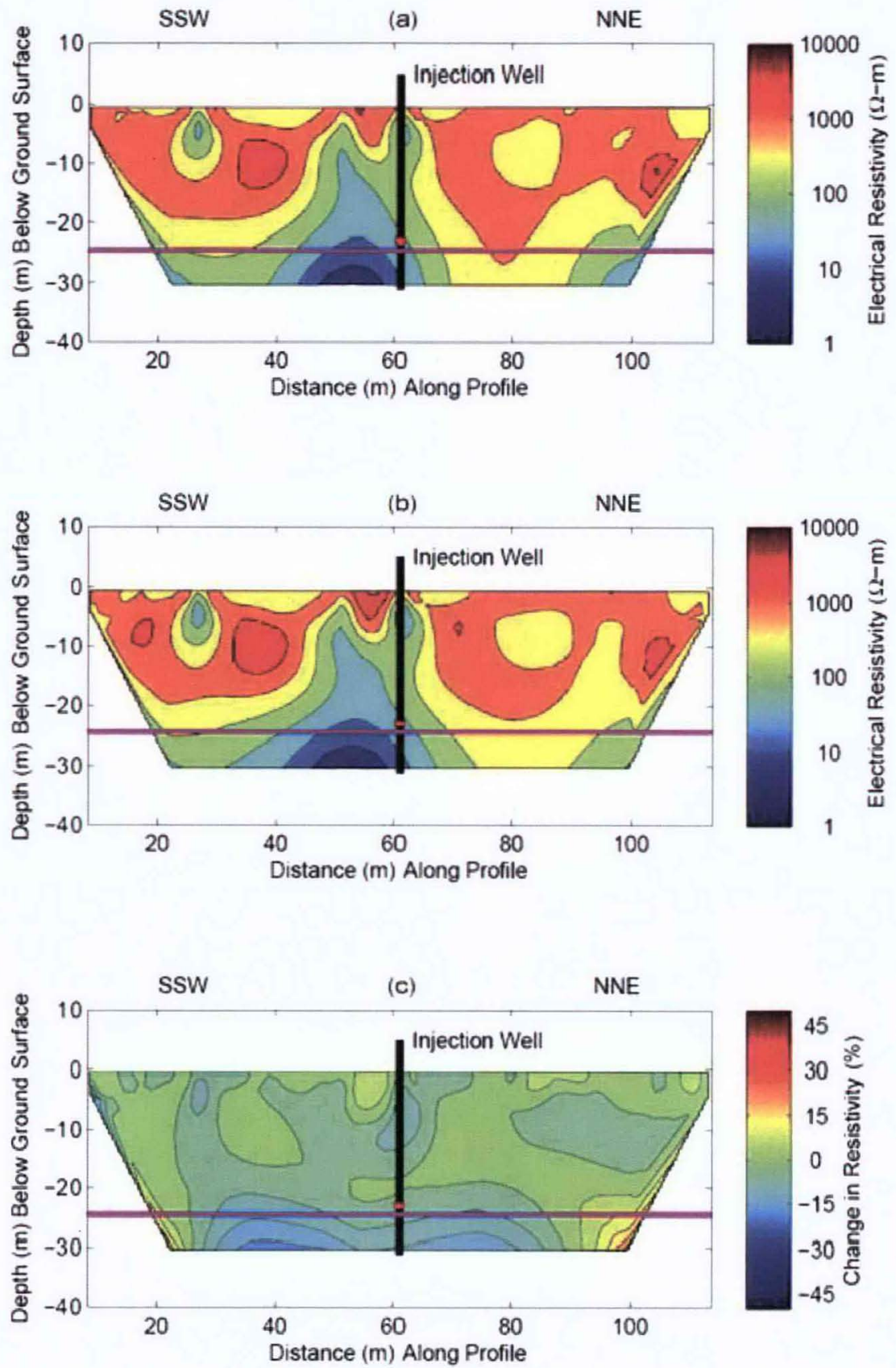

NOTE: (a) Pre-injection modeled electrical resistivity, root-mean-square misfit of 19 percent after four iterations. (b) Post-injection (time-lapse) modeled electrical resistivity, root-meansquare misfit of 15.3 percent after four iterations. (c) Relative percent difference between pre- and post-injection modeled electrical resistivity. The red mark above the water table indicates the location of the inflated packer and the horizontal magenta line indicates the average water table depth.

Figure 6-24. Resistivity Models Constructed by Smoothness-Constrained Time-Lapse Inversion of Pre- and Post-Injection Data 


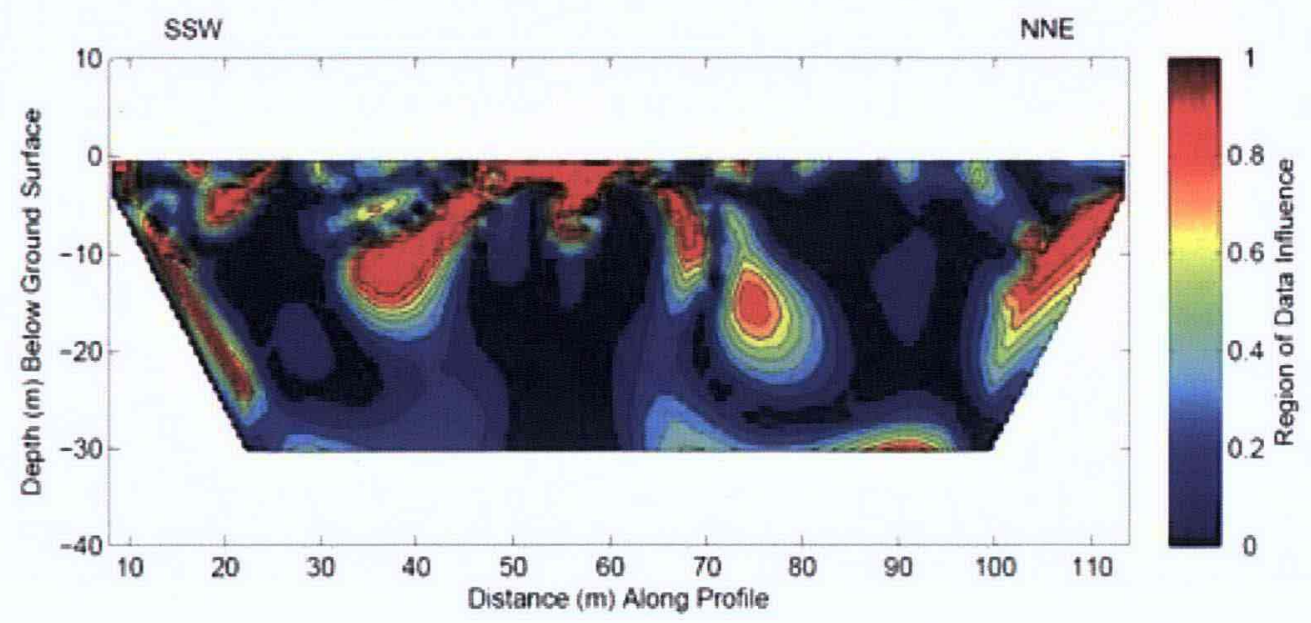

NOTE: Reference models of 123 ohm-meters and 244 ohm-meters were used to invert the data two separate times using default settings. Data fit for each inversion was similar, with a root-mean-square misfit of 15 to 16 percent after four iterations.

Figure 6-25. Region of Data Influent Index Calculated Using Post-Injection 1-Hz Resistivity Data

The choice of a cut-off value for the RDI is arbitrary, but often this choice is made in the region of steep gradient of the RDI. Based on this cut-off value (0.4), the model is better resolved at depth on the left end and in the middle. The default inversion depth (based on the maximum pseudo-depth of the data) appears to be an appropriate choice for these data. Equation 6-2 provides the calculation for RDI:

$$
R D I=\frac{a b s\left(m_{2}-m_{1}\right)}{a b s\left(m_{R E F 2}-m_{R E F 1}\right)}
$$

where $m_{1}$ is the model obtained by using the first reference model $\left(m_{R E F 1}\right)$ and $m_{2}$ is the model obtained by using reference the second reference model $\left(m_{\text {REF2 }}\right)$. 

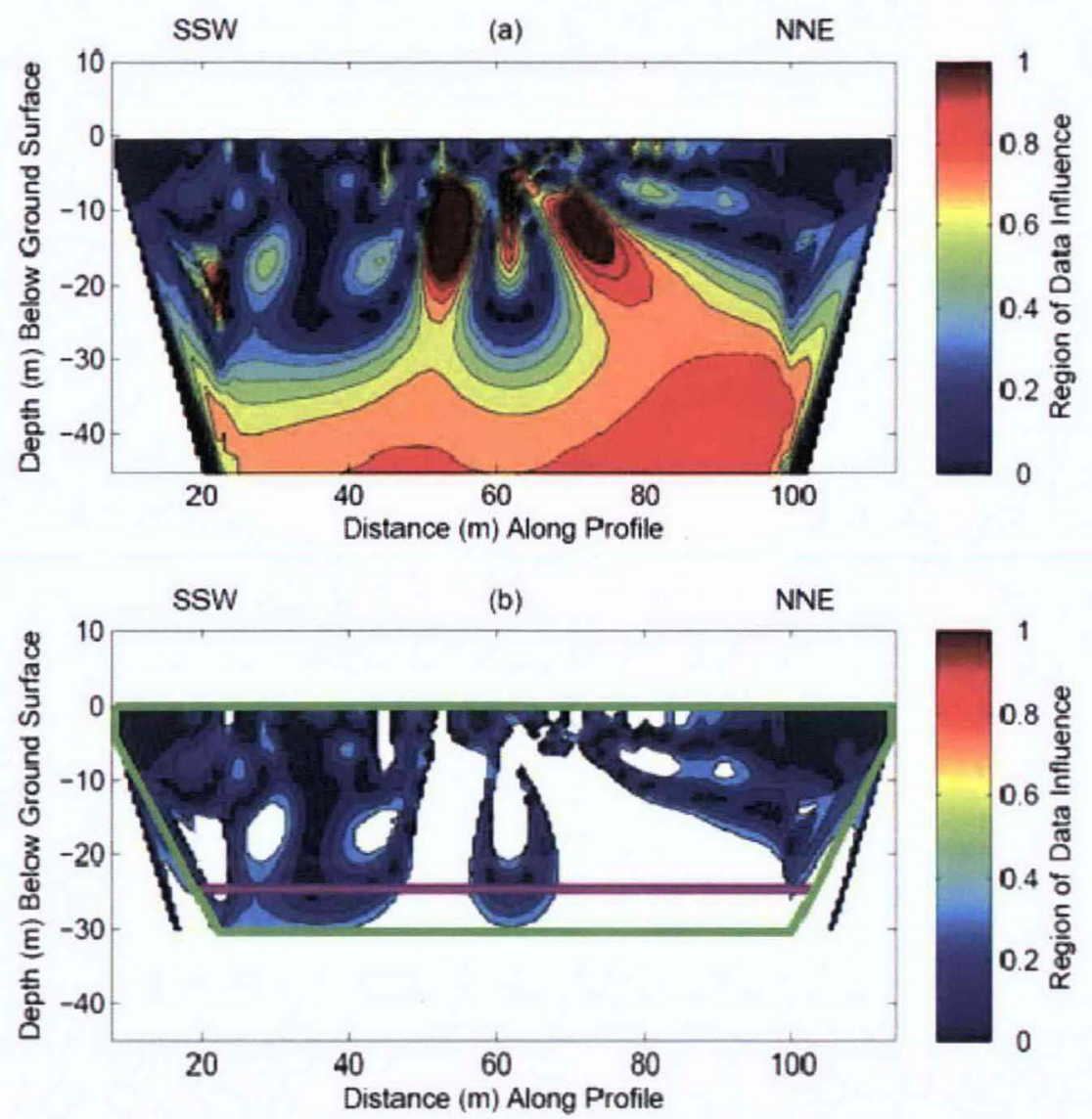

NOTE: To construct these plots, the $1-\mathrm{Hz}$ resistivity data were inverted for a model with a depth range of 1.5 times the maximum pseudo depth so that depth of resolution for the data could be examined. As for the previous figure, inversion was completed using reference models of 123 ohm-meters and 244 ohm-meters. (a) The RDI index for the entire depth range. (b) The region where the RDI index is less than 0.4 . The green outline indicates the region inverted for when constructing the time-lapse resistivity models. The horizontal magenta line indicates the average water table depth.

Figure 6-26. Analysis of Depth of Investigation for Resistivity Data

\section{Induced Polarization}

The post-injection IP data are shown in Figure 6-27. This figure includes the observed data and the predicted data calculated from the inverted models of post-injection IP response. Figure 6-28a and b shows the pre-injection, (a) post-injection, and (b) IP phase angle models. These plots are presented with the same color scale to facilitate comparison. Note that the smoothness constrained time-lapse inversion option is not available for IP data in the modeling software used to analyze these data. Figure 6-28c shows the raw difference between the pre- and post-injection IP phase angle models. Several localized anomalies occur in the range of 10 to 25 milliradians (note that this value is larger than the root-meansquare misfit of 4 to $7 \mathrm{mrad}$ ); however, the dominant response is centered on the injection well and is strongest near the bottom of the well. The IP phase lag increase is more than 50 milliradians in a region closely surrounding the well at a depth that correlates well with the injection depth of ZVI. This anomaly appears less laterally extensive than the anomaly seen in the resistivity difference, although there is some 
ambiguity in either case when choosing which contour to interpret as the outer edge of injected ZVI. Of all the geophysical results presented herein, the IP response provides the best estimate of the distance traveled by the ZVI (between 8 and $15 \mathrm{~m}[26.2$ and $49.2 \mathrm{ft}]$, depending on the contour chosen as the outer edge of the injection front) from the injection well. This is because the IP data are more sensitive to the presence of the iron particles and less sensitive to the presence of the polymer than the other methods (with the exception of magnetometry, which was of limited use in estimating the injection extent). One possible explanation for the IP anomaly not being centered at the location of the injection well is that a directional bias to the modeling occurs because only the reverse pole-dipole data were inverted to construct these models.
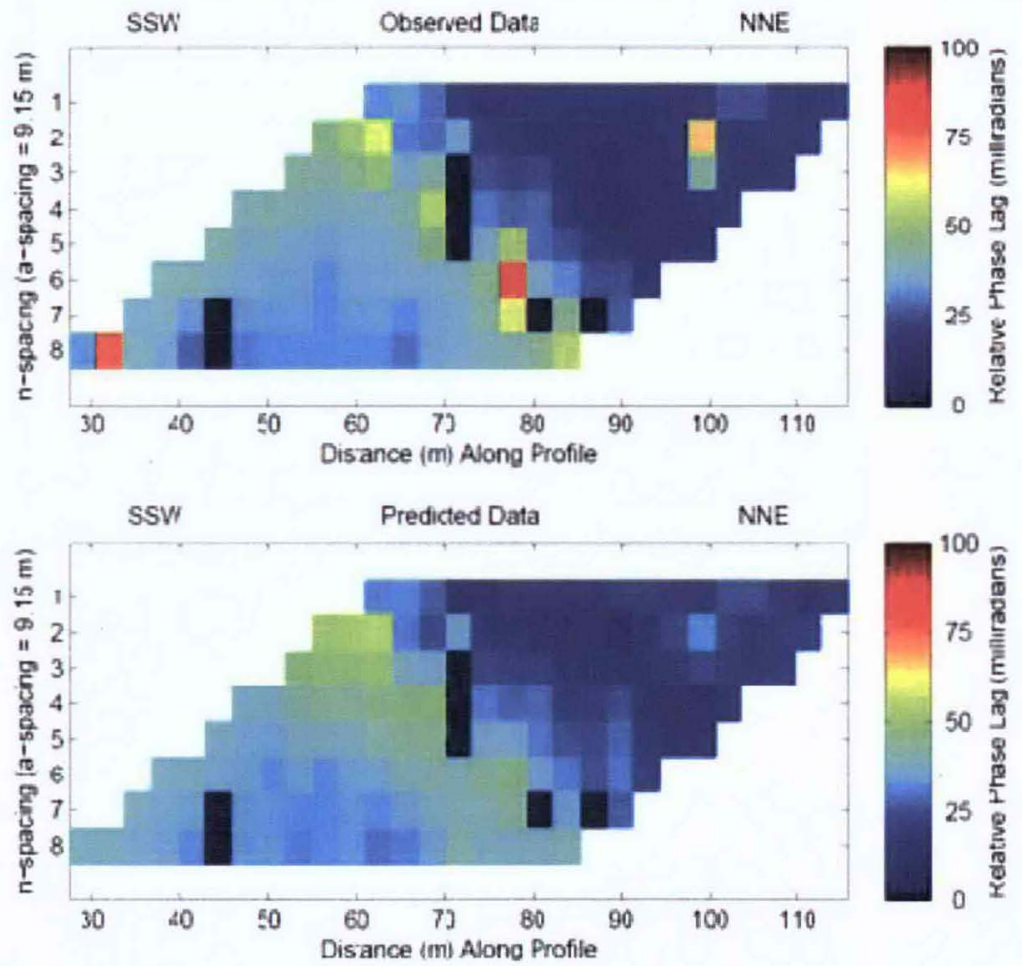

Figure 6-27. Post-Injection Reverse Pole-Dipole Induced Polarization Data 

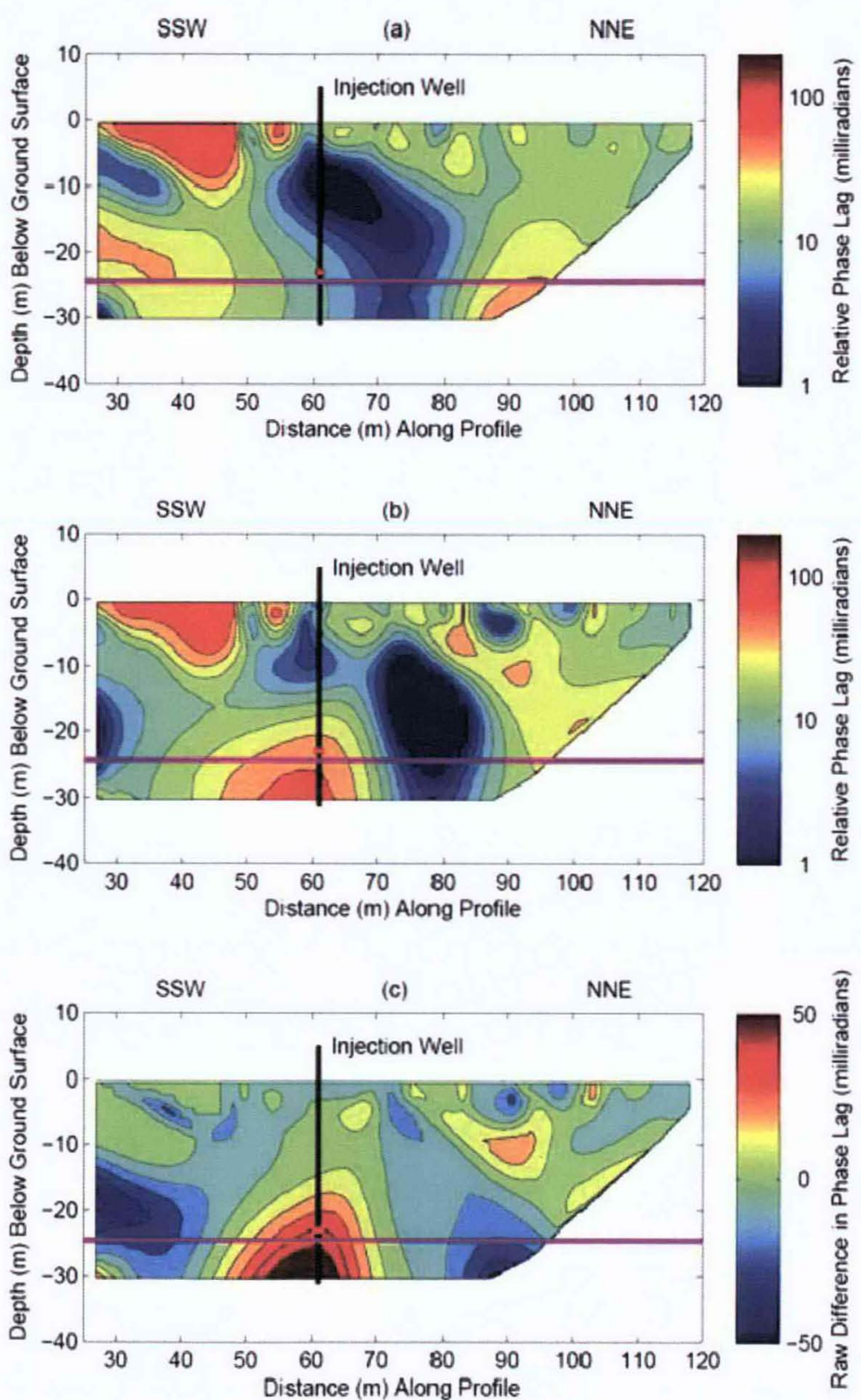

NOTE: (a) Pre-injection modeled IP response, root-mean-square error of 4.7 mrad after five iterations. (b) Post-injection modeled IP response, root-mean-square error of 6.8 mrad after five iterations. (c) Raw difference (post minus pre) between pre- and post-injection modeled induced polarization response. The red mark above the water table indicates the location of the inflated packer and the horizontal magenta line indicates the average water table depth.

Figure 6-28. Induced Polarization Models Constructed by Separate Inversion of Pre- and Post-Injection Data 


\section{Borehole Conductivity Logging}

The results of the borehole conductivity logging indicate that the ZVI injection reached at least to monitoring well D4-92 (the PVC-cased well), which is located approximately $3 \mathrm{~m}(9.8 \mathrm{ft}$ ) southeast of the injection well. The in-phase component of the conductivity (Figure 6-29) clearly shows a difference in the data below a depth of approximately $24 \mathrm{~m}(79 \mathrm{ft})$, which corresponds closely with the depth to the water table at the site. This indicates that the injected ZVI fluids have displaced and/or mixed with the groundwater throughout the saturated zone surrounding the well. Figure 6-29 also indicates that the data from downward and upward logging of the borehole show good repeatability of the results, with the exception of a few noisy data points in the region 10 to $15 \mathrm{~m} \mathrm{(32.8} \mathrm{to} 49.2 \mathrm{ft}$ ) below top of casing. The primary differences between pre- and post-injection are observed below a depth of $24 \mathrm{~m}(78.7 \mathrm{ft})$ and are attributed to the presence of conductive polymer, as well as ZVI within the formation following the ZVI injection.

(a)

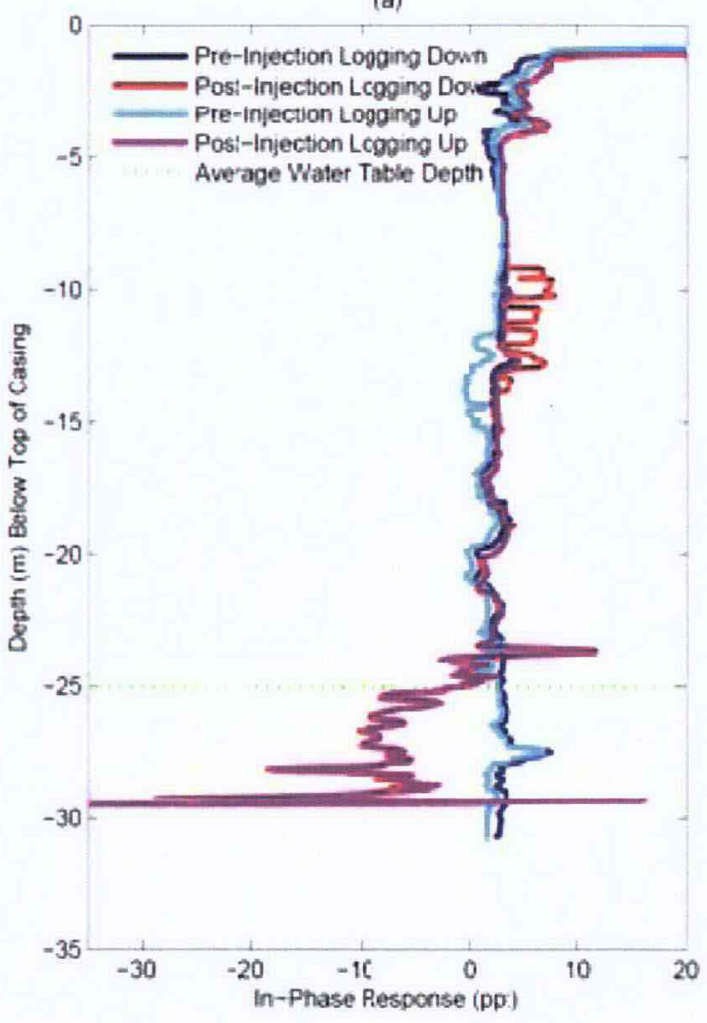

(b)

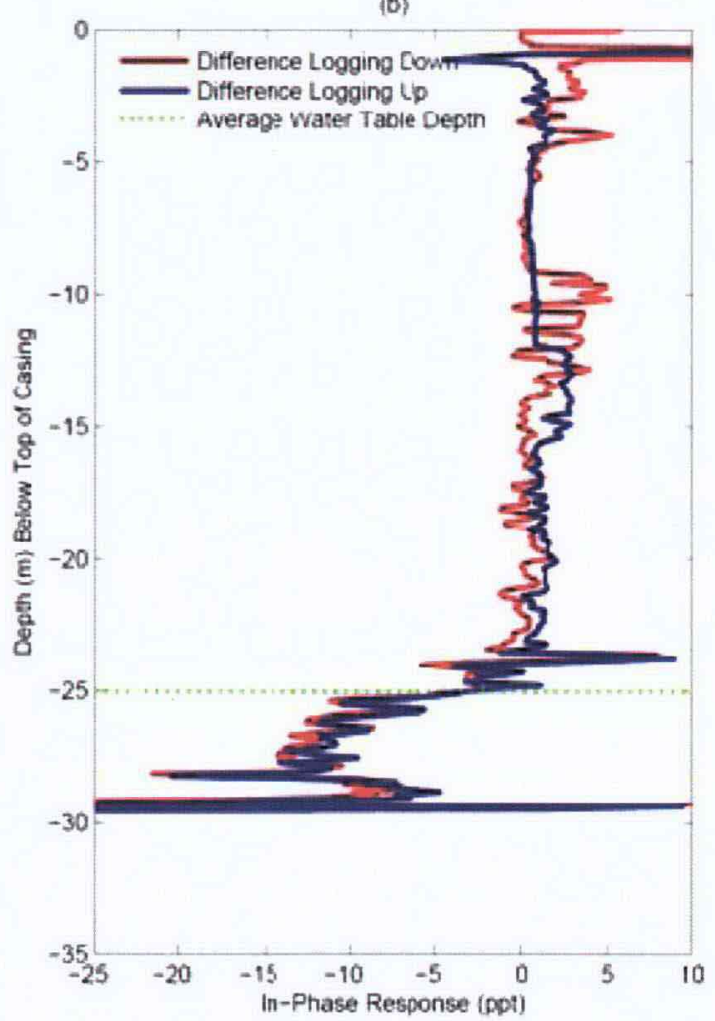

NOTE: (a) Plot of the in-phase component (ratio of the induced secondary magnetic field to the primary magnetic field in parts per thousand) of the conductivity. (b) Plots of the difference (raw) between the pre- and post-injection data.

Figure 6-29. Comparison of Pre- and Post-Injection Borehole Conductivity Data

Due to problems encountered with the borehole logging instrument, the quadrature component of the data is not correctly scaled; thus, quantitative comparison of the conductivity measured by the EM-39 with the conductivity modeled using the electrical resistivity data is not possible. However, by arbitrarily scaling the EM-39 quadrature component, the general shapes of the conductivity curves can be at least qualitatively compared. This comparison is shown in Figure 6-30. Note that the resistivity profile was 


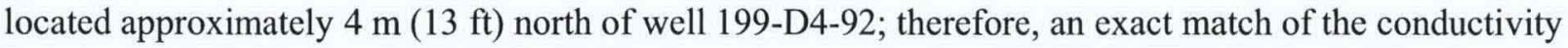
is not expected. The conductivity begins to increase at approximately $24 \mathrm{~m}$ (78.7-ft) depth (closely corresponding to the average water table depth), and the post-injection conductivity increases at a higher rate than does the pre-injection conductivity. The modeled conductivities correlate reasonably well with fluid conductivities measured in the boreholes (approximately $60 \mathrm{mS} / \mathrm{m}$ for reinjection and $110 \mathrm{mS} / \mathrm{m}$ for post-injection for well 199-D4-92).

\section{Time-Domain Electromagnetics}

The TEM surveying included six separate soundings located 4.14 to $12.49 \mathrm{~m}$ (13.6 to $41 \mathrm{ft})$ to the north and/or east of the injection well (Table 6-10). The results are presented in graphical format in Figure 6-31. The apparent resistivity was generally lower following the injection and was markedly lower for the later time windows in the data, which correspond to greater depths. This resistivity decrease is interpreted to result from the presence of the polymer and is thus an indirect indication of the presence of ZVI. The apparent resistivity decrease at depth was evident for all of the soundings except for loop \#1, which was located the furthest distance from the injection well $(12.49 \mathrm{~m}[41 \mathrm{ft}])$. Loop \#1 shows a slight decrease in resistivity in some time windows but almost no change in other time windows.

\section{Magnetics}

The post-injection total field magnetics data are shown for the lower (Figure 6-32) and the upper (Figure 6-33) sensors. The data pre- and post-injection are similar, suggesting that a data differencing approach could help in analyzing and interpreting the data. However, differencing the pre-injection data (Figure 6-34) and post-injection data (Figure 6-35) does not provide any useful insight into the extent of

the ZVI injection. This is likely due to the injection point being too deep, so the data difference observed at the surface falls within the noise level of the measurements. The most coherent result from the field magnetics data is the difference in the upper sensor data where a consistent increase in magnetic field extends as far as $4.9 \mathrm{~m}(16 \mathrm{ft})$ from the injection well (Figure 6-35).

\section{Mise a la Masse}

The post-injection apparent resistivity computed from the mise a la masse data is shown in Figure 6-36. This image of the resistivity is very similar to the pre-injection image. There is not a clear indication of the ZVI injection in the difference plot (Figure 6-37). It should be noted, however, that the data differences (Figure 6-37) are on the order of 5 to 15 percent when comparing pre- and post-injection data, while the standard deviations of these data were less than 1 percent of the observed values (both pre- and post-injection). This excellent data repeatability suggests that a time-lapse analysis approach, combined with an appropriate method for three-dimensional modeling of the data, could potentially be useful for imaging at the lateral and depth extents of the injection. 


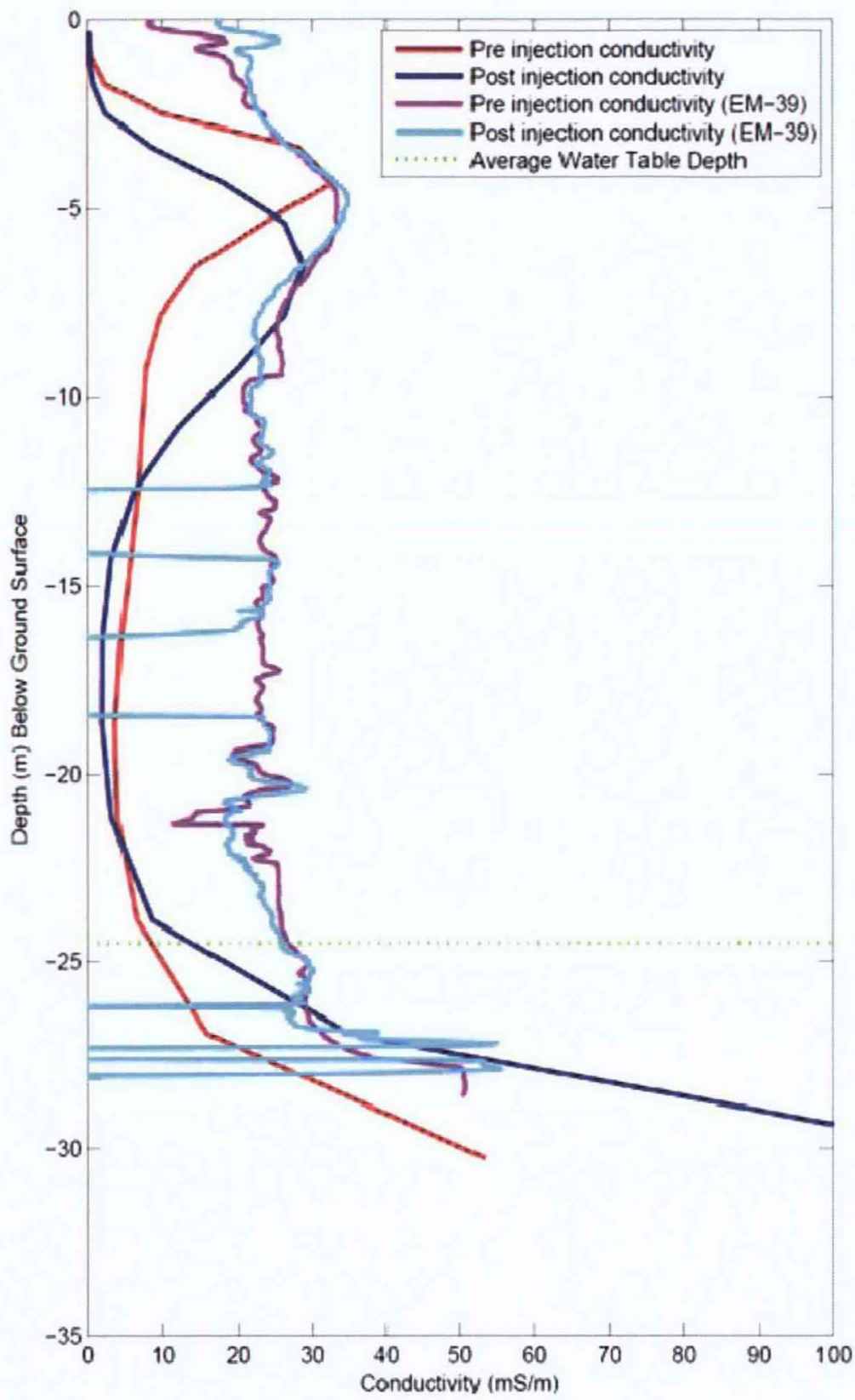

NOTE: The conductivity models are from separate inversion of the $1-\mathrm{Hz}$ resistivity data using default settings. Note that the curves shown here are one-dimensional models that have been extracted from the two-dimensional models. The location of these one-dimensional models is the point nearest the injection well. The EM-39 data depth axis was originally relative to the top of the casing but has been adjusted to depth below ground surface so that more direct comparison with the modeled conductivities is facilitated. The EM-39 data are scaled arbitrarily to facilitate qualitative comparison with the resistivity modeling.

Figure 6-30. Comparison of Modeling Results with EM-39 Borehole Conductivity Logging Results 
DOE/RL-2009-35, REV. 0

Table 6-10. Time-Domain Electromagnetic Receiver Loop Distance and Direction from Injection Well

\begin{tabular}{ccc}
\hline Loop \# & $\begin{array}{c}\text { Distance from } \\
\text { Injection Well, } \mathbf{m}\end{array}$ & $\begin{array}{c}\text { Direction } \\
\text { from Injection Well }\end{array}$ \\
\hline 1 & 12.49 & North-northeast \\
2 & 11.10 & Northeast \\
3 & 6.25 & Northeast \\
5 & 8.39 & East \\
6 & 4.14 & North \\
\hline
\end{tabular}
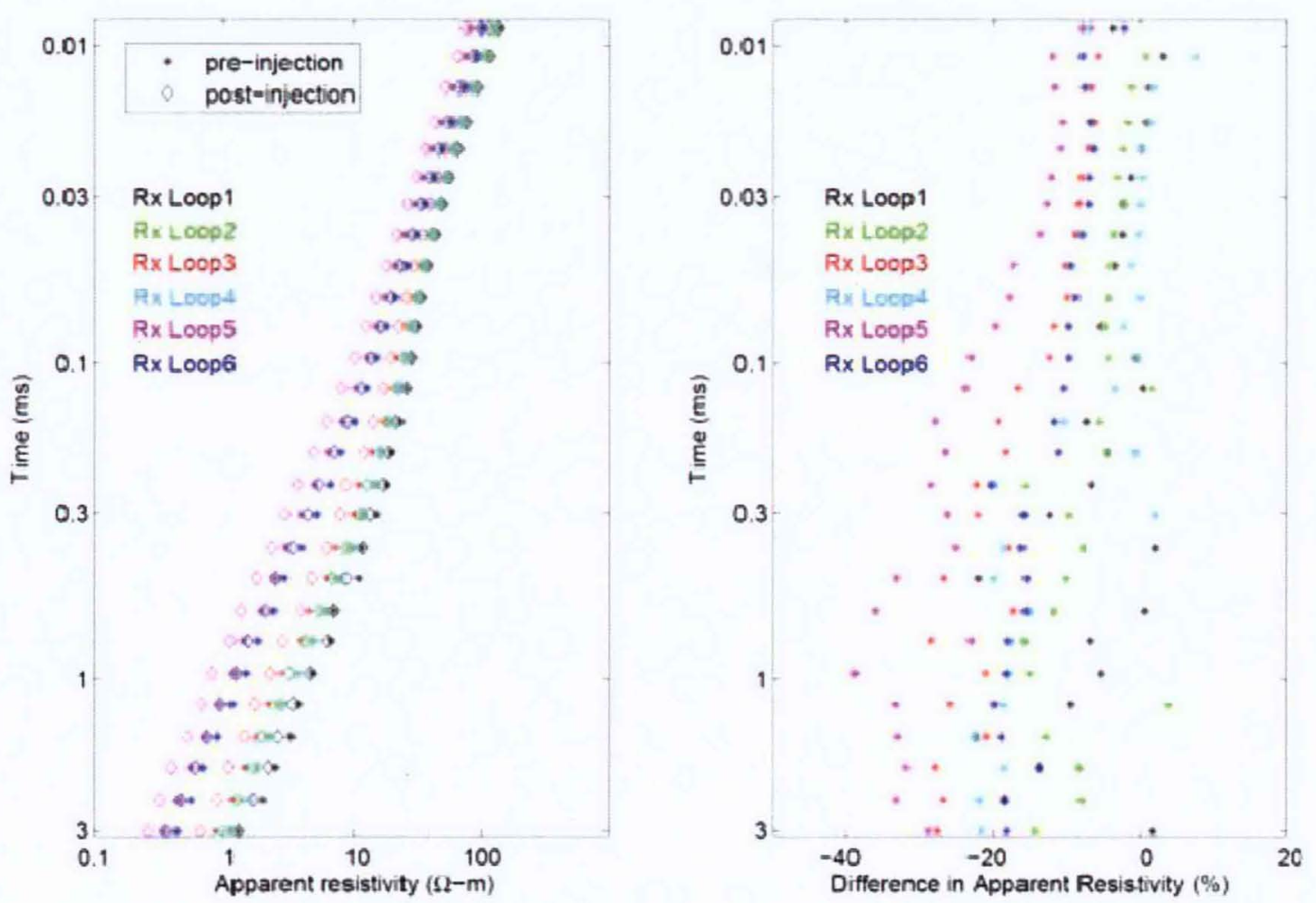

NOTE: The left plot shows the average (from two or more soundings) apparent resistivity for each receiver loop. The right plot shows the relative percent difference between the pre- and postinjection apparent resistivity. Note that later times indicate greater depth of investigation.

Figure 6-31. Comparison of Pre- and Post-Injection Apparent Resistivity Computed from Time-Domain Electromagnetic Data 


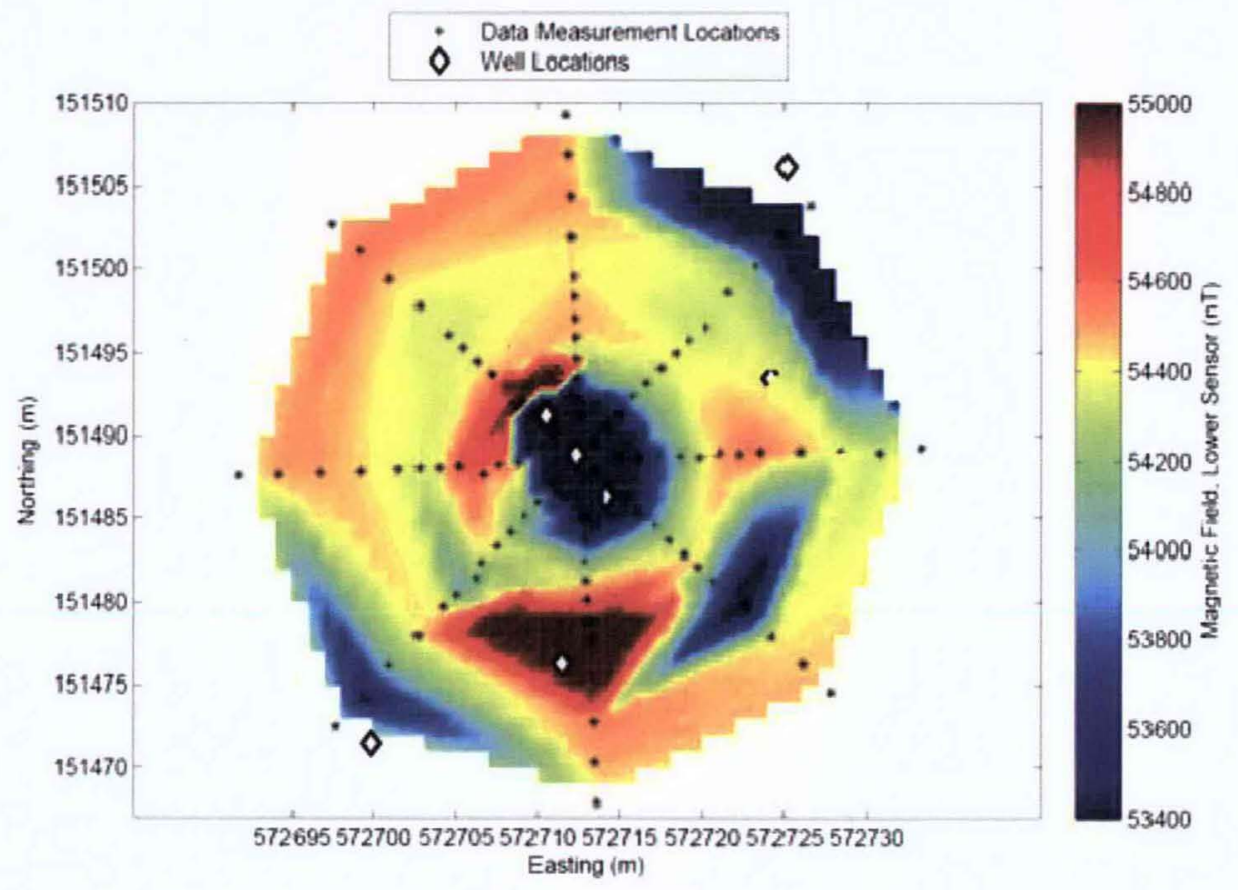

NOTE: The injection well is located at the center of the grid.

Figure 6-32. Observed Magnetic Field Data from Lower Sensor Post-Injection

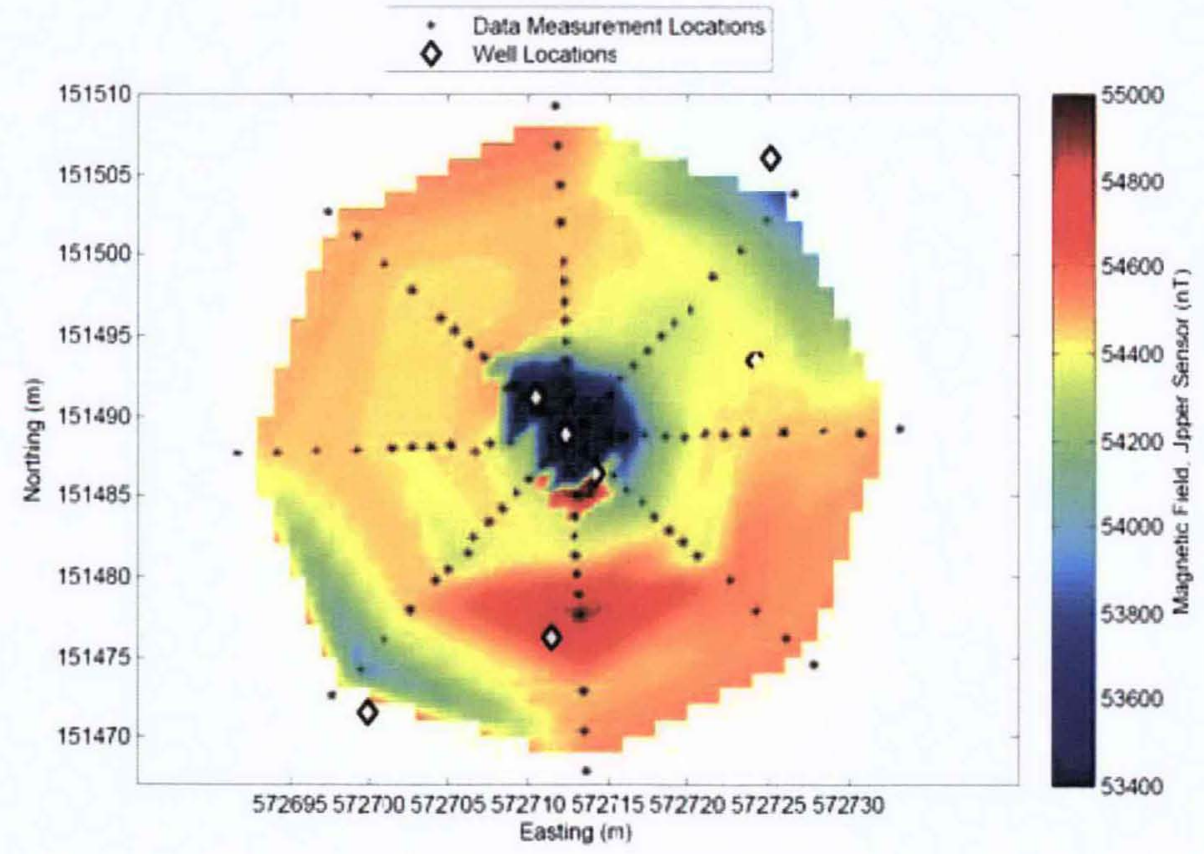

NOTE: The injection well is located at the center of the grid.

Figure 6-33. Observed Magnetic Field Data from Upper Sensor Post-Injection 


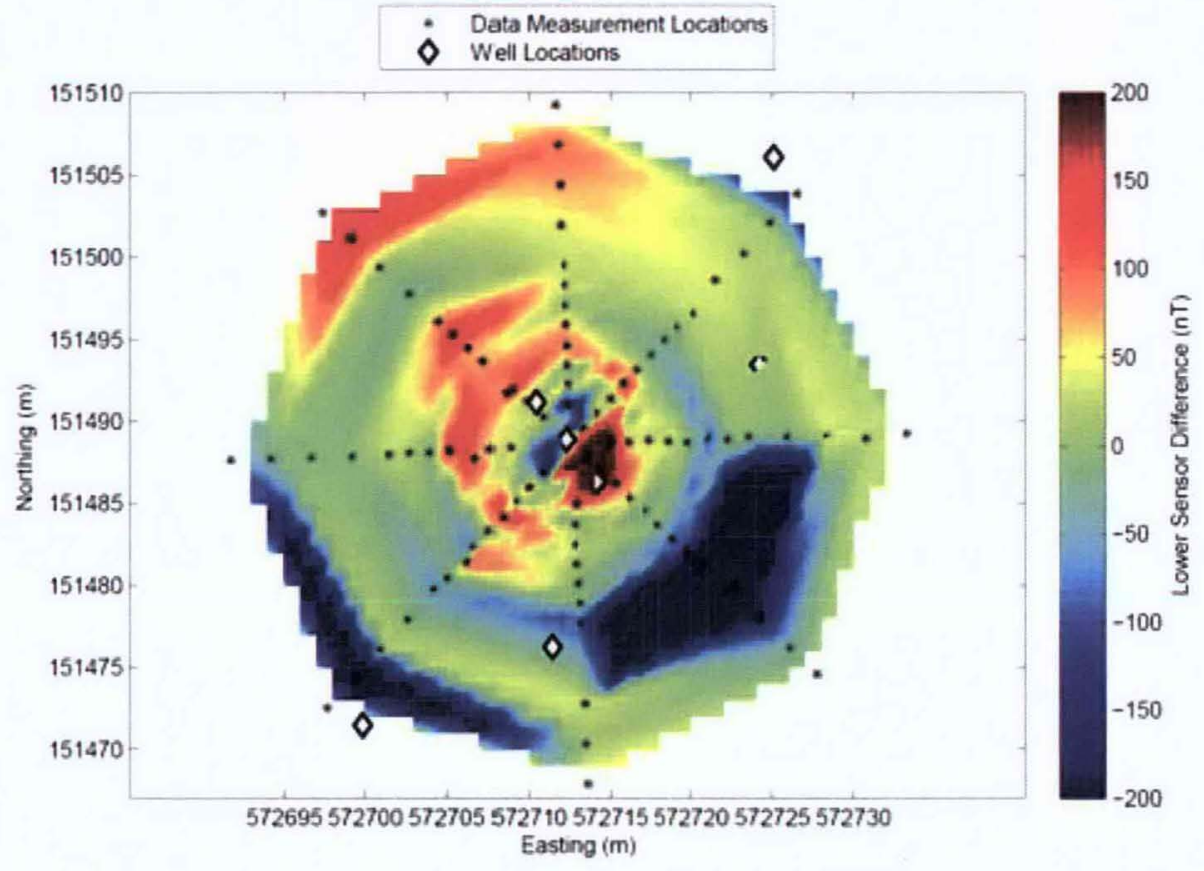

NOTE: The injection well is located at the center of the grid.

Figure 6-34. Raw Difference (Post- Minus Pre-Injection) in Magnetic Field for Lower Sensor

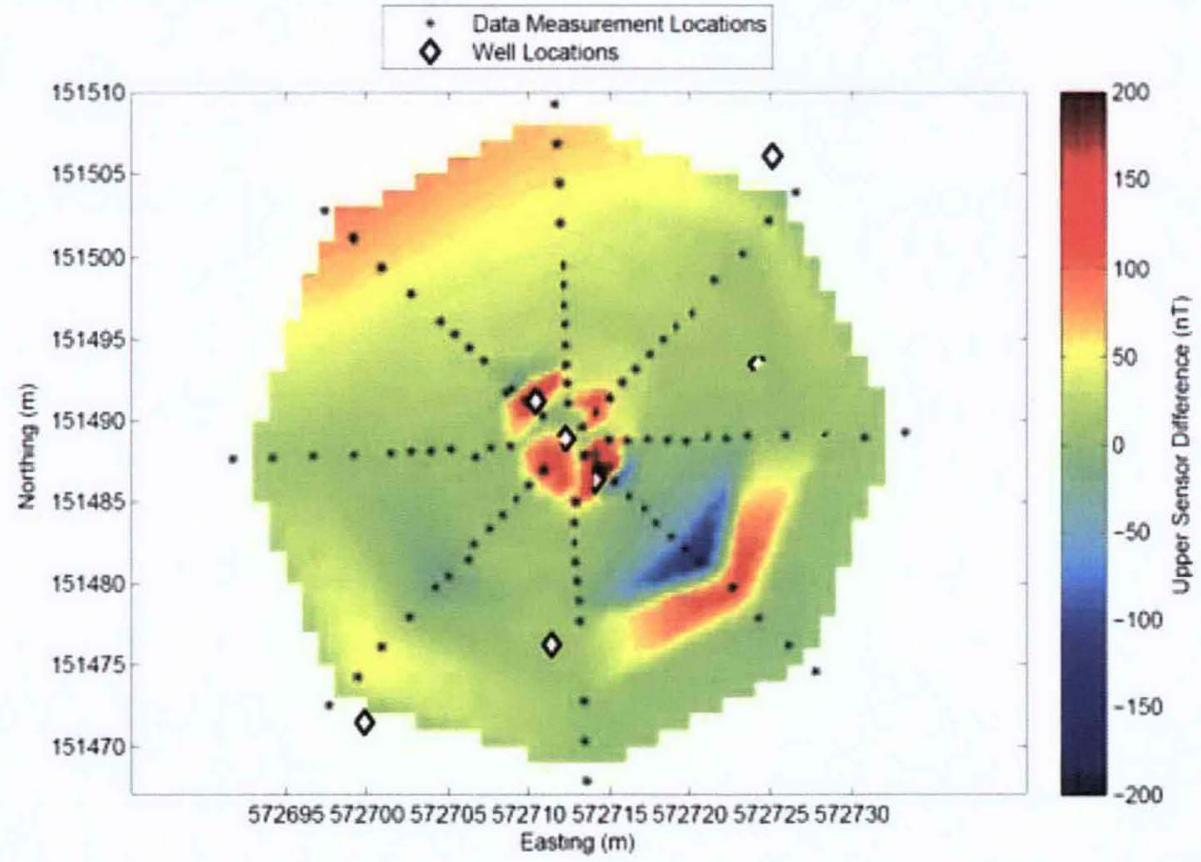

NOTE: The injection well is located at the center of the grid.

Figure 6-35. Raw Difference (Post- Minus Pre-Injection) in Magnetic Field for Upper Sensor 


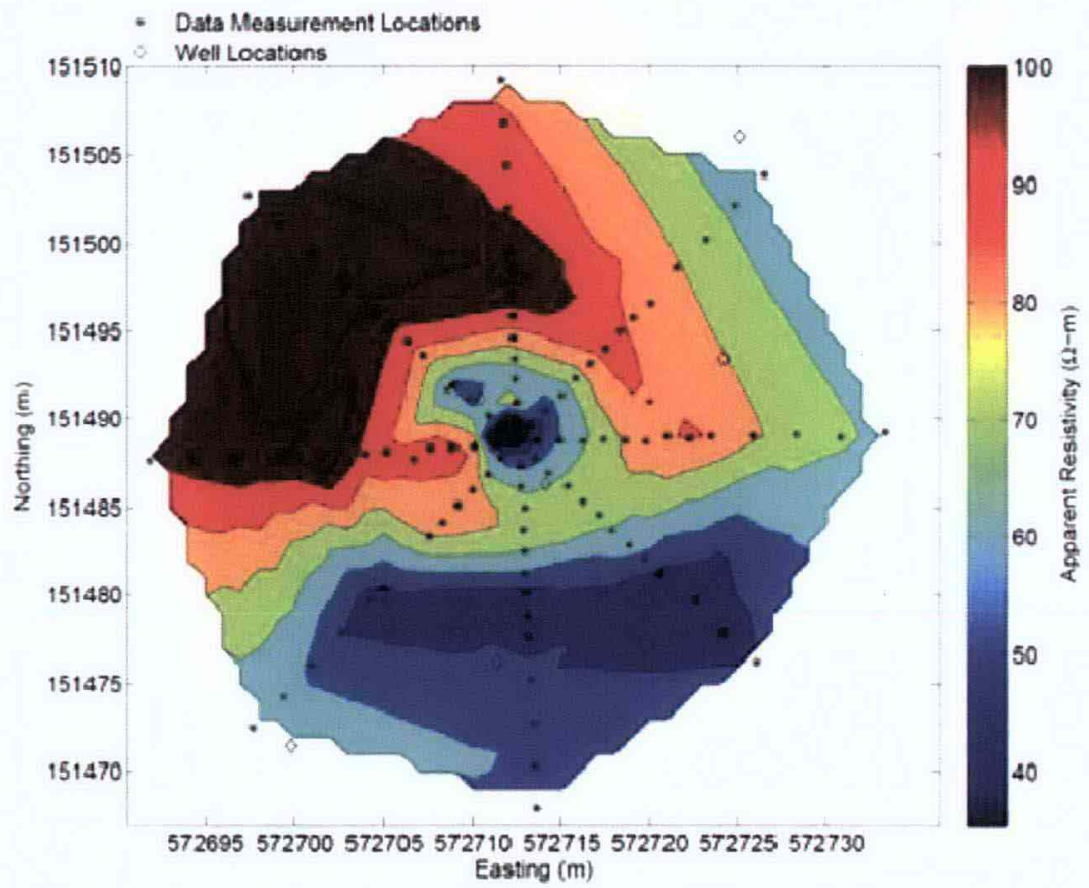

NOTE: Assumes a current injection at the ground surface elevation. The injection well is located at the center of the grid.

Figure 6-36. Post-Injection Apparent Resistivity Calculated from Mise a la Masse Data

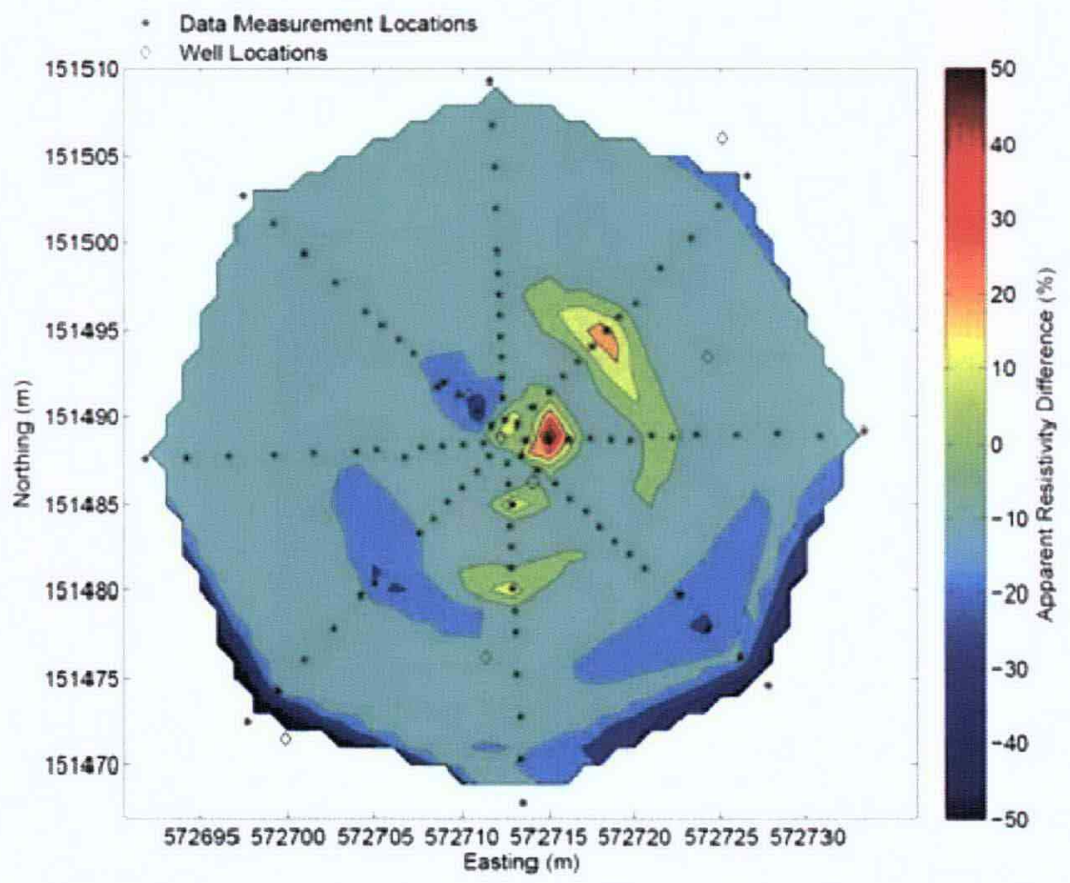

NOTE: The injection well is located at the center of the grid.

Figure 6-37. Percent Difference Between the Pre- and Post-Injection Apparent Resistivity Calculated from Mise a la Masse Data 
The post-injection relative phase difference between the injected current and the received potentials is shown in Figure 6-38. Again, these data are not easily interpreted or analyzed because of the complexities of the current injection. The anomaly in the phase difference observed near the center of the grid correlates well with the location of well 199-D4-93, which has a steel casing. This anomaly can be attributed to the steel well casing. However, there is also a persistent anomaly in the phase lag data in an east-west trending region located south of the injection well. This larger phase lag may be indicative of a clay lens or other low porosity material in this region. The possibility of this being a clay lens is also supported by the lower apparent resistivity observed in this region (see Figure 6-36). A plot of the raw difference in phase lag (Figure 6-39) shows that there is very little change (typically less than 10 milliradians) in the vicinity of the injection well following the injection. This difference in phase shift may be larger near the injection depth; however, without an appropriate three-dimensional modeling effort, it is difficult to determine where this relative phase shift occurs.

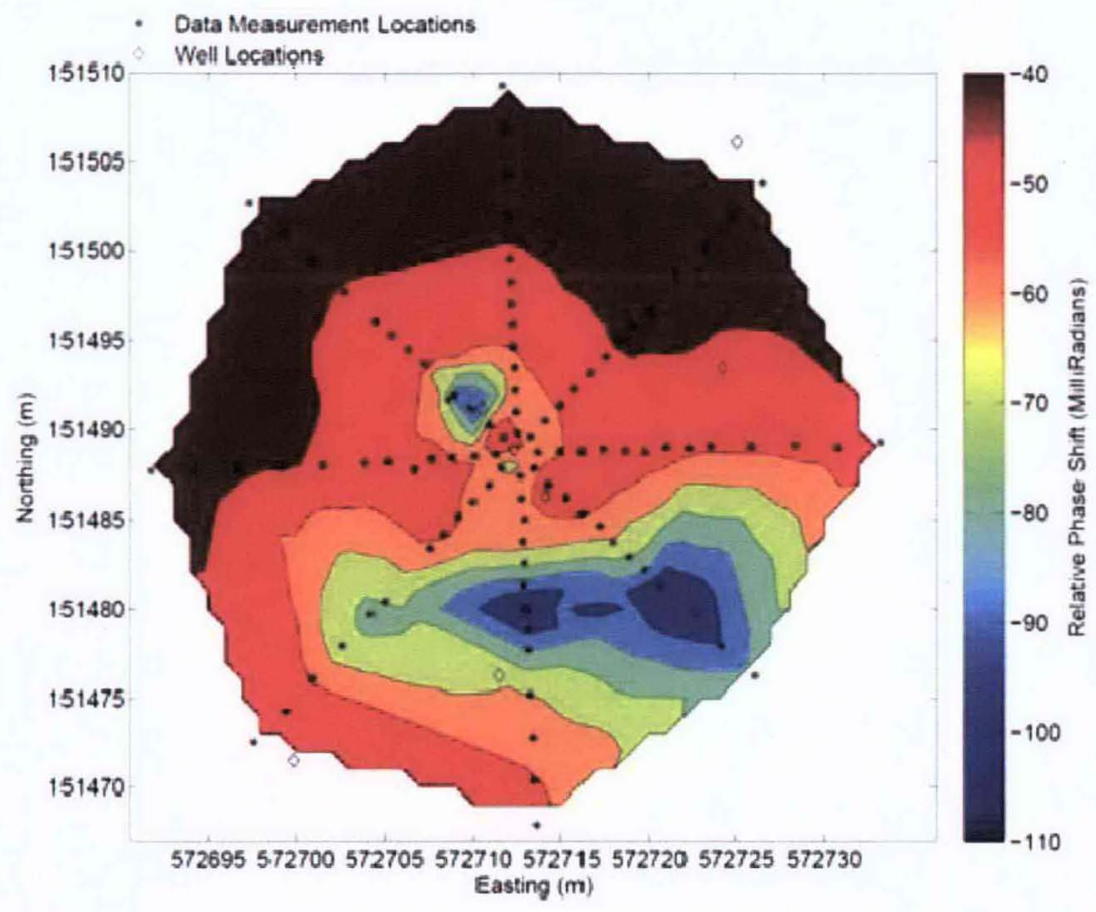

NOTE: The injection well is located at the center of the grid.

Figure 6-38. Relative Phase Shift Observed in Post-Injection Mise a la Masse Data 


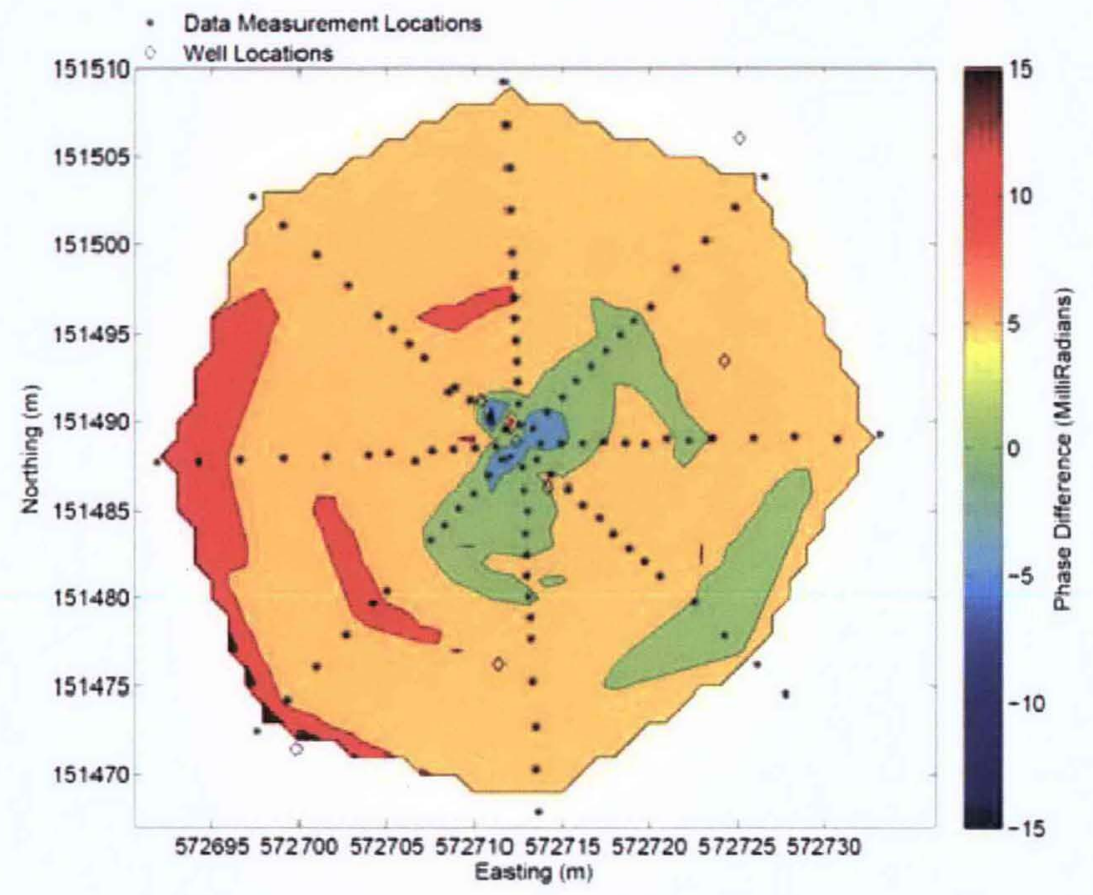

NOTE: The injection well is located at the center of the grid.

Figure 6-39. Raw Phase Shift Difference from Mise a la Masse Data

\subsubsection{Discussion of Geophysical Results}

Although some difficulties were encountered, overall the geophysical monitoring of the ZVI injection at the 100-D Area was successful. Semi-permanent locations were established for the data acquisition so the pre- and post-injection surveys could be compared using data differencing or other time-lapse analysis approaches. Survey locations were marked using wooden or rebar stakes, which were left in the ground upon completion of this work to facilitate possible future geophysical studies at this site. Generally, the data repeatability was excellent, with the exception of a few data outliers. The site itself was somewhat limiting regarding the options for a large variety of geophysical monitoring methods. One limiting factor was one nonmetallic-cased borehole present on the site. Having at least two nonmetallic-cased boreholes onsite would have allowed for high-resolution, cross-borehole imaging techniques (e.g., groundpenetrating radar and electrical resistivity tomography.)

Electrical conductivity was logged in a PVC-cased monitoring borehole using a EM-39 electromagnetic induction tool. Water sampling results indicate that the ZVI injection (at least the polymer) reached this borehole location within the first 24 hours of injection. The post-injection logging results showed a significant response to the ZVI injection. Logging during the injection was attempted, and it was determined that calibration of the logging sonde could not be conducted within the time constraints imposed by the sampling plan. The early breakthrough precluded further injection logging runs, and the close proximity of the monitoring borehole used for this logging did not allow determination the radial extent of the injection based on this single data point.

Surface-based geophysical methods had mixed results in monitoring the extent of the ZVI injection. Electrical resistivity and IP data proved to be the most successful geophysical methods at the ISRM barrier site in estimating the lateral extent of the injected ZVI. There remains some inherent ambiguity in 
the estimated vertical extent of the injection from these results due to modeling constraints and limited depth of investigation afforded by the survey design. A conservative estimate, consistent with the interpretation of the electrical resistivity and IP modeling and the TEM data differences, is that the radial

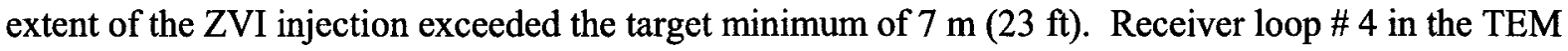
data is located $8.4 \mathrm{~m}(27.6 \mathrm{ft})$ from the injection well and shows a clear increase in conductivity at later time windows, thus providing further evidence that the $7 \mathrm{~m}(23-\mathrm{ft})$ target was likely exceeded.

Time constraints precluded acquisition of multiple two-dimensional electrical profiles for this particular monitoring effort. An improvement to the electrical data acquisition (given that cross-borehole access was not available) would be to acquire data along at least two or more intersecting profiles or on a threedimensional grid. This would allow more complete estimation of the injection extent, which is unlikely to be exactly circular in shape due to subsurface heterogeneities in hydraulic conductivity of the subsurface alluvial sediments found at the Hanford Site.

It is notable that most of the methods used for this study were sensitive to changes in conductivity and, therefore, were useful in determining the distance reached by the electrically conductive polymer injected along with the ZVI. The iron alone has a minimal effect on the fluid conductivity; thus, induced polarization and magnetics were the only methods capable of direct detection of the iron.

The total field magnetics data were of limited use in determining the extent of the ZVI injection. This resulted from a combination of factors, which may or may not be encountered at other injection sites. First, the site had a large number of permanent metallic objects (e.g., fences, well casings, and underground utilities), and the response of the magnetometer to these objects tended to dominate the data, thus obscuring the deeper geologic signature. By eliminating several data points corresponding to these sources of noise, repeatable pre- and post-injection data could be acquired. The second factor affecting the magnetic response was the depth of the injection. The magnetic field response decays strongly as a function of distance from the source. As a result, minor changes in the data acquired before and after injection were expected, which occurred at a depth exceeding $20 \mathrm{~m}(65.6 \mathrm{ft})$. In fact, because the differences that were seen in the data were near the ambient noise level of the data, it was not possible to attribute them as a response to the ZVI injection. The upper sensor data did appear to image a relatively consistent increase in magnetic field in a circular (approximately $5 \mathrm{~m}$ [16.4-ft]-diameter) region surrounding the injection well. However, this increase is directly centered on the location of the steel well casing and is likely influenced by the casing. Laboratory measurements of magnetic susceptibility in ZVI-emplaced sand columns indicated the promise of this technique for imaging the ZVI injection. Consequently, it should not be ruled out in future studies, especially if the injection is to occur nearer to the surface.

Mapping of the electrical potentials due to a current injection via the steel casing of the injection borehole also did not aid in determining the extent of the ZVI injection. Techniques are available for threedimensional inversion of these data, considering the steel casing as a line-source of electrical current. If the three-dimensional modeling can be completed, the mise a la masse technique may prove to be an effective method for imaging injections, such as the ZVI injection considered here. This mise a la masse data acquisition requires notably less field effort than two-dimensional electrical profiling and, consequently, should not be ruled out for future studies if the modeling challenges can be overcome. 


\subsubsection{Well 199-D4-26 Vacuum Slug Test Results}

The pre- and post-injection vacuum slug test results in the injection well indicated that hydraulic conductivity decreased in the aquifer after injection of the ZVI material. Both the pre- and post-injection test series were very repeatable, providing similar values. The three analytical test plots for the preinjection vacuum slug tests are shown in Figure 6-40. The two analytical test plots for the post-injection vacuum slug tests are shown in Figure 6-41. The summary of the vacuum slug test data is presented in Table 6-11.

The pre-injection slug test results were all similar, with an average hydraulic conductivity value of $0.0382 \mathrm{~cm} / \mathrm{s}$. As a check, the data were compared to the results of a short-term pumping test performed on the injection well during well development activities in March 2000, which found the transmissivity to be $185.8 \mathrm{~m}^{2} /$ day $\left(2,000 \mathrm{ft}^{2} /\right.$ day $)$. Dividing the transmissivity value by the thickness of the saturated portion of the aquifer $(6.4 \mathrm{~m}$ [21 ft]) yields a hydraulic conductivity value of $0.0336 \mathrm{~cm} / \mathrm{s}(95.24 \mathrm{ft} /$ day $)$. This value compares closely with the pre-injection vacuum slug test average of $0.0382 \mathrm{~cm} / \mathrm{s}$.

The post-injection vacuum slug test results showed a measurable drop in hydraulic conductivity value. The average of the two slug tests was $0.0142 \mathrm{~cm} / \mathrm{sec}$, which was a 270 percent reduction. The reduction was an expected result of pumping the ZVI solution into the formation where the solids are deposited in the pore spaces of the soil matrix, thus inhibiting groundwater flow. The reduction in permeability was also evidenced by the gradual increase in head observed in the well during the constant rate injection over the course of 5.25 days. The permeability reduction observed in the injection well was also similar to the reductions measured in the laboratory flow cell tests used to test the RNIP-M2 material (see Figure 4-53). 

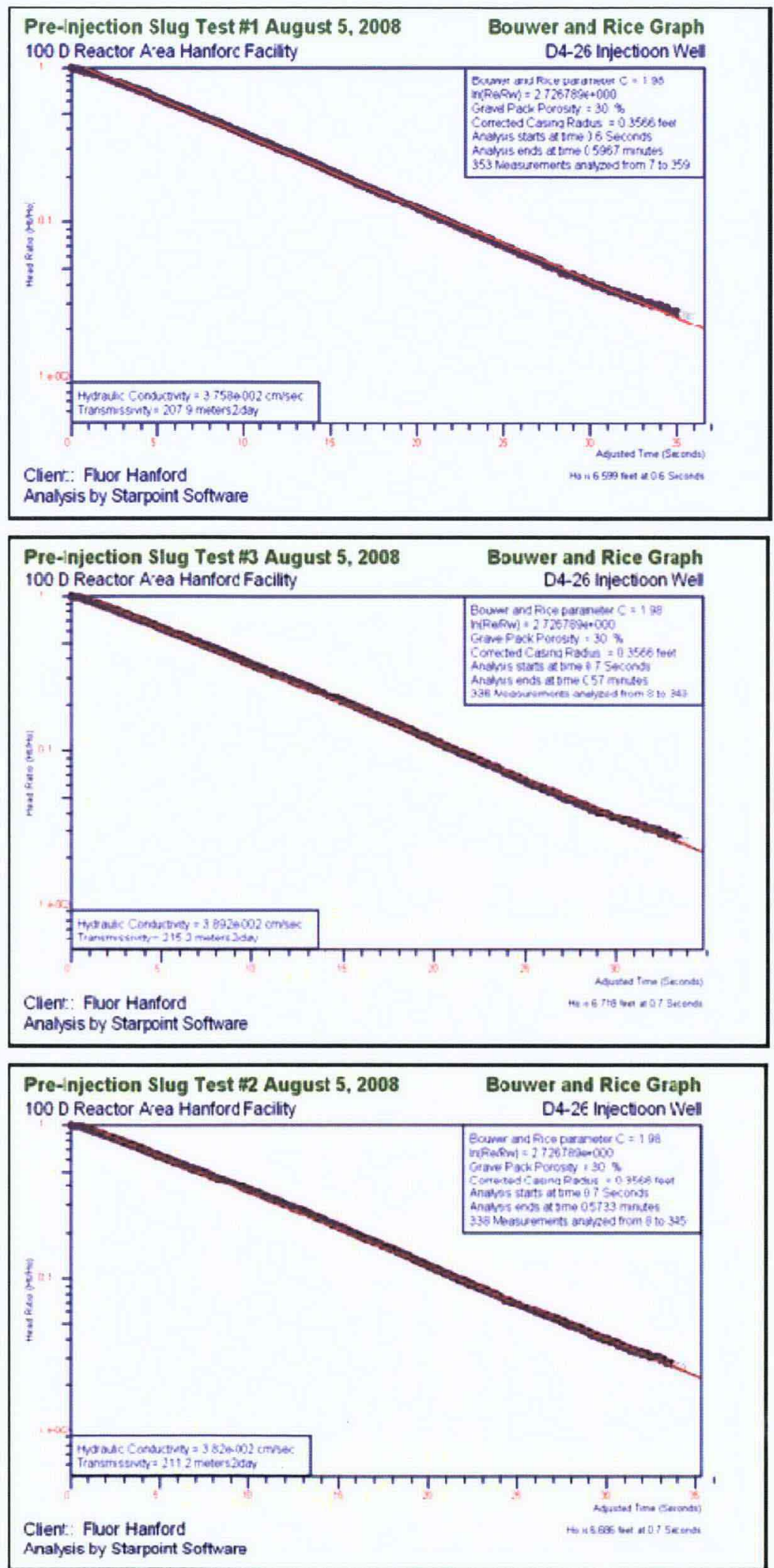

Figure 6-40. Pre-Injection Vacuum Slug Test Analytical Plots 

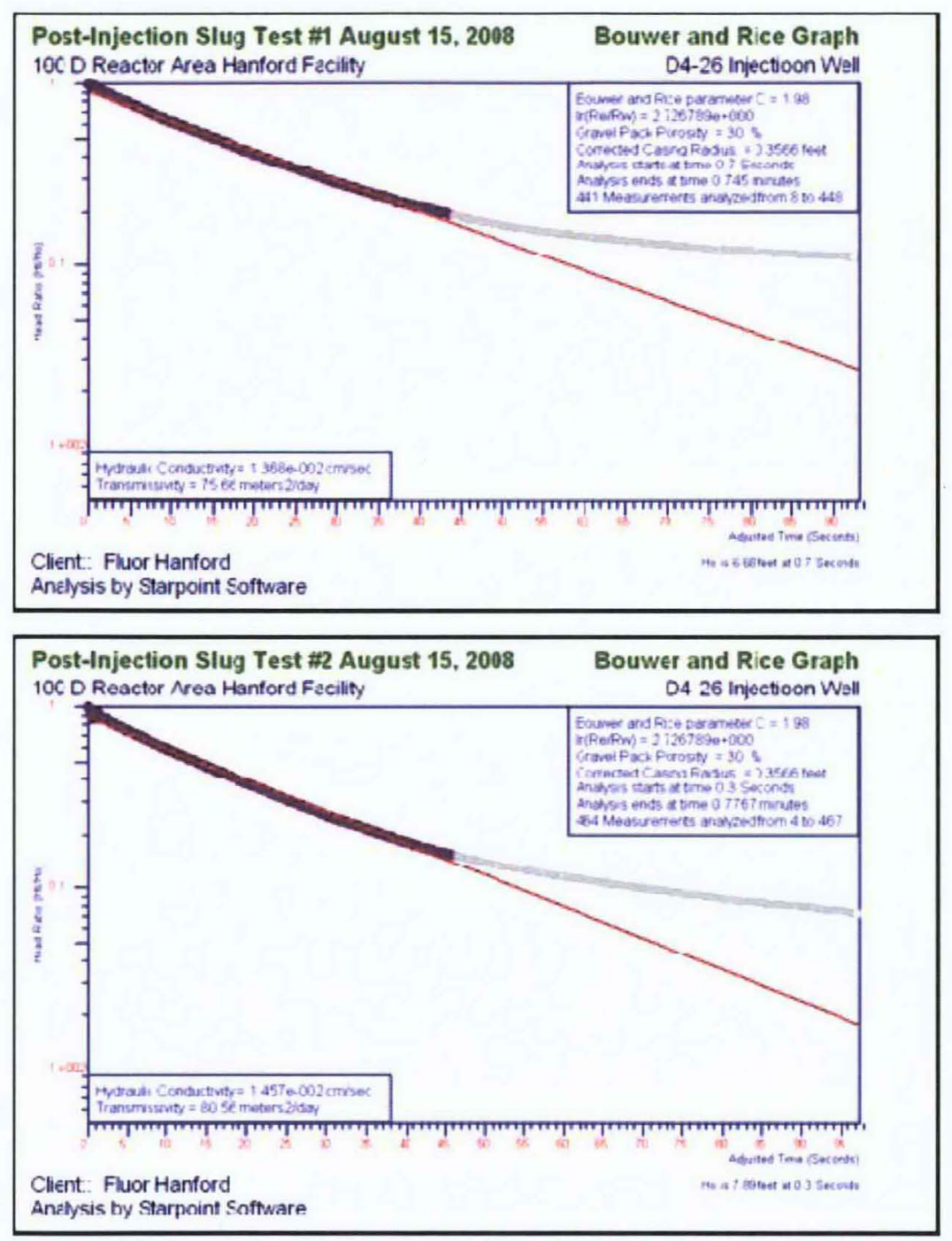

Figure 6-41. Post-Injection Vacuum Slug Test Analytical Plots

Table 6-11. Vacuum Slug Test Results for Injection Well 199-D4-26

\begin{tabular}{c|c|c|c}
\hline \multicolumn{1}{|c|}{ Test \# } & $\begin{array}{c}\text { Hydraulic Conductivity, } \\
\mathbf{c m} / \mathbf{s e c}\end{array}$ & $\begin{array}{c}\text { Average, } \\
\mathbf{c m} / \mathbf{s e c}\end{array}$ & $\begin{array}{c}\text { Decrease } \\
\text { in Permeability }\end{array}$ \\
\hline Pre-injection test \#1 & 0.0376 & \multirow{2}{*}{0.0382} & \\
\cline { 1 - 2 } Pre-injection test \#2 & 0.0382 & \multirow{2}{*}{$270 \%$} \\
\cline { 1 - 2 } Pre-injection test \#3 & 0.0389 & \multirow{2}{*}{0.0142} & \\
\cline { 1 - 2 } Post-injection test \#1 & 0.0137 & \\
\cline { 1 - 2 } Post-injection test \#2 & 0.0146 & \\
\hline
\end{tabular}




\subsubsection{Verification Well}

To evaluate how far from the injection well nZVI was emplaced into the aquifer, a new borehole was drilled and sampled in March 2009. Continuous soil samples were collected via split spoon sampler from

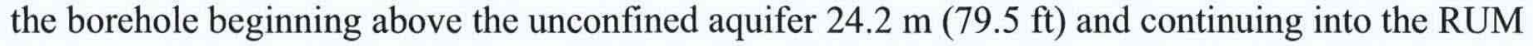
$31.0 \mathrm{~m}$ (101.8 ft). The borehole was drilled with cable-tool technology. Eleven 4-in split-spoon samples were collected, each containing four 6-in. Lexan liners. The borehole was completed as a groundwater monitoring well with 4-in PVC casing and 20-slot screen. The sampling plan describing this work is presented in Appendix E, Section E1.

One objective of this treatability test was to distribute the iron slurry at least $7 \mathrm{~m}(23.0 \mathrm{ft})$ from the injection well at a concentration of $0.10 \mathrm{wt} . \%(\sim 1,000 \mathrm{mg} \mathrm{Fe} / \mathrm{Kg})$. Therefore, the well was installed $7 \mathrm{~m}$ from well 199-D4-26. Additionally, the well was located along the traverse line used for the electrical resistance survey, so data gathered from the borehole could be used to help calibrate the geophysical models and refine interpretation of the data.

Figure 6-42 shows the location of the new well (199-D4-94) where samples were taken for analysis of the aquifer materials. The Washington State Plane coordinates for this well are Easting: $572713.36 \mathrm{~m}$, Northing: $151495.79 \mathrm{~m}$.

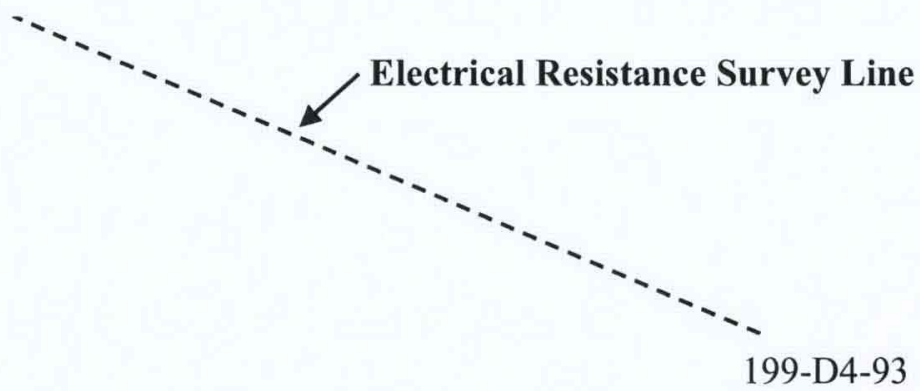

199-D4-25

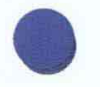

199-D4-26

199-D4-92

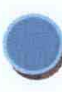

ISRM Monitoring Wells

nZVI Injection Well

Monitoring Wells, $3 \mathrm{~m}$ from Injection Well

nZVI Characterization Well

199-D4-27

Source: DOE/RL-2008-49

Figure 6-42. Location of New Well 199-D4-99 and Surrounding Wells 
After delivery to the laboratory, geophysical measurements were made on the intact cores and the samples were then homogenized in approximately $0.3-\mathrm{m}(1-\mathrm{ft})$ intervals. These samples were then sieved for grain size analysis and chemically analyzed for total iron. Description of this work and additional laboratory tests is in Appendix E.

The sampling and analysis data from the verification well produced the following conclusions.

- $\mathrm{nZVI}$ was successfully deposited in a high-conductivity layer at least $7 \mathrm{~m}(23.0 \mathrm{ft})$ from the point of injection, as evidenced by the above-background iron concentrations in the characterization well soils from the 95.5 to 97.7 interval.

- Hexavalent chromium is being reduced/immobilized in the aquifer, as shown by the increase in total chromium at the intervals that contain the most $\mathrm{nZVI}$.

- Gypsum formation is unlikely since the ion activity product for calcium and sulfate in the pore water was well below the gypsum solubility limit

- Resistivity was not useful in discerning the amount of iron within the samples. If all of the samples were saturated to the same degree, it might be possible to discriminate different levels of iron using only the electrical resistivity.

- The magnetic susceptibility appears to correlate reasonably well with the iron concentrations measured in the laboratory analyses, with the exception of the deepest 3 or 4 data points.

- The induced polarization data exhibit a weak correlation with the laboratory analyses. The highest chargeability measurements are centered on the peak of highest iron concentration, but there is no distinct peak in the chargeability measurements themselves.

\subsubsection{Post-Injection Groundwater Monitoring}

Following the 10-day post-injection groundwater monitoring (Section 6.1.4), a number of wells in and near the test location were sampled monthly or quarterly and analyzed for hexavalent chromium, metals, selected anions, and field parameters. Hexavalent chromium was analyzed in three separate efforts, colorimetry (spectrophotometric) in a laboratory using EPA Method 7196, colorimetry using a Hach ${ }^{\mathrm{TM}} \mathrm{kit}$ in the field, and ion chromatography using a procedure developed specifically for analyzing chromate. The ion chromatography analyses were initiated after laboratory and field analyses returned values higher than anticipated. This was caused by dissolved iron in the sample which colored the samples and absorbed light during colorimetry measurements, leading to anomalously high hexavalent chromium values.

The following discusses and summarizes the effects of the injection on groundwater composition in the pertinent wells.

\subsubsection{Injection Well}

Injection well 199-D4-26 showed the most dramatic changes in groundwater chemistry. Hexavalent chromium values plummeted after this well was injected, from a typical value greater than $600 \mu \mathrm{g} / \mathrm{L}$ in November to less than detection in April 2009 (reliable ion chromatography). Hexavalent chromium values were not obtained until spring 2009. Total chromium concentrations, with an average of $490 \mu \mathrm{g} / \mathrm{L}$ over the five Novembers prior to injection, fell to $18 \mu \mathrm{g} / \mathrm{L}$ (filtered) in November 2008. The following presents other significant comparisons of groundwater chemistry in this well before and after the test. 
- Iron increased from near detection (approximately $25 \mu \mathrm{g} / \mathrm{L}$ ) to a filtered value of $7,520 \mu \mathrm{g} / \mathrm{L}$ and an unfiltered value of $57,900 \mu \mathrm{g} / \mathrm{L}$.

- Dissolved oxygen fell from about $5,000 \mu \mathrm{g} / \mathrm{L}$ to 0 after the injection..

- Nitrate (as $\mathrm{N}$ in nitrate) decreased almost two orders of magnitude, from about $50,000 \mu \mathrm{g} / \mathrm{L}$ to about $1,500 \mu \mathrm{g} / \mathrm{L}$.

- Nitrite (as $\mathrm{N}$ in nitrite) did not appear to change significantly, although the data for the same time period vary widely from year to year (e.g., $92 \mu \mathrm{g} / \mathrm{L}$ in November $2003,476 \mu \mathrm{g} / \mathrm{L}$ in November 2007 ).

- There was no apparent effect on arsenic concentrations, as measured in November 2008.

- Manganese rose from less than detection (approximately $2 \mu \mathrm{g} / \mathrm{L}$ ) to $273 \mu \mathrm{g} / \mathrm{L}$ (filtered).

- $\quad$ pH rose by 2 to 3 units, and was 11 in May 2009.

- Uranium decreased from approximately $2 \mu \mathrm{g} / \mathrm{L}$ before the injection to $0.1 \mu \mathrm{g} / \mathrm{L}$ after injection.

\subsubsection{Wells $5 \mathrm{~m}$ From the Injection Well}

The nearest wells, upgradient well 199-D4-92 and downgradient well 199-D4-93, also show expected declines in reducible species (e.g., hexavalent chromium, nitrate) and increases in constituents that tend to be more mobile in their reduced forms (e.g., iron, manganese). Pre-injection chemistry for these wells is assumed to be very similar to the injection well because of their close proximity. These wells are not routinely sampled so there is a paucity of pre-injection data.

The following changes in groundwater chemistry after injection are the following.

- Hexavalent and total chromium decreased after the injection.

- Hexavalent chromium was measured at $74 \mu \mathrm{g} / \mathrm{L}$ in the upgradient well and $400 \mu \mathrm{g} / \mathrm{L}$ in the downgradient well in November 2008; these laboratory results were obtained by colorimetric measurements and are therefore suspect. Ion chromatographic analyses are not available for this time period, but later analyses using this method were below detection.

- Total chromium decreased to $66 \mu \mathrm{g} / \mathrm{L}$ in the upgradient well and $153 \mu \mathrm{g} / \mathrm{L}$ in the downgradient well (both filtered).

- Dissolved oxygen was not measured in the weeks after the test; it was less than $2 \mu \mathrm{g} / \mathrm{L}$ in May 2009 .

- Nitrate was measured at less than $100 \mu \mathrm{g} / \mathrm{L}$ after injection, and nitrite was below detection $(98.5 \mu \mathrm{g} / \mathrm{L})$.

- Arsenic values ranged from 0.9 to $14.3 \mu \mathrm{g} / \mathrm{L}$ (average $4.5 \mu \mathrm{g} / \mathrm{L}$ ) during and ten days after injection. No values were obtained for arsenic after this time.

- Manganese values rose to $305 \mu \mathrm{g} / \mathrm{L}$ in the upgradient well and $530 \mu \mathrm{g} / \mathrm{L}$ (filtered) in the downgradient well in November 2008, decreasing to background by mid-2009.

- $\mathrm{pH}$ rose to 11 after in both wells after injection, and was approximately 10.5 in June 2009 .

- Sulfate decreased by about 75 percent after the injection, then rose to near the pre-injection values.

- Uranium was not measured in these wells. 
- Ammonium (as ammonium ion) increased to over $4,000 \mu \mathrm{g} / \mathrm{L}$ in the upgradient well and nearly $3,000 \mu \mathrm{g} / \mathrm{L}$ in the downgradient well in the week following injection. It decreased to less than $1,000 \mu \mathrm{g} / \mathrm{L}$ in both wells in November 2008 and fell further by summer 2008.

- Lead rose to approximately $10 \mu \mathrm{g} / \mathrm{L}$ two weeks after injection; samples were not analyzed for lead again.

\subsubsection{Far-Downgradient Well}

Well 199-D4-38 is $64 \mathrm{~m} \mathrm{(210} \mathrm{ft)} \mathrm{northwest} \mathrm{of} \mathrm{the} \mathrm{injection} \mathrm{well,} \mathrm{in} \mathrm{the} \mathrm{approximate} \mathrm{direction} \mathrm{of}$ groundwater flow. Groundwater velocity is difficult to predict in this region because of river influences and heterogeneity of aquifer properties, but $0.3 \mathrm{~m} /$ day $(1 \mathrm{ft} /$ day) is often cited as an average. If this were the case, and if well 199-D4-38 is in the flow path of the region of injection, any effects on the groundwater would be detected in March 2009. No significant changes in groundwater chemistry are evident during this time, but there is a slight rise in manganese and iron in November 2008 and a very large increase in turbidity and unfiltered iron in August 2009 (see Figure 6-43), one year after the injection test was performed.

\subsubsection{Discussion}

The data collected from monitoring wells in and near the injection show that groundwater was significantly reduced in response to the test. Concentrations of dissolved oxygen, chromium, and nitrate plunged, but manganese increased. The reduced form of manganese is much more mobile than the oxidized form, which naturally occurs in oxic aquifers similar to the 100 Area unconfined aquifer.

Groundwater samples collected from well 199-D4-38, $64 \mathrm{~m} \mathrm{(210} \mathrm{ft)} \mathrm{downgradient} \mathrm{from} \mathrm{the} \mathrm{ZVI} \mathrm{injection}$ well, showed subtle effects three months after the test and significant effects one year after the test. These data support the hypothesis that dissolved constituents traveled downgradient at approximately $0.6 \mathrm{~m} / \mathrm{sec}$ and ZVI particles were transported this same distance at approximately $0.2 \mathrm{~m} / \mathrm{sec}$. The concentration of unfiltered iron in the downgradient well was approximately 5 orders of magnitude less than that deposited in the test area.

\subsection{Comparison to Test Objectives}

The test met the two primary performance criteria specified in the treatability test plan: (1) demonstrate that ZVI could be communicated in the high-permeability zones of the aquifer up to $7 \mathrm{~m}(23 \mathrm{ft})$ away from the injection well at sufficient concentrations, and (2) maintain a reducing environment to prevent hexavalent chromium from reaching the Columbia River.

Monitoring wells 199-D4-92 and 199-D4-93 were located $3 \mathrm{~m}(9.8 \mathrm{ft})$ from the injection well, and both showed ZVI breakthrough during ZVI injection. Up to $4 \mathrm{wt} \%$ of iron was also emplaced in the vicinity of the verification well, located $7 \mathrm{~m}(23.0 \mathrm{ft})$ away from the injection point; ZVI did not reach the monitoring wells located approximately $12 \mathrm{~m}(39 \mathrm{ft})$ away. Interpretation of the geophysics data suggests that the ZVI may have reached the $7 \mathrm{~m}(23-\mathrm{ft})$ radius; however, the data are still relatively experimental.

The longevity of the barrier will be determined by long-term monitoring of the downgradient wells. Initial water quality data verified that reducing conditions were created in the area of injection. The long-term reduction of hexavalent chromium will determine the success of the ZVI injection. 
DOE/RL-2009-35, REV. 0

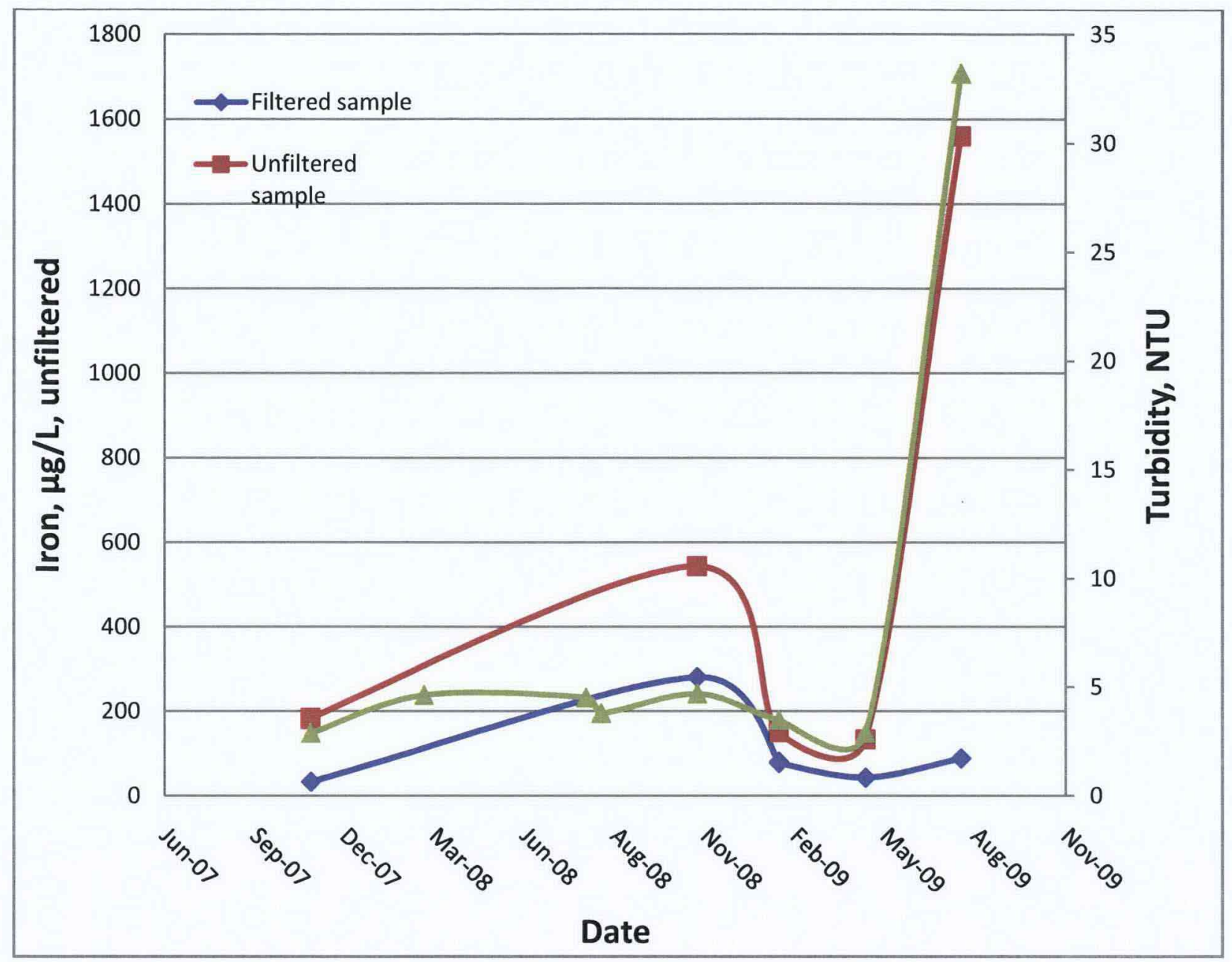

Figure 6-43. Plot of Unfiltered Iron and Turbidity in Groundwater from Well 199-D4-38.

\subsection{Variations from the Treatability Test Plan}

The procedures, as outlined in the treatability test plan, are presented in Chapter 5 . If a better procedure was discovered during the injection process, the procedure was documented, approved, and implemented into practice. Table 6-12 presents the modifications and additions made to the treatability test plan during the injection.

Table 6-12. Modifications and Additions to the Treatability Test Plan

\begin{tabular}{|c|c|c|}
\hline $\begin{array}{l}\text { Procedure Proposed in the } \\
\text { Treatability Test Plan }\end{array}$ & $\begin{array}{l}\text { Procedure Performed in the } \\
\text { Field }\end{array}$ & Rationale \\
\hline \multicolumn{3}{|l|}{ Modifications } \\
\hline $\begin{array}{l}\text { The injection solution was to } \\
\text { be prepared in } 6,000 \text {-gal } \\
\text { batches. }\end{array}$ & $\begin{array}{l}\text { The injection solution was } \\
\text { prepared in about } 2,300 \text {-gal } \\
\text { batches. }\end{array}$ & $\begin{array}{l}\text { After discussing the mixing and injection } \\
\text { procedure with Toda America, it was } \\
\text { concluded that smaller batches would } \\
\text { reduce ZVI contact time with water. This } \\
\text { would help provide the maximum reactive } \\
\text { lifetime of the particles. }\end{array}$ \\
\hline
\end{tabular}


Table 6-12. Modifications and Additions to the Treatability Test Plan

\begin{tabular}{|c|c|c|}
\hline $\begin{array}{l}\text { Procedure Proposed in the } \\
\text { Treatability Test Plan }\end{array}$ & $\begin{array}{l}\text { Procedure Performed in the } \\
\text { Field }\end{array}$ & Rationale \\
\hline $\begin{array}{l}\text { The injection solution was to } \\
\text { be recirculated through the } \\
\text { HSM before injection. }\end{array}$ & $\begin{array}{l}\text { The injection solution made a } \\
\text { single pass through the HSM } \\
\text { before injection. }\end{array}$ & $\begin{array}{l}\text { The process was modified as } \\
\text { recommended by Toda America to prevent } \\
\text { any premature loss of reactivity. }\end{array}$ \\
\hline $\begin{array}{l}\text { The injection solution was to } \\
\text { be recirculated continuously } \\
\text { with the diesel recirculation } \\
\text { pumps. }\end{array}$ & $\begin{array}{l}\text { The injection solution was "fluffed" } \\
\text { before injection an approximately } \\
\text { once an hour during injection to } \\
\text { ensure particle suspension. }\end{array}$ & $\begin{array}{l}\text { The process was modified as } \\
\text { recommended by Toda America to prevent } \\
\text { any premature loss of reactivity. }\end{array}$ \\
\hline $\begin{array}{l}\text { Sample monitoring wells using } \\
12-V \text { Tsunami sampling } \\
\text { pumps. }\end{array}$ & $\begin{array}{l}\text { Sampled monitoring wells using } \\
\text { hand bailers. }\end{array}$ & $\begin{array}{l}\text { The } 12-V \text { Tsunami sampling pumps } \\
\text { stopped working shortly into the injection. }\end{array}$ \\
\hline $\begin{array}{l}\text { Collect iron slurry QAVC } \\
\text { measurements from a sample } \\
\text { port on the injection flow } \\
\text { control system. }\end{array}$ & $\begin{array}{l}\text { Collected QAVQC measurements } \\
\text { from inside the poly-tank by } \\
\text { lowering the probe into the } \\
\text { injection solution through the } \\
\text { access port on the top of the tank. }\end{array}$ & $\begin{array}{l}\text { Ease of operation and eliminated any } \\
\text { waste solution. }\end{array}$ \\
\hline $\begin{array}{l}\text { Control injection stream with } \\
\text { high-flow and low-flow control. }\end{array}$ & $\begin{array}{l}\text { Controlled injection stream only } \\
\text { with high-flow control. }\end{array}$ & $\begin{array}{l}\text { Due to injection flow rate, the low-flow } \\
\text { control system was not required. }\end{array}$ \\
\hline $\begin{array}{l}\text { Nitrogen supplied in } 12 \text { high- } \\
\text { pressure T tanks - "gas } \\
\text { packs." }\end{array}$ & $\begin{array}{l}\text { Nitrogen supplied from two } \\
\text { sources: (1) 625-gal. trailer- } \\
\text { mounted cryogenic tank, and } \\
\text { (2) custom trailer containing } \\
\text { 108 3AA } 2400400-\mathrm{ft}^{3} \text { cylinders. }\end{array}$ & $\begin{array}{l}\text { The two sources provided a larger supply } \\
\text { of nitrogen without the need to change the } \\
\text { supply line. }\end{array}$ \\
\hline \multicolumn{3}{|l|}{ Additions } \\
\hline \multicolumn{3}{|c|}{$\begin{array}{l}\text { - A nitrogen sparge system was implemented to keep the particles in suspension. The nitrogen required to } \\
\text { maintain an oxygen deficient environment was added to the injection slurry through a set of sparge points } \\
\text { located in the bottom of the poly-tank. }\end{array}$} \\
\hline \multicolumn{3}{|c|}{$\begin{array}{l}\text { - The HSM did not provide enough suction to draw the injection slurry from the mixing tank so a } 110-\mathrm{V} \text { centrifugal } \\
\text { pump was added as a HSM feed pump. The pump was installed to supply the } \mathrm{ZVI} \text { injection solution at } 53 \mathrm{~L} / \mathrm{min} \\
\text { (14 gallons per minute) to the inlet of the HSM. }\end{array}$} \\
\hline \multicolumn{3}{|c|}{$\begin{array}{l}\text { - A 10-micron bag filter was added inline on the service water supply line to eliminate any suspended solids and } \\
\text { sediment, which may interfere with the mixing and injection process. } \\
\text { - An anchoring system was added to secure the mixing tanks. }\end{array}$} \\
\hline \multicolumn{3}{|l|}{ HSM = high shear mixer } \\
\hline \multicolumn{3}{|l|}{$\mathrm{QA}=$ quality assurance } \\
\hline \multicolumn{3}{|l|}{$\mathrm{QC} \quad=$ quality control } \\
\hline \multicolumn{3}{|l|}{$\mathrm{ZVI}=$ zero-valent iron } \\
\hline
\end{tabular}

\subsection{Conclusions from Field Injection}

Use of nitrogen as a sparging gas was successful at keeping RNIP-M2 suspended in the mixing tanks at a flow rate of 150 to 175 standard $\mathrm{ft}^{3} / \mathrm{hr}$. The nitrogen was also effective at creating an inert atmosphere (approximately 2 percent oxygen) in the mixing tanks.

The equipment selected for the project was robust enough to withstand the rigors of the injection demonstration and handled the ZVI mixture without incident (leaks and failures). 
The use of an injection well packer is not necessary for future injection projects in similar settings using the same injection material. The packer was placed down the injection well in case there was an unexpected increase in the pressure (head) required to inject the RNIP-M2 material during the pilot test.

Injection of the RNIP-M2 material into the aquifer at the 100-D area was similar to the results observed in laboratory flow cell tests, the sand tank test, and the modeling. A minor amount of pressure increase (head) was necessary to maintain a constant flow rate of $53 \mathrm{~L} / \mathrm{min}(14 \mathrm{gpm})$. The increase amounted to $2.5 \mathrm{psi}$ (5.2 $\mathrm{ft}$ of water) over a 5-day period.

Vacuum slug testing performed on the injection well before and after injection determined that the ZVI mixture caused decrease in hydraulic conductivity of the aquifer material immediately around the well by a factor of 2.7 . The starting hydraulic conductivity was $0.0382 \mathrm{~cm} / \mathrm{sec}$ and the ending hydraulic conductivity was $0.0142 \mathrm{~cm} / \mathrm{s}$.

Well 199-D4-93, located $3 \mathrm{~m}(9.8 \mathrm{ft})$ downgradient from the injection well was the first monitoring well to be influenced by the injection of ZVI material, followed by well 199-D4-92, based on visual observations of the water sampled from the wells. Water in well 199-D4-25 was affected by the injection toward the end of the test, as indicated by the presence of polymer (brown colored water with a soapy appearance). A verification borehole located $7 \mathrm{~m}(23.0 \mathrm{ft})$ from the injection well showed that $\mathrm{nZVI}$ was successfully deposited in a high conductivity layer near the bottom of the aquifer.

Hexavalent chromium is being reduced/immobilized in the aquifer, as shown by the increase in total chromium at the intervals that contain the most nZVI.

Gypsum formation is unlikely since the ion activity product for calcium and sulfate in the pore water was well below the gypsum solubility limit

The monitoring data collected during injection were consistent with the visual observations. The temperature and $\mathrm{pH}$ data increased in the three influenced wells (199-D4-92, 199-D4-93, and 199-D4-25). The ORP and DO measurements showed significant decreases in the two closest monitoring wells, signifying that nZVI was influencing the geochemistry in the immediate area around the wells. No significant changes in ORP or DO were observed in the outer two monitoring wells, indicating that the iron depositional front had not advanced as far as $12.8 \mathrm{~m}(42 \mathrm{ft})$ away.

The borehole induction logs from the PVC-cased monitoring well showed a significant response to ZVI injection. The logged well was located $3 \mathrm{~m}(9.8 \mathrm{ft})$ from the injection well, therefore a response in this well does not aid in determining the maximum extent of the injection. A preferred monitoring scenario would include at least one other PVC-cased well to allow for cross-well imaging of the injection.

It was determined that lateral resolution of the injection influence was more crucial than total depth of investigation in determining the relative success of the injection, and it was used to design the data acquisition accordingly. As a result, electrical resistivity and IP surveys were useful for estimating the lateral extent of the injected ZVI, but not the depth. A conservative estimate, consistent with the electrical resistivity and IP modeling results, is that the radial extent of the ZVI injection exceeded the minimum target of $7 \mathrm{~m}(23 \mathrm{ft})$.

Time-lapse inversion of the TEM data might be useful for constraining the depths at which the conductivities begin to increase more rapidly. The differences in pre- and post-injection data are significantly larger than the noise level observed in the data.

The majority of the geophysical methods used in this study were sensitive to changes in electrical conductivity; however, the presence of ZVI alone has minimal effect on the fluid conductivity. In the 
case of this injection, the conductive polymer injected with the ZVI was responsible for the observed conductivity increase. If other types of ZVI are injected in the future, IP and magnetic susceptibility measurements should be included in the monitoring plan. These two methods are sensitive to the presence of the iron rather than the conductive polymer.

For this particular injection, the total field magnetic data were of limited use in determining the extent of the injection. This resulted from a combination of factors, including a thick vadose zone and an abundance of steel-cased wells that may or may not be encountered at other injection sites. Total field magnetic data acquisition required notably less field effort than two-dimensional electrical profiling and, thus, should not be ruled out for future studies if the site conditions are favorable.

An alternative option for magnetic imaging is to use a borehole magnetic susceptibility tool to log the susceptibility as a function of depth and, if more than one nonmetallic-cased borehole were available, as a function of distance from the injection well.

\subsection{Quality Assurance/Quality Control}

All necessary QA/QC procedures were followed during field ZVI injection to ensure that the data acquired during the injection testing were valid and the results were within acceptable quality limits for the project. These procedures included providing qualified field personnel who reviewed and understood all planning documents, material specifications, test equipment designs, and specifications prior to beginning of field activities; were familiar with the project concept and scope; and were trained in maintaining written and electronic logs of all data, equipment calibration records, and samples. The activities used to ensure that the field ZVI injection testing met the quality requirements for the project are described below.

\subsubsection{Data Validation and Use}

A written log of the various injection procedures was recorded by all personnel conducting the testing in bound logbooks with sequentially numbered pages. A separate logbook was maintained for mixing, injection, oxygen and nitrogen monitoring, and monitoring wells. All of the data were electronically logged or recorded on data collection sheets or logbooks (using waterproof, non-smear ink) as necessary to document the test. Each new test day was identified by the date at the top of the logbook page. Each new entry was designated by a time of day and was started on a new line.

At a minimum, the field notes included the following:

- Date and time of data acquisition

- Equipment used

- Data acquired (including units)

- Observations relevant to field conditions.

All electronically recorded data were downloaded to a laptop computer and transferred to a flash drive twice per day to create a backup of the data. Data from each sampling event were compiled into a database for this project and entered into electronic spreadsheets for further analysis. Photographs and digital/video images were taken and noted in the logbook for reference to be cataloged and retained for future reference. All errors were struck through with a single line, followed by the correction and initials of the person making the change. Any modifications or additions to the proposed treatability test plan were documented, approved, and implemented. 


\subsubsection{Qualified Personnel}

Field work was completed by qualified, properly trained personnel familiar with the concepts related to the project. All personnel attended specific training and were badged. A pre-work meeting was attended by all field personnel to discuss any safety issues and to update all involved personnel on the schedule, equipment changes, and procedures. In addition, a field walkdown was conducted at the site prior to field work to discuss safety, equipment placement, utility availability, and procedures to be used during field injection activities.

\subsubsection{Equipment}

All equipment used at the site was routinely checked prior to data acquisition to ensure that it was functioning according to manufacturer specifications. Equipment calibration was performed as described in the following subsection.

\subsubsection{Calibration}

All equipment was routinely checked prior to data acquisition to ensure that it was functioning according to manufacturer specifications. Calibration records for the equipment used were available in the field. Calibration procedures included calibration of the Instrumentation Northwest CT2X/PT2X down-hole probes and the in-line flow meters prior to the startup of nZVI injection, as well as calibration of the YSI556 MPS multi-parameter probe and Orion specific conductivity meter prior to injection and twice daily during injection to ensure that accurate measurements were obtained.

\subsubsection{Nano-Size Zero-Valent Iron Slurry Preparation}

To ensure repeatable, accurate $\mathrm{nZVI}$ slurry, the following QA/QC procedures were implemented during slurry preparation:

- The Hanford service water that was placed in the poly mixing tanks was measured using dual, in-line flow meters. When the readings from the two flow meters were not identical, the average of the two readings was used for the volumetric calculations.

- The concentrated RNIP-M2 solution was weighed before addition to the mixing tank.

- The specific conductivity of the injection solution was compared to the specific conductivity of a 1 percent solids standard solution at ambient conditions to ensure that the proper proportions were obtained during the mixing procedure. The injection slurry was required to be within a RPD range of 15 percent when compared to the 1 percent solids standard.

\subsection{Costs/Schedule - Field Injection}

For the purposes of this discussion, the Field Injection effort was considered to be performed by the workscope described in Task 6 through Task 9 of the contract for this work. Task 6 covered the 50 percent and 100 percent design of the field injection, as well as the procurement and shop assembly of injection equipment. Task 7 included the procurement of the RNIP-M2 ZVI material, field assembly of the injection system, injection, and demobilization of the injection equipment. Task 8 covered monitoring of the field injection, as well as analysis of post-injection bore-hole samples. Task 9 covered final reporting on the ZVI project. 


\subsubsection{Cost}

Tasks 6 through 9 were funded at a fixed price of $\$ 878,529.63$. Of this amount, $\$ 317,788.98$ (approximately 36 percent of the total) was designated for the procurement of RNIP-M2 nZVI. Table 6-13 identifies the funding by task.

Table 6-13. Field Injection Cost Summary

\begin{tabular}{|c|c|}
\hline Task & Fixed Price \\
\hline $\begin{array}{c}\text { Task } 6 \text { - Design and Construct Injection System } \\
\text { Task } 6 \mathrm{a} \quad 50 \% \text { Design } \\
\text { Task } 6 \mathrm{~b} \quad 100 \% \text { Design }\end{array}$ & $\begin{array}{l}\$ 73,065.14 \\
\$ 73,065.14\end{array}$ \\
\hline $\begin{array}{c}\text { Task } 7 \text { - Field Injection } \\
\text { Task } 7 \mathrm{a} \text { Injection Material } \\
\text { Task } 7 \mathrm{~b} \text { Field Injection }\end{array}$ & $\begin{array}{l}\$ 317,788.98 \\
\$ 278,235.98\end{array}$ \\
\hline Task 8 - Monitoring & $\$ 59,767.69$ \\
\hline Task 9 - Treatability Test Report & $\$ 76,606.70$ \\
\hline Total & $\$ 878,529.73$ \\
\hline
\end{tabular}

\subsubsection{Schedule}

The schedule for field injection was finalized in April 2008, which is shown in Table 6-14. It should be noted that the monitoring task was not completed as of September 11, 2008, because the soil boring described in Section 6.2.5 had not been drilled as of that time.

Table 6-14. Field Injection Schedule

\begin{tabular}{l|c|c}
\multicolumn{1}{c|}{ Task } & Task Start & Task End \\
\hline $\begin{array}{l}\text { Task 6- Design and Construct Injection System } \\
\text { Task 6a 50\% Design }\end{array}$ & April 21, 2008 & May 9, 2008 \\
Task 6b 100\% Design & May 12, 2008 & May 30, 2008 \\
\hline Task 7- Field Injection & July 21, 2008 & September 11, 2008 \\
\hline Task 8-Monitoring & August 11, 2008 & September 11, 2008 \\
\hline Task 9-Treatability Test Report & May 13, 2008 & December 15, 2008 \\
\hline
\end{tabular}

\subsection{Key Contacts - Treatability Test (Field Injection)}

The roles and responsibilities of personnel involved in the RNIP-M2 pilot demonstration are presented in Table 4-19. 


\section{$7 \quad$ References}

Bowen, R., 1986, Groundwater, $2^{\text {nd }}$ Edition, Springer-Verlag, New York.

Cantrell, K., D. I. Kaplan, and T. J. Gilmore, 1997, "Injection of Colloidal Fe ${ }^{0}$ Particles in Sand with Shear-Thinning Fluids," in J. Environ. Eng., 123:786-791.

Comprehensive Environmental Response, Compensation, and Liability Act of 1980, 42 USC 9601, et seq. http://www.epa.gov/oecaagct/lcla.html\#Hazardous\%20Substance\%20Responses.

DOE/RL-97-01, 2005, Interim Action Waste Management Plan for the 100-HR-3 and 100-KR-4 Operable Units, Rev. 5, U.S. Department of Energy, Richland Operations Office, Richland, Washington. http://www5.hanford.gov/arpir/?content=findpage\&AKey=DA01311800

DOE/RL-2003-63, 2003, Sampling and Analysis Plan for In Situ Redox Manipulation Project, Rev. 0, U.S. Department of Energy, Richland Operations Office, Richland, Washington. http://www5.hanford.gov/arpir/?content=findpage\&AKey=D6455099

DOE/RL-2005-97, 2005, Fiscal Year 2005 Annual Summary Report for the In Situ Redox Manipulation Operations, Rev. 0, U.S. Department of Energy, Richland Operations Office, Richland, Washington. http://www5.hanford.gov/arpir/?content=findpage\&AKey=DA02798007

DOE/RL-2008-49, 2008, Treatability Test Plan for Injecting Zero-Valent Iron Into an In Situ Redox Manipulation Well, Rev. 0, U.S. Department of Energy, Richland Operations Office, Richland, Washington.

EPA 440/5-85-001, 1985, Ambient Water Quality Criteria for Ammonia - 1984, U.S. Environmental Protection Agency, Washington, D.C.

http://yosemite.epa.gov/water/owrcCatalog.nsf/9da204a4b4406ef885256ae0007a79c7/c95ee6 d2f1b843dd85256b060072304b!OpenDocument

EPA/540/R-92/071a, 1992, Guidance for Conducting Treatability Studies Under CERCLA - Final, U.S. Environmental Protection Agency, Washington, D.C. http://www.epa.gov/superfund/policy/remedy/pdfs/540r-92071a-s.pdf

Fruchter, J. S., C. R. Cole, M. D. Williams, V. R. Vermeul, J. E. Amonette, J. E., Szecsody, J. D. Istok, and M. D. Humphrey, 2000, "Creation of a Subsurface Permeable Treatment Zone for Aqueous Chromate Contamination Using In Situ Redox Manipulation," in Ground Water Monitoring \& Remediation, 20:66-77.

Gillham, R. W., and S. F. O'Hannesin, 1994, “Enhanced Degradation of Halogenated Aliphatics by ZeroValent Iron," in Ground Water, 32:958-967.

Gu, Y., 2003, “Automated Scanning Electron Microscope Based Mineral Liberation Analysis,” in $J$. Minerals \& Materials Characterization \& Engineering, 2:33-41.

Kaplan, D. I., K. J. Cantrell, T. W. Wietsma, and M. A. Potter, 1996, "Retention of Zero-Valent Iron Colloids by Sand Columns: Application to Chemical Barrier Formation," J. of Environmental Quality, 25:1086-1094.

Lee, T., H. Lim, Y. Lee, and J. Park, 2003, "Use of Waste Iron Metal for Removal of Cr(VI) from Water," in Chemosphere, 53:479. 
Legrand, L., A. El Figuigui, F. Mercier, and A. Chausse, 2004, "Reduction of Aqueous Chromate by $\mathrm{Fe}(\mathrm{II}) / \mathrm{Fe}$ (III) Carbonate Green Rust Kinetic and Mechanistic Studies," in Environ. Sci. and Tech., 38:4587-4595.

Loke, M. H., and R. D. Barker, 2006, "Rapid Least-Squares Inversion of Apparent Resistivity Pseudosections by a Quasi-Newton Method," in Geophysical Prospecting, 44:131-152.

Oldenburg, D. W., and Y. Li, 1999, "Estimating Depth of Investigation in DC Resistivity and IP Surveys," in Geophysics, 64:403-416.

Pettine, M., L. D’Ottone, L. Campanella, F. J. Millero, and R. Passsino, 1998, "The Reduction of Chromium(VI) by Iron(II) in Aqueous Solutions," in Geochimica et Cosmochimica Acta, 62(9):1509-1519.

PNNL-12086, 1999, Hanford Site Groundwater Monitoring for Fiscal Year 1998, Rev. 0, Pacific Northwest National Laboratory, Richland, Washington. http:/www.osti.gov/energycitations/servlets/purl/4737-QwSbLq/webviewable/4737.pdf

PNNL-14112, 2002, Groundwater Monitoring Plan for the 216-B-3 Trench on the Hanford Site, Rev. 0, Pacific Northwest National Laboratory, Richland, Washington. http://www.pnl.gov/main/publications/external/technical_reports/PNNL-14112.pdf

PNNL-15499, 2005, Effect of Geochemical and Physical Heterogeneity on the Hanford 100-D Area In Situ Redox Manipulation Barrier Longevity, Rev. 1, Pacific Northwest National Laboratory, Richland, Washington. http://www.pnl.gov/main/publications/external/technical_reports/PNNL-15499Rev1.pdf

PNNL-15573, 2005, An Experimental Study of Micron-Size Zero-Valent Iron Emplacement in Permeable Porous Media Using Polymer-Enhanced Fluids, Rev. 0, Pacific Northwest National Laboratory, Richland, Washington. http://www.pnl.gov/main/publications/external/technical_reports/PNNL-15573.pdf

PNNL-16424, 2007, Treatability Test Plan for an In Situ Biostimulation Reducing Barrier, Rev. 0, Pacific Northwest National Laboratory, Richland, Washington. http://www.pnl.gov/main/publications/external/technical reports/PNNL-16424.pdf

PNNL-18218, 2009, Electromagnetic Borehole Flowmeter Surveys at Selected In Situ Redox Manipulation Barrier Wells, Zero-Valent Iron Site, Hanford, Washington, Rev. 0, Pacific Northwest National Laboratory, Richland, Washington.

Ponder, S. M., J. G. Darab, J. Bucher, D. Caulder, I. Craig, L. Davis, N. Edelstein, W. Lukens, H. Nitsche, L. Rao, D. K. Shuh, and T. E. Mallouk, 2001, "Surface Chemistry and Electrochemistry of Supported Zero Valent Iron Nanoparticles in the Remediation of Aqueous Metal Contaminants," in Chem. Mater, 13:479-486.

SGW-38942, 2008, Calendar Year 2008 Semi-Annual Technical Memorandum for the 100-HR-3, 100-KR-4, and 100-NR-2 Pump-and-Treat Operations, Rev. 0, CH2M Hill Plateau Remediation Company, Richland, Washington.

U.S. Department of Energy, 2004, U.S. Department of Energy Hanford Site-Evaluation of Amendments for Mending the ISRM Barrier, Technical Assistance Project \#33, Final Technical Solutions Report, dated November 2004, Office of Environmental Management, Washington, D.C. http://costperformance.org/remediation/pdf/project33 evaluating_amend.pdf 
EPA, Ecology, and DOE, 1999, County, Washington, Amended Record of Decision Summary and Responsiveness Summary (100-HR-3 Operable Unit), U.S. Environmental Protection Agency, Washington State Department of Ecology, and U.S. Department of Energy, Olympia, Washington.

WAC 173-160, "Minimum Standards for Construction and Maintenance of Wells," Washington Administrative Code. http://apps.leg.wa.gov/WAC/default.aspx?cite=173-160

Waldrop, W. R., and J. K. Waldrop, 2004, Electromagnetic Borehole Flowmeter Test of the Wells of 100-D Area In Situ Redox Manipulation (ISRM) Barrier Site, Hanford Site, State of Washington, Quantum Engineering Corporation, Loudon, Tennessee.

Westerhoff, P., 2003, "Reduction of Nitrate, Bromate, and Chorate by Zero Valent Iron ( $\left.\mathrm{Fe}^{0}\right)$," in J. Environ. Engineering., 129(1):10-16.

WMP-281 19, 2005, Mending the In Situ Redox Manipulation Barrier, Rev. 0, Fluor Hanford Inc., Richland, Washington.

Yarmoff, J. A., and C. Amrhein, 1999, Fundamental Studies of the Removal of Contaminants from Ground and Wastewaters via Reductions by Zero-Valent Metals, DE-FG07-96ER14707, University of California, Riverside, California. 
DOE/RL-2009-35, REV. 0

This page intentionally left blank.

7-4 
DOE/RL-2009-35, REV. 0

\section{Appendix A}

\section{Sand Tank Test Plan and Data}


DOE/RL-2009-35, REV. 0

This page intentionally left blank. 


\section{Test Plan:}

\section{Zero-Valent Iron Tank Scale Injection}

\section{Prepared by:}

MSE Technology Applications, Inc.

200 Technology Way

P.O. Box 4078

Butte, Montana 59702

Revision 00

March 10, 2008 
MSE Review and Approval Signatures

MSE Technology Applications, Inc.

Prepared By: Gilbert M. Zemansky, Sr. Hydrogeologist

Date

Reviewed By: Mary Ann Harrington-Baker, Project Manager

Date

Reviewed By: Mary Ann Harrington - Baker, Quality Assurance Manager

Date

Approved By: Scott Nuthak, MSE Health and Safety

Date

Approved By: Tom Burkhart, Operations Division Manager

Date

Approved By: Andrea Hart, DOE Manager

Date

Approved By: Jeff LeFever, DOE Program Manager

Date 
DOE/RL-2009-35, REV.0

Revision 00

\section{This Page Intentionally Left Blank}




\section{TABLE OF CONTENTS}

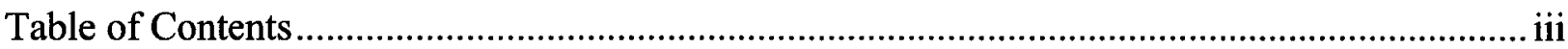

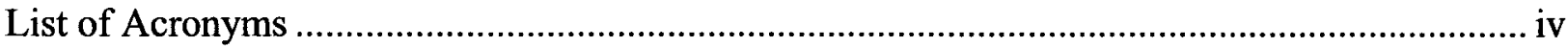

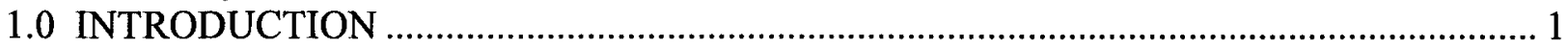

2.0 BACKGROUND nZVI AND MZVI INJECTION INFORMATION …............................. 2

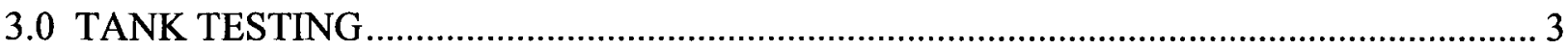

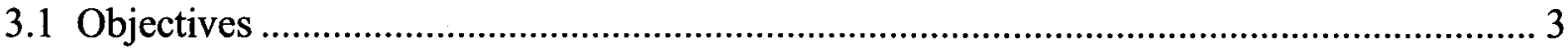

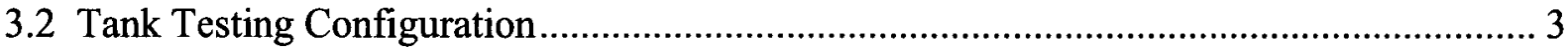

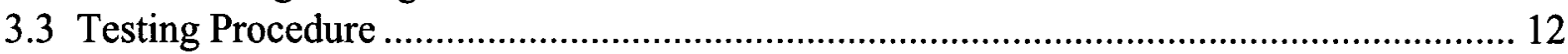

3.3.1 Tank Filling and Flushing and Pre-Injection Testing ................................................... 12

3.3.2 Hydraulic Conductivity Testing........................................................................... 12

3.3.3 Baseline Water Quality Sampling......................................................................... 15

3.3.4 Injection Equipment and Injection........................................................................... 16

3.3.5 Sampling After Completion of Injection .................................................................. 18

3.4 Data Analysis, Evaluation, and Reporting ................................................................... 19

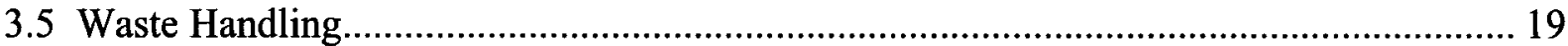

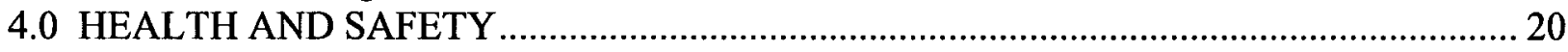

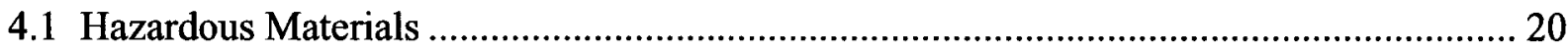

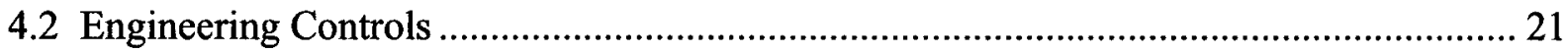

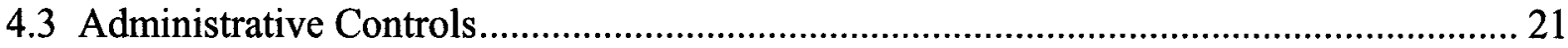

4.4 Personal Protective Equipment (PPE) ……………................................................... 22

4.5 First Aid and Emergency Response.......................................................................... 22

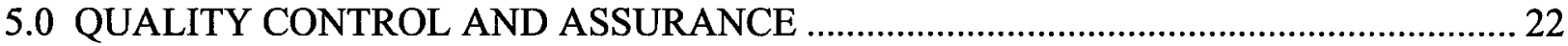

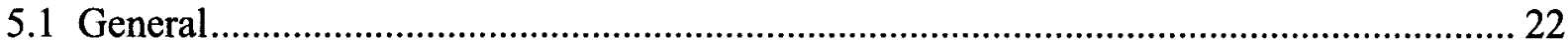

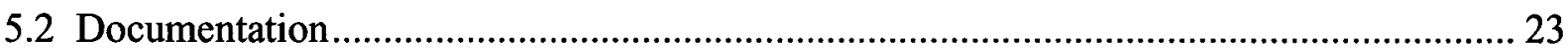

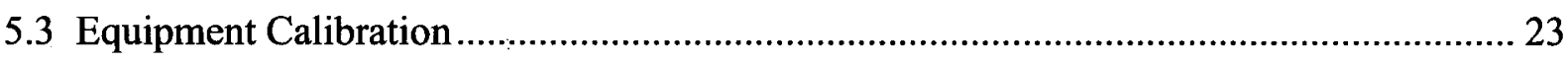

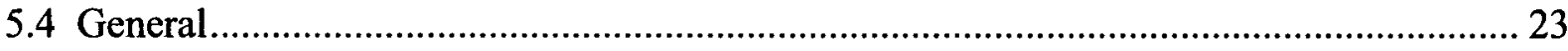

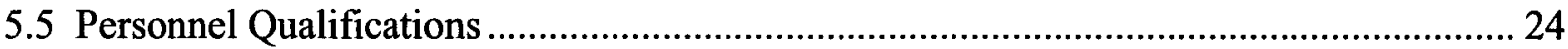

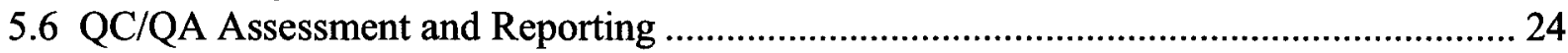

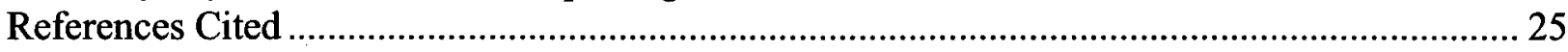

\section{LIST OF TABLES}

Table 3-1: Comparison of Hanford Ground Water and Butte Potable Water............................... 11

Table 4-1: Hazardous Materials and Exposure/Physical Data........................................................ 21 


\section{LIST OF FIGURES}

Figure 3-1: Tank Used for Testing Colloidal Silica Injection .................................................... 4

Figure 3-2: Side and Cross-Sectional View of Tank Apparatus................................................... 13

Figure 3-3: Plan, Side, and Oblique Views of Tank Lid ........................................................... 14

\section{LIST OF ACRONYMS}

$\begin{array}{ll}\text { CS } & \text { Colloidal silica } \\ \text { DO } & \text { Dissolved oxygen } \\ \text { DOE } & \text { U.S. Department of Energy } \\ \text { EM } & \text { DOE Office of Environmental Management } \\ \text { ID } & \text { Inner diameter } \\ \text { ISRM } & \text { In situ redox manipulation } \\ \text { MSE-TA } & \text { MSE Technology Applications, Inc. } \\ \text { MZVI } & \text { Micron-size zero-valent iron } \\ \text { nZVI } & \text { Nano-size zero-valent iron } \\ \text { OD } & \text { Outer diameter } \\ \text { ORP } & \text { Oxidation-reduction potential } \\ \text { PRB } & \text { Permeable reactive barrier } \\ \text { PVC } & \text { Polyvinyl chloride } \\ \text { QA } & \text { Quality assurance } \\ \text { QC } & \text { Quality control } \\ \text { USEPA } & \text { U.S. Environmental Protection Agency } \\ \text { ZVI } & \text { Zero-valent iron }\end{array}$




\subsection{INTRODUCTION}

An extensive In Situ Redox Manipulation (ISRM) permeable reactive barrier (PRB) was installed at the $100 \mathrm{H}$ area of U.S. Department of Energy's (DOE's) Hanford Site in Washington in September 1995 to prevent chromate from reaching the Columbia River (Fruchter, et al., 2000 and Oostrom, 2005). However, subsequent detection of chromate in downgradient monitoring wells indicates that there has been "premature chromium breakthrough." This breakthrough has been attributed to "the presence of high-permeability zones in the aquifer." It has been proposed to enhance the barrier's reductive capacity by injecting micron size zero-valent iron (MZVI) into the high-permeability zones (Oostrom, 2005).

MSE Technology Applications, Inc. (MSE-TA) has extensive experience in the assessment and remediation of soil and ground water and has received a contract from Fluor Hanford to test ZVI injection for the specific purpose of mending the above PRB at the Hanford Site. This research has involved batch and column or flow cell research. Additional column or flow cell research work is currently underway. DOE's Office of Environmental Management (EM) has authorized tank scale ZVI injection research by MSE-TA to provide intermediate scale information between column and full-scale field application of the selected form of ZVI as a "cost sharing task" to MSE-TA's ZVI contract with Fluor Hanford. This work is to be accomplished prior to field injection.

The agreed upon scope of this tank scale injection work is as follows (Section 1.11, DOE-Task 102 Change Control form, 10 December 2007):

1. To conduct a ZVI injection in a controlled environment that may be excavated as necessary to visually verify the extent of injection and, thereby, to validate the injection model determined from batch and column testing.

2. To evaluate methods for determining if field injection criteria have been met.

3. To refine injection techniques and slurry formulations prior to scaling up for field injection.

This test plan outlines the test apparatus which will be used and the methods which will be employed for injection and evaluation of injection results. Since the proposed work will be building on experience from column or flow cell research which is presently underway (this research will be completed prior to commencement of the tank scale injection work that is a part of this plan), there may be need to revise this test plan accordingly as new information from ongoing column or flow cell research becomes available. Background information from column or flow cell research and its impact with regard to this tank scale injection research is briefly summarized in Section 2.0 of this test plan. Section 3.0 presents the actual test plan for this tank scale research including sampling and analysis and quality assurance (QA). 


\subsection{BACKGROUND NZVI AND MZVI INJECTION INFORMATION}

MSE-TA was originally tasked with completing laboratory testing to demonstrate the feasibility of injecting MZVI for repair of the ISRM barrier at the Hanford Site using the Micropowder ${ }^{\mathrm{TM}}$ S-3700 form of MZVI and associated surfactant and polymer. This was the form tested by Oostrom, et al. (2005). However, in initial column tests completed in March 2007 it was found that the reaction rate of this form of MZVI was too slow to adequately address project concerns and that little $\mathrm{Cr}^{+6}$ reduction was occurring.

In response to this finding, the scope of the project was modified and MSE-TA was tasked with investigating various ZVI materials to determine which were: (1) injectable into the Ringold E soils of the 100-D area at the Hanford Site; and (2) could effectively reduce the $\mathrm{Cr}^{+6}$ present in ground water there.

There are many factors which influence the fate of ZVI when injected into a ground water aquifer. These include particle size, solution $\mathrm{pH}$, ionic strength, soil or aquifer composition, and ground water flow velocity $(\mathrm{Li}, 2006)$. In combination, these factors do not always lead to intuitive results. For example, although it might be expected that smaller nano-size ZVI (nZVI) particles might be more mobile in an aquifer system than larger MZVI, field tests have indicated that particle aggregation occurs rapidly with $\mathrm{nZVI}$ and, therefore, without the use of appropriate "delivery vehicles" $n Z$ VI particles "may migrate only a few inches to a few feet from the point of injection" (Li, et al., 2006).

The mechanisms that remove nZVI and MZVI particles from fluids injected into aquifers are those common to porous media filtration in general. They may be grouped into two categories: (1) mechanisms that transport particles from the bulk fluid to the vicinity of aquifer (i.e., filter) grains; and (2) mechanisms that result in attachment of particles to aquifer grains in close proximity. Transport mechanisms include physical forces arising from fluid flow (e.g., interception, surface filtration, inertial capture, internal trapping, gravity sedimentation, and diffusion). Some of these mechanisms physically remove particles (e.g., surface filtration and internal trapping) while others only bring particles into proximity to the aquifer grains and other mechanisms controlled by surface and fluid chemistry are required to keep them attached by adsorption (Stevenson, 1997 and Elimelech, et al., 1995).

Filtration theory "predicts that particle collisions with... (aquifer grains) are most frequent for very small $(<50 \mathrm{~nm})$ and larger ( $>3 \mathrm{um}$ ) particles," but even for optimum size particles numerous collisions can be expected over short distances. Additionally, colloidal chemistry causes aggregation of optimum size particles. Therefore, ZVI transport may be enhanced by addition of agents that prevent aggregation and control adsorption by reducing sticking efficiency (Schrick, et al., 2004). Research indicates that $\mathrm{nZVI}$ particle aggregation is a function of concentration and that without surface coatings nZVI particles will become micron-size in a matter of minutes. However, particle-particle and particle-media interactions can be minimized resulting in enhanced transport by the addition of polyelectrolyte, surfactants, or cellulose/polysaccharide surface coatings (Lowery, et al., 2005). 


\subsection{TANK TESTING}

\subsection{Objectives}

The laboratory testing will be completed at the MSE facility in Butte, Montana. Fully functional experimental and analytical laboratories are available there. The purpose of the laboratory testing is to conduct a ZVI injection in a controlled environment that may be excavated as necessary to visually verify the extent of injection and, thereby, to validate the injection model determined from batch and column testing. The injection model from column testing will have been developed taking fluid samples within a linear flow situation. Data from tank testing will involve both fluid and solid samples taken within a radial flow situation. In addition, tank scale testing, by simulating a field injection as closely as possible, will provide for the testing and refinement of injection techniques and ZVI slurry formulations prior to scaling up for actual field injection. Tank scale testing will also allow for evaluation of methods to determine if field injection criteria have been met.

\subsection{Tank Testing Configuration}

Testing will take place within a cylindrical steel tank. The tank is constructed of 0.25 " carbon steel plate rolled to 60" (5 feet) outer diameter (OD) with a longitudinal seam weld on the side and a flat plate bottom. This yields an inner diameter (ID) of 59.5". The sides of the tank will be lined with a synthetic drain sheet. This will also serve as a filtering device for the bottom outlet fittings. This drainage provision is intended to facilitate horizontal flow from the central injection well to the side walls of the tank. Four fittings, each with a shutoff valve, will be installed at locations in each quadrant of the bottom of the tank to allow for water from the drain sheet to exit the tank and for ultimate drainage of the tank at the end of the test. These fittings will be sufficient size to drain water from the tank at the planned injection rate for the test of an estimated maximum of 4 gallons/minute (gpm). In addition to providing a flow outlet, they will be used for obtaining water quality measurements and samples. Data from locations in each quadrant may also provide information relevant to questions of flow symmetry through the tank. There will be a flexible clear plastic hose coming off of each fitting held vertically in position to a level above the top of the tank. The mount for this hose will be calibrated so that the water level in the hose may be measured accurately with respect to the top of casing elevations of all wells and injection well pressure tubing (see further discussion of these below).

The internal volume of this tank filled to the top (not counting the drain sheet) would be approximately 96.5 feet $^{3}$. Assuming the side wall drain sheet to be 0.25 " thick (actual thickness will depend on availability and final product selection), the available internal volume of the tank would be 94.9 feet $^{3}$. There is no blueprint for this tank; however, Figure 3-1 presents a photograph of the top of a 4 foot diameter tank that was similarly outfitted and used in the same project in 1999 in which injection of colloidal silica (CS) was tested.

The tank will be filled with two size ranges of clean silica sand. Information on the properties of these is as follows: 


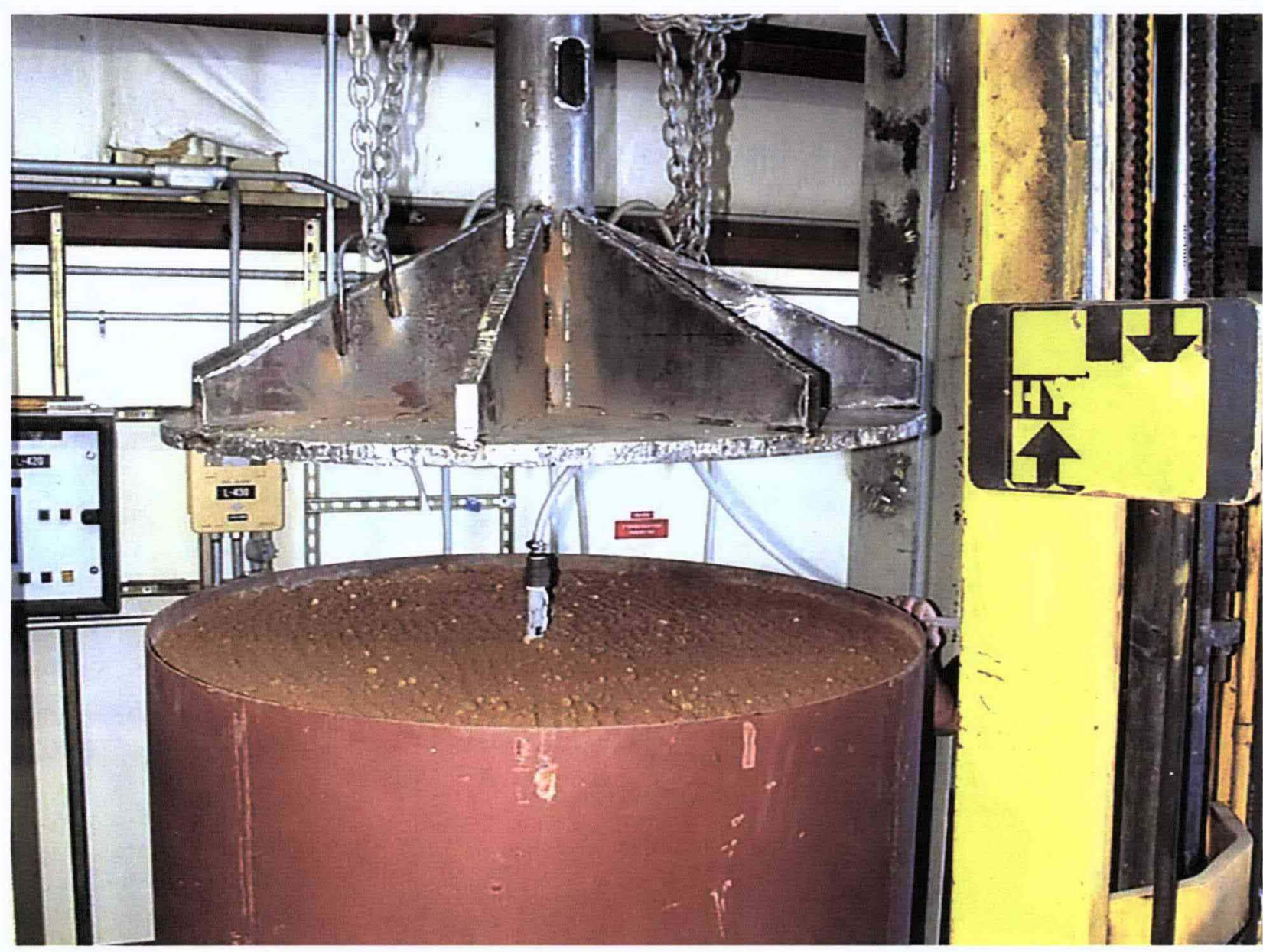

Figure 3-1: Tank Used for Testing Colloidal Silica Injection 
1. 10-20 mesh (10X20). According to data provided by a supplier of such sand, it is typically 95 percent silica, 0.10 percent $\mathrm{Fe}_{2} \mathrm{O}_{3}$, and the bulk of it is in the very coarse sand size range. Particle size distribution data also provided by this supplier indicates that this sand is fairly uniform (uniformity coefficient of 1.36) and has a median grain size of $1.43 \mathrm{~mm}$ (Oglebay Norton Industrial Sands, Inc., 1996 and 2007).

2. 30-70 mesh (30X70). Data on the chemical composition of this size range sand is unavailable. However, judging from the available data on other size ranges it can be expected that the fraction of silica will be marginally lower and the fraction of $\mathrm{Fe}_{2} \mathrm{O}_{3}$, will be substantially higher (on the order of three to four times as high as 10X20 mesh silica sand). For example, a supplier of such sand indicates that 20X40 sand typically is about 92 percent silica and 0.26 percent $\mathrm{Fe}_{2} \mathrm{O}_{3}$ while -40 sand is typically about 84 percent silica and 0.57 percent $\mathrm{Fe}_{2} \mathrm{O}_{3}$. The bulk of $30 \mathrm{X} 70$ sand is in the medium sand size range. Particle size distribution data also provided by this supplier indicates that the sand is fairly uniform (uniformity coefficient of 1.69 ) and has a median grain size of $0.32 \mathrm{~mm}$ (Oglebay Norton Industrial Sands, Inc., 2007).

Three samples of each size sand (10X20 and 30X70) will be analyzed for total iron to provide additional information and a baseline for later comparison (see Section 3.2.5 below).

As illustrated in Figure 3-2, these sands will be placed in three depth ranges with 3 feet of $30 \times 70$ mesh sand being placed at the bottom of the tank, 1 foot of $10 \times 20$ mesh sand being placed on top of that, and the remaining foot of the tank being filled with 30X70 mesh sand to a level 3" below the top of the tank. The sand will be compacted as it is loaded. Either of two methods may be used: (1) placement in 3" to 6" lifts around the artificial injection well borehole discussed below and mechanically compacted; or (2) compacted using one or more linear motion vibrators. At this point, research is continuing into the technical requirements for appropriate vibration equipment as well as availability and cost. The top level of each different type of sand (30X70 and 10X20) will be scarified to reduce the possibility of minor channelization. This configuration of different sands is intended to simulate a scaled down version of the Hanford site situation in which there is roughly a 1 foot thick layer having relatively high hydraulic conductivity sandwiched between materials having relatively lower hydraulic conductivity. Based on laboratory testing and the calculation of hydraulic conductivity using empirical equations and particle size distribution curves for each type sand, it is expected that the two sands involved will have a hydraulic conductivity contrast on the order of 20:1 (i.e., the hydraulic conductivity of the 12-20 mesh sand is on the order of 20 times higher than that for the 30-70 mesh sand).

A well will be installed in the center of the tank to simulate wells at Hanford that might be used for injection (e.g., well number 199-D4-37). The well will be constructed of 6" nominal diameter 304 stainless steel casing and screen (6.61" OD and 6.21" ID). The screen will be 4 feet long wire wrap screen having 0.020 " slots. This is consistent with the type of screens installed at Hanford, for example well number 199-D4-37 (Bechtel, 2000). The only difference is that wells at Hanford were constructed of 316 stainless steel. 304 stainless steel is less costly than 316 stainless steel and has the same hydraulic characteristics, but depending on geochemistry may be less resistant to corrosion. The screen has an intake flow area of 62 
inch $^{2}$ /foot. An artificial borehole will be created for this well using 12 " nominal diameter Schedule 40 polyvinyl chloride (PVC) casing (12.75" OD and 11.72" ID). The stainless steel well will be centered within the PVC casing and the annular space filled with 10-20 silica sand to within 6" of the top of the sand. Metal guides will be installed on the bottom of the tank to keep the well in place and help center both the well and PVC artificial borehole while the well is being constructed. The PVC artificial borehole will be slowly retracted as the filter pack is placed. The remaining annular space at the top of the borehole will be filled with granular bentonite to make a seal, after which retraction of the PVC casing will be completed. The granular bentonite will be hydrated with potable water.

Two series of 2" nominal diameter steel drive points to serve as observation wells will also be installed in the tank after the sand has been placed by driving them into the sand. The drive points have a 6" pointed head and drive cap to facilitate accomplishing this. These will be placed along opposite radials from the injection well at two different depths and radial distances. One series will consist of two wells at radial distances of 1 and 2 feet from the center of the injection well and screened in the center of the bottom 3 feet thick $30 \times 70$ sand layer (i.e., from approximately 1 to 2 feet above the bottom of the tank or 4 to 3 feet depth below the top of the tank). The screens for these wells consist of a galvanized steel perforated pipe wrapped in 60 gauze stainless steel (equivalent to 0.010 " slot size) covered with a heavy duty perforated stainless steel jacket. These wells will not have a filter pack other than the $30 \times 70$ sand layer they are installed within or a bentonite annular seal. The actual length of the screen for these drive points as sold is 30". This will be reduced to 9" by shortening the screen section and adding appropriate fitting and blank pipe to drive point, if possible, after procurement or by sealing the upper 21 " of the screen using silicone sealant and tape.

The second series of drive point observation wells will also consist of two wells of the same size and general construction as the foregoing ones and at radial distances of 1 and 2 feet but on the opposite side of the injection well from the deep observation wells. These will be screened within the coarser 10X20 sand layer (i.e., from approximately 3 to 4 feet above the bottom of the tank. These wells will not have a filter pack other than the 10X20 sand layer they are installed within or a bentonite annular seal. Care will be taken to ensure that the entire screen of these wells is surrounded by the $10 \times 20$ sand filter pack. As noted above, the length of the screen will be reduced to 9" by one of two possible methods. The target depth places 1.5 " of $10 \mathrm{X} 20$ sand below and above the screen.

The tops of all four observation wells will project approximately 1 foot above the top of the tank through watertight fittings in the steel lid. Caps will be installed on the tops of these wells. The wells will provide access for sampling water within the tank prior to, during, and after nZVI injection and for obtaining water level measurements.

Taking well volumes into consideration (a center 6" injection well and four radially located 2" observation wells as indicated below), the total volume of sand required is approximately 87.35 feet $^{3}$. This is apportioned between $10 \times 20$ sand (a volume of $29.94 \mathrm{feet}^{3}$ ) and 30x70 sand (a volume of $67.41 \mathrm{feet}^{3}$ ). The volume of bentonite required is $0.31 \mathrm{feet}^{3}$. 
Injection and observation well top of casing (TOC) elevations will be precisely determined with respect to each other, discharge tubing, and injection well pressure tubing (see further discussion of these items above and below).

After the wells have been constructed, the tank will be completely filled with potable water to the top of the sand. Potable water at MSE's facility comes from the Butte public water supply system (sourced from surface streams near Butte). The quality of this water in comparison to Hanford ground water quality is indicated in Table 1 below. For the available data which can be compared for the same variables, there are similarities and dissimilarities. Ground water at Hanford apparently has somewhat higher $\mathrm{pH}$ and substantially higher concentrations of many of the major ions. However, iron concentrations may be roughly comparable. These differences are not expected to have any impact on test results with respect to ZVI injection and transport.

Table 3-1: Comparison of Hanford Ground Water and Butte Potable Water

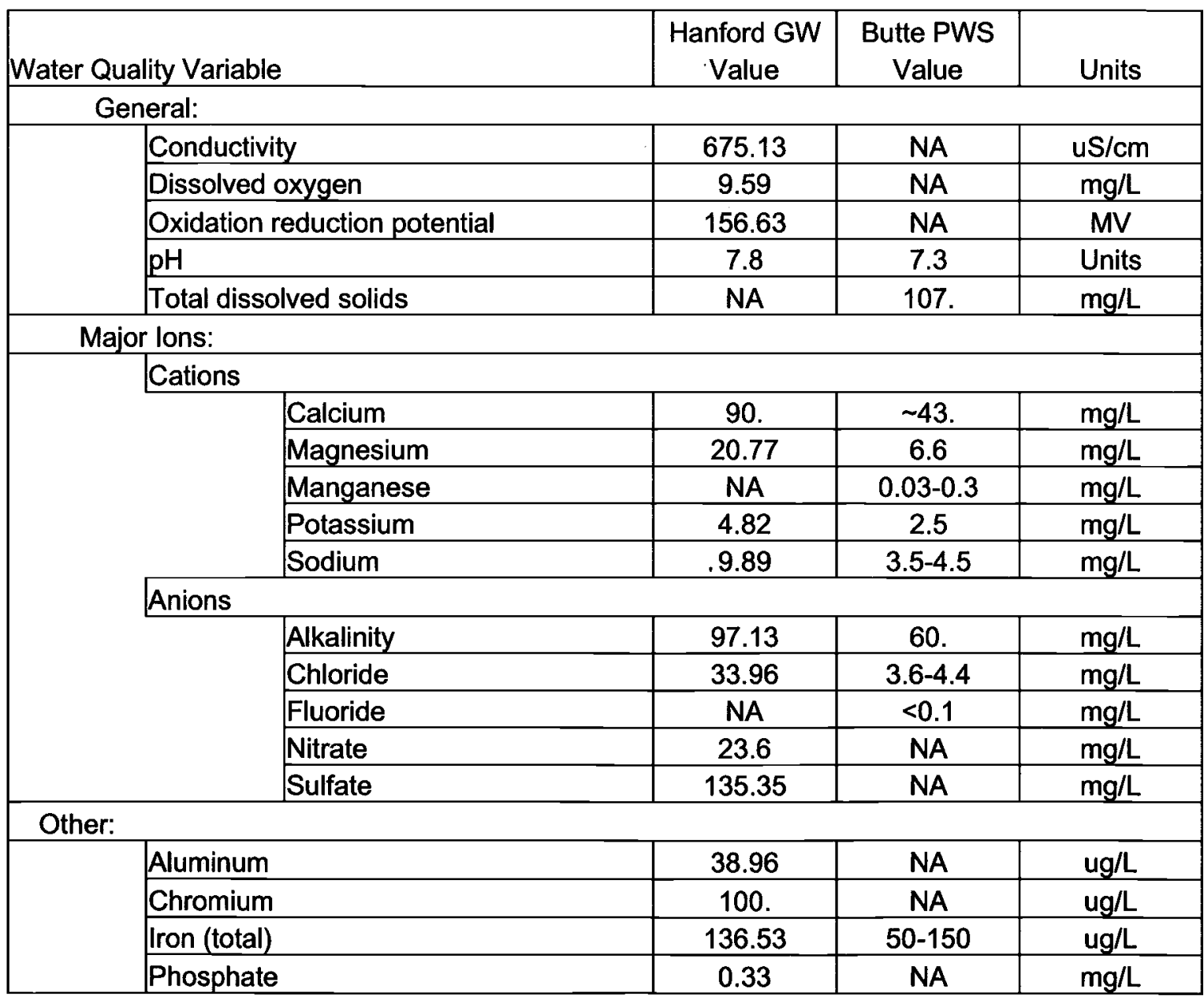

Comparison of mean Hanford ground water (GW) quality with representative Butte public water supply (PWS) water quality. Hanford data from page 3-7 of FY2005 ISRM Summary Report. Butte data from personal communication with M. Hovan, Manager of Water Treatment, Butte, Mt. "NA" indicates data not available. 
Injection equipment will then be installed in the well. The nZVI solution will be injected by pumping through flexible hose to a 1.5" nominal diameter steel downcomer (1.9" OD) installed in the center of the well through a single hole well cap with a flexible compression seal at the injection well TOC. The injection hose will have a pressure rating of at least $50 \mathrm{psig}$ and be connected to the steel downcomer by lockable quick release (i.e., cam lock) couplings. The $\mathrm{nZVI}$ and water slurry will be pumped through the hose to the injection pipe.

The top of the tank will be covered by a steel lid having a hollow center column with a side slot in it (similar to the lid used during CS testing in 1999 shown in Figure 3-1). The hollow center column of the lid will have an ID of approximately 6.75" to allow for the top of the injection well and a watertight seal between the injection well and the hollow center column. The flexible hose for nZVI and water slurry will enter the hollow center column through the side slot in it for connection to the injection pipe. There will be a " $T$ " connection off of the injection line with additional clear plastic tubing. The level of nZVI and water slurry in this tubing can be measured with respect to well TOC to indicate injection well pressure. The lid will exert a small amount of pressure on the top of the saturated sand. The injection well pressure tubing elevation will be determined accurately with respect to injection and observation well TOCs and discharge tubing (see discussion of these items above).

Drawings showing side and cross-sectional views of the tank with the lid in place and plan, side, and oblique views of the lid separately are presented as Figures 3-2 and 3-3, respectively. 'The lid resting on the top of the sand applies a small amount of pressure to it which contains the sand and water during injection. This is augmented by having the tank positioned within a frame.

\subsection{Testing Procedure}

\subsubsection{Tank Filling and Flushing and Pre-Injection Testing}

After the installation of sand and equipment in the tank is completed, as noted in Section 3.1 above, the tank will be filled with potable water to the top of the sand. Additional water will be pumped into the tank through the injection system and drained through the bottom discharge lines until three pore volumes have been flushed through the system. Assuming a porosity of 0.35 , each pore volume would be roughly 229 gallons of water. At the injection rate of $3 \mathrm{gpm}$, it would take about 76 minutes to pump each pore volume through.

\subsubsection{Hydraulic Conductivity Testing}

The hydraulic conductivity of the sand within the tank will be tested in several ways prior to, during, and after the injection:

\footnotetext{
${ }^{1}$ The reinforcement members on the tank top shown in Figures 3-2 and 3-3 were are a carry-over from higher pressure colloidal silica tank testing. In view of the small amount of pressure involved, such reinforcement members will not be used for ZVI injection tank testing. 


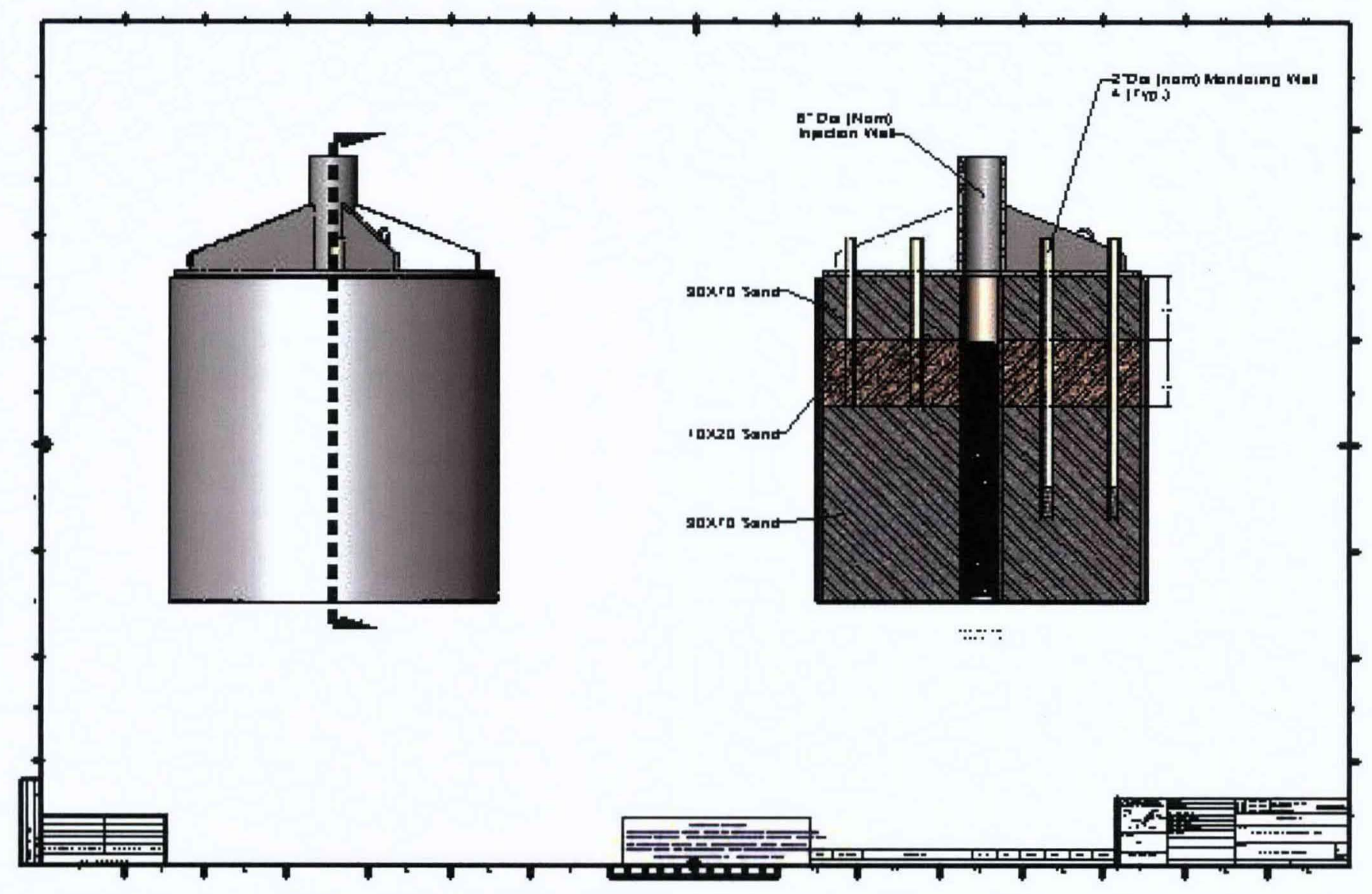

Figure 3-2: Side and Cross-Sectional View of Tank Apparatus 


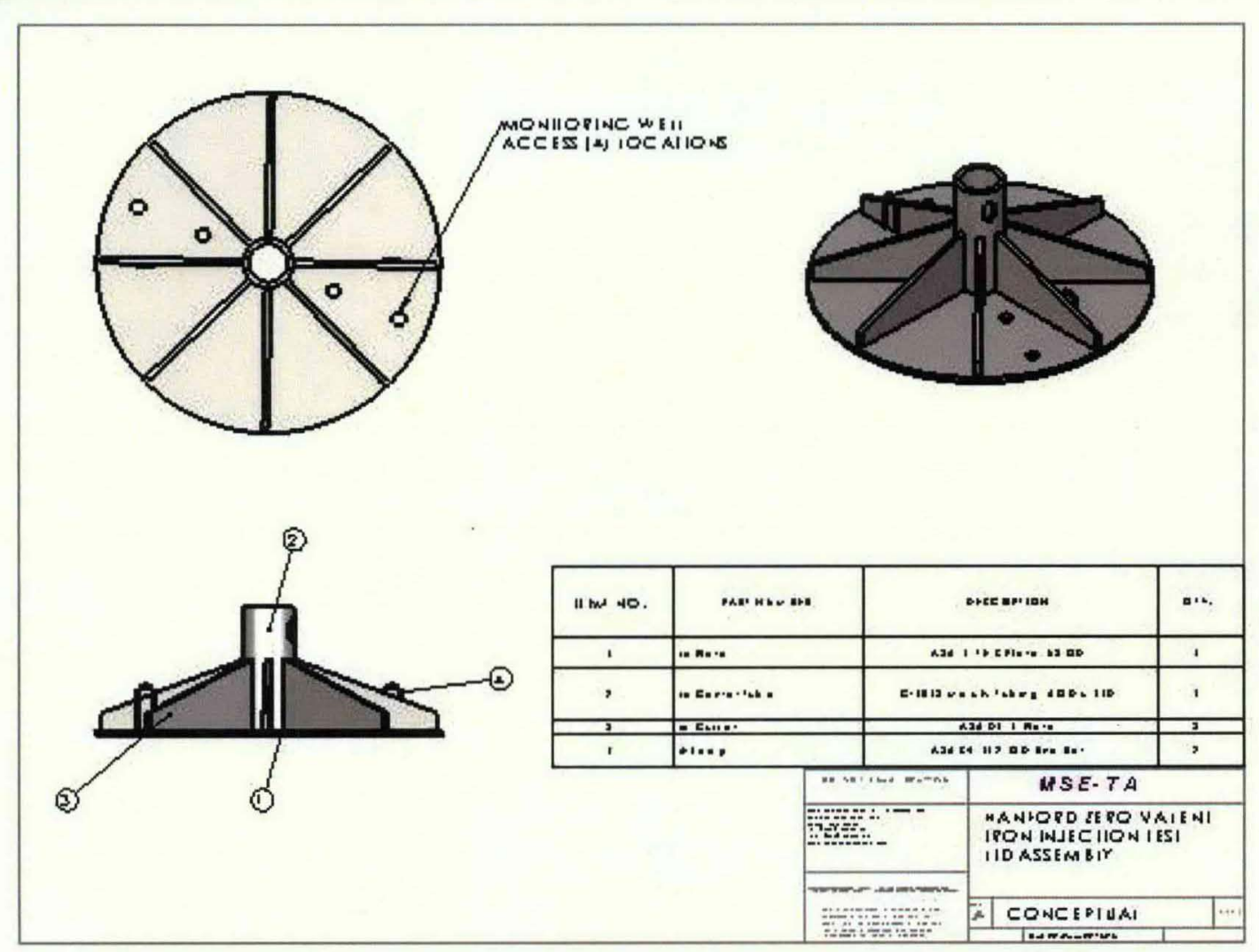

Figure 3-3: Plan, Side, and Oblique Views of Tank Lid 
1. Rising water level and/or falling water level (i.e., slug-out and/or slug-in, respectively) tests will be conducted in all four 2 " nominal diameter observation wells prior to and after the injection event. The slug will be produced either by use of an actual physical slug or pneumatically. Water level data will be obtained using electronic data loggers.

2. Rising water level and/or falling water level (i.e., slug-out and/or slug-in, respectively) tests will be conducted in the 6" nominal diameter injection well prior to and after the injection event. The slug will be produced either by the use of an actual physical slug or pneumatically. Water level data will be obtained using electronic data loggers. Water levels in the two observation wells closest to the injection well (i.e., at radial distances of 1 foot) will also be monitored using electronic data loggers.

2. During the injection phase, water level measurements in all four observation wells, pressure in the injection well, and the injection flow rate (as determined both by the flow of water exiting the discharge points and by an in-line flow meter on the injection hose) will be recorded at 15 minute intervals during the first hour of the test and 30 minute intervals thereafter. Flow rate at the discharge points will be determined by recording the time taken to fill graduated cylinders, graduated buckets, or other suitable calibrated containers. These data will be used to indicate bulk hydraulic conductivity of the sand in the tank as a whole using the Thiem equation.

Procedures for rising water level tests will include the use of an electronic data logger to collect recovery water level data and utilization of an appropriate sized slug (actual physical or pneumatically produced) to produce a suitable response (on the order of at least 1 foot).

Rising and/or falling water level test data will be analyzed using Version 4 of Aqtesolv computer software and the Bouwer and Rice (1976) solution method unless there is indication of an oscillatory response. In that case, preference will be given to use of the Butler-Zhan (2004) solution or other similar solution capable of resolving oscillatory response data.

\subsubsection{Baseline Water Quality Sampling}

After hydraulic testing has been accomplished, baseline field water quality measurements and samples will be taken for the following parameters from all six sampling points (see below):

1. Field measurements -

a. Conductivity.

b. Dissolved oxygen (DO).

c. Oxidation-reduction potential (ORP).

d. $\mathrm{pH}$.

e. Temperature.

2. Samples for laboratory analysis - Total and dissolved iron (one sample to be preserved with nitric acid and one sample to be filtered using a new disposable 
0.45 micron filter and preserved with nitric acid). Both samples will be collected in new $50 \mathrm{~mL}$ polyethylene containers provided by the MSE-TA laboratory. These samples will be hand-delivered to the MSE-TA laboratory and analyzed for iron using U.S. Environmental Protection Agency (USEPA) method 6010.

Sampling points will be as follows:

1. All four 2" nominal diameter observation wells (two screened in the high hydraulic conductivity depth interval and two screened in the upper relatively low hydraulic conductivity depth interval).

2. Each of the two bottom discharge lines from the tank.

It is anticipated that field measurement data will be obtained during upcoming flow cell testing that can be used to determine the utility of measurements for these five variables and whether one or more should be dropped. Samples for field measurements and laboratory analysis will be taken using peristaltic pumps. The baseline sample will be taken after purging three well volumes. Additional potable water will be added via the injection well in conjunction with well purging for baseline sampling. Subsequent samples during $\mathrm{nZVI}$ injection will be taken after purging one well volume. The water volume in this case will be made up by the ongoing injection. Well volumes are approximately:

1. Deep $30 \times 70$ sand observation wells

2. Shallow $10 \times 20$ sand observation wells

3. Injection well
0.6 gallons

0.3 gallons

7.0 gallons

\subsubsection{Injection Equipment and Injection}

After the tank has been filled and flushed, slug testing of observation wells and the injection well accomplished, and baseline water quality measurements and samples obtained, the tank injection will be performed (simulating an actual field injection). In preparation for the injection, injection equipment will be installed. This will consist of an injection pump, 1.5" diameter steel downcomer, well cap, and flexible hose from the injection pump to the steel downcomer, and inline flow meter. The injection pump will feed out of the same tank filled with nZVI solution used for flow cell testing (see Section 3.2.5). The steel downcomer will be inserted into the center of the 6 " nominal diameter well through a well cap with a compressible fitting to obtain a seal. The flexible hose from the injection pump will be attached to the top of the steel injection pipe and the lid placed onto the top of the sand and over the pipe. The tops of the four 2" nominal diameter observation wells will be secured in place through watertight fittings in the lid.

When the lid is in-place and the injection apparatus connected and ready, a tank injection (simulated a field injection) will be performed using RNIP-M2. The ingredients for RNIP-M2 are elemental iron ( $\mathrm{Fe}$ ), magnetite (an iron oxide $\mathrm{Fe}_{3} \mathrm{O}_{4}$ ), a water-soluble polymer, and water (Toda, 2008). The water-soluble polymer is for the purpose of stabilizing the iron dispersion so that it may be injected further into the aquifer. RNIP-M2 is an nZVI water-based slurry formulation manufactured by Toda America. The specific pump, flow rate, and slurry iron 
concentration to be used may be modified depending on experience from ongoing column or flow cell research being conducted by MSE-TA. However, based on preliminary information, it is anticipated that one of several available centrifugal pumps with a capacity on the order of 5 gpm will be used at a flow rate on the order of $3 \mathrm{gpm}$. This is based on the expectation that flow rates in the field will be on the order of 10 to $15 \mathrm{gpm}$ through wells with screens that are 15 feet long yielding approximate mean injection rates of $1 \mathrm{gpm} /$ foot. The open area of the screen would be capable of handling this flow rate at a mean velocity on the order of $0.32 \mathrm{feet} / \mathrm{minute}$ ( $140 \mathrm{~m} /$ day). Assuming an effective porosity of 0.35 , this would be reduced by the sand adjacent to the screen to a value of about $0.23 \mathrm{feet} / \mathrm{minute}(100 \mathrm{~m} /$ day $)$. This velocity would decrease to $0.025 \mathrm{feet} / \mathrm{minute}(11 \mathrm{~m} / \mathrm{day})$ at the drain sheet on the tank wall. These values are close to the seepage velocities which will be tested in flow cell experiments (MSE, 2008).

The period of the injection has been calculated to be approximately 98 minutes. This is based on achieving five pore volumes of flow through the relatively high $\mathrm{K} 10 \mathrm{X} 20$ sand layer, assuming a $\mathrm{K}$ contrast between $10 \times 20$ and $30 \times 70$ sand of a factor of $20,0.35$ porosity, and a retardation factor of 5 (de Boer, 2007).

The quality of water in all four observation wells and the four bottom discharge lines leaving the tank will be periodically monitored for the variables listed above using field measuring equipment. Information on how these variables may change during the period of the test will be developed during upcoming flow cell testing. However, it would be expected that with sufficient time under aerobic conditions that conductivity and $\mathrm{pH}$ would increase and DO and ORP would decrease. No change in temperature is expected. In addition to field measurements, qualitative observations of turbidity and color will be made. Initially, there should be little, if any, turbidity and color. As the ZIV injection fluid reaches a monitoring point turbidity should increase and color change through gray to black. Attention will first be focused on the two observation wells closest to the injection screen. Field measurements will commence when there is a noticeable change in turbidity and color at either of the closest two observation wells (presumably, the well screened in relatively high $\mathrm{K} 10 \times 20$ sand). Starting at that time, all variables will be measured at 15 minute intervals and samples taken for laboratory analysis of total and dissolved iron. Similarly, field measurements will continue for the closest low K $30 \times 70$ sand well and sequentially from the further away high $\mathrm{K} 10 \times 20$ sand observation well and then from the bottom discharge lines after there has been a noticeable change in turbidity and color at those locations. The measurement times at those locations will be blended with ongoing measurements at the closest observation well(s) so that a round of measurements is taken at the same 15 minute interval. Additionally, samples will be taken to be analyzed by the laboratory for total and dissolved iron every 15 minutes at the same locations once there has been an indicative change in turbidity and color or field measurements. These frequencies may be modified before the test if results from ongoing column or flow cell research indicated that is advisable or during the test based on observations as the test progresses.

At the completion of the injection, a final round of water quality measurements and samples for laboratory analysis will be obtained from all four observation wells and the discharge lines.

If it is assumed that the injection goes for 98 minutes, that each sampling round involves eight locations, that baseline samples are taken prior to the injection, that samples are taken during the 
injection at a 15 minute frequency, and that samples are taken at the end of the injection, this would mean a maximum of about 56 water samples each for laboratory analysis of both total and dissolved iron (i.e., a maximum total of 112 water samples). It appears likely that the actual number of samples will be substantially lower than that. For example, based on the $\mathrm{K}$ contrast, it is possible that no samples at will be taken from the deep wells screened in low $\mathrm{K} 30 \mathrm{X} 70$ sand other than pre- and post-injection ones.

\subsubsection{Sampling After Completion of Injection}

The injection apparatus will be disconnected when the injection has been completed, the lid raised off of the tank, the injection well cap removed, and the steel downcomer removed from the injection well. Sand will be hand excavated from the tank to allow for obtaining aquifer matrix samples to be tested for total iron concentration. The excavation process will begin with the draining of water from the tank using all bottom drain lines. The four observation wells will be left in place as long as possible during excavation to mark their position. When it becomes necessary to remove them, their position will be marked with wooden rods or stakes. The excavation will commence with removal of the top 7" layer of sand. Photographs will be taken of each stage of the excavation process using a digital camera. Samples of sand at the following radial locations and depths will be sequentially obtained at nominal vertical depths of 0.75 feet (bottom of low K 30 X70 sand layer above high K layer), 1.5 feet (center of high K 10X20 sand layer), 2.5 feet (top of low K $30 \times 70$ sand below high K layer), and 3.5 feet below the top of the tank $(4.25,3.5,2.5$, and 1.5 feet above the bottom of the tank, respectively):

1. Adjacent to the injection well screen.

2. At a distance of 1.0 foot from the center of the injection well.

3. At a distance of 1.5 feet from the center of the injection well.

4. At a distance of 2.0 feet from the center of the injection well.

5. Adjacent to the tank wall.

These samples will be taken along two tank diameters. The first diameter will be along the axis of the tank where the observation wells were installed. Therefore, sand samples will be taken adjacent to the center of the same screen which supplied fluid samples for analysis. The second tank diameter will be perpendicular to the first. Since there are 10 sampling locations along each diameter and four depth intervals being sampled, there will be a total of 80 sand samples for analysis. Each sample will be collected in new Zip-Loc plastic bags and analyzed for total iron using USEPA method 6010. The amount of sample required is approximately $5 \mathrm{~g}$. In addition, as noted in Section 3.1 above, at least three samples of each type of sand (10X20 and 30X70) will be analyzed for total iron to provide a comparative baseline. 


\subsection{Data Analysis, Evaluation, and Reporting}

During preparation for the tank test and as the test proceeds, all information will be compiled by the designated project hydrogeologist. Duplicate copies of data sheets and field notebook pages will be prepared at the completion of each working day and kept by the project technical supervisor (both of paper and electronic information). This includes making a photocopy of the new entries in bound project notebooks. At the completion of the tank test, all data will be comprehensively compiled, reviewed, analyzed, and evaluated and a final project report prepared.

Data analysis differs depending on the type and quality of data. For example, analysis of hydraulic test data from slug tests prior to and after the injection will be performed using Version 4 of Aqtesolv computer software and the Bouwer and Rice (1976) solution method or, in the event of an oscillatory response, the Butler and Zhan (2004) solution method to estimate near well test interval hydraulic conductivity while flow and water level data during the injection phase will be used with the Thiem equation to calculate bulk hydraulic conductivity for the tank as a whole.

Analysis of fluid chemistry data will involve plots to determine time series trends. Comparisons will also be made of fluid sample results for iron with results for iron in adjacent sand samples to determine whether or not the injection produced a measurable correlation between changes in fluid and sand chemistry. Similarly, hydraulic tests performed on wells before and after the injection will allow consideration of the special variations in aquifer matrix hydraulic properties and the impact of the injection on them. Additionally, it will be possible to analyze hydraulic conductivity estimates over time from Thiem equation calculations to see if there is an observable change in bulk aquifer hydraulic properties as the injection proceeds and how these bulk data estimates compare with location specific results from before and after injection slug tests.

The final project report will delineate methods used, document all project data, present analysis and evaluation of that data, and provide conclusions and recommendations derived from the tank test.

\subsection{Waste Handling}

All wastes generated during this project will be handled in accordance with applicable federal, state, and local requirements and facility waste handling procedures.

Prior to the injection test, the tank will be flushed with three pore volumes of potable water. The 687 gallons of wastewater from this flushing process will be discharged to the sanitary sewer system. The primary waste expected to be generated as a result of the injection test will be spent ZVI injection fluids (diluted in water and with loss of iron through deposition in the sand) and sand injected with ZVI. Fluid ZVI wastes will consist of a combination of potable water mixed with ZVI fluids. As noted in Section 3.3.4 above, the RNIP-M2 ZVI fluid which will be used consists of a mixture of elemental iron ( $\mathrm{Fe}$ ), magnetite (iron oxide $\mathrm{Fe}_{3} \mathrm{O}_{4}$ ), water-soluble 
polymer, and water. The objective for the injection fluid is an iron concentration of $1 \%$ iron by weight. Some of this iron will be deposited within the sand in the tank so that wastewater iron concentrations will be less than $1 \%$ by weight. All of these ingredients are relatively innocuous (i.e., iron, polymer, and water). A maximum of 1,143 gallons of water mixed with RNIP-M2 will be produced if five pore volumes are injected. It is expected that the actual injection volume will be substantially less. This wastewater could be discharged to the sanitary sewer system if found acceptable by officials at the Butte wastewater treatment plant (WWTP). If the maximum of 1,143 gallons of wastewater was actually generated and contained iron at the full injection concentration of $1 \%$ by weight (i.e., none of the injected iron deposited in the sand), approximately 95 pounds of iron would be contained in it. As noted above, the amount of iron likely to be in wastewater ultimately generated by this test would be substantially less than this level because the total volume will probably be much less than five pore volumes and the objective is to deposit most of the iron within tank sand.

The wastewater as generated will contain water soluble polymer for the purpose of keeping the iron suspended. Butte operates an activated sludge (i.e., secondary treatment via aeration) WWTP at a mean flow rate of 3.4 million/gallons per day (MGD) (Evans, 2008). This volume of wastewater provides a high degree of dilution capability which would be expected to offset the stabilizing effect of the water-soluble polymer. Any remaining ZVI will undergo oxidation under the aerobic conditions of the sewer system and the WWTP, first to ferrous and then to ferric iron. Ferric iron is relatively insoluble and, therefore, will form ferric hydroxide which can be removed by sedimentation at the WWTP.

It will be necessary to discuss disposal of wastewater with the City of Butte to obtain their permission for this discharge via their industrial pre-treatment program. An alternative method of disposal would be temporary storage in open drums or tanks, aeration, and either evaporation or chemical destabilization. The remaining sludge could be disposed of to a landfill after drying.

\subsection{HEALTH AND SAFETY}

Experiments presented in this test plan will be conducted in an experimental laboratory at the MSE Testing Facility. All activities shall be conducted in accordance with MSE's Chemical Hygiene Plan (CHP) and MSE's Hazard Communication Program, as documented in the MSE Health and Safety Program Manual, Part 8, Section 6; and Section 1; respectively. The MSE Health and Safety Director (Scott Nuthak) will serve as the Chemical Hygiene Officer (CHO) and Charlie Brown will serve as the Environmental Coordinator for this project. Material Safety Data Sheets (MSDS) for all chemicals used in the experiments will be kept on file in the laboratory and shall be readily available throughout the project duration. All containers shall be properly labeled with their content and hazard.

\subsection{Hazardous Materials}

As noted in Section 3 above, the only chemical expected to be used in this test is the ZVI formulation RNIP-M2. The MSDS for this chemical identifies the ingredients as being 
elemental iron ( $\mathrm{Fe}$ ), magnetite (the iron oxide $\mathrm{Fe} 3 \mathrm{O} 4$ ), water-soluble polymer, and water. This will be further diluted with potable water provided from the Butte public water supply. As always, it is imperative that all personnel follow safe laboratory practices, practice good personal hygiene, and wear appropriate personal protective equipment (PPE). Personnel will be required to review this health and safety plan and acknowledge that they will abide by it. At no time, will personnel safety and health be compromised for testing. If a task cannot be performed safely, it will not be performed. Industrial Hygiene monitoring will be performed at the discretion of the CHO. Monitoring may be required if any dust is generated. Information on the exposure limits for ZVI ingredients are indicated in Table 4-1 below. Information on the exposure limit for silica sand is also listed in Table 4-1.

Table 4-1: Hazardous Materials and Exposure/Physical Data

\begin{tabular}{|l|l|l|l|}
\hline Chemical & PEL/TLV & H-F-R & Hazards \\
\hline MZVI & $5 \mathrm{mg} / \mathrm{m}^{3}$ & $1-1-1$ & Irritant \\
\hline Polymer & $5 \mathrm{mg} / \mathrm{m}^{3}$ & $1-0-1$ & Irritant \\
\hline Silica Sand & $0.3 \mathrm{mg} / \mathrm{m}^{3}$ & $3-0-0$ & Carcinogenic \\
\hline $\begin{array}{l}\text { PEL/TLV = Permissible exposure limit/threshold limit value } \\
\text { H-F-R = Health - Fire - Reactivity Ratings }\end{array}$
\end{tabular}

\subsection{Engineering Controls}

Engineering controls shall be used where appropriate. These include proper grounding on all electrical equipment.

\subsection{Administrative Controls}

A general test area will be demarcated for this project within the MSE experimental laboratory building and restricted to project personnel only. Proper chemical storage that includes separating incompatibles will be practiced. Chemicals shall not be left out of their respective storage cabinets.

Personnel shall practice good personal hygiene at all times. This includes, no eating, smoking, chewing gum, chewing tobacco, or drinking in the test area. Hands shall be washed thoroughly after removing protective gloves and before leaving the test area and hands shall be kept away from the eyes and face when wearing protective gloves. Eating and drinking shall only be allowed in the break area of the building. Smoking is prohibited inside the building. 


\subsection{Personal Protective Equipment (PPE)}

Standard laboratory protective equipment includes will be used where appropriate. This includes laboratory coats, safety glasses, and impervious latex or nitrile gloves.

Additionally, due to the hazard of dust from dry silica sand, it will be necessary to wear respirators with HEPA filters while loading the test tank with dry silica sand to preclude exposure to dust from the silica sand. Hard-toed shoes will be required when handling heavy objects (pumps, rigging, buckets, etc.). Since operations personnel are fit tested, they should perform dry silica sand loading. During any overhead work (i.e., silica sand loading and lid placement and removal) hardhats will be required.

\subsection{First Aid and Emergency Response}

The MSDS for RNIP-M2 specifies the following first aid and emergency procedures:

1. "Eyes - Flush with copious amounts of water for at least 5 minutes and obtain medical attention."

2. "Skin - Wash skin with soap and water, when the slurry is stuck."

In the event of any need for such treatment, other persons present shall dial "333". The emergency eyewash/shower is located within the test area. The use of PPE, the laboratory hood, good personal hygiene, and safe work procedures should prevent exposures from occurring via inhalation, ingestion, and absorption. The potential for injection hazards is not likely, given the nature of work.

All spills shall be reported to the $\mathrm{CHO}$ and actions shall be taken to minimize spillage, area contamination, and personnel exposure.

\subsection{Hoisting/Rigging and Heavy Equipment}

All hoisting/rigging and heavy equipment operation (i.e., forklift and manlift) shall be performed by qualified Operations personnel only. No person(s) shall place any body part(s) under suspended load for any reason. Be watchful for pinchpoints and placement of hands and fingers.

\subsection{QUALITY CONTROL AND ASSURANCE}

\subsection{General}

Quality control and assurance (QC/QA) is facilitated through adherence to a written workplan consistent with standard procedures, such as those specified in this workplan, and which has been properly reviewed and approved. This workplan will be reviewed by senior MSE-TA 
management (including the Program Manager, Division Manager, Health and Safety, QA Manager, and Project Manager) before finalization. In addition, during all phases of implementation of this workplan progress will be reviewed with the Project Manager.

\subsection{Documentation}

Measurements and observations shall be recorded immediately after having been made and, as appropriate shall be verified by repeat measurements (e.g., water levels measured by electrical tape) and compared with prior data for the measurement point. In the event of any questionable measurement, the measurement will be repeated. If the measurement is still questionable, instrument calibration shall be checked and, if necessary, another scientists/engineer requested to verify the measurement. All project data (including bound field notebooks, data sheets, etc.) will be placed in the project file upon completion of testing.

\subsection{Equipment Calibration}

All measurement instruments will be calibrated prior to use (e.g., multiparameter water quality probes) or installation (e.g., the in-line flow meter) in accordance with manufacturer's instructions. With regard to field water quality instruments, it is expected that a YSI multiparameter probe will be used for the measurement of conductivity, DO, ORP, $\mathrm{pH}$, and temperature. However, other available equipment with similar capability may also be used. Calibration in accordance with manufacturer's instructions will be performed at the beginning of each working day prior to instrument use. Calibration will be checked in the event of questionable readings, at a minimum of every three hours of instrument use, and at the completion of the final sampling event for each working day. If at any time calibration has been found to have drifted more than 10 percent or, in the case of $\mathrm{pH}$, more than 0.2 units from the check standard, the instrument shall be recalibrated.

Flow meter measurements during the injection test will be checked against manually made measurements of tank drainage. To the extent possible, all drainage flow rate measurements will be made twice and the calculated mean of the two measurements used.

\subsection{General}

Sampling and analysis QC/QA is also a function of the application of standard procedures by trained personnel using proper equipment. Standard QC/QA procedures include the purging of wells prior to sampling and the use of clean sampling equipment and, where applicable when dedicated equipment is not being used, decontamination of sample contacting equipment prior to use at different locations. The following QC/QA procedures shall apply:

1. Purging wells - Wells will be purged prior to sampling as specified in Section 3.3.3 above. 
2. Sample contacting equipment will be dedicated whenever possible (e.g., tubing used to extract samples from wells). Where this is not practical, sample contacting equipment will be decontaminated between uses at different locations.

Decontamination shall be accomplished by washing in a potable water and Alconox (or other suitable non-phosphate detergent) solution, rinsing with potable water, and either air drying or drying with a clean paper towel.

3. Field duplicates - For each type of sample being analyzed by the laboratory, at least one sample in every 20 samples shall be a QA blind duplicate taken sequentially during the sampling process.

4. Laboratory QC/QA - The QC/QA checks incorporated into standard USEPA procedures for iron analysis and implementing MSE-TA protocols will be adhered to including method blanks, duplicates, matrix spikes, and laboratory control samples. An audit of laboratory sample results shall be conducted and results from it provided as a part of the project final report. The maximum number of samples that might be generated as a part of this project is estimated at 168 water samples (assuming injection of five pore volumes of ZVI fluid) and 83 sand samples plus 14 field duplicates or a total of 263 samples. However, it is expected that the actual number of water samples will be substantially less than 168 .

\subsection{Personnel Qualifications}

Personnel working on this project in the experimental laboratory shall be experience in experimental laboratory setup, operation, and sampling. They will be responsible for ensuring that records or documentation are kept in project notebooks and/or on project data sheets. They will be responsible for ensuring that all operational and sampling procedures are followed and documented. MSE analytical laboratory personnel shall perform all laboratory analysis in accordance with MSE Analytical Laboratory procedures. Data reduction and analysis shall be completed under the direction of the MSE Project Engineer/Geologist. The MSE Project QA Officer shall conduct QC/QA activities.

\subsection{QC/QA Assessment and Reporting}

MSE will assess data quality and include results of this assessment in the project report. The project report will include results of laboratory data validation and a summary of data quality indicators. Data validation will be conducted in accordance with MSE's Quality Assurance Plan. 


\section{REFERENCES CITED}

Bechtel. 2000. Well construction and completion summary for well number 199-D4-37.

de Boer, C. 2007. Characteristics and mobility of zero-valent nano-iron in porous media: a laboratory assessment study. Environmental Hydrogeology Group, University of Utrecht, 26 September, 102 pages.

Elimelech, M. 1995. Particle Deposition and Aggregation: Measurement, Modeling, and Simulation, Butterworth-Heinemann, Woburn, MA, 441 pages.

Evans, Bruce. 2008. Personal communication. Chief Operator, Butte Wastewater Treatment Plant, Butte, MT.

Fruchter, et al. 2000. Creation of a subsurface permeable treatment zone for aqueous chromate contamination using in situ redox manipulation. Ground Water Monitoring \& Remediation, Spring, pages 66-77.

$\mathrm{Li}$, et al. 2006. Zero-valent iron nanoparticles for abatement of environmental pollutants: materials and engineering aspects. Critical Reviews in Solid State and Materials Sciences, Vol. 31 , pages 111-122.

Lowery, G., et al. 2005. Nanoiron in the subsurface: how far will it go and how does it change? Paper presented at U.S. EPA Workshop on Nanotechnology for Site Remediation, U.S. Department of Commerce, Washington, DC, 21 October.

MSE. 2008. Test Plan for ZVI Distribution in Soil Injected with ZVI/dispersant/Water. MSE, February.

Oglebay Norton Industrial Sands, Inc. 1996. Physical and chemical data sheet. Chemical data from August 1996 study. Colorado Springs, CO, 1 page.

Oglebay Norton Industrial Sands, Inc. 2007. Particle size distribution sheets for $12 \times 20$ and $30 \times 70$ sands dated 17 October. Colorado Springs, CO, 2 page.

Oostrom, M., et al. 2005. Experimental study of micron-size zero-valent iron emplacement in permeable porous media using polymer-enhanced fluids. Report PNNL-15573, Pacific Northwest National Laboratory, Richland, WA.

Saleh, N., et al. 2007. Surface modifications enhance nanoiron transport and NAPL targeting in saturated porous media. Environmental Engineering Science, Vol. 24, No. 1, pages 45-57.

Schrick, B., et al. 2004. Delivery vehicles for zerovalent metal nanoparticles in soil and groundwater. Chem. Mater., Vol. 16, ,pages 2187-2193. 
Stevenson, D.G. 1997. Water Treatment Unit Processes, Imperial College Press, London, 474 pages.

Toda. 2008. Material safety data sheet for RNIP-M2. Schaumberg, IL, 3 pages. 


\section{ZERO-VALENT IRON (ZVI) TANK SCALE INJECTION}

Prepared by:

MSE Technology Applications, Inc.

200 Technology Way

P.O. Box 4078

Butte, Montana 59702

Revision 00

July 23,2008 
DOE/RL-2009-35, REV.0

Revision 00

This Page Intentionally Left Blank 
MSE Review and Approval Signatures

MSE Technology Applications, Inc.

Prepared By: Gilbert M. Zemansky, Sr. Hydrologist

Date

Reviewed By: Marek Zaluski, Staff Hydrogeologist

Date

Reviewed By: Steve Antonioli, Project Manager

Date

Approved By: Andrea Hart, DOE Manager

Date

Approved By: Jeff LeFever, DOE Program Manager

Date 
DOE/RL-2009-35, REV.0

Revision 00

This Page Intentionally Left Blank

MSE Technology Applications, Inc. 


\section{TABLE OF CONTENTS}

EXECUTIVE SUMMARY .................................................................................. 7

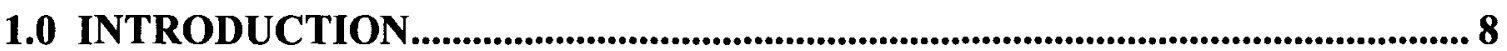

2.0 LABORATORY TESTING AND ANALYSIS PROCECURES....................... 9

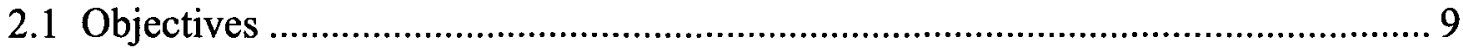

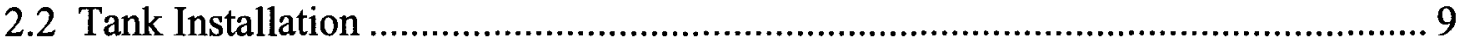

2.3 Pre-Injection Preparation and Testing ........................................................ 13

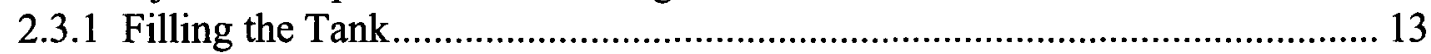

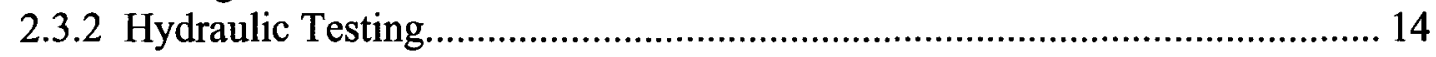

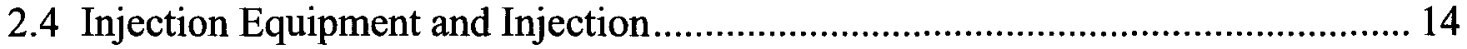

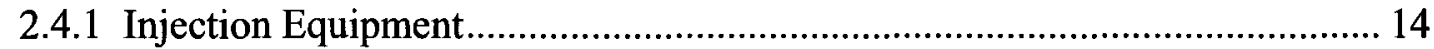

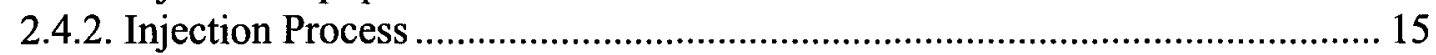

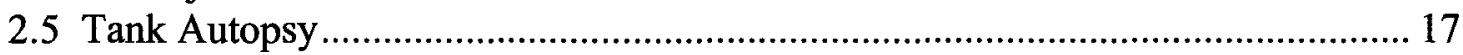

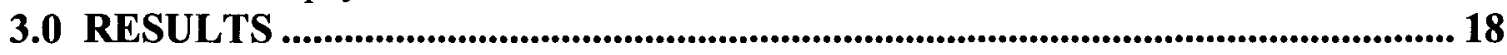

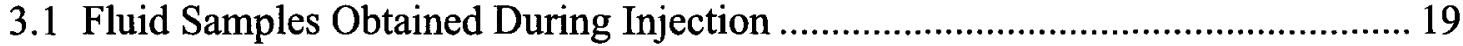

3.2 Iron Deposition Results..................................................................... 20

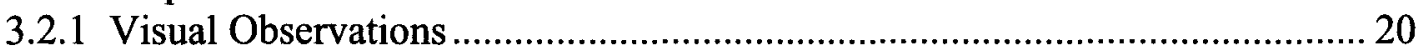

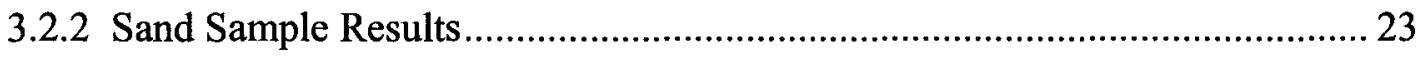

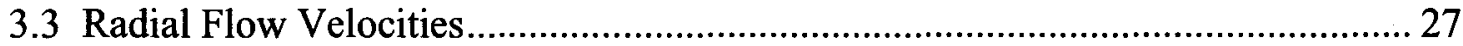

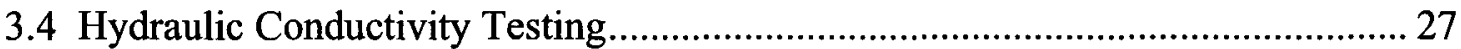

4.0 ANALYTICAL QUALITY ASSURANCE................................................... 28

5.0 CONCLUSIONS $\quad 29$

References Cited......................................................................... 30

\section{List of Tables}

Table 1: Final Top of Tank Configuration and Water Levels ....................................... 12

Table 2: Hanford and Butte Ground Water (GW) Quality ......................................... 13

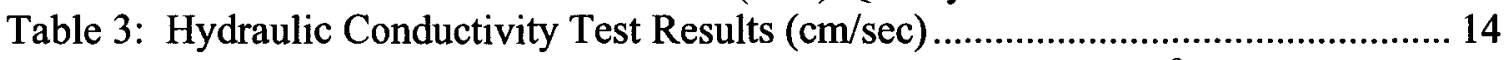

Table 4: Mean Temeratures During Hydraulic Conductivity Testing $\left({ }^{\circ} \mathrm{C}\right) \ldots \ldots \ldots \ldots \ldots 12$

\section{List of Figures}

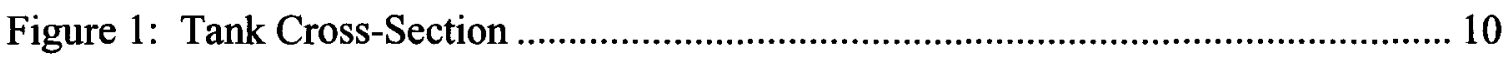

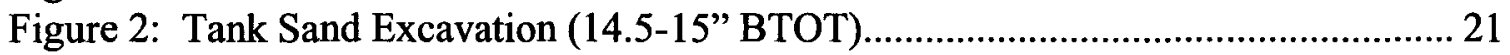

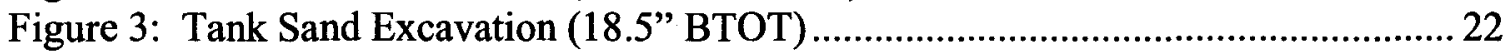

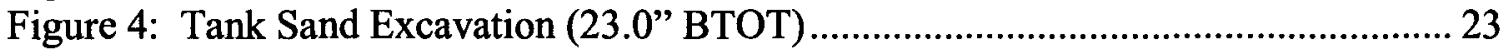

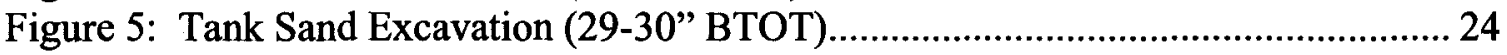

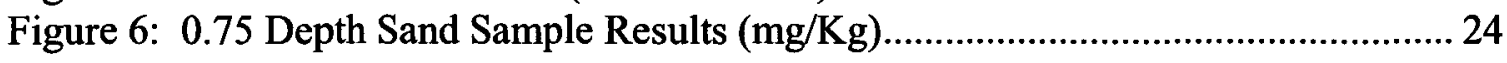

MSE Technology Applications, Inc. 


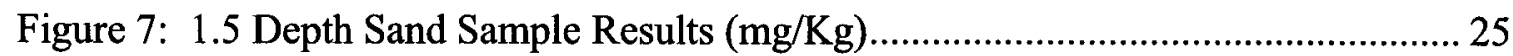

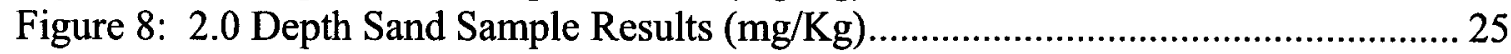

Figure 9: 2.5 Depth Sand Sample Results (mg/Kg) ................................................ 26

\section{List of Appendices}

A: $\quad$ Hydraulic Test Aqtesolv Plots

B: Injection Test Measurements Data

Table 1 - Field Water Quality Measurements

Table 2 - Injection Related Data

Table 3 - Water Level Data

C: $\quad$ Laboratory Analytical Reports

Table 1 - Tank Injection Test Fluid Samples (23 Apr 08)

Table 2 - Tank Sand Sample Results

Analytical Data and Quality Assurance Review 


\section{EXECUTIVE SUMMARY}

MSE has conducted research focused on demonstrating the feasibility of using zerovalent iron (ZVI) to repair portions of the In Situ Redox Manipulation (ISRM) barrier located in the 100-D area of the U.S. Department of Energy Hanford Site in Washington. This barrier was installed to intercept and reduce hexavalent chromium in order to prevent its entering the Columbia River. Laboratory batch and column tests were initially performed. Based on these tests, the nano size ZVI formulation RNIP-M2 was selected for tank scale testing as an intermediate step prior to a full scale field injection.

A tank scale injection of nano size ZVI was conducted in April 2008. A cylindrical tank 5 feet in diameter and 5 feet high with an artificial aquifer and injection well were utilized. The artificial aquifer consisted of a 1 foot thick layer of very coarse sand sandwiched between an underlying 3 foot layer and an overlying 1 foot layer of medium sand. The injection well was a 6 inch nominal diameter stainless steel well with a continuous wound screen having a slot size of 0.020 inches, similar to those actually installed at the Hanford site. Shallow and deep monitoring wells were installed in the very coarse and medium sand, respectively, for hydraulic testing and water quality sampling.

An injection of 300 gallons of $1 \%$ solids solution $(9,030 \mathrm{mg} / \mathrm{L}$ total iron) of RNIP-M2 was performed at a flow rate of approximately $3 \mathrm{gpm}$. This was calculated to achieve five pore volumes of flow through the very coarse sand layer. During the injection, water samples were obtained from both the monitoring wells and tank effluent lines. After the injection, the tank was drained down and samples of sand were taken. Water and sand samples were analyzed for total iron.

Visual observations indicated ZVI deposition in the very coarse sand with the highest total iron concentrations found in a black colored ring located between the roughly 1 to 2 feet in radius from the center of the tank. Quantitative results from sand samples were consistent with visual observations indicating peak total iron concentrations on the order of $2,000 \mathrm{mg} / \mathrm{Kg}$, in comparison to background concentrations of total iron in the very coarse sand of several hundred $\mathrm{mg} / \mathrm{Kg}$. Hydraulic testing before and after the injection indicated a marginal reduction in hydraulic conductivity for the very coarse sand and the tank as a whole, but not for the medium sand farthest from the injection well. 


\title{
Zero-Valent Iron Tank Scale Injection
}

\author{
23 July 2008
}

\subsection{INTRODUCTION}

MSE Technology Applications, Inc. (MSE), was tasked by the U.S. Department of Energy's (DOE) Office of Environmental Managament (EM) with conducting a tank scale laboratory injection of zero-valent iron (ZVI). This work constitutes intermediate scale research between the laboratory batch and column or flow cell testing performed by MSE under contract to Fluor Hanford in 2007 and 2008 and a proposed field injection at the Hanford Site. All of this research has been focused on demonstrating the feasibility of using nano size ZVI to repair portions of the In Situ Redox Manipulation (ISRM) barrier located in the 100-D area of the Hanford Site.

The ISRM barrier was installed to remediate a chromium groundwater plume in Hanford's 100-D Area by reduction of the $\mathrm{Cr}^{+6}$ in the groundwater to $\mathrm{Cr}^{+3}$ through the injection of sodium dithionite into the aquifer, thus creating a chemically reduced environment (Fruchter, et al., 2000 and Oostrom, et al., 2007). Localized signs of failure of the barrier defined by the presence of $\mathrm{Cr}^{6+}$ in some wells were discovered 18 months after they were treated. The most probable cause of the premature barrier breakdown was determined to be heterogeneities in the aquifer where laterally discontinuous units with high permeability and lower inherent reductive capacity (because of lower iron content) were reoxidized faster than the less permeable layers. A Technical Assistance Panel (TAP) recommended that an alternative technology (injection of MZVI/polymer) be tested and possibly deployed to mend the barrier to eliminate the need of periodically reinjecting the ISRM wells with sodium dithionite.

The TAP recommended that the reduction potential of co-contaminants and generation of byproducts be considered and monitored. The TAP recommended considering all potential geochemical impacts to the aquifer system from $\mathrm{MZVI} /$ polymer injection, specifically the potential for the MZVI to convert nitrate to ammonia and the formation of carbonate due to the generation of high $\mathrm{pH}$ conditions in the groundwater. Following recommendations from the TAP, Fluor Hanford issued a request for proposal (RFP) to provide the laboratory testing, numerical modeling, and associated fieldwork for the $\mathrm{MZVI} /$ polymer injection. MSE was awarded this work for the investigation of MZVI as a remedy for repairing the ISRM. In May 2007, Fluor Hanford modified the scope of work to stop laboratory testing on the preferred micron size material and to investigate other zero valent iron (ZVI) materials which should be considered as candidates for injection into the ISRM barrier.

MSE first conducted batch scale testing of ZVI formulations and subsequently performed column or flow cell tests of two specific nano size ZVI formulations (Polymetallix and 
RNIP-M2). As a result of this work, MSE recommended the use of RNIP-M2 for the field injection. RNIP-M2 is a formulation of nano size iron in a polymer carrier that facilitates transport in porous media. As an intermediate step between the laboratory flow cell testing and field injection, MSE performed this laboratory tank scale injection. The tank scale injection was intended to refine the actual injection procedures that would be used in the field. This document constitutes a report of the tank scale injection test.

\subsection{LABORATORY TESTING AND ANALYSIS PROCECURES}

\subsection{Objectives}

Laboratory testing and data analysis were completed at the MSE facility in Butte, Montana. This facility maintains fully functional experimental and analytical laboratories. The purpose of the laboratory testing was to conduct a ZVI injection in a controlled environment in which fluid samples could be obtained during the injection and the sand could be excavated after the injection to verify the extent and distribution of ZVI from the injection. In contrast with the linear flow situation of flow cell testing that preceded the tank scale injection, flow for the tank test was radially outward from a centrol injection well. Tank scale testing, by simulating an field injection as closely as possible, also provided for the testing and refinement of injection techniques prior to scaling up for actual field injection.

\subsection{Tank Installation}

Complete details regarding the laboratory work as proposed are contained in the March 2008 test plan (MSE, 2008). Key aspects of that plan and modifications to it as performed are presented in this section of the report. The tank scale injection test took place within a 5 foot diameter cylindrical steel tank 5 feet in height. The tank was constructed from 0.25 " carbon steel plate, giving it outer and inner diameters (OD and ID), respectively, of 60 inches and 59.5 inches. A schematic drawing of this tank is shown in Figure 1 below. The tank was raised 16" off the floor of the building using 8" square wood cribbing stacked two high. This provided sufficient room for the pneumatic vibrator installated on the bottom center of the tank (see further discussion of this vibrator below).

The sides of the tank were lined with a synthetic drain sheet approximately another 0.25 " think. Because this material was only available in 4 foot wide rolls, the lining was installed with an overlapping section. This served as an essentially constant head drainage boundary for injection water reaching the inner walls of the tank. Four fittings, each with a shutoff valve and a secondary connection for sampling purposes, were installed on $90^{\circ}$ radials around the bottom periphery of the tank. These were connected via flexible clear tubing first to a floor drain while testing and flushing the tank and later during the injection test to holding containers for storage of spent ZVI fluid drained from 
the tank after injection. Having four discharge locations ensured that there would besufficient capacity for the largest likely injection flow rates. It was also intended that effluent sampling lines in each tank quadrant would make it possible to evaluate symmetry of flow issues.

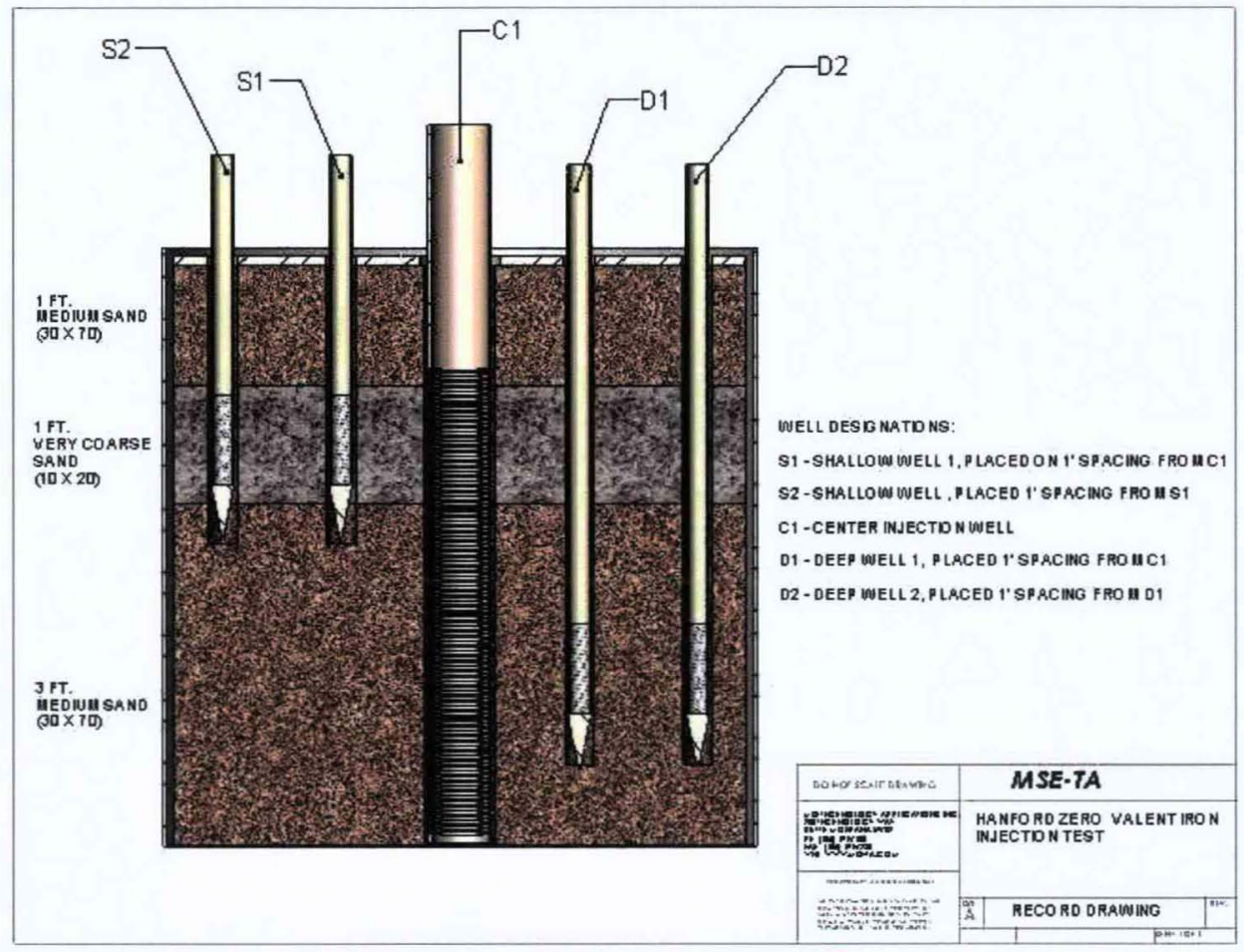

Figure 1: Tank Cross-Section

The full internal volume of the tank (not counting the drain sheet) was about 96.5 feet $^{3}$. Most of this volume was filled with two size ranges of clean silica sand (very coarse and medium) in three layers to form an artificial aquifer. Relevent data on this sand provided by the manufacturer is as follows (Oglebay Norton Industrial Sands, Inc., 1996 and 2007):

Very Coarse (10X20 mesh size) - This sand typically is $95 \%$ silica and contains about $0.1 \% \mathrm{Fe}_{2} \mathrm{O}_{3}$. Median grain size is $1.43 \mathrm{~mm}$ with a uniformity coefficient of 1.36 (very uniform).

Medium (30X70 mesh size) - Data specific to this mesh size sand is unavailable. However, data for the closest size sand indicates that in comparison to 10X20 sand the silica fraction may be marginally smaller (in the 84 to $92 \%$ range) and that $\mathrm{Fe}_{2} \mathrm{O}_{3}$ content may be larger (in the 0.26 to $0.57 \%$ range). Median grain size is $0.32 \mathrm{~mm}$ with a uniformity coefficient of 1.69 (very uniform). 
Three samples of each type sand were submitted to MSE's analytical laboratory for baseline total iron analysis.

The sand was loaded into the tank from the bottom up. As shown in Figure 1, the bottom layer consisted of 3 feet of medium (30X70) sand. This sand was loaded in 6 inch lifts, saturated with fresh water, and compacted using a pneumatic piston vibrator (a Cougar Industries, Inc. Model No. LI-16 operated with low pressure air) mounted on a piece of channel iron welded to the center bottom of the tank. A 1 foot layer of very coarse (10X20) sand was placed on top of this. It was also loaded in 6 inch lifts and compacted using the pneumatic piston vibrator. A final 1 foot layer of medium (30X70) sand was placed on top of the very coarse sand. To minimize penetration of this sand into the underlying very coarse sand, it was manually packed without using the pneumatic piston vibrator. It is expected that compaction was sufficient to achieve on the order of 0.35 porosity (about the porosity achieved during packing of flow cells used in earlier ZVI laboratory experiments conducted by MSE).

A 6 inch nominal diameter Schedule 10 grade 304 stainless steel Johnson screen (ID of 6.357 ', OD of 6.625", and wall thickness of 0.134 ") with a nominal length of 4 feet of 0.020 " slot size well screen (actual slotted length of 49.875 ") with a 3 feet long section of blank casing welded on top of it (total length of 7 feet and 3.375 " screen and casing) was installed in the center of the tank to simulated a typical Hanford Site well that could be used for injection in the field [e.g., well number 199-D4-37 (Bechtel, 2000)]. The bottom of the well was covered by a plate welded to it. Guides were welded to the bottom of the tank to center the well and a section of 12 " nominal diameter polyvinyl chloride (PVC) pipe was used as an artificial borehole. It was positioned around the well prior to installation of sand layers. With the well centered within it as would be the case if it was being installed within a 12" diameter borehole, it allowed for installation of a sand filter pack within the annular space between the inside of the PVC pipe and the outside of the well screen and casing. The annual space between the PVC pipe and well screen was packed with very coarse sand (10X20) and the PVC gradually extracted as sand layers were loaded.

At one point during this process it was noted that vibration had caused the well screen to rise approximately 3.25 " above the bottom of the tank. Taking into account that the first slot of the screen was about 1.7" above the bottom of the screen, that the bottom of the screen was installed 3.25" above the bottom of the tank, and that the slotted portion of the screen was actually about 48.175 inches long, the top of the slotted portion of the screen was about 52.9 inches above the bottom of the tank. Due to space limitations, the top of the sand filter pack was installed 3" above the top of the screen. This allowed for a final sealing of the annular space with about 3.75 " of hydrated granular bentonite.

The top of the tank was covered with a 1" thick steel plate marginally smaller than the ID of the tank. There were 5 holes cut in the top plate to allow for well penetrations. These were all along one diameter of the tank. The largest penetration was in the center of the lid for the injection well. The annular space between the OD of the injection well casing and edge of the hole was sealed with bentonite. 
The other four penetrations allowed for installation of 2" nominal diameter stainless steel drive point wells. These were obtained from the Dean Bennett Supply Company in Denver, Colorado. Each drive point well had a central 9" long screen section build around 2" nominal diameter (OD of 2.375" and ID of 2.0625") ductile iron pipe with six columns of 0.5 " diameter drilled in it. This pipe was covered with a stainless steel 60 gauze wrap (equivalent to 0.010 " slot size) which was in turn covered by an outer stainless steel jacket with 0.125 " staggered perforations. The drive head on the bottom of the screen was a tapered octagonal cast iron point about 7.625 " long having a diameter at the bottom of the screen of 2.8125". At the top of the screen there was a 2.0625 ' long internally threaded collar for attachment of blank pipe casing.

Two of the drive points were installed with the screen covering the central portion of the very coarse sand layer. These had 2 feet of blank pipe casing over the screen so that the top of casing was approximately 1 foot above the top of the tank and were referred to as shallow monitoring wells. The center of the monitoring well closest to the injection well was located 1 foot from the center of the tank (i.e., about 7.5" between from the outside of the injection well to the outside of the) and was designated S1. The center of the monitoring well closest to the tank wall was located 2 feet from the center of the tank (i.e., 1 foot radially outward from S1) and was designated S2. The other two drive points were installed with the screen covering the central portion of the lower 3 foot thick medium sand layer. These had four feet of blank pipe casing over the screen so that, again, the top of casing was approximately 1 foot above the top of the tank and were referred to as deep monitoring wells. They were spaced radially outward from the center of the tank in an identical manner as the shallow wells and were similarly designated D1 and D2. A cast iron cap was screwed onto the top of each well at the time of installation for driving them into place. They were then manually driven through the holes in the tank lid using a sludge hammer. The annular space between the OD of the monitoring well casings and the edge of the hole through the lid was filled with silicon sealer.

The final configuration of the top of well casings (TOC) above the tank lid is indicated in Table 1.

Table 1: Final Top of Tank Configuration and Water Levels

\begin{tabular}{|l|c|c|c|}
\hline \multirow{2}{*}{ Well ID } & Top Casing & \multicolumn{2}{|c|}{ Water Level (feet BTOC) } \\
\cline { 3 - 4 } & Feet ATL $^{1}$ & Static & Testing \\
\hline Injection Well & 2.469 & 2.735 & NM \\
\hline S1 & 1.094 & 1.35 & 2.20 \\
\hline S2 & 1.089 & 1.345 & 2.19 \\
\hline D1 & 1.094 & 1.35 & 2.22 \\
\hline D2 & 0.9427 & 1.245 & 2.12 \\
\hline
\end{tabular}

\footnotetext{
1 "ATL" means above top of tank lid. "BTOC" means below top of well casing. "NM" means not measured.
} 


\subsection{Pre-Injection Preparation and Testing}

\subsubsection{Filling the Tank}

After the installation of sand and wells in the tank, the tank was filled with fresh water. The laboratory obtains its water from the Butte public water supply (PWS), which in the vicinity of MSE's facility is obtained from local ground water. The quality of this water in comparison with Hanford ground water quality is indicated in Table 1.

Table 2: Hanford and Butte Ground Water (GW) Quality

\begin{tabular}{|c|c|c|c|c|c|}
\hline \multirow{2}{*}{ WQ Variable } & \multicolumn{2}{|c|}{ Hanford GW } & \multirow[b]{2}{*}{ Butte PWS } & \multirow{2}{*}{$\begin{array}{c}\text { Pre-Injection } \\
\text { Sample }\end{array}$} & \multirow[b]{2}{*}{ Units } \\
\hline & 100D Area & 200W Area & & & \\
\hline \multicolumn{6}{|l|}{ General: } \\
\hline Conductivity & 675.13 & NA & NA & 175. & $\mathrm{uS} / \mathrm{cm}$ \\
\hline DO & 9.59 & NA & NA & 5. & $\mathrm{mg} / \mathrm{L}$ \\
\hline ORP & 156.63 & NA & NA & 214.4 & $\mathrm{mV}$ \\
\hline $\mathrm{PH}$ & 7.8 & 7.95 & 7.3 & 6.97 & units \\
\hline TDS & NA & NA & 107. & NA & $\mathrm{mg} / \mathrm{L}$ \\
\hline \multicolumn{6}{|l|}{ Major lons: } \\
\hline \multicolumn{6}{|l|}{ Cations } \\
\hline \begin{tabular}{|l|l|} 
& Calcium \\
\end{tabular} & 90. & 32.7 & $\sim 43$ & 17.1 & $\mathrm{mg} / \mathrm{L}$ \\
\hline Magnesium & 20.77 & 12.6 & 6.6 & 6.72 & $\mathrm{mg} / \mathrm{L}$ \\
\hline Manganese & NA & 0.01 & $0.03-0.3$ & NA & $\mathrm{mg} / \mathrm{L}$ \\
\hline Potassium & 4.82 & 4.26 & 2.5 & 2.36 & $\mathrm{mg} / \mathrm{L}$ \\
\hline Sodium & 9.89 & 10.7 & $3.5-4.5$ & 4.14 & $\mathrm{mg} / \mathrm{L}$ \\
\hline \multicolumn{6}{|l|}{ Anions } \\
\hline \begin{tabular}{l|l} 
& Alkalinity \\
\end{tabular} & 97.13 & 120.8 & 60. & 51.26 & $\mathrm{mg} / \mathrm{L}$ \\
\hline Chloride & 33.96 & NA & $3.6-4.4$ & 3.98 & $\mathrm{mg} / \mathrm{L}$ \\
\hline \begin{tabular}{|l|} 
Fluoride \\
\end{tabular} & NA & 0.8 & $<0.1$ & NA & $\mathrm{mg} / \mathrm{L}$ \\
\hline \begin{tabular}{|l|} 
Nitrate \\
\end{tabular} & 23.6 & NA & NA & 0.05 & $\mathrm{mg} / \mathrm{L}$ \\
\hline Sulfate & 135.35 & 4.21 & NA & 21.7 & $\mathrm{mg} / \mathrm{L}$ \\
\hline \multicolumn{6}{|l|}{ Other: } \\
\hline Aluminum & 38.96 & 150. & NA & NA & $\mathrm{ug} / \mathrm{L}$ \\
\hline Chromium & 100. & NA & NA & NA & $\mathrm{ug} / \mathrm{L}$ \\
\hline Iron (total) & 136.53 & 108. & $50-150$ & 800. & $\mathrm{ug} / \mathrm{L}$ \\
\hline Phosphate & 0.33 & 0.04 & NA & NA & $\mathrm{mg} / \mathrm{L}$ \\
\hline
\end{tabular}

After it was filled, the tank was flushed with fresh water through the injection well. Flushing occurred over a period of days and exceeded the three pore volumes planned. Water discharged during flushing was directed to building floor drains. Additionally, during this time procedures were refined for hydraulic control to balance water being injected into the tank and water exiting the tank. 


\subsubsection{Hydraulic Testing}

Multiple falling water level (i.e., slug out) tests were conducted in the injection well and all four monitoring wells using pneumatic techniques. The data were recorded electronically using a transducer and data logger system with a collection frequency of 10 data points/second. Data were analyzed using Version 4.0 of the computer program Aqtesolv and the Bouwer and Rice solution. Aquifer saturated thickness was assumed equal to well screen length. This is consistent with the likelihood that, despite partial penetration, flow is essentially horizontal. Aqtesolv plots are presented in Appendix A. Hydraulic conductivity results are summarized in Table 3. Mean temperatures during this testing are shown in Table 4.

Table 3: Hydraulic Conductivity Test Results $(\mathrm{cm} / \mathrm{sec})$

\begin{tabular}{|l|c|c|c|c|c|c|c|c|c|c|}
\hline & \multicolumn{5}{|c|}{ Well: Pre-Injection } & \multicolumn{5}{c|}{ Well: Post-Injection } \\
\cline { 2 - 11 } Test & S1 & S2 & D1 & D2 & Injection & S1 & S2 & D1 & D2 & Injection \\
\hline$\# 1$ & 0.52 & 0.51 & 0.031 & 0.021 & 0.068 & 0.41 & 0.42 & 0.025 & 0.021 & 0.054 \\
\hline$\# 2$ & 0.53 & 0.50 & 0.031 & 0.018 & 0.074 & 0.41 & 0.43 & 0.026 & 0.021 & 0.056 \\
\hline$\# 3$ & - & - & - & - & 0.083 & - & - & - & - & 0.055 \\
\hline$\# 4$ & - & - & - & - & 0.072 & - & - & - & - & 0.054 \\
\hline$\# 5$ & - & - & - & - & 0.074 & - & - & - & - & - \\
\hline M6 & - & - & - & - & 0.074 & - & - & - & - & - \\
\hline Mean & 0.52 & 0.50 & 0.031 & 0.020 & 0.074 & 0.41 & 0.43 & 0.026 & 0.021 & 0.055 \\
\hline
\end{tabular}

Table 4: Mean Temperatures During Hydraulic Conductivity Testing ( ${ }^{\circ} \mathrm{C}$ )

\begin{tabular}{|l|c|c|c|c|c|c|c|c|c|c|}
\hline \multirow{3}{*}{ Test } & \multicolumn{4}{|c|}{ Well: Pre-Injection } & \multicolumn{5}{c|}{ Well: Post-Injection } \\
\cline { 2 - 11 } & S1 & S2 & D1 & D2 & Injection & S1 & S2 & D1 & D2 & Injection \\
\hline$\# 1$ & 19.9 & 20.0 & 18.9 & 19.7 & 18.9 & 22.1 & 21.2 & 17.6 & 19.2 & 18.5 \\
\hline$\# 2$ & 20.0 & 20.1 & 19.1 & 19.8 & 18.8 & 22.2 & 21.2 & 17.8 & 19.6 & 18.7 \\
\hline$\# 3$ & & - & - & - & 18.8 & - & - & - & - & 18.6 \\
\hline$\# 4$ & & - & - & - & 18.8 & - & - & - & - & 18.6 \\
\hline$\# 5$ & & - & - & - & 18.7 & - & - & - & - & - \\
\hline$\# 6$ & & - & - & - & 18.7 & - & - & - & - & - \\
\hline Mean & 20.0 & 20.1 & 19.0 & 19.8 & 18.8 & 22.2 & 21.2 & 17.7 & 19.4 & 18.6 \\
\hline
\end{tabular}

Pre-injection results are roughly consistent with the types of sand involved.

\subsection{Injection Equipment and Injection}

\subsubsection{Injection Equipment}

The same equipment used for flow cell testing conducted by MSE for Fluor Hanford in March and April 2008 was used for this tank-scale injection. This consisted of a 320 gallon nominal capacity cylindrical plastic tank (approximately 3.5 feet in diameter and 4 feet long) in which the RNIP-M2 ZVI fluid was mixed with fresh water. The same concentration used for flow cell testing was used for the tank-scale injection (i.e., $1 \%$ solids equivalent to $9,030 \mathrm{mg} / \mathrm{L}$ total iron). A batch of approximately 300 gallons of ZVI 
fluid was prepared for this injection. It was estimated that this volume of ZVI fluid would be sufficient to inject for a period of 100 minutes at a rate of approximately $3 \mathrm{gpm}$. This period would correspond to about five pore volumes of flow through the high $\mathrm{K}$ very coarse $10 \times 20$ sand. This calculation was based on a $\mathrm{K}$ contrast for the very coarse and medium sand of $20: 1$, a porosity of 0.35 , and a retardation factor of 5 (de Boer, 2007).

There were seven penetrations to the mixing tank. Two were suction penetrations near the bottom of the tank. One of these was for a line to a pump that was used to recirculate ZVI fluid back into the tank helping to keep it well mixed (with the penetration back into the tank at a higher level on the side of the tank). The other suction line was to the inlet or an IKA Process Plant 2000/4 machine (known as a "disperger"). This machine is a single-stage device using three ultra high shear rotor-stator combinations to produce high shearing energies intended to maintain the small nano size of the ZVI fluid dispersion (IKA, 2008). The disperger also discharged back to the tank at a higher level on the other side from the recirculation line. Two of the remaining penetrations were for injecting nitrogen gas into the top of the tank to maintain a nitrogen atmosphere over the ZVI fluid and monitoring the oxygen concentration in that atmosphere to ensure sufficient nitrogen was being injected. The seventh penetration was a line to the suction side of the pump used to inject ZVI fluid through the central well into the tank. The pipe from this pump to the tank was 1-1/4" nominal diameter (1.38" ID) galvanized pipe. There were cutoff values, a sampling line, a digital flow meter and totalizer, and a pressure gage in this line.

A transducer was also installed at depth in the injection well to monitor effective water levels in the injection well during the test.

\subsubsection{Injection Process}

\subsubsection{Baseline Tank Sampling}

Baseline tank water samples were obtained prior to the injection. These included all four monitoring wells and the four tank effluent penetrations. Field measurements of conductivity, dissolved oxygen (DO), oxidation-reduction potential (ORP), $\mathrm{pH}$, and temperature were taken for the monitoring well samples and one of the effluent samples (E2) using a YSI multiparameter probe. Results from field measurements are presented in Appendix B Table 1.

Samples from the four monitoring wells were obtained after purging three well volumes. Purging and sampling was performed using a dedicated peristaltic pump. Tank effluent lines were purged and sampled under static pressure. Samples were placed in $250 \mathrm{~mL}$ polyethylene containers and preserved by the addition of $1 \mathrm{~mL}$ of concentrated hydrochloric acid $(\mathrm{HCl})$ immediately after sampling. After addition of $1 \mathrm{~mL}$ HCL they were stored in a refrigerator in the laboratory where the tank test was taking place. At the completion of the tank test, all samples were delivered to the MSE laboratory. Standard chain-of-custody procedures were followed. An additional $24 \mathrm{~mL}$ of $\mathrm{HCl}$ was added to 
the sample after delivery to MSE's laboratory. Samples were analyzed by the MSE laboratory for total iron using a modified digestion process and U.S. Environmental Protection Agency (USEPA) method 6010.

\subsubsection{Injection}

The injection commenced at 1350 on 23 April 2008. Flow was maintained at a rate of approximately $3.1 \mathrm{gpm}$ until shortly before the end of the test. The average for both instanteous flow and totalizer readings for elapsed times from 3 to 90 minutes is $3.1 \mathrm{gpm}$. It appears from the instantaneous reading at elapsed time 96.5 minutes that flow was starting to decline as the level of ZVI fluid in the mixing tank neared bottom. The pump lost suction in about one more minute and the test was concluded at time 97.7 minutes. All flow measurements are listed in Appendix B Table 2. Also listed in that table are oxygen measurements in the atmosphere above the ZVI fluid in the mixing tank during the test (a mean of $8 \mathrm{ppm}$ ) and other measurements related to the injection (injection pressure and the level of water in the injection well). Injection pressure (i.e., the pressure measured by a gage downstream of the flow totalizer on the discharge side of the injection pump) was a mean of $1.8 \mathrm{psi}$. This would be equivalent to the amount of head to overcome in order to pump injected fluid up to the tank and does not indicate any buildup of backpressure from the injection. Similarly, the water level in the injection well varied from 3.90 to 4.31 feet above the transducer in the well. This variation appears to have been above and below the static water level on the order of 4.01 feet before the injection commenced. It is apparent at a flow rate of $3.1 \mathrm{gpm}$ the injection was flowing readily from the injection well into and through the sand without buildup of any substantial backpressure.

The quality of water in the monitoring wells was sequentially observed for indications of ZVI fluid starting with the closest well (S1) in very coarse sand and then moving to $S 2$, D1, and D2. This was in fact the order of impact observed. Indications of ZVI fluid impact included visual observations of turbidity and color and measurements of field variables. When these observations indicated that ZVI fluids were impacting the quality of water in the well, sampling of the well commenced on a frequency of every 15 minutes. Such indications were observed in the case of well S1 in about 9 minutes after the injection commenced. Therefore, a sample was taken at the elapsed time of 10 minutes into the test (clock time of 1400) and every 15 minutes thereafter until flow stopped. Shortly afterwards, ZVI fluid impact was noted in well S2 and then in effluent. These points were added to the sampling schedule with the next sample from S1 (clock time of 1415). An indication of ZVI fluid impact was not seen for wells D1 and D2 until relatively late in the test. Well D1 was added to the sampling schedule at a clock time of 1445 (elapsed time of 55 minutes) and well D2 was added to the final sampling round at a clock time of 1530 . Water levels in the four monitoring wells were also measured shortly after the injection commenced and at 15 minutes intervals thereafter. These are listed in Appendix B Table 3. 
Samples obtained from monitoring wells during the injection were taken after purging one well volume and processed in the same manner as those taken during baseline tank sampling. Field variables were measured as time permitted but could not be measured for all monitoring wells at all sampling times. Results for field measurements are presented in Appendix B Table 1.

\subsection{Tank Autopsy}

After completion of the injection test, the tank was emptied of all fluids that could be drained by gravity from it through the effluent lines at the bottom of the tank. Sand in the tank was then carefully excavated using clean hand tools and a vacuum to obtain visual observations (recorded via digital camera) of ZVI deposition and sand samples for laboratory analysis. The test plan called for sampling sand from five radial locations along perpendicular diameters at four depth levels (i.e., a total of 20 samples for each depth and 80 samples for the tank as a whole). The radial locations were as follows:

1. Adjacent to the injection well screen (i.e., approximately 3.5 " from the center of the injection well.

2. At a distance of 1.0 foot from the center of the injection well (e.g., in the immediate vicinity of shallow monitoring well S1 or deep monitoring well D1).

3. At a distance of 1.5 feet from the center of the injection well (e.g., half way between shallow or deep monitoring wells).

4. At a distance of 2.0 feet from the center of the injection well (e.g., in the immediate vicinity of shallow monitoring well S2 or deep monitoring well D2).

5. Adjacent to the drain sheet at the tank wall.

The depths were as follows:

1. Near the bottom of the top low K $30 \times 70$ sand layer at a nominal depth of 0.75 feet below the top of the tank (BTOT).

2. In the center of the high $\mathrm{K} 10 \mathrm{X} 20$ sand layer at a nominal depth of 1.5 feet BTOT.

3. Near the top of the bottom low K $30 \times 70$ sand layer at a nominal depth of 2.5 feet BTOT.

4. In the center of the bottom low $\mathrm{K} 30 \times 70$ sand layer at a nominal depth of 3.5 feet BTOT. 
In addition, based on visual observations during excavation, a fifth depth was added. This was the lower part of the high $\mathrm{K} 10 \mathrm{X} 20$ sand layer at a nominal depth of 2.0 feet BTOT.

The procedure developed by MSE for preserving and extracting iron from these samples was as follows:

1. Samples weighing approximately 26 grams were placed in new $100 \mathrm{~mL}$ widemouth high density polyethylene (HDPE) wide mount bottles. The bottles had been weighed in advance and the tared weights recorded. Sample mass was estimated based on volume.

2. The sample was evaporated to dryness in the tared bottle at a temperature of approximately $160^{\circ} \mathrm{F}$ and then the combined weight of the sample and bottle was measured and recorded.

3. The sample was acidified with $5 \mathrm{~mL}$ of concentrated nitric acid and $25 \mathrm{~mL}$ of concentrated $\mathrm{HCl}$. The nitric acid assisted in degradation of the polymer portion of the RNIP-M2 ZVI fluid and, in part, combined with $\mathrm{HCl}$ to make aqua regia.

4. Carefully allow sample to foam and off-gas under a ventilating hood for at least 24 hours.

Samples were then delivered to the MSE laboratory for analysis using USEPA method 6010. All sample digestate volumes were $200 \mathrm{~mL}$.

Waste materials (both ZVI fluids and sand) were contained, treated, and disposed of in compliance with all applicable regulatory requirements.

\subsection{RESULTS}

Results from laboratory analysis of fluid and sand samples during the tank injection test are presented in reports from MSE's laboratory (copies provided in Appendix C) and summarized in Appendix C Tables 1 and 2, respectively). Because sand samples were digested in concentrated nitric and hydrochloric acids and the digestates provided to the laboratory for analysis, results in laboratory reports for both fluid and sand samples are in units of $\mathrm{mg} / \mathrm{L}$. For sand samples, the data used in converting $\mathrm{mg} / \mathrm{L}$ units of iron in digestate fluids is shown in Appendix C Table 2 along with results in $\mathrm{mg}$ of iron per $\mathrm{Kg}$ of combined iron and sand $(\mathrm{mg} / \mathrm{Kg})$. Results are also provided in the table for three blanks of each type of sand $(10 \times 20$ and $30 \times 70)$, information on the concentration of iron

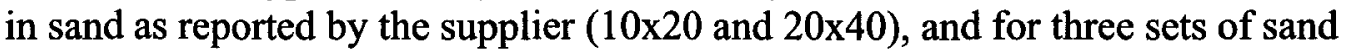
standards to which known masses of RNIP-M2 iron were added at five concentrations each. 


\subsection{Fluid Samples Obtained During Injection}

Fluid sample results are presented in Appendix C Table 1. Baseline total iron concentrations in the tank were relatively consistent varying from $0.734 \mathrm{mg} / \mathrm{L}$ to 0.850 $\mathrm{mg} / \mathrm{L}$, depending on the monitoring well or effluent line sampled, and with a mean value of $0.790 \mathrm{mg} / \mathrm{L}$. No particular pattern related to location was evident.

An increase in iron concentration in the shallow monitoring well closest to the injection well (S1) was detected within the first 10 minutes after the injection began. The result for the initial sample was $210 \mathrm{mg} / \mathrm{L}$. The concentration of iron in samples for this well increased as the injection proceeded reaching a maximum value of $738 \mathrm{mg} / \mathrm{L}$ just prior to completion of the injection. The decline in iron concentration reported in the final sample probably reflects the that collection of that sample was not completed until after the injection ceased.

An increase in iron concentration in the shallow monitoring well further away from the injection well (S2) was detected a short time later and a sample was taken 15 minutes after the first sample from monitoring well S1. The result for the initial sample was 37 $\mathrm{mg} / \mathrm{L}$. Subsequent samples varied between 37 and $49 \mathrm{mg} / \mathrm{L}$ with a mean value of 44 $\mathrm{mg} / \mathrm{L}$. There was no apparent time related trend in these results.

An increase in iron concentration in the deep monitoring well closest to the injection well (D1) was detected about 30 minutes after sampling began in S2. The result for the initial sample was $9 \mathrm{mg} / \mathrm{L}$. Subsequent sample results continually increased until the completion of the test to a level of $54 \mathrm{mg} / \mathrm{L}$.

There was no apparent increase in iron concentration in the deep monitoring well further away from the injection well (D2) until just before the end of the test. The single sample taken from this well at that time had a concentration of $23 \mathrm{mg} / \mathrm{L}$ iron.

It was apparent that iron in the effluent from the tank was increasing by the time that sampling of S2 commenced. The mean of the four samples of effluent taken at that time was $44 \mathrm{mg} / \mathrm{L}$. There was no apparent trend in effluent concentrations. Reported values varied from 40 to $72 \mathrm{mg} / \mathrm{L}$ after the initial sampling and had a mean value of $58 \mathrm{mg} / \mathrm{L}$. This level was marginally higher than the mean value of samples obtained from monitoring well S2.

The initial sample of influent being injected into the tank was taken over a half hour after the injection commenced. This sample was reported to have an iron concentration of 610 $\mathrm{mg} / \mathrm{L}$. Reported concentrations of iron in subsequent influent samples increased gradually until the last two samples. The sample taken immediately prior to completion of the test had a reported iron concentration of $1,360 \mathrm{mg} / \mathrm{L}$ (more than double the initial sample) and the final sample taken as the injection was stopping was reported to have a very high concentration of $27,000 \mathrm{mg} / \mathrm{L}$. These reported influent concentrations differ radically from the calculated mixture at $1 \%$ solids of RNIP-M2 ZVI of $9,033 \mathrm{mg} / \mathrm{L}$ total iron. As with earlier flow cell testing, the sampling connection to the injection line was a 
branch installed at a $90^{\circ}$ angle from the flowstream. As was noted with influent samples at the four flow velocities used in that experiment, reported sample concentrations declined as velocities increased. The flow velocity for the tank injection was much greater than the flow velocity for any of the flow cell runs and the reported concentration in this case was the lowest of all. It is concluded that the relatively low influent sample results for all samples prior to the final one were an artifact of the sampling and analysis process and that the actual influent concentration was close to the calculated mixture value of $9,033 \mathrm{mg} / \mathrm{L}$, but that there may have been a slight increasing trend during the test related to settlement in the mixing tank over time. With regard to the final sample, it may have represented the final dregs of fluid from the mixing tank as the injection was concluding and is not considered in any way to be representative of injected ZVI fluid for more than a very short period.

\subsection{Iron Deposition Results}

Visual observations of ZVI-caused discoloration of sand during excavation and total iron concentrations in sand samples taken after injection provide the best indication of actual iron deposition achieved in the sand matrix during the injection. In accordance with the test plan, sand samples were to be taken at depths of $0.75,1.5,2.5$, and 3.5 feet below the top of the tank (BTOT). These depths were selected to provide indications of the impact of the injection on the very coarse sand.

\subsubsection{Visual Observations}

During excavation of sand from the tank after the injection, visual observations were recorded in a $\log$ book and digital photographs taken at selected depth intervals. In accordance with the test plan, the tank was to be excavated in stages with observations recorded at the above selected depths. Any additional interesting observations encountered would also be investigated. The following observations during excavation are pertinent ${ }^{2}$ :

1. 9" BTOT - This depth was in the top 1 foot thick medium sand layer just below the bentonite seal above the injection well screen. It was selected to provide information on the impact of the injection on the bottom of the medium sand layer overlying the very coarse sand through which the ZVI injection was expected to primarily move. There was visible black discoloration of the very coarse sand filter pack around the top of the injection well screen forming a 6" radius ring around the injection well. However, medium sand beyond the filter pack to the tank wall was clean in appearance.

\footnotetext{
${ }^{2}$ Observations and samples are keyed to designated depths and radials. Radials $\mathrm{A}$ and $\mathrm{C}$ are on the diameter going through the monitoring wells with Radial A through the shallow wells and Radial $\mathrm{C}$ through the deep wells. Radials B and D are on the perpendicular diameter with Radial B in the clockwise direction from Radial A and Radial D in the clockwise direction from Radial C.
} 
2. 14.5-15" BTOT - This depth was near the top of the 1 foot thick very coarse sand layer. A color change was noted when the excavation reached the top of the very coarse sand layer. Three concentric rings were observed around the injection well (see Figure 2). The orientation of Figure 2 shows the shallow monitoring wells to the left of the central injection well (along Radial A) and the deep monitoring wells to the right (along Radial C). Close to the well screen the sand had a brownish discoloration (extending from 5 to 8.25 " in distance from the well screen). This graded into a light gray discoloration area (extending from the brownish discoloration to 11.75 to 15.25 " from the well screen). A black ring occurred beyond that (extending from the gray discoloration to 18 to 21 " from the well screen). Beyond the black ring the sand appeared clean. The extent of the black ring was about 9.5 " from the tank wall along Radial D (foreground of Figure 2) and 7.5" from the tank wall along Radial B (behind the injection well in the top center of Figure 2).

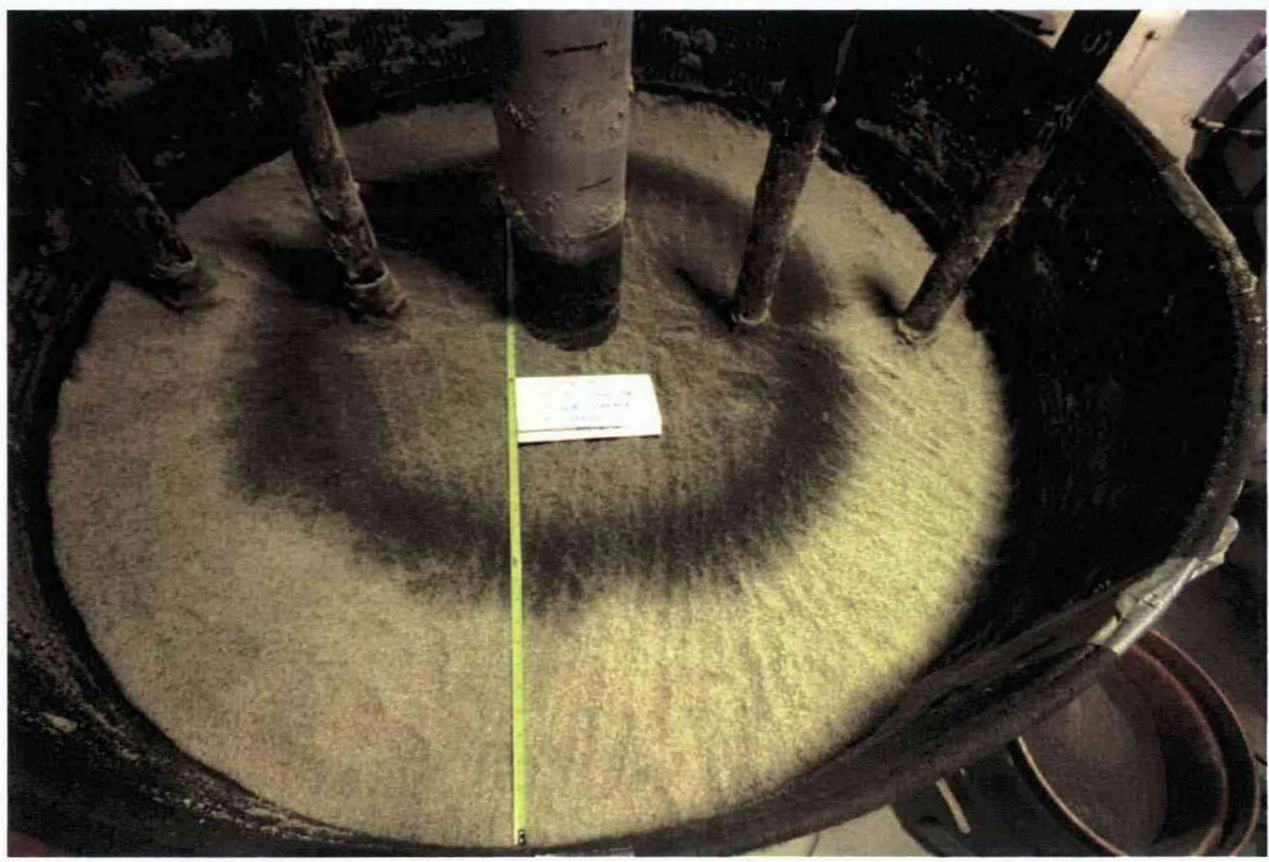

Figure 2: Tank Sand Excavation (14.5-15” BTOT)

3. 18.5" BTOT - This depth was near the center of the very coarse sand layer. The same three discoloration zones were visible (see Figure 3). However, in comparison with the 14.5 to 15 " depth, the edge of the brown discoloration extended marginally further away from the well screen ( 7.5 to 9"), the gray discoloration zone was thinner (extending to about the same distance from the well screen), and the black zone was wider (extending to 19.5 to 24.5 " from the well screen. The black discoloration zone ring is approximately centered between the monitoring wells. There is apparently clean sand between the outward edge of the black ring and the tank wall. The mid depth points of the shallow monitoring well screens are visible along Radial A to the left of the central injection well in Figure 3. 


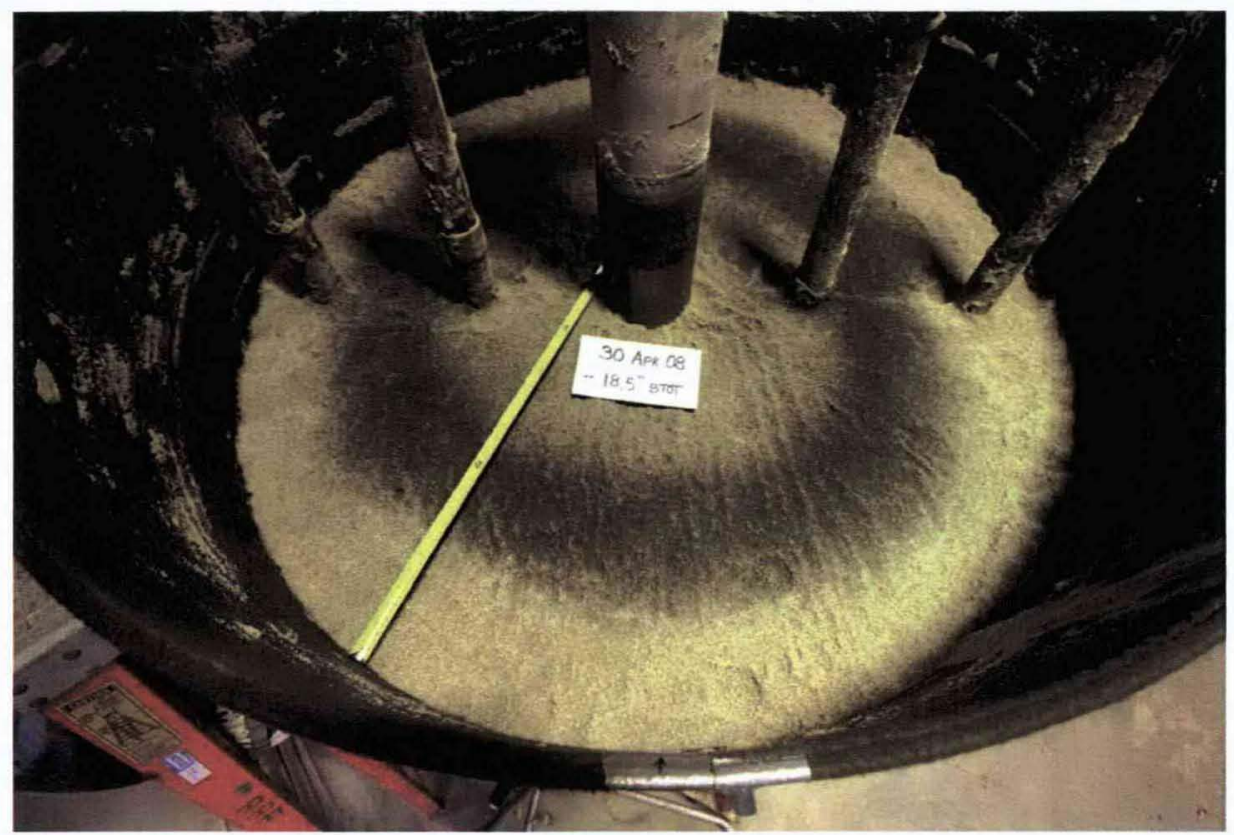

Figure 3: Tank Sand Excavation (18.5” BTOT)

4. 23.0-23.5" BTOT - This depth was near the bottom of the very coarse sand layer. The same three discoloration zones were visible (see Figure 4).

However, the brownish discoloration ring extended to about where the gray ring previously ended at the 18.5 " depth and the positions of the black and gray zones were reversed. With the exception of a "shadow" apparently caused by the deep monitoring well 2 feet from the center of the tank, the ring of gray discoloration extended to within about 0.75 " of the tank wall. The full well screens of the shallow monitoring wells are visible along Radial A to the left of the central injection well in Figure 4.

5. 29-30" BTOT - This depth was near the top of the 3 foot thick medium sand layer underlying the very coarse sand layer. The appearance of the sand at this depth was very similar to the medium sand at the 8-9" depth. The only discoloration was a black ring in the very coarse sand filter pack around the well screen (see Figure 5). This was surrounded by a concentric ring 0.5 to 0.75 " thick of almost white medium size sand. It can be seen in Figure 5 that at this depth the shallow monitoring wells are no longer present (their positions are indicated by wire rods stuck in the sand). 


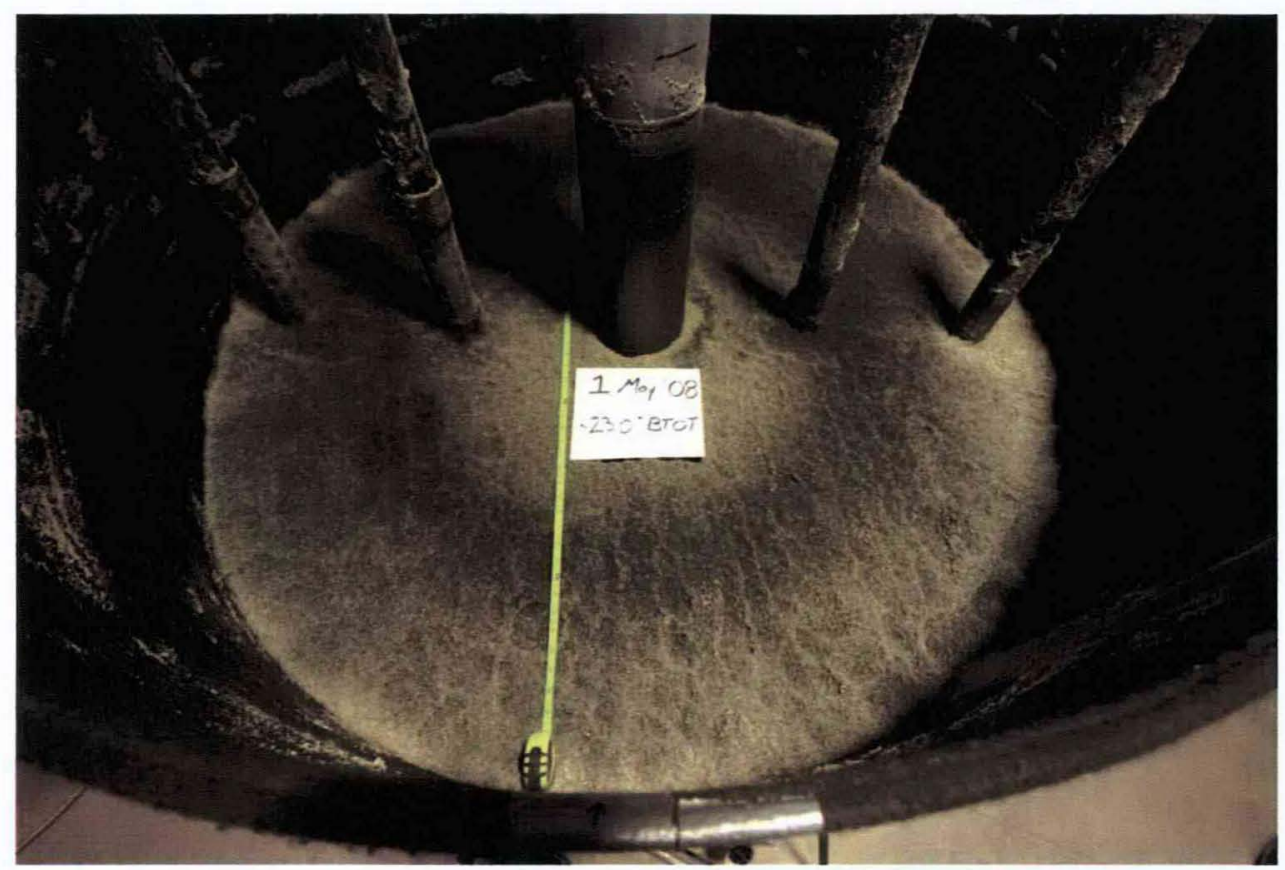

Figure 4: Tank Sand Excavation (23.0” BTOT)

6. 41-42" BTOT - This depth was near the center of the 3 foot thick medium sand layer underlying the very coarse sand layer. The appearance of the sand at this depth was very similar to the medium sand at both the 8-9" and 29-30" depths. The only discoloration was a black ring in the very coarse sand filter pack around the well screen.

\subsubsection{Sand Sample Results}

The test plan called for taking sand samples along the A, B, C, and D radials at four nominal depths $(0.75,1.5,2.5$, and 3.5 feet BTOT). A fifth nominal depth of 2.0 feet BTOT was added during excavation based on visual observations. Samples were taken adjacent to the screen, on the inside of the closest monitoring well to the screen, midway between monitoring wells, at the second monitoring well, and at the tank wall (nominal distances of $0.25,1.0,1.5,2.0$ and 2.5 feet from the center of the injection well).

Analytical results for sand samples are presented in laboratory reports (see Appendix C) and summarized in Appendix C Table 2. Results are also plotted in Figures 6, 7, 8, and 9 for the $0.75,1.5,2.0$, and 2.5 nominal depths, respectively.

Results are generally consistent with visual observations with the highest iron concentrations occurring in samples from the black sand ring. When background sand iron concentrations are taken into account, there was essentially no iron deposition found in the medium sand. As can be seen in Figure 6, iron concentrations were enriched in the 


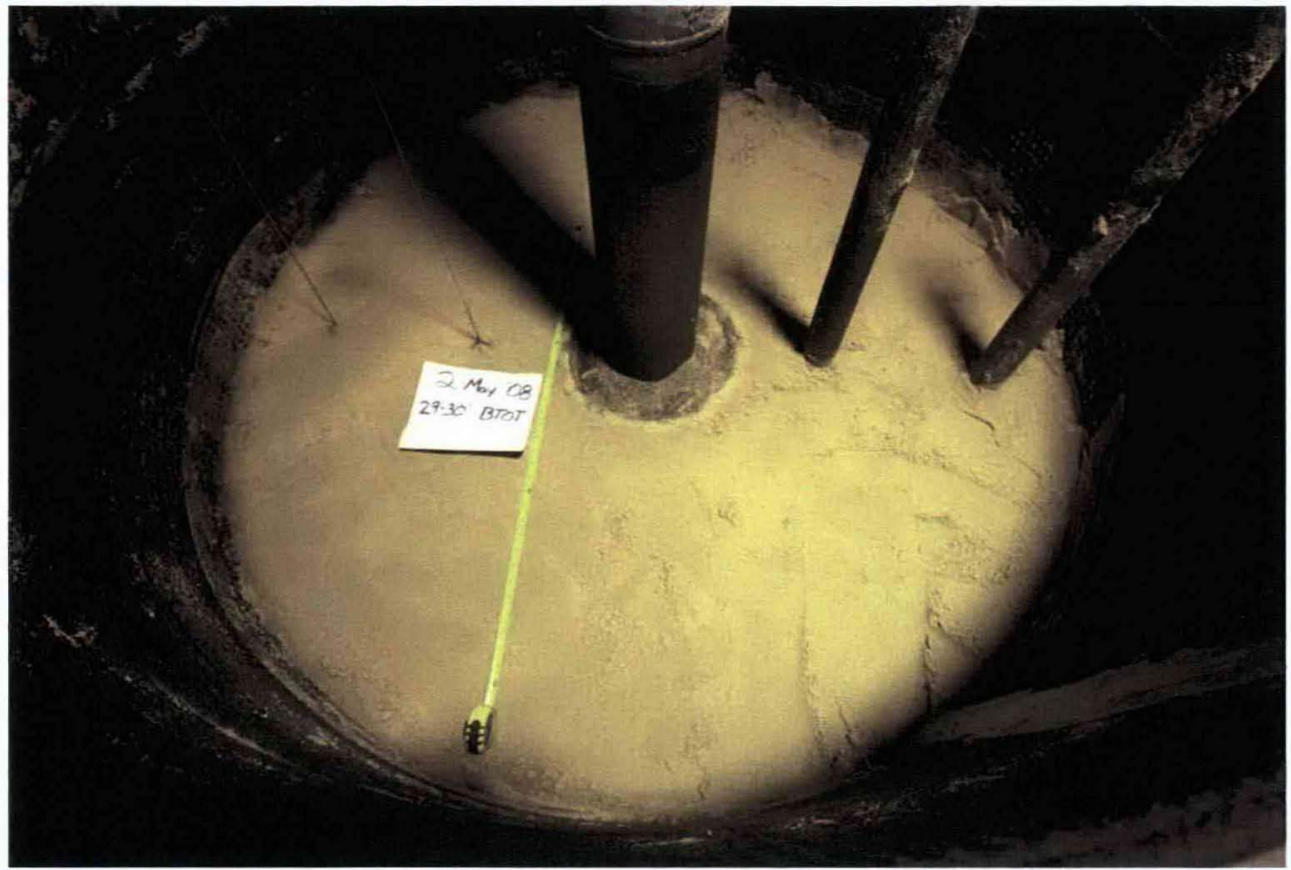

Figure 5: Tank Sand Excavation (29-30" BTOT)

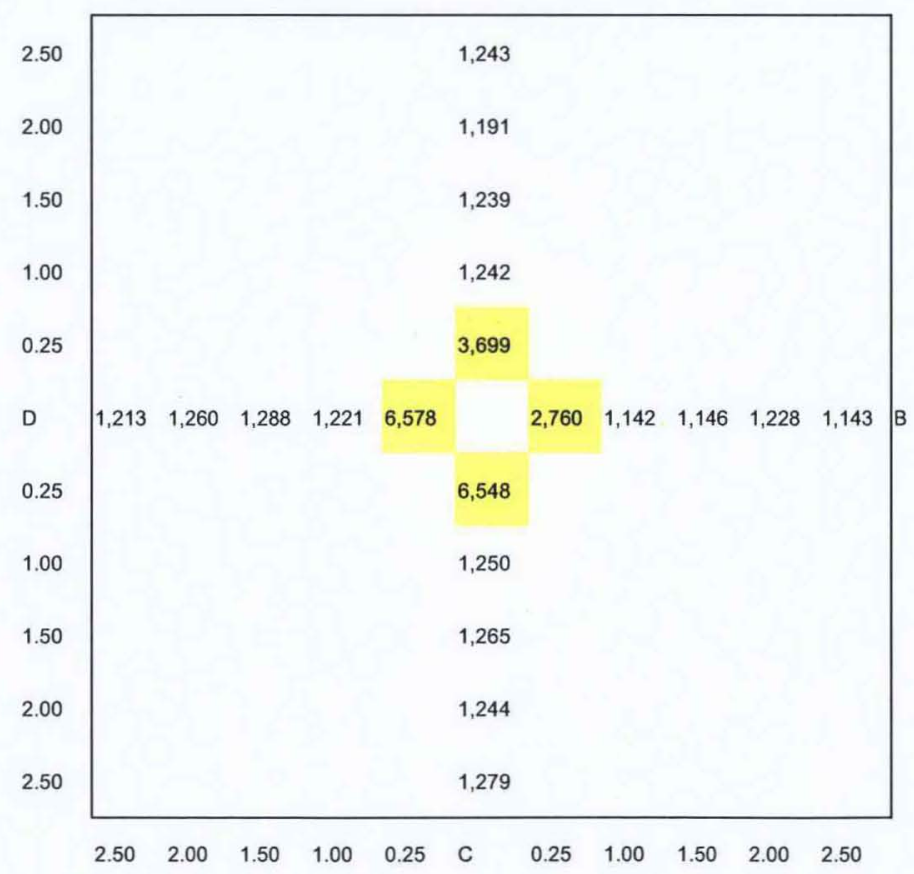

Figure 6: 0.75 Depth Sand Sample Results $(\mathrm{mg} / \mathrm{Kg})^{3}$

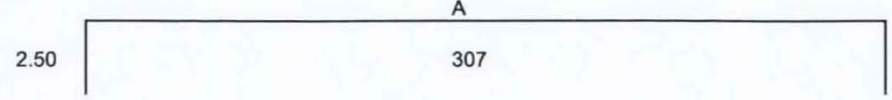

\footnotetext{
${ }^{3}$ Yellow indicates value is greater than background for sand involved. This footnote also applies to Figures 7 and 8.
} 


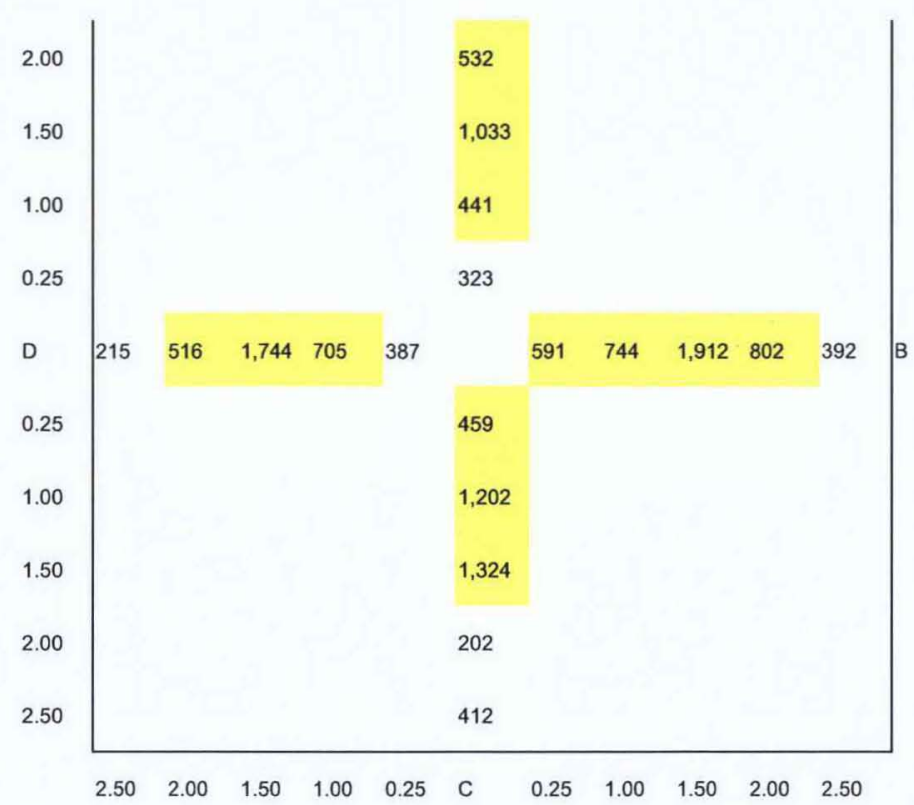

Figure 7: 1.5 Depth Sand Sample Results (mg/Kg)

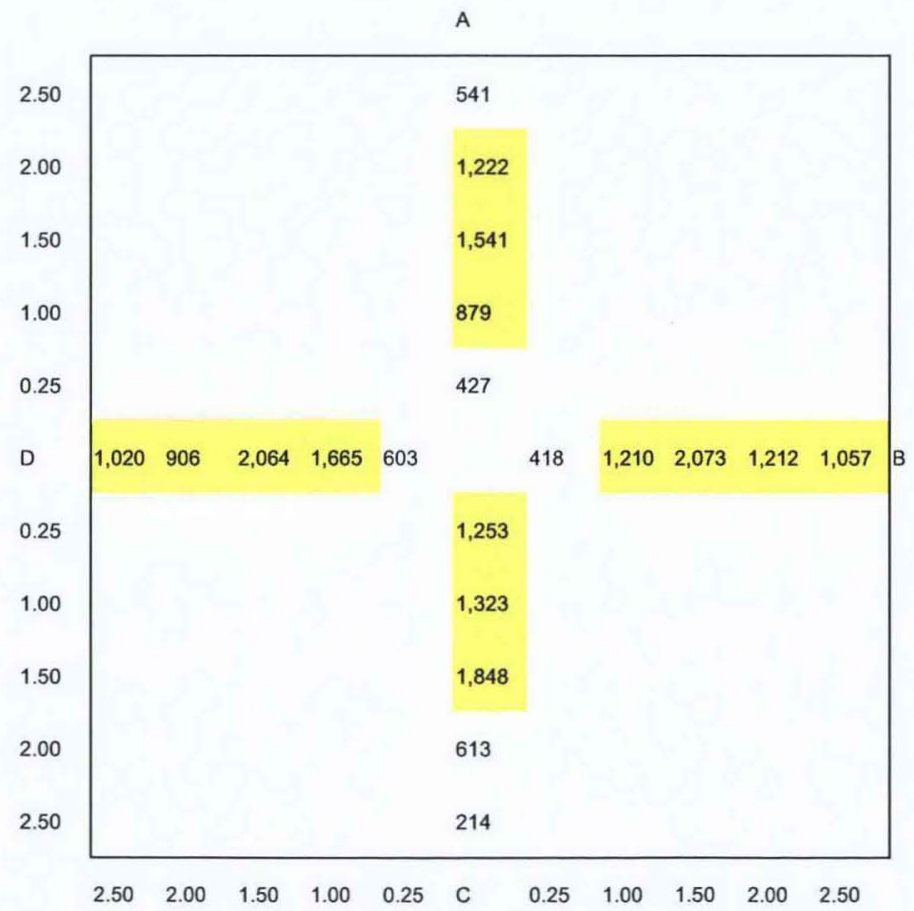

Figure 8: 2.0 Depth Sand Sample Results (mg/Kg)

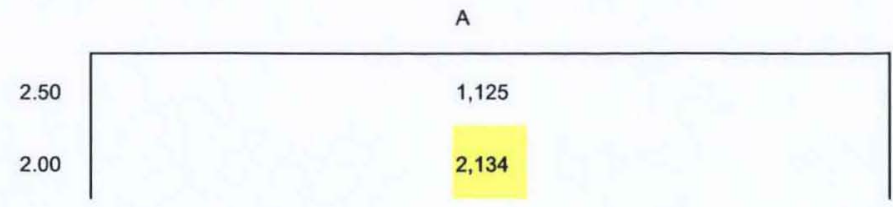

MSE Technology Applications, Inc. 


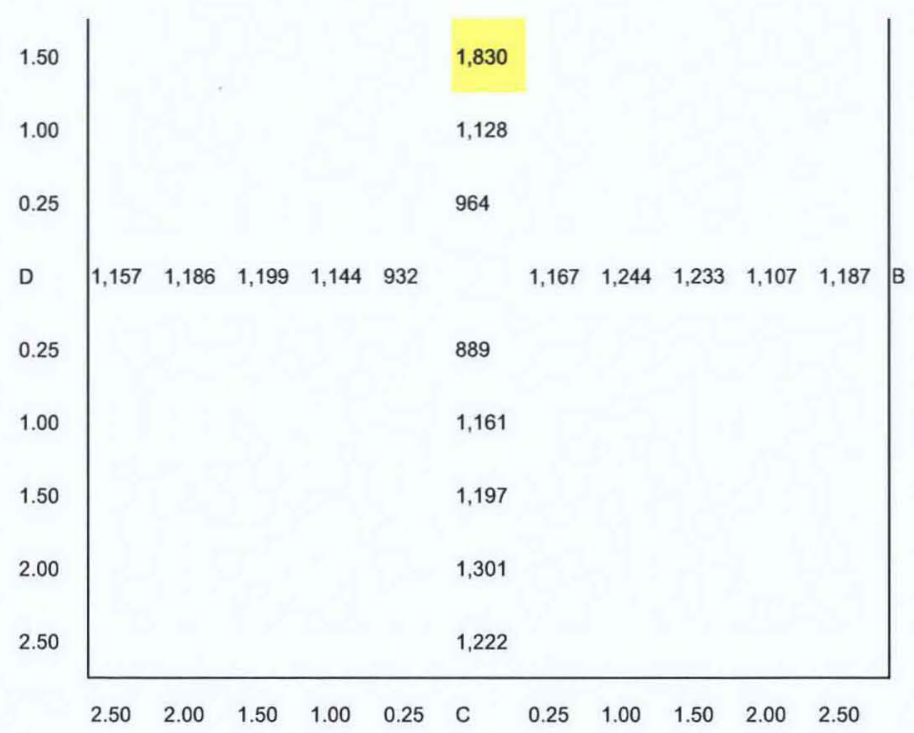

Figure 9: 2.5 Depth Sand Sample Results (mg/Kg)

very coarse sand filter pack near the injection well at the 0.75 foot nominal depth level but were consistent with natural background values for samples further from the well screen in medium sand. In constrast, iron concentrations close to the injection well in the very coarse sand layer (nominal depths of 1.5 and 2.0 feet) varied but were mostly at levels consistent with natural background values or only marginally elevated beyond them. Iron concentrations then increased with radial distance from the injection well to reach peak values at 1.5 feet from the center of the injection well before declining towards natural background values near the tank wall. This pattern of iron deposition was very symmetrical for the 1.5 feet depth level but was less so in the case of the 2.0 feet depth level at the bottom of the high hydraulic conductivity layer, being preferentially skewed in the direction of the B and D radials, where iron deposition was generally greater in extent and reached higher concentrations. This may have been a result of marginal interference with flow by the presence of the monitoring wells in the direction of the $\mathrm{A}$ and $\mathrm{C}$ radials.

With two exceptions, no iron deposition is indicated for the two deepest depths in medium sand (i.e., 2.5 and 3.5 depth levels). As indicated in Figure 9 for the 2.5 feet depth level, some iron deposition is indicated along the A radial at 1.5 and 2.0 feet from the center of the injection well. It is clear that this iron did not reach that location by direct travel from the injection well through medium sand as no deposition is indicated at the 0.25 and 1.0 feet locations. It is more likely that this represents some type of vertical transport from the shallow monitoring well located directly above the 2.0 feet location. The tapered drive point for this well was 7-5/8" long and, therefore, would have reached almost to the 2.5 feet depth level. The exceptions for the 3.5 feet depth level are two locations immediately adjacent to the injection well screen (not shown in a figure herein). Results for all other sample locations for these two depth levels are consistent with natural background iron levels for this medium sand. 
Taking natural background sand iron concentrations into account, these data indicate that peak enrichment by ZVI iron deposition during this 100 minute injection test was on the order of $1,500 \mathrm{mg} / \mathrm{Kg}$ in the very coarse $10 \times 20$ sand.

\subsection{Radial Flow Velocities}

In contrast with the linear flow situation in earlier flow cell testing performed by MSE, flow in the tank injection test was radially outward from the injection well. Therefore, the effective flow area increased and flow or seepage velocity decreased as a linear function of radial distance from the well. Assuming all $3.1 \mathrm{gpm}$ of flow was directed through the 1 foot thick very coarse sand high hydraulic conductivity layer ${ }^{4}$, flow velocities would have been as follows:

\section{$\underline{\text { Radial Distance (ft) }}$}

1.

2.

3

4.

5.
0.25

1.0

1.5

2.0

2.5
Flow Velocity (ft/day)

983

271

181

136

109

This compares to flows ranging from approximately 43 to $525 \mathrm{ft} /$ day during flow cell testing. The relatively high flow velocities close to the well screen may have been responsible for the limited degree of iron deposition in that zone with velocities declining on the order of $50 \%$ before substantial deposition occurred.

\subsection{Hydraulic Conductivity Testing}

Results of hydraulic conductivity tests performed in individual wells before and after the injection test are presented in Section 2.3.2 and summarized in Table 3. The tests performed were slug tests. These types of tests attempt to measure hydraulic conductivity within a relatively short distance of the well screen. Pre-injection tests are roughly consistent with the types of sand involved (i.e., mean values of about $0.52 \mathrm{~cm} / \mathrm{sec}$ for very coarse sand, $0.025 \mathrm{~cm} / \mathrm{sec}$ for medium sand, and $0.074 \mathrm{~cm} / \mathrm{sec}$ for the combined material screened by the injection well). Post-injection tests indicated marginal decreases in hydraulic conductivity for the very coarse sand (i.e., by $19 \%$ to $0.42 \mathrm{~cm} / \mathrm{sec}$ ) tested by shallow wells, the material screened by the injection well (i.e., by $26 \%$ to $0.055 \mathrm{~cm} / \mathrm{sec}$ ), and the well closest to the injection well (D1) screened in medium sand (i.e., by $16 \%$ to $0.026 \mathrm{~cm} / \mathrm{sec}$ ), but no substantial change in the case of the well further from the injection well (D2) screened in medium sand. This is consistent with the hypothesis that sufficient iron deposition occurred in the very coarse sand to cause the marginal decrease observed in testing and that iron was not transported to any degree through the medium sand.

\footnotetext{
${ }^{4}$ This is a conservative assumption. In actuality, a minor portion of the flow would also go through the medium sand layers.
} 
Temperature information presented in Table 3 indicates only a minor possible role for that variable. Temperatures for pre- and post-injection hydraulic testing were very similar in the case of the injection well and for well D2 screened in medium sand. However, in the cases of shallow wells screened in very coarse sand post-injection testing took place at a temperature of about $2{ }^{\circ} \mathrm{C}$ higher. All other factors being equal, an increase in water temperature means a decrease in both density and dynamic viscosity. Since hydraulic conductivity is directly proportional to intrinsic permeability and density and inversely proportional to intrinsic permeability and dynamic viscosity, the change in density divided by the change in dynamic viscosity for a given temperature range is indicative of the overall impact on hydraulic conductivity (Fetter, 1994). The numbers show that the temperature effect in this case would produce hydraulic conductivity results for post-injection testing of the shallow wells that would be about 2.5 percent higher than would otherwise be the case if the temperature had not changed. Therefore, the $19 \%$ decrease in for results from the shallow wells in very coarse sand is probably an underestimate (since it can be assumed that hydraulic conductivity results for postinjection testing in this wells would have been lower if the temperature had not been higher).

Additional information on effective bulk hydraulic conductivity is available from water level measurements taken in monitoring wells during the injection test and application of the Theim equation. The Theim equation is conventionally used to calculate hydraulic conductivity under steady state conditions for the cone of depression surround a discharging well (Fetter, 1994). However, it may be applied to the cone of impression around a well being used for injection as in this case. Although there was variation in head conditions due to the nature of this test and the manner in which tank effluent was controlled to balance flow, the head differential as applied in the Theim equation was fairly stable. For the data in Appendix B Table 3, it average about 0.03 feet between monitoring wells $\mathrm{S} 1$ and $\mathrm{S} 2$. The hydraulic conductivities calculated for these data ranged from about 0.135 to $0.185 \mathrm{~cm} / \mathrm{sec}$. This compares to values of 0.52 to 0.42 $\mathrm{cm} / \mathrm{sec}$ noted above from pre- and post-injection slug testing.

\subsection{ANALYTICAL QUALITY ASSURANCE}

Laboratory data quality were checked in three ways: (1) data were reviewed as a whole for consistency with reasonable expectations based on general theory; (2) unidentified field duplicates were taken of sand samples; and (3) laboratory quality control data were internally validated. This validation was performed at the same time earlier flow cell test data were reviewed.

As a whole, laboratory data appeared to be consistent with reasonable expectations based on general theory or, in the case of unexpected anomalies, could be explained by reasonable theories (e.g., lower than expected measurements of iron injection concentration may be an artifact of sampling procedures and the increase in 
concentrations at the end of the test may reflect aging or settling of RNIP-M2 in the mixing tank prior to injection).

In the case of field duplicate sand samples (identified by the initials "DL" after the sample number), reported iron concentrations in the duplicate were reasonably close to those in original samples. Relative percent differences (RPDs) were all less than 5\%.

An internal validation of laboratory quality control data was performed by MSE. This resulted in no flags or data qualifiers being specified. Most indicators were considered within limits. The only noteworthy comments were that in some cases preparation blank results were elevated, but still significantly below sample concentrations, and matrix spike/matrix spike duplicate results were often unusable because sample concentrations were much greater than the spike (particularly with regard to iron). Copies of data validation review summary sheets for each laboratory work order (WO) number are provided in Appendix C. The summary sheet provided in Appendix C qualifies some flow cell test data but no tank test data.

\subsection{CONCLUSIONS}

This tank scale injection confirmed that the general methodology for mixing and injection of nano size ZVI developed during flow cell testing could be successfully translated to the field circumstances of an injection well in a sand aquifer. This information formed the basis for the field injection methods subsequently used at Hanford.

An explanation for the iron deposition pattern observed both visually and in sand sample results is uncertain. This pattern differed from that observed during flow cell testing in which velocities were such as to ensure laminar flow. It is hypothesized that this pattern reflects flow rates that may have inhibited filtration due to exceedance of laminar conditions and velocity changes occurring as a function of radial flow.

Sedimentation is a primary mechanism for particle filtration in porous media. However, sedimentation of particles under conditions of horizontal flow is a function of velocity vectors in both the horizontal (i.e., advective flow) and vertical directions (i.e., downward settling under the force of gravity). Radially outward horizontal flow from an injection well would be highest at the well screen and decrease linearly with distance from it. Therefore, the dark ring produced at a radial distance of 1 foot from the center of the tank may reflect increased sedimentation resulting from decreasing flow velocity.

Reynold's numbers calculated for the velocities and median sand grain size involved, would indicate that flow in proximity to the well screen may have been turbulent but became laminar within 1 foot of the center of the tank. The Reynold's number at the well screen would have been 4.4 , a value within the transitional range between laminar and turbulent flow in which turbulent flow is possible. The Reynold's number 1 foot from the center of the tank was 1.2, a value close to the upper end of the laminar flow range 
(Bear and Verruijt, 1987). Additional laboratory testing at different horizontal flow velocities within a radial flow field would be necessary to confirm this hypothesis. The presence of polymer in the ZVI fluid is an additional factor that may have influenced sedimentation in this case.

\section{References Cited}

Bear, J. and A. Verruijt. 1987. Modeling Groundwater Flow and Pollution, Springer, NY, 764 pages.

Bechtel. 2000. Well construction and completion summary for well number 199-D4-37.

Elimelech, M. 1995. Particle Deposition and Aggregation: Measurement, Modeling, and Simulation, Butterworth-Heinemann, Woburn, MA, 441 pages.

Fetter, C.W. 1994. Applied Hydrogeology, $3^{\text {rd }}$ Ed., Prentice Hall, Englewood Cliffs, NJ, 691 pages.

Fruchter, et al. 2000. Creation of a subsurface permeable treatment zone for aqueous chromate contamination using in situ redox manipulation. Ground Water Monitoring \& Remediation, Spring, pages 66-77.

Li, et al. 2006. Zero-valent iron nanoparticles for abatement of environmental pollutants: materials and engineering aspects. Critical Reviews in Solid State and Materials Sciences, Vol. 31, pages 111-122.

Lowery, G., et al. 2005. Nanoiron in the subsurface: how far will it go and how does it change? Paper presented at U.S. EPA Workshop on Nanotechnology for Site Remediation, U.S. Department of Commerce, Washington, DC, 21 October.

MSE. 2008. Test Plan for ZVI Distribution in Soil Injected with ZVI/dispersant/Water. MSE, February.

Oglebay Norton Industrial Sands, Inc. 1996. Physical and chemical data sheet. Chemical data from August 1996 study. Colorado Springs, CO, 1 page.

Oglebay Norton Industrial Sands, Inc. 2007. Particle size distribution sheets for $12 \times 20$ and $30 \times 70$ sands dated 17 October. Colorado Springs, CO, 2 page.

Oostrom, M., et al. 2005. Experimental study of micron-size zero-valent iron emplacement in permeable porous media using polymer-enhanced fluids. Report PNNL15573, Pacific Northwest National Laboratory, Richland, WA. 
Saleh, N., et al. 2007. Surface modifications enhance nanoiron transport and NAPL targeting in saturated porous media. Environmental Engineering Science, Vol. 24, No. 1 , pages 45-57.

Schrick, B., et al. 2004. Delivery vehicles for zerovalent metal nanoparticles in soil and groundwater. Chem. Mater., Vol. 16, pages 2187-2193.

Stevenson, D.G. 1997. Water Treatment Unit Processes, Imperial College Press, London, 474 pages. 
DOE/RL-2009-35, REV. 0

This page intentionally left blank. 
DOE/RL-2009-35, REV. 0

\section{Appendix B}

\section{Laboratory Test Plans}


DOE/RL-2009-35, REV. 0

This page intentionally left blank. 


\section{Test Plan For Laboratory Testing and Numerical Modeling TO SUPPORT THE MICRON-SIZED ZERO-VALENT IRON (MZVI) INJECTION PROJECT}

Prepared by:

MSE Technology Applications, Inc.

200 Technology Way

P.O. Box 4078

Butte, Montana 59701

Revision 01

January 22, 2007 
DOE/RL-2009-35, REV.0

This Page Intentionally Left Blank 


\section{MSE REVIEW AND APPROVAL SIGNATURES}

\section{MSE Technology Applications, Inc.}

Prepared By: David Reichhardt, Test Engineer

Reviewed By: Mark Ewanic, Project Manager

Reviewed By: Mary Ann Harrington - Baker, Quality Assurance Manager

Approved By: Scott Nuthak, MSE Health and Safety

Approved By: Tom Burkhart, Operations Division Manager

Approved By: Andrea Hart, MSE Program Manager

MSE Technology Applications, Inc

TEST PLAN FOR LABORATORY TESTING AND NUMERICAL MODELING TO SUPPORT THE MICRON-SIZED ZERO-

VALENT IRON (MZVI) INJECTION PROJECT
Date

Date

Date

Date

Date

Date 


\section{This Page Intentionally Left Blank}




\section{TABLE OF CONTENTS}

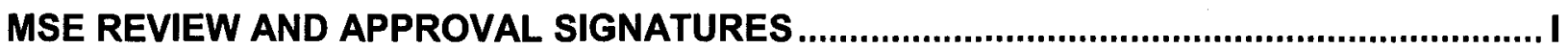

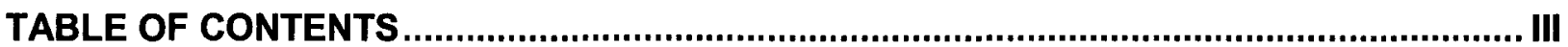

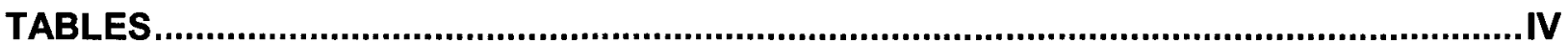

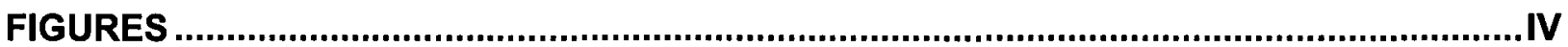

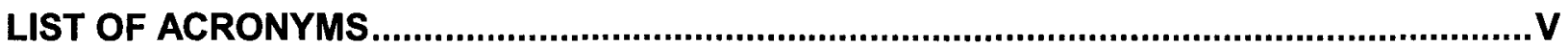

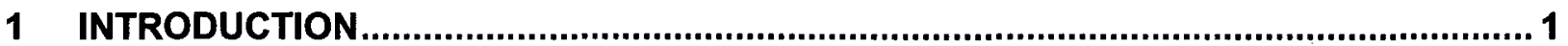

2 LABORATORY TESTING OBJECTIVES AND DATA QUALITY …............................... 2

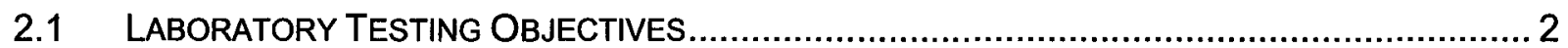

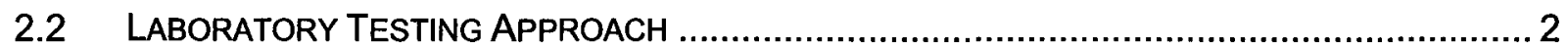

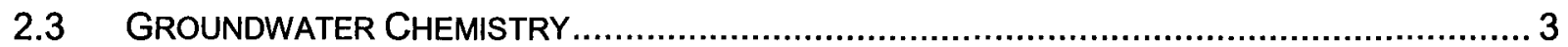

2.4 PLANNED MEASUREMENTS AND ANALYSES.............................................................. 4

2.4.1 Primary Measurements and Analyses ....................................................................

2.4.2 Secondary Measurements and Analyses....................................................................5

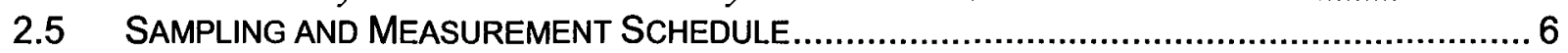

2.5.1 Geochemical Sampling and Measurement …………….................................................

2.5.2 Permeability Testing ..........................................................................................

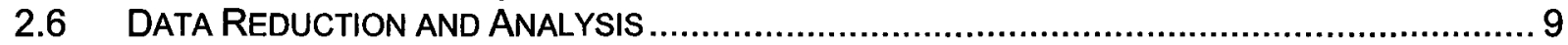

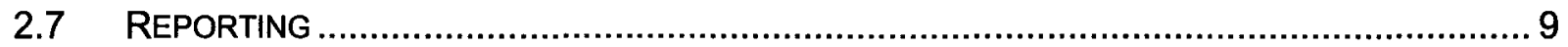

3 PROCEDURES

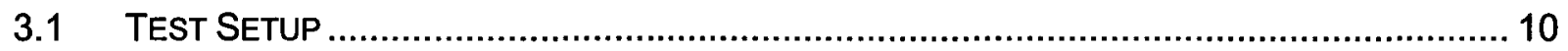

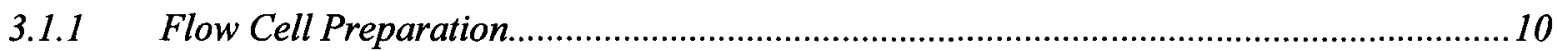

3.1.1.1 Flow Cell Materials ................................................................................................10

3.1.1.2 Permeability Testing Cell Materials..............................................................................11

3.1.1.3 Flow and/or Permeability Cell Construction ................................................................11

3.1.1.4 Flow and/or Permeability Cell Packing Equipment ......................................................12

3.1.1.5 Flow Cell Packing Procedures ....................................................................................12

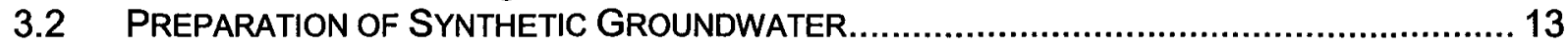

3.2.1 Synthetic Groundwater Materials ............................................................................13

3.2.2 Synthetic Groundwater Preparation Equipment …………………………....................13

3.2.3 Synthetic Groundwater Preparation Procedures ..............................................................13

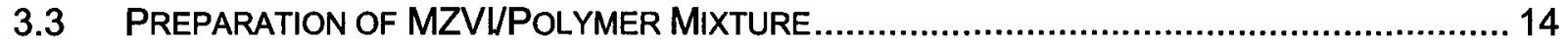

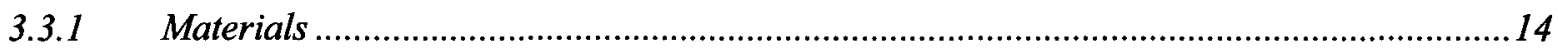

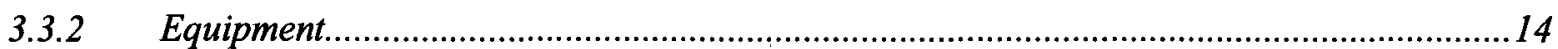

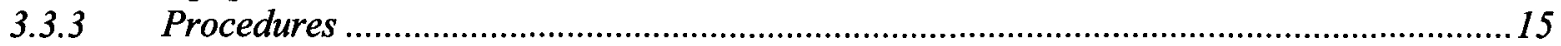

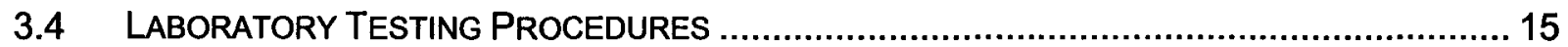

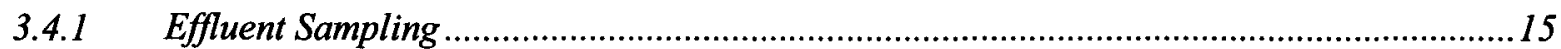

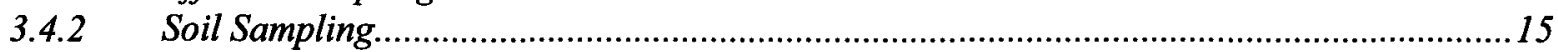

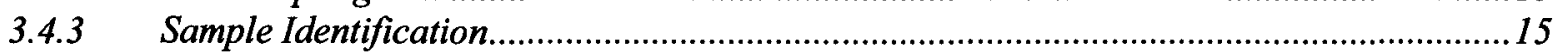

3.4.4 Permeability Testing and Continuous Head Differential Measurement Procedures............16

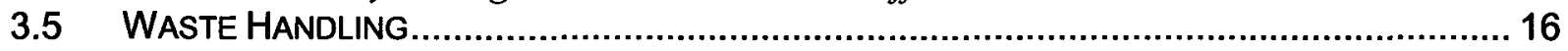

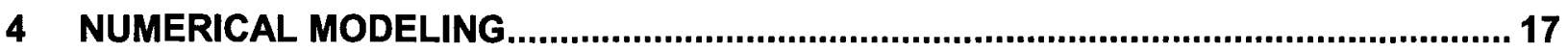




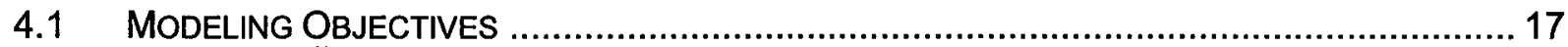

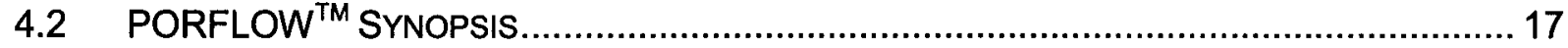

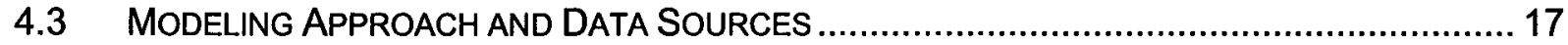

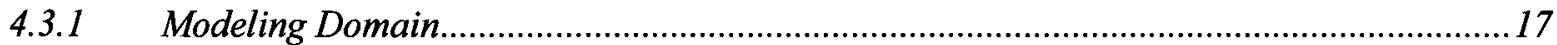

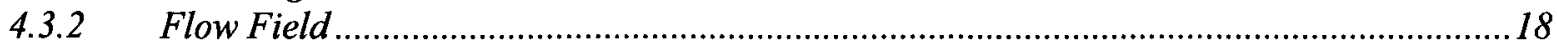

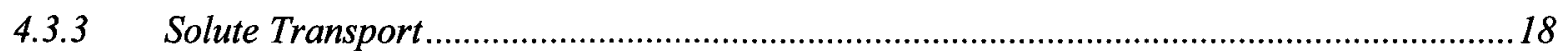

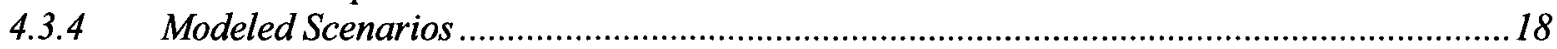

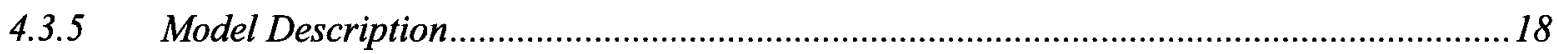

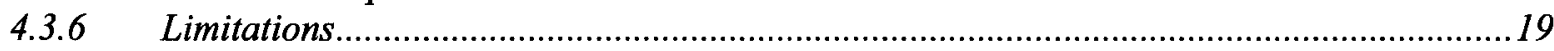

5 HEALTH AND SAFETY ................................................................................. 20

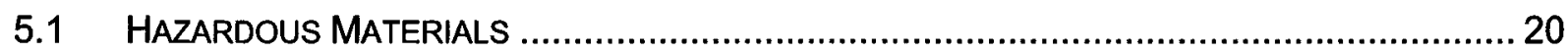

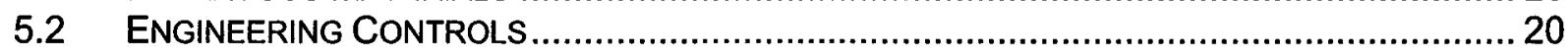

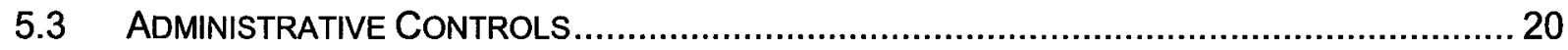

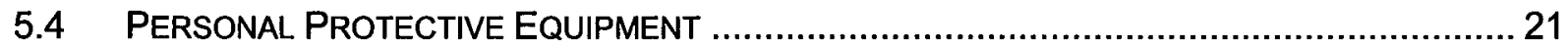

5.5 FIRST AID AND EMERGENCY RESPONSE ...................................................... 21

6 QUALITY CONTROL AND QUALITY ASSURANCE ............................................... 22

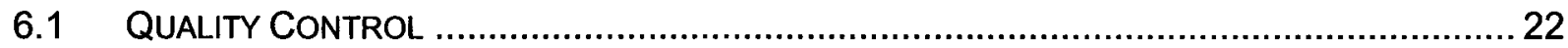

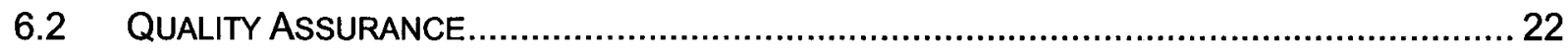

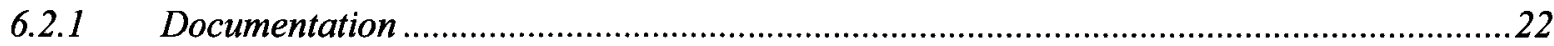

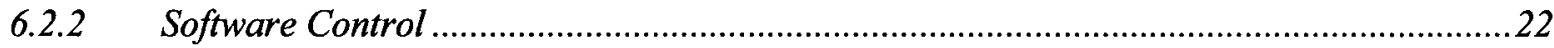

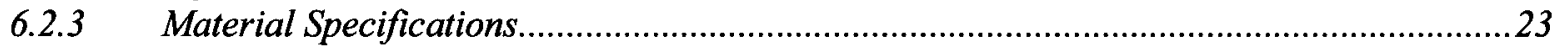

6.2.4 Test Equipment Designs and Specifications............................................................23

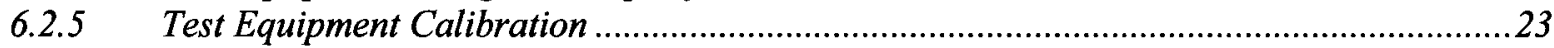

6.2.6 Personnel Qualifications...................................................................................23

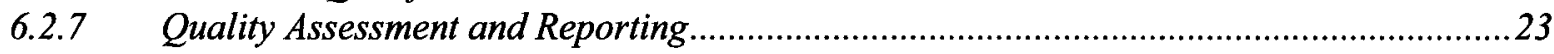

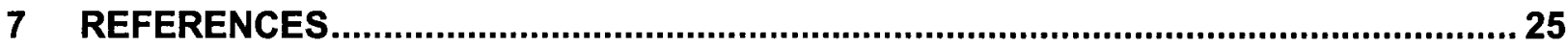

TABLES

Table 1. Groundwater chemistry of Hanford 100-D Area. ................................................... 4

Table 2. Primary Measurements and Analyses. .......................................................... 5

Table 3. Secondary Measurements and Analyses........................................................ 5

Table 4. Sampling, analysis, and measurement schedule. .............................................. 8

Table 5. Reagents for 1,900 Liters of Synthetic Hanford 100-D Area Groundwater. ................ 13

Table 6. Effluent-sample identification system................................................................... 16

Table 7. Hazardous materials and exposure/physical data............................................... 20

\section{FIGURES}

Figure 1. Layout of laboratory setup....................................................................... 12 


\section{LIST OF ACRONYMS}

$\begin{array}{ll}\text { 3D } & \text { 3-dimensional } \\ \text { CFR } & \text { Code of Federal Regulations } \\ \text { CHO } & \text { Chemical Hygiene Officer } \\ \text { CHP } & \text { Chemical Hygiene Plan } \\ \text { CPU } & \text { central processing unit } \\ \text { Cr }^{3+} & \text { trivalent chrome } \\ \text { Cr }^{6+} & \text { hexavalent chrome } \\ \text { DI } & \text { deionized (water) } \\ \text { DOE } & \text { U. S. Department of Energy } \\ \text { GW } & \text { groundwater } \\ \text { H-F-R } & \text { Health - Fire - Reactivity Ratings } \\ \text { ISRM } & \text { In situ Redox Manipulation (ISRM) } \\ \text { Lab Prms. } & \text { laboratory parameters } \\ \text { MSDS } & \text { Material Safety Data Sheets } \\ \text { MSE } & \text { MSE Technology Applications, Inc. } \\ \text { MZVI } & \text { micron-sized zero-valent iron } \\ \text { ORP } & \text { oxidation-reduction potential } \\ \text { OSHA } & \text { Occupational Safety and Health Administration } \\ \text { PEL/TLV } & \text { Permissible Exposure Limit / Threshold Limit Value } \\ \text { PNNL } & \text { Pacific Northwest National Labs } \\ \text { PPE } & \text { personal protective equipment } \\ \text { PV } & \text { pore Volume } \\ \text { PVC } & \text { poly vinyl chloride } \\ \text { QA } & \text { quality assurance } \\ \text { QAP } & \text { Quality Assurance Plan } \\ \text { QC } & \text { quality control } \\ \text { RFP } & \text { request for proposal } \\ \text { RPD } & \text { relative percent difference } \\ \text { RSD } & \text { relative standard deviation } \\ \text { SCBA } & \text { self-contained breathing apparatus } \\ \text { TAP } & \text { Technical Assistance Panel } \\ \end{array}$




\section{INTRODUCTION}

MSE Technology Applications, Inc., (MSE) under subcontract to Fluor Hanford (Fluor Hanford Contract \#30994) has been tasked with completing laboratory testing, numerical modeling and associated field work related to injection of micron-sized zero-valent iron (MZVI) into the subsurface at the 100-D Area at the U.S. Department of Energy (DOE) Hanford Site, Washington State. The purpose of this work is to demonstrate the feasibility of using MZVI to repair portions of the In situ Redox Manipulation (ISRM) barrier located in the 100-D Area of the Hanford Site.

The ISRM barrier was installed to remediate a chromium groundwater plume in Hanford's 100-D Area by reduction of the $\mathrm{Cr}^{6+}$ in the groundwater to $\mathrm{Cr}^{3+}$ through the injection of sodium dithionite into the aquifer, thus creating a chemically reduced environment (DOE/RL, 2005). Localized signs of failure in the barrier (defined by the presence of $\mathrm{Cr}^{6+}$ in the treated wells) were discovered in some wells 18 months after they were treated. The most probable cause of the premature barrier breakdown was determined to be heterogeneities in the aquifer where laterally discontinuous units with high permeability and lower inherent reductive capacity (because of lower iron content) were reoxidized faster than the less permeable layers. A Technical Assistance Panel (TAP) recommended that an alternative technology (injection of MZVI/polymer) be tested and possibly deployed to mend the barrier, and to eliminate the need of periodically re-injecting the ISRM wells with sodium dithionite.

The TAP recommended that the reduction potential of co-contaminants and generation of byproducts must be considered and monitored. The TAP recommended considering all potential geochemical impacts to the aquifer system from the MZVI/polymer injection, specifically the potential for the MZVI to convert nitrate to ammonia and the formation of carbonate due to the generation of high $\mathrm{pH}$ conditions in the groundwater. Following the recommendations from the TAP, Fluor Hanford issued a request for proposals (RFP) to provide the laboratory testing, numerical modeling and associated fieldwork for the MZVI/polymer injection.

This document addresses the requirements of Task 1: Laboratory Test Plan of the subcontract, which includes development of a laboratory test plan (to assess the changes to the geochemistry of the aquifer system associated with the ISRM barrier following the injection of the $\mathrm{MZVI} /$ polymer mixture) and a plan for numerical modeling of the proposed MZVI/polymer injections. The laboratory testing will be completed under Task 2 of the subcontract and the numerical modeling is covered under Task 3 of the subcontract. The laboratory work and numerical modeling must be completed to support the Treatability Test Plan (Task 4), which has a May 18, 2007 deliverable date. 


\section{LABORATORY TESTING OBJECTIVES AND DATA QUALITY}

The laboratory testing and data analysis will be completed at the MSE facility in Butte, Montana. The MSE facility has fully functional experimental and analytical laboratories. The purpose of the laboratory testing will be to evaluate geochemical changes that may adversely affect groundwater after injection of MZVI. The objectives of this testing are listed in the following sections.

\subsection{Laboratory Testing Objectives}

The laboratory testing objectives as specified in the RFP included the following:

- Evaluating changes in water chemistry when groundwater of similar composition to that at the 100-D Area reacts with MZVI emplaced in the aquifer with emphasis on:

- pH changes;

- The influence of strongly reducing conditions on nitrate (e.g., does it reduce all the way to ammonia?); and

- Changes in carbonate concentration due to high $\mathrm{pH}$ (high carbonate concentrations may decrease the aquifer permeability);

- Evaluating the passivation of the MZVI under field conditions (e.g. high groundwater carbonate).

\subsection{Laboratory Testing Approach}

The laboratory work will build upon previous work completed by Pacific Northwest National Labs (PNNL) in 2005 (Oostrom et al., 2005) in regards to the injection of the MZVI/polymer mixture. The results of this PNNL laboratory work with follow-on flow cell experiments identified an MZVI/polymer mixture as having a high probability for success. The mixture identified was made up of the colloidal iron S-3700 Fe ${ }^{0}$ Colloids (International Specialty Products, Wayne, NJ), with a $1 \%$ by weight (w/w) Fe-concentration and $0.001 \%$ aerosol (Sigma Chemical, St. Louis, MO) and the polymer Slurry Pro CDP (K.B. Technology, Chattanooga, TN), at a $0.02 \% \mathrm{w} / \mathrm{w}$ concentration. MSE will complete the proposed laboratory work using this MZVI/polymer mixture. We assume that Fluor Hanford will provide all the necessary information to prepare the PNNL-identified and tested polymer-enhanced MZVI.

The laboratory testing will be based on flow cell studies designed to simulate the entire injection process from pre-injection through post-injection. A flow cell is essentially a column maintained in a horizontal position. A set of flow cells for the geochemical portion of the laboratory testing will be made up of Hanford Ringold E soils from the 100-D Area. A second set of flow cells designed for permeability testing will be made up using 12/20 Accusand. The soils in the flow cells will be saturated with water of a similar geochemical composition as the groundwater from the 100-D Area and allowed to reach a geochemical equilibrium.

MZVI and polymer in the prescribed ratio will be injected into the flow cells. We will use a $0.02-$ $\mathrm{cm} / \mathrm{sec}$ injection-rate (Oostrom et al., 2005), which is based on the injection rate PNNL lab work determined to be most effective at distributing the MZVI. MSE will acquire effluent samples from the flow cells at prescribed times during the laboratory injection simulation to characterize changes in the groundwater chemistry as a function of the pore volumes of MZVI and polymer injected. Following the completion of the MZVI and polymer injections, we will allow groundwater to flow through the flow cells and will continue to collect effluent samples for analysis. In addition to the effluent sampling, we will also remove selected flow cells from the 
test setup periodically over the course of the injections and analyze the soils from the flow cells for iron. This will require multiple flow cells to ensure that an adequate number of flow cells are available for soil sampling and effluent sampling for the duration of the testing. A series of control flow cells that will only have groundwater flowing through them during the entire testing process will also be set up. Effluent and soil samples from the control flow cells will be analyzed in parallel with the samples from test flow cells.

The $\mathrm{pH}$, oxidation-reduction potential (ORP), specific conductance, dissolved oxygen, and temperature of the effluent from the flow cells will be measured on a regular basis. Samples of the effluent will be analyzed for nitrogen as ammonia; nitrogen as nitrate and nitrite; alkalinity; iron speciation; and total and hexavalent chromium. The soil samples will be analyzed using laboratory analytical methods to determine how much iron was deposited in the formation. Additionally, optical microscopy will be used to qualitatively estimate the amount of iron oxyhydroxides that have formed.

MSE anticipates that if passivation of the MZVI does occur during the injections, it will be primarily due to the formation of iron oxy-hydroxides (Yarmoff et al, 1999). Therefore, the "amount of iron passivation" will be based on the amount of iron oxy-hydroxide that forms in the flow cells, which may be observed through any number of microscopic techniques (e.g., optical microscopy, XRF, SCM, etc.). If formation of a significant amount of iron oxy-hydroxide is observed, then the assumption that there is an increased potential for passivation of iron could be made. Furthermore, a decrease in the rate of $\mathrm{Cr}^{6+}$ reduction with increasing volume of groundwater flushed through the system may also be an indication of iron passivation. If there is a positive correlation between the formation of the iron oxy-hydroxides and a decrease in the rate of reduction of $\mathrm{Cr}^{6+}$, this will further support the assumption that iron passivation is related to the iron oxy-hydroxide formation.

To assess changes in the permeability of the soils (possibly due to the precipitation of carbonates or other inhibiting byproducts) permeability testing will be conducted prior to $\mathrm{MZVI} /$ polymer injection and following the injection. Additionally, the head differentials across the flow cells will be monitored during the injection process. It should be noted that the head differentials measured when only water is flowing through the flow cells cannot be directly compared to head differentials obtained when the MZVI/polymer is flowing through the cells due to distinctly different fluid properties. This is discussed further in Section 3.4.4.

In conjunction with the analytical work, MSE may also use selected flow cell samples to investigate the effects MZVI injection may have on the electrical properties of the saturated sediment. Results from this work would be used to assess the feasibility of using geophysics (e.g., electrical resistivity tomography or electrical self-potential) for assessing/monitoring the MZVI injection in the field (Task 8).

\subsection{Groundwater Chemistry}

The average groundwater chemistry as per the Fluor Hanford RFP is presented in Table 1. This data will be used to create the synthetic groundwater and to establish the detection limits for the analytical methods used in the geochemical testing. 
Table 1. Groundwater chemistry of Hanford 100-D Area.

\begin{tabular}{|c|c|c|}
\hline Analytes & Average Value & Units \\
\hline Alkalinity & 97.13 & $\mathrm{mg} / \mathrm{L}$ \\
\hline Aluminum & 38.96 & $\mu g / L$ \\
\hline Calcium & 90.00 & $\mathrm{mg} / \mathrm{L}$ \\
\hline Chloride & 33.96 & $\mathrm{mg} / \mathrm{L}$ \\
\hline Chromium $^{(1)}$ & 100 & $\mu g / L$ \\
\hline Dissolved oxygen & 9.59 & $\mathrm{mg} / \mathrm{L}$ \\
\hline Iron (Total) & 136.53 & $\mu g / L$ \\
\hline Magnesium & 20.77 & mg/L \\
\hline Nitrate & 23.60 & $\mathrm{mg} / \mathrm{L}$ \\
\hline Oxidation Reduction Potential & 156.63 & $\mathrm{mV}$ \\
\hline $\mathrm{pH}$ & 7.80 & $\mathrm{pH}$ \\
\hline Phosphate & 0.33 & $\mathrm{mg} / \mathrm{L}$ \\
\hline Potassium & 4.82 & $\mathrm{mg} / \mathrm{L}$ \\
\hline Sodium & 9.89 & $\mathrm{mg} / \mathrm{L}$ \\
\hline Specific Conductance & 675.13 & $\mu \mathrm{S} / \mathrm{cm}$ \\
\hline Sulfate & 135.35 & $\mathrm{mg} / \mathrm{L}$ \\
\hline
\end{tabular}

\subsection{Planned Measurements and Analyses}

Measurements and analyses are divided into primary and secondary classifications depending on the data use. The primary data will be used to answer the laboratory testing objectives listed in Section 2.1. The secondary data are for laboratory quality control purposes and to provide data for numerical modeling and injection design.

All laboratory analyses and measurements will be completed by MSE's onsite laboratory. Use of an offsite laboratory is not anticipated.

\subsubsection{Primary Measurements and Analyses}

Table 2 lists the analyses, sample matrix, analytical methods, and required detection limits for the primary measurements and analyses. 
Table 2. Primary Measurements and Analyses.

\begin{tabular}{|l|l|l|l|}
\hline Measurement/Analysis & Matrix & Analytical/Measurement Method & Detection Limit \\
\hline $\mathrm{pH}$ & Pore fluid & EPA 150.1 & $0.1 \mathrm{SU}$ \\
\hline ORP & Pore fluid & SM 2580 & $1 \mathrm{mV}$ \\
\hline Nitrogen as ammonia & Pore fluid & EPA 350.2 & $0.05 \mathrm{mg} / \mathrm{L}$ \\
\hline Nitrogen as nitrate and nitrite & Pore fluid & EPA 353.2 & $0.05 \mathrm{mg} / \mathrm{L}$ \\
\hline Alkalinity & Pore fluid & EPA 310.1 & $5 \mathrm{mg}$ CaCO $/ \mathrm{L}$ \\
\hline Iron speciation & Pore fluid & SM 3500 - Fe D & $0.05 \mathrm{mg} / \mathrm{L}$ \\
\hline Total and hexavalent chromium & Pore fluid & Total (EPA 200.9) / Hex (SW 7196A) & $0.001 / 0.005 \mathrm{mg} / \mathrm{L}$ \\
\hline Iron speciation & Soils & $\begin{array}{l}\text { As described in PNNL-15499, } \\
\text { Section 3.5 }\end{array}$ & To Be Determined \\
\hline $\begin{array}{l}\text { Alkalinity (Acid-Neutralization } \\
\text { Method) }\end{array}$ & Soils & ASA (1965) 91-4 & $1 \mathrm{mg} / \mathrm{Kg}$ as CaCO \\
\hline Permeability testing & Soils & $\begin{array}{l}\text { ASTM D-2434 Standard Test Method } \\
\text { for Permeability of Granular Soils } \\
\text { (Constant Head) }\end{array}$ & $\begin{array}{l}2.5 \mathrm{~mm} \text { pore fluid head differential } \\
\text { over } 1 \mathrm{~meter}\end{array}$ \\
\hline Iron oxy-hydroxides & Microscopy Techniques & Qualitative assessment \\
\hline
\end{tabular}

\subsubsection{Secondary Measurements and Analyses}

Table 3 lists the secondary measurements and analyses with associated sample matrix, analytical methods, and required detection limits. These are primarily laboratory parameters and will be measured in the experimental laboratory during the injection testing.

Table 3. Secondary Measurements and Analyses.

\begin{tabular}{|l|l|l|l|}
\hline Measurement/Analysis & Matrix & Analytical/Measurement Method & Detection Limit \\
\hline Specific Conductance & Pore fluid & Laboratory meter & $\begin{array}{l}0.001-0.1 \mathrm{~ms} / \mathrm{cm} \\
\text { (range dependent) }\end{array}$ \\
\hline Dissolved Oxygen & Pore fluid & Laboratory meter & $0.1 \%$ air saturation $0.01 \mathrm{mg} / \mathrm{L}$ \\
\hline Viscosity & Pore fluid & Laboratory methods (viscometer) & $1 \mathrm{cP}$ \\
\hline Density & Pore fluid & Laboratory methods & $0.1 \mathrm{mg} / \mathrm{L}$ \\
\hline Temperature & Pore fluid & Laboratory meter & $0.01{ }^{\circ} \mathrm{C}$ \\
\hline Injection flow rate & Pore fluid & $\begin{array}{l}\text { Setting positive displacement pump } \\
\text { pumping rate }\end{array}$ & $1 \mathrm{ml} / \mathrm{min}$ \\
\hline Injection pressure & Pore fluid & Manometer & $\begin{array}{l}2.5 \mathrm{~mm} \text { pore fluid head differential } \\
\text { over } 1 \mathrm{~meter}\end{array}$ \\
\hline
\end{tabular}


The $\mathrm{pH}$, ORP, specific conductance, and dissolved oxygen data will be used initially to determine when the flow cells and groundwater have reached a geochemical equilibrium. The viscosity and density data will be used for quality control and for the numerical modeling. The temperature data are required to support the $\mathrm{pH}$ measurement and the other parameters listed in Table 2 and Table 3.

Parameters listed in Table 3, and ORP and pH from Table 2 will be analyzed and recorded regularly in the $\mathrm{MZVI} /$ polymer mixture prior to injection to ensure the mixture is uniform throughout the laboratory testing.

Injection pressure and flow rate will be monitored to provide input for the geochemical model and field injection design. This data will also be used to ensure that the tests are completed under uniform injection conditions.

\subsection{Sampling and Measurement Schedule}

\subsubsection{Geochemical Sampling and Measurement}

Samples will be drawn from the effluent for analysis according to the sampling schedule shown in Table 4. The sampling schedule is based on the number of pore volumes injected for both the $\mathrm{MZVI} /$ polymer mixture and groundwater following the injection period. Two sets of flow cells are shown in Table 4: MZVI/polymer Injection Flow Cells and a set of Experimental Control Flow Cells. The experimental control flow cells included in the laboratory testing will only have water flowing through them. Once a flow cell has been taken off line and the soil has been sampled, it will no longer be available for additional effluent or soil sampling.

There will be a total of 11 flow cells used for the geochemical sampling and measurements to ensure primary samples and duplicates (for quality assurance) are available for both effluent and soil samples over the entire course of the testing.

The pore fluid samples will be analyzed for the full suite of analytes listed in Table 2 for each sampling event. Soil samples obtained from the flow cells will be analyzed according to Table 2. Laboratory parameters $(\mathrm{pH}$, specific conductance, dissolved oxygen, temperature, etc.) listed in Table 2 and Table 3 will be monitored on a regular basis as shown in Table 4.

Fluid density and viscosity measurements will be made when the MZVI/polymer mixture is initially made up and then daily during the injection tests and following preparation of any additional MZVI/polymer mixtures.

Equilibrium conditions will be determined by monitoring the $\mathrm{pH}$, dissolved oxygen, temperature, Eh, and conductivity of the effluent. When the effluent values equal the influent values, for at least five consecutive measurements, the system will be considered to be in equilibrium. Values will be considered equal when the relative percent differences between all influent and effluent parameters are less than $10 \%$.

\subsubsection{Permeability Testing}

An additional set of 3 Permeability Testing Cells (not shown in Table 4) will also be included in the laboratory testing. Permeability testing will be performed on each of the Permeability Testing Cells using differential pressure transducers and a data logger prior to MZVI/polymer injection and following the completion of the injection.

Head differentials will be measured across all of the flow cells (MZVI/polymer Injection, Experimental Control, and Permeability Testing Cells) prior to, during, and after the MZVI/polymer injections using either manometers installed on the flow tubes and/or differential pressure transducers (not all flow cells will be equipped with differential pressure transducers). 
Effluent from the Permeability Testing Cells will be analyzed for $\mathrm{pH}, \mathrm{ORP}$, specific conductance, dissolved oxygen, and temperature according to the sampling schedule for the MZVI/polymer Injection Flow Cells listed in Table 4. This data will be used to establish comparability between the Permeability Testing Cells and the MZVI/polymer Injection Flow Cells so that any results obtained from one set of flow cells can be related to the other flow cells. 
Table 4. Sampling, analysis, and measurement schedule.

\begin{tabular}{|c|c|c|c|c|c|c|c|c|c|c|c|}
\hline \multirow{2}{*}{$\begin{array}{l}\text { Sampling } \\
\text { Schedule }\end{array}$} & \multicolumn{8}{|c|}{ MZVI Injection Flow Cells } & \multicolumn{3}{|c|}{$\begin{array}{c}\text { Experimental Control Flow } \\
\text { Cells }\end{array}$} \\
\hline & 1 & 2 & 3 & 4 & 5 & 6 & 7 & 8 & 9 & 10 & 11 \\
\hline Pre-injection & $\begin{array}{c}\text { Lab Prms. } \\
\text { Pore Fluid } \\
\text { Soil }^{\mathrm{D}}\end{array}$ & $\begin{array}{l}\text { Lab Prms. } \\
\text { Pore Fluid }\end{array}$ & $\begin{array}{l}\text { Lab Prms. } \\
\text { Pore Fluid }\end{array}$ & Lab Prms. & Lab Prms. & Lab Prms. & Lab Prms. & Lab Prms. & $\begin{array}{l}\text { Lab Prms. } \\
\text { Pore Fluid }\end{array}$ & Lab Prms. & Lab Prms. \\
\hline $1 / 2$ PV MZVI & -- & Lab Prms. & Lab Prms. L L & Lab Prms. L L & Lab Prms. & Lab Prms. & Lab Prms. & Lab Prms. & Lab Prms. & Lab Prms. & Lab Prms. \\
\hline 3 PV MZVI & -- & $\begin{array}{c}\text { Lab Prms. } \\
\text { Pore Fluid } \\
\text { Soil }\end{array}$ & $\begin{array}{l}\text { Lab Prms. } \\
\text { Pore Fluid }\end{array}$ & $\begin{array}{l}\text { Lab Prms. } \\
\text { Pore Fluid }\end{array}$ & Lab Prms. & Lab Prms. & Lab Prms. & Lab Prms. & $\begin{array}{l}\text { Lab Prms. } \\
\text { Pore Fluid }\end{array}$ & Lab Prms. & Lab Prms. \\
\hline 6 PV MZVI & - & -- & Lab Prms. L & Lab Prms. L & Lab Prms. & Lab Prms. & Lab Prms. & Lab Prms. & Lab Prms. & Lab Prms. & Lab Prms. \\
\hline 9 PV MZVI & - & -- & $\begin{array}{c}\text { Lab Prms. } \\
\text { Pore Fluid } \\
\text { Soil }^{D}\end{array}$ & $\begin{array}{l}\text { Lab Prms. } \\
\text { Pore Fluid }\end{array}$ & $\begin{array}{l}\text { Lab Prms. } \\
\text { Pore Fluid }\end{array}$ & Lab Prms. & Lab Prms. & Lab Prms. & $\mid \begin{array}{c}\text { Lab Prms. } \\
\text { Pore Fluid } \\
\text { Soil }^{\mathrm{D}}\end{array}$ & $\begin{array}{l}\text { Lab Prms. } \\
\text { Pore Fluid }\end{array}$ & Lab Prms. \\
\hline 12 PV MZVI & - & - & -- & Lab Prms. & Lab Prms. & Lab Prms. & Lab Prms. & Lab Prms. & -- & Lab Prms. & Lab Prms. \\
\hline 15 PV MZVI & -- & -- & -- & $\begin{array}{c}\text { Lab Prms. } \\
\text { Pore Fluid } \\
\text { Soil }\end{array}$ & $\begin{array}{l}\text { Lab Prms. } \\
\text { Pore Fluid }\end{array}$ & $\begin{array}{l}\text { Lab Prms. } \\
\text { Pore Fluid }\end{array}$ & Lab Prms. & Lab Prms. & -- & $\begin{array}{l}\text { Lab Prms. } \\
\text { Pore Fluid }\end{array}$ & $\begin{array}{l}\text { Lab Prms. } \\
\text { Pore Fluid }\end{array}$ \\
\hline 20 PV MZVI & - & - & -- & -- & Lab Prms. & Lab Prms. & Lab Prms. & Lab Prms. & -- & Lab Prms. & Lab Prms. \\
\hline 30 PV MZVI & - & -- & -- & -- & $\begin{array}{c}\text { Lab Prms. } \\
\text { Pore Fluid } \\
\text { Soil }^{\mathrm{D}}\end{array}$ & $\begin{array}{l}\text { Lab Prms. } \\
\text { Pore Fluid }\end{array}$ & $\begin{array}{l}\text { Lab Prms. } \\
\text { Pore Fluid }\end{array}$ & Lab Prms. & -- & $\begin{array}{c}\text { Lab Prms. } \\
\text { Pore Fluid } \\
\text { Soil }\end{array}$ & $\begin{array}{l}\text { Lab Prms. } \\
\text { Pore Fluid }\end{array}$ \\
\hline 1 PV GW & -- & -- & - & -- & -- & $\begin{array}{c}\text { Lab Prms. } \\
\text { Pore Fluid } \\
\text { Soil }\end{array}$ & $\begin{array}{l}\text { Lab Prms. } \\
\text { Pore Fluid }\end{array}$ & $\begin{array}{l}\text { Lab Prms. } \\
\text { Pore Fluid }\end{array}$ & - & -- & Lab Prms. \\
\hline 5 PV GW & -- & -- & -- & -- & -- & -- & Lab Prms. & Lab Prms. & - & -- & Lab Prms. \\
\hline 10 PV GW & -- & - & - & -- & - & -- & $\mid \begin{array}{c}\text { Lab Prms. } \\
\text { Pore Fluid } \\
\text { Soil }^{D}\end{array}$ & $\begin{array}{l}\text { Lab Prms. } \\
\text { Pore Fluid }\end{array}$ & -- & -- & $\begin{array}{l}\text { Lab Prms. } \\
\text { Pore Fluid }\end{array}$ \\
\hline 15 PV GW & -- & -- & -- & -- & -- & -- & -- & Lab Prms. & -- & -- & Lab Prms. \\
\hline 20 PV GW & -- & -- & -- & -- & - & -- & -- & $\begin{array}{c}\text { Lab Prms. } \\
\text { Pore Fluid } \\
\text { Soil }\end{array}$ & -- & -- & $\begin{array}{c}\text { Lab Prms. } \\
\text { Pore Fluid } \\
\text { Soil }^{\mathrm{D}}\end{array}$ \\
\hline \multicolumn{3}{|c|}{ Total Lab Parameter Measurements } & & & & & & 61 & & & 25 \\
\hline \multicolumn{3}{|c|}{ Total Pore Fluid Sample Analyses } & & & & & & 21 & & & 10 \\
\hline \multicolumn{3}{|c|}{ Total Soil Sample Analyses } & & & & & & 12 & & & 5 \\
\hline \multicolumn{12}{|c|}{$\begin{array}{l}\text { (d) Duplicate samples will be collected for these soil samples for quality assurance purposes. } \\
\text { - Flow cell used for soil sample, no longer available for effluent sampling. } \\
\text { PV = Pore Volume } \\
\text { GW = Groundwater } \\
\text { Lab Prms. = Laboratory parameters including pH, ORP, conductivity, dissolved oxygen, temperature }\end{array}$} \\
\hline
\end{tabular}




\subsection{Data Reduction and Analysis}

Data from each sampling event will be compiled into a database for this project. The database will include a record of all paper copies of sampling records, chain of custody sheets, and analytical laboratory reports. It will also include the project laboratory logbook and instrument calibration records. In addition to the paper copies of the data, all numerical values obtained from the testing will be entered into an electronic spreadsheet for further analysis.

For each sampling event, an appropriate statistic describing the data (i.e., average with standard deviation) will be calculated for each parameter. These values will be plotted as functions of pore volumes injected. Additionally, data from the MZVI/polymer Injection Flow Cells will be compared to the data form the Experimental Control Flow Cells to determine if significant changes to the geochemistry and permeability are occurring.

\section{$2.7 \quad$ Reporting}

Methodologies and results from the laboratory testing will be included in the Treatability Test Plan (Task 4), along with the laboratory scale parameters needed to design a field injection system. Other information that will be included in the laboratory-testing portion of the Treatability Test Plan will include the laboratory Quality Assurance (QA) report and any photographs taken during the laboratory setup and testing. 


\section{PROCEDURES}

Procedures for constructing and packing the flow cells, establishing steady state equilibrium flow and pressure conditions, taking measurements, and collecting water and soil samples are outlined in this section. If, during the execution of any of these procedures, a better procedure or procedures are discovered, which are more efficient and/or cost effective and produce the desired quality and results, the new procedure or procedures shall be documented, approved, and implemented.

\subsection{Test Setup}

Detailed drawings of the flow cells and laboratory setup are shown in Figure 1. The laboratory testing will be conducted using MZVI/polymer Injection Flow Cells and Experimental Control Flow Cells packed with Ringold Unit E soils from the 100-D Area and the Permeability Testing Cells packed with 12/20 Accusand. The flow cells and permeability testing cells will be connected to a series of pumps to provide controlled injection of the MZVI/polymer mixture and synthesized groundwater through the packed flow cells. MZVI/polymer mixture will not be injected into the Experimental Control Flow Cells; these cells will only have the synthesized groundwater injected through them.

The MZVI/polymer mixture will be maintained in a tank with a mixing system designed to keep the $\mathrm{MZVI}$ in suspension in the polymer. Flow cell effluent will be discharged to a common waste tank were the polymer can break down. Excess water will be allowed to evaporate from the tank to reduce the amount of waste material requiring disposal (primarily due to the chromium in the water).

\subsubsection{Flow Cell Preparation}

The MZVI/polymer Injection Flow Cells and Experimental Control Flow Cells will be constructed using 5.08-cm (2-inch) nominal diameter by $60-\mathrm{cm}$ long clear PVC pipe. The Permeability Testing Cells will be constructed from $7.62-\mathrm{cm}(3.0$-inch) nominal diameter by 1 -meter long clear PVC pipe. The ends of each flow cell will be fit with threaded couplings and the couplings will be connected to an injection system at the inlets and effluent drainage system at the outlets. The flow cells will also be fit with sight glasses (manometers) at each end for monitoring head loss across the flow cells.

The flow cells will be maintained in a horizontal position during the injection simulations to representatively simulate the injection process and the settling of MZVI out of suspension due to gravity.

\subsubsection{Flow Cell Materials}

The materials required for preparation of each flow cell includes the following:

1. 1 length of $5.08-\mathrm{cm}(2.0$-inch) nominal diameter by $60-\mathrm{cm}$ (23.62-inch) long clear PVC pipe;

2. 2 5.08-cm (2-inch) PVC NPT Female $x$ socket-weld pipe adapters;

3. 2 5.08-cm (2-inch) $\times 2.54-\mathrm{cm}$ (1-inch) PVC reducing bushings (male $\times$ female);

4. 2 2.54-cm (1-inch) PVC ball valves; 
5. 2 coarse-meshed screens measuring approximately $5.08-\mathrm{cm}$ (2-inch). The screens will be properly sized to permit the flow of the MZVI and synthesized groundwater, while ensuring that the density and volume of placed Ringold $E$ soil does not change significantly during filling and saturation of the flow cells;

6. 2 sight glasses (manometers) measuring approximately $1.0-\mathrm{cm}$ in diameter and $20-\mathrm{cm}$ long installed at each end of the flow cell;

7. 2,300 grams of Hanford Ringold E soils sieved to eliminate all greater than $25.4 \mathrm{~mm}$ particles;

8. PVC Cement and Teflon tape.

\subsubsection{Permeability Testing Cell Materials}

The materials required for preparation of each permeability testing cell includes the following:

1. 1 length of $7.62-\mathrm{cm}$ (3.0-inch) nominal diameter by $100-\mathrm{cm}(39.37-\mathrm{inch})$ long clear PVC pipe;

2. 2 7.62-cm (3.0-inch) PVC NPT Female $x$ socket-weld pipe adapters

3. 2 7.62-cm (3.0-inch) $\times 2.54-\mathrm{cm}$ (1-inch) PVC reducing bushings (male $\times$ female);

4. 2 2.54-cm (1-inch) PVC ball valves;

5. 2 coarse-meshed screens measuring approximately $7.62-\mathrm{cm}(3.0-i n c h)$ in diameter. The screens will be properly sized to permit the flow of the MZVI and synthesized groundwater, while ensuring that the density and volume of placed Accusand does not change significantly during filling and saturation of the flow cells;

6. 2 sight glasses (manometers) measuring approximately $1.0-\mathrm{cm}$ in diameter and $20-\mathrm{cm}$ long installed at each end of the flow cell;

9. 2,300 grams of 12/20 Accusand

7. PVC Cement and Teflon tape.

\subsubsection{Flow and/or Permeability Cell Construction}

The flow cells or permeability testing cells are constructed using the same procedures with the appropriate materials listed in Sections 3.1.1.1 and 3.1.1.2. The construction procedures are as follows:

1. Secure PVC NPT Female $x$ socket-weld pipe adapters to both ends of clear PVC pipe using PVC cement;

2. Drill and tap holes for sight glasses in the pipe adapters $(60-\mathrm{cm}$ spacing for flow cells or $100-\mathrm{cm}$ spacing for permeability testing cells);

3. Place duct tape over sight glass (manometer) tube holes;

4. Place one screen against inside face of busing and insert into pipe adapter at one end of the flow cell and secure it firmly using Teflon tape to create a seal;

5. Insert PVC ball valve into busing using Teflon tape to seal;

6. Assemble remaining ball valve and busing assembly for installation following the filling of the cell with either soil or Accusand. 


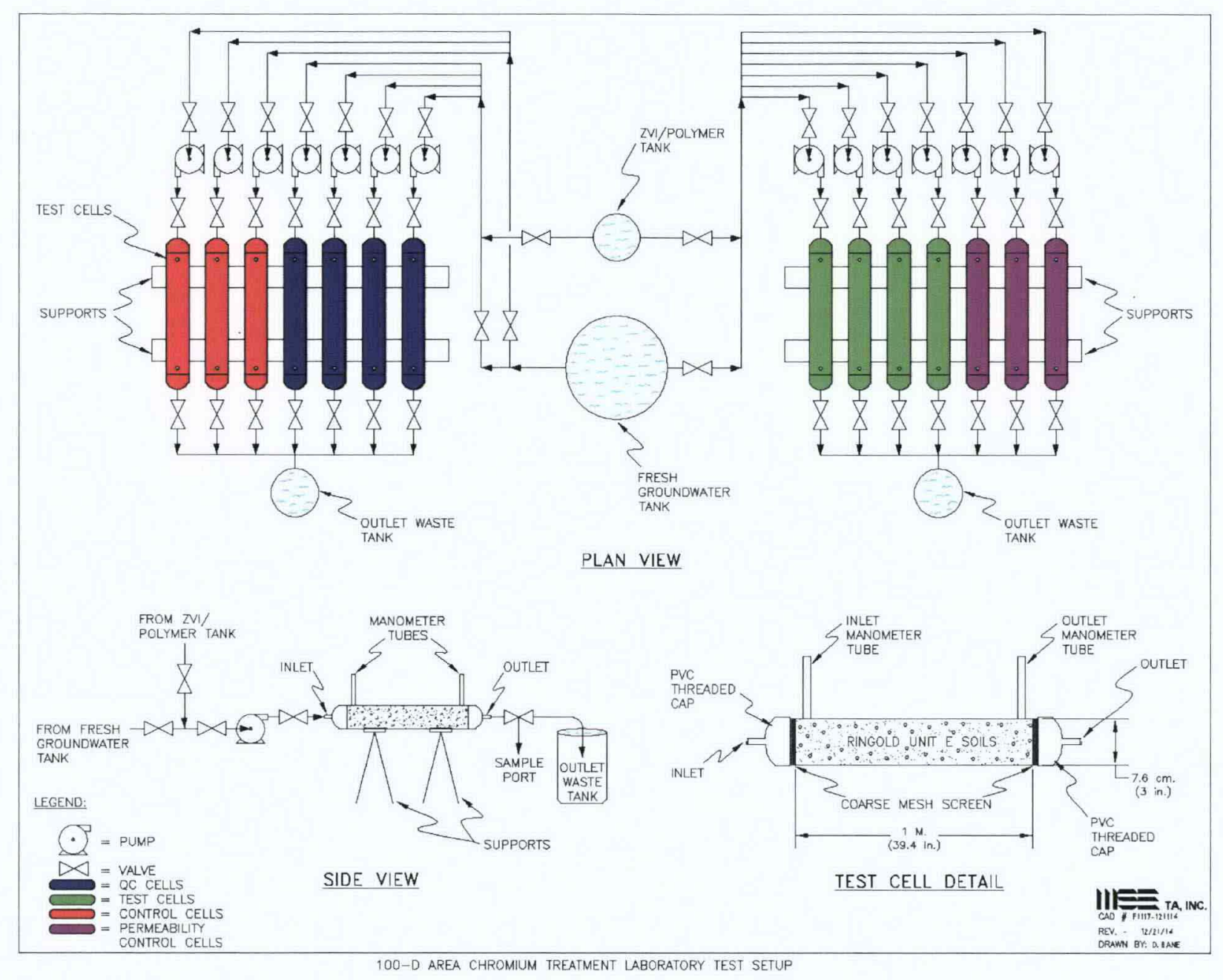

Figure 1. Layout of laboratory setup.

\subsubsection{Flow and/or Permeability Cell Packing Equipment}

Preparation of the flow and/or permeability cells will require the following laboratory equipment.

1. Scale for weighing soil (needs to have a $15 \mathrm{~kg}$ capacity)

2. Vibrating table for packing columns

3. Miscellaneous hand tools.

\subsubsection{Flow Cell Packing Procedures}

1. Inspect the flow cell prior to filling, making sure any soil, residue, etc. is removed;

2. Make initial measurements of the inside diameter and length of the clean and empty flow cell and the length between the centerline of the two sight glasses (manometers). Record measurements in the logbook;

3. Weigh clean and empty flow cell prior to filling (tare weight). Record tare weight in the logbook; 
4. Split off representative approximately 2,300 gram sample of either Hanford Ringold E soils or Accusand as appropriate for the type of cell being constructed;

5. Begin pouring the pre-weighed Hanford Ringold E soils or Accusand slowly into the flow cell while continuously vibrating the flow cell on a vibrating table. Fill the flow cell until the soil/sand is flush with the lip of the flow cell;

6. Secure the second screen firmly against the inside of the second busing;

7. Thread the second busing onto the open end of the cell;

8. Weigh the assembled and packed cell. Record weight of packed cell in the logbook.

\subsection{Preparation of Synthetic Groundwater}

The synthetic groundwater that will be used for equilibration of the flow cells and for injecting into the flow cells following the MZVI/polymer injections will be prepared according to the following procedures.

\subsubsection{Synthetic Groundwater Materials}

The types and amounts of chemical reagents listed in the Table 5 will be used to formulate 1,900 liters ( 500 gallons) of synthetic groundwater that will mimic the geochemical makeup of the 100-D Area groundwater. The reagents will be mixed and allowed to dissolve in 1,900 liters of deionized (DI) water. The container will have the headspace purged with nitrogen to prevent the oxidation of iron, which in turn could affect the stability of the hexavalent chromium.

Table 5. Reagents for 1,900 Liters of Synthetic Hanford 100-D Area Groundwater.

\begin{tabular}{|l|l|l|}
\hline Reagent & Mass & Units \\
\hline $\mathrm{AlCl}_{3} \bullet \mathrm{H}_{2} \mathrm{O}$ & 0.7600 & grams \\
\hline $\mathrm{CaCl}_{2}$ & 95.00 & grams \\
\hline $\mathrm{CaCO}_{3}$ & 190.0 & grams \\
\hline $\mathrm{CaSO}_{4}$ & 152.0 & grams \\
\hline $\mathrm{K}_{2} \mathrm{Cr}_{2} \mathrm{O}_{7}$ & 0.5320 & grams \\
\hline $\mathrm{KCl}$ & 17.10 & grams \\
\hline $\mathrm{FeSO}_{4} \bullet 7 \mathrm{H} 2 \mathrm{O}$ & 1.292 & grams \\
\hline $\mathrm{MgSO}_{4} \bullet 7 \mathrm{H} 2 \mathrm{O}$ & 380.0 & grams \\
\hline $\mathrm{Na}_{2} \mathrm{HPO}_{4} \bullet 7 \mathrm{H} 2 \mathrm{O}$ & 1.900 & grams \\
\hline $\mathrm{NaHCO}_{3}$ & 95.00 & grams \\
\hline $\mathrm{NaNO}_{3}$ & 62.70 & grams \\
\hline
\end{tabular}

\subsubsection{Synthetic Groundwater Preparation Equipment}

1. 2,000-liter (500-gallon) polyethylene tank;

2. High Purity Nitrogen;

3. Stirring Apparatus.

\subsubsection{Synthetic Groundwater Preparation Procedures}

The following steps will be followed to develop the synthetic groundwater. 
1. Add 1,900 liters of deionized water to the 2,000 -liter polyethylene tank, and set up stirring apparatus.

2. Begin nitrogen flow into the headspace of the container.

3. Accurately weigh out each of chemical reagent in Table 5 and set aside. Weighing and mixing the $\mathrm{K}_{2} \mathrm{Cr}_{2} \mathrm{O}_{7}$ will be completed using a fume hood.

4. Transfer each weighed portion of reagent to the 2,000-liter tank filled with 1,900 liters of DI water while stirring.

5. Allow soluble salts to dissolve before addition of the moderately soluble salts (i.e. $\mathrm{CaCO}_{3}$ and $\mathrm{CaSO}_{4}$ ).

6. After all the reagents have appeared to dissolve, check the solution $\mathrm{pH}, \mathrm{Eh}$, dissolved oxygen and conductivity.

7. After more than 24 hours (assuming mixture is at equilibrium) recheck the solution $\mathrm{pH}$, ORP, dissolved oxygen and specific conductance. Solution $\mathrm{pH}$ and alkalinity may be adjusted if necessary by varying the amount of $\mathrm{NaHCO}_{3}$ added to the solution. Submit a sample for laboratory analysis of chemical constituents.

\subsection{Preparation of MZVI/Polymer Mixture}

The MZVI/Polymer mixture selected by MSE should be handled and prepared according to the procedures outlined in the following section. Based on previous laboratory work conducted using a mixture with similar proportions as the mixture proposed by MSE (Oostrom et al. 2005) and based on discussions with technical personnel at K.B. International LLP (SlurryPro® CDP ${ }^{\mathrm{TM}}$ manufacturer), we do not anticipate any incompatibilities between the S-3700 MVZI and SlurryPro CDP. The MZVI will require handling and preparation procedures that minimize or prevent oxidation of the iron prior to injection into the soils.

\subsubsection{Materials}

The materials required for preparation of the MZVI/Polymer mixture includes the following:

1. Micropowder® Iron S-3700 (International Specialty Products, Wayne, NJ):

- 10 grams per liter of MZVI/polymer mixture that will be prepared;

2. Aerosol (Sigma Chemical, St. Louis, MO):

- 0.01 grams per liter of MZVI/polymer mixture that will be prepared;

3. SlurryProß $C D P^{T M}(K B$ International LLP, Houston, $T X)$ :

- 0.2 grams per liter of $\mathrm{MZVI} /$ polymer mixture that will be prepared;

4. Nitrogen or Argon inert gas;

5. Fresh/tap water:

- Amount of water should be equal to the number of liters of $\mathrm{MZVI} /$ polymer mixture that will be prepared.

\subsubsection{Equipment}

1. 2,000-liter (500-gallon) polyethylene mixing tank;

2. 3 Clamp-on portable mixers.

3. Scale (10 kg capacity) 


\subsubsection{Procedures}

The MZVI/polymer preparation will follow the procedures outlined in Oostrum et al, 2005. All testing will be conducted with a $1 \%$ by-weight iron-concentration colloid-suspension containing a $0.001 \%$ aerosol (Sigma Chemical, St. Louis, MO) surfactant. The $\mathrm{Fe}^{0}$ particles will be dispersed in the surfactant before the polymer is added.

MSE is assuming that a nitrogen blanket will be required to keep the MZVI from oxidizing prior to injection.

1. Install 2 clamp-on portable mixers in the 2,000-liter (500-gallon) tank and add appropriate amount of fresh tap water

2. Record specific conductance, and $\mathrm{pH}$ of water.

3. In a well ventilated area, measure Micropowder@ Iron S-3700 and aerosol and pour into the 2,000-liter (500-gallon) mixing tank containing the fresh tap water while continuously mixing the water;

4. Add the SlurryPro ${ }^{\circledR} C D P^{T M}$ at a rate suggested by KB International LLP to the 2,000 -liter (500-gallon) mixing tank containing the fresh tap water, Micropowder® Iron S-3700 and aerosol while continuously mixing;

5. Continuously mix contents and record specific gravity, viscosity and pH until mixture is within mixing tolerances.

\subsection{Laboratory Testing Procedures}

The laboratory testing include the injection procedures for both the synthetic groundwater and the MZVI/polymer mixture, sampling and laboratory parameter measurements of the effluent from the columns, sampling of the soils in the columns, and performing the constant head tests.

\subsubsection{Effluent Sampling}

Samples of the effluent for laboratory testing will be obtained from the effluent sampling ports included in the test apparatus. The effluent samples will be collected in properly labeled sample containers provided by the MSE Analytical Laboratory and preserved according to the laboratory directions. The sampling containers shall be rinsed three times using effluent prior to collecting the sample. The rinsate shall be properly disposed in the effluent waste tank.

\subsubsection{Soil Sampling}

Soil samples will be obtained from designated flow cells by isolating and removing the flow cell from the system. Once the flow cell has been removed, the end plug will be unscrewed and the soils emptied into a clean mixing tub and mixed to form a homogeneous composite sample. An appropriate amount of sample will be removed from the composite sample and placed into a labeled sample container. The soil sample will be immediately transferred to the MSE Analytical Laboratory for analysis.

\subsubsection{Sample Identification}

The sample labels will list the project sample number, data and time of sampling, sampler's name, and the analyses that are to be run on the sample. The effluent-sample identification system is shown in Table 6 . The effluent sample will be immediately transferred to the MSE Analytical Laboratory for analysis. 
Table 6. Effluent-sample identification system.

\begin{tabular}{|l|l|l|l|l|}
\hline Project Name & Matrix & Flow Cell Group & Flow Cell Number & Sample Event \\
\hline MZVI & $\begin{array}{l}\text { SOIL - SOIL } \\
\text { EFFLUENT - EFF }\end{array}$ & $\begin{array}{l}\text { Primary - 1 } \\
\text { Control - 2 } \\
\text { Permeability - 3 }\end{array}$ & $\begin{array}{l}\text { 01, 02, 03, 04, etc. } \\
\text { Use 2 digit format }\end{array}$ & $\begin{array}{l}01,02,03, \ldots . . \\
\text { Use 2 digit format }\end{array}$ \\
\hline Example Sample Numbers & $\begin{array}{l}\text { Second sampling event } \\
9 \text { PV MZVI Effluent Sample }\end{array}$ \\
\hline - Primary flow cell group, cell 2 & MZVI-EFF-10202 \\
\hline - Control flow cell group, cell 1 & MZVI-EFF-20102 \\
\hline - Permeability flow cell group, cell 3 & MZVI-EFF-30302 \\
\hline
\end{tabular}

\subsubsection{Permeability Testing and Continuous Head Differential Measurement Procedures}

Continuous head differential measurements will be made throughout the testing using the permeability testing flow cells. In addition to these continuous head differential measurements, head differentials will be measured across each of the primary and control flow cells using the installed manometer tubes. These head differentials will be recorded at the same times as effluent samples are collected for either laboratory analysis or for laboratory parameter analysis.

Permeability values will be calculated from the head differentials for the data prior to injection of the $\mathrm{MZVI} /$ polymer and for the data obtained following the injections. Data obtained during the $\mathrm{MZVI/polymer} \mathrm{injection} \mathrm{will} \mathrm{be} \mathrm{analyzed} \mathrm{separately} \mathrm{from} \mathrm{the} \mathrm{pre} \mathrm{and} \mathrm{post} \mathrm{injection} \mathrm{data} \mathrm{because}$ the MZVI/polymer mixture may behave as a non-Newtonian fluid and therefore the head differentials measured during the $\mathrm{MZVI} /$ polymer injection phase will not be comparable to the data obtained during the groundwater injection phase. The head differential data obtained during the $\mathrm{MZVI} /$ polymer injection may provide important information for the numerical modeling and field-injection system design and therefore will be recorded.

Head differentials will be measured using two methods: differential pressure transducers connected to data loggers; and manual reading of the manometers. The 6-inch flow cell will be connected to an existing set of pressure differential transducers and data logging system located in the MSE Experimental Laboratory. The system will be started at the beginning of the testing and run continuously during the entire testing period. Flow will also be recorded on the data loggers. Manual measurements will be made by inspection for the manometers on each of the flow cells and the data recorded to the nearest millimeter. The number of pore volumes that have been injected through the flow cells at this time will also be recorded.

\subsection{Waste Handling}

All waste will be handled in accordance with all applicable federal, state, and local regulations and facility waste handling procedures. 


\section{NUMERICAL MODELING}

\subsection{Modeling Objectives}

The objective of the modeling efforts is to use a numerical model to predict the behavior of iron injection into a high conductivity channel in the ISRM barrier. The goals of this task will be to approximate the maximum distance iron can be injected from a single point, the concentration of iron 7 meters from injection (assuming it can be communicated to that distance), and dilution of the polymer under field hydrologic conditions. A flow and solute transport model PORFLOW ${ }^{\mathrm{TM}}$ Version 5 will be used to accomplish these objectives.

\subsection{PORFLOW ${ }^{\mathrm{TM}}$ Synopsis}

PORFLOW ${ }^{\mathrm{TM}}$ is a general purpose software developed by Analytic \& Computational Research, Inc. (ACRI 1999) for simulation of transient or steady-state multiphase fluid flow, heat, salinity, and mass transport in multiphase, variably saturated, porous or fractured media with dynamic phase change. The geometry of the modeled domain may be structured or unstructured, 2D, 3D, Cartesian, or cylindrical. The media modeled may be heterogeneous and anisotropic. Injection or pumping sources may be present, and chemical reactions or radioactive decay may take place. From the numerical point of view, PORFLOW ${ }^{\mathrm{TM}}$ is a hybrid of a finite volume with a finite element mesh code written in FORTRAN.

PORFLOW ${ }^{\top M}$ has a Graphical User Interface (GUI), a preprocessor for entering geometry, boundary conditions, and flow, transport, and dynamic phase change relationships. A postprocessor, AcrPLOT, generates charts, flow vectors, contours, grids, 3D surface plots, and $X-Y$ cross-sections at any direction.

\subsection{Modeling Approach and Data Sources}

The modeling efforts using PORFLOW ${ }^{\mathrm{TM}}$ will focus on simulating the flow field in an aquifer (saturated medium) affected by injection of a polymer laden with the MZVI. Two separate models will be created for wells 199-D4-26 and 199-D4-37, respectively. Although, the model domain for each well will be different to reflect hydrogeologic conditions at each location, the technical approach to the modeling and general assumptions will be the same. Both are described in the following sections.

\subsubsection{Modeling Domain}

The model will encompass a "block" of the unconfined aquifer around the injection well. This domain will be discretized in the vertical direction in the manner that reflects geological and hydrogeologic stratification as recorded in the borehole log for the given injection well, and the results of subsequent investigations reported by Waldrop and Waldrop, (2004). Other available reports, documents and publication will be examined to assign appropriate values of hydraulic parameters for each stratum including an anisotropy ratio for horizontal to vertical hydraulic conductivity values. In case of a lack of site-specific information, well-documented values for similar sites will be used. All strata will be horizontal and continuous throughout the domain, i.e. they will have a uniform thickness within the horizontal extent of the modeling domain.

The horizontal extent of the domain will be set far enough so that the domain boundaries do not interfere with the cone of "impression" created by injection activities. Discretization of the model domain in the horizontal plane will be dictated by hydraulic parameters of strata and numerical requirements of PORFLOW ${ }^{\mathrm{TM}}$ to converge to the defensible solution using appropriate tolerance criteria. 


\subsubsection{Flow Field}

To minimize the undesired spreading of the MZVI laden polymer in the aquifer due to the regional groundwater flow system, the actual field injection activities are scheduled for the month of July when, due to high water stages in the Columbia River, the groundwater table is relatively flat. This timing of the field implementation allows modeling the injection processes set in a flow field that is affected only by the injection itself. Such modeling is most efficiently conducted using a radially symmetric flow set within a cylindrical coordinates system. Modeling using cylindrical coordinates provides a 3-dimensional (3D) flow field (the feature especially important for simulation of injection processes through a well) using significantly less central processing unit (CPU) time. Consequently, within the same period, more alternative injection scenarios can be simulated for a model that uses cylindrical coordinates than for those models that use 3D Cartesian coordinate systems.

\subsubsection{Solute Transport}

The modeling will consider transport of two substances within the model domain, the MZVI laden polymer, and the MZVI itself.

Concentrations of the MZVI laden polymer in groundwater will be simulated using PORFLOW ${ }^{\top M}$ capabilities of handling flow of miscible fluids of different density and viscosity. This will require entries of values for the longitudinal and transversal (in vertical direction) coefficients of hydrodynamic dispersion for the porous medium modeled. Also required for the modeling will be values for the diffusion coefficient of the shear-thinning fluid containing polymers in groundwater. If data supporting functional relationship of the diffusion coefficient and the flow velocity of the shear-thinning fluid containing polymer exist, such a relationship will be included in the modeling process. Similarly, the functional relationship of viscosity of the shear-thinning fluid containing polymer and the flow velocity will be modeled, if supporting data exist. PORFLOW ${ }^{\mathrm{TM}}$ is capable of utilizing such relationships for its calculation if they (the relationships) are defined in the input file either as a table or as a mathematical function.

PORFLOW ${ }^{\top M}$ will calculate the concentration of MZVI in the polymer, and thus the concentration of iron that falls out of the polymer, using a pseudo-solute-transport approach. This is because even micro-size particles of iron behave in the fluid more like solids than dissolved constituents. Nevertheless, a pseudo-isotherm approach will be used to quantify the relationship of the rate that iron particles fall out of the polymer, and the flow velocity of the polymer, as well as its viscosity at given locus of the model domain and the duration of injection. Such relationships will be defined based on tabulated data for column experiments reported in the report by Oostrom et al, (2005). We are proposing using multivariable regression analysis of measurements reported by Oostrom to develop the pseudo-isotherms. It is also expected that laboratory experiments conducted for Task 2 of this project may provide useful information for defining those pseudoisotherms.

\subsubsection{Modeled Scenarios}

The model will be run for several scenarios. The number of scenarios will depend on the CPU time needed for each simulation and the available project budget. Our overall plan is to model a single well injection setup over a range of injection rates and hydraulic parameters of the aquifer. We propose to use hydraulic parameters of the aquifer indicated by the available data and bracket them rather than just include one additional set of parameters.

\subsubsection{Model Description}

Output options that will be used to present the modeling results include concentration iso-lines, flow lines (flow vectors), and time verses concentration $X-Y$ plots. 


\subsubsection{Limitations}

All models developed as described above will be quantitative, though conceptual in their nature. This is because there is no field data that could be used for calibration of these models. If such data were discovered during the setup process of the model, we would consider using it for this purpose. Nevertheless the model will be essential for setting injection parameters and selection of the equipment to be used. We are cognizant that it should be possible to calibrate the model after the injection is completed. However, these efforts are not included in the scope of work for this project. The "appropriateness" of our model, due to the lack of calibration data, it will be based on our professional judgment and the assistance of reasonable and competent reviewers. 


\section{HEALTH AND SAFETY}

Experiments presented in this test plan will be conducted in the Experimental Laboratory at the MSE Testing Facility. All activities shall be conducted in accordance with MSE's Chemical Hygiene Plan (CHP) and MSE's Hazard Communication Program, as documented in the MSE Health and Safety Program Manual, Part 8, Section 6; and Section 1; respectively. The MSE Health and Safety Director (Scott Nuthak) will serve as the Chemical Hygiene Officer (CHO) and Charlie Brown will serve as the Environmental Coordinator for this project. Material Safety Data Sheets (MSDS) for all chemicals used in the experiments will be kept on file in the laboratory and shall be readily available throughout the project duration. All containers shall be properly labeled with their content and hazard.

\subsection{Hazardous Materials}

Table 7 identifies chemicals that will be used in the preparation of the synthetic groundwater and/or for sample preservation. It is imperative that all personnel follow safe laboratory practices, practice good personal hygiene, and don appropriate personal protective equipment (PPE). Personnel will be required to review this Safety Plan and acknowledge that they will abide by it. At no time, will personnel safety and health be compromised for testing. If a task cannot be performed safely, it will not be performed. Industrial Hygiene monitoring will be performed at the discretion of the CHO. Chrome ${ }^{6+}$ is listed in OSHA's Toxic and Hazardous Substance List, 29 CFR 1910, Subpart 2. As such, contact the $\mathrm{CHO}$ prior to handling $\mathrm{Cr}^{6+}$. Monitoring may be required if any dust is generated.

Table 7. Hazardous materials and exposure/physical data.

\begin{tabular}{|l|l|l|l|}
\hline Chemical & PELTLV & H-F-R & Hazards \\
\hline MZVI & $5 \mathrm{mg} / \mathrm{M}^{3}$ & $1-1-1$ & Irritant \\
\hline Polymer & $5 \mathrm{mg} / \mathrm{M}^{3}$ & $1-0-1$ & Irritant \\
\hline Chrome 6+ & $2.5 \mu \mathrm{g} / \mathrm{M}^{3}$ & $3-0-1$ & Oxidizer, irritant, kidneys, respiratory system \\
\hline $\begin{array}{l}\text { PELTLV = Permissible exposure limit/threshold limit value } \\
\text { H-F-R = Health - Fire - Reactivity Ratings }\end{array}$ \\
\hline
\end{tabular}

\subsection{Engineering Controls}

Engineering controls shall be used where appropriate. These include catch basins designed to contain any spillage, laboratory fume hoods, and proper grounding on all electrical equipment.

\subsection{Administrative Controls}

A general test area will be demarcated for this project within the MSE Experimental Laboratory building and restricted to project personnel only. Proper chemical storage that includes separating incompatibles will be practiced. Chemicals shall not be left out of their respective storage cabinets.

Personnel shall practice good personal hygiene at all times. This includes, no eating, smoking, chewing gum, chewing tobacco, or drinking in the test area: hands shall be washed thoroughly after removing protective gloves and before leaving the test area; and hands shall be kept away from the eyes and face when wearing protective gloves. Eating and drinking shall only be allowed in the break area of the building. Smoking is prohibited inside the building. 


\subsection{Personal Protective Equipment}

Standard laboratory protective equipment includes: laboratory coat, safety glasses, and impervious latex or neoprene gloves.

\subsection{First Aid and Emergency Response}

During any emergency event, consult the MSDS as necessary. However, in any case of chemicals contacting unprotected skin or eyes, flush with water for a minimum of 15 minutes. During that time, someone shall dial "333" and request an ambulance. The emergency eyewash/shower is located within 30 feet of the laboratory hood. In the event of an inhalation exposure, get to fresh air and someone shall dial 333. Nobody should attempt to rescue a person down if bad air is suspected, unless the $\mathrm{CHO}$ gives approval to enter based on air monitoring. The emergency brigade shall be requested with self-contained breathing apparatus (SCBAs), as appropriate. The use of PPE, the laboratory hood, good personal hygiene, and safe work procedures should prevent exposures from occurring via inhalation, ingestion, and absorption. The potential for injection hazards is not likely, given the nature of work.

In the event of a spill or fire that risks personnel, evacuate the building and dial 333. Only qualified personnel equipped with SCBAs should attempt to extinguish incipient-stage fires that involve hazardous chemicals. The $\mathrm{CHO} /$ Emergency Coordinator shall only authorize re-entry.

In the event of spills, absorbing materials are provided in the building, including the sorbents used in the experiments. Additionally, chemical quantities are very small. All spills shall be reported to the $\mathrm{CHO}$ and actions shall be taken to minimize spillage, area contamination, and personnel exposure.

Any chemical wastes generated will be disposed of in accordance with applicable state regulations per the MSE Environmental Coordinator. 


\section{QUALITY CONTROL AND QUALITY ASSURANCE}

\subsection{Quality Control}

Quality control will be maintained during the laboratory testing through test setup replicates, sample splits, and blanks. Quality control for the analytical laboratory analysis will be according to the MSE Analytical Laboratory quality control procedures.

The test design includes a significant number of process replicate samples for each sampling event (i.e., multiple flow cells). Additionally, there will be sample splits randomly acquired from individual flow cells over the course of the laboratory testing. The sample splits will include one soil sample split and three pore fluid sample splits (one from each set of flow cells). The relative percent difference (RPD) for each set of sample splits will be calculated; results must be within $+/-15 \%$. Laboratory parameters (i.e., pH, ORP, etc) will be based on three independent measurements per sampling event. The average value and standard deviation of the three measurements will be reported.

The system temperature will be monitored to ensure that is within the expected field conditions of 15 to $18^{\circ} \mathrm{C}\left(60\right.$ to $\left.65^{\circ} \mathrm{F}\right)$. The experimental laboratory temperature is maintained in this range.

\subsection{Quality Assurance}

Quality assurance will include reviewing all relevant laboratory documentation to ensure procedures are followed and the results are within the acceptable quality limits of the project. This will include reviewing all planning documents, material specifications, test equipment designs and specifications, personnel qualifications, equipment calibration records, and quality control sample results.

\subsubsection{Documentation}

Documentation that will be reviewed includes the laboratory test plan, experimental laboratory project logbook, and the analytical laboratory reports.

\subsubsection{Software Control}

The specialized software identified by MSE to be used for the Testing Micron-Size Iron Injection For Mending An Existing Permeable Reactive Barrier project, includes PORFLOW ${ }^{\mathrm{TM}}$ Version 5.0. The PORFLOW ${ }^{T M}$ software is commercially available. The MSE Corporate Software Process addresses management and control of the PORFLOWTM software, which is under the oversight of our Information Technology Services Group. Among the requirements of this process are: the company purchases only licensed software, software is tracked internally to be in compliance with license requirements and periodically software audits are done to ensure that software is installed where records indicate it is and being used as intended.

The identification of errors in the output of the software is managed under the project specific Quality Assurance Plan (QAP), which is part of the Design and Development process. As determined by the quality level described in the QAP, the accuracy of the results of the analysis performed by the software will receive Independent Technical (peer) Review by a qualified staff member. If errors are detected, the vendor recommended process for analyzing the sources of error will be implemented, new results produced and the Independent Technical Review performed again. Records of the Independent Technical Review are kept as part of the requirements of the Quality Management System. 


\subsubsection{Material Specifications}

The materials specifications include materials specified for the testing apparatus, any chemicals used to prepare the synthetic groundwater, and any consumable items required for sampling. The material specifications are listed in Section 3 Procedures.

\subsubsection{Test Equipment Designs and Specifications}

The test equipment designs and specifications are listed in Section 3 Procedures.

\subsubsection{Test Equipment Calibration}

The test equipment will be calibrated according to manufactures specifications and frequency prior to and during the testing.

\subsubsection{Personnel Qualifications}

Personnel working on the project in the experimental laboratory will be experienced in experimental laboratory setup, column testing, and sampling. The experimental laboratory personnel will be responsible for ensuring that all instruments are properly calibrated and that proper calibration records or documentation are kept in the project logbook. The experimental laboratory personnel will be responsible for ensuring that all sampling procedures are followed and documented in the project logbook. The MSE analytical laboratory personnel will perform the laboratory analysis according to the MSE Analytical Laboratory procedures. Data reduction and analysis will be completed under the direction of the MSE Project Engineer. The MSE Project QA Officer will conduct the quality control and quality assurance activities.

\subsubsection{Quality Assessment and Reporting}

MSE will assess the data quality and include the results of the assessment in the laboratory report. The quality assessment report will include results from the data validation process and a summary of the calculated data quality indicators. The data validation process will be conducted according to the MSE Quality Assurance Plan and consist of a review of the laboratory reports to ensure all QAVC procedures were followed and that the results of the analyses meet the project quality requirements. The data quality indicators that will be included in the report are precision, bias, and completeness.

Precision will be determined from either a relative percent difference (RPD) calculation or from a relative standard deviation (RSD). These will be calculated as follows:

$$
\begin{gathered}
R P D=\frac{X_{1}-X_{2}}{\bar{X}} \times 100 \% \\
R S D=\left(\sqrt{\frac{\sum\left(X_{i}-\bar{X}\right)^{2}}{n-1}}\right) \times \frac{1}{\bar{X}} \times 100 \%
\end{gathered}
$$

Equation 1

Where:

$$
\begin{aligned}
& \mathrm{X}_{\mathrm{i}}=\mathrm{i}^{\text {th }} \text { data value, } \\
& \bar{X}=\text { Average value of data, and }
\end{aligned}
$$




$$
n=\text { number of samples }
$$

Completeness will be based on the percentage of useable analytical values as compared to the planned number of values. 


\section{REFERENCES}

DOE/RL, 2005, "Fiscal Year 2005 Annual Summary Report for the In Situ Redox Manipulation Operations". DOE/RL-2005-97, Rev. 0.

Gibbs CR. 1976. "Characterization and Application of Ferrozine Iron Reagent as a Ferrous Iron Indicator." Analytical Chemistry, 48(8):1197-1200.

Heron G, TH Christensen, and JC Tjell. 1994a. "Oxidation Capacity of Aquifer Sediments." Environmental Science and Technology, 28:153-159.

Heron G, C Crouzet, AC Bourg, and TH Christensen. 1994b. "Speciation of $\mathrm{Fe}$ (II) and $\mathrm{Fe}$ (III) in Contaminated Aquifer Sediments Using Chemical Extraction Techniques." Environmental Science and Technology, 28:1698-1705.

Oostrom, M., T.W. Wietsma, M.A. Covert, V.R. Vermeul, 2005. Experimental Study of MicronSize Zero-Valent Iron Emplacement in Permeable Porous Media using PolymerEnhanced Fluids. PNNL-15573

Waldrop, William R. and Joan K. Waldrop, 2004. Electromagnetic Borehole Flowmeter Test Of the Wells of 100-D Area In Situ Redox Manipulation (ISRM) Barrier Site, Hanford Site, State of Washington. Quantum Engineering Corporation, Loudon, Tennessee 37774.

Yarmoff, J. A. et al, 1999. Fundamental studies of the removal of contaminants from ground and wastewaters via reductions by zero-valent metals, DE-FG07-96ER14707, University of California, Riverside. 


\section{Draft \\ Test Plan \\ ZVI Screening Tests \\ October 2, 2007}




\section{Summary:}

This document is a draft Test Plan for screening of zero valent iron materials that were the highest ranked in a literature search and preliminary laboratory tests performed by MSE. It is the result of discussions held with personnel from Fluor Hanford, MSE and subject matter experts for the project.

The Test Plan covers three areas of testing:

A. Batch testing to determine the ability of the candidate materials to remove chromium from a mixture of silica sand and water. The batch tests will be performed in triplicate;

B. Injection test to assess the changes in the permeability of the soils (possibly due to the precipitation of carbonates, iron oxy-hydroxides or other inhibiting byproducts), the amount of iron that can be injected into soils, and the physical stability of the iron after injection. Data from these tests will be used to select the best performing ZVI materials for further laboratory geochemical testing. As planned the injection tests will be performed in duplicate and;

C. Column tests to screen the ZVI materials that prove most promising in Steps $A$ and $\mathrm{B}$ to reduce $\mathrm{Cr}^{6+}$ over a moderate time. These will be used to assess reactivity of the different $Z V I$ materials. As planned the column test will be performed at two iron concentrations for each surviving material to be determined after reviewing the results of Step B.

For planning purposes it is assumed that all 8 materials survive to the column tests. The Plan will obviously be modified as results warrant. 


\section{PART A BATCH TEST}

\subsection{Statement of Purpose}

In an earlier scope of work MSE developed a database that contains 30 separate Zero Valent Iron (ZVI) materials. From the scoring system associated with this database, six ZVI materials scored at a level high enough for further testing. Those six materials are: RNIP-10DS; EZVI; NanoFe Slurry II; NanoFe Slurry I; Polyflon Particles; and Zloy. In addition, two separate materials manufactured by MetaMateria Partners LLC. specifically for this project will also be tested. This portion of the test plan describes the first of a series of tests that will be conducted for the purpose of screening the remaining ZVI materials. Specifically, this test will determine the ability of the ZVI materials, without any dispersants, to remove dissolved hexavalent chromium. A surrogate groundwater containing dissolved hexavalent chromium mixed with silica sand will be treated with a small concentration of ZVI for four hours.

\subsection{Apparatus}

Multi-station rotary shaker

$250 \mathrm{ml}$ Erlenmeyer flasks with screw top lids

Listed ZVI materials

Silica sand@100 mesh

Surrogate groundwater with approximately 500 micrograms per Liter of dissolved, hexavalent chromium

Multimeter capable of measuring solution conductivity, dissolved oxygen, $\mathrm{pH}, \mathrm{ORP}$ and temperature.

30-milliliter syringes

Disposable syringe filters with pore openings of 0.2 microns

Liquid sample containers

Nitric acid

Logbook

\subsection{Procedure}

Prepare 10 Liters of surrogate ground water using the formula in Appendix $A$ and allow it to stand for approximately 18 hours.

Prior to beginning the initial series of tests, pour out an aliquot of the surrogate ground water into an appropriate vessel and with the Mulitmeter measure the solution conductivity, dissolved oxygen, $\mathrm{pH}, \mathrm{ORP}$ and temperature. Record those readings into the project logbook. Filter 25 milliliters of the surrogate groundwater using a 30 -milliliter syringe and 0.2 -micron syringe filter into a liquid sample container for laboratory analysis of dissolved chromium. Preserve the dissolved chromium sample using 0.1 to $0.2 \mathrm{mls}$ $\mathrm{HNO}_{3}$ and label the liquid sample container appropriately. Filter 25 milliliters of the surrogate groundwater using a 30 -milliliter syringe and 0.2 -micron syringe filter into a liquid sample container for laboratory analysis of nitrate. No preservative will be added to the sample collected for nitrate analysis. Label the nitrate liquid sample container appropriately. Record the groundwater sample labeling information in the logbook.

For each of the ZVI materials to be tested, weigh out 200 grams of the surrogate groundwater into a clean, sealable, glass, $250 \mathrm{ml}$.- Erlenmeyer flask. Weigh out 50 
grams of 100-mesh silica sand and add it to the surrogate groundwater in the flask. Weigh out the amount of ZVI product that will yield 1.5 grams of solid iron and add it to the surrogate groundwater in the flask. (This value is twice the value of 0.73 grams of solid iron per sample previously derived from the average value of total $\mathrm{Fe}^{3+}$ of $0.059 \%$ by weight present in Hanford formation sediments (Fruchter et al, 2000). It was agreed to use this value in these tests as it was indicated by Fluor Hanford that the 0.059 value could be a low. Seal the flask with a lid and label it with the name of the ZVI product. Finally, swirl the flask to thoroughly distribute the contents and place the sealed flask on the rotary shaker. The rotary shaker will be set to operate at a speed of 225 rotations per minute. After a period of 4 hours, remove the flask from the rotary shaker and measure the solution conductivity, $\mathrm{pH}$, ORP and temperature. Record those readings into the project log book. Filter 25 milliliters of the solution using a 30-milliliter syringe and 0.2 -micron syringe filter into a liquid sample container for laboratory analysis of dissolved chromium. Preserve the dissolved chromium sample using 0.1 to $0.2 \mathrm{mls}$ of 15.8 normal $\mathrm{HNO}_{3}$ and label the liquid sample container appropriately as per the $\mathrm{ZVI}$ product and test set. Filter 25 milliliters of the solution using a 30-milliliter syringe and 0.2-micron syringe filter into a liquid sample container for laboratory analysis of nitrate. This sample is not preserved. Label the nitrate liquid sample container appropriately again as per the ZVI product and the test series. Denote in the logbook the two samples taken of the solution. Each of the $\mathrm{ZVI}$ products will be tested using this procedure in triplicate and the flask label accordingly.

A control sample that does not contain any $\mathrm{ZVI}$ product will also be prepared and tested in the same manner as the ZVI bearing samples. To prepare this control sample, weigh out 200 grams of the surrogate groundwater into a clean, glass, sealable, 250-ml. Erlenmeyer flask. Weigh out 50 grams of 100-mesh silica sand and add it to the surrogate groundwater in the flask. Seal the flask with a lid and label it as the control sample. Finally, swirl the flask to thoroughly distribute the contents and place the sealed jar on the rotary shaker. The rotary shaker will be set to operate at a speed of 225 rotations per minute. After a period of 4 hours, remove the flask from the rotary shaker and measure the solution conductivity, $\mathrm{pH}, \mathrm{ORP}$ and temperature. Record those readings into the project log book. Filter 25 milliliters of the solution using a 30 -milliliter syringe and 0.2-micron syringe filter into a liquid sample container for laboratory analysis of dissolved chromium. Preserve the dissolved chromium sample using 0.1 to $0.2 \mathrm{mls}$ $\mathrm{HNO}_{3}$ and label the liquid sample container appropriately as per the control sample of the appropriate test set. Filter 25 milliliters of the solution using a 30-milliliter syringe and 0.2-micron syringe filter into a liquid sample container for laboratory analysis of nitrate. This sample is not preserved. Label the nitrate liquid sample container appropriately again as per the control sample of the appropriate test series. Record in the labeling information in the logbook for the two samples taken of the control solution. A control sample will be prepared and tested using this procedure in triplicate and the flasks label as appropriate.

Submit the dissolved chromium and nitrate samples to the analytical laboratory for analysis with a properly prepared Chain-of-Custody-Laboratory, MSE Form 169

The flasks should be thoroughly cleaned and the solid material disposed of into a 5gallon bucket that has been labeled as waste from this project. The effluent should be less than 5 milligrams per liter in concentration and as such can be disposed to the POTW. 
DOE/RL-2009-35, REV.0

\section{References:}

Fruchter, J.S., C.R Cole, M.D. Williams, V.R. Vermeul, I.E Amonette, J.E Szecsody, I.D Istok. 2000. Creation of a Subsurface Permeable Treatment Zone for Aqueous

Chromate Contamination Using In Situ Redox Manipulation. Groundwater Monitoring and Remediation, V XX No. 2, 2000 pp. 66-76. 
Appendix A

Surrogate Groundwater Formulation

\begin{tabular}{|l|c|c|c|}
\hline \multicolumn{1}{|c|}{ Constituent } & $\begin{array}{c}\text { Hanford } \\
\text { Water } \\
\text { Conc. }\end{array}$ & Units & $\begin{array}{c}\text { Calculated } \\
\text { Surrogate } \\
\text { GW Conc. }\end{array}$ \\
\hline \hline Alkalinity (as $\left.\mathrm{HCO}_{3}\right)$ & 97.13 & $\mathrm{mg} / \mathrm{L}$ & 100.2 \\
\hline Calcium & 90 & $\mathrm{mg} / \mathrm{L}$ & 94.2 \\
\hline Chloride & 33.96 & $\mathrm{mg} / \mathrm{L}$ & 30.7 \\
\hline Chromium & 100 & $\mu \mathrm{g} / \mathrm{L}$ & 553 \\
\hline Magnesium & 20.77 & $\mathrm{mg} / \mathrm{L}$ & 21.1 \\
\hline Nitrate as $\mathrm{NO}_{3}{ }^{-}$ & 23.6 & $\mathrm{mg} / \mathrm{L}$ & 61.0 \\
\hline Potassium & 4.82 & $\mathrm{mg} / \mathrm{L}$ & 0.00 \\
\hline Sodium & 9.89 & $\mathrm{mg} / \mathrm{L}$ & 17.6 \\
\hline Sulfate & 135.35 & $\mathrm{mg} / \mathrm{L}$ & 135 \\
\hline
\end{tabular}

\begin{tabular}{|l|r|l|}
\hline Salts added: & & \\
\hline & Mass & Units \\
\hline $\mathrm{CaCl}_{2} \cdot 2 \mathrm{H}_{2} \mathrm{O}$ & 0.60 & $\mathrm{~g}$ \\
\hline $\mathrm{CaCO}_{3}$ & 0.84 & $\mathrm{~g}$ \\
\hline $\mathrm{Ca}\left(\mathrm{NO}_{3}\right)_{2} \cdot 4 \mathrm{H}_{2} \mathrm{O}$ & 1.10 & $\mathrm{~g}$ \\
\hline $\mathrm{Na}_{2} \mathrm{Cr}_{2} \mathrm{O} 7 \cdot 2 \mathrm{H}_{2} \mathrm{O}$ & 0.015 & $\mathrm{~g}$ \\
\hline $\mathrm{MgSO}_{4} \cdot 7 \mathrm{H}_{2} \mathrm{O}$ & 2.03 & $\mathrm{~g}$ \\
\hline $\mathrm{NaHCO}_{3}$ & 0.60 & $\mathrm{~g}$ \\
\hline $\mathrm{H}_{2} \mathrm{SO}_{4}$ (conc.) & 0.51 & $\mathrm{~g}$ \\
\hline & & \\
\hline & 2.5 & gallons \\
\hline & 9.5 & liters \\
\hline
\end{tabular}




\section{PART B- INJECTABILITY TESTS}

\subsection{LABORATORY TESTING OBJECTIVES AND DATA QUALITY}

\subsection{Laboratory Testing Approach}

MSE proposes to perform laboratory injectability testing with as many as 8 different Zero Valent Iron (ZVI) materials to determine their injectability, assess the physical stability of the $\mathrm{ZVI}$ after injection and investigate the changes in the permeability of the soils (possibly due to the precipitation of carbonates, iron oxy-hydroxides or other inhibiting byproducts). The results of the injectability tests will be used to select the best performing ZVI materials for further laboratory geochemical and injectability testing.

Depending on the results of the Batch Screening Test (Part A of this Test Plan), as many as 17 injectability flow cells $(8 \mathrm{ZVI}$ materials per flow cell run in duplicate and 1 control cell) will be included as part of the laboratory screening test program. The injectability testing will consist of two phases, (1) Injection of ZVI with a carrier fluid containing water and a specific dispersing additive and (2) Flushing with Hanford surrogate groundwater.

ZVI/carrier fluid will be injected in each of the injectability flow cells for a total of 20 pore volumes. Head loss across the injectability flow cells and turbidity of the effluent will be measured during $\mathrm{ZVI} /$ carrier fluid injections using manometers (sight glasses) and a portable turbidity meter, respectively. Head loss records will be used to evaluate changes in permeability of the tested soil and turbidity measurements will be used to assess the suspended ZVI content in the effluent. The injectability flow cells will be visually inspected and photographed periodically during $Z \mathrm{~V} / /$ carrier fluid injection. Upon completion of the $\mathrm{ZVI} /$ carrier fluid injections ( 20 pore volumes), the flow cells will again be visually inspected and photographed. Effluent samples will be collected and analyzed for total and dissolved iron concentration, and soil samples will be removed from the up gradient and down gradient ends of the flow cells and analyzed for total iron concentration.

Following completion of the ZVI/carrier fluid injections, Hanford surrogate groundwater will be flushed through the flow cells. Head loss and turbidity will continue to be measured during the groundwater flush. Upon completion of the groundwater flush, each of the flow cells will again be visually inspected and photographed and effluent and soil samples will again be removed and analyzed for iron.

One control flow cell will also be included in the testing program, which will be flushed with Hanford surrogate groundwater only. One effluent sample and one soil sample will be collected from the control cell as a baseline measurement of total iron concentration. Head loss and turbidity measurements will also be collected from the control cell during the groundwater flush and in parallel with the samples from the other flow cells.

\subsection{Sampling and Analysis Schedule}

Table 1 lists the analyses, analytical methods and required detection limits for the primary measurements and analyses that will be performed during the injectability testing. 
Table 1. Primary Measurements and Analyses.

\begin{tabular}{|l|l|l|l|}
\hline Measurement/Analysis & Matrix & Analytical/Measurement Method & Detection Limit \\
\hline Turbidity & Pore fluid & EPA 180.1 & $0.1 \mathrm{NTU}$ \\
\hline Total and dissolved iron & Pore fluid & $\begin{array}{l}\text { ICP-AES, Methods SW3050B and } \\
\text { SW6010 }\end{array}$ & $0.015 \mathrm{mg} / \mathrm{L}$ \\
\hline Head Loss & Pore fluid & $\begin{array}{l}\text { ASTM D-2434 Standard Test Method for } \\
\text { Permeability of Granular Soils (Constant } \\
\text { Head) }\end{array}$ & $\begin{array}{l}2.5 \mathrm{~mm} \text { pore fluid head } \\
\text { differential over } 1 \text { meter }\end{array}$ \\
\hline Total iron & Soil & $\begin{array}{l}\text { ICP-AES, Methods SW3050B and } \\
\text { SW6010 }\end{array}$ & $3.0 \mathrm{mg} / \mathrm{kg}$ \\
\hline Iron emplacement & Soils & Visual methods & Qualitative assessment \\
\hline
\end{tabular}

Turbidity measurements, effluent pore fluid sampling, soil sampling and head loss measurements will be performed during injection testing in accordance with the sampling schedule shown in Table 2. The sampling schedule is based on the number of pore volumes injected of ZVI/carrier fluid or Hanford surrogate groundwater injected. Three sets of flow cells are shown in Figure 1: ZVI Injectability Flow Cells, Duplicate ZVI Injectability Flow Cells and one Control Cell. The ZVI injectability flow cells and Duplicate ZVI injectability flow cells will be injected with ZVI/carrier fluid and subsequently flushed with surrogate groundwater, while the Control Cell will only be flushed with surrogate groundwater.

Turbidity measurements will be performed on the $\mathrm{ZVI} /$ carrier fluid mixture when it is initially mixed and following preparation of new batches of the mixture. Turbidity will also be measured in the control cell effluent prior to $\mathrm{ZVI} /$ carrier fluid injection and in the flow cell effluents during injection of ZVI/carrier fluid and Hanford surrogate groundwater. Turbidity will be measured using a portable turbidity meter that will be calibrated to standards as per the instruction manual. To convert turbidity NTU units into suspended ZVI concentrations, a calibration curve will be prepared (prior to injection testing) by measuring turbidity of known dilutions of the influent $\mathrm{ZVI} /$ carrier fluid. Effluent and soil samples will be analyzed for iron by ICP-AES in accordance with Methods SW3050B and SW6010.

\subsection{Data Reduction and Analysis}

Data from each sampling event will be compiled into a database for this project. The database will include a record of all paper copies of sampling records, chain of custody sheets, and analytical laboratory reports. It will also include the project laboratory logbook and instrument calibration records. In addition to the paper copies of the data, all numerical values obtained from the testing will be entered into an electronic spreadsheet for further analysis 
Table 2. Sampling \& Analysis Schedule for the Injectability Test Plan (Part B).

\begin{tabular}{|c|c|c|c|c|c|c|c|c|c|c|c|c|c|c|c|c|c|c|}
\hline \multirow{2}{*}{\multicolumn{2}{|c|}{ Sampling Event }} & \multicolumn{8}{|c|}{ ZVI Injectability Flow Cells } & \multicolumn{8}{|c|}{ Duplicate ZVI Injectability Flow Cells } & \multirow{2}{*}{$\begin{array}{c}\text { Control Cell } \\
\# 17 \\
\end{array}$} \\
\hline & & \#1 & \#2 & $\# 3$ & $\# 4$ & $\# 5$ & $\# 6$ & \#7 & \#8 & \#9 & $\# 10$ & $\# 11$ & $\# 12$ & $\# 13$ & $\# 14$ & $\# 15$ & \#16 & \\
\hline \multirow{9}{*}{ 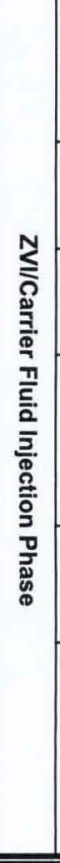 } & $\begin{array}{c}\text { Sampling event 0-1 } \\
\text { Pre-injection }\end{array}$ & $\begin{array}{l}\text { Head } \\
\text { Loss }\end{array}$ & $\begin{array}{l}\text { Head } \\
\text { Loss }\end{array}$ & $\begin{array}{l}\text { Head } \\
\text { Loss }\end{array}$ & $\begin{array}{l}\text { Head } \\
\text { Loss }\end{array}$ & $\begin{array}{l}\text { Head } \\
\text { Loss }\end{array}$ & $\begin{array}{l}\text { Head } \\
\text { Loss }\end{array}$ & $\begin{array}{l}\text { Head } \\
\text { Loss }\end{array}$ & $\begin{array}{l}\text { Head } \\
\text { Loss }\end{array}$ & $\begin{array}{l}\text { Head } \\
\text { Loss }\end{array}$ & $\begin{array}{l}\text { Head } \\
\text { Loss }\end{array}$ & $\begin{array}{l}\text { Head } \\
\text { Loss }\end{array}$ & $\begin{array}{l}\text { Head } \\
\text { Loss }\end{array}$ & $\begin{array}{l}\text { Head } \\
\text { Loss }\end{array}$ & $\begin{array}{l}\text { Head } \\
\text { Loss }\end{array}$ & $\begin{array}{l}\text { Head } \\
\text { Loss }\end{array}$ & $\begin{array}{l}\text { Head } \\
\text { Loss }\end{array}$ & $\begin{array}{l}\text { Turbid. } \\
\text { Pore Fluid } \\
\text { Head Loss } \\
\text { Soil } \\
\end{array}$ \\
\hline & $\begin{array}{c}\text { Sampling event } 02 \\
\quad 1 \mathrm{PV} Z \mathrm{~V} \mathrm{I}\end{array}$ & $\begin{array}{c}\text { Turbid. } \\
\text { Head } \\
\text { Loss }\end{array}$ & $\begin{array}{c}\text { Turbid. } \\
\text { Head } \\
\text { Loss }\end{array}$ & \begin{tabular}{|c} 
Turbid. \\
Head \\
Loss \\
\end{tabular} & $\begin{array}{c}\text { Turbid. } \\
\text { Head } \\
\text { Loss }\end{array}$ & $\begin{array}{c}\text { Turbid. } \\
\text { Head } \\
\text { Loss } \\
\end{array}$ & $\begin{array}{c}\text { Turbid. } \\
\text { Head } \\
\text { Loss }\end{array}$ & $\begin{array}{c}\text { Turbid. } \\
\text { Head } \\
\text { Loss } \\
\end{array}$ & $\begin{array}{c}\text { Turbid. } \\
\text { Head } \\
\text { Loss }\end{array}$ & \begin{tabular}{|l} 
Turbid. \\
Head \\
Loss \\
\end{tabular} & $\begin{array}{c}\text { Turbid. } \\
\text { Head } \\
\text { Loss }\end{array}$ & $\begin{array}{c}\text { Turbid. } \\
\text { Head } \\
\text { Loss }\end{array}$ & $\begin{array}{c}\text { Turbid. } \\
\text { Head } \\
\text { Loss }\end{array}$ & $\begin{array}{c}\text { Turbid. } \\
\text { Head } \\
\text { Loss }\end{array}$ & $\begin{array}{c}\text { Turbid. } \\
\text { Head } \\
\text { Loss }\end{array}$ & $\begin{array}{c}\text { Turbid. } \\
\text { Head } \\
\text { Loss }\end{array}$ & $\begin{array}{c}\text { Turbid. } \\
\text { Head } \\
\text { Loss }\end{array}$ & $\begin{array}{l}\text { Turbid. } \\
\text { Head Loss }\end{array}$ \\
\hline & $\begin{array}{c}\text { Sampling event } 03 \\
\quad 3 \text { PV ZVI }\end{array}$ & $\begin{array}{c}\text { Turbid. } \\
\text { Head } \\
\text { Loss }\end{array}$ & $\begin{array}{c}\text { Turbid. } \\
\text { Head } \\
\text { Loss }\end{array}$ & $\begin{array}{c}\text { Turbid. } \\
\text { Head } \\
\text { Loss }\end{array}$ & $\begin{array}{c}\text { Turbid. } \\
\text { Head } \\
\text { Loss }\end{array}$ & $\begin{array}{c}\text { Turbid. } \\
\text { Head } \\
\text { Loss }\end{array}$ & $\begin{array}{c}\text { Turbid. } \\
\text { Head } \\
\text { Loss }\end{array}$ & $\begin{array}{c}\text { Turbid. } \\
\text { Head } \\
\text { Loss }\end{array}$ & $\begin{array}{l}\text { Turbid. } \\
\text { Head } \\
\text { Loss }\end{array}$ & $\begin{array}{l}\text { Turbid. } \\
\text { Head } \\
\text { Loss }\end{array}$ & $\begin{array}{c}\text { Turbid. } \\
\text { Head } \\
\text { Loss }\end{array}$ & $\begin{array}{c}\text { Turbid. } \\
\text { Head } \\
\text { Loss }\end{array}$ & $\begin{array}{c}\text { Turbid. } \\
\text { Head } \\
\text { Loss }\end{array}$ & $\begin{array}{c}\text { Turbid. } \\
\text { Head } \\
\text { Loss }\end{array}$ & $\begin{array}{c}\text { Turbid. } \\
\text { Head } \\
\text { Loss }\end{array}$ & $\begin{array}{c}\text { Turbid. } \\
\text { Head } \\
\text { Loss }\end{array}$ & $\begin{array}{c}\text { Turbid. } \\
\text { Head } \\
\text { Loss }\end{array}$ & $\begin{array}{l}\text { Turbid. } \\
\text { Head Loss }\end{array}$ \\
\hline & $\begin{array}{c}\text { Sampling event } 04 \\
\quad 6 \text { PV ZVI }\end{array}$ & $\begin{array}{l}\text { Turbid. } \\
\text { Pore } \\
\text { Fluid }\end{array}$ & $\begin{array}{l}\text { Turbid. } \\
\text { Pore } \\
\text { Fluid }\end{array}$ & $\begin{array}{l}\text { Turbid. } \\
\text { Pore } \\
\text { Fluid }\end{array}$ & $\begin{array}{c}\text { Turbid. } \\
\text { Pore } \\
\text { Fluid }\end{array}$ & $\begin{array}{l}\text { Turbid. } \\
\text { Pore } \\
\text { Fluid }\end{array}$ & $\begin{array}{l}\text { Turbid. } \\
\text { Pore } \\
\text { Fluid }\end{array}$ & $\begin{array}{l}\text { Turbid. } \\
\text { Pore } \\
\text { Fluid }\end{array}$ & $\begin{array}{c}\text { Turbid. } \\
\text { Pore } \\
\text { Fluid }\end{array}$ & $\begin{array}{l}\text { Turbid. } \\
\text { Pore } \\
\text { Fluid }\end{array}$ & $\begin{array}{c}\text { Turbid. } \\
\text { Pore } \\
\text { Fluid }\end{array}$ & $\begin{array}{l}\text { Turbid. } \\
\text { Pore } \\
\text { Fluid }\end{array}$ & $\begin{array}{l}\text { Turbid. } \\
\text { Pore } \\
\text { Fluid }\end{array}$ & $\begin{array}{l}\text { Turbid. } \\
\text { Pore } \\
\text { Fluid }\end{array}$ & $\begin{array}{l}\text { Turbid. } \\
\text { Pore } \\
\text { Fluid }\end{array}$ & $\begin{array}{l}\text { Turbid. } \\
\text { Pore } \\
\text { Fluid }\end{array}$ & $\begin{array}{l}\text { Turbid. } \\
\text { Pore } \\
\text { Fluid }\end{array}$ & $\begin{array}{l}\text { Turbid. } \\
\text { Head Loss }\end{array}$ \\
\hline & & $\begin{array}{l}\text { Head } \\
\text { Loss }\end{array}$ & $\begin{array}{l}\text { Head } \\
\text { Loss }\end{array}$ & $\begin{array}{l}\text { Head } \\
\text { Loss }\end{array}$ & $\begin{array}{l}\text { Head } \\
\text { Loss }\end{array}$ & $\begin{array}{l}\text { Head } \\
\text { Loss }\end{array}$ & $\begin{array}{l}\text { Head } \\
\text { Loss }\end{array}$ & $\begin{array}{l}\text { Head } \\
\text { Loss }\end{array}$ & $\begin{array}{l}\text { Head } \\
\text { Loss }\end{array}$ & $\begin{array}{l}\text { Head } \\
\text { Loss }\end{array}$ & $\begin{array}{l}\text { Head } \\
\text { Loss }\end{array}$ & $\begin{array}{l}\text { Head } \\
\text { Loss }\end{array}$ & $\begin{array}{l}\text { Head } \\
\text { Loss }\end{array}$ & $\begin{array}{l}\text { Head } \\
\text { Loss }\end{array}$ & $\begin{array}{l}\text { Head } \\
\text { Loss }\end{array}$ & $\begin{array}{l}\text { Head } \\
\text { Loss }\end{array}$ & $\begin{array}{l}\text { Head } \\
\text { Loss }\end{array}$ & \\
\hline & $\begin{array}{l}\text { Sampling event } 05 \\
\quad 12 \text { PV ZVI }\end{array}$ & $\begin{array}{c}\text { Turbid. } \\
\text { Head } \\
\text { Loss }\end{array}$ & $\begin{array}{c}\text { Turbid. } \\
\text { Head } \\
\text { Loss }\end{array}$ & $\begin{array}{l}\text { Turbid. } \\
\text { Head } \\
\text { Loss }\end{array}$ & $\begin{array}{c}\text { Turbid. } \\
\text { Head } \\
\text { Loss }\end{array}$ & $\begin{array}{l}\text { Turbid. } \\
\text { Head } \\
\text { Loss }\end{array}$ & $\begin{array}{c}\text { Turbid. } \\
\text { Head } \\
\text { Loss }\end{array}$ & $\begin{array}{c}\text { Turbid. } \\
\text { Head } \\
\text { Loss }\end{array}$ & $\begin{array}{c}\text { Turbid. } \\
\text { Head } \\
\text { Loss }\end{array}$ & $\begin{array}{l}\text { Turbid. } \\
\text { Head } \\
\text { Loss }\end{array}$ & $\begin{array}{c}\text { Turbid. } \\
\text { Head } \\
\text { Loss }\end{array}$ & $\begin{array}{c}\text { Turbid. } \\
\text { Head } \\
\text { Loss }\end{array}$ & $\begin{array}{c}\text { Turbid. } \\
\text { Head } \\
\text { Loss }\end{array}$ & $\begin{array}{c}\text { Turbid. } \\
\text { Head } \\
\text { Loss }\end{array}$ & $\begin{array}{c}\text { Turbid. } \\
\text { Head } \\
\text { Loss }\end{array}$ & $\begin{array}{c}\text { Turbid. } \\
\text { Head } \\
\text { Loss }\end{array}$ & $\begin{array}{c}\text { Turbid. } \\
\text { Head } \\
\text { Loss }\end{array}$ & $\begin{array}{l}\text { Turbid. } \\
\text { Head Loss }\end{array}$ \\
\hline & Sampling event 06 & $\begin{array}{c}\text { Turbid. } \\
\text { Pore } \\
\text { Fluid }\end{array}$ & $\begin{array}{c}\text { Turbid. } \\
\text { Pore } \\
\text { Fluid }\end{array}$ & $\begin{array}{l}\text { Turbid. } \\
\text { Pore } \\
\text { Fluid }\end{array}$ & $\begin{array}{c}\text { Turbid. } \\
\text { Pore } \\
\text { Fluid }\end{array}$ & $\begin{array}{l}\text { Turbid. } \\
\text { Pore } \\
\text { Fluid }\end{array}$ & $\begin{array}{c}\text { Turbid. } \\
\text { Pore } \\
\text { Fluid }\end{array}$ & $\begin{array}{c}\text { Turbid. } \\
\text { Pore } \\
\text { Fluid }\end{array}$ & $\begin{array}{c}\text { Turbid. } \\
\text { Pore } \\
\text { Fluid }\end{array}$ & $\begin{array}{c}\text { Turbid. } \\
\text { Pore } \\
\text { Fluid }\end{array}$ & $\begin{array}{c}\text { Turbid. } \\
\text { Pore } \\
\text { Fluid }\end{array}$ & $\begin{array}{c}\text { Turbid. } \\
\text { Pore } \\
\text { Fluid }\end{array}$ & $\begin{array}{c}\text { Turbid. } \\
\text { Pore } \\
\text { Fluid }\end{array}$ & $\begin{array}{c}\text { Turbid. } \\
\text { Pore } \\
\text { Fluid }\end{array}$ & $\begin{array}{c}\text { Turbid. } \\
\text { Pore } \\
\text { Fluid }\end{array}$ & $\begin{array}{c}\text { Turbid. } \\
\text { Pore } \\
\text { Fluid }\end{array}$ & $\begin{array}{c}\text { Turbid. } \\
\text { Pore } \\
\text { Fluid }\end{array}$ & $\begin{array}{l}\text { Turbid. } \\
\text { Head Loss }\end{array}$ \\
\hline & $20 \mathrm{PV} Z \mathrm{ZVI}$ & $\begin{array}{l}\text { Head } \\
\text { Loss }\end{array}$ & $\begin{array}{l}\text { Head } \\
\text { Loss }\end{array}$ & $\begin{array}{l}\text { Head } \\
\text { Loss }\end{array}$ & $\begin{array}{l}\text { Head } \\
\text { Loss }\end{array}$ & $\begin{array}{l}\text { Head } \\
\text { Loss }\end{array}$ & $\begin{array}{l}\text { Head } \\
\text { Loss }\end{array}$ & $\begin{array}{l}\text { Head } \\
\text { Loss }\end{array}$ & $\begin{array}{l}\text { Head } \\
\text { Loss }\end{array}$ & $\begin{array}{l}\text { Head } \\
\text { Loss }\end{array}$ & $\begin{array}{l}\text { Head } \\
\text { Loss }\end{array}$ & $\begin{array}{l}\text { Head } \\
\text { Loss }\end{array}$ & $\begin{array}{l}\text { Head } \\
\text { Loss }\end{array}$ & $\begin{array}{l}\text { Head } \\
\text { Loss }\end{array}$ & $\begin{array}{l}\text { Head } \\
\text { Loss }\end{array}$ & $\begin{array}{l}\text { Head } \\
\text { Loss }\end{array}$ & $\begin{array}{l}\text { Head } \\
\text { Loss }\end{array}$ & \\
\hline & & Soil & Soil & Soil & Soil & Soil & Soil & Soil & Soil & Soil & Soil & Soil & Soil & Soil & Soil & Soil & Soil & \\
\hline \multirow{6}{*}{ 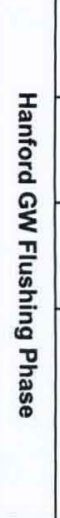 } & $\begin{array}{c}\text { Sampling event } 07 \\
1 \mathrm{PV} \mathrm{GW}\end{array}$ & $\begin{array}{c}\text { Turbid. } \\
\text { Head } \\
\text { Loss }\end{array}$ & $\begin{array}{c}\text { Turbid. } \\
\text { Head } \\
\text { Loss }\end{array}$ & $\begin{array}{c}\text { Turbid. } \\
\text { Head } \\
\text { Loss } \\
\end{array}$ & $\begin{array}{c}\text { Turbid. } \\
\text { Head } \\
\text { Loss }\end{array}$ & $\begin{array}{c}\text { Turbid. } \\
\text { Head } \\
\text { Loss } \\
\end{array}$ & $\begin{array}{c}\text { Turbid. } \\
\text { Head } \\
\text { Loss }\end{array}$ & $\begin{array}{c}\text { Turbid. } \\
\text { Head } \\
\text { Loss }\end{array}$ & $\begin{array}{c}\text { Turbid. } \\
\text { Head } \\
\text { Loss }\end{array}$ & $\begin{array}{l}\text { Turbid. } \\
\text { Head } \\
\text { Loss }\end{array}$ & $\begin{array}{c}\text { Turbid. } \\
\text { Head } \\
\text { Loss }\end{array}$ & $\begin{array}{c}\text { Turbid. } \\
\text { Head } \\
\text { Loss }\end{array}$ & $\begin{array}{c}\text { Turbid. } \\
\text { Head } \\
\text { Loss }\end{array}$ & $\begin{array}{c}\text { Turbid. } \\
\text { Head } \\
\text { Loss }\end{array}$ & $\begin{array}{c}\text { Turbid. } \\
\text { Head } \\
\text { Loss }\end{array}$ & $\begin{array}{c}\text { Turbid. } \\
\text { Head } \\
\text { Loss }\end{array}$ & $\begin{array}{c}\text { Turbid. } \\
\text { Head } \\
\text { Loss }\end{array}$ & $\begin{array}{l}\text { Turbid. } \\
\text { Head Loss }\end{array}$ \\
\hline & $\begin{array}{c}\text { Sampling event } 08 \\
5 \text { PV GW }\end{array}$ & $\begin{array}{c}\text { Turbid. } \\
\text { Head } \\
\text { Loss }\end{array}$ & $\begin{array}{c}\text { Turbid. } \\
\text { Head } \\
\text { Loss }\end{array}$ & $\begin{array}{c}\text { Turbid. } \\
\text { Head } \\
\text { Loss }\end{array}$ & $\begin{array}{c}\text { Turbid. } \\
\text { Head } \\
\text { Loss }\end{array}$ & $\begin{array}{c}\text { Turbid. } \\
\text { Head } \\
\text { Loss }\end{array}$ & $\begin{array}{c}\text { Turbid. } \\
\text { Head } \\
\text { Loss }\end{array}$ & $\begin{array}{c}\text { Turbid. } \\
\text { Head } \\
\text { Loss }\end{array}$ & $\begin{array}{c}\text { Turbid. } \\
\text { Head } \\
\text { Loss }\end{array}$ & $\begin{array}{l}\text { Turbid. } \\
\text { Head } \\
\text { Loss }\end{array}$ & $\begin{array}{c}\text { Turbid. } \\
\text { Head } \\
\text { Loss }\end{array}$ & $\begin{array}{c}\text { Turbid. } \\
\text { Head } \\
\text { Loss }\end{array}$ & $\begin{array}{c}\text { Turbid. } \\
\text { Head } \\
\text { Loss }\end{array}$ & $\begin{array}{c}\text { Turbid. } \\
\text { Head } \\
\text { Loss }\end{array}$ & $\begin{array}{c}\text { Turbid. } \\
\text { Head } \\
\text { Loss }\end{array}$ & $\begin{array}{c}\text { Turbid. } \\
\text { Head } \\
\text { Loss }\end{array}$ & $\begin{array}{c}\text { Turbid. } \\
\text { Head } \\
\text { Loss }\end{array}$ & $\begin{array}{l}\text { Turbid. } \\
\text { Head Loss }\end{array}$ \\
\hline & $\begin{array}{c}\text { Sampling event } 09 \\
10 \mathrm{PV} \text { GW }\end{array}$ & $\begin{array}{c}\text { Turbid. } \\
\text { Head } \\
\text { Loss }\end{array}$ & $\begin{array}{c}\text { Turbid. } \\
\text { Head } \\
\text { Loss }\end{array}$ & $\begin{array}{c}\text { Turbid. } \\
\text { Head } \\
\text { Loss }\end{array}$ & $\begin{array}{c}\text { Turbid. } \\
\text { Head } \\
\text { Loss }\end{array}$ & $\begin{array}{l}\text { Turbid. } \\
\text { Head } \\
\text { Loss }\end{array}$ & $\begin{array}{c}\text { Turbid. } \\
\text { Head } \\
\text { Loss }\end{array}$ & $\begin{array}{c}\text { Turbid. } \\
\text { Head } \\
\text { Loss }\end{array}$ & $\begin{array}{c}\text { Turbid. } \\
\text { Head } \\
\text { Loss }\end{array}$ & $\begin{array}{l}\text { Turbid. } \\
\text { Head } \\
\text { Loss }\end{array}$ & $\begin{array}{c}\text { Turbid. } \\
\text { Head } \\
\text { Loss }\end{array}$ & $\begin{array}{c}\text { Turbid. } \\
\text { Head } \\
\text { Loss }\end{array}$ & $\begin{array}{c}\text { Turbid. } \\
\text { Head } \\
\text { Loss }\end{array}$ & $\begin{array}{c}\text { Turbid. } \\
\text { Head } \\
\text { Loss }\end{array}$ & $\begin{array}{c}\text { Turbid. } \\
\text { Head } \\
\text { Loss }\end{array}$ & $\begin{array}{c}\text { Turbid. } \\
\text { Head } \\
\text { Loss }\end{array}$ & $\begin{array}{c}\text { Turbid. } \\
\text { Head } \\
\text { Loss }\end{array}$ & $\begin{array}{l}\text { Turbid. } \\
\text { Head Loss }\end{array}$ \\
\hline & Sampling event 10 & $\begin{array}{c}\text { Turbid. } \\
\text { Pore } \\
\text { Fluid }\end{array}$ & $\begin{array}{c}\text { Turbid. } \\
\text { Pore } \\
\text { Fluid }\end{array}$ & $\begin{array}{c}\text { Turbid. } \\
\text { Pore } \\
\text { Fluid }\end{array}$ & $\begin{array}{c}\text { Turbid. } \\
\text { Pore } \\
\text { Fluid }\end{array}$ & $\begin{array}{l}\text { Turbid. } \\
\text { Pore } \\
\text { Fluid }\end{array}$ & $\begin{array}{c}\text { Turbid. } \\
\text { Pore } \\
\text { Fluid }\end{array}$ & $\begin{array}{c}\text { Turbid. } \\
\text { Pore } \\
\text { Fluid }\end{array}$ & $\begin{array}{c}\text { Turbid. } \\
\text { Pore } \\
\text { Fluid }\end{array}$ & $\begin{array}{l}\text { Turbid. } \\
\text { Pore } \\
\text { Fluid }\end{array}$ & $\begin{array}{c}\text { Turbid. } \\
\text { Pore } \\
\text { Fluid }\end{array}$ & $\begin{array}{c}\text { Turbid. } \\
\text { Pore } \\
\text { Fluid }\end{array}$ & $\begin{array}{c}\text { Turbid. } \\
\text { Pore } \\
\text { Fluid }\end{array}$ & $\begin{array}{c}\text { Turbid. } \\
\text { Pore } \\
\text { Fluid }\end{array}$ & $\begin{array}{l}\text { Turbid. } \\
\text { Pore } \\
\text { Fluid }\end{array}$ & $\begin{array}{c}\text { Turbid. } \\
\text { Pore } \\
\text { Fluid }\end{array}$ & $\begin{array}{c}\text { Turbid. } \\
\text { Pore } \\
\text { Fluid }\end{array}$ & $\begin{array}{l}\text { Turbid. } \\
\text { Head Loss }\end{array}$ \\
\hline & $20 \mathrm{PV}$ GW & $\begin{array}{l}\text { Head } \\
\text { Loss }\end{array}$ & $\begin{array}{l}\text { Head } \\
\text { Loss }\end{array}$ & $\begin{array}{l}\text { Head } \\
\text { Loss }\end{array}$ & $\begin{array}{l}\text { Head } \\
\text { Loss }\end{array}$ & $\begin{array}{l}\text { Head } \\
\text { Loss }\end{array}$ & $\begin{array}{l}\text { Head } \\
\text { Loss }\end{array}$ & $\begin{array}{l}\text { Head } \\
\text { Loss }\end{array}$ & $\begin{array}{l}\text { Head } \\
\text { Loss }\end{array}$ & $\begin{array}{l}\text { Head } \\
\text { Loss }\end{array}$ & $\begin{array}{l}\text { Head } \\
\text { Loss }\end{array}$ & $\begin{array}{l}\text { Head } \\
\text { Loss }\end{array}$ & $\begin{array}{l}\text { Head } \\
\text { Loss }\end{array}$ & $\begin{array}{l}\text { Head } \\
\text { Loss }\end{array}$ & $\begin{array}{l}\text { Head } \\
\text { Loss }\end{array}$ & $\begin{array}{l}\text { Head } \\
\text { Loss }\end{array}$ & $\begin{array}{l}\text { Head } \\
\text { Loss }\end{array}$ & \\
\hline & & Soil & Soil & Soil & Soil & Soil & Soil & Soil & Soil & Soil & Soil & Soil & Soil & Soil & Soil & Soil & Soil & \\
\hline
\end{tabular}

Note: $\quad P V=$ Pore Volume

$\mathrm{GW}=$ Hanford Surrogate Groundwater

Turbid. $=$ Turbidity Measurement

Pore Fluid = Total \& Dissolved Iron Analysis (ICP-AES Method)

Soil = Total Iron Analysis (ICP-AES Method) 


\subsection{PREPARATION, SAMPLING \& ANALYSIS PROCEDURES}

Procedures for constructing and packing the injectability flow cells, preparing the $\mathrm{ZVI} /$ carrier fluid mixtures, establishing steady state conditions, injecting fluids, taking measurements, and collecting water and soil samples are outlined in the following section. If, during the execution of any of these procedures, a better procedure or procedures are discovered, which are more efficient and/or cost effective and produce the desired quality and results, the new procedure or procedures shall be documented, approved, and implemented.

\subsection{TEST SETUP}

The laboratory testing will be conducted using injectability flow cells packed with saturated Accusand having a customized particle size range similar to the zones of highly permeable Hanford Ringold E soils from the 100-D area. A proto-type flow cell will be constructed prior to injection testing to ensure the proper hydraulic permeability is established. The remaining flow cells will be constructed once the proto-type operation is successful. The flow cells will be connected to a series of pumps to provide controlled injection of the ZVI/carrier fluid mixture and Hanford surrogate groundwater. Approximately 175 gallons of ZVI/carrier fluid and 125 gallons of Hanford surrogate groundwater will be required to perform the injectability testing. Procedures for preparing the surrogate groundwater have been summarized in Part $A$ of this test plan.

The ZVI/carrier fluid mixture will be maintained in a tank with a mixing system designed to keep the ZVI in suspension in the carrier fluid. The effluent will be discharged to a common waste tank and will be disposed of in accordance with applicable state regulations per the MSE Environmental Coordinator.

\subsubsection{Injectability Flow Cell Preparation}

The injectability testing will be performed in clear PVC pipe measuring approximately $7.62-\mathrm{cm}$ (3.0-inch) in diameter by $100-\mathrm{cm}$ (39.37-inch) in length. MSE has plenty of clear PVC pipe in storage and should not have to purchase any for the injectability testing. The ends of each flow cell will be fit with threaded couplings and the couplings will be connected to an injection system at the inlets and effluent drainage system at the outlets. The flow cells will also be fitted with sight glasses (manometers) at each end for monitoring head loss across the flow cells. The outlet of each flow cell will be elevated above the top of the centerline of the flow cell to maintain complete saturation of the cell. The flow cells will be maintained in a horizontal position during the injection testing to representatively simulate the injection process and any settling of ZVI out of suspension due to gravity. Each flow cell will be labeled \#1 through \#17 according to Table 1.

\subsubsection{Injectability Flow Cell Materials}

The materials required for preparation of each injectability flow cell includes the following:

1. 1 length of $7.62-\mathrm{cm}$ (3.0-inch) nominal diameter by $100-\mathrm{cm}$ (39.37-inch) long clear PVC pipe;

2. $27.62-\mathrm{cm}(3.0-$ inch) PVC NPT Female socket-weld pipe adapters;

3. $27.62-\mathrm{cm}$ (3.0-inch) $\times 2.54-\mathrm{cm}$ (1-inch) PVC reducing bushings (male $\times$ female);

4. $10.6-\mathrm{cm}(0.25$-inch) NPT female $x$ male elbow;

5. 2 2.54-cm (1-inch) PVC ball valves; 
6. Dense stone measuring approximately $0.6-\mathrm{cm}(0.25-\mathrm{inch})$ in diameter. The dense stone will be placed in the flow cell between the Accusand and the end caps;

7. 4 coarse-meshed screens measuring approximately $7.62-\mathrm{cm}(3.0-i n c h)$ in diameter. The screens will be properly sized to permit the flow of the $\mathrm{ZVI}$ and surrogate groundwater, while ensuring that the density and volume of placed Accusand does not change significantly during filling and saturation of the flow cells.

8. 2 sight glasses (manometers) installed near the inlet and outlet of the flow cell;

9. 7,300 grams of Accusand; and

10. PVC Cement and Teflon tape.

\subsubsection{Injectability Flow Cell Packing Equipment}

Preparation of the injectability flow cells will require the following laboratory equipment.

1. Scale for weighing soil (15 kg capacity);

2. Vibrating table for packing flow cells; and

3. Miscellaneous hand tools.

\subsubsection{Injectability Flow Cell Packing Procedures}

1. Inspect the flow cell prior to filling, making sure any soil, residue, etc. is removed;

2. Drill 4-threaded soil sample ports measuring approximately 2.0 -cm $(0.75$-inch $)$ in diameter along the top of the flow cell and place threaded caps in each sample port. The 4 sample ports should be placed at a distance measuring approximately $1 / 6$ and $1 / 3$ of the length of the flow cell, measured from the ends of the flow cell. Two of the sample ports will be furnished with appropriate fittings to attach the sight glasses (manometers);

3. Make initial measurements of the inside diameter and length of the clean and empty flow cell and the length between the centerline of the two sight glasses (manometers).

Record measurements in the logbook;

4. Weigh clean and empty flow cell prior to filling (tare weight). Record tare weight in the logbook;

5. Split off representative approximately 7,300 gram sample of Accusand;

6. Measure the weight of the two end plugs and the four screens;

7. Secure the first screen firmly against the inside of the bushing at the bottom of the flow cell;

8. Place approximately 200 grams of dense stone on top of the first screen. Measure the actual weight of dense stone placed in the cell;

9. Place the second screen on top of the dense stone;

10. Begin pouring the pre-weighed Accusand slowly into the flow cell while continuously vibrating the flow cell on a vibrating table. Fill the flow cell until the Accusand is flush with the lip of the flow cell;

11. Place the third screen on top of the Accusand;

12. Place approximately $\mathbf{2 0 0}$ grams of dense stone on top of the third screen. Measure the actual weight of dense stone placed in the cell;

13. Secure the fourth screen firmly against the inside of the bushing at the top of the flow cell;

14. Thread the second bushing onto the open end of the cell;

15. Measure the actual dimensions of dense stone and Accusand placed in the flow cell;

16. Weigh the assembled and packed cell. Record weight of packed cell in the logbook; and

17. Label the flow cell and place on injection stand. 
Once the flow cell is packed, it will be placed in a vertical position and saturated by slowly flushing the flow cell with surrogate Hanford groundwater from the base of the flow cell until all air bubbles are removed. Once saturated, the flow cell will be placed in a horizontal position for injection testing.

\subsection{Preparation of ZVI/Carrier Fluid Mixture}

The ZVI/carrier fluid mixtures should be handled and prepared according to the procedures outlined in the following section. The ZVI will require handling and preparation procedures that satisfy health and safety concerns and minimize or prevent oxidation of the iron prior to injection into the soils.

\subsubsection{Materials}

The materials required for preparation of the $\mathrm{ZVI} /$ carrier fluid mixture includes the following:

1. ZVI Material:

- 10 grams of solid ZVI material per liter of ZVI/carrier fluid mixture that will be prepared;

2. Aerosol 22 (Sigma Chemical, St. Louis, MO):

- 0.01 grams per liter of ZVI/carrier fluid mixture that will be prepared (for all ZVI materials that do not have a vendor-preferred carrier fluid or come pre-packaged with a carrier fluid; and

3. Fresh or filtered tap water:

- Amount of water should be equal to the number of liters of $\mathrm{ZVI} /$ carrier fluid mixture that will be prepared; and

4. Nitrogen inert gas;

\subsubsection{Equipment}

1. 3 75-liter (20-gallon) polyethylene mixing tanks;

2. Manual stirring rod;

3. 3 Clamp-on portable mixers; and

4. Scale (10 kg capacity).

\subsubsection{Procedures}

The ZVI/carrier fluid mixture will be prepared with a $1 \%$ by-weight ZVI material concentration. For simplicity and ease of testing, a maximum of three $\mathrm{ZVI} /$ carrier fluid mixtures will be prepared and injected in parallel at one time. All ZVI materials that do not have a vendor-preferred carrier fluid or that do not come pre-packaged with a carrier fluid will be suspended in water using a $0.001 \%$ concentration of Aerosol 22 (Sigma Chemical, St. Louis, MO) surfactant prior to injection. MSE is assuming that a nitrogen blanket will be required to keep the ZVI mixture from oxidizing prior to injection. The procedures for preparing the $\mathrm{ZVI} /$ carrier fluid mixtures are as follows:

1. Add appropriate amount of fresh tap water to the 75-liter (20-gallon) mixing tank;

2. In a well ventilated area, measure ZVI material and surfactant and pour into the 75-liter (20-gallon) mixing tank containing the fresh tap water while continuously mixing the water with the manual stirring rod; 
3. Install clamp-on portable mixer and route power cord through the top of the mixing tank lid;

4. Setup nitrogen gas bottle and route feed tubes through the top of the mixing tank lid;

5. Seal lid onto the mixing tank and turn on nitrogen gas supply; and

6. Turn on portable mixer.

\subsubsection{Preparation of Hanford Surrogate Groundwater}

Hanford surrogate groundwater will be used during injection testing to equilibrate the flow cells and flush the flow cells following $\mathrm{ZVI} /$ carrier fluid injection. The surrogate groundwater will be prepared in accordance with Section 3.0 of Part A of this Test Plan and in a manner that mimics the geochemical makeup of the 100-D Area groundwater.

\subsection{Laboratory Testing Procedures}

Injection procedures, sampling of the effluent and soils in the flow cells, sample identification, and differential head measurements will be performed according to the procedures outlined in the following subsection. Any chemical wastes generated will be disposed of in accordance with applicable state regulations per the MSE Environmental Coordinator.

\subsubsection{Fluid Injection}

\subsubsection{ZVI/Carrier Fluid Injection}

The ZVI/carrier fluid will be injected into the flow cells using a peristaltic pump with a preset flow at a rate set within the range that would exist in the proximity of the injection well during field injection. The radial flow field that will be created during the field injection the flow rate will decrease logarithmically with the distance from the injection well. Consequently, the injection rate during the injection testing will need to be arbitrarily selected. MSE has decided to use an injection rate expected to be present at $3.5 \mathrm{~m}$ from the injection well (approximately half of the target field injection distance of 7-m). This flow rate will be calculated based on the Szecsody et al (2005) data and final information from the Electromagnetic Flowmeter Survey performed by PNNL in August 2007.

$\mathrm{ZVI/carrier} \mathrm{fluid} \mathrm{injection} \mathrm{rate} \mathrm{measurements} \mathrm{will} \mathrm{be} \mathrm{made} \mathrm{as} \mathrm{verification} \mathrm{at} \mathrm{the} \mathrm{same} \mathrm{times} \mathrm{as}$ turbidity measurement and effluent sample collections are performed. Additional measurements of the flow rate will be performed as needed, but not less than twice a day. The flow rate will be measured by collecting effluent in a graduated cylinder over a recorded time.

\subsubsection{Groundwater Flush}

Hanford surrogate groundwater will be injected into the flow cells using a peristaltic pump following injection of the ZVl/carrier fluid. The flow rate for the Hanford surrogate water flushing the flow cells should be comparable to the $4.5 \mathrm{ft} / \mathrm{d}$ rate of the groundwater flowing through the high permeable zone of the Ringold sediments under natural average regional hydraulic gradient. However, to be on the conservative side in an estimate of the ZVI particle stability within the solid matrix, the flow rate for the flow cell will be $9 \mathrm{ft} / \mathrm{d}$, which is approximately twice the rate of the regional flow. Surrogate groundwater flow rate will be set and recorded as described in Section 2.3.1.1 above. 


\subsubsection{Effluent Sampling}

Samples of the effluent for laboratory testing will be obtained from the effluent sampling ports included in the test apparatus and tested for turbidity and total iron. The effluent samples for total iron will be collected in properly labeled sample containers provided by the MSE Analytical Laboratory and preserved in accordance with Section 3.0 of Part A of this Test Plan. The sampling containers shall be rinsed three times using effluent prior to collecting the sample. The rinsate shall be properly disposed in the effluent waste tank.

\subsubsection{Soil Sampling}

Once injection of the $\mathrm{ZVI} /$ carrier fluid and surrogate Hanford groundwater are complete, the threaded caps in the four sample ports located along the flow cell will be removed to provide access for soil sampling. A stainless steel coring device will be inserted into the sample ports to collect the soil sample through the entire thickness of the flow cell. The two samples from the influent end of the flow cell will be emptied into one mixing tub and the two samples from the effluent end of the flow cell will be emptied into another mixing tub. Once the samples have been emptied into clean mixing tubs, they will be mixed to form a homogeneous composite sample from the influent and a homogenous composite sample from the effluent ends of the flow cell. An appropriate amount of sample will be removed from each composite sample and placed into a labeled sample container. The soil sample will be immediately transferred to the MSE Analytical Laboratory for analysis. The void that is created during soil sampling will be backfilled and lightly tamped with Acccusand.

\subsubsection{Sample Identification}

The sample labels will list the project sample number, data and time of sampling, sampler's name, and the analyses that are to be run on the sample. The effluent and soil sample identification system is shown in Table 3

Table3. Effluent and soil sample identification system.

\begin{tabular}{|c|c|c|c|c|c|}
\hline \multicolumn{2}{|c|}{ Project Name } & Matrix & Flow Cell Group & Flow Cell Number & Sample Event \\
\hline \multicolumn{2}{|c|}{ ZVI-B } & $\begin{array}{l}\text { SOIL - SOIL } \\
\text { EFFLUENT - EFF }\end{array}$ & $\begin{array}{l}\text { Primary - } 1 \\
\text { Duplicate - } 2 \\
\text { Control -3 }\end{array}$ & $\begin{array}{l}01,02,03,04 \text {, etc. } \\
\text { Use } 2 \text { digit format }\end{array}$ & $\begin{array}{l}01,02,03, \ldots . . \\
\text { Use } 2 \text { digit format }\end{array}$ \\
\hline \multicolumn{6}{|c|}{ Example Sample Numbers } \\
\hline \multicolumn{6}{|c|}{$\begin{array}{l}\text { Third sampling event } \\
3 \text { PV ZVI Effluent Sample }\end{array}$} \\
\hline - & Primary flow cell group, cell \#2 & \multicolumn{4}{|c|}{ ZVIB-EFF-10203 } \\
\hline - & Duplicate flow cell group, cell \#10 & \multicolumn{4}{|c|}{ ZVIB-EFF-21003 } \\
\hline - & Control flow cell group, cell \#17 & \multicolumn{4}{|c|}{ ZVIB-EFF-31703 } \\
\hline
\end{tabular}

\subsubsection{Injectability Testing and Continuous Head Differential Measurement Procedures}

Head differential measurements will be performed across each of the primary and duplicate flow cells by manually measuring the manometer tubes installed at the influent and effluent of the flow cells. Measurements will be made to the nearest millimeter. These head differentials will be recorded at the same times as turbidity measurement and effluent sample collections are 
performed. Additional measurements will be performed as needed, but not less than twice a day.

Permeability values will be calculated from the head differentials for the data prior to injection of the $\mathrm{ZVI}$ /carrier fluid and for the data obtained following the injections. Data obtained during the $\mathrm{ZVI} /$ carrier fluid injection will be analyzed separately from the pre and post injection data because the $\mathrm{ZVI} /$ carrier fluid mixture may behave differently than the Hanford surrogate water and therefore the head differentials measured during the $\mathrm{ZVI} /$ carrier fluid injection phase will not be comparable to the data obtained during the surrogate groundwater flushing phase. The head differential data obtained during the ZVI/carrier fluid injection may provide important information for the numerical modeling and field-injection system design and therefore will be recorded. 


\section{Part C: Small Column Reactivity Test}

\subsection{Objectives}

The objective of the small column reactivity test is:

An initial screening of potential iron sources based on their reduction of $\mathrm{Cr}(\mathrm{VI})$ over a moderate time in a field simulation through the use of small columns.

The small column reactivity test will serve as the final elimination process before advancing two selected irons to the Geochemical Test in Section II of the proposed path forward.

\section{$1.1 \quad$ Laboratory Testing Approach}

For each iron, two $75 \mathrm{~mm}$ ( 3 inch) $\times 500 \mathrm{~mm}$ ( 20 inch) clear PVC columns will be used to test the iron's ability to reduce $\mathrm{Cr}(\mathrm{VI})$ under flow conditions. The columns will be arranged in a vertical array and fed a continuous solution of Hanford surrogate groundwater at a rate of approximately $3 \mathrm{~mL} / \mathrm{min}$ to achieve a column seepage velocity close to $3.3 \mathrm{~m} /$ day $(11 \mathrm{ft} /$ day). The surrogate groundwater will simulate the aquifer conditions at the $100 \mathrm{D}$ site and contain a hexavalent chromium concentration of $500 \mathrm{ppb}$. Each column will be filled with a mix of surrogate groundwater, saturated, highly permeable (particle size not to exceed $7.5 \mathrm{~mm}$ ) Ringold $\mathrm{K}$ soil, and ZVI material. Two different concentrations of each iron sample will be mixed into the column packing material. The iron concentration will be a functional relationship of the deliverable iron for each individual ZVI material as determined by the injection results obtained in Part B of the screening process. The concentrations mixed in the column will be consistent with the high-end and low-end concentrations for each injected iron source. Before packing, the iron will be mixed with the selected dispersant and the Ringold soils as a saturated paste to ensure an even distribution of $\mathrm{ZVI}$ material throughout the column. The iron materials will be tested over an injection of 20 pore volumes of surrogate groundwater. Based on the results of this small column reactivity test, two final ZVI sources will be selected to advance to the final Geochemical Test in Section II.

\subsection{Primary Measurements and Analyses}

The main constituents of concern in the Small Column Reactivity tests are dissolved chromium and nitrate. A critical characteristic of the ZVI material is its ability to reduce a continuous supply of chromate over an extended period of time. Total organic carbon will be analyzed to evaluate the mobility and longevity of the dispersant in the column. In the field, the dispersant is meant to increase the mobility of the ZVI material during the injection and then wash out leaving the emplaced ZVI material adsorbed to the aquifer matrix. Table 1 presents the analyses, sample matrix, analytical methods and detection limits for the primary measurements and analyses. 
Table 1. Primary Analyses

\begin{tabular}{|l|l|l|l|}
\hline Measurement/Analysis & Matrix & Analytical Method & Detection Limit \\
\hline Chromium & Pore fluid & ICP-AES SW 6010 & $20 \mathrm{ug} / \mathrm{L}$ \\
\hline Nitrogen as ammonia & Pore fluid & EPA 350.2 & $0.05 \mathrm{mg} / \mathrm{L}$ \\
\hline Nitrogen as nitrate and nitrite & Pore fluid & EPA 353.2 & $0.05 \mathrm{mg} / \mathrm{L}$ \\
\hline Total Organic Carbon & Pore fluid & EPA 415.1 & $0.10 \mathrm{mg} / \mathrm{L}$ \\
\hline
\end{tabular}

1. Dissolved chromium will be measured; it is assumed that this measurement will represent hexavalent chromium

\subsection{Secondary Measurements and Analyses}

A reducing environment is required for the formation of $\mathrm{Cr}(\mathrm{III})$ precipitates. Dissolved oxygen and oxidation-reduction potential will be measured to quantify the extent of the reducing environment produced by a particular ZVI material. Total organic carbon is of interest to determine when the dispersant is flushed out of the system. Other parameters such as temperature and $\mathrm{pH}$ will also be measured at each sampling interval. While, pressure head differential and test column flow rate will be measured on an as need basis with no less than two measurements per day. A summary of each analysis can be seen in Table 2.

Table 2. Secondary Analyses

\begin{tabular}{|l|l|l|l|l|}
\hline Measurement/AnalysIs & Matrix & Analytical Method & Detection Limit & Precision \\
\hline Dissolved Oxygen & Pore fluid & YSI-556 & $0.1 \mathrm{mg} / \mathrm{L}$ & $20 \% \mathrm{RPD}$ \\
\hline $\begin{array}{l}\text { Oxidation-Reduction } \\
\text { Potential }\end{array}$ & Pore fluid & YSI-556 & $10 \mathrm{mV}$ & $20 \% \mathrm{RPD}$ \\
\hline $\mathrm{pH}$ & Pore fluid & YSI-556 & $0.1 \mathrm{SU}$ & $0.2 \mathrm{SU}$ \\
\hline Temperature & Pore fluid & YSI-556 & $0.05^{\circ} \mathrm{C}$ & $0.5^{\circ} \mathrm{C}$ \\
\hline Pressure Head Differential & Pore fluid & Sight Glass & $\begin{array}{l}2.5 \mathrm{~mm} \text { pore fluid over } 1 \\
\text { meter sight glass }\end{array}$ & $5 \mathrm{~mm}$ \\
\hline Test Cell Flow Rate & Pore fluid & Volume Elapsed Time & $0.1 \mathrm{~mL} / \mathrm{min}$ & $0.2 \mathrm{ml} / \mathrm{min}$ \\
\hline
\end{tabular}

\subsection{Sampling and Measurement Schedule}

Samples will be drawn from the effluent for analysis according to the sampling schedule shown in Table 3. The sampling schedule is based on the number of pore volumes injected. The pore fluid samples will be analyzed for the full suite of analytes listed in Table 1 for each sampling event. The sampling events will take place after 1, 5, 10 and 20 pore volumes of surrogate groundwater have passed through the columns. Laboratory parameters $(\mathrm{pH}$, oxidationreduction potential, dissolved oxygen and temperature) will be sampled in conjunction with the fluid samples along with an additional set taken after 15 pore volumes of surrogate groundwater has passed through the columns. For quality control purposes, a control column will be tested. The control column will not contain any ZVI but will be packed with Ringold soils and flushed with the surrogate groundwater solution. A complete summary of the sampling schedule can be seen in Table 3. 
DOE/RL-2009-35, REV.0

\begin{tabular}{|c|c|c|c|c|c|c|c|c|c|}
\hline \multicolumn{10}{|c|}{ High Iron Concentration } \\
\hline \multirow{2}{*}{$\begin{array}{l}\text { Sampling } \\
\text { Schedule }\end{array}$} & \multicolumn{8}{|c|}{ ZVI Geochemical Test Columns } & \multirow{2}{*}{\begin{tabular}{|c} 
Control Column \\
$9 \mathrm{H}$
\end{tabular}} \\
\hline & $1 \mathrm{H}$ & $2 \mathrm{H}$ & $3 \mathrm{H}$ & $4 \mathrm{H}$ & $5 \mathrm{H}$ & $6 \mathrm{H}$ & $7 \mathrm{H}$ & $8 \mathrm{H}$ & \\
\hline 1 PV GW & $\begin{array}{c}\text { Lab } \\
\text { Params. } \\
\text { Fluid } \\
\text { Samples }\end{array}$ & $\begin{array}{c}\text { Lab } \\
\text { Params. } \\
\text { Fluid } \\
\text { Samples }\end{array}$ & \begin{tabular}{|c|} 
Lab \\
Params. \\
Fluid \\
Samples
\end{tabular} & $\begin{array}{c}\text { Lab } \\
\text { Params. } \\
\text { Fluid } \\
\text { Samples }\end{array}$ & $\begin{array}{c}\text { Lab } \\
\text { Params. } \\
\text { Fluid } \\
\text { Samples }\end{array}$ & $\begin{array}{c}\text { Lab } \\
\text { Params. } \\
\text { Fluid } \\
\text { Samples }\end{array}$ & $\begin{array}{c}\text { Lab } \\
\text { Params. } \\
\text { Fluid } \\
\text { Samples }\end{array}$ & $\begin{array}{c}\text { Lab } \\
\text { Params. } \\
\text { Fluid } \\
\text { Samples }\end{array}$ & $\begin{array}{l}\text { Lab Params. } \\
\text { Fluid Samples }\end{array}$ \\
\hline 5 PV GW & $\begin{array}{c}\text { Lab } \\
\text { Params. } \\
\text { Fluid } \\
\text { Samples }\end{array}$ & $\begin{array}{l}\text { Lab } \\
\text { Params. } \\
\text { Fluid } \\
\text { Samples }\end{array}$ & \begin{tabular}{|c} 
Lab \\
Params. \\
Fluid \\
Samples
\end{tabular} & $\begin{array}{c}\text { Lab } \\
\text { Params. } \\
\text { Fluid } \\
\text { Samples }\end{array}$ & \begin{tabular}{|c|} 
Lab \\
Params. \\
Fluid \\
Samples
\end{tabular} & $\begin{array}{c}\text { Lab } \\
\text { Params. } \\
\text { Fluid } \\
\text { Samples }\end{array}$ & $\begin{array}{c}\text { Lab } \\
\text { Params. } \\
\text { Fluid } \\
\text { Samples }\end{array}$ & $\begin{array}{c}\text { Lab } \\
\text { Params. } \\
\text { Fluid } \\
\text { Samples }\end{array}$ & $\begin{array}{l}\text { Lab Params. } \\
\text { Fluid Samples }\end{array}$ \\
\hline 10 PV GW & $\begin{array}{c}\text { Lab } \\
\text { Params. } \\
\text { Fluid } \\
\text { Samples }\end{array}$ & $\begin{array}{c}\text { Lab } \\
\text { Params. } \\
\text { Fluid } \\
\text { Samples }\end{array}$ & \begin{tabular}{|c} 
Lab \\
Params. \\
Fluid \\
Samples
\end{tabular} & $\begin{array}{c}\text { Lab } \\
\text { Params. } \\
\text { Fluid } \\
\text { Samples }\end{array}$ & \begin{tabular}{|c} 
Lab \\
Params. \\
Fluid \\
Samples
\end{tabular} & $\begin{array}{c}\text { Lab } \\
\text { Params. } \\
\text { Fluid } \\
\text { Samples }\end{array}$ & $\begin{array}{c}\text { Lab } \\
\text { Params. } \\
\text { Fluid } \\
\text { Samples }\end{array}$ & $\begin{array}{c}\text { Lab } \\
\text { Params. } \\
\text { Fluid } \\
\text { Samples }\end{array}$ & $\begin{array}{l}\text { Lab Params. } \\
\text { Fluid Samples }\end{array}$ \\
\hline 15 PV GW & \begin{tabular}{|c} 
Lab \\
Params.
\end{tabular} & $\begin{array}{c}\text { Lab } \\
\text { Params. }\end{array}$ & $\begin{array}{c}\text { Lab } \\
\text { Params. }\end{array}$ & $\begin{array}{c}\text { Lab } \\
\text { Params. }\end{array}$ & \begin{tabular}{|c|} 
Lab \\
Params.
\end{tabular} & $\begin{array}{c}\text { Lab } \\
\text { Params. }\end{array}$ & $\begin{array}{c}\text { Lab } \\
\text { Params. }\end{array}$ & $\begin{array}{c}\text { Lab } \\
\text { Params. }\end{array}$ & Lab Params. \\
\hline 20 PV GW & $\begin{array}{c}\text { Lab } \\
\text { Params. } \\
\text { Fluid } \\
\text { Samples }\end{array}$ & $\begin{array}{c}\text { Lab } \\
\text { Params. } \\
\text { Fluid } \\
\text { Samples }\end{array}$ & \begin{tabular}{|c} 
Lab \\
Params. \\
Fluid \\
Samples
\end{tabular} & $\begin{array}{c}\text { Lab } \\
\text { Params. } \\
\text { Fluid } \\
\text { Samples }\end{array}$ & $\begin{array}{c}\text { Lab } \\
\text { Params. } \\
\text { Fluid } \\
\text { Samples }\end{array}$ & $\begin{array}{c}\text { Lab } \\
\text { Params. } \\
\text { Fluid } \\
\text { Samples }\end{array}$ & \begin{tabular}{|c} 
Lab \\
Params. \\
Fluid \\
Samples
\end{tabular} & $\begin{array}{c}\text { Lab } \\
\text { Params. } \\
\text { Fluid } \\
\text { Samples }\end{array}$ & $\begin{array}{l}\text { Lab Params. } \\
\text { Fluid Samples }\end{array}$ \\
\hline
\end{tabular}

Table 3A. Sampling, analysis, and measurement schedule. 
DOE/RL-2009-35, REV.0

\begin{tabular}{|c|c|c|c|c|c|c|c|c|c|}
\hline \multicolumn{10}{|c|}{ Low Iron Concentration } \\
\hline \multirow{2}{*}{$\begin{array}{l}\text { Sampling } \\
\text { Schedule }\end{array}$} & \multicolumn{8}{|c|}{ ZVI Geochemical Test Column } & \multirow{2}{*}{\begin{tabular}{|c|} 
Control Column \\
$9 \mathrm{~L}$
\end{tabular}} \\
\hline & $1 \mathrm{~L}$ & $2 \mathrm{~L}$ & 3L & 4L & $5 \mathrm{~L}$ & $6 \mathrm{~L}$ & 7L & $8 \mathrm{~L}$ & \\
\hline 1 PV GW & $\begin{array}{c}\text { Lab } \\
\text { Params. } \\
\text { Fluid } \\
\text { Samples }\end{array}$ & $\begin{array}{c}\text { Lab } \\
\text { Params. } \\
\text { Fluid } \\
\text { Samples }\end{array}$ & $\begin{array}{c}\text { Lab } \\
\text { Params. } \\
\text { Fluid } \\
\text { Samples }\end{array}$ & $\begin{array}{c}\text { Lab } \\
\text { Params. } \\
\text { Fluid } \\
\text { Samples }\end{array}$ & $\begin{array}{c}\text { Lab } \\
\text { Params. } \\
\text { Fluid } \\
\text { Samples }\end{array}$ & $\begin{array}{c}\text { Lab } \\
\text { Params. } \\
\text { Fluid } \\
\text { Samples }\end{array}$ & $\begin{array}{c}\text { Lab } \\
\text { Params. } \\
\text { Fluid } \\
\text { Samples }\end{array}$ & \begin{tabular}{|c} 
Lab \\
Params. \\
Fluid \\
Samples
\end{tabular} & $\begin{array}{l}\text { Lab Params. } \\
\text { Fluid Samples }\end{array}$ \\
\hline 5 PV GW & $\begin{array}{c}\text { Lab } \\
\text { Params. } \\
\text { Fluid } \\
\text { Samples }\end{array}$ & $\begin{array}{c}\text { Lab } \\
\text { Params. } \\
\text { Fluid } \\
\text { Samples }\end{array}$ & $\begin{array}{c}\text { Lab } \\
\text { Params. } \\
\text { Fluid } \\
\text { Samples }\end{array}$ & $\begin{array}{c}\text { Lab } \\
\text { Params. } \\
\text { Fluid } \\
\text { Samples }\end{array}$ & $\begin{array}{c}\text { Lab } \\
\text { Params. } \\
\text { Fluid } \\
\text { Samples }\end{array}$ & $\begin{array}{c}\text { Lab } \\
\text { Params. } \\
\text { Fluid } \\
\text { Samples }\end{array}$ & $\begin{array}{c}\text { Lab } \\
\text { Params. } \\
\text { Fluid } \\
\text { Samples }\end{array}$ & $\begin{array}{c}\text { Lab } \\
\text { Params. } \\
\text { Fluid } \\
\text { Samples }\end{array}$ & $\begin{array}{l}\text { Lab Params. } \\
\text { Fluid Samples }\end{array}$ \\
\hline 10 PV GW & $\begin{array}{c}\text { Lab } \\
\text { Params. } \\
\text { Fluid } \\
\text { Samples }\end{array}$ & $\begin{array}{c}\text { Lab } \\
\text { Params. } \\
\text { Fluid } \\
\text { Samples }\end{array}$ & $\begin{array}{c}\text { Lab } \\
\text { Params. } \\
\text { Fluid } \\
\text { Samples }\end{array}$ & $\begin{array}{c}\text { Lab } \\
\text { Params. } \\
\text { Fluid } \\
\text { Samples }\end{array}$ & $\begin{array}{c}\text { Lab } \\
\text { Params. } \\
\text { Fluid } \\
\text { Samples }\end{array}$ & $\begin{array}{c}\text { Lab } \\
\text { Params. } \\
\text { Fluid } \\
\text { Samples }\end{array}$ & $\begin{array}{c}\text { Lab } \\
\text { Params. } \\
\text { Fluid } \\
\text { Samples }\end{array}$ & \begin{tabular}{|c} 
Lab \\
Params. \\
Fluid \\
Samples
\end{tabular} & $\begin{array}{l}\text { Lab Params. } \\
\text { Fluid Samples }\end{array}$ \\
\hline 15 PV GW & \begin{tabular}{|c|} 
Lab \\
Params.
\end{tabular} & $\begin{array}{c}\text { Lab } \\
\text { Params. }\end{array}$ & $\begin{array}{c}\text { Lab } \\
\text { Params. }\end{array}$ & $\begin{array}{c}\text { Lab } \\
\text { Params. }\end{array}$ & $\begin{array}{c}\text { Lab } \\
\text { Params. }\end{array}$ & $\begin{array}{c}\text { Lab } \\
\text { Params. }\end{array}$ & $\begin{array}{c}\text { Lab } \\
\text { Params. }\end{array}$ & $\begin{array}{c}\text { Lab } \\
\text { Params. }\end{array}$ & Lab Params. \\
\hline 20 PV GW & $\begin{array}{c}\text { Lab } \\
\text { Params. } \\
\text { Fluid } \\
\text { Samples }\end{array}$ & $\begin{array}{c}\text { Lab } \\
\text { Params. } \\
\text { Fluid } \\
\text { Samples }\end{array}$ & $\begin{array}{c}\text { Lab } \\
\text { Params. } \\
\text { Fluid } \\
\text { Samples }\end{array}$ & \begin{tabular}{|c} 
Lab \\
Params. \\
Fluid \\
Samples
\end{tabular} & $\begin{array}{c}\text { Lab } \\
\text { Params. } \\
\text { Fluid } \\
\text { Samples }\end{array}$ & $\begin{array}{c}\text { Lab } \\
\text { Params. } \\
\text { Fluid } \\
\text { Samples }\end{array}$ & $\begin{array}{c}\text { Lab } \\
\text { Params. } \\
\text { Fluid } \\
\text { Samples }\end{array}$ & \begin{tabular}{|c} 
Lab \\
Params. \\
Fluid \\
Samples
\end{tabular} & $\begin{array}{l}\text { Lab Params. } \\
\text { Fluid Samples }\end{array}$ \\
\hline \multicolumn{3}{|c|}{ Total Lab Parameter Measurements } & \multicolumn{7}{|c|}{90} \\
\hline \multicolumn{3}{|c|}{ Total Pore Fluid Sample Analyses } & \multicolumn{7}{|c|}{72} \\
\hline \multicolumn{10}{|c|}{$\begin{array}{l}\text { PV = Pore Volume } \\
\text { GW = Surrogate Groundwater } \\
\text { Lab Prms. = Laboratory parameters including } \mathrm{pH}, \mathrm{ORP} \text {, dissolved oxygen, temperature }\end{array}$} \\
\hline
\end{tabular}

Table 3B. Sampling, analysis, and measurement schedule. 


\subsection{Data Reduction and Analysis}

Data from each sampling event will be compiled into a database for this project. The database will include a record of all paper copies of sampling records, chain of custody sheets, and analytical laboratory reports. It will also include the project laboratory logbook and instrument calibration records. In addition to the paper copies of the data, all numerical values obtained from the testing will be entered into an electronic spreadsheet for further analysis.

For each sampling event, an appropriate statistic describing the data (i.e., average with standard deviation) will be calculated for each parameter. These values will be plotted as functions of pore volumes injected. Additionally, data from the ZVI small reactivity columns will be compared to the data from the Control column to determine if a significant change to the geochemistry is occurring.

\subsection{PREPARATION, SAMPLING \& ANALYSIS PROCEDURES}

The preparation, sampling and analysis for the Small Column Reactivity tests are designed as a function of prior conditions in Part B: Injectability Test Plan. For this reason, if more efficient/ improved procedures are discovered to benefit the project these methods can be approved and implemented into the test plan for Part C.

\section{$2.1 \quad$ Test Setup}

The laboratory testing will be conducted using the geochemical test cells packed with saturated Ringold soils, the tested ZVI material and the appropriate dispersant. The columns will be arranged vertically and connected to a series of pumps to provide controlled injection of the Hanford surrogate groundwater. Procedures for preparing the surrogate groundwater have been summarized in Part A of this test plan.

Before starting the entire small column reactivity test, which could possibly as many as 18 columns, a trial column will be assembled using one of the ZVI materials using this test procedure. This will serve to fine tune the process so adjustments can be made before the complete test is carried out.

Effluent from the testing will be discharged to a common waste tank.

\subsection{Column Preparation}

The small columns will be made of clear PVC pipe measuring approximately $7.62-\mathrm{cm}$ (3.0-inch) in diameter by $50-\mathrm{cm}$ (19.69-inch) in length. The ends of each column will be fitted with threaded couplings and the couplings will be connected to an injection system at the inlets and effluent drainage system at the outlets. The columns will be maintained in a vertical position during the injection simulations to provide consistent contact time between the chromium rich Hanford surrogate groundwater and the tested ZVI material. Each column will be labeled \#1 through \#19 according to Table 3.

\subsubsection{Column Cell Materials}

The materials required for preparation of each column includes the following: 
1. 1 length of $7.62-\mathrm{cm}(3.0-\mathrm{inch})$ nominal diameter by $50-\mathrm{cm}$ (19.69-inch) long clear PVC pipe;

2. 2 7.62-cm (3.0-inch) PVC NPT Female $x$ socket-weld pipe adapters;

3. 2 7.62-cm (3.0-inch) $\times 2.54-\mathrm{cm}$ (1-inch) PVC reducing bushings (male $\times$ female);

4. 2 2.54-cm (1-inch) PVC ball valves;

5. Dense stone measuring approximately $0.6-\mathrm{cm}(0.25$-inch) in diameter. The dense stone will be placed in the test cell between the Ringold soil and the end caps;

6. 4 coarse-meshed screens measuring approximately $7.62-\mathrm{cm}(3.0$-inch) in diameter. The screens will be properly sized to permit the flow of surrogate groundwater. One screen will be placed between the end caps and the dense stone and the second screen will be placed between the dense stone and the Ringold soil;

7. 2 sight glasses (manometers) measuring approximately $1.0-\mathrm{cm}(0.4$-inch) in diameter and of appropriate length will be installed at the inlet (base) and outlet (top) of the column;

8. $2.21^{*} 10^{-3} \mathrm{~m}^{3}$ of Ringold soil; and

9. PVC Cement and Teflon tape.

\subsubsection{Small Cell Packing Equipment}

Preparation of the columns will require the following laboratory equipment.

1. Scale for weighing soil (15 kg capacity);

2. Spatula for mixing the ZVI, soil, and sand into a homogeneous paste

3. Miscellaneous hand tools.

\subsubsection{Small Cell Packing Material Preparation}

A mix of surrogate groundwater, saturated, highly permeable (particle size not to exceed $7.5 \mathrm{~mm}$ ) Ringold soil, and ZVI material will be mixed and packed into each column. The material will be mixed as a saturated paste with two different concentrations (based on the minimum and maximum deliverable concentrations of the individual ZVI material in Part B - Injectability Testing) of ZVI material.

\subsubsection{Small Column Packing Procedure}

Preparation of the ZVI material/soil paste for filling the column is a two-stage process. First, a slurry of the $\mathrm{ZVI}$ and any dispersant/carrier is made. The $\mathrm{ZVI} /$ dispersant/carrier slurry is then added to the Ringold soil and a uniform paste is made that is saturated or slightly under saturated with water. The $\mathrm{ZVI} /$ soil paste is scooped into the column until it is completely filled; throughout the filling process, care is taken to exclude any trapped air. A trial ZVI/soil paste will be made prior to making the test ZVI/soil slurry, where a sample of the Ringold soil will be used to determine the approximate amount of water needed to create a saturated paste. The paste contains the appropriate water content when no supernatant water separates from the paste after being allowed to stand, unmixed, for at least four hours. The surface of the paste should be just glistening, but no free water should form on the surface. At this water content the pore space will be completely occupied with water. Preparation of the ZVI slurry and ZVI/soil paste is described below. 
1. Split off a representative, approximately 2,300 gram, sample of Hanford Ringold soil. Place the sample into a pre-weighed 2 liter plastic or glass beaker and weigh accurately, set aside;

2. Weigh and record the appropriate amount of $\mathrm{ZVI}$ for the selected $\mathrm{ZVI} /$ soil ratio, in a plastic or glass $250 \mathrm{ml}$ beaker;

3. Add with agitation de-ionized water to the $250 \mathrm{ml}$ beaker, containing the ZVI, to make a uniform, free-flowing slurry. Be careful not to add more water than is necessary to make the ZVI/Soil saturated paste.

4. Add the $Z \mathrm{VI} /$ de-ionized water slurry to the soil, as appropriate, in the 2 liter beaker and mix thoroughly. Add water as needed to make a paste. The paste must be saturated or slightly deficient in water, so that upon standing, no pooling or puddling of water appears on the surface of the paste.

5. Record the mass of the paste.

\subsection{Preparation of Hanford Surrogate Groundwater}

The Hanford surrogate groundwater will be prepared to simulate the average aquifer conditions experienced at the Hanford site. The procedure for the preparation of this surrogate solution is detailed in section 3.0 of Part $A$ of this test plan.

\subsection{Laboratory Testing Procedures}

Sampling of the effluent pore fluid and constant measurements should be performed according to the procedures outlined in the following section.

\subsection{Effluent Sampling}

Samples of the effluent for laboratory testing will be obtained from the effluent sampling ports included in the test apparatus. The effluent samples will be collected in properly labeled sample containers provided by the MSE Analytical Laboratory and preserved according to the laboratory directions. The sampling containers shall be rinsed three times using effluent prior to collecting the sample. The rinsate shall be properly disposed in the effluent waste tank.

\subsection{Sample Identification}

The sample labels will list the project sample number, date and time of sampling, sampler's name, and the analyses that are to be run on the sample. The effluent and soil sample identification system is shown in Table 2. 
Table 2. Effluent and soil sample identification system.

\begin{tabular}{|c|c|c|c|c|c|c|}
\hline \multicolumn{2}{|c|}{ Project Name } & \multicolumn{2}{|l|}{ Matrix } & Test Column Group & $\begin{array}{l}\text { Test Column } \\
\text { Number }\end{array}$ & Sample Event \\
\hline \multicolumn{2}{|c|}{$\mathrm{ZVI}-\mathrm{C}$} & \multicolumn{2}{|c|}{ EFFLUENT - EFF } & $\begin{array}{l}\text { Primary - } 1 \\
\text { Duplicate - } 2 \\
\text { Control -3 }\end{array}$ & $\begin{array}{l}01,02,03,04, \text { etc. } \\
\text { Use } 2 \text { digit format }\end{array}$ & $\begin{array}{l}01,02,03, \ldots \ldots \\
\text { Use } 2 \text { digit format }\end{array}$ \\
\hline \multicolumn{7}{|c|}{ Example Sample Numbers } \\
\hline \multicolumn{7}{|c|}{$\begin{array}{l}\text { Third sampling event } \\
10 \text { PV ZVI Effluent Sample }\end{array}$} \\
\hline - & \multicolumn{2}{|c|}{ Primary test cell group, cell 2} & \multicolumn{4}{|c|}{ ZVI-EFF-10203 } \\
\hline - & \multicolumn{2}{|c|}{ Duplicate test cell group, cell 1} & \multicolumn{4}{|c|}{ ZVI-EFF-20103 } \\
\hline - & \multicolumn{2}{|c|}{ Control flow test group, cell 3} & \multicolumn{4}{|c|}{ ZVI-EFF-30303 } \\
\hline
\end{tabular}

\section{Health and Safety}

Experiments presented in this test plan will be conducted in the Experimental Laboratory at the MSE Testing Facility. All activities shall be conducted in accordance with MSE's Chemical Hygiene Plan (CHP) and MSE's Hazard Communication Program, as documented in the MSE Health and Safety Program Manual, Part 8, Section 6; and Section 1; respectively. The MSE Health and Safety Director (Scott Nuthak) will serve as the Chemical Hygiene Officer (CHO). In addition any required waste handling and management will be conducted under the guidance of the MSE Environmental Coordinator (Charlie Brown). Material Safety Data Sheets (MSDS) for all chemicals and materials used in the experiments will be kept on file in the laboratory and shall be readily available throughout the project duration. All containers shall be properly labeled with their content and hazard.

\section{Engineering Controls}

Engineering controls shall be used where appropriate. These include catch basins designed to contain any spillage, laboratory fume hoods, and proper grounding on all electrical equipment.

\section{Administrative Controls}

A general test area will be demarcated for this project within the MSE Experimental Laboratory building and restricted to project personnel only. Proper chemical storage that includes separating incompatibles will be practiced. Chemicals shall not be left out of their respective storage cabinets.

Personnel shall practice good personal hygiene at all times. This includes, no eating, smoking, chewing gum, chewing tobacco, or drinking in the test area: hands shall be washed thoroughly after removing protective gloves and before leaving the test area; and hands shall be kept away from the eyes and face when wearing protective gloves. Eating and drinking shall only be allowed in the break area of the building. Smoking is prohibited inside the building. 


\section{Personal Protective Equipment}

Standard laboratory protective equipment includes: laboratory coat, safety glasses, and impervious latex or neoprene gloves.

\section{First Aid and Emergency Response}

During any emergency event, consult the MSDS as necessary. However, in any case of chemicals contacting unprotected skin or eyes, flush with water for a minimum of 15 minutes. During that time, someone shall dial "333" and request an ambulance. The emergency eyewash/shower is located within 30 feet of the laboratory hood. In the event of an inhalation exposure, get to fresh air and someone shall dial 333. Nobody should attempt to rescue a person down if bad air is suspected, unless the $\mathrm{CHO}$ gives approval to enter based on air monitoring. The emergency brigade shall be requested with self-contained breathing apparatus (SCBAs), as appropriate. The use of PPE, the laboratory hood, good personal hygiene, and safe work procedures should prevent exposures from occurring via inhalation, ingestion, and absorption. The potential for injection hazards is not likely, given the nature of work. In the event of a spill or fire that risks personnel, evacuate the building and dial 333. Only qualified personnel equipped with SCBAs should attempt to extinguish incipient-stage fires that involve hazardous chemicals. The $\mathrm{CHO} /$ Emergency Coordinator shall only authorize re-entry. In the event of spills, absorbing materials are provided in the building, including the sorbents used in the experiments. Additionally, chemical quantities are very small. All spills shall be reported to the $\mathrm{CHO}$ and actions shall be taken to minimize spillage, area contamination, and personnel exposure.

\section{Waste Disposal}

Any chemical wastes generated will be disposed of in accordance with applicable state regulations per the MSE Environmental Coordinator. 


\title{
Test Plan For Geochemical Testing of Zero-VAlent IRON (ZVI) FOR POTENTIAL USE AT HANFORD'S IN SITU REDOX MANIPULATION BARRIER
}

\author{
Prepared by: \\ MSE Technology Applications, Inc. \\ 200 Technology Way \\ P.O. Box 4078 \\ Butte, Montana 59701
}

Revision 02

January 28, 2008 
DOE/RL-2009-35, REV.0

\section{This Page Intentionally Left Blank}




\section{MSE Review and Approval Signatures}

\section{MSE Technology Applications, Inc.}

Prepared By: Gary Wyss, Geochemist / Analytical Chemist

Approved By: Mary Ann Harrington-Baker, Project Manager

Approved by: Charlie Brown, Environmental Compliance Officer

Approved by: Scott Nuthak, Health and Safety Officer

Approved by: Tom Burkhart, Operations Manager

Approved by: Andrea Hart, DOE-EM Manager

Approved By: Jeff LeFever, DOE Program Manager
Date

Date

Date

Date

Date

Date

Date 
DOE/RL-2009-35, REV.0

This Page Intentionally Left Blank 


\section{TABLE OF CONTENTS}

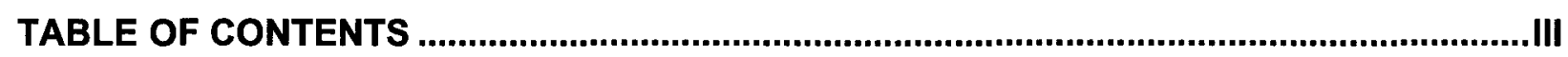

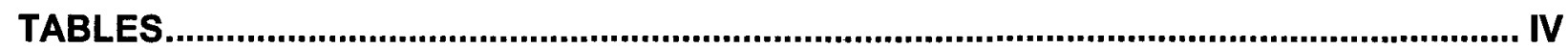

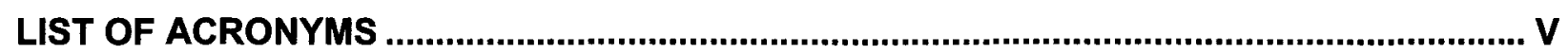

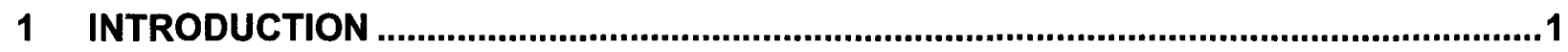

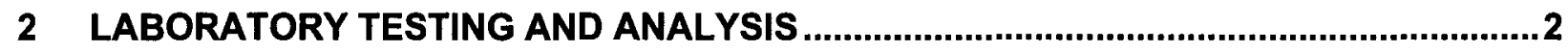

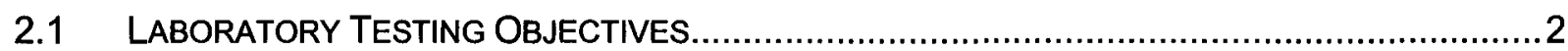

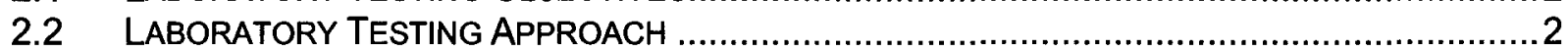

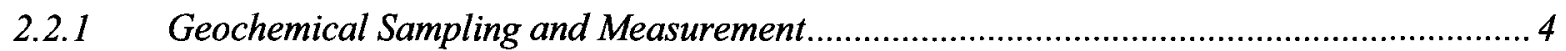

2.3 GROUNDWATER CHEMISTRY FORMULATION ....................................................

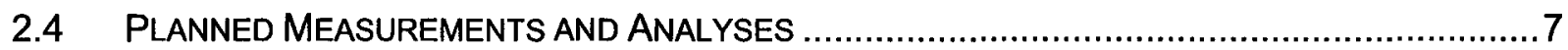

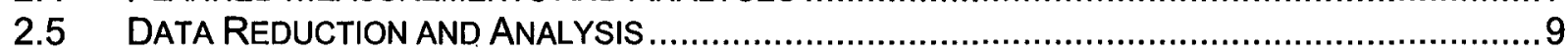

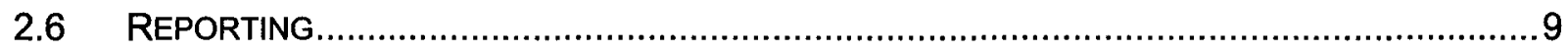

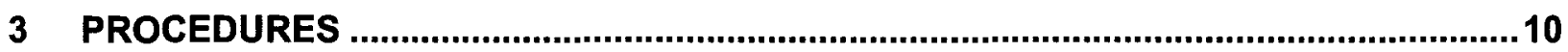

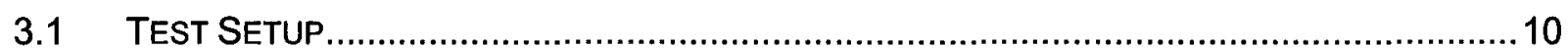

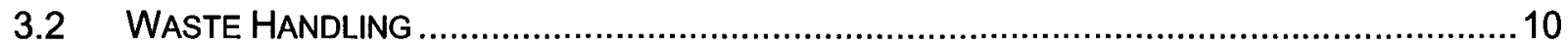

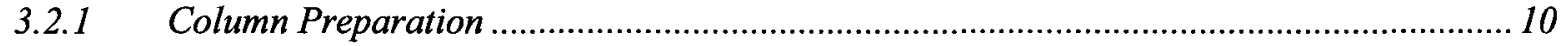

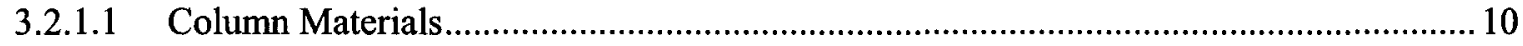

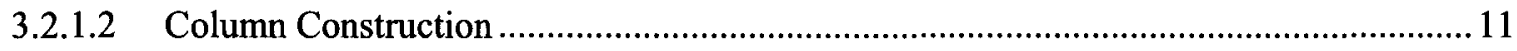

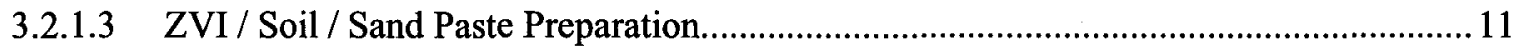

3.2.1.4 Column Filling Equipment............................................................................. 12

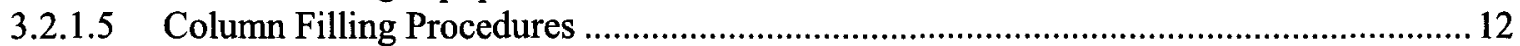

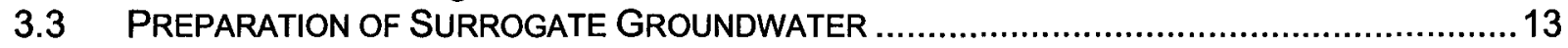

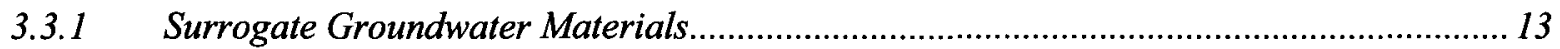

3.3.2 Surrogate Groundwater Preparation Equipment ..................................................... 13

3.3.3 Surrogate Groundwater Preparation Procedures ....................................................... 14

3.4 FIELD AND LABORATORY TESTING PROCEDURES ............................................ 14

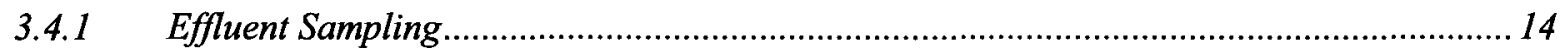

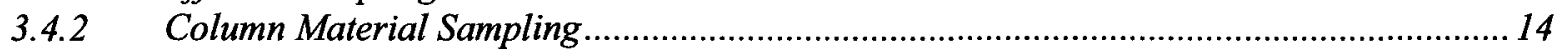

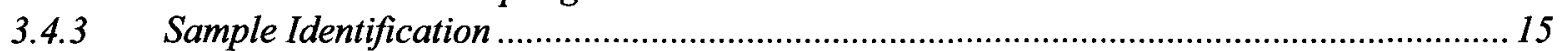

3.4.4 Head Differential Measurement Procedures ............................................................... 15

4 HEALTH AND SAFETY .............................................................................................. 16

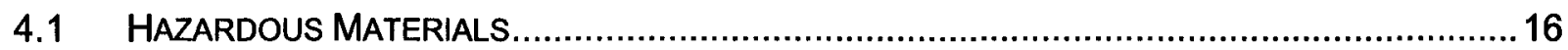

4.2 ENGINEERING CONTROLS ............................................................................. 16

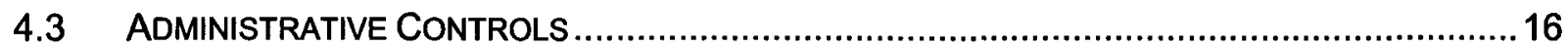

4.4 PERSONAL PROTECTIVE EQUIPMENT .............................................................. 17

4.5 FIRST AID AND EMERGENCY RESPONSE........................................................ 17

5 QUALITY CONTROL AND QUALITY ASSURANCE................................................18

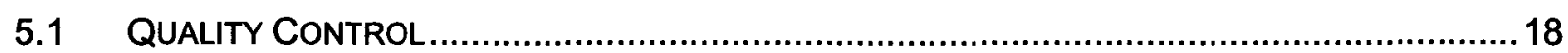

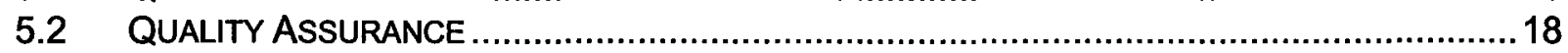

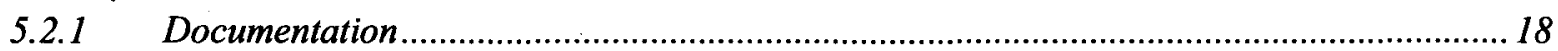

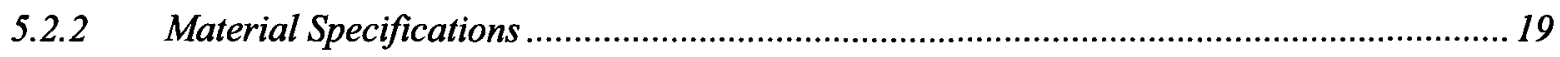

5.2.3 Test Equipment Designs and Specifications ......................................................... 19 


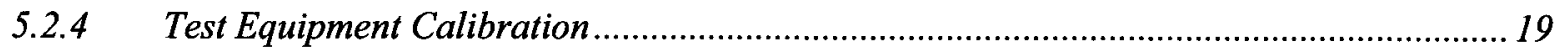

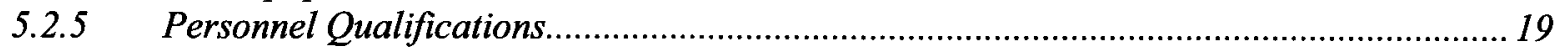

5.2.6 Quality Assessment and Reporting …...................................................................... 19

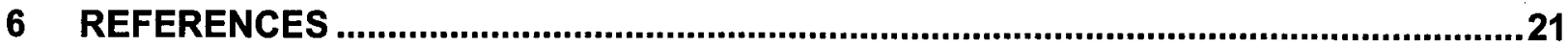

\section{TABLES}

Table 1. ZVl's Selected for Geochemical Testing .......................................................... 2

Table 2. Sampling Schedule and Measurements ....................................................... 5

Table 3. Column Configuration ................................................................................ 6

Table 4. Groundwater Chemistry of Hanford 100-D Area. ...................................................

Table 5. Chemical Based Measurements and Analyses. ................................................... 8

Table 6. Physical Measurements and Analyses ............................................................8

Table 7. Reagents for 200 Liters of Surrogate Hanford 100-D Area Groundwater................... 13

Table 8. Effluent Sample Identification System. ............................................................... 15

Table 9. Hazardous Materials and Exposure/Physical Data............................................... 16

Table 10. Field Measurement Quality Control Acceptance Ranges. .................................... 18 


\section{LIST OF ACRONYMS}

3D

3-dimensional

CFR Code of Federal Regulations

$\mathrm{CHO} \quad$ Chemical Hygiene Officer

CHP Chemical Hygiene Plan

CPU central processing unit

$\mathrm{Cr}^{3+} \quad$ trivalent chrome

$\mathrm{Cr}^{6+} \quad$ hexavalent chrome

DI deionized (water)

DOE U.S. Department of Energy

GW groundwater

H-F-R Health - Fire - Reactivity Ratings

ISRM In situ Redox Manipulation (ISRM)

Lab Prms. laboratory parameters

MSDS Material Safety Data Sheets

MSE MSE Technology Applications, Inc.

MZVI micron-sized zero-valent iron

ORP oxidation-reduction potential

OSHA Occupational Safety and Health Administration

PEL/TLV Permissible Exposure Limit / Threshold Limit Value

PNNL Pacific Northwest National Labs

PPE personal protective equipment

PV pore Volume

PVC poly vinyl chloride

QA quality assurance

QAP Quality Assurance Plan

QC quality control

RFP request for proposal

RPD relative percent difference

RSD relative standard deviation

SCBA self-contained breathing apparatus

TAP Technical Assistance Panel 


\section{INTRODUCTION}

MSE Technology Applications, Inc., (MSE) under subcontract to Fluor Hanford (Fluor Hanford Contract \#30994) has been tasked with completing laboratory testing, numerical modeling, and associated field work related to injection of micron size zero-valent iron (MZVI) into the subsurface at the 100-D Area at the U.S. Department of Energy (DOE) Hanford Site, Washington State. The purpose of this work is to demonstrate the feasibility of using MZVI to repair portions of the In situ Redox Manipulation (ISRM) barrier located in the 100-D Area of the Hanford Site.

The ISRM barrier was installed to remediate a chromium groundwater plume in Hanford's 100-D Area by reduction of the $\mathrm{Cr}^{6+}$ in the groundwater to $\mathrm{Cr}^{3+}$ through the injection of sodium dithionite into the aquifer, thus creating a chemically reduced environment (DOE/RL, 2005). Localized signs of failure in the barrier (defined by the presence of $\mathrm{Cr}^{6+}$ in the treated wells) were discovered in some wells 18 months after they were treated. The most probable cause of the premature barrier breakdown was determined to be heterogeneities in the aquifer where laterally discontinuous units with high permeability and lower inherent reductive capacity (because of lower iron content) were reoxidized faster than the less permeable layers. A Technical Assistance Panel (TAP) recommended that an alternative technology (injection of MZVI/polymer) be tested and possibly deployed to mend the barrier, and to eliminate the need of periodically re-injecting the ISRM wells with sodium dithionite.

The TAP recommended that the reduction potential of co-contaminants and generation of byproducts must be considered and monitored. The TAP recommended considering all potential geochemical impacts to the aquifer system from the MZVI/polymer injection, specifically the potential for the MZVI to convert nitrate to ammonia and the formation of carbonate due to the generation of high $\mathrm{pH}$ conditions in the groundwater. Following the recommendations from the TAP, Fluor Hanford issued a request for proposal (RFP) to provide the laboratory testing, numerical modeling, and associated fieldwork for the MZVI/polymer injection. MSE was awarded the work for the investigation of MZVI as a remedy for repairing the ISRM. In May 2007 Fluor Hanford modified the scope of work to stop laboratory testing on the preferred micron size material and to investigate other zero valent iron (ZVI) materials, which should be considered as candidates for injection into the ISRM barrier. This document addresses the requirements of Task 10c Geochemical Testing of Selected Zero Valent Iron of the subcontract, which includes development of a laboratory test plan to assess the changes to the geochemistry of the aquifer system associated with the ISRM barrier following the injection of the ZVI/dispersant mixture. The laboratory work must be completed to support the Treatability Test Plan (Task 4), which has an April 2008 deliverable date. 


\section{LABORATORY TESTING AND ANALYSIS}

The laboratory testing and data analysis will be completed at the MSE facility in Butte, Montana. The MSE facility has fully functional experimental and analytical laboratories. The purpose of the laboratory testing will be to evaluate geochemical changes in a simulated aquifer environment after injection of ZVI, including those that may adversely affect groundwater quality. The objectives of this testing are listed in the following sections.

\subsection{Laboratory Testing Objectives}

The geochemical testing objectives as specified in the RFP included the following:

- Evaluating changes in water chemistry when surrogate groundwater of similar composition to that at the 100-D Area reacts with ZVI emplaced in the aquifer with emphasis on:

o $\mathrm{pH}$ changes;

- The effect of ZVI-induced reducing conditions on nitrate (e.g., conversion to ammonia);

- Changes in carbonate concentration due to high pH (high carbonate concentrations may decrease the aquifer permeability);

- Ability of ZVI impregnated Ringold soil to remove/reduce $\mathrm{Cr}^{6+}$;

- Assess passivation by the formation of iron hyrdoxy-oxides or other secondary minerals on the ZVI material.

\subsection{Laboratory Testing Approach}

The laboratory work for Task $10 \mathrm{c}$ will focus on only the geochemical reactivity of the two chosen ZVls, RNIP-M2 from Toda Japan and Polymetallix from Crane-Polyflon. Table 1 presents the ZVI's with their composition, dispersant and some physical characteristics.

Table 1. ZVl's Selected for Geochemical Testing

\begin{tabular}{|c|c|c|c|c|c|c|}
\hline $\mathrm{ZVI}$ & Manufacturer & $\begin{array}{l}\text { Particle } \\
\text { Size } \\
\text { Distribution }\end{array}$ & Dispersant & $\begin{array}{l}\text { Shipped } \\
\text { form of } \\
\text { material }\end{array}$ & Coating & $\begin{array}{l}\% \text { Iron in } \\
\text { the } \\
\text { material }\end{array}$ \\
\hline RNIP - M2 & Toda America & $\begin{array}{l}D_{50}-70 \\
\text { nanometers }\end{array}$ & Sodium polyaspartate & $\begin{array}{l}\text { Water- } \\
\text { based } \\
\text { slurry: } \\
80 \% \\
\text { water, } \\
17 \% \\
\text { solids, } \\
\text { and } 3 \% \\
\text { polymeric } \\
\text { additive }\end{array}$ & $\begin{array}{l}\text { Magnetite } \\
\text { coating } \\
\text { surrounding } \\
\text { alpha-iron } \\
\text { core }\end{array}$ & Unknown \\
\hline Polymetallix & $\begin{array}{l}\text { Crane - } \\
\text { Polyflon }\end{array}$ & $\begin{array}{l}100 \text { to } 200 \\
\text { nanometer }\end{array}$ & $\begin{array}{l}\text { Vendor recommendation } \\
5-10 \% \text { sodium } \\
\text { hexametaphosphate }\end{array}$ & Slurry & None & $>99$ \\
\hline
\end{tabular}


The ZVI selection process consisted of a literature search and preliminary reactivity and injection tests. The literature search identified 30 micron-sized and nano-sized zero-valent iron products that were commercially available. Next, side-by-side screening study comparisons of the initial $30 \mathrm{ZVI}$ materials were conducted using geochemical batch tests which reduced the initial number of ZVI materials under consideration to 8. Subsequently, injection flow cell (horizontal columns) experiments on the top 8 reduced the number of $Z \mathrm{VI}$ materials under consideration to 3 . Finally, the results of column geochemical tests resulted in the selection of the final $2 \mathrm{ZVI}$ materials to be used for detailed geochemical and injection testing. Injection testing will be the focus of Task $10 \mathrm{~d}$ and will not be discussed in detail under the test plan for geochemical testing Task 10c.

The experiments will use vertical columns packed with ZVI and Ringold sediment, which will be flushed with surrogate groundwater at a specified flow rate. The specified flow rate will be set to mimic twice the linear velocity ( $\sim 9$ feet/day) of the high permeability zones in the Ringold formation under the natural regional gradient.

The laboratory test set up will be based on the geochemical screening studies conducted under Task 10. The columns will be designed to simulate the aquifer conditions after ZVI emplacement. Choice of the column length is arbitrary, but will yield a residence time within the column of approximately 300 minutes. This time is more than sufficient for nano-scale ZVI particles to reduce $\mathrm{Cr}^{+6}$ to $\mathrm{Cr}^{+3}$ that has been shown to be an exceedingly rapid process (Ponder,et.al, 2000). The columns will be packed with Hanford Ringold soils with surrogate water pumped through each of the columns. The surrogate water chemical composition will be similar to the groundwater from the 100-D Area.

The column testing will commence with the ZVI and dispersant/carrier being mixed with the Ringold soil and packed into the column. MSE will acquire effluent samples from the geochemical columns at prescribed pore volumes during the study to identify changes in the groundwater chemistry as a function of the effluent volume. In addition to the effluent sampling, one column for each ZVI being tested will be submitted for mineralogical examination at the end of testing. One control column, containing only Ringold's soil (i.e. - no ZVI), will be set up for the test. Effluent from the control column will be analyzed in parallel with the samples from the experimental columns.

The column effluent $\mathrm{pH}$, oxidation-reduction potential (ORP), specific conductance, dissolved oxygen, and temperature will be measured at the prescribed pore volume intervals listed in Table 2. Samples of the effluent will be analyzed for nitrogen as ammonia, nitrate, and nitrite; alkalinity; sulfate; iron speciation; and total and hexavalent chromium as also shown in Table 2.

Mineralogical analysis using mineral liberation analysis (MLA) that incorporates additional hardware interfaced to the scanning electron microscope (SEM). MLA utilizes the ability of the SEM to provide consistent grey-levels for each mineral in a "back-scattered electron" (BSE) image of the sample. Minerals produce different grey-levels that are proportional to their average molecular weight. The $x-$ rays produced by the electron beam impact are used to confirm the mineral phases in the sample. MLA will be used to qualitatively estimate mineral phases including the amount of iron oxy-hydroxides that have formed during the reaction of the $\mathrm{ZVI}$ with $\mathrm{Cr}^{6+}$. MSE anticipates that if passivation of the ZVI does occur, it will be primarily due to the formation of iron oxy-hydroxides (Yarmoff et al, 1999). Therefore, the "amount of iron passivation" will be based on the amount of iron oxy-hydroxide that forms in the columns, which may be observed through MLA. If formation of a significant amount of iron oxy-hydroxide is observed, then the assumption that there is an increased potential for passivation of iron could be made. Furthermore, a decrease in the amount of $\mathrm{Cr}^{6+}$ reduction with increasing volume of groundwater flushed through the system may also be an indication of iron passivation. If there is a positive correlation between the formation of the iron oxy-hydroxides and a decrease in the amount of reduction of $\mathrm{Cr}^{6+}$, this will further support the assumption that iron passivation is related to the iron oxy-hydroxide formation. 
Additionally, the head differentials across the column will be monitored.. This will indicate fouling of the columns, which may be due to a reduction in the permeability from iron-chromium oxy-hydroxide formation as the test progresses. This is discussed further in Section 0.

\subsubsection{Geochemical Sampling and Measurement}

As was stated above, effluent will be collected for field measurements (i.e. - temperature, pH, ORP, $\mathrm{SC}$, and DO) and laboratory samples from each of the experimental columns according to the sampling schedule shown in Table 2.

The sampling schedule is based on the number of pore volumes of effluent. The sampling schedule has been extended to 40 pore volumes based on the preliminary chromium results from the geochemical screening tests, conducted by MSE in November 2007. In those tests, the RNIP and Polymetallix products, at the ZVI concentration of $1.5 \%$, showed no sign of break through of $\mathrm{Cr}^{6+}$ at 20 pore volumes as such the columns will be run to 40 pore volumes to better ensure that breakthrough will occur in the columns and/or passivation of the ZVI will occur to an extent that is measurable.

The effluent analyses are shown in Table 2 and the configuration is presented in Table 3 . There will be nine experimental columns for each ZVI. One control column, containing only Ringold soil will be set up to monitor baseline conditions. Each $\mathrm{ZVI}$ - soil mixture will be run in triplicate (for quality assurance) to determine experimental and analytical variability. The $Z V I$ concentrations $\left(C_{l}, C_{\| l}\right.$, and $\mathrm{C}_{\mathrm{III}}$ ) in the soil mixture were determined from the amount of ZVI remaining in the column after flushing in the injection screening tests and geochemical screening tests. The ZVI concentration in the columns after flushing was calculated from the iron analyses after emplacement and subtracting solids removed during flushing. The average of amount of RNIP and Polymetallix remaining in the column after flushing was 1.7 and $2.0 \%(w / w)$, respectively. However, it was discovered during the screening geochemical tests, that it is only possible to load the RNIP ZVI at $1.5 \%(\mathrm{w} / \mathrm{w})$ because the product is shipped with $17 \%(\mathrm{w} / \mathrm{w})$ water. For comparability between products, the high ZVI material concentration will be set at $1.5 \%\left(\mathrm{C}_{1}\right)$ for both RNIP and Polymetallix. The mid concentration $\left(\mathrm{C}_{11}\right)$ will be at $1 / 10$ the $C_{\mid}$concentration, $C_{\| I}=0.15 \%$ and the low concentration $\left(C_{111}\right)$ will be at $1 / 100$ the $C_{\mid}$ concentration, $\mathrm{C}_{\| I}=0.015 \%$.

Column effluent will be analyzed for the full suite of analytes listed in Table 2 for each ZVI and Ringold soil combination. One column for each $\mathrm{ZVI}$ at $\mathrm{C}_{\mid}$will be dedicated for MLA analysis at the completion of the column tests. The column material will be analyzed for iron-chromium oxy-hydroxides by MLA. It is recommended that a column from each $\mathrm{ZVI}$ at $\mathrm{C}_{\mid}$be cut open and visually examined for the presence of ferrous and ferric compounds. Visual examination may provide insight as to whether $\mathrm{Fe}^{0}$ reacts completely to $\mathrm{Fe}(\mathrm{III})$ or may exist as $\mathrm{Fe}(\mathrm{II})$ indicated by green staining or secondary mineral formation. The kinetics of the reaction between $\mathrm{Fe}^{0}$ and $\mathrm{Cr}(\mathrm{VI})$ are faster than for the reaction between $\mathrm{Fe}(\mathrm{II})$ and $\mathrm{Cr}(\mathrm{VI})$ (Pettine, et al., 1998; Legrand, et al. 2004). If the reaction between $\mathrm{ZVI}$ and the components in the surrogate water produce $\mathrm{Fe}(\mathrm{II})$, this could have implications on the longevity for ZVI injected into the Ringold formation.

Laboratory analysis and field measurements will be monitored as scheduled in Table 2. 
DOE/RL-2009-35, REV.0

Table 2. Sampling Schedule and Measurements

\begin{tabular}{|c|c|c|c|c|c|c|c|c|c|c|c|c|c|c|c|c|c|}
\hline \multirow[b]{3}{*}{ 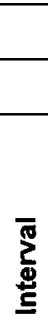 } & \multirow[b]{3}{*}{ 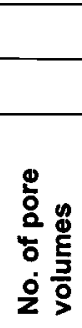 } & \multirow[b]{3}{*}{ 늘 } & \multicolumn{15}{|c|}{ Measurements } \\
\hline & & & \multicolumn{6}{|c|}{ Field Parameters } & \multicolumn{9}{|c|}{ Laboratory Parameters } \\
\hline & & & 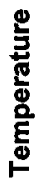 & $\dot{j}$ & I & 吕 & $\frac{a}{\Delta}$ & 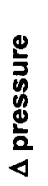 & $\begin{array}{l}\frac{2}{5} \\
\frac{5}{0} \\
\qquad\end{array}$ & 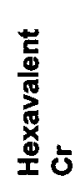 & 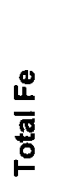 & 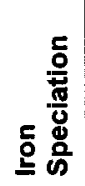 & 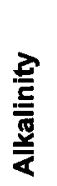 & 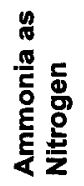 & 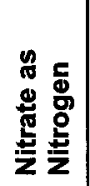 & 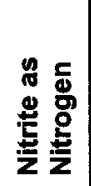 & 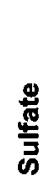 \\
\hline$t_{0}$ & 0 & 3 & $\sqrt{ }$ & $\bar{V}$ & $\sqrt{ }$ & $\sqrt{ }$ & $\sqrt{ }$ & $\sqrt{ }$ & - & $\sqrt{ }$ & - & $\sqrt{ }$ & $\sqrt{ }$ & $\sqrt{ }$ & $\sqrt{ }$ & $\sqrt{ }$ & $\sqrt{ }$ \\
\hline$t_{1}$ & 4 & 19 & $\sqrt{ }$ & $\sqrt{ }$ & $\sqrt{ }$ & $\sqrt{ }$ & $\sqrt{ }$ & $\sqrt{ }$ & $\sqrt{ }$ & $\sqrt{ }$ & $\sqrt{ }$ & $\sqrt{ }$ & $\sqrt{ }$ & $\sqrt{ }$ & $\sqrt{ }$ & $\sqrt{ }$ & $\sqrt{ }$ \\
\hline$t_{2}$ & 9 & 19 & $\sqrt{ }$ & $\sqrt{ }$ & $\sqrt{ }$ & $\sqrt{ }$ & $\sqrt{ }$ & $\sqrt{ }$ & - & $\sqrt{ }$ & - & $\sqrt{ }$ & $\sqrt{ }$ & $\sqrt{ }$ & $\sqrt{ }$ & $\sqrt{ }$ & $\sqrt{ }$ \\
\hline$t_{3}$ & 14 & 19 & $\sqrt{ }$ & $\sqrt{ }$ & $\sqrt{ }$ & $\sqrt{ }$ & $\sqrt{ }$ & $\sqrt{ }$ & - & $\sqrt{ }$ & -- & $\sqrt{ }$ & $\sqrt{ }$ & $\sqrt{ }$ & $\sqrt{ }$ & $\sqrt{ }$ & $\sqrt{ }$ \\
\hline$t_{4}$ & 20 & 19 & $\sqrt{ }$ & $\sqrt{ }$ & $\sqrt{ }$ & $\sqrt{ }$ & $\sqrt{ }$ & $\sqrt{ }$ & - & $\sqrt{ }$ & - & $\sqrt{ }$ & $\sqrt{ }$ & $\sqrt{ }$ & $\sqrt{ }$ & $\sqrt{ }$ & $\sqrt{ }$ \\
\hline$t_{5}$ & 26 & 19 & $\sqrt{ }$ & $\sqrt{ }$ & $\sqrt{ }$ & $\sqrt{ }$ & $\sqrt{ }$ & $\sqrt{ }$ & - & $\sqrt{ }$ & - & $\sqrt{ }$ & $\sqrt{ }$ & $\sqrt{ }$ & $\sqrt{ }$ & $\sqrt{ }$ & $\sqrt{ }$ \\
\hline$t_{6}$ & 33 & 19 & $\sqrt{ }$ & $\sqrt{ }$ & $\sqrt{ }$ & $\sqrt{ }$ & $\sqrt{ }$ & $\sqrt{ }$ & - & $\sqrt{ }$ & - & $\sqrt{ }$ & $\sqrt{ }$ & $\sqrt{ }$ & $\sqrt{ }$ & $\sqrt{ }$ & $\sqrt{ }$ \\
\hline$t_{7}$ & 40 & 19 & $\sqrt{ }$ & $\sqrt{ }$ & $\sqrt{ }$ & $\sqrt{ }$ & $\sqrt{ }$ & $\sqrt{ }$ & $\sqrt{ }$ & $\sqrt{ }$ & $\sqrt{ }$ & $\sqrt{ }$ & $\sqrt{ }$ & $\sqrt{ }$ & $\sqrt{ }$ & $\sqrt{ }$ & $\sqrt{ }$ \\
\hline \multicolumn{11}{|c|}{ Number of field parameter measurements: } & \multicolumn{7}{|c|}{816} \\
\hline \multicolumn{11}{|c|}{ Number of laboratory parameter measurements: } & \multicolumn{7}{|c|}{895} \\
\hline \multicolumn{11}{|c|}{ Number of samples submitted to the analytical laboratory: } & \multicolumn{7}{|c|}{117} \\
\hline \multicolumn{11}{|c|}{${ }^{1}$ Number of samples for MLA analysis: } & \multicolumn{7}{|c|}{2} \\
\hline \multicolumn{11}{|c|}{ Number of columns for visual inspection of ZVI oxidation: } & \multicolumn{7}{|c|}{2} \\
\hline
\end{tabular}


DOE/RL-2009-35, REV.0

Table 3. Column Configuration

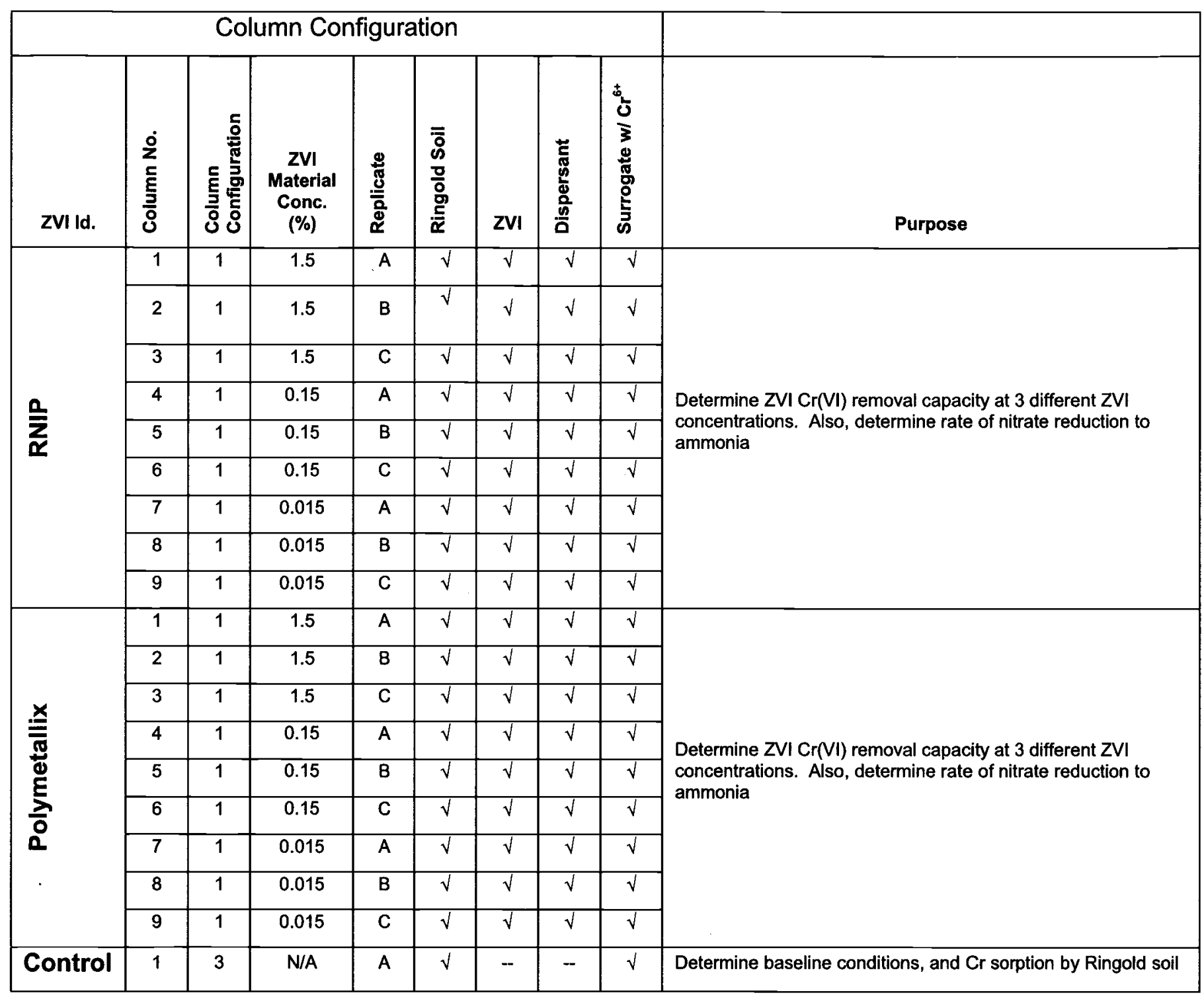




\subsection{Groundwater Chemistry Formulation}

The average groundwater chemistry as per the Fluor Hanford RFP is presented in Table 4. These data will be used in formulation of the surrogate groundwater and to establish the detection limits required for the analytical methods used in the geochemical testing.

Table 4. Groundwater Chemistry of Hanford 100-D Area.

\begin{tabular}{|c|c|c|}
\hline Analytes & Average Value & Units \\
\hline Alkalinity & 97.13 & $\mathrm{mg} / \mathrm{L}$ \\
\hline Aluminum & 38.96 & $\mu g / L$ \\
\hline Calcium & 90.00 & $\mathrm{mg} / \mathrm{L}$ \\
\hline Chloride & 33.96 & $\mathrm{mg} / \mathrm{L}$ \\
\hline Chromium $^{(1)}$ & 100 & $\mu g / L$ \\
\hline Dissolved oxygen & 9.59 & $\mathrm{mg} / \mathrm{L}$ \\
\hline Iron (Total) & 136.53 & $\mu g / L$ \\
\hline Magnesium & 20.77 & $\mathrm{mg} / \mathrm{L}$ \\
\hline Nitrate & 23.60 & $\mathrm{mg} / \mathrm{L}$ \\
\hline Oxidation Reduction Potential & 156.63 & $\mathrm{mV}$ \\
\hline $\mathrm{pH}$ & 7.80 & standard units \\
\hline Phosphate & 0.33 & $\mathrm{mg} / \mathrm{L}$ \\
\hline Potassium & 4.82 & $\mathrm{mg} / \mathrm{L}$ \\
\hline Sodium & 9.89 & $\mathrm{mg} / \mathrm{L}$ \\
\hline Specific Conductance & 675.13 & $\mu \mathrm{S} / \mathrm{cm}$ \\
\hline Sulfate & 135.35 & $\mathrm{mg} / \mathrm{L}$ \\
\hline
\end{tabular}

\subsection{Planned Measurements and Analyses}

All laboratory analyses and measurements will be completed by MSE's onsite analytical laboratory. Use of an offsite analytical laboratory is not anticipated.

Table 5 lists the analyses, sample matrix, analytical methods, and required detection limits for the chemical based measurements and analyses. 
Table 5. Chemical Based Measurements and Analyses.

\begin{tabular}{|l|l|l|l|}
\hline Measurement/Analysis & Matrix & $\begin{array}{l}\text { Analytical/Measurement } \\
\text { Method }\end{array}$ & Detection Limit \\
\hline $\mathrm{pH}$ & Effluent & EPA 150.1 & $0.1 \mathrm{SU}$ \\
\hline ORP & Effluent & SM 2580 & $1 \mathrm{mV}$ \\
\hline Nitrogen as ammonia & Effluent & EPA 350.2 & $0.05 \mathrm{mg} / \mathrm{L}$ \\
\hline Dissolved Oxygen & Effluent & YSI $556 \mathrm{MPS}$ & $0.1 \%$ air saturation $0.01 \mathrm{mg} / \mathrm{L}$ \\
\hline Nitrogen as nitrate & Effluent & EPA 300.0 & $0.05 \mathrm{mg} / \mathrm{L}$ \\
\hline Nitrogen as nitrite & Effluent & EPA 300.0 & $0.05 \mathrm{mg} / \mathrm{L}$ \\
\hline Alkalinity & Effluent & EPA 310.1 & $5 \mathrm{mg} \mathrm{CaCO} / \mathrm{L}$ \\
\hline Iron speciation & Effluent & SM 3500 - Fe D & $0.05 \mathrm{mg} / \mathrm{L}$ \\
\hline Total chromium & Effluent & EPA 200.9 & $0.001 \mathrm{mg} / \mathrm{L}$ \\
\hline Hexavalent chromium & Effluent & SW 7196A & $0.005 \mathrm{mg} / \mathrm{L}$ \\
\hline
\end{tabular}

Table 6 lists the physical measurements with associated sample matrix, analytical methods, and required detection limits.

Table 6. Physical Measurements and Analyses

\begin{tabular}{|l|l|l|l|}
\hline Measurement/Analysis & Matrix & $\begin{array}{l}\text { Analytical/Measurement } \\
\text { Method }\end{array}$ & Detection Limit \\
\hline Specific Conductance & Effluent & YSI $556 \mathrm{MPS}$ & $\begin{array}{l}0.001-0.1 \mathrm{~ms} / \mathrm{cm} \\
\text { (range dependent) }\end{array}$ \\
\hline Iron oxy-hydroxides & $\begin{array}{l}\text { Column } \\
\text { Material }\end{array}$ & MLA & Qualitative assessment \\
\hline Temperature & Effluent & YSI 556 MPS & $0.01^{\circ} \mathrm{C}$ \\
\hline Flow rate & Effluent & Effluent Collection & $1 \mathrm{ml} / \mathrm{min}^{\circ}$ \\
\hline Differential pressure & $\begin{array}{l}\text { Pore } \\
\text { water }\end{array}$ & Manometer (sight glass) & $\begin{array}{l}0.5 \mathrm{~cm} \text { pore fluid head } \\
\text { differential over } 60 \mathrm{~cm}\end{array}$ \\
\hline
\end{tabular}

The $\mathrm{pH}, \mathrm{ORP}$, specific conductance, and dissolved oxygen data will be used to monitor the geochemical conditions in the columns. The temperature data are required to support the $\mathrm{pH}$ measurement and the other parameters listed in Table 5 and Table 6.

Differential pressure will be monitored by visual inspection of the "sight glass" manometers while the flow rate will be periodically measured by means of a timed filing of a known volume. Both of these parameters will be used to indicate column fouling. 


\subsection{Data Reduction and Analysis}

Data from each sampling event will be compiled into a database. The database will include a record of all paper copies of sampling records, chain of custody sheets, and analytical laboratory reports. It will also include project laboratory logbook(s) and instrument calibration records. In addition to the paper copies of the data, all numerical values obtained from the testing will be entered into an electronic spreadsheet for further analysis.

For each sampling event, an appropriate statistic describing the data (i.e., average with standard deviation) will be calculated for each parameter. These average values including the range for the triplicate values will be plotted as functions of pore volumes of effluent (i.e. - sampling event). Additionally, data from the ZVI-containing columns (Configurations 1 and 2) will be compared to the data from the control columns (Configuration 3 ) to determine if significant differences in the geochemistry are occurring.

The data will be analyzed to determine the changes in the geochemical conditions within the columns and the changes that are occurring to the ZVI materials. In addition the changes will be compared for the two materials to determine which of the materials will provide a better repair to the barrier relative to reactivity and longevity.

\subsection{Reporting}

Methodologies and results from the field measurements and laboratory testing will be included in the Geochemical Laboratory Testing Report. Any Quality Assurance (QA) audits or reports and pertinent photographs taken during the laboratory setup and testing will be included in the Geochemical Laboratory Test Report. 


\section{PROCEDURES}

Column construction procedures, packing methods, field measurements, and effluent collection are outlined in this section. If, during the execution of any of these procedures, a better procedure or procedures are discovered, which are more efficient and/or cost effective and produce the desired quality and results, the new procedure or procedures shall be documented, approved, and implemented.

\subsection{Test Setup}

The laboratory testing will be conducted using ZVI, dispersant(s) and Ringold soils packed in the experimental columns. The control column will be packed with Ringold soil, with no ZVI. Surrogate groundwater will be pumped from bottom to top through each column using a peristaltic pump.

Column effluent will be collected and the volume recorded to determine the number of pore volumes that have passed through the test material. The pore volume, of the columns will be determined by using a prototype column that is packed with dry Ringold sedimentary material and then filled with water. The pore volume of the prototype column will be used as the pore volume for each of the individual columns. The pore volume of each of the test columns will vary due to inherent differences in the material contained within the columns and small procedural differences caused by different individuals packing different columns. However, these differences should be small in comparison to the amount of water pumped through any one column for the duration of the test. As such, any error produced by using a single value for the pore volume of all the columns should be negligible.

\subsection{Waste Handling}

All waste will be handled in accordance with all applicable federal, state, and local regulations and facility waste handling procedures.

After the appropriate measurements and sampling, the waste will be collected in a common waste tank before disposal. Contents of the waste container should be acceptable for direct disposal into the municipal sewer, since chromium levels will not exceed hazardous levels $(5 \mathrm{mg} \mathrm{Cr} / \mathrm{L})$. The surrogate groundwater feed solution will have a maximum concentration of $0.6 \mathrm{mg} \mathrm{Cr} / \mathrm{L}$ and the effluent will not be concentrated with respect to the feed solution.

\subsubsection{Column Preparation}

The columns will be prepared using 7.62-cm (3-inch) nominal diameter by $60-\mathrm{cm}$ (23.62-inch) long clear PVC pipe.

The column diameter was chosen so that it would be10 times greater than the diameter of the largest particles in the sieved Ringold soil. The ends of each column will be fitted with threaded couplings that are connected to a drainage system at the outlets. The columns will also be fitted with sight glasses (manometers) at each end for monitoring pressure in the column.

\subsubsection{Column Materials}

The materials required for preparation of each column includes the following:

1. 1 length of $7.62-\mathrm{cm}$ (3.0-inch) nominal diameter by $60-\mathrm{cm}$ (23.62-inch) long clear PVC pipe;

2. 2-7.62-cm (3-inch) PVC NPT Female $x$ socket-weld pipe adapters;

3. 2-7.62-cm (3-inch) hexagonal plugs; 
4. 2-0.64-cm (1/4 -inch) PVC ball valves;

5. 1 size No.13 $\frac{1}{2}$ black neoprene (rubber) stopper;

6. Assorted tees, elbows, nipples, adapters, and bushings;

7. 4 coarse-meshed screens measuring approximately $7.62-\mathrm{cm}$ (3-inch). The screens will be properly sized to permit the flow of the surrogate groundwater;

8. 2 sight glasses (manometers) measuring approximately $1.0-\mathrm{cm}$ in diameter and $244-\mathrm{cm}$ long installed at the influent end (bottom) of the column and $41-\mathrm{cm}$ long at the effluent end (top) of the column;

9. 4,200 grams of Hanford Ringold soils sieved to eliminate all greater than $7.62 \mathrm{~mm}(0.30$-inch) particles and less than 200 mesh $(0.074 \mathrm{~mm}, 0.0024$-inch). ;

10. PVC Cement and Teflon tape; and

11. Dense stone.

\subsubsection{Column Construction}

The columns are constructed using the same procedures with the appropriate materials listed in Sections 3.2.1.1 and. The construction procedures are as follows:

1. Secure PVC NPT Female $x$ socket-weld pipe adapters to both ends of clear PVC pipe using PVC cement;

2. Drill and tap holes for sight glasses in the pipe adapters (45.7-cm spacing);

3. Insert $1 / 2$-inch $\times 1 / 4$-inch reducing bushing, plugged with $1 / 4$-inch hexagonal plug during the packing procedure;

4. Insert 3-inch hexagonal plug into pipe adapter at one end of the column and secure it firmly using Teflon tape and sealant to create a leak-proof seal;

5. Assemble remaining ball valve and bushing assembly for installation following the filling of the column with either soil or artificial sand.

\subsubsection{ZVI / Soil / Sand Paste Preparation}

1. Preparation of the soil and ZVI material for filling the column will be conducted under a nitrogen blanket or in a glove box to prevent premature oxidation of the ZVI. First, a slurry of the $\mathrm{ZVI}$ and any dispersant/carrier using de-ionized (DI) water is made. The $\mathrm{ZVI} /$ dispersant/carrier slurry is then added to the Ringold soil and a uniform paste is made that is undersaturated with DI water. The ZVI paste is scooped into the column until it is completely filled; the columns are filled using the "tamping method" described in Section 3.1 .1 .5 , to consistently pack the column.

The amount of water ( $~ 580$ grams) needed to make the $\mathrm{ZVI} /$ soil slurry is based on the amount used in the preliminary geochemical study, Task 10 Part $C$. When the soil/surrogate sand/ZVI slurry is at this water content the pore space will be nearly completely occupied with water.

Preparation of the ZVI slurry and ZVI/soil/artificial sand paste is described below.

1. Split off a representative, approximately 4,200 gram, sample of the Hanford Ringold soil for the column being constructed. Place the sample into a pre-weighed 2 liter plastic or glass beaker and weigh accurately, set aside;

2. Weigh and record the appropriate amount of $Z \mathrm{VI}$ for the selected $\mathrm{ZVI}$ /soil ratio, in a plastic or glass $250 \mathrm{ml}$ beaker; 
3. Add ZVI to agitated DI water/dispersant mixture, to make a uniform free-flowing slurry. Be careful not to add more water than is necessary to make the ZVI saturated paste;

4. Add the $\mathrm{ZVI} /$ de-ionized water slurry to the soil in the 2 liter beaker and mix thoroughly. Add water as needed to make the paste. The paste must be near saturation with water, so that upon standing, no pooling or puddling of water appears on the surface of the paste; and

5. Record the mass of the paste.

\subsubsection{Column Filling Equipment}

Preparation of the columns will require the following laboratory equipment.

1. Scale for weighing soil (needs to have a $15 \mathrm{~kg}$ capacity);

2. Funnel;

3. Scoop for ZVI/soil paste and miscellaneous hand tools;

4. Vibrator table; and

5. Rubber tamping device.

\subsubsection{Column Filling Procedures}

1. Inspect the column with stoppers, plugs and screens prior to filling, making sure any soil, residue, etc. is removed;

2. Make initial measurements of the inside diameter and length of the clean and empty column and the length between the centerline of the two sight glasses (manometers). Record measurements in the logbook;

3. Place mesh screen in the bottom of the column, firmly against the end cap;

4. Weigh a clean and empty column prior to filling (tare weight). Record tare weight in the logbook;

5. Fill the influent end cap region with 640 grams of dense stone, followed by emplacement of one of the 3-inch coarse-meshed screen to contain and separate the dense stone from the column material;

6. Zero the scale, weigh and record the weight of the column in the logbook;

7. On the vibrator table, begin transferring the pre-weighed Hanford Ringold slowly into the column while allowing the paste to settle in the column. The "tamping method" developed consists of the following steps:

a) Add a lift (scoop) of material to the column, approximately 3-inches of material after compaction;

b) tamp lightly 10 times with the rubber tamper;

c) settle material in the column by $10-15$ seconds on the vibrating table;

d) tamp 25 times using $11 / 2$ - foot strokes;

e) etch the surface, this will promote bonding between the layers (lifts);

f) repeat steps a through e until the soil ZVI mixture is flush with the upper fitting on the column. 
8. Place the second coarse-meshed screen firmly against the freshly loaded column material. Once the screen is positioned, add 300 grams of dense stone to completely fill the remaining space in the column;

9. Position the one-holed No. $131 / 2$ rubber stopper on top of the dense stone;

10. Thread the second end-cap onto the open end of the column, and secure until the rubber stopper exerts pressure the dense stone, as indicated by "crunching" of the dense stone;

11. Weigh the assembled and packed column. Record weight of packed column in the logbook;

12. Collect the unused Ringold soil/ZVI mixture into a pan and dry at $100 \circ \mathrm{C}$ to remove moisture

13. Weigh the dried unused Ringold soil/ZVI mixture to determine the amount of Ringold soil/ZVI mixture was loaded into the column.

\subsection{Preparation of Surrogate Groundwater}

The surrogate groundwater that will be used for the column testing will be prepared according to the following procedures.

\subsubsection{Surrogate Groundwater Materials}

The reagent salts and amounts to make 200 liters ( $\sim 50$ gallons) of surrogate groundwater are listed in Table 7. The surrogate groundwater is formulated to contain the major components present in the Hanford 100-D Area groundwater and possess the characteristics responsible for its geochemical behavior. Hexavalent chromium will be added at $-550 \mathrm{ug} \mathrm{Cr} / \mathrm{L}$ to test the ZVI's ability to remove (reduce) chromium. The nitrate concentration is set at $60 \mathrm{mg} \mathrm{NO}_{3}{ }^{-} / \mathrm{L}$ to indicate ZVI's effect on: 1) the reduction of nitrate to nitrite and ammonia and 2) high nitrate on the removal of hexavalent chromium.

The reagents will be mixed and allowed to dissolve in 200 liters of DI water. Since the barrel will be open to ambient air and calcium is added in excess, the equilibrium calcium concentration will likely be around 60 to $75 \mathrm{mg} \mathrm{Ca} / \mathrm{L}$. The surrogate is equilibrated in ambient air for at least 24 hours to reach saturation with calcium and stabilize the ORP. The dissolved oxygen level in the surrogate will be maintained by aeration in the barrel. The dissolved oxygen levels will primarily depend on the surrogate solution temperature.

Table 7. Reagents for 200 Liters of Surrogate Hanford 100-D Area Groundwater.

\begin{tabular}{|l|l|l|}
\hline Reagent & Mass & Units \\
\hline $\mathrm{CaCl}_{2} \bullet 2 \mathrm{H}_{2} \mathrm{O}$ & 12.68 & Grams \\
\hline $\mathrm{CaCO}_{3}$ & 17.75 & Grams \\
\hline $\mathrm{Ca}\left(\mathrm{NO}_{3}\right)_{2} \bullet 4 \mathrm{H}_{2} \mathrm{O}$ & 23.25 & Grams \\
\hline $\mathrm{Na}_{2} \mathrm{Cr}_{2} \mathrm{O}_{7} \bullet 2 \mathrm{H}_{2} \mathrm{O}$ & 0.317 & Grams \\
\hline $\mathrm{MgSO}_{4} \bullet 7 \mathrm{H}_{2} \mathrm{O}$ & 42.86 & Grams \\
\hline $\mathrm{NaHCO}_{3}$ & 12.68 & Grams \\
\hline $\mathrm{H}_{2} \mathrm{SO}_{4}$ (concentrated) & 10.79 & Grams \\
\hline
\end{tabular}

\subsubsection{Surrogate Groundwater Preparation Equipment}

1. 200-liter (55-gallon) polyethylene tank;

2. Laboratory balance; 
3. Stirring Apparatus.

\subsubsection{Surrogate Groundwater Preparation Procedures}

The following steps will be followed to develop the synthetic groundwater.

1. Add 200 liters of de-ionized water to the 55-gallon polyethylene tank, and set up stirring apparatus;

2. Accurately weigh out each of chemical reagent in Table 7 and set aside. Care will be exercised during weighing and mixing to ensure none of the salts become airborne, so that accidental exposure is eliminated;

3. Transfer each weighed portion of reagent to the 55-gallon tank filled with 200 liters of DI water while stirring;

4. Allow soluble salts to dissolve before addition of the moderately soluble salt (i.e. $-\mathrm{CaCO}_{3}$ );

5. After all the reagents have appeared to dissolve, check the solution $\mathrm{pH}, \mathrm{ORP}$, dissolved oxygen and specific conductance;

6. Begin aeration of the surrogate groundwater mixture;

7. After more than 24 hours (assuming mixture is at equilibrium) recheck the solution $\mathrm{pH}, \mathrm{ORP}$, dissolved oxygen and specific conductance. Solution $\mathrm{pH}$ and alkalinity may be adjusted if necessary by varying the amount of $\mathrm{NaHCO}_{3}$ added to the solution. Submit a sample for laboratory analysis of chemical constituents.

\subsection{Field and Laboratory Testing Procedures}

The field tests include monitoring the surrogate groundwater, column effluent and sampling the column material.

\subsubsection{Effluent Sampling}

Samples of the effluent for laboratory testing will be collected from the silicone tube connected to the effluent end of the column. The effluent samples will be collected in properly labeled sample containers provided by the MSE Analytical Laboratory and preserved according to the appropriate analytical method. The sampling containers shall be rinsed three times with the effluent prior to collecting the sample. The rinsate shall be properly disposed in the effluent waste tank. The amount of effluent (number of pore volumes) that has passed through the columns at this time will also be recorded.

\subsubsection{Column Material Sampling}

Column material samples will be obtained from the high $\mathrm{ZVI}$ concentration column $\left(\mathrm{C}_{1}\right)$ at the conclusion of the experiment. Once the column has been removed, the influent end plug will be unscrewed and the material from the first 2-inches will be emptied into a clean plastic or glass container. The sample will be placed into a labeled sample container. The sample will be taken to the Metallurgy Department at Montana Tech for MLA.

One column from each $\mathrm{ZVI}$ at the high $\mathrm{ZVI}\left(\mathrm{C}_{1}\right)$ concentration will be cut open for visual examination. The purpose of the visual examination is to look for indications of the oxidation state of reacted ZVI. 
The presence of ferrous iron may be observed by the presence of green staining on the Ringold soil and/or green secondary mineral formation; whereas, ferric iron may leave a reddish-brown stain on the Ringold soil and/or secondary mineral formation. The highest probability of observing any type of staining would be in the high $\mathrm{ZVI}\left(\mathrm{C}_{\mathrm{l}}\right)$ columns.

\subsubsection{Sample Identification}

The sample labels will list the project sample number, data and time of sampling, sampler's name, and the analyses that are to be run on the sample. The effluent sample identification system is shown in Table 8. The effluent sample will be immediately transferred to the MSE Analytical Laboratory for analysis.

Table 8. Effluent Sample Identification System.

\begin{tabular}{|c|c|c|c|}
\hline ZVI Material Identifier & Matrix & Column Number & Sampling Event \\
\hline $\begin{array}{l}\text { RNIP - RNIP-MS } \\
\text { POLY - Polymetallix } \\
\text { CON - control }\end{array}$ & $\begin{array}{l}\text { INFLUENT (FEED) - INF } \\
\text { EFFLUENT - EFF }\end{array}$ & $\begin{array}{l}00,01,02,03, \ldots 9 \\
\text { Use } 2 \text { digit format }\end{array}$ & $\begin{array}{l}0,1,2,3,4,5,6 \\
\text { Use 1-digit format }\end{array}$ \\
\hline \multicolumn{4}{|l|}{ Example Sample Numbers } \\
\hline \multicolumn{2}{|c|}{ Feed solution taken at the beginning of testing } & \multicolumn{2}{|l|}{ INF-00-0 } \\
\hline \multicolumn{2}{|c|}{ Feed solution taken at second sampling event ( $\sim 9 \mathrm{PV})$} & \multicolumn{2}{|l|}{ INF-00-2 } \\
\hline \multicolumn{4}{|l|}{$\begin{array}{l}\text { RNIP @ } 1.5 \% \\
\text { Effluent sample } \\
\text { Second sampling event ( } 9 \text { PV) }\end{array}$} \\
\hline $\begin{array}{l}\text { Ringold soil w/ dispersant, } \\
\text { replicate no.2, column } 2\end{array}$ & \multicolumn{3}{|l|}{ RNIP-EFF-02-02 } \\
\hline \multicolumn{4}{|l|}{$\begin{array}{l}\text { Polymetallix @ } 0.15 \% \\
\text { Effluent sample } \\
\text { Fourth sampling event ( 20 PV) }\end{array}$} \\
\hline $\begin{array}{l}\text { - Ringold soil w/ dispersant, } \\
\text { replicate no.3, column } 9\end{array}$ & \multicolumn{3}{|l|}{ POLY-EFF-09-4 } \\
\hline $\begin{array}{l}\text { Control column } \\
\text { Effluent sample } \\
\text { Third sampling event ( 14 PV) }\end{array}$ & \multicolumn{3}{|l|}{ CON-EFF-01-3 } \\
\hline
\end{tabular}

\subsubsection{Head Differential Measurement Procedures}

Head differential measurements will be made throughout the testing in the column. Head differentials will be recorded at the same times as effluent samples are collected for either laboratory analysis or when field measurements are taken.

Permeability values will be calculated from the head differentials. The permeability values may be used for the injection segment of the project.

Head differentials will be measured manually, reading the water level difference between the manometers. Manual measurements will be made by inspection for the manometers on each of the columns and the data recorded to the nearest millimeter $(\mathrm{mm})$. 


\section{HEALTH AND SAFETY}

Experiments presented in this test plan will be conducted in an Experimental Laboratory at the MSE Testing Facility. All activities shall be conducted in accordance with MSE's Chemical Hygiene Plan (CHP) and MSE's Hazard Communication Program, as documented in the MSE Health and Safety Program Manual, Part 8, Section 6; and Section 1; respectively. The MSE Health and Safety Director (Scott Nuthak) will serve as the Chemical Hygiene Officer ( $\mathrm{CHO}$ ) and Charlie Brown will serve as the Environmental Coordinator for this project. Material Safety Data Sheets (MSDS) for all chemicals used in the experiments will be kept on file in the laboratory and shall be readily available throughout the project duration. All containers shall be properly labeled with their content and hazard.

\subsection{Hazardous Materials}

Table 9 identifies chemicals that will be used in the preparation of the synthetic groundwater and/or for sample preservation. It is imperative that all personnel follow safe laboratory practices, practice good personal hygiene, and wear appropriate personal protective equipment (PPE). Personnel will be required to review this Safety Plan and acknowledge that they will abide by it. At no time, will personnel safety and health be compromised for testing. If a task cannot be performed safely, it will not be performed. Industrial Hygiene monitoring will be performed at the discretion of the $\mathrm{CHO}$. Chrome $^{6+}$ is listed in OSHA's Toxic and Hazardous Substance List, 29 CFR 1910, Subpart 2. As such, contact the $\mathrm{CHO}$ prior to handling $\mathrm{Cr}^{6+}$. Monitoring may be required if any dust is generated.

Table 9. Hazardous Materials and Exposure/Physical Data.

\begin{tabular}{|l|l|l|l|}
\hline Chemical & PELTLV & H-F-R & Hazards \\
\hline MZVI & $5 \mathrm{mg} / \mathrm{M}^{3}$ & $1-1-1$ & Irritant \\
\hline Polymer & $5 \mathrm{mg} / \mathrm{M}^{3}$ & $1-0-1$ & Irritant \\
\hline Chrome 6+ & $2.5 \mu \mathrm{g} / \mathrm{M}^{3}$ & $3-0-1$ & Oxidizer, irritant, kidneys, respiratory system \\
\hline $\begin{array}{l}\text { PEL/TLV = Permissible exposure limit/threshold limit value } \\
\text { H-F-R = Health - Fire - Reactivity Ratings }\end{array}$ \\
\hline
\end{tabular}

\subsection{Engineering Controls}

Engineering controls shall be used where appropriate. These include catch basins designed to contain any spillage, laboratory fume hoods, and proper grounding on all electrical equipment.

\subsection{Administrative Controls}

A general test area will be demarcated for this project within the MSE Experimental Laboratory building and restricted to project personnel only. Proper chemical storage that includes separating incompatibles will be practiced. Chemicals shall not be left out of their respective storage cabinets.

Personnel shall practice good personal hygiene at all times. This includes, no eating, smoking, chewing gum, chewing tobacco, or drinking in the test area. Hands shall be washed thoroughly after removing protective gloves and before leaving the test area and hands shall be kept away from the eyes and face when wearing protective gloves. Eating and drinking shall only be allowed in the break area of the building. Smoking is prohibited inside the building. 


\subsection{Personal Protective Equipment}

Standard laboratory protective equipment includes: laboratory coat, safety glasses, and impervious latex or nitrile gloves.

\subsection{First Aid and Emergency Response}

During any emergency event, consult the MSDS as necessary. However, in any case of chemicals contacting unprotected skin or eyes, flush with water for a minimum of 15 minutes. During that time, someone shall dial "333" and request an ambulance. The emergency eyewash/shower is located within 30 feet of the laboratory hood. In the event of an inhalation exposure, get to fresh air and someone should dial 333. Nobody should attempt to rescue a person down if bad air is suspected, unless the $\mathrm{CHO}$ gives approval to enter based on air monitoring. The emergency brigade shall be requested with self-contained breathing apparatus (SCBAs), as appropriate. The use of PPE, the laboratory hood, good personal hygiene, and safe work procedures should prevent exposures from occurring via inhalation, ingestion, and absorption. The potential for injection hazards is not likely, given the nature of work.

In the event of a spill or fire that risks personnel, evacuate the building and dial 333. Only qualified personnel equipped with SCBAs should attempt to extinguish incipient-stage fires that involve hazardous chemicals. The $\mathrm{CHO} /$ Emergency Coordinator shall only authorize re-entry.

In the event of spills, absorbing materials are provided in the building, including the sorbents used in the experiments. Additionally, chemical quantities are very small. All spills shall be reported to the $\mathrm{CHO}$ and actions shall be taken to minimize spillage, area contamination, and personnel exposure.

Any chemical wastes generated will be disposed of in accordance with applicable state regulations per the MSE Environmental Coordinator. 


\section{QUALITY CONTROL AND QUALITY ASSURANCE}

\subsection{Quality Control}

Quality control will be maintained during the laboratory testing through test setup replicates (i.e. three replicates for each column), sample splits, and blanks. Quality control for the analytical laboratory analysis will be according to the MSE Analytical Laboratory quality control procedures.

The test design includes a significant number of process replicate samples for each sampling event (i.e., multiple columns). Additionally, there will be blanks and sample splits randomly acquired at a frequency of $5 \%$ from individual columns over the course of the geochemical testing. The column configuration is set up in triplicate, so the data from triplicate column effluent sample can be evaluated. The relative percent difference (RPD) for each primary column configuration will be calculated. The YSI 556 Mulitprobe system (MPS) will be calibrated initially and as needed thereafter. Quality control will be maintained for the field parameters (i.e., pH, ORP, SC) by comparison of the meter readings to the standard solution certified values (see Table 10 for standard solution acceptance range). If the meter reading is outside the solution's acceptance range, the YSI 556 MPS will be recalibrated for the out of compliance parameter. After the meter is recalibrated the standard solution will be reanalyzed and the value recorded in the project logbook.

The system temperature will be monitored to ensure that it is within the expected field conditions of 15 to $18^{\circ} \mathrm{C}\left(60\right.$ to $\left.65^{\circ} \mathrm{F}\right)$. The experimental laboratory temperature is maintained in this range.

Table 10. Field Measurement Quality Control Acceptance Ranges.

\begin{tabular}{|l|l|l|l|}
\hline Parameter & $\begin{array}{l}\text { Standard Solution } \\
\text { Concentration }\end{array}$ & Acceptance Range & Units \\
\hline $\mathrm{pH}$ & 5.00 & $4.85-5.15$ & $\mathrm{SU}$ \\
\hline $\mathrm{pH}$ & 4.01 & $3.85-4.15$ & $\mathrm{SU}$ \\
\hline $\mathrm{pH}$ & 7.00 & $6.85-7.15$ & $\mathrm{SU}$ \\
\hline $\mathrm{pH}$ & 10.01 & $9.85-10.15$ & $\mathrm{SU}$ \\
\hline $\mathrm{ORP}$ & $237.5 @ 20^{\circ} \mathrm{C}$ & $\begin{array}{l}+/-20 \mathrm{mV} \text { of certified } \\
\text { value }\end{array}$ & $\mathrm{mV}$ \\
\hline $\mathrm{SC}$ & 1413 & $1375-1450$ & umhos/cm \\
\hline
\end{tabular}

\subsection{Quality Assurance}

Quality assurance will include reviewing all relevant laboratory documentation to ensure procedures are followed and the results are within the acceptable quality limits of the project. This will include reviewing all planning documents, material specifications, test equipment designs and specifications, personnel qualifications, equipment calibration records, and quality control sample results.

\subsubsection{Documentation}

Documentation that will be reviewed includes the laboratory test plan, experimental laboratory project logbook, and the analytical laboratory reports. 


\subsubsection{Material Specifications}

The materials specifications include materials specified for the testing apparatus, any chemicals used to prepare the synthetic groundwater, and any consumable items required for sampling. The material specifications are listed in Section 3 Procedures.

\subsubsection{Test Equipment Designs and Specifications}

The test equipment designs and specifications are listed in Section 3 Procedures.

\subsubsection{Test Equipment Calibration}

The test equipment will be calibrated according to manufacturer's specifications and frequency prior to and during the testing.

\subsubsection{Personnel Qualifications}

Personnel working on the project in the experimental laboratory will be experienced in experimental laboratory setup, column testing, and sampling. The experimental laboratory personnel will be responsible for ensuring that all instruments are properly calibrated and that proper calibration records or documentation are kept in the project logbook. The experimental laboratory personnel will be responsible for ensuring that all sampling procedures are followed and documented in the project logbook. The MSE analytical laboratory personnel will perform the laboratory analysis according to the MSE Analytical Laboratory procedures. Data reduction and analysis will be completed under the direction of the MSE Project Engineer. The MSE Project QA Officer will conduct the quality control and quality assurance activities.

\subsubsection{Quality Assessment and Reporting}

MSE will assess the data quality and include the results of the assessment in the laboratory report. The quality assessment report will include results from the data validation process and a summary of the calculated data quality indicators. The data validation process will be conducted according to the MSE Quality Assurance Plan and consist of a review of the laboratory reports to ensure all QA/QC procedures were followed and that the results of the analyses meet the project quality requirements. The data quality indicators that will be included in the report are precision, bias, and completeness.

Precision will be determined from either a relative percent difference (RPD) calculation or from a relative standard deviation (RSD). These will be calculated as follows: 


$$
R P D=\frac{X_{1}-X_{2}}{\bar{X}} \times 100 \%
$$

$$
R S D=\left(\sqrt{\frac{\sum\left(X_{i}-\bar{X}\right)^{2}}{n-1}}\right) \times \frac{1}{\bar{X}} \times 100 \%
$$

Where:

$$
\begin{aligned}
& \mathrm{X}_{\mathrm{i}}=\mathrm{i}^{\text {th }} \text { data value, } \\
& \bar{X}=\text { Average value of data, and } \\
& \mathrm{n}=\text { number of samples }
\end{aligned}
$$

Completeness will be based on the percentage of useable analytical values as compared to the submitted number of values. 


\section{REFERENCES}

DOE/RL, 2005, "Fiscal Year 2005 Annual Summary Report for the In Situ Redox Manipulation Operations". DOE/RL-2005-97, Rev. 0.

Gibbs CR. 1976. "Characterization and Application of Ferrozine Iron Reagent as a Ferrous Iron Indicator." Analytical Chemistry, 48(8):1197-1200.

Heron G, TH Christensen, and JC Tjell. 1994a. "Oxidation Capacity of Aquifer Sediments." Environmental Science and Technology, 28:153-159.

Heron G, C Crouzet, AC Bourg, and TH Christensen. 1994b. "Speciation of Fe(II) and Fe(III) in Contaminated Aquifer Sediments Using Chemical Extraction Techniques." Environmental Science and Technology, 28:1698-1705.

Legrand, L., El Figuigui, A., Mercier, F., Chausse, A., 2004. "Reduction of aqueous chromate by $\mathrm{Fe}(\mathrm{II}) / \mathrm{Fe}$ (III) carbonate green rust kinetic and mechanistic studies." Environmental Science and Technology, $38(17), 4587-4595$.

Oostrom, M., T.W. Wietsma, M.A. Covert, V.R. Vermeul, 2005. Experimental Study of Micron-Size Zero-Valent Iron Emplacement in Permeable Porous Media using Polymer-Enhanced Fluids. PNNL-15573

Pettine, M., D'ottone, L., Campanella, L., Millero, F.J., Passion, R., 1998. "The reduction of chromium (VI) by iron (II) in aqueous solutions." Geochmica Cosmochimica Acta 62 (9), 1509-1519.

Ponder, S.M., Darab, J.G., Bucher, J., Caulder, D., Craig, I., Davis, L., Edelstein, N., Lukens, W., Nitsche, H., Rao, L., Shuh, D.K., Mallouk, T.E., 2001. "Surface chemistry and electgrochemistry of supported zerovalent iron nanoparticles in the remediation of aqueous metal contaminants." Chem. Mater. 13 (2), 479-486.

Waldrop, William R. and Joan K. Waldrop, 2004. Electromagnetic Borehole Flowmeter Test Of the Wells of 100-D Area In Situ Redox Manipulation (ISRM) Barrier Site, Hanford Site, State of Washington. Quantum Engineering Corporation, Loudon, Tennessee 37774.

Yarmoff, J. A. et al, 1999. Fundamental studies of the removal of contaminants from ground and wastewaters via reductions by zero-valent metals, DE-FG07-96ER14707, University of California, Riverside. 


\section{TEST PLAN FOR ZERO-VALENT IRON (ZVI) DISTRIBUtION IN SOIL INJECTED WITH ZVI/DISPERSANT/WATER FOR POTENTIAL USE AT HANFORD'S IN SITU REDOX MANIPULATION BARRIER}

Prepared by:

MSE Technology Applications, Inc.

200 Technology Way

P.O. Box 4078

Butte, Montana 59701

Revision 01

February 26, 2008 
DOE/RL-2009-35, REV.0

\section{This Page Intentionally Left Blank}




\section{TABLE OF CONTENTS}

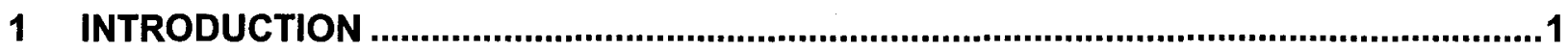

2 LABORATORY TESTING AND ANALYSIS ...............................................................

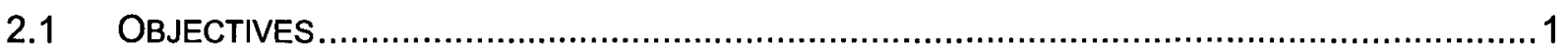

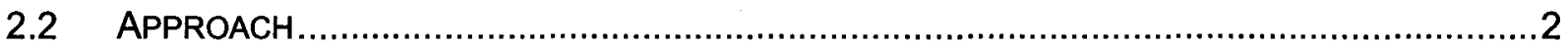

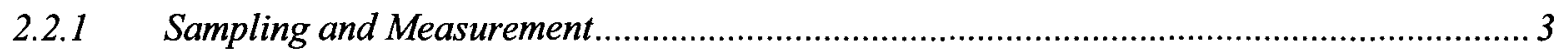

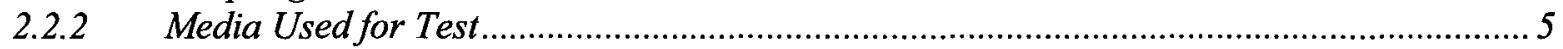

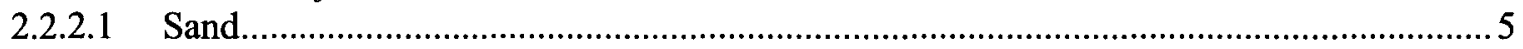

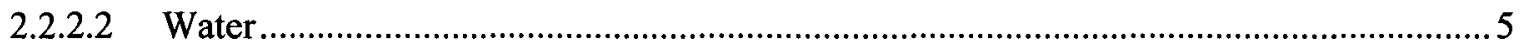

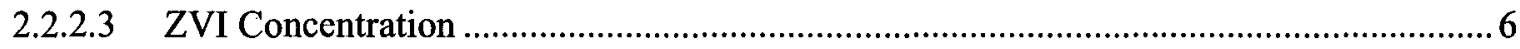

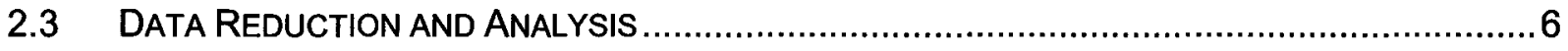

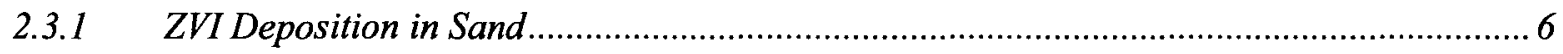

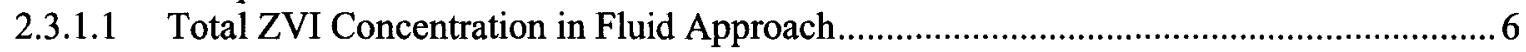

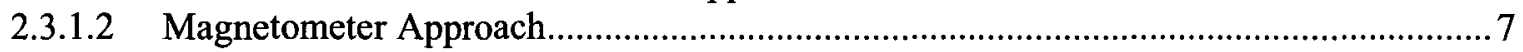

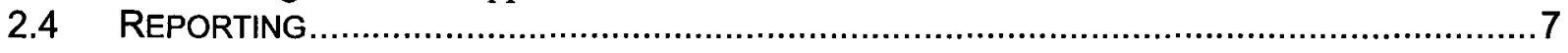

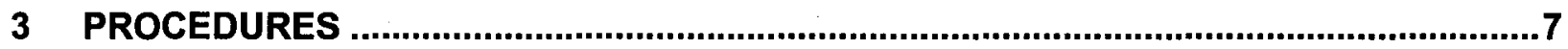

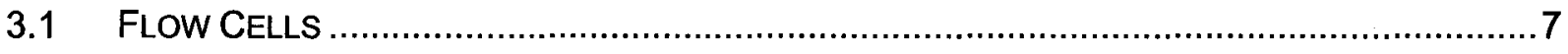

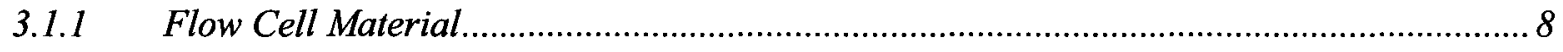

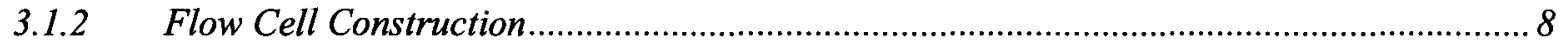

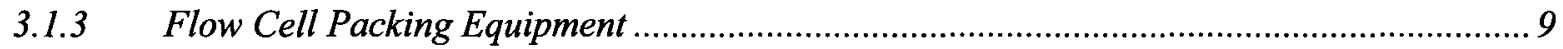

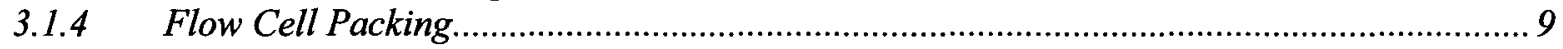

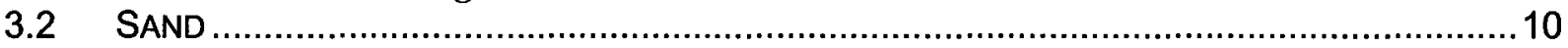

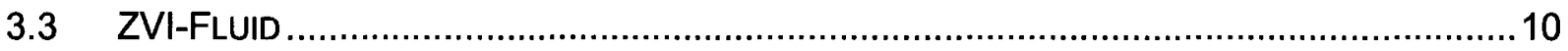

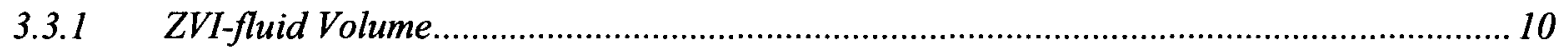

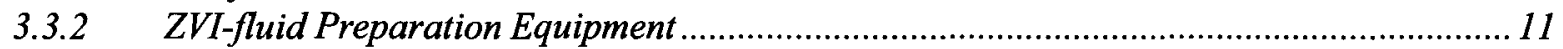

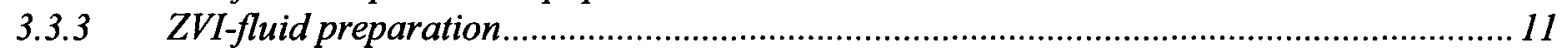

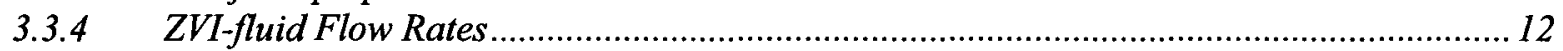

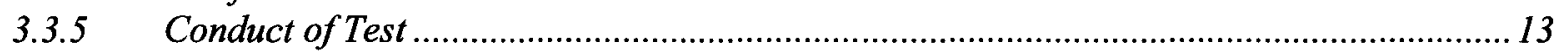

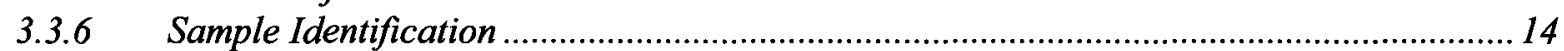

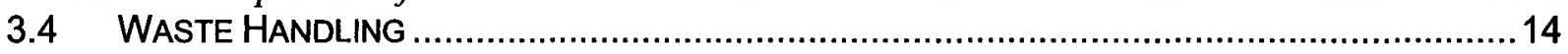

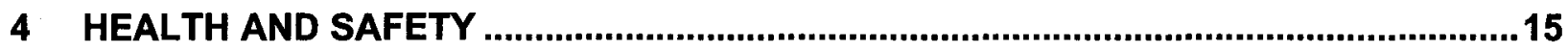

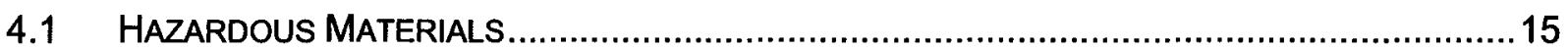

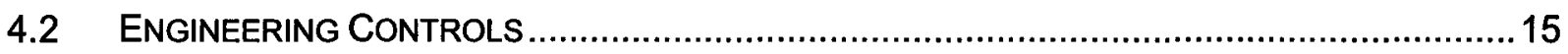

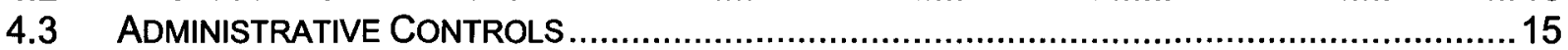

4.4 PERSONAL PROTECTIVE EQUIPMENT ............................................................. 16

4.5 FIRST AID AND EMERGENCY RESPONSE......................................................... 16

5 QUALITY CONTROL AND QALITY ASSURANCE.................................................16

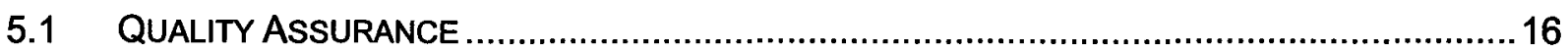

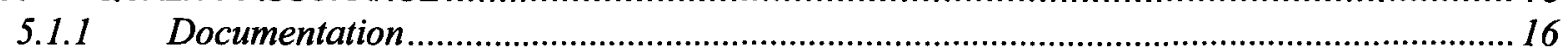

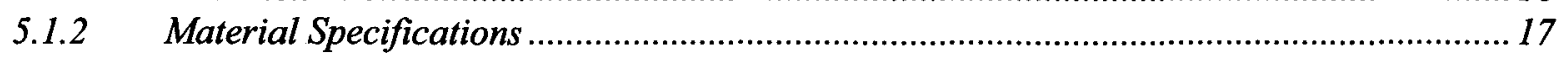

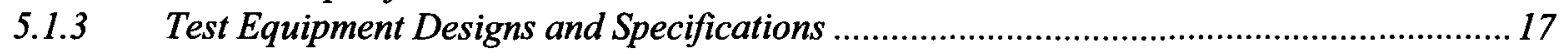

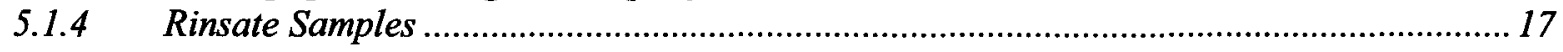

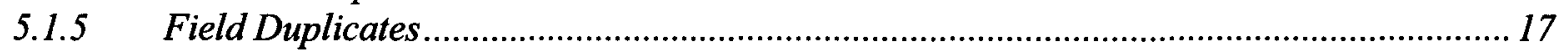

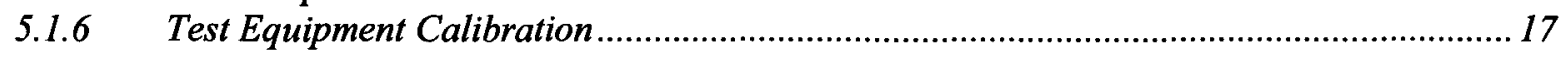


5.1.7 Personnel Qualifications.......................................................................................... 17

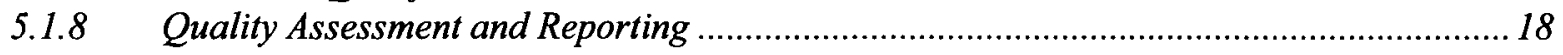

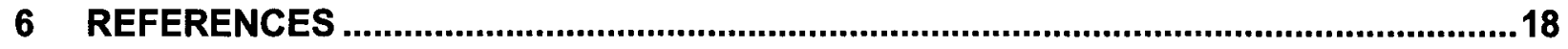

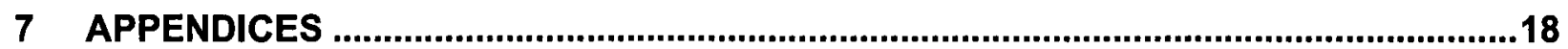

\section{List of Figures}

Figure 1 Flow Cell Schematic Diagram.....................................................................

\section{List of Tables}

Table 1 ZVI Selected for Injection Testing ................................................................

Table 2 Sampling and Measurements Location........................................................... 4

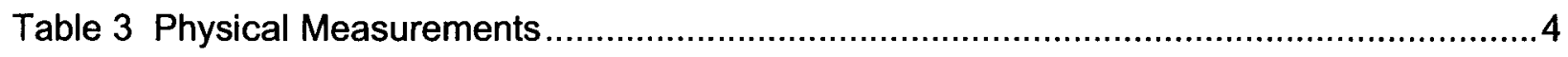

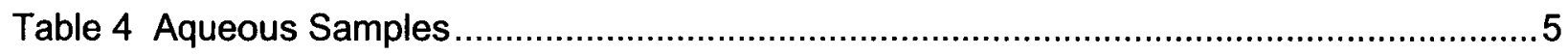

Table 5 Main Parameters of Particle Size Distribution for Sands $12 \times 20$ and $10 \times 20 \ldots \ldots \ldots \ldots \ldots . . .5$

Table 6 Oglebay Sand 10X20 Needed for Testing ..................................................... 10

Table 7 Volumes of ZVI-fluids Needed for the Injection Test............................................... 11

Table 8 ZVI-fluid Flow Velocity and Sampling intervals ................................................ 12

Table 9 Nominal Sampling and Measuring Time and Locations ........................................13

Table 10 ZVI-fluid Sample Identification System ..................................................... 14

Table 11 Hazardous Materials and Exposure/physical Data ............................................... 15 


\section{LIST OF ACRONYMS}

$\begin{array}{ll}\text { CFR } & \text { Code of Federal Regulations } \\ \text { CHO } & \text { Chemical Hygiene Officer } \\ \text { CHP } & \text { Chemical Hygiene Plan } \\ \text { CPU } & \text { central processing unit } \\ \mathrm{Cr}^{3+} & \text { trivalent chrome } \\ \mathrm{Cr}^{6+} & \text { hexavalent chrome } \\ \text { DI } & \text { deionized (water) } \\ \text { gpm } & \text { gallons per minute } \\ \text { DOE } & \text { U. S. Department of Energy } \\ \text { H-F-R } & \text { Health - Fire - Reactivity Ratings } \\ \text { ISRM } & \text { In situ Redox Manipulation (ISRM) } \\ \text { MSDS } & \text { Material Safety Data Sheets } \\ \text { MSE } & \text { MSE Technology Applications, Inc. } \\ \text { MZVI } & \text { micron-sized zero-valent iron } \\ \text { OSHA } & \text { Occupational Safety and Health Administration } \\ \text { PEL/TLV } & \text { Permissible Exposure Limit / Threshold Limit Value } \\ \text { PNNL } & \text { Pacific Northwest National Labs } \\ \text { PPE } & \text { personal protective equipment } \\ \text { PV } & \text { pore Volume } \\ \text { PVC } & \text { poly vinyl chloride } \\ \text { QA } & \text { quality assurance } \\ \text { QAP } & \text { Quality Assurance Plan } \\ \text { QC } & \text { quality control } \\ \text { RFP } & \text { request for proposal } \\ \text { SCBA } & \text { self-contained breathing apparatus } \\ \text { TAP } & \text { Technical Assistance Panel } \\ \text { ZVI } & \text { Zero-valent iron } \\ & \end{array}$




\section{INTRODUCTION}

MSE Technology Applications, Inc., (MSE) under subcontract to Fluor Hanford (Fluor Hanford Contract \#30994) has been tasked with completing laboratory testing, numerical modeling, and associated fieldwork related to injection of micron size zero-valent iron (MZVI) into the subsurface at the 100-D Area at the U.S. Department of Energy (DOE) Hanford Site, Washington State. The purpose of this work is to demonstrate the feasibility of using MZVI to repair portions of the In situ Redox Manipulation (ISRM) barrier located in the 100-D Area of the Hanford Site.

The ISRM barrier was installed to remediate a chromium groundwater plume in Hanford's 100-D Area by reduction of the $\mathrm{Cr}^{6+}$ in the groundwater to $\mathrm{Cr}^{3+}$ through the injection of sodium dithionite into the aquifer, thus creating a chemically reduced environment (DOE/RL, 2005). Localized signs of failure in the barrier (defined by the presence of $\mathrm{Cr}^{6+}$ in the treated wells) were discovered in some wells 18 months after they were treated. The most probable cause of the premature barrier breakdown was determined to be heterogeneities in the aquifer where laterally discontinuous units with high permeability and lower inherent reductive capacity (because of lower iron content) were reoxidized faster than the less permeable layers. A Technical Assistance Panel (TAP) recommended that an alternative technology (injection of $\mathrm{MZVI} /$ polymer) be tested and possibly deployed to mend the barrier, and to eliminate the need of periodically re-injecting the ISRM wells with sodium dithionite.

The TAP recommended that the reduction potential of co-contaminants and generation of byproducts must be considered and monitored. The TAP recommended considering all potential geochemical impacts to the aquifer system from the MZVI/polymer injection, specifically the potential for the MZVI to convert nitrate to ammonia and the formation of carbonate due to the generation of high $\mathrm{pH}$ conditions in the groundwater. Following the recommendations from the TAP, Fluor Hanford issued a request for proposal (RFP) to provide the laboratory testing, numerical modeling, and associated fieldwork for the MZVI/polymer injection. MSE was awarded the work for the investigation of MZVI as a remedy for repairing the ISRM. In May 2007 Fluor Hanford modified the scope of work to stop laboratory testing on the preferred micron size material and to investigate other zero valent iron (ZVI) materials, which should be considered as candidates for injection into the ISRM barrier.

This document addresses the requirements of Task 10d, ZVI Column Injection Test, to define the amount of ZVI deposited in long flow cells that will be filled with sand and injected with a mix of ZVI and dispersant/polymer in water identified in Task 10. The result of the experiment will be used for modeling purposes to recommend injection parameters for the field injection operation.

\section{LABORATORY TESTING AND ANALYSIS}

\subsection{Objectives}

The laboratory testing and data analysis will be completed at the MSE facility in Butte, Montana, which maintains fully functional experimental and analytical laboratories. The purpose of the laboratory testing is to determine the distribution of ZVI removed from the

$\mathrm{ZVI} /$ dispersant/polymer/water mix (ZVI-fluid) and deposited in the clean sand during injection of the $\mathrm{ZVI}$-fluid. It is considered that the amount of ZVI deposited in the sand represents ZVI that was adsorbed to sand grains and/or precipitated due to gravity. It is expected that the results of this experiment will allow formulation of a mathematical expression to evaluate ZVI deposition as a function of distance, time of injection, and ZVI-fluid velocity. Such a functional relationship is needed for computer modeling of the field injection process. It is anticipated that the developed function might need to be extrapolated beyond the original data set. 


\subsection{Approach}

The test objectives will be achieved by conducting lab experiments using numerous flow cells, filled with grade 10X20 Colorado Silica Sand, and injected with a ZVI-fluid. The flow cells (Figure 1), built as approximately 10 feet $(3 \mathrm{~m})$ long and 3-inch $(75 \mathrm{~mm})$ nominal diameter transparent pipes, will be configured for horizontal flow.

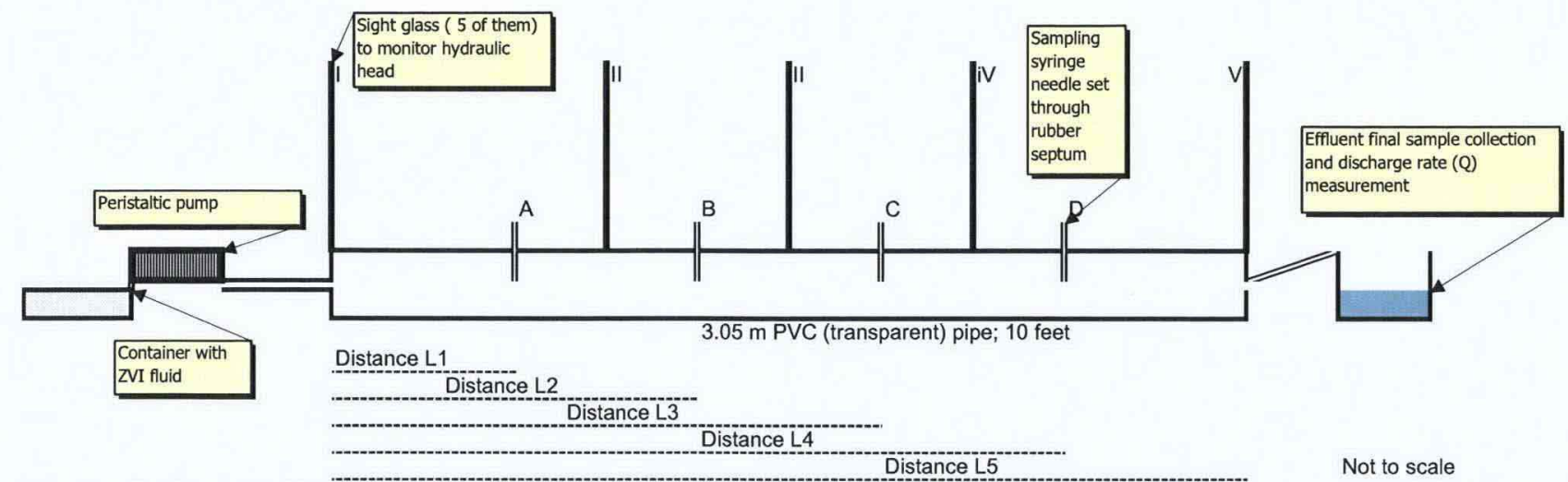

Figure 1 Flow Cell Schematic Diagram

Each flow cell will have sampling ports to collect fluid samples to be analyzed for total iron concentration. The sampling ports will be installed every 24 inches $(0.61 \mathrm{~m})$ along the flow cell. The mass of ZVI deposited in the sand will be determined from the time-integrated difference between the mass of ZVI present in the fluid at the given sampling location and the ZVI remaining in the ZVI-fluid at the next sampling location. These data will provide information regarding the ZVI mass deposited as a function of distance from the injection point.

Because ZVI will be ultimately emplaced in the aquifer using injection wells, which by definition create a radial flow pattern in which the volumetric flow rate of injected fluids decreases with distance from the well, it is important to evaluate the relationship between ZVI deposition and ZVI-fluid velocity. This will be accomplished by utilizing four different volumetric flow rates (i.e., ZVI-fluid velocities) through the flow cells.

ZVI-fluid will be injected into the flow cells for a time period equal to the duration needed to inject five pore volumes (PV's) into flow cells flowing at the lowest flow rate. Five PV's coincides with the maximum number of PV's expected during the field injection. The number of PV's injected into the flow cells flowing at a greater flow rate than the lowest velocity will differ by the ratio of their respective flow velocities. Fluid samples will be collected after injection of each of the first five PV's and then at the time interval coinciding with the sampling time at the lowest flow rate. These data will provide information relating the mass of deposited ZVI with time expressed as both dimensionless time (PV) and actual time.

Two ZVI-fluid formulations will be tested (see Table 1). These formulations are: (1) RNIP-M2; and (2) Polymetallix. The testing of two ZVI-fluid formulations at four volumetric flow rates or fluid velocities will require a total of eight flow cell experimental runs. 
TABLE 1 ZVI SELECTED FOR INJECTION TESTING

\begin{tabular}{|c|c|c|c|c|c|c|}
\hline$\overline{Z V I}$ & Manufacturer & $\begin{array}{c}\text { Particle Size } \\
\text { Distribution }\end{array}$ & Dispersant & $\begin{array}{c}\text { Shipped form } \\
\text { of material }\end{array}$ & Coating & $\begin{array}{l}\text { \% Iron in } \\
\text { the } \\
\text { material }\end{array}$ \\
\hline RNIP - M2 & Toda America & $\begin{array}{l}D_{50}-70 \\
\text { nanometers }\end{array}$ & $\begin{array}{l}\text { Olefin maleic } \\
\text { copolymer }\end{array}$ & $\begin{array}{l}80 \% \text { water, } \\
17-18 \% \text { solids, } \\
\text { and } 2-3 \% \\
\text { polymer }\end{array}$ & $\begin{array}{l}\text { Magnetite } \\
\text { coating } \\
\text { surrounding } \\
\text { alpha-iron } \\
\text { core }\end{array}$ & $\begin{array}{l}65 \% \mathrm{ZVI} \\
\text { (per } \\
\text { vendor's } \\
\text { informati } \\
\text { on) }\end{array}$ \\
\hline Polymetallix & $\begin{array}{l}\text { Crane - } \\
\text { Polyflon }\end{array}$ & $\begin{array}{l}100 \text { to } 200 \\
\text { nanometer }\end{array}$ & $\begin{array}{l}\text { Vendor } \\
\text { recommendation } 5 \% \\
\text { to } 10 \% \text { sodium } \\
\text { hexametaphosphate }\end{array}$ & $\begin{array}{l}\text { Water-based } \\
\text { paste, } 54 \% \\
\text { solids }\end{array}$ & None & $>99$ \\
\hline
\end{tabular}

There is always the possibility in laboratory testing that an experimental run will fail for unforeseen reasons. To limit the potential for loss of data if that should occur and to provide information allowing a check on data quality, flow cell experimental conditions will be run in duplicate. This requires a total of 16 experimental runs. In addition, one control flow cell will be injected with deionized water. The fluid velocity in that cell will be at an intermediate level "b" (see Table 2).

It is anticipated that data acquired from the test described above, will be suitable to determine functional relationships for the following independent variables: (1) distance from the injection point; (2) volumetric flow rate or ZVI-fluid velocity; and (3) time or dimensionless time expressed as pore volumes injected. Functional relationships will be assessed using multivariate regression analysis.

Finally, head differentials along the flow cells will be monitored during each experimental run. This will provide information indicating whether or not ZVI deposition and resulting iron oxyhydroxide formation increases (as the test progresses) to a level sufficient to cause fouling of the sand matrix in the flow cells resulting in measurable reduction in hydraulic conductivity.

\subsubsection{Sampling and Measurement}

For each ZVI-fluid, aqueous samples for chemical analyses of total iron concentration will be collected from sampling ports $A, B, C$ and $D$ located along the flow cells, from the influent tank, and from the effluent of each flow cell. The samples will be analyzed using EPA methods 3005A and 6010C, respectively, for sample digestion and analysis.

Nominal flow rates, a, b, c, and d, from lowest to highest respectively, will be set on peristaltic pumps that will be used to inject ZVI fluid to the given pair of flow cells. The flow rates will be checked by measuring the flow rate of the effluent from each flow cell using a graduated cylinder and stopwatch. If any discrepancy is found, measurements of effluent flow rate will be considered correct and used for further data interpretation and related calculations.

Measurements of hydraulic heads will be taken using sight glasses located along the flow cells. Each flow cell will be equipped with five sight glasses (I, II, III, IV and V). The sixth data point for the hydraulic head measurements will be constant for each flow cell as it will be the height of the effluent outlet. All measurements of hydraulic head will be taken with respect to the upper surface of the flow cell placed horizontally on a level bench.

Aqueous samples and field measurements will be taken as listed in Table 2. 
TABLE 2 SAMPLING AND MEASUREMENTS LOCATION

\begin{tabular}{|c|c|c|c|c|c|c|c|c|c|c|c|c|c|c|c|}
\hline \multirow[t]{2}{*}{ Fluid } & \multirow{2}{*}{ 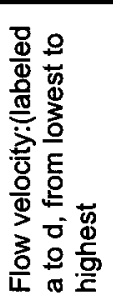 } & \multirow[t]{2}{*}{$\begin{array}{l}\text { Cell } \\
\text { ID }\end{array}$} & \multicolumn{6}{|c|}{$\begin{array}{l}\text { Location of aqueous } \\
\text { sample for total } \mathrm{Fe}\end{array}$} & \multicolumn{5}{|c|}{$\begin{array}{l}\text { Location of hydraulic } \\
\text { head measurements } \\
(\mathrm{mm})\end{array}$} & \multirow{2}{*}{ 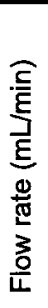 } & \multirow[t]{2}{*}{ Comment } \\
\hline & & & & A & $B$ & $\mathrm{C}$ & 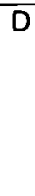 & 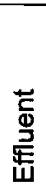 & 1 & II & III & IV & V & & \\
\hline $\mathrm{H}, \mathrm{O}$ & b & 0 & $x$ & & & & & $x$ & $x$ & $x$ & $x$ & $x$ & $x$ & $x$ & Control cell \\
\hline \multirow{8}{*}{$\begin{array}{l}\sum_{1}^{Y} \\
\text { 足 } \\
\text { 呆 }\end{array}$} & \multirow[t]{2}{*}{ a } & 1 & \multirow[t]{2}{*}{$x$} & $x$ & $x$ & $x$ & $x$ & $x$ & $x$ & $x$ & $x$ & $x$ & $x$ & $x$ & \\
\hline & & 2 & & $x$ & $x$ & $x$ & $x$ & $x$ & $x$ & $x$ & $x$ & $x$ & $x$ & $x$ & \\
\hline & \multirow{2}{*}{ b } & 3 & \multirow[t]{2}{*}{$x$} & $x$ & $x$ & $x$ & $x$ & $x$ & $x$ & $x$ & $x$ & $x$ & $x$ & $x$ & \\
\hline & & 4 & & $x$ & $x$ & $x$ & $x$ & $x$ & $x$ & $x$ & $x$ & $x$ & $x$ & $x$ & \\
\hline & \multirow{2}{*}{ c } & 5 & \multirow[t]{2}{*}{$x$} & $x$ & $x$ & $x$ & $x$ & $x$ & $x$ & $x$ & $x$ & $x$ & $x$ & $\mathrm{x}$ & \\
\hline & & 6 & & $x$ & $x$ & $x$ & $x$ & $x$ & $x$ & $x$ & $x$ & $x$ & $x$ & $x$ & \\
\hline & \multirow{2}{*}{ d } & 7 & \multirow[t]{2}{*}{$x$} & $x$ & $x$ & $x$ & $x$ & $x$ & $x$ & $x$ & $x$ & $x$ & $x$ & $x$ & \\
\hline & & 8 & & $x$ & $x$ & $x$ & $x$ & $x$ & $x$ & $x$ & $x$ & $x$ & $x$ & $x$ & \\
\hline \multirow{7}{*}{ 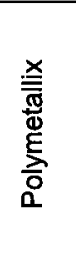 } & \multirow{2}{*}{ a } & 9 & \multirow[t]{2}{*}{$x$} & $x$ & $x$ & $x$ & $x$ & $x$ & $x$ & $x$ & $x$ & $x$ & $x$ & $x$ & \\
\hline & & 10 & & $x$ & $x$ & $x$ & $x$ & $x$ & $x$ & $x$ & $x$ & $x$ & $x$ & $x$ & \\
\hline & \multirow{3}{*}{ b } & 11 & \multirow{3}{*}{$x$} & $x$ & $x$ & $x$ & $x$ & $x$ & $x$ & $x$ & $x$ & $x$ & $x$ & $x$ & \\
\hline & & 12 & & $x$ & $x$ & $x$ & $x$ & $x$ & $x$ & $x$ & $x$ & $x$ & $x$ & $x$ & \\
\hline & & 14 & & $x$ & $x$ & $x$ & $x$ & $x$ & $x$ & $x$ & $x$ & $x$ & $x$ & $x$ & \\
\hline & \multirow[t]{2}{*}{ d } & 15 & \multirow[t]{2}{*}{$x$} & $x$ & $x$ & $x$ & $x$ & $x$ & $x$ & $x$ & $x$ & $x$ & $x$ & $x$ & \\
\hline & & 16 & & $x$ & $x$ & $x$ & $x$ & $x$ & $x$ & $x$ & $x$ & $x$ & $x$ & $x$ & \\
\hline
\end{tabular}

* For flow cells 1 through 16 , one sample of influent will be taken if fed by the same influent

The physical measurements will be taken as specified in Table 3.

TABLE 3 PHYSICAL MEASUREMENTS

\begin{tabular}{|l|l|l|l|}
\hline Measurement & Method & Units & Accuracy \\
\hline Hydraulic head & Metric tape & $\mathrm{mm}$ & $\pm 1 \mathrm{~mm}$ \\
\hline Flow rate & $\begin{array}{l}\text { Graduated cylinder } \\
\text { over } 30 \text { seconds }\end{array}$ & $\mathrm{mL} / \mathrm{min}$ & $\begin{array}{l} \pm 0.5 \mathrm{~mL} \text { or } 1 \% \text { of the volume } \\
\text { collected (whichever is greater), and } \\
\pm 1 \text { second }\end{array}$ \\
\hline Time & Stop watch & Military time / hours \& minutes & 1 minute \\
\hline
\end{tabular}

SAMPLES FOR CHEMICAL ANALYSIS WILL BE COLLECTED AND ANALYZED AS SPECIFIED IN TABLE 4. 
TABLE 4 AQUEOUS SAMPLES

\begin{tabular}{|c|c|c|c|c|c|c|c|}
\hline Matrix & Method of collection & $\begin{array}{l}\text { Volume } \\
\text { (mL) }\end{array}$ & $\begin{array}{l}\text { Sample } \\
\text { bottle }\end{array}$ & Preservation & Analyte & $\begin{array}{l}\text { Analytical } \\
\text { method }\end{array}$ & $\begin{array}{l}\text { Detection } \\
\text { limit }\end{array}$ \\
\hline \multirow[t]{2}{*}{$\begin{array}{l}\text { ZVI } \\
\text { fluid }\end{array}$} & $\begin{array}{l}\text { For ports } A \text { through } D \text { : using } \\
\text { a syringe with needle set to } \\
\text { the center of the flow cell } \\
\text { through a rubber stopper. }\end{array}$ & 25 & $\begin{array}{l}50 \mathrm{ml} \\
\text { centrifuge } \\
\text { tube }\end{array}$ & $\mathrm{HNO}_{3}$ & $\begin{array}{l}\text { Total } \\
\text { iron }\end{array}$ & $\begin{array}{l}\text { EPA methods } \\
3005 A / 6010 \mathrm{C}\end{array}$ & $\begin{array}{l}0.015 \\
\mathrm{mg} / \mathrm{L}\end{array}$ \\
\hline & $\begin{array}{l}\text { Grab samples of influent and } \\
\text { effluent }\end{array}$ & 50 & $\begin{array}{l}50 \mathrm{ml} \\
\text { centrifuge } \\
\text { tube }\end{array}$ & $\mathrm{HNO}_{3}$ & $\begin{array}{l}\text { Total } \\
\text { iron }\end{array}$ & $\begin{array}{l}\text { EPA methods } \\
3005 \mathrm{~A} / 6010 \mathrm{C}\end{array}$ & $\begin{array}{l}0.015 \\
\mathrm{mg} / \mathrm{L}\end{array}$ \\
\hline
\end{tabular}

\subsubsection{Media Used for Test}

\subsubsection{Sand}

Because only a limited amount of Ringold sediment is available, the flow cells will be filled with Oglebay Norton Industrial Sands, Inc. 10x20 sand. This sand is comparable with the 12/20 Accusand (Unimin Corporation, La Sueur, MN) used by Oostrom et al, 2006 for his experiments to determine injectibility of Micro Powder MZVI S-3700 suspended in polymer additives. Oostrom (2006) stated that $12 / 20$ Accusand has a hydraulic conductivity $(K)$ of $0.5 \mathrm{~cm} / \mathrm{s}$, which is comparable to the hydraulic conductivity value of high-permeability Ringold porous media (Szecsody et al. 2005).

Because Oglebay Norton Industrial Sands, Inc. 10x20 sand is more readily available in the Butte area than the Unimin Corporation product, it was selected for the injectibility test in question. Also, the particle size distribution of the Oglebay Norton $10 \times 20$ sand is very similar to that of the Unimin $12 \times 20$ sand. The main parameters of particle size distribution for both sands are presented in Table 5.

TABLE 5 MAIN PARAMETERS OF PARTICLE SIZE DISTRIBUTION FOR SANDS 12X20 AND 10X20

\begin{tabular}{|l|l|l|l|l|}
\hline Sand & D10 $(\mathrm{mm})$ & $\mathrm{D} 60(\mathrm{~mm})$ & $\begin{array}{l}\text { Uniformity } \\
\text { coefficient } \\
\text { (D60/D10) }\end{array}$ & Blend \\
\hline $10 \times 20$ sand & 1.11 & 1.52 & 1.36 & $\begin{array}{l}30 \% 10 \times 14 \& \\
70 \% 12 \times 20\end{array}$ \\
\hline $12 \times 20$ sand & 1.12 & 1.52 & 1.35 & $100 \% 12 \times 20$ \\
\hline
\end{tabular}

Preliminary permeability tests on the $10 X 20$ sand conducted by MSE indicate a K value of $0.8 \mathrm{~cm} / \mathrm{s}$.

\subsubsection{Water}

Water from Hanford's water supply system will be used for dilution of the ZVI-fluid during field injection. Similarly, potable water available at MSE's facility in Butte will be used during the injectibility test. 


\subsubsection{ZVI Concentration}

de Boer (2007) used four different concentrations, on a solids basis, of RNIP-M2 (10 g/L, $1 \mathrm{~g} / \mathrm{L}, 0.1$ $\mathrm{g} / \mathrm{L}$ and $0.01 \mathrm{~g} / \mathrm{L}$ ) in the injection fluid and determined a strong relationship of the initial ZVI concentration and its travel distance in sand. He determined that the higher ZVI concentration in the injection fluid, the less retarded is ZVI transport. However, other experts have indicated they would expect better ZVI mobility during injection from lower ZVI concentrations (Lowry, 2008 and Tratnyek, 2008). In view of this lack of conclusive data, it would be appropriate to test at least two ZVI injection concentrations. Unfortunately, doing so is not possible given the budget limitations of this project. Therefore, the concentration of $1 \%$ by weight or $10 \mathrm{~g} / \mathrm{L} \mathrm{ZVI}$ in the injection fluid, used and recommended by Oostrom, et al. (2006), will also be used in this project. Because RNIP-M2 is composed of approximately $65 \% \mathrm{ZVI}$ and $35 \%$ magnetite, the $10 \mathrm{~g} / \mathrm{L} \mathrm{ZVI}$ concentration is the approximately 1.3 times higher than the highest concentration tested by de Boer.

\subsection{Data Reduction and Analysis}

Data from each sampling event will be compiled into a database. The database will include a record of all paper copies of sampling records, chain of custody sheets, and analytical laboratory reports. It will also include project laboratory logbook(s) and instrument calibration records. In addition to the paper copies of the data, all numerical values obtained from the testing will be entered into an electronic spreadsheet for further analysis.

Because the injection test will be conducted in duplicates no statistical analysis for confidence intervals will be conducted.

\subsubsection{ZVI Deposition in Sand}

\subsubsection{Total ZVI Concentration in Fluid Approach}

Total iron concentration results from samples of ZVI-fluid collected during flow cell runs constitute the main data set for the development of a mathematical relationship of $\mathrm{ZVI}$ deposited in sand as a function of distance, ZVI-fluid velocity, and injection time. These data will allow estimation of the amount of iron deposited in each flow cell interval (between sampling locations) and over the combined length of the flow cell. The mass of iron deposited within each section is determined by a mass balance of the iron entering and leaving that section during the time period between samples. The mass entering a section for a given time period is calculated using the product of the mean iron concentration from samples taken at the beginning and end of that time period, the flow rate (constant for each series of measurements in a test run), and the length of that time period. The mass deposited within a section in a given time period is obtained by subtracting the mass leaving an interval from the mass entering over that time period. Calculations will be facilitated by an Excel spreadsheet.

Excel calculated values of mass deposited in flow cells intervals will be used for defining a multiple linear regression (MLR). MLR fits data from a set of potential explanatory variables (i.e., independent $x_{1}, x_{2}, \ldots x_{n}$ variables) to minimize the sum of squares of the deviations between the calculated variable (i.e., dependent $y$ variable) and data for it. The general relationship is in the following form:

$$
y=a_{0}+a_{1}^{*} x_{1}+a_{2}^{*} x_{2}+\ldots+a_{n}^{*} x_{n}
$$

Where $a_{0}$ is the $y$-axis intercept and the $a_{1}, a_{2}, \ldots$ and $a_{n}$ values are calculated best fit coefficients. For the data collected from the injection test in question, 
$y$ is $\mathrm{ZVI}$ mass deposited in sand,

$X_{1}$ is the distance of a sampling point from the injection inlet,

$x_{2}$ is the flow velocity (different for each pair of flow cells), and

$x_{3}$ is the measure of injection time (e.g. pore volume or time of injection)

Depending on the distribution of $a_{1}, a_{2}$, and $a_{3}$ the data series may be transformed (e.g. $\log$ values) to better fit the MLR

\subsubsection{Magnetometer Approach}

Although, de Boer (2007) developed a method to determine concentration of ZVI present in a flow cell at the given time, that method could not be used in this study for the following reasons:

1. A sophisticated magnetometer used by de Boer is not readily available;

2. The method requires a laboratory setting with no magnetic material present within 5 feet distance from the flow cell.

3. The magnetometer used by de Boer can accommodate a flow cell not larger than 1.5-inch diameter.

4. Reduction and interpretation of the collected data would need to be subcontracted.

5. Instrumentation used by de Boer was yet to be calibrated for continuously changing ZVI concentration.

\section{$2.4 \quad$ Reporting}

Methodologies and results from the laboratory testing will be included in the Report on the Laboratory Testing of ZVI Distribution in Soil Injected with ZVI/dispersant/water. Any Quality Assurance (QA) audits or reports and pertinent photographs taken during the laboratory setup and testing will be included in the Test Report.

\section{PROCEDURES}

Flow cell construction procedures, packing methods, lab measurements, injection procedure, and effluent collection are outlined in this section. If, during the execution of any of these procedures, a better procedure or procedures are discovered, which are more efficient and/or cost effective and produce the desired quality and results, the new procedure or procedures shall be documented, approved, and implemented.

Constructing and pre-testing a prototype flow cell of the same dimensions will most likely minimize these potential alterations. After the prototype flow cell is considered adequate, seventeen flow cells will be manufactured, loaded with sand material and tested.

\subsection{Flow Cells}

The flow cells will be prepared using 7.62-cm (3-inch) nominal diameter by $305-\mathrm{cm}$ (10-foot) long clear PVC pipe. The ends of each flow cell will be fitted with female threaded adapters. The inlet coupling will be connected to an injection tube while the outlet coupling will be connected to a drainage system. The flow cells will also be fitted with four sampling ports located at $61.1 \mathrm{~cm}(24-$ inch) intervals along the flow cell and six sight glasses located midway distance between sampling ports and at each end of a flow cell. 
Each sampling port will be constructed of a plastic fitting, which accommodates an 11-mm diameter rubber septum of the type usually used for gas chromatograph (GC) analyses. A 4-inch long syringe needle will be installed in the septum to provide means to draw a ZVI fluid sample.

\subsubsection{Flow Cell Material}

The materials required for preparation of each flow cell includes the following:

1. 1 length of $7.62-\mathrm{cm}(3.0-$ inch) nominal diameter by $305-\mathrm{cm}$ (10-foot) long clear PVC pipe;

2. 2-7.62-cm (3-inch) PVC NPT Female $x$ socket-weld pipe adapters;

3. 2-7.62-cm (3-inch) hexagonal plugs;

4. 2-0.64-cm ( $1 / 4-$ inch $)$ PVC ball valves;

5. 1 size No. $13 \frac{1}{2}$ black neoprene (rubber) stopper;

6. Assorted tees, elbows, nipples, adapters, and bushings;

7. 4 coarse-meshed screens measuring approximately $7.62-\mathrm{cm}$ (3-inch). The screens will be properly sized to permit the flow of the surrogate groundwater;

8. Six sight glasses measuring approximately $1.0-\mathrm{cm}$ in diameter and $244-\mathrm{cm}$ long:

9. Five plastic $1 / 4$-inch plastic fitting to accommodate $\mathrm{GC}$ septa;

10. Five 4-inch long gauge 20 syringe needles;

11. Five $30 \mathrm{~mL}$ syringes;

12. Five luer lock end caps to temporarily cap a needle when the fluid from the syringe is emptied to a transfer container;

13. PVC Cement and Teflon tape; and

14. Dense stone.

\subsubsection{Flow Cell Construction}

The procedures for flow cell construction are as follows:

1. Secure PVC NPT Female $x$ socket-weld pipe adapters to both ends of clear PVC pipe using PVC cement;

2. Drill and tap $1 / 4$ " holes for plastic fittings that constitute sampling ports $(61 \mathrm{~cm}$ [24 -inch spacing]);

3. Drill and tap $1 / 4$ " holes for sight glasses located in the mid distance between the sampling ports, and sampling ports and both ends of the flow cell;

4. Insert GC septa into the sampling ports;

5. Cap the needle with a luer lock end cap or with a $30 \mathrm{~mL}$ syringe;

6. Install hex plugs (over the filter-sponge) in the tapped holes for sight glasses;

7. Insert 3-inch hexagonal plug, with a $1 / 4$ " tapped hole in the lower part of the plug, into pipe adapter at one end of the flow cell and secure it firmly using Teflon tape and sealant to create a leak-proof seal. The tapped hole of the plug must be at the opposite site $\left(180^{\circ}\right.$ angle) of the sampling ports; 
8. Fill the flow cell with $10 \times 20$ sand and dense stone, while holding the flow cell in the vertical position (see section 3.1.3 below);

9. Insert 3-inch hexagonal plug, with a $1 / 2$-inch tapped hole in the center of the plug, at the other end of the pipe and secure it firmly using Teflon tape and sealant to create a leak-proof seal;

10. Place the flow cell in horizontal position on the bench;

11. Replace plugs with sight glasses;

12. Assemble remaining ball valves, and hook up the flow cell to a ZVI fluid supply tube.

\subsubsection{Flow Cell Packing Equipment}

Packing of the flow cell will require the following laboratory equipment

1. Scale for weighing sand (15 kg. capacity);

2. Graduated cylinder of $1 \mathrm{~L}$ capacity;

3. Funnel;

4. Scoop for water-saturated sand and miscellaneous hand tools;

5. FMC Syntron Power Pulse vibrator table ;

6. Wrenches to set 3-inch hexagonal plugs, hex plugs and plastic fittings.

\subsubsection{Flow Cell Packing}

Several experiments were conducted with a prototype flow cell to refine the packing procedure. The resulting procedure is listed below:

1. Assemble the flow cell with the outlet end cap, all the sampling ports, and with hex plugs in place of the sight glasses;

2. Place the flow cell in a vertical position;

3. Place a coarse screen in the bottom of the flow cell;

4. Add $325 \mathrm{~g}$ of $1 / 4$ " dense stone;

5. Place a coarse screen on top of the dense stone;

6. Add $100 \mathrm{~mL}$ of de-ionized water to dense stone;

7. Vibrate flow cell in a vertical position using a vibrator set on level 8 , to settle dense stone.

8. Add $10 / 20$ silica sand using the following procedure:

a. Mix at ratio of one kilogram $10 \times 20$ silica sand with $215 \mathrm{~mL}$ of de-ionized (DI) water.

b. Constantly vibrate the flow cell

c. Slowly add the sand mixture with a sprinkling motion.

d. Maintain $1 / 2-1$ inch of standing water on top of the packed material.

9. Install a 4-inch long syringe needle in a septum as the packing material reaches each sampling port. The following procedure should be followed:

a. Insert the syringe needle its full length through the sampling port septum.

b. Align the needle opening with the flow cell outlet. 
c. Force air through the needle with a syringe body to ensure the needle is free of any obstruction.

d. Plug the syringe needle with a luer lock end cap.

10. Continue adding packing material and completing sample ports until the flow cell is fully packed past the last sight glass.

11. Place a screen on top of the packed $10 \times 20$ silica sand.

12. Add dense stone until the material is approximately one inch from the end of the flow cell.

13. Place a screen on top of the dense stone.

14. Tighten the inlet end cap (filled with a \#13.5 rubber stopper) until the dense stone is compressed.

15. Place and secure the packed flow cell on the injection bench.

16. Replace the hex plugs with the appropriate filters and sight glasses.

17. Retract the needles in order to align the needle opening with the center of the flow cell.

\subsection{Sand}

ZVI-fluid will be injected to the flow cells packed with $10 \times 20$ mix of Oglebay Norton Industrial Sands, Inc. The amount of sand needed for each flow cell and for the entire testing is included in Table 6.

TABLE 6 OGLEBAY SAND 10X20 NEEDED FOR TESTING

\begin{tabular}{|c|c|c|c|c|c|c|c|c|}
\hline \multirow{2}{*}{$\begin{array}{l}\text { Flow cell } \\
\text { diameter } \\
\text { (inch) }\end{array}$} & \multirow{2}{*}{$\begin{array}{c}\text { Volume in } \\
1 \text {-foot } \\
\text { length }(L)\end{array}$} & \multirow{2}{*}{$\begin{array}{c}\text { Bulk } \\
\text { density of } \\
\text { sand } \\
\text { (kg/L) }\end{array}$} & \multirow{2}{*}{$\begin{array}{l}\text { Dry weight } \\
\text { in } 1 \text {-foot } \\
\text { length (Lb) }\end{array}$} & \multirow{2}{*}{$\begin{array}{l}\text { Flow cell } \\
\text { length (ft) }\end{array}$} & \multicolumn{2}{|c|}{ One flow cell } & \multicolumn{2}{|c|}{17 flow cells } \\
\hline & & & & & $\begin{array}{l}\text { Weight } \\
\text { (Lb) }\end{array}$ & $\begin{array}{c}\text { Volume } \\
\left(\mathrm{ft}^{3}\right)\end{array}$ & $\begin{array}{l}\text { Weight } \\
\text { (Lb) }\end{array}$ & $\begin{array}{c}\text { Volume } \\
\left(\mathrm{ft}^{3}\right)\end{array}$ \\
\hline & 1.39 & 2 & 6.1 & 10.0 & 61 & 0.51 & 1039 & \\
\hline
\end{tabular}

\section{$3.3 \quad$ ZVI-Fluid}

As stated in Section 2.2, Table 1 the injectibility of two ZVI-fluids, RNIP - M2 and Polymetallix, will be tested, with each ZVI-fluid laden with the same, $1 \%$ by weight of ZVI. ZVI-fluid will be prepared in a manner, which mimics the procedure that will be used during the field injection. For the Polymetallix it will involve mixing dispersant with water and then adding Polymetallix slurry. For RNIP-M2, which is supplied as slurry already mixed with dispersant, the slurry will be added to water for dilution and mixing.

\subsubsection{ZVl-fluid Volume}

Assuming an effective porosity for the packed flow cell of $0.35,254.6$ gallons of each ZVI will be needed to complete the test that will involve injection of ZVI-fluid into flow-cells over the same time period equal to the duration needed to inject five pore volumes (PV) into flow cells flowing at the lowest flow rate. Details of the calculations are included in Table 7 
TABLE 7 VOLUMES OF ZVI-FLUIDS NEEDED FOR THE INJECTION TEST

\begin{tabular}{|c|c|c|c|c|c|c|c|}
\hline \multirow{2}{*}{$\begin{array}{l}\text { Flow } \\
\text { velocity }\end{array}$} & \multirow[t]{2}{*}{ PV (L) } & \multirow{2}{*}{$\begin{array}{l}\text { Time for } \\
\text { one PV } \\
\text { (min) }\end{array}$} & \multirow{2}{*}{$\begin{array}{l}\text { Time of } \\
\text { injection } \\
(\mathrm{min})\end{array}$} & \multirow{2}{*}{$\begin{array}{c}\text { Number of } \\
\text { PV } \\
\end{array}$} & \multicolumn{2}{|c|}{ ZVI volume (L) } & \multirow{2}{*}{\begin{tabular}{|l|}
$\begin{array}{c}\text { ZVI volume } \\
\text { (gal) }\end{array}$ \\
$\begin{array}{l}\text { Duplicate } \\
\text { flow cells }\end{array}$ \\
\end{tabular}} \\
\hline & & & & & $\begin{array}{l}\text { One flow } \\
\text { cell }\end{array}$ & $\begin{array}{l}\text { Duplicate } \\
\text { flow cells }\end{array}$ & \\
\hline a & 4.6 & 328 & 1641 & 5.0 & $\begin{array}{r}23.2 \\
\end{array}$ & \begin{tabular}{|r|}
46.4 \\
\end{tabular} & \begin{tabular}{|r|}
12.3 \\
\end{tabular} \\
\hline b & 4.6 & 143 & 1641 & 11.5 & 53.3 & 107 & 28.2 \\
\hline c & 4.6 & 62 & 1641 & 26.5 & 122.6 & 245 & 64.9 \\
\hline $\mathrm{d}$ & 4.6 & 27 & 1641 & 60.8 & 282.1 & 564 & 149.2 \\
\hline & & RNIP_ & orPolv & I": & & 962.4 & 254.6 \\
\hline
\end{tabular}

\subsubsection{ZVl-fluid Preparation Equipment}

Preparing ZVI-fluid will require the following laboratory equipment

1. Two-liter beaker;

2. Scale for weighing ZVI (1 kg capacity);

3. Scale for weighing water (100 kg capacity);

4. Ultrasonic mixer, colloid mill or other disperger.

\subsubsection{ZVl-fluid preparation}

In general, preparation of each ZVI fluid will follow the procedures recommended by the ZVI vendors. According to these procedures, a standard paddle mixer rotating gently to reduce introduction of oxygen to ZVI-fluid is recommended for RNIP-M2. Mixing of polymetallix requires usage of a colloid mill (Appendix A). However, because this procedure was developed for large-quantity field applications, it will need to be scaled down to match the needs of a laboratory-scale experiment. The necessary scaling procedures are currently been discussed with the polymetallix vendor.

Both RNIP-M2 and Polymetallix come in concentrated slurries, which requires dilution before injection. The materials will be injected at a $1 \%$ concentration by weight of ZVI. For an injection of five pore volumes, each flow cell will require approximately $25 \mathrm{~L}$ of injection solution. RNIP-M2 is shipped in a solution containing $18 \%$ solids and $2 \%$ dispersant creating a slurry density of approximately 1,200 $\mathrm{g} / \mathrm{L}$. The following procedure will be used to mix the injection solution for RNIP-M2:

1. Measure out $23.65 \mathrm{~L}$ of de-ionized water,

2. Slowly add $1,731 \mathrm{~g}$ of $18 \%$ RNIP-M2 slurry to water while mixing,

3. Let mix for $1 \mathrm{hr}$ before injection.

4. To avoid aggregation of ZVI (de Boer 2007), the RNIP-M2 injection fluid will be injected to the flow cells via in-line colloid mill, sonic mixer or other disperger that will ensure that ZVI molecules are in its original non-aggregated form.

Polymetallix is shipped in two forms: (1) a paste containing $54 \%$ solids, or (2) a slurry containing $8 \%$ solids. For the injection test the slurry form will be used. The following procedure will be used to mix $25 \mathrm{~L}$ of the injection solution for Polymetallix:

1. Measure out $21.84 \mathrm{~L}$ of de-ionized water,

2. Add $25.25 \mathrm{~g}$ of sodium hexametaphosphate while mixing, 
3. Slowly add $3.16 \mathrm{~L}$ of $8 \%$ Polymetallix to the mixing solution,

4. Mix contents for $1 \mathrm{hr}$ before injection

5. To avoid aggregation of ZVI (Appendix A), the Polymetallix injection fluid will be injected to the flow cells via in-line colloid mill, sonic mixer or other disperger that will ensure that ZVI molecules are in its original non-aggregated form.

\subsubsection{ZVl-fluid Flow Rates}

The flow velocities of ZVI-fluid flowing through each of four flow cells have been determined based on expected seepage velocity during the field injection at the rate not exceeding of 15 gallons per minute (gpm). The lowest velocity (marked "a" in Table 2) is related to the expected seepage velocity 10.8 feet from the well. Similarly, the highest velocity (marked "d" in Table 2) is related to the expected seepage velocity 0.8 feet from the center of the injection well. The value for highest velocity was checked with regard to the upper limit applicability for Darcy' law and was found acceptable. The Reynold's number for these flow conditions was calculated as 0.76 , thus was significantly lower than the value of 10 given by Bowen, 1986 as the upper limit for which the divergence from Darcy's low is still acceptable. Intermediate velocities, designated as " $b$ " and " $c$ " in Table 2, were set as approximately 2.3 and 9 times higher, respectively than the lowest velocity.

ZVI-flow velocities and related values are given in Table 8. Nominal sampling and measuring time times in a chronological order are listed in Table 9.

TABLE 8 ZVI-FLUID FLOW VELOCITY AND SAMPLING INTERVALS

\begin{tabular}{|c|c|c|c|c|c|c|}
\hline \multicolumn{3}{|c|}{ ZVI-fluid velocity } & \multirow{2}{*}{$\begin{array}{l}\text { Flow rate for } 3 \text { " } \\
\text { diameter flow cell } \\
\text { at } 0.35 \text { effective } \\
\text { porosity ( } \mathrm{mL} / \mathrm{min} \text { ) }\end{array}$} & \multirow{2}{*}{$\begin{array}{l}\text { Expected } \\
\text { hydraulic } \\
\text { head } \\
\text { differential } \\
(\mathrm{cm})\end{array}$} & \multirow{2}{*}{$\begin{array}{c}\text { Expected } \\
\text { hydraulic } \\
\text { gradient (-) }\end{array}$} & \multirow{2}{*}{$\begin{array}{l}\text { Elapsed } \\
\text { time for } \\
\text { sampling } \\
\text { (min) }\end{array}$} \\
\hline $\begin{array}{c}\text { Table } 2 \\
\text { designation }\end{array}$ & $\begin{array}{c}\text { Seepage } \\
\text { velocity (ft/d) }\end{array}$ & $\begin{array}{l}\text { Darcy flux } \\
\text { (ft/d) }\end{array}$ & & & & \\
\hline a & 43 & 15 & 14 & 2 & 0.007 & $\begin{array}{c}328, \\
656,984,1312 \\
\text { and } 1641\end{array}$ \\
\hline$b$ & 99 & 35 & 32 & 4.6 & 0.015 & $\begin{array}{c}143,285,428 \\
571,714 \\
984,1312 \\
\text { and } 1641\end{array}$ \\
\hline c & 228 & 80 & 75 & 10.6 & 0.035 & $\begin{array}{c}62,124,186, \\
248,310 \\
656,984, \\
1312, \text { and } \\
1641\end{array}$ \\
\hline d & 525 & 184 & 172 & 24 & 0.081 & $\begin{array}{c}27,54,81, \\
108,135, \\
328,656, \\
984,1312, \\
\text { and } 1641\end{array}$ \\
\hline
\end{tabular}


TABLE 9 NOMINAL SAMPLING AND MEASURING TIME AND LOCATIONS

\begin{tabular}{|c|c|c|c|c|c|c|c|}
\hline \multicolumn{2}{|c|}{$\begin{array}{l}\text { Nominal time } \\
\text { elapsed for } \\
\text { sampling or } \\
\text { measuring point }\end{array}$} & \multicolumn{4}{|c|}{$\begin{array}{l}\text { Sample collection: } \\
\text { Sampling ports A, B, C, D and effluent; } \\
\text { Influent - one sample per set of flow cells that run } \\
\text { simultaneously } \\
\text { Measurements: } \\
\text { Hydraulic head at sight glasses I, II, III, IV and V } \\
\text { Flow rate at effluent }\end{array}$} & \multirow[t]{2}{*}{$\begin{array}{l}\text { Sample of } \\
\text { influent } \\
\text { only }\end{array}$} & \multirow[t]{2}{*}{ Commen } \\
\hline minutes & $\begin{array}{l}\text { hours } \\
\& \text { min }\end{array}$ & $14 \mathrm{~mL} / \mathrm{min}$ & $\begin{array}{l}\mathrm{b} \\
32 \mathrm{~mL} / \mathrm{min}\end{array}$ & $\begin{array}{l}\mathrm{c} \\
75 \mathrm{~mL} / \mathrm{min}\end{array}$ & $\begin{array}{l}\text { d } \\
172 \mathrm{~mL} / \mathrm{min}\end{array}$ & & \\
\hline 0 & $0: 00$ & & & & & $x$ & \\
\hline 27 & $0: 27$ & & & & $x$ & & \\
\hline 54 & $0: 54$ & & & & $x$ & & \\
\hline 62 & $1: 03$ & & & $x$ & & & \\
\hline 81 & $1: 21$ & & & & $x$ & & \\
\hline 108 & $1: 48$ & & & & $x$ & & \\
\hline 124 & $2: 04$ & & & $x$ & & & \\
\hline 135 & $2: 15$ & & & & $x$ & & \\
\hline 143 & $2: 23$ & & $x$ & & & & \\
\hline 186 & $3: 06$ & & & $x$ & & & \\
\hline 248 & $4: 08$ & & & $x$ & & & \\
\hline 285 & $4: 45$ & & $x$ & & & & \\
\hline 310 & $5: 10$ & & & $x$ & & & \\
\hline 328 & $5: 28$ & $x$ & & & $x$ & & \\
\hline 571 & $9: 31$ & & $x$ & & & & \\
\hline 656 & $10: 56$ & $x$ & & $x$ & $x$ & & \\
\hline 714 & $11: 54$ & & $x$ & & & & \\
\hline 984 & $16: 24$ & $x$ & $x$ & $x$ & $x$ & & \\
\hline 1312 & $21: 52$ & $x$ & $x$ & $x$ & $x$ & & \\
\hline 1641 & $27: 31$ & $x$ & $x$ & $x$ & $x$ & & \\
\hline
\end{tabular}

\subsubsection{Conduct of Test}

Flow cells will be positioned horizontally on a bench, and injected with ZVI-fluids delivered by peristaltic pumps at rates specific for the given pair of flow cells (Table 8).

Samples of ZVI fluid will be collected using syringes with needles whose tips will protrude $50 \%$ of the diameter $(37 \mathrm{~mm})$ into the sand packed flow cells. It is expected that sampling will take place as specified in (Table 8). The procedures for sampling are as follows:

1. Label sample bottles for the entire test;

2. Shortly before turning on a peristaltic pump, collect ZVI-fluid from the feed source;

3. Shortly before the sampling time, replace a luer-lock cap with a sampling syringe;

4. Shortly before the sampling time, measure the flow rate at the flow cell outlet using a graduated cylinder;

5. Use fluid form graduated cylinder (item 4) for total iron analyses;

6. Starting with sampling port $\mathrm{A}$ and following down the flow direction collect samples of ZVIfluid; 
Personnel shall practice good personal hygiene at all times. This includes, no eating, smoking, chewing gum, chewing tobacco, or drinking in the test area. Hands shall be washed thoroughly after removing protective gloves and before leaving the test area and hands shall be kept away from the eyes and face when wearing protective gloves. Eating and drinking shall only be allowed in the break area of the building. Smoking is prohibited inside the building.

\subsection{Personal Protective Equipment}

Standard laboratory protective equipment includes: laboratory coat, safety glasses, and impervious latex or nitrile gloves.

In addition a respirator with HEPA filter needs to be used while dealing with dry silica sand (Appendix 2). No contact lenses and make-up may be used.

\subsection{First Aid and Emergency Response}

During any emergency event, consult the MSDS as necessary. However, in any case of chemicals contacting unprotected skin or eyes, flush with water for a minimum of 15 minutes. During that time, someone shall dial "333" and request an ambulance. The emergency eyewash/shower is located within 30 feet of the laboratory hood. In the event of an inhalation exposure, get to fresh air and someone should dial 333. Nobody should attempt to rescue a person down if bad air is suspected, unless the $\mathrm{CHO}$ gives approval to enter based on air monitoring. The emergency brigade shall be requested with self-contained breathing apparatus (SCBAs), as appropriate. The use of PPE, the laboratory hood, good personal hygiene, and safe work procedures should prevent exposures from occurring via inhalation, ingestion, and absorption. The potential for injection hazards is not likely, given the nature of work.

In the event of a spill or fire that risks personnel, evacuate the building and dial 333. Only qualified personnel equipped with SCBAs should attempt to extinguish incipient-stage fires that involve hazardous chemicals. The CHO/Emergency Coordinator shall only authorize re-entry.

In the event of spills, absorbing materials are provided in the building, including the sorbents used in the experiments. Additionally, chemical quantities are very small. All spills shall be reported to the $\mathrm{CHO}$ and actions shall be taken to minimize spillage, area contamination, and personnel exposure.

Any chemical wastes generated will be disposed of in accordance with applicable state regulations per the MSE Environmental Coordinator.

\section{QUALITY CONTROL AND QALITY ASSURANCE}

\subsection{Quality Assurance}

Quality assurance will include reviewing all relevant laboratory documentation to ensure procedures are followed and the results are within the acceptable quality limits of the project. This will include reviewing all planning documents, material specifications, test equipment designs and specifications, personnel qualifications, equipment calibration records, and quality control sample results.

\subsubsection{Documentation}

Documentation that will be reviewed includes the laboratory test plan, experimental laboratory project logbook, and the analytical laboratory reports. 


\subsubsection{Material Specifications}

The materials specifications include materials specified for the testing apparatus, ZVI provided by vendors, and any consumable items required for sampling. The material specifications are listed in Section 3, Procedures.

\subsubsection{Test Equipment Designs and Specifications}

The test equipment designs and specifications are listed in Section 3, Procedures.

\subsubsection{Rinsate Samples}

To assure no cross-contamination of aqueous samples collected using syringes, one rinsate sample from a rinsed syringe for each flow cell will be collected.

\subsubsection{Field Duplicates}

EPA generally recommends that field duplicates be collected for analysis at a rate of $5 \%$ of sample throughput for RCRA and CERCLA monitoring. The purpose of field duplicate samples is to provide an indication of the variability of the complete sampling and analysis process, but of prime importance is the variability of the sample matrix (EPA, 2008). As such, it should be conducted by splitting a thoroughly mixed sample. When that cannot be accomplished, sequentially taken co-located samples provide the best alternative.

In this case, since available syringe volume precludes splitting a thoroughly mixed sample, only colocated samples can be obtained. In view of the nature of this research, it can be expected that the matrix being sampled is relatively variable and, therefore, co-located samples will have limited utility. For this reason, a fewer number of such samples is warranted and a rate of $2.5 \%$, in combination with standard laboratory quality control methods (i.e., method blanks, matrix spike/matrix spike duplicates, and laboratory control samples) will be sufficient. Operationally, this means that at least one field duplicate sample will be collected for each flow cell run and that, in the case of higher flow rates, two field duplicates will be collected. Field duplicate samples will be submitted to the laboratory as double-blind samples.

\subsubsection{Test Equipment Calibration}

With the exception of chemical laboratory equipment used to analyze samples for total iron, no equipment used for testing will require calibration.

\subsubsection{Personnel Qualifications}

Personnel working on the project in the experimental laboratory will be experienced in experimental laboratory setup, flow cell testing, and sampling. The experimental laboratory personnel will be responsible for ensuring that records or documentation are kept in the project logbook. The experimental laboratory personnel will be responsible for ensuring that all sampling procedures are followed and documented in the project logbook. The MSE analytical laboratory personnel will perform the laboratory analysis according to the MSE Analytical Laboratory procedures. Data reduction and analysis will be completed under the direction of the MSE Project Engineer. The MSE Project QA Officer will conduct the quality control and quality assurance activities. 


\subsubsection{Quality Assessment and Reporting}

MSE will assess the data quality and include the results of the assessment in the laboratory report. The quality assessment report will include results from the data validation process and a summary of the calculated data quality indicators. The data validation process will be conducted according to the MSE Quality Assurance Plan and consist of a review of the laboratory reports to ensure all QAVC procedures were followed and that the results of the analyses meet the project quality requirements.

Because the injection test will be conducted in duplicates no statistical analysis for confidence interval or bias will be conducted.

\section{REFERENCES}

de Boer, Cjestmir, 2007. Characteristics and Mobility of Zero-Valent Nano-Iron in Porous Media, a Laboratory Assessment Study. Master thesis at University of Utrecht, Faculty of Geosciences, Department of Earth Sciences, Environmental Hydrogeology Group.

Bowen, R. 1986. Groundwater, Springer, NY, 444 pages.

Lowry and Tratnyek, 2008. Conference call in January, 2008.

Oostrom, M., T.W. Wietsma, M.A. Covert, V.R. Vermeul, 2006. Micron-Size Zero-Valent Iron Emplacement in Porous Media Using Polymer Additives: Column and Flow Cell Experiments Hydrology Days, 2006

Szecsody JE, VR Vermeul, JS Fruchter, MD Williams, BJ Devary, JL Philips, M Rockhold, and Y Liu. 2005. Effect of geochemical and physical heterogeneity on the Hanford 100D area in situ redox manipulation barrier longevity. PNNL-15449, Pacific Northwest National Laboratory, Richland, Washington.

\section{APPENDICES}

1 A. Crane Polyflon Multi-Pass, Inline Processing

2. Material Safety Data Sheet No. 71 Quartz 


\begin{tabular}{|c|c|}
\hline $\begin{array}{r}\text { TELEPHONE: } \\
\text { FAX: } \\
\text { MODEM: } \\
\text { E-MUi: } \\
\text { WOS poO }\end{array}$ & $\begin{array}{l}\text { (203) 840-7555 } \\
(203) 840-7505 \\
(203) 840-7584 \\
\text { infolpolyilon.com } \\
\text { hiti:/hwm.polyion.com }\end{array}$ \\
\hline
\end{tabular}

\section{CRANE}

POLYFLON COMPANY

\section{POLYFLON}

\section{Multi-Pass, In-Line Processing}

The following discussion reviews the multi-pass processing options, the equipment requirements, and the processing times required for each option. There are thres options to accomplish multiple passes while. procissing in-line: 1) mixers. in series, 2) two tanks with a singlo mixer, 3) one tank and a single mixer operating in a recirculation mode. Due to the capital costs of option one and floor space/tank requirements for option two, many plants implement option three. The processing time required with option three is :longer than the other options. This discussion provides for a quick calculation of the required processing time asouming a certain $\%$ of the batch is processed for a given number of "paseses" through tho mill.

For discussion purposes, it is sesumed that the batch size is 1000 gallons, 4 pases through a high-ahear device are required, and the maximum processing for the high-sheir unit is $50 \mathrm{gpm}$. For simplicity, the colloid mill is referenced es the in-line, high-abee provesing unit, but the divaveion is juat as appliceble to a pipelino mixer.

Option 1) Four colloid mills used in series allow the entire 1,000-gellon betch to be procesed in a single pere The finished product would be milled the required four times, and the entire procedure would take 20 minution (1,000 gal. (950 gom).

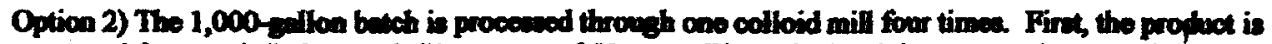

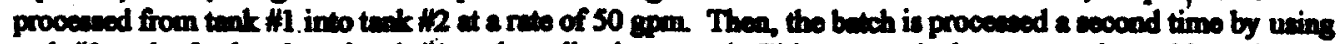

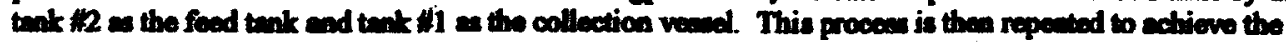

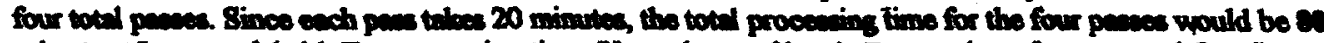

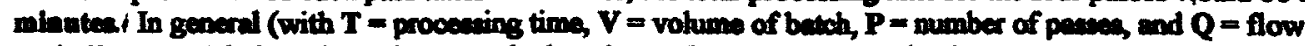

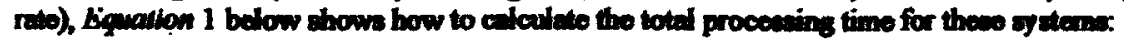

$T(\min )=P \times \frac{Y(\operatorname{mil})}{Q(\text { epm })} \quad$ (Equation 1$)$

For this discusacion, the above formula yiolds 80 minates ( 4 passes $X 1,000 \mathrm{gal} / 50 \mathrm{gpm}$ )

Option 3) One tank and one colloid mill are ueed and the product is recirculated through the mill and back to the foed tank. This option results in material procesed through the colloid mill discharging beck into a tank with material thet has received loss processing. For this reason, Lquation I cannot be applied directly. However, If one assumes that the colloid mill discharge is matintaneously distributed uniformly throughout the batch tank (a reasonable aseumption for a property designed motorized agitator), a straightformard statistical enalysis leads to the desired formula. (The details of the analysis cen bo found on pages 20-27 of Volume 42 (1959) of the Joumal of Datry Sctence.)

Unfortunately, the complexity of the formula from this analysis makes it impostible to directly calculate the needed correction factor to axtisfy the final formula. A computer analysis can generate a table contrining the necessary information by selocting a range of common values for the number of passes (P) and the fraction of the betch receiving $P$ pasees $(f)$, and then using numerical methods to calculate the corresponding values of $m$ for eech possible combination. 
The results for the time correction factor $\mathbf{m}$ are listed in the following table:

\section{Time Correction Factor (m)}

\begin{tabular}{|c|cccccc|}
\multicolumn{1}{c}{} & \multicolumn{7}{c}{ P ( \% of batch processed for P number of passes) } \\
\hline P(\#ses) & $\mathbf{0 . 7 0 0}$ & $\mathbf{0 . 8 0 0}$ & $\mathbf{0 . 9 0 0}$ & $\mathbf{0 . 9 5 0}$ & $\mathbf{0 . 9 9 0}$ & $\mathbf{0 . 9 9 9}$ \\
\cline { 2 - 7 } 1 & 1.781 & 2.543 & 3.577 & 4.500 & 6.473 & 9.118 \\
2 & 3.440 & 4.160 & 5.248 & 6.244 & 8.377 & 11.213 \\
3 & 4.704 & 5.479 & 6.661 & 7.741 & 10.039 & 13.060 \\
4 & 5.870 & 6.709 & 7.988 & 9.150 & 11.603 & 14.793 \\
5 & 6.999 & 7.902 & 9.273 & 10.513 & 13.108 & 16.455 \\
6 & 8.109 & 9.074 & 10.532 & 11.842 & 14.571 & 18.062 \\
7 & 9.208 & 10.233 & 11.771 & 13.148 & 16.000 & 19.626 \\
8 & 10.301 & 11.380 & 12.995 & 14.434 & 17.403 & 21.156 \\
9 & 11.387 & 12.518 & 14.207 & 15.705 & 18.783 & 22.657 \\
10 & 12.469 & 13.651 & 15.407 & 16.962 & 20.145 & 24.134 \\
11 & 13.548 & 14.776 & 16.599 & 18.208 & 21.490 & 25.590 \\
12 & 14.623 & 15.898 & 17.782 & 19.443 & 22.821 & 27.026 \\
\hline
\end{tabular}

Very accurate values for $m$ are obtained, if the desired values for $P$ and $f$ are listed in the table above. Altematively, approximate values are obtained by interpolation and extrapolation to $P$ and $f$ values that are not listed in the table. Although these reoults are not as precise as the tabulated ones, they are adequate.

Since this is a statiatical situation, it cannot be guaranteed that $100 \%$ of the 1,000 gallon batch has undergone the desired four paseses. It is necessary to choose a certainty level. If a $99 \%$ certainty level is acceptable, then for this discussion the values of $P=4$ and $f=0.990$ yiald an $m$ valee of 11.6 (as indicated by the Table). Using this correction factor in Equation 1 inctead of the $P$ value, a lotal recirculation time is calculated as:

$T(\min )=m \times \frac{V(r)])}{Q(f p m)}=([11.6][1,000 \mathrm{gal}) /(50 \mathrm{gpm})=232$ minutes

Therefore after 232 minutes of continuous recirculation at a rate of $50 \mathrm{gpm}, 99 \%$ of a 1,000-gallon batch will have received at least 4 passes though the colloid mill.

NOTE Additional analysis of this example shows that after 232 minutes of recirculation, a small portion of the batch (0.05\%) will have received as many as 24 passes. To guarantee thet only $1 \%$ of the batch receives less than four passes, it is necessary that much of the batch receive many more passes than targeted, and is the reason for the long recycle time. If the recycle time is shortened (and the statistics described above are ignored) to the 80 minute recycle time calculated with $P=4$ for the two-tank system, only $38.9 \%$ of the batch would receive at least the desired four passes. Although the fraction of the batch that receives much more work than necessary is reduced, it allows a large portion of the batch to remain inadequately processed and compromise product quality. 


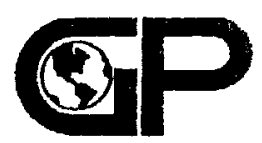

\author{
Genium Publishing Corporation \\ 1145 Catalyn Street \\ Schenectady, NY 12303-1836 USA \\ (518) 377-8854
}

\author{
Material Safety Data Sheets Collection: \\ Sheet No. 71 \\ Quartx \\ Issued: 7/80 Revision: A, 4/90
}

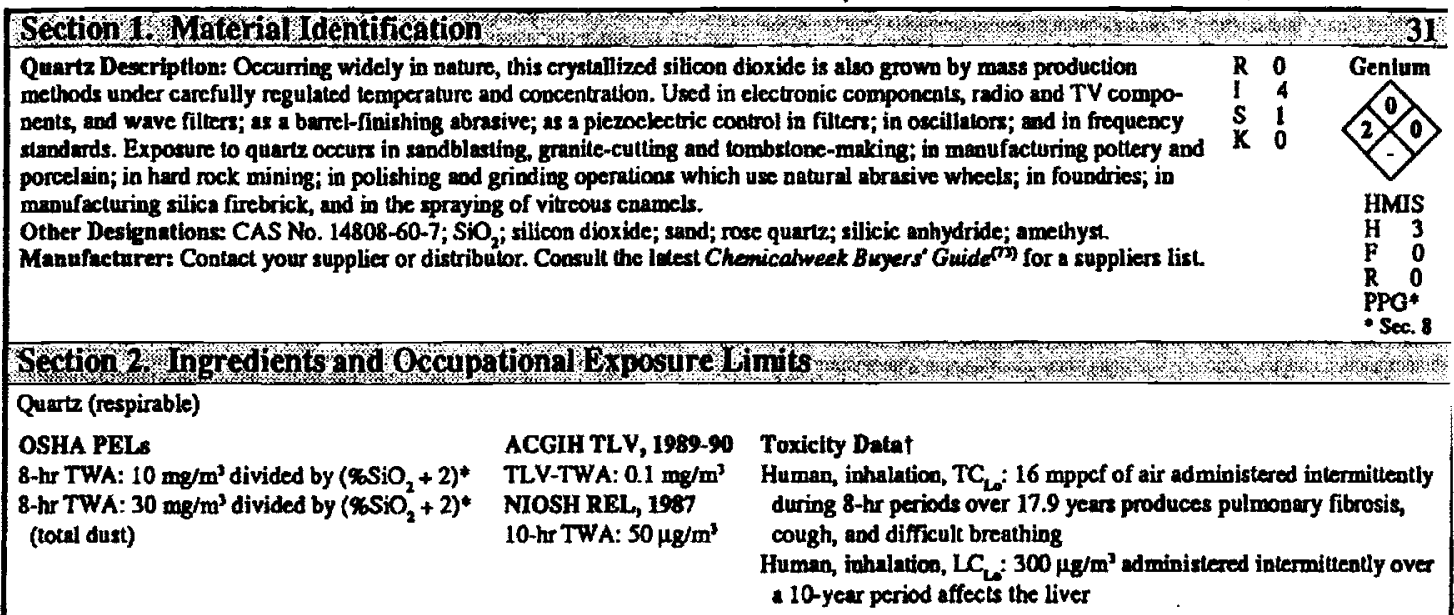

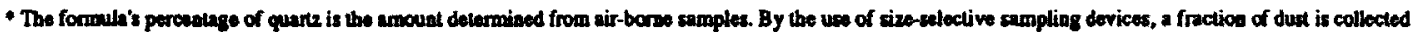

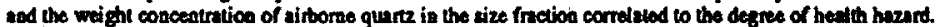

t Ses NIOSH, RTECS VV7330000\%, for additional dats on tumorigetic and toxicity offects.

Y

Bolling Polnt: 4064 T/2230 $\mathrm{C} \quad$ Molecular Welght: $60.09 \mathrm{~g} / \mathrm{mol}$

Melting Polnt: $3110^{\circ} \mathrm{F} / 1710^{\circ} \mathrm{C} \quad$ Speelnc Gravity $\left(\mathrm{H}_{2} \mathrm{O}=1\right.$ at $\left.39^{\circ} \mathrm{F} / 4^{\circ} \mathrm{C}\right): 2.65$

Vapor Preseure: $10 \mathrm{~mm}$ at 3150 \% $/ 1732^{\circ} \mathrm{C} \quad$ Water Solubility: Insoluble

Mohs Hardness: 7

Appearance and Odor: If quartz is pure, it is a white powder or coloriess crystals. No odor.

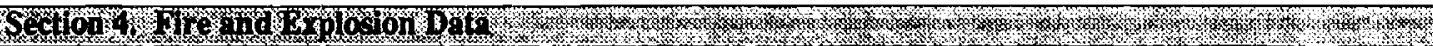
\begin{tabular}{|l|l|l|l|l|}
\hline Fiash Point: None reported & Autoignition Temperature: None reported & LEL: None reported & UEL: None reported
\end{tabular}

Extinguinhing Media: Since this material is nopcombustible, use extingtishing media spropriate to the surrounding fire.

Special Fire-fighting Procedures: Since fire may produce toxic fumes, wear a self-contained breathing apparatus (SCBA) with a full facepiece

operated in the pressure-demand or positive-pressure mode. Be aware of nooff from fire control methods. Do pot release to sewers or walerways.

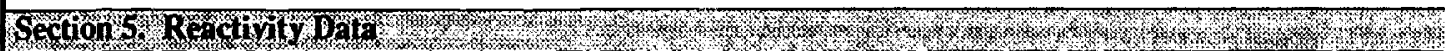
Stabilty/Polymerization: Quertz is stable at room lemperature in closed containers under normal storage and haodling conditions. Hazardous polymerization canook occur.

Chemical Incompatlbilties: Quartz dissolves readily in hydrofluoric acid, forming silicon telrafluoride, a corrosive gas. It reacis violently with powerful oxidizers such us chlorine trifluoride (ClF), manganese trifluoride $(\mathrm{MoF}$ ), oxygen diffuoride (OF, ), vinylacetate, and certain other fluorine-containing compounds. It is attacked by strong alkalis. Upon heating at high temperatures, quartz combines chemically with many melallic oxides.

Hezardous Products of Decomposition: When exposed to high temperalures, quartz (amorphous silica) can change crystal structure to form tridymile (above $1588^{\circ} \mathrm{F} / 870^{\circ} \mathrm{C}$ ) or cristobalite (above $2678^{\circ} \mathrm{F} / 1470^{\circ} \mathrm{C}$ ), which have greater health hazards than quartz.

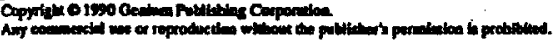


No. 11 Quanz $4 / 90$

Section 6. Health Hazard Data

Carcinogenicity: Although neither the NTP nor OSHA lists quartz as a carcinogen, the IARC slates that there is "sufficient evidence for the carcinogenicily of crystalline silica to experimental animals" and "limited evidence" with respect 10 humms."

Summary of Risks: Prolonged exposure to respirable crystalline quartz may causc a delayed chronic hung injury (silicosis). Simple silicosis occurs affer 20+ years exposure, acceleraled silicosis after 5 to 15 years, and acule gilicosis occurs after 1 to 3 years. Acute silicosis may occur among sandblesters and tunnel workers, who are exposed to heavy concentrations of respirable crystalline quarzz. Slificosis symptoms include the formalion of nodules of scar tissue in the lunes. This chronic scarring leads $t_{0}$ a progressive massive fibrosis, of ten actompanied by increased susceptibitity to pulmonary tuberculosis and other respiratory infections. Progressive massive fibrosis may be accompanied by right heart enlargement, heart failure, and pulmowary failure. Continued exposure to quantities of frec-silica-containing dust advancing age, and smoking increase the discase's progression. If uberculosis does nol prove fatal, eventual cardiac failure or destruction of lung tissuc with anoxemia will. Medlcal Conditions Aggravated by Lone-Term Exposure: A disabling. progressive, and pometimes falal pulmonary fibrosis that often aggravates other pulmonary conditions and respiratory infections may resull from long-term exposure.

Target Organs: Respiratory systcm, skio.

Primary Entry Routes: Inhalation.

Acule ETrects: Acule silicosis is manifested by dyspnea, fever, cough, and weight loss. In cases of exposures to very high conceatrations in short periods of time, severe respiratory symptoms may lead to death. Exposure to both crystalline and amorphous quartz dust has a drying effect on the skin and mucous membrapes.

Chronic Erfects: The chronic symploms include cough, dyspnea, wheezing, increased susceptibility to tuberculosis, decreased chest expansion, and repealed nonspecific chest illoesses. Chronic exposure may also cause fissures, thickening, and general breakdown of the sidn. Pulmoosty function impairment may be progressive with pulmonary infections and cardiac decompensation. As the disease progresses, shorloess of breath worseus, the cough more productive, extreme dyspaea and cyanosis, marked fatigue, loss of appetite, pleuritic pain, and total incapacity to work. FIRST AID

Eyes: Flush immediately, including under the cyelids, gently but thoroughly with flooding amounts of runaing water for at least 15 min.

Skin: Quickby remove contaminated clothing. After rinsing affected stin with hooding amounts of water, wash it with soap and water.

Inhalntion: Remove exposed person to fresh air and support breathing as needed.

Ingestion: Never give anything by mouth to an unconscious or convulsing person. If ingested, have a conscious person drink I to 2 glasses of water, then induce repeated vomiling until womit is clear.

After first aid, get appropriate in-plent, paramedic, or community medleal support.

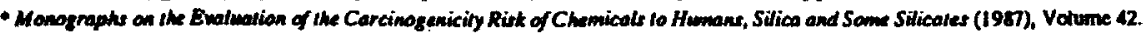

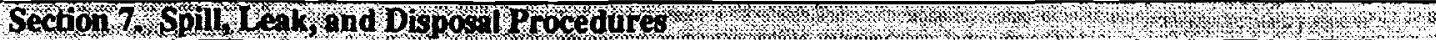

Spillheak: Notify safety personnel of lerge spills. Provide adequate ventiletion. Clemup personncl need protection ageinst eye contact and dust inhalation. Use dustess systems (vacuum or wet sweeping) for cleanup so that airborne dust does not exceed the PEL. Do not dry sweep. Carefully clean up spills without geaerating dust clouds and place waste into closeble containers. Follow applicable OSHA regulations (29 CFR 1910.120).

Disposal: Contuct your supplier or a liceased contractor for detailed recommeodations. Follow applicable Federal, state, and local regulations. EPA Desiguntions

RCRA Harardous Weste (40 CFR 261.33): Not listed

CERCL A Hazardous Substance (40 CFR 302.4): Not listed

SARA Extremely Hezardous Substance ( 40 CFR 355): Not listed

SARA Toxic Chemical ( 40 CFR 372.65): Not listed

OSHA Dertengtions

Listed as an Air Contaminent (29 CFR 1910.1000, Table Z-3)

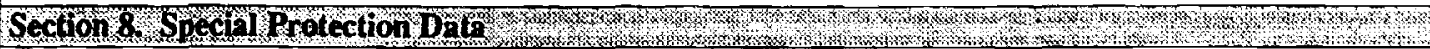

Gogeles: Wear protective eyeglasses or chemicel safety goentes, per OSHA eye- ad face-protection regulations (29 CFR 1910.133).

Reopirator: Follow OSHA respirator reguilations (29 CFR 1910. 134) and, if pecessury, wear a NHOSH-pproved respirator. Any dust respintor is efficient for a particulate concentration of $5 X$ PEL or less. Any dust respirator (exeept single-ux) is efficient for 10X PEL or less. A highefficiency particulate filter respirator with a full facopiece is necessary for $50 X \mathrm{PEL}$ or less. A powered air-purifying respirator with a high efficiency particulate filter is decessary for $500 X \mathrm{PEL}$ or less. For emergency or nonroutine operations (cleaning spills, reaclor vessels, or storage tanks) or if the purticulate concentration is greater than S00X PEL weer an SCBA.

Warning: Air-purifying respirators do not prolect worten in axyzeo-deficient atmospheres.

Other: Wear imparvious gloves, boots, aprons, and geundels to prevent protonged or repeated skin contact.

Ventilation: Provide ganeral and local explosion-proof ventilation systems to maintain aurborne concentrations below the OSHA PELs, ACGIH TLV, and NIOSH REL Local exhaust ventilation is preferred since it prevents contaminant dispersion inlo the work area by controlling it at its source.(105)

Safety Stations: Make available in the work urea emergency eyewesh stations, safety/quick-dreach showers, and washing facilities.

Contaminated Equlpment: Never wear contact lenses in the work area: soft lenses may absorb, and all lenses concentrale, irritants. Remove this material from your shoes and equipment. Launder contaminaled clothing before wearing.

Comments: Never eat, drink, or smoke in work areas. Practice good personal hygiede after using this maltrial, especially before eating, drinting, smoking, using the bilet, or applying cosmetics.

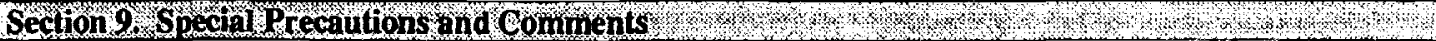
Storage Requirements: Store respirable crystalline quartz in closed containers in a dry, well-ventilated area.

Englneering Controls: Avoid dust inhaiation and contact with eyes. Adequate veotilation is esseotial. Minimize dust in the work area ind maintain air concentralions below the TLV (Sec. 2). Practice good housekeeping. Do nol allow dust to collect on walls, floors, sills, ledges, machinery, or equipment. Fit test respirators in wcoordance with OSHA regulations. Provide preplacement and annual physical exams for exposed workers, with emphasis on respiratory and cardiovaseular systems. Prevent exposing those individuals with pulmonary disease.

Transportation Data (49 CFR 172.101, .102): Not listed

MSDS Collection References: 1, 2-12, 19, 24-27, 31, 34, 37, 38, 71, 73, 87-89, 100, 103, 123, 126, 127

Prepared by: MJ Allison, BS; Industrial Hygicne Review: DJ Wilson, CIH; Medical Review: MJ Hardies, MD

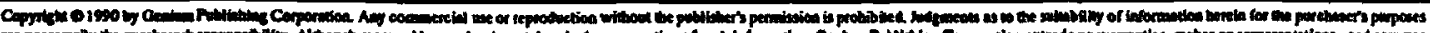

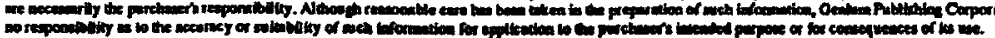




\section{DRAFT}

\section{Work PLAN FOR NUMERICAL MOdELING OF ZERO-VALENT IRON (ZVI) INJECTION IN RINGOLD AQUIFER FOR POTENTIAL USE AT HANFORD'S IN SITU REDOX MANIPULATION BARRIER}

Prepared by:

MSE Technology Applications, Inc.

200 Technology Way

P.O. Box 4078

Butte, Montana 59701

Revision 00

March 2008 
DOE/RL-2009-35, REV.0

This Page Intentionally Left Blank 


\section{TABLE OF CONTENTS}

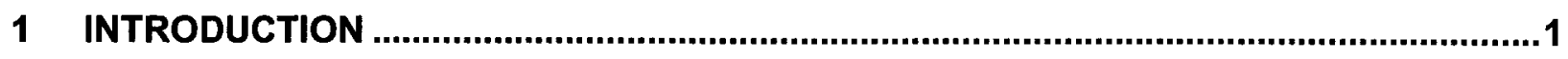

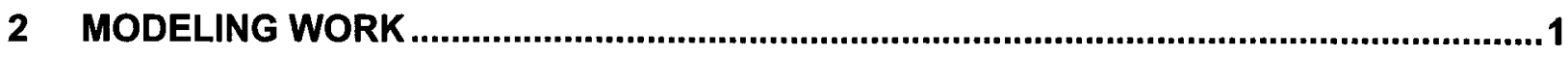

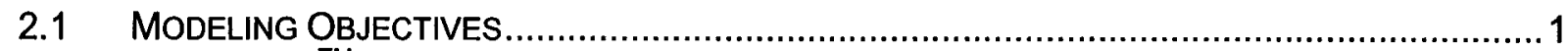

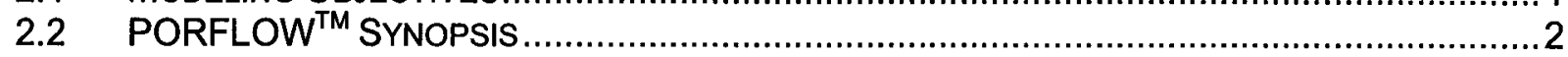

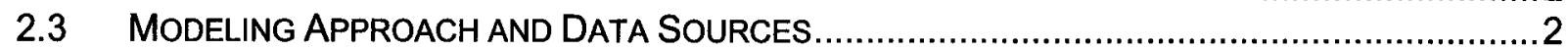

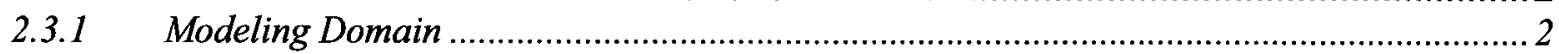

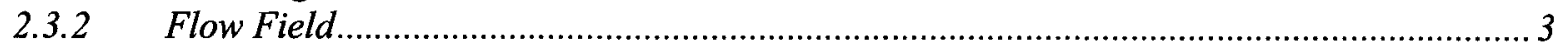

2.3.3 ZVI Transport

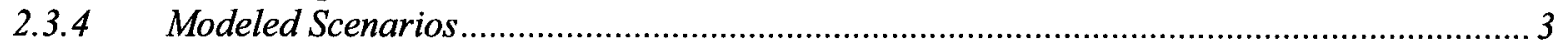

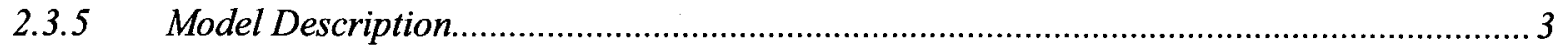

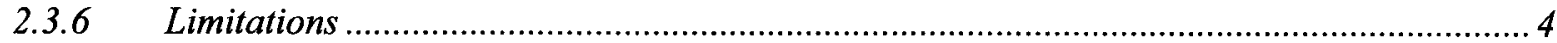

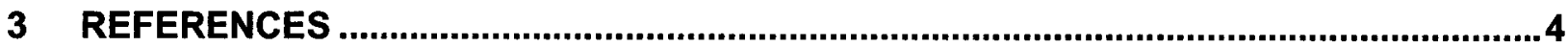




\section{LIST OF ACRONYMS}

2D

$3 \mathrm{D}$

CPU

$\mathrm{Cr}^{3+}$

$\mathrm{Cr}^{6+}$

DOE

GUI

ISRM

MSE

MZVI

PNNL

RFP

RNIP

TAP

ZVI two-dimensional

three-dimensional

central processing unit

trivalent chrome

hexavalent chrome

U. S. Department of Energy

Graphical User Interface

In situ Redox Manipulation (ISRM)

MSE Technology Applications, Inc.

micron-sized zero-valent iron

Pacific Northwest National Labs

request for proposal

Reactive Nano Scale Iron Particles produced by Toda Corporation

Technical Assistance Panel

Zero-valent iron 


\section{INTRODUCTION}

MSE Technology Applications, Inc., (MSE) under subcontract to Fluor Hanford (Fluor Hanford Contract \#30994) has been tasked with completing laboratory testing, numerical modeling, and associated fieldwork related to injection of micron size zero-valent iron (MZVI) into the subsurface at the 100-D Area at the U.S. Department of Energy (DOE) Hanford Site, Washington State. The purpose of this work is to demonstrate the feasibility of using MZVI to repair portions of the In situ Redox Manipulation (ISRM) barrier located in the 100-D Area of the Hanford Site.

The ISRM barrier was installed to remediate a chromium groundwater plume in Hanford's 100-D Area by reduction of the $\mathrm{Cr}^{6+}$ in the groundwater to $\mathrm{Cr}^{3+}$ through the injection of sodium dithionite into the aquifer, thus creating a chemically reduced environment (DOE/RL, 2005). Localized signs of failure in the barrier (defined by the presence of $\mathrm{Cr}^{6+}$ in the treated wells) were discovered in some wells 18 months after they were treated. The most probable cause of the premature barrier breakdown was determined to be heterogeneities in the aquifer where laterally discontinuous units with high permeability and lower inherent reductive capacity (because of lower iron content) were reoxidized faster than the less permeable layers. A Technical Assistance Panel (TAP) recommended that an alternative technology (injection of $\mathrm{MZVl} /$ polymer) be tested and possibly deployed to mend the barrier, and to eliminate the need of periodically re-injecting the ISRM wells with sodium dithionite.

The TAP recommended that the reduction potential of co-contaminants and generation of byproducts must be considered and monitored. The TAP recommended considering all potential geochemical impacts to the aquifer system from the MZVI/polymer injection, specifically the potential for the MZVI to convert nitrate to ammonia and the formation of carbonate due to the generation of high $\mathrm{pH}$ conditions in the groundwater. Following the recommendations from the TAP, Fluor Hanford issued a request for proposal (RFP) to provide the laboratory testing, numerical modeling, and associated fieldwork for the MZVI/polymer injection. MSE was awarded the work for the investigation of MZVI as a remedy for repairing the ISRM. In May 2007 Fluor Hanford modified the scope of work to stop laboratory testing on the preferred micron size material and to investigate other zero valent iron (ZVI) materials, which should be considered as candidates for injection into the ISRM barrier.

This document addresses the requirements of Task 10e, Numerical Modeling of ZVI Injection in the Ringold Aquifer. Injected ZVI-fluid will comprise ZVI suspended in a carrier fluid, which will be water augmented with dispersant and polymer. The result of the modeling will be used to determine whether the injection of ZVI-fluid is feasible and if so what would be the recommended discharge rates and duration of injection for the field injection operation. Selection of ZVI, its reactivity and injectibility were addressed in earlier documents produced for the project (MSE, 2008 a and MSE, 2008 b).

\section{MODELING WORK}

\subsection{Modeling Objectives}

The objective of the modeling efforts is to use a numerical model to predict the behavior of ZVI-fluid injected into a high conductivity strata in the ISRM barrier. The goals of this task will be to approximate the maximum distance iron can be injected from a single point, and the concentration of iron 7 meters from injection (assuming it can be transported to that distance). A flow and solute transport model PORFLOW ${ }^{\mathrm{MM}}$ Version 5 will be used to accomplish these objectives. 


\subsection{PORFLOW ${ }^{\mathrm{TM}}$ Synopsis}

PORFLOW ${ }^{\mathrm{TM}}$ is a general purpose software developed by Analytic \& Computational Research, Inc. (ACRI 1999) for simulation of transient or steady-state multiphase fluid flow, heat, salinity, and mass transport in multiphase, variably saturated, porous or fractured media with dynamic phase change. The geometry of the modeled domain may be structured or unstructured, two-dimensional (2D), threedimensional (3D), Cartesian, or cylindrical. The media modeled may be heterogeneous and anisotropic. Injection or pumping sources may be present, and chemical reactions or radioactive decay may take place. From the numerical point of view, PORFLOW ${ }^{T M}$ is a hybrid of a finite volume with a finite element mesh code written in FORTRAN.

PORFLOW ${ }^{\mathrm{TM}}$ has a Graphical User Interface (GUI), a preprocessor for entering geometry, boundary conditions, and flow, transport, and dynamic phase change relationships. A post-processor, AcrPLOT, generates charts, flow vectors, contours, grids, 3D surface plots, and $X-Y$ cross-sections at any direction.

\subsection{Modeling Approach and Data Sources}

The modeling effort using PORFLOW ${ }^{\mathrm{TM}}$ will focus on simulation of the groundwater flow field and emplacement of $Z \mathrm{VI}$ into the aquifer (saturated medium) by injection of $Z \mathrm{VI}$ fluid through injection well 199-D4-37.

Currently there is no modeling procedure that could be followed or software that has been identified to determine transport of ZVI in an aquifer (Lowry and Tratnyek, 2008). Therefore, the modeling approach described in this plan is experimental in its nature, but it is sound with respect to the input data that were developed through laboratory testing (MSE-TA 2008 b).

\subsubsection{Modeling Domain}

The model will encompass a "block" of the unconfined aquifer around the injection well. This domain will be discretized in the vertical direction in the manner that reflects geological and hydrogeologic stratification as recorded in the borehole log of the injection well, and the results of subsequent investigations reported by Waldrop and Waldrop, 2004 with modifications provided by PNNL, 2007. Other available reports, documents and publication will be examined to assign appropriate values of hydraulic parameters for each stratum including an anisotropy ratio for horizontal to vertical hydraulic conductivity values. In case of a lack of site-specific information, well-documented values for similar sites will be used. All strata will be horizontal and continuous throughout the domain, i.e. they will have a uniform thickness within the horizontal extent of the modeling domain.

The horizontal extent of the domain will be set most likely $100 \mathrm{ft}(30.5 \mathrm{~m})$ away from the injection well so that the domain boundaries do not interfere with the cone of "impression" created by injection activities. Discretization of the model domain in the horizontal plane will be dictated by hydraulic parameters of strata and numerical requirements of PORFLOW' ${ }^{\mathrm{TM}}$ to converge to the defensible solution using appropriate tolerance criteria. 


\subsubsection{Flow Field}

Modeling work will involve simulation of flow of ZVI fluid emplaced in groundwater through an injection well. The ZVI-fluid will contain ZVI either in the form of reactive nano-scale iron particles (RNIP) manufactured by Toda Corporation or in the form of Polymetallix produced by Polyflon Company - a Crane Corporation. The selection of ZVI-fluid for the modeling and then field injection will be made based on the laboratory study as described in MSE 2008 a and MSE $2008 \mathrm{~b}$. Both ZVI fluids are water based with additives, olefin maleic copolymer and sodium hexametaphosphate for RNIP and Polymetallix, respectively. Because the concentration of either additive in the injection fluid is approximately 0.002 , or $0.2 \%$, it is reasonable to assume that the physical properties of the fluid (density and viscosity) will be those for pure water. Presence, and gradual separation (deposition) of ZVI particles that are originally suspended in the fluid will be addressed through transport mechanisms as described in section 2.3.3.

To minimize undesired spreading of the ZVI fluid in the aquifer due to the regional groundwater flow system, the actual field injection activities are scheduled for the month of July when, due to high water stages in the Columbia River, the groundwater table is relatively flat. This timing of the field implementation allows modeling the injection processes set in a flow field that is affected only by the injection itself. Such modeling is most efficiently conducted using a radially symmetric flow set within a cylindrical coordinates system. Modeling using cylindrical coordinates provides a 3-dimensional (3D) flow field (the feature especially important for simulation of injection processes through a well) using significantly less central processing unit (CPU) time. Consequently, within the same period, more alternative injection scenarios can be simulated for a model that uses cylindrical coordinates than for those models that use 3D Cartesian coordinate systems.

\subsubsection{ZVI Transport}

PORFLOW ${ }^{\top M}$ will calculate the concentration of $Z \mathrm{VI}$ in the injection fluid, and thus the concentration of iron that falls out of the fluid, using a pseudo-solute-transport approach. This is because nano-size particles of iron behave in the fluid more like solids than dissolved constituents. Nevertheless, a pseudo-isotherm approach will be used to quantify the relationship of the rate that iron particles fall out of the fluid. The isotherm equation, as defined through laboratory study (MSE-TA, $2008 \mathrm{~b}$ ), will include the relationship between ZVI deposition as a function of distance, time of injection, and ZVIfluid velocity. This functional relationship will be incorporated in the PORFLOW ${ }^{\mathrm{TM}}$ simulation algorithm utilizing its unique ability to accommodate user define functions.

\subsubsection{Modeled Scenarios}

The model will be run for several injection scenarios. The number of scenarios will greatly depend on the complexity of the user-defined function used to simulate deposition of the ZVI in the aquifer. The more complex the function, the greater the computational time required to converge to the acceptable solution. The overall plan is to model a single well injection setup over a range of injection rates and hydraulic parameters of the aquifer. The basic hydraulic parameters used for modeling will be those listed by Oostrom, et al. (2006) and Szecsody et al. (2005).

\subsubsection{Model Description}

Output options that will be used to present the modeling results include concentration iso-lines, flow lines (flow vectors), and time verses concentration $X-Y$ plots. 


\subsubsection{Limitations}

All models developed as described above will be quantitative, though conceptual in their nature. This is because there is no field data that could be used for calibration of these models. Nevertheless the model will be essential for setting injection parameters and selection of the equipment to be used. We are cognizant that it should be possible to calibrate the model after the injection is completed. However, these efforts are not included in the scope of work for this project. Due to the lack of calibration data, the "appropriateness" of the model will be based on the professional judgment of the modeler and the assistance of reasonable and competent reviewers.

\section{REFERENCES}

Lowry and Tratnyek, 2008. Conference call in January, 2008.

MSE-TA, 2008 a. Test Plan for Geochemical Testing of Zero-Valent Iron (ZVI) for Potential use at Hanford's Site Redox manipulation Barrier.

MSE-TA, 2008 b. Test Plan for Zero-valent Iron (ZVI) Distribution in Soil Injected with ZVI fluid.

PNNL, 2007. E-mail communication with Darrell Newcomer on the 2007 investigations using Electromagnetic Borehole Flowmeter on selected wells of 100-D Area In Situ Redox Manipulation (ISRM) Barrier Site Hanford Site, State of Washington.

Oostrom, M., T.W. Wietsma, M.A. Covert, V.R. Vermeul, 2006. Micron-Size Zero-Valent Iron Emplacement in Porous Media Using Polymer Additives: Column and Flow Cell Experiments Hydrology Days, 2006

Szecsody JE, VR Vermeul, JS Fruchter, MD Williams, BJ Devary, JL Philips, M Rockhold, and Y Liu. 2005. Effect of geochemical and physical heterogeneity on the Hanford 100D area in situ redox manipulation barrier longevity. PNNL-15449, Pacific Northwest National Laboratory, Richland, Washington.

Waldrop, W.R., J.K Waldrop, 2004. Electromagnetic Borehole Flowmeter Test of the Wells of 100-D Area In Situ Redox Manipulation (ISRM) Barrier Site Hanford Site, State of Washington. Quantum Engineering Corporation 
DOE/RL-2009-35, REV. 0

\section{Appendix C}

\section{Laboratory Test Results}


DOE/RL-2009-35, REV. 0

This page intentionally left blank. 


\section{Appendix C \\ Laboratory Test Results}

This appendix presents the results from laboratory testing performed for the modeling and field injection activities associated with the selection and subsequent injection of a ZVI product into the subsurface at the 100-D Area at the Hanford Site. 


\section{C1 Micron-Sized Zero-Valent Iron Testing}

\begin{tabular}{|c|c|c|c|c|c|c|c|c|c|}
\hline \multicolumn{10}{|c|}{ Data-Sponge Iron Powder Lab Parameters } \\
\hline & & \multicolumn{2}{|c|}{ Elapsed Time } & \multirow[b]{2}{*}{ Temp $\left({ }^{\circ} \mathrm{C}\right)$} & \multirow[b]{2}{*}{ SC (uS/cm) } & \multirow[b]{2}{*}{$\mathrm{DO}(\mathrm{mg} / \mathrm{L})$} & \multirow[b]{2}{*}{$\mathbf{p H}$} & \multirow[b]{2}{*}{$\mathrm{pH}(\mathrm{mV})$} & \multirow[b]{2}{*}{ ORP (mV) } \\
\hline Date & Time & Minutes & Hours & & & & & & \\
\hline \multicolumn{10}{|c|}{ Baseline for Surrogate GW } \\
\hline $04 / 27 / 07$ & $13: 15: 11$ & -168.43 & -2.81 & 19.00 & 632 & 7.96 & 6.66 & 15.5 & 91 \\
\hline $04 / 27 / 07$ & $13: 20: 11$ & -163.43 & -2.72 & 19.31 & 634 & 7.25 & 7.53 & -34.7 & 57 \\
\hline $04 / 27 / 07$ & $13: 25: 11$ & -158.43 & -2.64 & 19.61 & 636 & 7.32 & 7.70 & -44.6 & 49 \\
\hline $04 / 27 / 07$ & 13:30:11 & -153.43 & -2.56 & 19.91 & 637 & 7.29 & 7.76 & -48.6 & 44 \\
\hline $04 / 27 / 07$ & 13:35:11 & -148.43 & -2.47 & 20.18 & 638 & 7.26 & 7.79 & -50.2 & 42 \\
\hline $04 / 27 / 07$ & $13: 40: 11$ & -143.43 & -2.39 & 20.45 & 639 & 7.22 & 7.80 & -51.1 & 41 \\
\hline $04 / 27 / 07$ & $13: 45: 11$ & -138.43 & -2.31 & 20.69 & 639 & 7.18 & 7.81 & -51.7 & 41 \\
\hline $04 / 27 / 07$ & 13:50:11 & -133.43 & -2.22 & 20.92 & 639 & 7.14 & 7.83 & -52.5 & 40 \\
\hline $04 / 27 / 07$ & 13:55:11 & -128.43 & -2.14 & 21.14 & 639 & 7.10 & 7.83 & -52.6 & 40 \\
\hline \multicolumn{10}{|c|}{ Addition of MZVI } \\
\hline $04 / 27 / 07$ & $14: 00: 11$ & -123.43 & -2.06 & 21.34 & 639 & 7.06 & 7.83 & -52.6 & 40 \\
\hline $04 / 27 / 07$ & 14:05:11 & -118.43 & -1.97 & 21.53 & 639 & 7.02 & 7.83 & -52.5 & 40 \\
\hline $04 / 27 / 07$ & 14:10:11 & -113.43 & -1.89 & 21.71 & 639 & 6.98 & 7.83 & -52.6 & 40 \\
\hline $04 / 27 / 07$ & 14:15:11 & -108.43 & -1.81 & 21.89 & 639 & 6.94 & 7.83 & -52.8 & 40 \\
\hline $04 / 27 / 07$ & $14: 20: 11$ & -103.43 & -1.72 & 22.05 & 639 & 6.90 & 7.83 & -52.7 & 40 \\
\hline $04 / 27 / 07$ & 14:25:11 & -98.43 & -1.64 & 22.2 & 639 & 6.88 & 7.82 & -52.5 & 40 \\
\hline $04 / 27 / 07$ & 14:30:11 & -93.43 & -1.56 & 22.34 & 639 & 6.84 & 7.82 & -52.4 & 41 \\
\hline $04 / 27 / 07$ & $14: 35: 11$ & -88.43 & -1.47 & 22.48 & 639 & 6.81 & 7.82 & -52.3 & 41 \\
\hline $04 / 27 / 07$ & $14: 40: 11$ & -83.43 & -1.39 & 22.61 & 640 & 6.78 & 7.82 & -52.3 & 41 \\
\hline $04 / 27 / 07$ & $14: 45: 11$ & -78.43 & -1.31 & 22.73 & 640 & 6.75 & 7.82 & -52.3 & 41 \\
\hline $04 / 27 / 07$ & 14:50:11 & -73.43 & -1.22 & 22.85 & 640 & 6.72 & 7.82 & -52.3 & 42 \\
\hline $04 / 27 / 07$ & 14:55:11 & -68.43 & -1.14 & 22.96 & 640 & 6.69 & 7.82 & -52.4 & 42 \\
\hline $04 / 27 / 07$ & 15:00:11 & -63.43 & -1.06 & 23.06 & 640 & 6.67 & 7.82 & -52.4 & 42 \\
\hline $04 / 27 / 07$ & $15: 05: 11$ & -58.43 & -0.97 & 23.16 & 640 & 6.64 & 7.82 & -52.6 & 42 \\
\hline $04 / 27 / 07$ & 15:10:11 & -53.43 & -0.89 & 23.25 & 640 & 6.62 & 7.82 & -52.8 & 42 \\
\hline $04 / 27 / 07$ & 15:15:11 & -48.43 & -0.81 & 23.34 & 640 & 6.60 & 7.83 & -53.1 & 42 \\
\hline $04 / 27 / 07$ & $15: 20: 11$ & -43.43 & -0.72 & 23.42 & 640 & 6.60 & 7.83 & -53.2 & 42 \\
\hline $04 / 27 / 07$ & $15: 25: 11$ & -38.43 & -0.64 & 23.5 & 640 & 6.57 & 7.84 & -53.6 & 42 \\
\hline $04 / 27 / 07$ & 15:30:11 & -33.43 & -0.56 & 23.57 & 640 & 6.55 & 7.84 & -53.7 & 42 \\
\hline $04 / 27 / 07$ & $15: 35: 11$ & -28.43 & -0.47 & 23.64 & 640 & 6.54 & 7.84 & -54.0 & 42 \\
\hline $04 / 27 / 07$ & $15: 40: 11$ & -23.43 & -0.39 & 23.7 & 640 & 6.54 & 7.84 & -54.0 & 43 \\
\hline $04 / 27 / 07$ & $15: 45: 11$ & -18.43 & -0.31 & 23.76 & 640 & 6.53 & 7.84 & -54.0 & 42 \\
\hline $04 / 27 / 07$ & $15: 50: 11$ & -13.43 & -0.22 & 23.82 & 641 & 6.51 & 7.84 & -53.8 & 43 \\
\hline $04 / 27 / 07$ & $15: 55: 11$ & -8.43 & -0.14 & 23.88 & 641 & 6.52 & 7.84 & -53.8 & 43 \\
\hline $04 / 27 / 07$ & $16: 00: 11$ & -3.43 & -0.06 & 23.93 & 641 & 6.55 & 7.85 & -54.4 & 29 \\
\hline $04 / 27 / 07$ & 16:03:37 & 0.00 & 0.00 & 23.95 & 641 & 6.50 & 7.49 & -32.8 & 178 \\
\hline $04 / 27 / 07$ & $16: 13: 37$ & 10.00 & 0.17 & 24.1 & 643 & 6.10 & 7.83 & -53.0 & 87 \\
\hline $04 / 27 / 07$ & $16: 23: 37$ & 20.00 & 0.33 & 24.22 & 644 & 6.05 & 7.83 & -53.1 & 75 \\
\hline $04 / 27 / 07$ & $16: 33: 37$ & 30.00 & 0.50 & 24.33 & 645 & 6.01 & 7.84 & -53.9 & 66 \\
\hline $04 / 27 / 07$ & $16: 43: 37$ & 40.00 & 0.67 & 24.42 & 645 & 5.98 & 7.87 & -55.6 & 62 \\
\hline $04 / 27 / 07$ & $16: 53: 37$ & 50.00 & 0.83 & 24.5 & 644 & 5.91 & 7.89 & -56.7 & 58 \\
\hline $04 / 27 / 07$ & $17: 03: 37$ & 60.00 & 1.00 & 24.56 & 644 & 5.85 & 7.89 & -56.9 & 56 \\
\hline $04 / 27 / 07$ & $17: 13: 37$ & 70.00 & 1.17 & 24.62 & 645 & 5.77 & 7.90 & -57.7 & 54 \\
\hline $04 / 27 / 07$ & $17: 23: 37$ & 80.00 & 1.33 & 24.67 & 645 & 5.69 & 7.91 & -58.3 & 52 \\
\hline $04 / 27 / 07$ & $17: 33: 37$ & 90.00 & 1.50 & 24.72 & 645 & 5.61 & 7.92 & -58.7 & 50 \\
\hline $04 / 27 / 07$ & $17: 43: 37$ & 100.00 & 1.67 & 24.76 & 646 & 5.77 & 7.93 & -59.2 & 49 \\
\hline $04 / 27 / 07$ & $17: 53: 37$ & 110.00 & 1.83 & 24.8 & 646 & 5.62 & 7.94 & -59.9 & 48 \\
\hline $04 / 27 / 07$ & 18:03:37 & 120.00 & 2.00 & 24.83 & 646 & 5.62 & 7.95 & -60.3 & 47 \\
\hline $04 / 27 / 07$ & $18: 13: 37$ & 130.00 & 2.17 & 24.86 & 646 & 5.59 & 7.95 & -60.5 & 46 \\
\hline $04 / 27 / 07$ & $18: 23: 37$ & 140.00 & 2.33 & 24.89 & 646 & 5.53 & 7.96 & -60.9 & 45 \\
\hline $04 / 27 / 07$ & 18:33:37 & 150.00 & 2.50 & 24.92 & 646 & 5.49 & 7.97 & -61.5 & 45 \\
\hline $04 / 27 / 07$ & $18: 43: 37$ & 160.00 & 2.67 & 24.94 & 646 & 5.42 & 7.97 & -61.9 & 44 \\
\hline $04 / 27 / 07$ & $18: 53: 37$ & 170.00 & 2.83 & 24.97 & 646 & 5.40 & 7.98 & -62.5 & 44 \\
\hline $04 / 27 / 07$ & $19: 03: 37$ & 180.00 & 3.00 & 24.99 & 646 & 5.35 & 7.99 & -62.9 & 43 \\
\hline $04 / 27 / 07$ & 19:13:37 & 190.00 & 3.17 & 25.02 & 646 & 5.40 & 8.00 & -63.4 & 42 \\
\hline $04 / 27 / 07$ & 19:23:37 & 200.00 & 3.33 & 25.06 & 646 & 5.31 & 8.01 & -64.1 & 41 \\
\hline $04 / 27 / 07$ & 19:33:37 & 210.00 & 3.50 & 25.08 & 646 & 5.25 & 8.02 & -64.7 & 40 \\
\hline $04 / 27 / 07$ & $19: 43: 37$ & 220.00 & 3.67 & 25.1 & 647 & 5.22 & 8.03 & -65.4 & 39 \\
\hline $04 / 27 / 07$ & 19:53:37 & 230.00 & 3.83 & 25.12 & 647 & 5.13 & 8.04 & -65.7 & 39 \\
\hline
\end{tabular}




\begin{tabular}{|c|c|c|c|c|c|c|c|c|c|}
\hline & & Elapsed & Time & & & & & & \\
\hline Date & Time & Minutes & Hours & Temp $\left({ }^{\circ} \mathrm{C}\right)$ & $\mathrm{SC}$ (uS/cm) & $\mathrm{DO}(\mathrm{mg} / \mathrm{L})$ & pH & $\mathrm{pH}(\mathrm{mV})$ & ORP \\
\hline $04 / 27 / 07$ & $20: 03: 37$ & 240.00 & 4.00 & 25.13 & 647 & 5.09 & 8.04 & -66.1 & 38 \\
\hline $04 / 27 / 07$ & $20: 13: 37$ & 250.00 & 4.17 & 25.14 & 647 & 5.05 & 8.05 & -66.6 & 38 \\
\hline $04 / 27 / 07$ & $20: 23: 37$ & 260.00 & 4.33 & 25.15 & 647 & 5.03 & 8.06 & -66.9 & 37 \\
\hline $04 / 27 / 07$ & $20: 33: 37$ & 270.00 & 4.50 & 25.16 & 647 & 5.00 & 8.06 & -67.3 & 37 \\
\hline $04 / 27 / 07$ & $20: 43: 37$ & 280.00 & 4.67 & 25.16 & 647 & 4.95 & 8.07 & -67.7 & 36 \\
\hline $04 / 27 / 07$ & $20: 53: 37$ & 290.00 & 4.83 & 25.17 & 647 & 4.93 & 8.08 & -68.2 & 36 \\
\hline $04 / 27 / 07$ & $21: 03: 37$ & 300.00 & 5.00 & 25.17 & 647 & 4.87 & 8.09 & -68.8 & 35 \\
\hline $04 / 27 / 07$ & $21: 13: 37$ & 310.00 & 5.17 & 25.17 & 647 & 4.83 & 8.10 & -69.3 & 35 \\
\hline $04 / 27 / 07$ & $21: 23: 37$ & 320.00 & 5.33 & 25.18 & 647 & 4.79 & 8.11 & -69.9 & 34 \\
\hline $04 / 27 / 07$ & $21: 33: 37$ & 330.00 & 5.50 & 25.18 & 647 & 4.76 & 8.12 & -70.4 & 33 \\
\hline $04 / 27 / 07$ & $21: 43: 37$ & 340.00 & 5.67 & 25.18 & 647 & 4.72 & 8.12 & -70.9 & 33 \\
\hline $04 / 27 / 07$ & $21: 53: 37$ & 350.00 & 5.83 & 25.18 & 647 & 4.70 & 8.13 & -71.3 & 32 \\
\hline $04 / 27 / 07$ & $22: 03: 37$ & 360.00 & 6.00 & 25.19 & 647 & 4.66 & 8.14 & -71.8 & 31 \\
\hline $04 / 27 / 07$ & $22: 13: 37$ & 370.00 & 6.17 & 25.19 & 647 & 4.64 & 8.15 & -72.4 & 30 \\
\hline $04 / 27 / 07$ & $22: 23: 37$ & 380.00 & 6.33 & 25.19 & 647 & 4.60 & 8.16 & -73.1 & 29 \\
\hline $04 / 27 / 07$ & $22: 33: 37$ & 390.00 & 6.50 & 25.19 & 647 & 4.58 & 8.18 & -74.0 & 28 \\
\hline $04 / 27 / 07$ & $22: 43: 37$ & 400.00 & 6.67 & 25.19 & 647 & 4.58 & 8.19 & -74.7 & 27 \\
\hline $04 / 27 / 07$ & $22: 53: 37$ & 410.00 & 6.83 & 25.19 & 648 & 4.57 & 8.20 & -75.3 & 26 \\
\hline $04 / 27 / 07$ & $23: 03: 37$ & 420.00 & 7.00 & 25.18 & 648 & 4.56 & 8.21 & -75.9 & 25 \\
\hline $04 / 27 / 07$ & $23: 13: 37$ & 430.00 & 7.17 & 25.18 & 648 & 4.54 & 8.22 & -76.6 & 24 \\
\hline $04 / 27 / 07$ & $23: 23: 37$ & 440.00 & 7.33 & 25.18 & 648 & 4.51 & 8.23 & -77.1 & 23 \\
\hline $04 / 27 / 07$ & $23: 33: 37$ & 450.00 & 7.50 & 25.18 & 648 & 4.48 & 8.24 & -77.7 & 22 \\
\hline $04 / 27 / 07$ & $23: 43: 37$ & 460.00 & 7.67 & 25.17 & 648 & 4.46 & 8.25 & -78.5 & 21 \\
\hline $04 / 27 / 07$ & $23: 53: 37$ & 470.00 & 7.83 & 25.17 & 648 & 4.44 & 8.27 & -79.3 & 20 \\
\hline $04 / 28 / 07$ & $0: 03: 37$ & 480.00 & 8.00 & 25.16 & 648 & 4.40 & 8.28 & -80.0 & 19 \\
\hline $04 / 28 / 07$ & $0: 13: 37$ & 490.00 & 8.17 & 25.16 & 648 & 4.37 & 8.29 & -80.5 & 18 \\
\hline $04 / 28 / 07$ & $0: 23: 37$ & 500.00 & 8.33 & 25.15 & 648 & 4.35 & 8.29 & -80.9 & 17 \\
\hline $04 / 28 / 07$ & $0: 33: 37$ & 510.00 & 8.50 & 25.15 & 648 & 4.31 & 8.30 & -81.4 & 16 \\
\hline $04 / 28 / 07$ & $0: 43: 37$ & 520.00 & 8.67 & 25.14 & 648 & 4.29 & 8.31 & -81.7 & 15 \\
\hline $04 / 28 / 07$ & $0: 53: 37$ & 530.00 & 8.83 & 25.14 & 648 & 4.28 & 8.32 & -82.2 & 15 \\
\hline $04 / 28 / 07$ & 1:03:37 & 540.00 & 9.00 & 25.13 & 648 & 4.25 & 8.32 & -82.3 & 14 \\
\hline $04 / 28 / 07$ & $1: 13: 37$ & 550.00 & 9.17 & 25.12 & 648 & 4.23 & 8.32 & -82.7 & 14 \\
\hline $04 / 28 / 07$ & $1: 23: 37$ & 560.00 & 9.33 & 25.12 & 648 & 4.19 & 8.33 & -83.0 & 13 \\
\hline $04 / 28 / 07$ & $1: 33: 37$ & 570.00 & 9.50 & 25.11 & 648 & 4.16 & 8.33 & -83.2 & 13 \\
\hline $04 / 28 / 07$ & $1: 43: 37$ & 580.00 & 9.67 & 25.1 & 648 & 4.11 & 8.34 & -83.5 & 12 \\
\hline $04 / 28 / 07$ & 1:53:37 & 590.00 & 9.83 & 25.09 & 648 & 4.11 & 8.34 & -83.8 & 12 \\
\hline $04 / 28 / 07$ & 2:03:37 & 600.00 & 10.00 & 25.08 & 648 & 4.07 & 8.35 & -84.0 & 12 \\
\hline $04 / 28 / 07$ & 2:13:37 & 610.00 & 10.17 & 25.07 & 648 & 4.07 & 8.35 & -84.5 & 12 \\
\hline $04 / 28 / 07$ & $2: 23: 37$ & 620.00 & 10.33 & 25.06 & 648 & 4.05 & 8.36 & -84.8 & 12 \\
\hline $04 / 28 / 07$ & $2: 33: 37$ & 630.00 & 10.50 & 25.04 & 648 & 4.02 & 8.36 & -85.0 & 11 \\
\hline $04 / 28 / 07$ & $2: 43: 37$ & 640.00 & 10.67 & 25.03 & 649 & 4.01 & 8.37 & -85.3 & 10 \\
\hline $04 / 28 / 07$ & $2: 53: 37$ & 650.00 & 10.83 & 25.01 & 649 & 4.00 & 8.38 & -86.1 & 9 \\
\hline $04 / 28 / 07$ & 3:03:37 & 660.00 & 11.00 & 25 & 649 & 3.96 & 8.39 & -86.6 & 9 \\
\hline $04 / 28 / 07$ & $3: 13: 37$ & 670.00 & 11.17 & 24.98 & 649 & 3.90 & 8.40 & -86.9 & 8 \\
\hline $04 / 28 / 07$ & $3: 23: 37$ & 680.00 & 11.33 & 24.97 & 649 & 3.84 & 8.40 & -87.2 & 8 \\
\hline $04 / 28 / 07$ & $3: 33: 37$ & 690.00 & 11.50 & 24.95 & 648 & 3.81 & 8.40 & -87.4 & 8 \\
\hline $04 / 28 / 07$ & $3: 43: 37$ & 700.00 & 11.67 & 24.93 & 648 & 3.76 & 8.41 & -87.7 & 8 \\
\hline $04 / 28 / 07$ & $3: 53: 37$ & 710.00 & 11.83 & 24.91 & 648 & 3.72 & 8.41 & -87.8 & 8 \\
\hline $04 / 28 / 07$ & $4: 03: 37$ & 720.00 & 12.00 & 24.89 & 648 & 3.67 & 8.41 & -88.0 & 8 \\
\hline $04 / 28 / 07$ & $4: 13: 37$ & 730.00 & 12.17 & 24.87 & 648 & 3.67 & 8.42 & -88.3 & 8 \\
\hline $04 / 28 / 07$ & $4: 23: 37$ & 740.00 & 12.33 & 24.85 & 648 & 3.72 & 8.43 & -88.7 & 7 \\
\hline $04 / 28 / 07$ & $4: 33: 37$ & 750.00 & 12.50 & 24.82 & 648 & 3.74 & 8.43 & -89.0 & 7 \\
\hline $04 / 28 / 07$ & $4: 43: 37$ & 760.00 & 12.67 & 24.8 & 648 & 3.72 & 8.44 & -89.3 & 7 \\
\hline $04 / 28 / 07$ & $4: 53: 37$ & 770.00 & 12.83 & 24.78 & 648 & 3.68 & 8.44 & -89.6 & 7 \\
\hline $04 / 28 / 07$ & 5:03:37 & 780.00 & 13.00 & 24.76 & 648 & 3.70 & 8.44 & -89.8 & 6 \\
\hline $04 / 28 / 07$ & $5: 13: 37$ & 790.00 & 13.17 & 24.73 & 648 & 3.75 & 8.45 & -90.2 & 6 \\
\hline $04 / 28 / 07$ & $5: 23: 37$ & 800.00 & 13.33 & 24.71 & 648 & 3.74 & 8.46 & -90.5 & 6 \\
\hline $04 / 28 / 07$ & $5: 33: 37$ & 810.00 & 13.50 & 24.68 & 648 & 3.74 & 8.46 & -90.8 & 6 \\
\hline $04 / 28 / 07$ & $5: 43: 37$ & 820.00 & 13.67 & 24.66 & 648 & 3.71 & 8.47 & -91.1 & 6 \\
\hline $04 / 28 / 07$ & $5: 53: 37$ & 830.00 & 13.83 & 24.64 & 648 & 3.72 & 8.47 & -91.3 & 6 \\
\hline
\end{tabular}




\begin{tabular}{|c|c|c|c|c|c|c|c|c|c|}
\hline & & Elapse & Time & & & & & & \\
\hline Date & Time & Minutes & Hours & Temp $\left({ }^{\circ} \mathrm{C}\right)$ & $\mathrm{SC}(\mathrm{uS} / \mathrm{cm})$ & $\mathrm{DO}(\mathrm{mg} / \mathrm{L})$ & $\mathrm{pH}$ & $\mathrm{pH}(\mathrm{mV})$ & ORP \\
\hline $04 / 28 / 07$ & $6: 03: 37$ & 840.00 & 14.00 & 24.61 & 648 & 3.71 & 8.48 & -91.6 & 6 \\
\hline $04 / 28 / 07$ & $6: 13: 37$ & 850.00 & 14.17 & 24.59 & 648 & 3.55 & 8.48 & -91.9 & 6 \\
\hline $04 / 28 / 07$ & $6: 23: 37$ & 860.00 & 14.33 & 24.56 & 648 & 3.64 & 8.49 & -92.2 & 6 \\
\hline $04 / 28 / 07$ & $6: 33: 37$ & 870.00 & 14.50 & 24.54 & 648 & 3.67 & 8.49 & -92.4 & 6 \\
\hline $04 / 28 / 07$ & $6: 43: 37$ & 880.00 & 14.67 & 24.51 & 647 & 3.61 & 8.49 & -92.6 & 6 \\
\hline $04 / 28 / 07$ & $6: 53: 37$ & 890.00 & 14.83 & 24.48 & 647 & 3.64 & 8.50 & -92.9 & 6 \\
\hline $04 / 28 / 07$ & $7: 03: 37$ & 900.00 & 15.00 & 24.46 & 647 & 3.70 & 8.50 & -93.2 & 5 \\
\hline $04 / 28 / 07$ & $7: 13: 37$ & 910.00 & 15.17 & 24.43 & 647 & 3.58 & 8.51 & -93.3 & 6 \\
\hline $04 / 28 / 07$ & $7: 23: 37$ & 920.00 & 15.33 & 24.4 & 647 & 3.61 & 8.51 & -93.6 & 6 \\
\hline $04 / 28 / 07$ & $7: 33: 37$ & 930.00 & 15.50 & 24.38 & 647 & 3.72 & 8.51 & -93.8 & 5 \\
\hline $04 / 28 / 07$ & $7: 43: 37$ & 940.00 & 15.67 & 24.35 & 647 & 3.65 & 8.52 & -94.0 & 6 \\
\hline $04 / 28 / 07$ & $7: 53: 37$ & 950.00 & 15.83 & 24.32 & 647 & 3.58 & 8.52 & -94.2 & 6 \\
\hline $04 / 28 / 07$ & $8: 03: 37$ & 960.00 & 16.00 & 24.3 & 647 & 3.72 & 8.53 & -94.5 & 5 \\
\hline $04 / 28 / 07$ & $8: 13: 37$ & 970.00 & 16.17 & 24.27 & 647 & 3.59 & 8.53 & -94.7 & 5 \\
\hline $04 / 28 / 07$ & $8: 23: 37$ & 980.00 & 16.33 & 24.24 & 647 & 3.57 & 8.53 & -94.9 & 6 \\
\hline $04 / 28 / 07$ & $8: 33: 37$ & 990.00 & 16.50 & 24.21 & 647 & 3.56 & 8.54 & -95.2 & 6 \\
\hline $04 / 28 / 07$ & $8: 43: 37$ & 1000.00 & 16.67 & 24.18 & 647 & 3.73 & 8.54 & -95.3 & 6 \\
\hline $04 / 28 / 07$ & $8: 53: 37$ & 1010.00 & 16.83 & 24.16 & 647 & 3.60 & 8.54 & -95.5 & 6 \\
\hline $04 / 28 / 07$ & $9: 03: 37$ & 1020.00 & 17.00 & 24.13 & 647 & 3.48 & 8.55 & -95.7 & 6 \\
\hline $04 / 28 / 07$ & 9:13:37 & 1030.00 & 17.17 & 24.1 & 647 & 3.56 & 8.55 & -96.1 & 6 \\
\hline $04 / 28 / 07$ & $9: 23: 37$ & 1040.00 & 17.33 & 24.07 & 647 & 3.72 & 8.56 & -96.2 & 5 \\
\hline $04 / 28 / 07$ & $9: 33: 37$ & 1050.00 & 17.50 & 24.05 & 647 & 3.65 & 8.56 & -96.4 & 6 \\
\hline $04 / 28 / 07$ & $9: 43: 37$ & 1060.00 & 17.67 & 24.02 & 647 & 3.57 & 8.56 & -96.5 & 6 \\
\hline $04 / 28 / 07$ & $9: 53: 37$ & 1070.00 & 17.83 & 24 & 647 & 3.73 & 8.57 & -96.7 & 5 \\
\hline $04 / 28 / 07$ & $10: 03: 37$ & 1080.00 & 18.00 & 23.98 & 647 & 3.68 & 8.57 & -97.0 & 5 \\
\hline $04 / 28 / 07$ & $10: 13: 37$ & 1090.00 & 18.17 & 23.96 & 647 & 3.65 & 8.58 & -97.3 & 5 \\
\hline $04 / 28 / 07$ & $10: 23: 37$ & 1100.00 & 18.33 & 23.94 & 647 & 3.70 & 8.58 & -97.6 & 5 \\
\hline $04 / 28 / 07$ & $10: 33: 37$ & 1110.00 & 18.50 & 23.92 & 647 & 3.68 & 8.59 & -97.9 & 4 \\
\hline $04 / 28 / 07$ & $10: 43: 37$ & 1120.00 & 18.67 & 23.91 & 647 & 3.68 & 8.59 & -98.1 & 4 \\
\hline $04 / 28 / 07$ & $10: 53: 37$ & 1130.00 & 18.83 & 23.9 & 647 & 3.65 & 8.59 & -98.2 & 4 \\
\hline $04 / 28 / 07$ & $11: 03: 37$ & 1140.00 & 19.00 & 23.88 & 647 & 3.58 & 8.59 & -98.3 & 4 \\
\hline $04 / 28 / 07$ & $11: 13: 37$ & 1150.00 & 19.17 & 23.87 & 648 & 3.58 & 8.60 & -98.7 & 4 \\
\hline $04 / 28 / 07$ & $11: 23: 37$ & 1160.00 & 19.33 & 23.86 & 649 & 3.70 & 8.62 & -99.7 & 0 \\
\hline $04 / 28 / 07$ & $11: 33: 37$ & 1170.00 & 19.50 & 23.86 & 648 & 3.85 & 8.62 & -99.7 & -1 \\
\hline $04 / 28 / 07$ & $11: 43: 37$ & 1180.00 & 19.67 & 23.85 & 648 & 3.91 & 8.60 & -98.9 & 1 \\
\hline $04 / 28 / 07$ & $11: 53: 37$ & 1190.00 & 19.83 & 23.85 & 648 & 3.93 & 8.61 & -99.3 & 2 \\
\hline $04 / 28 / 07$ & $12: 03: 37$ & 1200.00 & 20.00 & 23.85 & 647 & 3.92 & 8.61 & -99.4 & 2 \\
\hline $04 / 28 / 07$ & $12: 13: 37$ & 1210.00 & 20.17 & 23.85 & 647 & 3.83 & 8.61 & -99.1 & 2 \\
\hline $04 / 28 / 07$ & $12: 23: 37$ & 1220.00 & 20.33 & 23.85 & 647 & 3.80 & 8.60 & -98.9 & 4 \\
\hline $04 / 28 / 07$ & $12: 33: 37$ & 1230.00 & 20.50 & 23.85 & 647 & 3.84 & 8.60 & -98.8 & 6 \\
\hline $04 / 28 / 07$ & $12: 43: 37$ & 1240.00 & 20.67 & 23.86 & 647 & 3.90 & 8.60 & -98.7 & 7 \\
\hline $04 / 28 / 07$ & $12: 53: 37$ & 1250.00 & 20.83 & 23.87 & 647 & 3.88 & 8.60 & -98.6 & 8 \\
\hline $04 / 28 / 07$ & $13: 03: 37$ & 1260.00 & 21.00 & 23.88 & 647 & 3.95 & 8.60 & -98.7 & 8 \\
\hline $04 / 28 / 07$ & $13: 13: 37$ & 1270.00 & 21.17 & 23.89 & 647 & 3.90 & 8.60 & -98.8 & 9 \\
\hline $04 / 28 / 07$ & $13: 23: 37$ & 1280.00 & 21.33 & 23.91 & 647 & 3.95 & 8.61 & -99.0 & 9 \\
\hline $04 / 28 / 07$ & $13: 33: 37$ & 1290.00 & 21.50 & 23.93 & 647 & 3.98 & 8.61 & -99.2 & 9 \\
\hline $04 / 28 / 07$ & 13:43:37 & 1300.00 & 21.67 & 23.95 & 647 & 3.98 & 8.61 & -99.3 & 9 \\
\hline $04 / 28 / 07$ & $13: 53: 37$ & 1310.00 & 21.83 & 23.97 & 647 & 3.93 & 8.61 & -99.5 & 9 \\
\hline $04 / 28 / 07$ & $14: 03: 37$ & 1320.00 & 22.00 & 23.99 & 647 & 3.99 & 8.62 & -99.6 & 8 \\
\hline $04 / 28 / 07$ & $14: 13: 37$ & 1330.00 & 22.17 & 24.02 & 647 & 3.97 & 8.62 & -99.8 & 8 \\
\hline $04 / 28 / 07$ & $14: 23: 37$ & 1340.00 & 22.33 & 24.04 & 647 & 3.97 & 8.62 & -99.8 & 7 \\
\hline $04 / 28 / 07$ & $14: 33: 37$ & 1350.00 & 22.50 & 24.07 & 647 & 3.97 & 8.62 & -100.0 & 8 \\
\hline $04 / 28 / 07$ & 14:43:37 & 1360.00 & 22.67 & 24.1 & 647 & 3.99 & 8.62 & -100.1 & 8 \\
\hline $04 / 28 / 07$ & $14: 53: 37$ & 1370.00 & 22.83 & 24.13 & 647 & 3.95 & 8.62 & -100.2 & 8 \\
\hline $04 / 28 / 07$ & $15: 03: 37$ & 1380.00 & 23.00 & 24.16 & 647 & 3.94 & 8.63 & -100.3 & 8 \\
\hline $04 / 28 / 07$ & $15: 13: 37$ & 1390.00 & 23.17 & 24.19 & 647 & 3.72 & 8.63 & -100.4 & 8 \\
\hline $04 / 28 / 07$ & $15: 23: 37$ & 1400.00 & 23.33 & 24.23 & 647 & 3.88 & 8.63 & -100.6 & 7 \\
\hline $04 / 28 / 07$ & $15: 33: 37$ & 1410.00 & 23.50 & 24.26 & 647 & 3.73 & 8.63 & -100.7 & 7 \\
\hline $04 / 28 / 07$ & $15: 43: 37$ & 1420.00 & 23.67 & 24.29 & 647 & 3.71 & 8.63 & -100.8 & 6 \\
\hline
\end{tabular}




\begin{tabular}{|c|c|c|c|c|c|c|c|c|c|}
\hline & & Elapsed & Time & & & & & & \\
\hline Date & Time & Minutes & Hours & Temp ( $\left.{ }^{\circ} \mathrm{C}\right)$ & $\mathrm{SC}(\mathrm{uS} / \mathrm{cm})$ & $\mathrm{DO}(\mathrm{mg} / \mathrm{L})$ & $\mathbf{p H}$ & $\mathrm{pH}(\mathrm{mV})$ & ORP \\
\hline $04 / 28 / 07$ & $15: 53: 37$ & 1430.00 & 23.83 & 24.32 & 647 & 3.86 & 8.63 & -100.9 & 6 \\
\hline $04 / 28 / 07$ & $16: 03: 37$ & 1440.00 & 24.00 & 24.36 & 647 & 3.84 & 8.64 & -101.1 & 6 \\
\hline $04 / 28 / 07$ & $16: 13: 37$ & 1450.00 & 24.17 & 24.39 & 648 & 3.62 & 8.64 & -101.2 & 6 \\
\hline $04 / 28 / 07$ & $16: 23: 37$ & 1460.00 & 24.33 & 24.42 & 648 & 3.88 & 8.64 & -101.2 & 6 \\
\hline $04 / 28 / 07$ & $16: 33: 37$ & 1470.00 & 24.50 & 24.45 & 648 & 3.73 & 8.64 & -101.4 & 6 \\
\hline $04 / 28 / 07$ & $16: 43: 37$ & 1480.00 & 24.67 & 24.49 & 648 & 3.73 & 8.64 & -101.5 & 6 \\
\hline $04 / 28 / 07$ & $16: 53: 37$ & 1490.00 & 24.83 & 24.52 & 648 & 3.96 & 8.64 & -101.4 & 6 \\
\hline $04 / 28 / 07$ & $17: 03: 37$ & 1500.00 & 25.00 & 24.55 & 648 & 3.69 & 8.64 & -101.5 & 5 \\
\hline $04 / 28 / 07$ & $17: 13: 37$ & 1510.00 & 25.17 & 24.58 & 648 & 3.63 & 8.65 & -101.7 & 5 \\
\hline $04 / 28 / 07$ & $17: 23: 37$ & 1520.00 & 25.33 & 24.61 & 648 & 3.59 & 8.65 & -101.7 & 5 \\
\hline $04 / 28 / 07$ & $17: 33: 37$ & 1530.00 & 25.50 & 24.65 & 648 & 3.84 & 8.65 & -101.8 & 4 \\
\hline $04 / 28 / 07$ & $17: 43: 37$ & 1540.00 & 25.67 & 24.68 & 648 & 3.85 & 8.65 & -101.9 & 5 \\
\hline $04 / 28 / 07$ & $17: 53: 37$ & 1550.00 & 25.83 & 24.72 & 648 & 3.81 & 8.65 & -102.0 & 4 \\
\hline $04 / 28 / 07$ & $18: 03: 37$ & 1560.00 & 26.00 & 24.76 & 648 & 3.86 & 8.65 & -102.1 & 3 \\
\hline $04 / 28 / 07$ & $18: 13: 37$ & 1570.00 & 26.17 & 24.8 & 648 & 3.91 & 8.65 & -102.3 & 3 \\
\hline $04 / 28 / 07$ & $18: 23: 37$ & 1580.00 & 26.33 & 24.84 & 648 & 3.73 & 8.66 & -102.6 & 2 \\
\hline $04 / 28 / 07$ & $18: 33: 37$ & 1590.00 & 26.50 & 24.89 & 648 & 3.71 & 8.66 & -102.7 & 1 \\
\hline $04 / 28 / 07$ & 18:43:37 & 1600.00 & 26.67 & 24.93 & 648 & 3.77 & 8.66 & -102.6 & 1 \\
\hline $04 / 28 / 07$ & $18: 53: 37$ & 1610.00 & 26.83 & 24.97 & 648 & 3.67 & 8.66 & -102.7 & 2 \\
\hline $04 / 28 / 07$ & $19: 03: 37$ & 1620.00 & 27.00 & 25.01 & 648 & 3.88 & 8.66 & -102.7 & 3 \\
\hline $04 / 28 / 07$ & $19: 13: 37$ & 1630.00 & 27.17 & 25.06 & 648 & 3.82 & 8.66 & -102.7 & 3 \\
\hline $04 / 28 / 07$ & $19: 23: 37$ & 1640.00 & 27.33 & 25.1 & 648 & 3.62 & 8.66 & -102.8 & 3 \\
\hline $04 / 28 / 07$ & $19: 33: 37$ & 1650.00 & 27.50 & 25.14 & 648 & 3.75 & 8.66 & -102.8 & 4 \\
\hline $04 / 28 / 07$ & $19: 43: 37$ & 1660.00 & 27.67 & 25.18 & 648 & 3.61 & 8.66 & -102.7 & 4 \\
\hline $04 / 28 / 07$ & $19: 53: 37$ & 1670.00 & 27.83 & 25.23 & 648 & 3.58 & 8.67 & -103.0 & 4 \\
\hline $04 / 28 / 07$ & $20: 03: 37$ & 1680.00 & 28.00 & 25.27 & 648 & 3.70 & 8.66 & -103.0 & 4 \\
\hline $04 / 28 / 07$ & $20: 13: 37$ & 1690.00 & 28.17 & 25.31 & 648 & 3.65 & 8.67 & -103.1 & 4 \\
\hline $04 / 28 / 07$ & $20: 23: 37$ & 1700.00 & 28.33 & 25.35 & 648 & 3.68 & 8.66 & -103.0 & 4 \\
\hline $04 / 28 / 07$ & $20: 33: 37$ & 1710.00 & 28.50 & 25.39 & 648 & 3.67 & 8.67 & -103.2 & 4 \\
\hline $04 / 28 / 07$ & $20: 43: 37$ & 1720.00 & 28.67 & 25.43 & 648 & 3.66 & 8.67 & -103.5 & 5 \\
\hline $04 / 28 / 07$ & $20: 53: 37$ & 1730.00 & 28.83 & 25.47 & 648 & 3.75 & 8.67 & -103.4 & 5 \\
\hline $04 / 28 / 07$ & $21: 03: 37$ & 1740.00 & 29.00 & 25.5 & 649 & 3.62 & 8.67 & -103.5 & 5 \\
\hline $04 / 28 / 07$ & $21: 13: 37$ & 1750.00 & 29.17 & 25.54 & 649 & 3.56 & 8.67 & -103.5 & 6 \\
\hline $04 / 28 / 07$ & $21: 23: 37$ & 1760.00 & 29.33 & 25.57 & 649 & 3.45 & 8.67 & -103.4 & 6 \\
\hline $04 / 28 / 07$ & $21: 33: 37$ & 1770.00 & 29.50 & 25.6 & 649 & 3.47 & 8.67 & -103.5 & 6 \\
\hline $04 / 28 / 07$ & $21: 43: 37$ & 1780.00 & 29.67 & 25.63 & 649 & 3.46 & 8.67 & -103.5 & 6 \\
\hline $04 / 28 / 07$ & $21: 53: 37$ & 1790.00 & 29.83 & 25.66 & 649 & 3.58 & 8.67 & -103.5 & 6 \\
\hline $04 / 28 / 07$ & $22: 03: 37$ & 1800.00 & 30.00 & 25.69 & 649 & 3.61 & 8.67 & -103.7 & 6 \\
\hline $04 / 28 / 07$ & $22: 13: 37$ & 1810.00 & 30.17 & 25.72 & 649 & 3.69 & 8.67 & -103.7 & 5 \\
\hline $04 / 28 / 07$ & $22: 23: 37$ & 1820.00 & 30.33 & 25.75 & 649 & 3.57 & 8.68 & -103.9 & 4 \\
\hline $04 / 28 / 07$ & $22: 33: 37$ & 1830.00 & 30.50 & 25.77 & 649 & 3.63 & 8.68 & -103.9 & 3 \\
\hline $04 / 28 / 07$ & $22: 43: 37$ & 1840.00 & 30.67 & 25.79 & 649 & 3.65 & 8.68 & -103.8 & 4 \\
\hline $04 / 28 / 07$ & $22: 53: 37$ & 1850.00 & 30.83 & 25.81 & 649 & 3.59 & 8.68 & -103.8 & 5 \\
\hline $04 / 28 / 07$ & $23: 03: 37$ & 1860.00 & 31.00 & 25.84 & 649 & 3.56 & 8.68 & -103.8 & 6 \\
\hline $04 / 28 / 07$ & $23: 13: 37$ & 1870.00 & 31.17 & 25.86 & 649 & 3.62 & 8.68 & -103.9 & 6 \\
\hline $04 / 28 / 07$ & $23: 23: 37$ & 1880.00 & 31.33 & 25.88 & 649 & 3.56 & 8.68 & -104.1 & 6 \\
\hline $04 / 28 / 07$ & $23: 33: 37$ & 1890.00 & 31.50 & 25.9 & 649 & 3.50 & 8.68 & -104.0 & 6 \\
\hline $04 / 28 / 07$ & $23: 43: 37$ & 1900.00 & 31.67 & 25.92 & 649 & 3.46 & 8.68 & -104.1 & 7 \\
\hline $04 / 28 / 07$ & $23: 53: 37$ & 1910.00 & 31.83 & 25.93 & 649 & 3.45 & 8.68 & -104.1 & 7 \\
\hline $04 / 29 / 07$ & $0: 03: 37$ & 1920.00 & 32.00 & 25.95 & 649 & 3.47 & 8.68 & -104.2 & 8 \\
\hline $04 / 29 / 07$ & $0: 13: 37$ & 1930.00 & 32.17 & 25.97 & 649 & 3.50 & 8.68 & -104.2 & 9 \\
\hline $04 / 29 / 07$ & $0: 23: 37$ & 1940.00 & 32.33 & 25.98 & 649 & 3.47 & 8.68 & -104.2 & 9 \\
\hline $04 / 29 / 07$ & $0: 33: 37$ & 1950.00 & 32.50 & 26 & 649 & 3.48 & 8.68 & -104.3 & 10 \\
\hline $04 / 29 / 07$ & $0: 43: 37$ & 1960.00 & 32.67 & 26.01 & 649 & 3.50 & 8.68 & -104.4 & 10 \\
\hline $04 / 29 / 07$ & $0: 53: 37$ & 1970.00 & 32.83 & 26.02 & 649 & 3.47 & 8.69 & -104.5 & 10 \\
\hline $04 / 29 / 07$ & 1:03:37 & 1980.00 & 33.00 & 26.04 & 649 & 3.51 & 8.69 & -104.5 & 10 \\
\hline $04 / 29 / 07$ & 1:13:37 & 1990.00 & 33.17 & 26.05 & 649 & 3.48 & 8.69 & -104.6 & 11 \\
\hline $04 / 29 / 07$ & 1:23:37 & 2000.00 & 33.33 & 26.05 & 649 & 3.52 & 8.69 & -104.7 & 11 \\
\hline $04 / 29 / 07$ & $1: 33: 37$ & 2010.00 & 33.50 & 26.06 & 649 & 3.51 & 8.69 & -104.7 & 11 \\
\hline
\end{tabular}




\begin{tabular}{|c|c|c|c|c|c|c|c|c|c|}
\hline & & Elapse & Time & & & & & & \\
\hline Date & Time & Minutes & Hours & Temp ( $\left.{ }^{\circ} \mathrm{C}\right)$ & $\mathrm{SC}(\mathrm{uS} / \mathrm{cm})$ & $\mathrm{DO}(\mathrm{mg} / \mathrm{L})$ & $\mathrm{pH}$ & $\mathrm{pH}(\mathrm{mV})$ & ORP \\
\hline $04 / 29 / 07$ & $1: 43: 37$ & 2020.00 & 33.67 & 26.07 & 649 & 3.48 & 8.69 & -104.7 & 12 \\
\hline $04 / 29 / 07$ & $1: 53: 37$ & 2030.00 & 33.83 & 26.07 & 649 & 3.47 & 8.69 & -104.8 & 12 \\
\hline $04 / 29 / 07$ & $2: 03: 37$ & 2040.00 & 34.00 & 26.07 & 649 & 3.48 & 8.69 & -104.8 & 13 \\
\hline $04 / 29 / 07$ & $2: 13: 37$ & 2050.00 & 34.17 & 26.08 & 649 & 3.45 & 8.69 & -104.9 & 13 \\
\hline $04 / 29 / 07$ & $2: 23: 37$ & 2060.00 & 34.33 & 26.08 & 649 & 3.45 & 8.69 & -105.0 & $\overline{14}$ \\
\hline $04 / 29 / 07$ & $2: 33: 37$ & 2070.00 & 34.50 & 26.08 & 649 & 3.46 & 8.70 & -105.1 & 15 \\
\hline $04 / 29 / 07$ & $2: 43: 37$ & 2080.00 & 34.67 & 26.08 & 649 & 3.49 & 8.70 & -105.2 & 15 \\
\hline $04 / 29 / 07$ & $2: 53: 37$ & 2090.00 & 34.83 & 26.08 & 649 & 3.51 & 8.70 & -105.4 & 14 \\
\hline $04 / 29 / 07$ & $3: 03: 37$ & 2100.00 & 35.00 & 26.08 & 649 & 3.51 & 8.70 & -105.6 & 10 \\
\hline $04 / 29 / 07$ & $3: 13: 37$ & 2110.00 & 35.17 & 26.08 & 649 & 3.52 & 8.71 & -105.7 & 7 \\
\hline $04 / 29 / 07$ & $3: 23: 37$ & 2120.00 & 35.33 & 26.07 & 649 & 3.53 & 8.71 & -105.9 & 5 \\
\hline $04 / 29 / 07$ & $3: 33: 37$ & 2130.00 & 35.50 & 26.07 & 649 & 3.52 & 8.71 & -106.0 & 3 \\
\hline $04 / 29 / 07$ & $3: 43: 37$ & 2140.00 & 35.67 & 26.06 & 649 & 3.51 & 8.71 & -106.1 & 0 \\
\hline $04 / 29 / 07$ & $3: 53: 37$ & 2150.00 & 35.83 & 26.06 & 649 & 3.50 & 8.71 & -106.1 & -1 \\
\hline $04 / 29 / 07$ & $4: 03: 37$ & 2160.00 & 36.00 & 26.05 & 649 & 3.48 & 8.72 & -106.3 & -2 \\
\hline $04 / 29 / 07$ & $4: 13: 37$ & 2170.00 & 36.17 & 26.04 & 649 & 3.47 & 8.72 & -106.3 & -2 \\
\hline $04 / 29 / 07$ & $4: 23: 37$ & 2180.00 & 36.33 & 26.03 & 649 & 3.46 & 8.72 & -106.3 & -2 \\
\hline $04 / 29 / 07$ & $4: 33: 37$ & 2190.00 & 36.50 & 26.02 & 649 & 3.42 & 8.72 & -106.3 & -1 \\
\hline $04 / 29 / 07$ & $4: 43: 37$ & 2200.00 & 36.67 & 26.01 & 649 & 3.41 & 8.72 & -106.3 & 0 \\
\hline $04 / 29 / 07$ & $4: 53: 37$ & 2210.00 & 36.83 & 26 & 649 & 3.42 & 8.72 & -106.3 & 1 \\
\hline $04 / 29 / 07$ & $5: 03: 37$ & 2220.00 & 37.00 & 25.99 & 649 & 3.43 & 8.71 & -106.2 & 0 \\
\hline $04 / 29 / 07$ & $5: 13: 37$ & 2230.00 & 37.17 & 25.97 & 649 & 3.43 & 8.71 & -106.1 & -6 \\
\hline $04 / 29 / 07$ & $5: 23: 37$ & 2240.00 & 37.33 & 25.96 & 650 & 3.43 & 8.72 & -106.3 & -12 \\
\hline $04 / 29 / 07$ & $5: 33: 37$ & 2250.00 & 37.50 & 25.94 & 650 & 3.42 & 8.72 & -106.7 & -16 \\
\hline $04 / 29 / 07$ & $5: 43: 37$ & 2260.00 & 37.67 & 25.92 & 649 & 3.34 & 8.72 & -106.6 & -12 \\
\hline $04 / 29 / 07$ & $5: 53: 37$ & 2270.00 & 37.83 & 25.9 & 648 & 3.31 & 8.72 & -106.7 & -10 \\
\hline $04 / 29 / 07$ & $6: 03: 37$ & 2280.00 & 38.00 & 25.88 & 648 & 3.31 & 8.72 & -106.7 & -8 \\
\hline $04 / 29 / 07$ & $6: 13: 37$ & 2290.00 & 38.17 & 25.87 & 648 & 3.35 & 8.73 & -106.8 & -9 \\
\hline $04 / 29 / 07$ & $6: 23: 37$ & 2300.00 & 38.33 & 25.85 & 648 & 3.36 & 8.73 & -106.8 & -8 \\
\hline $04 / 29 / 07$ & $6: 33: 37$ & 2310.00 & 38.50 & $25 . \overline{83}$ & 648 & 3.33 & 8.73 & -106.9 & -7 \\
\hline $04 / 29 / 07$ & $6: 43: 37$ & 2320.00 & 38.67 & 25.81 & 648 & 3.27 & 8.73 & -106.9 & -5 \\
\hline $04 / 29 / 07$ & $6: 53: 37$ & 2330.00 & 38.83 & 25.79 & 648 & 3.31 & 8.73 & -106.9 & -4 \\
\hline $04 / 29 / 07$ & $7: 03: 37$ & 2340.00 & 39.00 & 25.76 & 648 & 3.32 & 8.73 & -107.0 & -3 \\
\hline $04 / 29 / 07$ & $7: 13: 37$ & 2350.00 & 39.17 & 25.74 & 648 & 3.33 & 8.73 & -107.0 & -2 \\
\hline $04 / 29 / 07$ & $7: 23: 37$ & 2360.00 & 39.33 & 25.71 & 648 & 3.40 & 8.73 & -107.1 & -2 \\
\hline $04 / 29 / 07$ & $7: 33: 37$ & 2370.00 & 39.50 & 25.69 & 648 & 3.33 & 8.73 & -107.1 & -1 \\
\hline $04 / 29 / 07$ & $7: 43: 37$ & 2380.00 & 39.67 & 25.66 & 648 & 3.40 & 8.73 & -107.1 & -1 \\
\hline $04 / 29 / 07$ & $7: 53: 37$ & 2390.00 & 39.83 & 25.64 & 647 & 3.35 & 8.73 & -107.2 & 1 \\
\hline $04 / 29 / 07$ & $8: 03: 37$ & 2400.00 & 40.00 & 25.61 & 647 & 3.34 & 8.73 & -107.2 & 2 \\
\hline $04 / 29 / 07$ & $8: 13: 37$ & 2410.00 & 40.17 & 25.59 & 647 & 3.34 & 8.74 & -107.3 & 4 \\
\hline $04 / 29 / 07$ & $8: 23: 37$ & 2420.00 & 40.33 & 25.56 & 647 & 3.32 & 8.74 & -107.4 & 5 \\
\hline $04 / 29 / 07$ & $8: 33: 37$ & 2430.00 & 40.50 & 25.53 & 647 & 3.27 & 8.74 & -107.4 & 6 \\
\hline $04 / 29 / 07$ & $8: 43: 37$ & 2440.00 & 40.67 & 25.51 & 647 & 3.39 & 8.74 & -107.5 & 8 \\
\hline $04 / 29 / 07$ & $8: 53: 37$ & 2450.00 & 40.83 & 25.48 & 647 & 3.29 & 8.74 & -107.5 & 9 \\
\hline $04 / 29 / 07$ & $9: 03: 37$ & 2460.00 & 41.00 & 25.45 & 647 & 3.29 & 8.74 & -107.5 & 10 \\
\hline $04 / 29 / 07$ & $9: 13: 37$ & 2470.00 & 41.17 & 25.42 & 647 & 3.38 & 8.74 & -107.5 & 10 \\
\hline $04 / 29 / 07$ & $9: 23: 37$ & 2480.00 & 41.33 & 25.4 & 647 & 3.39 & 8.74 & -107.6 & 11 \\
\hline $04 / 29 / 07$ & $9: 33: 37$ & 2490.00 & 41.50 & 25.37 & 647 & 3.40 & 8.74 & -107.6 & 11 \\
\hline $04 / 29 / 07$ & $9: 43: 37$ & 2500.00 & 41.67 & 25.35 & 647 & 3.38 & 8.74 & -107.6 & 11 \\
\hline $04 / 29 / 07$ & $9: 53: 37$ & 2510.00 & 41.83 & 25.33 & 647 & 3.42 & 8.74 & -107.7 & 11 \\
\hline $04 / 29 / 07$ & $10: 03: 37$ & 2520.00 & 42.00 & 25.3 & 647 & 3.38 & 8.74 & -107.7 & 11 \\
\hline $04 / 29 / 07$ & $10: 13: 37$ & 2530.00 & 42.17 & 25.28 & 647 & 3.38 & 8.75 & -107.8 & 11 \\
\hline $04 / 29 / 07$ & $10: 23: 37$ & 2540.00 & 42.33 & 25.26 & 647 & 3.43 & 8.75 & -107.8 & 9 \\
\hline $04 / 29 / 07$ & $10: 33: 37$ & 2550.00 & 42.50 & 25.24 & 647 & 3.38 & 8.75 & -107.8 & 8 \\
\hline $04 / 29 / 07$ & $10: 43: 37$ & 2560.00 & 42.67 & 25.22 & 647 & 3.38 & 8.75 & -107.9 & 8 \\
\hline $04 / 29 / 07$ & $10: 53: 37$ & 2570.00 & 42.83 & 25.2 & 647 & 3.37 & 8.75 & -107.9 & 8 \\
\hline $04 / 29 / 07$ & $11: 03: 37$ & 2580.00 & 43.00 & 25.19 & 647 & 3.33 & 8.75 & -107.9 & 9 \\
\hline $04 / 29 / 07$ & $11: 13: 37$ & 2590.00 & 43.17 & 25.17 & 646 & 3.25 & 8.75 & -107.9 & 10 \\
\hline $04 / 29 / 07$ & $11: 23: 37$ & 2600.00 & 43.33 & 25.16 & 647 & 3.23 & 8.75 & -107.9 & 11 \\
\hline
\end{tabular}




\begin{tabular}{|c|c|c|c|c|c|c|c|c|c|}
\hline & & Elapsec & Time & & & & & & \\
\hline Date & Time & Minutes & Hours & Temp ( $\left.{ }^{\circ} \mathrm{C}\right)$ & SC (uS/cm) & DO (mg/L) & $\mathrm{pH}$ & $\mathrm{pH}(\mathrm{mV})$ & ORP \\
\hline $04 / 29 / 07$ & $11: 33: 37$ & 2610.00 & 43.50 & 25.14 & 647 & 3.21 & 8.75 & -107.9 & 12 \\
\hline $04 / 29 / 07$ & $11: 43: 37$ & 2620.00 & 43.67 & 25.13 & 647 & 3.23 & 8.75 & -108.0 & 12 \\
\hline $04 / 29 / 07$ & $11: 53: 37$ & 2630.00 & 43.83 & 25.12 & 647 & 3.28 & 8.75 & -108.0 & 12 \\
\hline $04 / 29 / 07$ & $12: 03: 37$ & 2640.00 & 44.00 & 25.11 & 648 & 3.30 & 8.75 & -108.0 & 12 \\
\hline $04 / 29 / 07$ & $12: 13: 37$ & 2650.00 & 44.17 & 25.1 & 648 & 3.39 & 8.75 & -108.1 & 8 \\
\hline $04 / 29 / 07$ & $12: 23: 37$ & 2660.00 & 44.33 & 25.09 & 648 & 3.50 & 8.76 & -108.4 & -8 \\
\hline $04 / 29 / 07$ & $12: 33: 37$ & 2670.00 & 44.50 & 25.08 & 648 & 3.57 & 8.75 & -108.1 & -18 \\
\hline $04 / 29 / 07$ & $12: 43: 37$ & 2680.00 & 44.67 & 25.07 & 648 & 3.60 & 8.75 & -107.9 & -12 \\
\hline $04 / 29 / 07$ & $12: 53: 37$ & 2690.00 & 44.83 & 25.06 & 648 & 3.57 & 8.75 & -108.0 & 0 \\
\hline $04 / 29 / 07$ & $13: 03: 37$ & 2700.00 & 45.00 & 25.06 & 647 & 3.63 & 8.75 & -108.0 & 5 \\
\hline $04 / 29 / 07$ & 13:13:37 & 2710.00 & 45.17 & 25.06 & 647 & 3.63 & 8.75 & -108.1 & 6 \\
\hline $04 / 29 / 07$ & 13:23:37 & 2720.00 & 45.33 & 25.06 & 647 & 3.53 & 8.75 & -108.0 & 8 \\
\hline $04 / 29 / 07$ & $13: 33: 37$ & 2730.00 & 45.50 & 25.06 & 647 & 3.50 & 8.75 & -107.8 & 13 \\
\hline $04 / 29 / 07$ & $13: 43: 37$ & 2740.00 & 45.67 & 25.07 & 647 & 3.57 & 8.74 & -107.7 & 18 \\
\hline $04 / 29 / 07$ & 13:53:37 & 2750.00 & 45.83 & 25.07 & 647 & 3.57 & 8.74 & -107.6 & 21 \\
\hline $04 / 29 / 07$ & 14:03:37 & 2760.00 & 46.00 & 25.08 & 647 & 3.60 & 8.74 & -107.5 & 24 \\
\hline $04 / 29 / 07$ & 14:13:37 & 2770.00 & 46.17 & 25.09 & 647 & 3.64 & 8.74 & -107.5 & 27 \\
\hline $04 / 29 / 07$ & $14: 23: 37$ & 2780.00 & 46.33 & 25.11 & 647 & 3.68 & 8.74 & -107.4 & 28 \\
\hline $04 / 29 / 07$ & $14: 33: 37$ & 2790.00 & 46.50 & 25.13 & 647 & 3.64 & 8.74 & -107.5 & 28 \\
\hline $04 / 29 / 07$ & $14: 43: 37$ & 2800.00 & 46.67 & 25.14 & 647 & 3.64 & 8.74 & -107.5 & 27 \\
\hline $04 / 29 / 07$ & $14: 53: 37$ & 2810.00 & 46.83 & 25.16 & 647 & 3.56 & 8.74 & -107.4 & 28 \\
\hline $04 / 29 / 07$ & $15: 03: 37$ & 2820.00 & 47.00 & 25.18 & 647 & 3.68 & 8.74 & -107.4 & 28 \\
\hline $04 / 29 / 07$ & $15: 13: 37$ & 2830.00 & 47.17 & 25.21 & 646 & 3.67 & 8.74 & -107.5 & 26 \\
\hline $04 / 29 / 07$ & $15: 23: 37$ & 2840.00 & 47.33 & 25.23 & 646 & 3.73 & 8.74 & -107.4 & 23 \\
\hline $04 / 29 / 07$ & $15: 33: 37$ & 2850.00 & 47.50 & 25.26 & 646 & 3.67 & 8.74 & -107.4 & 22 \\
\hline $04 / 29 / 07$ & 15:43:37 & 2860.00 & 47.67 & 25.28 & 646 & 3.77 & 8.74 & -107.3 & 24 \\
\hline $04 / 29 / 07$ & $15: 53: 37$ & 2870.00 & 47.83 & 25.31 & 646 & 3.57 & 8.74 & -107.4 & 23 \\
\hline $04 / 29 / 07$ & $16: 03: 37$ & 2880.00 & 48.00 & 25.34 & 646 & 3.57 & 8.74 & -107.4 & 26 \\
\hline $04 / 29 / 07$ & $16: 13: 37$ & 2890.00 & 48.17 & 25.37 & 646 & 3.47 & 8.74 & -107.3 & 28 \\
\hline $04 / 29 / 07$ & $16: 23: 37$ & 2900.00 & 48.33 & 25.41 & 646 & 3.33 & 8.74 & -107.3 & 29 \\
\hline $04 / 29 / 07$ & $16: 33: 37$ & 2910.00 & 48.50 & 25.44 & 646 & 3.60 & 8.74 & -107.3 & 30 \\
\hline $04 / 29 / 07$ & $16: 43: 37$ & 2920.00 & 48.67 & 25.47 & 646 & 3.66 & 8.74 & -107.3 & 30 \\
\hline $04 / 29 / 07$ & $16: 53: 37$ & 2930.00 & 48.83 & 25.51 & 646 & 3.43 & 8.74 & -107.3 & 29 \\
\hline $04 / 29 / 07$ & 17:03:37 & 2940.00 & 49.00 & 25.54 & 646 & 3.62 & 8.74 & -107.3 & 30 \\
\hline $04 / 29 / 07$ & $17: 13: 37$ & 2950.00 & 49.17 & 25.58 & 646 & 3.67 & 8.73 & -107.3 & 29 \\
\hline $04 / 29 / 07$ & $17: 23: 37$ & 2960.00 & 49.33 & 25.61 & 646 & 3.58 & 8.74 & -107.3 & 28 \\
\hline $04 / 29 / 07$ & $17: 33: 37$ & 2970.00 & 49.50 & 25.65 & 646 & 3.59 & 8.74 & -107.4 & 25 \\
\hline $04 / 29 / 07$ & $17: 43: 37$ & 2980.00 & 49.67 & 25.69 & 646 & 3.52 & 8.74 & -107.4 & 22 \\
\hline $04 / 29 / 07$ & $17: 53: 37$ & 2990.00 & 49.83 & 25.73 & 646 & 3.62 & 8.74 & -107.4 & 20 \\
\hline $04 / 29 / 07$ & $18: 03: 37$ & 3000.00 & 50.00 & 25.78 & 646 & 3.54 & 8.73 & -107.2 & 18 \\
\hline $04 / 29 / 07$ & $18: 13: 37$ & 3010.00 & 50.17 & 25.82 & 646 & 3.56 & 8.73 & -107.2 & 16 \\
\hline $04 / 29 / 07$ & $18: 23: 37$ & 3020.00 & 50.33 & 25.86 & 646 & 3.46 & 8.73 & -107.1 & 21 \\
\hline $04 / 29 / 07$ & $18: 33: 37$ & 3030.00 & 50.50 & 25.9 & 646 & 3.51 & 8.73 & -107.0 & 23 \\
\hline $04 / 29 / 07$ & $18: 43: 37$ & 3040.00 & 50.67 & 25.95 & 647 & 3.54 & 8.73 & -107.0 & 23 \\
\hline $04 / 29 / 07$ & $18: 53: 37$ & 3050.00 & 50.83 & 25.99 & 647 & 3.51 & 8.73 & -107.1 & 20 \\
\hline $04 / 29 / 07$ & $19: 03: 37$ & 3060.00 & 51.00 & 26.03 & 647 & 3.74 & 8.73 & -107.0 & 23 \\
\hline $04 / 29 / 07$ & $19: 13: 37$ & 3070.00 & 51.17 & 26.07 & 647 & 3.49 & 8.73 & -107.0 & 22 \\
\hline $04 / 29 / 07$ & $19: 23: 37$ & 3080.00 & 51.33 & 26.11 & 647 & 3.47 & 8.73 & -107.0 & 22 \\
\hline $04 / 29 / 07$ & $19: 33: 37$ & 3090.00 & 51.50 & 26.16 & 647 & 3.40 & 8.73 & -107.0 & 23 \\
\hline $04 / 29 / 07$ & $19: 43: 37$ & 3100.00 & 51.67 & 26.2 & 647 & 3.50 & 8.73 & -107.0 & 24 \\
\hline $04 / 29 / 07$ & $19: 53: 37$ & 3110.00 & 51.83 & 26.23 & 647 & 3.40 & 8.72 & -106.9 & 25 \\
\hline $04 / 29 / 07$ & $20: 03: 37$ & 3120.00 & 52.00 & 26.27 & 647 & 3.49 & 8.73 & -106.9 & 24 \\
\hline $04 / 29 / 07$ & $20: 13: 37$ & 3130.00 & 52.17 & 26.31 & 647 & 3.52 & 8.73 & -107.0 & 21 \\
\hline $04 / 29 / 07$ & $20: 23: 37$ & 3140.00 & 52.33 & 26.35 & 647 & 3.49 & 8.73 & -107.0 & 19 \\
\hline $04 / 29 / 07$ & $20: 33: 37$ & 3150.00 & 52.50 & 26.39 & 647 & 3.42 & 8.72 & -106.9 & 19 \\
\hline $04 / 29 / 07$ & $20: 43: 37$ & 3160.00 & 52.67 & 26.42 & 647 & 3.53 & 8.72 & -106.8 & 21 \\
\hline $04 / 29 / 07$ & $20: 53: 37$ & 3170.00 & 52.83 & 26.46 & 647 & 3.44 & 8.72 & -106.7 & 22 \\
\hline $04 / 29 / 07$ & $21: 03: 37$ & 3180.00 & 53.00 & 26.49 & 647 & 3.23 & 8.72 & -106.7 & 22 \\
\hline $04 / 29 / 07$ & $21: 13: 37$ & 3190.00 & 53.17 & 26.52 & 647 & 3.22 & 8.72 & -106.6 & 26 \\
\hline
\end{tabular}




\begin{tabular}{|c|c|c|c|c|c|c|c|c|c|}
\hline & & Elapsed & Time & & & & & & \\
\hline Date & Time & Minutes & Hours & Temp ( $\left.{ }^{\circ} \mathrm{C}\right)$ & $\mathrm{SC}$ (uS/cm) & $\mathrm{DO}(\mathrm{mg} / \mathrm{L})$ & $\mathrm{pH}$ & $\mathrm{pH}(\mathrm{mV})$ & ORP \\
\hline $04 / 29 / 07$ & $21: 23: 37$ & 3200.00 & 53.33 & 26.55 & 647 & 3.26 & 8.72 & -106.5 & 26 \\
\hline $04 / 29 / 07$ & $21: 33: 37$ & 3210.00 & 53.50 & 26.59 & 647 & 3.44 & 8.72 & -106.5 & 27 \\
\hline $04 / 29 / 07$ & $21: 43: 37$ & 3220.00 & 53.67 & 26.62 & 647 & 3.38 & 8.72 & -106.5 & 27 \\
\hline $04 / 29 / 07$ & 21:53:37 & 3230.00 & 53.83 & 26.65 & 647 & 3.36 & 8.72 & -106.5 & 25 \\
\hline $04 / 29 / 07$ & $22: 03: 37$ & 3240.00 & 54.00 & 26.68 & 647 & 3.25 & 8.71 & -106.5 & 26 \\
\hline $04 / 29 / 07$ & $22: 13: 37$ & 3250.00 & 54.17 & 26.71 & 647 & 3.35 & 8.71 & -106.4 & 29 \\
\hline $04 / 29 / 07$ & $22: 23: 37$ & 3260.00 & 54.33 & 26.74 & 647 & 3.59 & 8.71 & -106.5 & 30 \\
\hline $04 / 29 / 07$ & $22: 33: 37$ & 3270.00 & 54.50 & 26.76 & 647 & 3.43 & 8.71 & -106.5 & 23 \\
\hline $04 / 29 / 07$ & $22: 43: 37$ & 3280.00 & 54.67 & 26.78 & 647 & 3.34 & 8.71 & -106.5 & 20 \\
\hline $04 / 29 / 07$ & $22: 53: 37$ & 3290.00 & 54.83 & 26.8 & 647 & 3.28 & 8.71 & -106.4 & 22 \\
\hline $04 / 29 / 07$ & $23: 03: 37$ & 3300.00 & 55.00 & 26.82 & 647 & 3.29 & 8.71 & -106.5 & 26 \\
\hline $04 / 29 / 07$ & $23: 13: 37$ & 3310.00 & 55.17 & 26.83 & 647 & 3.30 & 8.71 & -106.5 & 29 \\
\hline $04 / 29 / 07$ & $23: 23: 37$ & 3320.00 & 55.33 & 26.83 & 647 & 3.31 & 8.71 & -106.5 & 31 \\
\hline $04 / 29 / 07$ & $23: 33: 37$ & 3330.00 & 55.50 & 26.84 & 647 & 3.29 & 8.71 & -106.5 & 33 \\
\hline $04 / 29 / 07$ & $23: 43: 37$ & 3340.00 & 55.67 & 26.84 & 647 & 3.30 & 8.71 & -106.5 & 33 \\
\hline $04 / 29 / 07$ & $23: 53: 37$ & 3350.00 & 55.83 & 26.84 & 647 & 3.28 & 8.72 & -106.6 & 27 \\
\hline $04 / 30 / 07$ & $0: 03: 37$ & 3360.00 & 56.00 & 26.84 & 647 & 3.32 & 8.72 & -106.6 & 24 \\
\hline $04 / 30 / 07$ & $0: 13: 37$ & 3370.00 & 56.17 & 26.84 & 647 & 3.33 & 8.72 & -106.6 & 22 \\
\hline $04 / 30 / 07$ & $0: 23: 37$ & 3380.00 & 56.33 & 26.83 & 647 & 3.32 & 8.72 & -106.6 & 17 \\
\hline $04 / 30 / 07$ & $0: 33: 37$ & 3390.00 & 56.50 & 26.83 & 647 & 3.33 & 8.72 & -106.6 & 14 \\
\hline $04 / 30 / 07$ & $0: 43: 37$ & 3400.00 & 56.67 & 26.83 & 647 & 3.33 & 8.72 & -106.6 & 9 \\
\hline $04 / 30 / 07$ & $0: 53: 37$ & 3410.00 & 56.83 & 26.82 & 647 & 3.35 & 8.72 & -106.6 & 5 \\
\hline $04 / 30 / 07$ & 1:03:37 & 3420.00 & 57.00 & 26.82 & 647 & 3.33 & 8.72 & -106.6 & 2 \\
\hline $04 / 30 / 07$ & $1: 13: 37$ & 3430.00 & 57.17 & 26.81 & 647 & 3.27 & 8.72 & -106.7 & 3 \\
\hline $04 / 30 / 07$ & $1: 23: 37$ & 3440.00 & 57.33 & 26.8 & 647 & 3.23 & 8.71 & -106.5 & 4 \\
\hline $04 / 30 / 07$ & $1: 33: 37$ & 3450.00 & 57.50 & 26.79 & 647 & 3.24 & 8.71 & -106.4 & 3 \\
\hline $04 / 30 / 07$ & $1: 43: 37$ & 3460.00 & 57.67 & 26.77 & 648 & 3.28 & 8.71 & -106.3 & -3 \\
\hline $04 / 30 / 07$ & $1: 53: 37$ & 3470.00 & 57.83 & 26.76 & $6 \overline{48}$ & 3.28 & 8.71 & -106.4 & -12 \\
\hline $04 / 30 / 07$ & $2: 03: 37$ & 3480.00 & 58.00 & 26.73 & 647 & 3.12 & 8.72 & -106.6 & -9 \\
\hline $04 / 30 / 07$ & $2: 13: 37$ & 3490.00 & 58.17 & 26.71 & 647 & 3.16 & 8.72 & -106.6 & -8 \\
\hline $04 / 30 / 07$ & $2: 23: 37$ & 3500.00 & 58.33 & 26.69 & 647 & 3.20 & 8.72 & -106.6 & -9 \\
\hline $04 / 30 / 07$ & $2: 33: 37$ & 3510.00 & 58.50 & 26.67 & 647 & 3.21 & 8.72 & -106.6 & -10 \\
\hline $04 / 30 / 07$ & $2: 43: 37$ & 3520.00 & 58.67 & 26.64 & 647 & 3.22 & 8.72 & -106.6 & -9 \\
\hline $04 / 30 / 07$ & 2:53:37 & 3530.00 & 58.83 & 26.62 & 646 & 3.26 & 8.72 & -106.6 & -17 \\
\hline $04 / 30 / 07$ & 3:03:37 & 3540.00 & 59.00 & 26.6 & 646 & 3.25 & 8.72 & -106.6 & -22 \\
\hline $04 / 30 / 07$ & 3:13:37 & 3550.00 & 59.17 & 26.57 & 646 & 3.25 & 8.72 & -106.5 & -22 \\
\hline $04 / 30 / 07$ & $3: 23: 37$ & 3560.00 & 59.33 & 26.55 & 646 & 3.26 & 8.72 & -106.6 & -28 \\
\hline $04 / 30 / 07$ & $3: 33: 37$ & 3570.00 & 59.50 & 26.53 & 646 & 3.27 & 8.72 & -106.6 & -34 \\
\hline $04 / 30 / 07$ & $3: 43: 37$ & 3580.00 & 59.67 & 26.52 & 647 & 3.27 & 8.72 & -106.5 & -41 \\
\hline $04 / 30 / 07$ & $3: 53: 37$ & 3590.00 & 59.83 & 26.5 & 648 & 3.28 & 8.71 & -106.4 & -39 \\
\hline $04 / 30 / 07$ & $4: 03: 37$ & 3600.00 & 60.00 & 26.49 & 648 & 3.28 & 8.72 & -106.4 & -34 \\
\hline $04 / 30 / 07$ & $4: 13: 37$ & 3610.00 & 60.17 & 26.47 & 648 & 3.28 & 8.72 & -106.5 & -34 \\
\hline $04 / 30 / 07$ & $4: 23: 37$ & 3620.00 & 60.33 & 26.46 & 648 & 3.27 & 8.72 & -106.5 & -32 \\
\hline $04 / 30 / 07$ & $4: 33: 37$ & 3630.00 & 60.50 & 26.44 & 648 & 3.28 & 8.72 & -106.5 & -31 \\
\hline $04 / 30 / 07$ & $4: 43: 37$ & 3640.00 & 60.67 & 26.43 & 648 & 3.27 & 8.72 & -106.5 & -26 \\
\hline $04 / 30 / 07$ & $4: 53: 37$ & 3650.00 & 60.83 & 26.41 & 647 & 3.23 & 8.72 & -106.4 & -19 \\
\hline $04 / 30 / 07$ & $5: 03: 37$ & 3660.00 & 61.00 & 26.4 & 647 & 3.26 & 8.72 & -106.5 & -21 \\
\hline $04 / 30 / 07$ & $5: 13: 37$ & 3670.00 & 61.17 & 26.39 & 648 & 3.27 & 8.72 & -106.4 & -23 \\
\hline $04 / 30 / 07$ & $5: 23: 37$ & 3680.00 & 61.33 & 26.37 & 647 & 3.26 & 8.72 & -106.4 & -18 \\
\hline $04 / 30 / 07$ & $5: 33: 37$ & 3690.00 & 61.50 & 26.36 & 648 & 3.26 & 8.72 & -106.4 & -15 \\
\hline $04 / 30 / 07$ & $5: 43: 37$ & 3700.00 & 61.67 & 26.34 & 647 & 3.23 & 8.72 & -106.4 & -12 \\
\hline $04 / 30 / 07$ & $5: 53: 37$ & 3710.00 & 61.83 & 26.33 & 647 & 3.27 & 8.72 & -106.4 & -16 \\
\hline $04 / 30 / 07$ & $6: 03: 37$ & 3720.00 & 62.00 & 26.32 & 647 & 3.27 & 8.72 & -106.4 & -14 \\
\hline $04 / 30 / 07$ & $6: 13: 37$ & 3730.00 & 62.17 & 26.3 & 647 & 3.26 & 8.71 & -106.3 & -14 \\
\hline $04 / 30 / 07$ & $6: 23: 37$ & 3740.00 & 62.33 & 26.29 & 647 & 3.23 & 8.71 & -106.3 & -10 \\
\hline $04 / 30 / 07$ & $6: 33: 37$ & 3750.00 & 62.50 & 26.27 & 647 & 3.23 & 8.71 & -106.3 & -5 \\
\hline $04 / 30 / 07$ & $6: 43: 37$ & 3760.00 & 62.67 & 26.26 & 647 & 3.27 & 8.71 & -106.3 & -7 \\
\hline $04 / 30 / 07$ & $6: 53: 37$ & 3770.00 & 62.83 & 26.24 & 646 & 3.17 & 8.71 & -106.3 & -2 \\
\hline $04 / 30 / 07$ & $7: 03: 37$ & 3780.00 & 63.00 & 26.23 & 646 & 3.11 & 8.71 & -106.3 & 4 \\
\hline
\end{tabular}




\begin{tabular}{|c|c|c|c|c|c|c|c|c|c|}
\hline & & Elapsed Time & & & & & & \\
\hline Date & Time & Minutes & Hours & Temp ( $\left.{ }^{\circ} \mathbf{C}\right)$ & SC (uS/cm) & DO (mg/L) & pH & pH (mV) & ORP \\
\hline $04 / 30 / 07$ & $7: 13: 37$ & 3790.00 & 63.17 & 26.21 & 646 & 3.15 & 8.71 & -106.2 & 5 \\
\hline $04 / 30 / 07$ & $7: 23: 37$ & 3800.00 & 63.33 & 26.2 & 646 & 3.23 & 8.71 & -106.2 & -1 \\
\hline $04 / 30 / 07$ & $7: 33: 37$ & 3810.00 & 63.50 & 26.18 & 646 & 3.27 & 8.71 & -106.2 & -6 \\
\hline $04 / 30 / 07$ & $7: 43: 37$ & 3820.00 & 63.67 & 26.16 & 646 & 3.29 & 8.71 & -106.2 & -6 \\
\hline $04 / 30 / 07$ & $7: 53: 37$ & 3830.00 & 63.83 & 26.15 & 646 & 3.26 & 8.71 & -106.1 & -4 \\
\hline $04 / 30 / 07$ & $8: 03: 37$ & 3840.00 & 64.00 & 26.13 & 646 & 3.21 & 8.71 & -106.1 & 1 \\
\hline $04 / 30 / 07$ & $8: 13: 37$ & 3850.00 & 64.17 & 26.11 & 645 & 3.22 & 8.71 & -106.1 & 3 \\
\hline $04 / 30 / 07$ & $8: 23: 37$ & 3860.00 & 64.33 & 26.1 & 645 & 3.20 & 8.71 & -106.1 & 6 \\
\hline $04 / 30 / 07$ & $8: 33: 37$ & 3870.00 & 64.50 & 26.08 & 645 & 3.18 & 8.71 & -106.1 & 9 \\
\hline $04 / 30 / 07$ & $8: 43: 37$ & 3880.00 & 64.67 & 26.06 & 645 & 3.20 & 8.71 & -106.1 & 11 \\
\hline $04 / 30 / 07$ & $8: 53: 37$ & 3890.00 & 64.83 & 26.04 & 645 & 3.21 & 8.71 & -106.0 & 12 \\
\hline $04 / 30 / 07$ & $9: 03: 37$ & 3900.00 & 65.00 & 26.02 & 645 & 3.23 & 8.71 & -106.0 & 13 \\
\hline $04 / 30 / 07$ & $9: 13: 37$ & 3910.00 & 65.17 & 26 & 645 & 3.27 & 8.71 & -106.0 & 12 \\
\hline $04 / 30 / 07$ & $9: 23: 37$ & 3920.00 & 65.33 & 25.98 & 645 & 3.30 & 8.71 & -105.9 & 7 \\
\hline $04 / 30 / 07$ & $9: 33: 37$ & 3930.00 & 65.50 & 25.96 & 645 & 3.28 & 8.71 & -105.9 & 3 \\
\hline $04 / 30 / 07$ & $9: 43: 37$ & 3940.00 & 65.67 & 25.95 & 645 & 3.33 & 8.71 & -105.9 & -1 \\
\hline $04 / 30 / 07$ & $9: 53: 37$ & 3950.00 & 65.83 & 25.93 & 645 & 3.30 & 8.71 & -105.9 & -2 \\
\hline $04 / 30 / 07$ & $10: 03: 37$ & 3960.00 & 66.00 & 25.91 & 645 & 3.25 & 8.71 & -105.9 & 3 \\
\hline $04 / 30 / 07$ & $10: 13: 37$ & 3970.00 & 66.17 & 25.9 & 645 & 3.19 & 8.71 & -105.8 & 8 \\
\hline $04 / 30 / 07$ & $10: 23: 37$ & 3980.00 & 66.33 & 25.88 & 645 & 3.19 & 8.71 & -105.8 & 11 \\
\hline $04 / 30 / 07$ & $10: 33: 37$ & 3990.00 & 66.50 & 25.87 & 645 & 3.17 & 8.71 & -105.8 & 12 \\
\hline
\end{tabular}

\begin{tabular}{|c|c|c|c|c|c|c|c|}
\hline \multicolumn{8}{|c|}{ Analytical lab results MZM testing } \\
\hline \multirow[b]{2}{*}{ Sample } & \multicolumn{3}{|c|}{$\mathrm{Gr}_{\mathrm{r}}$} & \multicolumn{3}{|c|}{$\mathbf{N}$} & \multirow[b]{2}{*}{ NOTES: } \\
\hline & $\begin{array}{l}\text { TOTAL } \\
\text { (mg'L) }\end{array}$ & $\begin{array}{c}C r+6 \\
(m g / L)\end{array}$ & $\begin{array}{c}\% \mathrm{Cr}+6 \\
\text { Reduced }\end{array}$ & $\begin{array}{c}\text { Ammonia- } \\
\mathrm{NH}_{3} \\
\left(\mathrm{mg}^{\prime} \mathrm{L}\right)\end{array}$ & $\begin{array}{c}\text { Nitrite-No } \\
(\mathbf{m g} / \mathrm{L})\end{array}$ & $\begin{array}{l}\text { Nitrate-NO }{ }^{3} \\
\text { (mg/L) }\end{array}$ & \\
\hline Hanford Surrogate GW & 0.303 & 0.245 & $0.0 \%$ & 0.521 & & & Baseline of $\mathrm{Cr}$-spiked surrogate Hanford groundwater \\
\hline MZM & 0.153 & 0.131 & $46.5 \%$ & 0.921 & & & $\begin{array}{l}\text { Sample of surrogate Hanford GW that was in contact with only MZV) (1\% } \\
\text { wW) for } 66.3 \text {-hours }\end{array}$ \\
\hline MZVI+Aerosol & 0.128 & 0.121 & $50.6 \%$ & & & & $\begin{array}{l}\text { Sample of surrogate Hanford GW that was in contact with } \mathrm{MZVI}(1 \% \text { w/w) } \\
\text { and Aerosol } 22(0.001 \% \text { w/w) for } 66.0 \text {-hours }\end{array}$ \\
\hline MZVi+Polymer+Aerosol & 0.223 & 0.163 & $33.5 \%$ & & & & $\begin{array}{l}\text { Sample of surrogate Hanford GW that was in contaci with MZVI (1\% w/w), } \\
\text { Slumy Pro CDP polymer (0.02\% w'w), and Aerosol } 22(0.001 \% \text { w'w) for } \\
66.5 \text { hours }\end{array}$ \\
\hline Sponge inon Powder & 0.011 & 0.000 & $100.0 \%$ & & & & $\begin{array}{l}\text { Sample of surogate Hanford GW that was in contact with only "Sponge } \\
\text { Iron Powder" }(1 \% \text { w/w) for } 66.5 \text {-hours }\end{array}$ \\
\hline
\end{tabular}


Determination of GW Injection Pressures

\begin{tabular}{|c|c|c|c|c|c|c|}
\hline \multirow{2}{*}{$\begin{array}{c}\text { Pump Rate } \\
(\mathbf{m L} / \mathbf{m i n})\end{array}$} & \multicolumn{2}{|c|}{ Water Column Height (in) for Column: } & \multicolumn{3}{c|}{ Injection Pressure (psi) for Column: } \\
\cline { 2 - 7 } & $\mathbf{1 1}$ & $\mathbf{1 2}$ & AVERAGE & $\mathbf{1 1}$ & $\mathbf{1 1}$ & 12 \\
\hline 0 & 0.00 & 0.00 & 0.00 & 0.00 & 0.00 & 0.00 \\
\hline 1.4 & 8.25 & 8.00 & 8.13 & 0.30 & 0.29 & 0.29 \\
\hline 2 & 11.38 & 11.00 & 11.19 & 0.41 & 0.40 & 0.40 \\
\hline 5 & 27.25 & 26.75 & 27.00 & 0.98 & 0.97 & 0.98 \\
\hline 10 & 55.25 & 54.75 & 55.00 & 2.00 & 1.98 & 1.99 \\
\hline 15 & 80.50 & 80.00 & 80.25 & 2.91 & 2.89 & 2.90 \\
\hline
\end{tabular}

Using Equation from Trend Line

$\mathrm{m}=0.1937$

$b=0.0148$

\begin{tabular}{|c|c|c|c|}
\hline $\begin{array}{c}\text { Pump Rate } \\
\text { (mL/min) }\end{array}$ & $\begin{array}{c}\text { Injection } \\
\text { Pressure (psi) }\end{array}$ & Feet of Water & $\begin{array}{c}\text { Inches of } \\
\text { Water }\end{array}$ \\
\hline 0 & 0.0 & 0.0 & 0.4 \\
\hline 1 & 0.2 & 0.5 & 5.8 \\
\hline 2 & 0.4 & 0.9 & 11.1 \\
\hline 5 & 1.0 & 2.3 & 27.2 \\
\hline 10 & 2.0 & 4.5 & 54.0 \\
\hline 15 & 2.9 & 6.7 & 80.8 \\
\hline 20 & 3.9 & 9.0 & 107.7 \\
\hline 25 & 4.9 & 11.2 & 134.5 \\
\hline 30 & 5.8 & 13.4 & 161.3 \\
\hline
\end{tabular}

\begin{tabular}{|c|c|c|c|c|c|c|c|c|}
\hline \multicolumn{9}{|c|}{ MZVI Settling Data } \\
\hline \multicolumn{3}{|c|}{ Polymer Concentration: $0.01 \%$} & \multicolumn{4}{|c|}{ S.G. Correction Factor ${ }^{* \star}(a)$ : } & \multirow{2}{*}{\multicolumn{2}{|c|}{$\begin{array}{r}0.796 \\
995\end{array}$}} \\
\hline & & & Dry Mass of Par & rticles ir & Sample (V & N) $(\mathrm{g})$ : & & \\
\hline Date \& Time & $\begin{array}{l}\text { Minutes } \\
\text { Elapsed }\end{array}$ & $\begin{array}{c}\text { Hydrometer } \\
\text { Measurement }\end{array}$ & $\begin{array}{l}\% \text { Particles in } \\
\text { Suspension* }\end{array}$ & $\begin{array}{c}\text { Temp } \\
\left({ }^{\circ} \mathrm{C}\right)\end{array}$ & $\begin{array}{c}\mathrm{SC} \\
(\mathrm{mS} / \mathrm{cm})\end{array}$ & $\begin{array}{c}\mathrm{DO} \\
(\mathrm{mg} / \mathrm{L})\end{array}$ & $\begin{array}{c}\mathrm{pH} \\
\text { (SU) }\end{array}$ & $\begin{array}{l}\text { ORP } \\
\text { (mv) }\end{array}$ \\
\hline $3 / 13 / 0711: 07$ & 0 & 1 & N/A & 18.09 & 178 & 6.75 & 6.68 & 62.4 \\
\hline $3 / 13 / 0711: 14$ & 2 & 1 & N/A & 18.28 & 177 & 6.64 & 7.23 & 67.0 \\
\hline $3 / 13 / 07 \quad 12: 34$ & 5 & 1 & N/A & 18.66 & 171 & 7.05 & 7.10 & 108.4 \\
\hline 3/13/07 13:01 & 10 & 1.5 & N/A & 18.83 & 167 & 6.47 & 6.99 & 135.0 \\
\hline $3 / 13 / 0713: 40$ & 15 & 0.5 & N/A & 18.91 & 172 & 6.78 & 6.76 & 173.0 \\
\hline $3 / 13 / 0714: 10$ & 30 & 0.5 & N/A & 18.85 & 172 & 6.50 & 7.12 & 160.2 \\
\hline $3 / 13 / 0714: 40$ & 60 & 0.5 & N/A & 18.61 & 175 & 6.48 & 6.89 & 172.4 \\
\hline $3 / 13 / 07 \quad 17: 15$ & 215 & 0 & N/A & 20.27 & 177 & 6.44 & 7.07 & 153.6 \\
\hline $3 / 14 / 0712: 30$ & 1370 & 0 & $\mathrm{~N} / \mathrm{A}$ & 17.99 & 184 & 6.34 & 7.60 & 130.8 \\
\hline $3 / 13 / 07 / 11 \cdot 10$ & & & 1000 & 102 & 170 & 600 & & \\
\hline $3 / 13 / 0711: 19$ & $\frac{0}{2}$ & $\frac{12.0}{9}$ & $72 \%$ & $\frac{18.2}{18.32}$ & $\frac{176}{177}$ & $\frac{0.80}{6.68}$ & $\frac{1.01}{730}$ & $\frac{65.0}{720}$ \\
\hline $3 / 13 / 0712: 37$ & 5 & 6 & $48 \%$ & 18.66 & 172 & 7.27 & 6.97 & 118.4 \\
\hline 3/13/07 13:06 & 10 & 5.5 & $44 \%$ & 18.88 & 173 & 6.54 & 7.11 & 136.7 \\
\hline $3 / 13 / 07$ 13:44 & 15 & 4.5 & $36 \%$ & 18.83 & 175 & 7.39 & 7.07 & 161.1 \\
\hline $3 / 13 / 07$ 14:14 & 30 & 3 & $24 \%$ & 18.99 & 167 & 6.64 & 7.13 & 159.8 \\
\hline $3 / 13 / 07$ 14:44 & 60 & 2 & $16 \%$ & 18.7 & 174 & 6.38 & 7.16 & 159.1 \\
\hline $3 / 13 / 07$ 17:19 & 215 & 0.25 & $2 \%$ & 19.99 & 180 & 6.58 & 7.12 & 148.8 \\
\hline $3 / 14 / 07$ 12:34 & 1370 & 0 & $0 \%$ & 17.81 & 178 & 6.42 & 7.31 & 121.1 \\
\hline
\end{tabular}

*\% Particles in Suspension $(P)=(R \times a / W) \times 100$, where $R=$ Corrected Hydrometer Measurement, 


\begin{tabular}{|l|l|c|c|c|c|c|c|c|}
\hline \multicolumn{9}{|c|}{ MZVI Settling Data } \\
\hline \\
\hline
\end{tabular}

*\% Particles in Suspension $(P)=(R \times a / W) \times 100$, where $R=$ Corrected Hydrometer Measurement,

\begin{tabular}{|c|c|c|c|c|c|c|c|c|}
\hline \multicolumn{9}{|c|}{ MZVI Settling Data } \\
\hline \multicolumn{3}{|c|}{ Polymer Concentration: $\mathbf{0 . 0 2 \%}$} & \multirow{2}{*}{\multicolumn{4}{|c|}{ S.G. Correction Factor ${ }^{* *}$ (a): }} & \multicolumn{2}{|c|}{0.829} \\
\hline & & & & rticles ir & Sample (1 & W) $(g)$ : & 9.95 & \\
\hline Date \& Time & $\begin{array}{l}\text { Minutes } \\
\text { Elapsed }\end{array}$ & $\begin{array}{c}\text { Hydrometer } \\
\text { Measurement }\end{array}$ & $\begin{array}{l}\% \text { Particles in } \\
\text { Suspension* }\end{array}$ & $\begin{array}{c}\text { Temp } \\
\left({ }^{\circ} \mathrm{C}\right)\end{array}$ & $\begin{array}{c}\mathrm{SC} \\
(\mathrm{mS} / \mathrm{cm})\end{array}$ & $\begin{array}{c}\mathrm{DO} \\
\text { (mg/L) }\end{array}$ & $\begin{array}{l}\mathrm{pH} \\
\text { (SU) }\end{array}$ & $\begin{array}{l}\text { ORP } \\
\text { (mv) }\end{array}$ \\
\hline $3 / 13 / 0711: 25$ & 0 & 1.5 & N/A & 18.18 & 181 & 6.30 & 7.40 & 79.8 \\
\hline $3 / 13 / 07 \quad 11: 32$ & 2 & 1 & N/A & 18.16 & 171 & 6.31 & 7.29 & 91.6 \\
\hline $3 / 13 / 07$ 12:40 & 5 & 1 & N/A & 18.56 & 180 & 6.79 & 7.19 & 113.6 \\
\hline $3 / 13 / 07$ 13:11 & 10 & 1 & N/A & 18.73 & 173 & 6.41 & 7.39 & 124.4 \\
\hline $3 / 13 / 07$ 13:48 & 15 & 0.5 & N/A & 18.81 & 177 & 6.81 & 7.19 & 159.9 \\
\hline $3 / 13 / 07$ 14:18 & 30 & 0.5 & N/A & 18.95 & 184 & 6.52 & 7.13 & 144.3 \\
\hline $3 / 13 / 07 \quad 14: 48$ & 60 & 0.5 & N/A & 18.82 & 175 & 6.46 & 7.24 & 164.7 \\
\hline $3 / 13 / 0717: 24$ & 216 & 0 & $\mathrm{~N} / \mathrm{A}$ & 19.96 & 183 & 6.61 & 7.16 & 145.1 \\
\hline $3 / 14 / 07$ 12:38 & 1370 & 0 & $\mathrm{~N} / \mathrm{A}$ & 17.82 & 185 & 6.24 & 7.37 & 122.0 \\
\hline & & & & & & & & \\
\hline $3 / 13 / 07$ 11:28 & 0 & 12 & $100 \%$ & 18.26 & 184 & 11.38 & 7.32 & 87.6 \\
\hline $3 / 13 / 07$ 11:37 & 2 & 11 & $92 \%$ & 18.42 & 174 & 6.38 & 7.06 & 100.8 \\
\hline $3 / 13 / 0712: 47$ & 5 & 10.5 & $88 \%$ & 18.93 & 178 & 6.92 & 6.91 & 134.6 \\
\hline $3 / 13 / 07$ 13:16 & 10 & 9 & $75 \%$ & 19.08 & 181 & 6.64 & 7.44 & 118.6 \\
\hline $3 / 13 / 07$ 13:52 & 15 & 9 & $75 \%$ & 19.22 & 177 & 6.50 & 7.23 & 152.6 \\
\hline $3 / 13 / 07$ 14:22 & 30 & 8 & $67 \%$ & 18.81 & 179 & 6.82 & 7.22 & 148.7 \\
\hline $3 / 13 / 0714: 52$ & 60 & 5 & $42 \%$ & 18.89 & 178 & 7.04 & 7.31 & 161.4 \\
\hline $3 / 13 / 07$ 17:28 & 216 & 3 & $25 \%$ & 20.09 & 185 & 6.22 & 7.29 & 141.2 \\
\hline $3 / 14 / 07$ 12:42 & 1370 & 1 & $8 \%$ & 17.73 & 191 & 6.63 & 7.41 & 119.6 \\
\hline
\end{tabular}

$* \%$ Particles in Suspension $(P)=(R \times a / W) \times 100$, where R=Corrected Hydrometer Measurement, 
DOE/RL-2009-35, REV. 0

\section{C2 Batch Screening Test}

\begin{tabular}{|c|c|c|c|c|c|c|c|c|c|c|}
\hline \multicolumn{11}{|c|}{ ZV1 Materials Reactivity Testing - Part A } \\
\hline \multirow[b]{2}{*}{ Description } & \multicolumn{10}{|c|}{ MATERIAL } \\
\hline & $\begin{array}{l}\text { Surrogate } \\
\text { ZVI GW }^{1}\end{array}$ & $\begin{array}{l}\text { RNIP - } \\
\text { 10DS }\end{array}$ & EZVI & NanoFe II & NanoFe I & $\begin{array}{c}\text { Poly } \\
\text { Metallix }\end{array}$ & Zloy & $\begin{array}{c}\text { Meta Materia } \\
{ }^{\prime \prime} \mathrm{D}^{2}\end{array}$ & \begin{tabular}{|c} 
Meta Materia \\
"E"
\end{tabular} & Control $^{3}$ \\
\hline \multicolumn{11}{|c|}{ Reacitivity Part A - Test \#1 - October 10, 2007} \\
\hline Temp $\left({ }^{\circ} \mathrm{C}\right)$ & 19.51 & 24.78 & 24.23 & 24.08 & 23.83 & 23.65 & 24.11 & 23.68 & 23.66 & 23.53 \\
\hline S.C. (uS $/ \mathrm{cm})$ & 597 & 595 & 559 & 634 & 685 & 634 & $4 \overline{64}$ & 1305 & 2110 & $6 \overline{60}$ \\
\hline Dissolved $\mathrm{O}_{2}(\mathrm{mg} / \mathrm{L})$ & 6.24 & 0.25 & 2.13 & 3.71 & 0.57 & 5.2 & 3.27 & 5.18 & 4.34 & 5.35 \\
\hline $\mathrm{pH}(\mathrm{SU})$ & 7.41 & 9.03 & 9.2 & 8.43 & 9.05 & 7.86 & 9.3 & 9.22 & 9.28 & 7.62 \\
\hline ORP (mV) & 217.2 & 45.4 & 201.8 & 198.4 & 151.7 & $\mathbf{1 7 4 . 4}$ & 159.8 & 191.7 & 172 & 185.9 \\
\hline $\mathrm{Cr}^{\text {+t }}$ (Dissolved) & 602 & ND & ND & ND & ND & ND & ND & 504 & 402 & 601 \\
\hline \multicolumn{11}{|c|}{ Reacitivity Part A - Test \#2 - October 11, 2007} \\
\hline Temp $\left({ }^{\circ} \mathrm{C}\right)$ & 18.65 & 21 & 21.55 & 21.1 & 21.81 & 22 & 20.91 & 20.62 & 21.3 & $20 . \overline{44}$ \\
\hline S.C. (uS $/ \mathrm{cm})$ & 594 & 580 & 527 & 620 & 651 & 595 & 437 & 1227 & 1975 & 637 \\
\hline Dissolved $\mathrm{O}_{2}(\mathrm{mg} / \mathrm{L})$ & 6.04 & 0.46 & 0.3 & 1.51 & 0.34 & 4.52 & 0.87 & 5.57 & 5.3 & 5.62 \\
\hline $\mathrm{pH}(\mathrm{SU})$ & 7.27 & 8.94 & 9.57 & 8.61 & 9.13 & 7.81 & 9.23 & 9.18 & 9.26 & 7.83 \\
\hline ORP (mV) & 253.1 & 81 & 212.2 & 155.9 & 116 & 102.1 & 77.9 & 155 & 187.2 & 168.4 \\
\hline $\mathrm{Cr}^{+6}$ (Dissolved) & 593 & ND & ND & ND & ND & ND & ND & 507 & 357 & 590 \\
\hline \multicolumn{11}{|c|}{ Reacitivity Part A - Test \#3 - October 12, 2007} \\
\hline Temp $\left({ }^{\circ} \mathrm{C}\right)$ & 17.86 & 21.59 & 21.7 & 21.6 & 22.21 & 22.01 & 22.58 & 22.58 & 22.36 & 22.86 \\
\hline S.C. $(\mathrm{uS} / \mathrm{cm})$ & 595 & 538 & 493 & 610 & 630 & 599 & 422 & 781 & 1475 & 636 \\
\hline Dissolved $\mathrm{O}_{2}(\mathrm{mg} / \mathrm{L})$ & 6.48 & 0.37 & $0 . \overline{26}$ & 3.3 & 0.37 & 2.45 & 0.21 & 5.57 & 4.89 & 6.23 \\
\hline $\mathrm{pH}(\mathrm{SU})$ & 7.31 & 8.76 & 9.36 & 8.63 & 9.07 & 7.85 & 9.32 & 8.96 & $9 . \overline{23}$ & 7.25 \\
\hline $\operatorname{ORP}(\mathrm{mV})$ & 320.9 & 144.2 & 220.2 & 218.2 & 234.6 & 201.3 & 182.4 & 199.8 & 203.1 & 260.8 \\
\hline $\mathrm{Cr}^{16}$ (Dissolved) & 622 & ND & ND & ND & ND & $\mathrm{ND}$ & ND & 502 & 456 & 600 \\
\hline \multicolumn{11}{|l|}{ Reacitivity Part A - Averages } \\
\hline Temp $\left({ }^{\circ} \mathrm{C}\right)$ & 18.67 & 22.46 & 22.49 & 22.26 & 22.62 & 22.55 & 22.53 & 22.29 & 22.44 & 22.28 \\
\hline S.C. (uS/cm) & 595 & 571 & 526 & 621 & 655 & 609 & 441 & 1104 & 1853 & 644 \\
\hline Dissolved $\mathrm{O}_{2}$ (mg/L) & 6.25 & 0.36 & 0.90 & 2.84 & 0.43 & 4.06 & 1.45 & 5.44 & 4.84 & 5.73 \\
\hline $\mathrm{pH}(\mathrm{SU})$ & 7.33 & 8.91 & 9.38 & 8.56 & 9.08 & 7.84 & 9.28 & 9.12 & 9.26 & 7.57 \\
\hline $\operatorname{ORP}(\mathrm{mV})$ & 263.7 & 90.2 & $21 \uparrow .4$ & 190.8 & 167.4 & 159.3 & 140.0 & 182.2 & 187.4 & 205.0 \\
\hline $\mathrm{Cr}^{+6}$ (Dissolved) & 606 & ND & ND & ND & ND & ND & ND & 504 & 405 & 597 \\
\hline \multicolumn{11}{|c|}{ Surrogate ZVI groundwater does not contain ZVI material or silica sand and was analyzed prior to each respective batch test. } \\
\hline \multicolumn{11}{|c|}{${ }^{2}$ Due to insufficient sample available for MetaMateria " $\mathrm{D}$ " in Test $\# 3,0.85$ grams was used instead of the 2.34 grams used in the previous two tests. } \\
\hline \multicolumn{11}{|c|}{${ }^{3}$ Controt sample contains surrogate groundwater, silica sand, but no $\mathrm{ZVI}$ and was analyzed at the end of the 4-hour batch test. } \\
\hline $\mathrm{ND}=$ Non Detect & & & & & & & & & & \\
\hline
\end{tabular}




\section{C3 Injection Screening Test}

\begin{tabular}{|c|c|c|c|c|c|c|c|c|c|}
\hline & & & \multicolumn{2}{|c|}{ Sample } & \multicolumn{5}{|c|}{ Parameters Measured } \\
\hline Date & Time & Flow Cell & $\begin{array}{l}\text { Start } \\
(\mathrm{ml})\end{array}$ & \begin{tabular}{|l} 
End \\
$(\mathrm{ml})$
\end{tabular} & $\begin{array}{c}\text { Temp. } \\
\left({ }^{\circ} \mathrm{C}\right)\end{array}$ & $\begin{array}{c}\mathrm{SC} \\
(\mathrm{mS} / \mathrm{cm})\end{array}$ & $\begin{array}{c}\text { DO } \\
(\mathrm{mg} / \mathrm{L})\end{array}$ & \begin{tabular}{|c|}
$\mathrm{pH}$ \\
(SU)
\end{tabular} & $\begin{array}{l}\text { ORP } \\
\text { (mv) }\end{array}$ \\
\hline $3 / 14 / 2007$ & $8: 58$ & 0 & -- & -- & 19.33 & 629 & 6.71 & 7.47 & 50.0 \\
\hline $3 / 15 / 2007$ & $9: 31$ & 0 & -- & -- & 18.47 & 634 & 7.23 & 7.85 & 64.1 \\
\hline $3 / 14 / 2007$ & $12: 22$ & 3 & 0 & 270 & 20.33 & 352 & 6.95 & 7.80 & 12.3 \\
\hline $3 / 14 / 2007$ & $13: 42$ & 3 & 270 & 540 & 20.73 & 421 & 7.04 & 8.07 & 29.0 \\
\hline $3 / 14 / 2007$ & $12: 17$ & 4 & 0 & 270 & 20.15 & 268 & 6.90 & 8.11 & 23.3 \\
\hline $3 / 14 / 2007$ & $13: 42$ & 4 & 270 & 540 & 20.65 & 352 & 6.28 & 8.17 & 54.7 \\
\hline $3 / 14 / 2007$ & $12: 42$ & 4 & 540 & 1040 & 21.03 & 630 & 6.27 & 8.01 & 29.5 \\
\hline $3 / 14 / 2007$ & $22: 42$ & 4 & 1040 & 1310 & 20.97 & 608 & 6.77 & 7.55 & 90.4 \\
\hline $3 / 15 / 2007$ & $8: 40$ & 4 & 1310 & 2225 & 20.08 & 641 & 7.55 & 8.13 & 51.9 \\
\hline $3 / 15 / 2007$ & $11: 11$ & 4 & 2284 & 2534 & 20.47 & 638 & 6.79 & 8.19 & 124.3 \\
\hline $3 / 15 / 2007$ & $14: 04$ & 4 & 2534 & 2824 & 21.24 & 641 & 6.93 & 8.14 & 100.6 \\
\hline $3 / 15 / 2007$ & 19:02 & 4 & 2824 & 3324 & 20.77 & 636 & 7.34 & 8.08 & 98.8 \\
\hline $3 / 15 / 2007$ & $9: 01$ & 4 & 3324 & 3474 & 20.28 & 619 & 7.05 & 7.97 & 83.5 \\
\hline $3 / 16 / 2007$ & $8: 32$ & 4 & 3629 & 4629 & 20.02 & 641 & 7.30 & 8.10 & 58.1 \\
\hline $3 / 16 / 2007$ & $11: 17$ & 4 & 4629 & 4919 & 20.56 & 635 & 7.52 & 8.14 & 140.3 \\
\hline $3 / 14 / 2007$ & $12: 24$ & 7 & 0 & 270 & 20.18 & 450 & 6.58 & 8.00 & -1.6 \\
\hline $3 / 14 / 2007$ & $13: 42$ & 7 & 270 & 540 & 20.90 & 558 & 6.66 & 8.08 & 40.3 \\
\hline $3 / 14 / 2007$ & $20: 40$ & 7 & 540 & 1040 & 21.44 & 530 & 5.68 & 7.95 & 31.9 \\
\hline $3 / 14 / 2007$ & $22: 49$ & 7 & 1040 & 1310 & 20.61 & 529 & 6.43 & 7.99 & 65.0 \\
\hline $3 / 15 / 2007$ & $9: 55$ & 7 & 1310 & 2225 & 20.15 & 619 & 6.99 & 8.06 & 61.9 \\
\hline $3 / 15 / 2007$ & 12:09 & 7 & 2225 & 2475 & 20.72 & 640 & 7.25 & 8.12 & 83.0 \\
\hline $3 / 15 / 2007$ & $15: 09$ & 7 & 2475 & 2750 & 21.53 & 634 & 6.05 & 8.09 & 79.6 \\
\hline $3 / 14 / 2007$ & $13: 42$ & 11 & 270 & 540 & 21.10 & 644 & 6.39 & 7.99 & 11.0 \\
\hline $3 / 14 / 2007$ & $20: 41$ & 11 & 540 & 1040 & 21.20 & 628 & 5.97 & 7.89 & 86.0 \\
\hline $3 / 14 / 2007$ & $22: 51$ & 11 & 1040 & 1310 & 20.51 & 628 & 6.53 & 8.00 & 82.7 \\
\hline $3 / 15 / 2007$ & $10: 16$ & 11 & 1315 & 2257 & 20.25 & 645 & 6.91 & 8.08 & 11.0 \\
\hline $3 / 15 / 2007$ & $12: 34$ & 11 & 2225 & 2467 & 20.52 & 648 & 7.65 & 8.05 & 54.3 \\
\hline $3 / 15 / 2007$ & $15: 49$ & 11 & 2467 & 2747 & 21.67 & 648 & 6.96 & 8.04 & 102.2 \\
\hline $3 / 15 / 2007$ & $19: 26$ & 11 & 2747 & 3087 & 21.04 & 647 & 9.07 & 8.00 & 111.8 \\
\hline $3 / 15 / 2007$ & $21: 06$ & 11 & 3087 & 3237 & 20.46 & 633 & 6.57 & 8.00 & 88.7 \\
\hline $3 / 16 / 2007$ & $9: 46$ & 11 & 3362 & 4362 & 20.60 & 646 & 7.49 & 7.99 & 75.4 \\
\hline $3 / 14 / 2007$ & $13: 42$ & 12 & 270 & 540 & 20.77 & 641 & 6.67 & 8.02 & 96.3 \\
\hline $3 / 14 / 2007$ & $20: 38$ & 12 & 220 & 750 & 21.54 & 625 & 6.14 & 7.94 & 63.4 \\
\hline $3 / 15 / 2007$ & $10: 55$ & 12 & 1270 & 2298 & 20.24 & 643 & 7.13 & 8.12 & 114.7 \\
\hline $3 / 15 / 2007$ & $12: 39$ & 12 & 2298 & 2457 & 20.59 & 643 & 7.52 & 8.11 & 92.1 \\
\hline $3 / 15 / 2007$ & $15: 53$ & 12 & 2457 & 2747 & 21.93 & 643 & 7.59 & 8.01 & 99.7 \\
\hline $3 / 15 / 2007$ & 19:33 & 12 & 2747 & 3077 & 20.62 & 644 & 7.20 & 8.11 & 133.1 \\
\hline $3 / 15 / 2007$ & $21: 11$ & 12 & 3077 & 3224 & 20.08 & 643 & 6.88 & 8.10 & 98.1 \\
\hline $3 / 16 / 2007$ & $9: 56$ & 12 & 3447 & 4447 & 20.72 & 644 & 7.46 & 7.94 & 99.4 \\
\hline $3 / 16 / 2007$ & $17: 52$ & 4 & 4919 & 5219 & 21.20 & 639 & 7.17 & 8.07 & 97.0 \\
\hline $3 / 16 / 2007$ & $15: 32$ & 11 & 4362 & 4882 & 21.76 & 636 & 6.01 & 7.92 & 104.1 \\
\hline $3 / 16 / 2007$ & $15: 33$ & 12 & 4447 & 4957 & 21.53 & 642 & 6.10 & 8.00 & 104.9 \\
\hline $3 / 16 / 2007$ & $17: 05$ & 11 & 4882 & 5022 & 21.75 & 644 & 6.59 & 7.89 & 108.9 \\
\hline $3 / 16 / 2007$ & $17: 06$ & 12 & 4957 & 5097 & 21.39 & 643 & 6.85 & 8.01 & 107.8 \\
\hline $3 / 17 / 2007$ & $17: 42$ & 4 & 5539 & 7789 & 19.93 & 639 & 6.72 & 7.91 & $\overline{157.3}$ \\
\hline $3 / 17 / 2007$ & $17: 46$ & 11 & 5165 & 7075 & 20.35 & 640 & 6.63 & 8.01 & $\overline{141.6}$ \\
\hline $3 / 17 / 2007$ & $17: 52$ & 12 & 5372 & 7297 & 20.23 & 634 & 6.88 & 8.08 & 142.3 \\
\hline $3 / 20 / 2007$ & $11: 00$ & 11 & & & 18.20 & 627 & 6.90 & 7.62 & 104.7 \\
\hline $3 / 20 / 2007$ & $11: 00$ & 12 & & & 18.23 & & & & \\
\hline $3 / 20 / 2007$ & $11: 34$ & 4 & & & 18.65 & & & & \\
\hline $3 / 20 / 2007$ & $9: 45$ & BaseWater & & & 17.32 & & & & \\
\hline $3 / 20 / 2007$ & $15: 35$ & 12 & & & 19.23 & & & & \\
\hline $3 / 20 / 2007$ & $15: 35$ & 11 & & & 19.06 & & & & \\
\hline $3 / 20 / 2007$ & $15: 35$ & 4 & & & 19.03 & & & & \\
\hline $3 / 20 / 2007$ & $15: 57$ & $1 \mathrm{P}$ & & & 19.02 & & & & \\
\hline $3 / 20 / 2007$ & $15: 57$ & $2 P$ & & & 18.74 & & & & \\
\hline $3 / 20 / 2007$ & $15: 57$ & $3 P$ & & & 19.08 & & & & \\
\hline $3 / 20 / 2007$ & $15: 57$ & 4P & & & 19.11 & & & & \\
\hline
\end{tabular}


DOE/RL-2009-35, REV. 0

\begin{tabular}{|l|c|c|c|c|c|c|c|c|c|}
\hline & & & Sample & \multicolumn{5}{|c|}{ Parameters Measured } \\
\hline Date & Time & Flow Cell & $\begin{array}{c}\text { Start } \\
(\mathbf{m l})\end{array}$ & $\begin{array}{c}\text { End } \\
(\mathbf{m l})\end{array}$ & $\begin{array}{c}\text { Temp. } \\
\left.\mathbf{(}{ }^{\circ} \mathbf{C}\right)\end{array}$ & $\begin{array}{c}\text { SC } \\
(\mathbf{m S} / \mathbf{c m})\end{array}$ & $\begin{array}{c}\text { DO } \\
(\mathbf{m g} / \mathbf{L})\end{array}$ & $\begin{array}{c}\text { pH } \\
(\mathbf{S U})\end{array}$ & $\begin{array}{c}\text { ORP } \\
(\mathbf{m v})\end{array}$ \\
\hline $3 / 21 / 2007$ & $11: 02$ & BaseWater & & & 17.00 & & & & \\
\hline $3 / 21 / 2007$ & $11: 08$ & Poly/MZVI & & & 15.87 & & & & \\
\hline $3 / 21 / 2007$ & $10: 26$ & 12 & & & 17.53 & & & & \\
\hline $3 / 21 / 2007$ & $10: 25$ & 11 & & 17.46 & & & & & \\
\hline $3 / 21 / 2007$ & $10: 24$ & 4 & & & 17.56 & & & & \\
\hline $3 / 21 / 2007$ & $10: 23$ & $1 \mathrm{P}$ & & & 17.06 & & & & \\
\hline $3 / 21 / 2007$ & $10: 22$ & $2 \mathrm{P}$ & & & 16.76 & & & & \\
\hline $3 / 21 / 2007$ & $10: 21$ & $3 \mathrm{P}$ & & & 17.25 & & & & \\
\hline $3 / 21 / 2007$ & $10: 21$ & $4 \mathrm{P}$ & & & 17.61 & & & & \\
\hline $3 / 22 / 2007$ & $8: 21$ & $1 \mathrm{P}$ & & & 17.43 & & & & \\
\hline $3 / 22 / 2007$ & $8: 18$ & $2 \mathrm{P}$ & & & 17.38 & & & & \\
\hline $3 / 22 / 2007$ & $8: 15$ & $3 \mathrm{P}$ & & & 16.97 & & & & \\
\hline $3 / 22 / 2007$ & $8: 14$ & $4 \mathrm{P}$ & & & 17.20 & & & & \\
\hline $3 / 22 / 2007$ & $8: 23$ & 4 & & & 17.60 & & & & \\
\hline $3 / 22 / 2007$ & $8: 24$ & 11 & & & 17.35 & & & & \\
\hline $3 / 22 / 2007$ & $8: 25$ & 12 & & & 17.26 & & & & \\
\hline $3 / 22 / 2007$ & $10: 18$ & BaseWater & & & 16.01 & & & & \\
\hline $3 / 22 / 2007$ & $10: 45$ & Poly/MZVI & & & 24.03 & & & & \\
\hline $3 / 22 / 2007$ & $14: 45$ & $4 \mathrm{P}$ & & & 19.10 & & & & \\
\hline $3 / 22 / 2007$ & $14: 55$ & $3 \mathrm{P}$ & & & 19.08 & & & & \\
\hline $3 / 22 / 2007$ & $15: 13$ & $2 \mathrm{P}$ & & & 19.22 & & & & \\
\hline $3 / 22 / 2007$ & $14: 56$ & $1 \mathrm{P}$ & & & 19.32 & & & & \\
\hline $3 / 22 / 2007$ & $16: 05$ & $4 \mathrm{P}$ & & & 19.98 & & & & \\
\hline $3 / 22 / 2007$ & $16: 06$ & $3 \mathrm{P}$ & & & 20.16 & & & & \\
\hline $3 / 22 / 2007$ & $4: 04$ & $2 \mathrm{P}$ & & & 19.95 & & & & \\
\hline $3 / 22 / 2007$ & $4: 06$ & $1 \mathrm{P}$ & & & 20.23 & & & & \\
\hline $3 / 22 / 2007$ & $15: 03$ & 4 & & & 19.56 & & & & \\
\hline $3 / 22 / 2007$ & $15: 03$ & 11 & & & 19.56 & & & & \\
\hline $3 / 22 / 2007$ & $16: 57$ & $1 \mathrm{P}$ & & & 19.37 & & & & \\
\hline $3 / 22 / 2007$ & $17: 03$ & $4 \mathrm{P}$ & & & 20.18 & & & & \\
\hline $3 / 22 / 2007$ & $17: 06$ & $3 \mathrm{P}$ & & & 20.10 & & & & \\
\hline $3 / 22 / 2007$ & $17: 05$ & $2 \mathrm{P}$ & & & 19.99 & & & & \\
\hline
\end{tabular}


DOE/RL-2009-35, REV. 0

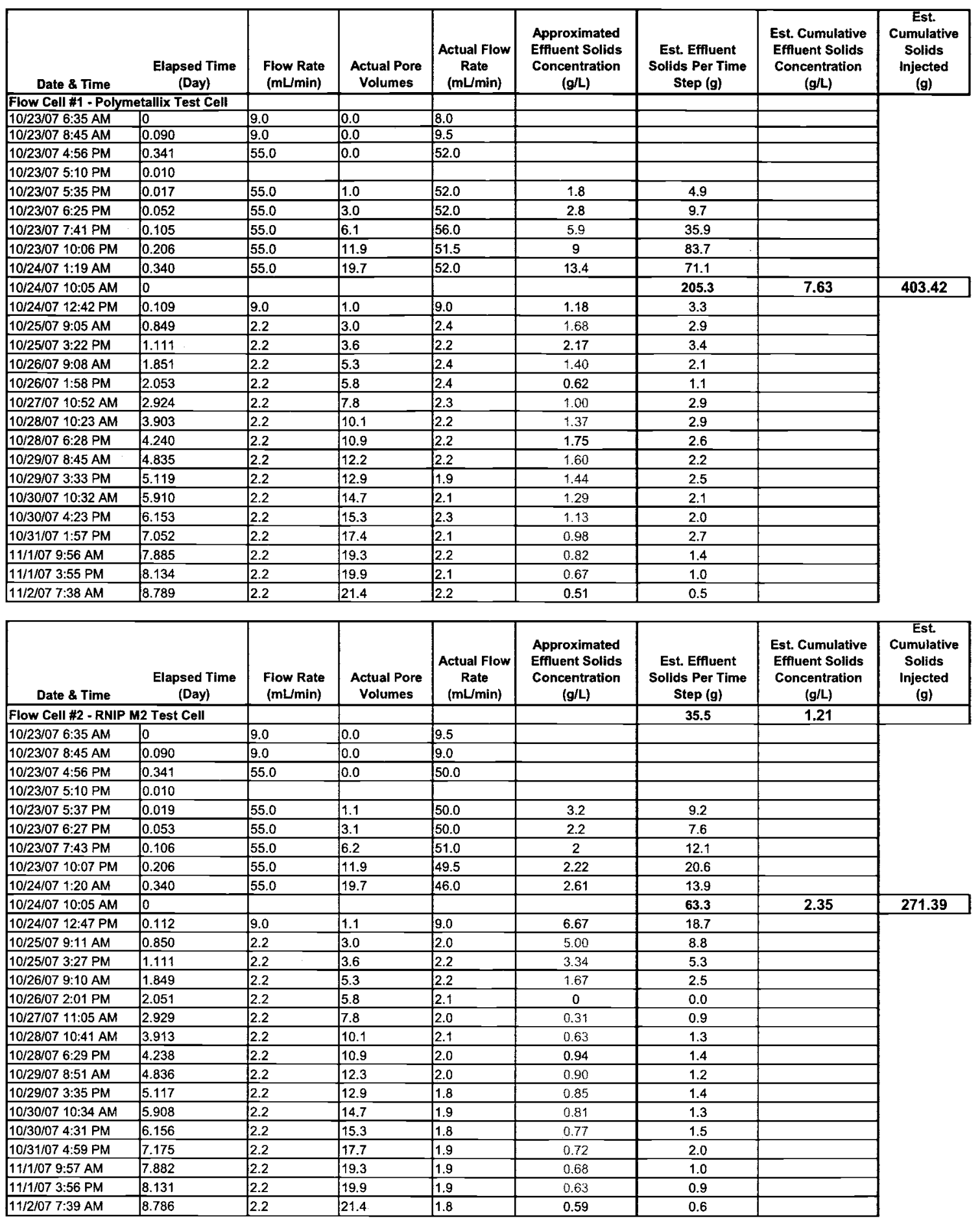


DOE/RL-2009-35, REV. 0

\begin{tabular}{|c|c|c|c|c|c|c|c|c|}
\hline Date \& Time & $\begin{array}{c}\text { Elapsed Time } \\
\text { (Day) }\end{array}$ & $\begin{array}{c}\text { Flow Rate } \\
(\mathrm{mL} / \mathrm{min})\end{array}$ & $\begin{array}{l}\text { Actual Pore } \\
\text { Volumes }\end{array}$ & $\begin{array}{c}\text { Actual Flow } \\
\text { Rate } \\
\text { (mL/min) }\end{array}$ & $\begin{array}{c}\text { Approximated } \\
\text { Effluent Solids } \\
\text { Concentration } \\
\text { (g/L) }\end{array}$ & $\begin{array}{l}\text { Est. Effluent } \\
\text { Solids Per Time } \\
\text { Step (g) }\end{array}$ & $\begin{array}{c}\text { Est. Cumulative } \\
\text { Effluent Solids } \\
\text { Concentration } \\
(g / L)\end{array}$ & $\begin{array}{c}\text { Est. } \\
\text { Cumulative } \\
\text { Solids } \\
\text { Injected } \\
\text { (g) }\end{array}$ \\
\hline \multicolumn{2}{|c|}{ Flow Cell \#3 - EZV1 Test Cell } & & & & & 48.9 & 1.67 & \\
\hline 10/23/07 6:35 AM & 0 & 9.0 & 0.0 & 8.8 & & & & \\
\hline 10/23/07 8:45 AM & 0.090 & 9.0 & 0.0 & 9.0 & & & & \\
\hline 10/23/07 5:03 PM & 0.346 & 55.0 & 0.0 & 51.0 & & & & \\
\hline 10/23/07 5:10 PM & 0.005 & & & & & & & \\
\hline 10/23/07 5:38 PM & 0.019 & 55.0 & 1.1 & 49.0 & 0 & 0.0 & & \\
\hline 10/23/07 6:27 PM & 0.053 & 55.0 & 3.1 & 50.0 & 0.2 & 0.7 & & \\
\hline 10/23/07 7:45 PM & 0.108 & 55.0 & 6.2 & 49.5 & 0.2 & 1.2 & & \\
\hline 10/23/07 10:08 PM & 0.207 & 55.0 & 12.0 & 49.5 & 0.2 & 1.8 & & \\
\hline 10/24/07 1:21 AM & 0.341 & 55.0 & 19.7 & 49.0 & 0 & 0.0 & & \\
\hline $10 / 24 / 0710: 05 \mathrm{AM}$ & 0 & & & & & 3.8 & 0.14 & 270.32 \\
\hline 10/24/07 12:47 PM & 0.112 & 9.0 & 1.1 & 9.0 & 1.11 & 3.1 & & \\
\hline 10/25/07 9:12 AM & 0.851 & 2.2 & 3.0 & 2.2 & 1.04 & 1.8 & & \\
\hline 10/25/07 3:28 PM & 1.112 & 2.2 & 3.6 & 1.8 & 0.97 & 1.5 & & \\
\hline 10/26/07 9:13 AM & 1.851 & 2.2 & 5.4 & 1.8 & 0.90 & 1.3 & & \\
\hline 10/26/07 2:03 PM & 2.053 & 2.2 & 5.8 & 1.8 & 0.83 & 1.4 & & \\
\hline 10/27/07 11:17 AM & 2.938 & 2.2 & 7.9 & 1.8 & 0.55 & 1.6 & & \\
\hline $10 / 28 / 0710: 50 \mathrm{AM}$ & 3.919 & 2.2 & 10.1 & 1.7 & 0.28 & 0.6 & & \\
\hline 10/28/07 6:30 PM & 4.238 & 2.2 & 10.9 & 2.0 & 0 & 0.0 & & \\
\hline 10/29/07 8:53 AM & 4.838 & 2.2 & 12.3 & 2.1 & 0.12 & 0.2 & & \\
\hline 10/29/07 3:38 PM & 5.119 & 2.2 & 12.9 & 1.8 & 0.23 & 0.4 & & \\
\hline 10/30/07 10:36 AM & 5.909 & 2.2 & 14.7 & 1.8 & 0.35 & 0.6 & & \\
\hline 10/30/07 4:34 PM & 6.158 & 2.2 & 15.3 & 1.9 & 0.47 & 0.8 & & \\
\hline 10/31/07 2:05 PM & 7.054 & 2.2 & 17.4 & 1.7 & 0.58 & 1.6 & & \\
\hline 11/1/07 9:58 АM & 7.883 & 2.2 & 19.3 & 1.8 & 0.70 & 1.2 & & \\
\hline 11/1/07 3:57 PM & 8.132 & 2.2 & 19.9 & 1.8 & 0.81 & 1.2 & & \\
\hline $11 / 2 / 077: 40 \mathrm{AM}$ & 8.787 & 2.2 & 21.4 & 1.8 & 0.93 & 1.0 & & \\
\hline \multirow{2}{*}{\multicolumn{3}{|c|}{\begin{tabular}{|cc|c} 
Date \& Time & $\begin{array}{c}\text { Elapsed Time } \\
\text { (Day) }\end{array}$ & $\begin{array}{c}\text { Flov } \\
\text { (mL }\end{array}$ \\
Flow Cell \#7 - Polymetallix Duplicate Cell &
\end{tabular}}} & \multirow[t]{2}{*}{$\begin{array}{c}\text { Actual Pore } \\
\text { Volumes }\end{array}$} & $\begin{array}{c}\text { Actual Flow } \\
\text { Rate } \\
\text { (mL/min) }\end{array}$ & $\begin{array}{c}\text { Approximated } \\
\text { Effluent Solids } \\
\text { Concentration } \\
(\mathrm{g} / \mathrm{L})\end{array}$ & $\begin{array}{c}\text { Est. Effluent } \\
\text { Solids Per Time } \\
\text { Step (g) }\end{array}$ & $\begin{array}{c}\text { Est. Cumulative } \\
\text { Effluent Solids } \\
\text { Concentration } \\
(g / L)\end{array}$ & $\begin{array}{l}\text { Est. } \\
\text { Cumulative } \\
\text { Solids } \\
\text { Injected } \\
\text { (g) }\end{array}$ \\
\hline & & & & & & 18.3 & 0.63 & \\
\hline 10/23/07 6:35 AM & 0 & 9.0 & 0.0 & 9.0 & & & & \\
\hline 10/23/07 8:45 AM & 0.090 & 9.0 & 0.0 & 7.0 & & & & \\
\hline 10/23/07 4:56 PM & 0.341 & 55.0 & 0.0 & 54.0 & & & & \\
\hline 10/23/07 5:10 PM & 0.010 & & & & & & & \\
\hline 10/23/07 5:36 PM & 0.018 & 55.0 & 1.0 & 50.0 & 3.4 & 9.5 & & \\
\hline 10/23/07 6:26 PM & 0.053 & 55.0 & 3.1 & 53.0 & 2.6 & 9.0 & & \\
\hline $10 / 23 / 07$ 7:42 PM & 0.106 & 55.0 & 6.1 & 54.0 & 5.74 & 12.9 & & \\
\hline 10/23/07 7:48 PM & 0.110 & 55.0 & 6.4 & 54.0 & 6.06 & 24.0 & & \\
\hline 10/23/07 10:06 PM & 0.206 & 55.0 & 11.9 & 47.0 & 6.38 & 58.2 & & \\
\hline $10 / 24 / 071: 20 \mathrm{AM}$ & 0.340 & 55.0 & 19.7 & 12.5 & 5.6 & 29.9 & & \\
\hline $10 / 24 / 07 \uparrow 0: 05 \mathrm{AM}$ & 0 & & & & & 143.6 & 5.33 & 404.25 \\
\hline $10 / 24 / 07$ 12:46 PM & 0.112 & 9.0 & 1.1 & 9.5 & 1.43 & 4.0 & & \\
\hline 10/25/07 9:05 AM & 0.847 & 2.2 & 3.0 & 2.0 & 1.28 & 2.3 & & \\
\hline 10/25/07 3:26 PM & 1.111 & 2.2 & 3.6 & 2.2 & 1.13 & 1.8 & & \\
\hline 10/26/07 9:09 AM & 1.849 & 2.2 & 5.3 & 2.3 & 0.98 & 1.5 & & \\
\hline $10 / 26 / 07$ 1:59 PM & 2.051 & 2.2 & 5.8 & 2.3 & 0.83 & 1.4 & & \\
\hline 10/27/07 11:00 AM & 2.926 & 2.2 & 7.8 & 2.3 & 0.55 & 1.6 & & \\
\hline $10 / 28 / 07$ 10:36 AM & 3.910 & 2.2 & 10.1 & 2.2 & 0.28 & 0.6 & & \\
\hline 10/28/07 6:28 PM & 4.237 & 2.2 & 10.9 & 2.3 & 0 & 0.0 & & \\
\hline 10/29/07 8:51 AM & 4.837 & 2.2 & 12.3 & 2.0 & 0.10 & 0.1 & & \\
\hline 10/29/07 8:52 AM & 4.837 & 2.2 & 12.3 & 2.0 & 0.20 & 0.1 & & \\
\hline 10/29/07 3:34 PM & 5.117 & 2.2 & 12.9 & 2.1 & 0.30 & 0.5 & & \\
\hline 10/30/07 10:32 AM & 5.907 & 2.2 & 14.7 & 2.0 & 0.40 & 0.7 & & \\
\hline 10/30/07 4:30 PM & 6.156 & 2.2 & 15.3 & 2.0 & 0.49 & 0.9 & & \\
\hline 10/31/07 1:59 PM & 7.051 & 2.2 & 17.4 & 2.0 & 0.59 & 1.6 & & \\
\hline 11/1/07 9:56 AM & 7.882 & 2.2 & 19.3 & 2.2 & 0.69 & 1.2 & & \\
\hline 11/1/07 3:55 PM & 8.131 & 2.2 & 19.9 & 2.2 & 0.79 & 1.1 & & \\
\hline $11 / 2 / 077: 39 \mathrm{AM}$ & 8.787 & 2.2 & 21.4 & 2.1 & 0.89 & 0.9 & & \\
\hline
\end{tabular}


DOE/RL-2009-35, REV. 0

\begin{tabular}{|c|c|c|c|c|c|c|c|c|}
\hline Date \& Time & $\begin{array}{l}\text { Elapsed Time } \\
\text { (Day) }\end{array}$ & $\begin{array}{c}\text { Flow Rate } \\
\text { (mL/min) }\end{array}$ & $\begin{array}{l}\text { Actual Pore } \\
\text { Volumes }\end{array}$ & $\begin{array}{c}\text { Actual Flow } \\
\text { Rate } \\
\text { (mL/min) }\end{array}$ & $\begin{array}{c}\text { Approximated } \\
\text { Effluent Solids } \\
\text { Concentration } \\
(g / L)\end{array}$ & $\begin{array}{l}\text { Est. Effluent } \\
\text { Solids Per Time } \\
\text { Step (g) }\end{array}$ & $\begin{array}{c}\text { Est. Cumulative } \\
\text { Effluent Solids } \\
\text { Concentration } \\
(g / L)\end{array}$ & $\begin{array}{c}\text { Est. } \\
\text { Cumulative } \\
\text { Solids } \\
\text { Injected } \\
\text { (g) }\end{array}$ \\
\hline \multicolumn{2}{|c|}{ Flow Cell \#8 - RNIP M2 Duplicate Cell } & & & & & 20.2 & 0.69 & \\
\hline 10/23/07 6:35 AM & 0 & 9.0 & 0.0 & 9.0 & & & & \\
\hline 10/23/07 8:45 AM & 0.090 & 9.0 & 0.0 & 9.5 & & & & \\
\hline 10/23/07 5:03 PM & 0.346 & 55.0 & 0.0 & 51.0 & & & & \\
\hline 10/23/07 5:10 PM & 0.005 & & & & & & & \\
\hline 10/23/07 5:38 PM & 0.019 & 55.0 & 1.1 & 50.0 & 2.8 & 8.1 & & \\
\hline 10/23/07 6:27 PM & 0.053 & 55.0 & 3.1 & 50.0 & 2.2 & 7.6 & & \\
\hline 10/23/07 7:44 PM & 0.107 & 55.0 & 6.2 & 50.0 & 2.08 & 12.6 & & \\
\hline $10 / 23 / 0710: 08 \mathrm{PM}$ & 0.207 & 55.0 & 12.0 & 49.5 & 2.2 & 20.3 & & \\
\hline 10/24/07 1:20 AM & 0.340 & 55.0 & 19.7 & 49.5 & 2.2 & 11.6 & & \\
\hline 10/24/07 10:05 AM & 0 & & & & & 60.3 & 2.24 & 271.39 \\
\hline 10/24/07 12:47 PM & 0.112 & 9.0 & 1.1 & 9.0 & 2.22 & 6.2 & & \\
\hline 10/25/07 9:12 AM & 0.851 & 2.2 & 3.0 & 2.0 & 2.12 & 3.7 & & \\
\hline 10/25/07 3:27 PM & 1.111 & 2.2 & 3.6 & 2.0 & 2.02 & 3.2 & & \\
\hline 10/26/07 9:12 AM & 1.851 & 2.2 & 5.4 & 2.0 & 1.92 & 2.9 & & \\
\hline 10/26/07 2:02 PM & 2.052 & 2.2 & 5.8 & 2.0 & 1.82 & 3.1 & & \\
\hline $10 / 27 / 0711: 1+A M$ & 2.933 & 2.2 & 7.9 & 2.0 & 1.60 & 4.7 & & \\
\hline 10/28/07 10:46 AM & 3.916 & 2.2 & 10.1 & 2.0 & 1.38 & 2.9 & & \\
\hline 10/28/07 6:29 PM & 4.238 & 2.2 & 10.9 & 1.9 & 1.16 & 1.7 & & \\
\hline $10 / 29 / 078: 52 \mathrm{AM}$ & 4.837 & 2.2 & 12.3 & 2.1 & 1.21 & 1.7 & & \\
\hline 10/29/07 3:37 PM & 5.118 & 2.2 & 12.9 & 2.0 & 1.26 & 2.1 & & \\
\hline 10/30/07 10:35 AM & 5.908 & 2.2 & 14.7 & 2.0 & 1.31 & 2.1 & & \\
\hline 10/30/07 4:33 PM & 6.157 & 2.2 & 15.3 & 1.9 & $1.3 \hat{0}$ & 2.5 & & \\
\hline 10/31/07 2:00 PM & 7.051 & 2.2 & 17.4 & 1.9 & 1.40 & 3.8 & & \\
\hline 11/1/07 9:57 AM & 7.882 & 2.2 & 19.3 & 2.0 & 1.45 & 2.5 & & \\
\hline 11/1/07 3.56 PM & 8.131 & 2.2 & 19.9 & 2.0 & 1.50 & 2.2 & & \\
\hline 11/2/07 7:40 AM & 8.787 & 2.2 & 21.4 & 2.0 & 1.55 & 1.6 & & \\
\hline \multirow{2}{*}{\multicolumn{2}{|c|}{\begin{tabular}{|cc} 
Date \& Time & $\begin{array}{c}\text { Elapsed Time } \\
\text { (Day) }\end{array}$ \\
Flow Cell $\$ 9-$ Ezyl Duplicate Cell
\end{tabular}}} & $\begin{array}{c}\text { Flow Rate } \\
\text { (mL/min) }\end{array}$ & $\begin{array}{l}\text { Actual Pore } \\
\text { Volumes }\end{array}$ & $\begin{array}{c}\text { Actual Flow } \\
\text { Rate } \\
\text { (mL/min) }\end{array}$ & $\begin{array}{c}\text { Approximated } \\
\text { Effluent Solids } \\
\text { Concentration } \\
(g / L)\end{array}$ & $\begin{array}{c}\text { Est. Effluent } \\
\text { Solids Per Time } \\
\text { Step (g) }\end{array}$ & $\begin{array}{c}\text { Est. Cumulative } \\
\text { Effluent Solids } \\
\text { Concentration } \\
(g / L)\end{array}$ & $\begin{array}{c}\text { Est. } \\
\text { Cumulative } \\
\text { Solids } \\
\text { Injected } \\
\text { (g) }\end{array}$ \\
\hline & & & & & & 46.9 & 1.60 & \\
\hline 10/23/07 6:35 AM & 10 & 9.0 & 0.0 & 9.0 & & & & \\
\hline $10 / 23 / 078: 45 \mathrm{AM}$ & 0.090 & 9.0 & 0.0 & 9.0 & & & & \\
\hline 10/23/07 5:03 PM & 0.346 & 55.0 & 0.0 & 50.0 & & & & \\
\hline 10/23/07 5:10 PM & 0.005 & & & & & & & \\
\hline 10/23/07 5:38 PM & 0.019 & 55.0 & 1.1 & 50.0 & 0.2 & 0.6 & & \\
\hline 10/23/07 6:28 PM & 0.054 & 55.0 & 3.1 & 49.0 & 0.2 & 0.7 & & \\
\hline 10/23/07 7:45 PM & 0.108 & 55.0 & 6.2 & 49.0 & 0.2 & 1.2 & & \\
\hline 10/23/07 10:08 PM & 0.207 & 55.0 & 12.0 & 49.0 & 0.2 & 1.8 & & \\
\hline $10 / 24 / 07$ 1:21 AM & 0.341 & 55.0 & 19.7 & 48.5 & 0.4 & 2.1 & & \\
\hline $10 / 24 / 07$ 10:05 AM & 10 & & & & & 6.5 & 0.24 & 270.32 \\
\hline 10/24/07 12:48 PM & 0.113 & 9.0 & 1.1 & 8.5 & 0 & 0.0 & & \\
\hline 10/25/07 9:12 AM & 0.850 & 2.2 & 3.0 & 1.9 & 0 & 0.0 & & \\
\hline 10/25/07 3:28 PM & 1.111 & 2.2 & 3.6 & 1.8 & 0 & 0.0 & & \\
\hline $10 / 26 / 07$ 9:15 AM & 1.852 & 2.2 & 5.4 & 1.9 & 0 & 0.0 & & \\
\hline $10 / 26 / 072: 05$ PM & 2.053 & 2.2 & 5.8 & 2.0 & 0 & 0.0 & & \\
\hline 10/27/07 11:22 AM & 2.940 & 2.2 & 7.9 & 1.8 & 0 & 0.0 & & \\
\hline $10 / 28 / 07$ 10:55 AM & 3.922 & 2.2 & 10.2 & 1.8 & 0 & 0.0 & & \\
\hline 10/28/07 6:30 PM & 4.238 & 2.2 & 10.9 & 1.8 & 0 & 0.0 & & \\
\hline $10 / 29 / 078: 53$ AM & 4.837 & 2.2 & 12.3 & 2.1 & 0.09 & 0.1 & & \\
\hline $10 / 29 / 073: 38 \mathrm{PM}$ & 5.118 & 2.2 & 12.9 & 1.8 & 0.17 & 0.3 & & \\
\hline $10 / 30 / 07$ 10:37 AM & 5.909 & 2.2 & 14.8 & 1.9 & 0.26 & 0.4 & & \\
\hline $10 / 30 / 074: 35 \mathrm{PM}$ & 6.158 & 2.2 & 15.3 & 1.8 & 0.34 & 0.6 & & \\
\hline $10 / 31 / 07$ 2:02 PM & 7.051 & 2.2 & 17.4 & 1.9 & 0.43 & 1.2 & & \\
\hline 11/1/07 9:59 AM & 7.883 & 2.2 & 19.3 & 1.8 & 0.51 & 0.9 & & \\
\hline 11/1/07 3.58 PM & 8.132 & 2.2 & 19.9 & 2.0 & 0.60 & 0.9 & & \\
\hline $11 / 2 / 07$ 7:42 AM & 8.787 & 2.2 & 21.4 & 2.0 & 0.68 & 0.7 & & \\
\hline
\end{tabular}


DOE/RL-2009-35, REV. 0

\begin{tabular}{|c|c|c|c|c|c|c|c|c|}
\hline Date \& Time & $\begin{array}{c}\text { Elapsed Time } \\
\text { (Day) }\end{array}$ & $\begin{array}{c}\text { Flow Rate } \\
\text { (mL/min) }\end{array}$ & $\begin{array}{c}\text { Actual Pore } \\
\text { Volumes }\end{array}$ & $\begin{array}{c}\text { Actual Flow } \\
\text { Rate } \\
\text { (mL/min) }\end{array}$ & $\begin{array}{c}\text { Approximated } \\
\text { Effiuent Solids } \\
\text { Concentration } \\
(g / L) \\
\end{array}$ & $\begin{array}{c}\text { Est. Effluent } \\
\text { Solids Per Time } \\
\text { Step (g) }\end{array}$ & $\begin{array}{c}\text { Est. Cumulative } \\
\text { Effluent Solids } \\
\text { Concentration } \\
(g / L) \\
\end{array}$ & $\begin{array}{c}\text { Est. } \\
\text { Cumulative } \\
\text { Solids } \\
\text { Injected } \\
\text { (g) }\end{array}$ \\
\hline \multicolumn{2}{|c|}{ Flow Cell \#4 - Zloy Test Cell } & & & & & 5.0 & 0.17 & \\
\hline 11/1/07 6:39 AM & 0 & 9.0 & 0.0 & 8.7 & & & & \\
\hline 11/1/07 8:03 AM & 0.058 & 9.0 & 0.0 & 9.1 & & & & \\
\hline 11/1/07 11:00 AM & 0.123 & 9.0 & 0.0 & 9.1 & & & & \\
\hline $11 / 1 / 07$ 2:37 PM & 0.151 & 9.0 & 0.0 & 9.4 & & & & \\
\hline $11 / 6 / 078: 09 \mathrm{AM}$ & 4.731 & 2.2 & 0.0 & 2.2 & & & & \\
\hline $11 / 6 / 078: 58$ AM & 0.034 & 55.0 & 0.0 & 55.0 & & & & \\
\hline $11 / 6 / 079: 32 \mathrm{AM}$ & 0.024 & & & & & & & \\
\hline $11 / 6 / 079: 58 \mathrm{AM}$ & 0.018 & 55.0 & 1.0 & 55.0 & 0.21 & 0.6 & & \\
\hline $11 / 6 / 07$ 10:47 AM & 0.052 & 55.0 & 3.0 & 54.0 & 0.41 & 1.5 & & \\
\hline 11/6/07 12:09 PM & 0.109 & 55.0 & 6.3 & 53.0 & 0.38 & 2.3 & & \\
\hline 11/6/07 2:30 PM & 0.207 & 55.0 & 12.0 & 39.0 & 2.82 & 26.3 & & \\
\hline 11/6/07 5:48 PM & 0.344 & 55.0 & 19.9 & 10.3 & 0.27 & 1.5 & & \\
\hline 11/7/07 12:06 PM & 0 & 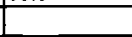 & & & & 32.2 & 1.18 & 269.25 \\
\hline 11/7/07 2:49 PM & 0.113 & 9.0 & 1.1 & 9.1 & 1.10 & 0.9 & & \\
\hline 11/7/07 3:17 PM & 0.019 & 9.0 & 0.2 & & 0.82 & 0.5 & & \\
\hline 11/8/07 10:10 AM & 0.787 & 2.2 & 2.0 & 2.3 & 0.55 & 1.5 & & \\
\hline 11/9/07 8:45 AM & 1.728 & 2.2 & 4.2 & 2.3 & 0.27 & 0.5 & & \\
\hline 11/9/07 4:18 PM & 2.042 & 2.2 & 4.9 & 2.3 & 0 & 0.0 & & \\
\hline 11/10/07 2:08 PM & 2.952 & 2.2 & 7.0 & 2.0 & 0 & 0.0 & & \\
\hline 11/11/07 8:07 PM & 4.201 & 2.2 & 9.9 & 2.2 & 0 & 0.0 & & \\
\hline $11 / 12 / 07$ 9:55 AM & 4.776 & 2.2 & 11.2 & 2.2 & 0 & 0.0 & & \\
\hline 11/12/07 3:58 PM & 5.028 & 2.2 & 11.8 & 2.2 & 0 & 0.0 & & \\
\hline 11/13/07 1:13 PM & 5.914 & 2.2 & 13.9 & 2.2 & 0 & 0.0 & & \\
\hline $11 / 13 / 075: 25 \mathrm{PM}$ & 6.089 & 2.2 & 14.3 & 2.2 & 0 & 0.0 & & \\
\hline 11/14/07 4:14 PM & 7.040 & 2.2 & 16.5 & 2.2 & 0 & 0.0 & & \\
\hline $11 / 15 / 078: 25$ AM & 7.714 & 2.2 & 18.0 & 2.3 & 0 & 0.0 & & \\
\hline $11 / 15 / 07$ 4:34 PM & 8.053 & 2.2 & 18.8 & 2.4 & 0 & 0.0 & & \\
\hline $11 / 16 / 07$ 10:00 AM & 8.780 & 2.2 & 20.5 & 1.8 & 0 & 0.0 & & \\
\hline \multirow{2}{*}{\multicolumn{2}{|c|}{\begin{tabular}{|cc} 
Date \& Time & $\begin{array}{c}\text { Elapsed Time } \\
\text { (Day) }\end{array}$ \\
Flow Cell \#5 - NanoFe I Test Cell
\end{tabular}}} & $\begin{array}{c}\text { Flow Rate } \\
\text { (mL/min) }\end{array}$ & $\begin{array}{l}\text { Actual Pore } \\
\text { Volumes }\end{array}$ & $\begin{array}{c}\text { Actual Flow } \\
\text { Rate } \\
\text { (mL/min) }\end{array}$ & $\begin{array}{c}\text { Approximated } \\
\text { Effluent Solids } \\
\text { Concentration } \\
(g / L)\end{array}$ & $\begin{array}{l}\text { Est. Effluent } \\
\text { Solids Per Time } \\
\text { Step (g) }\end{array}$ & $\begin{array}{c}\text { Est. Cumulative } \\
\text { Effluent Solids } \\
\text { Concentration } \\
(g / L)\end{array}$ & $\begin{array}{c}\text { Est. } \\
\text { Cumulative } \\
\text { Solids } \\
\text { Injected } \\
\text { (g) }\end{array}$ \\
\hline & & & & & & 3.5 & 0.13 & \\
\hline 11/1/07 6:41 AM & 0 & 9.0 & 0.0 & 8.9 & & & & \\
\hline 11/1/07 8:05 AM & 0.058 & 9.0 & 0.0 & 9.4 & & & & \\
\hline 11/1/07 11:00 AM & 0.122 & 9.0 & 0.0 & 9.2 & & & & \\
\hline 11/1/07 2:38 PM & 0.151 & 9.0 & 0.0 & 8.8 & & & & \\
\hline 11/6/07 8:09 AM & 4.730 & 2.2 & 0.0 & 2.2 & & & & \\
\hline 11/6/07 8:57 AM & 0.033 & 55.0 & 0.0 & 55.0 & & & & \\
\hline 11/6/07 9:32 AM & 0.024 & & & & & & & \\
\hline 11/6/07 9:59 AM & 0.019 & 55.0 & 1.1 & 52.0 & 2.5 & 7.2 & & \\
\hline 11/6/07 10:50 AM & 0.054 & 55.0 & 3.1 & 54.0 & 2.26 & 8.0 & & \\
\hline 11/6/07 12:08 PM & 0.108 & 55.0 & 6.3 & 53.0 & 2.08 & 12.7 & & \\
\hline $11 / 6 / 072: 32 \mathrm{PM}$ & 0.208 & 55.0 & 12.1 & 55.0 & 3.39 & 24.0 & & \\
\hline $11 / 6 / 074: 25 \mathrm{PM}$ & 0.287 & 55.0 & 16.6 & 49.0 & 2.61 & 8.1 & & \\
\hline $11 / 7 / 07$ 12:06 PM & 0 & & & & & 60.0 & 2.64 & 228.06 \\
\hline 11/7/07 2:51 PM & 0.115 & 9.0 & 1.1 & 9.0 & 3.33 & 2.9 & & \\
\hline 11/7/07 3:17 PM & 0.018 & 9.0 & 0.2 & & 2.50 & 1.6 & & \\
\hline $11 / 8 / 07$ 10:1 $\mathrm{AM}$ & 0.787 & 2.2 & 2.0 & 2.0 & 1.67 & 4.6 & & \\
\hline $11 / 9 / 078: 45$ AM & 1.728 & 2.2 & 4.2 & 2.0 & 0.83 & 1.7 & & \\
\hline 11/9/07 4:21 PM & 2.044 & 2.2 & 4.9 & 2.1 & 0 & 0.0 & & \\
\hline $11 / 10 / 072: 09 \mathrm{PM}$ & 2.953 & 2.2 & 7.0 & 1.9 & 0 & 0.0 & & \\
\hline 11/11/07 8:09 PM & 4.203 & 2.2 & 9.9 & 1.9 & 0 & 0.0 & & \\
\hline $11 / 12 / 079.58 \mathrm{AM}$ & 4.778 & 2.2 & 11.2 & 2.0 & 0 & 0.0 & & \\
\hline 11/12/07 3:59 PM & 5.029 & 2.2 & 11.8 & 1.8 & 0 & 0.0 & & \\
\hline $11 / 13 / 07$ 1:14 PM & 5.915 & 2.2 & 13.9 & 1.8 & 0 & 0.0 & & \\
\hline $11 / 13 / 07$ 5:26 PM & 6.090 & 2.2 & 14.3 & 1.7 & 0 & 0.0 & & \\
\hline 11/14/07 4:15 PM & 7.040 & 2.2 & 16.5 & 1.8 & 0 & 0.0 & & \\
\hline $11 / 15 / 078: 26 \mathrm{AM}$ & 7.715 & 2.2 & 18.0 & 1.8 & 0 & 0.0 & & \\
\hline $11 / 15 / 074: 38 \mathrm{PM}$ & 8.056 & 2.2 & 18.8 & 1.9 & 0 & 0.0 & & \\
\hline $11 / 16 / 07$ 10:01 AM & 8.781 & 2.2 & 20.5 & 1.9 & 0 & 0.0 & & \\
\hline
\end{tabular}


DOE/RL-2009-35, REV. 0

\begin{tabular}{|c|c|c|c|c|c|c|c|c|}
\hline Date \& Time & $\begin{array}{c}\text { Elapsed Time } \\
\text { (Day) }\end{array}$ & $\begin{array}{l}\text { Flow Rate } \\
\text { (mL/min) }\end{array}$ & $\begin{array}{c}\text { Actual Pore } \\
\text { Volumes }\end{array}$ & $\begin{array}{c}\text { Actual Flow } \\
\text { Rate } \\
\text { (mL/min) }\end{array}$ & $\begin{array}{c}\text { Approximated } \\
\text { Effluent Solids } \\
\text { Concentration } \\
(g / L)\end{array}$ & $\begin{array}{l}\text { Est. Effluent } \\
\text { Solids Per Time } \\
\text { Step (g) }\end{array}$ & $\begin{array}{c}\text { Est. Cumulative } \\
\text { Effluent Solids } \\
\text { Concentration } \\
(g / L)\end{array}$ & $\begin{array}{c}\text { Est. } \\
\text { Cumulative } \\
\text { Solids } \\
\text { Injected } \\
\text { (g) }\end{array}$ \\
\hline \multicolumn{2}{|c|}{ Flow Cell \#6 - NanoFe $\|$ Test Cell } & & & & & 10.6 & 0.38 & \\
\hline $11 / 1 / 076: 42 \mathrm{AM}$ & 0 & 9.0 & 0.0 & 9.5 & & & & \\
\hline 11/1/07 8:06 AM & 0.058 & 9.0 & 0.0 & 8.8 & & & & \\
\hline 11/1/07 11:00 AM & 0.121 & 9.0 & 0.0 & 9.2 & & & & \\
\hline 11/1/07 2:40 PM & 0.153 & 9.0 & 0.0 & 9.2 & & & & \\
\hline $11 / 6 / 078: 07$ AM & 4.727 & 2.2 & 0.0 & 2.2 & & & & \\
\hline $11 / 6 / 078: 59$ AM & 0.036 & 55.0 & 0.0 & 55.0 & & & & \\
\hline 11/6/07 9:32 AM & 0.023 & & & & & & & \\
\hline $11 / 6 / 07$ 10:02 AM & 0.021 & 55.0 & 1.2 & 56.0 & 4.2 & 12.5 & & \\
\hline $11 / 6 / 07$ 10:50 AM & 0.054 & 55.0 & 3.1 & 52.0 & 3.96 & 13.5 & & \\
\hline 11/6/07 12:06 PM & 0.107 & 55.0 & 6.2 & 57.0 & 3.72 & 22.8 & & \\
\hline 11/6/07 2:33 PM & 0.209 & 55.0 & 12.1 & 53.0 & 3.57 & 22.0 & & \\
\hline 11/6/07 3:50 PM & 0.262 & 55.0 & 15.2 & & 4.19 & 8.9 & & \\
\hline $11 / 7 / 07$ 12:06 PM & 0 & & & & & 79.7 & 3.83 & 208.11 \\
\hline 11/7/07 2:51 PM & 0.115 & 9.0 & 1.1 & 9.5 & 1.05 & 0.8 & & \\
\hline 11/7/07 3:17 PM & 0.018 & & & & 0.79 & & & \\
\hline 11/8/07 10:13 AM & 0.789 & 2.2 & 1.8 & 2.4 & 0.53 & 1.4 & & \\
\hline $11 / 9 / 078: 50$ AM & 1.731 & 2.2 & 4.0 & 2.4 & 0.26 & 0.5 & & \\
\hline $11 / 9 / 074: 25 \mathrm{PM}$ & 2.047 & 2.2 & 4.7 & 2.0 & 0 & 0.0 & & \\
\hline $11 / 10 / 072: 11 \mathrm{PM}$ & 2.954 & 2.2 & 6.8 & 2.2 & 0.58 & 2.0 & & \\
\hline 11/11/07 8:10 PM & 4.203 & 2.2 & 9.7 & 2.2 & 1.15 & 3.3 & & \\
\hline $11 / 12 / 07$ 9:59 AM & 4.779 & 2.2 & 11.1 & 2.2 & 1.01 & 1.3 & & \\
\hline $11 / 12 / 07$ 4:01 PM & 5.031 & 2.2 & 11.6 & 2.3 & 0.86 & 1.6 & & \\
\hline $11 / 13 / 07$ 1:14 PM & 5.915 & 2.2 & 13.7 & 2.3 & 0.72 & 1.2 & & \\
\hline $11 / 13 / 075: 28 \mathrm{PM}$ & 6.091 & 2.2 & 14.1 & 2.4 & 0.58 & 1.0 & & \\
\hline 11/14/07 4:17 PM & 7.042 & 2.2 & 16.3 & 2.2 & 0.43 & 1.1 & & \\
\hline $11 / 15 / 078: 28 \mathrm{AM}$ & 7.716 & 2.2 & 17.9 & 2.3 & 0.29 & 0.5 & & \\
\hline $11 / 15 / 074: 40 \mathrm{PM}$ & 8.058 & 2.2 & 18.7 & 2.3 & 0.14 & 0.2 & & \\
\hline 11/16/07 10:06 AM & 8.784 & 2.2 & 20.3 & 2.3 & 0 & 0.0 & & \\
\hline \multirow{2}{*}{\multicolumn{2}{|c|}{\begin{tabular}{|cc} 
Date \& Time & $\begin{array}{c}\text { Elapsed Time } \\
\text { (Day) }\end{array}$ \\
Flow Cell \#10 - Zloy Duplicate Cell \\
\end{tabular}}} & $\begin{array}{c}\text { Flow Rate } \\
\text { (mL/min) }\end{array}$ & $\begin{array}{c}\text { Actual Pore } \\
\text { Volumes }\end{array}$ & $\begin{array}{c}\text { Actual Flow } \\
\text { Rate } \\
\text { (mL/min) } \\
\end{array}$ & $\begin{array}{c}\text { Approximated } \\
\text { Effluent Solids } \\
\text { Concentration } \\
\text { (g/L) }\end{array}$ & $\begin{array}{c}\text { Est. Effluent } \\
\text { Solids Per Time } \\
\text { Step (g) }\end{array}$ & $\begin{array}{c}\text { Est. Cumulative } \\
\text { Effluent Solids } \\
\text { Concentration } \\
(g / L) \\
\end{array}$ & $\begin{array}{c}\text { Est. } \\
\text { Cumulative } \\
\text { Solids } \\
\text { Injected } \\
\text { (g) }\end{array}$ \\
\hline & & & & & & 15.0 & 0.54 & \\
\hline $11 / 1 / 076: 40 \mathrm{AM}$ & 0 & 9.0 & & 8.9 & & & & \\
\hline 11/1/07 8:04 AM & 0.058 & 9.0 & 0.0 & 9.0 & & & & \\
\hline 11/11/07 11:00 AM & 0.122 & 9.0 & 0.0 & 8.8 & & & & \\
\hline 11/1/07 2:37 PM & 0.151 & 9.0 & 0.0 & 9.0 & + & & & \\
\hline 11/6/07 8:02 AM & 4.726 & 2.2 & 0.0 & 2.2 & & & & \\
\hline 11/6/07 8:58 AM & 0.039 & 55.0 & 0.0 & 55.0 & & & & \\
\hline 11/6/07 9:32 AM & 0.024 & & & & & & & \\
\hline 11/6/07 9:59 AM & 0.019 & 55.0 & 1.1 & 52.0 & 0.38 & 1.1 & & \\
\hline 11/6/07 10:49 AM & 0.053 & 55.0 & 3.1 & 54.0 & 0.21 & 0.8 & & \\
\hline 11/6/07 12:09 PM & 0.109 & 55.0 & 6.3 & 56.0 & 4.64 & 28.3 & & \\
\hline $11 / 6 / 07$ 2:3† PM & 0.208 & 55.0 & 12.0 & 32.0 & 2.81 & 26.2 & & \\
\hline 11/6/07 5:48 PM & 0.344 & 55.0 & 19.9 & 16.8 & 0.17 & 0.9 & & \\
\hline 11/7/07 12:06 PM & 0 & & & & & 57.3 & 2.10 & 269.25 \\
\hline $11 / 7 / 072: 50 \mathrm{PM}$ & 0.114 & 9.0 & 1.1 & 8.9 & 0 & 0.0 & & \\
\hline 11/7/07 3:17 PM & 0.019 & & & & 0 & & & \\
\hline 11/8/07 10:10 AM & 0.787 & 2.2 & 1.8 & 2.2 & 0 & 0.0 & & \\
\hline 11/9/07 8:45 AM & 1.728 & 2.2 & 4.0 & 2.0 & 0 & 0.0 & & \\
\hline 11/9/07 4:20 PM & 2.044 & 2.2 & 4.7 & 2.2 & 0 & 0.0 & & \\
\hline 11/10/07 2:09 PM & 2.953 & 2.2 & 6.8 & 2.0 & 0.36 & 1.2 & & \\
\hline 11/11/07 8:08 PM & 4.202 & 2.2 & 9.7 & 2.1 & 0.73 & 2.1 & & \\
\hline 11/12/07 9.57 AM & 4.778 & 2.2 & 11.1 & 2.4 & 0.63 & 0.8 & & \\
\hline 11/12/07 3.58 PM & 5.028 & 2.2 & 11.6 & 2.1 & 0.52 & 1.1 & & \\
\hline 11/13/07 5:25 PM & 6.089 & 2.2 & 14.1 & 1.6 & 0.42 & 1.3 & & \\
\hline 11/14/07 4:14 PM & 7.040 & 2.2 & 16.3 & 2.2 & 0.31 & 0.8 & & \\
\hline $11 / 15 / 078: 26$ AM & 7.715 & 2.2 & 17.9 & 2.2 & 0.21 & 0.3 & & \\
\hline 11/15/07 4:34 PM & 8.053 & 2.2 & 18.7 & 1.7 & 0.10 & 0.2 & & \\
\hline $11 / 16 / 07 \quad 10: 00 \mathrm{AM}$ & 8.780 & 2.2 & 20.3 & 2.2 & 0 & 0.0 & & \\
\hline
\end{tabular}


DOE/RL-2009-35, REV. 0

\begin{tabular}{|c|c|c|c|c|c|c|c|c|}
\hline Date \& Time & $\begin{array}{c}\text { Elapsed Time } \\
\text { (Day) }\end{array}$ & $\begin{array}{c}\text { Flow Rate } \\
\text { (mL/min) }\end{array}$ & $\begin{array}{l}\text { Actual Pore } \\
\text { Volumes }\end{array}$ & $\begin{array}{c}\text { Actual Flow } \\
\text { Rate } \\
\text { (mL/min) }\end{array}$ & $\begin{array}{c}\text { Approximated } \\
\text { Effiuent Solids } \\
\text { Concentration } \\
(g / L)\end{array}$ & $\begin{array}{c}\text { Est. Effluent } \\
\text { Solids Per Time } \\
\text { Step (g) }\end{array}$ & $\begin{array}{c}\text { Est. Cumulative } \\
\text { Effluent Solids } \\
\text { Concentration } \\
(g / L)\end{array}$ & $\begin{array}{c}\text { Est. } \\
\text { Cumulative } \\
\text { Solids } \\
\text { Injected } \\
\text { (g) } \\
\end{array}$ \\
\hline \multicolumn{2}{|c|}{ Flow Cell \#11 - NanoFe I Duplicate Cell } & & & & & 7.9 & 0.28 & \\
\hline 11/1/07 6:42 AM & 0 & 9.0 & 0.0 & 9.4 & & & & \\
\hline $11 / 1 / 078: 05 \mathrm{AM}$ & 0.058 & 9.0 & 0.0 & 9.5 & & & & \\
\hline $11 / 1 / 07$ 11:00 AM & 0.122 & 9.0 & 0.0 & 8.5 & & & & \\
\hline 11/1/07 2:39 PM & 0.152 & 9.0 & 0.0 & 9.6 & & & & \\
\hline 11/6/07 8:07 AM & 4.728 & 2.2 & 0.0 & 2.2 & & & & \\
\hline $11 / 6 / 078: 56 \mathrm{AM}$ & 0.034 & 55.0 & 0.0 & 55.0 & & & & \\
\hline 11/6/07 9:32 AM & 0.025 & & & & & & & \\
\hline 11/6/07 9:59 AM & 0.019 & 55.0 & 1.1 & 54.0 & 2.41 & 6.9 & & \\
\hline $11 / 6 / 07$ 10:49 AM & 0.053 & 55.0 & 3.1 & 52.0 & 2.04 & 7.2 & & \\
\hline 11/6/07 12:07 PM & 0.108 & 55.0 & 6.2 & 58.0 & 2.07 & 12.7 & & \\
\hline 11/6/07 2:32 PM & 0.208 & 55.0 & 12.1 & 21.0 & 4.17 & 24.3 & & \\
\hline 11/6/07 3:39 PM & 0.255 & 55.0 & 14.8 & & 3.43 & 6.3 & & \\
\hline 11/7/07 12:06 PM & 0 & & & & & 57.4 & 2.84 & 202.66 \\
\hline 11/7/07 2:51 PM & 0.115 & 9.0 & 1.1 & 9.6 & 1.04 & 0.8 & & \\
\hline 11/7/07 3:17 PM & 0.018 & & & & 0.78 & & & \\
\hline 11/8/07 10:12 AM & 0.788 & 2.2 & 1.8 & 1.8 & 0.52 & 1.4 & & \\
\hline 11/9/07 8:45 AM & 1.728 & 2.2 & 4.0 & 2.5 & 0.26 & 0.5 & & \\
\hline 11/9/07 4:23 PM & 2.046 & 2.2 & 4.7 & 2.2 & 0 & 0.0 & & \\
\hline 11/10/07 2:10 PM & 2.953 & 2.2 & 6.8 & 2.4 & 0 & 0.0 & & \\
\hline 11/11/07 8:09 PM & 4.203 & 2.2 & 9.7 & 2.2 & 0 & 0.0 & & \\
\hline $11 / 12 / 07$ 9:59 AM & 4.779 & 2.2 & 11.1 & 2.5 & 0 & 0.0 & & \\
\hline $11 / 12 / 07$ 4:00 PM & 5.030 & 2.2 & 11.6 & 2.5 & 0 & 0.0 & & \\
\hline $11 / 13 / 07$ 1:15 PM & 5.915 & 2.2 & 13.7 & 2.4 & 0 & 0.0 & & \\
\hline 11/13/07 5:27 PM & 6.090 & 2.2 & 14.1 & 2.1 & 0 & 0.0 & & \\
\hline 11/14/07 4:16 PM & 7.041 & 2.2 & 16.3 & 2.5 & 0 & 0.0 & & \\
\hline 11/15/07 8:27 AM & 7.715 & 2.2 & 17.9 & 2.5 & 0 & 0.0 & & \\
\hline 11/15/07 4:39 PM & 8.057 & 2.2 & 18.7 & 2.2 & 0 & 0.0 & & \\
\hline $11 / 16 / 07$ 10:02 AM & 8.781 & 2.2 & 20.3 & 2.3 & 0 & 0.0 & & \\
\hline
\end{tabular}

\begin{tabular}{|c|c|c|c|c|c|c|c|c|}
\hline Date \& Time & $\begin{array}{l}\text { Elapsed Time } \\
\text { (Day) }\end{array}$ & $\begin{array}{c}\text { Flow Rate } \\
\text { (mL/min) }\end{array}$ & $\begin{array}{l}\text { Actual Pore } \\
\text { Volumes }\end{array}$ & $\begin{array}{c}\text { Actual Flow } \\
\text { Rate } \\
\text { (mLmin) }\end{array}$ & $\begin{array}{c}\text { Approximated } \\
\text { Effluent Solids } \\
\text { Concentration } \\
(g / L)\end{array}$ & $\begin{array}{l}\text { Est. Effluent } \\
\text { Solids Per Time } \\
\text { Step (g) }\end{array}$ & $\begin{array}{c}\text { Est. Cumulative } \\
\text { Effluent Solids } \\
\text { Concentration } \\
(g / L)\end{array}$ & $\begin{array}{c}\text { Est. } \\
\text { Cumulative } \\
\text { Solids } \\
\text { Injected } \\
\text { (g) }\end{array}$ \\
\hline \multicolumn{3}{|c|}{ Flow Cell \#12 - NanoFe II Duplicate Cell } & & & & 2.7 & 0.10 & \\
\hline $11 / 1 / 076: 44 \mathrm{AM}$ & 0 & 9.0 & & 9.0 & & & & \\
\hline $11 / 1 / 078: 07$ AM & 0.058 & 9.0 & 0.0 & 8.8 & & & & \\
\hline $11 / 1 / 07$ 11:02 AM & 0.122 & 9.0 & 0.0 & 9.0 & & & & \\
\hline 11/1/07 2:46 PM & 0.156 & 9.0 & 0.0 & 8.9 & & & & \\
\hline 11/6/07 8:05 AM & 4.722 & 2.2 & 0.0 & 2.2 & & & & \\
\hline $11 / 6 / 078: 54 \mathrm{AM}$ & 0.034 & 55.0 & 0.0 & 55.0 & & & & \\
\hline $11 / 6 / 079: 32$ AM & 0.026 & & & & & & & \\
\hline $11 / 6 / 07$ 10:02 AM & 0.021 & 55.0 & 1.2 & 54.0 & 3.53 & 10.3 & & \\
\hline $11 / 6 / 07$ 10:48 AM & 0.053 & 55.0 & 3.1 & 58.0 & 3.65 & 12.4 & & \\
\hline $11 / 6 / 07$ 12:06 PM & 0.107 & 55.0 & 6.2 & 53.0 & 3.77 & 23.5 & & \\
\hline 11/6/07 2:35 PM & 0.210 & 55.0 & 12.2 & 56.0 & 4.51 & 27.8 & & \\
\hline 11/6/07 3:50 PM & 0.262 & 55.0 & 15.2 & & 3.97 & 8.2 & & \\
\hline $11 / 7 / 07$ 12:06 PM & 0 & & & & & 82.2 & 3.96 & 208.11 \\
\hline 11/7/07 2:52 PM & 0.115 & 9.0 & 1.1 & 8.7 & 1.15 & 0.9 & & \\
\hline $11 / 7 / 073: 17 \mathrm{PM}$ & 0.017 & & & & 0.86 & & & \\
\hline 11/8/07 10:14 AM & 0.790 & 2.2 & 1.8 & 1.8 & 0.57 & 1.6 & & \\
\hline 11/9/07 9:08 AM & 1.744 & 2.2 & 4.0 & 2.0 & 0.29 & 0.6 & & \\
\hline 11/9/07 4:27 PM & 2.049 & 2.2 & 4.7 & 2.2 & 0 & 0.0 & & \\
\hline $11 / 10 / 072: 11 \mathrm{PM}$ & 2.954 & 2.2 & 6.8 & 2.2 & 0.31 & 1.0 & & \\
\hline $11 / 11 / 078: 11 \mathrm{PM}$ & 4.204 & 2.2 & 9.7 & 2.1 & 0.61 & 1.8 & & \\
\hline $11 / 12 / 0710: 00 \mathrm{AM}$ & 4.780 & 2.2 & 11.1 & 2.2 & 0.53 & 0.7 & & \\
\hline $11 / \uparrow 2 / 074.01 \mathrm{PM}$ & 5.031 & 2.2 & 11.6 & 2.2 & 0.46 & 0.8 & & \\
\hline 11/13/07 1:14 PM & 5.915 & 2.2 & 13.7 & 2.1 & 0.38 & 0.6 & & \\
\hline 11/13/07 5:28 PM & 6.091 & 2.2 & 14.1 & 2.2 & 0.31 & 0.5 & & \\
\hline 11/14/07 4:18 PM & 7.042 & 2.2 & 16.3 & 2.3 & 0.23 & 0.6 & & \\
\hline $11 / 15 / 078: 28$ AM & 7.716 & 2.2 & 17.9 & 2.3 & 0.15 & 0.2 & & \\
\hline $11 / 15 / 07$ 4:41 PM & 8.058 & 2.2 & 18.7 & 2.1 & 0.08 & 0.1 & & \\
\hline $11 / 16 / 07$ 10:07 AM & 8.785 & 2.2 & 20.3 & 2.1 & 0 & 0.0 & & \\
\hline
\end{tabular}


DOE/RL-2009-35, REV. 0

\begin{tabular}{|c|c|c|c|c|c|c|c|c|}
\hline Date \& Time & $\begin{array}{c}\text { Elapsed Time } \\
\text { (Day) }\end{array}$ & $\begin{array}{c}\text { Flow Rate } \\
(\mathrm{mL} / \mathrm{min})\end{array}$ & $\begin{array}{c}\text { Actual Pore } \\
\text { Volumes }\end{array}$ & \begin{tabular}{|c} 
Actual Flow \\
Rate \\
(mL/min)
\end{tabular} & $\begin{array}{c}\text { Approximated } \\
\text { Effiuent Solids } \\
\text { Concentration } \\
\left(g^{\prime} L\right) \\
\end{array}$ & $\begin{array}{c}\text { Est. Effluent } \\
\text { Soilds Per Time } \\
\text { Step (g) }\end{array}$ & $\begin{array}{c}\text { Est. Cumulative } \\
\text { Effiuent Solids } \\
\text { Concentration } \\
(g / L) \\
\end{array}$ & $\begin{array}{l}\text { Est. } \\
\text { Cumulative } \\
\text { Solids } \\
\text { Injected } \\
\text { (g) }\end{array}$ \\
\hline \multicolumn{2}{|c|}{ Flow Cell \#13 - Control Cell } & & & & & 9.5 & 0.34 & \\
\hline $11 / 1 / 076: 46 \mathrm{AM}$ & 0 & 9.0 & & 9.1 & & & & \\
\hline $11 / 1 / 078: 08 \mathrm{AM}$ & 0.057 & 9.0 & 0.0 & 9.0 & & & & \\
\hline 11/1/07 11:02 AM & 0.121 & 9.0 & 0.0 & 9.0 & & & & \\
\hline 11/1/07 11:46 AM & 0.031 & 9.0 & 0.0 & 9.1 & & & & \\
\hline 11/6/07 8:04 AM & 4.846 & 2.2 & 0.0 & 2.2 & & & & \\
\hline 11/6/07 8:53 AM & 0.034 & 55.0 & 0.0 & 55.0 & & & & \\
\hline 11/6/07 9:32 AM & 0.027 & & & & & & & \\
\hline 11/6/07 10:02 AM & 0.021 & 55.0 & 1.2 & 54.0 & 0.61 & 1.8 & & \\
\hline $11 / 6 / 07$ 10:48 AM & 0.053 & 55.0 & 3.1 & 54.0 & 0.39 & 1.3 & & \\
\hline $11 / 6 / 07$ 12:05 PM & 0.106 & 55.0 & 6.2 & 55.0 & 0.55 & 3.4 & & \\
\hline 11/6/07 2:36 PM & 0.211 & 55.0 & 12.2 & 55.0 & 0.55 & 5.2 & & \\
\hline 11/6/07 5:50 PM & 0.346 & 55.0 & 20.0 & 55.0 & 0.36 & 1.9 & & \\
\hline 11/7/07 12:06 PM & 0 & & & & & 13.7 & 0.50 & 0.00 \\
\hline 11/7/07 2:52 PM & 0.115 & 9.0 & 1.1 & 8.6 & 0 & 0.0 & & \\
\hline 11/7/07 3:17 PM & 0.017 & & & & 0 & & 0.0 & \\
\hline 11/8/07 10:14 AM & 0.790 & 2.2 & 1.8 & 2.3 & 0 & 0.0 & & \\
\hline 11/9/07 9:10 AM & 1.745 & 2.2 & 4.0 & 2.1 & 0 & 0.0 & & \\
\hline 11/9/07 4:30 PM & 2.051 & 2.2 & 4.7 & 2.2 & 0 & & & \\
\hline 11/40/07 2:11 PM & 2.954 & 2.2 & 6.8 & 2.2 & 0 & 0.0 & & \\
\hline 11/11/07 8:11 PM & 4.204 & 2.2 & 9.7 & 2.3 & 0 & 0.0 & & \\
\hline $11 / 12 / 07$ 10:01 AM & 4.781 & 2.2 & 11.1 & 2.4 & 0 & 0.0 & & \\
\hline 11/12/07 4:02 PM & 5.031 & 2.2 & 11.7 & 2.2 & 0 & 0.0 & & \\
\hline 11/13/07 1:17 PM & 5.917 & 2.2 & 13.7 & 2.4 & 0 & 0.0 & & \\
\hline 11/13/07 5:29 PM & 6.092 & 2.2 & 14.1 & 2.1 & 0 & 0.0 & & \\
\hline 11/14/07 4:19 PM & 7.043 & 2.2 & 16.3 & 2.1 & 0 & 0.0 & & \\
\hline 11/15/07 8:29 AM & 7.717 & 2.2 & 17.9 & 2.2 & 0 & 0.0 & & \\
\hline 11/15/07 4:42 PM & 8.059 & 2.2 & 18.7 & 2.0 & 0 & 0.0 & & \\
\hline $11 / 16 / 07$ 10:07 AM & 8.785 & 2.2 & 20.3 & 1.9 & 0 & 0.0 & & \\
\hline Date \& Time & $\begin{array}{c}\begin{array}{c}\text { Elapsed Time } \\
\text { (Day) }\end{array} \\
\end{array}$ & $\begin{array}{c}\text { Flow Rate } \\
\text { (mLmin) }\end{array}$ & $\begin{array}{c}\text { Actual Pore } \\
\text { Volumes }\end{array}$ & $\begin{array}{c}\text { Actual Flow } \\
\text { Rate } \\
\text { (mL/min) }\end{array}$ & $\begin{array}{c}\text { Approximated } \\
\text { Effluent Solids } \\
\text { Concentration } \\
(g / L)\end{array}$ & $\begin{array}{c}\text { Est. Effluent } \\
\text { Solids Per Time } \\
\text { Step (g) }\end{array}$ & $\begin{array}{c}\text { Est. Cumulative } \\
\text { Effluent Solids } \\
\text { Concentration } \\
(g / L) \\
\end{array}$ & $\begin{array}{c}\text { Est. } \\
\text { Cumulative } \\
\text { Solids } \\
\text { Injected } \\
\text { (g) }\end{array}$ \\
\hline \multicolumn{9}{|c|}{ Flow Cell \#14-Micropowder Test Cell } \\
\hline 11/30/07 7:12 AM & 0.000 & 2.2 & & 2.2 & & & & \\
\hline 11/30/07 8:26 AM & 0.000 & 2.2 & & 2.1 & & & & \\
\hline 11/30/07 9:30 AM & 0.000 & & & & & & & \\
\hline 11/30/07 9:55 AM & 0.017 & 55.0 & 1.0 & 58 & 0.45 & 1.2 & & \\
\hline $11 / 30 / 0710: 45 \mathrm{AM}$ & 0.052 & 55.0 & 3.0 & 57.5 & 1.04 & 3.6 & & \\
\hline 11/30/07 12:00 PM & 0.104 & 55.0 & 6.0 & 56.5 & 0.71 & 4.4 & & \\
\hline 11/30/07 2:30 PM & 0.208 & 55.0 & 12.1 & 57 & 0.88 & 8.4 & & \\
\hline $11 / 30 / 075: 49 \mathrm{PM}$ & 0.347 & 55.0 & 20.1 & 56 & 1.24 & 6.8 & & \\
\hline 12/1/07 9:00 AM & 0.000 & & & & & 24.4 & 0.89 & 275.55 \\
\hline $12 / 1 / 0711: 26 \mathrm{AM}$ & 0.101 & 9.0 & 1.0 & 9.1 & 0 & 0.0 & & \\
\hline $12 / 2 / 07$ 7:00 PM & 1.417 & 2.2 & 3.3 & 2 & to & 0.0 & & \\
\hline $12 / 3 / 078: 45 \overline{A M}$ & 1.990 & 2.2 & 4.6 & 2.2 & 0 & 0.0 & & \\
\hline $12 / 3 / 07$ 10:47 АM & 2.074 & 2.2 & 4.8 & 2.1 & to & 0.0 & & \\
\hline 12/3/07 1:08 PM & 2.172 & 2.2 & 5.0 & 2.1 & 0 & 0.0 & & \\
\hline 12/3/07 4:29 PM & 2.312 & 2.2 & 5.4 & 2.1 & 0 & 0.0 & & \\
\hline 12/4/07 12:01 PM & 3.126 & 2.2 & 7.2 & 2.1 & 0 & 0.0 & & \\
\hline 12/4/07 3:18 PM & 3.262 & 2.2 & 7.6 & 2.1 & 10 & 0.0 & & \\
\hline $12 / 5 / 078: 36 \mathrm{AM}$ & 3.983 & 2.2 & 9.2 & 2.1 & 10 & 0.0 & & \\
\hline 12/5/07 4:54 PM & 4.329 & 2.2 & 10.0 & 2.1 & 10 & 0.0 & & \\
\hline $12 / 6 / 07$ 10:25 AM & 5.059 & 2.2 & 11.7 & 2.1 & 10 & 0.0 & & \\
\hline 12/6/07 3:40 PM & 5.278 & 2.2 & 12.2 & 2.1 & to & 0.0 & & \\
\hline 12/7/07 8:28 AM & 5.978 & 2.2 & 13.8 & 2.1 & 10 & 0.0 & & \\
\hline $12 / 7 / 071: 59 \mathrm{PM}$ & 6.208 & 2.2 & 14.4 & 2.1 & 0 & 0.0 & & \\
\hline $12 / 9 / 074: 39 \mathrm{PM}$ & 8.319 & 2.2 & 19.3 & 2.1 & to & 0.0 & & \\
\hline $12 / 10 / 076: 40 \mathrm{AM}$ & 8.903 & 2.2 & 20.6 & 2.1 & 10 & 0.0 & & \\
\hline
\end{tabular}


DOE/RL-2009-35, REV. 0

\begin{tabular}{|c|c|c|c|c|c|c|c|c|}
\hline Date \& Time & $\begin{array}{l}\text { Elapsed Time } \\
\text { (Day) }\end{array}$ & $\begin{array}{c}\text { Flow Rate } \\
\text { (mL/min) }\end{array}$ & $\begin{array}{l}\text { Actual Pore } \\
\text { Volumes }\end{array}$ & $\begin{array}{c}\text { Actual Flow } \\
\text { Rate } \\
\text { (mL/min) }\end{array}$ & $\begin{array}{c}\text { Approximated } \\
\text { Effluent Solids } \\
\text { Concentration } \\
\text { (g/L) }\end{array}$ & $\begin{array}{l}\text { Est. Effluent } \\
\text { Solids Per Time } \\
\text { Step (g) }\end{array}$ & $\begin{array}{c}\text { Est. Cumulative } \\
\text { Effluent Solids } \\
\text { Concentration } \\
(g / L)\end{array}$ & $\begin{array}{c}\text { Est. } \\
\text { Cumulative } \\
\text { Solids } \\
\text { Injected } \\
\text { (g) }\end{array}$ \\
\hline \multicolumn{4}{|c|}{ Flow Cell \#15 - Micropowder Duplicate Cell } & & & 0.0 & & \\
\hline $11 / 30 / 077: 12 \mathrm{AM}$ & 0.000 & 2.2 & & 2 & & & & \\
\hline 11/30/07 8:27 AM & 0.000 & 2.2 & & 2.3 & & & & \\
\hline 11/30/07 9:30 AM & 0.000 & & & & & & & \\
\hline $11 / 30 / 079: 55 \mathrm{AM}$ & 0.017 & 55.0 & 1.0 & 55 & 0.41 & 1.1 & & \\
\hline $11 / 30 / 07$ 10:45 AM & 0.052 & 55.0 & 3.0 & 54.5 & 0.73 & 2.5 & & \\
\hline 11/30/07 12:00 PM & 0.104 & 55.0 & 6.0 & 54.5 & 0.73 & 4.5 & & \\
\hline $11 / 30 / 072: 30 \mathrm{PM}$ & 0.208 & 55.0 & 12.1 & 54.5 & 0.55 & 5.3 & & \\
\hline 11/30/07 5:49 PM & 0.347 & 55.0 & 20.1 & 54 & 1.28 & 7.0 & & \\
\hline 12/1/07 9:00 AM & 0.000 & & & & & 20.4 & 0.74 & 275.55 \\
\hline 12/1/07 11:26 AM & 0.101 & 9 & 1.0 & 8.7 & 0 & 0.0 & & \\
\hline 12/2/07 7:01 PM & 7.417 & 2.2 & 3.3 & 2 & 10 & 0.0 & & \\
\hline $12 / 3 / 078: 45 \mathrm{AM}$ & 1.990 & 2.2 & 4.6 & 2.1 & 0 & 0.0 & & \\
\hline $12 / 3 / 07$ 10:48 AM & 2.075 & 2.2 & 4.8 & 2.2 & 0 & 0.0 & & \\
\hline $12 / 3 / 071: 08 \mathrm{PM}$ & 2.172 & 2.2 & 5.0 & 2.2 & to & 0.0 & & \\
\hline 12/3/07 4:30 PM & 2.313 & 2.2 & 5.4 & 2.2 & 0 & 0.0 & & \\
\hline 12/4/07 12:01 PM & 3.126 & 2.2 & 7.2 & 2.2 & 0 & 0.0 & & \\
\hline 12/4/07 3:18 PM & 3.262 & 2.2 & 7.6 & 2.2 & 10 & 0.0 & & \\
\hline $12 / 5 / 078: 36 \mathrm{AM}$ & 3.983 & 2.2 & 9.2 & 2.2 & 0 & 0.0 & & \\
\hline $12 / 5 / 074: 54 \mathrm{PM}$ & 4.329 & 2.2 & 10.0 & 2.2 & 10 & 0.0 & & \\
\hline $12 / 6 / 0710: 25 \mathrm{AM}$ & 5.059 & 2.2 & 11.7 & 2.2 & 0 & 0.0 & & \\
\hline 12/6/07 3:40 PM & 5.278 & 2.2 & 12.2 & 2.2 & 10 & 0.0 & & \\
\hline $12 / 7 / 078: 28 \mathrm{AM}$ & 5.978 & 2.2 & 13.8 & 2.2 & 0 & 0.0 & & \\
\hline $12 / 7 / 071: 59 \mathrm{PM}$ & 6.208 & 2.2 & 14.4 & 2.2 & 0 & 0.0 & & \\
\hline 12/9/07 4:37 PM & 8.317 & 2.2 & 19.3 & 2.2 & 0 & 0.0 & & \\
\hline $12 / 10 / 076: 40$ AM & 8.903 & 2.2 & 20.6 & 2.2 & 0 & 0.0 & & \\
\hline
\end{tabular}


Emplaced Iron and Effluent Summary

\begin{tabular}{|c|c|c|c|c|c|c|c|c|c|c|c|c|c|c|c|c|c|c|c|c|c|}
\hline \multirow[t]{2}{*}{$\begin{array}{r}\text { Flow } \\
\text { Cell } \\
\# \\
\end{array}$} & \multirow[t]{2}{*}{$\begin{array}{c}\text { ZI } \\
\text { Material }\end{array}$} & \multirow[t]{2}{*}{\begin{tabular}{|c|}
$\begin{array}{c}\text { Test or } \\
\text { Duplicate } \\
\text { Cell }\end{array}$ \\
\end{tabular}} & \multirow[t]{2}{*}{\begin{tabular}{|l|} 
\\
Influent \\
Effluent
\end{tabular}} & \multicolumn{2}{|c|}{ Before Injection } & \multicolumn{5}{|c|}{ Effluent During Injection } & \multicolumn{4}{|c|}{ Effluent During Flushing } & \multicolumn{3}{|c|}{ Soil After Injection } & \multicolumn{4}{|c|}{ Soil After Flushing } \\
\hline & & & & $\begin{array}{l}\text { Influent } \\
\text { Solids } \\
\text { Conc. } \\
\text { (mg/L) }\end{array}$ & $\begin{array}{l}\text { Soil K } \\
(\mathrm{cm} / \mathrm{s})\end{array}$ & $\begin{array}{c}\text { Est. } \\
\text { Solids } \\
\text { Mass } \\
\text { Injected } \\
\text { (g) }\end{array}$ & \begin{tabular}{|} 
Cumulative \\
Effuent \\
Solids \\
Mass (g)
\end{tabular} & $\begin{array}{c}\text { Est. } \\
\text { Solids in } \\
\text { Cell After } \\
\text { Injection } \\
\text { (g) }\end{array}$ & \begin{tabular}{|c|} 
Est. \\
Percent \\
Solids \\
Emplaced \\
in Cell (\%)
\end{tabular} & $\begin{array}{c}\text { Final } \\
\text { Effluent } \\
\text { Fe Conc. } \\
\text { (mg/L) }\end{array}$ & $\begin{array}{c}\text { Est. } \\
\text { Cumulative } \\
\text { Effluent } \\
\text { Salids } \\
\text { Mass (g) }\end{array}$ & $\begin{array}{l}\text { Est. } \\
\text { Solids in } \\
\text { Cell } \\
\text { After } \\
\text { Flushing } \\
\text { (g) }\end{array}$ & $\begin{array}{c}\text { Est. } \\
\text { Percent } \\
\text { Solids } \\
\text { Flushed } \\
\text { from Cell } \\
(\%)\end{array}$ & $\begin{array}{c}\text { Final } \\
\text { Efluent } \\
\mathrm{Fe} \\
\text { Conc. } \\
\text { (mg/L) }\end{array}$ & \begin{tabular}{|c|} 
Est. \\
Percent \\
Fe \\
Emplaced \\
in Core \\
Sample \\
$(\%)^{*}$
\end{tabular} & $\begin{array}{c} \\
\text { Soil K } \\
\text { After } \\
\text { Injection } \\
(\mathrm{cm} / \mathrm{s})\end{array}$ & $\mid \begin{array}{c}\text { Change in } \\
\text { KDuring } \\
\text { Injection } \\
\text { (Multiplier) }\end{array}$ & \begin{tabular}{|c|} 
Est. \\
Percent \\
Fe \\
Flushed \\
into Core \\
Sample \\
$(\%)^{*}$
\end{tabular} & \begin{tabular}{|c|} 
\\
Soil K \\
After \\
Flushing \\
$(\mathrm{cm} / \mathrm{s})$
\end{tabular} & $\begin{array}{l}\text { Change in } \\
\text { KDuring } \\
\text { Flushing } \\
\text { Multiplier }\end{array}$ & $\begin{array}{l}\text { Change in } \\
\text { K During } \\
\text { Injection } \\
\text { Testing } \\
\text { (Multiplier) }\end{array}$ \\
\hline 1 & Polymetallix & TC & $\ln$ & $1.50 \mathrm{E}+07$ & $8.89 \mathrm{E}-02$ & 403.42 & 191.6 & 211.82 & 52.51 & $3.09 \mathrm{E}+06$ & 35.5 & \begin{tabular}{|l|}
176.32 \\
\end{tabular} & 16.76 & 654 & 3.48 & 0.01 & -8.80 & 0.67 & 0.01 & 1.08 & -8.13 \\
\hline 1 & Polymetallix & $T C$ & Ef & $1.50 \mathrm{E}+07$ & $6.89 \mathrm{E}-02$ & 403.42 & 191.6 & 211.82 & 52.51 & $3.09 \mathrm{E}+06$ & 35.5 & 176.32 & 16.76 & 654 & 4.05 & 0.01 & -8.80 & 0.85 & 0.01 & 1.08 & -8.13 \\
\hline 7 & Polymetallix & $D C$ & $\ln$ & $1.50 E+07$ & $5.72 \mathrm{E}-02$ & 404.25 & 129.9 & 274.35 & 67.87 & $2.33 E+06$ & 20.2 & 254.15 & 7.36 & 1350 & 4.53 & 0.00 & -310.77 & 0.86 & 0.00 & 1.22 & -254.55 \\
\hline 7 & Polymetallix & $D C$ & Ef & $1.50 \mathrm{E}+07$ & $5.72 \mathrm{E}-02$ & 404.25 & 129.9 & 274.35 & 67.67 & $2.33 \mathrm{E}+06$ & 20.2 & 254.15 & 7.36 & 1350 & 3.10 & 0.00 & -310.77 & 0.67 & 0.00 & 1.22 & .254 .55 \\
\hline 2 & RNIP-M2 & TC & $\ln$ & 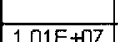 & 9 & 27,39 & 496 & 22170 & 8172 & $573 F_{+01}$ & 489 & 17289 & 2005 & 305 & 673 & 003 & -119 & 065 & 0 & -166 & -197 \\
\hline$\frac{2}{2}$ & RNIP-M2 & TC & $E f$ & $1.01 \mathrm{E}+07$ & $4.00 \mathrm{E}-02$ & 271.39 & 49.6 & 221.79 & $\frac{01.12}{81.72}$ & \begin{tabular}{|l|}
$\mid 6.73 E+05$ \\
$6.73 E+50$
\end{tabular} & 48.9 & 172.89 & 22.05 & 305 & 3.28 & 0.03 & -1.19 & 0.03 & $\frac{0.02}{0.02 .}$ & $\frac{-1.50}{-1.66}$ & $\begin{array}{l}-1.97 \\
-1.97\end{array}$ \\
\hline 8 & RNIP-M2 & $\mathrm{DC}$ & $\ln$ & $1.01 E+07$ & $7.63 \mathrm{E}-02$ & 271.39 & $\frac{-35.0}{46.6}$ & 224.79 & 82.83 & $\mid \begin{array}{l}\mid .051 \mathrm{E}+05 \\
2.41\end{array}$ & $\frac{40.5}{46.9}$ & 177.89 & 20.86 & 197 & 8.76 & 0.03 & -2.85 & 0.82 & 0.04 & 1.42 & -2.02 \\
\hline 8 & RNIP-M2 & $D C$ & $E f$ & $1.01 E+07$ & $7.63 \mathrm{E}-02$ & 271.39 & 46.6 & 224.79 & 82.83 & $2.41 \mathrm{E}+05$ & 46.9 & 177.89 & 20.86 & 197 & 3.30 & 0.03 & -2.85 & 0.21 & 0.04 & 1.42 & -2.02 \\
\hline & & & & & & & & & & & & & & & & & & & & & \\
\hline 3 & $E Z \mathrm{~V}$ & TC & $\ln$ & $1.00 E+07$ & $4.86 \mathrm{E}-02$ & 270.32 & 0 & 270.32 & 100.00 & $2.94 \mathrm{E}+01$ & 18.3 & 252.02 & 6.77 & 15 & 0.12 & 0.07 & 1.40 & 0.10 & 0.08 & 1.12 & 1.57 \\
\hline 3 & $E Z \mathrm{~V}$ & TC & $E f$ & $1.00 E+07$ & $4.86 \mathrm{E}-02$ & 270.32 & 0 & 270.32 & 100.00 & $\mid 2.94 \mathrm{E}+01$ & 18.3 & 252.02 & 6.77 & 15 & 0.11 & 0.07 & 1.40 & 0.08 & 0.08 & 1.12 & 1.57 \\
\hline 9 & EZVI & $\mathrm{DC}$ & $\ln$ & $1.00 \mathrm{E}+07$ & $3.58 \mathrm{E}-02$ & 270.32 & 0 & 270.32 & 100.00 & $|0.00 \mathrm{E}+00|$ & 5 & 265.32 & 1.85 & 17.1 & 0.09 & 0.05 & 1.44 & 0.07 & 0.06 & 1.09 & 1.56 \\
\hline 9 & $E M$ & $\mathrm{DC}$ & Ef & $1.00 E+07$ & $3.58 \mathrm{E}-02$ & 270.32 & 0 & 270.32 & 100.00 & $0.00 \mathrm{E}+00$ & 5 & 265.32 & 1.85 & 17.1 & 0.09 & 0.05 & 1.44 & 0.12 & 0.06 & 1.09 & 1.56 \\
\hline & & & & & & & & & & & & & & & & & & & & & \\
\hline 4 & Z-Lay & TC & $\ln$ & $9.87 \mathrm{E}+06$ & $3.81 \mathrm{E}-02$ & 269.25 & 18.5 & 250.75 & 93.13 & $5.82 \mathrm{E}+03$ & 3.5 & 247.25 & 1.40 & 298 & 0.44 & 0.00 & -80.36 & 0.23 & 0.00 & .4 .76 & -382.28 \\
\hline 4 & Z-Loy & $T C$ & $\overline{E f}$ & $9.07 E+06$ & $3.81 \mathrm{E}-02$ & 269.25 & 18.5 & 250.75 & 93.13 & $5.02 \mathrm{E}+03$ & 3.5 & 247.25 & 1.40 & 298 & 0.72 & 0.00 & -80.36 & 0.12 & 0.00 & -4.76 & -382.28 \\
\hline 10 & Z-Loy & $\mathrm{DC}$ & in & $9.87 \mathrm{E}+06$ & $5.03 \mathrm{E}-02$ & 269.25 & 43.6 & 225.65 & 83.81 & $1.15 \mathrm{E}+04$ & 7.9 & 217.75 & 3.50 & 1060 & 0.66 & 0.00 & .342 .29 & 0.12 & 0.00 & -2.41 & .825 .82 \\
\hline 10 & Z-Lay & $D C$ & Ef & $9.87 E+06$ & $5.03 \mathrm{E}-02$ & 269.25 & 43.6 & 225.65 & 83.81 & $1.15 E+04$ & 7.9 & 217.75 & 3.50 & 1060 & 0.29 & 0.00 & -342.29 & 0.17 & 0.00 & -2.41 & -825.82 \\
\hline & & & & & & & & & & & & & & & & & & & & & \\
\hline 5 & NanoFe I & $T C$ & In & $1.00 E+07$ & $3.31 \mathrm{E}-02$ & 228.06 & 46.3 & 181.76 & 79.70 & $7.56 \mathrm{E}+04$ & 10.6 & 171.16 & 5.83 & 259 & 0.56 & 0.00 & -7.58 & 0.18 & 0.00 & -11.58 & -87.79 \\
\hline 5 & NanoFe I & TC & Ef & $1.00 \mathrm{E}+07$ & $3.31 \mathrm{E}-02$ & 228.06 & 46.3 & 181.76 & 79.70 & $7.56 \mathrm{E}+04$ & 10.6 & 171.16 & 5.83 & 259 & 0.80 & 0.00 & -7.58 & 0.12 & 0.00 & -11.58 & -87.79 \\
\hline 11 & NanoFel & $\overline{D C}$ & $\ln$ & $1.00 E+07$ & $2.48 \mathrm{E}-02$ & 202.66 & 43.7 & 158.96 & 78.44 & $7.02 \mathrm{E}+04$ & 2.7 & 156.26 & 1.70 & 183 & 0.65 & 0.00 & -48.81 & 0.22 & 0.00 & $\begin{array}{l}.7 .52 \\
\end{array}$ & -367.20 \\
\hline 11 & NanoFe I & $D C$ & Ef & $1.00 E+07$ & $2.48 \mathrm{E}-02$ & 202.66 & 43.7 & 158.96 & 78.44 & $7.02 \mathrm{E}+04$ & 2.7 & 156.26 & 1.70 & 183 & 0.89 & 0.00 & -48.81 & 0.21 & 0.00 & -7.52 & -367.20 \\
\hline & & & & & & & & & & & & & & & & & & & & & \\
\hline 6 & NanoFe II & TC & In & $1.00 \mathrm{E}+07$ & $2.82 \mathrm{E} \cdot 02$ & 208.11 & 66 & 142.11 & 68.29 & $2.28 \mathrm{E}+05$ & 15 & 127.11 & 10.56 & 0 & 1.55 & 0.03 & -1.01 & 0.35 & 0.03 & -1.01 & -1.02 \\
\hline 6 & NanoFe II & TC & Ef & $9.00 E+07$ & $2.82 \mathrm{E}-\mathrm{D} 2$ & 208.11 & 65 & 142.11 & 68.29 & $2.28 \mathrm{E}+05$ & 15 & 127.11 & 10.56 & 0 & 0.23 & 0.03 & -1.01 & 0.12 & 0.03 & -1.01 & -1.02 \\
\hline 12 & NanoFe II & $D C$ & $\ln$ & $1.00 E+07$ & $2.60 \mathrm{E} \cdot 02$ & 208.11 & 67.9 & 140.21 & 67.37 & $2.20 \mathrm{E}+05$ & 9.5 & 130.71 & 6.78 & 14.8 & 1.01 & 0.03 & 1.03 & 0.29 & 0.03 & -1.06 & -1.03 \\
\hline 12 & NanoFe II & $\mathrm{DC}$ & Ef & $1.00 E+07$ & $2.60 \mathrm{E}-02$ & 208.11 & 67.9 & 140.21 & 67.37 & $2.20 \mathrm{E}+05$ & 9.5 & 130.71 & 6.78 & 14.8 & 0.24 & 0.03 & 1.03 & 0.10 & 0.03 & -1.06 & -1.03 \\
\hline & & & & & & & & & & & & & & & & & & & & & \\
\hline 14 & $5-3700$ & TC & $\ln$ & $1.00 \mathrm{E}+07$ & $2.82 \mathrm{E}-02$ & 275.55 & 10.7 & 264.85 & 96.12 & $6.43 \mathrm{E}+05$ & 0 & 264.85 & 0 & 0 & 1.29 & 0.01 & -2.87 & N/A & 0.05 & 5.19 & 1.81 \\
\hline 14 & 5.3700 & $T C$ & Ef & $1.00 \mathrm{E}+07$ & $2.82 \mathrm{E}-02$ & 275.55 & 10.7 & 264.85 & 96.12 & $6.43 \mathrm{E}+05$ & 0 & 264.85 & 0 & 0 & 0.37 & 0.01 & -2.87 & N/A & 0.05 & 5.19 & 1.81 \\
\hline 15 & $5-3700$ & $D C$ & $\ln$ & $1.00 E+07$ & $3.86 \mathrm{E}-02$ & 275.55 & 6.7 & 258.05 & 97.57 & $7.05 E+05$ & 0 & 268.05 & 0 & 0 & 1.52 & 0.01 & -3.05 & $\mathrm{~N} / \mathrm{A}$ & 0.05 & 4.46 & 1.46 \\
\hline 15 & $5-3700$ & $\mathrm{OC}$ & Ef & $1.00 E+07$ & $3.86 \mathrm{E}-02$ & 275.55 & 6.7 & 268.85 & 97.57 & $7.05 \mathrm{E}+05$ & 0 & 268.85 & 0 & 0 & 0.33 & 0.01 & -3.05 & N/A & 0.06 & 4.46 & 1.46 \\
\hline & & & & & & & & & & & & & & & & & & & & & \\
\hline 13 & Control & - & $\ln$ & $0.00 \mathrm{E}+00$ & $4.66 \mathrm{E}-02$ & 0 & 0 & a & & 0 & 0 & 0 & D & 0 & 0.09 & 0.06 & 1.22 & 0.06 & 0.08 & 1.45 & 1.76 \\
\hline 13 & Control & - & $E f$ & $0.00 E+\infty 0$ & $4.66 \mathrm{E}-02$ & 0 & $\overline{0}$ & 0 & & 0 & 0 & 0 & D & 0 & 0.10 & 0.06 & 1.22 & 0.10 & 0.08 & 1.45 & 1.76 \\
\hline
\end{tabular}

Cravimetric Methods-ASTM D2216

Hydraulic Conductivity ( $K$ ) was determined by Constant Head Permeability Testing-ASTM 0234

N $/ A=$ Sample results not available 


\begin{tabular}{|c|c|c|c|c|c|c|c|c|c|}
\hline \multicolumn{10}{|c|}{ ZVI Injection Scoring Results } \\
\hline ZVI Material & $\begin{array}{l}\text { Solids } \\
\text { Distribution in } \\
\text { Flow Cells } \\
\text { (Visual Obs.) }\end{array}$ & Score & $\begin{array}{l}\text { Avg. } \\
\text { Reduction in } \\
\text { K Complete } \\
\text { (Multiplier) }\end{array}$ & Score & $\begin{array}{l}\text { Avg. Soilds } \\
\text { Emplaced } \\
\text { After } \\
\text { Injection (\%) }\end{array}$ & Score & $\begin{array}{c}\text { Avg. Solids } \\
\text { Remaining } \\
\text { After Flush } \\
(\%)\end{array}$ & Score & $\begin{array}{l}\text { TOTAL } \\
\text { SCORE }\end{array}$ \\
\hline Micropowder S-3700 & $>3 / 4$ & 3 & 1.65 & 5 & 96.85 & 4 & 100 & 4 & 16 \\
\hline RNIP-M2 & $1 / 2$ to $3 / 4$ & 1 & -2.0 & 5 & 82.25 & 3 & 79 & 1 & 10 \\
\hline Polymetallix & Full & 5 & -131.3 & 1 & 60.2 & 1 & 87.9 & 2 & 9 \\
\hline Z-Loy & Full & 5 & -603.9 & Eliminated & - & - & - & - & Eliminated \\
\hline NanoFe I & Full & 5 & -227.5 & Eliminated & - & - & - & - & Eliminated \\
\hline NanoFe II & $<1 / 2$ & Eliminated & - & - & - & - & - & - & Eliminated \\
\hline EZVI & $<1 / 2$ & Eliminated & - & - & - & - & - & - & Eliminated \\
\hline
\end{tabular}

\begin{tabular}{|c|c|c|c|c|c|c|c|c|c|c|c|c|c|}
\hline \multicolumn{14}{|c|}{ ZVI Geochemical Scoring Results } \\
\hline \multirow[t]{2}{*}{ ZVI Material } & \multicolumn{2}{|c|}{$\begin{array}{l}\text { Avg. } \\
\text { Chromium } \\
\text { Reduction } \\
(\%)\end{array}$} & \multicolumn{2}{|c|}{ Score } & \multicolumn{2}{|c|}{$\begin{array}{c}\text { Avg. Nitrate } \\
\text { Reduction (\%)/ } \\
\text { Avg. Ammonia } \\
\text { Production (mg/L) }\end{array}$} & \multicolumn{2}{|c|}{ Score } & \multicolumn{2}{|c|}{$\begin{array}{l}\text { Undesirable By-Products } \\
\text { Produced or Injected }\end{array}$} & \multicolumn{2}{|c|}{ Score } & \multirow[t]{2}{*}{$\begin{array}{l}\text { TOTAL } \\
\text { SCORE }\end{array}$} \\
\hline & $\begin{array}{l}\text { High } \\
\text { Conc }\end{array}$ & $\begin{array}{l}\text { Low } \\
\text { Conc } \\
\end{array}$ & $\begin{array}{l}\text { High } \\
\text { Conc } \\
\end{array}$ & $\begin{array}{l}\text { Low } \\
\text { Conc } \\
\end{array}$ & $\begin{array}{l}\text { High } \\
\text { Conc }\end{array}$ & $\begin{array}{l}\text { Low } \\
\text { Conc } \\
\end{array}$ & $\begin{array}{l}\text { High } \\
\text { Conc }\end{array}$ & $\begin{array}{l}\text { Low } \\
\text { Conc } \\
\end{array}$ & $\begin{array}{l}\text { High } \\
\text { Conc } \\
\end{array}$ & $\begin{array}{l}\text { Low } \\
\text { Conc } \\
\end{array}$ & $\begin{array}{l}\text { High } \\
\text { Conc }\end{array}$ & $\begin{array}{l}\text { Low } \\
\text { Conc }\end{array}$ & \\
\hline RNIP-M2 & $>97$ & $>97$ & 5 & 5 & $24.6 / 1.29$ & $2.6 / 0.33$ & 1 & 3 & Organic Carbon & None & 1 & 2 & 17 \\
\hline Polymetallix & $>97$ & 47 & 5 & 2 & $3.9 / 1.45$ & $4.3 / 1.10$ & 2 & 2 & Phosphate & Phosphate & 0 & 0 & 11 \\
\hline Micropowder S-3700 & 1 & 0 & 0 & 0 & $2.4 / 0.10$ & $1.8 / 0.30$ & 3 & 3 & Organic Carbon & Organic Carbon & 0 & 0 & 6 \\
\hline
\end{tabular}


DOE/RL-2009-35, REV. 0

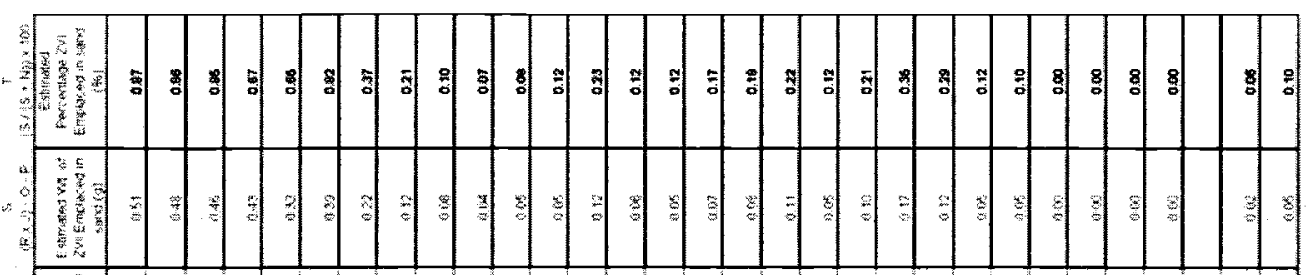

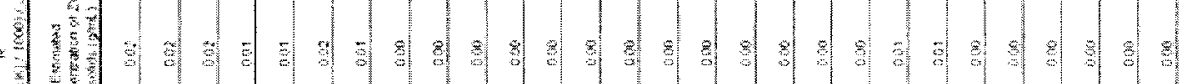

(3)

(3.

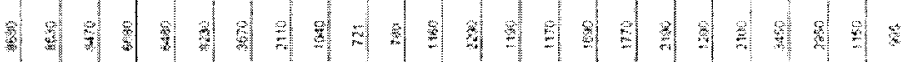

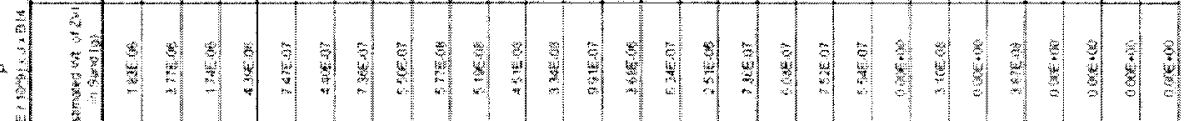

s.

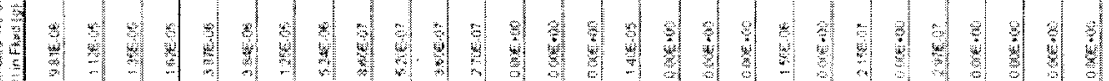

$=$$$
\text { : }
$$

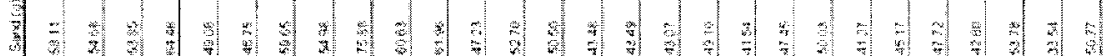

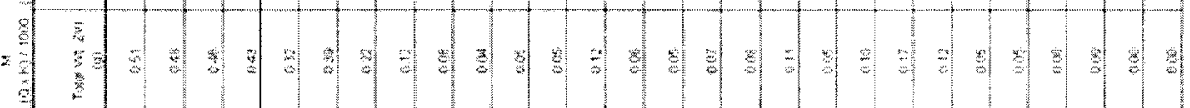

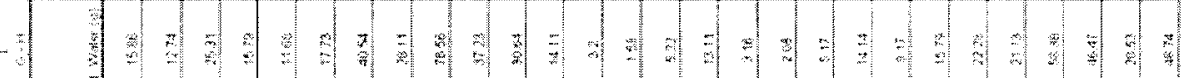

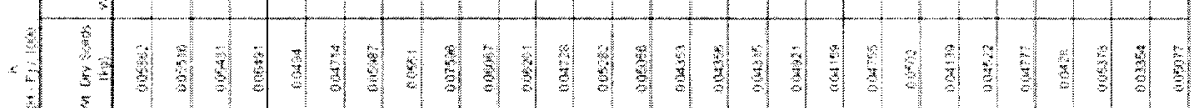

s.

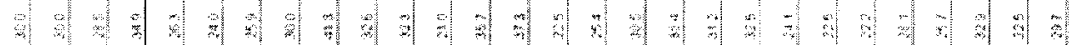

3.

.

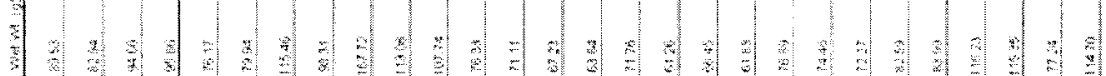

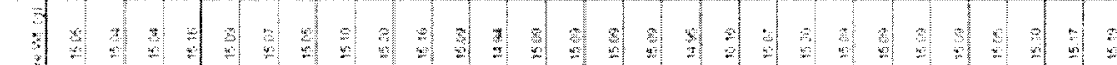

7 1

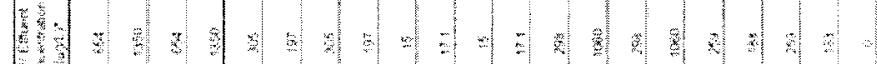

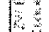

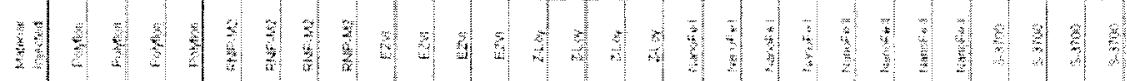

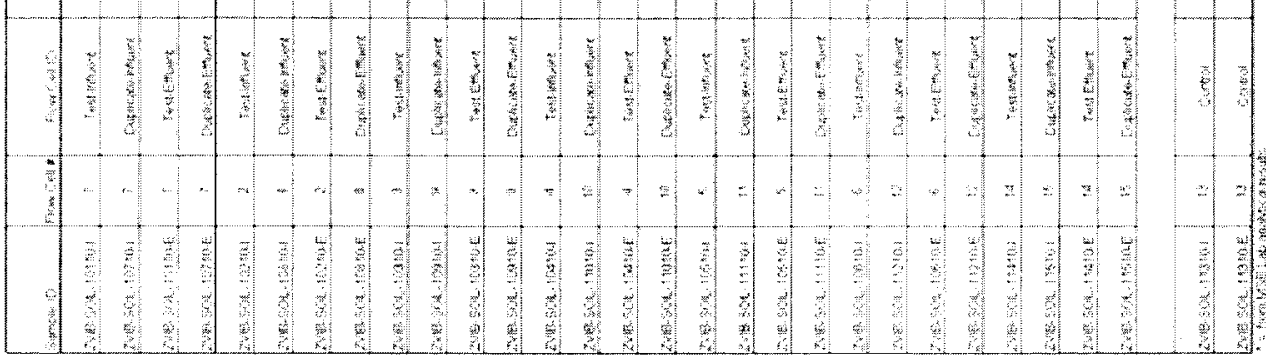




\begin{tabular}{|c|c|c|c|c|c|c|c|c|c|c|c|c|c|c|c|c|c|}
\hline \multirow[b]{2}{*}{ A } & \multicolumn{17}{|c|}{ Emplaced Iron Calculations During Injection } \\
\hline & $\mathrm{B}$ & $\mathrm{C}$ & $\bar{D}$ & $\bar{E}$ & $\mathrm{~F}$ & $\mathrm{G}$ & $\mathrm{H}$ & 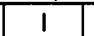 & 1 & $\mathrm{~K}$ & $L$ & $\mathrm{M}$ & $\mathrm{N}$ & 0 & $P$ & $\mathrm{Q}$ & $\mathbf{R}$ \\
\hline S ample ID & $\begin{array}{c}\text { Flow } \\
\text { C ell } \\
\# \\
\end{array}$ & $\begin{array}{c}\text { Flow } \\
\text { Cell } \\
1 D^{1} \\
\end{array}$ & $\begin{array}{l}\text { Material } \\
\text { Injected }\end{array}$ & $\begin{array}{c}V I \\
\text { E ffluent } \\
\text { Conc. } \\
(\mu \mathrm{g} \Lambda)^{2} \\
\end{array}$ & \begin{tabular}{|c|} 
Tare \\
Wt. \\
$(\mathrm{g})$ \\
\end{tabular} & $\begin{array}{c}\text { Tare }+ \\
\text { Wet } \\
\text { Wt. (g) }\end{array}$ & $\begin{array}{l}\text { Tare } \\
+ \text { Dry } \\
\text { Wt. } \\
\text { (g) }\end{array}$ & \begin{tabular}{|l|}
\multicolumn{2}{|c|}{ Appro) } \\
$\begin{array}{l}\text { Total } \\
(\mathrm{mL})\end{array}$ \\
\end{tabular} & \begin{tabular}{|c|} 
Dr. Vol. \\
D olids \\
(mL) \\
\end{tabular} & \begin{tabular}{|c|} 
Wt. \\
Dry \\
Solids \\
$(\mathrm{kg})^{3}$ \\
\end{tabular} & \begin{tabular}{|c|} 
Wt. \\
Water \\
$(g)^{4}$ \\
\end{tabular} & $\begin{array}{l}\text { Total } \\
W \mathrm{t} . \\
\mathrm{ZVI} \\
(\mathrm{g})^{5}\end{array}$ & $\begin{array}{c}\text { Wt. } \\
\text { S and } \\
(g)^{6}\end{array}$ & $\begin{array}{c}\text { Est. Wt. } \\
\text { of ZVI in } \\
\text { Fluid } \\
(\mathrm{g})^{7}\end{array}$ & $\begin{array}{c}\text { Est. Wt. } \\
\text { of ZVI in } \\
S \text { and } \\
(\mathrm{g})^{8}\end{array}$ & $\begin{array}{c}\text { ZVI conc. in } \\
\text { lab soil } \\
\text { sample } \\
(\mathrm{mg} / \mathrm{kg})^{2}\end{array}$ & $\begin{array}{l}\text { Est. } \\
\text { Conc. of } \\
\text { ZVI in } \\
\text { solids } \\
\end{array}$ \\
\hline ZVIB-SOIL-10106-I & 1 & $\mathrm{TI}$ & Polyfion & 3090000 & 15.07 & 63.62 & 47.20 & 32.1 & 27.0 & 0.032 & 16.42 & 1.14 & 30.99 & 0.0158 & 0.00777 & 35500 & 0.04 \\
\hline ZVIB-S OIL-10706-I & 7 & $\mathrm{DI}$ & Polyflon & 2330000 & 15.07 & 76.11 & 52.70 & 38.6 & 24.0 & 0.038 & 23.41 & 1.74 & 35.89 & 0.0340 & 0.00521 & 46300 & 0.07 \\
\hline ZVIB-S OIL-10106-E & 1 & $T E$ & Polyflon & 3090000 & 15.07 & 89.60 & 52.90 & 45.0 & 27.0 & 0.038 & 36.7 & 1.59 & 36.24 & 0.0556 & 0.00777 & 42100 & 0.06 \\
\hline ZVIB-S OIL-10706-E & 7 & $\mathrm{DE}$ & Polyflon & 2330000 & 15.07 & 68.58 & 50.00 & 32.1 & 25.5 & 0.035 & 18.58 & 1.10 & 33.83 & 0.0154 & 0.00553 & 31600 & 0.04 \\
\hline ZVIB-S OIL-10206-I & 2 & $\mathrm{TI}$ & R NIP-M2 & 673000 & 15.07 & 62.60 & 41.20 & 41.8 & 21.0 & 0.026 & 21.4 & 1.64 & 24.49 & 0.0140 & 0.00132 & 62800 & 0.08 \\
\hline ZVIB-S OIL-10806-I & 8 & $\mathrm{DI}$ & RNIP-M2 & 241000 & 15.07 & 122.59 & 61.90 & 88.4 & 30.0 & 0.047 & 60.69 & 4.12 & 42.71 & 0.0141 & 0.00067 & 87900 & 0.14 \\
\hline ZVIB-S OIL-10206-E & 2 & $\overline{T E}$ & RNIP-M2 & 673000 & 15.07 & 133.85 & 50.20 & 64.3 & 22.5 & 0.035 & 83.65 & 1.18 & 33.95 & 0.0281 & 0.00141 & 33600 & 0.05 \\
\hline ZVIB-S OIL-10806-E & 8 & $\overline{D E}$ & RNIP-M2 & 241000 & 15.07 & 172.24 & 62.60 & 78.8 & 27.0 & 0.048 & 109.6 & 1.58 & 45.95 & 0.0125 & 0.00061 & 33300 & 0.06 \\
\hline ZVIB-S OIL-10306-I & 3 & $\overline{T I}$ & $E Z V I$ & 29.4 & 15.07 & 122.32 & 52.20 & 75.5 & 18.0 & 0.037 & 70.12 & 0.04 & 37.09 & 0.0000 & 0.00000 & 1180 & 0.00 \\
\hline ZVIB-S OIL-10906-I & 9 & DI & EZVI & 0 & 15.07 & 98.16 & 44.60 & 72.3 & 15.0 & 0.03 & 53.56 & 0.03 & 29.50 & 0.0000 & 0.00000 & 872 & 0.00 \\
\hline ZVIB-S OIL-10306-E & 3 & $T E$ & EZVI & 29.4 & 15.07 & 115.91 & 47.50 & 73.9 & 13.5 & 0.032 & 68.41 & 0.04 & 32.39 & 0.0000 & 0.00000 & 1130 & 0.00 \\
\hline ZVIB-S OIL-10906-E & 9 & $\overline{D E}$ & $E Z V I$ & 0 & 15.07 & 110.26 & 69.30 & 69.1 & 27.0 & 0.054 & 40.96 & 0.05 & 54.18 & 0.0000 & 0.00000 & 932 & 0.00 \\
\hline ZVIB-S OIL-10406-I & 4 & $\mathrm{TI}$ & Z-Loy & 5820 & 15.01 & 58.78 & 52.48 & 26.1 & 26.1 & 0.037 & 6.3 & 0.16 & 37.31 & 0.0000 & 0.00001 & 4360 & 0.01 \\
\hline ZVIB-S OIL-11006-I & 10 & DI & Z-Loy & 11500 & 15.03 & 64.17 & 60.63 & 35.8 & 35.8 & 0.046 & 3.54 & 0.30 & 45.30 & 0.0000 & 0.00004 & 580 & 0.01 \\
\hline ZVIB-S OIL-10406-E & 4 & TE & Z-Loy & 5820 & 15.04 & 69.30 & 65.31 & 42.6 & 42.6 & 0.05 & 3.99 & 0.36 & 49.91 & 0.0000 & 0.00002 & 7180 & 0.01 \\
\hline ZVIB-SOIL-11006-E & 10 & $\overline{D E}$ & Z-Loy & 11500 & 15.07 & 62.55 & 53.53 & 27.3 & 27.3 & 0.038 & 9.02 & 0.11 & 38.35 & 0.0000 & 0.00003 & 2870 & 0.00 \\
\hline ZVIB-S OIL-10506-I & 5 & $\mathrm{TI}$ & NanoFe I & 75600 & 15.05 & 70.13 & 66.88 & 40.2 & 40.2 & 0.052 & 3.25 & 0.29 & 51.54 & 0.0000 & 0.00028 & 5590 & 0.01 \\
\hline ZVIB-S OIL-11106-I & 11 & DI & NanoFe I & 70200 & 15.16 & 67.40 & 64.27 & 30.5 & 30.5 & 0.049 & 3.13 & 0.32 & 48.79 & 0.0000 & 0.00020 & 480 & 0.01 \\
\hline ZVIB-SOIL-10506-E & 5 & $T E$ & NanoFe I & 75600 & 15.16 & 98.14 & 72.49 & 57.5 & 30.1 & 0.057 & 25.65 & 0.46 & 56.87 & 0.0021 & 0.00021 & 8070 & 0.02 \\
\hline ZVIB-S OIL-11106-E & 11 & $\mathrm{DE}$ & NanoFe I & 70200 & 15.17 & 95.52 & 71.02 & 53.0 & 28.1 & 0.056 & 24.5 & 0.50 & 55.35 & 0.0017 & 0.00018 & 8930 & 0.02 \\
\hline ZVIB-S OIL -10606-I & 6 & $T I$ & NanoFe II & 228000 & 14.87 & 88.49 & 74.35 & \begin{tabular}{|l|}
41.8 \\
\end{tabular} & 37.0 & 0.059 & 14.14 & 0.92 & 58.56 & 0.0011 & 0.00078 & 15500 & 0.02 \\
\hline ZVIB-S OIL-11206-I & 12 & $\mathrm{DI}$ & NanoFe II & 220000 & 15.08 & 88.27 & 73.15 & 49.4 & 35.0 & 0.058 & 15.12 & 0.59 & 57.48 & 0.0032 & 0.00072 & 10200 & 0.02 \\
\hline ZVIB-S OIL-10606-E & 6 & $T E$ & NanoFe II & 228000 & 15.17 & 101.64 & 79.34 & 54.6 & 45.0 & 0.064 & 22.3 & 0.15 & 64.02 & 0.0022 & 0.00096 & 2360 & 0.00 \\
\hline ZVIB-S OIL-11206-E & 12 & $\overline{D E}$ & NanoFe II & 220000 & 15.16 & 124.06 & 78.30 & 69.1 & 38.2 & 0.063 & 45.76 & 0.16 & 62.98 & 0.0068 & 0.00078 & 2500 & 0.00 \\
\hline ZVIB-S OIL-11406-I & 14 & $\mathrm{TI}$ & $5-3700$ & 643000 & 15.08 & 76.47 & 61.52 & 38.6 & 23.6 & 0.046 & 14.95 & 0.61 & 45.83 & 0.0096 & 0.00141 & 13100 & 0.03 \\
\hline ZVIB-S OIL-11506-I & 15 & $\mathrm{DI}$ & $5-3700$ & 705000 & 15.08 & 73.34 & 55.94 & 38.9 & 24.1 & 0.041 & 17.4 & 0.63 & 40.23 & 0.0104 & 0.00158 & 15500 & 0.03 \\
\hline ZVIB-SOIL-11406-E & 14 & $T E$ & $5-3700$ & 643000 & 15.08 & 87.94 & 73.76 & 43.4 & 30.5 & 0.059 & 14.18 & 0.23 & 58.45 & 0.0083 & 0.00183 & 3880 & 0.01 \\
\hline ZVIB-S OIL-11506-E & 15 & $D E$ & $5-3700$ & 705000 & 15.08 & 55.79 & 46.90 & 25.3 & 18.0 & 0.032 & 8.89 & 0.11 & 31.71 & 0.0051 & 0.00118 & 3470 & 0.01 \\
\hline ZVIB-5 OIL-11306-I & 13 & $\mathrm{Cl}$ & None & 0 & 15.07 & 79.78 & 55.34 & 48.2 & 25.7 & 0.04 & 24.44 & 0.04 & 40.23 & 0.0000 & 0.00000 & 888 & 0.00 \\
\hline ZVIB-SOIL-11306-E & 13 & $\mathrm{CE}$ & None & 0 & 15.20 & 139.90 & 81.38 & 90.0 & 34.6 & 0.066 & 58.52 & 0.06 & 66.12 & 0.0000 & 0.00000 & 977 & 0.00 \\
\hline & ${ }^{1} D=D u$ & licate & $T=$ Test, $C$ & $=$ Control 1 & $I=\operatorname{lnfluer}$ & $n t, E=E F$ & ffluent & & & & & & & & & & \\
\hline
\end{tabular}

Assumptions:

1) The ZVI concentration in the sand pores and in the free fluid is equal to the effluent ZVI conentration after injection of 20 PV's of ZVI or GW.

2) The ZVI concentration in the sand pores of the sample is equal to the ZVI concentration in the free fluid of the sample.

Givens:

S and $9 \%$ 
Porosity Calculations

A

B

c

D

E

G

$\mathrm{H}$

1

Approximate Volum

Sample ID

Flow Cell \# Flow Cell ID

| Material Injected Tare Wh. (g) I Tare + Wet Wt.

None

\begin{tabular}{l|l}
15.07 & 79.78 \\
\hline
\end{tabular}

79.78

55.34

\begin{tabular}{c|c|c} 
otal (mL) & Dry Solids (mL) & Material \\
\hline 48.2 & 25.7 & 64.71
\end{tabular} 25.7

\begin{tabular}{|l|l|l}
\hline ZMB-SOLL-SOLL-11306-E & 13 & Control-Influent \\
\hline \hline
\end{tabular}

None

81.38

90.0

Density of Water $=$

$1 \mathrm{~g} / \mathrm{mL}$ 


\begin{tabular}{|c|c|c|c|c|c|c|c|c|}
\hline \multicolumn{9}{|c|}{ Screening Injection Test Summary- Head } \\
\hline Date \& Time & $\begin{array}{c}\text { Elapsed } \\
\text { Time } \\
\text { (Day) }\end{array}$ & $\begin{array}{c}\text { Flow } \\
\text { Rate } \\
(\mathrm{mL} / \mathrm{min})\end{array}$ & \begin{tabular}{|c|} 
Actual \\
Pore \\
Volumes
\end{tabular} & $\begin{array}{c}\text { Actual } \\
\text { Flow } \\
\text { Rate } \\
\text { (mL/min) }\end{array}$ & \begin{tabular}{|c} 
Inlet \\
Head \\
(in)
\end{tabular} & $\begin{array}{c}\text { Outlet } \\
\text { Head } \\
\text { (in) }\end{array}$ & \begin{tabular}{|c} 
Head \\
Difference \\
(in)
\end{tabular} & $\begin{array}{l}\text { Hydraulic } \\
\text { Conductivity } \\
\text { (cm/s) }\end{array}$ \\
\hline \multicolumn{9}{|c|}{ Flow Cell \#1 - Polymetallix Test Cell } \\
\hline 10/23/07 6:35 & 0 & 9.0 & 0.0 & 8.0 & 6.63 & 5.13 & 1.5 & $5.65 \mathrm{E}-02$ \\
\hline $10 / 23 / 078: 45$ & 0.090 & 9.0 & 0.0 & 9.5 & 6.63 & 5.25 & 1.38 & $7.30 \mathrm{E}-02$ \\
\hline 10/23/07 16:56 & 0.341 & 55.0 & 0.0 & 52.0 & 12.63 & 5.5 & 7.13 & $7.73 \mathrm{E}-02$ \\
\hline 10/23/07 17:10 & 0.010 & & & & & & & \\
\hline 10/23/07 17:35 & 0.017 & 55.0 & 1.0 & 52.0 & 18 & 5.63 & 12.37 & $4.46 \mathrm{E}-02$ \\
\hline $10 / 23 / 0718: 25$ & 0.052 & 55.0 & 3.0 & 52.0 & 29.63 & 6 & 23.63 & $2.33 \mathrm{E}-02$ \\
\hline 10/23/07 19:41 & 0.105 & 55.0 & 6.1 & 56.0 & 45.81 & 6.75 & 39.06 & $1.52 \mathrm{E}-02$ \\
\hline $10 / 23 / 0722: 06$ & 0.206 & 55.0 & 11.9 & 51.5 & 77.88 & 8.75 & 69.13 & $7.90 \mathrm{E}-03$ \\
\hline $10 / 24 / 071: 19$ & 0.340 & 55.0 & 19.7 & 52.0 & 80.75 & 10.38 & 70.37 & $7.83 \mathrm{E}-03$ \\
\hline $10 / 24 / 0710: 05$ & 0 & & & & & & & \\
\hline $10 / 24 / 0712: 42$ & 0.109 & 9.0 & 1.0 & 9.0 & 14.5 & 5.13 & 9.37 & $1.02 \mathrm{E}-02$ \\
\hline $10 / 25 / 079: 05$ & 0.849 & 2.2 & 3.0 & 2.4 & 12.19 & 5 & 7.19 & $3.54 \mathrm{E}-03$ \\
\hline $10 / 25 / 0715: 22$ & 1.111 & 2.2 & 3.6 & 2.2 & 11.5 & 5 & 6.5 & $3.59 \mathrm{E}-03$ \\
\hline $10 / 26 / 079: 08$ & 1.851 & 2.2 & 5.3 & 2.4 & 13 & 5 & 8 & $3.18 \mathrm{E}-03$ \\
\hline $10 / 26 / 0713: 58$ & 2.053 & 2.2 & 5.8 & 2.4 & 12.5 & 5 & 7.5 & $3.39 \mathrm{E}-03$ \\
\hline $10 / 27 / 07 \quad 10: 52$ & 2.924 & 2.2 & 7.8 & 2.3 & 11 & 5.06 & 5.94 & $4.10 \mathrm{E}-03$ \\
\hline $10 / 28 / 07 \quad 10: 23$ & 3.903 & 2.2 & 10.1 & 2.2 & 9.19 & 5.06 & 4.13 & $5.65 \mathrm{E}-03$ \\
\hline $10 / 28 / 0718: 28$ & 4.240 & 2.2 & 10.9 & 2.2 & 8.38 & 5 & 3.38 & $6.90 \mathrm{E}-03$ \\
\hline $10 / 29 / 078: 45$ & 4.835 & 2.2 & 12.2 & 2.2 & 7.38 & 5.13 & 2.25 & $1.04 \mathrm{E}-02$ \\
\hline $10 / 29 / 0715: 33$ & 5.119 & 2.2 & 12.9 & 1.9 & 7.25 & 5.06 & 2.19 & $9.20 \mathrm{E}-03$ \\
\hline $10 / 30 / 07 \quad 10: 32$ & 5.910 & 2.2 & 14.7 & 2.1 & 7.06 & 5 & 2.06 & $1.08 \mathrm{E}-02$ \\
\hline $10 / 30 / 0716: 23$ & 6.153 & 2.2 & 15.3 & 2.3 & 7.19 & 5.06 & 2.13 & $1.14 \mathrm{E}-02$ \\
\hline $10 / 31 / 0713: 57$ & 7.052 & 2.2 & 17.4 & 2.1 & 7.69 & 5 & 2.69 & $8.27 \mathrm{E}-03$ \\
\hline $11 / 1 / 079: 56$ & 7.885 & 2.2 & 19.3 & 2.2 & 7.63 & 5.06 & 2.57 & $9.07 \mathrm{E}-03$ \\
\hline $11 / 1 / 07$ 15:55 & 8.134 & 2.2 & 19.9 & 2.1 & 7.69 & 5 & 2.69 & $8.27 \mathrm{E}-03$ \\
\hline $11 / 2 / 077: 38$ & 8.789 & 2.2 & 21.4 & 2.2 & 7.81 & 5.06 & 2.75 & $8.48 \mathrm{E}-03$ \\
\hline \multicolumn{9}{|c|}{ Flow Cell \#2 - RNIP M2 Test Cell } \\
\hline $10 / 23 / 076: 35$ & 0 & 9.0 & 0.0 & 9.5 & 7.56 & 5 & 2.56 & $3.93 E-02$ \\
\hline $10 / 23 / 078: 45$ & 0.090 & 9.0 & 0.0 & 9.0 & 7.63 & 5.13 & 2.5 & $3.82 \mathrm{E}-02$ \\
\hline $10 / 23 / 0716: 56$ & 0.341 & 55.0 & 0.0 & 50.0 & 18.25 & 5.75 & 12.5 & $4.24 \mathrm{E}-02$ \\
\hline $10 / 23 / 0717: 10$ & 0.010 & & & & & & & \\
\hline $10 / 23 / 0717: 37$ & 0.019 & 55.0 & 1.1 & 50.0 & 18.75 & 5.88 & 12.87 & $4.12 \mathrm{E}-02$ \\
\hline $10 / 23 / 0718: 27$ & 0.053 & 55.0 & 3.1 & 50.0 & 17.5 & 5.88 & 11.62 & $4.56 \mathrm{E}-02$ \\
\hline $10 / 23 / 0719: 43$ & 0.106 & 55.0 & 6.2 & 51.0 & 16.88 & 5.75 & 11.13 & $4.86 \mathrm{E}-02$ \\
\hline $10 / 23 / 0722: 07$ & 0.206 & 55.0 & 11.9 & 49.5 & 17.25 & 5.75 & 11.5 & $4.56 \mathrm{E}-02$ \\
\hline $10 / 24 / 071: 20$ & 0.340 & 55.0 & 19.7 & 46.0 & 20.5 & 6 & 14.5 & $3.36 \mathrm{E}-02$ \\
\hline $10 / 24 / 0710: 05$ & 0 & & & & & & & \\
\hline $10 / 24 / 0712: 47$ & 0.112 & 9.0 & 1.1 & 9.0 & 6.88 & 5 & 1.88 & $5.07 \mathrm{E}-02$ \\
\hline $10 / 25 / 079: 11$ & 0.850 & 2.2 & 3.0 & 2.0 & 5.38 & 4.81 & 0.57 & $3.72 \mathrm{E}-02$ \\
\hline $10 / 25 / 07 \quad 15: 27$ & 1.111 & 2.2 & 3.6 & 2.2 & 5.44 & 4.88 & 0.56 & $4.16 \mathrm{E}-02$ \\
\hline $10 / 26 / 079: 10$ & 1.849 & 2.2 & 5.3 & 2.2 & 5.5 & 4.75 & 0.75 & $3.11 \mathrm{E}-02$ \\
\hline $10 / 26 / 0714: 01$ & 2.051 & 2.2 & 5.8 & 2.1 & 5.5 & 4.88 & 0.62 & $3.59 \mathrm{E}-02$ \\
\hline $10 / 27 / 0711: 05$ & 2.929 & 2.2 & 7.8 & 2.0 & 5.56 & 4.81 & 0.75 & $2.83 \mathrm{E}-02$ \\
\hline $10 / 28 / 07 \quad 10: 41$ & 3.913 & 2.2 & 10.1 & 2.1 & 5.63 & 4.75 & 0.88 & $2.53 \mathrm{E}-02$ \\
\hline $10 / 28 / 0718: 29$ & 4.238 & 2.2 & 10.9 & 2.0 & 5.63 & 4.81 & 0.82 & $2.59 \mathrm{E}-02$ \\
\hline $10 / 29 / 078: 51$ & 4.836 & 2.2 & 12.3 & 2.0 & 5.75 & 4.75 & 1 & $2.12 \mathrm{E}-02$ \\
\hline $10 / 29 / 0715: 35$ & 5.117 & 2.2 & 12.9 & 1.8 & 5.75 & 4.75 & 1 & $1.91 \mathrm{E}-02$ \\
\hline $10 / 30 / 07 \quad 10: 34$ & 5.908 & 2.2 & 14.7 & 1.9 & 5.81 & 4.81 & 1 & $2.01 \mathrm{E}-02$ \\
\hline $10 / 30 / 0716: 31$ & 6.156 & 2.2 & 15.3 & 1.8 & 5.81 & 4.81 & 1 & $1.91 \mathrm{E}-02$ \\
\hline 10/31/07 16:59 & 7.175 & 2.2 & 17.7 & 1.9 & 5.81 & 4.75 & 1.06 & $1.90 \mathrm{E}-02$ \\
\hline $11 / 1 / 079: 57$ & 7.882 & 2.2 & 19.3 & 1.9 & 5.81 & 4.81 & 1 & $2.01 \mathrm{E}-02$ \\
\hline $11 / 1 / 0715: 56$ & 8.131 & 2.2 & 19.9 & 1.9 & 5.81 & 4.81 & 1 & $2.01 \mathrm{E}-02$ \\
\hline $11 / 2 / 077: 39$ & 8.786 & 2.2 & 21.4 & 1.8 & 5.75 & 4.81 & 0.94 & $2.03 \mathrm{E}-02$ \\
\hline
\end{tabular}




\begin{tabular}{|c|c|c|c|c|c|c|c|c|}
\hline \multicolumn{9}{|c|}{ Screening Injection Test Summary- Head } \\
\hline Date \& Time & $\begin{array}{c}\text { Elapsed } \\
\text { Time } \\
\text { (Day) }\end{array}$ & $\begin{array}{c}\text { Flow Rate } \\
\text { (mL/min) }\end{array}$ & $\begin{array}{c}\text { Actual } \\
\text { Pore } \\
\text { Volumes }\end{array}$ & $\begin{array}{c}\text { Actual } \\
\text { Flow } \\
\text { Rate } \\
\text { (mL/min) }\end{array}$ & $\begin{array}{l}\text { Inlet } \\
\text { Head } \\
\text { (in) }\end{array}$ & $\begin{array}{l}\text { Outlet } \\
\text { Head } \\
\text { (in) }\end{array}$ & $\begin{array}{c}\text { Head } \\
\text { Difference } \\
\text { (in) }\end{array}$ & $\begin{array}{l}\text { Hydraulic } \\
\text { Conductivity } \\
(\mathrm{cm} / \mathrm{s})\end{array}$ \\
\hline \multicolumn{9}{|c|}{ Flow Cell \#3 - EZVI Test Cell } \\
\hline 10/23/07 6:35 & 0 & 9.0 & 0.0 & \begin{tabular}{|l|l}
8.8 & \\
\end{tabular} & 7.06 & 5 & 2.06 & $4.53 \mathrm{E}-02$ \\
\hline $10 / 23 / 078: 45$ & 0.090 & 9.0 & 0.0 & 9.0 & 7.25 & 5.13 & 2.12 & $4.50 \mathrm{E}-02$ \\
\hline 10/23/07 17:03 & 0.346 & 55.0 & 0.0 & 51.0 & 15.5 & 5.75 & 9.75 & $5.54 \mathrm{E}-02$ \\
\hline 10/23/07 17:10 & 0.005 & & & & & & & \\
\hline $10 / 23 / 0717: 38$ & 0.019 & 55.0 & 1.1 & 49.0 & 15.38 & 5.63 & 9.75 & $5.33 \mathrm{E}-02$ \\
\hline 10/23/07 18:27 & 0.053 & 55.0 & 3.1 & 50.0 & 15 & 5.75 & 9.25 & $5.73 \mathrm{E}-02$ \\
\hline 10/23/07 19:45 & 0.108 & 55.0 & 6.2 & 49.5 & 14.44 & 5.5 & 8.94 & $5.87 \mathrm{E}-02$ \\
\hline 10/23/07 22:08 & 0.207 & 55.0 & 12.0 & 49.5 & 13.5 & 5.63 & 7.87 & $6.67 \mathrm{E}-02$ \\
\hline $10 / 24 / 071: 21$ & 0.341 & 55.0 & 19.7 & 49.0 & 13.38 & 5.75 & 7.63 & $6.81 \mathrm{E}-02$ \\
\hline 10/24/07 10:05 & 0 & & & & & & & \\
\hline $10 / 24 / 07$ 12:47 & 0.112 & 9.0 & 1.1 & 9.0 & 6.13 & 5 & 1.13 & $8.44 \mathrm{E}-02$ \\
\hline $10 / 25 / 079: 12$ & 0.851 & 2.2 & 3.0 & 2.2 & 5.25 & 4.75 & 0.5 & $4.66 \mathrm{E}-02$ \\
\hline $10 / 25 / 07 \quad 15: 28$ & 1.112 & 2.2 & 3.6 & 1.8 & 5.31 & 5 & 0.31 & $6.15 \mathrm{E}-02$ \\
\hline $10 / 26 / 079: 13$ & 1.851 & 2.2 & 5.4 & 1.8 & 5.25 & 4.88 & 0.37 & $5.16 \mathrm{E}-02$ \\
\hline 10/26/07 14:03 & 2.053 & 2.2 & 5.8 & 1.8 & 5.25 & 4.81 & 0.44 & $4.34 \mathrm{E}-02$ \\
\hline $10 / 27 / 07 \quad 11: 17$ & 2.938 & 2.2 & 7.9 & 1.8 & 5.19 & 4.88 & 0.31 & $6.15 \mathrm{E}-02$ \\
\hline $10 / 28 / 07 \quad 10: 50$ & 3.919 & 2.2 & 10.1 & 1.7 & 5.25 & 4.88 & 0.37 & $4.87 \mathrm{E}-02$ \\
\hline $10 / 28 / 07$ 18:30 & 4.238 & 2.2 & 10.9 & 2.0 & 5.25 & 4.88 & 0.37 & $5.73 \mathrm{E}-02$ \\
\hline 10/29/07 8:53 & 4.838 & 2.2 & 12.3 & 2.1 & 5.25 & 4.88 & 0.37 & $6.02 \mathrm{E}-02$ \\
\hline $10 / 29 / 07 \quad 15: 38$ & 5.119 & 2.2 & 12.9 & 1.8 & 5.13 & 4.81 & 0.32 & $5.96 \mathrm{E}-02$ \\
\hline 10/30/07 10:36 & 5.909 & 2.2 & 14.7 & 1.8 & 5.13 & 4.88 & 0.25 & $7.63 \mathrm{E}-02$ \\
\hline $10 / 30 / 07 \quad 16: 34$ & 6.158 & 2.2 & 15.3 & 1.9 & 5.19 & 4.88 & 0.31 & $6.50 \mathrm{E}-02$ \\
\hline 10/31/07 14:05 & 7.054 & 2.2 & 17.4 & 1.7 & 5.13 & 4.88 & 0.25 & $7.21 \mathrm{E}-02$ \\
\hline 11/1/07 9:58 & 7.883 & 2.2 & 19.3 & 1.8 & 5.19 & 4.94 & 0.25 & $7.63 \mathrm{E}-02$ \\
\hline $11 / 1 / 07$ 15:57 & 8.132 & 2.2 & 19.9 & 1.8 & 5.19 & 4.88 & 0.31 & $6.15 \mathrm{E}-02$ \\
\hline $11 / 2 / 077: 40$ & 8.787 & 2.2 & 21.4 & \begin{tabular}{|l|}
1.8 \\
\end{tabular} & \begin{tabular}{|l|}
5.19 \\
\end{tabular} & 4.94 & 0.25 & $7.63 \mathrm{E}-02$ \\
\hline \multicolumn{9}{|c|}{ Flow Cell \#4 - Zloy Test Cell } \\
\hline 11/1/07 6:39 & 0 & 9.0 & 0.0 & \begin{tabular}{|l|}
8.7 \\
\end{tabular} & 8.13 & 5.56 & 2.57 & $3.59 \mathrm{E}-02$ \\
\hline 11/1/07 8:03 & 0.058 & 9.0 & 0.0 & 9.1 & 8.19 & 5.56 & 2.63 & $3.67 \mathrm{E}-02$ \\
\hline 11/1/07 11:00 & 0.123 & 9.0 & 0.0 & 9.1 & 8.13 & 5.56 & 2.57 & $3.75 \mathrm{E}-02$ \\
\hline 11/1/07 14:37 & 0.151 & 9.0 & 0.0 & 9.4 & 8.19 & 5.63 & 2.56 & $3.89 \mathrm{E}-02$ \\
\hline 11/6/07 8:09 & 4.731 & 2.2 & 0.0 & 2.2 & 5.69 & 5.06 & 0.63 & $3.70 \mathrm{E}-02$ \\
\hline 11/6/07 8:58 & 0.034 & 55.0 & 0.0 & 55.0 & 22.19 & 8.56 & 13.63 & $4.28 \mathrm{E}-02$ \\
\hline 11/6/07 9:32 & 0.024 & & & & & & & \\
\hline 11/6/07 9:58 & 0.018 & 55.0 & 1.0 & 55.0 & 23 & 9 & 14 & $4.16 \mathrm{E}-02$ \\
\hline $11 / 6 / 07 \quad 10: 47$ & 0.052 & 55.0 & 3.0 & 54.0 & 59 & 9 & 50 & $1.14 \mathrm{E}-02$ \\
\hline $11 / 6 / 0712: 09$ & 0.109 & 55.0 & 6.3 & 53.0 & 274.43 & 48 & 226.43 & $2.48 \mathrm{E}-03$ \\
\hline $11 / 6 / 0714: 30$ & 0.207 & 55.0 & 12.0 & 39.0 & 831.6 & 1241.86 & 410.26 & $1.01 \mathrm{E}-03$ \\
\hline $11 / 6 / 0717: 48$ & 0.344 & 55.0 & 19.9 & 10.3 & 1330.56 & 1100.48 & 230.08 & $4.75 \mathrm{E}-04$ \\
\hline 11/7/07 12:06 & 0 & & & & & & & \\
\hline $11 / 7 / 0714: 49$ & 0.113 & 9.0 & 1.1 & 9.1 & 435.2 & 182.95 & 252.25 & $3.82 \mathrm{E}-04$ \\
\hline $11 / 7 / 07 \quad 15: 17$ & 0.019 & 9.0 & 0.2 & & & & & \\
\hline $11 / 8 / 07 \quad 10: 10$ & 0.787 & 2.2 & 2.0 & 2.3 & 415.8 & 110.88 & 304.92 & 8.00 E-05 \\
\hline $11 / 9 / 078: 45$ & 1.728 & 2.2 & 4.2 & 2.3 & 415.8 & 110.88 & 304.92 & $8.00 \mathrm{E}-05$ \\
\hline $11 / 9 / 07 \quad 16: 18$ & 2.042 & 2.2 & 4.9 & 2.3 & 385.31 & 110.88 & 274.43 & $8.88 \mathrm{E}-05$ \\
\hline 11/10/07 14:08 & 2.952 & 2.2 & 7.0 & 2.0 & 382.54 & 108.11 & 274.43 & $7.72 \mathrm{E}-05$ \\
\hline 11/11/07 20:07 & 4.201 & 2.2 & 9.9 & 2.2 & 374.22 & 83.16 & 291.06 & $8.01 \mathrm{E}-05$ \\
\hline 11/12/07 9:55 & 4.776 & 2.2 & 11.2 & 2.2 & 363.13 & 110.88 & 252.25 & $9.24 \mathrm{E}-05$ \\
\hline 11/12/07 15:58 & 5.028 & 2.2 & 11.8 & 2.2 & 360.36 & 110.88 & 249.48 & $9.35 \mathrm{E}-05$ \\
\hline $11 / 13 / 07$ 13:13 & 5.914 & 2.2 & 13.9 & 2.2 & 346.5 & 110.88 & 235.62 & $9.90 \mathrm{E}-05$ \\
\hline $11 / 13 / 07 \quad 17: 25$ & 6.089 & 2.2 & 14.3 & 2.2 & 360.36 & 113.65 & 246.71 & $9.45 \mathrm{E}-05$ \\
\hline $11 / 14 / 07$ 16:14 & 7.040 & 2.2 & 16.5 & 2.2 & 329.87 & 116.42 & 213.45 & $1.09 \mathrm{E}-04$ \\
\hline $11 / 15 / 078: 25$ & 7.714 & 2.2 & 18.0 & 2.3 & 321.55 & 113.65 & 207.9 & $1.17 \mathrm{E}-04$ \\
\hline 11/15/07 16:34 & 8.053 & 2.2 & 18.8 & 2.4 & 313.24 & 116.42 & 196.82 & $1.29 \mathrm{E}-04$ \\
\hline 11/16/07 10:00 & 8.780 & 2.2 & 20.5 & 1.8 & 304.92 & 113.65 & 191.27 & $9.97 \mathrm{E}-05$ \\
\hline
\end{tabular}


DOE/RL-2009-35, REV. 0

\begin{tabular}{|c|c|c|c|c|c|c|c|c|}
\hline \multicolumn{9}{|c|}{ Screening Injection Test Summary- Head } \\
\hline Date \& Time & $\begin{array}{c}\text { Elapsed } \\
\text { Time } \\
\text { (Day) }\end{array}$ & $\begin{array}{c}\text { Flow } \\
\text { Rate } \\
\text { (mL/min) }\end{array}$ & $\begin{array}{c}\text { Actual } \\
\text { Pore } \\
\text { Volumes }\end{array}$ & $\begin{array}{c}\text { Actual } \\
\text { Flow } \\
\text { Rate } \\
\text { (mL/min) }\end{array}$ & $\begin{array}{c}\text { Inlet } \\
\text { Head } \\
\text { (in) }\end{array}$ & $\begin{array}{c}\text { Outlet } \\
\text { Head } \\
\text { (in) }\end{array}$ & $\begin{array}{c}\text { Head } \\
\text { Difference } \\
\text { (in) }\end{array}$ & $\begin{array}{c}\text { Hydraulic } \\
\text { Conductivity } \\
(\mathrm{cm} / \mathrm{s})\end{array}$ \\
\hline \multicolumn{9}{|c|}{ Flow Cell \#5 - NanoFe I Test Cell } \\
\hline $11 / 1 / 076: 41$ & 0 & 9.0 & 0.0 & 8.9 & 7.94 & 5 & 2.94 & $3.21 \mathrm{E}-02$ \\
\hline $11 / 1 / 078: 05$ & 0.058 & 9.0 & 0.0 & 9.4 & 7.88 & 4.56 & 3.32 & $3.00 \mathrm{E}-02$ \\
\hline $11 / 1 / 0711: 00$ & 0.122 & 9.0 & 0.0 & 9.2 & 7.88 & 5 & 2.88 & $3.39 \mathrm{E}-02$ \\
\hline $11 / 1 / 0714: 38$ & 0.151 & 9.0 & 0.0 & 8.8 & 7.88 & 5 & 2.88 & $3.24 \mathrm{E}-02$ \\
\hline $11 / 6 / 078: 09$ & 4.730 & 2.2 & 0.0 & 2.2 & 5.38 & 4.69 & 0.69 & $3.38 \mathrm{E}-02$ \\
\hline $11 / 6 / 078: 57$ & 0.033 & 55.0 & 0.0 & 55.0 & 22.5 & 6.44 & 16.06 & $3.63 \mathrm{E}-02$ \\
\hline $11 / 6 / 079: 32$ & 0.024 & & & & & & & \\
\hline $11 / 6 / 079: 59$ & 0.019 & 55.0 & 1.1 & 52.0 & 22.88 & 6.5 & 16.38 & $3.36 \mathrm{E}-02$ \\
\hline $11 / 6 / 0710: 50$ & 0.054 & 55.0 & 3.1 & 54.0 & 40.5 & 6.13 & 34.37 & 1.67E-02 \\
\hline $11 / 6 / 0712: 08$ & 0.108 & 55.0 & 6.3 & 53.0 & 95 & 6 & 89 & $6.31 E-03$ \\
\hline $11 / 6 / 0714: 32$ & 0.208 & 55.0 & 12.1 & 55.0 & 63.76 & 5.06 & 58.7 & $9.93 E-03$ \\
\hline $11 / 6 / 07 \quad 16: 25$ & 0.287 & 55.0 & 16.6 & 49.0 & 124.6 & 5.5 & 119.06 & $4.36 \mathrm{E}-03$ \\
\hline $11 / 7 / 0712: 06$ & 0 & & & & & & & \\
\hline $11 / 7 / 0714: 51$ & 0.115 & 9.0 & 1.1 & 9.0 & 69.3 & 4.88 & 64.42 & $1.48 \mathrm{E}-03$ \\
\hline $11 / 7 / 07$ 15:17 & 0.018 & 9.0 & 0.2 & & & & & \\
\hline $11 / 8 / 07 \quad 10: 11$ & 0.787 & 2.2 & 2.0 & 2.0 & 63.76 & 4.75 & 59.01 & $3.59 \mathrm{E}-04$ \\
\hline $11 / 9 / 078: 45$ & 1.728 & 2.2 & 4.2 & 2.0 & 62.37 & 4.88 & 57.49 & $3.69 \mathrm{E}-04$ \\
\hline $11 / 9 / 0716: 21$ & 2.044 & 2.2 & 4.9 & 2.1 & \begin{tabular}{|l|}
60.98 \\
\end{tabular} & 4.75 & 56.23 & $3.96 \mathrm{E}-04$ \\
\hline $11 / 10 / 0714: 09$ & 2.953 & 2.2 & 7.0 & 1.9 & 60.98 & 4.75 & 56.23 & $3.58 \mathrm{E}-04$ \\
\hline $11 / 11 / 0720: 09$ & 4.203 & 2.2 & 9.9 & 1.9 & 60.98 & 4.88 & 56.1 & $3.59 E-04$ \\
\hline $11 / 12 / 079: 58$ & 4.778 & 2.2 & 11.2 & 2.0 & 63.76 & 4.75 & 59.01 & $3.59 E-04$ \\
\hline $11 / 12 / 0715: 59$ & 5.029 & 2.2 & 11.8 & 1.8 & 60.98 & 4.75 & 56.23 & $3.39 \mathrm{E}-04$ \\
\hline $11 / 13 / 07$ 13:14 & 5.915 & 2.2 & 13.9 & 1.8 & 60.98 & 4.75 & 56.23 & $3.39 E-04$ \\
\hline $11 / 13 / 0717: 26$ & 6.090 & 2.2 & 14.3 & 1.7 & 63.76 & 4.75 & 59.01 & $3.05 E-04$ \\
\hline $11 / 14 / 0716: 15$ & 7.040 & 2.2 & 16.5 & 1.8 & 63.76 & 4.63 & 59.13 & $3.23 E-04$ \\
\hline $11 / 15 / 078: 26$ & 7.715 & 2.2 & 18.0 & 1.8 & 63.76 & 4.75 & 59.01 & $3.23 E-04$ \\
\hline $11 / 15 / 07$ 16:38 & 8.056 & 2.2 & 18.8 & 1.9 & 60.98 & 4.63 & 56.35 & $3.57 E-04$ \\
\hline $11 / 16 / 0710: 01$ & 8.781 & 2.2 & 20.5 & 1.9 & 58.21 & 4.75 & 53.46 & 3.77 E-04 \\
\hline \multicolumn{9}{|c|}{ Flow Cell \#6 - NanoFe II Test Cell } \\
\hline $11 / 1 / 076: 42$ & 0 & 9.0 & 0.0 & 9.5 & 8.19 & 4.81 & 3.38 & $2.98 \mathrm{E}-02$ \\
\hline $11 / 1 / 078: 06$ & 0.058 & 9.0 & 0.0 & 8.8 & 10.38 & 7 & 3.38 & $2.76 \mathrm{E}-02$ \\
\hline $11 / 1 / 0711: 00$ & 0.121 & 9.0 & 0.0 & 9.2 & 8.25 & 4.81 & 3.44 & $2.83 E-02$ \\
\hline $11 / 1 / 0714: 40$ & 0.153 & 9.0 & 0.0 & 9.2 & 8.25 & 4.88 & 3.37 & $2.89 E-02$ \\
\hline $11 / 6 / 078: 07$ & 4.727 & 2.2 & 0.0 & 2.2 & 5.44 & 4.5 & 0.94 & $2.48 E-02$ \\
\hline $11 / 6 / 078: 59$ & 0.036 & 55.0 & 0.0 & 55.0 & 25.38 & 5.88 & 19.5 & $2.99 \mathrm{E}-02$ \\
\hline $11 / 6 / 079: 32$ & 0.023 & & & & & & & \\
\hline $11 / 6 / 07 \quad 10: 02$ & 0.021 & 55.0 & 1.2 & 56.0 & 24.63 & 5.81 & 18.82 & $3.15 \mathrm{E}-02$ \\
\hline $11 / 6 / 07 \quad 10: 50$ & 0.054 & 55.0 & 3.1 & 52.0 & \begin{tabular}{|l|}
23 \\
\end{tabular} & 5.81 & 17.19 & $3.21 \mathrm{E}-02$ \\
\hline $11 / 6 / 0712: 06$ & 0.107 & 55.0 & 6.2 & 57.0 & 23 & 5.81 & 17.19 & $3.51 E-02$ \\
\hline $11 / 6 / 07$ 14:33 & 0.209 & 55.0 & 12.1 & 53.0 & 25.31 & 5.81 & 19.5 & $2.88 \mathrm{E}-02$ \\
\hline $11 / 6 / 07 \quad 15: 50$ & 0.262 & 55.0 & 15.2 & & & & & \\
\hline $11 / 6 / 0715: 44$ & 0.258 & 55.0 & 15.0 & 56.0 & 27.06 & 5.88 & 21.18 & $2.80 \mathrm{E}-02$ \\
\hline $11 / 7 / 0712: 06$ & 0 & & & & & & & \\
\hline $11 / 7 / 0714: 51$ & 0.115 & 9.0 & 1.1 & 9.5 & 8.88 & 4.63 & 4.25 & $2.37 E-02$ \\
\hline $11 / 7 / 0715: 17$ & 0.018 & & & & & & & \\
\hline $11 / 8 / 07 \quad 10: 13$ & 0.789 & 2.2 & 1.8 & 2.4 & 5.63 & 4.5 & 1.13 & $2.25 E-02$ \\
\hline $11 / 9 / 078: 50$ & 1.731 & 2.2 & 4.0 & 2.4 & 5.63 & 4.5 & 1.13 & $2.25 \mathrm{E}-02$ \\
\hline $11 / 9 / 0716: 25$ & 2.047 & 2.2 & 4.7 & 2.0 & 5.63 & 4.5 & 1.13 & $1.88 \mathrm{E}-02$ \\
\hline $11 / 10 / 0714: 11$ & 2.954 & 2.2 & 6.8 & 2.2 & 5.63 & 4.5 & 1.13 & $2.06 E-02$ \\
\hline 11/11/07 20:10 & 4.203 & 2.2 & 9.7 & 2.2 & 5.63 & 4.5 & 1.13 & $2.06 E-02$ \\
\hline $11 / 12 / 079: 59$ & 4.779 & 2.2 & 11.1 & 2.2 & 5.56 & 4.5 & 1.06 & $2.20 \mathrm{E}-02$ \\
\hline $11 / 12 / 0716: 01$ & 5.031 & 2.2 & 11.6 & 2.3 & 5.63 & 4.5 & 1.13 & $2.16 E-02$ \\
\hline $11 / 13 / 0713: 14$ & 5.915 & 2.2 & 13.7 & 2.3 & 5.56 & 4.44 & 1.12 & $2.18 \mathrm{E}-02$ \\
\hline $11 / 13 / 0717: 28$ & 6.091 & 2.2 & 14.1 & 2.4 & 5.56 & 4.56 & 1 & $2.54 \mathrm{E}-02$ \\
\hline 11/14/07 16:17 & 7.042 & 2.2 & 16.3 & 2.2 & 5.56 & 4.5 & 1.06 & $2.20 \mathrm{E}-02$ \\
\hline $11 / 15 / 078: 28$ & 7.716 & 2.2 & 17.9 & 2.3 & 5.31 & 4.31 & 1 & $2.44 \mathrm{E}-02$ \\
\hline
\end{tabular}




\begin{tabular}{|c|c|c|c|c|c|c|c|c|}
\hline \multicolumn{9}{|c|}{ Screening Injection Test Summary- Head } \\
\hline Date \& Time & $\begin{array}{c}\text { Elapsed } \\
\text { Time } \\
\text { (Day) }\end{array}$ & \begin{tabular}{|} 
Flow Rate \\
(mL/min)
\end{tabular} & $\begin{array}{c}\text { Actual } \\
\text { Pore } \\
\text { Volumes }\end{array}$ & $\begin{array}{c}\text { Actual } \\
\text { Flow } \\
\text { Rate } \\
\text { (mL/min) }\end{array}$ & $\begin{array}{c}\text { Inlet } \\
\text { Head } \\
\text { (in) }\end{array}$ & $\begin{array}{l}\text { Outlet } \\
\text { Head } \\
\text { (in) }\end{array}$ & $\begin{array}{c}\text { Head } \\
\text { Difference } \\
\text { (in) }\end{array}$ & $\begin{array}{c}\text { Hydraulic } \\
\text { Conductivity } \\
(\mathrm{cm} / \mathrm{s})\end{array}$ \\
\hline \multicolumn{9}{|c|}{ Flow Cell \#7 - Polymetallix Duplicate Cell } \\
\hline 10/23/07 6:35 & 0 & 9.0 & 0.0 & 9.0 & 6.5 & 4.81 & 1.69 & $5.64 \mathrm{E}-02$ \\
\hline $10 / 23 / 078: 45$ & 0.090 & 9.0 & 0.0 & 7.0 & 6.63 & 4.88 & 1.75 & 4.24E-02 \\
\hline 10/23/07 16:56 & 0.341 & 55.0 & 0.0 & 54.0 & 13.75 & 5.88 & 7.87 & $7.27 E-02$ \\
\hline 10/23/07 17:10 & 0.010 & & & & & & & \\
\hline 10/23/07 17:36 & 0.018 & 55.0 & 1.0 & 50.0 & 27.13 & 5.88 & 21.25 & $2.49 E-02$ \\
\hline $10 / 23 / 07$ 18:26 & 0.053 & 55.0 & 3.1 & 53.0 & 58.88 & 6.88 & 52 & $1.08 \mathrm{E}-02$ \\
\hline $10 / 23 / 07$ 19:42 & 0.106 & 55.0 & 6.1 & 54.0 & 96.25 & 8.44 & 87.81 & $6.52 E-03$ \\
\hline $10 / 23 / 0719: 48$ & 0.110 & 55.0 & 6.4 & 54.0 & 110.88 & 10.75 & 100.13 & $5.72 \mathrm{E}-03$ \\
\hline 10/23/07 22:06 & 0.206 & 55.0 & 11.9 & 47.0 & 623.7 & 19.38 & 604.32 & $8.24 E-04$ \\
\hline $10 / 24 / 071: 20$ & 0.340 & 55.0 & 19.7 & 12.5 & 734.58 & 14.63 & 719.95 & $1.84 \mathrm{E}-04$ \\
\hline $10 / 24 / 07 \quad 10: 05$ & 0 & & & & & & & \\
\hline $10 / 24 / 0712: 46$ & 0.112 & 9.0 & 1.1 & 9.5 & 471.24 & 5.5 & 465.74 & $2.16 E-04$ \\
\hline 10/25/07 9:05 & 0.847 & 2.2 & 3.0 & 2.0 & 191.27 & 5.56 & 185.71 & 1.14E-04 \\
\hline $10 / 25 / 0715: 26$ & 1.111 & 2.2 & 3.6 & 2.2 & 194.04 & 5.75 & 188.29 & 1.24E-04 \\
\hline 10/26/07 9:09 & 1.849 & 2.2 & 5.3 & 2.3 & 196.81 & 5.88 & 190.93 & $1.28 \mathrm{E}-04$ \\
\hline $10 / 26 / 07 \quad 13: 59$ & 2.051 & 2.2 & 5.8 & 2.3 & 180.18 & 6.25 & 173.93 & $1.40 E-04$ \\
\hline $10 / 27 / 0711: 00$ & 2.926 & 2.2 & 7.8 & 2.3 & 138.6 & 6.19 & 132.41 & $1.84 E-04$ \\
\hline 10/28/07 10:36 & 3.910 & 2.2 & 10.1 & 2.2 & 105.34 & 6.19 & 99.15 & $2.35 E-04$ \\
\hline $10 / 28 / 0718: 28$ & 4.237 & 2.2 & 10.9 & 2.3 & 55.44 & 5.5 & 49.94 & $4.88 \mathrm{E}-04$ \\
\hline $10 / 29 / 078: 51$ & 4.837 & 2.2 & 12.3 & 2.0 & 94 & 4.75 & 89.25 & $2.38 E-04$ \\
\hline $10 / 29 / 078: 52$ & 4.837 & 2.2 & 12.3 & 2.0 & 194.04 & 4.75 & 189.29 & $1.12 E-04$ \\
\hline $10 / 29 / 0715: 34$ & 5.117 & 2.2 & 12.9 & 2.1 & 85.93 & 4.94 & 80.99 & $2.75 E-04$ \\
\hline $10 / 30 / 0710: 32$ & 5.907 & 2.2 & 14.7 & 2.0 & 94.25 & 4.88 & 89.37 & $2.37 \mathrm{E}-04$ \\
\hline $10 / 30 / 0716: 30$ & 6.156 & 2.2 & 15.3 & 2.0 & 94.25 & 4.88 & 89.37 & $2.37 E-04$ \\
\hline $10 / 31 / 0713: 59$ & 7.051 & 2.2 & 17.4 & 2.0 & 97.02 & 4.88 & 92.14 & 2.30 E-04 \\
\hline $11 / 1 / 079: 56$ & 7.882 & 2.2 & 19.3 & 2.2 & 102.56 & 4.88 & 97.68 & $2.39 E-04$ \\
\hline $11 / 1 / 07$ 15:55 & 8.131 & 2.2 & 19.9 & 2.2 & 103.95 & 4.88 & 99.07 & $2.35 \mathrm{E}-04$ \\
\hline $11 / 2 / 077: 39$ & 8.787 & 2.2 & 21.4 & 2.1 & 103.95 & 4.88 & 99.07 & $2.25 E-04$ \\
\hline \multicolumn{9}{|c|}{ Flow Cell \#8 - RNIP M2 Duplicate Cell } \\
\hline 10/23/07 6:35 & 0 & 9.0 & 0.0 & 9.0 & 6.25 & 4.88 & 1.37 & $6.96 \mathrm{E}-02$ \\
\hline $10 / 23 / 078: 45$ & 0.090 & 9.0 & 0.0 & 9.5 & 6.25 & 5 & 1.25 & $8.06 \mathrm{E}-02$ \\
\hline 10/23/07 17:03 & 0.346 & 55.0 & 0.0 & 51.0 & 12.5 & 5.63 & 6.87 & 7.87E-02 \\
\hline 10/23/07 17:10 & 0.005 & & & & & & & \\
\hline 10/23/07 17:38 & 0.019 & 55.0 & 1.1 & 50.0 & 12.63 & 5.63 & 7 & 7.57E-02 \\
\hline 10/23/07 18:27 & 0.053 & 55.0 & 3.1 & 50.0 & 12.38 & 5.75 & 6.63 & $7.99 \mathrm{E}-02$ \\
\hline $10 / 23 / 07$ 19:44 & 0.107 & 55.0 & 6.2 & 50.0 & 12.13 & 5.63 & 6.5 & $8.15 E-02$ \\
\hline 10/23/07 22:08 & 0.207 & 55.0 & 12.0 & 49.5 & 13.13 & 5.63 & 7.5 & $7.00 \mathrm{E}-02$ \\
\hline $10 / 24 / 071: 20$ & 0.340 & 55.0 & 19.7 & 49.5 & 25.25 & 5.63 & 19.62 & $2.67 E-02$ \\
\hline $10 / 24 / 0710: 05$ & 0 & & & & & & & \\
\hline $10 / 24 / 0712: 47$ & 0.112 & 9.0 & 1.1 & 9.0 & 5.75 & 4.75 & 1 & 9.54E-02 \\
\hline $10 / 25 / 079: 12$ & 0.851 & 2.2 & 3.0 & 2.0 & 5 & 4.56 & 0.44 & $4.82 \mathrm{E}-02$ \\
\hline $10 / 25 / 0715: 27$ & 1.111 & 2.2 & 3.6 & 2.0 & 5.06 & 4.63 & 0.43 & $4.93 \mathrm{E}-02$ \\
\hline $10 / 26 / 079: 12$ & 1.851 & 2.2 & 5.4 & 2.0 & 5 & 4.56 & 0.44 & $4.82 E-02$ \\
\hline 10/26/07 14:02 & 2.052 & 2.2 & 5.8 & 2.0 & 5 & 4.56 & 0.44 & 4.82E-02 \\
\hline $10 / 27 / 0711: 11$ & 2.933 & 2.2 & 7.9 & 2.0 & 5 & 4.63 & 0.37 & $5.73 E-02$ \\
\hline $10 / 28 / 07 \quad 10: 46$ & 3.916 & 2.2 & 10.1 & 2.0 & 5.06 & 4.63 & 0.43 & $4.93 \mathrm{E}-02$ \\
\hline $10 / 28 / 0718: 29$ & 4.238 & 2.2 & 10.9 & 1.9 & 5 & 4.63 & 0.37 & $5.44 \mathrm{E}-02$ \\
\hline $10 / 29 / 078: 52$ & 4.837 & 2.2 & 12.3 & 2.1 & 5.13 & 4.63 & 0.5 & 4.35E-02 \\
\hline $10 / 29 / 0715: 37$ & 5.118 & 2.2 & 12.9 & 2.0 & 5.13 & 4.63 & 0.5 & $4.24 \mathrm{E}-02$ \\
\hline 10/30/07 10:35 & 5.908 & 2.2 & 14.7 & 2.0 & 5.19 & 4.63 & 0.56 & $3.79 \mathrm{E}-02$ \\
\hline $10 / 30 / 0716: 33$ & 6.157 & 2.2 & 15.3 & 1.9 & 5.19 & 4.63 & 0.56 & $3.60 \mathrm{E}-02$ \\
\hline $10 / 31 / 0714: 00$ & 7.051 & 2.2 & 17.4 & 1.9 & 5.19 & 4.63 & 0.56 & $3.60 \mathrm{E}-02$ \\
\hline $11 / 1 / 079: 57$ & 7.882 & 2.2 & 19.3 & 2.0 & 5.25 & 4.63 & 0.62 & $3.42 \mathrm{E}-02$ \\
\hline $11 / 1 / 07$ 15:56 & 8.131 & 2.2 & 19.9 & 2.0 & 5.25 & 4.63 & 0.62 & $3.42 E-02$ \\
\hline $11 / 2 / 077: 40$ & 8.787 & 2.2 & 21.4 & 2.0 & 5.19 & 4.63 & 0.56 & $3.79 E-02$ \\
\hline
\end{tabular}




\begin{tabular}{|c|c|c|c|c|c|c|c|c|}
\hline \multicolumn{9}{|c|}{ Screening Injection Test Summary- Head } \\
\hline Date \& Time & $\begin{array}{c}\text { Elapsed } \\
\text { Time } \\
\text { (Day) }\end{array}$ & $\begin{array}{c}\text { Flow } \\
\text { Rate } \\
\text { (mL/min) }\end{array}$ & $\begin{array}{c}\text { Actual } \\
\text { Pore } \\
\text { Volumes }\end{array}$ & $\begin{array}{c}\text { Actual } \\
\text { Flow } \\
\text { Rate } \\
\text { (mL/min) }\end{array}$ & \begin{tabular}{|c} 
Inlet \\
Head \\
(in)
\end{tabular} & $\begin{array}{c}\text { Outlet } \\
\text { Head } \\
\text { (in) }\end{array}$ & \begin{tabular}{|c} 
Head \\
Difference \\
(in)
\end{tabular} & $\begin{array}{l}\text { Hydraulic } \\
\text { Conductivity } \\
\text { (cm/s) }\end{array}$ \\
\hline \multicolumn{9}{|c|}{ Flow Cell \#9 - EZVI Duplicate Cell } \\
\hline $10 / 23 / 076: 35$ & 0 & 9.0 & 0.0 & 9.0 & 8.88 & 5.81 & 3.07 & $3.11 \mathrm{E}-02$ \\
\hline $10 / 23 / 078: 45$ & 0.090 & 9.0 & 0.0 & 9.0 & 9 & 5.88 & 3.12 & $3.06 \mathrm{E}-02$ \\
\hline $10 / 23 / 0717: 03$ & 0.346 & 55.0 & 0.0 & 50.0 & 20 & 8.38 & 11.62 & $4.56 \mathrm{E}-02$ \\
\hline $10 / 23 / 0717: 10$ & 0.005 & & & & & & & \\
\hline $10 / 23 / 0717: 38$ & 0.019 & 55.0 & 1.1 & 50.0 & 19.75 & 8.25 & 11.5 & $4.61 \mathrm{E}-02$ \\
\hline $10 / 23 / 0718: 28$ & 0.054 & 55.0 & 3.1 & 49.0 & 19.63 & 8.5 & 11.13 & $4.67 \mathrm{E}-02$ \\
\hline $10 / 23 / 0719: 45$ & 0.108 & 55.0 & 6.2 & 49.0 & 19.38 & 8.44 & 10.94 & $4.75 \mathrm{E}-02$ \\
\hline $10 / 23 / 0722: 08$ & 0.207 & 55.0 & 12.0 & 49.0 & 18.88 & 8.63 & 10.25 & $5.07 \mathrm{E}-02$ \\
\hline $10 / 24 / 071: 21$ & 0.341 & 55.0 & 19.7 & 48.5 & 18.75 & 8.75 & 10 & $5.14 \mathrm{E}-02$ \\
\hline $10 / 24 / 07 \quad 10: 05$ & 0 & & & & & & & \\
\hline $10 / 24 / 0712: 48$ & 0.113 & 9.0 & 1.1 & 8.5 & 7 & 5.63 & 1.37 & $6.58 \mathrm{E}-02$ \\
\hline $10 / 25 / 079: 12$ & 0.850 & 2.2 & 3.0 & 1.9 & 5.75 & 5.25 & 0.5 & $4.03 \mathrm{E}-02$ \\
\hline $10 / 25 / 0715: 28$ & 1.111 & 2.2 & 3.6 & 1.8 & 5.75 & 5.25 & 0.5 & $3.82 \mathrm{E}-02$ \\
\hline $10 / 26 / 079: 15$ & 1.852 & 2.2 & 5.4 & 1.9 & 5.69 & 5.19 & 0.5 & $4.03 \mathrm{E}-02$ \\
\hline $10 / 26 / 07 \quad 14: 05$ & 2.053 & 2.2 & 5.8 & 2.0 & 5.63 & 5.25 & 0.38 & $5.58 \mathrm{E}-02$ \\
\hline $10 / 27 / 0711: 22$ & 2.940 & 2.2 & 7.9 & 1.8 & 5.69 & 5.25 & 0.44 & $4.34 \mathrm{E}-02$ \\
\hline $10 / 28 / 07 \quad 10: 55$ & 3.922 & 2.2 & 10.2 & 1.8 & 5.69 & 5.31 & 0.38 & $5.02 \mathrm{E}-02$ \\
\hline $10 / 28 / 0718: 30$ & 4.238 & 2.2 & 10.9 & 1.8 & 5.69 & 5.25 & 0.44 & $4.34 \mathrm{E}-02$ \\
\hline $10 / 29 / 078: 53$ & 4.837 & 2.2 & 12.3 & 2.1 & 5.75 & 5.25 & 0.5 & $4.45 \mathrm{E}-02$ \\
\hline $10 / 29 / 07$ 15:38 & 5.118 & 2.2 & 12.9 & 1.8 & 5.69 & 5.25 & 0.44 & $4.34 \mathrm{E}-02$ \\
\hline $10 / 30 / 07 \quad 10: 37$ & 5.909 & 2.2 & 14.8 & 1.9 & 5.69 & 5.25 & 0.44 & $4.58 \mathrm{E}-02$ \\
\hline $10 / 30 / 07$ 16:35 & 6.158 & 2.2 & 15.3 & 1.8 & 5.69 & 5.31 & 0.38 & $5.02 \mathrm{E}-02$ \\
\hline 10/31/07 14:02 & 7.051 & 2.2 & 17.4 & 1.9 & 5.63 & 5.25 & 0.38 & $5.30 \mathrm{E}-02$ \\
\hline $11 / 1 / 079: 59$ & 7.883 & 2.2 & 19.3 & 1.8 & 5.69 & 5.31 & 0.38 & $5.02 \mathrm{E}-02$ \\
\hline $11 / 1 / 0715: 58$ & 8.132 & 2.2 & 19.9 & 2.0 & 5.69 & 5.31 & 0.38 & $5.58 \mathrm{E}-02$ \\
\hline $11 / 2 / 077: 42$ & 8.787 & 2.2 & 21.4 & 2.0 & 5.69 & 5.31 & 0.38 & $5.58 \mathrm{E}-02$ \\
\hline \multicolumn{9}{|c|}{ Flow Cell \#10 - Zloy Duplicate Cell } \\
\hline 11/1/07 6:40 & 0 & 9.0 & & 8.9 & 7 & 5.19 & 1.81 & $5.21 \mathrm{E}-02$ \\
\hline 11/1/1/07 8:04 & 0.058 & 9.0 & 0.0 & 9.0 & 7.06 & 5.19 & 1.87 & $5.10 \mathrm{E}-02$ \\
\hline 11/1/07 11:00 & 0.122 & 9.0 & 0.0 & 8.8 & 7 & 5.13 & 1.87 & $4.99 \mathrm{E}-02$ \\
\hline 11/1/07 14:37 & 0.151 & 9.0 & 0.0 & 9.0 & 7.06 & 5.19 & 1.87 & $5.10 \mathrm{E}-02$ \\
\hline 11/6/07 8:02 & 4.726 & 2.2 & 0.0 & 2.2 & 5.63 & 5.06 & 0.57 & $4.09 \mathrm{E}-02$ \\
\hline $11 / 6 / 078: 58$ & 0.039 & 55.0 & 0.0 & 55.0 & 15.88 & 5.63 & 10.25 & $5.69 \mathrm{E}-02$ \\
\hline 11/6/07 9:32 & 0.024 & & & & & & & \\
\hline $11 / 6 / 079: 59$ & 0.019 & 55.0 & 1.1 & 52.0 & 17.88 & 5.56 & 12.32 & $4.47 \mathrm{E}-02$ \\
\hline 11/6/07 10:49 & 0.053 & 55.0 & 3.1 & 54.0 & 85 & 5.63 & 79.37 & $7.21 \mathrm{E}-03$ \\
\hline $11 / 6 / 07 \quad 12: 09$ & 0.109 & 55.0 & 6.3 & 56.0 & 232.9 & 6.5 & 226.35 & $2.62 \mathrm{E}-03$ \\
\hline 11/6/07 14:31 & 0.208 & 55.0 & 12.0 & 32.0 & 831.6 & 8.25 & 823.35 & $4.12 \mathrm{E}-04$ \\
\hline $11 / 6 / 0717: 48$ & 0.344 & 55.0 & 19.9 & 16.8 & 1220 & 7.94 & 1211.74 & $1.47 \mathrm{E}-04$ \\
\hline $11 / 7 / 0712: 06$ & 0 & & & & & & & \\
\hline $11 / 7 / 0714: 50$ & 0.114 & 9.0 & 1.1 & 8.9 & 756.8 & 5.5 & 751.26 & $1.26 \mathrm{E}-04$ \\
\hline 11/7/07 15:17 & 0.019 & & & & & & & \\
\hline 11/8/07 10:10 & 0.787 & 2.2 & 1.8 & 2.2 & 659.7 & 5.63 & 654.106 & $3.56 \mathrm{E}-05$ \\
\hline $11 / 9 / 078: 45$ & 1.728 & 2.2 & 4.0 & 2.0 & 644.5 & 5.38 & 639.11 & $3.32 \mathrm{E}-05$ \\
\hline $11 / 9 / 0716: 20$ & 2.044 & 2.2 & 4.7 & 2.2 & 554.4 & 5.25 & 549.15 & $4.25 \mathrm{E}-05$ \\
\hline $11 / 10 / 0714: 09$ & 2.953 & 2.2 & 6.8 & 2.0 & 584.9 & 5.25 & 579.64 & $3.66 \mathrm{E}-05$ \\
\hline $11 / 11 / 0720: 08$ & 4.202 & 2.2 & 9.7 & 2.1 & 507.3 & 5.38 & 501.9 & $4.43 \mathrm{E}-05$ \\
\hline $11 / 12 / 079: 57$ & 4.778 & 2.2 & 11.1 & 2.4 & 487.9 & 5.19 & 482.68 & $5.27 \mathrm{E}-05$ \\
\hline $11 / 12 / 0715: 58$ & 5.028 & 2.2 & 11.6 & 2.1 & 485.1 & 5.25 & 479.85 & $4.64 E-05$ \\
\hline $11 / 13 / 07$ 17:25 & 6.089 & 2.2 & 14.1 & 1.6 & 582.1 & 5.13 & 576.99 & $2.94 \mathrm{E}-05$ \\
\hline 11/14/07 16:14 & 7.040 & 2.2 & 16.3 & 2.2 & 523.9 & 5.25 & 518.66 & $4.50 \mathrm{E}-05$ \\
\hline $11 / 15 / 078: 26$ & 7.715 & 2.2 & 17.9 & 2.2 & 443.5 & 5.25 & 438.27 & $5.32 \mathrm{E}-05$ \\
\hline 11/15/07 16:34 & 8.053 & 2.2 & 18.7 & 1.7 & 413 & 5.13 & 407.9 & $4.42 \mathrm{E}-05$ \\
\hline $11 / 16 / 07 \quad 10: 00$ & 8.780 & 2.2 & 20.3 & 2.2 & 388.1 & 5.25 & 382.83 & $6.09 \mathrm{E}-05$ \\
\hline
\end{tabular}




\begin{tabular}{|c|c|c|c|c|c|c|c|c|}
\hline \multicolumn{9}{|c|}{ Screening Injection Test Summary- Head } \\
\hline Date \& Time & $\begin{array}{c}\text { Elapsed } \\
\text { Time } \\
\text { (Day) }\end{array}$ & \begin{tabular}{|c|} 
Flow Rate \\
(mL/min)
\end{tabular} & $\begin{array}{c}\text { Actual } \\
\text { Pore } \\
\text { Volumes }\end{array}$ & $\begin{array}{l}\text { Actual } \\
\text { Flow } \\
\text { Rate } \\
\text { (mL/min) }\end{array}$ & $\begin{array}{l}\text { Inlet } \\
\text { Head } \\
\text { (in) }\end{array}$ & $\begin{array}{l}\text { Outlet } \\
\text { Head } \\
\text { (in) }\end{array}$ & $\begin{array}{c}\text { Head } \\
\text { Difference } \\
\text { (in) }\end{array}$ & $\begin{array}{c}\text { Hydraulic } \\
\text { Conductivity } \\
\text { (cm/s) }\end{array}$ \\
\hline \multicolumn{9}{|c|}{ Flow Cell \#11 - NanoFe I Duplicate Cell } \\
\hline $11 / 1 / 076: 42$ & 0 & \begin{tabular}{|l|l|l}
9.0 \\
\end{tabular} & 0.0 & 9.4 & 8.94 & 5.06 & 3.88 & 2.57E-02 \\
\hline $11 / 1 / 078: 05$ & 0.058 & 9.0 & 0.0 & 9.5 & 11 & 7.19 & 3.81 & $2.64 \mathrm{E}-02$ \\
\hline $11 / 1 / 0711: 00$ & 0.122 & 9.0 & 0.0 & 8.5 & 9 & 5 & 4 & $2.25 \mathrm{E}-02$ \\
\hline $11 / 1 / 0714: 39$ & 0.152 & 9.0 & 0.0 & 9.6 & 9 & 5 & 4 & $2.54 \mathrm{E}-02$ \\
\hline $11 / 6 / 078: 07$ & 4.728 & 2.2 & 0.0 & 2.2 & 5.88 & 4.88 & 1 & $2.33 \mathrm{E}-02$ \\
\hline $11 / 6 / 078: 56$ & 0.034 & 55.0 & 0.0 & 55.0 & 28.75 & 5.88 & 22.87 & $2.55 \mathrm{E}-02$ \\
\hline $11 / 6 / 079: 32$ & 0.025 & & & & & & & \\
\hline $11 / 6 / 079: 59$ & 0.019 & 55.0 & 1.1 & 54.0 & 30 & 5.94 & 24.06 & $2.38 E-02$ \\
\hline $11 / 6 / 0710: 49$ & 0.053 & 55.0 & 3.1 & 52.0 & 72.25 & 5.88 & 66.37 & $8.30 E-03$ \\
\hline $11 / 6 / 0712: 07$ & 0.108 & 55.0 & 6.2 & 58.0 & 249.48 & 6 & 243.48 & 2.52E-03 \\
\hline $11 / 6 / 0714: 32$ & 0.208 & 55.0 & 12.1 & 21.0 & 443.52 & 5.63 & 437.89 & $5.08 \mathrm{E}-04$ \\
\hline $11 / 6 / 0715: 39$ & 0.255 & 55.0 & 14.8 & & & & & \\
\hline $11 / 7 / 0712: 06$ & 0 & & & & & & & \\
\hline $11 / 7 / 0714: 51$ & 0.115 & 9.0 & 1.1 & 9.6 & 454.61 & 5.25 & 449.36 & $2.26 E-04$ \\
\hline $11 / 7 / 0715: 17$ & 0.018 & & & & & & & \\
\hline 11/8/07 10:12 & 0.788 & 2.2 & 1.8 & 1.8 & 307.69 & 5.06 & 302.63 & $6.30 \mathrm{E}-05$ \\
\hline $11 / 9 / 078: 45$ & 1.728 & 2.2 & 4.0 & 2.5 & 318.78 & 5.25 & 313.53 & $8.45 \mathrm{E}-05$ \\
\hline $11 / 9 / 0716: 23$ & 2.046 & 2.2 & 4.7 & 2.2 & 318.78 & 5.19 & 313.59 & $7.44 \mathrm{E}-05$ \\
\hline $11 / 10 / 0714: 10$ & 2.953 & 2.2 & 6.8 & 2.4 & 346.5 & 5.06 & 341.44 & $7.45 \mathrm{E}-05$ \\
\hline $11 / 11 / 0720: 09$ & 4.203 & 2.2 & 9.7 & 2.2 & 349.27 & 5.13 & 344.14 & $6.78 \mathrm{E}-05$ \\
\hline $11 / 12 / 079: 59$ & 4.779 & 2.2 & 11.1 & 2.5 & 360.36 & 5.06 & 355.3 & $7.46 \mathrm{E}-05$ \\
\hline $11 / 12 / 0716: 00$ & 5.030 & 2.2 & 11.6 & 2.5 & 357.59 & 5.13 & 352.46 & $7.52 \mathrm{E}-05$ \\
\hline $11 / 13 / 0713: 15$ & 5.915 & 2.2 & 13.7 & 2.4 & 360.36 & 5.06 & 355.3 & $7.16 \mathrm{E}-05$ \\
\hline $11 / 13 / 0717: 27$ & 6.090 & 2.2 & 14.1 & 2.1 & 360.36 & 5.06 & 355.3 & $6.26 \mathrm{E}-05$ \\
\hline $11 / 14 / 07$ 16:16 & 7.041 & 2.2 & 16.3 & 2.5 & 340.96 & 5.06 & 335.9 & $7.89 E-05$ \\
\hline $11 / 15 / 078: 27$ & 7.715 & 2.2 & 17.9 & 2.5 & 349.27 & 5.13 & 344.14 & $7.70 E-05$ \\
\hline $11 / 15 / 0716: 39$ & 8.057 & 2.2 & 18.7 & 2.2 & 343.73 & 5.13 & 338.6 & $6.89 E-05$ \\
\hline $11 / 16 / 0710: 02$ & 8.781 & 2.2 & 20.3 & 2.3 & 365.9 & 5.13 & 360.77 & $6.76 \mathrm{E}-05$ \\
\hline \multicolumn{9}{|c|}{ Flow Cell \#12 - NanoFe II Duplicate Cell } \\
\hline $11 / 1 / 076: 44$ & 0 & \begin{tabular}{l|l|}
9.0 \\
\end{tabular} & & 9.0 & 8.5 & 4.94 & 3.56 & $2.68 \mathrm{E}-02$ \\
\hline $11 / 1 / 078: 07$ & 0.058 & 9.0 & 0.0 & 8.8 & 8.5 & 4.88 & 3.62 & $2.58 \mathrm{E}-02$ \\
\hline $11 / 1 / 0711: 02$ & 0.122 & 9.0 & 0.0 & 9.0 & 8.5 & 4.94 & 3.56 & $2.68 \mathrm{E}-02$ \\
\hline $11 / 1 / 0714: 46$ & 0.156 & 9.0 & 0.0 & 8.9 & 8.5 & 4.88 & 3.62 & $2.61 \mathrm{E}-02$ \\
\hline $11 / 6 / 078: 05$ & 4.722 & 2.2 & 0.0 & 2.2 & 5.38 & 4.38 & 1 & $2.33 E-02$ \\
\hline $11 / 6 / 078: 54$ & 0.034 & 55.0 & 0.0 & 55.0 & 26.56 & 5.31 & 21.25 & $2.74 \mathrm{E}-02$ \\
\hline $11 / 6 / 079: 32$ & 0.026 & & & & & & & \\
\hline $11 / 6 / 07 \quad 10: 02$ & 0.021 & 55.0 & 1.2 & 54.0 & 26.38 & 6.44 & 19.94 & $2.87 E-02$ \\
\hline $11 / 6 / 07 \quad 10: 48$ & 0.053 & 55.0 & 3.1 & 58.0 & 24.5 & 6.5 & 18 & $3.42 E-02$ \\
\hline $11 / 6 / 0712: 06$ & 0.107 & 55.0 & 6.2 & 53.0 & 23.56 & 6.25 & 17.31 & $3.25 E-02$ \\
\hline $11 / 6 / 0714: 35$ & 0.210 & 55.0 & 12.2 & 56.0 & 25.31 & 6.38 & 18.93 & $3.14 \mathrm{E}-02$ \\
\hline $11 / 6 / 0715: 50$ & 0.262 & 55.0 & 15.2 & & & & & \\
\hline $11 / 6 / 0715: 44$ & 0.258 & 55.0 & 15.0 & 51.0 & 26.63 & 6.56 & 20.07 & 2.69E-02 \\
\hline $11 / 7 / 0712: 06$ & 0 & & & & & & & \\
\hline $14 / 7 / 0714: 52$ & 0.115 & 9.0 & 1.1 & 8.7 & 8.19 & 4.5 & 3.69 & $2.50 \mathrm{E}-02$ \\
\hline $11 / 7 / 07$ 15:17 & 0.017 & & & & & & & \\
\hline $11 / 8 / 07$ 10:14 & 0.790 & 2.2 & 1.8 & 1.8 & 5.44 & 4.5 & 0.94 & $2.03 E-02$ \\
\hline $11 / 9 / 079: 08$ & 1.744 & 2.2 & 4.0 & 2.0 & 5.5 & 4.63 & 0.87 & $2.44 \mathrm{E}-02$ \\
\hline $11 / 9 / 0716: 27$ & 2.049 & 2.2 & 4.7 & 2.2 & 5.44 & 4.5 & 0.94 & $2.48 \mathrm{E}-02$ \\
\hline $11 / 10 / 0714: 11$ & 2.954 & 2.2 & 6.8 & 2.2 & 5.44 & 4.5 & 0.94 & $2.48 \mathrm{E}-02$ \\
\hline $11 / 11 / 0720: 11$ & 4.204 & 2.2 & 9.7 & 2.1 & 5.5 & 4.5 & 1 & $2.23 E-02$ \\
\hline $11 / 12 / 0710: 00$ & 4.780 & 2.2 & 11.1 & 2.2 & 5.38 & 4.5 & 0.88 & $2.65 E-02$ \\
\hline $11 / 12 / 0716: 01$ & 5.031 & 2.2 & 11.6 & 2.2 & 5.44 & 4.5 & 0.94 & $2.48 \mathrm{E}-02$ \\
\hline $11 / 13 / 0713: 14$ & 5.915 & 2.2 & 13.7 & 2.1 & 5.31 & 4.5 & 0.81 & $2.75 E-02$ \\
\hline $11 / 13 / 0717: 28$ & 6.091 & 2.2 & 14.1 & 2.2 & 5.38 & 4.5 & 0.88 & $2.65 \mathrm{E}-02$ \\
\hline $11 / 14 / 0716: 18$ & 7.042 & 2.2 & 16.3 & 2.3 & 5.31 & 4.5 & 0.81 & $3.01 \mathrm{E}-02$ \\
\hline $11 / 15 / 078: 28$ & 7.716 & 2.2 & 17.9 & 2.3 & 5.31 & 4.5 & 0.81 & $3.01 \mathrm{E}-02$ \\
\hline
\end{tabular}




\begin{tabular}{|c|c|c|c|c|c|c|c|c|}
\hline \multicolumn{9}{|c|}{ Screening Injection Test Summary- Head } \\
\hline Date \& Time & $\begin{array}{c}\text { Elapsed } \\
\text { Time } \\
\text { (Day) }\end{array}$ & $\begin{array}{c}\text { Flow } \\
\text { Rate } \\
(\mathrm{mL} / \mathrm{min})\end{array}$ & $\begin{array}{c}\text { Actual } \\
\text { Pore } \\
\text { Volumes }\end{array}$ & $\begin{array}{c}\text { Actual } \\
\text { Flow } \\
\text { Rate } \\
\text { (mL/min) }\end{array}$ & \begin{tabular}{|c|} 
Inlet \\
Head \\
(in)
\end{tabular} & $\begin{array}{c}\text { Outlet } \\
\text { Head } \\
\text { (in) }\end{array}$ & \begin{tabular}{|c} 
Head \\
Difference \\
(in)
\end{tabular} & $\begin{array}{l}\text { Hydraulic } \\
\text { Conductivity } \\
\text { (cm/s) }\end{array}$ \\
\hline \multicolumn{9}{|c|}{ Flow Cell \#13 - Control Cell } \\
\hline 11/1/07 6:46 & 0 & 9.0 & & \begin{tabular}{|l|l}
9.1 & 1 \\
\end{tabular} & 6.13 & 4.19 & 1.94 & 4.97E-02 \\
\hline 11/1/07 8:08 & 0.057 & 9.0 & 0.0 & 9.0 & 6.06 & 4.13 & 1.93 & $4.94 \mathrm{E}-02$ \\
\hline 11/1/07 11:02 & 0.121 & 9.0 & 0.0 & 9.0 & 6.13 & 4.13 & 2 & $4.77 \mathrm{E}-02$ \\
\hline 11/1/07 11:46 & 0.031 & 9.0 & 0.0 & 9.1 & 6.13 & 4.06 & 2.07 & $4.66 \mathrm{E}-02$ \\
\hline 11/6/07 8:04 & 4.846 & 2.2 & 0.0 & 2.2 & 4.88 & 3.94 & 0.94 & $2.48 \mathrm{E}-02$ \\
\hline $11 / 6 / 078: 53$ & 0.034 & 55.0 & 0.0 & 55.0 & 14.5 & 5 & 9.5 & $6.14 \mathrm{E}-02$ \\
\hline 11/6/07 9:32 & 0.027 & & & & & & & \\
\hline 11/6/07 10:02 & 0.021 & 55.0 & 1.2 & 54.0 & 14.5 & 4.94 & 9.56 & $5.99 \mathrm{E}-02$ \\
\hline $11 / 6 / 07 \quad 10: 48$ & 0.053 & 55.0 & 3.1 & 54.0 & 14.63 & 4.94 & 9.69 & 5.91E-02 \\
\hline 11/6/07 12:05 & 0.106 & 55.0 & 6.2 & 55.0 & 14.75 & 5.13 & 9.62 & $6.06 \mathrm{E}-02$ \\
\hline 11/6/07 14:36 & 0.211 & 55.0 & 12.2 & 55.0 & 14.94 & 5.13 & 9.81 & 5.94E-02 \\
\hline $11 / 6 / 07 \quad 17: 50$ & 0.346 & 55.0 & 20.0 & 55.0 & 15.44 & 5.19 & 10.25 & $5.69 \mathrm{E}-02$ \\
\hline 11/7/07 12:06 & 0 & & & & & & & \\
\hline $11 / 7 / 0714: 52$ & 0.115 & 9.0 & 1.1 & 8.6 & 4.63 & 3.94 & 0.69 & 1.32E-01 \\
\hline 11/7/07 15:17 & 0.017 & & & & & & & \\
\hline 11/8/07 10:14 & 0.790 & 2.2 & 1.8 & 2.3 & 4.25 & 3.94 & 0.31 & $7.86 \mathrm{E}-02$ \\
\hline $11 / 9 / 079: 10$ & 1.745 & 2.2 & 4.0 & 2.1 & 4.25 & 4.13 & 0.12 & $1.85 \mathrm{E}-01$ \\
\hline 11/9/07 16:30 & 2.051 & 2.2 & $\begin{array}{ll}4.7 \\
\end{array}$ & 2.2 & 4.25 & 3.88 & 0.37 & $6.30 \mathrm{E}-02$ \\
\hline 11/10/07 14:11 & 2.954 & 2.2 & 6.8 & 2.2 & 4.25 & 3.94 & 0.31 & $7.52 \mathrm{E}-02$ \\
\hline 11/11/07 20:11 & 4.204 & 2.2 & 9.7 & 2.3 & 4.25 & 4.06 & 0.19 & $1.26 \mathrm{E}-01$ \\
\hline $11 / 12 / 0710: 01$ & 4.781 & 2.2 & 11.1 & 2.4 & 4.25 & 3.88 & 0.37 & $6.88 \mathrm{E}-02$ \\
\hline 11/12/07 16:02 & 5.031 & 2.2 & 11.7 & 2.2 & 4.25 & 3.94 & 0.31 & $7.52 \mathrm{E}-02$ \\
\hline 11/13/07 13:17 & 5.917 & 2.2 & 13.7 & 2.4 & 4.19 & 3.94 & 0.25 & $1.02 \mathrm{E}-01$ \\
\hline $11 / 13 / 0717: 29$ & 6.092 & 2.2 & 14.1 & 2.1 & 4.25 & 3.94 & 0.31 & $7.18 \mathrm{E}-02$ \\
\hline 11/14/07 16:19 & 7.043 & 2.2 & 16.3 & 2.1 & 4.19 & 3.88 & 0.3075 & $7.24 \mathrm{E}-02$ \\
\hline $11 / 15 / 078: 29$ & 7.717 & 2.2 & 17.9 & 2.2 & 4.25 & 3.94 & 0.31 & $7.52 \mathrm{E}-02$ \\
\hline $11 / 15 / 0716: 42$ & 8.059 & 2.2 & 18.7 & 2.0 & 4.19 & 3.88 & 0.3075 & $6.89 \mathrm{E}-02$ \\
\hline 11/16/07 10:07 & 8.785 & 2.2 & 20.3 & 1.9 & 4.38 & 4.13 & 0.245 & $8.22 \mathrm{E}-02$ \\
\hline \multicolumn{9}{|c|}{ Flow Cell \#14 - Micropowder Test Cell } \\
\hline 11/30/07 7:12 & 0.000 & \begin{tabular}{l|l}
2.2 \\
\end{tabular} & & \begin{tabular}{|l|}
2.2 \\
\end{tabular} & 5.75 & 4.875 & 0.875 & $2.66 \mathrm{E}-02$ \\
\hline $11 / 30 / 078: 26$ & 0.000 & 2.2 & 0.0 & 2.1 & 5.625 & 4.875 & 0.75 & $2.97 \mathrm{E}-02$ \\
\hline 11/30/07 9:30 & 0.000 & & & & & & & \\
\hline 11/30/079:55 & 0.017 & 55.0 & 1.0 & 58 & 88.58 & 11.38 & 77.205 & $7.96 \mathrm{E}-03$ \\
\hline $11 / 30 / 0710: 45$ & 0.052 & 55.0 & 3.0 & 57.5 & 80.27 & 9.5 & 70.77 & $8.61 \mathrm{E}-03$ \\
\hline $11 / 30 / 0712: 00$ & 0.104 & 55.0 & 6.0 & 56.5 & 67 & 9.125 & 57.875 & $1.03 \mathrm{E}-02$ \\
\hline $11 / 30 / 0714: 30$ & 0.208 & 55.0 & 12.1 & 57 & 68.5 & 9.375 & 59.125 & $1.02 \mathrm{E}-02$ \\
\hline $11 / 30 / 0717: 49$ & 0.347 & 55.0 & 20.1 & 56 & 70 & 9.5 & 60.5 & $9.81 \mathrm{E}-03$ \\
\hline $12 / 1 / 079: 00$ & 0.000 & & & & & & & \\
\hline 12/1/07 11:26 & 0.101 & 9.0 & 1.0 & 9.1 & 7.75 & 5 & 2.75 & $3.51 \mathrm{E}-02$ \\
\hline 12/2/07 19:00 & 1.417 & 2.2 & 3.3 & 2 & 5.438 & 4.813 & 0.625 & $3.39 \mathrm{E}-02$ \\
\hline $12 / 3 / 078: 45$ & 1.990 & 2.2 & 4.6 & 2.2 & 5.375 & 4.75 & 0.625 & $3.73 E-02$ \\
\hline $12 / 3 / 07 \quad 10: 47$ & 2.074 & 2.2 & 4.8 & 2.1 & 5.375 & 4.813 & 0.5625 & $3.96 \mathrm{E}-02$ \\
\hline $12 / 3 / 07$ 13:08 & 2.172 & 2.2 & 5.0 & 2.3 & 5.438 & 4.875 & 0.5625 & $4.33 \mathrm{E}-02$ \\
\hline $12 / 3 / 07$ 16:29 & 2.312 & 2.2 & 5.4 & 2.2 & 5.375 & 4.813 & 0.5625 & $4.15 \mathrm{E}-02$ \\
\hline $12 / 4 / 0712: 01$ & 3.126 & 2.2 & 7.2 & 2.3 & 5.438 & 4.875 & 0.5625 & $4.33 \mathrm{E}-02$ \\
\hline 12/4/07 15:18 & 3.262 & 2.2 & 7.6 & 2.3 & 5.438 & 4.875 & 0.5625 & $4.33 \mathrm{E}-02$ \\
\hline 12/5/07 8:36 & 3.983 & 2.2 & 9.2 & 2.3 & 5.438 & \begin{tabular}{|l|}
4.813 \\
\end{tabular} & 0.625 & $3.90 \mathrm{E}-02$ \\
\hline $12 / 5 / 07$ 16:54 & 4.329 & 2.2 & 10.0 & 2.2 & 5.375 & 4.875 & 0.5 & $4.66 \mathrm{E}-02$ \\
\hline 12/6/07 10:25 & 5.059 & 2.2 & 11.7 & 2.3 & 5.375 & 4.813 & 0.5625 & $4.33 \mathrm{E}-02$ \\
\hline $12 / 6 / 0715: 40$ & 5.278 & 2.2 & 12.2 & 2.3 & 5.438 & 4.813 & 0.625 & $3.90 \mathrm{E}-02$ \\
\hline $12 / 7 / 078: 28$ & 5.978 & 2.2 & 13.8 & 2.4 & 5.375 & 4.875 & 0.5 & $5.09 \mathrm{E}-02$ \\
\hline 12/7/07 13:59 & 6.208 & 2.2 & 14.4 & 2.2 & 5.375 & \begin{tabular}{|l|}
4.875 \\
\end{tabular} & 0.5 & $4.66 \mathrm{E}-02$ \\
\hline $12 / 9 / 0716: 39$ & 8.319 & 2.2 & 19.3 & 2.2 & 5.375 & \begin{tabular}{|l|}
4.875 \\
\end{tabular} & 0.5 & $4.66 \mathrm{E}-02$ \\
\hline $12 / 10 / 076: 40$ & 8.903 & 2.2 & 20.6 & 2.1 & 5.25 & 4.813 & 0.4375 & $5.09 \mathrm{E}-02$ \\
\hline
\end{tabular}




\begin{tabular}{|c|c|c|c|c|c|c|c|c|}
\hline \multicolumn{9}{|c|}{ Screening Injection Test Summary- Head } \\
\hline Date \& Time & $\begin{array}{c}\text { Elapsed } \\
\text { Time } \\
\text { (Day) }\end{array}$ & $\begin{array}{c}\text { Flow Rate } \\
\text { (mL/min) }\end{array}$ & $\begin{array}{c}\text { Actual } \\
\text { Pore } \\
\text { Volumes }\end{array}$ & $\begin{array}{c}\text { Actual } \\
\text { Flow } \\
\text { Rate } \\
\text { (mL/min) }\end{array}$ & $\begin{array}{c}\text { Inlet } \\
\text { Head } \\
\text { (in) }\end{array}$ & $\begin{array}{l}\text { Outlet } \\
\text { Head } \\
\text { (in) }\end{array}$ & $\begin{array}{c}\text { Head } \\
\text { Difference } \\
\text { (in) }\end{array}$ & $\begin{array}{c}\text { Hydraulic } \\
\text { Conductivity } \\
(\mathrm{cm} / \mathrm{s})\end{array}$ \\
\hline \multicolumn{9}{|c|}{ Flow Cell \#15 - Micropowder Duplicate Cell } \\
\hline $11 / 30 / 077: 12$ & 0.000 & 2.2 & & 2 & 5.5 & 4.875 & 0.625 & $3.39 \mathrm{E}-02$ \\
\hline $11 / 30 / 078: 27$ & 0.000 & 2.2 & 0.0 & 2.3 & 5.4375 & 4.875 & 0.5625 & $4.33 \mathrm{E}-02$ \\
\hline $11 / 30 / 079: 30$ & 0.000 & & & & & & & \\
\hline $11 / 30 / 079: 55$ & 0.017 & 55.0 & 1.0 & 55 & 83.04 & 9.125 & 73.915 & $7.89 \mathrm{E}-03$ \\
\hline $11 / 30 / 0710: 45$ & 0.052 & 55.0 & 3.0 & 54.5 & 69.2 & 7.9375 & 61.2625 & $9.43 \mathrm{E}-03$ \\
\hline $11 / 30 / 0712: 00$ & 0.104 & 55.0 & 6.0 & 54.5 & 50.5625 & 7.625 & 42.9375 & $1.35 \mathrm{E}-02$ \\
\hline $11 / 30 / 0714: 30$ & 0.208 & 55.0 & 12.1 & 54.5 & 51.125 & 7.875 & 43.25 & $1.34 \mathrm{E}-02$ \\
\hline $11 / 30 / 0717: 49$ & 0.347 & 55.0 & 20.1 & 54 & 53 & 7.8125 & 45.1875 & 1.27E-02 \\
\hline 12/1/07 9:00 & 0.000 & & & & & & & \\
\hline $12 / 1 / 0711: 26$ & 0.101 & 9 & 1.0 & 8.7 & 6.375 & 4.75 & 1.625 & 5.67E-02 \\
\hline $12 / 2 / 07$ 19:01 & 1.417 & 2.2 & 3.3 & 2 & 5.125 & 4.8125 & 0.3125 & $6.78 \mathrm{E}-02$ \\
\hline $12 / 3 / 078: 45$ & 1.990 & 2.2 & 4.6 & 2.1 & 5.1875 & 4.75 & 0.4375 & $5.09 \mathrm{E}-02$ \\
\hline $12 / 3 / 0710: 48$ & 2.075 & 2.2 & 4.8 & 2.2 & 5.375 & 4.8125 & 0.5625 & $4.15 \mathrm{E}-02$ \\
\hline $12 / 3 / 0713: 08$ & 2.172 & 2.2 & 5.0 & 2.2 & 5.1875 & 4.8125 & 0.375 & $6.22 \mathrm{E}-02$ \\
\hline $12 / 3 / 0716: 30$ & 2.313 & 2.2 & 5.4 & 2 & 5.1875 & 4.8125 & 0.375 & $5.65 \mathrm{E}-02$ \\
\hline $12 / 4 / 0712: 01$ & 3.126 & 2.2 & 7.2 & 2 & 5.1875 & 4.8125 & 0.375 & $5.65 \mathrm{E}-02$ \\
\hline $12 / 4 / 0715: 18$ & 3.262 & 2.2 & 7.6 & 2.25 & 5.1875 & 4.875 & 0.3125 & $7.63 E-02$ \\
\hline $12 / 5 / 078: 36$ & 3.983 & 2.2 & 9.2 & 2.1 & 5.125 & 4.8125 & 0.3125 & $7.12 \mathrm{E}-02$ \\
\hline $12 / 5 / 0716: 54$ & 4.329 & 2.2 & 10.0 & 2.1 & 5.1875 & 4.8125 & 0.375 & 5.94E-02 \\
\hline $12 / 6 / 0710: 25$ & 5.059 & 2.2 & 11.7 & 2.2 & 5.125 & 4.75 & 0.375 & $6.22 \mathrm{E}-02$ \\
\hline $12 / 6 / 0715: 40$ & 5.278 & 2.2 & 12.2 & 2.2 & 5.125 & 4.75 & 0.375 & $6.22 \mathrm{E}-02$ \\
\hline $12 / 7 / 078: 28$ & 5.978 & 2.2 & 13.8 & 2.2 & 5.125 & 4.75 & 0.375 & $6.22 \mathrm{E}-02$ \\
\hline $12 / 7 / 0713: 59$ & 6.208 & 2.2 & 14.4 & 2.2 & 5.125 & 4.8125 & 0.3125 & $7.46 \mathrm{E}-02$ \\
\hline $12 / 9 / 0716: 37$ & 8.317 & 2.2 & 19.3 & 2.2 & 5.125 & 4.75 & 0.375 & $6.22 \mathrm{E}-02$ \\
\hline $12 / 10 / 076: 40$ & 8.903 & 2.2 & 20.6 & 2 & 5.1875 & 4.8125 & 0.375 & $5.65 \mathrm{E}-02$ \\
\hline
\end{tabular}


C4 Geochemical Screening

\begin{tabular}{|c|c|c|c|c|c|c|c|}
\hline \multicolumn{8}{|c|}{ Geochemical Screening Parameters } \\
\hline $\begin{array}{l}\text { Date and } \\
\text { Time }\end{array}$ & $\begin{array}{c}\text { Flow } \\
\text { Rate } \\
\text { (mL/min) }\end{array}$ & $\begin{array}{c}\text { Actual } \\
\text { Pore } \\
\text { Volumes }\end{array}$ & $\begin{array}{l}\text { Temp } \\
\left({ }^{\circ} \mathrm{C}\right)\end{array}$ & $\begin{array}{c}\mathrm{SC} \\
(\mathrm{uS} / \mathrm{cm})\end{array}$ & $\begin{array}{c}\mathrm{DO} \\
(\mathrm{mg} / \mathrm{L})\end{array}$ & $\begin{array}{l}\mathrm{pH} \\
\text { (SU) }\end{array}$ & $\begin{array}{l}\text { ORP } \\
(\mathrm{mV})\end{array}$ \\
\hline \multicolumn{8}{|c|}{ 1L - Micropowder Low } \\
\hline 11/16/07 19:44 & 0 & 0 & & & & & \\
\hline $11 / 17 / 075: 05$ & 2.2 & 1.8 & 19.04 & & 6.84 & 8.07 & 147 \\
\hline $11 / 17 / 0720: 35$ & 2.2 & 4.8 & 19.72 & 622 & 8.85 & 7.98 & 186.4 \\
\hline 11/18/07 22:35 & 2.2 & 9.9 & 18.25 & 608 & 6.93 & 7.94 & 209.2 \\
\hline $11 / 19 / 0723: 48$ & 2.2 & 14.8 & 17.66 & 640 & 6.16 & 8.09 & 206.3 \\
\hline $11 / 21 / 076: 41$ & 2.2 & 20.8 & 16.67 & 628 & 7.32 & 7.64 & 218.7 \\
\hline \multicolumn{8}{|c|}{ 1H - Micropowder High } \\
\hline 11/16/07 19:44 & 0 & 0 & & & & & \\
\hline 11/17/075:05 & 2.2 & 1.8 & 19.48 & & 6.64 & 8.08 & 134 \\
\hline $11 / 17 / 0720: 40$ & 2.2 & 4.8 & 19.63 & 608 & 8.22 & 7.91 & 183.5 \\
\hline 11/18/07 22:43 & 2.2 & 9.9 & 18.55 & 599 & 6.26 & 7.9 & 207.9 \\
\hline 11/19/07 23:52 & 2.2 & 14.8 & 15.92 & 601 & 6.7 & 8.03 & 208.8 \\
\hline $11 / 21 / 076: 44$ & 2.2 & 20.8 & 17.38 & 619 & 7.34 & 7.74 & 218.1 \\
\hline \multicolumn{8}{|l|}{ 2L-RNIP Low } \\
\hline $11 / 16 / 07$ 19:44 & 0 & 0 & & & & & \\
\hline $11 / 17 / 075: 05$ & 2.2 & 1.8 & 18.96 & & 6.37 & 8.29 & 119.8 \\
\hline $11 / 17 / 0720: 51$ & $2 . \overline{2}$ & 4.9 & 19.8 & 626 & 7.14 & 8.2 & 175.4 \\
\hline $11 / 18 / 0722: 45$ & 2.2 & 9.9 & 18.1 & 585 & 6.57 & 8.18 & 198.2 \\
\hline 11/19/07 23:58 & 2.2 & 14.8 & 16.04 & 606 & 6.38 & 8.28 & 205.9 \\
\hline 11/21/07 6:47 & 2.2 & 20.8 & 17.24 & 611 & 6.95 & 8.06 & 217.3 \\
\hline \multicolumn{8}{|l|}{ 2H - RNIP High } \\
\hline 11/16/07 19:44 & 0 & 0 & & & & & \\
\hline $11 / 17 / 075: 05$ & 2.2 & 1.8 & 19.27 & & 0.36 & 10.34 & 82.1 \\
\hline $11 / 17 / 0720: 58$ & 2.2 & 4.9 & 19.5 & 919 & 5.8 & 10.47 & 156.7 \\
\hline $11 / 18 / 0722: 49$ & 2.2 & 9.9 & 17.91 & 614 & 6.45 & 9.96 & 172.9 \\
\hline $11 / 20 / 070: 04$ & 2.2 & 14.8 & 15.56 & 551 & 6.75 & 9.44 & 198.1 \\
\hline $11 / 21 / 076: 50$ & 2.2 & 20.8 & 17.14 & 535 & 7.04 & 8.83 & 213.4 \\
\hline \multicolumn{8}{|c|}{ 3L - Polymetallix Low } \\
\hline 11/16/07 19:44 & 0 & 0 & & & & & \\
\hline $11 / 17 / 075: 05$ & 2.2 & 1.8 & 19.38 & & 6.7 & 7.84 & 129.2 \\
\hline $11 / 17 / 0720: 44$ & 2.2 & 4.9 & 19.52 & 631 & 7.86 & 7.65 & 181.3 \\
\hline $11 / 18 / 0722: 53$ & 2.2 & 9.9 & 18.29 & 610 & 6.05 & 7.89 & 183.4 \\
\hline $11 / 20 / 070: 10$ & 2.2 & 14.9 & 13.86 & 611 & 7.09 & 7.93 & 203.3 \\
\hline $11 / 21 / 076: 53$ & 2.2 & 20.8 & 17.25 & 621 & 6.95 & 7.8 & 215 \\
\hline \multicolumn{8}{|c|}{ 3H - Polymetallix High } \\
\hline \begin{tabular}{|l|}
$11 / 16 / 07 ~ 19: 44$ \\
\end{tabular} & $\begin{array}{l}0 \\
\end{array}$ & 0 & & & & & \\
\hline 11/17/07 5:05 & 2.2 & 1.8 & 18.76 & & 3.7 & 7.99 & 54.6 \\
\hline $11 / 17 / 0720: 55$ & 2.2 & 4.9 & 19.66 & 940 & 7.35 & 8.55 & 169.3 \\
\hline 11/18/07 22:57 & 2.2 & 10.0 & 18.23 & 711 & 6.68 & 8.58 & 179 \\
\hline $11 / 20 / 070: 15$ & 2.2 & 14.9 & 13.6 & 599 & 7.31 & 7.86 & 200.9 \\
\hline $11 / 21 / 076: 55$ & 2.2 & 20.8 & 17.22 & 610 & 7.52 & 7.67 & 214.2 \\
\hline \multicolumn{8}{|l|}{ Control } \\
\hline 11/16/07 19:44 & 0 & 0 & & & & & \\
\hline 11/17/07 5:05 & 2.2 & 1.8 & 19.04 & & 6.53 & 8.06 & 128.9 \\
\hline $11 / 17 / 0720: 47$ & 2.2 & 4.9 & 19.57 & 617 & 7.63 & 7.92 & 179.6 \\
\hline $11 / 18 / 0722: 59$ & 2.2 & 10.0 & 18.12 & 590 & 6.72 & 7.81 & 187 \\
\hline 11/20/07 0:22 & 2.2 & 14.9 & 14.05 & 594 & 7.07 & 7.99 & 200.2 \\
\hline $11 / 21 / 076: 59$ & 2.2 & 20.8 & 17.02 & 619 & 8.01 & 7.89 & 213.8 \\
\hline
\end{tabular}


DOE/RL-2009-35, REV. 0

\begin{tabular}{|c|c|c|c|c|c|c|}
\hline \multicolumn{7}{|c|}{ Geochemical Screening Head } \\
\hline Date \& Time & $\begin{array}{c}\text { Elapsed } \\
\text { Time } \\
\text { (Day) }\end{array}$ & $\begin{array}{c}\text { Flow Rate } \\
\text { (mLimin) }\end{array}$ & $\begin{array}{c}\text { Actual } \\
\text { Pore } \\
\text { Volumes }\end{array}$ & $\begin{array}{c}\text { Head } \\
\text { Difference } \\
\text { (in) }\end{array}$ & $\begin{array}{c}\text { Hydraulic } \\
\text { Conductivity } \\
\text { (cmis) }\end{array}$ & $\begin{array}{c}\text { Hydraulic } \\
\text { Conductivity } \\
\text { (ftd) }\end{array}$ \\
\hline \multicolumn{7}{|c|}{ 1L-Micropowder Low } \\
\hline $11 / 16 / 0719: 44$ & 0 & 0 & 0.0 & 0.00 & & \\
\hline 11/17/07 1:12 & 0.228 & 2.3 & 1.1 & 0.88 & $1.73 \mathrm{E}-02$ & 49.04 \\
\hline 11/17/07 5:05 & 0.162 & 2.3 & 1.9 & 0.88 & 1.73E-02 & 49.04 \\
\hline $11 / 17 / 0723: 20$ & 0.760 & 2.3 & 5.6 & 0.88 & 1.73E-02 & 49.04 \\
\hline $11 / 18 / 0722: 35$ & 0.969 & 2.3 & 10.3 & 0.75 & $2.02 \mathrm{E}-02$ & 57.22 \\
\hline $11 / 19 / 0711: 53$ & 0.554 & 2.3 & 13.0 & 0.75 & $2.02 E-02$ & 57.22 \\
\hline $11 / 19 / 0723: 23$ & 0.479 & 2.4 & 15.5 & 0.75 & $2.11 \mathrm{E}-\mathrm{02}$ & 59.70 \\
\hline $11 / 20 / 079: 40$ & $0.42 \theta$ & 2.3 & 17.6 & 0.81 & 1.86E-02 & 52.81 \\
\hline $11 / 20 / 0715: 50$ & 0.257 & 2.2 & 18.8 & 0.75 & $1.93 E-02$ & 54.73 \\
\hline $11 / 21 / 077: 50$ & 0.667 & 2.4 & 22.2 & 0.75 & $2.11 \mathrm{E}-02$ & 59.70 \\
\hline \multicolumn{7}{|c|}{ 1H-Micropowrder High } \\
\hline $11 / 16 / 0719: 44$ & 0 & 0 & 0.0 & 0.00 & & \\
\hline $11 / 17 / 071: 12$ & 0.228 & 2.6 & 1.3 & 2.00 & $8.56 \mathrm{E}-03$ & 24.25 \\
\hline $11 / 17 / 075: 05$ & 0.162 & 1.7 & 1.8 & 1.88 & 5.97E-03 & 16.92 \\
\hline $11 / 17 / 0723: 20$ & 0.760 & 1.4 & 4.1 & 2.00 & $4.61 E-03$ & 13.06 \\
\hline 11/18/07 22:39 & 0.972 & 2.5 & 9.2 & 2.00 & $8.23 \mathrm{E}-03$ & 23.32 \\
\hline $11 / 19 / 0711: 53$ & 0.551 & 2.1 & 11.7 & 2.00 & $6.91 E-03$ & 19.59 \\
\hline 11/19/07 23:23 & 0.479 & 2.7 & 14.4 & 1.88 & $9.48 \mathrm{E}-03$ & 26.87 \\
\hline $11 / 20 / 079: 40$ & 0.428 & 2 & 16.3 & 1.88 & 7.02E-03 & 19.90 \\
\hline $11 / 20 / 0715: 50$ & 0.257 & 2.3 & 17.5 & 2.00 & $7.57 \mathrm{E}-03$ & 21.46 \\
\hline $11 / 21 / 077: 50$ & 0.667 & 2.4 & 20.9 & 2.00 & $7.90 \mathrm{E}-03$ & 22.39 \\
\hline \multicolumn{7}{|l|}{ 2L-RNIP Low } \\
\hline $11 / 16 / 0719: 44$ & 0 & 0 & 0.0 & 0.00 & & \\
\hline $11 / 17 / 071: 14$ & 0.229 & 2.4 & 1.2 & 17.13 & $9.22 \mathrm{E}-04$ & 2.61 \\
\hline $11 / 17 / 075: 05$ & 0.160 & 2.4 & 2.0 & 14.25 & 1.11E-03 & 3.14 \\
\hline $11 / 17 / 0723: 20$ & 0.760 & 2 & 5.2 & 15.38 & $8.56 E-04$ & 2.43 \\
\hline $11 / 18 / 0722.44$ & 0.975 & 2.3 & 10.0 & 16.25 & $9.32 \mathrm{E}-04$ & 2.64 \\
\hline $11 / 19 / 0711: 53$ & 0.548 & 2.4 & 12.8 & 18.13 & $8.72 \mathrm{E}-04$ & 2.47 \\
\hline $11 / 19 / 0723: 23$ & 0.479 & 2.3 & 15.1 & 19.00 & $7.97 E-04$ & 2.26 \\
\hline 11/20/07 9:40 & 0.428 & 2.2 & 17.1 & 19.13 & $7.57 \mathrm{E}-04$ & 2.15 \\
\hline $11 / 20 / 0715: 50$ & 0.257 & 2.2 & 18.3 & 19.13 & 7.57 E-04 & 2.15 \\
\hline $11 / 21 / 077: 50$ & 0.667 & 2.5 & 21.8 & 18.75 & $8.78 \mathrm{E}-04$ & 2.49 \\
\hline \multicolumn{7}{|l|}{$\overline{2 H-R N I P ~ H i g h ~}$} \\
\hline $11 / 16 / 07 \quad 19: 44$ & $\mathrm{C}$ & 0 & 0.0 & Q.DO & & \\
\hline $11 / 17 / 071: 14$ & 0.229 & 2.8 & 1.4 & 110.99 & 1.66E-04 & 0.47 \\
\hline 11/17/07 5:05 & D. 160 & 2 & 2.0 & 100.08 & $1.32 \mathrm{E}-04$ & 0.37 \\
\hline $11 / 17,0723: 20$ & 0.760 & 2.3 & 5.8 & 19.00 & 7.97E-04 & 2.26 \\
\hline $11 / 18 / 0722: 48$ & 0.978 & 2 & 9.9 & 18.13 & $7.26 \mathrm{E}-04$ & 2.06 \\
\hline $11 / 19 / 0711: 53$ & 0.545 & 2 & 12.2 & 16.88 & $7.80 \mathrm{E}-\mathrm{0} 4$ & 2.21 \\
\hline 11/19/07 23:23. & 0.479 & 2.2 & 14.4 & 16.63 & $8.71 \mathrm{E}-04$ & 2.47 \\
\hline $11 / 20 / 079: 40$ & 0.428 & 2 & 16.3 & 14.38 & $9.16 \mathrm{E}-04$ & 2.60 \\
\hline $11 / 20 / 07$ 15:50 & 0.257 & 2.1 & 17.4 & 13.25 & 1.04E-03 & 2.96 \\
\hline $11 / 21 / 077: 50$ & 0.667 & 2.5 & 20.9 & 12.50 & $1.32 \mathrm{E}-03$ & 3.73 \\
\hline \multicolumn{7}{|c|}{ 3L-Polymetallix Low } \\
\hline $11 / 16 / 0719: 44$ & 0 & 0 & 0.0 & 0.00 & & \\
\hline $11 / 17 / 071: 15$ & 0.230 & 1.8 & 0.9 & 4.50 & $2.63 E-03$ & 7.46 \\
\hline $11 / 17 / 075: 05$ & 0.160 & 2.6 & 1.8 & 3.63 & $4.72 \mathrm{E}-03$ & 13.38 \\
\hline $11 / 17 / 0723: 20$ & 0.760 & 2.7 & 6.1 & 3.94 & $4.51 E-03$ & 12.79 \\
\hline $11 / 18 / 0722: 51$ & 0.980 & 2 & 10.3 & 3.13 & $4.21 E-03$ & 11.94 \\
\hline $11 / 19 / 0711: 53$ & 0.543 & 2 & 12.6 & 4.13 & $3.19 E-03$ & 9.05 \\
\hline $11 / 19 / 0723: 23$ & 0.479 & 2.3 & 14.9 & 4.00 & $3.78 \mathrm{E}-03$ & 10.73 \\
\hline $11 / 20 / 079: 40$ & 0.428 & 1.9 & 16.6 & 4.00 & $3.13 \mathrm{E}-03$ & 8.86 \\
\hline $11 / 20 / 0715: 50$ & 0.257 & 2.1 & 17.8 & 4.00 & $3.46 \mathrm{E}-03$ & 9.80 \\
\hline 11/21/07 7:50 & 0.667 & 2 & 20.6 & 4.00 & $3.29 E-03$ & 9.33 \\
\hline 3H-Polymetallix & High & & & & & \\
\hline $11 / 16 / 07$ 19:44 & 0 & 0 & 0.0 & 0.00 & & \\
\hline $11 / 17 / 07$ 1:15 & 0.230 & 2.7 & 1.3 & 3.13 & $5.69 \mathrm{E}-03$ & 16.12 \\
\hline $11 / 17 / 075: 05$ & 0.160 & 2.1 & 2.0 & 1.86 & $7.37 E-03$ & 20.90 \\
\hline $11 / 17 / 0723: 20$ & 0.760 & 1.3 & 4.1 & 1.75 & $4.89 \mathrm{E}-03$ & 13.86 \\
\hline $11 / 18.0722: 55$ & 0.983 & 2 & 8.3 & 1.88 & $7.02 E-03$ & 19.90 \\
\hline $11 / 19 / 0711.53$ & 0.540 & 1.9 & 10.5 & 1.75 & $7.15 \mathrm{E}-03$ & 20.26 \\
\hline 11/19/07 23:23 & 0.479 & 2.3 & 12.8 & 1.75 & $8.65 \mathrm{E}-03$ & 24.52 \\
\hline $11 / 20 / 079: 40$ & 0.428 & 1.9 & 14.5 & 1.63 & $7.70 \mathrm{E}-03$ & 21.81 \\
\hline $11 / 20 / 0715: 50$ & 0.257 & 2 & 15.6 & 1.63 & $8.10 \mathrm{E}-03$ & 22.96 \\
\hline $11 / 21 / 077: 50$ & 0.667 & 2.1 & 18.6 & 1.50 & $9.21 \mathrm{E}-03$ & 26.12 \\
\hline Control & & & & & & \\
\hline $11 / 16 / 0719: 44$ & 0 & 0 & 0.0 & 0.00 & & \\
\hline $11 / 17 / 071: 17$ & 0.231 & 2.2 & 1.1 & 22.13 & $6.54 \mathrm{E}-04$ & 1.86 \\
\hline $11 / 17 / 075: 05$ & 0.158 & 2.8 & 2.0 & 22.38 & 8.24E-04 & 2.33 \\
\hline $11 / 17 / 0723: 20$ & 0.760 & 2 & 5.2 & 24.19 & $5.44 \mathrm{E}-04$ & 1.54 \\
\hline $11 / 18 / 0723: 00$ & 0.986 & 2 & 9.4 & 24.25 & $5.43 \mathrm{E}-04$ & 1.54 \\
\hline $11 / 19 / 0711: 53$ & 0.537 & 2.3 & 12.0 & 24.13 & $6.27 E-04$ & 1.78 \\
\hline $11 / 19 / 0723: 23$ & 0.479 & 2.1 & 14.2 & 24.50 & $5.64 \mathrm{E}-04$ & 1.60 \\
\hline $11 / 20 / 079: 40$ & 0.428 & 2.4 & 16.4 & 26.63 & $5.93 E-04$ & 1.68 \\
\hline $11 / 20 / 0715: 50$ & 0.257 & 2.1 & 17.5 & 24.75 & $5.58 \mathrm{E}-04$ & 1.58 \\
\hline $11 / 21 / 077: 50$ & 0.667 & 2.3 & 20.8 & 24.68 & $6.09 E-04$ & 1.73 \\
\hline
\end{tabular}


DOE/RL-2009-35, REV. 0

\begin{tabular}{|c|c|c|c|c|c|c|}
\hline \multicolumn{7}{|c|}{ Geochemical Screening Analytical } \\
\hline $\begin{array}{l}\text { Sampling } \\
\text { Event }\end{array}$ & $\begin{array}{c}\text { Pore } \\
\text { Volumes }\end{array}$ & $\begin{array}{c}\text { Nitrogen, } \\
\text { Nitrate-Nitrite } \\
\text { (mg/L) }\end{array}$ & $\begin{array}{l}\text { Phosphorus } \\
\text { (mg/L) }\end{array}$ & $\begin{array}{l}\text { Chromium } \\
\text { (ug/L) }\end{array}$ & $\begin{array}{c}\text { Ammonia } \\
(\mathrm{mg} / \mathrm{L})\end{array}$ & $\begin{array}{l}\text { Total Organic } \\
\text { Carbon (mg/L) }\end{array}$ \\
\hline \multicolumn{7}{|c|}{ Surrogate GW } \\
\hline 0 & 0 & 12.7 & 60 & 572 & 0.12 & 0.7 \\
\hline \multicolumn{7}{|c|}{$1 \mathrm{~L}$ - Micropowder Low } \\
\hline 1 & 1.8 & 4.87 & 386 & 57 & 0.85 & 55.7 \\
\hline 2 & 4.8 & 12.6 & 388 & 863 & 0.16 & 10.3 \\
\hline 3 & 9.9 & 12.3 & 103 & 564 & 1.04 & 6.64 \\
\hline 5 & 20.8 & 12.5 & 104 & 594 & ND & 2 \\
\hline \multicolumn{7}{|c|}{ 1H - Micropowder High } \\
\hline 1 & 1.8 & 4.3 & 791 & 50.4 & 1.70 & 46.1 \\
\hline 2 & 4.8 & 12.3 & 471 & 633 & 0.12 & 10.5 \\
\hline 3 & 9.9 & 12.5 & 77 & 496 & 0.26 & 7.08 \\
\hline 5 & 20.8 & 12.4 & 149 & 568 & 2.19 & 2.41 \\
\hline \multicolumn{7}{|c|}{ 2L - RNIP Low } \\
\hline 1 & 1.8 & 12.3 & 213 & ND & ND & 76.4 \\
\hline 2 & 4.9 & 12.2 & 44 & ND & 0.48 & 11.1 \\
\hline 3 & 9.9 & 12.4 & 36 & ND & 0.83 & 3.58 \\
\hline 5 & 20.8 & 12.5 & 95 & ND & 0.80 & 3.85 \\
\hline \multicolumn{7}{|c|}{ 2H - RNIP High } \\
\hline 1 & 1.8 & 10.9 & 70 & ND & 1.95 & 590 \\
\hline 2 & 4.9 & 10.1 & 90 & ND & 3.17 & 17.1 \\
\hline 3 & 9.9 & 9.7 & 47 & ND & 2.00 & 7.73 \\
\hline 5 & 20.8 & 8.94 & 101 & ND & 5.08 & 3.59 \\
\hline \multicolumn{7}{|c|}{ 3L - Polymetallix Low } \\
\hline 1 & 1.8 & 3.43 & 54539 & ND & 4.70 & 314 \\
\hline 2 & 4.9 & & 9334 & 222 & 2.74 & 18 \\
\hline 3 & 9.9 & 11.9 & 5532 & 307 & 1.65 & 7.57 \\
\hline 5 & 20.8 & 12.4 & 2621 & 382 & 0.83 & 4.5 \\
\hline \multicolumn{7}{|c|}{ 3H - Polymetallix High } \\
\hline 1 & 1.8 & 10.7 & 345566 & 281 & $9.73^{*}$ & 1760 \\
\hline 2 & 4.9 & 12.6 & 68195 & ND & 3.64 & -- \\
\hline 3 & 10.0 & 11.8 & 17615 & ND & 2.16 & 15 \\
\hline 5 & 20.8 & 12.2 & 1445 & ND & 1.47 & 5.94 \\
\hline \multicolumn{7}{|l|}{ Control } \\
\hline $\begin{array}{r}1 \\
\end{array}$ & 1.8 & 6.22 & 514 & ND & 0.48 & 77.5 \\
\hline 2 & 4.9 & 12.7 & 454 & 481 & 1.51 & 11.4 \\
\hline 3 & 10.0 & 12.3 & 92 & 508 & ND & 3.94 \\
\hline 5 & 20.8 & 12.6 & 145 & 524 & 0.31 & -- \\
\hline
\end{tabular}


C5 Advanced Geochemical Test

\begin{tabular}{|c|c|c|c|c|c|c|c|c|c|c|c|c|c|c|c|c|c|c|c|}
\hline \multicolumn{20}{|c|}{ Advanced Geochemical Tests Analytical Results and Parameters } \\
\hline Sample ID & $\begin{array}{c}\text { Date } \\
\text { Collected }\end{array}$ & $\begin{array}{l}\text { Alkalinity } \\
\text { (as mgll } \\
\mathrm{CaCO}_{3} \text { ) }\end{array}$ & $\begin{array}{c}\mathrm{Cr}^{6+} \\
(\mathrm{mg} / \mathrm{L})\end{array}$ & $\begin{array}{c}\text { Total } \\
\mathrm{Cr} \\
(\mu g / \mathrm{L})\end{array}$ & $\begin{array}{c}\text { Diss. } \\
\mathrm{Cr} \\
\left(\mu g^{\prime} \mathrm{L}\right)\end{array}$ & $\begin{array}{c}\mathrm{SO}_{4}{ }^{2} \\
(\mathrm{mg} / \mathrm{L})\end{array}$ & $\begin{array}{l}\mathrm{NH}_{4}{ }^{2-} \\
(\mathrm{mg} / \mathrm{L})\end{array}$ & $\begin{array}{c}\mathrm{NO}_{3}{ }^{3} \\
(\mathrm{mg} / \mathrm{L})\end{array}$ & $\begin{array}{c}\mathrm{NO}_{2}{ }^{7} \\
(\mathrm{mg} / \mathrm{L})\end{array}$ & $\mid \begin{array}{c}\mathrm{Fe}^{2+} \\
(\mathrm{mg} / \mathrm{L})\end{array}$ & $\begin{array}{l}\mathrm{Fe}^{3+} \\
(\mathrm{mg} / \mathrm{L})\end{array}$ & $\mid \begin{array}{c}\text { Total } \\
\mathrm{Fe} \\
(\mathrm{mg} / \mathrm{L})\end{array}$ & $\mid \begin{array}{c}\text { Total } \\
\mathrm{Fe} \\
(\mu \mathrm{g} / \mathrm{L})\end{array}$ & $\begin{array}{c}\text { Diss. } \\
\mathrm{Fe} \\
\left(\mu g^{\prime} L\right)\end{array}$ & $\begin{array}{c}\text { Temp } \\
\text { (OC) }\end{array}$ & $\begin{array}{c}\mathrm{SC} \\
(\mathrm{mS} / \mathrm{cm})\end{array}$ & $\left|\begin{array}{c}\mathrm{DO} \\
(\mathrm{mg} / \mathrm{L})\end{array}\right|$ & $\begin{array}{c}\mathrm{pH} \\
(\mathrm{SU})\end{array}$ & $\begin{array}{l}\text { ORP } \\
\text { (mV) }\end{array}$ \\
\hline INF-00-2 & $2 / 16 / 2008$ & ND & ND & NT & NT & ND & 2.14 & ND & ND & ND & ND & NT & NT & NT & NT & NT & NT & NT & NT \\
\hline INF-00-4 & $2 / 21 / 2008$ & ND & ND & NT & NT & $\mathrm{ND}$ & 1.24 & ND & ND & ND & ND & NT & NT & NT & NT & NT & NT & NT & NT \\
\hline INF-00-6 & \begin{tabular}{|l|}
$3 / 3 / 2008$ \\
\end{tabular} & ND & ND & ND & NT & ND & 2.53 & ND & ND & ND & ND & ND & ND & NT & NT & NT & NT & NT & NT \\
\hline INF-00-0 & $2 / 12 / 2008$ & 78.0 & 0.510 & 599 & 593 & 134 & ND & 13.0 & ND & $\mathrm{ND}$ & ND & $\mathrm{ND}$ & $\mathrm{ND}$ & ND & NT & NT & NT & NT & NT \\
\hline INF-00-3 & \begin{tabular}{|l|}
$2 / 18 / 2008$ \\
\end{tabular} & 65.0 & 0.545 & NT & NT & 123 & ND & 12.5 & ND & ND & ND & NT & NT & NT & NT & NT & NT & NT & NT \\
\hline INF-00-5 & $2 / 25 / 2008$ & 68.0 & 0.527 & NT & NT & 129 & ND & 13.0 & ND & ND & ND & $\overline{\mathrm{N} T}$ & NT & NT & NT & NT & NT & NT & NT \\
\hline INF-01-4 & $2 / 21 / 2008$ & NT & 0.540 & NT & NT & 127 & ND & 12.9 & ND & ND & ND & NT & NT & NT & NT & NT & NT & NT & $\overline{N T}$ \\
\hline INF-01-6 & \begin{tabular}{|l|}
$3 / 3 / 2008$ \\
\end{tabular} & 63.6 & 0.494 & 585 & NT & 138 & 1.09 & 13.5 & ND & ND & ND & $\mathrm{ND}$ & ND & NT & NT & NT & NT & NT & NT \\
\hline CON-EFF-01-1 & $2 / 13 / 2008$ & 73.6 & 0.507 & 536 & 547 & 136 & 1.06 & 12.8 & ND & ND & ND & ND & ND & ND & 18.98 & 607 & 7.12 & 7.82 & 211.8 \\
\hline CON-EFF-01-2 & $2 / 16 / 2008$ & 68.8 & 0.531 & NT & NT & 134 & 1.59 & 12.6 & 0.182 & ND & ND & NT & NT & NT & 19.10 & 596 & 6.49 & 7.88 & 108.1 \\
\hline CON-EFF-01-3 & $2 / 18 / 2008$ & 66.8 & 0.526 & NT & NT & 126 & 2.95 & 12.4 & 0.130 & ND & ND & NT & NT & NT & 19.30 & 613 & 6.10 & 7.97 & 229.7 \\
\hline CON-EFF-0t-4 & $2 / 21 / 2008$ & 69.4 & 0.512 & NT & NT & 127 & 2.26 & 12.4 & 0.237 & ND & ND & NT & NT & NT & \begin{tabular}{|l|}
20.24 \\
\end{tabular} & 608 & 6.27 & 7.91 & 166.9 \\
\hline CON-EFF-01-5 & \begin{tabular}{|l|}
$2 / 25 / 2008$ \\
\end{tabular} & 71.0 & 0.502 & NT & NT & 128 & ND & 12.7 & 0.318 & ND & ND & NT & NT & NT & 20.50 & 616 & 6.33 & 7.91 & 223.4 \\
\hline CON-EFF-01-6 & $3 / 3 / 2008$ & 65.2 & 0.494 & 569 & NT & 138 & 0.925 & 13.2 & 0.312 & NT & NT & ND & ND & NT & 20.48 & 617 & 6.07 & 7.94 & 199.3 \\
\hline POLY-EFF-01-1 & $2 / 13 / 2008$ & 56.4 & ND & ND & ND & 127 & 3.36 & 9.65 & 0.176 & ND & ND & 250 & 250 & ND & 19.00 & 577 & 6.53 & 7.92 & -50.8 \\
\hline POLY-EFF-01-2 & $2 / 16 / 2008$ & 80.0 & ND & NT & $\overline{\text { NT }}$ & 132 & ND & 5.58 & 3.05 & ND & ND & NT & NT & NT & 19.19 & 562 & 5.62 & 7.97 & -141.3 \\
\hline POLY-EFF-01-3 & $2 / 18 / 2008$ & 76.0 & ND & NT & NT & 128 & 0.630 & 0.524 & 3.85 & ND & ND & NT & NT & NT & 19.88 & 550 & 5.84 & \begin{tabular}{|l|}
8.32 \\
\end{tabular} & 231.0 \\
\hline POLY-EFF-01-4 & $2 / 21 / 2008$ & 74.2 & ND & NT & NT & 129 & ND & 11.2 & 0.324 & NDD & ND & NT & NT & NT & 21.20 & 609 & 5.69 & 8.00 & 199.6 \\
\hline POLY-EFF-01-5 & $2 / 25 / 2008$ & 74.4 & ND & NT & NT & 127 & ND & 11.4 & 0.186 & ND & ND & NT & NT & NT & 21.27 & 621 & 6.35 & 8.00 & 211.7 \\
\hline POLY-EFF-01-6 & \begin{tabular}{|l|}
$3 / 3 / 2008$ \\
\end{tabular} & 69.8 & ND & ND & NT & 137 & ND & 12.2 & 0.263 & ND & ND & ND & ND & NT & 21.11 & 619 & 5.51 & 8.05 & 179.0 \\
\hline POLY-EFF-02-1 & $2 / 13 / 2008$ & 94.0 & ND & ND & ND & 122 & 1.52 & 7.81 & ND & ND & ND & 525 & 525 & ND & 19.10 & 609 & 6.39 & 8.15 & -11.5 \\
\hline POLY-EFF-02-2 & $2 / 16 / 2008$ & 70.4 & ND & NT & NT & 134 & ND & 5.29 & 2.38 & ND & ND & NT & NT & NT & 19.35 & 558 & 6.34 & 7.99 & -92.5 \\
\hline POLY-EFF-02-3 & \begin{tabular}{|l|}
$2 / 18 / 2008$ \\
\end{tabular} & 68.0 & ND & NT & NT & 128 & 4.63 & ND & 1.86 & ND & ND & NT & NT & NT & 19.73 & 534 & 5.87 & 8.43 & 230.3 \\
\hline POLY-EFF-02-4 & $2 / 21 / 2008$ & 74.4 & ND & NT & NT & 130 & 1.07 & 10.7 & 0.317 & ND & ND & NT & NT & INT & 21.10 & 609 & 6.07 & 8.06 & 203.4 \\
\hline POLY-EFF-02-5 & $2 / 25 / 2008$ & 78.0 & ND & NT & NT & 129 & ND & 10.4 & 0.233 & ND & ND & NT & NT & NT & 21.15 & 617 & 6.53 & 8.00 & 214.0 \\
\hline POLY-EFF-02-6 & $3 / 3 / 2008$ & 70.0 & ND & ND & NT & 140 & ND & 12.2 & 0.179 & ND & ND & ND & ND & NT & 21.10 & 619 & 5.83 & \begin{tabular}{l|}
8.05 \\
\end{tabular} & 178.8 \\
\hline POLY-EFF-03-1 & $2 / 13 / 2008$ & 74.4 & ND & ND & ND & 128 & 0.634 & 10.3 & 0.472 & $\overline{N D D}$ & ND & 180 & 180 & ND & 19.14 & 603 & 6.58 & 8.05 & -43.8 \\
\hline POLY-EFF-03-2 & \begin{tabular}{|l|}
$2 / 16 / 2008$ \\
\end{tabular} & 78.8 & ND & NT & NT & 133 & ND & 6.08 & 3.10 & ND & ND & NT & NT & NT & 19.14 & 571 & 5.62 & 7.94 & -72.8 \\
\hline POLY-EFF-03-3 & $2 / 18 / 2008$ & 70.2 & ND & NT & NT & 127 & 3.31 & ND & 1.27 & NDD & ND & NT & NT & NT & 19.81 & 527 & 5.53 & 8.35 & 235.7 \\
\hline POLY-EFF-03-4 & $2 / 21 / 2008$ & 76.0 & ND & NT & NT & 130 & 2.12 & $\$ 1.1$ & 0.240 & ND & ND & NTT & NT & NT & 21.09 & 609 & 5.86 & 7.96 & 205.7 \\
\hline POLY-EFF-03-5 & $2 / 25 / 2008$ & 75.6 & $\mathrm{ND}$ & NT & NT & 130 & ND & 11.4 & 0.108 & ND & ND & NT & NT & NT & 21.19 & 618 & 5.52 & 7.96 & 207.1 \\
\hline POLY-EFF-03-6 & $3 / 3 / 2008$ & 69.6 & ND & ND & NT & 136 & 1.28 & 12.1 & 0.120 & ND & ND & 82.4 & 82.4 & NT & 21.01 & 617 & 5.62 & \begin{tabular}{l|}
7.95 \\
\end{tabular} & \begin{tabular}{|l|}
168.3 \\
\end{tabular} \\
\hline POLY-EFF-04-1 & $2 / 13 / 2008$ & 80.0 & 0.0301 & ND & ND & 134 & $\mathrm{ND}$ & 12.1 & 0.170 & ND & ND & ND & ND & ND & 19.38 & 600 & 6.12 & 7.69 & \begin{tabular}{|l|}
220.8 \\
\end{tabular} \\
\hline POLY-EFF-04-2 & $2 / 16 / 2008$ & 70.6 & 0.266 & NT & NT & 135 & 1.26 & 11.6 & 0.906 & $\mathrm{ND}$ & ND & NT & NT & $\overline{N T}$ & 18.75 & 595 & 5.54 & 7.69 & \begin{tabular}{|l|}
227.7 \\
\end{tabular} \\
\hline POLY-EFF-04-3 & $2 / 18 / 2008$ & 68.4 & 0.313 & NT & NT & 130 & 4.70 & 11.7 & 0.685 & $\mathrm{ND}$ & ND & NT & NT & NT & 19.66 & 613 & 5.81 & 7.77 & 250.6 \\
\hline POLY-EFF-04-4 & $2 / 21 / 2008$ & 69.2 & 0.363 & NT & NT & 128 & 2.32 & 11.6 & 0.431 & ND & ND & NT & NT & NT & 21.06 & 608 & 5.70 & 7.80 & \begin{tabular}{|l|}
208.4 \\
\end{tabular} \\
\hline POLY-EFF-04-5 & $2 / 25 / 2$ & 70.8 & 0.402 & NT & NT & 128 & ND & 12.1 & 0.290 & ND & ND & NT & NT & NT & 21.20 & 619 & 6.65 & 7.81 & \begin{tabular}{|l|}
219.1 \\
\end{tabular} \\
\hline POLY-EFF-04-6 & $3 / 3 / 2008$ & 68.0 & 0.401 & 467 & NT & 138 & 1.91 & 12.9 & 0.210 & ND & ND & ND & ND & NT & 21.03 & 616 & 6.68 & 7.90 & 182.1 \\
\hline POLY-EFF-05-1 & $2 / 13 / 2008$ & 76.8 & 0.0695 & 60.0 & 68.0 & 137 & ND & 12.3 & 0.232 & ND & ND & ND & ND & ND & 19.87 & 593 & 6.31 & \begin{tabular}{ll|}
7.73 \\
\end{tabular} & 219.8 \\
\hline POLY-EFF-05-2 & $2 / 16$ & 70.4 & 0.288 & NT & NT & 134 & 4.42 & 11.6 & 0.921 & ND & ND & NT & NT & NT & 19.02 & 596 & 5.39 & 7.67 & 229.6 \\
\hline POLY-EFF-05-3 & $2 / 18 / 2008$ & 83.6 & 0.330 & NT & NT & 129 & 4.52 & 11.7 & 0.470 & ND & ND & NT & NT & NT & 19.32 & 613 & 6.26 & 7.77 & 254.9 \\
\hline POLY-EFF-05-4 & $2 / 21 / 2008$ & 69.2 & 0.374 & NT & NT & 128 & $\frac{1.69}{1.69}$ & 11.6 & 0.386 & ND & NDD & NT & NT & NT & 21.09 & 607 & 6.01 & 7.79 & \begin{tabular}{|l|}
209.8 \\
\end{tabular} \\
\hline POLY-EFF-05-5 & $2 / 25 / 2008$ & 73.6 & 0.407 & NT & NT & 126 & ND & 11.8 & 0.354 & ND & ND & NT & NT & NT & 21.24 & 621 & 6.00 & 7.85 & 219.8 \\
\hline POLY-EFF-05-6 & $3 / 3 / 2008$ & 66.8 & 0.412 & 481 & NT & 141 & ND & 12.9 & 0.309 & ND & ND & ND & ND & NT & 20.92 & 615 & 6.30 & 7.90 & 177.4 \\
\hline POLY-EFF-06-1 & $2 / 13 / 2008$ & 78.0 & 0.0518 & ND & ND & 133 & 3.88 & 12.2 & 0.168 & ND & ND & ND & ND & ND & 19.46 & 598 & 6.42 & 7.78 & 215.4 \\
\hline POLY-EFF-06-2 & $2 / 16 / 2008$ & 69.6 & 0.285 & NT & NT & 131 & 3.03 & 11.5 & 0.778 & ND & ND & NT & NT & NT & 18.81 & 597 & 5.93 & 7.70 & 227.0 \\
\hline POLY-EFF-06-3 & $2 / 18 / 2008$ & 70.0 & 0.369 & NT & NT & 130 & 2.70 & 11.9 & 0.554 & ND & ND & NT & NT & NT & 18.94 & 606 & 5.87 & \begin{tabular}{l|l}
7.74 \\
\end{tabular} & 254.8 \\
\hline POLY-EFF-06-4 & $2 / 21 / 2008$ & 71.2 & 0.377 & NT & NT & 131 & 1.40 & 12.0 & 0.509 & $\mathrm{ND}$ & ND & NT & NT & NT & 20.93 & 605 & 5.71 & 7.78 & 207.0 \\
\hline POLY-EFF-06-5 & $2 / 25 / 2008$ & 71.6 & 0.415 & NT & NT & 126 & ND & 12.0 & 0.320 & ND & ND & NT & NT & NT & 21.14 & 621 & 5.92 & \begin{tabular}{l|l|}
7.82 \\
\end{tabular} & 218.7 \\
\hline POLY-EFF-06-6 & & 64.0 & 0.417 & 491 & NT & 135 & ND & 12.9 & 0.229 & ND & ND & ND & ND & NT & 20.52 & 617 & 6.10 & 7.89 & 179.1 \\
\hline POLY-EFF-07-1 & $2 / 13 / 2008$ & 72.8 & 0.468 & 522 & 501 & 135 & ND & 12.6 & ND & ND & ND & ND & ND & ND & 19.42 & 594 & 6.92 & 7.79 & 212.2 \\
\hline POLY-EFF-07-2 & \begin{tabular}{|l|}
$2 / 16 / 2008$ \\
\end{tabular} & 72.8 & 0.480 & NT & NT & 132 & 4.01 & 12.4 & 0.304 & ND & ND & NT & NT & NT & 18.75 & 596 & 6.21 & 7.81 & 221.6 \\
\hline POLY-EFF-07-3 & \begin{tabular}{|l|}
$2 / 18 / 2008$ \\
\end{tabular} & 72.4 & 0.535 & NT & NT & 129 & 4.43 & 12.5 & 0.158 & ND & ND & NT & NT & NT & 18.78 & 603 & 6.77 & 7.77 & \begin{tabular}{|l|}
254.2 \\
\end{tabular} \\
\hline POLY-EFF-07-4 & $2 / 21 / 2008$ & 66.0 & 0.507 & NT & NT & 130 & 2.10 & 12.3 & 0.184 & ND & ND & NT & NT & NT & 20.90 & 605 & 6.20 & \begin{tabular}{l|l|}
7.86 \\
\end{tabular} & 203.9 \\
\hline POLY-EFF-07-5 & $2 / 25 / 2008$ & 74.0 & 0.497 & NT & NT & 130 & ND & 12.4 & 0.284 & NDD & ND & NT & NT & NT & 21.11 & 620 & 6.55 & 7.90 & 223.5 \\
\hline POLY-EFF-07-6 & & 65.2 & 0.466 & 543 & NT & 137 & ND & 12.8 & 0.270 & ND & NDD & ND & ND & NT & 20.76 & 617 & 6.19 & \begin{tabular}{l|l}
7.93 \\
\end{tabular} & 184.6 \\
\hline POLY-EFF-08-1 & $2 / 13 / 2008$ & 72.4 & 0.481 & 522 & 519 & 136 & ND & 12.8 & ND & ND & ND & ND & ND & ND & 19.50 & 603 & 7.19 & \begin{tabular}{l|l}
7.87 \\
\end{tabular} & 210.7 \\
\hline POLY-EFF-08-2 & $2 / 16 / 2008$ & 72.2 & 0.514 & NT & NT & 134 & 3.68 & 12.5 & 0.346 & ND & ND & NT & NT & NT & 19.19 & 594 & 6.14 & 7.78 & 228.6 \\
\hline POLY-EFF-08-3 & $2 / 18 / 2008$ & 67.6 & 0.536 & NT & NT & 130 & 2.71 & 12.7 & 0.204 & ND & ND & NT & NT & NT & 19.02 & 606 & 6.64 & 7.86 & 239.6 \\
\hline POLY-EFF-08-4 & $2 / 21 / 2008$ & 66.8 & 0.514 & $\mathrm{NT}$ & NT & 132 & 1.97 & 12.7 & 0.325 & ND & ND & NT & NT & NT & 20.72 & 606 & 6.54 & 7.88 & 201.7 \\
\hline POLY-EFF-08-5 & $2 / 25 / 2008$ & 71.4 & 0.509 & NT & NT & 126 & ND & 12.3 & 0.390 & NDD & ND & NT & NT & NT & 21.00 & 621 & 6.86 & 7.93 & 218.5 \\
\hline
\end{tabular}




\begin{tabular}{|c|c|c|c|c|c|c|c|c|c|c|c|c|c|c|c|c|c|c|c|}
\hline \multicolumn{20}{|c|}{ Advanced Geochemical Tests Analytical Results and Parameters } \\
\hline Sample ID & $\begin{array}{c}\text { Date } \\
\text { Cotlected }\end{array}$ & $\begin{array}{l}\text { Alkalinity, } \\
\text { (as } \mathrm{mg}^{\prime} / \\
\mathrm{CaCO}_{3} \text { ) }\end{array}$ & $\mid \begin{array}{c}\mathrm{Cr}^{6+} \\
(\mathrm{mg} / \mathrm{L})\end{array}$ & $\begin{array}{c}\text { Total } \\
\mathrm{Cr} \\
(\mu g / \mathrm{L})\end{array}$ & $\begin{array}{l}\text { Dissol } \\
\text { ved Cr } \\
(\mu g / L)\end{array}$ & $\left\{\begin{array}{l}\mathrm{SO}_{4}^{2-} \\
(\mathrm{mg} / \mathrm{L})\end{array}\right.$ & $\left|\begin{array}{c}\mathrm{NH}_{4}{ }^{2} \\
(\mathrm{mg} / \mathrm{L})\end{array}\right|$ & $\begin{array}{l}\mathrm{NO}_{3}{ }^{7} \\
(\mathrm{mg} / \mathrm{L})\end{array}$ & $\mid \begin{array}{c}\mathrm{NO}_{2}{ }^{3} \\
(\mathrm{mg} / \mathrm{L})\end{array}$ & $\begin{array}{l}\mathrm{Fe}^{2+} \\
(\mathrm{mg} / \mathrm{L})\end{array}$ & $\mid \begin{array}{c}\mathrm{Fe}^{3+} \\
(\mathrm{mg} / \mathrm{L})\end{array}$ & $\begin{array}{c}\text { Total } \\
\mathrm{Fe} \\
(\mathrm{mg} / \mathrm{L})\end{array}$ & $\left|\begin{array}{c}\text { Total } \\
\mathrm{Fe} \\
(\mu g / \mathrm{L})\end{array}\right|$ & $\begin{array}{c}\text { Diss. } \\
\text { Fe } \\
(\mu g / L)\end{array}$ & $\begin{array}{c}\text { Temp } \\
\text { (OC) }\end{array}$ & $\begin{array}{c}\mathrm{sc} \\
(\mathrm{mS} / \mathrm{cm})\end{array}$ & $\left|\begin{array}{c}D O \\
(m g / L)\end{array}\right|$ & $\begin{array}{c}\mathrm{pH} \\
\text { (SU) }\end{array}$ & $\begin{array}{l}\text { ORP } \\
\text { (mV) }\end{array}$ \\
\hline POLY-EFF-08-6 & $3 / 3 / 2008$ & 63.6 & 0.480 & 535 & NT & 138 & 1.46 & 13.1 & 0.322 & ND & ND & ND & ND & NT & 20.84 & 616 & 6.95 & 7.98 & 187.9 \\
\hline POLY-EFF-09-1 & $2 / 13 / 2008$ & 70.4 & 0.495 & 525 & 511 & 133 & ND & 12.5 & 0.154 & ND & ND & ND & ND & ND & 19.22 & 596 & 6.97 & 7.81 & 212.2 \\
\hline POLY-EFF-09-2 & $2 / 16 / 2008$ & 68.0 & 0.521 & NT & NT & 131 & 4.51 & 12.0 & 0.433 & ND & ND & NT & NT & NT & 19.08 & 597 & 6.52 & 7.82 & 72.0 \\
\hline POLY-EFF-09-3 & $2 / 18 / 2008$ & 75.6 & 0.531 & NT & NT & 130 & 3.09 & 12.7 & 0.205 & ND & ND & NT & NT & NT & 19.30 & 606 & 6.82 & 7.79 & 253.4 \\
\hline POLY-EFF-09-4 & $2 / 21 / 2008$ & 68.0 & 0.514 & NT & NT & 132 & 1.54 & 12.6 & 0.310 & ND & ND & NT & INT & $\mathrm{Nr}$ & 20.25 & 603 & 6.62 & 7.89 & 204.7 \\
\hline POLY-EFF-09.5 & $2 / 25 / 2008$ & 71.8 & 0.507 & NT & NT & 128 & ND & 12.3 & 0.417 & ND & ND & NT & NT & NT & 20.70 & 608 & 6.91 & 7.90 & 222.3 \\
\hline POLY-EFF-09-6 & $3 / 3 / 2008$ & 64.0 & 0.480 & 529 & NT & 139 & 1.03 & 12.9 & 0.358 & ND & ND & ND & ND & NT & 20.60 & 613 & 6.58 & 7.94 & 183.8 \\
\hline RNIP-EFF-01-1 & $2 / 13 / 2008$ & 180 & 0.160 & 52.0 & ND & 131 & ND & 9.28 & 0.138 & 4.05 & 25.2 & 80700 & 80700 & 25800 & 19.72 & 730 & 5.34 & 10.05 & -93.5 \\
\hline RNIP-EFF-01-2 & $2 / 16 / 2008$ & 72.0 & 0.0187 & NT & NT & 122 & 3.45 & 8.28 & 0.145 & ND & 0.615 & NT & NT & NT & 19.47 & 602 & 5.94 & 10.05 & -173.1 \\
\hline RNIP-EFF-01-3 & $2 / 18 / 2008$ & 51.6 & ND & NT & NT & 118 & 4.17 & 6.96 & 0.142 & ND & ND & NT & NT & NT & 19.89 & 540 & 6.18 & 9.73 & -114.4 \\
\hline RNIP-EFF-01-4 & $2 / 21 / 2008$ & 40.0 & ND & NT & NT & 118 & 4.62 & 6.65 & 0.249 & ND & ND & $\mathbf{N \top}$ & NT & NT & 21.49 & 502 & 6.10 & 9.38 & -133.2 \\
\hline RNIP-EFF-01-5 & $2 / 25 / 2008$ & 39.8 & ND & NT & NT & 123 & 2.85 & 6.68 & 0.509 & ND & ND & NT & NT & NT & 21.10 & 502 & 5.95 & 9.17 & -117.6 \\
\hline RNIP-EFF-01-6 & $3 / 3 / 2008$ & 36.4 & ND & ND & NT & 133 & 14.5 & 6.82 & 0.561 & ND & ND & 673 & 673 & NT & \begin{tabular}{|l|}
21.16 \\
\end{tabular} & 511 & 5.94 & 9.09 & -179.0 \\
\hline RNIP-EFF-02-1 & $2 / 13 / 2008$ & 160 & 0.191 & 55.0 & ND & 132 & 3.12 & 9.52 & 0.166 & 2.42 & 24.1 & 100000 & 10000 & NT & 19.68 & 728 & 4.41 & 10.04 & -97.4 \\
\hline RNIP-EFF-02-2 & $2 / 16 / 2008$ & 100 & 0.0159 & NT & NT & 124 & ND & 6.74 & 0.154 & ND & 0.927 & NT & NT & NT & 19.54 & 610 & 6.80 & 9.98 & -79.5 \\
\hline RNIP-EFF-02-3 & $2 / 18 / 2008$ & 79.8 & 0.0161 & NT & NT & 110 & 3.16 & 5.25 & 0.0880 & NDD & ND & $\overline{N T}$ & NT & NT & 20.42 & 555 & 5.97 & 10.06 & -121.6 \\
\hline RNIP-EFF-02-4 & $2 / 21 / 2008$ & 43.2 & ND & NT & NT & 115 & 9.87 & 5.55 & 0.150 & ND & ND & NT & NT & NT & 21.46 & 492 & 5.96 & 9.40 & -106.3 \\
\hline RNIP-EFF-02-5 & $2 / 25 / 2008$ & 40.0 & ND & NT & NT & 122 & 3.15 & 6.82 & 0.301 & ND & ND & NT & NT & NT & 21.12 & 503 & 6.22 & 9.39 & -68.8 \\
\hline RNIP-EFF-02-6 & $3 / 3 / 2008$ & 58.0 & ND & ND & NT & 134 & 19.1 & 6.09 & 0.289 & ND & ND & 1240 & 1240 & 30700 & 20.93 & 501 & 5.89 & 9.14 & -138.0 \\
\hline RNIP-EFF-03-1 & $2 / 13 / 2008$ & 156 & 0.136 & 58.0 & ND & 133 & ND & 9.68 & 0.141 & 1.75 & 20.8 & 75900 & 75900 & 24100 & 19.68 & 725 & 5.37 & 10.12 & -62.5 \\
\hline RNIP-EFF-03-2 & $2 / 16 / 2008$ & 79.0 & 0.0173 & NT & NT & 121 & 3.24 & 8.22 & 0.156 & ND & 1.02 & NT & NT & NT & 19.72 & 603 & 6.10 & 9.97 & -139.5 \\
\hline RNIP-EFF-03-3 & $2 / 18 / 2008$ & 51.0 & ND & NT & NT & 119 & 3.97 & 7.12 & 0.108 & ND & ND & NT & NT & NT & 19.32 & 523 & 6.26 & 9.58 & -115.7 \\
\hline RNIP-EFF-03-4 & $2 / 21 / 2008$ & 44.2 & ND & NT & NT & 119 & 14.6 & 6.64 & 0.136 & ND & ND & NT & NT & NT & 21.23 & 504 & 5.55 & 9.24 & -120.5 \\
\hline RNIP-EFF-03-5 & $2 / 25 / 2008$ & 41.0 & ND & NT & NT & 120 & ND & 6.61 & 0.214 & ND & ND & NT & NT & NT & 21.04 & 502 & 6.34 & 9.20 & -56.9 \\
\hline RNIP-EFF-03-6 & $3 / 3 / 2008$ & 57.8 & ND & ND & NT & 127 & 11.6 & 6.68 & 0.299 & ND & ND & 780 & 780 & NT & 21.06 & 514 & 5.79 & 9.08 & -130.9 \\
\hline RNIP-EFF-04-1 & $2 / 13 / 2008$ & 72.8 & ND & ND & ND & 134 & ND & 11.1 & 0.476 & ND & ND & 367 & 367 & 52.0 & 19.35 & 589 & 6.94 & 8.17 & 98.3 \\
\hline RNIP-EFF-04-2 & $2 / 16 / 2008$ & 72.4 & ND & NT & NT & 132 & 2.11 & 10.7 & 0.973 & ND & ND & NT & NT & NT & 19,30 & 591 & 6.61 & 8.39 & 10.1 \\
\hline RNIP-EFF-04-3 & $2 / 18 / 2008$ & 68.8 & ND & NT & NT & 125 & 2.16 & 9.81 & 0.945 & ND & ND & NT & NT & NT & 19.59 & 599 & 6.67 & 8.44 & -11.8 \\
\hline RNIP-EFF-04-4 & $2 / 21 / 2008$ & 66.4 & ND & NT & NT & 130 & 2.27 & 7.79 & 1.79 & ND & ND & NT & NT & NT & 21.16 & 580 & 5.93 & 8.47 & $-27,3$ \\
\hline RNIP-EFF-04-5 & $2 / 25 / 2008$ & 75.6 & ND & NT & NT & 129 & 1.31 & 4.05 & 4.26 & ND & ND & NT & NT & NT & 21.03 & 585 & 5.74 & 8.62 & 113.9 \\
\hline RNIP-EFF-04-6 & $3 / 3 / 2008$ & 71.2 & ND & ND & NT & 140 & 0.946 & 10.6 & 1.85 & ND & ND & 161 & 161 & NT & 21.21 & 621 & 4.81 & 8.69 & 80.3 \\
\hline RNIP-EFF-05-1 & $2 / 13 / 2008$ & 80.0 & ND & ND & ND & 133 & ND & 10.7 & 0.524 & ND & ND & 329 & 329 & ND & 19.17 & 584 & 7.32 & 8.22 & 149.6 \\
\hline RNIP-EFF-05-2 & $2 / 16 / 2008$ & 72.2 & ND & NT & NT & 133 & ND & 10.6 & 0.946 & ND & ND & NT & NT & NT & 19.56 & 591 & 6.91 & 8.40 & -19.9 \\
\hline RNIP-EFF-05-3 & $2 / 18 / 2008$ & 64.8 & ND & NT & NT & 127 & 1.74 & 10.4 & 0.753 & ND & ND & NT & NT & NT & 19.57 & 597 & 6.74 & 8.46 & 67.2 \\
\hline RNIP-EFF-05-4 & $2 / 21 / 2008$ & 66.0 & ND & NT & NT & 128 & 3.18 & 9.16 & 1.41 & ND & ND & NT & NT & NT & 21.10 & 587 & 6.77 & 8.47 & 70.1 \\
\hline RNIP-EFF-05-5 & $2 / 25 / 2008$ & 71.8 & ND & NT & NT & 129 & 2.14 & 3.67 & 4.15 & ND & ND & NT & NT & NT & 21.05 & 578 & 6.71 & 8.60 & 138.1 \\
\hline RNIP-EFF-05-6 & $3 / 3 / 2008$ & 70.0 & ND & ND & NT & 140 & 0.864 & 10.8 & 1.19 & ND & ND & 176 & 176 & NT & \begin{tabular}{|l|}
21.26 \\
\end{tabular} & 615 & 5.93 & 8.70 & 101.2 \\
\hline RNIP-EFF-06-1 & $2 / 13 / 2008$ & 77.2 & ND & ND & ND & 133 & ND & 10.7 & 0.450 & ND & ND & 960 & 960 & 59.8 & $\begin{array}{l}19.07 \\
\end{array}$ & 586 & 7.50 & 8.24 & 166.2 \\
\hline RNIP-EFF-06-2 & $2 / 16 / 2008$ & 69.2 & ND & NT & NT & 127 & 4.01 & 10.2 & 0.770 & ND & ND & NT & NT & NT & 19.31 & 588 & 6.84 & 8.42 & 3.0 \\
\hline RNIP-EFF-06-3 & $2 / 18 / 2008$ & 68.8 & ND & NT & NT & 124 & 3.60 & 9.66 & 0.732 & ND & ND & NT & NT & NT & 19.58 & 589 & 7.03 & 8.48 & 113.1 \\
\hline RNIP-EFF-06-4 & $2 / 21 / 2008$ & 67.6 & ND & NT & NT & 131 & 3.33 & 8.73 & 1.45 & ND & ND & NT & NT & NT & 21.08 & 584 & 6.69 & 8.48 & 80.9 \\
\hline RNIP-EFF-06-5 & $2 / 25 / 2008$ & 76.4 & ND & NT & NT & 127 & 2.03 & 5.28 & 2.84 & ND & ND & NT & NT & tNT & 21.12 & 581 & 6.66 & 8.65 & 167.7 \\
\hline RNIP-EFF-06-6 & $3 / 3 / 2008$ & 68.0 & ND & ND & NT & 139 & 2.41 & 10.1 & 1.74 & ND & ND & 203 & 203 & NT & 21.14 & 614 & 6.23 & 8.65 & 124.9 \\
\hline RNIP-EFF-07-1 & $2 / 13 / 2008$ & 88.4 & 0.130 & 144 & 143 & 131 & 1.04 & 12.4 & 0.0914 & ND & ND & ND & ND & ND & \begin{tabular}{|l|}
19.19 \\
\end{tabular} & 602 & 6.32 & 7.85 & 201.5 \\
\hline RNIP-EFF-07-2 & $2 / 16 / 2008$ & 70.0 & 0.359 & NT & NT & 133 & 3.52 & 12.5 & 0.204 & ND & ND & NT & NT & NT & 19.52 & 597 & 6.07 & 7.94 & 141.2 \\
\hline RNIP-EFF-07-3 & $2 / 18 / 2008$ & 70.0 & 0.397 & NT & NT & 129 & 3.37 & 12.7 & 0.184 & ND & ND & NT & INT & NT & 19.65 & 614 & 6.75 & 7.96 & 236.9 \\
\hline RNIP-EFF-07-4 & $2 / 21 / 2008$ & 67.2 & 0.405 & NT & NT & 127 & 2.63 & 12.5 & 0.217 & ND & ND & NT & NT & NT & 21.14 & 607 & 6.69 & 7,92 & 203.9 \\
\hline RNIP-EFF-07-5 & $2 / 25 / 2008$ & 72.2 & 0.432 & NT & NT & 127 & 4.82 & 12.6 & 0.172 & ND & ND & NT & NT & NT & 21.10 & 621 & 6.80 & 7.95 & 206.4 \\
\hline RNIP-EFF-07-6 & $3 / 3 / 2008$ & 62.2 & 0.423 & 509 & NT & 138 & 2.09 & 13.3 & 0.175 & ND & ND & $\mathrm{ND}$ & ND & NT & 21.13 & 617 & 5.96 & 7.96 & 170.4 \\
\hline RNIP-EFF-08-1 & $2 / 13 / 2008$ & 87.6 & 0.0545 & 50.0 & ND & 136 & 1.16 & 12.9 & 0.112 & ND & ND & ND & ND & ND & 18.72 & 602 & 6.50 & 7.91 & 168.1 \\
\hline RNIP-EFF-08-2 & $2 / 16 / 2008$ & 64.8 & 0.321 & NT & NT & 133 & 3.21 & 12.2 & 0.489 & ND & ND & NT & NT & NT & 18.88 & 599 & 6.22 & 7.92 & 123.2 \\
\hline RNIP-EFF-08-3 & $2 / 18 / 2008$ & 72.4 & 0.363 & NT & NT & 125 & 3.84 & 12.2 & 0.290 & ND & ND & NT & NT & NT & 19.50 & 613 & 7.12 & 7.97 & 236.1 \\
\hline RNIP-EFF-08-4 & $2 / 21 / 2008$ & 68.4 & 0.389 & NT & NT & 131 & 2.18 & 12.7 & 0.368 & ND & ND & NT & NT & NT & 20.97 & 607 & 6.50 & 7.92 & 200.5 \\
\hline RNIP-EFF-08-5 & $2 / 25 / 2008$ & 69.2 & 0.422 & NT & NT & 129 & ND & 12.7 & 0.233 & ND & ND & NT & NT & NT & 21.17 & 622 & 6.23 & 7.99 & 207.3 \\
\hline RNIP-EFF-08-6 & $3 / 3 / 2008$ & 65.0 & 0.412 & 499 & NT & 141 & 16.8 & 13.5 & 0.187 & ND & ND & ND & ND & NT & \begin{tabular}{|l|}
21.13 \\
\end{tabular} & 618 & 6.22 & 8.03 & 172.6 \\
\hline RNIP-EFF-09-1 & $2 / 13 / 2008$ & 72.0 & 0.141 & 133 & 146 & 135 & ND & 12.9 & 0.0922 & ND & ND & ND & ND & ND & 18.19 & 598 & 7.22 & 7.95 & 147.4 \\
\hline RNIP-EFF-09-2 & $2 / 16 / 2008$ & 65.2 & $0.38 \uparrow$ & NT & NT & 131 & 3.62 & 12.3 & 0.309 & ND & ND & NT & NT & NT & 19.11 & 596 & 6.91 & 7.94 & $\$ 20.5$ \\
\hline RNIP-EFF-09-3 & $2 / 18 / 2008$ & 64.6 & 0.417 & NT & NT & 126 & 4.73 & 12.3 & 0.204 & ND & ND & NT & NT & NT & 18.70 & 607 & 6.75 & 7.95 & 234.6 \\
\hline RNIP-EFF-09-4 & $2 / 21 / 2008$ & 66.4 & 0.496 & NT & NT & 126 & 2.27 & 12.2 & 0.256 & ND & ND & NT & NTT & NT & 20.71 & 608 & 6.46 & 7.92 & 197.9 \\
\hline RNIP-EFF-09-5 & $2 / 25 / 2008$ & 71.2 & 0.449 & NT & NT & 128 & ND & 12.7 & 0.290 & ND & ND & NT & NT & NT & 21.10 & 621 & 6.93 & 7.98 & 206.4 \\
\hline RNIP-EFF-09-6 & $3 / 3 / 2008$ & 64.8 & 0.441 & 496 & NT & 137 & 0.843 & 13.1 & 0.330 & ND & ND & ND & $\mathrm{ND}$ & NT & 20.84 & 614 & 6.73 & 7.97 & 176.7 \\
\hline
\end{tabular}




\section{C6 Advanced Flow Cell Injection}

\section{Example MDS Calculation for Flow Cell 8}

Referring to the spreadsheet for flow cell \#8 in Appendix C, Section C6 as an example, the process for arriving at the values shown was as follows.

1. Flow cell lengths (distances to sampling ports and lengths of defined volumes for mass deposition values), volumes (fluid pore space for defined volumes and volume of sand assuming porosity of 0.35 ), and mass of sand (assuming sand grain density of $2.65 \mathrm{~g} / \mathrm{cm}^{3}$ ) are presented in Section 1 of the spreadsheet.

2. Sample data in $\mathrm{mg} / \mathrm{L}$ from Appendix $\mathrm{C} 6$ were pasted into the second section of the spreadsheet. The distance from the influent end of the flow cell to the sampling port in $\mathrm{cm}$ is listed in the first section of the spreadsheet. Below the lower far right corner of the data the mean flow rate of $184.3 \mathrm{~mL} / \mathrm{min}$ is listed and below the influent sample concentration results (I) the mean value of $3,176 \mathrm{mg} / \mathrm{L}$ for all influent samples is given. This value was substantially less than the concentration of $9,030 \mathrm{mg} / \mathrm{L}$ based on the mass of RNIP-M2 slurry mixed and dilution water.

3. The cumulative mass of total iron deposited throughout the entire flow cell over elapsed time was calculated in the third section of the spreadsheet in units of $\mathrm{mg}$. This was based on a simple mass balance where cumulated mass deposition for a given elapsed time (MD) equaled cumulative influent mass MI for that elapsed time minus the sum of mass suspended in each sampling port defined segment ( $\Sigma M S)$ for that elapsed time minus cumulative effluent mass for that elapsed time (ME). The resulting equation for this would be: Cum MD $=$ Cum MI $-\sum$ Cum MS - Cum ME. The required values shown in the spreadsheet for this calculation were obtained as follows:

a. MI over each time interval was calculated as the produce of the theoretical ZVI concentration as mixed $(9,033 \mathrm{mg} / \mathrm{L})$ multiplied times the flow rate $(184.3 \mathrm{~mL} / \mathrm{min})$ and the time for the sampling interval (e.g., 27 minutes from the initiation of flow to the first sample time). This yields an MI for the first time interval of $44,949 \mathrm{mg} / \mathrm{L}$. Cumulative MI for a given elapsed time is simply the sum of individual time interval MI values to that point. Therefore, the cumulative MI at the end of the second time interval was $89,898 \mathrm{mg}$ and the cumulative MI for the entire run was $2,731,907 \mathrm{mg}$.

b. ME was calculated in the same was as MI except that the concentration used was the mean for the time interval. Zero was assumed for the initial concentration. Therefore, the mass of total iron exiting the flow cell during the first time interval was calculated using a concentration of $4 \mathrm{mg} / \mathrm{L}$ (the mean of $0 \mathrm{mg} / \mathrm{L}$ and the final concentration for the time interval of $9 \mathrm{mg} / \mathrm{L}$ ). When multiplied by the flow rate and time, this produced a value of $22 \mathrm{mg}$. Cumulative effluent iron mass for the entire run was $1,066,126 \mathrm{mg}$ (approximately $39 \%$ of influent).

c. An estimate of the total iron mass contained in the fluid within each

d. The segment of the flow cell was calculated for elapsed time using the concentration from sampling ports and the designated volume of flow cell on either side of the sampling port. For example, the mass of $1,457 \mathrm{mg}$ for the first segment of the flow cell (from the influent end to a point half way between sampling ports $A$ and $B$ ) was calculated using the sampling port $A$ concentration of $903 \mathrm{mg} / \mathrm{L}$ and the pore volume of that segment. The pore volume of that segment, as shown in the first section of the spreadsheet was $1,613 \mathrm{~mL}$. The mass suspended in each flow cell segment was calculated in the same manner. The mass of iron suspended 
throughout the pore space of the entire flow cell ( $\Sigma M S)$ is the sum of all MS values for all five segments.

4. Cumulative mass deposition during each time interval for each flow cell segment was apportioned using both data and judgment. This was accomplished in the fourth section of the spreadsheet in units of $\mathrm{mg}$. For example, where sample port concentrations were relatively low (this means concentrations about $200 \mathrm{mg} / \mathrm{L}$ or less for samples from Ports B through E), it was assumed that mass deposition was negligible and a value of zero was assigned (e.g., the last four segments of flow cell 8 for the first time interval). As concentrations increased beyond $200 \mathrm{mg} / \mathrm{L}$ in a flow cell segment, it was assumed that deposition had commenced. In those cases, total deposition for the flow cell was apportioned between segments based on suspended mass (MS) ratios. For example, the cumulative mass deposition of $129,739 \mathrm{mg}$ for the entire flow cell by the end of the third time interval was apportioned between the first and second segments of the flow cell based on suspended masses of 4,081 $\mathrm{mg}$ and $277 \mathrm{mg}$, respectively. Therefore, 94 percent of the mass deposition was assigned to the first segment and the remainder to the second segment.

Input data used for multiple linear regression (MLR) are shown in a spreadsheet also presented in Appendix C6. With two alterations and unit conversions, these data were used to arrive at a relationship between mass deposition and time, distance in the flow cell, and flow velocity. The two alterations were:

- Because it was evident that important changes in fluid total iron concentrations occurred prior to the first sampling port (port A) in the cases of flow cells 1 and 3, it was necessary to estimate iron deposition based on visual observations of the ZVI front in these flow cells. For these flow cells, distances less than that of port $\mathrm{A}$ were used instead of the location of port $\mathrm{A}$.

- Because negative deposition occurred during the final time interval in flow cell 8 , those data not used. It is possible that the same phenomena responsible for this effect on the data for the final time interval also had some impact on data for the preceding time interval that were used. This introduces some degree of uncertainty into the data and calculations based on them.

The following unit conversions were applied:

- Recorded sampling times in minutes were converted to units of seconds.

- Distances measured in $\mathrm{cm}$ were converted to units of $\mathrm{m}$.

- Volumetric flow rates in $\mathrm{mL} / \mathrm{min}$ were converted to flow or seepage velocities in units $\mathrm{of} \mathrm{m} / \mathrm{sec}$. In this conversion, a porosity of 0.35 was assumed.

- Mass deposition values in of iron in mg were converted to concentrations in terms of flow cell sand in units of $\mathrm{kg}$-iron $/ \mathrm{kg}$-sand. In this conversion, a porosity of 0.35 and a density of sand of $2.65 \mathrm{~g} / \mathrm{cm}^{3}$ were assumed. 
DOE/RL-2009-35, REV. 0

\begin{tabular}{|c|c|c|c|c|c|c|c|c|c|c|}
\hline \multicolumn{11}{|c|}{ Head and Flow Measurements } \\
\hline \multirow{2}{*}{$\begin{array}{l}\text { Flow } \\
\text { Cell ID }\end{array}$} & \multirow[b]{2}{*}{ Start Time } & \multirow{2}{*}{$\begin{array}{c}\text { Elap Time } \\
\text { Min }\end{array}$} & \multirow{2}{*}{$\begin{array}{c}\text { Pore } \\
\text { Volume }\end{array}$} & \multicolumn{5}{|c|}{ Head $(\mathrm{cm})$} & \multirow{2}{*}{$\begin{array}{l}\text { Flow } \\
\mathrm{mL} / \mathrm{min}\end{array}$} & \multirow{2}{*}{$\frac{\text { Stdev }}{\text { Mean }}$} \\
\hline & & & & 1 & II & III & IV & $\mathrm{V}$ & & \\
\hline \multirow[t]{7}{*}{0} & \multirow[t]{7}{*}{$4 / 9 / 0810: 40$} & 183 & 1.28 & 14.1 & 12.9 & 12.0 & 10.6 & 9.2 & 30.8 & \\
\hline & & 275 & 1.92 & 14.1 & 13.0 & 12.1 & 10.9 & 9.1 & 28.0 & \\
\hline & & 554 & 3.87 & 13.9 & 12.5 & 11.9 & 10.5 & 9.1 & 33.6 & \\
\hline & & 702 & 4.91 & 13.4 & 12.4 & 11.6 & 10.5 & 8.8 & 36.4 & \\
\hline & & 946 & 6.62 & 12.8 & 11.8 & 11.0 & 9.9 & 8.2 & 30.9 & \\
\hline & & 1,430 & 10.00 & 13.5 & 12.4 & 11.5 & 10.5 & 8.7 & 32.0 & \\
\hline & & 1,630 & 11.40 & 13.6 & 12.5 & 11.5 & 10.4 & 8.9 & 31.6 & \\
\hline Mean & & & & 13.6 & 12.5 & 11.7 & 10.5 & 8.9 & 31.9 & \\
\hline Stdev & & & & & & & & & 2.6 & 8.2 \\
\hline \multirow[t]{7}{*}{1} & \multirow[t]{7}{*}{$4 / 7 / 08$ 19:06 } & 182 & 0.55 & 9.3 & 9.0 & 8.8 & 8.0 & 7.5 & 14.6 & \\
\hline & & 332 & 1.01 & 9.5 & 9.0 & 8.6 & 8.0 & 7.7 & 14.3 & \\
\hline & & 638 & 1.95 & 10.0 & 9.2 & 8.8 & 8.0 & 7.5 & 15.4 & \\
\hline & & 863 & 2.63 & 11.0 & 9.2 & 8.8 & 8.2 & 7.6 & 14.5 & \\
\hline & & 1,139 & 3.47 & 12.5 & 9.2 & 8.8 & 8.2 & \begin{tabular}{|c|}
7.6 \\
\end{tabular} & $\overline{14.6}$ & \\
\hline & & 1,449 & 4.42 & 14.3 & 9.5 & 8.9 & 8.4 & 7.6 & 14.6 & \\
\hline & & 1,616 & 4.93 & 16.0 & 9.4 & 8.8 & 8.4 & 7.5 & 14.3 & \\
\hline Mean & & & & & & & & & 14.6 & \\
\hline Stdev & & & & & & & & & 0.4 & 2.5 \\
\hline \multirow[t]{7}{*}{2} & \multirow[t]{7}{*}{$4 / 7 / 0819: 06$} & 182 & 0.55 & 13.0 & 12.4 & 12.8 & 12.1 & 11.3 & 13.2 & \\
\hline & & 332 & 1.01 & 13.3 & 13.6 & 13.3 & 12.5 & 11.8 & 14.4 & \\
\hline & & 638 & 1.95 & 13.4 & 13.1 & 12.9 & 12.2 & 11.4 & 15.6 & \\
\hline & & 863 & 2.63 & 14.2 & 12.9 & 12.7 & 12.1 & 11.2 & 16.8 & \\
\hline & & 1,139 & 3.47 & 14.7 & 12.2 & 11.6 & 11.3 & 10.2 & 14.8 & \\
\hline & & 1,449 & 4.42 & 16.3 & 12.2 & 11.8 & 11.3 & 10.3 & 14.7 & \\
\hline & & 1,616 & 4.93 & 18.2 & 12.3 & 11.8 & 11.4 & 10.3 & 14.9 & \\
\hline \multirow{2}{*}{$\begin{array}{l}\text { Mean } \\
\text { Stdev }\end{array}$} & & & & & & & & & 14.9 & \\
\hline & & & & & & & & & 1.1 & 7.4 \\
\hline \multirow[t]{7}{*}{3} & \multirow[t]{7}{*}{$4 / 9 / 0810: 40$} & 183 & 1.28 & 13.4 & 12.1 & 10.9 & 9.4 & 7.9 & 37.0 & \\
\hline & & 275 & 1.92 & 13.4 & 12.0 & 10.6 & 9.5 & 8.1 & 38.2 & \\
\hline & & 554 & 3.87 & 13.1 & 11.5 & 10.3 & 9.3 & 8.1 & 34.6 & \\
\hline & & 702 & 4.91 & 12.9 & 10.9 & 10.1 & 9.0 & 7.6 & 37.2 & \\
\hline & & 939 & 6.57 & 12.9 & 11.0 & 9.9 & 8.9 & 7.6 & 29.8 & \\
\hline & & 1,430 & 10.00 & 16.1 & 11.5 & 10.4 & 9.3 & 7.2 & 37.0 & \\
\hline & & 1,630 & 11.40 & 27.8 & 11.0 & 10.1 & 9.1 & 7.9 & 35.6 & \\
\hline Mean & & & & & & & & & 35.6 & \\
\hline Stdev & & & & & & & & & 2.8 & 7.9 \\
\hline 4 & $4 / 9 / 08 \quad 10: 40$ & 183 & 1.28 & 13.2 & 11.5 & 10.3 & 9.2 & 8.1 & 36.0 & \\
\hline & & 275 & 1.92 & 13.5 & 11.4 & 10.2 & 9.3 & 7.8 & 35.6 & \\
\hline & & 554 & 3.87 & 13.8 & 10.9 & 10.2 & 9.2 & 8.1 & 36.0 & \\
\hline & & 702 & 4.91 & 13.6 & 10.9 & 10.0 & 9.0 & 7.7 & 36.0 & \\
\hline & & 943 & 6.59 & 14.0 & 10.9 & 10.0 & 9.0 & \begin{tabular}{|c|}
7.7 \\
\end{tabular} & 39.4 & \\
\hline & & 1,430 & 10.00 & 20.0 & 11.4 & 10.5 & 9.4 & 7.8 & 37.3 & \\
\hline & & 1,630 & 11.40 & 37.1 & 14.7 & 10.5 & 9.3 & 7.9 & 36.0 & \\
\hline Mean & & & & & & & & & 36.6 & \\
\hline Stdev & & & & & & & & & 1.3 & 3.7 \\
\hline 5 & $4 / 7 / 08$ 19:06 & 48 & 0.77 & 18.9 & 16.9 & 14.9 & 12.5 & 9.0 & 89.0 & \\
\hline & & 107 & 1.73 & 20.0 & 17.0 & 15.2 & 12.8 & 9.1 & 89.0 & \\
\hline & & 174 & 2.81 & 21.4 & 16.5 & 14.9 & 12.5 & 9.1 & 89.0 & \\
\hline & & 229 & 3.69 & 22.5 & 16.3 & 14.7 & 12.5 & 9.0 & 88.5 & \\
\hline & & 291 & 4.69 & 24.2 & 15.8 & 14.3 & 12.4 & 9.1 & 87.0 & \\
\hline & & 638 & 10.29 & 38.5 & 21.0 & 13.8 & 12.1 & 9.1 & 88.0 & \\
\hline
\end{tabular}


DOE/RL-2009-35, REV. 0

\begin{tabular}{|c|c|c|c|c|c|c|c|c|c|c|}
\hline \multicolumn{11}{|c|}{ Head and Flow Measurements ${ }^{1}$} \\
\hline \multirow{2}{*}{$\begin{array}{l}\text { Flow } \\
\text { Cell ID }\end{array}$} & \multirow[b]{2}{*}{ Start Time } & \multirow{2}{*}{$\begin{array}{c}\text { Elap Time } \\
\text { Min }\end{array}$} & \multirow{2}{*}{$\begin{array}{c}\text { Pore } \\
\text { Volume }\end{array}$} & \multicolumn{5}{|c|}{ Head $(\mathrm{cm})$} & \multirow{2}{*}{$\begin{array}{c}\text { Flow } \\
\mathrm{mL} / \mathrm{min}\end{array}$} & \multirow{2}{*}{$\frac{\text { Stdev }}{\text { Mean }}$} \\
\hline & & & & 1 & II & III & IV & $\bar{V}$ & & \\
\hline \multirow[t]{4}{*}{5} & & 873 & 14.08 & 54.6 & 31.7 & 20.1 & 12.3 & 9.2 & 87.0 & \\
\hline & & 1,132 & 18.26 & 69.0 & 44.3 & 31.5 & 19.7 & 9.2 & 87.5 & \\
\hline & & 1,442 & 23.26 & 80.2 & 54.7 & 39.7 & 26.8 & 10.1 & 86.5 & \\
\hline & & 1,614 & 26.03 & 87.4 & 59.2 & 42.5 & 28.6 & 10.4 & 87.0 & \\
\hline Mean & & & & & & & & & 87.9 & \\
\hline Stdev & & & & & & & & & 1.0 & 1.1 \\
\hline \multirow[t]{10}{*}{6} & \multirow[t]{10}{*}{ 4/7/08 19:06 } & 48 & 0.77 & 17.1 & 15.2 & 13.1 & 11.2 & 8.5 & 76.0 & \\
\hline & & 107 & 1.73 & 18.0 & 15.2 & 13.4 & 11.4 & 8.4 & 77.0 & \\
\hline & & 174 & 2.81 & 19.0 & 14.7 & 13.1 & 11.3 & 8.5 & 78.0 & \\
\hline & & 229 & 3.69 & 19.9 & 14.7 & 13.1 & 11.2 & 8.4 & 77.0 & \\
\hline & & 291 & 4.69 & 20.9 & 14.2 & 12.7 & 11.1 & 8.3 & 77.5 & \\
\hline & & 638 & 10.29 & 34.2 & 16.1 & 12.3 & 10.8 & 8.5 & 78.0 & \\
\hline & & 873 & 14.08 & 49.5 & 24.3 & 13.9 & 10.9 & 8.5 & 77.0 & \\
\hline & & 1,132 & 18.26 & 62.9 & 35.8 & 23.6 & 12.8 & 8.5 & 76.0 & \\
\hline & & 1,442 & 23.26 & 77.4 & 50.3 & 36.7 & 24.0 & 9.0 & 77.0 & \\
\hline & & 1,614 & 26.03 & 85.9 & 55.4 & 40.9 & 27.0 & 9.5 & 77.5 & \\
\hline Mean & & & & & & & & & 77.1 & \\
\hline Stdev & & & & & & & & & 0.7 & 0.9 \\
\hline \multirow[t]{7}{*}{7} & \multirow[t]{7}{*}{$4 / 9 / 08 \quad 10: 40$} & 36 & 1.33 & 32.7 & 27.6 & 23.0 & 18.1 & 10.9 & 180.0 & \\
\hline & & 97 & 3.59 & 31.9 & 25.1 & 20.9 & 16.8 & 10.4 & 170.0 & \\
\hline & & 157 & 5.81 & 32.9 & 24.3 & 20.2 & 16.2 & 10.3 & 170.0 & \\
\hline & & 630 & 23.33 & 36.8 & 26.6 & 18.9 & 15.0 & 10.0 & 168.0 & \\
\hline & & 951 & 35.22 & 40.0 & 29.1 & 20.8 & 14.7 & 9.8 & 168.0 & \\
\hline & & 1,417 & 52.48 & 66.6 & 50.6 & 38.5 & 26.7 & 10.4 & 168.0 & \\
\hline & & 1,627 & 60.26 & 100.9 & 76.3 & 56.5 & 37.5 & 11.6 & 170.0 & \\
\hline Mean & & & & & & & & & 170.6 & \\
\hline Stdev & & & & & & & & & 4.3 & 2.5 \\
\hline \multirow[t]{7}{*}{8} & \multirow[t]{7}{*}{$4 / 9 / 08 \quad 10: 40$} & 36 & 1.33 & 38.2 & 31.9 & 27.0 & 21.6 & 14.3 & 184.0 & \\
\hline & & 97 & 3.59 & 36.7 & 28.4 & 23.6 & 19.0 & 13.0 & 184.0 & \\
\hline & & 157 & 5.81 & 37.7 & 28.4 & 22.9 & 18.4 & 12.8 & 188.0 & \\
\hline & & 630 & 23.33 & 43.7 & 33.0 & 24.5 & 17.5 & 12.4 & 184.0 & \\
\hline & & 956 & 35.41 & 47.3 & 35.5 & 26.7 & 18.4 & 11.7 & 168.0 & \\
\hline & & 1,417 & 52.48 & 71.9 & 55.2 & 41.9 & 29.0 & 12.9 & 190.0 & \\
\hline & & 1,627 & 60.26 & 108.8 & 82.4 & 60.4 & 40.0 & 14.5 & 192.0 & \\
\hline Mean & & & & & & & & & 184.3 & \\
\hline Stdev & & & & & & & & & 7.9 & 4.3 \\
\hline \multirow[t]{8}{*}{9} & \multirow[t]{8}{*}{$3 / 19 / 0820: 24$} & 39 & 0.12 & 9.4 & 9.1 & 8.6 & 8.3 & 7.8 & 16.0 & \\
\hline & & 104 & 0.32 & 9.2 & 9.0 & 8.5 & 8.2 & 7.6 & 13.4 & \\
\hline & & 328 & 1.00 & 9.8 & 9.5 & 8.9 & 8.3 & 7.7 & 15.2 & \\
\hline & & 626 & 1.91 & 11.1 & 10.8 & 10.3 & 9.8 & 9.2 & 14.0 & \\
\hline & & 951 & 2.90 & 9.8 & 9.6 & 9.1 & 8.7 & 8.1 & 14.7 & \\
\hline & & 1,184 & 3.61 & 13.9 & 9.2 & 8.6 & 8.3 & 7.7 & 14.1 & \\
\hline & & 1,262 & 3.85 & 25.5 & 9.3 & 8.7 & 8.3 & 7.7 & 13.8 & \\
\hline & & 1,620 & 4.94 & 120.5 & 9.7 & 9.2 & 8.6 & 8.0 & 13.8 & \\
\hline Mean & & & & & & & & & 14.4 & \\
\hline Stdev & & & & & & & & & 0.6 & 4.2 \\
\hline 10 & $3 / 19 / 08 \quad 20: 24$ & 39 & 0.12 & 10.0 & 9.7 & 9.4 & 8.8 & 8.0 & 16.3 & \\
\hline & & 104 & 0.32 & 10.0 & 9.7 & 9.3 & 9.0 & 8.1 & 14.0 & \\
\hline & & 328 & 1.00 & 10.2 & 9.9 & 9.7 & 9.1 & 8.0 & 14.4 & \\
\hline & & 626 & 1.91 & 10.2 & 10.0 & 9.6 & 9.0 & 8.1 & 15.0 & \\
\hline & & 951 & 2.90 & 9.9 & 9.8 & 9.4 & 9.0 & 8.2 & 14.1 & \\
\hline
\end{tabular}


DOE/RL-2009-35, REV. 0

\begin{tabular}{|c|c|c|c|c|c|c|c|c|c|c|}
\hline & & & Hea & $\mathrm{d}$ and Flo & w Measur & $e^{e n t s}{ }^{1}$ & & & & \\
\hline Flow & & Elap Time & \begin{tabular}{l|} 
Pore \\
\end{tabular} & & & $\mathrm{ad}(\mathrm{cm})$ & & & Flow & Stdev \\
\hline Cell ID & Start Time & Min & Volume & 1 & II & III & IV & $\bar{V}$ & $\mathrm{~mL} / \mathrm{min}$ & $\overline{\text { Mean }}$ \\
\hline 10 & & 1,184 & 3.61 & 10.8 & 9.6 & 9.2 & 8.9 & 8.1 & 14.3 & \\
\hline & & 1,262 & 3.85 & 17.7 & 9.7 & 9.4 & 8.7 & 8.0 & 14.1 & \\
\hline & & 1,620 & 4.94 & 106.0 & 9.8 & 9.2 & 8.8 & 8.0 & 13.8 & \\
\hline Mean & & & & & & & & & 14.5 & \\
\hline Stdev & & & & & & & & & 0.8 & 5.6 \\
\hline 11 & $3 / 21 / 08 \quad 12: 21$ & 74 & 0.52 & 13.7 & 12.1 & 10.7 & 9.8 & 8.3 & 32.0 & \\
\hline & & 160 & 1.12 & 15.5 & 13.8 & 12.3 & 10.9 & 8.6 & 31.6 & \\
\hline & & 271 & 1.90 & 21.7 & 14.1 & 12.9 & 11.7 & 9.3 & 32.4 & \\
\hline & & 511 & 3.57 & 214.0 & 12.7 & 11.8 & 10.8 & 8.9 & 33.1 & \\
\hline & & 549 & 3.84 & $=4547$ & 12.5 & 11.4 & 10.7 & 8.8 & 34.6 & \\
\hline & & 700 & 4.90 & 429.0 & 12.5 & 11.5 & 10.5 & 8.6 & 33.2 & \\
\hline & & 995 & 6.96 & 836.7 & 167.0 & 11.0 & 10.2 & 8.9 & 28.4 & \\
\hline & & 1,246 & 8.71 & $1,462.3$ & 154,7 & 51.2 & 10.2 & 8.6 & 33.6 & \\
\hline & & 1,499 & 10.48 & $2,003.8$ & 365.5 & 152.9 & 13.9 & 8.9 & 34.0 & \\
\hline & & $1,5 \overline{89}$ & 11.11 & $2,320.0$ & 492.3 & 187.5 & 20.3 & 10.0 & 34.9 & \\
\hline Mean & & & & & & & & & 32.8 & \\
\hline Stdev & & & & & & & & & 1.9 & 5.7 \\
\hline 12 & $3 / 21 / 08 \quad 12: 21$ & 74 & 0.52 & 12.6 & 11.2 & 10.2 & 9.2 & 7.9 & 35.0 & \\
\hline & & 160 & 1.12 & 15.2 & 12.3 & 11.4 & 9.8 & 8.0 & 33.2 & \\
\hline & & 271 & 1.90 & 39.4 & 12.2 & 11.3 & 10.0 & 8.3 & 31.6 & \\
\hline & & 511 & 3.57 & 191.0 & 10.7 & 10.7 & 9.6 & 8.3 & 32.9 & \\
\hline & & 549 & 3.84 & 1758 & 11.8 & 10.8 & 9.8 & 8.2 & 35.3 & \\
\hline & & 700 & 4.90 & 246.1 & 11.3 & 10.5 & 9.5 & 8.0 & 33.6 & \\
\hline & & 995 & 6.96 & 674.9 & 156.0 & 10.2 & 9.3 & 8.2 & 34.6 & \\
\hline & & 1,246 & 8.71 & $1,061.7$ & 5098 & 31.0 & 9.2 & 8.0 & 32.4 & \\
\hline & & 1,499 & 10.48 & $1,617.0$ & 724.2 & 118.6 & 12.2 & 8.9 & 33.8 & \\
\hline & & 1,589 & 11.11 & $1,898.4$ & 801.6 & 159.7 & 16.1 & 9.1 & 35.0 & \\
\hline Mean & & & & & & & & & 33.7 & \\
\hline Stdev & & & & & & & & & 1.2 & 3.7 \\
\hline 13 & $3 / 19 / 08 \quad 20: 24$ & 40 & 0.645161 & 16.7 & 14.8 & 13.1 & 11.1 & 8.3 & 78.0 & \\
\hline & & 120 & 1.935484 & 16.6 & 14.8 & 13.2 & 11.3 & 8.3 & 77.0 & \\
\hline & & 180 & 2.903226 & 15.9 & 14.3 & 12.8 & 10.9 & 8.4 & 77.5 & \\
\hline & & 244 & 3.935484 & 15.8 & 13.9 & 12.5 & 10.7 & 8.3 & 78.5 & \\
\hline & & 308 & 4.967742 & 15.2 & 14 & 12.5 & 11 & 8.3 & 77.0 & \\
\hline & & 636 & 10.25806 & 16.7 & 13.8 & 12.3 & 10.6 & 8.3 & 76.0 & \\
\hline & & 948 & 15.29032 & 20.8 & 14.5 & 12.8 & 11.2 & 8.7 & 78.0 & \\
\hline & & 1177 & 18.98387 & 75.5 & 19.6 & 12.7 & 11.1 & 8.5 & 76.0 & \\
\hline & & 1268 & 20.45161 & 140.2 & 70.3 & 12.8 & 11.1 & 8.5 & 75.5 & \\
\hline & & 1620 & 26.12903 & 344.4 & 1687 & 124.8 & 63.3 & 10.3 & 78.0 & \\
\hline Mean & & & & & & & & & 77.2 & \\
\hline Stdev & & & & & & & & & 1.0 & 1.3 \\
\hline 14 & $3 / 19 / 0820: 24$ & 40 & 0.65 & 16.6 & 14.6 & 13.1 & 11.5 & 8.8 & 75.5 & \\
\hline & & 120 & 1.94 & 16.5 & 14.9 & 13.5 & 11.8 & 9.0 & 76.0 & \\
\hline & & 180 & 2.90 & 15.7 & 14.3 & 12.9 & 11.2 & 9.0 & 76.5 & \\
\hline & & 244 & 3.94 & 15.6 & 14.1 & 13.0 & 11.1 & 9.0 & 77.0 & \\
\hline & & 308 & 4.97 & 15.8 & 13.8 & 13.0 & 11.2 & 8.9 & 77.0 & \\
\hline & & 636 & 10.26 & 16.5 & 13.7 & 12.5 & 11.2 & 8.9 & 76.5 & \\
\hline & & $\overline{948}$ & 15.29 & 20.7 & 14.7 & 13.5 & 12.1 & 9.7 & 76.0 & \\
\hline & & 1,177 & 18.98 & 57.2 & 15.1 & 13.0 & 11.4 & 9.1 & 76.0 & \\
\hline & & 1,268 & 20.45 & 101.7 & 34.8 & 13.0 & 11.4 & 9.1 & 75.0 & \\
\hline
\end{tabular}




\begin{tabular}{|c|c|c|c|c|c|c|c|c|c|c|}
\hline \multicolumn{11}{|c|}{ Head and Flow Measurements ${ }^{1}$} \\
\hline \multirow{2}{*}{$\begin{array}{l}\text { Flow } \\
\text { Cell ID }\end{array}$} & \multirow[b]{2}{*}{ Start Time } & \multirow{2}{*}{$\begin{array}{c}\text { Elap Time } \\
\text { Min }\end{array}$} & \multirow{2}{*}{$\begin{array}{c}\text { Pore } \\
\text { Volume }\end{array}$} & \multicolumn{5}{|c|}{ Head $(\mathrm{cm})$} & \multirow{2}{*}{$\begin{array}{c}\text { Flow } \\
\mathrm{mL} / \mathrm{min}\end{array}$} & \multirow{2}{*}{$\frac{\text { Stdev }}{\text { Mean }}$} \\
\hline & & & & 1 & II & III & IV & $V$ & & \\
\hline 14 & & 1,620 & 26.13 & 548.4 & 2040 & 100.5 & 46.3 & 10.5 & 76.5 & \\
\hline Mean & & & & & & & & & 76.2 & \\
\hline Stdev & & & & & & & & & 0.6 & 0.8 \\
\hline \multirow[t]{11}{*}{15} & \multirow[t]{11}{*}{$3 / 21 / 0812: 21$} & 37 & 1.37 & 39.5 & 31.3 & 26.8 & 21.1 & 11.8 & 178.0 & \\
\hline & & 62 & 2.30 & 42.2 & 30.2 & 25.7 & 20.8 & 12.3 & 172.0 & \\
\hline & & 93 & 3.44 & 47.7 & 29.8 & 25.3 & 20.1 & $\overline{12.3}$ & 178.0 & \\
\hline & & 113 & 4.19 & 52.3 & 30.6 & 25.4 & 20.6 & 12.8 & 180.0 & \\
\hline & & 159 & 5.89 & 64.2 & 31.6 & 26.3 & 21.0 & $\overline{13.3}$ & 176.0 & \\
\hline & & 344 & 12.74 & 196.5 & 135.5 & 89.4 & 26.1 & 14.7 & 180.0 & \\
\hline & & 631 & 23.37 & 3376 & 295.4 & 3937 & 2812 & 35.5 & 180.0 & \\
\hline & & 957 & 35.44 & 632.7 & 569.5 & 660.9 & 429.0 & 51.4 & 177.0 & \\
\hline & & 1,264 & 46.81 & $1,905.3$ & $1,202.2$ & 892.8 & 506.2 & 65.5 & 178.0 & \\
\hline & & 1,497 & 55.44 & $2,959.9$ & $1,828.0$ & $1,188.2$ & 653.8 & 72.7 & 166.0 & \\
\hline & & 1,597 & 59.15 & $3,163.8$ & $1,898.4$ & $1,125.0$ & 590.6 & 68.2 & 114.0 & \\
\hline Mean & & & & & & & & & 170.8 & \\
\hline Stdev & & & & & & & & & 19.3 & 11.3 \\
\hline \multirow[t]{11}{*}{16} & \multirow{11}{*}{$3 / 21 / 0812: 21$} & 37 & 1.37 & 35.1 & 27.3 & 23.4 & 18.9 & 11.8 & 170.0 & \\
\hline & & 62 & 2.30 & 36.7 & 26.0 & 22.3 & 18.1 & 11.8 & 168.0 & \\
\hline & & 93 & 3.44 & 43.5 & 25.2 & 21.2 & 17.3 & 11.6 & 170.0 & \\
\hline & & 113 & 4.19 & 49.0 & 25.3 & 21.2 & 17.3 & $\overline{11.6}$ & 176.0 & \\
\hline & & 159 & 5.89 & 63.9 & 25.5 & 21.3 & 17.4 & 11.8 & 172.0 & \\
\hline & & 344 & 12.74 & 183.0 & 113.1 & 71.8 & 22.0 & 12.2 & 172.0 & \\
\hline & & 631 & 23.37 & 478.0 & 407.7 & 274.3 & (W02.3 & 32.0 & 173.0 & \\
\hline & & 957 & 35.44 & 738.1 & 632.7 & 485.1 & 456.9 & 47.4 & 174.0 & \\
\hline & & 1,264 & 46.81 & $2,038.9$ & $1,188.2$ & 738.1 & 506.2 & 52.5 & 174.0 & \\
\hline & & 1,497 & 55.44 & $2,988.1$ & $1,546.9$ & 843.8 & 548.4 & 48.5 & 99.0 & \\
\hline & & 1,597 & 59.15 & $3,023.1$ & $1,532.6$ & 766.3 & 492.3 & 44.2 & 72.0 & \\
\hline Mean & & & & & & & & & 156.4 & \\
\hline Stdev & & & & & & & & & 35.6 & 22.8 \\
\hline
\end{tabular}

1. From left to right, "Flow Cell ID" identifies the flow cell involved, "Start Time" is the date and time the flow cell run commenced, "Elap Time" is the elapsed time for the run at which listed measurements were obtained, "Pore Volume" is the calculated pore volume (elapsed time divided by the theoretical time for one pore volume shown as the first sampling time for each flow cell velocity in Table 9), "Head" is the measurement for head obtained in installed sight glasses (see Figure 1 and Table 6 for locations), and "Flow" based on measurement of the volume over time for flow cell effluent collected in graduated cylinders. Spreadsheet cells shaded orangish-brown indicate first reading obtained after sight glass replaced with higher range pressure gage. Right hand column labelled "Stdev/Mean" is the standard deviation of flow measurements divided by their mean and expressed as percent. 
DOE/RL-2009-35, REV. 0

\begin{tabular}{|c|c|c|c|c|c|}
\hline \multicolumn{6}{|c|}{ Oxygen Levels Injection ZVI Fluid $^{1}$} \\
\hline Flow Cell Run & Flow Cells & Start Time & Dates & $\begin{array}{l}\text { Elap Time } \\
\text { Min }\end{array}$ & $\% \mathrm{O}_{2}$ \\
\hline \multirow[t]{5}{*}{ Poly \# 1} & \multirow[t]{5}{*}{$9,10,13$, and 14} & \multirow[t]{5}{*}{$20: 24$} & \multirow[t]{5}{*}{ 19-21 Mar 08} & 0 & 0.0 \\
\hline & & & & 60 & 2.1 \\
\hline & & & & 240 & 1.7 \\
\hline & & & & 1,087 & 8.4 \\
\hline & & & & 1,620 & 0.0 \\
\hline \multirow[t]{7}{*}{ Poly \# 2} & \multirow[t]{7}{*}{$11,12,15$, and 16} & \multirow[t]{7}{*}{$12: 21$} & \multirow[t]{7}{*}{ 21-22 Mar 08} & 0 & 0.0 \\
\hline & & & & 301 & 7.9 \\
\hline & & & & 834 & 6.2 \\
\hline & & & & 1,083 & 7.1 \\
\hline & & & & 1,211 & 3.9 \\
\hline & & & & 1,456 & 3.3 \\
\hline & & & & 1,620 & 0.0 \\
\hline \multirow[t]{9}{*}{ RNIP \# 1} & \multirow[t]{9}{*}{$1,2,5$, and 6} & \multirow[t]{9}{*}{ 19:06 } & \multirow[t]{9}{*}{ 7-8 Apr 08} & -157 & 11.3 \\
\hline & & & & -21 & 6.6 \\
\hline & & & & 142 & 5.0 \\
\hline & & & & 239 & $\overline{6.4}$ \\
\hline & & & & 392 & 4.6 \\
\hline & & & & 614 & 3.6 \\
\hline & & & & 749 & 3.5 \\
\hline & & & & 902 & 3.6 \\
\hline & & & & 1,186 & 4.9 \\
\hline \multirow[t]{11}{*}{ RNIP \# 2} & \multirow[t]{11}{*}{$3,4,7$, and 8} & \multirow[t]{11}{*}{$10: 40$} & \multirow[t]{11}{*}{ 9-10 Apr 08} & -430 & 18.3 \\
\hline & & & & -400 & 12.7 \\
\hline & & & & -300 & 9.9 \\
\hline & & & & -230 & 8.6 \\
\hline & & & & -155 & 5.7 \\
\hline & & & & -113 & 3.9 \\
\hline & & & & 121 & 3.8 \\
\hline & & & & 272 & 4.4 \\
\hline & & & & 797 & 3.4 \\
\hline & & & & 1,520 & 3.4 \\
\hline & & & & 1,620 & 3.1 \\
\hline
\end{tabular}

1. "Elap Time" is elapsed time from start of flow cell runs in minutes and " $\mathrm{OO}_{2}$ " is percent of oxygen overlying ZVI fluid in mixing tank with nitrogen gas atmosphere. 
DOE/RL-2009-35, REV. 0

\begin{tabular}{|c|c|c|c|c|c|c|c|c|c|c|c|}
\hline \multicolumn{12}{|c|}{ Field Water Quality Measurements (Flow Cell Influent-Effluent) ${ }^{t}$} \\
\hline \multirow{2}{*}{$\begin{array}{l}\text { Flow } \\
\text { Cell } \\
\text { ID }\end{array}$} & \multicolumn{4}{|c|}{ Time } & \multicolumn{5}{|c|}{ Variable } & \multirow[b]{2}{*}{ Turbidity } & \multirow[b]{2}{*}{ Color } \\
\hline & $\begin{array}{l}\text { Run Start } \\
\text { Clock }\end{array}$ & $\begin{array}{l}\text { Measurement } \\
\text { Clock }\end{array}$ & $\begin{array}{l}\text { Elapsed } \\
\text { Min }\end{array}$ & Location & $\begin{array}{l}\text { Cond } \\
\text { uS } / \mathrm{cm}\end{array}$ & $\begin{array}{c}\mathrm{DO} \\
\mathrm{mg} / \mathrm{L}\end{array}$ & $\begin{array}{l}\text { ORP } \\
m V\end{array}$ & $\begin{array}{l}\mathrm{pH} \\
\text { units }\end{array}$ & $\begin{array}{l}\mathrm{T} \\
{ }^{\circ} \mathrm{C}\end{array}$ & & \\
\hline \multicolumn{12}{|c|}{ Polymetallix Runs: } \\
\hline 14 & $3 / 19 / 200820: 24$ & $3 / 19 / 200821: 20$ & 56 & Effluent & 82 & 4.87 & 212 & 7.38 & 20.94 & Clear & Light yellow-brown \\
\hline 14 & " & $3 / 20 / 20081: 46$ & 322 & Effluent & 796 & 3.63 & -280 & 9.28 & 24.78 & High & Black \\
\hline 14 & " & $3 / 20 / 20083: 35$ & 431 & Effluent & 813 & 2.00 & -307 & 9.28 & 24.81 & High & Black \\
\hline 14 & $"$ & $3 / 20 / 20086: 10$ & 586 & Effluent & 844 & 1.88 & -336 & 9.32 & 26.11 & High & Black \\
\hline 14 & $"$ & $3 / 20 / 2008 \quad 10: 06$ & 812 & Effluent & 899 & 2.54 & -346 & 9.36 & 24.52 & High & Black \\
\hline 14 & $"$ & $3 / 20 / 2008$ 10:06 & 812 & Influent & 922 & 0.54 & -439 & 0.34 & 33.07 & High & Black \\
\hline 14 & $"$ & $3 / 20 / 2008$ 16:54 & 1,230 & Influent & 969 & 0.69 & -428 & 9.31 & 31.00 & High & Black \\
\hline 14 & " & $3 / 20 / 200816: 54$ & 1,230 & Effluent & 918 & 2.40 & -329 & 9.36 & 25.38 & High & Black \\
\hline \multicolumn{12}{|c|}{ RNIP-M2 Runs: } \\
\hline 6 & $4 / 7 / 200819: 06$ & $4 / 7 / 200821: 00$ & 114 & Effluent & 791 & 5.99 & 121 & 10.70 & 18.60 & $E$ & - \\
\hline 1 & " & $4 / 8 / 20084: 29$ & 563 & Influent & 1,047 & 0.55 & -560 & 11.02 & 25.20 & High & Black \\
\hline 1 & 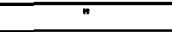 & $4 / 8 / 20083: 58$ & 532 & Effluent & 539 & 5.99 & 93 & 9.83 & 18.09 & - & - \\
\hline 5 & $\bar{n}$ & $4 / 8 / 20084: 45$ & 579 & Influent & 1,053 & 0.36 & \begin{tabular}{|c|}
-573 \\
\end{tabular} & 10.83 & 29.88 & High & Black \\
\hline 5 & $"$ & $4 / 8 / 20084: 14$ & 549 & Effluent & 1,005 & 1.35 & -40 & 11.09 & 24.83 & - & - \\
\hline 6 & " & $4 / 8 / 2008 \quad 14: 39$ & 1,173 & Effluent & 984 & 1.40 & -100 & 11.00 & 18.92 & - & - \\
\hline 0 & $4 / 9 / 2008 \quad 10: 40$ & $4 / 9 / 2008$ 17:30 & 410 & Influent & 13 & 6.22 & 185 & 7.08 & $16 . \overline{06}$ & Clear & - \\
\hline 0 & " & $4 / 9 / 200817: 30$ & 410 & Effluent & 5 & 6.78 & 229 & 6.30 & 14.88 & - & - \\
\hline 8 & " & $4 / 9 / 200821: 20$ & 640 & Influent & 962 & 0.56 & -584 & 10.78 & 27.66 & High & Black \\
\hline 8 & " & $4 / 9 / 200821: 20$ & 640 & Effluent & 918 & 2.40 & -11 & 11.09 & 25.90 & - & - \\
\hline 4 & $"$ & $4 / 10 / 080: 00$ & 800 & Influent & 935 & 4.53 & -543 & 11.12 & 30.30 & High & Black \\
\hline 4 & " & $4 / 10 / 080: 00$ & 800 & Effluent & 943 & 2.19 & 301 & 8.06 & 20.14 & - & - \\
\hline 4 & " & $4 / 10 / 081: 12$ & 872 & Effluent & 967 & 2.74 & 50 & 10.80 & 19.05 & $E$ & - \\
\hline 0 & $n$ & $4 / 10 / 081: 40$ & 900 & Effluent & 41 & 5.57 & 358 & 5.68 & 18.86 & - & - \\
\hline 7 & " & $4 / 10 / 085: 00$ & 1,100 & Effluent & 1,791 & 0.57 & -105 & 11.34 & 29.50 & & $E$ \\
\hline
\end{tabular}

1. "Run Start" and "Measurement" times are clock times run commenced and measurement was made, respectively, while "Elapsed" time is time in minutes since run started. Location is either flow cell "Influent" or "Effluent." Variable abbreviations ane "Cond" for conductivity, "DO" for dissolved oxygen, "ORP" for oxidation-reduction potential, and " $T$ " for temperature. 
DOE/RL-2009-35, REV. 0

\begin{tabular}{|c|c|c|c|c|c|c|c|c|c|}
\hline \multicolumn{10}{|c|}{ RNIP-M2 Flow Cell Laboratory Analysis Results ${ }^{1,2}$} \\
\hline \multirow[b]{2}{*}{$\begin{array}{l}\text { Flow } \\
\text { Cell }\end{array}$} & \multirow[b]{2}{*}{\begin{tabular}{|l} 
Elapsed \\
Time
\end{tabular}} & \multicolumn{7}{|c|}{ Sample Location } & \multirow[b]{2}{*}{ Remarks } \\
\hline & & $\begin{array}{c}\text { Influent } \\
0\end{array}$ & $\begin{array}{c}\text { Port A } \\
66\end{array}$ & \begin{tabular}{c|} 
Port B \\
127.25
\end{tabular} & \begin{tabular}{c|} 
Port C \\
188.5
\end{tabular} & $\begin{array}{l}\text { Port D } \\
249.25\end{array}$ & $\begin{array}{l}\text { Port E } \\
308\end{array}$ & $\begin{array}{c}\text { Effluent } \\
315.25\end{array}$ & \\
\hline \multirow[t]{7}{*}{0} & 143 & 4.4 & 4.6 & 1.2 & 6.3 & \begin{tabular}{r|r|r|}
2.7 \\
\end{tabular} & 1.6 & $\begin{array}{r}0.2 \\
6.2\end{array}$ & Control \\
\hline & 285 & 10.0 & $<0.1$ & 0.4 & 0.6 & 8.2 & 1.5 & 1.2 & \\
\hline & 571 & 4.5 & $<0.1$ & 0.3 & 0.5 & 3.1 & 0.6 & 1.9 & \\
\hline & 714 & 24.7 & 7.4 & 3.8 & 2.3 & 0.9 & 8.5 & 6.0 & \\
\hline & 984 & 0.4 & 0.3 & 0.8 & 0.4 & 0.3 & 0.4 & 0.6 & \\
\hline & 1,312 & 0.6 & 0.2 & 0.4 & 0.3 & 0.2 & 0.4 & 0.6 & \\
\hline & 1,641 & 0.9 & 0.5 & 0.5 & 0.5 & 0.2 & 0.6 & 0.8 & \\
\hline Mean & & 6.5 & 2.6 & 1.0 & 1.6 & 2.2 & 1.9 & 2.4 & \\
\hline \multirow[t]{5}{*}{1} & 328 & 4,630 & 129 & 147 & 125 & 99 & 56 & 53 & ZVI Front Did Not Reach Port A \\
\hline & 656 & 15,900 & 121 & 104 & 154 & 192 & 191 & 172 & \\
\hline & 984 & 12,200 & 124 & 110 & 123 & 132 & 145 & 134 & \\
\hline & 1,312 & 13,000 & 117 & 108 & 112 & 105 & 118 & 102 & \\
\hline & 1,641 & 9,510 & 222 & 141 & 132 & 119 & 128 & 125 & $\mathrm{DL}=117$ \\
\hline Mean & & 11,048 & 123 & 122 & 129 & 129 & 128 & 117 & \\
\hline \multirow[t]{5}{*}{2} & 328 & 5,490 & 137 & 148 & 132 & 106 & 41 & 37 & ZVI Front Did Not Reach Port A \\
\hline & 656 & 14,100 & 120 & 137 & 162 & 172 & 175 & 162 & \\
\hline & 984 & 11,900 & 117 & 112 & 116 & 125 & 149 & 121 & \\
\hline & 1,312 & 9,240 & 128 & 120 & 118 & 118 & 120 & 112 & \\
\hline & 1,641 & 10,900 & 218 & 148 & 126 & 139 & 116 & 117 & $\mathrm{DL}=125$ \\
\hline Mean & & 10,326 & 126 & 133 & 131 & 132 & 120 & 110 & \\
\hline \multirow[t]{7}{*}{3} & 143 & 2,460 & 66 & 78 & 83 & 76 & 52 & 49 & \\
\hline & 285 & 2,970 & 45 & 60 & 67 & 76 & 76 & 69 & \\
\hline & 571 & 1,570 & 43 & 43 & 43 & 54 & 53 & 53 & \\
\hline & 714 & 17,800 & 53 & 46 & 48 & 52 & 52 & 51 & \\
\hline & 984 & 14,700 & 55 & 45 & 48 & 49 & 46 & 44 & \\
\hline & 1,312 & 22,300 & 64 & 57 & 54 & 54 & 54 & 49 & \\
\hline & 1,641 & 46,900 & 71,100 & 88 & 76 & 78 & 66 & 63 & ZVI Front Max $\sim 96 \mathrm{~cm}$ at $1,706 \mathrm{~min}$ \\
\hline Mean & & 10,300 & 54 & 60 & 60 & 63 & 57 & 54 & \\
\hline \multirow[t]{7}{*}{4} & 143 & 6,120 & 59 & 83 & 85 & 63 & 48 & 44 & \\
\hline & 285 & 3,680 & 45 & 58 & 72 & 78 & 81 & 72 & \\
\hline & 571 & 3,560 & 43 & 43 & 46 & 52 & 55 & 51 & \\
\hline & 714 & 17,500 & 50 & 46 & 47 & 50 & 48 & 49 & \\
\hline & 984 & 22,400 & 50 & 44 & 43 & 42 & 48 & 45 & \\
\hline & 1,312 & 10,400 & 73 & 59 & 53 & 54 & 50 & 49 & ZVI Front $\sim 99 \mathrm{~cm}$ at $1,610 \mathrm{~min}$ \\
\hline & 1,641 & 45,700 & 44,400 & $\begin{array}{ll}37,700 \\
\end{array}$ & 91 & 74 & 71 & 67 & ZVI Front $\mathrm{Max} \sim 127 \mathrm{~cm}$ at $1,706 \mathrm{~min}$ \\
\hline Mean & & 10,610 & 53 & 55 & 62 & 59 & 57 & 54 & \\
\hline
\end{tabular}




\begin{tabular}{|c|c|c|c|c|c|c|c|c|c|}
\hline \multicolumn{10}{|c|}{ RNIP-M2 Flow Cell Laboratory Analysis Results ${ }^{1}$} \\
\hline \multirow[b]{2}{*}{$\begin{array}{l}\text { Flow } \\
\text { Cell }\end{array}$} & \multirow[b]{2}{*}{$\begin{array}{l}\text { Elapsed } \\
\text { Time }\end{array}$} & \multicolumn{7}{|c|}{ Sample Location } & \multirow[b]{2}{*}{ Remarks } \\
\hline & & $\begin{array}{c}\text { Influent } \\
0\end{array}$ & $\begin{array}{c}\text { Port A } \\
66\end{array}$ & $\begin{array}{l}\text { Port B } \\
127.25\end{array}$ & $\begin{array}{c}\text { Port C } \\
188.5\end{array}$ & $\begin{array}{l}\text { Port D } \\
249.25\end{array}$ & $\begin{array}{c}\text { Port E } \\
308\end{array}$ & $\begin{array}{c}\text { Effluent } \\
315.25\end{array}$ & \\
\hline \multirow[t]{9}{*}{5} & 62 & 3,980 & 78 & 98 & 122 & 116 & 89 & 81 & \\
\hline & 124 & 4,380 & 78 & 83 & 97 & 107 & 98 & 101 & \\
\hline & 186 & 4,640 & 306 & 81 & 85 & 94 & 92 & 97 & \\
\hline & 248 & 3,000 & 1,540 & 91 & 79 & 84 & 93 & 84 & \\
\hline & 310 & 3,260 & 10,000 & 109 & 98 & 107 & 102 & 105 & ZVI Front $-126 \mathrm{~cm}$ at $566 \mathrm{~min}$ \\
\hline & 656 & 9,660 & 18,800 & 8,790 & 129 & 111 & 116 & 111 & \\
\hline & 984 & 11,500 & 11,200 & 16,800 & 18,500 & 3,090 & 117 & 113 & $D L=112$ \\
\hline & 1,312 & 9,710 & 12,900 & 15,100 & 27,800 & 27,700 & 15,000 & 4,590 & ZVI Front $\sim 269 \mathrm{~cm}$ at $1,101 \mathrm{~min}$ \\
\hline & 1,641 & 6,840 & 20,700 & 10,400 & 19,300 & 13,200 & 9,300 & 935 & Observed 6 May 2008 \\
\hline Mean & & 6,330 & 8,400 & 5,728 & 7,357 & 4,957 & 2,779 & 691 & \\
\hline \multirow[t]{9}{*}{6} & 62 & 3,670 & 79 & 110 & 115 & 71 & 7 & 8 & \\
\hline & 124 & 3,480 & 77 & 83 & 100 & 109 & 115 & 113 & \\
\hline & 186 & 2,910 & 87 & 84 & 87 & 102 & 108 & 97 & \\
\hline & 248 & 3,070 & 128 & 92 & 85 & 90 & 98 & 97 & \\
\hline & 310 & 2,780 & 2,550 & 106 & 106 & 102 & 104 & 100 & ZVI Front $\sim 66 \mathrm{~cm}$ at $383 \mathrm{~min}$ \\
\hline & 656 & 5,290 & 29,600 & 10,800 & 121 & 113 & 115 & 106 & $Z V \mid$ Front $\sim 138 \mathrm{~cm}$ at $736 \mathrm{~min}$ \\
\hline & 984 & 10,100 & 34,700 & 20,600 & 27,800 & 134 & 105 & 100 & $Z V \mid$ Front $-181 \mathrm{~cm}$ at $924 \mathrm{~min}, \mathrm{DL}=108$ \\
\hline & 1,312 & 7,600 & 26,200 & 29,400 & 34,900 & 43,600 & 131 & 119 & ZVI Front $-227 \mathrm{~cm}$ at $1,101 \mathrm{~min}$ \\
\hline & 1,641 & 8,210 & 31,000 & 16,900 & 26,000 & 40,000 & 33,500 & 6,470 & Observed 6 May $2008, D L=8,470$ \\
\hline Mean & & 5,234 & 13,825 & 8,686 & 9,924 & 9,369 & 3,809 & 801 & \\
\hline \multirow[t]{10}{*}{7} & 27 & 3,500 & 467 & 148 & 47 & 7 & 5 & 9 & \\
\hline & 54 & 3,530 & 1,190 & 86 & 67 & $71 \mid$ & 75 & 70 & \\
\hline & 81 & 3,910 & 1,482 & 113 & 58 & 65 & 72 & 63 & \\
\hline & 108 & 2,980 & 1,910 & 166 & 54 & 55 & 61 & 53 & \\
\hline & 135 & 2,950 & 2,180 & 264 & 52 & 52 & 53 & 55 & \\
\hline & 328 & 2,640 & 5,460 & 1,010 & 162 & 37 & 35 & 38 & ZVI Front $\sim 77 \mathrm{~cm}$ at 192 \\
\hline & 656 & 1,370 & 4,630 & 12,500 & 819 & 78 & 42 & 43 & $Z \mathrm{~V} \mid$ Front $-117 \mathrm{~cm}$ at 340 \\
\hline & 984 & 3,720 & 15,400 & 16,400 & 14,800 & 235 & 49 & 51 & \\
\hline & 1,312 & 6,190 & 13,200 & 20,000 & 22,700 & 19,700 & 1,300 & 668 & Last observation at 1,080 \\
\hline & 1,641 & 28,700 & 51,100 & 60,900 & 54,100 & 52,300 & 40,600 & 23,600 & Observed 6 May 2008 \\
\hline Mean & & 3,421 & 9,702 & 11,159 & 9,286 & 7,260 & 4,229 & 2,465 & \\
\hline \multirow[t]{10}{*}{8} & 27 & 3,660 & 903 & 189 & 141 & 20 & 12 & 9 & \\
\hline & 54 & 3,590 & 1,850 & 174 & 76 & 71 & 78 & 76 & \\
\hline & 81 & 3,740 & 2,530 & 271 & 63 & 65 & 66 & 63 & \\
\hline & 108 & 3,380 & 3,320 & 414 & 75 & 57 & 59 & 55 & \\
\hline & 135 & 3,280 & 2,600 & 495 & 75 & 53 & 55 & 56 & \\
\hline & 328 & 2,430 & 5,080 & 3,800 & 313 & 63 & 38 & 33 & ZVI Front $\sim 86 \mathrm{~cm}$ at 192 \\
\hline & 656 & 1,100 & 3,790 & 3,620 & 3,160 & 191 & 46 & 47 & \\
\hline & 984 & 2,160 & 23,300 & 9,110 & 9,460 & 2,930 & 59 & 49 & \\
\hline & 1,312 & 5,230 & 10,600 & 16,400 & 20,000 & 22,200 & 15,700 & 3,280 & Last observation at 1,080 \\
\hline & 1,641 & 3,190 & 55,000 & 58,400 & 60,400 & 48,300 & 44,900 & 28,300 & Observed 6 May 2008 \\
\hline Mean & & 3,176 & 10,897 & 9,287 & 9,376 & 7,395 & 6,101 & 3,197 & \\
\hline
\end{tabular}

1. "Elapsed Time" is time in minutes since flow cell run commenced. Numbers below sampling locations are position along flow cell in $\mathrm{cm}$. Gray shaded cells indicate that the "ZVI front"had passed that sampling location when the sample was taken. Additional remarks about the location of the ZVIfront are presented in the far right hand column. The location of the ZVI front was indicated by a change in color of the sand from a natural light brown to black. This was measured in centimeters from the downstream end of the flow cell end fitting. Because observations of the $Z V I$ front were not recorded after time 1,101 minutes for flow cells 5 and 6 or 1,080 minutes for flow cells 7 and 8 , it cannot be determined from observations whether the ZVI front had passed Ports $D$ or $E$ when those samples were taken at time 1,312 minutes. Therefore, lack of shading for those cells is not based on data.

2. Light brown shading for influent or the first one or two segments of flow cells indicates average excludes last value in column. 
DOE/RL-2009-35, REV. 0

\begin{tabular}{|c|c|c|c|c|c|}
\hline \multicolumn{6}{|c|}{ ZVI Front Observations } \\
\hline $\begin{array}{l}\text { Elapsed Time } \\
\text { Min }\end{array}$ & $\begin{array}{c}\text { Pore } \\
\text { Volume }\end{array}$ & $\begin{array}{c}\text { ZVI Front } \\
\text { Distance }(\mathrm{cm})^{1}\end{array}$ & \begin{tabular}{|c|} 
Elapsed Time \\
Min
\end{tabular} & $\begin{array}{c}\text { Pore } \\
\text { Volume }\end{array}$ & $\begin{array}{c}\text { ZVI Front } \\
\text { Distance }(\mathrm{cm})^{1}\end{array}$ \\
\hline \multicolumn{6}{|c|}{ RNIP-M2 Flow Cell Injection Runs } \\
\hline \multicolumn{3}{|c|}{$\begin{array}{l}\text { Flow Cell: } 1 \\
\text { Start Time: } 4 / 7 / 08 \quad 7: 06: 00 \text { PM } \\
\text { Pore Volume: } 328 \text { minutes }\end{array}$} & \multicolumn{3}{|c|}{$\begin{array}{l}\text { Flow Cell: } 2 \\
\text { Start Time: } 4 / 7 / 2008 \text { 7:06:00 PM } \\
\text { Pore Volume: } 328 \text { minutes }\end{array}$} \\
\hline 739 & 2.25 & 11.0 & \begin{tabular}{|l|l}
739 & \\
\end{tabular} & 2.25 & 7.0 \\
\hline 1,103 & 3.36 & 20.3 & 1,103 & 3.36 & 22.1 \\
\hline 1,455 & 4.44 & 35.6 & 1,455 & 4.44 & 32.1 \\
\hline 1,674 & 5.10 & 43.8 & 1,674 & 5.10 & 41.6 \\
\hline \multicolumn{3}{|c|}{$\begin{array}{l}\text { Flow Cell: } 3 \\
\text { Start Time: } 4 / 9 / 08 \quad 10: 40: 00 \mathrm{AM} \\
\text { Pore Volume: } 143 \text { minutes }\end{array}$} & \multicolumn{3}{|c|}{$\begin{array}{l}\text { Flow Cell: } 4 \\
\text { Start Time: } 4 / 9 / 2008 \quad 10: 40: 00 \mathrm{AM} \\
\text { Pore Volume: } 143 \text { minutes }\end{array}$} \\
\hline 192 & 1.34 & 10.8 & \begin{tabular}{|l|l|}
192 & \\
\end{tabular} & 1.34 & 9.4 \\
\hline 609 & 4.26 & 20.0 & 609 & 4.26 & 24.4 \\
\hline 789 & 5.52 & 22.2 & 789 & 5.52 & 25.7 \\
\hline 1,080 & 7.55 & 25.7 & 1,080 & 7.55 & 33.0 \\
\hline 1,532 & 10.71 & 50.2 & 1,532 & 10.71 & 72.4 \\
\hline 1,610 & 11.26 & 67.9 & 1,610 & 11.26 & 98.7 \\
\hline 1,706 & 11.93 & 95.9 & 1,706 & 11.93 & 127.6 \\
\hline \multicolumn{3}{|c|}{$\begin{array}{l}\text { Flow Cell: } 5 \\
\text { Start Time: } 4 / 7 / 08 \text { 7:06:00 PM } \\
\text { Pore Volume: } 62 \text { minutes } \\
\end{array}$} & \multicolumn{3}{|c|}{$\begin{array}{l}\text { Flow Cell: } 6 \\
\text { Start Time: } 4 / 7 / 08 \text { 7:06:00 PM } \\
\text { Pore Volume: } 62 \text { minutes } \\
\end{array}$} \\
\hline 166 & 2.68 & 39.4 & \begin{tabular}{|l|l|}
166 \\
\end{tabular} & 2.68 & 29.2 \\
\hline 383 & 6.18 & 73.3 & 383 & 6.18 & 66.4 \\
\hline 566 & 9.13 & 126.4 & 566 & 9.13 & 100.5 \\
\hline 736 & 11.87 & 172.7 & 736 & 11.87 & 138.4 \\
\hline 924 & 14.90 & 218.6 & 924 & 14.90 & 181.0 \\
\hline 1,101 & 17.76 & 268.9 & 1,101 & 17.76 & 227.3 \\
\hline 1,641 & 26.47 & Full Length & \begin{tabular}{|l|l|}
1,641 \\
\end{tabular} & 26.47 & Full Length \\
\hline \multicolumn{3}{|c|}{$\begin{array}{l}\text { Flow Cell: } 7 \\
\text { Start Time: } 4 / 9 / 08 \text { 10:40:00 AM } \\
\text { Pore Volume: } 27 \text { minutes }\end{array}$} & \multicolumn{3}{|c|}{$\begin{array}{l}\text { Flow Cell: } 8 \\
\text { Start Time: } 4 / 9 / 08 \quad 10: 40: 00 \text { AM } \\
\text { Pore Volume: } 27 \text { minutes }\end{array}$} \\
\hline 70 & 2.59 & 33.3 & $\begin{array}{r}70 \\
\end{array}$ & 2.59 & 30.5 \\
\hline 192 & 7.11 & 77.5 & 192 & 7.11 & 85.7 \\
\hline 340 & 12.59 & 117.2 & 340 & 12.59 & 118.1 \\
\hline 687 & 25.44 & 142.9 & 687 & 25.44 & 150.5 \\
\hline 1,080 & 40.00 & 181.0 & 1,080 & 40.00 & 181.3 \\
\hline 1,641 & 60.78 & Full Length & 1,641 & 60.78 & Full Length \\
\hline
\end{tabular}


DOE/RL-2009-35, REV. 0

\begin{tabular}{|c|c|c|c|c|c|}
\hline \multicolumn{6}{|c|}{ ZVI Front Observations } \\
\hline $\begin{array}{l}\text { Elapsed Time } \\
\text { Min }\end{array}$ & $\begin{array}{c}\text { Pore } \\
\text { Volume }\end{array}$ & $\begin{array}{c}\text { ZVI Front } \\
\text { Distance }(\mathrm{cm})\end{array}$ & $\begin{array}{c}\text { Elapsed Time } \\
\text { Min }\end{array}$ & $\begin{array}{c}\text { Pore } \\
\text { Volume }\end{array}$ & $\begin{array}{c}\text { ZVI Front } \\
\text { Distance }(\mathrm{cm}) \\
\end{array}$ \\
\hline \multicolumn{6}{|c|}{ Polymetallix Flow Cell Injection Runs } \\
\hline \multicolumn{3}{|c|}{$\begin{array}{l}\text { Flow Cell: } 9 \\
\text { Start Time: } 3 / 19 / 2008 \text { 8:24:00 PM } \\
\text { Pore Volume: } 328 \text { minutes }\end{array}$} & \multicolumn{3}{|c|}{$\begin{array}{l}\text { Flow Cell: } 10 \\
\text { Start Time: } 3 / 19 / 2008 \quad 8: 24: 00 \text { PM } \\
\text { Pore Volume: } 328 \text { minutes }\end{array}$} \\
\hline 1,516 & 4.62 & 21.0 & 1,516 & 4.62 & 21.0 \\
\hline 1,676 & 5.11 & 33.0 & 1,676 & 5.11 & 34.0 \\
\hline \multicolumn{3}{|c|}{$\begin{array}{l}\text { Flow Cell: } 11 \\
\text { Start Time: } 3 / 21 / 2008 \text { 12:21:00 PM } \\
\text { Pore Volume: } 143 \text { minutes }\end{array}$} & \multicolumn{3}{|c|}{$\begin{array}{l}\text { Flow Cell: } 12 \\
\text { Start Time: } 3 / 21 / 2008 \text { 12:21:00 PM } \\
\text { Pore Volume: } 143 \text { minutes }\end{array}$} \\
\hline 295 & 2.06 & 13.5 & 295 & 2.06 & 13.6 \\
\hline 499 & 3.49 & 33.6 & 499 & 3.49 & 37.2 \\
\hline 673 & 4.71 & 64.0 & 673 & 4.71 & 64.0 \\
\hline 813 & 5.69 & 93.9 & 813 & 5.69 & 92.6 \\
\hline 1,034 & 7.23 & 145.1 & 1,034 & 7.23 & 139.0 \\
\hline 1,224 & 8.56 & 179.6 & 1,224 & 8.56 & 170.2 \\
\hline 1,345 & 9.41 & 199.1 & 1,345 & 9.41 & 194.0 \\
\hline 1,513 & 10.58 & 243.3 & 1,513 & 10.58 & 233.2 \\
\hline \multicolumn{3}{|c|}{$\begin{array}{l}\text { Flow Cell: } 13 \\
\text { Start Time: } 3 / 19 / 2008 \text { 8:24:00 PM } \\
\text { Pore Volume: } 62 \text { minutes }\end{array}$} & \multicolumn{3}{|c|}{$\begin{array}{l}\text { Flow Cell: } 14 \\
\text { Start Time: } 3 / 19 / 2008 \text { 8:24:00 PM } \\
\text { Pore Volume: } 62 \text { minutes }\end{array}$} \\
\hline 1,150 & 18.55 & 80.4 & 1,150 & 18.55 & 77.6 \\
\hline 1,371 & 22.11 & 182.0 & 1,371 & 22.11 & 163.9 \\
\hline 1,516 & 24.45 & 270.0 & 1,516 & 24.45 & 258.0 \\
\hline 1,676 & 27.03 & 305.0 & 1,676 & 27.03 & 305.0 \\
\hline \multicolumn{3}{|c|}{$\begin{array}{l}\text { Flow Cell: } 15 \\
\text { Start Time: } 3 / 21 / 2008 \text { 12:21:00 PM } \\
\text { Pore Volume: } 27 \text { minutes } \\
\end{array}$} & \multicolumn{3}{|c|}{$\begin{array}{l}\text { Flow Cell: } 16 \\
\text { Start Time: } 3 / 21 / 2008 \quad 12: 21: 00 \text { PM } \\
\text { Pore Volume: } 27 \text { minutes }\end{array}$} \\
\hline 297 & 11.00 & 187.9 & 297 & 11.00 & 172.5 \\
\hline 347 & 12.85 & 226.9 & 347 & 12.85 & 225.7 \\
\hline
\end{tabular}

1. "ZVI Front Distance" defined as distance from downstream end of influent cap to extent of black discoloration of sand produced by ZVI fluid in centimeters. 
DOE/RL-2009-35, REV. 0

1

FLOW CELL 8

$\begin{array}{lcccccccc} & \text { I } & \text { A } & \text { B } & \text { C } & \text { D } & \text { E } & \text { F } & \text { Total } \\ \text { Distance }(\mathrm{cm}) & 0 & 66 & 127.25 & 188.5 & 249.25 & 308 & 315.25 & \\ & & \text { I-A } & \text { A-B } & \text { B-C } & \text { C-D } & \text { D-E } & \text { E-F } & \\ \text { Volume Water }\left(\mathrm{cm}^{3}\right) & & 1,102 & 1,023 & 1,023 & 1,014 & 981 & 121 & 5,263 \\ & & \text { I-A/B } & \text { A/B-B/C } & \text { B/C-C/D } & \text { C/D-D/E } & \text { D/E-F } & & 315.25 \\ \text { Volume Length }\left(\mathrm{cm}^{3}\right) & & 97 & 61 & 61 & 60 & 37 & & 5,263 \\ \text { Volume Water }\left(\mathrm{cm}^{3}\right) & & 1,613 & 1,023 & 1,018 & 997 & 611 & 9,774 \\ \text { Volume Sand }\left(\mathrm{cm}^{3}\right) & & 2,996 & 1,899 & 1,891 & 1,852 & 1,136 & 25,901\end{array}$

2

Mass Sand $(\mathrm{Kg})$

Reported Sample Results (all concentrations in $\mathrm{mg} / \mathrm{L}$ )

\begin{tabular}{|c|c|c|c|c|c|c|c|c|c|}
\hline \multirow[b]{2}{*}{ Flow Cell } & \multirow[b]{2}{*}{ Time } & & 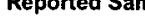 & 'Pл & 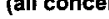 & 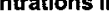 & migrts & & \\
\hline & & 1 & $\begin{array}{c}A \\
66\end{array}$ & $\begin{array}{c}\text { B } \\
127.25\end{array}$ & $\begin{array}{c}C \\
188.5\end{array}$ & $\begin{array}{c}\text { D } \\
249.25\end{array}$ & $\begin{array}{c}\mathbf{E} \\
308\end{array}$ & $F$ & $Q(\mathrm{~mL} / \mathrm{min})$ \\
\hline 8 & 27 & 3,660 & 903 & 189 & 141 & 20 & 12 & 9 & \\
\hline & 54 & 3,590 & 1,850 & 174 & 76 & 71 & 78 & 76 & \\
\hline & 81 & 3,740 & 2,530 & 271 & 63 & 65 & 66 & 63 & \\
\hline & \begin{tabular}{|l|}
108 \\
\end{tabular} & 3,380 & 3,320 & 414 & 75 & 57 & 59 & 55 & \\
\hline & 135 & 3,280 & $\begin{array}{r}2,600 \\
\end{array}$ & 495 & 75 & 53 & 55 & 56 & \\
\hline & 328 & 2,430 & - & 3800 & 313 & 63 & 38 & 33 & \\
\hline & 656 & 1,100 & 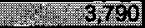 & 19148 9620 & 3,160 & 191 & 46 & 47 & \\
\hline & 984 & 2,160 & 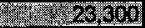 & 15/ 90 & 9,460 & 2,930 & 59 & 49 & \\
\hline & 1,312 & 5,230 & 2t 19600 & 37T, & 2000 & 22,200 & 15,700 & 3,280 & \\
\hline & 1,641 & 3,190 & 125155000 & 2045800 & 60100 & 2. 40,600 & 3 44000 & 28,300 & \\
\hline
\end{tabular}

44949.111

184

3

Time Interval Suspended Mass (mg)

$\mathrm{cm}^{2} \mathrm{X}-\mathrm{S}$ are

47.70

\begin{tabular}{|c|c|c|c|c|c|c|c|c|c|c|}
\hline Time & Calc Inf & Cum Inf & I-AVB & A/B-B/C & $\mathrm{B} / \mathrm{C}-\mathrm{C} / \mathrm{D}$ & C/D-D/E & D/E-F & Eff & Cum Eff & $\begin{array}{c}47.70 \\
\text { Cum MD }\end{array}$ \\
\hline 27 & 44,949 & 44,949 & 1,457 & 193 & 144 & 20 & 7 & 22 & 22 & 43,105 \\
\hline 54 & 44,949 & 89,898 & 2,984 & 178 & 77 & 70 & 48 & 212 & 234 & 86,307 \\
\hline 81 & 44,949 & 134,847 & 4,081 & 277 & 65 & 64 & 40 & 347 & 581 & 129,739 \\
\hline 108 & 44,949 & 179,796 & 5,355 & 424 & 76 & 56 & 36 & 294 & 875 & 172,974 \\
\hline 135 & 44,949 & 224,746 & 4,194 & 506 & 76 & 53 & 34 & 277 & 1,152 & 218,731 \\
\hline 328 & 321,303 & 546,048 & 8,194 & 3,886 & 319 & 63 & 23 & 1,599 & 2,750 & 530,813 \\
\hline 656 & 546,048 & $1,092,097$ & 6.114 & 3,702 & 3,218 & 191 & 28 & 2,432 & 5,183 & $1,073,662$ \\
\hline 984 & 546,048 & $1,638,145$ & 37,585 & 9,315 & 9,634 & 2,923 & 36 & 2,902 & 8,084 & $1,570,56 \overline{9}$ \\
\hline 1,312 & 546,048 & $2,184,194$ & 17,099 & 16,769 & 20,367 & 22,144 & 9,599 & 100,620 & 108,704 & $1,989,511$ \\
\hline 1,641 & 547,713 & $2,731,907$ & 88,720 & 59,715 & 61,508 & 48,178 & 27,453 & 957,422 & $1,066,126$ & $1,380,206$ \\
\hline
\end{tabular}

4

\begin{tabular}{|c|c|c|c|c|c|c|}
\hline \multirow[b]{2}{*}{ Time } & \multicolumn{5}{|c|}{ Time Interval Deposition (mg) } & \multirow[b]{2}{*}{ MD } \\
\hline & I-AB & $\mathrm{A} / \mathrm{B}-\mathrm{B} / \mathrm{C}$ & $\mathrm{B} / \mathrm{C}-\mathrm{C} / \mathrm{D}$ & C/D-D/E & $D / E-F$ & \\
\hline 27 & 43,105 & 0 & 0 & 0 & 0 & 43,105 \\
\hline 54 & 86,307 & 0 & 0 & 0 & 0 & 86,307 \\
\hline 81 & 121,479 & 8,260 & 0 & 0 & 욕 & 129,739 \\
\hline 108 & 160,290 & 12,684 & 0 & 0 & 의 & 172,974 \\
\hline 135 & 195,172 & 23,559 & 0 & 요 & 여 & 218,731 \\
\hline 328 & 350,809 & 166,344 & 13,660 & 요 & 의 & 530,813 \\
\hline 656 & 503,635 & 304,931 & 265,096 & 0 & 의 & $1,073,662$ \\
\hline 984 & 992,824 & 246,066 & 254,477 & 77,203 & 0 & $1,570,569$ \\
\hline 1,312 & 395,657 & 388,037 & 471,285 & 512,406 & 222,127 & $1,989,511$ \\
\hline 1.641 & 428,789 & 288,609 & 297,275 & 232,850 & 132,683 & $1,380,206$ \\
\hline
\end{tabular}




\begin{tabular}{|c|c|c|c|c|c|c|c|}
\hline \multicolumn{8}{|c|}{ Flow Cell Segment and Total Cumulative Mass Deposition (mg) ${ }^{1}$} \\
\hline Flow Cell & $\begin{array}{l}\text { Time } \\
\text { min }\end{array}$ & $\begin{array}{c}\text { I-A/B } \\
0.660 \mathrm{~m} \\
7.94 \mathrm{Kg}\end{array}$ & $\begin{array}{l}\text { A/B-B/C } \\
1.273 \mathrm{~m} \\
5.03 \mathrm{Kg}\end{array}$ & $\begin{array}{l}\mathrm{B} / \mathrm{C}-\mathrm{C} / \mathrm{D} \\
1.885 \mathrm{~m} \\
5.01 \mathrm{Kg}\end{array}$ & $\begin{array}{l}\text { C/D-D/E } \\
2.493 \mathrm{~m} \\
4.91 \mathrm{Kg}\end{array}$ & $\begin{array}{c}\mathrm{D} / \mathrm{E}-\mathrm{F} \\
3.080 \mathrm{~m} \\
3.01 \mathrm{Kg}\end{array}$ & $\begin{array}{c}\text { Cum MD } \\
\text { mg }\end{array}$ \\
\hline \multirow[t]{5}{*}{1} & 328 & 42,511 & 0 & 0 & 0 & 0 & 42,511 \\
\hline & 656 & 85,081 & 0 & 0 & 0 & 0 & 85,081 \\
\hline & 984 & 127,715 & 0 & 0 & 0 & 0 & 127,715 \\
\hline & 1,312 & 170,475 & 0 & 0 & 0 & 0 & 170,475 \\
\hline & 1,641 & 213,077 & 0 & 0 & $\overline{0}$ & $\overline{0}$ & 213,077 \\
\hline \multirow[t]{7}{*}{3} & 143 & 45,860 & 0 & 0 & 0 & 0 & 45,860 \\
\hline & 285 & 91,225 & 0 & 0 & 0 & 0 & 91,225 \\
\hline & 571 & 182,573 & 0 & 0 & 0 & 0 & 182,573 \\
\hline & 714 & 228,292 & 0 & 0 & $\overline{0}$ & $\overline{0}$ & 228,292 \\
\hline & 984 & 314,660 & 0 & 0 & 0 & 0 & 314,660 \\
\hline & 1,312 & 419,595 & 0 & 0 & 0 & 0 & 419,595 \\
\hline & 1,641 & 524,740 & 0 & 0 & 0 & 0 & 524,740 \\
\hline \multirow[t]{9}{*}{5} & 62 & 48,486 & 0 & 0 & 0 & 0 & 48,486 \\
\hline & 124 & 97,263 & 0 & 0 & 0 & 0 & 97,263 \\
\hline & 186 & 145,617 & 0 & $\overline{0}$ & 0 & $\overline{0}$ & 145,617 \\
\hline & 248 & 192,361 & 0 & 0 & 0 & 0 & 192,361 \\
\hline & 310 & 227,296 & 0 & 0 & 0 & 0 & 227,296 \\
\hline & 656 & 367,043 & 108,630 & 0 & 0 & 0 & 475,673 \\
\hline & 984 & 225,897 & 214,678 & 236,198 & 38,604 & 0 & 715,378 \\
\hline & 1,312 & 176,866 & 131,663 & 241,246 & 235,795 & 78,294 & 863,865 \\
\hline & 1,641 & 429,379 & 137,465 & 253,610 & 170,210 & 73,260 & $1,063,925$ \\
\hline \multirow[t]{10}{*}{8} & 27 & 43,105 & 0 & 0 & 0 & 0 & 43,105 \\
\hline & 54 & 86,307 & 0 & 0 & 0 & 0 & 86,307 \\
\hline & 81 & 121,479 & 8,260 & 0 & 0 & 0 & 129,739 \\
\hline & 108 & 160,290 & 12,684 & 0 & $\overline{0}$ & 0 & 172,974 \\
\hline & 135 & 195,172 & 23,559 & 0 & 0 & $\underline{0}$ & 218,731 \\
\hline & 328 & 350,809 & 166,344 & 13,660 & 0 & 0 & 530,813 \\
\hline & 656 & 503,635 & 304,931 & 265,096 & 0 & 0 & $1,073,662$ \\
\hline & 984 & 992,824 & 246,066 & 254,477 & 77,203 & 0 & $1,570,569$ \\
\hline & 1,312 & 395,657 & 388,037 & 471,285 & 512,406 & 222,127 & $1,989,511$ \\
\hline & 1,641 & 428,789 & 288,609 & 297,275 & 232,850 & 132,683 & $1,380,206$ \\
\hline
\end{tabular}


DOE/RL-2009-35, REV. 0

\begin{tabular}{|c|c|c|c|c|c|}
\hline \multicolumn{6}{|c|}{ MLR Input } \\
\hline Flow Cell & $\begin{array}{l}\text { Flow Cell } \\
\text { Segment }\end{array}$ & $\begin{array}{l}\text { Time } \\
\text { sec }\end{array}$ & $\begin{array}{c}\text { Distance } \\
\mathrm{m}\end{array}$ & $\begin{array}{c}\text { Velocity } \\
\mathrm{m} / \mathrm{sec}\end{array}$ & $\begin{array}{c}\text { MDS } \\
\mathrm{Kg}-\mathrm{F} / \mathrm{Kg}-\mathrm{S}\end{array}$ \\
\hline 1 & I-A/B & 19,680 & 0.66 & 0.00015 & 0.106385745 \\
\hline 1 & I-A/B & 39,360 & 0.66 & 0.00015 & 0.106459539 \\
\hline 1 & I-A/B & 59,040 & 0.66 & 0.00015 & 0.090409857 \\
\hline 1 & $\mathrm{I}-\mathrm{A} / \mathrm{B}$ & 78,720 & 0.66 & 0.00015 & 0.070884504 \\
\hline 1 & I-A/B & 98,460 & 0.66 & 0.00015 & 0.061164132 \\
\hline 1 & $\mathrm{~A} / \mathrm{B}-\mathrm{B} / \mathrm{C}$ & 19,680 & 1.27 & 0.00015 & 0 \\
\hline 1 & $\mathrm{~A} / \mathrm{B}-\mathrm{B} / \mathrm{C}$ & 39,360 & 1.27 & 0.00015 & $\overline{0}$ \\
\hline 1 & $\mathrm{~A} / \mathrm{B}-\mathrm{B} / \mathrm{C}$ & 59,040 & 1.27 & 0.00015 & 0 \\
\hline 1 & A/B-B/C & 78,720 & 1.27 & 0.00015 & 0 \\
\hline 1 & $A / B-B / C$ & 98,460 & 1.27 & 0.00015 & 0 \\
\hline 1 & $B / C-C / D$ & 19,680 & 1.89 & 0.00015 & 0 \\
\hline 1 & $\mathrm{~B} / \mathrm{C}-\mathrm{C} / \mathrm{D}$ & 39,360 & 1.89 & 0.00015 & $\overline{0}$ \\
\hline 1 & $\mathrm{~B} / \mathrm{C}-\mathrm{C} / \mathrm{D}$ & 59,040 & 1.89 & 0.00015 & 0 \\
\hline 1 & $B / C-C / D$ & 78,720 & 1.89 & 0.00015 & 0 \\
\hline 1 & $\mathrm{~B} / \mathrm{C}-\mathrm{C} / \mathrm{D}$ & 98,460 & 1.89 & 0.00015 & 0 \\
\hline 1 & C/D-D/E & 19,680 & 2.49 & 0.00015 & 0 \\
\hline 1 & C/D-D/E & 39,360 & 2.49 & 0.00015 & 0 \\
\hline 1 & C/D-D/E & 59,040 & 2.49 & 0.00015 & 0 \\
\hline 1 & C/D-D/E & 78,720 & 2.49 & 0.00015 & 0 \\
\hline 1 & C/D-D/E & 98,460 & 2.49 & 0.00015 & 0 \\
\hline 1 & D/E-F & 19,680 & 3.08 & 0.00015 & $\overline{0}$ \\
\hline 1 & $\mathrm{D} / \mathrm{E}-\mathrm{F}$ & 39,360 & 3.08 & 0.00015 & $\overline{0}$ \\
\hline 1 & $\mathrm{D} / \mathrm{E}-\mathrm{F}$ & 59,040 & 3.08 & 0.00015 & 0 \\
\hline 1 & D/E-F & 78,720 & 3.08 & 0.00015 & 0 \\
\hline 1 & D/E-F & 98,460 & 3.08 & 0.00015 & 0 \\
\hline 3 & I-A/B & 8,580 & 0.66 & 0.00036 & 0.069659929 \\
\hline 3 & I-A/B & 17,100 & 0.66 & 0.00036 & 0.086727607 \\
\hline 3 & $1-A / B$ & 34,260 & 0.66 & 0.00036 & 0.116415157 \\
\hline 3 & $1-A / B$ & 42,840 & 0.66 & 0.00036 & 0.131056036 \\
\hline 3 & I-A/B & 59,040 & 0.66 & 0.00036 & 0.156631204 \\
\hline 3 & I-A/B & 78,720 & 0.66 & 0.00036 & 0.133942694 \\
\hline 3 & $\mathrm{I}-\mathrm{A} / \mathrm{B}$ & 98,460 & 0.66 & 0.00036 & 0.06635301 \\
\hline 3 & A/B-B/C & 8,580 & 1.27 & 0.00036 & 0 \\
\hline 3 & $\mathrm{~A} / \mathrm{B}-\mathrm{B} / \mathrm{C}$ & 17,100 & 1.27 & 0.00036 & 0 \\
\hline 3 & $\mathrm{~A} / \mathrm{B}-\mathrm{B} / \mathrm{C}$ & 34,260 & 1.27 & 0.00036 & 0 \\
\hline 3 & $\mathrm{~A} / \mathrm{B}-\mathrm{B} / \mathrm{C}$ & 42,840 & 1.27 & 0.00036 & 0 \\
\hline 3 & $\mathrm{~A} / \mathrm{B}-\mathrm{B} / \mathrm{C}$ & 59,040 & 1.27 & 0.00036 & 0 \\
\hline 3 & $A / B-B / C$ & 78,720 & 1.27 & 0.00036 & $\overline{0}$ \\
\hline 3 & $\mathrm{~A} / \mathrm{B}-\mathrm{B} / \mathrm{C}$ & 98,460 & 1.27 & 0.00036 & 0 \\
\hline 3 & $B / C-C / D$ & 8,580 & 1.89 & 0.00036 & 0 \\
\hline 3 & $\mathrm{~B} / \mathrm{C}-\mathrm{C} / \mathrm{D}$ & 17,100 & 1.89 & 0.00036 & 0 \\
\hline 3 & $B / C-C / D$ & 34,260 & 1.89 & 0.00036 & 0 \\
\hline 3 & $\mathrm{~B} / \mathrm{C}-\mathrm{C} / \mathrm{D}$ & 42,840 & 1.89 & 0.00036 & 0 \\
\hline 3 & $B / C-C / D$ & 59,040 & 1.89 & 0.00036 & 0 \\
\hline 3 & $\mathrm{~B} / \mathrm{C}-\mathrm{C} / \mathrm{D}$ & 78,720 & 1.89 & 0.00036 & 0 \\
\hline 3 & $B / C-C / D$ & 98,460 & 1.89 & 0.00036 & 0 \\
\hline 3 & C/D-D/E & 8,580 & 2.49 & 0.00036 & 0 \\
\hline 3 & C/D-D/E & 17,100 & 2.49 & 0.00036 & 0 \\
\hline 3 & C/D-D/E & 34,260 & 2.49 & 0.00036 & 0 \\
\hline 3 & C/D-D/E & 42,840 & 2.49 & 0.00036 & 0 \\
\hline
\end{tabular}


DOE/RL-2009-35, REV. 0

\begin{tabular}{|c|c|c|c|c|c|}
\hline \multicolumn{6}{|c|}{ MLR Input } \\
\hline Flow Cell & $\begin{array}{l}\text { Flow Cell } \\
\text { Segment }\end{array}$ & $\begin{array}{l}\text { Time } \\
\text { sec }\end{array}$ & $\begin{array}{c}\text { Distance } \\
\mathrm{m}\end{array}$ & $\begin{array}{l}\text { Velocity } \\
\mathrm{m} / \mathrm{sec}\end{array}$ & $\begin{array}{c}\text { MDS } \\
\mathrm{Kg}-\mathrm{F} / \mathrm{Kg}-\mathrm{S}\end{array}$ \\
\hline 3 & C/D-D/E & 59,040 & 2.49 & 0.00036 & 0 \\
\hline 3 & C/D-D/E & 78,720 & 2.49 & 0.00036 & 0 \\
\hline 3 & C/D-D/E & 98,460 & 2.49 & 0.00036 & 0 \\
\hline 3 & D/E-F & 8,580 & 3.08 & 0.00036 & 0 \\
\hline 3 & D/E-F & 17,100 & 3.08 & 0.00036 & $\overline{0}$ \\
\hline 3 & $\mathrm{D} / \mathrm{E}-\mathrm{F}$ & 34,260 & 3.08 & 0.00036 & 0 \\
\hline 3 & D/E-F & 42,840 & 3.08 & 0.00036 & $\overline{0}$ \\
\hline 3 & $\mathrm{D} / \mathrm{E}-\mathrm{F}$ & 59,040 & 3.08 & 0.00036 & 0 \\
\hline 3 & D/E-F & 78,720 & 3.08 & 0.00036 & 0 \\
\hline 3 & D/E-F & 98,460 & 3.08 & 0.00036 & 0 \\
\hline 5 & $1-A / B$ & 3,720 & 0.66 & 0.00088 & 0.006107377 \\
\hline 5 & $|-A| B$ & 7,440 & 0.66 & 0.00088 & 0.012251242 \\
\hline 5 & I-A/B & 11,160 & 0.66 & 0.00088 & 0.018341978 \\
\hline 5 & I-A/B & 14,880 & 0.66 & 0.00088 & 0.024229926 \\
\hline 5 & I-A/B & 18,600 & 0.66 & 0.00088 & 0.02863036 \\
\hline 5 & $1-A / B$ & 39,360 & 0.66 & 0.00088 & 0.046232857 \\
\hline 5 & $\mathrm{I}-\mathrm{A} / \mathrm{B}$ & 59,040 & 0.66 & 0.00088 & 0.028454123 \\
\hline 5 & $1-A / B$ & 78,720 & 0.66 & 0.00088 & 0.02227818 \\
\hline 5 & $\mid-A / B$ & 98,460 & 0.66 & 0.00088 & 0.054084794 \\
\hline 5 & $\mathrm{~A} / \mathrm{B}-\mathrm{B} / \mathrm{C}$ & 3,720 & 1.27 & 0.00088 & 0 \\
\hline 5 & $\mathrm{~A} / \mathrm{B}-\mathrm{B} / \mathrm{C}$ & 7,440 & 1.27 & 0.00088 & $\overline{0}$ \\
\hline 5 & $A / B-B / C$ & 11,160 & 1.27 & 0.00088 & 0 \\
\hline 5 & $\mathrm{~A} / \mathrm{B}-\mathrm{B} / \mathrm{C}$ & 14,880 & 1.27 & 0.00088 & 0 \\
\hline 5 & $\mathrm{~A} / \mathrm{B}-\mathrm{B} / \mathrm{C}$ & 18,600 & 1.27 & 0.00088 & 0 \\
\hline 5 & $\mathrm{~A} / \mathrm{B}-\mathrm{B} / \mathrm{C}$ & 39,360 & 1.27 & 0.00088 & 0.021587892 \\
\hline 5 & $\mathrm{~A} / \mathrm{B}-\mathrm{B} / \mathrm{C}$ & 59,040 & 1.27 & 0.00088 & 0.042662589 \\
\hline 5 & $\mathrm{~A} / \mathrm{B}-\mathrm{B} / \mathrm{C}$ & 78,720 & 1.27 & 0.00088 & 0.026165159 \\
\hline 5 & $\mathrm{~A} / \mathrm{B}-\mathrm{B} / \mathrm{C}$ & 98,460 & 1.27 & 0.00088 & 0.027318251 \\
\hline 5 & $\mathrm{~B} / \mathrm{C}-\mathrm{C} / \mathrm{D}$ & 3,720 & 1.89 & 0.00088 & 0 \\
\hline 5 & $\mathrm{~B} / \mathrm{C}-\mathrm{C} / \mathrm{D}$ & 7,440 & 1.89 & 0.00088 & 0 \\
\hline 5 & $\mathrm{~B} / \mathrm{C}-\mathrm{C} / \mathrm{D}$ & 11,160 & 1.89 & 0.00088 & 0 \\
\hline 5 & $\mathrm{~B} / \mathrm{C}-\mathrm{C} / \mathrm{D}$ & 14,880 & 1.89 & 0.00088 & 0 \\
\hline 5 & $\mathrm{~B} / \mathrm{C}-\mathrm{C} / \mathrm{D}$ & 18,600 & 1.89 & 0.00088 & 0 \\
\hline 5 & $\mathrm{~B} / \mathrm{C}-\mathrm{C} / \mathrm{D}$ & 39,360 & 1.89 & 0.00088 & 0 \\
\hline 5 & $\mathrm{~B} / \mathrm{C}-\mathrm{C} / \mathrm{D}$ & 59,040 & 1.89 & 0.00088 & 0.047126525 \\
\hline 5 & $\mathrm{~B} / \mathrm{C}-\mathrm{C} / \mathrm{D}$ & 78,720 & 1.89 & 0.00088 & 0.04813362 \\
\hline 5 & $\mathrm{~B} / \mathrm{C}-\mathrm{C} / \mathrm{D}$ & 98,460 & 1.89 & 0.00088 & 0.050600464 \\
\hline 5 & $\mathrm{C} / \mathrm{D}-\mathrm{D} / \mathrm{E}$ & 3,720 & 2.49 & 0.00088 & 0 \\
\hline 5 & C/D-D/E & 7,440 & 2.49 & 0.00088 & 0 \\
\hline 5 & $\mathrm{C} / \mathrm{D}-\mathrm{D} / \mathrm{E}$ & 11,160 & 2.49 & 0.00088 & 0 \\
\hline 5 & C/D-D/E & 14,880 & 2.49 & 0.00088 & 0 \\
\hline 5 & C/D-D/E & 18,600 & 2.49 & 0.00088 & 0 \\
\hline 5 & C/D-D/E & 39,360 & 2.49 & 0.00088 & 0 \\
\hline 5 & C/D-D/E & 59,040 & 2.49 & 0.00088 & 0.007863981 \\
\hline 5 & $\mathrm{C} / \mathrm{D}-\mathrm{D} / \mathrm{E}$ & 78,720 & 2.49 & 0.00088 & 0.048033288 \\
\hline 5 & C/D-D/E & 98,460 & 2.49 & 0.00088 & 0.03467307 \\
\hline 5 & D/E-F & 3,720 & 3.08 & 0.00088 & 0 \\
\hline 5 & D/E-F & 7,440 & 3.08 & 0.00088 & 0 \\
\hline 5 & $D / E-F$ & 11,160 & 3.08 & 0.00088 & 0 \\
\hline 5 & $\mathrm{D} / \mathrm{E}-\mathrm{F}$ & 14,880 & 3.08 & 0.00088 & 0 \\
\hline
\end{tabular}


DOE/RL-2009-35, REV. 0

\begin{tabular}{|c|c|c|c|c|c|}
\hline \multicolumn{6}{|c|}{ MLR Input } \\
\hline Flow Cell & $\begin{array}{l}\text { Flow Cell } \\
\text { Segment }\end{array}$ & $\begin{array}{c}\text { Time } \\
\text { sec }\end{array}$ & $\begin{array}{c}\text { Distance } \\
\mathrm{m}\end{array}$ & $\begin{array}{l}\text { Velocity } \\
\mathrm{m} / \mathrm{sec}\end{array}$ & $\begin{array}{c}\text { MDS } \\
\mathrm{Kg}-\mathrm{F} / \mathrm{Kg}-\mathrm{S}\end{array}$ \\
\hline 5 & D/E-F & 18,600 & 3.08 & 0.00088 & 0 \\
\hline 5 & $D / E-F$ & 39,360 & 3.08 & 0.00088 & 0 \\
\hline 5 & D/E-F & 59,040 & 3.08 & 0.00088 & 0 \\
\hline 5 & D/E-F & 78,720 & 3.08 & 0.00088 & 0.026019917 \\
\hline 5 & D/E-F & 98,460 & 3.08 & 0.00088 & 0.024347108 \\
\hline 8 & I-A/B & 1,620 & 0.66 & 0.001839872 & 0.005429465 \\
\hline 8 & $1-A / B$ & 3,240 & 0.66 & 0.001839872 & 0.010871217 \\
\hline 8 & $\mid-A / B$ & 4,860 & 0.66 & 0.001839872 & 0.015301534 \\
\hline 8 & I-A/B & 6,480 & 0.66 & 0.001839872 & 0.02019015 \\
\hline 8 & $\mathrm{I}-\mathrm{A} / \mathrm{B}$ & 8,100 & 0.66 & 0.001839872 & 0.02458395 \\
\hline 8 & $1-A / B$ & 19,680 & 0.66 & 0.001839872 & 0.044188012 \\
\hline 8 & I-A/B & 39,360 & 0.66 & 0.001839872 & 0.063438069 \\
\hline 8 & I-A/B & 59,040 & 0.66 & 0.001839872 & 0.125056523 \\
\hline 8 & $1-A / B$ & 78,720 & 0.66 & 0.001839872 & 0.049837122 \\
\hline 8 & A/B-B/C & 1,620 & 1.27 & 0.001839872 & 0 \\
\hline 8 & $\mathrm{~A} / \mathrm{B}-\mathrm{B} / \mathrm{C}$ & 3,240 & 1.27 & 0.001839872 & 0 \\
\hline 8 & $\mathrm{~A} / \mathrm{B}-\mathrm{B} / \mathrm{C}$ & 4,860 & 1.27 & 0.001839872 & 0.001641444 \\
\hline 8 & $\mathrm{~A} / \mathrm{B}-\mathrm{B} / \mathrm{C}$ & 6,480 & 1.27 & 0.001839872 & 0.002520672 \\
\hline 8 & $\mathrm{~A} / \mathrm{B}-\mathrm{B} / \mathrm{C}$ & 8,100 & 1.27 & 0.001839872 & 0.004681792 \\
\hline 8 & $\mathrm{~A} / \mathrm{B}-\mathrm{B} / \mathrm{C}$ & 19,680 & 1.27 & 0.001839872 & 0.033057203 \\
\hline 8 & $\mathrm{~A} / \mathrm{B}-\mathrm{B} / \mathrm{C}$ & 39,360 & 1.27 & 0.001839872 & 0.060598388 \\
\hline 8 & $\mathrm{~A} / \mathrm{B}-\mathrm{B} / \mathrm{C}$ & 59,040 & 1.27 & 0.001839872 & 0.048900192 \\
\hline 8 & $\mathrm{~A} / \mathrm{B}-\mathrm{B} / \mathrm{C}$ & 78,720 & 1.27 & 0.001839872 & 0.077113904 \\
\hline 8 & $\mathrm{~B} / \mathrm{C}-\mathrm{C} / \mathrm{D}$ & 1,620 & 1.89 & 0.001839872 & 0 \\
\hline 8 & $\mathrm{~B} / \mathrm{C}-\mathrm{C} / \mathrm{D}$ & 3,240 & 1.89 & 0.001839872 & $\overline{0}$ \\
\hline 8 & $\mathrm{~B} / \mathrm{C}-\mathrm{C} / \mathrm{D}$ & 4,860 & 1.89 & 0.001839872 & 0 \\
\hline 8 & $\mathrm{~B} / \mathrm{C}-\mathrm{C} / \mathrm{D}$ & 6,480 & 1.89 & 0.001839872 & 0 \\
\hline 8 & $\mathrm{~B} / \mathrm{C}-\mathrm{C} / \mathrm{D}$ & 8,100 & 1.89 & 0.001839872 & 0 \\
\hline 8 & $B / C-C / D$ & 19,680 & 1.89 & 0.001839872 & 0.002725499 \\
\hline 8 & $\mathrm{~B} / \mathrm{C}-\mathrm{C} / \mathrm{D}$ & 39,360 & 1.89 & 0.001839872 & 0.052892354 \\
\hline 8 & $\mathrm{~B} / \mathrm{C}-\mathrm{C} / \mathrm{D}$ & 59,040 & 1.89 & 0.001839872 & 0.050773445 \\
\hline 8 & $\mathrm{~B} / \mathrm{C}-\mathrm{C} / \mathrm{D}$ & 78,720 & 1.89 & 0.001839872 & 0.094031237 \\
\hline 8 & $\mathrm{C} / \mathrm{D}-\mathrm{D} / \mathrm{E}$ & 1,620 & 2.49 & 0.001839872 & 0 \\
\hline 8 & C/D-D/E & 3,240 & 2.49 & 0.001839872 & 0 \\
\hline 8 & $\mathrm{C} / \mathrm{D}-\mathrm{D} / \mathrm{E}$ & 4,860 & 2.49 & 0.001839872 & 0 \\
\hline 8 & C/D-D/E & 6,480 & 2.49 & 0.001839872 & 0 \\
\hline 8 & C/D-D/E & 8,100 & 2.49 & 0.001839872 & 0 \\
\hline 8 & C/D-D/E & 19,680 & 2.49 & 0.001839872 & 0 \\
\hline 8 & C/D-D/E & 39,360 & 2.49 & 0.001839872 & 0 \\
\hline 8 & C/D-D/E & 59,040 & 2.49 & 0.001839872 & 0.015726759 \\
\hline 8 & C/D-D/E & 78,720 & 2.49 & 0.001839872 & 0.104380947 \\
\hline 8 & D/E-F & 1,620 & 3.08 & 0.001839872 & 0 \\
\hline 8 & $\mathrm{D} / \mathrm{E}-\mathrm{F}$ & 3,240 & 3.08 & 0.001839872 & 0 \\
\hline 8 & $D / E-F$ & 4,860 & 3.08 & 0.001839872 & 0 \\
\hline 8 & D/E-F & 6,480 & 3.08 & 0.001839872 & 0 \\
\hline 8 & $D / E-F$ & 8,100 & 3.08 & 0.001839872 & 0 \\
\hline 8 & $\mathrm{D} / \mathrm{E}-\mathrm{F}$ & 19,680 & 3.08 & 0.001839872 & 0 \\
\hline 8 & $\mathrm{D} / \mathrm{E}-\mathrm{F}$ & 39,360 & 3.08 & 0.001839872 & 0 \\
\hline 8 & D/E-F & 59,040 & 3.08 & 0.001839872 & 0 \\
\hline 8 & D/E-F & 78,720 & 3.08 & 0.001839872 & 0.073820755 \\
\hline
\end{tabular}


DOE/RL-2009-35, REV. 0

SUMMARY MLR OUTPUT

\begin{tabular}{lr}
\hline \multicolumn{2}{c}{ Regression Statistics } \\
\hline Multiple R & 0.591991011 \\
R Square & 0.350453357 \\
Adjusted R Squ & 0.337106508 \\
Standard Error & 0.027488478 \\
Observations & 150 \\
\hline
\end{tabular}

ANOVA

\begin{tabular}{|c|c|c|c|c|c|c|c|c|}
\hline & $d f$ & SS & $M S$ & $F$ & Significance $F$ & & & \\
\hline Regression & 3 & 0.059521534 & 0.019840511 & 26.25738565 & $1.21492 \mathrm{E}-13$ & & & \\
\hline Residual & 146 & 0.110319994 & 0.000755616 & & & & & \\
\hline Total & 149 & 0.169841528 & & & & & & \\
\hline & Coefficients & Standard Error & t Stat & $P$-value & Lower 95\% & Upper 95\% & Lower $95.0 \%$ & Upper $95.0 \%$ \\
\hline Intercept & 0.032181217 & 0.007578337 & 4.246474716 & $3.84716 \mathrm{E}-05$ & 0.017203804 & 0.047158631 & 0.017203804 & 0.047158631 \\
\hline Time (sec) & 3.77181E-07 & 7.57626E-08 & 4.978453518 & 1.78332E-06 & 2.27447E-07 & 5.26914E-07 & 2.27447E-07 & $5.26914 \mathrm{E}-07$ \\
\hline Dist (m) & -0.019203475 & 0.002618796 & -7.332940584 & 1.42923E-11 & -0.024379121 & -0.014027829 & -0.024379121 & -0.014027829 \\
\hline $\mathrm{Vel}(\mathrm{m} / \mathrm{sec})$ & 8.440941266 & 3.693892544 & 2.285107421 & 0.023746976 & 1.140532881 & 15.74134965 & 1.140532881 & 15.74134965 \\
\hline
\end{tabular}




\section{C7 Modeling}

The following provides an example of the input file for PORFLOW ${ }^{\mathrm{TM}}$ modeling for $14 \mathrm{gpm} \mathrm{nZVI}$ fluid injection rate.

$$
l====\text { PROBLEM IDENTIFICATION }====l
$$

TITLE MZ14BF ZVI RNIP NANO IRON INJECTION PROJECT

USER MAREK ZALUSKI

GRID 109 BY 82

PROBLEM WITH FREE SURFACE X K FACTOR=0:01 !INVOKE RICHRDS EQUATION MODE GRAVITY VECTOR $-9.810 . \overline{0}$ !ORIENTATION OF GRAVITY VECTOR

DATUM 5,0,0 !INITIAL WATER LEVEL LOCATION

COORDINATES CYLINDRICAL X R BLOCK 1 'MAREK.GRD'

ALLOCATE ZVI

ALLOCATE ZVIC

ALLOCATE ZVIK

ALLOCATE ZVIR

ALLOCATE CONSERVE

ALLOCATE RETARDED

ALLOCATE KHYDRAULIC

LOCATE ID=A

$(2,2)$ TO $(2,81)$

LOCATE ID=B

$(3,2)$ TO $(6,81)$

LOCATE ID=C

$(7,2)$ TO $(9,81)$

LOCATE ID=D

$(10,2)$ TO $(11,81)$

LOCATE ID=E

LOCATE ID $=F$

$(12,2)$ TO $(12,81)$

LOCATE ID=G

$(13,2)$ TO $(14,81)$

LOCATE ID $=\mathrm{H}$

$(15,2)$ TO $(15,81)$

$(16,2)$ TO $(17,81)$

LOCATE ID=GENERAL $(2,2)$ TO $(108,81)$ !ALL DOMAIN INCLUDING WELL

LOCATE ID=HANFORD $(49,2)$ TO $(108,81)$ !HANFORD INCLUDING WELL LOCATE ID=SATURATED $(2,2)$ TO $(18,81)$

LOCATE ID=VADOSE $(19,2)$ TO $(108,81)$

LOCATE ID=SANDPACK $(2,2)$ TO $(26,5)$ !INCLUDING SCREEN (INJECTION)

LOCATE ID=INJECTION LIST 'INJECTION.LOC' 34 ITEMS FOR SCREEN

LOCATE ID=INACTIVE LIST 'INACTIVE.LOC' 328 ITEMS FOR GROUTED CASING ABOVE PACKER SET KHYDRAULIC ID=A 2.3E-3

SET KHYDRAULIC ID=B 7.3E-4

SET KHYDRAULIC ID=C $1.9 E-4$

SET KHYDRAULIC ID=D 1E-07

SET KHYDRAULIC ID=E 3.5E-4

SET KHYDRAULIC ID=F 8.6E-5

SET KHYDRAULIC ID=G 4.6E-4

SET KHYDRAULIC ID $=\mathrm{H} 1.3 \mathrm{E}-4$

SET ZVI ZALUSKI

$(2,2) \mathrm{Q}=0.00127$, TSTART $=1$, TEND $=417403 \mathrm{FRAC}=0.850 .032183 .77 \mathrm{E}-7$ 0.0192 24.12 PRINT 'ZAL.HIS' ALWAYS

SET ZVIC ZALUSKI CONSERVE $\quad(2,2) \mathrm{Q}=0.00127$, TSTART $=1$, TEND $=417403 \mathrm{FRAC}=0.850 .03218$ 3.77E-7 -0.0192 24.12 PRINT 'ZAL.HIS' ALWAYS

SET ZVIK ZALUSKI KHYDRAULIC $(2,2) Q=0.00127$, TSTART $=1$, TEND $=417403$ FRAC $=0.850 .03218$ 3.77E-7 -0.0192 24.12 PRINT 'ZAL.HIS' ALWAYS

SET ZVIR ZALUSKI RETARDED $\quad(2,2) \mathrm{Q}=0.00127$, TSTART $=1$, TEND $=417403 \mathrm{FRAC}=0.850 .03218$ 3.77E-7 -0.0192 24.12 PRINT 'ZAL.HIS' ALWAYS

$l====$ GEOMETRY SPECIFICATIONS $\quad====\mid$ 
MATERIAL TYPE 4 AS THE SUBREGION ID = GENERAL ! K=16 M/D !ALL DOMAIN INCLUDING WELL

, BUT USED ONLY FOR UNSAT RINGOLD

MATERIAL TYPE 1 AS THE SUBREGION ID = HANFORD $! \mathrm{K}=125 \mathrm{M} / \mathrm{D}$ !HANFORD INCLUDING WELL MATERIAL TYPE 11 AS THE SUBREGION ID = A

MATERIAL TYPE 12 AS THE SUBREGION ID = B

MATERIAL TYPE 13 AS THE SUBREGION ID $=\mathrm{C}$

MATERIAL TYPE 14 AS THE SUBREGION ID = D

MATERIAL TYPE 15 AS THE SUBREGION ID = E

MATERIAL TYPE 16 AS THE SUBREGION ID $=F$

MATERIAL TYPE 17 AS THE SUBREGION ID $=\mathrm{G}$

MATERIAL TYPE 18 AS THE SUBREGION ID $=\mathrm{H}$

MATERIAL TYPE 9 AS THE SUBREGION ID = INACTIVE !K=1.E-6 M/D FOR GROUTED CASING ABOVE PACKER

MATERIAL TYPE 3 AS THE SUBREGION ID = SANDPACK !K=691 M/D !INCLUDING SCREEN

(INJECTION)

MATERIAL TYPE 19 AS THE SUBREGION ID = INJECTION !K=1000000 M/D FOR SCREEN SECTION SYMMETRY R-

BOUNDARY X-FLUX OF P 0.0 !NO FLOW BOUNDARY

BOUNDARY $X+F L U X$ OF P $0.0 \quad$ !NO FLOW BOUNDARY

BOUNDARY Y+ FLUX OF P 0.0 ID=VADOSE !NO FLOW BOUNDARY

BOUNDARY $Y+V A L U E$ OF H 0.0 ID=SATURATED !BOUNDARY CONDITION FOR TOTAL HEAD BOUNDARY X- CONSERVE FLUX $=0$

BOUNDARY $X+$ CONSERVE VALUE $=0$

BOUNDARY $Y+$ CONSERVE GRAD $=0$

BOUNDARY $X$ - RETARDED FLUX $=0$

BOUNDARY $X+$ RETARDED VALUE $=0$

BOUNDARY $Y+$ RETARDED GRAD $=0$

SET INITIAL VALUE OF H 0.0 !REFERENCE TOTAL HEAD AT START

SOURCE FLOW ID =INJECTION TOTAL $Q=0.000141$ RETARDED $=1$ CONSERVE $=1 . \quad ! M^{\wedge} 3 / \mathrm{S}$

DENSITY OF FLUID 1000

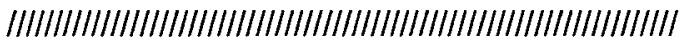

$l===$ SOLID MATRIX PROPERTIES $\quad====1$

FOR TYPE 4

MATERIAL DENSITY 2600

MATERIAL POROSITY 0.3

TRANSPORT FOR CONSERVE KD $=0 . D M=1 . E-16$

TRANSPORT FOR RETARDED KD=0.005 DM $=1 . \mathrm{E}-16$

HYDRAULLIC PROPERTIES 0.0 1.9E-5 1.9E-4 !

FOR TYPE 1

MATERIAL DENSITY 2600

MATERIAL POROSITY 0.3

TRANSPORT FOR CONSERVE KD $=0 . D M=1 . E-16$

TRANSPORT FOR RETARDED KD $=0.005 \mathrm{DM}=1 . \mathrm{E}-16$

HYDRAULLIC PROPERTIES 0.0 1.4E-4 1.4E-3 !

FOR TYPE 9 !INACTIVE REGION

MATERIAL DENSITY 2600

MATERIAL POROSITY 0.3

TRANSPORT FOR CONSERVE KD $=0 . D M=1 . E-16$

TRANSPORT FOR RETARDED KD $=0.005 \mathrm{DM}=1 . \mathrm{E}-16$

HYDRAULLIC PROPERTIES 0.0 1.000E-11 1.000E-11 !

FOR TYPE 11 !ZONE A

MATERIAL DENSITY 2600

MATERIAL POROSITY 0.3

TRANSPORT FOR CONSERVE KD $=0 . D M=1 . E-16$

TRANSPORT FOR RETARDED KD=0.005 DM $=1 . E-16$ 
HYDRAULLIC PROPERTIES 0.0 2.3E-04 2.3E-03

FOR TYPE 12 !ZONE B

MATERIAL DENSITY 2600

MATERIAL POROSITY 0.3

TRANSPORT FOR CONSERVE KD $=0 . D M=1 . E-16$

TRANSPORT FOR RETARDED KD $=0.005 \mathrm{DM}=1 . \mathrm{E}-16$

HYDRAULLIC PROPERTIES 0.0 7.3E-05 7.3E-04

FOR TYPE 13 !ZONE C

MATERIAL DENSITY 2600

MATERIAL POROSITY 0.3

TRANSPORT FOR CONSERVE KD $=0 . D M=1 . E-16$

TRANSPORT FOR RETARDED KD=0.005 DM = $1 . \mathrm{E}-16$

HYDRAULLIC PROPERTIES 0.0 1.9E-05 1.9E-04

FOR TYPE 14 !ZONE D

MATERIAL DENSITY 2600

MATERIAL POROSITY 0.3

TRANSPORT FOR CONSERVE KD $=0 . D M=1 . E-16$

TRANSPORT FOR RETARDED KD $=0.005 \mathrm{DM}=1 . \mathrm{E}-16$

HYDRAULLIC PROPERTIES 0.0 1E-08 1E-07

FOR TYPE 15 !ZONE E

MATERIAL DENSITY 2600

MATERIAL POROSITY 0.3

TRANSPORT FOR CONSERVE KD=0. DM $=1 . E-16$

TRANSPORT FOR RETARDED $K D=0.005 \mathrm{DM}=1 . \mathrm{E}-16$

HYDRAULLIC PROPERTIES 0.0 3.5E-05 3.5E-04

FOR TYPE 16 !ZONE F

MATERIAL DENSITY 2600

MATERIAL POROSITY 0.3

TRANSPORT FOR CONSERVE KD=0. DM $=1 . E-16$

TRANSPORT FOR RETARDED KD $=0.005 \mathrm{DM}=1 . \mathrm{E}-16$

HYDRAULLIC PROPERTIES 0.0 8.6E-06 8.6E-05

FOR TYPE 17 !ZONE G

MATERIAL DENSITY 2600

MATERIAL POROSITY 0.3

TRANSPORT FOR CONSERVE KD=0. DM $=1 . E-16$

TRANSPORT FOR RETARDED KD $=0.005 \mathrm{DM}=1 . \mathrm{E}-16$

HYDRAULLIC PROPERTIES 0.0 4.6E-05 4.6E-04

FOR TYPE 18 ! ZONE H

MATERIAL DENSITY 2600

MATERIAL POROSITY 0.3

TRANSPORT FOR CONSERVE KD=0. DM $=1 . E-16$

TRANSPORT FOR RETARDED KD $=0.005 \mathrm{DM}=1 . \mathrm{E}-16$

HYDRAULLIC PROPERTIES 0.0 1.3E-05 1.3E-04

FOR TYPE 3

MATERIAL DENSITY 2600

MATERIAL POROSITY 0.3

TRANSPORT FOR CONSERVE KD $=0 . \mathrm{DM}=1 . \mathrm{E}-16$

TRANSPORT FOR RETARDED KD $=0.005 \mathrm{DM}=1 . \mathrm{E}-16$

HYDRAULLIC PROPERTIES 0.0 8.0E-3 8.0E-3 !

FOR TYPE 19 !INJECTION ZONE

MATERIAL DENSITY 1010

MATERIAL POROSITY 1

TRANSPORT FOR CONSERVE KD=0. DM $=1 . E-16$

TRANSPORT FOR RETARDED KD $=0.005 \mathrm{DM}=1 . \mathrm{E}-16$

HYDRAULLIC PROPERTIES $0.0 \quad 1.2 E+11.2 E+1$

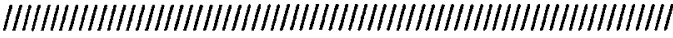


DOE/RL-2009-35, REV. 0

I SOLUTION CONTROL AND OUTPUT IIIIIIIIIIIIIIIIIIIIIIIIIIIIIIIIIIIIIIIIIIIIIIIIIIIIIIIIIIIIIIIIIIIII

CONVERGENCE FLOW REFERENCE 1.0E-8 10

CONVERGENCE P 1.0E-12 10

DIAGNOSTICS OUTPUT AT NODE $(13,5)$ TIME U P CONSERVE ZVIK BP PRINT FOR EVERY 10 STEPS

STAT ZVIK ID=A 'STAT_A.OUT' EVERY 86400 TIME STAT ZVIK ID=B 'STAT_B.OUT' EVERY 86400 TIME STAT ZVIK ID=C 'STAT_C.OUT' EVERY 86400 TIME STAT ZVIK ID=D 'STAT_D.OUT' EVERY 86400 TIME STAT ZVIK ID=E 'STATIE.OUT' EVERY 86400 TIME STAT ZVIK ID=F 'STAT_F.OUT' EVERY 86400 TIME STAT ZVIK ID=G 'STAT'G.OUT' EVERY 86400 TIME STAT ZVIK ID=H 'STAT_H.OUT' EVERY 86400 TIME

STAT ZVIK ID=INJECTION 'STAT_INJECTION.OUT' EVERY 86400 TIME STAT ZVIK ID=SANDPACK 'STAT_SANDPACK.OUT' EVERY 86400 TIME SAVE UVPHS ZVI ZVIC ZVIK ZVIR CONSERVE RETARDED KHYDRAULIC SEQUENCE EVERY 86400 SECONDS TIME

OUTPUT U V P H S ZVI ZVIC ZVIK ZVIR CONSERVE RETARDED KHYDRAULIC STAT NARROW SOLVE 4174031001.051000

WRITE ZVIK VOL 'VOL_TOTAL_14.OUT'

WRITE ZVIK VOL ID=A 'VOL_A.OUT'

WRITE ZVIK VOL ID=B 'VOL_B.OUT'

WRITE ZVIK VOL ID=C 'VOL_C.OUT'

WRITE ZVIK VOL ID=D 'VOL_D.OUT'

WRITE ZVIK VOL ID=E 'VOL_E.OUT'

WRITE ZVIK VOL ID=F 'VOL_F.OUT'

WRITE ZVIK VOL ID=G 'VOL_G.OUT'

WRITE ZVIK VOL ID=H 'VOL_H.OUT'

WRITE ZVIK VOL ID=INJECTION 'VŌLINJEC.OUT'

WRITE ZVIK VOL ID=SANDPACK 'VOL_SANDPACK.OUT'

END 
DOE/RL-2009-35, REV. 0

\section{Appendix D}

Field Test Plans 
DOE/RL-2009-35, REV. 0

This page intentionally left blank. 


\section{Field Test Plans}

This appendix contains the field test plans.

\section{D1 Field Injection Data Tables and Well Transducer Data}

\begin{tabular}{|c|c|c|c|c|c|c|c|}
\hline \multicolumn{8}{|c|}{ Well D4-25 YSI Data } \\
\hline Date \& Time & Sampler & $\begin{array}{c}\text { Sample } \\
\text { Collection } \\
\text { Method }\end{array}$ & $\begin{array}{c}\text { Temp } \\
\left({ }^{\circ} \mathrm{C}\right)\end{array}$ & $\begin{array}{c}\text { DO } \\
(\mathrm{mg} / \mathrm{L})\end{array}$ & $\begin{array}{l}\mathrm{pH} \\
\text { (SU) }\end{array}$ & $\begin{array}{c}\text { SC } \\
(\mu \mathrm{S} / \mathrm{cm})\end{array}$ & $\begin{array}{l}\text { ORP } \\
(\mathrm{mV})\end{array}$ \\
\hline $8 / 9 / 080: 52$ & NAJ & purged & 17.58 & 6.41 & 8.12 & 1022 & 110.2 \\
\hline $8 / 9 / 0810: 47$ & $\mathrm{KP}$ & flow cell & 17.48 & 4.38 & 8.29 & 993 & -21.9 \\
\hline $8 / 9 / 0813: 27$ & $\mathrm{KP}$ & flow cell & 17.68 & 3.97 & 8.35 & 963 & -4.8 \\
\hline $8 / 9 / 0817: 55$ & $\mathrm{KP}$ & flow cell & 17.36 & & 8.33 & 944 & -2.7 \\
\hline $8 / 9 / 0821: 43$ & NAJ & purged & 16.97 & 3.56 & 8.42 & 930 & 189.0 \\
\hline $8 / 10 / 082: 40$ & NAJ & purged & 16.50 & 4.18 & 7.90 & 852 & 63.0 \\
\hline $8 / 10 / 085: 32$ & NAJ & purged & 16.86 & 4.18 & 7.82 & 875 & 41.0 \\
\hline $8 / 10 / 0811: 40$ & KP & purged & 18.65 & 3.00 & 8.63 & 767 & 92.9 \\
\hline $8 / 10 / 0813: 55$ & $\mathrm{KP}$ & purged & 18.08 & 3.51 & 8.70 & 864 & 184.5 \\
\hline 8/10/08 17:50 & $\mathrm{KP}$ & \multicolumn{6}{|c|}{ pump stopped working } \\
\hline $8 / 10 / 0822: 10$ & NAJ & purged & 17.56 & 3.18 & 8.66 & 684 & 150.0 \\
\hline $8 / 11 / 083: 02$ & NAJ & purged & 17.01 & 3.55 & 8.34 & 765 & 73.5 \\
\hline $8 / 11 / 087: 00$ & NAJ & purged & 18.05 & 3.29 & 8.81 & 750 & 19.4 \\
\hline $8 / 11 / 0815: 45$ & $\mathrm{KP}$ & bailer & 20.10 & 3.08 & 8.50 & 791 & 158.2 \\
\hline $8 / 11 / 0820: 27$ & NAJ & bailer & 17.43 & 4.87 & 7.80 & 733 & 58.9 \\
\hline $8 / 11 / 0820: 44$ & NAJ & bailer & 20.06 & 3.26 & 8.39 & 735 & 151.8 \\
\hline 8/12/08 0:15 & NAJ & bailer & 16.83 & 2.18 & 8.49 & 725 & 97.4 \\
\hline 8/12/08 3:38 & NAJ & bailer & 16.88 & 2.22 & 8.30 & 719 & 80.8 \\
\hline $8 / 12 / 087: 40$ & $\mathrm{KP}$ & bailer & 17.31 & 2.62 & 8.55 & 703 & 54.0 \\
\hline $8 / 12 / 0811: 27$ & $\mathrm{KP}$ & bailer & 18.87 & 3.36 & 8.27 & 719 & 163.6 \\
\hline $8 / 12 / 0815: 20$ & $\mathrm{KP}$ & bailer & 18.53 & 3.11 & 8.01 & 704 & 119.5 \\
\hline $8 / 12 / 08$ 19:31 & NAJ & bailer & 18.64 & 2.75 & 8.30 & 695 & \\
\hline $8 / 12 / 0823: 04$ & NAJ & bailer & 18.05 & 3.03 & 8.42 & 679 & 64.8 \\
\hline $8 / 13 / 083: 15$ & NAJ & bailer & 17.61 & 3.20 & 8.70 & 670 & 79.3 \\
\hline $8 / 13 / 087: 47$ & NAJ & bailer & 19.19 & 2.85 & 8.79 & 672 & 53.8 \\
\hline $8 / 13 / 08$ 11:35 & $\mathrm{KP}$ & bailer & 20.76 & 3.23 & 8.73 & 669 & 129.2 \\
\hline $8 / 13 / 08$ 15:30 & KP & bailer & 19.57 & 3.30 & 8.66 & 668 & 44.0 \\
\hline $8 / 13 / 08 \quad 19: 21$ & KP & bailer & 19.23 & 3.30 & 8.72 & 668 & 130.2 \\
\hline $8 / 13 / 0822: 04$ & $\mathrm{KP}$ & bailer & 18.57 & 3.33 & 8.71 & 659 & 101.8 \\
\hline $8 / 14 / 081: 53$ & $\mathrm{KM}$ & bailer & 18.05 & 3.45 & 8.85 & 648 & 53.6 \\
\hline $8 / 14 / 085: 55$ & $A L$ & bailer & 17.39 & 3.54 & 8.94 & 646 & 37.8 \\
\hline $8 / 14 / 089: 25$ & $\mathrm{KP}$ & bailer & 18.91 & & 8.90 & 643 & -25.5 \\
\hline $8 / 14 / 0813: 30$ & $\mathrm{KP}$ & bailer & 19.68 & 3.64 & 8.94 & 649 & 41.2 \\
\hline $8 / 14 / 08$ 17:26 & $\mathrm{KP}$ & bailer & 20.49 & 3.20 & 8.78 & 651 & -21.8 \\
\hline $8 / 14 / 0822: 40$ & NAJ & bailer & 19.86 & 3.35 & 8.85 & 633 & -58.2 \\
\hline 8/16/08 10:34 & $A L$ & bailer & 25.32 & 2.94 & 8.76 & 627 & -16.5 \\
\hline $8 / 18 / 0811: 00$ & $A L$ & bailer & 31.25 & 2.89 & 8.68 & 611 & -45.3 \\
\hline $8 / 20 / 087: 33$ & $\mathrm{KP}$ & bailer & 18.13 & 2.94 & 8.74 & 626 & -25.2 \\
\hline $8 / 22 / 086: 45$ & $\mathrm{KP}$ & bailer & 16.80 & 3.95 & 8.81 & 677 & 103.0 \\
\hline
\end{tabular}


DOE/RL-2009-35, REV. 0

\begin{tabular}{|c|c|c|c|c|c|c|c|}
\hline \multicolumn{8}{|c|}{ Well D4-27 YSI Data } \\
\hline Date \& Time & Sampler & $\begin{array}{c}\text { Sample } \\
\text { Collection } \\
\text { Method }\end{array}$ & $\begin{array}{l}\text { Temp } \\
\left({ }^{\circ} \mathrm{C}\right)\end{array}$ & $\begin{array}{c}\mathrm{DO} \\
(\mathrm{mg} / \mathrm{L})\end{array}$ & $\begin{array}{c}\mathrm{pH} \\
\text { (SU) }\end{array}$ & $\begin{array}{c}\mathrm{SC} \\
(\mu \mathrm{S} / \mathrm{cm})\end{array}$ & $\begin{array}{l}\text { ORP } \\
(\mathrm{mV})\end{array}$ \\
\hline $8 / 9 / 082: 58$ & NAJ & purged & 17.29 & 4.52 & 7.70 & 647 & 112.0 \\
\hline $8 / 9 / 085: 35$ & NAJ & purged & 17.63 & 2.84 & 7.92 & 654 & 86.5 \\
\hline $8 / 9 / 08$ 9:19 & NAJ & purged & 18.28 & 2.15 & 8.16 & 658 & 26.5 \\
\hline $8 / 9 / 0813: 30$ & $\mathrm{KP}$ & flow cell & 17.61 & 2.88 & 8.18 & 664 & -32.5 \\
\hline $8 / 9 / 0817: 33$ & $\mathrm{KP}$ & flow cell & 17.79 & 3.00 & 8.15 & 665 & -4.8 \\
\hline $8 / 9 / 0822: 49$ & NAJ & purged & 16.93 & 4.04 & 8.06 & 653 & 164.7 \\
\hline 8/10/08 1:40 & NAJ & purged & 17.00 & 3.71 & 7.69 & 662 & 33.8 \\
\hline $8 / 10 / 085: 57$ & NAJ & purged & 16.70 & 3.19 & 7.71 & 655 & 70.5 \\
\hline $8 / 10 / 08$ 10:16 & $\mathrm{KP}$ & purged & 17.86 & 3.44 & 7.84 & 674 & 251.4 \\
\hline $8 / 10 / 08 \quad 14: 35$ & $\mathrm{KP}$ & purged & 17.87 & 3.43 & 8.26 & 667 & 200.4 \\
\hline $8 / 10 / 0817: 30$ & $\mathrm{KP}$ & purged & 17.68 & 4.17 & 8.22 & 656 & 163.4 \\
\hline $8 / 10 / 08$ 23:02 & NAJ & purged & 17.34 & 3.42 & 7.61 & 637 & 62.0 \\
\hline $8 / 11 / 080: 27$ & NAJ & purged & 16.96 & 3.55 & 7.90 & 636 & 61.0 \\
\hline $8 / 11 / 0815: 40$ & $\mathrm{KP}$ & bailer & 20.08 & 2.66 & 8.23 & 713 & 138.0 \\
\hline $8 / 11 / 0821: 00$ & NAJ & bailer & 17.47 & 3.21 & 7.97 & 673 & 155.20 \\
\hline $8 / 12 / 080: 38$ & NAJ & bailer & 16.52 & 2.85 & 8.26 & 637 & 134.10 \\
\hline 8/12/08 3:49 & NAJ & bailer & 16.58 & 3.14 & 8.05 & 653 & 85.90 \\
\hline $8 / 12 / 087: 55$ & $\mathrm{KP}$ & bailer & 18.16 & 3.43 & 8.26 & 680 & 87.50 \\
\hline $8 / 12 / 08 \quad 11: 40$ & KP & bailer & 20.72 & 3.32 & 7.96 & 683 & 162.20 \\
\hline $8 / 12 / 0815: 30$ & $\mathrm{KP}$ & bailer & 18.96 & 3.51 & 7.99 & 678 & 144.90 \\
\hline $8 / 12 / 08$ 19:42 & NAJ & bailer & 17.74 & 3.44 & 7.99 & 676 & 134.50 \\
\hline $8 / 12 / 0823: 17$ & NAJ & bailer & 17.49 & 2.98 & 8.16 & 663 & 82.3 \\
\hline $8 / 13 / 083: 24$ & NAJ & bailer & 17.04 & 3.00 & 8.18 & 666 & 101.3 \\
\hline $8 / 13 / 088: 00$ & NAJ & bailer & 18.06 & 3.46 & 8.22 & 667 & 97.4 \\
\hline 8/13/08 11:46 & $\mathrm{KP}$ & bailer & 19.62 & 3.22 & 8.28 & 663 & 149.1 \\
\hline $8 / 13 / 08 \quad 15: 42$ & $\mathrm{KP}$ & bailer & 19.24 & 3.11 & 8.23 & 656 & 84.6 \\
\hline $8 / 13 / 0819: 30$ & $\mathrm{KP}$ & bailer & 17.70 & 3.19 & 8.30 & 660 & 130.1 \\
\hline $8 / 13 / 0822: 16$ & $\mathrm{KP}$ & bailer & 17.82 & 3.50 & 8.34 & 656 & -2.7 \\
\hline $8 / 14 / 082: 09$ & $\mathrm{KM}$ & bailer & 17.18 & 3.11 & 8.32 & 647 & 104.8 \\
\hline 8/14/08 6:10 & $\mathrm{AL}$ & bailer & 16.52 & 3.73 & 8.19 & 654 & 77.4 \\
\hline 8/14/08 9:37 & $\mathrm{KP}$ & bailer & 18.24 & 3.46 & 8.40 & 654 & 12.6 \\
\hline $8 / 14 / 08 \quad 13: 54$ & $\mathrm{KP}$ & bailer & 18.72 & 3.49 & 8.36 & 659 & -12.9 \\
\hline $8 / 14 / 0817: 35$ & NAJ & bailer & 19.64 & 4.75 & 8.31 & 660 & -18.0 \\
\hline $8 / 14 / 0820: 45$ & NAJ & bailer & 18.35 & 3.03 & 8.21 & 641 & -40.6 \\
\hline $8 / 16 / 08 \quad 10: 55$ & $A L$ & bailer & 23.76 & 3.51 & 8.21 & 654 & -17.2 \\
\hline $8 / 18 / 08 \quad 11: 30$ & $A L$ & bailer & 29.05 & 3.23 & 8.13 & 663 & -36.0 \\
\hline $8 / 20 / 087: 55$ & $\mathrm{KP}$ & bailer & 17.30 & 3.00 & 8.07 & 651 & -18.5 \\
\hline $8 / 22 / 08$ 7:05 & $\mathrm{KP}$ & bailer & 16.18 & 3.60 & 8.18 & 684 & 136.6 \\
\hline
\end{tabular}




\begin{tabular}{|c|c|c|c|c|c|c|c|}
\hline \multicolumn{8}{|c|}{ Well D4-92 YSI Data } \\
\hline Date \& Time & Sampler & $\begin{array}{c}\text { Sample } \\
\text { Collection } \\
\text { Method }\end{array}$ & $\begin{array}{c}\text { Temp } \\
\left({ }^{\circ} \mathrm{C}\right)\end{array}$ & $\begin{array}{c}\text { DO } \\
(\mathrm{mg} / \mathrm{L})\end{array}$ & $\begin{array}{c}\mathrm{pH} \\
(\mathrm{SU})\end{array}$ & $\begin{array}{c}\text { SC } \\
(\mu \mathrm{S} / \mathrm{cm})\end{array}$ & $\begin{array}{l}\text { ORP } \\
(\mathrm{mV})\end{array}$ \\
\hline $8 / 9 / 080: 30$ & NAJ & purged & 18.16 & 3.07 & 8.13 & 677 & -12.4 \\
\hline $8 / 9 / 085: 25$ & NAJ & purged & 17.28 & 5.84 & 7.65 & 638 & 64.0 \\
\hline $8 / 9 / 088: 25$ & NAJ & purged & 17.68 & 5.37 & 8.74 & 604 & 59.3 \\
\hline $8 / 9 / 08$ 10:21 & $\mathrm{KP}$ & flow cell & 18.37 & 3.65 & 8.83 & 553 & -94.3 \\
\hline $8 / 9 / 0813: 40$ & $\mathrm{KP}$ & flow cell & 18.43 & 4.08 & 9.03 & 513 & -98.5 \\
\hline $8 / 9 / 08$ 18:08 & $\mathrm{KP}$ & flow cell & 18.55 & 2.69 & 9.17 & 497 & -126.5 \\
\hline $8 / 9 / 0823: 20$ & NAJ & purged & 19.65 & 1.59 & 9.52 & 526 & -127.8 \\
\hline $8 / 10 / 083: 03$ & NAJ & purged & 18.59 & 0.55 & 10.08 & 539 & -380.0 \\
\hline $8 / 10 / 086: 08$ & NAJ & purged & 18.88 & 0.51 & 10.18 & 561 & -359.0 \\
\hline $8 / 10 / 08$ 10:26 & $\mathrm{KP}$ & purged & 20.98 & 0.06 & 10.26 & 583 & -388.2 \\
\hline $8 / 10 / 0813: 32$ & $\mathrm{KP}$ & purged & 21.56 & 0.25 & 10.33 & 605 & -427.1 \\
\hline $8 / 10 / 0817: 17$ & $\mathrm{KP}$ & purged & 21.58 & 0.14 & 10.43 & 640 & -417.0 \\
\hline $8 / 10 / 0820: 30$ & NAJ & purged & 21.71 & 0.51 & 10.47 & 635 & -427.0 \\
\hline $8 / 11 / 081: 31$ & NAJ & purged & 19.30 & 0.60 & 10.35 & 609 & -388.8 \\
\hline $8 / 11 / 083: 50$ & NAJ & purged & 21.17 & 0.63 & 10.22 & 597 & -356.0 \\
\hline $8 / 11 / 08 \quad 14: 46$ & KP & bailer & 25.19 & 0.50 & 10.81 & 1462 & -436.0 \\
\hline $8 / 11 / 0818: 25$ & $\mathrm{KP}$ & bailer & 26.51 & 0.24 & 10.88 & 1662 & -491.6 \\
\hline $8 / 11 / 0820: 46$ & NAJ & bailer & 24.66 & 0.57 & & 871 & -427.00 \\
\hline $8 / 12 / 080: 27$ & NAJ & bailer & 24.42 & 0.61 & & 981 & -472.00 \\
\hline $8 / 12 / 084: 15$ & NAJ & bailer & 22.54 & 0.25 & 11.28 & 965 & \begin{tabular}{|l|}
-763.10 \\
\end{tabular} \\
\hline $8 / 12 / 088: 10$ & KP & bailer & 24.72 & 0.19 & 11.20 & 962 & -757.20 \\
\hline $8 / 12 / 0811: 45$ & $\mathrm{KP}$ & bailer & 26.48 & 0.19 & 11.21 & 990 & -582.00 \\
\hline $8 / 12 / 08$ 15:32 & $\mathrm{KP}$ & bailer & 27.06 & 0.33 & 11.14 & 1018 & -565.60 \\
\hline $8 / 12 / 0819: 52$ & NAJ & bailer & 22.48 & 0.20 & 11.16 & 1003 & -660.90 \\
\hline $8 / 12 / 0823: 58$ & NAJ & bailer & 25.99 & 0.18 & 11.25 & 1016 & \begin{tabular}{|l|}
-644.0 \\
\end{tabular} \\
\hline $8 / 13 / 083: 44$ & NAJ & bailer & 25.08 & 0.23 & 11.22 & 1005 & -642.0 \\
\hline $8 / 13 / 088: 36$ & NAJ & bailer & 26.57 & 0.15 & 11.10 & 1027 & -650.3 \\
\hline $8 / 13 / 0811: 57$ & $\mathrm{KP}$ & bailer & 26.60 & 0.37 & 11.07 & 1014 & -415.7 \\
\hline $8 / 13 / 0816: 00$ & $\mathrm{KP}$ & bailer & 27.84 & $\overline{0.12}$ & 11.10 & 1032 & -354.5 \\
\hline $8 / 13 / 08$ 19:43 & $\mathrm{KP}$ & bailer & 28.22 & $\overline{0.16}$ & 11.15 & 1053 & -519.7 \\
\hline $8 / 13 / 0822: 25$ & $\mathrm{KP}$ & bailer & 27.50 & 0.23 & 11.20 & 1043 & -567.6 \\
\hline $8 / 14 / 082: 19$ & KM & bailer & 26.30 & 0.27 & 11.23 & 1016 & -621.4 \\
\hline $8 / 14 / 086: 23$ & $\mathrm{AL}$ & bailer & 23.23 & 0.31 & 11.35 & 1018 & -609.3 \\
\hline $8 / 14 / 089: 48$ & $\mathrm{KP}$ & bailer & 27.10 & 0.17 & 11.19 & 1032 & -504.9 \\
\hline $8 / 14 / 0814: 09$ & $\mathrm{KP}$ & bailer & 27.37 & 0.13 & 11.20 & 1039 & -621.8 \\
\hline $8 / 14 / 08 \quad 17: 39$ & NAJ & bailer & 27.18 & 0.23 & 11.26 & 1047 & -545.0 \\
\hline $8 / 14 / 0822: 50$ & NAJ & bailer & 25.13 & 0.18 & 11.23 & 999 & -596.1 \\
\hline $8 / 15 / 0812: 00$ & $\mathrm{KM}$ & bailer & 26.77 & 0.21 & 11.23 & 1146 & -621.6 \\
\hline $8 / 16 / 0811: 17$ & $A L$ & bailer & 27.21 & 0.20 & 11.29 & 1051 & -625.3 \\
\hline $8 / 17 / 088: 50$ & $A L$ & bailer & 25.08 & 0.28 & 11.31 & 1079 & -576.7 \\
\hline $8 / 18 / 0816: 30$ & $A \mathrm{AL}$ & bailer & 26.48 & $\overline{0.43}$ & 11.09 & 1074 & -431.8 \\
\hline $8 / 19 / 089: 26$ & $\mathrm{CM}$ & bailer & 21.89 & 0.26 & 11.29 & 1148 & -574.1 \\
\hline $8 / 20 / 088: 00$ & $\mathrm{KP}$ & bailer & 21.86 & 0.25 & 11.28 & 1081 & -526.7 \\
\hline $8 / 21 / 087: 35$ & $\mathrm{KP}$ & bailer & 20.30 & 0.33 & 11.40 & 1103 & -555.3 \\
\hline $8 / 22 / 087: 21$ & $\mathrm{KP}$ & bailer & 21.11 & 0.30 & 11.41 & 1134 & -655.2 \\
\hline $8 / 23 / 086: 00$ & $\mathrm{KP}$ & bailer & 19.20 & 0.39 & 11.45 & 1119 & -631.0 \\
\hline
\end{tabular}




\begin{tabular}{|c|c|c|c|c|c|c|c|}
\hline \multicolumn{8}{|c|}{ Well D4-93 YSI Data } \\
\hline Date \& Time & Sampler & $\begin{array}{c}\text { Sample } \\
\text { Collection } \\
\text { Method }\end{array}$ & $\begin{array}{c}\text { Temp } \\
\left({ }^{\circ} \mathrm{C}\right)\end{array}$ & $\begin{array}{c}\mathrm{DO} \\
\text { (mg/L) }\end{array}$ & $\begin{array}{l}\text { pH } \\
\text { (SU) }\end{array}$ & $\begin{array}{c}S C \\
(\mu S / c m)\end{array}$ & $\begin{array}{l}\text { ORP } \\
(\mathrm{mV})\end{array}$ \\
\hline $8 / 9 / 088: 45$ & NAJ & purged & 29.15 & 0.64 & 10.34 & 556 & -332.5 \\
\hline $8 / 9 / 0811: 38$ & $\mathrm{KP}$ & flow cell & 25.72 & 0.85 & 10.42 & 706 & NA \\
\hline 8/9/08 15:30 & $\mathrm{KP}$ & flow cell & 25.06 & 0.90 & 10.49 & 655 & -283.0 \\
\hline $8 / 9 / 0818: 25$ & $\mathrm{KP}$ & flow cell & 24.93 & 1.90 & 10.42 & 626 & -198.7 \\
\hline $8 / 9 / 0823: 45$ & NAJ & purged & 21.60 & 0.43 & 9.87 & 483 & -424.6 \\
\hline $8 / 10 / 083: 20$ & NAJ & purged & 20.46 & 0.64 & 10.25 & 541 & -422.0 \\
\hline $8 / 10 / 086: 29$ & NAJ & purged & 20.56 & 0.21 & 10.46 & 594 & -436.3 \\
\hline $8 / 10 / 089: 15$ & $\mathrm{KP}$ & purged & 23.51 & 0.20 & 10.94 & 742 & -478.3 \\
\hline $8 / 10 / 08$ 13:00 & $\mathrm{KP}$ & purged & 24.98 & 0.17 & 11.19 & 847 & -471.9 \\
\hline $8 / 10 / 08 \quad 16: 55$ & $\mathrm{KP}$ & purged & 26.02 & 0.48 & 10.97 & 831 & -469.2 \\
\hline $8 / 10 / 0821: 01$ & NAJ & purged & 24.42 & 0.33 & 11.08 & 802 & -474.2 \\
\hline $8 / 11 / 082: 05$ & NAJ & purged & 22.79 & 0.45 & 11.24 & 844 & -483.8 \\
\hline $8 / 11 / 085: 35$ & NAJ & purged & 18.49 & 0.52 & 11.52 & 940 & -501.1 \\
\hline $8 / 11 / 08 \quad 17: 45$ & $\mathrm{KP}$ & purged & 30.13 & 0.78 & 10.94 & 1701 & -514.6 \\
\hline $8 / 11 / 0821: 41$ & NAJ & purged & 24.43 & 0.50 & & 1002 & -521.4 \\
\hline $8 / 12 / 081: 18$ & NAJ & purged & 22.92 & 0.27 & 11.42 & 1010 & -761.3 \\
\hline $8 / 12 / 084: 32$ & NAJ & purged & 22.20 & 0.24 & 11.33 & 979 & \\
\hline $8 / 12 / 088: 45$ & $\mathrm{KP}$ & purged & 23.56 & 0.20 & 11.30 & 998 & -789.0 \\
\hline $8 / 12 / 08 \quad 12: 00$ & $\mathrm{KP}$ & purged & 26.25 & 0.16 & 11.31 & 1053 & -692.5 \\
\hline $8 / 12 / 0815: 50$ & $\mathrm{KP}$ & purged & 26.57 & 0.16 & 11.29 & 1064 & -675.3 \\
\hline $8 / 12 / 0820: 22$ & NAJ & purged & 25.56 & 0.18 & 11.28 & 1020 & -728.6 \\
\hline $8 / 13 / 080: 15$ & NAJ & purged & 23.46 & 0.17 & 11.28 & 1015 & -717.2 \\
\hline $8 / 13 / 08$ 3:58 & NAJ & purged & 24.36 & 0.18 & 11.32 & 1029 & -710.3 \\
\hline $8 / 13 / 088: 55$ & $\widehat{N A J}$ & purged & 27.29 & 0.11 & 11.28 & 1029 & -730.9 \\
\hline $8 / 13 / 08$ 12:10 & $\mathrm{KP}$ & purged & 26.28 & 0.19 & 11.26 & 1030 & -672.9 \\
\hline $8 / 13 / 0816: 30$ & $\mathrm{KP}$ & purged & 27.53 & 0.11 & 11.26 & 1067 & -668.4 \\
\hline $8 / 13 / 0819: 53$ & $\widehat{K P}$ & purged & 25.74 & 0.15 & 11.33 & 1031 & -630.7 \\
\hline $8 / 13 / 0822: 34$ & $\mathrm{KP}$ & purged & 23.69 & 0.21 & 11.36 & 1025 & -662.5 \\
\hline $8 / 14 / 082: 32$ & $\mathrm{KM}$ & purged & 21.72 & 0.28 & 11.41 & 1022 & -674.9 \\
\hline $8 / 14 / 085: 32$ & $A L$ & purged & 21.66 & 0.20 & 11.29 & 971 & -683.4 \\
\hline $8 / 14 / 0810: 05$ & $\mathrm{KP}$ & purged & 25.66 & 0.13 & 11.24 & 1021 & -700.0 \\
\hline $8 / 14 / 08$ 14:22 & $\mathrm{KP}$ & purged & 25.34 & 0.08 & 11.25 & 1030 & -722.7 \\
\hline $8 / 14 / 08$ 18:00 & $\mathrm{KP}$ & purged & 27.08 & 0.16 & 11.17 & 1050 & -626.5 \\
\hline $8 / 14 / 0823: 10$ & NAJ & purged & 23.50 & 0.20 & 11.19 & 1029 & -641.0 \\
\hline $8 / 15 / 0812: 00$ & $K M$ & purged & 27.31 & 0.27 & 11.14 & 1176 & -635.8 \\
\hline $8 / 16 / 0811: 30$ & $A L$ & bailer & 28.30 & 0.13 & 11.17 & 1065 & -647.6 \\
\hline $8 / 17 / 088: 50$ & $\mathrm{AL}$ & bailer & 26.49 & 0.50 & 11.20 & 1053 & -607.3 \\
\hline $8 / 18 / 08 \quad 16: 30$ & $A L$ & bailer & 25.05 & 0.32 & 10.96 & 1081 & -544.2 \\
\hline 8/19/08 9:00 & $\mathrm{CM}$ & bailer & 21.90 & 0.24 & 11.23 & 1143 & -528.2 \\
\hline $8 / 20 / 088: 25$ & $\mathrm{KP}$ & bailer & 22.46 & 0.25 & 11.17 & 1066 & -600.8 \\
\hline $8 / 21 / 087: 47$ & $\mathrm{KP}$ & bailer & 21.15 & 0.31 & 11.31 & 1087 & -577.1 \\
\hline $8 / 22 / 087: 40$ & $\mathrm{KP}$ & bailer & 22.30 & 0.25 & 11.30 & 1126 & -653.5 \\
\hline $8 / 23 / 086: 10$ & $\mathrm{KP}$ & bailer & 20.72 & 0.29 & 11.35 & 1115 & -632.5 \\
\hline
\end{tabular}


DOE/RL-2009-35, REV. 0

\begin{tabular}{|c|c|c|}
\hline \multicolumn{3}{|c|}{ Well D4-25 Water Levels } \\
\hline Date \& Time & Sampler & $\begin{array}{l}\text { Water Level } \\
\text { from TOC (ft) }\end{array}$ \\
\hline $8 / 9 / 08 \quad 10: 24$ & $\mathrm{CM}$ & 84.36 \\
\hline $8 / 9 / 0815: 50$ & $\mathrm{CM}$ & 84.35 \\
\hline $8 / 10 / 080: 18$ & NAJ & 84.41 \\
\hline $8 / 10 / 083: 45$ & NAJ & 84.38 \\
\hline $8 / 10 / 086: 40$ & NAJ & 84.39 \\
\hline $8 / 10 / 08$ 12:15 & $C M$ & 84.35 \\
\hline $8 / 10 / 0817: 26$ & $\overline{\mathrm{CM}}$ & 84.31 \\
\hline $8 / 10 / 0823: 05$ & $\overline{\mathrm{NAJ}}$ & 84.34 \\
\hline $8 / 11 / 0822: 29$ & NAJ & 84.29 \\
\hline $8 / 12 / 081: 23$ & NAJ & 84.29 \\
\hline $8 / 12 / 083: 44$ & NAJ & 84.29 \\
\hline $8 / 12 / 085: 30$ & & 84.30 \\
\hline $8 / 12 / 087: 45$ & $\mathrm{KP}$ & 84.30 \\
\hline $8 / 12 / 0811: 30$ & $\mathrm{KP}$ & 84.27 \\
\hline $8 / 12 / 08$ 15:20 & $\mathrm{KP}$ & 84.24 \\
\hline $8 / 12 / 08$ 19:59 & $\overline{N A J}$ & 84.24 \\
\hline 8/12/08 23:04 & NAJ & 84.25 \\
\hline $8 / 12 / 083: 15$ & NAJ & 84.29 \\
\hline $8 / 13 / 087: 20$ & $\overline{N A J}$ & 84.25 \\
\hline $8 / 13 / 0811: 35$ & $\mathrm{KP}$ & 84.25 \\
\hline $8 / 13 / 0815: 30$ & $\mathrm{KP}$ & 84.22 \\
\hline 8/13/08 19:21 & $\mathrm{KP}$ & 84.22 \\
\hline $8 / 13 / 0822: 11$ & $\mathrm{CM}$ & 84.27 \\
\hline $8 / 14 / 081: 53$ & KM & 84.52 \\
\hline 8/14/08 5:55 & $A L$ & 84.63 \\
\hline 8/14/08 9:25 & $\mathrm{KP}$ & 84.67 \\
\hline $8 / 14 / 0813: 30$ & $\mathrm{KP}$ & 84.69 \\
\hline $8 / 14 / 0817: 26$ & $\mathrm{KP}$ & 84.75 \\
\hline $8 / 14 / 0822: 40$ & NAJ & 84.77 \\
\hline $8 / 15 / 0811: 36$ & $\mathrm{KM}$ & 84.85 \\
\hline 8/16/08 10:34 & $\mathrm{AL}$ & 84.91 \\
\hline $8 / 16 / 0811: 00$ & $\mathrm{AL}$ & 85.03 \\
\hline $8 / 22 / 086: 45$ & $\mathrm{KP}$ & 85.33 \\
\hline
\end{tabular}




\begin{tabular}{|c|c|c|}
\hline \multicolumn{3}{|c|}{ Well D4-27 Water Levels } \\
\hline Date \& Time & Sampler & $\begin{array}{l}\text { Water Level } \\
\text { from TOC (ft) }\end{array}$ \\
\hline $8 / 9 / 0810: 10$ & $\mathrm{CM}$ & 84.77 \\
\hline $8 / 9 / 0815: 58$ & $\mathrm{CM}$ & 84.91 \\
\hline $8 / 10 / 080: 15$ & $\overline{\mathrm{NAJ}}$ & 85.02 \\
\hline $8 / 10 / 083: 43$ & $\overline{N A J}$ & 84.99 \\
\hline $8 / 10 / 086: 10$ & NAJ & 84.99 \\
\hline $8 / 10 / 08 \quad 11: 33$ & $\mathrm{CM}$ & 84.95 \\
\hline $8 / 10 / 08$ 17:21 & $\mathrm{CM}$ & 84.95 \\
\hline $8 / 10 / 0823: 51$ & $\overline{\text { NAJ }}$ & 84.97 \\
\hline $8 / 11 / 082: 57$ & NAJ & 85.03 \\
\hline $8 / 11 / 0822: 32$ & NAJ & 84.93 \\
\hline $8 / 12 / 08$ 1:25 & NAJ & 84.95 \\
\hline $8 / 12 / 083: 53$ & NAJ & 84.94 \\
\hline 8/12/085:20 & NAJ & 84.96 \\
\hline 8/12/08 8:00 & $\mathrm{KP}$ & 84.95 \\
\hline $8 / 12 / 08$ 11:40 & $\mathrm{KP}$ & 84.93 \\
\hline $8 / 12 / 08$ 15:30 & $\mathrm{KP}$ & 84.93 \\
\hline $8 / 12 / 08$ 19:31 & NAJ & 84.92 \\
\hline $8 / 12 / 0823: 17$ & $\overline{\mathrm{NAJ}}$ & 84.94 \\
\hline $8 / 13 / 083: 24$ & NAJ & 84.94 \\
\hline $8 / 13 / 087: 50$ & $\overline{N A J}$ & 84.92 \\
\hline $8 / 13 / 08 \quad 11: 46$ & $\mathrm{KP}$ & 84.94 \\
\hline $8 / 13 / 08$ 15:42 & $\mathrm{KP}$ & 84.90 \\
\hline $8 / 13 / 08 \quad 19: 30$ & $\overline{K P}$ & 84.90 \\
\hline $8 / 13 / 0822: 16$ & $\mathrm{KP}$ & 84.98 \\
\hline $8 / 14 / 082: 09$ & $\overline{K M}$ & 85.12 \\
\hline 8/14/08 6:10 & $\mathrm{AL}$ & 85.20 \\
\hline 8/14/08 9:37 & $\mathrm{KP}$ & 85.22 \\
\hline $8 / 14 / 08$ 13:54 & $\mathrm{KP}$ & 85.25 \\
\hline $8 / 14 / 0817: 35$ & $\overline{\text { NAJ }}$ & 85.29 \\
\hline $8 / 14 / 0822: 45$ & NAJ & 85.31 \\
\hline $8 / 15 / 08 \quad 11: 27$ & & 85.36 \\
\hline $8 / 16 / 08 \quad 10: 55$ & $\mathrm{AL}$ & 85.44 \\
\hline $8 / 18 / 08$ 11:30 & $\overline{\mathrm{AL}}$ & 85.56 \\
\hline $8 / 22 / 087: 05$ & $\overline{K P}$ & 85.85 \\
\hline
\end{tabular}




\begin{tabular}{|c|c|c|}
\hline \multicolumn{3}{|c|}{ Well D4-92 Water Levels } \\
\hline Date \& Time & Sampler & $\begin{array}{l}\text { Water Level } \\
\text { from TOC (ft) }\end{array}$ \\
\hline $8 / 9 / 08$ 10:15 & $\mathrm{CM}$ & 84.60 \\
\hline 8/9/08 15:49 & $\mathrm{CM}$ & 84.31 \\
\hline $8 / 10 / 08$ 0:12 & NAJ & 84.53 \\
\hline $8 / 10 / 083: 40$ & NAJ & 84.40 \\
\hline 8/10/08 6:32 & NAJ & 84.39 \\
\hline $8 / 10 / 0811: 40$ & $\mathrm{CM}$ & 84.21 \\
\hline $8 / 10 / 0818: 00$ & $\mathrm{CM}$ & 84.31 \\
\hline $8 / 10 / 0823: 49$ & NAJ & 84.29 \\
\hline $8 / 11 / 082: 50$ & NAJ & 84.35 \\
\hline $8 / 11 / 0822: 35$ & NAJ & 84.18 \\
\hline $8 / 12 / 081: 36$ & NAJ & 84.16 \\
\hline $8 / 12 / 084: 34$ & $\overline{N A J}$ & 84.39 \\
\hline $8 / 12 / 085: 18$ & NAJ & 84.18 \\
\hline 8/12/08 8:15 & $\mathrm{KP}$ & 84.18 \\
\hline $8 / 12 / 0811: 45$ & KP & 84.08 \\
\hline $8 / 12 / 08 \quad 15: 32$ & $\mathrm{KP}$ & 83.91 \\
\hline $8 / 12 / 08 \quad 19: 45$ & NAJ & 83.85 \\
\hline $8 / 12 / 0823: 30$ & NAJ & 83.75 \\
\hline $8 / 13 / 083: 33$ & $\overline{\text { NAJ }}$ & 83.60 \\
\hline 8/13/08 8:05 & NAJ & 83.26 \\
\hline $8 / 13 / 0811: 57$ & $\mathrm{KP}$ & 82.88 \\
\hline $8 / 13 / 0816: 00$ & KP & 82.46 \\
\hline $8 / 13 / 0819: 43$ & $\overline{\mathrm{KP}}$ & 82.60 \\
\hline $8 / 13 / 0822: 25$ & KP & 82.81 \\
\hline $8 / 14 / 082: 19$ & $\mathrm{KM}$ & 84.66 \\
\hline $8 / 14 / 080: 23$ & $\overline{A L}$ & 84.83 \\
\hline 8/14/08 9:48 & KP & 84.89 \\
\hline $8 / 14 / 0814: 09$ & $\mathrm{KP}$ & 84.93 \\
\hline $8 / 14 / 08 \quad 17: 39$ & NAJ & 84.95 \\
\hline $8 / 14 / 0822: 50$ & NAJ & 85.04 \\
\hline $8 / 16 / 08 \quad 0: 00$ & KM & 85.11 \\
\hline $8 / 16 / 0811: 17$ & $\overline{\mathrm{AL}}$ & 85.23 \\
\hline $8 / 14 / 088: 50$ & $\overline{\mathrm{AL}}$ & 85.28 \\
\hline $8 / 18 / 08 \quad 16: 30$ & $\overline{\mathrm{AL}}$ & 85.32 \\
\hline $8 / 21 / 087: 35$ & $\mathrm{KP}$ & 85.59 \\
\hline $8 / 22 / 087: 21$ & KP & 85.64 \\
\hline $8 / 23 / 086: 00$ & KP & 85.63 \\
\hline
\end{tabular}


DOE/RL-2009-35, REV. 0

\begin{tabular}{|r|c|c|}
\hline \multicolumn{3}{|c|}{ Well D4-93 Water Levels } \\
\hline Date \& Time & Sampler & $\begin{array}{c}\text { Water Level } \\
\text { from TOC (ft) }\end{array}$ \\
\hline $8 / 9 / 0810: 19$ & $\mathrm{CM}$ & 83.73 \\
\hline $8 / 9 / 0815: 48$ & $\mathrm{CM}$ & 83.66 \\
\hline $8 / 10 / 080: 05$ & NAJ & 84.07 \\
\hline $8 / 10 / 083: 30$ & NAJ & 83.61 \\
\hline $8 / 10 / 086: 45$ & NAJ & 83.59 \\
\hline $8 / 10 / 0812: 11$ & $\mathrm{CM}$ & 83.51 \\
\hline $8 / 10 / 0817: 32$ & $\mathrm{CM}$ & 83.22 \\
\hline $8 / 10 / 0823: 58$ & NAJ & 83.65 \\
\hline $8 / 11 / 082: 55$ & NAJ & 83.62 \\
\hline $8 / 11 / 0822: 32$ & NAJ & 82.14 \\
\hline $8 / 12 / 081: 32$ & NAJ & 81.78 \\
\hline $8 / 12 / 084: 40$ & NAJ & 82.40 \\
\hline $8 / 12 / 085: 16$ & NAJ & 81.76 \\
\hline $8 / 12 / 089: 00$ & KP & 81.65 \\
\hline $8 / 12 / 0812: 00$ & KP & 81.55 \\
\hline $8 / 12 / 0815: 50$ & KP & 81.75 \\
\hline $8 / 12 / 0820: 09$ & NAJ & 81.19 \\
\hline $8 / 13 / 080: 15$ & NAJ & 81.71 \\
\hline $8 / 13 / 083: 48$ & NAJ & 80.92 \\
\hline $8 / 13 / 088: 55$ & NAJ & 80.95 \\
\hline $8 / 13 / 0812: 10$ & KP & 80.63 \\
\hline $8 / 13 / 0816: 30$ & KP & 80.47 \\
\hline $8 / 13 / 0819: 53$ & KP & 80.37 \\
\hline $8 / 14 / 082: 32$ & KM & 83.72 \\
\hline $8 / 14 / 085: 32$ & AL & 84.02 \\
\hline $8 / 14 / 0810: 05$ & KP & 85.49 \\
\hline $8 / 14 / 0814: 22$ & KP & 84.43 \\
\hline $8 / 14 / 0817: 24$ & & 84.43 \\
\hline $8 / 14 / 0823: 10$ & NAJ & 85.45 \\
\hline $8 / 16 / 080: 00$ & KM & 84.54 \\
\hline $8 / 16 / 0811: 30$ & AL & 84.52 \\
\hline $8 / 17 / 08$ & AL & 84.67 \\
\hline $8 / 18 / 0816: 30$ & AL & 84.72 \\
\hline $8 / 19 / 088: 00$ & CM & 84.84 \\
\hline $8 / 21 / 087: 47$ & KP & 84.98 \\
\hline $8 / 22 / 087: 4086: 10$ & KP & 85.03 \\
\hline & & 85.01 \\
\hline
\end{tabular}


DOE/RL-2009-35, REV. 0

\begin{tabular}{|c|c|c|c|c|c|c|c|c|c|c|c|c|c|c|}
\hline \multicolumn{15}{|c|}{ Field Injection Mixing Data } \\
\hline & & \multicolumn{3}{|c|}{ 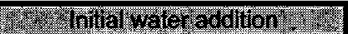 } & & & \multicolumn{3}{|c|}{ X Top of water W } & \multicolumn{5}{|c|}{ QAVQ } \\
\hline Batch & Tank & $\begin{array}{c}\text { FMt } \\
\text { gallons } \\
\end{array}$ & $\begin{array}{l}\text { Fin? } \\
\text { gallons }\end{array}$ & $\begin{array}{l}\text { Average } \\
\text { gallons }\end{array}$ & $\begin{array}{c}\text { ZVI } \\
(18 \%) \text { kg }\end{array}$ & $\begin{array}{c}\text { Rinse } \mathrm{H}_{2} \mathrm{O} \\
\text { gallons }\end{array}$ & $\begin{array}{l}F T 1 \\
\text { gailos }\end{array}$ & $\begin{array}{l}\text { FMP } \\
\text { gallons }\end{array}$ & $\begin{array}{l}\text { Average } \\
\text { gallons }\end{array}$ & $\begin{array}{c}\mathrm{SC} \\
\mathrm{uS} / \mathrm{cm}\end{array}$ & $\begin{array}{l}\mathrm{T} \\
{ }^{\circ} \mathrm{C} \\
\end{array}$ & $\begin{array}{l}\mathrm{SC} \text { std } \\
\mathrm{uS} / \mathrm{cm}\end{array}$ & $\begin{array}{l}\mathrm{T} \\
{ }^{\circ} \mathrm{C} \\
\end{array}$ & $\begin{array}{c}\text { RPD } \\
\% \\
\end{array}$ \\
\hline 1 & $\bar{N}$ & 498474 & 201023 & 799749 & 471.7 & & 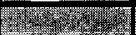 & 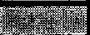 & 162.3 & 1065 & 35.3 & 1102 & 39.4 & $3.41 \%$ \\
\hline 2 & $\bar{S}$ & 196868 & 201236 & 9199962 & 473.4 & 11.8 & 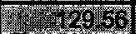 & 12786 & W2871. & 1070 & 29.9 & 1062 & 26.9 & $0.75 \%$ \\
\hline 3 & $\bar{N}$ & 199229 & 20074 & 49998 & 470.8 & 42.8 & 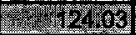 & 125.49 & 1246 & 1046 & 25.3 & 053 & 24.1 & $0.67 \%$ \\
\hline 4 & $\underline{S}$ & 0.197605 & 201213 & 1995:09 & 474.4 & 81.3 & 10606 & 60782 & 0720 & 1056 & 24.8 & 031 & 19.6 & $2.40 \%$ \\
\hline 5 & $\overline{\mathrm{N}}$ & 108432 & 201409 & 199921 & 468.2 & 8.8 & 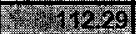 & 11205 & 11267 & 1053 & 23.8 & 025 & 18.1 & $2.69 \%$ \\
\hline 6 & $\bar{s}$ & (198367 & 201627 & VI99917 & 473.4 & 1.8 & 39560 & 60158 & (398357 & 1195 & 26.9 & 1059 & 24.8 & $12.07 \%$ \\
\hline 7 & $\bar{N}$ & $198 \% 86$ & 201502 & 1098.4 & 481.0 & .8 & 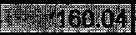 & M6 & 164.09: & 1199 & 32.3 & 1069 & 30.3 & $11.46 \%$ \\
\hline 8 & & $108 \sqrt{29}$ & 261498 & $=1999.64$ & 475.8 & & 190000 & 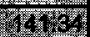 & M14.6\% & 1033 & 32.8 & 083 & 36.2 & $4.73 \%$ \\
\hline$\overline{9}$ & & 198769 & 801209 & 4999.89 & 484.5 & & If. & Whas & 7720 & 1018 & 30.2 & 1070 & 30.6 & $.98 \%$ \\
\hline 10 & & 199696 & 201246 & 20042 & 475.1 & & 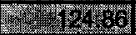 & 1255 & 25.20 & 1080 & 25.2 & 1043 & 23 & $.49 \%$ \\
\hline 11 & & 15845 & 2009965 & 1996.37 & 463.4 & & 500 & 500 & So0.67 & 1057 & 21.8 & 1028 & 17.9 & $.78 \%$ \\
\hline & & 1004,07 & 201461 & 200434 & 478.5 & & 3at & 26155 & 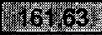 & 045 & 22.3 & 011 & 16.1 & $31 \%$ \\
\hline 13 & & 200020 & 40064 & 200032 & 474.0 & & I 14285 & 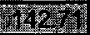 & 1166 & 032 & 19 & 055 & 15.2 & $0 \%$ \\
\hline 14 & $s$ & 799 & 201003 & 206092 & 83.7 & & 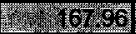 & 16740 & 16740 & U67 & 26.2 & 057 & & \\
\hline 15 & & 1966,58 & 200627 & 2000093 & 483.2 & & 16928 & 16996 & 669.64 & 061 & $\overline{29.1}$ & 088 & 38.8 & $\overline{51 \%}$ \\
\hline 16 & $\mathrm{~s}$ & 10972 & 201083 & 19200108 & 75.4 & .8 & 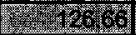 & 278 & 2662 & 1058 & 28 & 052 & 31.3 & $57 \%$ \\
\hline 17 & $\bar{N}$ & 7199896 & $2 0 \longdiv { 2 0 5 2 }$ & 200024 & 75.6 & .2 & $1,111 \%$ & 117 6 & 11752 & 1063 & 27.7 & 068 & 32.3 & $47 \%$ \\
\hline 18 & s & 1989,83 & 200637 & 1994.85 & 469.0 & & 194.25 & 12472 & 12448 & 1060 & 25.9 & 031 & 21.2 & $77 \%$ \\
\hline 19 & $\bar{N}$ & 27998.06 & 202085 & 200974 & 75.4 & & 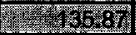 & 1362 & 3557 & 1050 & 24.3 & 028 & 16.9 & $2 \%$ \\
\hline 20 & & 1996.25 & 2012.5 & 200 & & & $\sqrt{2}$ & 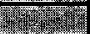 & $20 \% 1$ & & 23.7 & 017 & 15.4 & \\
\hline 21 & & 200016 & 20007 & 2000.4 & 474 & & $1 \times 14282$ & 142,4 & 44262 & & 23.1 & 005 & 13.1 & \\
\hline 22 & 5 & 198275 & 201576 & 200776 & & & 1.4T 15952 & 159.62 & 159.57 & 36 & 24.1 & 1067 & 28.2 & $4 \%$ \\
\hline 23 & & $22 \times 324$ & 295512 & 214932 & 417. & & 0000 & 8000 & $10.00 \%$ & 1048 & 26.3 & 095 & 41.6 & \\
\hline 24 & & 19928 & 20087 & 200079 & 476. & & 479590 & 1360 & 160097 & 065 & $\overline{28.4}$ & 086 & 38.5 & \\
\hline 25 & & (1997. & 200658 & 200035 & & & 112289 & 12265 & 122.6 & 1056 & 28.2 & 095 & 42.1 & $33 \%$ \\
\hline 26 & & (1905: & 200560 & 2000.58 & & & 政 & 741448 & 1887.79 & 4 & 27.2 & 074 & 34.9 & $44 \%$ \\
\hline 27 & & 202128 & 108825 & 200637 & 59.6 & 8 & 17x & 3-1; & 31.05 & 1068 & 25.1 & 034 & 22.4 & $24 \%$ \\
\hline 28 & $\mathrm{~s}$ & 199586 & 20003 & 20002159 & 473.6 & & 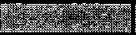 & 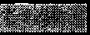 & 11864 & 998 & 24.1 & 024 & 17.9 & $2.57 \%$ \\
\hline 29 & $\mathrm{~N}$ & 201262 & 195662 & 199692 & 471.4 & & $14+34.94$ & 13048 & 13270 & 984 & 23.3 & 009 & 15.2 & $2.51 \%$ \\
\hline 30 & $\bar{s}$ & 201006 & $2004 / 8$ & 2000664 & & & Thert & 118.62 & 14882 & 1035 & 23.5 & 010 & 16.1 & $2.44 \%$ \\
\hline 31 & $\bar{N}$ & 109825 & $20034+8$ & $2000 \% 7$ & 483.8 & & 767603 & 165.4 & 16572 & 86 & 26.1 & 091 & 38.3 & $32 \%$ \\
\hline 32 & $s$ & 10976 & 20006 & 4999994 & & & 18 20100 & 1415 & $114=27$ & & 27.3 & 101 & 45 & $8 \%$ \\
\hline 33 & & 12005.36 & 109207 & 1998,2 & & & 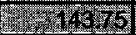 & 13927 & 17476 & & 28.6 & & 29 & \\
\hline 34 & & 203227 & 196300 & 199809 & & & 729.60 & 12286 & 126.18 & & $\overline{28.2}$ & 37 & 24.2 & \\
\hline 3 & & $1997 / 2$ & 12003.5 & 200044 & & & 240.79 & 8964 & 80.69 & & 26.7 & 35 & & \\
\hline 3 & $s$ & 19542 & 3260480 & 199980 & & & 7. 152,66 & 15303 & 1528 & 5 & 25.7 & 48 & 23.2 & \\
\hline 3 & $\Lambda$ & 109322 & 2009.43 & 2009.85 & & & 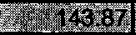 & 143.90 & 14389 & & 25 & 030 & & \\
\hline 38 & $\underline{s}$ & 0 & 2006.05 & $2000: 87$ & & & 279.16 & 223.16 & 122437 & & 19.2 & 35 & 4.5 & \\
\hline 39 & $\bar{N}$ & 2084.34 & 202270 & 202852 & 4 & & 0.00 & 0.00 & 0.00 & 30 & 24.8 & 049 & 30.1 & \\
\hline 40 & $\mathrm{~s}$ & 200746 & 1991,45 & W1999:47 & & & 158:04 & 155.54 & 156.79 & 1060 & 27.2 & 066 & 4 & \\
\hline 41 & $\mathrm{~N}$ & 202554 & 1978.41 & 200198 & 475.8 & 109.8 & 129.14 & 122.68 & 15i 125.91 & 1070 & 28.8 & 1056 & 26.8 & $1.32 \%$ \\
\hline 42 & $s$ & 2045.52 & 195032 & 199792 & 475.0 & 104.0 & (2) 132.64 & 125.93 & 12929 & 1030 & 29.8 & 1040 & 25.2 & $0.97 \%$ \\
\hline 43 & $\mathrm{~N}$ & 10222 & 97492 & 99858 & & & 428.32 & 40775 & 418,04 & 1010 & 29.6 & 1054 & 33.5 & $4.26 \%$ \\
\hline TALS & & reter & 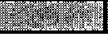 & 85211.8 & 20196.6 & 3066.0 & 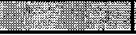 & 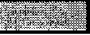 & 6034.67 & & & & & \\
\hline
\end{tabular}


DOE/RL-2009-35, REV. 0

\begin{tabular}{|c|r|r|r|r|r|r|}
\hline \multicolumn{7}{|c|}{ ZVI Injection Rate } \\
\hline Batch & ZVI Injection rate (gpm) & Average \\
\hline 1 & 14.00 & 14.00 & 13.98 & 13.95 & & 13.98 \\
\hline 2 & 13.89 & 13.93 & 13.76 & 13.71 & 13.76 & 13.81 \\
\hline 3 & 14.00 & 13.91 & 13.89 & & & 13.93 \\
\hline 4 & 13.89 & 13.80 & & & & 13.85 \\
\hline 5 & 14.09 & 14.00 & & & & 14.05 \\
\hline 6 & 14.02 & 13.91 & 13.93 & 13.87 & 13.87 & 13.92 \\
\hline 7 & 13.93 & 13.93 & 13.84 & 13.82 & & 13.88 \\
\hline 8 & 14.17 & 14.20 & 14.17 & 14.11 & 14.11 & 14.15 \\
\hline 9 & 14.04 & 13.98 & 13.91 & & & 13.98 \\
\hline 10 & 14.04 & 13.98 & 13.87 & & & 13.96 \\
\hline 11 & 13.95 & 13.78 & & & & 13.87 \\
\hline 12 & 14.04 & 13.98 & & & & 14.01 \\
\hline 13 & 13.95 & 14.13 & & & & 14.04 \\
\hline 14 & 14.13 & 14.09 & 14.04 & 13.95 & & 14.05 \\
\hline 15 & 14.09 & 14.17 & 14.15 & & & 14.14 \\
\hline 16 & 14.26 & 14.26 & 14.17 & 14.06 & & 14.19 \\
\hline 17 & 14.24 & 14.15 & & & & 14.20 \\
\hline 18 & 14.09 & & & & & 14.09 \\
\hline 19 & 14.06 & & & & & 14.06 \\
\hline 20 & 13.91 & & & & & 13.91 \\
\hline 21 & 14.17 & & & & & 14.17 \\
\hline 22 & 14.26 & 14.15 & 14.09 & & & 14.17 \\
\hline 23 & 14.04 & 14.06 & 14.06 & & & 14.05 \\
\hline 24 & 14.65 & 14.11 & & & & 14.38 \\
\hline 25 & 14.00 & 14.06 & 14.04 & & & 14.03 \\
\hline 26 & 14.06 & & & & & 14.06 \\
\hline 27 & 14.09 & 13.98 & 13.89 & & & 13.99 \\
\hline 28 & 14.09 & 14.15 & & & & 14.12 \\
\hline 29 & 14.00 & 13.98 & & & & 13.99 \\
\hline 30 & 14.26 & 14.17 & 13.95 & & & 14.13 \\
\hline 31 & 14.24 & 14.13 & & & & 14.19 \\
\hline 32 & 14.35 & 14.15 & 14.20 & & & 14.23 \\
\hline 33 & 14.20 & 14.15 & & & & 14.18 \\
\hline 34 & 14.13 & & & & & 14.13 \\
\hline 35 & 14.02 & 13.93 & & & & 13.98 \\
\hline 36 & 14.04 & & & & & 14.04 \\
\hline 37 & 14.02 & 13.98 & & & & 14.00 \\
\hline 38 & 14.15 & & & & & 14.15 \\
\hline 39 & 14.22 & 14.04 & & & & 14.13 \\
\hline 40 & 14.15 & 14.09 & & & & 14.12 \\
\hline 41 & 14.13 & 14.28 & & & & 14.21 \\
\hline 42 & 14.20 & & & & & 14.20 \\
\hline 43 & 14.13 & 14.23 & & & & 14.18 \\
\hline AVERAGE & & & & & 14.07 \\
\hline
\end{tabular}




\begin{tabular}{|c|c|c|c|c|c|c|c|c|c|c|c|c|c|}
\hline \multicolumn{14}{|c|}{ Oxygen Levels in Mixing Tanks } \\
\hline & & & \multicolumn{4}{|c|}{$\mathrm{O}_{2}$ levels (\%) } & \multirow[b]{3}{*}{ Date } & & & \multicolumn{4}{|c|}{$\mathrm{O}_{2}$ levels (\%) } \\
\hline \multirow[b]{2}{*}{ Date } & \multirow[b]{2}{*}{ Time } & \multirow[b]{2}{*}{ Batch } & \multicolumn{3}{|c|}{ Sample Port } & \multirow[b]{2}{*}{ Avg } & & \multirow[b]{2}{*}{ Time } & \multirow[b]{2}{*}{ Batch } & \multicolumn{3}{|c|}{ Sample Port } & \multirow[b]{2}{*}{ Avg } \\
\hline & & & N1 & N2 & N3 & & & & & S1 & S2 & S3 & \\
\hline $8 / 8$ & $11: 36$ & 1 & 14.5 & & & 14.5 & $8 / 8$ & $17: 20$ & 2 & 18.6 & 19.0 & 19.1 & 18.9 \\
\hline $8 / 8$ & $11: 56$ & 1 & 11.5 & & & 11.5 & $8 / 8$ & $17: 51$ & 2 & 13.5 & 14.2 & 14.5 & 14.1 \\
\hline $8 / 8$ & $12: 27$ & 1 & 8.0 & 9.1 & 9.4 & 8.8 & $8 / 8$ & $18: 09$ & 2 & 10.4 & 11.6 & 12.1 & 11.4 \\
\hline $8 / 8$ & $14: 28$ & 1 & 3.4 & 3.2 & 3.2 & 3.3 & $8 / 8$ & 19:07 & 2 & 6.5 & 6.4 & 6.2 & 6.4 \\
\hline$\overline{8 / 8}$ & $16: 20$ & 1 & 1.9 & & & 1.9 & $8 / 8$ & $\overline{19: 46}$ & 2 & 4.5 & 4.2 & 4.2 & 4.3 \\
\hline $8 / 8$ & $17: 20$ & 1 & 1.6 & 1.5 & 1.4 & 1.5 & $8 / 8$ & $21: 08$ & 2 & 2.4 & 2.4 & 3.0 & 2.6 \\
\hline $8 / 8$ & $23: 23$ & 3 & 1.8 & 1.1 & 0.9 & 1.3 & $8 / 8$ & $21: 30$ & 2 & 2.2 & 2.5 & 2.2 & 2.3 \\
\hline $8 / 9$ & $5: 00$ & 5 & 1.9 & 0.9 & 0.8 & 1.2 & $8 / 8$ & $22: 00$ & 2 & 2.0 & & & 2.0 \\
\hline $8 / 9$ & 10:27 & 7 & 2.0 & 1.7 & 1.6 & 1.8 & $8 / 9$ & $0: 14$ & 4 & 2.3 & 2.1 & 1.7 & 2.0 \\
\hline $8 / 9$ & $11: 36$ & 7 & 3.0 & 2.0 & 1.1 & 2.0 & $8 / 9$ & $2: 00$ & 4 & & 2.1 & 2.6 & 2.4 \\
\hline $8 / 9$ & $12: 23$ & 7 & 0.9 & 1.1 & 1.4 & 1.1 & $8 / 9$ & $6: 30$ & 6 & 3.0 & 3.2 & 3.1 & 3.1 \\
\hline $8 / 9$ & $16: 51$ & 9 & 3.0 & 3.0 & 4.8 & 3.6 & $8 / 9$ & $10: 03$ & 6 & 1.2 & 1.5 & 1.7 & 1.5 \\
\hline $8 / 9$ & $17: 31$ & 9 & 1.8 & 1.8 & 2.3 & 2.0 & $8 / 9$ & $14: 03$ & & 1.8 & 1.3 & 1.6 & 1.6 \\
\hline $8 / 9$ & $23: 10$ & 11 & 2.8 & 3.1 & 3.2 & 3.0 & $8 / 9$ & $15: 43$ & & 2.3 & 1.6 & 2.3 & 2.1 \\
\hline $8 / 10$ & $5: 28$ & 13 & 1.7 & 1.8 & 2.1 & 1.9 & $8 / 9$ & $19: 32$ & 10 & & 3.4 & 3.2 & 3.3 \\
\hline $8 / 10$ & $7: 25$ & 13 & 1.9 & 1.5 & 1.4 & $\overline{1.6}$ & $8 / 10$ & $5: 25$ & 12 & 1.8 & 2.2 & 1.5 & 1.8 \\
\hline $8 / 10$ & $10: 10$ & 15 & 8.8 & 8.8 & 8.7 & 8.8 & $8 / 10$ & $9: 29$ & 14 & 1.3 & 0.8 & 0.7 & 0.9 \\
\hline $8 / 10$ & $11: 21$ & 15 & 4.9 & 4.7 & 4.8 & 4.8 & $8 / 10$ & 13:05 & 16 & 0.9 & 0.9 & 0.9 & 0.9 \\
\hline $8 / 10$ & $12: 57$ & 15 & 2.5 & 3.0 & 3.9 & 3.1 & $8 / 10$ & $14: 12$ & 16 & 1.3 & 1.8 & 1.8 & 1.6 \\
\hline $8 / 10$ & $14: 20$ & 15 & 2.2 & 2.7 & 2.6 & 2.5 & $8 / 10$ & $16: 30$ & 16 & 4.7 & 5.1 & 5.3 & 5.0 \\
\hline $8 / 10$ & $16: 30$ & 17 & 1.7 & 1.4 & 1.4 & 1.5 & $8 / 10$ & $22: 15$ & 18 & 2.3 & 2.0 & 2.4 & 2.2 \\
\hline $8 / 10$ & $18: 30$ & 17 & 2.4 & 2.1 & 2.2 & 2.2 & $8 / 11$ & $8: 15$ & 22 & 1.2 & 0.9 & 1.3 & 1.1 \\
\hline $8 / 11$ & $8: 10$ & 21 & 2.3 & 1.8 & 1.7 & 1.9 & $8 / 11$ & $10: 30$ & 24 & & 1.7 & & 1.7 \\
\hline $8 / 11$ & $10: 30$ & 23 & & 1.6 & & 1.6 & $8 / 11$ & $15: 00$ & 24 & & 5.0 & & \\
\hline $8 / 11$ & $13: 44$ & 23 & & 2.4 & & 2.4 & $8 / 11$ & $21: 01$ & 26 & 1.4 & 1.3 & 1.3 & 1.3 \\
\hline $8 / 11$ & $14: 55$ & 25 & & 1.3 & & 1.3 & $8 / 12$ & $2: 53$ & 28 & 1.4 & 1.1 & 1.3 & 1.3 \\
\hline $8 / 11$ & $21: 05$ & 27 & 1.8 & 1.7 & 1.6 & 1.7 & $8 / 12$ & $7: 20$ & 30 & & 1.9 & & $\overline{1.9}$ \\
\hline $8 / 12$ & $2: 47$ & 29 & 2.7 & 2.9 & 3.1 & 2.9 & $8 / 12$ & $14: 30$ & 32 & & 1.8 & & 1.8 \\
\hline $8 / 12$ & $8: 50$ & 31 & & 1.9 & & 1.9 & $8 / 12$ & $17: 30$ & 34 & & 1.8 & & 1.8 \\
\hline $8 / 12$ & $11: 20$ & 31 & 1.9 & 1.9 & 1.8 & 1.9 & $8 / 12$ & $23: 57$ & 36 & 1.3 & 1.3 & 1.3 & 1.3 \\
\hline $8 / 12$ & $14: 30$ & 33 & & 1.8 & & 1.8 & $8 / 13$ & $3: 24$ & 38 & 1.4 & 1.4 & 1.3 & 1.4 \\
\hline $8 / 12$ & $17: 30$ & 35 & & 1.9 & & 1.9 & $8 / 13$ & $13: 15$ & 42 & & 1.7 & & 1.7 \\
\hline $8 / 12$ & $23: 48$ & 35 & 1.7 & 2.5 & 2.2 & 2.1 & & & & & & & \\
\hline $8 / 13$ & $3: 28$ & 37 & 1.3 & 1.4 & 1.6 & 1.4 & & & & & & & \\
\hline
\end{tabular}


DOE/RL-2009-35, REV. 0

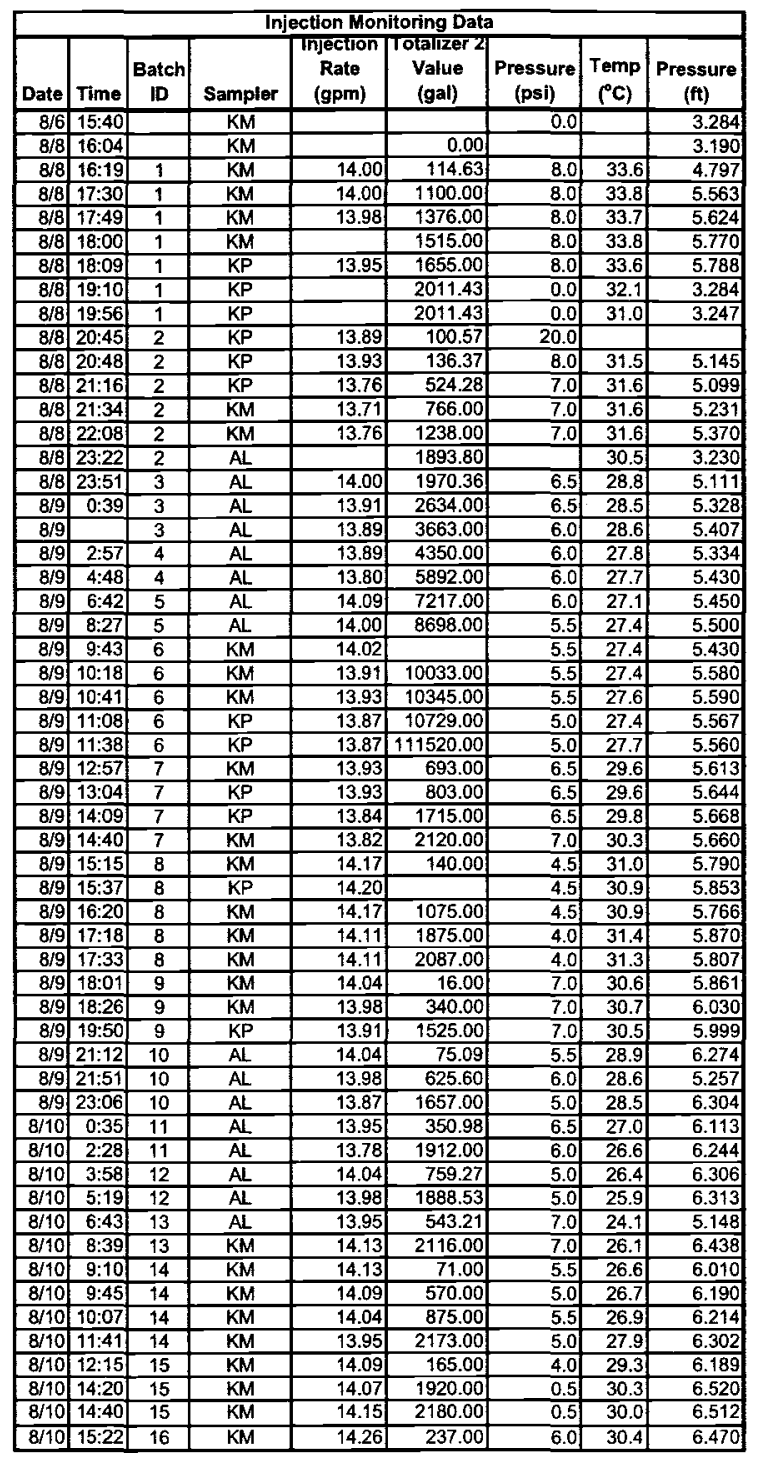

\begin{tabular}{|c|c|c|c|c|c|c|c|c|}
\hline \multicolumn{9}{|c|}{ Injection Monitoring Data } \\
\hline Date & Time & Batch ID & Sampler & $\begin{array}{c}\text { Injection } \\
\text { Rate } \\
\text { (gpm) }\end{array}$ & $\begin{array}{c}\text { Totalizer } \\
2 \text { Value } \\
\text { (gal) }\end{array}$ & $\begin{array}{c}\text { Pressure } \\
\text { (psi) }\end{array}$ & {$\left[\begin{array}{c}\text { Temp } \\
\left.{ }^{\circ} \mathrm{C}\right)\end{array}\right.$} & $\begin{array}{c}\text { Pressure } \\
\text { (ft) }\end{array}$ \\
\hline $8 / 10$ & 16:16 & 16 & $\mathrm{KM}$ & 14.26 & 1000.00 & 6.0 & 30.4 & 6.400 \\
\hline $8 / 10$ & $17: 08$ & 16 & $\mathrm{KM}$ & 14.17 & 1745.00 & 6.0 & 30.9 & 6.445 \\
\hline $8 / 10$ & $17: 31$ & 16 & $\mathrm{KM}$ & 14.06 & 2075.00 & 6.5 & 31.1 & 6.441 \\
\hline $8 / 10$ & 18:01 & 17 & KM & 14.24 & 2504.00 & 6.5 & 30.3 & 6.684 \\
\hline $8 / 10$ & $18: 46$ & 17 & $\overline{K M}$ & 14.15 & 3066.00 & 6.5 & 30.0 & 6.730 \\
\hline $8 / 10$ & $22: 25$ & 18 & $\mathrm{AL}$ & 14.09 & 964.78 & 7.0 & 27.8 & 6.903 \\
\hline $8 / 11$ & \begin{tabular}{|l|}
$0: 47$ \\
\end{tabular} & 19 & $\mathrm{AL}$ & 74.06 & 515.52 & 4.5 & 26.8 & 6.861 \\
\hline $8 / 11$ & 4:01 & 20 & $\overline{A L}$ & 73.91 & 875.80 & 5.5 & 25.7 & 6.976 \\
\hline $8 / 11$ & $8: 04$ & 21 & KM & 14.17 & 1800.00 & 3.0 & 25.8 & 7.170 \\
\hline $8 / 11$ & $8: 47$ & 22 & $\mathrm{KM}$ & 14.26 & 80.00 & 2.5 & 26.4 & 6.962 \\
\hline $8 / 11$ & $9: 05$ & 22 & KM & 14.15 & 310.00 & 2.5 & 26.7 & 7.110 \\
\hline $8 / 19$ & $11: 03$ & 22 & KM & 14.09 & 1990.00 & 2.5 & 27.4 & 7.299 \\
\hline $8 / 11$ & $11: 39$ & 23 & $\mathrm{KM}$ & 14.04 & 145.00 & 2.0 & 28.8 & 7.155 \\
\hline $8 / 11$ & $12: 37$ & 23 & $\mathrm{KM}$ & 14.06 & 955.00 & 0.5 & & \\
\hline $8 / 11$ & $14: 05$ & 23 & $\overline{K M}$ & 14.06 & 2185.00 & 0.5 & 29.8 & 7.335 \\
\hline $8 / 11$ & $15: 06$ & 24 & KM & 14.35 & 703.00 & -0.5 & 30.9 & 7.443 \\
\hline $8 / 11$ & \begin{tabular}{|l|}
$16: 35$ \\
\end{tabular} & 24 & $\mathrm{KM}$ & 14.11 & 1975.00 & -0.5 & 31.8 & 7.500 \\
\hline $8 / 11$ & 18:08 & 25 & $\mathrm{KM}$ & 14.00 & 962.00 & 3.5 & 30.8 & 7.700 \\
\hline $8 / 11$ & $18: 50$ & 25 & $\mathrm{KP}$ & 14.06 & 1548.00 & 3.5 & 30.8 & 7.638 \\
\hline $8 / 11$ & 19:07 & 25 & KM & 14.04 & 1776.00 & 2.0 & 31.0 & 7.779 \\
\hline $8 / 11$ & $20: 26$ & 26 & $\mathrm{AL}$ & 14.06 & 2737.41 & 2.5 & 29.6 & 7.844 \\
\hline $8 / 11$ & $23: 16$ & 27 & $\mathrm{AL}$ & 14.09 & 132.32 & 4.5 & 27.6 & 7.846 \\
\hline $8 / 12$ & $23: 16$ & 27 & $\overline{A L}$ & 13.98 & 622.92 & 4.5 & 27.7 & 7.721 \\
\hline $8 / 12$ & $1: 10$ & 27 & $\overline{A L}$ & 13.89 & 1786.50 & 4.0 & 27.6 & 7.698 \\
\hline $8 / 12$ & $3: 00$ & 28 & $\overline{\mathrm{AL}}$ & 14.09 & 956.18 & 3.5 & 26.4 & 8.023 \\
\hline $8 / 12$ & $4: 05$ & 28 & $\mathrm{AL}$ & 74.15 & 1904.58 & 3.0 & 26.4 & 7.867 \\
\hline $8 / 12$ & $5: 07$ & 29 & $\mathrm{AL}$ & 14.00 & 413.65 & 5.0 & 26.2 & 7.718 \\
\hline $8 / 12$ & $7: 01$ & 29 & $\overline{\mathrm{AL}}$ & 13.98 & 2002.50 & 4.5 & 26.4 & 7.843 \\
\hline $8 / 12$ & $7: 50$ & 30 & $\mathrm{KM}$ & 74.26 & 209.00 & 2.5 & 26.0 & 8.200 \\
\hline $8 / 12$ & $8: 12$ & 30 & $\mathrm{KM}$ & 14.17 & 900.00 & 2.0 & 26.3 & 8.249 \\
\hline $8 / 12$ & $10: 16$ & 30 & $\mathrm{KM}$ & 13.95 & 2269.00 & 2.0 & 27.6 & 8.462 \\
\hline $8 / 12$ & $11: 36$ & 31 & $\overline{K M}$ & 14.24 & 1020.00 & 0.5 & 28.8 & 8.480 \\
\hline $8 / 12$ & $12: 45$ & 31 & $\overline{K M}$ & 14.13 & 2015.00 & 0.5 & 29.4 & 8.514 \\
\hline $8 / 12$ & 13:16 & 32 & $\mathrm{KM}$ & 14.35 & 74.00 & 2.0 & 30.0 & 8.618 \\
\hline $8 / 12$ & $14: 51$ & 32 & $M$ & 14.15 & 1399.00 & 2.0 & 30.6 & 8.557 \\
\hline $8 / 12$ & 15:45 & 32 & KM & 14.20 & 2176.00 & 1.0 & 30.9 & 8.473 \\
\hline $8 / 12$ & $17: 21$ & 33 & $\mathrm{KP}$ & 14.20 & 1254.00 & 1.0 & 31.4 & 8.468 \\
\hline $8 / 12$ & $18: 00$ & 3 & $\mathrm{KM}$ & 14.15 & 1781.00 & 0.5 & 31.4 & 8.655 \\
\hline $8 / 12$ & 49:23 & 34 & $\mathrm{AL}$ & 14.13 & 605.76 & 0.5 & 30.7 & 8.753 \\
\hline $8 / 12$ & $20: 04$ & 35 & $\overline{A L}$ & 14.02 & 44.35 & 1.5 & 29.3 & 8.764 \\
\hline $8 / 12$ & $23: 43$ & 35 & $\overline{\mathrm{AL}}$ & 13.93 & 1815.62 & 2.0 & 28.8 & 8.700 \\
\hline $8 / 13$ & 1:11 & 36 & $\mathrm{AL}$ & 14.04 & 725.26 & 3.0 & 27.9 & 8.853 \\
\hline $8 / 13$ & $3: 17$ & 37 & $\overline{A L}$ & 14.02 & 00.11 & 4.0 & 27.3 & 8.688 \\
\hline $8 / 13$ & $4: 15$ & 3 & $\overline{A L}$ & 13.98 & 27.47 & 3.5 & 27.5 & 8.844 \\
\hline $8 / 13$ & $6: 09$ & 38 & $\overline{A L}$ & 14.15 & 163.62 & 0.0 & 27.1 & 8.874 \\
\hline $8 / 13$ & $9: 31$ & 39 & $\mathrm{AL}$ & 14.22 & 622.41 & 0.0 & 27.5 & 9.008 \\
\hline $8 / 13$ & $11: 11$ & 3 & $\mathrm{~K}$ & 14.04 & 2100.00 & 0.0 & 28.2 & 9.384 \\
\hline $8 / 13$ & $13: 48$ & 40 & $\mathrm{KM}$ & 14.15 & 1966.00 & 1.0 & 26.9 & 8.167 \\
\hline $8 / 13$ & $14: 08$ & 40 & $\overline{K M}$ & 14.09 & 2239.00 & 1.0 & 26.9 & 8.211 \\
\hline $8 / 13$ & $15: 28$ & 41 & KM & 14.13 & 916.00 & 1.0 & 31.9 & 8.453 \\
\hline $8 / 43$ & \begin{tabular}{|l|}
$17: 02$ \\
\end{tabular} & 41 & KM & 14.28 & 2267.00 & 1.0 & 32.4 & 9.674 \\
\hline $8 / 13$ & $\begin{array}{l}19: 14 \\
\end{array}$ & & & & 1800.00 & 1.0 & 32.9 & 9.981 \\
\hline $8 / 13$ & $20: 35$ & 43 & KM & 14.13 & 400.00 & 1.0 & 32.1 & 10.210 \\
\hline $8 / 13$ & $21: 15$ & 43 & KM & 14.23 & 964.00 & 1.0 & 31.9 & 10.388 \\
\hline $8 / 14$ & $\begin{array}{l}7: 09 \\
\end{array}$ & & & & & & 29.8 & 3.398 \\
\hline
\end{tabular}

Well Transducer Data: Shaded orange means the numbers were deemed outliers and omitted from analysis.

Shaded gray means than transducer was lowered $\sim 10$ feet and appropriate calculations were made for analysis. 


\begin{tabular}{|c|c|c|c|}
\hline \multicolumn{4}{|c|}{ D4.25c } \\
\hline $\mathrm{Rec}$ & & Temp & \\
\hline$\#$ & Deter Time & ${ }^{\circ} \mathrm{C}$ & HS/am \\
\hline & $8 / 7 / 200810: 41$ & 16.6 & 884.0 \\
\hline 2 & $8 / 7 / 2008 \quad 10.43$ & 16.6 & \begin{tabular}{|l|}
883.7 \\
\end{tabular} \\
\hline 3 & 8772008 10:45 & 16.6 & 884.7 \\
\hline 4 & $877 / 200810: 47$ & 16.6 & 884.5 \\
\hline 5 & $8772008 \quad 10: 49$ & 16.6 & 884.5 \\
\hline 6 & $8 / 7 / 200810: 51$ & 16.6 & 884.9 \\
\hline 7 & $877 / 200810: 53$ & 16.6 & 884.6 \\
\hline 8 & $87 / 2008$ 10:55 & 16.6 & 884.8 \\
\hline 9 & $87 / 2008$ 10:50 & 16.6 & \begin{tabular}{|l|}
884.6 \\
\end{tabular} \\
\hline 10 & $87 / 12008$ 10:59 & 16.6 & 884.9 \\
\hline 11 & $87 / 200811: 01$ & 16.6 & 885.1 \\
\hline 12 & 871200 & 16.6 & 885.1 \\
\hline 13. & $87 / 2000$ & 16.6 & 885.1 \\
\hline 14| & $87 / 200811: 07$ & 16.6 & 885.0 \\
\hline 15 & $87 / 20$ & 16.6 & 885.1 \\
\hline 16 & $877 / 20$ & 16.6 & 885.3 \\
\hline 17 & $87 / 20$ & 16.6 & \begin{tabular}{|l|}
885.7 \\
\end{tabular} \\
\hline 18 & $87 / 20$ & 16.6 & 886.0 \\
\hline 19 & $87 / 200$ & 16.6 & \begin{tabular}{|l|}
888.1 \\
\end{tabular} \\
\hline 20 & 877200 & 16.6 & 893.6 \\
\hline 21 & $87 / 2000$ & 16.6 & 896.8 \\
\hline 22 & $87 / 20$ & 16.6 & \begin{tabular}{|l|}
901.0 \\
\end{tabular} \\
\hline 23 & $8 / 7 / 2$ & 16.6 & 901. \\
\hline 24 & $87 / 20$ & 16.6 & 907.7 \\
\hline 25 & $877 / 20$ & 16.6 & 907.2 \\
\hline 26. & $87 / 20$ & 16.6 & 907.6 \\
\hline 27 & $8 / 720$ & 16.6 & 833.4 \\
\hline 28 & 87120 & 16.5 & 798.1 \\
\hline 29 & $8 / 72$ & 16.5 & 779.1 \\
\hline 30 & $8 \pi / 2$ & 16.5 & $\pi 7.1$ \\
\hline 31 & $8 / 7 / 2$ & 16.5 & 775. \\
\hline 32 & $8 / 720$ & 16.5 & 774 \\
\hline 33 & $8 / 71200$ & 16.5 & 774.3 \\
\hline 34 & $87 / 2$ & 16.5 & 773.2 \\
\hline 35 & $8 / 7 / 2$ & 16.5 & $\pi 2$ \\
\hline 36 & $87 / 2$ & 16.5 & 771. \\
\hline 37 & $8 \sqrt{7 / 20}$ & 16.5 & 771. \\
\hline 38 & $87 / 200$ & 16.5 & 771.1 \\
\hline 39 & $87 / 2$ & 16.5 & 770.8 \\
\hline 40 & $87 / 20$ & 16.5 & $7 \pi 0$. \\
\hline 41 & & 16.5 & 769.9 \\
\hline 42 & $87 \pi$ & 16.5 & 769.7 \\
\hline 43 & & 16.5 & 769.5 \\
\hline 44 & $8 / 7 / 2$ & 16.5 & \begin{tabular}{|l|l|}
768.8 \\
\end{tabular} \\
\hline 45 & 87120 & 16.5 & 769.1 \\
\hline 46 & & 16.5 & $767 !$ \\
\hline 47 & & 16.5 & 767. \\
\hline 48 & & 16.5 & 767. \\
\hline 49 & $87 / 2$ & 16.5 & 767. \\
\hline 50 & & 16.5 & 766. \\
\hline & & 16.5 & 766. \\
\hline 52 & $87 \pi$ & 16.5 & 766. \\
\hline & & 16.5 & 765. \\
\hline 54 & $87 / 2$ & 16.5 & \begin{tabular}{|l|l}
764.7 \\
\end{tabular} \\
\hline 56 & & 16.5 & 764.5 \\
\hline 56 & 87120 & 16.5 & 760.6 \\
\hline 5] & $87 / 20$ & 16.5 & 759. \\
\hline & & 16.5 & \begin{tabular}{|l}
759. \\
\end{tabular} \\
\hline 59 & $87 / 20$ & 16.5 & 758.8 \\
\hline & & 16.5 & \begin{tabular}{|l|}
758. \\
\end{tabular} \\
\hline & & 16.5 & \\
\hline 즈 & & 16.5 & 757. \\
\hline & $87 / 2$ & 16.5 & 756.8 \\
\hline 64 & $87 / 20$ & 16.5 & 755. \\
\hline & & 16.5 & \\
\hline & $877 / 2$ & 16.5 & 756 \\
\hline 67 & & 16.5 & 754.8 \\
\hline & $87 / 20$ & 16.5 & \\
\hline 69 & 871200 & 16.5 & 753.7 \\
\hline $\mathrm{O}_{2}$ & & 16.5 & \begin{tabular}{|l|l}
753.1 \\
\end{tabular} \\
\hline & $8 / 7 / 20$ & 165 & \\
\hline & & & \\
\hline
\end{tabular}

\begin{tabular}{|c|c|c|c|}
\hline \multicolumn{4}{|c|}{$D 4-25 c$} \\
\hline$R \in C$ & & Temp & \\
\hline$\#$ & DeterTime & ${ }^{\circ} \mathrm{C}$ & $\mu \mathrm{sic}$ \\
\hline 72 & 87720081300 & 16.5 & 7 \\
\hline 73 & $87 / 200813: 05$ & & \\
\hline 74 & $87 / 200813: 07$ & 16.5 & 751 \\
\hline 75 & 871200813.09 & 16.5 & 750 \\
\hline 76 & $871200813: 11$ & 16.5 & \\
\hline$\overline{7}$ & $87 / 2008$ 13:13 & 16.5 & 749.7 \\
\hline 78 & $87 / 2008$ 13:15 & 16.5 & \\
\hline 79 & $87 / 2008$ 13:17 & 16.5 & 748 \\
\hline 80 & 8772008 13:19 & 16.5 & 655 \\
\hline 81 & $8 / 7200813: 21$ & 16.5 & 654 \\
\hline 82 & $877200813: 23$ & 16.5 & 653. \\
\hline 83 & $87 / 200813: 25$ & 16.5 & 652 \\
\hline 84 & $87 / 200813: 27$ & 16.5 & 651 \\
\hline 85 & $877200813: 29$ & 16.5 & 651. \\
\hline 86 & $87 / 200813: 31$ & 16.6 & \\
\hline 87 & $8 / 7200813: 33$ & 16.6 & 870 \\
\hline 88 & $877200813: 35$ & 16.7 & \\
\hline 89 & $87 / 2008$ 13:37 & 16.7 & 849 \\
\hline 90 & $877200813: 39$ & 16.7 & 34. \\
\hline 91 & $87 / 200813: 41$ & 16.7 & \\
\hline 92 & $8 / 7200813: 43$ & 16.7 & 844 \\
\hline 93 & 8772006 & 16.7 & 844 \\
\hline 94 & $87 / 200$ & 16.7 & 843 \\
\hline 96 & $87 / 200$ & 16.7 & 843 \\
\hline 96 & 877200 & 16.7 & \\
\hline 97 & 13.53 & 16.7 & 841. \\
\hline 98 & 13:56 & 16.7 & 841 \\
\hline 9 & $8 / 720$ & 16.7 & \\
\hline 100 & 87120 & 16.7 & 840. \\
\hline 101 & $87 / 20$ & 16.7 & \\
\hline 100 & $87 / 20$ & 16.7 & 841 \\
\hline 103 & $8 / 72008$ 14:05 & 16.7 & 841 \\
\hline 104 & $87 / 2008$ 14:07 & 16.7 & \\
\hline 105 & 4:09 & 16.7 & $\overline{342}$ \\
\hline 106 & $87 / 20$ & 16.7 & 43 \\
\hline 107 & $87 / 20$ & 16.7 & 343 \\
\hline 108 & 14:15 & 16.7 & 44 \\
\hline 109 & $87 / 200$ & 16.7 & 844 \\
\hline 110 & $87 / 20$ & 16.7 & 845 \\
\hline 111 & $87 / 20$ & 16.7 & 846 \\
\hline 112 & & 16.7 & 846 \\
\hline 113 & 14:25: & 16.7 & 847 \\
\hline 114 & & 16.7 & 848 \\
\hline 115 & $14: 29$ & 16.7 & 849 \\
\hline 116 & $8 / 720$ & 16.7 & 850 \\
\hline 117 & $87 / 20$ & 16.7 & 850 \\
\hline 118 & $4: 35$ & 16.7 & 51. \\
\hline 119 & & 16.7 & 852 \\
\hline 120 & & 16.7 & 53 \\
\hline 121 & & 16.7 & \\
\hline 122 & $87 / 20$ & 16.7 & 854 \\
\hline 123 & $87 / 20$ & 16.7 & 854 \\
\hline 124 & & 16.7 & \\
\hline 125 & $4: 49$ & 16.7 & 854 \\
\hline 126 & & 16.7 & 855 \\
\hline 127 & 14:53 & 16.7 & \\
\hline 128 & & 16.7 & $85 x$ \\
\hline 129 & & 16.7 & \\
\hline 130 & $14: 50$ & 16.7 & 85 \\
\hline 131 & & 16.7 & 857 \\
\hline 132 & $5: 03$ & 16.7 & \\
\hline 133 & 15.05 & 16.7 & 858 \\
\hline 134 & & 16.7 & \\
\hline 135 & $87 / 20$ & 16.7 & 859 \\
\hline 136 & & 16.7 & 859 \\
\hline 137. & & 16.7 & \\
\hline 138 & 15:15 & 16.7 & 859 \\
\hline & $87 / 200$ & 16.7 & 860 \\
\hline 140 & $87 / 200$ & \begin{tabular}{|l|}
16.7 \\
\end{tabular} & 860 \\
\hline 141 & $87 / 2008$ 15:21 & \begin{tabular}{|l|}
16.7 \\
\end{tabular} & 861 \\
\hline 142 & $87 / 200815: 23$ & 16.7 & \\
\hline & & & \\
\hline
\end{tabular}

\begin{tabular}{|c|c|c|c|}
\hline \multicolumn{4}{|c|}{$D 425 \mathrm{C}$} \\
\hline $\mathrm{Bc}$ & & Temp & \\
\hline$\#$ & Date/Time & ${ }^{\circ} \mathrm{C}$ & ps/an \\
\hline 143 & $87 / 200815: 25$ & 16.7 & 861 \\
\hline 144) & $87 / 200815: 27$ & 16.7 & 861. \\
\hline 145 & $87 / 200815: 29$ & 16.7 & $8 \% 2$ \\
\hline 146 & $87 / 2008$ 15:31 & 16.7 & 862.4 \\
\hline 147 & $87 / 200815: 33$ & 16.7 & 862.7 \\
\hline 148 & $87 / 2008$ 15:35 & 16.7 & 863 \\
\hline 149 & 8772008 15:37 & 16.7 & 863. \\
\hline 150 & $87 / 2008$ १5:39 & 16.7 & 863. \\
\hline 151 & $87 / 2008$ 15:41 & 16.7 & 863. \\
\hline 152 & $871200815: 43$ & 16.7 & 864.0 \\
\hline 153 & $87 / 200815: 45$ & 16.7 & 864. \\
\hline 154 & $87 / 200815: 47$ & 16.7 & \\
\hline 155 & $87 / 2008$ 15:49 & 16.7 & 864. \\
\hline 156 & $87 / 2008$ 15:51 & 16.7 & 864. \\
\hline 150 & $87 / 200815: 53$ & 16.7 & 865. \\
\hline 158 & $87 / 2000$ 15:55 & 16.7 & 864. \\
\hline 159 & $87 / 2008$ 15:57 & 16.7 & 865. \\
\hline 160 & $87 / 2008$ 15:50 & 16.6 & 865. \\
\hline 161 & $87 / 200816: 01$ & 16.7 & \\
\hline 162 & $8 / 7 / 200816: 03$ & 16.7 & 864. \\
\hline 1 1๘ & $87 / 2008$ 16:05 & 16.7 & 865. \\
\hline 164 & $87 / 2008$ 16:07 & 16.7 & \\
\hline 165 & $87 / 2008$ 16:00 & 16.7 & 866. \\
\hline$\overline{10 t}$ & $87 / 20$ & 16.6 & \\
\hline 167 & $87 / 20$ & 16.7 & 864 \\
\hline 168 & $87 / 20$ & 16.6 & 865. \\
\hline 169 & 87120 & 16.6 & 865 . \\
\hline 170 & $87 / 200$ & 16.7 & 865. \\
\hline 171 & $87 / 20$ & 16.7 & 865 \\
\hline 172 & $87 / 2006$ & 16.7 & 865. \\
\hline 173 & $87 / 200$ & 16.7 & 866 \\
\hline 174 & $87 / 20$ & 16.7 & \\
\hline 175 & $87 / 20$ & 16.6 & 866 \\
\hline 176 & $87 \pi 20$ & 16.7 & 866 \\
\hline 17 & 87120 & 16.6 & 867. \\
\hline 178 & $87 / 20$ & 16.7 & 966 \\
\hline 179 & $87 / 20$ & 16.6 & 867 \\
\hline 180 & $87 / 2$ & 16.6 & 867 \\
\hline 181 & 87720 & 16.7 & 857 \\
\hline 182 & $87 / 20$ & 16.7 & 867 \\
\hline 183 & $87 / 20$ & 16.7 & 867 \\
\hline 184 & $87 / 20$ & 16.7 & 867. \\
\hline 185 & $87 / 20$ & 16.7 & \\
\hline 186 & $87 / 20$ & 16.7 & 868 \\
\hline 187 & & 16.7 & \\
\hline 18 & $87 / 20$ & 16.7 & \\
\hline 189 & & 16.7 & \\
\hline & & 16.6 & \\
\hline 191 & 87720 & 16.7 & 869 . \\
\hline & & 16.7 & \\
\hline 193 & $87 / 20$ & 16.6 & \\
\hline 194 & & 16.6 & 8 \\
\hline 195 & 8772 & 16.6 & \\
\hline 196 & & 16.7 & \\
\hline 19 & & 16.7 & \\
\hline 198 & $87 / 20$ & 16.7 & \\
\hline & & 16.7 & \\
\hline 200 & $87 / 20$ & 16.7 & \\
\hline & & 16.6 & \\
\hline 202 & $87 / 20$ & 10.0 & \\
\hline 203 & $87 / 200$ & 16.7 & \\
\hline & & & \\
\hline 205 & $87 / 200$ & 16.6 & 870 \\
\hline & & 16.6 & \\
\hline 20 & $87 / 20$ & 16.7 & \\
\hline 206 & 871200 & 16.7 & \\
\hline 20 & $87 / 200$ & & \\
\hline 210 & $87 / 200$ & 16.6 & 871 \\
\hline 2111 & $87 / 200$ & 16.6 & \\
\hline & 87720 & & \\
\hline 213 & $87 / 20$ & & $8 / 7$ \\
\hline & & & \\
\hline
\end{tabular}

\begin{tabular}{|c|c|c|c|}
\hline \multicolumn{4}{|c|}{$D 425 \mathrm{C}$} \\
\hline $\mathrm{ReC}$ & & Temp & SC \\
\hline$\#$ & DateTime & ${ }^{\circ} \mathrm{C}$ & $\mu S_{c m}$ \\
\hline 214 & $87 / 2008$ 17:47 & 16.6 & 8720 \\
\hline 215 & 8712008 17:49 & 16.7 & 8721 \\
\hline 216 & $8 / 72008$ 17:51 & 16.6 & 8723 \\
\hline 217 & $87 / 200817: 53$ & 16.6 & 8728 \\
\hline 218 & $87 / 200817: 55$ & 16.6 & 8727 \\
\hline 219 & $87 / 2008$ 17:57 & 16.6 & 873.0 \\
\hline 200 & $8 / 7 / 2008$ 17:59 & 16.6 & 8729 \\
\hline 221 & $87 / 2008$ 18:01 & 16.6 & 8725 \\
\hline$\overline{222}$ & $87 / 200818: 03$ & 16.6 & 873. \\
\hline 223 & $87 / 2008$ 18:06 & 16.6 & 873.4 \\
\hline 224 & $87 / 200818: 07$ & 16.6 & 873.2 \\
\hline 225 & $87 / 200818: 09$ & 16.6 & \\
\hline 226 & $87 / 2008$ 18:11 & 16.6 & 873.4 \\
\hline 227 & $8 / 7200818: 13$ & 16.6 & 873.4 \\
\hline$\overline{228}$ & $87 / 2008$ 18:15 & 16.6 & 873.7 \\
\hline 220 & $87 / 2008$ 18:17 & 16.6 & 874.1 \\
\hline 230 & $87 / 200818: 19$ & 16.6 & 873.9 \\
\hline 231 & $87 / 200818: 21$ & 16.7 & 874.5 \\
\hline 232 & $87 / 200818: 23$ & 16.6 & 874.4 \\
\hline 233 & $87 / 2008$ 18:25 & 16.6 & 874.4 \\
\hline 234 & $87 / 200818: 27$ & 16.6 & 874.8 \\
\hline 235 & $87 / 200818: 20$ & 16.6 & 874.7 \\
\hline 236 & $87 / 2008$ 18:31 & 16.6 & 874.4 \\
\hline 237 & $87 / 2008$ 18:33 & 16.7 & 874.5 \\
\hline 238 & $87 / 200818: 36$ & 16.6 & 874.6 \\
\hline 239 & $87 / 200818: 37$ & 16.7 & 874.7 \\
\hline 240 & $87 / 200818: 30$ & 16.6 & 874. \\
\hline 241 & 8772008 18:41 & 16.6 & 874. \\
\hline 242 & $87 / 200818: 43$ & 16.7 & 875. \\
\hline 243 & $87 / 200818: 45$ & 16.6 & 875. \\
\hline 244 & $87 / 200818: 47$ & 16.6 & 875.8 \\
\hline 245 & $87 / 200818: 49$ & 16.6 & 876. \\
\hline 246 & $87 / 2008$ 18:51 & 16.6 & 875.8 \\
\hline 247 & $87 / 200818: 53$ & 16.6 & 876. \\
\hline 248 & $87 / 200818: 50$ & 16.7 & 876.2 \\
\hline 249 & $87 / 2008$ 18:57 & 16.6 & 876.9 \\
\hline 250 & $87 / 200818: 50$ & 16.6 & 876. \\
\hline 251 & $87 / 2008$ 19:01 & 16.6 & 876. \\
\hline 252 & $8 / 7 / 200819: 08$ & 16.6 & 876. \\
\hline 253 & $87 / 200819: 05$ & 16.6 & 876 \\
\hline 254 & $87 / 200819: 07$ & 16.6 & 876 \\
\hline 255 & $87 / 2008$ १९:09 & 16.6 & 876.5 \\
\hline 256 & 87720 & 16.6 & 877.1 \\
\hline 257 & $87 / 200819.13$ & 16.6 & 877. \\
\hline 258 & $87 / 20$ & 16.6 & 877. \\
\hline 250 & $87 / 200$ & 16.6 & 877.8 \\
\hline 260 & $87 / 20$ & 16.6 & 877. \\
\hline 261 & $87 / 200019.21$ & 16.6 & 877.3 \\
\hline 262 & $87 / 200819: 23$ & 16.6 & 877.3 \\
\hline 263 & $87 / 200819.25$ & 16.6 & 877.8 \\
\hline 264 & $87 / 200819.27$ & 16.6 & 878. \\
\hline 265 & $87 / 2$ & 16.6 & 877. \\
\hline 266 & $87 / 20$ & 16.6 & 877.8 \\
\hline 267 & 87120 & 16.6 & 878 \\
\hline 268 & $87 / 20$ & 16.6 & 876. \\
\hline 260 & $8 / 7200819: 37$ & 16.6 & 877.8 \\
\hline 270 & $87 / 200819.39$ & 16.7 & 877 \\
\hline 271 & $87 / 200819.41$ & 16.6 & 878 \\
\hline 272 & $87 / 200819: 43$ & 16.6 & 878.0 \\
\hline 273 & $87 / 200819.45$ & 16.6 & 878.1 \\
\hline 274 & $87 / 200819.47$ & 16.6 & 878 \\
\hline 275 & & & 878 \\
\hline 276 & $87 / 200819.51$ & 16.6 & 878.6 \\
\hline $2 \pi$ & $87 / 200819.53$ & 16.6 & 878. \\
\hline 278 & $87 / 200819.56$ & 16.6 & 879. \\
\hline 279 & $87 / 200819.57$ & 16.6 & 879. \\
\hline 280 & $87 / 200819.59$ & $\overline{16.6}$ & $8 \pi$ \\
\hline 281 & $87 / 200820: 001$ & 16.6 & 879.1 \\
\hline 282 & $87 / 200820: 03$ & 16.6 & 879.3 \\
\hline 283 & $87 / 200820: 05$ & 16.6 & 879.3 \\
\hline 284 & $87 / 200820: 07$ & 16.6 & 879 \\
\hline & & & \\
\hline
\end{tabular}

\begin{tabular}{|c|c|c|c|}
\hline \multicolumn{4}{|c|}{ D425C } \\
\hline $\operatorname{Rec}$ & & Temp & $\mathrm{SC}$ \\
\hline$\#$ & Dater/ime & ${ }^{\circ} \mathrm{C}$ & $\mu S G r$ \\
\hline 286 & $87 / 200820: 11$ & 16.6 & 879.8 \\
\hline 28 त्र & $87 / 200820: 13$ & 16.6 & 880.2 \\
\hline 288 & $87 / 200820: 15$ & 16.6 & 879.8 \\
\hline 289 & $87 / 200820: 17$ & 16.6 & 879.8 \\
\hline 290 & $87 / 200820: 19$ & 16.6 & 879.6 \\
\hline 291 & $87 / 200820: 21$ & 16.6 & 879.6 \\
\hline 292 & 87120082023 & 16.6 & 879.8 \\
\hline 293 & $871200820: 25$ & 16.6 & 879.8 \\
\hline 294 & $871200820: 27$ & 16.6 & \\
\hline 295 & $871200820: 29$ & 16.6 & 879.8 \\
\hline 296 & $871200820: 31$ & 16.6 & 879.3 \\
\hline 297 & 871200820.33 & 16.6 & 879.6 \\
\hline 298 & $871200820: 35$ & 16.6 & 879.9 \\
\hline 299 & $87 / 200820: 37$ & 16.6 & 879. \\
\hline 300 & $87 / 200820: 39$ & 16.6 & 879. \\
\hline 301 & $871200820: 41$ & 16.6 & 879.1 \\
\hline 302 & $871200820: 43$ & 16.6 & 879.3 \\
\hline 303 & $87 / 200820: 45$ & 16.6 & 879. \\
\hline 304 & $87 / 200820.47$ & 16.6 & 879. \\
\hline 306 & $87 / 200820: 49$ & 16.6 & 879.2 \\
\hline 306 & $87 / 200820: 51$ & 16.6 & 878.8 \\
\hline 307 & $87 / 200820: 53$ & 16.6 & 878.8 \\
\hline 308 & $87 / 200820: 55$ & 16.6 & 878.7 \\
\hline 309 & $87 / 200820: 57$ & 16.6 & 878.5 \\
\hline 310 & $87 / 200820.59$ & 16.6 & 878.4 \\
\hline 311 & $87 / 200621: 01$ & 16.6 & 878.3 \\
\hline 312 & $871200821: 03$ & 16.6 & 878. \\
\hline 313 & $87 / 200821: 06$ & 16.6 & 878. \\
\hline 314 & $87 / 200821: 07$ & 16.6 & 878. \\
\hline 315 & $87 / 200821: 09$ & 16.6 & 877. \\
\hline 316 & $87 / 200821: 11$ & 16.6 & 877.7 \\
\hline 317 & $87 / 200821: 13$ & 16.6 & $8 \pi$. \\
\hline 318 & $871200821: 15$ & 16.6 & 877. \\
\hline 319 & $87 / 200821: 17$ & 16.6 & 877.5 \\
\hline 320 & $87 / 200821: 19$ & 16.6 & 877. \\
\hline 321 & $87 / 200821: 21$ & 16.6 & 877. \\
\hline 322 & $87 / 200821: 23$ & 16.6 & 877. \\
\hline 323 & $87 / 200821: 25$ & 16.6 & 877. \\
\hline 324 & $87 / 200821: 27$ & 16.6 & 877. \\
\hline 325 & $87 / 200$ & 16.6 & 87. \\
\hline 326 & $87 / 200821: 31$ & 16.6 & 877. \\
\hline 327 & $87 / 200821: 33$ & 16.6 & $8 \pi 7$ \\
\hline 328 & $87 / 2000$ & 16.6 & $8 \pi 7$. \\
\hline 320 & $87 / 200821: 37$ & 16.6 & 876. \\
\hline 330 & $87 / 200$ & 16.6 & 877. \\
\hline 331 & $87 / 2006$ & 16.7 & 876. \\
\hline 330 & $87 / 200$ & 16.6 & 876. \\
\hline 333 & $87 / 200$ & 16.6 & 876.8 \\
\hline 334 & 871200 & 16.6 & 877.2 \\
\hline 335 & $87 / 20$ & 16.6 & 877.4 \\
\hline 336 & $8 / 7 / 200821: 51$ & 16.6 & 87.2 \\
\hline 337 & $87 / 20$ & 16.6 & 877. \\
\hline 338 & $87 / 200$ & 16.6 & 877. \\
\hline 339 & 87720 & 16.6 & 877. \\
\hline 340 & 87120 & 16.7 & 876.7 \\
\hline 341 & $8 / 720082201$ & 16.6 & 877.2 \\
\hline 342 & & & 877. \\
\hline 343 & 877200822205 & 16.6 & 877. \\
\hline 344 & $87 / 200$ & 16.6 & 877. \\
\hline 345 & $87 / 200$ & 16.6 & 876. \\
\hline 346 & $87 / 200822: 11$ & 16.6 & 877. \\
\hline 347 & $871200822 \div 13$ & 16.6 & 877. \\
\hline 348 & $87 / 20082215$ & 16.6 & 876. \\
\hline 349 & $87 / 20062217$ & 16.6 & 876. \\
\hline 350 & $87 / 200822 \div 19$ & 16.6 & 877. \\
\hline 351 & 871200822221 & 16.6 & 877. \\
\hline 352 & $87 / 200$ & 16.6 & 87. \\
\hline 353 & $87 / 20082225$ & 16.6 & 877.2 \\
\hline 354 & $87 / 20082227$ & 16.6 & 87.2 \\
\hline 355 & $87 / 200822: 29$ & 16.6 & 87.6 \\
\hline & & & \\
\hline & & & \\
\hline
\end{tabular}




\begin{tabular}{|c|c|c|c|c|c|c|c|c|c|c|c|c|c|c|c|c|c|c|c|}
\hline \multicolumn{4}{|c|}{$D 425 c$} & \multicolumn{4}{|c|}{$D 425 c$} & & $D 4.25 \mathrm{c}$ & & & & $D 4.25 \mathrm{C}$ & & & & $D 425 \mathrm{C}$ & & \\
\hline acc & & Templ & $\mathrm{SC}$ & $\mathrm{Bc}$ & & Temp & $\mathrm{SC}$ & ect & & Temp & SC & $\mathrm{Bec}$ & & Temp: & & $R \in C$ & & Temp & $\mathrm{SC}$ \\
\hline$\#$ & DaterTime & ${ }^{\circ} \mathrm{C}$ & $\mu \mathrm{S} / \mathrm{cm}$ & $\#$ & zaterTime & ${ }^{\circ} \mathrm{C}$ & $\mu \mathrm{S} / \mathrm{cm}$ & $\#$ & DakeTime & ${ }^{\circ} \mathrm{C}$ & $\mu \mathrm{sicm}$ & $\#$ & DaterTime & ${ }^{\circ} \mathrm{C}$ & HS/cm & $\#$ & DateTime & ${ }^{\circ} \mathrm{C}$ & \\
\hline 356 & $87 / 200822: 31$ & 16.6 & 877.6 & 427 & $8 / 8 / 20080: 53$ & 16.6 & 877.7 & 498 & $8 / 820083: 15$ & 16.6 & ब) 882.8 & & $88: 20085: 37$ & 16.6 & 876.1 & 640 & $8 / 8 / 20087: 59$ & 16.6 & 879.0 \\
\hline 357 & 87720082233 & 16.6 & 877.7 & 428 & & 16.6 & 877.8 & & & 16.6 & 8828 & 570 & & & & & & 16.6 & \\
\hline 358 & $871200822: 35$ & 16.6 & 877.6 & 429 & $8 / 8 / 2000005$ & 16.6 & 878.3 & 500 & $8820083: 19$ & 16.6 & \begin{tabular}{|l|l|}
6 & 883.5 \\
\end{tabular} & 571 & $88: 20085: 41$ & 16.6 & 875.8 & 642 & $8 / 820088: 03$ & 16.6 & 878.9 \\
\hline 359 & $87 / 20082237$ & 16.6 & 877.8 & 430 & $8 / 8 / 20000: 59$ & & 877.8 & & & 16.6 & \begin{tabular}{|l|l|}
6 & 883.7 \\
\end{tabular} & $5 / 2$ & & & 875.7 & & & 16.6 & \\
\hline 360 & $87 / 20082239$ & 16.6 & 877.6 & 431 & $8 / 8 / 20081: 01$ & 16.6 & 877.7 & 502 & $8 / 8 / 20083: 23$ & 16.6 & 883.9 & 573 & $8 / 820085: 45$ & 16.6 & 875.0 & 644 & $8 / 8 / 20088: 07$ & 16.6 & 879 \\
\hline 361 & $87 / 20082241$ & 16.6 & 877.3 & 432 & $8 / 820081: 03$ & 16.6 & 878.1 & 503 & $8 / 820083.25$ & 16.6 & 883.7 & 574 & $88 / 20085: 47$ & 16.6 & 874.9 & & & 16.6 & \\
\hline 362 & $87 / 200822443$ & 16.6 & 877.8 & 433 & $8 / 8 / 20081: 05$ & 16.6 & 878.1 & 504 & $8 / 820083: 27$ & 16.6 & 884.0 & 575 & $8 / 8 / 20085: 49$ & 16.6 & \begin{tabular}{|l|}
874.9 \\
\end{tabular} & 646 & $8 / 8 / 20088: 11$ & 16.6 & 879.3 \\
\hline 363 & 877200822445 & 16.6 & 877.1 & 434 & $8 / 8 / 20081: 07$ & 16.6 & 878.5 & 505 & $8 / 8 / 20083: 29$ & 16.7 & 883.3 & 576 & $88200085: 51$ & 16.6 & \begin{tabular}{|l|}
874.2 \\
\end{tabular} & & & 16.6 & \\
\hline 364 & $8 / 720082247$ & 16.6 & 877.1 & 435 & $8 / 8 / 20081: 09$ & 16.6 & 875.0 & 506 & $8 / 820083: 31$ & 16.6 & 884.2 & 577 & $88200085: 53$ & 16.6 & \begin{tabular}{|l|}
874.0 \\
\end{tabular} & 648 & 8/820088:15 & 16.6 & 878.5 \\
\hline 365 & $87 / 20082249$ & 16.6 & 877.2 & 436 & $8 / 8 / 20081: 11$ & 16.6 & 874.8 & 507 & $8 / 8 / 20083: 33$ & 16.6 & 884.4 & 578 & $8 / 8 / 20085: 55$ & & \begin{tabular}{|l|}
873.9 \\
\end{tabular} & 649 & & 16.6 & \\
\hline 366 & $877200822: 51$ & 16.6 & 877.4 & 437 & $8 / 8 / 20081: 13$ & 16.6 & 875.4 & 508 & $8 / 8 / 20083: 35$ & 16.6 & 883.9 & 579 & $8 / 820005: 57$ & 16.6 & 873.8 & 650 & 8/820088:19 & 16.6 & 878.6 \\
\hline 367 & 87720082255 & 16.6 & 877.1 & 438 & $8 / 8 / 20081: 15$ & 16.6 & \begin{tabular}{|l|l|}
6 & 874.0 \\
\end{tabular} & 509 & $8 / 820083: 37$ & 16.6 & \begin{tabular}{|l|l|}
6 & 884.3 \\
\end{tabular} & 580 & $8 / 820005: 59$ & & \begin{tabular}{|l|}
873.6 \\
\end{tabular} & 651 & & 16.6 & \\
\hline 368 & $87 / 20082256$ & 16.6 & 877.1 & 439 & $8 / 8 / 20081: 17$ & 16.6 & \begin{tabular}{|l|l|}
6 & 874.4 \\
\end{tabular} & 510 & $8 / 8 / 20083: 39$ & 16.6 & \begin{tabular}{|l|l|}
6884.9 \\
\end{tabular} & 581 & $8 / 8200086: 01$ & 16.6 & \begin{tabular}{|l|}
873.9 \\
\end{tabular} & 652 & $8 / 8 / 20088: 23$ & 16.6 & 878 \\
\hline 369 & $87 / 200822: 57$ & 16.6 & 877.2 & 440 & $8 / 8 / 20081: 19$ & 16.6 & \begin{tabular}{|l|l|}
6 & 874.7 \\
\end{tabular} & 511 & $8 / 820083: 41$ & 16.6 & \begin{tabular}{|l|l|}
6 & 884.5 \\
\end{tabular} & 582 & $8 / 8 / 20086: 03$ & 16.6 & 873.5 & 653 & & 16.6 & \\
\hline 370 & $87 / 200822: 59$ & 16.6 & 877.0 & 441 & $8 / 8 / 20081: 21$ & 16.6 & \begin{tabular}{l|l|}
6 & 874.7 \\
\end{tabular} & 512 & $8 / 820083: 43$ & 16.6 & \begin{tabular}{|l|l|}
6884.8 \\
\end{tabular} & 583 & $88120086: 05$ & 16.6 & 873.3 & 654 & $8 / 820088: 27$ & 16.6 & 877.8 \\
\hline 371 & $8 / 7200823: 01$ & 16.6 & 877.0 & 442 & $8 / 8 / 20081: 23$ & 16.6 & \begin{tabular}{l|l|}
6 & 874.7 \\
\end{tabular} & 513 & $8 / 8 / 20083: 45$ & 16.6 & 884.7 & 584 & $8 / 8200086: 07$ & 16.7 & 873.1 & 655 & $8 / 820088: 20$ & 16.6 & 877.8 \\
\hline 372 & $87 / 200823: 03$ & 16.6 & 877.2 & 443 & $8 / 8 / 20081: 25$ & 16.6 & \begin{tabular}{l|l|}
6 & 874.9 \\
\end{tabular} & 514 & $8 / 8220083: 47$ & 16.6 & 885.4 & 585 & $8 / 820086: 09$ & 16.6 & 8728 & 656 & & 16.6 & \\
\hline 373 & $8 / 7200823: 06$ & 16.6 & 877.0 & 444 & $8 / 8 / 20081: 27$ & 16.6 & \begin{tabular}{|l|l|}
6 & 875.1 \\
\end{tabular} & 515 & $8 / 820$ & 16.7 & 884.5 & 586 & $8 / 8 / 20086: 11$ & 16.6 & 8728 & 657 & $888: 33$ & 16.6 & 876 \\
\hline 374 & $8 / 7200823: 07$ & 16.6 & 87.2 & 445 & $8 / 8 / 20081: 29$ & 16.6 & \begin{tabular}{|l|l|}
6 & 874.8 \\
\end{tabular} & 516 & & 16.6 & 885.1 & 587 & $8 / 8 / 20086: 13$ & 16.6 & 8725 & 658 & $888: 35$ & 16.6 & 876 \\
\hline 375 & $8 \pi / 2008$ & 16.6 & 87.2 & 446 & $8 / 8 / 2008$ & 16.6 & 874.5 & 517 & $8 / 8 / 20$ & 16.6 & 885.3 & 588 & $8 / 8200086: 15$ & 16.6 & 8724 & 659 & $88: 37$ & 16.6 & 876 \\
\hline 376 & $8 \pi / 2000$ & 16.6 & 877.3 & 447 & & 16.6 & 874.5 & 518 & & 16.6 & 885.0 & 589 & & 16.6 & 8721 & 660 & & 16.6 & \\
\hline 377 & $8 / 720$ & 16.6 & 877.4 & 448 & $8 / 8 / 20081: 35$ & 16.6 & \begin{tabular}{|l|l|}
6 & 874.4 \\
\end{tabular} & 519 & $8 / 8 / 20$ & 16.6 & 884.9 & 590 & $8 / 820086: 19$ & 16.6 & 872.0 & 661 & $38: 41$ & 16.6 & 876 \\
\hline 378 & $87 / 20$ & 16.6 & 877.1 & 449 & $8 / 8 / 200$ & 16.6 & \begin{tabular}{l|l|}
6 & 874.3
\end{tabular} & 520 & & 16.6 & 884.6 & 591 & & 16.6 & 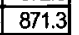 & 662 & & 76.6 & \\
\hline 379 & $87 / 20$ & 16.6 & 877.1 & 450 & $8 / 8200$ & 16.6 & \begin{tabular}{|l|l|}
6 & 874.5 \\
\end{tabular} & 521 & $8 / 8 / 2$ & 16.6 & 884.2 & 592 & 86.23 & 16.6 & 871.3 & 663 & $38: 45$ & 16.6 & 876 \\
\hline 380 & 8772 & 16.6 & 876.6 & 451 & $8 / 8 / 20$ & 16.6 & \begin{tabular}{|l|l|}
6 & 874.4 \\
\end{tabular} & 522 & & 16.6 & 883.9 & 593 & & 16.6 & 871.1 & 664 & & & \\
\hline 381 & $87 / 2$ & 16.6 & 877.0 & 452 & $8 / 8 / 20$ & 16.6 & \begin{tabular}{|l|l|}
6 & 874.6 \\
\end{tabular} & 523 & 4:05: & 16.6 & 884.3 & 594 & 36.27 & 16.6 & 871.3 & 665 & $88: 49$ & 16.6 & 878 \\
\hline 382 & $87 / 2$ & 16.6 & 876.7 & 453 & $8 / 8 / 20$ & 16.6 & \begin{tabular}{|l|l|}
6 & 875.0 \\
\end{tabular} & 524 & & 16.6 & 883.8 & 596 & & 16.6 & 871.2 & 666 & & & \\
\hline 383 & 87120 & 16.6 & 876.6 & 454 & $8 / 8 / 20$ & 16.6 & \begin{tabular}{|l|l|}
6 & 874.6 \\
\end{tabular} & 525 & $8 / 8 / 2$ & 16.6 & \begin{tabular}{|l|l|l|}
6 & 883.8 \\
\end{tabular} & 596 & $6: 31$ & 16.6 & 871.5 & 667 & $8: 53$ & 16.6 & 879 \\
\hline 384 & $87 / 2$ & 16.6 & 876.4 & 455 & & 16.6 & \begin{tabular}{l|l}
6 & 874.7 \\
\end{tabular} & 526 & & 16.6 & \begin{tabular}{|l|l|}
6 & 883.4
\end{tabular} & 597 & & 16.6 & 871. & 668 & & 16.6 & \\
\hline 385 & 87720 & 16.6 & 876.7 & 456 & $8 / 8 / 20$ & 16.6 & \begin{tabular}{|l|l|}
6 & 874.2 \\
\end{tabular} & 527 & $4: 13$ & 16.6 & $\begin{array}{ll}6 & 883 . \\
\end{array}$ & 598 & $6: 35$ & 16.6 & 870. & 669 & & 16.6 & 879 \\
\hline 386 & $8 / 72$ & 16.6 & 876.5 & 457 & $1: 53$ & 16.6 & \begin{tabular}{|l|l|}
6 & 874.6
\end{tabular} & 528 & & 16.6 & 683. & 599 & & 16.6 & 870 & 670 & & 16.6 & \\
\hline 387 & $87 / 2$ & 16.6 & 876.5 & 458 & $8 / 8 / 20$ & 16.6 & 874.2 & 529 & 4:17 & 16.6 & \begin{tabular}{|l|l|l}
6 & 883.1
\end{tabular} & 600 & $6: 39$ & 16.6 & 871. & 671 & $9: 01$ & 16.6 & 880 \\
\hline 388 & $8 \pi$ & 16.6 & 876.7 & 459 & & 16.6 & 874.3 & 530 & & 16.6 & \begin{tabular}{l|l}
6883.2 \\
\end{tabular} & 601 & & 16.6 & 870. & 672 & & 10. & \\
\hline 389 & $87 / 2$ & 16.6 & 876.7 & 460 & $8 / 8 / 2$ & 16.6 & 874.5 & 531 & & 16.6 & \begin{tabular}{|l|l|}
6 & 883. \\
\end{tabular} & 602 & $6: 43$ & 16.6 & 871. & 673 & 39.05 & 16.6 & 880 \\
\hline 390 & & 16.6 & 876.6 & 461 & & 16.6 & 874.5 & 532 & & 16.6 & \begin{tabular}{|l|l|}
6 & 882. \\
\end{tabular} & 603 & & 16.6 & 870 & 674 & & ib. & \\
\hline 391 & & 16.6 & 876.6 & 462 & 203 & 16.6 & 874.7 & 533 & $4: 25$ & 16.6 & \begin{tabular}{l|l}
6 & 882.2
\end{tabular} & 604 & 6:47 & 16.6 & 869 & 675 & $9: 09$ & 16.6 & 880 \\
\hline 392 & $3: 43$ & 16.6 & 876.8 & 463 & 205 & 16.6 & 874.9 & 534 & & 16.6 & \begin{tabular}{l|l}
6 & 882 \\
\end{tabular} & 605 & 6.49 & 16.6 & 86 & 676 & & 16.6 & \\
\hline 393 & & 16.6 & 876 . & 464 & 207 & 16.6 & 875.5 & 535 & & 16.6 & \begin{tabular}{|l|l|}
6 & 882 \\
\end{tabular} & 606 & & 16.6 & 870 & $\overline{7}$ & & 16.6 & 880 \\
\hline 394 & & 16.7 & 876. & 465 & & 16.6 & 877.0 & 536 & & 16.6 & \begin{tabular}{|l|l}
6882 \\
\end{tabular} & 607 & & 16.6 & 87 & 678 & & 16.6 & 880 \\
\hline 395 & & 16.6 & 876.9 & 466 & & 16.6 & 877.2 & 537 & & & \begin{tabular}{|l|l|}
6 & 882 \\
\end{tabular} & 608 & & 16.6 & 86 & 679 & & 16.6 & 880 \\
\hline 396 & & 16.7 & 876.7 & 467 & & 16.6 & 877.2 & 538 & & 16.6 & $\begin{array}{ll}6881 \\
6\end{array}$ & 609 & & 16.6 & 865 & 680 & & 16.6 & 880 \\
\hline 397 & & 16.6 & 877.0 & 468 & & 16.6 & 877.7 & 539 & & 16.6 & \begin{tabular}{l|l}
6 & 881 \\
\end{tabular} & 610 & & 16.6 & 80 & 681 & & 16.6 & 880 \\
\hline 398 & & 16.6 & 877.0 & 469 & & 16.6 & 878.1 & 540 & & 16.6 & 881 & 611 & & 16.6 & 86 & 682 & & 16.6 & $88 x$ \\
\hline 399 & & 16.6 & 876.6 & 470 & & 16.6 & 877.7 & 541 & & 16.6 & $\begin{array}{ll}6 & 88\end{array}$ & 612 & & 16.6 & & 683 & & 16.6 & 88 \\
\hline 400 & & 16.6 & 876.7 & 471 & & 16.6 & 878.0 & 542 & & 16.6 & $\begin{array}{ll}6 & 88 \\
\end{array}$ & 613 & & 16.6 & & 684 & & 16.6 & 879 \\
\hline 401 & & 16.6 & 876.9 & 472 & & 16.6 & 877.7 & 543 & & 16.6 & $\begin{array}{ll}688 \\
6\end{array}$ & 61 & & 16.6 & & 685 & & & 879 \\
\hline 402 & & 16.6 & 876.6 & 473 & & 16.6 & 878.2 & 544 & & 16.6 & & 6 & & 16.6 & & 686 & & 16.6 & 878 \\
\hline 403 & & 16.6 & 87 & 474 & & 16.7 & 877.2 & 545 & & 16.6 & \begin{tabular}{|l|l|}
6 & 88
\end{tabular} & 6 & & 16.6 & 86 & 87 & & 16.6 & 878 \\
\hline 404 & & 16.6 & 876 & 475 & & 16.6 & 877.4 & 546 & & 16.6 & \begin{tabular}{|l|l|}
6 & 88 \\
\end{tabular} & 61 & & 16.6 & 86 & 388 & & 16.6 & 878 \\
\hline 405 & & 16.6 & 876.2 & 476 & & 16.6 & 878 & & & 18.6 & & 6 & & 16.6 & & 689 & & 16.6 & \\
\hline 406 & & 16.6 & 876 & 477 & & 16.6 & 879 & 548 & & 16.6 & $\begin{array}{ll}6 & 88 \\
\end{array}$ & $\overline{6}$ & & 16.6 & & 690 & & 16.6 & 876 \\
\hline 407| & & 16.6 & 876. & 478 & & 16.6 & 879 & 549 & & 16.6 & & 6 & & 16.6 & & & & 16.6 & \\
\hline 408 & & 16.6 & 87 & 479 & & 16.6 & 879 & 550 & & 16.6 & & 6 & & 16.6 & 87 & 692 & & 16.6 & 879 \\
\hline 409 & & 16.6 & 875 & 480 & & 16.6 & \begin{tabular}{|l|l}
6 & $8 \pi$ \\
\end{tabular} & 551 & & 16.6 & & & & & & & & 16.6 & \\
\hline 410 & & 16.6 & 876 & 481 & & 16.6 & 879 & 552 & & 16.6 & & $\underline{\sigma}$ & & 16.6 & 87 & 694 & & 16.6 & 879 \\
\hline 411 & & 16.6 & 876 & & & 16.6 & & & & & & & & & & & & & \\
\hline 412 & & 16.6 & 876 & 48 & & 16.6 & 880 & 554 & & 16.6 & & 62 & & 16.6 & 873 & 696 & 39:51 & 16.6 & 878 \\
\hline 413 & & 16.6 & & & & 16.6 & & & & & & & & & & & & 16. & \\
\hline 414 & & 16.6 & 87 & 485 & & 16.7 & 881. & 556 & & 16.6 & $\begin{array}{ll}68 \\
6\end{array}$ & 62 & & 16.6 & 87 & 98 & $89: 55$ & 16.6 & 879 \\
\hline 415 & & 16.6 & 87 & & & 16.6 & & & & 16.6 & & & & 16.6 & & & & & \\
\hline 416 & & 16.6 & 877 & 487 & & 16.6 & 881.8 & 5 & & 16.6 & & 629 & & 16.6 & 878 & 700 & $9: 59$ & 16.6 & 876 \\
\hline 417 & & 16.6 & & 488 & & 16.6 & & & & 16.6 & & & & 16.6 & & & & & \\
\hline 418 & 0.35 & 16.6 & 876.7 & 489 & $8 / 8 / 2$ & 16.6 & 881. & 560 & & 16.6 & \begin{tabular}{|l|l|}
6 & 87 \\
\end{tabular} & 631 & & 16.6 & 878 & 02 & $10: 03$ & 16.6 & 878 \\
\hline \begin{tabular}{|l|}
419 \\
\end{tabular} & & 16.6 & & 490 & & 16.6 & & & & & \begin{tabular}{l|l}
6 & 87 \\
\end{tabular} & & & & & & & & \\
\hline 420 & & 16.6 & 87 & 491 & & 16.6 & 882,4 & 562 & $8 / 8 / 2$ & 16.6 & \begin{tabular}{l|l}
6 & 878 \\
\end{tabular} & 633 & $87: 45$ & 16.6 & 87 & 704 & $310: 07$ & 16.6 & 879 \\
\hline 421 & & 16.6 & & 492 & & 16.6 & 8824 & & & & & & & & & & & & \\
\hline 422 & & 16.6 & 877 & 493 & $8 / 8 / 2$ & 16.6 & 8822 & 564 & $8 / 812$ & 16.6 & \begin{tabular}{l|l}
6 & 877
\end{tabular} & 635 & $87: 49$ & 16.6 & 878 & $n 6$ & $810: 11$ & 16.6 & 878 \\
\hline 423 & & 16.6 & 877.2 & 494 & & 16.6 & \begin{tabular}{|l|l}
6 & 882 \\
\end{tabular} & 565 & & 16.6 & & $\bar{\sigma}$ & & 16.6 & & & & 16 & \\
\hline 424 & & 16.6 & 877.1 & 495 & & 16.6 & $\begin{array}{ll}6 & 882 \\
\end{array}$ & 566 & $8 / 8 / 2$ & 16.6 & \begin{tabular}{l|l}
6 & 877
\end{tabular} & 637 & $37: 53$ & 16.6 & 878 & 08 & $810: 15$ & 16.6 & 877 \\
\hline 425 & $8 / 8 / 20080: 49$ & 16.6 & 877.3 & 496 & & 16.6 & 8820 & 567 & & 16.6 & & 638 & & 16.6 & & & & 16.6 & 878 \\
\hline 426 & $8 / 8 / 20080.51$ & 16.6 & 877. & 497 & $8 / 8 / 20083: 13$ & 16.6 & 882.9 & 568 & $8 / 820085: 35$ & 16.6 & \begin{tabular}{|l|l|}
6 & 876.2 \\
\end{tabular} & 639 & $8 / 820087: 5$ & 16.6 & 879.2 & 710 & $8 / 8 / 200810: 19$ & 16.6 & 877. \\
\hline & & & & & & & & & & & & & & & & & & & \\
\hline
\end{tabular}


DOE/RL-2009-35, REV. 0

\begin{tabular}{|c|c|c|c|c|c|c|c|c|c|c|c|c|c|c|c|c|c|c|}
\hline \multicolumn{4}{|c|}{$D 425 \mathrm{C}$} & \multicolumn{4}{|c|}{$D 4-25 c$} & \multicolumn{4}{|c|}{$D 4-25 c$} & & $D 4-25 \mathrm{C}$ & & & & $D 425 c$ & \\
\hline Rec & & Temp & $S C$ & $\mathrm{Rec}$ & & Termp & $S C$ & $\operatorname{Rec}$ & & Temp| & $\mathrm{SC}$ & Rec| & & Temp & SC & $\operatorname{Rec}$ & & Temp \\
\hline$\#$ & Date/Time & ${ }^{\circ} \mathrm{C}$ & $\mu \mathrm{S} / \mathrm{cm}$ & $\#$ & Deter/ime & ${ }^{\circ} \mathrm{C}$ & $\mu \mathrm{s} / \mathrm{am}$ & $\#$ & Date/Time & \begin{tabular}{ll|l}
${ }^{\circ} \mathrm{C}$ & \\
\end{tabular} & $\mu S / \mathrm{am}$ & $\#$ & Date/Time & ${ }^{\circ} \mathrm{C}$ & $\mu \mathrm{s} / \mathrm{cm}$ & $\#$ & DateTime & \\
\hline 711 & $8 / 8 / 2008$ 10:21 & 16.6 & 877.7 & 782 & $8 / 8 / 200812: 43$ & $\overline{16.6}$ & 884.9 & 853 & $8 / 8 / 2008$ 15:05 & 16.6 & 891.8 & 924 & $8 / 8 / 2008$ 17:27 & 16.7 & 897.4 & 995 & $8 / 8 / 200819: 49$ & 16.6 \\
\hline 712 & $8 / 8 / 2008$ 10:23 & 16.6 & 877.5 & 783 & $8 / 8120081245$ & 16.6 & 884.8 & 854 & $8 / 8 / 200815: 07$ & 16.6 & \begin{tabular}{|l|}
8921. \\
\end{tabular} & 925 & $8 / 8 / 200817: 20$ & 16.6 & \begin{tabular}{|l|}
897.7 \\
\end{tabular} & 996 & $8 / 8 / 200819: 51$ & 16.6 \\
\hline 713 & $8 / 8 / 2008$ 10:25 & 16.6 & 87.9 & 784 & $8 / 8 / 200812: 47$ & 16.6 & 884.3 & 855 & $8 / 8 / 2008$ 15:09 & 16.6 & 8920 & 926 & $8 / 8 / 2008$ 17:31 & 16.6 & 898.2 & 997 & $8 / 8 / 200819: 53$ & 16.6 \\
\hline 714 & $8 / 8 / 2008$ 10:27 & 16.6 & 878.1 & 785 & $8 / 8 / 2008$ 12:49 & 16.6 & 884.3 & 856 & $8 / 8 / 2008$ 15:11 & 16.6 & 892.6 & 927 & $8 / 8 / 2008$ 17:33 & 16.6. & 897.7 & 998 & $8 / 8 / 2008$ 19:55 & 16.6 \\
\hline 715 & $8 / 8 / 2008$ 10:29 & 16.6 & 878.5 & 786 & $8 / 8 / 200812: 51$ & 16.6 & 884.9 & 857 & $8 / 8 / 200815: 13$ & 16.6 & 892.5 & 928 & $8 / 8 / 200817: 35$ & 16.6 & \begin{tabular}{|l|}
897.6 \\
\end{tabular} & 999 & $8 / 8 / 200819: 57$ & \\
\hline 716 & $8 / 8 / 2008$ 10:31 & 16.6 & 87.0 & 787 & $8 / 8 / 200812: 53$ & 16.6 & 884.2 & 858 & $8 / 8 / 2008$ 15:15 & 16.6 & 893.2 & 920 & $8 / 8 / 2008$ 17:37 & 16.6 & 897.4 & 1000 & $8 / 8 / 200819.59$ & 16.6 \\
\hline 717 & $8 / 8 / 2008 \quad 10: 33$ & 16.6 & 878.7 & 788 & $8 / 8 / 200812: 55$ & 16.6 & 885.5 & 859 & $8 / 8 / 2008$ 15:17 & 16.6 & 899.1 & 930 & $8 / 82008$ 17:39 & 16.6 & 897.6 & 1001 & $8 / 8 / 200820: 01$ & 16.6 \\
\hline 718 & $8 / 8 / 2008$ 10:35 & 16.6 & 878.9 & 789 & $8 / 8200812: 57$ & 16.6 & 885.6 & 860 & $8 / 8 / 200815: 19$ & 16.6 & 893.7 & 931 & $8 / 8: 2008$ 17:41 & 16.6 & 897.1 & 1002 & 8/8/200820:03 & 16.6 \\
\hline 719 & $8 / 822008$ 10:37 & 16.6 & 879.4 & 790 & $8 / 8 / 200812: 59$ & 16.6 & 884.3 & 861 & $8 / 8 / 2008$ 15:21 & 16.6 & 892.4 & 932 & $8 / 8 / 2008$ 17:43 & 16.6 & 806.9 & 1003 & 8/8:200820:05 & 16.6 \\
\hline 720 & $8 / 8 / 2008 \quad 10: 39$ & 16.6 & 879.9 & 791 & $8 / 8 / 2008$ 13:01 & 16.6 & 883.7 & 862 & $8 / 8 / 200815: 23$ & 16.6 & 892.3 & 933 & $8 / 82008$ 17:45 & 16.6 & 896.8 & 1004 & $8 / 82000820: 07$ & \\
\hline 721 & $8 / 8 / 2008$ 10:41 & 16.6 & 879.8 & 792 & $8 / 8 / 200813: 03$ & $\overline{16.6}$ & 884.6 & 863 & $8 / 8 / 2008$ 15:25 & 16.6 & 8922 & 934 & $8 / 8 / 200817: 47$ & 16.6 & 896.7 & 1005 & $8 / 8 / 200820: 09$ & 16.6 \\
\hline 722 & 8/8/2008 10:43 & 16.6 & 879.3 & 793 & $8 / 8 / 200813: 05$ & 16.6 & 884.4 & 864 & 8/8/2008 15:27 & 16.6 & 891.7 & 935 & $8 / 8 / 2008$ 17:49 & 16.6 & 896.9 & 1006 & 8/8/200820:11 & 16.6 . \\
\hline 723 & $8 / 8 / 2008$ 10:45 & 16.6 & 879.9 & 794 & $8 / 8 / 200813: 07$ & 16.6 & 883.5 & 865 & $8 / 8 / 200815: 20$ & 16.6 & 890.9 & 936 & $8 / 8 / 2008$ 17:51 & 16.6 & 896.3 & 1007 & $8 / 8 / 200820: 13$ & 16.6 \\
\hline 724 & $8 / 8 / 2008$ 10:47 & 16.6 & 879.3 & 795 & $8 / 8 / 200813: 09$ & 16.6 & 883.4 & 866 & $8 / 8 / 2008$ 15:31 & 16.6 & 890.7 & 937 & $8 / 82008$ 17:53 & 16.6 & 896.1 & 1008 & $8 / 8 / 200820: 15$ & 16.6 \\
\hline 725 & $8 / 8 / 2008$ 10:49 & 16.6 & 878.8 & 796 & 8/8/2008 13:11 & 16.6 & 884.3 & 867 & $8 / 8 / 2008$ 15:33 & 16.6 & \begin{tabular}{|l|}
890.2 \\
\end{tabular} & 938 & $8 / 8 / 2008$ 17:55 & 16.6 & 895.6 & 1009 & $8 / 8 / 200820: 17$ & \\
\hline 726 & $8 / 8 / 2008$ 10:51 & 16.6 & 879.2 & 797 & $8 / 8 / 2008$ 13:13 & 16.6 & 883.7 & 868 & $8 / 8 / 2008+15: 35$ & 16.6 & \begin{tabular}{|l|}
889.9 \\
\end{tabular} & 939 & $8 / 8 / 2008$ 17:57 & 16.6 & 895.8 & 1010 & 8/8/200820:19 & 16.6 \\
\hline 727 & $8 / 8 / 2008$ 10:53 & 16.6 & 880.2 & 798 & $8 / 8 / 2008$ 13:15 & 16.6 & 884.9 & 869 & $8 / 8 / 2008$ 15:37 & 16.6 & 890.2 & 940 & $8 / 8 / 2008$ 17:59 & 16.6 & 895.3 & 1011 & $8 / 8200820.21$ & 16.6 \\
\hline 728 & $8 / 8 / 2008$ 10:55 & 16.6 & 880.2 & 799 & $8 / 8 / 2008$ 13:17 & 16.6 & 884.3 & 870 & $8 / 8 / 2008$ 15:39 & 16.6 & 890.2 & 941 & $8 / 82008$ 18:01 & 16.6 & 894.8 & 1012 & $8 / 8200820: 23$ & 16.6 \\
\hline 729 & $8 / 82008$ 10:57 & 16.6 & 879.8 & 800 & $8 / 8 / 2008$ 13:19 & 16.6 & 884.8 & 871 & $8 / 8 / 2008$ 15:41 & 16.6 & 890.0 & 942 & $8 / 8 / 200818: 03$ & 16.6 & 894.3 & 1013 & $8 / 8200820.25$ & $\overline{16.6}$ \\
\hline 730 & $8 / 8 / 2008$ 10:59 & 16.6 & \begin{tabular}{|l|}
880.0 \\
\end{tabular} & 801 & $8 / 8 / 2008$ 13:21 & 16.6 & 884.2 & 872 & $8 / 8 / 2008$ 15:43 & 16.6 & 890.0 & 943 & $8 / 8 / 2008$ 18:05 & 16.6 & 894.0 & 1014 & $8 / 8 / 200820: 27$ & \\
\hline 731 & $8 / 8 / 2008$ 11:01 & 16.6 & 880.0 & 802 & $8 / 8 / 200813: 23$ & 16.6 & 884.6 & 873 & $8 / 8 / 2008$ 15:45 & 16.6 & 890.3 & 944 & $8 / 8 / 2008$ 18:07 & 16.6 & 893.6 & 1015 & $8 / 8 / 200820: 29$ & 16.6 \\
\hline 732 & $8 / 8 / 2008$ 11:03 & 16.6 & 879.4 & 803 & $8 / 8 / 2008$ 13:25 & 16.6 & 884.3 & 874 & $8 / 8 / 2008$ 15:47 & 16.6 & \begin{tabular}{|l|}
890.3 \\
\end{tabular} & 945 & $8 / 8 / 200818: 09$ & 16.6 & 893.2 & 1016 & 8/8/200820:31 & 16.6 \\
\hline 733 & $8 / 822008$ 11:05 & 16.6 & 878.4 & 804 & $8 / 8 / 2008$ 13:27 & 16.6 & 885.3 & 875 & $8 / 8 / 2008$ 15:49 & 16.6 & 889.9 & 946 & 8/8/2008 18:11 & 16.6 & 8928 & 1017 & $820: 33$ & 16.6 \\
\hline 734 & $8 / 8 / 2008$ 11:07 & 16.6 & 880.2 & 805 & $8 / 8 / 200813: 29$ & 16.6 & 884.3 & 876 & $8 / 8 / 2008 \quad 15: 51$ & 16.6 & \begin{tabular}{|l|}
890.5 \\
\end{tabular} & 947 & 318:13 & 16.6 & 8923 & 1018 & $8 / 8 / 200820: 35$ & 16.6 \\
\hline 735 & $8 / 8 / 2008$ 11:09 & 16.6 & 881.4 & 806 & $8 / 8 / 2008$ 13:31 & 16.6 & 883.9 & 877 & $8 / 8 / 2008$ 15:53 & 16.6 & 889.8 & 948 & $8 / 8 / 2008$ 18:15 & 16.6 & 891.7 & 1019 & $0820: 37$ & \\
\hline 736 & $8 / 8 / 2008$ 11:11 & 16.6 & 880.2 & 807 & $8 / 8 / 200813: 33$ & 16.6 & 884.6 & 878 & $8 / 8 / 2008$ 15:55 & 16.6 & 890.0 & 949 & $8 / 8 / 2008$ 18:17 & 16.6 & 891.2 & 1020 & $8 / 8 / 200820: 39$ & 16.6 \\
\hline 737 & $8 / 8 / 2008$ 11:13 & 16.7 & 879.8 & 808 & $8 / 8 / 2008$ 13:35 & 16.6 & 884.3 & 879 & 8/8/2008 15:57 & 16.6 & 890.1 & 950 & 8/8/2008 18:19 & 16.6 & 890.3 & 1021 & $8 / 82200820.41$ & 16.6 \\
\hline 738 & 8/8/2008 11:15 & 16.6 & 878.8 & 809 & $8 / 8200$ & 16.6 & 884.4 & 880 & $8 / 8 / 200815: 59$ & 16.6 & 890.0 & 951 & 18:21 & 16.6 & 889.9 & 1022 & $820: 43$ & \\
\hline 739 & $8 / 8 / 2008$ 11:17 & 16.7 & 879.4 & 810 & $8 / 8 / 2008$ 13:39 & $\overline{16.6}$ & 885.3 & 881 & $8 / 8 / 200816: 01$ & 16.6 & 889.9 & 952 & $8 / 8 / 200818: 23$ & 16.6 & 889.0 & 1023 & $8 / 8200820: 45$ & 16.6 \\
\hline 740 & $8 / 8 / 2008$ 11:19 & 16.6 & 880.0 & 811 & $8 / 8 / 200813: 41$ & 16.6 & 881.6 & 882 & $8 / 8 / 200816: 03$ & 16.6 & 890.4 & 953 & $8818: 25$ & 16.6 & 888.2 & 1024 & $820: 47$ & 16.6 \\
\hline 741 & $8 / 8 / 2008$ 11:21 & 16.6 & 879.5 & 812 & $8 / 8 / 2008$ 13:43 & 16.6 & 884.9 & 883 & $8 / 8 / 200816: 05$ & 16.6 & 890.3 & 954 & 8/8/2008 18:27 & 16.6 & 887.9 & 1025 & $8 / 8: 200820: 49$ & 16.6 \\
\hline 742 & $8 / 8 / 200$ & 16.6 & 880.3 & 813 & $8 / 82000133: 45$ & 16.6 & 884.6 & 884 & $816: 07$ & 16.6 & 890.2 & 955 & 318:22 & 16.6 & 887.8 & 1026 & $0820: 51$ & 16.6 \\
\hline 743 & $8 / 8 / 20$ & 16.6 & 878.6 & 814 & $8 / 8 / 2$ & 16.6 & 883.5 & 885 & $816: 09$ & 16.6 & & 956 & 8/8/2008 18:31 & 16.6 & 886.4 & 1027 & $8 / 81200820: 53$ & 16.6 \\
\hline 744 & $8 / 8 / 200$ & 16.6 & 880.0 & 815 & $8 / 8 / 200$ & 16.6 & 883.3 & 886 & $8 / 8 / 2008 \quad 16: 11$ & 16.6 & \begin{tabular}{|l|}
889.9 \\
\end{tabular} & 957 & $8 / 8 / 2008$ 18:33 & 16.6 & 885.0 & 1028 & $8 / 8200820: 55$ & 16.6 \\
\hline 745 & $8 / 8 / 2008$ 11:20 & 16.6 & 881.0 & 816 & $8 / 8 / 200$ & 16.6 & 883.3 & 887 & $8 / 8 / 2008$ 16:13 & 16.6 & \begin{tabular}{|l|}
889.7 \\
\end{tabular} & 958 & $8 / 82008$ 18:35 & 16.7 & 884.1 & 1029 & 820:57 & 16.6 \\
\hline 746 & $8 / 8 / 2008$ 11:31 & 16.6 & 881.5 & 817 & $8 / 8 / 20$ & 16.6 & 884.6 & 888 & $8 / 8 / 2008$ 16:15 & 16.6 & 889.8 & 950 & 318:37 & 16.6 & 884. & 1030 & $820: 59$ & $\overline{16.6}$ \\
\hline 747 & $8 / 8 / 200$ & 16.6 & 8823 & 818 & $8 / 8 / 20$ & 16.6 & 884.8 & 889 & $816: 17$ & 16.6 & 888.0 & 960 & 08 18:39 & 16.6 & 885.2 & 1031 & $821: 01$ & 16.6 \\
\hline 748 & $8 / 8 / 20$ & 16.6 & 881.0 & 819 & $8 / 8 / 20$ & 16.6 & 885.4 & 890 & $8 / 8 / 2008$ 16:19 & 16.6 & 888.7 & 961 & $8 / 8 / 2008$ 18:41 & 16.6 & 885.1 & 1032 & $8 / 8 / 200821: 03$ & 16.6 \\
\hline 749 & $8 / 8 / 20 x$ & 16.6 & 882.5 & 820 & $8 / 8 / 20$ & 16.6 & 885.6 & 891 & $8 / 8 / 200816: 21$ & 16.6 & 889.8 & 962 & $8 / 8 / 200818: 43$ & 16.7 & 884.2 & 1033 & $8 / 82000821: 05$ & 16.6 \\
\hline 750 & $8 / 8 / 200$ & 16.6 & 8823 & 821 & $8 / 8 / 200$ & 16.6 & 885.5 & 892 & $8 / 8 / 200816: 23$ & 16.6 & 890 . & 963 & $8 / 8 / 2008$ 18:45 & 16.6 & 884.1 & 1034 & 21:07 & 16.6 \\
\hline 751 & $8 / 8 / 20$ & 16.6 & 881.8 & 822 & $8 / 8 / 2$ & 16.6 & 8824 & 893 & $816: 25$ & 16.6 & 890.3 & 964 & 18:47 & 16.7 & 8823 & 1035 & 321:09 & 16.6 \\
\hline 752 & $8 / 8 / 20$ & 16.6 & 881.6 & 823 & $8 / 8 / 20$ & 16.6 & 880.3 & 894 & $8 / 8 / 2008$ 16:27 & 16.6 & 890.6 & 965 & $8 / 8 / 200818: 49$ & 16.6 & 880. & 1036 & 821:11 & 16.6 \\
\hline 753 & $8 / 8 / 20$ & 16.6 & 881.3 & 824 & $8 / 8 / 20$ & 16.6 & 876.2 & 895 & $816: 20$ & 16.6 & \begin{tabular}{|l|}
890.8 \\
\end{tabular} & 966 & 18:51 & 16.6 & 876 & 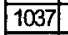 & $21: 13$ & 16.6 \\
\hline 754 & $8 / 8 / 20$ & 16.6 & 881.0 & 825 & $8 / 8 / 20$ & 16.6 & 878.1 & 896 & $816: 31$ & 16.6 & 891.5 & 967 & $18: 53$ & 16.6 & 878 & 10 & $821: 15$ & $\overline{16.6}$ \\
\hline 755 & $8 / 8 / 20$ & 16.6 & 8821 & 826 & $8 / 8 / 20$ & 16.6 & 880.4 & 897 & $8 / 8 / 200816: 33$ & 16.6 & 891.2 & 968 & $0818: 55$ & 16.6 & 877. & 1039 & 821:17 & 16.7 \\
\hline 756 & $8 / 8 / 20$ & 16.7 & 881.8 & 827 & $8 / 8 / 2$ & 16.6 & 883.1 & 898 & 116:35 & 16.7 & 891.3 & 969 & 18:57 & 16.7 & 876. & 1040 & $21: 19$ & \\
\hline 757 & $8 / 8 / 200811: 53$ & 16.6 & 8822 & 828 & $8 / 8 / 2008$ 14:15 & 16.6 & 884.1 & 899 & $8 / 8 / 2008+6: 37$ & 16.6 & 8927 & 970 & $8 / 8 / 200818: 59$ & 16.6 & 876. & 1041 & $821: 21$ & 16.6 \\
\hline 758 & $8 / 8 / 20$ & 16.6 & 881. & 829 & $8 / 8$ & 16.6 & 884.4 & 900 & $16: 39$ & $\begin{array}{l}16.6 \\
\end{array}$ & 893.0 & 971) & 19:01 & 16.7 & 875. & 1042 & & 16.6 \\
\hline 759 & $8 / 8 / 20$ & 16.6 & 8828 & 830 & 4:19 & 76.6 & 885.8 & 901 & $816: 41$ & 16.6 & \begin{tabular}{|l|l|}
893.1 \\
\end{tabular} & 972 & $8 / 8 / 200819.03$ & 16.7 & 874. & 1043 & $821: 25$ & 16.6 \\
\hline 760 & $8 / 8 / 20$ & 16.6 & 8820 & 831 & $8 / 8 / 2$ & 16.6 & 887.0 & 902 & $16: 43$ & 16.6 & 893.1 & 973 & 19:05 & 16.6 & 873 & 1044 & $21: 27$ & 16.7 \\
\hline 761 & $8 / 8 / 20$ & 16.6 & 881.3 & 832 & $8 / 8 / 2$ & 16.6 & 887.9 & 903 & 16:45 & 16.6 & 893.8 & 974 & 19:07 & 16.6 & 873 & 10 & $21: 29$ & \\
\hline 762 & $8 / 8 / 20$ & 16.7 & 881. & 833 & $8 / 8 /$ & 16.6 & 888.9 & 904 & $316: 47$ & 16.6 & 894.3 & 975 & $819: 09$ & 16.6 & 872 & 1046 & $21: 31$ & 16.6 \\
\hline 763 & $8 / 8 / 20$ & 16.6 & $\overline{881.4}$ & 834 & & 16.6 & 888.5 & 905 & $16: 49$ & & 894.5 & 976 & 19:11 & 16.6 & 872 & & $21: 33$ & 166 \\
\hline 764 & 88220 & 16.6 & 882. & 835 & $814: 29$ & 16.6 & 889.9 & 906 & $8 / 8 / 2008$ 16:51 & 16.7 & 894.8 & 97 & 08 19:13 & 16.6 & 871 & 1048 & $821: 35$ & 16.6 \\
\hline 765 & $8 / 8 / 20$ & 16.6 & 8821 & 836 & 4:31 & 16.6 & 890.1 & 907 & 16:53 & 16.6 & 895.9 & 978 & 19.15 & 16.6 & 871 & 190 & & 16.6 \\
\hline 766 & $8 / 8 / 20$ & 16.6 & 8822 & 837 & 4:33 & 76.6 & 890.2 & 908 & $16: 55$ & 16.6 & 895.3 & 979 & $819: 17$ & 16.6 & 871 & $\sqrt{105}$ & $821: 39$ & 16.6 \\
\hline 767 & $8 / 8 / 200812: 13$ & 16.6 & 883.5 & 838 & $8 / 8 / 20$ & 16.6 & 890.7 & 909 & 16:57 & 16.6 & 895.7 & 980 & 319:19 & 16.6 & 870 & 1051 & $21: 41$ & 16.6 \\
\hline 768 & $8 / 822008$ 12:15 & 16.6 & 883.3 & & & 16.6 & 891.2 & 910 & & 16.6 & 896.3 & & $8 / 8 / 2$ & 16.6 & & & & \\
\hline 769 & $8 / 8 / 2008$ 12:17 & 16.6 & 883.1 & 840 & $14: 39$ & 16.6 & 891.4 & 911 & $8 / 8 / 2008$ 17:01 & $\begin{array}{l}16.6 \\
\end{array}$ & 896.0 & 982 & $8 / 8 / 2008$ 19:23 & 16.6 & 871. & 1053 & $821: 45$ & 16.6 \\
\hline 770 & $8 / 8200$ & 16.6 & 882 & 841 & 14:41 & 16.6 & 891.6 & 912 & $17: 03$ & 16.6 & 896.6 & 983 & & 16.6 & & 1054 & & \\
\hline$\pi 1$ & $8 / 8 / 200$ & 16.6 & 884. & 842 & 14:43 & 16.6 & 8922 & 913 & 17:05 & 16.6 & 897. & 984 & 819.27 & 16.7 & 871 & 1055 & $8 / 8 / 200821: 49$ & 16 \\
\hline$\pi / 2$ & $8 / 8 / 2008$ 12:23 & 16.6 & 883.5 & 843 & $8 / 8 / 20$ & 16.6 & 891.7 & 914 & 377:07 & 16.6 & \begin{tabular}{|l|}
897.0 \\
\end{tabular} & 985 & $819: 20$ & 16.6 & 871. & 1056 & 21:51 & 16.6 \\
\hline$\pi 7$ & 8/8/2008 12:25 & 16.6 & 884.1 & 844 & 14:47 & 16.6 & 891.9 & 915 & & 16.6 & \begin{tabular}{|l|}
897.7 \\
\end{tabular} & 986 & $819: 31$ & 16.6 & 872 & 1057 & $21: 53$ & 16.6 \\
\hline 774 & $8 / 8 / 2008$ 12:27 & 16.6 & 883.1 & 845 & $8 / 8 / 2008$ 14:49 & 16.6 & 891.7 & 916 & $8 / 8 / 2008$ 17:11 & 16.6 & 897.2 & 987 & $8 / 8 / 2008$ 19:33 & 16.6 & 875. & 1058 & $821: 55$ & 16.6 \\
\hline 775 & $8 / 8 / 20081229$ & 16.6 & 883.9 & 846 & & 16.6 & 891.9 & 917 & & \begin{tabular}{|l|}
16.6 \\
\end{tabular} & & 988 & & 16.7 & 877. & & & 16.6 \\
\hline 776 & $8 / 8 / 200812: 31$ & 16.6 & 884.6 & 847 & $814: 53$ & 16.6 & 891.0 & 918 & $8 / 8 / 2008$ 17:15 & 16.6 & 899.1 & 989 & $8 / 8 / 2008$ 19:37 & 16.6 & 874 & 1060 & $8 / 8 / 200821: 59$ & 16.6 \\
\hline 77 & $8 / 8 / 2008$ 12:33 & 16.7 & 883.8 & 848 & $8 / 8 / 200814: 55$ & 16.6 & \begin{tabular}{|l|}
891.6 \\
89
\end{tabular} & 919 & $8 / 8 / 2008$ 17:17 & 16.6 & \begin{tabular}{|l|}
897.8 \\
\end{tabular} & 990 & $8 / 8 / 2008$ 19:39 & 16.6 & 876. & 1061 & $322: 01$ & 16.7 \\
\hline 778 & $8 / 8 / 2008$ 12:35 & 16.6 & 885. & 849 & $8 / 8 / 2008$ 14:57 & 16.6 & 891.3 & 920 & $8 / 8 / 2008$ 17:19 & 16.6 & 897.8 & 991 & $8 / 8 / 2008$ 19:41 & 16.6 & 875. & & 82203 & 16.6 \\
\hline 779 & $8 / 8 / 2008$ 12:37 & 16.6 & 884.2 & 850 & $8 / 8 / 20$ & 16.6 & 891.2 & 921 & $8 / 8 / 2008$ 17:21 & 16.6 & \begin{tabular}{|l|}
897.7 \\
\end{tabular} & 992. & $8 / 8 / 200819: 43$ & 16.6 & \begin{tabular}{|l|}
873.4 \\
\end{tabular} & 1063 & $8 / 8 / 20082205$ & 16.6 \\
\hline 780 & $8 / 8 / 200812: 39$ & 16.6 & 8825 & 851 & $8 / 8 / 2008$ 15:01 & 16.6 & 891.5 & 922 & $8 / 8 / 2008$ 17:23 & 16.6 & \begin{tabular}{|l|}
898.4 \\
\end{tabular} & 993 & $8 / 8 / 2008$ 19:45 & 16.6 & \begin{tabular}{|l|}
871.8 \\
\end{tabular} & 1064 & $8 / 8200822: 07$ & 16.6 \\
\hline 781 & $8 / 8 / 2008$ 12:41 & 16.6 & 884.1 & 852 & $8 / 8 / 200815: 03$ & 16.6 & 891.8 & 923 & $8 / 8 / 2008$ 17:25 & \begin{tabular}{|l|}
16.6 \\
\end{tabular} & 898.1 & 994 & $8 / 8 / 200819.47$ & 16.7 & 871.4 & 1065 & $8 / 8200822: 09$ & 16.6 \\
\hline
\end{tabular}




\begin{tabular}{|c|c|c|c|c|c|c|c|c|c|c|c|c|c|c|c|c|c|c|}
\hline \multicolumn{3}{|c|}{ D4-25C } & \multicolumn{4}{|c|}{$D 425 \mathrm{C}$} & \multicolumn{4}{|c|}{$\mathrm{D} 425 \mathrm{C}$} & & $D 425 \mathrm{C}$ & & & & D425c & & \\
\hline Rec & & Temp SC & $\operatorname{Rec}$ & & Temp & or & $\operatorname{Rec}$ & & Temp & & $\operatorname{Rec}$ & & Termp & & $\mathrm{Rec}$ & & Temp & \\
\hline$\#$ & DaeTime & \begin{tabular}{|c|c|c|c|}
${ }^{\circ} \mathrm{C}$ & $1 \mathrm{~s} / \mathrm{c}$ \\
\end{tabular} & $\#$ & DeterTime & ${ }^{\circ} \mathrm{C}$ & $\mu \mathrm{S} / \mathrm{cm}$ & $\#$ & Dete/Time & ${ }^{\circ} \mathrm{C}$ & $\mathrm{HS} / \mathrm{am}$ & $\#$ & DaterTime & ${ }^{\circ} \mathrm{C}$ & $\mu \mathrm{s} / \mathrm{cm}$ & $\#$ & Dete/Time & \begin{tabular}{|l|}
${ }^{\circ} \mathrm{C}$ \\
\end{tabular} & $\mathrm{sScm}$ \\
\hline 1066 & $8 / 8200822: 11$ & \begin{tabular}{l|l}
16.6 & 853.9 \\
\end{tabular} & 1137 & $920080: 33$ & 16.6 & 840.9 & 1208 & 8920002255 & 16.7 & 814.0 & 1279 & $89 / 20085: 17$ & 16.6 & 784.1 & 1350 & $89 / 20087: 39$ & 16.7 & 781.3 \\
\hline 1067 & $8 / 8200822: 13$ & \begin{tabular}{l|l|}
16.6 & 853.4 \\
\end{tabular} & 1138 & 8920000.35 & 16.6 & \begin{tabular}{|l|}
841.7 \\
\end{tabular} & 1209 & 892008257 & 16.7 & 814.0 & 1280 & $89200085: 19$ & 16.7 & 783.8 & 1351 & $8 / 9 / 20087: 41$ & 16.7 & 774.7 \\
\hline 1068 & 881200822115 & \begin{tabular}{l|l|}
16.6 & 853.4 \\
\end{tabular} & 1139 & 899200000.37 & 16.6 & 840.9 & 1210 & $89 / 2008250$ & 16.7 & 813.8 & 1281 & & 16.7 & 783.4 & 1352 & $89920087: 43$ & 16.7 & 776.6 \\
\hline 1069 & $8 / 8200822: 17$ & \begin{tabular}{l|l|}
16.6 & 853.4 \\
\end{tabular} & 1140 & $8 / 9 / 200000: 39$ & 16.7 & \begin{tabular}{|l|}
840.4 \\
\end{tabular} & 1211 & $89920083: 01$ & 16.7 & 814.1 & 1282 & $89120085: 23$ & 16.6 & 783.2 & 1353 & $89920087: 45$ & 16.6 & 776.3 \\
\hline 1070 & $8 / 8 / 200822: 19$ & \begin{tabular}{|l|l|}
16.6 & 852.9 \\
\end{tabular} & 1141 & $89920080: 41$ & 16.6 & \begin{tabular}{|l|}
8421 \\
\end{tabular} & 1212 & $89920083: 03$ & 16.7. & 813.4 & 1283 & $89120085: 25$ & 16.6 & \begin{tabular}{|l|}
784.5 \\
\end{tabular} & 1354 & $8 / 9 / 200087: 47$ & 16.7 & 771.9 \\
\hline 1071 & $8 / 8200822: 21$ & \begin{tabular}{|l|l|}
16.6 & 853.4 \\
\end{tabular} & 1142 & $89920080: 43$ & 16.6 & \begin{tabular}{|l|}
8428 \\
\end{tabular} & \begin{tabular}{|l|}
1213 \\
\end{tabular} & $89 / 20083: 05$ & 16.7 & 8125 & 1284 & $89 / 20085: 27$ & 16.7 & 788.5 & 1356 & $8 / 9 / 20087: 49$ & 16.7 & 773.7 \\
\hline 1072 & $8 / 8200822 \cdot 23$ & \begin{tabular}{|l|l|}
16.7 & 8529 \\
\end{tabular} & 1143 & $89 / 20080.45$ & 16.6 & \begin{tabular}{|l|}
8425 \\
\end{tabular} & 1214 & $89920083: 07$ & 16.7 & 8128 & 1285 & $89 / 20085: 29$ & 16.6 & 790.6 & 1356 & $89 / 20087: 51$ & 16.7 & 775.0 \\
\hline 1073 & $8 / 81200822: 25$ & \begin{tabular}{|l|l|}
16.6 & 853.9 \\
\end{tabular} & 1144 & $89 / 20080: 47$ & 16.6 & \begin{tabular}{|l|}
843.3 \\
\end{tabular} & 1215 & $89920083: 09$ & 16.6 & 8125 & 1286 & $89 / 20085: 31$ & 16.6 & 790.8 & 1357 & & 16.7 & \\
\hline 1074 & $8 / 8200822: 27$ & \begin{tabular}{|l|l|}
16.6 & 854.4 \\
\end{tabular} & 1145 & $8 / 920080: 49$ & 16.6 & 848.1 & 1216 & $8 / 9 / 20083: 11$ & 16.7 & 8121 & 1287 & $89200085: 33$ & 16.7 & 790.7 & 1358 & $8 / 9 / 200087: 55$ & 16.7 & 7722 \\
\hline 1075 & $8 / 8200822: 29$ & \begin{tabular}{l|l|}
16.6 & 854.5 \\
\end{tabular} & 1146 & $89 / 20080.51$ & 16.6 & 884.0 & 1217 & $89220083: 13$ & 16.6 & 8127 & 1288 & $8 / 9 / 20005: 35$ & 16.6 & \begin{tabular}{|l|}
790.7 \\
\end{tabular} & 1359 & $89 / 200087: 5$ & 16.6 & 775.3 \\
\hline 1076 & $881200822: 31$ & \begin{tabular}{|l|l|}
16.6 & 854.8 \\
\end{tabular} & 1147 & 8920080.53 & 16.7 & 9220 & 1218 & $89920083: 15$ & 16.7 & 811.9 & 1289 & $89200085: 37$ & 16.6 & 790.9 & 1360 & $89 / 200087: 59$ & 16.7 & 776.0 \\
\hline 107 & $88200822: 33$ & \begin{tabular}{|l|l|}
16.6 & 854.7 \\
\end{tabular} & \begin{tabular}{|l|}
1148 \\
\end{tabular} & 8920000.55 & 16.7 & 856.6 & 1219 & $89 / 20083: 17$ & 16.6 & 8120 & 1290 & $8 / 920085: 39$ & 16.6 & 790.4 & 1361 & $89 / 20088: 01$ & 16.7 & 773.4 \\
\hline 1078 & 888200822335 & \begin{tabular}{|l|l|}
16.6 & 855.1 \\
\end{tabular} & 1149 & $89920000: 5$ & 16.7 & 834.4 & 1220 & $89920083: 19$ & 16.7 & 811.1 & 1291 & $89920085: 41$ & 16.7 & 790.1 & 1362 & & 16.6 & 771.5 \\
\hline 1079 & $8 / 820082237$ & \begin{tabular}{|l|l|}
16.6 & 855.1 \\
\end{tabular} & 1150 & $89120000: 59$ & 16.7 & 836.4 & 1221 & $819200083: 21$ & 16.7 & 810.8 & 1292 & $8 / 920085: 43$ & 16.6 & 790.5 & 1363 & $89 / 20008: 05$ & 16.7 & 771.9 \\
\hline 1080 & $8 / 8 / 200822: 39$ & 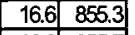 & 1151 & $89: 20081: 01$ & 16.7 & 841.4 & 122 & $89 / 20083: 23$ & 16.7 & 810.3 & 1293 & $89920085: 45$ & 16.6 & 790.0 & 1364 & 88:07 & 16.7 & 7729 \\
\hline 1081 & $8 / 8 / 200822: 41$ & \begin{tabular}{|l|l|}
16.6 & 855.7 \\
\end{tabular} & 1152 & $89920081: 03$ & 16.7 & 846.2 & 1223 & $8 / 9 / 20083: 25$ & 16.7 & 810.1 & 1294 & $8 / 9200085: 47$ & 16.7 & 789.7 & 1365 & & 16.6 & \\
\hline 1082 & $8 / 8 / 200822: 43$ & \begin{tabular}{l|l|}
16.6 & 855.2 \\
\end{tabular} & 1153 & $89 / 20081: 05$ & 16.7 & 846.0 & 1224 & $89 / 20083: 27$ & 16.7 & 809.3 & 1295 & $89200085: 49$ & 16.6 & 789.6 & 1366 & 088:11 & 16.7 & 7723 \\
\hline 1083 & $8 / 8 / 200822: 45$ & \begin{tabular}{l|l|}
16.6 & 855.3 \\
\end{tabular} & 1154 & $89200081: 07$ & 16.6 & 845.2 & 1225 & $89 / 20$ & 16.7 & 809.4 & 1296 & $899200085: 51$ & 16.7 & 789.4 & 1367 & & 16.7 & 772.5 \\
\hline 1084 & 818120082247 & \begin{tabular}{l|l|}
16.655 .6 \\
\end{tabular} & \begin{tabular}{|l|l|}
1156 \\
\end{tabular} & $89 / 20081: 09$ & 16.7 & 843.5 & 1226 & 89920 & 16.7 & 809.3 & 1297 & $89120085: 53$ & 16.6 & 789.4 & 1368 & $88: 15$ & 16.7 & 770.7 \\
\hline 1085 & $8 / 8 / 200822: 49$ & \begin{tabular}{|l|l|}
16.6 & 855.3 \\
\end{tabular} & 1156 & $89 / 20081: 11$ & 16.7 & 843.1 & 1227 & $89 / 20083: 33$ & 16.7 & 809.0 & 1298 & $8 / 920008: 55$ & 16.7 & 789.3 & 1369 & 8:17 & 16.7 & 771.6 \\
\hline 1086 & $8 / 8200822: 51$ & \begin{tabular}{l|l|}
16.6 & 855.5 \\
\end{tabular} & 1157 & 892000 1:13 & 16.7 & 8424 & 1228 & & 16.7 & 808.6 & 1299 & $89920085: 57$ & 16.6 & 789.3 & 1370 & & 16.7 & 773.1 \\
\hline 1087 & $822: 53$ & \begin{tabular}{l|l|}
16.6 & 855.2 \\
\end{tabular} & \begin{tabular}{|c|}
1158 \\
\end{tabular} & $81: 15$ & 16.6 & 8423 & 1220 & 8992 & 16.7 & 808.1 & 1300 & $89920085: 59$ & 16.6 & \begin{tabular}{|l|}
789.2 \\
\end{tabular} & 1371 & 8.21 & 16.7 & 773.5 \\
\hline 1088 & $8 / 81200822: 55$ & \begin{tabular}{|l|l|}
16.6 & 855.0 \\
\end{tabular} & 1159 & $81: 17$ & 16.7 & 843.0 & 1230 & $8 / 9 / 20$ & 16.7 & 807.4 & 1301 & $8 / 9200086: 01$ & 16.6 & 788.8 & 1372 & & 16.7 & 771.6 \\
\hline 1089 & $882000822: 57$ & \begin{tabular}{|l|l|}
16.6 & 854.8 \\
\end{tabular} & 1160 & $8 / 92008$ 1:19 & 16.7 & 8422 & 1231 & $8 / 9 / 20083: 41$ & 16.7 & 806.7 & 1302 & $819200086: 03$ & 16.7 & \begin{tabular}{|l|}
788.7 \\
\end{tabular} & 1373 & $88: 25$ & 16.7 & 771.9 \\
\hline 1090 & $8 / 8200822: 59$ & \begin{tabular}{l|l|}
16.6 & 858.2 \\
\end{tabular} & 1161 & $89: 90081: 21$ & 16.7 & $\overline{8426}$ & 1232 & $89920083: 43$ & 16.7 & 806.7 & 1303 & $8920086: 05$ & 16.6 & 788.7 & 1374 & 88:27 & 16.7 & 773.1 \\
\hline 1091 & $88 / 20$ & \begin{tabular}{l|l|}
16.6 & 858.7 \\
\end{tabular} & 1162 & $81: 23$ & 16.7 & 8427 & 1233 & & 16.7 & 805.8 & 1304 & 8992 & 16.7 & & 1375 & & 16.7 & \\
\hline 1092 & $818: 200823: 03$ & \begin{tabular}{|l|l|}
16.6 & 856.0 \\
\end{tabular} & 1163 & $881: 25$ & 16.7 & 8428 & 1234 & $8 / 9200$ & 16.6 & 806.1 & 1305 & $86: 09$ & 16.7. & 788.4 & \begin{tabular}{|l|}
1376 \\
\end{tabular} & 8:31 & 16.7 & 769.6 \\
\hline 1093 & $8 / 820$ & \begin{tabular}{|l|l|}
16.6 & 854.2 \\
\end{tabular} & 1164 & $31: 27$ & 16.7 & 842.1 & 1235 & $8 / 92$ & 16.7 & 805.6 & 1306 & 8992 & 16.7 & \begin{tabular}{|l|}
788.2 \\
\end{tabular} & 137 & $8: 33$ & 16.7 & 773.1 \\
\hline 1094 & $8 / 8200$ & \begin{tabular}{|l|l|}
16.6 & 853.2 \\
\end{tabular} & 1165 & $81: 29$ & 16.7 & 8420 & 1236 & $8 / 9 / 2$ & 16.7 & 805.5 & 1307 & 36:13 & 16.6 & 788.3 & 1378 & $38: 35$ & 16.7 & 770.3 \\
\hline 1095 & 888200 & \begin{tabular}{|l|l|}
16.6 & 851.4 \\
\end{tabular} & 1196 & $89 \sqrt{2}$ & 16.6 & 841. & 1237 & $8 / 920$ & 16.7 & 804.8 & 1308 & 886:15 & 16.7 & 788.1 & 1379 & $88: 37$ & 16.7 & 770.5 \\
\hline 1096 & $8 / 8 / 200823: 11$ & \begin{tabular}{l|l|}
16.6 & 850.7 \\
\end{tabular} & \begin{tabular}{|l|}
1167 \\
\end{tabular} & $081: 33$ & 16.6 & 841. & 1238 & $8 / 9 / 20$ & 16.7 & 804.3 & 1309 & $89920086: 17$ & 16.6 & 788.6 & 1380 & 88:39 & 16.7 & 768.6 \\
\hline 1097 & $8 / 8 / 200823: 13$ & \begin{tabular}{l|l|}
16.6 & 850.4 \\
\end{tabular} & 1168 & $81: 35$ & 16.7 & 840.2 & 1239 & $89 \sqrt{20}$ & 16.7 & 803.5 & 1310 & $36: 19$ & 16.6 & 788. & 1381 & $8: 41$ & 16.7 & 768.4 \\
\hline 1098 & $8 / 8 / 20$ & \begin{tabular}{|l|l|}
16.6 & 849.1 \\
\end{tabular} & 1169 & $81: 37$ & 16.7 & 840. & 1240 & $89 / 20$ & 16.6 & 8028 & 1311 & $86: 21$ & 16.6 & 788. & 1382 & & 16.7 & 768 \\
\hline 1099 & $8 / 820 x$ & \begin{tabular}{l|l|}
16.7 & 847.8 \\
\end{tabular} & 1170 & $81: 39$ & 16.7 & 840.6 & 1241 & 8992 & 16.6 . & 801.8 & 1312 & $36: 23$ & 16.7 & \begin{tabular}{|l|l}
788.1 \\
\end{tabular} & 1383 & $8: 45$ & 16.7 & 768.2 \\
\hline 1100 & 88820 & \begin{tabular}{l|l}
16.6 & 847.7 \\
\end{tabular} & 1171 & $11: 41$ & 16.6 & 840.1 & 1242 & 8992 & 16.7 & 801.1 & 1313 & 86.25 & 16.7 & \begin{tabular}{|l|}
788.1 \\
\end{tabular} & 1384 & 8.47 & 16.7 & 765.2 \\
\hline 1101 & 823:21 & \begin{tabular}{l|l|}
16.6 & 846.8 \\
\end{tabular} & 1172 & $81: 43$ & 16.7 & 839.8 & 1243 & $89 / 2$ & 16.6 & 800.4 & 1314 & $899200086: 27$ & 16.6 & 788. & 1385 & $8: 49$ & 16.7 & 766.2 \\
\hline 1102 & $8 / 8200823: 23$ & \begin{tabular}{l|l|l|}
16.7 & 845.6 \\
\end{tabular} & 1173 & $81: 45$ & 16.7 & 839. & 1244 & $89 / 2$ & 16.6 & 800. & 1315 & $86: 29$ & 16.7 & 788.1 & 1386 & 8.51 & 16.7 & 764.8 \\
\hline 1103 & $88820 x$ & \begin{tabular}{l|l|}
16.6 & 845.2 \\
\end{tabular} & 1174 & $81: 47$ & 16.6 & \begin{tabular}{|l|}
838.0 \\
\end{tabular} & 1245 & $89 \sqrt{2}$ & 16.6 & 799. & 1316 & 36:31 & 16.6 & \begin{tabular}{|l|}
788.4 \\
\end{tabular} & \begin{tabular}{|l|}
1387 \\
\end{tabular} & $8: 53$ & 16.7 & 765.0 \\
\hline 1104 & $8 / 8 / 20$ & \begin{tabular}{l|l|}
16.6 & 843.6 \\
\end{tabular} & 1175 & $37: 49$ & 16.6 & 838.0 & 1246 & 8912 & 16.7 & 798.9 & 1317 & 892 & 16.7 & 793. & 1388 & $8: 55$ & 16.7 & 766.2 \\
\hline 1105 & $8 / 820 x$ & \begin{tabular}{l|l|}
16.6 & 843.4 \\
\end{tabular} & 1176 & 1:51 & 16.7 & 837.7 & 1247 & $89 / 2$ & 16.7 & 798.6 & 1318 & 8912 & 16.6 & 808 & 1389 & $8: 57$ & 16.7 & 766.4 \\
\hline 1106 & 818120 & \begin{tabular}{l|l|}
16.6 & 8426 \\
\end{tabular} & $11 \pi$ & 892 & 16.6 & 837.9 & 1248 & & 16.7 & 798.2 & 1319 & & 16.6 & 802 & 1390 & & 16.7 & 765.6 \\
\hline 1107 & $8 / 820$ & $\begin{array}{l}16.6 \\
842.3 \\
\end{array}$ & 1178 & 31:55 & 16.6 & 836. & 1249 & 892 & 16.7 & 797.7 & 1320 & $86: 39$ & 16.6 & 800 & 1391 & 9:01 & 16.7 & 765.6 \\
\hline 1108 & 3:35 & \begin{tabular}{l|l|}
16.6 & 841.7 \\
\end{tabular} & 1179 & & 16.7 & 836. & 1250 & & 16.6 & 797 & 1321 & & 16.6 & 794 & 1392 & & 16.7 & 763.3 \\
\hline 1109 & & \begin{tabular}{l|l}
16.6 & 841.0 \\
\end{tabular} & 1180 & & 16.7 & 895.7 & 1251 & & 16.6 & 797. & 1322 & & 16.6 & 793 & 1393 & $9: 05$ & 16.7 & 764.3 \\
\hline 1110 & $8 / 820$ & \begin{tabular}{l|l|}
16.6 & 840.5 \\
\end{tabular} & 1181 & 8912 & 16.7 & 834.4 & 1252 & 8992 & 16.6 & 797.4 & 1323 & $86: 45$ & 16.6 & 793. & 1394 & 9.07 & 16.7 & 765.8 \\
\hline 1111 & $8 / 8 / 20$ & \begin{tabular}{l|l|}
16.7 & 840.2 \\
\end{tabular} & 1182 & & 16.7 & 833.5 & 1253 & & 16.6 & 796.8 & 1324 & & 16.6 & 795 & 1395 & & 16.7 & 763.2 \\
\hline 1112 & $8 / 820$ & \begin{tabular}{l|l|l}
16.7 & 839.5 \\
\end{tabular} & 1183 & 3205 & 16.7 & 832 & 1254 & 89 & 16.6 & 796.8 & 1325 & 8992 & 16.6 & 796. & 1396 & 9911 & 16.7 & 764.3 \\
\hline 1113 & $8 / 8 / 20$ & \begin{tabular}{l|l|}
16.7 & 839. \\
\end{tabular} & 1184 & & 16.6 & 832 & 1255 & & 16.7 & 796 & 1326 & & 16.6 & 796 & 139 & & 16.7 & 771.2 \\
\hline 1114 & $8 / 820$ & \begin{tabular}{l|l|}
16.6 & 839 \\
\end{tabular} & 1185 & $89 / 4$ & 16.6 & 833. & 1256 & & 16.6 & 796 & 1327 & 899 & 16.6 & 796 & & & 16.7 & 777.2 \\
\hline 1115 & $88 / 20$ & \begin{tabular}{l|l|l|}
16.6 & 837.9 \\
\end{tabular} & 1186 & & 16.7 & 831. & 1257 & & 16.6 & 796 & 1328 & 899 & 16.7 & 794 & 1399 & $9: 17$ & 16.7 & 782.8 \\
\hline 1116 & $3: 51$ & \begin{tabular}{l|l|}
16.6 & 838.5 \\
\end{tabular} & & & 16.6 & 832 & 1258 & & 16.7 & 796 & 1320 & & 16.6 & 794 & & & 16.7 & \\
\hline 1117 & $88 / 20$ & \begin{tabular}{l|l|}
16.6 & 837.3 \\
\end{tabular} & 1188 & 32.15 & 16.7 & 8329 & 1259 & $8 / 9 / 2$ & 16.7 & 796.0 & 1330 & 8992 & 16.6 & 793 & 1401 & 9.21 & 16.6 & 790.6 \\
\hline 1118 & 88220 & \begin{tabular}{l|l|}
16.6 & 835.7 \\
\end{tabular} & 1189 & & 16.6 & 833. & 1260 & & 16.6 & 796 & 1331 & & 16.7 & & \begin{tabular}{|l|l|}
1402 \\
\end{tabular} & & 16.7 & \\
\hline 1119 & $88 / 20$ & \begin{tabular}{l|l|}
16.6 & 835.2 \\
\end{tabular} & 1190 & & 16.6 & 834. & 1261 & & 16.6 & 795 & 1332 & & 16.6 & & 1403 & 9.25 & 16.7 & 785.9 \\
\hline 1120 & $8 / 812$ & \begin{tabular}{l|l|}
16.6 & 835.7 \\
\end{tabular} & 1191 & & 16.6 & 834. & 1262 & & 16.7 & 79 & 1333 & & 16.6 & $\overline{79}$ & & & 16.7 & 774.9 \\
\hline 1121 & 80:01 & \begin{tabular}{l|l}
16.6 & 835.0 \\
\end{tabular} & 11 & & 16.6 & 833 & 1263 & & 16.7 & 796 & 1334 & 37:07 & 16.7 & & 140 & & 16.6 & 767.2 \\
\hline 1122 & $89 / 2$ & \begin{tabular}{l|l|}
16.6 & 835.5 \\
\end{tabular} & 1193 & & 16.7 & 830. & 1264 & & 16.6 & 796 & 1335 & 8912 & 16.7 & 787 & 1406 & & 16.7 & 768.9 \\
\hline 1123 & & \begin{tabular}{l|l}
16.6 & 835.7 \\
\end{tabular} & 1194 & & 16.6 & 829 & 1265 & & 16.6 & & 1336 & & 16.7 & & & & 16.7 & 7682 \\
\hline 1124 & $8 / 9 / 20$ & \begin{tabular}{l|l|l}
16.6 & 835.9 \\
\end{tabular} & 1195 & $89 / 2$ & 16.6 & 823.7 & 1266 & & 16.6 & 795.6 & 1337 & $37: 13$ & 16.6 & 787 & 1408 & 89.35 & 16.7 & 770.3 \\
\hline 1125 & & \begin{tabular}{l|l|}
16.6 & 836.5 \\
\end{tabular} & 1196 & & 16.6 & 850.9 & 1267 & & 16.6 & & 1338 & & 16.6 & & & & 16.7 & 767.7 \\
\hline 1126 & $80: 11$ & \begin{tabular}{l|l|}
16.6 & 836.5 \\
\end{tabular} & \begin{tabular}{|l|l|}
1197 \\
\end{tabular} & 233 & 16.6 & 837.2 & 1268 & & 16.6 & 795.3 & 1339 & 87:17 & 16.6 & 785 & 1410 & 39.39 & 16.7 & 7795 \\
\hline 1127. & & \begin{tabular}{l|l|}
16.6 & 837.1 \\
\end{tabular} & 1198 & & 16.6 & 833.7 & 1269 & & 16.6 & 795.4 & 1340 & & 16.7 & 780 & 1411 & & 16.7 & 768.8 \\
\hline 1128: & & \begin{tabular}{l|l|l}
16.6 & 837.3 \\
\end{tabular} & 1199 & & 16.6 & 828. & 1270 & & 16.6 . & & 1341 & & 16.6 & & & & 16.6 & 767.1 \\
\hline 1129 & $8 / 9200080: 17$ & \begin{tabular}{l|l|}
16.7 & 836.5 \\
\end{tabular} & 1200 & $8 / 920$ & 16.7 & 812 & \begin{tabular}{|l|}
1271 \\
\end{tabular} & $89 / 2$ & 16.7 & 794.8 & 1342 & $89920007: 23$ & 16.6 & 780 & 1413 & 39:45 & 16.7 & 770.6 \\
\hline 1130 & & \begin{tabular}{l|l|}
16.6 & 837.6 \\
\end{tabular} & 1201 & 8241 & 16.7 & 817. & 1272 & & 16.6 . & & 1343 & $89920087: 25$ & 16.6 & & & & 16.7 & 776.3 \\
\hline 1131 & 899200080.21 & \begin{tabular}{l|l|}
16.6 & 838.7 \\
\end{tabular} & 1202 & 8243 & 16.7 & 817.0 & 1273 & $85: 05$ & 16.6 & 794.8 & 1344 & $087: 27$ & 16.6 & 784. & 1415 & 089.49 & 16.7 & 783.6 \\
\hline 1132 & $8 / 9 / 20080: 23$ & \begin{tabular}{l|l|}
16.6 & 839.2 \\
\end{tabular} & 1203 & 8245 & 16.7 & 817. & 1274 & $35: 07$ & 16.7 & 794.5 & 1345 & $087: 29$ & 16.7 & 782 & 1416 & & \begin{tabular}{|c|}
16.7 \\
\end{tabular} & 788.4 \\
\hline 1133 & $89 / 20080.25$ & \begin{tabular}{l|l}
16.6 & 840. \\
\end{tabular} & 1204 & 3247 & 16.7 & 812 & & & 16.6 & & 1346 & $87: 31$ & 16.6 & & & 39.53 & 16.7 & 7905 \\
\hline 1134 & $89 / 20080.27$ & \begin{tabular}{l|l}
16.6 & 841.2 \\
\end{tabular} & 1205 & 892008249 & 16.7 & \begin{tabular}{|l|l|}
814.7 \\
\end{tabular} & \begin{tabular}{|l|}
1276 \\
\end{tabular} & $8 / 920085: 11$ & 16.6 & 793.2 & 1347 & $8 / 9200087: 33$ & 16.7 & 780 & 1418 & 889.55 & 16.7 & 794.0 \\
\hline 1135 & $89120080: 29$ & \begin{tabular}{l|l}
16.6 & $841 .$. \\
\end{tabular} & 1206 & 892008251 & 16.7 & \begin{tabular}{|l|}
813.1 \\
\end{tabular} & $12 \pi$ & & 16.6 & $88 /$. & \begin{tabular}{|l|}
1348 \\
\end{tabular} & $89 / 20087: 35$ & 16.7 & $1 / 9$ & 1419 & & 16.7 & 796.2 \\
\hline 1136 & $8 / 9 / 20080: 31$ & \begin{tabular}{l|l|}
16.6 & 840.8 \\
\end{tabular} & 1207 & $89 / 2008253$ & 16.7 & \begin{tabular}{|l|}
813.0 \\
\end{tabular} & 1278 & $8 / 920085: 15$ & 16.6 & \begin{tabular}{|l|}
787.1 \\
\end{tabular} & 1349 & $8 / 9 / 20087: 37$ & 16.7 & \begin{tabular}{|l|}
779.8 \\
\end{tabular} & 1420 & $89 / 20089.59$ & 16.7 & 797.2 \\
\hline
\end{tabular}




\begin{tabular}{|c|c|c|c|c|c|c|c|c|c|c|c|c|c|c|c|c|c|c|c|}
\hline \multicolumn{4}{|c|}{$D 4-25 c$} & \multicolumn{4}{|c|}{$D 425 \mathrm{C}$} & \multicolumn{4}{|c|}{$D 425 \mathrm{C}$} & & $D 425 \mathrm{C}$ & & & & $D 425 c$ & & \\
\hline $\mathrm{Rec}$ & & Temp & SC & $\mathrm{Rec}$ & & Termp & $\mathrm{SC}$ & $\operatorname{Rec}$ & & Temp & $S$ & $\mathrm{ReC}$ & & Temp & SC & $\operatorname{Rec}$ & & Terno & $\Phi$ \\
\hline$\#$ & DeterTime & ${ }^{\circ} \mathrm{C}$ & $\mu \mathrm{s} / \mathrm{cm}$ & $\#$ & DateTime & ${ }^{\circ} \mathrm{C}$ & $\mathrm{H} \mathrm{s} \mathrm{cm}$ & $\#$ & DateTime & ${ }^{\circ \mathrm{C}}$ & $\mu \mathrm{s} / \mathrm{cm}$ & $\#$ & DateTime & $\begin{array}{ll}{ }^{\circ} \mathrm{C} \\
\end{array}$ & $\mu \mathrm{s} / \mathrm{cm}$ & $\#$ & DetelTime & ${ }^{\circ} \mathrm{C}$ & $\mathrm{s} \mathrm{s} \mathrm{cm}$ \\
\hline 1421 & 8920008 10:01 & 16.7 & \begin{tabular}{|l|}
797.0 \\
\end{tabular} & 1492 & 89200011223 & 16.7 & 786.1 & & $89 / 2008$ 14:45 & 16.7 & 7924 & 1634 & $89 / 2008$ 17:07 & 16.6 & \begin{tabular}{|l|}
790.8 \\
\end{tabular} & 1704 & 8992008 19:27 & 16.7 & 785.0 \\
\hline & 92008 10:03 & 16.7 & \begin{tabular}{|l|}
798.0 \\
\end{tabular} & (3) & 89120081225 & 16.7 & 786.3 & 1564 & 8920008 14:47 & 16.7 & 792.3 & 635 & $89: 2008$ 17:09 & 16.6 & 791.3 & 1705 & $892000819: 20$ & 167 & 784.8 \\
\hline & 9200810.05 & 16.7 & 796.0 & & 892000 12:27 & 16.6 & 786.9 & 1565 & 8992008 14:49 & 16.7 & \begin{tabular}{|l|l|}
791.8 \\
\end{tabular} & 336 & 8922008 17:11 & 16.6. & 790.1 & 1706 & $8 / 9200819.31$ & 16.6 & 785.6 \\
\hline 1424 & 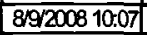 & 16.7 & \begin{tabular}{|l|}
797.8 \\
\end{tabular} & 1495 & $89 / 20081220$ & 16.7 & 787.6 & 1566 & 8920008 14:51 & 16.7 & 7927 & 1637 & 8992008 17:13 & 16.6 & 790.7 & 1707 & 89200819.33 & 167 & 785.0 \\
\hline & $89 / 200810: 09$ & 16.6 & \begin{tabular}{|l|}
796.5 \\
\end{tabular} & 1496 & & 16.7 & 788.6 & 1567 & $89 / 2008$ 14:53 & 16.7 & 7926 & 1638 & $89 / 2008$ 17:15 & 16.6 & 790.4 & 1708 & $8 / 920008$ 19:35 & 166 & \\
\hline 1426 & $89 / 2008$ 10:11 & 16.7 & 795.8 & 1497 & 8920081233 & 16.7 & 788.9 & 1568 & $89 / 2008$ 14:55 & 16.7 & 7929 & 1639 & 892008 17:17 & 16.6 & 789.8 & 1709 & 8920008 19:37 & 16.7 & 784.4 \\
\hline 1427 & $89200810: 13$ & 16.7 & 796.0 & 1498 & 89200081235 & 16.7 & 789.4 & 1569 & 892008 14:57 & 16.7 & \begin{tabular}{|l|}
787.2 \\
\end{tabular} & 1640 & 8992008 17:19 & 16.6 & 788.1 & 1710 & $8 / 92008$ 19:39 & 16.7 & 784.8 \\
\hline 1428 & 89/2008 10:15 & 16.7 & 794.6 & 1499 & 8920081237 & 16.6 & 789.6 & 150 & $89 / 2008$ 14:59 & 16.7 & \begin{tabular}{|l|}
790.3 \\
\end{tabular} & 1641 & $89 / 2008$ 17:21 & 16.6 & 789.8 & 711 & 892000819.41 & 167 & \\
\hline 1420 & 89/2008 10:17 & 16.7 & 793.2 & 1500 & $89 / 20081239$ & 16.7 & 790.5 & 1571 & $89 / 2008$ 15:01 & 16.7 & \begin{tabular}{|l|}
788.9 \\
\end{tabular} & 1642 & $89 / 2008$ 17:23 & 16.6 & 788.6 & 1712 & 89.9200819 .43 & 16.7 & 784.0 \\
\hline 1430 & $89 / 2008$ 10:19 & 16.7 & 794.0 & 1501 & & 16.7 & 791.2 & 1572 & $89 / 200815: 03$ & 16.6 & 788.2 & 1643 & & 16.6 & 789.0 & \begin{tabular}{|l|}
1713 \\
\end{tabular} & 892000819.45 & 16.7 & \\
\hline 1431 & \begin{tabular}{|l|l}
892008 10:21 \\
\end{tabular} & 16.7 & 799.1 & 1502 & 8920081243 & 16.7 & 791.4 & 1573 & $89 / 2008$ 15:05 & 16.7 & 789.3 & \begin{tabular}{|l|}
1644 \\
\end{tabular} & $89 / 2008$ 17:27 & 16.7 & 789.3 & \begin{tabular}{|l|}
1714 \\
\end{tabular} & 8992008 19:47 & 16.7 & 781.2 \\
\hline 1432 & 892008 10:23 & 16.6 & 796.5 & 1503 & 8920081245 & 16.7 & 790.7 & 1574 & $89 / 2008$ 15:07 & 16.7 & 787.9 & 1645 & $89 / 2008$ 17:29 & 16.6 & 789.6 & 1715 & 899200819.49 & 16.7 & 779.5 \\
\hline & $89 / 200810: 25$ & 16.6 & \begin{tabular}{|l|}
798.5 \\
\end{tabular} & 1504 & 892008 1247 & 16.7 & 791.3 & 1575 & 8992008 15:09 & 16.7 & 787.1 & 1646 & $89 / 2008$ 17:31 & 16.7 & 789.4 & 1716 & & 16.7 & \\
\hline 1434 & $89 / 20$ & 16.7 & \begin{tabular}{|l|l|}
798.7 \\
\end{tabular} & 1505 & 8920081249 & 16.6 & 7920 & 1576 & $89 / 2000815: 11$ & 16.7 & 788.4 & 1647 & $89 / 2008$ 17:33 & 16.7 & 789.7 & 1717 & $892000819: 53$ & 16.6 & 778.8 \\
\hline & $89 / 200$ & 16.7 & 795.2 & 1506 & 8920081251 & 16.7 & 7920 & 1577 & & 16.7 & 790.9 & & $89 / 2008$ 17:35 & 16.6 & 790.0 & 1718 & 892000819.55 & 16.7 & \\
\hline 1436 & $892200810: 31$ & 16.7 & 790.7 & 1507 & $89 / 20081253$ & 16.6 & 793.2 & 1578 & $892000815: 15$ & 16.7 & \begin{tabular}{|l|l|}
790.9 \\
\end{tabular} & 1649 & $89 / 2008$ 17:37 & 16.6 & 789.8 & 1719 & 892008 19:57 & 16.7 & 778.4 \\
\hline 1437 & 892000810.33 & 16.7 & 791.1 & 1508 & 8920081255 & 16.7 & 793.3 & 1579 & 8992008 15:17 & 16.7 & 788.9 & 1650 & 892008 17:30 & 16.6 & 789.9 & 1720 & $8 / 9200819.59$ & 16.7 & \\
\hline 1438 & $891200810: 35$ & 16.7 & 7922 & 1509 & 8912008 12:5] & 16.6 & 794.0 & 1580 & $89 / 2008$ 15:19 & 16.6 & 789.0 & 1651 & $89 / 2008$ 17:41 & 16.6 & 789.7 & 1721 & & 16.6 & 778.6 \\
\hline 1439 & 89.2008 10.37 & 16.7 & 7922 & 1510 & 89200 & 16.6 & 794.1 & 1581 & $89 / 2008$ 15:21 & 16.7 & 788.7 & 1652 & 17:43 & 16.6 & 781.4 & 172 & $820: 03$ & 16.7 & 776.1 \\
\hline 1440 & $89 / 200$ & 16.7 & 786.9 & 1511 & 89200 & 16.6 & 794.2 & 1582 & 89120 & 16.7 & & 1653 & 17:45 & 16.7 & 778.1 & 1723 & & 16.7 & \\
\hline 1441 & $89 / 20$ & 16.7 & 785.3 & 1512 & 8920 & 16.6 & 794.0 & 1583 & 8 15:25 & 16.7 & 788.9 & 1654 & $89 / 2008$ 17:47 & 16.7 & 7925 & 1724 & 10820:07 & 16.7 & 772.5 \\
\hline & 899220 & 16.7 & 795.8 & 1513 & & 16.6 & 794.0 & 1584 & $89 \sqrt{20}$ & 16.7 & 788.5 & 1655 & $317: 49$ & 16.7 & 804.9 & 1725 & & 16.6 & \\
\hline 1443 & $89 / 2008$ 10:45 & 16.7 & 797.2 & 1514 & 8920008 13:07 & 16.7 & 794.0 & 1585 & 815:29 & 16.6 & 790.4 & & $89 / 2008$ 17:51 & 16.7 & 7928 & 1726 & $8 / 9200820: 11$ & 16.7 & 770.2 \\
\hline 1444 & $89 / 200$ & 16.7 & 798.0 & 1515 & 89200 & 16.6 & 794.8 & 1586 & 8 15:31 & 16.7 & 790.1 & 165 & $317: 53$ & 16.7 & 9006 & 1727 & $20: 13$ & 16.7 & $7 \sqrt[23]{3}$ \\
\hline 1445 & $89 / 20$ & 16.7 & 796.6 & 1516 & 8920 & 16.6 & 794.4 & 1587 & 15:33 & 16.6 & 791. & 1658 & $17: 55$ & 16.7 & & 1728 & & 167 & \\
\hline 1446 & 892 & 16.7 & 7924 & 1517 & 89220 & 16.6 & 794.2 & 1588 & $815: 35$ & 16.7 & 791.1 & 1659 & $17: 57$ & 16.7 & 877.6 & 1729 & $20: 17$ & 16.6 & 768.0 \\
\hline 1447 & 8920 & 16.7 & 7920 & 1518 & 89920 & 16.6 & 791.6 & 1589 & 89920 & 16.7 & 790.3 & 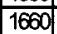 & $317: 59$ & 16.7 & 778.7 & 1730 & & 16.7 & \\
\hline 1448 & 8920 & 16.7 & 800.8 & 1519 & 8920 & 16.7 & 793.4 & 1590 & 815:39 & 16.6 & 788. & 1661 & $818: 01$ & 16.7 & 785.0 & 1731 & 320:21 & 16.7 & 754.5 \\
\hline$\overline{14}$ & 89200 & 16.7 & 803.1 & 1520 & 89200 & 16.7 & 786.1 & 1591| & 89920 & 16.7 & 788. & 1662 & 318:03 & 16.7 & 790.1 & 1732 & 320.23 & 167 & 764.4 \\
\hline$\overline{144}$ & 89200 & 16.7 & 8025 & 1521 & $13: 21$ & 16.7 & 783.0 & 1592 & $815: 43$ & 16.6 & 789.8 & 1663 & $818: 05$ & 16.7 & 774.6 & 1733 & $320: 25$ & 16.7 & 767.4 \\
\hline 1451 & 89200 & 16.7 & 801.3 & 1522 & 89120 & 16.7 & 780.9 & 1593 & $15: 45$ & 16.7 & 790. & 1664 & 18:07 & 16.7 & 781. & 1734 & 20.27 & 16.6 & 768.8 \\
\hline 1452 & 892 & 16.7 & 801. & 1523 & 8912 & 16.7 & 780.5 & 1594 & 15:47| & 16.6 & 790 & 1665 & 18:09 & 16.7 & & 1735 & & 16.7 & \\
\hline 1453 & $89 / 20$ & 16.7 & 801.5 & 1524 & $89 / 20$ & 16.7 & 781.6 & 1590 & $15: 49$ & 16.6 & 791.6 & 1666 & $\mid 18: 11$ & 16.7 & 763. & 1736 & 20.31 & 16.7 & 764.7 \\
\hline 1454 & 8920 & 16.7 & \begin{tabular}{|l}
801. \\
\end{tabular} & 1525 & 8912 & 16.7 & 796.8 & 1596 & $89 \sqrt{2}$ & 16.6 & 791. & 1667 & 18:13 & 16.7 & 756. & 1737 & $20: 33$ & 16.7 & 769.5 \\
\hline 1455 & $89 / 2$ & 16.7 & 801. & 1526 & & 16.7 & 797.5 & 1597 & $15: 53$ & 16.6 & 792 & 1668 & 18:15 & 16.7 & 755 & 1738 & 20.35 & 16.7 & 769.2 \\
\hline 1456 & 8912 & 16.7 & \begin{tabular}{|l}
801. \\
\end{tabular} & 1527 & $89 / 20$ & 16.7 & 786. & 1598 & $89 / 2$ & 16.7 & 793 & 56 & $18: 17$ & 16.7 & 749 & 1739 & $20: 37$ & 16.6 & 767.4 \\
\hline & & 16.7 & \begin{tabular}{|l|l}
801.3 \\
\end{tabular} & 1528 & 8920 & 16.7 & 788. & 1599 & 15:57 & 16.6 & 793 & 1670 & 18:19 & 16.7 & & 1740 & $320: 39$ & 167 & 768.1 \\
\hline 1458 & & $\overline{16.7}$ & 800.9 & 1529 & $89 / 20$ & 16.7 & 789.7 & 1600 & $15: 59$ & 16.6 & 793 & 671 & 18.21 & $\overline{16.7}$ & 759. & 1741 & $20: 41$ & 16.7 & 767.4 \\
\hline 145 & 89 & 16.7 & 800.2 & 1530 & 8912 & 16.7 & 789 & 1601 & $16: 01$ & 16.7 & 79 & 1672 & 8.23 & 16.7 & 73 & 174 & 0.43 & 16.6 & \\
\hline 1460 & & 16.7 & 800.0 & 1531 & 892 & $\begin{array}{l}6.7 \\
\end{array}$ & 784.8 & 1602 & $16: 03$ & 16.6 & 793.5 & \begin{tabular}{|l|}
1673 \\
\end{tabular} & 18:25 & 16.7 & 739. & 174 & $20: 45$ & 16.7 & 769.2 \\
\hline 1461 & & 16.7 & \begin{tabular}{|l}
798 \\
\end{tabular} & 1532 & $89 x$ & 16.7 & 785 & 1603 & 16.05 & 16.7 & 794 & 1674 & |8.27 & 16.7 & 733 & 1744 & 00.47 & 167 & 760.7 \\
\hline & & 16.7 & 798 & 1533 & & $\{6.7$ & 78 & 1604 & & 16.7 & 794 & 167 & & 16. & & & & 16.7 & 760 \\
\hline 1463 & 89 & 16.7 & \begin{tabular}{|l|l|}
798 \\
\end{tabular} & 1534 & & 16.7 & 789 & 1605 & & 16.7 & 79 & 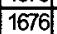 & & 16.7 & 78 & 174 & 20051 & 16.7 & 757.4 \\
\hline 14 & & 16.7 & 797. & \begin{tabular}{|l|}
1535 \\
\end{tabular} & & 16.7 & 789.8 & 1606 & 16:11 & 16.7 & 794 & 1677 & $18: 33$ & 16.7 & 783. & \begin{tabular}{|l|}
1747 \\
\end{tabular} & 20.53 & 16.7 & 760.1 \\
\hline$\overline{14}$ & 8992 & 16.7 & 797. & \begin{tabular}{|c|}
1536 \\
\end{tabular} & 892 & 16.7 & 788.8 & 1607 & 16:13 & 16.6 & 794 & & & 16.7 & 781 & 174 & 20.55 & 16.7 & 7621 \\
\hline$\overline{144}$ & & 16.7 & 796. & 1537 & & 16.7 & 789. & 1608 & $6: 15$ & 16.6 & 79 & 6 & & 16.7 & $\overline{7 n}$ & & 0.57 & 16.7 & \\
\hline 1467 & & 16.7 & 793. & 1538 & & 16.7 & 7925 & 1609 & & 16.6 & & 1680 & & 16.7 & $7 \pi 9$ & & & 16.7 & 763.4 \\
\hline 1468 & & 16.7 & 791 & 1539 & & 16.7 & 794.0 & 1610 & $16: 19$ & 16.6 & 794 & 68 & 18:41 & 16.7 & $m$ & & & 16.7 & 766. \\
\hline & & 16.7 & 793.2 & 1540 & & \begin{tabular}{|c|}
16.7 \\
\end{tabular} & & 1611 & & 16.7 & 79 & $\overline{168}$ & & 16.7 & $7 \pi$ & & & 167 & 766.7 \\
\hline 1470 & $89 / 2$ & 16.7 & 792.8 & 1541 & & 16.7 & 794 & 1612 & & 16.6 & 79 & & & 16.7 & $\pi$ & & & 16. & \\
\hline 14 & & 16.7 & & 1542 & & 16.7 & 794 & 1613 & & 16.6 & 79 & & & 16.7 & $7 \pi$ & & & 16.7 & 766.7 \\
\hline 1472 & & 16.7 & 79 & 1543 & & & & 1614 & & 16.7 & & & & & & & & & \\
\hline 14 & & 16.7 & 791 & 1544 & & 16.7 & 792 & 1615 & $6: 29$ & 16.6 & 79 & 168 & & 16.7 & $\pi$ & & & 16.7 & 768.2 \\
\hline & & 16.7 & & 154 & & 16.7 & & & & 16.6 & & & & & & & & & \\
\hline 1475 & & 16.7 & \begin{tabular}{|l}
791.2 \\
\end{tabular} & 1546 & 14:11 & 16.7 & 791. & 1617 & $6 \cdot 3$ & 16.7 & 792 & $\overline{168}$ & & 16.7 & 784 & & & 16.7 & 768.5 \\
\hline & & 16.7 & \begin{tabular}{|l}
791.5 \\
\end{tabular} & \begin{tabular}{|l|l|}
1547 \\
\end{tabular} & & 16.7 & 790. & 1618 & & & & & & 16.7 & & & & & \\
\hline 147 & & 16.7 & 791 & 1548 & & 16.7 & 791 & & & 16.7 & & & & 16.7 & & & & 16.6 & \\
\hline & & 16.7 & \begin{tabular}{|l}
791 \\
\end{tabular} & 1549 & & 16.7 & 791. & 1620 & $66: 39$ & 16.6 & 794 & 1691 & & 16.7 & 78 & 61) & & 16.7 & \\
\hline & & 16.7 & \begin{tabular}{|l}
791. \\
\end{tabular} & & & 16.7 & & & & 16.6 & 794 & & & 16.7 & & & & 96.7 & \\
\hline & & 16.7 & \begin{tabular}{|l|}
790. \\
\end{tabular} & 1551 & & 16.7 & 792 & & & 16.6 & 794 & 693 & & 16.7 & 78 & & & 16.7 & 72 \\
\hline & & & 789 & 1552 & & 16.7 & & & & 16.6 & & 162 & & & & & & 167 & \\
\hline 1482 & 89200 & 16.7 & \begin{tabular}{|l|}
787. \\
\end{tabular} & \begin{tabular}{|c|}
1553 \\
\end{tabular} & 892000 & 16.7 & 7926 & 1624 & 16:47 & 16.6 & \begin{tabular}{|l|l|}
793 \\
\end{tabular} & 1695 & 19.09 & 16.7 & 78 & 1765 & 21:20 & 16.7 & 7729 \\
\hline & & 16.7 & & \begin{tabular}{|c|}
1554 \\
\end{tabular} & & \begin{tabular}{|c|}
16.7 \\
\end{tabular} & & 1625 & & 16.7 & & & & 16.7 & & & & & \\
\hline 1484 & 1207 & 16.7 & \begin{tabular}{|l|}
784.6 \\
\end{tabular} & 1555 & $14: 20$ & 16.7 & 793.5 & 1626 & $16: 51$ & 16.7 & 792 & 1697 & & 16.7 & 784 & \begin{tabular}{|l|}
1767 \\
\end{tabular} & $21: 33$ & 16.7 & 773.7 \\
\hline 1485 & $89 / 20081200$ & 16.7 & \begin{tabular}{|l|}
783.7 \\
\end{tabular} & 1556 & & 16.7 & 7927 & 1627 & $8816: 53$ & 16.6 & 790 & 698 & & 16.7 & 784 & 768 & & 16.7 & 773.7 \\
\hline 1486 & & 16.7 & 783. & 1557 & & 16.7 & 792 & & & 16.7 & & & & 16.7 & & & & 16.6 & \\
\hline 1487 & 8920081213 & \begin{tabular}{|l|}
16.7 \\
\end{tabular} & 783.5 & 1558 & 892008 14:35 & 16.7 & 792 & 1629 & $89 / 200816: 57$ & 16.7 & 792 & 1700 & $89 / 2008+9.19$ & 16.7 & 785 & \begin{tabular}{|l|}
1770 \\
\end{tabular} & $89 / 200821: 39$ & 16.7 & 773. \\
\hline 1488 & $89 / 20081215$ & \begin{tabular}{|l|}
16.7 \\
\end{tabular} & 783.6 & 1559 & & 16.7 & 793 & & $89200016: 59$ & 16.6 & 792 & & & 16. & & & & 16.7 & 7727 \\
\hline 1489 & $89 / 20081217$ & 16.7 & 784. & 1560 & $89 / 2$ & 16.7 & 793. & 16 & 17:01 & 16.6 & 792 & 170 & 19:23 & 16.7 & 785 & & $21: 43$ & 16.7 & 770.9 \\
\hline 1490 & $89 / 2008$ 12:19 & 16.7 & 785. & & 14:41 & 16.7 & 792 & & 17:03 & 16.7 & 791. & & 19.25 & 10.01 & 784.5 & $7 \pi 3$ & $21: 45$ & 16.7 & 770. \\
\hline
\end{tabular}


DOE/RL-2009-35, REV. 0

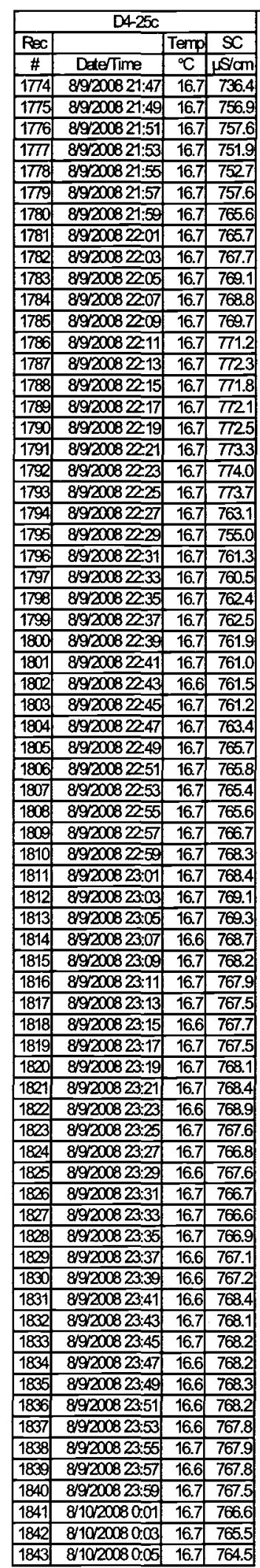

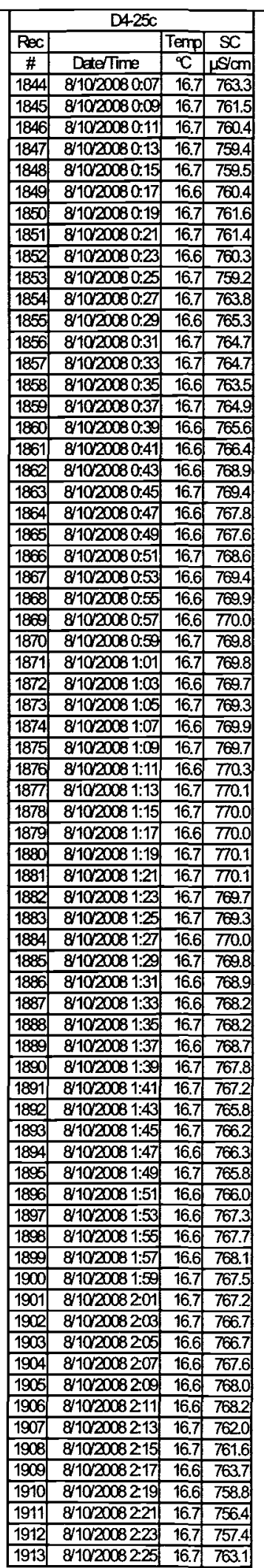

\begin{tabular}{|c|c|c|c|}
\hline \multicolumn{4}{|c|}{ D425c } \\
\hline $\operatorname{Rec}$ & & & \\
\hline$\#$ & DakeTime & & \\
\hline 1914 & $8 / 1020002227$ & 16.6 & 764 \\
\hline 1915 & $8 / 1020008220$ & 16.6 & 765 \\
\hline 916 & $8 / 1020082: 31$ & 16.7 & \\
\hline & 102008233 & 16.6 & 767 \\
\hline 18 & 1020008235 & 16.6 & \\
\hline 1919 & $8 / 1020082-37$ & 16.6 & 769. \\
\hline 1920 & $8 / 102008233$ & 16.7 & \\
\hline 1921 & 1002008241 & 16.7 & 759. \\
\hline 1922 & $10 / 2008243$ & 16.7 & 727. \\
\hline 1923 & 8245 & 16.7 & \\
\hline 1924 & $8 / 102008247$ & 16.7 & 746. \\
\hline 1925 & & 16.7 & \\
\hline 1926 & $8 / 1020$ & 16.7 & 750. \\
\hline 1927 & 32.53 & 16.7 & 752 \\
\hline 1928 & 3255 & 16.7 & \\
\hline 1929 & $8 / 102008257$ & 16.7 & 755 \\
\hline 1930 & & 16.7 & \\
\hline 1931 & $8 / 10 / 2 x$ & 16.7 & 757. \\
\hline 1932 & $33: 03$ & 16.7 & \\
\hline & $8 / 102$ & 16.7 & \\
\hline 1934 & $8 / 102$ & 16.7 & 758 \\
\hline 1935 & $8 / 102$ & 16.7 & \\
\hline 1936 & $8 / 1012$ & 16.7 & 755. \\
\hline 1937 & $3: 13$ & 16.6 & \\
\hline 1938 & $8 / 102$ & 16.7 & 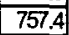 \\
\hline 1939 & & 16.7 & 758 \\
\hline 1940 & & 16.7 & \\
\hline 1941 & & 16.6 & 761. \\
\hline 1942 & $8 / 10$ & 16.7 & \\
\hline 1943 & & 16.7 & 761. \\
\hline 1944 & & 16.7 & \\
\hline 1945 & $8 / 102$ & 16.7 & 762 \\
\hline 1946 & & 16.7 & 763 \\
\hline 1947 & & 16.7 & 764 \\
\hline 1948 & & 16.7 & 763 \\
\hline 1949 & & 16.7 & 764 \\
\hline 1950 & & 16.7 & \\
\hline 1951 & & 16.7 & 76 \\
\hline 1952 & $8 / 1012$ & $\frac{0.37}{16.7}$ & $\frac{\pi}{7}$ \\
\hline 1953 & & 16.7 & 762 \\
\hline 1954 & & 16.7 & 756 \\
\hline 1955 & & 16.6 & 700 \\
\hline 1956 & & 16.6 & 760 \\
\hline 1907 & & 16.7 & \\
\hline 1958 & & 16.7 & 76 \\
\hline 1959 & & 16.6 & 762 \\
\hline 1960 & & 16.7 & \\
\hline 1961 & & 16.7 & 763 \\
\hline 1962 & & 16.7 & \\
\hline 1963 & 05 & 16.7 & \\
\hline 1964 & & 16.6 & \\
\hline 1965 & & 16.7 & \\
\hline 866 & & 16.7 & $76 x$ \\
\hline 1967 & & 16.7 & \\
\hline 1968 & & 16.6 & \\
\hline 1969 & & & \\
\hline 1970 & & 16.6 & \\
\hline 1971 & & 16.7 & \\
\hline 1972 & & 16.7 & \\
\hline 1973 & & 16.7 & \\
\hline 1974 & & & \\
\hline 1975 & & 16.7 & 766 \\
\hline & & & \\
\hline 1977 & & 16.6 & \\
\hline & & & \\
\hline & & 16.6 & \\
\hline 1980 & & 16.6 & 768 \\
\hline & & & \\
\hline & & 16.7 & \\
\hline & & & \\
\hline
\end{tabular}

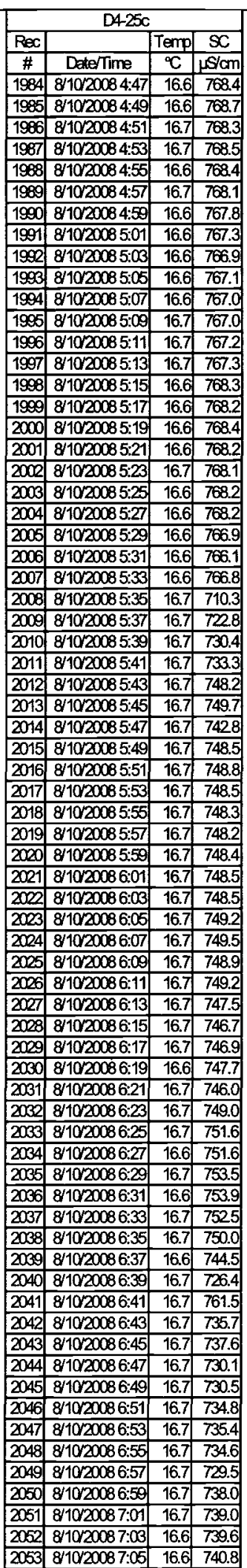

\begin{tabular}{|c|c|c|c|}
\hline \multicolumn{4}{|c|}{ D425C } \\
\hline $\mathrm{Rec}$ & & Termp & \\
\hline$\#$ & DaterTime & ${ }^{\circ} \mathrm{C}$ & $1 \mathrm{~s} / \mathrm{cm}$ \\
\hline 2054 & $8 / 10 / 20087: 07$ & 16.7 & 741.2 \\
\hline 2055 & $8 / 10 / 20087: 00$ & 16.7 & 741.0 \\
\hline 2056 & $8 / 1020087: 11$ & 16.7 & 743.0 \\
\hline 2007 & $8 / 1020087: 13$ & 16.7 & 740.7 \\
\hline 2058 & $8 / 1020087: 15$ & 16.6 & 747.3 \\
\hline 2050 & $8 / 1020087: 17$ & 16.7 & 748.8 \\
\hline & $8 / 1020087: 19$ & 16.7 & 748.8 \\
\hline 2061 & $8 / 1020087: 21$ & 16.7 & 750.8 \\
\hline & $8 / 1020087: 23$ & 16.6 & \\
\hline 2063 & $8 / 10220087: 25$ & 16.7 & 7526 \\
\hline 2064 & $8 / 1020087: 27$ & 16.7 & 750.4 \\
\hline 2065 & $8 / 1020087: 20$ & 16.6 & $748 . \mathrm{s}$ \\
\hline 2006 & $8 / 1020087: 31$ & 16.7 & 749.4 \\
\hline 2067 & $8 / 1020087: 33$ & 16.7 & 749.4 \\
\hline 2068 & $8 / 10 / 20087: 35$ & 16.6 & 748.0 \\
\hline 2069 & $8 / 10 / 20087: 37$ & 16.7 & 747.7 \\
\hline 2070 & $8 / 10220087: 39$ & 16.7 & 748.8 \\
\hline 2071 & $8 / 1020087: 41$ & 16.6 & 749.3 \\
\hline 2072 & $8 / 10 / 20087: 43$ & 16.7 & 749.9 \\
\hline 2073 & $8 / 10 / 20087: 45$ & 16.7 & 748.9 \\
\hline 2074 & $8 / 10 / 20087: 47$ & 16.7 & 748.8 \\
\hline 2075 & $8 / 10 / 20$ & 16.7 & 748.1 \\
\hline 2076 & $8 / 1020087: 51$ & 16.7 & 747.9 \\
\hline 2077 & $8 / 10200$ & 16.7 & 739.7 \\
\hline 2078 & $8 / 1020$ & 16.6 & 740.8 \\
\hline 2079 & $8 / 1020087: 57$ & 16.6 & 736.6 \\
\hline 2080 & $8 / 10 / 20087: 59$ & 16.7 & 736.8 \\
\hline 2081 & $8 / 1020088.01$ & 16.7 & 737.1 \\
\hline 2082 & $8 / 1020$ & 16.6 & 736.9 \\
\hline 2083 & $8 / 1020$ & 16.7 & 738.7 \\
\hline 2084 & $8 / 10 / 20$ & 16.6 & 738.8 \\
\hline 2085 & $8 / 1020088: 09$ & 16.6 & 736.6 \\
\hline 2086 & 8/10/2008 8:11 & 16.6 & 740.4 \\
\hline 2087 & $8 / 1020088.13$ & 16.7 & 735.9 \\
\hline 2008 & $8 / 10 / 200$ & 16.7 & 737.9 \\
\hline 2009 & $8 / 10200$ & 16.7 & 734.8 \\
\hline 2090 & $8 / 10 / 20$ & 16.6 & 734.4 \\
\hline 2091 & $8 / 10 / 20$ & 16.6 & 734.0 \\
\hline 2092 & $8 / 1020$ & 16.7 & 733.6 \\
\hline 2003 & $8 / 10 / 20$ & 16.6 & 734.4 \\
\hline 2094 & $8 / 1020088: 27$ & 16.6 & 731.6 \\
\hline 2095 & $8 / 1020$ & 16.6 & 731.5 \\
\hline 2006 & $8 / 1020088: 31$ & 16.7 & 733.0 \\
\hline 2097 & $8 / 102$ & 16.6 & 739.0 \\
\hline 2008 & $8 / 10120$ & 16.6 & 736.6 \\
\hline & $8 / 10 / 2$ & 16.7 & 734.9 \\
\hline 2100 & 1020 & 16.6 & 735.7 \\
\hline 2101 & $8 / 1020088: 41$ & 16.6 & 733.2 \\
\hline & $8 / 1020$ & 16.7 & 733.0 \\
\hline 2103 & $8 / 10: 20088: 45$ & 16.7 & 729.2 \\
\hline 2104 & $8 / 10 / 20088: 47$ & 16.6 & 736.4 \\
\hline 2106 & $8 / 10120$ & 16.6 & 738.3 \\
\hline 2106 & $8 / 10$ & 16.7 & 736.0 \\
\hline 2107 & 10020 & 16.6 & 740.2 \\
\hline 2108 & $8 / 10 / 20$ & 16.7 & $\overline{741.4}$ \\
\hline & & 16.7 & \\
\hline 211 & $8 / 10 / 20088: 59$ & 16.6 & 739.8 \\
\hline & & 16.6 & 739. \\
\hline 2112 & $8 / 1020089.03$ & 16.6 & 739. \\
\hline 2113 & $8 / 10: 20089.05$ & 16.7 & \\
\hline & $8 / 10 / 20089.07$ & 16.7 & 741.3 \\
\hline 2115 & $8 / 1020$ & 16.6 & 740.4 \\
\hline & $8 / 10120$ & 16.6 & \\
\hline$\overline{21}$ & 8/10/20089:13 & 16.7 & 7420 \\
\hline & 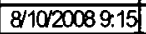 & 16.6 & 742.3 \\
\hline 2119 & $8 / 1020089.17$ & 16.7 . & 741.0 \\
\hline 2120 & $8 / 1020089.19$ & 16.7 & 744.8 \\
\hline 212 & $8 / 10220089: 21$ & 16.7 & 7425 \\
\hline 212 & $8 / 1020089: 23$ & 16.6 & 733 \\
\hline & $810000^{8}$ 9? & & \\
\hline
\end{tabular}


DOE/RL-2009-35, REV. 0

\begin{tabular}{|c|c|c|c|c|c|c|c|c|c|c|c|c|c|c|c|c|c|c|}
\hline \multicolumn{3}{|c|}{$D 425 c$} & \multicolumn{4}{|c|}{ D425c } & \multicolumn{4}{|c|}{$D 425 c$} & & $D 425 c$ & & & & $0425 c$ & & \\
\hline$P \in$ & & Temp & 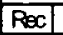 & & Temp & $S C$ & $\mathrm{Rec}$ & & Temp & & $\mathrm{BEC}$ & & Termp & SC & $\mathrm{Rec}$ & & Templ & SC \\
\hline$\#$ & Date/Time & \begin{tabular}{l|l|}
${ }^{\circ} \mathrm{C}$ & $\mu \mathrm{s} / \mathrm{cm}$ \\
\end{tabular} & $\#$ & DeterTime & ${ }^{\circ} \mathrm{C}$ & $\mathrm{HS} / \mathrm{cm}$ & $\#$ & Date/lime & ${ }^{\circ} \mathrm{C}$ & $\mu \mathrm{s} / \mathrm{cm}$ & $\#$ & DeterTime & ${ }^{\circ} \mathrm{C}$ & $\mu \mathrm{s} / \mathrm{cm}$ & $\#$ & Dete/ime & ${ }^{\circ} \mathrm{C}$ & $\mathrm{s} / \mathrm{cm}$ \\
\hline 2124 & $8 / 1020009.27$ & 734.9 & & $8 / 10200$ & 16.7 & 693.0 & 2264 & $8 / 102008$ 14:07 & 16.7 & 700.6 & 2334 & $8 / 10200016 \cdot 27$ & 16.7 & & 2404 & $8 / 10200818: 47$ & 25.3 & 12 \\
\hline 2125 & 811020009.29 & 734.9 & 195 & $8 / 10200811: 49$ & 16.7 & 606.5 & 2265 & $8 / 102008$ 14:09 & 16.7 & 708.5 & 2336 & $8 / 10200816: 20$ & 16.7 & 696.8 & 2405 & $8 / 10200818: 49$ & 25.2 & 13 \\
\hline 2126 & 81020089.31 & 740.1 & 96 & 8102008 11:51 & 16.7 & 6920 & 2260 & $8 / 102008$ 14:11 & 16.7 & 7120 & 336 & $8 / 10200816: 31$ & 16.7 & 6927 & 100 & $8 / 10200818: 51$ & 252 & 13 \\
\hline 127 & & \begin{tabular}{l|l|}
16.6 & 740.1 \\
\end{tabular} & & & 167 & 688.0 & 2267 & 8/102008 14:13 & 16.7 & 711.1 & 33त्त & $8 / 10200816: 33$ & 16.7 & 689.0 & & & 251 & 13 \\
\hline 128 & $8 / 1020009.35$ & \begin{tabular}{|l|l|}
16.6 & 738.3 \\
\end{tabular} & 2198 & $8 / 102008$ 11:55 & 16.7 & 6860 & 2268 & $8 / 102008$ 14:15 & 16.7 & 709.9 & 338 & $8 / 10200816: 36$ & 16.7 & 66 & 408 & $8 / 10200818: 56$ & 20 & 13 \\
\hline 2129 & $8 / 1020089.37$ & \begin{tabular}{l|l|}
16.7 & 736.1 \\
\end{tabular} & 2199 & $8 / 10200811: 57$ & 16.7 & 690.2 & 2269 & $8 / 102008$ 14:17 & 16.7 & 726.8 & 339 & $8 / 102000816.37$ & 167 & 6963 & WA & $8 / 102008$ 18:57 & 24.9 & 13 \\
\hline 2130 & $8 / 10 / 20089.39$ & \begin{tabular}{|l|l|}
16.7 & 730.5 \\
\end{tabular} & & $8 / 102008$ 11:50 & 16.7 & 690.8 & 2270 & & 16.7 & 727.0 & 2340 & $8 / 102000816: 39$ & 16.7 & & & & 269 & 113 \\
\hline 2131 & $8 / 1020009.41$ & \begin{tabular}{|l|l|}
16.7 & 731.7 \\
\end{tabular} & 2201 & $8 / 1020081201$ & 16.7 & 697.0 & 2271 & $8 / 10200814: 21$ & 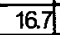 & 698.0 & 2341 & $8 / 10200081644$ & 167 & 6828 & & $8 / 102200819: 01$ & 248 & 1.3 \\
\hline 2132 & $8 / 1020089.43$ & 16.6 & 2200 & $8 / 1020081203$ & 16.7 & 700.1 & 2272 & $8 / 10200814: 23$ & 16.7 & 6060 & 2342 & $8 / 1020008$ 16:43 & 16.7 & 6850 & 412 & $\overline{00819: 03}$ & 24.7 & $\sqrt{13}$ \\
\hline 2133 & $8 / 1020009.45$ & 16.6 & & $8 / 1020081205$ & 16.7 & 707.0 & 2273 & $8 / 102008$ 14:25 & 16.7 & & 2343 & $8 / 10 / 200816 \cdot 45$ & 167 & & & $0819: 06$ & 246 & $\overline{13}$ \\
\hline 2134 & $8 / 10200099.47$ & 16.6 & 2204 & 811020081207 & 16.7 & 7152 & 2274 & $8 / 100200814: 27$ & 16.7 & 705.3 & 2344 & $8 / 102008$ 16:47| & 16.7 & 681.0 & 2414 & $8 / 102000619: 07$ & 245 & 13 \\
\hline 2136 & $8 / 1020069.49$ & \begin{tabular}{l|l|}
16.7 & 7332 \\
\end{tabular} & 2006 & 81200 & 16.7 & 717.8 & 2275 & $0814: 29$ & 16.7 & 707.0 & 2345 & $8 / 10 / 200816: 49$ & 16.7 & 678.8 & 415 & 819.09 & 24.4 & 13 \\
\hline 2136 & $8 / 10200099.51$ & \begin{tabular}{|l|l|}
16.6 & 731.9 \\
\end{tabular} & 206 & 1211 & 16.7 & 7180 & 2276 & $114: 31$ & 16.7 & & 2346 & $8 / 102008$ 16:51 & 16.7 & 679.2 & & 819.11 & 24.3 & 13 \\
\hline 2137 & $8 / 1020009.53$ & \begin{tabular}{|l|l|}
166 & 7321 \\
\end{tabular} & 2007 & 31213 & 16.7 & 720.4 & $22 \pi$ & $8 / 102$ & 16.7 & 706.7 & 347 & $8 / 10200816: 53$ & 16.7 & 678.4 & & $8 / 10 / 2008$ 19:13 & $\overline{243}$ & 19 \\
\hline 2138 & $8 / 1020009.56$ & \begin{tabular}{l|l|}
16.6 & 736.3 \\
\end{tabular} & 2008 & 81215 & 16.7 & 720.0 & 2278 & 8 14:36 & 16.7 & 707.0 & 2348 & $8 / 10200816: 50$ & 16.7 & 676.8 & 2418 & 08 19.15 & 243 & 13 \\
\hline 2139 & 39.57 & \begin{tabular}{l|l|}
16.6 & 731.6 \\
\end{tabular} & 2009 & 1217 & 16.7 & 724.5 & 2279 & 14:37 & 16.7 & & 2349 & $8 / 10200816: 57$ & $16 \sqrt{16}$ & & & 008 19.17 & 242 & \\
\hline 2140 & $8 / 102$ & \begin{tabular}{|l|l|}
16.7 & 730.9 \\
\end{tabular} & 2210 & & 16.7 & 727.7 & 2280 & $8 / 102$ & 16.7 & 708.2 & 2350 & $8 / 10 / 200816: 59$ & 16.7 & 684.8 & 2420 & & 24.1 & 12 \\
\hline 2141 & $8 / 102008$ 10:01 & \begin{tabular}{|l|l|}
16.7 & 733.0 \\
\end{tabular} & 2211 & $8 / 1020001221$ & 16.7 & 719.0 & 2281 & 8 14:41 & 16.7 & 711.8 & 2351 & $8 / 102008$ 17:01 & 16.7 & 678.8 & 2421 & $8 / 10 / 200819: 21$ & 24 & 1.3 \\
\hline 2142 & $8 / 102 x$ & \begin{tabular}{l|l|}
16.6 & 7326 \\
\end{tabular} & 2212 & $8 / 102$ & 16.7 & 718.6 & 2282 & 14:43 & 16.7 & 7124 & 2352 & $8 / 10 / 200817: 03$ & 16.7 & 677.1 & 2420 & 819.23 & 20.9 & 13 \\
\hline 2143 & $8 / 102$ & \begin{tabular}{l|l|}
16.6 & 733.5 \\
\end{tabular} & 2213 & 1225 & 16.7 & 718.7 & 2283 & & 16.7 & 709.5 & 2353 & $8 / 10 / 200817: 05$ & 16.7 & 681.2 & 242 & & 239 & 13 \\
\hline 2144 & $8 / 1020$ & 16.6 & 2214 & $8 / 10200$ & 16.7 & 714.2 & 2284 & 814:47 & 16.7 & 710.7 & 2354 & $8 / 102008$ 17:07 & 16.7 & 680.7 & 2424 & 8619.27 & 237 & 13 \\
\hline 2145 & $8 / 1 \alpha^{\prime 2}$ & 16.6 & 2215 & 8102 & $16 \sqrt{7}$ & 721.2 & 2285 & $8 / 10^{\prime 2}$ & 16.7 & 7027 & 2355 & $817: 09$ & 16.7 & 675 & 2425 & 819.29 & 206 & 18 \\
\hline 2146 & $8 / 10$ & 16.7 & 2216 & & 16.7 & 724.0 & 2286 & 14:51 & 16.7 & & 2356 & $817: 11$ & 16.7 & $\overline{6 / 2}$ & & & 235 & 13 \\
\hline 2147 & $8110^{\prime 2}$ & 16.7 & 2217 & 1233 & 16.7 & 7225 & 2287 & $14: 53$ & 16.7 & 704.8 & 2357 & $817: 13$ & 16.7 & 675.5 & 421 & 19.33 & 234 & 12 \\
\hline 2148 & $8 / 102$ & 16.6 & 2218 & 1235 & 167 & 723.4 & 2288 & $8 / 102$ & 16.7 & 715 & 2358 & $817: 15$ & 16.6 & 688.2 & 428 & 19.35 & 233 & 1.3 \\
\hline 2149 & $8 / 102$ & 16.7 & 2219 & & 16.7 & 710. & 2289 & $8 / 102$ & 16.7 & & 2350 & & 16.7 & & 420 & & 232 & 1.3 \\
\hline 2150 & $8 / 102$ & 16.6 & 2200 & 239 & 16.7 & 712 & 2290 & $8 / 10$ & 16.6 & 718. & 2360 & 17:19 & 16.7 & 672 & 430 & 1939 & 231 & 13 \\
\hline 2151 & $8 / 102$ & 16.7 & 2221 & 1241 & 16.7 & 719.2 & 2291 & 810 & 16.7 & 709. & 2361 & 817:21 & 16.7 & 672 & 431 & 19.41 & 24 & \\
\hline 2152 & $8 / 102$ & 16.6 & 222 & & 16.7 & $\overline{717.5}$ & 2292 & 810 & 16.7 & & 2362 & 17:23 & 16.6 & 676.8 & & & 220 & 13 \\
\hline 2153 & $8 / 10^{\prime}$ & 16.7 & 2223 & 245 & 16.7 & $\overline{717.8}$ & 2293 & 8110 & 16.7 & 710.2 & 2363 & 17:25 & 16.7 & $683 !$ & 130 & 19.45 & $22 \mathrm{~g}$ & 118 \\
\hline 2154 & & 16.7 & 2224 & 1247 & 167 & 714 & 2294 & & 16.7 & $\overline{714}$ & 2364 & 17:27 & 16.6 & 678 & & & 228 & 113 \\
\hline 2150 & $8 / 102$ & 16.6 & & $8 / 102$ & 16.7 & 715. & & & 16.7 & & 2365 & & 16.6 & $6 \pi$ & 35 & & 227 & 1.3 \\
\hline 2156 & $8 / 10^{\prime \prime 2}$ & 16.7 & 2226 & $8 / 10$ & 16.6 & 7128 & 2296 & & 16.7 & 709.6 & 2306 & $17: 31$ & 16.6 & 678. & 因 & 19.51 & 227 & 1.3 \\
\hline 2157 & 8110 & 166 & 2227 & & 16.7 & 711 & 2297 & & 16.7 & & 2367 & & 16.7 & & & 19.53 & 226 & \\
\hline 2158 & 81102 & 16.7 & 2228 & 81102 & 16.7 & 711. & 2296 & 810 & 16.7 & & 2368 & 17:35 & 16.7 & 676 & & 19.56 & 225 & 13 \\
\hline 2159 & & 16.7 & 2229 & 257 & 16.7 & 713.4 & 2290 & & 16.7 & 703 & 2369 & $17: 37$ & 16.7 & 680 & & 19.5 & 224 & 13 \\
\hline 2160 & $8 / 10$ & 16.7 & 2230 & 250 & 16.7 & 716 & 2300 & & 16.7 & 70 & 2370 & & 16.6 & 678 & & & 223 & 14 \\
\hline 2161 & $8 / 102$ & 16.6 & 2231 & & 16.7 & 718 & 2301 & & 16.7 & & 2371 & $17: 41$ & 16.7 & 684 & $447]$ & 20,01 & 223 & 13 \\
\hline 2162 & $8 / 10$ & 16.6 & 2232 & & 16.7 & 719. & 2302 & & 16.7 & & 2372 & $7: 43$ & 16.7 & 682 & & & 222 & 14 \\
\hline 2163 & $8 / 10$ & 16.6 & 2233 & & 16.7 & 719 & 2303 & & 16.7 & 697 & 2373 & 17:45 & 16.7 & 699 & $\sqrt{42}$ & 2005 & 22 & 14 \\
\hline 2164 & $8 / 10^{\prime 2}$ & 16.6 & 2234 & 13.07 & 167 & 718.3 & 2304 & $15 \cdot 27$ & 16.6 & 694.7 & 2374 & 17:47 & 16.7 & 707. & 444 & 32000 & 22 & 114 \\
\hline 2165 & & \begin{tabular}{l|l}
16.7 & 7252 \\
\end{tabular} & & & 16.7 & 714. & 2306 & & 16.7 & 69 & 2375 & 7:49 & 16.7 & 704. & & & 22 & 10 \\
\hline 2166 & $8 / 10$ & \begin{tabular}{l|l}
16.6 & 727.7 \\
\end{tabular} & 2236 & 311 & 167 & 718 & 2306 & & 16.7 & $6 x$ & & 17:51 & 16.7 & 69 & & & 21.9 & 114 \\
\hline 2167 & & \begin{tabular}{l|l|}
16.7 \\
\end{tabular} & 2237 & & 16.7 & $\overline{714}$ & 200 & & 16.7 & & & & 167 & $\overline{709}$ & & & 21.8 & 14 \\
\hline 2168 & & 166 & & & 16.7 & 714. & & & 16.7 & 690 & & & 166 & 1 & & & 218 & 14 \\
\hline 2169 & & $\begin{array}{l}16.7 \\
\end{array}$ & 2230 & & 16.7 & $\overline{711}$ & 2309 & 5.37 & 16.7 & $\overline{7 m}$ & & 17:57 & 161 & & & & 21.6 & 114 \\
\hline 2170 & & $\begin{array}{l}167 \\
167 \\
\end{array}$ & 2240 & & 16.6 & & & & 16.7 & & 3380 & & 19 & & & & 217 & 1.4 \\
\hline 2171 & & \begin{tabular}{l|l}
16.6 & 7 \\
\end{tabular} & & & 16.7 & & & & 16.7 & & 2381 & & 2121 & & & & 21.6 & \\
\hline 2172 & & 16.7 & 2242 & & 16.7 & 709 & 2312 & & 16.7 & 70 & 2382 & & 225 & & 2452 & 20.23 & 21.6 & 14 \\
\hline 2173 & & 16.7 & & & 16.7 & 712 & 2313 & & 16.7 & 696 & & & 235 & & & & 21.6 & 14 \\
\hline 2174 & & 16.6 & & & 16.7 & & & & 16.6 & & & & 24.1 & & & & 17.7 & \\
\hline 2175 & & \begin{tabular}{l|l}
16.6 & 7 \\
\end{tabular} & 2245 & 320 & 16.7 & $\overline{714}$ & 2315 & & 16.7 & & 85 & & 24.7 & & 155 & & 17i & 8669 \\
\hline 2176 & & \begin{tabular}{l|l|}
16.7 & 72 \\
\end{tabular} & 2246 & & 16.7 & 69 & 2316 & & 16.7 & & & & 26 & & & & 16.8 & \\
\hline $217 \pi$ & & \begin{tabular}{l|l|}
16.6 & 72 \\
\end{tabular} & & & 16.7 & & & & 16.6 & & & & 251 & & & & 16.7 & \\
\hline 2178 & & 16.6 & 2248 & $3: 35$ & 16.7 & 705.8 & 2318 & & 16.7 & & 2388 & & 252 & & & 0.36 & 16.7 & 704.5 \\
\hline 2179 & & & & & 16.7 & 697 & & & & & & & & & & & 16.7 & \\
\hline 2180 & & $\begin{array}{l}16.7 \\
7\end{array}$ & & & $\overline{16}$ & & & & 16.7 & & & & 255 & & & & 16.7 & \\
\hline 2181 & & \begin{tabular}{l|l|}
16.7 & 71 \\
\end{tabular} & 2251 & & 16.7 & 707 & 2321 & & 16.6 & 68 & & & 256 & & & & 16.7 & 677.6 \\
\hline 2182 & & & 2252 & & 16.7 & & & & 16.7 & & & & & & & & 16. & \\
\hline 2183 & & 16.7 & 2253 & & & & & & 16.7 & & & 18.27 & 257 & & & & 16.7 & \\
\hline 2184 & $8 / 10$ & \begin{tabular}{l|l|}
16.6 & 715 \\
\end{tabular} & 2254 & & 16.7 & 694 & 2324 & & 16.7 & 693 & & 1827 & 257 & & 406 & & 16.7 & 681.1 \\
\hline 2185 & & $\begin{array}{l}16.6 \quad 72 \\
\end{array}$ & 2256 & & & & & & 16.7 & & & & & & & & & \\
\hline 2186 & & & & & 16.7 & & & & & & & & 257] & & & & 167 & \\
\hline 2187 & $8102 x$ & 16.7 & 2250 & 81102 & 16.6 & 696 & 2327 & $16: 13$ & 16.7 & 693 & 2397 & $818: 33$ & 255 & & 2467 & 320.53 & 16.7 & 6839 \\
\hline 2188 & & \begin{tabular}{l|l}
16.6 & 725.2 \\
\end{tabular} & 2258 & & 16.7 & 703 & 2328 & & 16.7 & & 2398 & 18:35 & 25.4 & & & & 66.7 & \\
\hline 2189 & & & & $13 \cdot 5$ & 16 . & & & & & & & & & & & & 16.7 & \\
\hline 2990 & & \begin{tabular}{l|l|}
16.7 & 7420 \\
\end{tabular} & 2260 & & 16.7 & 691. & 2300 & $16 \cdot 19$ & 16.7 & 696 & 2400 & 18.39 & 254 & & 2470 & 20.59 & 16.7 & 685.8 \\
\hline 2191 & & \begin{tabular}{|l|l|}
16.7 & 763.2 \\
\end{tabular} & 2061 & & 16.7 & 680 & 2331 & & 16.7 & & & & 254 & & & & 16.7 & \\
\hline 2192 & & \begin{tabular}{|l|l|}
16.7 & 717.8 \\
\end{tabular} & 2062 & & 16.7 & 698. & 2332 & & 16.7 & 690 & & & 255 & s. & 24 & 821:03 & 16.7 & \\
\hline 2199 & $8 / 10200811: 45$ & \begin{tabular}{|l|l|}
16.7 & 690.4 \\
\end{tabular} & 2263 & $8 / 102008$ 14:05 & 16.7 & 700.5 & 2333 & $8 / 10200016: 25$ & 16.7 & \begin{tabular}{|l|}
698.1 \\
\end{tabular} & & $8 / 10200818: 45$ & 254 & & & $8 / 10200821: 06$ & 16.7 & \\
\hline
\end{tabular}


DOE/RL-2009-35, REV. 0

\begin{tabular}{|c|c|c|c|c|c|c|c|c|c|c|c|c|c|c|c|}
\hline \multicolumn{4}{|c|}{$D 425 \mathrm{C}$} & \multicolumn{4}{|c|}{ D425c } & \multicolumn{4}{|c|}{ D425c } & \multicolumn{4}{|c|}{$D 425 \mathrm{c}$} \\
\hline & & & SC & & & Temp & SC & $\operatorname{Rec}$ & & Temp & $S C$ & $\mathrm{Rec}$ & & Temp & \\
\hline$\#$ & DaterTime & ${ }^{\circ} \mathrm{C}$ & $\mathrm{H} / \mathrm{cm}$ & $\#$ & Dede/Time & ${ }^{\circ} \mathrm{C}$ & $\mu \mathrm{s} / \mathrm{m}$ & $\#$ & Date/Time & ${ }^{\circ} \mathrm{C}$ & $\mu \mathrm{s} / \mathrm{am}$ & $\#$ & Dade/Trme & ${ }^{\circ \mathrm{C}}$ & $\mathrm{HS} / \mathrm{cm}$ \\
\hline 247 & $8 / 10 / 200821: 07$ & \begin{tabular}{l|l|}
16.7 \\
\end{tabular} & 690.9 & \begin{tabular}{|l|}
2544 \\
\end{tabular} & $8 / 10 / 200823: 27$ & 16.7 & 697.2 & 2614 & 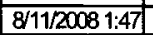 & 16.8 & 694.6 & 2684 & $8 / 11 / 20084: 07$ & 16.7 & 679.8 \\
\hline & \begin{tabular}{|l|l|}
$810200821: 09$ \\
\end{tabular} & 16.7 & 600.9 & 2545 & $8 / 10200823: 29$ & 16.7 & 697.5 & & 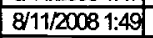 & 16.8 & 694.5 & & $8 / 11 / 20084: 00$ & 16.7 & \\
\hline & $8 / 10 / 200821: 11$ & 16.7 & 690.4 & 546 & $8 / 10 / 200823: 31$ & 16.7 & 696.9 & 616 & $8 / 11 / 20081: 51$ & 16.8 & 694.1 & 686 & $8 / 11 / 20084: 11$ & 16.7 & 680.2 \\
\hline $247 \pi$ & $8 / 10 / 200821: 13$ & 16.7 & 691.2 & 2547 & $8 / 10 / 200823: 33$ & 16.7 & 696.9 & 2617 & $8 / 11 / 20081: 53$ & 16.8 & 694.3 & 2687 & $8 / 11 / 20084: 13$ & 16.7 & 681.5 \\
\hline & $8110200821: 15$ & 16.7 & 691.2 & & $8 / 10 / 200823: 35$ & 16.7 & 697.1 & 2618 & $8 / 11 / 20081: 55$ & 16.8 & 694.1 & 2688 & $8 / 11 / 20084: 15$ & 16.7 & 680.8 \\
\hline 2479 & $8110200821: 17$ & 16.7 & 691.8 & 2549 & $8 / 10 / 200823-37$ & 16.7 & 697.5 & 2619 & $8 / 11 / 20081: 55$ & 16.8 & 694.1 & 2689 & $8 / 11 / 20084: 17$ & 16.7 & 680.5 \\
\hline 2480 & $8 / 10200821: 19$ & 16.7 & 691.8 & \begin{tabular}{|l|}
2550 \\
\end{tabular} & $8 / 10 / 200823: 39$ & 16.7 & 698.6 & 2620 & $8 / 11 / 20081: 59$ & 16.8 & 694.3 & 2690 & $8 / 11 / 20084: 19$ & 16.7 & 680.8 \\
\hline & & 16.7 & 690.1 & 25501 & $8 / 10200823: 41$ & 16.7 & 698.8 & 2621 & $8 / 11 / 2008201$ & 16.8 & 694.6 & 2691 & $8 / 11 / 20084: 21$ & 16.7 & \\
\hline 2482 & $8 / 10 / 200821: 23$ & 16.7 & 690.9 & \begin{tabular}{|l|}
2552 \\
\end{tabular} & $8 / 10 / 200823: 43$ & 16.7 & 699.3 & 262 & $8 / 11 / 2008203$ & 16.8 & 694.9 & 2692 & $8 / 11 / 20084: 23$ & 16.7 & 679.9 \\
\hline 2483 & $8 / 101200821: 25$ & 16.7 & 688.8 & 2553 & $8 / 10 / 200823: 45$ & 16.7 & 699.3 & 262 & $8 / 11 / 2008205$ & 16.8 & 694.6 & 2693 & $8 / 11 / 20084: 22$ & 16.7 & 680.5 \\
\hline & $8 / 10 / 200821: 27$ & 16.7 & 687.4 & 2554 & $8 / 10 / 2000823: 47$ & 16.7 & 699.6 & 2624 & $8 / 11 / 2008207$ & 16.8 & 694.6 & 2694 & $8 \longdiv { 1 1 / 2 0 0 8 4 : 2 7 }$ & 16.7 & \\
\hline 2485 & $8 / 10 / 200821: 20$ & 16.7 & 6826 & 2555 & $8 / 10 / 200823: 49$ & 16.7 & 609.5 & 2625 & $8 / 11 / 2008209$ & 16.8 & 694.6 & 2696 & $8 / 11 / 20084: 20$ & 16.7 & 680.3 \\
\hline 2486 & $8 / 10 / 200821: 31$ & 16.7 & 681.3 & 2556 & $8 / 10200823: 51$ & 16.7 & 699.6 & 2626 & $8 / 11 / 2008211$ & 16.8 & 694.5 & 2696 & $8 / 11 / 20084: 31$ & 16.7 & 680.7 \\
\hline 2487 & $8 / 102200821: 33$ & 16.7 & 689.2 & 2507 & $8 / 10 / 200823: 53$ & 16.7 & 700.1 & 2627 & $8 / 11 / 20082: 13$ & 16.8 & 694.4 & 2697 & $8 / 11 / 20084: 33$ & 16.7 & 680.4 \\
\hline 2488 & $8 / 10200821: 35$ & 16.7 & 689.1 & 2558 & $810200823: 55$ & 16.7 & 700.4 & 2628 & $8 / 11 / 2008215$ & 16.8 & 694.2 & 2696 & $8 / 11 / 20084: 35$ & 16.7 & 680.4 \\
\hline 2489 & $8 / 10 / 20$ & 16.7 & 688.0 & 2559 & $8 / 10 / 200823: 5$ & 16.7 & 700.1 & 262 & 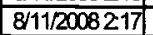 & 16.7 & 693.9 & & $8 / 11 / 20084: 37$ & 16.7 & \\
\hline 2490 & $810200821: 39$ & $\begin{array}{ll}16.7 \\
\end{array}$ & 688.2 & $2560 \mid$ & $8 / 102000823: 59$ & 16.7 & 701.8 & 2630 & $8 / 11 / 2008219$ & $\begin{array}{ll}16.7 \\
\end{array}$ & 694.2 & 2700 & $8 / 11 / 20084: 39$ & 16.7 & 680.2 \\
\hline 2491 & $8110200821: 41$ & 16.7 & 687.4 & 2561 & $8 / 11 / 20080: 01$ & 16.7 & 703.2 & 2631 & $8 / 11 / 2008221$ & 16.7 & 694.1 & 2701 & $8 / 11 / 20084: 41$ & 16.7 & 680.4 \\
\hline & $8 / 10220$ & 16.7 & 686.7 & 2562 & $8 / 11 / 20080: 03$ & 16.7 & 7020 & 2653 & $8 / 11 / 2008223$ & 16.8 & 694.2 & 2702 & $8 / 11 / 20084: 43$ & 19 & \\
\hline 2499 & $8 / 10200821: 45$ & 16.7 & 686.6 & 2563 & $8 / 11 / 20080: 05$ & 16.7 & 7026 & 263 & $8 / 11 / 2008225$ & 16.8 & 690.7 & 2700 & $8 / 11 / 20084: 45$ & 16.7 & 680.4 \\
\hline 2494 & $8 / 10220$ & 16.7 & 686.2 & 2564 & $80: 07$ & 16.7 & 703.4 & 2634 & $8 / 11 / 2008227$ & 16.7 & 694.0 & 2704 & $8 / 11 / 20084: 47$ & 16.7 & 680.1 \\
\hline 2496 & 8102 & 16.7 & 686.3 & 2565 & 80:09 & 16.7 & 7028 & 2635 & $8 / 11 / 2008229$ & 16.7 & 693.8 & 2706 & & 16.7 & \\
\hline 2496 & $8 / 1 \alpha^{2}$ & 16.7 & 686.2 & 2506 & 880:11 & 16.7 & 703.3 & 2636 & $8 / 11 / 2008231$ & 16.7 & 693.9 & 2706 & $084: 51$ & 16.7 & 680.7 \\
\hline 2497 & $8 / 102$ & 16.7 & 685.9 & \begin{tabular}{|l|}
2567 \\
\end{tabular} & $8 / 11 / 2$ & 16.7 & 7027 & 2637 & $82: 33$ & 16.7 & & 2707 & $084: 53$ & 16.7 & 680.6 \\
\hline 2498 & $8 / 10200821: 55$ & 16.7 & 683.7 & 2568 & $8 / 11 / 20080: 15$ & 16.7 & 7026 & 2638 & $8 / 11 / 2008235$ & 16.7 & 693.6 & 2708 & $8 / 11 / 20084: 55$ & 16.7 & 681.1 \\
\hline 2499 & 81102 & 16.7 & 683.7 & 2569 & 80:17 & 16.7 & 7027 & 2630 & 8237 & 16.7 & 693.1 & 2709 & $8 / 11 / 20084: 57$ & 16.7 & 681.7 \\
\hline 2500 & $8 / 102$ & 16.7 & 683.0 & 2570 & 80:19 & 16.7 & 703.3 & 2640 & 8239 & 16.7 & 693.4 & 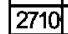 & $884: 59$ & 16.7 & 681.8 \\
\hline 2501 & $8 / 10 / 2$ & 16.7 & 6828 & 2571 & 80.21 & 16.7 & 703. & 2641 & $8 / 11 / 2$ & 16.7 & 692 & 2711 & $85: 01$ & 16.7 & 6828 \\
\hline 2502 & $8 / 1020$ & 16.7 & 6833 & 2572 & $8 / 11 / 20080.23$ & 16.7 & 702.2 & 2642 & $8 / 11 / 2008243$ & 16.7 & 691.7 & 2712 & $085: 03$ & 16.7 & 682.5 \\
\hline 2503 & $8 / 10 / 20$ & 16.7 & 688.8 & 2573 & $8 / 11 / 20080.25$ & 16.7 & 700.2 & 2643 & $8 / 11 / 2008245$ & 16.7 & 6921 & 2713 & $8 / 11 / 20085: 05$ & 16.7 & 6828 \\
\hline 2504 & 81102 & 16.7 & 690.3 & 2574 & 80.27 & 16.7 & 700.7 & 2644 & 3247 & 16.7 & 690.9 & 2714 & $85: 07$ & 16.7 & 684.3 \\
\hline 2505 & 811020 & 16.7 & 695.2 & 2575 & $8 / 11$ & 16.7 & 695. & 2645 & $8 / 11 /$ & 16.7 & 688.6 & 2715 & $8 / 11$ & 16.7 & 683.5 \\
\hline 2506 & $8 / 10220082211$ & 16.7 & 6923 & 2576 & 30.31 & 16.7 & 691. & 2646 & 8251 & 16.7 & 687.4 & 2716 & & 16.7 & 683.4 \\
\hline 2507 & $8 / 10 / 20$ & 16.7 & 673.5 & $25 \pi$ & $8 / 11$ & 16.7 & 689. & 2647 & 8253 & 16.7 & 687. & 2717 & $085: 13$ & 16.7 & 683.9 \\
\hline 2508 & $8 / 1022$ & 16.7 & 671.8 & 2578 & $8 / 111$ & 16.7 & 689. & 2648 & $8 / 11 / 2$ & 16.7 & 687.0 & 2718 & $85: 15$ & 16.7 & 684.6 \\
\hline 2509 & $8 / 10 / 2$ & 16.7 & 675.2 & 2579 & $8 / 111$ & 16.7 & 688. & 2649 & 8257 & 16.7 & 606.7 & \begin{tabular}{|l|}
2719 \\
\end{tabular} & $8 / 11$ & 16.7 & 684.9 \\
\hline 2510 & $8 / 1 \alpha$ & 16.7 & 676.2 & 2580 & $8 / 11$ & 16.7 & 687 & 2650 & 3259 & 16.7 & 686.2 & 2720 & $35: 19$ & 16.7 & 684.7 \\
\hline 2511 & $8110^{\prime 2}$ & 16.7 & 676.9 & \begin{tabular}{|l|}
2581 \\
\end{tabular} & 80.41 & 16.7 & 687.6 & 265 & 83.01 & 16.7 & 678.3 & 272 & & 16.7 & 684.8 \\
\hline 2512 & 8110 & 16.7 & 691.2 & \begin{tabular}{|l|}
2582 \\
\end{tabular} & 80.43 & 16.7 & 687. & 265 & 83.03 & 16.7 & 672 & 272 & $8 / 11 / 20085: 23$ & 16.7 & 684.9 \\
\hline 2513 & $8 / 102$ & 16.7 & 689. & 2583 & 30.45 & 16.7 & 685 & 265 & 8305 & 16.7 & 679 & 2723 & $85: 25$ & 16.7 & 684.9 \\
\hline 2514 & $8 / 10 \%$ & 16.7 & 6921 & 2584 & & 16.7 & 685. & 265 & & 16.7 & 68 & 2724 & & 16.7 & 685.2 \\
\hline 2515 & $8 / 10$ & 16.7 & 691.6 & \begin{tabular}{|l|}
2585 \\
\end{tabular} & 0.49 & 16.7 & 687. & 265 & & 16.7 & 67 & 2725 & & 16.7 & 685.2 \\
\hline 2516 & & 16.7 & 690.9 & 2586 & 80.51 & 16.7 & 679. & 2656 & 3:11 & 16.7 & 678.7 & 2726 & & 16.7 & 685.2 \\
\hline 2517 & $8 / 10$ & 16.7 & 690.1 & \begin{tabular}{|l|}
2587 \\
\end{tabular} & $8 / 11$ & 16.7 & 680 & 265 & & 16.7 & 67 & 2727 & & 16.7 & 684.5 \\
\hline 2518 & $8110 / 2$ & 16.7 & 690 & \begin{tabular}{|l|}
2588 \\
\end{tabular} & $8 / 11 / 4$ & 16.7 & 684. & 265 & $83: 15$ & 16.7 & 67 & 2728 & $085: 35$ & 16.7 & 683.3 \\
\hline 2519 & $8 / 10$ & 16.7 & 689.8 & 2589 & & 16.7 & 688. & 2656 & & 16.7 & 67 & 2729 & & 16.7 & 678.8 \\
\hline 2520 & 8110 & 16.7 & 690.4 & 2590 & & 16.7 & 691. & 266 & & 16.7 & 67 & & & 167 & 680.1 \\
\hline 2521 & $8 / 10$ & 16.7 & 690. & \begin{tabular}{|l|}
2591 \\
\end{tabular} & $81: 01$ & 16.7 & 676 & 2661 & 83.21 & 16.7 & 67 & 2731 & & 16.7 & 681.2 \\
\hline & & 16.7 & 690 & \begin{tabular}{|l|}
2592 \\
\end{tabular} & & & & & & 16. & & & & 16.7 & 6824 \\
\hline 2523 & $8 / 10 / 2$ & 16.7 & 690.3 & \begin{tabular}{|l|}
2593 \\
\end{tabular} & $81: 05$ & 16.7 & 680. & 260 & $083: 25$ & 16.7 & 678 & 273 & $85: 45$ & 16.7 & 6824 \\
\hline 2524 & 8110 & 16.7 & 689.8 & \begin{tabular}{|l|}
2594 \\
\end{tabular} & & 16.7 & 683. & 2664 & & 16.7 & 67 & 2734 & & 16.7 & 6827 \\
\hline 2525 & & 16.7 & 690.0 & 2595 & & 16.7 & 652 & $266^{x}$ & $33: 29$ & 16.7 & & & & 167 & 6825 \\
\hline 2526 & $8 / 1$ & 16.7 & 689 & 2596 & & 16.7 & 65 & 2666 & $3: 31$ & 16.7 & 67 & 2736 & $5: 51$ & 16.7 & 6824 \\
\hline 2527 & & 16.7 & 689 & 2597 & & & 66 & & & & & \begin{tabular}{|l|}
2737 \\
\end{tabular} & & 16.7 & 6826 \\
\hline 2528 & $8 / 10$ & 16.7 & 689.5 & 2598 & $881: 15$ & 16.8 & 692 & 2668 & 883.35 & 16.7 & 67 & \begin{tabular}{|l|}
2738 \\
\end{tabular} & $085: 55$ & 16.7 & 6822 \\
\hline 2520 & $8 / 10$ & 16.7 & 689.1 & 2599 & & 16.9 & 694. & 266 & & 16.7 & 67 & 2730 & & 16.7 & 683.4 \\
\hline 2530 & $8 / 10$ & 16.7 & 689. & 2600 & & 16.8 & 693. & & & 16.7 & & & & 16.7 & 683.8 \\
\hline 2531 & $8 / 10 / 2$ & 16.7 & 689.2 & \begin{tabular}{|l|}
26001 \\
\end{tabular} & & 16.8 & 690. & 2671 & & 16.7 & $6 \pi$ & 2741 & & 16.7 & 683.7 \\
\hline 2532 & & 16.7 & 689. & \begin{tabular}{|l|}
2602 \\
\end{tabular} & & & & & & & & & & 16.7 & 683.5 \\
\hline 2533 & $8 / 10 / 20$ & 16.7 & 689.0 & \begin{tabular}{|l|}
2603 \\
\end{tabular} & $81: 25$ & 16.8 & 691. & 2673 & $83: 45$ & 16.7 & 67 & \begin{tabular}{|l|l|}
2743 \\
\end{tabular} & $86: 05$ & 16.7 & 683.3 \\
\hline 2534 & $8 / 102$ & 16.7 & 689. & \begin{tabular}{|l|}
2604 \\
\end{tabular} & & 16.8 & 692 & 2674 & & 16.7 & 67 & 744 & & 16.7 & 683.8 \\
\hline 2535 & $8 / 10$ & 16.7 & 690. & 2605 & & 16.8 & 693. & & & 16.7 & & & & & 684.5 \\
\hline 2536 & 811020 & 16.7 & 690 & 2606 & $8 / 11 /$ & 16.8 & $\begin{array}{l}3693 . \\
3\end{array}$ & 26 & $8 / 11 / 20083.51$ & 16.7 & $6 \pi$ & 2746 & $86: 11$ & 16.7 & 684.8 \\
\hline 2537 & $8 / 102$ & 16.7 & 691 & \begin{tabular}{|l|}
2607 \\
\end{tabular} & & 16.8 & 694. & 2677 & & 16.7 & $6 \pi$ & 2747 & & 16.7 & 684.1 \\
\hline 2538 & $23: 15$ & 16.7 & 691 & 2608 & & 16.8 & 694. & & $83: 55$ & 16.7 & & & $36: 15$ & 16.7 & \\
\hline 2539 & $8 / 10 / 20$ & 16.7 & 692.7 & 2609 & $81: 37$ & 16.8 & 694. & 2679 & 8/11/20083:57 & 16.7 & 68 & 2749 & $86: 17$ & 16.7 & 683.7 \\
\hline 2540 & & 117 & & 2610 & & 16.8 & & 1 & & 16.7 & & 10 & & 16.7 & 671.9 \\
\hline 2541 & $8110200823: 21$ & 16.7 & 694. & 2611 & $8 / 11 / 20081: 41$ & 16.8 & \begin{tabular}{|l|l}
3894. \\
\end{tabular} & 2681 & $8 / 11 / 20084: 01$ & 16.7 & 680 & 2751 & $8 / 11 / 20086: 21$ & 16.7 & 675.7 \\
\hline 2542 & $8 / 10200823: 23$ & 16.7 & 695.8 & 2612 & $881: 43$ & 16.8 & 694 & 2682 & $8 / 11 / 20084: 03$ & 16.7 & 68 & 2752 & $8 / 11 / 20086: 23$ & 167 & 6683 \\
\hline 2543 & 81102200823.25 & 16.7 & 697.6 & \begin{tabular}{|l|}
2613 \\
\end{tabular} & $81: 45$ & 16.8 & 694 & & & 16.7 & & & & & \\
\hline
\end{tabular}

\begin{tabular}{|c|c|c|c|}
\hline \multicolumn{4}{|c|}{$D 425 \mathrm{c}$} \\
\hline $\mathrm{Rec}$ & & Temp & \\
\hline$\#$ & Dade/Time & ${ }^{\circ} \mathrm{C}$ & $\mathrm{s} / \mathrm{am}$ \\
\hline $7 \sqrt{53}$ & $8 / 11 / 20086: 25$ & 17.3 & 496 \\
\hline$\overline{54}$ & $8 / 11 / 20086: 27$ & 17.5 & 496 \\
\hline 755 & $8 / 11 / 20086: 29$ & 174 & 5142 \\
\hline 756 & $8 / 11 / 20086: 31$ & 776 & 503.5 \\
\hline 57 & $8 / 11 / 20086.33$ & 17.4 & 498.5 \\
\hline 2758 & $8 / 11 / 20086: 35$ & 172 & 511.9 \\
\hline 759 & $8 / 11 / 20086: 37$ & 17. & 5307 \\
\hline & $8 / 11 / 20086: 39$ & 17 & 6120 \\
\hline 7761 & $8 / 11 / 20086: 41$ & 16.9 & 600.9 \\
\hline & $8 / 11 / 20086: 43$ & 16.9 & 687.8 \\
\hline & $8 / 11 / 20086: 45$ & 16.9 & 581.5 \\
\hline 64 & $8 / 11 / 20086: 47$ & 16.9 & 600.6 \\
\hline & $8 / 11 / 20086: 49$ & 16.9 & \\
\hline 706 & $8 / 11 / 20086: 51$ & 16.8 & 595.0 \\
\hline 767 & $8 / 11 / 20086: 53$ & 16.8 & 605.8 \\
\hline & 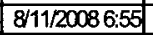 & 16.8 & 6027 \\
\hline 769 & $8111 / 20086: 57$ & 16.8 & 626.9 \\
\hline $27 \pi$ & $8 / 11 / 20086.50$ & 16.7 & 634.6 \\
\hline $2 \pi 1$ & $8 / 11 / 20087: 01$ & 16.7 & 6628 \\
\hline & $8 / 11 / 20087: 03$ & 16.7 & 611.9 \\
\hline & $8 / 11 / 20087: 05$ & 16.8 & 6423 \\
\hline $2 \pi 74$ & $8 / 11 / 20087: 07$ & 16.7 & 650.1 \\
\hline 2775 & 8/11/20087:09 & 16.7 & 635.1 \\
\hline 2776 & $8 / 11 / 20087: 11$ & 16.7 & ๘29.2 \\
\hline & $8 / 11 / 20087: 13$ & 16.7 & 637.6 \\
\hline $2 \pi 8$ & $8 / 11 / 20087: 15$ & 16.7 & 713.3 \\
\hline & $8 / 11 / 20087: 17$ & 16.7 & 645. \\
\hline 780 & $8 / 11 / 20087: 19$ & 16.8 & 667.4 \\
\hline 2781 & $8 / 11 / 20087: 21$ & 16.7 & 680.2 \\
\hline 27 & $8 / 11 / 20087: 23$ & 16.8 & 673.5 \\
\hline 83 & $8111 / 20087: 25$ & 16.7 & 670.7 \\
\hline 2784 & $8 / 11 / 20087: 27$ & 16.7 & 670.1 \\
\hline & $8 / 11 / 200087: 29$ & 16.7 & 670.1 \\
\hline 7786 & $8 / 11 / 2$ & 16.7 & 669.0 \\
\hline 2787 & $8 / 11 / 20087: 33$ & 16.7 & 6684 \\
\hline & $8 / 11 / 20087: 35$ & 16.7 & 668.6 \\
\hline 2789 & $8 / 11 / 2$ & 16.7 & 666.6 \\
\hline & $8 / 11 / 2$ & 16.7 & 666.1 \\
\hline 2791 & $8 / 11 / 20087: 41$ & 16.7 & 666.9 \\
\hline 2792 & $8 / 11 / 20087: 43$ & 16.7 & 667.0 \\
\hline & $8 / 11 /$ & 16.7 & 665.1 \\
\hline & $8 / 11 / 2$ & 16.7 & 664.1 \\
\hline & $87: 49$ & 16.7 & 6628 \\
\hline & $8 / 11 / 20087: 51$ & 16.8 & 6625 \\
\hline 2797 & $8 / 11 / 2$ & 16.8 & 671.5 \\
\hline & $8 / 11$ & 16.7 & 673.3 \\
\hline & $887: 57$ & 16.7 & 675.8 \\
\hline 2800 & & 16.7 & $676 .$. \\
\hline 2801 & $8 / 11 / 2$ & 16.7 & 678. \\
\hline 2802 & $8 / 11 / 20088: 03$ & 16.7 & 678.3 \\
\hline & $8 / 11 / 20088: 05$ & 16.7 & 674.5 \\
\hline 04 & $8 / 11 / 2$ & 16.7 & 680.2 \\
\hline 8005 & $8 / 11 /$ & 16.7 & 674.5 \\
\hline & $8 / 11 / 2$ & 16.7 & 673.9 \\
\hline 2807 & $8 / 11 / 2$ & 16.7 & 678.0 \\
\hline & & 16.7 & 679.5 \\
\hline & $8 / 11 / 2$ & 16.7 & 682 \\
\hline 2810 & $8 / 11$ & 16.7 & 680.9 \\
\hline & & 16.7 & 680.2 \\
\hline 2812 & $8 / 11 / 2008: 23$ & 16.7 & 679.6 \\
\hline 2813 & $8 / 11 / 20088: 25$ & 16.7 & 679.5 \\
\hline & $8 / 11 / 20088.27$ & 16.7 & 684. \\
\hline 2815 & $8 / 11 / 20088.29$ & 16.7 & 685.6 \\
\hline 2816 & & 16.7 & 685.7 \\
\hline & 8/11/20088:33 & \begin{tabular}{l|l|}
16.7 \\
\end{tabular} & 685.2 \\
\hline 2818 & $8 / 11 / 20088: 35$ & 16.7 & 683.4 \\
\hline & $8 / 11 / 20088: 37$ & 16.7 & 683.8 \\
\hline & $8 / 11 / 20088: 39$ & 16.7 & 681.6 \\
\hline 821 & $8 / 11 / 20088: 41$ & 16.7 & 677.6 \\
\hline & & & \\
\hline
\end{tabular}




\begin{tabular}{|c|c|c|c|c|c|c|c|c|c|c|c|c|c|c|c|c|c|c|}
\hline \multicolumn{4}{|c|}{$D 425 c$} & \multicolumn{4}{|c|}{$D 4-25 c$} & \multicolumn{4}{|c|}{$D 425 \mathrm{C}$} & \multicolumn{3}{|c|}{$D 425 \mathrm{C}$} & & & & \\
\hline $\mathrm{Rec}$ & & Tam & $S C$ & $\mathrm{REC}$ & & Temp & SC & $\mathrm{Rec}$ & & Temp| & & $\operatorname{Rec}$ & & Termp SC & $\mathrm{Rec}$ & & Temp & \\
\hline$\#$ & DeterTime & ${ }^{\circ} \mathrm{C}$ & $\mu \mathrm{s} / \mathrm{cm}$ & $\#$ & DeterTime & \begin{tabular}{l|}
${ }^{\circ} \mathrm{C}$ \\
\end{tabular} & $\mu \mathrm{sicm}$ & \# & DateTime & \begin{tabular}{l|l|}
${ }^{\circ} \mathrm{C}$ \\
\end{tabular} & $\mu \mathrm{s} / \mathrm{cm}$ & $\#$ & Date/Time & \begin{tabular}{|l|l|}
${ }^{\circ} \mathrm{C}$ & $\mu S / \mathrm{cm}$ \\
\end{tabular} & $\#$ & Dete/Time & \begin{tabular}{|l|}
${ }^{\circ} \mathrm{C}$ \\
\end{tabular} & $\mu \mathrm{siom}$ \\
\hline & 1/20088:43 & 16.7 & 675.8 & & $8 / 11 / 2008$ 11:01 & 16.7 & 6728 & $\overline{x 96}$ & $8 / 11 / 200813: 19$ & 167 & 643.9 & & $8 / 11 / 2008$ 15:37 & \begin{tabular}{l|l|}
16.7 & 628.5 \\
\end{tabular} & 3098 & $8 / 11 / 2008$ 17:55 & & \\
\hline 823 & $8 / 11 / 20088: 45$ & 16.7 & 676.8 & & $8 / 11 / 200811: 03$ & 16.7 & 6728 & 2961 & $8 / 11 / 200813: 21$ & 16.7 & 644.0 & 3030 & $8 / 11 / 200815: 39$ & 628.5 & 309 & $8 / 11 / 200817: 57$ & 16.7 & 615.8 \\
\hline 24 & $8 / 11 / 20088: 47$ & 16.7 & 678.7 & & $8 / 11 / 200811: 05$ & 16.7 & 679.0 & 2962 & $8 / 11 / 200813: 23$ & 16.7 & 644.2 & 3031 & $8 / 11 / 2008$ 15:41 & \begin{tabular}{l|l|}
16.7 & 628.1 \\
\end{tabular} & 100 & $8 / 11 / 200817: 59$ & 16.7 & \\
\hline 25 & $8 / 11 / 20088: 49$ & 16.7 & 677.1 & 94 & $8 / 11 / 200811: 07$ & 16.7 & 678.9 & & $8 / 11 / 200813: 25$ & 16.7 & 644.4 & & $8 / 11 / 200815: 43$ & \begin{tabular}{l|l|}
16.7 & 627.9 \\
\end{tabular} & & & 16.7 & 614.9 \\
\hline 2826 & $8 / 11 / 20088: 51$ & 16.7 & 675.9 & 395 & $8 / 11 / 200811: 09$ & 16.7 & 67.0 & \begin{tabular}{|l|}
2964 \\
\end{tabular} & $8 / 11 / 200813: 27$ & 16.7 & 644.0 & 3033 & $8 / 11 / 200815: 45$ & 627.7 & 3102 & $8 / 11 / 200818: 03$ & 16.7 & 614.6 \\
\hline 827 & $11 / 20088: 53$ & 16.7 & 676.0 & & 8/11/2008 11:11 & 16.7 & 673.2 & & $8 / 11 / 200813: 20$ & 16.7 & & & & \begin{tabular}{l|l|}
16.7 & 626.8 \\
\end{tabular} & 103 & & 16.7 & \\
\hline 2828 & $8 / 11 / 20088: 55$ & 16.7 & 674.9 & 897 & 8/11/2008 11:13 & 16.7 & 672.2 & 2966 & $8 / 11 / 2008$ 13:31 & 16.7 & 644.3 & 3036 & $8 / 11 / 200815: 49$ & \begin{tabular}{l|l|}
16.7 & 626.8 \\
\end{tabular} & 3104 & $8 / 11 / 200818: 07$ & 16.7 & 614.5 \\
\hline 829 & 088.57 & 16.7 & 673.8 & 398 & 8/11/2008 11:15 & 16.7 & 668.5 & \begin{tabular}{|l|}
2967 \\
\end{tabular} & $8 / 11 / 200813: 33$ & 16.7 & 644.3 & 3006 & $8 / 11 / 200815: 51$ & 626.8 & 105 & $0818: 09$ & 16.7 & 613.5 \\
\hline 30 & 388.59 & 16.7 & 671.7 & & & 16.7 & 669.5 & 2968 & $8 / 11 / 200813: 35$ & 16.7 & 644.3 & & & 16.7 & & & & \\
\hline 831 & $8 / 11 / 20089: 01$ & 16.7 & 674.7 & 2900 & 8/11/2008 11:19 & 16.7 & 665.5 & 2969 & $8 / 11 / 2008$ 13:37 & 16.7 & 643.9 & 3038 & $8 / 11 / 2008$ 15:50 & \begin{tabular}{l|l|}
16.7 & 626.4 \\
\end{tabular} & 107 & $8 / 11 / 200818: 13$ & 16.7 & 613.5 \\
\hline 832 & 089.03 & 16.7 & 67.5 & 2901 & $8 / 11 / 20$ & 16.7 & 665.9 & 2970 & $8 / 11 / 200813: 39$ & 16.7 & 6429 & 3039 & 08 15:57 & \begin{tabular}{l|l|}
16.7 & 626.5 \\
\end{tabular} & 108 & $8 / 11 / 200818: 15$ & 16.7 & 613.4 \\
\hline 833 & 89.05 & 16.7 & 675.9 & 2902 & 311:23 & 16.7 & 664.2 & \begin{tabular}{|l|}
2971 \\
\end{tabular} & $8 / 11 / 200813: 41$ & 16.7 & 641.9 & 3040 & & 16.7 & & & & \\
\hline 8934 & $8 / 11 / 20089: 07$ & 16.7 & 677.2 & 2903 & $8 / 11 / 200811: 25$ & 16.7 & 663.7 & \begin{tabular}{|l|}
2972 \\
\end{tabular} & $8 / 11 / 200813: 43$ & 16.7 & 641.4 & 3041 & $8 / 11 / 2008$ 16:01 & 626.0 & 5110 & D8 18:19 & 16.7 & 6129 \\
\hline 835 & $089: 09$ & 16.7 & 676.5 & 2904 & $8 / 11 / 20$ & 16.7 & 663.4 & \begin{tabular}{|l|}
2973 \\
\end{tabular} & $8 / 11 / 200813: 45$ & 16.7 & 6420 & 3042 & 08 16:03 & 626.1 & 1111 & $818: 21$ & 16.7 & $670 . \pi$ \\
\hline 2836 & 089.11 & 16.7 & 678.4 & 2905 & $8 / 11 / 20$ & 16.7 & 658.7 & \begin{tabular}{|l|}
2974 \\
\end{tabular} & $8 / 11 / 200813: 47$ & 16.7 & 639.8 & 3043 & & 626.1 & & & 16.7 & \\
\hline 2837 & 089.13 & 16.7 & 678.1 & 2906 & $8 / 11 / 20$ & 16.7 & 6624 & 2975 & $813: 49$ & 16.7 & 640.0 & 3044 & $816: 07$ & 626.1 & 113 & $818: 25$ & 16.7 & 610.8 \\
\hline 338 & 89.15 & 16.7 & 678.8 & 2907 & 1:33 & 16.7 & 663.8 & 76 & $13: 51$ & 16.7 & 639.4 & 3045 & $316: 09$ & 16.7 & 174 & & 16.7 & \\
\hline 339 & 89:17 & 16.7 & 678.0 & 2908 & $8 / 11 / 2$ & 16.7 & 665.8 & 297 & $8111 / 20$ & 16.7 & & 3046 & 816:11 & 625.7 & 115 & $318: 29$ & 16.7 & 6120 \\
\hline 2840 & 89:19: & 16.7 & 67.8 & 2909 & $8 / 11 / 2$ & 16.7 & 666.4 & 2978 & 8111120 & 16.7 & 640.0 & 3047 & $16: 13$ & 625.5 & 116 & $318: 31$ & 16.7 & 611.8 \\
\hline 8841 & & 16.7 & 679.6 & 2910 & & 16.7 & 661.3 & 2979 & $13: 57$ & 16.7 & & & & 16.7 & & & 16.7 & \\
\hline 842 & 089.23 & 16.7 & 689.7 & 2911 & $8 / 11 / 20$ & 16.7 & 658.9 & 2980 & $8 / 11 / 20$ & 16.7 & 640.7 & 3049 & $816: 17$ & \begin{tabular}{l|l|}
16.7 & 624.3 \\
\end{tabular} & 118 & $818: 35$ & 16.7. & 611.7 \\
\hline 843 & 9.25 & 16.7 & 691.2 & 2912 & $8 / 11 / 20$ & 16.7 & 6623 & \begin{tabular}{|l|}
2981 \\
\end{tabular} & 14:00 & 16.7 & 640.4 & 3050 & 16:19 & 16.7 & 119 & 18:37 & 16.7 & 611.7 \\
\hline 2844 & 9.27 & 16.7 & 688.6 & 2913 & & 16.7 & 662.7 & \begin{tabular}{|l|}
2982 \\
\end{tabular} & & 16.7 & & 3051 & & 16.7 & 120 & & 16.7 & \\
\hline 845 & $89: 29$ & 16.7 & 688.3 & 2914 & $8 / 11 / 2$ & 16.7 & 664.6 & 2983 & 14:05 & 16.7 & 639.2 & 3052 & $16: 23$ & 623.2 & 121 & $18: 41$ & 16.7 & 610.8 \\
\hline 846 & 889.31 & 16.7 & 684.9 & 2915 & & 16.7 & 661.9 & 2984 & & 16.7 & & 3053 & $316: 25$ & 16.7 & & & 16.7 & \\
\hline 847 & 889.33 & 16.7 & 680.8 & 2916 & $8 / 11 / 20$ & 16.7 & 659.7 & 2985 & $8 / 11 / 20$ & 16.7 & 638.3 & 3054 & $816: 27$ & 623.0 & 123 & $818: 45$ & 16.7 & 611.1 \\
\hline 848 & 9935 & 16.7 & 680.9 & 2917 & $8 / 11 / 2$ & 16.7 & 660.2 & \begin{tabular}{|l|}
2906 \\
\end{tabular} & 14:11 & 16.7 & 638.1 & 3050 & 16:29 & 16.7 & 124 & $18: 47$ & 16.7 & 611.2 \\
\hline 2849 & 9.37 & 16.7 & 681.4 & 2918 & $8 / 11 /$ & 16.7 & 660.5 & \begin{tabular}{|l|}
2987 \\
\end{tabular} & 14:13 & 16.7 & 637.5 & 3050 & 16:31 & 16.7 & & & 16.7 & \\
\hline 850 & 89.39 & 16.7 & 685. & 2919 & $8 / 11 / 2$ & 16.7 & 656.8 & 2988 & 14:15 & 16.7 & 635.9 & 3050 & $16: 33$ & 16.7 & 1260 & $18: 51$ & 16.7 & 610. \\
\hline 851 & & 16.7 & 690.5 & 2920 & & 16.7 & 657.2 & & 14:17 & 16.7 & 634. & 3058 & 16:35 & 16.7 & & $18: 53$ & 16.7 & 610.6 \\
\hline 2852 & 89.43 & 16.7 & 688.9 & 21 & $8 / 111$ & 16.7 & 657.3 & 2990 & $8 / 11 / 2$ & 16.7 & ธ35. & 3059 & 16:37 & 16.7 & 128 & 18.55 & 16.7 & 10.4 \\
\hline 853 & 9.45 & 16.7 & 686.5 & 2922 & $8 / 11$ & 16.7 & 666.1 & \begin{tabular}{|l|}
2991 \\
\end{tabular} & 14:21 & 16.7 & 632 & 3060 & 16.39 & \begin{tabular}{l|l}
16.7 & 619 \\
\end{tabular} & 129 & 18.57 & 16.7 & 610.6 \\
\hline 2854 & 9.47 & 16.7 & 690.5 & $\overline{203}$ & & 16.7 & 658. & \begin{tabular}{|l|}
2992 \\
\end{tabular} & $8 / 111$ & 16.7 & ๘34. & 3061 & & \begin{tabular}{|l|l}
16.7 & 620 \\
\end{tabular} & 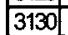 & 18.59 & 16.7 & \\
\hline 2856 & 88.49 & 16.7 & 690.6 & 2924 & & 16.7 & 661 & & 14:25 & 16.7 & & 3062 & & 16.7 & & & 16.7 & \\
\hline 556 & 9.51 & 16.7 & 696.1 & 2925 & 200 & 16.7 & 665 & 2994 & 14:27 & 16.7 & 63 & 3063 & $16: 45$ & 16.7 & 132 & & 16.7 & 600 \\
\hline 857 & 9.53 & 16.7 & 695.5 & 2926 & & 16.7 & 666. & \begin{tabular}{|l|}
2996 \\
\end{tabular} & & 16.7 & 63 & 3064 & $6: 4$ & 16.7 & & & 16.7 & \\
\hline 858 & & 16.7 & 697.4 & 2927 & & 16.7 & 669.7 & 2996 & $4: 31$ & 16.7 & 63 & 3065 & & 16.7 & & & 16.7 & 609.6 \\
\hline 859 & 9.57 & 16.7 & 695.8 & 28 & 215 & 16.7 & 657 & \begin{tabular}{|l|}
2997 \\
\end{tabular} & 14:33 & 16.7 & 6 & 3066 & & 16.7 & & & 16.7 & \\
\hline 2860 & $8 / 111$ & 16.7 & 694.6 & 2929 & & 16.7 & 650 & 2998 & $14: 35$ & 16.7 & 632 & 3067 & 16.53 & 16.7 & & 19.11 & 16.7 & 609.9 \\
\hline 861 & & 16.7 & 696.0 & 2930 & & 16.7 & 657. & 299 & & 16.7 & 632.6 & 3068 & & 16.7 & & & 16.7 & 609. \\
\hline 8062 & 10.03 & 16.7 & 691.4 & 31 & & 16.7 & 656. & 3000 & 14:39 & 16.7 & 6327 & 3069 & 16.5ी & 16.7 & & 19.15 & 16.7 & 610. \\
\hline & & 16.7 & 691.0 & 2932 & & 16.7 & & \begin{tabular}{|l|}
3001 \\
\end{tabular} & & 16.7 & & 3070 & & 16.7 & & & $16 . \%$ & 609. \\
\hline 964 & & 16.7 & 687.8 & 2033 & 225 & 16.7 & 658 & \begin{tabular}{|l|}
3002 \\
\end{tabular} & & 16.7 & 632 & 3071 & & 16.7 & & & 16.7 & 69 \\
\hline 865 & 500 & 16.7 & ⿹ 686.3 & 2934 & & 16.7 & 65 & \begin{tabular}{|l|}
3003 \\
\end{tabular} & 4:45 & \begin{tabular}{|c|}
16.7 \\
\end{tabular} & 633. & 3072 & & 16.7 & |41] & & 16.7 & 609.7 \\
\hline 66 & & 16.7 & t 6855 & & & \begin{tabular}{|c|}
16.7 \\
\end{tabular} & & \begin{tabular}{|l|}
3004 \\
\end{tabular} & & 16.7 & 631. & 307 & & 16.7 & & & 16.7 & 608 \\
\hline 867 & & 16.7 & 606.1 & & & 16.7 & 65 & 005 & & 16.7 & 632 & & & 16.7 & & & 16.7 & 607. \\
\hline & & \begin{tabular}{|l|}
16.7 \\
\end{tabular} & 683.5 & & & 16.7 & & & & 16.7 & ॠ3 & & & 16.7 & & & 10.1 & 607. \\
\hline al & & 16.7 & 687.0 & & & 16.7 & 642 & & & 16.7 & & & & 16.7 & & & 16. & 607. \\
\hline 8870 & 10:19 & 16.7 & 686.9 & 2939 & & 16.7 & 644.1 & 3008 & $4: 55$ & 16.7 & 632 & 3077 & 17:13 & \begin{tabular}{l|l}
16.7 & 618.7 \\
\end{tabular} & 146 - & 19.31 & 16.7 & 607.0 \\
\hline 871 & & 16.7 & 687.7 & & & & & & & 16.7 & 632 & & & $\begin{array}{l}16.7 \\
1\end{array}$ & & & & \\
\hline 872 & & 16.7 & 686.7 & $\overline{441}$ & & & & & & 16.7 & 632 & & & 16.7 & & & 16.7 & \\
\hline 873 & & 16.7 & 686. & 2942 & & 16.7 & & 3011 & & 16.7 & {$[3$} & 308 & & 16.7 & & & 16.7 & \\
\hline ard & & 16.7 & 696 & & & & & & & 16.7 & & & & & & & 167 & \\
\hline 2875 & 10:29 & 16.7 & 685.7 & 2944 & & 16.7 & 644.9 & \begin{tabular}{|l|}
3013 \\
\end{tabular} & 15.06 & 16.7 & 632 & 3082 & & \begin{tabular}{l|l|}
16.7 & 618.3 \\
\end{tabular} & 151 & & 16.7 & 606 \\
\hline & & & & & & & & & & 16.7 & & & & & & & & \\
\hline 287 & & 16.7 & 68 & & & & & & & 16.7 & & & & \begin{tabular}{l|l|}
16.7 & 617 \\
\end{tabular} & & 19.45 & 16.7 & \\
\hline 2878 & & 16.7 & 679. & 2947 & & 16.7 & & & & 16.7 & 63 & 3085 & & \begin{tabular}{l|l|}
16.7 & 617. \\
\end{tabular} & & & 16.7 & 606. \\
\hline 2879 & & 16.7 & & & & & & & & & & & & & & & & \\
\hline 2880 & $10: 39$ & \begin{tabular}{|l|}
16.7 \\
\end{tabular} & 678.8 & 2949 & 12.57 & 16.7 & 646.3 & \begin{tabular}{|l|}
3018 \\
\end{tabular} & & 16.7 & 625.8 & 3087 & 17:33 & \begin{tabular}{l|l|}
16.7 & 616.4 \\
\end{tabular} & 156 & 19.51 & 16.7 & 607.0 \\
\hline 8891 & & 16.7 & & & & 16.7 & 646.0 & & & 16.7 & 629. & 3088 & & & & & 16. & \\
\hline 2882 & & 16.7 & 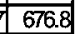 & & & & & & & 16.7 & & & & 16.7 & & & & \\
\hline 2883 & & 16.7 & 676.1 & 2952 & & $\begin{array}{l}16.7 \\
\end{array}$ & & 30021 & & 16.7 & 620 & 3090 & & \begin{tabular}{l|l|}
16.7 & 617. \\
\end{tabular} & 159 & 19.57 & 16.7 & 607. \\
\hline 2884 & & & & 2953 & & & & & & & & & & & & & & \\
\hline 2885 & $310: 49$ & \begin{tabular}{|l|}
16.7 \\
\end{tabular} & $\begin{array}{ll}074.4 \\
\end{array}$ & 2964 & 13:07 & 16.7 & 646.5 & 3023 & $15: 25$ & 16.7 & 627. & 3092 & $317: 43$ & \begin{tabular}{l|l|}
16.7 & 615.4 \\
\end{tabular} & 3161 & 20:01 & 16.7 & 606.8 \\
\hline 2886 & & \begin{tabular}{|l|}
16.7 \\
\end{tabular} & 674.7 & 2966 & 13:09 & 16.7 & 645 & \begin{tabular}{|l|}
3024 \\
\end{tabular} & $815: 27$ & 16.7 & 628. & 3093 & $817: 45$ & \begin{tabular}{ll|l}
16.7 & 615. \\
\end{tabular} & 162 & & 6.7 & 606. \\
\hline 2887 & $8 / 1$ & \begin{tabular}{|l|}
16.7 \\
\end{tabular} & 673.7 & & 13:19 & 16.8 & & & & 16.7 & & 3094 & & & & & & \\
\hline 2888 & 810:55 & \begin{tabular}{|l|}
16.7 \\
\end{tabular} & 678.3 & 2967 & 13:13 & 16.7 & 646 & 30026 & & 16.7 & 628 & 309 & 17:49 & \begin{tabular}{l|l|}
16.7 & 615.9 \\
\end{tabular} & 3164 & 320:07 & 16.7 & 605. \\
\hline 2889 & & 16.7 & V 673.3 & 2958 & & \begin{tabular}{l|l|}
16.7 \\
\end{tabular} & \begin{tabular}{|l|}
645.3 \\
\end{tabular} & 30027 & & 16.7 & 628. & $300 x$ & & \begin{tabular}{|l|l|}
16.7 & 616 \\
\end{tabular} & 165 & & & 604. \\
\hline & & 16.7 & & & & 16.7 & & & & 16.7 & $0<0$ & & & & & & & \\
\hline
\end{tabular}


DOE/RL-2009-35, REV. 0

\begin{tabular}{|c|c|c|c|c|c|c|}
\hline \multicolumn{3}{|c|}{$D 4-25 C$} & \multicolumn{4}{|c|}{$D 4-25 c$} \\
\hline $\mathrm{ReC}$ & & \begin{tabular}{l|l} 
Temp & SC
\end{tabular} & $\mathrm{ReC}$ & & Temp & \\
\hline$\#$ & DeterTime & \begin{tabular}{l|l|l|l|}
${ }^{\circ} \mathrm{C}$ & $\mu \mathrm{am}$ \\
\end{tabular} & $\#$ & DeterTime & ${ }^{\circ} \mathrm{C}$ & $\mathrm{LStam}$ \\
\hline 3167 & $8 / 11 / 200820: 13$ & \begin{tabular}{l|l|}
16.7 & 604.9 \\
\end{tabular} & 3236 & $8 / 11 / 20082231$ & 16.7 & 598.3 \\
\hline 3168 & $8 / 11 / 200820: 15$ & \begin{tabular}{l|l|}
16.7 & 604.9 \\
\end{tabular} & 3237 & $8 / 11 / 200822: 33$ & 16.7 & 598.2 \\
\hline 3169 & $8 / 11 / 200820: 17$ & $\begin{array}{l}16.7 \\
167\end{array}$ & 3238 & $8 / 11 / 200822: 35$ & 16.7 & 597.5 \\
\hline 3170 & \begin{tabular}{|l|l|}
$811 / 200820.19$ \\
\end{tabular} & $\begin{array}{ll}16.7 & 604.5 \\
\end{array}$ & 3239 & $8 / 11 / 20082237$ & 16.7 & 596.8 \\
\hline 3171 & $8 / 11 / 200820.21$ & 604.2 & 3240 & $8 / 11 / 20082239$ & 16.7 & 596.9 \\
\hline 3172 & $8 / 11 / 200820.23$ & 604.2 & 3241 & $8 / 11 / 20082241$ & 16.7 & 596.8 \\
\hline 3173 & $8 / 11 / 200820: 25$ & 167 & 3242 & $8 / 11 / 20082243$ & 16.7 & 596.7 \\
\hline 3174 & $8 / 11 / 200820: 27$ & 603.8 & 3243 & $8 / 11 / 200822445$ & 16.7 & 596.6 \\
\hline 3175 & $8 / 11 / 200820: 29$ & 604.1 & 3244 & $8 / 11 / 200822-47$ & 16.7 & 596.8 \\
\hline 3176 & $8 / 11 / 200820.31$ & 16.7 & 3245 & $8 / 11 / 20082249$ & 16.7 & 597.3 \\
\hline 3177 & $8 / 11 / 200820: 33$ & \begin{tabular}{l|l|}
16.7 & 603.7 \\
\end{tabular} & 3246 & $8 / 11 / 20082251$ & 16.7 & 597.1 \\
\hline 3178 & $8 / 11 / 200820.35$ & \begin{tabular}{l|l}
167 & 603.5 \\
\end{tabular} & 3247 & $8 / 11 / 200822: 53$ & 16.7 & 596.6 \\
\hline 3179 & $8 / 11 / 200820,37$ & 603.1 & 3248 & $8 / 11 / 20082256$ & 16.7 & 596.9 \\
\hline 3180 & $8 / 11 / 200820.39$ & $\begin{array}{l}16.7 \\
603.2 \\
\end{array}$ & 3249 & $8 / 11 / 200822: 5$ & 16.7 & 595.9 \\
\hline 3181 & $8 / 11 / 200820.41$ & \begin{tabular}{l|l|}
16.7 & 600.3 \\
\end{tabular} & 3250 & $8 / 11 / 20082250$ & 16.7 & 596.0 \\
\hline 3182 & $8 / 11 / 200820: 43$ & \begin{tabular}{l|l}
16.7 & 608.5 \\
\end{tabular} & 3251 & $8 / 11 / 200823: 01$ & $16 . \overline{7}$ & 596.9 \\
\hline 3183 & $8 / 11 / 200820.45$ & \begin{tabular}{l|l|}
16.7 & 600.5 \\
\end{tabular} & 3252 & $8 / 11 / 200023: 03$ & 16.7 & 596.6 \\
\hline 3184 & $8 / 11 / 200820.47$ & \begin{tabular}{l|l|}
16.7 & 600.4 \\
\end{tabular} & 3253 & $8 / 11 / 200823: 05$ & 16.7 & 596.7 \\
\hline 3185 & $8 / 11 / 200820,49$ & \begin{tabular}{l|l|}
16.7 & 603.2 \\
\end{tabular} & 3254 & $8 / 11 / 200823: 07$ & 16.7 & 596.5 \\
\hline 3186 & $8 / 11 / 200820.51$ & \begin{tabular}{l|l}
16.7 & 602.6 \\
\end{tabular} & 3255 & $8 / 11 / 200823: 09$ & 16.7 & 595.7 \\
\hline उ18त्त & $8 / 11 / 200820: 53$ & $\begin{array}{ll}16.7 & 6029 \\
\end{array}$ & 3256 & $8 / 11 / 200823: 11$ & 16.7 & 595.7 \\
\hline 3188 & $8 / 11 / 200820: 50$ & 603.4 & 3257 & $8 / 11 / 200823: 13$ & 16.7 & 595.7 \\
\hline 3189 & $8 / 11 / 200820.57$ & 603.2 & 3258 & $8 / 11 / 200823: 15$ & 16.7 & 595.7 \\
\hline 3190 & $8 / 11 / 200820.50$ & \begin{tabular}{|l|l|}
16.7 & 6029 \\
\end{tabular} & 3259 & $8 / 11 / 200823: 17$ & 16.7 & 595.6 \\
\hline 3191 & $8 / 11 / 200821: 01$ & \begin{tabular}{l|l|}
16.7 & 60026 \\
\end{tabular} & 3260 & $8 / 11 / 200823: 19$ & 16.7 & 595.3 \\
\hline 3192 & $8 / 11 / 200821: 03$ & 6025 & 3261 & $8 / 11 / 200823: 21$ & 16.7 & 595.4 \\
\hline 3193 & $8111 / 200821: 06$ & 6025 & 3262 & $8 / 11 / 200823: 23$ & 16.7 & 595.4 \\
\hline 3194 & 8/11/200821:07 & 6025 & 3263 & $8 / 11 / 200823: 25$ & 76.7 & 596.5 \\
\hline 3195 & $8 / 11 / 200821: 09$ & \begin{tabular}{l|l|}
16.7 & 6024 \\
\end{tabular} & 3264 & $8 / 11 / 200023: 27$ & 16.7 & 596.4 \\
\hline 3196 & $8 / 11 / 200821: 11$ & \begin{tabular}{l|l}
16.7 & 6020 \\
\end{tabular} & 3265 & $8 / 11 / 200823: 29$ & 16.7 & 596.6 \\
\hline 3197] & $8 / 11 / 200821: 13$ & 16.7 & 3266 & 8/11/2008 23:31 & 16.7 & 596.6 \\
\hline 3198 & $8 / 11 / 200821: 15$ & 601.9 & 3267 & $8 / 11 / 2000823: 33$ & 16.7 & 596.0 \\
\hline 3199 & $8 / 11 / 200821: 17$ & 16.7 & 3268 & $8 / 11 / 200823: 36$ & 16.7 & 565.0 \\
\hline 3200 & $8 / 11 / 200821: 19$ & 601.6 & 3269 & $8 / 11 / 200023: 37$ & 16.7 & 595.1 \\
\hline 3201 & $8 / 11 / 200821: 21$ & \begin{tabular}{l|l|}
16.7 & 601.7 \\
\end{tabular} & 3270 & $8 / 11 / 200823: 39$ & 16.7 & 596.0 \\
\hline 3202 & $8 / 11 / 200821: 23$ & \begin{tabular}{l|l|}
16.7 & 601.7 \\
\end{tabular} & 3271 & $8 / 11 / 200823: 41$ & 16.7 & 596.0 \\
\hline 3203 & $8 / 1 / 200821: 25$ & 601.5 & 3272 & $8 / 11 / 200823: 43$ & 16.7 & 596.2 \\
\hline 3204 & $8 / 11 / 200821: 27$ & 16.7 & 3273 & $8 / 11 / 200823: 45$ & 16.7 & 595.1 \\
\hline 3205 & $8 / 11 / 200821: 29$ & 16.7 & 3274 & $8 / 11 / 200823: 47$ & 16.7 & 595.0 \\
\hline 3206 & $8 / 11 / 200821: 31$ & \begin{tabular}{l|l|}
16.7 & 601.5 \\
\end{tabular} & 3275 & $8 / 11 / 200823: 49$ & 16.7 & 594.9 \\
\hline 3207 & $8 / 11 / 200821: 33$ & \begin{tabular}{l|l|}
167 & 601.7 \\
\end{tabular} & 3276 & $8 / 11 / 200823: 51$ & 16.7 & 596.1 \\
\hline 3208 & $8 / 11 / 200821: 35$ & 16.7 & $32 \pi$ & $8 / 11 / 200823: 53$ & 16.7 & 596.0 \\
\hline 3209 & 8/11/200821:37 & \begin{tabular}{l|l}
16.7 & 601.6 \\
\end{tabular} & 3278 & $00823: 50$ & 16.7 & 594.9 \\
\hline 3210 & $8 / 11 / 200821: 39$ & $\begin{array}{ll}16.7 & 600.4\end{array}$ & 3279 & $8 / 11 / 200823: 57$ & 16.7 & 594.9 \\
\hline 3211 & $8 / 11 / 200821: 41$ & $\begin{array}{ll}16.7 & 600.6\end{array}$ & 3280 & $8 / 11 / 200823: 59$ & 16.7 & 594.5 \\
\hline 3212 & $8 / 11 / 200821: 43$ & \begin{tabular}{l|l|}
16.7 & 600.7 \\
\end{tabular} & 3281 & $20080: 01$ & 16.7 & 594.3 \\
\hline 3213 & $8 / 11 / 200821: 45$ & \begin{tabular}{l|l}
16.7 & 600.5 \\
\end{tabular} & 3282 & $8 / 12 / 200000003$ & 16.7 & 594.1 \\
\hline 3214 & $8 / 11 / 200821: 47$ & \begin{tabular}{l|l|}
16.7 & 600.2 \\
\end{tabular} & 3283 & $8 / 12 / 200800.05$ & 16.7 & 585.2 \\
\hline 3215 & $8 / 11 / 200821: 49$ & \begin{tabular}{l|l|}
16.7 & 600.2 \\
\end{tabular} & 3284 & $8 / 1220080: 07$ & 16.7 & 585.3 \\
\hline 3216 & 8/11/200821:51 & \begin{tabular}{l|l}
167 & 599.7
\end{tabular} & 3285 & $8 / 12220080009$ & 16.7 & 596.0 \\
\hline 3217 & $8 / 11 / 200821: 53$ & \begin{tabular}{l|l|}
16.7 & 599.7 \\
\end{tabular} & 3286 & $8 / 12 / 20080: 11$ & 16.7 & 584.2 \\
\hline 3218 & $8 / 11 / 200821: 50$ & \begin{tabular}{l|l|}
16.7 & 599.5 \\
\end{tabular} & 3287 & $8 / 12 / 20080: 13$ & 16.7 & 5828 \\
\hline 3219 & $8 / 11 / 200821: 57$ & 16.7 & 3288 & $8 / 12200000: 15$ & 16.7 & 579.5 \\
\hline 3220 & $8 / 11 / 200821: 59$ & 16.7 & 3289 & $8 / 12 / 20080: 17$ & 16.7 & 581.2 \\
\hline 3221 & $8 / 11 / 20082201$ & 16.7 & 3290 & $8 / 12 / 20080: 19$ & 16.7 & 580.9 \\
\hline 3220 & $8 / 11 / 20082203$ & 16.7 & 3291 & $8 / 12 / 20080: 21$ & 16.7 & 583.0 \\
\hline 3223 & $8 / 11 / 20082206$ & \begin{tabular}{l|l|}
16.7 & 599.7 \\
\end{tabular} & 3292 & $8 / 1220080: 23$ & 16.8 & 5821 \\
\hline 3224 & $8 / 11 / 20082207$ & $\begin{array}{l}16.7 \\
599.6 \\
\end{array}$ & 3293 & $8 / 1220000-25$ & 16.7 & 5822 \\
\hline 3225 & $8 / 11 / 20082200$ & \begin{tabular}{l|l|}
16.7 & 599.2 \\
\end{tabular} & 3294 & $8 / 12 / 20080: 27$ & 16.7 & 585.2 \\
\hline 3226 & $8 / 11 / 20082211$ & \begin{tabular}{l|l}
16.7 & 598.8 \\
\end{tabular} & 3295 & $8 / 12120080.29$ & 16.7 & 584.8 \\
\hline 3227 & $8 / 11 / 20082213$ & $\begin{array}{l}16.7 \\
599.5\end{array}$ & 3296 & $8 / 12 / 20080.31$ & 16.7 & 584.2 \\
\hline 3228 & $8 / 11 / 20082215$ & \begin{tabular}{l|l|}
16.7 & 599.9 \\
\end{tabular} & 3297 & $8 / 12 / 20080.33$ & 16.7 & 584.0 \\
\hline 3229 & $8 / 11 / 20082217$ & \begin{tabular}{l|l|}
16.7 & 599.3 \\
\end{tabular} & 3298 & $8 / 12 / 20080.35$ & 16.7 & 5827 \\
\hline 3230 & $8 / 11 / 20082211$ & \begin{tabular}{l|l|}
16.7 & 599.3 \\
\end{tabular} & 3299 & $8 / 12 / 20080: 37$ & 16.7 & 5824 \\
\hline 3231 & $8 / 11 / 20082221$ & \begin{tabular}{l|l|}
16.7 & 599.1 \\
\end{tabular} & 3300 & $8 / 12 / 20080: 39$ & 16.7 & 5826 \\
\hline 3232 & $8 / 11 / 20082223$ & \begin{tabular}{l|l|}
16.7 & 598.7 \\
\end{tabular} & 3301 & $8 / 1220080: 41$ & 16.8 & 5825 \\
\hline 3233 & $8 / 11 / 20082225$ & \begin{tabular}{l|l}
16.7 & 598.7 \\
\end{tabular} & 3302 & $8 / 1220080: 43$ & 16.7 & 5826 \\
\hline 3234 & $\mid 8 / 11 / 20082227$ & \begin{tabular}{l|l}
16.7 & 598.5 \\
\end{tabular} & 3303 & $8 / 1220080.45$ & 16.7 & 5829 \\
\hline 3235 & $\mid 8 / 11 / 20082220$ & \begin{tabular}{l|l|}
16.7 & 598.4 \\
\end{tabular} & 3304 & $8 / 12 / 20080: 47$ & 16.7 & 5829 \\
\hline
\end{tabular}

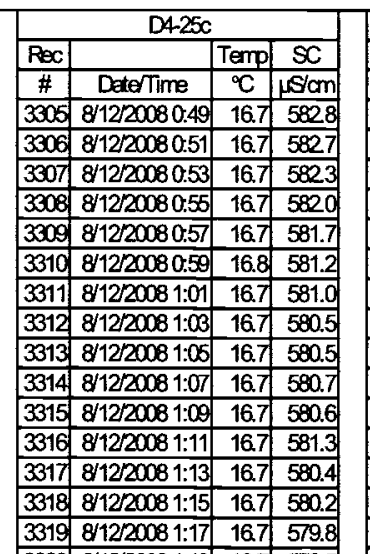

\begin{tabular}{|l|l|l|l|}
\hline 3320 & $8 / 1220081: 19$ & 16.7 & 579.5 \\
\hline
\end{tabular} \begin{tabular}{|l|l|l|l|}
\hline 3321 & $8 / 12 / 20081: 21$ & 16.7 & 579.6 \\
\hline
\end{tabular} \begin{tabular}{|l|l|l|l|}
\hline 3022 & $8 / 12200081: 23$ & 16.8 & 579.7 \\
\hline
\end{tabular} \begin{tabular}{|l|l|l|l|}
\hline 3323 & $8 / 12200081: 25$ & 16.7 & 585.6 \\
\hline
\end{tabular} \begin{tabular}{|l|l|l|l|}
\hline 3324 & $8 / 12200081: 27$ & 16.7 & 587.7 \\
\hline
\end{tabular} \begin{tabular}{|l|l|l|l|}
\hline 3325 & $8 / 12200081: 20$ & 16.7 & 590.0 \\
\hline
\end{tabular}

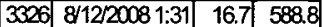
\begin{tabular}{|l|l|l|l|}
\hline 3327 & $8112200081: 33$ & 16.8 & 589.5 \\
\hline
\end{tabular} \begin{tabular}{|l|l|l|l|}
\hline 3328 & $8 / 12200081: 35$ & 16.7 & 599.2 \\
\hline 352 & 81220081 & 16. & 5896 \\
\hline
\end{tabular} \begin{tabular}{l|l|l|l|}
33320 & $8 / 1220081: 37$ & 16.8 & 588.6 \\
\hline
\end{tabular} \begin{tabular}{|l|l|l|l|}
\hline 3330 & $812220081: 39$ & 16.8 & 588.7 \\
\hline
\end{tabular}

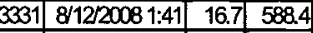
\begin{tabular}{|l|l|l|l|}
\hline 3332 & $8 / 1220081: 43$ & 16.8 & 588.3 \\
\hline
\end{tabular} \begin{tabular}{|l|l|l|l|}
\hline 3333 & $8 / 1220081: 45$ & 16.8 & 588.5 \\
\hline 330 & $81220081: 4$ & 168 & 588.5 \\
\hline
\end{tabular} \begin{tabular}{|l|l|l|l|}
\hline 3334 & $8 / 12 / 20081: 47$ & 16.8 & 588.5 \\
\hline
\end{tabular}

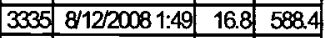
\begin{tabular}{|l|l|l|l|}
\hline 3336 & $8112200081: 51$ & 16.8 & 588.2 \\
\hline
\end{tabular} \begin{tabular}{|l|l|l|l|}
33337 & $8 / 12200081: 53$ & 16.8 & 588.0 \\
\hline
\end{tabular}

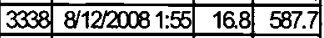
\begin{tabular}{l|l|l|l|}
33039 & $8 / 12 / 20081: 57$ & 16.8 & 587.6 \\
\hline
\end{tabular} \begin{tabular}{|l|l|l|l|}
\hline 3340 & $8 / 1220081: 50$ & 16.7 & 587.4 \\
\hline
\end{tabular} \begin{tabular}{l|l|l|l|}
\hline 3341 & $8 / 122008201$ & 16.8 & 506.9 \\
\hline
\end{tabular} \begin{tabular}{|l|l|l|l|}
\hline 3342 & $8 / 1220002203$ & 16.8 & 587.2 \\
\hline
\end{tabular} \begin{tabular}{|lll|l|l|}
\hline 3343 & $8 / 122008206$ & 16.8 & 586.4 \\
\hline 344 & 812008207 & 168 & 5060
\end{tabular} \begin{tabular}{|l|l|l|l|}
\hline 3344 & 81222008207 & 16.8 & 586.0 \\
\hline
\end{tabular} \begin{tabular}{llllll}
3345 & $812 / 2008200$ & 16.8 & 586.6 \\
\hline
\end{tabular} \begin{tabular}{|l|l|l|l|}
\hline 3346 & $8 / 1220082: 11$ & 16.7 & 586.2 \\
\hline 347 & 812208213 & 168 & 565.7 \\
\hline
\end{tabular} \begin{tabular}{|l|l|l|l|}
\hline 3347 & $8 / 1220008213$ & 168 & 585.7 \\
\hline
\end{tabular} \begin{tabular}{lllll}
\hline 3348 & $8 / 12 / 2008215$ & 16.8 & 585.3 \\
\hline
\end{tabular} \begin{tabular}{|l|l|l|l|}
\hline 3349 & $8 / 122008217$ & 16.8 & 565.0 \\
\hline
\end{tabular} \begin{tabular}{|l|l|l|l|}
\hline 3350 & 81222008219 & 16.8 & 584.6 \\
\hline
\end{tabular} \begin{tabular}{l|l|l|l|}
33351 & $8 / 1220002221$ & 16.8 & 584.2 \\
\hline
\end{tabular} \begin{tabular}{|l|l|l|l|}
\hline 3352 & 811220082223 & 16.7 & 583.9 \\
\hline 353 & 8122008225 & 168 & 5831 \\
\hline
\end{tabular} \begin{tabular}{|l|l|l|l|}
\hline 3353 & 81220008225 & 16.8 & 583.1 \\
\hline
\end{tabular} \begin{tabular}{|l|l|l|l|}
\hline 3354 & 81222008227 & 16.8 & 5829 \\
\hline
\end{tabular} \begin{tabular}{|lllll}
\hline 3355 & 81222008229 & 16.7 & 5828 \\
\hline
\end{tabular} \begin{tabular}{|l|l|l|l|}
\hline 3356 & $8 / 122008231$ & 168 & 5825 \\
\hline
\end{tabular} \begin{tabular}{|l|l|l|l|}
\hline 3307 & $8 / 1220002333$ & 16.8 & 5826 \\
\hline
\end{tabular} \begin{tabular}{|l|l|l|l|}
\hline 3358 & $8 / 122008235$ & 16.7 & 5823 \\
\hline 3 & 812208237 & 168 & 5813 \\
\hline
\end{tabular} \begin{tabular}{l|l|l|l|}
3359 & $8 / 1220008237$ & 16.8 & 581.3 \\
\hline
\end{tabular} \begin{tabular}{|l|l|l|l|}
\hline 3360 & $8 / 122008239$ & 16.8 & 580.9 \\
\hline
\end{tabular} \begin{tabular}{|l|l|l|l|}
\hline 3361 & $8 / 122008241$ & 16.8 & 581.6 \\
\hline
\end{tabular} \begin{tabular}{|l|l|l|l|}
\hline 3362 & $8 / 1220002243$ & 16.8 & 581.6 \\
\hline
\end{tabular} \begin{tabular}{|l|l|l|l|}
\hline 3363 & 81122008245 & 16.7 & 581.8 \\
\hline 306 & 812200824 & 168 & 5819 \\
\hline
\end{tabular} \begin{tabular}{|l|l|l|l|}
\hline 3364 & $8 / 122008247$ & 16.8 & 581.9 \\
\hline
\end{tabular} \begin{tabular}{lllll}
\hline 3065 & $8112 / 20082449$ & 16.8 & 581.7 \\
\hline
\end{tabular} \begin{tabular}{|l|l|l|l|}
\hline 3366 & $8 / 1222008251$ & 168 & 581.8 \\
\hline
\end{tabular} \begin{tabular}{|l|l|l|l|}
\hline 3367 & $8 / 122008253$ & 168 & 581.7 \\
\hline
\end{tabular} \begin{tabular}{|l|l|l|l|}
\hline 3068 & $8 / 1220008255$ & 16.8 & 581.5 \\
\hline
\end{tabular} \begin{tabular}{|l|l|l|l|}
\hline 3369 & $8 / 1220008257$ & 16.8 & 581.9 \\
\hline
\end{tabular} \begin{tabular}{|l|l|l|l|}
\hline 3370 & $8 / 122008259$ & 168 & 581.9 \\
\hline
\end{tabular} \begin{tabular}{|l|l|l|l|}
\hline 3371 & $8 / 1220083.01$ & 16.8 & 581.6 \\
\hline
\end{tabular} \begin{tabular}{ll|l|l|l|}
3372 & 81220008303 & 168 & 5815 \\
\hline
\end{tabular} \begin{tabular}{|l|l|l|l|}
\hline 3373 & $8 / 12 / 20083: 05$ & 16.8 & 580.8 \\
\hline
\end{tabular}

\begin{tabular}{|c|c|c|c|}
\hline \multicolumn{4}{|c|}{$D 425 c$} \\
\hline $\operatorname{Rec}$ & & Temp & \\
\hline$\#$ & DaterTime & ${ }^{\circ} \mathrm{C}$ & $\mu \mathrm{s} / \mathrm{cm}$ \\
\hline 3374 & $8 / 12 / 20083: 07$ & 16.8 & 580.5 \\
\hline 75 & $8 / 12 / 20083: 00$ & 16.8 & 580.4 \\
\hline & $8 / 12 / 20063: 11$ & 16.8 & 580.2 \\
\hline 377 & $8 / 12 / 20083: 13$ & 16.8 & 579.3 \\
\hline & $8 / 1220083: 15$ & 16.8 & 579.3 \\
\hline & $8 / 12200083: 17$ & 16.8 & 578.9 \\
\hline 380 & $8 / 12 / 20083: 19$ & 16.8 & 578.8 \\
\hline 3381 & 811220083321 & 16.8 & 578.2 \\
\hline & $8 / 12 / 2008323$ & 16.8 & 578.2 \\
\hline 3383 & $8 / 122008325$ & 16.8 & 578.6 \\
\hline 3384 & $8 / 1220083: 27$ & 16.8 & 578.3 \\
\hline & $8 / 12 / 20083: 2$ & 16.8 & 579.0 \\
\hline 806 & $8 / 12200033: 31$ & 16.8 & 579.8 \\
\hline 887 & $8 / 12 / 20083: 33$ & 16.8 & 580.2 \\
\hline & $8 / 12 / 20083: 35$ & $\overline{16.8}$ & 580.0 \\
\hline & $8 / 12 / 20083: 37$ & 16.8 & 579.8 \\
\hline 390 & $8 / 12 / 20083: 39$ & 16.8 & 5724 \\
\hline & $8 / 12 / 2008344$ & 16.8 & $5 \pi .7$ \\
\hline & $8 / 12 / 20083-43$ & $\overline{16.8}$ & 5720 \\
\hline 3993 & $8 / 12 / 20083: 45$ & 16.8 & 571.7 \\
\hline 3994 & $8 / 2 / 20083: 47$ & 16.8 & 574.6 \\
\hline & $8 / 12 / 20083: 49$ & 16.8 & 575.0 \\
\hline 396 & $8 / 12200033: 51$ & 16.8 & 575.5 \\
\hline 3397 & $8 / 12 / 20083: 53$ & 16.8 & 575.7 \\
\hline & $8 / 12200033.55$ & 16.8 & 575.5 \\
\hline 309 & $8 / 12 / 20083.51$ & 16.8 & 575.8 \\
\hline 3400 & $8 / 1220008359$ & 16.8 & 575.6 \\
\hline 01 & $8 / 12200084: 01$ & 16.8 & 575.7 \\
\hline & $8 / 1220008403$ & 16.8 & 575.7 \\
\hline 3403 & $812 / 20084: 05$ & 16.8 & 575.4 \\
\hline 3404 & $8 / 12 / 20084: 07$ & 16.8 & $\overline{575.1}$ \\
\hline 05 & $8 / 12220084: 09$ & 16.8 & 575.3 \\
\hline 3406 & $8 / 12 / 20084: 11$ & 16.8 & 574.9 \\
\hline 3407 & $8 / 12 / 20084: 13$ & 16.8 & 574.6 \\
\hline & $8 / 12220084: 15$ & 16.8 & 574.4 \\
\hline 3409 & $8 / 12 / 20084: 17$ & 16.8 & 574.8 \\
\hline 3410 & $8 / 12 / 20084: 19$ & 16.8 & 574.7 \\
\hline & $8 / 12 / 20084: 21$ & 16.8 & $5 / 4.4$ \\
\hline 3412 & $8 / 12 / 20084: 23$ & 16.8 & 574.3 \\
\hline & $8 / 12 / 20084: 25$ & 16.8 & $5 \overline{54.3}$ \\
\hline & $811220084: 27$ & 16.8 & 574.7 \\
\hline 3415 & $8 / 12 / 20084: 29$ & 16.8 & 574.7 \\
\hline & $8 / 12200$ & 16.8 & 575.1 \\
\hline & $8 / 12 / 20084: 33$ & 16.8 & 575.2 \\
\hline 3418| & $8 / 12 / 20084: 35$ & 16.8 & 575.3 \\
\hline & $8 / 12 / 20084: 37$ & 16.8 & 574.9 \\
\hline 420 & $8 / 12 / 20084: 39$ & 16.8 & 574.8 \\
\hline 3421 & $8 / 12 / 20084: 41$ & 16.8 & 575.4 \\
\hline & $8 / 12 / 20084: 43$ & 16.8 & 575.8 \\
\hline 23 & $8 / 12 / 20084: 45$ & 16.8 & 575.7 \\
\hline 24 & $8 / 12 / 20084: 47$ & 16.8 & 575.4 \\
\hline & $8 / 12 / 20084: 49$ & 16.8 & 575.7 \\
\hline 426 & $8 / 12 / 20084: 51$ & 168 & 5754 \\
\hline & $8 / 12 / 20084: 53$ & 16.8 & 575.1 \\
\hline & $8 / 12 / 20084: 55$ & 16.8 & 574.7 \\
\hline & $8 / 12 / 20084: 57$ & 16.8 & 574.2 \\
\hline 3430 & $8 / 12 / 20084: 50$ & 16.8 & 574.3 \\
\hline 3431 & $8 / 12 / 20085: 01$ & 16.8 & \\
\hline & $8 / 12 / 20085: 03$ & 16.8 & 573.5 \\
\hline 3433 & $8 / 12 / 20085: 05$ & 16.8 & 573.4 \\
\hline 34 & $8 / 12 / 20085: 07$ & 16.8 & 538 \\
\hline & $8 / 12 / 20085: 09$ & 16.8 & 573.9 \\
\hline 3436 & $8 / 12 / 20085: 11$ & 16.8 & 573.8 \\
\hline & $8 / 12 / 20085: 13$ & 16.8 & \\
\hline 3438 & $8 / 12 / 20085: 15$ & 16.8 & $\overline{574.4}$ \\
\hline 3439 & $8 / 12 / 20085: 17$ & 16.8 & 575.4 \\
\hline 3440 & & 16.8 & 575.7 \\
\hline 3441 & $8 / 12 / 200055: 21$ & 16.8 & 574.8 \\
\hline 3442 & $8 / 12 / 20085: 23$ & & \\
\hline
\end{tabular}




\begin{tabular}{|c|c|c|c|c|c|c|c|c|c|c|c|c|c|c|c|c|}
\hline \multicolumn{3}{|c|}{$D 425 c$} & \multicolumn{3}{|c|}{$D 425 c$} & \multicolumn{4}{|c|}{$D 425 c$} & \multicolumn{3}{|c|}{$D 425 c$} & \multicolumn{4}{|c|}{$D 425 \mathrm{C}$} \\
\hline $\operatorname{Rec}$ & & Term SC & $\mathrm{ec}$ & & Temp SC & $\operatorname{Rec}$ & & Temp & & $\operatorname{Rec}$ & & \begin{tabular}{|l|l|} 
Temp & SC \\
\end{tabular} & $\operatorname{Rec}$ & & Temp & \\
\hline$\#$ & DeteTime & \begin{tabular}{|l|l|}
${ }^{\circ} \mathrm{C}$ & $\mu \mathrm{s} o \mathrm{~m}$ \\
\end{tabular} & $\#$ & Dete/Time & \begin{tabular}{l|l|l|l}
${ }^{\circ} \mathrm{C}$ & $\mu \mathrm{S} / \mathrm{m}$ \\
\end{tabular} & $\#$ & DeterTime & \begin{tabular}{|l|}
${ }^{\circ} \mathrm{C}$ \\
\end{tabular} & $\mu \mathrm{S} / \mathrm{cm}$ & $\#$ & DeterTime & \begin{tabular}{l|l|l}
${ }^{\circ} \mathrm{C}$ & $\mu \mathrm{s} / \mathrm{m}$ \\
\end{tabular} & $\#$ & DateTime & ${ }^{\circ} \mathrm{C}$ & $\mathrm{s} / \mathrm{am}$ \\
\hline & $8 / 12 / 20087: 41$ & \begin{tabular}{l|l|}
16.8 & 568.0 \\
\end{tabular} & & $8 / 12 / 20069.5$ & 16.8566 .2 & & $8 / 12 / 20081213$ & 16.8 & & 3715 & $8 / 12 / 200814: 29$ & & 3783 & $112 / 2008$ 46:45 & 160 & \\
\hline 112 & $2220007: 43$ & \begin{tabular}{l|l}
16.8 & 567.8 \\
\end{tabular} & & $8 / 12 / 20089.59$ & \begin{tabular}{l|l}
16.8 & 564.8 \\
\end{tabular} & & $8 / 12 / 20001215$ & 16.8 & 557.4 & & 08 14:31 & \begin{tabular}{l|l|}
16.9 & 553.2 \\
\end{tabular} & & $8 / 12200816: 47$ & 16.9 & 551.7 \\
\hline 3513 & $2220007: 45$ & \begin{tabular}{l|l}
16.8 & 57.1 \\
\end{tabular} & 881 & $8 / 1225008$ 10:01 & \begin{tabular}{|l|l|}
16.8 & 564.9 \\
\end{tabular} & 3649 & $8 / 12 / 20081217$ & 16.8 & 557.6 & \begin{tabular}{|l|l|}
3717 \\
\end{tabular} & $8 / 12 / 200814: 33$ & \begin{tabular}{|l|l|}
16.9 & 5529 \\
\end{tabular} & 85 & $8 / 12 / 200816: 49$ & 16.9 & 551.6 \\
\hline 3514 & $12200087: 47$ & \begin{tabular}{l|l|}
16.8 & 579.9 \\
\end{tabular} & 3582 & $8 / 12 / 200810003$ & \begin{tabular}{l|l|}
16.8 & 564.7 \\
\end{tabular} & & $8 / 12200081219$ & 16.8 & 507.5 & 3718 & & \begin{tabular}{l|l|}
16.953 .1 \\
\end{tabular} & & $8 / 12 / 2000816: 51$ & 16.9 & \\
\hline 515 & & \begin{tabular}{l|l|}
16.8 & 578.1 \\
\end{tabular} & 3583 & $8 / 122000810.06$ & \begin{tabular}{l|l}
16.8 & 563.9 \\
\end{tabular} & & 811220001221 & 16.8 & 557.5 & 3719 & $8 / 12 / 200814: 37$ & \begin{tabular}{|l|l|}
16.9 & 553.8 \\
\end{tabular} & & & 16.9 & 551.7 \\
\hline 3516 & 12220007751 & \begin{tabular}{|l|l|}
16.8 & $5 \pi .8$ \\
\end{tabular} & 3584 & $8 / 12 / 200810: 07$ & \begin{tabular}{|l|l|}
16.8 & 564.4 \\
\end{tabular} & 3652 & $8 / 12 / 20081223$ & 16.8 & 557.7 & 3720 & $8 / 12 / 200814: 39$ & \begin{tabular}{l|l|}
16.9 & 553.8 \\
\end{tabular} & 3788 & $812 / 200816: 50$ & 16.9 & 551.6 \\
\hline 3517 & $8 / 12200087: 53$ & \begin{tabular}{l|l|}
16.8 & 575.6 \\
\end{tabular} & 3585 & $8 / 12 / 200810.00$ & \begin{tabular}{|l|l|}
16.8 & 564.0 \\
\end{tabular} & 3663 & $8 / 12 / 20081225$ & 16.8 & 557.8 & 3721 & $8 / 12 / 200814: 41$ & $\begin{array}{l}16.9 \\
554.0 \\
\end{array}$ & 89 & $816: 57$ & 16.9 & \\
\hline 3518 & $8112200087: 55$ & \begin{tabular}{l|l}
16.8 & 574.9 \\
\end{tabular} & 3586 & $8 / 12 / 2008$ 10.11 & $\begin{array}{l}16.8 \\
1644.0 \\
\end{array}$ & 3654 & $8 / 12 / 20001227$ & 16.8 & 507.1 & 3722 & $8 / 12 / 2008$ 14:43 & \begin{tabular}{l|l|}
16.9 & 553.5 \\
\end{tabular} & & & 16.9 & 551.3 \\
\hline 3519 & $12 / 200087: 50$ & \begin{tabular}{l|l|}
16.8 & 574.9 \\
\end{tabular} & 3587 & $8 / 12 / 200810.13$ & \begin{tabular}{l|l|}
16.8 & 564.7 \\
\end{tabular} & 3650 & $8 / 12 / 20081220$ & 16.8 & 557.7 & 3723 & $8 / 12 / 200814: 45$ & \begin{tabular}{|l|l|}
16.9 & 554.9 \\
\end{tabular} & 3791 & $8 / 12 / 2008$ 17:01 & 16.9 & 551.2 \\
\hline 3520 & $77: 50$ & \begin{tabular}{l|l|}
16.8 & 54.8 \\
\end{tabular} & 3588 & $8 / 12 / 200810.15$ & \begin{tabular}{l|l|}
16.8 & 565.6 \\
\end{tabular} & 3656 & $8 / 12 / 20081231$ & 16.8 & 557.3 & 3724 & $8 / 12 / 200814: 47$ & \begin{tabular}{|l|l|}
16.9 & 554.4 \\
\end{tabular} & 92 & $317: 03$ & 16.9 & \\
\hline 3521) & $8112 / 2$ & \begin{tabular}{l|l}
16.8 & 544.5 \\
\end{tabular} & 3589 & $8 / 12 / 2008$ 10:17 & \begin{tabular}{l|l|}
16.8 & 565.8 \\
\end{tabular} & 3607 & $8 / 1220001233$ & 16.8 & 556.8 & 3725 & & \begin{tabular}{|l|l|}
16.955 .4 \\
\end{tabular} & & & 16.9 & 5511 \\
\hline 3522 & 8:03: & $\begin{array}{l}16.85 / 5.0 \\
\end{array}$ & 3500 & $8 / 12 / 200810.19$ & \begin{tabular}{|l|l|}
16.8 & 565.1 \\
\end{tabular} & 3658 & $8 / 12 / 20081235$ & 16.8 & 507.0 & 3726 & $8 / 12 / 2008$ 14:51 & \begin{tabular}{|l|l|}
16.9 & 554.7 \\
\end{tabular} & 3794 & $8 / 12200817: 07$ & 16.9 & 550.9 \\
\hline 3523 & $8 / 12 / 2$ & \begin{tabular}{l|l}
16.8 & 574.6 \\
\end{tabular} & 3591 & $8 / 12 / 200810.21$ & \begin{tabular}{|l|l|}
16.8 & 564.4 \\
\end{tabular} & 3659 & $8 / 12 / 200012,37$ & 16.8 & 507.6 & 3727 & 814:53 & \begin{tabular}{|l|l|}
16.953 .5 \\
\end{tabular} & 96 & $17: 09$ & 16.9 & \\
\hline 3524 & & \begin{tabular}{l|l}
16.8 & 574.4 \\
\end{tabular} & 3502 & $8 / 12200810: 23$ & \begin{tabular}{l|l}
16.8 & 563.9 \\
\end{tabular} & 3600 & $8 / 12 / 20081239$ & 16.8 & 507.5 & 3728 & & \begin{tabular}{l|l|}
16.9533 .0 \\
\end{tabular} & & & 16.9 & \\
\hline 3625 & 8.09 & \begin{tabular}{l|l|}
16.8 & 574.3 \\
\end{tabular} & 3503 & $8 / 12200810.25$ & \begin{tabular}{l|l}
168 & 5637 \\
\end{tabular} & 3661 & $8 / 12 / 20081241$ & 16.8 & 557.0 & 3720 & 008 14:57 & \begin{tabular}{l|l|}
16.953 .2 \\
\end{tabular} & 97 & 817:13 & 16.9 & 549.6 \\
\hline 3526 & $8 / 122$ & \begin{tabular}{l|l|}
16.8 & 57.37 \\
\end{tabular} & 3594 & $8 / 12 / 20$ & \begin{tabular}{l|l|}
16.8 & 563.6 \\
\end{tabular} & 3662 & $8 / 12 / 20$ & 16.8 & 507.9 & 3730 & 14:59 & \begin{tabular}{l|l|}
16.9528 \\
\end{tabular} & 98 & 17:15 & 16.9 & \\
\hline 3527 & $8 / 12 / 2$ & \begin{tabular}{l|l|}
16.8 & 573.6 \\
\end{tabular} & 3506 & $8 / 12 / 20$ & \begin{tabular}{l|l|}
16.8 & 5628 \\
\end{tabular} & 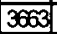 & $8 / 12 / 20$ & 16.8 & 555.4 & 3731 & & \begin{tabular}{|l|l|}
16.9 & 551.9 \\
\end{tabular} & & & 16.9 & \\
\hline 3528 & $8 / 122$ & \begin{tabular}{l|l}
16.8 & 573.9 \\
\end{tabular} & 3506 & $8 / 12 / 200$ & \begin{tabular}{l|l|l|}
16.8620 \\
\end{tabular} & 3664 & 81247 & 16.8 & 555.4 & 3732 & $815: 03$ & \begin{tabular}{|l|l|}
16.9 & 5521 \\
\end{tabular} & 300 & 17:19 & 16.9 & 550.0 \\
\hline 3629 & $8 / 12 /$ & \begin{tabular}{l|l|}
16.8 & 573.8 \\
\end{tabular} & 3597 & $8 / 12 / 2$ & \begin{tabular}{l|l|}
16.8 & 560.9 \\
\end{tabular} & 3660 & $8 / 12 / 2$ & 16.8 & 554.9 & 3733 & $8 / 12 / 2$ & \begin{tabular}{l|l|}
16.9 & 551.9 \\
\end{tabular} & 801 & & 16.9 & 550.2 \\
\hline 3530 & $8 / 12$ & \begin{tabular}{l|l}
16.8 & 573.7 \\
\end{tabular} & 3598 & $8 / 12 / 2$ & \begin{tabular}{l|l|}
16.8 & 560.6 \\
\end{tabular} & 3666 & $8 / 12 / 2$ & 16.8 & 554.6 & 3734 & & \begin{tabular}{l|l|}
16.9 & 551.6 \\
\end{tabular} & 302 & & 16.9 & \\
\hline 3531 & $8 / 12 / 2$ & \begin{tabular}{l|l|}
16.8 & 5736 \\
\end{tabular} & 3599 & $8 / 12 \sqrt{2}$ & \begin{tabular}{l|l|}
16.8 & 561.1 \\
\end{tabular} & 3607 & 1253 & 16.9 & 554.6 & 3736 & 15.09 & \begin{tabular}{l|l|l}
16.9 & 551.3 \\
\end{tabular} & 3803 & $17: 25$ & 16.9 & 549.7 \\
\hline 3532 & $8 / 12 /$ & \begin{tabular}{l|l|}
16.8 & 573.5 \\
\end{tabular} & 3600 & $8 / 122$ & \begin{tabular}{l|l}
16.8 & 560.7 \\
\end{tabular} & 3668 & $8 / 12 / 2$ & 16.8 & 554.4 & 3736 & 15:11 & \begin{tabular}{l|l|l|}
16.9 & 551.5 \\
\end{tabular} & 304 & & 16.9 & 549.9 \\
\hline 3533 & $8 / 12$ & \begin{tabular}{l|l}
16.8 & 573.1 \\
\end{tabular} & 3601 & $8 / 12 / 2$ & \begin{tabular}{l|l|}
16.8 & 500.5 \\
\end{tabular} & 3609 & $8 / 12 / 2$ & 16.8 & 554.2 & 3737 & & \begin{tabular}{l|l}
16.9 & 551.3 \\
\end{tabular} & 005 & & 16.9 & 549.8 \\
\hline 3634 & & \begin{tabular}{l|l|}
16.8 & 573.1 \\
\end{tabular} & 3602 & $8 / 12 t$ & \begin{tabular}{l|l}
16.8 & 560.1 \\
\end{tabular} & 3670 & 1259 & 16.8 & 554.2 & 3738 & & \begin{tabular}{l|l}
16.9 & 551.3 \\
\end{tabular} & 3806 & & 3.9 & 550.1 \\
\hline 3536 & $8 / 12 \pi$ & $\begin{array}{l}16.8 \\
\end{array}$ & 3603 & $8 / 122$ & \begin{tabular}{l|l}
16.8 & 560.3 \\
\end{tabular} & 3671 & $8 / 12 \pi$ & 16.8 & 555.4 & 3739 & & \begin{tabular}{l|l|}
16.9 & 551, \\
\end{tabular} & 307 & & 169 & 549.3 \\
\hline 3536 & 31 & $\begin{array}{l}6.8 \quad 5729 \\
\end{array}$ & 3604 & $8 / 1212$ & $\begin{array}{l}16.8 \\
1660.0 \\
\end{array}$ & 672 & & 16.8 & 554. & 3740 & & 16.9 & 808 & & 16.9 & \\
\hline 3537 & $8 / 12$ & $\begin{array}{ll}16.8 \quad 5 / 27 \\
\end{array}$ & 3605 & $8 / 12 / 2$ & \begin{tabular}{l|l}
16.8 & 560.3 \\
\end{tabular} & 3673 & $8 / 12 / 2$ & 16.8 & 554.5 & 3741 & & $\begin{array}{l}16.9 \\
\end{array}$ & 09 & & 3.9 & 549.7 \\
\hline 3538 & $8 / 12$ & \begin{tabular}{l|l}
16.8 & 5725 \\
\end{tabular} & 3606 & 81121 & \begin{tabular}{l|l}
16.8 & 560.2 \\
\end{tabular} & 3674 & & 16.8 & 554.3 & 3742 & & $\begin{array}{l}69 \\
656\end{array}$ & 10 & & 16.9 & 551.0 \\
\hline 3539 & $8 / 12 t$ & \begin{tabular}{l|l}
16.8 & $5 / 23$ \\
\end{tabular} & 3607 & $8 / 122$ & \begin{tabular}{l|l}
16.8 & 500.2 \\
\end{tabular} & 3675 & $8 / 12 / 2$ & 16.8 & 554.6 & 3743 & 15:25 & 16.9 & 111 & & 16.9 & 550.5 \\
\hline 3540 & $8 / 12$ & \begin{tabular}{l|l|}
16.8 & 5720 \\
\end{tabular} & 3608 & $8 / 122$ & \begin{tabular}{l|l}
16.8 & 560.8 \\
\end{tabular} & 3676 & & 16.8 & 554.5 & 3744 & & \begin{tabular}{l|l}
16.9 & 554. \\
\end{tabular} & 312 & & 16.9 & 550.5 \\
\hline 3541 & & \begin{tabular}{l|l}
16.8 & 51.7 \\
\end{tabular} & 3609 & & $\begin{array}{l}16.8 \\
1560 .\end{array}$ & 3677 & & 16.8 & 554 & 45 & & & 3801 & & 16.9 & 550.7 \\
\hline 3542 & $8 / 12 / 2$ & \begin{tabular}{|l|l|}
16.8 & 571.4 \\
\end{tabular} & 3610 & 81122 & \begin{tabular}{l|l|}
16.8 & 560.9 \\
\end{tabular} & 3678 & 13:15: & 16.9 & 554.3 & 3746 & 15:31 & 16.9 & 3814 & 17:47 & 16.9 & 550.4 \\
\hline 3543 & 45 & \begin{tabular}{l|l}
16.8 & 570.5 \\
\end{tabular} & 3611 & & \begin{tabular}{l|l|}
168 & 561.7 \\
\end{tabular} & 3679 & 3.17 & 16.9 & 554.2 & 3747 & & 16.9 & 315 & & 16.9 & 551.0 \\
\hline 3544 & & \begin{tabular}{l|l}
16.8 & 510 \\
\end{tabular} & 3612 & $8 / 12 /$ & \begin{tabular}{l|l|}
16.8 & $562:$ \\
\end{tabular} & 3680 & & 16.9 & 554 & 3748 & & $\begin{array}{l}16.95 \\
5\end{array}$ & & & 16.9 & 550.6 \\
\hline 3545 & 812 & $\begin{array}{l}16.8 \\
570.9 \\
\end{array}$ & 3613 & $8 / 12 / 2$ & \begin{tabular}{l|l|}
16.8 & 562 \\
\end{tabular} & 3681 & $8 / 12$ & 16.9 & 553 & 3749 & & $16.9 \sqrt{5}$ & 317 & & 16.9 & 550.5 \\
\hline 3546 & & \begin{tabular}{ll|l}
16.8 & 5688 \\
\end{tabular} & 3614 & $8 / 12$ & $\begin{array}{l}16.8 \\
\end{array}$ & 3682 & & 16.9 & 553.5 & 3750 & & 16.9 & & & 16.9 & 550.1 \\
\hline 3547 & & \begin{tabular}{l|l}
16.8 & 569 \\
\end{tabular} & 3615 & $8 / 12$ & \begin{tabular}{ll|l}
168 & 563 \\
\end{tabular} & 683 & & 16.8 & 553 & & & 16.9 & & & 3.9 & 549.7 \\
\hline 3548 & $8 / 12$ & \begin{tabular}{l|l|}
16.8 & $5 \pi$ \\
\end{tabular} & 3616 & & $\begin{array}{l}16.8 \\
156 \\
\end{array}$ & 3684 & & 16.9 & 553 & 3752 & & & ed & & 16.9 & 549.5 \\
\hline 3549 & & \begin{tabular}{l|l}
16.8 & 508 \\
\end{tabular} & 3617 & & \begin{tabular}{c|c|}
16.8528 \\
\end{tabular} & 6806 & & 16.9 & 552 & 53 & & 16.9 & & & 6.9 & 549.5 \\
\hline 3550 & & \begin{tabular}{l|l}
16.8 & 567. \\
\end{tabular} & 3618 & & \begin{tabular}{l|l|l}
16.8 & 56 \\
\end{tabular} & 606 & & 16.9 & 502 & 54 & & 16.9 & & & 16.9 & 549.5 \\
\hline 3551 & & \begin{tabular}{l|l|}
16.8 & 56 \\
\end{tabular} & & & \begin{tabular}{l|l|}
16.8 & 562.9 \\
\end{tabular} & 36 & & 16.9 & 552 & & & & & & 16.9 & 550.0 \\
\hline 3562 & & \begin{tabular}{l|l}
16.8 & 566 \\
\end{tabular} & 3620 & & \begin{tabular}{l|l}
16.8 & 5627 \\
\end{tabular} & 689 & & 16.8 & 553. & 56 & & 16.9 & & & 16.9 & 551.0 \\
\hline 3653 & & \begin{tabular}{l|l|}
16.8 & 566.8 \\
\end{tabular} & 3621 & & \begin{tabular}{l|l|}
16.8 & 562 \\
\end{tabular} & 3689 & & 16.9 & 553.8 & 375 & & \begin{tabular}{l|l}
16.9 & 552 \\
\end{tabular} & 825 & 8.09 & 16.9 & 551.5 \\
\hline 3554 & & \begin{tabular}{l|l}
16.8 & 567. \\
\end{tabular} & 3622 & & $\begin{array}{l}16.8 \\
5628 \\
\end{array}$ & 3690 & & 16.9 & 553 & 58 & & & & & 16.9 & 5526 \\
\hline 3556 & & \begin{tabular}{l|l}
16.8 & 565. \\
\end{tabular} & 3623 & & \begin{tabular}{l|l}
16.8 & 561.3 \\
\end{tabular} & 3691 & & 16.9 & & & & & & & 16.9 & 552 \\
\hline 356 & & \begin{tabular}{l|l}
16.8 & 565. \\
\end{tabular} & 3624 & $8 / 12$ & \begin{tabular}{l|l}
16.8 & 5621 \\
\end{tabular} & 369 & & 16.9 & 553 & 376 & & \begin{tabular}{l|l|}
16.9 & 551 \\
\end{tabular} & $x$ & $8: 15$ & 16.9 & 550.6 \\
\hline 3567 & & \begin{tabular}{l|l}
16.8 & 565 \\
\end{tabular} & 3625 & & \begin{tabular}{|l|l|}
16.8 & 560.3 \\
\end{tabular} & & & 16.9 & 554 & bi & & & & & 16.9 & 549.6 \\
\hline 3558 & & \begin{tabular}{l|l}
16.8 & 564 \\
\end{tabular} & 3626 & & $\begin{array}{l}16.8 \\
15 x \\
\end{array}$ & & & 16.9 & 553 & & & & & & 16.9 & 5487 \\
\hline 356 & & \begin{tabular}{l|l}
16.8 & 562 \\
\end{tabular} & 3627 & & $\begin{array}{l}16.8 \\
\end{array}$ & 695 & & 16.9 & 553 & $7 \pi$ & & 16.9 & & 8:21 & 16.9 & 549.1 \\
\hline 3560 & & \begin{tabular}{l|l}
16.8 & 56 \\
\end{tabular} & 362 & & & & & 16.9 & 553 & & & & & & 16.9 & 548. \\
\hline 3561 & & \begin{tabular}{l|l}
16.8 & 56 \\
\end{tabular} & & & 16.85 & & & 16.9 & 55 & & & & & & 6.9 & $548 .$. \\
\hline 3662 & & \begin{tabular}{l|l}
16.8 & 563. \\
\end{tabular} & 3630 & & 16.8507. & 3698 & & 16.9 & 552 & & & & & & 16.9 & 547. \\
\hline 3663 & & \begin{tabular}{l|l}
16.8 & 563. \\
\end{tabular} & & & & & & 16.9 & & & & & & & & 548. \\
\hline 3564 & & \begin{tabular}{l|l}
16.8 & 563. \\
\end{tabular} & 3632 & $8 / 12$ & $\begin{array}{l}16.8 \\
1507.3\end{array}$ & 700 & & 16.9 & 553 & 3768 & & \begin{tabular}{l|l|}
16.9551 \\
\end{tabular} & 36 & $8: 31$ & 16.9 & 548.1 \\
\hline 3665 & & \begin{tabular}{ll|l}
16.8 & 563. \\
\end{tabular} & 363 & & \begin{tabular}{l|l}
16.8 & 556.8 \\
\end{tabular} & & & 16.9 & 553 & & & & & & 16.9 & 548. \\
\hline 3606 & & \begin{tabular}{l|l}
16.8 & 562 \\
\end{tabular} & 3634 & & & & & 16.9 & & & & & & & 16.9 & \\
\hline 3567 & 9.33 & \begin{tabular}{l|l}
16.8 & 5622 \\
\end{tabular} & 3635 & $8 / 12$ & \begin{tabular}{l|l}
16.8 & 555.9 \\
\end{tabular} & 3703 & $8 / 12$ & 16.9 & 553. & 3771 & 16:21 & $\begin{array}{l}16.9 \\
551 .\end{array}$ & 339 & & 16.9 & 548.3 \\
\hline 3668 & & \begin{tabular}{l|l|}
16.8 & 561. \\
\end{tabular} & 3636 & & & & & 16.9 & 553 & & & & & & 16.9 & \\
\hline 3569 & & \begin{tabular}{|l|l|}
16.8 & 56 \\
\end{tabular} & & & & & & 16.9 & & & & & & & & \\
\hline 3570 & & \begin{tabular}{l|l}
16.8 & 561 \\
\end{tabular} & 3638 & & $\begin{array}{ll}16.95 & 554 \\
\end{array}$ & 3706 & & 16.9 & 553 & 3774 & & \begin{tabular}{l|l|}
16.9 & 55 \\
\end{tabular} & 442 & & 16.9 & 548.6 \\
\hline 3571 & & \begin{tabular}{l|l|}
16.8 & 562 \\
\end{tabular} & 3639 & & & & & 16.9 & 553 & & & & & & 16.9 & \\
\hline 3672 & & \begin{tabular}{|l|l|}
16.8 & $56^{3}$ \\
\end{tabular} & 3640 & & \begin{tabular}{l|l}
16.8 & 555 \\
\end{tabular} & & & & & & & & & & & \\
\hline 3573 & & $\begin{array}{l}16.8 \\
1563 . \\
\end{array}$ & 3641 & $8 / 12 / 20$ & $\begin{array}{ll}16.8 & 554 \\
\end{array}$ & 3709 & & 16.9 & 553 & $3 \pi 77$ & & $\begin{array}{l}16.9 \\
1562 \\
\end{array}$ & 345. & & 16.9 & 48.0 \\
\hline 3574 & & \begin{tabular}{l|l}
16.8 & 564 \\
\end{tabular} & & & & & & 16.9 & 55 & & & & & & 16.9 & 18.1 \\
\hline 3575 & & \begin{tabular}{l|l}
16.8 & 56 \\
\end{tabular} & & & $\begin{array}{lll}16.8 & 556 . \\
\end{array}$ & & & 16.9 & & & & $160=5$ & & & 16.9 & \\
\hline 3576 & $8 / 1220009.51$ & $\begin{array}{l}16.8 \\
1.867 . \\
\end{array}$ & 3644 & $8 / 12 / 20081207$ & $\begin{array}{l}168 \\
1656.7 \\
\end{array}$ & 3712 & $8 / 12 / 2$ & 16.9 & 553 & 3780 & & \begin{tabular}{l|l|l}
16.9 & 552 \\
\end{tabular} & 3848. & & 16.9 & 547.4 \\
\hline 577 & 39.53 & \begin{tabular}{l|l}
16.8 & 568. \\
\end{tabular} & 36 & & $\begin{array}{c}16.8 \quad 556.9 \\
\end{array}$ & 3713 & & 16.9 & 55 & 3781 & & \begin{tabular}{l|l|l}
16.9 & 562 \\
\end{tabular} & 849 & & 16.9 & \\
\hline & & $\begin{array}{l}16.8 \\
1.867 . \\
\end{array}$ & & & & & & 16.9 & & & & & & & & \\
\hline
\end{tabular}


DOE/RL-2009-35, REV. 0

\begin{tabular}{|c|c|c|c|c|c|c|c|c|c|c|c|c|c|c|c|c|c|c|c|}
\hline \multicolumn{4}{|c|}{$D 425 c$} & \multicolumn{4}{|c|}{$D 425 \mathrm{C}$} & \multicolumn{4}{|c|}{$D 4-25 c$} & \multicolumn{4}{|c|}{$D 425 c$} & & $D 425 c$ & & \\
\hline Pec & & & & $\operatorname{Rec}$ & & Tem & SC & $\mathrm{Rec}$ & & Temp & $\mathrm{SC}$ & $\mathrm{ReC}$ & & Temp & $S C$ & $\mathrm{REC}$ & & Tenp & 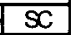 \\
\hline & 3967279287 & & 547.2 & \# & Dete/Time & ${ }^{\circ} \mathrm{C}$ & psiam & \# & DeterTime & ${ }^{\circ} \mathrm{C}$ & $\mathrm{Ham}$ & $\#$ & DateTime & ${ }^{\circ} \mathrm{C}$ & $\mathrm{HS \textrm {sm }}$ & $\#$ & DaterTime & ${ }^{\circ} \mathrm{C}$ & $8 \mathrm{~cm}$ \\
\hline & $8 / 12 / 200819003$ & 69 & 548.0 & 919 & $8 / 12 / 200821: 17$ & 1 & 548.7 & 87 & $8 / 12 / 200823: 33$ & 17 & 547.0 & 4055 & $8 / 13 / 20081: 49$ & 17 & 550.5 & 4123 & $8 / 13 / 20084: 05$ & 17.1 & \\
\hline 863 & $8 / 122200819: 06$ & 16.9 & 549.6 & 3920 & $8 / 12 / 200821: 19$ & 17 & 548.5 & 3988 & $8 / 12 / 200823.35$ & 17 & 546.7 & 4056 & $8 / 13200081: 51$ & 17 & 550.0 & 124. & $8 / 13 / 20084: 07$ & 17.1 & 546.7 \\
\hline 8664 & $8 / 12 / 2000819: 07$ & 16.9 & 558.0 & 3921 & $8 / 12 / 200821 \cdot 21$ & 1 & 548.2 & 3989 & $812 / 200822: 37$ & 17 & 546.8 & 400 & $8 / 1320081: 53$ & 17 & 549.4 & 125 & $8 / 13 / 20084: 09$ & 17.1 & 545.8 \\
\hline 856 & \begin{tabular}{|c|}
$8 / 2 / 200819: 00$ \\
\end{tabular} & 16.9 & 554.3 & 3922 & $8 / 12 / 200821: 23$ & 1 & 549.0 & 3990 & $8 / 12 / 200825339$ & 17 & 546.7 & & $8 / 1320081: 55$ & 17 & 547.9 & & & 17.1 & 544.7 \\
\hline 3856 & \begin{tabular}{|c|}
$8 / 122000819: 11$ \\
\end{tabular} & 16.9 & 5524 & 3023 & $8112 / 2000821: 25$ & 1 & 548.7 & 3901 & $8 / 12 / 20082344$ & 17 & 547.5 & 4050 & $8 / 13 / 20081: 57$ & 17 & 548.6 & 4127 & $8 / 13 / 20084: 13$ & 17.1 & 546.1 \\
\hline 3857 & \begin{tabular}{|c|}
$8 / 122000819: 13$ \\
\end{tabular} & 16.9 & 553.6 & 3924 & $8 / 12 / 200021: 27$ & 1 & 549.6 & 3992 & $8 / 12 / 200823: 43$ & 17 & 548.1 & 4060 & $8 / 13 / 20081: 59$ & 17 & 548.1 & 128 & $8 / 13 / 20084: 15$ & 17.1 & 545.4 \\
\hline 3858 & $8 / 12 / 200819.15$ & 16.9 & 5524 & 3925 & $8 / 12 / 200821: 29$ & & 548.8 & 3993 & $8 / 12 / 200823: 45$ & 17 & 547.3 & 4061 & $8 / 13 / 2008201$ & 17 & 547.5 & 120 & & 17.1 & 546.3 \\
\hline 3809 & $\mid 8 / 12 / 200819: 17$ & 16.9 & 554.0 & 3926 & $8 / 12 / 200821: 31$ & 1 & 549.2 & 3994 & $8 / 12 / 200823: 47$ & 17 & 547.5 & 4062 & $8 / 132000203$ & 17 & 548.9 & 130 & $8 / 13200084: 19$ & $\overline{17.1}$ & 546.0 \\
\hline 3000 & $8 / 122000819: 19$ & 16.9 & 555.5 & 3927 & $8 / 12200021: 33$ & 1 & 549.6 & 3996 & 8112200823.49 & 17 & 548.1 & 4063 & $8 / 132008205$ & 17 & 548.7 & 131 & $8 / 1320084: 21$ & 17.1 & 544.6 \\
\hline 3861 & \begin{tabular}{|l|}
$8 / 12 / 200819 \cdot 21$ \\
\end{tabular} & 16.9 & 556.3 & 3928 & $8 / 12 / 200821: 35$ & & 549.9 & 3996 & $8 / 12 / 200823: 51$ & 17 & 549.0 & 264 & $8 / 13 / 2008207$ & 17 & 548.8 & 132 & & 17.1 & \\
\hline 3062 & $8 / 12220081923$ & 16.9 & 557.6 & 3929 & $8 / 12 / 200821: 37$ & 1 & 549.3 & 3997 & $8 / 12 / 200823: 53$ & 17 & 548.2 & 4065 & $8 / 13 / 2008200$ & 177 & 548.7 & 133 & $811320084: 25$ & 17.1 & 545.2 \\
\hline 3963 & $8 / 12 / 200019.25$ & 16.9 & 558.4 & 3930 & $8 / 12 / 200821: 39$ & & 5488 & 3908 & $8 / 122000823.55$ & 17 & 548.5 & 4006 & $8 / 13 / 2008211$ & 17 & 548.0 & 134 & $8 / 13220084: 27$ & 17.1 & 546.1 \\
\hline 3964 & $8 / 122200819: 27$ & 16.9 & 560.7 & 39031 & $\mid 8 / 12 / 200821: 41$ & & 547.7 & 3009 & $8 / 12 / 200823 \cdot 57$ & 17 & 548.5 & 067 & $8 / 13 / 2008213$ & 17 & 548.8 & 135 & & 17.1 & \\
\hline 3965 & $8 / 122200819: 29$ & 16.9 & 559.7 & 3902 & $8 / 12 / 200821: 43$ & & 5480 & 4000 & $8 / 12 / 200823.59$ & 17 & 548.8 & 4068 & $8 / 132000215$ & 17 & 549.3 & 136. & $8 / 1320084: 31$ & 17.1 & 546.3 \\
\hline 3066 & $8 / 12 / 2008$ 19:31 & 16.9 & 564.5 & 3003 & $8 / 12 / 200821: 45$ & & 549.5 & 4001 & 81320080001 & 17 & 548.9 & 4069 & 82217 & 17 & 549.2 & 137 & $8 / 13 / 20084: 33$ & 17.1 & 546.0 \\
\hline 3867 & $8 / 12 / 200819.33$ & 16.9 & 554.1 & 3934 & $8 / 12 / 200821: 47$ & & 549.0 & 4000 & $8 / 13 / 20080: 03$ & 17 & 549.5 & & $8 / 13 / 2008219$ & 17 & 549.5 & & & 17.1 & \\
\hline 3968 & $8 / 12 / 2000$ 19.36 & 16.9 & 556.0 & 3935 & $8 / 12 / 200821: 49$ & & 549.9 & 4003 & $8 / 13 / 200000: 05$ & 17 & 550.0 & 77 & $8 / 13 / 2000221$ & 17 & 549.5 & 139 & D84:37 & 17.1 & 545.2 \\
\hline 3869 & \begin{tabular}{|l|l|}
$8 / 2000819: 37$ \\
\end{tabular} & 16.9 & 555.4 & 3906 & \begin{tabular}{|l|l}
$8 / 12 / 200821: 51$ \\
\end{tabular} & & 561.3 & 4004 & $8 / 1320080: 07$ & 17 & 548.6 & 072 & 3223 & 17 & 549.4 & 140 & $84: 39$ & 17.1 & 545.2 \\
\hline 3870 & 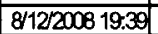 & 17 & 553.4 & 3937 & $8 / 12 / 200$ & & 561.5 & 4005 & 8:00 & 17 & 548.7 & 7 & $8 / 13 / 20002225$ & '17 & 548.4 & 141 & & 17.1 & \\
\hline 3871 & \begin{tabular}{|l|l|}
$8 / 12 / 2008$ 19.41 \\
\end{tabular} & 16.9 & 5566 & 3938 & $8 / 12 / 200821: 50$ & & 548.9 & 4006 & $8 / 13 / 20080-11$ & 17 & 5486 & 074 & $8 / 13 / 2008227$ & 17 & 547.9 & 142 & $8 / 13 / 20084: 43$ & 17.1 & 545.9 \\
\hline 3872 & $8 / 12 / 20081994$ & 16.9 & 557.7 & 3939 & $8 / 12 / 20$ & & 549.1 & 4007 & $80: 13$ & 17 & 547.5 & 4075 & 3229 & 17 & 546.2 & 143 & $34: 45$ & 17.1 & 546.7 \\
\hline 3873 & $8 / 12 / 200819: 45$ & 16.9 & 556.7 & 3940 & $8 / 12 / 20$ & & 5522 & 4008 & 8:-15 & 17 & 547.3 & $\sqrt{7}$ & 8231 & 17 & 547.8 & 144 & & 17.1 & \\
\hline 3874 & \begin{tabular}{|l|l|}
$8 / 122000819: 47$ \\
\end{tabular} & 16.9 & 555.3 & 3941 & $8 / 12 / 2008$ 22:01 & & 551.8 & 4000 & $8 / 13 / 20080: 17$ & 17 & 548.5 & 37 & $8 / 13 / 2008233$ & 17 & 547.1 & 145 & $84: 49$ & 17.1 & 544.5 \\
\hline 3875 & $8 / 12 / 2000$ & 16.9 & 554.7 & 3042 & $8 / 12 / 2$ & & 551.9 & 4010 & $0: 19$ & 17 & 548.8 & 78 & 236 & 17 & 547.6 & 146 & $4: 51$ & 17.1 & 545.9 \\
\hline 3876 & $8 / 122200819.5$ & 16.9 & 554.2 & 3943 & $8 / 12 / 20$ & & 549. & 4011 & 30.21 & 17 & 548.5 & $\pi$ & 3237 & 17 & 545.8 & 147 & & 17.1 & \\
\hline 3877 & \begin{tabular}{|l|l|}
$8 / 12 / 200819: 53$ \\
\end{tabular} & 16.9 & 553.5 & 3944 & $8 / 12 / 200822 \cdot 07$ & & 549.0 & 4012 & & 17 & 548 & 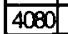 & 8239 & 17 & 547 & 148 & $4: 55$ & 17.1 & 545.6 \\
\hline 3878 & $8 / 12 / 20$ & 169 & 5520 & 3945 & $8112 / 2$ & $\overline{1}$ & 549.3 & 4013 & $8 / 132$ & 17 & 547.6 & 081 & 241 & 17 & 546 & 149 & $4: 57$ & 17.1 & 545.6 \\
\hline 3879 & 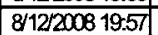 & 169 & 5523 & 3946 & $8 / 12 / 20$ & & 548 & 4014 & 30.27 & 17 & 547.8 & 182 & 8243 & 17 & 547 & 150 & & 17.1 & \\
\hline 3880 & \begin{tabular}{|l|l|}
$8 / 12200819.59$ \\
\end{tabular} & 16.9 & 550.7 & 3947 & $8 / 12 / 20082213$ & $\overline{1}$ & 547. & 4015 & 80.29 & 17 & 546 & & $8 / 13 / 2008245$ & 17 & 547 & & & 17.1 & 546.1 \\
\hline 3881 & $8 / 1220$ & 169 & 549.2 & 3948 & $8 / 12 / 2$ & & 547.3 & 4016 & $0: 31$ & 17 & 547. & 804 & 3247 & 17 & 546 & 152 & & 17.1 & 545.8 \\
\hline 3882 & $8 / 12 / 20082000$ & 16.9 & 549. & 3949 & $8 / 12 / 2$ & & 549 & 4017 & & 17 & 547. & 86 & 249 & 17 & 546 & 150 & & 17.1 & \\
\hline 3883 & $8 / 12 / 200020: 05$ & 16.9 & 550. & 3950 & 2219 & 1 & 548. & 4018 & & 17 & 547. & & 251 & 17 & 544 & 1541 & & 17.1 & 546.7 \\
\hline 3884 & $8 / 12 / 2$ & 16.9 & 549. & 3951 & $8 / 12$ & & 548 & 4019 & & 17 & 545 & 867 & 253 & 17 & 546 & 56 & & 17.1 & 545.4 \\
\hline 3085 & $8 / 12 /$ & 16.9 & 549 & 3952 & $8 / 12 /$ & 1 & 550 & 4020 & & 17 & 545. & & 255 & 17 & 54 & 156 & & 17.1 & 545.5 \\
\hline 3806 & $8 / 12 / 2$ & 16.9 & 548. & 3953 & $8 / 121$ & & 550.4 & 4021 & & 17 & 546. & t) & 257 & 17 & 546 & & & 17. & 545.2 \\
\hline 3887 & $8 / 12$ & 16.9 & 548. & 3954 & $8 / 2$ & 1 & 550 & 4022 & & 17 & 547. & 90 & 259 & 17 & 54 & & & 17. & 545.6 \\
\hline 3888 & $8 / 12 / 20$ & 16.9 & 548. & 3055 & $8 / 12$ & $\overline{1}$ & 550 & 4023 & 0.45 & 17 & 547. & 091 & 33:01 & 17 & 547 & 59 & 35:17 & 17.1 & 546.8 \\
\hline 3889 & $8 / 12 / 20$ & 16.9 & 548 & 3056 & $8 / 12$ & & 551.1 & 4024 & & 17 & 546. & 或 & & 17 & 546 & & & 17.1 & 546.9 \\
\hline 3890 & $8 / 12$ & 16.9 & 548 & 3957 & $8 / 12$ & & 551. & 4025 & & & 54 & 93 & 3.05 & 17 & 54 & & & 17.1 & 547.3 \\
\hline 3891 & $8 / 12 / 2$ & 16.9 & 5483 & 3958 & $8 / 121$ & & 547.4 & 4026 & 30.51 & 17 & 545 & 4094 & 3.07 & 17 & 545 & 162 & & 17.1 & 547.5 \\
\hline 3992 & & 39 & 549 & 3969 & & & 548 & 4027 & & 17 & 54 & & & 17 & & & & 17.1 & 547.1 \\
\hline 3993 & $8 / 12$ & 16.9 & 549 & 3960 & $8 / 12$ & & 550. & 4028 & & 17 & 54 & 96 & & 17 & 546 & 164 & & 17.1 & 547.6 \\
\hline 3894 & 20.27 & 16.9 & 549.1 & 3961 & & & 5521 & 4020 & & 17 & 54 & व97| & $3: 13$ & 17 & 54 & 165 & & 17.1 & 546.4 \\
\hline 3695 & & 2.9 & 54 & 3962 & & & 551.0 & 4030 & & 17 & 54 & & & 17 & & & & 17. & 547.0 \\
\hline 3896 & 0.31 & 16.9 & 548 & 3963 & 245 & 1 & 550 & 4031 & & 17 & 547 & 99 & $3: 17$ & 17 & 547 & & & 17. & 547. \\
\hline 3897 & $8 / 12$ & 16.9 & & 3964 & & & 5 & 4032 & & 17 & & & & 17 & & & & 17. & 546 . \\
\hline 3898 & $8 / 12$ & 3.9 & 548 & 3965 & 249 & & 55 & 4033 & & 17 & 54 & & & & 54 & & & 17. & 546 \\
\hline 3890 & $20: 37$ & 16.9 & 548 & 3966 & 2251 & 1 & 551 & 4034 & & 17 & $54 \mathrm{C}$ & & 3.23 & 17 & & & & 17. & 546 \\
\hline 3900 & & 16.9 & 54 & 3967 & & & 550 & $40 x^{x}$ & & 17 & & & & 17 & & & & 17. & 546.5 \\
\hline 3901 & & 16.9 & & 3908 & & & & & & & & & & 17.1 & & & & & 546.5 \\
\hline 3902 & $20: 43$ & 16.9 & 549 & 3969 & 2257 & 1 & 551.7 & 4037 & & 17 & 549 & 06 & $3: 29$ & 17.1 & 54 & 73 & & 17.1 & 545.7 \\
\hline 3903 & & 16.9 & 546 & & & & & & & 17 & & & & 17.1 & & & & 17.1 & 545 \\
\hline 3904 & & 16.9 & & 3971 & & 1 & 55 & & & 17 & & & & 17.1 & & & & 17. & 545 \\
\hline 3905 & $8 / 12 / 2$ & 17 & 549 & 3972 & $23: 03$ & 1 & 551. & 4040 & & 17 & 55 & & & 17.1 & & & & 17.1 & 543. \\
\hline 3006 & & 16.9 & 55 & 3973 & & $\overline{1}$ & & & & 7 & & & & 17.1 & & & & 17.1 & \\
\hline 3907 & 053 & 16.9 & 55 & & $3: 07$ & $\overline{1}$ & 56 & & & 17 & 54 & & $3: 39$ & 17.1 & & & $5: 56$ & 17.1 & 545. \\
\hline 3908 & & 16.9 & 548 & 3975 & $23: 09$ & $\overline{1}$ & 5551 & & & 17 & & & & 17.1 & 54 & & & 17.1 & 544. \\
\hline 3909 & & 16.9 & $54{ }^{\circ}$ & & & 1 & & & & 17 & & & & 17.1 & & & & & \\
\hline 3910 & 20.59 & 6.9 & $54 c$ & & $3: 13$ & 1 & 55 & & & 17 & & & $3: 45$ & 17.1 & & & & 17.1 & 542 \\
\hline 3911 & & 16.9 & 54 & 3978 & & 1 & 551 & & & 17 & & & & 17 & & & & 17. & 543. \\
\hline 3912 & & & & & & & & & & & & & & 17.1 & & & & & \\
\hline 3913 & $8 / 12 / 200821: 06$ & 17 & 548. & 3900 & $23: 19$ & 1 & 550. & 4048 & 1:35 & 17 & 540 & & 3.51 & 17.1 & 547 & 184 & 36:07 & 17.1 & 544.7 \\
\hline 3914 & $8 / 12 / 200$ & 16.9 & 547 & 3981 & $23: 21$ & 1 & 547 & 4049 & & 17 & 549 & & & 17.1 & 546. & 185 & & 17.1 & 545. \\
\hline 3915 & & & & & & & & & & 17 & & & & 17.1 & & & & . & \\
\hline 3916 & 8/12/200821:11 & 17 & 548.2 & 3983 & $8 / 12 / 200823: 25$ & 1 & 547.3 & & $81: 41$ & 17 & 548 & & $33: 57$ & 17.1 & 548.4 & 187 & $6: 13$ & 17.1 & 544.9 \\
\hline 3917 & $8 / 12 / 20$ & 17 & 548. & 3984 & 323:27 & & 547 & 4052 & & 17 & 548 & & & 17.1 & 547. & 188 & & 17.1 & \\
\hline 3918 & & 17 & 548 & 3925 & $8 / 12 / 2$ & & 547 & & & 17 & $56 x$ & & & 17.1 & 54 & & & 17.1 & \\
\hline & & & & & 23:31 & & 547.1 & 4054 & $81: 47$ & 17 & 550.2 & $\longdiv { 4 1 2 }$ & $84: 03$ & 17.1 & 547.4 & & $36: 19$ & 17.1 & 5462 \\
\hline
\end{tabular}




\begin{tabular}{|c|c|c|c|c|c|c|c|c|c|c|c|c|c|c|c|c|c|}
\hline \multicolumn{4}{|c|}{$D 425 c$} & \multicolumn{4}{|c|}{$D 4-25 c$} & \multicolumn{3}{|c|}{$D 4-25 c$} & \multicolumn{4}{|c|}{$D 4-25 c$} & \multicolumn{3}{|c|}{ D425C } \\
\hline $\mathrm{rec}$ & & $\mathrm{mp}$ & $\mathrm{SC}$ & $\theta$ & & $\mathrm{cmb}$ & & $\mathrm{Rec}$ & & \begin{tabular}{|l|l|} 
Temp & SC \\
\end{tabular} & Rec & & Temp & rr & $\mathrm{Rec}$ & & Tem \\
\hline$\#$ & derTime & & $\mu s / c m$ & \# & DeterTime & \begin{tabular}{l|}
${ }^{\circ}$ \\
\end{tabular} & $\mu \mathrm{S} / \mathrm{cm}$ & \# & Date/Time & \begin{tabular}{|l|l|l|c|}
${ }^{\circ} \mathrm{C}$ & $\mu \mathrm{cm}$ \\
\end{tabular} & \# & DeterTime & ${ }^{\circ} \mathrm{C}$ & $\mu \mathrm{s} / \mathrm{am}$ & $\#$ & Date/Time & \\
\hline & & .1 & 546.4 & 259 & & 17.1 & 545.2 & 1327 & $8 / 13 / 200810: 53$ & \begin{tabular}{|l|l|}
17.2 & 544.9 \\
\end{tabular} & & $8 / 13 / 200813: 09$ & 17.2 & & & $3 / 13 / 200815: 25$ & \\
\hline 192 & $3 / 20086: 23$ & 17.1 & 545.7 & 4260 & $13 / 20088: 39$ & 17.1 & 546.4 & & $8 / 13 / 200810: 55$ & 545.4 & 1396 & $8 / 13 / 2008$ 13:11 & 17.2 & 538.6 & 164 & $/ 13 / 2008$ 15:27 & \\
\hline 193 & $320086: 25$ & & 546.4 & 4261 & $3 / 13 / 20088: 41$ & 17.1 & 545.4 & 1329 & $8 / 13 / 200810: 5$ & \begin{tabular}{|l|}
545.2 \\
\end{tabular} & 397. & $8 / 13 / 200813: 13$ & 17.2 & 537.6 & 165 & $113 / 200815: 29$ & \\
\hline 94 & & & 546.2 & 262 & & 17.1 & 544.9 & & $8 / 13 / 200810.59$ & \begin{tabular}{l|l|}
17.2 & 544.7 \\
\end{tabular} & & & 17.2 & & & 008 15:31 & \\
\hline 95 & $86: 20$ & 17.1 & 545.3 & 4263 & $8 / 13 / 20088: 45$ & 17.1 & 546.1 & 33 & $8 / 13 / 200611: 01$ & 545.5 & 1399 & $8 / 13 / 2008$ 13:17 & 17.2 & 539.3 & 467 & $1 / 13 / 2008$ 15:33 & 17 \\
\hline 96 & $86: 31$ & 17.1 & 545.8 & 4264 & $8 / 13 / 20088: 47$ & 17.2 & 545.4 & 4332 & $8 / 13 / 200811: 03$ & \begin{tabular}{|l|l|}
17.2 & 543.1 \\
\end{tabular} & 4400 & $8 / 13 / 2008$ 13:19 & 17.2 & 537.8 & 468 & $8 / 13 / 200815: 35$ & \\
\hline 97 & & 17.1 & 545.9 & 4265 & $8 / 13 / 20088: 49$ & 17.1 & $\overline{545.8}$ & & $8 / 13 / 200811: 05$ & \begin{tabular}{|l|l|}
17.2 & 543.8 \\
\end{tabular} & 4401 & $8 / 13 / 2008$ 13:21 & 17.2 & & & & \\
\hline 198 & $86: 35$ & 17.1 & 546.4 & 4266 & $8 / 13 / 20088: 51$ & 17.2 & 545.6 & 4334 & $8 / 13 / 2008$ 11:07 & 544.2 & 4402 & $13 / 200813: 23$ & 17.2 & 538.6 & 470 & $8815: 39$ & \\
\hline 199 & $86: 37$ & 17.1 & 546.2 & 4267 & $8 / 13 / 20088: 53$ & 17.2 & 543.5 & 4335 & $8 / 13 / 200811: 09$ & \begin{tabular}{l|l|}
17.2 & 544.1 \\
\end{tabular} & 4403 & $8 / 13 / 200813: 25$ & 17.2 & 538.2 & 471 & $0815: 41$ & \\
\hline 200 & & 17.1 & 544.8 & 4268 & $8 / 13 / 20088: 50$ & 17.2 & 545.0 & 433 & $8 / 13 / 200811: 11$ & \begin{tabular}{l|l|}
17.2 & 544.7 \\
\end{tabular} & 4404 & $8 / 13 / 200813: 27$ & 17.2 & & 472 & $0815: 43$ & \\
\hline 4201 & $86: 41$ & 17.1 & 543.6 & 4269 & $8 / 13 / 20088: 57$ & 17.2 & 545.1 & 4337 & $8 / 13 / 20$ & \begin{tabular}{|l|l|}
17.2 & 540.4 \\
\end{tabular} & 4405 & $8 / 13 / 200813: 20$ & 17.2 & & 473 & $\overline{08815: 45}$ & \\
\hline 202 & $36: 43$ & 17.1 & 546.0 & 4270 & $8 / 13 / 20088: 59$ & 17.2 & 546.0 & 4338 & $8 / 13 / 20$ & \begin{tabular}{|l|l|}
17.2 & 5423 \\
\end{tabular} & 106 & $813: 31$ & 17.2 & 540 & 474 & $0815: 47$ & \\
\hline & & & 545.9 & 4271 & $8 / 13 / 20089: 01$ & 17.1 & 546.0 & 1200 & $8 / 13 / 20$ & \begin{tabular}{l|l|}
17.2 & 542.6 \\
\end{tabular} & 107 & $813: 33$ & 17.2 & & & $815: 49$ & \\
\hline 4204 & $36: 47$ & 17.1 & 545. & 4272 & $8 / 13 / 20089: 03$ & 17.1 & 545.4 & 4340 & 11:19 & \begin{tabular}{l|l|}
17.2 & 543.4 \\
\end{tabular} & 4408 & & 17.2 & 540 & 476 & $0815: 51$ & \\
\hline 205 & 86:49 & 17.1 & 545.8 & 4273 & $8 / 13 / 20089.05$ & 17.1 & 543.4 & 4341 & $8 / 13 / 2$ & \begin{tabular}{l|l}
17.2 & 542. \\
\end{tabular} & 4409 & $8813: 37$ & 17.2 & $53 x$ & 477 & $815: 53$ & \\
\hline 206 & & 7.1 & 546.2 & 4274 & $8 / 13 / 20089: 07$ & 17.2 & 5421 & & $8 / 13 / 2$ & 17.2 & & $313: 39$ & 17.2 & & 478 & $815: 56$ & \\
\hline 4207 & & .1 & 544.7 & \begin{tabular}{|l|}
4275 \\
\end{tabular} & & 17.1 & 544.5 & 4343 & $8 / 13 / 2$ & 543.6 & 4411 & & 17.2 & & 479 & $815: 57$ & \\
\hline 208 & $6: 55$ & 17.1 & 546.1 & 4276 & $8 / 13 / 20089.11$ & 17.2 & 5429 & 4344 & $8 / 13 / 2$ & 5427 & 12 & $813: 43$ & 17.2 & 539 & 180 & $315: 59$ & \\
\hline 200 & & 7.1 & 545.1 & \begin{tabular}{|l|}
$42 \pi 7$ \\
\end{tabular} & & 17.2 & 541.5 & & $8 / 13 / 2$ & 17.2 & & 13:45 & 17.2 & & 481 & & \\
\hline 4210 & & .1 & 544.0 & 4278 & $8 / 13 / 20089: 15$ & 17.1 & 540.1 & 4346 & & 540.7 & 414 & $813: 47$ & 17.2 & & 482 & $316: 03$ & \\
\hline 4211 & & 17.1 & 544.3 & 4279 & $8 / 13 / 20089: 17$ & 17.1 & 5424 & 4347 & $8 / 13 / 2$ & 541.3 & 4415 & $813: 49$ & 17.2 & $53 x$ & 183 & $316: 06$ & \\
\hline 212 & & 17.1 & 544.2 & & & 17.2 & 542 & & $8 / 13 / 2$ & 17.2 & & & 17.2 & & 184 & 316:07 & \\
\hline 4213 & & 17.1 & 544.9 & 4281 & $8 / 13 / 20089: 21$ & 17.2 & 5422 & 4349 & $8 / 13 / 2$ & 545.3 & 4417 & $813: 53$ & 17.2 & $53 x$ & 485 & $816: 09$ & \\
\hline 4214 & 7:07 & 17.1 & 544.8 & 4282 & $8 / 13 / 20$ & 17.2 & 542.9 & 4350 & $8 / 13$ & 17.2 & 4418 & 313:55 & 17.2 & & 186 & 16:11 & 17 \\
\hline 215 & & & & & & 17.2 & $\overline{5425}$ & & & 17.2 & & & 17.2 & & & $316: 13$ & \\
\hline 4216 & 7:11 & 17.1 & 544. & 4284 & $8 / 13 / 20089.27$ & 17.2 & 543.3 & 352 & $8 / 13 / 2$ & 17.2 & 4420 & $813: 59$ & 17.2 & 54 & 488 & 316:15 & \\
\hline 4217 & & 17.1 & 544. & \begin{tabular}{|l|}
42855 \\
\end{tabular} & $8 / 13$ & 17.2 & 542 & 4353 & $8 / 13$ & 17.2 & 4421 & 14:01 & 17.2 & 54 & & 16:17 & \\
\hline 4218 & & 7.1 & 54 & 4286 & & 17.2 & 543. & 4354 & & 17.2 & & & 17.2 & & & 16:19 & \\
\hline 4219 & $37: 17$ & 7.1 & 545. & \begin{tabular}{|l|}
4287 \\
\end{tabular} & $8 / 13 / 20089.33$ & 17.2 & $\overline{543}$ & 4355 & $8 / 13 / 2$ & 17.2 & 423 & $814: 05$ & 17.2 & 537 & 191 & $316: 21$ & 17 \\
\hline 220 & & 17.1 & 545 & 4288 & $8 / 13$ & 17.2 & 543. & 356 & & 17.2 & 24 & 14:07 & 17.2 & & & $16: 23$ & 17 \\
\hline 4221 & & .1 & 542 & \begin{tabular}{|l|}
4289 \\
\end{tabular} & $8 / 13$ & 17.2 & 543 & 357 & & 17.2 & & $14: 09$ & 17.2 & & & $16: 25$ & \\
\hline 22 & & & 541. & 4290 & & 17.2 & 543 & 435 & & 17.2 & & & 17.2 & & 194 & $16: 27$ & 17 \\
\hline 23 & & 17.1 & 544 & 291 & $9: 41$ & 17.2 & 543 & 3 & & 17.2 & 427 & $14: 13$ & 17.3 & 53 & 196 & $16: 29$ & 17 \\
\hline 4224 & & .1 & 542 & 292 & & 17.2 & 542 & & & 17.2 & & $14: 15$ & 17.2 & & 196 & $16: 31$ & \\
\hline 225 & & 17.1 & 543. & 293 & & 17.2 & $54^{3}$ & & & 17.2 & & & 17.2 & & & & \\
\hline 226 & & 17.1 & 543. & 294 & 9.47 & 17.2 & 543 & 362 & $8 / 13$ & 17.2 & 130 & 14:19 & 17.2 & 54 & 9 & $16: 35$ & \\
\hline 4227 & & .1 & 54 & \begin{tabular}{|l|}
42965 \\
\end{tabular} & 39.49 & 17.2 & 54 & & & 17.2 & 431 & 14:21 & 17.2 & 54 & 190 & 16:37 & \\
\hline 228 & & .1 & 543. & \begin{tabular}{|l|}
4296 \\
\end{tabular} & & 17.2 & 54 & & & 17.2 & & & 17.2 & & & & \\
\hline 229 & & 7.1 & & 297 & & 17.2 & 54 & & & \begin{tabular}{l|l}
17.2 & 54
\end{tabular} & & $14: 25$ & 17.2 & & & $16: 41$ & \\
\hline 4230 & & 17.1 & 54 & \begin{tabular}{|l|}
4298 \\
\end{tabular} & $8 / 13 /$ & 17.2 & & 4366 & & 17.2 & 434 & $14: 27$ & 17.2 & 54 & 502 & $16: 43$ & 17 \\
\hline 231 & & 17.1 & & 4290 & & 17.2 & 543 & 4367 & & 17.2 & & $14: 29$ & 17.2 & & & & \\
\hline 4232 & & .1 & & 300 & & 17.2 & 542 & & & 17.2 & & & 17.2 & & & $16: 47$ & \\
\hline 4233 & & 17.1 & 54 & \begin{tabular}{|l|}
4301 \\
\end{tabular} & & 17.2 & 54 & 4369 & & 17.2 & 137 & & 17.2 & 54 & 506 & $16: 49$ & 17 \\
\hline 234 & & & & & & 17.2 & 54 & & & 17.2 & & & 17.2 & & & & 17 \\
\hline 4235 & & & 546 & & & 17.2 & 54 & & & \begin{tabular}{l|l}
17.2 & 5 \\
\end{tabular} & & $14: 37$ & 17.2 & & & & \\
\hline 4236 & & .1 & & 4304 & & 17.2 & & & & 17.2 & & 14.5 & 17.2 & & & & \\
\hline 37 & & & & & & 7.2 & & & & 17.2 & & & & & & & \\
\hline 238 & & & 54 & & & 17.2 & & & & \begin{tabular}{l|l}
17.2 & 5 \\
\end{tabular} & & & 17.2 & & & $16: 59$ & \\
\hline 239 & & & & & & & & & & \begin{tabular}{l|l|}
17.2 & 5 \\
\end{tabular} & & & 17.2 & & & & \\
\hline 240 & & & & & & & & & & & & & & & & & \\
\hline 4241 & & 1.1 & & & & 17.2 & 54 & & & 17.2 & 45 & $14: 49$ & 17.2 & 53 & 513 & $17: 05$ & \\
\hline 242 & & & & & & 17.2 & & & & \begin{tabular}{l|l}
17.2 & 53 \\
\end{tabular} & & & 17.2 & & & & \\
\hline 243 & & & & & & 17.2 & & & & & & & 17.2 & & & & \\
\hline 4244 & & 17.1 & 547 & \begin{tabular}{|l|}
4312 \\
\end{tabular} & & 17.2 & 543 & & & \begin{tabular}{|l|l}
17.2 & 540 \\
\end{tabular} & 448 & $14: 55$ & 17.3 & & 16 & & 17 \\
\hline & & & & & & & & & & \begin{tabular}{l|l}
17.2 & 54 \\
\end{tabular} & & & 17.2 & & & & \\
\hline 4246 & & & & & & 17 & & & & & & & 17.2 & & & & \\
\hline 247 & & \begin{tabular}{|l|l|}
17.1 \\
\end{tabular} & & & & 17.2 & & & & 17.2 & & 8 & 17.2 & & & & \\
\hline & & & & & & 17.2 & & & & 17.2 & & & 17.2 & & & & \\
\hline 4249 & & & & & & & & & & \begin{tabular}{l|l}
17.2 & 538 \\
\end{tabular} & & $15: 05$ & 17.2 & 53 & & & \\
\hline 50 & & 17.1 & & & & 17.2 & & & & 17.2 & & & 17.2 & & & & \\
\hline 251 & & & & & & & & & & & & & 17.2 & & & & \\
\hline 4252 & $8: 23$ & 17.1 & 548. & & 8810.39 & 17.2 & $\overline{544}$ & & & \begin{tabular}{l|l}
17.2 & 54 \\
\end{tabular} & & 15:11 & 17.2 & $54 \mathrm{C}$ & 224 & 317:27 & \\
\hline 253 & & 17.1 & 548 & & & 17.2 & 54 & & & \begin{tabular}{l|l}
17.2 & 539
\end{tabular} & & & 17.2 & 53 & 525 & & \\
\hline 4254 & & & & & & & & & & & & & 17.2 & & & & \\
\hline 4255 & & 17.1 & \begin{tabular}{|l|l|} 
\\
\end{tabular} & \begin{tabular}{|l|}
4323 \\
\end{tabular} & 13200810.45 & 17.2 & 545.2 & & & \begin{tabular}{l|l}
17.2 & 539 \\
\end{tabular} & & $815: 17$ & 17.2 & 538 & 227 & $817: 33$ & \\
\hline 256 & & 17.1 & 546.6 & 4324 & & 17.2 & 543 & \begin{tabular}{|l|}
4392 \\
\end{tabular} & & \begin{tabular}{l|l}
17.2 & 538. \\
\end{tabular} & 60 & 815:19 & 17.2 & 544 & 228 & & 17 \\
\hline 4257] & & 17.11 & $\begin{array}{l}45.7 \\
\end{array}$ & 4325 & & 17.2 & 543 & & & \begin{tabular}{l|l}
17.2 & 53 \\
\end{tabular} & 4467 & $315: 21$ & 17.2 & & 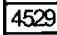 & & \\
\hline 172 & $8: 35$ & 17.1 & \begin{tabular}{|l|l|} 
& 546.7 \\
\end{tabular} & \begin{tabular}{|l|}
4326 \\
\end{tabular} & $8 / 13 / 200810.51$ & 17.2 & 544.1 & & & \begin{tabular}{l|l}
17.2 & 538 \\
\end{tabular} & & 15:23 & 17.2 & 537 & & $17: 39$ & \\
\hline
\end{tabular}


DOE/RL-2009-35, REV. 0

\begin{tabular}{|c|c|c|c|c|c|c|c|c|c|c|c|c|c|c|c|c|c|}
\hline \multicolumn{4}{|c|}{ D425c } & \multicolumn{4}{|c|}{$D 425 \mathrm{C}$} & \multicolumn{4}{|c|}{$0425 \mathrm{C}$} & \multicolumn{3}{|c|}{ D425C } & \multicolumn{3}{|c|}{ D425c } \\
\hline $\mathrm{Pec}$ & & Temp & & $R x$ & & Tenp & $\mathrm{SC}$ & Recl & & Temp & $\overline{S C}$ & $\mathrm{Rex}$ & & \begin{tabular}{|l|l} 
Temp & SC \\
\end{tabular} & $\mathrm{ReC}$ & & Temp SC \\
\hline \# & DetelTime & & $\mu \mathrm{sam}$ & $\#$ & Dete/Time & & psiom & & DaterTime & ${ }^{\circ} \mathrm{C}$ & sisom & \# & DaterTime & \begin{tabular}{|l|l|}
${ }^{\circ} \mathrm{C}$ & $\mu \mathrm{s} \mathrm{cm}$ \\
\end{tabular} & $\#$ & Date/Time & \begin{tabular}{|l|l|}
${ }^{\circ} \mathrm{H}$ & $\mu \mathrm{s} / \mathrm{m}$ \\
\end{tabular} \\
\hline & $8 / 132008$ 17:41 & 17.3 & 539.9 & & $8 / 13 / 200819.57$ & 17.3 & 540.7 & 1607 & $8 / 13 / 20082213$ & 17.4 & 536.3 & 4736 & 0080.29 & \begin{tabular}{|l|l|}
17.4 & 544.2 \\
\end{tabular} & & $8 / 142008245$ & \begin{tabular}{l|l}
17.3 & 5625 \\
\end{tabular} \\
\hline 4532 & $8 / 13 / 200817: 43$ & 17.3 & 539.6 & 4600 & $8 / 13 / 200819.59$ & 17.3 & 539.4 & 4008 & $8 / 1320082215$ & 17.3 & 537.9 & 4736 & $8 / 1420080.31$ & \begin{tabular}{|l|l|}
17.4 & 544.8 \\
\end{tabular} & 804 & 81142008247 & 5623 \\
\hline 4533 & $8 / 13 / 200817: 45$ & 17.3 & 538.6 & \begin{tabular}{|l|}
46007 \\
\end{tabular} & $8 / 13 / 200820: 01$ & 17.3 & 537.7 & 469 & $8 / 13 / 200822-17$ & 17.4 & 596.9 & 4737 & $8 / 14 / 20080.33$ & \begin{tabular}{|l|l|}
17.4 & 544.5 \\
\end{tabular} & b & $8 / 14 / 2008244$ & 17.3 \\
\hline & $8 / 13 / 2008$ 17:47 & 17.3 & 539.1 & 4600 & & 17.3 & 5384 & 4670 & $8 / 13 / 20082219$ & 17.3 & 537.1 & 47308 & & \begin{tabular}{|l|l|}
17.4 & 544.9 \\
\end{tabular} & & & \begin{tabular}{l|l|}
17.3 & 554.0
\end{tabular} \\
\hline 4536 & $8 / 13200817: 49$ & 17.3 & 539.9 & 4603 & $8 / 13 / 200820005$ & 17.3 & 539.4 & 4671 & $8 / 1320082221$ & 17.3 & 537.4 & 4739 & $8 / 1420080.37$ & \begin{tabular}{|l|l|}
17.4 & 545.8 \\
\end{tabular} & 4807 & $8 / 14 / 2008253$ & 17.3 \\
\hline 4536 & $8 / 13 / 200817: 51$ & 17.3 & 540.1 & 4604 & $8 / 13 / 200820007$ & 17.3 & 538.8 & 4672 & $8 / 13 / 20082223$ & 17.4 & 537.3 & 4740 & $8 / 14 / 20080.39$ & \begin{tabular}{|l|l|}
17.4 & 5460 \\
\end{tabular} & 4808 & $8 / 142008256$ & \begin{tabular}{l|l|}
17.3 & 550.5 \\
\end{tabular} \\
\hline 45037 & $8 / 13 / 200817: 53$ & 17.3 & 537.8 & 4606 & $8 / 13 / 200820: 09$ & 17.3 & 540.3 & 4673 & $813 / 20082225$ & 17.4 & 535.5 & \begin{tabular}{|l|}
4741 \\
\end{tabular} & $8 / 14 / 20080.41$ & \begin{tabular}{|l|l|}
17.4 & 546.2 \\
\end{tabular} & & $8 / 142008257$ & \begin{tabular}{|l|l|}
17.3 & 560.1 \\
\end{tabular} \\
\hline 4538 & $8 / 13 / 200817: 5$ & 17.3 & 539.0 & 4606 & $8 / 13 / 200820: 11$ & 17.3 & 538.9 & 4674 & $8 / 13 / 20082227$ & 17.4 & 535.4 & 4742 & $8 / 14 / 20080.43$ & \begin{tabular}{|l|l|}
17.4 & 5451 \\
\end{tabular} & 4810 & & \begin{tabular}{l|l}
17.3 & 550.9 \\
\end{tabular} \\
\hline 4539 & $8 / 13 / 2008$ 17:57 & 17.3 & 539.8 & 4607 & $8 / 13 / 200820: 13$ & 17.3 & 540.9 & 4675 & 811320082220 & 17.4 & 536.0 & \begin{tabular}{|l|}
4743 \\
\end{tabular} & $8 / 1420080.45$ & 5455 & 4811 & $8 / 1420003: 01$ & \begin{tabular}{|l|l|}
17.3 & 560.5 \\
\end{tabular} \\
\hline 4540 & $8 / 13 / 200817: 59$ & 17.3 & 536.8 & 4608 & $8 / 13 / 200820.15$ & 17.3 & 538.5 & 4676 & $8 / 1320082231$ & 17.4 & 536.8 & \begin{tabular}{|l|}
4744 \\
\end{tabular} & $8 / 1420080: 47$ & 5456 & 4812 & $8 / 14 / 20083: 03$ & \begin{tabular}{|l|l|}
17.3 & 551.0 \\
\end{tabular} \\
\hline 4541 & $8 / 13 / 2008$ 18:01 & 17.3 & & 4609 & $8 / 13 / 200820.17$ & 17.3 & 540.3 & 467 & $8 / 13 / 20082233$ & 17.4 & & 1745 & & \begin{tabular}{l|l|}
17.4 & 546.1 \\
\end{tabular} & & & \begin{tabular}{l|l|}
17.3 & 548.5 \\
\end{tabular} \\
\hline 4542 & $8 / 13 / 200818: 03$ & 17.3 & 539.5 & 4610 & $8 / 13 / 200820: 19$ & 17.3 & 537.2 & 4678 & $8 / 13 / 20082235$ & 17.4 & 538.6 & 4746 & $8 / 14 / 2$ & \begin{tabular}{l|l|}
17.4 & 546.2 \\
\end{tabular} & 4814 & $8 / 14 / 20083: 07$ & \begin{tabular}{|l|l|}
17.3 & 560.2 \\
\end{tabular} \\
\hline 4543 & $8 / 13 / 200818: 05$ & 17.3 & 539.4 & 4611 & $8 / 13 / 200820.21$ & 17.3 & 5384 & 4679 & $8 / 1320082237$ & 17.4 & 538.4 & 4747 & $8 / 14 / 20080.53$ & \begin{tabular}{|l|l|}
17.4 & 546.1 \\
\end{tabular} & 4815 & $8 / 14 / 20083: 00$ & \begin{tabular}{l|l|}
17.3 & 550.7 \\
\end{tabular} \\
\hline 4544 & $8 / 13 / 200818: 07$ & 17.3 & 539.3 & 4612 & $8 / 13200820: 23$ & 17.3 & 538.0 & 4680 & $8 / 1320082239$ & 17.4 & 540.3 & 4748 & $8 / 1420080.50$ & \begin{tabular}{|l|l|}
17.4 & 547.0 \\
\end{tabular} & 4816 & $8 / 14 / 20083: 11$ & \begin{tabular}{l|l}
17.3 & 550.2 \\
\end{tabular} \\
\hline 4545 & $8 / 13200818: 09$ & 17,3 & 540.5 & 4613 & $8 / 13 / 200020.25$ & 17.3 & 539.4 & 4681 & $8 / 13 / 20082241$ & 17.4 & 541.1 & 4749 & & \begin{tabular}{|l|l|}
17.4 & 547.1 \\
\end{tabular} & 4817 & & 17.3 \\
\hline 4546 & $8 / 13 / 200818: 11$ & 17.3 & 538.2 & 4614 & $8 / 13 / 200820: 27$ & 17.3 & 538.4 & 4682 & $8 / 13 / 20082243$ & 17.4 & 540.3 & 4750 & $8 / 14 / 20080.59$ & \begin{tabular}{|l|l|}
17.4 & 547.8 \\
\end{tabular} & 4818 & $8 / 14 / 20083: 15$ & \begin{tabular}{l|l}
17.3 & 549.9 \\
\end{tabular} \\
\hline 4547 & $8 / 13 / 200818: 13$ & 17.3 & 5380 & 4615 & $8 / 132$ & 17.3 & 5382 & 4683 & $8 / 1 / 20082245$ & 17.4 & 540.7 & 4751 & $8 / 14 / 2$ & \begin{tabular}{|l|l|}
17.4 & 547.2 \\
\end{tabular} & 4819 & $083: 17$ & \begin{tabular}{l|l|}
17.3 & 549.5 \\
\end{tabular} \\
\hline 4548 & $8 / 13 / 2$ & 17.3 & 537.7 & 4616 & $8 / 13 / 2$ & 17.3 & & 4684 & 82247 & 17.4 & 540.7 & 4752 & & \begin{tabular}{|l|l|}
17.4 & 546.9 \\
\end{tabular} & 4820 & & \begin{tabular}{|l|l|}
17.3 & 549.4 \\
\end{tabular} \\
\hline 4549 & $8 / 13 / 200818: 17$ & 17.3 & 5383 & 4617 & $8 / 13 / 2$ & 17.3 & 539.7 & 4686 & $8 / 13 / 20082249$ & 17.4 & 541.1 & 4753 & $8 / 142$ & \begin{tabular}{|l|l|}
17.4 & 546.8 \\
\end{tabular} & 4821 & $83: 21$ & \begin{tabular}{l|l|}
17.4 & 549.7 \\
\end{tabular} \\
\hline 4550 & $8 / 13 / 200818: 19$ & 17.3 & 5335 & 4618 & $820: 35$ & 17.3 & 539.9 & 4686 & $8 / 13 / 20082251$ & 17.4 & 540.3 & 4754 & $8 / 142$ & \begin{tabular}{|l|l|}
17.4 & 547.1 \\
\end{tabular} & 4822 & $83: 23$ & \begin{tabular}{|l|l|}
17.3 & 550.1
\end{tabular} \\
\hline 4551 & 18.21 & 17.3 & 539.0 & 4619 & 20.37 & 17.3 & 54 & 4687 & 082253 & 17.4 & 541.2 & 4755 & $8 / 14$ & \begin{tabular}{|l|l|}
17.4 & 547.8 \\
\end{tabular} & 4822 & $83: 25$ & \begin{tabular}{l|l}
17.3 & 550.1
\end{tabular} \\
\hline 4552 & $8 / 13 / 200818: 23$ & 17.3 & 539.4 & 4620 & $200: 39$ & 17.3 & 541.2 & 4688 & 82255 & 17.4 & 540.3 & 4756 & $8 / 14$ & \begin{tabular}{|l|l|}
17.4 & 548.4 \\
\end{tabular} & 4824 & $83: 27$ & \begin{tabular}{l|l|}
17.3 & 549.9 \\
\end{tabular} \\
\hline 4553 & $8 / 13 / 200818: 25$ & 17.3 & 537.5 & 4621 & $820: 41$ & 17.3 & 541.3 & 4639 & 082257 & 17.4 & 539.1 & 475र्त्र & $8 / 14$ & \begin{tabular}{|l|l|}
17.4 & 549.0 \\
\end{tabular} & 4825 & $83: 29$ & \begin{tabular}{l|l}
17.3 & 550.3 \\
\end{tabular} \\
\hline 4554 & $8 / 13 / 2$ & 17.3 & 533.1 & 4622 & $20: 43$ & 17.3 & 540.7 & 4690 & 82259 & 17.4 & 539.0 & 4758 & $8 / 14$ & \begin{tabular}{|l|l|}
17.4 & 548.4 \\
\end{tabular} & 4826 & $33: 31$ & \begin{tabular}{c|c|}
17.3 & 549.1 \\
\end{tabular} \\
\hline 4565 & $00818: 29$ & 17.3 & & 4623 & $8 / 13 / 2$ & 17.3 & & 4691 & $823: 01$ & 17.4 & 537.5 & 4750 & & \begin{tabular}{l|l|}
17.4 & 548 \\
\end{tabular} & 4827 & & \begin{tabular}{l|l|}
17.3 & 550.1 \\
\end{tabular} \\
\hline 4556 & $8 / 13 / 200818: 31$ & 17.3 & 538.9 & 4624 & $8 / 13 / 200820: 47$ & 17.3 & 540.3 & 4692 & $8823: 03$ & 17.4 & 538.1 & 4760 & $1: 19$ & \begin{tabular}{|l|l|}
17.4 & 548.1 \\
\end{tabular} & 828 & 83:30 & \begin{tabular}{l|l}
17.3 & 549.5 \\
\end{tabular} \\
\hline 4507 & $8 / 13 / 2$ & 17.3 & 5420 & 4625 & $8 / 132$ & 17.3 & 540.3 & 4603 & $323: 05$ & 17.4 & 538.3 & 761 & & \begin{tabular}{|l|l|}
17.4 & 547.1 \\
\end{tabular} & 829 & $3: 37$ & \begin{tabular}{l|l}
17.3 & 549.8 \\
\end{tabular} \\
\hline 4558 & 00818.35 & 17.3 & 541.0 & 4626 & $8 / 13 / 2$ & 17.3 & & 4694 & 00823.07 & 17.4 & 539.0 & & & \begin{tabular}{l|l|}
17.4 & 548.5 \\
\end{tabular} & 830 & $83: 39$ & \begin{tabular}{l|l|l|}
17.3 & 550.4 \\
\end{tabular} \\
\hline 4569 & $00818: 37$ & 17.3 & 541.6 & 4627 & 820.53 & 17.4 & & 4695 & $00823: 09$ & 17.4 & 538.0 & 4763 & $8 / 142$ & 5486 & 4831 & $83: 41$ & \begin{tabular}{l|l}
17.3500 .6 \\
\end{tabular} \\
\hline 4560 & $8 / 13$ & 17.3 & 541.9 & 4628 & $8 / 13$ & 17.3 & 5386 & 4696 & 23:11 & 17.4 & 537.4 & 4764 & $8 / 14$ & \begin{tabular}{|l|l|}
17.4 & 547.2 \\
\end{tabular} & 4832 & $3: 43$ & $\begin{array}{ll}17.3 & 550.6\end{array}$ \\
\hline 4561 & $18: 41$ & 17.3 & 5421 & 4629 & $8 / 13$ & 17.3 & & 4697 & $23: 13$ & 17.4 & 538.2 & 4765 & & \begin{tabular}{l|l}
17.4 & 547.7 \\
\end{tabular} & 333 & & \begin{tabular}{l|l|}
17.3 & 550.4 \\
\end{tabular} \\
\hline 4562 & $8 / 132$ & 17.3 & 540.5 & 4630 & $8 / 13 / 2$ & 17.3 & & 4698 & B23:15 & 17.4 & 538.3 & & & \begin{tabular}{l|l|}
17.4 & 547.2 \\
\end{tabular} & 4834 & 83:47 & \begin{tabular}{l|l}
17.3 & 560.4 \\
\end{tabular} \\
\hline 4563 & 18:45 & 17.3 & 540.9 & 4631 & $8 / 13$ & 17.3 & 539. & 4699 & 823:17 & 17.4 & 539.1 & 4767 & & \begin{tabular}{l|l}
17.4 & 547.7 \\
\end{tabular} & 4835 & & \begin{tabular}{l|l|}
17.3 & 550.7 \\
\end{tabular} \\
\hline 4564 & $8 / 13$ & 17.3 & 541. & 4632 & 21:03 & 17.3 & 538 & 4700 & 23:19 & 17.4 & 539.1 & 4768 & & $\begin{array}{ll}17.4 & 548.5 \\
\end{array}$ & 4806 & & $\begin{array}{lll}17.3 & 550 .\end{array}$ \\
\hline 4565 & $8 / 13 / 200818: 49$ & 17.3 & 540.2 & 4633 & $8 / 13200021: 05$ & 17.3 & & 47001 & $823: 21$ & 17.4 & 539.5 & 4769 & $8 / 14 / 2$ & \begin{tabular}{l|l|}
17.4 & 547. \\
\end{tabular} & 4837 & $83: 53$ & \begin{tabular}{l|l}
17.3 & 550. \\
\end{tabular} \\
\hline 4566 & $8 / 13 / 200818: 51$ & 17.3 & 540.8 & 4634 & $8 / 13 / 200821: 07$ & 17.3 & 537.2 & 4702 & 82323 & 17.4 & 539 & 4770 & & \begin{tabular}{l|l|}
17.4 & 547. \\
\end{tabular} & 4838 & 83:50 & \begin{tabular}{|l|l|}
17.3 & 550.8
\end{tabular} \\
\hline 4567 & & 17.3 & 540.5 & 4635 & $8 / 13$ & 17.3 & 536.8 & 4703 & 323.25 & 17.4 & 540. & 4771 & & \begin{tabular}{l|l|}
17.4548 \\
\end{tabular} & $189 x$ & $3: 57$ & \begin{tabular}{|l|l}
17.3 & 560
\end{tabular} \\
\hline 4568 & $18: 56$ & 17.3 & 540.5 & 4636 & 21:11 & 17.3 & 538 & 4704 & $323: 27$ & 17.4 & 540 & 4772 & & \begin{tabular}{|l|l|}
17.4 & 547
\end{tabular} & 4840 & & \begin{tabular}{|l|l}
17.3 & 550.
\end{tabular} \\
\hline 4569 & 318:57 & 17.3 & 540.5 & \begin{tabular}{|l|}
4637 \\
\end{tabular} & & 17.3 & & 4705 & & 17.4 & 540. & $47 \pi 3$ & & \begin{tabular}{l|l}
17.4 & 547
\end{tabular} & 4841 & $34: 01$ & \begin{tabular}{|l|l}
17.3 & 560.4 \\
\end{tabular} \\
\hline $45 \pi 0$ & & 17.3 & 540.4 & 4638 & & 17.3 & 538. & 4706 & 3.31 & 17.4 & 542 & 4774 & & \begin{tabular}{l|l}
17.4 & 547.
\end{tabular} & 4842 & & \begin{tabular}{|l|l|l}
17.3 & 560. \\
\end{tabular} \\
\hline 4571 & 319.01 & 17.3 & 539.1 & 4639 & $2: 17$ & 17.3 & & 4707 & 2033 & 17.4 & 541 & & & \begin{tabular}{l|l}
17.3 & 548
\end{tabular} & 4843 & 4:05 & \begin{tabular}{l|l}
17.3 & 550.4
\end{tabular} \\
\hline $45 / 2$ & $19: 03$ & 17.3 & 539.3 & 4640 & & 17.3 & \begin{tabular}{|l|}
538.3 \\
\end{tabular} & 4708 & 23.36 & 17.4 & 541 & 4776 & & \begin{tabular}{l|l}
17.4 & 547
\end{tabular} & 4844 & $84: 07$ & \begin{tabular}{c|c}
17.3 & 550.3
\end{tabular} \\
\hline 4573 & & 17.3 & 539. & 4641 & & 17.3 & & 4709 & 3.37 & 17.4 & 541 & $47 \pi$ & & \begin{tabular}{l|l}
17.4 & 547.
\end{tabular} & 45 & & \begin{tabular}{|l|l}
17.3 & 550.4
\end{tabular} \\
\hline 4574 & 99.07 & 17.3 & 539 & 4642 & & 17.3 & & 4710 & 3.39 & 17.4 & 542 & & & \begin{tabular}{|l|l}
17.3 & 548.
\end{tabular} & 4846 & $4: 11$ & \begin{tabular}{l|l}
17.3 & 550. \\
\end{tabular} \\
\hline 4575 & & 17.3 & 540.2 & \begin{tabular}{|l|l|}
4643 \\
\end{tabular} & $21: 25$ & 17.3 & 537.8 & 4711 & $23: 41$ & 17.4 & 541 & $47 \pi 9$ & & \begin{tabular}{l|l}
17.4 & 545 \\
\end{tabular} & 4847 & 14:13 & \begin{tabular}{l|l}
17.3 & 550.0
\end{tabular} \\
\hline $45 \pi 6$ & & 17.3 & 540. & \begin{tabular}{|l|}
4644 \\
\end{tabular} & & 17.3 & 538 & 4712 & $20: 43$ & 17.4 & 541 & & & \begin{tabular}{|l|l|}
17.4 & 562 \\
\end{tabular} & 348 & & \begin{tabular}{|l|l}
17.3 & 550.
\end{tabular} \\
\hline 45ता & & 17.3 & 540. & 4645 & & 17.3 & & & & 17.4 & 542 & & & \begin{tabular}{l|l}
17.3 & 546
\end{tabular} & 1849 & & \begin{tabular}{l|l}
17.3 & 550.
\end{tabular} \\
\hline 4578 & 19.15 & 17.3 & 540.1 & 4646 & $1: 31$ & 17.3 & 538.7 & 4714 & $23: 47$ & 17.3 & 5424 & \begin{tabular}{|l|}
4782 \\
\end{tabular} & $\overline{8 / 14}$ & \begin{tabular}{l|l}
17.4 & 560.
\end{tabular} & 4850 & 4:19 & \begin{tabular}{l|l}
$17.3 \quad 550.6$
\end{tabular} \\
\hline & & 17.3 & 540. & \begin{tabular}{|l|}
4647 \\
\end{tabular} & & 17.3 & 538 & 4715 & & 17.4 & 541 & \begin{tabular}{|l|}
4783 \\
\end{tabular} & & \begin{tabular}{l|l|l}
17.4 & 552 \\
\end{tabular} & 851 & & \begin{tabular}{|l|l}
17.3 & 550.8
\end{tabular} \\
\hline 4580 & & 17.3 & $5 x$ & \begin{tabular}{|l|}
4648 \\
\end{tabular} & & 17.3 & & & & 17.4 & 54 & & & \begin{tabular}{l|l|l}
17.4 & 56
\end{tabular} & 4852 & & \begin{tabular}{l|l}
17.3 & 551.
\end{tabular} \\
\hline 4581 & 19.21 & 17.2 & 517. & 4649 & 1:37 & 17.3 & 537. & 4717 & 23.53 & 17.4 & 542 & 4785 & & \begin{tabular}{l|l}
17.4 & 557
\end{tabular} & 4853 & $34: 25$ & \begin{tabular}{l|l}
17.3 & 551.
\end{tabular} \\
\hline 4582 & & 17.3 & 534 & 4650 & & 17.3 & 538 & 18 & & 17.4 & 54 & & & \begin{tabular}{l|l}
17.4 & 557
\end{tabular} & 854 & & $\begin{array}{ll}17.3 & 550\end{array}$ \\
\hline 4583 & 19.25 & 17.3 & $53 x$ & 4651 & & & & & & 17.4 & 54 & & & \begin{tabular}{|l|l}
17.4 & 557 \\
\end{tabular} & & & \begin{tabular}{l|l}
17.3 & 550.
\end{tabular} \\
\hline 4584 & 319.27 & 17.3 & 5328 & \begin{tabular}{|l|l|}
4652 \\
\end{tabular} & $321: 43$ & 17.3 & 538.4 & 4720 & 323.59 & 17.4 & 5429 & \begin{tabular}{|l|}
4788 \\
\end{tabular} & $8 / 14$ & \begin{tabular}{l|l}
17.4566. \\
\end{tabular} & 4856 & $4: 31$ & \begin{tabular}{|l|l}
17.3 & 550.4 \\
\end{tabular} \\
\hline 4585 & 19.29 & 17.3 & 535. & 4653 & & 17.3 & 538. & 4721 & & 17.4 & 543. & 4789 & & 17.3556 & 4807 & & \begin{tabular}{|l|l}
17.3 & 550.5
\end{tabular} \\
\hline & & 17.3 & 536 & 4654 & & & & & & 17.4 & & & & 17.4564 & & & \begin{tabular}{|l|l}
17.3 & 550. \\
\end{tabular} \\
\hline 4587 & 819.33 & 17.3 & 533. & \begin{tabular}{|l|l|}
4655 \\
\end{tabular} & $21: 49$ & 17.3 & 538.3 & 4723 & 880.05 & 17.4 & 542 & \begin{tabular}{|l|}
4791 \\
\end{tabular} & & \begin{tabular}{|l|l|}
17.3 & 564 \\
\end{tabular} & 4859 & 44:37 & \begin{tabular}{l|l}
17.3 & 550.4 \\
\end{tabular} \\
\hline 4588 & 819.35 & 17.3 & 536. & 4656 & & 17.4 & 537.7 & 4724 & & 17.4 & 543 & 4792 & & \begin{tabular}{l|l|}
17.4 & 564 \\
\end{tabular} & 4860 & & \begin{tabular}{l|l}
17.3550 .3 \\
\end{tabular} \\
\hline 4580 & $819: 37$ & 17.3 & 538 & 460 ? & & & 536. & & & 17.4 & 543 & & & $\begin{array}{ll}17.4 \quad 552 \\
\end{array}$ & 49 & & \begin{tabular}{l|l}
17.3 & 549. \\
\end{tabular} \\
\hline 4500 & $19: 39$ & 17.3 & 537. & & $1: 55$ & 17.3 & 537. & 4726 & 80.11 & 17.4 & 54 & 4794 & & $\begin{array}{ll}17.4 & 553 \\
\end{array}$ & 4862 & $4: 43$ & \begin{tabular}{l|l}
17.3 & 549. \\
\end{tabular} \\
\hline 4591 & $8 / 13 / 200819.41$ & 17.3 & 536. & 4659 & $8 / 13 / 2$ & 17.3 & 537. & 4727 & & 17.4 & 543 & 4796 & & \begin{tabular}{l|l}
$17.350^{2}$ \\
\end{tabular} & 4863 & & \begin{tabular}{l|l}
17.3 & 549. \\
\end{tabular} \\
\hline 4592 & $0819: 43$ & 17.3 & 539 & 4660 & & 17.3 & 538 & 4728 & & 17.4 & $54^{2}$ & 4796 & & \begin{tabular}{l|l}
17.3 & 55 \\
\end{tabular} & 864 & & \begin{tabular}{l|l}
17.3 & 549. \\
\end{tabular} \\
\hline 4593 & $0819: 45$ & 17.3 & 540 & 4661 & & & 538 & & & & & & & \begin{tabular}{l|l}
17.3 & 55 \\
\end{tabular} & 4865 & & \begin{tabular}{l|l}
17.3 & 549. \\
\end{tabular} \\
\hline 4594 & $8 / 13 / 200819: 47$ & 17.3 & 538. & 4602 & 0822.03 & 17.3 & 536. & 4730 & $8 / 1420080: 19$ & 17.4 & 543 & 4798 & $8 / 14 / 2$ & \begin{tabular}{l|l|}
17.3 & 550 \\
\end{tabular} & 4806 & $34: 51$ & \begin{tabular}{l|l}
17.3 & 549. \\
\end{tabular} \\
\hline 4505 & 200819.49 & 17.3 & 537. & 4663 & 22205 & 17.3 & 533 & 4731 & & 17.4 & 542 & 4799 & & \begin{tabular}{l|l}
17.3 & 550 \\
\end{tabular} & 4967 & & \begin{tabular}{l|l|}
17.3 & 549. \\
\end{tabular} \\
\hline 4596 & 0819.51 & 17.3 & 540 & & & & & & & & & & & \begin{tabular}{l|l|}
17.3552 \\
\end{tabular} & 4868 & & \begin{tabular}{l|l}
17.3 & 548. \\
\end{tabular} \\
\hline 4597 & $8 / 13 / 200819.53$ & 17.3 & 539.1 & 4605 & $8 / 13 / 20082200$ & 17.3 & 537.4 & 4733 & $8 / 14 / 20080.25$ & 17.4 & 544. & 4801 & $814 / 2$ & \begin{tabular}{|l|l|}
17.3 & 551.8 \\
\end{tabular} & 4869 & $34: 57$ & \begin{tabular}{|l|l|}
17.3 & 549.4 \\
\end{tabular} \\
\hline 4898 & 00819.55 & 17.3 & 539. & 4666 & 2211 & 17.4 & 537.6 & 4734 & $080: 27$ & 17.4 & $\overline{544.0}$ & 4800 & $8 / 142$ & \begin{tabular}{|l|l|}
17.4 & 551.6 \\
\end{tabular} & 4870 & $8 / 14 / 20084: 59$ & \begin{tabular}{l|l}
17.3 & 549.3 \\
\end{tabular} \\
\hline
\end{tabular}




\begin{tabular}{|c|c|c|c|c|c|c|c|c|c|c|c|c|c|c|}
\hline \multicolumn{3}{|c|}{$D 425 c$} & \multicolumn{3}{|c|}{$D 425 C$} & \multicolumn{3}{|c|}{$D 425 c$} & \multicolumn{3}{|c|}{ D425c } & \multicolumn{3}{|c|}{$D 4-25 c$} \\
\hline $\operatorname{Rec}$ & & Temp SC & $a c$ & & Temp & $\operatorname{Rec}$ & & Temp & $R e c$ & & Temp & $\mathrm{F} \in \mathrm{C}$ & & Temp \\
\hline$\#$ & Date/ime & \begin{tabular}{l|l|}
${ }^{\circ} \mathrm{C}$ & $\mu \mathrm{s} / \mathrm{m}$ \\
\end{tabular} & \# & Dete/Time & \begin{tabular}{l|l|}
${ }^{\circ} \mathrm{C}$ & $1 \mathrm{Som}$ \\
\end{tabular} & \#\# & Deterime & \begin{tabular}{|l|l|l|l|l}
${ }^{\circ} \mathrm{C}$ & . \\
\end{tabular} & $\#$ & DateTime & \begin{tabular}{|l|l|}
${ }^{\circ} \mathrm{C}$ & $\mu \mathrm{s} / \mathrm{mm}$ \\
\end{tabular} & \# & DeteTime & \begin{tabular}{c|c|}
${ }^{\circ} \mathrm{C}$ & $\mu \mathrm{som}$ \\
\end{tabular} \\
\hline & 8/14/20085:01 & \begin{tabular}{l|l|}
17.3 & 549.8 \\
\end{tabular} & & $8 / 14 / 20087: 17$ & \begin{tabular}{l|l|}
17.3 & 557.3 \\
\end{tabular} & 007 & $8 / 1420089.33$ & \begin{tabular}{|l|l|}
17.3 & 560.8 \\
\end{tabular} & & $8 / 14 / 200811: 49$ & \begin{tabular}{|l|l|}
17.3 & 564.8 \\
\end{tabular} & 5143 & $8 / 14 / 2008$ 14:06 & \begin{tabular}{|l|l|}
17.3551 .1 \\
\end{tabular} \\
\hline & $8 / 14 / 20085: 03$ & \begin{tabular}{|l|l|}
17.3 & 549.9 \\
\end{tabular} & 440 & 8/14/20087:19 & \begin{tabular}{l|l|}
17.3 & 507.1 \\
\end{tabular} & 5008 & $8 / 1420089.35$ & \begin{tabular}{|l|l|}
17.3 & 564.4 \\
\end{tabular} & & $8 / 14 / 200811: 51$ & \begin{tabular}{|l|l|}
17.3 & 564.9 \\
\end{tabular} & & 08 14:07 & 17.3 \\
\hline & $8 / 1420085: 06$ & \begin{tabular}{|l|l|}
17.3 & 549.7 \\
\end{tabular} & 4941 & $8 / 14 / 20087: 21$ & \begin{tabular}{|l|l|}
17.3 & 507.7 \\
\end{tabular} & 5009 & $8 / 1420089.37$ & \begin{tabular}{l|l|}
17.3565 .2 \\
\end{tabular} & 507 & $8 / 14 / 200811: 53$ & \begin{tabular}{|l|l|}
17.3 & 564.8 \\
\end{tabular} & 145 & 142008 14:09 & \begin{tabular}{|l|l|}
17.3 & 550.1 \\
\end{tabular} \\
\hline & $814 / 20085: 07$ & \begin{tabular}{|l|l|}
17.3 & 550.2 \\
\end{tabular} & 4942 & $8 / 14 / 20087: 23$ & \begin{tabular}{l|l|l|}
17.4 & 567.7 \\
\end{tabular} & 5010 & $8 / 1420089.39$ & \begin{tabular}{l|l|}
17.3 & 560.1 \\
\end{tabular} & & $8 / 14 / 200811: 50$ & \begin{tabular}{l|l|}
17.3 & 564.8 \\
\end{tabular} & & 142008 14:11 & \begin{tabular}{|l|l|}
17.3 & 553.6 \\
\end{tabular} \\
\hline & $81420085: 09$ & \begin{tabular}{l|l|}
17.3 & 550.5 \\
\end{tabular} & 943 & $8 / 14 / 20087: 25$ & \begin{tabular}{|l|l|}
17.3 & 569.1 \\
\end{tabular} & 5011 & $8 / 1420089.41$ & \begin{tabular}{l|l}
17.3 & 566.1 \\
\end{tabular} & & $8 / 142008$ 11:50 & \begin{tabular}{l|l|}
17.3 & 564.5 \\
\end{tabular} & $\overline{147}$ & $8 / 142008$ 14:13 & \begin{tabular}{l|l|}
17.3 & 553.5 \\
\end{tabular} \\
\hline 876 & $8 / 14 / 20085: 11$ & \begin{tabular}{|l|l|}
17.3 & 550.4 \\
\end{tabular} & 4944 & $8 / 14 / 20087: 27$ & \begin{tabular}{|l|l|}
17.3 & 568.2 \\
\end{tabular} & 5012 & $8 / 14 / 20089.43$ & \begin{tabular}{|l|l|}
17.3 & 566.3 \\
\end{tabular} & 5080 & $8 / 14 / 200811: 59$ & \begin{tabular}{|l|l|}
17.3 & 564.0 \\
\end{tabular} & 5148 & 8142008 14:15 & \begin{tabular}{|l|l|}
17.3 & 554.7 \\
\end{tabular} \\
\hline 87T- & $8 / 14 / 20085: 13$ & \begin{tabular}{|l|l|}
17.3 & 550.7 \\
\end{tabular} & 4945 & $8 / 14 / 20087: 20$ & \begin{tabular}{|l|l|}
17.3 & 567.4 \\
\end{tabular} & 5013 & $8 / 1420089.45$ & 566.3 & 5081 & $8 / 14 / 20081201$ & \begin{tabular}{l|l|}
17.3 & 550.1 \\
\end{tabular} & 5149 & $8 / 142008$ 14:17 & \begin{tabular}{l|l|}
17.3 & 554.2 \\
\end{tabular} \\
\hline & 81/420085:15 & \begin{tabular}{l|l|}
17.3 & 550.9 \\
\end{tabular} & 4946 & & \begin{tabular}{l|l|}
17.3 & 507.1 \\
\end{tabular} & 5014 & & \begin{tabular}{l|l}
17.3 & 565.7 \\
\end{tabular} & 5082 & $8 / 14 / 20081203$ & \begin{tabular}{|l|l|}
17.3 & 563.3 \\
\end{tabular} & & & \begin{tabular}{l|l}
17 & 55
\end{tabular} \\
\hline 79 & $8 / 14 / 20085: 17$ & \begin{tabular}{|l|l|}
17.3 & 551.1 \\
\end{tabular} & 4947 & $8 / 1420087: 33$ & \begin{tabular}{l|l|}
17.3 & 55.7 \\
\end{tabular} & 5015 & $8 / 1420089.49$ & \begin{tabular}{l|l}
17.3 & 565.5 \\
\end{tabular} & 5083 & $8 / 14 / 20081205$ & \begin{tabular}{|l|l|}
17.3 & 5627 \\
\end{tabular} & 5151 & $8 / 142008$ 14:21 & 17.3 \\
\hline 800 & $81420085: 19$ & \begin{tabular}{|l|l|}
17.3 & 551.4 \\
\end{tabular} & 4948 & $8 / 14 / 20087: 30$ & \begin{tabular}{l|l|}
17.3 & 557.6 \\
\end{tabular} & 5016 & $8 / 1420089.51$ & \begin{tabular}{|l|l|}
17.3 & 564.4 \\
\end{tabular} & 5084 & $8 / 14 / 20081207$ & \begin{tabular}{|l|l|}
17.3 & 5529 \\
\end{tabular} & 5152 & $8 / 142008$ 14:23 & 553.8 \\
\hline 81 & $8 / 14 / 20085: 27$ & \begin{tabular}{|l|l|}
17.3 & 551.3 \\
\end{tabular} & 4949 & $8 / 14 / 20087: 37$ & \begin{tabular}{|l|l|}
17.3 & 508.1 \\
\end{tabular} & 5017 & $8 / 1420089.53$ & \begin{tabular}{|l|l|}
17.3 & 563.1 \\
\end{tabular} & 5085 & $8 / 1420081209$ & \begin{tabular}{|l|l|}
17.3 & 553.3 \\
\end{tabular} & 5153 & $8 / 14200814: 25$ & 17.3 \\
\hline 82 & $8 / 14 / 20085: 23$ & \begin{tabular}{l|l|}
17.3 & 551.7 \\
\end{tabular} & 4950 & $8 / 14 / 20087: 39$ & \begin{tabular}{l|l|}
17.3 & 558.4 \\
\end{tabular} & $5 \mathrm{Mg}$ & $8 / 1420089.50$ & \begin{tabular}{l|l|}
17.3 & 5028 \\
\end{tabular} & & $8 / 14 / 20081211$ & \begin{tabular}{|l|l|}
17.3 & 553.3 \\
\end{tabular} & & & 17.3 \\
\hline 883 & $8 / 14 / 20085: 25$ & \begin{tabular}{l|l}
17.3 & 551.6 \\
\end{tabular} & 4951 & $8 / 14 / 20087: 41$ & \begin{tabular}{l|l|}
17.3 & 55.7 \\
\end{tabular} & 5019 & $8 / 1420089.57$ & 550.6 & 5087 & $8 / 14 / 20081213$ & \begin{tabular}{|l|l|}
17.3 & 553.7 \\
\end{tabular} & 5155 & $8 / 14200814: 2$ & 17.3 \\
\hline 384 & $814 / 20085: 27$ & \begin{tabular}{l|l|}
17.3 & 551.7 \\
\end{tabular} & 4952 & $8 / 14 / 20087: 43$ & \begin{tabular}{l|l|}
17.3 & 558.3 \\
\end{tabular} & 5020 & $8 / 14 / 20089.59$ & \begin{tabular}{|l|l|}
17.3 & 558.9 \\
\end{tabular} & 5088 & $8 / 1420001215$ & \begin{tabular}{l|l|}
17.3 & 553.9 \\
\end{tabular} & 5156 & $0814: 31$ & 17.3 \\
\hline 85 & $8 / 14 / 20085: 29$ & \begin{tabular}{l|l|}
17.3 & 551.9 \\
\end{tabular} & 4953 & $8 / 14 / 20087: 45$ & \begin{tabular}{l|l|}
17.3 & 558.9 \\
\end{tabular} & 50021 & $8 / 14 / 2$ & \begin{tabular}{|l|l|}
17.3 & 557.9 \\
\end{tabular} & 5089 & $8 / 1420081217$ & \begin{tabular}{|l|l|}
17.3 & 564.5 \\
\end{tabular} & 515 & 88 14:33 & 17.3 \\
\hline 306 & $8 / 14 / 20085: 31$ & \begin{tabular}{l|l|}
17.3 & 551.5 \\
\end{tabular} & 4954 & $8 / 1420037: 47$ & \begin{tabular}{l|l|}
17.3 & 558.8 \\
\end{tabular} & 5022 & $8 / 142$ & \begin{tabular}{l|l|}
17.3 & 558.1 \\
\end{tabular} & 5090 & 81219 & \begin{tabular}{|l|l|}
17.3 & 554.6 \\
\end{tabular} & 5158 & 08 14:35 & \begin{tabular}{l|l|}
17.3 & 555.0 \\
\end{tabular} \\
\hline 1887 & $8 / 14 / 20085: 33$ & \begin{tabular}{|l|l|}
17.3 & 5020 \\
\end{tabular} & 4956 & $8 / 14 / 20087: 49$ & 509.2 & 5023 & $8 / 14 / 2008$ 10:05 & 17.3 & 5091 & 81221 & \begin{tabular}{l|l}
17.3 & 555.5 \\
\end{tabular} & 5159 & 28 14:37 & \begin{tabular}{l|l|}
17.3 & 555.3 \\
\end{tabular} \\
\hline 888 & $8 / 14 / 20085: 33$ & \begin{tabular}{|l|l|}
17.3 & 5521 \\
\end{tabular} & 4956 & $8 / 1420$ & \begin{tabular}{|l|l|}
17.3 & 559.9 \\
\end{tabular} & 5024 & $310: 07$ & \begin{tabular}{l|l|}
17.3 & 507.8 \\
\end{tabular} & 5092 & 31223 & \begin{tabular}{|l|l|}
17.3 & 566.0 \\
\end{tabular} & 176 & 314:39 & \begin{tabular}{l|l|}
17.3 & 556.1 \\
\end{tabular} \\
\hline & $8 / 14 / 20085: 37$ & \begin{tabular}{|l|l|}
17.3 & 5524 \\
\end{tabular} & 4957 & $8 / 14 / 2$ & \begin{tabular}{l|l}
17.3 & 559.2 \\
\end{tabular} & 5025 & $8 / 14 / 2$ & \begin{tabular}{|l|l|}
17.3 & 556.1 \\
\end{tabular} & 5093 & 31225 & \begin{tabular}{|l|l|}
17.3 & 566.6 \\
\end{tabular} & & 314:41 & \begin{tabular}{l|l}
17.3 & 556.4 \\
\end{tabular} \\
\hline 890 & $8 / 14 / 20085: 39$ & \begin{tabular}{l|l|}
17.3 & 5527 \\
\end{tabular} & 4958 & $8 / 14 / 20087: 50$ & \begin{tabular}{l|l|}
17.3 & 558.2 \\
\end{tabular} & 5026 & $8 / 14 / 2008$ 10:11 & \begin{tabular}{l|l|}
17.3 & 555.9 \\
\end{tabular} & 5094 & $8 / 14 / 20081227$ & \begin{tabular}{|l|l|}
17.3 & 566.3 \\
\end{tabular} & 5162 & $0814: 43$ & \begin{tabular}{l|l}
17.3 & 556.3 \\
\end{tabular} \\
\hline 1891 & $8 / 1420008541$ & \begin{tabular}{l|l|}
17.3 & 5524 \\
\end{tabular} & 4959 & 81412 & \begin{tabular}{l|l|}
17.3 & 508.4 \\
\end{tabular} & 5007 & 10:13 & \begin{tabular}{l|l|}
17.3 & 556.8 \\
\end{tabular} & 5005 & 3122 & \begin{tabular}{l|l|}
17.3 & 566.3 \\
\end{tabular} & 5163 & $314: 45$ & 17.3 \\
\hline 1892 & $8114 / 20085: 43$ & \begin{tabular}{|l|l|}
17.3 & 5524 \\
\end{tabular} & 4960 & $8 / 14 / 2$ & 17.3 & 5028 & $8 / 14 /$ & \begin{tabular}{l|l}
17.3 & 557.7 \\
\end{tabular} & 5006 & 31231 & \begin{tabular}{l|l}
17.3 & 556.8 \\
\end{tabular} & 164 & & \begin{tabular}{l|l}
17.3 & 557.2
\end{tabular} \\
\hline 1893 & $8 / 14 / 20085445$ & \begin{tabular}{l|l|}
17.3 & 5525 \\
\end{tabular} & 4961 & $8 / 14 / 2$ & \begin{tabular}{l|l|}
17.3 & 550.0 \\
\end{tabular} & 5029 & $8 / 14 / 2$ & 17.3 & 5097 & 31233 & \begin{tabular}{|l|l|}
17.3 & 556.9 \\
\end{tabular} & 165 & 314:49 & \begin{tabular}{l|l}
17.3 & 557.6 \\
\end{tabular} \\
\hline 894 & $8 / 14 / 20085447$ & \begin{tabular}{l|l}
17.3 & 5525 \\
\end{tabular} & 4962 & $8 / 14 /$ & \begin{tabular}{l|l|}
17.3 & 558.6 \\
\end{tabular} & 5030 & $8 / 14 / 2$ & \begin{tabular}{l|l|}
17.3 & 557.0 \\
\end{tabular} & 5098 & 31235 & \begin{tabular}{l|l|}
17.3 & 557.1 \\
\end{tabular} & 5166 & 14:51 & \begin{tabular}{l|l}
17.3 & 557.7 \\
\end{tabular} \\
\hline 1895 & $8 / 14 / 20085449$ & \begin{tabular}{l|l|}
17.3 & 550.2 \\
\end{tabular} & 4963 & $8 / 14 / 2$ & 17.3 & 5001 & $8 / 14$ & \begin{tabular}{l|l}
17.3 & 507.3 \\
\end{tabular} & 009 & 1237 & \begin{tabular}{l|l}
17.3 & 567.4 \\
\end{tabular} & 167 & 14:53 & \begin{tabular}{l|l}
17.3 & 558.8 \\
\end{tabular} \\
\hline 896 & $8 / 14 / 2008555$ & \begin{tabular}{|l|l|}
17.3 & 541.0 \\
\end{tabular} & 4964 & $8 / 14 / 2$ & \begin{tabular}{l|l|}
17.3 & 558.3 \\
\end{tabular} & & $8 / 14$ & 17.3 & 5100 & 1239 & $\begin{array}{l}17.3 \\
57 .\end{array}$ & 160 & $314: 55$ & \begin{tabular}{l|l}
17.3 & 558.9 \\
\end{tabular} \\
\hline 4897 & $8 / 14 / 20085553$ & \begin{tabular}{|l|l|}
17.3 & 545.2 \\
\end{tabular} & 4965 & $8 / 14 / 2$ & \begin{tabular}{|l|l|}
17.3 & 559.0 \\
\end{tabular} & 5003 & 310.25 & 17.3 & 5101 & 31241 & \begin{tabular}{l|l}
17.3 & 557.5 \\
\end{tabular} & 1100 & 14:5n & 17.3558 .8 \\
\hline 896 & $8 / 14 / 20$ & \begin{tabular}{l|l|}
17.3 & 5484 \\
\end{tabular} & 4906 & $8 / 14 / 2$ & 17.3 & 5034 & $8 / 14 / 2$ & \begin{tabular}{l|l}
17.3 & 557.2 \\
\end{tabular} & 5102 & 31243 & \begin{tabular}{l|l}
17.3 & 567.6 \\
\end{tabular} & 5170 & $14: 59$ & \begin{tabular}{l|l}
17.3 & 550.4 \\
\end{tabular} \\
\hline 489 & $8 / 14 / 2008555$ & \begin{tabular}{l|l|}
17.3 & 551.3 \\
\end{tabular} & 4967 & $814 /$ & 17.3 & 5035 & $8 / 14$ & \begin{tabular}{l|l}
17.3 & 556.0 \\
\end{tabular} & 5103 & 1245 & \begin{tabular}{l|l}
17.3 & 557.6 \\
\end{tabular} & 5171 & 15:01 & \begin{tabular}{l|l}
17.3 & 55 \\
\end{tabular} \\
\hline 900 & $8 / 142008559$ & \begin{tabular}{|l|l|}
17.3 & 551.1 \\
\end{tabular} & 4968 & $8 / 14 / 2$ & 17.3 & 5036 & 10:31 & 17.3 & 5104 & 31247 & \begin{tabular}{l|l|}
17.3 & 587.6 \\
\end{tabular} & 172 & $315: 03$ & \begin{tabular}{l|l}
17.3 & 558.2
\end{tabular} \\
\hline 901 & $8 / 14 /$ & \begin{tabular}{l|l}
17.3 & 551.8 \\
\end{tabular} & 4969 & $8 / 14$ & 17.3 & 5037 & $0: 33$ & \begin{tabular}{l|l|}
17.3 & 553.9 \\
\end{tabular} & 5105 & 1249 & \begin{tabular}{l|l|l}
17.3 & 557.5 \\
\end{tabular} & 173 & $15: 05$ & 17.3 \\
\hline 1900 & $8 / 14 / 20086003$ & \begin{tabular}{ll|l}
17.3 & 551. \\
\end{tabular} & 4970 & $8 / 14 / 2$ & 17.3 & 5038 & 10:35 & \begin{tabular}{l|ll}
17.3 & 5554. \\
\end{tabular} & 5106 & 1251 & \begin{tabular}{l|l}
17.3 & 557.4 \\
\end{tabular} & 5174 & $15: 07$ & 17.3 \\
\hline 4903 & $8 / 14 / 2008600$ & \begin{tabular}{l|l}
17.3 & 551. \\
\end{tabular} & 4971 & $8 / 14 /$ & 17.3 & 5009 & 10:37 & 17.3 & 5107 & 1253 & 17.356 & 175 & $15: 09$ & \begin{tabular}{l|l}
17.3 & 558.3 \\
\end{tabular} \\
\hline 4904 & $8 / 14 / 2$ & \begin{tabular}{l|l|}
17.3 & 5525 \\
\end{tabular} & 4972 & & 17.3 & 5040 & 10.39 & \begin{tabular}{l|l}
17.3 & 554.7 \\
\end{tabular} & 108 & 1250 & \begin{tabular}{l|l}
17.3 & 556.7 \\
\end{tabular} & & 15:11 & \begin{tabular}{l|l}
17.3 & 559.1 \\
\end{tabular} \\
\hline 4906 & 814 & \begin{tabular}{l|l}
17.3 & 552 \\
\end{tabular} & 4973 & & 17.3 & 5041 & & \begin{tabular}{l|l}
17.3 & 555. \\
\end{tabular} & & 257 & \begin{tabular}{l|l|}
17.3 & 556.8 \\
\end{tabular} & & $15: 13$ & 17.3 \\
\hline 4906 & $8 / 142008611$ & \begin{tabular}{l|l|}
17.3 & 5527 \\
\end{tabular} & 4974 & $814 \sqrt{2}$ & 17.3 & 5042 & 10.43 & 17.3 & 5110 & 1259 & 17.3 & 178 & 15.15 & \begin{tabular}{l|l}
17.3 & 55.9 \\
\end{tabular} \\
\hline & & \begin{tabular}{|l|l|}
17.3 & 5530 \\
\end{tabular} & 4975 & $8 / 14 / 2$ & 17.3 & 5043 & & 17.3 & 5111 & & 17.3 & & 15:17 & \begin{tabular}{l|l}
17.3 & 560.5 \\
\end{tabular} \\
\hline & $8 / 14 / 20$ & \begin{tabular}{l|l}
17.3 & 5530 \\
\end{tabular} & 4976 & $8 / 14$ & 17.3 & 5044 & & 17.3 & 112 & $3: 03$ & \begin{tabular}{l|l}
17.3 & 564 \\
\end{tabular} & & & \begin{tabular}{l|l}
17.3 & 550.3 \\
\end{tabular} \\
\hline 900 & $8 / 14 / 20$ & \begin{tabular}{l|l}
17.3 & $553:$ \\
\end{tabular} & $497 \pi$ & $8 / 14$ & 17.3 & 5045 & 310.49 & \begin{tabular}{l|l|}
17.3 & 566.2 \\
\end{tabular} & 5113 & 13.05 & \begin{tabular}{l|l|}
17.3 & 555.1 \\
\end{tabular} & 5181 & $315: 21$ & \begin{tabular}{l|l|}
17.3 & $562 t$ \\
\end{tabular} \\
\hline & & \begin{tabular}{l|l}
17.3 & 553.3 \\
\end{tabular} & 4978 & & 17.3 & 5046 & 310.51 & \begin{tabular}{|l|l|}
17.3 & 566.7 \\
\end{tabular} & 114 & 1300 & \begin{tabular}{|l|l|}
17.3 & 554.5 \\
\end{tabular} & & $15: 23$ & \begin{tabular}{l|l}
17.3 & $562 !$ \\
\end{tabular} \\
\hline & & $\begin{array}{l}17.35 x \\
5\end{array}$ & 4979 & 814 & 17.3 & 047 & 811 & \begin{tabular}{l|l}
17.3 & 557.0 \\
\end{tabular} & 115 & $13: 09$ & \begin{tabular}{l|l}
17.3 & 553. \\
\end{tabular} & & $15: 25$ & 17.3 \\
\hline 491 & $8 / 14$ & \begin{tabular}{l|l}
17.3 & 553. \\
\end{tabular} & 4900 & & 17.3 & 048 & & \begin{tabular}{l|l}
17.3 & 556. \\
\end{tabular} & 1116 & |3:11 & \begin{tabular}{l|l}
17.3 & 553 \\
\end{tabular} & & $15: 27$ & \begin{tabular}{l|l}
17.3 & 565.7 \\
\end{tabular} \\
\hline 4913 & & 17.3 & 4981 & & 17.3 & 5049 & 10.5 & 17.3 & 1177 & 3:13 & 17.3 & 185 & $5: 29$ & \begin{tabular}{l|l|}
17.3 & 564.6 \\
\end{tabular} \\
\hline & & $\begin{array}{l}17.35 \\
5 x\end{array}$ & 4982 & & 17.3 & 500 & & 17.3 & & & 17.3 & & & \begin{tabular}{l|l}
17.35 \\
5
\end{tabular} \\
\hline 491 & & \begin{tabular}{l|l}
17.35 & 5 \\
\end{tabular} & 4963 & & 17.3 & 5051 & & \begin{tabular}{l|l}
17.3 & 556 \\
\end{tabular} & 119 & 13:17 & 17.3 & & $15: 33$ & 17.3 \\
\hline 4916 & & \begin{tabular}{ll|l}
17.3 & 5 \\
\end{tabular} & 4984 & & 17.3 & 5052 & & 17.3 & 5120 & $13: 19$ & 17.3 & 188 & 15:36 & \begin{tabular}{l|l}
17.3 & 563.6 \\
\end{tabular} \\
\hline & & 17.35 & 4905 & & 17.3 & 5053 & & 17.3 & & & \begin{tabular}{l|l|}
17.3 & 55 \\
\end{tabular} & & & $17.3 \sqrt{56}$ \\
\hline 491 & & 17.35 & 986 & & 17.3 & 5054 & & \begin{tabular}{l|l}
17.3 & 554.3 \\
\end{tabular} & & 1323 & \begin{tabular}{l|l}
17.3 & 565 \\
\end{tabular} & & & \begin{tabular}{l|l}
17.3 & $5 \pi$ \\
\end{tabular} \\
\hline 4919 & $8 / 14 / 2$ & $\begin{array}{lll}17.3 & 554 . \\
\end{array}$ & 4987 & $8 / 14$ & 17.3 & 5055 & & 17.3 & 5123 & $13: 25$ & 17.3 & 191 & $15: 41$ & \begin{tabular}{c|c}
17.3 & 51.6 \\
\end{tabular} \\
\hline & & $\begin{array}{ll}17.35 \\
5\end{array}$ & 4988 & & 17.3 & & & \begin{tabular}{l|l}
17.3 & 554.2 \\
\end{tabular} & & & \begin{tabular}{l|l|}
17.3 & 561 \\
\end{tabular} & & & $\begin{array}{l}17.35 \\
5\end{array}$ \\
\hline 4921 & & \begin{tabular}{l|l}
17.355 \\
\end{tabular} & 4969 & & 17.3 & क्तो & & \begin{tabular}{l|l}
17.3 & 553.2 \\
\end{tabular} & & $3: 29$ & \begin{tabular}{l|l}
17.3 & 558 \\
\end{tabular} & & 15:45 & \begin{tabular}{l|l}
17.3 & $5 \pi$ \\
\end{tabular} \\
\hline 492 & $8 / 14 / 20$ & \begin{tabular}{l|l}
17.3 & 554.4 \\
\end{tabular} & 4990 & $8 / 14$ & 17.3 & 5058 & 11:15 & 17.3 & 5126 & 13.31 & \begin{tabular}{l|l}
17.2 & 555 \\
\end{tabular} & 194 & 15:47 & \begin{tabular}{l|l}
17.3 & 574.3 \\
\end{tabular} \\
\hline 4923 & & \begin{tabular}{l|l|l}
17.3 & $5 x$ \\
\end{tabular} & 4991 & & \begin{tabular}{l|l|}
17.3 & 556.2 \\
\end{tabular} & 5059 & & \begin{tabular}{l|l}
17.3 & 55 \\
\end{tabular} & & & \begin{tabular}{l|l}
17.255 \\
\end{tabular} & & & \begin{tabular}{l|l}
17.3 & 51 \\
\end{tabular} \\
\hline 4924 & & \begin{tabular}{l|l}
17.3 & $5 x$ \\
\end{tabular} & 4992 & & \begin{tabular}{l|l}
17.3 & 556. \\
\end{tabular} & & & \begin{tabular}{l|l}
17.3 & 55 \\
\end{tabular} & & & $\begin{array}{ll}17.2 & 55 \\
\end{array}$ & & & \begin{tabular}{l|l|}
17.3 & 5 \\
\end{tabular} \\
\hline 4925 & $8 / 14 / 20086: 49$ & \begin{tabular}{l|l}
17.3 & 555.4 \\
\end{tabular} & 4993 & $8 / 14 / 2$ & 17.3 & 5061 & $11: 21$ & 17.3 & 5129 & 13:37 & \begin{tabular}{l|l}
17.3 & 549. \\
\end{tabular} & 5197 & $15: 53$ & \begin{tabular}{c|c}
17.3 & 579.8
\end{tabular} \\
\hline 4926 & & $\begin{array}{l}17.3 \\
55 \\
\end{array}$ & 4994 & & \begin{tabular}{l|l|}
17.3 & 556.6 \\
\end{tabular} & 5062 & & \begin{tabular}{l|l}
17.3 & 550 \\
\end{tabular} & & & \begin{tabular}{l|l}
17.3 & 549 \\
\end{tabular} & & & \begin{tabular}{l|l}
17.3 & 574. \\
\end{tabular} \\
\hline 4927 & & & 4995 & & \begin{tabular}{l|l}
17.3 & 556.9 \\
\end{tabular} & 5003 & & \begin{tabular}{l|l}
17.3 & 553 \\
\end{tabular} & & & $\begin{array}{ll}17.3 & 549 \\
\end{array}$ & & & $\begin{array}{l}17.3 \\
51.6 \\
\end{array}$ \\
\hline 4928 & $8 / 14 / 200$ & \begin{tabular}{l|l|}
17.3 & 556.3 \\
\end{tabular} & 4996 & $8 / 14 /$ & \begin{tabular}{l|l}
17.3 & 557.0 \\
\end{tabular} & 5064 & $11: 27$ & \begin{tabular}{l|l}
17.3 & 553.5 \\
\end{tabular} & 5132 & $13: 43$ & \begin{tabular}{l|l}
17.3 & 549 \\
\end{tabular} & 5200 & 15:59 & \begin{tabular}{l|l}
17.3 & $5 / 6.7$ \\
\end{tabular} \\
\hline 4920 & $8 / 14 / 20$ & \begin{tabular}{l|l}
17.3 & 557.2 \\
\end{tabular} & 4997 & & \begin{tabular}{|l|l}
17.3 & 507. \\
\end{tabular} & 5065 & & \begin{tabular}{l|l}
17.3 & 553 \\
\end{tabular} & 133 & 13:45 & \begin{tabular}{l|l}
17.3 & 549.5 \\
\end{tabular} & 001 & 16.01 & \begin{tabular}{l|l}
17.3 & $5 / 6.7$ \\
\end{tabular} \\
\hline 1930 & & & 4958 & & \begin{tabular}{l|l}
17.3 & 557. \\
\end{tabular} & 5066 & & \begin{tabular}{l|l}
17.3 & 552 \\
\end{tabular} & & & \begin{tabular}{l|l}
17.3 & 550.7
\end{tabular} & & & \begin{tabular}{l|l}
17.3 & $5 / 5$. \\
\end{tabular} \\
\hline 4931 & $8 / 14 / 20087: 01$ & \begin{tabular}{l|l}
17.3 & 557.4 \\
\end{tabular} & 4999 & $814 /$ & \begin{tabular}{l|l|}
17.3 & 557.1 \\
\end{tabular} & 5067 & $8 / 14$ & $\begin{array}{ll}17.3 & 551 \\
\end{array}$ & $513^{2}$ & $13: 49$ & $\begin{array}{l}17.3 \\
550 \\
\end{array}$ & 5203 & 816:05 & \begin{tabular}{l|l|}
17.3 & 576.4 \\
\end{tabular} \\
\hline 4932 & $8 / 14 / 20087: 03$ & \begin{tabular}{l|l}
17.3 & 55.2 \\
\end{tabular} & 5000 & $8 / 1420089.19$ & \begin{tabular}{l|l}
17.35 & 55.6 \\
\end{tabular} & 5068 & $8 / 14 /$ & \begin{tabular}{l|l}
17.3 & 551 \\
\end{tabular} & 5136 & $313: 51$ & \begin{tabular}{l|l}
17.3 & 549 \\
\end{tabular} & 204 & 16:07 & \begin{tabular}{l|l}
17.3 & 57.5 \\
\end{tabular} \\
\hline 4933 & $8 / 14 / 20087: 05$ & \begin{tabular}{l|l|}
17.3 & 557.1 \\
\end{tabular} & 5001 & & \begin{tabular}{l|l|l}
17.3 & 557. \\
\end{tabular} & 5069 & & \begin{tabular}{l|l}
17.3 & 55 \\
\end{tabular} & 137 & 135.53 & \begin{tabular}{l|l}
17.3 & 54 \\
\end{tabular} & $x$ & $16: 09$ & \begin{tabular}{l|l}
17.3 & 577.2 \\
\end{tabular} \\
\hline 4934 & 8/14/20087:07 & \begin{tabular}{l|l}
17.356 .8 \\
\end{tabular} & 5002 & & \begin{tabular}{l|l}
17.3 & 551. \\
\end{tabular} & 5070 & & \begin{tabular}{l|l|}
17.3 & 55 \\
\end{tabular} & & & \begin{tabular}{|l|l|}
17.3 & $54 k$ \\
\end{tabular} & & 16:11 & \begin{tabular}{l|l}
17.3 & 57. \\
\end{tabular} \\
\hline 4936 & $8 / 14 / 20087: 09$ & \begin{tabular}{l|l}
17.3 & 556.9 \\
\end{tabular} & 5003 & $8 / 14 / 20089.25$ & \begin{tabular}{l|l}
17.3 & 548. \\
\end{tabular} & 5071 & $311: 41$ & \begin{tabular}{l|l}
17.3 & 554. \\
\end{tabular} & 5139 & 813.57 & \begin{tabular}{l|l}
17.3 & 549 \\
\end{tabular} & 5207 & $8 / 142008$ 16:13 & \begin{tabular}{l|l|}
17.3 & 575.9 \\
\end{tabular} \\
\hline 4936 & $8 / 14 / 20087: 11$ & \begin{tabular}{l|l|}
17.3 & 556.9 \\
\end{tabular} & 5004 & $8 / 14 / 20089.27$ & \begin{tabular}{l|l|l}
17.3 & 562. \\
\end{tabular} & 5072 & $8 / 14 / 2$ & \begin{tabular}{l|l|l|}
17.3 & 554 \\
\end{tabular} & 5140 & 313.59 & \begin{tabular}{l|l}
17.3 & 549 \\
\end{tabular} & 208 & 316:15 & $\begin{array}{l}17.3 \\
574.2\end{array}$ \\
\hline 4937 & $8 / 14 / 20087: 13$ & \begin{tabular}{l|l}
17.3 & 556.6 \\
\end{tabular} & 5005 & $8 / 1420089: 20$ & \begin{tabular}{l|l}
17.3 & 559. \\
\end{tabular} & 5073 & & 17.355 & 5141 & 314:01 & \begin{tabular}{l|l}
17.3 & 551 \\
\end{tabular} & $2 \Delta$ & $316: 17$ & $\begin{array}{l}17.3 \\
573.2\end{array}$ \\
\hline 938 & $8 / 14 / 20087: 15$ & \begin{tabular}{l|l|}
17.3 & 556.8 \\
\end{tabular} & 5006 & $089: 31$ & \begin{tabular}{l|l|}
17.3 & 559.7 \\
\end{tabular} & 5071 & $0811: 47$ & \begin{tabular}{|l|l|}
17.3 & 554.7 \\
\end{tabular} & 5142 & $314: 03$ & \begin{tabular}{|l|l|}
17.3 & 551.0 \\
\end{tabular} & & 316.19 & \begin{tabular}{l|l}
17.3 & $5 / 2$ \\
\end{tabular} \\
\hline
\end{tabular}




\begin{tabular}{|c|c|c|}
\hline \multicolumn{3}{|c|}{$D 425 \mathrm{C}$} \\
\hline $\mathrm{Pec}$ & & Temp SC \\
\hline$\#$ & DateTime & \begin{tabular}{|l|l|}
${ }^{\circ} \mathrm{C}$ & $\mu \mathrm{s} / \mathrm{m}$ \\
\end{tabular} \\
\hline 5211 & $8 / 14 / 2008$ 16:21 & \begin{tabular}{|l|l|}
17.3 & 571.9 \\
\end{tabular} \\
\hline 5212 & $8 / 14 / 200816: 23$ & \begin{tabular}{l|l|}
17.3 & 571.0 \\
\end{tabular} \\
\hline 5213 & $8 / 14200816.25$ & \begin{tabular}{|l|l|}
17.3 & 569.5 \\
\end{tabular} \\
\hline 5214 & $8 / 14 / 2008$ 16:27 & \\
\hline 5215 & $8 / 14 / 200816.20$ & \begin{tabular}{l|l|}
17.3 & 568.9 \\
\end{tabular} \\
\hline 5216 & $8 / 14 / 2008$ 16:31 & \begin{tabular}{|l|l|}
17.3568 .2 \\
\end{tabular} \\
\hline 5217 & $8 / 14200816: 33$ & \begin{tabular}{l|l|l|}
17.3 & 567.9 \\
\end{tabular} \\
\hline 5218 & $8 / 14 / 200816.35$ & \begin{tabular}{l|l|}
17.3 & 567.2 \\
\end{tabular} \\
\hline 5219 & $8 / 14 / 200816: 37$ & \begin{tabular}{l|l|}
17.3 & 566.3 \\
\end{tabular} \\
\hline 5220 & $8 / 14 / 200816.39$ & \begin{tabular}{l|l|}
17.3 & 565.8 \\
\end{tabular} \\
\hline 5221 & $8 / 14 / 200816,41$ & \begin{tabular}{c|c|}
17.3566 .0 \\
\end{tabular} \\
\hline 5202 & $8 / 14 / 200816: 43$ & \begin{tabular}{|l|l|}
17.3 & 565.8 \\
\end{tabular} \\
\hline 5223 & $8 / 14 / 200816.45$ & \begin{tabular}{l|l|}
17.3 & 566.6 \\
\end{tabular} \\
\hline 5224 & $8 / 14 / 200816.47$ & \begin{tabular}{l|l|}
17.3 & 567.2 \\
\end{tabular} \\
\hline 5225 & $8 / 14200816: 49$ & \begin{tabular}{|l|l|}
17.3 & 567.7 \\
\end{tabular} \\
\hline 5226 & $8 / 14 / 200816: 51$ & \begin{tabular}{l|l|}
17.3 & 568.9 \\
\end{tabular} \\
\hline 5227 & $8 / 14 / 200816: 53$ & \begin{tabular}{l|l}
17.3 & 560.4 \\
\end{tabular} \\
\hline 5228 & $8 / 14200816.55$ & \begin{tabular}{|l|l|}
17.3 & 570.2 \\
\end{tabular} \\
\hline 5229 & $8 / 14200816.57$ & \begin{tabular}{l|l|}
17.3 & 510.2 \\
\end{tabular} \\
\hline 5230 & $8 / 14 / 200816.59$ & \begin{tabular}{|l|l|}
17.3 & 50.0 \\
\end{tabular} \\
\hline 5231 & \begin{tabular}{|l|l}
$8 / 14 / 2008$ 17:01 \\
\end{tabular} & \begin{tabular}{|l|l|}
17.3 & 569.9 \\
\end{tabular} \\
\hline 5232 & $8 / 142008$ 17:03 & \begin{tabular}{l|l|}
17.3 & 569.7 \\
\end{tabular} \\
\hline 5233 & $8 / 14200817: 05$ & \begin{tabular}{l|l|}
17.3 & 569.0 \\
\end{tabular} \\
\hline 5234 & $8 / 14 / 2008$ 17:07 & \begin{tabular}{l|l|}
17.3 & 5689 \\
\end{tabular} \\
\hline 5235 & $8 / 142008$ 17:09 & \begin{tabular}{l|l|}
17.3 & 5686 \\
\end{tabular} \\
\hline 5236 & \begin{tabular}{|l|}
$8 / 14200817: 11$ \\
\end{tabular} & \begin{tabular}{|l|l|}
17.3 & 568.7 \\
\end{tabular} \\
\hline 5237 & $8 / 14200817: 13$ & \begin{tabular}{l|l|}
17.3 & 567.9 \\
\end{tabular} \\
\hline 5238 & $8 / 14200817: 15$ & \begin{tabular}{l|l|}
17.3 & 567.6 \\
\end{tabular} \\
\hline 5239 & $8 / 14 / 2008$ 17:17 & \begin{tabular}{l|l|}
17.3 & 567.2 \\
\end{tabular} \\
\hline 5240 & $8 / 14 / 200817: 19$ & \begin{tabular}{l|l|}
17.3 & 566.0 \\
\end{tabular} \\
\hline 5241 & $8 / 14 / 2008$ 17:21 & \begin{tabular}{|l|l|}
17.3 & 5652 \\
\end{tabular} \\
\hline 5242 & $8 / 14 / 200817: 23$ & \begin{tabular}{l|l|}
17.3 & 564.8 \\
\end{tabular} \\
\hline 5243 & $88 / 142008$ 17:25 & \begin{tabular}{l|l}
17.3 & 564.8 \\
\end{tabular} \\
\hline 5244 & $8 / 14200817: 27$ & \begin{tabular}{|l|l|}
17.3 & 561.7 \\
\end{tabular} \\
\hline 5245 & $8 / 14200817: 29$ & \begin{tabular}{l|l|}
17.3 & 563.8 \\
\end{tabular} \\
\hline 5246 & $8 / 14200817: 31$ & \begin{tabular}{|l|l|}
17.3 & 564.4 \\
\end{tabular} \\
\hline 5247 & $8 / 14 / 200817: 33$ & \begin{tabular}{l|l|}
17.3 & 564.7 \\
\end{tabular} \\
\hline 5248 & $8 / 142008$ 117:35 & \begin{tabular}{l|l|}
17.3 & 565.9 \\
\end{tabular} \\
\hline 5249 & $8114 / 200817: 37$ & \begin{tabular}{l|l|}
17.3 & 566.1 \\
\end{tabular} \\
\hline 5250 & $8 / 14 / 200817: 39$ & \begin{tabular}{l|l|}
17.3 & 566.6 \\
\end{tabular} \\
\hline 5251 & $8 / 14 / 200817: 41$ & \begin{tabular}{|l|l|}
17.3 & 566.8 \\
\end{tabular} \\
\hline 5252 & $8 / 14 / 200817: 43$ & \begin{tabular}{|l|l|}
17.3 & 566.4 \\
\end{tabular} \\
\hline 5253 & $8 / 14 / 200817: 45$ & \begin{tabular}{|l|l|}
17.3 & 567.0 \\
\end{tabular} \\
\hline 5254 & $8 / 14 / 2008$ 17:47 & \begin{tabular}{|l|l|}
17.3 & 566.5 \\
\end{tabular} \\
\hline 5255 & $8 / 14 / 200817: 49$ & \begin{tabular}{|l|l|}
17.3 & 566.4 \\
\end{tabular} \\
\hline 5256 & $8 / 142008$ 17:51 & \begin{tabular}{|l|l|}
17.3 & 555.7 \\
\end{tabular} \\
\hline 5257 & $8 / 14 / 200817: 53$ & \begin{tabular}{|l|l|}
17.3 & 556.0 \\
\end{tabular} \\
\hline 5258 & $8 / 14200817: 55$ & \begin{tabular}{l|l}
17.3 & 555.7 \\
\end{tabular} \\
\hline 5259 & $8 / 142008$ 17:57 & \begin{tabular}{|l|l|}
17.3 & 555.1 \\
\end{tabular} \\
\hline 5260 & $8 / 14 / 2008$ 17:59 & \begin{tabular}{l|l|}
17.3 & 555.2 \\
\end{tabular} \\
\hline 5261 & $8 / 14 / 200818: 01$ & \begin{tabular}{l|l|}
17.3 & 555.7 \\
\end{tabular} \\
\hline 5262 & $8 / 14200818: 03$ & \begin{tabular}{|l|l|}
17.3 & 555.9 \\
\end{tabular} \\
\hline 5263 & $8 / 14 / 2008$ 18:05 & \begin{tabular}{|l|l|}
17.3 & 556.1 \\
\end{tabular} \\
\hline 5264 & $8 / 14 / 200818.07$ & \begin{tabular}{l|l|}
17.3 & 556.8 \\
\end{tabular} \\
\hline 5265 & $8 / 1420081800$ & \begin{tabular}{l|l|}
17.3 & 557.4 \\
\end{tabular} \\
\hline 5266 & $8 / 14 / 2008$ 18:11 & \begin{tabular}{|l|l|}
17.3 & 55.1 \\
\end{tabular} \\
\hline 5267 & $8 / 14 / 200818 \cdot 13$ & \begin{tabular}{|l|l|}
17.3 & 507.1 \\
\end{tabular} \\
\hline 5268 & $8 / 14 / 200818: 15$ & \begin{tabular}{|l|l|}
17.3 & 55.9 \\
\end{tabular} \\
\hline 5269 & \begin{tabular}{|l|l|}
$8 / 1420081817$ \\
\end{tabular} & \begin{tabular}{l|l|}
17.3 & 558.6 \\
\end{tabular} \\
\hline 5270 & $8 / 14 / 200818: 19$ & \begin{tabular}{|l|l|}
17.2 & 558.1 \\
\end{tabular} \\
\hline 5271 & $8 / 14 / 2008$ 18:21 & \begin{tabular}{l|l|}
17.2 & 557.4 \\
\end{tabular} \\
\hline 5272 & $8 / 14 / 200818.23$ & \begin{tabular}{l|l|}
17.3 & 507.6 \\
\end{tabular} \\
\hline 5273 & $8 / 14 / 2008$ 18:25 & \begin{tabular}{l|l|}
17.3 & 557.2 \\
\end{tabular} \\
\hline 5274 & $8 / 14 / 2008$ 18.27 & \begin{tabular}{l|l|}
17.3 & 557.6 \\
\end{tabular} \\
\hline 5275 & $8 / 14200818: 29$ & \begin{tabular}{|l|l|}
17.3 & 558,4 \\
\end{tabular} \\
\hline 5276 & $8 / 14 / 2008$ 18:31 & \begin{tabular}{l|l|}
17.3 & 558.2 \\
\end{tabular} \\
\hline 5्या & $8 / 14 / 200318.33$ & \begin{tabular}{l|l|}
17.3 & 558.2 \\
\end{tabular} \\
\hline 5278 & $8 / 14200818.35$ & \begin{tabular}{c|c|}
17.3 & 568.3 \\
\end{tabular} \\
\hline
\end{tabular}

\begin{tabular}{|c|c|c|}
\hline \multicolumn{3}{|c|}{ D425c } \\
\hline $\mathrm{ReC}$ & & \begin{tabular}{|l|l|} 
Temp & SC \\
\end{tabular} \\
\hline$\#$ & DateTime & \begin{tabular}{|l|l|}
${ }^{\circ} \mathrm{C}$ & $\mu \mathrm{S} / \mathrm{cm}$ \\
\end{tabular} \\
\hline 5279 & $8 / 14200818: 37$ & \begin{tabular}{|l|l|}
17.3 & 558.5 \\
\end{tabular} \\
\hline 5280 & $8 / 14200818: 39$ & \begin{tabular}{l|l|}
17.3 & 558.5 \\
\end{tabular} \\
\hline 5281 & $8 / 142008$ 18:41 & \begin{tabular}{|l|l|}
17.3 & 558.5 \\
\end{tabular} \\
\hline 5282 & $8114200818: 43$ & 5082 \\
\hline 5283 & $8 / 14200818: 45$ & 558.0 \\
\hline 5284 & $8 / 14200818: 47$ & 558.0 \\
\hline 5285 & $8 / 14200818: 49$ & 57.7 \\
\hline 5206 & $8 / 14200818: 51$ & 507.9 \\
\hline 5287 & $8 / 14200818: 53$ & \begin{tabular}{l|l|}
17.3 & 557.9 \\
\end{tabular} \\
\hline 5280 & $814200818: 55$ & \begin{tabular}{|l|l|}
17.3 & 558.3 \\
\end{tabular} \\
\hline 5209 & $8114200818: 5$ & \begin{tabular}{l|l}
17.3 & 558.4
\end{tabular} \\
\hline 5290 & $8 / 14200818: 50$ & \begin{tabular}{|l|l|}
17.3 & 558.5 \\
\end{tabular} \\
\hline 5291 & 814200019901 & 558.8 \\
\hline 5292 & 8114200819.03 & 17.3558 .7 \\
\hline 5293 & $8 / 14200819: 05$ & 5586 \\
\hline 5294 & $8 / 14200819.07$ & \begin{tabular}{|l|l|}
17.3 & 558.8 \\
\end{tabular} \\
\hline 5229 & $8 / 14200819.09$ & \begin{tabular}{l|l|}
17.2 & 558.9 \\
\end{tabular} \\
\hline 5296 & $8 / 14200819.11$ & \begin{tabular}{|l|l|}
17.3 & 558.9 \\
\end{tabular} \\
\hline 5297 & $8 / 14200819.13$ & \begin{tabular}{|l|l|}
17.3 & 558.7 \\
\end{tabular} \\
\hline
\end{tabular}

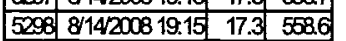

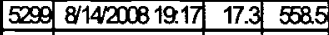
\begin{tabular}{|l|l|l|l|}
\hline 5300 & $8 / 14200819.19$ & 17.3 & 55.9 \\
\hline 501 & 8142081921 & 17.3 & 5582 \\
\hline
\end{tabular} \begin{tabular}{|l|l|l|l|}
5301 & $8 / 14200819.21$ & 17.3 & 558.2 \\
\hline
\end{tabular}

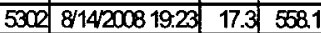
\begin{tabular}{|l|l|l|l|l|}
\hline 5303 & $8 / 142008$ & 19.25 & 17.3 & 557.9 \\
\hline 5304 & 81120081927 & 17.3 & 55.8 \\
\hline
\end{tabular} \begin{tabular}{|l|l|l|l|}
5304 & 81142000819.27 & 17.3 & 557.8 \\
\hline
\end{tabular} \begin{tabular}{|l|l|l|l|}
\hline 5305 & $8 / 14200819.29$ & 17.3 & 557.4 \\
\hline 5306 & $8 / 1420081931$ & 17.3 & 55.9 \\
\hline
\end{tabular}

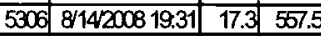

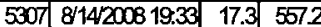

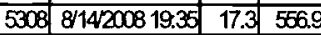

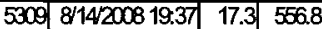

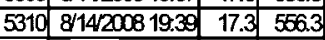

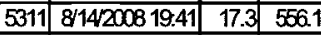

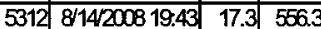
\begin{tabular}{|lllll}
5313 & 81142008 & 19.45 & 17.3 & 556.5 \\
\hline
\end{tabular}

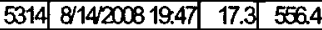

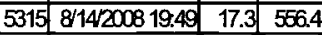
\begin{tabular}{|l|l|l|l|}
\hline 5316 & 8114200819.51 & 17.3 & 556.3 \\
\hline
\end{tabular} \begin{tabular}{|l|l|l|l|}
\hline 5317 & 8142200819.53 & 17.3 & 566.5 \\
\hline
\end{tabular}

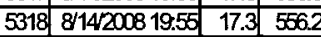
\begin{tabular}{|l|l|l|l|}
\hline 5319 & 8142000819.57 & 17.3 & 556.0 \\
\hline 50 & 8120081950 & 1.3 & 560 \\
\hline
\end{tabular}

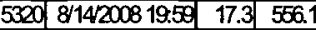
\begin{tabular}{|l|l|l|l|}
53221 & 8114200820001 & 17.3 & 566.1 \\
\hline
\end{tabular} \begin{tabular}{|l|l|l|l|}
\hline 5322 & 8114200820003 & 17.3 & 556.2 \\
\hline
\end{tabular} \begin{tabular}{|lll|l|l|}
\hline 5323 & $8 / 142008200.05$ & 17.3 & 556.1 \\
\hline
\end{tabular} \begin{tabular}{|l|l|l|l|}
\hline 5324 & $8 / 14200820007$ & 17.3 & 556.2 \\
\hline
\end{tabular} \begin{tabular}{|l|l|l|l|}
\hline 5325 & 8114200820009 & 17.3 & 566.3 \\
\hline
\end{tabular} \begin{tabular}{|l|l|l|l|}
55326 & $8 / 14200820: 11$ & 17.3 & 566.1 \\
\hline
\end{tabular}

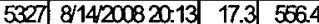
\begin{tabular}{|l|l|l|l|}
\hline 5328 & $8114200820: 15$ & 17.3 & 566.5 \\
\hline 532 & 814200820.17 & 17.3 & 565. \\
\hline
\end{tabular} \begin{tabular}{lllll}
5329 & $8 / 14200820: 17$ & 17.3 & 556.4 \\
\hline
\end{tabular} \begin{tabular}{|l|l|l|l|}
\hline 5330 & $8 / 14200820: 19$ & 17.3 & 556.3 \\
\hline
\end{tabular} \begin{tabular}{|l|l|l|l|}
\hline 5331 & $8114200820: 21$ & 17.3 & 556.4 \\
\hline
\end{tabular} \begin{tabular}{|l|l|l|l|}
5332 & 81142008202.23 & 17.3 & 556.2 \\
\hline
\end{tabular}

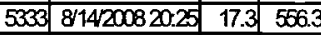
\begin{tabular}{|l|l|l|l|}
\hline 5334 & $8142000820: 27$ & 17.3 & 566.3 \\
\hline
\end{tabular} \begin{tabular}{|l|l|l|l|}
\hline 5336 & 81442008202.29 & 17.3 & 556.0 \\
\hline
\end{tabular} \begin{tabular}{|lllll}
53306 & $8114200820: 31$ & 17.3 & 556.2 \\
\hline
\end{tabular} \begin{tabular}{|l|l|l|l|}
5337 & $814200820: 33$ & 17.3 & 556.0 \\
\hline
\end{tabular} \begin{tabular}{|l|l|l|l|}
\hline 5338 & $8114200820: 36$ & 17.3 & 556.3 \\
\hline
\end{tabular} \begin{tabular}{l|l|l|l|}
55339 & 8114200820.37 & 17.3 & 556.3 \\
\hline
\end{tabular} \begin{tabular}{|l|l|l|l|}
55340 & $8 / 1420082003$ & 17.3 & 556.1 \\
\hline
\end{tabular} \begin{tabular}{|l|lll|}
5341 & $8 / 14200820: 41$ & 17.3 & 556.3 \\
\hline 5
\end{tabular} \begin{tabular}{lllll}
5342 & $814200820: 43$ & 17.3 & 556.3 \\
\hline
\end{tabular} \begin{tabular}{lllll}
5343 & $8 / 14200820: 45$ & 17.3 & 556.4 \\
\hline
\end{tabular} \begin{tabular}{lllll}
53344 & $8 / 14200820: 47$ & 17.3 & 556.3 \\
\hline
\end{tabular} \begin{tabular}{|l|l|l|l|}
\hline 5345 & $8142200820: 49$ & 17.3 & 556.5 \\
\hline
\end{tabular} \begin{tabular}{|l|l|l|l|}
\hline 5346 & $8 / 14200820.51$ & 17.3 & 556.4 \\
\hline
\end{tabular}

\section{\begin{tabular}{|c|c|c|c|}
\hline \multicolumn{3}{|c|}{ D425c } \\
\hline Rac & & Terp & SC \\
\hline$\#$ & DeteTime & ${ }^{\circ} \mathrm{C}$ & HSiom \\
\hline
\end{tabular} \begin{tabular}{lllll}
5347 & $8 / 14200820.53$ & 17.3 & 556.5 \\
\hline
\end{tabular} \begin{tabular}{|l|l|l|l|}
\hline 5348 & $8 / 14200820.55$ & 17.3 & 556.9 \\
\hline
\end{tabular} \begin{tabular}{|l|l|l|l|}
5349 & $814 / 200820.57$ & 17.3 & 566.5 \\
\hline
\end{tabular} \begin{tabular}{|l|l|l|l|}
5350 & 8114200820.59 & 17.3 & 557.1 \\
\hline
\end{tabular} \begin{tabular}{|l|l|l|l|}
\hline 5351 & $8 / 14200821: 01$ & 17.3 & 566.8 \\
\hline
\end{tabular} \begin{tabular}{llll}
5352 & $8 / 14 / 200821: 03$ & 17.3 & 566.8 \\
\hline
\end{tabular} \begin{tabular}{llll}
5353 & $8 / 14200821: 05$ & 17.3 & 556.8 \\
\hline
\end{tabular} \begin{tabular}{lllll}
\hline 5354 & $81142000821: 07$ & 17.3 & 556.6 \\
\hline
\end{tabular}} \begin{tabular}{|l|l|l|l|}
\hline 5350 & $8114200821: 09$ & 17.3 & 556.7 \\
\hline
\end{tabular} \begin{tabular}{lllll}
5356 & $8 / 14200821: 11$ & 17.3 & 566.6 \\
\hline
\end{tabular} \begin{tabular}{|l|l|l|l|}
\hline 5357 & $8 / 14200821: 13$ & 17.3 & 556.5 \\
\hline
\end{tabular} \begin{tabular}{|l|l|l|l|}
\hline 5358 & $8 / 14200821: 15$ & 17.3 & 556.7 \\
\hline
\end{tabular} \begin{tabular}{|l|l|l|l|}
\hline 5309 & $8114 / 200821: 17$ & 17.3 & 556.7 \\
\hline
\end{tabular} \begin{tabular}{|l|l|l|l|}
\hline 5300 & $814200821: 19$ & 17.3 & 556. \\
\hline
\end{tabular} \begin{tabular}{l|l|l|l|}
\hline 5361 & $8114200821: 21$ & 17.3 & 556.8 \\
\hline
\end{tabular} \begin{tabular}{|l|l|l|l|}
\hline 5362 & $8 / 14200821: 23$ & 17.3 & 566.7 \\
\hline
\end{tabular} \begin{tabular}{lllll}
5363 & $8114 / 200821: 25$ & 17.3 & 556.7 \\
\hline
\end{tabular} \begin{tabular}{l|lll|l|}
50364 & $8142000821: 27$ & 17.3 & 556.7 \\
\hline
\end{tabular} \begin{tabular}{lllll}
5306 & $8 / 14200821: 20$ & 17.3 & 506.6 \\
\hline
\end{tabular} \begin{tabular}{|l|l|l|l|}
\hline 5366 & $8114200821: 31$ & 17.3 & 566.5 \\
\hline 50 & 8120082130 & 17.3 & 5567 \\
\hline
\end{tabular} \begin{tabular}{|ll|l|l|}
\hline 5367 & $8 / 14200821: 33$ & 17.3 & 566.7 \\
\hline
\end{tabular} \begin{tabular}{l|l|l|l|}
\hline 5368 & $8 / 14200821: 35$ & 17.3 & 566. \\
\hline
\end{tabular} \begin{tabular}{|l|l|l|l|}
\hline 5369 & $81142000821: 37$ & 17.3 & 566.5 \\
\hline
\end{tabular} \begin{tabular}{lllll}
5370 & $8 / 14200821: 39$ & 17.3 & 566 \\
\hline
\end{tabular} \begin{tabular}{|l|l|l|l|}
\hline 5371 & $8 / 14200821: 41$ & 17.3 & 566.7 \\
\hline
\end{tabular} \begin{tabular}{|l|l|l|l|}
\hline 5372 & $8114200821: 43$ & 17.3 & 5668 \\
\hline
\end{tabular} \begin{tabular}{|l|l|l|l|}
\hline 5373 & $8114200821: 45$ & 17.3 & 556. \\
\hline
\end{tabular} \begin{tabular}{|l|l|l|l|}
\hline 5374 & $8142000821: 47$ & 17.3 & 566.7 \\
\hline
\end{tabular} \begin{tabular}{|l|l|l|l|}
5375 & $8 / 14200821: 49$ & 17.3 & 566 \\
\hline
\end{tabular} \begin{tabular}{|l|l|l|l|}
\hline 5376 & $8114200821: 51$ & 17.3 & 566.6 \\
\hline 5 & 8120082153 & 17.3 & 506 \\
\hline
\end{tabular} \begin{tabular}{|l|l|l|l|}
\hline 5377 & $8 / 14 / 200821: 53$ & 17.3 & 566.7 \\
\hline
\end{tabular} \begin{tabular}{lllll}
5378 & $8 / 14200821: 55$ & 17.3 & 566.9 \\
\hline
\end{tabular} \begin{tabular}{lllll}
5379 & $814200821: 57$ & 17.3 & 566.8 \\
\hline
\end{tabular} \begin{tabular}{|lllll}
53300 & $8 / 14200821: 59$ & 17.2 & 5568 \\
\hline
\end{tabular} \begin{tabular}{|l|l|l|l|}
\hline 5381 & 814220082201 & 17.3 & 566.6 \\
\hline
\end{tabular} \begin{tabular}{|l|l|l|l|}
\hline 5382 & $8 / 1420082203$ & 17.3 & 566.5 \\
\hline
\end{tabular} \begin{tabular}{lllll}
5383 & 814200032205 & 17.3 & 566.6 \\
\hline
\end{tabular} \begin{tabular}{lllll}
53384 & 8114200082207 & 17.3 & 556.4 \\
\hline
\end{tabular} \begin{tabular}{|lll|l|}
53385 & 811420082209 & 17.3 & 566 \\
\hline
\end{tabular} \begin{tabular}{|l|l|l|l|}
\hline $53 \% 6$ & $8 / 1420082211$ & 17.3 & 566.8 \\
\hline
\end{tabular} \begin{tabular}{|lllll}
5387 & 814200082213 & 17.3 & 566 \\
\hline
\end{tabular} \begin{tabular}{|l|lll|}
\hline 5388 & 81420082215 & 17.3 & 566.7 \\
\hline
\end{tabular}

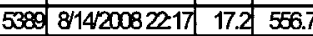
\begin{tabular}{|l|l|l|l|}
\hline 5390 & 81420082219 & 17.3 & 566.7 \\
\hline
\end{tabular} \begin{tabular}{|l|l|l|l|}
5391 & 811420082221 & 17.3 & 5566 \\
\hline
\end{tabular} \begin{tabular}{lll|ll}
5392 & 8114200822223 & 17.2 & 556. \\
\hline
\end{tabular} \begin{tabular}{|l|l|l|l|}
5396 & 8142200822225 & 17.2 & 5568 \\
\hline
\end{tabular} \begin{tabular}{l|l|lll}
5394 & $8 / 142008222.27$ & 17.2 & 556.7 \\
\hline
\end{tabular} \begin{tabular}{l|l|l|l|}
5395 & 8114200822229 & 17.2 & 556. \\
\hline
\end{tabular} \begin{tabular}{lllll}
53966 & 814220082231 & 17.2 & 566.8 \\
\hline
\end{tabular} \begin{tabular}{|l|l|l|l|}
\hline 5397 & $8 / 14 / 20082233$ & 17.3 & 566.8 \\
\hline
\end{tabular} \begin{tabular}{|l|l|l|l|}
\hline 5398 & 811420082235 & 17.3 & 566. \\
\hline
\end{tabular} \begin{tabular}{llllll}
5390 & $8114 / 200822337$ & 17.3 & 566.8 \\
\hline
\end{tabular} \begin{tabular}{lllll}
5400 & $8 / 14200822339$ & 17.3 & 556. \\
\hline
\end{tabular} \begin{tabular}{lllll}
5401 & $8 / 14200822241$ & 17.2 & 556.7 \\
\hline
\end{tabular}

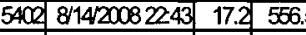
\begin{tabular}{lllll}
5403 & 811420082245 & 17.2 & 556,7 \\
\hline
\end{tabular} \begin{tabular}{lllll}
5404 & 8114200082247 & 17.2 & 567.5 \\
\hline
\end{tabular} $54068 / 1420082249017.2553 .5$ 5406 8/14/2008 2251 17.2503 \begin{tabular}{lllll}
5407 & $8 / 1420082253$ & 17.3 & 551.7 \\
\hline 540 & 81120032250 & 172 & 502
\end{tabular} \begin{tabular}{lllll}
5408 & 81420082255 & 17.2 & 552 \\
\hline
\end{tabular} \begin{tabular}{lllll}
5409 & $8 / 142008225$ & 17.3 & 5520 \\
\hline
\end{tabular} \begin{tabular}{llll}
$5410.8 / 1420082259$ & 17.3 & 5023 \\
\hline
\end{tabular} \begin{tabular}{lllll}
5411 & $8 / 14 / 200823: 01$ & 17.3 & 5623 \\
\hline 54
\end{tabular} \begin{tabular}{lllll}
5412 & $8 / 14 / 200823: 03$ & 17.3 & 552 \\
\hline
\end{tabular}

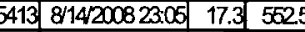
\begin{tabular}{|l|l|l|l|}
\hline 5414 & $8 / 142008223: 07$ & 17.3 & 5526 \\
\hline
\end{tabular}

\begin{tabular}{|c|c|c|c|c|c|c|c|}
\hline \multicolumn{4}{|c|}{$D 425 \mathrm{C}$} & \multicolumn{4}{|c|}{$D 425 c$} \\
\hline $\mathrm{RBC}$ & & Temp & $S C$ & $\mathrm{Pec}$ & & Terng & $S C$ \\
\hline$\#$ & Dete/Time & ${ }^{\circ} \mathrm{C}$ & $\mu \mathrm{S} / \mathrm{m}$ & $\#$ & DeteTime & ${ }^{\circ} \mathrm{C}$ & $\mathrm{s} / \mathrm{cm}$ \\
\hline 15 & $8 / 14200823.00$ & 17.3 & 5025 & & $8 / 15 / 20081: 25$ & 17.3 & \\
\hline 5416 & $8 / 14200823: 11$ & 17.3 & 5522 & 484 & $8 / 15 / 20081: 27$ & 17.3 & 52 \\
\hline 117 & $14200823+3$ & 17.3 & 5524 & & $811520081: 29$ & 17.3 & \\
\hline & $14200823: 15$ & 17.3 & 5525 & & $8 / 1520081: 31$ & 17.3 & \\
\hline 5419 & $8 / 14200823: 17$ & 17.3 & 5523 & & $8 / 15200081: 33$ & 17.3 & 503.3 \\
\hline 5420 & $8 / 14200823: 19$ & 17.3 & 5522 & 5488 & $8 / 15 / 20081: 35$ & 17.3 & 553.1 \\
\hline & $8 / 14 / 20082321$ & 17.3 & 5524 & 5489 & $8 / 1520081: 37$ & 17.3 & \\
\hline 5422 & 1420082323 & 17.3 & 5022 & 5490 & $8 / 15 / 20081: 39$ & 17.3 & 5527 \\
\hline 5423 & $8 / 14200823: 25$ & 17.3 & 5024 & 5491 & $8 / 15 / 20081: 41$ & 17.3 & 553.1 \\
\hline 5424 & $8 / 14 / 200823: 27$ & 17.3 & 5623 & 5492 & $8 / 15 / 20081: 43$ & 17.3 & \\
\hline & $8 / 14 / 200823: 20$ & 17.3 & 5623 & & $8 / 15 / 20081: 45$ & 17.3 & \\
\hline 5426 & $8 / 14 / 200823: 31$ & 17.3 & 5625 & 5494 & $8 / 1520081: 47$ & 17.3 & 553. \\
\hline 5427 & $8 / 14 / 200823: 33$ & 17.3 & 5625 & 5496 & $081: 49$ & 17.3 & 5526 \\
\hline 5428 & $8 / 14 / 200825: 35$ & 17.3 & 5026 & & $8 / 15 / 20$ & 17.3 & \\
\hline 5429 & $8 / 14200823: 37$ & 17.3 & 553.3 & 3497 & $8 / 15 / 20$ & 17.3 & \\
\hline 5430 & $8 / 14 / 200825: 39$ & 17.3 & 563.2 & 5498 & $881: 50$ & 17.3 & 5527 \\
\hline 5431 & $8 / 14 / 20$ & 17.3 & 563.3 & 5499 & $8 / 15 / 20$ & 17.3 & 5525 \\
\hline 5432 & 2543 & 17.3 & 563.3 & & $8 / 15 / 20$ & 17.3 & \\
\hline 5433 & $8 / 14 / 200823: 45$ & 17.3 & 5536 & $\overline{5601}$ & $8 / 15 / 2$ & 17.3 & 552 \\
\hline 5434 & $8 / 14 / 20082347$ & 17.3 & 553.2 & 5500 & $8 / 15 / 2$ & 17.3 & 551. \\
\hline 5436 & $8 / 142$ & 17.3 & 5636 & 5603 & $8 / 15 / 2$ & 17.3 & \\
\hline 543 के & $8 / 14 / 2$ & 17.3 & 5538 & & $8 / 15 / 2$ & 17.3 & \\
\hline 5437 & $8 / 1420$ & 17.3 & 5537 & & & 17.3 & 550 . \\
\hline 5438 & $814 \alpha$ & 17.3 & 563.6 & 06 & 211 & 17.3 & 551. \\
\hline 5439 & $8 / 14 / 20$ & & 5534 & & $8 / 15 / 2$ & 17.3 & \\
\hline 5440 & $8 / 1420$ & 17.3 & 553.5 & 5608 & 3215 & 17.3 & 551.2 \\
\hline 5441 & & 17.3 & 503.1 & 5600 & $8 / 154$ & 17.3 & 560. \\
\hline 5442 & & 17.3 & 5030 & 510 & 219 & 17.3 & \\
\hline 5443 & 30.05 & 17.3 & 5529 & 5611 & $8 / 15$ & 17.3 & \\
\hline 5444 & & 17.3 & $\overline{553.1}$ & 5512 & $8 / 15)^{2}$ & 17.3 & 550. \\
\hline 5445 & & 17.3 & 553.3 & 513 & $8 / 15 /$ & 17.3 & 550. \\
\hline 5446 & & 17.3 & 553 & $\overline{5614}$ & $8 / 15$ & 17.3 & \\
\hline 5447 & & 17.3 & 5632 & & & 17.3 & 550. \\
\hline 5448 & & $\frac{17.3}{17.3}$ & 5528 & & $8 / 15$ & 17.2 & 550 \\
\hline 5449 & & 17.3 & 553.1 & 5617 & $8 / 15$ & 17.3 & \\
\hline 5450 & & 17.3 & & 5518 & & 17.3 & 549 \\
\hline 5451 & & 17 & 552 & & & 17.3 & 49. \\
\hline 5452 & & & 553 & & & 17.3 & \\
\hline 5453 & 0.25 & 17.3 & 5529 & 5521 & $8 / 15$ & 17.3 & \\
\hline 5454 & & 17.2 & 5625 & 502 & & 17.3 & \\
\hline 5455 & & & 5028 & & & 17.3 & \\
\hline 5456 & & 17.3 & 5027 & 524 & & 17.3 & \\
\hline 5457 & & 17.3 & 5524 & & & 17.3 & \\
\hline 5458 & & $\overline{17}$ & 5625 & & & 17.3 & \\
\hline 5459 & & 17.3 & 5625 & 5627 & & 17.3 & \\
\hline 5460 & & 17.3 & 5024 & & & 17.3 & \\
\hline 5461 & & & 5622 & & & 17.3 & \\
\hline 5462 & & 17.3 & 5523 & 5530 & & 17.3 & \\
\hline 5463 & & 17.3 & 5023 & & & 17.3 & \\
\hline 5464 & & 17 & 552 & & & 17.3 & \\
\hline 5465 & & 17.2 & 5524 & 5523 & & 17.3 & 551. \\
\hline 5466 & & 17.3 & 5521 & 563 & & 17.3 & \\
\hline 5467 & & 17.3 & 5521 & & & 172 & \\
\hline 5468 & & 17.3 & 5522 & 5506 & & 17.3 & 551 \\
\hline 5469 & & 17.3 & 5520 & 5537 & & 17.3 & \\
\hline 54 & & & & & & 17.3 & \\
\hline 5471 & & 17.3 & 55 & & & 17.2 & \\
\hline 5472 & & 17.3 & 5520 & 55 & & 17.2 & \\
\hline 5473 & & 17.3 & 502 & & & 172 & \\
\hline 5474 & & 17.3 & 552 & & & 17.3 & \\
\hline 5475 & & 17.3 & 552 & 5543 & $8 / 15 / 2$ & 17.3 & \\
\hline 5476 & & 17.3 & 552 & & & 17.2 & \\
\hline 5477 & & & 552 & & & 17.3 & \\
\hline 5478 & $81: 15$ & 17.3 & 5525 & 5546 & $8 / 152$ & 17.3 & \\
\hline 5479 & & 17.3 & 552 & 5547 & & 17.3 & \\
\hline 5480 & & 17.3 & 552 & & & 17.3 & \\
\hline 5481 & & 17.3 & 5528 & 5549 & $8 / 15 / 20083: 37$ & 17.2 & \\
\hline 5482 & 1.23 & 173 & 552 & & $8 / 15 / 20083: 39$ & 173 & \\
\hline
\end{tabular}




\begin{tabular}{|c|c|c|c|c|c|c|c|c|c|c|c|}
\hline \multicolumn{4}{|c|}{$D 425 C$} & \multicolumn{4}{|c|}{$D 425 \mathrm{C}$} & \multicolumn{4}{|c|}{ D425c } \\
\hline Rec & & Temp & $S C$ & $\mathrm{Fec}$ & & Terp & \begin{tabular}{|l|}
$S C$ \\
\end{tabular} & Rec & & Termp & $\mathrm{SC}$ \\
\hline$\#$ & DeteTime & ${ }^{\circ} \mathrm{C}$ & $\mu \mathrm{s} / \mathrm{cm}$ & $\#$ & Dete/Time & ${ }^{\circ} \mathrm{C}$ & LS/am & $\#$ & Date/Time & ${ }^{\circ} \mathrm{C}$ & $\mu \mathrm{s} / \mathrm{m}$ \\
\hline 5551 & $8 / 15 / 20083: 41$ & 17.3 & 5486 & 5619 & $8 / 1520085: 57$ & 17.3 & 5427 & 5687 & $81520088: 13$ & 17.2 & 546.3 \\
\hline 5652 & $81520083: 43$ & 17.3 & 547.8 & 5020 & 8152008559 & 17.3 & 5428 & 5688 & 8152008815 & 17.2 & 546.3 \\
\hline 5553 & $8 / 15 / 20083: 45$ & 17.3 & 547.9 & 5621 & $815 / 2008601$ & 17.3 & 543.0 & 5689 & $8 / 1520088: 17$ & 17.2 & 5462 \\
\hline 5554 & 8152008347 & 17.2 & 5480 & 5022 & $8 / 15 / 2008603$ & 17.3 & 5426 & 5600 & 8152008819 & 17.2 & 546.3 \\
\hline 5665 & $8 / 15 / 2008349$ & 17.3 & 547.3 & 5623 & $8 / 15 / 20086: 05$ & 17.3 & 5427 & 5691 & $8 / 15 / 2008821$ & 17.2 & 546.1 \\
\hline 5666 & $8 / 1520083.51$ & 17.3 & 547.8 & 5624 & $8 / 15 / 20086: 07$ & 17.3 & 5429 & 5692 & $8 / 15 / 20088.23$ & 17.2 & 546.3 \\
\hline 5567 & $8 / 15 / 2008353$ & 17.3 & 547.4 & 5625 & $8 / 15 / 2008609$ & 17.3 & 5427 & 5693 & $8 / 15 / 20088: 25$ & 17.2 & 5462 \\
\hline 5658 & $8 / 15 / 2008355$ & 17.3 & 547.4 & 5026 & $8 / 15 / 20086: 11$ & 17.3 & 5427 & 5694 & $8 / 15 / 20088: 27$ & 17.2 & 546.1 \\
\hline 5560 & $8 / 152008357$ & 17.3 & 547.3 & 5627 & $8 / 15 / 20086: 13$ & 17.3 & 5427 & 5695 & $8 / 15 / 2008829$ & 17.2 & 546.3 \\
\hline 5660 & $8 / 5 / 2008359$ & 17.2 & 547.7 & 5628 & $8 / 15 / 20086: 15$ & 17.3 & 5425 & 5696 & $8 / 15 / 20088: 31$ & 17.2 & 546.1 \\
\hline 5661 & $815 / 20084: 01$ & 17.3 & 547.6 & 5629 & $8 / 15 / 20086: 17$ & 17.3 & 5429 & 5697 & $8 / 15 / 20088: 33$ & 17.2 & 5462 \\
\hline 5662 & $8 / 15 / 20084: 03$ & 17.2 & 547.8 & 5630 & $8 / 15 / 20086: 19$ & 17.3 & 5426 & 5698 & $8 / 1520088: 35$ & 17.2 & 546.2 \\
\hline 5563 & $8 / 15 / 20084: 05$ & 17.3 & 547.4 & 5631 & $8 / 15 / 20086.21$ & 17.3 & 5427 & 5609 & $8 / 15 / 20088: 37$ & 17.2 & 546.3 \\
\hline 5664 & $8 / 15 / 20084: 07$ & 17.3 & 547.3 & 5632 & $8 / 15 / 20086.23$ & 17.3 & 5427 & 5700 & $8 / 15 / 20088: 30$ & 17.2 & 546.2 \\
\hline 5565 & $81520084: 00$ & 17.3 & 547.5 & 5633 & $8115 / 20086: 25$ & 17.3 & 5428 & 5701 & $8 / 15 / 20088: 41$ & 17.2 & 546.5 \\
\hline 5566 & $8 / 15 / 20084: 11$ & 17,2 & 547.3 & 5034 & $8 / 15 / 2008.6: 27$ & 17.3 & 5429 & 5700 & $8 / 1520088: 43$ & 17.3 & 546.4 \\
\hline 5667 & $8 / 15 / 20084: 13$ & 17.3 & 547.5 & 5635 & $8 / 15 / 2008629$ & 17.3 & 5428 & 5703 & $8 / 15 / 20088: 45$ & 17.2 & 546.3 \\
\hline 5568 & $8 / 15 / 20084: 15$ & 17.3 & 547.2 & 5636 & $8 / 15 / 20086: 31$ & 17.3 & 5428 & 5704 & $8 / 15 / 20088.4 \overrightarrow{7}$ & 17.2 & 546.2 \\
\hline 5669 & $8 / 1520084: 17$ & 17.3 & 547.3 & 5637 & $8 / 15 / 20086.33$ & 17.3 & 5429 & 5705 & $815220088: 49$ & 17.2 & 546.4 \\
\hline $56 \pi$ & $8 / 15 / 20084: 19$ & 17.3 & 547.3 & 5638 & $8 / 15 / 20086.35$ & 17.3 & 5426 & 5706 & 8.51 & 17.2 & 546.4 \\
\hline 5571 & $8 / 15 / 20084: 21$ & 17.3 & 547.1 & 5639 & $815 / 20086.37$ & 17.3 & 5424 & 5707 & $8 / 15 / 2008853$ & 17.2 & 546.7 \\
\hline 5672 & $8 / 15 / 20084: 23$ & 17.3 & 546.8 & 5640 & $8 / 15 / 20086: 39$ & 17.3 & 5424 & 5708 & $8 / 15 / 2008855$ & 17.2 & 546.7 \\
\hline 5073 & $8 / 15 / 2008425$ & 17.3 & 547.0 & 5641 & $8 / 15 / 2$ & 17.3 & 542.2 & 5709 & $8: 57$ & 17.2 & 546.9 \\
\hline 5574 & $8 / 15 / 20084: 27$ & 17.3 & 546.9 & 5642 & $8 / 15 / 20$ & 17.3 & 5422 & 5710 & $8 / 15 / 2$ & 17.2 & 546.8 \\
\hline $55 / 5$ & $8 / 15 / 20084: 29$ & 17.3 & 546.7 & 5643 & $8 / 15 / 20086: 45$ & 17.3 & 5422 & 5711 & $8 / 15 / 20089.01$ & 17.2 & 547.0 \\
\hline 5576 & $8 / 15 / 20084: 31$ & 17.3 & 546.9 & 5644 & $8 / 15 / 200$ & 17.3 & 5426 & 5712 & $8 / 15 / 2$ & 17.2 & 546.7 \\
\hline 5577 & $8 / 15 / 20084: 33$ & 17.3 & 546.6 & 5645 & $8 / 15 / 200$ & 17.3 & 5425 & 5713 & $8 / 15 / 2$ & 17.2 & 546.7 \\
\hline 5578 & $8 / 15 / 20084: 35$ & 17.3 & 546.9 & 5646 & $8 / 15 / 200$ & 17.3 & 5429 & 5714 & $8 / 15 / 20$ & 17.2 & 546.7 \\
\hline 5579 & $8 / 15 / 20084: 37$ & 17.3 & 546.3 & 5647 & $8 / 1520086: 53$ & 17.3 & 5427 & 5715 & $8 / 15 / 20089.09$ & 17.2 & 546.7 \\
\hline 5580 & $8 / 15 / 20084: 30$ & 17.3 & 5462 & 5648 & $8 / 15 / 20086.55$ & 17.3 & 544.1 & 5716 & 9.11 & 17.2 & 546.6 \\
\hline 5581 & $8 / 15 / 20084: 41$ & 17.3 & 546.4 & 5649 & 6.57 & 17.3 & 544.5 & 5717 & $8 / 15$ & 17.2 & 546.8 \\
\hline 5682 & $811520084: 43$ & 17.3 & 546.3 & 5650 & $8 / 1520086.59$ & 17.3 & 544.9 & 5718 & $8 / 15200$ & 17.2 & 546.9 \\
\hline 5683 & $81520084: 45$ & 17.3 & 546.1 & 5651 & 811 & 17.3 & 544.5 & 5719 & $8 / 15$ & 17.2 & 547.0 \\
\hline 5584 & $8 / 15 / 20084: 47$ & 17.3 & 545.8 & 562 & $8 / 1520$ & 17.3 & 544.6 & 5720 & & 17.2 & 5467 \\
\hline 5686 & $8 / 15 / 20084: 49$ & 17.3 & 545.5 & 5653 & $8 / 1520$ & 17.3 & 544.7 & 5721 & $8 / 15$ & 17.2 & 546.4 \\
\hline 5596 & $8 / 15 / 20084: 51$ & 17.3 & 544.9 & 5654 & $8 / 15 / 200$ & 17.2 & 544.5 & 572 & $8 / 15 / 2$ & 17.2 & 546.2 \\
\hline 5687 & $8 / 15 / 20084: 53$ & 17.3 & 545.5 & 565 & $8 / 15 / 200$ & 17.3 & 544.6 & 5723 & $8 / 15 / 20089.25$ & 17.2 & 546.1 \\
\hline 5588 & $8 / 15$ & 17.3 & 545.5 & 5656 & $8 / 15 / 2$ & 17.2 & 544.8 & 5724 & $8 / 5$ & 17.2 & 545.9 \\
\hline 5599 & $8 / 15 / 20084: 57$ & $\overline{17.3}$ & 545.6 & 5657 & $8 / 15 / 20087: 13$ & 17.2 & 545.0 & 5725 & $8 / 15 / 20089.29$ & 17.2 & 547.2 \\
\hline 5500 & $8 / 15 / 20084: 50$ & $\overline{17.3}$ & 545.2 & 5658 & $8 / 15 / 20087: 15$ & 17.3 & 545.1 & 5726 & 9.31 & 17.2 & 546.8 \\
\hline 5591 & $8 / 15$ & $\overline{17.3}$ & 545.1 & 5659 & $87: 17$ & 17.2 & 545.6 & 5727 & 9.33 & 17.2 & 546.2 \\
\hline 5592 & $8 / 15,20085: 03$ & 17.3 & 545.6 & 5660 & 7:19: & 17.3 & 545.5 & 5728 & $8 / 152$ & 17.2 & 545.6 \\
\hline 5693 & $8 / 1520085: 05$ & 17.3 & 544.6 & 5661 & 8/15/20087:21 & 17.2 & 545.9 & 5729 & $8 / 15 / 20089.37$ & 17.2 & 545.6 \\
\hline 5504 & $8 / 152008507$ & 17.3 & $\overline{544.9}$ & 562 & $37: 23$ & 17.2 & 546.0 & 5730 & 89.39 & 17.2 & 545.9 \\
\hline 5696 & $8 / 15 / 2008500$ & 17.3 & 545.0 & 5663 & 37.25 & 17.3 & 546.1 & 5731 & $8 / 15 / 20$ & 17.2 & 546.2 \\
\hline 5596 & $8 / 15 / 20085: 11$ & 17.3 & 544.4 & 5664 & $8 / 15 / 20087: 27$ & 17.3 & 546.0 & 5732 & $8 / 15 / 200$ & 17.2 & 546.6 \\
\hline 5697 & $8 / 15 / 20085: 13$ & 17.3 & 544.9 & 5665 & $8 / 15 / 20087: 29$ & 17.3 & 546.4 & 573 & $8 / 15 / 20089.45$ & 17.2 & 546.8 \\
\hline 5698 & $8 / 15 / 20085: 15$ & 17.3 & 544.7 & 5666 & $8 / 15 / 200$ & 17.3 & 546.6 & 5734 & $8 / 15 / 20$ & 17.2 & 546.9 \\
\hline 5099 & $8 / 15 / 20085: 17$ & 17.3 & 544.4 & 5667 & $8 / 15 / 20087: 33$ & 172 & 546.4 & 5735 & $8 / 15 / 20$ & 17.2 & 547.0 \\
\hline 5600 & $8 / 15 / 20085: 19$ & 17.3 & 544.0 & 5668 & $8 / 15 / 20087: 35$ & 17.3 & 546.4 & 5736 & $8 / 15 / 20089.51$ & 17.2 & 547.5 \\
\hline 5601 & $8 / 15 / 20085-21$ & 17.3 & 543.9 & 569 & $8 / 15 / 20087: 37$ & 17.3 & 546.5 & 5737 & $8 / 152008953$ & 17.2 & 547.7 \\
\hline 5600 & $8 / 15 / 20085: 23$ & $\overline{17.3}$ & 543.8 & 5670 & $8 / 15 / 200$ & 17.3 & 546.7 & 5738 & $8 / 15 / 20089.55$ & 17.2 & 547.9 \\
\hline 5603 & $8 / 15 / 20085: 25$ & 17.3 & 543.3 & 5671 & $8 / 15 / 20087: 41$ & 17.3 & 546.4 & 5739 & $8 / 15 / 2$ & 17.2 & 547.7 \\
\hline 5604 & $8 / 15 / 20085: 27$ & 17.3 & 543.5 & 5672 & $8 / 15 / 20087: 43$ & 17.3 & 547.0 & 5740 & $8 / 15 / 20089.59$ & 17.2 & 547.5 \\
\hline 5606 & $8 / 15 / 20085: 29$ & $\overline{17.3}$ & 543.4 & 5673 & $8 / 15 / 20087: 45$ & 17.3 & 546.3 & 5741 & $8 / 15 / 200810: 01$ & 17.2 & 547.4 \\
\hline 5606 & $815 / 20085: 31$ & $\overline{17.3}$ & 543.3 & 5674 & $8 / 15 / 20087: 47$ & 17.3 & 545.9 & 5742 & $8 / 15 / 2008$ 10:03 & 17.3 & 546.9 \\
\hline 5607 & $8 / 1520085: 33$ & 17.3 & 543.2 & 5675 & $8 / 15 / 20087: 49$ & 17.2 & 545.1 & 5743 & $8 / 15 / 200810: 05$ & 17.3 & 546.5 \\
\hline 5608 & $8 / 15 / 20085: 35$ & 17.3 & 5429 & 5676 & $8 / 15 / 20087: 51$ & 17.3 & 545.3 & 5744 & $8 / 15 / 200810.07$ & 17.2 & 547.7 \\
\hline 5609 & $815 / 20085: 37$ & 17.3 & 5429 & 5677 & $815 / 20087: 53$ & 17.2 & 545.4 & 5745 & $8 / 15 / 200810.09$ & 17.2 & 5483 \\
\hline 5610 & $8 / 15 / 2008539$ & 17.3 & \begin{tabular}{|l|l|}
543.1 \\
\end{tabular} & 5678 & $81520087: 55$ & 17.2 & 545.4 & 5746 & $8 / 15200810.11$ & 17.2 & 5484 \\
\hline 5611 & $8 / 15 / 20085441$ & 17.3 & 543.1 & 5679 & $8 / 15 / 20087: 57$ & 17.2 & 546.0 & 5747 & 815200810.13 & 17.2 & 549.1 \\
\hline 5612 & $8 / 15 / 20085: 43$ & 17.3 & 5429 & 5680 & $8 / 15 / 20087: 59$ & 17.2 & 546.1 & 5748 & $8 / 15200810: 15$ & 17.2 & 548.5 \\
\hline 5613 & $8 / 15 / 20085: 45$ & 17.3 & 543.0 & 5681 & $8 / 15 / 20088: 01$ & 172 & 5459 & 5749 & $8 / 15 / 200810.17$ & 17.2 & 549.0 \\
\hline 5614 & $8 / 15 / 2008547$ & 17.3 & 543.1 & 5682 & $8 / 15 / 20088: 03$ & 17.3 & 546.3 & 5750 & 8/152000 10:19 & 17.2 & 5502 \\
\hline 5615 & $8 / 15 / 20085: 49$ & 17.3 & 543.2 & 5683 & $8 / 15 / 20088: 05$ & 17.2 & 546.4 & 5751 & $8 / 15 / 200810: 21$ & 17.2 & 549.6 \\
\hline 5616 & $8 / 15 / 20085: 51$ & 17.3 & 5429 & 5684 & $815 / 20088: 07$ & 17.2 & 546.0 & 5752 & $8 / 15 / 200810: 23$ & 17.2 & 549.5 \\
\hline 5617 & $8 / 15 / 20085: 53$ & 17.3 & 5429 & 5085 & $8 / 15 / 20088: 09$ & 17,2 & \begin{tabular}{|l|}
546.3 \\
\end{tabular} & 5753 & $8 / 15 / 200810.25$ & 17.2 & 549.1 \\
\hline 5618 & $8 / 15 / 20085: 55$ & 17.3 & 5429 & 5086 & $8 / 15 / 20088: 11$ & 17.2 & 546.4 & 5754 & $815 / 200810: 27$ & 77 & 549.6 \\
\hline
\end{tabular}

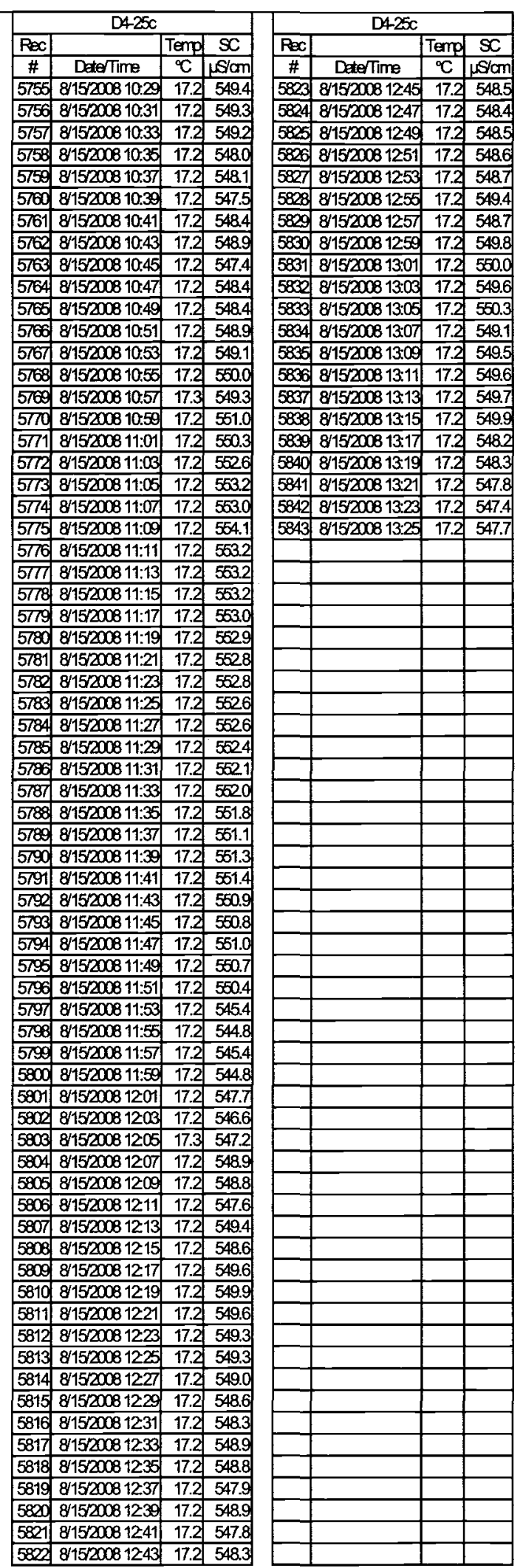




\begin{tabular}{|c|c|c|c|c|c|c|c|c|c|c|c|c|c|c|c|c|c|c|c|}
\hline \multicolumn{4}{|c|}{$D 425 p$} & \multicolumn{4}{|c|}{$D 4250$} & \multicolumn{4}{|c|}{$2425 p$} & \multicolumn{4}{|c|}{$D 425 p$} & & D4250 & & \\
\hline $\mathrm{ReC}$ & & Pres & Temp & $\mathrm{Rec}$ & & Pres & Temp & Rec| & & Pres & Termp & $\mathrm{Rec}$ & & Pres & Temp & $\mathrm{ReC}$ & & Pres & Temp \\
\hline$\#$ & DateTime & psi & ${ }^{\circ} \mathrm{C}$ & $\#$ & Dete/Time & psi & ${ }^{\circ} \mathrm{C}$ & $\#$ & DaterTime & \begin{tabular}{|l|}
$p s i$ \\
\end{tabular} & ${ }^{\circ} \mathrm{C}$ & $\#$ & Dete/Time & $p s i$ & ${ }^{\circ} \mathrm{C}$ & $\#$ & Deter/Time & psi & ${ }^{\circ} \mathrm{C}$ \\
\hline & $87 / 2000810: 42$ & 1.585 & 17.0 & 69 & $87 / 20081258$ & 7,640 & 16.5 & 137 & $8 / 7200015 ; 14$ & 1.635 & 16.6 & 206 & $87 / 200817: 30$ & 1.632 & 16.6 & 273 & $87 / 2008$ 19:46 & 1.635 & 16.6 \\
\hline 2 & $87 / 2008$ 10:44 & 1.587 & 16.9 & 70 & $87 / 200813: 00$ & 7.609 & 165 & 138 & $87 / 200815: 16$ & 1.636 & 16.7 & 206 & $87 / 2008$ 17:32 & 1.631 & 16.6 & 274 & $87 / 2008$ 19:48 & 1.634 & 16.7 \\
\hline & $87 / 2008$ 10:46 & 1.587 & 16.8 & 71 & $87 / 2008$ 13:002 & 7.640 & 165 & 139 & $877200815: 18$ & 1.636 & 16.7 & 207 & $87 / 2008$ 17:34 & 1.632 & 16.6 & 275 & $87 / 2008$ 19:50 & 1.634 & 16.6 \\
\hline 4 & $87 / 2008$ 10:48 & 1.589 & 16.7 & 72 & $87 / 2008$ 13:04 & 7.640 & 16.5 & 140 & $87 / 200815: 20$ & 1.636 & 16.7 & 206 & $87 / 2008$ 17:36 & 1.632 & $16 . t$ & 276 & $87 / 2008$ 19:52 & 1.634 & 16.7 \\
\hline 5 & $87 / 200810: 50$ & 1.589 & 16.7 & 73 & $87 / 200813: 06$ & 7.640 & 16.5 & 141 & $87 / 200815: 22$ & 1.636 & 167 & 209 & 8712008 17:38 & 1.633 & 16.6 & $2 \pi$ & $87 / 200819: 54$ & 1.633 & 16.6 \\
\hline & $877200810: 52$ & 1.590 & 16.6 & 74 & $87 / 2008$ 13:06 & 7.641 & 165 & 142 & $87 / 200815: 24$ & 1.636 & 16.7 & 210 & $87 / 2008$ 17:40 & 1.634 & 16.7 & 278 & $87 / 200819.56$ & 1.633 & 16.6 \\
\hline & $87 / 200810: 54$ & 1.590 & 16.7 & 75 & $87 / 200813: 10$ & 7.641 & 165 & 143 & $87 / 200815: 26$ & 1.635 & 16.7 & 211 & $87 / 2008$ 17:42 & 1.634 & 17 & 279 & $87 / 200819.58$ & 1.633 & 16.6 \\
\hline 8 & $87 / 200810.56$ & 1.500 & 16.6 & 76 & $87 / 2008$ 13:12 & 7.69 & 165 & 144 & $87 / 200815: 28$ & 1.634 & 16.7 & 212 & $87 / 2008$ 17:44 & 1.634 & 16.6 & 280 & $87 / 200820: 00$ & 1.633 & 16.6 \\
\hline & $87 / 200810.58$ & 1.591 & 16.7 & $\pi$ & $87 / 2008$ 13:14 & 7.639 & 165 & 145 & $8 / 7200815: 30$ & 1.634 & 16.7 & 213 & $87 / 20008$ 17:46 & 1.634 & 16.7 & 281 & $87 / 200820: 02$ & 1.633 & 16.6 \\
\hline 10 & $8772008+1: 00$ & 1.590 & 16.7 & 78 & $87 / 200813: 16$ & 7630 & 165 & 146 & $8 / 7200815: 32$ & 1.635 & 16.7 & 214 & $87 / 2008$ 17:48 & 1.634 & 167 & 282 & $87 / 200820004$ & \begin{tabular}{|l|}
1.633 \\
\end{tabular} & 16.7 \\
\hline 11 & $87 / 2008$ 11:02 & 1.596 & 16.7 & 79 & $8 / 72008$ 13:18 & 7.630 & 165 & 147| & $8 / 7 / 200815: 34$ & 1.636 & 16.7 & 215 & 8772008 17:50 & 1.633 & 16.6 & 283 & $87 / 200820006$ & \begin{tabular}{|l|}
1.634 \\
\end{tabular} & 16.6 \\
\hline 12 & $87 / 2008$ 11:04 & 1.598 & 16.6 & 80 & $87 / 2008$ 13:20 & 7700 & 165 & 148 & $8 / 7 / 2008$ 15:36 & 1.637 & 16.7 & 216 & $87 / 2008$ 17:52 & 1.634 & 16.6 & 284 & 871200820008 & 1.634 & 16.6 \\
\hline 13 & $87 / 200811: 06$ & 1.603 & 16.6 & 81 & 8712008 13:22 & 7.700 & 165 & 149 & $87 / 200815: 38$ & 1.638 & 16.7 & 217 & $87 / 20008$ 17:54 & 1.633 & $\overline{16.7}$ & 285 & $87 / 200820: 10$ & 1.634 & 16.7 \\
\hline 14 & $877 / 2008$ 11:06 & 1.611 & 16.6 & 82 & $87 / 2008$ 13:24 & 7.698 & 165 & 150 & $87 / 200615: 40$ & 1.638 & 16.7 & 218 & $87 / 2008$ 17:56 & 1.633 & 16.7 & 286 & $8 / 7200820: 12$ & 1.633 & 16.6 \\
\hline 15 & $87 / 2008$ 11:10 & 1.637 & 16.6 & 83 & 8712008 13:26 & 7.686 & 16.5 & 151 & $87 / 200815: 42$ & 1.636 & 16.7 & 219 & $87 / 2008$ 17:58 & 1.633 & 16.6 & 287 & $7 / 2000$ 20:-14 & \begin{tabular}{|l|l|}
1.632 \\
\end{tabular} & 16.6 \\
\hline 16 & 8772008 11:12 & 1.67 & 167 & 84 & $87 / 200013: 28$ & 7.601 & 165 & 152 & $87 / 200815: 44$ & 1.635 & 16.7 & 20 & $87 / 2008$ 18:00 & 1.633 & 16. & 288 & & 1.632 & 16.6 \\
\hline 17 & 8772008 11:14 & 1.700 & 16.6 & 85 & $87 / 200813: 30$ & 0.002 & 16.6 & 153 & $87 / 200615: 46$ & 1.635 & 16.7 & 221 & $87 / 2008$ 18:02 & 1.633 & 16.6 & 289 & $7 / 200820: 18$ & 1.631 & 16.6 \\
\hline 18 & $87 / 200$ & 1750 & 16.6 & 86 & $87 / 200813: 32$ & 1.637 & 16.6 & 154 & $877200015: 48$ & 1.635 & 16.7 & 202 & $87 / 2008$ 18:04 & 1.634 & 16.6 & 290 & $87 / 200820: 20$ & 1.631 & 16.7 \\
\hline 19 & $87 / 200$ & 1790 & 16.6 & 87 & $8 / 7200813: 34$ & 1.784 & 16.6 & $15 \hat{5}$ & $8 / 7 / 200815: 50$ & 1.635 & 16.7 & 223 & $87 / 200818: 06$ & 1.63 & 16.6 & 291 & & 1.632 & 16.6 \\
\hline 20 & $877200811: 20$ & 1.848 & 166 & 88 & $87 / 200813: 36$ & 1.632 & 16.7 & 156 & $877200815: 52$ & 1.635 & 16.7 & 224 & $87 / 200818: 08$ & 1.633 & 16.6 & 292 & 820.24 & 1.633 & 16.6 \\
\hline 21 & $87 / 200$ & 1.884 & 16.6 & 89 & 8772008 13:38 & 1.626 & 16.7 & 157 & $87 / 20$ & 1.634 & 16.6 & 225 & $87 / 20$ & 1.633 & 16. & 293 & 820:26 & 1.633 & 16.6 \\
\hline 20 & $87 / 200811: 24$ & 1.909 & 16.6 & 90 & $87 / 2008$ 13:40 & 1.631 & 16.7 & 158 & $87 / 20$ & 1.635 & 16.7 & 226 & $87 / 20$ & 1.632 & 16.7 & 294 & 820.28 & 1.632 & 16.6 \\
\hline 23 & $87 / 200811: 26$ & 1.969 & 16.6 & 91 & $87 / 2008$ 13:42 & 1.634 & 16.7 & 150 & $87 / 2$ & 1.635 & 16.7 & 227 & $87 / 2$ & 1.633 & 16 & 296 & $20: 30$ & 1.632 & 16.6 \\
\hline 24 & $87 / 2008$ 11:28 & 230 & 166 & 92 & $87 / 2008$ 13:44 & 1.634 & 16.7 & 160 & $87 / 20$ & 1.635 & 16.6 & 228 & 318:16 & 1.632 & $\frac{10}{16}$ & 296 & $820: 32$ & \begin{tabular}{|l|}
1.631 \\
\end{tabular} & 16. \\
\hline 25 & $87 / 200$ & 2341 & 16.6 & 93 & $87 / 2008$ 13:46 & 1.632 & 16.7 & 161 & $87 / 2$ & 1.635 & 16.7 & 229 & $87 / 2$ & 1.632 & & 297 & $20 \cdot 34$ & 1.630 & 16. \\
\hline 26 & $87 / 20$ & 2431 & 16.6 & 94 & $871200813: 48$ & 1.631 & 16.7 & 162 & $87 / 20$ & 1.635 & 16.7 & 230 & $8 / 7 / 2$ & 1.633 & 16. & 298 & $20: 36$ & 1.629 & 16.6 \\
\hline 27 & $87 / 20$ & 7.680 & 166 & 96 & $87 / 200$ & 1.631 & 16.7 & 163 & $87 / 20$ & 1.635 & 167 & 231 & $8 / 7 / 2$ & 1.633 & & 299 & 20.38 & 1.627 & 16. \\
\hline 28 & $877 / 200$ & 7.67 & 166 & 96 & $87 / 20$ & 1.631 & 16.7 & 164 & $8 / 72$ & 1.635 & 16. & 232 & $8: 24$ & 1.632 & & 300 & & 1.628 & 16. \\
\hline 20 & $87 / 20$ & 7.672 & 16.5 & 97 & $87 / 20$ & 1.631 & 16.7 & 165 & $87 / 2$ & 1.635 & 16.7 & 233 & $87 / 2$ & 1.632 & 16. & 301 & $20: 42$ & 1.628 & 16.7 \\
\hline 30 & $87 / 20$ & 7.66 & 16.6 & 98 & $87 / 20$ & 1.631 & 16.7 & 160 & 87712 & 1.634 & & 234 & & 1.631 & & 302 & 320:44 & 1.628 & 16.7 \\
\hline 31 & $87 / 20081$ & 7.664 & 16.5 & 99 & $87 / 200$ & 1.632 & 16.7 & 167 & $8 / 7 / 2$ & 1.63 & 16.7 & 236 & $87 / 2$ & 1.631 & $\overline{16}$ & 303 & $820: 46$ & 1.628 & 16.6 \\
\hline 32 & $87 / 200$ & 7.658 & 16.5 & 100 & $87 / 200$ & 1.633 & 16.7 & 168 & $8 / 7 / 2$ & 1.633 & 16.7 & 236 & $87 / 2$ & 1.632 & 16. & 304 & 20:48 & 1.627 & 16.7 \\
\hline 33 & $87 / 20$ & 7.663 & 165 & 101 & $87 / 20$ & 1.634 & 16.7 & 169 & 8712 & \begin{tabular}{|l|l|}
3 & 1.633 \\
\end{tabular} & 16.7 & 237 . & $87 / 2$ & 1.632 & & 305 & 20.50 & 1.627 & 16.6 \\
\hline 34 & $87 / 200811: 48$ & 7,658 & 165 & 102 & $87 / 200814: 04$ & 1.633 & 16.7 & 170 & & 1.633 & 16.7 & 238 & $87 / 2008$ 18:36 & 1.633 & 16. & 306 & $87 / 200820.52$ & 1.627 & 16.7 \\
\hline 36 & $87 / 200$ & 7.607 & 165 & 103 & $87 / 20$ & 1.632 & 16.7 & 171 & $87 / 2$ & 1.632 & 16.7 & 239 & & 1.633 & 16 & 307 & $20: 54$ & 1.628 & 16.6 \\
\hline 36 & $87 / 20$ & 7.60 & 165 & 104 & $8 / 720$ & 1.632 & $\overline{16 .}$ & 172 & $8 / 72$ & 4.632 & 16.7 & 240 & & 1.633 & & 308 & 20.56 & 1.628 & 16. \\
\hline 37 & 877200 & 7.65 & 166 & 106 & $87 / 2008$ 14:10 & 1.631 & 16.7 & 173 & $87 / 2$ & 苛 1.633 & 16.7 & 241 & $8 / 120$ & 1.634 & 16. & 309 & $8620: 58$ & 1.628 & 16.6 \\
\hline 38 & $87 / 2$ & 7.649 & 166 & 106 & 8712 & 1.630 & 16.7 & 174 & & 31.633 & 16.7 & 242 & & 1.634 & & & & 1.628 & 16.7 \\
\hline 39 & $87 / 2$ & 7699 & 16. & 107 & $87 / 20$ & 1.620 & 16. & 175 & $87 / 2$ & 1.632 & 16.6 & 243 & & 1.635 & & & & 1.628 & 16. \\
\hline 40 & $87 / 20$ & 7649 & 165 & 108 & & 1.620 & 16. & 176 & & 1.632 & 16. & 244 & & 1.636 & & 312 & 21:04 & 1.628 & 16. \\
\hline 41 & $87 / 20$ & 7648 & 16. & 109 & $87 / 2$ & 1.629 & 16. & $17 \pi$ & & 1.632 & 16.7 & 245 & & 1.65 & $\overline{16}$ & & 11:06 & 1.628 & 16. \\
\hline 42 & $87 / 200$ & 7.646 & 16. & 110 & 87120 & 1.620 & 16 & 178 & 8712 & 1.633 & 16.7 & 246 & & 1.634 & & & & 1.628 & 16. \\
\hline 43 & & 7.646 & 16. & 111 & & 1.630 & 16 & 179 & & 31.633 & 16.7 & 247 & & 1.634 & & & & 1.628 & \\
\hline 44 & 87120 & 7.645 & 16. & 112 & $87 / 2$ & 1.630 & 16 & 180 & & 1.634 & 16.7 & 248 & & 1.634 & & & & \begin{tabular}{|l|l|}
1.62 \\
\end{tabular} & 16. \\
\hline 45 & 87120 & 7.645 & 16.5 & 113 & $87 / 2$ & 1.620 & 16 & 181 & $87 \pi$ & 1.634 & 16. & 249 & & 1.635 & & 1 & $21: 14$ & \begin{tabular}{|l|l|}
1.629 \\
\end{tabular} & $\overline{16}$ \\
\hline 46 & $87 / 20$ & 7645 & 165 & 114. & $87 / 2$ & 1.629 & 16. & 182 & & 1.633 & 16.7 & 250 & & 1.630 & & & & \begin{tabular}{|l|}
1.629 \\
\end{tabular} & 16. \\
\hline 47 & & 7645 & 16.5 & 115 & & 1.630 & 16. & 183 & & 1.633 & 16.6 & 251 & & 1.636 & & & & \begin{tabular}{|l|}
1.628 \\
\end{tabular} & 16 \\
\hline 48 & 87720 & 7,645 & 6.5 & 116 & 8712 & 1.632 & 16.7 & 184 & & 1.634 & 16.7 & 252 & & 1.636 & 16. & $3 x$ & $21: 20$ & 1.628 & 16. \\
\hline 49 & & 7.644 & 16.5 & 117 & & 1.633 & 16. & 185 & & 1.634 & 16.6 & 253 & & 1.06 & & & & \begin{tabular}{|l|}
1.628 \\
\end{tabular} & 16. \\
\hline 50 & 8772 & 7.643 & 16 & 118 & & 1.633 & $\overline{16}$ & 106 & & 1.634 & & 254 & & 1.635 & & & & 1.629 & 16 \\
\hline 51 & & 7.643 & 16. & 119 & & 1.632 & 16. & 187 & & 1.633 & 16 & 255 & & 1.634 & 16 & 323 & & 1.629 & \\
\hline & $87 / 20$ & 7.642 & 16 & 120 & & 1.632 & & 188 & & \begin{tabular}{|c|c|}
6 \\
\end{tabular} & & 256 & & 1.633 & & & & 1.630 & \\
\hline 53 & $87 / 20$ & 7.641 & 16. & 121 & $87 / 2$ & 1.632 & 16 & 189 & & 31.633 & & 257 & 9.14 & 1.634 & & & $21: 30$ & \begin{tabular}{|l|}
1.630 \\
\end{tabular} & 16. \\
\hline 54 & $87 / 2$ & 7,640 & 16. & 122 & & 1.633 & $\overline{16}$ & 190 & & 1.634 & 16 & 258 & & 1.634 & & & & \begin{tabular}{|l|}
1.630 \\
\end{tabular} & 16 \\
\hline & & 7.629 & 16 & 123 & & & & & & & & 259 & & & & & & & \\
\hline 56 & 877200 & 77.651 & 16.5 & 124 & 8772 & 1.633 & 16. & 192 & & 1.635 & 16.6 & 260 & & 1.635 & 16. & 32 & $21: 36$ & 1.620 & 16. \\
\hline 57 & $87 / 20$ & 7.649 & 16.5 & 125 & $87 / 20$ & 1.633 & 16. & 193 & & 1.634 & 16. & 261 & & 1.635 & 16. & & & 1.028 & 16. \\
\hline & 87720 & 7.647 & & 126 & & & & 194 & & 1,635 & & 262 & & & & & & 1.628 & \\
\hline 59 & $87 / 200$ & 7.646 & 165 & 127 & $87 / 200$ & 1.633 & 16.7 & 196 & $87 / 2$ & 1.635 & 16.6 & 263 & $87 / 2$ & 1.635 & 16 . & 331 & $821: 42$ & 1.629 & 16.7 \\
\hline 60 & & 7.645 & 16.5 & 128 & & 1.633 & 16. & 196 & & 1.634 & & 264 & & 1.635 & 16 & & & 1.629 & \\
\hline 61 & & 7.644 & & 120 & & 1.634 & & 197 & & 41.634 & & 265 & & 1.634 & & & & 1.630 & \\
\hline 62 & 87720081244 & 7.643 & 16.5 & 130 & $87 / 2008$ 15:00 & 1.635 & 16.7 & 198 & $87 / 2$ & 1.633 & 16.7 & 266 & 819.32 & 1.634 & 16.7 & 334 & $21: 48$ & 1.629 & 16.7 \\
\hline 63 & $87 / 200$ & 7.642 & 165 & 131 & & 1.635 & 16. & 199 & & 31.633 & 16.7 & 267 & & 1.635 & & & & 1.629 & \\
\hline 64 & $877 / 2$ & 7.641 & 16. & 132 & $87 / 20$ & 1.635 & 16.7 & 200 & & 1.633 & & 268 & & 1.635 & & & & 1.629 & \\
\hline 66 & 81250 & 7641 & 165 & 133 & $87 / 200$ & 1.635 & 16. & 201 & $8 / 7 / 2$ & 1.632 & 16. & 269 & 319.38 & 1.635 & 16.7 & 337 & 821:54 & 1.620 & 76. \\
\hline 6 & $87 / 200$ & 7.641 & 16. & 134 & $87 / 2008$ 15:06 & 1.634 & 16 & 202 & $87 / 200817: 24$ & 1.632 & 16. & 270 & & 1.635 & 16 & & & 1.629 & \\
\hline 67 & $877 / 20081254$ & 7.641 & 16. & 135 & $87 / 2008$ 15:10 & 1.634 & 16. & 2003 & & 1.632 & 16 & 271 & & 1.636 & & & & 1.629 & 16 \\
\hline 68 & 87720081256 & 7.641 & 16.5 & 136 & $87 / 2000815: 12$ & 1.634 & 16.7 & 204 & $87 / 200817: 28$ & 31.632 & 16.6 & 272 & $8 / 7 / 2008$ 19:44 & 1.635 & 16.6 & 340 & 82200 & 1.628 & 16.8 \\
\hline
\end{tabular}


DOE/RL-2009-35, REV. 0

\begin{tabular}{|c|c|c|c|c|c|c|c|c|c|c|c|c|c|c|c|c|c|c|}
\hline \multicolumn{4}{|c|}{$D 4250$} & \multicolumn{4}{|c|}{$D 425 p$} & \multicolumn{4}{|c|}{$D 4-25 p$} & \multicolumn{4}{|c|}{$D 425 p$} & & $D 4-25 p$ & \\
\hline $\operatorname{Rec}$ & & Pres & Temp & $\operatorname{Rec}$ & & Pres & Temp & $\operatorname{Rec}$ & & Pres & Temp & $\operatorname{Rec}$ & & Pres & Temp & $\operatorname{Rec}$ & & Pres \\
\hline$\#$ & DeterTime & psi & ${ }^{\circ} \mathrm{C}$ & $\#$ & DaterTime & \begin{tabular}{|l|}
$p s i$ \\
\end{tabular} & ${ }^{\circ} \mathrm{C}$ & $\#$ & Dete/Time & psi & ${ }^{\circ} \mathrm{C}$ & $\#$ & DeteTime & psi & ${ }^{\circ} \mathrm{C}$ & $\#$ & Date/Time & psi \\
\hline 341 & $87 / 20082202$ & 1.627 & 16.6 & 409 & $8 / 8 / 20080: 18$ & 7.626 & 16.6 & $4 \pi$ & $8 / 8 / 2008234$ & 1.625 & 16.6 & 545 & $8 / 8 / 20084: 50$ & 1.620 & 16.6 & 613 & $8 / 8 / 20087: 06$ & 1.613 \\
\hline 342 & $87 / 200822204$ & 1.627 & 16.6 & 410 & $8 / 8 / 20000: 20$ & 1.625 & 16.6 & 478 & $8 / 82008236$ & 1.625 & 16.6 & 546 & $8 / 8 / 20084: 52$ & 1.620 & 16.7 & 614 & $88 / 20087: 08$ & 1,613 \\
\hline 343 & $877200822: 06$ & 1.628 & 16.7 & 411 & $8 / 8 / 20000: 22$ & 1.625 & 16.6 & 479 & $8 / 8 / 2008238$ & 1.625 & 16.6 & 547 & $88 / 20084: 54$ & 1.620 & 16.6 & 615 & $8 / 8 / 20087: 10$ & 1.613 \\
\hline 344 & $87 / 20082208$ & 1.628 & 16.6 & 412 & $8 / 8 / 20080.24$ & 1.626 & 16.6 & 480 & $8 / 8 / 2008240$ & 1.625 & 16.6 & 548 & $8 / 8 / 20084: 56$ & 1.621 & 16.6 & 616 & $820087: 12$ & 1.614 \\
\hline 345 & $87 / 20082210$ & 1.628 & 16.6 & 413 & $8 / 8 / 20080: 26$ & 1.628 & 16.7 & 481 & 81820002242 & 1.625 & 16.6 & 549 & $88 / 20084: 58$ & 1.621 & 16.7 & 617 & $8 / 820087: 14$ & 1.616 \\
\hline 346 & $87 / 20082212$ & 1.62 & 16.7 & 414 & $8 / 8 / 20080.28$ & 1.628 & 16.6 & 482 & $88 / 2008244$ & 1.623 & 16.6 & 550 & $8 / 8 / 20085: 00$ & 1.620 & 16.6 & 618 & $8 / 8 / 20087: 16$ & 1.616 \\
\hline 347 & $87 / 20082214$ & 1.620 & 16.6 & 415 & $8 / 8 / 20080: 30$ & 1.627 & 16.6 & 483 & $88 / 2008246$ & 1.622 & 16.6 & 551 & $8 / 8 / 20085: 02$ & 1.619 & 16.6 & 619 & $8820087: 18$ & 1.616 \\
\hline 348 & $877200822=16$ & 1.629 & 16.6 & 416 & $8 / 82.20080 .32$ & 1.626 & 16.7 & 484 & 8812008248 & 1.621 & 16.6 & 552 & $8 / 8: 20085: 04$ & 1.618 & 16.7 & 620 & $8 / 820007: 20$ & 1.615 \\
\hline 349 & 87720082218 & 1.628 & 16.6 & 417 & $8 / 8 / 20000.34$ & 1.625 & 16.6 & 485 & $8 / 8 / 2008250$ & 1.621 & 16.6 & 553 & $8 / 8 / 20085: 06$ & 1.618 & 16.6 & 621 & $8 / 820087: 22$ & 1.615 \\
\hline 350 & 87120082220 & 1.627 & 16.6 & 418 & $8 / 820080.36$ & 1.625 & 16.7 & 486 & $8 / 8 / 2008252$ & 1.620 & 16.7 & 554 & $8 / 8 / 20085: 08$ & 1.649 & 16.6 & 622 & $8 / 8 / 20087: 24$ & 1.615 \\
\hline 351 & 87720082222 & 1.627 & 16.6 & 419 & $8 / 820080.38$ & 1.625 & 16.6 & 487 & 8882008254 & 1.620 & 16.6 & 555 & $8 / 8 / 20085: 10$ & 1.620 & 16.6 & 623 & $8 / 8 / 20087: 26$ & 1.615 \\
\hline 352 & $87 / 200822224$ & 1.627 & 16.7 & 420 & $8 / 8 / 20080: 40$ & 1.625 & 16.6 & 488 & $8 / 82008256$ & 1.621 & 16.6 & 556 & $8 / 8 / 20085: 12$ & 1.620 & 16.7 & 624 & $8 / 8 / 20087: 28$ & 1.615 \\
\hline 353 & $87 / 20082226$ & 1.627 & 16.6 & 421 & $8 / 820080.42$ & 1.625 & 16.6 & 489 & $8 / 8 / 2008258$ & 1.622 & 16.6 & 557 & $8 / 8 / 2008514$ & 1.620 & 16.7 & 625 & $8 / 820087: 30$ & 1.614 \\
\hline 354 & 877200822228 & 1.628 & 16.6 & 422 & $8 / 820080.44$ & 1.625 & 16.7 & 490 & $8 / 8 / 2008300$ & 1.623 & 16.6 & 558 & $8 / 8 / 20085: 16$ & 1.620 & 16.7 & 626 & $8 / 820087: 32$ & 1.614 \\
\hline 355 & $87 / 20082230$ & 1.628 & 16.6 & 423 & $8 / 8 / 20080.46$ & 1.625 & 16.7 & 491 & $8 / 820083002$ & 1.624 & 16.6 & 559 & $8 / 82008518$ & 1.619 & 16.6 & 627 & $8 / 8 / 20087: 34$ & 1.615 \\
\hline 356 & $87 / 20082232$ & 1.628 & 16.7. & 424 & $8 / 8 / 20080: 48$ & 1.626 & 16.7 & 492 & $8 / 8 / 20083: 04$ & 1.625 & 16.6 & 560 & $8 / 8 / 20085: 20$ & 1.619 & 16.6 & 628 & $8 / 820087: 36$ & 1.616 \\
\hline 35त्र & $87 / 20082234$ & 1.628 & 16.6 & 425 & $8 / 8 / 20080: 50$ & 1.627 & 16.6 & 493 & $8 / 8 / 20083: 06$ & 1.625 & 16.6 & 561 & $8 / 8 / 20085: 22$ & 1.620 & 16.7 & 629 & $8 / 8 / 20087: 38$ & 1.616 \\
\hline 358 & $87 / 20082236$ & 1.627 & 16.6 & 426 & $8 / 8 / 20000.52$ & 1.626 & 16.6 & 494 & $8 / 8 / 20083: 08$ & 1.624 & 16.6 & 562 & $8 / 8 / 20085: 24$ & 1.620 & 16.6 & 630 & $8 / 8 / 20087: 40$ & 1.615 \\
\hline 359 & $87 / 20082238$ & 1.628 & 16.6 & 427 & $8 / 8 / 20080: 54$ & 1.626 & 16.7 & 495 & $8 / 8 / 20083: 10$ & 1.623 & 16.6 & 563 & $88 / 20085: 26$ & 1.620 & 16.6 & 631 & $8 / 8 / 20087: 42$ & 1.614 \\
\hline 360 & 87720082240 & 1.628 & 16.6 & 428 & $88 / 20080: 56$ & 1.626 & 16.7 & 496 & $8 / 8 / 20083: 12$ & 1.623 & 16.6 & 564 & $88 / 20085: 28$ & 1.620 & 16.6 & 632 & $8 / 8 / 20087: 44$ & 1.615 \\
\hline 361 & $87 / 20062242$ & 1.628 & 16.6 & 429 & $8 / 8 / 20080.58$ & 1.626 & 16.7 & 497 & $8 / 8 / 20083: 14$ & 1.623 & 16.6 & 565 & $8 / 8 / 20085: 30$ & 1.620 & 16.6 & 633 & $8 / 8 / 20087: 46$ & 1.616 \\
\hline 362 & $87 / 20082244$ & 1.620 & 16.6 & 430 & $8 / 8 / 20081: 00$ & 1.626 & 16.7 & 498 & $20083: 16$ & 1.623 & 16.6 & 566 & $8 / 8200$ & 1.619 & 16.6 & 634 & $820087: 48$ & 1.616 \\
\hline 363 & $87 / 20082246$ & 1.629 & 16.6 & 431 & $8 / 8 / 20081: 02$ & 1.626 & 16.6 & 499 & $8 / 8 / 20083: 18$ & 1.623 & 16.6 & 567 & $8 / 8 / 20085: 34$ & 1.619 & 16.6 & 635 & $8 / 8 / 20087: 50$ & 1.615 \\
\hline 364 & 87120082248 & 1.630 & 16.6 & 432 & $8 / 8 / 20081: 04$ & 1.626 & 16.6 & 500 & $8 / 8 / 20083.20$ & 1.623 & 16.6 & 568 & $88 / 200$ & 1.68 & 16. & 636 & $820087: 52$ & 1.614 \\
\hline 365 & 87720082250 & 1.630 & 16.6 & 433 & $8 / 820081: 06$ & 1.626 & 16.6 & 501 & 008322 & 1.623 & 16.6 & 569 & $8 / 820$ & 1.618 & 16.6 & 637 & $8 / 8 / 20087: 54$ & 1.614 \\
\hline 366 & $87 / 20082252$ & 1.629 & 16.6 & 434 & $8 / 820081: 08$ & 1.626 & 16.6 & 502 & 20083.24 & 1.623 & 16.7 & $5 \% 0$ & $8 / 820085440$ & 1.617 & 16.6 & 638 & $8 / 8 / 20087: 56$ & 1.614 \\
\hline 367 & $8 / 7 / 200$ & 1.629 & 16.7 & 435 & $88 / 20081: 10$ & 1.627 & 16.6 & 503 & 83326 & 1.623 & 16.6 & 571 & $8 / 8200$ & 1.618 & 16 & 639 & $8 / 20087: 58$ & 1.614 \\
\hline 368 & $877 / 20082256$ & 1.629 & 16.7 & 436 & $8 / 820$ & 1.627 & 16.6 & 504 & & 1.623 & 16.7 & 572 & $8 / 8 / 20085: 44$ & 1.619 & & 640 & $320088: 00$ & 1.612 \\
\hline 369 & $87 / 20062258$ & 1.629 & 16.6 & 437 & $8 / 8 / 20081: 14$ & 1.626 & 16.6 & 505 & $83: 30$ & 1.622 & 16.6 & 573 & $8 / 8200$ & 1.619 & 16.6 & 641 & $8 / 8 / 2008 \& 02$ & 1.611 \\
\hline 370 & $87 / 200823: 00$ & 1.629 & 16.6 & 438 & $8 / 8 / 20081: 16$ & 1.627 & 16.6 & 506 & $83: 32$ & 1.62 & 16.6 & 574 & $8 / 8 / 20$ & 1.619 & 16. & 642 & $18 / 20088: 04$ & 1.611 \\
\hline 371 & $87 / 200823: 02$ & 1.630 & 16.6 & 439 & $8 / 8200081: 18$ & 1.627 & 16.6 & 507 & $8 / 8 / 200833.34$ & 1.62 & 16.6 & 575 & $8 / 8 / 20085: 50$ & 1.618 & 16. & 643 & $8820088: 06$ & 1.613 \\
\hline 372 & $87 / 20$ & 1.620 & 16.7 & 440 & $8 / 8 / 20081: 20$ & 1.627 & 16.6 & 508 & $8 / 8 / 20063: 36$ & 1.622 & 16.6 & 576 & $8 / 8 / 20085: 52$ & 1.617 & 16. & 644 & $820088: 08$ & 1.614 \\
\hline 373 & $87 / 20$ & 1.628 & 16.6 & 441 & $8 / 8 / 20081: 22$ & 1.625 & 16.6 & 509 & $8 / 8 / 20083: 38$ & 1.621 & 16.6 & $5 \pi$ & $8 / 820085: 54$ & 1.618 & 16 & 645 & $8 / 820088: 10$ & 1.615 \\
\hline 374 & $87 / 200823: 08$ & 1.628 & 16.6 & 442 & $8 / 8200081: 24$ & 1.626 & 16.6 & 510 & $8 / 8 / 20083: 40$ & 1.621 & 16.6 & 578 & $8 / 8 / 20085: 56$ & 1.618 & 16. & 646 & $8 / 20088: 12$ & 1.616 \\
\hline 375 & $87 / 20$ & 1.629 & 16.6 & 443 & $8820081: 26$ & 1.627 & 16.6 & 511 & $83: 42$ & 1.620 & 16.6 & 579 & $8 / 820085: 58$ & 1.617 & $\overline{16 .}$ & 647 & 8/8/20088:14 & 1.616 \\
\hline 376 & $87 / 20$ & 1.630 & 16.7 & 444 & $8 / 8220081: 28$ & 1.627 & 16.6 & 512 & $83: 44$ & 1.620 & 16.6 & 580 & $8 / 8 / 20086: 00$ & 1.617 & 16 & 648 & $8 / 20088: 16$ & 1.615 \\
\hline 37 & $87 / 200823: 14$ & 1.630 & 16.6 & 445 & 8812008 & 1.626 & 16.6 & 513 & 33.46 & 1.621 & 16.6 & 581 & $8 / 8 / 200066: 02$ & 1.617 & 16 & 649 & $88 / 20088: 18$ & 1.615 \\
\hline 378 & $87 / 2$ & 1,630 & 16.6 & 446 & $88 / 20$ & 1.626 & 16.6 & 514 & $\overline{3.48}$ & 1.623 & 16.6 & 582 & $8 / 8 / 20$ & 1.617 & 16.7 & 650 & $8 / 8 / 20088: 20$ & 1.614 \\
\hline 379 & $87 / 2$ & 1.620 & 16.6 & 447 & $8 / 8 / 20081: 34$ & 1.625 & 16.6 & 515 & 8350 & 1.623 & 16.6 & 583 & $8 / 82008$ & 1.617 & 16 & 601 & $38200088: 22$ & 1.614 \\
\hline 380 & $87 / 20$ & 1.620 & 16.6 & 448 & $8 / 8 / 20$ & 1.624 & 16.6 & 516 & & 1.623 & 16.7 & 584 & & 1.617 & & & $\overline{824}$ & 1.614 \\
\hline 381 & 8772 & 1.629 & 16.6 & 449 & $8 / 8220$ & 1.625 & 16.6 & 517 & & 1.622 & 16.6 & 585 & $8 / 8 / 2$ & 1.618 & 16. & 653 & $18 / 20088: 26$ & 1.613 \\
\hline 382 & 87120 & 1.630 & 16.6 & 450 & $8 / 82200$ & 1.624 & 16.7 & 518 & & 1.62 & 16.6 & 586 & $8 / 8 / 20$ & 1.618 & 16.7 & 654 & $8820088: 28$ & 1.613 \\
\hline 383 & 8712 & 1.630 & 16.6 & 451 & $8 / 8200$ & 1.62 & 16.6 & 519 & & 1.621 & 16.6 & 587 & $8 / 8 / 20$ & 1.619 & 16 & 5 & $8: 30$ & 1.612 \\
\hline 334 & $87 / 2$ & 1.630 & 16.6 & 452 & $88 / 20$ & 1.624 & 16.6 & 520 & & 1.620 & 16.6 & 588 & 88200 & 1.619 & 16. & 656 & $38: 32$ & 1.612 \\
\hline 385 & $87 / 200$ & 1.630 & 16.6 & 453 & $8 / 2200$ & 1.625 & 16.6 & 521 & $4: 02$ & 1.620 & 16.6 & 589 & $8 / 8 / 200$ & 1.618 & 16.6 & 650 & $8 / 820088: 34$ & 1.611 \\
\hline 386 & $8 / 7200$ & 1.632 & 16.6 & 454 & $8 / 820$ & 1.625 & 16.6 & 522 & & 1.621 & 16.7 & 590 & & 1.617 & 16.6 & & & 1.610 \\
\hline 387 & $87 / 20$ & 1.632 & 16.6 & 455 & $88 / 20$ & 1.625 & 16.6 & 523 & & 1.621 & 16.6 & 591 & $8 / 820086: 22$ & 1.616 & $\overline{16.6}$ & 659 & $3 / 20088: 38$ & 1.611 \\
\hline 388 & $8 / 7200$ & 1.632 & 16.6 & 456 & $88 / 20$ & 1.624 & 16.6 & 524 & $4: 08$ & 1.62 & 16.6 & 592 & $8 / 8 / 2$ & 1.616 & 16.7 & 660 & $88: 40$ & 1.611 \\
\hline 389 & & 1.631 & 16.6 & 457 & $8 / 8 / 2$ & 1.624 & 16.6 & 525 & & 1.621 & 16.6 & 593 & $8 / 8 / 2$ & 1.617 & 16.6 & & $8: 42$ & 1.612 \\
\hline 390 & $87 / 2$ & 1.630 & 16.6 & 458 & $8 / 8 / 200$ & 1.624 & 16.6 & 526 & & 1.620 & 16.7 & 594 & $8 / 8 / 200$ & 1.617 & 16.6 & 662 & $81820008: 4$ & 1.613 \\
\hline 391. & $87 / 2$ & 1.630 & 16.6 & 459 & 8812 & 1.623 & 16. & 527. & & 1.620 & 16.7 & 595 & 88220 & 1.617 & 16.6 & & $8: 46$ & 1.613 \\
\hline 392 & & 1.630 & 16.6 & 460 & & 1.623 & 16. & 52 & & 1.621 & 16.6 & 596 & $8 / 820$ & 1.617 & 16.6 & 664 & $8 / 8 / 20088: 48$ & 1.613 \\
\hline 393 & $87 / 200823: 46$ & 1.629 & 16.6 & 461 & $8 / 8 / 20082002$ & 1.62 & 16.6 & 529 & $4: 18$ & 1.621 & 16.6 & 597 & 88120 & 1.617 & 16.6 & 665 & $8 / 820088: 50$ & 1.611 \\
\hline 394 & 871200 & 1.629 & 16.6 & 462 & 882200 & 1.624 & 16.6 & 530 & & 1.621 & 16.6 & 598 & & 1.617 & 16.6 & & & 1.611 \\
\hline 395 & $8771200823: 50$ & 1.630 & 16.6 & 463. & $8 / 8 / 200$ & 1.625 & 16.6 & 531 & & 1.621 & 16.6 & 599 & $8 / 8 / 20$ & 1.617 & 16.6 & & $8 / 8 / 20088.54$ & 1.610 \\
\hline 396 & $8 / 7200823: 52$ & 1.629 & 16.7 & 464 & $8 / 8 / 2008208$ & 1.626 & 16.6 & 532 & $4: 24$ & 1.620 & 16.6 & 600 & $8 / 8 / 20$ & 1.618 & 16.6 & 668 & $8 / 8 / 20088: 56$ & 1.611 \\
\hline 397 & $87 / 200823: 54$ & 1.629 & 16.7 & 465 & & 1.625 & 16.6 & 533 & & 1.619 & 16.7 & 601 & & 1.618 & 16.6 & & & 1.611 \\
\hline 396 & $87 / 200$ & 1.627 & 16.7 & 466 & $8 / 8 / 200$ & 1.625 & 16. & 534 & & 1.619 & 16.7 & 602 & $8 / 8 / 2000$ & 1.618 & 16.6 & 6 & $8 / 8 / 20089.00$ & 1.611 \\
\hline 399 & $877200823: 58$ & 1.627 & 16.6 & 467 & $8 / 8 / 2008214$ & 1.625 & 16. & 535 & $8 / 8 / 2$ & 1.619 & 16.6 & 603 & $8 / 8 / 200$ & 1.618 & 16.6 & 6 & $818 / 20089.08$ & 1.610 \\
\hline 400 & & 1.626 & 16.7 & 468 & 8882008216 & 1.625 & & 536 & & 1.620 & 16.6 & 604 & $8 / 8 / 200$ & 1.618 & & & & \\
\hline 401 & $8 / 8 / 20080: 02$ & 1.627 & 16.7 & 469 & $8 / 8 / 2008218$ & 1.625 & 16.6 & 537 & $84: 34$ & 1.620 & 16.6 & 605 & $8 / 8220$ & 1.618 & 16.6 & 673 & 88220089.06 & 1.611 \\
\hline 402 & $88 / 20080: 04$ & 1.627 & 16.7 & 470 & $8 / 82008220$ & 1.623 & 16.6 & 538 & $8 / 820084: 36$ & 1.020 & 16.6 & 606 & $8 / 8 / 20086: 52$ & 1.616 & 16.6 & 74 & 88820089.06 & 1.613 \\
\hline 403 & & 1.626 & 16.6 & 471 & & 1.623 & 16.6 & 539 & & 1.620 & 16.6 & 607 & $8 / 8 / 20086: 54$ & 1.612 & & & & 1.614 \\
\hline 404 & $8 / 820080.08$ & 1.625 & 16.6 & 472 & $8 / 820002224$ & 1.624 & 16.6 & 540 & $084: 40$ & 1.620 & 16.6 & 608 & $8 / 820086: 56$ & 1.610 & 16.6 & 676 & $8 / 8 / 20089.12$ & 1.614 \\
\hline 405 & $8 / 8 / 20080.10$ & 1.626 & 16.6 & 473 & $88 / 2008226$ & 1.625 & 16.6 & 541 & $8 / 820084: 42$ & 1.621 & 16.6 & 609 & $88 / 20086: 58$ & 1.609 & 16.6 & 677 & $8 / 8 / 20089.14$ & 1.613 \\
\hline 406 & & 1.626 & 16.7 & 474 & $8 / 82008228$ & 1.625 & 16.6 & 542 & & 1.621 & 16.6 & 610 & & 1.610 & & 8 & $8 / 8 / 20089.16$ & 1.613 \\
\hline 407 & $8 / 820080-14$ & 1.626 & 16.6 & 475 & $8 / 8 / 2008230$ & 1.625 & 16.6 & 543 & $8 / 820084: 46$ & 1.621 & 16.7 & 611 & $8 / 820087: 02$ & 1.612 & 16.7 & 679 & $8 / 820069.18$ & 1.612 \\
\hline 408 & $8 / 8 / 20080: 16$ & 1.626 & 16.6 & 476 & $8 / 8 / 2008232$ & 1.625 & 16.6 & 544 & $8 / 8 / 20084: 48$ & 1.621 & 16.6 & 612 & $88 / 20087: 04$ & 1.612 & 16.6 & 600 & $8 / 8 / 20089.20$ & 1.610 \\
\hline
\end{tabular}




\begin{tabular}{|c|c|c|c|c|c|c|c|}
\hline \multicolumn{4}{|c|}{$D 4-25 p$} & \multicolumn{4}{|c|}{ D425p } \\
\hline Rec & & Pres 1 & Ternp & $P \in C$ & & Pres & Termp \\
\hline$\#$ & DaterTime & \begin{tabular}{|l|l|}
$p s i$ \\
\end{tabular} & ${ }^{\circ} \mathrm{C}$ & $\#$ & DeterTime & \begin{tabular}{|l|}
$p s i$ \\
\end{tabular} & ${ }^{\circ} \mathrm{C}$ \\
\hline 885 & $8 / 8200016: 10$ & 1.616 & 16.6 & 953 & $8 / 8200818: 26$ & 1.605 & 16.6 \\
\hline 886 & $8 / 8 / 200816: 12$ & 1.619 & 16.7 & 954 & $88 / 200818: 28$ & 1.701 & 16.6 \\
\hline 887 & $8 / 8 / 20081614$ & 1.626 & 16.6 & 956 & $88200818: 30$ & 1.705 & 16.6 \\
\hline 888 & $8 / 8 / 200816: 16$ & 1.633 & 16.6 & 956 & $8 / 8 / 2008$ 18:32 & 1.703 & 16.6 \\
\hline 889 & $8 / 8 / 200816: 18$ & 1.638 & 16.6 & 967 & $88200818: 34$ & 1.697 & 16.6 \\
\hline 890 & $8 / 8 / 200816: 20$ & 1.642 & 16.6 & 958 & 882008 18:36 & 1.696 & 16.6 \\
\hline 891 & $88 / 200816: 22$ & 1.646 & 16.6 & 969 & 882008 18:38 & 1.689 & 16.6 \\
\hline 892 & $8 / 8 / 200816: 24$ & 1.650 & 16.6 & 960 & $882200818-40$ & 1.683 & 16.6 \\
\hline 893 & $8 / 8 / 20081626$ & 1.652 & 16.6 & 961 & $882000818: 42$ & 1.679 & 16.7 \\
\hline 894 & $8 / 8 / 200816: 28$ & 1.65 & 16.6 & 962 & $8 / 82008$ 18:44 & 1.678 & 16.6 \\
\hline 896 & $8 / 8: 200816: 30$ & 1.60 & 16.6 & 963 & $8 / 8200818: 46$ & 1.674 & 16.7 \\
\hline 896 & $8 / 8 / 2008$ 16:32 & 1.659 & 76.6 & 964 & $88200818: 48$ & 1.672 & 16.6 \\
\hline 897 & $8 / 8 / 200816.34$ & 1.661 & 16.6 & 965 & $8 / 8: 2008$ 18:50 & 1.671 & 16.7 \\
\hline 898 & $8 / 8 / 200816: 36$ & 1.663 & 16.6 & 960 & $8 / 82008$ 18:52 & 1.673 & 16.6 \\
\hline 890 & $8 / 8 / 2008$ 16:38 & 1.665 & 16.6 & 967 & $8 / 8200818: 54$ & 1.675 & 16.6 \\
\hline 900 & $8 / 8 / 200816: 40$ & 1.607 & 16.7 & 968 & $8 / 8200618.56$ & 1.675 & 16.6 \\
\hline 901 & $8 / 8 / 200016: 42$ & 1.600 & 16.6 & 900 & $88200818: 58$ & 1.674 & 16.6 \\
\hline 902 & $8 / 82000816: 44$ & 1.670 & 16.6 & 970 & $88200819: 00$ & 1.670 & 16.6 \\
\hline 900 & $8 / 82000816: 46$ & 1.672 & 16.6 & 971 & 88200819.02 & 1.659 & 16.6 \\
\hline 904 & $88200816: 48$ & 1.673 & 16.6 & 972 & 88200819.04 & 1.652 & 166 \\
\hline 905 & $88200816: 50$ & 1.673 & 16.6 & 973 & 88200819.06 & 1.644 & 16.6 \\
\hline 906 & $88 / 2008$ 16:52 & 1.674 & 16.6 & 974 & 88200819.08 & 1.638 & 16.6 \\
\hline 907 & $8 / 8200816: 54$ & 1.676 & 16.6 & 975 & $8 / 82008$ 19:10 & 1.634 & 16.6 \\
\hline 908 & $8 / 8 / 200816: 56$ & 1.677 & 16.6 & 976 & 8820008 19:12 & 1.630 & 16.6 \\
\hline 909 & $8 / 8200816: 58$ & 1.678 & 16.6 & 977 & $8 / 8200819.14$ & 1.626 & 16.6 \\
\hline 910 & $8 / 8 / 2008$ 17:00 & 1.679 & 16.7 & 978 & $8 / 82008$ 19:16 & 1.622 & 16.6 \\
\hline 911 & 8/82008 17:02 & 1.680 & 16.6 & 979 & $8 / 8200819.18$ & 1.621 & 16.6 \\
\hline 912 & 8182008 17:04 & 1.682 & 16.6 & 980 & $8 / 820081920$ & 1.619 & 16.6 \\
\hline 913 & $8 / 8 / 2008$ 17:06 & 1.683 & 16.6 & 981 & 88200819.22 & 1.65 & 166 \\
\hline 914 & $8 / 8 / 2008$ 17:08 & 1.680 & 16.6 & 962 & $8 / 8200819.24$ & 1.661 & 16.8 \\
\hline 915 & $8 / 82008$ 17:10 & 1.696 & 16.6 & 983 & $8 / 8200819.26$ & 1.650 & 17.1 \\
\hline 916 & $8 / 8 / 2008$ 17:12 & 1.687 & 16.6 & 984 & $8 / 8200819.28$ & 1.660 & 16.8 \\
\hline 917 & $8 / 8 / 2008$ 17:14 & 1.687 & 16.6 & 985 & 882000819.30 & 1.658 & 16.7 \\
\hline 918 & $8 / 8 / 2008$ 17:16 & 1.688 & 16.6 & 96 & $8 / 8200819.32$ & 1.656 & 16.7 \\
\hline 919 & $8 / 8 / 2008$ 17:18 & 1.688 & 16.6 & 987 & $88 / 200819: 34$ & 1.654 & 16.7 \\
\hline 980 & $88 / 200817: 20$ & 1.698 & 16.6 & 968 & $8 / 8200819.36$ & 1.653 & 166 \\
\hline 921 & $888200817: 22$ & 1.689 & 16.6 & 989 & $8 / 82000819.38$ & 1.654 & 16.6 \\
\hline 922 & $8 / 82000817: 24$ & 1.690 & 16.6 & 990 & $8 / 8 / 200819.40$ & 1.655 & 16.7 \\
\hline 923 & $88: 200817: 26$ & 1.691 & 16.6 & 991 & $8 / 8 / 200019.42$ & 1.656 & 16.6 \\
\hline 924 & $8 / 8: 200817: 28$ & 1.69 & 16.6 & 992 & $8 / 82000819: 44$ & 1.656 & 16.7 \\
\hline 925 & $8 / 82008$ 17:30 & 1.691 & 16.6 & 993 & $8 / 8 / 200819: 46$ & 1.655 & 16.6 \\
\hline 926 & $88 / 2008$ 17:32 & 1.602 & 16.6 & 994 & $8 / 8200819.48$ & 1.655 & 16.6 \\
\hline 927 & $8 / 8 / 2008$ 17:34 & 1.693 & 16.6 & 995 & $88 / 200819.50$ & 1.654 & 16.6 \\
\hline 928 & $8 / 8200817: 36$ & 1.693 & 16.6 & 996 & $8 / 8200819.52$ & 1.653 & 16.6 \\
\hline 929 & $8 / 82000177: 38$ & 1.693 & 16.6 & 997 & $8 / 8200019.54$ & 1.653 & 16.6 \\
\hline 930 & $88: 200817: 40$ & 1.694 & 16.6 & 998 & $8 / 8 / 200819.56$ & 1.653 & 166 \\
\hline 931 & $8 / 8 / 2008$ 17:42 & 1.695 & 16.6 & 999 & $8 / 8 / 200019.58$ & 1.652 & 16.6 \\
\hline 932 & $8 / 8 / 200817: 44$ & 1.695 & 16.6 & 1000 & $8 / 8 / 200820: 00$ & 1.652 & 16.6 \\
\hline 933 & $8 / 82008$ 17:46 & 1.696 & 16.6 & 1001 & $8 / 8 / 200820: 02$ & 1.652 & 16.6 \\
\hline 934 & $8 / 820008 \quad 17: 48$ & 1.697 & 16.6 & 1002 & $8 / 8200820: 04$ & 1.650 & 166 \\
\hline 936 & $8 / 8 / 2008 \quad 17: 50$ & 1.698 & 16.6 & 1003 & $88 / 200820: 06$ & 1.649 & 16.6 \\
\hline 936 & 8820008 17:52 & 1.609 & 16.6 & 1004 & $8 / 8200820.08$ & 1.648 & 16.6 \\
\hline 937 & $8 / 8: 200817: 54$ & 1.700 & 16.7 & 1005 & $8 / 8200820.10$ & 1.656 & 16.6 \\
\hline 938 & 8/872008 17:56 & 1.701 & 16.6 & 1006 & $8 / 8200820.12$ & 1.663 & 16.6 \\
\hline 939 & $8 / 8 / 200817: 58$ & 1.701 & 16.6 & 1007 & $8 / 8200020: 14$ & 1.668 & 16.6 \\
\hline 940 & $8 / 82008+18: 00$ & 1.701 & 16.6 & 1008 & $8 / 8200820.16$ & 1.672 & 16.6 \\
\hline 941 & $8 / 8200018: 02$ & 1.701 & 16.6 & 1000 & $8 / 8200820: 18$ & 1.668 & 16.6 \\
\hline 942 & $8 / 822008+8: 04$ & 1.701 & 16.6 & 1010 & $88 / 20082020$ & 1.663 & 16.6 \\
\hline 943 & $8 / 8200818: 06$ & 1.701 & 16.6 & 1011 & $88 / 20082022$ & 1.661 & 16.6 \\
\hline 944 & $8 / 8200818: 08$ & 1.702 & 16.6 & 1012 & $8 / 8200020.24$ & 1.658 & 166 \\
\hline 945 & $8 / 8 / 200818: 10$ & 1.704 & 16.6 & 1013 & $8 / 8200820.26$ & 1.65 & 16.7 \\
\hline 946 & $888200818: 12$ & 1.706 & 16.6 & 1014 & 818200820.28 & 1.656 & 16.6 \\
\hline 947 & $8 / 8200818: 14$ & 1.704 & 16.7 & 1015 & $8 / 8 / 2008200.30$ & 1.607 & 16.7 \\
\hline 948 & $88200818: 16$ & 1.703 & 16.6 & 1016 & $8 / 8 / 200820: 32$ & 1.656 & 16.6 \\
\hline 949 & $8 / 8200818: 18$ & 1.702 & 16.6 & 1017 & $8 / 8200020.34$ & 1.656 & 16.6 \\
\hline 960 & $8 / 8: 200818: 20$ & 1.701 & 16.6 & 1018 & $8 / 8 / 200820: 30$ & 1.655 & 16.6 \\
\hline 951 & $8 / 8200818: 22$ & 1.700 & 16.6 & 1019 & $8 / 8 / 2000200.36$ & 1.654 & 16.6 \\
\hline 952 & $8 / 8: 200818: 24$ & 1.700 & 16.6 & 1020 & $8 / 8 / 200820: 40$ & 1.658 & 16.7 \\
\hline
\end{tabular}


DOE/RL-2009-35, REV. 0
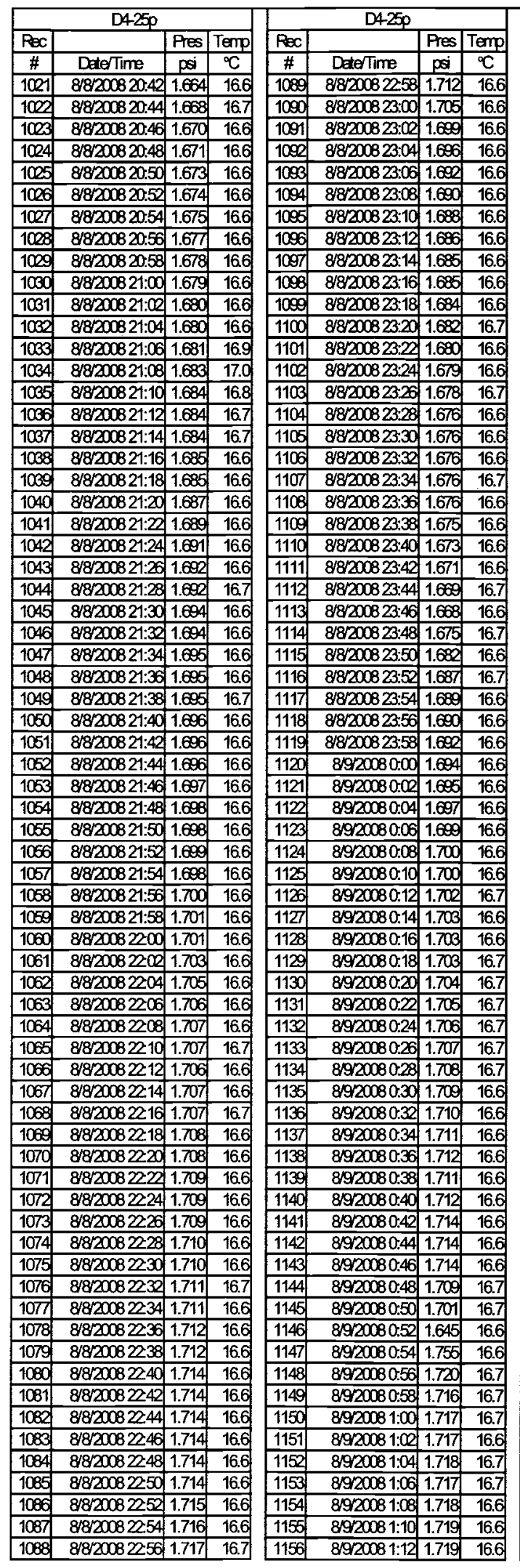

\begin{tabular}{|c|c|c|c|}
\hline \multicolumn{4}{|c|}{$D 425 p$} \\
\hline $\operatorname{Rec}$ & & Pes & Temp \\
\hline \# & Dete/Time & $p s i$ & ${ }^{\circ} \mathrm{C}$ \\
\hline 115 & $89920081: 14$ & 1.718 & 16.6 \\
\hline 1158 & $89200081: 16$ & 1.719 & 16.6 \\
\hline 1159 & $89200081: 18$ & 1.720 & 16.7 \\
\hline 1160 & $8920081: 20$ & 1.721 & 16.6 \\
\hline 1161 & $8920081: 22$ & 1.72 & 16.6 \\
\hline 11ब्य & $89120081: 24$ & 1.724 & 16.7 \\
\hline 116 & $89200081: 26$ & 1.725 & 16.6 \\
\hline 1164 & $8920081: 28$ & 1.725 & 16.6 \\
\hline 1165 & $89: 20081: 30$ & 1.726 & 16.7 \\
\hline 1166 & $8920081: 32$ & 1.725 & 16.7 \\
\hline $1+67$ & $89 / 20081: 34$ & 1.725 & 166 \\
\hline 1168 & $8920081: 36$ & 1.725 & 16.7 \\
\hline 1169 & $89: 20081: 38$ & 1.726 & 16.6 \\
\hline 1170 & $8920081: 40$ & 1.727 & 16.6 \\
\hline 1171 & $89920081: 42$ & 1.729 & 16.6 \\
\hline 1172 & $8920081: 44$ & 1.730 & 16.7 \\
\hline 1173 & $8920081: 46$ & 1.729 & 16.6 \\
\hline 1174 & $8920081: 48$ & 1.729 & 16.7 \\
\hline 1175 & $8920081: 50$ & 1.729 & 16.6 \\
\hline 1176 & $8920081: 52$ & 1.728 & 16.6 \\
\hline 1177 & $89200081: 54$ & 1.728 & 16.6 \\
\hline 1178 & $8920081: 56$ & 1.727 & 16.6 \\
\hline 1179 & $89 / 20081: 58$ & 1.728 & 16.7 \\
\hline 1180 & 892008200 & 1.729 & 16.6 \\
\hline 1181 & 892008202 & 1.729 & 16.7 \\
\hline 1182 & 892008204 & 1.729 & 16.7 \\
\hline 1183 & 892008206 & 1.728 & 16.7 \\
\hline 1184 & 892008208 & 1.726 & 16.6 \\
\hline 1185 & 892008210 & 1.719 & 16.7 \\
\hline 1186 & 892008212 & 1.714 & 16.6 \\
\hline 1187 & 892008214 & 1.710 & 16.6 \\
\hline 1188 & 892008216 & 1.706 & 16.6 \\
\hline 1189 & 892008218 & 1.704 & 16.6 \\
\hline 1190 & 892008220 & 1.702 & 16.6 \\
\hline 1191 & $89 / 200822$ & 1.701 & 16.7 \\
\hline 1192 & 892008224 & 1.705 & 16.6 \\
\hline 1193 & 892008226 & 1.710 & 16.7 \\
\hline 1194 & 892008228 & 1.714 & 16.6 \\
\hline 1195 & 892008230 & 1.712 & 16.6 \\
\hline 1196 & 892008232 & 1.718 & 166 \\
\hline 1197| & 892008234 & 1.721 & 16.6 \\
\hline 1198 & 892008236 & 1.72 & 16.6 \\
\hline 1199 & 892008238 & 1.726 & 16.6 \\
\hline 1200 & 892008240 & 1.724 & 16.6 \\
\hline 1201 & 892008242 & 1.726 & 16.6 \\
\hline 1202 & 892008244 & $\mid 1.72 \pi$ & 16.6 \\
\hline 1203 & 892008246 & 1.728 & 16.7 \\
\hline 1204 & 892008248 & 1.729 & 16.7 \\
\hline 1205 & 892008250 & 1.729 & 16.7 \\
\hline 1206 & 892008252 & 1.730 & 16.7 \\
\hline 1207 & 892008254 & 1.730 & 16.7 \\
\hline 1208 & $89 / 2008256$ & 1.730 & 16.6 \\
\hline 1209 & 892008258 & 1.730 & 16.7 \\
\hline 1210 & $89 / 2008300$ & 1.730 & 16.7 \\
\hline 1211 & $89 / 2008302$ & 1.730 & 167 \\
\hline 1212 & $89 / 20083: 04$ & 1.731 & 167 \\
\hline 1213 & 892008306 & 1.733 & 166 \\
\hline 1214 & $8920003: 08$ & 1.732 & 16.7 \\
\hline 1215 & $89 / 20083: 10$ & 1.732 & 166 \\
\hline 1216 & 8920003312 & 1.733 & 167 \\
\hline 1217 & $89 / 20083: 14$ & 1.732 & 16.7 \\
\hline 1218 & $89 / 20083: 16$ & 1.732 & 167 \\
\hline 1219 & 892008318 & 1.733 & 16.6 \\
\hline 1220 & 892008320 & 1.733 & 16.7 \\
\hline 1221 & 892008322 & 1.733 & 167 \\
\hline 122 & 892006324 & 1.734 & 16.7 \\
\hline 1223 & 892008326 & 1.734 & 166 \\
\hline 1224 & $8 / 920083: 28$ & 1.734 & 16.8 \\
\hline
\end{tabular}

\begin{tabular}{|c|c|c|c|}
\hline \multicolumn{4}{|c|}{ D4250 } \\
\hline Recl & & Pres & Temp \\
\hline \# & Deter/Tme & psi & ${ }^{\circ} 0$ \\
\hline 1225 & $89920083: 30$ & 1.735 & \\
\hline 1226 & $89120083: 3$ & 1.736 & 16. \\
\hline 1227 & $89200083: 34$ & 1.736 & 1 \\
\hline 1228 & & 1.736 & $\overline{16}$ \\
\hline 1229 & $9920083: 38$ & 1.736 & 16. \\
\hline 1230 & $8920083: 40$ & $\mid 1.737$ & $\overline{16}$. \\
\hline 1231 & $8920083: 42$ & 1.737 & 16. \\
\hline 232 & & 1.737 & 16 \\
\hline 1233 & $89200083: 46$ & 1.735 & 16. \\
\hline 1234 & $8920083: 48$ & 1.735 & 16.6 \\
\hline 235 & & 1.736 & 167 \\
\hline 236 & & 1.738 & 16. \\
\hline 237 & 8920083.54 & 1.739 & 166 \\
\hline 1238 & 892 & 1.739 & 16. \\
\hline 33 & 58 & 1.739 & \\
\hline 1240 & 892 & 1.739 & 16 \\
\hline 1241 & 9920 & 1.740 & 16. \\
\hline 242 & 392 & 1.741 & \\
\hline 1243 & 899 & 1.741 & 16. \\
\hline 1244 & & 1.741 & 16. \\
\hline 1245 & 892 & 1.741 & \\
\hline 1246 & 892 & 1.742 & \\
\hline 1247 & 8920 & 1.742 & 16. \\
\hline 1248 & 492 & 1.742 & 16. \\
\hline 1249 & & 1.742 & \\
\hline 1250 & 892 & 1.742 & 6. \\
\hline 1251 & & 1.743 & 16. \\
\hline 1252 & 1.24 & 1.743 & 16. \\
\hline 1253 & 892 & 1.743 & 16. \\
\hline 1254 & 892 & 1.743 & 16. \\
\hline 1256 & 892 & 1.744 & \\
\hline 1256 & & 1.745 & 16. \\
\hline 1257 & & 1.745 & 16. \\
\hline 1258 & 3 & 1.745 & 16. \\
\hline 1250 & 38 & 1.745 & 16. \\
\hline 1260 & & 1.745 & 16. \\
\hline 1261 & & 1,746 & 16. \\
\hline 1262 & 44 & 1.746 & 16. \\
\hline 1263 & $: 46$ & 1.746 & 16. \\
\hline 1264 & & 1.746 & 16. \\
\hline 1265 & 5 & 1.746 & 11 \\
\hline 1266 & 5.52 & 1.746 & 16. \\
\hline 1267 & & 1.746 & 16. \\
\hline 1268 & 56 & 1.745 & \\
\hline 1269 & $4: 58$ & 1.744 & 16. \\
\hline 1270 & & 1.743 & 16. \\
\hline 1271 & 02 & 1.743 & \\
\hline 1272 & 04 & 1.744 & 16. \\
\hline 1273. & & 1.741 & 16. \\
\hline 1274) & 992 & 1.733 & \\
\hline 1275. & & 1.727 & 16 \\
\hline 1276 & & 1.723 & 16. \\
\hline $12 \pi$ & & 1.720 & \\
\hline 1278 & & 1.718 & \\
\hline 1279 & & 1.717 & 16. \\
\hline 1280 & & 1.715 & \\
\hline 1281 & & 1.711 & \\
\hline 1282 & & 1.710 & 16. \\
\hline 1283 & & 1.717 & \\
\hline 1284 & & 1.722 & \\
\hline 1285 & & 1.726 & 16. \\
\hline 1286 & & $\sqrt{1.728}$ & 16 \\
\hline 1287 & & 1.730 & \\
\hline 1288 & & 1.732 & \\
\hline 1289 & & 1.733 & 16. \\
\hline 1290| & & 1.734 & \\
\hline 1291 & & 1.735 & 1 \\
\hline 1292 & & 1.737 & \\
\hline
\end{tabular}

\begin{tabular}{|c|c|c|c|}
\hline \multicolumn{4}{|c|}{$D 425 p$} \\
\hline$P A x$ & & Pres & \\
\hline \# & DeterTime & psi & \\
\hline 1293 & $8920085: 46$ & & \\
\hline 1294 & $920085: 48$ & 1.738 & \\
\hline 1295 & $9200085: 50$ & 1.739 & \\
\hline 1206 & 92008555 & 1.739 & \\
\hline 1297 & & 1.740 & 16 \\
\hline 1298 & $89200085: 56$ & 1.740 & 16 \\
\hline 1209 & $89200085: 58$ & 1.741 & \\
\hline 1300 & & 1.740 & \\
\hline 1301 & 8920008602 & 1.741 & \\
\hline 1302 & $89200066: 04$ & 1.743 & \\
\hline 1303 & $8920086: 06$ & 1.744 & \\
\hline 1304 & & 1.745 & 4 \\
\hline 1305 & $8920086: 10$ & 1.745 & \\
\hline 1306 & $89200066: 12$ & 1.746 & \\
\hline 1307 & $36: 14$ & 1.746 & \\
\hline 1308 & $89200066: 16$ & 1.748 & 17 \\
\hline 1309 & $89200086: 18$ & 1.748 & 16 . \\
\hline 1310 & $86: 20$ & 1.748 & \\
\hline 1311 & $36: 22$ & 1.748 & \\
\hline 1312 & $8920086: 24$ & 1.749 & \\
\hline 1313 & $6: 26$ & 1.750 & 16. \\
\hline 1314 & & 1.749 & \\
\hline 1315 & $8920006: 30$ & 1.750 & \\
\hline 1316 & 3.32 & 1.750 & \\
\hline 1317 & $6: 34$ & 1.751 & \\
\hline 1318 & 6.36 & 1.751 & 16. \\
\hline 1319 & $: 38$ & 1.751 & 16 \\
\hline 1320 & $5: 40$ & 1.752 & \\
\hline 1321 & $6: 42$ & 1.752 & 16 . \\
\hline 1322 & 892 & 1.752 & 16 \\
\hline 1323 & 3920 & 1.752 & \\
\hline 1324 & $6: 48$ & 1.752 & \\
\hline 1325 & & 1.752 & 1 \\
\hline 1326 & 52 & 1.753 & \\
\hline 1327 & 54 & 1.753 & \\
\hline 1328 & $86: 56$ & 1.752 & 16. \\
\hline 1329 & & 1.752 & \\
\hline 1330 & $7: 00$ & 1.751 & \\
\hline 1331 & $7: 02$ & 1.752 & 1 \\
\hline 1332 & $: 04$ & 1.752 & 16 \\
\hline 1333 & $7: 06$ & 1.753 & \\
\hline 1334 & $7: 08$ & 1.752 & \\
\hline 1335 & & 1.752 & 16 \\
\hline 1336 & 3920 & 1.752 & \\
\hline 1337 & $: 14$ & 1.752 & \\
\hline 1338 & & 1.752 & 16 \\
\hline 1339 & 7:18 & 1.754 & \\
\hline 1340 & & 1.754 & \\
\hline 1341 & & 1.753 & $\overline{16}$ \\
\hline 1342 & $7: 24$ & 1.754 & \\
\hline 1343 & $7: 26$ & 1.756 & \\
\hline 1344 & & 1.756 & \\
\hline 1345 & 30 & 1.756 & \\
\hline 1346 & 32 & 1.755 & \\
\hline 1347 & & 1.754 & \\
\hline 1348 & & 1.755 & \\
\hline 1349 & & 1.755 & \\
\hline 1350 & $7: 40$ & 1.756 & \\
\hline 1351 & & 1.756 & \\
\hline 1352 & $7: 44$ & 1.754 & \\
\hline 1353 & $7: 46$ & 1.753 & \\
\hline 1354 & & 1.754 & \\
\hline 1356 & 50 & 1.756 & \\
\hline 1356 & $87: 52$ & 1.756 & 16 \\
\hline 1357 & & 1.756 & \\
\hline 1358 & & 1.756 & \\
\hline 1359 & $7: 58$ & 1.757 & \\
\hline 1360 & & 1.75 & \\
\hline
\end{tabular}




\begin{tabular}{|c|c|c|c|}
\hline \multicolumn{4}{|c|}{$D 4250$} \\
\hline $\operatorname{Pac}$ & & Pres & Temp \\
\hline$\#$ & DeterTime & psi & ${ }^{\circ} \mathrm{C}$ \\
\hline 1361. & $89200088: 02$ & 1.757 & 16.7 \\
\hline 1362 & $89920088: 04$ & 1.75 & 16.6 \\
\hline 1363 & 89920088:06 & 1.758 & 16.7 \\
\hline 1364 & $8920008: 08$ & 1.757 & 16.7 \\
\hline 1365 & $89920088: 10$ & 1.756 & 16.7 \\
\hline 1366 & $89920088: 12$ & 1.755 & 16.7 \\
\hline 1367 & $8920008: 14$ & 1.756 & 16.6 \\
\hline 1368 & $8920008: 16$ & 1.75 & 16.6 \\
\hline 1369 & 8/920088:18 & 1.755 & 16.7 \\
\hline 1370 & $89920088: 20$ & 1.757 & 16.6 \\
\hline 1371 & $8920008: 22$ & 1.756 & 16.7 \\
\hline 1372 & $8920088: 24$ & 1.754 & 16.7 \\
\hline 1373 & $8920088: 26$ & 1.754 & 16.6 \\
\hline 1374 & $89920088: 28$ & 1.756 & 16.7 \\
\hline 1375 & 8920088.30 & 1.758 & 16.7 \\
\hline 1376 & $8 / 920088: 32$ & 1.759 & 16.7 \\
\hline $13 \pi$ & $8 / 920088.34$ & 1.760 & 16.6 \\
\hline 1378 & $8 / 920088: 36$ & 1.761 & 16.6 \\
\hline 1379 & 89920088.38 & 1.762 & 16.7 \\
\hline 1380 & $8 / 920008: 40$ & 1.761 & 16.7 \\
\hline 1381 & $89120088: 42$ & 1.761 & 16.6 \\
\hline 1382 & $8 / 920088.44$ & 1.760 & 16.7 \\
\hline 1383 & $8 / 920088: 46$ & 1.759 & 16.6 \\
\hline 1384 & $89920088: 48$ & 1.758 & 16.6 \\
\hline 1385 & $89920088: 50$ & 1.758 & 16.7 \\
\hline 1386 & $89920088: 52$ & 1.758 & 16.6 \\
\hline 1387 & $8920008: 54$ & 1.760 & 16.6 \\
\hline 1388 & 89920088.56 & 1.760 & 16.7 \\
\hline 1389 & 89920088.58 & 1.759 & 16.6 \\
\hline 1390 & 89.20089 .00 & 1.758 & 16.6 \\
\hline 1391 & 89920089.02 & 1.758 & 16.7 \\
\hline 1392 & $89200089: 04$ & 1.760 & 16.7 \\
\hline 1393 & $8920009: 06$ & 1.760 & 16.6 \\
\hline 1394 & $89920089: 08$ & 1.761 & 16.6 \\
\hline 1395 & 8920009.10 & 1.756 & 16.7 \\
\hline 1396 & 89200089.12 & 1.748 & 16.7 \\
\hline 1397 & 8920089.14 & 1.743 & 16.6 \\
\hline 1398 & 8920089.16 & 1.738 & 16.6 \\
\hline 1399 & 89920089.18 & 1.734 & 16.6 \\
\hline 1400 & $8920089: 20$ & 1.731 & 16.6 \\
\hline 1401 & 89920089.22 & 1.728 & 16.7 \\
\hline 1402 & $89920089: 24$ & 1.730 & 16.7 \\
\hline 1403 & $8 / 920009.26$ & 1.736 & 16.6 \\
\hline 1404 & $8 / 920089: 28$ & 1.740 & 16.7 \\
\hline 1405 & $8 / 920089: 30$ & 1.743 & 16.7 \\
\hline 1406 & $8 / 920089.32$ & 1.746 & 16.7 \\
\hline 1407 & 89920089.34 & \begin{tabular}{|l|l}
1.747 \\
\end{tabular} & 16.6 \\
\hline 1408 & 89920089936 & 1.747 & 16.6 \\
\hline 1409 & 89920089.38 & 1.748 & 16.6 \\
\hline 1410 & 89920089440 & 1.749 & 16.7 \\
\hline 1411 & $8 / 920089.42$ & 1.750 & 16.7 \\
\hline 1412 & 8/920089:44 & 1.751 & 16.6 \\
\hline 1413 & 89920089.46 & 1.752 & 16.7 \\
\hline 1414 & 89200089.48 & 1.753 & 16.6 \\
\hline 1415 & 89200089.50 & 1.753 & 16.6 \\
\hline 1416 & 8920089.52 & 1.753 & 16.7 \\
\hline 1417 & $8 / 9200089.54$ & 1.753 & 16.6 \\
\hline 1418 & 89920089.56 & 1.753 & 16.7 \\
\hline 1419 & $8 / 9200089.58$ & 1.753 & 16.7 \\
\hline 1420 & $89: 2008$ 10:00 & 1.754 & 16.7 \\
\hline 1421 & 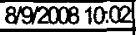 & 1.756 & 16.7 \\
\hline 1422 & $89: 2008$ 10:04 & 1.755 & 16.6 \\
\hline 1423 & 8920008 10:06 & 1.756 & 16.7 \\
\hline 1424 & $8 / 92008$ 10:08 & 1.756 & 16.7 \\
\hline 1425 & $89200810: 10$ & 1.756 & 16.6 \\
\hline 1426 & 8992008 10:12 & 1.756 & 16.7 \\
\hline 1427 & $8 / 9 / 2008$ 10:14 & 1.756 & 16.6 \\
\hline 1428 & 8/9/2008 10:16 & 1.756 & 16.6 \\
\hline
\end{tabular}

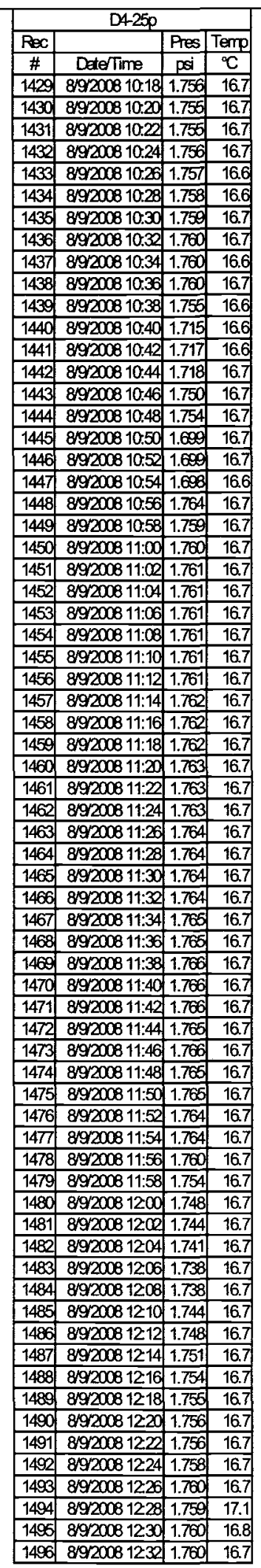

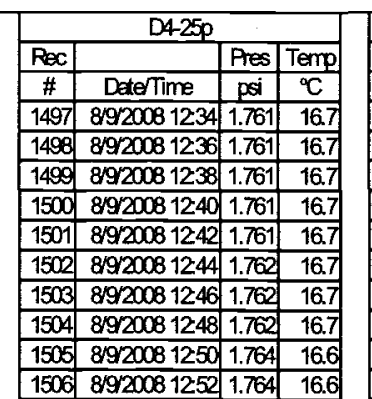

\begin{tabular}{|l|l|l|l|}
\hline 1506 & 8920081252 & 1.764 & 16.6 \\
\hline 1507 & 8920081254 & 1.76 & 16.7 \\
\hline
\end{tabular} \begin{tabular}{|l|l|l|l|}
\hline 1507 & 89200081254 & 1.764 & 16.7 \\
\hline 1508 & 8920081256 & 1.765 & 16.7 \\
\hline
\end{tabular} \begin{tabular}{|l|l|l|l|}
\hline 1508 & 8920081256 & 1.765 & 16.7 \\
\hline
\end{tabular} \begin{tabular}{|l|l|l|l|}
\hline 1509 & 8920081258 & 1.763 & 16.7 \\
\hline 1510 & 8920081300 & 1.764 & 16.6 \\
\hline
\end{tabular} \begin{tabular}{|l|l|l|l|}
\hline 1510 & 8920081300 & 1.764 & 16.6 \\
\hline 1511 & 892081300 & 1.764 & 16.7 \\
\hline
\end{tabular} \begin{tabular}{|l|l|l|l|}
\hline 1511 & 89200081302 & 1.764 & 16.7 \\
\hline
\end{tabular} \begin{tabular}{|l|l|l|l|}
\hline 1512 & 819200081304 & 1.764 & 16.7 \\
\hline 1513 & 8920081300 & 1764 & 16.6 \\
\hline
\end{tabular} \begin{tabular}{|l|l|l|l|}
\hline 1513 & 8920081306 & 1.764 & 16.6 \\
\hline
\end{tabular}

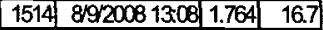
\begin{tabular}{|l|l|l|l|}
\hline 1515 & $892000813: 10$ & 1.764 & 16.7 \\
\hline
\end{tabular} \begin{tabular}{|l|l|l|l|}
\hline 1516 & $89200813: 12$ & 1.765 & 16.7 \\
\hline
\end{tabular} \begin{tabular}{|l|l|l|l|}
\hline 1517 & $89200813: 14$ & 1.765 & 16.7 \\
\hline 1518 & $89200813: 16$ & 1766 & 16.7 \\
\hline
\end{tabular} \begin{tabular}{|l|l|l|l|}
\hline 1518 & $892000813: 16$ & 1.766 & 16.7 \\
\hline 1519 & 8920081318 & 1702 & 16.7 \\
\hline
\end{tabular} \begin{tabular}{|l|l|l|l|}
\hline 1519 & $8 / 9200813: 18$ & 1.702 & 16.7 \\
\hline 1520 & 8920081320 & 1.69 & 16.7 \\
\hline
\end{tabular} \begin{tabular}{|l|l|l|l|}
\hline 1520 & 89200813220 & 1.694 & 16.7 \\
\hline 1521 & 89200813.22 & 1.691 & 16.7 \\
\hline
\end{tabular} \begin{tabular}{|l|l|l|l|}
\hline 1521 & $89200813: 22$ & 1.691 & 16.7 \\
\hline 1522 & 8920081324 & 1601 & 16.7 \\
\hline
\end{tabular} \begin{tabular}{|l|l|l|l|}
\hline 1522 & 892000813.24 & 1.691 & 16.7 \\
\hline 1523 & 8920081326 & 1.688 & 16.7 \\
\hline
\end{tabular} \begin{tabular}{|l|l|l|l|}
\hline 1523 & 8920081326 & 1.688 & 16.7 \\
\hline 1524 & 8920081328 & 1.76 & 167 \\
\hline
\end{tabular} \begin{tabular}{|l|l|l|l|}
\hline 1524 & $892000813: 28$ & 1.776 & 16.7 \\
\hline 1525 & 8920081330 & 1763 & 16.7 \\
\hline
\end{tabular} \begin{tabular}{|l|l|l|l|}
\hline 1525 & $892200813: 30$ & 1.763 & 16.7 \\
\hline
\end{tabular} \begin{tabular}{|l|l|l|l|}
\hline 1526 & $892200813: 32$ & 1.765 & 16.7 \\
\hline 1527 & 89200813.37 & 1.795 & 16.7 \\
\hline
\end{tabular}

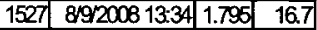
\begin{tabular}{|l|l|l|l|}
\hline 1528 & $892200813: 36$ & 1.795 & 16.7 \\
\hline 1529 & 89200813.30 & 1.795 & 16.7 \\
\hline
\end{tabular} \begin{tabular}{|l|l|l|l|}
\hline 1529 & $8 / 9 / 200813: 38$ & 1.795 & 16.7 \\
\hline 1530 & 8920081340 & 1.795 & 16.7 \\
\hline
\end{tabular} \begin{tabular}{|l|l|l|l|}
\hline 1530 & $8 / 9200813: 40$ & 1.795 & 16.7 \\
\hline
\end{tabular}

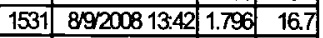
\begin{tabular}{|l|l|l|l|}
\hline 1532 & $892200813: 44$ & 1.796 & 16.7 \\
\hline 1533 & 89200813.46 & 1.796 & 16.7 \\
\hline
\end{tabular} \begin{tabular}{|l|l|l|l|}
\hline 1533 & 899200813.46 & 1.796 & 16.7 \\
\hline
\end{tabular} \begin{tabular}{|l|l|l|l|}
\hline 1534 & 8920081348 & 1.796 & 16.7 \\
\hline 1530 & 89200813.50 & 1.796 & 16.7 \\
\hline
\end{tabular}

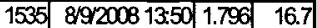
\begin{tabular}{|l|l|l|l|}
\hline 1536 & 8920081352 & 1.796 & 16.7 \\
\hline 1537 & 8920031354 & 1.797 & 16.7 \\
\hline
\end{tabular} \begin{tabular}{|l|l|l|l|}
\hline 1537 & $8 / 92000813: 54$ & 1.797 & 16.7 \\
\hline
\end{tabular} \begin{tabular}{|l|l|l|l|}
\hline 1538 & 892000813.56 & 1.796 & 16.7 \\
\hline 1539 & 8920081358 & 1.79 & 16.7 \\
\hline
\end{tabular}

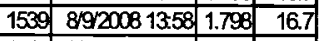
\begin{tabular}{|l|l|l|l|}
\hline 1540 & $89200814: 00$ & 1.796 & 16.7 \\
\hline
\end{tabular} \begin{tabular}{|l|l|l|l|}
\hline 1541 & $892000814: 02$ & 1.798 & 167 \\
\hline
\end{tabular} \begin{tabular}{|l|l|l|l|}
\hline 1542 & $89200814: 04$ & 1.797 & 16.7 \\
\hline
\end{tabular}

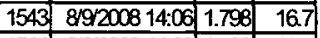

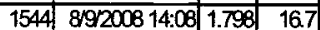
\begin{tabular}{|l|l|l|l|}
\hline 1545 & $89200814: 10$ & 1.798 & 16.7 \\
\hline
\end{tabular}

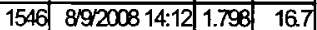
\begin{tabular}{|l|l|l|l|}
\hline 1547 & $892000814: 14$ & 1.798 & 16.7 \\
\hline 1548 & $89200814: 16$ & 1.799 & 16.7 \\
\hline
\end{tabular} \begin{tabular}{|l|l|l|l|}
\hline 1548 & $8 / 9200814: 16$ & 1.799 & 16.7 \\
\hline 1549 & $89200814: 18$ & 1.800 & 16.7 \\
\hline
\end{tabular}

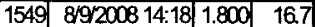

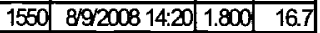
\begin{tabular}{|l|l|l|l|}
\hline 1551 & $89200814: 22$ & 1.801 & 16.7 \\
\hline 1520 & $89200814: 24$ & 1.800 & 16.7 \\
\hline
\end{tabular}

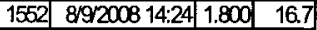
\begin{tabular}{|l|l|l|l|}
\hline 1553 & $899200814: 26$ & 1.800 & 16.7 \\
\hline
\end{tabular} \begin{tabular}{|l|l|l|l|}
\hline 1554 & $8 / 9200814: 28$ & 1.800 & 16.7 \\
\hline
\end{tabular} \begin{tabular}{|l|l|l|l|}
\hline 1555 & $892000814: 30$ & 1.800 & 16.7 \\
\hline
\end{tabular} \begin{tabular}{|l|l|l|l|}
\hline 1556 & $89200814: 32$ & 1.800 & 16.7 \\
\hline
\end{tabular}

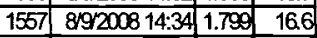

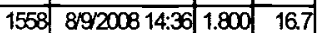

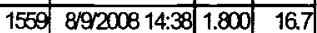
\begin{tabular}{lllll|}
\hline 1560 & 892008 & $14: 40$ & 1.800 & 16.7 \\
\hline
\end{tabular} \begin{tabular}{|l|l|l|l|}
\hline 1561 & $899200814: 42$ & 1.799 & 16.7 \\
\hline 1502 & $89200814: 44$ & 1799 & 16.6 \\
\hline
\end{tabular} \begin{tabular}{|l|l|l|l|}
\hline 1562 & $89200814: 44$ & 1.799 & 16.6 \\
\hline
\end{tabular}

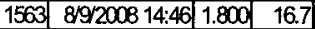

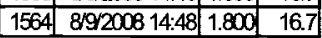

\begin{tabular}{|c|c|c|c|c|c|c|c|}
\hline \multicolumn{4}{|c|}{ D425p } & \multicolumn{4}{|c|}{$D 4-25 p$} \\
\hline $\operatorname{Rec}$ & & Pres & Temp & $\mathrm{Rec}$ & & Pres & Temp \\
\hline \# & Dete-Time & psi & ${ }^{\circ} \mathrm{C}$ & \# & DaterTime & psi & \\
\hline 1565 & $89200814: 50$ & 1.798 & 16.7 & 1633 & 8992008 17:06 & 1.806 & 16.7 \\
\hline 1566 & $899200814: 52$ & 1.800 & 16.7 & 1634 & 8992008 17:08 & 1.807 & \\
\hline 1567 . & $8 / 9200814: 54$ & 1.800 & 16.7 & 1635 & 8192008 17:10 & 1.807 & \\
\hline 1568 & $892000814: 56$ & 1.799 & 16.7 & 1636 & $8 / 92000817: 12$ & 1.806 & 16.7 \\
\hline 1569 & $892000814: 58$ & 1.793 & 16.6 & 1637 & $892000817: 14$ & 1.805 & \\
\hline 1570 & $899200815: 00$ & 1.786 & 16.7 & 1638 & $8 / 92008$ 17:16 & 1.807 & \\
\hline 1571 & $892000815: 02$ & 1.781 & 16.7 & 1639 & & 1.807 & \\
\hline 1572 & $899200815: 04$ & 1.778 & 16.7 & 1640 & 892008 17:20 & 1.806 & \\
\hline 1573 & $89200815: 06$ & $1.7 \pi$ & 16.7 & 1641 & $899200817: 22$ & 1.805 & \\
\hline 1574 & $89200815: 08$ & 1.782 & 16.7 & 1642 & $8 / 920008$ 17:24 & 1.806 & \\
\hline 1575 & $89200815: 10$ & 1.784 & 16.7 & 1643 & $89 / 2008$ 17:26 & 1.806 & \\
\hline 1576 & $89200815: 12$ & 1.789 & 16.6 & 1644 & $8 / 9200817: 28$ & 1.806 & 6.7 \\
\hline $15 \pi$ & $892000815: 14$ & 1.790 & 16.7 & 1645 & $899200817: 30$ & 1.807 & \\
\hline 1578 & $892000815: 16$ & 1.790 & 16.6 & 1646 & $17: 32$ & 1.806 & \\
\hline 1579 & $899200815: 18$ & 1.792 & 16.7 & 1647 & $17: 34$ & 1.805 & \\
\hline 1580 & $899200815: 20$ & 1.792 & 16.7 & 1648 & $8 / 9200817: 36$ & 1.805 & \\
\hline 1581 & 8992 & 1.793 & 16.6 & 1649 & $17: 38$ & 1.806 & \\
\hline 1582 & $0815: 24$ & 1.794 & 16.6 & 1650 & $17: 40^{4}$ & 1.806 & \\
\hline 1583 & $892000815: 26$ & 1.794 & 16.6 & 1651 & $899200817: 42$ & 1.793 & 2. \\
\hline 1584 & $899200815: 28$ & 1.795 & 16.7 & 1652 & $000817: 44$ & 1.808 & \\
\hline 1585 & 8992 & 1.795 & 16.7 & 165 & 17:46 & $1 . \overline{810}$ & \\
\hline 1586 & $00815: 32$ & 1.796 & 16.6 & 1654 & $17: 48$ & 1.803 & \\
\hline 1587 & $899200815: 34$ & 1.797 & 16.6 & 1655 & $00817: 50$ & 1.794 & \\
\hline 1588 & 892 & 1.797 & 16.7 & 1656 & & 1.730 & \\
\hline 1589 & 89 & 1.796 & 16.6 & 165 & $77-54$ & 1.678 & \\
\hline 1590 & $815: 40$ & 1.797 & 16.6 & 1658 & 17:56 & 1.671 & \\
\hline 1591 & $0815: 42$ & 1.796 & 16.7 & 1650 & & 1.772 & \\
\hline 1592 & & 1.798 & 16.7 & 1600 & & 1.774 & \\
\hline 1503 & $9815: 46$ & 1.798 & 16.7 & 1661 & $8: 02$ & 1.772 & 6.7 \\
\hline 1594 & $0815: 48$ & 1.797 & 16.7 & 1602 & 18:04 & 1.778 & \\
\hline 1596 & $15: 50$ & 1.798 & & 1663 & & 1.785 & \\
\hline 1596 & & & 10.7 & 1664 & & 1.787 & \\
\hline 1597 & 0815.54 & 1.800 & 16.7 & 1665 & & 1.790 & 3.7 \\
\hline 1598: & $0815: 56$ & 1.797 & 16.6 & 1666 & & 1.791 & \\
\hline 1599 & 8 & 1.790 & 16.6 & 1667 & $8: 14$ & 1.799 & \\
\hline 1600 & 892 & 1.799 & 16.6 & 1668 & 18:16 & 1.793 & \\
\hline 1601 & & 1.799 & 16.6 & 1609 & & 1.796 & \\
\hline 1602 & & 1.796 & 16.7 & 1670 & & 1.796 & \\
\hline 1603 & & 1.800 & 16.7 & 1671 & & 1.796 & \\
\hline 1604 & $16: 08$ & 1.799 & 16.7 & 1672 & & 1.798 & \\
\hline 1605 & & 1.796 & 16.6 & 1673 & & 1.798 & \\
\hline 1606 & & 1.800 & 16.7 & 1674 & & 1.799 & \\
\hline 1607 & $6: 14$ & 1.796 & 16.6 & 1675 & & 1.798 & 16.7 \\
\hline 1608 & & 1.800 & 16.6 & 1676 & & 1.798 & 16.7 \\
\hline 1609 & & 1.801 & 16.7 & 1677 & & 1.800 & \\
\hline 1610 & & 1.802 & 10.1 & 1678 & & 1.799 & \\
\hline 1611 & 89 & 1.800 & 16.7 & 1679 & $3: 38$ & 1.799 & \\
\hline 1612 & $00816: 24$ & 1.802 & 16.6 & 1680 & & 1.800 & \\
\hline 1613 & $0816: 26$ & 1.803 & & 1681 & & 1.799 & \\
\hline 1614 & & 1.803 & 16.6 & & & 1.801 & \\
\hline 1615 & & 1.804 & 16.7 & 1683 & $0818: 46$ & 1.801 & \\
\hline 1616 & & 1.803 & 17.1 & 1684 & $00818: 48$ & 1.800 & \\
\hline 1617 & & 1.804 & & 1685 & 18:50 & 1.802 & \\
\hline 1618 & & 1.804 & 16.7 & 1686 & & 1.802 & \\
\hline 1619 & $892000816: 38$ & 1.805 & 16.7 & 1687 & 89200818.54 & 1.801 & \\
\hline 1620 & $899200816: 40$ & 1.805 & 16.7 & 1688 & $8: 56$ & 1.801 & \\
\hline 1621 & $899200816: 42$ & 1.805 & 16.7 & 1689 & $8: 58$ & 1.802 & \\
\hline 162 & & 1.806 & 16.7 & 1690 & & 1.802 & \\
\hline 1623 & $899200016: 46$ & 1.805 & 16.6 & 1601 & 892000 & 1,803 & \\
\hline 1624 & $899200816: 48$ & 1.805 & 16.7 & 1692 & 9.04 & 1.800 & \\
\hline 1625 & $899200816: 50$ & 1.805 & 16.7 & 1693 & 89200819.06 & 1.800 & \\
\hline 1626 & $899200816: 52$ & 1.805 & 16.6 & 1694 & $8 / 9200819.08$ & 1.800 & \\
\hline 1627 & $89200816: 54$ & 1.805 & 16.7 & 1606 & $89200819: 10$ & 1.802 & 16.7 \\
\hline 1628 & $89200816: 56$ & 1.806 & 16.7 & 1696 & $89200819: 12$ & 1.801 & \\
\hline 1629 & $89200816: 58$ & 1.806 & 16.7 & 1697 & 89200819.14 & 1.800 & \\
\hline 1630 & & 1.807 & 16.7 & 1698 & $89200819: 16$ & 1.80 & 16.7 \\
\hline 1631 & $892200817: 02$ & 1.806 & 16.6 & 1699 & $89200819: 18$ & 1.800 & 16.7 \\
\hline 1632 & 8912008 17:04 & 1.807 & 16.6 & 1700 & $89200819: 20$ & 1.802 & 16.7 \\
\hline
\end{tabular}




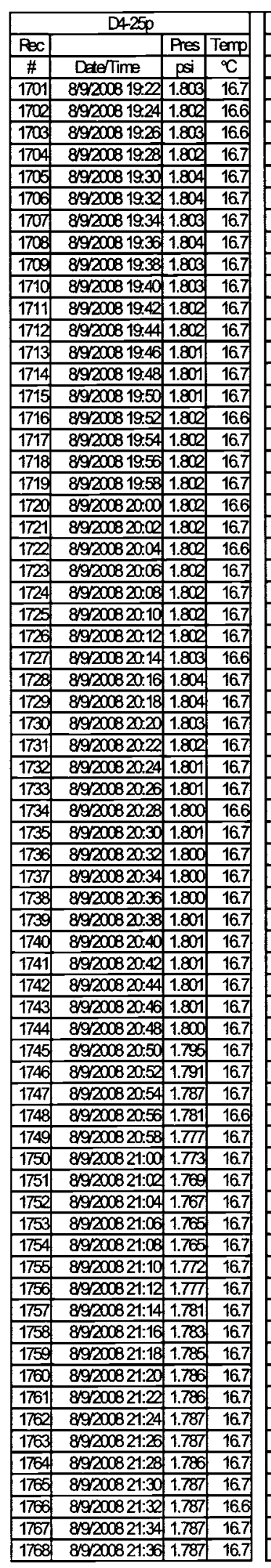

\begin{tabular}{|c|c|c|c|}
\hline \multicolumn{4}{|c|}{$D 425 p$} \\
\hline $\mathrm{Rec}$ & & Pres & Temp \\
\hline$\#$ & DaterTime & psi & ${ }^{\infty} \mathrm{C}$ \\
\hline 1769 & $89 / 200821: 38$ & 1.787 & 16.7 \\
\hline 1770 & $891200821: 40$ & 1.788 & 16.7 \\
\hline 1771 & $892000821: 42$ & 1.788 & 16.7 \\
\hline 1772 & $8 / 9200821: 44$ & 1.788 & 16.6 \\
\hline 1773 & $89 / 200821: 46$ & 1.732 & 16.7 \\
\hline 1774 & $891200821: 48$ & 1.754 & 16.7 \\
\hline 1775 & $89 / 200821: 50$ & 1.797 & 16.7 \\
\hline 1776 & $892000821: 52$ & 1.792 & 16.7 \\
\hline $177 \pi$ & $89200821: 54$ & 1.79 & 16.7 \\
\hline 1778 & $892000821: 50$ & 1.792 & 16.7 \\
\hline 1779 & $892000821: 58$ & 1.792 & 16.7 \\
\hline 1780 & 8920082200 & 1.792 & 16.7 \\
\hline 1781 & 8920082201 & 1.792 & 16.7 \\
\hline 1782 & 8920082204 & 1.793 & $\overline{16.7}$ \\
\hline 1783 & 8920082206 & 1.799 & 16.7 \\
\hline 1784 & 8920082208 & 1.794 & 16.7 \\
\hline 1785 & 8920082210 & 1.794 & 16.7 \\
\hline 1786 & 8920082212 & 1.794 & 16.7 \\
\hline 1787 & 8920082214 & 1.794 & 16.6 \\
\hline 1788 & 89200082216 & 1.793 & 16.7 \\
\hline 1789 & 8920082218 & 1.793 & 16.7 \\
\hline 1790 & 89200022220 & 1.793 & 16.6 \\
\hline 1791 & 8920082222 & 1.794 & 16.7 \\
\hline 1792 & 8920082224 & 1.794 & 16.7 \\
\hline 1793 & 8920082226 & 1.751 & 16.7 \\
\hline 1794 & 8920082228 & 1.792 & 16.7 \\
\hline 1795 & 8920082230 & 1.794 & 16.7 \\
\hline 1796 & $89 / 20082232$ & 1.795 & 16.6 \\
\hline 1797 & 892008223 & 1.795 & 16.7 \\
\hline 1798 & 8920082236 & 1.795 & 16.7 \\
\hline 1799 & 8920082238 & 1.796 & 16.7 \\
\hline 1800 & 8920082240 & 1.795 & 16.6 \\
\hline 1801 & 89200082242 & 1.796 & 16.7 \\
\hline 1802 & 8920082244 & 1.794 & 16.7 \\
\hline 1803 & 8920082246 & 1.794 & 16.7 \\
\hline 1804 & 8920002248 & 1.794 & 16.7 \\
\hline 1805 & 89200082250 & 1.796 & 16.7 \\
\hline 1806 & 892000825 & 1.796 & 16.7 \\
\hline 1807 & 8920082254 & 1.795 & 16.7 \\
\hline 1808 & 89200082256 & 1.796 & 16.7 \\
\hline 1809 & 89200082250 & 1.795 & 16.7 \\
\hline 1810 & $892000823: 00$ & 1.796 & 16.6 \\
\hline 1811 & 89200022300 & 1.795 & 16.7 \\
\hline 1812 & $89200823: 04$ & 1.796 & 16.7 \\
\hline 1813 & $89200023: 06$ & 1.796 & 16.7 \\
\hline 1814 & $89200023: 06$ & 1.796 & 16.7 \\
\hline 1815 & $89200825: 10$ & 1.797 & 16.7 \\
\hline 1816 & $89200823: 12$ & 1.797 & 16.7 \\
\hline 1817 & $89200023: 14$ & 1.798 & 16.7 \\
\hline 1818 & $89200825: 16$ & 1.798 & 16.6 \\
\hline 1819 & $89200823: 18$ & 1.798 & 16.7 \\
\hline 1820 & 8920082320 & 1.796 & 16.7 \\
\hline 1821 & $89200823: 22$ & 1.797 & 16.7 \\
\hline 1822 & $89200824: 24$ & 1.796 & 16.7 \\
\hline 1823 & $89 / 20082326$ & 1.796 & 16.7 \\
\hline 1824 & 8990082528 & 1.797 & 16.6 \\
\hline 1825 & 89200082330 & 1.797 & 16.7 \\
\hline 1826 & 899200825.32 & 1.797 & 16.7 \\
\hline 1827 & 89200082334 & 1.797 & 16.7 \\
\hline 1828 & 89920082333 & 1.797 & 16.7 \\
\hline 1829 & $89 / 20082333$ & 1.798 & 16.7 \\
\hline 1830 & 89200082540 & 1.798 & 16.6 \\
\hline 1831 & 89920082342 & 1.796 & 16.7 \\
\hline 1832 & 89200082544 & 1.798 & 16.7 \\
\hline 1833 & 8920082346 & 1.798 & 16.7 \\
\hline 1834 & 8920082344 & 1.797 & 16.7 \\
\hline 1835 & 8920082350 & 1.798 & 16.7 \\
\hline 1836 & 8920008235 & 1.796 & 16.6 \\
\hline
\end{tabular}

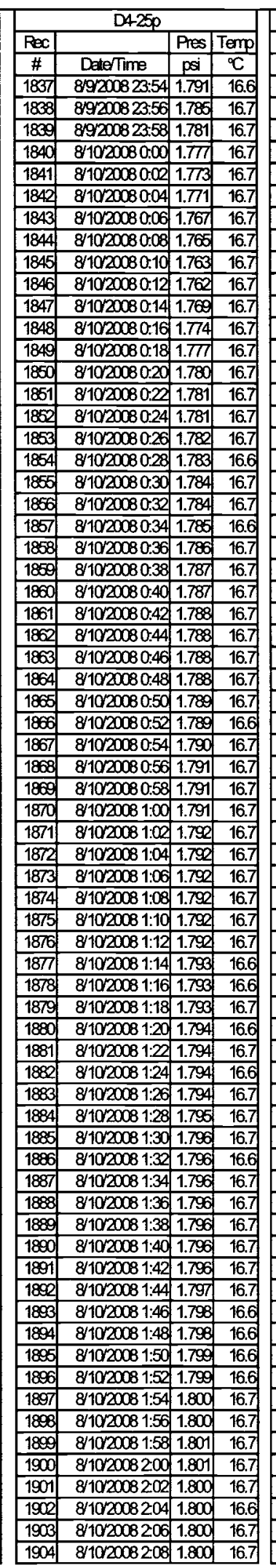

\begin{tabular}{|c|c|c|c|}
\hline \multicolumn{4}{|c|}{$D 425 p$} \\
\hline Pec & & Pres & \\
\hline$\#$ & DeteTime & $\mathrm{psi}$ & \\
\hline 1973 & $8 / 10200084: 26$ & 1.805 & \\
\hline 1974 & & 1.806 & \\
\hline 1975 & $1020084: 30$ & 1.806 & \\
\hline 1976 & $10: 20084: 32$ & 1.806 & \\
\hline 1977 & & & \\
\hline 1978 & $1020084: 36$ & 1.806 & \\
\hline 1979 & $10220084: 38$ & 1.806 & 16 \\
\hline 1980 & $10: 20084: 40$ & 1.806 & \\
\hline 1981) & & 1.807 & \\
\hline 1982 & $1020084: 44$ & 1.808 & \\
\hline 1983 & $1020084: 46$ & 1.808 & \\
\hline 1984 & & 1.809 & \\
\hline 1986 & $084: 50$ & 1.809 & \\
\hline 1986 & $084: 52$ & 1.809 & \\
\hline 1987. & $84: 54$ & 1.808 & 16 \\
\hline 1988 & & 1.807 & \\
\hline 1909 & $84: 58$ & 1.807 & \\
\hline 1990 & $5: 00$ & 1.807 & \\
\hline 1991 & & 1.807 & \\
\hline 1992 & & 1.807 & \\
\hline 1993 & & 1.807 & \\
\hline 1994 & & 1.807 & \\
\hline 1995 & & 1.807 & \\
\hline 1996 & & 1.808 & \\
\hline 1997. & & 1.800 & \\
\hline 1998: & & 1.809 & \\
\hline 1999 & & 1.800 & \\
\hline 2000 & & 1.800 & \\
\hline 2001 & & 1.809 & \\
\hline 2002 & $85: 24$ & 1.810 & \\
\hline 2003 & & 1.810 & 16 \\
\hline 2004 & & 1.810 & \\
\hline 2006 & & 1.810 & \\
\hline 2006 & & 1.810 & 16 \\
\hline 2007 & & 1.668 & \\
\hline 2008 & & 1.797 & \\
\hline 2000 & & 1.806 & \\
\hline 2010 & & 1.808 & \\
\hline 2011 & & 1.808 & \\
\hline 2012 & & 1.803 & \\
\hline 2013 & & 1.809 & \\
\hline 2014 & & 1.807 & \\
\hline 2015 & & 1.803 & \\
\hline 2016 & & 1.798 & \\
\hline 2017 & & 1.793 & \\
\hline 2018 & & 1.790 & \\
\hline 2019 & & 1.787 & \\
\hline 2020 & & 1.784 & \\
\hline 2021 & & 1.781 & \\
\hline 2022 & & 1.779 & \\
\hline 2023 & & 1.77 & \\
\hline 2024 & & 1.782 & 16 \\
\hline 2025 & & 1.786 & \\
\hline 2026 & & 1.788 & \\
\hline 2027 & & 1.791 & 16 \\
\hline 2028 & & 1.798 & \\
\hline 2029 & & 1.793 & \\
\hline 2000 & & 1.794 & \\
\hline 2031 & & 1.796 & \\
\hline 2003 & & 1.796 & \\
\hline 2003 & & 1.796 & \\
\hline 2034 & & 1.797 & \\
\hline 2035 & & 1.798 & \\
\hline 2006 & & 1.800 & \\
\hline 2003 & & 1.800 & 16 \\
\hline 2008 & & 1.800 & \\
\hline 2009 & & 1.801 & \\
\hline 2040 & & 1.801 & \\
\hline
\end{tabular}




\begin{tabular}{|c|c|c|c|}
\hline \multicolumn{4}{|c|}{ D425p } \\
\hline $\mathrm{Rec}$ & & Pres & Temp \\
\hline \# & Date/Time & psi & ${ }^{\circ} \mathrm{C}$ \\
\hline 2041 & 81020086.42 & 1.801 & 167 \\
\hline 2042 & $810 / 2008644$ & 1.801 & 16.7 \\
\hline 2043 & $8 / 102008646$ & 1.802 & 16.6 \\
\hline 2044 & $811020086: 48$ & 1.801 & 16.7 \\
\hline 2045 & 8102008650 & 1.802 & 16.7 \\
\hline 2046 & $8 / 1020086.52$ & 1.800 & 16.7 \\
\hline 2047 & 81020086.54 & 1.802 & 16.6 \\
\hline 2048 & 81020086.56 & 1.803 & 16.7 \\
\hline 2049 & $8 / 10 / 20086: 58$ & 1.803 & 16.7 \\
\hline 2050 & $8 / 10 / 20087: 00$ & 1.803 & 16.7 \\
\hline 2051 & $8110200087: 02$ & 1.803 & 16.6 \\
\hline 2052 & $8 / 10200087: 04$ & 1.804 & 16.7 \\
\hline 2053 & $8 / 10 / 20087: 06$ & 1.804 & 16.6 \\
\hline 2054 & $8 / 10200087: 08$ & 1.804 & 16.7 \\
\hline 2055 & $8 / 10200087: 10$ & 1.803 & 16.6 \\
\hline 2056 & $8 / 1020087: 12$ & 1.803 & 16.6 \\
\hline 2057 & $8 / 10 / 20087: 14$ & 1.803 & 16.7 \\
\hline 2058 & $81020087: 16$ & 1.804 & 16.7 \\
\hline 2000 & $8 / 1020087: 18$ & 1.805 & 16.7 \\
\hline 2060 & $8 / 10200087: 20$ & 1.805 & 16.7 \\
\hline 2061 & $81020087: 22$ & 1.805 & 16.7 \\
\hline 2002 & $810 / 20087: 24$ & 1.806 & 16.6 \\
\hline 2063 & $810220087: 26$ & 1.807 & 16.7 \\
\hline 2064 & $81020087: 28$ & 1.807 & 167 \\
\hline 206 & $810220087: 30$ & 1.808 & 16.7 \\
\hline 206 & $81020087: 32$ & 1.808 & 167 \\
\hline 2067 & $810 / 20087: 34$ & 1.808 & 166 \\
\hline 2068 & $8 / 10220087: 36$ & 1.808 & 16.6 \\
\hline 2069 & $8 / 1020087: 38$ & 1.808 & 16.7 \\
\hline 2070 & $8 / 1020087: 40$ & 1.808 & 16.7 \\
\hline 2071 & $8 / 10200087: 42$ & 1.808 & 16.7 \\
\hline 2072 & $81020087: 44$ & 1.808 & 16.7 \\
\hline 2073 & $81020087: 46$ & 1.807 & 16.7 \\
\hline 2074 & $81020087: 48$ & 1.807 & 16.7 \\
\hline 2075 & $8 / 1020087: 50$ & 1.807 & 16.6 \\
\hline 2076 & $811020087: 52$ & 1.807 & 16.6 \\
\hline 2077 & $811020087: 54$ & 1.807 & 166 \\
\hline 2078 & $8 / 10200087: 56$ & 1.807 & 16.6 \\
\hline 2079 & $8 / 1020007: 58$ & 1.808 & 16.6 \\
\hline 2080 & $8 / 102008800$ & 1.808 & 16.7 \\
\hline 2081 & $8 / 1020088: 02$ & 1.809 & 16.7 \\
\hline 2002 & $8 / 102008804$ & 1.809 & 16.6 \\
\hline 2003 & $8 / 1020088: 06$ & 1.809 & 16.7 \\
\hline 2084 & $8 / 10 / 2008808$ & 1.810 & 16.6 \\
\hline 2085 & $8 / 10 / 20088: 10$ & 1.809 & 16.7 \\
\hline 2006 & $81020088: 12$ & 1.810 & 16.6 \\
\hline 2087 & $8 / 10 / 2008814$ & 1.810 & 16.7 \\
\hline 2088 & 8102008816 & 1.810 & 16.7 \\
\hline 2089 & $8 / 10 / 2008818$ & 1.810 & 16.7 \\
\hline 2090 & $8 / 10 / 20088: 20$ & 1.810 & 16.7 \\
\hline 2001 & $8 / 10 / 20088: 20$ & 1.810 & 16.7 \\
\hline 2092 & $8 / 10 / 2008824$ & 1.810 & 16.7 \\
\hline 2093 & $810 / 2008826$ & 1.810 & 16.7 \\
\hline 2094 & $8 / 10 / 20088: 28$ & 1.810 & 16.6 \\
\hline 2005 & $8 / 1020088: 30$ & 1.810 & 16.6 \\
\hline 2006 & 81020088.32 & 1.811 & 16.7 \\
\hline 2097 & $8 / 1020088: 34$ & 1.812 & 16.7 \\
\hline 2098 & $8 / 1020088.36$ & 1.812 & 16.6 \\
\hline 2099 & $8 / 1020088: 38$ & 1.812 & 16.7 \\
\hline 2100 & $8 / 102008840$ & 1.812 & 16.7 \\
\hline 2101 & $8 / 10 / 2008842$ & 1.812 & 16.7 \\
\hline 2100 & $8 / 102008844$ & 1.812 & 16.6 \\
\hline 2103 & $8 / 102008846$ & 1.812 & 16.7 \\
\hline 2104 & $8 / 102008848$ & 1.812 & 16.7 \\
\hline 2105 & $8 / 1020088.50$ & 1.810 & 16.7 \\
\hline 2106 & $8 / 1020088.52$ & 1.804 & 16.7 \\
\hline 2107 & $8 / 102008854$ & 1.801 & 16.7 \\
\hline 2108 & 8102008856 & 1.796 & 167 \\
\hline
\end{tabular}

\begin{tabular}{|c|c|c|c|}
\hline \multicolumn{4}{|c|}{ D4250 } \\
\hline Rec & & Pres & Temp \\
\hline$\#$ & Dater/ime & psi & ${ }^{2} \mathrm{C}$ \\
\hline 2109 & $8 / 1020088.58$ & 1.792 & 16.7 \\
\hline 2110 & $8 / 1020089.00$ & 1.789 & 16.6 \\
\hline 2111 & $8 / 1020089.00$ & 1.787 & 16.7 \\
\hline 2112 & $8 / 1020089.04$ & 1.784 & 16.7 \\
\hline 2113 & $8 / 1020089.06$ & 1.784 & 16.6 \\
\hline 2114 & $8 / 1020089.08$ & 1.788 & 16.7 \\
\hline 2115 & $8 / 1020089.10$ & 1.792 & 16.7 \\
\hline 2116 & $8 / 1020089.12$ & 1.794 & 16.6 \\
\hline 2117 & $8 / 1020089.14$ & 1.796 & 16.7 \\
\hline 2118 & $8 / 1020089.16$ & 1.797 & 16.6 \\
\hline 2119 & $8 / 1020089.18$ & 1.798 & 16.6 \\
\hline 212 & 8102008920 & 1.798 & 16.6 \\
\hline
\end{tabular}
\begin{tabular}{|l|l|l|l|}
\hline 2120 & 811020089.20 & 1.799 & 16.6 \\
\hline
\end{tabular}

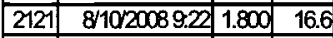
\begin{tabular}{|l|l|l|l|}
\hline 2122 & $8 / 1020089.24$ & 1.801 & 16.7 \\
\hline 2123 & $8 / 10200089.26$ & 1.802 & 16.6 \\
\hline 224 & $8 / 10089.20$ & 1.009 & 16.6 \\
\hline
\end{tabular} \begin{tabular}{|l|l|l|l|}
\hline 2124 & $8 / 1020089.28$ & 1.803 & 16.6 \\
\hline 226 & $8 / 020089.30$ & 1.03 & 16.7 \\
\hline
\end{tabular}

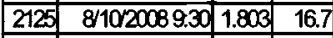
\begin{tabular}{|l|l|l|l|}
\hline 2126 & $8 / 1020089.32$ & 1.803 & 16.6 \\
\hline & 8102003934 & 1.804 & 16.7 \\
\hline
\end{tabular} \begin{tabular}{|l|l|l|l|}
\hline 2127 & $8 / 1020089.34$ & 1.804 & 16.7 \\
\hline
\end{tabular} \begin{tabular}{|l|l|l|l|}
\hline 2128 & $8 / 1020089.36$ & 1.804 & 16.7 \\
\hline 2129 & $8 / 1020089.38$ & 1.804 & 16.7 \\
\hline 230 & $8 / 20089.40$ & 1.806 & 16.6 \\
\hline
\end{tabular} \begin{tabular}{|l|l|l|l|}
\hline 2130 & $8 / 10200089.40$ & 1.806 & 16.6 \\
\hline
\end{tabular}

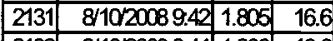
\begin{tabular}{|l|l|l|l|}
\hline 2132 & $8 / 1020089.44$ & 1.806 & 16.6 \\
\hline 2133 & $8 / 10200089.46$ & 1.806 & 16.7 \\
\hline 2134 & 8102008.48 & 1.807 & 16.7 \\
\hline
\end{tabular} \begin{tabular}{|l|l|l|l|}
\hline 2134 & $8 / 10200089.48$ & 1.807 & 16.7 \\
\hline
\end{tabular} \begin{tabular}{|l|l|l|l|}
\hline 2135 & $8 / 10200089.50$ & 1.807 & 16.7 \\
\hline 2136 & $8 / 1020089.52$ & 1.808 & 16.6 \\
\hline
\end{tabular} \begin{tabular}{|l|l|l|l|}
\hline 2136 & $8 / 1020089.52$ & 1.808 & 16.6 \\
\hline 2137 & 811020089.54 & 1.809 & 16.7 \\
\hline 2 & $8 / 102008956$ & 1.810 & 16.7 \\
\hline
\end{tabular} \begin{tabular}{|l|l|l|l|}
\hline 2138 & $8 / 10200089.56$ & 1.810 & 16.7 \\
\hline 2130 & $8 / 102008958$ & 1.810 & 16.7 \\
\hline
\end{tabular} \begin{tabular}{|c|r|r|r|}
\hline 2139 & $8 / 10200089.58$ & 1.810 & 16.7 \\
\hline 2140 & $8 / 10200810.00$ & 1.810 & 16.6 \\
\hline 210 & 81020810.02 & 1.80 & \\
\hline
\end{tabular} \begin{tabular}{|l|l|l|l|}
\hline 2140 & $8102200810: 00$ & 1.810 & 16.6 \\
\hline 2141 & $810200610: 02$ & 1.810 & 16.7 \\
\hline 2142 & 810200810.04 & 1.810 & 16.7 \\
\hline
\end{tabular} \begin{tabular}{lllll}
2142 & $8 / 102000$ & 10.04 & 1.810 & 16.7 \\
\hline 240 & &
\end{tabular}

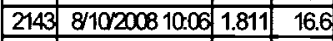

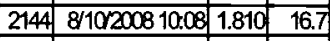

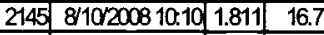
\begin{tabular}{|l|l|l|l|}
\hline 2146 & 810200810.12 & 1.811 & 16.6 \\
\hline 2147 & $8110200810: 11$ & 1.811 & 167 \\
\hline
\end{tabular}

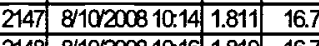
\begin{tabular}{|l|l|l|l|}
\hline 2148 & 810200810.16 & 1.810 & 16.7 \\
\hline 2149 & 8110200810.18 & 1.811 & 16.7 \\
\hline 2150 & 81020081020 & 1.81 & 16.7 \\
\hline
\end{tabular}

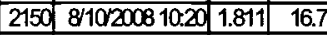
\begin{tabular}{l|l|l|l|}
\hline 2151 & $8 / 10200810.22$ & 1.811 & 16.6 \\
\hline 215 & $8 / 1020081024$ & 1.811 & 16. \\
\hline
\end{tabular}

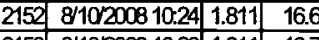
\begin{tabular}{|l|l|l|l|}
\hline 2153 & 810200810.20 & 1.811 & 16.7 \\
\hline 2154 & 8102200810.28 & 1.811 & 16.7 \\
\hline
\end{tabular}

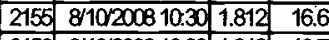
\begin{tabular}{|l|l|l|l|}
\hline 2156 & $8 / 102000810: 32$ & 1.812 & 16.7 \\
\hline 2157 & $8 / 10200810.34$ & 1.812 & 16.6 \\
\hline
\end{tabular}

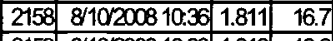

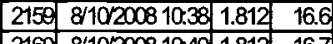

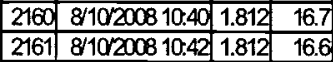

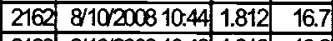

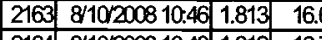

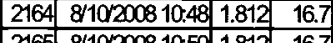

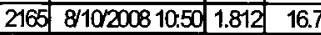

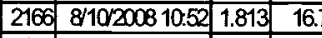

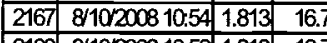

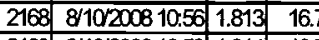

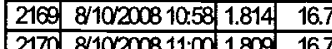
\begin{tabular}{|l|l|l|l|}
\hline 2170 & $8 / 10200811: 00$ & 1.809 & 16.7 \\
\hline 2171 & $8 / 10200811: 02$ & 1.810 & 16.7 \\
\hline 212 & $81020081: 04$ & 1.7 & 1.7 \\
\hline
\end{tabular} \begin{tabular}{|ll|l|l|}
\hline 2172 & $8102000811: 04$ & 1.810 & 16.7 \\
\hline
\end{tabular}

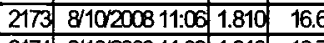

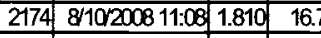

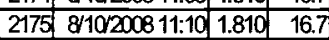

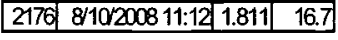

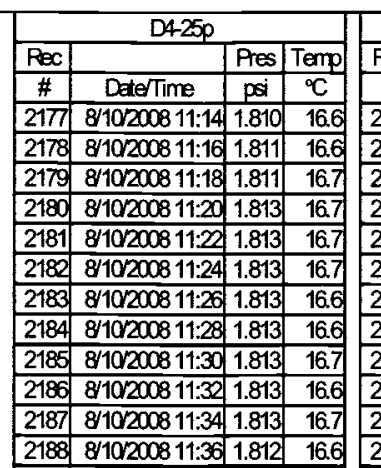

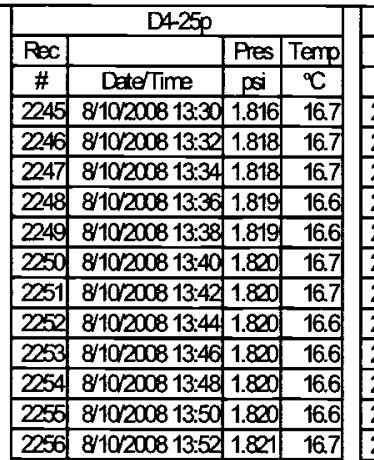

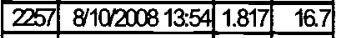

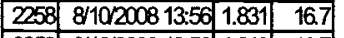

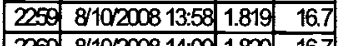

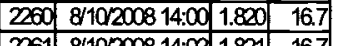

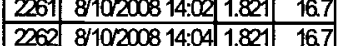

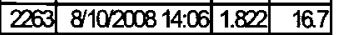

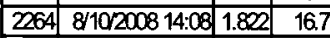

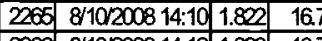
\begin{tabular}{|l|l|l|l|}
\hline 2266 & 8102008 14:12 & 1.822 & 467 \\
\hline 267
\end{tabular}

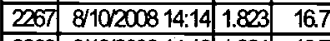

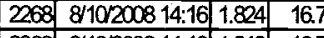
\begin{tabular}{|l|l|l|l|}
\hline 2260 & $8 / 10200814: 18$ & 1.818 & 16.7 \\
\hline 2270 & $8110200814: 20$ & 182 & 167 \\
\hline
\end{tabular} \begin{tabular}{|l|l|l|l|}
\hline 2270 & $8110200814: 20$ & 1.823 & 16.7 \\
\hline 227 & $810200814: 2$ & 182 & 16.7 \\
\hline
\end{tabular}

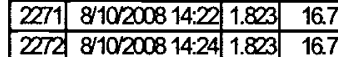

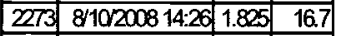

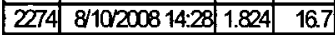

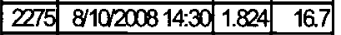
\begin{tabular}{|l|l|l|l|}
\hline 2276 & $8102000814: 32$ & 1.824 & 16.7 \\
\hline 2 & $8100081: 3$ & 1.25 & 16 \\
\hline
\end{tabular}

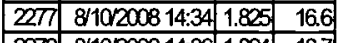

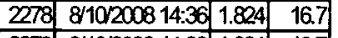
\begin{tabular}{|l|l|l|l|}
\hline 2279 & $8 / 10 / 200814: 38$ & 1.824 & 16.7 \\
\hline 200 & $8110200814: 40$ & 1.825 & 167 \\
\hline
\end{tabular}

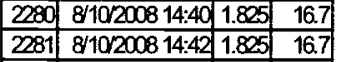

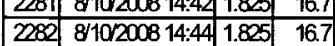

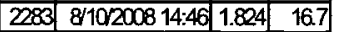

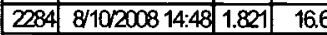

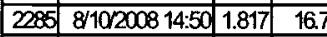
\begin{tabular}{|l|l|l|l|}
\hline 2206 & 8102000814.52 & 1.811 & 16.6 \\
\hline
\end{tabular}

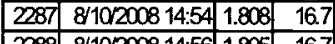

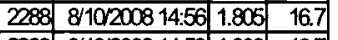

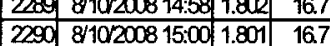

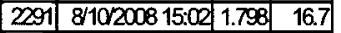

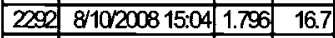

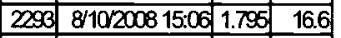

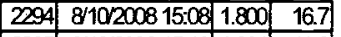

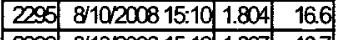
\begin{tabular}{|l|l|l|l|}
\hline 2296 & $810200815: 12$ & 1.807 & 167 \\
\hline 207 & 8100200815 & 1.00 & 167 \\
\hline
\end{tabular}

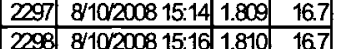
\begin{tabular}{|l|l|r|r|}
\hline 2298 & $8 / 10: 200815: 16$ & 1.810 & 16.7 \\
\hline 2299 & $8 / 10 / 200815: 18$ & 1.811 & 16.7 \\
\hline 200 & 81020081520 & 1810 & 167 \\
\hline
\end{tabular}

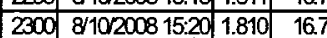

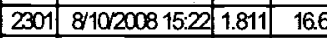

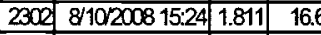
\begin{tabular}{|l|l|l|l|}
\hline 2303 & $8 / 102200815: 26$ & 1.812 & 16.7 \\
\hline 204 & 810200152 & 18 & 16 \\
\hline
\end{tabular}

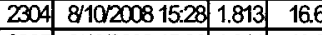

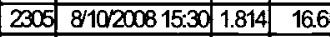

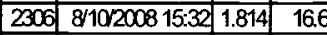

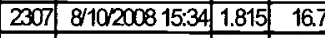
\begin{tabular}{|l|l|l|l|}
\hline 2308 & $8 / 10200815: 36$ & 1.816 & 166 \\
\hline 2300 & 8102008 & 1530 & 186
\end{tabular}

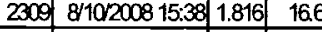

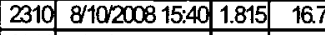

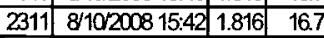

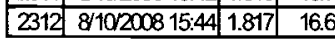

\begin{tabular}{|c|c|c|c|}
\hline \multicolumn{4}{|c|}{$D 425 p$} \\
\hline $\operatorname{Rec}$ & & Pres & \\
\hline$\#$ & DeteTime & psi & \\
\hline 2313 & $8 / 10^{2} 200815: 46$ & 1.816 & \\
\hline 2314 & $8 / 102000815: 48$ & 1.817 & \\
\hline 2315 & $8 / 10200815: 50$ & 1.818 & \\
\hline 2316 & $8 / 10200815: 50$ & 1.818 & \\
\hline 2317 & $8 / 10200815: 54$ & 1.819 & \\
\hline 2318 & $8 / 10200815: 56$ & 1.819 & \\
\hline 2319 & $8 / 10200015: 58$ & 1.819 & \\
\hline 2320 & $8 / 102000316: 00$ & 1.818 & \\
\hline 2321 & $8 / 10200816: 02$ & 1.819 & \\
\hline 232 & $8 / 10200816: 04$ & 1.820 & \\
\hline 2323 & $8 / 10200816: 06$ & 1.820 & \\
\hline 2324 & $8 / 1020$ & 1.821 & \\
\hline 2325 & $8 / 10200016: 10$ & 1.820 & 16. \\
\hline 2326 & $8 / 102$ & 1.820 & \\
\hline & $8 / 102$ & 1.821 & \\
\hline 2328 & $8 / 102$ & 1.821 & \\
\hline 2329 & $8 / 102$ & 1.821 & \\
\hline 2330 & $8 / 102$ & 1.822 & \\
\hline 2331 & 81102 & 1.822 & \\
\hline & $8 / 1020$ & 1.823 & \\
\hline 33 & $8 / 102$ & 1.823 & \\
\hline 2334 & $8 / 102$ & 1.823 & \\
\hline & $8 / 102 x$ & 1.823 & \\
\hline 2336 & $8 / 10^{\prime}$ & 1.823 & \\
\hline 37 & $8 / 102$ & 1.823 & \\
\hline & $8 / 102$ & 1.824 & \\
\hline 2339 & $8 / 10^{x}$ & 1.824 & \\
\hline 2340 & $8 / 102$ & 1.825 & \\
\hline 2341 & $8 / 10$ & 1.823 & \\
\hline 2342 & $8 / 10$ & 1.823 & \\
\hline 2343 & $8 / 10$ & 1.823 & \\
\hline 2344 & $8 / 10^{x}$ & 1.823 & \\
\hline & $8 / 10 / 2$ & 1.823 & 16. \\
\hline 2346 & & 1.823 & \\
\hline 2347 & $8 / 10 / 2$ & 1.823 & \\
\hline 2348 & $8 / 102$ & 1.824 & \\
\hline 2349 & & 1.824 & \\
\hline 2350 & & 1.824 & \\
\hline 2351 & & 1.824 & \\
\hline 2352 & & 1.825 & \\
\hline 2353 & $8 / 10$ & 1.825 & \\
\hline 2354 & $8 / 10$ & 1.826 & \\
\hline 56 & & 1.825 & \\
\hline 56 & $8 / 10$ & 1.825 & \\
\hline 2357 & $8 / 10$ & 1.826 & \\
\hline & & 1.825 & \\
\hline 59 & & 1.825 & \\
\hline 2360 & $8 / 1$ & 1.824 & \\
\hline & & 1.823 & \\
\hline 2 & & 1.824 & \\
\hline 63 & $7: 26$ & 1.824 & \\
\hline 64 & & 1.824 & \\
\hline & & & \\
\hline 66 & & 1.824 & \\
\hline 2367 & $8 / 10$ & 1.824 & \\
\hline & & 1.824 & \\
\hline 29 & & 1.824 & \\
\hline 2370 & $8 / 10 / 2$ & 1.825 & 16 \\
\hline 71 & & 1.825 & \\
\hline & & & \\
\hline 2373 & $8 / 10 / 2$ & 1.825 & \\
\hline 74. & & 1.818 & \\
\hline & & 1.846 & \\
\hline & 77:52 & 1.836 & \\
\hline 2377 & $8 / 10 / 2 x$ & 0.356 & \\
\hline 2378 & & 0.005 & \\
\hline 2379 & $8 / 10$ & & \\
\hline & & & \\
\hline
\end{tabular}


DOE/RL-2009-35, REV. 0

\begin{tabular}{|c|c|c|c|}
\hline \multicolumn{4}{|c|}{$D 425 p$} \\
\hline $\operatorname{Rec}$ & & Pres & Temp \\
\hline \# & DateTime & psi & ${ }^{\circ} \mathrm{C}$ \\
\hline 2380 & $8 / 10200018: 00$ & 0.004 & 204 \\
\hline 2381 & $8 / 1020081802$ & 0.001 & 229 \\
\hline 2382 & $8 / 10200018: 04$ & 0000 & 244 \\
\hline 2383 & $8 / 1020081806$ & 000 & 253 \\
\hline 2384 & 810200018.08 & 0000 & 258 \\
\hline 2385 & $8 / 10200818.10$ & 0000 & 261 \\
\hline 2396 & $8 / 10200818: 12$ & 0.002 & 263 \\
\hline 2387 & $8 / 10200818: 14$ & 000 & 263 \\
\hline 2388 & $8 / 10200018: 16$ & 0.002 & 262 \\
\hline 2389 & $8 / 10200018: 18$ & 0.000 & 263 \\
\hline 2300 & $8 / 10200818: 20$ & 0601 & 263 \\
\hline 2391 & $8 / 10200818.22$ & 0002 & 263 \\
\hline 2390 & $8 / 102000818: 24$ & 0.003 & 263 \\
\hline 2393 & $8 / 10200818: 26$ & 0001 & 262 \\
\hline 2394 & $8 / 10200818: 28$ & 0001 & 261 \\
\hline 2396 & $8 / 10200818: 30$ & 0.001 & 260 \\
\hline 2306 & $8 / 10200818: 32$ & 000 & 259 \\
\hline 2390 & $8 / 10200018: 34$ & C.028 & 258 \\
\hline 2398 & $8 / 10200018: 36$ & 0.001 & 256 \\
\hline 2309 & $8 / 10 / 200818: 38$ & 0.000 & 256 \\
\hline 2400 & $8 / 10200018: 40$ & 0001 & 256 \\
\hline 2401 & $8 / 1020081842$ & 0000 & 257 \\
\hline 2402 & $8 / 10200081844$ & 0,000 & 257 \\
\hline 2400 & $8 / 10200818: 46$ & 0000 & 256 \\
\hline 2404 & $8 / 10200818: 48$ & 0.001 & 256 \\
\hline 2406 & $8 / 10200818.50$ & 0.001 & 254 \\
\hline 2406 & $8 / 10200818.52$ & 0.000 & 253 \\
\hline 2407 & $8 / 10200818: 54$ & 0.001 & 252 \\
\hline 2408 & $8 / 10200818: 56$ & 0.000 & 251 \\
\hline 2400 & $8 / 10200818: 58$ & 000 & 251 \\
\hline 2410 & $8 / 10200019.00$ & 0,000 & 250 \\
\hline 2411 & $8 / 10200819.02$ & 0.000 & 249 \\
\hline 2412 & $8 / 102000819.04$ & 0.000 & 24.8 \\
\hline 2413 & $8 / 102000819.06$ & 0,000 & 24.7 \\
\hline 2414 & $8 / 10200819.08$ & 0000 & 24.6 \\
\hline 2415 & $8 / 10200819.10$ & 0000 & 24.5 \\
\hline 2416 & $8 / 10200819.12$ & 0.000 & 24.4 \\
\hline 2417 & $8 / 102008$ 19.14 & 0.000 & 244 \\
\hline 2418 & $8 / 10200819.16$ & 0.000 & 244 \\
\hline 2419 & $8 / 10200819.18$ & 0.000 & 24.3 \\
\hline 2420 & $8 / 10200819.20$ & 0.000 & 24.1 \\
\hline 2421 & $8 / 10200819.22$ & 0.000 & 24.1 \\
\hline 2422 & $8 / 10200019.24$ & 0,000 & 240 \\
\hline 2423 & $8 / 10200019.26$ & 0.000 & 239 \\
\hline 2424 & $8 / 10200019.28$ & 0,000 & 238 \\
\hline 2425 & $8 / 10200819.30$ & 0.000 & 236 \\
\hline 2426 & $8 / 102000619.32$ & 0000 & 236 \\
\hline 2427 & $8 / 102000819.34$ & 0.001 & 234 \\
\hline 2428 & $8 / 10200819.36$ & 0.000 & 233 \\
\hline 2429 & $8 / 10200819.38$ & 0.000 & 283 \\
\hline 2430 & $8 / 10200819.40$ & 0.000 & 231 \\
\hline 2439 & $8 / 10200819.42$ & 0000 & 231 \\
\hline 2432 & $8 / 10200819.44$ & 0.001 & 220 \\
\hline 2433 & $8 / 10200019.46$ & 0.000 & 229 \\
\hline 2434 & $8 / 10200819.48$ & 0.000 & 228 \\
\hline 2435 & $8 / 10200819.50$ & 0001 & 228 \\
\hline 2436 & $8 / 10200819.52$ & 0,000 & 227 \\
\hline 2437 & $8 / 102000819.54$ & 0.000 & 226 \\
\hline 2438 & $8 / 10200819.56$ & 0.000 & 225 \\
\hline 2439 & $8 / 10200819.58$ & 0.001 & 224 \\
\hline 2440 & $8 / 102000820000$ & 0.001 & 224 \\
\hline 2441 & $8 / 10200020000$ & 0.000 & 223 \\
\hline 2442 & $8 / 10200820: 04$ & 0.000 & 222 \\
\hline 2443 & $8 / 10200820.06$ & 0.00 & 221 \\
\hline 2444 & $8 / 10200820.08$ & 0.001 & 220 \\
\hline 2445 & $8 / 10200820-10$ & 0.001 & 220 \\
\hline
\end{tabular}

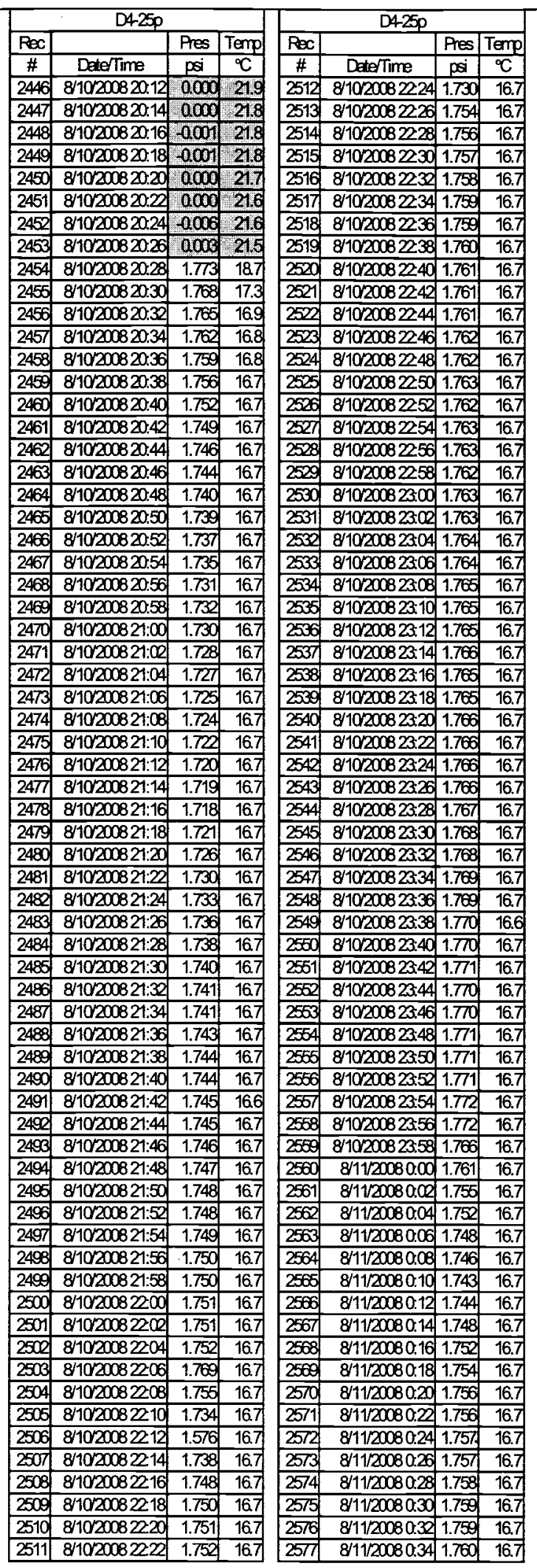

\begin{tabular}{|c|c|c|c|c|c|c|c|}
\hline \multicolumn{4}{|c|}{$D 4-25 p$} & \multicolumn{4}{|c|}{ D425p } \\
\hline $\mathrm{Rec}$ & & Pres & Temp & $\mathrm{ReC}$ & & Pres: & Temp \\
\hline \# & DeterTime & psi & ${ }^{\circ} \mathrm{C}$ & $\#$ & DaterTime & \begin{tabular}{|l|}
$p s i$ \\
\end{tabular} & ${ }^{\circ} \mathrm{C}$ \\
\hline & $8 / 11 / 20080: 36$ & & 167 & 2644 & $8 / 11 / 2008248$ & 1.779 & \\
\hline 2579 & $8 / 11 / 20080: 38$ & 1.762 & 167 & 2645 & $8 / 11 / 2008250$ & 1.78 & 168 \\
\hline 2580 & $8 / 11 / 20080-40$ & 1.762 & 16.7 & 2646 & $8 / 11 / 2008252$ & $1.7 \pi 6$ & 16.8 \\
\hline 2581 & $8 / 11 / 20080.42$ & 1.763 & 16.7 & 2647 & $8 / 11 / 2008254$ & 1.771 & 16.8 \\
\hline 2582 & $8 / 11 / 20080.44$ & 1.763 & 167 & 2648 & $8 / 11 / 2008256$ & 1.766 & 16.8 \\
\hline 2583 & $8 / 11 / 20080.46$ & 1.764 & 16.7 & 2649 & $8 / 11 / 2008258$ & 1.761 & 16.8 \\
\hline 2584 & $8 / 11 / 200000: 48$ & 1.764 & 16.7 & 2650 & $8 / 11 / 20083: 00$ & 1.760 & 16.8 \\
\hline 2585 & $8 / 11 / 20000.50$ & 1.763 & 16.7 & 2651 & $8 / 11 / 2008302$ & 1.762 & 16.8 \\
\hline 2586 & $8 / 11 / 20080.52$ & 1.785 & 167 & 2652 & $8 / 11 / 2008304$ & 1.764 & \\
\hline 2587 & $8 / 11 / 20080.54$ & 1.767 & 167 & 2663 & $8 / 11 / 2008306$ & 1.767 & $\overline{1}$ \\
\hline 2588 & $8 / 11 / 20080.56$ & 1.765 & 167 & 2654 & $8 / 11 / 2008308$ & 1.768 & 16.8 \\
\hline 2589 & $8 / 11 / 20080.58$ & 1.760 & 167 & 2655 & $811120083 \cdot 10$ & 1.70 & 16.8 \\
\hline 2590 & $8 / 11 / 20081: 00$ & 1.764 & 167 & 2656 & $8 / 11 / 20083: 12$ & 1.770 & \\
\hline 2591 & $8 / 11 / 20081: C$ & 1.767 & 16.7 & 2600 & $8 / 11 / 20083.14$ & 1.771 & 16 . \\
\hline 2592 & $8 / 11 / 20081: 04$ & 1.768 & 16.7 & 2658 & $8 / 11 / 2008316$ & 1.72 & 16.8 \\
\hline 2593 & $8 / 11 / 20081: 06$ & 1.707 & 16.7 & 2659 & $8 / 11 / 20083+8$ & $1.7 \pi 2$ & 16.8 \\
\hline 2594 & $8 / 11 / 20$ & 1.652 & 16.7 & 2660 & $8 / 11 / 20083: 20$ & $1.7 \pi 2$ & \\
\hline 2505 & $8 / 11 / 20081: 10$ & 1.93 & 16.7 & 2661 & $8 / 11 / 2008322$ & 1.773 & 16.8 \\
\hline 2506 & $8 / 11 / 2$ & 2009 & 167 & 2662 & $8 / 11 / 2008324$ & 1.773 & 16.8 \\
\hline 2597 & $8 / 11 / 2$ & 2118 & 167 & 2663 & $8 / 11 / 2008326$ & 1.774 & 16.8 \\
\hline 2598 & $8 / 11 / 2$ & 1.825 & 168 & 2064 & $8 / 11 / 2008328$ & 1.774 & \\
\hline 2599 & $8 / 11 / 20081: 18$ & 1.783 & 16.8 & 2665 & $8 / 11 / 2008330$ & 1.774 & 16.8 \\
\hline 2600 & $8 / 11 / 20081: 20$ & 1.779 & 168 & 2666 & $8 / 11 / 20083332$ & 1.774 & 16.8 \\
\hline 2601 & $8 / 11 / 2$ & 1.776 & 168 & 2667 & $8 / 11 / 2008334$ & 1.774 & \\
\hline 2602 & $8 / 11 / 2$ & 1.775 & 16.8 & 2668 & $8 / 11 / 2008336$ & 1.775 & \\
\hline 2603 & $8 / 11 / 20081: 26$ & 1.775 & 16.8 & 2669 & 81112008338 & 1.775 & 16.8 \\
\hline 2604 & $8 / 11 / 20$ & 1.774 & 16.8 & 2670 & $8 / 11 / 20083440$ & 1.775 & 16.8 \\
\hline 2605 & $8 / 1 / 2$ & 1.774 & 16.8 & 2671 & $8 / 11 / 2$ & 1.775 & 16.8 \\
\hline 2606 & $8 / 11 / 20081: 32$ & 1.773 & 16.8 & 2672 & $8 / 11 / 20083: 44$ & 1.776 & 16.8 \\
\hline 2607 & $8 / 11 / 20$ & 1.772 & 16.8 & 2673 & $8 / 11 / 2008346$ & 1.776 & 16.7 \\
\hline 2608 & $8 / 11 / 2$ & 1.772 & 168 & 2674 & $8 / 11 / 2008348$ & 1.776 & 16.8 \\
\hline 2609 & $8 / 11 / 2$ & 1.773 & 168 & 2675 & $8 / 11 / 2008350$ & 1.776 & 167 \\
\hline 2610 & $8 / 11 / 2$ & $1.7 \pi 2$ & 168 & 2676 & $8 / 11 / 20$ & 1.776 & 16.7 \\
\hline 2611 & $8 / 11 / 2$ & 1.772 & 16.8 & $267 \pi$ & $8 / 11 / 20$ & $1.7 \pi$ & 16.8 \\
\hline 2612 & $8 / 11 / 20081: 44$ & 1.773 & 16.8 & 2678 & $8111 / 20083556$ & 1.779 & $\overline{16 .}$ \\
\hline 2613 & $8 / 11 / 20081: 46$ & $1.7 \pi$ & 16.8 & 2679 & $811 / 20083.58$ & 1.781 & 168 \\
\hline 2614 & $8 / 11 / 20$ & 1.773 & 16.8 & 2680 & & 1.780 & 16.8 \\
\hline 2615 & $8 / 11 / 2$ & 1.774 & 16.8 & 2681 & $8111 / 2$ & 1.780 & 16.7 \\
\hline 2616 & $8 / 11 / 20$ & 1.77 & 16.8 & 2682 & $8 / 11 / 20084: 04$ & 1.780 & 16.8 \\
\hline 2617 & $8 / 11 / 2008$ 1:54 & 1.775 & 16.8 & 2683 & $8 / 11 / 20084: 06$ & 1.779 & 16.7 \\
\hline 2618 & $8 / 11 / 2$ & 1.775 & 16.8 & 2684 & & 1.780 & 16.8 \\
\hline 2619 & $8 / 11 / 2$ & 1.775 & 16.8 & 2690 & $8 / 11 / 20084: 10$ & 1.780 & 16.7 \\
\hline 2620 & $8 / 11 / 2008200$ & 1.775 & 16.8 & 2686 & 8/11/20084:12 & 1.779 & $\overline{168}$ \\
\hline 2621 & $8 / 11 / 2008202$ & 1.774 & 16.8 & 2687 & $8 / 11$ & 1.780 & 167 \\
\hline 2622 & $8 / 11 / 2$ & 1.775 & 16.8 & 2688 & & 1.780 & $\overline{16}$ \\
\hline 2623 & $8 / 11 / 20$ & 1.775 & 168 & 2689 & $8 / 11 / 20084: 18$ & 1.781 & 16 \\
\hline 2624 & $8 / 11 / 20$ & 1.774 & 16.8 & 2690 & $8 / 11 / 20084: 20$ & 1.780 & 167 \\
\hline 2625 & $8 / 11 / 2$ & 1.774 & 16.8 & 2691 & 4:22 & 1.780 & 167 \\
\hline 2626 & $8 / 11 / 20$ & 1.775 & 168 & 2692 & $8 / 11 / 20084: 24$ & 1.779 & 16 \\
\hline 2627 & $8 / 11 / 2008214$ & 1.775 & 16.8 & 2693 & $8 / 11 / 20084: 26$ & 1.779 & 167 \\
\hline 2628 & $8 / 11 / 20$ & 1.776 & 16.8 & 2694 & $8 / 11$ & 1.779 & 167 \\
\hline 2629 & $8 / 11 / 2$ & 1.776 & 16.8 & 2696 & $8 / 11$ & 1.779 & 167 \\
\hline 2630 & $8 / 11 / 2008220$ & $1.7 \pi$ & 16.8 & 2696 & $811 / 20084: 32$ & 1.779 & 167 \\
\hline 2631 & $8 / 11 / 2008222$ & $1.7 \pi$ & 16.8 & 2697 & $8 / 11 / 20064: 34$ & 1.779 & 167 \\
\hline 2632 & $8 / 11 / 2$ & 1.776 & 168 & 2698 & & 1.779 & 16.7 \\
\hline 2633 & $8 / 11 / 2$ & 1.776 & 16.8 & 2699 & & 1.779 & \\
\hline 2634 & $8 / 11 / 2008228$ & 1.776 & 16.8 & 2700 & $8 / 11 / 20084: 40$ & 1.779 & 16.7 \\
\hline 2635 & 81112008230 & 1.776 & 16.8 & 2701 & $8 / 11 / 20084: 42$ & 1.780 & 16.7 \\
\hline 2636 & $8 / 11 / 20$ & $1.7 \pi$ & 16.8 & $2 \pi 02$ & $8 / 11 / 2$ & 1.780 & 16.7 \\
\hline 2637 & $8 / 11 / 2008234$ & $1.7 \pi$ & 16.8 & 2703 & $8 / 11 / 2$ & 1.780 & \\
\hline 2638 & $8 / 11 / 2008236$ & $1.77 \pi$ & 16.8 & 2704 & $8 / 11 / 20084: 48$ & 1.781 & 16.7 \\
\hline 2639 & $8 / 11 / 20082,38$ & 1.777 & 16.8 & 2706 & $8 / 11 / 20084: 50$ & 1.781 & 167 \\
\hline 2640 & $8 / 11 / 2008240$ & 1.77 & 16.8 & 2706 & $8 / 11 / 20$ & 1.782 & 167 \\
\hline 2641 & $8 / 11 / 2008242$ & $1.7 \pi$ & 16.8 & 2707 & $8 / 11 / 20084: 54$ & 1.782 & 16.7 \\
\hline 2642 & $8 / 11 / 2008244$ & 1.778 & 16.8 & 2708 & $8 / 11 / 20084: 56$ & 1.782 & 16.7 \\
\hline 2643 & $8 / 11 / 2008246$ & 1.79 & 16.8 & 2700 & & 1.782 & 16.7 \\
\hline
\end{tabular}




\begin{tabular}{|c|c|c|c|c|c|c|c|c|c|c|c|c|c|c|c|c|c|c|c|}
\hline \multicolumn{4}{|c|}{ D4250 } & \multicolumn{4}{|c|}{$D 425 p$} & \multicolumn{4}{|c|}{ D425p } & \multicolumn{4}{|c|}{ D425p } & \multicolumn{4}{|c|}{ D425p } \\
\hline $\mathrm{R} B \mathrm{C}$ & & Pres & Terp & $\mathrm{Rec}$ & & Pres:1 & Temp & $\mathrm{Rac}$ & & Pres & Temp & $\mathrm{Rec}$ & & Pres 1 & Terpp & $\mathrm{Rec}$ & & Pres & Temp \\
\hline$\#$ & DateTime & psi & ${ }^{\circ} \mathrm{C}$ & $\#$ & Dete/Time & \begin{tabular}{|l|}
$p s i$ \\
\end{tabular} & ${ }^{\circ}$ & $\#$ & Dater/ime & $p \dot{s}$ & ${ }^{\circ} \mathrm{C}$ & \# & Date/Time & psi & ${ }^{\circ} \mathrm{C}$ & \# & Date/Tirre & pai & ${ }^{\circ} \mathrm{C}$ \\
\hline 2710 & $811 / 20085: 00$ & 1.782 & 16.7 & 2776 & $8 / 11 / 20087: 12$ & 1.587 & 16.8 & 2842 & 811120089.24 & 1.804 & 168 & 2908 & $8 / 11200811: 36$ & 1.818 & 16.8 & 2974 & $8 / 11200813448$ & 6 & \\
\hline 2711 & & 1.783 & 16.7 & $2 \pi 7$ & $8 / 11 / 20087: 14$ & 1.589 & 16.8 & \begin{tabular}{|l|}
2843 \\
\end{tabular} & $8 / 11 / 20089.26$ & 1.806 & 16.8 & 2009 & $8 / 11 / 200311: 38$ & 1.819 & 16.8 & 2975 & $8 / 11 / 20081350$ & 607 & \\
\hline 2712 & $8 / 11 / 2008504$ & 1.78 & 167 & $27 / 8$ & $8 / 11 / 20087: 16$ & 1.583 & 16.8 & 2844 & $8 / 11 / 20089.28$ & 1.808 & 168 & 2910 & $8 / 11200811: 40$ & 1.820 & 16.7 & 2976 & $8 / 11 / 20081352$ & 60 & \\
\hline 2713 & $8 / 11 / 20085006$ & 1.782 & 16.7 & $2 \pi 9$ & 8/11/20087:18 & 1.796 & 168 & 2845 & $8 / 11 / 20089.30$ & 1.809 & 168 & 2911 & $8 / 11 / 200811: 42$ & 1.821 & 16.7 & 2977 & $8 / 11 / 20081354$ & 60 & \\
\hline 2714 & $8 / 11 / 2008508$ & 1.782 & 16.7 & 2780 & $8 / 11 / 20087: 20$ & 1.761 & 16.8 & 2846 & $8 / 11 / 20089.32$ & 1.811 & 16.8 & 2912 & $8 / 11 / 200811: 44$ & 1.821 & 16.7 & 2978 & $8 / 11 / 200813.56$ & 610.6 & \\
\hline 2715 & $8 / 11 / 20085: 10$ & 1.781 & 16.7 & 2781 & $8 / 11 / 20087: 22$ & 1.767 & 16.8 & \begin{tabular}{|l|}
2847 \\
\end{tabular} & $8 / 11 / 20089.34$ & 1.812 & 16.8 & 2913 & $8 / 11200811: 46$ & 1.820 & 167 & 2979 & $8 / 11 / 20081358$ & 6008 & \\
\hline 2716 & $8 / 11 / 20085: 12$ & 1.781 & 16.7 & 278 & $8 / 11 / 20087: 24$ & $1.7 \pi 0$ & 16.8 & 2848 & $8 / 11 / 20089.36$ & 1.813 & 168 & 2014 & $8 / 11 / 200811: 48$ & 1.822 & 16.7 & 2980 & $8 / 11 / 200814: 00$ & & \\
\hline 2717 & $8 / 11 / 20085: 14$ & 1.781 & 16.7 & 2783 & $8 / 11 / 20087: 26$ & 1.772 & 168 & 2849 & $8 / 11 / 20069.38$ & 1.814 & 168 & 2915 & $8 / 11 / 200811: 50$ & 1.823 & 167 & 2091 & $8 / 11 / 200814: 02$ & 60 & \\
\hline 2718 & $8 / 11 / 20085: 16$ & 1.780 & 16.7 & 2784 & $8 / 11 / 20087: 28$ & 1.773 & 16.8 & 286 & $8 / 11 / 20089.40$ & 1.814 & 168 & 2916 & $8 / 11 / 200811: 52$ & 1.823 & 16.7 & 2982 & $8 / 11 / 200814: 04$ & 6008 & $\sqrt{176}$ \\
\hline 2719 & $8 / 11 / 20085: 18$ & 1.781 & 16.7 & 2786 & $8 / 11 / 20087: 30$ & 1.775 & 16.8 & \begin{tabular}{|l|}
2851 \\
\end{tabular} & $8 / 11 / 20069.42$ & 1.814 & 168 & 2917 & $8 / 11 / 2008$ 11:54 & 1.823 & 167 & 2983 & $8 / 11 / 200814: 06$ & 60 & \\
\hline 2720 & $8 / 11 / 2008520$ & 1.781 & 16.7 & 2786 & $8 / 11 / 20087: 32$ & 1.776 & 16.8 & 2065 & $8 / 11 / 20089.44$ & 1.815 & 168 & 2918 & $8 / 112008$ 11:56 & 1.824 & & 2994 & $8 / 11 / 200814: 08$ & 600 & \\
\hline 2721 & $8 / 11 / 2008522$ & 1.782 & 16.7 & 2787 & $087: 34$ & $1.7 \pi T$ & 16.8 & \begin{tabular}{|l|}
2853 \\
\end{tabular} & $8 / 11 / 20089.46$ & 1.815 & 168 & \begin{tabular}{|l|}
2919 \\
\end{tabular} & $8 / 11 / 2$ & 1.825 & 167 & 2986 & 814:10 & & \\
\hline 272 & $8 / 11 / 20085: 24$ & 1.782 & 16.7 & 2788 & $8 / 11 / 20087: 36$ & 1.778 & 16.8 & 2854 & $8 / 11 / 20089.48$ & 1.816 & 168 & 2920 & $8 / 11 / 20081200$ & 1.825 & 167 & 2906 & $8 / 11 / 200814: 12$ & 607 & \\
\hline 2723 & $8 / 11 / 20085: 26$ & 1.782 & 16.7 & 2789 & $811 / 20087: 38$ & 1.779 & 16.8 & 2885 & $8 / 11 / 2008950$ & 1.816 & 167 & 2021 & $8 / 11 / 20081202$ & 1.825 & 167 & 2987 & $8 / 11200814: 14$ & 606 & \\
\hline 2724 & $8 / 11$ & 1.782 & 16.7 & 2790 & $087: 40$ & 1.780 & 16.8 & 2836 & $8 / 11 / 20089.52$ & 1.816 & 16.8 & 2922 & $8 / 11 / 20081204$ & 1.825 & 167 & 2988 & $30814: 16$ & 604 & \\
\hline 2725 & 8530 & 1.781 & 16.7 & 2791 & $087: 42$ & 1.780 & 16.8 & 285 & $8 / 11 / 20089.54$ & 1.816 & 16.8 & 2923 & $8 / 11 / 20081206$ & 1.825 & 167 & 2989 & & & \\
\hline 2726 & $8 / 11 / 2$ & 1.781 & 16.7 & 2792 & $8 / 11 / 20087: 44$ & 1.780 & 16.8 & 2858 & $8 / 11 / 20089.56$ & 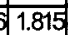 & 168 & 2924 & 3081208 & 1.825 & 167 & 2990 & $0814: 20$ & 15068 & \\
\hline 2727 & $8 / 1120085: 34$ & 1.780 & 16.7 & 2793 & \begin{tabular}{|l|}
$8 / 1120087: 46$ \\
\end{tabular} & 1.781 & 16.8 & 2859 & $8 / 11 / 20089.58$ & 1.816 & 16.7 & 2025 & $8 / 11 / 20081210$ & 1.826 & 16.7 & 2991 & $8 / 11 / 200814: 22$ & 606 & \\
\hline 2728 & $8 / 11 / 20085 ; 36$ & 1.771 & 16.7 & 2794 & $0087: 48$ & 1.781 & 17.1 & \begin{tabular}{|l|}
2860 \\
\end{tabular} & $8 / 11 / 200810.00$ & 1.816 & 16.8 & 2926 & 1212 & 1.826 & 16.7 & 2992 & $0814: 24$ & 6004 & $1+46$ \\
\hline 2729 & $8 / 11 / 2$ & 1.772 & 16.7 & 2796 & $8 \overline{87: 50}$ & 1.782 & 17.1 & 2061 & 00610,02 & 1.816 & $\overline{168}$ & 2927 & 81214 & 1.826 & & 2093 & $814: 26$ & $\sqrt{1002}$ & \\
\hline 2730 & $8 / 11 / 20085440$ & 1.768 & 16.7 & 2796 & $8 / 11$ & 1.782 & 16.9 & 2802 & $8 / 11 / 2$ & 1.817 & & 2928 & 3081216 & 1.827 & & 2994 & & 669 & \\
\hline 2731 & $8 / 11 / 20085 ; 42$ & 1.765 & 16.7 & 2797 & $0087: 54$ & 1.783 & 168 & 2863 & $8 / 11 / 200810006$ & 可 1.818 & 168 & 2029 & $8 / 11 / 20081218$ & 1.827 & 167 & 2996 & $0814: 30$ & 6006 & \\
\hline 2732 & $8 / 11 / 20085 ; 44$ & 41.72 & 16.7 & 2798 & 087.56 & 1.784 & 168 & 2864 & $8 / 11 / 2008$ 10:08 & 1.818 & 16.8 & \begin{tabular}{|l|}
2030 \\
\end{tabular} & $8 / 11 / 20081220$ & 1.826 & 167 & \begin{tabular}{|l|}
2996 \\
\end{tabular} & $8 / 11 / 2008$ 14:32 & 600 & 94 \\
\hline 2733 & $8 / 111$ & 1.759 & 16.7 & 2799 & $87: 58$ & 1.784 & 16.8 & 2806 & 810.10 & 1.818 & $\overline{16.8}$ & 2931 & 122 & 1.826 & 167 & 2997 & B14:34 & 6006 & \\
\hline 2734 & $8 / 11 / 2$ & 1.75 & 16.7 & 2800 & & 1.784 & 16.8 & 2806 & $8 / 11 /$ & 1.818 & & 2902 & 31224 & 1.825 & & 2908 & 814:36 & 60 & \\
\hline 2736 & $8 / 11 / 20085550$ & 1.754 & 16.7 & 2801 & $8 / 11$ & 1.784 & 16.8 & 2867 & $\overline{00810: 14}$ & 1.818 & 16.7 & 2903 & 081226 & 1.826 & 16.7 & 2909 & $814: 38$ & 605 & \\
\hline 2736 & $8 / 112008552$ & 1.752 & 16.7 & 2800 & 08804 & 1.784 & 16.8 & 2868 & $00810: 16$ & 1.818 & 16.7 & \begin{tabular}{|l|}
2034 \\
\end{tabular} & 0081228 & 1.829 & 17.2 & 3000 & $0814: 40$ & 6000 & 10 \\
\hline 2737 & & 1.750 & 167 & 2803 & 8806 & 1.784 & 168 & 2809 & $8 / 11$ & 1.818 & 16.8 & 2996 & 31230 & 1.831 & 17.1 & 3001 & $314: 42$ & $60 \%$ & \\
\hline 2738 & $8 / 11$ & 1.749 & 16.7 & 2804 & 08806 & 1.784 & 168 & 2870 & 0810.20 & 1.819 & 16. & 2936 & 81232 & 1.833 & 169 & 3002 & 814:44 & 600 & \\
\hline 2739 & $8 / 11 / 2$ & 1.753 & 16.7 & 2806 & $88: 10$ & 1.786 & 16.8 & \begin{tabular}{|l|}
2871 \\
\end{tabular} & $8 / 11$ & 1.819 & & 2037 & 1234 & 1.861 & 16.8 & 3003 & $814: 46$ & 6.06 & \\
\hline 2740 & $8 / 11 / 2$ & 1.757 & 16.7 & 2806 & $8 / 11$ & 1.787 & 16.8 & 2872 & $8 \overline{10.24}$ & 1.819 & 16.8 & 2938 & 1236 & 600 & & 3004 & $814: 48$ & 600 & \\
\hline 2741 & $8 / 11 / 2$ & 1.760 & 16.7 & 2807 & & 1.787 & 16.8 & 2873 & 0810.26 & 至 1.819 & 168 & 2909 & 1238 & 660 & 47.0 & 3006 & $0814: 50$ & 609 & \\
\hline 2742 & & 1.762 & 167 & 2008 & 811 & 1.788 & 16.8 & 2874 & 810.28 & 1.820 & 168 & 2940 & 31240 & 604 & $\sqrt{72}$ & 3006 & 88 14:52 & 6068 & \\
\hline 2743 & $8 / 11$ & 1.762 & 16.7 & 2800 & 8 & 1.788 & 168 & 2875 & $8 / 11$ & 1.820 & & 2941 & 1242 & 600 & & कित्रे & $314: 54$ & 6668 & \\
\hline 2744 & $8 / 11 / 2$ & 1.763 & 16.7 & \begin{tabular}{|l|}
2810 \\
\end{tabular} & & 1.729 & 168 & \begin{tabular}{|l}
2876 \\
\end{tabular} & & 1.820 & 16. & \begin{tabular}{|l|}
2942 \\
\end{tabular} & 31244 & 60 & & 3008 & $814: 56$ & 6608 & \\
\hline 2745 & $8 / 11 / 2$ & 1.764 & 16.7 & 2811 & & 1.789 & 168 & \begin{tabular}{|l|}
2877 \\
\end{tabular} & & 4.821 & 16.7 & \begin{tabular}{|l|}
2943 \\
\end{tabular} & 31246 & $0.60 \%$ & 47 & 3000 & $314: 58$ & 6063 & 雨的 \\
\hline 2746 & & 1.765 & 16.7 & 2812 & & 1.789 & 16.8 & \begin{tabular}{|l|}
2878 \\
\end{tabular} & & 61.82 & 16 & 2944 & 31248 & 6048 & $\sqrt{16}$ & 3010 & $15: 00$ & 60 & \\
\hline 2747 & & 1.766 & 167 & \begin{tabular}{|l|}
2813 \\
\end{tabular} & & 1.789 & 168 & \begin{tabular}{|l|l|}
2879 \\
\end{tabular} & & 81.82 & & 2945 & & 608 & & & $15: 02$ & 608 & \\
\hline 2748 & $8 / 11$ & 1.76 & 16.7 & 22814 & & 1.790 & 168 & \begin{tabular}{|l|}
2880 \\
\end{tabular} & $8 / 11$ & 01.822 & 16. & \begin{tabular}{|l|}
2946 \\
\end{tabular} & 81252 & 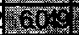 & & 301 & 0 & 1600 & \\
\hline 2749 & $8 / 11$ & 1.766 & 16.7 & \begin{tabular}{|l|}
2815 \\
\end{tabular} & & 1.790 & 168 & 2881 & & (2) 1.821 & 16.7 & \begin{tabular}{|l|}
2947 \\
\end{tabular} & 31254 & 5615 & (20) & 3013 & $815: 06$ & 6 & \\
\hline 2750 & & 1.821 & 16.7 & \begin{tabular}{|l|}
2816 \\
\end{tabular} & & 1.791 & 168 & \begin{tabular}{|l|l|}
2880 \\
\end{tabular} & & 41.82 & 168 & 2948 & & S & and & & & 16060 & \\
\hline 2751 & & 1.656 & 16.7 & \begin{tabular}{|l|}
2817 \\
\end{tabular} & & 1.791 & 16.8 & \begin{tabular}{|l|l|}
2883 \\
\end{tabular} & & 21.82 & & 2949 & & 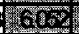 & & & $15: 10$ & 1600 & \\
\hline 2752 & $8 / 11$ & 1.980 & 16.8 & 2818 & & 1.79 & 16.8 & \begin{tabular}{|l|}
2834 \\
\end{tabular} & $0810: 48$ & 31.822 & 16 & \begin{tabular}{|l|}
2960 \\
\end{tabular} & 13000 & 5052 & 10 & 3016 & $0815: 12$ & 7600 & \\
\hline 2753 & $8 / 11 /$ & 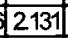 & 17.2 & 2819 & & 1.792 & 16.8 & 2386 & $0810: 50$ & 1.822 & 16. & \begin{tabular}{|l|}
2051 \\
\end{tabular} & 1302 & 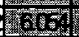 & 16 & 3017 & $815: 14$ & 660 & 11 \\
\hline 2754 & & 2147 & 17.4 & 2820 & & 1.788 & 168 & \begin{tabular}{|l|}
2806 \\
\end{tabular} & & 1.822 & 16. & 2962 & & 465 & & & & 66031 & \\
\hline 2756 & $8 / 11$ & 1.861 & 17.4 & \begin{tabular}{|l|}
2821 \\
\end{tabular} & & 1.785 & 168 & 2887 & $8 / 11 /$ & 41.823 & 16. & 2953 & & 16.5 & & & & 1606 & \\
\hline 2756 & $8 / 11$ & $\sqrt{1.621}$ & $\overline{17.5}$ & \begin{tabular}{|l|}
2822 \\
\end{tabular} & 8844 & 1.784 & 168 & \begin{tabular}{|l}
2888 \\
\end{tabular} & & 60 & & 2964 & & 6064 & & & $15: 20$ & 60 & \\
\hline $2 / 5$ & $8 / 11 /$ & 1.463 & 17.4 & 2823 & & 1.78 & 16.8 & 2890 & 81 & 8.823 & 16.8 & 205 & 13.10 & (n) & 108 & 021 & $15: 22$ & 606 & \\
\hline 2758 & & 1.436 & 17.3 & 2824 & & 1.788 & 16.8 & \begin{tabular}{|l|l|}
2890 \\
\end{tabular} & & & 16. & 2056 & & 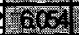 & & & & 6091 & \\
\hline 2759 & & 1.423 & 17.1 & 2825 & & 1.790 & 168 & \begin{tabular}{|l|}
2891 \\
\end{tabular} & & 1.822 & & 2050 & & 6054 & & & & 6ers? & \\
\hline 2760 & $8 / 11$ & 1.416 & 16.9 & 2826 & 58852 & 1.792 & 168 & 2899 & $0811: 04$ & 4.822 & 16.7 & \begin{tabular}{|l|}
2058 \\
\end{tabular} & $13: 16$ & 6068 & 167 & 3024 & $815: 28$ & 16058 & \\
\hline 2761 & $8 / 11 /$ & 1.52 & 16.9 & \begin{tabular}{|l|}
2827 \\
\end{tabular} & $8 / 1$ & 1.793 & 168 & \begin{tabular}{|l|l|}
2899 \\
\end{tabular} & & 61.822 & 167 & \begin{tabular}{|l|}
2968 \\
\end{tabular} & & 6054 & 12167 & 3025 & $15: 30$ & $\sqrt{6064}$ & $3 x$ \\
\hline 2762 & & 1.521 & 16.9 & 2828 & & 1.795 & 168 & 2894 & & & 16. & 2960 & & $\sqrt{6050}$ & & & & 6003 & \\
\hline 2763 & & 1.761 & 16.9 & 2829 & & 1.796 & 168 & \begin{tabular}{|l}
2896 \\
\end{tabular} & & $0 \longdiv { 1 . 8 }$ & & 2961 & & 7605 & & & & 600 & \\
\hline 2764 & & 1.763 & 16.9 & \begin{tabular}{|l|l|}
2830 \\
\end{tabular} & & 1.796 & 168 & 2896 & & 2.823 & 16. & \begin{tabular}{|l|}
2962 \\
\end{tabular} & & 6050 & & & 31536 & $\sqrt{6065}$ & \\
\hline 2765 & $811 /$ & 1.570 & 16.9 & \begin{tabular}{|l|}
2831 \\
\end{tabular} & 089.0 & 1.708 & 168 & \begin{tabular}{|l|}
2897 \\
\end{tabular} & 811 & 4.824 & 167 & \begin{tabular}{|l|}
2963 \\
\end{tabular} & 0813.26 & 6060 & 168 & 000 & $315: 38$ & $\sqrt{606}$ & 71 \\
\hline 2766 & & 1.549 & 16. & \begin{tabular}{|l|}
2832 \\
\end{tabular} & & \begin{tabular}{|l}
1.798 \\
\end{tabular} & 16.8 & 2898 & & 可 1.824 & 16 & 2964 & & 600 & & & & $\sqrt{6003}$ & \\
\hline 2767 & & 1.541 & 16 & \begin{tabular}{|l|}
2833 \\
\end{tabular} & & 1.799 & 16.8 & \begin{tabular}{|l|l|}
2899 \\
\end{tabular} & & 81.824 & & 2965 & 1330 & 600 & & & & $\sqrt{6006}$ & \\
\hline 2768 & & 1.536 & $\overline{16}$ & 2834 & & 1.800 & 168 & & & 01.825 & & 2906 & & 606 & & & $315 ; 4$ & 6006 & \\
\hline 2769 & $8 / 11$ & 1.533 & 16.8 & \begin{tabular}{|l|}
2835 \\
\end{tabular} & 0089.10 & 1.801 & 16.8 & 2000 & $200811: 2$ & 21.825 & 16.8 & 2967 & 00813.34 & 6ब्ठ & 16 & 3033 & 081546 & 6065 & 16 \\
\hline $27 \pi 0$ & $8 / 11 /$ & 1.531 & 16.8 & 2836 & & 1.801 & 168 & 2902 & & 41.825 & 167 & 2968 & & 6006 & & 3034 & 815448 & $\sqrt{600}$ & \\
\hline $2 \pi 7$ & & 1.531 & 16.8 & \begin{tabular}{|l|}
2837 \\
\end{tabular} & & 1.801 & 16.8 & 2903 & & 61.823 & 16. & 2969 & 31338 & 6000 & 5168 & 3030 & & 6066 & \\
\hline $2 \pi 72$ & & 1.816 & 16.8 & \begin{tabular}{|l|}
2838 \\
\end{tabular} & & 1.801 & 168 & & & 81.819 & & $29 \pi$ & & 6000 & & & $8815: 52$ & 梮 & \\
\hline $2 \pi 73$ & & 1.761 & 16.8 & 2839 & 089.18 & 1.800 & 168 & 2905 & $8 / 11 / 200$ & 01.815 & 16.7 & \begin{tabular}{|l|}
2971 \\
\end{tabular} & 81342 & 606 & 168 & 3037 & $8 / 11 / 200815: 54$ & 6006 & 16 \\
\hline 2774 & $8 / 111$ & 1.594 & 16.8 & 2840 & & 1.800 & 16.8 & 2006 & $8 / 11 / 2008$ & 1.815 & 167 & 2974 & $8 / 11 / 2000$ 13444 & 6 & 1168 & 3038 & 081556 & $\sqrt{6060}$ & $\sqrt{16}$ \\
\hline $2 \sqrt{2 / 5}$ & & 1.590 & 16.8 & \begin{tabular}{|l|}
2841 \\
\end{tabular} & & 1.803 & 16.8 & 2907 & & 41.817 & 168 & 2973 & 31346 & $\sqrt{6006}$ & 166 & & 881558 & $\sqrt{6060}$ & 16 \\
\hline
\end{tabular}


DOE/RL-2009-35, REV. 0

\begin{tabular}{|c|c|c|c|c|c|c|c|}
\hline \multicolumn{4}{|c|}{ D425p } & \multicolumn{4}{|c|}{ D425p } \\
\hline$P A C$ & & Pres & Temp & $P A x$ & & Pres & Temp \\
\hline$\#$ & Date/Time & psi & ${ }^{\circ} \mathrm{C}$ & \# & Dete/Time & $p i$ & \\
\hline 3040 & $8 / 11 / 200616: 00$ & 600 & 16:4 & 3106 & $8 / 11 / 20081812$ & 30701 & \\
\hline 3041 & $8 / 11 / 200816: 02$ & 606 & 16: & 3107 & $8 / 11 / 20081814$ & SWOR & \\
\hline 3042 & $8 / 1 / 200816: 04$ & 607 & (6) & 3108 & $8 / 11 / 20081816$ & 60 & \\
\hline 3043 & $8 / 11 / 20081606$ & 606 & 167 & 3100 & $8 / 11 / 20081818$ & (OWI & \\
\hline 3044 & $8 / 11 / 20081608$ & $60 \%$ & 616 & 3110 & $8 / 11 / 20081820$ & 601 & \\
\hline 3045 & $8 / 11 / 200816: 10$ & कीज & 156 & 3111 & $8 / 11 / 20081822$ & 160 & \\
\hline 3046 & $8 / 11 / 200816: 12$ & 2610 & 3.67\% & 3112 & $8 / 11 / 20081824$ & $6 \mathrm{~ms}$ & \\
\hline 3047 & $8 / 11 / 200816: 14$ & 606 & 167 & 3113 & $8 / 11 / 20081826$ & WII & \\
\hline 3048 & $811 / 200816: 16$ & 600 & (6) & 3114 & $8 / 11 / 20081828$ & 6012 & \\
\hline 3049 & $8 / 11 / 200816: 18$ & $60 \%$ & W68 & 3115 & $8 / 11 / 20081830$ & WNG & 3. \\
\hline 3050 & $8 / 11 / 200816: 20$ & 6006 & 167 & 3116 & $8 / 11 / 200818: 32$ & 6us & \\
\hline 3051 & $8 / 11 / 200816: 22$ & 6028 & 67 & 3117 & $8 / 11 / 200818: 34$ & 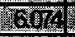 & \\
\hline 3062 & $8 / 11 / 20081624$ & 606: & 1616 & 3118 & $8 / 11 / 20001836$ & $6 \%$ & \\
\hline 3053 & $8 / 11 / 20081626$ & 6068 & 167 & 3119 & $8 / 11 / 20081838$ & $2 \mathrm{SO}_{4}$ & \\
\hline 3054 & $8 / 11 / 20081628$ & 603 & 167 & 3120 & $8 / 11 / 20081840$ & 6074 & \\
\hline 3056 & $8 / 11 / 20081630$ & $60 \%$ & 14767 & 3121 & $8 / 11 / 20081842$ & WOK & \\
\hline 3069 & $8 / 11 / 20081632$ & 60 & 366 & 3122 & $8 / 11 / 20081844$ & 6104 & \\
\hline 3050 & $8 / 11 / 20081634$ & 600 & 186in & 3123 & $8 / 11 / 20081846$ & 607 & \\
\hline 3058 & $8 / 11 / 200816.36$ & 612 & 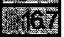 & 3124 & $8 / 11 / 20081848$ & mon & \\
\hline 3069 & $8 / 11 / 200816.38$ & Q16\% & 166 & 3125 & $8 / 11 / 20081850$ & (6) & \\
\hline 3060 & $8 / 11 / 20081640$ & 606 & 1201 & 3126 & $8 / 11 / 20081852$ & $16 \%$ & \\
\hline 3061 & $8 / 11 / 20081642$ & $\mathrm{LCO}_{2}$ & 16 & 3127 & $8 / 11 / 200618.54$ & 8.16 & \\
\hline 306 & $8 / 11 / 20081644$ & Wre & 162 & 3128 & $8 / 11 / 20061856$ & TwT & \\
\hline 3063 & $8 / 11 / 200816: 46$ & $61 \%$ & IIII & 3129 & $8 / 11 / 20081858$ & $6 \mathrm{R}$ & \\
\hline 3064 & $8 / 11 / 20081648$ & Tha & I.6. & 3130 & $8 / 11 / 200819.00$ & Wor: & \\
\hline 306्त & $8 / 11 / 200816: 50$ & 606 & 1867 & 3131 & $8 / 11 / 20081900$ & 60\% & \\
\hline 3060 & $8 / 11 / 200816.52$ & $600 \mathrm{~s}$ & 1964 & 3132 & $8 / 11 / 200819.04$ & 20 & \\
\hline $306 \pi$ & $8 / 11 / 20081654$ & $62 \%$ & 16 & 3133 & $8 / 11 / 200819.06$ & 3074 & \\
\hline 3068 & $811 / 200816.56$ & 619 & 1at & 3134 & $8111 / 20081906$ & P(T) & \\
\hline 3069 & $8 / 11 / 20081658$ & 6037 & (67) & 3135 & $8 / 11 / 200819.10$ & 60\% & \\
\hline 3070 & $8 / 11 / 200817: 00$ & 696 & W14 & 3136 & $8 / 11 / 200819.12$ & 6n & \\
\hline 3071 & $8 / 11 / 200817: 02$ & 60 & Ixtat: & 3137 & $8 / 11 / 200819.14$ & owh & \\
\hline 3072 & $8 / 11 / 200817: 04$ & 567 & 468 & 3138 & $8 / 11 / 200819.16$ & $6 \mathrm{O}$ & WET \\
\hline 3073 & $8 / 11 / 200817: 06$ & 600 & 161 & 3139 & $8 / 11 / 200819.18$ & 601 & \\
\hline 3074 & $8 / 11 / 200817: 08$ & $60 \%$ & 615: & 3140 & $8 / 11 / 200819.20$ & 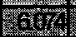 & \\
\hline 3075 & $8 / 11 / 200817: 10$ & 6016 & 167 & 3141 & $8 / 11 / 200819.22$ & Hom & 12 \\
\hline 3076 & $8 / 11 / 200817: 12$ & 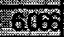 & 12167 & 3142 & $8 / 11 / 200819.24$ & WII & \\
\hline 3077 & $8 / 11 / 200817: 14$ & $60 \%$ & 167 & 3143 & $8 / 11 / 200819.26$ & (6) & \\
\hline 3078 & $8 / 11 / 200817: 16$ & 600 & & 3144 & $8 / 11 / 200819.28$ & 60 & \\
\hline 3079 & $8 / 11 / 200817: 18$ & (68) & 1167 & 3145 & $8 / 11 / 200819.30$ & by & 67\% \\
\hline 3000 & $8 / 11 / 200817: 20$ & 60 & 467 & 3146 & $8 / 11 / 20081932$ & $60 \%$ & \\
\hline 3081 & $8 / 11 / 200817: 22$ & No & 167 & 3147 & $8 / 11 / 200819.34$ & 2018 & \\
\hline 3082 & $8 / 11 / 200817: 24$ & 606 & 167 & 3148 & $8 / 11 / 200819.36$ & 3.16 & 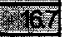 \\
\hline 3083 & $8 / 11 / 200817: 26$ & 60 & 167 & 3149 & $8 / 11 / 200619.38$ & aurs & 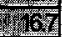 \\
\hline 3084 & $8 / 11 / 200817: 28$ & 616 & 167 & 3150 & $8 / 11 / 200819.40$ & Fing & \\
\hline 3005 & $8 / 11 / 200817: 30$ & 606 & 168 & 3151 & $8 / 11 / 200819.42$ & 6.6\% & \\
\hline 3006 & $8 / 11 / 200817: 30$ & 60 & 167 & 3152 & $8 / 11 / 200819.44$ & 60 & \\
\hline 3087 & $8 / 11 / 200817: 34$ & 6:168 & 67 & 3153 & $8 / 11 / 200819.46$ & 5. & 467 \\
\hline 3088 & $8 / 11 / 200817: 36$ & 60 & $\sqrt{167}$ & 3154 & $8 / 11 / 200819.48$ & 693 & 467 \\
\hline 3009 & $8 / 11 / 200817: 38$ & 6106 & 1967 & 3155 & $8111 / 200819.50$ & onger & \\
\hline 3000 & $8 / 11 / 200817: 40$ & 606 & 167\% & 3156 & $8 / 11 / 200819.52$ & 600 & \\
\hline 3091 & $8 / 11 / 200817: 42$ & 606 & 967 & 3157 & $8 / 11 / 200819.54$ & 100 & \\
\hline 3090 & $8 / 11 / 200817: 44$ & 60 & 167 & 3158 & $8 / 11 / 200819.56$ & 60 & \\
\hline 3009 & $8 / 11 / 200817: 46$ & 60 & 167 & 3159 & $8 / 11 / 200819.58$ & 616 & \\
\hline 3004 & $8 / 11 / 200817: 48$ & 607 & 67 & 3160 & $8 / 11 / 200820,00$ & 606 & 17 \\
\hline 3096 & $8 / 11 / 200817: 50$ & 607 & 167 & 3161 & $8 / 11 / 200820: 00$ & (10) & \\
\hline 3006 & $8 / 11 / 200817: 52$ & 607 & 167 & 3162 & $8 / 11 / 20082004$ & 602 & \\
\hline 3097 & $8 / 11 / 200817: 54$ & (601 & S67 & 3163 & $8 / 11 / 200820.06$ & 606 & 15 \\
\hline 3098 & $8 / 11 / 200817: 56$ & 160\% & 1617 & 3164 & $8 / 11 / 20082008$ & 60 & 2167 \\
\hline 3090 & $8 / 11 / 200817: 58$ & 60 & 12 & 3165 & $8 / 11 / 200820.10$ & 601 & 167 \\
\hline 3100 & $8 / 11 / 20081800$ & 60 & 167 & 3166 & $8 / 11 / 200820: 12$ & $60 \mathrm{H}$ & 167 \\
\hline 310 & $8 / 1 / 20081800$ & 6074 & 1678 & 3167 & $8 / 11 / 200820: 14$ & 6ros & 167 \\
\hline 3100 & $8 / 11 / 20081804$ & 607 & 167 & 3168 & $8 / 11 / 200620.16$ & 606 & 167 \\
\hline 3109 & $8 / 11 / 20081806$ & 607 & 167 & 3169 & $8 / 11 / 200620.18$ & $6 \%$ & 16 \\
\hline 3104 & $8 / 11 / 20081808$ & 607 & 167 & $31 \pi$ & $8 / 11 / 200820.20$ & 6\%on & 167 \\
\hline 3105 & $8 / 11 / 20081810$ & 607 & 6167 & 3171 & $8 / 11 / 20082022$ & 607 & 5167 \\
\hline
\end{tabular}

\begin{tabular}{|c|c|c|}
\hline \multicolumn{3}{|c|}{$\overline{D 425 p}$} \\
\hline $\mathrm{Bec}$ & & \begin{tabular}{l|l} 
Pes & Temp
\end{tabular} \\
\hline$\frac{\#}{210}$ & DateTime & psi \\
\hline & $8 / 1120082024$ & \\
\hline & 8111200820206 & 16.67) \\
\hline & $8 / 11 / 200820: 28$ & 6067 \\
\hline 3175 & $8 / 11 / 200820: 30$ & \\
\hline & $8 / 11200020232$ & 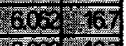 \\
\hline & 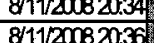 & 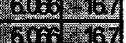 \\
\hline & $8 / 11 / 20082038$ & 16007 \\
\hline 3180 & $8 / 11 / 200020040$ & 6067167 \\
\hline & $8 / 11200820142$ & 6067467 \\
\hline & $8 / 11 / 200820: 44$ & \\
\hline & $8111 / 200820: 46$ & 6067 \\
\hline 3184 & $8 / 11 / 200820: 48$ & 6007 \\
\hline & $8 / 11 / 200820: 50$ & 60067 \\
\hline & $8 / 11 / 200020: 52$ & \\
\hline & $8 / 11 / 200820.54$ & \begin{tabular}{c|c|c|}
6000 & 0
\end{tabular} \\
\hline & 811200820.56 & 6000767 \\
\hline & $8 / 11200820.58$ & 607.6 \\
\hline & $8 / 11200821: 00$ & 600,169 \\
\hline & $8 / 11 / 200821: 02$ & \\
\hline 3192 & $8 / 11200821: 04$ & 6007 \\
\hline & $8 / 11 / 200821: 06$ & fि0 \\
\hline & $8 / 11200821: 06$ & 6074 13. \\
\hline & $8 / 11 / 200821: 10$ & $6074016:$ \\
\hline & 8/11/200821:12 & \\
\hline & $8 / 11 / 200821: 14$ & 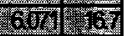 \\
\hline & $8 / 11 / 200821: 16$ & 60न्ता \\
\hline & $8 / 11200821: 18$ & 6074 \\
\hline 3200 & $8 / 11 / 200821: 20$ & 16021967 \\
\hline & $8111200821: 22$ & 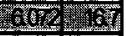 \\
\hline & $8 / 11 / 200821: 24$ & 76020 \\
\hline & $0821: 26$ & 600.616 \\
\hline & $8 / 11 / 200821: 28$ & 6074 \\
\hline & $8 / 11 / 200021: 30$ & 6003164 \\
\hline & 8/11/200821:32 & Gore \\
\hline & $8 / 11 / 200821: 34$ & 607467 \\
\hline & & 60ल \\
\hline 3209 & $8 / 11 / 200821: 38$ & 6974762 \\
\hline 3210 & $8 / 11 / 200821: 40$ & 20, 1961 \\
\hline & $8 / 11200821: 42$ & \\
\hline & $8 / 11 / 200821: 44$ & \\
\hline & & \\
\hline & & mas \\
\hline 3215 & $8 / 11200821: 50$ & 60740 \\
\hline & $8111200821: 52$ & 6074167 \\
\hline & & 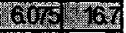 \\
\hline$\frac{32}{2}$ & $8111200821: 56$ & 6005 \\
\hline & $\frac{811 / 201<2,1200}{811 / 2008}$ & 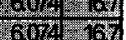 \\
\hline & $8 / 1120082202$ & 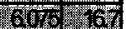 \\
\hline & $8 / 1120082204$ & 6070 \\
\hline & $8 / 11 / 20082206$ & 60767167 \\
\hline & $811 / 2$ & $607 / 10$ \\
\hline & $811 / 20082210$ & $\overline{6013}$ \\
\hline & 811120082212 & 6003 \\
\hline & $8 / 11 / 20082214$ & $60 \mathrm{Gr} / 167$ \\
\hline & $8 / 1120082216$ & 600604167 \\
\hline & & 6076.16 \\
\hline & & 6076) \\
\hline & & 60त6 \\
\hline & $8 / 11 / 20082224$ & 6006 \\
\hline & $8 / 1120082226$ & \begin{tabular}{ll|l|}
60767 & 167 \\
\end{tabular} \\
\hline 44 & & $607658 \%$ \\
\hline & & 6076. \\
\hline & $8111 / 20082239$ & 6006 \\
\hline & $8 / 11 / 20082234$ & $60 \mathrm{~m} 16$ \\
\hline
\end{tabular}

\begin{tabular}{|c|c|c|c|}
\hline \multicolumn{4}{|c|}{ D4-25p } \\
\hline $\mathrm{REC}$ & & Pres & Temp \\
\hline$\#$ & DeteTime & $p s i$ & ${ }^{\circ} \mathrm{C}$ \\
\hline 3238 & $8 / 11 / 20082236$ & 1607 & 767 \\
\hline 3239 & $8111 / 20082238$ & $60 \times$ & 76 \\
\hline 3240 & $8 / 11 / 20082240$ & spro & (6) \\
\hline 3241 & $8 / 11 / 20002242$ & 69 & $\sqrt{27}$ \\
\hline 3242 & $8 / 11 / 20082244$ & 26 & (6/7) \\
\hline 3243 & $8 / 11 / 20082246$ & $60 \mathrm{~g}$ & W167 \\
\hline 3244 & $8 / 11 / 20082248$ & $60 \%$ & (1) \\
\hline 3245 & $811 / 20082250$ & 60 & (1978 \\
\hline 3246 & $8111 / 20082252$ & 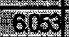 & (x) \\
\hline 3247 & $8 / 11 / 20082254$ & $60 \%$ & 467 \\
\hline 3248 & $8 / 11 / 20082256$ & 604 & (1) \\
\hline 3249 & $8 / 11 / 20082258$ & 6045 & 767 \\
\hline 3250 & $8 / 11 / 20082300$ & 60 & (67) \\
\hline 3251 & $8 / 11 / 20082302$ & $60 \%$ & 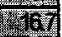 \\
\hline 3252 & $8 / 11 / 20082304$ & 604 & 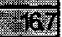 \\
\hline 3253 & $8111 / 20082306$ & $60 \%$ & Wha" \\
\hline 3254 & $8 / 11 / 20082308$ & $60 \%$ & \\
\hline 3255 & $8 / 11 / 200823: 10$ & 60 & \\
\hline 3256 & $8 / 11 / 200823: 12$ & 606 & 67 \\
\hline 3257 & $8 / 11 / 20082314$ & 6008 & \\
\hline 3258 & $8 / 11 / 20082316$ & 6ros & \\
\hline 3250 & $8111 / 20082318$ & 2615 & (3) \\
\hline 3260 & $8 / 11 / 20082320$ & 666 & 86 \\
\hline 3261 & $8111 / 20082322$ & 60 & $\sqrt{167}$ \\
\hline 3262 & $8 / 11 / 20082324$ & $60 \%$ & 1367 \\
\hline 3263 & $8 / 11 / 20082326$ & 600 & $12 \mathrm{ar}$ \\
\hline 3264 & $8 / 11 / 20082328$ & 603 & 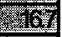 \\
\hline 3260 & $8 / 1 / 20082330$ & 601 & MT: \\
\hline 3266 & $8 / 11 / 20082332$ & 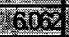 & 167 \\
\hline 3267 & $8 / 11 / 20082334$ & $60 \mathrm{~s}$ & 867 \\
\hline 3268 & $8111 / 20082336$ & 605 & 46\% \\
\hline 3269 & $8111 / 20082338$ & 608 & 86 \\
\hline 3270 & $8111 / 200823440$ & 668 & 107 \\
\hline 3271 & 8111200823.42 & 60 & Th \\
\hline 3272 & $8111 / 20082344$ & 608 & \\
\hline 3273 & $8111 / 200823.46$ & 616 & M \\
\hline 3274 & $8 / 11 / 20082348$ & 603 & 46. \\
\hline 3275 & $8 / 11 / 20082350$ & 600 & 816\% \\
\hline 3276 & $8 / 11 / 20082352$ & 606 & 16\% \\
\hline 3277 & $811 / 200823.54$ & 666 & 1SW \\
\hline 3278 & $8111 / 200823.56$ & 600 & 167 \\
\hline 3279 & $8 / 11 / 200823.58$ & 606 & 167 \\
\hline 3280 & $8 / 12 / 20080.00$ & 606 & 767 \\
\hline 3281 & $8 / 12 / 20080.02$ & 606 & (167) \\
\hline 3282 & $8 / 12 / 20080.04$ & 584 & 167 \\
\hline 3283 & $8 / 12 / 20080.06$ & 1.733 & 16.8 \\
\hline 3284 & $8 / 1220080: 08$ & 1.734 & 169 \\
\hline 3285 & $8 / 2 / 20080.10$ & 1.735 & 17.0 \\
\hline 3206 & $8 / 12 / 20080: 12$ & 1.741 & 17.4 \\
\hline 3287 & $8 / 12 / 20080: 14$ & 1.736 & 16.9 \\
\hline 3288 & $8 / 12 / 20080: 16$ & 1.732 & 16.8 \\
\hline 3289 & $8 / 12 / 20080.18$ & 1.735 & 16.8 \\
\hline 3290 & $8 / 12 / 20080.20$ & 1.736 & 168 \\
\hline 3291 & $8 / 12 / 20080.22$ & 1.737 & 168 \\
\hline 3292 & $8 / 12 / 20080.24$ & 1.737 & 16.8 \\
\hline 3293 & $8 / 12 / 20080.26$ & 1.738 & 168 \\
\hline 3294 & $8 / 12 / 20080.28$ & 1.738 & 168 \\
\hline 3296 & $8 / 2 / 20080.30$ & 1.738 & 168 \\
\hline 3296 & $812 / 20080.32$ & 1.739 & 168 \\
\hline 3297 & $8 / 12 / 20080.34$ & 1.739 & 168 \\
\hline 3298 & $8 / 2 / 20080: 36$ & 1.739 & 16.8 \\
\hline 3299 & $8 / 12 / 20080.38$ & 1.740 & 16.8 \\
\hline 3300 & $8 / 1220080.40$ & 1.739 & 16.8 \\
\hline 3301 & $8 / 2 / 20080: 42$ & 1.739 & 16.8 \\
\hline 3300 & $8 / 12 / 20080.44$ & 1.739 & 16.8 \\
\hline 3303 & $8 / 2 / 20080.46$ & 1.739 & 16.8 \\
\hline
\end{tabular}

\begin{tabular}{|c|c|c|c|}
\hline \multicolumn{4}{|c|}{ D425p } \\
\hline $\mathrm{PeC}$ & & Pres! & Temp \\
\hline$\#$ & Deterlime & psi & \\
\hline & \begin{tabular}{|l|l|}
$8 / 2200000: 48$ \\
\end{tabular} & & 16.8 \\
\hline 306 & & & 168 \\
\hline 3006 & 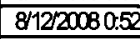 & 1.739 & 16.8 \\
\hline 3307 & 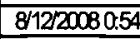 & 1.739 & 168 \\
\hline & $8 / 12 / 200000.56$ & 1.740 & 168 \\
\hline & $8 / 1220080.58$ & 1.740 & 168 \\
\hline & 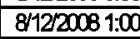 & & \\
\hline & $8 / 12 / 200081: 08$ & 1.740 & 16.8 \\
\hline 3312 & $8 / 12200081: 04$ & 1.740 & 16.8 \\
\hline & $8 / 1220081: 06$ & 1.740 & 16.8 \\
\hline & \begin{tabular}{|l|l|}
$8 / 1220081: 08$ \\
\end{tabular} & & 168 \\
\hline & $8 / 12 / 20081: 10$ & 1.740 & 16.8 \\
\hline 3316 & $8 / 12200081: 12$ & 1.740 & 16.8 \\
\hline 3317 & $8 / 1220081: 14$ & 1.740 & 168 \\
\hline & 8/12/20081:16 & 1.741 & 16.8 \\
\hline 3319 & 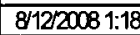 & & \\
\hline 3320 & 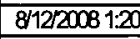 & \begin{tabular}{|l|}
1.741 \\
\end{tabular} & 16.8 \\
\hline 3321 & \begin{tabular}{|l|}
$8 / 1220081: 22$ \\
\end{tabular} & $|1.741|$ & 168 \\
\hline & $8 / 1220001: 24$ & 1.744 & 16.8 \\
\hline & $8 / 1220001: 26$ & 1.742 & 16.8 \\
\hline & $8 / 12 / 20081: 28$ & 1.743| & 16.8 \\
\hline & $8112200081: 30$ & 1.742 & 16.8 \\
\hline & \begin{tabular}{|l|}
$8112200081: 32$ \\
\end{tabular} & 1.742 & 16.8 \\
\hline & $8112200081: 34$ & \begin{tabular}{|l|l|}
1.742 \\
\end{tabular} & 16.8 \\
\hline 3238 & 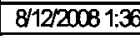 & \begin{tabular}{|c|}
1.743 \\
\end{tabular} & 168 \\
\hline 3329 & 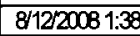 & 1.743 & 16.8 \\
\hline 3300 & $\sqrt{8 / 12 / 20081: 40}$ & $\mid$ & 16.8 \\
\hline 3331 & \begin{tabular}{|l|l}
$8 / 12200081: 42$ \\
\end{tabular} & 1.742 & 168 \\
\hline & $\sqrt{8 / 12 / 20081: 44}$ & $\mid$ & 16.8 \\
\hline 3333 & 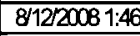 & 1.734 & 16.8 \\
\hline 3334 & $8 / 12200081: 48$ & 1.730 & 16.8 \\
\hline & $8 / 1220081: 50$ & 1.726 & 16.8 \\
\hline & 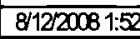 & 1.724 & 16.8 \\
\hline & $8 / 12200081: 54$ & 1.725 & 16.8 \\
\hline 3338 & $8 / 1220001: 56$ & $1.72 \pi$ & 16.8 \\
\hline 3339 & $8112200081: 58$ & 1.729 & 16.8 \\
\hline 3340 & $\sqrt{8 / 1220008200}$ & 1.731 & 168 \\
\hline 3341 & $8 / 12 / 2008200$ & 1.732 & 168 \\
\hline 3342 & \begin{tabular}{|l|}
$8 / 12 / 20082004$ \\
\end{tabular} & 1.733 & 16.8 \\
\hline 3343 & $8 / 12 / 2008206$ & 1.733 & 16.8 \\
\hline 3344 & & 1.734 & 16.8 \\
\hline 3345 & $\sqrt{8 / 12 / 2008210}$ & 1.734 & \\
\hline$\frac{3346}{334}>2$ & $\sqrt{8 / 12 / 2008212}$ & 1734 & 168 \\
\hline 3347 & $8 / 1220008214$ & 1.735 & 16.8 \\
\hline & \begin{tabular}{|l}
$8 / 122008216$ \\
\end{tabular} & 1.730 & 16.8 \\
\hline 3349 & $8 / 12 / 2008218$ & 1.735 & 16.8 \\
\hline 3350 & $8 / 1220008220$ & 1.736 & 16.8 \\
\hline 3351 & $8 / 2 / 2 x$ & 1.736 & 16.8 \\
\hline 3352 & 81222000224 & 1.737 & 16.8 \\
\hline 3353 & $\sqrt{8 / 1220008226}$ & 1.73त्त & 16.8 \\
\hline 3354 & $8 / 1220002228$ & $1.73 \pi$ & 16.8 \\
\hline 3356 & 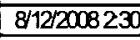 & & 16.8 \\
\hline 3356 & 8 & 1.730 & 16.8 \\
\hline 3357 & $8 / 12 / 2008234$ & 1.73र्त & 16.8 \\
\hline & $812 / 2008236$ & 1737 & $\frac{168}{168}$ \\
\hline 3309 & $\sqrt{8 / 12 / 2008236}$ & 1.737 & 168 \\
\hline 3300 & $8 / 12 / 2000240$ & 1.737 & 168 \\
\hline 3301 & $\sqrt{8 / 12 / 2008242}$ & 1.7399 & 168 \\
\hline 3362 & $8 / 222008244$ & 1739 & 16.8 \\
\hline 3363 & $8 / 2 / 2008246$ & 1.740 & 168 \\
\hline 3364 & 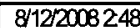 & 1.740 & \\
\hline 3365 & 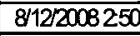 & 1.741 & 168 \\
\hline 3006 & $8 / 122008252$ & 1.741 & 168 \\
\hline 3367 & $8 / 122008254$ & 1.741 & 168 \\
\hline 3308 & $8 / 12 / 2008256$ & 1.742 & 168 \\
\hline & $8 / 12 / 2008258$ & 1.742 & 168 \\
\hline
\end{tabular}


DOE/RL-2009-35, REV. 0

\begin{tabular}{|c|c|c|c|c|c|c|c|c|c|c|c|c|c|c|c|c|c|c|c|}
\hline \multicolumn{4}{|c|}{ D425p } & \multicolumn{4}{|c|}{$D 425 p$} & \multicolumn{4}{|c|}{ D425p } & & $D 4250$ & & & & $D 425 p$ & & \\
\hline $\mathrm{Rec}$ & & Pres & Temp & $\mathrm{Rec}$ & & Pres & Temp & $\operatorname{Rec}$ & & \begin{tabular}{|l|l|} 
Pres \\
\end{tabular} & Ternp & 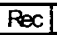 & & Pres & Temp & $\operatorname{Rec}$ & & Pres & Temp \\
\hline$\#$ & Dete/Time & \begin{tabular}{l|l} 
psi \\
\end{tabular} & ${ }^{\circ} \mathrm{C}$ & $\#$ & Date/Time & \begin{tabular}{l|l}
$p s i$ \\
\end{tabular} & ${ }^{\circ} \mathrm{C}$ & $\#$ & DaterTime & psi & ${ }^{\circ} \mathrm{C}$ & $\#$ & Date/Time & psi & & $\#$ & Dade/Time & \begin{tabular}{|l|}
$\mathrm{psi}$ \\
\end{tabular} & ${ }^{\circ} \mathrm{C}$ \\
\hline 3370 & $8 / 1220083: 00$ & 1.742 & 16.8 & 3436 & $8 / 12 / 20085: 12$ & 1.743 & 16.8 & 3505 & $8 / 12 / 20087: 30$ & 1.734 & 16.8 & 374 & $8 / 12 / 20089.48$ & 1.749 & 16.8 & 3643 & $8 / 12 / 20081206$ & 1.762 & 16.8 \\
\hline 3371 & $8 / 12200083: 02$ & 1.742 & 16.8 & 3437 & $8 / 12 / 20085: 14$ & 1.743 & 16.8 & 3506 & $8 / 12 / 20087: 32$ & 1.720 & 16.8 & 3575 & $8 / 12 / 20089.50$ & 1.749 & & 644 & $8 / 12 / 20081208$ & 1.762 & \\
\hline 3372 & $8 / 1220083: 04$ & 1.742 & 16.8 & 438 & $8 / 12 / 20085: 16$ & 1.742 & 16.8 & 3507 & $8 / 12220087: 34$ & 1.726 & 16.8 & 3576 & $8 / 12 / 20089.52$ & 1.749 & & 345 & $8 / 12 / 200812: 10$ & 1.761 & 16.8 \\
\hline 3373 & $8 / 1220083: 06$ & 1.742 & 16.8 & 3439 & 8/12/20085:-18 & 1.742 & 16.8 & 3508 & $8 / 12 / 20087: 36$ & 1.723 & 16.8 & $35 \pi$ & $8 / 12 / 20089.54$ & 1.750 & 16.8 & 3646 & $8 / 12 / 20081212$ & 1.762 & 16.8 \\
\hline 3374 & $8 / 1220083.08$ & 1.741 & 16.8 & 3440 & $8 / 12 / 20085: 20$ & 1.742 & 16.8 & 3600 & $8 / 12 / 20087: 38$ & 1.722 & 16.8 & 3578 & $8 / 12 / 20089.56$ & 1.750 & 16.8 & 3647 & $8 / 12 / 20081214$ & 1.762 & 16.9 \\
\hline 3375 & $8 / 1220083: 10$ & 1.741 & 16.8 & 3441 & $8 / 12 / 20085: 22$ & 1.743 & 16.8 & 3510 & $8 / 12 / 20087: 40$ & 1.725 & 16.8 & 3579 & $8 / 12 / 20089.58$ & 1.750 & 16.8 & 3648 & $8 / 12 / 2008$ 1216 & 1.762 & 16.9 \\
\hline 3376 & 8/12/20083:12 & 1.742 & 16.8 & 3442 & $8 / 12 / 20085: 24$ & 1.743 & 17.3 & 3511 & $8 / 12 / 20087: 42$ & 1.728 & 16.8 & 3580 & $8 / 12 / 2000810: 00$ & 1.750 & 16.8 & 3649 & $8 / 12 / 20081218$ & 1.762 & 16.9 \\
\hline 337 & $8 / 1220083: 14$ & 1.742 & 16.8 & 3443 & $812 / 20085: 26$ & 1.743 & 17.4 & 3512 & $8 / 12 / 20087: 44$ & 1.736 & & 3581 & $8 / 12 / 200810: 02$ & 1.750 & & 3650 & & 1.763 & \\
\hline 3378 & $8 / 1220083: 16$ & 1.742 & 16.8 & 3444 & $8 / 12 / 20085: 28$ & 1.744 & 17.1 & 3513 & $8 / 1220087: 46$ & 1.726 & 16.8 & 3582 & $8 / 12 / 200810: 04$ & 1.750 & 16.8 & 3651 & $8 / 12 / 20081222$ & 1.763 & 16.8 \\
\hline 3379 & $8 / 1220083: 18$ & 1.743 & 16.8 & 3445 & $8 / 12 / 20085: 30$ & 1.743 & 16.9 & 3514 & $8 / 12 / 20087: 48$ & 1.733 & 16.8 & 3583 & $8 / 12 / 200810: 06$ & 1.749 & 16.8 & 3652 & $8 / 1220001224$ & 1.764 & 16.9 \\
\hline 3380 & $8 / 1220083: 20$ & 1.743 & 16.8 & 3446 & $8 / 12 / 20085: 32$ & 1.743 & 16.8 & 3515 & $8 / 1220087: 50$ & 1.735 & 16.8 & 3584 & $8 / 12 / 200810: 08$ & 1.749 & & & $8 / 12220081226$ & 1.764 & 16.9 \\
\hline 3381 & $8 / 1220083: 22$ & 1.743 & 16.8 & 3447त & $8 / 12 / 20085: 34$ & 1.744 & 16.8 & 3516 & $8 / 12200087: 52$ & 1.736 & 16.8 & 3585 & $8 / 12 / 2008$ 10:10 & 1.749 & 16.8 & 3654 & $8 / 12 / 20081228$ & 1.764 & 16.9 \\
\hline 3382 & $8 / 12 / 20083: 24$ & 1.743 & 16.8 & 3448 & $8 / 12 / 20085: 36$ & 1.743 & 17.1 & 3517 & $8 / 12 / 20087: 54$ & 1.736 & 16.8 & 3586 & $8 / 12 / 2008$ 10:12 & 1.749 & 16.8 & 3655 & $8 / 1220081230$ & 1.764 & 16.9 \\
\hline & $8 / 12120083: 26$ & 1.743 & 16.8 & 3449 & $8 / 12 / 20085: 38$ & 1.744 & $\overline{17.1}$ & 3518 & $8 / 12220087: 56$ & 1.737 & 16.8 & 3587 & $8 / 12 / 200810: 14$ & 1.749 & & 3656 & & & 169 \\
\hline 3384 & $8 / 12 / 20083: 28$ & 1.744 & 16.8 & 3450 & $8 / 12 / 20085: 40$ & 1.745 & 16.9 & 3519 & $8 / 12 / 20087: 58$ & 1.737 & 16.8 & 3588 & $8 / 12 / 200810: 16$ & 1.750 & 16.8 & 365 & $8 / 12 / 20081234$ & 1.763 & 16.9 \\
\hline 3385 & $8 / 12 / 20083: 30$ & 1.744 & 16.8 & 3451 & $8 / 12 / 20085: 42$ & 1.744 & 16.8 & 3520 & $8 / 12 / 20088: 00$ & 1.738 & 16.8 & 3589 & $8 / 12 / 200810: 18$ & 1.749 & & & $8 / 12 / 2$ & 1.764 & \\
\hline 3306 & $8 / 1220083: 32$ & 1.743 & 16.8 & 3452 & $8 / 12 / 20085: 44$ & 1.745 & 16.8 & 3521 & $8 / 12 / 20088: 02$ & 1.738 & 16.8 & 3590 & $8 / 12 / 200010: 20$ & 1.748 & 16. & 250 & 0812338 & 1.763 & 16.9 \\
\hline 3387 & $8 / 1220083: 34$ & 1.743 & 16.8 & 3453 & $8 / 12 / 20085: 46$ & 1.745 & 16.8 & 3522 & $8 / 12 / 20088: 04$ & 1.738 & 16.8 & 3591 & $8 / 12 / 20$ & 1.746 & 16.8 & 3660 & 81240 & 1.764 & 16.9 \\
\hline 3388 & $8 / 1220$ & 1.743 & 16.8 & 3454 & $8 / 12 / 20085: 48$ & 1.745 & 16.8 & 3523 & $8 / 12 / 20088: 06$ & 1.730 & 16.8 & 3592 & $8 / 12 / 20$ & 1.742 & & & 81242 & \begin{tabular}{|l|l|}
1.765 \\
\end{tabular} & \\
\hline 3389 & $8 / 12200083.38$ & 1.744 & 16.8 & 3455 & $8 / 12 / 20085: 50$ & 1.745 & 16.8 & 3524 & $8 / 12 / 20088: 08$ & 1.740 & 16.8 & 3593 & $8 / 12 / 200810: 26$ & 1.741 & 16.8 & $36 \pi 2$ & $8 / 12 / 20081244$ & 1.765 & 16.9 \\
\hline 3390 & $8 / 12200$ & 1.728 & 16.8 & 3456 & $8 / 12 / 20085: 52$ & 1.746 & 16.8 & 3625 & $8 / 12 / 20088: 10$ & 1.740 & 16.8 & 3594 & $8 / 12 / 200810: 28$ & 1.742 & 16.8 & $363^{3}$ & $8 / 12 / 20081246$ & \begin{tabular}{|l|}
1.764 \\
\end{tabular} & 17.1 \\
\hline 3391 & $8 / 12220$ & 1.743 & 16.8 & 345त्त्री & $8 / 12 / 20085: 54$ & 1.746 & 16.8 & 3526 & $8 / 12 / 20$ & 1.741 & 16.8 & 3595 & $8 / 12 / 20$ & 1.743 & & & & 1.765 & \\
\hline 3392 & $8 / 12220$ & 1.744 & 16.8 & 3458 & $8 / 12 / 20085: 56$ & 1.746 & 16.8 & 3527 & $8 / 12 / 20$ & 1.741 & 16.8 & 3596 & $8 / 12 / 20$ & 1.745 & 16. & 3665 & 31250 & 1.764 & 16.9 \\
\hline 3393 & $8 / 12 / 2$ & 1.745 & 16.8 & 3459 & $8 / 12 / 20085: 58$ & 1.746 & 16.8 & 3528 & $8 / 12 / 20$ & 1.741 & 16.8 & 3597 & $8 / 12 / 20$ & 1.746 & 16. & 3606 & & 1.765 & 16.9 \\
\hline 3394 & $8 / 12 / 20$ & 1.744 & 16.8 & 3460 & $8 / 12 / 20086: 00$ & 1.747 & 16.8 & 3529 & $8 / 12 / 20$ & $1.74 t$ & 16.8 & 3598 & $8 / 12 / 200810.36$ & 1.746 & 16. & 3667 & 81254 & 1.765 & 16.9 \\
\hline 3390 & $8 / 12 / 20$ & 1.744 & 16.8 & 3461 & $8 / 1220086: 02$ & 1.747 & 16.8 & 3530 & $8 / 12 / 20088: 20$ & 1.742 & 16.8 & 3590 & $8 / 12 / 20$ & 1.747 & 16. & 3668 & 31256 & 1.765 & 16.8 \\
\hline 3396 & $8 / 122$ & 1.745 & 16.8 & 3462 & $8 / 12 / 20086: 04$ & 1.747 & 16.8 & 3531 & $8 / 12 / 2$ & 1.742 & & 3600 & $8 / 12 / 2$ & 1.748 & & 3669 & 1258 & 1.765 & 16.8 \\
\hline 3397 & $8 / 12 / 2$ & 1.745 & 16.8 & 3463 & $8 / 12 / 20086006$ & 1.748 & 16.8 & 3532 & $8 / 12 / 2$ & 1.742 & 16.8 & 3601 & $8 / 12 / 2$ & 1.748 & 16 . & & $13: 00$ & 1.765 & 16.9 \\
\hline 3398 & $8 / 12 / 2$ & 1.745 & 16.8 & 3464 & $8 / 12 / 20086: 08$ & 1.747 & 16.8 & 3533 & $8 / 12 / 20$ & 1.742 & 16.8 & 3602 & $8 / 12 / 2$ & 1.748 & 16. & 3671 & & 1.766 & 16.9 \\
\hline 3399 & $8 / 122$ & 1.745 & 16.8 & 3465 & $8 / 12 / 20086: 10$ & 1.747 & 16.8 & 3534 & $8 / 12 / 20088: 28$ & 1.743 & 16.8 & 3603 & $8 / 12 / 2$ & 1.748 & & 3672 & & 1.766 & 16.9 \\
\hline 3400 & $8 / 122$ & 1.746 & 16.8 & 3466 & $8 / 12 / 20086: 12$ & 1.747 & 16.8 & 3535 & $8 / 12 / 20$ & 1.741 & 16.8 & 3604 & $8 / 12 / 2$ & 1.748 & 16.8 & 3673 & 13:06 & 1.766 & 16.9 \\
\hline 3401 & $8 / 12 \pi$ & 1.746 & 16.8 & 3467 & $8 / 12 / 20086: 14$ & 1.747 & 16.8 & 3536 & $8 / 12 / 2$ & 1.743 & 16. & 3606 & $8 / 12 / 2$ & 1.748 & & 3674 & 13.08 & 1.765 & 16.8 \\
\hline 3402 & 811220 & 1.746 & 16.8 & 3468 & $8 / 1220086: 16$ & 1.747 & 16.8 & 3537 & $8 / 1 / 20$ & 1.743 & 16.8 & 3606 & $8 / 12 / 2$ & 1.749 & 16.8 & 3675 & 313:10 & 1.761 & $\frac{16.9}{x}$ \\
\hline 3403 & $8 / 12 / 2$ & 1.746 & 16.8 & 3469 & $8 / 122200$ & 1.747 & 16.8 & 3538 & $8 / 12 / 2$ & 1.744 & 16. & 3607 & $8 / 12 / 2$ & 1.749 & 16. & 3676 & $13: 12$ & 1.756 & 16.9 \\
\hline 3404 & $8 / 122$ & 1.746 & 16.8 & 3470 & $8 / 12 / 20086: 20$ & 1.747 & 16.8 & 3539 & $8 / 12 / 20$ & 1.744 & 16. & 3608 & $8 / 12 / 2$ & 1.749 & & $36 \pi$ & $13: 14$ & 1.75 & 16. \\
\hline 3405 & & 1.746 & 16.8 & 3471 & $8 / 12 / 20086: 22$ & 1.746 & 16.8 & 3540 & $8 / 12 / 20$ & 1.745 & 16.8 & 3609 & $8 / 12 / 2$ & 1.749 & 16. & 3678 & 13:16 & 1.759 & 16.9 \\
\hline 3406 & $8 / 12$ & 1.746 & 16.8 & 3472 & $8 / 12 / 20$ & 1.746 & 16. & \begin{tabular}{|l|}
3541 \\
\end{tabular} & $8 / 12$ & 1.745 & & 3610 & $8 / 12$ & 1.750 & & 3679 & 13:18 & 1.760 & 16.5 \\
\hline 3407 & $8 / 12 / 2$ & 1.746 & 16.8 & 3473 & $8 / 12 / 20086: 26$ & 1.746 & 16.8 & 3542 & $8 / 12 / 2$ & 1.745 & 16. & 3611 & $8 / 12 / 2$ & 1.750 & 16 & 3680 & $13: 20$ & 1.761 & 16.9 \\
\hline 3408 & $8 / 12 t$ & 1.746 & 16.8 & 3474 & $8 / 12 / 20$ & 1.746 & 16.8 & 3543 & $8 / 12 / 4$ & 1.745 & 16.8 & 3612 & & 1.750 & 16. & 3081 & $13: 22$ & 1.762 & 16.9 \\
\hline 3409 & $8 / 12 / 2$ & 1.746 & 16.8 & 3475 & $8 / 12 / 20086: 30$ & 1.746 & 16. & 3544 & $8 / 12 /$ & 1.745 & 16 & 3613 & $8 / 12 / 2$ & 1.751 & 16. & 3682 & $13: 24$ & 1.762 & 16. \\
\hline 3410 & & 1.746 & 16 & 476 & & 1.746 & 16.8 & 3545 & & 1.746 & 16. & 36 & & 1.7 & & 36 & & 1.762 & 16.9 \\
\hline 3411 & $8 / 12 / 2$ & 1.747 & 16. & 3477 & $8 / 12 / 20086: 34$ & 1.746 & 16. & 3546 & $8 / 12$ & 1.746 & 16 & 361 & & 1.751 & & 684 & 13.28 & 1.763 & 16. \\
\hline 3412 & $8 / 12 / 2$ & 1.747 & 16.8 & 3478 & $8 / 12 / 200$ & 1.74 . & 16.8 & 3547 & $8 / 12 /$ & 1.746 & 16. & 3616 & & 1.751 & 16. & 3685 & $13: 30$ & 1.762 & 16.8 \\
\hline 3413 & $8 / 12 / 2$ & 1.747 & 16.8 & 3479 & $8 / 12 / 20$ & 1.747 & 16.8 & 3548 & & 1.746 & 16. & 361 & & 1.751 & & & & 1.763 & 16.5 \\
\hline 3414 & $8 / 12$ & 1.747 & 16.8 & 3480 & $8 / 12 / 20$ & 1.747 & 16.8 & 3549 & $8 / 12 /$ & 1.747 & 16 & $\overline{3618}$ & $8 / 12$ & 1.751 & & 687 & $13: 34$ & 1.764 & 16. \\
\hline 3415 & $8 / 12$ & 1.748 & 16. & 3481 & $8 / 12 / 2$ & 1.747 & 16.8 & 3550 & & 1.747 & 16. & 36 & & 1.752 & 16 & 3688 & & 1.765 & 16.9 \\
\hline 3416 & $8 / 12$ & 1.746 & 16. & 3482 & $8 / 12 / 200$ & 1.747 & 16. & 3551 & & 1.747 & 16 & 362 & $8 / 12$ & 1.752 & & & 13:38 & 1.765 & 16. \\
\hline 3417 & $8 / 12 / 2$ & 1.741 & 16.8 & 3483 & $8 / 12 / 200$ & 1.747 & 16.8 & 3552 & $8 / 12 /$ & 1.747 & 16. & 3621 & 812 & 1.752 & 16. & 3690 & $13: 40$ & 1.765 & 16.5 \\
\hline 3418 & $8 / 12 / 2$ & 1.736 & 16.8 & 3484 & $8 / 12 / 200$ & 1.747 & 16.8 & 3553 & & 1.747 & $\overline{16}$ & 3622 & & 1.752 & & & & 1.765 & 16.9 \\
\hline 3419 & $8 / 12$ & 1.732 & 16.8 & 3485 & $8 / 12 / 20$ & 1.747 & 16.8 & 3554 & $8 / 12$ & 1.747 & 16 & 3623 & $8 / 12$ & 1.760 & & & $13: 44$ & 1.765 & 16. \\
\hline 3420 & & 1.734 & 16 & 3486 & $8 / 12 / 2$ & 1.747 & 16. & 3555 & $8 / 12$ & 1.747 & 16 & 3624 & & 1.751 & $\overline{16}$ & & & 1.765 & 16.9 \\
\hline 3421 & & 1.737 & $\overline{16}$ & 3487 & & 1.747 & & रुद्ध & & 1.748 & & & & & & & & 1.766 & \\
\hline 342 & $8 / 12 / 2$ & 1.737 & 16.8 & 3488 & $8 / 12 / 20086: 56$ & 1.748 & 16.8 & 3507 & $8 / 12 / 2$ & 1.748 & 16. & 3626 & $8 / 12 \pi$ & 1.75 & 16 & 3695 & 313.50 & 1.766 & $\overline{16.5}$ \\
\hline 3423 & $8 / 12 t$ & 1.738 & 16.8 & 3489 & & 1.748 & 16 & 3558 & & 1.748 & & 362 & & & & & & & \\
\hline 3424 & $8 / 12$ & 1.739 & 16 & $21 \mathrm{~d}$ & $8 / 12 / 20$ & 1.748 & 16 & 3559 & $8 / 12$ & 1.748 & 16 & 362 & $8 / 12$ & 1.75 & & & $13: 54$ & 1.766 & 16. \\
\hline 3425 & $8 / 12 \pi$ & 1.740 & 16.8 & 3491 & $8 / 12 / 200$ & 1.748 & 16.8 & 3560 & $8 / 12 /$ & 1.748 & 16. & 3629 & $8 / 12$ & 1.750 & 16 & 88 & & 1.767 & 16.5 \\
\hline 3426 & & 1.741 & & 3492 & & 1.749 & & 3561 & & 1.749 & & & & & & & & & \\
\hline 3427 & $8 / 12 \pi$ & 1.741 & 16.8 & 3498 & $8 / 12 / 20087: 06$ & 1.749 & 16.8 & 3562 & $8 / 12 / 2$ & 1.749 & 16.8 & 3631 & $8 / 122$ & 1.760 & 16 & 3700 & 14:00 & 1.767 & 16.5 \\
\hline 3428 & $8 / 12 \pi$ & 1.742 & 16.8 & 3494 & $8 / 12 / 20087: 08$ & 1.749 & 16.8 & 3563 & & 1.750 & 16 & 3632 & & & & & & & \\
\hline 3429 & $8 / 12 / 2$ & 1.742 & 16 & 3495 & $8 / 12 / 20087: 10$ & 1.748 & 16 & 3564 & $8 / 12 / 2$ & 1.751 & 16 & 363 & $8 / 12 / 2$ & 1.761 & 16. & & $14: 04$ & 1.767 & 16.9 \\
\hline 3430 & $8 / 12 / 2$ & 1.742 & 16.8 & 3496 & $8 / 12 / 20087: 12$ & 1.748 & 16.8 & 3565 & $8 / 12 / 20$ & 1.749 & 17. & 3634 & $8 / 12 / 2$ & 1.760 & 16 & 703 & 14:06 & 1.767 & 16.9 \\
\hline 3431 & & 1.742 & & 3497 & & 1.748 & & & & & & & & & & & & & \\
\hline 3432 & $8 / 1220$ & 1.742 & 16.8 & 3498 & $8 / 12 / 20087: 16$ & 1.748 & 16.8 & 3567 & $8 / 12 / 20089.34$ & 1.749 & 16.9 & 3636 & 81122 & 1.761 & 16 . & 3705 & $314: 10$ & 1.768 & 16.5 \\
\hline 3433 & $8 / 122$ & 1.743 & 16.8 & 3499 & $8 / 12 / 20087: 18$ & 1.748 & 16.8 & 3568 & $8 / 12 / 20089.36$ & 1.748 & 16. & 3637 & & 1.761 & 16. & 06 & & 1.768 & 16. \\
\hline 3434 & $8 / 12 t$ & 1.743 & 16.8 & 3500 & $8 / 12 / 20087: 20$ & 1.748 & 16. & & $8 / 12 / 20089.38$ & 1.748 & & 3638 & $8 / 12 / 2$ & 1.762 & & & & 1.768 & \\
\hline 3435 & $8 / 12 / 200085: 10$ & 1.743 & 16.8 & 3501 & $8 / 12 / 20087: 22$ & 1.747 & 16.8 & 3570 & $8 / 12 / 20089.40$ & 1.748 & 16.8 & 3639 & $8 / 12 / 200811: 58$ & 1.762 & 16. & 3708 & $314: 16$ & 1.768 & 16.9 \\
\hline & & & & 3502 & $8 / 12 / 20087: 24$ & 1.745 & 16.8 & 3571 & $8 / 12 / 20089.42$ & 1.748 & & 3640 & & \begin{tabular}{|l|l}
1.761 \\
\end{tabular} & & & & 1.768 & \\
\hline & & & & 3503 & $8 / 12 / 20087: 26$ & 1.742 & 16.8 & 3572 & $8 / 12 / 200089.44$ & 1.748 & 16.8 & 3641 & $8 / 12 / 20081202$ & 1.761 & 16. & & $314: 20$ & 1.768 & 16.9 \\
\hline & & & & 3504 & $8 / 12 / 20087: 28$ & 1.738 & 16.8 & 3573 & $8 / 12 / 20089.46$ & 1.748 & 16.8 & 3642 & $8 / 12 / 2$ & 1.762 & & & 8112 & 1.768 & \\
\hline
\end{tabular}


DOE/RL-2009-35, REV. 0

\begin{tabular}{|c|c|c|c|c|c|c|c|c|c|c|c|c|c|c|c|c|c|c|c|}
\hline \multicolumn{4}{|c|}{$D 425 p$} & \multicolumn{4}{|c|}{$D 4-25 p$} & \multicolumn{4}{|c|}{$D 425 p$} & & $D 425 p$ & & & & D425p & & \\
\hline $\mathrm{Pec}$ & & Pres & Temp & $\mathrm{Bac}$ & & Pres | & Termp & $\operatorname{Rec}$ & & Pres! & Temp & $\mathrm{PeC}$ & & Pres & Temp & $\mathrm{REC}$ & & Pres & Femp \\
\hline$\#$ & DateTime & psi & ${ }^{\circ} \mathrm{C}$ & $\#$ & Dadertime & psi & ${ }^{\circ} \mathrm{C}$ & $\#$ & Date/Time & psi & & $\#$ & DateTime & psi & ${ }^{\circ} \mathrm{C}$ & $\#$ & Dete-Time & psi & \\
\hline 3712 & $8 / 12200814: 24$ & 1.768 & 16.9 & 378 & $8 / 12 / 200816: 42$ & $1.7 \pi 6$ & 16.9 & 3850 & $8 / 12 / 200819: 00$ & 1.776 & 16.9 & 3919 & $8 / 12 / 200821: 18$ & 1.779 & 17.0 & 9988 & $8 / 12200823: 36$ & 1.779 & 17.0 \\
\hline 3713 & $8 / 12 / 200814: 26$ & 1.768 & 16.9 & 3782 & $8 / 12 / 200816: 44$ & $1.7 \pi 6$ & 16.9 & 3851 & $8 / 12 / 200019: 02$ & 1.776 & 16.9 & 3920 & $8 / 12 / 200821: 20$ & 1.780 & 17.0 & 3989 & $8 / 12 / 200823: 38$ & 1.779 & 17.0 \\
\hline 3714 & $8 / 122200814: 28$ & 1.769 & 16.9 & & $8 / 12 / 200816: 46$ & 1.776 & 16.9 & 3852 & $8 / 12 / 200819: 04$ & 1.776 & 16.9 & 3921 & $8 / 12 / 200821: 22$ & 1.780 & 17.0 & 3990 & $8 / 12 / 200823: 40$ & 1.780 & 17.0 \\
\hline 3715 & $8 / 12200814: 30$ & 1.709 & 16.9 & 3784 & $8 / 12 / 2000816: 48$ & 1.776 & 16.9 & 3853 & $8 / 122200819.06$ & 1.776 & 16.9 & 3922 & $8 / 12 / 200821: 24$ & 1.780 & 17.0 & 39091 & $8 / 12 / 200823: 42$ & 1.780 & 17.0 \\
\hline 371ब्रे & $8 / 12200814: 32$ & 1.769 & 16.9 & 3785 & & 1.776 & 16.9 & 3854 & $8 / 12200049908$ & 1.776 & 16.9 & 3923 & $8 / 12 / 200821: 26$ & $1.7 \mathrm{~T}$ & 16.9 & 3002 & $8 / 12200823: 44$ & 1.780 & 17.0 \\
\hline 3717 & $8 / 12200814: 34$ & 1.769 & 16.9 & 3786 & $8 / 12 / 200816: 52$ & $1.7 / 5$ & 16.9 & 3856 & $8 / 12200819.10$ & 1.77 & 16.9 & 3924 & $8 / 12 / 200821: 28$ & 1.778 & 17.0 & 3903 & $8 / 122200823: 46$ & 1.780 & 17.0 \\
\hline 3718 & $8 / 12 / 200814: 36$ & 1.770 & 16.9 & 3787 & $8 / 12 / 200016: 54$ & 1.775 & 16.9 & 3856 & $8 / 12 / 200819: 12$ & 1.77 & 16.9 & 3925 & $8 / 12 / 200821: 30$ & 1.775 & 17.0 & 3904 & $8 / 12 / 200823: 48$ & \begin{tabular}{|l|}
1.781 \\
\end{tabular} & 17.0 \\
\hline 3719 & & 1.770 & 16.9 & 3788 & $8 / 12 / 200016: 56$ & 1.775 & 16.9 & 3857 & $8 / 12 / 200819.14$ & 1.776 & 16.9 & 3926 & $8 / 12 / 200821: 32$ & 1.770 & 17.0 & 3996 & $8 / 12 / 200823: 50$ & \begin{tabular}{|l|}
1.781 \\
\end{tabular} & 17.0 \\
\hline 3720 & $8 / 1222008$ 14:40 & 1.770 & 16.9 & 3789 & $8 / 12 / 200016: 58$ & 1.776 & 16.9 & 3858 & $8 / 12 / 200819: 16$ & 1.77 & 16.9 & उ927 & $8 / 12 / 200821: 34$ & 1.767 & 17.0 & 3906 & $8 / 12 / 200823: 52$ & 1.781 & 17.1 \\
\hline 3721 & $8 / 12 / 200814: 42$ & 1.769 & 16.9 & 3790 & $8 / 12 / 200817: 00$ & 1.776 & 16.9 & 3859 & $8 / 122200819: 18$ & 1.77 & 16.9 & 3928 & $8 / 122200821: 36$ & 1.767 & 17.0 & 3997 & $8 / 12 / 200823: 54$ & 1.781 & 17.0 \\
\hline 372 & $8 / 1222008$ 14:44 & 1.760 & 16.9 & 3791 & $8 / 12 / 200817: 02$ & 1.776 & 16.9 & 3860 & $8 / 12 / 2 x$ & 1.77 & 16.9 & 3009 & $8 / 12 / 200821: 38$ & 1.768 & 17.0 & 3998 & & & \\
\hline 3723 & $8 / 12 / 200814: 46$ & 1.770 & 16.9 & 3792 & $8 / 12 / 200817: 04$ & $1.7 \pi$ & 16.9 & 3861 & $8 / 12 / 200819 \cdot 22$ & 1.77 & 16.9 & 3930 & $8 / 122200821: 40$ & 1.770 & 17.0 & 3099 & $8 / 12 / 200823: 58$ & 1.780 & 17.0 \\
\hline 3724 & $8 / 12 / 200814: 48$ & 1.770 & 16.9 & 3793 & $8 / 1 / 2008$ 17:06 & $1.7 \pi$ & 16.9 & 3862 & $8 / 1220$ & 1.77 & 16.9 & 3931 & $8 / 12 / 200821: 42$ & 1.771 & 17.0 & 4000 & $8 / 13 / 20080: 00$ & 1.780 & 17.0 \\
\hline 3725 & $81122000814: 50$ & 1.770 & 16.9 & 3794 & $8 / 12 / 200817: 08$ & 1.776 & 16.9 & 3863 & $8 / 12 / 2$ & 1.77 & 16.9 & 3902 & $8 / 12200821: 44$ & 1.77 & 17.0 & 4001 & & 1.780 & 170 \\
\hline 3726 & $8 / 12 / 2000$ & 1.770 & 16.9 & 3796 & $8 / 12 / 2008$ 17:10 & $1.7 \pi$ & 16.9 & 3864 & 819.28 & 1.77 & 16.9 & 3933 & $821: 46$ & 1.772 & 17.0 & 4002 & $880: 04$ & 1.779 & 17.0 \\
\hline 3727 & & \begin{tabular}{|l|}
1.771 \\
\end{tabular} & 16.9 & & & $1.7 \pi$ & 16.9 & 3865 & $8 / 12 / 2$ & 1.77 & 16.9 & 3934 & $8 / 12 / 20$ & 1.773 & 17.0 & 4003 & & 1.780 & 17.0 \\
\hline 3728 & $8 / 12 / 200814: 56$ & 1.771 & 16.9 & 3797 & $8 / 122000$ 17:14 & $1.7 \pi$ & 16.9 & 3866 & $8 / 122$ & 1.778 & 16.9 & 3935 & $8 / 12 / 200821: 50$ & 1.774 & 16.9 & 4004 & & 1.780 & 17.0 \\
\hline 3729 & 811220 & 1.771 & 16.9 & 3798 & $8 / 1220$ & $1.7 \pi$ & 17.1 & 3967 & $8 / 12 / 2$ & 1.773 & 16.9 & 3906 & $8 / 12 / 20$ & 1.775 & 17.0 & 4006 & $30: 10$ & 1.780 & 17.0 \\
\hline 3730 & $8 / 12 / 2$ & 1.771 & 16.9 & 3799 & $8 / 12 / 20$ & $1.7 \pi$ & 17.0 & 3968 & $8 / 12 / 2$ & 1.77 & 16.9 & 3937 & & 1.775 & 17.0 & 4006 & & 1.780 & 770 \\
\hline 3731 & $8 / 12 / 200815: 02$ & \begin{tabular}{ll|}
1.771 \\
\end{tabular} & 16.9 & 3800 & $8 / 12 / 20$ & $1.7 m$ & 16.9 & 3860 & $8 / 12 /$ & 1.77 & 16.9 & 3938 & $821: 56$ & 1.775 & 17.0 & 007 & $080: 14$ & 1.779 & 17.1 \\
\hline 3732 & $8 / 12 / 2 x$ & 1.772 & 16.9 & 3801 & $8 / 12 / 2$ & 1.778 & 16.9 & 3870 & $g / 12 /$ & 1.77 & 16.9 & 3939 & $8 / 12 / 2$ & 1.775 & 17.0 & 4008 & & $1.77 t$ & \\
\hline 3733 & $8 / 12 / 200$ & 1.772 & 16.9 & 3802 & $8 / 12 / 2$ & 1.778 & 16.9 & 3871 & $8 / 12$ & 1.77 & 16.9 & 3940 & $8 / 12 / 2$ & 1.776 & 17.0 & 4009 & $080: 18$ & \begin{tabular}{|l|}
1.771 \\
\end{tabular} & 17.0 \\
\hline 3734 & $8 / 12 / 2$ & 1.771 & 16.9 & 3803 & $8 / 12 / 2$ & $1.7 \pi$ & 16.9 & 3872 & $8 / 12 / 2$ & 1.77 & 16.9 & 3941 & $8 / 12 / 2$ & $1.7 / 6$ & 17.0 & 4010 & $30: 20$ & 1.767 & 17.0 \\
\hline 3735 & $8 / 12 / 2$ & 1.771 & 16.9 & 3804 & $8 / 12 / 2$ & $1.7 \pi$ & & 3873 & $8 / 12$ & 1.77 & 17.0 & 3942 & & 1.776 & & & & 1.765 & \\
\hline 3736 & $8 / 12 / 2$ & \begin{tabular}{|l|}
1.771 \\
\end{tabular} & 16.9 & 3805 & $8 / 12 / 2$ & $1.7 m$ & 16.9 & 3874 & $19: 48$ & 1.77 & 16.9 & 3943 & 32206 & 1.776 & 17.0 & 4012 & & \begin{tabular}{|l|l|}
1.766 \\
\end{tabular} & 17.0 \\
\hline 3730 & $8 / 12 / 2$ & \begin{tabular}{|l|}
1.771 \\
\end{tabular} & 16.9 & 3806 & $8 / 12 / 2$ & 1.77 & 16. & 3875 & $8 / 12$ & 1.777 & 16.9 & 3944 & 32208 & 1.775 & 17. & 4013 & & 1.767 & 17.0 \\
\hline 3738 & $8 / 12 / 2008$ & 1.771 & 16.9 & 3807 & $8 / 12 / 2$ & 1.778 & 16. & 3876 & $8 / 12$ & 1.77 & 16.9 & 3945 & $8 / 12 / 2$ & 1.77 & 17.3 & 4014 & & 1.769 & 17.0 \\
\hline 3730 & $8 / 12 / 2$ & 1.771 & 16.9 & 3808 & $8 / 12 / 2$ & 1.778 & 16.9 & 3877 & $8 / 12$ & 1.77 & 16.9 & 3946 & $22: 12$ & 1.77 & 17.1 & 4015 & 00 & 1.770 & 17.0 \\
\hline 3740 & $8 / 122$ & 1.748 & 16.9 & 3809 & $8 / 12 / 2$ & 1.778 & 16.9 & 3878 & & 1.77 & 16.9 & 3947 & & 1.77 & & & & 1.771 & \\
\hline 3741 & $8 / 12 / 2$ & 1.770 & 16.9 & 3810 & $8 / 12 / 2$ & 1.778 & 16.9 & 3879 & $8 / 12$ & 1.776 & 16.9 & 3948 & & 1.776 & 17.1 & 4017 & $80: 34$ & 1.772 & 17.0 \\
\hline 3742 & $8 / 1212$ & \begin{tabular}{|l|}
1.772 \\
\end{tabular} & 16.9 & 3811 & $8 / 12$ & $1.7 \pi 8$ & 16.9 & 3880 & $8 / 12$ & 1.776 & 17. & 3949 & & 1.776 & 17. & $\because$ & & 1.772 & 17.1 \\
\hline 3743 & $8 / 12 / 2$ & 1.773 & 16.9 & 3812 & $8 / 12 / 2$ & 1.778 & 16.9 & 3881 & $8 / 12$ & 1.776 & 16.5 & 3950 & $8 / 12$ & $1.7 \pi$ & 17. & $\frac{7}{4}$ & & 1.773 & 17.0 \\
\hline 3744 & $8 / 122$ & $1.7 / 3$ & 16.9 & 3813 & $8 / 12 / 2$ & 1.778 & 16.9 & 3882 & $8 / 12$ & 1.77 & 16.5 & 3961 & & $1.7 \pi$ & 17. & 400 & & 1.774 & 17.0 \\
\hline 3745 & $8 / 122$ & 1.772 & 16.9 & 3814 & $8 / 12 / 2$ & 1.778 & 16.9 & 3883 & 8112 & 1.777 & 16.5 & 3952 & 2224 & $1.7 \pi$ & & & & 1.774 & 17.0 \\
\hline 3746 & & 1.773 & 16.9 & 3815 & $8 / 12$ & 1.778 & 16.8 & 3884 & & 1.777 & 17.0 & 3963 & & 1.778 & 17 & & & 1.775 & 17.0 \\
\hline 3747 & $8 / 12 / 2$ & 1.773 & 16.9 & 3816 & 812 & 1.778 & 16. & 3885 & 8112 & 1.77 & 16. & 3954 & 228 & $1.7 \pi$ & 17. & 40 & & 1.775 & 17.0 \\
\hline 3748 & $8 / 12 / 2$ & 1.774 & 16.9 & 3817 & $8 / 12 / 2$ & $1.7 \pi$ & 16.9 & 3886 & $8 / 12$ & 1.778 & 16.9 & 3956 & $8 / 12$ & 1.778 & 17. & 4024 & & 1.775 & 17.1 \\
\hline 3749 & $8 / 12 / 2$ & \begin{tabular}{|l|}
1.774 \\
\end{tabular} & 16.9 & 3818 & $8 / 12 / 2$ & 1.778 & 16 . & 3887 & $8 / 12$ & 1.77 & 16.9 & 3966 & & 1.78 & 17. & & & 1.775 & 17.0 \\
\hline 3750 & $8 / 12 / 2$ & \begin{tabular}{|l|}
1.775 \\
\end{tabular} & 16.9 & 3819 & $8 / 12$ & 1.77 & 16 . & 3888 & & $1.7 \pi$ & 16.5 & 3967 & 2734 & 1.779 & 17 & & & 1.776 & 17.1 \\
\hline 3751 & $8 / 12$ & \begin{tabular}{|l|l}
1.775 \\
\end{tabular} & 16.9 & 3820 & & 1.778 & 16.9 & 3889 & & 1.77 & 16.9 & 3968 & & 1.778 & 17. & 4027 & & 1.775 & 17.0 \\
\hline 3752 & $8 / 12 / 2$ & 1.775 & 16.9 & 3821 & & 1.79 & 16.9 & 3890 & & 1.778 & 16.9 & 3969 & & 1.77 & & & & 1.776 & 17.1 \\
\hline 3753 & $8 / 12 / 2$ & 1.776 & 16.9 & 3822 & $8 / 12 / 2$ & 1.778 & 16.8 & 3891 & $8 / 12$ & 1.778 & 16. & 3960 & & $1.7 \pi$ & 17. & & & 1.775 & 17.1 \\
\hline 3754 & $8 / 12 / 2$ & 1.775 & 16.9 & 3823 & & 1.778 & 16. & 3892 & & 1.778 & 16. & 3961 & & 1.77 & & & & & 17.1 \\
\hline 3755 & $8 / 12 / 2$ & \begin{tabular}{|l}
1.775 \\
\end{tabular} & 16.9 & 3824 & 8112 & 1.778 & 16. & 3893 & & 1.778 & 17. & 3962 & & 1.776 & & & & 1.774 & 17.0 \\
\hline 3756 & $8 / 12 /$ & \begin{tabular}{|l|}
1.775 \\
\end{tabular} & 16.9 & 3825 & & 1.778 & 16. & 3894 & & 1.778 & 16 & 3963 & & 1.77 & 17 & & & \begin{tabular}{|l|}
1.775 \\
\end{tabular} & 17.1 \\
\hline 3757 & $8 / 12 /$ & \begin{tabular}{|l|}
1.771 \\
\end{tabular} & 16.9 & 3826 & & 1.778 & & 3895 & & 1.778 & 16. & & & $1.7 \pi$ & & & & \begin{tabular}{|l|l}
1.775 \\
\end{tabular} & 17.1 \\
\hline 3758 & $8 / 12 t$ & 1.768 & 16.9 & 3827 & $8 / 12$ & 1.778 & 16.8 & 3896 & $8 / 12$ & 1.778 & 17.0 & 3965 & & 1.77 & 17. & 40 & & 1.776 & 17.1 \\
\hline 3750 & $8 / 12 / 2$ & 1.768 & 16.9 & 3828 & & 1.778 & 16. & 3897 & & 1.778 & 16. & 3966 & & 1.778 & & & & & 17.1 \\
\hline 3760 & $8 / 12 \pi$ & \begin{tabular}{|l|l|}
1.760 \\
\end{tabular} & 16.9 & 3829 & & $1.7 \mathrm{~T}$ & & 3898 & $8 / 12$ & 1.778 & 16 . & (1) & & $1.7 \pi$ & & & & 1. & 17.1 \\
\hline 3761 & $8 / 12$ & \begin{tabular}{|l|}
1.771 \\
\end{tabular} & 16.9 & 3830 & & $1.7 \mathrm{M}$ & 16. & 3899 & & 1.778 & 17. & 3968 & & 1.77 & & & & 1.776 & 17.1 \\
\hline 3702 & & \begin{tabular}{|l|}
1.771 \\
\end{tabular} & 16.9 & 3831 & & $1.7 \mathrm{M}$ & & 3900 & & 1.778 & & & & 1.77 & & & & & \\
\hline 3763 & $8 / 12 t$ & 1.772 & 16.9 & 3832 & $8 / 12$ & 1.778 & 16.9 & 3901 & $8 / 12$ & 1.778 & 16.9 & 3970 & $8 / 12$ & $1.7 \pi$ & 17. & 403 & & 1.776 & 17.0 \\
\hline 3764 & $8 / 12 \pi$ & 1.772 & 16.9 & 3833 & & 1.779 & 16 & 3902 & & 1.778 & 17. & 3971 & & 1.77 & & & & & 17.1 \\
\hline 3765 & 10 & 1.772 & 16.9 & 3834 & & $1.7 m$ & & 3903 & & 1.7 & 17 & 2970 & & 1.77 & & & & 1.77 & 171 \\
\hline 3766 & & \begin{tabular}{|l|l|}
1.772 \\
\end{tabular} & 16.9 & 3835 & & 1.780 & 16. & 3904 & & 1.778 & 17.0 & 3973 & & 1.77 & 17 & & & 1.77 & 17.1 \\
\hline 3767 & $8 / 12 t$ & \begin{tabular}{|l}
1.772 \\
\end{tabular} & 16.9 & 3836 & & 1.779 & & 3905 & & & & 3974 & & $1 . \pi 7$ & & & & & \\
\hline 3768 & $8 / 12 / 2$ & 1.773 & 16.9 & 3837 & & 1.779 & 16. & 3906 & & 1.778 & 17. & 3975 & & $1.7 \pi$ & 17. & & & 1.77 & 17.1 \\
\hline 3769 & $8 / 12 / 2$ & \begin{tabular}{|l}
1.773 \\
\end{tabular} & 16.9 & 3838 & & 1.780 & & 3907 & & & & 976 & & 1.721 & & & & & \\
\hline $37 \pi$ & $8 / 12 / 2$ & \begin{tabular}{|l|l}
1.773 \\
\end{tabular} & 16.9 & 3839 & & $1.7 \%$ & & 3908 & & 1.7 & & & & 1.774 & & & & \begin{tabular}{|l|}
1.778 \\
\end{tabular} & \\
\hline 3771 & & \begin{tabular}{|l|l|}
1.774 \\
\end{tabular} & 16.9 & 3840 & & 1.775 & 16.9 & 3909 & & 1.778 & 17.0 & 3978 & & 1.77 & 17. & & & \begin{tabular}{|l|l|}
1.778 \\
\end{tabular} & 17.1 \\
\hline 372 & $8 / 12 \pi$ & \begin{tabular}{|l|}
1.774 \\
\end{tabular} & & 3841 & & 1.77 & & 3910 & & 1.779 & & 3979 & & 1.778 & & & & \begin{tabular}{|l|}
1.778 \\
\end{tabular} & \\
\hline 3773 & $8 / 122200816: 26$ & 1.77 & 16.9 & 3842 & & 1.771 & 16.9 & 3011 & & 1.779 & 17.0 & 3980 & $23: 20$ & $1.7 \pi$ & 17.0 & & & 1.778 & 17.0 \\
\hline 3774 & & 1.774 & 16.9 & 3843 & & 1.772 & & 3912 & & 1.779 & 17.0 & 3981 & & 1.778 & & & & & \\
\hline 3775 & $8 / 12 / 200816: 30$ & 1.775 & 16.9 & 3844 & 18:48 & 1.773 & 16.9 & 3913 & & 1.779 & 17.0 & 3982 & $23: 24$ & 1.779 & 17.6 & & & 1.778 & 17.1 \\
\hline 3776 & $8 / 12200816: 32$ & 1.775 & 16.9 & 3845 & & 1.774 & 16.9 & 3914 & & 1.780 & 17.0 & 3983 & & 1.779 & 17.0 & 4062 & & 1.778 & 17.1 \\
\hline 377 & $8 / 12 / 2$ & 1.775 & 16.9 & 3846 & & 1.775 & & & & 1.780 & & 3984 & & 1.779 & & & & 1.778 & \\
\hline 3778 & $8 / 12200$ & 1.775 & 16.9 & 3847 & $8 / 12 / 2$ & 1.775 & 16. & 3916 & $21: 12$ & 1.780 & 16.5 & 3985 & $23: 30$ & 1.779 & 17.0 & & & 1.778 & 17.0 \\
\hline 3779 & $8 / 2200816: 38$ & 1.776 & 16.9 & 3848 & $8 / 12 / 2$ & 1.775 & 16.9 & 3917 & $8 / 2 /$ & 1.779 & 16.5 & 3906 & & 1.779 & & & & 1.778 & 17.1 \\
\hline 3780 & 17000 16. & & 16.9 & 3849 & $8 / 12 / 200818: 58$ & 1.75 & & $39+8$ & $21: 16$ & & & & & 1.779 & & & & 1.77 & 17.0 \\
\hline
\end{tabular}


DOE/RL-2009-35, REV. 0

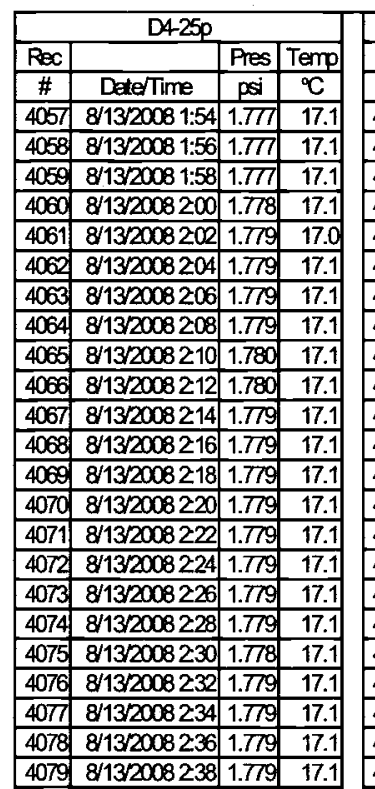

\begin{tabular}{|l|l|l|l|}
\hline 4080 & $8 / 13 / 2008240$ & 1.779 & 17.1 \\
\hline
\end{tabular}

\begin{tabular}{|l|l|l|l|}
\hline 4081 & $8 / 13 / 2008242$ & 1.779 & 17.1 \\
\hline
\end{tabular}

\begin{tabular}{|l|l|l|l|}
\hline 4082 & $8 / 13 / 2008244$ & 1.778 & 17.1 \\
\hline 4083 & $8 / 132008246$ & 1.778 & 17.1 \\
\hline
\end{tabular}

\begin{tabular}{|l|l|l|l|}
\hline 4083 & $813 / 2008246$ & 1.778 & 17.1 \\
\hline 4084 & 8132008248 & 1.779 & 17.1 \\
\hline
\end{tabular}

\begin{tabular}{|l|l|l|l|}
\hline 4084 & $8 / 13 / 2008248$ & 1.779 & 17.1 \\
\hline
\end{tabular}

\begin{tabular}{|l|l|l|l|}
\hline 4085 & $8 / 13 / 2008250$ & 1.779 & 17.1 \\
\hline 4086 & $8 / 132008252$ & 1.719 & 17.1 \\
\hline
\end{tabular}

\begin{tabular}{|l|l|l|l|}
\hline 4086 & $8 / 13 / 2008252$ & 1.779 & 17.1 \\
\hline 4087 & $8 / 32008254$ & 1.77 & 17.1 \\
\hline
\end{tabular}

\begin{tabular}{|l|l|l|l|}
\hline 4087 & $8 / 13 / 2008254$ & 1.779 & 17.1 \\
\hline
\end{tabular}

\begin{tabular}{|l|l|l|l|}
\hline 4088 & $8 / 13 / 2008256$ & 1.778 & 17.1 \\
\hline 4089 & $8 / 13200258$ & 1.77 & 17.1 \\
\hline
\end{tabular}

\begin{tabular}{|l|l|l|l|}
\hline 4089 & $8 / 13 / 2008258$ & 1.779 & 17.1 \\
\hline
\end{tabular}

\begin{tabular}{|l|l|l|l|}
\hline 4090 & $8 / 13 / 2008300$ & 1.778 & 17.1 \\
\hline 4001 & $8 / 132008300$ & 1.778 & 17.1 \\
\hline
\end{tabular}

\begin{tabular}{|l|l|l|l|}
\hline 4091 & $8 / 13 / 20083: 02$ & 1.779 & 17.1 \\
\hline 4092 & $8 / 13 / 20083: 04$ & 1.778 & 17.1 \\
\hline
\end{tabular}

\begin{tabular}{lllll}
4092 & $8 / 13 / 20083: 04$ & 1.778 & 17.1 \\
\hline
\end{tabular}

\begin{tabular}{|l|l|l|l|}
\hline 4093 & $8 / 13 / 20083.06$ & 1.775 & 17.1 \\
\hline 4094 & $8 / 1320083.08$ & 1.770 & 17.1 \\
\hline
\end{tabular}

\begin{tabular}{l|l|l|l|}
\hline 4094 & $813 / 2008308$ & 1.770 & 17.1 \\
\hline
\end{tabular}

\begin{tabular}{|l|l|l|l|}
\hline 4095 & $8 / 13 / 20083: 10$ & 1.766 & 17.1 \\
\hline
\end{tabular}

\begin{tabular}{|l|l|l|l|}
\hline 4096 & $813 / 20083: 12$ & 1.764 & 17.1 \\
\hline 4097 & $8 / 1320083: 14$ & 1.765 & 17.1 \\
\hline
\end{tabular}

\begin{tabular}{|l|l|l|l|}
\hline 4097 & $8 / 13 / 20083: 14$ & 1.765 & 17.1 \\
\hline 4098 & $8 / 332083: 16$ & 1768 & 17.1 \\
\hline
\end{tabular}

\begin{tabular}{|l|l|l|l|}
\hline 4008 & $8 / 13 / 20083: 16$ & 1.768 & 17.1 \\
\hline 4008 & $8 / 1320083: 18$ & 1.710 & 17.1 \\
\hline
\end{tabular}

\begin{tabular}{|l|l|l|l|}
\hline 4099 & $8 / 1320083: 18$ & 1.770 & 17.1 \\
\hline
\end{tabular}

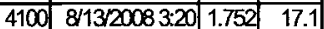

\begin{tabular}{|l|l|l|l|}
\hline 4101 & $8 / 13 / 20083: 22$ & 1.770 & 17.1 \\
\hline 4102 & $8 / 3 / 208324$ & 17 & 17.1 \\
\hline
\end{tabular}

\begin{tabular}{|l|l|l|l|}
\hline 4102 & $8 / 13 / 20083: 24$ & $1.7 / 2$ & 17.1 \\
\hline 4103 & $8 / 3 / 2003326$ & 1.772 & 17.1 \\
\hline
\end{tabular}

\begin{tabular}{l|l|l|l|}
\hline 4103 & $8 / 13 / 20083: 26$ & 1.772 & 17.1 \\
\hline
\end{tabular}

\begin{tabular}{|l|l|l|l|}
\hline 4104 & $8 / 13 / 20083: 28$ & 1.772 & 17.1 \\
\hline 4106 & $8 / 132008330$ & 1.772 & 17.1 \\
\hline
\end{tabular}

\begin{tabular}{|l|l|l|l|}
\hline 4105 & $8 / 13 / 2008330$ & 1.772 & 17.1 \\
\hline
\end{tabular}

\begin{tabular}{|l|l|l|r|}
\hline 4106 & $8 / 13 / 200833$ & 1.772 & 17.1 \\
\hline 4107 & $8 / 132008334$ & $1.7 / 2$ & 17.1 \\
\hline
\end{tabular}

\begin{tabular}{|l|l|l|l|}
\hline 4107 & $8 / 13 / 20083334$ & $1.7 / 2$ & 17.1 \\
\hline 4108 & $8 / 132008336$ & 1.772 & 17.1 \\
\hline
\end{tabular}

\begin{tabular}{|l|l|l|l|}
\hline 4108 & $8 / 132008336$ & 1.772 & 17.1 \\
\hline
\end{tabular}

\begin{tabular}{|l|l|l|l|}
\hline 4109 & $8 / 13 / 2008338$ & 1.773 & 17.1 \\
\hline 4110 & $8 / 3 / 2008330$ & 1.773 & 17.1 \\
\hline
\end{tabular}

\begin{tabular}{|l|l|l|l|}
\hline 4110 & $8 / 13 / 20083: 40$ & 1.773 & 17.1 \\
\hline 4111 & $8 / 3 / 20083.4$ & 173 & 17.1 \\
\hline
\end{tabular}

\begin{tabular}{|l|l|l|l|}
\hline 4111 & $8 / 13 / 20083: 42$ & 1.773 & 17.1 \\
\hline
\end{tabular}

\begin{tabular}{|l|l|l|l|}
\hline 4112 & $813 / 2008344$ & 1.773 & 17.1 \\
\hline 4113 & $8 / 320083$ & 1774 & 17.1 \\
\hline
\end{tabular}

\begin{tabular}{|l|l|l|l|}
\hline 4113 & $8 / 13 / 20083.46$ & 1.774 & 17.1 \\
\hline 4114 & $8 / 320083.48$ & 1.74 & 17. \\
\hline
\end{tabular}

\begin{tabular}{|l|l|l|l|l|}
\hline 4114 & $8 / 13 / 20083: 48$ & 1.774 & 17 \\
\hline
\end{tabular}

\begin{tabular}{|l|l|l|l|}
\hline 4115 & $8 / 13 / 20083: 50$ & 1.774 & 17.1 \\
\hline
\end{tabular}

\begin{tabular}{|l|l|l|l|}
\hline 4116 & $8 / 1320083.52$ & 1.774 & 17.1 \\
\hline
\end{tabular}

\begin{tabular}{|l|l|l|l|}
\hline 4117 & $8 / 132008354$ & 1.775 & 17.1 \\
\hline 4118 & $8 / 13200835$ & 1774 & 17.1 \\
\hline
\end{tabular}

\begin{tabular}{|l|l|l|l|}
\hline 4118 & $8 / 132008355$ & 1.774 & 17.1 \\
\hline 4119 & $8 / 132008358$ & 1.774 & 17.1 \\
\hline
\end{tabular}

\begin{tabular}{|l|l|l|l|}
\hline 4119 & $8 / 13 / 2008358$ & 1.774 & 17.1 \\
\hline 4120 & $8 / 132083: 00$ & 1.74 & 17.1 \\
\hline
\end{tabular}

\begin{tabular}{|l|l|l|l|}
\hline 4120 & $8 / 1320084: 00$ & 1.774 & 17.1 \\
\hline 4121 & $8 / 13 / 20084: 02$ & 1.774 & 17.1 \\
\hline
\end{tabular}

\begin{tabular}{|l|l|l|l|}
\hline 4121 & $8 / 13 / 20084: 02$ & 1.774 & 17.1 \\
\hline 4122 & $81320084: 04$ & 1774 & 17.6 \\
\hline
\end{tabular}

\begin{tabular}{|l|l|l|l|}
\hline 4122 & $8 / 1320084: 04$ & 1.774 & 17.6 \\
\hline
\end{tabular}

\begin{tabular}{|l|l|l|l|}
\hline 4123 & $8 / 13 / 20084: 06$ & 1.774 & 17.4 \\
\hline 4124 & $8 / 3 / 20084: 08$ & 1.774 & 17.2 \\
\hline
\end{tabular}

\begin{tabular}{|l|l|l|l|}
\hline 4124 & $8 / 13 / 20084: 08$ & 1.774 & 17.2 \\
\hline 4125 & $8 / 13 / 20084: 0$ & 1173 & 17.1 \\
\hline
\end{tabular}

\begin{tabular}{|l|l|l|l|}
\hline 4125 & $8 / 13 / 20084: 10$ & 1.773 & 17.1 \\
\hline
\end{tabular}

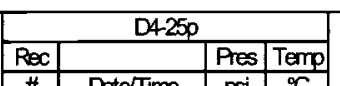

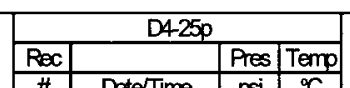
\begin{tabular}{|c|c|c|c|}
\hline$\#$ & Date/Time & psi & ${ }^{\circ} \mathrm{C}$ \\
\hline 4126 & $8 / 13 / 20084: 12$ & 1.773 & 17.1 \\
\hline 4127 & $8 / 13 / 20084: 14$ & 1.73 & 17.1 \\
\hline
\end{tabular} \begin{tabular}{|l|l|l|l|}
\hline 4126 & 81320084.12 & $1.7 / 3$ & 17.1 \\
\hline 4127 & $8 / 1320084: 14$ & 1.773 & 17.1 \\
\hline 4128 & $8 / 13 / 20084: 1$ & 1.774 & 17.1
\end{tabular} \begin{tabular}{|l|l|l|l|}
\hline 4128 & $8 / 13 / 20084: 16$ & 1.774 & 17.1 \\
\hline 4129 & $8 / 13 / 20084: 18$ & 1.774 & 17.1 \\
\hline
\end{tabular} \begin{tabular}{|l|l|l|l|}
\hline 4129 & $8 / 13 / 20084: 18$ & 1.774 & 17.1 \\
\hline 4130 & $8 / 3 / 20084: 20$ & 1.74 & 17.1 \\
\hline
\end{tabular} \begin{tabular}{|l|l|l|l|}
\hline 4130 & $8 / 13 / 20084: 20$ & 1.774 & 17.1 \\
\hline 4131 & $8 / 13 / 2008422$ & 1775 & 17.1 \\
\hline
\end{tabular} \begin{tabular}{|l|l|l|l|}
\hline 4131 & $8 / 13 / 20084: 22$ & 1.775 & 17.1 \\
\hline 4132 & $8 / 3 / 20084: 24$ & 1.775 & 17.1 \\
\hline
\end{tabular} \begin{tabular}{|l|l|l|l|}
\hline 4132 & $8 / 13 / 20084: 24$ & 1.775 & 17.1 \\
\hline 4130 & $8 / 132008420$ & 1.775 & 17.1 \\
\hline
\end{tabular} \begin{tabular}{|l|l|l|l|}
\hline 4133 & $8 / 13 / 20084: 26$ & 1.775 & 17.1 \\
\hline 4134 & $8 / 32008428$ & 1.776 & 17.1 \\
\hline
\end{tabular} \begin{tabular}{|l|l|l|l|}
\hline 4134 & $8 / 13 / 20084: 28$ & 1.776 & 17.1 \\
\hline
\end{tabular} \begin{tabular}{|l|l|l|l|}
\hline 4135 & $8 / 13 / 20084: 30$ & 1.776 & 17.1 \\
\hline 4136 & $8 / 1320084.32$ & 1776 & 171 \\
\hline
\end{tabular} \begin{tabular}{|l|l|l|l|}
\hline 4136 & $8 / 13 / 20084: 32$ & 1.776 & 17.1 \\
\hline 4137 & $8 / 1320084: 34$ & 1.776 & 17.1 \\
\hline
\end{tabular} \begin{tabular}{|l|l|l|l|}
\hline 4137 & $8 / 13 / 20084: 34$ & 1.776 & 17.1 \\
\hline 4138 & $81320084: 36$ & 1.776 & 17.1 \\
\hline
\end{tabular} \begin{tabular}{|l|l|l|l|}
\hline 4138 & $8 / 13 / 20084: 36$ & 1.776 & 17.1 \\
\hline 4139 & $8 / 132008438$ & 1.776 & 17.1 \\
\hline
\end{tabular} \begin{tabular}{|l|l|l|l|}
\hline 4139 & $8 / 13 / 20084: 38$ & 1.776 & 17.1 \\
\hline 4140 & $81320084: 40$ & 1.776 & 17.1 \\
\hline
\end{tabular} \begin{tabular}{|l|l|l|l|}
\hline 4140 & $8 / 13 / 20084: 40$ & 1.776 & 17.1 \\
\hline 4141 & $8 / 13 / 20084: 42$ & 1.776 & 17.1 \\
\hline
\end{tabular} \begin{tabular}{|l|l|l|l|}
\hline 4141 & $8 / 13 / 20084: 42$ & $1.7 / 6$ & 17.1 \\
\hline 4142 & $8 / 13 / 20084: 44$ & 1.776 & 17.1 \\
\hline 4143 & $8 / 1320084: 46$ & 1.776 & 17. \\
\hline
\end{tabular} \begin{tabular}{|l|l|l|l|}
\hline 4142 & $8 / 13 / 20084.44$ & 1.776 & 17.1 \\
\hline 4143 & $8 / 13 / 20084.46$ & 1.776 & 17.1 \\
\hline
\end{tabular} \begin{tabular}{|l|l|l|l|}
\hline 4144 & $8 / 13 / 20084: 48$ & 1.776 & 17.1 \\
\hline
\end{tabular} \begin{tabular}{|l|l|l|l|}
\hline 4145 & $8 / 13 / 20084: 50$ & 1.776 & 17.1 \\
\hline 4146 & $8 / 13 / 20084: 52$ & 1.776 & 17.1 \\
\hline
\end{tabular} \begin{tabular}{|l|l|l|l|}
\hline 4147 & $8 / 13 / 20084: 54$ & 1.776 & 17.1 \\
\hline
\end{tabular} \begin{tabular}{l|l|l|l|}
\hline 4148 & $8 / 13 / 20084: 56$ & 1.776 & 17.1 \\
\hline
\end{tabular} \begin{tabular}{|l|l|l|l|}
\hline 4149 & $8 / 1320084: 58$ & 1.776 & 17.1 \\
\hline
\end{tabular} \begin{tabular}{l|l|l|l|}
4150 & $8 / 13 / 20085: 00$ & 1.777 & 17.1 \\
\hline 4151 & $8 / 3 / 20085$ & 1.77 & 17.1 \\
\hline
\end{tabular} \begin{tabular}{|l|lll|}
\hline 4151 & $8 / 13 / 20085: 02$ & 1.777 & 17.1 \\
\hline 4152 & $8 / 3 / 20085: 04$ & 1777 & 17.1 \\
\hline
\end{tabular} \begin{tabular}{|l|l|l|l|}
\hline 4152 & $8 / 13 / 20085: 04$ & 1.777 & 17.1 \\
\hline
\end{tabular} \begin{tabular}{|l|l|l|l|}
\hline 4154 & $8 / 13 / 20085: 08$ & 1.777 & 17.1 \\
\hline
\end{tabular} \begin{tabular}{|l|l|l|l|}
\hline 4155 & $8 / 13 / 20085: 10$ & 1.777 & 17.1 \\
\hline 4156 & $8 / 13 / 20085: 12$ & 1777 & 17.1 \\
\hline
\end{tabular} \begin{tabular}{|l|l|l|l|}
\hline 4156 & $8 / 1320085: 12$ & 1.777 & 17.1 \\
\hline 415 & $8 / 13 / 20085: 14$ & $17 \pi$ & 171 \\
\hline
\end{tabular} \begin{tabular}{|l|l|l|l|}
\hline 4158 & $8 / 13 / 20085: 16$ & 1.777 & 17.1 \\
\hline
\end{tabular} \begin{tabular}{l|l|l|l|}
\hline 4159 & $8 / 13 / 20085: 18$ & 1.777 & 17.1 \\
\hline 4160 & $8 / 132008520$ & 1.77 & 17.1 \\
\hline
\end{tabular} \begin{tabular}{l|l|l|l|}
\hline 4160 & $8 / 13 / 20085: 20$ & 1.777 & 17.1 \\
\hline
\end{tabular} \begin{tabular}{l|l|l|l|}
\hline 4161 & $8 / 13 / 20085: 22$ & 1.777 & 17.1 \\
\hline 4162 & $8 / 132008524$ & 177 & 17.1 \\
\hline
\end{tabular} \begin{tabular}{|l|l|l|l|}
\hline 4162 & $8 / 1320085: 24$ & 1.777 & 17.1 \\
\hline 4163 & 8132008520 & 1.76 & 17.1 \\
\hline
\end{tabular} \begin{tabular}{l|l|l|l|}
\hline 4163 & $8 / 13 / 20085: 26$ & 1.776 & 17.1 \\
\hline
\end{tabular} \begin{tabular}{|l|l|l|l|}
\hline 4164 & $8 / 13 / 20085: 28$ & 1.776 & 17.1 \\
\hline 4165 & $8 / 13 / 20085: 30$ & 1.776 & 17.1 \\
\hline
\end{tabular} \begin{tabular}{|l|l|l|l|}
\hline 4165 & $8 / 13 / 20085: 30$ & 1.776 & 17.1 \\
\hline 4166 & $8 / 32008532$ & 1776 & 17.1 \\
\hline
\end{tabular} \begin{tabular}{|l|l|l|l|}
\hline 4166 & $8 / 13 / 20085: 32$ & 1.776 & 17.1 \\
\hline
\end{tabular} \begin{tabular}{|l|l|l|l|}
\hline 4167 & $8 / 13 / 20085-34$ & 1.776 & 17.1 \\
\hline 4168 & $8 / 13 / 20085 \% 36$ & 1.776 & 17. \\
\hline
\end{tabular} \begin{tabular}{|l|l|l|l|}
\hline 4168 & $8 / 1320085: 36$ & 1.776 & 17.1 \\
\hline 4108 & $8 / 132008538$ & 1.77 & 17. \\
\hline
\end{tabular} \begin{tabular}{|l|l|l|l|}
\hline 4169 & $813 / 20085: 38$ & 1.777 & 17.1 \\
\hline 4170 & $8 / 1320085: 40$ & 1.777 & 17.1 \\
\hline
\end{tabular} \begin{tabular}{l|l|l|l|}
\hline 4171 & $8 / 13 / 20085: 42$ & 1.777 & 17.1 \\
\hline
\end{tabular} \begin{tabular}{|l|l|l|l|}
\hline 4172 & $8 / 13 / 20085: 44$ & 1.778 & 17 \\
\hline 4173 & $8 / 13 / 2085: 4$ & 1.77 & 17.1 \\
\hline
\end{tabular} \begin{tabular}{|l|l|l|l|}
\hline 4173 & $8 / 13 / 20085: 46$ & 1.778 & 17.1 \\
\hline
\end{tabular} \begin{tabular}{|l|l|l|l|}
4174 & $8 / 1320085: 48$ & 1.778 & 17.1 \\
\hline
\end{tabular} \begin{tabular}{|l|l|l|l|}
\hline 4175 & $8 / 13 / 20085550$ & 1.778 & 17.1 \\
\hline 4176 & $8 / 132008552$ & 1.777 & 17.1 \\
\hline
\end{tabular} \begin{tabular}{|l|l|l|l|}
\hline 4176 & $8 / 13 / 20085: 52$ & 1.777 & 17.1 \\
\hline 417 & 8132008554 & 1.777 & 17.1 \\
\hline
\end{tabular} \begin{tabular}{l|l|l|l|}
\hline 4177 & $8 / 13 / 20085: 54$ & 1.777 & 17.1 \\
\hline
\end{tabular} \begin{tabular}{|l|l|l|l|}
\hline 4178 & $8 / 13 / 20085: 56$ & 1.775 & 17.1 \\
\hline 417 & $8 / 1320085.58$ & $1.7 / 0$ & 17.1 \\
\hline
\end{tabular} \begin{tabular}{|l|l|l|l|}
\hline 4179 & $8 / 13 / 20085: 58$ & 1.770 & 17.1 \\
\hline 4180 & $8 / 1320086.00$ & 1.766 & 17.1 \\
\hline
\end{tabular} \begin{tabular}{|l|l|l|l|}
\hline 4180 & $8 / 13 / 20086: 00$ & 1.766 & 17.1 \\
\hline 418 & $8 / 13 / 20086: 02$ & 1.765 & 17.1 \\
\hline
\end{tabular} \begin{tabular}{|l|l|l|l|}
\hline 4181 & $8 / 13 / 20086: 02$ & 1.765 & 17.1 \\
\hline
\end{tabular} \begin{tabular}{|l|l|l|l|}
\hline 4182 & $8 / 13 / 20086: 04$ & 1.766 & 17.1 \\
\hline
\end{tabular} \begin{tabular}{|l|l|l|l|}
\hline 4183 & $8 / 13 / 20086: 06$ & 1.767 & 17 \\
\hline 4184 & $81320086: 08$ & 1.768 & 17.1 \\
\hline
\end{tabular} \begin{tabular}{|l|l|l|l|}
\hline 4184 & $8 / 13 / 20086: 08$ & 1.768 & 17.1 \\
\hline
\end{tabular} \begin{tabular}{|c|c|c|c|}
\hline 4185 & $8 / 1320086: 10$ & 1.769 & 17.1 \\
\hline
\end{tabular} \begin{tabular}{|l|l|l|l|}
\hline 4186 & $8 / 13 / 20086: 12$ & 1.769 & 17 \\
\hline
\end{tabular} \begin{tabular}{|l|l|l|l|}
\hline 4187 & $8 / 13 / 20086: 14$ & 1.770 & 17.1 \\
\hline
\end{tabular} \begin{tabular}{|l|l|l|l|}
\hline 4188 & $8 / 1320086: 16$ & 1.770 & 17 \\
\hline 4189 & $8 / 13 / 20086: 18$ & 1.77 & 17.1 \\
\hline
\end{tabular} \begin{tabular}{|l|l|l|l|}
\hline 4189 & $8 / 13 / 20086: 18$ & 1.771 & 17. \\
\hline
\end{tabular} \begin{tabular}{|l|l|l|l|}
\hline 4190 & $8 / 13 / 20086: 20$ & $1.7 / 2$ & 17. \\
\hline 4191 & $8 / 1320082$ & $1.7 / 2$ & 17.1 \\
\hline
\end{tabular} \begin{tabular}{|l|l|l|l|}
\hline 4192 & $8 / 13 / 20086: 24$ & 1.772 & 17.1 \\
\hline 4193 & $8 / 1320086: 20$ & $1.7 / 2$ & 17.1 \\
\hline
\end{tabular} \begin{tabular}{l|l|l|l|}
4193 & $8 / 13 / 20086: 26$ & 1.772 & 17.1 \\
\hline
\end{tabular} \begin{tabular}{|l|l|l|l|}
\hline 4194 & $8 / 13 / 20086: 28$ & 1.772 & 17.1 \\
\hline
\end{tabular}

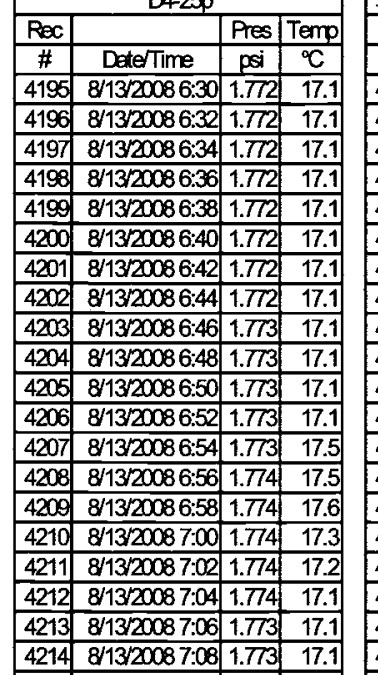

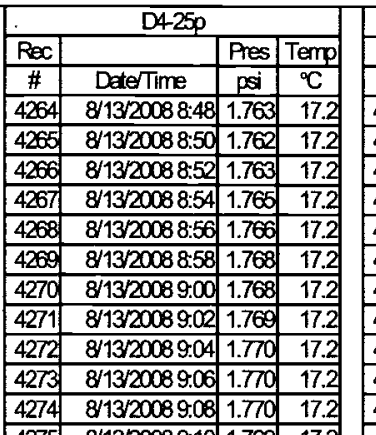
\begin{tabular}{|l|l|l|l|}
\hline 4275 & $8 / 13 / 20089.10$ & 1.769 & 17.2 \\
\hline 4276 & $8 / 13 / 20089.12$ & 1.770 & 172 \\
\hline
\end{tabular} \begin{tabular}{l|l|l|l|}
\hline 4277 & $8 / 13 / 20089.14$ & 1.770 & 17.2 \\
\hline 4
\end{tabular} \begin{tabular}{|l|l|l|l|}
\hline 4278 & $8 / 13 / 20089: 16$ & 1.771 & 17.2 \\
\hline
\end{tabular} \begin{tabular}{|l|l|l|l|}
\hline 4279 & $8 / 13 / 20089.18$ & $1.77 t$ & 17.2 \\
\hline 4280 & 81320089.20 & $1.7 / 2$ & 17.2 \\
\hline
\end{tabular} \begin{tabular}{|l|l|l|l|}
\hline 4280 & $8 / 13 / 20089.20$ & $1.7 / 2$ & 17.2 \\
\hline
\end{tabular} \begin{tabular}{|l|l|l|l|}
\hline 4281 & $8 / 13 / 20089.22$ & 1.772 & 17.2 \\
\hline 4202 & $8 / 1320089.24$ & 1.772 & 17.2 \\
\hline
\end{tabular} \begin{tabular}{|l|l|l|l|}
\hline 4282 & $8 / 13 / 20089.24$ & 1.772 & 17.2 \\
\hline 4283 & $8 / 13 / 200892$ & 1.773 & 172 \\
\hline
\end{tabular} \begin{tabular}{|c|c|c|c|}
\hline 4284 & $8 / 13 / 20089.26$ & $1.7 / 3$ & 17.2 \\
\hline 4280089.28 & $1.7 / 3$ & 17.2 \\
\hline
\end{tabular} \begin{tabular}{|l|l|l|l|}
\hline 4285 & $8 / 13 / 20089.30$ & 1.773 & 17.2 \\
\hline 4286 & $8 / 1320089.32$ & 1.774 & 17.2 \\
\hline
\end{tabular} \begin{tabular}{|l|l|l|l|}
\hline 4286 & $8 / 13 / 20089.32$ & 1.774 & 17.2 \\
\hline 4287 & $8 / 3 / 20089.34$ & 1.773 & 17.2 \\
\hline
\end{tabular} \begin{tabular}{|l|l|l|l|}
\hline 4287 & $8 / 13 / 20089: 34$ & 1.773 & 17.2 \\
\hline 4288 & $8 / 3 / 20089.36$ & 1.773 & 17.2 \\
\hline
\end{tabular} \begin{tabular}{|l|l|l|l|}
\hline 4288 & $8 / 13 / 20089.36$ & 1.773 & 17.2 \\
\hline 4289 & $813 / 20089.38$ & 1.774 & 17.2 \\
\hline
\end{tabular} \begin{tabular}{|l|l|l|l|}
\hline 4289 & $8 / 13 / 20089.38$ & 1.774 & 17.2 \\
\hline 4290 & $8 / 13 / 20089.40$ & 1774 & 17.2 \\
\hline
\end{tabular} \begin{tabular}{|l|l|l|l|}
\hline 4290 & $8 / 13 / 20089.40$ & 1.774 & 17.2 \\
\hline 4291 & $8 / 1320089.42$ & 1775 & 17.2 \\
\hline
\end{tabular} \begin{tabular}{l|l|l|l|}
\hline 4291 & $8 / 13 / 20089.42$ & 1.775 & 17.2 \\
\hline 4292 & $8 / 13 / 20089.44$ & 1.775 & 17.2 \\
\hline 4299 & $8 / 13 / 20089.46$ & 1.775 & 17.2 \\
\hline
\end{tabular} \begin{tabular}{|l|l|l|l|}
\hline 4293 & $8 / 13 / 20089.46$ & 1.775 & 17.2 \\
\hline
\end{tabular} \begin{tabular}{|l|l|l|l|}
\hline 4294 & $8 / 13 / 20089.48$ & 1.775 & 17.2 \\
\hline 4206 & $8 / 13 / 2008950$ & 1.775 & 172 \\
\hline
\end{tabular} \begin{tabular}{|l|l|l|l|}
\hline 4295 & $8 / 13 / 20089.50$ & 1.775 & 17.2 \\
\hline 4296 & $8 / 13 / 20089.52$ & 1.775 & 17.2 \\
\hline 4297 & $8 / 1320089.54$ & 1.775 & 17.2 \\
\hline
\end{tabular} \begin{tabular}{|l|l|l|l|}
\hline 4296 & $8 / 13 / 20089.52$ & $1.7 / 5$ & 17.2 \\
\hline 4297 & $8 / 1320089.54$ & 1.775 & 17.2 \\
\hline 4298 & $8 / 1320089.56$ & 1.75 & 17. \\
\hline
\end{tabular} \begin{tabular}{|l|l|l|l|}
\hline 4298 & $8 / 13 / 20089.56$ & 1.775 & 17.2 \\
\hline 4299 & $8 / 13 / 2089.58$ & 1.775 & 17.2 \\
\hline
\end{tabular} \begin{tabular}{|l|l|l|l|}
\hline 4299 & $8 / 13 / 20089.58$ & 1.775 & 17.2 \\
\hline 4300 & $8 / 13200810.00$ & 1.776 & 17.2 \\
\hline
\end{tabular} \begin{tabular}{|l|l|l|l|}
\hline 4300 & $8 / 13 / 200810: 00$ & 1.776 & 17.2 \\
\hline 4301 & $8 / 13 / 20811000$ & 1.75 & 17.2 \\
\hline
\end{tabular} \begin{tabular}{|l|l|l|l|}
\hline 4301 & $8 / 13 / 200810: 02$ & 1.775 & 17.2 \\
\hline 4302 & $8 / 13 / 200810: 04$ & 1.775 & 17.2 \\
\hline
\end{tabular} \begin{tabular}{|l|l|l|l|}
\hline 4302 & $8 / 13 / 200810: 04$ & 1.775 & 17.2 \\
\hline 4303 & $8 / 13 / 200810: 06$ & 1.775 & 172 \\
\hline
\end{tabular} \begin{tabular}{|c|c|c|c|}
\hline 4303 & $8 / 13 / 200810: 06$ & 1.775 & 17.2 \\
\hline 4304 & $8 / 13200810.08$ & 1.776 & 17.2 \\
\hline
\end{tabular}

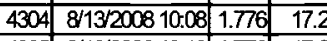
\begin{tabular}{|l|l|l|l|}
\hline 4305 & $8 / 13 / 200810: 10$ & 1.776 & 17.2 \\
\hline 4306 & $8 / 13200810.12$ & 176 & 17.2 \\
\hline
\end{tabular} \begin{tabular}{|l|l|l|l|}
\hline 4306 & $8 / 13 / 200810: 12$ & 1.776 & 17.2 \\
\hline
\end{tabular} \begin{tabular}{|l|l|l|l|}
\hline 4307 & $8 / 13 / 200810.14$ & 1.776 & 17.2 \\
\hline 4308 & $8 / 32008110.16$ & 176 & 17.2 \\
\hline
\end{tabular}

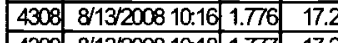
\begin{tabular}{|l|l|l|l|l|}
\hline 4309 & $8 / 13 / 2008$ & 10.18 & 1.777 & 17.2 \\
\hline 4310 & $8 / 13 / 2008$ & 10.20 & 1.76 & 17.2 \\
\hline
\end{tabular}

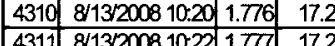

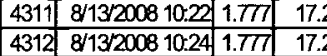
\begin{tabular}{|l|l|l|l|}
\hline 4313 & $813 / 200810.26$ & 1.777 & 17.2 \\
\hline 4314 & $8 / 13200810.28$ & 1.777 & 17.2 \\
\hline
\end{tabular}

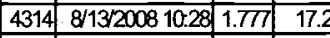
\begin{tabular}{|l|l|l|l|}
\hline 4315 & $8 / 13 / 200810: 30$ & 1.777 & 17.2 \\
\hline 4316 & 813320810.32 & 1.77 & 17.2 \\
\hline
\end{tabular}

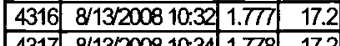

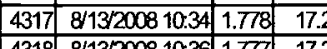
\begin{tabular}{|l|l|l|l|}
\hline 4318 & $8 / 13 / 200810.36$ & 1.777 & 17.2 \\
\hline 4319 & $8 / 13200810.38$ & 1.777 & 17. \\
\hline 4320 & $8 / 13200810.40$ & 1.77 & 172 \\
\hline
\end{tabular}

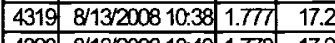
\begin{tabular}{|l|l|l|l|}
\hline 4320 & $8 / 13 / 200810.40$ & 1.778 & 17.2 \\
\hline 4321 & $8 / 13 / 200810.42$ & 1.777 & 17.2 \\
\hline 432 & $8 / 13200810: 44$ & 1 & 17 \\
\hline
\end{tabular}

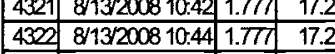

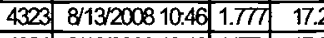

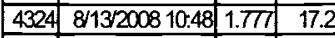

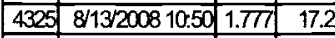

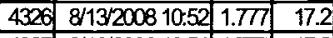

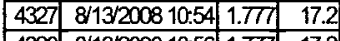
\begin{tabular}{|c|c|c|c|}
\hline 4328 & $8 / 13 / 200810: 56$ & 1.777 & 17.2 \\
\hline 4320 & 8113200810.58 & 1778 & 172 \\
\hline
\end{tabular} \begin{tabular}{|l|l|l|l|}
\hline 4329 & $813 / 200810.58$ & 1.778 & 17.2 \\
\hline 4330 & $8 / 13200811 \cdot 00$ & 1777 & 172 \\
\hline
\end{tabular} \begin{tabular}{|l|l|l|l|}
\hline 4330 & $8 / 13 / 200811: 00$ & 1.777 & 17.2 \\
\hline 4331 & $813 / 200811: 02$ & 1.778 & 172 \\
\hline
\end{tabular} \begin{tabular}{|l|l|l|l|}
\hline 4331 & $8 / 13 / 200811: 02$ & 1.778 & 17.2 \\
\hline 4332 & $8 / 13 / 200811: 04$ & 1.778 & 17.2 \\
\hline
\end{tabular}

\begin{tabular}{|c|c|c|c|}
\hline \multicolumn{4}{|c|}{$D 425 p$} \\
\hline $\mathrm{Rec}$ & & Pres & Tem \\
\hline & Dete/Time & psi & \\
\hline 4333 & $8 / 13 / 200811: 06$ & 1.778 & \\
\hline 334 & $13 / 200811: 08$ & 1.778 & \\
\hline 335 & $13 / 200811: 10$ & 1.778 & \\
\hline 336 & $8 / 13 / 200811: 12$ & 1.778 & \\
\hline 337 & $8 / 13 / 200811: 14$ & 1.778 & \\
\hline 338 & $8 / 13 / 200811: 16$ & 1.778 & \\
\hline 4339 & $3 / 2008$ 11:18 & 1.778 & \\
\hline 4340 & $8 / 13 / 2008+1: 20$ & 1.778 & \\
\hline 4341 & $8 / 13 / 200811: 22$ & 1.778 & \\
\hline 342 & $00811: 24$ & 1.778 & \\
\hline 4343 & $00811: 26$ & 1.776 & \\
\hline 4344 & $8 / 13 / 200811: 28$ & 1.772 & \\
\hline 4345 & & 1.768 & \\
\hline 4346 & $311: 32$ & 1.767 & \\
\hline 4347 & $811: 34$ & 1.768 & \\
\hline 4348 & & 1.769 & \\
\hline 4349 & $11: 38$ & 1.765 & \\
\hline 4360 & $311: 40$ & 1.771 & \\
\hline 4351 & & $1.7 / 2$ & \\
\hline 4362 & $1: 44$ & 1.773 & \\
\hline 4353 & $11: 46$ & 1.773 & \\
\hline 4354 & $11: 48$ & 1.773 & \\
\hline 4355 & & 1.774 & \\
\hline 4356 & $11: 52$ & 1.774 & \\
\hline 4357 & & 1.775 & \\
\hline 4358 & & 1.775 & \\
\hline 4359 & & 1.775 & \\
\hline 4360 & 1200 & 1.776 & \\
\hline 4361 & 1202 & 1.775 & \\
\hline 4362 & & 1.775 & \\
\hline 4363 & & 1.776 & \\
\hline 4364 & & 1.776 & \\
\hline 4365 & & 1.776 & \\
\hline 4366 & 212 & 1.776 & \\
\hline 4367 & & 1.77 & \\
\hline 4368 & & 1.778 & \\
\hline 4369 & 218 & 1.778 & \\
\hline 4370 & 1220 & $1.7 \pi$ & \\
\hline 4371 & 1222 & 1.777 & \\
\hline 4372 & & 1.77 & \\
\hline 4373 & $8 / 1$ & 1.77 & \\
\hline 4374 & & 1.77 & \\
\hline 4375 & & 1.778 & \\
\hline 4376 & 232 & 1.778 & \\
\hline 4377 & & 1.778 & \\
\hline 4378 & 1236 & 1.77 & \\
\hline 4379 & $8 / 1$ & 1.77 & \\
\hline 4380 & & 1.778 & \\
\hline 4381 & & 1.778 & \\
\hline 4382 & & 1.779 & \\
\hline 4383 & & 1.779 & \\
\hline 4384 & 248 & 1.779 & \\
\hline 4385 & & 1.779 & \\
\hline 4386 & & 1.779 & \\
\hline 4387 & & 1.779 & \\
\hline 4388 & & 1.779 & \\
\hline 4389 & & 1.779 & \\
\hline 4390 & & 1.779 & \\
\hline 4391 & & 1.780 & \\
\hline 4392 & & 1.780 & \\
\hline 4393 & & 1.780 & \\
\hline 4394 & & 1.780 & \\
\hline 4395 & & 1.781 & \\
\hline 4396 & & 1.781 & \\
\hline 4397 & & 1.782 & \\
\hline 4398 & 081316 & 1.782 & \\
\hline 4399 & & 1.782 & \\
\hline 4400 & & 1.782 & \\
\hline 4401 & $8 / 13 / 20081322$ & 1.782 & \\
\hline
\end{tabular}




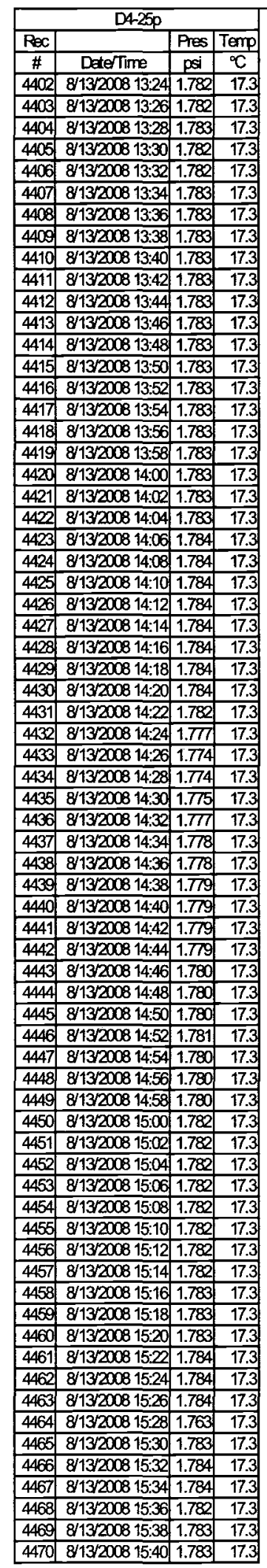

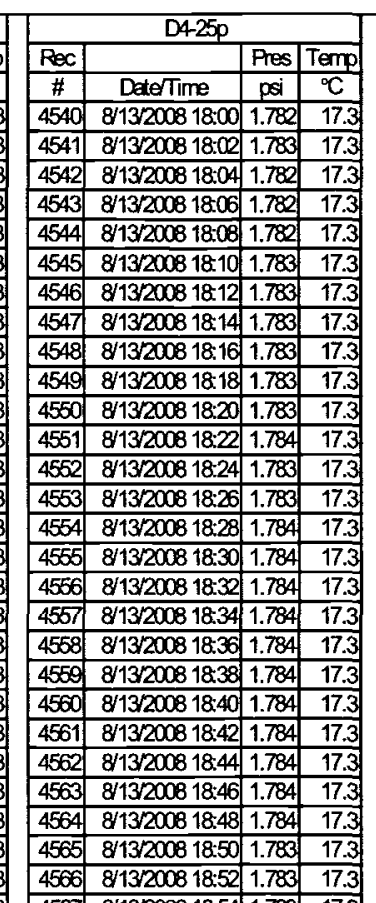

\begin{tabular}{|l|l|l|l|}
\hline 4506 & $8 / 13 / 200818.52$ & 1.783 & 17.3 \\
\hline 4567 & $8 / 13 / 200818.54$ & 1.783 & 17.3 \\
\hline
\end{tabular}

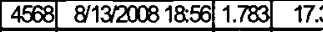
\begin{tabular}{|l|l|l|l|}
\hline 4569 & $8 / 13 / 200818: 58$ & 1.784 & 17.3 \\
\hline $45 / 2$ & $8 / 13200819.00$ & 1.783 & 17.3 \\
\hline
\end{tabular} \begin{tabular}{|l|l|l|l|}
\hline 4570 & $8 / 13 / 200819.00$ & 1.783 & 17.3 \\
\hline 4571 & $8 / 13200819.02$ & 1.83 & 17.3 \\
\hline
\end{tabular} \begin{tabular}{|l|l|l|l|}
\hline 4571 & $8 / 13 / 200819.02$ & 1.783 & 17.3 \\
\hline $45 / 2$ & $8 / 13 / 200819.04$ & 1783 & 17.3 \\
\hline
\end{tabular} \begin{tabular}{|l|l|l|l|}
\hline 4572 & $8 / 13 / 200819.04$ & 1.783 & 17.3 \\
\hline 4573 & $8 / 13 / 20081906$ & 1.783 & 17. \\
\hline
\end{tabular}

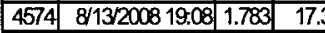
\begin{tabular}{|l|l|l|l|}
\hline 4575 & $8 / 13 / 200819.10$ & 1.783 & 17.3 \\
\hline $45 / 6$ & $8 / 13200819.12$ & 1783 & 17.3 \\
\hline
\end{tabular} \begin{tabular}{|l|l|l|l|}
\hline 4576 & $8 / 13 / 200819.12$ & 1.783 & 17.3 \\
\hline 4576 & $8 / 13200819.14$ & 1783 & 17.3 \\
\hline
\end{tabular} \begin{tabular}{|l|l|l|l|}
\hline 4577 & $8 / 13 / 200819.14$ & 1.783 & 17.3 \\
\hline 458 & $8 / 13200819.16$ & 1783 & 17. \\
\hline
\end{tabular} \begin{tabular}{|l|l|l|l|}
\hline 4578 & $8 / 13 / 200819.16$ & 1.783 & 17.3 \\
\hline 4579 & 8113200819.18 & 1.783 & 17.3 \\
\hline
\end{tabular} \begin{tabular}{|l|l|l|l|}
\hline 4579 & $8 / 13 / 200819.18$ & 1.783 & 17.3 \\
\hline
\end{tabular} \begin{tabular}{|l|l|l|l|}
\hline 4580 & $8 / 13 / 200819.20$ & 1.789 & 17.3 \\
\hline 4581 & $8 / 13 / 200819.2$ & 1.782 & 17.3 \\
\hline
\end{tabular} \begin{tabular}{|l|l|l|l|}
\hline 4581 & $813 / 200819.22$ & 1.782 & 17.3 \\
\hline 4582 & $813 / 200819.24$ & 1.84 & 17.3 \\
\hline
\end{tabular}

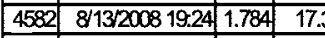
\begin{tabular}{|l|l|l|l|}
\hline 4583 & $8 / 13200819.26$ & 1.785 & 17.3 \\
\hline 4584 & $813 / 200819.2$ & 1.785 & 17.3 \\
\hline
\end{tabular} \begin{tabular}{|c|c|c|c|}
\hline 4584 & $8 / 13 / 200819.28$ & 1.785 & 17.3 \\
\hline 4585 & $8 / 13 / 200819.30$ & 1.785 & 17.3 \\
\hline
\end{tabular} \begin{tabular}{|l|l|l|l|}
\hline 4585 & $8 / 13 / 200819.30$ & 1.785 & 17.3 \\
\hline 4586 & $8 / 3 / 200819.32$ & 1785 & 17.3 \\
\hline
\end{tabular} \begin{tabular}{|l|l|l|l|}
\hline 4586 & $8 / 13 / 200819.32$ & 1.785 & 17.3 \\
\hline 4587 & $8 / 13 / 20081933$ & 1.786 & 17.3 \\
\hline
\end{tabular} \begin{tabular}{|l|l|l|l|}
\hline 4587 & $8 / 13 / 200819.34$ & 1.786 & 17.3 \\
\hline 4588 & $813 / 200819.36$ & 1.86 & 17.4 \\
\hline
\end{tabular}

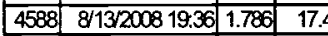
\begin{tabular}{|l|l|l|l|}
\hline 4589 & $8 / 13 / 200819.38$ & 1.786 & 17.3 \\
\hline
\end{tabular} \begin{tabular}{|l|l|l|l|}
\hline 4590 & $8 / 13 / 200819.40$ & 1.786 & 17.4 \\
\hline 4599 & $8 / 13200819.42$ & 1.785 & 17.4 \\
\hline
\end{tabular} \begin{tabular}{|l|l|l|l|}
\hline 4591 & $8 / 13 / 200819.42$ & 1.785 & 17.4 \\
\hline 4502 & $8 / 13200819.44$ & 1.785 & 17.4 \\
\hline
\end{tabular}

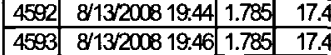
\begin{tabular}{|l|l|l|l|}
\hline 4594 & $8 / 13 / 200819.48$ & 1.785 & 17.4 \\
\hline 4595 & $8 / 3 / 200819.50$ & 1.785 & 17.4 \\
\hline
\end{tabular} \begin{tabular}{|l|l|l|l|}
\hline 4596 & $8 / 13 / 200819.50$ & 1.785 & 17.4 \\
\hline
\end{tabular}

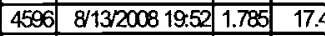

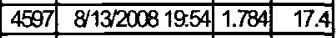
\begin{tabular}{|l|l|l|l|}
\hline 4508 & $8 / 13 / 200819.56$ & 1.783 & 17.7 \\
\hline
\end{tabular} \begin{tabular}{|l|l|l|l|}
\hline 4599 & $813 / 200819.58$ & 1.782 & 17.6 \\
\hline 4600 & 813200820.00 & 1780 & 17.4 \\
\hline
\end{tabular} \begin{tabular}{|l|l|l|l|}
\hline 4600 & $8 / 13 / 200820.00$ & 1.780 & 17.4 \\
\hline 400 & $8 / 13200820.02$ & 1777 & 17.4 \\
\hline
\end{tabular} \begin{tabular}{|l|l|l|l|}
\hline 4601 & $8 / 13200820: 02$ & 1.777 & 17.4 \\
\hline 4602 & $8 / 13200820: 04$ & 1774 & 17.4 \\
\hline
\end{tabular} \begin{tabular}{|l|l|l|l|}
\hline 4602 & $8 / 13 / 200820: 04$ & 1.774 & 17.4 \\
\hline 4603 & $8 / 13200820: 06$ & 177 & 17.4 \\
\hline
\end{tabular} \begin{tabular}{|l|l|l|l|}
\hline 4603 & $8 / 13 / 200820: 06$ & 1.770 & 17.4 \\
\hline 4604 & $8 / 13200820.08$ & 1706 & 17.4 \\
\hline
\end{tabular} \begin{tabular}{|l|l|l|l|}
\hline 4604 & $8 / 13 / 200820: 08$ & 1.766 & 17.4 \\
\hline 4605 & $8 / 132008200$ & 1.64 & 17.4 \\
\hline
\end{tabular} \begin{tabular}{|l|l|l|l|}
\hline 4605 & $8 / 13 / 200820: 10$ & 1.764 & 17.4 \\
\hline 4606 & $8 / 13200820$ & 1.760 & 17.4 \\
\hline
\end{tabular} \begin{tabular}{|l|l|l|l|}
\hline 4606 & $8 / 13 / 200820: 12$ & 1.766 & 17.4 \\
\hline
\end{tabular} \begin{tabular}{|l|l|l|l|}
\hline 4607 & $8 / 13 / 200820: 14$ & 1.768 & 17.4 \\
\hline 4608 & $8 / 13 / 200820.16$ & 1.770 & 17.4 \\
\hline
\end{tabular}

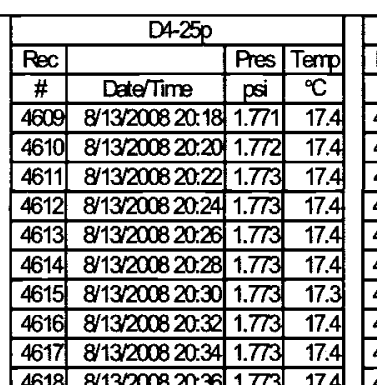

\begin{tabular}{|c|c|c|c|}
\hline \multicolumn{3}{|c|}{ D4-25p } \\
\hline Rec & & Pres & Temp \\
\hline$\#$ & DateTime & psi & ${ }^{\circ} \mathrm{C}$ \\
\hline
\end{tabular} \begin{tabular}{|c|c|c|c|}
\hline H & Late Time & psi & C \\
\hline 4678 & 81320082236 & 1.736 & 17.4 \\
\hline 4679 & 81320082238 & 1.734 & 17.4 \\
\hline
\end{tabular} \begin{tabular}{|l|l|l|l|}
\hline 4679 & $8 / 13200822: 38$ & 1.734 & 17.4 \\
\hline 4680 & $8 / 1320082240$ & 1.733 & 17.4 \\
\hline
\end{tabular} \begin{tabular}{|l|l|l|l|}
\hline 4680 & $8 / 13 / 20082240$ & 1.733 & 17.4 \\
\hline
\end{tabular} \begin{tabular}{|l|l|l|l|}
\hline 4681 & $8 / 13 / 20082242$ & 1.732 & 17.4 \\
\hline 4682 & $8 / 3 / 2082244$ & 1.73 & 17.4 \\
\hline
\end{tabular} \begin{tabular}{|l|l|l|l|}
\hline 4682 & $8 / 13 / 20082244$ & 1.731 & 17.4 \\
\hline 4683 & $8 / 1320082246$ & 1.730 & 17.4 \\
\hline
\end{tabular} \begin{tabular}{|l|l|l|l|}
\hline 4683 & $8 / 13 / 20082246$ & 1.730 & 17.4 \\
\hline 4684 & $8 / 1320082248$ & 1.729 & 17.4 \\
\hline
\end{tabular} \begin{tabular}{|l|l|l|l|}
\hline 4684 & $8 / 13 / 200822.48$ & 1.729 & 17.4 \\
\hline 4685 & $8 / 1320082250$ & 1.728 & 17.4 \\
\hline
\end{tabular} \begin{tabular}{|l|l|l|l|}
\hline 4685 & $813 / 20082250$ & 1.728 & 17.4 \\
\hline 4686 & $8 / 132008225$ & 1.727 & 17.4 \\
\hline
\end{tabular} \begin{tabular}{|l|l|l|l|}
\hline 4686 & $8 / 13 / 20082252$ & 1.727 & 17.4 \\
\hline
\end{tabular} \begin{tabular}{|l|l|l|l|}
\hline 4687 & $8 / 13 / 20082254$ & 1.726 & 17.4 \\
\hline 4688 & $8 / 1320082256$ & 1.724 & 17.4 \\
\hline
\end{tabular} \begin{tabular}{|l|l|l|l|}
\hline 4688 & $8 / 13 / 20082256$ & 1.724 & 17.4 \\
\hline 468 & $8 / 1320082258$ & 1.724 & 17.4 \\
\hline
\end{tabular} \begin{tabular}{|l|l|l|l|}
\hline 4689 & $8 / 13 / 20082258$ & 1.724 & 17.4 \\
\hline
\end{tabular} \begin{tabular}{|l|l|l|l|}
\hline 4690 & $8 / 13 / 200823: 00$ & 1.722 & 17.4 \\
\hline
\end{tabular} \begin{tabular}{|l|l|l|l|}
\hline 4691 & $8 / 13 / 200823: 02$ & 1.721 & 17.4 \\
\hline 4692 & $8 / 13200823.04$ & 1.720 & 17.4 \\
\hline
\end{tabular} \begin{tabular}{|l|l|l|l|}
\hline 4692 & $8 / 13 / 200823: 04$ & 1.720 & 17.4 \\
\hline 4600 & $8 / 13200823.06$ & 1.718 & 17.4 \\
\hline
\end{tabular} \begin{tabular}{|l|l|l|l|}
\hline 4603 & $8 / 13 / 200823: 06$ & 1.718 & 17.4 \\
\hline 4694 & $8 / 13 / 200823: 08$ & 1.718 & 17.4 \\
\hline 4695 & $8 / 13 / 20083: 10$ & 1716 & 17.4 \\
\hline
\end{tabular} \begin{tabular}{|l|l|l|l|}
\hline 4696 & $8 / 13 / 200823: 10$ & 1.716 & 17.4 \\
\hline 4696 & $8 / 3 / 200823: 12$ & 1.715 & 17.4 \\
\hline
\end{tabular}

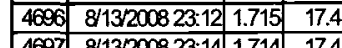
\begin{tabular}{|l|l|l|l|}
\hline 4697 & $8 / 13 / 200823: 14$ & 1.714 & 17.4 \\
\hline
\end{tabular} \begin{tabular}{|l|l|l|l|}
\hline 4698 & $8 / 13 / 200823: 16$ & 1.713 & 17.4 \\
\hline
\end{tabular} \begin{tabular}{|l|l|l|l|}
\hline 4699 & $813 / 200823: 18$ & 1.711 & 17.4 \\
\hline 4700 & $8 / 1320082320$ & 1711 & 17.4 \\
\hline
\end{tabular} \begin{tabular}{|l|l|l|l|}
\hline 4700 & $8 / 13 / 200823: 20$ & 1.711 & 17.4 \\
\hline 470 & $8 / 3 / 200832$ & 1.710 & 17.4 \\
\hline
\end{tabular} \begin{tabular}{|l|l|l|l|}
\hline 4701 & $8 / 13 / 200823: 22$ & 1.710 & 17.4 \\
\hline 4702 & $8 / 13200823: 24$ & 1.709 & 17.4 \\
\hline 4700 & $8 / 1320082326$ & 1.708 & 17.4 \\
\hline
\end{tabular} \begin{tabular}{|l|l|l|l|}
\hline 4702 & $8 / 13 / 200823: 24$ & 1.709 & 17.4 \\
\hline 4703 & $8 / 13 / 200823: 26$ & 1.708 & 17.4 \\
\hline
\end{tabular} \begin{tabular}{|l|l|l|l|}
\hline 4703 & $813 / 200823: 26$ & 1.708 & 17.4 \\
\hline 4704 & $813 / 200823: 28$ & 1.708 & 17.4 \\
\hline 4706 & $8 / 13200823.30$ & 1.707 & 17.4 \\
\hline
\end{tabular} \begin{tabular}{|l|l|l|l|}
\hline 4705 & $8 / 13 / 200823: 30$ & 1.707 & 17.4 \\
\hline 4706 & $8 / 13200823.32$ & 1.706 & 17.4 \\
\hline
\end{tabular} \begin{tabular}{|l|l|l|l|}
\hline 4706 & $8 / 13 / 200823: 32$ & 1.706 & 17.4 \\
\hline 4707 & $8 / 3 / 200823.37$ & 1705 & 17.4 \\
\hline
\end{tabular} \begin{tabular}{|l|l|l|l|}
\hline 4706 & $8 / 13 / 200823: 34$ & 1.705 & 17.4 \\
\hline 4707 & $8 / 13 / 200823.36$ & 1708 & 17.4 \\
\hline
\end{tabular} \begin{tabular}{|l|l|l|l|}
\hline 4708 & $8 / 13 / 200823: 36$ & 1.705 & 17.4 \\
\hline 400 & $8 / 13200823: 38$ & 1770 & 17.4 \\
\hline
\end{tabular} \begin{tabular}{|l|l|l|l|}
\hline 4709 & $8 / 13 / 200823: 38$ & 1.703 & 17.4 \\
\hline 4710 & $8 / 13200823.40$ & 1.703 & 17.4 \\
\hline
\end{tabular} \begin{tabular}{|l|l|l|l|}
\hline 4710 & $8 / 13 / 200823: 40$ & 1.703 & 17.4 \\
\hline 4711 & $8 / 13200823.42$ & 1701 & 17.4 \\
\hline
\end{tabular} \begin{tabular}{|l|l|l|l|}
\hline 4711 & $8 / 13 / 200823: 42$ & 1.701 & 17.4 \\
\hline 471 & $8 / 13200823.4$ & 1.700 & 17.4 \\
\hline
\end{tabular} \begin{tabular}{|l|l|l|l|}
\hline 4712 & $8 / 13 / 200823: 44$ & 1.700 & 17.4 \\
\hline 4713 & $8 / 132082356$ & 1700 & 17.4 \\
\hline
\end{tabular} \begin{tabular}{|l|l|l|l|}
\hline 4713 & $8 / 13 / 200823: 46$ & 1.700 & 17.4 \\
\hline 4714 & $8 / 1200823.46$ & 1.609 & 17.4 \\
\hline
\end{tabular} \begin{tabular}{|l|l|l|l|}
\hline 4714 & $8 / 13 / 200823: 48$ & 1.609 & 17.4 \\
\hline 4715 & $8 / 1320082350$ & 1.608 & 17.4 \\
\hline
\end{tabular} \begin{tabular}{|l|l|l|l|}
\hline 4715 & $8 / 13200823.50$ & 1.698 & 17.4 \\
\hline 4716 & $8 / 13200823.52$ & 1.697 & 17.4 \\
\hline
\end{tabular} \begin{tabular}{|l|l|l|l|}
\hline 4716 & $8 / 13 / 200823: 52$ & 1.697 & 17.4 \\
\hline 4717 & $8 / 12200823.54$ & 1.606 & 17.4 \\
\hline
\end{tabular} \begin{tabular}{|c|c|c|c|}
\hline 4717 & $8 / 13 / 200823: 54$ & 1.696 & 17.4 \\
\hline 4718 & 813200823.56 & 1.696 & 17.4 \\
\hline
\end{tabular} \begin{tabular}{|l|l|l|l|}
\hline 4718 & $8 / 13 / 200823: 56$ & 1.696 & 17.4 \\
\hline 475 & $8 / 13200823.58$ & 1.695 & 17.4 \\
\hline
\end{tabular} \begin{tabular}{|l|l|l|l|}
\hline 4719 & $813 / 200823.58$ & 1.695 & 17.4 \\
\hline 4720 & $8 / 2 / 20080.00$ & 1.695 & 17.4 \\
\hline
\end{tabular} \begin{tabular}{|l|l|l|l|}
\hline 4720 & $8 / 14 / 20080: 00$ & 1.695 & 17.4 \\
\hline 472 & $8 / 1 / 20080: 02$ & 1.694 & 17.4 \\
\hline
\end{tabular} \begin{tabular}{|l|l|l|l|}
\hline 4721 & $8 / 4 / 20080: 02$ & 1.694 & 17.4 \\
\hline 4722 & $8 / 14 / 20080: 04$ & 1.694 & 17.4 \\
\hline
\end{tabular} \begin{tabular}{|l|l|l|l|}
\hline 4723 & $8 / 14 / 20080-06$ & 1.693 & 17.4 \\
\hline 4724 & $8 / 142000000$ & 1.692 & 17.4 \\
\hline
\end{tabular} \begin{tabular}{|l|l|l|l|}
\hline 4724 & $8 / 1420080: 08$ & 1.692 & 17.4 \\
\hline 4725 & $8 / 4 / 2000: 0$ & 1.691 & 17.4 \\
\hline
\end{tabular} \begin{tabular}{|l|l|l|l|}
\hline 4725 & $8 / 14 / 20080: 10$ & 1.691 & 17.4 \\
\hline 4726 & $8 / 14 / 20080: 12$ & 1.600 & 17.4 \\
\hline
\end{tabular} \begin{tabular}{|l|l|l|l|}
\hline 4726 & $8 / 14 / 20080: 12$ & 1.690 & 17.4 \\
\hline 4727 & $8 / 4 / 20080: 4$ & 1.690 & 17.4 \\
\hline
\end{tabular} \begin{tabular}{|l|l|l|l|}
\hline 4727 & $8 / 14 / 20080: 14$ & 1.690 & 17.4 \\
\hline 4728 & $8 / 14 / 20080: 16$ & 1.689 & 17.4 \\
\hline
\end{tabular} \begin{tabular}{|c|c|c|c|}
\hline 4729 & $8 / 14 / 20080: 18$ & 1.689 & 17.4 \\
\hline 4730 & $8 / 4 / 2000.20$ & 1.687 & 17.4 \\
\hline
\end{tabular} \begin{tabular}{|l|l|l|l|}
\hline 4730 & $8 / 14 / 20080: 20$ & 1.687 & 17.4 \\
\hline 4731 & $8 / 14 / 20080: 22$ & 1.686 & 17.4 \\
\hline 4732 & $8 / 420080.6$ & 1.68 & 17.4 \\
\hline
\end{tabular} \begin{tabular}{|l|l|l|l|}
\hline 4732 & $8 / 1420080.24$ & 1.686 & 17.4 \\
\hline
\end{tabular} \begin{tabular}{|l|l|l|l|}
\hline 4733 & $8 / 14 / 20080: 26$ & 1.686 & 17.4 \\
\hline 4734 & $8 / 14 / 20080: 28$ & 1.685 & 17.4 \\
\hline 4735 & $8 / 4 / 20080.30$ & 1.684 & 17.4 \\
\hline
\end{tabular} \begin{tabular}{|l|l|l|l|}
\hline 4735 & $8 / 14 / 20080: 30$ & 1.684 & 17.4 \\
\hline 4736 & $8 / 4 / 20080.32$ & 1.683 & 17.4 \\
\hline
\end{tabular} \begin{tabular}{|l|l|l|l|}
\hline 4736 & $8 / 14 / 20080: 32$ & 1.683 & 17.4 \\
\hline
\end{tabular} \begin{tabular}{|l|l|l|l|}
\hline 4737 & $814 / 20080.34$ & 1.682 & 17.4 \\
\hline 4738 & $8 / 420080.36$ & 1.68 & 17.4 \\
\hline
\end{tabular} \begin{tabular}{|l|l|l|l|}
\hline 4738 & $8 / 14 / 20080: 36$ & 1.681 & 17.4 \\
\hline 4739 & $8 / 4 / 20080: 38$ & 1.680 & 17.4 \\
\hline
\end{tabular} \begin{tabular}{|l|l|l|l|}
\hline 4739 & $8 / 14 / 20080: 38$ & 1.680 & 17.4 \\
\hline 4740 & $8 / 4 / 20080.40$ & 1.680 & 17.4 \\
\hline
\end{tabular} \begin{tabular}{|l|l|l|l|}
\hline 4740 & $8 / 14 / 20080: 40$ & 1.680 & 17.4 \\
\hline 474 & $8 / 4 / 20080: 42$ & 1.680 & 17.4 \\
\hline
\end{tabular} \begin{tabular}{|l|l|l|l|}
\hline 4741 & $8 / 14 / 20080: 42$ & 1.680 & 17.4 \\
\hline 472 & $8 / 20080: 44$ & 1.680 & 17.4 \\
\hline
\end{tabular} \begin{tabular}{|l|l|l|l|}
\hline 4742 & $8 / 14 / 20080: 44$ & 1.680 & 17.4 \\
\hline 4743 & $8 / 420080: 46$ & 1.679 & 17.4 \\
\hline
\end{tabular} \begin{tabular}{|l|l|l|l|}
\hline 4743 & $8 / 1420080: 46$ & 1.679 & 17.4 \\
\hline 4744 & $8 / 420080.46$ & 1.679 & 17.4 \\
\hline
\end{tabular} \begin{tabular}{|l|l|l|l|}
\hline 4744 & $8 / 14 / 20080.48$ & 1.679 & 17.4 \\
\hline 4745 & $8 / 4 / 20080.50$ & 1.679 & 17.4 \\
\hline
\end{tabular} \begin{tabular}{|l|l|l|l|}
\hline 4745 & $8 / 14 / 20080.50$ & 1.679 & 17.4 \\
\hline 4746 & $8 / 14 / 20080.52$ & 1.678 & 17.4 \\
\hline
\end{tabular} 
DOE/RL-2009-35, REV. 0

\begin{tabular}{|c|c|c|c|c|c|c|c|c|c|c|c|c|c|c|c|c|c|c|c|}
\hline \multicolumn{4}{|c|}{$D 425 p$} & \multicolumn{4}{|c|}{ D4-25p } & \multicolumn{4}{|c|}{ D425p } & & D4-25p & & & & D4-25p & & \\
\hline Pec & & Pres & Temp & $\mathrm{ReC}$ & & Pres & Temp & $\mathrm{ReC}$ & & Pres & Temp & Rec & & Pres & Temp & $\operatorname{Pec}$ & & Pres & Temp \\
\hline$\#$ & DaterTime & psi & ${ }^{\circ} \mathrm{C}$ & \# & DaderTime & psi & & \# & Date/7ime & \begin{tabular}{|l|}
$\mathrm{psi}$ \\
\end{tabular} & ${ }^{\circ} \mathrm{C}$ & $\#$ & DateTime & psi & ${ }^{\circ} \mathrm{C}$ & $\#$ & Datedime & & \\
\hline 4747 & $8 / 14 / 20080.54$ & 1.678 & 17.4 & 4816 & $8 / 14 / 20083: 12$ & 1.644 & 17.4 & 4885 & $8 / 14 / 20085: 30$ & 1.620 & 17.4 & 4954 & $8 / 14 / 20087: 48$ & 1.00 & 17.4 & 5023 & $8 / 14 / 2008$ 10:06 & 1.591 & 17.4 \\
\hline 4748 & $8 / 14 / 20080.56$ & $1 . \overline{6} \overrightarrow{7}$ & 17.4 & 4817 & $8 / 14 / 20083: 14$ & 1.643 & 17.4 & 4886 & $8 / 14 / 20085: 32$ & 1.620 & 17.4 & 4955 & $8 / 14 / 20087: 50$ & 1.603 & 17.4 & 5024 & $8 / 14 / 2008$ 10:08 & 1.591 & 17.4 \\
\hline 4749 & $8 / 14 / 20080.58$ & 1.676 & 17.4 & & $8 / 14 / 20083: 16$ & 1.643 & 17.4 & & $8 / 14 / 20085: 34$ & 1.620 & 17.4 & 4956 & $8 / 14 / 20087: 52$ & 1.603 & 17.4 & 5025 & & 1.590 & 17.4 \\
\hline 4750 & $8 / 14 / 20081: 00$ & 1.676 & 17.4 & 4819 & $8 / 14 / 20083: 18$ & 1.643 & 17.4 & 4888 & $8 / 14 / 20085: 36$ & 1.620 & 17.4 & 4967 & $8 / 14 / 20087: 54$ & 1.603 & 17.4 & 5026 & $8 / 14 / 2008$ 10:12 & 1.590 & 17.4 \\
\hline 4751 & $8 / 14 / 2008$ 1:02 & 1.675 & 17.4 & 4820 & $8 / 14 / 20083: 20$ & 1.643 & 17.4 & 4889 & $8 / 14 / 20085: 38$ & 1.620 & 17.4 & 4958 & $8 / 14 / 20087: 56$ & 1.602 & 17.9 & 5027 & $8 / 14 / 2008$ 10:14 & 1.590 & 17.4 \\
\hline 4752 & $8 / 14 / 20081: 04$ & 1.674 & 17.4 & 4821 & $8 / 14 / 20083: 22$ & 1.643 & 17.4 & 4890 & $8 / 14 / 20085: 40$ & 1.619 & 17.4 & 4959 & $8 / 14 / 20087: 58$ & 1.602 & 17.5 & 5028 & $8 / 14 / 2008$ 10:16 & 1.590 & 17.4 \\
\hline 4753 & $8 / 14 / 20081: 06$ & 1.674 & 17.4 & 4822 & $8 / 14 / 20083: 24$ & 1.643 & 17.4 & 4891 & $8 / 14 / 20085: 42$ & 1.618 & 17.4 & 4960 & 8/14/20088:00 & 1.601 & 17.4 & 5029 & $8 / 14 / 2008$ 10:18 & 1.590 & 17.4 \\
\hline 4754 & $8 / 14 / 20081: 08$ & 1.673 & 17.4 & 4823 & $8 / 14 / 20083: 26$ & 1.642 & 17.4 & & $8 / 14 / 20085: 44$ & 1.619 & 17.3 & 4961 & & 1.601 & & 5030 & & & \\
\hline 4756 & $8 / 14 / 20081: 10$ & 1.673 & 17.4 & 4824 & $8 / 14 / 20083: 28$ & 1.642 & 17.4 & 4893 & $8 / 14 / 20085: 46$ & 1.619 & 17.4 & 4962 & $8 / 14 / 20088: 04$ & 1.601 & 17.4 & 5031 & $8 / 14 / 200810: 22$ & 1.590 & 17.4 \\
\hline 4756 & $8 / 14 / 200081: 12$ & 1.672 & 17.4 & 4825 & $8 / 14 / 20083: 30$ & 1.641 & 17.4 & 4894 & $8 / 14 / 20085: 48$ & 1.619 & 17.4 & 4963 & $8 / 14200088: 06$ & 1.601 & 17.4 & 5032 & $8 / 14 / 200810: 24$ & 1.590 & 17.4 \\
\hline 4757 & $8 / 14 / 20$ & 1.672 & 17.4 & 4826 & $8 / 14 / 20083: 32$ & 1.641 & 17.4 & 4895 & $8 / 14 / 20085: 50$ & 1.617 & 17.3 & 4964 & & 1.600 & 17.4 & 5033 & & & 17.4 \\
\hline 4758 & $8 / 14 / 20081: 16$ & 1.671 & 17.4 & 4827 & $8 / 14 / 20083: 34$ & 1.640 & 17.4 & 4896 & $8 / 14 / 20085: 52$ & 1.617 & 17.3 & 4965 & 8/14/20088:10 & 1.600 & 17.4 & 5034 & $8 / 14 / 2008$ 10:28 & 1.590 & 17.4 \\
\hline 4759 & $8 / 14 / 2$ & 1.671 & 17.4 & \begin{tabular}{|l|l|}
4828 \\
\end{tabular} & $8 / 14 / 20083: 36$ & 1.640 & 17.4 & 4897 & $8 / 14 / 20085: 54$ & 1.617 & 17.3 & 4966 & $8 / 14 / 20088: 12$ & 1.600 & 17.4 & 5035 & $8 / 14 / 2008$ 10:30 & 1.589 & 17.4 \\
\hline 4760 & $8 / 14 / 2$ & 1.670 & 17.4 & 4829 & $8 / 14 / 20 x$ & 1.639 & 17.4 & 4898 & $8 / 14 / 20085: 56$ & 1.599 & 17.3 & 4967 & & 1.600 & 17.4 & 5036 & & 1.589 & 17.4 \\
\hline 4761 & $8 / 1420081: 22$ & 1.670 & 17.4 & 4830 & $8 / 14 / 20083: 40$ & 1.638 & 17.4 & 4899 & $8 / 14 / 20085: 58$ & 1.615 & 17.4 & 4968 & $8 / 14 / 20088: 16$ & 1.599 & 17.4 & 5037 & $8 / 14 / 200810: 34$ & 1.589 & 17.4 \\
\hline 4762 & $8 / 14 / 2$ & 1.669 & 17.4 & 4831 & $8 / 14 / 200$ & 1.699 & 17.4 & 4900 & $8 / 14 / 20086: 00$ & 1.616 & 17.4 & 4969 & $8 / 14 / 20088: 18$ & 1.599 & 17.4 & 5038 & $8 / 14 / 200810: 36$ & 1.589 & 17.4 \\
\hline 4763 & $8 / 14 / 2$ & 1.668 & 17.4 & 4832 & $8 / 14 / 200$ & 1.638 & 17.4 & 4901 & $8 / 14 / 20086: 02$ & 1.616 & 17.4 & 4970 & $8 / 14 / 20088: 20$ & 1.590 & 17.4 & 5039 & $8 / 14200810: 38$ & 1.589 & 17.4 \\
\hline 4764 & $8 / 142$ & 1.667 & 17.4 & 4833 & $8 / 14 / 2$ & 1.638 & 17.4 & 4902 & $8 / 14 / 20$ & 1.616 & 17.4 & 4971 & $088: 22$ & 1.599 & 17.4 & 5040 & $8 / 14 / 2008$ 10:40 & 1.589 & 17.4 \\
\hline 4765 & $8 / 14 / 2$ & 1.667 & 17.4 & 4834 & $8 / 14 / 2$ & 1.638 & 17.4 & 4903 & $8 / 14 / 2$ & 1.615 & 17.4 & 4972 & & 1.590 & 17.4 & 5041 & $8 / 14 / 2008$ 10:42 & 1.589 & 17.4 \\
\hline 4766 & $8 / 14 / 2$ & 1.666 & 17.4 & 4835 & $8 / 14 / 2$ & 1.638 & 17.4 & 4904 & $8 / 14 / 20086: 08$ & 1.615 & 17.4 & 4973 & $8 / 14 / 20088: 26$ & 1.599 & 17.4 & 5042 & $8 / 14 / 2008$ 10:44 & 1.588 & 17.4 \\
\hline 4767 & $8 / 14 / 2$ & 1.667 & 17.4 & 4836 & $8 / 14 / 2$ & 1.638 & 17.4 & 4905 & $8 / 14 / 20$ & 1.615 & 17.4 & 4974 & $8 / 14 / 20088: 28$ & 1.598 & 17.4 & 5043 & $8 / 14 / 200810: 46$ & 1.588 & 17.4 \\
\hline 4768 & $8 / 14 / 2$ & 1.665 & 17.4 & \begin{tabular}{|l|}
4837 \\
\end{tabular} & $8 / 14 /$ & 1.637 & 17.4 & 4906 & $8 / 14 / 2$ & 1.614 & 17.4 & 4975 & & 1.598 & 17.4 & 5044 & & 1.58 & 17.4 \\
\hline 4769 & $8 / 14 / 20$ & 1.664 & 17.4 & 4838 & $8 / 14 /$ & 1.636 & 17.4 & 4907 & $8 / 14 / 2$ & 1.614 & 17.4 & 4976 & & 1.598 & 17.4 & 5045 & $8 / 14 / 200810: 50$ & 1.588 & 17.4 \\
\hline 4770 & $8 / 14 / 2$ & 1.66 & 17.4 & 4839 & $8 / 14 / 2$ & 1.635 & 17.4 & 4908 & $8 / 14 / 2$ & 1.614 & 17.4 & 4977 & & 1.598 & 17. & 5046 & $8 / 14 / 200810-52$ & 1.588 & 17.4 \\
\hline 4771 & $8 / 14 / 2$ & 1.662 & 17.4 & 4840 & $8 / 14 / 2$ & 1.635 & 17.4 & 4909 & $8 / 14 / 2$ & 1.614 & 17.4 & 4978 & & 1.598 & 17.4 & 5047 & $8 / 14 / 200810: 54$ & 1.589 & 17.4 \\
\hline 4772 & $8 / 14 / 2$ & 1.663 & 17.4 & \begin{tabular}{|l|}
4841 \\
\end{tabular} & $8 / 14 / 2$ & 1.635 & $\overline{17.4}$ & 4910 & $8 / 14 / 20086: 20$ & 1.614 & 17.4 & 4979 & $8 / 14 / 2$ & 1.597 & 17.4 & 5048 & $8 / 14200810: 56$ & 1.588 & 17.4 \\
\hline 4773 & $8 / 14 / 2$ & 1.66 & 17.4 & \begin{tabular}{|l|l|}
4842 \\
\end{tabular} & $8 / 14 /$ & 1.635 & 17.4 & 4911 & $8 / 14 / 2$ & 1.613 & & 4980 & & 1.597 & & 504 & $810: 58$ & 1.589 & 17.3 \\
\hline 4774 & $8 / 14 / 2$ & 1.66 & 17.4 & 4843 & $8 / 14 /$ & 1.634 & 17.4 & 4912 & $8 / 14 / 2$ & 1.612 & $17 \overline{17.4}$ & 4981 & & 1.597 & 17.4 & 50 & $811: 00$ & 1.588 & 17.4 \\
\hline 4775 & $8 / 14 / 2$ & 1.662 & 17.4 & 4844 & $8 / 14 /$ & 1.634 & 17.4 & 4913 & $8 / 14 /$ & 1.613 & 17.4 & 4962 & & 1.597 & 17. & 5051 & $311: 02$ & 1.588 & 17.4 \\
\hline 4776 & $8 / 14 / 2$ & 1.661 & 17.4 & 4845 & $8 / 14$ & 1.634 & 17.4 & 4914 & $8 / 14 / 2$ & 1.613 & 17.4 & 4983 & & 1.597 & 17. & 5052 & $8811: 04$ & 1.588 & 17.4 \\
\hline $47 \pi$ & $8 / 14 / 2$ & 1.661 & 17.4 & 4846 & $8 / 14$ & 1.634 & 17.4 & 4915 & $8 / 14 / 20$ & 1.612 & 17.4 & 4984 & $8 / 14$ & 1.597 & 17.4 & 5053 & 311:06 & 1.588 & 17.4 \\
\hline 4778 & $8 / 14 /$ & 1.661 & 17.4 & \begin{tabular}{|l|l}
4847 \\
\end{tabular} & $8 / 14$ & 1.634 & 17.4 & 4916 & $8 / 14$ & 1.611 & 17.4 & 4965 & & 1.596 & 17 & 505 & 11:08 & 1.588 & 17.3 \\
\hline 479 & $8 / 14$ & 1.661 & 17.4 & \begin{tabular}{|l|l}
4848 \\
\end{tabular} & 814 & 1.633 & 17.4 & 4917 & $8 / 14 /$ & 1.611 & 17.4 & 4986 & & 1.597 & 17. & 50 & $811: 10$ & 1.588 & 17.3 \\
\hline 4780 & $8 / 14 /$ & 1.611 & 17.4 & \begin{tabular}{|l}
4849 \\
\end{tabular} & $8 / 14$ & 1.633 & 17.4 & 4918 & $8 / 14$ & 1.611 & $\overline{17.4}$ & 4987 & & 1.597 & 17. & 505 & $8 / 14 / 2$ & 1.588 & 17.4 \\
\hline 4781 & $8 / 14 / 2$ & 1.65 & 17.4 & 4850 & $8 / 14$ & 1.632 & 17. & 4919 & $8 / 14$ & 1.610 & 17. & 4988 & & 1.597 & 17 & 505 & $8 / 14$ & 1.588 & 17.4 \\
\hline 4782 & $8 / 142$ & 1.659 & 17.4 & 4851 & & 1.632 & 17. & 4920 & $8 / 14$ & 1.610 & 17.4 & 4989 & & 1.506 & 17. & 50 & $8 / 14$ & 1.587 & 17.4 \\
\hline 4783 & $8 / 14$ & 1.658 & 17.4 & 4852 & $8 / 14 /$ & 1.632 & 17. & 4921 & $8 / 14$ & 1.610 & 17. & 4990 & & 1.596 & 17 & 505 & 1:18 & 1.587 & 17.4 \\
\hline 4784 & $8 / 14 /$ & 1.658 & 17.4 & 4853 & $8 / 14 /$ & $\begin{array}{l}0.632 \\
\end{array}$ & 17.4 & 4922 & $8 / 14 /$ & 1.609 & 17.4 & 4991 & & 1.595 & 17. & 506 & 311:20 & 1.587 & 17.4 \\
\hline 4785 & $8 / 14$ & 1.658 & 17.4 & \begin{tabular}{|l|}
4854 \\
\end{tabular} & & 1.630 & 17.4 & 4923 & & 1.609 & 17.4 & 4992 & & 1.595 & 17. & 5061 & & 1.586 & 17.4 \\
\hline 4786 & $8 / 14$ & 1.65 & 17.4 & 4855 & & 1.630 & 17. & 4924 & $8 / 14$ & 1.609 & 17.4 & 4993 & & 1.595 & 17 & 506 & $8 / 14$ & 1.586 & 17.4 \\
\hline 4787 & $8 / 14$ & 1.65 & 17.4 & 4856 & & 1.630 & 17.4 & 4925 & & 1.609 & 17.4 & 4994 & & 1.595 & 17 & & & 1.506 & 17.4 \\
\hline 4788 & & 1.656 & 17.4 & 4857 & & 1.630 & 17. & 4926 & & 1.609 & 17.4 & 4995 & & 1.505 & 17. & 50 & $8 / 14$ & 1.586 & 17.3 \\
\hline 4789 & $8 / 14 / 2$ & 1.656 & 17.4 & 4858 & $8 / 14$ & 1.629 & 17.4 & 4927 & $8 / 14$ & 1.608 & 17.4 & 4996 & & 1.595 & 17. & 5065 & $0811: 30$ & 1.586 & 17.4 \\
\hline 4790 & & 1.655 & 17.4 & 4859 & & 1.629 & 17. & 4928 & & 1.608 & 17.4 & 4997 & & 1.595 & 17. & & & 1.586 & 17.4 \\
\hline 4791 & $8 / 14$ & 1.655 & 17.4 & 4860 & & 1.628 & 17. & 4929 & $8 / 14$ & 1.608 & 17.4 & 4998 & & 1.596 & & $\overline{50}$ & & 1.586 & 17.3 \\
\hline 4792 & $8 / 14$ & 1.655 & 17.4 & \begin{tabular}{|l|}
4861 \\
\end{tabular} & & 1.628 & 17. & 4930 & & 1.608 & 17.4 & 4999 & & 1.595 & 17 & 50 & & 1.586 & 17.4 \\
\hline 4793 & & 1.655 & 17.4 & 4962 & & 1.627 & 17. & 4931 & & 1.608 & 17.4 & 5000 & & 1.595 & 17 & & $8 / 14$ & 1.585 & $\overline{17.4}$ \\
\hline 4794 & $8 / 14$ & 1.654 & 17.4 & 4863 & $8 / 14$ & 21.627 & 17.4 & 4932 & $8 / 14$ & 1.607 & 17.4 & 5001 & 89.22 & 1.505 & 17. & 5070 & 311:40 & 1.585 & 17.3 \\
\hline 4795 & & 1.654 & 17.4 & \begin{tabular}{|l|}
4864 \\
\end{tabular} & & 1.627 & 17. & \begin{tabular}{|l|l|}
4993 \\
\end{tabular} & & 1.607 & 17.4 & 5002 & & 1.583 & 17. & 5071 & & 1.585 & 17.4 \\
\hline 4796 & & 1.653 & 17.4 & 48665 & & 1.627 & 17. & \begin{tabular}{|l|}
4934 \\
\end{tabular} & $8 / 14$ & 1.607 & 17. & 5003 & & 1.593 & & & & 1.585 & 17.4 \\
\hline 4797 & $8 / 14$ & $1.6 \overline{3}$ & 17.4 & 4866 & & 1.627 & 17. & 4995 & & 1.607 & 17. & 5004 & & 1.593 & 17 & 50 & & 1.585 & $\overline{17.3}$ \\
\hline 4798 & & 1.653 & 17.4 & 4867 & & 1.626 & & & & 1.606 & & & & 1.594 & & & & 1.585 & \\
\hline 4790 & 814 & 1.652 & 17.4 & 4868 & $8 / 14$ & 1.626 & 17. & 4937 & & 1.606 & 17.4 & 5006 & & 1.594 & 17. & 5075 & $11: 50$ & 1.585 & 17.3 \\
\hline 4800 & & 1.651 & 17.4 & 4869 & & 1.625 & 17. & 4938 & & 1.606 & 17.4 & & & 1.594 & & & & 1.585 & 17.4 \\
\hline 4801 & & 1.661 & 17.4 & \begin{tabular}{|l|}
4870 \\
\end{tabular} & & 1.625 & 17. & 4939 & & 1.605 & & 5008 & & 1.594 & & & & 1.584 & 17.3 \\
\hline 4802 & $8 / 14$ & 1.66 & 17.4 & 4871 & & 1.624 & 17. & 4940 & & 1.606 & 17.4 & 5009 & & 1.594 & 17. & 5078 & & 1.584 & 17.4 \\
\hline 4803 & & 1.661 & 17.4 & 4872 & & & & & & 1.606 & & & & & & & & 1.584 & \\
\hline 4804 & $8 / 14$ & 1.650 & 17.4 & 4873 & $8 / 14$ & 1.623 & 17. & 4942 & $8 / 14$ & 1.606 & 17.4 & 5011 & & 1.593 & 17. & 5080 & $12: 00$ & 1.584 & 17.4 \\
\hline 4805 & $8 / 14$ & 1.650 & 17.4 & 4874 & & 1.62 & 17. & 4943 & & 1.606 & $\overline{17.4}$ & & & 1.593 & 17. & Do & & 1.583 & 17.3 \\
\hline 4806 & $8 / 14$ & 1.650 & 17.4 & \begin{tabular}{|l|}
4875 \\
\end{tabular} & & 1.622 & & & & 1.606 & & & & 1.593 & & & 1204 & 1.583 & \\
\hline 4807 & $8 / 14 / 2$ & 1.649 & 17.4 & 4876 & & 1.62 & 17. & 4945 & & 1.604 & 17.4 & 5014 & & 1.593 & 17. & 083 & 1206 & 1.583 & 17.3 \\
\hline 4808 & & 1.648 & 17.4 & & & & & & & & & & & & & & & & \\
\hline 4809 & $8 / 14 / 2$ & 1.647 & 17.4 & \begin{tabular}{|l|}
4878 \\
\end{tabular} & $8 / 14$ & 1.623 & 17. & 4947 & $8 / 14$ & 1.604 & 17.4 & 5016 & & 1.593 & 17.4 & 5085 & $812: 10$ & 1.583 & 17.4 \\
\hline 4810 & $8 / 14 \pi$ & 1.647 & 17.4 & \begin{tabular}{|l|}
4879 \\
\end{tabular} & & 1.623 & 17. & 4948 & & 1.603 & 17.4 & 5017 & & 1.593 & 17.4 & 6006 & & 1.583 & 17.4 \\
\hline 4811 & & 1.646 & 17.4 & 4880 & & 1.623 & & 4949 & & 1.604 & & & & & & & 1214 & 1.583 & $\overline{173}$ \\
\hline 4812 & $8114 \sqrt{2}$ & 1.645 & 17.4 & 4881 & $8 / 14$ & 1.623 & 17. & 4950 & $8 / 14 / 20087: 40$ & 1.604 & 17.4 & 5019 & 9.58 & 1.592 & 17.4 & 5088 & $8812: 16$ & 1.583 & 17.3 \\
\hline 4813 & $8 / 14 / 2$ & 1.645 & 17.4 & 4882 & & 1.62 & 17. & 4951 & & 1.004 & 17. & 5020 & & 1.592 & & 5089 & & \begin{tabular}{|l}
1.583 \\
\end{tabular} & 17.3 \\
\hline 4814 & & 1.645 & 17.4 & & & 1.621 & & 4952 & & 1.604 & 11 & 5021 & & 1.592 & 17.4 & & $812: 20$ & 1.583 & 17.4 \\
\hline 4815 & 8/14/20083:10 & 1.644 & 17.4 & 4884 & $8 / 14 / 2$ & 31.621 & $\overline{17.4}$ & 4953 & $7: 46$ & 1.604 & 17.4 & 5022 & $8 / 14 / 200810: 04$ & 1.591 & 17.4 & & 81222 & 1.583 & 17. \\
\hline
\end{tabular}


DOE/RL-2009-35, REV. 0

\begin{tabular}{|c|c|c|c|c|c|c|c|c|c|c|c|c|c|c|c|c|c|c|c|}
\hline \multicolumn{4}{|c|}{ D425p } & \multicolumn{4}{|c|}{ D425p } & \multicolumn{4}{|c|}{$D 425 p$} & & $D 4-25 p$ & & & & $D 425 p$ & & \\
\hline$P x$ & & Pres: & Temp & $\mathrm{Bec}$ & & Pres & Temp & $R e c$ & & Pres! & Temp & $\operatorname{Rec}$ & & Pres & Tenp & Rec & & Pres & $\mathrm{emp}$ \\
\hline \# & Date/Time & psi & ${ }^{\circ} \mathrm{C}$ & $\#$ & Date-Time & psi & ${ }^{\circ} \mathrm{C}$ & $\#$ & DeterTime & psi & & $\#$ & Date-Time & $p s i$ & ${ }^{\circ} \mathrm{C}$ & $\#$ & Date/Time & $\mathrm{psi}$ & \\
\hline 5092 & $8 / 14 / 2008+224$ & 1.583 & 17.3 & 5161 & $8 / 14 / 200814: 42$ & $1.57 \pi$ & 17.3 & & $8 / 14 / 200817: 00$ & 1.571 & 17.3 & 5290 & $8 / 14 / 200819.18$ & 1.564 & 17.3 & 5368 & $8 / 14 / 200821: 36$ & 1.557 & 17.3 \\
\hline 5093 & $8 / 14 / 20081226$ & 1.582 & 17.3 & 5162 & $8 / 14 / 200814: 44$ & $1.5 \pi$ & 17.3 & 5231 & $8 / 14 / 200817: 02$ & 1.570 & 17.3 & 5300 & $8 / 14 / 2008+9.20$ & 1.564 & 17.3 & & $8 / 14 / 200821: 38$ & 1.567 & 17.3 \\
\hline 5094 & & 1.583 & 17.3 & & & & 17.3 & & $8 / 14200817: 04$ & 1.570 & 17.3 & 5301 & $8 / 14 / 200819.22$ & 1.564 & 17.3 & & & 1.557 & \\
\hline 5095 & $8 / 14 / 20081230$ & 1.582 & 17.3 & 5164 & $8 / 14 / 200814: 48$ & 1.578 & 17.3 & 5233 & $8 / 14 / 200817: 06$ & 1.570 & 17.3 & 5302 & $8 / 14 / 200819.24$ & 1.563 & 17.3 & 5371 & $8 / 14 / 200821: 42$ & 1.556 & 17.3 \\
\hline 5096 & $8 / 14 / 20081232$ & 1.582 & 17.4 & 5165 & $8 / 14 / 200814: 50$ & & 17.4 & 5234 & $8 / 14 / 200817: 08$ & $1.5 \pi$ & 17.3 & 5303 & $8 / 14 / 200819.26$ & 1.563 & 17.3 & 5372 & $8 / 14 / 200821: 44$ & 1.557 & 17.3 \\
\hline 5097 & $8 / 14 / 20081234$ & 1.582 & 17.3 & 5166 & $8 / 14 / 200814: 52$ & 1.57 & 17.3 & 5235 & $8 / 14 / 200817: 10$ & 1.570 & 17.3 & 5304 & $8 / 14 / 200819.28$ & 1.563 & 17.3 & 5373 & $8 / 14 / 200821: 46$ & 1.550 & $\overline{17.3}$ \\
\hline 5098 & $8 / 14 / 20081236$ & 1.582 & 17.4 & 5167 & $8 / 14 / 200014: 54$ & $1.5 \pi$ & 17.4 & 5236 & $8 / 14 / 2008$ 17:12 & 1.570 & 17.3 & 5305 & $8 / 14 / 200819: 30$ & 1.563 & 17.3 & 5374 & $8 / 14 / 200821: 48$ & 1.507 & 17.3 \\
\hline 5099 & & 1.582 & 17.3 & 5168 & & & 17.3 & & $8 / 14 / 2008$ 17:14 & & 17.3 & 5306 & $8 / 14 / 200819.32$ & & 17.3 & 5375 & & 1.557 & 17.3 \\
\hline 5100 & $8 / 14 / 20081240$ & 1.582 & 17.3 & 5169 & $8 / 14200814: 58$ & $1.5 \pi$ & 17.4 & 5238 & $8 / 14 / 200817: 16$ & 1.570 & 17.3 & 5307 & $8 / 14 / 2008$ 19:34 & 1.563 & 17.3 & 5376 & $8 / 14 / 200821: 52$ & 1.557 & 17.3 \\
\hline 5101 & $8 / 14 / 20$ & 1.582 & 17.3 & 5170 & $8 / 14200815: 00$ & 1.56 & 17.4 & 5239 & $8 / 14 / 2008$ 17:18 & 1.570 & 17.3 & 5308 & $8 / 14 / 200819.36$ & 1.563 & 17.3 & $53 \pi$ & $8 / 142000821: 54$ & 1.557 & 17.3 \\
\hline 5102 & $8 / 14 / 20$ & 1.582 & 17.3 & 5 & $8 / 14200815: 02$ & 1.576 & 17.3 & 5240 & $8 / 14 / 20$ & 1.570 & 17.3 & & & 1.563 & 17.3 & & & 1.557 & $\overline{17.3}$ \\
\hline 5103 & $8 / 14 / 20081246$ & 1.581 & 17.3 & 5172 & $8 / 14 / 200815: 04$ & 1.576 & 17.4 & 5241 & $8 / 14 / 2008$ 17:22 & 1.570 & 17.3 & 5310 & $8 / 14 / 200819: 40$ & 1.563 & 17.3 & 5379 & $8 / 14 / 200821: 58$ & 1.557 & 17.3 \\
\hline 5104 & $8 / 14 / 20$ & 1.581 & 17.4 & \begin{tabular}{|l|l|}
5173 \\
\end{tabular} & $8 / 14200815: 06$ & 1.576 & 17.3 & 5242 & $8 / 14 / 200817: 24$ & 1.50 & 17.4 & 5311 & $8 / 14 / 200819.42$ & 1.562 & 17.3 & 5380 & $8 / 14 / 200822-00$ & 1.557 & $\overline{17.3}$ \\
\hline 5105 & & 1.581 & 17.3 & 5174 & $8 / 14 / 200$ & 1.576 & 17.3 & 5243 & & & 17.3 & & & 1.562 & 17.3 & 5381 & & 1.567 & \\
\hline 5106 & $8 / 14 / 200$ & 1.581 & 17.3 & 5175 & $8 / 14 \sqrt{2}$ & $1.5 \pi$ & 17.4 & 5244 & $8 / 14 / 2$ & 1.560 & 17.3 & 5313 & 819.46 & 1.562 & 17.3 & 5382 & $822: 04$ & 1.556 & 17.3 \\
\hline 5107 & $8 / 14 / 20$ & 1.581 & 17.3 & 5176 & $8 / 14 / 20$ & $1.57 \pi$ & 17.3 & 5245 & $8 / 14 / 2$ & 1.567 & 17.3 & 5314 & $8 / 14 / 2008$ 19:48 & 1.562 & 17.3 & 5383 & & 1.556 & 17.3 \\
\hline 5108 & $8 / 14 / 20$ & 1.581 & 17.3 & 5177 & $8 / 14 / 20$ & 1.577 & 17.4 & 5246 & $8 / 14 / 2$ & 1.568 & 17.3 & 5315 & $8 / 14 / 200819.50$ & 1.562 & 17.3 & 5384 & $822: 08$ & 1.556 & 17.3 \\
\hline 5109 & $8 / 14 / 2$ & 1.581 & 17.3 & 5178 & $8 / 142$ & $1.5 \pi$ & 17.4 & 5247 & $8 / 14 / 2$ & 1.568 & 17.3 & 5316 & 819.52 & 1.562 & 17.3 & 5385 & 82210 & 1.556 & $\overline{17.3}$ \\
\hline 5110 & $8 / 14 / 2$ & 1.580 & 17.3 & 5170 & & & 17.4 & 5248 & & 1.568 & 17.3 & 5317 & & 1.561 & 17.3 & & & 1.556 & \\
\hline 5111 & $8 / 14 / 20$ & 1.580 & 17.3 & 5180 & $8 / 14 \sqrt{2}$ & 1.576 & 17.4 & 5249 & $8 / 14 / 2$ & 1.568 & 17.3 & 5318 & $8 / 14 / 200819.56$ & 1.561 & 17.3 & 5387 & $8 / 14 / 20082214$ & \begin{tabular}{|l|}
1.556 \\
\end{tabular} & 17.3 \\
\hline 5112 & $8 / 14 / 2$ & 1.580 & 17.3 & 5181 & $8 / 14 / 2$ & 1.576 & 17.3 & 5250 & $8 / 14 / 4$ & 1.568 & 17.3 & 5319 & 19.58 & 1.561 & 17.3 & 5388 & 32216 & 1.555 & $\overline{17.3}$ \\
\hline 5113 & $8 / 14 / 2$ & 1.581 & 17.3 & 5182 & & 1.576 & 17.3 & 5251 & & 1.568 & 17.3 & 5320 & & 1.562 & & 5389 & & 1.555 & 17.3 \\
\hline 5114 & $8 / 14$ & \begin{tabular}{|l|l|}
3.580 \\
\end{tabular} & 17.8 & 5183 & $8 / 14$ & 1.575 & 17.3 & 5252 & $8 / 14$ & \begin{tabular}{|c|}
1.567 \\
\end{tabular} & 17.3 & 5321 & $20: 02$ & 1.561 & 17.3 & 5390 & 32220 & 1.555 & $\overline{17.3}$ \\
\hline 5115 & $8 / 14 / 2$ & 1.580 & 18.0 & 5184 & $8 / 14 /$ & 1.575 & 17.4 & 5253 & $8 / 14$ & 1.568 & 17.3 & 5322 & 820.04 & 1.561 & 17.3 & 391 & & 1.555 & 17.3 \\
\hline 5116 & $8 / 14 / 2$ & 1.581 & 17.9 & 5185 & & 1.575 & 17.3 & 5254 & $8 / 14 /$ & 1.568 & 17.3 & 5323 & $8 / 14 /$ & 1.561 & 17.3 & 5392 & 32224 & 1.565 & 17.3 \\
\hline 5117 & $8 / 14 / 2$ & 1.581 & 17.8 & 5186 & $8 / 14 / 2$ & 1.575 & 17.4 & 5256 & $8 / 14$ & 1.568 & 17.3 & 5324 & 20.08 & 1.562 & $\begin{array}{l}17.3 \\
\end{array}$ & 5393 & 2226 & 1.555 & 17.3 \\
\hline 5118 & $8 / 14 / 2$ & 1.581 & 17.5 & 5187 & $8 / 14$ & 1.574 & 17.3 & 5256 & & 1.568 & 17.3 & 5325 & & 1.561 & & 5394 & $22 \cdot 28$ & 1.555 & 17.3 \\
\hline 5119 & & 1.581 & 17.4 & 5188 & & 1.575 & 17.3 & 525 & & 1.569 & 17.3 & 5326 & & 1.56 & 17.3 & 5305 & 2230 & 1.555 & $\overline{17.3}$ \\
\hline 5120 & $8 / 14$ & 1.580 & 17.3 & 5189 & $8 / 14$ & 1.574 & 17.4 & 5258 & $8 / 14$ & 1.568 & 17.3 & 5327 & $20: 14$ & 1.561 & 17.3 & 5396 & 2232 & 1.555 & 17.3 \\
\hline 5121 & $8 / 142$ & 1.580 & 17.3 & 5 & & & 17.3 & 5250 & $8 / 14$ & & $\begin{array}{l}17.3 \\
\end{array}$ & 5328 & & 1.561 & & 5397 & $22: 34$ & 1.555 & 17.3 \\
\hline 5122 & $8 / 14 / 2$ & 1.580 & 17.3 & 5191 & $8 / 14$ & \begin{tabular}{|l|}
1.574 \\
\end{tabular} & 17.3 & 5260 & $8 / 14$ & 1.568 & 17.3 & 5329 & 20.18 & 1.561 & 17.3 & 5396 & $22: 36$ & 1.555 & 17.3 \\
\hline 5123 & $8 / 14$ & 1.580 & 17.3 & 5192 & $8 / 14$ & 1.574 & 17.3 & 5261 & & 1.568 & 17.3 & 5330 & & 1.56 & & 5399 & 2238 & 1.555 & 17.3 \\
\hline 5124 & $8 / 14 /$ & 1.581 & 17.3 & 5193 & & 1.574 & 17.4 & 5262 & $8 / 14$ & 1.567 & 17.3 & 5331 & 320.22 & & $\begin{array}{l}17.3 \\
\end{array}$ & 400 & 2240 & 1.555 & 17.3 \\
\hline 5125 & $8 / 14$ & 1.580 & 17.3 & 5194 & & 1.574 & 17.4 & 5263 & & 1.567 & 17.3 & 5332 & 0.24 & & 17. & 5401 & $22: 42$ & 1.555 & 17.3 \\
\hline 5126 & $8 / 14$ & 1.560 & 17.3 & 5195 & $8 / 14$ & 1.574 & 17.4 & 5264 & $8 / 14 /$ & 1.567 & 17.3 & 5333 & 320.26 & 1.50 & 17.3 & 5402 & $22: 44$ & 1.555 & 17.3 \\
\hline 5127 & & 1.579 & 17.3 & 5196 & & \begin{tabular}{|l|l|}
1.574 \\
\end{tabular} & 17.3 & 5265 & & 1.567 & 17.3 & 5334 & 20.28 & 1.56 & 17.3 & 03 & $22: 46$ & 1.555 & 17. \\
\hline $5+28$ & $8 / 14$ & 1.567 & 17.3 & 5197 & $8 / 14$ & 1.574 & 17.4 & 5266 & & 1.567 & 17.3 & 5335 & 20.30 & 1.56 & 17.3 & 404 & $22: 48$ & 1.521 & 17. \\
\hline 5120 & & 31.564 & 17.3 & 5198 & & 1.573 & 17.3 & 5267 & & 1.567 & 17.3 & 5336 & 20.32 & 1.560 & 17. & 405 & 2250 & 1.562 & 17.2 \\
\hline 5130 & $8 / 14$ & 1.578 & 17.3 & 5199 & & 1.573 & 17.4 & 5260 & & 1.567 & 17.3 & 5337 & 20.34 & 1.560 & $\begin{array}{l}17.3 \\
\end{array}$ & & & 1.554 & $\overline{17.3}$ \\
\hline 5131 & & 1.578 & 17.3 & 5200 & & 1.573 & 17.3 & 5260 & & 1.566 & 17.3 & 5338 & $20: 36$ & 1.56 & 17. & 107 & & 1.554 & 17. \\
\hline 5132 & & 1.579 & 17.3 & 5201 & & 1.573 & 17.3 & 5270 & & 1.566 & 17.3 & & & 1.5 & & & & 1.554 & 17. \\
\hline 5133 & $8 / 14$ & 1.579 & 17.3 & 5202 & & 1.574 & 17.3 & 527 & & 1.566 & 17.3 & 5340 & 20.40 & 1.5 & 17 & 109 & 2258 & \begin{tabular}{|l|l}
1.555 \\
\end{tabular} & $\overline{17.3}$ \\
\hline 5134 & & 1.519 & 17.3 & 5203 & & \begin{tabular}{|l|l}
1.574 \\
\end{tabular} & 17.3 & 5272 & & 1.566 & 17.3 & 5341 & 20.42 & 1.559 & 17. & 5410 & $23: 00$ & 1.556 & 17.3 \\
\hline 5135 & & 1.579 & 17.3 & 5204 & & \begin{tabular}{|l|l|}
1.574 \\
\end{tabular} & 17.4 & 5273 & & 1.566 & 17.3 & 5342 & & & & & & 1.554 & $\overline{17.3}$ \\
\hline 5136 & & 1.579 & 17.3 & 5200 & & 1.573 & 17.3 & 5274 & & 1.566 & & 5343 & & & & & & 1.554 & \\
\hline 5137 & & 41.580 & 17.3 & 5206 & & 1.572 & 17.3 & 527 & & 1.5 & $\overline{17.3}$ & 5344 & & 1.5 & & & & 1.564 & 17. \\
\hline 5138 & & $\begin{array}{l}01.580 \\
\end{array}$ & 17.3 & 507 & & 1.572 & 17.3 & 527 & & 1.5 & & & & & & & & \begin{tabular}{|l|l|}
1.554 \\
\end{tabular} & \\
\hline 5139 & & 31.579 & 17.3 & 5208 & & 1.572 & 17.3 & 5277 & & 1.566 & 17.3 & 5346 & & \begin{tabular}{|l}
1.559 \\
\end{tabular} & 17. & & & 1.554 & 17.3 \\
\hline 5140 & & 1.580 & 17.3 & 5200 & & 1.572 & 17.3 & 527 & & & 17.3 & 5347 & & & & & & 1.554 & \\
\hline 5141 & & 1.580 & 17.3 & 70 & & 1.572 & 17.3 & & & 1.566 & & 5348 & & & & & & 1.554 & \\
\hline 5142 & & 1.579 & 17.3 & 5211 & & 1.572 & 17.3 & 5280 & & 1.566 & 17.3 & & & & & & & 1.55 & 17.3 \\
\hline 5143 & & 1.579 & 17.3 & & & 1.572 & 17.3 & 5281 & & & & & & & & & & & \\
\hline 5144 & & $1.5 \%$ & 17.3 & 5213 & & 1.572 & 17.3 & 5282 & & 1.565 & 17.3 & 5351 & & 1.558 & 17. & 5420 & $23: 20$ & 1.553 & 17.3 \\
\hline 5145 & & 1.578 & 17.3 & 5214 & & & 17.3 & 528 & & & & 5352 & & & & & & & \\
\hline 5146 & & 1.579 & 17.3 & & & 1.571 & 17.3 & & & 1.565 & & & & & & & & 1.553 & \\
\hline 5147 & & 1.579 & 17.3 & 5216 & & 1.571 & 17.3 & 5285 & & 1.564 & 17.3 & 5354 & & 1.55 & 17.3 & & & 1.553 & 17.3 \\
\hline 5148 & & 1.579 & & & & 1.571 & & & & & & & & & & & & & \\
\hline 5149 & & $1.5 \%$ & 17.3 & 5218 & & 1.571 & 17.4 & 5287 & & 1.5 & 17.3 & 5356 & & 1.56 & 17. & 5425 & $23: 30$ & 1.553 & $\overline{17.3}$ \\
\hline 5150 & & 1.578 & 17.3 & 5219 & & & 17.3 & 5238 & & & & & & & & & & 1.000 & \\
\hline 5151 & & 1.578 & 17.3 & & & 1.571 & 17.3 & & & 1.5 & & 5358 & & 1.5 & & & & 1.553 & \\
\hline 5152 & & 1.578 & 17.3 & 5221 & & 1.572 & 17.3 & 5290 & & 1.565 & 17.3 & 5359 & & 1.559 & $\overline{17.3}$ & & & 1.553 & $17.3^{3}$ \\
\hline 5153 & & 1.578 & 17.3 & & & 1.572 & & & & & & & & & & & & 1.553 & \\
\hline 5154 & $8 / 14$ & 1.578 & 17.3 & 5223 & 16:46 & 1.572 & 17.3 & 5292 & & 1.564 & 17.3 & 5361 & $821: 22$ & 1.558 & 17.3 & 5430 & 23:40 & 1.552 & 17.3 \\
\hline 5155 & & 1.57 & 17.3 & 5224 & & 1.572 & 17.3 & 5293 & & 1.565 & 17.3 & 5362 & & 1.558 & 17.3 & & & 1.553 & \\
\hline 5156 & & 1.578 & 17.3 & & & 1.571 & 17.4 & & & & & & & & & & & 1.552 & \\
\hline 5157 & & 1.57 & 17.3 & 5226 & & 1.571 & 17.3 & 5295 & & 1.5 & 17.3 & 5364 & $821: 28$ & 1.558 & 17.3 & 5433 & & 1.552 & \\
\hline 5158 & & 1.577 & 17.3 & & & 1.571 & 17.3 & 500 & & & 17.3 & 5365 & & 1.558 & & & & 1.552 & \\
\hline 5159 & $8 / 14 / 2$ & 1.578 & 17.3 & 5228 & & 1.571 & 17.4 & 5297 & & 1.564 & 17.3 & 5366 & $8 / 14 / 200821: 32$ & 1.557 & 17.3 & 5435 & $23: 50$ & 1.552 & 17.3 \\
\hline 5160 & $14: 40$ & 1.58 & 17.3 & 5229 & $6: 58$ & 1.571 & 17.3 & 5298 & & 1.564 & & 5367 & $21: 34$ & 1.507 & & 436 & $23: 52$ & 1.552 & \\
\hline
\end{tabular}




\begin{tabular}{|c|c|c|c|}
\hline \multicolumn{4}{|c|}{ D4-25p } \\
\hline $\mathrm{Pec}$ & & Pres & Termp \\
\hline$\#$ & DaterTirne & psi & ${ }^{\circ} \mathrm{C}$ \\
\hline 5437 & $8 / 14 / 200823: 54$ & 1.551 & 17.3 \\
\hline 5438 & $8 / 14 / 200823556$ & 1.551 & 17.3 \\
\hline 5439 & $8 / 14 / 200823: 58$ & 1.551 & 17.3 \\
\hline 5440 & $8 / 15 / 20080: 00$ & 1.552 & 17.3 \\
\hline 5441 & $8 / 15 / 20080: 02$ & 1.552 & 17.3 \\
\hline 5442 & $8 / 15 / 20080: 04$ & 1,551 & 17.3 \\
\hline 5443 & $8 / 15 / 20080.06$ & 1,551 & 17.3 \\
\hline 5444 & $8 / 5 / 20080.08$ & 1.551 & 17.3 \\
\hline 5445 & $8 / 15 / 20080.10$ & 1.551 & 17.3 \\
\hline 5446 & $8 / 15 / 20080: 12$ & 1.551 & 17.3 \\
\hline 5447 & $8 / 15 / 20080: 14$ & 1.551 & 17.3 \\
\hline 5448 & $8 / 15 / 20080.16$ & 1.551 & 17.3 \\
\hline 5449 & 8/15/20080:18 & 1.551 & 17.3 \\
\hline 5450 & $8115 / 20080: 20$ & 1.551 & 17.3 \\
\hline 5451 & $8 / 15 / 20080: 22$ & 1.551 & 17.3 \\
\hline 5452 & $8 / 15 / 20080.24$ & 1.551 & 17.3 \\
\hline 5453 & $8 / 15 / 20080.26$ & 1.551 & 17.3 \\
\hline 5454 & $8 / 15 / 20080: 28$ & 1.551 & 17.3 \\
\hline 5450 & $8 / 15 / 20080: 30$ & 1.551 & 17.3 \\
\hline 5456 & $8 / 15 / 20080.32$ & 1.551 & 17.3 \\
\hline 5457 & $8 / 15 / 20080.34$ & 1.550 & 17.3 \\
\hline 5458 & $8 / 15 / 20080: 36$ & 1.550 & 17.3 \\
\hline 5450 & $8 / 15 / 20080.38$ & 1.550 & 17.3 \\
\hline 5460 & $8 / 15 / 20080: 40$ & 1.550 & 17.3 \\
\hline 5461 & $8 / 15 / 20080: 42$ & 1.550 & 17.3 \\
\hline 5462 & $8 / 15 / 20080: 44$ & 1.550 & 17.3 \\
\hline 5463 & $8 / 15 / 20080-46$ & 1.550 & 17.3 \\
\hline 5464 & $8 / 15 / 20080: 48$ & 1.549 & 17.3 \\
\hline 5465 & $8 / 15 / 20080: 50$ & 1.549 & 17.3 \\
\hline 5466 & $8 / 15 / 20080: 52$ & 1.549 & 17.3 \\
\hline 5467 & $8 / 15 / 20080: 54$ & 1.549 & 17.3 \\
\hline 5468 & $8 / 15 / 20080.56$ & 1.549 & 17.3 \\
\hline 5469 & $8 / 15 / 20080.58$ & 1.549 & 17.3 \\
\hline 5470 & $8 / 15 / 20081: 00$ & 1.549 & 17.3 \\
\hline 5471 & $8 / 15 / 20081: 02$ & 1.550 & 17.3 \\
\hline 5472 & $8 / 15 / 20081: 04$ & 1.550 & 17.3 \\
\hline 5473 & $8 / 15 / 20081: 06$ & 1.550 & 17.3 \\
\hline 5474 & $8 / 15 / 20081: 08$ & 1.550 & 17.3 \\
\hline 5475 & $8 / 15 / 20081: 10$ & 1.549 & 17.3 \\
\hline 5476 & $8 / 15 / 20081: 12$ & 1.549 & 17.3 \\
\hline 5477 & $8 / 15 / 20081: 14$ & 1.549 & 17.3 \\
\hline 5478 & $8 / 15 / 20081: 16$ & 1.549 & 17.3 \\
\hline 5479 & $8 / 15 / 20081: 18$ & 1.549 & 17.3 \\
\hline 5480 & $8 / 15 / 20081: 20$ & 1.548 & 17.3 \\
\hline 5481 & $8 / 15 / 20081: 22$ & 1.549 & 17.3 \\
\hline 5482 & $8 / 15 / 20081: 24$ & 1.548 & 17.3 \\
\hline 5483 & $8 / 15 / 20081: 26$ & 1.548 & 17.3 \\
\hline 5484 & $8 / 15 / 20081: 28$ & 1.548 & 17.3 \\
\hline 5485 & $8 / 15 / 20081: 30$ & 1.548 & 17.3 \\
\hline 5486 & $8 / 15 / 20081: 32$ & 1.548 & 17.3 \\
\hline 5487 & $8 / 15 / 20081: 34$ & 1.548 & 17.3 \\
\hline 5488 & $8 / 15 / 20081: 36$ & 1.548 & 17.3 \\
\hline 5489 & $8 / 15 / 20081: 38$ & 1.547 & 17.3 \\
\hline 5490 & $8 / 15 / 20081: 40$ & 1.547 & 17.3 \\
\hline 5491 & $8 / 15 / 20081: 42$ & \begin{tabular}{|l|l|}
1.547 \\
\end{tabular} & 17.3 \\
\hline 5492 & $8 / 15 / 20081: 44$ & 1.547 & 17.3 \\
\hline 5498 & $8 / 15 / 20081: 46$ & 1.547 & 17.3 \\
\hline 5494 & $8 / 15 / 20081: 48$ & 1.547 & 17.3 \\
\hline 5495 & $8 / 15 / 20081: 50$ & 1.547 & 17.3 \\
\hline 5496 & $8 / 15 / 20081: 52$ & 1.547 & 17.3 \\
\hline 5497 & $8 / 15 / 20081: 54$ & 1.547 & 17.3 \\
\hline 5496 & $8 / 15 / 20081: 56$ & 1.547 & 17.3 \\
\hline 5499 & $8 / 15 / 20081: 58$ & 1.547 & 17.3 \\
\hline 5500 & $8 / 15 / 2008200$ & 1.547 & 17.3 \\
\hline 5501 & $8 / 15 / 20082: 02$ & 1.547 & 17.3 \\
\hline 5500 & $8 / 15 / 20082: 04$ & 1.546 & 17.3 \\
\hline 5603 & $8 / 15 / 2008206$ & 1.546 & 17.3 \\
\hline 5504 & $8 / 15 / 2008208$ & 1.546 & 17.3 \\
\hline 5505 & $8 / 15 / 2008210$ & 1.547 & 17.3 \\
\hline
\end{tabular}

\begin{tabular}{|c|c|c|c|}
\hline \multicolumn{4}{|c|}{$0425 p$} \\
\hline $\mathrm{Rec}$ & & Pres & Termp \\
\hline \# & Dater/me & psi & ${ }^{\circ} \mathrm{C}$ \\
\hline 5506 & $8 / 15 / 2008212$ & 1.547 & 17.3 \\
\hline 5507 & $8 / 15 / 2008214$ & 1.546 & 17.3 \\
\hline 5508 & $8 / 15 / 2008216$ & 1.546 & 17.3 \\
\hline 5509 & $8 / 15 / 2008218$ & 1.546 & 17.3 \\
\hline 5510 & $8 / 152008220$ & 1.545 & 17.3 \\
\hline 5511 & $8 / 15 / 2008222$ & 1.546 & 17.3 \\
\hline 5612 & $8 / 15 / 2008224$ & 1.545 & 17.3 \\
\hline 5613 & $8 / 15 / 2008226$ & 1.546 & 17.3 \\
\hline 5514 & $8 / 15 / 2008228$ & 1.545 & 17.3 \\
\hline 5615 & $8 / 15 / 2008230$ & 1.546 & 17.3 \\
\hline 5516 & $8 / 152008232$ & 1.545 & 17.3 \\
\hline 5517 & $8 / 15 / 2008234$ & 1.545 & 17.3 \\
\hline 5618 & $8 / 15 / 2008236$ & 1.545 & 17.3 \\
\hline 5519 & $8 / 15 / 2008238$ & 1.545 & 17.3 \\
\hline 5620 & $8 / 15 / 2008240$ & 1.544 & 17.3 \\
\hline 5521 & $8 / 15 / 2008242$ & 1.544 & 17.3 \\
\hline 5622 & $8 / 15 / 2008244$ & 1.544 & 17.3 \\
\hline 5623 & $8 / 15 / 2008246$ & 1.545 & 17.3 \\
\hline 5524 & $8 / 15 / 2008248$ & 1.543 & 17.3 \\
\hline 5525 & $8 / 15 / 2008250$ & 1.544 & 17.3 \\
\hline 5526 & $8 / 15 / 2008252$ & 1.544 & 17.3 \\
\hline 5627 & $8 / 15 / 2008254$ & 1.544 & 17.3 \\
\hline 5528 & $8 / 15 / 2008256$ & 1.544 & 17.3 \\
\hline 5029 & $8 / 15 / 2008258$ & 1.545 & 17.3 \\
\hline 5530 & $8 / 15 / 20083: 00$ & 1.544 & 17.3 \\
\hline 5531 & $8 / 15 / 20083: 02$ & 1.544 & 17.3 \\
\hline 5532 & $8 / 15 / 20083: 04$ & 1.544 & 17.3 \\
\hline 5533 & $8 / 15 / 20083: 06$ & 1.544 & 17.3 \\
\hline 5534 & $8 / 15 / 20083: 08$ & 1.543 & 17.3 \\
\hline 5535 & $8 / 15 / 20083: 10$ & 1.543 & 17.3 \\
\hline 5536 & $8 / 15 / 20083: 12$ & 1.543 & 17.3 \\
\hline 5537 & $8 / 15 / 20083: 14$ & 1.542 & 17.3 \\
\hline 5538 & 8/15/20083:16 & 1.542 & 17.3 \\
\hline 5539 & $8 / 15 / 20083: 18$ & 1.542 & 17.3 \\
\hline 5540 & $8 / 15 / 20083: 20$ & \begin{tabular}{|l|}
1.542 \\
\end{tabular} & 17.3 \\
\hline 5541 & $8 / 15 / 20083: 22$ & 1.541 & 17.3 \\
\hline 5542 & $8 / 15 / 20083: 24$ & 1.541 & 17.3 \\
\hline 5543 & $8 / 15 / 20083: 26$ & 1.541 & 17.3 \\
\hline 5644 & $8 / 15 / 20083: 28$ & 1.541 & 17.3 \\
\hline 5545 & $8 / 15 / 20083: 30$ & 1.542 & 17.3 \\
\hline 5546 & $8 / 15 / 20083: 32$ & 1.542 & 17.3 \\
\hline 5647 & $8 / 15 / 20083: 34$ & 1.541 & 17.3 \\
\hline 5548 & $8 / 15 / 20083: 36$ & 1.542 & 17.3 \\
\hline 5549 & $8 / 15 / 20083.38$ & 1.542 & 17.3 \\
\hline 5650 & $8 / 15 / 20083: 40$ & 1.541 & 17.3 \\
\hline 5551 & $8 / 15 / 20083: 42$ & 1.542 & 17.3 \\
\hline 5552 & $8 / 15 / 20083: 44$ & 1.542 & 17.3 \\
\hline 5553 & $8 / 15 / 20083: 46$ & 1.541 & 17.3 \\
\hline 5654 & $8 / 1520083: 48$ & 1.541 & 17.3 \\
\hline 5555 & $8 / 15 / 20083: 50$ & 1.541 & 17.3 \\
\hline 5556 & $8 / 15 / 20083552$ & 1.541 & 17.3 \\
\hline 5507 & $8 / 15 / 20083: 54$ & 1.541 & 17.3 \\
\hline 5658 & $8 / 15 / 20083: 56$ & 1.541 & 17.3 \\
\hline 5559 & $8 / 15 / 20083: 58$ & 1.541 & 17.3 \\
\hline 5560 & $8 / 15 / 2008$ 4:00 & 1.541 & 17.3 \\
\hline 5561 & $8 / 15 / 20084: 02$ & 1.540 & 17.3 \\
\hline 5562 & $8 / 15 / 20084: 04$ & 1.540 & 17.3 \\
\hline 5663 & $8 / 15 / 20084: 06$ & 1.540 & 17.3 \\
\hline 5564 & 8/15/2008 4:08 & 1.540 & 17.3 \\
\hline 5565 & $8 / 15 / 20084: 10$ & 1.540 & 17.3 \\
\hline 5566 & 8/15/20084:12 & 1.541 & 17.3 \\
\hline 5567 & $8 / 15 / 20084: 14$ & 1.541 & 17.3 \\
\hline 5668 & 8/15/2008 4:16 & \begin{tabular}{|l|}
1.541 \\
\end{tabular} & 17.3 \\
\hline 5569 & $8 / 15 / 20084: 18$ & 1.540 & 17.3 \\
\hline 5670 & $8 / 15 / 20084: 20$ & 1.541 & 17.3 \\
\hline 5671 & $8 / 15 / 20084: 22$ & 1.541 & 17.3 \\
\hline 5572 & $8 / 15 / 20084: 24$ & 1.541 & 17.3 \\
\hline 5573 & $8 / 15 / 20084: 26$ & 1.541 & 17.3 \\
\hline 5574 & $8 / 15 / 20084: 28$ & 1.541 & 17.3 \\
\hline
\end{tabular}

\begin{tabular}{|c|c|c|c|}
\hline \multicolumn{4}{|c|}{$D 425 p$} \\
\hline Rec & & Pres & Temp \\
\hline$\#$ & DateTime & psi & ${ }^{\circ} \mathrm{C}$ \\
\hline 5575 & $8 / 15 / 20084: 30$ & $0 \mid \frac{1.541}{0}$ & 17.3 \\
\hline 5076 & $8 / 15 / 20084: 32$ & 21.540 & 17.3 \\
\hline 557 & $8 / 15 / 20084: 34$ & 4.540 & 17.3 \\
\hline 558 & $8 / 15 / 20084: 36$ & 6 & 17.3 \\
\hline 5579 & $8 / 1520084: 38$ & 81.540 & 17.3 \\
\hline 5580 & $8 / 15 / 20084: 40$ & 1.539 & 17.3 \\
\hline 5581 & $8 / 15 / 20084: 42$ & 21.539 & 17.3 \\
\hline 5582 & $8 / 15 / 20084: 44$ & 41.538 & 17.3 \\
\hline 5583 & $8 / 15 / 20084: 46$ & 6 1.538 & 17.3 \\
\hline 5584 & $8 / 15 / 20084: 48$ & \begin{tabular}{l|l|l|l|l|l|}
8 & 1.537 \\
\end{tabular} & $\frac{11.4}{173}$ \\
\hline 5585 & $8 / 15 / 20084: 50$ & 01.537 & 17.3 \\
\hline 5586 & $8 / 15 / 20084: 52$ & 21.538 & 17.3 \\
\hline 5587 & $8 / 15 / 20084: 54$ & 4 & 17.3 \\
\hline 5588 & $8 / 15 / 20084: 56$ & 6.538 & 17.3 \\
\hline 5589 & $8 / 15 / 20084: 58$ & 81.538 & 17.3 \\
\hline 5590 & $8 / 15 / 20085: 00$ & 1.538 & 17.3 \\
\hline 5591 & $8 / 15 / 20085: 02$ & 1.538 & 17.3 \\
\hline 5592 & $8 / 15200085: 04$ & 4.539 & 17.3 \\
\hline 5593 & $8 / 15 / 20085: 06$ & 1.538 & 17.3 \\
\hline 5594 & $8 / 15 / 20085: 08$ & \begin{tabular}{|l|l|}
3 & 1.538 \\
\end{tabular} & 17.3 \\
\hline 5505 & $8 / 15 / 20085: 10$ & 1.538 & 17.3 \\
\hline 5506 & $8 / 15 / 20085: 12$ & 1.538 & 17.3 \\
\hline 5597| & $8 / 15 / 20085: 14$ & 1.538 & 17.3 \\
\hline 5598 & $8 / 15 / 20085: 16$ & | 1.537 & 17.3 \\
\hline 5599 & $8 / 15 / 20085: 18$ & 31.537 & 17.3 \\
\hline 5600 & $8 / 15 / 20085: 20$ & 1.538 & 17.3 \\
\hline 5601 & $8 / 1 5 \longdiv { 2 0 0 8 5 : 2 0 }$ & 1.537 & 17.3 \\
\hline 5602 & $8 / 15 / 20085: 24$ & 1.537 & 17.3 \\
\hline 5603 & $8 / 15 / 20085: 26$ & 1.537 & 17.3 \\
\hline 5004 & $8 / 15 / 20085: 28$ & 1.536 & 17.3 \\
\hline 5605 & $8 / 15 / 20085: 30$ & 1.536 & 17.3 \\
\hline 5606 & $8 / 15 / 20085: 32$ & 1.536 & 17.3 \\
\hline 5607 & $8 / 15 / 20085: 34$ & 1.536 & 17.3 \\
\hline 5608 & $8 / 15 / 2008536$ & \begin{tabular}{|c|c|}
1.536 \\
\end{tabular} & 17.3 \\
\hline 5609 & $8 / 15 / 20085: 38$ & 3.56 & 17.3 \\
\hline 5610 & $8 / 15 / 20085: 40$ & 1.536 & 17.3 \\
\hline 5611 & $8 / 15 / 20085: 42$ & 1.535 & 17.3 \\
\hline 5612 & $8 / 15 / 20085: 44$ & 1.536 & 17.3 \\
\hline 5613 & $8 / 15 / 20085: 46$ & 1.536 & 17.3 \\
\hline 5614 & $8 / 1520085: 48$ & 31.536 & 17.3 \\
\hline 5615 & $8 / 15 / 20085: 50$ & 1.536 & 17.3 \\
\hline 5616 & $8 / 15 / 20085: 52$ & 1.536 & 17.3 \\
\hline 5617 & $8 / 15 / 20085: 54$ & 1.535 & 17.3 \\
\hline 5618 & $8 / 15 / 20085: 56$ & 1.535 & 17.3 \\
\hline 5619 & $8 / 15 / 20085: 58$ & 1.534 & 17.3 \\
\hline 5620 & $8 / 15 / 20086: 00$ & 1.534 & 17.3 \\
\hline 5621 & $8 / 15 / 20086: 02$ & 1.535 & 17.3 \\
\hline 562 & $8 / 15 / 20086: 04$ & 1.535 & 17.3 \\
\hline 5623 & $8 / 15 / 20086: 06$ & 1.535 & 17.3 \\
\hline 5624 & $8 / 15 / 20086: 08$ & 1.535 & 17.3 \\
\hline 5625 & $8 / 15 / 20086: 10$ & 1.534 & 17.3 \\
\hline 5626 & $8 / 15 / 20086: 12$ & 1.534 & 17.3 \\
\hline 5627 & $8 / 15 / 20086: 14$ & 1.535 & 17.3 \\
\hline 5628 & $8 / 15 / 20086: 16$ & 1.535 & 17.3 \\
\hline 5629 & $8 / 15 / 20086: 18$ & 1.535 & 17.3 \\
\hline 5630 & $8 / 45 / 20086: 20$ & 1.535 & 17.3 \\
\hline 5631 & $8 / 15 / 20086: 22$ & 1.535 & 17.3 \\
\hline 5632 & $8 / 15 / 20086: 24$ & \begin{tabular}{|l|l|}
1.534 \\
\end{tabular} & 17.3 \\
\hline 5633 & $8 / 45 / 20086: 26$ & 1.534 & 17.3 \\
\hline 5634 & $8 / 15 / 20086: 28$ & 1.534 & 17.3 \\
\hline 5635 & $8 / 15 / 20086: 30$ & 1.534 & 17.3 \\
\hline 5636 & $8 / 15 / 20086: 32$ & 1.534 & 17.3 \\
\hline 5637 & $8 / 15 / 20086: 34$ & 1.533 & 17.3 \\
\hline 5638 & $8 / 15 / 20086: 36$ & 1.533 & 17.3 \\
\hline 5639 & $8 / 15 / 20086: 38$ & 1.533 & 17.3 \\
\hline 5640 & $8 / 15 / 20086: 40$ & 1.534 & 17.3 \\
\hline 5641 & $8 / 15 / 20086: 42$ & 1.533 & 17.3 \\
\hline 5642 & $8 / 15 / 20086: 44$ & 1.534 & \\
\hline 5643 & $8 / 15 / 20086: 46$ & 1.534 & 17.3 \\
\hline
\end{tabular}

\begin{tabular}{|c|c|c|c|}
\hline \multicolumn{4}{|c|}{ D4-25p } \\
\hline $\mathrm{PeC}$ & & Pres & Temp \\
\hline$\#$ & DaterTime & psi & ${ }^{\circ} \mathrm{C}$ \\
\hline 5644 & $8 / 15 / 20086: 48$ & 1.533 & 17.3 \\
\hline 5645 & $8 / 15 / 20086: 50$ & 1.532 & 17.3 \\
\hline 5646 & $8 / 15 / 20086: 52$ & 1.532 & 17.3 \\
\hline 5647 & $8 / 15 / 20086: 54$ & 1.532 & 17.3 \\
\hline 5648 & $8 / 15 / 20086: 56$ & 1.533 & 17.3 \\
\hline 5649 & $8 / 15 / 20086.58$ & 1.533 & 17.3 \\
\hline 5650 & $8 / 15 / 20087: 00$ & 1.533 & 17.3 \\
\hline 5651 & $8 / 15 / 20087: 02$ & 1.533 & 17.3 \\
\hline 5652 & $8 / 15 / 20087: 04$ & 1.533 & 17.3 \\
\hline 5653 & $8 / 15 / 20087: 06$ & 1.533 & 17.3 \\
\hline 5654 & $8 / 15 / 20087: 08$ & 1.533 & 17.3 \\
\hline 5655 & $8 / 15 / 20087: 10$ & 1.532 & 17.3 \\
\hline 5656 & $8 / 15 / 20087: 12$ & 1.533 & 17.3 \\
\hline 5607 & $8 / 15 / 20087: 14$ & 1.533 & 17.3 \\
\hline 5658 & $8 / 15 / 20087: 16$ & 1.53 & 17.3 \\
\hline 5659 & $8 / 15 / 20087: 18$ & 1.532 & 17.3 \\
\hline 5600 & 8/15/20087:20 & 1.532 & 17.3 \\
\hline 5661 & $8 / 15 / 20087: 2$ & 1.532 & 17.3 \\
\hline 5662 & $8 / 15 / 20087: 24$ & 1.532 & 17.3 \\
\hline 5663 & $8 / 15 / 20087: 26$ & 1.532 & 17.3 \\
\hline 5664 & $8 / 15 / 20087: 28$ & 1.532 & 17.3 \\
\hline 5665 & $8 / 15 / 20087: 30$ & 1.532 & 17.3 \\
\hline 5660 & $8 / 15 / 20087: 32$ & 1.532 & 17.3 \\
\hline 5667 & $8 / 15 / 20087: 34$ & 1.531 & 17.3 \\
\hline 5668 & $8 / 15 / 20087: 36$ & 1.531 & 17.3 \\
\hline 5669 & $8 / 15 / 20087: 38$ & 1.532 & 17.3 \\
\hline 5670 & $8 / 15 / 20087: 40$ & 1.532 & 17.3 \\
\hline 5671 & $8 / 15 / 20087: 42$ & 1.532 & 17.3 \\
\hline 5672 & $8 / 15 / 20087: 44$ & 1.532 & 17.3 \\
\hline 5673 & $8 / 15 / 20087: 46$ & 1.532 & 17.3 \\
\hline 5674 & $8 / 15 / 20087: 48$ & 1.532 & 17.3 \\
\hline 5675 & $8 / 15 / 20087: 50$ & 1.531 & 17.3 \\
\hline 5676 & $8 / 15 / 20087: 52$ & 1.532 & 17.3 \\
\hline 567 & $8 / 15 / 20087: 54$ & 1.532 & 17.3 \\
\hline 5678 & $8 / 15 / 20087: 56$ & 1.532 & 17.3 \\
\hline 5679 & $8 / 15 / 20087: 58$ & 1.532 & 17.3 \\
\hline 5680 & $8 / 1520088: 00$ & 1.532 & 17.3 \\
\hline 5681 & $8 / 15 / 20088: 02$ & 1.532 & 17.3 \\
\hline 5682 & $8 / 15 / 2008804$ & 1.531 & 17.3 \\
\hline 5683 & $8 / 15 / 20088.06$ & 1.531 & 17.3 \\
\hline 5684 & $8 / 15 / 20088: 08$ & 1.531 & 17.3 \\
\hline 5685 & $8 / 15 / 20088: 10$ & 1.531 & 17.3 \\
\hline 5686 & $8 / 15 / 20088: 12$ & 1.531 & 17.3 \\
\hline 5687 & $8 / 15 / 20088: 14$ & 1.531 & 17.3 \\
\hline 5688 & $8 / 15 / 20088: 16$ & 1.531 & 17.3 \\
\hline 5689 & $8 / 15 / 20088: 18$ & 1.531 & 17.3 \\
\hline 5690 & $8 / 15 / 20088: 20$ & 1.530 & 17.3 \\
\hline 5691 & $8 / 15 / 20088: 22$ & 1.530 & 17.3 \\
\hline 5692 & $8 / 15 / 20088: 24$ & 1.530 & 17.3 \\
\hline 5693 & $8 / 15 / 20088.26$ & 1.520 & 17.3 \\
\hline 5694 & $8 / 15 / 20088: 28$ & 1.529 & 17.3 \\
\hline 5695 & $8 / 15 / 2008: 30$ & 1.520 & 17.3 \\
\hline 5696 & $8 / 15 / 20088: 32$ & 1.520 & 17.3 \\
\hline 5697 & $8 / 15 / 20088: 34$ & 1.530 & 17.3 \\
\hline 5698 & $8 / 15 / 20088: 36$ & 1.531 & 17.3 \\
\hline 5699 & $8 / 15 / 20088: 38$ & 1.530 & 17.3 \\
\hline 5700 & $8 / 15 / 20088: 40$ & 1.530 & 17.3 \\
\hline 5701 & $8 / 15 / 20088: 42$ & 1.530 & 17.3 \\
\hline 5700 & $8 / 15 / 20088: 44$ & 1.530 & 17.3 \\
\hline 5703 & $8 / 15 / 20088.46$ & 1.520 & 17.3 \\
\hline 5704 & $8 / 15 / 20088: 48$ & 1.530 & 17.3 \\
\hline 5706 & $8 / 15 / 20088: 50$ & 1.530 & 17.3 \\
\hline 5706 & $8 / 15 / 20088.52$ & 1.530 & 17.3 \\
\hline 5707 & $8 / 15 / 20088: 54$ & 1.530 & 17.3 \\
\hline 5708 & $8 / 15 / 20088: 56$ & 1.530 & 17.3 \\
\hline 5709 & $8 / 15 / 20088: 58$ & 1.530 & 17.3 \\
\hline 5710 & $8 / 15 / 20089000$ & 1.530 & 17.3 \\
\hline 5711 & $8 / 15 / 20089: 02$ & 1.530 & 17.3 \\
\hline 5712 & $8 / 15 / 20089.04$ & 1.530 & 17.3 \\
\hline
\end{tabular}

\begin{tabular}{|c|c|c|c|}
\hline \multicolumn{4}{|c|}{$D 425 p$} \\
\hline $\mathrm{Rec}$ & & Pres & Temp \\
\hline$\#$ & Date/Time & psi & ${ }^{\circ} \mathrm{C}$ \\
\hline 5713 & $8 / 15 / 20089.06$ & 1.530 & 17.3 \\
\hline 5714 & $8 / 15 / 20089.08$ & 1.530 & 17.3 \\
\hline 5715 & $8 / 15 / 20089.10$ & 1.530 & 17.3 \\
\hline 5716 & $8 / 15 / 20089.12$ & 1.530 & 17.3 \\
\hline 5717 & $8 / 15 / 20089: 14$ & 1.530 & 17.3 \\
\hline 5718 & $8 / 15 / 20089: 16$ & 1.530 & 17.3 \\
\hline 5719 & $8 / 15 / 20089.18$ & 1.529 & 17.3 \\
\hline 5720 & $8 / 15 / 20089.20$ & 1.530 & 17.3 \\
\hline $5 / 21$ & $8 / 15120089: 22$ & 1.530 & 17.3 \\
\hline 572 & $8 / 15 / 20089.24$ & 1.529 & 17.3 \\
\hline 5723 & $8 / 15 / 20089.26$ & 1.529 & 17.3 \\
\hline 5724 & $8 / 15 / 20089.28$ & 1.529 & 17.3 \\
\hline 5725 & $8 / 15 / 20089: 30$ & 1.528 & 17.3 \\
\hline 5726 & $8 / 15 / 20089.32$ & 1.528 & 17.3 \\
\hline 5727 & $8 / 15 / 20089.34$ & 1.528 & 17.3 \\
\hline 5728 & $8 / 15 / 20089.36$ & 1.528 & 17.3 \\
\hline 5729 & $8 / 15 / 20089.38$ & 1.528 & 17.3 \\
\hline 5730 & $8 / 15 / 20089.40$ & 1.528 & 17.3 \\
\hline 5731 & $8 / 15 / 20089.42$ & 1.528 & 17.3 \\
\hline 5732 & $8 / 15 / 20089: 44$ & 1.528 & 17.3 \\
\hline 5733 & $8 / 15 / 20089.46$ & 1.528 & 17.3 \\
\hline $5 / 34$ & $8 / 15 / 20089: 48$ & 1.528 & 17.3 \\
\hline 5736 & $8115 / 20089.50$ & 1.528 & 17.3 \\
\hline 5736 & $8 / 15 / 20089: 52$ & 1.528 & 17.3 \\
\hline 5737 & $8 / 15 / 20089.54$ & 1.528 & 17.3 \\
\hline 5738 & $8 / 15 / 20089.56$ & 1.528 & 17.3 \\
\hline 5739 & $8 / 15 / 20089.58$ & 1.528 & 17.3 \\
\hline 5740 & $8 / 15 / 200810: 00$ & 1.528 & 17.3 \\
\hline 5741 & $8 / 15 / 2008$ 10:02 & 1.528 & 17.3 \\
\hline 5742 & $8 / 15 / 200810: 04$ & 1.528 & 17.3 \\
\hline 5743 & $8 / 15 / 200810: 06$ & 1.529 & 17.3 \\
\hline 574 & $8 / 15 / 200810: 08$ & 1.529 & 17.3 \\
\hline 5745 & $8 / 15 / 2008$ 10:10 & 1.520 & 17.3 \\
\hline 5746 & $8 / 15 / 2008$ 10:12 & 1.528 & 17.3 \\
\hline 5747 & $8 / 15 / 200810: 14$ & 1.529 & 17.3 \\
\hline 5748 & $8 / 15 / 2008$ 10:16 & 1.528 & 17.3 \\
\hline 5749 & $8 / 15 / 2008$ 10:18 & 1.528 & 17.3 \\
\hline 5750 & $8 / 15 / 200810: 20$ & 1.528 & 17.3 \\
\hline 5751 & $8 / 15200810.22$ & 1.528 & 17.3 \\
\hline $5 / 52$ & $8 / 15 / 200810: 24$ & 1.527 & 17.3 \\
\hline 5753 & $8 / 15 / 200810.26$ & 1.527 & 17.3 \\
\hline 5754 & $8 / 15 / 2008$ 10:28 & 1.528 & 17.3 \\
\hline 5750 & $8 / 15 / 200810: 30$ & 1.527 & 17.3 \\
\hline 5756 & $8 / 15 / 200810: 32$ & 1.528 & 17.3 \\
\hline 5757 & $8 / 15 / 200810: 34$ & 1.527 & 17.3 \\
\hline 5758 & $8 / 151200810.36$ & 1.527 & 17.3 \\
\hline 5759 & $8 / 15 / 200810.38$ & 1.527 & 17.3 \\
\hline 5760 & $8 / 15 / 200810: 40$ & 1.527 & 17.3 \\
\hline 5761 & $8 / 15 / 200810: 42$ & 1.528 & 17.3 \\
\hline 5762 & $8 / 15 / 200810: 44$ & 1.527 & 17.3 \\
\hline $5 \times 63$ & $8 / 15 / 200810.46$ & 1.527 & 17.3 \\
\hline 5764 & $8 / 15 / 200810.48$ & 1.527 & 17.3 \\
\hline 5765 & $8 / 15 / 200810: 50$ & 1.526 & 17.3 \\
\hline 5766 & $8 / 15 / 200810: 52$ & 1.527 & 17.3 \\
\hline 5767 & $8 / 15 / 2008$ 10:54 & 1.526 & 17.3 \\
\hline 5768 & $8 / 15 / 2008$ 10:56 & 1.527 & 17.3 \\
\hline 576 & $8 / 15 / 200810: 58$ & 1.527 & 17.3 \\
\hline 5770 & $8 / 15200811: 00$ & 1.526 & 17.3 \\
\hline 5771 & $8 / 15 / 2008$ 11:02 & 1.526 & 17.3 \\
\hline $5 / 2$ & $8 / 15 / 2008$ 11:04 & 1.527 & 17.3 \\
\hline 5773 & $8115200811: 06$ & 1.527 & 17.3 \\
\hline 574 & $8 / 15 / 2008$ 11:08 & 1.527 & 17.3 \\
\hline $5 / 75$ & $8 / 15 / 2008$ 11:10 & 1.527 & 17.3 \\
\hline 5776 & $8 / 15 / 2008$ 11:12 & 1.527 & 17.3 \\
\hline $5 \pi 7$ & $8 / 15 / 2008$ 11:14 & 1.527 & 17.3 \\
\hline $5 / 78$ & $8 / 152008$ 11:16 & 1.527 & 17.3 \\
\hline 5779 & $8 / 15 / 200811: 18$ & 1.527 & 17.3 \\
\hline 5780 & $8 / 15 / 2008$ 11:20 & 1.527 & 17.3 \\
\hline 5781 & $8 / 15 / 200811: 22$ & 1.527 & 17.3 \\
\hline
\end{tabular}




\begin{tabular}{|c|c|c|c|c|c|c|c|c|c|c|c|c|c|c|c|c|c|c|c|}
\hline \multicolumn{4}{|c|}{$D 425 p$} & \multicolumn{4}{|c|}{ D425p } & \multicolumn{4}{|c|}{ D425p } & \multicolumn{4}{|c|}{ D425p } & & $D 425 p$ & & \\
\hline $\mathrm{BeC}$ & & Pres & Temp & $\mathrm{BeC}$ & & Pres & Temp & $\mathrm{FeC}$ & & Pres & Temp & $R e c$ & & & Temp & \begin{tabular}{|l|l}
$\operatorname{Rec}$ \\
\end{tabular} & & Pres & Temp \\
\hline$\#$ & DeterTime & psi & ${ }^{\circ} \mathrm{C}$ & $\#$ & Dater/ime & psi & ${ }^{\circ} \mathrm{C}$ & $\#$ & Date/Time & psi & ${ }^{\circ} \mathrm{C}$ & $\#$ & Daterime & psi & ${ }^{\circ} \mathrm{C}$ & $\#$ & DateTime & psi & \\
\hline 5782 & $8 / 15 / 200811: 24$ & 1.527 & 17.3 & & & & & & & & & & & & & & & & \\
\hline 5783 & $8 / 152000111: 26 \mid$ & 1.527 & 17.3 & & & & & & & & & & & & & & & & \\
\hline 5784 & $8 / 15 / 200811: 28$ & 1.526 & 17.3 & & & & & & & & & & & & & & & & \\
\hline 5785 & $8 / 15 / 200811: 30$ & 1.526 & 17.3 & & & & & & & & & & & & & & & & \\
\hline 5786 & $8 / 15200811: 32$ & 1.527 & 17.3 & & & & & 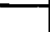 & & & & & & & & & & & 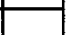 \\
\hline 5787 & $8 / 15 / 200811: 34$ & 1.526 & 17.3 & - & & & & & & & & & & & & & & & \\
\hline 5788 & $8 / 15200811: 36$ & 1.527 & 17.3 & & & & & E- & & & & & & & & & & & \\
\hline 5789 & $8 / 15200811: 38$ & 1.526 & 17.3 & E & & & & & & & & & & & & & & & \\
\hline 5790 & $8 / 15200811: 40$ & 1.526 & 17.3 & ב & & & & & & & & & & & & & & & \\
\hline $5 \% 91$ & $8 / 152000111: 42$ & 1.526 & 17.3 & & & & & & & & & - & & & & & & & \\
\hline 5192 & $8 / 15200811: 44$ & 1.526 & 17.3 & & & & & & & & & & & & & & & & \\
\hline 5793 & \begin{tabular}{|l|l|}
$8 / 200811: 46 \mid$ \\
\end{tabular} & 1.526 & 17.3 & 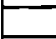 & & & & & & & & & & & & & & & \\
\hline 5794 & $8 / 15 / 200811: 48$ & 1.526 & 17.3 & & & & & & & & & & & & & & & & \\
\hline 5795 & 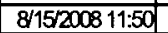 & 1.526 & 17.3 & 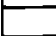 & & & & & & & & & & & & & & & \\
\hline 5796 & \begin{tabular}{|l|l|}
$8 / 2008+1: 52$ \\
\end{tabular} & 1.527 & 17.3 & 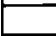 & & & & & & & & & & & & & & & \\
\hline 5797 & $8 / 15 / 200811: 54$ & 1.527 & 17.3 & - & & & & & & & & & & & & & & & \\
\hline 5798 & \begin{tabular}{|l|l|}
$8 / 15200811: 56$ \\
\end{tabular} & 1.526 & 17.3 & E & & & & & & & & - & & & & & & & \\
\hline 5799 & \begin{tabular}{|l|l|}
$815200811: 58$ \\
\end{tabular} & 1.526 & 17.3 & - & & & & & & & & 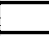 & & & & - & & & \\
\hline 5000 & \begin{tabular}{|l|l|l|l}
$815200812: 000$ \\
\end{tabular} & 1.526 & 17.3 & 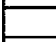 & & & & & & & & & & & & 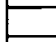 & & & \\
\hline 5001 & \begin{tabular}{|c|}
$8 / 15 / 200812: 02$ \\
\end{tabular} & 1.526 & 17.3 & & & & & & & & & & & & & & & & \\
\hline 5802 & \begin{tabular}{|l|l|}
$815 / 200812: 04$ \\
\end{tabular} & 1.525 & 17.3 & 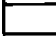 & & & & & & & & & & & & & & & \\
\hline 5803 & \begin{tabular}{|l|l|}
$815 / 200812: 06$ \\
\end{tabular} & 1.526 & 17.3 & 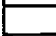 & & & & & & & & & & & & & & & \\
\hline 5804 & \begin{tabular}{|l|l|}
$8 / 15 / 200812: 08$ \\
\end{tabular} & 1.525 & 17.3 & E & & & & & & & & & & & & & & & \\
\hline 5805 & 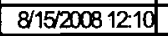 & 1.525 & 17.3 & E & & & & E & & & & E & & & & & & & \\
\hline 5806 & 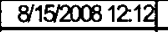 & 1.526 & 17.3 & - & & & & & & & & 品 & & & & 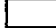 & & & \\
\hline 5807 & 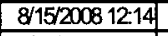 & 1.526 & 17.3 & 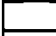 & & & & E & & & & \begin{tabular}{|l} 
\\
\end{tabular} & & & & & & & \\
\hline 5808 & \begin{tabular}{|l|l|}
$8 / 200812: 16$ \\
\end{tabular} & 1.525 & 17.3 & E & & & & & & & & 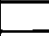 & & & & E & & & \\
\hline 5809 & 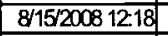 & 1.525 & 17.3 & 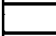 & & & & $E$ & & E & & E & & & & E & & - & \\
\hline 5810 & $8 / 15 / 20081220$ & 1.525 & 17.3 & 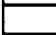 & & & & & & & & & & & & & & & \\
\hline 5811 & $8 / 15 / 20081222$ & 1.524 & 17.3 & - & & & & & & & & & & & & & & 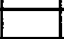 & \\
\hline 5812 & \begin{tabular}{|l|l|}
$8 / 15 / 200812: 24$ \\
\end{tabular} & 1.525 & 17.3 & E & & & & & & & & & & & & & & - & \\
\hline 5813 & \begin{tabular}{|l|}
$8115 / 200812226$ \\
\end{tabular} & 1.525 & 17.3 & $E$ & & & & & & & & 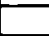 & & & & & & - & \\
\hline 5814 & $8 / 15 / 20081228$ & 1.525 & 17.3 & 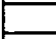 & & & & E & & & & & & & & & & & \\
\hline 5815 & \begin{tabular}{|l|l|}
11520081230 \\
\end{tabular} & 1.525 & 17.3 & 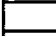 & & & & E & & & & 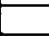 & & & & & & & \\
\hline 5816 & \begin{tabular}{|l|l|}
$8 / 20081232$ \\
\end{tabular} & 1.526 & 17.3 & 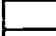 & & & & 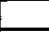 & & & 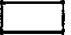 & 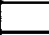 & & & & & & 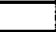 & \\
\hline 5817 & $8 / 15 / 200812: 34$ & 1.525 & 17.3 & - & & & & 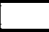 & & & & 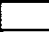 & & & & & & 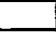 & \\
\hline 5818 & $8 / 15 / 20081236$ & 1.526 & 17.3 & 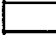 & & & & & & & & & & & & & & & \\
\hline 58819 & $8 / 15 / 200812: 38$ & 1.526 & 17.3 & 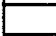 & & & & & & & & 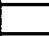 & & & & & & 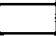 & \\
\hline 5820 & $8 / 15 / 20081240$ & 1.526 & 17.3 & - & & & & & & & & 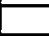 & & & & & & 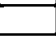 & \\
\hline 5821 & $8 / 15 / 200812: 42$ & 1.526 & 17.3 & 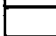 & & & & & & & & & & & & & & 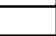 & \\
\hline 5822 & \begin{tabular}{|l|l|}
$8 / 20081244$ \\
\end{tabular} & 1.525 & 17.3 & - & & & & & & & & - & & & & & & & \\
\hline 5823 & $8 / 15 / 20081246$ & 1.526 & 17.3 & - & & & & & & & & & & & & & & & \\
\hline 5824 & $8 / 15 / 20081248$ & 1.525 & 477.3 & 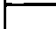 & & & & 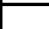 & & & & & & & & & & & \\
\hline 5825 & $8 / 15 / 20081250$ & 1.525 & 17.3 & 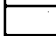 & & & & E & & & & 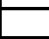 & & & & & & & \\
\hline 5826 & $8 / 15 / 20081252$ & 1.525 & 17.3 & E & & & & - & & & E & & & & & & & & Z \\
\hline 5827 & $8 / 15 / 20081254$ & 1.525 & 17.3 & E & & & & & & & & 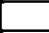 & & & & & & & ב \\
\hline 5828 & $8 / 15 / 200812.56$ & 1.525 & & 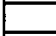 & & & & 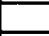 & & & 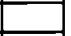 & & & & & & & & - \\
\hline 5829 & $8 / 15 / 20081258$ & 1.524 & 17.3 & 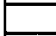 & & & & & & & & 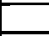 & & & & & & & \\
\hline 5830 & $8 / 15 / 200813: 00$ & 1.525 & 17.3 & 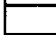 & & & & 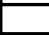 & & & - & 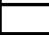 & & & & & & 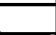 & \\
\hline 5831 & $8 / 15 / 2008$ 13:02 & 1.524 & 17.3 & 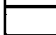 & & & & & & & & - & & & & & & & \\
\hline 5832 & $8 / 15 / 2008$ 13:04 & 1.525 & 17.3 & 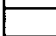 & & & & & & & - & & & & & & & & \\
\hline 5833 & $8 / 15 / 2008$ 13:06 & 1.524 & 17.3 & 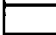 & & & & & & & 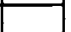 & & & & - & - & & 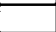 & - \\
\hline 5834 & \begin{tabular}{|l|l|}
$8 / 15200813: 08$ \\
\end{tabular} & 1.524 & 17.3 & & & & & & & & & & & & & & & & \\
\hline 5835 & $8 / 15 / 200813: 10$ & 1.525 & 17.3 & + & & & & & & & & 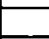 & & & 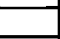 & & & & \\
\hline 5836 & $8 / 15200013: 12$ & 1.524 & 17.3 & 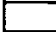 & & & & 口 & & & - & E & & & 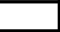 & 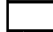 & & & \\
\hline 5837 & 8/15/2008 13:14 & 1.523 & 17.3 & E & & & & & & & $\square$ & - & & & - & - & & - & \\
\hline 5838 & 8/15/2008 13:16 & 1.523 & 17.3 & $E$ & & & & & & & - & $\square$ & & & 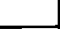 & $\square$ & & 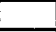 & \\
\hline 5839 & $8 / 15 / 200813: 18$ & 1.523 & 17.3 & & & & & & & & - & 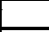 & & & 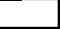 & & & & \\
\hline 5840 & $8115 / 200813: 20$ & 1.523 & 17.3 & & & & & & & & 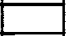 & 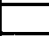 & & & Z & ב & & & \\
\hline 5841 & $8 / 15 / 200813: 22$ & 1.523 & 17.3 & 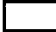 & & & & & & & & 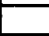 & & & - & 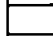 & & & \\
\hline 5842 & $8 / 15 / 200813: 24$ & 1.522 & 17.4 & & & & & & & & & & & & & & & & \\
\hline 5844 & \begin{tabular}{|l|l|}
$8152200813: 26$ \\
\end{tabular} & 1.522 & \begin{tabular}{|l|l|}
117.8 \\
\end{tabular} & & & & & & & & & 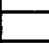 & & & & & & & \\
\hline & & & & & & & & & & & & E & & & & & & & \\
\hline & & & & & & & & & & & 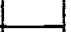 & - & & & & 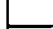 & & - & \\
\hline & & & & & & & & & & & & - & & & - & 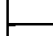 & & 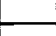 & \\
\hline & & & & & & & & & & & - & - & & & - & 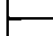 & & - & \\
\hline & & & & & & & & & & & & 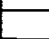 & & & - & L & & 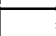 & \\
\hline & & & & & & & & & & & & 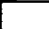 & & & 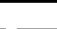 & & & & \\
\hline
\end{tabular}



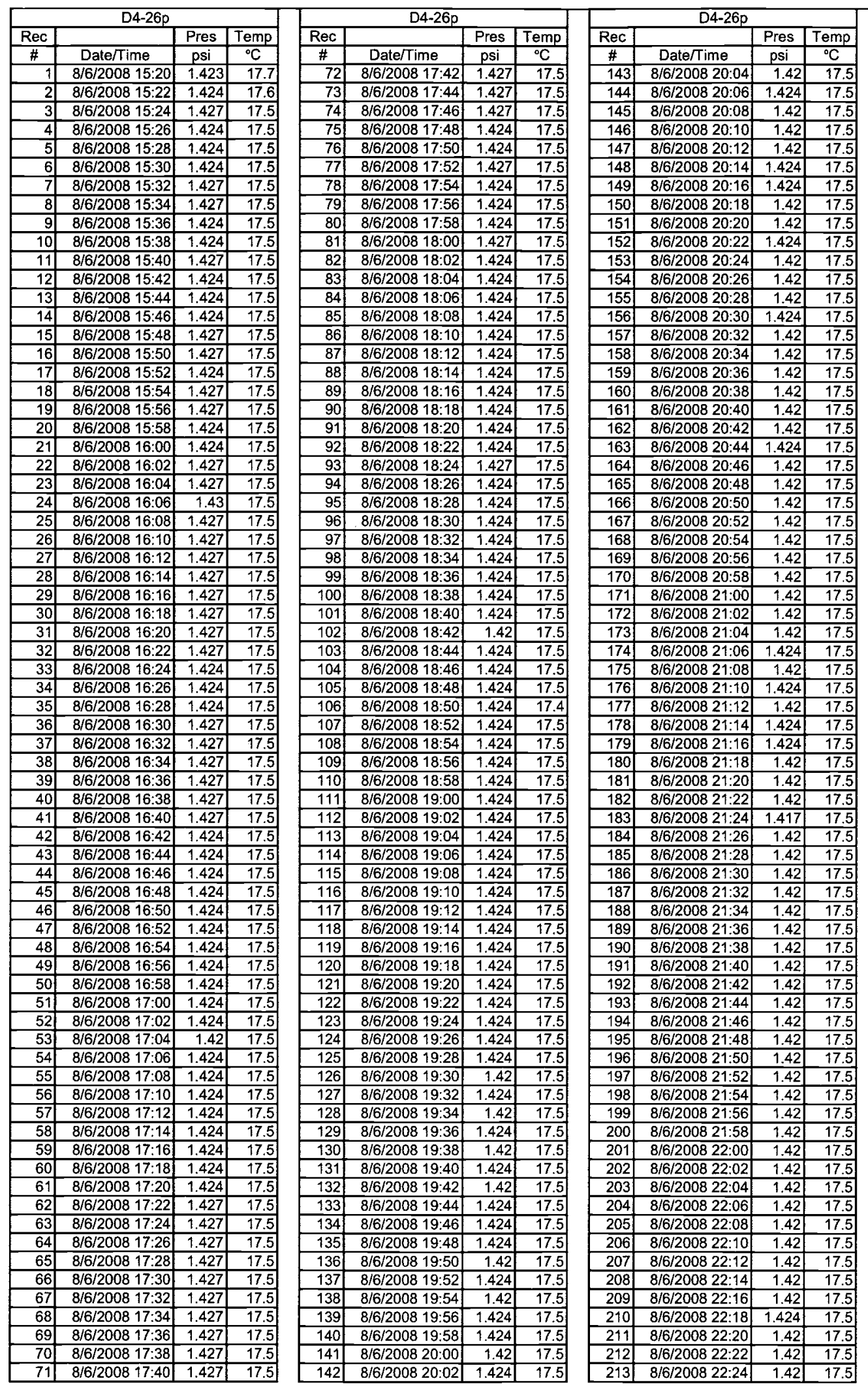

\begin{tabular}{|c|c|c|c|}
\hline \\
\hline & & Pres & \\
\hline$\#$ & Date/Time & psi & ${ }^{\circ} \mathrm{C}$ \\
\hline & 8/6/2008 22:26 & 1.42 & 17.5 \\
\hline & 8/6/2008 22:28 & & \\
\hline & $8 / 6 / 200822: 30$ & 1.42 & 17.5 \\
\hline & 12008 22:32 & 1.42 & 17.5 \\
\hline & 22:34 & 1.42 & \\
\hline & $822: 36$ & 1.42 & 17. \\
\hline & 6/2008 22:38 & & \\
\hline & i/2008 22:40 & 1.42 & 17 \\
\hline & 8/2008 22:42 & & \\
\hline & 8/6/2008 22:44 & $\overline{1.42} \quad \mathrm{Y}$ & \\
\hline 224 & $8 / 6 / 200822: 46$ & & 17. \\
\hline 225 & $8 / 6 / 200822: 48$ & $\overline{1.42}$ & 17. \\
\hline & 6/2008 22:50 & & \\
\hline & $8 / 6 / 200822: 52$ & 1.42 & 17. \\
\hline 228 & $8 / 6 / 200822: 54$ & 1.42 & 17. \\
\hline 229 & $8 / 6 / 200822: 56$ & $\overline{1.42}$ & 17. \\
\hline 230 & $8 / 6 / 200822: 58$ & $\overline{1.42}$ & 17. \\
\hline 231 & $823: 00$ & & \\
\hline & $8 / 6 / 200823: 02$ & 1.42 & \\
\hline & 8/6/2008 23:04 & & 17. \\
\hline 234 & 6/2008 23: & 1.42 & 17. $>\mathrm{l}$ \\
\hline & 23:08 & & \\
\hline 236 & 6/2008 23:10 & 1.417 & 17 \\
\hline 237 & 8/6/2008 23:12 & 1.42 & \\
\hline 238 & 8/6/2008 23:14 & $1.42 \quad \longrightarrow>$ & 17. \\
\hline & 6/2008 23:16 & $1.42 \quad>>$ & \\
\hline 240 & 8/6/2008 23:18 & 1.42 & 17. \\
\hline 241 & 6/2008 23:20 & 1.42 & \\
\hline 242 & $8 / 6 / 200823: 22$ & & \\
\hline 243 & $8 / 6 / 200823: 24$ & $\overline{1.42}$ & \\
\hline 244 & $8 / 6 / 200823: 26$ & 1.42 & \\
\hline & $8 / 6 / 200823: 28$ & 1.42 & \\
\hline & $823: 30$ & & \\
\hline 247 & $8 / 6 / 200823: 32$ & 1.42 & \\
\hline 248 & & & \\
\hline 249 & & 1.42 & \\
\hline 250 & $23: 38$ & 1.42 & \\
\hline 251 & $23: 40$ & 1.42 & 17. \\
\hline & $8 / 6 / 200823: 42$ & 1.42 & 17. \\
\hline 253 & $8 / 6 / 200823: 44$ & 1.42 & 17. \\
\hline 254 & & 1.42 & 17. \\
\hline & B 23:48 & 1.42 & \\
\hline 256 & $1823: 50$ & $1.42 \quad>$ & \\
\hline 257 & $8 / 6 / 200$ & 1.42 & \\
\hline 258 & $8 / 6 / 20$ & $1.42 \quad>$ & \\
\hline & & & \\
\hline 260 & $8 / 6 / 20$ & $\overline{1.42} \quad \mathrm{P}$ & \\
\hline 261 & $8 / 7 / 2$ & 1.42 & \\
\hline & $\pi / 2$ & 1.4 & \\
\hline & & 1.4 & \\
\hline 264 & & 1.4. & \\
\hline & & 1.4 & \\
\hline & $8 / 7 / 20$ & 1.42 & \\
\hline 267 & $8 / 7 / 200$ & 1.42 & \\
\hline & & 1.42 & \\
\hline & & 1.4 & \\
\hline 270 & & 1.42 & \\
\hline 271 & $8 / 7 / 26$ & 1.42 & \\
\hline & & 1.42 & \\
\hline & & 1.42 & 17. \\
\hline & & 1.417 & \\
\hline & & $1.4 .4-5$ & \\
\hline & & & \\
\hline & & 1.42 & \\
\hline & $8 / 7$ & 1.42 & \\
\hline & & 1.42 & \\
\hline & & 1.42 & \\
\hline & & 1.42 & \\
\hline & & 1.42 & \\
\hline & & $142>$ & \\
\hline 284 & $8 / 7 / 200$ & 1.42 & 17. \\
\hline
\end{tabular}




\begin{tabular}{|c|c|c|c|}
\hline \multicolumn{4}{|c|}{$\bar{D} 4-26 p$} \\
\hline $\operatorname{Rec}$ & & Pres & Temp \\
\hline$\#$ & Date/Time & psi & ${ }^{\circ} \mathrm{C}$ \\
\hline 285 & $8 / 7 / 20080: 48$ & 1.42 & 17.5 \\
\hline 286 & $8 / 7 / 20080: 50$ & 1.42 & 17.4 \\
\hline 287 & $8 / 7 / 20080: 52$ & 1.42 & 17.5 \\
\hline 288 & $8 / 7 / 20080: 54$ & 1.424 & 17.5 \\
\hline 289 & $8 / 7 / 20080: 56$ & 1.42 & 17.5 \\
\hline 290 & $8 / 7 / 20080: 58$ & 1.42 & 17.4 \\
\hline 291 & $8 / 7 / 20081: 00$ & 1.42 & 17.5 \\
\hline 292 & $8 / 7 / 20081: 02$ & 1.42 & 17.5 \\
\hline 293 & $8 / 7 / 2008$ 1:04 & 1.42 & 17.5 \\
\hline 294 & $8 / 7 / 2008$ 1:06 & 1.42 & 17.5 \\
\hline 295 & $8 / 7 / 20081: 08$ & 1.417 & 17.5 \\
\hline 296 & $8 / 7 / 20081: 10$ & 1.42 & 17.5 \\
\hline 297 & $8 / 7 / 2008$ 1:12 & 1.417 & 17.5 \\
\hline 298 & $8 / 7 / 2008$ 1:14 & 1.417 & 17.5 \\
\hline 299 & $8 / 7 / 2008$ 1:16 & 1.42 & 17.5 \\
\hline 300 & $8 / 7 / 2008$ 1:18 & 1.417 & 17.5 \\
\hline 301 & $8 / 7 / 2008$ 1:20 & 1.42 & 17.5 \\
\hline 302 & $8 / 7 / 20081: 22$ & 1.42 & 17.5 \\
\hline 303 & $8 / 7 / 20081: 24$ & 1.417 & 17.5 \\
\hline 304 & $8 / 7 / 2008$ 1:26 & 1.417 & 17.5 \\
\hline 305 & $8 / 7 / 2008 \quad 1: 28$ & 1.417 & 17.5 \\
\hline 306 & $8 / 7 / 20081: 30$ & 1.417 & 17.5 \\
\hline 307 & $8 / 7 / 20081: 32$ & 1.42 & 17.5 \\
\hline 308 & $8 / 7 / 20081: 34$ & 1.417 & 17.5 \\
\hline 309 & $8 / 7 / 20081: 36$ & 1.42 & 17.5 \\
\hline 310 & $8 / 7 / 2008$ 1:38 & 1.42 & 17.5 \\
\hline 311 & $8 / 7 / 2008$ 1:40 & 1.42 & 17.5 \\
\hline 312 & $8 / 7 / 20081: 42$ & 1.417 & 17.5 \\
\hline 313 & $8 / 7 / 20081: 44$ & 1.42 & 17.5 \\
\hline 314 & $8 / 7 / 2008$ 1:46 & 1.42 & 17.5 \\
\hline 315 & $8 / 7 / 20081: 48$ & 1.417 & 17.5 \\
\hline 316 & $8 / 7 / 2008$ 1:50 & 1.42 & 17.5 \\
\hline 317 & $8 / 7 / 20081: 52$ & 1.417 & 17.5 \\
\hline 318 & $8 / 7 / 20081: 54$ & 1.417 & 17.4 \\
\hline 319 & $8 / 7 / 20081: 56$ & 1.417 & 17.5 \\
\hline 320 & $8 / 7 / 20081: 58$ & 1.417 & 17.5 \\
\hline 321 & $8 / 7 / 20082: 00$ & 1.417 & 17.5 \\
\hline 322 & 8/7/2008 2:02 & 1.417 & 17.5 \\
\hline 323 & $8 / 7 / 20082: 04$ & 1.417 & 17.5 \\
\hline 324 & $8 / 7 / 20082: 06$ & 1.417 & 17.5 \\
\hline 325 & $8 / 7 / 20082: 08$ & 1.417 & 17.5 \\
\hline 326 & $8 / 7 / 20082: 10$ & 1.417 & 17.5 \\
\hline 327 & $8 / 7 / 20082: 12$ & 1.417 & 17.5 \\
\hline 328 & $8 / 7 / 2008$ 2:14 & 1.417 & 17.5 \\
\hline 329 & $8 / 7 / 20082: 16$ & 1.417 & 17.5 \\
\hline 330 & 8/7/2008 2:18 & 1.414 & 17.5 \\
\hline 331 & $8 / 7 / 2008$ 2:20 & 1.417 & 17.5 \\
\hline 332 & $8 / 7 / 20082: 22$ & 1.417 & 17.5 \\
\hline 333 & $8 / 7 / 20082: 24$ & 1.417 & 17.4 \\
\hline 334 & $8 / 7 / 20082: 26$ & 1.417 & 17.5 \\
\hline 335 & $8 / 7 / 20082: 28$ & 1.417 & 17.5 \\
\hline 336 & $8 / 7 / 20082: 30$ & & 17.5 \\
\hline 337 & $8 / 7 / 2008 \quad 2: 32$ & 1.417 & 17.5 \\
\hline 338 & $8 / 7 / 20082: 34$ & 1.417 & 17.5 \\
\hline 339 & $8 / 7 / 20082: 36$ & 1.417 & 17.5 \\
\hline 340 & $8 / 7 / 20082: 38$ & 1.417 & 17.5 \\
\hline 341 & $8 / 7 / 20082: 40$ & 1.417 & 17.5 \\
\hline 342 & $8 / 7 / 20082: 42$ & 1.417 & 17.5 \\
\hline 343 & $8 / 7 / 20082: 44$ & 414 & 17.5 \\
\hline 344 & $8 / 7 / 20082: 46$ & 1.414 & 17.5 \\
\hline 345 & $8 / 7 / 20082: 48$ & 1.414 & 17.5 \\
\hline 346 & $8 / 7 / 20082: 50$ & 1.414 & 17.5 \\
\hline 347 & $8 / 7 / 20082: 52$ & 1.417 & 17.5 \\
\hline 348 & $8 / 7 / 20082: 54$ & 1.414 & 17.5 \\
\hline 349 & $8 / 7 / 20082: 56$ & 1.417 & 17.5 \\
\hline 350 & $8 / 7 / 20082: 58$ & 1.417 & 17.5 \\
\hline 351 & $8 / 7 / 20083: 00$ & 1.417 & 17.5 \\
\hline 352 & $8 / 7 / 20083: 02$ & 1.414 & 17.5 \\
\hline 353 & $8 / 7 / 20083: 04$ & 1.414 & 17.5 \\
\hline 354 & $8 / 7 / 20083: 06$ & 1.417 & 17.5 \\
\hline 355 & $8 / 7 / 20083: 08$ & 1.417 & 17. \\
\hline
\end{tabular}

\begin{tabular}{|c|c|c|c|}
\hline \multicolumn{4}{|c|}{ D4-26p } \\
\hline $\operatorname{Rec}$ & & Pres & Temp \\
\hline$\#$ & Date/Time & psi & ${ }^{\circ} \mathrm{C}$ \\
\hline 356 & $8 / 7 / 20083: 10$ & 1.417 & 17.5 \\
\hline 357 & $8 / 7 / 2008$ 3:12 & 1.417 & 17.5 \\
\hline 358 & $8 / 7 / 2008$ 3:14 & 1.414 & 17.4 \\
\hline 359 & 8/7/2008 3:16 & 1.417 & 17.5 \\
\hline 360 & $8 / 7 / 20083: 18$ & 1.414 & 17.5 \\
\hline 361 & $8 / 7 / 20083: 20$ & 1.414 & 17.5 \\
\hline 362 & $8 / 7 / 20083: 22$ & 1.414 & 17.4 \\
\hline 363 & $8 / 7 / 20083: 24$ & 1.414 & 17.5 \\
\hline 364 & $8 / 7 / 20083: 26$ & 1.414 & 17.5 \\
\hline 365 & $8 / 7 / 20083: 28$ & 1.414 & 17.5 \\
\hline 366 & $8 / 7 / 20083: 30$ & 1.414 & 17.5 \\
\hline 367 & $8 / 7 / 20083: 32$ & 1.414 & 17.5 \\
\hline 368 & $8 / 7 / 20083: 34$ & 1.414 & 17.4 \\
\hline 369 & $8 / 7 / 20083: 36$ & 1.414 & 17.5 \\
\hline 370 & $8 / 7 / 20083: 38$ & 1.414 & 17.5 \\
\hline 371 & $8 / 7 / 20083: 40$ & 1.414 & 17.5 \\
\hline 372 & $8 / 7 / 20083: 42$ & 1.414 & 17.5 \\
\hline 373 & $8 / 7 / 20083: 44$ & 1.414 & 17.5 \\
\hline 374 & $8 / 7 / 20083: 46$ & 1.414 & \\
\hline 375 & $8 / 7 / 20083: 48$ & 1.414 & 17.5 \\
\hline 376 & $8 / 7 / 20083: 50$ & 1.414 & 17.5 \\
\hline 377 & $8 / 7 / 20083: 52$ & 1.414 & 17.5 \\
\hline 378 & $8 / 7 / 20083: 54$ & 1.414 & 17.5 \\
\hline 379 & $8 / 7 / 20083: 56$ & 1.414 & \\
\hline 380 & $8 / 7 / 20083: 58$ & 1.41 & 17.5 \\
\hline 381 & $8 / 7 / 20084: 00$ & 1.414 & 17.5 \\
\hline 382 & $8 / 7 / 20084: 02$ & 1.414 & 17. \\
\hline 383 & $8 / 7 / 20084: 04$ & 1.414 & 17.5 \\
\hline 384 & $8 / 7 / 20084: 06$ & 1.41 & 17.5 \\
\hline 385 & $8 / 7 / 20084: 08$ & 1.414 & 17.5 \\
\hline 386 & $8 / 7 / 20084: 10$ & 1.414 & 17. \\
\hline 387 & $8 / 7 / 20084: 12$ & 1.414 & 17.5 \\
\hline 388 & $8 / 7 / 20084: 14$ & 1.414 & 17.5 \\
\hline 389 & $8 / 7 / 20084: 16$ & 1.414 & 17. \\
\hline 390 & $3 / 7 / 20084: 18$ & 1.414 & 17.5 \\
\hline 391 & $8 / 7 / 20084: 20$ & 1.414 & 17.5 \\
\hline $3 \overline{92}$ & $8 / 7 / 20084: 22$ & 1.414 & 17.5 \\
\hline 393 & $77 / 20084: 24$ & 1.41 & 17.5 \\
\hline 394 & $3 / 7 / 20084: 26$ & 1.41 & 17 \\
\hline 395 & $77 / 20084: 28$ & 1.414 & 17. \\
\hline 396 & $8 / 7 / 20084: 30$ & 1.41 & 17. \\
\hline 397 & $8 / 7 / 20084: 32$ & 1.414 & 17 \\
\hline 398 & $/ 7 / 20084: 34$ & 1.41 & 17. \\
\hline 399 & $84: 36$ & 1.41 & 17.5 \\
\hline 400 & $/ 7 / 20084: 38$ & 1.414 & 17. \\
\hline 401 & $8 / 7 / 20084: 40$ & 1.41 & 17. \\
\hline 402 & $84: 42$ & 1.41 & 17 \\
\hline 403 & $77 / 20084: 44$ & 1.41 & 17 \\
\hline 404 & $4: 46$ & 1.41 & 17. \\
\hline 405 & $/ 7 / 20084: 48$ & 1.414 & 17 \\
\hline 406 & $/ 7 / 20084: 50$ & 1.414 & 17. \\
\hline 407 & $8 / 7 / 20084: 52$ & 1.414 & 17 \\
\hline 408 & $8 / 7 / 20084: 54$ & 1.41 & 17. \\
\hline 409 & $7 / 20084: 56$ & 1.41 & 17. \\
\hline 410 & $84: 58$ & 1.41 & 17. \\
\hline 411 & $85: 00$ & 1.4 & 17 \\
\hline 412 & $7 / 20085: 02$ & 1.41 & 17. \\
\hline 413 & $7 / 20085: 04$ & 1.41 & 17. \\
\hline 414 & $8 / 7 / 20085: 06$ & & 17. \\
\hline 415 & $8 / 7 / 20085: 08$ & 1.41 & 17.5 \\
\hline 416 & $7 / 20085: 10$ & 1.41 & 17.5 \\
\hline 417 & $/ 7 / 20085: 12$ & & 17 \\
\hline 418 & $7 / 20085: 14$ & 1.41 & 17 \\
\hline 419 & $8 / 7 / 20085: 16$ & & \\
\hline 420 & $8 / 7 / 20085: 18$ & 1.41 & 17. \\
\hline 421 & $17 / 20085: 20$ & 1.41 & 17. \\
\hline 422 & $8 / 7 / 20085: 22$ & 1.41 & 17. \\
\hline 423 & $8 / 7 / 20085: 24$ & 1.41 & 17.5 \\
\hline 424 & $8 / 7 / 20085: 26$ & & 17. \\
\hline 425 & $8 / 7 / 20085: 28$ & 1.41 & 17.5 \\
\hline 426 & $8 / 7 / 20085: 30$ & 1.41 & 17. \\
\hline
\end{tabular}

\begin{tabular}{|c|c|c|c|}
\hline \multicolumn{4}{|c|}{ D4-26p } \\
\hline $\operatorname{Rec}$ & & Pres & Temp \\
\hline$\#$ & Date/Time & psi & ${ }^{\circ} \mathrm{C}$ \\
\hline 427 & $8 / 7 / 20085: 32$ & 1.41 & 17.5 \\
\hline 428 & $8 / 7 / 20085: 34$ & 1.41 & 17.5 \\
\hline 429 & $8 / 7 / 20085: 36$ & 1.41 & 17.5 \\
\hline 430 & $8 / 7 / 20085: 38$ & 1.41 & 17.5 \\
\hline 431 & $8 / 7 / 20085: 40$ & 1.407 & 17.5 \\
\hline 432 & $8 / 7 / 20085: 42$ & 1.41 & 17.5 \\
\hline 433 & $8 / 7 / 20085: 44$ & 1.41 & 17.5 \\
\hline 434 & $8 / 7 / 20085: 46$ & 1.41 & 17.5 \\
\hline 435 & $8 / 7 / 20085: 48$ & 1.41 & 17.5 \\
\hline 436 & $8 / 7 / 20085: 50$ & 1.41 & 17.4 \\
\hline 437 & $8 / 7 / 20085: 52$ & 1.41 & 17.5 \\
\hline 438 & $8 / 7 / 20085: 54$ & 1.41 & 17.5 \\
\hline 439 & $8 / 7 / 20085: 56$ & 1.41 & 17.5 \\
\hline 440 & $8 / 7 / 20085: 58$ & 1.41 & 17.5 \\
\hline 441 & $8 / 7 / 20086: 00$ & 1.41 & 17.5 \\
\hline 442 & $8 / 7 / 20086: 02$ & 1.41 & 17.5 \\
\hline 443 & $8 / 7 / 20086: 04$ & 1.41 & 17.5 \\
\hline 444 & $8 / 7 / 20086: 06$ & 1.41 & 17.5 \\
\hline 445 & $8 / 7 / 20086: 08$ & 1.41 & 17.5 \\
\hline 446 & $8 / 7 / 20086: 10$ & 1.41 & 17.5 \\
\hline 447 & $8 / 7 / 20086: 12$ & 1.41 & 17.5 \\
\hline 448 & $8 / 7 / 20086: 14$ & 1.41 & 17.5 \\
\hline 449 & $8 / 7 / 20086: 16$ & 1.41 & 17.5 \\
\hline 450 & $8 / 7 / 20086: 18$ & 1.41 & 17.5 \\
\hline 451 & $8 / 7 / 20086: 20$ & 1.41 & 17.5 \\
\hline 452 & $8 / 7 / 20086: 22$ & 1.41 & 17.5 \\
\hline 453 & $8 / 7 / 20086: 24$ & 1.41 & 17.5 \\
\hline 454 & $8 / 7 / 20086: 26$ & 1.41 & 17.5 \\
\hline 455 & $8 / 7 / 20086: 28$ & 1.41 & 17.5 \\
\hline 456 & $8 / 7 / 20086: 30$ & 1.41 & 17.5 \\
\hline 457 & $8 / 7 / 20086: 32$ & 1.41 & 17.5 \\
\hline 458 & $8 / 7 / 20086: 34$ & 1.41 & 17.5 \\
\hline 459 & $8 / 7 / 20086: 36$ & 1.41 & 17.5 \\
\hline 460 & $8 / 7 / 20086: 38$ & 1.41 & 17.5 \\
\hline 461 & $8 / 7 / 20086: 40$ & 1.41 & 17.5 \\
\hline 462 & $8 / 7 / 20086: 42$ & 1.41 & 17.4 \\
\hline 463 & $8 / 7 / 20086: 44$ & 1.41 & 17.5 \\
\hline 464 & $8 / 7 / 20086: 46$ & 1.41 & 17.5 \\
\hline 465 & $8 / 7 / 20086: 48$ & 1.41 & 17.5 \\
\hline 466 & $8 / 7 / 20086: 50$ & 1.41 & 17.5 \\
\hline 467 & $8 / 7 / 20086: 52$ & 1.41 & 17.5 \\
\hline 468 & $8 / 7 / 20086: 54$ & 1.41 & 17.5 \\
\hline 469 & $8 / 7 / 20086: 56$ & 1.407 & 17.5 \\
\hline 470 & $8 / 7 / 20086: 58$ & 1.41 & 17.5 \\
\hline 471 & $8 / 7 / 20087: 00$ & 1.41 & 17.5 \\
\hline 472 & $8 / 7 / 20087: 02$ & 1.41 & 17.5 \\
\hline 473 & $8 / 7 / 20087: 04$ & 1.41 & 17.5 \\
\hline 474 & $8 / 7 / 20087: 06$ & 1.41 & 17.5 \\
\hline 475 & $8 / 7 / 20087: 08$ & 1.41 & 17.5 \\
\hline 476 & $8 / 7 / 20087: 10$ & 1.41 & 17.5 \\
\hline 477 & $8 / 7 / 20087: 12$ & 1.41 & 17.5 \\
\hline 478 & $8 / 7 / 20087: 14$ & 1.41 & 17.5 \\
\hline 479 & $8 / 7 / 2008$ 7:16 & 1.41 & 17.5 \\
\hline 480 & $8 / 7 / 20087: 18$ & 1.41 & 17.5 \\
\hline 481 & $8 / 7 / 20087: 20$ & 1.407 & 17.5 \\
\hline 482 & $8 / 7 / 2008$ 7:22 & 1.41 & 17.5 \\
\hline 483 & $8 / 7 / 20087: 24$ & 1.41 & 17.5 \\
\hline 484 & $8 / 7 / 20087: 26$ & 1.41 & 17.5 \\
\hline 485 & $8 / 7 / 20087: 28$ & 1.41 & 17.5 \\
\hline 486 & $8 / 7 / 20087: 30$ & 1.41 & 17.5 \\
\hline 487 & $8 / 7 / 20087: 32$ & 1.407 & 17.5 \\
\hline 488 & $8 / 7 / 20087: 34$ & 1.41 & 17.4 \\
\hline 489 & $8 / 7 / 20087: 36$ & 1.41 & 17.5 \\
\hline 490 & $8 / 7 / 20087: 38$ & 1.41 & 17.4 \\
\hline 491 & $8 / 7 / 20087: 40$ & 1.41 & 17.5 \\
\hline 492 & $8 / 7 / 20087: \overline{42}$ & 1.41 & $\begin{array}{ll}17.5 \\
\end{array}$ \\
\hline 493 & $8 / 7 / 20087: 44$ & 1.41 & 17.5 \\
\hline 494 & $8 / 7 / 20087: 46$ & 1.41 & 17.5 \\
\hline 495 & $8 / 7 / 20087: 48$ & 1.407 & 17.5 \\
\hline 496 & $8 / 7 / 20087: 50$ & 1.407 & 17.5 \\
\hline 497 & $8 / 7 / 20087: 52$ & 1.407 & 17.5 \\
\hline
\end{tabular}

\begin{tabular}{|c|c|c|c|}
\hline \multicolumn{4}{|c|}{ D4-26p } \\
\hline $\operatorname{Rec}$ & & Pres & Temp \\
\hline$\#$ & Date/Time & psi & ${ }^{\circ} \mathrm{C}$ \\
\hline 498 & $8 / 7 / 20087: 54$ & 1.407 & 17.5 \\
\hline 499 & $8 / 7 / 20087: 56$ & 1.407 & 17.5 \\
\hline 500 & $8 / 7 / 20087: 58$ & 1.403 & 17.5 \\
\hline 501 & 8/7/20088:00 & 1.407 & 17.5 \\
\hline 502 & $8 / 7 / 20088: 02$ & 1.407 & 17.4 \\
\hline 503 & $8 / 7 / 20088: 04$ & 1.407 & 17.5 \\
\hline 504 & $8 / 7 / 20088: 06$ & 1.41 & 17.5 \\
\hline 505 & $8 / 7 / 20088: 08$ & 1.407 & 17.5 \\
\hline 506 & $8 / 7 / 20088: 10$ & 1.41 & 17.5 \\
\hline 507 & $8 / 7 / 20088: 12$ & 1.407 & 17.5 \\
\hline 508 & $8 / 7 / 20088: 14$ & 1.407 & 17.5 \\
\hline 509 & $8 / 7 / 20088: 16$ & 1.407 & 17.4 \\
\hline 510 & $8 / 7 / 20088: 18$ & 1.407 & 17.5 \\
\hline 511 & $8 / 7 / 20088: 20$ & 1.407 & 17.5 \\
\hline 512 & $8 / 7 / 20088: 22$ & 1.407 & 17.5 \\
\hline 513 & $8 / 7 / 20088: 24$ & 1.407 & 17.5 \\
\hline 514 & $8 / 7 / 20088: 26$ & 1.407 & 17.5 \\
\hline 515 & $8 / 7 / 20088: 28$ & 1.407 & 17.4 \\
\hline 516 & $8 / 7 / 20088: 30$ & 1.407 & 17.5 \\
\hline 517 & $8 / 7 / 20088: 32$ & 1.407 & 17.5 \\
\hline 518 & $8 / 7 / 20088: 34$ & 1.407 & 17.5 \\
\hline 519 & $8 / 7 / 20088: 36$ & 1.407 & 17.5 \\
\hline 520 & $8 / 7 / 20088: 38$ & 1.407 & 17.4 \\
\hline 521 & $8 / 7 / 20088: 40$ & 1.407 & 17.5 \\
\hline 522 & $8 / 7 / 20088: 42$ & 1.407 & 17.4 \\
\hline 523 & $8 / 7 / 20088: 44$ & 1.407 & 17.5 \\
\hline 524 & $77 / 20088: 46$ & 1.407 & 17.4 \\
\hline 525 & $8 / 7 / 20088: 48$ & 1.407 & 17.5 \\
\hline 526 & $88: 50$ & 1.407 & 17.5 \\
\hline 527 & $8 / 7 / 20088: 52$ & 1.407 & 17.5 \\
\hline 528 & $8 / 7 / 20088: 54$ & 1.403 & 17.5 \\
\hline 529 & $8 / 7 / 20088: 56$ & 1.407 & 17.5 \\
\hline 530 & $8 / 7 / 20088: 58$ & 1.403 & 17.5 \\
\hline 531 & $89: 00$ & 1.403 & 17.5 \\
\hline 532 & $8 / 7 / 200$ & 1.403 & 17.5 \\
\hline 533 & $89: 04$ & 1.403 & 17.5 \\
\hline 534 & $89: 06$ & 1.403 & 17.5 \\
\hline 535 & $89: 08$ & 1.403 & 17.5 \\
\hline 536 & $89: 10$ & 1.403 & 17.5 \\
\hline 537 & $8 / 7 / 20$ & 1.407 & 17.5 \\
\hline 538 & $9: 14$ & 1.407 & 17.5 \\
\hline 539 & $89: 16$ & 1.407 & 17.5 \\
\hline 540 & $9: 18$ & 1.407 & 17.5 \\
\hline 541 & 9:20 & 1.407 & 17.5 \\
\hline 542 & $39: 22$ & 1.407 & 17.5 \\
\hline 543 & $9: 24$ & 1.407 & 17.5 \\
\hline 544 & $9: 26$ & 1.407 & 17. \\
\hline 545 & $9: 28$ & 1.407 & 17.5 \\
\hline 546 & $9: 30$ & 1.407 & 17.4 \\
\hline 547 & $9: 32$ & 1.407 & 17. \\
\hline 548 & $9: 34$ & 1.407 & 17. \\
\hline 549 & $9: 36$ & 1.407 & 17. \\
\hline 550 & 9:38 & 1.407 & 17. \\
\hline 551 & $8 / 7 / 200$ & 1.407 & 17. \\
\hline 552 & & 1.407 & 17. \\
\hline 553 & $9: 44$ & 1.407 & 17.5 \\
\hline 554 & $39: 46$ & 1.407 & 17. \\
\hline 555 & $39: 48$ & 1.407 & 17. \\
\hline 556 & $39: 50$ & 1.407 & 17 \\
\hline 557 & $8 / 7 / 20089: 52$ & 1.41 & 17. \\
\hline 558 & $8 / 7 / 20089: 54$ & 1.407 & 17.4 \\
\hline 559 & $8 / 7 / 20089: 56$ & 1.41 & 17. \\
\hline 560 & $39: 58$ & 1.41 & 17. \\
\hline 561 & $/ 2008$ 10:00 & 1.41 & 17.5 \\
\hline 562 & $/ 2008 \quad 10: 02$ & 1.41 & 17.5 \\
\hline 563 & $7 / 2008$ 10:04 & 1.41 & 17. \\
\hline 564 & & 1.407 & \\
\hline 565 & $7 / 2008 \quad 10: 08$ & 1.407 & 17. \\
\hline 566 & $7 / 2008 \quad 10: 10$ & 1.41 & 17. \\
\hline 567 & $7 / 2008$ 10:12 & 1.41 & 17. \\
\hline 568 & $8 / 7 / 200810: 14$ & 1.41 & 17. \\
\hline
\end{tabular}




\begin{tabular}{|c|c|c|c|c|c|c|c|c|c|c|c|c|c|c|c|}
\hline \multicolumn{4}{|c|}{ D4-26p } & \multicolumn{4}{|c|}{ D4-26p } & \multicolumn{4}{|c|}{ D4-26p } & \multicolumn{4}{|c|}{ D4-26p } \\
\hline $\operatorname{Rec}$ & & Pres & Temp & Rec & & Pres & Temp & $\operatorname{Rec}$ & & Pres & Temp & $\operatorname{Rec}$ & & Pres & Temp \\
\hline$\#$ & Date/Time & psi & ${ }^{\circ} \mathrm{C}$ & $\#$ & Date/Time & psi & ${ }^{\circ} \mathrm{C}$ & $\#$ & Date/Time & psi & ${ }^{\circ} \mathrm{C}$ & $\#$ & Date/Time & psi & ${ }^{\circ} \mathrm{C}$ \\
\hline 569 & $8 / 7 / 200810: 16$ & 1.41 & 17.5 & 640 & $8 / 7 / 200812: 38$ & 1.41 & 17.5 & 711 & $8 / 7 / 200815: 00$ & 1.417 & 17.5 & $\begin{array}{ll}782 \\
\end{array}$ & $8 / 7 / 2008 \quad 17: 22$ & 1.414 & 17.5 \\
\hline 570 & $8 / 7 / 200810: 18$ & 1.41 & 17.5 & 641 & $8 / 7 / 200812: 40$ & 1.41 & 17.5 & 712 & $8 / 7 / 200815: 02$ & 1.417 & 17.5 & 783 & $8 / 7 / 200817: 24$ & 1.414 & 17.5 \\
\hline 571 & $8 / 7 / 2008 \quad 10: 20$ & 1.41 & 17.5 & 642 & $8 / 7 / 200812: 42$ & 1.414 & 17.5 & 713 & $8 / 7 / 200815: 04$ & 1.417 & 17.5 & 784 & $8 / 7 / 2008 \quad 17: 26$ & 1.414 & 17.5 \\
\hline 572 & $8 / 7 / 200810: 22$ & 1.41 & 17.5 & 643 & $8 / 7 / 200812: 44$ & 1.41 & 17.5 & 714 & $8 / 7 / 200815: 06$ & 1.417 & 17.5 & 785 & $8 / 7 / 2008 \quad 17: 28$ & 1.414 & 17.5 \\
\hline 573 & $8 / 7 / 200810: 24$ & 1.41 & 17.5 & 644 & $8 / 7 / 200812: 46$ & 1.41 & 17.5 & 715 & $8 / 7 / 200815: 08$ & 1.417 & 17.5 & 786 & $8 / 7 / 200817: 30$ & 1.414 & 17.5 \\
\hline 574 & $8 / 7 / 200810: 26$ & 1.41 & 17.5 & 645 & $8 / 7 / 200812: 48$ & 1.41 & 17.5 & 716 & $8 / 7 / 200815: 10$ & 1.417 & 17.5 & 787 & $8 / 7 / 2008 \quad 17: 32$ & 1.414 & 17.5 \\
\hline 575 & $8 / 7 / 200810: 28$ & 1.41 & 17.5 & 646 & $8 / 7 / 200812: 50$ & 1.41 & 17.5 & 717 & $8 / 7 / 200815: 12$ & 1.42 & 17.4 & 788 & $8 / 7 / 2008 \quad 17: 34$ & 1.414 & 17.5 \\
\hline 576 & $8 / 7 / 200810: 30$ & 1.41 & 17.5 & 647 & $8 / 7 / 2008 \quad 12: 52$ & 1.41 & 17.5 & 718 & $8 / 7 / 200815: 14$ & 1.42 & 17.5 & 789 & $8 / 7 / 2008 \quad 17: 36$ & 1.414 & 17.5 \\
\hline 577 & $8 / 7 / 200810: 32$ & 1.41 & 17.5 & 648 & $8 / 7 / 200812: 54$ & 1.414 & 17.5 & 719 & $8 / 7 / 200815: 16$ & 1.42 & 17.5 & 790 & $8 / 7 / 2008 \quad 17: 38$ & 1.414 & 17.5 \\
\hline 578 & $8 / 7 / 2008 \quad 10: 34$ & 1.41 & 17.4 & 649 & $8 / 7 / 200812: 56$ & 1.41 & 17.5 & 720 & $8 / 7 / 200815: 18$ & 1.42 & 17.5 & 791 & $8 / 7 / 2008 \quad 17: 40$ & 1.414 & 17.5 \\
\hline 579 & $8 / 7 / 200810: 36$ & 1.414 & 17.5 & 650 & $8 / 7 / 200812: 58$ & 1.41 & 17.5 & 721 & $8 / 7 / 200815: 20$ & 1.42 & 17.5 & 792 & $8 / 7 / 2008 \quad 17: 42$ & 1.414 & 17.5 \\
\hline 580 & $8 / 7 / 200810: 38$ & 1.414 & 17.5 & 651 & $8 / 7 / 200813: 00$ & 1.41 & 17.5 & 722 & $8 / 7 / 200815: 22$ & 1.42 & 17.5 & 793 & $8 / 7 / 200817: 44$ & 1.414 & 17.4 \\
\hline 581 & $8 / 7 / 200810: 40$ & 1.41 & 17.5 & 652 & $8 / 7 / 200813: 02$ & 1.41 & 17.5 & 723 & $8 / 7 / 200815: 24$ & 1.42 & 17.4 & 794 & $8 / 7 / 2008 \quad 17: 46$ & 1.417 & 17.5 \\
\hline 582 & $8 / 7 / 2008 \quad 10: 42$ & 1.41 & 17.5 & 653 & $8 / 7 / 200813: 04$ & 1.414 & 17.4 & 724 & $8 / 7 / 200815: 26$ & 1.417 & 17.5 & 795 & $8 / 7 / 2008 \quad 17: 48$ & 1.414 & 17.5 \\
\hline $5 \overline{83}$ & $8 / 7 / 2008 \quad 10: 44$ & 1.41 & 17.5 & 654 & $8 / 7 / 200813: 06$ & 1.41 & 17.5 & 725 & $8 / 7 / 200815: 28$ & 1.417 & 17.4 & 796 & $8 / 7 / 2008 \quad 17: 50$ & 1.414 & 17.5 \\
\hline 584 & $8 / 7 / 2008 \uparrow 0: 46$ & 1.407 & 17.5 & 655 & $8 / 7 / 200813: 08$ & 1.414 & 17.5 & 726 & $8 / 7 / 200815: 30$ & 1.417 & 17.5 & 797 & $8 / 7 / 2008 \quad 17: 52$ & 1.414 & 17.5 \\
\hline 585 & $8 / 7 / 200810: 48$ & 1.41 & 17.5 & 656 & $8 / 7 / 200813: 10$ & 1.414 & 17.5 & 727 & $8 / 7 / 200815: 32$ & 1.42 & 17.5 & 798 & $8 / 7 / 2008 \quad 17: 54$ & 1.414 & 17.5 \\
\hline 586 & $8 / 7 / 200810: 50$ & 1.41 & 17.5 & 657 & $8 / 7 / 200813: 12$ & 1.41 & 17.5 & 728 & $8 / 7 / 200815: 34$ & 1.42 & 17.5 & 799 & $8 / 7 / 2008 \quad 17: 56$ & 1.414 & 17.5 \\
\hline 587 & 00810.52 & 1.41 & 17.5 & 658 & $8 / 7 / 200813: 14$ & 1.41 & 17.5 & 729 & $8 / 7 / 200815: 36$ & 1.42 & 17.5 & 800 & $8 / 7 / 2008 \quad 17: 58$ & 1.414 & 17.5 \\
\hline 588 & 008 10:54 & 1.41 & 17.4 & 659 & $8 / 7 / 200813: 16$ & 1.41 & 17.5 & 730 & $8 / 7 / 200815: 38$ & 1.42 & 17.5 & 801 & $8 / 7 / 200818: 00$ & 1.414 & 17.5 \\
\hline 589 & $00810: 56$ & 1.41 & 17.5 & 660 & $8 / 7 / 200813: 18$ & 1.41 & 17.5 & 731 & $8 / 7 / 200815: 40$ & 1.42 & 17.5 & 802 & $8 / 7 / 200818: 02$ & 1.414 & 17.5 \\
\hline 590 & $8 / 7 / 200810: 58$ & 1.41 & 17.5 & 661 & $8 / 7 / 200813: 20$ & 1.414 & 17.5 & 732 & $8 / 7 / 200815: 42$ & 1.42 & 17.4 & 803 & $8 / 7 / 200818: 04$ & 1.414 & 17.5 \\
\hline 591 & $8 / 7 / 200811: 00$ & 1.407 & 17.5 & 662 & $8 / 7 / 200813: 22$ & 1.414 & 17.5 & 733 & $8 / 7 / 200815: 44$ & 1.42 & 17.5 & 804 & $8 / 7 / 200818: 06$ & 1.414 & 17.5 \\
\hline 592 & $8 / 7 / 200811: 02$ & 1.41 & 17.5 & 663 & $8 / 7 / 200813: 24$ & 1.414 & 17.5 & 734 & $8 / 7 / 200815: 46$ & $1.41 \overline{7}$ & 17.5 & 805 & $8 / 7 / 200818: 08$ & 1.414 & 17.4 \\
\hline 593 & $200811: 04$ & 1.407 & 17.5 & 664 & $8 / 7 / 200813: 26$ & 1.414 & 17.4 & 735 & $008+5: 48$ & 1.42 & 17.5 & 806 & $8818: 10$ & 1.414 & 17.5 \\
\hline 594 & $00811: 06$ & 1.41 & 17.4 & 665 & $8 / 7 / 200813: 28$ & 1.414 & 17.5 & 736 & $00815: 50$ & 1.42 & 17.5 & 807 & $318: 12$ & 1.414 & 17.5 \\
\hline 595 & $0811: 08$ & 1.407 & 17.5 & 666 & $8813: 30$ & 1.41 & 17.5 & 737 & $00815: 52$ & 1.417 & 17.5 & 808 & $8: 14$ & 1.414 & 17.5 \\
\hline 596 & $8 / 7 / 200811: 10$ & 1.41 & 17.4 & 667 & $8 / 7 / 2008 \quad 13: 32$ & 1.41 & 17.5 & 738 & $8 / 7 / 200815: 54$ & 1.417 & 17.5 & 809 & $8 / 7 / 200818: 16$ & 1.414 & 17.5 \\
\hline 597 & $8 / 7 / 200811: 12$ & 1.407 & 17.5 & 668 & $8 / 7 / 200813: 34$ & 1.414 & 17.5 & 739 & $8 / 7 / 200815: 56$ & 1.42 & 17.5 & 810 & $8 / 7 / 200818: 18$ & 1.414 & 17.5 \\
\hline 598 & $8 / 7 / 200811: 14$ & 1.407 & 17.5 & 669 & $8 / 7 / 200813: 36$ & 1.414 & 17.4 & 740 & $8 / 7 / 200815: 58$ & 1.42 & 17.5 & 811 & $8 / 7 / 200818: 20$ & 1.414 & 17.5 \\
\hline 599 & $8 / 7 / 200811: 16$ & 1.41 & 17.5 & 670 & $8 / 7 / 200813: 38$ & 1.417 & 17.5 & 741 & $8 / 7 / 200816: 00$ & 1.42 & 17.5 & 812 & $818: 22$ & 1.414 & 17.5 \\
\hline 600 & $8 / 7 / 200811: 18$ & 1.407 & 17.5 & 671 & $8 / 7 / 200813: 40$ & 1.417 & 17.5 & 742 & $00816: 02$ & 1.42 & 17.5 & 813 & $818: 24$ & 1.414 & 17.5 \\
\hline 601 & $0811: 20$ & 1.407 & 17.5 & 672 & $813: 42$ & 1.417 & 17.5 & 743 & $0816: 04$ & 1.42 & 17.4 & 814 & $8: 26$ & 1.414 & 17.5 \\
\hline 602 & $8 / 7 / 200811: 22$ & 1.407 & 17.5 & 673 & $8 / 7 / 200813: 44$ & 1.417 & 17.5 & 744 & $8 / 7 / 200816: 06$ & 1.42 & 17.5 & 815 & $8 / 7 / 2008 \quad 18: 28$ & 1.41 & 17.4 \\
\hline 603 & $8 / 7 / 200811: 24$ & 1.41 & 17.5 & 674 & $8 / 7 / 200813: 46$ & 1.414 & 17.5 & 745 & $8 / 7 / 200816: 08$ & 1.42 & 17.4 & 816 & $8 / 7 / 200818: 30$ & 1.41 & 17.5 \\
\hline 604 & $8 / 7 / 200811: 26$ & 1.41 & 17.5 & 675 & $8 / 7 / 200813: 48$ & 1.414 & 17.5 & 746 & $8 / 7 / 200816: 10$ & 1.42 & 17.5 & 817 & $8 / 7 / 200818: 32$ & 1.414 & 17.5 \\
\hline 605 & $8 / 7 / 200811: 28$ & 1.41 & 17.5 & 676 & $8 / 7 / 200813: 50$ & 1.414 & 17.5 & 747 & $8 / 7 / 200816: 12$ & 1.417 & 17.5 & 818 & $818: 34$ & 1.414 & 17.5 \\
\hline 606 & $8 / 7 / 200811: 30$ & 1.407 & 17.5 & 677 & $8 / 7 / 200813: 52$ & 1.414 & 17.5 & 748 & $0816: 14$ & 1.417 & 17.5 & 819 & 18:36 & 1.414 & 17.5 \\
\hline 607 & $811: 32$ & 1.41 & 17.5 & 678 & $813: 54$ & 1.414 & 17.5 & 749 & $0816: 16$ & 1.417 & 17.5 & 820 & $18: 38$ & 1.414 & 17.5 \\
\hline 608 & $0811: 34$ & 1.41 & 17.5 & 679 & $0813: 56$ & 1.417 & 17.4 & 750 & $0816: 18$ & 1.417 & 17.5 & 821 & $18: 40$ & 1.414 & 17.5 \\
\hline 609 & $8 / 7 / 200811: 36$ & 1.41 & 17.5 & 680 & $8 / 7 / 200813: 58$ & 1.417 & 17.5 & 751 & $8 / 7 / 2008+6: 20$ & 1.417 & 17.4 & 822 & $8 / 7 / 200818: 42$ & 1.414 & 17.5 \\
\hline 610 & $8 / 7 / 200811: 38$ & 1.41 & 17.5 & 681 & $8 / 7 / 200814: 00$ & 1.417 & 17.4 & 752 & $8 / 7 / 200816: 22$ & 1.417 & 17.5 & 823 & $8 / 7 / 200818: 44$ & 1.417 & 17.5 \\
\hline 611 & $8 / 7 / 200811: 40$ & 1.41 & 17.5 & 682 & $8 / 7 / 200814: 02$ & 1.417 & 17.5 & 753 & $8 / 7 / 200816: 24$ & 1.417 & 17.5 & 824 & $8 / 7 / 200818: 46$ & 1.417 & 17.5 \\
\hline 612 & $8 / 7 / 200811: 42$ & 1.41 & 17.5 & 683 & $8 / 7 / 200814: 04$ & 1.417 & 17.5 & 754 & $8 / 7 / 2008+6: 26$ & $1.4 \uparrow 7$ & 17.5 & 825 & $318: 48$ & 1.417 & 17.4 \\
\hline 613 & $811: 44$ & 1.41 & 17.5 & 684 & $14: 06$ & 1.414 & 17.4 & 755 & $816: 28$ & 1.417 & 17.5 & 826 & $8 / 7 /$ & 1.417 & 17.5 \\
\hline 614 & $8 / 7 / 200811: 46$ & 1.41 & 17.5 & 685 & $0814: 08$ & 1.414 & 17.5 & 756 & $0816: 30$ & 1.451 & 17.5 & 827 & $18: 52$ & 1.414 & 17.5 \\
\hline 615 & $8 / 7 / 200811: 48$ & 1.41 & 17.5 & 686 & $00814: 10$ & 1.414 & 17.5 & 757 & $8 / 7 / 200816: 32$ & 1.414 & 17.5 & 828 & $8 / 7 / 200818: 54$ & 1.414 & 17.5 \\
\hline 616 & $8 / 7 / 200811: 50$ & 1.414 & 17.5 & 687 & $8 / 7 / 200814: 12$ & 1.414 & 17.5 & 758 & $8 / 7 / 200816: 34$ & 1.414 & 17.5 & 829 & $8 / 7 / 200818: 56$ & 1.414 & 17.4 \\
\hline 617 & $8 / 7 / 200811: 52$ & 1.41 & 17.5 & 688 & $8 / 7 / 200814: 14$ & 1.414 & 17.5 & 759 & $8 / 7 / 20081 \overline{6: 36}$ & 1.414 & 17.4 & 830 & $8 / 7 / 200818: 58$ & 1.417 & 17.5 \\
\hline 618 & $8 / 7 / 200811: 54$ & 1.407 & 17.5 & 689 & $8 / 7 / 200814: 16$ & 1.414 & 17.4 & 760 & $8 / 7 / 200816: 38$ & 1.414 & 17.5 & 831 & $8 / 7 / 200819: 00$ & 1.417 & 17.4 \\
\hline 619 & $08+1: 56$ & 1.41 & 17.5 & 690 & $8 / 7 / 200814: 18$ & 1.414 & 17.5 & 761 & $816: 40$ & 1.414 & 17.5 & 832 & $19: 02$ & 1.417 & 17.5 \\
\hline 620 & $811: 58$ & 1.41 & 17.4 & 691 & $814: 20$ & 1.414 & 17.5 & 762 & $816: 42$ & 1.417 & 17.5 & 833 & $8 / 7 /$ & 1.417 & 17.5 \\
\hline 621 & $8812: 00$ & 1.41 & 17.4 & 692 & $814: 22$ & 1.414 & 17.5 & 763 & $816: 44$ & 1.414 & 17.5 & 834 & $19: 06$ & 1.417 & 17.5 \\
\hline 622 & $10812: 02$ & 1.414 & 17.5 & 693 & $8 / 7 / 200814: 24$ & 1.414 & 17.5 & 764 & $0816: 46$ & 1.414 & 17.5 & 835 & $19: 08$ & 1.414 & 17.5 \\
\hline 623 & $8 / 7 / 200812: 04$ & 1.41 & 17.5 & 694 & $8 / 7 / 200814: 26$ & 1.41 & 17.5 & 765 & $8 / 7 / 200816: 48$ & 1.414 & 17.5 & 836 & $8 / 7 / 200819: 10$ & 1.414 & 17.5 \\
\hline 624 & $8 / 7 / 200812: 06$ & 1.41 & 17.5 & 695 & $8 / 7 / 200814: 28$ & 1.414 & 17.5 & 766 & $8 / 7 / 200816.50$ & 1.414 & 17.5 & 837 & $8 / 7 / 2008$ 19:12 & 1.414 & 17.5 \\
\hline 625 & $8 / 7 / 200812: 08$ & 1.41 & 17.5 & 696 & $8 / 7 / 200814: 30$ & 1.414 & 17.5 & 767 & $8 / 7 / 200816: 52$ & 1.414 & 17.5 & 838 & $8 / 7 / 200819: 14$ & 1.414 & 17.5 \\
\hline 626 & $8 / 7 / 200812: 10$ & 1.414 & 17.5 & 697 & $8 / 7 / 200814: 32$ & 1.417 & 17.5 & 768 & $8 / 7 / 200816: 54$ & 1.414 & 17.5 & 839 & $8 / 7 / 2008 \quad 19: 16$ & 1.417 & 17.4 \\
\hline 627 & $0812: 12$ & 1.414 & 17.5 & 698 & $8 \longdiv { 1 4 : 3 4 }$ & 1.417 & 17.5 & 769 & $916: 56$ & 1.414 & 17.5 & 840 & $19: 18$ & 1.414 & 17.5 \\
\hline 628 & $8 / 7 / 200812: 14$ & 1.414 & 17.5 & 699 & $8 / 7 / 200814: 36$ & 1.417 & 17.5 & 770 & $8 / 7 / 200816: 58$ & 1.414 & 17.5 & 841 & $8 / 7 / 200819: 20$ & 1.414 & 17.5 \\
\hline 629 & $8 / 7 / 200812: 16$ & 1.414 & 17.5 & 700 & $8 / 7 / 200814: 38$ & 1.417 & 17.5 & 771 & $8 / 7 / 200817: 00$ & 1.414 & 17.5 & 842 & $8 / 7 / 2008 \quad 19: 22$ & 1.414 & 17.5 \\
\hline 630 & $8 / 7 / 200812: 18$ & 1.41 & 17.5 & 701 & $8 / 7 / 200814: 40$ & 1.414 & 17.5 & 772 & $8 / 7 / 200817: 02$ & 1.414 & 17.4 & 843 & $8 / 7 / 200819: 24$ & 1.414 & 17.5 \\
\hline 631 & $8 / 7 / 200812: 20$ & 1.414 & 17.5 & 702 & $8 / 7 / 200814: 42$ & 1.414 & 17.5 & 773 & $8 / 7 / 2008 \quad 17: 04$ & 1.417 & 17.5 & 844 & $8 / 7 / 200819: 26$ & 1.414 & 17.5 \\
\hline 632 & $8 / 7 / 200812: 22$ & 1.41 & 17.5 & 703 & $8 / 7 / 200814: 44$ & 1.417 & 17.5 & 774 & $8 / 7 / 2008 \quad 17: 06$ & 1.414 & 17.5 & 845 & $8 / 7 / 2008 \quad 19: 28$ & 1.414 & 17.5 \\
\hline 633 & $8 / 7 / 200812: 24$ & & 17.5 & 704 & $8 / 7 / 200814: 46$ & 1.417 & 17.5 & 775 & $8 / 7 / 200817: 08$ & 1.414 & 17.5 & 846 & $8 / 7 / 200819: 30$ & 1.414 & 17.5 \\
\hline 634 & $8 / 7 / 200812: 26$ & 1.41 & 17.5 & 705 & $8 / 7 / 200814: 48$ & 1.417 & 17.5 & 776 & $8 / 7 / 200817: 10$ & 1.417 & 17.5 & 847 & $8 / 7 / 200819: 32$ & 1.414 & 17.5 \\
\hline 635 & $8 / 7 / 2008 \quad 12: 28$ & 1.41 & 17.5 & 706 & $8 / 7 / 200814: 50$ & 1.417 & 17.5 & 777 & $8 / 7 / 2008 \quad 17: 12$ & 1.417 & 17.5 & 848 & $8 / 7 / 200819: 34$ & 1.414 & 17.5 \\
\hline 636 & $8 / 7 / 200812: 30$ & 1.407 & 17.5 & 707 & $8 / 7 / 200814: 52$ & 1.414 & 17.5 & 778 & $8 / 7 / 2008 \quad 17: 14$ & 1.414 & 17.5 & 849 & $8 / 7 / 200819: 36$ & 1.414 & 17.5 \\
\hline 637 & $8 / 7 / 200812: 32$ & 1.407 & 17.5 & 708 & $8 / 7 / 2008+4: 54$ & 1.417 & 17.5 & 779 & $8 / 7 / 2008 \quad 17: 16$ & 1.414 & 17.4 & 850 & $8 / 7 / 2008 \quad 19: 38$ & 1.414 & 17.5 \\
\hline 638 & $8 / 7 / 200812: 34$ & 1.41 & 17.5 & 709 & $8 / 7 / 200814: 56$ & 1.417 & 17.5 & 780 & $8 / 7 / 2008 \quad 17: 18$ & 1.414 & 17.5 & 851 & $8 / 7 / 200819: 40$ & 1.414 & 17.5 \\
\hline 639 & $8 / 7 / 200812: 36$ & 1.41 & 17.5 & 710 & $8 / 7 / 200814: 58$ & 1.42 & 17.4 & 781 & $8 / 7 / 200817: 20$ & 1.414 & 17.4 & 852 & $8 / 7 / 2008 \quad 19: 42$ & 1.414 & 17.5 \\
\hline
\end{tabular}


DOE/RL-2009-35, REV. 0

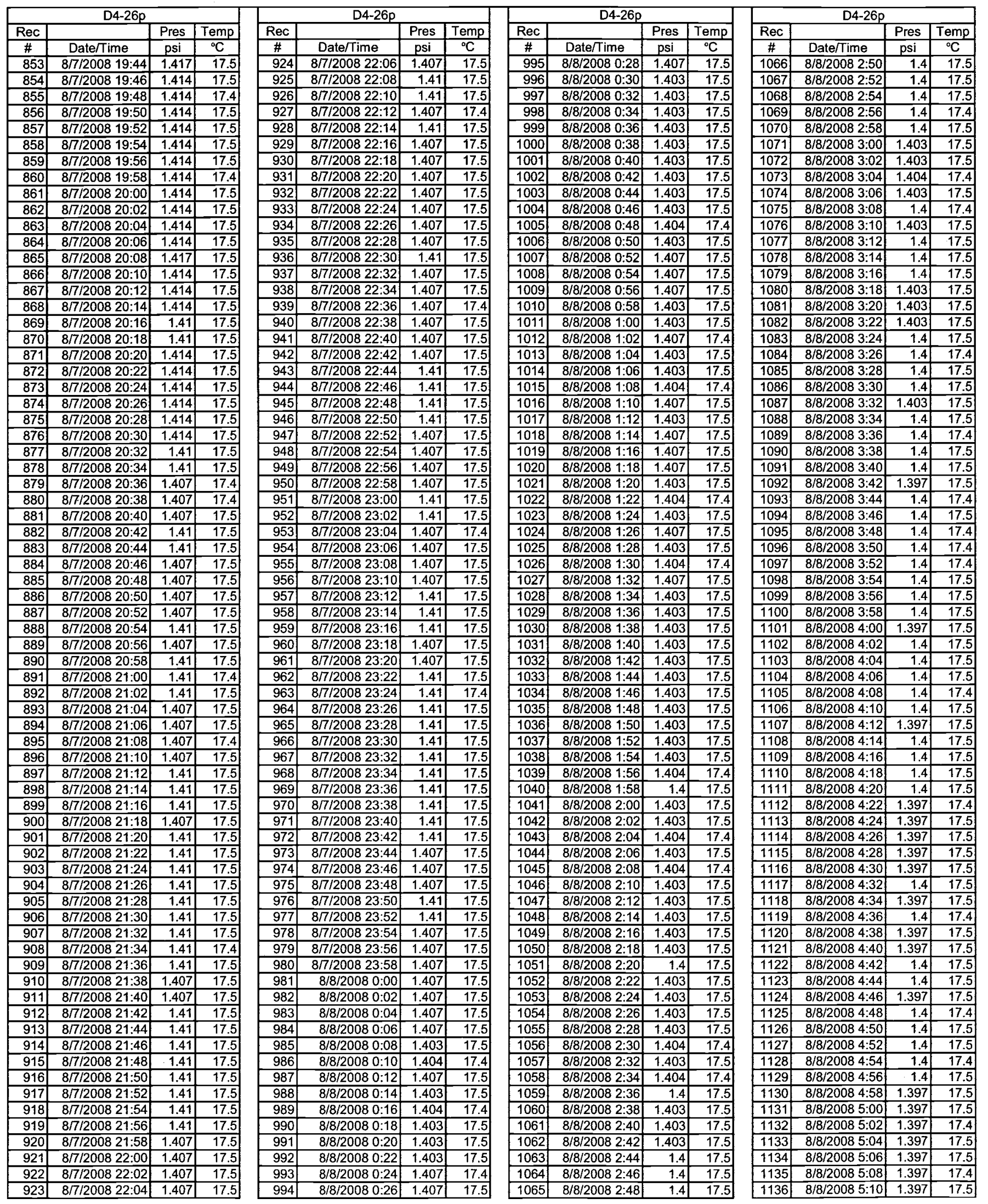


DOE/RL-2009-35, REV. 0

\begin{tabular}{|c|c|c|c|c|c|c|c|c|c|c|c|c|c|c|c|}
\hline \multicolumn{4}{|c|}{ D4-26p } & \multicolumn{4}{|c|}{ D4-26p } & \multicolumn{4}{|c|}{ D4-26p } & \multicolumn{4}{|c|}{ D4-26p } \\
\hline $\operatorname{Rec}$ & & Pres & Temp & $\operatorname{Rec}$ & & Pres & Temp & $\operatorname{Rec}$ & & Pres & Temp & $\operatorname{Rec}$ & & Pres & Temp \\
\hline$\#$ & DaterTime & psi & ${ }^{\circ} \mathrm{C}$ & $\#$ & Date/Time & psi & ${ }^{\circ} \mathrm{C}$ & $\#$ & Date/Time & $\mathrm{psi}$ & ${ }^{\circ} \mathrm{C}$ & $\#$ & Date/Time & psi & ${ }^{\circ} \mathrm{C}$ \\
\hline 1137 & $8 / 8 / 20085: 12$ & 1.397 & 17.4 & 1208 & $8 / 8 / 20087: 34$ & 1.393 & 17.5 & 1279 & $8 / 8 / 20089: 56$ & 1.387 & 17.5 & 1350 & $8 / 8 / 200812: 18$ & 1.387 & 17.5 \\
\hline 1138 & $8 / 8 / 20085: 14$ & 1.397 & 17.5 & 1209 & 8/8/2008 7:36 & 1.393 & 17.4 & 1280 & 8/8/2008 9:58 & 1.39 & 17.5 & 1351 & $8 / 8 / 2008$ 12:20 & 1.387 & 17.5 \\
\hline 1139 & $8 / 8 / 20085: 16$ & 1.397 & 17.5 & 1210 & $8 / 8 / 20087: 38$ & 1.393 & 17.5 & 1281 & $8 / 8 / 200810: 00$ & 1.39 & 17.5 & 1352 & $8 / 8 / 2008$ 12:22 & 1.383 & 17.4 \\
\hline 1140 & $8 / 8 / 20085: 18$ & 1.397 & 17.5 & 1211 & $8 / 8 / 20087: 40$ & 1.39 & 17.5 & 1282 & $8 / 8 / 200810: 02$ & 1.39 & 17.5 & 1353 & $8 / 8 / 200812: 24$ & 1.387 & 17.5 \\
\hline 1141 & $8 / 8 / 20085: 20$ & 1.397 & 17.5 & 1212 & 8/8/2008 7:42 & 1.39 & 17.5 & 1283 & $8 / 8 / 2008 \quad 10: 04$ & 1.39 & 17.5 & 1354 & $8 / 8 / 2008$ 12:26 & 1.383 & 17.5 \\
\hline 1142 & $8 / 8 / 20085: 22$ & 1.397 & 17.5 & 1213 & 8/8/2008 7:44 & 1.393 & 17.5 & 1284 & $8 / 8 / 2008$ 10:06 & 1.387 & 17.5 & 1355 & $8 / 8 / 2008$ 12:28 & 1.383 & 17.5 \\
\hline 1143 & 8/8/2008 5:24 & 1.397 & 17.5 & 1214 & $8 / 8 / 20087: 46$ & 1.393 & 17.5 & 1285 & $8 / 8 / 2008$ 10:08 & 1.39 & 17.4 & 1356 & $8 / 8 / 2008 \quad 12: 30$ & 1.387 & 17.5 \\
\hline 1144 & $8 / 8 / 20085: 26$ & 1.4 & 17.4 & 1215 & $8 / 8 / 20087: 48$ & 1.393 & 17.5 & 1286 & $8 / 8 / 200810: 10$ & 1.389 & 17.9 & 1357 & $8 / 8 / 200812: 32$ & 1.383 & 17.4 \\
\hline 1145 & $8 / 8 / 20085: 28$ & 1.397 & 17.5 & 1216 & $8 / 8 / 20087: 50$ & 1.39 & 17.5 & 1287 & $8 / 8 / 2008 \quad 10: 12$ & 1.39 & 17.8 & 1358 & $8 / 8 / 2008 \quad 12: 34$ & 1.383 & 17.4 \\
\hline 1146 & $8 / 8 / 20085: 30$ & 1.397 & 17.5 & 1217 & $8 / 8 / 20087: 52$ & 1.39 & 17.5 & 1288 & $8 / 8 / 2008$ 10:14 & 1.39 & 17.6 & 1359 & $8 / 8 / 200812: 36$ & 1.387 & 17.5 \\
\hline 1147 & $8 / 8 / 20085: 32$ & 1.397 & 17.5 & 1218 & $8 / 8 / 20087: 54$ & 1.393 & 17.5 & 1289 & $8 / 8 / 2008 \quad 10: 16$ & 1.39 & 17.5 & 1360 & $8 / 8 / 2008 \quad 12: 38$ & 1.387 & 17.5 \\
\hline 1148 & $8 / 8 / 20085: 34$ & 1.397 & 17.5 & 1219 & $8 / 8 / 20087: 56$ & 1.39 & 17.5 & 1290 & $8 / 8 / 2008 \quad 10: 18$ & 1.39 & 17.5 & 1361 & $8 / 8 / 200812: 40$ & 1.387 & 17.5 \\
\hline 1149 & $8 / 8 / 20085: 36$ & 1.397 & 17.5 & 1220 & $8 / 8 / 20087: 58$ & 1.39 & 17.5 & 1291 & $8 / 8 / 200810: 20$ & 1.39 & 17.5 & 1362 & $8 / 8 / 200812: 42$ & 1.387 & 17.5 \\
\hline 1150 & $8 / 8 / 20085: 38$ & 1.393 & 17.4 & 1221 & 8/8/2008 8:00 & 1.39 & 17.5 & 1292 & $8 / 8 / 2008 \quad 10: 22$ & 1.387 & 17.5 & 1363 & $8 / 8 / 2008$ 12:44 & 1.387 & 17.5 \\
\hline 1151 & $8 / 8 / 20085: 40$ & 1.397 & 17.5 & 1222 & 8/8/2008 8:02 & 1.387 & 17.5 & 1293 & $8 / 8 / 2008 \quad 10: 24$ & 1.387 & 17.5 & 1364 & $8 / 8 / 2008$ 12:46 & 1.387 & 17.5 \\
\hline 1152 & $8 / 8 / 20085: 42$ & 1.397 & 17.5 & 1223 & 8/8/2008 8:04 & 1.387 & 17.5 & 1294 & $8 / 8 / 2008$ 10:26 & 1.387 & 17.5 & 1365 & $8 / 8 / 2008$ 12:48 & 1.387 & 17.5 \\
\hline 1153 & $8 / 8 / 20085: 44$ & 1.397 & 17.5 & 1224 & $8 / 8 / 20088: 06$ & 1.39 & 17.5 & 1295 & $8 / 8 / 2008 \quad 10: 28$ & 1.387 & 17.5 & 1366 & $8 / 8 / 2008$ 12:50 & 1.387 & 17.5 \\
\hline 1154 & $8 / 8 / 20085: 46$ & 1.397 & 17.5 & 1225 & $8 / 8 / 20088: 08$ & 1.39 & 17.4 & 1296 & $8 / 8 / 200810: 30$ & 1.387 & 17.4 & 1367 & $8 / 8 / 2008$ 12:52 & 1.383 & 17.5 \\
\hline 1155 & $8 / 8 / 20085: 48$ & 1.397 & 17.5 & 1226 & 8/8/2008 8:10 & 1.393 & 17.5 & 1297 & $8 / 8 / 2008 \quad 10: 32$ & 1.387 & 17.5 & 1368 & $8 / 8 / 200812: 54$ & 1.383 & 17.4 \\
\hline 1156 & $8 / 8 / 20085: 50$ & 1.397 & 17.5 & 1227 & 8/8/2008 8:12 & 1.393 & 17.5 & 1298 & $8 / 8 / 200810: 34$ & 1.387 & 17.5 & 1369 & $8 / 8 / 2008$ 12:56 & 1.383 & 17.5 \\
\hline 1157 & $8 / 8 / 20085: 52$ & 1.393 & 17.5 & 1228 & $8 / 8 / 20088: 14$ & 1.393 & 17.5 & 1299 & $8 / 8 / 2008 \quad 10: 36$ & 1.387 & 17.5 & 1370 & $8 / 8 / 200812: 58$ & 1.383 & 17.5 \\
\hline 1158 & $8 / 8 / 20085: 54$ & 1.397 & 17.4 & 1229 & 8/8/2008 8:16 & 1.393 & 17.5 & 1300 & $8 / 8 / 200810: 38$ & 1.387 & 17.4 & 1371 & 8/8/2008 13:00 & 1.387 & 17.5 \\
\hline 1159 & $8 / 8 / 20085: 56$ & 1.397 & 17.5 & 1230 & 8/8/2008 8:18 & 1.39 & 17.5 & 1301 & $8 / 8 / 2008 \quad 10: 40$ & 1.387 & 17.5 & 1372 & $8 / 8 / 2008$ 13:02 & 1.383 & 17.5 \\
\hline 1160 & $8 / 8 / 20085: 58$ & 1.393 & 17.5 & 1231 & 8/8/2008 8:20 & 1.39 & 17.5 & 1302 & $8 / 8 / 2008 \quad 10: 42$ & 1.387 & 17.5 & 1373 & $8 / 8 / 2008$ 13:04 & 1.383 & 17.5 \\
\hline 1161 & $8 / 8 / 20086: 00$ & 1.393 & 17.5 & 1232 & $8 / 8 / 20088: 22$ & 1.39 & 17.5 & 1303 & $8 / 8 / 2008 \quad 10: 44$ & 1.387 & 17.4 & 1374 & $8 / 8 / 200813: 06$ & 1.383 & 17.5 \\
\hline 1162 & $8 / 8 / 20086: 02$ & 1.393 & 17.5 & 1233 & $8 / 8 / 20088: 24$ & 1.39 & 17.5 & 1304 & $8 / 8 / 2008 \quad 10: 46$ & 1.387 & 17. & 1375 & $0813: 08$ & 1.383 & 17.5 \\
\hline 1163 & $8 / 8 / 20086: 04$ & 1.393 & 17.5 & 1234 & $8 / 8 / 20088: 26$ & 1.39 & 17.5 & 1305 & $8 / 8 / 200810: 48$ & 1.387 & 17. & 1376 & 8/8/2008 13:10 & 1.383 & 17.5 \\
\hline 1164 & $8 / 8 / 2008$ 6:06 & 1.393 & 17.5 & 1235 & $8 / 8 / 20088: 28$ & 1.387 & 17.5 & 1306 & $8 / 8 / 2008 \quad 10: 50$ & 1.387 & 17.5 & 1377 & $8 / 8 / 2008$ 13:12 & 1.383 & 17.5 \\
\hline 1165 & $8 / 8 / 200$ & 1.397 & 17. & 1236 & 8/8/2008 8:30 & 1.39 & 17.4 & 1307 & $8 / 8 / 200810: 52$ & 1.387 & 17. & 1378 & $8 / 8 / 2008$ 13:14 & 1.383 & 17.5 \\
\hline 1166 & $8 / 8 / 20086: 10$ & 1.393 & 17.5 & 1237 & $8 / 8 / 20088: 32$ & 1.39 & 17.5 & 1308 & $8 / 8 / 200810: 54$ & 1.387 & 17. & 1379 & 8/8/2008 13:16 & 1.383 & 17.4 \\
\hline 1167 & 8/8/2008 6:12 & 1.393 & 17.5 & 1238 & 8/8/2008 8:34 & 1.387 & 17.5 & 1309 & $8 / 8 / 2008 \quad 10: 56$ & 1.387 & 17.5 & 1380 & $8 / 8 / 200813: 18$ & 1.383 & 17.5 \\
\hline 1168 & $8 / 8 / 20086: 14$ & 1.397 & 17.4 & 1239 & $8 / 8 / 20088: 36$ & 1.387 & 17.5 & 1310 & $8 / 8 / 2008 \quad 10: 58$ & 1.387 & 17.5 & 1381 & $8 / 8 / 200813: 20$ & 1.383 & 17.5 \\
\hline 1169 & $8 / 8 / 2008$ 6:16 & 1.397 & 17.4 & 1240 & $8 / 8 / 20088: 38$ & 1.387 & 17.4 & 1311 & $8 / 8 / 200811: 00$ & 1.387 & 17. & 1382 & $0813: 22$ & 1.383 & 17.5 \\
\hline 1170 & $8 / 8 / 20086: 18$ & 1.393 & 17. & 1241 & $8 / 8 / 20088: 40$ & 1.39 & 17.5 & 1312 & $8 / 8 / 200811: 02$ & 1.387 & 17. & 1383 & $8 / 8 / 200813: 24$ & 1.383 & 17.5 \\
\hline 1171 & $8 / 8 / 20086: 20$ & 1.393 & 17.5 & 1242 & $8 / 8 / 20088: 42$ & 1.39 & 17.5 & 1313 & $8 / 8 / 200811: 04$ & 1.387 & 17.4 & 1384 & $8 / 8 / 200813: 26$ & 1.383 & 17.4 \\
\hline 1172 & $8 / 8 / 200$ & 1.393 & 17. & 1243 & $88: 44$ & 1.39 & 17.5 & 1314 & $8 / 8 / 2008$ 11:06 & 1.387 & 17. & 1385 & $813: 28$ & 1.383 & 17.5 \\
\hline 1173 & $8 / 8 / 2008$ 6:24 & 1.393 & 17.5 & 1244 & $8 / 8 / 20088: 46$ & 1.39 & 17.4 & 1315 & $8 / 8 / 200811: 08$ & 1.387 & 17. & 1386 & $8 / 8 / 200813: 30$ & 1.387 & 17.5 \\
\hline 1174 & $8 / 8 / 20086: 26$ & 1.393 & 17.5 & 1245 & $8 / 8 / 20088: 48$ & 1.39 & 17.5 & 1316 & $8 / 8 / 200811: 10$ & 1.383 & 17.5 & 1387 & $8 / 8 / 200813: 32$ & 1.383 & 17.5 \\
\hline 1175 & $8 / 8 / 20086: 28$ & 1.393 & 17.5 & 1246 & $8 / 8 / 20088: 50$ & 1.387 & 17.5 & 1317 & $8 / 8 / 200811: 12$ & 1.383 & 17. & 1388 & $0813: 34$ & 1.383 & 17.5 \\
\hline 1176 & $86: 30$ & 1.393 & 17.5 & 1247 & $8 / 8 / 20088: 52$ & 1.39 & 17.4 & 1318 & $8 / 8 / 2008 \quad 11: 14$ & 1.387 & 17. & 1389 & $313: 36$ & 1.383 & 17.5 \\
\hline 1177 & $8 / 8 / 20$ & 1.393 & 17.5 & 1248 & $88: 54$ & 1.387 & 17.5 & 1319 & $0811: 16$ & 1.387 & 17. & 1390 & $813: 38$ & 1.383 & 17.5 \\
\hline 1178 & $8 / 8 / 20$ & 1.393 & 17.5 & 1249 & $188: 56$ & 1.387 & 17 & 1320 & $8 / 8 / 200811: 18$ & 1.383 & 17.5 & 1391 & $0813: 40$ & 1.383 & 17.5 \\
\hline 1179 & $8 / 8 / 20$ & 1.393 & 17. & 1250 & $38: 58$ & 1.387 & 17. & 1321 & $8 / 8 / 200811: 20$ & 1.387 & 17 & 1392 & $813: 42$ & 1.383 & 17.5 \\
\hline 1180 & 8/8/2008 6:38 & 1.393 & 17.4 & 1251 & $089: 00$ & 1.387 & 17.5 & 1322 & $8 / 8 / 200811: 22$ & 1.387 & 17. & 1393 & $8 / 8 / 200813: 44$ & 1.383 & 17.5 \\
\hline 1181 & $8 / 8 / 20086: 40$ & 1.393 & 17.5 & 1252 & $089: 02$ & 1.387 & & 1323 & $8 / 8 / 200811: 24$ & 1.387 & 17. & 1394 & $813: 46$ & 1.383 & 17.5 \\
\hline 1182 & $6: 42$ & 1.397 & 17.5 & 1253 & $8 / 8 / 20089: 04$ & 1.387 & 17. & 1324 & $8 / 8 / 200811: 26$ & 1.387 & 17. & 1395 & 08 13:48 & 1.383 & 17.5 \\
\hline 1183 & $6: 44$ & 1.397 & 17 & 1254 & 9:06 & 1.39 & 17 & 1325 & & & & & 113:50 & 1.383 & 17.5 \\
\hline 1184 & $6: 46$ & 1.397 & 17.8 & 1255 & $89: 08$ & 1.39 & 17. & 1326 & $8 / 8 / 200811: 30$ & 1.38 & 17 & 1397 & $0813: 52$ & 1.383 & 17.4 \\
\hline 1185 & $8 / 8 / 20$ & 1.397 & 17 & 1256 & $89: 10$ & 1.39 & 17 & 1327 & $811: 32$ & 1.387 & 17 & 1398 & $313: 54$ & 1.383 & 17.5 \\
\hline 1186 & $6: 50$ & 1.393 & 17 & 1257 & $389: 12$ & 1.39 & & 1328 & $8 / 200811: 34$ & 1.387 & & 13 & 13:56 & 1.383 & 17.5 \\
\hline 1187 & $8 / 8 / 20$ & 1.393 & 17. & 1258 & $9: 14$ & 1.39 & 17. & 1329 & $811: 36$ & 1.387 & 17 & 1400 & $813: 58$ & 1.383 & 17.5 \\
\hline 1188 & & 1.39 & & 1259 & & & & & & & & & $814: 00$ & 1.383 & \\
\hline 1189 & $8 / 8 / 20086: 56$ & 1.387 & 17.5 & 1260 & $8 / 8 / 20089: 18$ & 1.39 & 17.5 & 1331 & $8 / 8 / 200811: 40$ & 1.387 & 17. & 1402 & $8 / 8 / 200814: 02$ & 1.383 & 17.5 \\
\hline 1190 & $8 / 8 / 20086: 58$ & 1.387 & 17.5 & 1261 & & 1.387 & & & $8 / 8 / 200811: 42$ & 1.387 & & & 08 14:04 & 1.383 & 17.5 \\
\hline 1191 & $8 / 8 / 20$ & 1.39 & 17. & 1262 & $89: 22$ & 1.383 & 17 & 1333 & $0811: 44$ & 1.383 & 17. & 1404 & $0814: 06$ & 1.383 & 17.5 \\
\hline 1192 & $8 / 20087: 02$ & 1.39 & 17 & 1263 & $9: 24$ & 1.387 & & 13 & & 1.3 & & & $314: 08$ & 1.383 & 17.5 \\
\hline 1193 & 8/8/2008 7:04 & 1.30 & 17. & 1264 & 9:26 & 1.3 & & 1335 & $11: 48$ & & & 1406 & $314: 10$ & 1.383 & 17.5 \\
\hline 1194 & $8 / 8 / 200$ & 1.39 & 17.5 & 1265 & $39: 28$ & 1.387 & 17.5 & 1336 & $8 / 8 / 200811: 50$ & 1.387 & 17. & 1407 & $8 / 8 / 2008$ 14:12 & 1.383 & 17.5 \\
\hline 1195 & $8 / 8 / 200$ & & & 1266 & & & & 1337 & & & & & & 1.383 & 17.5 \\
\hline 1196 & $8 / 8 / 20087: 10$ & 1.39 & 17.5 & 1267 & $8 / 8 / 20089: 32$ & 1.387 & 17.5 & 1338 & $8 / 8 / 200811: 54$ & 1.387 & 17.5 & 1409 & $8 / 8 / 2008$ 14:16 & 1.383 & 17.5 \\
\hline 1197 & $8 / 8 / 20087: 12$ & 1.393 & 17. & 1268 & $8 / 8 / 20089: 34$ & 1.387 & 17. & 1339 & & 1.387. & & 1410 & j8 14:18 & 1.383 & 17.5 \\
\hline 1198 & $37: 14$ & 1.393 & 17 & 1269 & & 1.387 & 17. & 1340 & $811: 58$ & 1.387 & & 1411 & $814: 20$ & 1.383 & 17.5 \\
\hline 1199 & $8 / 8 / 20087: 16$ & 1.393 & 17. & 1270 & $8 / 8 / 20089: 38$ & 1.39 & 17.5 & 1341 & $8 / 8 / 200812: 00$ & 1.383 & 17.5 & 1412 & $0814: 22$ & 1.383 & 17.4 \\
\hline 1200 & $8 / 8 / 20087: 18$ & 1.393 & 17. & 1271 & $8 / 8 / 20089: 40$ & 1.387 & & 1342 & $8 / 8 / 200812: 02$ & 1.383 & 17.5 & 1413 & $0814: 24$ & 1.383 & 17.5 \\
\hline 1201 & $8 / 8 / 20087: 20$ & 1.393 & 17.5 & 1272 & $8 / 8 / 20089: 42$ & 1.387 & 17.5 & 1343 & $8 / 8 / 2008 \quad 12: 04$ & 1.387 & 17.4 & 1414 & $8 / 8 / 2008$ 14:26 & 1.383 & 17.5 \\
\hline 1202 & $8 / 8 / 20087: 22$ & 1.393 & 17. & 1273 & $8 / 8 / 20089: 44$ & 1.387 & 17.5 & & $8 / 8 / 2008$ 12:06 & 1.383 & 17.5 & & $8 / 8 / 200814: 28$ & 1.383 & 17.5 \\
\hline 1203 & $8 / 8 / 20087: 24$ & 1.393 & 17. & 1274 & $8 / 8 / 20089: 46$ & 1.39 & 17.5 & 1345 & $8 / 8 / 2008$ 12:08 & 1.387 & 17.5 & 1416 & $8 / 8 / 200814: 30$ & 1.383 & 17.5 \\
\hline 1204 & $8 / 8 / 20087: 26$ & 1.393 & 17. & 1275 & $8 / 8 / 20089: 48$ & 1.39 & 17.5 & 1346 & $8 / 8 / 2008$ 12:10 & 1.383 & 17.5 & 1417 & $8 / 8 / 200814: 32$ & 1.38 & 17.5 \\
\hline 1205 & $8 / 8 / 20087: 28$ & 1.393 & 17.5 & 1276 & $8 / 8 / 2008$ 9:50 & 1.39 & 17.5 & 1347 & $8 / 8 / 200812: 12$ & 1.387 & 17.5 & 1418 & $8 / 8 / 200814: 34$ & 1.383 & 17.5 \\
\hline 1206 & $8 / 8 / 20087: 30$ & 1.39 & 17.5 & 1277 & $8 / 8 / 20089: 52$ & 1.39 & 17.4 & 1348 & $8 / 8 / 2008$ 12:14 & 1.383 & 17.5 & 1419 & $8 / 8 / 200814: 36$ & 1.383 & 17.5 \\
\hline
\end{tabular}


DOE/RL-2009-35, REV. 0

\begin{tabular}{|c|c|c|c|}
\hline \multicolumn{4}{|c|}{ D4-26p } \\
\hline $\operatorname{Rec}$ & & Pres & Temp \\
\hline$\#$ & Date/Time & $\mathrm{psi}$ & ${ }^{\circ} \mathrm{C}$ \\
\hline 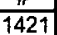 & $8 / 8 / 200814: 40$ & 1.38 & 17 \\
\hline 1422 & $8 / 200814: 42$ & 1.383 & 17.5 \\
\hline 23 & 3/2008 14:44 & 1.38 & 17.5 \\
\hline 24 & $8 / 200814: 46$ & 1.38 & 175 \\
\hline 1425 & $8 / 8 / 2008$ 14:48 & 1.38 & 17.5 \\
\hline 1426 & $8 / 2008 \quad 14: 50$ & 1.38 & 17.5 \\
\hline 1427 & $8 / 200814: 52$ & 1.38 & 17.5 \\
\hline 1428 & $8 / 200814: 54$ & 1.383 & 17.5 \\
\hline 1429 & $8 / 200814: 56$ & 1.38 & 175 \\
\hline 1430 & $8 / 200814: 58$ & 1.383 & 17.5 \\
\hline 1431 & $8 / 2008 \quad 15: 00$ & 1.383 & \\
\hline 1432 & $8 / 200815: 02$ & 1.383 & 17.5 \\
\hline 1433 & $8 / 200815: 04$ & 1.38 & \\
\hline 1434 & $8 / 8 / 200815: 06$ & 1.383 & 17.5 \\
\hline 1435 & $8 / 200815: 08$ & 1.38 & 17.5 \\
\hline 1436 & $8 / 2008$ 15:10 & 1.383 & 17.5 \\
\hline 1437 & $8 / 200815: 12$ & 1.383 & 17.5 \\
\hline 1438 & $3 / 2008 \quad 15: 14$ & 1.383 & \\
\hline 1439 & $8 / 2008 \quad 15: 16$ & 1.383 & 17.4 \\
\hline 1440 & $8 / 2008 \quad 15: 18$ & 1.38 & \\
\hline 1441 & $8 / 8 / 200815: 20$ & 1.383 & 17.4 \\
\hline 1442 & $3 / 2008$ 15:22 & 1.383 & 17.5 \\
\hline 1443 & $8 / 200815: 24$ & 1.383 & 17.4 \\
\hline 1444 & $8 / 200815: 26$ & 1.383 & 17.4 \\
\hline 1445 & $8 / 200815: 28$ & 1.383 & 17.4 \\
\hline 144 & $08 \quad 15: 30$ & 1.383 & 17.5 \\
\hline 1447 & $3 / 2008 \quad 15: 32$ & 1.383 & 17.4 \\
\hline 1448 & $3 / 200815: 34$ & 1.383 & 17.5 \\
\hline 144 & $815: 36$ & 1.383 & 17.4 \\
\hline 1450 & $3 / 200815: 38$ & 1.383 & 17.5 \\
\hline 1451 & $3 / 200815: 40$ & 1.383 & 7.4 \\
\hline 1452 & $3 / 200815: 42$ & 1.383 & 17. \\
\hline 1453 & $315: 44$ & 1.383 & 17. \\
\hline 1454 & $315: 46$ & 1.383 & 17.5 \\
\hline 1455 & $5: 48$ & 1.38 & 17.4 \\
\hline 1456 & $5: 50$ & 1.383 & 7.9 \\
\hline 145 & $5: 52$ & 1.379 & 18. \\
\hline 1458 & $815: 54$ & 1.379 & 17. \\
\hline 145 & $15: 56$ & 1.383 & 17.9 \\
\hline 146 & $15: 58$ & 1.383 & 17.8 \\
\hline 146 & & 1.383 & 17. \\
\hline$\frac{170}{146}$ & $6: 02$ & 1.38 & 17.6 \\
\hline 146 & & 1.383 & \\
\hline 146 & 16:06 & 1.38 & 17. \\
\hline 1465 & $16: 08$ & 1.38 & 17. \\
\hline 146 & & 1.38 & 17. \\
\hline 1467 & $16: 12$ & 1.643 & 22.7 \\
\hline 146 & & 1.93 & 30. \\
\hline 1469 & & 2.03 & 32. \\
\hline 147 & & 2.065 & 33. \\
\hline 147 & $16: 20$ & 2.127 & 33. \\
\hline 147 & & 2.133 & \\
\hline 147 & & 2.17 & 33. \\
\hline 147 & & 2.18 & 33.3 \\
\hline 147 & & 2.2 & 33.3 \\
\hline 147 & & 2.218 & 33.6 \\
\hline 147 & & 2.217 & \\
\hline 147 & & & 33.3 \\
\hline 147 & & 2.261 & \\
\hline$\frac{148}{148}$ & & 2.265 & 33.4 \\
\hline 148 & & 2.265 & \\
\hline 148 & $8 / 8 / 2008+6: 42$ & 2.292 & 33.6 \\
\hline$\frac{176}{148}$ & & 2.283 & \\
\hline 148 & $816: 46$ & 2.292 & 33.4 \\
\hline 48 & & & 33.3 \\
\hline 1486 & $8 / 8 / 20$ & 2.305 & 33. \\
\hline 48 & $8 / 8 / 200816: 52$ & 2.316 & 33.6 \\
\hline 148 & $8 / 8 / 2008+6: 54$ & 2.305 & \\
\hline 489 & $816: 56$ & 2.336 & 33.4 \\
\hline 1490 & $8 / 8 / 20$ & 2.339 & 33.4 \\
\hline 49 & $8 / 8 / 200817: 00$ & 2.357 & \\
\hline
\end{tabular}

\begin{tabular}{|c|c|c|c|}
\hline \multicolumn{4}{|c|}{ D4-26p } \\
\hline $\operatorname{Rec}$ & & Pres & $\overline{\text { Temp }}$ \\
\hline$\#$ & Date/Time & psi & ${ }^{\circ} \mathrm{C}$ \\
\hline 1492 & $8 / 8 / 200817: 02$ & 2.346 & 33.5 \\
\hline 1493 & $8 / 8 / 200817: 04$ & 2.343 & 33.4 \\
\hline 1494 & $8 / 8 / 2008$ 17:06 & 2.339 & 33.4 \\
\hline 1495 & $8 / 8 / 2008 \quad 17: 08$ & 2.376 & 33.4 \\
\hline 1496 & $8 / 8 / 200817: 10$ & 2.366 & 33.4 \\
\hline 1497 & $8 / 8 / 200817: 12$ & 2.349 & 33.4 \\
\hline 1498 & $8 / 8 / 2008$ 17:14 & 2.39 & 33.4 \\
\hline 1499 & $8 / 8 / 2008 \quad 17: 16$ & 2.359 & 33.4 \\
\hline 1500 & $8 / 8 / 200817: 18$ & 2.39 & 33.4 \\
\hline 1501 & $8 / 8 / 200817: 20$ & 2.376 & 33.4 \\
\hline 1502 & $8 / 8 / 200817: 22$ & 2.349 & 33.4 \\
\hline 1503 & $8 / 8 / 200817: 24$ & 2.4 & 33.4 \\
\hline 1504 & $8 / 8 / 200817: 26$ & 2.42 & 33.4 \\
\hline 1505 & $8 / 8 / 200817: 28$ & 2.39 & 33.4 \\
\hline 1506 & $8 / 8 / 200817: 30$ & 2.391 & 33.8 \\
\hline 1507 & $8 / 8 / 2008 \quad 17: 32$ & 2.397 & 33.4 \\
\hline 1508 & $8 / 8 / 200817: 34$ & 2.427 & 33.4 \\
\hline 1509 & $8 / 8 / 200817: 36$ & 2.414 & 33.4 \\
\hline 1510 & $8 / 8 / 2008$ 17:38 & 2.42 & $\overline{33.4}$ \\
\hline 1511 & $8 / 8 / 200817: 40$ & 2.427 & 33.4 \\
\hline 1512 & $8 / 8 / 2008$ 17:42 & 2.43 & $\overline{33.4}$ \\
\hline 1513 & $8 / 8 / 200817: 44$ & 2.403 & 33.4 \\
\hline 1514 & $8 / 8 / 200817: 46$ & 2.43 & 33.4 \\
\hline 1515 & $8 / 8 / 200817: 48$ & 2.448 & 33.4 \\
\hline 1516 & $8 / 8 / 200817: 50$ & 2.441 & 33.6 \\
\hline 1517 & $8 / 8 / 200817: 52$ & 2.448 & 33.4 \\
\hline 1518 & $8 / 8 / 2008 \quad 17: 54$ & 2.464 & 33.4 \\
\hline 1519 & $8 / 8 / 200817: 56$ & 2.458 & 33.4 \\
\hline 1520 & $8 / 8 / 200817: 58$ & 2.492 & 33.4 \\
\hline 1521 & $8 / 8 / 200818: 00$ & 2.469 & 33.8 \\
\hline 1522 & $8 / 8 / 200818: 02$ & 2.462 & 33.6 \\
\hline 1523 & $8 / 8 / 200818: 04$ & 2.465 & 33.8 \\
\hline 1524 & $8 / 8 / 200818: 06$ & 2.492 & 33.5 \\
\hline 1525 & $8 / 8 / 2008$ & 2.488 & 33.6 \\
\hline 1526 & $8 / 8 / 200818: 10$ & 2.489 & 33.8 \\
\hline 1527 & $8 / 8 / 200818: 12$ & 2.515 & 33.4 \\
\hline 1528 & $8 / 8 / 200818: 14$ & 2.474 & 33.4 \\
\hline 1529 & $8 / 8 / 200818: 16$ & 2.492 & 33.8 \\
\hline 1530 & 8/8/2008 18:18 & 2.512 & 33.5 \\
\hline 1531 & $8 / 8 / 20$ & 2.498 & 33.4 \\
\hline 1532 & $8 / 8 / 20$ & 2.485 & 33.7 \\
\hline 1533 & $8 / 8 / 200818: 24$ & 2.512 & 33.4 \\
\hline$\overline{1534}$ & $8 / 8 / 200$ & 2.508 & 33.4 \\
\hline 1535 & $8 / 8 / 200818: 28$ & 2.512 & 33.4 \\
\hline 1536 & & 2.502 & 33.7 \\
\hline 1537 & $8 / 8 / 200$ & 2.522 & 33.4 \\
\hline 1538 & $8 / 8 / 20$ & 2.508 & 33.2 \\
\hline 1539 & 80 & 1.486 & 33.1 \\
\hline 1540 & & 1.453 & 33.1 \\
\hline 1541 & $8 / 8 / 2008$ & 1.442 & 32.9 \\
\hline 1542 & $8 / 8 / 20$ & 1.438 & 32.7 \\
\hline 1543 & $8 / 8 / 20$ & 1.434 & 32.5 \\
\hline 1544 & $8 / 8 / 2008$ 18:46 & 1.431 & 32.4 \\
\hline 1545 & & 1.427 & 32.4 \\
\hline 1546 & $8 / 8 / 200$ & 1.427 & 32.3 \\
\hline 1547 & $8 / 8 / 20$ & 1.431 & 32.4 \\
\hline 1548 & $8 / 8 / 200$ & 1.431 & 32.4 \\
\hline 1549 & $8 / 8 / 2008$ 18:56 & 1.431 & 32.4 \\
\hline 1550 & $8 / 8 / 200818: 58$ & 1.431 & 32.4 \\
\hline 1551 & & $\overline{43}$ & 32.3 \\
\hline 1552 & $8 / 8 / 200819$ & 1.43 & 32.1 \\
\hline 1553 & $8 / 8 / 2008$ & 1.43 & 32.1 \\
\hline 1554 & $8 / 8 / 2008$ 19:06 & 1.426 & 32 \\
\hline 1555 & $8 / 8 / 2008$ 19:08 & 1.426 & 32 \\
\hline 1556 & 8/8/2008 19:10 & 1.427 & 32.1 \\
\hline 1557 & $8 / 8 / 200819: 12$ & 1.422 & 31.8 \\
\hline 1558 & $8 / 8 / 200819: 14$ & 1.419 & 31.7 \\
\hline 1559 & $8 / 8 / 200819: 16$ & 1.419 & 31.5 \\
\hline 1560 & $8 / 8 / 200$ & 1.419 & 31.5 \\
\hline 1561 & $8 / 8 / 200819: 20$ & 1.419 & 31.6 \\
\hline 1562 & $8 / 8 / 200819: 22$ & 1.419 & 31. \\
\hline
\end{tabular}

\begin{tabular}{|c|c|c|c|}
\hline \multicolumn{4}{|c|}{ D4-26p } \\
\hline $\operatorname{Rec}$ & & Pres & Temp \\
\hline$\#$ & Date/Time & $\mathrm{psi}$ & ${ }^{\circ} \mathrm{C}$ \\
\hline 563 & $8 / 8 / 2008 \quad 19: 24$ & 9.415 & 31.4 \\
\hline 1564 & $3 / 2008 \quad 19: 26$ & 1.415 & 31.4 \\
\hline 565 & $8 / 2008 \quad 19: 28$ & 1.412 & 31.4 \\
\hline 1566 & $8 / 2008$ 19:30 & 1.412 & 31.6 \\
\hline 567 & $8 / 2008 \quad 19: 32$ & 1.408 & 31.2 \\
\hline 1568 & $8 / 2008 \quad 19: 34$ & 1.405 & \\
\hline 569 & $/ 8 / 2008 \quad 19: 36$ & 1.408 & 31.3 \\
\hline 1570 & $8 / 2008 \quad 19: 38$ & 1.408 & 31.3 \\
\hline 1571 & $8 / 2008 \quad 19: 40$ & $1 . \overline{408}$ & 31.2 \\
\hline 1572 & $3 / 2008 \quad 19: 42$ & 1.408 & 31.1 \\
\hline 1573 & $8 / 2008 \quad 19: 44$ & 1.411 & 311 \\
\hline 1574 & $8 / 2008 \quad 19: 46$ & 1.408 & 31.1 \\
\hline 1575 & $8 / 2008 \quad 19: 48$ & 1.408 & 31.1 \\
\hline 1576 & $8 / 200819: 50$ & 1.407 & 31 \\
\hline 1577 & $8 / 2008$ 19:52 & 1.407 & \\
\hline 1578 & $8 / 2008 \quad 19: 54$ & 1.407 & $\overline{30.9}$ \\
\hline 1579 & $8 / 2008$ 19:56 & 1.407 & 30.9 \\
\hline 1580 & $8 / 2008$ 19:58 & 1.404 & \\
\hline 1581 & $/ 200820: 00$ & 1.407 & 30.8 \\
\hline 1582 & $/ 200820: 02$ & 1.404 & \\
\hline 1583 & $3 / 200820: 04$ & 1.404 & 30.8 \\
\hline 1584 & $3 / 200820: 06$ & 1.4 & 30.8 \\
\hline 1585 & $8 / 8 / 200820: 08$ & 1.495 & 30.8 \\
\hline 1586 & $3 / 200820: 10$ & 2.32 & 31 \\
\hline 1587 & $3 / 200820: 12$ & 2.328 & 31.6 \\
\hline 1588 & $1200820: 14$ & 2.241 & 31.7 \\
\hline 1589 & $3 / 200820: 16$ & 2.156 & 31.8 \\
\hline 1590 & $1200820: 18$ & 1.443 & 31.8 \\
\hline 1591 & $20: 20$ & 1.432 & 31.7 \\
\hline 1592 & $320: 22$ & 1.425 & 31.6 \\
\hline 1593 & $200820: 24$ & 1.422 & 31.5 \\
\hline 1594 & $3 / 200820: 26$ & 1.418 & 31.3 \\
\hline 1595 & $8 / 2008 \quad 20: 28$ & 1.415 & 31.3 \\
\hline 1596 & $/ 200820: 30$ & 1.415 & 31.2 \\
\hline 1597 & $20: 32$ & 1.41 & 31.1 \\
\hline 1598 & & 1.4 & \\
\hline 1599 & $20: 36$ & 1.411 & 30. \\
\hline 1600 & $20: 38$ & 1.411 & 30. \\
\hline 1601 & $320: 40$ & 2.05 & 30.8 \\
\hline 1602 & $820: 42$ & 2.165 & 31.2 \\
\hline 1603 & $20: 44$ & 2.186 & 31.3 \\
\hline 1604 & $20: 46$ & 2.149 & 31.8 \\
\hline 1605 & & 2.223 & 31.5 \\
\hline 1606 & $820: 50$ & 2.227 & 31. \\
\hline 1607 & $820: 52$ & 2.254 & 31.4 \\
\hline 1608 & $20: 54$ & 2.25 & 31. \\
\hline 1609 & $820: 56$ & 2.257 & 31.5 \\
\hline 1610 & & 2.278 & \\
\hline 161 & & 2.274 & 31. \\
\hline 1612 & $21: 02$ & 2.267 & 31. \\
\hline 1613 & & 2.27 & $\overline{1.3}$ \\
\hline 1614 & & 2.277 & \\
\hline 1615 & $321: 08$ & 2.257 & 31.3 \\
\hline 1616 & & & \\
\hline 161 & & 2.267 & \\
\hline 161 & & 2.267 & \\
\hline 1619 & & 2.213 & \\
\hline 1620 & & 2.234 & \\
\hline 1621 & & 2.22 & \\
\hline 162 & & 2.24 & 31.3 \\
\hline 162 & & 2.25 & \\
\hline 1624 & $3 / 200821: 26$ & 2.25 & 31.3 \\
\hline 1625 & & 2.226 & \\
\hline 1626 & $3 / 200821:$ & 2.247 & \\
\hline 1627 & & 2.274 & \\
\hline 1628 & 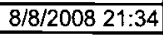 & 2.244 & \\
\hline 1629 & & 2.25 & \\
\hline 1630 & $200821: 38$ & & \\
\hline 1631 & & 2.253 & (1.8 \\
\hline 1632 & & 2.24 & \\
\hline & $8 / 8 / 200821: 44$ & 2.267 & \\
\hline
\end{tabular}

\begin{tabular}{|c|c|c|c|}
\hline \multicolumn{4}{|c|}{ D4-26p } \\
\hline $\operatorname{Rec}$ & & Pres & Temp \\
\hline$\#$ & Date/Time & psi & ${ }^{\circ} \mathrm{C}$ \\
\hline 1634 & $8 / 8 / 200821: 46$ & 2.28 & 31.2 \\
\hline 1635 & $8 / 8 / 200821: 48$ & 2.267 & 31.2 \\
\hline 1636 & $8 / 8 / 200821: 50$ & 2.267 & 31.2 \\
\hline 1637 & $8 / 8 / 200821: 52$ & 2.27 & 31.2 \\
\hline 1638 & $8 / 8 / 200821: 54$ & 2.29 & 31.2 \\
\hline 1639 & $8 / 8 / 200821: 56$ & 2.263 & 31.1 \\
\hline 1640 & $8 / 8 / 200821: 58$ & 2.284 & 31.1 \\
\hline 1641 & $8 / 8 / 200822: 00$ & 2.297 & 31.1 \\
\hline 1642 & $8 / 8 / 200822: 02$ & 2.287 & 31.1 \\
\hline 1643 & $8 / 8 / 200822: 04$ & 2.28 & 31.1 \\
\hline 1644 & $8 / 8 / 200822: 06$ & 2.294 & 31.1 \\
\hline 1645 & $8 / 8 / 200822: 08$ & 2.298 & 31.6 \\
\hline 1646 & $8 / 8 / 200822: 10$ & 2.294 & 31.2 \\
\hline 1647 & $8 / 8 / 200822: 12$ & 2.294 & 31.1 \\
\hline 1648 & 8/8/2008 22:14 & 2.287 & 31.1 \\
\hline 1649 & $8 / 8 / 200822: 16$ & 2.304 & 31 \\
\hline 1650 & $8 / 8 / 200822: 18$ & 2.307 & 31 \\
\hline 1651 & $8 / 8 / 200822: 20$ & 2.307 & 31 \\
\hline 1652 & $8 / 8 / 200822: 22$ & 2.31 & 31 \\
\hline 1653 & $8 / 8 / 200822: 24$ & 2.307 & 31 \\
\hline 1654 & $8 / 8 / 200822: 26$ & 2.317 & 31 \\
\hline 1655 & $8 / 8 / 200822: 28$ & 2.324 & 31 \\
\hline 1656 & $8 / 8 / 200822: 30$ & 2.307 & 30.9 \\
\hline 1657 & $8 / 8 / 200822: 32$ & 2.327 & 30.9 \\
\hline 1658 & $8 / 8 / 200822: 34$ & 2.32 & 30.9 \\
\hline 1659 & $8 / 8 / 200822: 36$ & 2.317 & 30.9 \\
\hline 1660 & $8 / 8 / 200822: 38$ & 2.317 & 30.9 \\
\hline 1661 & $8 / 8 / 200822: 40$ & 2.324 & 30.9 \\
\hline 1662 & $8 / 8 / 200822: 42$ & 2.3 & 30.9 \\
\hline 1663 & $8 / 8 / 200822: 44$ & 2.3 & 30.9 \\
\hline 1664 & $8 / 8 / 200822: 46$ & 2.303 & 30.8 \\
\hline 1665 & $8 / 8 / 200822: 48$ & 2.29 & 30.9 \\
\hline 1666 & $8 / 8 / 200822: 50$ & 2.334 & 30.8 \\
\hline 1667 & $8 / 8 / 200822: 52$ & 2.31 & 30.8 \\
\hline 1668 & $8 / 8 / 200822: 54$ & 2.307 & 30.8 \\
\hline 1669 & $0822: 56$ & 2.29 & 30.8 \\
\hline 1670 & $8 / 8 / 200822: 58$ & 1.492 & 30.8 \\
\hline 1671 & $8 / 8 / 200823: 00$ & 1.475 & 30.8 \\
\hline 1672 & $0823: 02$ & 1.464 & 30.7 \\
\hline 1673 & $0823: 04$ & 1.457 & 30.6 \\
\hline 1674 & $823: 06$ & 1.454 & 30.4 \\
\hline 1675 & $0823: 08$ & 1.45 & 30.4 \\
\hline 1676 & $823: 10$ & 1.447 & $\overline{30.4}$ \\
\hline 1677 & $8 / 8 / 200823: 12$ & 1.447 & 30.3 \\
\hline 1678 & $8 / 8 / 200823: 14$ & 1.443 & 30.3 \\
\hline 1679 & $0823: 16$ & 1.443 & 30.3 \\
\hline 1680 & $823: 18$ & 1.443 & 30.3 \\
\hline 1681 & $0823: 20$ & 1.44 & 30.3 \\
\hline 1682 & & 1.437 & 30.5 \\
\hline 1683 & $823: 24$ & 1.433 & 30.1 \\
\hline 1684 & $23: 26$ & 1.436 & 29.9 \\
\hline 1685 & $823: 28$ & 1.432 & 29.8 \\
\hline 1686 & $823: 30$ & 1.432 & 29.8 \\
\hline 1687 & $823: 32$ & 1.429 & 29.8 \\
\hline 1688 & $8 / 8 / 200823: 34$ & 1.432 & $29: 7$ \\
\hline 1689 & 8/8/2008 23:36 & 1.432 & \\
\hline 1690 & $08 \quad 23: 38$ & 1.432 & 29.6 \\
\hline 1691 & $0823: 40$ & 1.429 & 29.6 \\
\hline 1692 & $0823: 42$ & 1.425 & 29.5 \\
\hline 1693 & $0823: 44$ & 1.425 & 29.4 \\
\hline 1694 & $8 / 8 / 200823: 46$ & 1.547 & 29.4 \\
\hline 1695 & $8 / 8 / 200823: 48$ & 2.188 & 28.6 \\
\hline 1696 & $8 / 8 / 200823: 50$ & 2.215 & \\
\hline 1697 & $8 / 8 / 200823: 52$ & 2.218 & 28.6 \\
\hline 1698 & $8 / 8 / 200823: 54$ & 2.222 & 28.4 \\
\hline 1699 & $8 / 8 / 200823: 56$ & 2.252 & 28.3 \\
\hline 1700 & $8 / 8 / 200823: 58$ & 2.252 & \\
\hline 1701 & $8 / 9 / 20080: 00$ & 2.245 & 28.3 \\
\hline 170 & $8 / 9 / 20080$ & 2.286 & 28 \\
\hline 1703 & $8 / 9 / 20080: 04$ & 2.265 & 28 \\
\hline 1704 & $8 / 9 / 20080: 06$ & 2.265 & 28 \\
\hline
\end{tabular}


DOE/RL-2009-35, REV. 0

\begin{tabular}{|c|c|c|c|c|c|c|c|c|c|c|c|c|c|c|c|}
\hline \multicolumn{4}{|c|}{ D4-26p } & \multicolumn{4}{|c|}{ D4-26p } & \multicolumn{4}{|c|}{ D4-26p } & \multicolumn{4}{|c|}{ D4-26p } \\
\hline $\operatorname{Rec}$ & & Pres & Temp & $\operatorname{Rec}$ & & Pres & Temp & $\operatorname{Rec}$ & & Pres & Temp & $\operatorname{Rec}$ & & Pres & Temp \\
\hline$\#$ & Date/Time & psi & ${ }^{\circ} \mathrm{C}$ & $\#$ & Date/Time & psi & ${ }^{\circ} \mathrm{C}$ & $\#$ & Date/Time & psi & ${ }^{\circ} \mathrm{C}$ & \# & Date/Time & psi & ${ }^{\circ} \mathrm{C}$ \\
\hline 1705 & $8 / 9 / 20080: 08$ & 2.252 & 28.3 & 1776 & $8 / 9 / 20082: 30$ & 2.278 & 27.6 & 1847 & $8 / 9 / 20084: 52$ & 2.346 & 27.4 & 1918 & $8 / 9 / 20087: 14$ & 2.365 & 26.9 \\
\hline 1706 & $8 / 9 / 20080: 10$ & 2.259 & 28.3 & 1777 & $8 / 9 / 2008$ 2:32 & 2.295 & 27.6 & 1848 & $8 / 9 / 20084: 54$ & 2.369 & 27.3 & 1919 & $8 / 9 / 20087: 16$ & 2.389 & 26.9 \\
\hline 1707 & $8 / 9 / 20080: 12$ & 2.286 & 28.3 & 1778 & $8 / 9 / 20082: 34$ & 2.292 & 27.6 & 1849 & $8 / 9 / 20084: 56$ & 2.356 & 27.3 & 1920 & $8 / 9 / 20087: 18$ & 2.396 & 26.9 \\
\hline 1708 & $8 / 9 / 20080: 14$ & 2.272 & 28.3 & 1779 & $8 / 9 / 20082: 36$ & 2.295 & 27.6 & 1850 & $8 / 9 / 20084: 58$ & 2.345 & 27.2 & 1921 & $8 / 9 / 20087: 20$ & 2.369 & 26.9 \\
\hline 1709 & $8 / 9 / 20080: 16$ & 2.282 & 28.3 & 1780 & $8 / 9 / 20082: 38$ & 2.288 & 27.6 & 1851 & $8 / 9 / 20085: 00$ & 2.339 & 27.2 & 1922 & $8 / 9 / 20087: 22$ & 2.379 & 27 \\
\hline 1710 & $8 / 9 / 20080: 18$ & 2.279 & 28.3 & 1781 & $8 / 9 / 20082: 40$ & 2.309 & 27.6 & 1852 & $8 / 9 / 20085: 02$ & 2.352 & 27.2 & 1923 & $8 / 9 / 20087: 24$ & 2.382 & 26.9 \\
\hline 1711 & $8 / 9 / 20080: 20$ & 2.265 & 28.3 & 1782 & $8 / 9 / 20082: 42$ & 2.288 & 27.6 & 1853 & $8 / 9 / 20085: 04$ & 2.335 & 27.2 & 1924 & $8 / 9 / 20087: 26$ & 2.386 & 26.9 \\
\hline 1712 & $8 / 9 / 20080: 22$ & 2.259 & 28.3 & 1783 & $8 / 9 / 20082: 44$ & 2.332 & 27.6 & 1854 & $8 / 9 / 20085: 06$ & 1.608 & 27.2 & 1925 & $8 / 9 / 20087: 28$ & 2.376 & 26.9 \\
\hline 1713 & $8 / 9 / 20080: 24$ & 2.262 & 28.3 & 1784 & $8 / 9 / 20082: 46$ & 2.288 & 27.6 & 1855 & $8 / 9 / 20085: 08$ & 1.524 & 27.2 & 1926 & $8 / 9 / 20087: 30$ & 2.389 & 26.9 \\
\hline 1714 & $8 / 9 / 20080: 26$ & 2.292 & 28.3 & 1785 & $8 / 9 / 20082: 48$ & 2.339 & 27.6 & 1856 & $8 / 9 / 20085: 10$ & 1.507 & 27.2 & 1927 & $8 / 9 / 20087: 32$ & 2.372 & 26.9 \\
\hline 1715 & $8 / 9 / 20080: 28$ & 2.286 & 28.3 & 1786 & $8 / 9 / 20082: 50$ & 2.322 & 27.6 & 1857 & $8 / 9 / 20085: 12$ & 1.503 & 27.2 & 1928 & $8 / 9 / 20087: 34$ & 2.362 & 26.9 \\
\hline 1716 & $8 / 9 / 20080: 30$ & 2.286 & 28.3 & 1787 & $8 / 9 / 20082: 52$ & 2.342 & 27.6 & 1858 & $8 / 9 / 20085: 14$ & 1.496 & 27.1 & 1929 & $8 / 9 / 20087: 36$ & 2.362 & 26.9 \\
\hline 1717 & $8 / 9 / 20080: 32$ & 2.299 & 28.3 & 1788 & $8 / 9 / 20082: 54$ & 2.298 & 27.6 & 1859 & $8 / 9 / 20085: 16$ & 1.493 & 27.1 & 1930 & $8 / 9 / 20087: 38$ & 2.379 & 26.9 \\
\hline 1718 & $8 / 9 / 20080: 34$ & 2.299 & 28.2 & 1789 & $8 / 9 / 20082: 56$ & 2.332 & 27.6 & 1860 & $8 / 9 / 20085: 18$ & 1.49 & 27.1 & 1931 & $8 / 9 / 20087: 40$ & 2.389 & 26.9 \\
\hline 1719 & $8 / 9 / 20080: 36$ & 2.282 & 28.2 & 1790 & $8 / 9 / 20082: 58$ & 2.295 & 27.9 & 1861 & $8 / 9 / 20085: 20$ & 1.486 & 27.1 & 1932 & $8 / 9 / 20087: 42$ & 2.382 & 26.9 \\
\hline 1720 & $8 / 9 / 20080: 38$ & 2.289 & 28.2 & 1791 & $8 / 9 / 20083: 00$ & 2.346 & 27.6 & 1862 & $8 / 9 / 20085: 22$ & 1.48 & 27.1 & 1933 & $8 / 9 / 20087: 44$ & 2.396 & 26.9 \\
\hline 1721 & $8 / 9 / 20080: 40$ & 2.313 & 28.3 & 1792 & $8 / 9 / 20083: 02$ & 2.332 & 27.6 & 1863 & $8 / 9 / 20085: 24$ & 2.775 & 26.9 & 1934 & $8 / 9 / 20087: 46$ & 2.376 & 26.9 \\
\hline 1722 & $8 / 9 / 20080: 42$ & 2.313 & 28.4 & 1793 & $8 / 9 / 20083: 04$ & 2.319 & 27.5 & 1864 & $8 / 9 / 20085: 26$ & 2.264 & 26.9 & 1935 & $8 / 9 / 20087: 48$ & 2.409 & 26.9 \\
\hline 1723 & $8 / 9 / 20080: 44$ & 2.32 & 28.3 & 1794 & $8 / 9 / 20083: 06$ & 2.315 & 27.5 & 1865 & $8 / 9 / 20085: 28$ & 2.298 & 27 & 1936 & $8 / 9 / 20087: 50$ & 2.379 & 26.9 \\
\hline 1724 & $8 / 9 / 20080: 46$ & 2.319 & 28.2 & 1795 & $8 / 9 / 20083: 08$ & 2.308 & 27.5 & 1866 & $8 / 9 / 20085: 30$ & 2.305 & 27 & 1937 & $8 / 9 / 20087: 52$ & 2.396 & 26.9 \\
\hline 1725 & $8 / 9 / 20080: 48$ & 2.289 & 28.2 & 1796 & $8 / 9 / 20083: 10$ & 2.319 & 27.5 & 1867 & $8 / 9 / 20085: 32$ & 2.325 & 27 & 1938 & $8 / 9 / 20087: 54$ & 2.386 & 26.9 \\
\hline 1726 & $8 / 9 / 20080: 50$ & 2.319 & 28.2 & 1797 & $8 / 9 / 20083: 12$ & 2.319 & 27.5 & 1868 & $8 / 9 / 20085: 34$ & 2.311 & 27.1 & 1939 & $8 / 9 / 20087: 56$ & 2.369 & 26.9 \\
\hline 1727 & $0080: 52$ & 2.313 & 28.2 & 1798 & $8 / 9 / 20083: 14$ & 2.309 & 27.6 & 1869 & $8 / 9 / 20085: 36$ & 2.322 & 27.1 & 1940 & $8 / 9 / 20087: 58$ & 2.396 & 26.9 \\
\hline 1728 & $8 / 9 / 20080: 54$ & 2.299 & 28.2 & 1799 & $8 / 9 / 20083: 16$ & 2.305 & 27.5 & 1870 & $8 / 9 / 20085: 38$ & 2.349 & 27 & 1941 & $8 / 9 / 20088: 00$ & 2.386 & 26.9 \\
\hline 1729 & $8 / 9 / 20080: 56$ & 2.302 & 28.1 & 1800 & $8 / 9 / 20083: 18$ & 2.322 & 27.5 & 1871 & $8 / 9 / 20085: 40$ & 2.328 & 27 & 1942 & $8 / 9 / 20088: 02$ & 2.379 & 26.9 \\
\hline 1730 & $0080: 58$ & 2.319 & 28.1 & 1801 & $8 / 9 / 20083: 20$ & 2.332 & 27.5 & 1872 & $8 / 9 / 20085: 42$ & 2.332 & 27 & 1943 & $8 / 9 / 2008$ 8:04 & 2.403 & 26.9 \\
\hline 1731 & $8 / 9 / 20081: 00$ & 2.316 & 28.1 & 1802 & $8 / 9 / 20083: 22$ & 2.332 & 27.5 & 1873 & $8 / 9 / 20085: 44$ & 2.345 & 26.9 & 1944 & $8 / 9 / 20088: 06$ & 2.423 & 26.9 \\
\hline 1732 & $8 / 9 / 20081: 02$ & 2.299 & 28.1 & 1803 & $8 / 9 / 20083: 24$ & 2.329 & 27.5 & 1874 & $8 / 9 / 20085: 46$ & 2.318 & 26.9 & 1945 & $8 / 9 / 20088: 08$ & 2.392 & 26.8 \\
\hline 1733 & $8 / 9 / 20081: 04$ & 2.326 & 28.1 & 1804 & $8 / 9 / 20083: 26$ & 2.329 & 27.5 & 1875 & $8 / 9 / 20085: 48$ & 2.355 & 26.9 & 1946 & $8 / 9 / 20088: 10$ & 2.362 & 26.9 \\
\hline 1734 & $8 / 9 / 20081: 06$ & 2.316 & 28.1 & 1805 & $8 / 9 / 20083: 28$ & 2.366 & 27.5 & 1876 & $8 / 9 / 20085: 50$ & 2.339 & 27.3 & 1947 & $88: 12$ & 2.396 & 26.9 \\
\hline 1735 & $0081: 08$ & 2.289 & 28.1 & 1806 & $8 / 9 / 20083: 30$ & 2.346 & 27.4 & 1877 & $8 / 9 / 20085: 52$ & 2.362 & 27.3 & 1948 & $88: 14$ & 2.416 & 26.9 \\
\hline 1736 & $8 / 9 / 20081: 10$ & 2.309 & 28.1 & 1807 & $8 / 9 / 20083: 32$ & 2.329 & 27.5 & 1878 & $8 / 9 / 20085: 54$ & 2.325 & 27.3 & 1949 & $8 / 9 / 20088: 16$ & 2.355 & 26.9 \\
\hline 1737 & $8 / 9 / 20081: 12$ & 2.326 & 28.1 & 1808 & $8 / 9 / 20083: 34$ & 2.329 & 27.5 & 1879 & $8 / 9 / 20085: 56$ & 2.322 & 27.4 & 1950 & $8 / 9 / 2008$ 8:18 & 2.396 & 26.9 \\
\hline 1738 & $8 / 9 / 20081: 14$ & 2.333 & 28.1 & 1809 & $8 / 9 / 20083: 36$ & 2.332 & 27.5 & 1880 & $8 / 9 / 20085: 58$ & 2.332 & 27.4 & 1951 & $8 / 9 / 20088: 20$ & 2.372 & 26.9 \\
\hline 1739 & $81: 16$ & 2.333 & 28.1 & 1810 & $8 / 9 / 20083: 38$ & 2.346 & 27.4 & 1881 & $8 / 9 / 20086: 00$ & 2.339 & 27.4 & 1952 & $88: 22$ & 2.43 & 27.1 \\
\hline 1740 & $8 / 9 / 20081: 18$ & 2.323 & 28.1 & 1811 & $8 / 9 / 20083: 40$ & 2.342 & 27.4 & 1882 & $8 / 9 / 20086: 02$ & 2.332 & 27.4 & 1953 & $8 / 9 / 20088: 24$ & 2.356 & 27.4 \\
\hline 1741 & $8 / 9 / 20081: 20$ & 2.316 & 28.1 & 1812 & $8 / 9 / 20083: 42$ & 2.332 & 27.4 & 1883 & $8 / 9 / 20086: 04$ & 2.335 & 27.4 & 1954 & $88: 26$ & 2.376 & 27.4 \\
\hline 1742 & $8 / 9 / 20081: 22$ & 2.34 & 28.1 & 1813 & $8 / 9 / 20083: 44$ & 2.055 & 27.4 & 1884 & $8 / 9 / 20086: 06$ & 2.325 & 27.3 & 1955 & $88: 28$ & 2.376 & 26.9 \\
\hline 1743 & $881: 24$ & 2.323 & 28.1 & 1814 & $0083: 46$ & 2.322 & 27.4 & 1885 & $8 / 9 / 20086: 08$ & 2.335 & 27.3 & 1956 & $88: 30$ & 2.362 & 26.9 \\
\hline 1744 & $81: 26$ & 2.343 & 28.1 & 1815 & $83: 48$ & 2.322 & 27.4 & 1886 & $8 / 9 / 20086: 10$ & 2.322 & 27.2 & 1957 & $88: 32$ & 2.365 & 27 \\
\hline 1745 & $8 / 9 / 20081: 28$ & 2.346 & 28.1 & 1816 & $8 / 9 / 20083: 50$ & 2.319 & 27.4 & 1887 & $8 / 9 / 20086: 12$ & 2.339 & 27.1 & 1958 & $8 / 9 / 20088: 34$ & 2.399 & 26.9 \\
\hline 1746 & $8 / 9 / 20081: 30$ & 2.313 & 28.1 & 1817 & $8 / 9 / 20083: 52$ & 2.322 & 27.4 & 1888 & $8 / 9 / 20086: 14$ & 2.345 & 27.1 & 1959 & $88: 36$ & 2.386 & 26.9 \\
\hline 1747 & $81: 32$ & 2.357 & 28.1 & 1818 & $8 / 9 / 20083: 54$ & 2.312 & 27.4 & 1889 & $8 / 9 / 20086: 16$ & 2.335 & 27 & 1960 & $88: 38$ & 2.379 & 26.9 \\
\hline 1748 & $31: 34$ & 2.323 & 28.1 & 1819 & $83: 56$ & 2.332 & 27.4 & 1890 & $886: 18$ & 2.345 & 27 & 1961 & $88: 40$ & 2.379 & 26.9 \\
\hline 1749 & $8 / 9 / 20081: 36$ & 2.34 & 28.1 & 1820 & $8 / 9 / 20083: 58$ & 2.356 & 27.4 & 1891 & $8 / 9 / 20086: 20$ & 2.352 & 26. & 1962 & $8 / 9 / 20088: 42$ & 2.392 & 26.9 \\
\hline 1750 & $81: 38$ & 2.323 & 28.1 & 1821 & $84: 00$ & 2.325 & 27.4 & 1892 & $86: 22$ & 2.342 & 26. & 1963 & $8: 44$ & 2.372 & 26.9 \\
\hline 1751 & $1: 40$ & 2.329 & 28. & 1822 & $34: 02$ & 2.329 & 27.4 & 1893 & $86: 24$ & 2.328 & 26. & 1964 & $88: 46$ & 2.392 & 26.9 \\
\hline 1752 & $8 / 9 / 20081: 42$ & 2.329 & 28.1 & 1823 & $8 / 9 / 20084: 04$ & 2.339 & 27.4 & 1894 & $8 / 9 / 20086: 26$ & 2.352 & 26.8 & 1965 & $8 / 9 / 20088: 48$ & 2.379 & 26.9 \\
\hline 1753 & $8 / 9 / 20081: 44$ & 2.333 & 28.1 & 1824 & $8 / 9 / 20084: 06$ & 2.346 & 27.4 & 1895 & $8 / 9 / 20086: 28$ & 2.338 & 26.9 & 1966 & $88: 50$ & 2.386 & 26.9 \\
\hline 1754 & $81: 46$ & 2.34 & 28.1 & 1825 & $8 / 9 / 20084: 08$ & 2.356 & 27.4 & 1896 & $8 / 9 / 20086: 30$ & 2.352 & 26. & 1967 & $8 / 9 / 20088: 52$ & 2.386 & 26.9 \\
\hline 1755 & $11: 48$ & 2.326 & 28. & 1826 & $84: 10$ & 2.359 & 27.4 & 1897 & $86: 32$ & 2.369 & 26. & 1968 & & 2.392 & 26.9 \\
\hline 1756 & $31: 50$ & 2.353 & 28. & 1827 & $84: 12$ & 2.349 & 27.3 & 1898 & $086: 34$ & 2.355 & 26. & 1969 & $8 / 9 / 20088: 56$ & 2.382 & 26.9 \\
\hline 1757 & $31: 52$ & 2.333 & 28.6 & 1828 & $84: 14$ & 2.376 & 27.3 & 1899 & $886: 36$ & 2.372 & 26. & 1970 & $88: 58$ & 2.406 & 26.9 \\
\hline 1758 & & 2.313 & 28.6 & 1829 & $84: 16$ & 2.339 & 27.3 & 1900 & $886: 38$ & 2.352 & 26. & 1971 & $89: 00$ & 2.382 & 26.9 \\
\hline 1759 & $8 / 9 / 20081: 56$ & 2.353 & 28.3 & 1830 & $84: 18$ & 2.335 & 27.3 & 1901 & $8 / 9 / 20086: 40$ & 2.372 & 26.9 & 1972 & $089: 02$ & 2.362 & 26.9 \\
\hline 1760 & $0081: 58$ & 2.356 & 28.1 & 1831 & $8 / 9 / 20084: 20$ & 2.352 & 27.3 & 1902 & $8 / 9 / 20086: 42$ & 2.386 & 27. & 1973 & $8 / 9 / 20089: 04$ & 2.389 & 26.9 \\
\hline 1761 & $0082: 00$ & 2.319 & 28.1 & 1832 & $8 / 9 / 20084: 22$ & 2.335 & 27.3 & 1903 & $8 / 9 / 20086: 44$ & 2.369 & 27. & 1974 & $8 / 9 / 20089: 06$ & 2.399 & 26.9 \\
\hline 1762 & $32: 02$ & 2.329 & 28 & 1833 & $84: 24$ & 2.335 & 27.3 & 1904 & $86: 46$ & 2.382 & 26. & 775 & $89: 08$ & 1.909 & 26.9 \\
\hline 1763 & $2: 04$ & 2.353 & 28 & 1834 & $84: 26$ & 2.349 & 27.3 & 190 & $886: 48$ & 2.345 & 26. & 1976 & $89: 10$ & 1.581 & 26.9 \\
\hline 1764 & $82: 06$ & 2.326 & 28 & 1835 & $84: 28$ & 2.318 & 27.3 & 1906 & $8 / 9 / 20086: 50$ & 2.348 & 26. & 1977 & $8 / 9 / 20089: 12$ & 1.533 & 26.9 \\
\hline 1765 & $82: 08$ & 1.585 & 28 & & $84: 30$ & 2.366 & 27.3 & 1907 & & 2.399 & 26. & 1978 & & 1.517 & 26.9 \\
\hline 1766 & $8 / 9 / 20082: 10$ & 1.521 & 28 & 1837 & $84: 32$ & 2.356 & 27.3 & 1908 & $8 / 9 / 20086: 54$ & 2.396 & 26. & 1979 & $89: 16$ & 1.513 & 26.9 \\
\hline 1767 & $8 / 9 / 20082: 12$ & 1.504 & 28 & 1838 & $8 / 9 / 20084: 34$ & 2.359 & 27.3 & 1909 & $8 / 9 / 20086: 56$ & 2.359 & 26. & 1980 & $8 / 9 / 20089: 18$ & 1.506 & 26.9 \\
\hline 1768 & $8 / 9 / 20082: 14$ & 1.494 & 27.9 & 1839 & $8 / 9 / 20084: 36$ & 2.349 & 27.3 & 1910 & $8 / 9 / 20086: 58$ & 2.369 & 26. & 1981 & $8 / 9 / 20089: 20$ & 1.5 & 26.9 \\
\hline 1769 & $82: 16$ & 1.491 & 27.9 & 1840 & $8 / 9 / 20084: 38$ & 2.339 & 27.3 & 1911 & $8 / 9 / 20087: 00$ & 2.399 & 26. & 1982 & $889: 22$ & 1.496 & 26.8 \\
\hline 1770 & $8 / 9 / 20082: 18$ & 1.487 & 27.9 & 1841 & $8 / 9 / 20084: 40$ & 2.362 & 27.3 & 1912 & $8 / 9 / 20087: 02$ & 2.399 & 26. & 1983 & $89: 24$ & 2.267 & 26.9 \\
\hline 1771 & $8 / 9 / 20082: 20$ & 1.48 & 27.9 & 1842 & $8 / 9 / 20084: 42$ & 2.369 & 27.3 & 1913 & $8 / 9 / 20087: 04$ & 2.386 & 26.9 & 1984 & $8 / 9 / 20089: 26$ & 2.294 & 26.9 \\
\hline 1772 & $8 / 9 / 20082: 22$ & 1.791 & 27.9 & 1843 & $8 / 9 / 20084: 44$ & 2.352 & 27.3 & 1914 & $8 / 9 / 20087: 06$ & 2.399 & 26. & 1985 & $8 / 9 / 20089: 28$ & 2.315 & 26.9 \\
\hline 1773 & $8 / 9 / 20082: 24$ & 2.285 & 27.9 & 1844 & $8 / 9 / 20084: 46$ & 2.372 & 27.3 & 1915 & $8 / 9 / 20087: 08$ & 2.362 & 26. & 1986 & $8 / 9 / 20089: 30$ & 2.315 & 26.9 \\
\hline 1774 & $8 / 9 / 20082: 26$ & 2.234 & 27.7 & 1845 & $8 / 9 / 20084: 48$ & 2.353 & 27.7 & 1916 & $8 / 9 / 20087: 10$ & 2.406 & 26.9 & 1987 & $8 / 9 / 20089: 32$ & 2.359 & 26.9 \\
\hline 1775 & $8 / 9 / 20082: 28$ & 2.258 & 27.6 & 1846 & $8 / 9 / 20084: 50$ & 2.339 & 27.3 & 1917 & $8 / 9 / 20087: 12$ & 2.376 & 26.9 & 1988 & $8 / 9 / 20089: 34$ & 2.328 & 26.9 \\
\hline
\end{tabular}


DOE/RL-2009-35, REV. 0

\begin{tabular}{|c|c|c|c|}
\hline \multicolumn{4}{|c|}{ D4-26p } \\
\hline $\operatorname{Rec}$ & & Pres & Temp \\
\hline$\#$ & Date/Time & psi & ${ }^{\circ} \mathrm{C}$ \\
\hline 1989 & $8 / 9 / 20089: 36$ & 2.372 & 27 \\
\hline 1990 & $8 / 9 / 20089: 38$ & 2.369 & 27 \\
\hline 1991 & $8 / 9 / 20089: 40$ & 2.359 & 27 \\
\hline 1992 & $8 / 9 / 20089: 42$ & 2.369 & 27.2 \\
\hline 1993 & $8 / 9 / 20089: 44$ & 2.359 & 27.2 \\
\hline 1994 & $8 / 9 / 20089: 46$ & 2.376 & 27.1 \\
\hline 1995 & $8 / 9 / 20089: 48$ & 2.386 & 27.1 \\
\hline 1996 & $8 / 9 / 20089: 50$ & 2.386 & 27 \\
\hline 1997 & $8 / 9 / 20089: 52$ & 2.389 & 27 \\
\hline 1998 & $8 / 9 / 20089: 54$ & 2.382 & 27 \\
\hline 1999 & $8 / 9 / 20089: 56$ & 2.396 & 27.1 \\
\hline 2000 & $8 / 9 / 20089: 58$ & 2.389 & 27.1 \\
\hline 2001 & $8 / 9 / 2008 \quad 10: 00$ & 2.379 & 27.1 \\
\hline 2002 & $8 / 9 / 200810: 02$ & 2.389 & 27.1 \\
\hline 2003 & $8 / 9 / 200810: 04$ & 2.379 & 27.1 \\
\hline 2004 & $8 / 9 / 2008 \quad 10: 06$ & 2.372 & 27.1 \\
\hline 2005 & $8 / 9 / 200810: 08$ & 2.383 & 27.5 \\
\hline 2006 & $8 / 9 / 200810: 10$ & 2.396 & 27.1 \\
\hline 2007 & $8 / 9 / 200810: 12$ & 2.369 & 27.1 \\
\hline 2008 & $8 / 9 / 200810: 14$ & 2.379 & 27.1 \\
\hline 2009 & $8 / 9 / 200810: 16$ & 2.386 & 27.1 \\
\hline 2010 & $8 / 9 / 200810: 18$ & 2.39 & 27.4 \\
\hline 2011 & $8 / 9 / 200810: 20$ & 2.393 & 27.2 \\
\hline 2012 & $8 / 9 / 200810: 22$ & 2.43 & 27.2 \\
\hline 2013 & $8 / 9 / 200810: 24$ & 2.362 & 27.2 \\
\hline 2014 & $8 / 9 / 200810: 26$ & 2.396 & 27.2 \\
\hline 2015 & $8 / 9 / 200810: 28$ & 2.403 & 27.2 \\
\hline 2016 & $8 / 9 / 200810: 30$ & 2.399 & 27.2 \\
\hline 2017 & $8 / 9 / 200810: 32$ & 2.393 & 27.2 \\
\hline 2018 & $8 / 9 / 200810: 34$ & 2.389 & 27.2 \\
\hline 2019 & $8 / 9 / 2008$ 10:36 & 2.396 & 27.2 \\
\hline 2020 & $8 / 9 / 200810: 38$ & 2.393 & 27.2 \\
\hline 2021 & $8 / 9 / 200810: 40$ & 2.39 & 27.6 \\
\hline 2022 & $8 / 9 / 200810: 42$ & 2.427 & 27.3 \\
\hline 2023 & $8 / 9 / 200810: 44$ & 2.396 & 27.3 \\
\hline 2024 & $8 / 9 / 200810: 46$ & 2.41 & 27.3 \\
\hline 2025 & $8 / 9 / 200810: 48$ & 2.403 & 27.2 \\
\hline 2026 & $8 / 9 / 200810: 50$ & 2.413 & 27.2 \\
\hline 2027 & $8 / 9 / 200810: 52$ & 2.444 & 27.3 \\
\hline 2028 & $8 / 9 / 2008 \quad 10: 54$ & 2.393 & 27.2 \\
\hline 2029 & $8 / 9 / 200810: 56$ & 2.423 & 27.3 \\
\hline 2030 & $8 / 9 / 200810: 58$ & 2.403 & 27.3 \\
\hline 2031 & $8 / 9 / 200811: 00$ & 2.396 & 27.3 \\
\hline 2032 & $8 / 9 / 200811: 02$ & 2.406 & 27.3 \\
\hline 2033 & $8 / 9 / 200811: 04$ & 2.4 & 27.3 \\
\hline 2034 & $8 / 9 / 200811: 06$ & 2.41 & 27.3 \\
\hline 2035 & $8 / 9 / 200811: 08$ & 2.396 & 27.4 \\
\hline 2036 & $8 / 9 / 200811: 10$ & 2.386 & 27.6 \\
\hline 2037 & $8 / 9 / 200811: 12$ & 2.386 & 27.4 \\
\hline 2038 & $8 / 9 / 200811: 14$ & 2.417 & 27.4 \\
\hline 2039 & $8 / 9 / 200811: 16$ & 2.42 & 27.4 \\
\hline 2040 & $8 / 9 / 200811: 18$ & 2.417 & 27.4 \\
\hline 2041 & $8 / 9 / 200811: 20$ & 2.406 & 27.4 \\
\hline 2042 & $8 / 9 / 200811: 22$ & 2.44 & 27.5 \\
\hline 2043 & $8 / 9 / 2008 \quad 11: 24$ & 2.4 & 27.5 \\
\hline 2044 & $8 / 9 / 200811: 26$ & 2.423 & 27.5 \\
\hline 2045 & $8 / 9 / 200811: 28$ & 2.417 & 27.5 \\
\hline 2046 & $8 / 9 / 200811: 30$ & 2.407 & 27.5 \\
\hline 2047 & $8 / 9 / 200811: 32$ & 2.417 & 27.6 \\
\hline 2048 & $8 / 9 / 200811: 34$ & 2.42 & 27.6 \\
\hline 2049 & $8 / 9 / 200811: 36$ & 2.42 & 27.6 \\
\hline 2050 & $8 / 9 / 200811: 38$ & 2.424 & 27.6 \\
\hline 2051 & $8 / 9 / 200811: 40$ & 2.437 & 27.6 \\
\hline 2052 & $8 / 9 / 200811: 42$ & 2.41 & 27.7 \\
\hline 2053 & $8 / 9 / 200811: 44$ & 2.434 & 27.6 \\
\hline 2054 & $8 / 9 / 200811: 46$ & 2.417 & 27.6 \\
\hline 2055 & $8 / 9 / 200811: 48$ & 2.407 & 27.6 \\
\hline 2056 & $8 / 9 / 200811: 50$ & 2.441 & 27.7 \\
\hline 2057 & $8 / 9 / 200811: 52$ & 2.403 & 27.7 \\
\hline 2058 & $8 / 9 / 200811: 54$ & 2.092 & 27.8 \\
\hline 2059 & $8 / 9 / 200811: 56$ & 1.94 & 28 \\
\hline
\end{tabular}

\begin{tabular}{|c|c|c|c|}
\hline \multicolumn{4}{|c|}{ D4-26p } \\
\hline $\operatorname{Rec}$ & & Pres & $\overline{T e m p}$ \\
\hline$\#$ & Date/Time & psi & ${ }^{\circ} \mathrm{C}$ \\
\hline 2060 & $8 / 9 / 200811: 58$ & 1.677 & 28.2 \\
\hline 2061 & $8 / 9 / 200812: 00$ & 1.613 & 28.2 \\
\hline 2062 & $8 / 9 / 2008$ 12:02 & 1.575 & 28.2 \\
\hline 2063 & $8 / 9 / 2008$ 12:04 & 1.545 & 28.1 \\
\hline 2064 & $8 / 9 / 200812: 06$ & 1.525 & 28.1 \\
\hline 2065 & $8 / 9 / 200812: 08$ & 2.438 & 28.7 \\
\hline 2066 & $8 / 9 / 2008$ 12:10 & 2.402 & 29.1 \\
\hline 2067 & $8 / 9 / 2008 \quad 12: 12$ & 2.433 & 29.3 \\
\hline 2068 & $8 / 9 / 200812: 14$ & 2.405 & 29.3 \\
\hline 2069 & $8 / 9 / 200812: 16$ & 2.395 & 29.3 \\
\hline 2070 & $8 / 9 / 200812: 18$ & 2.409 & 29.3 \\
\hline 2071 & $8 / 9 / 200812: 20$ & 2.429 & 29.3 \\
\hline 2072 & $8 / 9 / 2008$ 12:22 & 2.419 & 29.3 \\
\hline 2073 & $8 / 9 / 200812: 24$ & 2.406 & 29.3 \\
\hline 2074 & $8 / 9 / 200812: 26$ & 2.443 & 29.3 \\
\hline 2075 & $8 / 9 / 200812: 28$ & 2.419 & 29.4 \\
\hline 2076 & $8 / 9 / 200812: 30$ & 2.409 & 29.4 \\
\hline 2077 & $8 / 9 / 200812: 32$ & 2.412 & 29.4 \\
\hline 2078 & $8 / 9 / 2008 \quad 12: 34$ & 2.429 & 29.4 \\
\hline 2079 & $8 / 9 / 2008$ 12:36 & 2.416 & 29.4 \\
\hline 2080 & $8 / 9 / 2008 \quad 12: 38$ & 2.412 & 29.4 \\
\hline 2081 & $8 / 9 / 200812: 40$ & 2.429 & 29.4 \\
\hline 2082 & $8 / 9 / 2008 \quad 12: 42$ & 2.44 & 29.4 \\
\hline 2083 & $8 / 9 / 200812: 44$ & 2.419 & 29.4 \\
\hline 2084 & $8 / 9 / 200812: 46$ & 2.443 & 29.4 \\
\hline 2085 & $8 / 9 / 200812: 48$ & 2.423 & 29.4 \\
\hline 2086 & $8 / 9 / 200812: 50$ & 2.456 & 29.4 \\
\hline 2087 & $8 / 9 / 200812: 52$ & 2.433 & $\overline{29.4}$ \\
\hline 2088 & $8 / 9 / 200812: 54$ & 2.45 & 29.4 \\
\hline 2089 & $8 / 9 / 200812: 56$ & 2.429 & 29.4 \\
\hline 2090 & $8 / 9 / 200812: 58$ & 2.467 & 29.8 \\
\hline 2091 & $8 / 9 / 200813: 00$ & 2.443 & 29.5 \\
\hline 2092 & $8 / 9 / 200813: 02$ & 2.436 & 29.5 \\
\hline 2093 & $8 / 9 / 2008$ 13:04 & 2.429 & $\overline{29.4}$ \\
\hline 2094 & $8 / 9 / 200813: 06$ & 2.443 & 29.5 \\
\hline 2095 & $8 / 9 / 2008$ 13:08 & 2.426 & 29.4 \\
\hline 2096 & $8 / 9 / 200813: 10$ & 2.443 & 29.5 \\
\hline 2097 & $8 / 9 / 200813: 12$ & 2.453 & 29.5 \\
\hline 2098 & $8 / 9 / 2008$ 13:14 & 2.436 & 29.6 \\
\hline 2099 & $8 / 9 / 2008$ 13:16 & 2.46 & 29.6 \\
\hline 2100 & $8 / 9 / 200813: 18$ & 2.426 & 29.6 \\
\hline 2101 & $8 / 9 / 200813: 20$ & 2.433 & 29.6 \\
\hline 2102 & $8 / 9 / 200$ & 2.453 & 29.5 \\
\hline 2103 & $8 / 9 / 200813: 24$ & 2.447 & 29.7 \\
\hline 2104 & $8 / 9 / 20$ & $2.4 \overline{3}$ & 29.6 \\
\hline 2105 & $8 / 9 / 200$ & 2.433 & 29.6 \\
\hline 2106 & $8 / 9 / 2008$ 13:30 & 2.44 & 29.6 \\
\hline 2107 & $8 / 9 / 2008$ 13:32 & 2.43 & 29.6 \\
\hline 2108 & $8 / 9 / 200$ & 2.43 & 29.6 \\
\hline 2109 & $813: 36$ & 2.43 & 29.6 \\
\hline 2110 & $8 / 9 / 2008$ 13:38 & 2.443 & 29.6 \\
\hline 2111 & $8 / 9 / 200813: 40$ & 2.463 & 29.6 \\
\hline 2112 & $8 / 9 / 200813: 42$ & 2.436 & 29.6 \\
\hline 2113 & $8 / 9 / 200813: 44$ & 2.467 & 29.7 \\
\hline 2114 & $8 / 9 / 200813: 46$ & 2.45 & 29.7 \\
\hline 2115 & $8 / 9 / 200813: 48$ & 2.457 & 29.7 \\
\hline 2116 & $8 / 9 / 200813: 50$ & 2.447 & 29. \\
\hline 2117 & $813: 52$ & 2.437 & 29.7 \\
\hline 2118 & $8 / 9 / 2008$ 13:54 & 2.457 & 29.7 \\
\hline 2119 & $8 / 9 / 2008$ 13:56 & 2.437 & 29.7 \\
\hline 2120 & $8 / 9 / 200813: 58$ & 2.433 & 29.7 \\
\hline 2121 & $8 / 9 / 200814: 00$ & 2.453 & 29.7 \\
\hline 2122 & $8 / 9 / 200814: 02$ & 2.426 & 29.8 \\
\hline 2123 & $8 / 9 / 200814: 04$ & 2.454 & 29.8 \\
\hline 2124 & $8 / 9 / 200814: 06$ & 2.454 & 29.8 \\
\hline 2125 & $8 / 9 / 200814: 08$ & 2.47 & 29.7 \\
\hline 2126 & $8 / 9 / 200814: 10$ & 2.464 & 29 . \\
\hline 2127 & $8 / 9 / 2008$ 14:12 & 2.437 & 29.9 \\
\hline 2128 & $8 / 9 / 2008$ 14:14 & 2.474 & 29.9 \\
\hline 2129 & $8 / 9 / 2008 \quad 14: 16$ & 2.447 & 29.9 \\
\hline 2130 & $8 / 9 / 2008 \quad 14: 18$ & 2.467 & 29 . \\
\hline
\end{tabular}

\begin{tabular}{|c|c|c|c|}
\hline \multicolumn{4}{|c|}{ D4-26p } \\
\hline $\operatorname{Rec}$ & & Pres & Temp \\
\hline$\#$ & Date/Time & psi & ${ }^{\circ} \mathrm{C}$ \\
\hline 2131 & $8 / 9 / 200814: 20$ & 2.481 & 29. \\
\hline 2132 & $9 / 2008 \quad 14: 22$ & 2.478 & 29.9 \\
\hline 2133 & $9 / 2008$ 14:24 & 2.471 & 30 \\
\hline 2134 & $9 / 2008$ 14:26 & 2.474 & 30 \\
\hline 2135 & $/ / 2008$ 14:28 & 2.518 & 30 \\
\hline 2136 & $9 / 200814: 30$ & 2.467 & 30 \\
\hline 2137 & /9/2008 $14: 32$ & 2.464 & 3 \\
\hline 2138 & 9/2008 14:34 & 2.488 & 3 \\
\hline 2139 & 9/2008 14:36 & 2.488 & \\
\hline 2140 & $9 / 2008$ 14:38 & 2.474 & 3 \\
\hline 2141 & $9 / 2008$ 14:40 & 2.485 & \\
\hline 2142 & $9 / 2008$ 14:42 & 2.474 & 30.1 \\
\hline 2143 & $9 / 2008$ 14:44 & 2.498 & \\
\hline 2144 & $9 / 200814: 46$ & 2.461 & 30.1 \\
\hline 2145 & 9/2008 14:48 & 2.495 & \\
\hline 2146 & $9 / 2008$ 14:50 & 2.491 & 30.1 \\
\hline 2147 & $9 / 200814: 52$ & 2.454 & 30.1 \\
\hline 2148 & $9 / 2008 \quad 14: 54$ & 2.491 & \\
\hline 2149 & $9 / 2008 \quad 14: 56$ & 1.859 & 30.1 \\
\hline 2150 & $9 / 2008 \quad 14: 58$ & 1.582 & \\
\hline 2151 & $3 / 200815: 00$ & 1.528 & 30.2 \\
\hline 2152 & $9 / 2008$ 15:02 & 1.771 & \\
\hline 2153 & $9 / 2008$ 15:04 & 1.487 & 30.2 \\
\hline 2154 & $9 / 2008$ 15:06 & 2.377 & \\
\hline 2155 & 9/2008 15:08 & 2.472 & 30.5 \\
\hline 2156 & 9/2008 15:10 & 2.482 & 30. \\
\hline 2157 & $9 / 200815: 12$ & 2.502 & \\
\hline 2158 & $1 / 200815: 14$ & 2.506 & 30. \\
\hline 2159 & $815: 16$ & 2.503 & 30. \\
\hline 2160 & $815: 18$ & 2.513 & 30.6 \\
\hline 2161 & $315: 20$ & 2.516 & 30.6 \\
\hline 2162 & $315: 22$ & 2.526 & 30.6 \\
\hline 2163 & & 2.492 & 30. \\
\hline 2164 & & 2.529 & 30. \\
\hline 2165 & $815: 28$ & 2.516 & 30. \\
\hline 2166 & $815: 30$ & 2.52 & 30. \\
\hline 2167 & $5: 32$ & 2.536 & 30. \\
\hline 2168 & $15: 34$ & 2.523 & 30.8 \\
\hline 2169 & $815: 36$ & 2.563 & 30.7 \\
\hline 2170 & & 2.5 & \\
\hline 2171 & & 2.516 & $\overline{30.8}$ \\
\hline 2172 & & 2.50 & \\
\hline 2173 & & 2.519 & \\
\hline 2174 & & 2.492 & 30. \\
\hline 2175 & & 2.489 & 30. \\
\hline 2176 & & 2.536 & 30. \\
\hline 2177 & & & \\
\hline 2178 & & 2.513 & 30.8 \\
\hline 2179 & & & \\
\hline 2180 & & 2.506 & 30. \\
\hline 218 & & 2.516 & 30. \\
\hline 218 & & 2.51 & 31. \\
\hline 218 & & 2.533 & \\
\hline 2184 & & 2.4 & 30. \\
\hline 2185 & & & 30 . \\
\hline 2186 & & 2.506 & 30. \\
\hline 2187 & & 2.533 & 30.9 \\
\hline 2188 & & 2.489 & \\
\hline 2189 & $8 / 9 / 200816: 16$ & 2.5 & 31.3 \\
\hline 2190 & & 2.51 & \\
\hline 2191 & $8 / 9 / 20$ & 2.506 & 30.6 \\
\hline 2192 & & 2.513 & \\
\hline 2193 & $9 / 20$ & 2.54 & \\
\hline 2194 & & 2.506 & \\
\hline 2195 & & 2.52 & \\
\hline 2196 & $9 / 200816: 30$ & 2.513 & 30.5 \\
\hline & 19100816.32 & 2.52 & 30. \\
\hline 2198 & $8 / 9 / 200816: 34$ & 2.53 & 31 \\
\hline 2199 & & 2.547 & 30. \\
\hline 2200 & $8 / 9 / 200816: 38$ & 2.523 & 30. \\
\hline 2201 & $8 / 9 / 200816: 40$ & 250 & 30 \\
\hline
\end{tabular}

\begin{tabular}{|c|c|c|c|}
\hline \multicolumn{4}{|c|}{ D4-26p } \\
\hline $\operatorname{Rec}$ & & Pres & Temp \\
\hline$\#$ & Date/Time & psi & ${ }^{\circ} \mathrm{C}$ \\
\hline 2202 & $8 / 9 / 200816: 42$ & 2.51 & 30.9 \\
\hline 2203 & $8 / 9 / 200816: 44$ & 2.533 & 31 \\
\hline 2204 & $8 / 9 / 200816: 46$ & 2.537 & 31 \\
\hline 2205 & $8 / 9 / 200816: 48$ & 2.517 & 31 \\
\hline 2206 & $8 / 9 / 2008$ 16:50 & 2.537 & 31 \\
\hline 2207 & $8 / 9 / 200816: 52$ & 2.544 & 31 \\
\hline 2208 & $8 / 9 / 200816: 54$ & 2.517 & 31 \\
\hline 2209 & $8 / 9 / 2008 \quad 16: 56$ & 2.517 & 31 \\
\hline 2210 & $8 / 9 / 200816: 58$ & 2.527 & 31 \\
\hline 2211 & $8 / 9 / 200817: 00$ & 2.533 & 31 \\
\hline 2212 & $8 / 9 / 2008$ 17:02 & 2.513 & 31 \\
\hline 2213 & $8 / 9 / 200897: 04$ & 2.506 & 31 \\
\hline 2214 & $8 / 9 / 2008$ 17:06 & 2.537 & 31 \\
\hline 2215 & $8 / 9 / 2008 \quad 17: 08$ & 2.53 & 31 \\
\hline 2216 & $8 / 9 / 2008$ 17:10 & 2.537 & 31 \\
\hline 2217 & $8 / 9 / 2008 \quad 17: 12$ & 2.547 & 31 \\
\hline 2218 & $8 / 9 / 2008$ 17:14 & 2.524 & $\overline{31.4}$ \\
\hline 2219 & $8 / 9 / 200817: 16$ & 2.537 & 31.2 \\
\hline 2220 & $8 / 9 / 200817: 18$ & 2.524 & 31.4 \\
\hline 2221 & $8 / 9 / 200817: 20$ & 2.544 & 31.1 \\
\hline 2222 & $8 / 9 / 200817: 22$ & 2.544 & 31 \\
\hline 2223 & $8 / 9 / 200817: 24$ & 2.547 & 31 \\
\hline 2224 & $8 / 9 / 200817: 26$ & 2.533 & 31 \\
\hline 2225 & $8 / 9 / 200817: 28$ & 2.53 & 31 \\
\hline 2226 & $8 / 9 / 200817: 30$ & 2.54 & 31 \\
\hline 2227 & $8 / 9 / 2008 \quad 17: 32$ & 2.54 & 31 \\
\hline 2228 & $8 / 9 / 2008 \quad 17: 34$ & 2.52 & 31.3 \\
\hline 2229 & $8 / 9 / 200817: 36$ & 2.527 & 31.1 \\
\hline 2230 & $8 / 9 / 2008$ 17:38 & 2.496 & 31 \\
\hline 2231 & $8 / 9 / 2008$ 17:40 & 2.54 & 31 \\
\hline 2232 & $8 / 9 / 200817: 42$ & 2.547 & 31 \\
\hline 2233 & $8 / 9 / 200817: 44$ & 2.517 & 31.3 \\
\hline 2234 & $8 / 9 / 200817: 46$ & 1.621 & 31.1 \\
\hline 2235 & $8 / 9 / 200817: 48$ & 1.658 & 31.1 \\
\hline 2236 & $8 / 9 / 200817: 50$ & 1.54 & 31.3 \\
\hline 2237 & $8 / 9 / 2008$ 17:52 & 1.509 & 31.2 \\
\hline 2238 & $8 / 9 / 200817: 54$ & 1.496 & 31.1 \\
\hline 2239 & $8 / 9 / 2008$ 17:56 & 1.488 & 30.9 \\
\hline 2240 & $8 / 9 / 2008$ 17:58 & 1.488 & 30.8 \\
\hline 2241 & $8 / 9 / 200818: 00$ & 1.488 & 30.6 \\
\hline 2242 & $8 / 9 / 2008 \uparrow 8: 02$ & 2.695 & 30.5 \\
\hline 2243 & $8 / 9 / 200818: 04$ & 2.543 & 30.8 \\
\hline 2244 & $8 / 9 / 2008$ 18:06 & 2.539 & 30.5 \\
\hline 2245 & $8 / 9 / 200818: 08$ & 2.573 & 30.4 \\
\hline 2246 & $8 / 9 / 200818: 10$ & 2.556 & 30.4 \\
\hline 2247 & $8 / 9 / 2008$ 18:12 & 2.566 & 30.4 \\
\hline 2248 & $8 / 9 / 200818: 14$ & 2.583 & 30.4 \\
\hline 2249 & $8 / 9 / 200818: 16$ & 2.59 & 30.4 \\
\hline 2250 & $8 / 9 / 200818: 18$ & 2.57 & 30.4 \\
\hline 2251 & $8 / 9 / 200818: 20$ & 2.59 & 30.4 \\
\hline 2252 & $8 / 9 / 200818: 22$ & 2.607 & 30.4 \\
\hline 2253 & $8 / 9 / 200818: 24$ & 2.587 & 30.4 \\
\hline 2254 & $8 / 9 / 2008$ 18:26 & 2.59 & 30.5 \\
\hline 2255 & $8 / 9 / 200818: 28$ & 2.621 & 30.6 \\
\hline 2256 & $8 / 9 / 200818: 30$ & 2.607 & 30.5 \\
\hline 2257 & $8 / 9 / 200818: 32$ & 2.61 & 30.4 \\
\hline 2258 & $8 / 9 / 200818: 34$ & 2.654 & 30.4 \\
\hline 2259 & $8 / 9 / 200818: 36$ & 2.603 & 30.4 \\
\hline 2260 & $8 / 9 / 2008$ 18:38 & 2.624 & 30.4 \\
\hline 2261 & $8 / 9 / 200818: 40$ & 2.617 & 30.6 \\
\hline 2262 & $8 / 9 / 200818: 42$ & 2.604 & 30.6 \\
\hline 2263 & $8 / 9 / 2008$ 18:44 & 2.614 & 30.5 \\
\hline 2264 & $8 / 9 / 200818: 46$ & 2.62 & 30.4 \\
\hline 2265 & $8 / 9 / 200818: 48$ & 2.624 & 30.4 \\
\hline 2266 & $8 / 9 / 200818: 50$ & 2.593 & 30.4 \\
\hline 2267 & $8 / 9 / 2008$ 18:52 & 2.604 & 30.5 \\
\hline 2268 & $8 / 9 / 200818: 54$ & 2.61 & 30.5 \\
\hline 2269 & $8 / 9 / 200818: 56$ & 2.617 & 30.4 \\
\hline 2270 & $8 / 9 / 2008$ 18:58 & 2.607 & 30.4 \\
\hline 2271 & $8 / 9 / 200819: 00$ & 2.62 & 30.4 \\
\hline 2272 & $8 / 9 / 200819: 02$ & 2.614 & 30.5 \\
\hline
\end{tabular}




\begin{tabular}{|c|c|c|c|}
\hline \multicolumn{4}{|c|}{ D4-26p } \\
\hline Rec & & Pres & Temp \\
\hline$\#$ & Date/Time & psi & ${ }^{\circ} \mathrm{C}$ \\
\hline 2273 & $8 / 9 / 2008$ 19:04 & 2.604 & 30.5 \\
\hline 2274 & $8 / 9 / 2008$ 19:06 & 2.627 & 30.5 \\
\hline 2275 & $8 / 9 / 200819: 08$ & 2.587 & 30.5 \\
\hline 2276 & $8 / 9 / 200819: 10$ & 2.61 & 30.4 \\
\hline 2277 & $8 / 9 / 200819: 12$ & 2.624 & 30.4 \\
\hline 2278 & $8 / 9 / 200819: 14$ & 2.597 & 30.4 \\
\hline 2279 & $8 / 9 / 200819: 16$ & 2.597 & 30.4 \\
\hline 2280 & $8 / 9 / 200819: 18$ & 2.617 & 30.5 \\
\hline 2281 & $8 / 9 / 2008$ 19:20 & 2.603 & 30.4 \\
\hline 2282 & $8 / 9 / 200819: \overline{22}$ & 2.587 & 30.4 \\
\hline 2283 & $8 / 9 / 200819: 24$ & 2.614 & 30.4 \\
\hline 2284 & $8 / 9 / 2008$ 19:26 & 2.603 & 30.4 \\
\hline 2285 & $8 / 9 / 200819: 28$ & 2.607 & 30.4 \\
\hline 2286 & 8/9/2008 19:30 & 2.62 & 30.4 \\
\hline 2287 & $8 / 9 / 2008$ 19:32 & 2.59 & 30.4 \\
\hline 2288 & $8 / 9 / 200819: 34$ & 2.614 & 30.4 \\
\hline 2289 & $8 / 9 / 200819: 36$ & 2.6 & 30.4 \\
\hline 2290 & $8 / 9 / 2008 \quad 19: 38$ & 2.607 & 30.4 \\
\hline 2291 & $8 / 9 / 200819: 40$ & 2.614 & 30.4 \\
\hline 2292 & $8 / 9 / 200819: 42$ & 2.617 & $\overline{30.4}$ \\
\hline 2293 & $8 / 9 / 200819: 44$ & 2.624 & 30.4 \\
\hline 2294 & $8 / 9 / 200819: 46$ & 2.63 & 30.4 \\
\hline 2295 & $8 / 9 / 200819: 48$ & 2.597 & 30.4 \\
\hline 2296 & $8 / 9 / 200819: 50$ & 2.607 & 30.4 \\
\hline 2297 & $8 / 9 / 200819: 52$ & 2.621 & 30.8 \\
\hline 2298 & $8 / 9 / 200819: 54$ & 2.593 & 30.4 \\
\hline 2299 & $8 / 9 / 200819: 56$ & 2.607 & 30.4 \\
\hline 2300 & $8 / 9 / 200819: 58$ & 2.593 & 30.5 \\
\hline 2301 & $8 / 9 / 200820: 00$ & 2.6 & 30.4 \\
\hline 2302 & $8 / 9 / 200820: 02$ & 2.603 & 30.4 \\
\hline 2303 & $8 / 9 / 200820: 04$ & 2.603 & 30.4 \\
\hline 2304 & $8 / 9 / 200820: 06$ & 2.607 & 30.4 \\
\hline 2305 & $8 / 9 / 200820: 08$ & 2.617 & 30.3 \\
\hline 2306 & $8 / 9 / 200820: 10$ & 2.61 & 30.3 \\
\hline 2307 & $8 / 9 / 200820: 12$ & 2.603 & 30.3 \\
\hline 2308 & $8 / 9 / 200820: 14$ & 2.6 & 30.3 \\
\hline 2309 & $8 / 9 / 200820: 16$ & 2.61 & 30.3 \\
\hline 2310 & $8 / 9 / 200820: 18$ & 2.63 & 30.3 \\
\hline 2311 & $8 / 9 / 200820: 20$ & 2.634 & 30.3 \\
\hline 2312 & 8/9/2008 20:22 & 2.641 & 30.5 \\
\hline 2313 & $8 / 9 / 200820: 24$ & 2.623 & 30.3 \\
\hline 2314 & $8 / 9 / 200820: 26$ & 2.64 & 30.3 \\
\hline 2315 & $8 / 9 / 200820: 28$ & 2.654 & 30.3 \\
\hline 2316 & $8 / 9 / 200820: 30$ & 2.654 & 30.3 \\
\hline 2317 & $8 / 9 / 200820: 32$ & 2.633 & 30.2 \\
\hline 2318 & $8 / 9 / 200820: 34$ & 2.637 & 30.2 \\
\hline 2319 & $8 / 9 / 200820: 36$ & 2.647 & 30.2 \\
\hline 2320 & $8 / 9 / 200820: 38$ & 2.63 & 30.2 \\
\hline 2321 & $8 / 9 / 200820: 40$ & 2.637 & 30.2 \\
\hline 2322 & $8 / 9 / 200820: 42$ & 2.64 & 30.1 \\
\hline 2323 & $8 / 9 / 200820: 44$ & 2.637 & 30.1 \\
\hline 2324 & $8 / 9 / 200820: 46$ & 2.644 & 30.4 \\
\hline 2325 & $8 / 9 / 200820: 48$ & 1.981 & 30.1 \\
\hline 2326 & $8 / 9 / 200820: 50$ & 1.868 & 29.6 \\
\hline 2327 & $8 / 9 / 200820: 52$ & 1.567 & 29.1 \\
\hline 2328 & $8 / 9 / 200820: 54$ & 1.539 & 28.8 \\
\hline 2329 & $8 / 9 / 200820: 56$ & 1.505 & 28.7 \\
\hline 2330 & $8 / 9 / 200820: 58$ & 1.485 & 28.8 \\
\hline 2331 & $8 / 9 / 200821: 00$ & 1.475 & 28.9 \\
\hline 2332 & $8 / 9 / 200821: 02$ & 1.469 & 29.1 \\
\hline 2333 & $8 / 9 / 200821: 04$ & 1.465 & 29.3 \\
\hline 2334 & $8 / 9 / 200821: 06$ & 1.466 & 29.4 \\
\hline 2335 & $8 / 9 / 200821: 08$ & 2.808 & 29.1 \\
\hline 2336 & $8 / 9 / 200821: 10$ & 2.709 & 28.6 \\
\hline 2337 & $8 / 9 / 200821: 12$ & 2.713 & 28.9 \\
\hline 2338 & $8 / 9 / 200821: 14$ & 2.695 & 28.6 \\
\hline 2339 & $8 / 9 / 200821: 16$ & 2.709 & 28.5 \\
\hline 2340 & $8 / 9 / 200821: 18$ & 2.702 & 28.5 \\
\hline 2341 & $8 / 9 / 200821: 20$ & 2.705 & 28.5 \\
\hline 2342 & $8 / 9 / 200821: 22$ & 2.702 & 28.5 \\
\hline 2343 & $8 / 9 / 200821: 24$ & 2.705 & 28.4 \\
\hline
\end{tabular}

\begin{tabular}{|c|c|c|c|}
\hline \multicolumn{4}{|c|}{ D4-26p } \\
\hline & & Pres & Temp \\
\hline$\#$ & Date/Time & psi & ${ }^{\circ} \mathrm{C}$ \\
\hline 2344 & $8 / 9 / 200821: 26$ & 2.712 & 28.4 \\
\hline 2345 & $8 / 9 / 200821: 28$ & 2.698 & \\
\hline 346 & $8 / 9 / 200821: 30$ & 2.688 & 28.4 \\
\hline 347 & $8 / 9 / 200821: 32$ & 2.678 & 28.4 \\
\hline 348 & $8 / 9 / 200821: 34$ & 2.722 & 28.4 \\
\hline 2349 & $8 / 9 / 200821: 36$ & 2.671 & 28.4 \\
\hline 2350 & $8 / 9 / 200821: 38$ & 2.702 & 28.4 \\
\hline 2351 & $8 / 9 / 200821: 40$ & 2.705 & 28.4 \\
\hline 2352 & $8 / 9 / 200821: 42$ & 2.739 & 28.4 \\
\hline 2353 & $8 / 9 / 200821: 44$ & 2.705 & 28.4 \\
\hline 2354 & $8 / 9 / 200821: 46$ & 2.749 & 28.4 \\
\hline 2355 & $8 / 9 / 200821: 48$ & 2.719 & 28.4 \\
\hline 2356 & $8 / 9 / 200821: 50$ & 2.709 & 28.4 \\
\hline 2357 & $8 / 9 / 200821: 52$ & 2.719 & 28.5 \\
\hline 2358 & $8 / 9 / 200821: 54$ & 2.729 & 28.5 \\
\hline 2359 & $8 / 9 / 200821: 56$ & 2.732 & 28.4 \\
\hline 2360 & $8 / 9 / 200821: 58$ & 2.719 & 28.3 \\
\hline 2361 & $8 / 9 / 200822: 00$ & 2.722 & \\
\hline 2362 & $8 / 9 / 200822: 02$ & 2.722 & 28.3 \\
\hline 2363 & $8 / 9 / 200822: 04$ & 2.732 & 28.3 \\
\hline 2364 & $9 / 200822: 06$ & 2.719 & 28.5 \\
\hline 2365 & $8 / 9 / 200822: 08$ & 2.725 & 28.3 \\
\hline 2366 & $8 / 9 / 200822: 10$ & 2.705 & \\
\hline 2367 & $9 / 200822: 12$ & 2.742 & 28.3 \\
\hline 2368 & 9/2008 22:14 & 2.735 & \\
\hline 2369 & 9/2008 22:16 & 2.725 & 28.3 \\
\hline 2370 & 9/2008 22:18 & 2.763 & 28.3 \\
\hline 2371 & $8 / 9 / 200822: 20$ & 2.739 & 28.3 \\
\hline 2372 & $822: 22$ & 2.719 & 28. \\
\hline 2373 & $322: 24$ & 2.756 & 28.3 \\
\hline 2374 & $822: 26$ & 2.722 & 28. \\
\hline 2375 & $22: 28$ & 2.742 & 28. \\
\hline 2376 & $22: 30$ & 2.742 & 28.2 \\
\hline 2377 & $22: 32$ & 2.746 & 28.2 \\
\hline 2378 & $22: 34$ & 2.725 & 28.2 \\
\hline 2379 & $22: 36$ & 2.735 & 28.2 \\
\hline 2380 & $22: 38$ & 2.729 & 28.2 \\
\hline 2381 & & 2.742 & 28.2 \\
\hline 2382 & $\overline{42}$ & 2.729 & 28.2 \\
\hline 2383 & $22: 44$ & 2.729 & 28.2 \\
\hline 2384 & & 2.715 & 28. \\
\hline 2385 & 48 & 2.746 & 28. \\
\hline 2386 & & 2.7 & 28.2 \\
\hline 2387 & 52 & 2.732 & 28.2 \\
\hline 2388 & $22: 54$ & 2.712 & 28.2 \\
\hline 2389 & $22: 56$ & 2.742 & 28. \\
\hline 2390 & 58 & 2.745 & 28. \\
\hline 2391 & & & 28. \\
\hline 2392 & 02 & 2.7 & 28. \\
\hline 2393 & 04 & 2.75 & 28.1 \\
\hline 2394 & & 2.7 & \\
\hline 2395 & 08 & 2.722 & 28. \\
\hline 2396 & & 2.732 & \\
\hline 2397 & 12 & 2.772 & 28.1 \\
\hline 2398 & & 2.732 & \\
\hline 2399 & 1912 & 2.725 & 27.9 \\
\hline 2400 & & 2.732 & 27. \\
\hline 2401 & & 2.742 & \\
\hline 2402 & $9 / 2$ & 2.728 & 27 \\
\hline 2403 & & & \\
\hline 2404 & & 2.7 & \\
\hline 2405 & & 2.748 & 27.8 \\
\hline 2406 & $8 / 9 / 20$ & 2.735 & \\
\hline 2407 & $8 / 9 / 20$ & 2.718 & 27.8 \\
\hline 2408 & & & \\
\hline 240 & $8 / 9 / 20$ & 2.7 & \\
\hline 2410 & & 2.731 & 27.8 \\
\hline & $8 / 9 / 2$ & & \\
\hline 241 & $323: 42$ & 2.715 & 27. \\
\hline 2413 & $8 / 9 / 2$ & 2.701 & 27 . \\
\hline & $8 / 9 / 200823: 46$ & 2721 & \\
\hline
\end{tabular}

\begin{tabular}{|c|c|c|c|}
\hline \multicolumn{4}{|c|}{ D4-26p } \\
\hline $\operatorname{Rec}$ & & Pres & Temp \\
\hline$\#$ & Date/Time & psi & ${ }^{\circ} \mathrm{C}$ \\
\hline 2415 & $8 / 9 / 200823: 48$ & 2.755 & 27.6 \\
\hline 2416 & $8 / 9 / 200823: 50$ & 2.711 & 27.6 \\
\hline 2417 & $8 / 9 / 200823: 52$ & 2.048 & 27.6 \\
\hline 2418 & $8 / 9 / 200823: 54$ & 1.608 & 27.2 \\
\hline 2419 & $8 / 9 / 200823: 56$ & 1.53 & 27 \\
\hline 2420 & $8 / 9 / 200823: 58$ & 1.547 & 26.9 \\
\hline 2421 & $8 / 10 / 20080: 00$ & 1.499 & 26.6 \\
\hline 2422 & $8 / 10 / 20080: 02$ & 1.486 & $\overline{26.4}$ \\
\hline 2423 & $8 / 10 / 20080: 04$ & 1.482 & \\
\hline 2424 & $8 / 10 / 20080: 06$ & 1.479 & 26.8 \\
\hline 2425 & $8 / 10 / 20080: 08$ & 1.476 & 26.9 \\
\hline 2426 & $8 / 10 / 20080: 10$ & 1.483 & 27.1 \\
\hline 2427 & $8 / 10 / 20080: 12$ & 2.517 & 26.8 \\
\hline 2428 & $8 / 10 / 20080: 14$ & 2.565 & \\
\hline 2429 & $8 / 10 / 20080: 16$ & 2.626 & 26.7 \\
\hline 2430 & $8 / 10 / 20080: 18$ & 2.622 & 26.8 \\
\hline 2431 & $8 / 10 / 20080: 20$ & 2.629 & 26.8 \\
\hline 2432 & $8 / 10 / 20080: 22$ & 2.643 & 26.8 \\
\hline 2433 & $8 / 10 / 20080: 24$ & 2.626 & 26.8 \\
\hline 2434 & $8 / 10 / 20080: 26$ & 2.639 & 26.8 \\
\hline 2435 & $8 / 10 / 20080: 28$ & 2.653 & 26.8 \\
\hline 2436 & $8 / 10 / 20080: 30$ & 2.646 & 26.8 \\
\hline 2437 & $8 / 10 / 20080: 32$ & 2.636 & 26.7 \\
\hline 2438 & $8 / 10 / 20080: 34$ & 2.639 & 26.7 \\
\hline 2439 & $8 / 10 / 20080: 36$ & 2.65 & 27.1 \\
\hline 2440 & $8 / 10 / 20080: 38$ & 2.653 & 26.8 \\
\hline 2441 & $8 / 10 / 20080: 40$ & 2.653 & 26.8 \\
\hline 2442 & $8 / 10 / 20080: 42$ & 2.619 & 26.7 \\
\hline 2443 & $8 / 10 / 20080: 44$ & 2.659 & 26.7 \\
\hline 2444 & $8 / 10 / 20080: 46$ & 2.68 & 26.7 \\
\hline 2445 & $8 / 10 / 20080: 48$ & 2.663 & 26.7 \\
\hline 2446 & $8 / 10 / 20080: 50$ & 2.673 & 26.7 \\
\hline 2447 & $8 / 10 / 20080: 52$ & 2.67 & 26.7 \\
\hline 2448 & $80: 54$ & 2.663 & 26.7 \\
\hline 2449 & $080: 56$ & 2.7 & 26.7 \\
\hline 2450 & $8 / 10 / 20080: 58$ & 2.69 & 26.6 \\
\hline 2451 & $8 / 10 / 20081: 00$ & 2.666 & 26.6 \\
\hline 2452 & 1:02 & 2.67 & 26.6 \\
\hline 2453 & $81: 04$ & 2.666 & 26.6 \\
\hline 2454 & & 2.67 & 26.6 \\
\hline 2455 & $081: 08$ & 2.676 & 26.6 \\
\hline 2456 & $81: 10$ & 2.7 & 26.6 \\
\hline 2457 & & 2.666 & 26.6 \\
\hline 2458 & $8 / 10 / 20081: 14$ & 2.666 & 26.6 \\
\hline $24 \overline{59}$ & 2008 1:16 & 2.676 & 26.6 \\
\hline 2460 & $881: 18$ & 2.697 & 26.6 \\
\hline 2461 & & 2.68 & 26.6 \\
\hline 2462 & $81: 22$ & 2.666 & 26.6 \\
\hline 2463 & $1: 24$ & 2.683 & 26.6 \\
\hline 2464 & & 2.68 & 26.6 \\
\hline 2465 & $120081: 28$ & 2.683 & 26.6 \\
\hline 2466 & & 2.72 & 26.5 \\
\hline 2467 & $081: 32$ & 2.71 & 26.6 \\
\hline 2468 & & 2.68 & 26.5 \\
\hline 2469 & $81: 36$ & 2.693 & 26.5 \\
\hline 2470 & $8 / 10 / 20081: 38$ & 2.683 & 26.5 \\
\hline 2471 & & 2.707 & 26.5 \\
\hline 2472 & $8 / 10 / 20081: 42$ & 2.673 & 26.5 \\
\hline 2473 & & 2.71 & 26.4 \\
\hline 2474 & $8 / 10 / 20081: 46$ & 2.707 & 26.4 \\
\hline 2475 & & 2.703 & 26.4 \\
\hline 2476 & $081: 50$ & 2.703 & 26.4 \\
\hline 2477 & $8 / 10 / 20081: 52$ & 2.693 & 26.4 \\
\hline 2478 & $8 / 10 / 20081: 54$ & 2.686 & 26.4 \\
\hline 2479 & & 2.676 & \\
\hline 2480 & $081: 58$ & 2.727 & 26.4 \\
\hline 2481 & $8 / 10 /$ & 2.696 & 26.4 \\
\hline 2482 & $8 / 10 / 20082: 02$ & 2.69 & 26.4 \\
\hline 2483 & $8 / 10 / 20082: 04$ & 2.696 & 26.4 \\
\hline 2484 & $8 / 10 / 20082: 06$ & 2.706 & 26.4 \\
\hline 2485 & $8 / 10 / 20082: 08$ & 2.69 & 26. \\
\hline
\end{tabular}

\begin{tabular}{|c|c|c|c|}
\hline \multicolumn{4}{|c|}{ D4-26p } \\
\hline $\operatorname{Rec}$ & & Pres & Temp \\
\hline \# & Date/Time & psi & ${ }^{\circ} \mathrm{C}$ \\
\hline 2486 & $8 / 10 / 20082: 10$ & 2.686 & 26.4 \\
\hline 2487 & $8 / 10 / 20082: 12$ & 2.693 & 26.4 \\
\hline 2488 & $8 / 10 / 2008$ 2:14 & 2.703 & 26.4 \\
\hline 2489 & $8 / 10 / 20082: 16$ & 2.69 & 26.3 \\
\hline 2490 & $8 / 10 / 20082: 18$ & 2.71 & 26.3 \\
\hline 2491 & $8 / 10 / 2008$ 2:20 & 2.7 & 26.3 \\
\hline 2492 & $8 / 10 / 20082: 22$ & 2.686 & 26.3 \\
\hline 2493 & $8 / 10 / 20082: 24$ & 2.7 & $26 . \overline{3}$ \\
\hline 2494 & $8 / 10 / 20082: 26$ & 2.703 & 26.3 \\
\hline 2495 & $8 / 10 / 20082: 28$ & 2.663 & 26.4 \\
\hline 2496 & $8 / 10 / 20082: 30$ & 2.713 & 26.3 \\
\hline 2497 & $8 / 10 / 20082: 32$ & 2.71 & 26.1 \\
\hline 2498 & $8 / 10 / 20082: 34$ & 2.716 & 26.1 \\
\hline 2499 & $8 / 10 / 20082: 36$ & 2.706 & 26.1 \\
\hline 2500 & $8 / 10 / 20082: 38$ & 2.723 & 26.1 \\
\hline 2501 & $8 / 10 / 20082: 40$ & 2.723 & 26.1 \\
\hline 2502 & $8 / 10 / 20082: 42$ & 2.767 & 26 \\
\hline 2503 & $8 / 10 / 20082: 44$ & 2.703 & 26 \\
\hline 2504 & $8 / 10 / 20082: 46$ & 2.706 & 26 \\
\hline 2505 & $8 / 10 / 20082: 48$ & 2.52 & 25.9 \\
\hline 2506 & $8 / 10 / 20082: 50$ & 1.925 & 25.9 \\
\hline 2507 & $8 / 10 / 20082: 52$ & 1.617 & 25.3 \\
\hline 2508 & $8 / 10 / 20082: 54$ & 1.549 & 25 \\
\hline 2509 & $8 / 10 / 20082: 56$ & 1.522 & 24.9 \\
\hline 2510 & $8 / 10 / 20082: 58$ & 1.502 & 25 \\
\hline 2511 & $8 / 10 / 20083: 00$ & 1.499 & 25.4 \\
\hline 2512 & $8 / 10 / 20083: 02$ & 1.492 & 25.6 \\
\hline 2513 & $8 / 10 / 20083: 04$ & 1.489 & 25.8 \\
\hline 2514 & 8/10/2008 3:06 & 2.787 & 25.8 \\
\hline 2515 & $8 / 10 / 20083: 08$ & 2.777 & 26 \\
\hline 2516 & $8 / 10 / 20083: 10$ & 2.75 & 26.1 \\
\hline 2517 & $8 / 10 / 20083: 12$ & 2.747 & 26.1 \\
\hline 2518 & $8 / 10 / 20083: 14$ & 2.737 & 26.1 \\
\hline 2519 & $8 / 10 / 20083: 16$ & 2.74 & 26.1 \\
\hline 2520 & $8 / 10 / 20083: 18$ & 2.744 & 26.1 \\
\hline 2521 & $8 / 10 / 20083: 20$ & 2.74 & 26.1 \\
\hline 2522 & $8 / 10 / 20083: 22$ & 2.73 & 26.1 \\
\hline 2523 & $8 / 10 / 20083: 24$ & 2.73 & 26.1 \\
\hline 2524 & $8 / 10 / 20083: 26$ & 2.73 & $\overline{26.1}$ \\
\hline 2525 & $8 / 10 / 20083: 28$ & 2.73 & 26.1 \\
\hline 2526 & $8 / 10 / 20083: 30$ & 2.74 & 26.1 \\
\hline 2527 & $8 / 10 / 20083: 32$ & 2.747 & 26.1 \\
\hline 2528 & $8 / 10 / 20083: 34$ & 2.733 & 26.1 \\
\hline 2529 & $8 / 10 / 20083: 36$ & 2.73 & 26.1 \\
\hline 2530 & $8 / 10 / 20083: 38$ & 2.737 & 26 \\
\hline 2531 & $8 / 10 / 20083: 40$ & 2.72 & 26 \\
\hline 2532 & $8 / 10 / 20083: 42$ & 2.76 & 26.1 \\
\hline 2533 & $8 / 10 / 20083: 44$ & 2.727 & 26 \\
\hline 2534 & $8 / 10 / 20083: 46$ & 2.723 & 26 \\
\hline 2535 & $8 / 10 / 20083: 48$ & 2.73 & 26 \\
\hline 2536 & $8 / 10 / 20083: 50$ & 2.73 & 26 \\
\hline 2537 & $8 / 10 / 20083: 52$ & 2.747 & 25.9 \\
\hline 2538 & $8 / 10 / 20083: 54$ & 2.727 & 26.3 \\
\hline 2539 & $8 / 10 / 20083: 56$ & 2.75 & 26.2 \\
\hline 2540 & $8 / 10 / 20083: 58$ & 2.743 & 26 \\
\hline 2541 & $8 / 10 / 20084: 00$ & 2.733 & 25.9 \\
\hline 2542 & $8 / 10 / 20084: 02$ & 2.733 & 25.9 \\
\hline 2543 & $8 / 10 / 20084: 04$ & 2.743 & 25.9 \\
\hline 2544 & $8 / 10 / 20084: 06$ & 2.743 & 25.9 \\
\hline 2545 & $8 / 10 / 20084: 08$ & 2.747 & 25.9 \\
\hline 2546 & $8 / 10 / 20084: 10$ & 2.75 & 25.9 \\
\hline 2547 & $8 / 10 / 20084: 12$ & 2.733 & 25.9 \\
\hline 2548 & $8 / 10 / 20084: 14$ & 2.73 & 25.9 \\
\hline 2549 & $8 / 10 / 20084: 16$ & 2.733 & 25.9 \\
\hline 2550 & $8 / 10 / 20084: 18$ & 2.743 & 25.9 \\
\hline 2551 & $8 / 10 / 20084: 20$ & 2.74 & 25.9 \\
\hline 2552 & $8 / 10 / 20084: 22$ & 2.757 & 25.9 \\
\hline 2553 & $8 / 10 / 20084: 24$ & 2.757 & 25.9 \\
\hline 2554 & $8 / 10 / 20084: 26$ & 2.743 & 25.9 \\
\hline 2555 & $8 / 10 / 20084: 28$ & 2.757 & 25.9 \\
\hline 2556 & $8 / 10 / 20084: 30$ & 2.74 & 25.9 \\
\hline
\end{tabular}


DOE/RL-2009-35, REV. 0

\begin{tabular}{|c|c|c|c|c|c|c|c|c|c|c|c|c|c|c|c|}
\hline \multicolumn{4}{|c|}{ D4-26p } & \multicolumn{4}{|c|}{ D4-26p } & \multicolumn{4}{|c|}{ D4-26p } & \multicolumn{4}{|c|}{ D4-26p } \\
\hline Rec & & Pres & Temp & $\operatorname{Rec}$ & & Pres & Temp & $\operatorname{Rec}$ & & Pres & Temp & $\operatorname{Rec}$ & & Pres & Temp \\
\hline$\#$ & Date/Time & psi & ${ }^{\circ} \mathrm{C}$ & $\#$ & Date/Time & psi & ${ }^{\circ} \mathrm{C}$ & $\#$ & Date/Time & psi & ${ }^{\circ} \mathrm{C}$ & $\#$ & Date/Time & psi & ${ }^{\circ} \mathrm{C}$ \\
\hline 2557 & $8 / 10 / 20084: 32$ & 2.757 & 25.9 & 2628 & $8 / 10 / 20086: 54$ & 2.763 & 25.6 & 2699 & $8 / 10 / 20089: 16$ & 2.619 & 26.4 & 2770 & $8 / 10 / 200811: 38$ & 2.735 & 27.4 \\
\hline 2558 & $8 / 10 / 20084: 34$ & 2.76 & 25.8 & 2629 & $8 / 10 / 20086: 56$ & 2.77 & 25.6 & 2700 & $8 / 10 / 20089: 18$ & 2.635 & 26.4 & 2771 & $8 / 10 / 200811: 40$ & 2.748 & 27.4 \\
\hline 2559 & $8 / 10 / 20084: 36$ & 2.737 & 25.8 & 2630 & $8 / 10 / 20086: 58$ & 2.78 & 25.6 & 2701 & $8 / 10 / 20089: 20$ & 2.662 & 26.3 & 2772 & $8 / 10 / 200811: 42$ & 2.765 & 27.5 \\
\hline 2560 & $8 / 10 / 20084: 38$ & 2.74 & 25.9 & 2631 & $8 / 10 / 20087: 00$ & 2.801 & 25.6 & 2702 & $8 / 10 / 20089: 22$ & 2.663 & 26.4 & 2773 & $8 / 10 / 200811: 44$ & 2.742 & 27.9 \\
\hline 2561 & $8 / 10 / 20084: 40$ & 2.747 & 25.8 & 2632 & $8 / 10 / 20087: 02$ & 2.801 & 25.6 & 2703 & $8 / 10 / 20089: 24$ & 2.649 & 26.4 & 2774 & $8 / 10 / 2008$ 11:46 & 2.718 & 27.6 \\
\hline 2562 & $8 / 10 / 20084: 42$ & 2.743 & 25.8 & 2633 & $8 / 10 / 20087: 04$ & 2.787 & 25.6 & 2704 & $8 / 10 / 20089: 26$ & 2.659 & 26.4 & 2775 & $8 / 10 / 200811: 48$ & 2.528 & 27.5 \\
\hline 2563 & $8 / 10 / 20084: 44$ & 2.747 & 25.8 & 2634 & $8 / 10 / 20087: 06$ & 2.78 & 25.6 & 2705 & $8 / 10 / 20089: 28$ & 2.666 & 26.4 & 2776 & $8 / 10 / 200811: 50$ & 1.687 & 27.9 \\
\hline 2564 & $8 / 10 / 20084: 46$ & 2.76 & 25.8 & 2635 & $8 / 10 / 20087: 08$ & 2.784 & 25.6 & 2706 & $8 / 10 / 20089: 30$ & 2.669 & 26.4 & 2777 & $8 / 10 / 200811: 52$ & 1.605 & 27.6 \\
\hline 2565 & $8 / 10 / 20084: 48$ & 2.747 & 25.8 & 2636 & $8 / 10 / 20087: 10$ & 2.77 & 25.6 & 2707 & $8 / 10 / 20089: 32$ & 2.652 & 26.4 & 2778 & $8 / 10 / 200811: 54$ & 1.568 & 27.6 \\
\hline 2566 & $0084: 50$ & 2.74 & 25.8 & 2637 & $8 / 10 / 20087: 12$ & 2.777 & 25.6 & 2708 & $8 / 10 / 20089: 34$ & 2.663 & 26.4 & 2779 & $8 / 10 / 200811: 56$ & 1.554 & 27.5 \\
\hline 2567 & $8 / 10 / 20084: 52$ & 2.753 & 25.8 & 2638 & $8 / 10 / 20087: 14$ & 2.78 & 25.6 & 2709 & $8 / 10 / 20089: 36$ & 2.666 & 26.4 & 2780 & $8 / 10 / 200811: 58$ & 1.544 & 27.5 \\
\hline 2568 & $8 / 10 / 20084: 54$ & 2.743 & 25.8 & 2639 & $8 / 10 / 20087: 16$ & 2.767 & 25.6 & 2710 & $8 / 10 / 20089: 38$ & 2.683 & 26.4 & 2781 & $8 / 10 / 200812: 00$ & 1.537 & 27.4 \\
\hline 2569 & $8 / 10 / 20084: 56$ & 2.736 & 25.8 & 2640 & $8 / 10 / 20087: 18$ & 2.777 & 25.7 & 2711 & $0 / 20089: 40$ & 2.676 & 26.5 & 2782 & $8 / 10 / 200812: 02$ & 1.534 & 27.3 \\
\hline 2570 & $84: 58$ & 2.73 & 25.8 & 2641 & $8 / 10 / 20087: 20$ & 2.787 & 25.7 & 2712 & $8 / 10 / 20089: 42$ & 2.669 & 26.5 & 2783 & $8 / 10 / 200812: 04$ & 2.634 & 28 \\
\hline 2571 & $85: 00$ & 2.726 & 25.8 & 2642 & $8 / 10 / 20087: 22$ & 2.784 & 25.6 & 2713 & $8 / 10 / 20089: 44$ & 2.673 & 26.5 & 2784 & $8 / 10 / 200812: 06$ & 2.631 & 28.8 \\
\hline 2572 & $8 / 10 / 20085: 02$ & 2.747 & 25.8 & 2643 & $20087: 24$ & 2.791 & 25.6 & 2714 & J/2008 9:46 & 2.687 & 26.9 & 2785 & $8 / 10 / 2008$ 12:08 & 2.645 & 29 \\
\hline 2573 & $8 / 10 / 20085: 04$ & 2.743 & 25.8 & 2644 & $8 / 10 / 20087: 26$ & 2.791 & 25.6 & 2715 & $8 / 10 / 20089: 48$ & 2.673 & 26.6 & 2786 & $8 / 10 / 200812: 10$ & 2.655 & 29.1 \\
\hline 2574 & & 2.747 & 25.8 & 2645 & $0087: 28$ & 2.807 & 25.6 & 2716 & $20089: 50$ & 2.68 & 26.5 & 2787 & $00812: 12$ & 2.659 & 29.1 \\
\hline 2575 & & 2.699 & 25.8 & 2646 & $0087: 30$ & 2.794 & 25.6 & 2717 & $20089: 52$ & 2.69 & 26.5 & 2788 & $00812: 14$ & 2.672 & 29.1 \\
\hline 2576 & $0085: 10$ & 2.743 & 25.8 & 2647 & $0087: 32$ & 2.797 & 25.6 & 2718 & $8 / 10 / 20089: 54$ & 2.696 & 26.5 & $\begin{array}{l}2789 \\
278\end{array}$ & $200812: 16$ & $\begin{array}{l}2.683 \\
2.68\end{array}$ & 29.3 \\
\hline 2577 & $8 / 10 / 20085: 12$ & 2.743 & 25.8 & 2648 & $8 / 10 / 20087: 34$ & 2.78 & 25.6 & 2719 & $8 / 10 / 20089: 56$ & 2.673 & 26.6 & 2790 & $8 / 10 / 2008$ 12:18 & 2.696 & 29.1 \\
\hline 2578 & $85: 14$ & 2.764 & 25.8 & 2649 & $0087: 36$ & 2.791 & 25.6 & 2720 & $20089: 58$ & 2.68 & 26.6 & 2791 & $8 / 10 / 200812: 20$ & 2.703 & 29.1 \\
\hline 2579 & & 2.743 & 25.7 & 2650 & $0087: 38$ & 2.784 & 25.6 & 2721 & $10810: 00$ & 2.707 & 26.6 & 2792 & $00812: 22$ & 2.716 & 29.2 \\
\hline 2580 & & 2.78 & 25.7 & 2651 & $0087: 40$ & 2.794 & 25.6 & 2722 & $0810: 02$ & 2.683 & 26.6 & 2793 & $812: 24$ & 2.696 & 29.2 \\
\hline 2581 & $35: 20$ & 2.74 & 25.9 & 2652 & $087: 42$ & 2.814 & 25.7 & 2723 & $08 \quad 10: 04$ & 2.676 & 26.6 & 2794 & $200812: 26$ & 2.713 & 29.3 \\
\hline 2582 & $85: 22$ & 2.72 & 25.8 & 2653 & $0087: 44$ & 2.777 & 25.6 & 2724 & $0810: 06$ & 2.707 & 26.6 & 2795 & $8 / 10 / 2008$ 12:28 & 2.693 & 29.3 \\
\hline 2583 & $85: 24$ & 2.726 & 25.7 & 2654 & $0087: 46$ & 2.797 & 25.6 & 2725 & $0810: 08$ & 2.69 & 26.8 & 2796 & $8 / 10 / 200812: 30$ & 2.74 & 29.3 \\
\hline 2584 & & 2.73 & 25.7 & 2655 & $0087: 48$ & 2.777 & 25.6 & 2726 & $0810: 10$ & 2.693 & 26.7 & 2797 & $0812: 32$ & 2.713 & 29.3 \\
\hline 2585 & & 2.706 & & & & 2.787 & 25.6 & 2727 & & 2.697 & 26.7 & 2798 & $0812: 34$ & 2.71 & 29.3 \\
\hline 2586 & $85: 30$ & 2.74 & 25.6 & 2657 & $087: 52$ & 2.787 & 25.6 & 2728 & $810: 14$ & 2.693 & 26.7 & 2799 & $0812: 36$ & 2.73 & 29.3 \\
\hline 2587 & $35: 32$ & 2.747 & 25.6 & 2658 & $087: 54$ & 2.784 & 25.6 & 2729 & $810: 16$ & 2.713 & 26.6 & 2800 & $00812: 38$ & 2.717 & 29.3 \\
\hline 2588 & $5: 34$ & 2.733 & 25.6 & 2659 & 008 7:56 & 2.794 & 25.6 & 2730 & $810: 18$ & 2.69 & 26.6 & 2801 & $812: 40$ & 2.713 & 29.3 \\
\hline 2589 & & 2.726 & 25.6 & 2660 & & 2.794 & & 2731 & & 2.68 & & 2802 & $812: 42$ & 2.74 & 29.3 \\
\hline 2590 & $5: 38$ & 2.723 & 25.6 & 2661 & & 2.797 & & & & 2.71 & 26.7 & 2803 & & 2.717 & 29.3 \\
\hline 2591 & $5: 40$ & 2.719 & 25.6 & 2662 & $088: 02$ & 2.784 & 25.6 & 2733 & $310: 24$ & 2.703 & 26.7 & 2804 & $00812: 46$ & 2.727 & 29.3 \\
\hline 2592 & $35: 42$ & 2.723 & 25.8 & 2663 & $088: 04$ & 2.787 & 25.6 & 2734 & $810: 26$ & 2.683 & 26.8 & 2805 & $0812: 48$ & 2.747 & 29.3 \\
\hline 2593 & $5: 44$ & 2.716 & 25.6 & 2664 & $088: 06$ & 2.784 & 25.6 & 2735 & $810: 28$ & 2.683 & 26.8 & 2806 & $812: 50$ & 2.737 & 29.3 \\
\hline 2594 & & 2.496 & 25.5 & 2665 & $88: 08$ & 2.807 & 25.6 & 2736 & & 2.714 & 26.8 & 2807 & $812: 52$ & 2.734 & 29.3 \\
\hline 2595 & $5: 48$ & 2.645 & 25.4 & 2666 & $88: 10$ & 2.784 & 25.6 & 2737 & $10: 32$ & 2.69 & 27.2 & 2808 & & 2.744 & 29.3 \\
\hline 2596 & $5: 50$ & 1.613 & 24.4 & 2667 & $88: 12$ & 2.774 & 25.6 & 2738 & $10: 34$ & 2.707 & 27.3 & 2809 & $812: 56$ & 2.73 & 29.3 \\
\hline 2597 & $5: 52$ & 1.562 & 24. & 2668 & $88: 14$ & 2.777 & 25.6 & 2739 & $810: 36$ & 2.728 & 27.3 & 2810 & $812: 58$ & 2.737 & 29.3 \\
\hline 2598 & & 1.532 & & 2669 & $88: 16$ & 2.811 & & 2740 & $810: 38$ & 2.704 & 27 & 2811 & $813: 00$ & 2.761 & 29.3 \\
\hline 2599 & & & & & & 2.78 & & 2741 & & 2.714 & 26.8 & 2812 & & .744 & 29.3 \\
\hline 2600 & & 1.505 & 24.9 & & & 2.787 & 25.6 & 2742 & & & 26.8 & 2813 & & 2.768 & 29.8 \\
\hline 2601 & $6: 00$ & 1.498 & 25.1 & 2672 & $88: 22$ & 2.78 & 25.6 & 2743 & $310: 44$ & 2.703 & 26.7 & 2814 & 13:06 & 2.758 & 29.9 \\
\hline 2602 & $6: 02$ & 1.495 & 25.5 & 2673 & $88: 24$ & 2.78 & & 2744 & $310: 46$ & 2.697 & 26.7 & 2815 & $13: 08$ & 2.731 & 29.9 \\
\hline 2603 & & 1.495 & 25. & 2674 & $88: 26$ & 2.784 & 25 & 2745 & $10: 48$ & 2.686 & 26.7 & 2816 & $13: 10$ & 2.772 & 30 \\
\hline 2604 & & 2.256 & & 2675 & & 2.794 & & 2746 & & 2.71 & 26.7 & 2817 & $3: 12$ & 2.734 & 29.6 \\
\hline 2605 & & & & & & 2.78 & 25.6 & 2747 & $10: 52$ & 2.71 & 26.8 & 2818 & 13:14 & 2.737 & 29.5 \\
\hline 2606 & $36: 10$ & 2.736 & 25.6 & 2677 & $88: 32$ & 2.804 & 25.7 & 2748 & $10: 54$ & 2.703 & 26.8 & 2819 & $13: 16$ & 2.764 & 29.5 \\
\hline 2607 & $36: 12$ & 2.743 & & 2678 & $88: 34$ & 2.797 & & 2749 & $810: 56$ & 2.697 & 26.8 & 2820 & $13: 18$ & 2.754 & 29.5 \\
\hline 2608 & $6: 14$ & 2.736 & 25.8 & 2679 & $088: 36$ & 2.784 & 25.7 & 2750 & $810: 58$ & 2.69 & 26.8 & 2821 & $3: 20$ & 2.774 & 29.4 \\
\hline 2609 & & 2.743 & 25.8 & 2680 & & 2.791 & 26 & 2751 & & 2.7 & & 2822 & $3: 22$ & 2.748 & 29.6 \\
\hline$\frac{2000}{2610}$ & & & & & & & & & & 2.1 & & $\frac{2024}{2823}$ & & 2.744 & 29.5 \\
\hline 2611 & & 2.75 & & 2682 & & 2.797 & & & & 2.703 & 26.8 & 2824 & & 2.801 & 29.4 \\
\hline 2612 & $6: 22$ & 2.743 & 25.7 & 2683 & $088: 44$ & 2.77 & 25.8 & 2754 & $811: 06$ & 2.7 & 26.8 & 2825 & $13: 28$ & 2.774 & 29.5 \\
\hline 2613 & $6: 24$ & 2.784 & 25.7 & 2684 & $388: 46$ & 2.777 & 26.1 & 2755 & $811: 08$ & 2.71 & 26.8 & 2826 & $13: 30$ & 2.761 & 29.5 \\
\hline 2614 & & 2.763 & 25. & 2685 & $88: 48$ & 2.764 & & 2756 & & 2.714 & 26.8 & 2827 & $3: 32$ & 2.761 & 29.5 \\
\hline$\frac{2614}{2615}$ & & & & & & & & & & & & 2828 & & 2.751 & 29.4 \\
\hline 2616 & & 2.743 & 25.7 & 2687 & $88: 52$ & 1.982 & 25.8 & 2758 & $311: 14$ & 2.704 & 26.9 & 2829 & 13:36 & 2.757 & 29.4 \\
\hline$\frac{2617}{2617}$ & $36: 32$ & 2.763 & 25.7 & 2688 & $088: 54$ & 1.617 & 25.7 & 2759 & $811: 16$ & 2.71 & 26.9 & 2830 & $13: 38$ & 2.734 & 29.4 \\
\hline 2618 & $36: 34$ & 2.763 & 25.7 & 2689 & $088: 56$ & 1.546 & 25.6 & 2760 & $811: 18$ & 2.72 & 26.9 & 2831 & $0813: 40$ & 2.768 & 29.4 \\
\hline 2619 & & 2.76 & 25.7 & 2690 & $088: 58$ & 1.522 & 25.6 & 2761 & $811: 20$ & 2.71 & 26.9 & 2832 & $0813: 42$ & 2.785 & 29.5 \\
\hline 2620 & $36: 38$ & 2.77 & 25.7 & 2691 & $0089: 00$ & 1.516 & 25.7 & 2762 & $811: 22$ & 2.704 & 26.9 & $\frac{2004}{2833}$ & $0813: 44$ & 2.754 & 29.5 \\
\hline 2621 & $086: 40$ & 2.791 & 25.6 & 2692 & $0089: 02$ & 1.509 & 25.7 & 2763 & $0811: 24$ & 2.704 & 26.9 & 2834 & $813: 46$ & 2.754 & 29.5 \\
\hline$\frac{2021}{2622}$ & $8 / 10 / 20086: 42$ & 2.76 & 25.6 & 2693 & $20089: 04$ & 1.502 & 25.7 & 2764 & $0811: 26$ & 2.734 & 26.9 & 2835 & $108 \quad 13: 48$ & 2.757 & 29.5 \\
\hline 2623 & $8 / 10 / 20086: 44$ & 2.774 & 25.6 & 2694 & $8 / 10 / 20089: 06$ & 2.239 & 25.7 & 2765 & $8 / 10 / 200811: 28$ & 2.721 & 27.2 & 2836 & $8 / 10 / 200813: 50$ & 2.795 & 29.6 \\
\hline 2624 & $086: 46$ & 2.449 & 25.6 & 2695 & $8 / 10 / 20089: 08$ & 2.727 & 26.3 & 2766 & $8 / 10 / 200811: 30$ & 2.731 & 27.4 & 2837 & $8 / 10 / 2008 \quad 13: 52$ & 2.768 & 29.6 \\
\hline 2625 & 86.48 & 2.777 & 25.7 & 2696 & $8 / 10 / 20089: 10$ & 2.598 & 26.6 & 2767 & $8 / 10 / 200811: 32$ & 2.741 & 27.4 & 2838 & $8 / 10 / 2008 \quad 13: 54$ & 2.785 & 29.6 \\
\hline 2626 & $8 / 10 / 20086: 50$ & 2.767 & 25.6 & 2697 & $8 / 10 / 20089: 12$ & 2.608 & 26.4 & 2768 & $8 / 10 / 200811: 34$ & 2.728 & 27.4 & 2839 & $8 / 10 / 2008$ 13:56 & 2.788 & 29.6 \\
\hline 2627 & $8 / 10 / 20086: 52$ & 2.763 & 25.6 & 2698 & $8 / 10 / 20089: 14$ & 2.622 & 26.4 & 2769 & $8 / 10 / 200811: 36$ & 2.741 & 27.4 & 2840 & $8 / 10 / 2008$ 13:58 & 2.795 & 29.6 \\
\hline
\end{tabular}




\begin{tabular}{|c|c|c|c|c|c|c|c|c|c|c|c|c|c|c|c|}
\hline \multicolumn{4}{|c|}{$D 4-26 p$} & \multicolumn{4}{|c|}{ D4-26p } & \multicolumn{4}{|c|}{ D4-26p } & \multicolumn{4}{|c|}{ D4-26p } \\
\hline $\operatorname{Rec}$ & & Pres & Temp & $\operatorname{Rec}$ & & Pres & Temp & $\operatorname{Rec}$ & & Pres & Temp & $\operatorname{Rec}$ & & Pres & Temp \\
\hline$\#$ & Date/Time & psi & ${ }^{\circ} \mathrm{C}$ & $\#$ & Date/Time & psi & ${ }^{\circ} \mathrm{C}$ & $\#$ & Date/Time & psi & ${ }^{\circ} \mathrm{C}$ & $\#$ & Date/Time & psi & ${ }^{\circ} \mathrm{C}$ \\
\hline 2841 & $8 / 10 / 200814: 00$ & 2.771 & 29.6 & $\frac{n}{2912}$ & $8 / 10 / 2008 \quad 16: 22$ & 2.782 & 30.3 & 2983 & $8 / 10 / 2008$ 18:44 & 2.914 & 29.9 & 3054 & $8 / 10 / 200821: 06$ & 1.502 & 28.8 \\
\hline 2842 & $8 / 10 / 2008$ 14:02 & 2.795 & 29.6 & 2913 & $8 / 10 / 200816: 24$ & 2.759 & 30.3 & 2984 & $8 / 10 / 200818: 46$ & 2.914 & 30.1 & 3055 & $8 / 10 / 200821: 08$ & 1.505 & 28.9 \\
\hline 2843 & $8 / 10 / 200814: 04$ & 2.761 & 29.6 & 2914 & $8 / 40 / 2008 \quad 16: 26$ & 2.755 & 30.3 & 2985 & $8 / 10 / 2008 \quad 18: 48$ & 2.914 & 29.9 & 3056 & $8 / 10 / 200821: 10$ & 1.502 & 28.9 \\
\hline 2844 & $8 / 10 / 200814: 06$ & 2.768 & 29.6 & 2915 & $8 / 10 / 200816: 28$ & 2.749 & 30.3 & 2986 & $8 / 10 / 200818: 50$ & 2.91 & 29.9 & 3057 & $8 / 10 / 200821: 12$ & 1.502 & 28.9 \\
\hline 2845 & $8 / 10 / 2008$ 14:08 & 2.781 & 29.7 & 2916 & $8 / 10 / 200816: 30$ & 2.759 & 30.3 & 2987 & $8 / 10 / 200818: 52$ & 2.93 & 29.8 & 3058 & $8 / 10 / 200821: 14$ & 1.502 & 28.9 \\
\hline 2846 & $8 / 10 / 2008 \quad 14: 10$ & 2.822 & 29.8 & 2917 & $8 / 10 / 2008 \quad 16: 32$ & 2.759 & 30.3 & 2988 & $8 / 10 / 2008 \quad 18: 54$ & 2.914 & 29.9 & 3059 & $8 / 10 / 200821: 16$ & 1.502 & 28.9 \\
\hline 2847 & $8 / 10 / 2008 \quad 14: 12$ & 2.809 & 29.9 & 2918 & $8 / 10 / 200816: 34$ & 2.765 & 30.3 & 2989 & $8 / 10 / 200818: 56$ & 2.937 & 29.8 & 3060 & $8 / 10 / 200821: 18$ & 2.911 & 28 \\
\hline 2848 & $8 / 10 / 2008 \quad 14: 14$ & 2.866 & 29.9 & 2919 & $8 / 10 / 200816: 36$ & 2.759 & 30.3 & 2990 & $8 / 10 / 200818: 58$ & 2.914 & 29.8 & 3061 & $8 / 10 / 200821: 20$ & 2.901 & 27.8 \\
\hline 2849 & $8 / 10 / 2008$ 14:16 & 2.826 & 29.9 & 2920 & $8 / 10 / 200816: 38$ & 2.749 & 30.4 & 2991 & $8 / 10 / 2008$ 19:00 & 2.917 & 29.8 & 3062 & $8 / 10 / 200821: 22$ & 2.918 & 27.9 \\
\hline 2850 & $8 / 10 / 200814: 18$ & 2.86 & 29.9 & 2921 & $8 / 10 / 200816: 40$ & 2.739 & 30.6 & 2992 & $8 / 10 / 2008$ 19:02 & 2.917 & 29.8 & 3063 & $8 / 10 / 200821: 24$ & 2.924 & 27.9 \\
\hline 2851 & $8 / 10 / 2008$ 14:20 & 2.823 & 30.2 & 2922 & $8 / 10 / 200816: 42$ & 2.756 & 30.7 & 2993 & $8 / 10 / 200819: 04$ & 2.914 & 29.8 & 3064 & $8 / 10 / 200821: 26$ & 2.924 & 27.9 \\
\hline 2852 & $8 / 10 / 2008 \quad 14: 22$ & 2.853 & 29.9 & 2923 & $8 / 10 / 200816: 44$ & 2.763 & 30.7 & 2994 & $8 / 10 / 200819: 06$ & 2.917 & 29.8 & 3065 & $8 / 10 / 200821: 28$ & 2.938 & 27.9 \\
\hline 2853 & $8 / 10 / 200814: 24$ & 2.839 & & 2924 & $8 / 10 / 200816: 46$ & 2.766 & 30.7 & 2995 & $8 / 10 / 200819: 08$ & 2.91 & 29.8 & 3066 & $8 / 10 / 200821: 30$ & 2.941 & 27.9 \\
\hline 2854 & $8 / 10 / 2$ & 2.832 & 29.8 & 2925 & $8 / 10 / 200816: 48$ & 2.763 & 30.7 & 2996 & $8 / 10 / 200819: 10$ & 2.924 & 29.8 & 3067 & $8 / 10 / 200821: 32$ & 2.948 & 27.9 \\
\hline 2855 & $8 / 10 / 2008$ 14:28 & 2.869 & 29.8 & 2926 & $8 / 10 / 200816: 50$ & 2.78 & 30.7 & 2997 & $8 / 10 / 2008$ 19:12 & 2.924 & 29.8 & 3068 & $8 / 10 / 200821: 34$ & 2.958 & 27.9 \\
\hline 2856 & $8 / 10 / 200814: 30$ & 2.805 & 29.7 & 2927 & $8 / 10 / 200816: 52$ & 2.756 & 30.7 & 2998 & $8 / 10 / 200819: 14$ & 2.934 & 29.8 & 3069 & $8 / 10 / 200821: 36$ & 2.968 & 27.9 \\
\hline 2857 & $8 / 10 / 200814: 32$ & 2.809 & 29.7 & 2928 & $8 / 10 / 200816: 54$ & 2.797 & 30.7 & 2999 & $8 / 10 / 200819: 16$ & 2.944 & 29.8 & 3070 & $8 / 10 / 200821: 38$ & 2.965 & 27.8 \\
\hline 2858 & $8 / 10 / 200814: 34$ & 2.829 & 29.7 & 2929 & $8 / 10 / 200816: 56$ & 2.776 & 30.7 & 3000 & $8 / 10 / 200819: 18$ & 2.907 & 29.8 & 3071 & $8 / 10 / 200821: 40$ & 2.955 & 27.8 \\
\hline 2859 & $8 / 10 / 2$ & 2.825 & 29.7 & 2930 & $0816: 58$ & 2.773 & 30.7 & 3001 & $00819: 20$ & $\frac{2.001}{2.92}$ & 29.8 & 3072 & $200821: 42$ & 2.955 & 27.8 \\
\hline 2860 & $8 / 10$ & 2.839 & 29.9 & 2931 & $0817: 00$ & 2.787 & 30.7 & 3002 & $/ 200819: 22$ & 2.913 & 29.8 & 3073 & $00821: 44$ & 2.962 & 27.8 \\
\hline 2861 & $14: 40$ & 2.839 & 29.8 & 2932 & $817: 02$ & 2.793 & 30.7 & 3003 & $00819: 24$ & 2.93 & 29.8 & 3074 & $200821: 46$ & 2.965 & 27.8 \\
\hline 2862 & $8 / 10 / 200814: 42$ & 2.829 & 29.7 & 2933 & $8 / 10 / 200817: 04$ & 2.78 & 30.7 & 3004 & $2008+9: 26$ & 2.914 & 29.8 & 3075 & $8 / 10 / 200821: 48$ & 2.962 & 27.8 \\
\hline 2863 & $8 / 10 / 200814: 44$ & 2.612 & 29.6 & 2934 & $8 / 10 / 2008$ 17:06 & 2.773 & 30.7 & 3005 & $8 / 10 / 200819: 28$ & 2.907 & 29.8 & 3076 & $8 / 10 / 200821: 50$ & 2.989 & 27.8 \\
\hline 2864 & $8 / 10 / 200814: 46$ & 2.318 & 29.8 & 2935 & $8 / 10 / 2008 \quad 17: 08$ & 2.77 & 30.9 & 3006 & $8 / 10 / 200819: 30$ & 2.927 & 29.8 & 3077 & $8 / 10 / 200821: 52$ & 2.992 & 27.8 \\
\hline$\frac{2865}{2865}$ & & & 30.4 & 2936 & $00817: 10$ & 2.797 & 30.8 & 3007 & $00819: 32$ & 2.924 & 29.8 & 3078 & $00821: 54$ & 2.985 & 27.8 \\
\hline$\frac{2004}{2866}$ & & 1.707 & 30.5 & 2937 & $817: 12$ & 2.773 & 30.7 & 3008 & $00819: 34$ & 2.91 & 29.8 & 3079 & $00821: 56$ & 2.975 & 27.8 \\
\hline 2867 & $14: 52$ & 1.64 & 30.5 & 2938 & $817: 14$ & 2.79 & 30.7 & 3009 & $00819: 36$ & 2.91 & 29.8 & 3080 & $00821: 58$ & 2.985 & 27.8 \\
\hline 2868 & $814: 54$ & 1.592 & 30.4 & 2939 & $817: 16$ & 2.78 & 30.6 & 3010 & $00819: 38$ & 2.913 & 29.8 & 3081 & $00822: 00$ & 2.978 & 27.8 \\
\hline 2869 & $814: 56$ & 1.565 & 30.4 & 2940 & $0817: 18$ & 2.797 & 30.6 & 3011 & $00819: 40$ & 2.917 & 29.7 & 3082 & $200822: 02$ & 2.975 & 27.8 \\
\hline 2870 & $8 / 10 / 2008$ 14:58 & 1.548 & 30.3 & 2941 & $30817: 20$ & 2.766 & 30.6 & 3012 & $00819: 42$ & 2.9 & 29.7 & 3083 & $8 / 10 / 200822: 04$ & 2.992 & 27.8 \\
\hline 2871 & $8 / 10 / 200815: 00$ & 1.538 & 30.3 & 2942 & $8 / 10 / 200817: 22$ & 2.786 & 30.6 & 3013 & $200819: 44$ & 2.9 & 29.7 & 3084 & $8 / 10 / 200822: 06$ & 2.988 & 27.8 \\
\hline$\frac{2811}{2872}$ & & 1.531 & 30.1 & 2943 & $8 / 40 / 2008 \quad 17: 24$ & 2.78 & 30.6 & 3014 & $200819: 46$ & 2.91 & 29.7 & 3085 & $8 / 10 / 200822: 08$ & 2.978 & 27.8 \\
\hline 2873 & $15: 04$ & & 29.8 & 2944 & $0817: 26$ & 2.786 & & 3015 & & 2.913 & 29.7 & 3086 & & & 27.8 \\
\hline 2874 & $15: 06$ & 2.68 & 29.9 & 2945 & $0817: 28$ & 2.797 & 30.6 & 3016 & $0819: 50$ & 2.923 & 29.7 & 3087 & $0822: 12$ & 2.982 & 27.8 \\
\hline 2875 & $815: 08$ & 2.83 & 30.1 & 2946 & $08 \quad 17: 30$ & 2.777 & 30.8 & 3017 & $00819: 52$ & 2.903 & 29.7 & 3088 & $200822: 14$ & 2.988 & 27.8 \\
\hline 2876 & $8 / 10 / 200815: 10$ & 2.84 & 30.2 & 2947 & $08 \quad 17: 32$ & 2.815 & 31.2 & 3018 & $00819: 54$ & 2.9 & 29.7 & 3089 & $200822: 16$ & 2.995 & 27.8 \\
\hline 2877 & $8 / 10 / 2008$ 15:12 & 2.857 & 30.2 & 2948 & $0817: 34$ & 2.831 & 30.9 & 3019 & $00819: 56$ & 2.904 & 30.1 & 3090 & $00822: 18$ & 3.005 & 27.8 \\
\hline 2878 & $15: 14$ & 2.846 & 30.1 & 2949 & $00817: 36$ & 2.827 & 30.9 & 3020 & $00819: 58$ & 2.91 & 29.7 & 3091 & $00822: 20$ & 2.982 & 27.8 \\
\hline 2879 & & & 30.2 & 2950 & (1) & 2.858 & 30.8 & 3021 & $00820: 00$ & 2.937 & 29.7 & 3092 & $00822: 22$ & & 27.7 \\
\hline 2880 & & 2.82 & 30.3 & 2951 & $817: 40$ & 2.841 & 30.8 & 3022 & $820: 02$ & 2.92 & 29.6 & 3093 & $0822: 24$ & 2.985 & 27.7 \\
\hline 2881 & $815: 20$ & 2.803 & 30.3 & 2952 & $817: 42$ & 2.834 & 30.8 & 3023 & $00820: 04$ & 2.92 & 29.6 & 3094 & $0822: 26$ & 2.985 & 27.9 \\
\hline 2882 & $8 / 10 / 2008$ 15:22 & 2.81 & 30.4 & 2953 & $0817: 44$ & 2.814 & 30.9 & 3024 & $00820: 06$ & 2.913 & 29.6 & 3095 & $0822: 28$ & 2.992 & 27.8 \\
\hline 2883 & $8 / 10 / 2008$ 15:24 & 2.816 & 30.3 & 2954 & $00817: 46$ & 2.077 & 30.8 & 3025 & $00820: 08$ & 2.9 & 29.6 & 3096 & $0822: 30$ & 2.988 & 27.7 \\
\hline 2884 & $8 / 10 / 200815: 26$ & 2.816 & 30.3 & 2955 & $00817: 48$ & 1.718 & 30.8 & 3026 & $00820: 10$ & 2.917 & 29.6 & 3097 & $00822: 32$ & 2.992 & 27.7 \\
\hline$\frac{2885}{2885}$ & & & 30.3 & 2956 & $00817: 50$ & 1.688 & 30.8 & 3027 & $00820: 12$ & 2.903 & 29.6 & 3098 & $10822: 34$ & & 27.6 \\
\hline$\frac{2004}{2886}$ & & & & & 817:52 & 2.847 & & & & 2.903 & 29.6 & 3099 & $822: 36$ & & 27.6 \\
\hline 2887 & & 2.826 & 30.2 & 2958 & & 2.877 & 29.9 & 3029 & $0820: 16$ & 2.917 & 29.6 & 3100 & $0822: 38$ & 2.995 & 27.6 \\
\hline 2888 & $15: 34$ & 2.819 & 30.1 & 2959 & $817: 56$ & 2.88 & 29.9 & 3030 & $0820: 18$ & 2.917 & 29.6 & 3101 & $0822: 40$ & 3.002 & 27.7 \\
\hline 2889 & $815: 36$ & 2.819 & 30.2 & 2960 & $00817: 58$ & 2.89 & 29.9 & 3031 & $00820: 20$ & 2.9 & 29.5 & 3102 & $0822: 42$ & 3.015 & 27.6 \\
\hline 2890 & $8 / 10 / 200815: 38$ & 2.82 & 30.3 & 2961 & $0818: 00$ & 2.887 & 29.9 & 3032 & $00820: 22$ & 2.893 & 29.5 & 3103 & $0822: 44$ & 3.012 & 27.6 \\
\hline 2891 & $8 / 10 / 200815: 40$ & 2.836 & 30.3 & 2962 & 008 18:02 & 2.893 & 29.8 & 3033 & $00820: 24$ & 2.927 & 29.5 & 3104 & $3822: 46$ & 3.019 & 27.6 \\
\hline 2892 & & & & 2963 & $0818: 04$ & 2.89 & 29.8 & 3034 & $0820: 26$ & 2.9 & 29.5 & 3105 & $822: 48$ & 3.015 & 27.6 \\
\hline 2893 & & & & 2964 & $318: 06$ & 2.884 & 30.2 & 3035 & $820: 28$ & 2.896 & 29.4 & 3106 & $822: 50$ & 3.0 & 27.6 \\
\hline$\frac{2070}{2894}$ & & & & & & & & & & & & & $822: 52$ & & 27. \\
\hline 2895 & $15: 48$ & 2.796 & 30.3 & 2966 & $818: 10$ & 2.9 & 29.9 & 3037 & $0820: 32$ & 2.203 & 29.4 & 3108 & $0822: 54$ & 3.005 & 27.6 \\
\hline 2896 & $15: 50$ & 2.799 & 30.3 & 2967 & $818: 12$ & 2.903 & 29.8 & 3038 & $0820: 34$ & 2.138 & 29 & 3109 & $0822: 56$ & 3.039 & 27.6 \\
\hline 2897 & $815: 52$ & 2.796 & 30.3 & 2968 & $10818: 14$ & 2.893 & 29.8 & 3039 & $00820: 36$ & 1.951 & 28.5 & 3110 & $00822: 58$ & 3.002 & 27.6 \\
\hline 2898 & $8 / 10 / 2008 \quad 15: 54$ & 2.806 & 30.3 & 2969 & $30818: 16$ & 2.91 & 29.8 & 3040 & $0820: 38$ & 1.94 & 28 & 3111 & $0823: 00$ & 3.009 & 27.6 \\
\hline 2899 & $315: 56$ & 2.799 & 30.3 & 2970 & $30818: 18$ & 2.893 & 29.8 & 3041 & $0820: 40$ & 1.646 & 27.4 & 3112 & $0823: 02$ & 3.002 & 27.6 \\
\hline 2900 & & 2.779 & & 2971 & $9818: 20$ & 2.914 & 29.8 & 3042 & $0820: 42$ & 1.588 & 27.5 & 3113 & $0823: 04$ & 3.002 & 27.6 \\
\hline 2901 & & & & 2972 & $818: 22$ & 2.9 & 29.8 & 3043 & $820: 44$ & 1.565 & 27.8 & 3114 & $823: 06$ & 3.012 & 27.5 \\
\hline 2902 & $8 / 10 / 2$ & 2.786 & 30.3 & 2973 & $0818: 24$ & 2.903 & 29.8 & 3044 & $00820: 46$ & 1.548 & 28 & 3115 & $00823: 08$ & 2.998 & 27.6 \\
\hline 2903 & $8 / 10 / 200816: 04$ & 2.776 & 30.3 & 2974 & $00818: 26$ & 2.904 & 30.1 & 3045 & $8 / 10 / 200820: 48$ & 1.538 & 28.1 & 3116 & $200823: 10$ & 3.009 & 27.5 \\
\hline 2904 & $8 / 10 / 200816: 06$ & 2.772 & 30.3 & 2975 & $8 / 10 / 200818: 28$ & 2.897 & 29.9 & 3046 & $8 / 10 / 200820: 50$ & 1.532 & 28.3 & 3117 & $8 / 10 / 200823: 12$ & 3.022 & 27.5 \\
\hline 2905 & $8 / 10 / 200816: 08$ & 2.765 & 30.3 & 2976 & $8 / 10 / 2008$ 18:30 & 2.91 & 29.9 & 3047 & $8 / 10 / 200820: 52$ & 1.525 & 28.4 & 3118 & $00823: 14$ & 3.022 & 27.5 \\
\hline 2906 & $8 / 10 / 2008 \quad 16: 10$ & 2.769 & 30.3 & 2977 & $8 / 10 / 2008 \quad 18: 32$ & 2.91 & 29.8 & 3048 & $8 / 10 / 200820: 54$ & 1.518 & 28.6 & 3119 & $8 / 10 / 200823: 16$ & 2.988 & 27.5 \\
\hline 2907 & $816: 12$ & 2.786 & 30.3 & 2978 & $8 / 10 / 200818: 34$ & 2.914 & 29.8 & 3049 & $8 / 10 / 200820: 56$ & 1.515 & 28.6 & 3120 & $8 / 10 / 200823: 18$ & 2.998 & 27.5 \\
\hline 2908 & $8 / 10 / 200816: 14$ & 2.762 & 30.3 & 2979 & $8 / 10 / 200818: 36$ & 2.934 & 29.8 & 3050 & $8 / 10 / 200820: 58$ & 1.512 & 28.7 & 3121 & $8 / 10 / 200823: 20$ & 3.005 & 27.5 \\
\hline 2909 & $8 / 10 / 200816: 16$ & 2.776 & 30.6 & 2980 & $8 / 10 / 200818: 38$ & 2.91 & 29.8 & 3051 & $8 / 10 / 200821: 00$ & 1.505 & 28.8 & 3122 & $8 / 10 / 200823: 22$ & 3.002 & 27.5 \\
\hline 2910 & $0816: 18$ & 2.762 & 30.3 & 2981 & $00818: 40$ & 2.914 & 29.8 & 3052 & $00821: 02$ & 1.509 & 28.8 & 3123 & $00823: 24$ & 3.019 & 27.4 \\
\hline 2911 & $8 / 10 / 2008 \quad 16: 20$ & 2.772 & 30.3 & 2982 & $8 / 10 / 2008 \quad 18: 42$ & 2.917 & 29.8 & 3053 & $8 / 10 / 200821: 04$ & 1.498 & 28.8 & 3124 & $8 / 10 / 200823: 26$ & 2.998 & 27.4 \\
\hline
\end{tabular}




\begin{tabular}{|c|c|c|c|}
\hline \multicolumn{4}{|c|}{ D4-26p } \\
\hline Rec & & Pres & Temp \\
\hline$\#$ & Date/Time & psi & ${ }^{\circ} \mathrm{C}$ \\
\hline 3125 & $8 / 10 / 200823: 28$ & 3.015 & 27.4 \\
\hline 3126 & $8 / 10 / 200823: 30$ & 3.012 & 27.4 \\
\hline 3127 & $8 / 10 / 200823: 32$ & 3.002 & 27.4 \\
\hline 3128 & $8 / 10 / 2008$ 23:34 & 3.019 & $\overline{27.4}$ \\
\hline 3129 & $8 / 10 / 200823: 36$ & 3.029 & 27.4 \\
\hline 3130 & $8 / 10 / 200823: 38$ & 3.005 & 27.4 \\
\hline 3131 & $8 / 10 / 200823: 40$ & 2.998 & 27.4 \\
\hline 3132 & $8 / 10 / 200823: 42$ & 3.002 & 27.4 \\
\hline 3133 & $8 / 10 / 200823: 44$ & 2.998 & 27.3 \\
\hline 3134 & $8 / 10 / 200823: 46$ & 3.008 & 27.3 \\
\hline 3135 & $8 / 10 / 200823: 48$ & 3.002 & 27.3 \\
\hline 3136 & $8 / 10 / 200823: 50$ & 3.001 & 27.3 \\
\hline 3137 & $8 / 10 / 200823: 52$ & 3.001 & 27.3 \\
\hline 3138 & $8 / 10 / 200823: 54$ & 3.001 & 27.2 \\
\hline 3139 & $8 / 10 / 200823: 56$ & 2.193 & 27.2 \\
\hline 3140 & $8 / 10 / 200823: 58$ & 1.739 & 26.4 \\
\hline 3141 & $8 / 11 / 20080: 00$ & 1.641 & 26.1 \\
\hline 3142 & $8 / 11 / 20080: 02$ & 1.587 & 26.1 \\
\hline 3143 & $8 / 11 / 20080: 04$ & 1.56 & 26.1 \\
\hline 3144 & $8 / 11 / 20080: 06$ & 1.543 & 26.2 \\
\hline 3145 & $8 / 11 / 20080: 08$ & 1.533 & 26.4 \\
\hline 3146 & $8 / 11 / 20080: 10$ & 1.591 & 26.6 \\
\hline 3147 & $8 / 11 / 20080: 12$ & 2.865 & 26.3 \\
\hline 3148 & $8 / 11 / 20080: 14$ & 2.94 & 26.3 \\
\hline 3149 & $8 / 11 / 20080: 16$ & 2.943 & 26.4 \\
\hline 3150 & $8 / 11 / 20080: 18$ & 2.936 & 26.4 \\
\hline 3151 & $8 / 11 / 20080: 20$ & 2.96 & 26.3 \\
\hline 3152 & $8 / 11 / 20080: 22$ & 2.933 & 26.3 \\
\hline 3153 & $8 / 11 / 20080: 24$ & 2.943 & 26.3 \\
\hline 3154 & $8 / 11 / 20080: 26$ & 2.94 & 26.3 \\
\hline 3155 & $8 / 11 / 20080: 28$ & 2.943 & 26.3 \\
\hline 3156 & $8 / 11 / 20080: 30$ & 2.957 & 26.3 \\
\hline 3157 & $8 / 11 / 20080: 32$ & 2.95 & 26.3 \\
\hline 3158 & $8 / 11 / 20080: 34$ & 2.95 & 26.3 \\
\hline 3159 & $8 / 11 / 20080: 36$ & 2.95 & 26.3 \\
\hline 3160 & $8 / 11 / 20080: 38$ & 2.947 & 26.3 \\
\hline 3161 & $8 / 11 / 20080: 40$ & 2.96 & 26.6 \\
\hline 3162 & $8 / 11 / 20080: 42$ & 2.964 & 26.8 \\
\hline 3163 & $8 / 11 / 20080: 44$ & 2.974 & 26.8 \\
\hline 3164 & $8 / 11 / 20080: 46$ & 2.981 & 26.8 \\
\hline 3165 & $8 / 11 / 20080: 48$ & 2.974 & 26.4 \\
\hline 3166 & $8 / 11 / 20080: 50$ & 2.987 & 26.3 \\
\hline 3167 & $8 / 11 / 20080: 52$ & 2.97 & 26.2 \\
\hline 3168 & $8 / 11 / 20080: 54$ & 2.98 & 26.2 \\
\hline 3169 & $8 / 11 / 2008 \quad 0: 56$ & 2.97 & 26.2 \\
\hline 3170 & $8 / 11 / 20080: 58$ & 2.974 & 26.2 \\
\hline 3171 & $8 / 11 / 20081: 00$ & 2.977 & 26.2 \\
\hline 3172 & $8 / 11 / 20081: 02$ & 2.977 & 26.2 \\
\hline 3173 & $8 / 11 / 20081: 04$ & 2.977 & 26.1 \\
\hline 3174 & $8 / 11 / 20081: 06$ & 2.994 & 26.2 \\
\hline 3175 & $8 / 11 / 20081: 08$ & 2.987 & 26.1 \\
\hline 3176 & $8 / 11 / 2008 \quad 1: 10$ & 2.994 & 26.1 \\
\hline 3177 & $8 / 11 / 20081: 12$ & 2.994 & 26.1 \\
\hline 3178 & $8 / 11 / 20081: 14$ & 2.997 & 26.1 \\
\hline 3179 & $8 / 11 / 20081: 16$ & 3.004 & 26.1 \\
\hline 3180 & $8 / 11 / 20081: 18$ & 2.99 & 26.1 \\
\hline 3181 & $8 / 11 / 20081: 20$ & 2.987 & 26.1 \\
\hline 3182 & $8 / 11 / 20081: 22$ & 2.994 & 26.1 \\
\hline 3183 & $8 / 11 / 20081: 24$ & 3.001 & 26.1 \\
\hline 3184 & $8 / 11 / 20081: 26$ & 3.011 & 26.1 \\
\hline 3185 & $8 / 11 / 20081: 28$ & 2.997 & 26.1 \\
\hline 3186 & $8 / 11 / 20081: 30$ & 3.004 & 26.1 \\
\hline 3187 & $8 / 11 / 20081: 32$ & 2.987 & 26.1 \\
\hline 3188 & $8 / 11 / 20081: 34$ & 2.994 & 26.1 \\
\hline 3189 & $8 / 11 / 20081: 36$ & 3.017 & 26.1 \\
\hline 3190 & $8 / 11 / 20081: 38$ & 3.014 & 26.1 \\
\hline 3191 & $8 / 11 / 20081: 40$ & 2.997 & 26.1 \\
\hline 3192 & $8 / 11 / 20081: 42$ & 3.011 & 26.1 \\
\hline 3193 & $8 / 11 / 20081: 44$ & 3 & 26.1 \\
\hline 3194 & $8 / 11 / 20081: 46$ & 3.011 & 26.1 \\
\hline 3195 & $8 / 11 / 20081: 48$ & 3.011 & 26.1 \\
\hline
\end{tabular}

\begin{tabular}{|c|c|c|c|}
\hline \multicolumn{4}{|c|}{ D4-26p } \\
\hline $\operatorname{Rec}$ & & Pres & Temp \\
\hline$\#$ & Date/Time & psi & ${ }^{\circ} \mathrm{C}$ \\
\hline 3196 & $8 / 11 / 20081: 50$ & 3.004 & 26.1 \\
\hline 3197 & $8 / 11 / 20081: 52$ & 3.007 & 26 \\
\hline 3198 & $11 / 20081: 54$ & 3.014 & 26.1 \\
\hline 3199 & $8 / 11 / 20081: 56$ & 3.017 & 26.1 \\
\hline 3200 & $8 / 11 / 20081: 58$ & 3.024 & 26 \\
\hline 3201 & $8 / 11 / 20082: 00$ & 3.021 & $\overline{26}$ \\
\hline 3202 & $8 / 11 / 20082: 02$ & 3.021 & 26 \\
\hline 3203 & $0082: 04$ & 3.024 & 26 \\
\hline 3204 & $0082: 06$ & 3.004 & 26 \\
\hline 3205 & $8 / 11 / 20082: 08$ & 2.997 & 26 \\
\hline 3206 & $8 / 11 / 20082: 10$ & 3.007 & 26 \\
\hline 3207 & $0082: 12$ & 3.021 & 26 \\
\hline 3208 & $0082: 14$ & 3.017 & 25.9 \\
\hline 3209 & $8 / 11 / 20082: 16$ & 3.007 & 25.9 \\
\hline 3210 & $20082: 18$ & 3.011 & 25.9 \\
\hline 3211 & $0082: 20$ & 3.004 & \\
\hline 3212 & $082: 22$ & 3.021 & 25.9 \\
\hline 3213 & $082: 24$ & 3 & 25.9 \\
\hline 3214 & $20082: 26$ & 3.007 & 25.9 \\
\hline 3215 & $082: 28$ & 3.021 & 25.9 \\
\hline 3216 & $882: 30$ & 3.01 & 25.9 \\
\hline 3217 & $82: 32$ & 3.021 & 25.9 \\
\hline 3218 & $082: 34$ & 2.994 & 25.9 \\
\hline 3219 & $0082: 36$ & 3.014 & 25.9 \\
\hline 3220 & $382: 38$ & 3.004 & 25.9 \\
\hline 3221 & $82: 40$ & 3.01 & 25.9 \\
\hline 3222 & $82: 42$ & 3.01 & 25.9 \\
\hline 3223 & $282: 44$ & 2.997 & $25 . \overline{8}$ \\
\hline 3224 & $082: 46$ & 3.021 & 25.8 \\
\hline 3225 & $082: 48$ & 3.004 & 25.8 \\
\hline 3226 & $82: 50$ & 2.3 & 25.8 \\
\hline 3227 & $82: 52$ & 1.867 & 25.2 \\
\hline 3228 & $82: 54$ & 1.694 & 24.8 \\
\hline 3229 & $82: 56$ & 1.62 & 24.8 \\
\hline 3230 & $82: 58$ & 1.579 & 24.8 \\
\hline 3231 & & 2.963 & 24. \\
\hline 3232 & $3: 02$ & 3.017 & 25.5 \\
\hline 3233 & 83:04 & 3.014 & 25.6 \\
\hline 3234 & $83: 06$ & 3.004 & 25.7 \\
\hline 3235 & & & \\
\hline 3236 & & 2.9 & 5.7 \\
\hline 3237 & $3: 12$ & 2.983 & 25.7 \\
\hline 3238 & $3: 14$ & 2.99 & 25.7 \\
\hline 3239 & $3: 16$ & 2.993 & 25.7 \\
\hline 3240 & $3: 18$ & & 25.7 \\
\hline 3241 & & 2.9 & 25.7 \\
\hline 3242 & $3: 22$ & 2.9 & 25.7 \\
\hline 3243 & $3: 24$ & 2.993 & 25.6 \\
\hline 3244 & & 2.993 & 25.6 \\
\hline 3245 & $3: 28$ & 2.98 & 25.6 \\
\hline 3246 & & & 25.6 \\
\hline 3247 & & 2.997 & 25.6 \\
\hline 3248 & & 3.01 & 25.6 \\
\hline 3249 & & & 25.6 \\
\hline 3250 & & 3.004 & 25.6 \\
\hline 3251 & & 3.02 & 25.6 \\
\hline 3252 & & 3.024 & 25.6 \\
\hline 3253 & $3: 44$ & 3.004 & 25.6 \\
\hline 3254 & $3: 46$ & 3.01 & 25.6 \\
\hline 3255 & $183: 48$ & 3.017 & 25.6 \\
\hline 3256 & $83: 50$ & 3.024 & 25.6 \\
\hline 3257 & $83: 52$ & 3.017 & 25. \\
\hline 3258 & & 3.017 & 25.6 \\
\hline 3259 & $83: 56$ & & 25.6 \\
\hline 3260 & $083: 58$ & 3.031 & 25.6 \\
\hline 3261 & $084: 00$ & 3.02 & 25.6 \\
\hline & $084: 02$ & 3.024 & 25.7 \\
\hline 3263 & $084: 04$ & 3.024 & 25.7 \\
\hline 3264 & $0 \overline{084: 06}$ & 3.037 & 25.6 \\
\hline 3265 & $0084: 08$ & 3.017 & 25.6 \\
\hline 3266 & $8 / 11 / 20084: 10$ & 3.041 & 25. \\
\hline
\end{tabular}

\begin{tabular}{|c|c|c|c|}
\hline \multicolumn{4}{|c|}{ D4-26p } \\
\hline $\operatorname{Rec}$ & & Pres & Temp \\
\hline$\#$ & Date/Time & psi & ${ }^{\circ} \mathrm{C}$ \\
\hline 3267 & $8 / 11 / 20084: 12$ & 3.024 & 25.6 \\
\hline 3268 & $8 / 11 / 20084: 14$ & 3.031 & 25.5 \\
\hline 3269 & $8 / 11 / 20084: 16$ & 3.024 & $\overline{25.5}$ \\
\hline 3270 & $8 / 11 / 20084: 18$ & 3.024 & 25.5 \\
\hline 3271 & $8 / 11 / 20084: 20$ & 3.024 & 25.5 \\
\hline 3272 & $8 / 11 / 20084: 22$ & 3.02 & 25.5 \\
\hline 3273 & $8 / 11 / 20084: 24$ & 3.014 & 25.5 \\
\hline 3274 & $8 / 11 / 20084: 26$ & 3.027 & 25.5 \\
\hline 3275 & $8 / 11 / 20084: 28$ & 3.02 & 25.5 \\
\hline 3276 & $8 / 11 / 20084: 30$ & 3.024 & 25.5 \\
\hline 3277 & $8 / 11 / 20084: 32$ & 3.02 & 25.5 \\
\hline 3278 & $8 / 11 / 20084: 34$ & 3.02 & 25.5 \\
\hline 3279 & $8 / 11 / 20084: 36$ & 3.024 & 25.4 \\
\hline 3280 & $8 / 11 / 20084: 38$ & 3.024 & 25.4 \\
\hline 3281 & $8 / 11 / 20084: 40$ & 3.027 & 25.4 \\
\hline 3282 & $8 / 11 / 20084: 42$ & 3.024 & 25.4 \\
\hline 3283 & $8 / 11 / 20084: 44$ & 3.017 & 25.4 \\
\hline 3284 & $8 / 11 / 20084: 46$ & 3.027 & 25.4 \\
\hline 3285 & $8 / 11 / 20084: 48$ & 3.024 & 25.4 \\
\hline 3286 & $8 / 11 / 20084: 50$ & $3.0 \overline{24}$ & 25.4 \\
\hline 3287 & $8 / 11 / 20084: 52$ & 3.034 & 25.4 \\
\hline 3288 & $8 / 11 / 20084: 54$ & 3.03 & 25.4 \\
\hline 3289 & $8 / 11 / 20084: 56$ & 3.034 & 25.4 \\
\hline 3290 & $8 / 11 / 20084: 58$ & 3.044 & 25.4 \\
\hline 3291 & $8 / 11 / 20085: 00$ & 3.037 & 25.4 \\
\hline 3292 & $8 / 11 / 20085: 02$ & 3.024 & 25.4 \\
\hline 3293 & $8 / 11 / 20085: 04$ & 3.02 & $25 . \overline{4}$ \\
\hline 3294 & $8 / 11 / 20085: 06$ & 3.02 & 25.4 \\
\hline 3295 & $8 / 11 / 20085: 08$ & 3.017 & 25.4 \\
\hline 3296 & $8 / 11 / 20085: 10$ & 3.027 & 25.3 \\
\hline 3297 & $8 / 11 / 20085: 12$ & 3.03 & 25.4 \\
\hline 3298 & $8 / 11 / 20085: 14$ & 3.027 & 25.3 \\
\hline 3299 & $8 / 11 / 20085: 16$ & 3.017 & 25.3 \\
\hline 3300 & $8 / 11 / 20085: 18$ & 3.027 & 25.3 \\
\hline 3301 & $8 / 11 / 20085: 20$ & 3.024 & 25.3 \\
\hline 3302 & $8 / 11 / 20085: 22$ & 3.02 & 25.3 \\
\hline 3303 & $8 / 11 / 20085: 24$ & 3.01 & 25.3 \\
\hline 3304 & $8 / 11 / 20085: 26$ & 3.017 & 25.3 \\
\hline 3305 & $8 / 11 / 20085: 28$ & 3.02 & 25.3 \\
\hline 3306 & $8 / 11 / 20085: 30$ & 3.017 & 25.2 \\
\hline 3307 & $8 / 11 / 20085: 32$ & 3.02 & 25.2 \\
\hline 3308 & $8 / 11 / 20085: 34$ & 2.77 & 25.1 \\
\hline 3309 & $8 / 11 / 20085: 36$ & 1.762 & 24.7 \\
\hline 3310 & $8 / 11 / 20085: 38$ & 1.694 & 24.8 \\
\hline 3311 & $8 / 11 / 20085: 40$ & 1.664 & 24.8 \\
\hline 3312 & $8 / 11 / 20085: 42$ & 1.644 & 24.7 \\
\hline 3313 & $8 / 11 / 20085: 44$ & 1.62 & 24.8 \\
\hline 3314 & $8 / 11 / 20085: 46$ & 1.573 & 24.8 \\
\hline 3315 & $8 / 11 / 20085: 48$ & 1.525 & 24.9 \\
\hline 3316 & $8 / 11 / 20085: 50$ & 1.532 & 24.9 \\
\hline 3317 & $8 / 11 / 20085: 52$ & 1.535 & 24.9 \\
\hline 3318 & $8 / 11 / 20085: 54$ & 1.563 & 25.1 \\
\hline 3319 & $8 / 11 / 20085: 56$ & 2.831 & 24.9 \\
\hline 3320 & $8 / 11 / 20085: 58$ & 2.932 & 25.1 \\
\hline 3321 & $8 / 11 / 20086: 00$ & 2.949 & 25.2 \\
\hline 3322 & $8 / 11 / 20086: 02$ & 2.953 & 25.3 \\
\hline 3323 & $8 / 11 / 20086: 04$ & 2.942 & 25.3 \\
\hline 3324 & $8 / 11 / 20086: 06$ & 2.956 & 25.3 \\
\hline 3325 & $8 / 11 / 20086: 08$ & 2.956 & 25.3 \\
\hline 3326 & $8 / 11 / 20086: 10$ & 2.953 & 25.3 \\
\hline 3327 & $8 / 11 / 20086: 12$ & 2.949 & 25.3 \\
\hline 3328 & $8 / 11 / 20086: 14$ & 2.966 & 25.3 \\
\hline 3329 & $8 / 11 / 20086: 16$ & 2.966 & 25.3 \\
\hline 3330 & $8 / 11 / 20086: 18$ & 2.959 & 25.3 \\
\hline 3331 & $8 / 11 / 20086: 20$ & 2.966 & 25.3 \\
\hline 3332 & $8 / 11 / 20086: 22$ & 2.986 & 25.3 \\
\hline 3333 & $8 / 11 / 20086: 24$ & 2.973 & 25.3 \\
\hline 3334 & $8 / 1 \uparrow / 20086: 26$ & 2.986 & 25.3 \\
\hline 3335 & $8 / 11 / 20086: 28$ & 3 & 25.3 \\
\hline 3336 & $8 / 11 / 20086: 30$ & 2.99 & 25.3 \\
\hline 3337 & $8 / 11 / 20086: 32$ & 2.983 & 25.3 \\
\hline
\end{tabular}

\begin{tabular}{|c|c|c|c|}
\hline \multicolumn{4}{|c|}{ D4-26p } \\
\hline & & & \\
\hline$\#$ & $\begin{array}{l}\text { Date/Time } \\
\end{array}$ & $\mathrm{psi}$ & \\
\hline & $\frac{8 / 111 / 20086: 34}{8 / 11 / 20086 \cdot 3}$ & & $\frac{25.5}{25.3}$ \\
\hline & $8 / 11 / 20086: 38$ & & \\
\hline & $20086: 40$ & $\overline{3.02}$ & 25. \\
\hline & 1/2008 6:42 & 3.01 & \\
\hline 3343 & $11 / 200$ & & \\
\hline 344 & & & \\
\hline & & & \\
\hline & & & \\
\hline & $11 / 20086: 52$ & 3.014 & \\
\hline & $\frac{1 / 20086: 54}{}$ & 3.024 & \\
\hline 49 & 11/2008 6:56 & 3.024 & \\
\hline & $11 / 20086:$ & 3.054 & \\
\hline 51 & $1 / 20$ & 3.057 & 25. \\
\hline & $11 / 2008$ & & \\
\hline & $11 / 20$ & 3.051 & \\
\hline & $8 / 11 / 20$ & & \\
\hline & $8 / 11 / 20087: 08$ & & \\
\hline & $8 / 11 / 20087: 10$ & & \\
\hline & $8 / 11 / 20087: 12$ & & \\
\hline 58 & $11 / 20087: 14$ & 3.058 & \\
\hline & $1 / 2008$ & 3.051 & \\
\hline & $1 / 200$ & $\overline{3.034}$ & \\
\hline & 11/2008 & 3.047 & \\
\hline & & 3.058 & \\
\hline & & & \\
\hline 664 & & & \\
\hline 65 & $8 / 11 / 2$ & 3.074 & \\
\hline 66 & $8 / 11 / 20$ & 3.064 & \\
\hline & $8 / 11 / 20$ & & \\
\hline & $8 / 11 / 20087: 34$ & 3.064 & 25. \\
\hline & $8 / 11 / 20087: 36$ & 3.058 & 25. \\
\hline & $11 / 200$ & 3.061 & \\
\hline & $\overline{1 / 26}$ & 3.058 & \\
\hline & & & 25. \\
\hline & & .061 & \\
\hline & & 3.051 & \\
\hline & & 3.074 & \\
\hline & & 3.0 & \\
\hline & & 3.0 & \\
\hline & & 3.098 & \\
\hline & $1 / 11$ & 3.091 & \\
\hline & $8 / 11 / 2008$ & 3.088 & 25. \\
\hline & $8 / 11 / 20$ & 3.09 & 25. \\
\hline & $\overline{11 / 2}$ & 3.1 & \\
\hline & & & \\
\hline & & \begin{tabular}{|c|}
3.098 \\
\end{tabular} & \\
\hline & & .095 & \\
\hline & & & \\
\hline & & & \\
\hline & & & \\
\hline & & & \\
\hline & & 3.11 & \\
\hline & & & \\
\hline & & & \\
\hline & & 3.0 & \\
\hline & & 3.0 & \\
\hline & & & \\
\hline & & 3.0 & \\
\hline & & & 25 \\
\hline & & & \\
\hline & & & \\
\hline & & & \\
\hline & & $A$ & \\
\hline & & & \\
\hline & 11 & 38.8 & \\
\hline & & 30 & \\
\hline & & $\overline{3.0}$ & \\
\hline & & 3.0 & \\
\hline & & 3.06 & \\
\hline & & & \\
\hline
\end{tabular}


DOE/RL-2009-35, REV. 0
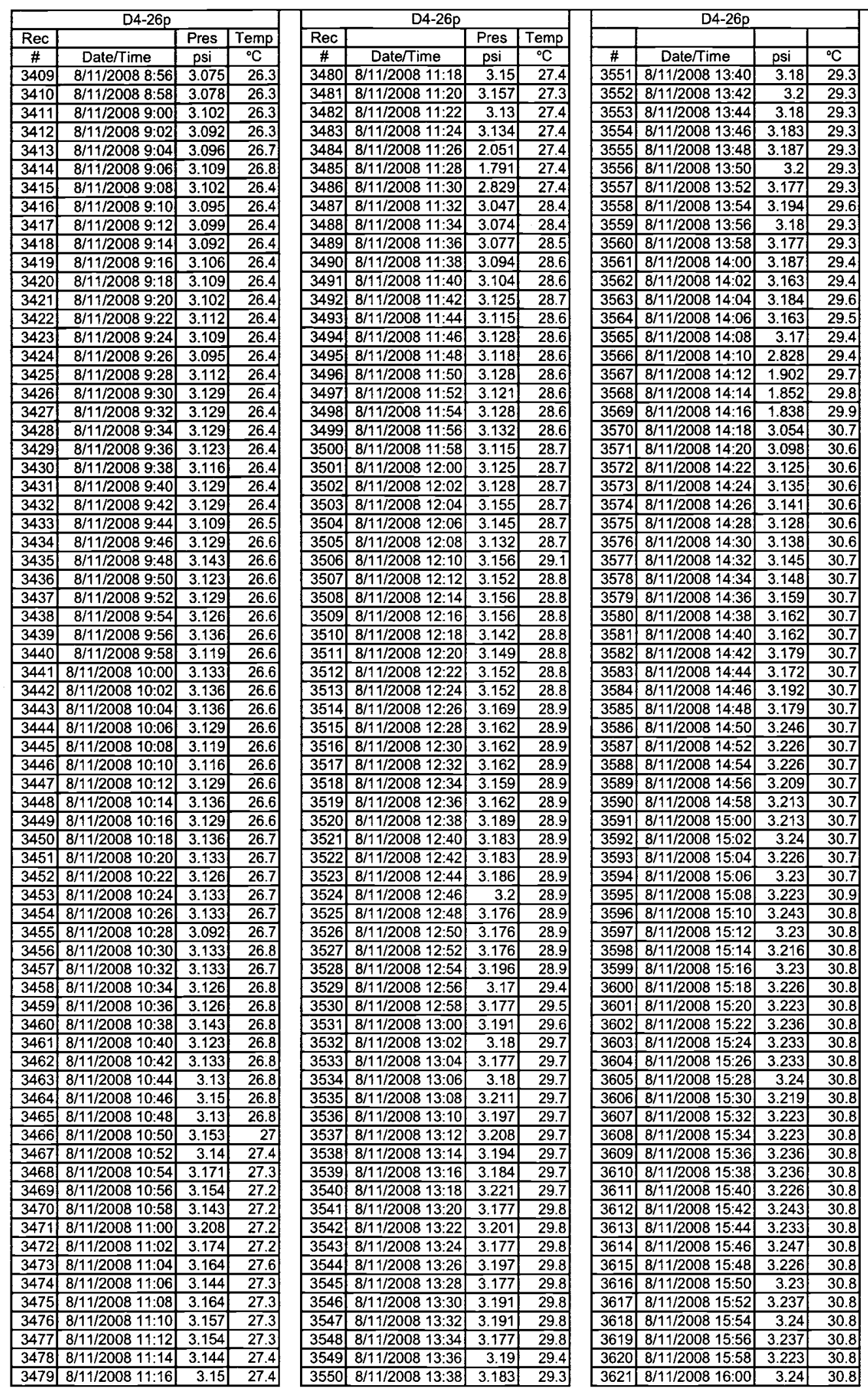

\begin{tabular}{|c|c|c|c|}
\hline \multicolumn{4}{|c|}{ D4-26p } \\
\hline Rec & & Pres & Temp \\
\hline & Date/Time & psi & \\
\hline & $11 / 2008$ 16: & & \\
\hline & $1 / 200816$ & & \\
\hline & S/11/2008 16:C & & \\
\hline & 8/11/2008 16:0 & 3.2 & 30. \\
\hline 3626 & $8 / 11 / 200816: 10$ & 3.23 & 30. \\
\hline & $8 / 11 / 2008$ 16:12 & & \\
\hline & 8/11/2008 16:14 & & \\
\hline & 11/2008 & & 30.5 \\
\hline & & & 30. \\
\hline & 11200816 & & \\
\hline & & & \\
\hline & $8 / 11 / 2008$ 16:2 & & \\
\hline & $8 / 11 / 200816: 2$ & 3.22 & \\
\hline & $8 / 11 / 2008$ 16:2 & & \\
\hline & 11/2008 16: & & \\
\hline & $8 / 11 / 2008$ 16:3 & 3.22 & 30. \\
\hline & $111 / 2008$ 16:34 & 3.237 & 30. \\
\hline & $8 / 11 / 2008$ 16:3 & 3.248 & 31. \\
\hline & $8 / 11 / 200816: 3$ & & 31. \\
\hline & $8 / 11 / 200816: 40$ & 3.316 & 31. \\
\hline & $8 / 11 / 2008$ 16:42 & 3.343 & 31. \\
\hline & $8 / 11 / 200816: 44$ & 3.333 & \\
\hline & $8 / 11 / 2008$ 16:46 & 3.337 & $31.8 \mathrm{~s}-\mathrm{s}$ \\
\hline & $8 / 11 / 200816: 48$ & 3.35 & \\
\hline & $8 / 11 / 2008$ 16:50 & & 31.8 \\
\hline & $8 / 11 / 200816: 52$ & & 31.8 \\
\hline 3648 & $8 / 11 / 200816: 54$ & 3.306 & 31.8 \\
\hline 3649 & 8/11/2008 16:5 & 2.789 & 31. \\
\hline & 8/11/2008 16: & 2.025 & 32. \\
\hline & $8817:$ & 1.87 & \\
\hline & 1/2008 17: & 3.391 & 31. \\
\hline & $8 / 11 / 200817: 04$ & 3.355 & \\
\hline & $8 / 11 / 200$ & & 30.1 \\
\hline & $8 / 11 / 20$ & 378 & 30. \\
\hline & 2008 17: & & \\
\hline & 200817 & 3.371 & \\
\hline & 17 & & \\
\hline & $17>>>$ & 3.364 & \\
\hline 3660 & 11 & 3.347 & \\
\hline & $8 / 1$ & & \\
\hline & $8 / 1$ & 3.361 & 30. \\
\hline 3663 & $\begin{array}{lll}8817: 24 & \\
\end{array}$ & 3.364 & 30. \\
\hline & $8 / 1$ & 3.341 & 30. \\
\hline & & 3.354 & \\
\hline 3666 & & 3.341 & 30. \\
\hline & & 3.334 & \\
\hline 3668 & $8 / 1$ & 3.341 & 30. \\
\hline 3669 & $8 / 11 / 20081$ & 3.347 & 30. \\
\hline & $8 / 11$ & 3.331 & 30. \\
\hline & & 3.344 & \\
\hline & & & \\
\hline & & & \\
\hline & & & \\
\hline & & & 30. \\
\hline & 120 & & 30. \\
\hline & $8 / 11 / 200$ & 35 & 30. \\
\hline & $8 / 11 / 20$ & & 30. \\
\hline & $8 / 1$ & 3.351 & 30. \\
\hline & & & \\
\hline & & 3.331 & \\
\hline 3682 & & 3.344 & 30. \\
\hline 88 & $8 / 17-2=$ & 3.331 & 30. \\
\hline & & & 30. \\
\hline & 18 & 348 & 30. \\
\hline & & & \\
\hline & & 344 & \\
\hline & 8:14 & 3.344 & 30. \\
\hline & 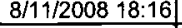 & 3.341 & 30 \\
\hline 3690 & 8/11/2008 18:18 & 3.324 & 30.6 \\
\hline & & & \\
\hline
\end{tabular}




\begin{tabular}{|c|c|c|c|}
\hline \multicolumn{4}{|c|}{ D4-26p } \\
\hline Rec & & Pres & Temp \\
\hline$\#$ & Date/Time & psi & ${ }^{\circ} \mathrm{C}$ \\
\hline 3691 & $8 / 11 / 200818: 20$ & 3.338 & 30.6 \\
\hline 3692 & $8 / 11 / 200818: 22$ & 3.317 & 30.6 \\
\hline 3693 & $8 / 11 / 200818: 24$ & 3.334 & 30.6 \\
\hline 3694 & $8 / 11 / 200818: 26$ & 3.327 & 30.6 \\
\hline 3695 & $8 / 11 / 200818: 28$ & 3.317 & 30.6 \\
\hline 3696 & $8 / 11 / 2008$ 18:30 & 3.324 & 30.6 \\
\hline 3697 & $8 / 11 / 200818: 32$ & 3.341 & 30.6 \\
\hline 3698 & $8 / 11 / 200818: \overline{34}$ & 3.331 & 30.6 \\
\hline 3699 & $8 / 11 / 200818: 36$ & 3.341 & 30.6 \\
\hline 3700 & $8 / 11 / 200818: 38$ & 3.307 & 30.6 \\
\hline 3701 & $8 / 11 / 200818: 40$ & 3.321 & 30.6 \\
\hline 3702 & $8 / 11 / 200818: 42$ & 3.311 & 30.6 \\
\hline 3703 & $8 / 11 / 2008$ 18:44 & 3.327 & 30.6 \\
\hline 3704 & $8 / 11 / 200818: 46$ & 3.331 & 30.9 \\
\hline 3705 & $8 / 11 / 200818: 48$ & 3.324 & 30.8 \\
\hline 3706 & $8 / 11 / 200818: 50$ & 3.317 & 30.7 \\
\hline 3707 & $8 / 11 / 200818: 52$ & 3.307 & 30.7 \\
\hline 3708 & $8 / 11 / 200818: 54$ & 3.314 & 30.7 \\
\hline 3709 & $8 / 11 / 200818: 56$ & 3.314 & 30.6 \\
\hline 3710 & $8 / 11 / 200818: 58$ & 3.317 & 30.7 \\
\hline 3711 & $8 / 11 / 200819: 00$ & 3.321 & 30.7 \\
\hline 3712 & $8 / 11 / 200819: 02$ & 3.314 & 30.7 \\
\hline 3713 & $8 / 11 / 200819: 04$ & 3.328 & 30.9 \\
\hline 3714 & $8 / 11 / 200819: 06$ & 3.365 & 30.8 \\
\hline 3715 & $8 / 11 / 200819: 08$ & 3.369 & 31.2 \\
\hline 3716 & $8 / 11 / 200819: 10$ & 3.375 & 30.9 \\
\hline 3717 & $8 / 11 / 2008$ 19:12 & 3.389 & 30.8 \\
\hline 3718 & $8 / 11 / 200819: 14$ & 3.372 & 30.8 \\
\hline 3719 & $8 / 11 / 200819: 16$ & 3.395 & 30.8 \\
\hline 3720 & $8 / 11 / 200819: 18$ & 3.379 & 30.8 \\
\hline 3721 & $8 / 11 / 200819: 20$ & 3.382 & 30.8 \\
\hline 3722 & $8 / 11 / 200819: 22$ & 3.389 & 30.8 \\
\hline 3723 & $8 / 11 / 200819: 24$ & 3.382 & 30.8 \\
\hline 3724 & $8 / 11 / 200819: 26$ & 3.368 & 30.8 \\
\hline 3725 & $8 / 11 / 200819: 28$ & 3.375 & 30.8 \\
\hline 3726 & $8 / 11 / 200819: 30$ & 3.334 & 30.8 \\
\hline 3727 & $8 / 11 / 200819: 32$ & 3.368 & 30.8 \\
\hline 3728 & $8 / 11 / 200819: 34$ & 3.358 & 30.8 \\
\hline 3729 & $8 / 11 / 200819: 36$ & 3.362 & 30.8 \\
\hline 3730 & $8 / 11 / 200819: 38$ & 3.338 & 30.8 \\
\hline 3731 & $8 / 11 / 200819: 40$ & 3.315 & 31 \\
\hline 3732 & $8 / 11 / 200819: 42$ & 2.656 & 31.2 \\
\hline 3733 & $8 / 11 / 2008$ 19:44 & 2.723 & 31 \\
\hline 3734 & $8 / 11 / 200819: 46$ & 1.911 & 30.9 \\
\hline 3735 & $8 / 11 / 200819: 48$ & 1.789 & 30.9 \\
\hline 3736 & $8 / 11 / 200819: 50$ & 1.718 & 30.9 \\
\hline 3737 & $8 / 11 / 200819: 52$ & 1.664 & 30.8 \\
\hline 3738 & $8 / 11 / 200819.54$ & 3.591 & 30.6 \\
\hline 3739 & $8 / 11 / 200819: 56$ & 3.443 & 29 \\
\hline 3740 & $8 / 11 / 200819: 58$ & 3.392 & 28.6 \\
\hline 3741 & $8 / 11 / 200820: 00$ & 3.413 & 28.9 \\
\hline 3742 & $8 / 11 / 200820: 02$ & 3.413 & 29.2 \\
\hline 3743 & $8 / 11 / 200820: 04$ & 3.413 & 29.3 \\
\hline 3744 & $8 / 11 / 200820: 06$ & 3.406 & 29.3 \\
\hline 3745 & $8 / 11 / 200820: 08$ & 3.396 & 29.3 \\
\hline 3746 & $8 / 11 / 200820: 10$ & 3.383 & 29.3 \\
\hline 3747 & $8 / 11 / 200820: 12$ & 3.393 & 29.3 \\
\hline 3748 & $8 / 11 / 200820: 14$ & 3.383 & 29.3 \\
\hline 3749 & $8 / 11 / 200820: 16$ & 3.389 & 29.3 \\
\hline 3750 & $8 / 11 / 200820: 18$ & 3.389 & 29.3 \\
\hline 3751 & $8 / 11 / 200820: 20$ & 3.376 & 29.3 \\
\hline 3752 & $8 / 11 / 200820: 22$ & 3.376 & 29.3 \\
\hline 3753 & $8 / 11 / 200820: 24$ & 3.389 & 29.3 \\
\hline 3754 & $8 / 11 / 200820: 26$ & 3.39 & 29.6 \\
\hline 3755 & $8 / 11 / 200820: 28$ & 3.396 & 29.3 \\
\hline 3756 & $8 / 11 / 200820: 30$ & 3.4 & 29.3 \\
\hline 3757 & $8 / 11 / 200820: 32$ & 3.393 & 29.3 \\
\hline 3758 & $8 / 11 / 200820: 34$ & 3.393 & 29.3 \\
\hline 3759 & $8 / 11 / 200820: 36$ & 3.393 & 29.3 \\
\hline
\end{tabular}

\begin{tabular}{|c|c|c|c|}
\hline \multicolumn{4}{|c|}{ D4-26p } \\
\hline $\operatorname{Rec}$ & & Pres & Temp \\
\hline$\#$ & Date/Time & psi & ${ }^{\circ} \mathrm{C}$ \\
\hline 3760 & $8 / 11 / 2008 \quad 20: 38$ & 3.39 & 29. \\
\hline 761 & $8 / 11 / 200820: 40$ & 3.393 & \\
\hline 3762 & $8 / 11 / 2008$ 20:42 & 3.4 & 29 \\
\hline 3763 & $8 / 11 / 200820: 44$ & & 29 \\
\hline 3764 & $8 / 11 / 200820: 46$ & $3 . \overline{383}$ & \\
\hline 3765 & $8 / 11 / 200820: 48$ & 3.393 & \\
\hline 3766 & $8 / 11 / 200820: 50$ & 3.379 & \\
\hline 3767 & $8 / 11 / 200820: 52$ & 3.387 & \\
\hline 3768 & $8 / 11 / 200820: 54$ & 3.393 & 29.3 \\
\hline 3769 & $8 / 11 / 200820: 56$ & 3.379 & \\
\hline 3770 & $8 / 11 / 200820: 58$ & 3.383 & 29 . \\
\hline 3771 & $8 / 11 / 200821: 00$ & 3.403 & 29.2 \\
\hline 3772 & $8 / 11 / 200821: 02$ & 3.383 & \\
\hline 3773 & $8 / 11 / 200821: 04$ & 3.383 & 29.2 \\
\hline 3774 & $8 / 11 / 200821: 06$ & 3.386 & 29.2 \\
\hline 3775 & $8 / 11 / 200821: 08$ & 3.369 & \\
\hline 3776 & $8 / 11 / 200821: 10$ & 3.386 & 29.2 \\
\hline 3777 & $8 / 11 / 200821: 12$ & 3.393 & \\
\hline 3778 & $11 / 200821: 14$ & 3.393 & \\
\hline 3779 & 11/2008 21:16 & 3.389 & 29. \\
\hline 3780 & $8 / 11 / 200821: 18$ & 3.379 & \\
\hline 3781 & $8 / 11 / 200821: 20$ & 3.383 & 29. \\
\hline 3782 & $821: 22$ & 3.376 & 29. \\
\hline 3783 & $8 / 11 / 200821: 24$ & 3.386 & \\
\hline 3784 & $8 / 11 / 200821: 26$ & 3.386 & 29.1 \\
\hline 3785 & $8 / 11 / 200821: 28$ & 3.376 & \\
\hline 3786 & $8 / 11 / 200821: 30$ & 3.389 & 29. \\
\hline 3787 & $3821: 32$ & 3.389 & 29.1 \\
\hline 3788 & $11 / 200821: 34$ & 3.369 & 29. \\
\hline 3789 & $8 / 11 / 200821: 36$ & 3.359 & 29.1 \\
\hline 3790 & $321: 38$ & 3.376 & 29. \\
\hline 3791 & $821: 40$ & 3.362 & 29. \\
\hline 3792 & $821: 42$ & 3.382 & 29.1 \\
\hline 3793 & $821: 44$ & 3.376 & 29. \\
\hline 3794 & $821: 46$ & 3.372 & 29. \\
\hline 3795 & $821: 48$ & 3.379 & 2 \\
\hline 3796 & $21: 50$ & 3.359 & \\
\hline 3797 & $321: 52$ & 3.369 & \\
\hline 3798 & $821: 54$ & 3.386 & \\
\hline 3799 & $821: 56$ & 3.382 & \\
\hline 3800 & $21: 58$ & 3.369 & 2 \\
\hline 3801 & 22:00 & 3.376 & \\
\hline 3802 & $22: 02$ & $\overline{3.362}$ & $\overline{2}$ \\
\hline 3803 & $22: 04$ & 3.355 & \\
\hline 3804 & $822: 06$ & 3.355 & \\
\hline 3805 & $22: 08$ & 3.342 & \\
\hline 3806 & 32:10 & 3.345 & 28. \\
\hline 3807 & & & 28. \\
\hline 3808 & $22: 14$ & 3.355 & 28. \\
\hline 3809 & $322: 16$ & 3.345 & 28. \\
\hline 3810 & $22: 18$ & 3.348 & 28. \\
\hline 3811 & 322:20 & 3.348 & 28. \\
\hline 3812 & & $\overline{3.3}$ & 28. \\
\hline 3813 & $22: 24$ & 3.355 & 28. \\
\hline 3814 & $322: 26$ & 3.348 & 28 \\
\hline 3815 & $232 \cdot 28$ & 3.342 & \\
\hline 3816 & $322: 30$ & 3.325 & 28. \\
\hline 3817 & $322: 32$ & 3.325 & 28. \\
\hline 3818 & $22: 34$ & 3.338 & \\
\hline 3819 & $822: 36$ & 3.034 & 28. \\
\hline 3820 & $822: 38$ & & 28. \\
\hline 3821 & $822: 40$ & 2.594 & 28. \\
\hline 3822 & $822: 42$ & 2.692 & 28. \\
\hline 3823 & & 2.739 & \\
\hline 3824 & $8 / 11 / 200822: 46$ & 2.475 & 28. \\
\hline 3825 & $11 / 200822: 48$ & 2.306 & 28. \\
\hline 3826 & $11 / 200822: 50$ & 2.059 & \\
\hline 3827 & \begin{tabular}{|l|}
$8 / 11 / 200822: 52$ \\
\end{tabular} & 1.937 & 28. \\
\hline 3828 & $8 / 11 / 200822: 54$ & 1.846 & \\
\hline
\end{tabular}

\begin{tabular}{|c|c|c|c|}
\hline \multicolumn{4}{|c|}{ D4-26p } \\
\hline $\operatorname{Rec}$ & & Pres & Temp \\
\hline$\#$ & Date/Time & psi & ${ }^{\circ} \mathrm{C}$ \\
\hline 3829 & $8 / 11 / 200822: 56$ & 1.768 & 28.4 \\
\hline 830 & $8 / 11 / 200822: 58$ & 1.704 & 28.4 \\
\hline 331 & $8 / 11 / 200823: 00$ & 1.647 & 28.4 \\
\hline 832 & $8 / 11 / 200823: 02$ & 3.551 & 28.4 \\
\hline & $8 / 11 / 200823: 04$ & 3.499 & 27.8 \\
\hline 3834 & $8 / 11 / 200823: 06$ & 3.438 & 27.8 \\
\hline 3835 & $8 / 11 / 200823: 08$ & 3.418 & 27.6 \\
\hline 3836 & $/ 111 / 200823: 10$ & 3.414 & 27.5 \\
\hline 3837 & $8 / 11 / 200823: 12$ & 3.377 & 27.8 \\
\hline 3838 & $/ 111 / 200823: 14$ & 3.37 & 27.4 \\
\hline 3839 & $8 / 11 / 200823: 16$ & 3.364 & 27.4 \\
\hline 3840 & $8 / 11 / 200823: 18$ & 3.367 & 27.4 \\
\hline 3841 & $8 / 11 / 200823: 20$ & 3.353 & \\
\hline 3842 & $8 / 11 / 200823: 22$ & 3.347 & 27.4 \\
\hline 3843 & $11 / 200823: 24$ & 3.343 & 27.4 \\
\hline 3844 & $11 / 200823: 26$ & 3.353 & \\
\hline 3845 & $8 / 11 / 200823: 28$ & 3.353 & 27.4 \\
\hline 3846 & $323: 30$ & 3.343 & 27.4 \\
\hline 3847 & $823: 32$ & 3.336 & 27.4 \\
\hline 3848 & $11 / 200823: 34$ & 3.35 & 27.4 \\
\hline 3849 & $323: 36$ & 3.33 & 27.4 \\
\hline 3850 & $8 / 11 / 200823: 38$ & 3.343 & 27.4 \\
\hline 3851 & $823: 40$ & 3.347 & 27.4 \\
\hline 3852 & $823: 42$ & 3.347 & 27.4 \\
\hline 3853 & $11 / 200823: 44$ & 3.343 & 27.4 \\
\hline 3854 & $323: 46$ & 3.34 & 27.8 \\
\hline 3855 & $8 / 11 / 200823: 48$ & 3.34 & 27.4 \\
\hline 3856 & $823: 50$ & 3.336 & 27.4 \\
\hline 3857 & $8 / 11 / 200823: 52$ & 3.347 & 27.4 \\
\hline 3858 & $11 / 200823: 54$ & 3.36 & 27.3 \\
\hline 3859 & $823: 56$ & 3.343 & 27.3 \\
\hline 3860 & $0823: 58$ & 3.357 & 27.3 \\
\hline 3861 & $080: 00$ & 3.357 & 27. \\
\hline 3862 & $80: 02$ & 3.35 & 27.3 \\
\hline 3863 & $8 / 12 / 20080: 04$ & 3.357 & 27.3 \\
\hline 3864 & $0: 06$ & 3.34 & 27.3 \\
\hline 3865 & & 3.404 & 27. \\
\hline 3866 & & 3.35 & 27.3 \\
\hline 3867 & $0: 12$ & 3.3 & 27. \\
\hline 368 & & 3.407 & 27.3 \\
\hline 3869 & 0:16 & 3.343 & 27 \\
\hline 3870 & & 3.36 & 27. \\
\hline 3871 & & 3.353 & 27.3 \\
\hline 3872 & & 3.353 & 27 \\
\hline 3873 & & 3.343 & 27. \\
\hline 3874 & & 3.34 & 27. \\
\hline 3875 & & 3.343 & 27. \\
\hline 76 & & & 27.3 \\
\hline 3877 & 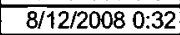 & & 27. \\
\hline 3878 & & 3.357 & 27.3 \\
\hline 3879 & & 3.343 & 27. \\
\hline 3880 & 38 & 3.3 & 27. \\
\hline 3881 & & 3.346 & 27. \\
\hline 3882 & & & \\
\hline 3883 & & 3.343 & 27 . \\
\hline 3884 & & 3.346 & 27. \\
\hline 3885 & & 3.34 & \\
\hline 3886 & & & 27.3 \\
\hline 3887 & & & \\
\hline 3888 & $080: 54$ & 3.346 & 27.2 \\
\hline 3889 & & 3.353 & 27. \\
\hline 3890 & & 3.346 & \\
\hline 3891 & & 3.346 & 27. \\
\hline 3892 & & & \\
\hline 3893 & $081: 04$ & 3.34 & 27.2 \\
\hline 3894 & $81: 06$ & 3.346 & 27.2 \\
\hline 3895 & & 3.343 & \\
\hline 3896 & $081: 10$ & 3.34 & 21 \\
\hline 3897 & & 3.333 & 27. \\
\hline
\end{tabular}

\begin{tabular}{|c|c|c|c|}
\hline \multicolumn{4}{|c|}{ D4-26p } \\
\hline$\overline{R e c}$ & & Pres & Temp \\
\hline$\#$ & Date/Time & psi & ${ }^{\circ} \mathrm{C}$ \\
\hline 3898 & $8 / 12 / 2008$ 1:14 & 3.336 & 27.2 \\
\hline 3899 & $8 / 12 / 20081: 16$ & 3.333 & 27.1 \\
\hline 3900 & $8 / 12 / 2008$ 1:18 & 3.319 & 27.1 \\
\hline 3901 & $8 / 12 / 20081: 20$ & 3.306 & 27.1 \\
\hline 3902 & $8 / 12 / 20081: 22$ & 3.313 & 27.1 \\
\hline 3903 & $8 / 12 / 20081: 24$ & 3.329 & 27.1 \\
\hline 3904 & $8 / 12 / 20081: 26$ & 3.316 & 27.1 \\
\hline 3905 & $8 / 12 / 20081: 28$ & 3.326 & 27.4 \\
\hline 3906 & $8 / 12 / 20081: 30$ & 3.35 & 27.1 \\
\hline 3907 & $8 / 12 / 20081: 32$ & 3.326 & 27.1 \\
\hline 3908 & $8 / 12 / 20081: 34$ & 3.329 & 27.1 \\
\hline 3909 & $8 / 12 / 20081: 36$ & 3.33 & 27.4 \\
\hline 3910 & $8 / 12 / 2008$ 1:38 & 3.323 & 27.1 \\
\hline 3911 & $8 / 12 / 20081: 40$ & 2.984 & 27.1 \\
\hline 3912 & $8 / 12 / 20081: 42$ & 2.487 & 26.9 \\
\hline 3913 & $8 / 12 / 2008$ 1:44 & 1.888 & 26.6 \\
\hline 3914 & $8 / 12 / 20081: 46$ & 1.767 & 26.7 \\
\hline 3915 & $8 / 12 / 2008$ 1:48 & 1.689 & 26.7 \\
\hline 3916 & $8 / 12 / 20081: 50$ & 1.78 & 26.8 \\
\hline 3917 & $8 / 12 / 20081: 52$ & 3.244 & 26.4 \\
\hline 3918 & $8 / 12 / 2008$ 1:54 & 3.396 & 26.3 \\
\hline 3919 & $8 / 12 / 2008$ 1:56 & 3.417 & 26.3 \\
\hline 3920 & $8 / 12 / 20081: 58$ & 3.417 & 26.3 \\
\hline 3921 & $8 / 12 / 20082: 00$ & 3.423 & 26.3 \\
\hline 3922 & $8 / 12 / 20082: 02$ & 3.44 & 26.3 \\
\hline 3923 & $8 / 12 / 20082: 04$ & 3.434 & 26.3 \\
\hline 3924 & $8 / 12 / 20082: 06$ & 3.447 & 26.3 \\
\hline 3925 & $8 / 12 / 20082: 08$ & 3.44 & 26.3 \\
\hline 3926 & $8 / 12 / 20082: 10$ & 3.454 & 26.3 \\
\hline 3927 & $8 / 12 / 20082: 12$ & 3.444 & 26.3 \\
\hline 3928 & $8 / 12 / 20082: 14$ & 3.45 & 26.3 \\
\hline 3929 & $8 / 12 / 20082: 16$ & 3.467 & 26.3 \\
\hline 3930 & $8 / 12 / 20082: 18$ & 3.433 & 26.3 \\
\hline 3931 & $8 / 12 / 20082: 20$ & 3.457 & 26.3 \\
\hline 3932 & $8 / 12 / 20082: 22$ & 3.444 & 26.3 \\
\hline 3933 & $8 / 12 / 20082: 24$ & 3.45 & 26.3 \\
\hline 3934 & $8 / 12 / 20082: 26$ & 3.447 & 26.3 \\
\hline 3935 & $8 / 12 / 20082: 28$ & 3.444 & 26.3 \\
\hline 3936 & $8 / 12 / 20082: 30$ & 3.447 & 26.3 \\
\hline 3937 & $8 / 12 / 20082: 32$ & 3.44 & 26.3 \\
\hline 3938 & $8 / 12 / 20082: 34$ & 3.447 & 26.3 \\
\hline 3939 & $8 / 12 / 20082: 36$ & 3.457 & 26.3 \\
\hline 3940 & $8 / 12 / 20082: 38$ & 3.454 & 26.3 \\
\hline 3941 & $8 / 12 / 20082: 40$ & 3.508 & 26.3 \\
\hline 3942 & $8 / 12 / 20082: 42$ & 3.477 & 26.3 \\
\hline 3943 & $8 / 12 / 20082: 44$ & 3.488 & 26.3 \\
\hline 3944 & $8 / 12 / 20082: 46$ & 3.484 & 26.2 \\
\hline 3945 & $8 / 12 / 20082: 48$ & 3.491 & 26.2 \\
\hline 3946 & $8 / 12 / 20082: 50$ & 3.484 & 26.2 \\
\hline 3947 & $8 / 12 / 20082: 52$ & 3.471 & 26.2 \\
\hline 3948 & $8 / 12 / 20082: 54$ & 3.477 & 26.2 \\
\hline 3949 & $8 / 12 / 20082: 56$ & 3.488 & 26.2 \\
\hline 3950 & $8 / 12 / 20082: 58$ & 3.474 & 26.2 \\
\hline 3951 & $8 / 12 / 20083: 00$ & 3.461 & 26.4 \\
\hline 3952 & $8 / 12 / 20083: 02$ & 3.484 & 26.3 \\
\hline 3953 & $8 / 12 / 20083: 04$ & 3.467 & 26.2 \\
\hline 3954 & $8 / 12 / 20083: 06$ & 3.471 & 26.2 \\
\hline 3955 & $8 / 12 / 20083: 08$ & 3.467 & 26.1 \\
\hline 3956 & $8 / 12 / 20083: 10$ & 3.471 & 26.2 \\
\hline 3957 & $8 / 12 / 20083: 12$ & 3.454 & 26.1 \\
\hline 3958 & 8/12/2008 3:14 & 3.46 & 26.1 \\
\hline 3959 & $8 / 12 / 20083: 16$ & 3.45 & 26.1 \\
\hline 3960 & $8 / 12 / 20083: 18$ & 3.454 & 26.1 \\
\hline 3961 & $8 / 12 / 20083: 20$ & 3.464 & 26.1 \\
\hline 3962 & $8 / 12 / 20083: 22$ & 3.46 & 26.1 \\
\hline 3963 & $8 / 12 / 20083: 24$ & 3.467 & 26.1 \\
\hline 3964 & $8 / 12 / 20083: 26$ & 3.437 & 26.1 \\
\hline 3965 & $8 / 12 / 20083: 28$ & 3.437 & 26.1 \\
\hline 3966 & $8 / 12 / 20083: 30$ & 3.444 & 26.1 \\
\hline
\end{tabular}




\begin{tabular}{|c|c|c|c|c|c|c|c|c|c|c|c|c|c|c|c|}
\hline \multicolumn{4}{|c|}{ D4-26p } & \multicolumn{4}{|c|}{ D4-26p } & \multicolumn{4}{|c|}{ D4-26p } & \multicolumn{4}{|c|}{ D4-26p } \\
\hline $\operatorname{Rec}$ & & Pres & Temp & $\operatorname{Rec}$ & & Pres & Temp & Rec & & Pres & Temp & Rec & & Pres & Temp \\
\hline$\#$ & Date/Time & psi & ${ }^{\circ} \mathrm{C}$ & $\#$ & Date/Time & psi & ${ }^{\circ} \mathrm{C}$ & $\#$ & Date/Time & psi & ${ }^{\circ} \mathrm{C}$ & $\#$ & Date/Time & psi & ${ }^{\circ} \mathrm{C}$ \\
\hline 3967 & $8 / 12 / 20083: 32$ & 3.433 & 26.1 & 4036 & $8 / 12 / 20085: 50$ & 3.389 & 25.9 & 4105 & $8 / 12 / 20088: 08$ & 3.596 & 25.8 & 4174 & $8 / 12 / 2008$ 10:26 & 3.679 & 28.2 \\
\hline 3968 & $8 / 12 / 20083: 34$ & 3.444 & 26.1 & 4037 & $8 / 12 / 20085: 52$ & 3.372 & 25.9 & 4106 & $8 / 12 / 20088: 10$ & 3.592 & 25.8 & 4175 & $8 / 12 / 200810: 28$ & 3.699 & 28.1 \\
\hline 3969 & $8 / 12 / 20083: 36$ & 3.423 & 26.1 & 4038 & $8 / 12 / 20085: 54$ & 3.376 & 25.9 & 4107 & $8 / 12 / 20088: 12$ & 3.579 & 25.8 & 4176 & $8 / 12 / 200810: 30$ & 3.709 & 28.1 \\
\hline 3970 & $8 / 12 / 20083: 38$ & 3.423 & 26.1 & 4039 & $8 / 12 / 20085: 56$ & 3.399 & 25.9 & 4108 & $8 / 12 / 20088: 14$ & 3.572 & 25.8 & 4177 & $8 / 12 / 200810: 32$ & 3.696 & 28.2 \\
\hline 3971 & $8 / 12 / 20083: 40$ & 3.423 & 26.1 & 4040 & $8 / 12 / 20085: 58$ & 3.393 & 25.9 & 4109 & $8 / 12 / 20088: 16$ & 3.582 & 25.8 & 4178 & $8 / 12 / 200810: 34$ & 3.696 & 28.2 \\
\hline 3972 & $8 / 12 / 20083: 42$ & 3.433 & 26.1 & 4041 & $8 / 12 / 20086: 00$ & 3.393 & 25.9 & 4110 & $8 / 12 / 20088: 18$ & 3.579 & 25.9 & 4179 & $8 / 12 / 2008$ 10:36 & 3.676 & 28.2 \\
\hline 3973 & $8 / 12 / 20083: 44$ & 3.423 & 26.1 & 4042 & $8 / 12 / 20086: 02$ & 3.383 & 25.9 & 4111 & $8 / 12 / 20088: 20$ & 3.585 & 25.9 & 4180 & $8 / 12 / 2008 \quad 10: 38$ & 3.692 & 28.2 \\
\hline 3974 & $8 / 12 / 20083: 46$ & 3.416 & 26.1 & 4043 & $8 / 12 / 20086: 04$ & 3.386 & 25.9 & 4112 & $8 / 12 / 20088: 22$ & 3.582 & 25.9 & 4181 & $8 / 12 / 200810: 40$ & 3.689 & 28.2 \\
\hline 3975 & $8 / 12 / 20083: 48$ & 3.423 & 26.1 & 4044 & $8 / 12 / 20086: 06$ & 3.372 & 25.9 & 4113 & $8 / 12 / 20088: 24$ & 3.579 & 25.9 & 4182 & $8 / 12 / 2008 \quad 10: 42$ & 3.679 & 28.2 \\
\hline 3976 & $8 / 12 / 20083: 50$ & 3.433 & 26.1 & 4045 & $8 / 12 / 20086: 08$ & 3.386 & 25.9 & 4114 & $8 / 12 / 20088: 26$ & 3.579 & 25.9 & 4183 & $8 / 12 / 2008 \quad 10: 44$ & 3.706 & 28.2 \\
\hline 3977 & $8 / 12 / 20083.52$ & 3.423 & 26.1 & 4046 & $8 / 12 / 20086: 10$ & 3.376 & 25.8 & 4115 & $8 / 12 / 20088: 28$ & 3.579 & 25.9 & 4184 & $8 / 12 / 2008 \quad 10: 46$ & 3.686 & 28.2 \\
\hline 3978 & $8 / 12 / 20083: 54$ & 3.42 & 26.1 & 4047 & $8 / 12 / 20086: 12$ & 3.399 & 25.8 & 4116 & $8 / 12 / 20088: 30$ & 3.575 & 26.2 & 4185 & $8 / 12 / 200810: 48$ & 3.682 & 28.3 \\
\hline 3979 & $8 / 12 / 20083: 56$ & 3.41 & 26 & 4048 & $8 / 12 / 20086: 14$ & 3.383 & 25.9 & 4117 & $8 / 12 / 20088: 32$ & 3.582 & 25.9 & 4186 & $8 / 12 / 2008 \quad 10: 50$ & 3.682 & 28.3 \\
\hline 3980 & $8 / 12 / 20083: 58$ & 3.403 & 26 & 4049 & $8 / 12 / 20086: 16$ & 3.386 & 25.8 & 4118 & $8 / 12 / 20088: 34$ & 3.589 & 25.9 & 4187 & $8 / 12 / 2008 \quad 10: 52$ & 3.679 & 28.3 \\
\hline 3981 & $84: 00$ & 3.42 & 26 & 4050 & $8 / 12 / 20086: 18$ & 3.376 & 25.8 & 4119 & $8 / 12 / 20088: 36$ & 3.575 & 25.9 & 4188 & $8 / 12 / 2008 \quad 10: 54$ & 3.682 & 28.3 \\
\hline 3982 & $8 / 12 / 20084: 02$ & 3.413 & 26 & 4051 & $8 / 12 / 20086: 20$ & 3.389 & 25.8 & 4120 & $8 / 12 / 20088: 38$ & 3.592 & 25.9 & 4189 & $8 / 12 / 2008 \quad 10: 56$ & 3.679 & 28.5 \\
\hline 3983 & $8 / 12 / 20084: 04$ & 3.406 & 26 & 4052 & $8 / 12 / 20086: 22$ & 3.382 & 25.8 & 4121 & $8 / 12 / 20088: 40$ & 3.582 & 26.1 & 4190 & $8 / 12 / 2008 \quad 10: 58$ & 3.672 & 28.4 \\
\hline 3984 & $8 / 12 / 20084: 06$ & 3.406 & 26.2 & 4053 & $8 / 12 / 20086: 24$ & 3.396 & 25.9 & 4122 & $8 / 12 / 20088: 42$ & 3.582 & 25.9 & 4191 & $8 / 12 / 200811: 00$ & 3.679 & 28.3 \\
\hline 3985 & 34:08 & 3.396 & 26 & 4054 & $8 / 12 / 20086: 26$ & 3.389 & 25.9 & 4123 & $8 / 12 / 20088: 44$ & 3.582 & 25.9 & 4192 & $00811: 02$ & 3.682 & 28.3 \\
\hline 3986 & $8 / 12 / 20084: 10$ & 3.389 & 26.1 & 4055 & $8 / 12 / 20086: 28$ & 3.383 & 25.9 & 4124 & $8 / 12 / 20088: 46$ & 3.582 & 25.9 & 4193 & $8 / 12 / 2008$ 11:04 & 3.672 & 28.3 \\
\hline 3987 & $8 / 12 / 20084: 12$ & 3.396 & 26 & 4056 & $8 / 12 / 20086: 30$ & 3.379 & 25.9 & 4125 & $8 / 12 / 20088: 48$ & 3.572 & 25.9 & 4194 & $8 / 12 / 200811: 06$ & 3.686 & 28.6 \\
\hline 3988 & $8 / 12 / 20084: 14$ & 3.372 & 25.9 & 4057 & $8 / 12 / 20086: 32$ & 3.372 & 25.8 & 4126 & $088: 50$ & 3.575 & 25.9 & 4195 & $8 / 12 / 200811: 08$ & 3.676 & 28.4 \\
\hline 3989 & $4: 16$ & 3.369 & 26 & 4058 & $86: 34$ & 3.383 & 25.9 & 4127 & $88: 52$ & 3.585 & 26 & 4196 & $0811: 10$ & 3.676 & 28.4 \\
\hline 3990 & $8 / 12 / 20084: 18$ & 3.372 & 25.9 & 4059 & $8 / 12 / 20086: 36$ & 3.389 & 25.9 & 4128 & $8 / 12 / 20088: 54$ & 3.579 & 26 & 4197 & $8 / 12 / 2008$ 11:12 & 3.672 & 28.4 \\
\hline 3991 & $8 / 12 / 20084: 20$ & 3.386 & 25.9 & 4060 & $8 / 12 / 20086: 38$ & 3.396 & 25.9 & 4129 & $8 / 12 / 20088: 56$ & 3.582 & 26 & 4198 & $8 / 12 / 200811: 14$ & 3.689 & 28.4 \\
\hline 3992 & $8 / 12 / 20084: 22$ & 3.379 & 25.9 & 4061 & $86: 40$ & 3.403 & 25.8 & 4130 & $88: 58$ & 3.562 & 26 & 4199 & $8 / 12 / 2008$ 11:16 & 3.669 & 28.4 \\
\hline 3993 & $8 / 12 / 20084: 24$ & 3.386 & 25.9 & 4062 & $8 / 12 / 20$ & 3.383 & 25.9 & 4131 & $89: 00$ & 3.589 & 26 & 4200 & $8 / 12 / 200811: 18$ & 3.686 & 28.4 \\
\hline 3994 & $884: 26$ & 3.373 & 26.3 & 4063 & $86: 44$ & 3.376 & 25.9 & 4132 & $089: 02$ & 3.579 & 26 & 4201 & $8 / 12 / 200811: 20$ & 3.676 & 28.4 \\
\hline 3995 & $8 / 12 / 20084: 28$ & 3.379 & 26 & 4064 & $8 / 12 / 20086: 46$ & 3.386 & 25.8 & 4133 & $8 / 12 / 20089: 04$ & 3.579 & 26 & 4202 & $8 / 12 / 200811: 22$ & 3.673 & 28.5 \\
\hline 3996 & $8 / 12 / 20084: 30$ & 2.95 & 25.9 & 4065 & $8 / 12 / 20086: 48$ & 3.379 & 25.9 & 4134 & $2 / 20089: 06$ & 3.579 & 26 & 4203 & $8 / 12 / 200811: 24$ & 3.713 & 28.5 \\
\hline 3997 & $4: 32$ & 1.959 & 25.9 & 4066 & & 3.389 & 25.8 & & $89: 08$ & 3.542 & 26.1 & 4204 & & 3.676 & 28.5 \\
\hline 3998 & $4: 34$ & 1.834 & 25.9 & 4067 & & 3.399 & 25.9 & 4136 & 39:10 & 3.569 & 26.1 & 4205 & & 3.676 & 28.5 \\
\hline 3999 & $8 / 12 / 20$ & 1.746 & 25.9 & 4068 & $86: 54$ & 3.386 & 25.9 & 4137 & 3:12 & 3.569 & 26.1 & 4206 & $8 / 12 / 200811: 30$ & 3.683 & 28.5 \\
\hline 4000 & $84: 38$ & 3.142 & 25.4 & 4069 & $86: 56$ & 3.393 & 25.9 & 4138 & $89: 14$ & 3.562 & 26.1 & 4207 & $8 / 12 / 200811: 32$ & 3.679 & 28.5 \\
\hline 4001 & $34: 40$ & 3.352 & 25.9 & 4070 & $8 / 12 / 20$ & 3.406 & 26.3 & 4139 & 9:16 & 3.569 & 26.1 & 4208 & $8 / 12 / 200811: 34$ & 3.673 & 28.5 \\
\hline 4002 & $84: 42$ & 3.43 & 26.1 & 4071 & $87: 00$ & 3.393 & 26.4 & 4140 & 9:18 & 3.575 & 26.1 & 4209 & $8 / 12 / 2008$ 11:36 & 3.676 & 28.6 \\
\hline 4003 & $8 / 12 / 20084: 44$ & 3.477 & 26.2 & 4072 & $87: 02$ & 3.406 & 26.1 & 4141 & $89: 20$ & 3.572 & 26.1 & 4210 & $8 / 12 / 200811: 38$ & 3.673 & 29 \\
\hline 4004 & $8 / 12 / 20084: 46$ & 3.413 & 26.1 & 4073 & $87: 04$ & 3.396 & 25.9 & 4142 & $89: 22$ & 3.569 & 26.1 & 4211 & $8 / 12 / 200811: 40$ & 3.633 & 29 \\
\hline 4005 & $8 / 12 / 20084: 48$ & 3.376 & 26 & 4074 & $87: 06$ & 3.399 & 25.9 & 4143 & & 3.569 & 26.1 & 4212 & $8 / 12 / 200811: 42$ & 3.649 & 28.6 \\
\hline 4006 & & 3.356 & 26 & 4075 & & & & & & & & 4213 & & 3.669 & 28.6 \\
\hline 4007 & $8 / 12 / 20084: 52$ & 3.349 & 26 & 4076 & $87: 10$ & 3.379 & 25.8 & 4145 & $89: 28$ & 3.559 & 26.1 & 4214 & $8 / 12 / 200811: 46$ & 3.669 & 28.6 \\
\hline 4008 & $8 / 12 / 20084: 54$ & 3.356 & 26 & 4077 & $8 / 12 / 20087: 12$ & 3.389 & 25.9 & 4146 & $89: 30$ & 3.599 & 26.1 & 4215 & $8 / 12 / 2008$ 11:48 & 3.656 & 28.6 \\
\hline 4009 & & 3.335 & 26 & 4078 & $8 / 12 / 20087: 14$ & 3.393 & 25. & & & 3.559 & & 4216 & $8 / 12 / 2$ & 3.666 & 28.6 \\
\hline 4010 & & & 26 & 4079 & & & & & & & & 4217 & $8 / 12$ & 3.646 & 28.6 \\
\hline 4011 & $8 / 12 / 20085: 00$ & 3.366 & 26 & 4080 & $8 / 12 / 20087: 18$ & 3.396 & 25.9 & 4149 & $8 / 12 / 20089: 36$ & 3.555 & 26.1 & 4218 & $8 / 12 / 200811: 54$ & 3.639 & 28.6 \\
\hline 4012 & $8 / 12 / 20085: 02$ & 3.349 & 26 & 4081 & $8 / 12 / 20087: 20$ & 3.19 & 25.9 & 4150 & $8 / 12 / 20089: 38$ & 3.562 & 26.1 & 4219 & $8 / 12 / 200811: 56$ & 3.652 & 28.7 \\
\hline 4013 & $85: 04$ & 3.366 & 26 & 4082 & $8 / 12 / 20087: 22$ & 2.48 & 25.9 & 4151 & $89: 40$ & 3.555 & 26.2 & 4220 & & 3.673 & 28.6 \\
\hline 4014 & & 3.376 & 26.3 & & & 2.3 & 25 & & & & 26.2 & 4221 & & 3.646 & 28.7 \\
\hline 4015 & $85: 08$ & 3.345 & 26.1 & 4084 & $87: 26$ & 2.246 & 25.1 & 4153 & $89: 44$ & 3.555 & 26.2 & 4222 & $00812: 02$ & 3.676 & 28.7 \\
\hline 4016 & $8 / 12 / 20085: 10$ & 3.356 & 26.1 & 4085 & $387: 28$ & 1.739 & 25.2 & 4154 & $89: 46$ & 3.582 & 26.2 & 4223 & $200812: 04$ & 3.636 & 28.7 \\
\hline 4017 & $8 / 12 / 20085: 12$ & 3.342 & 26 & 4086 & $387: 30$ & 1.668 & 25 & 4155 & $89: 48$ & 3.545 & 26.2 & 4224 & $200812: 06$ & 3.632 & 28.7 \\
\hline 4018 & & 3.356 & 26 & 4087 & & 1.637 & 25. & & & 3.548 & 26.2 & 4225 & & 3.632 & 28.7 \\
\hline 4019 & & & 26 & & & 1.627 & & & & 3.552 & 26.3 & 4226 & & 3.636 & 28.8 \\
\hline 4020 & $8 / 12 / 20085: 18$ & 3.356 & 26 & 4089 & $87: 36$ & 1.637 & 25.6 & 4158 & $89: 54$ & 3.548 & 26.3 & 4227 & $00812: 12$ & 3.632 & 28.8 \\
\hline 4021 & $8 / 12 / 20085: 20$ & 3.366 & 25.9 & 4090 & $8 / 12 / 20087: 38$ & 3.501 & 25.6 & 4159 & $8 / 12 / 200$ & 3.528 & 26.3 & 4228 & $8 / 12 / 200812: 14$ & 3.629 & 28.8 \\
\hline 4022 & $85: 22$ & 3.359 & 25.9 & 4091 & $87: 40$ & 3.714 & 25.7 & 4160 & $89: 58$ & 3.569 & 26.7 & 4229 & $8 / 12 / 200812: 16$ & 3.622 & 28.8 \\
\hline 4023 & & 3.352 & 25.9 & 4092 & $87: 42$ & 3.619 & 25.8 & & $8 / 12 / 200$ & 3.63 & 26.9 & 4230 & $8 / 12 / 200812: 18$ & 3.629 & 28.8 \\
\hline 4024 & $8 / 12 / 20085: 26$ & 3.393 & 25.9 & 4093 & $8 / 12 / 20087: 44$ & 3.575 & 25.8 & 4162 & $8 / 12 / 200$ & 3.668 & 27.1 & 4231 & $8 / 12 / 2008 \quad 12: 20$ & 3.632 & 28.8 \\
\hline 4025 & $8 / 12 / 20085: 28$ & 3.372 & 25.9 & 4094 & $8 / 12 / 20087: 46$ & 3.585 & 25.8 & 4163 & $8 / 12 / 20$ & 3.688 & 27.6 & 4232 & $8 / 12 / 2008$ 12:22 & 3.626 & 28.8 \\
\hline 4026 & $8 / 12 / 20085: 30$ & 3.369 & 25.9 & 4095 & $8 / 12 / 20087: 48$ & 3.568 & 25.8 & 4164 & $8 / 12 / 200810: 06$ & 3.709 & 27.6 & 4233 & $8 / 12 / 2008 \quad 12: 24$ & 3.626 & 28.8 \\
\hline 4027 & $8 / 12 / 20085: 32$ & 3.369 & 25.9 & 4096 & $8 / 12 / 20087: 50$ & 3.575 & 25.8 & 4165 & $8 / 12 / 200810: 08$ & 3.739 & 27.6 & 4234 & $8 / 12 / 2008$ 12:26 & 3.636 & 28.9 \\
\hline 4028 & $8 / 12 / 20085: 34$ & 3.366 & 25.9 & 4097 & $8 / 12 / 20087: 52$ & 3.562 & 26.1 & 4166 & $8 / 12 / 2008$ 10:10 & 3.705 & 27.6 & 4235 & $8 / 12 / 2008$ 12:28 & 3.66 & 29.1 \\
\hline 4029 & $8 / 12 / 20085: 36$ & $\overline{3.372}$ & 25.9 & 4098 & $8 / 12 / 20087: 54$ & 3.575 & 25.9 & 4167 & $8 / 12 / 2008$ 10:12 & 3.695 & 27.6 & 4236 & $8 / 12 / 2008$ 12:30 & 3.67 & 29.1 \\
\hline 4030 & $8 / 12 / 20085: 38$ & 3.379 & 25.9 & 4099 & $8 / 12 / 20087: 56$ & 3.562 & 25.8 & 4168 & $8 / 12 / 2008$ 10:14 & 3.651 & 27.6 & 4237 & $8 / 12 / 2008 \quad 12: 32$ & 3.69 & 29.1 \\
\hline 4031 & $8 / 12 / 20085: 40$ & 3.372 & 25.9 & 4100 & $8 / 12 / 20087: 58$ & 3.569 & 25.9 & & $8 / 12 / 2008$ 10:16 & 3.668 & 27.6 & 4238 & $8 / 12 / 200812: 34$ & 3.701 & 29.2 \\
\hline 4032 & $8 / 12 / 20085: 42$ & 3.369 & 25.9 & 4101 & $8 / 12 / 20088: 00$ & 3.552 & 25.8 & 4170 & $8 / 12 / 2008$ 10:18 & 3.367 & 27.3 & 4239 & $8 / 12 / 200812: 36$ & 3.694 & 29.2 \\
\hline 4033 & $8 / 12 / 20085: 44$ & 3.393 & 25.9 & 4102 & $8 / 12 / 20088: 02$ & 3.575 & 25.8 & 4171 & $8 / 12 / 2008$ 10:20 & 2.765 & 27.6 & 4240 & $8 / 12 / 2008 \quad 12: 38$ & 3.69 & 29.2 \\
\hline 4034 & $8 / 12 / 20085: 46$ & 3.376 & 25.9 & 4103 & $8 / 12 / 20088: 04$ & 3.575 & 25.8 & 4172 & $8 / 12 / 2008 \quad 10: 22$ & 2.289 & 27.9 & 4241 & $8 / 12 / 2008$ 12:40 & 3.701 & 29.2 \\
\hline 4035 & $8 / 12 / 20085: 48$ & 3.393 & 25.9 & 4104 & $8 / 12 / 20088: 06$ & 3.568 & 25.8 & 4173 & $8 / 12 / 2008 \quad 10: 24$ & $\begin{array}{l}2.542 \\
2.40\end{array}$ & 28.1 & 4242 & $8 / 12 / 2008 \quad 12: 42$ & 3.69 & 29.2 \\
\hline
\end{tabular}




\begin{tabular}{|c|c|c|c|}
\hline \multicolumn{4}{|c|}{ D4-26p } \\
\hline Rec & & Pres & Temp \\
\hline$\#$ & Date/Time & psi & ${ }^{\circ} \mathrm{C}$ \\
\hline 4243 & $8 / 12 / 200812: 44$ & 3.68 & 29.2 \\
\hline 4244 & $8 / 12 / 2008$ 12:46 & 3.69 & 29.2 \\
\hline 4245 & $8 / 12 / 2008$ 12:48 & 3.701 & 29.4 \\
\hline 4246 & $8 / 12 / 200812: 50$ & 3.694 & 29.6 \\
\hline 4247 & $8 / 12 / 200812: 52$ & 3.687 & 29.3 \\
\hline 4248 & $8 / 12 / 2008$ 12:54 & 3.677 & 29.3 \\
\hline 4249 & $8 / 12 / 200812: 56$ & 3.677 & 29.6 \\
\hline 4250 & $8 / 12 / 2008$ 12:58 & 3.64 & 29.3 \\
\hline 4251 & $8 / 12 / 200813: 00$ & 3.646 & 29.3 \\
\hline 4252 & $8 / 12 / 2008$ 13:02 & 3.65 & 29.3 \\
\hline 4253 & 8/12/2008 13:04 & 3.667 & 29.3 \\
\hline 4254 & $8 / 12 / 2008$ 13:06 & 3.166 & 29.3 \\
\hline 4255 & $8 / 12 / 2008$ 13:08 & 2.93 & 29.7 \\
\hline 4256 & $8 / 12 / 2008$ 13:10 & 1.968 & 30.6 \\
\hline 4257 & $8 / 12 / 200813: 12$ & 3.504 & 30.8 \\
\hline 4258 & $8 / 12 / 200813: 14$ & 3.705 & 30.1 \\
\hline 4259 & $8 / 12 / 2008$ 13:16 & 3.729 & 29.8 \\
\hline 4260 & $8 / 12 / 2008$ 13:18 & 3.722 & 30.1 \\
\hline 4261 & $8 / 12 / 2008$ 13:20 & 3.739 & 29.8 \\
\hline 4262 & 8/12/2008 13:22 & 3.732 & 29.8 \\
\hline 4263 & $8 / 12 / 2008$ 13:24 & 3.725 & 29.8 \\
\hline 4264 & $8 / 12 / 2008$ 13:26 & 3.725 & 29.8 \\
\hline 4265 & $8 / 12 / 2008$ 13:28 & 3.739 & 29.8 \\
\hline 4266 & $8 / 12 / 2008$ 13:30 & 3.732 & 29.8 \\
\hline 4267 & $8 / 12 / 2008$ 13:32 & 3.756 & 29.8 \\
\hline 4268 & $8 / 12 / 200813: 34$ & 3.718 & 29.8 \\
\hline 4269 & $8 / 12 / 200813: 36$ & 3.729 & 29.8 \\
\hline 4270 & $8 / 12 / 200813: 38$ & 3.732 & 29.8 \\
\hline 4271 & $8 / 12 / 200813: 40$ & 3.755 & 29.8 \\
\hline 4272 & $8 / 12 / 2008$ 13:42 & 3.752 & 29.8 \\
\hline 4273 & $8 / 12 / 2008$ 13:44 & 3.739 & 29.8 \\
\hline 4274 & $8 / 12 / 200813: 46$ & 3.745 & 29.8 \\
\hline $427 \overline{75}$ & $8 / 12 / 2008$ 13:48 & 3.735 & 29.8 \\
\hline 4276 & $8 / 12 / 200813: 50$ & 3.749 & 29.8 \\
\hline 4277 & $8 / 12 / 200813: 52$ & 3.732 & 29.8 \\
\hline 4278 & $8 / 12 / 200813: 54$ & 3.749 & 29.9 \\
\hline 4279 & $8 / 12 / 2008$ 13:56 & 3.763 & 29.9 \\
\hline 4280 & $8 / 12 / 2008$ 13:58 & 3.753 & 30.1 \\
\hline 4281 & $8 / 12 / 2008$ 14:00 & 3.743 & 30.1 \\
\hline 4282 & $8 / 12 / 2008$ 14:02 & 3.746 & 30.1 \\
\hline 4283 & $8 / 12 / 2008$ 14:04 & 3.756 & 30.1 \\
\hline 4284 & $8 / 12 / 2008$ 14:06 & 3.749 & 30.1 \\
\hline 4285 & $8 / 12 / 200814: 08$ & 3.743 & 30.1 \\
\hline 4286 & $8 / 12 / 200814: 10$ & 3.749 & 30.1 \\
\hline 4287 & $8 / 12 / 2008$ 14:12 & 3.719 & 30.1 \\
\hline $42 \overline{8}$ & $8 / 12 / 200814: 14$ & 3.753 & 30.1 \\
\hline 4289 & $8 / 12 / 2008 \quad 14: 16$ & 3.739 & 30.1 \\
\hline 4290 & $8 / 12 / 200814: 18$ & 3.732 & 30.1 \\
\hline 4291 & $8 / 12 / 200814: 20$ & 3.722 & 30.1 \\
\hline 4292 & $8 / 12 / 200814: 22$ & 3.736 & 30.1 \\
\hline 4293 & $8 / 12 / 200814: 24$ & 3.743 & 30.1 \\
\hline 4294 & $8 / 12 / 2008$ 14:26 & 3.739 & 30.2 \\
\hline 4295 & $8 / 12 / 200814: 28$ & 3.729 & 30.2 \\
\hline 4296 & $8 / 12 / 200814: 30$ & 3.729 & 30.2 \\
\hline 4297 & $8 / 12 / 2008$ 14:32 & 3.729 & 30.2 \\
\hline 4298 & $8 / 12 / 200814: 34$ & 3.729 & 30.3 \\
\hline 4299 & $8 / 12 / 200814: 36$ & 3.733 & 30.3 \\
\hline 4300 & $8 / 12 / 200814: 38$ & 3.726 & 30.3 \\
\hline 4301 & $8 / 12 / 200814: 40$ & 3.722 & 30.3 \\
\hline 4302 & $8 / 12 / 200814: 42$ & 3.719 & 30.3 \\
\hline 4303 & $8 / 12 / 200814: 44$ & 3.719 & 30.3 \\
\hline 4304 & $8 / 12 / 200814: 46$ & 3.733 & 30.3 \\
\hline 4305 & $8 / 12 / 200814: 48$ & 3.712 & 30.3 \\
\hline 4306 & $8 / 12 / 200814: 50$ & 3.706 & 30.7 \\
\hline 4307 & $8 / 12 / 200814: 52$ & 3.716 & 30.4 \\
\hline 4308 & $8 / 12 / 200814: 54$ & 3.716 & 30.3 \\
\hline 4309 & $8 / 12 / 2008$ 14:56 & 3.719 & 30.4 \\
\hline 4310 & $8 / 12 / 200814: 58$ & 3.736 & 30.5 \\
\hline 4311 & $8 / 12 / 2008$ 15:00 & 3.743 & 30.6 \\
\hline
\end{tabular}

\begin{tabular}{|c|c|c|c|}
\hline \multicolumn{4}{|c|}{ D4-26p } \\
\hline $\operatorname{Rec}$ & & Pres & Temp \\
\hline$\#$ & Date/Time & psi & ${ }^{\circ} \mathrm{C}$ \\
\hline 4312 & $8 / 12 / 200815: 02$ & 3.716 & $30 . \overline{6}$ \\
\hline 4313 & $8 / 12 / 2008$ 15:04 & 3.72 & 30.6 \\
\hline 4314 & $8 / 12 / 200815: 06$ & 3.71 & 30.6 \\
\hline 4315 & $8 / 12 / 200815: 08$ & 3.733 & 30.6 \\
\hline 4316 & $8 / 12 / 200815: 10$ & 3.713 & 30.6 \\
\hline 4317 & $8 / 12 / 200815: 12$ & 3.723 & 30.6 \\
\hline 4318 & $8 / 12 / 200815: 14$ & 3.726 & 30.5 \\
\hline 4319 & $8 / 12 / 200815: 16$ & 3.709 & 30.5 \\
\hline 4320 & $8 / 12 / 200815: 18$ & 3.709 & 30.5 \\
\hline 4321 & $8 / 12 / 2008$ 15:20 & 3.726 & 30.6 \\
\hline 4322 & $8 / 12 / 2008 \quad 15: 22$ & 3.716 & 30.6 \\
\hline 4323 & $8 / 12 / 200815: 24$ & 3.689 & 30.6 \\
\hline 4324 & $8 / 12 / 200815: 26$ & 3.71 & \\
\hline 4325 & $8 / 12 / 200815: 28$ & 3.679 & 30.7 \\
\hline 4326 & $8 / 12 / 2008 \quad 15: 30$ & 3.689 & 30.7 \\
\hline 4327 & $8 / 12 / 2008+5: 32$ & 3.693 & \\
\hline 4328 & $8 / 12 / 200815: 34$ & 3.696 & 30.7 \\
\hline 4329 & $8 / 12 / 2008$ 15:36 & 3.689 & 30.7 \\
\hline 4330 & $8 / 12 / 2008$ 15:38 & 3.679 & 30.6 \\
\hline 4331 & $8 / 12 / 200815: 40$ & 3.689 & 30.6 \\
\hline 4332 & $8 / 12 / 200815: 42$ & 3.666 & 30.7 \\
\hline 4333 & $8 / 12 / 2008 \quad 15: 44$ & 3.673 & 30.7 \\
\hline 4334 & $8 / 12 / 200815: 46$ & 3.656 & 31.1 \\
\hline 4335 & $8 / 12 / 200815: 48$ & 3.662 & 30.8 \\
\hline 4336 & $8 / 12 / 200815: 50$ & 3.683 & 30.7 \\
\hline 4337 & $8 / 12 / 200815: 52$ & 2.276 & 30.7 \\
\hline 4338 & $8 / 12 / 200815: 54$ & 2.005 & 30.7 \\
\hline 4339 & $8 / 12 / 200815: 56$ & 3.464 & 31.5 \\
\hline 4340 & $8 / 12 / 2008$ 15:58 & 3.612 & 31.1 \\
\hline 4341 & $8 / 12 / 200816: 00$ & 3.632 & 30.9 \\
\hline 4342 & $8 / 12 / 200816: 02$ & 3.643 & 30.9 \\
\hline 4343 & $8 / 12 / 200816: 04$ & 3.656 & 30.9 \\
\hline 4344 & $8 / 12 / 200816: 06$ & 3.656 & 30. \\
\hline 4345 & $8 / 12 / 20$ & 3.666 & 30 . \\
\hline 4346 & $8 / 12 / 2008$ 16:10 & 3.669 & 30.9 \\
\hline 4347 & $8 / 12 / 2008$ 16:12 & 3.676 & 30.9 \\
\hline 4348 & $8 / 12 / 200816: 14$ & 3.7 & 30.8 \\
\hline 4349 & $8 / 12 / 200816: 16$ & 3.666 & 30.8 \\
\hline 4350 & $8 / 12 / 20$ & 3.693 & 30. \\
\hline 4351 & $8 / 12 / 200816: 20$ & 3.68 & 30.5 \\
\hline 4352 & $8 / 12 / 2008$ 16:22 & 3.676 & 30.5 \\
\hline 4353 & $8 / 12 / 200816: 24$ & 3.69 & 30. \\
\hline 4354 & $8 / 12 / 2008$ 16:26 & 3.683 & 30.8 \\
\hline 4355 & $8 / 12 / 20$ & 3.68 & 30.5 \\
\hline 4356 & $8 / 12 / 200816: 30$ & 3.686 & 30.5 \\
\hline 4357 & $8 / 12 / 2008$ 16:32 & 3.68 & 30. \\
\hline 4358 & $0816: 34$ & 3.68 & 30.5 \\
\hline 4359 & $8 / 12 / 200816: 36$ & 3.68 & 30.9 \\
\hline 4360 & $8 / 12 / 200816: 38$ & 3.683 & 30. \\
\hline 4361 & $8 / 12 / 200816: 40$ & 3.67 & 30.9 \\
\hline 4362 & $8 / 12 / 2008$ 16:42 & 3.676 & 30.5 \\
\hline 4363 & $0816: 44$ & 3.683 & 30.5 \\
\hline 4364 & $8 / 12 / 2008$ 16:46 & 3.676 & 30.5 \\
\hline 4365 & & 3.69 & \\
\hline 4366 & $8 / 12 / 200816: 50$ & 3.68 & 30.9 \\
\hline 4367 & $8 / 12 / 200816: 52$ & 3.7 & 30.5 \\
\hline 4368 & $0816: 54$ & 3.676 & 30. \\
\hline 4369 & $8 / 12 / 200816: 56$ & 3.683 & 30. \\
\hline 4370 & & 3.673 & 30. \\
\hline 4371 & $8 / 12 / 200817: 00$ & 3.68 & 30. \\
\hline 4372 & $8 / 12 / 200817: 02$ & 3.676 & 30.9 \\
\hline 4373 & $8 / 12 / 2008 \quad 17: 04$ & 3.68 & \\
\hline 4374 & $8 / 12 / 2008$ 17:06 & 3.683 & 31 \\
\hline 4375 & $8 / 12 / 2008 \quad 17: 08$ & 3.673 & \\
\hline 4376 & $8 / 12 / 2008 \quad 17: 10$ & 3.68 & 30. \\
\hline 4377 & $8 / 12 / 200817: 12$ & 3.68 & 31 \\
\hline 4378 & $8 / 12 / 200817: 14$ & 3.687 & 31 \\
\hline 4379 & $8 / 12 / 2008$ 17:16 & 3.683 & \\
\hline 4380 & $8 / 12 / 2008 \quad 17: 18$ & 3.687 & 31. \\
\hline
\end{tabular}

\begin{tabular}{|c|c|c|c|}
\hline \multicolumn{4}{|c|}{ D4-26p } \\
\hline $\operatorname{Rec}$ & & Pres & \\
\hline$\#$ & Date/Time & psi & ${ }^{\circ} \mathrm{C}$ \\
\hline 4381 & $8 / 12 / 200817: 20$ & 3.677 & 31.5 \\
\hline 382 & $8 / 12 / 2008 \quad 17: 22$ & 3.684 & 31.3 \\
\hline 883 & $12 / 2008$ 17:24 & 3.687 & 31 \\
\hline 384 & $8 / 12 / 2008 \quad 17: 26$ & 3.673 & 31 \\
\hline & & 3.687 & \\
\hline 4386 & $12 / 200817: 30$ & 3.68 & 31 \\
\hline 4387 & $8 / 12 / 200817: 32$ & 3.67 & 31 \\
\hline & $8 / 12 / 200817: 34$ & 3.67 & 31 \\
\hline 4389 & $8 / 12 / 200817: 36$ & 3.646 & 31 \\
\hline 4390 & $12 / 2008$ 17:38 & 3.673 & 31 \\
\hline 4391 & $12 / 200817: 40$ & 3.69 & \\
\hline 4392 & $8 / 12 / 2008 \quad 17: 42$ & 3.676 & 31 \\
\hline & $8 / 12 / 2008$ 17:44 & & \\
\hline 4394 & $8 / 12 / 200817: 46$ & 3.663 & 31 \\
\hline 4395 & $8 / 12 / 2008 \quad 17: 48$ & 3.673 & $\overline{31}$ \\
\hline & $8 / 12 / 200817: 50$ & 3.67 & \\
\hline 4397 & $12 / 2008$ 17:52 & 3.67 & 31 \\
\hline 4398 & $8 / 12 / 200817: 54$ & 3.67 & 31.1 \\
\hline 4399 & $8 / 12 / 200817: 56$ & & \\
\hline 4400 & $8 / 12 / 200817: 58$ & 3.714 & 31.3 \\
\hline 4401 & $8 / 12 / 200818: 00$ & 3.758 & 31.3 \\
\hline 4402 & $12 / 200818: 02$ & 3.762 & 31. \\
\hline 4403 & $8 / 12 / 200818: 04$ & 3.765 & 31. \\
\hline 4404 & $8 / 12 / 2008 \overline{18: 06}$ & 3.748 & 31. \\
\hline 4405 & $8 / 12 / 200818: 08$ & 3.755 & 31.3 \\
\hline 4406 & 18:10 & 3.745 & 31. \\
\hline 4407 & 18:12 & 3.761 & $\overline{31 .}$ \\
\hline 4408 & $318: 14$ & 3.758 & 31. \\
\hline 4409 & $12 / 200818: 16$ & 3.748 & 31. \\
\hline 4410 & $12 / 200818: 18$ & 3.745 & $\overline{31.3}$ \\
\hline 4411 & 18:20 & 3.749 & 31.6 \\
\hline $4 \overline{4412}$ & 18:22 & 3.738 & 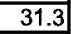 \\
\hline 4413 & 18:24 & 3.734 & 31. \\
\hline 4414 & $18: 26$ & 3.718 & 31. \\
\hline 4415 & $12 / 20$ & 3.717 & 31.2 \\
\hline 4416 & $12 / 20$ & 3.731 & 31.2 \\
\hline 4417 & $\overline{12 / 2}$ & 3.6 & 31.2 \\
\hline 4418 & $8: 34$ & 3.707 & \\
\hline 4419 & & 3.305 & 31.2 \\
\hline 4420 & $12 / 2$ & 2.26 & 31. \\
\hline 4421 & 40 & 2.2 & \\
\hline 4422 & 42 & 3.5 & 31. \\
\hline & & 3.73 & 30.6 \\
\hline 4424 & & 3.7 & 30.4 \\
\hline$\overline{442}$ & 48 & 3.746 & 30.6 \\
\hline & & 3.777 & 30. \\
\hline$\overline{442}$ & $\sqrt{21}$ & 3.773 & 30. \\
\hline 4428 & & 3.77 & 30.6 \\
\hline 4429 & & 3.787 & 30.6 \\
\hline 4430 & $12 / 20$ & 3.7 & $\overline{30 .}$ \\
\hline & & 3.787 & 30. \\
\hline & & 3.773 & \\
\hline & & 3.783 & 30.8 \\
\hline & & & \\
\hline & & 3.797 & \\
\hline & & 3.783 & 30.3 \\
\hline & & 3.794 & \\
\hline 4438 & 819:14 & 3.79 & 30.3 \\
\hline & & 3.787 & \\
\hline & & 3.78 & \\
\hline & 10.20 & 3.787 & 30. \\
\hline & & & \\
\hline 4443 & 319:24 & 3.797 & 30.6 \\
\hline & & 3.797 & 30. \\
\hline & & & \\
\hline 4446 & $12 / 200819: 30$ & 3.804 & \\
\hline & & 3.78 & \\
\hline & & 3.794 & \\
\hline 444 & $12 / 200819: 36$ & 3.807 & so. \\
\hline
\end{tabular}

\begin{tabular}{|c|c|c|c|}
\hline \multicolumn{4}{|c|}{$D 4-26 p$} \\
\hline $\operatorname{Rec}$ & & Pres & Temp \\
\hline$\#$ & Date/Time & psi & ${ }^{\circ} \mathrm{C}$ \\
\hline 4450 & $8 / 12 / 2008 \quad 19: 38$ & 3.79 & 30.3 \\
\hline 4451 & $8 / 12 / 2008 \quad 19: 40$ & 3.794 & 30.3 \\
\hline 4452 & $8 / 12 / 200819: 42$ & 3.787 & 30.3 \\
\hline 4453 & $8 / 12 / 2008$ 19:44 & 3.783 & 30.3 \\
\hline 4454 & $8 / 12 / 2008 \quad 19: 46$ & 3.8 & 30.3 \\
\hline 4455 & $8 / 12 / 2008$ 19:48 & 3.807 & 30.3 \\
\hline 4456 & $8 / 12 / 2008 \quad 19: 50$ & 3.797 & 30.3 \\
\hline 4457 & $8 / 12 / 2008$ 19:52 & 3.787 & 30.3 \\
\hline 4458 & $8 / 12 / 2008$ 19:54 & 3.783 & 30.3 \\
\hline 4459 & $8 / 12 / 2008$ 19:56 & 3.783 & 30.3 \\
\hline 4460 & $8 / 12 / 2008$ 19:58 & 3.787 & 30.3 \\
\hline 4461 & $8 / 12 / 200820: 00$ & 3.79 & 30.3 \\
\hline 4462 & $8 / 12 / 200820: 02$ & 3.783 & 30.3 \\
\hline 4463 & $8 / 12 / 200820: 04$ & 3.797 & 30.3 \\
\hline 4464 & $8 / 12 / 200820: 06$ & 3.777 & 30.3 \\
\hline 4465 & $8 / 12 / 200820: 08$ & 3.787 & 30.3 \\
\hline 4466 & $8 / 12 / 200820: 10$ & 3.787 & 30.3 \\
\hline 4467 & $8 / 12 / 200820: 12$ & 3.787 & 30.3 \\
\hline 4468 & $8 / 12 / 200820: 14$ & 3.78 & 30.3 \\
\hline 4469 & 8/12/2008 20:16 & 3.78 & 30.3 \\
\hline 4470 & $8 / 12 / 200820: 18$ & 3.797 & 30.3 \\
\hline 4471 & $8 / 12 / 200820: 20$ & 3.777 & 30.3 \\
\hline 4472 & $8 / 12 / 200820: 22$ & 3.777 & 30.3 \\
\hline 4473 & $8 / 12 / 20$ & 3.766 & 30.3 \\
\hline 4474 & $8 / 12 / 200820: 26$ & 3.756 & 30.3 \\
\hline 4475 & $8 / 12 / 200820: 28$ & 3.763 & 30.3 \\
\hline 4476 & $8 / 12 / 20$ & 3.77 & 30.3 \\
\hline 4477 & $8 / 12 / 20$ & 3.77 & 30.2 \\
\hline 4478 & $8 / 12 / 200820: 34$ & 3.77 & 30.3 \\
\hline 4479 & $8 / 12 / 200820: 36$ & 3.766 & 30.3 \\
\hline 4480 & $8 / 12 / 200820: 38$ & 3.777 & 30.3 \\
\hline 4481 & $8 / 12 / 200820: 40$ & 3.773 & 30.3 \\
\hline 4482 & $8 / 12 / 200820: 42$ & 3.773 & 30.2 \\
\hline 4483 & $8 / 12 / 20$ & 3.773 & 30.2 \\
\hline 4484 & $8 / 12 / 200820: 46$ & 3.776 & 30.2 \\
\hline 4485 & $8 / 12 / 200820: 48$ & 3.774 & 30.5 \\
\hline 4486 & $8 / 12 / 20$ & 3.756 & 30.3 \\
\hline 4487 & $8 / 12 / 20$ & 3.763 & 30.2 \\
\hline 4488 & $8 / 12 / 20$ & 3.766 & 30.2 \\
\hline 4489 & $8 / 12 / 20$ & 3.753 & 30.6 \\
\hline 4490 & $8 / 12 / 20$ & 3.76 & 30.3 \\
\hline 4491 & $8 / 12 / 20$ & 3.76 & 30.2 \\
\hline 4492 & $8 / 12 / 20$ & 3.753 & 30.1 \\
\hline 4493 & $8 / 12 / 20$ & 3.753 & 30.1 \\
\hline 4494 & $8 / 12 / 20$ & 3.756 & 30.1 \\
\hline 4495 & $8 / 12 / 20$ & 3.753 & 30.1 \\
\hline 4496 & $8 / 12 / 20$ & 3.743 & 30.1 \\
\hline 4497 & $8 / 12 / 20$ & 3.756 & 30.1 \\
\hline 4498 & $8 / 12 / 20$ & 3.753 & 30.1 \\
\hline 4499 & $8 / 12 / 20$ & 3.753 & 30.1 \\
\hline 4500 & $8 / 12 / 20$ & $\overline{3.742}$ & 30.1 \\
\hline 4501 & $8 / 12 / 20$ & 3.759 & 30.1 \\
\hline 4502 & $8 / 12 / 200821: 22$ & 3.739 & 30 \\
\hline 4503 & $8 / 12 / 20$ & 3.732 & 30.1 \\
\hline 4504 & $8 / 12 / 200821: 26$ & 3.279 & 30 \\
\hline 4505 & $8 / 12 / 200821: 28$ & 2.748 & 30 \\
\hline 4506 & $8 / 12 / 200821: 30$ & 2.079 & 30 \\
\hline 4507 & $8 / 12 / 200821: 32$ & 1.94 & 29.9 \\
\hline 4508 & $8 / 12 / 200821: 34$ & 3.532 & 29.5 \\
\hline 4509 & $8 / 12 / 200821: 36$ & 3.741 & 28.9 \\
\hline 4510 & $8 / 12 / 200821: 38$ & 3.724 & 28.8 \\
\hline 4511 & $8 / 12 / 200821: 40$ & 3.754 & 28.8 \\
\hline 4512 & $8 / 12 / 200821: 42$ & 3.768 & 28.8 \\
\hline 4513 & $8 / 12 / 200821: 44$ & 3.768 & 28.8 \\
\hline 4514 & $8 / 12 / 200821: 46$ & 3.774 & 28.8 \\
\hline 4515 & $8 / 12 / 200821: 48$ & 3.784 & 28.8 \\
\hline 4516 & $8 / 12 / 200821: 50$ & 3.795 & 28.8 \\
\hline 4517 & $8 / 12 / 200821: 52$ & 3.784 & 28.8 \\
\hline 4518 & $8 / 12 / 200821: 54$ & 3.795 & 28.8 \\
\hline
\end{tabular}




\begin{tabular}{|c|c|c|c|}
\hline \multicolumn{4}{|c|}{ D4-26p } \\
\hline $\operatorname{Rec}$ & & Pres & Temp \\
\hline$\#$ & Date/Time & psi & ${ }^{\circ} \mathrm{C}$ \\
\hline 4519 & $8 / 12 / 200821: 56$ & 3.839 & 28.8 \\
\hline 4520 & $8 / 12 / 200821: 58$ & 3.784 & 28.8 \\
\hline 4521 & $8 / 12 / 200822: 00$ & 3.784 & 28.8 \\
\hline 4522 & $8 / 12 / 200822: 02$ & 3.795 & 29.2 \\
\hline 4523 & $8 / 12 / 200822: 04$ & 3.805 & 29.3 \\
\hline 4524 & $8 / 12 / 200822: 06$ & 3.795 & 28.9 \\
\hline 4525 & $8 / 12 / 200822: 08$ & 3.781 & 28.8 \\
\hline 4526 & $8 / 12 / 200822: 10$ & 3.791 & 28.8 \\
\hline 4527 & $8 / 12 / 200822: 12$ & 3.784 & 28.8 \\
\hline 4528 & $8 / 12 / 200822: 14$ & 3.805 & 28.8 \\
\hline 4529 & $8 / 12 / 200822: 16$ & 3.791 & 28.8 \\
\hline 4530 & $8 / 12 / 200822: 18$ & 3.801 & 28.8 \\
\hline 4531 & $8 / 12 / 200822: 20$ & 3.791 & 28.8 \\
\hline 4532 & $8 / 12 / 200822: 22$ & 3.801 & 28.8 \\
\hline 4533 & $8 / 12 / 200822: 24$ & 3.791 & 28.8 \\
\hline 4534 & $8 / 12 / 200822: 26$ & 3.798 & 28.8 \\
\hline 4535 & $8 / 12 / 200822: 28$ & 3.795 & 28.8 \\
\hline 4536 & $8 / 12 / 200822: 30$ & 3.791 & 28.8 \\
\hline 4537 & $8 / 12 / 200822: 32$ & 3.808 & 28.8 \\
\hline 4538 & $8 / 12 / 200822: 34$ & 3.798 & 28.8 \\
\hline 4539 & $8 / 12 / 200822: 36$ & 3.788 & 28.8 \\
\hline 4540 & $8 / 12 / 200822: 38$ & 3.808 & 28.8 \\
\hline 4541 & $8 / 12 / 200822: 40$ & 3.795 & 28.8 \\
\hline 4542 & $8 / 12 / 200822: 42$ & 3.798 & 28.8 \\
\hline 4543 & $8 / 12 / 200822: 44$ & 3.784 & 28.8 \\
\hline 4544 & $8 / 12 / 200822: 46$ & 3.781 & 28.7 \\
\hline 4545 & $8 / 12 / 200822: 48$ & 3.788 & 28.7 \\
\hline 4546 & $8 / 12 / 200822: 50$ & 3.784 & 28.8 \\
\hline 4547 & $8 / 12 / 200822: 52$ & 3.784 & 28.7 \\
\hline 4548 & $8 / 12 / 200822: 54$ & 3.818 & 28.7 \\
\hline 4549 & $8 / 12 / 200822: 56$ & 3.784 & 28.7 \\
\hline 4550 & $8 / 12 / 200822: 58$ & 3.794 & 28.7 \\
\hline 4551 & $8 / 12 / 200823: 00$ & 3.798 & 28.7 \\
\hline 4552 & $8 / 12 / 200823: 02$ & 3.798 & 28.7 \\
\hline 4553 & $8 / 12 / 200823: 04$ & 3.781 & 28.7 \\
\hline 4554 & $8 / 12 / 200823: 06$ & 3.791 & 28.7 \\
\hline 4555 & $8 / 12 / 200823: 08$ & 3.798 & 28.7 \\
\hline 4556 & $8 / 12 / 2008$ 23:10 & 3.774 & 28.7 \\
\hline 4557 & $8 / 12 / 200823: 12$ & 3.788 & 28.7 \\
\hline 4558 & $8 / 12 / 200823: 14$ & 3.791 & 28.7 \\
\hline 4559 & $8 / 12 / 2008 \quad 23: 16$ & 3.791 & 28.7 \\
\hline 4560 & $8 / 12 / 200823: 18$ & 3.774 & 28.7 \\
\hline 4561 & $8 / 12 / 2008 \quad 23: 20$ & 3.774 & 28.7 \\
\hline 4562 & $8 / 12 / 200823: 22$ & 3.771 & 28.7 \\
\hline 4563 & $8 / 12 / 200823: 24$ & 3.805 & 28.7 \\
\hline 4564 & $8 / 12 / 200823: 26$ & 3.788 & 28.7 \\
\hline 4565 & $8 / 12 / 200823: 28$ & 3.781 & 28.7 \\
\hline 4566 & $8 / 12 / 200823: 30$ & 3.781 & 28.6 \\
\hline 4567 & $8 / 12 / 2008 \quad 23: 32$ & 3.784 & 28.7 \\
\hline 4568 & $8 / 12 / 200823: 34$ & 3.784 & 28.6 \\
\hline 4569 & $8 / 12 / 200823: 36$ & 3.788 & 28.6 \\
\hline 4570 & $8 / 12 / 200823: 38$ & 3.781 & 28.6 \\
\hline 4571 & $8 / 12 / 2008$ 23:40 & 3.781 & 28.6 \\
\hline 4572 & $8 / 12 / 200823: 42$ & 3.778 & 28.8 \\
\hline 4573 & $8 / 12 / 200823: 44$ & 3.795 & 28.8 \\
\hline 4574 & $8 / 12 / 200823: 46$ & 3.791 & 28.6 \\
\hline 4575 & $8 / 12 / 200823: 48$ & 3.778 & 28.6 \\
\hline 4576 & $8 / 12 / 200823: 50$ & 3.777 & 28.6 \\
\hline 4577 & $8 / 12 / 200823: 52$ & 3.788 & 28.6 \\
\hline 4578 & $8 / 12 / 200823: 54$ & 3.784 & 28.6 \\
\hline 4579 & $8 / 12 / 200823: 56$ & 3.804 & 28.6 \\
\hline 4580 & $8 / 12 / 200823: 58$ & 3.777 & 28.6 \\
\hline 4581 & $8 / 13 / 20080: 00$ & 3.784 & 28.6 \\
\hline 4582 & $8 / 13 / 20080: 02$ & 3.781 & 28.6 \\
\hline 4583 & $8 / 13 / 20080: 04$ & 3.781 & 28.6 \\
\hline 4584 & $8 / 13 / 20080: 06$ & 3.788 & 28.6 \\
\hline 4585 & $8 / 13 / 20080: 08$ & 3.774 & 28.5 \\
\hline 4586 & $8 / 13 / 20080: 10$ & 3.777 & 28.5 \\
\hline 4587 & $8 / 13 / 20080: 12$ & 3.321 & 28.5 \\
\hline
\end{tabular}

\begin{tabular}{|c|c|c|c|}
\hline \multicolumn{4}{|c|}{ D4-26p } \\
\hline$\overline{R e c}$ & & Pres & Temp \\
\hline$\#$ & Date/Time & psi & ${ }^{\circ} \mathrm{C}$ \\
\hline 4588 & $8 / 13 / 20080: 14$ & 2.783 & 28.5 \\
\hline 4589 & $8 / 13 / 20080: 16$ & 2.114 & 28.5 \\
\hline 590 & $8 / 13 / 20080: 18$ & 1.982 & 28.5 \\
\hline 91 & $8 / 13 / 20080: 20$ & 2.746 & 28.5 \\
\hline 4592 & $8 / 13 / 20080: 22$ & 3.699 & 27.8 \\
\hline 4593 & $8 / 13 / 20080: 24$ & 3.793 & 27.8 \\
\hline 4594 & $8 / 13 / 20080: 26$ & 3.79 & 27.8 \\
\hline 4595 & $8 / 13 / 20080: 28$ & 3.814 & 27.8 \\
\hline 4596 & $8 / 13 / 20080: 30$ & 3.837 & 27.8 \\
\hline 4597 & $8 / 13 / 20080: 32$ & 3.776 & 27.8 \\
\hline 4598 & $8 / 13 / 20080: 34$ & 3.82 & 27.8 \\
\hline 4599 & $8 / 13 / 20080: 36$ & 3.834 & 27.8 \\
\hline 4600 & $8 / 13 / 20080: 38$ & 3.807 & 27.8 \\
\hline 4601 & $8 / 13 / 20080: 40$ & 3.82 & 27.8 \\
\hline & $380: 42$ & & \\
\hline 4603 & $8 / 13 / 20080: 44$ & 3.847 & 27.7 \\
\hline 4604 & $080: 46$ & 3.834 & 27.8 \\
\hline & $080: 48$ & 3.834 & \\
\hline 4606 & $8 / 13 / 20080: 50$ & 3.847 & 27.7 \\
\hline 4607 & $80: 52$ & 3.834 & 27.7 \\
\hline 4608 & $80: 54$ & 3.834 & 27.7 \\
\hline 4609 & $080: 56$ & 3.837 & 27.7 \\
\hline 4610 & $8 / 13 / 20080: 58$ & 3.827 & 27.7 \\
\hline 4611 & $8 / 13 / 20081: 00$ & 3.851 & 27.7 \\
\hline 4612 & $81: 02$ & 3.847 & 27.7 \\
\hline 4613 & $81: 04$ & 3.841 & 27.7 \\
\hline 4614 & $081: 06$ & 3.844 & 27.7 \\
\hline 4615 & $1: 08$ & 3.83 & 27.7 \\
\hline 4616 & $1: 10$ & 3.851 & 27.7 \\
\hline 4617 & & 3.848 & 27.9 \\
\hline 4618 & $81: 14$ & 3.831 & 27.8 \\
\hline 4619 & $81: 16$ & 3.841 & 27.7 \\
\hline 4620 & $1: 18$ & 3.858 & 27.7 \\
\hline 4621 & $1: 20$ & $\overline{3.841}$ & 27.7 \\
\hline 4622 & & 3.841 & 27.7 \\
\hline 4623 & $1: 24$ & 3.837 & 27.7 \\
\hline 4624 & $381: 26$ & 3.83 & 27.7 \\
\hline 4625 & $1: 28$ & 3.834 & 27.7 \\
\hline 4626 & $1: 30$ & 3.814 & 27.7 \\
\hline 4627 & & 3.83 & 27.7 \\
\hline 4628 & & 3.837 & 27.7 \\
\hline 4629 & $31: 36$ & 3.834 & 27.6 \\
\hline 4630 & & 3.841 & 27.7 \\
\hline 4631 & $1: 40$ & 3.834 & 27. \\
\hline & & & 27.8 \\
\hline & & 3.807 & 27.6 \\
\hline 4634 & $81: 46$ & 3.844 & 27.6 \\
\hline & & 3.824 & 27.6 \\
\hline 4636 & & 3.837 & 27.8 \\
\hline & & 3.841 & 27.8 \\
\hline 4638 & & 3.827 & 27.6 \\
\hline 4639 & $81: 56$ & 3.817 & 27.6 \\
\hline & & 3.824 & 27.6 \\
\hline 4641 & & & 27.6 \\
\hline & & 3.841 & 27.6 \\
\hline 4643 & & 3.827 & \\
\hline 4644 & $82: 06$ & 3.844 & 27.6 \\
\hline & & 3.824 & 27.6 \\
\hline 4646 & & 3.7 & \\
\hline 4647 & $82: 12$ & 3.824 & 27.6 \\
\hline 4648 & & & \\
\hline 4649 & $82: 16$ & 3.844 & 27.6 \\
\hline 4650 & $82: 18$ & 3.817 & 27.6 \\
\hline & & 3.817 & \\
\hline 465 & $82: 22$ & 3.817 & 27.7 \\
\hline 4653 & & 3.814 & 27.8 \\
\hline 4654 & $082: 26$ & & \\
\hline 4655 & $82: 28$ & 3.817 & 27. \\
\hline 4656 & $8 / 13 / 20082: 30$ & & \\
\hline
\end{tabular}

\begin{tabular}{|c|c|c|c|}
\hline \multicolumn{4}{|c|}{ D4-26p } \\
\hline $\operatorname{Rec}$ & & Pres & Temp \\
\hline$\#$ & Date/Time & psi & ${ }^{\circ} \mathrm{C}$ \\
\hline 1657 & $8 / 13 / 20082: 32$ & 3.817 & 27.6 \\
\hline 658 & $8 / 13 / 20082: 34$ & 3.8 & 27.6 \\
\hline 659 & $8 / 13 / 20082: 36$ & 3.82 & 27.6 \\
\hline 660 & $3 / 13 / 20082: 38$ & 3.824 & \\
\hline & $8 / 13 / 20082: 40$ & 3.807 & 27.6 \\
\hline 4662 & $13 / 20082: 42$ & 3.803 & 27.6 \\
\hline & $8 / 13 / 20082: 44$ & 3.81 & 27.6 \\
\hline 664 & $8 / 13 / 20082: 46$ & 3.817 & 27.6 \\
\hline 665 & $8 / 13 / 20082: 48$ & 3.817 & 27.6 \\
\hline & $8 / 13 / 20082: 50$ & 3.803 & 27.6 \\
\hline 4667 & $8 / 13 / 20082: 52$ & 3.8 & 27.5 \\
\hline 4668 & $8 / 13 / 20082: 54$ & 3.796 & 27.5 \\
\hline 4669 & $8 / 13 / 20082: 56$ & 3.793 & 27.5 \\
\hline 4670 & $8 / 13 / 20082: 58$ & 3.78 & 27.5 \\
\hline 4671 & $8 / 13 / 20083: 00$ & 3.79 & 27.5 \\
\hline 4672 & $8 / 13 / 20083: 02$ & 3.543 & 27.4 \\
\hline 4673 & $8 / 13 / 20083: 04$ & 2.589 & 27.4 \\
\hline 4674 & $8 / 13 / 20083: 06$ & 2.109 & \\
\hline 4675 & $8 / 13 / 20083: 08$ & 2.001 & 27.3 \\
\hline 4676 & $8 / 13 / 20083: 10$ & 1.93 & 27.3 \\
\hline 4677 & $8 / 13 / 20083: 12$ & 3.556 & \\
\hline 4678 & $8 / 13 / 20083: 14$ & 3.715 & 27.1 \\
\hline 4679 & $83: 16$ & 3.745 & 27.1 \\
\hline 4680 & $8 / 13 / 20$ & 3.766 & 27.4 \\
\hline 4681 & $83: 20$ & 3.783 & 27.2 \\
\hline 4682 & $83: 22$ & 3.786 & 27.1 \\
\hline 4683 & $8 / 13 / 20083: 24$ & 3.796 & 27.1 \\
\hline 4684 & $83: 26$ & 3.82 & 27.1 \\
\hline 4685 & $33: 28$ & 3.803 & 27.1 \\
\hline 4686 & $33: 30$ & 3.823 & 27.1 \\
\hline 4687 & $3: 32$ & 3.813 & 27.1 \\
\hline 4688 & $8 / 13 /$ & 3.81 & 27.1 \\
\hline 4689 & $3: 36$ & 3.833 & 27.1 \\
\hline 4690 & $3: 38$ & 3.826 & 27.1 \\
\hline 4691 & & 3.84 & 27.1 \\
\hline 4692 & $3: 42$ & 3.83 & 27.1 \\
\hline 4693 & $3: 44$ & 3.826 & 27.1 \\
\hline 4694 & & 3.83 & 27.1 \\
\hline 4695 & $3: 48$ & 3.806 & 27.1 \\
\hline 4696 & & 3.837 & 27 \\
\hline 4697 & & 3.837 & 27.1 \\
\hline 4698 & & 3.823 & 27 \\
\hline 4699 & & 3.837 & 27 \\
\hline 4700 & & 3.82 & 27.4 \\
\hline 4701 & & 3.81 & 27.1 \\
\hline 4702 & & 3813 & 27.1 \\
\hline 4703 & & 8 & 27 \\
\hline 4704 & & & 27 \\
\hline 4705 & & 3.82 & 27 \\
\hline 4706 & & 3.847 & 27 \\
\hline 4707 & & & $\overline{27.2}$ \\
\hline 4708 & & 837 & 27.5 \\
\hline 4709 & & 4 & 27.6 \\
\hline 471 & & 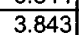 & 27.1 \\
\hline 4711 & & 3.843 & 27 \\
\hline 4712 & & & 27 \\
\hline 4713 & & 3.843 & 26.9 \\
\hline 4714 & & & \\
\hline 4715 & & & 26.9 \\
\hline 4716 & $20084: 30$ & 3.847 & 27 \\
\hline 4717 & & 3.84 & 26.9 \\
\hline 4718 & $34: 34$ & 3.864 & \\
\hline 4719 & $8 / 13 / 20084: 36$ & 3.85 & 26.9 \\
\hline$\overline{4720}$ & & 3.847 & \\
\hline 4721 & $884: 40$ & 3.843 & \\
\hline 4722 & $20084: 42$ & 3.857 & 26.9 \\
\hline 4723 & & 3.84 & \\
\hline 4724 & $8 / 13 / 20084: 46$ & 3.843 & 26. \\
\hline & 01120000 & & \\
\hline
\end{tabular}

\begin{tabular}{|c|c|c|c|}
\hline \multicolumn{4}{|c|}{ D4-26p } \\
\hline $\operatorname{Rec}$ & & Pres & Temp \\
\hline$\#$ & Date/Time & psi & ${ }^{\circ} \mathrm{C}$ \\
\hline 4726 & $8 / 13 / 20084: 50$ & 3.843 & 26 . \\
\hline 727 & $8 / 13 / 20084: 52$ & 3.837 & \\
\hline 4728 & $8 / 13 / 20084: 54$ & 3.843 & 26. \\
\hline 4729 & $8 / 13 / 20084: 56$ & 3.837 & 26. \\
\hline 730 & $8 / 13 / 20084: 58$ & 3.837 & \\
\hline 4731 & $8 / 13 / 20085: 00$ & 3.84 & 26.9 \\
\hline 4732 & $8 / 13 / 20085: 02$ & 3.86 & 26.9 \\
\hline 4733 & $8 / 13 / 20085: 04$ & 3.84 & 26. \\
\hline 4734 & $8 / 13 / 20085: 06$ & 3.857 & 26. \\
\hline 4735 & $8 / 13 / 20085: 08$ & 3.843 & \\
\hline 4736 & $8 / 13 / 20085: 10$ & 3.85 & 26. \\
\hline 4737 & $8 / 13 / 20085: 12$ & 3.85 & 26. \\
\hline 4738 & $8 / 13 / 20085: 14$ & 3.843 & \\
\hline 4739 & $8 / 13 / 20085: 16$ & 3.84 & 26. \\
\hline 4740 & $8 / 13 / 20085: 18$ & 3.836 & 26. \\
\hline 4741 & $8 / 13 / 20085: 20$ & 3.847 & \\
\hline 4742 & $8 / 13 / 20085: 22$ & 3.843 & 26.8 \\
\hline 743 & $085: 24$ & 3.836 & \\
\hline 4744 & $8 / 13 / 20085: 26$ & 3.836 & 26. \\
\hline 4745 & $8 / 13 / 20085: 28$ & 3.843 & 26. \\
\hline 4746 & $85: 30$ & 3.826 & \\
\hline 4747 & $8 / 13 / 20085: 32$ & 3.836 & 26. \\
\hline 4748 & $85: 34$ & 3.826 & 26.8 \\
\hline 4749 & $85: 36$ & 3.83 & \\
\hline 4750 & $285: 38$ & 3.826 & 26. \\
\hline 4751 & $8 / 13 / 20085: 40$ & 3.83 & \\
\hline 4752 & $8 / 13 / 20085: 42$ & 3.826 & 26.8 \\
\hline 4753 & $085: 44$ & 3.827 & 27. \\
\hline 4754 & $85: 46$ & 3.823 & 26. \\
\hline 4755 & $85: 48$ & 3.819 & 26.8 \\
\hline 4756 & $85: 50$ & 3.83 & 26. \\
\hline 4757 & $85: 52$ & 3.863 & \\
\hline 4758 & $85: 54$ & 2.94 & 26.8 \\
\hline 4759 & $85: 56$ & 2.139 & 26. \\
\hline 4760 & $85: 58$ & 2.024 & 26. \\
\hline 4761 & $6: 00$ & 3.474 & 26. \\
\hline 4762 & $36: 02$ & 3.714 & 26. \\
\hline 4763 & $36: 04$ & 3.779 & 26. \\
\hline 4764 & $6: 06$ & 3.792 & 26 . \\
\hline 4765 & $6: 08$ & 3.803 & 26. \\
\hline 476 & $6: 10$ & 3.806 & 26. \\
\hline 4767 & & 3.833 & 26. \\
\hline & $6: 14$ & 3.847 & 26 \\
\hline & $6: 16$ & 3.837 & 26 \\
\hline 4770 & $6: 18$ & 3.863 & 26. \\
\hline 771 & $6: 20$ & 3.87 & 26. \\
\hline 477 & $6: 22$ & 3.856 & 26. \\
\hline & $6: 24$ & 3.846 & 26. \\
\hline 4 & $6: 26$ & 3.853 & 26. \\
\hline 4775 & $36: 28$ & 3.856 & \\
\hline & & & \\
\hline $47 !$ & & 3.8 & \\
\hline 477 & & 3.873 & 26. \\
\hline & & & \\
\hline 4780 & $36: 38$ & 3.894 & 26. \\
\hline & & 3.873 & \\
\hline 47 & & 3.887 & \\
\hline & & 3.897 & 26. \\
\hline & & & \\
\hline 4785 & $86: 48$ & 3.884 & \\
\hline & & 3.884 & 26. \\
\hline 478 & $86: 52$ & 3.887 & \\
\hline 4788 & $8 / 13 / 20086: 54$ & 3.86 & 26. \\
\hline & & 3.873 & \\
\hline 4790 & $8 / 13 / 20086: 58$ & 3.873 & 26. \\
\hline 4791 & $8 / 13 / 20$ & 3.88 & 26. \\
\hline & $887: 02$ & 3.88 & \\
\hline 4793 & $8 / 13 / 20087: 04$ & 3.867 & 26.6 \\
\hline 4794 & $8 / 13 / 20087: 06$ & 3.88 & \\
\hline
\end{tabular}


DOE/RL-2009-35, REV. 0

\begin{tabular}{|c|c|c|c|c|c|c|c|c|c|c|c|c|c|c|c|}
\hline \multicolumn{4}{|c|}{ D4-26p } & \multicolumn{4}{|c|}{ D4-26p } & \multicolumn{4}{|c|}{ D4-26p } & \multicolumn{4}{|c|}{ D4-26p } \\
\hline $\operatorname{Rec}$ & & Pres & Temp & $\operatorname{Rec}$ & & Pres & Temp & $\operatorname{Rec}$ & & Pres & Temp & $\operatorname{Rec}$ & & Pres & Temp \\
\hline$\#$ & Date/Time & psi & ${ }^{\circ} \mathrm{C}$ & $\#$ & Date/Time & psi & ${ }^{\circ} \mathrm{C}$ & $\#$ & Date/Time & psi & ${ }^{\circ} \mathrm{C}$ & $\#$ & Date/Time & psi & \\
\hline 4795 & $8 / 13 / 20087: 08$ & 3.867 & 26.6 & 4864 & $8 / 13 / 20089: 26$ & 3.897 & 27.1 & 4933 & $8 / 13 / 2008 \quad 11: 44$ & 4.117 & 29.5 & 5002 & $\begin{array}{l}8 / 13 / 200814: 02 \\
\end{array}$ & 4.112 & 30.8 \\
\hline 4796 & $8 / 13 / 20087: 10$ & 3.846 & 26.6 & 4865 & $8 / 13 / 20089: 28$ & 3.904 & 27.1 & 4934 & $8 / 13 / 200811: 46$ & 4.137 & 29.5 & 5003 & $8 / 13 / 2008 \quad 14: 04$ & 4.099 & 30.8 \\
\hline 4797 & \begin{tabular}{|l|}
$8 / 13 / 20087: 12$ \\
\end{tabular} & 3.887 & 26.6 & 4866 & $8 / 13 / 20089: 30$ & 3.904 & 27.1 & 4935 & $8 / 13 / 2008 \quad 11: 48$ & 4.151 & 29.6 & 5004 & $8 / 13 / 2008$ 14:06 & 4.112 & 30.8 \\
\hline 4798 & $8 / 13 / 20087: 14$ & 3.9 & 26.6 & 4867 & $8 / 13 / 20089: 32$ & 3.895 & 27.6 & 4936 & $8 / 13 / 200811: 50$ & 4.12 & 29.6 & 5005 & $8 / 13 / 200814: 08$ & 4.092 & 31 \\
\hline 4799 & $8 / 13 / 20087: 16$ & 3.88 & 26.6 & 4868 & $8 / 13 / 20089: 34$ & 3.898 & 27.2 & 4937 & $8 / 13 / 200811: 52$ & 4.131 & 29.6 & 5006 & $8 / 13 / 2008 \quad 14: 10$ & 4.095 & 30.8 \\
\hline 4800 & $8 / 13 / 20087: 18$ & 3.884 & 26.6 & 4869 & $8 / 13 / 20089: 36$ & 3.901 & 27.1 & 4938 & $8 / 13 / 200811: 54$ & 4.127 & 29.6 & 5007 & \begin{tabular}{|ll}
$8 / 13 / 2008 \quad 14: 12$ \\
\end{tabular} & 4.099 & 30.8 \\
\hline 4801 & $8 / 13 / 20087: 20$ & 3.877 & 26.6 & 4870 & $8 / 13 / 20089: 38$ & 3.911 & 27.1 & 4939 & $8 / 13 / 2008$ 11:56 & 4.141 & 29.6 & 5008 & $8 / 13 / 2008 \quad 14: 14$ & 4.075 & 30.7 \\
\hline 4802 & $8 / 13 / 20087: 22$ & 3.887 & 26.6 & 4871 & $8 / 13 / 20089: 40$ & 3.901 & 27.1 & 4940 & $8 / 13 / 200811: 58$ & 4.137 & 29.6 & 5009 & \begin{tabular}{|lll}
$8 / 13 / 2008$ & $14: 16$ \\
\end{tabular} & 4.088 & 30.7 \\
\hline 4803 & \begin{tabular}{|l|}
$8 / 13 / 20087: 24$ \\
\end{tabular} & 3.89 & 26.6 & 4872 & $8 / 13 / 20089: 42$ & 3.901 & 27.1 & 4941 & $8 / 13 / 2008$ 12:00 & 4.148 & 30 & 5010 & \begin{tabular}{|lll}
$8 / 13 / 2008$ & $14: 18$ \\
\end{tabular} & 4.075 & 30.7 \\
\hline 4804 & \begin{tabular}{|l|}
$8 / 13 / 20087: 26$ \\
\end{tabular} & 3.887 & 26.6 & 4873 & $8 / 13 / 20089: 44$ & 3.881 & 27.2 & 4942 & $8 / 13 / 2008$ 12:02 & 4.154 & 29.6 & 5011 & $8 / 13 / 200814: 20$ & 2.827 & 30.6 \\
\hline 4805 & \begin{tabular}{|l|}
$8 / 13 / 20087: 28$ \\
\end{tabular} & 3.877 & 26.6 & 4874 & $8 / 13 / 20089: 46$ & 3.908 & 27.2 & 4943 & $8 / 13 / 200812: 04$ & 4.168 & 29.6 & 5012 & $8 / 13 / 200814: 22$ & 2.212 & 30.6 \\
\hline 4806 & $8 / 13 / 20087: 30$ & 3.877 & 26.6 & 4875 & $8 / 13 / 20089: 48$ & 3.921 & 27.2 & 4944 & $8 / 13 / 200812: 06$ & 4.181 & 29.6 & 5013 & $8 / 13 / 200814: 24$ & 2.103 & 30.6 \\
\hline 4807 & $8 / 13 / 20087: 32$ & 3.907 & 26.6 & 4876 & $8 / 13 / 20089: 50$ & 3.898 & 27.2 & 4945 & $8 / 13 / 2008 \quad 12: 08$ & 4.168 & 29.6 & 5014 & $8 / 13 / 200814: 26$ & 3.779 & 31.3 \\
\hline 4808 & $8 / 13 / 20087: 34$ & 3.88 & 26.6 & 4877 & $8 / 13 / 20089: 52$ & 3.915 & 27.2 & 4946 & $8 / 13 / 200812: 10$ & 4.161 & 29.6 & 5015 & $8 / 13 / 200814: 28$ & 3.951 & 31.3 \\
\hline 4809 & $8 / 13 / 20087: 36$ & 3.87 & 26.6 & 4878 & $8 / 13 / 20089: 54$ & 3.908 & 27.2 & 4947 & $8 / 13 / 200812: 12$ & 4.148 & 29.6 & 5016 & $\begin{array}{|ll|}8 / 13 / 2008 & 14: 30 \\
\end{array}$ & 3.988 & 31.3 \\
\hline 4810 & \begin{tabular}{|l|}
$8 / 13 / 20087: 38$ \\
\end{tabular} & 3.884 & 26.6 & 4879 & $8 / 13 / 20089: 56$ & 3.904 & 27.2 & 4948 & $8 / 13 / 2008$ 12:14 & 4.151 & 29.6 & 5017 & $00814: 32$ & 4.056 & 31.3 \\
\hline 4811 & $8 / 13 / 20087: 40$ & 3.88 & 26.6 & 4880 & $8 / 13 / 20089: 58$ & 3.901 & 27.2 & 4949 & 8/13/2008 12:16 & 4.151 & 29.6 & 5018 & $00814: 34$ & 4.046 & 31.3 \\
\hline 4812 & $8 / 13 / 20087: 42$ & 3.89 & 26.6 & 4881 & $8 / 13 / 2008$ 10:00 & 3.904 & 27.3 & 4950 & $8 / 13 / 200812: 18$ & 4.161 & 29.7 & 5019 & $8814: 36$ & 4.059 & 31.3 \\
\hline 4813 & $0087: 44$ & 3.897 & 26.6 & 4882 & $8 / 13 / 2008$ 10:02 & 3.894 & 27.3 & 4951 & $8 / 13 / 200812: 20$ & 4.151 & 29.7 & 5020 & $0814: 38$ & 4.062 & \\
\hline 4814 & $8 / 13 / 20087: 46$ & 3.9 & 26.6 & 4883 & $8 / 13 / 2008 \quad 10: 04$ & 3.894 & 27.3 & 4952 & $8 / 13 / 200812: 22$ & 4.141 & 29.9 & 5021 & $8 / 13 / 2008 \quad 14: 40$ & 4.066 & 31.3 \\
\hline 4815 & $8 / 13 / 20087: 48$ & 3.88 & 26.6 & 4884 & $8 / 13 / 200810: 06$ & 3.915 & 27.3 & 4953 & $8 / 13 / 2008$ 12:24 & 4.144 & 29.8 & 5022 & $0814: 42$ & 4.066 & 31.3 \\
\hline 4816 & $8 / 13 / 20087: 50$ & 3.887 & 26.6 & 4885 & $8 / 13 / 2008 \quad 10: 08$ & 3.911 & 27.3 & 4954 & $8 / 13 / 2008$ 12:26 & 4.141 & 29.7 & 5023 & $814: 44$ & 4.096 & 31.3 \\
\hline 4817 & $0087: 52$ & 3.887 & 26.6 & 4886 & $8 / 13 / 2008$ 10:10 & 3.901 & 27.3 & 4955 & $8 / 13 / 2008$ 12:28 & 4.134 & 29.7 & 5024 & $8 / 13 / 2008$ 14:46 & 4.066 & 31.3 \\
\hline 4818 & $0087: 54$ & 3.89 & 26.6 & 4887 & $8 / 13 / 2008 \quad 10: 12$ & 3.901 & 27.3 & 4956 & $8 / 13 / 200812: 30$ & 4.148 & 29.7 & 5025 & $814: 48$ & 4.066 & 31.3 \\
\hline 4819 & $8 / 13 / 20087: 56$ & 3.877 & 26.6 & 4888 & $8 / 13 / 200810: 14$ & 3.911 & 27.3 & 4957 & $0812: 32$ & 4.134 & 29.7 & 5026 & $0814: 50$ & 4.059 & 31.3 \\
\hline 4820 & $8 / 13 / 20087: 58$ & 3.884 & 26.6 & 4889 & $8 / 13 / 2008$ 10:16 & 3.908 & 27.3 & 4958 & $8 / 13 / 200812: 34$ & 4.148 & 29.7 & 5027 & $0814: 52$ & 4.073 & 31.3 \\
\hline 4821 & $0088: 00$ & 3.897 & 26.6 & 4890 & $8 / 13 / 2008$ 10:18 & 3.915 & 27.3 & 4959 & $0812: 36$ & 4.127 & 29.7 & 5028 & $0814: 54$ & 4.052 & 31.3 \\
\hline 4822 & \begin{tabular}{|l|}
$8 / 13 / 20088: 02$ \\
\end{tabular} & 3.897 & 26.6 & 4891 & $8 / 13 / 200810: 20$ & 3.908 & 27.3 & 4960 & $8 / 13 / 2008 \quad 12: 38$ & 4.138 & 29.8 & 5029 & $8 / 13 / 2008 \quad 14: 56$ & 4.066 & 31.3 \\
\hline 4823 & $088: 04$ & 3.88 & 26.7 & 4892 & $8 / 13 / 200810: 22$ & 3.898 & 27.3 & 4961 & $8 / 13 / 2$ & 4.137 & 29.7 & 5030 & $\begin{array}{llll}08 & 14: 58\end{array}$ & 4.076 & 31.3 \\
\hline 4824 & $088: 06$ & 3.877 & 26.7 & 4893 & $8 / 13 / 2008 \quad 10: 24$ & 3.894 & 27.3 & 4962 & $8 / 13 / 2$ & 4.121 & 29.8 & 5031 & $315: 00$ & 4.069 & 31.3 \\
\hline 4825 & $088: 08$ & 3.884 & 26.7 & 4894 & $8 / 13 / 2008 \quad 10: 26$ & 3.911 & 27.3 & 4963 & $8 / 13 / 2$ & 4.127 & 29.8 & 5032 & 15:02 & 4.073 & 31.3 \\
\hline 4826 & $5088: 10$ & 3.873 & 26.7 & 4895 & $8 / 13 / 200810: 28$ & 3.888 & 27.3 & 4964 & $0812: 46$ & 4.127 & 29. & 5033 & $0815: 04$ & 4.073 & 31.3 \\
\hline 4827 & $0088: 12$ & 3.877 & 26.7 & 4896 & $8 / 13 / 2008 \quad 10: 30$ & 3.894 & 27.3 & 4965 & $8 / 13 / 200812: 48$ & 4.114 & 29.8 & 5034 & $8 / 13 / 2008$ 15:06 & 4.063 & 31.3 \\
\hline 4828 & $88: 14$ & 3.877 & 26.7 & 4897 & $8 / 13 / 200810: 32$ & 3.898 & 27.4 & 4966 & $812: 50$ & 4.117 & 29.8 & 5035 & $815: 08$ & 4.073 & 31.6 \\
\hline 4829 & $88: 16$ & 3.873 & 26.7 & 4898 & $8 / 13 / 2008 \quad 10: 34$ & 3.898 & 27.4 & 4967 & $312: 52$ & 4.107 & 29. & 5036 & $15: 10$ & 4.083 & 31.4 \\
\hline 4830 & $88: 18$ & 3.917 & 26.7 & 4899 & $8 / 13 / 2008 \quad 10: 36$ & 3.884 & 27.4 & 4968 & $12: 54$ & 4.111 & 29 . & 5037 & 15:12 & 4.076 & 31.3 \\
\hline 4831 & $8: 20$ & 3.904 & 26.7 & 4900 & $810: 38$ & 3.905 & 27.4 & 4969 & $12: 56$ & 4.117 & 29. & 5038 & $15: 14$ & 4.083 & 31.3 \\
\hline 4832 & $8 / 13 / 4$ & 3.928 & 26.6 & 4901 & $8 / 13 / 2008 \quad 10: 40$ & 3.901 & 27.4 & 4970 & $8 / 13 / 200812: 58$ & 4.111 & 29. & 5039 & $815: 16$ & 4.066 & 31.3 \\
\hline 4833 & $88: 24$ & 3.917 & 26.7 & 4902 & $8 / 13 / 200810: 42$ & 3.915 & 27.4 & 4971 & $813: 00$ & 4.107 & 29. & 5040 & $8 / 13$ & 4.063 & 31.3 \\
\hline 4834 & $8: 26$ & 3.914 & 26.7 & 4903 & $810: 44$ & 3.918 & 27.4 & 4972 & 13:02 & 4.131 & 29. & 5041 & $815: 20$ & 4.059 & 31.4 \\
\hline 4835 & $38: 28$ & 3.921 & 26.7 & 4904 & $810: 46$ & 3.891 & 27.5 & 4973 & $3: 04$ & 4.104 & 29 & 5042 & 15:22 & 4.07 & 31.4 \\
\hline 4836 & $8: 30$ & 3.924 & 26.7 & 4905 & $10: 48$ & 3.946 & 27.8 & 4974 & $8 / 1$ & 4.107 & 29.8 & 5043 & $5: 24$ & 4.087 & 31.5 \\
\hline 4837 & $088: 32$ & 3.907 & 26.7 & 4906 & $8 / 13 / 2008$ 10:50 & 4.003 & 28 & 4975 & $8 / 13 / 200813: 08$ & 4.097 & 30 & 5044 & $0815: 26$ & 4.09 & 31.5 \\
\hline 4838 & $8 / 13$ & 3.904 & 26.7 & 4907 & $8 / 13 / 2008$ 10:52 & 4.047 & 28.1 & 4976 & $0813: 10$ & 4.094 & 29.9 & 5045 & & 4.09 & 31.7 \\
\hline 4839 & $8: 36$ & 3.901 & 26.7 & 4908 & $810: 54$ & 4.044 & 28.4 & 4977 & $13: 12$ & 4.09 & 29. & 5046 & $815: 30$ & 4.1 & 31.7 \\
\hline 4840 & $8 / 13$ & 3.901 & 27. & 4909 & $810: 56$ & 4.081 & 28.2 & 4978 & $3: 14$ & 4.094 & 29 . & 5047 & & 4.111 & 31.6 \\
\hline 4841 & \begin{tabular}{|l|l|}
$8 / 13$ \\
\end{tabular} & 3.907 & 26. & 4910 & $810: 58$ & 4.095 & 28.1 & 4979 & & 4.09 & 29 & 5048 & & 4.097 & 31.6 \\
\hline 4842 & $88: 42$ & 2.396 & 26.8 & 4911 & $811: 00$ & 4.102 & 28.1 & 4980 & $813: 18$ & 4.09 & 29.8 & 5049 & $815: 36$ & 4.1 & 31.6 \\
\hline 4843 & $88: 44$ & 2.125 & 26.7 & 4912 & $811: 02$ & 4.105 & 28.1 & 4981 & $313: 20$ & 4.087 & 29. & 5050 & & 4.104 & 31.6 \\
\hline 4844 & $8: 46$ & 2.027 & 26.8 & 4913 & $8 / 13 / 200811: 04$ & 4.115 & 28.1 & 4982 & $313: 22$ & 4.08 & 29 . & 5051 & 08 15:40 & 4.117 & 31.6 \\
\hline 4845 & $8: 48$ & 1.966 & 26. & 4914 & $811: 06$ & 4.091 & 28.1 & 4983 & $3: 24$ & 4.09 & 29 & 5052 & & 4.104 & 31.6 \\
\hline 4846 & & 3.613 & 26.9 & 4915 & & 4.085 & 28.1 & 4984 & & 4.087 & 29 & & & 4.104 & \\
\hline 4847 & $0088: 52$ & 3.755 & 26.9 & 4916 & $811: 10$ & 4.098 & 28.1 & 4985 & $0813: 28$ & 4.101 & 29.9 & 5054 & $815: 46$ & 4.093 & 31.6 \\
\hline 4848 & $8 / 13$ & 3.813 & 26.9 & 4917 & $811: 12$ & 4.081 & 28.1 & 4986 & & & 29 & 5055 & & 4.117 & 31.6 \\
\hline 4849 & 8.56 & 3.826 & 27 & 4918 & $811: 14$ & 4.071 & 28.1 & 4987 & 13:32 & 4.111 & 29 & 5056 & $15: 50$ & 4.097 & 31.6 \\
\hline 4850 & $38: 58$ & 3.847 & 27 & 4919 & $811: 16$ & 4.064 & 28.1 & 4988 & $3: 34$ & 4.063 & 29. & 5057 & $15: 52$ & 4.1 & 31.6 \\
\hline 4851 & & 3.833 & 27 & & & 4.054 & 28.3 & 4989 & & & 29 & 5058 & & 4.124 & \\
\hline 4852 & \begin{tabular}{|l|}
$8 / 13 / 20089: 02$ \\
\end{tabular} & 3.826 & 27 & 4921 & $811: 20$ & 4.058 & 28.1 & 4990 & $813: 38$ & 4.084 & 29. & 5059 & $30815: 56$ & 4.1 & 31.6 \\
\hline 4853 & $0089: 04$ & 3.82 & 27 & 4922 & $8 / 13 / 200811: 22$ & 3.679 & 28.1 & 4991 & $813: 40$ & 4.053 & 29. & 5060 & & 4.1 & 31.6 \\
\hline 4854 & $89: 06$ & 3.803 & 27 & 4923 & $8 / 13 / 2008 \quad 11: 24$ & 3.158 & 28.3 & 4992 & $813: 42$ & 4.074 & 30. & 5061 & $16: 00$ & 4.09 & \\
\hline 4855 & $8 / 13 /$ & 3.813 & 27 & 4924 & $8 / 13 / 2008$ 11:26 & 2.854 & 28.8 & 4993 & $313: 44$ & 4.068 & 30.6 & 5062 & $0816: 02$ & 4.107 & 31.6 \\
\hline 4856 & & 3.833 & 27 & 4925 & & 2.236 & 29.1 & 4994 & & 4.112 & 30 & & & 4.094 & \\
\hline 4857 & \begin{tabular}{|l|}
$8 / 13 / 20089: 12$ \\
\end{tabular} & 3.864 & 27.1 & 4926 & $8 / 13 / 2008$ 11:30 & 2.838 & 29.2 & 4995 & $0813: 48$ & 4.122 & 30.8 & 5064 & $16: 06$ & 4.104 & 31.6 \\
\hline 4858 & $8 / 13 / 20089: 14$ & 3.864 & 27.1 & 4927 & $8 / 13 / 2008+1: 32$ & 4.111 & 29.8 & 4996 & $8 / 13 / 200813: 50$ & 4.13 & 31.1 & 5065 & & 4.097 & 31.6 \\
\hline 4859 & & 3.881 & 27.1 & 4928 & & 4.168 & 29.6 & 4997 & & 4.122 & 30 & 5066 & & 4.1 & \\
\hline 4860 & \begin{tabular}{|l|}
$8 / 13 / 20089: 18$ \\
\end{tabular} & 3.891 & 27.1 & 4929 & $8 / 13 / 200811: 36$ & 4.134 & 29.5 & 4998 & $8 / 13 / 200813: 54$ & 4.129 & 30.8 & \begin{tabular}{|l|}
5067 \\
\end{tabular} & $\begin{array}{|ll|}8 / 13 / 2008 & 16: 12 \\
\end{array}$ & 4.083 & 31.6 \\
\hline 4861 & \begin{tabular}{|l|}
$8 / 13 / 20089: 20$ \\
\end{tabular} & 3.904 & 27.1 & 4930 & $8 / 13 / 2008$ 11:38 & 4.13 & 29.5 & 4999 & $813: 56$ & 4.122 & 30. & 5068 & $816: 14$ & 4.104 & 31.6 \\
\hline 4862 & \begin{tabular}{|l|}
$8 / 13 / 20089: 22$ \\
\end{tabular} & 3.884 & 27.1 & 4931 & $8 / 13 / 200811: 40$ & 4.127 & 29.5 & 5000 & $0813: 58$ & 4.133 & 30. & 5069 & & 4.094 & 31.6 \\
\hline 4863 & \begin{tabular}{|l|}
$8 / 13 / 20089: 24$ \\
\end{tabular} & 3.887 & 27.1 & 4932 & $8 / 13 / 2008 \quad 11: 42$ & 4.127 & 29.5 & 5001 & $8 / 13 / 200814: 00$ & 4.126 & 30.8 & 5070 & $8 / 13 / 2008 \quad 16: 18$ & 4.097 & 31.6 \\
\hline
\end{tabular}




\begin{tabular}{|c|c|c|c|}
\hline \multicolumn{4}{|c|}{ D4-26p } \\
\hline $\operatorname{Rec}$ & & Pres & Temp \\
\hline$\#$ & Date/Time & psi & ${ }^{\circ} \mathrm{C}$ \\
\hline 5071 & $8 / 13 / 200816: 20$ & 4.104 & 31.6 \\
\hline 5072 & $8 / 13 / 200816: 22$ & 4.087 & 31.6 \\
\hline 5073 & $8 / 13 / 200816: 24$ & 4.094 & 31.6 \\
\hline 5074 & $8 / 13 / 2008$ 16:26 & 4.1 & 31.7 \\
\hline 5075 & $8 / 13 / 200816: 28$ & 4.108 & 31.8 \\
\hline 5076 & $8 / 13 / 2008$ 16:30 & 4.121 & 31.9 \\
\hline 5077 & $8 / 13 / 200816: 32$ & 4.169 & 32.3 \\
\hline 5078 & $8 / 13 / 2008$ 16:34 & 4.145 & 32.1 \\
\hline 5079 & $8 / 13 / 200816: 36$ & 4.183 & 32.1 \\
\hline 5080 & $8 / 13 / 200816: 38$ & 4.189 & 32.2 \\
\hline 5081 & $8 / 13 / 200816: 40$ & 4.223 & 32.2 \\
\hline 5082 & $8 / 13 / 200816: 42$ & 4.22 & 32.3 \\
\hline 5083 & $8 / 13 / 2008 \quad 16: 44$ & 4.254 & 32.3 \\
\hline 5084 & $8 / 13 / 200816: 46$ & 4.24 & 32.2 \\
\hline 5085 & $8 / 13 / 200816: 48$ & 4.254 & 32.2 \\
\hline 5086 & $8 / 13 / 200816: 50$ & 4.25 & 32.2 \\
\hline 5087 & $8 / 13 / 200816: 52$ & 4.233 & 32.2 \\
\hline 5088 & $8 / 13 / 200816: 54$ & 4.244 & 32.2 \\
\hline 5089 & $8 / 13 / 200816: 56$ & 4.233 & 32.2 \\
\hline 5090 & $8 / 13 / 200816: 58$ & 4.21 & 32.2 \\
\hline 5091 & $8 / 13 / 200817: 00$ & 4.213 & 32.1 \\
\hline 5092 & $8 / 13 / 200817: 02$ & 4.203 & 32.1 \\
\hline 5093 & $8 / 13 / 200817: 04$ & 4.193 & 32.4 \\
\hline 5094 & $8 / 13 / 2008$ 17:06 & 3.635 & 32.1 \\
\hline 5095 & $8 / 13 / 200817: 08$ & 2.627 & 32.1 \\
\hline 5096 & $8 / 13 / 200817: 10$ & 3.903 & 32.6 \\
\hline 5097 & $8 / 13 / 200817: 12$ & 4.078 & 32.2 \\
\hline 5098 & $8 / 13 / 200817: 14$ & 4.135 & 32 \\
\hline 5099 & $8 / 13 / 200817: 16$ & 4.138 & 32 \\
\hline 5100 & $8 / 13 / 200817: 18$ & 4.162 & 32 \\
\hline 5101 & $8 / 13 / 200817: 20$ & 4.162 & 32 \\
\hline 5102 & $8 / 13 / 200817: 22$ & 4.169 & 32 \\
\hline 5103 & $8 / 13 / 200817: 24$ & 4.182 & 32.1 \\
\hline 5104 & $8 / 13 / 200817: 26$ & 4.179 & 32.1 \\
\hline 5105 & $8 / 13 / 200817: 28$ & 4.196 & 32.1 \\
\hline 5106 & $8 / 13 / 2008$ 17:30 & 4.199 & 32.1 \\
\hline 5107 & $8 / 13 / 2008$ 17:32 & 4.203 & 32.1 \\
\hline 5108 & $8 / 13 / 200817: 34$ & 4.203 & 32.1 \\
\hline 5109 & $8 / 13 / 200817: 36$ & 4.216 & 32.1 \\
\hline 5110 & $8 / 13 / 200817: 38$ & 4.209 & 32.1 \\
\hline 5111 & $8 / 13 / 200817: 40$ & 4.223 & 32.1 \\
\hline 5112 & $8 / 13 / 200817: 42$ & 4.206 & 32.1 \\
\hline 5113 & $8 / 13 / 200817: 44$ & 4.23 & 32.1 \\
\hline 5114 & $8 / 13 / 200817: 46$ & 4.237 & 32.1 \\
\hline 5115 & $8 / 13 / 200817: 48$ & 4.227 & 32.1 \\
\hline 5116 & $8 / 13 / 200817: 50$ & 4.227 & 32.2 \\
\hline 5117 & $8 / 13 / 200817: 52$ & 4.22 & 32.2 \\
\hline 5118 & $8 / 13 / 200817: 54$ & 4.24 & $\overline{32.2}$ \\
\hline 5119 & $8 / 13 / 200817: 56$ & 4.24 & 32.2 \\
\hline 5120 & $8 / 13 / 200817: 58$ & 4.233 & 32.2 \\
\hline 5121 & $8 / 13 / 200818: 00$ & 4.237 & 32.2 \\
\hline 5122 & $8 / 13 / 200818: 02$ & 4.237 & 32.2 \\
\hline 5123 & $8 / 13 / 200818: 04$ & 4.237 & 32.2 \\
\hline 5124 & $8 / 13 / 200818: 06$ & 4.251 & 32.4 \\
\hline 5125 & $8 / 13 / 200818: 08$ & 4.254 & 32.3 \\
\hline 5126 & $8 / 13 / 2008$ 18:10 & 4.22 & 32.3 \\
\hline 5127 & $8 / 13 / 2008$ 18:12 & 4.244 & 32.3 \\
\hline 5128 & $8 / 13 / 200818: 14$ & 4.25 & 32.3 \\
\hline 5129 & $8 / 13 / 200818: 16$ & 4.244 & 32.3 \\
\hline 5130 & $8 / 13 / 200818: 18$ & 4.24 & 32.3 \\
\hline 5131 & $8 / 13 / 2008$ 18:20 & 4.251 & 32.3 \\
\hline 5132 & $8 / 13 / 200818: 22$ & 4.247 & 32.3 \\
\hline 5133 & $8 / 13 / 200818: 24$ & 4.24 & 32.3 \\
\hline 5134 & $8 / 13 / 200818: 26$ & 4.254 & 32.3 \\
\hline 5135 & $8 / 13 / 200818: 28$ & 4.247 & 32.3 \\
\hline 5136 & $8 / 13 / 200818: 30$ & 4.254 & 32.4 \\
\hline 5137 & $8 / 13 / 200818: 32$ & 4.254 & 32.4 \\
\hline 5138 & $8 / 13 / 200818: 34$ & 4.284 & 32.3 \\
\hline 5139 & $8 / 13 / 200818: 36$ & 4.278 & 32.3 \\
\hline
\end{tabular}

\begin{tabular}{|c|c|c|c|}
\hline \multicolumn{4}{|c|}{ D4-26p } \\
\hline $\operatorname{Rec}$ & & Pres & Temp \\
\hline \# & Date/Time & psi & ${ }^{\circ} \mathrm{C}$ \\
\hline 5140 & $8 / 13 / 200818: 38$ & 4.278 & 32.3 \\
\hline 5141 & $8 / 13 / 2008$ 18:40 & 4.274 & 32.4 \\
\hline 5142 & $8 / 13 / 2008$ 18:42 & 4.274 & 32.4 \\
\hline$\overline{5143}$ & $8 / 13 / 200818: 44$ & 4.281 & 32.4 \\
\hline 5144 & $8 / 13 / 200818: 46$ & 4.271 & 32.4 \\
\hline 5145 & $8 / 13 / 200818: 48$ & 4.278 & 32.4 \\
\hline 5146 & $8 / 13 / 200818: 50$ & 4.271 & 32.4 \\
\hline 5147 & $8 / 13 / 2008$ 18:52 & 4.271 & 32.4 \\
\hline 5148 & $8 / 13 / 200818: 54$ & 4.288 & 32.4 \\
\hline 5149 & $8 / 13 / 200818: 56$ & 4.295 & 32.4 \\
\hline 5150 & $8 / 13 / 200818: 58$ & 4.288 & 32.4 \\
\hline 5151 & $8 / 13 / 200819: 00$ & 4.298 & 32.4 \\
\hline 5152 & $8 / 13 / 200819: 02$ & 4.285 & 32.4 \\
\hline 5153 & $8 / 13 / 200819: 04$ & 4.291 & 32.4 \\
\hline 5154 & $8 / 13 / 2008 \quad 19: 06$ & 4.302 & 32.5 \\
\hline 5155 & $8 / 13 / 2008$ 19:08 & 4.298 & 32.4 \\
\hline 5156 & $8 / 13 / 2008$ 19:10 & 4.336 & 32.5 \\
\hline 5157 & $8 / 13 / 2008$ 19:12 & 4.312 & 32.5 \\
\hline 5158 & $8 / 13 / 200819: 14$ & 4.329 & 32.8 \\
\hline 5159 & $8 / 13 / 200819: 16$ & 4.329 & 32.6 \\
\hline 5160 & $8 / 13 / 200819: 18$ & 4.315 & 32.5 \\
\hline 5161 & $8 / 13 / 200819: 20$ & 4.315 & 32.6 \\
\hline 5162 & $8 / 13 / 200819: 22$ & 4.353 & 32.6 \\
\hline 5163 & $8 / 13 / 2008 \quad 19: 24$ & 4.353 & 32.6 \\
\hline 5164 & $8 / 13 / 2008 \quad 19: 26$ & 4.359 & 32.6 \\
\hline 5165 & $8 / 13 / 200819: 28$ & 4.346 & 32.6 \\
\hline 5166 & $8 / 13 / 200819: 30$ & 4.356 & 32.6 \\
\hline 5167 & $8 / 13 / 200819: 32$ & 4.383 & 32.6 \\
\hline 5168 & $8 / 13 / 2008 \quad 19: 34$ & 4.369 & 32.6 \\
\hline 5169 & $8 / 13 / 200819: 36$ & 4.414 & 32.6 \\
\hline 5170 & $8 / 13 / 2$ & 4.393 & 32.6 \\
\hline 5171 & $8 / 13 / 20$ & 4.397 & 32.6 \\
\hline 5172 & $8 / 13 / 20$ & 4.403 & 32.6 \\
\hline 5173 & $819: 44$ & 4.407 & 32.6 \\
\hline 5174 & $0819: 46$ & 4.431 & 33 \\
\hline 5175 & 8 19:48 & 4.478 & 32.7 \\
\hline 5176 & $8 / 13 / 20$ & 4.484 & 32.6 \\
\hline 5177 & $8 / 13 / 2$ & 4.491 & 32.6 \\
\hline 5178 & $8 / 13 / 2$ & 3.747 & 32.6 \\
\hline 5179 & $8 / 13 / 2008 \quad 19: 56$ & 3.558 & 32.6 \\
\hline 5180 & $8 / 13 / 2008$ 19:58 & 3.457 & 32.7 \\
\hline 5181 & $0820: 00$ & 3.43 & 32.9 \\
\hline 5182 & & 3.531 & 32.6 \\
\hline 5183 & $320: 04$ & 2.935 & 32.3 \\
\hline 5184 & $8 / 13 / 200820: 06$ & 2.617 & 32.2 \\
\hline 5185 & $8 / 13 / 200820: 08$ & 4.331 & 32.2 \\
\hline 5186 & $0820: 10$ & 4.669 & 31.8 \\
\hline & $820: 12$ & 4.73 & 31.9 \\
\hline 518 & $20: 14$ & 4.649 & 31.8 \\
\hline 5189 & $0820: 16$ & 4.554 & 31.7 \\
\hline 5190 & & 4.527 & 31.7 \\
\hline 5191 & $8 / 13 / 200820: 20$ & 4.489 & 31.7 \\
\hline 5192 & & 4.486 & 31.2 \\
\hline 519 & $20: 24$ & 4.476 & 31.7 \\
\hline 5194 & $8 / 13 / 200820: 26$ & 4.466 & 31.7 \\
\hline 5195 & $8 / 13 / 200820: 28$ & 4.456 & 31.7 \\
\hline 5196 & $8 / 13 / 200820: 30$ & 4.442 & 31.7 \\
\hline 5197 & $820: 32$ & 4.442 & 31.8 \\
\hline & & 4.432 & 31.7 \\
\hline 5199 & $8 / 13 / 200820: 36$ & 4.429 & 32 \\
\hline 5200 & $8 / 13 / 200820: 38$ & 4.425 & 31.8 \\
\hline 5201 & $8 / 13 / 200820: 40$ & 4.442 & 31.8 \\
\hline 5202 & $8 / 13 / 200820: 42$ & 4.446 & 32.1 \\
\hline 5203 & & 4.452 & 31.8 \\
\hline 5204 & $8 / 13 / 200820: 46$ & 4.466 & 31.8 \\
\hline 5205 & $8 / 13 / 200820: 48$ & 4.466 & 31.7 \\
\hline 5206 & $8 / 13 / 200820: 50$ & 4.473 & 31. \\
\hline 5207 & $8 / 13 / 200820: 52$ & 4.466 & 31.8 \\
\hline 5208 & $8 / 13 / 200820: 54$ & 4.466 & 31. \\
\hline
\end{tabular}

\begin{tabular}{|c|c|c|c|}
\hline \multicolumn{4}{|c|}{ D4-26p } \\
\hline $\operatorname{Rec}$ & & Pres & Temp \\
\hline$\#$ & Date/Time & psi & ${ }^{\circ} \mathrm{C}$ \\
\hline 5209 & $8 / 13 / 200820: 56$ & 4.473 & 31.8 \\
\hline 5210 & $8 / 13 / 200820: 58$ & 4.476 & \\
\hline 5211 & $13 / 200821: 00$ & 4.486 & 31.8 \\
\hline 5212 & $8 / 13 / 200821: 02$ & 4.479 & 31.8 \\
\hline 5213 & $8 / 13 / 200821: 04$ & 4.489 & 31.8 \\
\hline 5214 & $8 / 13 / 200821: 06$ & 4.503 & 31.7 \\
\hline 5215 & $8 / 13 / 200821: 08$ & 4.483 & 31.7 \\
\hline 5216 & $8 / 13 / 200821: 10$ & 4.466 & 31.7 \\
\hline 5217 & $8 / 13 / 200821: 12$ & 4.479 & 31.7 \\
\hline 5218 & $8 / 13 / 2008$ 21:14 & 4.496 & \\
\hline 5219 & $8 / 13 / 200821: 16$ & 4.503 & 31.9 \\
\hline 5220 & $13 / 200821: 18$ & 4.5 & $\overline{31.8}$ \\
\hline & $13 / 200821: 20$ & 4.51 & \\
\hline 5222 & $8 / 13 / 200821: 22$ & 4.496 & 31.6 \\
\hline 5223 & $13 / 200821: 24$ & 4.472 & 31.6 \\
\hline 5224 & $13 / 200821: 26$ & 4.489 & \\
\hline 5225 & 13/2008 21:28 & 4.503 & 31.7 \\
\hline 5226 & $321: 30$ & 4.531 & $\overline{32.1}$ \\
\hline 5227 & $13 / 200821: 32$ & 4.54 & \\
\hline 5228 & $13 / 200821: 34$ & 4.567 & 31.7 \\
\hline 5229 & $821: 36$ & 4.57 & 31.6 \\
\hline 5230 & $8 / 13 / 200821: 38$ & 4.57 & 31.6 \\
\hline 5231 & $13 / 200821: 40$ & 4.553 & 31.6 \\
\hline 5232 & $821: 42$ & 4.574 & \\
\hline 5233 & $8 / 13 / 200821: 44$ & 4.56 & 31.5 \\
\hline 5234 & $321: 46$ & 4.574 & 31.5 \\
\hline 5235 & $321: 48$ & 4.587 & $\overline{31.4}$ \\
\hline 5236 & $821: 50$ & 4.587 & 31.4 \\
\hline 5237 & $821: 52$ & 4.58 & $\overline{31.4}$ \\
\hline 5238 & $8 / 13 / 20$ & 4.57 & 31.4 \\
\hline 5239 & $21: 56$ & 4.553 & $\overline{31.4}$ \\
\hline 5240 & $21: 58$ & 4.556 & 31.4 \\
\hline 5241 & $322: 00$ & 4.526 & 31.3 \\
\hline 5242 & $22: 02$ & 3.89 & 31.3 \\
\hline 5243 & $322: 04$ & 2.473 & 31.1 \\
\hline 5244 & $322: 06$ & 2.141 & 31 \\
\hline 5245 & 22:08 & 1.999 & 31 \\
\hline 5246 & $22: 10$ & 1.911 & 31. \\
\hline 5247 & $2: 12$ & 1.854 & 31. \\
\hline 5248 & $22: 14$ & 1.81 & 31. \\
\hline 5249 & $22: 16$ & 1.7 & 31.1 \\
\hline 5250 & $22: 18$ & 1.7 & 31 \\
\hline 5251 & $22: 20$ & 1.773 & 31 \\
\hline 5252 & $22: 22$ & 1.76 & 31.1 \\
\hline 5253 & $22: 24$ & 1.7 & 31. \\
\hline 5254 & & 1.74 & 31.1 \\
\hline 5255 & $22: 28$ & 1.7 & \\
\hline 5256 & $322: 30$ & 1.733 & 31.6 \\
\hline 5257 & & & \\
\hline 5258 & $22: 34$ & 1.7 & 31. \\
\hline 5259 & & & 31.1 \\
\hline 5260 & 2.20 & & \\
\hline 526 & $22: 40$ & & 31. \\
\hline 5262 & & & \\
\hline 5263 & $22: 44$ & 1.7 & \\
\hline 5264 & & 1.71 & 31.6 \\
\hline 526 & & & \\
\hline 5266 & $322: 50$ & 1.712 & 31. \\
\hline 5267 & & & \\
\hline 5268 & $22: 54$ & & \\
\hline 5269 & $22: 56$ & 1.712 & 31. \\
\hline & & & \\
\hline 5271 & $323: 00$ & & $\sqrt{31}$ \\
\hline 5272 & & & \\
\hline 5273 & & & \\
\hline 527 & $323: 06$ & 1.7 & \\
\hline 5275 & & 1.702 & \\
\hline 5276 & & & \\
\hline 527 & & & \\
\hline
\end{tabular}

\begin{tabular}{|c|c|c|c|}
\hline \multicolumn{4}{|c|}{ D4-26p } \\
\hline$\overline{\operatorname{Rec}}$ & & Pres & Temp \\
\hline$\#$ & Date/Time & psi & ${ }^{\circ} \mathrm{C}$ \\
\hline 5278 & $8 / 13 / 200823: 14$ & 1.698 & 30.9 \\
\hline 5279 & $8 / 13 / 200823: 16$ & 1.698 & 30.9 \\
\hline 5280 & \begin{tabular}{|l|}
$8 / 13 / 200823: 18$ \\
\end{tabular} & 1.702 & 30.9 \\
\hline 5281 & $8 / 13 / 200823: 20$ & 1.698 & 30.9 \\
\hline 5282 & $8 / 13 / 200823: 22$ & 1.695 & 30.9 \\
\hline 5283 & $8 / 13 / 200823: 24$ & 1.691 & 30.9 \\
\hline 5284 & $8 / 13 / 200823: 26$ & 1.691 & 30.9 \\
\hline 5285 & $8 / 13 / 200823: 28$ & 1.691 & 30.9 \\
\hline 5286 & $8 / 13 / 200823: 30$ & 1.691 & 30.9 \\
\hline 5287 & $8 / 13 / 200823: 32$ & 1.691 & 30.9 \\
\hline 5288 & $8 / 13 / 200823: 34$ & 1.685 & 30.9 \\
\hline 5289 & $8 / 13 / 200823: 36$ & 1.685 & 30.9 \\
\hline 5290 & $8 / 13 / 200823: 38$ & 1.685 & 30.9 \\
\hline 5291 & $8 / 13 / 200823: 40$ & 1.685 & 30.9 \\
\hline 5292 & $8 / 13 / 200823: 42$ & 1.684 & 30.9 \\
\hline 5293 & $8 / 13 / 200823: 44$ & 1.674 & \\
\hline 5294 & $8 / 13 / 200823: 46$ & 1.671 & 30.9 \\
\hline 5295 & $8 / 13 / 200823: 48$ & 1.678 & 30.9 \\
\hline 5296 & $8 / 13 / 200823: 50$ & 1.674 & 30.9 \\
\hline 5297 & $8 / 13 / 200823: 52$ & 1.671 & 30.9 \\
\hline 5298 & $8 / 13 / 200823: 54$ & 1.671 & 30.9 \\
\hline 5299 & $8 / 13 / 200823: 56$ & 1.664 & 30.9 \\
\hline 5300 & \begin{tabular}{|l}
$8 / 13 / 200823: 58$ \\
\end{tabular} & 1.664 & 30.9 \\
\hline 5301 & $8 / 14 / 20080: 00$ & 1.661 & 30.9 \\
\hline 5302 & $8 / 14 / 20080: 02$ & 1.657 & 30.9 \\
\hline 5303 & $8 / 14 / 20080: 04$ & 1.657 & 30.9 \\
\hline 5304 & $8 / 14 / 20080: 06$ & 1.657 & 30.9 \\
\hline 5305 & $8 / 14 / 20080: 08$ & 1.654 & 30.9 \\
\hline 5306 & $8 / 14 / 20080: 10$ & 1.651 & 30.8 \\
\hline 5307 & $8 / 14 / 20080: 12$ & 1.651 & 30.9 \\
\hline 5308 & $8 / 14 / 20080: 14$ & 1.651 & 30.9 \\
\hline 5309 & $8 / 14 / 20080: 16$ & 1.644 & 30.9 \\
\hline 5310 & $8 / 14 / 20080: 18$ & 1.644 & 30.8 \\
\hline 5311 & $8 / 14 / 20080: 20$ & 1.644 & 30.8 \\
\hline 5312 & $8 / 14 / 20080: 22$ & 1.647 & 30.8 \\
\hline 5313 & $8 / 14 / 20080: 24$ & 1.644 & 30.8 \\
\hline 5314 & $8 / 14 / 20080: 26$ & 1.644 & 30.8 \\
\hline 5315 & $8 / 14 / 20080: 28$ & 1.64 & 30.8 \\
\hline 5316 & $8 / 14 / 20080: 30$ & 1.637 & 30.8 \\
\hline 5317 & $8 / 14 / 20080: 32$ & 1.634 & 30.8 \\
\hline 5318 & $8 / 14 / 20080: 34$ & .1 .634 & 30.8 \\
\hline 5319 & $8 / 14 / 20080: 36$ & 1.63 & 30.8 \\
\hline 5320 & $8 / 14 / 20080: 38$ & 1,63 & 30.8 \\
\hline 5321 & $8 / 14 / 20080: 40$ & 1.63 & 30.8 \\
\hline 5322 & $8 / 14 / 20080: 42$ & 1.627 & 30.8 \\
\hline 5323 & $8 / 14 / 20080: 44$ & 1.63 & 30.8 \\
\hline 5324 & $8 / 14 / 20080: 46$ & 1.627 & 30.8 \\
\hline 5325 & $8 / 14 / 20080: 48$ & 1.627 & 30.8 \\
\hline 5326 & $8 / 14 / 20080: 50$ & 1.627 & 30.8 \\
\hline 5327 & $8 / 14 / 20080: 52$ & 1.62 & 30.8 \\
\hline 5328 & $8 / 14 / 20080: 54$ & 1.62 & 30.8 \\
\hline 5329 & $8 / 14 / 20080: 56$ & 1.617 & 30.7 \\
\hline 5330 & $8 / 14 / 20080: 58$ & 1.617 & 30.7 \\
\hline 5331 & $8 / 14 / 20081: 00$ & 1.617 & 30.7 \\
\hline 5332 & $8 / 14 / 20081: 02$ & 1.613 & 30.7 \\
\hline 5333 & 8/14/2008 1:04 & 1.613 & 30.7 \\
\hline 5334 & $8 / 14 / 20081: 06$ & 1.613 & 30.7 \\
\hline 5335 & $8 / 14 / 20081: 08$ & 1.61 & 30.7 \\
\hline 5336 & $8 / 14 / 20081: 10$ & 1.61 & 30.7 \\
\hline 5337 & $8 / 14 / 20081: 12$ & 1.61 & 30.7 \\
\hline 5338 & $8 / 14 / 20081: 14$ & 1.606 & 30.6 \\
\hline 5339 & $8 / 14 / 20081: 16$ & 1.606 & \\
\hline 5340 & $8 / 14 / 20081: 18$ & 1.606 & 30.6 \\
\hline 5341 & $8 / 14 / 20081: 20$ & 1.603 & 30.6 \\
\hline 5342 & $8 / 14 / 20081: 22$ & 1.599 & 30.6 \\
\hline 5343 & $8 / 14 / 20081: 24$ & 1.596 & 30.6 \\
\hline$\overline{5344}$ & $8 / 14 / 20081: 26$ & 1.596 & 30.6 \\
\hline 5345 & $8 / 14 / 20081: 28$ & 1.582 & 30.6 \\
\hline 5346 & $8 / 14 / 20081: 30$ & 1.586 & 30.6 \\
\hline
\end{tabular}




\begin{tabular}{|c|c|c|c|c|c|c|c|c|c|c|c|c|c|c|c|}
\hline \multicolumn{4}{|c|}{ D4-26p } & \multicolumn{4}{|c|}{ D4-26p } & \multicolumn{4}{|c|}{ D4-26p } & \multicolumn{4}{|c|}{ D4-26p } \\
\hline $\operatorname{Rec}$ & & Pres & Temp & $\operatorname{Rec}$ & & Pres & Temp & $\operatorname{Rec}$ & & Pres & Temp & Rec & & Pres & Temp \\
\hline$\#$ & Date/Time & psi & ${ }^{\circ} \mathrm{C}$ & $\#$ & Date/Time & psi & ${ }^{\circ} \mathrm{C}$ & $\#$ & Date/Time & psi & ${ }^{\circ} \mathrm{C}$ & $\#$ & Date/Time & psi & ${ }^{\circ} \mathrm{C}$ \\
\hline 5347 & $8 / 14 / 20081: 32$ & 1.589 & 30.6 & 5416 & $8 / 14 / 20083: 50$ & 1.544 & 30 & 5485 & $8 / 14 / 20086: 08$ & 1.486 & 29.4 & 5554 & $8 / 14 / 20088: 26$ & 1.458 & 29.1 \\
\hline 5348 & $8 / 14 / 20081: 34$ & 1.589 & 30.6 & 5417 & $8 / 14 / 20083: 52$ & 1.544 & 30 & 5486 & $8 / 14 / 20086: 10$ & 1.486 & 29.4 & 5555 & $8 / 14 / 20088: 28$ & 1.455 & 29.1 \\
\hline 5349 & $8 / 14 / 20081: 36$ & 1.589 & 30.6 & 5418 & $8 / 14 / 20083: 54$ & 1.541 & 30 & 5487 & $8 / 14 / 20086: 12$ & 1.486 & 29.4 & 5556 & $8 / 14 / 20088: 30$ & 1.458 & 29.1 \\
\hline 5350 & $8 / 14 / 20081: 38$ & 1.589 & 30.5 & 5419 & $8 / 14 / 20083: 56$ & 1.541 & 30 & 5488 & $8 / 14 / 20086: 14$ & 1.486 & 29.4 & 5557 & $8 / 14 / 20088: 32$ & 1.458 & 29.1 \\
\hline 5351 & $8 / 14 / 20081: 40$ & 1.589 & 30.6 & 5420 & $8 / 14 / 20083: 58$ & 1.538 & 30 & 5489 & $8 / 14 / 20086: 16$ & 1.486 & 29.4 & 5558 & $8 / 14 / 20088: 34$ & 1.455 & 29.1 \\
\hline 5352 & $8 / 14 / 20081: 42$ & 1.589 & 30.5 & 5421 & $8 / 14 / 20084: 00$ & 1.541 & 30 & 5490 & $8 / 14 / 20086: 18$ & 1.483 & 29.4 & 5559 & $8 / 14 / 20088: 36$ & 1.455 & 29.1 \\
\hline 5353 & $8 / 14 / 20081: 44$ & 1.592 & 30.5 & 5422 & $8 / 14 / 20084: 02$ & 1.537 & 29.9 & 5491 & $8 / 14 / 20086: 20$ & 1.483 & 29.4 & 5560 & $8 / 14 / 20088: 38$ & 1.452 & 29.1 \\
\hline 5354 & $8 / 14 / 20081: 46$ & 1.592 & 30.5 & 5423 & $8 / 14 / 20084: 04$ & 1.537 & 29.9 & 5492 & $8 / 14 / 20086: 22$ & 1.479 & 29.4 & 5561 & $8 / 14 / 20088: 40$ & 1.452 & 29.1 \\
\hline 5355 & $8 / 14 / 20081: 48$ & 1.572 & 30.5 & 5424 & $8 / 14 / 20084: 06$ & 1.534 & 29.9 & 5493 & $8 / 14 / 20086: 24$ & 1.483 & 29.4 & 5562 & $8 / 14 / 20088: 42$ & 1.451 & 29 \\
\hline 5356 & $8 / 14 / 20081: 50$ & 1.579 & 30.5 & 5425 & $8 / 14 / 20084: 08$ & 1.537 & 29.9 & 5494 & $8 / 14 / 20086: 26$ & 1.483 & 29.4 & 5563 & $8 / 14 / 20088: 44$ & 1.452 & 29.1 \\
\hline 5357 & $8 / 14 / 20081: 52$ & 1.582 & 30.4 & 5426 & $8 / 14 / 20084: 10$ & 1.534 & 29.9 & 5495 & $8 / 14 / 20086: 28$ & 1.483 & 29.4 & 5564 & $8 / 14 / 20088: 46$ & 1.451 & 29 \\
\hline 5358 & $8 / 14 / 20081: 54$ & 1.579 & 30.4 & 5427 & $8 / 14 / 20084: 12$ & 1.534 & 29.9 & 5496 & $8 / 14 / 20086: 30$ & 1.479 & 29.4 & 5565 & $8 / 14 / 20088: 48$ & 1.448 & 29 \\
\hline 5359 & $8 / 14 / 20081: 56$ & 1.572 & 30.4 & 5428 & $8 / 14 / 20084: 14$ & 1.534 & 29.9 & 5497 & $8 / 14 / 20086: 32$ & 1.482 & 29.4 & 5566 & $8 / 14 / 20088: 50$ & 1.448 & 29 \\
\hline 5360 & $8 / 14 / 20081: 58$ & 1.579 & 30.4 & 5429 & $8 / 14 / 20084: 16$ & 1.534 & 29.9 & 5498 & $8 / 14 / 20086: 34$ & 1.476 & 29.4 & 5567 & $8 / 14 / 20088: 52$ & 1.448 & 29 \\
\hline 5361 & $8 / 14 / 20082: 00$ & 1.579 & 30.4 & 5430 & $8 / 14 / 20084: 18$ & 1.531 & 29.9 & 5499 & $8 / 14 / 20086: 36$ & 1.483 & 29.4 & 5568 & $8 / 14 / 20088: 54$ & 1.448 & 29 \\
\hline 5362 & $8 / 14 / 20082: 02$ & 1.582 & 30.4 & 5431 & $8 / 14 / 20084: 20$ & 1.527 & 29.9 & 5500 & $8 / 14 / 20086: 38$ & 1.479 & 29.4 & 5569 & $8 / 14 / 20088: 56$ & 1.448 & 29 \\
\hline 5363 & 8/14/2008 2:04 & 1.579 & 30.4 & 5432 & $8 / 14 / 20084: 22$ & 1.531 & 29.9 & 5501 & $8 / 14 / 20086: 40$ & 1.479 & 29.4 & 5570 & $8 / 14 / 20088: 58$ & 1.448 & 29 \\
\hline 5364 & 8/14/2008 2:06 & 1.572 & 30.4 & 5433 & $8 / 14 / 20084: 24$ & 1.527 & 29.9 & 5502 & $8 / 14 / 20086: 42$ & 1.476 & 29.4 & 5571 & $8 / 14 / 20089: 00$ & 1.451 & 29 \\
\hline 5365 & $8 / 14 / 20082: 08$ & 1.575 & 30.4 & 5434 & $8 / 14 / 20084: 26$ & 1.524 & 29.9 & 5503 & $8 / 14 / 20086: 44$ & 1.472 & 29.4 & 5572 & $8 / 14 / 20089: 02$ & 1.445 & 29 \\
\hline 5366 & $8 / 14 / 20082: 10$ & 1.569 & 30.4 & 5435 & $8 / 14 / 20084: 28$ & 1.524 & 29.9 & 5504 & $8 / 14 / 20086: 46$ & 1.476 & 29.4 & 5573 & $8 / 14 / 20089: 04$ & 1.448 & 29 \\
\hline 5367 & $8 / 14 / 20082: 12$ & 1.572 & 30.4 & 5436 & $8 / 14 / 20084: 30$ & 1.524 & 29.8 & 5505 & $8 / 14 / 20086: 48$ & 1.476 & 29.4 & 5574 & $8 / 14 / 20089: 06$ & 1.448 & 28.9 \\
\hline 5368 & $8 / 14 / 20082: 14$ & 1.572 & 30.4 & 5437 & $8 / 14 / 20084: 32$ & 1.524 & 29.8 & 5506 & $8 / 14 / 20086: 50$ & 1.476 & 29.3 & 5575 & 8/14/2008 9:08 & 1.448 & 28.9 \\
\hline 5369 & $8 / 14 / 20082: 16$ & 1.572 & 30.4 & 5438 & $8 / 14 / 20084: 34$ & 1.524 & 29.8 & 5507 & $8 / 14 / 20086: 52$ & 1.479 & 29.3 & 5576 & $120089: 10$ & 1.445 & 28.9 \\
\hline 5370 & $8 / 14 / 20082: 18$ & 1.552 & 30.4 & 5439 & $0084: 36$ & 1.52 & 29.8 & 5508 & $8 / 14 / 20086: 54$ & 1.476 & 29.3 & 5577 & $0089: 12$ & 1.445 & 28.9 \\
\hline 5371 & $8 / 14 / 20082: 20$ & 1.569 & 30.4 & 5440 & $8 / 14 / 20084: 38$ & 1.52 & 29.8 & 5509 & $8 / 14 / 20086: 56$ & 1.476 & 29.3 & 5578 & $8 / 14 / 20089: 14$ & 1.445 & 28.9 \\
\hline 5372 & $8 / 14 / 20082: 22$ & 1.568 & 30.3 & 5441 & $8 / 14 / 20084: 40$ & 1.517 & 29.8 & 5510 & $8 / 14 / 20086: 58$ & 1.476 & 29.3 & 5579 & $8 / 14 / 20089: 16$ & 1.445 & 28.9 \\
\hline 5373 & $8 / 14 / 20082: 24$ & 1.568 & 30.3 & 5442 & $0084: 42$ & 1.513 & 29.8 & 5511 & $8 / 14 / 20087: 00$ & 1.476 & 29.3 & 5580 & $0089: 18$ & 1.441 & 28.9 \\
\hline 5374 & $8 / 14 / 20082: 26$ & 1.569 & 30.4 & 5443 & $8 / 14 / 20084: 44$ & 1.513 & 29.8 & 5512 & $8 / 14 / 20087: 02$ & 1.476 & 29.3 & 5581 & $8 / 14 / 20089: 20$ & 1.438 & 28.9 \\
\hline 5375 & $8 / 14 / 20082: 28$ & 1.565 & 30.3 & 5444 & $8 / 14 / 20084: 46$ & 1.513 & 29.8 & 5513 & $8 / 14 / 20087: 04$ & 1.476 & 29.3 & 5582 & 8/14/2008 9:22 & 1.438 & 28.9 \\
\hline 5376 & $8 / 14 / 20082: 30$ & 1.565 & 30.3 & 5445 & $0084: 48$ & 1.513 & 29.8 & 5514 & $8 / 14 / 20087: 06$ & 1.473 & 29.6 & 5583 & $089: 24$ & 1.434 & 28.9 \\
\hline 5377 & $082: 32$ & 1.565 & 30.3 & 5446 & $8 / 14 / 20084: 50$ & 1.513 & 29.7 & 5515 & $087: 08$ & 1.476 & 29.8 & 5584 & $889: 26$ & 1.434 & 28.9 \\
\hline 5378 & $082: 34$ & 1.619 & 30.3 & 5447 & $8 / 14 / 20084: 52$ & 1.513 & 29.7 & 5516 & $8 / 14 / 20087: 10$ & 1.473 & 29.6 & 5585 & $089: 28$ & 1.434 & 28.9 \\
\hline 5379 & $8 / 14 / 20082: 36$ & 1.697 & 30.3 & 5448 & $8 / 14 / 20084: 54$ & 1.513 & 29.8 & 5517 & $8 / 14 / 20087: 12$ & 1.472 & 29.4 & 5586 & $8 / 14 / 20089: 30$ & 1.438 & 28.9 \\
\hline 5380 & $082: 38$ & 1.69 & 30.3 & 5449 & 8/14/2008 4:56 & 1.513 & 29.7 & 5518 & $8 / 14 / 20087: 14$ & 1.476 & 29.3 & 5587 & $8 / 14 / 20089: 32$ & 1.438 & 28.9 \\
\hline 5381 & $082: 40$ & 1.67 & 30.3 & 5450 & $8 / 14 / 20084: 58$ & 1.507 & 29.7 & 5519 & $8 / 14 / 20087: 16$ & 1.472 & 29.3 & 5588 & $089: 34$ & 1.438 & 28.9 \\
\hline 5382 & $082: 42$ & 1.656 & 30.3 & 5451 & $20085: 00$ & 1.503 & 29.7 & 5520 & $087: 18$ & 1.472 & 29.3 & 5589 & $89: 36$ & 1.438 & 28.9 \\
\hline 5383 & $32: 44$ & 1.643 & 30.3 & 5452 & $85: 02$ & 1.507 & 29.7 & 5521 & $87: 20$ & 1.472 & 29.3 & 5590 & $89: 38$ & 1.438 & 28.9 \\
\hline 5384 & $82: 46$ & 1.629 & 30.3 & 5453 & $8 / 14 / 20085: 04$ & 1.507 & 29.7 & 5522 & $8 / 14 / 20087: 22$ & 1.475 & 29.3 & 5591 & $8 / 14 / 20089: 40$ & 1.438 & 28.9 \\
\hline 5385 & $82: 48$ & 1.619 & 30.3 & 5454 & 8/14/2008 5:06 & 1.507 & 29.7 & 5523 & $87: 24$ & 1.475 & 29.3 & 5592 & $089: 42$ & 1.438 & 28.9 \\
\hline 5386 & $082: 50$ & 1.612 & 30.3 & 5455 & $8 / 14 / 20085: 08$ & 1.506 & 29.6 & 5524 & $087: 26$ & 1.472 & 29.3 & 5593 & $0089: 44$ & 1.438 & 28.9 \\
\hline 5387 & $82: 52$ & 1.606 & 30 & 5456 & $85: 10$ & 1.503 & 29.6 & 5525 & $87: 28$ & 1.473 & 29. & 5594 & 39:46 & 1.438 & 28.9 \\
\hline 5388 & $2: 54$ & 1.599 & 30. & 5457 & $35: 12$ & 1.503 & 29. & 5526 & $37: 30$ & 1.462 & 29. & 5595 & 9:48 & 1.431 & 28.9 \\
\hline 5389 & $082: 56$ & 1.589 & 30.3 & 5458 & $8 / 14 / 20085: 14$ & 1.503 & 29.6 & 5527 & $8 / 14 / 20087: 32$ & 1.465 & 29.3 & 5596 & $8 / 14 / 20089: 50$ & 1.438 & 28.9 \\
\hline 5390 & $082: 58$ & 1.589 & 30.3 & 5459 & 8/14/2008 5:16 & 1.506 & 29.6 & 5528 & $87: 34$ & 1.465 & 29.2 & 5597 & $089: 52$ & 1.438 & 28.9 \\
\hline 5391 & $83: 00$ & 1.582 & 30.3 & 5460 & $85: 18$ & 1.503 & 29. & 5529 & $087: 36$ & 1.465 & 29.3 & 5598 & $089: 54$ & 1.431 & 28.9 \\
\hline 5392 & $33: 02$ & 1.579 & 30.3 & 5461 & $35: 20$ & 1.506 & 29.6 & 5530 & $87: 38$ & 1.465 & 29.2 & 5599 & $9: 56$ & 1.431 & 28.9 \\
\hline 5393 & $33: 04$ & 1.575 & 30. & 5462 & $5: 22$ & 1.506 & 29.6 & 5531 & $37: 40$ & 1.469 & 29.2 & 5600 & 9:58: & 1.431 & 28.9 \\
\hline 5394 & $083: 06$ & 1.572 & 30.2 & 5463 & $8 / 14 / 20085: 24$ & 1.506 & 29.6 & 5532 & $87: 42$ & 1.465 & 29.2 & 5601 & $810: 00$ & 1.428 & 28.9 \\
\hline 5395 & $33: 08$ & 1.568 & 30. & 5464 & $8 / 14 / 20085: 26$ & 1.503 & 29.6 & 5533 & $87: 44$ & 1.46 & 29.2 & 5602 & & 1.428 & 28.9 \\
\hline 5396 & $83: 10$ & 1.565 & 30. & 5465 & $85: 28$ & 1.503 & 29. & 5534 & $087: 46$ & 1.465 & 29.2 & 5603 & $810: 04$ & 1.431 & 28.9 \\
\hline 5397 & $83: 12$ & 1.568 & 30. & 5466 & $5: 30$ & 1.5 & 29 . & 5535 & $7: 48$ & 1.465 & 29. & 5604 & $0: 06$ & 1.424 & 28.8 \\
\hline 5398 & & 1.562 & 30 & 5467 & & 1.5 & 29 & 5536 & & & 29. & & & 1.424 & 28.8 \\
\hline 5399 & $0083: 16$ & 1.558 & 30.1 & 5468 & $8 / 14 / 20085: 34$ & 1.496 & 29.6 & 5537 & $8 / 14 / 20087: 52$ & 1.465 & 29.1 & 5606 & $810: 10$ & 1.427 & 28.8 \\
\hline 5400 & $083: 18$ & 1.561 & 30.1 & 5469 & $8 / 14 / 20085: 36$ & 1.496 & 29.6 & 5538 & & 1.465 & 29.1 & 5607 & & 1.424 & 28.8 \\
\hline 5401 & $83: 20$ & 1.558 & 30. & 5470 & $8 / 14 / 2$ & 1.496 & 29. & 5539 & $87: 56$ & 1.462 & 29.1 & 5608 & $810: 14$ & 1.424 & 28.8 \\
\hline 5402 & $83: 22$ & 1.558 & 30. & 5471 & $85: 40$ & 1.496 & 29. & 5540 & $87: 58$ & 1.462 & 29.1 & 5609 & 10:16 & 1.424 & 28.8 \\
\hline 5403 & & 1.558 & 30. & 5472 & & 1.496 & & 5541 & & & 29. & 5610 & & 1.424 & \\
\hline 5404 & $8 / 14 / 20083: 26$ & 1.555 & 30.1 & 5473 & $8 / 14 / 20085: 44$ & 1.496 & 29.6 & 5542 & 8/14/2008 8:02 & 1.462 & 29.1 & 5611 & $8 / 14 / 2008 \quad 10: 20$ & 1.421 & 28.8 \\
\hline 5405 & $8 / 14 / 20083: 28$ & 1.555 & 30.1 & 5474 & $8 / 14 / 20085: 46$ & 1.496 & 29.6 & 5543 & $88: 04$ & 1.462 & 29.1 & 5612 & $810: 22$ & 1.421 & 28.8 \\
\hline 5406 & $083: 30$ & 1.548 & 30.1 & 5475 & $8 / 14 / 20085: 48$ & 1.496 & 29.5 & 5544 & $88: 06$ & 1.462 & 29.1 & 5613 & $810: 24$ & 1.424 & \\
\hline 5407 & $8 / 14 / 20083: 32$ & 1.548 & 30.1 & 5476 & 8/14/20085:50 & 1.493 & 29.5 & 5545 & 8/14/2008 8:08 & 1.462 & 29.1 & 5614 & $810: 26$ & 1.417 & 28.8 \\
\hline 5408 & $0083: 34$ & 1.548 & 30.1 & 5477 & $8 / 14 / 20085: 52$ & 1.493 & 29.5 & 5546 & & 1.462 & 29.1 & 5615 & & 1.407 & 28.8 \\
\hline 5409 & $8 / 14 / 20083: 36$ & 1.548 & 30.1 & 5478 & $8 / 14 / 20085: 54$ & 1.493 & 29.5 & 5547 & $8 / 14 / 20088: 12$ & 1.462 & 29.1 & 5616 & $810: 30$ & 1.41 & 28.8 \\
\hline 5410 & $8 / 14 / 20083: 38$ & 1.548 & 30.1 & 5479 & $8 / 14 / 20085: 56$ & 1.493 & 29.5 & 5548 & 8/14/2008 8:14 & 1.462 & 29.1 & 5617 & $810: 32$ & 1.411 & 28.8 \\
\hline 5411 & $8 / 14 / 20083: 40$ & 1.544 & 30.1 & 5480 & $8 / 14 / 20085: 58$ & 1.496 & 29.5 & 5549 & 8/14/2008 8:16 & 1.462 & 29.1 & 5618 & $810: 34$ & 1.414 & \\
\hline 5412 & $8 / 14 / 20083: 42$ & 1.544 & 30.1 & 5481 & $8 / 14 / 20086: 00$ & 1.493 & 29.5 & 5550 & 8/14/2008 8:18 & 1.462 & 29.1 & 5619 & $8 / 14 / 2008$ 10:36 & 1.417 & 28.8 \\
\hline 5413 & $8 / 14 / 20083: 44$ & 1.544 & 30.1 & 5482 & 8/14/2008 6:02 & 1.489 & 29.5 & 5551 & $8 / 14 / 20088: 20$ & 1.462 & 29.1 & 5620 & $0810: 38$ & 1.417 & 28.8 \\
\hline 5414 & 8/14/2008 3:46 & 1.544 & 30 & 5483 & $8 / 14 / 20086: 04$ & 1.486 & 29.5 & 5552 & $8 / 14 / 20088: 22$ & 1.462 & 29.1 & 5621 & $0810: 40$ & 1.417 & 28.8 \\
\hline 5415 & $8 / 14 / 20083: 48$ & 1.544 & 30.1 & 5484 & $8 / 14 / 20086: 06$ & 1.486 & 29.4 & 5553 & $8 / 14 / 20088: 24$ & 1.462 & 29.1 & 5622 & $8 / 14 / 2008 \quad 10: 42$ & 1.417 & 28.8 \\
\hline
\end{tabular}




\begin{tabular}{|c|c|c|c|c|c|c|c|c|c|c|c|c|c|c|c|}
\hline \multicolumn{4}{|c|}{ D4-26p } & \multicolumn{4}{|c|}{ D4-26p } & \multicolumn{4}{|c|}{ D4-26p } & \multicolumn{4}{|c|}{ D4-26p } \\
\hline $\operatorname{Rec}$ & & Pres & Temp & $\operatorname{Rec}$ & & Pres & Temp & $\operatorname{Rec}$ & & Pres & Temp & $\operatorname{Rec}$ & & Pres & Temp \\
\hline$\#$ & Date/Time & psi & ${ }^{\circ} \mathrm{C}$ & $\#$ & Date/Time & psi & ${ }^{\circ} \mathrm{C}$ & $\#$ & Date/Time & psi & ${ }^{\circ} \mathrm{C}$ & $\#$ & Date/Time & psi & ${ }^{\circ} \mathrm{C}$ \\
\hline 5623 & $8 / 14 / 2008 \quad 10: 44$ & 1.414 & 28.8 & 5692 & $8 / 14 / 2008$ 13:02 & 1.407 & 28.6 & & & & & & & & \\
\hline 5624 & $8 / 14 / 200810: 46$ & 1.414 & 28.8 & 5693 & $8 / 14 / 2008$ 13:04 & 1.407 & 28.6 & & & & & & & & \\
\hline 5625 & $8 / 14 / 2008$ 10:48 & 1.414 & 28.8 & 5694 & $8 / 14 / 200813: 06$ & 1.403 & 28.6 & & & & & & & & \\
\hline 5626 & $8 / 14 / 2008$ 10:50 & 1.414 & 28.8 & 5695 & $8 / 14 / 200813: 08$ & 1.403 & 28.6 & & & & & & & & \\
\hline 5627 & $8 / 14 / 2008$ 10:52 & 1.414 & 28.8 & 5696 & $8 / 14 / 2008$ 13:10 & 1.407 & 28.6 & & & & & & & & \\
\hline 5628 & $8 / 14 / 2008$ 10:54 & 1.417 & 28.8 & 5697 & $8 / 14 / 2008 \quad 13: 12$ & 1.403 & 28.6 & & & & & & & & \\
\hline 5629 & $8 / 14 / 2008$ 10:56 & 1.414 & 28.8 & 5698 & $8 / 14 / 2008 \quad 13: 14$ & 1.407 & 28.5 & & & & & & & & \\
\hline 5630 & $8 / 14 / 2008$ 10:58 & 1.417 & 28.8 & 5699 & \begin{tabular}{|l|l|l|}
$8 / 2008$ & $13: 16$ \\
\end{tabular} & 1.407 & 28.6 & & & & & & & & \\
\hline 5631 & 8/14/2008 11:00 & 1.417 & 28.8 & 5700 & $8 / 14 / 2008$ 13:18 & 1.407 & 28.5 & & & & & & & & \\
\hline 5632 & 8/14/2008 11:02 & 1.417 & 28.8 & 5701 & $8 / 14 / 2008 \quad 13: 20$ & 1.407 & 28.6 & & & & & & & & \\
\hline 5633 & \begin{tabular}{|l|l|}
$8 / 14 / 2008$ 11:04 \\
\end{tabular} & 1.421 & 28.8 & 5702 & $8 / 14 / 2008 \quad 13: 22$ & 1.407 & 29 & & & & & & & & \\
\hline 5634 & $8 / 14 / 200811: 06$ & 1.417 & 28.8 & 5703 & $8 / 14 / 2008$ 13:24 & 1.408 & 29.1 & & & & & & & & \\
\hline 5635 & $8 / 14 / 2008$ 11:08 & 1.417 & 28.8 & 5704 & $8 / 14 / 200813: 26$ & 1.404 & 28.6 & & & & & & & & \\
\hline 5636 & $8 / 14 / 200811: 10$ & 1.417 & 28.8 & 5705 & $8 / 14 / 2008$ 13:28 & 1.403 & 28.5 & & & & & & & & \\
\hline 5637 & 8/14/2008 11:12 & 1.417 & 28.7 & 5706 & $8 / 14 / 2008$ 13:30 & 1.403 & 28.5 & & & & & & & & \\
\hline 5638 & $8 / 14 / 200811: 14$ & 1.417 & 28.7 & 5707 & $8 / 14 / 2008$ 13:32 & 1.4 & 28.5 & & & & & & & & \\
\hline 5639 & $8 / 14 / 200811: 16$ & 1.417 & 28.7 & 5708 & $8 / 14 / 2008$ 13:34 & 1.403 & 28.5 & & & & & & & & \\
\hline 5640 & $8 / 14 / 2008$ 11:18 & 1.414 & 28.7 & 5709 & $8 / 14 / 2008$ 13:36 & 1.4 & 28.5 & & & & & & & & \\
\hline 5641 & $8 / 14 / 2008$ 11:20 & 1.417 & 28.8 & 5710 & $8 / 14 / 2008+3: 38$ & 1.4 & 28.5 & & & & & & & & \\
\hline 5642 & $8 / 14 / 200811: 22$ & 1.414 & 28.7 & 5711 & $8 / 14 / 2008 \quad 13: 40$ & 1.4 & 28.5 & & & & & & & & \\
\hline 5643 & $8 / 14 / 2008$ 11:24 & 1.414 & 28.7 & 5712 & $8 / 14 / 2008 \quad 13: 42$ & 1.4 & 28.5 & & & & & & & & \\
\hline 5644 & $8 / 14 / 2008$ 11:26 & 1.414 & 28.7 & 5713 & $8 / 14 / 2008 \quad 13: 44$ & 1.4 & 28.5 & & & & & & & & \\
\hline 5645 & $8 / 14 / 2008$ 11:28 & 1.41 & 28.7 & 5714 & $8 / 14 / 2008 \quad 13: 46$ & 1.4 & 28.4 & & & & & & & & \\
\hline 5646 & $8 / 14 / 2008$ 11:30 & 1.41 & 28.7 & 5715 & $8 / 14 / 2008$ 13:48 & 1.4 & 28.4 & & & & & & & & \\
\hline 5647 & $8 / 14 / 200811: 32$ & 1.41 & 28.7 & 5716 & $8 / 14 / 200813: 50$ & 1.4 & 28.5 & & & & & & & & \\
\hline 5648 & $8 / 14 / 2008 \quad 11: 34$ & 1.41 & 28.7 & 5717 & $8 / 14 / 2008$ 13:52 & 1.4 & 28.5 & & & & & & & & \\
\hline 5649 & $8 / 14 / 200811: 36$ & 1.41 & 28.7 & 5718 & \begin{tabular}{|l|l|}
$8 / 14 / 2008$ & $13: 54$ \\
\end{tabular} & 1.4 & 28.4 & & & & & & & & \\
\hline 5650 & $8 / 14 / 200811: 38$ & 1.407 & 28.7 & 5719 & $8 / 14 / 2008$ 13:56 & 1.397 & 28.5 & & & & & & & & \\
\hline 5651 & $8 / 14 / 2008 \quad 11: 40$ & 1.41 & 28.7 & 5720 & $8 / 14 / 2008$ 13:58 & 1.397 & 28.4 & & & & & & & & \\
\hline 5652 & $8 / 14 / 2008$ 11:42 & 1.41 & 28.6 & 5721 & $8 / 14 / 200814: 00$ & 1.397 & 28.5 & & & & & & & & \\
\hline 5653 & $8 / 14 / 2008$ 11:44 & 1.414 & 28.6 & 5722 & $8 / 14 / 2008$ 14:02 & 1.393 & 28.4 & & & & & & & & \\
\hline 5654 & $8 / 14 / 2008$ 11:46 & 1.414 & 28.6 & 5723 & $8 / 14 / 2008 \quad 14: 04$ & 1.397 & 28.4 & & & & & & & & \\
\hline 5655 & $8 / 14 / 200811: 48$ & 1.41 & 28.6 & 5724 & \begin{tabular}{|l|l}
$8 / 14 / 2008$ & $14: 06$ \\
\end{tabular} & 1.397 & 28.4 & & & & & & & & \\
\hline 5656 & $8 / 14 / 200811: 50$ & 1.414 & 28.6 & 5725 & \begin{tabular}{|l|l}
$8 / 14 / 2008$ & $14: 08$ \\
\end{tabular} & 1.393 & 28.4 & & & & & & & & \\
\hline 5657 & $8 / 14 / 200811: 52$ & 1.41 & 28.6 & 5726 & $8 / 14 / 2008$ 14:10 & 1.397 & 28.4 & & & & & & & & \\
\hline 5658 & $8 / 14 / 2008 \quad 11: 54$ & 1.41 & 28.6 & 5727 & $8 / 14 / 2008$ 14:12 & 1.397 & 28.4 & & & & & & & & \\
\hline 5659 & $8 / 14 / 2008$ 11:56 & 1.41 & 28.6 & 5728 & $8 / 14 / 2008$ 14:14 & 1.393 & 28.4 & & & & & & & & \\
\hline 5660 & $8 / 14 / 2008 \quad 11: 58$ & 1.414 & 28.6 & 5729 & $8 / 14 / 2008$ 14:16 & 1.393 & 28.4 & & & & & & & & \\
\hline 5661 & $8 / 14 / 2008 \quad 12: 00$ & 1.414 & 28.6 & 5730 & $8 / 14 / 2008$ 14:18 & 1.393 & 28.6 & & & & & & & & \\
\hline 5662 & $8 / 14 / 2008 \quad 12: 02$ & 1.414 & 28.7 & 5731 & $8 / 14 / 2008$ 14:20 & 1.394 & 28.8 & & & & & & & & \\
\hline 5663 & $8 / 14 / 2008 \quad 12: 04$ & 1.41 & 28.6 & & & & & & & & & & & & \\
\hline 5664 & $8 / 14 / 2008 \quad 12: 06$ & 1.414 & 28.6 & & & & & & & & & & & & \\
\hline 5665 & $8 / 14 / 2008 \quad 12: 08$ & 1.414 & 28.6 & & & & & & & & & & & & \\
\hline 5666 & $8 / 14 / 2008 \quad 12: 10$ & 1.414 & 28.6 & & & & & & & & & & & & \\
\hline 5667 & $8 / 14 / 2008$ 12:12 & 1.414 & 28.6 & & & & & & & & & & & & \\
\hline 5668 & 8/14/2008 12:14 & 1.414 & 28.6 & & & & & & & & & & & & \\
\hline 5669 & $8 / 14 / 2008 \quad 12: 16$ & 1.414 & 28.6 & & & & & & & & & & & & \\
\hline 5670 & $8 / 14 / 2008 \quad 12: 18$ & 1.414 & 28.6 & & & & & & & & & & & & \\
\hline 5671 & $8 / 14 / 2008$ 12:20 & 1.414 & 28.6 & & & & & & & & & & & & \\
\hline 5672 & $8 / 14 / 2008$ 12:22 & 1.414 & 28.6 & & & & & & & & & & & & \\
\hline 5673 & $8 / 14 / 2008 \quad 12: 24$ & 1.41 & 28.6 & & & & & & & & & & & & \\
\hline 5674 & $8 / 14 / 2008$ 12:26 & 1.41 & 28.6 & & & & & & & & & & & & \\
\hline 5675 & $8 / 14 / 2008 \quad 12: 28$ & 1.414 & 28.6 & & & & & & & & & & & & \\
\hline 5676 & $8 / 14 / 2008$ 12:30 & 1.41 & 28.6 & & & & & & & & & & & & \\
\hline 5677 & $8 / 14 / 2008$ 12:32 & 1.41 & 28.6 & & & & & & & & & & & & \\
\hline 5678 & $8 / 14 / 2008 \quad 12: 34$ & 1.41 & 28.6 & & & & & & & & & & & & \\
\hline 5679 & $8 / 14 / 2008$ 12:36 & 1.414 & 28.6 & & & & & & & & & & & & \\
\hline 5680 & $8 / 14 / 2008 \quad 12: 38$ & 1.41 & 28.6 & & & & & & & & & & & & \\
\hline 5681 & $8 / 14 / 2008$ 12:40 & 1.41 & 28.6 & & & & & & & & & & & & \\
\hline 5682 & $8 / 14 / 2008$ 12:42 & 1.41 & 28.6 & & & & & & & & & & & & \\
\hline 5683 & $8 / 14 / 2008$ 12:44 & 1.407 & 28.6 & & & & & & & & & & & & \\
\hline 5684 & $8 / 14 / 2008$ 12:46 & 1.407 & 28.6 & & & & & & & & & & & & \\
\hline 5685 & $8 / 14 / 200812: 48$ & 1.407 & 28.6 & & & & & & & & & & & & \\
\hline 5686 & $8 / 14 / 2008$ 12:50 & 1.403 & 28.6 & & & & & & & & & & & & \\
\hline 5687 & $8 / 14 / 2008$ 12:52 & 1.407 & 28.6 & & & & & & & & & & & & \\
\hline 5688 & $8 / 14 / 2008$ 12:54 & 1.407 & 28.6 & & & & & & & & & & & & \\
\hline 5689 & $8 / 14 / 2008 \quad 12: 56$ & 1.407 & 28.6 & & & & & & & & & & & & \\
\hline 5690 & $8 / 14 / 2008$ 12:58 & 1.407 & 28.6 & & & & & & & & & & & & \\
\hline 5691 & $8 / 14 / 2008 \quad 13: 00$ & 1.407 & 28.6 & & & & & & & & & & & & \\
\hline
\end{tabular}




\begin{tabular}{|c|c|c|c|}
\hline \multicolumn{4}{|c|}{$D 427 \mathrm{c}$} \\
\hline $\mathrm{Pec}$ & & Temp & $\overline{S C}$ \\
\hline$\#$ & DateTime & ${ }^{\circ} \mathrm{C}$ & $\mu \mathrm{S} / \mathrm{am}$ \\
\hline & $87 / 200810: 30$ & 16.7 & 626.9 \\
\hline 2 & $87 / 200810: 32$ & 16.7 & 6265 \\
\hline 3 & $87 / 2008$ 10:34 & 16.7 & 626.9 \\
\hline 4 & $87 / 2008$ 10:36 & 16.7 & 626.7 \\
\hline 5 & $87 / 2000810: 38$ & 16.7 & 6267 \\
\hline$\frac{5}{6}$ & $87 / 2000810: 40$ & 16.7 & 6266 \\
\hline 7 & $87 / 2008$ 10:42 & 16.7 & 626.4 \\
\hline 8 & $87 / 2008$ 10:44 & 16.7 & 627. \\
\hline 9 & $87 / 200810: 46$ & 16.7 & 627 \\
\hline 10 & $87 / 200810: 48$ & 16.7 & 627 \\
\hline 11 & $87 / 200810.50$ & 16.7 & 627.2 \\
\hline 12 & $87 / 2008$ 10.52 & 16.7 & 626.9 \\
\hline 43 & $87 / 200810.54$ & 16.7 & 626.8 \\
\hline 14 & $87 / 200810.56$ & 16.7 & 626.7 \\
\hline 15 & $87 / 200810.58$ & 16.7 & 626.8 \\
\hline 16 & 8712008 11:00 & 16.7 & \begin{tabular}{|l|}
6267 \\
\end{tabular} \\
\hline 17 & 8772008 11:02 & 16.7 & 626.6 \\
\hline 18 & 8772008 11:04 & 16.7 & 626.7 \\
\hline 19 & $872000111: 06$ & 16.7 & 626.3 \\
\hline 20 & $877200811: 08$ & 16.7 & 626.1 \\
\hline 21 & $87 / 2008$ 11:10 & 16.7 & E261 \\
\hline 2 & $87 / 2008$ 11:12 & 16.7 & 6261 \\
\hline 23 & $87 / 2008$ 11:14 & 16.7 & 626.2 \\
\hline 24 & $87 / 2008$ 11:16 & 16.7 & 6261 \\
\hline 25 & $87 / 2008$ 11:18 & 16.7 & 6261 \\
\hline 26 & $87 / 200811: 20$ & 16.7 & 6261 \\
\hline $2 \pi$ & $87 / 200811: 2$ & 16.7 & 626 \\
\hline 28 & $87 / 2008$ 11:24 & 16.7 & 626 \\
\hline 2 & $87 / 200811: 26$ & 16.7 & 625.9 \\
\hline 30 & $87 / 2008$ 11:28 & 16.7 & 626 \\
\hline 31 & $87 / 2008$ 11:30 & 16.7 & 625.9 \\
\hline 32 & $877200811: 32$ & 16.7 & 625.9 \\
\hline 33 & $87 / 2008$ 11:34 & 16.7 & 226 \\
\hline 34 & $87 / 2008$ 11:36 & 16.7 & 625.9 \\
\hline 35 & $87 / 2000811: 38$ & 16.7 & 625.9 \\
\hline 36 & $87 / 200811: 40$ & 16.7 & 626.5 \\
\hline 37 & 8772008 11:42 & 16.7 & 626.4 \\
\hline 38 & $87 / 2008$ 11:44 & 16.7 & 626.4 \\
\hline 39 & 8772008 11:46 & 16.7 & 626.5 \\
\hline 40 & $87 / 200811: 48$ & 16.7 & 626.5 \\
\hline 41 & $87 / 2008$ 11:50 & 16.7 & 626.3 \\
\hline 42 & $87 / 200811: 52$ & 16.7 & 626.4 \\
\hline 43 & 8772008 11:54 & 16.7 & 6264 \\
\hline 44 & 8772008 11:56 & 16.7 & 626.4 \\
\hline 45 & $87 / 200811: 58$ & 16.7 & 626.3 \\
\hline 46 & 87720081200 & 16.7 & 526.4 \\
\hline 47 & $87 / 20081200$ & 16.7 & 626.3 \\
\hline 48 & $87 / 2008$ 12:04 & 16.7 & 6264 \\
\hline 49 & $87 / 20081206$ & 16.7 & 626.3 \\
\hline 50 & 87720001208 & 16.7 & 6264 \\
\hline 51 & $877200812 \cdot 10$ & 16.7 & 6263 \\
\hline 52 & 87720081212 & 16.7 & 626.2 \\
\hline 53 & $87 / 200812,14$ & 16.7 & 6263 \\
\hline 54 & $87 / 2008$ 1216 & 16.7 & 626.3 \\
\hline 55 & $87 / 20081218$ & 16.7 & 5263 \\
\hline 56 & $87 / 20081220$ & 16.7 & 6265 \\
\hline 5 & 8712008122 & 16.7 & 626.5 \\
\hline 58 & $87 / 20081224$ & 16.7 & 626.3 \\
\hline 59 & 87720081226 & 16.7 & 626.3 \\
\hline 60 & $87 / 20081228$ & 16.7 & 626.3 \\
\hline 61 & 87720081230 & 16.7 & 626.2 \\
\hline$\sqrt{2}$ & $87 / 20081232$ & 16.7 & 626.3 \\
\hline 6 & 8712008 12:34 & 167 & 6263 \\
\hline 64 & $87 / 20081236$ & 16.7 & 6262 \\
\hline 65 & $87 / 20081238$ & 16.7 & 526.4 \\
\hline 66 & $87 / 20081240$ & 16.7 & 6263 \\
\hline 67 & $87 / 20081242$ & 16.7 & 626.3 \\
\hline
\end{tabular}

\begin{tabular}{|c|c|c|c|c|c|c|}
\hline \multicolumn{3}{|c|}{ D427c } & \multicolumn{4}{|c|}{$D 427 \mathrm{c}$} \\
\hline $\operatorname{Rec}$ & & Temp $S \mathrm{C}$ & $\mathrm{ReC}$ & & Temp & $S C$ \\
\hline$\#$ & Date Time & \begin{tabular}{|l|l|}
${ }^{\circ} \mathrm{C}$ & $\mu \mathrm{S} / \mathrm{cm}$ \\
\end{tabular} & $\#$ & Dete/Time & & $\mu \mathrm{som}$ \\
\hline & $87 / 20081244$ & $\begin{array}{l}16.7 \\
626.3\end{array}$ & 135 & $87 / 20008$ 14:58 & 16.7 & 625 \\
\hline 69 & 87720081246 & \begin{tabular}{l|l|}
16.7 & 626.4 \\
\end{tabular} & 136 & $87 / 2008$ 15:00 & \begin{tabular}{|l|}
16.7 \\
\end{tabular} & 625 \\
\hline 70 & 87720081248 & \begin{tabular}{l|l|}
16.7 & 626.4 \\
\end{tabular} & 137 & $87 / 2008$ 15:02 & \begin{tabular}{|l|}
16.7 \\
\end{tabular} & 625 \\
\hline & $87 / 20081250$ & \begin{tabular}{|l|l|}
16.7 & 626.7 \\
\end{tabular} & 138 & $87 / 200815: 04$ & 16.7 & 625.1 \\
\hline & $87 / 20081252$ & $\begin{array}{ll}16.7 & 626.5 \\
\end{array}$ & 139 & $87 / 200815: 06$ & 167 & 625.4 \\
\hline 73 & 87720081254 & \begin{tabular}{|l|l|}
16.7 & 626.3 \\
\end{tabular} & 140 & $8 / 7 / 200015: 08$ & 16.7 & 625.5 \\
\hline 74 & $87 / 20081256$ & \begin{tabular}{|l|l|}
16.7 & 626.4 \\
\end{tabular} & 141 & $87 / 2008$ 15:10 & 16.7 & 625.8 \\
\hline 75 & $877 / 20081258$ & \begin{tabular}{|l|l|}
16.7 & 626.4 \\
\end{tabular} & 142 & $87 / 200815: 12$ & 16.7 & $\widetilde{65.5}$ \\
\hline & $87 / 20081300$ & $\begin{array}{l}16.7 \\
626.5\end{array}$ & 143 & $87 / 2008$ 15:14 & 16.7 & 625.4 \\
\hline 77 & $877 / 200813: 02$ & \begin{tabular}{|l|l|}
16.7 & 626.4 \\
\end{tabular} & 144 & $87 / 200815: 16$ & 16.7 & 625.5 \\
\hline 78 & $87 / 200813: 04$ & \begin{tabular}{|l|l|}
16.7 & 626.5 \\
\end{tabular} & 145 & $87 / 200815: 18$ & 16.7 & 625.7 \\
\hline 79 & $87 / 200813: 06$ & \begin{tabular}{|l|l|}
16.7 & 626.4 \\
\end{tabular} & 146 & $87 / 200815: 20$ & 16.7 & 625.5 \\
\hline & $87 / 200813: 08$ & \begin{tabular}{|l|l|}
16.7 & 626.5 \\
\end{tabular} & 47 & $87 / 2008$ 15:22 & 16.7 & 625.6 \\
\hline & $877200813: 10$ & \begin{tabular}{|l|l|}
16.825 .6 \\
\end{tabular} & 148 & $87 / 2008$ 15:24 & 16.7 & 625.6 \\
\hline 82 & $871200813: 12$ & $\begin{array}{|ll|}16.7 & 626.6 \\
\end{array}$ & 149 & $87 / 200815: 26$ & 16.7 & 625.6 \\
\hline 83 & $87 / 200813: 14$ & \begin{tabular}{|l|l|}
16.7 & 626.6 \\
\end{tabular} & 150 & $87 / 200815: 28$ & 16.7 & 625.2 \\
\hline & $87 / 200813: 16$ & \begin{tabular}{|l|l}
16.7 & 626.7 \\
\end{tabular} & 51 & $87 / 2008$ 15:30 & 16.7 & \\
\hline 85 & $87 / 200813: 18$ & \begin{tabular}{|l|l|}
16.7 & 626.5 \\
\end{tabular} & 152 & $87 / 2008$ 15:32 & 16.7 & 625.2 \\
\hline 86 & $87 / 2008$ 13:20 & \begin{tabular}{|l|l|}
16.7 & 626.6 \\
\end{tabular} & 153 & $87 / 2008$ 15:34 & 16.7 & 625.2 \\
\hline 87 & $877200813: 22$ & \begin{tabular}{|l|l|}
16.726 .6 \\
\end{tabular} & 154 & $87 / 2008$ 15:36 & 16.7 & \\
\hline 88 & $871200813: 24$ & $\begin{array}{l}16.7 \\
626.6\end{array}$ & 55 & $87 / 200815: 38$ & 16 & 625.3 \\
\hline 89 & $877200813: 26$ & $\begin{array}{l}16.7626 .6 \\
\end{array}$ & 156 & $8 / 7 / 200815: 40$ & 16.7 & 625.3 \\
\hline 90 & $87 / 200013: 28$ & \begin{tabular}{l|l|}
16.7 & 626.6 \\
\end{tabular} & 157 & 8772008 15:42 & 16.7 & 625.3 \\
\hline 91 & $87 / 2008$ 13:30 & \begin{tabular}{|l|l|}
16.7626 .7 \\
\end{tabular} & 158 & $87 / 20$ & 16.7 & 625.3 \\
\hline 92 & $87 / 200813: 32$ & \begin{tabular}{|l|l|}
16.7 & 626.8 \\
\end{tabular} & 159 & 87712008 15:46 & 16.7 & 625.5 \\
\hline 93 & $87 / 200813: 34$ & \begin{tabular}{|l|l|l|}
16.762 .7 \\
\end{tabular} & 160 & 8712008 15:48 & 16.7 & 625.5 \\
\hline 94 & $87 / 20$ & $\begin{array}{l}16.7 \\
626.6\end{array}$ & 161 & $87 / 2 x$ & 16.7 & 625.6 \\
\hline 95 & $87 / 20$ & \begin{tabular}{|l|l|}
16.7 & 626.7 \\
\end{tabular} & 162 & $87 \pi$ & \begin{tabular}{|l|}
16.7 \\
\end{tabular} & 625.6 \\
\hline 96 & $87 / 200813: 40$ & \begin{tabular}{|l|}
16.7 \\
626.7 \\
\end{tabular} & 163 & $877 / 200815: 54$ & 16.7 & 625.5 \\
\hline 97 & $87 / 200813: 42$ & 16.7626 .7 & 164 & 8772008 15:56 & 16.7 & 6256 \\
\hline & $87 / 20$ & $\begin{array}{l}16.7 \sqrt{626.6} \\
\end{array}$ & 65 & 8772008 15:58 & 16.7 & 625.5 \\
\hline & 87720 & $\begin{array}{l}16.7 \\
6226.8 \\
\end{array}$ & & $87 / 2$ & 16.7 & 625.6 \\
\hline 100 & $871200813: 48$ & $\begin{array}{l}16.7 \\
626.6 \\
\end{array}$ & 167 & $816: 02$ & 16.7 & 625.6 \\
\hline 101 & 87720 & $\begin{array}{ll}16.7 & 628.5 \\
\end{array}$ & 168 & $87 / 2$ & \begin{tabular}{|l|}
16.7 \\
\end{tabular} & 625.5 \\
\hline 102 & $87 / 200813: 52$ & \begin{tabular}{|l|l|}
16.7 & 624 \\
\end{tabular} & 69 & $87 / 200$ & 16.7 & 625.5 \\
\hline 103 & $87 / 200813: 54$ & \begin{tabular}{|l|l|}
16.7 & 626.7 \\
\end{tabular} & 170 & $877200816: 08$ & 16.7 & 625.6 \\
\hline 104 & $877200813: 56$ & $\begin{array}{ll}16.7 & 626.2 \\
\end{array}$ & 171 & $8 / 1200$ & 16.7 & 625.6 \\
\hline 105 & $87 / 2$ & $\begin{array}{l}16.7 \\
\end{array}$ & 172 & & 16.7 & 625.8 \\
\hline 106 & $877 / 20$ & \begin{tabular}{|l|l|}
16.724 .2 \\
\end{tabular} & 173 & $87 / 2$ & 16.7 & 625 \\
\hline 107 & $871200814: 02$ & \begin{tabular}{l|l|}
16.7 & 624.2 \\
\end{tabular} & 174 & $87 / 200816: 16$ & 16.7 & 625.5 \\
\hline 108 & $87 / 2008$ 14:04 & \begin{tabular}{l|l|}
16.7 & 624.3 \\
\end{tabular} & 175 & $87 / 2008$ 16:18 & 16.7 & 625.6 \\
\hline 109 & 87120 & $\begin{array}{l}6.7 \\
624.2 \\
\end{array}$ & 76 & $87 / 2$ & 16.7 & 625.6 \\
\hline 110 & 8772008 14:08 & $\begin{array}{lll}16.7 & 624.4\end{array}$ & $17 \pi$ & 8712 & 16.7 & 625.5 \\
\hline 111 & $87 / 200814: 10$ & \begin{tabular}{|l|l|}
16.7 & 624.4 \\
\end{tabular} & 178 & $87 / 200816: 24$ & 16.7 & 626 \\
\hline 112 & $87 / 20$ & \begin{tabular}{|l|l|}
16.7 & 624.5 \\
\end{tabular} & 9 & & 16.7 & 625.5 \\
\hline 113 & $87 / 20$ & \begin{tabular}{l|l|l|}
16.7 & 623.5 \\
\end{tabular} & 80 & 871 & 16.7 & 625.6 \\
\hline 114 & \begin{tabular}{|l|l|}
$87 / 2008$ & $14: 16$ \\
\end{tabular} & $16.7 \quad 623.5$ & 181 & $00816: 30$ & 16.7 & 625.6 \\
\hline 115 & $87 / 2008$ 14:18 & $\begin{array}{lll} & 16.7 & 623.5 \\
\end{array}$ & 182 & $0816: 32$ & 16.7 & 625.5 \\
\hline 116 & 87712 & \begin{tabular}{|l|l|l|}
16.7 & 623.8 \\
\end{tabular} & & & 16.7 & 625.6 \\
\hline 117 & $877200814: 22$ & \begin{tabular}{|l|l|l|}
16.7 & 623.8 \\
\end{tabular} & 184 & $16: 36$ & 16.7 & 625.5 \\
\hline 118 & $87 / 200814: 24$ & 16.7623 .9 & 185 & $16: 38$ & 16.7 & 625.5 \\
\hline 119 & $87 / 2$ & \begin{tabular}{|l|l|l|}
16.7 & 624.1 \\
\end{tabular} & & & 16.7 & 625.5 \\
\hline & $87 / 2$ & $16.7 \quad 623.9$ & & & 16.7 & 625.5 \\
\hline & $8 / 7 / 200814: 30$ & \begin{tabular}{|l|l|}
16.7 & 624.1 \\
\end{tabular} & 188 & $16: 44$ & 16.7 & 625.3 \\
\hline & $87 / 200814: 32$ & \begin{tabular}{|l|l|}
16.7 & 624 \\
\end{tabular} & 89 & $8 \pi / 2$ & 16.7 & 6254 \\
\hline 123 & $8 / 7200814: 34$ & \begin{tabular}{|l|l|}
16.7 & 624.5 \\
\end{tabular} & & & 16.7 & 625.4 \\
\hline 124 & $87 / 200814: 36$ & \begin{tabular}{|l|l|l}
16.7 & 624.5 \\
\end{tabular} & & 8712 & 16.7 & 625.3 \\
\hline 125 & $87 / 200814: 38$ & \begin{tabular}{|l|l|l|}
36.7 & 624.4 \\
\end{tabular} & 192 & $87 / 200816: 52$ & 16.7 & 625.3 \\
\hline & $87 / 200814: 40$ & $\begin{array}{l}16.7 \\
\end{array}$ & 93. & $87 / 2$ & 16.7 & 625.2 \\
\hline 127 & $87 / 2008$ 14:42 & 16.7624 .7 & & & 16.7 & 625.3 \\
\hline & $87 / 200814: 44$ & \begin{tabular}{|l|l|l|}
16.7 & 624.7 \\
\end{tabular} & 195 & $316: 58$ & 16.7 & 625.3 \\
\hline & 8772008 14:46 & \begin{tabular}{|l|l|l|}
16.7 & 624.7 \\
\end{tabular} & 196 & $87 / 200817: 00$ & 16.7 & 625.1 \\
\hline & $87 / 2008$ 14:48 & \begin{tabular}{|l|l|l|}
16.7 & 624.6 \\
\end{tabular} & 37 & & 16.7 & 625.2 \\
\hline 737 & $8 / 72008$ 14:50 & \begin{tabular}{|l|l|l|}
1624.9 \\
\end{tabular} & & $87 / 20$ & 16.7 & 625.1 \\
\hline & $8 / 7200814: 52$ & 16.7625 .2 & 199 & $87 / 200817: 06$ & 16.7 & 625.2 \\
\hline & $87 / 200814: 54$ & \begin{tabular}{|l|l|}
16.7 & 625.2 \\
\end{tabular} & 200 & $87 / 200817: 08$ & \begin{tabular}{|l|}
16.7 \\
\end{tabular} & 625 \\
\hline 134 & $87 / 200814: 56$ & \begin{tabular}{|l|l|l|}
16.7 & 625.2 \\
\end{tabular} & & $8 / 7 / 2008$ 17:10 & 16.7 & 625. \\
\hline
\end{tabular}

\begin{tabular}{|c|c|c|c|}
\hline \multicolumn{4}{|c|}{$D 4-27 \mathrm{c}$} \\
\hline$x$ & & Temp & $\mathrm{SC}$ \\
\hline$\#$ & DatedTime & ${ }^{\circ} \mathrm{C}$ & $\mu$ siom \\
\hline 02 & $877200817: 12$ & 16.7 & 625 \\
\hline 0.3 & 8772008 17:14 & 16.7 & 625.1 \\
\hline 04 & $87 / 200817: 16$ & 16.7 & \\
\hline 可 & $37 / 200817: 18$ & 16.7 & \\
\hline 206 & $872000817: 20$ & 16.7 & 62 \\
\hline 207 & $877200817: 22$ & 16.7 & 625.1 \\
\hline 208 & 8772008 17:24 & 16.7 & \\
\hline as & $87 / 200817: 26$ & 16.7 & 624. \\
\hline 210 & 8772008 17:28 & 16.7 & 62 \\
\hline 211 & $87 / 200817: 30$ & 16.7 & 625 \\
\hline 212 & $87 / 200817: 32$ & 16.7 & $\overline{624.9}$ \\
\hline 213 & $877200817: 34$ & 16.7 & $\tilde{2}^{25}$ \\
\hline 214 & $87 / 200817: 36$ & 16.7 & 623 \\
\hline 215 & $87 / 2008$ 17:38 & 16.7 & 623. \\
\hline 216 & $87 / 2008$ 17:40 & 16.7 & 623. \\
\hline 217 & $87 / 2008$ 17:42 & 16.7 & \\
\hline 218 & $8 / 7 / 2008$ 17:44 & 16.7 & 6 \\
\hline 219 & $87 / 2008$ 17:46 & 16.7 & 624.2 \\
\hline 220 & $87 / 2008$ 17:48 & 16.7 & 624. \\
\hline 221 & $87 / 2008$ 17:50 & 16.7 & \\
\hline 220 & $877200817: 52$ & 16.7 & 624.8 \\
\hline 223 & 8772008 17:54 & 16.7 & 624. \\
\hline 224 & $877200017: 56$ & 16.7 & 624. \\
\hline 225 & 8772008 17:58 & 16.7 & 62 \\
\hline 226 & $87 / 20081800$ & 16.7 & $\overline{624.8}$ \\
\hline 227 & $87 / 20$ & 16.7 & 624. \\
\hline 228 & $87 / 20081804$ & 16.7 & 624. \\
\hline 220 & 87720081806 & 16.7 & 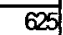 \\
\hline 230 & $87 / 200818: 08$ & 16.7 & $6^{2}$ \\
\hline 231 & 87720 & 16.7 & 624.9 \\
\hline 232 & 877200 & 16.7 & 624. \\
\hline 233 & $87 / 2008$ & 16.7 & 624. \\
\hline 234 & $87 / 2000$ & 16.7 & 624. \\
\hline 235 & $8 / 720$ & 16.7 & 624. \\
\hline 236 & $87 / 2006$ & 16.7 & $\omega^{2}$ \\
\hline 237 & $87 / 200818: 22$ & 16.7 & 62 \\
\hline 238 & $87 \pi$ & 16.7 & 2 \\
\hline 239 & 8712006 & 16.7 & 62 \\
\hline 240 & 877200 & 16.7 & 625 \\
\hline 241 & 877200 & 16.7 & 625. \\
\hline 242 & & 16.7 & 62 \\
\hline 243 & $87 / 20$ & 16.7 & 625 \\
\hline 244 & $87 / 20$ & 16.7 & 625. \\
\hline 245 & & 16.7 & 625. \\
\hline 246 & $8 / 7 / 20$ & 16.7 & 625. \\
\hline 247 & 877200 & 16.7 & 625. \\
\hline 248 & $87 / 200$ & 16.7 & 625. \\
\hline 49 & & 16.7 & 625 \\
\hline 250 & & 16.7 & 625. \\
\hline 251 & & 16.7 & 625 \\
\hline 252 & & 16.7 & 625. \\
\hline 253 & $87 / 20$ & 16.7 & 625 \\
\hline 254 & $87 / 200$ & 16.7 & 625. \\
\hline 255 & & 16.7 & 625. \\
\hline 256 & & 16.7 & $\overline{65}$ \\
\hline 250 & & 16. & \\
\hline 258 & $87 / 2006$ & 16.7 & 625. \\
\hline 250 & $87 / 200$ & 16.7 & 625. \\
\hline 260 & & 16.8 & \\
\hline 261 & & 16.7 & $\overline{6}$ \\
\hline 262 & $87 / 200$ & 16.7 & 625. \\
\hline 263 & 877200 & 16.7 & 625. \\
\hline 264 & & 16.8 & \\
\hline 265 & & 16.7 & 625. \\
\hline 266 & 871200819.20 & 16.7 & 625 \\
\hline 267 & 877200 & 16.8 & 625. \\
\hline 268 & $87 / 2008$ & & 625. \\
\hline
\end{tabular}

\begin{tabular}{|c|c|c|c|}
\hline \multicolumn{4}{|c|}{ D427c } \\
\hline $\operatorname{Rec}$ & & Temp & $S C$ \\
\hline \# & Daterlime & ${ }^{\circ} \mathrm{C}$ & $\mu S a$ \\
\hline 269 & $87 / 2008$ 19.26 & 16.7 & 626 \\
\hline $2 \pi$ & $871200819: 28$ & 16.7 & 626. \\
\hline 271 & 871200819.30 & 16.7 & 626 \\
\hline 272 & 871200819.32 & 16.7 & 626. \\
\hline 273 & $87 / 200819.34$ & 16.7 & 626. \\
\hline 274 & $87 / 200819: 36$ & 16.7 & $\sqrt{626}$ \\
\hline 275 & $87 / 200819.38$ & 16.7 & 206 \\
\hline 276 & $87 / 200819.40$ & 16.7 & 626 \\
\hline 277 & $87 / 200819.42$ & 16.7 & \\
\hline 278 & 871200819.44 & 16.7 & 626. \\
\hline 279 & $87 / 200819.46$ & 16.7 & 626. \\
\hline 280 & $87 / 200819.48$ & 16.8 & 625 \\
\hline 281 & $87 / 200819.50$ & 16.7 & 626 \\
\hline 282 & $87 / 200819.52$ & \begin{tabular}{|l|}
16.7 \\
\end{tabular} & \\
\hline 283 & $87 / 200819.54$ & 16.7 & 6 \\
\hline 284 & 877200819.56 & 16.7 & 627. \\
\hline 285 & $87 / 200819.58$ & 16.7 & 627. \\
\hline 286 & $87 / 20082000$ & 16.7 & 627. \\
\hline 287 & $87 / 200820: 02$ & 16.7 & 626. \\
\hline 288 & $87 / 20$ & 167 & 626. \\
\hline 289 & 87120 & 16.7 & 626 \\
\hline 290 & 871200820008 & 16.7 & 626. \\
\hline 291 & $87 / 200$ & 16.7 & 626. \\
\hline 292 & 20.12 & 16.7 & 626. \\
\hline 293 & $320: 14$ & 16.7 & 626 \\
\hline 294 & 871200 & 16.7 & 626. \\
\hline 296 & $87 / 20$ & 16.7 & 626. \\
\hline 296 & $20: 20$ & 16.7 & 626 \\
\hline 297 & 871200820.22 & 16.7 & 626. \\
\hline 298 & $87 / 200820: 24$ & 16.7 & 626. \\
\hline 299 & 8712 & 16.7 & 626. \\
\hline 300 & $87 / 20$ & 16.7 & 626. \\
\hline 301 & $87 / 20$ & 16.7 & 626. \\
\hline 302 & $87 / 20$ & 16.7 & 626. \\
\hline 303 & 8712 & 16.7 & 626 \\
\hline 304 & 20.36 & 16.7 & 626. \\
\hline 306 & 20.38 & 16.7 & 626. \\
\hline 306 & $87 / 2$ & 16.7 & 627. \\
\hline 307 & 87720 & 16.7 & 626. \\
\hline 308 & $87 / 20$ & 16.7 & 627. \\
\hline 309 & 87120 & 16.7 & 626. \\
\hline 310 & $87 / 2$ & 16.7 & 626 \\
\hline 311 & $87 / 2$ & 16.7 & 626 \\
\hline 312 & $87 / 20$ & 16.7 & 626. \\
\hline 313 & $87 / 20$ & 16.7 & 626 \\
\hline 314 & 8712 & 16.7 & $\sigma$ \\
\hline 315 & $87 / 20$ & 16.7 & $\sigma$ \\
\hline 316 & $87 / 212$ & 16.7 & 626. \\
\hline 317 & & t6.7 & 626 \\
\hline 318 & $87 / 2$ & 16.7 & 6 \\
\hline 319 & $21: 06$ & 16.7 & 626. \\
\hline 320 & $87 / 2$ & 16.7 & 626 \\
\hline 321 & $87 / 2$ & 16.7 & 626 \\
\hline 322 & 8712 & 16.7 & 626. \\
\hline 323 & $87 / 2$ & 16.7 & 626 \\
\hline 324 & & 16.7 & 626 \\
\hline 325 & 877200 & 16.7 & \\
\hline 326 & 821:20 & 16.7 & 626. \\
\hline 327 & $87 / 20$ & 16.7 & 626 \\
\hline 328 & $87 / 20$ & 16.7 & 626 \\
\hline 329 & $87 / 200$ & 16.7 & 626. \\
\hline 330 & $87 / 200821: 28$ & 16.7 & 626. \\
\hline 331 & $87 / 20$ & 16.7 & 626 \\
\hline 332 & $87 / 20$ & 16.7 & 626 \\
\hline 333 & $87 / 200821: 34$ & 16.7 & 626 \\
\hline 334 & $87 / 200821: 36$ & 16.7 & 626 \\
\hline 335 & & & 206 \\
\hline
\end{tabular}


DOE/RL-2009-35, REV. 0

\begin{tabular}{|c|c|c|c|}
\hline \multicolumn{4}{|c|}{$\mathrm{D} 427 \mathrm{c}$} \\
\hline 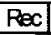 & & $\mathrm{cond}$ & $\mathrm{SC}$ \\
\hline & DeteTime & ${ }^{\circ} \mathrm{C}$ & $\mu \mathrm{s} / \mathrm{an}$ \\
\hline & $87 / 200821: 40$ & & \\
\hline 337. & $71200821: 42$ & 16.7 & 626.2 \\
\hline & $7 / 200821: 44$ & 16.7 & 626.2 \\
\hline & & 16.7 & \\
\hline 340 & $87 / 200821: 48$ & 16.7 & 626 \\
\hline 341 & $7 / 200821: 50$ & 16.7 & 626.1 \\
\hline 342 & $7 / 200821: 52$ & 16.7 & \\
\hline 343 & $77 / 200821: 54$ & 16.7 & 226. \\
\hline 344 & $87 / 200821: 56$ & 16.7 & 625.9 \\
\hline 345 & $87 / 200821: 58$ & 16.7 & 626.1 \\
\hline 346 & $87 / 20082200$ & 16.7 & \\
\hline 347 & $87 / 20082202$ & 16.7 & 625. \\
\hline 348 & $7 / 20082204$ & 16.7 & 625. \\
\hline 349 & $87 / 20082206$ & & \\
\hline 350 & $87 / 20082208$ & 16.7 & 625 \\
\hline 351 & $87 / 20082210$ & 16.7 & 625. \\
\hline 352 & $87 / 20082212$ & 16.7 & \\
\hline 353 & $87 / 20082214$ & 16.7 & 625 \\
\hline 354 & $87 / 20082216$ & 16.7 & 625. \\
\hline 356 & 82218 & 16.7 & 625 \\
\hline 356 & 82220 & & \\
\hline 357 & $87 / 2006$ & 16.7 & 625. \\
\hline 358 & 87720 & 16.7 & 625. \\
\hline 359 & $87 / 20$ & 16.7 & \\
\hline 360 & $87 / 20082228$ & 16.7 & 625 \\
\hline 361 & $87 / 2$ & 16.7 & 625 \\
\hline 362 & $87 / 20082232$ & 16.7 & 625 \\
\hline 363 & $87 / 20082234$ & 16. & \\
\hline 364 & $87 / 2$ & 16.7 & 625. \\
\hline 365 & $87 / 2$ & 16.7 & 625 \\
\hline 366 & $877 / 2$ & 16. & \\
\hline 367 & $87 / 2$ & 16.7 & 625 \\
\hline 368 & $87 / 2$ & 16.7 & 625 \\
\hline 369 & $87 / 2$ & 16.7 & \\
\hline 370 & & 16.7 & 625. \\
\hline 371 & $87 / 2$ & 16.7 & 625 \\
\hline 372 & $87 / 2$ & 16.7 & 625 \\
\hline 373 & & 16.7 & 625 \\
\hline 374 & 256 & 16. & 625 \\
\hline 375 & 2258 & 16.7 & 625 \\
\hline 376 & & 16.7 & 625 \\
\hline 37 & 3.02 & 16.7 & 625 \\
\hline 378 & $3 \cdot 04$ & 16.7 & 625 \\
\hline 379 & & 16.7 & \\
\hline 380 & $33: 08$ & 16.7 & 625 \\
\hline 381 & & 16.7 & 626. \\
\hline 382 & & 16. & 625 \\
\hline 383 & & 16.7 & 625 \\
\hline 384 & & 16. & 625 \\
\hline 385 & & 16. & 6 \\
\hline 386 & $3: 20$ & 16. & 625 \\
\hline 387 & & 16. & 625 \\
\hline 388 & & 16. & 625 \\
\hline 389 & $87 / 2$ & 16.7 & \\
\hline 390 & & 16.7 & 625 \\
\hline 391 & & 16. & 625 \\
\hline 392 & & 16.8 & \\
\hline 393 & & 16.7 & 625 \\
\hline 394 & $23: 36$ & 16.7 & 625 \\
\hline 39 & & 16.7 & \\
\hline 396 & & 16.7 & 625 \\
\hline 397 & $323: 42$ & 16.7 & 6 \\
\hline 39 & & 16.7 & \\
\hline 399 & & 16.7 & 625 \\
\hline 400 & $8 / 7 / 2008223: 48$ & 16.7 & \\
\hline 4011 & 871200 & 16.7 & $\tilde{\alpha}$ \\
\hline & & & \\
\hline
\end{tabular}

\begin{tabular}{|c|c|c|c|}
\hline \multicolumn{4}{|c|}{$\mathrm{D} 427 \mathrm{c}$} \\
\hline$x$ & & & \\
\hline & DeterTime & ${ }^{\circ} \mathrm{C}$ & $\mu \mathrm{s} / \mathrm{m}$ \\
\hline 103 & $877200823: 54$ & 16.7 & 625 \\
\hline 404 & $87 / 200823: 56$ & 16.7 & 624.8 \\
\hline 405 & $87 / 200823: 58$ & 16.7 & \\
\hline 406 & $8 / 820080: 00$ & 16.7 & 624. \\
\hline 407 & $820080: 02$ & 16.7 & 624.7 \\
\hline 408 & $8820000: 04$ & 16.7 & 624.9 \\
\hline 409 & & 16.7 & 624.7 \\
\hline 410 & $8820000: 08$ & 16.7 & 624.6 \\
\hline 411 & $8 / 820080: 10$ & 16.7 & 624.7 \\
\hline 112 & & 16.7 & \\
\hline 413 & $8 / 8 / 20080: 14$ & 16.7 & \begin{tabular}{|l|l|}
624.6 \\
\end{tabular} \\
\hline 414 & 88120080.16 & 16.7 & 624.5 \\
\hline 415 & $8820080: 18$ & 16.7 & 624. \\
\hline 416 & & 16.7 & 624. \\
\hline 417 & $88220080: 22$ & 16.7 & 624.6 \\
\hline 418 & 8820000.24 & 16.7 & 624.6 \\
\hline 19 & $8 / 820080: 26$ & 16.7 & \\
\hline 420 & 820080.28 & 16.7 & 524.9 \\
\hline 421 & $0: 30$ & 16.7 & 624.7 \\
\hline 422 & $18 / 20080.32$ & 16.7 & 624.5 \\
\hline 423 & $8 / 820080: 34$ & 16.7 & 624.6 \\
\hline 424 & $30: 36$ & 16.7 & 624.4 \\
\hline 425 & 80.38 & 16.7 & 624.6 \\
\hline 426 & $820080: 40$ & 16.7 & 624.5 \\
\hline 427 & 80.42 & 16.7 & 624.6 \\
\hline 428 & $0: 44$ & 16.7 & 624.6 \\
\hline 420 & 0,46 & 16.7 & 624.4 \\
\hline 430 & & 16.7 & 624.5 \\
\hline 431 & & 16.7 & 624. \\
\hline 432 & 0.52 & 16.7 & 624.2 \\
\hline 433 & 0.54 & 16.7 & 624. \\
\hline 434 & & 16.7 & 624. \\
\hline 435 & 5.58 & 16.7 & 624. \\
\hline 436 & & 16.7 & 623.9 \\
\hline 437 & & 16.7 & 62 \\
\hline 438 & & 16.7 & 62 \\
\hline 439 & & 16.7 & 623. \\
\hline 440 & & 16.7 & 623. \\
\hline 441 & & 16.7 & 623. \\
\hline 442 & & 16.7 & 623. \\
\hline 443 & & 16.7 & 623. \\
\hline 444 & & 16.7 & 623. \\
\hline 445 & $1: 18$ & 16.7 & 623.7 \\
\hline 446 & & 16.7 & 23. \\
\hline 447 & & 16.7 & 623 \\
\hline 448 & $1: 24$ & 16.7 & 623. \\
\hline 449 & & 16.7 & 623. \\
\hline 450 & & 16.7 & 23 \\
\hline 451 & & 16.7 & 623.6 \\
\hline 452 & & 16.7 & 623. \\
\hline 453 & & 16.7 & 623 \\
\hline 454 & 136 & 16.7 & 623.7 \\
\hline 455 & & 16.7 & 223. \\
\hline 456 & & 16.7 & $\overline{623}$ \\
\hline 457 & & 16.7 & 623. \\
\hline 458 & & 16.7 & 623. \\
\hline 459 & $: 46$ & 16.7 & 623 \\
\hline 460 & & 16.7 & 623.5 \\
\hline 461 & & 16.7 & 62 \\
\hline 462 & & 16.7 & \\
\hline 463 & $1: 54$ & 16.7 & 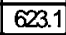 \\
\hline 464 & & 16.7 & 623.1 \\
\hline 465 & & 16.7 & \\
\hline 466 & & 16.7 & 623.1 \\
\hline 467 & & 16.7 & 623.3 \\
\hline 468 & & 16.7 & 623. \\
\hline 469 & & & $\Rightarrow$ \\
\hline
\end{tabular}

\begin{tabular}{|c|c|c|c|}
\hline \multicolumn{4}{|c|}{$\mathrm{D} 427 \mathrm{c}$} \\
\hline 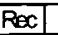 & & & \\
\hline \# & DateTime & & $\mu \mathrm{s} / \mathrm{d}$ \\
\hline 470 & $820082: 08$ & 16.7 & 623.1 \\
\hline 471 & 32008210 & 16.7 & 623.3 \\
\hline 472 & 32008212 & 16.7 & \\
\hline 473 & 12008214 & 16.7 & 623.4 \\
\hline 474 & 82008216 & $\begin{array}{l}16.7 \\
\end{array}$ & 623.3 \\
\hline 475 & 82008218 & 16.7 & \\
\hline 476 & $8 / 2008220$ & 16.7 & 623.4 \\
\hline 477 & 382008222 & 16.7 & 623.4 \\
\hline 478 & 82008224 & 16.7 & 623.4 \\
\hline 479 & $8 / 2008226$ & 16.7 & \\
\hline 480 & $8 / 82008228$ & 16.7 & 623.6 \\
\hline 481 & $8 / 82008230$ & 16.7 & 623.5 \\
\hline 482 & $8 / 8 / 2008232$ & 16.7 & \\
\hline 483 & 32008234 & 16.7 & 623. \\
\hline 484 & $8 / 8 / 2008236$ & 16.7 & 623.4 \\
\hline 485 & $8 / 8 / 2008238$ & 16.7 & 623.5 \\
\hline 486 & 182008240 & 16.7 & \\
\hline 487 & 82008242 & 16.7 & 623.5 \\
\hline 488 & $8 / 82008244$ & 16.7 & 623. \\
\hline 489 & $8 / 82008246$ & 16.7 & \\
\hline 490 & $8 / 820008248$ & \begin{tabular}{|l|}
16.7 \\
\end{tabular} & 623.5 \\
\hline 491 & $8 / 820008250$ & 16.7 & 623. \\
\hline 492 & 32008252 & 16.7 & \\
\hline 493 & 32008254 & 16.7 & 62 \\
\hline 494 & 22008256 & 16.7 & 623. \\
\hline 495 & 82008258 & 16.7 & 623. \\
\hline 496 & $8 / 20083: 00$ & 16.7 & 623 \\
\hline 497 & $120083: 02$ & 16.7 & 623. \\
\hline 498 & $320083: 04$ & 16.7 & 623. \\
\hline 499 & $120083: 06$ & 16.7 & 623. \\
\hline 500 & 2008308 & 16.7 & 623 \\
\hline 501 & $: 10$ & 16.7 & 623. \\
\hline 502 & $320083: 12$ & 16.7 & 623. \\
\hline 503 & $8 / 8 / 20083: 14$ & 16.7 & 62 \\
\hline 504 & 3:16 & 16.7 & 623. \\
\hline 505 & & 16.7 & 623. \\
\hline 506 & $8 / 820083: 20$ & 16.7 & 62 \\
\hline 507 & 22 & 16.7 & 623. \\
\hline 508 & & 16.7 & 623 \\
\hline 509 & $3: 26$ & 16.7 & 23. \\
\hline 510 & 28 & 16.7 & 623. \\
\hline 511 & & 16.7 & 623 \\
\hline 512 & $3: 32$ & 16.7 & 23. \\
\hline 513 & & 16.7 & 623. \\
\hline 514 & & 16.7 & $\sigma$ \\
\hline 515 & 338 & 16.7 & 623 \\
\hline 516 & & 16.7 & 623 \\
\hline 517 & & 16.7 & \\
\hline 518 & $3: 44$ & 16.7 & 23. \\
\hline 519 & & 16.7 & 623. \\
\hline 520 & 48 & 16.7 & $\bar{\sigma}$ \\
\hline 521 & 3.50 & 16.7 & 62 \\
\hline 522 & & 16.7 & 623 \\
\hline 523 & 154 & 16.7 & \\
\hline 524 & $3: 56$ & 16.7 & 623 \\
\hline 525 & & 16.7 & 62 \\
\hline 526 & 100 & 16.7 & \\
\hline 527 & $8 / 82008$ & 16.7 & 623. \\
\hline 528 & & 16.7 & 623. \\
\hline 529 & $: 06$ & 16.7 & 624. \\
\hline 530 & & 16.7 & 623. \\
\hline 531 & $8 / 82000$ & 16.7 & 62 \\
\hline 532 & & $\mid 16.7$ & 623. \\
\hline 533 & $8 / 8 / 20084: 14$ & 16.7 & \\
\hline 534 & ack & 16.7 & 623 \\
\hline 535 & $8 / 820084: 18$ & 16.7 & 6 \\
\hline 536 & $8 / 8 / 20084: 20$ & & \\
\hline
\end{tabular}

\begin{tabular}{|c|c|c|c|}
\hline \multicolumn{4}{|c|}{ D427c } \\
\hline 20 & & Tent & \\
\hline$\#$ & DeteTime & ${ }^{\circ} \mathrm{C}$ & $\mu \mathrm{Sk}$ \\
\hline 537 & $8 / 20084: 22$ & 16.7 & 623. \\
\hline 538 & $320084: 24$ & 16.7 & \\
\hline 539 & $8 / 20084: 26$ & $\overline{16.7}$ & $\tilde{\alpha 2}$ \\
\hline 540 & $8 / 8 / 20084: 28$ & $\begin{array}{ll}16.7 \\
\end{array}$ & \\
\hline 541 & $8 / 8 / 20084: 30$ & 16.7 & \\
\hline 542 & $8 / 820084: 32$ & 16.7 & \\
\hline 543 & $8 / 820084: 34$ & \begin{tabular}{|l|}
16.7 \\
\end{tabular} & 623 \\
\hline 544 & $8 / 820084: 36$ & 16.7 & \\
\hline 545 & $8820004: 38$ & 167 & \\
\hline 546 & $8 / 820084: 40$ & 167 & 62 \\
\hline 547 & $8 / 8 / 20084: 42$ & 16.7 & 623 \\
\hline 548 & $8 / 8 / 20084: 44$ & 16.7 & \\
\hline 549 & $8 / 820084: 46$ & 16.7 & \\
\hline 550 & $8 / 8220084: 48$ & 16.7 & 624 \\
\hline 551 & $8 / 8 / 20084: 50$ & 16.7 & 624 \\
\hline 552 & $8 / 820084: 52$ & 16.7 & \\
\hline 553 & $8 / 8 / 20084: 54$ & 16.7 & $\widetilde{24}$ \\
\hline 554 & $8 / 820084: 56$ & 16.7 & 624 \\
\hline 555 & $88 / 20084: 58$ & 16.7 & \\
\hline 556 & $8 / 820085: 00$ & 16.7 & \\
\hline 507 & $8 / 8 / 20085: 02$ & 16.7 & 624 \\
\hline 558 & 8/820085:04 & 16.7 & \\
\hline 550 & $8 / 820085: 06$ & 16.7 & 624 \\
\hline 560 & $8 / 8 / 20085: 08$ & 167 & 624 \\
\hline 561 & $8 / 820085: 10$ & 16.7 & 624 \\
\hline 502 & $8 / 8 / 20085: 12$ & 16.7 & 624. \\
\hline 563 & $8 / 8 / 20085: 14$ & 16.7 & 624. \\
\hline 564 & $8 / 820085: 16$ & 16.7 & 624 \\
\hline 565 & $8 / 8 / 20085: 18$ & 16.7 & 624 \\
\hline 566 & $8 / 8 / 20085: 20$ & 16.7 & 624 \\
\hline 567 & $5: 22$ & 16.7 & 624 \\
\hline 568 & $120085: 24$ & 16.7 & 624 \\
\hline 569 & $120085: 26$ & 16.7 & 624. \\
\hline 570 & $5: 28$ & 16.7 & 6 \\
\hline 571 & $3 / 20085: 30$ & 16.7 & $\sigma$ \\
\hline 572 & $8 / 8 / 20085: 32$ & 16.7 & 623 \\
\hline 573 & 34 & 167 & 623 \\
\hline 574 & $5: 36$ & 16.7 & 623 \\
\hline 575 & $8 / 8 / 200$ & 16.7 & 623 \\
\hline 576 & 40 & 167 & 62 \\
\hline 57? & 42 & 16.7 & 623 \\
\hline 578 & $8 / 8 / 200$ & 16.7 & 623. \\
\hline 579 & $5: 46$ & 16.7 & 623 \\
\hline 580 & $5: 48$ & 16.8 & 622 \\
\hline 581 & $5: 50$ & 16.7 & 623. \\
\hline 582 & & 16.7 & 623 \\
\hline 583 & 54 & 16.7 & \\
\hline 584 & $8 / 8 / 20085: 56$ & 167 & 62 \\
\hline 585 & & 167 & 623 \\
\hline 586 & $m$ & 167 & \\
\hline 587 & $8 / 8 / 20$ & 16.7 & 623 \\
\hline 588 & & 16.7 & 62 \\
\hline 589 & $8 / 8 / 2$ & 16.7 & \\
\hline 590 & $8 / 8 / 20$ & 16.7 & 623 \\
\hline 591 & & 16.7 & 623 \\
\hline 592 & 12 & 16.7 & 623 \\
\hline 593 & $8 / 820$ & 16.7 & 623. \\
\hline 594 & & 16.7 & 623 \\
\hline 595 & & 16.7 & \\
\hline $596-$ & $8 / 8 / 20086: 20$ & 16.7 & 623 \\
\hline 597 & $6: 22$ & 16.7 & 62 \\
\hline 598 & $6: 24$ & 16.7 & 620 \\
\hline 599 & $6: 26$ & 16.8 & \\
\hline 600 & $120086: 28$ & 16.7 & w \\
\hline 601 & $120086: 30$ & 16.7 & \\
\hline 602 & 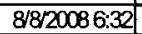 & 16.7 & 623 \\
\hline$\overline{60}$ & & & \\
\hline
\end{tabular}

\begin{tabular}{|c|c|c|c|}
\hline \multicolumn{4}{|c|}{ D427c } \\
\hline$R x$ & & Temp & $S C$ \\
\hline$\#$ & Dater/ime & ${ }^{\circ} \mathrm{C}$ & $\mu \mathrm{S} / \mathrm{cm}$ \\
\hline 604 & $8 / 8 / 20086: 36$ & 16.7 & 623.6 \\
\hline 606 & $88 / 20086: 38$ & 16.7 & 623.4 \\
\hline 606 & $8 / 82008640$ & 16.7 & 623.6 \\
\hline 607 & $8 / 820086: 42$ & 16.7 & 623.5 \\
\hline 608 & $8 / 820086.44$ & 16.7 & 623.7 \\
\hline 609 & $88 / 20086: 46$ & 16.7 & 623.t. \\
\hline 610 & $8 / 8 / 20086: 48$ & 16.7 & 623.5 \\
\hline 611 & $8 / 8 / 20086: 50$ & 16.7 & 6236 \\
\hline 612 & $8 / 820086: 52$ & 16.7 & 623.5 \\
\hline 613 & $88820086: 54$ & 16.7 & 623.5 \\
\hline 614 & $8 / 8 / 20086: 56$ & 16.7 & 623.5 \\
\hline 615 & $8 / 820086: 58$ & 16.7 & 623.6 \\
\hline 616 & $8 / 820087: 00$ & 16.7 & 223. \\
\hline 617 & $8 / 8 / 20087: 02$ & 16.7 & 623.5 \\
\hline 618 & $8 / 8220087: 04$ & 16.7 & 623.5 \\
\hline 619 & $8 / 820087: 06$ & 16.7 & $623 !$ \\
\hline 620 & $8 / 820087: 08$ & 16.7 & 623.5 \\
\hline 621 & $8 / 820087: 10$ & 16.7 & 623.5 \\
\hline 622 & $8 / 8 / 20087: 12$ & 16.7 & 623! \\
\hline 623 & $8 / 8 / 20087: 14$ & 16.7 & 623.5 \\
\hline 624 & $8 / 820087: 16$ & 16.7 & 623.7 \\
\hline 625 & $8 / 820087: 18$ & 16.7 & 623. \\
\hline 626 & $8 / 820087: 20$ & 16.7 & 623.6 \\
\hline 627. & $8 / 820087: 22$ & 16.7 & 623.5 \\
\hline 628 & $8 / 820087: 24$ & 16.7 & 623. \\
\hline E29 & $8 / 820087: 26$ & 16.7 & 623. \\
\hline 630 & $8 / 820087: 28$ & 16.7 & 623.6 \\
\hline 631 & $88 / 20087: 30$ & 16.7 & 623. \\
\hline 632 & $8 / 820087: 32$ & 16.7 & 623.7 \\
\hline 633 & $88120087: 34$ & 16.7 & 223.8 \\
\hline 634 & $8 / 8220087: 36$ & 16.7 & 623. \\
\hline 635 & $8 / 8 / 20087: 38$ & 16.7 & 623. \\
\hline 636 & $8 / 8 / 20087: 40$ & 16.7 & 623.6 \\
\hline 637 & $8 / 8 / 20087: 42$ & 16.7 & 623. \\
\hline 638 & $8 / 8 / 20087: 44$ & 16.7 & 623. \\
\hline 639 & $8 / 8 / 20087: 46$ & 16.7 & 623.6 \\
\hline 640 & $8 / 820087: 48$ & 16.7 & 523.7 \\
\hline 641 & $8 / 8200087: 50$ & 16.7 & 623. \\
\hline 642 & $8 / 820087: 52$ & 16.7 & 623.8 \\
\hline 643 & $8 / 8200087: 54$ & 16.7 & 623.7 \\
\hline 644 & $8 / 820087: 56$ & 16.7 & 623 \\
\hline 645 & $8 / 820087: 58$ & 16.7 & 623.5 \\
\hline 646 & $8 / 8 / 20088: 00$ & 16.7 & 623.8 \\
\hline 647 & $8 / 820088: 02$ & 16.7 & 623. \\
\hline 648 & $8 / 820088: 04$ & 16.7 & 623.9 \\
\hline 649 & $8 / 8 / 20088: 06$ & 16.7 & 624 \\
\hline 650 & $8 / 820088: 08$ & 16.7 & 62 \\
\hline 651 & $8 / 8 / 20088: 10$ & 16.7 & 623.8 \\
\hline 652 & $8 / 820088.12$ & 16.7 & 623.8 \\
\hline 653 & $8 / 820088: 14$ & 16.7 & 623.9 \\
\hline 654 & $8 / 8 / 20088: 16$ & \begin{tabular}{|l|}
16.7 \\
\end{tabular} & 624 \\
\hline 655 & $8 / 8 / 20088: 18$ & 16.7 & 623.9 \\
\hline 656 & $8 / 820088: 20$ & 16.7 & 223.5 \\
\hline 657 & $8 / 8 / 20088: 22$ & 16.7 & 623.9 \\
\hline 658 & $8 / 820088: 24$ & 16.7 & 623.8 \\
\hline 659 & $8 / 820088: 26$ & 16.7 & 62 \\
\hline 660 & $8 / 8 / 20088: 28$ & 16.7 & 623.9 \\
\hline 661 & $8 / 820088: 30$ & 16.7 & 623.9 \\
\hline 662 & $8 / 8220088: 32$ & 16.7 & 624 \\
\hline 663 & $8 / 8 / 20088: 34$ & 16.8 & $\sqrt[623]{23}$ \\
\hline 664 & $8 / 8 / 20088: 36$ & 16.7 & 624 \\
\hline 665 & $8 / 820088: 38$ & 16.7 & 624.3 \\
\hline 606 & $8 / 8 / 20088: 40$ & 16.7 & 624.5 \\
\hline 667 & $8 / 8 / 20088: 42$ & 16.7 & 624.4 \\
\hline 608 & $8 / 8 / 200088: 44$ & 16.7 & 624.4 \\
\hline 669 & $8 / 8 / 20088: 46$ & 16.7 & 624.3 \\
\hline 670 & $8 / 8 / 20088: 48$ & & 524 \\
\hline
\end{tabular}




\begin{tabular}{|c|c|c|c|}
\hline \multicolumn{4}{|c|}{ D427c } \\
\hline Pec & & Tend & $S C$ \\
\hline$\#$ & Date/Time & ${ }^{\circ} \mathrm{C} / \mathrm{F}$ & HSam \\
\hline 671 & $8 / 820088: 50$ & 16.7 & 624.2 \\
\hline 672 & $8 / 8 / 20088: 52$ & 16.7 & 624.4 \\
\hline 673 & $8 / 820088.54$ & 16.7 & 624.5 \\
\hline 674 & $8 / 820088: 56$ & 16.8 & 623.1 \\
\hline 675 & $8 / 820088: 58$ & 16.7 & 624.5 \\
\hline 676 & $8 / 8 / 20089.00$ & \begin{tabular}{|l|}
16.7 \\
\end{tabular} & 624.3 \\
\hline $6 \pi 7$ & $8 / 820089.02$ & \begin{tabular}{|l|}
16.7 \\
\end{tabular} & 624.1 \\
\hline 678 & $8 / 8 / 20089: 04$ & 16.7 & 624.3 \\
\hline 679 & $8 / 8 / 20089.06$ & \begin{tabular}{|l|}
16.7 \\
\end{tabular} & 624.1 \\
\hline 680 & 818120089.08 & \begin{tabular}{|l|}
16.7 \\
\end{tabular} & 624 \\
\hline 681 & $8 / 820089: 10$ & \begin{tabular}{|l|l|}
16.7 \\
\end{tabular} & 624.1 \\
\hline 602 & $8 / 8 / 20089: 12$ & \begin{tabular}{|l|}
16.7 \\
\end{tabular} & 624 \\
\hline 683 & $8 / 820089: 14$ & \begin{tabular}{|l|}
16.7 \\
\end{tabular} & 624.1 \\
\hline 684 & $8 / 8 / 20089.16$ & \begin{tabular}{|l|}
16.7 \\
\end{tabular} & 624 \\
\hline 685 & $8 / 8 / 20089.18$ & \begin{tabular}{|l|}
16.7 \\
\end{tabular} & 623.8 \\
\hline 686 & $8 / 8 / 20089: 20$ & 16.7 & 623.9 \\
\hline 687 & $8 / 82008922$ & \begin{tabular}{|l|l|}
16.8 \\
\end{tabular} & 6227 \\
\hline 688 & $8 / 8 / 20089.24$ & 16.7 & 624.2 \\
\hline 689 & 81820089.26 & \begin{tabular}{|l|}
16.7 \\
\end{tabular} & 624.8 \\
\hline 690 & 81820089.28 & \begin{tabular}{|l|l|}
16.7 \\
\end{tabular} & 624.8 \\
\hline 691 & $8 / 8 / 2008930$ & 16.7 & 624.8 \\
\hline 692 & $81820089: 32$ & 16.7 & 624.8 \\
\hline 693 & $8 / 8 / 20089.34$ & \begin{tabular}{|l|l|}
16.7 \\
\end{tabular} & 624.8 \\
\hline 694 & $8 / 820089.36$ & \begin{tabular}{|l|}
16.7 \\
\end{tabular} & 624.8 \\
\hline 695 & $8 / 8 / 20089.38$ & 167 & 624.7 \\
\hline 696 & $8 / 820089.40$ & \begin{tabular}{|l|l|}
16.7 \\
\end{tabular} & 624.8 \\
\hline 697 & $8 / 8 / 20089: 42$ & \begin{tabular}{|l|}
16.7 \\
\end{tabular} & 624.6 \\
\hline 698 & $8 / 8 / 20089.44$ & \begin{tabular}{|l|}
16.7 \\
\end{tabular} & 624.6 \\
\hline 699 & $8 / 8 / 20089.46$ & \begin{tabular}{|l|l|}
16.7 \\
\end{tabular} & 624.6 \\
\hline 700 & $8 / 8 / 20089.48$ & \begin{tabular}{|l|l|}
16.7 \\
\end{tabular} & 624.6 \\
\hline 701 & $8 / 8 / 20089.50$ & \begin{tabular}{|l|l|}
16.7 \\
\end{tabular} & 624.8 \\
\hline 702 & $8 / 8 / 20089.52$ & \begin{tabular}{|l|l|}
16.7 \\
\end{tabular} & 624.9 \\
\hline 703 & $8 / 820089.54$ & 16.7 & 624.8 \\
\hline 704 & $8 / 8 / 20089.56$ & \begin{tabular}{|c|}
16.8 \\
\end{tabular} & 623.8 \\
\hline 706 & $8 / 8 / 20089.58$ & \begin{tabular}{|l|}
16.7 \\
\end{tabular} & 624.9 \\
\hline 706 & $88 / 200810: 00$ & 16.7 & 625.1 \\
\hline 707 & $8 / 8 / 2008$ 10:02 & 16.7 & 625.3 \\
\hline 708 & $8 / 8 / 2008$ 10:04 & 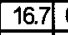 & 625.3 \\
\hline 709 & $8 / 8 / 2008$ 10:06 & 16.7 & 625.3 \\
\hline 710 & \begin{tabular}{|l|}
$8 / 200810: 08$ \\
\end{tabular} & 16.7 & 625.3 \\
\hline 711 & $8 / 8 / 2008$ 10:-10 & 16.7 & 625.4 \\
\hline 712 & $8 / 8 / 2008$ 10:12 & 16.7 & 625.4 \\
\hline 713 & $8 / 8 / 2008$ 10:14 & 16.7 & 625.3 \\
\hline 714 & $8 / 8 / 200810: 16$ & 16.7 & 625.3 \\
\hline 715 & $8 / 8 / 200810: 18$ & 16.7 & 625.2 \\
\hline 716 & $8 / 8200810: 20$ & 16.7 & 625.3 \\
\hline 717 & $8 / 8 / 200810: 22$ & \begin{tabular}{|l|}
16.7 \\
\end{tabular} & 625.4 \\
\hline 718 & $8 / 8 / 200810: 24$ & 16.7 & 625.2 \\
\hline 719 & $8 / 8 / 200810: 26$ & 16.7 & 625.3 \\
\hline 720 & $8 / 8 / 200810: 28$ & 16.7 & 625.3 \\
\hline 721 & $8 / 8200810.30$ & \begin{tabular}{|l|l|}
16.7 \\
\end{tabular} & 625.2 \\
\hline 722 & $8 / 8 / 200810.32$ & \begin{tabular}{|l|}
16.7 \\
\end{tabular} & 625.3 \\
\hline 723 & $8 / 8: 200810: 34$ & \begin{tabular}{|l|}
16.7 \\
\end{tabular} & 625.2 \\
\hline 724 & $8 / 82008$ 10:36 & \begin{tabular}{|l|}
16.7 \\
\end{tabular} & 626.1 \\
\hline 725 & $8 / 8 / 200810.38$ & \begin{tabular}{|l|}
16.7 \\
\end{tabular} & 625.7 \\
\hline 726 & $8 / 8 / 200810: 40$ & \begin{tabular}{|l|}
16.7 \\
\end{tabular} & 625.8 \\
\hline 727 & $8 / 8 / 200810: 42$ & \begin{tabular}{|l|}
16.7 \\
\end{tabular} & 625.9 \\
\hline 728 & $8 / 82008 \quad 10.44$ & \begin{tabular}{|l|}
16.7 \\
\end{tabular} & 625.8 \\
\hline 729 & $8 / 8 / 200810-46$ & \begin{tabular}{|l|}
16.7 \\
\end{tabular} & 625.7 \\
\hline 730 & $8 / 8200810.48$ & \begin{tabular}{|l|}
16.7 \\
\end{tabular} & 625.9 \\
\hline 731 & 888200810.50 & \begin{tabular}{|l|l|}
16.7 \\
\end{tabular} & 625.9 \\
\hline 732 & $8 / 8 / 200810.52$ & \begin{tabular}{|l|}
16.7 \\
\end{tabular} & 625.8 \\
\hline 733 & $8 / 8200810.54$ & 16.7 & 625.9 \\
\hline 734 & $8 / 82008$ 10:56 & 16.7 & 625.9 \\
\hline 735 & $8 / 8 / 200810: 58$ & 16.7 & 625.9 \\
\hline 736 & $8 / 82008$ 11:00 & 16.7 & 625.9 \\
\hline 737| & $8 / 8 / 2008$ 11:02 & 16.7 & 625.8 \\
\hline
\end{tabular}

\begin{tabular}{|c|c|c|}
\hline \multicolumn{3}{|c|}{ D427c } \\
\hline $\mathrm{Rec}$ & & Tend SC \\
\hline$\#$ & Date/Time & \begin{tabular}{|c|c|}
${ }^{\circ} \mathrm{C}$ & $\mu \mathrm{S} / \mathrm{cm}$ \\
\end{tabular} \\
\hline 738 & $88200811: 04$ & \begin{tabular}{l|l|}
16.7 & 625.9 \\
\end{tabular} \\
\hline 739 & $8 / 82200811: 06$ & \begin{tabular}{|l|l|}
16.7 & 625.8 \\
\end{tabular} \\
\hline 740 & $8 / 8 / 200811: 08$ & \begin{tabular}{|l|l|}
16.7 & 625.8 \\
\end{tabular} \\
\hline 741 & $8 / 82008$ 11:10 & \begin{tabular}{|l|l|}
16.7 & 625.7 \\
\end{tabular} \\
\hline 742 & $8 / 8200811: 12$ & \begin{tabular}{l|l|}
16.7 & 625.9 \\
\end{tabular} \\
\hline 743 & 882008 11:14 & \begin{tabular}{l|l|}
16.7 & $\mathbf{2} 6.2$ \\
\end{tabular} \\
\hline 744 & $8 / 82008$ 11:16 & \begin{tabular}{l|l|}
16.7 & 626 \\
\end{tabular} \\
\hline 745 & 882008 11:18 & \begin{tabular}{l|l|}
16.7 & 625.9 \\
\end{tabular} \\
\hline 746 & $8 / 8 / 200811: 20$ & \begin{tabular}{|l|l|}
16.7 & 625.9 \\
\end{tabular} \\
\hline 747 & $8 / 8 / 200811: 22$ & \begin{tabular}{|l|l|}
16.7 & $\boldsymbol{6} 25.8$ \\
\end{tabular} \\
\hline 748 & $8 / 8200811: 24$ & \begin{tabular}{l|l}
16.7 & 625.8 \\
\end{tabular} \\
\hline 749 & $8 / 8 / 200811: 26$ & \begin{tabular}{|l|l|}
16.7 & $\nwarrow 25.8$ \\
\end{tabular} \\
\hline 750 & $8 / 8 / 200811: 28$ & \begin{tabular}{|l|l|}
16.7 & 626.1 \\
\end{tabular} \\
\hline 751 & $8 / 8 / 2008$ 11:30 & \begin{tabular}{|l|l|}
16.7 & $\mathbf{2 5 . 7}$ \\
\end{tabular} \\
\hline 752 & $8 / 8200811: 32$ & \begin{tabular}{l|l|}
16.7 & 625.9 \\
\end{tabular} \\
\hline 753 & $8 / 8 / 200811: 34$ & \begin{tabular}{l|l|}
16.7 & 625.9 \\
\end{tabular} \\
\hline 754 & $8 / 8 / 200811: 36$ & \begin{tabular}{|l|l|}
16.7 & 625.6 \\
\end{tabular} \\
\hline 755 & $8 / 8200811: 38$ & \begin{tabular}{|l|l|}
16.7 & 625.9 \\
\end{tabular} \\
\hline 756 & $8 / 812008$ 11:40 & \begin{tabular}{|l|l|}
16.7 & 625.7 \\
\end{tabular} \\
\hline 757 & $8 / 8 / 200811: 42$ & \begin{tabular}{|l|l|}
16.7 & $\widetilde{25.7}$ \\
\end{tabular} \\
\hline 758 & $8 / 8 / 2008$ 11:44 & \begin{tabular}{|l|l|}
16.7 & 625.7 \\
\end{tabular} \\
\hline 758 & $8 / 8 / 2008$ 11:46 & \begin{tabular}{l|l|}
16.7 & 625.7 \\
\end{tabular} \\
\hline 760 & $8 / 8 / 2008$ 11:48 & \begin{tabular}{|l|l|}
16.7 & $\mathbf{2 5 . 5}$ \\
\end{tabular} \\
\hline 761 & $8 / 8 / 200811: 50$ & \begin{tabular}{l|l|}
16.7 & 625.9 \\
\end{tabular} \\
\hline 762 & $8 / 8200011: 52$ & \begin{tabular}{l|l|}
16.7 & $\widetilde{25.7}$ \\
\end{tabular} \\
\hline 763 & $8 / 8 / 200811: 54$ & \begin{tabular}{l|l|}
16.7 & $\approx 5.7$ \\
\end{tabular} \\
\hline 764 & $8 / 8 / 200811: 56$ & \begin{tabular}{|l|l|}
16.7 & $\approx 25.8$ \\
\end{tabular} \\
\hline 765 & $8 / 8 / 2008$ 11:58 & \begin{tabular}{|l|l|}
16.7 & $\mathbf{6 2 5 . 6}$ \\
\end{tabular} \\
\hline 766 & $8 / 8 / 20081200$ & \begin{tabular}{|l|l|}
16.7 & $\nwarrow 25.6$ \\
\end{tabular} \\
\hline 767 & $8 / 8 / 20081200$ & \begin{tabular}{|l|l|}
16.7 & 625.6 \\
\end{tabular} \\
\hline 768 & $8 / 8 / 20081204$ & \begin{tabular}{|l|l}
16.7 & 625.5 \\
\end{tabular} \\
\hline 769 & $8 / 8 / 20081206$ & \begin{tabular}{|l|l|}
16.7 & 625.6 \\
\end{tabular} \\
\hline $7 \pi 0$ & $8 / 8 / 20081200$ & \begin{tabular}{|l|l}
16.7 & 625.5 \\
\end{tabular} \\
\hline 771 & $8 / 820081210$ & \begin{tabular}{|l|l|}
16.7 & 625.5 \\
\end{tabular} \\
\hline$\pi 72$ & $8 / 8 / 20081212$ & \begin{tabular}{|l|l|}
16.7 & $\widetilde{2} 5.5$ \\
\end{tabular} \\
\hline 773 & $8 / 8 / 20081214$ & \begin{tabular}{|l|l|}
16.7 & 625.4 \\
\end{tabular} \\
\hline $7 \pi 4$ & $8 / 8 / 2008+216$ & \begin{tabular}{|l|l|}
16.7 & 625.5 \\
\end{tabular} \\
\hline 775 & $8 / 820081218$ & \begin{tabular}{|l|l|}
16.7 & 625.4 \\
\end{tabular} \\
\hline $7 \pi 6$ & $8 / 820081220$ & \begin{tabular}{|l|l|}
16.7 & $\approx 25.3$ \\
\end{tabular} \\
\hline$\pi 7$ & $8 / 8120081222$ & \begin{tabular}{|l|l|}
16.7 & 625.4 \\
\end{tabular} \\
\hline 778 & $8 / 8 / 20081224$ & \begin{tabular}{l|l|}
16.7 & 625.3 \\
\end{tabular} \\
\hline $7 \pi 9$ & $8 / 8120081226$ & \begin{tabular}{|l|l|}
16.7 & 624.6 \\
\end{tabular} \\
\hline 780 & $8 / 8 / 20081228$ & \begin{tabular}{|l|l}
16.7 & $\mathbf{2 5 . 3}$ \\
\end{tabular} \\
\hline 781 & $8 / 8 / 20081230$ & \begin{tabular}{|l|l}
16.7 & 625.2 \\
\end{tabular} \\
\hline 782 & $8 / 8 / 20081232$ & \begin{tabular}{|l|l}
16.7 & $\approx 25.3$ \\
\end{tabular} \\
\hline 783 & 88120081234 & \begin{tabular}{|l|l|}
16.7 & $\approx 25.1$ \\
\end{tabular} \\
\hline 784 & $8 / 8 / 20081236$ & \begin{tabular}{|l|l|}
16.7 & $\sigma 25.2$ \\
\end{tabular} \\
\hline 785 & $8 / 8 / 20081238$ & \begin{tabular}{|l|l|}
16.7 & 625.2 \\
\end{tabular} \\
\hline 786 & $8 / 8 / 200812440$ & \begin{tabular}{|l|l|}
16.7 & 625.4 \\
\end{tabular} \\
\hline 787 & $8 / 8 / 20081242$ & \begin{tabular}{|l|l|}
16.7 & 625.3 \\
\end{tabular} \\
\hline 788 & $8 / 8 / 20081244$ & \begin{tabular}{|l|l|}
16.7 & $\widetilde{2} 5.3$ \\
\end{tabular} \\
\hline 780 & $8 / 820081246$ & \begin{tabular}{|l|l|}
16.7 & 625.1 \\
\end{tabular} \\
\hline 790 & $8 / 820081248$ & \begin{tabular}{|l|l|}
16.7 & 625.4 \\
\end{tabular} \\
\hline 791 & $8 / 820081250$ & \begin{tabular}{|l|l|}
16.7 & 625.2 \\
\end{tabular} \\
\hline 792 & $8 / 820081252$ & \begin{tabular}{|l|l|}
16.7 & 625.3 \\
\end{tabular} \\
\hline 793 & $8 / 82008$ १2:54 & \begin{tabular}{|l|l|}
16.7 & 625.3 \\
\end{tabular} \\
\hline 794 & $8 / 820081256$ & \begin{tabular}{l|l}
16.7 & 625.3 \\
\end{tabular} \\
\hline 796 & $8 / 820081258$ & \begin{tabular}{|l|l|}
16.7 & 625.3 \\
\end{tabular} \\
\hline 796 & $88 / 2008$ 13:00 & \begin{tabular}{|l|l|}
16.7 & 625.2 \\
\end{tabular} \\
\hline 797 & $8 / 82008$ 13:02 & \begin{tabular}{|l|l|}
16.7 & $\approx 5.4$ \\
\end{tabular} \\
\hline 798 & $8887200813: 04$ & \begin{tabular}{|l|l|}
16.7 & 625.1 \\
\end{tabular} \\
\hline 799 & $8 / 8200813: 06$ & \begin{tabular}{|l|l|}
16.7 & $\nwarrow 25.5$ \\
\end{tabular} \\
\hline 800 & \begin{tabular}{|l|l|}
$8 / 200813: 08$ \\
\end{tabular} & \begin{tabular}{|l|l|}
16.7 & 625.3 \\
\end{tabular} \\
\hline 801 & $8 / 8 / 2008$ 13:10 & \begin{tabular}{|l|l|}
16.7 & 625.5 \\
\end{tabular} \\
\hline 802 & $8 / 82008$ 13:12 & \begin{tabular}{|l|l|}
16.7 & 625.4 \\
\end{tabular} \\
\hline 803 & $8 / 8 / 2008$ 13:14 & \begin{tabular}{|l|l|}
16.7 & 625.4 \\
\end{tabular} \\
\hline 804 & $8 / 8 / 2008$ 13:16 & \begin{tabular}{|l|l|}
16.7 & 625.4 \\
\end{tabular} \\
\hline
\end{tabular}

\begin{tabular}{|c|c|c|c|}
\hline \multicolumn{4}{|c|}{$D 427 \mathrm{c}$} \\
\hline $\mathrm{Pec}$ & & Temp & $S C$ \\
\hline$\#$ & DaterTime & ${ }^{\circ} \mathrm{C}$ & $\mu \mathrm{s} / \mathrm{m}$ \\
\hline 805 & $8 / 8200813: 18$ & 16.7 & 625.5 \\
\hline 806 & $88 / 200813: 20$ & 16.7 & 625.3 \\
\hline 807 & $8 / 8200813: 22$ & 16.7 & 625.5 \\
\hline 808 & $8 / 8200813: 24$ & 16.7 & 625.4 \\
\hline 809 & $8 / 8 / 200813: 26$ & 16.7 & 625.4 \\
\hline 810 & $8 / 8200813: 28$ & 16.7 & 625.4 \\
\hline 811 & $8 / 8 / 200813: 30$ & 16.7 & 625.3 \\
\hline 812 & $8 / 8200813: 32$ & 16.7 & 625.5 \\
\hline 813 & $8 / 8 / 200813: 34$ & 16.7 & 625.3 \\
\hline 814 & $8 / 8 / 200813: 36$ & 16.7 & 624.6 \\
\hline 815 & $8 / 8 / 200813: 38$ & 16.7 & 624.6 \\
\hline 816 & $8 / 8 / 200813: 40$ & 16.7 & 624.6 \\
\hline 817 & $8 / 8 / 200813: 42$ & 16.7 & $\approx 24.5$ \\
\hline 818 & $8 / 8 / 200813: 44$ & 16.7 & 624.4 \\
\hline 819 & $8 / 8 / 200813: 46$ & 16.7 & 624.6 \\
\hline 820 & $8 / 8 / 200813: 48$ & 16.7 & 624.7 \\
\hline 821 & $8 / 8 / 200813: 50$ & 16.7 & 624.5 \\
\hline 822 & $8 / 8200813: 52$ & 16.7 & 624.4 \\
\hline 823 & $8 / 8200813.54$ & 16.7 & 624.3 \\
\hline 824 & $8 / 8 / 200813: 56$ & 16.7 & \begin{tabular}{|l|}
624.3 \\
\end{tabular} \\
\hline 825 & $8 / 2000813: 58$ & 16.7 & 624.3 \\
\hline 826 & $8 / 8 / 200814: 00$ & 16.8 & $\overline{623.6}$ \\
\hline 827 & $8 / 8 / 2008$ 14:02 & 16.7 & 624.2 \\
\hline 828 & $8 / 8 / 200814: 04$ & 16.7 & \begin{tabular}{|l|}
624.3 \\
\end{tabular} \\
\hline 829 & $8 / 8 / 200814: 06$ & 16.7 & 624.6 \\
\hline 830 & $8 / 8 / 2008$ 14:08 & 16.7 & 624.2 \\
\hline 831 & $8 / 8200814: 10$ & 16.7 & 624.2 \\
\hline 832 & $8 / 8 / 2008$ 14:12 & 16.7 & 624.2 \\
\hline 8033 & $8 / 8200814: 14$ & 16.7 & 624.2 \\
\hline 834 & $8 / 82008$ 14:16 & 16.7 & 624.1 \\
\hline 835 & $8 / 8 / 2008$ 14:18 & $\begin{array}{ll}16.7 \\
\end{array}$ & 624.2 \\
\hline 836 & $8 / 8 / 200814: 20$ & 16.7 & $\widetilde{624.3}$ \\
\hline 837 & $88 / 200814: 22$ & 16.7 & $\overline{224.2}$ \\
\hline 838 & $8 / 8 / 2008$ 14:24 & $\begin{array}{ll}16.7 \\
\end{array}$ & 624.3 \\
\hline 839 & $8 / 8 / 200814: 26$ & 16.7 & @24.2 \\
\hline 840 & $8 / 8 / 200814: 28$ & 16.7 & 624.8 \\
\hline 841 & $8 / 8 / 200814: 30$ & 16.7 & 624.9 \\
\hline 842 & $8 / 8 / 2008$ 14:32 & 16.7 & 624.8 \\
\hline 843 & $8 / 8 / 2008$ 14:34 & 16.7 & 624.9 \\
\hline 844 & $8 / 8 / 200814: 36$ & 16.7 & 624.9 \\
\hline 845 & $8 / 8 / 200814: 38$ & 16.7 & 624.7 \\
\hline 846 & $8 / 8 / 200814: 40$ & 16.7 & 625 \\
\hline 847 & $8 / 8 / 2008$ 14:42 & 16.7 & 624.8 \\
\hline 848 & $8 / 8 / 200814: 44$ & 16.7 & 624.8 \\
\hline 849 & $8 / 8 / 2008$ 14:46 & 16.7 & 624.7 \\
\hline 850 & $8 / 8 / 200814: 48$ & 16.7 & 624.7 \\
\hline 851 & $8 / 8 / 200814: 50$ & 16.7 & 624.9 \\
\hline 852 & $8 / 8 / 200814: 52$ & 16.7 & 624.7 \\
\hline 853 & $8 / 8 / 200814: 54$ & 16.7 & 624.7 \\
\hline 854 & $8 / 8 / 2008$ 14:56 & 16.7 & 624.6 \\
\hline 855 & $8 / 8 / 200814: 58$ & 16.7 & \begin{tabular}{|l|}
624.7 \\
\end{tabular} \\
\hline 856 & $8 / 8 / 200815: 00$ & 16.7 & \begin{tabular}{|l|l|}
624.7 \\
\end{tabular} \\
\hline 857 & $88 / 200815: 02$ & 16.7 & $\approx 24.6$ \\
\hline 858 & $8 / 8 / 200815: 04$ & 16.7 & 624.5 \\
\hline 859 & $8 / 8 / 200815: 06$ & 16.7 & 624.5 \\
\hline 860 & $8 / 8200815: 08$ & 16.7 & 624.6 \\
\hline 861 & $8 / 8 / 200815: 10$ & 16.7 & 624.5 \\
\hline 862 & $8 / 8 / 200815: 12$ & 16.7 & 624.5 \\
\hline 863 & $8 / 8 / 200815: 14$ & 16.7 & 624.5 \\
\hline 864 & $8 / 8 / 200815: 16$ & 16.7 & 624.4 \\
\hline 865 & $8 / 8 / 200815: 18$ & 16.7 & 624.4 \\
\hline 866 & $8 / 8 / 200815: 20$ & 16.7 & 624.4 \\
\hline 867 & $8 / 8 / 200815: 22$ & 16.7 & 624.4 \\
\hline 868 & $8 / 8 / 200815: 24$ & 16.7 & \begin{tabular}{|l|l|}
624.4 \\
\end{tabular} \\
\hline 869 & $8 / 8 / 200815: 26$ & 16.7 & 624.3 \\
\hline 870 & $8 / 8 / 200815: 28$ & 16.7 & 624.4 \\
\hline 871 & $8 / 8 / 200815: 30$ & 16.7 & 624.2 \\
\hline
\end{tabular}

\begin{tabular}{|c|c|c|}
\hline \multicolumn{3}{|c|}{$D 427 \mathrm{C}$} \\
\hline $\operatorname{Rec}$ & & Tend $S C$ \\
\hline$\#$ & Dete-Time & \begin{tabular}{|l|l|l|}
${ }^{\circ} \mathrm{C}$ & $\mathrm{H} S \mathrm{~s} / \mathrm{cm}$ \\
\end{tabular} \\
\hline 872 & $8 / 8 / 200815: 32$ & 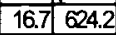 \\
\hline 873 & $8 / 82008$ 15:34 & \begin{tabular}{l|l|}
16.7 & 624.2 \\
\end{tabular} \\
\hline 874 & $8 / 8 / 2008$ 15:36 & \begin{tabular}{l|l|}
16.7 & 624.2 \\
\end{tabular} \\
\hline 875 & $8 / 8 / 2008$ 15:38 & \begin{tabular}{l|l|}
16.7 & 624 \\
\end{tabular} \\
\hline 876 & $8 / 8 / 200815: 40$ & \begin{tabular}{l|l|}
16.7 & 624.1 \\
\end{tabular} \\
\hline 877 & $8 / 8 / 200815: 42$ & \begin{tabular}{|l|l|}
16.7 & 624 \\
\end{tabular} \\
\hline 878 & $8 / 8 / 2008 \quad 15: 44$ & \begin{tabular}{|l|l|}
16.7 & 624 \\
\end{tabular} \\
\hline 879 & $8 / 8 / 2008$ 15:46 & \begin{tabular}{ll|l}
16.7 & 623.9 \\
\end{tabular} \\
\hline 880 & $8 / 8 / 200815: 48$ & \begin{tabular}{|l|l|}
16.7 & $\mathbf{6 2 4 . 1}$ \\
\end{tabular} \\
\hline 881 & $8 / 8 / 200815: 50$ & \begin{tabular}{|l|l|}
16.7 & 623.9 \\
\end{tabular} \\
\hline 882 & $8 / 8 / 200815: 52$ & \begin{tabular}{|l|l|}
16.7 & 623.9 \\
\end{tabular} \\
\hline 883 & $8 / 8 / 2008$ 15:54 & \begin{tabular}{|l|l|}
16.7 & 623.9 \\
\end{tabular} \\
\hline 884 & $818200815: 56$ & \begin{tabular}{|l|l|}
16.7 & 623.7 \\
\end{tabular} \\
\hline 885 & $8 / 8 / 200815: 58$ & \begin{tabular}{|l|l}
16.7 & 623.8 \\
\end{tabular} \\
\hline 886 & $8 / 8200816: 00$ & \begin{tabular}{|l|l|}
16.7 & 623.8 \\
\end{tabular} \\
\hline 887 & $8 / 82008$ 16:02 & \begin{tabular}{|l|l|}
16.7 & $\nwarrow 23.8$ \\
\end{tabular} \\
\hline 888 & $8 / 82008$ 16:04 & \begin{tabular}{|l|l|}
16.7 & 623.6 \\
\end{tabular} \\
\hline 889 & $8 / 8 / 200816: 06$ & \begin{tabular}{l|l|}
16.7 & 623.9 \\
\end{tabular} \\
\hline 890 & $8 / 8200816: 08$ & \begin{tabular}{l|l}
16.7 & 6229 \\
\end{tabular} \\
\hline 891 & $8 / 8 / 200816-10$ & \begin{tabular}{|l|r|}
16.7 & 623 \\
\end{tabular} \\
\hline 892 & 8882008 16:12 & \begin{tabular}{|l|l|}
16.7 & 6299 \\
\end{tabular} \\
\hline 893 & $8 / 8 / 2008$ 16:14 & \begin{tabular}{l|l|}
16.7 & 6229 \\
\end{tabular} \\
\hline 894 & $8 / 8 / 200816: 16$ & \begin{tabular}{|l|l|}
16.7 & 626 \\
\end{tabular} \\
\hline 895 & $8 / 8 / 2008$ 16:18 & \begin{tabular}{|l|l|}
16.7 & $\approx 23.9$ \\
\end{tabular} \\
\hline 896 & $8 / 8 / 2008$ 16:20 & $\begin{array}{l}16.7 \\
624.6 \\
\end{array}$ \\
\hline 897 & $8 / 8 / 200816: 22$ & \begin{tabular}{l|l|}
16.7 & 624.3 \\
\end{tabular} \\
\hline 898 & $8 / 8200816: 24$ & \begin{tabular}{l|l|}
16.7 & 626.5 \\
\end{tabular} \\
\hline 899 & $8 / 8 / 2008$ 16:26 & $\begin{array}{l}16.7 \\
624.6 \\
\end{array}$ \\
\hline 900 & $8 / 8 / 200816: 28$ & 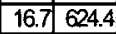 \\
\hline 901 & $8 / 8 / 200816: 30$ & \begin{tabular}{l|l|}
16.7 & 626.3 \\
\end{tabular} \\
\hline 902 & $8 / 8 / 200816: 32$ & \begin{tabular}{l|l|}
16.7 & 626.1 \\
\end{tabular} \\
\hline 903 & $8 / 8 / 2008$ 16:34 & \begin{tabular}{l|l}
16.7 & 626 \\
\end{tabular} \\
\hline 904 & $88 / 2008$ 16:36 & \begin{tabular}{|l|}
16.7 \\
\end{tabular} \\
\hline 905 & $8 / 8 / 2008$ 16:38 & \begin{tabular}{|l|l|}
16.7 & 626.9 \\
\end{tabular} \\
\hline 906 & $8 / 8200816: 40$ & \begin{tabular}{|l|l|}
16.7 & 626.9 \\
\end{tabular} \\
\hline 907 & 882008 16:42 & \begin{tabular}{|l|l|}
16.8 & 625.6 \\
\end{tabular} \\
\hline 908 & $8 / 8 / 200816: 44$ & \begin{tabular}{|l|l|}
16.7 & 626.9 \\
\end{tabular} \\
\hline 909 & $88 / 200816: 46$ & \begin{tabular}{|l|l|}
16.7 & 626.9 \\
\end{tabular} \\
\hline 910 & $8 / 8 / 2008$ 16:48 & \begin{tabular}{|l|l|}
16.7 & 625.8 \\
\end{tabular} \\
\hline 911 & $8 / 8 / 200816: 50$ & \begin{tabular}{|l|l|}
16.7 & 625.4 \\
\end{tabular} \\
\hline 912 & $8 / 8 / 200816: 52$ & \begin{tabular}{|l|l|}
16.7 & 625.7 \\
\end{tabular} \\
\hline 913 & 8/8/2008 16:54 & \begin{tabular}{|l|l|}
16.7 & 625.9 \\
\end{tabular} \\
\hline 914 & $8 / 8 / 200816: 56$ & \begin{tabular}{|l|l|}
16.7 & 626.8 \\
\end{tabular} \\
\hline 915 & $8 / 8 / 2008$ 16:58 & \begin{tabular}{|l|l|}
16.7 & 626.7 \\
\end{tabular} \\
\hline 916 & $8 / 8 / 2008$ 17:00 & \begin{tabular}{|l|l}
16.7 & 626.8 \\
\end{tabular} \\
\hline 917 & $8 / 8 / 2008$ 17:02 & \begin{tabular}{|l|l|}
16.7 & 626.7 \\
\end{tabular} \\
\hline 918 & $8 / 8 / 2008$ 17:04 & \begin{tabular}{l|l|}
16.7 & 626.7 \\
\end{tabular} \\
\hline 919 & $818 / 2008$ 17:06 & \begin{tabular}{|l|l|}
16.7 & 626.8 \\
\end{tabular} \\
\hline 920 & $8 / 8 / 2008$ 17:08 & \begin{tabular}{|l|l|}
16.7 & 626.6 \\
\end{tabular} \\
\hline 921$\}$ & $8 / 8 / 2008$ 17:10 & \begin{tabular}{|l|l|}
16.7 & 626.7 \\
\end{tabular} \\
\hline 922 & $8 / 8 / 2008$ 17:12 & \begin{tabular}{|l|l}
16.7 & 626.6 \\
\end{tabular} \\
\hline 923 & $8 / 8 / 2008$ 17:14 & \begin{tabular}{|l|l|}
16.7 & 626.7 \\
\end{tabular} \\
\hline 924 & $8 / 8 / 2008$ 17:16 & \begin{tabular}{|l|l|}
16.7 & 626.6 \\
\end{tabular} \\
\hline 925 & 8882008 17:18 & \begin{tabular}{|l|l|}
16.7 & 626.3 \\
\end{tabular} \\
\hline 926 & $8 / 8 / 2008$ 17:20 & \begin{tabular}{|l|l|}
16.7 & $\mathbf{6 2 6 . 4}$ \\
\end{tabular} \\
\hline 927 & $8 / 8200817: 22$ & \begin{tabular}{|l|l|}
16.7 & 626.3 \\
\end{tabular} \\
\hline 928 & $8 / 8 / 200817: 24$ & \begin{tabular}{|l|l|}
16.7 & 626.4 \\
\end{tabular} \\
\hline 929 & $8 / 82008$ 17:26 & \begin{tabular}{|l|l|}
16.8 & 625 \\
\end{tabular} \\
\hline 930 & $8 / 82008$ 17:28 & \begin{tabular}{|l|l|}
16.7 & 626.4 \\
\end{tabular} \\
\hline 931 & $8 / 8 / 2008$ 17:30 & 16.7626 .2 \\
\hline 932 & $8 / 8 / 2008$ 17:32 & \begin{tabular}{|l|l|}
16.7 & 626.3 \\
\end{tabular} \\
\hline 933 & $8 / 8 / 2008$ 17:34 & \begin{tabular}{|l|l|}
16.7 & 626.4 \\
\end{tabular} \\
\hline 934 & $818 / 200817: 36$ & \begin{tabular}{|l|l|}
16.7 & 626.4 \\
\end{tabular} \\
\hline 935 & $8 / 8 / 2008$ 17:38 & \begin{tabular}{|l|l|}
16.7 & 626.3 \\
\end{tabular} \\
\hline 936 & $8 / 8 / 2008$ 17:40 & \begin{tabular}{|l|l|}
16.7 & 626.4 \\
\end{tabular} \\
\hline 937 & $8 / 8 / 2008$ 17:42 & \begin{tabular}{|l|l|}
16.7 & 626.4 \\
\end{tabular} \\
\hline 938 & $8 / 8 / 2008$ 17:44 & \begin{tabular}{|l|l|}
16.7 & 626.3 \\
\end{tabular} \\
\hline
\end{tabular}

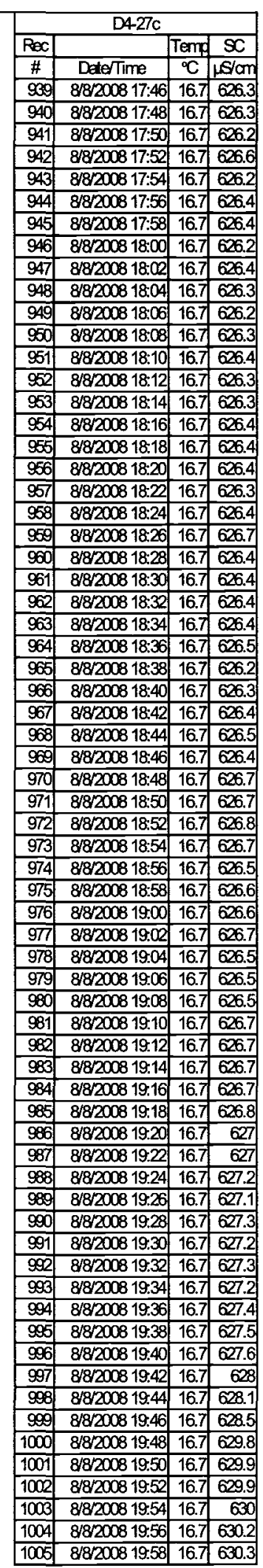


DOE/RL-2009-35, REV. 0

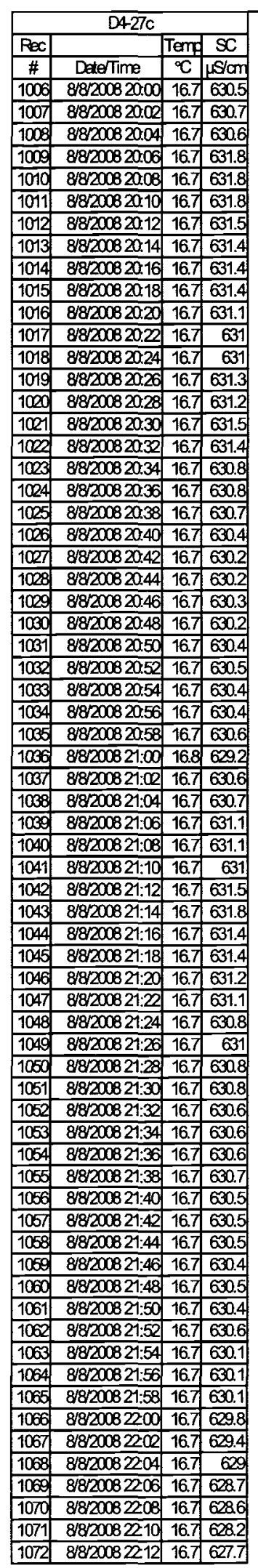

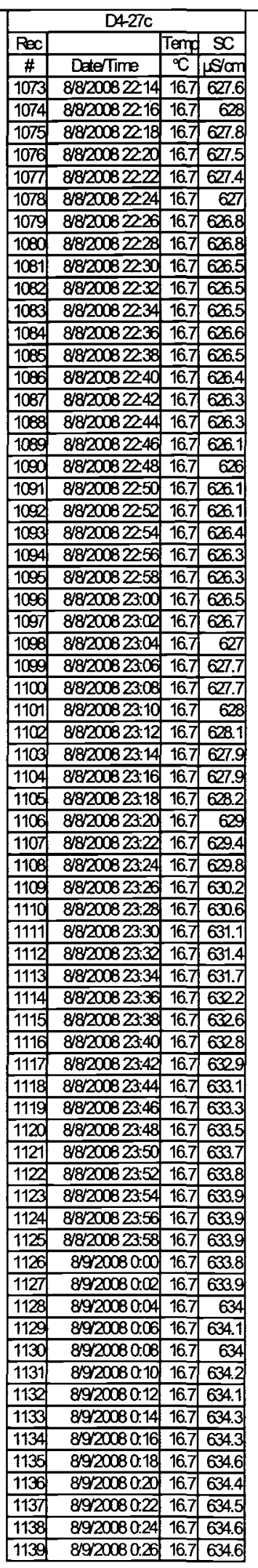

\begin{tabular}{|c|c|c|}
\hline \multicolumn{3}{|c|}{$\mathrm{D} 427 \mathrm{C}$} \\
\hline $\operatorname{Rac}$ & & Temp SC \\
\hline$\#$ & DetefTime & \\
\hline 1140 & & \\
\hline 1141 & 8920000.30 & \begin{tabular}{|l|l|l|}
16.7 & 634.7 \\
\end{tabular} \\
\hline 1142 & $8920000: 32$ & $2 1 6 . 7 \longdiv { 6 3 4 . 8 }$ \\
\hline 1143 & 89200000.34 & \begin{tabular}{|l|l|l|}
1635.1 \\
\end{tabular} \\
\hline 1144 & $8920000: 36$ & \begin{tabular}{|l|l|l|}
16.7 & 634.8 \\
\end{tabular} \\
\hline 1145 & 8920080.38 & \\
\hline 1146 & $89200000: 40$ & \begin{tabular}{|l|l|}
16.7 & 634.9 \\
\end{tabular} \\
\hline 1147 & 89200000442 & \begin{tabular}{|l|l|l|}
16.7 & 634.7 \\
\end{tabular} \\
\hline 1148 & 89200000.44 & \\
\hline 1149 & $8920080: 46$ & \\
\hline 1150 & 89200080.48 & 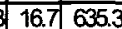 \\
\hline 1151 & 89200000.50 & \begin{tabular}{|l|l|}
16.7 & 635.1 \\
\end{tabular} \\
\hline & 8920000.52 & $\begin{array}{l}16.7 \\
1535.4 \\
\end{array}$ \\
\hline 1153 & 8920000.54 & \\
\hline 1154 & 89.20080 .56 & \\
\hline 1156 & 89200080.56 & \begin{tabular}{|l|l|l|l|} 
& 1635.5 \\
\end{tabular} \\
\hline 1156 & $89 / 2008$ 1:00 & 16.7635 .4 \\
\hline & $89920081: 02$ & \\
\hline 1158 & $8920081: 04$ & \\
\hline 1159 & $8920081: 06$ & \begin{tabular}{|l|l|}
16.7 & 635.6 \\
\end{tabular} \\
\hline 1160 & $8920001: 08$ & \begin{tabular}{|l|l|}
16.7 & 635.5 \\
\end{tabular} \\
\hline 1161 & $8 / 920081: 10$ & \begin{tabular}{|l|l|}
16.7 & 635.5 \\
\end{tabular} \\
\hline & $8920081: 12$ & \begin{tabular}{|l|l|}
16.7 & 635.4 \\
\end{tabular} \\
\hline 1163 & $8920001: 14$ & \begin{tabular}{|l|l|l|}
1635.4 \\
\end{tabular} \\
\hline 1164 & $8920001: 16$ & \begin{tabular}{|l|l|l|}
16.7 & $\approx 5.5$ \\
\end{tabular} \\
\hline 1165 & $8920001: 18$ & \begin{tabular}{|l|l|l|}
3635.4 \\
\end{tabular} \\
\hline & $8720081: 20$ & 16760358 \\
\hline 11167 & $8920001: 22$ & 16.765 \\
\hline 1168 & $8920001: 24$ & \begin{tabular}{|l|l|}
16.7 & 635.4 \\
\end{tabular} \\
\hline 1169 & $89920081: 26$ & \\
\hline & $8920081: 28$ & \begin{tabular}{|l|l|}
16.7 & 635.5 \\
\end{tabular} \\
\hline & $8 / 920081: 30$ & 16.7635 \\
\hline 1172 & $89200011: 32$ & \begin{tabular}{|l|l|l|}
16.7 & 635.5 \\
\end{tabular} \\
\hline 1173 & $8920001: 34$ & \begin{tabular}{|l|l|l|}
16.7 & 635.4 \\
\end{tabular} \\
\hline 1174 & $8920081: 36$ & \\
\hline & $8920081: 38$ & \\
\hline & 89200014 & $\begin{array}{ll}16,7 & 635 .\end{array}$ \\
\hline $117 \pi$ & $89920001: 42$ & \begin{tabular}{|l|l|l|l|l|}
1635.5 \\
\end{tabular} \\
\hline 1178 & $8920001: 44$ & \begin{tabular}{|l|l|l|}
1635.4 \\
\end{tabular} \\
\hline 1179 & $89 / 20081: 46$ & \\
\hline & $8920001: 48$ & \\
\hline 1181 & $8920001: 50$ & \begin{tabular}{|l|l|}
16.7 & 635. \\
\end{tabular} \\
\hline 1182 & $89200081: 52$ & \begin{tabular}{|l|l|}
16.7 & 635 \\
\end{tabular} \\
\hline & $8920081: 54$ & \begin{tabular}{|l|l|}
16.7 & 63 \\
\end{tabular} \\
\hline 1184 & $89200081: 56$ & \begin{tabular}{ll|l}
5 & 16.7 & 635 \\
\end{tabular} \\
\hline 1185 & & \\
\hline & & \begin{tabular}{|l|l|}
16.7 & 635. \\
\end{tabular} \\
\hline 1187 & 8912008 & \\
\hline 88 & 892000204 & \begin{tabular}{|l|l|}
16.7 & $63 x$ \\
\end{tabular} \\
\hline $118 c$ & 892008206 & \begin{tabular}{|l|l|}
16.7 & 635 \\
\end{tabular} \\
\hline 1190 & 892008208 & \begin{tabular}{|l|l|}
16.7 & 636. \\
\end{tabular} \\
\hline & 8972000210 & \begin{tabular}{|l|l|l|}
16.7 & 636. \\
\end{tabular} \\
\hline & $89 / 2008$ & 636 \\
\hline 1198 & 8920008214 & 10.40 \\
\hline 1194 & 8992008216 & \begin{tabular}{|l|l|l|}
16.7 & 636. \\
\end{tabular} \\
\hline 1195 & $89: 2008218$ & \begin{tabular}{|l|l|}
16.7 & 636. \\
\end{tabular} \\
\hline 196 & & \begin{tabular}{|l|l|l|}
16.7 & 636.5 \\
\end{tabular} \\
\hline 119 & $89 / 20$ & 16.7|637. \\
\hline & 89920082 & \\
\hline & 892000226 & 16.7 \\
\hline 1200 & 8920002228 & \begin{tabular}{|l|l|}
16.7 & 637. \\
\end{tabular} \\
\hline & 81920008230 & \begin{tabular}{|l|l|} 
& 638 \\
\end{tabular} \\
\hline & 92008232 & 1 \\
\hline & $89 / 200$ & \\
\hline & & \\
\hline & $8 / 92008238$ & \begin{tabular}{|l|l|}
16.7 & 638 \\
\end{tabular} \\
\hline & 92008240 & \begin{tabular}{|l|l|l|}
16.7 & 638 \\
\end{tabular} \\
\hline
\end{tabular}

\begin{tabular}{|c|c|c|c|}
\hline \multicolumn{4}{|c|}{$D 427 \mathrm{c}$} \\
\hline $\operatorname{Rec}$ & & Temp & $\mathrm{SC}$ \\
\hline \# & DeteTime & ${ }^{\circ} \mathrm{C}$ & $\mu \mathrm{s} / \mathrm{am}$ \\
\hline 1207 & $8 / 92008242$ & 167 & 6386 \\
\hline 1200 & 8992008244 & 16.7 & 638.6 \\
\hline 1200 & $8 / 92008246$ & 16.7 & 638.6 \\
\hline 1210 & 8920008248 & 16.7 & 645.4 \\
\hline 1211 & 892008250 & 16.7 & 646.5 \\
\hline 1212 & $8 / 92008252$ & 16.7 & 6464 \\
\hline 1213 & $8 / 92008254$ & 16.7 & 646.5 \\
\hline 1214 & 892008256 & 16.7 & 646.5 \\
\hline 1215 & $8 / 92008258$ & 16.7 & 646.5 \\
\hline 1216 & 8/920083:00 & 16.7 & 650.2 \\
\hline 1217 & $89920083: 02$ & 16.7 & 641.7 \\
\hline 1218 & $89920083: 04$ & 16.7 & 6422 \\
\hline 1219 & $8 / 920083: 06$ & 16.7 & 641.8 \\
\hline 1220 & $8 / 920003308$ & 16.7 & 6423 \\
\hline 1221 & $8 / 920003: 10$ & 16.7 & 6425 \\
\hline 122 & $8920003: 12$ & 16.7 & 6425 \\
\hline 1223 & $89920083: 14$ & 16.7 & 644.2 \\
\hline 1224 & $8920083: 16$ & 16.7 & 645.7 \\
\hline 1225 & $8920083: 18$ & 16.7 & 645.5 \\
\hline 1226 & $89920083: 20$ & 16.7 & 644 \\
\hline 1227 & $89920083: 22$ & 16.7 & 645.3 \\
\hline 1228 & $8 / 920083: 24$ & 16.7 & 645.1 \\
\hline 1229 & $8 / 920083: 26$ & 16.7 & 644.5 \\
\hline 1230 & $8 / 920083: 28$ & 16.7 & 644.1 \\
\hline 1231 & $89920083: 30$ & 16.7 & 644.4 \\
\hline 1232 & $89 / 20003: 32$ & 16.7 & 644.4 \\
\hline 1233 & 8920083:34 & 16.7 & 644.2 \\
\hline 1234 & 8/920083:36 & 16.7 & 644.6 \\
\hline 1236 & $8 / 920083: 38$ & 16.7 & 644.5 \\
\hline 1236 & $8 / 920083: 40$ & 16.7 & 644.3 \\
\hline 1237 & $8920083: 42$ & 16.7 & 644.5 \\
\hline 1238 & $8920083: 44$ & 16.7 & 644.7 \\
\hline 1239 & 8920083446 & 16.7 & 644.6 \\
\hline 1240 & $8920083: 48$ & 16.7 & 644.5 \\
\hline 1241 & $8920083: 50$ & 16.7 & 644.5 \\
\hline 1242 & $89920083: 52$ & 16.7 & 644.5 \\
\hline 1243 & $89200033: 54$ & 16.7 & 644.5 \\
\hline 1244 & $8920083: 56$ & 16.7 & 644.8 \\
\hline 1245. & $8920083: 58$ & 16.7 & 645 \\
\hline 1246. & $89920084: 00$ & 16.7 & 645 \\
\hline 1247 & $89920084: 02$ & 16.7 & 644.5 \\
\hline 1248 & 8/920084:04 & \begin{tabular}{|l|}
16.7 \\
\end{tabular} & 644.6 \\
\hline 1249 & $89920084: 06$ & 16.7 & 644.9 \\
\hline 1250 & $8 / 920084: 08$ & 16.7 & 645.2 \\
\hline 1251 & $8 / 920084: 10$ & 16.7 & 645.2 \\
\hline 1252 & $8920084: 12$ & 16.7 & 645.3 \\
\hline 1253 & $8920084: 14$ & 16.7 & 645.3 \\
\hline 1254 & $8920084: 16$ & 16.7 & 645.1 \\
\hline 1256 & $8920084: 18$ & 16.7 & 645.1 \\
\hline 1256 & $8920084: 20$ & 16.7 & 645.1 \\
\hline 1257 & $89 / 20084: 22$ & 16.7 & 644.9 \\
\hline 1258 & $89 / 20084: 24$ & 16.7 & 644.8 \\
\hline 1259 & $8920084: 26$ & 16.7 & 644.6 \\
\hline 1260 & $8920084: 28$ & 16.7 & 644.9 \\
\hline 1261 & $8920084: 30$ & 16.7 & 644.6 \\
\hline 1262 & $8920084: 32$ & 16.7 & 644.2 \\
\hline 1263 & $8920084: 34$ & 16.7 & 644.3 \\
\hline 1264 & $89200084: 36$ & 16.7 & 644.3 \\
\hline 1265 & $89920084: 38$ & 16.7 & 644 \\
\hline 1266 & $8920084: 40$ & 16.7 & 644.1 \\
\hline 1267 & $89200084: 42$ & 16.7 & 644 \\
\hline 1268 & $89 / 20064: 44$ & 16.7 & 644.2 \\
\hline 1269 & $89 / 20084: 46$ & 16.7 & 644.4 \\
\hline 1270 & $89 / 20084: 48$ & 16.7 & 644 \\
\hline 1271 & $89 / 20084: 50$ & 16.7 & 643.8 \\
\hline 1272 & $89 / 20084: 52$ & 16.7 & 643.9 \\
\hline 1273 & $8920084: 54$ & 167 & 643.5 \\
\hline
\end{tabular}

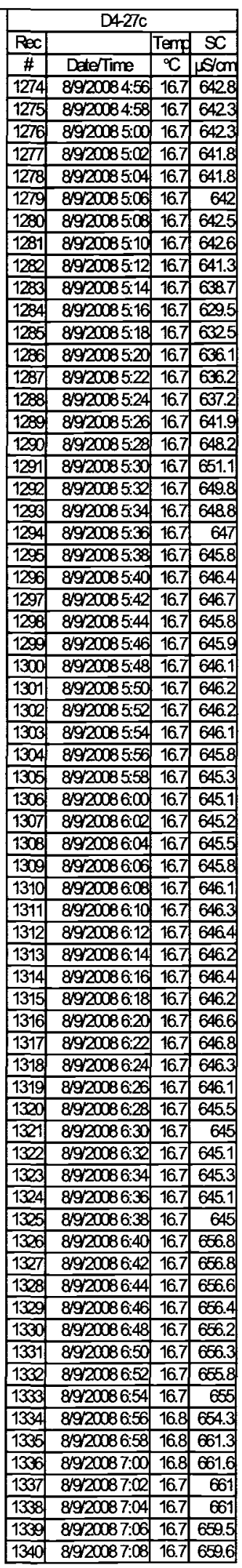




\begin{tabular}{|c|c|c|c|}
\hline \multicolumn{4}{|c|}{$D 427 \mathrm{c}$} \\
\hline Rec & & Tent & $S C$ \\
\hline \# & Dete/Time & ${ }^{\infty} \mathrm{C}$ & $\mathrm{pS} / \mathrm{mm}$ \\
\hline 1341 & $89920087: 10$ & 16.7 & 659.3 \\
\hline 1342 & $8 / 920087: 12$ & 16.7 & 659 \\
\hline 1343 & $8920087: 14$ & 16.7 & 6529 \\
\hline 1344 & $8920087: 16$ & 16.7 & 6528 \\
\hline 1345 & $8920067: 18$ & 16.7 & 6522 \\
\hline 1346 & $89120087: 20$ & 16.7 & 6526 \\
\hline 1347 & $8920087: 22$ & 16.7 & 653.1 \\
\hline 1348 & $89: 20087: 24$ & 16.7 & 6628 \\
\hline 1349 & $8920087: 26$ & 16.7 & 6524 \\
\hline 1350 & $8920007: 28$ & 16.7 & 6524 \\
\hline 1351 & $8920087: 30$ & 16.7 & 6526 \\
\hline 1352 & $8920087: 32$ & 16.7 & 6527 \\
\hline 1353 & $8 / 920087: 34$ & 16.7 & 6526 \\
\hline 1354 & $89 / 20087: 36$ & 16.8 & 651.7 \\
\hline 1355 & $89920087: 38$ & 16.7 & 6526 \\
\hline 1356 & $89 / 20087: 40$ & 16.7 & 6527 \\
\hline 1357 & $89200087: 42$ & 16.7 & 6628 \\
\hline 1358 & $8920087: 44$ & 16.7 & 6527 \\
\hline 1359 & $8920087: 46$ & 16.7 & 6527 \\
\hline 1360 & $8 / 920087: 48$ & 16.7 & 6527 \\
\hline 1361 & $8 / 920087: 50$ & 16.7 & 653 \\
\hline 1362 & $8920087: 52$ & 16.7 & 653.1 \\
\hline 1363 & $81920087: 54$ & 16.7 & 653.3 \\
\hline 1364 & $89 / 20087: 56$ & 16.7 & 653.1 \\
\hline 1365 & $8920087: 58$ & 16.7 & 653.1 \\
\hline 1306 & $8 / 9 / 20088: 00$ & 16.7 & 653.1 \\
\hline 1367 & $89 / 20088: 02$ & 16.7 & 653.3 \\
\hline 1368 & 89:20088:04 & 16.7 & 653.3 \\
\hline 1369 & $89920088: 06$ & 16.7 & 653.4 \\
\hline 1370 & $89920088: 08$ & 16.7 & 653.3 \\
\hline 1371 & $8920088: 10$ & 16.7 & 653.4 \\
\hline 1372 & 8920088:12 & \begin{tabular}{|l|}
16.7 \\
\end{tabular} & 653.5 \\
\hline 1373 & $8920088: 14$ & 16.7 & 653.5 \\
\hline 1374 & $8 / 920008: 16$ & 16.7 & 653.6 \\
\hline 1375 & $8920008: 18$ & 16.7 & 653.7 \\
\hline 1376 & $89120088: 20$ & 16.7 & 653.8 \\
\hline $137 \pi$ & $89 / 20088: 22$ & 16.7 & 653.8 \\
\hline 1378 & $8 / 920088: 24$ & \begin{tabular}{|l|}
16.7 \\
\end{tabular} & 653.7 \\
\hline 1379 & $89120088: 26$ & 16.7 & 653.7 \\
\hline 1380 & 89920088:28 & 16.7 & 653.7 \\
\hline 1381 & $8920088: 30$ & 16.7 & 653.9 \\
\hline 1382 & $8920088: 32$ & 16.7 & 653.8 \\
\hline 1383 & $8920088: 34$ & 16.7 & 653.9 \\
\hline 1384 & $8920008: 36$ & 16.7 & 654 \\
\hline 1385 & $8920008: 30$ & 16.7 & 654 \\
\hline 1386 & $81920008: 40$ & 16.7 & 654 \\
\hline 1387 & $81920088: 42$ & 16.7 & 654.3 \\
\hline 1388 & $89 / 20088: 44$ & 16.7 & 654 \\
\hline 1389 & $8 / 9200088: 46$ & 16.7 & 654.1 \\
\hline 1390 & $89 / 20088: 48$ & 16.7 & 656.2 \\
\hline 1391 & $8 / 9200088: 50$ & 16.7 & 656.2 \\
\hline 1392 & $8 / 9 / 20088: 52$ & 16.7 & 656.3 \\
\hline 1393 & $89120088: 54$ & \begin{tabular}{|l|}
16.7 \\
\end{tabular} & 656.2 \\
\hline 1394 & $89120088: 56$ & 16.7 & 656.2 \\
\hline 1396 & $8 / 920088: 58$ & 16.7 & 656.1 \\
\hline 1396 & 892008900 & 16.7 & 656.1 \\
\hline 1397| & 89120089.02 & 16.7 & 656.1 \\
\hline 1398 & 8920089.04 & \begin{tabular}{|l|}
16.7 \\
\end{tabular} & 655.7 \\
\hline 1399 & $8920089: 06$ & 16.7 & 656 \\
\hline 1400 & 8920089.08 & \begin{tabular}{|l|}
16.7 \\
\end{tabular} & 656.1 \\
\hline 1401 & 89220089.10 & 16.7 & 656.1 \\
\hline 1402 & $8 / 9 / 20089.12$ & 16.7 & 655.7 \\
\hline 1403 & 8920089.14 & 16.7 & 655.7 \\
\hline 1404 & $8 / 920089.16$ & 16.7 & 655.7 \\
\hline 1405 & $8 / 920089.18$ & \begin{tabular}{|l|}
16.7 \\
\end{tabular} & 657.1 \\
\hline 1406 & $8 / 920089.20$ & 16.8 & 657.4 \\
\hline 1407 & $8 / 92008922$ & 16.8 & 6026 \\
\hline
\end{tabular}

\begin{tabular}{|c|c|c|c|}
\hline \multicolumn{4}{|c|}{ D427c } \\
\hline $\operatorname{Rec}$ & & Temp & $S C$ \\
\hline & DateTime & ${ }^{\circ} \mathrm{C}$ & $\mu \mathrm{S} / \mathrm{cm}$ \\
\hline & 8920009.24 & 16.8 & 664 \\
\hline 09 & 89200039.26 & 16.8 & 663 \\
\hline 1410 & 8920089.28 & 16.8 & 664.2 \\
\hline 1411 & 8920089.30 & 16.7 & 664.2 \\
\hline 1412 & 8920089.32 & 16.7 & 663.4 \\
\hline 1413 & 8920089.34 & 16.7 & 665. \\
\hline 1414 & $89 / 20089.36$ & 16.7 & 663.7 \\
\hline 1415 & $89 / 20089.38$ & 16.7 & 663.4 \\
\hline 1416 & $8920089: 40$ & 16.7 & 663.3 \\
\hline 1417 & 8920089.42 & 16.7 & 664 \\
\hline 1418 & 8920089.44 & 16.7 & 663.1 \\
\hline 1419 & 89200099.46 & 16.7 & 663.8 \\
\hline 1420 & 8920089.48 & 16.7 & 662 \\
\hline 1421 & 8920089.50 & 16.7 & 662 \\
\hline 1422 & 89120089.52 & 16.7 & 6621 \\
\hline 1423 & $89 / 200$ & 16.7 & 661.8 \\
\hline 1424 & 89720 & 16.7 & \\
\hline 1425 & 8920089.58 & 16.7 & 660 . \\
\hline 1426 & 8992008 & 16.7 & 660.4 \\
\hline 1427 & 89200 & 16.7 & 660.1 \\
\hline 1428 & 89200 & 16.7 & \\
\hline 1429 & 892000 & 16.7 & 659.5 \\
\hline 1430 & 8920 & 16.7 & 658 \\
\hline 1431 & 899200 & 16.7 & 658 \\
\hline 1432 & $89 / 2008$ 10:12 & 16.7 & 658 \\
\hline 1433 & 892008 10:14 & 16.7 & 658.2 \\
\hline 1434 & 89920 & 16.7 & 658. \\
\hline 1435 & 89920 & 16.7 & 658 \\
\hline 1436 & 89200 & 16.7 & 658 \\
\hline 1437 & 8920 & 16.7 & 658 \\
\hline 1438 & 8912006 & 16.7 & 658. \\
\hline 1439 & 899200 & 16.7 & 658 \\
\hline 1440 & 899200 & 16.7 & 658 \\
\hline 1441 & 89920 & 16.7 & 658. \\
\hline 1442 & $8 / 920$ & 16.7 & 674. \\
\hline 1443 & $8 / 9200$ & 16.7 & 675. \\
\hline 1444 & 8920 & 16.7 & 675. \\
\hline 1445 & 89920 & 16.7 & 675 \\
\hline 1446 & 89920 & 16.7 & 675 \\
\hline 1447 & 89920 & 16.7 & 676. \\
\hline 1448 & 8992 & 16.7 & 676. \\
\hline 1449 & 89920 & 16.7 & 676 . \\
\hline 1450 & 89920 & 16.7 & 676. \\
\hline 1451 & 89920 & 16.7 & 676. \\
\hline 1452 & $8 / 920$ & 16.7 & 676. \\
\hline 1453 & 89120 & 16.7 & 676. \\
\hline 1454 & 8992 & 16.7 & 676. \\
\hline 1455 & 8992 & 16.7 & 676 \\
\hline 1456 & $8 / 920$ & 16.7 & 678 \\
\hline 1457 & 8920 & 16.7 & 683. \\
\hline 1458 & 89920 & 16.7 & 68 \\
\hline 1459 & 8992 & 16.7 & 684. \\
\hline 1460 & $89 / 20$ & 16.7 & 687. \\
\hline 1461 & $89 / 2$ & 16.7 & 685 \\
\hline 1462 & 89120 & 16.7 & 684 \\
\hline 1463 & 89920 & 16.7 & 684. \\
\hline 1464 & $89 / 20$ & 16.7 & 683. \\
\hline 1465 & 89920 & \begin{tabular}{|l|l}
16.7 \\
\end{tabular} & 68 \\
\hline 1466 & & 16.7 & 684. \\
\hline 1467 & 8920 & 16.7 & 681. \\
\hline 1468 & $8 / 920$ & 16.7 & 679 \\
\hline 1469 & $8 / 920$ & 16.7 & 678 \\
\hline 1470 & 8920 & 16.7 & 677 \\
\hline 1471 & 8920 & 16.7 & 677. \\
\hline & $89 / 200$ & 16.7 & 676 \\
\hline $14 \sqrt{3}$ & $89 / 20$ & 16.7 & 676. \\
\hline & & & \\
\hline
\end{tabular}

\begin{tabular}{|c|c|c|c|}
\hline \multicolumn{4}{|c|}{ D4-27c } \\
\hline $\operatorname{Rec}$ & & Temp & $S C$ \\
\hline \# & Dete/Time & ${ }^{\circ} \mathrm{C}$ & $\mu S a n$ \\
\hline & $8 / 9 / 200011: 38$ & 16.7 & \\
\hline & $8 / 92008$ 11:40 & 16.7 & 679 \\
\hline 1477 & 8992008 11:42 & 16.7 & 678 \\
\hline 1478 & $899200811: 44$ & 16.8 & 67 \\
\hline 79 & $89 / 200811: 46$ & 16.7 & 676. \\
\hline 180 & $8 / 9 / 200811: 48$ & 16.7 & 675. \\
\hline 1481 & $8 / 9 / 200811: 50$ & 16.7 & 674.8 \\
\hline 1482 & $89 / 200811: 52$ & \begin{tabular}{|l|}
16.7 \\
\end{tabular} & 675 \\
\hline & $8 / 9 / 200011: 54$ & 16.7 & \\
\hline 1484 & $8 / 92008$ 11:56 & 16.7 & 674. \\
\hline 1485 & $8 / 9 / 2008$ 11:58 & 16.7 & 674.5 \\
\hline 1486 & $8 / 9 / 200$ & 16.7 & 674. \\
\hline & $89 / 200$ & 16.7 & \\
\hline 1488 & $8 / 9 / 200$ & 16.7 & 67 \\
\hline 1489 & $8 / 9 / 20081206$ & 16.7 & 674.5 \\
\hline 1490 & 8992 & 16.7 & 675. \\
\hline 1491 & $8 / 9 / 20$ & 16.7 & \\
\hline 1492 & $8 / 9 / 200$ & 16.7 & 675.3 \\
\hline 1493 & $8 / 9 / 200$ & 16.7 & 675. \\
\hline 1494 & $8 / 9 / 20$ & 16.7 & 674.6 \\
\hline 1496 & $8 / 9 / 2$ & 16.7 & 674 \\
\hline 1496 & $8 / 9 / 20$ & 16.7 & 674 \\
\hline 1497 & 89920 & 16.7 & 674. \\
\hline 1498 & $8 / 9 / 20$ & 16.8 & 673. \\
\hline 1499 & $8 / 9 / 20$ & 16.7 & 675. \\
\hline 1500 & $8 / 9 / 20$ & 16.7 & 674.6 \\
\hline 1501 & 899 & 16.7 & 673. \\
\hline 1502 & $8 / 9 / 20$ & 16.7 & $6 / 2$ \\
\hline 1503 & $8 / 9200081234$ & 167 & $\sqrt{22}$ \\
\hline 1504 & 8920 & $\begin{array}{ll}16.7 \\
\end{array}$ & 672 \\
\hline 1505 & $89 / 20$ & 16.7 & 672 \\
\hline 1506 & $8 / 9 / 20$ & 16.7 & 672 \\
\hline 1507 & $89 / 20$ & 16.7 & 672.3 \\
\hline 1508 & $89 / 2$ & 16.7 & 672 \\
\hline 1509 & $8 / 9 / 200$ & 16.7 & 672. \\
\hline 1510 & $8 / 9 / 20$ & 16.7 & 672 \\
\hline 1511 & 89120 & 16.7 & 67 \\
\hline 12 & $8 / 9120$ & 16.7 & 671. \\
\hline 1513 & 89920 & 16.7 & 671. \\
\hline 1514 & $8 / 9 / 20$ & 16.7 & 671. \\
\hline & $89 \sqrt{2}$ & 16.7 & 671. \\
\hline 1516 & 89120 & 16.7 & 671. \\
\hline 1517 & $89 / 20$ & 16.7 & 671. \\
\hline & $89 \sqrt{2}$ & 16.7 & 671. \\
\hline & 89220 & 16.7 & 671. \\
\hline 1520 & $8 / 9 / 20$ & 16.7 & 671. \\
\hline 1521 & $8 / 9 / 2$ & 16.7 & 671. \\
\hline & $8 / 9 / 2$ & 16.7 & 671. \\
\hline 1523 & $899 / 20$ & 16.7 & 670 \\
\hline 1524 & $89 / 20$ & 16.7 & 670. \\
\hline 1525 & 89912 & 16.7 & 670. \\
\hline 1526 & $8 / 9 / 2$ & 16.7 & \\
\hline 1527 & $89 / 20$ & 16.7 & 668. \\
\hline 1528 & $89 / 20$ & 16.7 & 668. \\
\hline & 89920 & 16.7 & 668 \\
\hline 1530 & $8 / 9 / 20$ & 16.7 & 668 \\
\hline 1531 & $8 / 9 / 20$ & 16.7 & 66 \\
\hline & & 16.7 & 673 \\
\hline & 89920008 13:34 & 16.7 & 673 \\
\hline 1534 & $8 / 9 / 200813: 36$ & 16.7 & 673.2 \\
\hline 1535 & $89 / 200813: 38$ & 16.7 & 67 \\
\hline 36 & $8 / 9 / 200$ & 16.7 & 676. \\
\hline & $8 / 91200$ & 16.7 & 675. \\
\hline 1538 & $8 / 9 / 2008$ 13:44 & 16.8 & 674. \\
\hline & $8 / 9 / 200013: 46$ & 16.7 & 674.2 \\
\hline 1540 & $8 / 9200013: 48$ & 16.7 & 679.3 \\
\hline & & & \\
\hline
\end{tabular}

\begin{tabular}{|c|c|c|c|}
\hline \multicolumn{4}{|c|}{$D 427 c$} \\
\hline $\mathrm{Rec}$ & & Ternd & $\mathrm{SC}$ \\
\hline$\#$ & Date/Time & ${ }^{\circ} \mathrm{C}$ & $\mathrm{\mu s} / \mathrm{om}$ \\
\hline 1542 & $8 / 9 / 2008$ 13:52 & 16.7 & 695.8 \\
\hline 1543 & $89 / 200813: 54$ & 16.7 & 684.1 \\
\hline 1544 & 8992008 13:56 & 16.7 & 688.4 \\
\hline 1545 & $89 / 2008$ 13:58 & 16.7 & 679.6 \\
\hline 1546 & 8992008 14:00 & 16.8 & 678.8 \\
\hline 1547 & $8 / 9 / 2008$ 14:02 & 16.7 & 678.9 \\
\hline 1548 & $8 / 9 / 2008$ 14:04 & 16.7 & 678.9 \\
\hline 1549 & $89 / 2008$ 14:06 & 16.7 & 679.1 \\
\hline 1550 & $89 / 2008$ 14:08 & 16.7 & 679.2 \\
\hline 1551 & $89 / 2008$ 14:10 & 16.8 & 679.1 \\
\hline 1552 & $8 / 9200814: 12$ & 16.7 & 679.4 \\
\hline 1553 & $8 / 9 / 2008$ 14:14 & 16.8 & 679.4 \\
\hline 1554 & $8 / 9 / 2008$ 14:16 & 16.8 & 679.4 \\
\hline 1555 & $8 / 9 / 2008$ 14:18 & 16.8 & 680.1 \\
\hline 1556 & $8 / 9 / 200814: 20$ & 16.8 & 680.2 \\
\hline 1550 & $89 / 2008$ 14:22 & $\begin{array}{l}16.8 \\
\end{array}$ & 679.6 \\
\hline 1558 & $8 / 9 / 2008$ 14:24 & 16.8 & 679.2 \\
\hline 1550 & 8912008 14:26 & 16.8 & 679 \\
\hline 1560 & $8 / 9 / 200814: 28$ & 16.8 & 679.2 \\
\hline 1561 & $8 / 9 / 2008$ 14:30 & 16.8 & 679.2 \\
\hline 1562 & $8 / 9 / 200814: 32$ & 16.8 & 679 \\
\hline 1563 & $89 / 2008$ 14:34 & 16.8 & 679.5 \\
\hline 1564 & $8 / 9 / 2008$ 14:36 & 16.8 & 680.5 \\
\hline 1565 & $8 / 9 / 2008$ 14:38 & 16.8 & 679.9 \\
\hline 1566 & $8 / 9 / 2008$ 14:40 & \begin{tabular}{|l|}
16.7 \\
\end{tabular} & 680.2 \\
\hline 1567 & $89 / 200814: 42$ & $\begin{array}{l}16.8 \\
\end{array}$ & 680.3 \\
\hline 1568 & $89 / 2008$ 14:44 & 16.7 & 680.3 \\
\hline 1569 & 892008 14:46 & 16.7 & 679.9 \\
\hline $15 \%$ & $89 / 200814: 48$ & 16.8 & 679.7 \\
\hline 1571 & $89 / 200814: 50$ & 16.7 & 679.5 \\
\hline 1572 & $89 / 200814: 52$ & 16.7 & 679.3 \\
\hline 1573 & $8 / 9 / 2008$ 14:54 & 16.7 & 679.3 \\
\hline 1574 & $89 / 2008$ 14:56 & 16.7 & 679.4 \\
\hline 15/5 & $89 / 200014: 58$ & 16.7 & 679.4 \\
\hline 1576 & $89 / 2008$ 15:00 & 16.7 & 679 \\
\hline $15 \pi$ & $8 / 9 / 200815: 02$ & 16.7 & 678.4 \\
\hline 1578 & $8 / 9 / 2008$ 15:04 & 16.7 & 678.5 \\
\hline $15 \% 9$ & $8 / 9 / 200815.06$ & 16.7 & 680.1 \\
\hline 1580 & $8 / 9 / 200815: 08$ & 16.7 & 680.4 \\
\hline 1581 & $8 / 9 / 2008$ 15:10 & 16.7 & 680.1 \\
\hline 1582 & $89 / 200815: 12$ & 16.7 & 681.6 \\
\hline 1583 & 892008 15:14 & 16.7 & 680.8 \\
\hline 1584 & $8 / 9 / 2008 \quad 15: 16$ & 16.7 & 680.3 \\
\hline 1585 & 89/2008 15:18 & 16.7 & 681.5 \\
\hline 1586 & $8 / 9 / 2008$ 15:20 & 16.7 & 681.9 \\
\hline 1587 & $89 / 200815: 22$ & 16.7 & 679.9 \\
\hline 1588 & $8 / 9 / 2008+5: 24$ & 16.7 & 679.2 \\
\hline 1589 & $8 / 9 / 200815: 26$ & 16.7 & 679.1 \\
\hline 1590 & $8 / 9 / 2008$ 15:28 & 16.7 & 678.9 \\
\hline 1591 & $8 / 9 / 2008$ 15:30 & 16.7 & 678.7 \\
\hline 1592 & $89 / 2008$ 15:32 & 16.7 & 678.8 \\
\hline 1593 & $89 / 200815: 34$ & 16.7 & 678.8 \\
\hline 1594 & $8 / 9 / 200815: 36$ & 16.7 & 678.5 \\
\hline 1595 & $89 / 200815: 38$ & 16.7 & 678.6 \\
\hline 1596. & $89 / 200815: 40$ & 16.7 & 678.6 \\
\hline 1590 & $8 / 9 / 2008$ 15:42 & 16.7 & 676.7 \\
\hline 1598 & $8 / 9 / 2008$ 15:44 & 16.7 & 678.7 \\
\hline 1590 & $8 / 9 / 200815: 46$ & 16.7 & 678.8 \\
\hline 1600 & $8 / 9 / 200815: 48$ & 16.7 & 679 \\
\hline 1601 & $892000815: 50$ & 16.7 & 679 \\
\hline 1600 & $8 / 9 / 2008$ 15:52 & 16.7 & 678.8 \\
\hline 1603 & $8 / 9 / 200815: 54$ & 16.7 & 680.8 \\
\hline 1604 & $89 / 200815: 56$ & 16.7 & 684.1 \\
\hline 1606 & $892000815: 58$ & 16.7 & 684.4 \\
\hline 1606 & $89 / 200816: 00$ & 16.7 & 683.2 \\
\hline 1607 & $89 / 200816: 02$ & 16.8 & 682.8 \\
\hline 1608 & $8 / 9 / 2008$ 16:04 & 16.7 & 682.8 \\
\hline
\end{tabular}

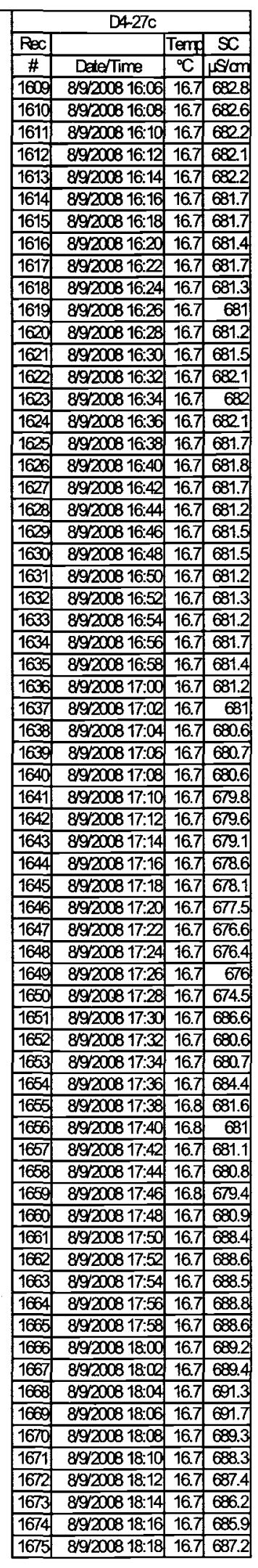




\begin{tabular}{|c|c|c|c|c|c|c|c|c|c|c|c|c|c|c|c|c|c|}
\hline \multicolumn{3}{|c|}{ D427c } & \multicolumn{3}{|c|}{ D4-27c } & \multicolumn{4}{|c|}{ D427c } & \multicolumn{4}{|c|}{$D 427 \mathrm{c}$} & \multicolumn{4}{|c|}{$D 427 c$} \\
\hline $\mathrm{Rec}$ & & Temp & $\mathrm{R} \otimes \mathrm{C}$ & & Temp $S C$ & $\operatorname{Rec}$ & & Teng & $S C$ & Rec & & Tend & $S C$ & $\operatorname{Rec}$ & & Temp & $\mathrm{SC}$ \\
\hline \# & DaterTime & \begin{tabular}{|l|l|}
${ }^{\circ} \mathrm{C}$ & $\mu \mathrm{s} / \mathrm{cm}$ \\
\end{tabular} & $\#$ & Date-Time & \begin{tabular}{|l|l|l|l|}
${ }^{\circ} \mathrm{C}$ & $\mu \mathrm{s}$ \\
\end{tabular} & $\#$ & DeterTime & ${ }^{\circ} \mathrm{C}$ & psicm & $\#$ & Dete/Tirne & \begin{tabular}{|l|l|}
${ }^{\circ} \mathrm{P}$ \\
\end{tabular} & $\mu \mathrm{s} / \mathrm{m}$ & $\#$ & Date/Time & $\begin{array}{ll}{ }^{\circ} \mathrm{C} \\
\end{array}$ & $\mu \mathrm{S} / \mathrm{cm}$ \\
\hline & $8 / 9 / 200818: 20$ & \begin{tabular}{|l|l|}
16.7 & 686.6 \\
\end{tabular} & 1743 & $8912008200: 34$ & $\begin{array}{l}16.7 \\
\end{array}$ & 1810 & $89 / 20082248$ & 16.7 & & 1877 & $8 / 10 / 20081: 02$ & 16.7 & 683.4 & 1944 & $8 / 10 / 20083: 16$ & 16.7 & 687.8 \\
\hline 577 & $89200818 \cdot 22$ & \begin{tabular}{|l|l|}
16.7 & 606 \\
\end{tabular} & 1744 & $89 / 200820.36$ & \begin{tabular}{l|l|}
16.7 & 683.2 \\
\end{tabular} & 1811 & $89 / 20082250$ & 16.7 & 683.8 & 1878. & $8 / 1020081: 04$ & 16.7 & \begin{tabular}{|l|}
683.4 \\
\end{tabular} & 1945 & $1020083 \cdot 18$ & 16.7 & 687 \\
\hline 1678 & 8992008 18:24 & \begin{tabular}{|l|l|}
16.7 & 686.2 \\
\end{tabular} & 1745 & $89 / 200820.38$ & \begin{tabular}{l|l|}
16.7 & 6826 \\
\end{tabular} & 1812 & $89 / 20082252$ & 16.7 & 679.9 & 1879 & $8 / 1020081: 06$ & 16.7 & 683 & 1946 & $8 / 1020083: 20$ & 16.7 & 686.9 \\
\hline 1679 & $818: 26$ & \begin{tabular}{|l|l|}
16.7 & 686.8 \\
\end{tabular} & 1746 & $8 / 9 / 200820.40$ & $\begin{array}{l}16.7 \\
\end{array}$ & 1813 & 82254 & 16.7 & 680.5 & 1880 & & 16.7 & \begin{tabular}{|l|}
6827 \\
\end{tabular} & 1947 & & 16.7 & \\
\hline 1680 & 892008 18:28 & \begin{tabular}{l|l|}
16.7 & 606.7 \\
\end{tabular} & 1747 & $892000820: 42$ & \begin{tabular}{l|l|}
16.7 & 681.8 \\
\end{tabular} & 1814 & 20082256 & 16.7 & 681.8 & 1881 & $8 / 10 / 20081: 10$ & 16.7 & 6829 & 1948 & & 16.7 & \\
\hline 1681 & $8 / 92008$ 18:30 & \begin{tabular}{|l|l|}
16.7 & 687.6 \\
\end{tabular} & 1748 & $89 / 200820.44$ & \begin{tabular}{l|l|}
16.7 & 682 \\
\end{tabular} & 1815 & 8920082258 & 16.7 & 681.6 & 1882 & $8 / 1020081: 12$ & 16.7 & \begin{tabular}{|l|l|}
6828 \\
\end{tabular} & 1949 & $8 / 1020083: 26$ & 16.7 & 685.7 \\
\hline 1682 & 8992008 18:32 & \begin{tabular}{|l|l|}
16.7 & 685.8 \\
\end{tabular} & 1749 & $8 / 9 / 200820.46$ & \begin{tabular}{|l|l|}
16.7 & 681.3 \\
\end{tabular} & 1816 & $89 / 200823: 00$ & 16.7 & 681.8 & 1883 & $8 / 10 / 20081: 14$ & 16.7 & 6829 & 1950 & $8 / 1020083: 28$ & 16.7 & 685.9 \\
\hline 1683 & & \begin{tabular}{|l|l|}
16.7 & 685.4 \\
\end{tabular} & 1750 & $89 / 200820.48$ & \begin{tabular}{|l|l|}
16.7 & 681.3 \\
\end{tabular} & 1817 & $892000823: 02$ & 16.7 & 681.3 & 1884 & $8 / 1020081: 16$ & 16.7 & 6628 & 1951 & & 16.7 & 686 \\
\hline 1684 & $818: 36$ & \begin{tabular}{|r|r|}
16.7 & 685.1 \\
\end{tabular} & \begin{tabular}{|l|}
1751 \\
\end{tabular} & $89 / 200820.50$ & \begin{tabular}{l|l|}
16.7 & 681.5 \\
\end{tabular} & 1818 & $89 / 200823: 04$ & 16.7 & 679.8 & 1806 & $8 / 10 / 20081: 18$ & 16.7 & 6827 & 1952 & $8 / 1020083: 32$ & 16.7 & 687 \\
\hline 1685 & $892000818: 38$ & \begin{tabular}{|l|l|}
16.7 & 685.7 \\
\end{tabular} & 1752 & 892000820.52 & $\begin{array}{l}16.7 \\
681.3 \\
\end{array}$ & 1819 & $819 / 200823: 06$ & 16.7 & 680.1 & 1886 & $8 / 10 / 20081: 20$ & 16.7 & 6825 & 1953 & $83: 34$ & 16.7 & 690.5 \\
\hline 1626 & $18: 40$ & \begin{tabular}{|l|l|}
16.7 & 685 \\
\end{tabular} & 1753 & 899200820.54 & \begin{tabular}{l|l|}
16.7 & 680.8 \\
\end{tabular} & 1820 & 823:06 & 16.7 & 680.1 & 1887 & $8 / 1020081: 22$ & 167 & 681.9 & 1954 & & & \\
\hline 1687 & $188: 42$ & \begin{tabular}{|l|l|}
16.7 & 684.6 \\
\end{tabular} & 1754 & $899200820: 56$ & \begin{tabular}{|l|l|}
16.7 & 680.1 \\
\end{tabular} & 1821 & 823:10 & 16.7 & 680.8 & 1888 & $8 / 10 / 20081: 24$ & 16.7 & 681.9 & 1956 & $83: 38$ & 16.7 & 688.4 \\
\hline 1688 & 892008 18:44 & \begin{tabular}{|l|l|}
16.7 & 684.3 \\
\end{tabular} & 1755 & $89 / 200820: 58$ & \begin{tabular}{l|l|}
16.7 & 680.7 \\
\end{tabular} & 1822 & $823: 12$ & 16.7 & 679.7 & 1889 & $8 / 1020081: 26$ & 16.7 & \begin{tabular}{|l|}
681.9 \\
\end{tabular} & 1966 & $83: 40$ & 16.7 & 687.8 \\
\hline 1689 & $18: 46$ & \begin{tabular}{|l|l|}
16.7 & 684.7 \\
\end{tabular} & 1756 & $89 / 200$ & \begin{tabular}{l|l|}
16.7 & 681 \\
\end{tabular} & 1823 & 23:14 & 16.7 & 679.5 & 1890 & $8 / 10 / 20081: 28$ & 16.7 & 682 & 1960 & & 16.8 & \\
\hline 1690 & 18.48 & \begin{tabular}{|l|l|}
16.7 & 685.9 \\
\end{tabular} & $175 \sqrt{\mid}$ & $89 / 20$ & \begin{tabular}{l|l|}
16.7 & 680.1 \\
\end{tabular} & 1824 & 323:16 & 16.8 & 679.8 & 1891 & $8 / 1020081: 30$ & 16.7 & 681.9 & 1958 & & 16.7 & \\
\hline 1691 & 818:50 & \begin{tabular}{|l|l|}
16.7 & 685.8 \\
\end{tabular} & 1758 & $8 / 9 / 2$ & \begin{tabular}{l|l|}
16.7 & 679.1 \\
\end{tabular} & 1825 & 823:18: & 16.7 & 679 & 1892 & $8 / 1020001: 32$ & \begin{tabular}{|l|}
16.7 \\
\end{tabular} & 6621 & 1950 & $83: 46$ & 16.7 & 689.6 \\
\hline 1692 & 18:52 & \begin{tabular}{|l|l|}
16.7 & 685.3 \\
\end{tabular} & 1759 & 21:06 & \begin{tabular}{l|l|}
16.7 & 678.8 \\
\end{tabular} & 1826 & $23: 20$ & 16.7 & 678.9 & 1893 & $8 / 1020001: 34$ & 16.7 & 681.9 & 1960 & $3: 48$ & 16.7 & 000.1 \\
\hline 1603 & & \begin{tabular}{|r|r|}
16.7 & 683.8 \\
\end{tabular} & 1760 & & \begin{tabular}{l|l|}
16.7 & 679.7 \\
\end{tabular} & 1827 & & 16.7 & 679.2 & 1894 & & & \begin{tabular}{|l|}
681.7 \\
\end{tabular} & 1961 & & 16.7 & \\
\hline 1694 & 318:56 & \begin{tabular}{|l|l|}
16.7 & 683.5 \\
\end{tabular} & 1761 & $899 x$ & \begin{tabular}{l|l|}
16.7 & 679.5 \\
\end{tabular} & 1828 & $323: 24$ & 16.7 & 680.9 & 1895 & $8 / 1020081: 38$ & 16.7 & \begin{tabular}{|l|}
681.8 \\
\end{tabular} & 1962 & $8 / 10$ & 16.7 & 686.5 \\
\hline 1695 & 18:58 & \begin{tabular}{|l|l|}
16.7 & 683.3 \\
\end{tabular} & $17 \approx 2$ & $89 \sqrt{20}$ & \begin{tabular}{l|l|}
16.7 & 679.5 \\
\end{tabular} & 1829 & $23: 26$ & 16.7 & 681.7 & 1896 & $8 / 1020$ & 16.7 & 6826 & 1963 & $8 / 10$ & 16.7 & 685.8 \\
\hline 1696 & $19: 00$ & \begin{tabular}{l|l|}
16.7 & 683.5 \\
\end{tabular} & 1763 & $8 / 9 \sqrt{2}$ & \begin{tabular}{|l|l|}
16.7 & 680.1 \\
\end{tabular} & 1830 & $23: 28$ & 16.7 & 681.3 & 1897 & $8 / 102$ & & & 1964 & & 16.7 & \\
\hline 1697 & 819.02 & \begin{tabular}{|l|l|}
16.7 & 684 \\
\end{tabular} & 1764 & 21:16 & $\begin{array}{l}16.7 \\
680 . \\
\end{array}$ & 1831 & 23:30 & 16.7 & 681.1 & 1898 & $8 / 1020081: 44$ & 16.7 & 6881 & 1965 & & 16.7 & 666.8 \\
\hline 1698 & $8819: 04$ & \begin{tabular}{l|l|}
16.7 & 684.3 \\
\end{tabular} & 1765 & 892 & \begin{tabular}{l|l}
16.7 & 680.9 \\
\end{tabular} & 1832 & $323: 32$ & 16.7 & 681.2 & 1899 & $8 / 1020081: 46$ & 16.7 & 687.9 & 1966 & $8 / 10$ & 16.7 & 636.9 \\
\hline 1699 & 19.06 & \begin{tabular}{l|l|}
16.7 & 683.8 \\
\end{tabular} & 1766 & $8 / 9 / 20$ & \begin{tabular}{l|l|}
16.7 & 680.9 \\
\end{tabular} & 1833 & $23: 34$ & 16.7 & 680.9 & 1900 & 31:48 & 16.7 & 6884 & 1967 & & & \\
\hline 1700 & $19: 08$ & \begin{tabular}{|l|l|}
16.7 & 683.6 \\
\end{tabular} & 1767 & & \begin{tabular}{l|l}
16.7 & 680. \\
\end{tabular} & \begin{tabular}{|l|}
1834 \\
\end{tabular} & $23: 36$ & 16.7 & 680.9 & 1901 & & 16.7 & & 1968 & & 16.7 & 86.1 \\
\hline 1701 & 19:10 & \begin{tabular}{|l|l|}
16.7 & 684.2 \\
\end{tabular} & 1768 & $8 / 92$ & \begin{tabular}{l|l}
16.7 & 680. \\
\end{tabular} & 1835 & 23:38 & 16.7 & 680.8 & 1902 & $81: 52$ & 16.7 & 688.3 & 1969 & 4:06 & 16.7 & 686.2 \\
\hline 1702 & 9912 & \begin{tabular}{|l|l|}
16.7 & 684.5 \\
\end{tabular} & 1769 & $8 / 920$ & \begin{tabular}{l|l|l|}
16.7 & 680.8 \\
\end{tabular} & 1836 & $323: 40$ & 16.7 & 681.4 & 1903 & $8 / 10200081: 54$ & 16.7 & \begin{tabular}{|l|}
687.3 \\
\end{tabular} & 1970 & 4:08 & $\ldots$ & 684.7 \\
\hline 1703 & 819.14 & \begin{tabular}{l|l|}
16.7 & 684 \\
\end{tabular} & 1770 & & \begin{tabular}{l|l|}
16.7 & 681. \\
\end{tabular} & \begin{tabular}{|l|}
1837 \\
\end{tabular} & & 16.7 & & 1904 & & & & 1971 & & 16. & \\
\hline 1704 & 819.16 & \begin{tabular}{|l|l|}
16.7 & 683.6 \\
\end{tabular} & 1771 & 1:30 & $\begin{array}{l}16.7 \\
680 . \\
\end{array}$ & 1838 & $23: 44$ & 16.7 & 679 & 1905 & & 16.7 & 685.4 & 1972 & & 16.7 & 83.4 \\
\hline 1705 & 99.18 & \begin{tabular}{|l|l|}
16.7 & 683.5 \\
\end{tabular} & $17 / 2$ & 8912 & 16.7 & 1839 & $3: 46$ & 16.7 & 679.1 & 1906 & & 16.7 & 68 & 1973 & & 16.7 & 33.2 \\
\hline 1706 & 319.20 & \begin{tabular}{|l|r|}
16.7 & 683 \\
\end{tabular} & 1773 & 8992 & \begin{tabular}{l|l|}
16.7 & 680.9 \\
\end{tabular} & 1840 & 23:48 & 16.7 & 680.6 & 1907 & & 16.7 & & 1974 & & 16.7 & \\
\hline 1707 & 319.22 & \begin{tabular}{l|l|}
16.7 & 683.2 \\
\end{tabular} & 1774 & & \begin{tabular}{|l|l|}
16.7 & 681 \\
\end{tabular} & 1841 & $23: 50$ & 16.7 & 682 & 1908 & & 16.7 & 685 & 1975 & & 16.7 & 6828 \\
\hline 1708 & & $\begin{array}{l}16.7 \\
6.884 .\end{array}$ & 1775 & & \begin{tabular}{|l|l|}
16.7 & 680.9 \\
\end{tabular} & 1842 & $3: 52$ & 16.7 & 683.5 & 1909 & & 16.7 & 685 & 976 & & 16.7 & 83.7 \\
\hline 1700 & 19.26 & $\begin{array}{l}16.7 \\
1683 \\
\end{array}$ & 1776 & & \begin{tabular}{|l|l|}
16.7 & 680.2 \\
\end{tabular} & 1843 & $23: 54$ & 16.7 & 683.5 & 1910 & & 16.7 & 68 & 1977 & & 16.7 & \\
\hline 1710 & 19.28 & \begin{tabular}{l|l|}
16.7 & 683.8 \\
\end{tabular} & $17 \pi$ & & \begin{tabular}{l|l|}
16.7 & 68 \\
\end{tabular} & 1844 & $23: 56$ & 16.7 & 685.8 & 1911 & & 16.7 & 68 & 1978 & 4:24 & 16.7 & 29 \\
\hline 1711 & & $\begin{array}{l}16.7 \\
685 . \\
\end{array}$ & 1778 & & \begin{tabular}{|l|l|}
16.7 & 679.6 \\
\end{tabular} & 1845 & $3: 58$ & 16.7 & 68 & 1912 & & 16.7 & 685 & 979 & & \begin{tabular}{|l|l|}
16.7 \\
\end{tabular} & 3224 \\
\hline 1712 & 99.32 & \begin{tabular}{l|l|}
16.7 & 686.7 \\
\end{tabular} & 1779 & & \begin{tabular}{l|l|l|l|}
16.7 & 679. \\
\end{tabular} & 1846 & $0: 00$ & 16.7 & 688. & 1913 & & 16.7 & 68 & 1980 & & 16.7 & 32 \\
\hline 1713 & 9.34 & \begin{tabular}{l|r|}
16.7 & 686 \\
\end{tabular} & 1780 & & \begin{tabular}{|l|l|}
16.7 & 679. \\
\end{tabular} & 1847 & $30: 02$ & 16.7 & $6 x$ & 1914 & 216 & \begin{tabular}{|l|}
16.7 \\
\end{tabular} & 686 & 1981 & $4: 30$ & 16.7 & 824 \\
\hline 1714 & & 16.7 & 1781 & & \begin{tabular}{|l|l|}
16.7 & 679.2 \\
\end{tabular} & 1848 & 0.04 & 16.7 & 691.4 & 1915 & & 16.7 & 686 & 1982 & & 16.7 & 682 \\
\hline 1715 & & \begin{tabular}{l|l|l|}
16.7 & 684.5 \\
\end{tabular} & 1782 & & \begin{tabular}{|l|l|}
16.7 & 679 \\
\end{tabular} & 1849 & 0.06 & 16.7 & & 1916 & & 16.7 & & 1983 & & 16.7 & 823 \\
\hline 1716 & 9.40 & \begin{tabular}{|l|l|}
16.7 & 684 \\
\end{tabular} & 1783 & & \begin{tabular}{|l|l|}
16.7 & 679 \\
\end{tabular} & 1850 & 0.08 & 16.7 & 693.6 & 1917 & & 16.7 & 687.5 & 1984 & $4: 36$ & 16.7 & 683 \\
\hline 1717 & & \begin{tabular}{|l|l}
16.7683 \\
\end{tabular} & 1784 & & $\begin{array}{ll}16.7 & 679 \\
\end{array}$ & 1851 & & 16.7 & 693.5 & 1918 & & 16.7 & & 985 & & 16.7 & 683.1 \\
\hline 1718 & 19.44 & $\begin{array}{l}16.7] 6821 \\
\end{array}$ & 1785 & & \begin{tabular}{ll|l}
16.7 & 679 \\
\end{tabular} & 1852 & $0: 12$ & 16.7 & 693. & 1919 & & 16.7 & 680 & 986 & & 16.7 & 688 \\
\hline 1719 & 19.46 & \begin{tabular}{|l|l|}
16.7 & 681.5 \\
\end{tabular} & 1786 & & 16.7 & 1853 & $0: 14$ & 16.7 & 693. & 1920 & & 16.7 & 688.8 & 1987 & & 16.7 & 6825 \\
\hline 1720 & & \begin{tabular}{|l|l|}
16.7 & 682 \\
\end{tabular} & 1787 & & \begin{tabular}{l|l|l|}
16.7 & 679.1 \\
\end{tabular} & 1854 & & 16.7 & t693.1 & 1921 & & 16.7 & & 198 & & 16.7 & 68 \\
\hline 1721 & & \begin{tabular}{|l|l|}
16.76828 \\
\end{tabular} & 1788 & & \begin{tabular}{l|l|}
16.7 & $6 \pi$ \\
\end{tabular} & 1855 & & 16.7 & & & & 16.7 & & 19 & & 16.7 & 681.7 \\
\hline 1722 & 9.52 & \begin{tabular}{l|l|}
16.7 & 683.2 \\
\end{tabular} & 1789 & & \begin{tabular}{l|l|l}
16.7 & 678.8 \\
\end{tabular} & 1856 & 0.20 & 16.7 & 696. & 1923 & 234 & 16.7 & 688 & 1990 & $4: 48$ & 16.7 & 31 \\
\hline 1723 & & \begin{tabular}{|l|l|}
16.7682 \\
\end{tabular} & 1790 & & \begin{tabular}{ll|l}
16.7 & 678.8
\end{tabular} & 1857 & & 16.7 & & 1924 & & 16.7 & 688 & & & 16.7 & 681.7 \\
\hline 1724 & & \begin{tabular}{|l|l|}
6323 \\
\end{tabular} & 1791 & & \begin{tabular}{|l|l|}
16.7 & 678.7 \\
\end{tabular} & 1858 & & 16.7 & & & & 16.7 & 688 & & & 16.7 & 681.4 \\
\hline 1725 & 9.58 & \begin{tabular}{|l|l|}
16.7 & 681.5 \\
\end{tabular} & 1792 & 89 & \begin{tabular}{ll|l}
16.7 & 678.7 \\
\end{tabular} & 1859 & 0.26 & 16.7 & $\begin{array}{ll}7698.5 \\
\end{array}$ & 1926 & 240 & 16.7 & 687 & 993 & $4: 54$ & 16.7 & 81.9 \\
\hline 1726 & & \begin{tabular}{|l|l|}
16.7 & 681.6 \\
\end{tabular} & 1798 & & \begin{tabular}{|l|l|}
16.7678 \\
\end{tabular} & 1860 & & 16.7 & & 1927 & & 16.7 & & & & 16.7 & \\
\hline 1727 & & \begin{tabular}{|l|l|}
16.7 & 682 \\
\end{tabular} & 1794 & & 16.767 & 1861 & & 16.7 & & & & & & & & 16.7 & \\
\hline 1728 & $0: 04$ & \begin{tabular}{|l|l|}
16.7 & 683.3 \\
\end{tabular} & 1795 & & \begin{tabular}{l|l|l|}
16.7 & 678.2 \\
\end{tabular} & 1862 & $00: 32$ & 16.7 & 701. & 1920 & 246 & 16.7 & 687 & 1996 & $5: 00$ & 16.7 & 680.9 \\
\hline 1729 & & 16.7683 .2 & 1796 & & \begin{tabular}{ll|l}
16.7 & 678.2
\end{tabular} & 1863 & & 16.7 & 702 & 1930 & & 16.7 & 689. & & & 16.7 & \\
\hline 1730 & & $16 \sqrt{6933}$ & 1797 & & 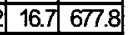 & 1864 & & 16.7 & & & & 16.7 & & 1908 & & 16.7 & \\
\hline 1731 & 20.10 & \begin{tabular}{|l|l|}
16.7683 .2 \\
\end{tabular} & 1798 & 89 & $\begin{array}{rl}16.7 & 677.5 \\
\end{array}$ & 1865 & 30.38 & 16.7 & 70 & 1932 & 252 & 16.7 & 688. & 1909 & $5: 06$ & 16.7 & 680.1 \\
\hline 1732 & & \begin{tabular}{|l|l|}
16.7 & 685.2 \\
\end{tabular} & 1799 & & \begin{tabular}{|l|l|}
16.7 & 677.2 \\
\end{tabular} & 1866 & & 16.7 & 703 & 1933 & & 16.7 & 680 & & & 16. $\mathrm{Y}$ & \\
\hline 1733 & & & 1800 & & & \begin{tabular}{|l|}
1867 \\
\end{tabular} & & & & & & & & & & 16.7 & \\
\hline 1734 & 20.16 & \begin{tabular}{|l|l|}
16.7 & 684.5 \\
\end{tabular} & 1801 & 89 & \begin{tabular}{|r|r|}
16.7 & 677.8 \\
\end{tabular} & 1868 & $80: 44$ & 16.7 & 702 & 1935 & 3258 & 16.7 & 690. & 2002 & $55: 12$ & 16.7 & 680.4 \\
\hline 1735 & $20: 18$ & \begin{tabular}{|l|l|l|}
16.7 & 683.4 \\
\end{tabular} & 1802 & & \begin{tabular}{|l|l|}
16.7 & 678 \\
\end{tabular} & 1869 & & 16.7 & 700.5 & 1936 & & \begin{tabular}{|l|}
16.7 \\
\end{tabular} & 693 & 003 & & 16.7 & 679.4 \\
\hline 1736 & & & 1803 & & $\begin{array}{lll}16.8 & 675.5 \\
\end{array}$ & $\mid \begin{array}{ll}1870 \\
\end{array}$ & & 16.7 & & & & 16.7 & 693 & & & 16.7 & \\
\hline 1737 & 20.2 & \begin{tabular}{|l|l|}
16.7 & 683.6 \\
\end{tabular} & 1804 & 2236 & \begin{tabular}{l|l|l|}
16.7 & 676.7 \\
\end{tabular} & 1871 & $0: 50$ & 16.7 & 684.8 & 1938 & $083: 04$ & 16.7 & 692 & 2005 & $35: 18$ & 16.7 & 679.8 \\
\hline 1738 & $8 / 9 / 200820: 24$ & \begin{tabular}{|l|l|l}
16.7 & 683.8 \\
\end{tabular} & 1805 & 2238 & \begin{tabular}{|l|l|}
16.7 & 677.9 \\
\end{tabular} & 1872 & $811 \alpha$ & 16.7 & (684. & 1939 & $0083: 06$ & 16.7 & 691. & 2006 & $35: 20$ & 16.7 & 679.7 \\
\hline 1739 & & & 1806 & & \begin{tabular}{|l|l|}
16.7 & 678.3 \\
\end{tabular} & 1873 & & \begin{tabular}{|l|}
16.7 \\
\end{tabular} & & 1940 & & & & & & & \\
\hline 1740 & $8 / 9 / 200820: 28$ & \begin{tabular}{|l|l|}
16.7 & 6825 \\
\end{tabular} & \begin{tabular}{|l|}
1807 \\
\end{tabular} & $22: 42$ & \begin{tabular}{|l|l|}
16.7 & 677 \\
\end{tabular} & 1874 & 0.56 & 16.7 & 684.3 & 1941 & $811020083: 10$ & 16.7 & 691 & 2008 & $85: 24$ & 16.7 & 679.7 \\
\hline 1741 & $8 / 9200820: 30$ & \begin{tabular}{|l|l|}
16.7 & 6828 \\
\end{tabular} & 1808 & $89 / 2$ & \begin{tabular}{|l|l|}
16.7 & 678.7 \\
\end{tabular} & 1875 & $8 / 1 \alpha_{2}^{\prime}$ & 16.7 & 684 & 1942 & $811020083: 12$ & 16.7 & 690.2 & 2009 & $85: 26$ & 16.7 & \\
\hline 1742 & $8 / 9 / 200820: 32$ & \begin{tabular}{|l|l|}
16.7 & 6821 \\
\end{tabular} & 1809 & 2246 & \begin{tabular}{|l|l|}
16.7 & 6824 \\
\end{tabular} & 1876 & $31: 00$ & 16.7 & 武 683.7 & 1943 & $8 / 1020083: 14$ & 16.7 & 688.6 & 2010 & $85: 28$ & & \\
\hline
\end{tabular}




\begin{tabular}{|c|c|c|c|c|c|c|c|c|c|c|c|c|c|c|c|c|c|c|}
\hline \multicolumn{4}{|c|}{$D 427 \mathrm{c}$} & \multicolumn{3}{|c|}{$D 427 \mathrm{c}$} & \multicolumn{4}{|c|}{ D427c } & \multicolumn{4}{|c|}{ D4-27c } & \multicolumn{4}{|c|}{$\mathrm{D} 427 \mathrm{c}$} \\
\hline $\operatorname{Rec}$ & & & & $\mathrm{Rec}$ & & Temp SC & Rec & & & $\mathrm{SC}$ & Rec & & Temp & $S C$ & $\mathrm{ReC}$ & & Temp & SC \\
\hline$\#$ & Date/Time & ${ }^{\circ} \mathrm{C}$ & $\mu s / \mathrm{m}$ & $\#$ & DatêTime & \begin{tabular}{|l|l|l|}
${ }^{\circ} \mathrm{C}$ & $\mu \mathrm{S} / \mathrm{cm}$ \\
\end{tabular} & $\#$ & DaterTime & ${ }^{\circ} \mathrm{C}$ & $\mu \mathrm{s} / \mathrm{cm}$ & $\#$ & DeteTime & ${ }^{\circ} \mathrm{C}$ & $\mu \mathrm{s} / \mathrm{cm}$ & $\#$ & Date/lime & ${ }^{\circ} \mathrm{C}$ & $\mu \mathrm{s} / \mathrm{am}$ \\
\hline & $8 / 10 / 20085: 30$ & 16 & 680.6 & & $8 / 1020087: 44$ & \begin{tabular}{l|l|}
16.7 & 684.6 \\
\end{tabular} & 2145 & $8 / 10 / 20089.58$ & 16.7 & 697 & & $8 / 10 / 20081212$ & 16.7 & & 2279 & $8 / 10200814: 26$ & & \\
\hline 2012 & & & & & $8 / 10 / 20087: 46$ & \begin{tabular}{|l|l|}
16.7 & 685.9 \\
\end{tabular} & 2146 & $8 / 10200010: 00$ & 16.7 & 695.6 & 2213 & $8 / 1020081214$ & 16.7 & 691.2 & 280 & & & 686.1 \\
\hline 2013 & $8 / 1020085: 34$ & 16.7 & 679.6 & 2080 & $8 / 1020087: 48$ & \begin{tabular}{l|l|}
16.7 & 686.7 \\
\end{tabular} & 2147 & $8 / 102000810: 02$ & 16.7 & 694 & 2214 & $8 / 1020081216$ & $16.7 \mid$ & 690.5 & 2281 & $8 / 10 / 2008$ 14:30 & 16.7 & 684.3 \\
\hline 2014 & $8 / 1020085: 36$ & 16.7 & 679.9 & 2081 & $81020087: 50$ & \begin{tabular}{l|l|}
16.7 & 687.5 \\
\end{tabular} & 2148 & $8 / 10 / 200810: 04$ & 16.7 & 694.9 & 2215 & $8 / 1020081218$ & 16.7 & 689.8 & 2282 & $102000814: 32$ & 16.7 & \\
\hline & $8 / 10 / 20085: 38$ & 16.7 & 679 & 2082 & $8 / 1020087: 52$ & \begin{tabular}{l|l|}
16.7 & 687.2 \\
\end{tabular} & 2149 & $8 / 10200810: 06$ & 16.7 & 697.6 & 2216 & $8 / 1020081220$ & 16.7 & 689.3 & 283 & $814: 34$ & & \\
\hline 2016 & $8 / 10 / 20085: 40$ & 16.7 & 679.1 & 2083 & $8 / 1020087: 54$ & \begin{tabular}{l|l|}
16.7 & 689.9 \\
\end{tabular} & 2150 & $8 / 10 / 200810: 08$ & 16.7 & 700.5 & \begin{tabular}{|l|}
2217 \\
\end{tabular} & $8 / 10120081222$ & 16.7 & 689.4 & 2284 & $8 / 10200814: 36$ & 16.7 & 685.8 \\
\hline 2017 & $8 / 10 / 20085: 42$ & 16.7 & 679.3 & 2084 & $8 / 1020087: 56$ & \begin{tabular}{l|l|}
16.7 & 691.9 \\
\end{tabular} & 2151 & $8 / 10 / 2008$ 10:10 & 16.7 & 698.2 & \begin{tabular}{|l|}
2218 \\
\end{tabular} & $8 / 10 / 20081224$ & 16.7 & 688.7 & 2285 & $8 / 10200014: 38$ & 16.7 & 688.3 \\
\hline & & & 679.4 & & $811020087: 58$ & \begin{tabular}{l|l|}
16.7 & 693.6 \\
\end{tabular} & 2152 & $8 / 10 / 2008$ 10:12 & & 695.9 & & $8 / 10220081226$ & 16.7 & & 2286 & 81102008 14:40 & 16.7 & \\
\hline 2019 & & 16.7 & 679.3 & 2006 & $8 / 1020088: 00$ & \begin{tabular}{|l|l|}
16.7 & 695.1 \\
\end{tabular} & 2153 & $8 / 102008$ 10:14 & \begin{tabular}{ll|}
16.7 \\
\end{tabular} & 695.7 & 2220 & $8 / 1020081228$ & 16.7 & 688.9 & 2287 & $814: 42$ & & 687.8 \\
\hline 2020 & $8 / 10 / 20085: 48$ & 16.7 & 679.4 & 2087 & $8 / 1020088: 02$ & \begin{tabular}{l|l|}
16.7 & 695.3 \\
\end{tabular} & 2154 & $8 / 102008$ 10:16 & 16.7 & 697.1 & 2021 & $8 / 102008$ 1230 & \begin{tabular}{|l|}
16.7 \\
\end{tabular} & 689.4 & 2288 & $8 / 102008$ 14:44 & 16.7 & 687 \\
\hline 2021 & $8 / 10 / 200$ & 16.7 & 679.3 & 2008 & $8 / 1020008: 04$ & \begin{tabular}{l|l|}
16.7 & 695.5 \\
\end{tabular} & 2155 & $8 / 10 / 2008$ 10:18 & 16.7 & 696.9 & 2222 & $8 / 1020081232$ & 16.7 & 690.8 & 2289 & $8 / 102008$ 14:46 & 16.7 & 681.4 \\
\hline & $8 / 10200$ & 16.7 & 679.5 & 20 & $8 / 1020088: 06$ & \begin{tabular}{l|l|}
16.7 & 697 \\
\end{tabular} & 2156 & $8 / 10 / 200$ & 16.7 & 696.5 & 2223 & $8 / 1020081234$ & 16.7 & 691.5 & 2290 & $314: 48$ & & \\
\hline 2023 & $8 / 10200$ & 16.7 & 678.7 & 2090 & $8 / 1020$ & \begin{tabular}{l|l|}
16.7 & 698.4 \\
\end{tabular} & 2157 & $8 / 10200010: 22$ & 16.7 & 695.6 & 2224 & $8 / 10200812336$ & 16.7 & 690.5 & 2291 & $8 / 10200814: 50$ & 16.7 & 6825 \\
\hline 2024 & $8 / 1020$ & 16.7 & 681.5 & 2091 & $8 / 1020088: 10$ & \begin{tabular}{|l|l|}
16.7 & 699.3 \\
\end{tabular} & 2158 & $8 / 102000810.24$ & 16.7 & 695.6 & 2225 & $8 / 10200812 ; 38$ & 16.7 & 691.7 & 2292 & $14: 52$ & 16.7 & 684.4 \\
\hline 2025 & $8 / 10 / 20$ & & 684.8 & 2092 & & \begin{tabular}{l|l|}
16.7 & 700.6 \\
\end{tabular} & 2159 & $8 / 10200810: 26$ & 16.7 & 696.5 & 2226 & 81240 & 16.7 & 691.7 & & $14: 54$ & 16.7 & \\
\hline 2026 & $8 / 1020$ & 16.7 & 685.5 & 2003 & $8 / 10 / 200$ & \begin{tabular}{l|l|}
16.7 & 701.3 \\
\end{tabular} & 2160 & $8 / 10 / 200$ & 16.7 & 696 & 2227 & 81242 & \begin{tabular}{|l|}
16.7 \\
\end{tabular} & 690.1 & 2294 & & 16.7 & 694.2 \\
\hline 20027 & $8 / 1020086: 02$ & 16.7 & 698.3 & 2094 & $8 / 1020088: 16$ & \begin{tabular}{l|l|}
16.7 & 701.6 \\
\end{tabular} & 2161 & $8 / 10 / 2008$ 10:30 & 16.7 & 625.1 & 2228 & $8 / 1020081244$ & 16.7 & 689 & \begin{tabular}{|l|}
2295 \\
\end{tabular} & $814: 58$ & 16.7 & 695.5 \\
\hline 2028 & $8 / 10 / 20$ & 16.7 & 698.7 & 2005 & $8 / 10 / 2$ & \begin{tabular}{l|l|}
16.7 & 7022 \\
\end{tabular} & $21 డ 2$ & $8 / 10 / 200$ & 16.7 & 693.5 & 2229 & 31246 & 16.7 & 688.8 & 2296 & 15:00 & 16.7 & 694.6 \\
\hline 2020 & $8 / 102$ & 16.7 & 697.8 & 2096 & $8 / 102$ & \begin{tabular}{l|l|}
16.7 & 702.7 \\
\end{tabular} & & $8 / 10220$ & 16.7 & 704.8 & 2230 & 31248 & 16.7 & & 2297 & & 16.7 & \\
\hline 20030 & $8 / 10 / 20$ & 16.7 & 697.1 & 2097 & $8 / 102$ & \begin{tabular}{l|l|}
16.7 & 704.2 \\
\end{tabular} & 2164 & $8 / 10200810: 36$ & 16.7 & 7029 & \begin{tabular}{|l|}
2231 \\
\end{tabular} & $8 / 1020081250$ & 16.7 & 690.6 & 2298 & $815: 04$ & 16.7 & 706.6 \\
\hline 2031 & 8102 & 16.7 & 696.7 & 2098 & $8 / 102$ & \begin{tabular}{l|l|}
16.7 & 704.5 \\
\end{tabular} & 2165 & $8 / 10 / 20$ & 16.7 & 7022 & 2232 & 11252 & 16.7 & 690.7 & 2299 & 15:06 & 16.7 & 695.4 \\
\hline 2003 & & & & 2009 & & \begin{tabular}{l|l|}
16.7 & 704.7 \\
\end{tabular} & 2166 & $8 / 1020$ & 16.7 & 7029 & & 1254 & 16.7 & 690.4 & 2300 & & 16.7 & \\
\hline 2003 & $8 / 102 x$ & 16.7 & 701.3 & 2100 & $8 / 102$ & \begin{tabular}{l|l|}
16.7 & 704.6 \\
\end{tabular} & 2167 & $8 / 1020$ & 16.7 & 703.2 & 2234 & 812.56 & 16.7 & 691.1 & 2301 & $15: 10$ & 16.7 & 704.5 \\
\hline 2034 & $8 / 102$ & 16.7 & 698.1 & 2101 & $8 / 10 /$ & \begin{tabular}{l|l|}
16.7 & 704.8 \\
\end{tabular} & 2168 & 811020 & 16.7 & 7026 & 2235 & 1258 & 16.7 & 691.2 & 2302 & 15:12 & \begin{tabular}{|l|}
16.7 \\
\end{tabular} & 701.4 \\
\hline 2035 & $8 / 10 \sqrt{2}$ & 16.7 & & $210 R$ & $8 / 102$ & \begin{tabular}{l|l|}
16.7 & $\pi$ \\
\end{tabular} & 2169 & 811020 & 16.7 & 700. & 236 & 13:00 & 16.7 & & 2303 & & 16.7 & 698. \\
\hline 20036 & $8 / 102$ & 16.7 & 696.6 & 2103 & $8 / 102$ & \begin{tabular}{l|l}
16.7 & 704 \\
\end{tabular} & 2170 & 810220 & 16.7 & 700.1 & 2237 & $8 / 10^{2}$ & 16.7 & 691.4 & 2304 & $15: 16$ & 16.7 & 697.2 \\
\hline 20037 & $8 / 70 / 2$ & 16.7 & 694.7 & 2104 & $8 / 10$ & $\begin{array}{l}16.7 \\
105\end{array}$ & 2171 & $8110 / 20$ & 16.7 & 698 & 238 & 13:04 & \begin{tabular}{|l|}
16.7 \\
\end{tabular} & 690.8 & 2305 & $8 / 10$ & 16.7 & 696.6 \\
\hline 2038 & $8 / 402$ & 16.7 & & 2106 & $8 / 10$ & \begin{tabular}{l|l|}
16.7 & $\pi$ \\
\end{tabular} & 2172 & 81102 & 16.7 & 686.8 & 239 & 13:06 & 16.7 & 690.1 & 2306 & $15: 20$ & 16.7 & 696.1 \\
\hline 2039 & $8 / 102$ & 16.7 & & 2106 & & $\begin{array}{ll}16.7 & 705 . \\
\end{array}$ & 2173 & 811020 & 16.7 & 686. & 2240 & 13:08 & \begin{tabular}{|l|}
16.7 \\
\end{tabular} & 689.7 & 2307 & 15:22 & 16.7 & 695.3 \\
\hline 2040 & $8 / 102$ & 16.7 & 694.9 & 2107 & $8 / 102$ & 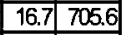 & 2174 & $8 / 10 \sqrt{20}$ & 16.7 & 686.8 & 2241 & & 16.7 & 688.6 & 2308 & 15:24 & 16.7 & 69 \\
\hline 2041 & 30 & 16.7 & 696 & 2108 & $8 / 102$ & $\begin{array}{l}16.7 \\
160 \\
\end{array}$ & 2175 & $8 / 102$ & 16.7 & 686 & 242 & 13:12 & \begin{tabular}{|l|}
16.7 \\
\end{tabular} & 688.7 & 2309 & $5: 26$ & 16.7 & 694. \\
\hline 2042 & & 16.7 & 696. & 2109 & & $\begin{array}{l}16.7 \\
105 . \\
\end{array}$ & 2176 & $8 / 1020$ & 16.7 & 68 & 2243 & 13:14 & \begin{tabular}{|l|}
16.7 \\
\end{tabular} & 689.2 & 2310 & $5: 28$ & 16.7 & 43. \\
\hline 2043 & & 16.7 & 694. & 2110 & & \begin{tabular}{l|l|l}
16.7 & 705.8 \\
\end{tabular} & $217 \pi$ & $8 / 1020$ & 16.7 & 68 & 2244 & 13:16 & 16.7 & 689.4 & 2311 & 15:30| & 16.7 & 23 \\
\hline 0044 & 1102 & 16.7 & 692 & 2111 & $8 / 10^{\prime}$ & \begin{tabular}{ll|l}
16.7 & 706. \\
\end{tabular} & 2178 & $8 / 102$ & 16.7 & 687. & 245 & 13:18 & 16.7 & 689.1 & 312 & $5: 32$ & 16.7 & 691.5 \\
\hline 2045 & 38 & 16.7 & 691 & 2112 & $8 / 10 / 2$ & \begin{tabular}{l|l|}
16.7 & 705.8 \\
\end{tabular} & 2179 & 1:06 & 16.7 & 687. & 2246 & $3: 20$ & 16.7 & 690.1 & $\overline{313}$ & & 16.7 & 690.7 \\
\hline 2046 & & 16.7 & & 2113 & & \begin{tabular}{l|l|}
16.7 & 706 \\
\end{tabular} & 2180 & & 16.7 & 687 & 2247 & & 16.7 & 690 & 2314 & $15: 36$ & 16.7 & 90.5 \\
\hline 2047 & 12 & 16.7 & 690 & 2114 & $8 / 102$ & \begin{tabular}{l|l|}
16.7 & 706.1 \\
\end{tabular} & 2181 & 10 & 16.7 & 689 & 248 & 13:24 & 16.7 & 690 & 315 & & 16.7 & 690.8 \\
\hline 2048 & 44 & 16.7. & 690. & 2115 & & \begin{tabular}{l|l|}
16.7 & 705 \\
\end{tabular} & 2182 & & $\begin{array}{ll}16.7 \\
\end{array}$ & 69 & $4 c$ & & 16.7 & & 316 & & 16.7 & 90. \\
\hline 2049 & $8 / 1$ & 16.7 & 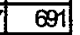 & 2116 & & $\begin{array}{l}16.7 \\
\end{array}$ & 2183 & & 16.7 & 689 & 2250 & 13:28 & 16.7 & 689.3 & 2317 & 15:42 & 16.7 & 690.2 \\
\hline 050 & & 16.7 & $\overline{\underline{\sigma}}$ & 2117 & & $\begin{array}{l}16.8 \\
104 \\
\end{array}$ & 2184 & & 16.7 & 6 & 251 & & 16.7 & 689 & 318 & $5: 44$ & 16.7 & 689.5 \\
\hline 2051 & & 16.7 & 691. & 2118 & & \begin{tabular}{l|l|l}
16.7 & 706 \\
\end{tabular} & 2185 & & $\begin{array}{l}16.7 \\
\end{array}$ & 691 & & & 16.7 & 689 & 319 & & 16.7 & 689. \\
\hline 2052 & $8 / 10$ & 16.7 & 6924 & 2119 & $8 / 10$ & 16.7 & 2186 & $8 / 10$ & 16.7 & 690 & \begin{tabular}{|l|}
2253 \\
\end{tabular} & 13:34 & \begin{tabular}{|l|}
16.7 \\
\end{tabular} & 689. & 2320 & $15: 48$ & 16.7 & \begin{tabular}{|l|}
689.7 \\
\end{tabular} \\
\hline & & 16.7 & 6924 & 2120 & & \begin{tabular}{|l|l|l|}
16.7 & 706.3 \\
\end{tabular} & 2187 & & 16.7 & 690 & 54 & & 16.7 & 689 & 321 & & 16. & 689.8 \\
\hline 054 & & 16.8 & 692 & 2121 & & \begin{tabular}{|l|l|}
16.7 & 706.2 \\
\end{tabular} & 2188 & & 16.7 & 689. & 2255 & $3: 38$ & 16.7 & 689 & $\bar{x}$ & & $\overline{16.7}$ & 6893 \\
\hline 0055 & $8 / 10$ & 16.7 & 693.2 & 2122 & $8 / 10$ & \begin{tabular}{|l|l|}
16.7 & 706 \\
\end{tabular} & 2189 & & 16.7 & 690 . & \begin{tabular}{|l|}
2256 \\
\end{tabular} & 3:40 & \begin{tabular}{|l|}
16.7 \\
\end{tabular} & 689.8 & 2323 & $5: 54$ & 16.7 & 688.6 \\
\hline 56 & & 16.7 & & 2123 & & $\begin{array}{l}16.7 \\
160\end{array}$ & 2190 & & 16.7 & 69 & & & \begin{tabular}{|l|}
16.7 \\
\end{tabular} & 690 & & & 16. & 688 \\
\hline कृता & & 16.7 & 69 & & & \begin{tabular}{|l|l|}
16.7 & 705 \\
\end{tabular} & & & 16.7 & 691 & 268 & & 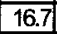 & 689.8 & & & $\overline{16}$ & 689.4 \\
\hline 058 & $8 / 10$ & 16.7 & 693. & 2125 & $8 / 10$ & \begin{tabular}{ll|l}
16.7 & 704. \\
\end{tabular} & 2192 & $8 / 10 / 2$ & 16.7 & 697.9 & 2259 & $13: 46$ & 16.7 & 689.9 & 2326 & & 16.7 & 689.7 \\
\hline 可 & & 16.7 & 703 & & & \begin{tabular}{l|l}
16.7 & 70 \\
\end{tabular} & 219 & & 16.7 & 6 & 260 & & 16.7 & 689 & & & 16. & 689.9 \\
\hline 2000 & & 16.7 & 706.7 & 2127 & & \begin{tabular}{l|l}
16.7 & 700 \\
\end{tabular} & & & 16.7 & 695 & 2701 & & \begin{tabular}{|l|}
16.7 \\
\end{tabular} & 689 & & & $\overline{16}$ & \\
\hline 2061 & & 16.7 & 686 & 2128 & & $\begin{array}{l}16.7 \\
701 .\end{array}$ & 2195 & & 16.7 & 698 & 2262 & & 16.7 & 689.5 & 2329 & & \begin{tabular}{|l|}
16.7 \\
\end{tabular} & 691.9 \\
\hline 062 & & 16.7 & 698. & & & \begin{tabular}{l|l|}
16.7 & 70 \\
\end{tabular} & 2196 & & 16.7 & 697. & & & \begin{tabular}{|l|}
16.7 \\
\end{tabular} & 689 & & & 16. & \\
\hline 2063 & & 16.7 & & 30 & & & & & 16.7 & & & & \begin{tabular}{|l|}
16.7 \\
\end{tabular} & 689 & & & & \\
\hline 2064 & $8 / 10$ & 16.7 & 691.3 & 2131 & $8 / 10$ & \begin{tabular}{l|l|}
16.7 & 700.6 \\
\end{tabular} & \begin{tabular}{|l|l|}
2198 \\
\end{tabular} & $8 / 1012$ & 16.7 & 695 & \begin{tabular}{|l|}
2265 \\
\end{tabular} & $13: 58$ & 16.7 & 690.1 & 2332 & $6: 12$ & 16.7 & 691.2 \\
\hline 065 & & 16.7 & 691 & 2132 & & \begin{tabular}{l|l|l}
16.7 & 60 \\
\end{tabular} & & & 16.7 & & & & 16.7 & 690 & & & 16. & \\
\hline 2066 & & 16.7 & & & & & & & 16.7 & & & & 167 & 690 & & & & \\
\hline 2067 & $8 / 10$ & 16.7 & 683.2 & 2134 & $8 / 10$ & \begin{tabular}{|l|l|}
16.7 & 698.6 \\
\end{tabular} & 2201 & 81102 & 16.7 & 695.2 & 2268 & 14:04 & 16.7 & 69 & 2335 & $6: 18$ & 16.7 & 688.4 \\
\hline 2068 & & 16.7 & 683 & 2135 & & \begin{tabular}{l|l|}
16.7 & 69 \\
\end{tabular} & 2202 & & 16.7 & 695 & 2269 & & \begin{tabular}{|l|}
16.7 \\
\end{tabular} & 689 & 2336 & & 6. & 689.7 \\
\hline 2069 & & & & & & & & & 16.7 & & & & & & & & & \\
\hline 2070 & $8 / 10$ & 16.7 & 683.1 & 2137 & 9.42 & \begin{tabular}{l|l|l}
16.7 & 690 \\
\end{tabular} & 2204 & $8 / 10 / 2$ & 16.7 & 696 & & 14:10 & 16.7 & 691.5 & 2338 & $16: 24$ & 16.7 & 691. \\
\hline 2071 & & 16.7 & 683 & 2138 & & \begin{tabular}{|l|l|}
16.7 & 69 \\
\end{tabular} & 2205 & & 16.7 & 60 & 2272 & & \begin{tabular}{|l|}
16.7 \\
\end{tabular} & 690.3 & 2339 & & 16. & 690.6 \\
\hline & & & & & & & & & 16.7 & & & & & & 2340 & & & \\
\hline 2073 & $8 / 102$ & 16.7 & 683 & 2140 & $8 / 10$ & \begin{tabular}{|l|l|}
16.7 & 69 \\
\end{tabular} & 2207 & $8 / 1020$ & 16.7 & 693 & 2274 & 14:16 & \begin{tabular}{|l|}
16.7 \\
\end{tabular} & 688.2 & 2341 & 6:30 & 16.7 & 689.8 \\
\hline 2074 & $8 / 10 / 2$ & 16.7 & 683.1 & 2141 & & \begin{tabular}{|l|l|}
16.7 & 696.7 \\
\end{tabular} & 2208 & & 16.7 & 692 & 2275 & & \begin{tabular}{|l|}
16.7 \\
\end{tabular} & 688. & 2342 & $16: 32$ & 16.7 & 689.2 \\
\hline & & & 683 & 142 & & \begin{tabular}{|l|l|}
16.7 & 697.7 \\
\end{tabular} & & & 6 & & 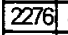 & & & 688 & 2343 & & & \\
\hline 207 & $8 / 102$ & 16.7 & 68 & 2143 & $8 / 1020$ & \begin{tabular}{|l|l|}
16.7 & 698.7 \\
\end{tabular} & 2210 & & 16.7 & 692 & $22 \pi$ & $14: 2$ & \begin{tabular}{|l|}
16.7 \\
\end{tabular} & 689 & 2344 & $16: 36$ & 16.7 & \\
\hline$\overline{077}$ & & 16.7 & 683. & & $9: 56$ & \begin{tabular}{|l|l|}
16.7 & 699 \\
\end{tabular} & 2211 & 2210 & 10.7 & 690.9 & 2278 & $14: 24$ & \begin{tabular}{|l|}
16.7 \\
\end{tabular} & 689.1 & 234 & 16:38 & & 925 \\
\hline
\end{tabular}


DOE/RL-2009-35, REV. 0

\begin{tabular}{|c|c|c|c|c|c|c|c|c|c|c|c|c|c|c|c|c|c|c|c|}
\hline \multicolumn{4}{|c|}{$\mathrm{D} 427 \mathrm{c}$} & \multicolumn{4}{|c|}{$D 427 c$} & \multicolumn{4}{|c|}{ D427c } & \multicolumn{4}{|c|}{ D427c } & & D4-27c & & \\
\hline $\operatorname{Rec}$ & & & & $R e c$ & & & & & & & & & & & & $\operatorname{Rec}$ & & Temp & $\mathrm{SC}$ \\
\hline$\#$ & DaterTime & \begin{tabular}{|l|}
${ }^{\circ} \mathrm{C}$ \\
\end{tabular} & $\mu \mathrm{S} / \mathrm{cm}$ & $\#$ & DatedTime & ${ }^{\circ} \mathrm{C}$ & psiam & \# & Date/Time & \begin{tabular}{|l|}
${ }^{\circ} \mathrm{C}$ \\
\end{tabular} & $\mu \mathrm{s} / \mathrm{cm}$ & $\#$ & DeterTime & ${ }^{\circ} \mathrm{C} / \mu$ & $\mu \mathrm{s} / \mathrm{m}$ & $\#$ & Date/Time & ${ }^{\circ} \mathrm{C}$ & $\mathrm{HS} / \mathrm{cm}$ \\
\hline & $8 / 10200816: 40$ & 16.7 & 691.6 & & $8110200818: 54$ & 16.7 & 689 & a & 8/10/200821:08 & 16.7 & 697.8 & & $8 / 102000823: 22$ & \begin{tabular}{|l|l|}
16.7 \\
\end{tabular} & 704.3 & 2614 & 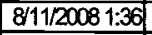 & & 705.7 \\
\hline & & & 691.2 & & $8 / 10200818: 56$ & 16.7 & 699.2 & & $8 / 102000821: 10$ & & 697.5 & & $200823: 24$ & & 701.2 & 2615 & & 16.7 & 705 \\
\hline 348 & $8 / 10200816: 44$ & 16.7 & 691 & 115 & $8 / 10200818: 58$ & 16.7 & 689.5 & 2482 & $8 / 102000821: 12$ & 16.7 & \begin{tabular}{|l|}
697.4 \\
\end{tabular} & 2549 & $8 / 10 / 200823: 26$ & \begin{tabular}{|l|l|}
16.7 \\
\end{tabular} & 701.4 & 2616 & $8 / 11 / 20081: 40$ & 16.7 & 704.1 \\
\hline 349 & $102000816: 46$ & 16.7 & 691.5 & 16 & $8 / 10200819: 00$ & 16.7 & 690.7 & 2483 & $8 / 10200021: 14$ & 16.7 & \begin{tabular}{|l|}
696.8 \\
\end{tabular} & 2550 & 8/10/200823:28 & \begin{tabular}{|l|l|}
16.7 \\
\end{tabular} & 7023 & 2617 & $8 / 11 / 20081: 42$ & 76.7 & 705.1 \\
\hline & & & 691.6 & & $8 / 102000819.02$ & 16.7 & 691.7 & & $821 \cdot 14$ & 16.7 & 696 & 5551 & $8 / 10200823: 30$ & 16.7 & 703.1 & & & 16. & \\
\hline 2351 & $8110200816: 50$ & 16.7 & 690.5 & 418 & $8 / 10200819: 04$ & 16.7 & 690.4 & 2485 & $8 / 10 / 200821: 18$ & 16.7 & 696.1 & 2552 & $8 / 10 / 200823: 32$ & 16.7 & 7032 & & $81: 46$ & 16.7 & 705.5 \\
\hline 2352 & $8 / 10200816: 52$ & 16.7 & 689.5 & 419 & $8 / 10200819.06$ & 16.7 & 689.1 & 2486 & $8821: 20$ & 16.7 & \begin{tabular}{|l|}
697.3 \\
\end{tabular} & 2553 & $8 / 10 / 200823: 34$ & 167 & 703.2 & 2620 & $8 / 11 / 20081: 48$ & 16.7 & 705.7 \\
\hline 2353 & 811020 & 16.7 & 690.9 & 2420 & $8 / 10200819.08$ & 16.7 & & 2487 & $8 / 10 \sqrt{2 x}$ & 16.7 & 695.5 & 2564 & $8 / 10200823: 36$ & 16.7 & 703.4 & 2021 & $081: 50$ & 16.7 & 705.1 \\
\hline 2354 & $8 / 1020$ & 16.7 & 690.9 & 2421 & $8 / 10200819.10$ & 16.7 & \begin{tabular}{|l|l|}
687.8 \\
\end{tabular} & & $821: 24$ & 16.7 & 693.6 & 2556 & $8 / 10200823: 38$ & 16.7 & 7028 & 2622 & & 16.7 & 703.1 \\
\hline 2355 & $8 / 10200816.58$ & 16.7 & 690.5 & 2422 & $8 / 10200819: 12$ & 16.7 & 6884 & 2489 & $8 / 10 / 200821: 26$ & 16.7 & 692 & 2566 & $8 / 10200823: 40$ & 167 & 7024 & 2623 & $081: 54$ & 16.7 & 7027 \\
\hline 2356 & $8 / 102008$ 17:00 & \begin{tabular}{|l|}
16.7 \\
\end{tabular} & 691.1 & 2423 & $8 / 10200819.14$ & 16.7 & 689.5 & 2490 & $8 / 10200021: 28$ & 16.7 & 691.2 & 2557 & $8 / 10200823: 42$ & \begin{tabular}{|l|}
16.7 \\
\end{tabular} & 703 & 2624 & $081: 56$ & 16.7 & 703.4 \\
\hline 2357 & $8 / 10 / 20$ & 16.7 & 691.8 & 2424 & $8 / 10200819.16$ & 16.7 & 690.1 & 2491 & $8 / 102$ & 16.7 & & 2558 & $8 / 102$ & \begin{tabular}{|l|}
16.7 \\
\end{tabular} & & & & 16.7 & \\
\hline 2358 & 811020 & 16.7 & 6925 & 2425 & $8110200819: 18$ & 16.7 & 690.2 & 2492 & 321:32 & 16.7 & 6924 & 2550 & $823: 46$ & 16.7 & 703.2 & 2626 & 3200 & 16.7 & 7029 \\
\hline 2359 & $8 / 10200817: 06$ & 16.7 & 691.9 & 2426 & $8 / 102008$ 19:20 & 16.7 & 690.7 & 2493 & $821: 34$ & 16.7 & 691.9 & 2560 & $823: 48$ & 16.7 & 703.2 & 2627 & 3202 & 16.7 & 703.7 \\
\hline 2360 & $8 / 10 / 2$ & 16.8 & 688.9 & 2427 & $8110200819: 22$ & 16.7 & & 2494 & 21:36 & 16.7 & 691.5 & 2561 & $323: 50$ & 16.7 & & 2628 & & 16.7 & 703.1 \\
\hline 2361 & $8 / 10 / 2$ & 16.7 & 690.2 & 2428 & $8 / 10200819.24$ & 16.7 & 689.3 & & $8 / 102$ & 16.7 & 690.9 & 2562 & & & & 2629 & & 16.7 & 703 \\
\hline 2362 & $8 / 1020$ & 16.7 & 690.5 & 2420 & 8110200819.26 & 16.7 & 688.6 & 2496 & $321: 40$ & 16.7 & 690.9 & 2563 & $823: 54$ & 16.7 & 703.3 & 2630 & 8208 & 16.7 & 703.1 \\
\hline 2363 & $8 / 102$ & 16.7 & 691.3 & 2430 & $8 / 1022$ & 16.7 & 689.4 & 2497 & $21: 42$ & 16.7 & 690.5 & 2564 & 23:56 & 16.7 & 705.3 & 2631 & & 16.7 & 702 \\
\hline 2364 & 81102 & 16.7 & 691.7 & 2431 & 81102 & 16.7 & & & $21: 44$ & \begin{tabular}{|l|l|}
16.7 \\
\end{tabular} & 690.7 & 2565 & & \begin{tabular}{|l|}
16.7 \\
\end{tabular} & & 2632 & & 16.7 & \\
\hline 2365 & $8 / 1020$ & 16.7 & 691.2 & 2432 & $8 / 1020$ & 16.7 & 690.4 & 2499 & 21:46 & 16.7 & 690.9 & 2566 & $80: 00$ & 16.7 & 703.1 & 2633 & 3214 & 16.7 & 701.6 \\
\hline 2366 & $8 / 102$ & 16.7 & 693.7 & 2433 & $8 / 102$ & 16.7 & 690.8 & 2500 & 21:48 & 16.7 & 690.7 & 2567 & $0: \infty$ & \begin{tabular}{|l|}
16.7 \\
\end{tabular} & 7021 & 2634 & & 16.7 & 699.7 \\
\hline 2367 & $8 / 102$ & 16.7 & & 2434 & 19:36 & 16.7 & & 2501 & $8 / 10$ & 16.7 & 690.4 & 2568 & & \begin{tabular}{|l|}
16.7 \\
\end{tabular} & & 635 & & 16.7 & \\
\hline 2368 & $8 / 102$ & 16.7 & 694.7 & 2435 & 81102 & 16.7 & 699.7 & 2502 & $8 / 10$ & 16.7 & 689.8 & 2569 & $0: 06$ & \begin{tabular}{|l|}
16.7 \\
\end{tabular} & 701.8 & 2636 & 220 & 16.7 & 697.8 \\
\hline 2369 & $8 / 102$ & 16.7 & 693.2 & 2436 & $8 / 1 \alpha^{2}$ & 16.7 & 689.9 & 2503 & $8 / 10$ & \begin{tabular}{|l|}
16.7 \\
\end{tabular} & 689.8 & 2570 & 0.08 & \begin{tabular}{|l|}
16.7 \\
\end{tabular} & 701.9 & 2637 & & 16.7 & 699.5 \\
\hline 2370 & 81102 & 16.7 & 695.6 & 2437 & $8 / 1 \alpha^{\prime}$ & \begin{tabular}{|l|l|}
16.7 \\
\end{tabular} & 699.7 & 2504 & $8 / 10$ & \begin{tabular}{|l|}
16.7 \\
\end{tabular} & 690.1 & 2571 & & \begin{tabular}{|l|}
16.7 \\
\end{tabular} & 7025 & 2638 & & 16.7 & 699.7 \\
\hline 2371 & $8 / 102$ & 16.7 & 698.9 & 2438 & 319.44 & 16.7 & 690.3 & 2506 & $8 / 10$ & 16.7 & 690.1 & 2572 & & \begin{tabular}{|l|}
16.7 \\
\end{tabular} & 700.7 & 2639 & 226 & 16.7 & 699.6 \\
\hline 2372 & $8 / 10 / 2$ & 16.7 & 689.1 & 2439 & $8 / 102$ & 16.7 & 696 & 2506 & $8 / 10$ & 16.7 & 690.7 & 2573 & $0: 14$ & \begin{tabular}{|l|}
16.7 \\
\end{tabular} & 703. & 2640 & & 16.7 & 700.2 \\
\hline 2373 & $811 \alpha^{\prime}$ & 16.7 & 681. & 2440 & 810 & 16.7 & \begin{tabular}{|l}
697. \\
\end{tabular} & 2507 & $22 \cdot 02$ & $\begin{array}{l}16.7 \\
\end{array}$ & 69 & 2574 & & \begin{tabular}{|l|}
16.7 \\
\end{tabular} & & 241 & 230 & 16.7 & 701.1 \\
\hline 2374 & $8 / 102$ & 16.7 & 6827 & 2441 & $8 / 10$ & 16.7 & 701. & 2508 & $8 / 10$ & 16.7 & 692 & 2575 & & \begin{tabular}{|l|}
16.7 \\
\end{tabular} & & & & \begin{tabular}{|c|}
6.7 \\
\end{tabular} & \\
\hline 2375 & $8 / 102$ & 16.7 & 6829 & \begin{tabular}{|l|}
2442 \\
\end{tabular} & $8 / 10$ & 16.7 & 704.5 & 2509 & 2206 & 16.7 & 691.8 & 2576 & & \begin{tabular}{|l|}
16.7 \\
\end{tabular} & 707. & 6643 & 234 & \begin{tabular}{|l|}
16.7 \\
\end{tabular} & 700.8 \\
\hline 2376 & $8 / 10$ & 16.7 & 6827 & 2443 & $8 / 10$ & 16.7 & 706.3 & 2510 & 208 & 16.7 & 691.5 & $25 \pi$ & & \begin{tabular}{|l|}
16.7 \\
\end{tabular} & 708 & 644 & & 16.7 & 700.5 \\
\hline 2377 & $8 / 10$ & 16.7 & 6828 & 2444 & $8 / 10$ & \begin{tabular}{|l|}
16.7 \\
\end{tabular} & 703.6 & 2511 & 210 & $\begin{array}{l}16.7 \\
\end{array}$ & 6926 & 2578 & & \begin{tabular}{|l|}
16.7 \\
\end{tabular} & & 645 & & 16.7 & 701.5 \\
\hline 2378 & $8 / 10 / 2$ & 16.7 & 683. & 2445 & & 16.7 & 702 & 2512 & $8 / 10$ & 16.7 & 6927 & 2579 & 0.26 & \begin{tabular}{|c|}
16.7 \\
\end{tabular} & 708.3 & 2646 & 240 & 16.7 & 700.7 \\
\hline 2379 & $8 / 10$ & 16.7 & 684. & 446 & & 16.7 & 700.3 & 2513 & 214 & 16.7 & 693.1 & 2580 & & \begin{tabular}{|l|}
16.7 \\
\end{tabular} & 699 & 2647 & & 16.7 & 699.3 \\
\hline 2380 & & 16.7 & 685. & 447 & $20: 02$ & 16.7 & 69 & 2514 & 216 & 16.7 & & 2581 & & \begin{tabular}{|l|}
16.7 \\
\end{tabular} & & & & 16.7 & 697.2 \\
\hline 2381 & $8 / 10$ & 16.7 & 687.5 & 2448 & $20: 04$ & 16.7 & 696 & 2515 & $8 / 10$ & 16.7 & & 2582 & 0.32 & \begin{tabular}{|l|}
16.7 \\
\end{tabular} & 702 & 2649 & 246 & 16.7 & 606.8 \\
\hline 2382 & $8 / 10$ & 16.7 & 688. & 2449 & $8 / 10$ & 16.7 & 696 & 2516 & 220 & 16.7 & 693.1 & 2583 & & \begin{tabular}{|l|}
16.7 \\
\end{tabular} & 684 & & & 16.7 & 698.1 \\
\hline 2383 & $8 / 10$ & 16.7 & 689 & 2450 & 0.08 & 16.7 & 69 & 17 & & 16.7 & \begin{tabular}{|l}
693. \\
\end{tabular} & 2584 & & 16.7 & & 2651 & & 16.7 & 698.4 \\
\hline 2384 & $8 / 102$ & \begin{tabular}{|l|}
16.7 \\
\end{tabular} & 689 & 2451 & 8110 & 16.7 & 693 & 2518 & 224 & \begin{tabular}{|l|}
16.7 \\
\end{tabular} & 69 & 2585 & 0.38 & \begin{tabular}{|l|l}
16.7 \\
\end{tabular} & 684.4 & 2652 & & 16.7 & 699.8 \\
\hline 2385 & & 16.7 & 689.7 & 2452 & & $\begin{array}{l}16.7 \\
\end{array}$ & 693 & 2519 & 226 & \begin{tabular}{|l|}
16.7 \\
\end{tabular} & 693.5 & 2586 & & \begin{tabular}{|l|}
16.7 \\
\end{tabular} & 68 & & & 16.7 & 707.5 \\
\hline 2386 & 8110 & 16.7 & 688. & 2453 & 8110 & 16.7 & 69 & 520 & 228 & 16.7 & 69 & 2587 & & \begin{tabular}{|l|}
16.7 \\
\end{tabular} & 685 & 2654 & & 16.7 & 687.6 \\
\hline 2387 & $8 / 10$ & 16.7 & 6887 & 2454 & $8 / 10$ & 16.7 & 693.6 & 2521 & 230 & \begin{tabular}{|l|l}
16.7 \\
\end{tabular} & 694. & 2588 & & \begin{tabular}{|l|}
16.7 \\
\end{tabular} & 68 & 6655 & & \begin{tabular}{|c|}
16.7 \\
\end{tabular} & 693.3 \\
\hline 2388 & & \begin{tabular}{|c|}
16.7 \\
\end{tabular} & & & & 16.7 & 693.6 & 2522 & & \begin{tabular}{|l|}
16.7 \\
\end{tabular} & & 2589 & & \begin{tabular}{|l|}
16.7 \\
\end{tabular} & & & & 76. & 680 \\
\hline 389 & 8110 & \begin{tabular}{|l|}
16.7 \\
\end{tabular} & 688 & & & 16.8 & 698 & 2523 & 234 & 16.7 & & 2590 & & \begin{tabular}{|l|}
16.7 \\
\end{tabular} & 69 & & & $\overline{16}$ & 68 \\
\hline 2390 & $8 / 102$ & 16.7 & 687.8 & 2457 & 0.22 & 16.7 & 694. & 2524 & 2236 & \begin{tabular}{|l|}
16.7 \\
\end{tabular} & 694 & 2591 & 7.50 & 16.7 & 694 & 2658 & & 16.7 & 680.5 \\
\hline 2391 & & १6.7 & & & & \begin{tabular}{|l|}
16.7 \\
\end{tabular} & & & & \begin{tabular}{|l|}
16.7 \\
\end{tabular} & & 2592 & & \begin{tabular}{|c|}
16.7 \\
\end{tabular} & & & & 16. & 680.3 \\
\hline 2392 & & 16.7 & 687 & & & \begin{tabular}{|c|}
16.7 \\
\end{tabular} & & 2526 & & \begin{tabular}{|l|}
16.7 \\
\end{tabular} & $\begin{array}{l}69 \\
\end{array}$ & 2593 & & & & & & $\overline{16}$ & 6755 \\
\hline 3993 & & 16.7 & 689. & 2460 & 0.28 & \begin{tabular}{|c|}
16.7 \\
\end{tabular} & 693.8 & 2527 & $8 / 10$ & \begin{tabular}{|l|}
16.7 \\
\end{tabular} & 696. & 2594 & 5.56 & \begin{tabular}{|l|}
16.7 \\
\end{tabular} & 694.3 & 661 & & 16.7 & 6829 \\
\hline 394 & & \begin{tabular}{|l|}
16.7 \\
\end{tabular} & & 2461 & & 16.7 & 6983 & 2528 & & \begin{tabular}{|l|}
16.7 \\
\end{tabular} & 696 & 2595 & & \begin{tabular}{|l|}
16.7 \\
\end{tabular} & & $66 \overline{2}$ & & $16 . \varepsilon$ & 6725 \\
\hline 39a & & 167 & 69 & & & 16.7 & & 2529 & & \begin{tabular}{|l|l|}
16.7 \\
\end{tabular} & & 2596 & & & 698 & & & & $\overline{6814}$ \\
\hline 396 & & 16.7 & 690. & 463 & 00.34 & \begin{tabular}{ll|}
16.7 \\
\end{tabular} & 6923 & 2530 & 248 & \begin{tabular}{|l|}
16.7 \\
\end{tabular} & 700.8 & 2597 & & \begin{tabular}{|l|}
16.7 \\
\end{tabular} & & 664 & & $\begin{array}{l}16.7 \\
\end{array}$ & 687.8 \\
\hline 2397 & & \begin{tabular}{|l|}
16.7 \\
\end{tabular} & 691. & & & \begin{tabular}{|l|l|}
16.7 \\
\end{tabular} & & 2531 & & \begin{tabular}{|l|}
16.7 \\
\end{tabular} & 689.2 & 2598 & & 16.7 & 69 & 665 & & 16.7 & 680.1 \\
\hline कवा & & \begin{tabular}{|l|}
16.7 \\
\end{tabular} & & & & 16.7 & & & & \begin{tabular}{|l|}
16.7 \\
\end{tabular} & & 2599 & & \begin{tabular}{|l|}
16.7 \\
\end{tabular} & & & & & \\
\hline 2399 & & 16.7 & 692 & & $20: 40$ & 16.7 & 694.8 & 2533 & 254 & \begin{tabular}{|l|}
16.7 \\
\end{tabular} & 683.8 & 2600 & & \begin{tabular}{|l|}
16.7 \\
\end{tabular} & 700. & 67 & & 16.7 & 673.3 \\
\hline 400 & & \begin{tabular}{|l|}
16.7 \\
\end{tabular} & 690.5 & & & 16.7 & 697 & 2534 & & \begin{tabular}{|l|}
16.7 \\
\end{tabular} & & 2601 & & \begin{tabular}{|c|}
16.7 \\
\end{tabular} & & & & 16.7 & 669.8 \\
\hline$\overline{40}$ & & & 690. & & & & & 2535 & & & & 2602 & & & & & & & \\
\hline 2402 & 8.32 & 16.7 & 680 & & $20: 46$ & \begin{tabular}{|l|l}
16.7 \\
\end{tabular} & 699 & 2536 & $3: 00$ & \begin{tabular}{|l|}
16.7 \\
\end{tabular} & 685.2 & 2603 & & \begin{tabular}{|l|}
16.7 \\
\end{tabular} & & & & \begin{tabular}{|c|}
16.7 \\
\end{tabular} & 670.7 \\
\hline 403 & $8 / 10$ & \begin{tabular}{|l|l}
16.7 \\
\end{tabular} & 690 & & & 16.7 & 690 & 2537 & & \begin{tabular}{|l|}
16.7 \\
\end{tabular} & 695.5 & 2604 & & \begin{tabular}{|l|}
16.7 \\
\end{tabular} & & & & 16.7 & 6721 \\
\hline 404 & & & 688 & & & & & 2538 & & & & 2000 & & & & & & 16.7 & \\
\hline 240 & & & 687 & & 20.52 & 16.7 & 69 & 2539 & 3009 & \begin{tabular}{|l|}
16.7 \\
\end{tabular} & & 2606 & & & & & & 16.7 & \\
\hline 2406 & $8 / 10$ & 16.7 & 687.5 & 2473 & $320: 54$ & \begin{tabular}{|l|}
16.7 \\
\end{tabular} & 698 & 2540 & $3: 08$ & \begin{tabular}{|l|}
16.7 \\
\end{tabular} & 696. & 2607 & $1: 22$ & \begin{tabular}{|l|l|}
16.7 \\
\end{tabular} & 704 & 2674 & & 16.7 & 676.4 \\
\hline 2407 & & $16 \pi$ & 68 & 174 & & 10.4 & 698. & 2541 & & \begin{tabular}{|l|}
16.7 \\
\end{tabular} & 700 & 2608 & & \begin{tabular}{|l|}
16.7 \\
\end{tabular} & & 2675 & & 16.7| & \\
\hline 2408 & & & 689 & & & & & & & & & & & & & & & 16.8 & \\
\hline 2409 & $8 / 10 / 20$ & \begin{tabular}{|l|l|}
16.7 \\
\end{tabular} & 691.7 & 2476 & $821: \infty$ & \begin{tabular}{|l|l|}
16.7 \\
\end{tabular} & 699.3 & 2543 & $823: 14$ & \begin{tabular}{l|l|}
16.7 \\
\end{tabular} & 703.7 & 2610 & $1: 28$ & \begin{tabular}{|l|}
16.7 \\
\end{tabular} & 704. & 2677 & 3342 & 16.7 & 669.6 \\
\hline & & \begin{tabular}{|l|}
16.7 \\
\end{tabular} & 690 & 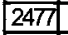 & & 16.7 & 697.9 & 2544 & & \begin{tabular}{|l|}
16.7 \\
\end{tabular} & 703 & 2611 & & \begin{tabular}{|l|}
16.7 \\
\end{tabular} & & 2678 & & 16.7 & 666.1 \\
\hline 411 & $8 / 1012$ & 16.7 & 689 & \begin{tabular}{|l|}
2478 \\
\end{tabular} & $8 / 10$ & \begin{tabular}{|l|l}
16.7 \\
\end{tabular} & $69 \%$ & & & & 70 & 2612 & & \begin{tabular}{|l|}
16.7 \\
\end{tabular} & & $20 / 9$ & & 16.7 & \\
\hline 412 & 18.52 & \begin{tabular}{|l|}
16.7 \\
\end{tabular} & 688.7 & 2479 & $21: 06$ & \begin{tabular}{|l|}
16.7 \\
\end{tabular} & 697.7 & 2546 & $23: 20$ & \begin{tabular}{|l|}
16.7 \\
\end{tabular} & 704.5 & 2613 & 34 & & & & 3:48 & & $/ 0$. \\
\hline
\end{tabular}




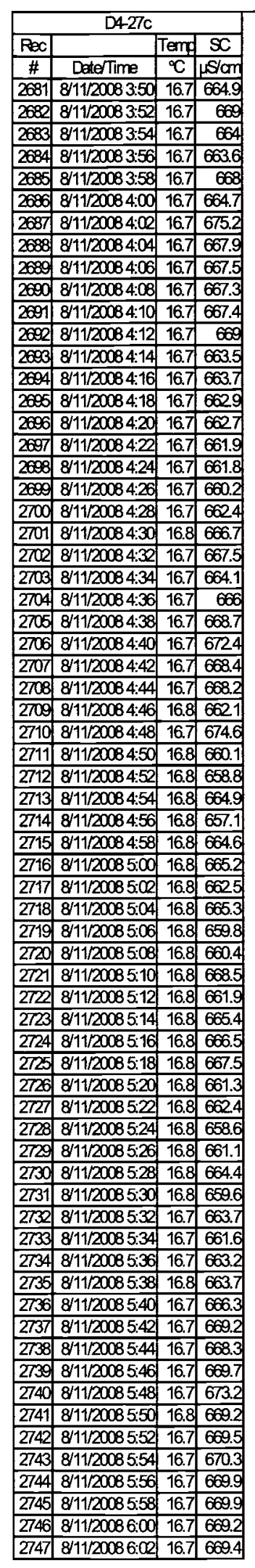

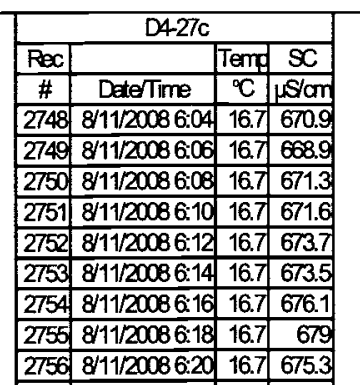

\begin{tabular}{|l|l|l|l|}
\hline 2756 & $8 / 11 / 20086.20$ & 16.7 & 675.3 \\
\hline 275 & $8 / 11 / 20086.20$ & 16.7 & 676.1 \\
\hline
\end{tabular} \begin{tabular}{|l|l|l|l|}
\hline 2758 & $8111 / 20086.24$ & 16.7 & 680.8 \\
\hline
\end{tabular} \begin{tabular}{|l|l|l|l|}
\hline 2759 & $8111 / 20086.26$ & 16.7 & 679.3 \\
\hline
\end{tabular} \begin{tabular}{|l|l|l|l|}
\hline 2760 & $811 / 20086: 28$ & 16.7 & 681.1 \\
\hline
\end{tabular} \begin{tabular}{|l|l|l|l|}
\hline 2761 & $8 / 1 / 20086: 30$ & 16.7 & 679.8 \\
\hline 2762 & $811 / 208632$ & 16.7 & 680.1 \\
\hline
\end{tabular} \begin{tabular}{|l|l|l|l|}
\hline 2702 & $8111 / 20086: 32$ & 16.7 & 680.1 \\
\hline
\end{tabular} \begin{tabular}{|l|l|l|l|}
\hline 2763 & $8 / 11 / 20086: 34$ & 16.7 & 679 \\
\hline
\end{tabular} \begin{tabular}{|l|l|l|l|}
\hline 2764 & $8 / 11 / 20086.36$ & 16.7 & 678.3 \\
\hline
\end{tabular} \begin{tabular}{|l|l|l|l|}
\hline 2765 & $8 / 11 / 20086: 38$ & 16.7 & 678.4 \\
\hline
\end{tabular} \begin{tabular}{|l|l|l|l|}
\hline 2766 & $8111 / 20086: 40$ & 16.7 & 670.4 \\
\hline
\end{tabular} \begin{tabular}{lllll}
\hline 2767 & $8111 / 20086: 42$ & 16.7 & 667.1 \\
\hline
\end{tabular} \begin{tabular}{|l|l|l|l|}
\hline 2768 & $8111 / 20086: 44$ & 16.7 & 673.4 \\
\hline
\end{tabular} \begin{tabular}{|l|l|l|l|}
\hline 2769 & $8 / 11 / 20086: 46$ & 16.7 & 6729 \\
\hline
\end{tabular} \begin{tabular}{|l|l|l|l|}
\hline 2770 & $8111 / 20086: 48$ & 16.7 & 676.3 \\
\hline
\end{tabular} \begin{tabular}{|l|l|l|l|}
\hline 2771 & $8 / 11 / 20086: 50$ & 16.7 & 676.4 \\
\hline
\end{tabular} \begin{tabular}{|l|lll|}
\hline $27 / 2$ & $8111 / 20086: 52$ & 16.7 & 673.7 \\
\hline
\end{tabular} \begin{tabular}{|l|l|l|l|}
\hline 2773 & $8 / 11 / 20086554$ & 16.7 & 681.2 \\
\hline 2744 & 8111200865 & 16.7 & 65.4 \\
\hline
\end{tabular} \begin{tabular}{|l|l|l|l|}
\hline 2774 & $8 / 11 / 20086: 56$ & 16.7 & 675.4 \\
\hline
\end{tabular} \begin{tabular}{|l|l|l|l|}
\hline 2775 & $8111 / 20086.58$ & 16.7 & 674.6 \\
\hline
\end{tabular} \begin{tabular}{|l|l|l|l|}
\hline 2776 & $8 / 11 / 20087: 00$ & 16.7 & 674.3 \\
\hline
\end{tabular} \begin{tabular}{|l|l|l|l|}
\hline 2777 & $8111 / 20087: 02$ & 16.7 & 671.8 \\
\hline
\end{tabular} \begin{tabular}{|l|l|l|l|}
\hline $27 / 8$ & $8141 / 2008$ 7:04 & 16.7 & 67 \\
\hline
\end{tabular} \begin{tabular}{|l|l|l|l|}
\hline 2779 & $8 / 11 / 20087: 06$ & 16.7 & 67 \\
\hline
\end{tabular} \begin{tabular}{|l|l|l|l|}
\hline 2780 & $8 / 11 / 20087: 08$ & 16.7 & 666.4 \\
\hline
\end{tabular} \begin{tabular}{|l|l|l|l|}
\hline 2781 & $811 / 20087: 10$ & 16.7 & 668.9 \\
\hline 2782 & $811 / 2008712$ & 167 & 667 \\
\hline
\end{tabular} \begin{tabular}{|l|l|l|l|}
\hline 2782 & $8 / 11 / 20087: 12$ & 16.7 & 667.9 \\
\hline
\end{tabular} \begin{tabular}{|l|l|l|l|}
\hline 2783 & $8 / 11 / 20087: 14$ & 16.7 & 668.4 \\
\hline 2784 & $811120087: 16$ & 16.7 & 667 \\
\hline
\end{tabular} \begin{tabular}{|l|l|l|l|}
\hline 2784 & $8 / 11 / 20087: 16$ & 16.7 & 667.9 \\
\hline
\end{tabular} \begin{tabular}{|l|l|l|l|}
\hline 2785 & $8 / 11 / 20087: 18$ & 16.7 & 66 \\
\hline
\end{tabular} \begin{tabular}{|l|l|l|l|}
\hline 2786 & $8111 / 20087: 20$ & 16.7 & 662 \\
\hline
\end{tabular} \begin{tabular}{|l|l|l|l|}
\hline 2787 & $8 / 11 / 20087.22$ & 16.7 & 663.9 \\
\hline
\end{tabular} \begin{tabular}{|l|l|l|l|}
\hline 2788 & $8 / 11 / 20087: 24$ & 16.7 & 66 \\
\hline
\end{tabular} \begin{tabular}{ll|l|l|l}
\hline 2789 & $8 / 11 / 20087: 26$ & 16.7 & 663. \\
\hline
\end{tabular} \begin{tabular}{|l|l|l|l|}
\hline 2790 & $8 / 11 / 20087: 28$ & 16.7 & 663.2 \\
\hline
\end{tabular} \begin{tabular}{l|l|l|l|}
\hline 2791 & $8 / 11 / 20087: 30$ & 16.7 & 662 \\
\hline
\end{tabular} \begin{tabular}{l|l|l|l|}
\hline 2792 & $8111 / 20087: 32$ & 16.7 & 661.8 \\
\hline
\end{tabular} \begin{tabular}{|l|l|l|l|}
\hline 2793 & $811 / 20087: 34$ & 16.7 & 6621 \\
\hline 2794 & $811 / 20087: 36$ & 16.7 & 661 \\
\hline
\end{tabular} \begin{tabular}{|l|l|l|r|}
\hline 2794 & $8 / 11 / 20087: 36$ & 16.7 & 661 \\
\hline
\end{tabular} \begin{tabular}{|l|l|l|l|}
\hline 2795 & $811 / 20087: 38$ & 16.7 & 667.7 \\
\hline
\end{tabular} \begin{tabular}{|l|l|l|l|}
\hline 2796 & $8 / 11 / 20087: 40$ & 16.7 & 663.2 \\
\hline
\end{tabular} \begin{tabular}{|l|l|l|l|}
\hline 2797 & $8 / 11 / 20087: 42$ & 16.7 & 666.6 \\
\hline
\end{tabular} \begin{tabular}{|l|l|l|l|}
\hline 2796 & $8111 / 20087: 44$ & 16.7 & 666.4 \\
\hline
\end{tabular} \begin{tabular}{|l|l|l|l|}
\hline 2799 & $8111 / 20087: 46$ & 16.7 & 667.1 \\
\hline
\end{tabular} \begin{tabular}{|l|l|l|l|}
\hline 2800 & $8 / 11 / 20087: 48$ & 16.7 & 666.2 \\
\hline
\end{tabular} \begin{tabular}{|l|l|l|l|}
\hline 2801 & $8 / 11 / 20087: 50$ & 16.7 & 664.5 \\
\hline 2002 & $8 / 11 / 20087: 52$ & 16.7 & 653.1 \\
\hline
\end{tabular} \begin{tabular}{|l|l|l|l|}
\hline 2800 & $8 / 11 / 20087: 52$ & 16.7 & 663.1 \\
\hline
\end{tabular} \begin{tabular}{|l|l|l|l|}
\hline 2803 & $8 / 11 / 20087: 54$ & 16.7 & 662.8 \\
\hline
\end{tabular} \begin{tabular}{l|ll|l|l|}
\hline 2804 & $8111 / 20087.56$ & 16.7 & 663.2 \\
\hline
\end{tabular} \begin{tabular}{|l|l|l|l|}
\hline 2805 & $8 / 11 / 20087: 58$ & 16.7 & 663.2 \\
\hline 2806 & $811 / 2008800$ & 16.7 & 663.8 \\
\hline
\end{tabular} \begin{tabular}{|l|l|l|l|}
\hline 2806 & $8 / 11 / 20088: 00$ & 16.7 & 663.8 \\
\hline 2807 & $811 / 20088: 00$ & 16.7 & 6643 \\
\hline
\end{tabular} \begin{tabular}{|l|l|l|l|}
\hline 2807 & $8 / 11 / 20088: 02$ & 16.7 & 664.3 \\
\hline 208 & $811 / 20088: 04$ & 16.7 & 664.1 \\
\hline
\end{tabular} \begin{tabular}{|l|l|l|l|}
\hline 2808 & $8 / 11 / 20088: 04$ & 16.7 & 664.1 \\
\hline
\end{tabular} \begin{tabular}{|l|l|l|l|}
\hline 2809 & $8 / 11 / 20088: 06$ & 16.7 & 663.1 \\
\hline 2810 & $811 / 2088.08$ & 16.7 & 661.0 \\
\hline
\end{tabular} \begin{tabular}{|l|l|l|l|}
\hline 2810 & $8 / 11 / 20088: 08$ & 16.7 & 661.6 \\
\hline 2811 & $8 / 1 / 20088: 10$ & 16.7 & 6623 \\
\hline
\end{tabular} \begin{tabular}{l|l|l|l|}
\hline 2811 & $8 / 11 / 20088: 10$ & 16.7 & 6623 \\
\hline
\end{tabular} \begin{tabular}{|l|l|l|l|}
\hline 2812 & $811 / 20088: 12$ & 16.7 & 663.2 \\
\hline
\end{tabular} \begin{tabular}{|l|l|l|l|}
\hline 2813 & $8 / 11 / 20088: 14$ & 16.7 & 663.1 \\
\hline
\end{tabular} \begin{tabular}{|l|l|l|l|}
\hline 2814 & $8 / 11 / 20088: 16$ & 16.7 & 663.5 \\
\hline
\end{tabular}

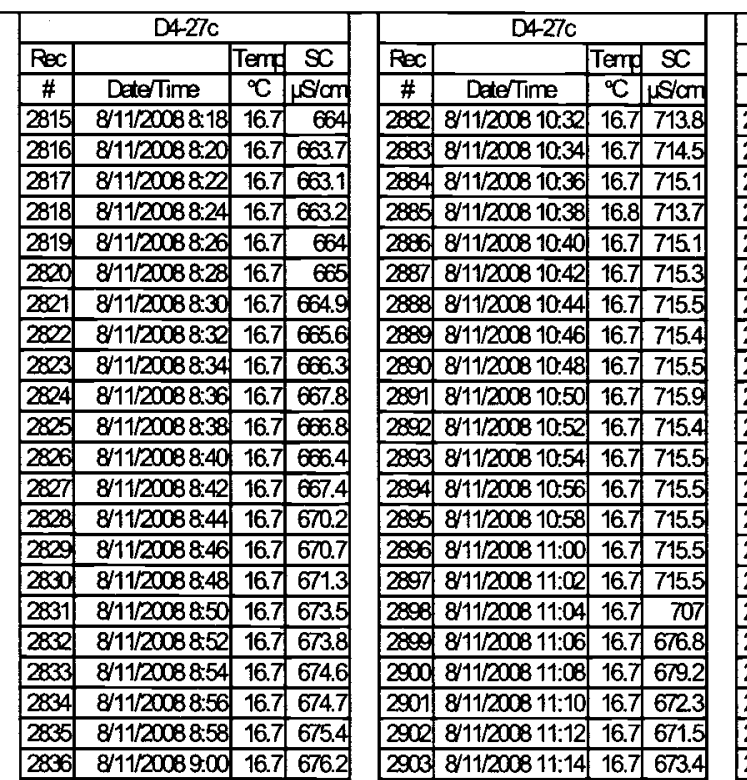

\begin{tabular}{|l|l|l|l|}
\hline 2837 & $811120089-02$ & 16.7 & 6750 \\
\hline
\end{tabular} \begin{tabular}{|l|l|l|l|}
\hline 2837 & $8 / 11 / 20089.02$ & 16.7 & 675.9 \\
\hline 2838 & $8 / 11 / 20089.04$ & 16.7 & 676.7 \\
\hline 289 & $811 / 20089.00$ & 16.7 & 677.0 \\
\hline
\end{tabular} \begin{tabular}{|l|l|l|l|}
\hline 2839 & $8 / 11 / 20089.06$ & 16.7 & 677.6 \\
\hline 280 & $8 / 1 / 20089.08$ & 16.7 & 678.6 \\
\hline
\end{tabular} \begin{tabular}{|l|l|l|l|}
\hline 2840 & $8 / 11 / 20089.08$ & 16.7 & 678.6 \\
\hline
\end{tabular} \begin{tabular}{|l|r|r|r|}
\hline 2841 & $8 / 11 / 20089.10$ & 16.7 & 680 \\
\hline 2842 & $811 / 20089.12$ & 16.7 & 680 \\
\hline
\end{tabular} \begin{tabular}{|l|l|l|l|}
\hline 2842 & $8 / 11 / 20089.12$ & 16.7 & 680.6 \\
\hline
\end{tabular} \begin{tabular}{|l|l|l|l|}
\hline 2843 & $8 / 11 / 20089.14$ & 16.7 & 681.1 \\
\hline 2844 & $8 / 11 / 2089.16$ & 16.7 & 682 \\
\hline
\end{tabular} \begin{tabular}{lll|l|l|}
\hline 2844 & $8 / 11 / 20089.16$ & 16.7 & 6823 \\
\hline
\end{tabular} \begin{tabular}{|l|l|l|l|}
\hline 2845 & $8 / 11 / 20089.18$ & 16.7 & 683.2 \\
\hline 2846 & $8 / 11 / 20089.20$ & 16.7 & 683.4 \\
\hline
\end{tabular} \begin{tabular}{|l|l|l|l|}
\hline 2846 & $8 / 11 / 20089.20$ & 16.7 & 683.4 \\
\hline
\end{tabular} \begin{tabular}{|l|l|l|l|}
\hline 2847 & $8 / 11 / 20089.22$ & 16.7 & 685 \\
\hline 288 & $811 / 20089.24$ & 16.7 & 6862 \\
\hline
\end{tabular} \begin{tabular}{|l|l|l|l|}
\hline 2848 & $811 / 20089.24$ & 16.7 & 686.2 \\
\hline 2849 & $811 / 20089.26$ & 16.7 & 686 \\
\hline
\end{tabular} \begin{tabular}{|l|l|l|l|}
\hline 2849 & $8 / 11 / 20089.26$ & 16.7 & 686 \\
\hline 2850 & $8 / 11 / 20089.28$ & 16.7 & 686 \\
\hline
\end{tabular} \begin{tabular}{|l|l|l|l|}
\hline 2850 & $8 / 11 / 20089.28$ & 16.7 & 686.6 \\
\hline 2851 & $811 / 20089.30$ & 16.7 & 687.3 \\
\hline
\end{tabular} \begin{tabular}{|l|l|l|l|}
\hline 2851 & $8 / 11 / 20089.30$ & 16.7 & 687.3 \\
\hline 2852 & $8 / 11 / 2008932$ & 16.7 & 688.6 \\
\hline
\end{tabular} \begin{tabular}{|l|l|l|l|}
\hline 2852 & $8 / 11 / 20089.32$ & 16.7 & 688.6 \\
\hline 2853 & $8 / 11 / 20089.34$ & 167 & 688.8 \\
\hline
\end{tabular} \begin{tabular}{|l|l|l|l|}
\hline 2853 & $8 / 11 / 20089.34$ & 16.7 & 688.8 \\
\hline
\end{tabular} \begin{tabular}{|l|r|r|r|}
\hline 2854 & $8 / 11 / 20089.36$ & 16.7 & 690 \\
\hline 2855 & $8 / 11 / 20089.38$ & 16.7 & 690.7 \\
\hline
\end{tabular} \begin{tabular}{|l|l|l|l|}
\hline 2855 & $8 / 11 / 20089.38$ & 16.7 & 690.7 \\
\hline 2856 & $811 / 20089.40$ & 16.7 & 691. \\
\hline
\end{tabular} \begin{tabular}{|l|l|l|l|}
\hline 2856 & $8 / 11 / 20089.40$ & 16.7 & 691.3 \\
\hline 2857 & $8 / 11 / 20089.42$ & 16.7 & 692.3 \\
\hline
\end{tabular} \begin{tabular}{|l|l|l|l|}
\hline 2858 & $8 / 11 / 20089.44$ & 16.7 & 6923 \\
\hline
\end{tabular} \begin{tabular}{|l|l|l|l|}
\hline 2859 & $8 / 11 / 20089.46$ & 16.7 & 692.7 \\
\hline 2600 & $8 / 11 / 20089.48$ & 16.7 & 693.1 \\
\hline
\end{tabular} \begin{tabular}{|l|l|l|l|}
\hline 2060 & $8 / 11 / 20089.48$ & 16.7 & 693.1 \\
\hline 2861 & $811 / 20089.50$ & 16.7 & 933.9 \\
\hline
\end{tabular} \begin{tabular}{|l|l|l|l|}
\hline 2861 & $8 / 11 / 20089.50$ & 16.7 & 693.9 \\
\hline 260 & $8 / 1 / 2008952$ & 16.7 & 694.4 \\
\hline
\end{tabular} \begin{tabular}{l|l|l|l}
\hline 2862 & $8 / 11 / 20089.52$ & 16.7 & 694.4 \\
\hline 2863 & $8 / 1 / 20089.54$ & 16.7 & 695 \\
\hline
\end{tabular} \begin{tabular}{|l|l|l|r|}
\hline 2863 & $8 / 11 / 20089.54$ & 16.7 & 696 \\
\hline
\end{tabular} \begin{tabular}{|l|l|l|l|}
\hline 2864 & $8 / 11 / 20089.56$ & 16.7 & 695.7 \\
\hline
\end{tabular} \begin{tabular}{|l|l|l|l|}
\hline 2865 & $8 / 11 / 20089.58$ & 16.7 & 696.1 \\
\hline 2666 & $8 / 11 / 200810.00$ & 16.7 & 696.7 \\
\hline
\end{tabular} \begin{tabular}{|l|l|l|l|}
\hline 2866 & $8 / 11 / 200810.00$ & 16.7 & 696.7 \\
\hline 2607
\end{tabular} \begin{tabular}{|l|l|l|l|}
\hline 2867 & $8 / 11 / 200810: 02$ & 16.7 & 697.1 \\
\hline 2668 & $8 / 11 / 00810.04$ & 16.7 & 697.0 \\
\hline
\end{tabular} \begin{tabular}{|l|l|l|l|}
\hline 2868 & $8111 / 200810.04$ & 16.7 & 697.6 \\
\hline 2808 & $811 / 200810.06$ & 16.7 & 6881 \\
\hline
\end{tabular} \begin{tabular}{l|l|l|l|l|}
\hline 2809 & $8 / 11 / 200810.06$ & 16.7 & 6981 \\
\hline
\end{tabular} \begin{tabular}{|l|l|l|l|}
\hline 2870 & $8 / 11 / 200810: 08$ & 16.7 & $\$ 8.8$ \\
\hline
\end{tabular} \begin{tabular}{|l|l|l|l|}
\hline 2871 & $8 / 11 / 200810.10$ & 16.8 & 690.3 \\
\hline 28
\end{tabular} \begin{tabular}{|l|l|l|l|}
\hline 2872 & $8 / 11 / 200810.12$ & 16.7 & 701.3 \\
\hline
\end{tabular} \begin{tabular}{|l|l|l|l|}
\hline 2873 & $8 / 11 / 200810.14$ & 16.7 & 702.4 \\
\hline
\end{tabular} \begin{tabular}{|l|l|l|l|}
\hline 2874 & $8 / 11 / 200810.16$ & 16.7 & 703.7 \\
\hline
\end{tabular} \begin{tabular}{|l|l|l|l|}
\hline 2875 & $8 / 11 / 200810.18$ & 16.7 & 705.1 \\
\hline
\end{tabular} \begin{tabular}{|l|l|l|l|}
\hline 2876 & $8 / 11 / 200810.20$ & 16.7 & 706.4 \\
\hline
\end{tabular} \begin{tabular}{|l|l|l|l|}
\hline 2877 & $8 / 11 / 200810: 22$ & 16.7 & 707.8 \\
\hline
\end{tabular} \begin{tabular}{|l|l|l|l|}
\hline 2878 & $8 / 11 / 200810.24$ & 16.7 & 700.6 \\
\hline 2879 & $811 / 200810.26$ & 16.8 & 709.6 \\
\hline
\end{tabular} \begin{tabular}{l|l|l|l|}
\hline 2879 & $8 / 11 / 200810.26$ & 16.8 & 709.6 \\
\hline
\end{tabular} \begin{tabular}{|l|l|l|l|}
\hline 2880 & $8 / 11 / 200810.28$ & 16.7 & 711.5 \\
\hline
\end{tabular} \begin{tabular}{|l|l|l|l|}
\hline 2881 & $8 / 11 / 200810.30$ & 16.7 & 7126 \\
\hline
\end{tabular}

\begin{tabular}{|c|c|c|}
\hline \multicolumn{3}{|c|}{$\mathrm{DA427C}$} \\
\hline $\operatorname{Rec}$ & & Tem S \\
\hline \# & Dete/Time & \begin{tabular}{l|l}
${ }^{\circ} \mathrm{C}$ & $\mu \mathrm{S} / \mathrm{o}$ \\
\end{tabular} \\
\hline 449 & $8 / 11 / 20081246$ & \\
\hline 60 & $8 / 11 / 20081248$ & 16.7 \\
\hline 51 & $8 / 11 / 20081250$ & 16.7 \\
\hline 52 & $8111 / 20081252$ & 16.7 \\
\hline & $8 / 11 / 20081254$ & 16.7 \\
\hline 564 & $8 / 11 / 20081256$ & 16.7 \\
\hline 505 & $8111 / 20081258$ & 16.7 \\
\hline 56. & $8 / 11 / 200813300$ & 16.7 \\
\hline $5 \sqrt{57}$ & $8111 / 200813: 02$ & \\
\hline 58 & $8 / 11 / 2008$ 13:04 & 16.7 \\
\hline 69 & $8 / 11 / 200813: 06$ & 16.7 \\
\hline 2960 & $8 / 11 / 200813: 08$ & 16.7 \\
\hline & $8 / 17 / 2$ & \\
\hline & $813: 12$ & 16.7 \\
\hline 963 & 8/11/2008 13:14 & 16.7 \\
\hline 964 & $8 / 11 / 2$ & $\begin{array}{l}16.7 \sqrt{67} \\
\end{array}$ \\
\hline & $8 / 11 / 2$ & \\
\hline 6 & $313: 20$ & 16.7 \\
\hline 607 & $8 / 11 / 20$ & \begin{tabular}{l|l|}
16.7 & 679.3 \\
\end{tabular} \\
\hline 2968 & $8 / 11 / 2$ & 16.7 \\
\hline 969 & $8 / 11 / 2$ & 16.7 \\
\hline 2970 & $8 / 11 / 2$ & 682 \\
\hline & $8 / 11 / 2$ & 16.7 \\
\hline 72 & $8 / 11 / 2$ & 16.7 \\
\hline 373 & $8 / 11 / 2$ & 16.7 \\
\hline 774 & $8 / 11 / 2$ & 16.7 \\
\hline 775 & $8 / 11 / 2$ & 685. \\
\hline 2976 & $8 / 11 / 2$ & 16.7 \\
\hline 297 & $8 / 11 / 2$ & $\begin{array}{l}16.7686 . \\
\end{array}$ \\
\hline 2978 & $8 / 11 / 2$ & \begin{tabular}{ll|l}
16.7 & 68 \\
\end{tabular} \\
\hline 79 & $8 / 11 /$ & 688. \\
\hline 980 & $8 / 11 / 20$ & 16.7 \\
\hline 2981 & $8 / 11 /$ & 16.7 \\
\hline 2962 & $8 / 11 / 2$ & 16.7 \\
\hline & $8 / 11$ & 693. \\
\hline 984 & $8 / 11 / 2$ & 16.7 \\
\hline 2985 & $8 / 11$ & 16.7 \\
\hline 806 & $8 / 11 /$ & 16.7 \\
\hline 987 & $8 / 11 /$ & 697. \\
\hline 2968 & $8 / 11 /$ & 16.7 \\
\hline 2989 & & 16.7 \\
\hline 90 & & 700. \\
\hline 901 & 14:10 & 701. \\
\hline 299 & 14:12 & 701. \\
\hline & $8 / 11$ & 702 \\
\hline 2094 & & 704. \\
\hline 2995 & $8 / 11 / 2$ & 16.7 \\
\hline 2996 & & 709. \\
\hline & & 16.7 \\
\hline & $8 / 11$ & 16.7 \\
\hline 2999 & $14: 26$ & 16.7 \\
\hline 3000 & & 715. \\
\hline 3001 & & 16.7 \\
\hline 3002 & 14:32 & 16.7 \\
\hline 3003 & & 16.7 \\
\hline 3004 & & 16.7 \\
\hline 3005 & 14:38 & 16.7 \\
\hline 3006 & $14: 40$ & 16.7 \\
\hline 3007 & 314:42 & $\begin{array}{l}16.7 \\
1716 . \\
\end{array}$ \\
\hline 3008 & 8 14:44 & 16.7 \\
\hline 3000 & $814: 46$ & \begin{tabular}{l|l|l|}
16.7 & 716 \\
\end{tabular} \\
\hline 3010 & $814: 48$ & \begin{tabular}{l|l|l|}
16.7 & 716 \\
\end{tabular} \\
\hline 3011 & $8 / 11 / 200814: 50$ & \begin{tabular}{|l|l|l|}
16.7 & 716. \\
\end{tabular} \\
\hline 3012 & $8 / 11 / 2$ & \begin{tabular}{ll|l}
16.7 & 716. \\
\end{tabular} \\
\hline 3013 & $814: 54$ & $\begin{array}{l}16 . \overline{7} \\
716 . \\
\end{array}$ \\
\hline 3014 & $14: 56$ & \begin{tabular}{l|l|l|}
16.7 & 716. \\
\end{tabular} \\
\hline & & \begin{tabular}{l|l|}
16.7 & 716 \\
\end{tabular} \\
\hline
\end{tabular}




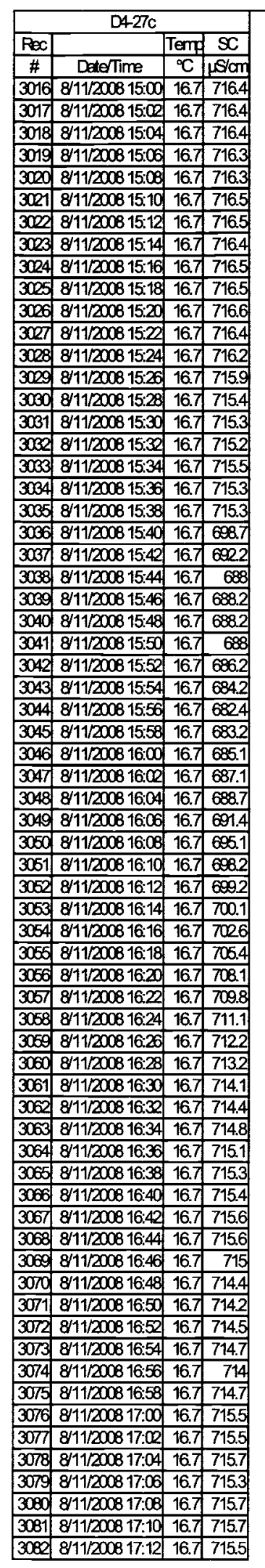

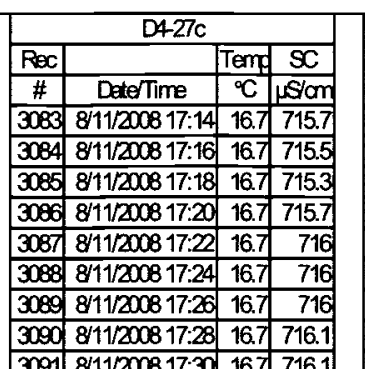

\begin{tabular}{|l|l|l|l|}
\hline 3001 & $8 / 1 / 200817: 30$ & 16.7 & 716.1 \\
\hline 3090 & $8 / 1 / 200817: 32$ & 16.7 & 716 \\
\hline
\end{tabular} \begin{tabular}{|l|l|l|r|}
\hline 3092 & $8 / 11 / 200817: 32$ & 16.7 & 716 \\
\hline 3083 & $8 / 11200817: 34$ & 16.7 & 715.8 \\
\hline
\end{tabular} \begin{tabular}{lllll}
3093 & $8 / 11 / 200817: 34$ & 16.7 & 715.8 \\
\hline
\end{tabular} \begin{tabular}{|l|l|l|l|}
\hline 3094 & $8 / 11 / 200817: 36$ & 16.7 & 715.9 \\
\hline
\end{tabular} \begin{tabular}{l|l|l|l|}
\hline 3095 & $8 / 11 / 200817: 38$ & 16.7 & 715.8 \\
\hline
\end{tabular} \begin{tabular}{|l|l|l|l|}
\hline 3096 & $811 / 200817: 40$ & 16.7 & 715.7 \\
\hline
\end{tabular} \begin{tabular}{|l|l|l|l|}
\hline 3097 & $8 / 11 / 200817: 42$ & 16.7 & 715.5 \\
\hline 3098 & $811 / 200817: 44$ & 16.7 & 715.6 \\
\hline
\end{tabular} \begin{tabular}{l|l|l|l|}
\hline 3098 & $8 / 11 / 200817: 44$ & 16.7 & 715.6 \\
\hline
\end{tabular} \begin{tabular}{|l|l|l|l|}
\hline 3099 & $8 / 11 / 200817: 46$ & 16.7 & 715.7 \\
\hline
\end{tabular} \begin{tabular}{|l|l|l|l|}
\hline 3100 & $8 / 11 / 200817: 48$ & 16.7 & 715.7 \\
\hline
\end{tabular} \begin{tabular}{|l|l|l|l|}
\hline 3101 & $8 / 11 / 200817: 50$ & 16.7 & 715.8 \\
\hline
\end{tabular} \begin{tabular}{|l|l|l|l|}
\hline 3102 & $8 / 11 / 200817: 52$ & 16.7 & 715.9 \\
\hline 3103 & $811 / 200817: 54$ & 16.7 & \\
\hline
\end{tabular} \begin{tabular}{|l|l|l|l|}
\hline 3103 & $8 / 11 / 200617: 54$ & 16.7 & 716 \\
\hline
\end{tabular} \begin{tabular}{|l|l|l|l|}
\hline 3104 & $8 / 11 / 200817: 56$ & 16.7 & 716.3 \\
\hline
\end{tabular} \begin{tabular}{|l|l|l|l|}
\hline 3105 & $8111 / 200817: 58$ & 16.7 & 716.3 \\
\hline
\end{tabular} \begin{tabular}{|l|l|l|l|}
\hline 3106 & $8111 / 200818: 00$ & 16.7 & 716.4 \\
\hline
\end{tabular} \begin{tabular}{|l|l|l|l|}
\hline 3107 & $8 / 11 / 2008$ 18:02 & 16.7 & 716.4 \\
\hline
\end{tabular} \begin{tabular}{|l|l|l|l|}
\hline 3108 & $811 / 20081804$ & 16.7 & 715.9 \\
\hline
\end{tabular} \begin{tabular}{|l|l|l|l|}
\hline 3109 & $811 / 200818: 06$ & 16.7 & 716.1 \\
\hline
\end{tabular} \begin{tabular}{|l|l|l|l|}
\hline 3110 & $8 / 11 / 200818: 08$ & 16.7 & 715.6 \\
\hline
\end{tabular} \begin{tabular}{|l|l|l|l|}
\hline 3111 & $811 / 200818: 10$ & 16.7 & 715.4 \\
\hline
\end{tabular} \begin{tabular}{lllll}
\hline 3112 & $8 / 11 / 200818: 12$ & 16.7 & 715.9 \\
\hline
\end{tabular} \begin{tabular}{|l|l|l|l|}
\hline 3113 & $8 / 11 / 200818: 14$ & 16.7 & 716.2 \\
\hline
\end{tabular} \begin{tabular}{|l|l|l|l|}
\hline 3114 & $811 / 200818: 16$ & 167 & 716 \\
\hline
\end{tabular} \begin{tabular}{|l|l|l|l|}
\hline 3115 & $8 / 11 / 200818: 18$ & 16.7 & 716.1 \\
\hline
\end{tabular} \begin{tabular}{|l|l|l|r|}
\hline 3116 & $8 / 11 / 20081820$ & 16.7 & 716 \\
\hline 3117 & $8 / 1 / 20081820$ & 167 & 7159 \\
\hline
\end{tabular} \begin{tabular}{llll|l}
\hline 3117 & $8 / 11 / 200818: 22$ & 16.7 & 715.9 \\
\hline
\end{tabular} \begin{tabular}{|l|l|l|l|}
\hline 3118 & $8 / 11 / 200818: 24$ & 16.7 & 715.9 \\
\hline
\end{tabular} \begin{tabular}{|l|l|l|l|}
\hline 3119 & $8 / 11 / 200818: 26$ & 16.7 & 715.7 \\
\hline
\end{tabular} \begin{tabular}{|l|l|l|l|}
\hline 3120 & $8 / 11 / 200818: 28$ & 16.7 & 715.9 \\
\hline
\end{tabular} \begin{tabular}{|l|l|l|l|}
\hline 3121 & $8 / 1 / 200818: 30$ & 16.7 & 715.8 \\
\hline
\end{tabular} \begin{tabular}{ll|l|l|}
\hline 3122 & $8 / 11 / 200818: 32$ & 16.7 & 715.9 \\
\hline
\end{tabular} \begin{tabular}{|l|l|l|l|}
\hline 3123 & $8111 / 2008$ 18:34 & 16.7 & 714.1 \\
\hline
\end{tabular} \begin{tabular}{|l|l|l|l|}
\hline 3124 & $8 / 11 / 2008$ 18:36 & 16.7 & 716.4 \\
\hline
\end{tabular} \begin{tabular}{l|l|l|l|}
3125 & $8 / 11 / 200818: 38$ & 16.7 & 717.3 \\
\hline
\end{tabular} \begin{tabular}{|l|l|l|l|}
\hline 3126 & $8 / 11 / 200818: 40$ & 16.7 & 717.2 \\
\hline
\end{tabular} \begin{tabular}{|l|l|l|l|}
\hline 3127 & $8 / 11 / 200818: 42$ & 16.7 & 7163 \\
\hline
\end{tabular} \begin{tabular}{|l|l|l|l|}
\hline 3128 & $8 / 11 / 200818: 44$ & 16.7 & 715.9 \\
\hline
\end{tabular}

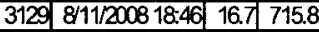

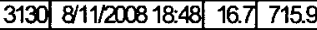
\begin{tabular}{|l|l|l|l|}
\hline 3131 & $811 / 200818: 50$ & 16.7 & 715.7 \\
\hline
\end{tabular} \begin{tabular}{l|l|l|l|}
\hline 3132 & $8 / 11 / 2008$ 18:52 & 16.7 & 716 \\
\hline
\end{tabular} \begin{tabular}{|l|l|l|l|}
\hline 3133 & $811 / 200818.54$ & 16.7 & 716.1 \\
\hline
\end{tabular} \begin{tabular}{|l|l|l|l|}
\hline 3134 & $8 / 1 / 200818: 56$ & 16.7 & 716.3 \\
\hline
\end{tabular} \begin{tabular}{|l|l|l|l|}
\hline 3135 & $811 / 20081858$ & 16.7 & 716.4 \\
\hline
\end{tabular} \begin{tabular}{ll|l|l|}
\hline 3136 & $811 / 200819.00$ & 16.7 & 716.4 \\
\hline
\end{tabular} \begin{tabular}{|l|l|l|l|}
\hline 3137 & $811 / 200819.02$ & 16.7 & 716.8 \\
\hline
\end{tabular} \begin{tabular}{|l|l|l|l|}
\hline 3138 & $8 / 11 / 200819.04$ & 16.7 & 716.6 \\
\hline
\end{tabular} \begin{tabular}{|l|l|l|l|}
\hline 3139 & $811 / 200819.06$ & 16.7 & 716.7 \\
\hline
\end{tabular} \begin{tabular}{lllll}
3140 & $811 / 200819.08$ & 16.7 & 716.8 \\
\hline
\end{tabular} \begin{tabular}{|l|l|l|l|}
\hline 3141 & $811 / 200819.10$ & 16.7 & 716.9 \\
\hline
\end{tabular} \begin{tabular}{|l|l|l|l|}
\hline 3142 & $8 / 11 / 200819.12$ & 16.7 & 716.9 \\
\hline
\end{tabular} \begin{tabular}{|l|l|l|l|}
\hline 3143 & $8 / 11 / 200819.14$ & 16.7 & 71 \\
\hline
\end{tabular} \begin{tabular}{|l|l|l|l|}
\hline 3144 & $811 / 200819.16$ & 16.7 & 717.1 \\
\hline
\end{tabular} \begin{tabular}{|l|l|l|l|}
\hline 3145 & 8111200819.18 & 16.7 & 717.2 \\
\hline
\end{tabular} \begin{tabular}{|l|l|l|l|}
\hline 3146 & $811 / 200819.20$ & 16.7 & 717.8 \\
\hline
\end{tabular} \begin{tabular}{|l|l|l|l|}
\hline 3147 & 8111200819.22 & 16.7 & 717.5 \\
\hline
\end{tabular} \begin{tabular}{|l|l|l|l|}
\hline 3148 & $811 / 200819.24$ & 16.7 & 717.4 \\
\hline
\end{tabular}

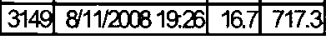

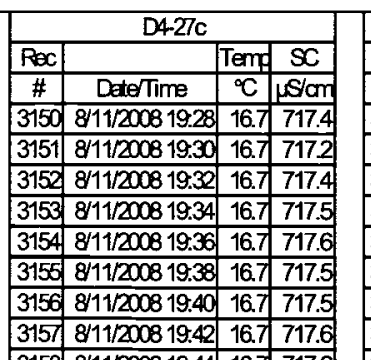

\begin{tabular}{|l|l|l|l|}
\hline 3158 & $811 / 200819.44$ & 16.7 & 717.6 \\
\hline
\end{tabular} \begin{tabular}{|l|l|l|l|}
\hline 3159 & $8111 / 200819.46$ & 16.7 & 717.5 \\
\hline 3100 & $811 / 200819.48$ & 16.7 & 716.4 \\
\hline
\end{tabular} \begin{tabular}{|l|l|l|l|}
\hline 3160 & $811 / 200819.48$ & 16.7 & 716.4 \\
\hline
\end{tabular} \begin{tabular}{|l|l|l|l|}
\hline 3161 & $8111 / 200819.50$ & 16.7 & 715.7 \\
\hline
\end{tabular} \begin{tabular}{l|l|l|l|}
\hline 3162 & $811 / 200819.52$ & 16.7 & 715.3 \\
\hline
\end{tabular} \begin{tabular}{|l|l|l|l|}
\hline 3163 & $811 / 200819.54$ & 16.7 & 716 \\
\hline
\end{tabular} \begin{tabular}{|l|l|l|l|}
\hline 3164 & $8111 / 200819.56$ & 16.7 & 715.7 \\
\hline
\end{tabular} \begin{tabular}{ll|l|l|}
\hline 3165 & $8111 / 200819.58$ & 16.7 & 715.6 \\
\hline
\end{tabular} \begin{tabular}{|l|l|l|l|}
\hline 3166 & $8111 / 200820.00$ & 16.7 & 715.5 \\
\hline
\end{tabular} \begin{tabular}{|l|l|l|l|}
\hline 3167 & $811 / 200820.02$ & 16.7 & 715.8 \\
\hline 3168 & $811 / 200820.04$ & 16.7 & 716.2 \\
\hline
\end{tabular} \begin{tabular}{|l|l|l|l|}
\hline 3168 & $811 / 200820.04$ & 16.7 & 716.2 \\
\hline
\end{tabular} \begin{tabular}{|l|l|l|l|}
\hline 3169 & $8111 / 20082006$ & 16.7 & 715.5 \\
\hline
\end{tabular} \begin{tabular}{|l|l|l|l|}
\hline 3170 & $811 / 200820.08$ & 16.7 & 716 \\
\hline
\end{tabular} \begin{tabular}{|l|l|l|l|}
\hline 3171 & $811 / 200820: 10$ & 16.7 & 7164 \\
\hline $31 / 2$ & $811 / 200820.12$ & 16.7 & 7163 \\
\hline
\end{tabular} \begin{tabular}{|ll|l|l|}
\hline 3172 & $811 / 200820.12$ & 16.7 & 716.3 \\
\hline
\end{tabular} \begin{tabular}{|l|l|l|l|}
\hline 3173 & $8111 / 200820.14$ & 16.7 & 715.7 \\
\hline 3174 & $811 / 20820.16$ & 16.7 & 7156 \\
\hline
\end{tabular} \begin{tabular}{|l|l|l|l|}
\hline 3174 & $8111 / 200820: 16$ & 16.7 & 715.6 \\
\hline
\end{tabular} \begin{tabular}{|l|l|l|l|}
\hline 3175 & $8111 / 200820: 18$ & 16.7 & 715.6 \\
\hline
\end{tabular} \begin{tabular}{|l|l|l|l|}
\hline 3176 & $811 / 200820: 20$ & 16.7 & 715.5 \\
\hline
\end{tabular} \begin{tabular}{lllll}
\hline 3177 & $8111 / 200820.22$ & 16.7 & 715.7 \\
\hline
\end{tabular} \begin{tabular}{|l|l|l|l|}
\hline 3178 & $8111 / 200820.24$ & 16.7 & 715.8 \\
\hline
\end{tabular} \begin{tabular}{|l|l|l|l|}
\hline 3179 & $811 / 200820: 26$ & 16.7 & 716.1 \\
\hline
\end{tabular} \begin{tabular}{|l|l|l|l|}
\hline 3180 & $8111 / 200820.28$ & 16.7 & 716.2 \\
\hline
\end{tabular} \begin{tabular}{|l|l|l|l|}
\hline 3181 & $8 / 11 / 200820.30$ & 16.7 & 716.2 \\
\hline
\end{tabular} \begin{tabular}{|l|l|l|l|}
\hline 3182 & $8111 / 20082032$ & 16.7 & 716.3 \\
\hline
\end{tabular} \begin{tabular}{|l|l|l|l|}
\hline 3183 & $811 / 200820.34$ & 16.7 & 716.4 \\
\hline
\end{tabular} \begin{tabular}{|l|l|l|l|}
\hline 3184 & $811 / 200820.36$ & 16.7 & 716.6 \\
\hline
\end{tabular} \begin{tabular}{|l|l|l|l|}
\hline 3186 & $8111 / 200820.38$ & 16.7 & 716.6 \\
\hline
\end{tabular} \begin{tabular}{|l|l|l|l|}
\hline $31 \& 6$ & $8111 / 200820.40$ & 16.7 & 716.5 \\
\hline
\end{tabular} \begin{tabular}{|l|l|l|l|}
\hline 3187 & $811 / 200820.42$ & 16.7 & 716.8 \\
\hline
\end{tabular} \begin{tabular}{|l|l|l|l|}
\hline 3188 & $811 / 200820: 44$ & 16.7 & 716.7 \\
\hline
\end{tabular} \begin{tabular}{|l|l|l|l|}
\hline 3189 & $8111 / 200820.46$ & 16.7 & 716.8 \\
\hline
\end{tabular} \begin{tabular}{|l|l|l|l|}
\hline 3190 & $8111 / 200820.48$ & 16.7 & 716.6 \\
\hline
\end{tabular} \begin{tabular}{|l|l|l|l|}
\hline 3191 & $8111 / 200820.50$ & 16.7 & 716.7 \\
\hline
\end{tabular} \begin{tabular}{|l|l|l|l|}
\hline 3192 & $8111 / 200820.52$ & 16.7 & 716.7 \\
\hline
\end{tabular} \begin{tabular}{|l|l|l|l|}
\hline 3193 & $8 / 11 / 200820.54$ & 167 & 7166 \\
\hline
\end{tabular} \begin{tabular}{|l|l|l|l|}
\hline 3194 & $811 / 200820.56$ & 16.7 & 697.8 \\
\hline
\end{tabular} \begin{tabular}{|l|l|l|l|}
\hline 3196 & $8111 / 200820.58$ & 16.7 & 697.5 \\
\hline
\end{tabular} \begin{tabular}{|l|l|l|l|}
\hline 3196 & $811 / 200821: 00$ & 16.7 & 697.1 \\
\hline
\end{tabular} \begin{tabular}{|l|l|l|l|}
\hline 3197 & $811 / 200821: 02$ & 16.7 & 700.3 \\
\hline
\end{tabular} \begin{tabular}{|l|l|l|l|}
\hline 3198 & $811 / 200821: 04$ & 16.7 & 700.3 \\
\hline
\end{tabular} \begin{tabular}{l|l|ll}
3199 & $8111 / 200821: 06$ & 16.7 & 700.5 \\
\hline
\end{tabular} \begin{tabular}{|l|l|l|l|}
\hline 3200 & $8111 / 200821: 08$ & 16.7 & 700.7 \\
\hline
\end{tabular} \begin{tabular}{|l|l|l|l|}
\hline 3201 & $8111 / 200821: 10$ & 16.7 & 7025 \\
\hline
\end{tabular} \begin{tabular}{|l|l|l|l|}
\hline 32002 & $8111 / 200821: 12$ & 16.7 & 706 \\
\hline
\end{tabular} \begin{tabular}{|l|l|l|l|}
\hline 3203 & $811 / 200821: 14$ & 16.7 & 708.2 \\
\hline 3204 & $811 / 200821: 16$ & 16.7 & 708. \\
\hline
\end{tabular} \begin{tabular}{|l|l|l|l|}
\hline 3204 & $811 / 200821: 16$ & 16.7 & 708.9 \\
\hline 3205 & $8111 / 200821: 16$ & 16.7 & \\
\hline
\end{tabular} \begin{tabular}{|l|l|l|l|}
\hline 3205 & $811 / 200821: 18$ & 16.7 & 700 \\
\hline
\end{tabular} \begin{tabular}{l|l|l|l|}
3206 & $8111 / 200821: 20$ & 16.7 & 709 \\
\hline
\end{tabular} \begin{tabular}{|l|l|l|l|}
\hline 3207 & $8 / 11 / 200821: 22$ & 16.7 & 710 \\
\hline 3208 & $8 / 1 / 200821: 24$ & 16.7 & 711.8 \\
\hline
\end{tabular} \begin{tabular}{|l|l|l|l|}
\hline 3208 & $8 / 11 / 200821: 24$ & 16.7 & 711.8 \\
\hline 320 & $8 / 1 / 200821: 20$ & 16.7 & 7131 \\
\hline
\end{tabular} \begin{tabular}{|l|l|l|l|}
\hline 3209 & $8111 / 200021: 26$ & 16.7 & 713.1 \\
\hline
\end{tabular} \begin{tabular}{|l|l|l|l|}
\hline 3210 & $811 / 200821: 28$ & 16.7 & 714.1 \\
\hline
\end{tabular} \begin{tabular}{|l|l|l|l|}
\hline 3211 & $811 / 200821: 30$ & 16.7 & 714.9 \\
\hline
\end{tabular} \begin{tabular}{|l|l|l|l|}
\hline 3212 & $8111 / 200821: 32$ & 16.7 & 715.5 \\
\hline 3213 & $811 / 200821: 34$ & 16.7 & 715.8 \\
\hline
\end{tabular} \begin{tabular}{|l|l|l|l|}
\hline 3213 & $811 / 200821: 34$ & 16.7 & 715.8 \\
\hline 3214 & $811 / 200821: 36$ & 16.7 & 716 \\
\hline
\end{tabular} \begin{tabular}{|l|l|l|l|}
\hline 3214 & $8111 / 200821: 36$ & 16.7 & 716 \\
\hline
\end{tabular} \begin{tabular}{|l|l|l|l|}
\hline 3215 & $811 / 200821: 38$ & 16.7 & 716.3 \\
\hline
\end{tabular} \begin{tabular}{|l|l|l|l|}
\hline 3216 & $811 / 200821: 40$ & 16.7 & 716.6 \\
\hline
\end{tabular}

\begin{tabular}{|c|c|c|c|c|c|c|c|}
\hline \multicolumn{4}{|c|}{ D427c } & \multicolumn{4}{|c|}{$D 427 \mathrm{C}$} \\
\hline $\mathrm{Pec}$ & & Temp & $S C$ & $R A C$ & & Temp & SC \\
\hline$\#$ & DaterTime & ${ }^{\circ} \mathrm{C}$ & $\mu \mathrm{s} / \mathrm{m}$ & $\#$ & DeterTime & ${ }^{\circ} \mathrm{C}$ & ps/am \\
\hline 3217 & $8 / 11 / 200821: 42$ & 16.7 & 716.7 & 3284 & $8 / 11 / 20082356$ & 16.8 & 717.4 \\
\hline 18 & $8 / 11 / 200821: 44$ & 16.7 & 716.9 & 3226 & $8 / 11 / 20082358$ & 16.7 & 718.4 \\
\hline 219 & $8 / 11 / 200821: 46$ & 16.7 & 716.8 & 3286 & $8 / 12 / 20080.00$ & 16.7 & 718.4 \\
\hline 200 & $8 / 11 / 200821: 48$ & 16.7 & 717.2 & 3287 & $8 / 12 / 20080.02$ & 16.7 & 7187 \\
\hline 3221 & $8 / 11 / 200821: 50$ & 16.7 & 716.9 & 3288 & $8 / 12 / 20080.04$ & 16.7 & 7186 \\
\hline 3220 & $8 / 11 / 200821: 52$ & 16.7 & 717.2 & 3289 & $8 / 2 / 20080.06$ & 16.7 & 7184 \\
\hline 3223 & $8 / 11 / 200821: 54$ & 16.7 & 717 & 3290 & $8 / 12 / 20080.08$ & 16.7 & 718.4 \\
\hline 3224 & $8 / 11 / 200821: 56$ & 16.7 & 716.9 & 3291 & $8 / 12 / 20080.10$ & 16.7 & 7182 \\
\hline 3225 & $8 / 11 / 200821: 58$ & 16.7 & 717 & 3292 & $8 / 12 / 20080.12$ & 16.7 & 7184 \\
\hline 3226 & $8 / 11 / 20082200$ & 16.7 & 716.9 & 3293 & $8 / 12 / 20080.14$ & 16.7 & 717.9 \\
\hline 3227 & $8 / 11 / 20082200$ & 16.7 & 717.2 & 3294 & $812 / 200$ & 16.7 & 717.6 \\
\hline 3228 & $8 / 11 / 20082204$ & 16.7 & & 3206 & $8 / 12 / 20$ & 16.7 & 717.8 \\
\hline 3229 & $8 / 11 / 20082206$ & 167 & 717.1 & 3296 & $8 / 12 / 20$ & 16.7 & 718 \\
\hline 3230 & $8 / 11 / 20082208$ & 16.7 & 717.2 & 3297 & $8 / 12 / 20$ & 16.7 & 7182 \\
\hline 3231 & $8 / 11 / 20082210$ & 16.7 & 717.3 & 3298 & $8 / 12 / 20$ & 16.7 & 718 \\
\hline 3232 & $8 / 11 / 20082212$ & 167 & 717 & 3299 & $8 / 12 / 2$ & 16.7 & 718.1 \\
\hline 3233 & $8 / 11 / 20082214$ & 16.7 & 717.3 & 3300 & $8 / 12$ & 16.7 & 718.4 \\
\hline 3234 & $8 / 11 / 20$ & 16.7 & 717.6 & 3301 & $8 / 12$ & 16.7 & 718.1 \\
\hline 3236 & $8 / 11 / 20082218$ & 16.7 & 717.4 & 3302 & $8 / 12 / 2$ & 16.7 & 7181 \\
\hline 3236 & 82220 & 16.7 & 717.3 & 3303 & $8 / 12 / 2$ & 16.7 & 718 \\
\hline 3237 & 8222 & 16.7 & 717.6 & 3304 & $8 / 12$ & 167 & 717 \\
\hline 238 & 82224 & 16.7. & 717.4 & 3305 & $812 /$ & 16.7 & 690.4 \\
\hline 3239 & 82226 & 16.7 & 717.5 & 3306 & $8 / 12$ & 16.7 & 684.5 \\
\hline 3240 & 82228 & 16.7 & 717.4 & 3307 & $8 / 12$ & 16.7 & 684.5 \\
\hline 3241 & $8 / 11$ & 16.7 & & 3308 & & 16.7 & 685.3 \\
\hline 242 & $8 / 11 / 20082232$ & 16.7 & 717.5 & 3309 & $8 / 12 \pi$ & 16.7 & 681.6 \\
\hline 3243 & $8 / 11 / 20082234$ & 16.7 & 717.3 & 3310 & $8 / 12$ & 16.7 & 676.5 \\
\hline 3244 & $8 / 11$ & 16.7 & 715.8 & 3311 & $8 / 12 /$ & 16.7 & 671.5 \\
\hline 245 & 32238 & 16.8 & 714.4 & 3312 & $8 / 12$ & 16.7 & 668.1 \\
\hline 246 & & & & 3313 & & 16.7 & 655.6 \\
\hline 3247 & $8 / 11$ & 16.7 & 715.9 & 3314 & $8 / 12$ & 16.7 & 664 \\
\hline 248 & 82244 & 16.7 & 716.1 & 3315 & $8 / 12$ & 16.7 & 663.5 \\
\hline 3249 & 32246 & 16.8 & 714.3 & 3316 & $8 / 12$ & 16.7 & 6028 \\
\hline 3250 & 2248 & 16.7 & 716 & 3317 & 812 & 16.7 & 6622 \\
\hline 3251 & 2250 & 16.7 & 715.9 & 3318 & $8 / 2$ & 16.7 & 627 \\
\hline 3252 & 82252 & 16.7 & 715.7 & 3319 & $8 / 2$ & 16.7 & 6029 \\
\hline 53 & 82254 & 16.7 & 715.6 & 3320 & & 16.7 & 663 \\
\hline 3254 & & 16.7 & & 3321 & & 16.7 & \\
\hline 256 & $8 / 1$ & 16.7 & 715.8 & 332 & $8 / 12$ & 16.7 & 674.5 \\
\hline 256 & $8 / 1$ & 16.7 & 715.9 & 3323 & $8 / 12$ & 16.7 & 704.3 \\
\hline 3257 & $8 / 11$ & 16.7 & 715.9 & 3324 & $8 / 12$ & 16.7 & 692 \\
\hline 558 & 2304 & 16.7 & 716.2 & 3325 & & 16.7 & 690.3 \\
\hline 259 & & 16.7 & & 3326 & $8 / 12$ & 16.7 & 6889 \\
\hline 3260 & $8 / 1$ & 16.7 & 717 & 3327 & $8 / 12$ & 16.7 & 6882 \\
\hline 261 & 310 & 16.7 & 717.5 & 3328 & & 16.7 & 6839 \\
\hline 3262 & & 16.7 & & 3329 & $8 / 12$ & 16.7 & 677.8 \\
\hline 3263 & $23: 14$ & 16.7 & 717.5 & 3330 & $8 / 12$ & 16.7 & 6823 \\
\hline 264 & 2316 & 16.7 & 717.5 & 3331 & $8 / 12$ & 16.7 & 694 \\
\hline 3265 & $8 / 11$ & 16.7 & 717.7 & 3332 & $8 / 12$ & 16.7 & 694.3 \\
\hline 266 & $23: 20$ & 16.8 & & 3333 & $8 / 12$ & 167 & 693.3 \\
\hline 3267 & 2322 & 16.7 & 718.4 & 3334 & $8 / 12$ & 16.7 & 688.3 \\
\hline 3268 & $8 / 11 /$ & 16.7 & 718.2 & 3335 & & 16.7 & 681.6 \\
\hline 3269 & 3.26 & 16.7 & 717.8 & 3336 & & 16.7 & 6725 \\
\hline 3270 & $8 / 11$ & 16.7 & & 3031 & $8 / 12$ & 16.7 & 670.1 \\
\hline 3271 & $8 / 11 / 200823: 30$ & 16.7 & \begin{tabular}{|l|}
717.9 \\
\end{tabular} & 3338 & $8 / 12$ & 16.7 & 670.4 \\
\hline 72 & $8 / 11$ & 16.7 & & 3339 & $8 / 12$ & 16.7 & 670.7 \\
\hline 273 & $8 / 11$ & 16.7 & 718.3 & 3340 & $8 / 12$ & 16.7 & 670.2 \\
\hline 3274 & 82336 & 16.7 & 718.4 & 3341 & $8 / 12$ & 16.7 & 6721 \\
\hline 3275 & $8^{\prime / 11 /}$ & 167 & 718.5 & 3342 & $8 / 12$ & 16.7 & 6751 \\
\hline 3276 & $8 / 11 / 20082340$ & 16.7 & & 3343 & $8 / 12$ & 16.7 & 674.5 \\
\hline $32 \pi 7$ & 0823.42 & 16.7 & 718.3 & 3344 & $8 / 12$ & 16.7 & 6726 \\
\hline 3278 & $8 / 11 / 200823.44$ & 16.7 & 7184 & 3345 & $8 / 12 / 2$ & 16.7 & 660.5 \\
\hline 3279 & $8 / 11 / 2000823: 46$ & 16.7 & 718.4 & 3346 & $82: 00$ & 16.7 & 6885 \\
\hline 280 & $8 / 11 / 200823.48$ & 16.7 & 7186 & 3347 & $8 / 2 /$ & 16.7 & 668 \\
\hline 3281 & $8 / 11 / 20082350$ & 16.7 & 7186 & 3348 & 8204 & 16.7 & 662 \\
\hline 882 & $8 / 11 / 200823.52$ & 16.7 & 718.6 & 3349 & $8 / 12 /$ & 16.7 & 6629 \\
\hline 283 & $0823: 54$ & 16.7 & 718.5 & 3350 & $8 / 12 / 20082,08$ & 16.7 & $\infty 91$ \\
\hline
\end{tabular}




\begin{tabular}{|c|c|c|c|c|c|c|c|c|c|c|c|c|c|c|c|c|c|c|c|}
\hline \multicolumn{4}{|c|}{$D 427 \mathrm{c}$} & \multicolumn{4}{|c|}{$D 427 \mathrm{c}$} & \multicolumn{4}{|c|}{$\mathrm{D} 427 \mathrm{C}$} & & $D 4-27 \mathrm{c}$ & & & & $D 427 \mathrm{C}$ & & \\
\hline $\mathrm{Rec}$ & & Tem & & Rec & & Tam & SC & $R e c$ & & Temp & & $\mathrm{Rec}$ & & Tent & $s c$ & $R \in C$ & & Temp & $\mathscr{S C}$ \\
\hline$\#$ & Date/Time & ${ }^{\circ} \mathrm{C}$ & $\mu \mathrm{s} / \mathrm{cm}$ & $\#$ & DateTime & ${ }^{\circ} \mathrm{C}$ & $\mu \mathrm{s} / \mathrm{m}$ & $\#$ & Date-Time & ${ }^{\circ} \mathrm{C}$ & $\mu \mathrm{s} / \mathrm{cm}$ & $\#$ & Dade/Time & ${ }^{\circ} \mathrm{C}$ & $\mu \mathrm{s} / \mathrm{m}$ & $\#$ & Date/Iime & ${ }^{\circ} \mathrm{C}$ & $\mathrm{s} / \mathrm{cm}$ \\
\hline 3351 & $8 / 12 / 20082 \cdot 10$ & 16.7 & 6624 & & $8 / 12 / 20084: 24$ & 16.7 & 654.7 & 3487 & $8 / 12 / 2008642$ & 16.7 & 657.5 & 3556 & $8 / 12 / 20089: 00$ & \begin{tabular}{c|}
16.7 \\
\end{tabular} & 649.9 & 3625 & $8 / 122008$ 11:18 & 16.7 & 648.3 \\
\hline 3352 & $8 / 12 / 20082: 12$ & 16.7 & 6621 & 3419 & $8 / 12220084: 26$ & 16.7 & 650.7 & 348 & $8 / 12 / 20086: 44$ & 16.7 & 658.8 & 3507 & $8 / 1220089.02$ & 16.7 & 649.5 & 3626 & $8 / 12 / 200811: 20$ & 16.7 & 646.8 \\
\hline 3353 & $8 / 12 / 20082-14$ & 16.7 & 6621 & & & 16.7 & 650 & 3489 & & & \begin{tabular}{|l|}
658.2 \\
\end{tabular} & & & 16.7 & & & & 16.7 & \\
\hline 3354 & $8 / 12 / 2008216$ & 16.7 & 662 & 3421 & $8 / 12 / 20084: 30$ & 16.7 & 647.5 & 3490 & $8 / 12 / 20086: 48$ & 16.7 & 658.9 & 3559 & $8 / 12 / 20089.06$ & 16.7 & 649.3 & 3628 & $8 / 12 / 200811: 24$ & 16.7 & 647.6 \\
\hline 3355 & $8 / 12 / 20082: 18$ & 16.7 & 663.3 & 3422 & $8 / 12 / 200084: 32$ & 16.7 & 645.8 & 3491 & $8 / 12 / 20086: 50$ & 16.7 & 659.2 & 3560 & $8 / 12 / 20089.08$ & 16.7 & 649 & 3620 & $8 / 12200811: 26$ & 16.7 & 649.3 \\
\hline 3356 & $8 / 12 / 2008220$ & 16.7 & 661.2 & 3423 & $8 / 12 / 20084: 34$ & 16.7 & 644.8 & 3492 & $8 / 12 / 20086.52$ & 16.7 & 658.4 & 3561 & $8 / 12 / 20069: 10$ & 16.7 & 648.8 & 3630 & $8 / 12 / 200811: 28$ & & \\
\hline 3357 & $8 / 12 / 2008222$ & 16.8 & 656.7 & 3424 & $8 / 12220084: 36$ & 16.7 & 645.8 & 3493 & $8 / 12 / 20086: 54$ & 16.7 & 658.6 & 3562 & $8 / 12 / 20069.12$ & 16.7 & \begin{tabular}{|l|}
649.7 \\
\end{tabular} & 3631 & \begin{tabular}{|l|l|}
$8 / 12 / 2008$ & $11: 30$ \\
\end{tabular} & 16.7 & 648.5 \\
\hline 3358 & $8 / 12 / 2008224$ & 16.7 & 659 & 3425 & $8 / 1220084: 38$ & 16.7 & 647.8 & 3494 & $8 / 12 / 20086: 56$ & 16.7 & \begin{tabular}{|l|}
659.5 \\
\end{tabular} & 3563 & $8 / 12 / 20089.14$ & 16.7 & 650 & 3632 & $8 / 122000811: 32$ & 16.7 & \\
\hline 3359 & $8 / 12 / 2008226$ & 16.8 & 659.4 & 3426 & $8 / 12 / 20084: 40$ & 16.7 & 649.7 & 3496 & $8 / 12 / 20086: 58$ & 16.7 & 659.1 & 3564 & $8 / 12 / 20089.16$ & 16.7 & 650.4 & & $8 / 12 / 200811: 34$ & 16.7 & 647.3 \\
\hline 3360 & $8 / 12 / 2008228$ & 16.7 & 661.9 & 3427 & $8 / 12 / 20084: 42$ & 16.7 & 650 & 3496 & $8 / 12 / 20087: 00$ & 16.7 & 659.9 & 3565 & $8 / 12 / 20069.18$ & 16.7 & 650.3 & 634 & $8 / 12 / 2008$ 11:36 & 16.7 & 646.5 \\
\hline 3361 & $8 / 12 / 2008230$ & 16.7 & 6021 & 3428 & & 16.7 & 650.4 & 3497 & & 16.7 & 659.8 & 3566 & $8 / 12 / 20089.20$ & 70.7 & \begin{tabular}{|l|}
650.7 \\
\end{tabular} & 635 & & \begin{tabular}{|l|}
16.7 \\
\end{tabular} & \\
\hline 3362 & $8 / 12 / 2008232$ & 16.7 & 660.3 & 3429 & $8 / 1220084: 46$ & 16.7 & 651 & 3498 & $8 / 12 / 20087: 04$ & 16.7 & 660.1 & 3567 & $8 / 12 / 20089: 22$ & 16.7 & 650.2 & 3636 & $8 / 12 / 200811: 40$ & 16.7 & 688.3 \\
\hline 3363 & $8 / 12 / 2$ & 16.7 & 658.2 & 3430 & $8 / 12 / 20084: 48$ & 16.7 & 651.3 & 3499 & $8 / 12220087: 06$ & 16.7 & 659.8 & 3568 & $8 / 12220089.24$ & 16.7 & \begin{tabular}{|l|}
648.5 \\
\end{tabular} & 3637 & $8 / 12 / 200811: 42$ & 16.7 & 694.5 \\
\hline 3364 & $8 / 12 / 20$ & 16.7 & 658.2 & 3431 & $8 / 12 / 2$ & 16.7 & (7) 651.8 & 3500 & $8 / 12 / 20087: 08$ & 16.7 & 658.3 & 3569 & $8 / 12 / 20089: 26$ & 16.7 & 648 & & $0811: 44$ & 16.7 & \\
\hline 3365 & $8 / 12 / 20082238$ & 16.7 & 658.9 & 3432 & $8 / 1220084: 52$ & 16.7 & 6523 & 3501 & $8 / 12 / 20087: 10$ & 16.7 & 656.9 & 3570 & $8 / 12 / 20089: 28$ & 16.7 & 648.2 & 3639 & $8 / 12 / 200811: 46$ & 16.7 & 687.7 \\
\hline 3366 & $8 / 12 / 20$ & 16.7 & 658.1 & 3433 & $8 / 12 / 20084: 54$ & 16.7 & 652.6 & 3502 & $8 / 12 / 20087: 12$ & 16.7 & 657 & 3571 & $8 / 12 / 20089.30$ & 16.7 & \begin{tabular}{|l|l|}
648.5 \\
\end{tabular} & 3640 & $811: 48$ & 16.7 & 687.3 \\
\hline 3367 & $8 / 12 / 20$ & 16.7 & 657.5 & 3434 & $8 / 1222$ & 16.7 & 652.1 & 3503 & $8 / 12 / 20087: 14$ & 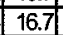 & 657.2 & 3572 & $8 / 12 / 20089.32$ & 16.7 & 649.1 & 3641 & $811: 50$ & 16.7 & \\
\hline 3368 & $8 / 12 / 2$ & 16.7 & 658.1 & 3435 & $884: 58$ & 16.7 & 652.3 & 3504 & $8 / 12 / 20087: 16$ & 16.7 & 656.4 & 3573 & $8 / 12 / 20089.34$ & \begin{tabular}{|l|}
16.7 \\
\end{tabular} & 649.1 & 3642 & $311: 52$ & 16.7 & 686.7 \\
\hline 3969 & 246 & 16.7 & 659 & & $85: 00$ & 16.7 & 652.9 & 3505 & $8 / 12 / 20087: 18$ & 16.7 & 656.3 & 3574 & $8 / 12 / 20089: 36$ & \begin{tabular}{|l|}
16.7 \\
\end{tabular} & 649.6 & 643 & & 16.7 & \\
\hline 3370 & $8 / 12 / 20$ & 16.7 & 658.9 & 3437 & $8 / 12 / 20$ & 16.7 & 653.1 & \begin{tabular}{|l|}
35006 \\
\end{tabular} & $8 / 12 / 20087: 20$ & 16.7 & \begin{tabular}{|l|}
654.9 \\
\end{tabular} & 3575 & $8 / 12 / 20089.38$ & \begin{tabular}{|l|}
16.7 \\
\end{tabular} & 650.1 & 3644 & $8 / 12 / 200811: 56$ & 16.7 & 678.9 \\
\hline 3371 & $8 / 12 / 20$ & 16.7 & 659 & 3438 & $8 / 12 / 2$ & 16.7 & 653.3 & \begin{tabular}{|l|}
3507 \\
\end{tabular} & $8 / 1220087: 22$ & 16.7 & \begin{tabular}{|l|}
655.1 \\
\end{tabular} & 3576 & $89: 40$ & \begin{tabular}{|l|}
16.7 \\
\end{tabular} & 650 & 3645 & $311: 58$ & 16.7 & 674.6 \\
\hline 3372 & $8 / 12 / 2$ & 16.7 & 659.4 & 3439 & $85: 06$ & 16.7 & 653.3 & \begin{tabular}{|l|}
3508 \\
\end{tabular} & $8 / 12 / 20$ & 16.7 & & $35 \pi$ & 39.42 & \begin{tabular}{|l|}
16.7 \\
\end{tabular} & & 3646 & & 16.7 & \\
\hline 3373 & $8 / 12 /$ & 16.7 & 659.3 & 3440 & $85: 08$ & 16.7 & 653.7 & 3500 & $8 / 1220$ & 16.7 & 652.7 & 3578 & 89.44 & \begin{tabular}{|l|}
16.7 \\
\end{tabular} & 648.8 & 647 & 11202 & 16.7 & 669.9 \\
\hline 3374 & $8 / 12 / 2$ & 16.7 & 658 & 3441 & $8 / 12 / 2$ & 16.7 & 653.3 & \begin{tabular}{|l|}
3510 \\
\end{tabular} & & 16.7 & 651.4 & 3579 & $8 / 12 / 20089.46$ & \begin{tabular}{|l|}
16.7 \\
\end{tabular} & \begin{tabular}{|l|}
648.8 \\
\end{tabular} & 3648 & & & \\
\hline 3375 & $8 / 12 / 20$ & 16.7 & 658.7 & 3442 & $85: 12$ & 16.7 & 653.5 & 3511 & $8 / 12 / 20$ & 16.7 & 651.6 & 3580 & $8 / 12 / 20089.48$ & \begin{tabular}{|l|}
16.7 \\
\end{tabular} & 649.7 & 3649 & 881206 & 16.7 & 658.9 \\
\hline 3376 & $8 / 12 / 2$ & 16.7 & 658.4 & 3443 & $8 / 12 / 2$ & 16.7 & 653.9 & 3512 & $8 / 12 / 2$ & 16.7 & 651.8 & 3581 & 9.50 & \begin{tabular}{|l|}
16.7 \\
\end{tabular} & 650 & 3650 & 31208 & 16.7 & 658 \\
\hline 337 & $8 / 12 / 2$ & 16.7 & 658.2 & 3444 & $8 / 12 / 2$ & 16.7 & 655.1 & 3513 & $8 / 12 / 2$ & 16.7 & 6528 & 3582 & $8 / 12$ & \begin{tabular}{|l|}
16.7 \\
\end{tabular} & 649.3 & 3651 & 31210 & 16.7 & 654.5 \\
\hline 3378 & $8 / 12 / 20083: 04$ & 16.7 & 659.1 & 3445 & $35: 18$ & 16.7 & 656.2 & \begin{tabular}{|l|}
3514 \\
\end{tabular} & $8 / 12$ & 16.7 & 655.4 & 3583 & 9.54 & \begin{tabular}{|l|}
16.7 \\
\end{tabular} & 649.4 & 3652 & 1212 & 16.7 & 65 \\
\hline 3379 & $8 / 12 /$ & 16.7 & 659.3 & 3446 & $8 / 12 / 2$ & 16.7 & 655.2 & 3515 & $8 / 12 / 20$ & 16.7 & 654.4 & 3584 & $8 / 12 / 2$ & \begin{tabular}{|l|}
16.7 \\
\end{tabular} & 649.4 & 3653 & 31214 & & 651.9 \\
\hline 3380 & $8 / 12 / 2$ & 16.7 & 657.8 & 3447 & $8 / 122$ & 16.7 & 655 & 3516 & $8 / 12 / 20$ & $\mid 16.7$ & & 3585 & 089.58 & 16.7 & 650.1 & 3654 & 81216 & 16.7 & 650.2 \\
\hline 3381 & $8 / 12 / 2$ & 16.7 & 658.5 & 3448 & $8 / 12 / 2$ & 16.7 & 691.2 & 3517 & $8 / 12$ & 16.7 & 651.6 & 3586 & $8 / 12 / 2$ & 16.7 & 649.3 & 3655 & $12: 18$ & 16.7 & 649.7 \\
\hline 3382 & $8 / 12 / 2$ & 16.7 & 659.2 & 3449 & $35: 26$ & 16.7 & 688 & 3518 & $8 / 12 / 2$ & 16.7 & 651.3 & 3587 & $8 / 12 / 2$ & \begin{tabular}{|l|}
16.7 \\
\end{tabular} & 648 & 3656 & 1220 & 16.7 & \\
\hline 3383 & $8 / 12 / 20$ & 16.7 & 659.4 & 3450 & 85:28 & 16.7 & 688.3 & 3519 & 77:46 & 16.7 & 6521 & 3588 & 10.04 & \begin{tabular}{|l|}
16.7 \\
\end{tabular} & 648 & 365 & 12.22 & 16.7 & 649.3 \\
\hline 3384 & $8 / 12 / 2$ & 16.7 & 663.2 & 3451 & 55:30 & 16.7 & 687.7 & 3520 & $8 / 12 / 2$ & 16.7 & 653. & 3589 & 10.06 & \begin{tabular}{|l|}
16.7 \\
\end{tabular} & 648 & 3658 & 1224 & 16.7 & 649.1 \\
\hline 3385 & $8 / 12 / 2$ & 16.7 & 665.9 & 3452 & $8 / 12$ & 16.7 & 686.4 & \begin{tabular}{|l|}
3521 \\
\end{tabular} & $8 / 1 / 20$ & 16.7 & 654. & 3590 & $8 / 12$ & 16.7 & 648 & 365 & 31226 & 16.7 & 650.3 \\
\hline 3386 & $8 / 12$ & 16.7 & 665.6 & 3453 & $8 / 12$ & 16.7 & 684.7 & 3522 & $8 / 12$ & 16.7 & 655.8 & 3591 & $8 / 12$ & \begin{tabular}{|l|}
16.7 \\
\end{tabular} & 648 & 3660 & 1228 & 16.7 & 648.1 \\
\hline 3387 & $8 / 12$ & 16.7 & 665.2 & 3454 & $8 / 12$ & 16.7 & 681.4 & 3523 & $8 / 12$ & 16.8 & 653. & 3592 & $8 / 12$ & \begin{tabular}{|l|}
16.7 \\
\end{tabular} & 648 & 3661 & 1230 & 16.7 & 648.4 \\
\hline 3388 & $8 / 1222$ & 16.7 & 663.6 & 3455 & $8 / 12$ & 16.7 & 677.5 & 3524 & $7: 56$ & 16.7 & 655.4 & 3593 & $10: 14$ & 16.7 & 649 & 3662 & 1232 & 16.7 & 648.1 \\
\hline 3389 & $8 / 12 / 2$ & 16.7 & 664 & 3456 & $8 / 12 / 2$ & 16.7 & 6762 & 3525 & $8 / 12 / 2$ & 16.7 & 700.6 & 3594 & $8 / 12$ & 16.7 & 649. & 3663 & 1234 & 16.7 & 649 \\
\hline 3390 & $8 / 12$ & 16.7 & 664.7 & 3457 & $55: 42$ & 16.7 & 674 & 3526 & $8 / 12 / 2$ & 16.7 & 70 & 3595 & & \begin{tabular}{|l|}
16.7 \\
\end{tabular} & 650. & 3664 & 1236 & 16.7 & 648.8 \\
\hline 3391 & $8 / 12$ & \begin{tabular}{c|}
16.7 \\
\end{tabular} & $\begin{array}{l}664.6 \\
\end{array}$ & 3458 & \begin{tabular}{|l|l|}
$8 / 12$ \\
\end{tabular} & 16.7 & 6726 & \begin{tabular}{|l|}
3527 \\
\end{tabular} & & 16.7 & 700.3 & 3596 & $8 / 12$ & \begin{tabular}{|c|}
16.7 \\
\end{tabular} & 649 & 3665 & & 16.7 & 649.5 \\
\hline 3392 & $8 / 12$ & 16.7 & 691.1 & 3459 & \begin{tabular}{|l|l}
$8 / 12$ \\
\end{tabular} & 16.7 & 669.3 & 3528 & $8 / 12$ & 16.7 & 7026 & 3597 & $8 / 12$ & \begin{tabular}{|l|}
16.7 \\
\end{tabular} & 649 & 3666 & 1240 & 16.7 & 649.8 \\
\hline 3393 & $8 / 12$ & 16.7 & 691 & 3460 & & 16.7 & 663 & 3520 & & 16.7 & & 3598 & & \begin{tabular}{|c|}
16.7 \\
\end{tabular} & 65 & 3667 & & 16.7 & 647.7 \\
\hline 3394 & & 16.7 & 690.8 & 2461 & & 16.7 & 661. & 3530 & $8 / 12$ & 16.7 & 699. & 3599 & $8 / 12$ & \begin{tabular}{|l|}
16.7 \\
\end{tabular} & 65 & 3668 & 1244 & 16.7 & 647.5 \\
\hline 3395 & $8 / 12$ & 16.7 & 6825 & 3462 & $8 / 12$ & 16.7 & 659.3 & \begin{tabular}{|l|}
3531 \\
\end{tabular} & $8 / 12$ & 16.7 & 693.8 & 3600 & & 16.7 & 653 & 3669 & 1246 & 16.7 & 645.9 \\
\hline 3396 & & \begin{tabular}{|c|}
16.7 \\
\end{tabular} & 672 & 3463 & & \begin{tabular}{|l|l}
6.7 \\
\end{tabular} & 657.8 & 3532 & & \begin{tabular}{|c|}
16.7 \\
\end{tabular} & \begin{tabular}{|c|}
6925 \\
\end{tabular} & 3601 & & \begin{tabular}{|c|}
16.7 \\
\end{tabular} & 651 & $36 \pi 0$ & & 16.7 & 646.2 \\
\hline 3397 & $8 / 12$ & 16.7 & 675.2 & 3464 & & 16.7 & 65 & 533 & $8 / 12 / 2$ & 16.7 & 689. & 3602 & & \begin{tabular}{|l|}
16.7 \\
\end{tabular} & 650 & 3671 & 1250 & 16.7 & 646.2 \\
\hline 3398 & $8 / 12$ & 16.7 & 674.5 & 3465 & & 36.7 & 655 & 3534 & & 16.8 & 67 & 3603 & & \begin{tabular}{|l|}
16.7 \\
\end{tabular} & & 3672 & & 16.7 & 47.1 \\
\hline 3399 & $8 / 12$ & 16.7 & 675.2 & & & 16.7 & & & & 16.7 & 676 & 30 & & \begin{tabular}{|l|}
167 \\
\end{tabular} & 64 & 367 & 1254 & 16. & 647.4 \\
\hline 3400 & $8 / 12$ & 16.7 & 669.7 & \begin{tabular}{|l|}
3467 \\
\end{tabular} & \begin{tabular}{|l|}
8112 \\
\end{tabular} & 16.7 & 655.6 & 3536 & $8 / 12$ & 16.7 & \begin{tabular}{|l|l|}
676.1 \\
\end{tabular} & 3605 & $10: 38$ & \begin{tabular}{|l|}
16.7 \\
\end{tabular} & \begin{tabular}{|l|l|}
647. \\
\end{tabular} & 3674 & 1256 & 16.7 & 647.5 \\
\hline 3401 & & 16.7 & 664.4 & 3468 & & 16.7 & 655 & 3537 & & 16.7 & 67 & 3606 & & & & 3675 & & 16.7 & ) \\
\hline 3402 & $8 / 12$ & 16.7 & 667.5 & 3469 & & \begin{tabular}{|l|l}
16.7 \\
\end{tabular} & 655 & & & 16.7 & 66 & & & 16.7 & 64 & 36 & $13: 00$ & 16.7 & 646.6 \\
\hline 3403 & & 16.7 & 6722 & 3470 & & \begin{tabular}{|l|l}
3 & 16.7 \\
\end{tabular} & 7 655 . & 3539 & & \begin{tabular}{|l|}
16.7 \\
\end{tabular} & 66 & 3608 & & \begin{tabular}{|c|}
16.7 \\
\end{tabular} & \begin{tabular}{|l|}
647 \\
\end{tabular} & 3677 & & 16.7 & 646.3 \\
\hline 3404 & & 16.7 & 666.2 & & & 16.7 & & & & 16.7 & & & & \begin{tabular}{|c|}
16.7 \\
\end{tabular} & & & & 167 & \\
\hline 3405 & $8 / 12 /$ & 16.7 & 665 & 3472 & $8 / 112$ & 16.7 & 657. & 354 & $8 / 12220$ & 16.7 & 660.7 & 3610 & 0.48 & \begin{tabular}{|l|}
16.7 \\
\end{tabular} & 64 & 3679 & $13: 06$ & 16.7 & 645.9 \\
\hline 3406 & & 16.7 & 663.8 & & & & & & & & & & & & & 3680 & & 16.7 & \\
\hline 3407 & & 16.7 & 668.6 & 3474 & $8 / 1$ & 16.7 & 7) 655.4 & 3543 & $8 / 12 / 20$ & 16.7 & 656 & & 0.52 & \begin{tabular}{|l|}
16.7 \\
\end{tabular} & 64 & 3681 & 13:10 & 16.7 & 646.2 \\
\hline 3408 & & 16.7 & 6723 & & & 16.7 & 765 & \begin{tabular}{|l|}
3544 \\
\end{tabular} & & \begin{tabular}{|l|}
16.7 \\
\end{tabular} & 65 & & & \begin{tabular}{|c|}
16.7 \\
\end{tabular} & 64 & 3682 & & 16.7 & 647.6 \\
\hline 3409 & & 16.7 & & & & & 7656 & & & 16.7 & 65 & & & \begin{tabular}{|l|}
16.7 \\
\end{tabular} & & 3683 & $13: 14$ & 16.7 & \\
\hline 3410 & $8 / 12$ & 16.7 & 673.8 & 3477 & $8 / 12 / 2$ & 16.7 & 6566.2 & 3546 & $8 / 2 / 200$ & 16.7 & 654. & 3615 & 10.58 & \begin{tabular}{|l|}
16.7 \\
\end{tabular} & 647 & 3684 & 13:16 & 16.7 & 647.1 \\
\hline 3411 & 4:10! & 16.7 & 665.6 & 3478 & & & & & & 16.7 & 656 & & & 16.7 & & & & & \\
\hline 3412 & & 16.7 & 668.1 & & & 16.7 & 7656 & 3548 & $8 / 12 / 20$ & 16.7 & & & & 16.7 & 647 & 3686 & $13: 20$ & 16.7 & 647.6 \\
\hline 3413 & $8 / 12$ & 16.7 & 659.4 & 3480 & & 316.7 & 657.1 & 3549 & $8 / 12 / 20088: 46$ & 16.7 & 654.9 & 3 & & \begin{tabular}{|l|}
16.7 \\
\end{tabular} & 648 & 3687 & 13:22 & 16.7 & 646.6 \\
\hline 3414 & & 16.7 & 656.2 & 3481 & & 16.7 & 656.1 & & & & & & & \begin{tabular}{|l|}
16.7 \\
\end{tabular} & & 3688 & 13:24 & 167 & \\
\hline 3415 & $8 / 1220084: 18$ & 16.7 & 661.8 & 3482 & $8 / 122$ & 16.7 & 656 & 3551 & $8 / 12 / 20088: 50$ & 16.7 & 654.6 & 3620 & $311: 08$ & \begin{tabular}{|l|}
16.7 \\
\end{tabular} & 648 & 3689 & $813: 26$ & 16.7 & 646.5 \\
\hline 3416 & $84: 20$ & 16.7 & 654.7 & 3483 & $66: 34$ & 16.7 & 7657 & 3552 & $8 / 12 / 20088: 52$ & 16.7 & 653.5 & 321 & & 16.7 & & 3690 & 813.28 & 16. & \\
\hline 3417 & $84: 22$ & 16.7 & 655.3 & 3484 & & 16.7 & 765 & & $8 / 12 / 20088: 54$ & 16.7 & 6526 & & & \begin{tabular}{|l|}
16.7 \\
\end{tabular} & & & $813: 30$ & 16.7 & 644.9 \\
\hline & & & & 3485 & $8 / 12 / 2$ & 16.7 & 7657. & 3554 & $8 / 12200088: 56$ & 16.7 & 650. & 3623 & $8 / 122$ & \begin{tabular}{|l|}
16.7 \\
\end{tabular} & 647 & 3692 & 313:32. & 16.7 & 643.9 \\
\hline & & & & & $36: 40$ & & 657. & 555 & $8 / 12220088: 58$ & 16.7 & 650 & & & \begin{tabular}{|l|}
16.7 \\
\end{tabular} & 648.4 & & $8 / 12$ & & 644.5 \\
\hline
\end{tabular}




\begin{tabular}{|c|c|c|c|c|c|c|c|c|c|c|c|c|c|c|c|c|c|c|c|}
\hline \multicolumn{4}{|c|}{$D 4-27 \mathrm{c}$} & \multicolumn{4}{|c|}{$D 427 c$} & \multicolumn{4}{|c|}{$D 427 \mathrm{C}$} & & $D 4-27 c$ & & & & D4-27c & & \\
\hline $\operatorname{Rec}$ & & & SC & $\mathrm{Rec}$ & & Temp & SC & $\operatorname{Rec}$ & & Temp & $S C$ & $R \in C$ & & Temp & $\overline{S C}$ & $\operatorname{Rec}$ & & Temp & $\mathrm{SC}$ \\
\hline$\#$ & & & $\mu \mathrm{S} / \mathrm{cm}$ & $\#$ & & ${ }^{\circ} \mathrm{C}$ & $\mu S / \mathrm{cm}$ & $\#$ & & & $\mathrm{HS} / \mathrm{cm}$ & $\#$ & & & & $\#$ & Date-Time & & \\
\hline $400 x$ & $8 / 13 / 20081: 06$ & 16.7 & 685.5 & 4108 & $8 / 13 / 20083: 24$ & 16.7 & 7687.3 & 4177 & $13 / 20085: 42$ & 16.7 & 672.2 & 4246 & $8 / 13 / 2008: 00$ & 16.7 & 678.3 & 4315 & $8 / 13 / 2008$ 10:18 & 16.7 & 684.8 \\
\hline & $13 / 2008$ 1:08 & 16.7 & 684.7 & & $8 / 13 / 20083: 26$ & 16.7 & $\sqrt{674 .}$ & 178 & $13 / 20085: 44$ & 16.7 & 670.9 & 247 & $13 / 20088: 02$ & 16.7 & 683.7 & 316 & $8 / 13 / 200810: 20$ & 16.7 & \\
\hline & & 16.7 & 683.9 & & & 16.7 & 7677.6 & & & & 670.4 & 248 & & 16.7 & 684.2 & & & 16.7 & \\
\hline 042 & $13 / 2008$ 1:12 & 16.7 & 684.4 & 4111 & $8 / 13 / 20083: 30$ & 16.7 & 7) 686.7 & 4180 & $8 / 13 / 20085: 48$ & 16.7 & 669.6 & 4249 & $8 / 13 / 20088: 06$ & \begin{tabular}{|l|}
16.7 \\
\end{tabular} & 684.2 & 4318 & $8 / 13 / 200810-24$ & 16.7 & 685.2 \\
\hline 343 & $8 / 13 / 20081: 14$ & 16.7 & 683.7 & 4112 & $8 / 13 / 20083: 32$ & 16.7 & 7684.4 & \begin{tabular}{|l|}
4181 \\
\end{tabular} & GISLWW J.u & 16.7 & 670 & \begin{tabular}{|l|}
4250 \\
\end{tabular} & $8 / 13 / 20068: 08$ & 16.7 & 684.4 & & $8 / 13 / 200810.26$ & $16 . \overline{7}$ & \\
\hline 44 & $8 / 13 / 20081: 16$ & 16.7 & 684 & 4113 & \begin{tabular}{|l|l|}
$8 / 13 / 20083: 34$ \\
\end{tabular} & 16.7 & 691.1 & 182 & & 16.7 & 670.9 & 4251 & & 16.7 & 684.5 & & & 16.7 & \\
\hline 4045 & $8 / 13 / 20081: 18$ & 16.7 & 684 & 4114 & $8 / 13 / 20083: 36$ & 16.7 & 7690.8 & \begin{tabular}{|l|l|}
4183 \\
\end{tabular} & $8 / 13 / 20085: 54$ & 16.7 & 670.1 & 4252 & $8 / 13 / 20088: 12$ & 16.7 & 684.8 & 4321 & $8 / 13 / 200810.30$ & 16.7 & 7688.6 \\
\hline & $8 / 13 / 20081: 20$ & 16.7 & 683.8 & & $8 / 13 / 20083: 38$ & & & 4184 & & 16.7 & 668.9 & & & 16.7 & 685.1 & & & & \\
\hline 4047 & $8 / 13 / 20081: 22$ & 16.7 & 683.7 & 4116 & $8 / 13 / 20083: 40$ & 16.7 & $\begin{array}{l}7690.3 \\
\end{array}$ & 4185 & $85: 58$ & 16.7 & 667.2 & \begin{tabular}{|l|}
4254 \\
\end{tabular} & $8 / 13 / 20088: 16$ & 16.7 & 685.9 & 323 & $8 / 13 / 200810-34$ & 16.7 & 690.2 \\
\hline 4048 & 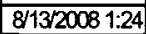 & 16.7 & 683.2 & \begin{tabular}{|l|l|l}
4117 & \\
\end{tabular} & $8 / 13 / 20083: 42$ & 16.7 & $7 \longdiv { 6 8 9 . 8 }$ & 4186 & $8 / 13 / 20086: 00$ & 16.7 & 665.6 & \begin{tabular}{|l|}
4255 \\
\end{tabular} & $8 / 13 / 20088: 18$ & \begin{tabular}{|l|}
16.7 \\
\end{tabular} & 686.7 & 324 & 08 10:36 & 16.7. & 7) 690.4 \\
\hline & & 16.7 & 683 & & $8 / 13 / 200$ & 16.7 & $\begin{array}{l}7689.8 \\
\end{array}$ & 187 & & 167 & 664.9 & \begin{tabular}{|l|}
4256 \\
\end{tabular} & & 16.7 & 686.7 & & & 16.7 & \\
\hline 4050 & $8 / 13 / 20081: 28$ & 16.7 & 682.9 & 4119 & $8 / 13 / 20083: 46$ & 16.7 & 7669.6 & \begin{tabular}{|l|}
4188 \\
\end{tabular} & $8 / 13 / 20086: 04$ & 16.7 & \begin{tabular}{|l|}
665.4 \\
\end{tabular} & \begin{tabular}{|l|}
4257 \\
\end{tabular} & $8 / 13 / 20088: 22$ & 16.7 & 686.9 & 4326 & $8 / 13 / 200810-40$ & 16.7 & 690 \\
\hline 4051 & $8 / 13 / 2$ & 16.7 & 6829 & 4120 & $8 / 13 / 200$ & 16.7 & \begin{tabular}{|l|l|}
7 & 689.8 \\
\end{tabular} & 4189 & $86: 06$ & \begin{tabular}{l|l}
16.7 \\
\end{tabular} & 668.3 & 4258 & $88: 24$ & 16.7 & 687.1 & 327 & 08 10:42 & \begin{tabular}{|c|}
16.7 \\
\end{tabular} & \begin{tabular}{|l|l|}
7 & 689.7 \\
\end{tabular} \\
\hline & $8 / 13 / 20$ & 16.7 & 681.9 & 4121 & & 16.7 & 689.6 & 4190 & & 16.7 & \begin{tabular}{|l|}
667.3 \\
\end{tabular} & \begin{tabular}{|l|}
4259 \\
\end{tabular} & & 16.7 & 687.1 & & $810: 44$ & 16.7 & \\
\hline 4053 & $8 / 13 / 20081: 34$ & 16.7 & 681.8 & 4122 & $8 / 13 / 20083: 52$ & 16.7 & \begin{tabular}{|l|l|}
7 & 689.8 \\
\end{tabular} & \begin{tabular}{|l|}
4191 \\
\end{tabular} & $8 / 13 / 20086: 10$ & 16.7 & \begin{tabular}{|l|}
662.9 \\
\end{tabular} & 4260 & $8 / 13 / 20088: 28$ & 16.7 & 686.9 & 4320 & $8 / 13 / 200810: 46$ & 16.7 & 690.6 \\
\hline 4054 & $8 / 13 / 20$ & 16.7 & 682.3 & 4123 & $8 / 13 / 20$ & 16.7 & 7) 689.6 & \begin{tabular}{|l|}
4192 \\
\end{tabular} & $86: 12$ & 16.7 & 663.9 & \begin{tabular}{|l|}
4261 \\
\end{tabular} & $88: 30$ & 16.7 & 686.9 & 4330 & 08 10:48 & 16.7 & 7690.3 \\
\hline 4055 & $8 / 13 / 20$ & 16.7 & 683 & 4124 & & 16.7 & 7 689.8 & & & 16.7 & 665 & \begin{tabular}{|l|}
4262 \\
\end{tabular} & & 16.7 & & & & 16.7 & 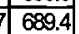 \\
\hline 056 & $8 / 13 / 2$ & 16.7 & 684.7 & 4125 & $8 / 13 / 2$ & 16.7 & \begin{tabular}{l|l}
7 & 689.8 \\
\end{tabular} & 4194 & $36: 16$ & 16.7 & 666.4 & 4263 & $38: 34$ & 16.7 & 686.4 & 332 & $810: 52$ & 16.7 & \begin{tabular}{|l|l|}
689.7 \\
\end{tabular} \\
\hline 057 & $8 / 13 / 20$ & 16.7 & 687.6 & 4126 & $8 / 13 / 2$ & 16.7 & $7 \quad 690$ & 4195 & & 16.7 & 665.9 & \begin{tabular}{|l|}
4264 \\
\end{tabular} & & 16.7 & 686.2 & 333 & $810: 54$ & 16.7 & 629.3 \\
\hline 4058 & $8 / 13 / 20081: 44$ & 16.7 & 687.3 & 4127 & & 16.7 & 7690.1 & 4196 & $36: 20$ & 16.7 & 664.3 & \begin{tabular}{|l|l|}
4265 \\
\end{tabular} & & 16.7 & 686.3 & 4334 & $810: 56$ & 16.7 & \begin{tabular}{|l|}
688.7 \\
\end{tabular} \\
\hline 4059 & $8 / 13 / 2$ & 16.7 & 686.8 & 4128 & $8 / 13 / 2$ & 16.7 & 690.3 & 4197 & $6: 2$ & 16.7 & \begin{tabular}{|l|}
661.6 \\
\end{tabular} & \begin{tabular}{|l|}
4266 \\
\end{tabular} & $8: 40$ & 16.7 & 686.8 & 4335 & $310: 58$ & 16.7 & 687.9 \\
\hline 1060 & $8 / 13 / 2$ & 16.7 & 687.5 & & & 16.7 & & & & & \begin{tabular}{|l|}
6626 \\
\end{tabular} & \begin{tabular}{|l|}
4267 \\
\end{tabular} & & 16.7 & & 336 & & 16.7 & \\
\hline 061 & $8 / 13 / 2$ & 16.7 & 688.3 & 4130 & $8 / 13 /$ & 16.7 & 7690.2 & \begin{tabular}{|l|}
4199 \\
\end{tabular} & $86: 26$ & 16.7 & 665.7 & 4268 & $88: 44$ & 16.7 & 686.7 & 337 & $0811: 02$ & 16.7 & \begin{tabular}{|l|l|}
7 & 686.7 \\
\end{tabular} \\
\hline 062 & $8 / 13 / 2$ & 16.7 & 689 & 4131 & $8 / 13$ & 16.7 & $7 \longdiv { 6 8 9 . 8 }$ & 4200 & $8 / 13$ & 16.7 & 668.2 & \begin{tabular}{|l|}
4269 \\
\end{tabular} & 8.46 & 16.7 & 686.5 & 338 & $11: 04$ & 16.7 & 686.2 \\
\hline 4063 & $8 / 13 / 2$ & 16.7 & 690.4 & 4132 & & 16.7 & 7690. & & & 16.7 & $m$ & \begin{tabular}{|l|}
4270 \\
\end{tabular} & & & & 339 & & 16.7 & 685.8 \\
\hline 4064 & $13 / 2$ & 16.7 & 690.9 & 4133 & $8 / 13$ & 16.7 & $7 \longdiv { 6 8 9 . 9 }$ & 4202 & & 16.7 & \begin{tabular}{|l|l}
666.8 \\
\end{tabular} & 4271 & $8: 50$ & 16.7 & 685.8 & 340 & & $\mid 16.7$ & 7685.5 \\
\hline 4065 & $8 / 13 / 2$ & 16.7 & 692 & & & 16.7 & & 203 & & 16.7 & 665.4 & 4272 & & 16.7 & 684.4 & \begin{tabular}{|c|}
4341 \\
\end{tabular} & & 16.7 & 7685.3 \\
\hline 4066 & $8 / 13 / 2$ & 16.7 & 692.7 & 4135 & $8 / 13$ & 16.7 & 7) 688.7 & 4204 & $8 / 13$ & 16.7 & 664.8 & 4273 & $38: 54$ & 16.7 & 685.2 & 4342 & $811: 12$ & 16.7 & 7685.4 \\
\hline 4067 & 02 & 16.7 & 693. & 136 & & 16.7 & 7) 688. & 4205 & & 16.7 & 663.2 & \begin{tabular}{|l|}
4274 \\
\end{tabular} & 8.56 & 16.7 & 679. & \begin{tabular}{|l|l|}
4343 \\
\end{tabular} & 11:14 & 16.7 & 7) 685.8 \\
\hline 4068 & $8 / 13 / 2$ & 16.7 & 694. & 37 & & 16.7 & 7) 688 & 4206 & & 16.7 & 663.4 & \begin{tabular}{|l|}
4275 \\
\end{tabular} & & 16.7 & 680 & 344 & $11: 16$ & 16.71 & \\
\hline 4069 & & 16.7 & 694. & 138 & & 16.7 & \begin{tabular}{l|l}
7688. \\
\end{tabular} & & & 16.7 & 66 & 4276 & & \begin{tabular}{|l|}
16.7 \\
\end{tabular} & & 345 & & 16.7 & 685.7 \\
\hline 1070 & 08 & 16.7 & 694 & & & 16.7 & 7) 689 & 208 & & 16.7 & 661 & 4277 & & \begin{tabular}{|l|}
16.7 \\
\end{tabular} & 68 & 346 & & 16.7 & 685.3 \\
\hline 4071 & & 16.7 & 695 . & \begin{tabular}{|l|}
4140 \\
\end{tabular} & & 16.7 & \begin{tabular}{l|l}
7 & 688.4 \\
\end{tabular} & 4209 & $8 / 13$ & 16.7 & 661 & \begin{tabular}{|l|}
4278 \\
\end{tabular} & 9.04 & 16.7 & 681. & \begin{tabular}{|l|}
4347 \\
\end{tabular} & 11:22 & 16.7 & 685.1 \\
\hline 4072 & & 16.7 & 695 & \begin{tabular}{|l|}
4141 \\
\end{tabular} & & 16.7 & 687.5 & 4210 & & 16.7 & 661. & 4279 & & 16.7 & 681 & 4348 & $11: 24$ & 16.7 & 6785.1 \\
\hline 4073 & & 16.7 & 696 & 42 & & 16.7 & & \begin{tabular}{|l|}
4211 \\
\end{tabular} & & \begin{tabular}{|l|}
16.7 \\
\end{tabular} & \begin{tabular}{|l|}
661 \\
\end{tabular} & 4280 & & 16.7 & 681 & 349 & & 16.7 & 685.1 \\
\hline 4074 & & 16.7 & 695. & & & 18.7 & & \begin{tabular}{|l|l|}
4212 \\
\end{tabular} & & 16.7 & 650 & 4281 & & \begin{tabular}{|l|}
16.7 \\
\end{tabular} & 6 & 350 & $11: 28$ & 16.7 & 7685.6 \\
\hline 4075 & & 16.7 & 69 & $\mid$ & & \begin{tabular}{|c|}
16.7 \\
\end{tabular} & \begin{tabular}{l|l}
7 & 68 \\
\end{tabular} & \begin{tabular}{|l|}
4213 \\
\end{tabular} & & \begin{tabular}{|c|}
16.7 \\
\end{tabular} & 659.6 & \begin{tabular}{|l|}
4282 \\
\end{tabular} & & \begin{tabular}{|l|}
16.7 \\
\end{tabular} & 680 & 351 & & 16.7 & \\
\hline 4076 & $8 / 13$ & 16.7 & 695.2 & 4145 & $8 / 13$ & 16.7 & $\begin{array}{ll}7684 . \\
\end{array}$ & 4214 & $8 / 13$ & 16.7 & 659 & \begin{tabular}{|l|}
4283 \\
\end{tabular} & 9.14 & 16.7 & 680.4 & 1352 & 11:32 & 16.7 & \begin{tabular}{l|l}
7 & 687.3
\end{tabular} \\
\hline 4077 & & 16.7 & 695.4 & 4146 & & 16.7 & $\begin{array}{ll}7 & 681 .\end{array}$ & 4215 & & 16.8 & 657.4 & 4284 & & 16.7 & 680 & & & 16.7 & $7 \quad 687$ \\
\hline 4078 & $8 / 13$ & 16.7 & 695 . & & & 16.7 & & 4216 & & 16.7 & 657. & \begin{tabular}{|l|}
428 \\
\end{tabular} & & \begin{tabular}{|l|}
16.7 \\
\end{tabular} & 68 & 35 & & 16.7 & \\
\hline 4079 & & 16.7 & 6 & \begin{tabular}{|l|}
4148 \\
\end{tabular} & & 16.7 & $\begin{array}{ll}7 & 680 .\end{array}$ & \begin{tabular}{|l|}
4217 \\
\end{tabular} & & 16.7 & 6 & 4286 & & \begin{tabular}{|l|}
16.7 \\
\end{tabular} & 681 & 4356 & 11:38 & 16.7 & 687.3 \\
\hline 080 & & 16.7 & 695 & \begin{tabular}{|l|l|l}
4149 \\
\end{tabular} & & 16.7 & \begin{tabular}{l|l}
77 & 678 \\
\end{tabular} & & & 16.7 & 656.7 & & & \begin{tabular}{|l|}
16.7 \\
\end{tabular} & 68 & & & 16.7 & 687.3 \\
\hline 4081 & & 16.7 & 695. & & & 16.7 & $\begin{array}{ll}7 & 6\end{array}$ & 4219 & & 16.7 & 657 & & & 16.7 & 68 & & & 16.7 & 687. \\
\hline 4082 & & 16.7 & 696 & & & 16.7 & \begin{tabular}{l|l}
77 & 654
\end{tabular} & & & 16.7 & 65 & 4 & & 16.7 & 68 & & & 16.7 & 687.4 \\
\hline 1083 & & 16.7 & 68 & & & .7 & & & & 16.7 & 656. & & & 16.7 & 68 & & & 16.7 & 687. \\
\hline 4084 & & 16.7 & 667. & & & 16.7 & 76 & & & 16.7 & 657 & \begin{tabular}{|l|}
4291 \\
\end{tabular} & & \begin{tabular}{|l|}
16.7 \\
\end{tabular} & 68 & 4360 & $11: 48$ & 16.7 & 689.9 \\
\hline 085 & & 16.7 & 678 & & & \begin{tabular}{|l|}
16.7 \\
\end{tabular} & & & & 16.7 & 656 & & & \begin{tabular}{|l|}
16.7 \\
\end{tabular} & & & & 16.7 & 691. \\
\hline 4086 & & 16.7 & 679 & & & 16.7 & 7 670 & & & 16.7 & 659 & & & 16.7 & 68 & & & 16.7 & 69 \\
\hline 4087 & & 16.7 & 68 & & & 16.7 & & & & 16.7 & 661 & & & 16.7 & 68 & & & 16.7 & 689.2 \\
\hline 4088 & & 16.7 & & & & 16.7 & & & & \begin{tabular}{|c|}
16.7 \\
\end{tabular} & ffr & & & 16.7 & 68 & & & 16.7 & 689.3 \\
\hline 4089 & & 16.7 & 684 & & & 16.7 & 7) 68 & & & 16.7 & \begin{tabular}{|l|}
661 \\
\end{tabular} & 4296 & & 16.7 & 68 & 4365 & & 16.7 & 7689.3 \\
\hline 4090 & & 16.7 & & & & & & & & & & & & & & & & 16.7 & 689. \\
\hline 4091 & & 16.7 & 676 & & & 16.7 & \begin{tabular}{l|l}
7 & 679 \\
\end{tabular} & & & 16.7 & & & & 16.7 & 67 & & & 16.7 & 689. \\
\hline 4092 & & 16.7 & 678. & & & 16.7 & $\begin{array}{l}767 \\
\end{array}$ & & & 16.7 & 66 & & & 16.7 & & & & 16.7 & 689. \\
\hline 4093 & & 16.7 & 68 & & & & & & & & & & & & & & & 16.7 & 689. \\
\hline 4094 & $8 / 13$ & 16.7 & 680.5 & & & 16.7 & $\begin{array}{ll}7 & 678\end{array}$ & & & \begin{tabular}{|c|}
16.7 \\
\end{tabular} & 664 & 301 & & \begin{tabular}{|l|}
16.7 \\
\end{tabular} & 680 & 370 & $12: 08$ & 16.7 & \begin{tabular}{l|l|l} 
& 689.1
\end{tabular} \\
\hline 1095 & & 16.7 & & & & & & & & & & & & & & & & & \\
\hline 4096 & & 16.7 & 687. & & & 16.7 & & & & 16 & & & & 16.7 & 68 & & & 16.7 & 689. \\
\hline 4097 & & 16.7 & 686 & & & \begin{tabular}{|l|l}
16.7 \\
\end{tabular} & 牙 676 & & & \begin{tabular}{|c|}
16.7 \\
\end{tabular} & \begin{tabular}{|l|}
661 \\
\end{tabular} & 4304 & & 16.7 & 683 & 373 & & 16.7 & 7) 689.1 \\
\hline 4098 & & & & & & & & & & 167 & & & & & & & & & \\
\hline 4099 & $8 / 13$ & 16.7 & 686 . & 4168 & $8 / 13$ & 16.7 & $\begin{array}{ll}7 & 673.5\end{array}$ & \begin{tabular}{|l|}
4237 \\
\end{tabular} & 77:42 & \begin{tabular}{|c|}
16.7 \\
\end{tabular} & 66 & 4306 & 10.00 & \begin{tabular}{|l|}
16.7 \\
\end{tabular} & 68 & 4375 & $312-18$ & 16.7 & 7689.3 \\
\hline 4100 & & & & & & 16.7 & & & & \begin{tabular}{|c|}
16.7 \\
\end{tabular} & 660 & & & 16.7 & 684 & & & & \\
\hline 4101 & & 16.7 & 687 & & & 16.7 & 674 & & & & & & & & & & & 16.7 & \\
\hline 4102 & $8 / 13 /$ & 16.7 & 687. & & & 16.7 & $\begin{array}{l}7 \\
674 .\end{array}$ & 4240 & & \begin{tabular}{|c|}
16.7 \\
\end{tabular} & 661 & 4300 & $10: 06$ & \begin{tabular}{ll|}
16.7 \\
\end{tabular} & 68 & $3 \pi$ & $12: 24$ & \begin{tabular}{|c|}
6.7 \\
\end{tabular} & 7688.9 \\
\hline 4103 & & & & & & & & & & 16.7 & & & & & & & & & 76 688. \\
\hline 4104 & $33: 16$ & $\begin{array}{l}16.7 \\
58\end{array}$ & 685.6 & \begin{tabular}{|l|l|}
4173 \\
\end{tabular} & $8 / 13 / 2$ & 16.7 & 7 673. & \begin{tabular}{|l|}
4242 \\
\end{tabular} & $77: 52$ & 16.7 & \begin{tabular}{|l|l|}
683 \\
\end{tabular} & \begin{tabular}{|l|}
4311 \\
\end{tabular} & 10.10 & \begin{tabular}{|l|}
16.7 \\
\end{tabular} & 683 & \begin{tabular}{|l|}
43380 \\
\end{tabular} & $312: 28$ & 16.7 & 7) 689 \\
\hline 4105 & & $\begin{array}{l}316.7 \\
3\end{array}$ & 686 & \begin{tabular}{|l|l}
4174 \\
\end{tabular} & $8 / 13$ & 16.7 & 7674. & \begin{tabular}{|l|}
4243 \\
\end{tabular} & & 16.7 & \begin{tabular}{|l|}
680 \\
\end{tabular} & \begin{tabular}{|l|}
4312 \\
\end{tabular} & & \begin{tabular}{|l|}
16.7 \\
\end{tabular} & 683 & 4381 & 31230 & 16.7 & \begin{tabular}{l|l|l}
7 & 688.4
\end{tabular} \\
\hline 4106 & & 16.7 & 686. & & & t & & \begin{tabular}{|l|}
4244 \\
\end{tabular} & & \begin{tabular}{|c|}
16.7 \\
\end{tabular} & \begin{tabular}{|l|}
677 \\
\end{tabular} & \begin{tabular}{|l|}
4313 \\
\end{tabular} & & \begin{tabular}{|l|}
16.7 \\
\end{tabular} & & 4382 & & & 7) 688.4 \\
\hline 4107 & $83: 22$ & 16.7 & & & $35: 40$ & 16.7 & 76728 & $\mid$ & $87: 58$ & \begin{tabular}{|c|}
16.7 \\
\end{tabular} & \begin{tabular}{|c|}
678.2 \\
\end{tabular} & 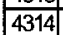 & 10.16 & \begin{tabular}{|l|}
16.7 \\
\end{tabular} & 684.6 & 4382 & $12: 34$ & & 87. \\
\hline
\end{tabular}




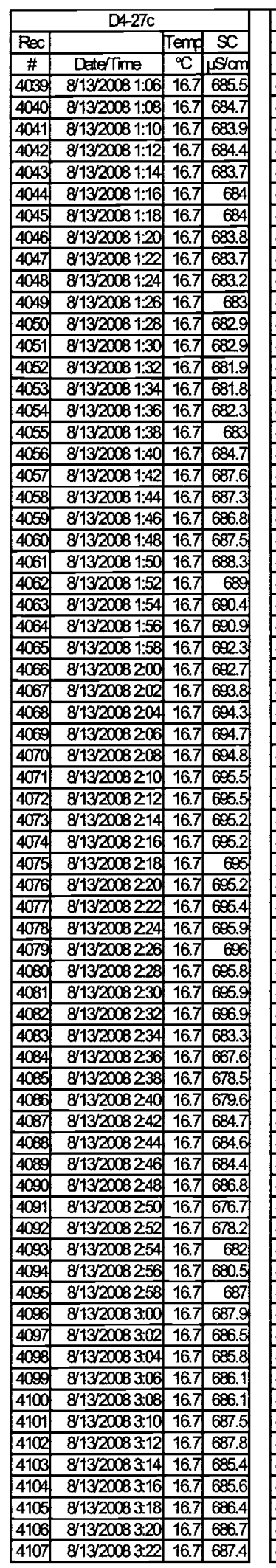

\begin{tabular}{|c|c|c|c|c|c|c|c|}
\hline \multicolumn{4}{|c|}{ D427c } & \multicolumn{4}{|c|}{ D427c } \\
\hline Rec & & Temp & $S C$ & $R \in C$ & & Temp & $\mathrm{SC}$ \\
\hline$\#$ & Dater/ime & ${ }^{\circ} \mathrm{C}$ & $\mathrm{\mu S} / \mathrm{cm}$ & $\#$ & Dater/ime & ${ }^{\circ} \mathrm{C} / \mathrm{p}$ & $\mathrm{\mu S \textrm {cm }}$ \\
\hline 4108 & $8 / 13 / 2008324$ & 16.7 & 687.3 & 4177 & $8 / 13 / 20085: 42$ & 16.7 & 672.2 \\
\hline 4109 & $8 / 13 / 20083: 26$ & 16.7 & \begin{tabular}{|l|}
674.3 \\
\end{tabular} & 4178 & $8 / 13 / 20085: 44$ & 16.7 & 670.9 \\
\hline 4110 & $8 / 13 / 20083: 28$ & 16.7 & 677.6 & 4179 & $8 / 13 / 20085: 46$ & 16.7 & 670.4 \\
\hline 4111 & $8 / 1320083: 30$ & 16.7 & 686.7 & 4180 & $8 / 13 / 20085: 48$ & 16.7 & 669.6 \\
\hline 4112 & $8 / 13 / 2008333$ & 16.7 & \begin{tabular}{|l|}
684.4 \\
\end{tabular} & \begin{tabular}{|l|}
4181 \\
\end{tabular} & $8 / 13 / 20085: 50$ & 16.7 & 670 \\
\hline 4113 & $8 / 13 / 20083: 34$ & 16.7 & 691.1 & 4182 & $8 / 13 / 20085: 52$ & 16.7 & 670.9 \\
\hline 4114 & $8113 / 20083: 36$ & 16.7 & 690.8 & \begin{tabular}{|l|}
4183 \\
\end{tabular} & $8 / 13 / 20085: 54$ & 16.7 & 670.1 \\
\hline 4115 & $8 / 13 / 20083: 38$ & 16.7 & 690.7 & \begin{tabular}{|l|}
4184 \\
\end{tabular} & $8 / 13 / 20085: 56$ & 16.7 & 668.9 \\
\hline 4116 & $8 / 13 / 20083: 40$ & 16.7 & 690.3 & 4185 & $8 / 13 / 20085: 58$ & 16.7 & 667.2 \\
\hline 4117 & $8 / 13 / 20083: 42$ & 16.7 & 689.8 & 4186 & $8 / 13 / 20086: 00$ & 16.7 & 665.6 \\
\hline 4118 & $8 / 13 / 20063: 44$ & 16.7 & 689.8 & \begin{tabular}{|l|}
4187 \\
\end{tabular} & $8 / 13 / 20086: 02$ & 16.7 & 664.9 \\
\hline 4119 & $8 / 13 / 20083: 46$ & 16.7 & 689.6 & 4188 & $8 / 13 / 20086: 04$ & 16.7 & 665.4 \\
\hline 4120 & $8 / 13 / 20083: 48$ & 16.7 & 689.8 & 4189 & $8 / 13 / 20086: 06$ & 167 & 668.3 \\
\hline 4121 & $811320083: 50$ & 16.7 & 689.6 & 4190 & $8 / 132008608$ & 16.7 & 667.3 \\
\hline 4122 & $8 / 13 / 20083.52$ & 16.7 & 609.8 & \begin{tabular}{|l|}
4191 \\
\end{tabular} & $8 / 13 / 20086: 10$ & 16.7 & 6629 \\
\hline 4123 & $8 / 13 / 20083: 54$ & 16.7 & 689.6 & \begin{tabular}{|l|}
4192 \\
\end{tabular} & $8 / 13 / 20086: 12$ & 16.7 & 663.9 \\
\hline 4124 & $8 / 13 / 20063: 56$ & 16.7 & 689.9 & \begin{tabular}{|l|}
4193 \\
\end{tabular} & $8 / 13 / 20086: 14$ & 16.7 & 665 \\
\hline 4125 & $8 / 13 / 20083: 58$ & 16.7 & 689.8 & \begin{tabular}{|l|}
4194 \\
\end{tabular} & $8 / 13 / 20086: 16$ & 16.7 & 666.4 \\
\hline 4126 & $8 / 13 / 20084: 00$ & 16.7 & 600 & \begin{tabular}{|l|}
4195 \\
\end{tabular} & $8 / 13 / 20086: 18$ & 16.7 & 665.9 \\
\hline 4127 & $8 / 13 / 20084: 02$ & 16.7 & 690.1 & \begin{tabular}{|l|}
4196 \\
\end{tabular} & $8 / 13 / 20086: 20$ & 16.7 & 664.3 \\
\hline 4128 & $8 / 13 / 20084: 04$ & 16.7 & 690.3 & \begin{tabular}{|l|}
4197 \\
\end{tabular} & $8 / 1320086: 22$ & 16.7 & 661.6 \\
\hline 4129 & $8 / 13 / 20084: 06$ & 16.7 & 690.1 & 4198 & $8 / 13 / 20086: 24$ & 16.7 & 6626 \\
\hline 4130 & $8 / 13 / 20084: 08$ & 16.7 & 690.2 & 4199 & $8 / 13 / 20086: 26$ & 16.7 & 665.7 \\
\hline \begin{tabular}{|l|}
4131 \\
\end{tabular} & $8 / 1320084: 10$ & 16.7 & 689.8 & 4200 & $8 / 13 / 20086: 28$ & 16.7 & 668.2 \\
\hline 4132 & $8 / 13 / 20084: 12$ & 16.7 & 690.3 & 4201 & $8 / 13 / 20086: 30$ & 16.7 & 668 \\
\hline \begin{tabular}{|l|}
4133 \\
\end{tabular} & $8 / 13 / 20084: 14$ & 167 & 689.9 & 4202 & $8 / 1320086: 32$ & 16.7 & 666.8 \\
\hline 4134 & $8 / 13 / 20084: 16$ & 16.7 & 689.9 & 4203 & $8 / 13 / 2008634$ & 16.7 & 665.4 \\
\hline 4135 & $8 / 13 / 20084: 18$ & 16.7 & 688.7 & 4204 & $8 / 13 / 20086: 36$ & 16.7 & 664.8 \\
\hline 4136 & $8 / 13 / 20084: 20$ & 16.7 & 688.5 & 4205 & $8 / 13 / 20086: 38$ & 16.7 & 663.2 \\
\hline 4137| & $8 / 13 / 20084: 22$ & 16.7 & 688.6 & 4206 & $8 / 13 / 20086: 40$ & 16.7 & 663.4 \\
\hline 4138 & $8 / 13 / 20084: 24$ & 16.7 & 688.7 & 4207 & $8 / 13 / 20086: 42$ & 16.7 & 663.1 \\
\hline 4139 & $8 / 13 / 20084: 26$ & 16.7 & 689.1 & 4208 & $8113 / 2008644$ & 16.7 & 661.9 \\
\hline 4140 & $8 / 13 / 20084: 28$ & 16.7 & 688.4 & 4209 & $8 / 13 / 20086: 46$ & 16.7 & 661.8 \\
\hline \begin{tabular}{|l|}
4141 \\
\end{tabular} & $8 / 13 / 20084: 30$ & 16.7 & 687.5 & $4210 \mid$ & $8 / 13 / 20086: 48$ & 16.7 & 661.5 \\
\hline 4142 & $8 / 1320084: 32$ & 16.7 & 687.8 & \begin{tabular}{|l|}
4211 \\
\end{tabular} & $8 / 13 / 20086: 50$ & 16.7 & 661.1 \\
\hline 4143 & $8 / 13 / 20084: 34$ & 16.7 & 687.3 & 4212 & $8 / 13 / 20086: 52$ & \begin{tabular}{|l|}
16.7 \\
\end{tabular} & 659.7 \\
\hline 4144 & $8 / 13 / 20084: 36$ & 16.7 & 685.4 & \begin{tabular}{|l|}
4213 \\
\end{tabular} & $8 / 13 / 20086: 54$ & 16.7 & 659.6 \\
\hline 4145 & $8 / 1320084: 38$ & 16.7 & 684.4 & \begin{tabular}{|l|}
4214 \\
\end{tabular} & $8 / 13 / 20086: 56$ & 16.7 & 659 \\
\hline 4146 & $8 / 13 / 20084: 40$ & 167 & 681.9 & \begin{tabular}{|l|}
4215 \\
\end{tabular} & $8 / 13 / 20086: 58$ & 16.8 & 657.4 \\
\hline \begin{tabular}{|l|}
4147 \\
\end{tabular} & $8 / 13 / 20084: 42$ & 16.7 & 6823 & \begin{tabular}{|l|}
4216 \\
\end{tabular} & $8 / 13 / 20087: 00$ & \begin{tabular}{|l|}
16.7 \\
\end{tabular} & 67.5 \\
\hline 4148 & $8 / 13 / 20084: 44$ & 16.7 & 680.6 & \begin{tabular}{|l|}
4217 \\
\end{tabular} & $8 / 13 / 20087: 02$ & \begin{tabular}{|l|}
16.7 \\
\end{tabular} & 657 \\
\hline 4149 & $8 / 13 / 20084: 46$ & 16.7 & 678.3 & 4218 & $8 / 1320008704$ & 16.7 & 656.7 \\
\hline 4150 & $8 / 13 / 20084: 48$ & 16.7 & 686 & 4219 & $8 / 1320087: 06$ & \begin{tabular}{|l|}
16.7 \\
\end{tabular} & 657.8 \\
\hline \begin{tabular}{|l|}
4151 \\
\end{tabular} & $8 / 1320004: 50$ & 16.7 & 654.5 & 4220 & $8 / 13 / 20087: 08$ & \begin{tabular}{|l|}
16.7 \\
\end{tabular} & 658 \\
\hline 4152 & $8 / 13 / 20084: 52$ & 16.7 & 658.2 & 4221 & $8 / 13 / 20087: 10$ & \begin{tabular}{|l|}
16.7 \\
\end{tabular} & 656.9 \\
\hline \begin{tabular}{|l|}
4153 \\
\end{tabular} & $8 / 13 / 20084: 54$ & 16.7 & 664.4 & 4222 & $8 / 1320087: 12$ & \begin{tabular}{|l|}
16.7 \\
\end{tabular} & 657 \\
\hline 4154 & $8 / 13 / 20084: 56$ & 16.7 & 671.8 & \begin{tabular}{|l|}
4223 \\
\end{tabular} & $8 / 13 / 20087: 14$ & \begin{tabular}{|l|}
16.7 \\
\end{tabular} & 656.2 \\
\hline 4155 & $8 / 13 / 20084: 58$ & 16.7 & 670.4 & 4224 & $8 / 13 / 20087: 16$ & \begin{tabular}{|l|}
16.7 \\
\end{tabular} & 659.1 \\
\hline 4156 & $8 / 13 / 20085: 00$ & 16.7 & 673.2 & 4225 & $8 / 13 / 20087: 18$ & \begin{tabular}{|l|}
16.7 \\
\end{tabular} & 661.5 \\
\hline 4157| & $8 / 13 / 20085: 02$ & 16.7 & 676.4 & 4226 & $8 / 13 / 20087: 20$ & 16.7 & 660.8 \\
\hline 4158 & $8 / 13 / 20085: 04$ & 16.7 & 681 & \begin{tabular}{|l|}
4227 \\
\end{tabular} & $8 / 13 / 20087: 22$ & 16.7 & 661.1 \\
\hline 4159 & $8 / 13 / 20085: 06$ & 16.7 & 680 & 4228 & $8 / 13 / 20087: 24$ & 16.7 & 661.6 \\
\hline 4160 & $8 / 13 / 20085: 08$ & 16.7 & 679.2 & 4229 & $8 / 13 / 20087: 26$ & \begin{tabular}{|l|}
16.7 \\
\end{tabular} & 662.4 \\
\hline \begin{tabular}{|l|}
4161 \\
\end{tabular} & $8 / 13 / 20085: 10$ & 167 & 679.1 & 4230 & $8 / 13 / 20087: 28$ & \begin{tabular}{|l|}
16.7 \\
\end{tabular} & 664.4 \\
\hline 4162 & $8 / 13 / 20085: 12$ & 16.7 & 679.3 & 4231 & $8 / 13 / 20087: 30$ & 16.7 & 664.7 \\
\hline 4163 & $8 / 13 / 20085: 14$ & 16.7 & 678.9 & 4232 & $8 / 13 / 20087: 32$ & 16.7 & 664.2 \\
\hline 4164 & $8 / 13 / 20085: 16$ & 16.7 & 676.8 & 4233 & $8 / 1320087: 34$ & \begin{tabular}{|l|}
16.7 \\
\end{tabular} & 663.1 \\
\hline 4165 & $8 / 13 / 20085: 18$ & 16.7 & 677.2 & \begin{tabular}{|l|}
4234 \\
\end{tabular} & $8 / 13 / 20087: 36$ & \begin{tabular}{|l|}
16.7 \\
\end{tabular} & 6625 \\
\hline 4166 & $8 / 13 / 20085: 20$ & 16.7 & 676.5 & 4235 & $8 / 13 / 20087: 38$ & \begin{tabular}{|l|}
16.7 \\
\end{tabular} & 661.4 \\
\hline \begin{tabular}{|l|}
4167 \\
\end{tabular} & $8 / 13 / 20085: 22$ & 16.7 & 675.3 & 4236 & $8 / 13 / 20087: 40$ & \begin{tabular}{|l|}
16.7 \\
\end{tabular} & 660.6 \\
\hline 4168 & $8 / 13 / 20085: 24$ & 16.7 & 673.5 & 4237 & $8 / 13 / 20087: 42$ & \begin{tabular}{|l|}
16.7 \\
\end{tabular} & 661 \\
\hline 4169 & $811320085: 26$ & 16.7 & 675 & 4238 & $8 / 1320087: 44$ & \begin{tabular}{|l|}
16.7 \\
\end{tabular} & 660.8 \\
\hline 4470 & $8 / 13 / 20085: 28$ & 16.7 & 674.7 & 4239 & $8 / 13 / 20087: 46$ & \begin{tabular}{|l|}
16.7 \\
\end{tabular} & 661.1 \\
\hline 4171 & $8 / 13 / 20085: 30$ & 16.7 & 674.4 & 4240 & $8 / 13 / 20087: 48$ & \begin{tabular}{|l|}
16.7 \\
\end{tabular} & 661.3 \\
\hline 4172 & $8 / 13 / 20085: 32$ & 16.7 & 674 & \begin{tabular}{|l|}
4241 \\
\end{tabular} & $8 / 13 / 20087: 50$ & \begin{tabular}{|l|}
16.7 \\
\end{tabular} & 6622 \\
\hline 4173 & $8 / 13 / 20085: 34$ & 16.7 & 673.6 & \begin{tabular}{|l|}
4242 \\
\end{tabular} & $8 / 13 / 20087: 52$ & 16.7 & 683.4 \\
\hline 4174 & $8 / 13 / 20085: 36$ & 16.7 & 674.5 & \begin{tabular}{|l|}
4243 \\
\end{tabular} & $8 / 13 / 20087: 54$ & 16.7 & 680.3 \\
\hline 4175 & $8 / 13 / 20085: 38$ & 16.7 & 675 & 4244 & $8 / 13 / 20087: 56$ & \begin{tabular}{|l|}
16.7 \\
\end{tabular} & 677.9 \\
\hline 4176 & $8 / 13 / 20085: 40$ & 16.7 & 6728 & \begin{tabular}{|l|}
4245 \\
\end{tabular} & $8 / 13220087: 58$ & \begin{tabular}{|l|}
16.7 \\
\end{tabular} & 678.2 \\
\hline
\end{tabular}

\begin{tabular}{|c|c|c|c|}
\hline \multicolumn{4}{|c|}{$D 4-27 \mathrm{c}$} \\
\hline & & Terng & \\
\hline \# & Date/Time & ${ }^{\circ} \mathrm{C}$ & $\mu \mathrm{S} / \mathrm{om}$ \\
\hline & $8 / 13 / 20068: 00$ & 16.7 & 6783 \\
\hline & & & \\
\hline 48 & $3 / 20088: 04$ & 16.7 & 684.2 \\
\hline 49 & , & 16.7 & \\
\hline 50 & & 16.7 & \\
\hline 51 & $1320088: 10$ & 16.7 & 684. \\
\hline & & & \\
\hline 253 & $8 / 13 / 20088: 14$ & 16.7 & 685 \\
\hline 254 & $8 / 13 / 20088: 16$ & 16.7 & 685. \\
\hline & & & \\
\hline 4256 & $8 / 13 / 20088: 20$ & 16.7 & 686.7 \\
\hline 4257 & $8 / 13 / 20088: 22$ & 16.7 & 686.9 \\
\hline 4258 & & 16.7 & \\
\hline 4259 & $8 / 13 / 20088: 26$ & 16.7 & 687.1 \\
\hline 4200 & $8 / 13 / 20088: 28$ & & \\
\hline 4261 & & 16.7 & \\
\hline 62 & $3 / 20088: 32$ & 16.7 & 686 \\
\hline & $3 / 20088: 34$ & & \\
\hline 4264 & $3 / 20088: 36$ & 16.7 & 686 \\
\hline 4265 & 88:38 & 16.7 & 686 \\
\hline 266 & & 16.7 & \\
\hline 4267 & $3 / 20088: 42$ & 16.7 & . \\
\hline 4268 & 88:44 & 16.7 & 686. \\
\hline 4269 & $38: 46$ & 16.7 & \\
\hline 4270 & $38: 48$ & 16.7 & 686. \\
\hline 4271 & & 16.7 & \\
\hline 4272 & $88: 52$ & 16.7 & \\
\hline 273 & & 16.7 & 685. \\
\hline 4274 & & 16.7 & \\
\hline 4275 & & 16.7 & 80. \\
\hline$\overline{276}$ & 9.00 & 16.7 & 31. \\
\hline 4277 & 9.00 & 16.7 & \\
\hline 4278 & & 16.7 & 681 \\
\hline 4279 & & 16.7 & 681. \\
\hline 280 & & 16.7 & 81. \\
\hline 281 & $39: 10$ & 16.7 & \\
\hline 4282 & & 16.7 & 680. \\
\hline 4283 & & 16.7 & 80. \\
\hline 4284 & & 16.7 & 80. \\
\hline 4285 & & 16.7 & \\
\hline$\overline{286}$ & & 16.7 & \\
\hline 4287 & & 16.7 & 681. \\
\hline 288 & & 16.7 & 81. \\
\hline 4289 & & 16.7 & 11. \\
\hline 4290 & & 16.7 & \\
\hline & & 16.7 & \\
\hline 4292 & & 16.7 & 81. \\
\hline & & 16.7 & 11. \\
\hline 4294 & & 16.7 & \\
\hline 296 & & 16.7 & 31. \\
\hline$\overline{m e}$ & & 16.7 & \\
\hline 4297 & & 16.7 & 79 \\
\hline & & 16.7 & \\
\hline 4299 & & 16.7 & 9 \\
\hline & & 16.7 & 79. \\
\hline & & & \\
\hline 4302 & 39.52 & 16.7 & 6 \\
\hline & & 16.7 & 33. \\
\hline 43 & & & \\
\hline 4305 & $8 / 13 / 20089: 58$ & 16.7 & \\
\hline & & & \\
\hline 4307 & $310: 02$ & 16.7 & 6 \\
\hline & & 16.7 & 683 \\
\hline & & 16.7 & \\
\hline & $8 / 13 / 200810.08$ & 16.7 & 683. \\
\hline & & & \\
\hline & & 16.7 & 683 \\
\hline & $8 / 13 / 2$ & 16.7 & 683. \\
\hline & & & \\
\hline
\end{tabular}

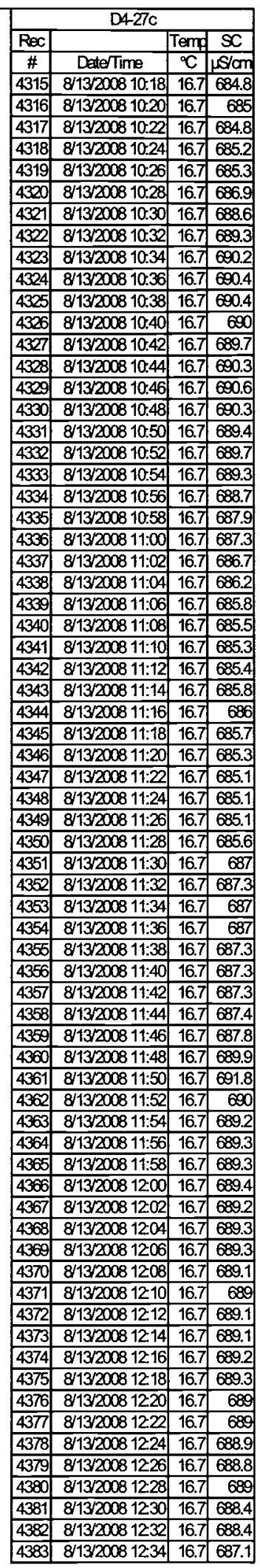




\begin{tabular}{|c|c|c|c|c|c|c|c|c|c|c|c|c|c|c|c|c|c|c|c|}
\hline \multicolumn{4}{|c|}{ D427c } & \multicolumn{4}{|c|}{$D 4-27 c$} & \multicolumn{4}{|c|}{ D4-27c } & & $D 4-27 c$ & & & & D4-27c & & \\
\hline $\operatorname{Rec}$ & & Temp & $\mathrm{SC}$ & $\mathrm{Rec}$ & & Temp & $S C$ & $\operatorname{Rec}$ & & Temp & $\mathrm{SC}$ & $\operatorname{Rec}$ & & Temp & $S C$ & $\mathrm{Rec}$ & & Temp & $\mathrm{SC}$ \\
\hline$\#$ & Date/Time & ${ }^{\circ} \mathrm{C}$ & $\mu \mathrm{S} / \mathrm{cm}$ & $\#$ & Dete/Time & & $\mu \mathrm{S} / \mathrm{cm}$ & $\#$ & Date/Time & & $\mu \mathrm{s} / \mathrm{am}$ & \# & DeterTime & & & $\#$ & Dete/Time & & \\
\hline 4039 & $8 / 13 / 20081: 06$ & 16.7 & 685.5 & 4108 & $8 / 13 / 20083: 24$ & 16.7 & 687.3 & 4177 & $8 / 13 / 20085: 42$ & 16.7 & 6722 & 4246 & $8 / 13 / 20088: 00$ & 16.7 & 678.3 & 4315 & $8 / 13 / 200810: 18$ & & 684.8 \\
\hline 040 & \begin{tabular}{|l|}
$8 / 13 / 20081: 08$ \\
\end{tabular} & \begin{tabular}{|l|}
16.7 \\
\end{tabular} & 684.7 & 4109 & $8 / 13 / 20083: 26$ & \begin{tabular}{|l|}
16.7 \\
\end{tabular} & 674.3 & 4178 & $8 / 13 / 20085: 44$ & 16.7 & 670.9 & 4247 & $8 / 13 / 20068: 02$ & 16.7 & 683.7 & 4316 & $8 / 13 / 200810: 20$ & 16.7 & 685 \\
\hline 041 & $\mid 8 / 13 / 2008$ 1:10 & \begin{tabular}{|l|}
16.7 \\
\end{tabular} & 683.9 & & $8 / 13 / 20083: 28$ & \begin{tabular}{|l|}
16.7 \\
\end{tabular} & 677.6 & 4179 & $8 / 13 / 20085: 46$ & 16.7 & 670.4 & 4248 & $8 / 13 / 20088: 04$ & 16.7 & 684.2 & 4317 & & 16.7 & 684.8 \\
\hline 42 & $8 / 1320081: 12$ & \begin{tabular}{|l|}
16.7 \\
\end{tabular} & 684.4 & 111 & $8 / 13 / 20083: 30$ & 16.7 & 686.7 & 4180 & $8 / 13 / 20085: 48$ & 16.7 & 669.6 & 4249 & $8 / 13 / 20088: 06$ & 16.7 & 684.2 & & $8 / 13 / 2008$ 10:24 & 16.7 & 685.2 \\
\hline 4043 & \begin{tabular}{|c|}
$8 / 13 / 2008$ 1:14 \\
\end{tabular} & \begin{tabular}{|l|}
16.7 \\
\end{tabular} & 683.7 & 4112 & $8 / 13 / 20083: 32$ & 16.7 & 684.4 & 4181 & $8 / 13 / 20085: 50$ & 16.7 & 670 & 4250 & $8 / 13 / 20088: 08$ & 16.7 & 684.4 & 4319 & $8 / 13 / 200810: 26$ & 16.7 & 685.3 \\
\hline 4044 & $8 / 13 / 20081: 16$ & \begin{tabular}{|l|}
16.7 \\
\end{tabular} & 684 & 13 & $8 / 13 / 20083: 34$ & 16.7 & 691.1 & 4182 & $8 / 13 / 20085: 52$ & 16.7 & 670.9 & 4251 & $8 / 13 / 20088: 10$ & 16.7 & & & & 16.7 & \\
\hline 4045 & $8 / 13 / 20081: 18$ & \begin{tabular}{|l|}
16.7 \\
\end{tabular} & 684 & 114 & $8 / 13 / 20083: 36$ & 16.7 & 690.8 & 4183 & $8 / 13 / 20085: 54$ & 16.7 & 670.1 & 4252 & $8 / 13 / 20088: 12$ & 16.7 & 684.8 & & $8 / 13 / 200810: 30$ & 16.7 & 688.6 \\
\hline 4046 & \begin{tabular}{|l|}
$8 / 13 / 20081: 20$ \\
\end{tabular} & \begin{tabular}{|l|}
16.7 \\
\end{tabular} & 683.8 & \begin{tabular}{|l|}
4115 \\
\end{tabular} & $8 / 13 / 20083: 38$ & 16.7 & 690.7 & 4184 & $8 / 13 / 20085: 56$ & 16.7 & 668.9 & 4253 & $8 / 13 / 20088: 14$ & 16.7 & 685.1 & 4322 & $8 / 13 / 200810: 32$ & 16.7 & 689.3 \\
\hline 4047 & $8 / 13 / 20081: 22$ & \begin{tabular}{|l|}
16.7 \\
\end{tabular} & 683.7 & \begin{tabular}{|l|}
4116 \\
\end{tabular} & $8 / 13220083: 40$ & 16.7 & 690.3 & 4185 & $8 / 13 / 20085: 58$ & 16.7 & 667.2 & 4254 & $8 / 1320088: 16$ & 16.7 & 685.9 & 4323 & $8 / 13 / 200810: 34$ & 16.7 & \\
\hline 4048 & $8 / 13 / 20081: 24$ & 16.7 & 683.2 & 4117 & $8 / 13 / 20083: 42$ & 16.7 & 689.8 & 4186 & 8/13/20086:00 & 16.7 & 665.6 & 4255 & $8 / 13 / 20088: 18$ & 16.7 & 686.7 & 4324 & & 16.7 & 690.4 \\
\hline 4049 & \begin{tabular}{|l|}
$8 / 13 / 2008$ \\
\end{tabular} & 16.7 & 683 & \begin{tabular}{|l|}
4118 \\
\end{tabular} & $8 / 13 / 20083: 44$ & 16.7 & 689.8 & 4187 & $8 / 13 / 20086: 02$ & 16.7 & 664.9 & 4256 & $8 / 13 / 20088: 20$ & 16.7 & 686.7 & 4325 & $8 / 13 / 200810: 38$ & 16.7 & 690.4 \\
\hline 4050 & $8 / 13 / 20081: 28$ & 16.7 & 6829 & \begin{tabular}{|l|}
4119 \\
\end{tabular} & $8 / 13 / 20083: 46$ & 16.7 & 689.6 & 4188 & $8 / 13 / 20086: 04$ & 16.7 & 665.4 & 4257 & $8 / 13 / 20088: 22$ & 16.7 & 686.9 & 4326 & $8 / 13 / 200810: 40$ & 16.7 & \\
\hline 4051 & \begin{tabular}{|c|}
$8 / 132008$ 1:30 \\
\end{tabular} & 16.7 & 6829 & 4120 & $8 / 13 / 20083: 48$ & 16.7 & 689.8 & 4189 & & 16.7 & 668.3 & \begin{tabular}{|l|}
4258 \\
\end{tabular} & & 16.7 & 687.1 & \begin{tabular}{|l|l|}
43227 \\
\end{tabular} & & 16.7 & \\
\hline 4052 & $8 / 13 / 20081: 32$ & 16.7 & 681.9 & \begin{tabular}{|l|}
4121 \\
\end{tabular} & $8 / 13 / 20083.50$ & 16.7 & 689.6 & 4190 & $8 / 13 / 20086: 08$ & \begin{tabular}{|l|}
16.7 \\
\end{tabular} & 667.3 & 4259 & $8 / 13 / 20088: 26$ & 16.7 & 687.1 & 4328 & $8 / 132200810: 44$ & 16.7 & 690.3 \\
\hline 4053 & $8 / 13 / 20081: 34$ & 16.7 & 681.8 & \begin{tabular}{|l|l|}
4122 \\
\end{tabular} & $8 / 13 / 20083: 52$ & \begin{tabular}{|l|}
16.7 \\
\end{tabular} & 689.8 & 4191 & $8 / 1320086: 10$ & \begin{tabular}{|l|}
16.7 \\
\end{tabular} & 6629 & 4260 & $8 / 13 / 20088: 28$ & 16.7 & 686.9 & 4329 & $8 / 13 / 200810: 46$ & 16.7 & \\
\hline 4054 & \begin{tabular}{|l|l|}
$8 / 20081: 36$ \\
\end{tabular} & 16.7 & 6823 & & $8 / 4 / 20083: 54$ & \begin{tabular}{|l|}
16.7 \\
\end{tabular} & 689.6 & 4192 & & 16.7 & 663.9 & 4261 & & 16.7 & 686.9 & & & 16.7 & \\
\hline 4055 & $8 / 13 / 20081: 38$ & 16.7 & 683 & 4124 & $8 / 13 / 20083: 56$ & 16.7 & 689.9 & 4193 & $8 / 13 / 20086: 14$ & \begin{tabular}{|l|}
16.7 \\
\end{tabular} & 665 & 4262 & $8 / 13 / 20088: 32$ & 16.7 & 686.8 & 4331 & $8 / 13 / 200810: 50$ & 16.7 & 689.4 \\
\hline 4056 & $8 / 13 / 20081: 40$ & 16.7 & 7) 684.7 & 4125 & $8 / 13 / 20083: 58$ & \begin{tabular}{|l|}
16.7 \\
\end{tabular} & 689.8 & 4194 & $0086: 16$ & 16.7 & 606.4 & 4263 & 088.34 & 16.7 & 686.4 & 4332 & $810: 52$ & 16.7 & 689.7 \\
\hline 056 & $8 / 13 / 2008$ 1:42 & 16.7 & 7687.6 & & $8 / 13 / 20004: 00$ & \begin{tabular}{|l|}
16.7 \\
\end{tabular} & 690 & 4195 & & 16.7 & 665.9 & 4264 & & 16.7 & & & & 16.7 & \\
\hline 4058 & \begin{tabular}{|l|l|}
$8 / 13 / 20081: 44$ \\
\end{tabular} & 16.7 & 687.3 & \begin{tabular}{|l|}
4127 \\
\end{tabular} & $8 / 13 / 20084: 02$ & 16.7 & 690.1 & 4196 & $8 / 13 / 20086: 20$ & 16.7 & 664.3 & 4265 & $8 / 13 / 2008: 38$ & 16.7 & 606.3 & 4334 & 08 10:56 & 16.7 & 688.7 \\
\hline 4050 & $8 / 13 / 20081: 46$ & 16.7 & 7686.8 & 4128 & $8 / 13 / 20084: 04$ & 16.7 & 600.3 & 4197 & $66: 2$ & 16.7 & 661.6 & 4266 & 38:40 & 16.7 & 686.8 & 4335 & $310: 58$ & 16.7 & 687.9 \\
\hline 060 & $8 / 13 / 20$ & 16.7 & 687.5 & & $8 / 13 / 200$ & 16.7 & 690.1 & 4198 & & 16.7 & 6626 & \begin{tabular}{|l|}
4267 \\
\end{tabular} & & 16.7 & 687 & 4336 & & 16.7 & \\
\hline 4061 & $8 / 13 / 20081: 50$ & 16.7 & \begin{tabular}{|l|l|}
7 & 688.3 \\
\end{tabular} & 4130 & $8 / 13 / 20084: 08$ & 16.7 & 690.2 & 4199 & $86: 26$ & 16.7 & 665.7 & 4268 & $8 / 13 / 20088: 44$ & 16.7 & 686.7 & 337 & $811: 02$ & 16.7 & 686.7 \\
\hline 062 & $8 / 13 / 2$ & 16.7 & $7 \quad 689$ & 4131 & $8 / 13 / 20$ & 16.7 & 689.8 & 4200 & $6: 28$ & 16.7 & 668.2 & 4269 & $38: 46$ & 16.7 & 686.9 & 4338 & 11:04 & 16.7 & 686.2 \\
\hline 4063 & $8 / 13 / 20$ & 16.7 & 690.4 & 4132 & $8 / 13 / 200$ & 16.7 & 690.3 & 4201 & $36: 30$ & 16.7 & 668 & 4270 & 88:48 & 16.7 & & & & 16.7 & 685.8 \\
\hline 4064 & $8 / 13 / 20081: 56$ & 16.7 & 690.9 & 4 & $8 / 13 / 20084: 14$ & 16.7 & 689.9 & 4202 & $86: 32$ & 16.7 & 666.8 & 4271 & 20088.50 & 16.7 & 685.8 & 4340 & $811: 08$ & 16.7 & 685.5 \\
\hline 4065 & $8 / 13 / 2$ & 16.7 & $7 \longdiv { 6 9 2 3 }$ & 4134 & $8 / 13 / 200$ & 16.7 & 689.9 & 4203 & $6: 34$ & 16.7 & 665.4 & 4272 & $88: 52$ & 16.7 & 684.4 & 4341 & 311:10 & 16.7 & 685.3 \\
\hline 4066 & $8 / 13 / 2008200$ & 16.7 & 76927 & 4135 & $8 / 13 / 200$ & \begin{tabular}{|l|}
16.7 \\
\end{tabular} & 688.7 & 4204 & $8 / 13$ & 16.7 & 664. & 4273 & 88.54 & 16.7 & 685 & & & 16.7 & \\
\hline 4067 & $8 / 13 / 20082-02$ & 16.7 & 693.8 & 4136 & $8 / 13 / 20084: 20$ & \begin{tabular}{|l|}
16.7 \\
\end{tabular} & 688.5 & 4206 & $6: 38$ & 16.7 & 663 & 4274 & $088: 56$ & \begin{tabular}{|l|}
16.7 \\
\end{tabular} & 679 & 4343 & 11:14 & 16.7 & 685.8 \\
\hline 4068 & $8 / 13 / 20$ & 16.7 & 694. & \begin{tabular}{|l|}
4137 \\
\end{tabular} & $8 / 13 / 200$ & 16.7 & 688.6 & 4206 & $6: 40$ & \begin{tabular}{|l|}
16.7 \\
\end{tabular} & 663. & 4275 & $8 / 13 / 20088: 58$ & 16.7 & 680 & 4344 & 311:16 & 16.7 & \\
\hline 4069 & $8 / 13 / 20$ & 16.7 & 694.7 & 4138 & $8 / 13 / 2$ & 16.7 & 688.7 & 4207 & $6: 42$ & \begin{tabular}{|l|}
16.7 \\
\end{tabular} & 663. & 4276 & & 16.7 & 681.3 & 4345 & 11:18 & 16.7 & 685.7 \\
\hline 4070 & & 16.7 & 694. & 4139 & $8 / 13 / 2$ & \begin{tabular}{|l|}
16.7 \\
\end{tabular} & 689.1 & 4208 & & 16.7 & 661. & 4277 & & 16.7 & 681.5 & 4346 & 11:20 & 16.7 & 685.3 \\
\hline 1071 & $8 / 13 / 2$ & 16.7 & 695 . & 140 & $8 / 13 / 2$ & \begin{tabular}{|l|}
16.7 \\
\end{tabular} & 688.4 & 4209 & $8 / 13$ & 16.7 & 661 & \begin{tabular}{|l|}
4278 \\
\end{tabular} & & 16.7 & 681. & 4347 & $11: 22$ & 16.7 & 685.1 \\
\hline 4072 & $8 / 13$ & 16.7 & 695. & 4141 & $8 / 13 / 2$ & 16.7 & 687.5 & 4210 & $6: 48$ & 16.7 & 661.5 & 4279 & $8 / 13$ & \begin{tabular}{|c|}
16.7 \\
\end{tabular} & 681.6 & 4348 & 11:24 & 16.7 & 685.1 \\
\hline & & 16.7 & 7695. & \begin{tabular}{|l|}
4142 \\
\end{tabular} & $8 / 13 / 22$ & \begin{tabular}{|l|}
16.7 \\
\end{tabular} & 687.8 & 4211 & & \begin{tabular}{|l|}
16.7 \\
\end{tabular} & 661. & 4280 & 99:08 & 16.7 & 681.5 & 4349 & $11: 26$ & 16.7 & 685.1 \\
\hline 4074 & $8 / 13$ & 16.7 & 695. & 143 & $8 / 13$ & 16.7 & 687 & 4212 & & 16.7 & 659. & 4281 & & 16.7 & & 4350 & $11: 28$ & 16.7 & 685.6 \\
\hline 4075 & $8 / 13$ & 16.7 & 695 & 4144 & $8 / 13 / 2$ & 16.7 & 685.4 & 4213 & $6: 54$ & 16.7 & 659.6 & \begin{tabular}{|l|}
4282 \\
\end{tabular} & 89:12 & 16.7 & 680.6 & 4351 & 11:30 & 16.7 & 687 \\
\hline 4076 & & 16.7 & 695.2 & 4145 & $8 / 13 / 2$ & 16.7 & 684. & 4214 & & \begin{tabular}{|l|}
16.7 \\
\end{tabular} & 65 & \begin{tabular}{|l|}
4283 \\
\end{tabular} & & 16.7 & 680.4 & 4352 & $11: 32$ & 16.7 & 687.3 \\
\hline 4077 & & 16.7 & 695.4 & 146 & & 16.7 & 681 & 4215 & & 16.8 & 657. & \begin{tabular}{|c|}
4284 \\
\end{tabular} & & \begin{tabular}{|l|}
16.7 \\
\end{tabular} & 680 & 4353 & $11: 34$ & 16.7 & 687 \\
\hline 4078 & $8 / 13$ & 16.7 & 7695.9 & \begin{tabular}{|l|}
4147 \\
\end{tabular} & $8 / 13 / 2$ & 16.7 & 6823 & 4216 & $7: 00$ & \begin{tabular}{|c|}
16.7 \\
\end{tabular} & 657.5 & \begin{tabular}{|l|}
4285 \\
\end{tabular} & $89: 18$ & 16.7 & 681.3 & 4354 & $811: 36$ & 16.7 & 687 \\
\hline 4079 & & 16.7 & 7) 69 & \begin{tabular}{|l|l|}
4148 \\
\end{tabular} & & 16.7 & 680 & \begin{tabular}{|l|l|}
4217 \\
\end{tabular} & $7: 02$ & \begin{tabular}{|l|}
16.7 \\
\end{tabular} & 65 & \begin{tabular}{|l|}
42806 \\
\end{tabular} & & 16.7 & 681.2 & 4356 & 11:38 & 16.7 & 687.3 \\
\hline 4080 & $8 / 11$ & 16.7 & 695. & 149 & $4: 46$ & \begin{tabular}{l|l|}
16.7 \\
\end{tabular} & 678.3 & 4 & & \begin{tabular}{|c|}
16.7 \\
\end{tabular} & 656. & \begin{tabular}{|l|l|}
4287 \\
\end{tabular} & & 16.7 & 681 & 4356 & $11: 40$ & 16.7 & 687.3 \\
\hline 4081 & & 16.7 & 7695.9 & \begin{tabular}{|l|}
4150 \\
\end{tabular} & & 16.7 & 686 & 4219 & & \begin{tabular}{|l|}
16.7 \\
\end{tabular} & 657.8 & 4 & 9.24 & 16.7 & 681 & 4357 & $11: 42$ & 16.7 & 687.3 \\
\hline 4082 & & $\begin{array}{l}16.7 \\
\end{array}$ & $\begin{array}{ll}7 & 696 .\end{array}$ & & & \begin{tabular}{|l|}
16.7 \\
\end{tabular} & 654.5 & 4220 & & \begin{tabular}{|l|}
16.7 \\
\end{tabular} & 65 & \begin{tabular}{|l|l|}
4289 \\
\end{tabular} & & 16.7 & 681 & & & 16.7 & 687.4 \\
\hline 4083 & $8 / 13$ & 16.7 & 683 & 152 & $4: 52$ & 16.7 & 658.2 & 4221 & & \begin{tabular}{|l|}
16.7 \\
\end{tabular} & 656 & \begin{tabular}{|l|}
4290 \\
\end{tabular} & & 16.7 & 681 & & 1:46 & 16.7 & 687.8 \\
\hline 4084 & & 16.7 & \begin{tabular}{l|l}
7 & 667.
\end{tabular} & \begin{tabular}{|l|}
4153 \\
\end{tabular} & & 16.7 & 664. & 4202 & & \begin{tabular}{|l|}
16.7 \\
\end{tabular} & 65 & $42^{2}$ & & 16.7 & & W & $11: 48$ & 16.7 & 689.9 \\
\hline 4085 & & 16.7 & $\begin{array}{ll}7678 \\
\end{array}$ & 4 & & 16.7 & & 4223 & & \begin{tabular}{|l|l}
16.7 \\
\end{tabular} & 656. & & & 16.7 & 681 & 12 & $11: 50$ & 16.7 & 691.8 \\
\hline 4086 & & 16.7 & 679. & 4155 & 4:58 & 16.7 & 670 & 4224 & & \begin{tabular}{|l|}
16.7 \\
\end{tabular} & 659 & \begin{tabular}{|l|}
4293 \\
\end{tabular} & 89.34 & 16.7 & 681. & 4362 & $311: 52$ & 16.7 & 600 \\
\hline 4087 & & 16.7 & 7684 & & & 16.7 & 673 & 4225 & & \begin{tabular}{|l|}
16.7 \\
\end{tabular} & 661. & 4294 & & 16.7 & 681 & 56 & & 16.7 & 689.2 \\
\hline 4088 & & 16.7 & $\begin{array}{ll}7 & 684\end{array}$ & & & 16.7 & 676. & & & \begin{tabular}{|l|}
16.7 \\
\end{tabular} & 660 & \begin{tabular}{|l|}
42965 \\
\end{tabular} & & 16.7 & & 1364 & & 16 & \\
\hline 4089 & $8 / 13$ & 16.7 & \begin{tabular}{l|l}
77 & 684
\end{tabular} & 4158 & 5.04 & \begin{tabular}{|l|}
16.7 \\
\end{tabular} & 681 & \begin{tabular}{|l|}
4227 \\
\end{tabular} & & \begin{tabular}{|l|}
16.7 \\
\end{tabular} & 661. & \begin{tabular}{|l|}
4296 \\
\end{tabular} & $8 / 13$ & 16.7 & 680 & 4365 & 11:58 & 16.7 & 689.3 \\
\hline 4090 & & \begin{tabular}{|l|l|}
16.7 \\
\end{tabular} & \begin{tabular}{l|l}
7 & 686
\end{tabular} & & & \begin{tabular}{|l|}
16.7 \\
\end{tabular} & 68 & 4228 & & \begin{tabular}{|l|}
16.7 \\
\end{tabular} & 661 & & & 16.7 & & & & \begin{tabular}{|c|}
16.7 \\
\end{tabular} & \\
\hline 4091 & & \begin{tabular}{|l|}
16.7 \\
\end{tabular} & \begin{tabular}{l|l}
7 & 676 \\
\end{tabular} & & & \begin{tabular}{|l|}
16.7 \\
\end{tabular} & 679. & 4220 & & \begin{tabular}{|l|}
16.7 \\
\end{tabular} & 602 & \begin{tabular}{|l|l|}
4298 \\
\end{tabular} & & $\mid 16.7$ & 67 & $\mid 367$ & 1202 & 16. & \\
\hline 4092 & $8 / 13$ & 16.7 & \begin{tabular}{l|l|}
7 & 678.2 \\
\end{tabular} & \begin{tabular}{|l|}
4161 \\
\end{tabular} & $8 / 13 / 2$ & \begin{tabular}{|l|}
16.7 \\
\end{tabular} & 679.1 & 4230 & & \begin{tabular}{|l|}
16.7 \\
\end{tabular} & 664. & 4299 & $9: 46$ & 16.7 & 679 & 4368 & $12: 04$ & \begin{tabular}{|c|}
16.7 \\
\end{tabular} & 689.3 \\
\hline 4093 & & 16.7 & \begin{tabular}{l|l}
77 & 68 \\
\end{tabular} & & & \begin{tabular}{|l|}
16.7 \\
\end{tabular} & 679 & 4231 & & \begin{tabular}{|l|}
16.7 \\
\end{tabular} & 664 & 4300 & & & & & & & 689.3 \\
\hline 4094 & & 16.7 & 680. & 163 & & 16.7 & 67 & 4232 & & \begin{tabular}{|l|}
16.7 \\
\end{tabular} & 664 & 44301 & 9.50 & 16.7 & 68 & & 1208 & 16.7 & 689.1 \\
\hline 4095 & $8 / 13$ & 16.7 & 68 & \begin{tabular}{|l|}
4164 \\
\end{tabular} & & \begin{tabular}{|l|}
16.7 \\
\end{tabular} & 676 & 4233 & & \begin{tabular}{|l|l}
16.7 \\
\end{tabular} & 663 & \begin{tabular}{|l|}
4302 \\
\end{tabular} & 99.52 & $\mid 16.7$ & 68 & 4371 & 31210 & 16.7 & 680 \\
\hline 4096 & & 16.7 & \begin{tabular}{l|l}
77 & 687. \\
\end{tabular} & & & \begin{tabular}{|l|}
16.7 \\
\end{tabular} & 67 & & & \begin{tabular}{|l|}
16.7 \\
\end{tabular} & 66 & 4303 & & & & & & & \\
\hline 4097 & & \begin{tabular}{|l|}
16.7 \\
\end{tabular} & \begin{tabular}{l|l}
7 & 686 \\
\end{tabular} & 166 & & \begin{tabular}{|l|}
16.7 \\
\end{tabular} & 67 & 423 & & \begin{tabular}{|l|}
16.7 \\
\end{tabular} & 661 & 4304 & 9956 & $|16.7|$ & 68 & & 1214 & 16.7 & 669.1 \\
\hline 4098 & $8 / 13 / 2$ & $\begin{array}{l}16.7 \\
\end{array}$ & \begin{tabular}{l|l}
7 & 685.
\end{tabular} & \begin{tabular}{|l|}
4167 \\
\end{tabular} & & \begin{tabular}{|l|}
16.7 \\
\end{tabular} & 675. & \begin{tabular}{|l|}
4236 \\
\end{tabular} & $7: 40$ & \begin{tabular}{|l|l}
16.7 \\
\end{tabular} & 660 & 4305 & 89.58 & $\mid 16.7$ & 684 & 4374 & 31216 & 16.7 & 689.2 \\
\hline 4000 & & \begin{tabular}{|l|}
16.7 \\
\end{tabular} & \begin{tabular}{l|l}
7 & 686 \\
\end{tabular} & & & \begin{tabular}{|l|}
16.7 \\
\end{tabular} & 673 & \begin{tabular}{|l|}
4237 \\
\end{tabular} & & 16.7 & & 4306 & & & & & & & \\
\hline 4100 & & \begin{tabular}{|l|}
16.7 \\
\end{tabular} & \begin{tabular}{l|l}
77 & 686.
\end{tabular} & & $85: 26$ & \begin{tabular}{|l|}
16.7 \\
\end{tabular} & & 4238 & $7: 44$ & 16.7 & 660 & \begin{tabular}{|l|}
4307 \\
\end{tabular} & $8 / 13$ & 11.7 & 684 & 4376 & 81220 & 16.7 & 68 \\
\hline 4101 & $8 / 13 / 2$ & \begin{tabular}{|l|}
16.7 \\
\end{tabular} & \begin{tabular}{l|l}
7 & 687. \\
\end{tabular} & 170 & $5: 28$ & 16.7 & 674.7 & \begin{tabular}{|l|}
4239 \\
\end{tabular} & $7: 46$ & \begin{tabular}{|l|}
16.7 \\
\end{tabular} & 661 & \begin{tabular}{|l|}
4308 \\
\end{tabular} & 10:04 & 16.7 & 683 & 377 & 122 & 16.7 & 689 \\
\hline 4102 & & \begin{tabular}{|l|}
16.7 \\
\end{tabular} & \begin{tabular}{l|l}
7 & 687.8 \\
\end{tabular} & & & 16.7 & 674. & 4240 & & & & 4309 & & & & & 312.24 & & \\
\hline 4103 & 33:14 & \begin{tabular}{|l|l|}
16.7 \\
\end{tabular} & \begin{tabular}{l|l|}
7 & 685.4 \\
\end{tabular} & \begin{tabular}{|l|l|}
4172 \\
\end{tabular} & $8 / 13 / 20085: 32$ & 16.7 & 67 & \begin{tabular}{|l|}
4241 \\
\end{tabular} & $7: 50$ & 16.7 & 662 & 4310 & 008 10:08 & 16.7 & 683 & 4379 & 081226 & 16.7 & 688.8 \\
\hline 4104 & $8 / 13 / 20$ & 16.7 & \begin{tabular}{l|l}
7 & 685. \\
\end{tabular} & 4173 & $8 / 13 / 20085: 34$ & \begin{tabular}{|l|}
16.7 \\
\end{tabular} & 673.6 & 4242 & $37: 52$ & 16.7 & 683 & 4311 & $8 / 13 / 2008$ 10:10 & 16.7 & 68 & 4380 & 81228 & 16.7 & \\
\hline 4105 & & \begin{tabular}{|l|}
16.7 \\
\end{tabular} & \begin{tabular}{l|l|}
7 & 686.4 \\
\end{tabular} & \begin{tabular}{|l|}
4174 \\
\end{tabular} & & 16.7 & 674. & 4243 & & \begin{tabular}{|l|}
16.7 \\
\end{tabular} & & & & & & & 081230 & & 688.4 \\
\hline 4106 & $8 / 13 / 20083: 20$ & 16.7 & \begin{tabular}{l|l|}
7 & 686.7 \\
\end{tabular} & \begin{tabular}{|l|l|}
4175 \\
\end{tabular} & $8 / 13 / 20085: 38$ & 16.7 & 67 & 4244 & $87: 56$ & 16.7 & $6 \pi$ & \begin{tabular}{|l|}
4313 \\
\end{tabular} & $8 / 13 / 2008$ 10:14 & 16.7 & 683. & \begin{tabular}{|l|l|}
4382 \\
\end{tabular} & $8 / 13 / 2008$ 12:32 & 16.7 & 688.4 \\
\hline 4107 & $083: 22$ & 16.7 & \begin{tabular}{l|l|}
77 & 687.4 \\
\end{tabular} & 4176 & $8 / 13 / 20085: 40$ & 16.7 & 6728 & \begin{tabular}{|l|}
4245 \\
\end{tabular} & $7: 58$ & \begin{tabular}{|l|}
16.7 \\
\end{tabular} & 678.2 & \begin{tabular}{|l|}
4314 \\
\end{tabular} & $8 / 13 / 2008$ 10:16 & 16.7 & $684 . t$ & 4383 & $8 / 13 / 200812-34$ & 6.7 & 687.1 \\
\hline
\end{tabular}




\begin{tabular}{|c|c|c|c|c|c|c|c|c|c|c|c|c|c|c|c|c|c|c|c|}
\hline \multicolumn{4}{|c|}{$\mathrm{D} 427 \mathrm{C}$} & \multicolumn{4}{|c|}{$\mathrm{D} 427 \mathrm{c}$} & \multicolumn{4}{|c|}{$D 427 \mathrm{c}$} & & $\mathrm{D} 427 \mathrm{c}$ & & & & $\mathrm{D} 427 \mathrm{c}$ & & \\
\hline $\operatorname{Roc}$ & & Tam & & $\operatorname{Rec}$ & & & $S C$ & $\operatorname{Rec}$ & & Temp & & $\mathrm{Rec}$ & & & $\mathrm{SC}$ & $R \mathrm{Re}$ & & Tennd & SC \\
\hline$\#$ & DeteTime & ${ }^{\circ} \mathrm{C}$ & LS/ & \# & Date/Time & & $\mu \mathrm{S} / \mathrm{mr}$ & $\#$ & Dater/ime & ${ }^{\circ} \mathrm{C}$ & $\mu \mathrm{S} / \mathrm{ar}$ & 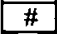 & DaterTime & ${ }^{\circ} \mathrm{C}$ & $\mathrm{HSTOM}$ & $\#$ & DaterTime & ${ }^{\circ} \mathrm{C}$ & $\mu \mathrm{S} / \mathrm{cm}$ \\
\hline & $8 / 13 / 20081236$ & & 686.5 & & $8 / 13 / 200814: 54$ & 16.7 & 684.2 & 452 & $8 / 13 / 2008$ 17:12 & 16.7 & & 1591 & $8 / 13 / 200819.30$ & 16.7 & 679.2 & 4660 & $8 / 13 / 200821: 48$ & & \\
\hline 85 & $8 / 13 / 20081238$ & 16.7 & 685.4 & 454 & $8 / 13 / 200814: 56$ & 16.7 & 683.8 & 4523 & $8 / 13 / 200817: 14$ & 16.7 & 6824 & 592 & $8 / 13 / 200819.32$ & 16.7 & 608 & 4661 & $8 / 13 / 200821: 50$ & 16.7 & 679.3 \\
\hline & $8 / 13 / 20081240$ & 16.7 & 685.5 & & $8 / 13 / 2008$ 14:58 & 16.7 & 683.7 & 4524 & $8 / 13 / 2008$ 17:16 & 16.7. & 682.3 & 4593 & $8 / 13 / 2008$ 19:34 & 16.7 & 600 & 4662 & & 16.7 & \\
\hline & $8 / 13 / 2008+242$ & 16.7 & 685.3 & 156 & & 16.7 & 683.5 & & $8 / 13 / 200817: 18$ & 16.7 & 681.3 & & & 16.7 & 675.3 & 4663 & $8 / 13 / 200821: 54$ & & 678.2 \\
\hline 388 & $8 / 13 / 20081244$ & 16.7 & 685.5 & 4457 & $8 / 13 / 200815: 02$ & 16.7 & 683.3 & 4526 & $8 / 13 / 2008$ 17:20 & 16.7 & 679.1 & 4595 & $1 / 13 / 2008$ 19:38 & 16.7 & 674.4 & 4664 & $8 / 13 / 200821: 56$ & 16.7 & 677.5 \\
\hline & $8 / 13 / 20081246$ & 16.7 & 685.7 & & $8 / 13 / 2$ & 16.7 & 683.4 & 4527 & & 16.7 & & & & 16.7 & & & & 16.7 & \\
\hline 390 & $8 / 13 / 20081248$ & 16.7 & 685.9 & 4450 & $8 / 13 / 20$ & 16.7 & 682.6 & 4528 & $8 / 13 / 2008$ 17:24 & 16.7 & 678.5 & 4597 & $8 / 13 / 200819.42$ & 16.7 & \begin{tabular}{|l|}
674.2 \\
\end{tabular} & 4666 & $8 / 13 / 20082200$ & 16.7 & 675.4 \\
\hline 391 & $8 / 13 / 20081250$ & 16.7 & 685.5 & 4460 & $315: 08$ & 16.7 & 682 & 4529 & 817:26 & 16.7 & 677.8 & 4598 & $8 / 13 / 200819.44$ & 16.7 & \begin{tabular}{|l|}
676.3 \\
\end{tabular} & 4667 & $8 / 13 / 20082202$ & 16.7 & 674.7 \\
\hline & & & 685.3 & & & & 681.9 & 4530 & & & & & & & & 4668 & & & \\
\hline 393 & $8 / 13 / 20081254$ & 16.7 & 685.3 & 4462 & $8 / 13 / 20$ & 16.7 & 682.3 & 4531 & $8 / 13 / 200817: 30$ & 16.7 & 674.8 . & 4600 & $8 / 13 / 200819: 48$ & 16.7 & 676.7 & 4669 & $8 / 13 / 20082206$ & 16.7 & 670.3 \\
\hline 394 & $8 / 13 / 200812.56$ & 16.7 & 7685.3 & $44 \sqrt[3]{3}$ & $8 / 13 / 20$ & 16.7 & 682.2 & 4532 & $8 / 13 / 2008$ 17:32 & 16.7 & \begin{tabular}{|l|}
669.6 \\
\end{tabular} & 4601 & $8 / 13 / 200819.50$ & 16.7 & 676.7 & 4670 & $8 / 13 / 20082208$ & 16.7 & 664.1 \\
\hline & & & & 4464 & & 16.8 & 679.9 & & $817: 34$ & 16.7 & 665.1 & 4602 & $8 / 13 / 200819.52$ & 16.7 & 676.5 & 4671 & & & \\
\hline 4396 & $8 / 13 / 2$ & 16.7 & 685.8 & 4465 & $8 / 13 / 20$ & 16.7 & 680.3 & 4534 & $8 / 13 / 200817: 36$ & 16.7 & 6626 & 4603 & $8 / 13 / 200819.54$ & 16.7 & 676.5 & 4672 & $8 / 13 / 200822: 12$ & 16.7 & 663.8 \\
\hline 4397 & $8 / 13 / 2$ & 16.7 & 685.3 & 4466 & $8 / 13 / 2$ & 16.7 & 678.9 & 4535 & 17:38 & 16.7 & 663.5 & 4604 & $8 / 13 / 200819.56$ & 16.7 & \begin{tabular}{|l|}
675.8 \\
\end{tabular} & 4673 & & 16.7 & \\
\hline & $8 / 13 / 2$ & 16.7 & 685.8 & 4467 & $8 / 13 / 20$ & 16.7 & 678 & 4536 & $317: 40$ & 16.7 & 663 & 4606 & & 16.7 & 675.2 & 4674 & & & 663.1 \\
\hline 4399 & $8 / 13 / 200813: 06$ & 16.7 & 686.2 & 4468 & $8 / 13 / 200815: 24$ & 16.7 & 676.1 & 4537 & 817:42 & 16.7 & 662.4 & 1606 & 320.00 & 16.7 & $\begin{array}{ll}674.7 \\
\end{array}$ & 4675 & 082218 & 16.7 & 664.5 \\
\hline 400 & $8 / 13 / 2$ & 16.7 & 686.2 & 4469 & $8 / 13$ & 16.7 & 675.6 & 4538 & $17: 44$ & 16.7 & 661.5 & 4607 & 320.02 & & & 4676 & & 16.7 & \\
\hline 4401 & $8 / 13 / 2$ & 16.7 & 686.5 & 4470 & $8 / 13$ & 16.7 & 674.3 & 4539 & 17:46 & 16.7 & 661.4 & 4608 & $8 / 13$ & 16.7 & \begin{tabular}{|l|}
671.5 \\
\end{tabular} & 4677 & $8 / 13 / 20082222$ & 16.7 & 664.7 \\
\hline 402 & $8 / 13 / 2$ & 16.7 & 686.3 & 4471 & $8 / 13 / 2$ & 16.7 & 673 & 4540 & $17: 48$ & 16.7 & \begin{tabular}{|l|}
663.1 \\
\end{tabular} & 4600 & $320: 06$ & 16.7 & 671.5 & 4678 & $822: 24$ & 16.7 & 665.8 \\
\hline 4003 & $8 / 13 / 2$ & 16.7 & 606.2 & 4472 & & 16.7 & 674.3 & 4541 & $17: 50$ & 16.7 & 662.9 & 017 & & & & 4679 & & & \\
\hline 4404 & $8 / 13 / 2$ & 16.7 & 686 & 4473 & $8 / 13 / 2$ & 16.7 & 673.8 & 4542 & 17:52 & 16.7 & 663.2 & 4611 & $320: 10$ & 16.7 & 664.2 & 4680 & $8 / 13 / 20082228$ & 16.7 & 667 \\
\hline 405 & $8 / 13 /$ & 16.7 & 7) 686.3 & 4474 & $8 / 13$ & 16.7 & 672.8 & 4543 & $17: 54$ & 167 & 662.7 & $\overline{612}$ & 320.12 & 16.7 & 666.4 & 4681 & 082230 & 16.7 & 667.2 \\
\hline 4406 & $8 / 13$ & 16.7 & 686.6 & 4475 & & 16.7 & 671.4 & 4544 & $7: 56$ & 16.7 & & & & 76.8 & 670. & 4682 & & & \\
\hline 107 & $8 / 13$ & 16.7 & 606.7 & 776 & $8 / 13$ & 16.7 & 671.9 & 4545 & $17: 58$ & 16.7 & 664.1 & $\overline{4614}$ & $20: 16$ & 16.7 & 606 & 4683 & 32234 & 16.7 & 667.8 \\
\hline 408 & $8 / 13$ & & \begin{tabular}{|l|}
687.4 \\
\end{tabular} & & & & 6881.2 & 4546 & & & \begin{tabular}{|l|l}
664.6 \\
\end{tabular} & & & 16.7 & 667.4 & 4684 & & & 667.7 \\
\hline 409 & $13: 26$ & 16.7 & 687.5 & 4478 & $8 / 13$ & 16.7 & 682.1 & 4547 & 18.02 & 16.7 & 665.4 & 4616 & $320: 20$ & 16.7 & 669.2 & 4685 & 822,38 & 16.7 & 667 \\
\hline 4410 & $8 / 13$ & 16.7 & 687.4 & 4479 & $8 / 13$ & 16.7 & 677.1 & 4548 & 88.04 & 16.7 & 666.3 & 4617 & 20.22 & 16.7 & 671 & 4606 & 82240 & 16.7 & 667.3 \\
\hline 4411 & $8 / 13 / 2$ & 16.7 & 687.4 & 4480 & & 16.7 & & 4549 & 18:06 & 16.7 & & 1618 & 20.24 & 16.7 & 672 & 4687 & & 16.7 & \\
\hline 4412 & $8 / 13 / 2$ & 16.7 & 687.7 & 481 & & 16.7 & 677.2 & 4550 & & \begin{tabular}{|c|}
16.7 \\
\end{tabular} & 666.2 & & $20: 26$ & 16.7 & 673 & 468 & 2244 & 16.7) & 668.8 \\
\hline$\overline{413}$ & $8 / 13$ & 16.7 & 687.8 & 182 & $8 / 13$ & 16.7 & 677.7 & \begin{tabular}{|l|}
45551 \\
\end{tabular} & & 16.7 & 666.2 & 620 & $20: 28$ & 16.7 & 673 & 468 & & 16.7 & 669.9 \\
\hline 4414 & $8 / 13$ & 16.7 & 688 & 4483 & $8 / 13$ & 16.7 & & \begin{tabular}{|l|l|}
4552 \\
\end{tabular} & $18: 12$ & \begin{tabular}{|l|}
16.7 \\
\end{tabular} & 666 & 4621 & $8 / 13$ & 16.7 & 672 & 4690 & 82248 & 16.7 & 670.3 \\
\hline 4415 & $8 / 13$ & 16.7 & 7688.5 & 4484 & $8 / 13$ & 16.7 & 678.1 & 4553 & $8: 14$ & 16.7 & 666 & 1522 & 20.32 & \begin{tabular}{|c|}
16.7 \\
\end{tabular} & 673 & 4691 & 2250 & 16.7 & 670.7 \\
\hline 4416 & $8 / 13$ & 16.7 & 4688.7 & 4485 & & 16.7 & 677. & 45554 & & \begin{tabular}{|l}
16.7 \\
\end{tabular} & 66 & $\overline{\sigma 2}$ & 0.34 & \begin{tabular}{|c|}
16.7 \\
\end{tabular} & 673 & 4692 & & 16.7 & 671. \\
\hline 4417 & & 16.7 & 6688.7 & 4486 & & 16.7 & & & & \begin{tabular}{|l|l}
16.7 \\
\end{tabular} & & & $20: 36$ & \begin{tabular}{|c|}
16.7 \\
\end{tabular} & & 469 & 2254 & 16.7 & 670.2 \\
\hline 4418 & & 16.7 & 688.7 & 87 & & 16.7 & 677. & 4556 & & 16.7 & 668.6 & & $20: 38$ & 16.7 & 673 & 469 & & 16.7 & 669.6 \\
\hline 4419 & $8 / 13$ & 16.7 & प) 688. & 4488 & $8 / 13$ & 16.7 & 678. & 4557 & & 16.7 & 668 & 1026 & $20: 40$ & \begin{tabular}{|c|}
16.7 \\
\end{tabular} & 673 & 4696 & 2258 & 16.7 & 670.3 \\
\hline & & 16.7 & 688. & & & 16.7 & $6 \pi$ & \begin{tabular}{|l|l|}
4558 \\
\end{tabular} & & \begin{tabular}{|l|}
16.7 \\
\end{tabular} & 667. & 4627 & $20: 42$ & 16.7 & 674 & 4696 & $23: 00$ & 16.7 & 6724 \\
\hline 4421 & $8 / 13$ & 16.7 & (7) 688. & 490 & & 16.7 & 678. & 4559 & & 16.7 & & & 20.44 & \begin{tabular}{l|l|}
16.7 \\
\end{tabular} & 67 & 4697 & & 16.7 & 6724 \\
\hline 4422 & & 16.7 & 7688.9 & 91 & & 16.7 & 678 & \begin{tabular}{|l|l|}
4560 \\
\end{tabular} & & 16.7 & 669 & $462 x$ & 20.46 & 16.7 & 675 & 4698 & $3: 04$ & 16.7 & 671.8 \\
\hline 4423 & & 16.7 & 6889.1 & 992 & & 16.7 & 677.7 & \begin{tabular}{|l|}
4561 \\
\end{tabular} & & 16.7 & 669.9 & & 00.48 & 16.7 & & & $23: 06$ & 16.7 & 671.9 \\
\hline 4424 & & 16.7 & 689 & 193 & & 16.7 & 677.5 & 4562 & $8: 32$ & 16.7 & 671.7 & & & 16.7 & 67 & 47 & & 16.7 & 6722 \\
\hline & & 16.8 & \begin{tabular}{l|l}
3688.4 \\
\end{tabular} & & & 16.7 & & & & 16.7 & & & & 16.7 & 67 & & & 16.7 & 673.4 \\
\hline 1126 & & 16.7 & 768 & 95 & & 16.7 & 678 & 564 & & 16.7 & 67 & & & 16.7 & & & & 16.7 & \\
\hline 4427 & $8 / 13$ & 16.7 & (1) 689 & 4496 & & 16.7 & 6 & 4565 & & 16.7 & & & 20.56 & 16.7 & 677 & 4703 & 23.14 & \begin{tabular}{|c|}
16.7 \\
\end{tabular} & 674.6 \\
\hline & & 16.7 & 688.8 & & & 16.7 & 678.5 & 4566 & & \begin{tabular}{|l|l}
16.7 \\
\end{tabular} & & & & \begin{tabular}{l|l|}
16.7 \\
\end{tabular} & & & & \begin{tabular}{|c|}
16.7 \\
\end{tabular} & 674.7 \\
\hline 4429 & & 16.7 & 7688.6 & & & 16.7 & 679.7 & 1567 & & 16.7 & & & & 16.7 & 67 & & & 16.7 & \\
\hline 44 & & 16.7 & 768 & & & 16.7 & & 45 & & 16.7 & & & & 16.7 & & & & 16.7 & 675.3 \\
\hline 4431 & & 16.7 & 7688 & & & 16.7 & 680 & & & 16.7 & & & & 16.7 & & & & 16.7 & 675.4 \\
\hline 4432 & & 16.7 & 7 688.2 & & & 16.7 & 681.2 & \begin{tabular}{|l|}
4570 \\
\end{tabular} & 848 & 16.7 & 677.5 & & & 16.7 & 67 & & 23.24 & 16.7 & 675.1 \\
\hline & & 16.7 & 688.2 & & & 16.7 & & & & $\begin{array}{l}16.7 \\
\end{array}$ & 678.4 & & & \begin{tabular}{|c|}
16.7 \\
\end{tabular} & & & & \begin{tabular}{|c|}
16.7 \\
\end{tabular} & 675.1 \\
\hline 4434 & & 16.7 & 7687.5 & & & 16.7 & & 4572 & & 16.7 & & & & 16.7 & & & & 16.7 & \\
\hline$\overline{44}$ & & 16.7 & 68 & & & 16.7 & & 4573 & & \begin{tabular}{|l|}
16.7 \\
\end{tabular} & 67 & & & $\begin{array}{l}16.7 \\
\end{array}$ & 678 & & & 16.7 & 675.3 \\
\hline & & 16.7 & 686 & & & 16.7 & & & & \begin{tabular}{|l|}
16.7 \\
\end{tabular} & & & & 16.7 & & & & 16.7 & 675.1 \\
\hline 4437 & $8 / 1$ & 16.7 & 685.7 & & $6: 40$ & 16.7 & 681 & 4575 & & 16.7 & 67 & 164 & & 16.7 & 678 & 13 & $23: 34$ & 16.7 & 675 \\
\hline & & 16.7 & 685.1 & & & 16.7 & 681. & & & 16.7 & & & & & & & & 16.7 & \\
\hline 4439 & & 16.7 & 685 & & & 16.7 & & & & 16.7 & & & & \begin{tabular}{|l|}
16.7 \\
\end{tabular} & & & $23: 38$ & 16.7 & 6752 \\
\hline 4440 & & 16.7 & 684.8 & & & 16.7 & & 4578 & & \begin{tabular}{|l|l}
16.7 \\
\end{tabular} & & & & $\begin{array}{l}16.7 \\
\end{array}$ & & & & 16.7 & 75.1 \\
\hline & & & & & & & & & & & & & & & & & & 16.7 & \\
\hline 4442 & $8 / 13$ & 16.7 & 683.9 & & & 16.7 & 682 & 4580 & 9.08 & 16.7 & 680 & 4649 & 21:26 & 16.7 & 68 & 718 & $23: 44$ & 16.7 & 675.7 \\
\hline & & 16.7 & 683.5 & & & 16.7 & & & & 16.7 & & & & 16.7 & & & & 167 & \\
\hline & & 16.7 & 683. & & & 16.7 & & & & 16.7 & 680. & & & 16.7 & & & $23: 48$ & 16.7 & 675. \\
\hline 4445 & & 16.7 & 683.5 & & & 16.7 & & 4583 & & 16.7 & 679. & 652 & & 16.7 & & & & 16.7 & \\
\hline & & & 683.7 & & & & & & & & 679.6 & & & & & & & 16.7 & \\
\hline 4447 & 14:42 & 16.7 & 683.7 & & $8 / 13$ & 16.7 & 683.6 & 4585 & 19:18 & 16.7 & 670 & 4654 & $821: 36$ & 16.7 & $679 !$ & 4723 & $823: 54$ & 16.7 & 674.9 \\
\hline 4448 & 8113 & 16.7 & 684.2 & & & 16.7 & 683.3 & \begin{tabular}{|l|l|}
4586 \\
\end{tabular} & & 16.7 & 679.1 & 4655 & & 16.7 & 679 & 4724 & & 16.7 & \\
\hline & $8 / 13$ & 16.7 & 684.6 & & & & 683.2 & 587 & & 16.7 & & & 21:40 & 16.7 & & & & 16. & \\
\hline & $8 / 13$ & $3 \longdiv { 1 6 . 7 }$ & 684 & & $8 / 13$ & 16.7 & 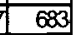 & \begin{tabular}{|l|l}
4588 \\
\end{tabular} & 8 19.24 & 16.7 & 678.8 & 4657 & $821: 42$ & 16.7 & 679 & 4726 & $080: 00$ & 16.7 & 674.8 \\
\hline 51 & 8113 & & 684.9 & & & 16.7 & 6828 & \begin{tabular}{|l|}
4589 \\
\end{tabular} & & 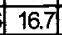 & & 4658 & $821: 44$ & 16.7 & & 4727 & & 16.7 & \\
\hline & & & & & & & & & & & & & & & & 728 & $8 / 14 / 20080004$ & 16.8 & \\
\hline
\end{tabular}


DOE/RL-2009-35, REV. 0

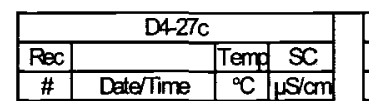
\begin{tabular}{|l|l|l|l|}
\hline 4720 & 8/14/2008 $0: 06$ & 16.7 & 674.3 \\
\hline
\end{tabular}

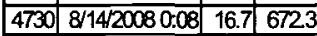
\begin{tabular}{|l|l|l|l|}
\hline 4731 & $8 / 14 / 20080: 10$ & 16.7 & 671.5 \\
\hline
\end{tabular}

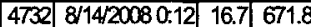
\begin{tabular}{|l|l|l|l|}
\hline 4733 & $8 / 14 / 20080: 14$ & 16.7 & 6722 \\
\hline 434 & $8 / 42008016$ & 16.7 & 671.8 \\
\hline
\end{tabular} \begin{tabular}{|l|l|l|l|}
\hline 4734 & $8 / 14 / 20080: 16$ & 16.7 & 671.8 \\
\hline
\end{tabular} \begin{tabular}{|l|l|l|l|}
\hline 4735 & $8 / 14 / 20080: 18$ & 16.7 & 6700 \\
\hline
\end{tabular} \begin{tabular}{|l|l|l|l|}
\hline 4736 & $8 / 14 / 20080: 20$ & 16.7 & 670.8 \\
\hline
\end{tabular} \begin{tabular}{|l|l|l|l|}
\hline 4737 & $8 / 14 / 20080: 22$ & 16.7 & 669.8 \\
\hline
\end{tabular} \begin{tabular}{|l|l|l|l|}
\hline 4738 & $8 / 14 / 20080: 24$ & 16.7 & 669.9 \\
\hline
\end{tabular}

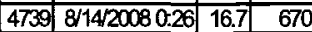
\begin{tabular}{|l|l|l|l|}
\hline 4740 & $8 / 14 / 20080.28$ & 16.7 & 670.3 \\
\hline
\end{tabular}

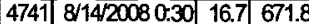

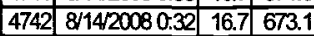

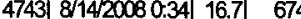

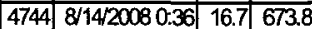

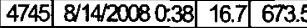
\begin{tabular}{|l|l|l|l|}
\hline 4746 & $8 / 14 / 20080: 40$ & 16.7 & 673.9 \\
\hline
\end{tabular}

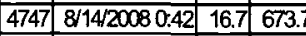
\begin{tabular}{|l|l|l|l|}
\hline 4748 & $8 / 14 / 200800: 44$ & 16.7 & 673.9 \\
\hline
\end{tabular} \begin{tabular}{|l|l|l|l|}
\hline 4749 & $8 / 14 / 20080: 46$ & 16.7 & 673.8 \\
\hline
\end{tabular}

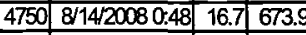

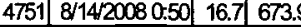

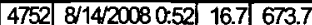
\begin{tabular}{|l|l|l|l|}
\hline 4753 & $8 / 14 / 20080: 54$ & 16.7 & 673.9 \\
\hline
\end{tabular}

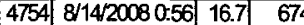
\begin{tabular}{|r|r|r|r|}
\hline 4755 & $8 / 14 / 20080.58$ & 16.7 & 674.3 \\
\hline
\end{tabular}

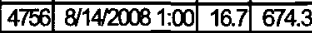
\begin{tabular}{|l|l|l|l|l|}
\hline 4757 & $8 / 14 / 2008$ & $1: 02$ & 16.7 & 674.2 \\
\hline
\end{tabular}

\begin{tabular}{|l|l|l|l|}
\hline 4758 & $8 / 14 / 2008$ 1:04 & 16.7 & 674.2 \\
\hline
\end{tabular}

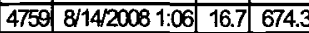
\begin{tabular}{|l|l|l|l|}
\hline 4760 & $8 / 14 / 20081: 08$ & 16.7 & 674.3 \\
\hline
\end{tabular} \begin{tabular}{|l|l|l|l|}
\hline 4761 & $8 / 14 / 20081: 10$ & 16.7 & 674.2 \\
\hline
\end{tabular} \begin{tabular}{|l|l|l|l|}
\hline 4762 & $8 / 14 / 20081: 12$ & 16.7 & 674.3 \\
\hline
\end{tabular} \begin{tabular}{|l|l|l|l|}
\hline $4763 / 14 / 2008$ & $1: 14$ & 16.7 & 674.4 \\
\hline
\end{tabular}

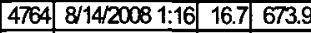
\begin{tabular}{|l|l|l|l|}
\hline 4765 & $8 / 14 / 2008$ 1:18 & 16.7 & 673.6 \\
\hline
\end{tabular} \begin{tabular}{|l|l|l|l|}
\hline 4766 & $8 / 14 / 20081: 20$ & 16.7 & 673. \\
\hline
\end{tabular} \begin{tabular}{|l|l|l|l|}
\hline 4767 & $8 / 14: 20081: 22$ & 16.7 & 673.4 \\
\hline
\end{tabular} \begin{tabular}{|l|l|l|l|l|}
\hline 4768 & $8 / 14 / 2008$ 1:24 & 16.7 & 673.3 \\
\hline
\end{tabular}

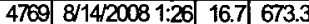

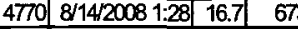

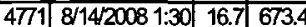

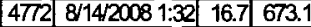

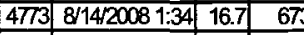

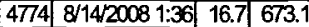
\begin{tabular}{|l|l|l|l|}
\hline 4775 & $8 / 14 / 2008$ & $1: 38$ & 16.7 \\
\hline
\end{tabular}

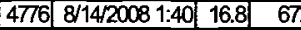

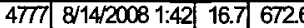

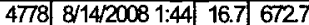

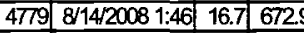
\begin{tabular}{|l|l|l|l|l|}
\hline 4780 & $8 / 14 / 2008$ & $1: 48$ & 16.7 & 672 \\
\hline
\end{tabular}

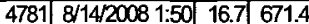

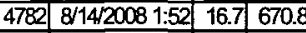
\begin{tabular}{|l|l|l|l|l|}
\hline $4783 / 14 / 2008$ & $1: 54$ & 16.7 & 670.7 \\
\hline
\end{tabular}

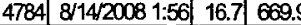

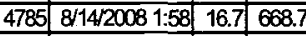
\begin{tabular}{|l|l|l|l|}
\hline 4786 & $8 / 14 / 20082: 00$ & 16.7 & 668.9 \\
\hline
\end{tabular} \begin{tabular}{|l|l|l|l|}
\hline 4787 & $8 / 1420082-07$ & 16.7 & 6684 \\
\hline
\end{tabular} \begin{tabular}{|l|l|l|l|}
\hline 4788 & $8 / 14 / 2008204$ & 16.7 & 668.1 \\
\hline
\end{tabular} \begin{tabular}{|l|l|l|l|}
\hline 4789 & $8 / 14 / 20082: 06$ & 16.7 & 668.5 \\
\hline
\end{tabular} \begin{tabular}{|l|l|l|l|}
\hline 4790 & $8 / 14 / 20082208$ & 16.7 & 667.7 \\
\hline
\end{tabular} \begin{tabular}{|l|l|l|l|}
\hline 4791 & $8 / 14 / 20082-10$ & 16.7 & 668.3 \\
\hline
\end{tabular} \begin{tabular}{|l|l|l|l|}
\hline 4792 & $8 / 14 / 20082: 12$ & 16.7 & 667.9 \\
\hline
\end{tabular} \begin{tabular}{|l|l|l|l|l|}
\hline 4793 & $8 / 14 / 2008214$ & 167 & 652 \\
\hline 4704 & 8142008216 & 167 & 6614 \\
\hline
\end{tabular} \begin{tabular}{|l|l|l|l|}
\hline 4794 & $8 / 14 / 20082: 16$ & 16.7 & 661.4 \\
\hline
\end{tabular} \begin{tabular}{|l|l|l|l|l|}
\hline 4795 & $8 / 14 / 2008218$ & 16.7 & 660.9 \\
\hline
\end{tabular} \begin{tabular}{|l|l|l|l|}
\hline 4796 & $8 / 14 / 20082220$ & 16.7 & 660.8 \\
\hline 4
\end{tabular} \begin{tabular}{|l|l|l|l|}
\hline $477 / 14 / 20082222$ & 16.7 & 660.5 \\
\hline 4797 & $8 / 2$ & \\
\hline
\end{tabular}
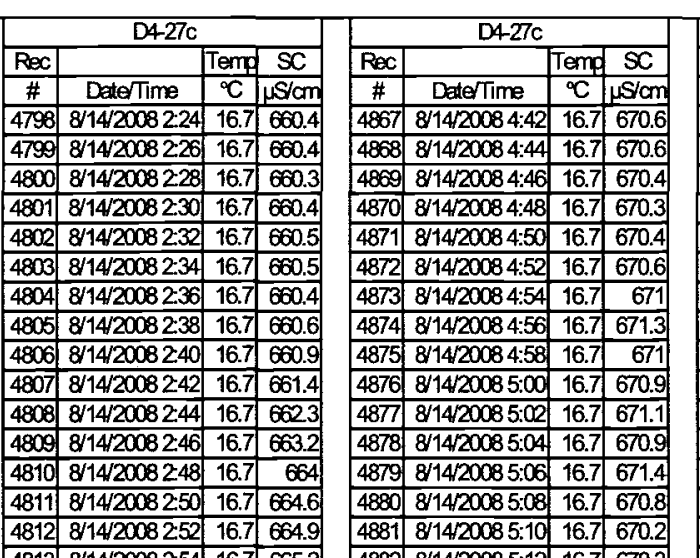

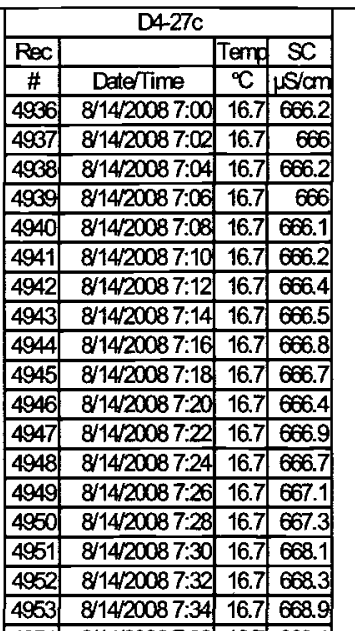
\begin{tabular}{|l|l|l|l|}
\hline 4883 & $8 / 14 / 20085: 14$ & 16.7 & 670.1 \\
\hline
\end{tabular} \begin{tabular}{|l|l|l|l|}
\hline 4884 & $8 / 14 / 20085: 16$ & 16.7 & 670.4 \\
\hline
\end{tabular} \begin{tabular}{|l|l|l|l|}
\hline 4885 & $8 / 14 / 20085: 18$ & 16.7 & 669.4 \\
\hline 4886 & $8 / 4 / 20085: 20$ & 16.7 & 669.1 \\
\hline
\end{tabular} \begin{tabular}{|l|l|l|l|}
\hline 4886 & $8 / 14 / 20085: 20$ & 16.7 & 669.1 \\
\hline 4867 & $8 / 4 / 2008522$ & 16.7 & 669.2 \\
\hline
\end{tabular} \begin{tabular}{|l|l|l|l|}
\hline 4887 & $8 / 14 / 20085: 22$ & 16.7 & 669.2 \\
\hline
\end{tabular} \begin{tabular}{|l|l|l|l|}
\hline 4888 & $8 / 14 / 20085: 24$ & 16.7 & 668. \\
\hline 4889 & $8 / 4 / 2008526$ & 16.7 & 667.9 \\
\hline
\end{tabular} \begin{tabular}{|l|l|l|l|}
\hline 4889 & $8 / 14 / 20085: 26$ & 16.7 & 667.9 \\
\hline
\end{tabular} \begin{tabular}{|l|l|l|l|}
\hline 4890 & $8 / 14 / 20085: 28$ & 16.7 & 668.2 \\
\hline
\end{tabular} \begin{tabular}{|l|l|l|l|}
\hline 4891 & $8 / 14 / 20085: 30$ & 16.7 & 667.4 \\
\hline 4892 & $8 / 14 / 20085: 32$ & 16.7 & 656.9 \\
\hline
\end{tabular} \begin{tabular}{|l|l|l|l|}
\hline 4892 & $8 / 14 / 20085: 32$ & 16.7 & 666 \\
\hline
\end{tabular} \begin{tabular}{|l|l|l|l|}
\hline 4893 & $8 / 14 / 20085: 34$ & 16.7 & 667.5 \\
\hline
\end{tabular} \begin{tabular}{|l|l|l|l|}
\hline 4894 & $8 / 14 / 20085: 36$ & 16.7 & 667 \\
\hline 4985 & $8 / 14 / 2085: 38$ & 16.7 & 666.6 \\
\hline
\end{tabular} \begin{tabular}{|l|l|l|l|}
\hline 4895 & $8 / 14 / 20085: 38$ & 16.7 & 666.6 \\
\hline
\end{tabular} \begin{tabular}{|l|l|l|l|}
\hline 4896 & $8 / 14 / 20085: 40$ & 16.7 & 666.4 \\
\hline
\end{tabular} \begin{tabular}{|l|l|l|r|}
\hline 4897 & $8 / 14 / 20085: 42$ & 16.7 & 666 \\
\hline
\end{tabular} \begin{tabular}{|l|l|l|l|}
\hline 4898 & $8 / 14 / 20085: 44$ & 16.7 & 665 \\
\hline
\end{tabular} \begin{tabular}{|l|l|l|l|}
\hline 4899 & $8 / 14 / 20085: 46$ & 16.7 & 665.8 \\
\hline
\end{tabular} \begin{tabular}{|l|l|l|l|}
\hline 4900 & $8 / 14 / 20085: 48$ & 16.7 & 665.5 \\
\hline
\end{tabular} \begin{tabular}{|l|l|l|l|}
\hline 4901 & $8 / 14 / 20085: 50$ & 16.7 & 665.2 \\
\hline
\end{tabular} \begin{tabular}{|l|l|l|l|}
\hline 4902 & $8 / 14 / 20085: 52$ & 16.7 & 664.8 \\
\hline
\end{tabular} \begin{tabular}{|l|l|l|l|}
\hline 4903 & $8 / 14 / 20085: 54$ & 16.7 & 664.6 \\
\hline 4904 & $8 / 14 / 20085: 56$ & 16.7 & 664.5 \\
\hline
\end{tabular} \begin{tabular}{|l|l|l|l|}
\hline 4904 & $814 / 20085: 56$ & 16.7 & 664.5 \\
\hline
\end{tabular} \begin{tabular}{|l|l|l|l|}
\hline 4905 & $8 / 14 / 20085: 58$ & 16.7 & 664.5 \\
\hline 4006 & $8 / 14 / 20086: 00$ & & 6649 \\
\hline
\end{tabular} \begin{tabular}{|l|l|l|l|}
\hline 4906 & $8 / 14 / 20086: 00$ & 16.7 & 664.9 \\
\hline 4907 & $8 / 14 / 20066: 00$ & 16.8 & 65.4 \\
\hline
\end{tabular} \begin{tabular}{|l|l|l|l|}
\hline 4907 & $8 / 14 / 20086: 02$ & 16.8 & 663.4 \\
\hline
\end{tabular} \begin{tabular}{|l|l|l|l|}
\hline 4908 & $8 / 14 / 20086: 04$ & 16.7 & 666.6 \\
\hline 4908 & $8 / 14 / 20086: 06$ & 16.7 & 668.8 \\
\hline
\end{tabular} \begin{tabular}{|l|l|l|l|}
\hline 4909 & $8 / 14 / 20086: 06$ & 16.7 & 668.8 \\
\hline 4910 & $8 / 14 / 20086.08$ & 16.7 & 6728 \\
\hline
\end{tabular} \begin{tabular}{|l|l|l|l|}
\hline 4910 & $8 / 14 / 20086: 08$ & 16.7 & 672.8 \\
\hline
\end{tabular} \begin{tabular}{|l|l|l|l|}
\hline 4911 & $8 / 14 / 20086: 10$ & 16.7 & 652 \\
\hline 4912 & $8 / 4 / 20086: 12$ & 16.7 & 6524 \\
\hline
\end{tabular} \begin{tabular}{|l|l|l|l|}
\hline 4912 & $8 / 14 / 20086: 12$ & 16.7 & 6624 \\
\hline
\end{tabular} \begin{tabular}{|l|l|l|l|}
\hline 4913 & $8 / 14 / 20086: 14$ & 16.7 & 6623 \\
\hline
\end{tabular} \begin{tabular}{|l|l|l|l|}
\hline 4914 & $814 / 20086: 16$ & 16.7 & 6623 \\
\hline
\end{tabular} \begin{tabular}{|l|l|l|l|}
\hline 4915 & $8 / 14 / 20086: 18$ & 16.7 & 6626 \\
\hline
\end{tabular} \begin{tabular}{|l|l|l|l|}
\hline 4916 & $8 / 14 / 20086: 20$ & 16.7 & 662.5 \\
\hline
\end{tabular} \begin{tabular}{|l|l|l|l|}
\hline 4917 & $8 / 14 / 20086: 22$ & 16.7 & 662. \\
\hline 4918 & $814 / 20086.24$ & 16.7 & 6626 \\
\hline
\end{tabular} \begin{tabular}{|l|l|l|l|}
\hline 4918 & $8 / 14 / 20086: 24$ & 16.7 & 6626 \\
\hline
\end{tabular} \begin{tabular}{|l|l|l|l|}
\hline 4919 & $8 / 14 / 20086: 26$ & 16.7 & 6626 \\
\hline
\end{tabular} \begin{tabular}{|l|l|l|l|}
\hline 4920 & $8 / 14 / 20086: 28$ & 16.7 & 662 \\
\hline
\end{tabular} \begin{tabular}{|l|l|l|l|}
\hline 4921 & $8 / 14 / 20086: 30$ & 16.7 & 663.2 \\
\hline 4922 & $8 / 4 / 2008633$ & 16. & 653.1 \\
\hline
\end{tabular} \begin{tabular}{|l|l|l|l|}
\hline 4922 & $8 / 14 / 20086: 32$ & 16.7 & 663. \\
\hline
\end{tabular} \begin{tabular}{|l|l|l|l|}
\hline 4923 & $8 / 14 / 20086: 34$ & 16.7 & 663.3 \\
\hline 4924 & $814 / 20086: 36$ & 16.7 & 663.5 \\
\hline
\end{tabular} \begin{tabular}{|l|l|l|l|}
\hline 4924 & $8 / 14 / 20086: 36$ & 16.7 & 663 \\
\hline
\end{tabular} \begin{tabular}{|l|l|l|l|}
\hline 4925 & $8 / 14 / 20086: 38$ & 16.7 & 663.9 \\
\hline
\end{tabular} \begin{tabular}{|l|l|l|l|}
\hline 4926 & $8 / 14 / 20086: 40$ & 16.7 & 664.1 \\
\hline
\end{tabular} \begin{tabular}{|l|l|l|l|}
\hline 4927 & $814 / 20086: 42$ & 167 & 664 \\
\hline
\end{tabular} \begin{tabular}{|l|l|l|l|}
\hline 4928 & $8 / 14 / 20086: 44$ & 16.7 & 664 \\
\hline
\end{tabular} \begin{tabular}{|l|l|l|l|}
\hline 4929 & $8 / 14 / 20086: 46$ & 16.7 & 664. \\
\hline
\end{tabular} \begin{tabular}{|l|l|l|l|}
\hline 4930 & $8 / 14 / 20086: 48$ & 16.7 & 664.8 \\
\hline
\end{tabular} \begin{tabular}{|l|l|l|l|}
\hline 4931 & $8 / 14 / 20086: 50$ & 16.7 & 664.8 \\
\hline
\end{tabular} \begin{tabular}{|l|l|l|l|}
\hline 4932 & $8 / 14 / 20086: 52$ & 16.7 & 665.4 \\
\hline
\end{tabular} \begin{tabular}{|l|l|l|l|}
49933 & $8 / 14 / 20086: 54$ & 16.7 & 665.7 \\
\hline
\end{tabular} \begin{tabular}{|l|l|l|l|}
\hline 4934 & $8 / 14 / 20086: 56$ & 16.7 & 665.8 \\
\hline 4935 & $8 / 14 / 2086: 58$ & 16.7 & 665.8 \\
\hline
\end{tabular} \begin{tabular}{|l|l|l|l|}
\hline 4935 & $8 / 14 / 20086: 58$ & 16.7 & 665.8 \\
\hline
\end{tabular} \begin{tabular}{|l|l|l|l|}
\hline 4954 & $8 / 14 / 20087: 36$ & 16.7 & 669.4 \\
\hline 4955 & $8 / 14 / 20087: 38$ & 16.7 & 669.7 \\
\hline
\end{tabular} \begin{tabular}{|l|l|l|l|}
\hline 4966 & $8 / 14 / 20087: 40$ & 16.7 & 670.6 \\
\hline
\end{tabular} \begin{tabular}{|l|l|l|l|}
\hline 4957 & $8 / 14 / 20087: 42$ & 16.7 & 670.6 \\
\hline 4958 & $8 / 14 / 20087: 41$ & 16.7 & 670.9 \\
\hline
\end{tabular} \begin{tabular}{|l|l|l|}
\hline $8 / 14 / 20087: 44$ & 16.7 & 670.9 \\
\hline
\end{tabular} \begin{tabular}{|l|l|l|}
\hline $8 / 14 / 20087: 46$ & 16.7 & 671.1 \\
\hline $8 / 4 / 20087: 48$ & 16.7 & 671.1 \\
\hline
\end{tabular} \begin{tabular}{|l|l|l|l|}
\hline 4960 & $8 / 14 / 20087: 48$ & 16.7 & 671.1 \\
\hline
\end{tabular} \begin{tabular}{|l|l|l|l|}
\hline 4961 & $8 / 14 / 20087: 50$ & 16.7 & 670.9 \\
\hline
\end{tabular} \begin{tabular}{|l|l|l|l|}
\hline 4962 & $8 / 14 / 20087: 52$ & 16.7 & 670.8 \\
\hline
\end{tabular} \begin{tabular}{|l|l|l|l|}
\hline 4963 & $8 / 14 / 20087: 54$ & 16.7 & 671 \\
\hline
\end{tabular} \begin{tabular}{|l|l|l|r|}
\hline 4964 & $8 / 14 / 20087: 56$ & 16.7 & 670.9 \\
\hline
\end{tabular} \begin{tabular}{l|l|l|l|}
\hline 4965 & $8 / 14 / 20087: 58$ & 16.7 & 670.8 \\
\hline
\end{tabular} \begin{tabular}{l|l|l|l|}
\hline 4966 & $8 / 14 / 20088: 00$ & 16.7 & 670.8 \\
\hline 4967
\end{tabular} \begin{tabular}{|l|l|l|l|}
\hline 4967 & $8 / 14 / 20088: 02$ & 16.7 & 671.1 \\
\hline
\end{tabular} \begin{tabular}{|l|l|l|l|}
\hline 4968 & $8 / 14 / 20088: 04$ & 16.7 & 671.4 \\
\hline 4960 & $8 / 4 / 20088.06$ & 16.7 & 671.9 \\
\hline
\end{tabular} \begin{tabular}{|l|l|l|l|}
\hline 4969 & $8 / 14 / 20088.06$ & 16.7 & 671.9 \\
\hline
\end{tabular} \begin{tabular}{|l|l|l|l|}
\hline 970 & $81420088: 08$ & 16.7 & 671.7 \\
\hline
\end{tabular} \begin{tabular}{|l|l|l|l|}
\hline 4971 & $8 / 14 / 20088: 10$ & 16.7 & 6721 \\
\hline 4972 & $8 / 4 / 20088: 12$ & 16.7 & 6721 \\
\hline
\end{tabular} \begin{tabular}{|l|l|l|l|}
\hline 4972 & $8 / 14 / 20088: 12$ & 16.7 & 6721 \\
\hline
\end{tabular} \begin{tabular}{|l|l|l|l|}
\hline 4973 & $8 / 14 / 20088: 14$ & 16.7 & 671.7 \\
\hline
\end{tabular} \begin{tabular}{|c|c|c|c|}
\hline 4974 & $8 / 1420088: 16$ & 16.7 & 671.7 \\
\hline
\end{tabular} \begin{tabular}{|l|l|l|l|}
\hline 4975 & $8 / 14 / 20088: 18$ & 16.7 & 671.9 \\
\hline 49
\end{tabular} \begin{tabular}{ll|l|l|}
\hline $814 / 20088: 20$ & 16.7 & 671.5 \\
\hline
\end{tabular} \begin{tabular}{|l|l|l|l|}
\hline 4977 & $8 / 14 / 20088: 22$ & 16.8 & 670.5 \\
\hline
\end{tabular} \begin{tabular}{|l|l|l|l|}
\hline 4978 & $8 / 14 / 20088: 24$ & 16.7 & 6726 \\
\hline
\end{tabular} \begin{tabular}{|l|l|l|l|}
\hline 4979 & $8 / 14 / 20088226$ & 16.7 & 671.9 \\
\hline
\end{tabular} \begin{tabular}{|l|l|l|l|}
\hline 4980 & $8 / 14 / 20088: 28$ & 16.7 & 670.9 \\
\hline
\end{tabular} \begin{tabular}{|l|l|l|l|}
\hline 4981 & $8 / 14 / 20088: 30$ & 16.7 & 671.1 \\
\hline
\end{tabular} \begin{tabular}{|l|l|l|l|}
\hline 4982 & $8 / 14 / 20088: 32$ & 16.7 & 671 \\
\hline
\end{tabular} \begin{tabular}{|l|l|l|l|}
\hline 4983 & $8 / 14 / 20088: 34$ & 16.7 & 670.8 \\
\hline 4884
\end{tabular} \begin{tabular}{|l|l|l|l|}
\hline 4984 & $8 / 14 / 20088: 36$ & 16.7 & 670.6 \\
\hline
\end{tabular} \begin{tabular}{|l|l|l|l|}
\hline 4985 & $8 / 14 / 20088: 38$ & 16.7 & 670.6 \\
\hline
\end{tabular} \begin{tabular}{|l|l|l|l|}
\hline 4986 & $8 / 14 / 20088: 40$ & 16.7 & 670.7 \\
\hline 4987 & $814 / 20088: 42$ & 16.7 & 670.6 \\
\hline
\end{tabular} \begin{tabular}{|l|l|l|l|}
\hline 4987 & $8 / 14 / 20088: 42$ & 16.7 & 670.6 \\
\hline
\end{tabular} \begin{tabular}{|l|l|l|l|}
\hline 4988 & $8 / 14 / 20088: 44$ & 16.7 & 670.6 \\
\hline 4989 & $8 / 14 / 20088.46$ & 16.7 & 60.5 \\
\hline
\end{tabular} \begin{tabular}{|l|l|l|l|}
\hline 4989 & $8 / 14 / 20088: 46$ & 16.7 & 670.5 \\
\hline
\end{tabular} \begin{tabular}{|l|l|l|l|}
\hline 4991 & $8 / 14 / 20088: 50$ & 16.7 & 670.7 \\
\hline 4992 & $8 / 14 / 20088: 52$ & 16.7 & 670.7 \\
\hline
\end{tabular} \begin{tabular}{|l|l|l|l|}
\hline 4993 & $8 / 14 / 20088.54$ & 16.7 & 670.9 \\
\hline 4994
\end{tabular} \begin{tabular}{|l|l|l|l|}
\hline 4994 & $8 / 14 / 20088.56$ & 16.7 & 670.5 \\
\hline 4995 & $8 / 4 / 20088.58$ & 16.7 & 670.3 \\
\hline
\end{tabular} \begin{tabular}{|l|l|l|l|}
\hline 4996 & $8 / 14 / 20088: 58$ & 16.7 & 670.3 \\
\hline 4986 & $8 / 4 / 20089: 00$ & 16.8 & 659.3 \\
\hline
\end{tabular} \begin{tabular}{|l|l|l|l|}
\hline 4996 & $8 / 14 / 20089.00$ & 16.8 & 659.3 \\
\hline 4997 & $8 / 14 / 20089.02$ & 16.7 & 670 \\
\hline
\end{tabular} \begin{tabular}{|l|l|l|l|}
\hline 4997 & $8 / 14 / 20089.02$ & 16.7 & 670 \\
\hline
\end{tabular} \begin{tabular}{|l|l|l|l|}
\hline 4998 & $8 / 14 / 20089.04$ & 16.7 & 669.9 \\
\hline 4999 & $8 / 14 / 2089.06$ & 16.7 & 669.9 \\
\hline
\end{tabular} \begin{tabular}{|l|l|l|l|}
\hline 4999 & $8 / 14 / 20089.06$ & 16.7 & 669.9 \\
\hline
\end{tabular} \begin{tabular}{|l|l|l|l|}
\hline 5000 & $8 / 14 / 20089.08$ & 16.7 & 670 \\
\hline
\end{tabular} \begin{tabular}{|l|r|r|r|}
\hline 5001 & $8 / 14 / 20089.10$ & 16.7 & 69.9 \\
\hline 5002 & $8 / 4 / 20089.12$ &
\end{tabular} \begin{tabular}{|l|l|l|l|}
\hline 5002 & $8 / 14 / 20089.12$ & 16.7 & 670 \\
\hline 5003 & $8 / 14 / 20089.14$ & 16.7 & 670 \\
\hline 5004 & $8 / 14 / 20089.16$ & 16.7 & 669.9 \\
\hline
\end{tabular} \begin{tabular}{|l|r|r|r|}
\hline 5003 & $8 / 14 / 20089.14$ & 16.7 & 670 \\
\hline 5004 & $8 / 14 / 20089.16$ & 16.7 & 669.9 \\
\hline
\end{tabular} \begin{tabular}{|l|l|l|l|}
\hline 4990 & $8 / 14 / 20088: 48$ & 16.7 & 670.6 \\
\hline $4991 / 2008.50$ & 16.7 & 670.7 \\
\hline
\end{tabular}

\begin{tabular}{|c|c|c|c|}
\hline \multicolumn{4}{|c|}{ D4-27c } \\
\hline$R e c$ & & Temp & SC \\
\hline \# & Date Time & ${ }^{\circ} \mathrm{C}$ & HS/an \\
\hline 5005 & $8 / 14 / 20089.18$ & 16.7 & 670.3 \\
\hline 5006 & $8 / 14 / 20089.20$ & 16.7 & 670.1 \\
\hline 5007 & $8 / 14 / 20089.22$ & 16.8 & 668.6 \\
\hline 5008 & $8 / 14 / 20089.24$ & 16.7 & 670.2 \\
\hline 5000 & $8 / 14 / 20089.26$ & 16.7 & 670.5 \\
\hline 5010 & $8 / 14 / 20089.28$ & 16.7 & 670.4 \\
\hline 5011 & $8 / 14 / 20089.30$ & 16.7 & 670.4 \\
\hline 5012 & $8 / 14 / 20089.32$ & 16.7 & 670.4 \\
\hline 5013 & 39.34 & 16.7 & 667 \\
\hline 5014 & $8 / 14 / 20089.36$ & 16.7 & 650.8 \\
\hline 5015 & $8 / 14 / 20089.38$ & 16.7 & 654.4 \\
\hline 5016 & & 16.7 & 655 \\
\hline 5017 & 9.42 & 16.7 & 655.2 \\
\hline 5018 & 9.44 & 16.7 & 655.3 \\
\hline 5019 & 9.46 & $\overline{16.7}$ & 655.4 \\
\hline 5020 & & 16.7 & 655.5 \\
\hline 5021 & & 16.7 & 655.7 \\
\hline 5020 & 9.52 & 16.7 & 655.8 \\
\hline 5023 & 39.54 & 16.7 & 656.6 \\
\hline 5024 & 9.56 & 16.7 & 657.2 \\
\hline 5025 & & 16.7 & 657.7 \\
\hline 5026 & $8 / 14$ & 16.7 & 658.8 \\
\hline 5027 & $8 / 14$ & $\overline{16.7}$ & 659.8 \\
\hline 5028 & $8 / 14$ & 16.7 & 661.1 \\
\hline 5029 & 81 & 16.7 & 661.9 \\
\hline 5030 & $8 / 14$ & 16.7 & 661.9 \\
\hline 50031 & $8 / 14$ & 16.7 & 6623 \\
\hline 5032 & & 16.7 & \\
\hline 5003 & & 16.7 & 6624 \\
\hline 5034 & $8 / 1$ & 16.7 & 662.9 \\
\hline 5035 & $8 / 14$ & 16.7 & 663.9 \\
\hline 5036 & $8 / 14$ & 16.7 & 664.6 \\
\hline 5037 & & 16.7 & \\
\hline 5038 & $8 / 1$ & 16.7 & 665.5 \\
\hline 5039 & $8 / 14$ & 16.8 & 664.5 \\
\hline 5040 & & $\overline{16.7}$ & 66 \\
\hline 5041 & & 16.7 & 666 \\
\hline 5042 & $8 / 14$ & 16.7 & 667.2 \\
\hline 5043 & $8 / 1$ & 16.7 & 667.2 \\
\hline 5044 & & $\overline{16.7}$ & 667.6 \\
\hline 5045 & & 16.7 & 667. \\
\hline 5046 & 81 & 16.7 & 668 \\
\hline 5047 & 814 & 16.7 & 668.3 \\
\hline 5048 & $8 / 14$ & 16.7 & 66 \\
\hline 5049 & & 16.7 & \\
\hline 5050 & & 16.7 & 668.5 \\
\hline 5051 & & 16.7 & 668.4 \\
\hline 5052 & & 16.7 & 668.4 \\
\hline 5053 & $8 / 14$ & $\overline{16.7}$ & 668.5 \\
\hline 5054 & $8 / 14$ & 16.7 & 668 \\
\hline 356 & $8 / 14$ & 16.7 & \\
\hline 5056 & $8 / 14$ & 16.7 & \\
\hline 5057 & & 16.7 & 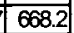 \\
\hline 5058 & & 16.7 & 66 \\
\hline & & 16.7 & 668 \\
\hline 5060 & $8 / 14$ & 16.7 & \\
\hline 5061 & $8 / 14$ & $\overline{16.7}$ & 668 \\
\hline 5062 & $8 / 14$ & 6.7 & 66 \\
\hline & & 10 & \\
\hline & $8 / 14$ & 16.7 & \\
\hline 5065 & $8 / 14 / 20$ & $\overline{16.7}$ & 668.2 \\
\hline 5066 & $8 / 14 / 2$ & 16.7 & 667.9 \\
\hline 5067 & $8 / 14 / 2$ & 16.7 & \\
\hline & & 16.7 & 667 \\
\hline 5069 & $8 / 14 / 2$ & 16.7 & 667. \\
\hline 5070 & $8 / 14 / 20$ & 16.7 & 667.9 \\
\hline 5071 & $8 / 14 / 200811: 30$ & 16.7 & \\
\hline 5072 & & 16.7 & \\
\hline & & & \\
\hline
\end{tabular}




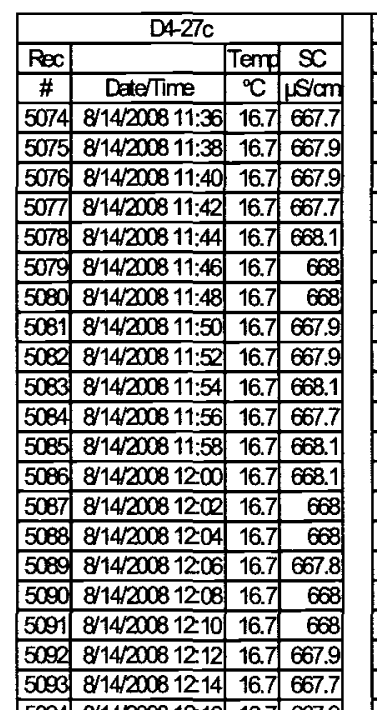

\begin{tabular}{|l|l|l|l|}
\hline 5094 & $8 / 14 / 20081216$ & 16.7 & 667.9 \\
\hline 5006 & $814 / 2081218$ & 16.7 & 66.9 \\
\hline
\end{tabular}

\begin{tabular}{l|l|l|l|}
\hline 5095 & $8 / 14 / 20081218$ & 16.7 & 667.9 \\
\hline
\end{tabular}

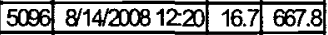

\begin{tabular}{|l|l|l|l|}
\hline 5097 & $8 / 14 / 20081222$ & 16.7 & 667.9 \\
\hline 500 & 8142008122 & 1.6 & 606 \\
\hline
\end{tabular}

\begin{tabular}{|l|l|l|r|}
\hline 5008 & $8 / 14 / 20081224$ & 16.7 & 668 \\
\hline 5099 & $8 / 14 / 20081226$ & 16.7 & 668 \\
\hline 5100 & $8 / 1420081228$ & 16.7 & 660 \\
\hline
\end{tabular}

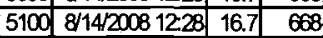

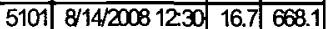

\begin{tabular}{|l|l|l|l|}
\hline 5102 & $8 / 14 / 200812.32$ & 16.7 & 668.2 \\
\hline
\end{tabular}

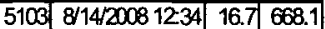

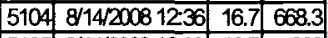

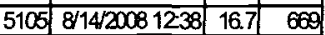

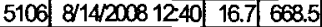

\begin{tabular}{|l|l|l|l|}
\hline 5107 & $8 / 14 / 20081242$ & 16.7 & 668.6 \\
\hline
\end{tabular}

\begin{tabular}{|l|l|l|l|}
\hline 5108 & $8 / 14 / 20081244$ & 16.7 & 668.9 \\
\hline
\end{tabular}

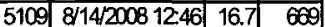

\begin{tabular}{|l|l|l|l|}
\hline 5110 & $8 / 14 / 20081248$ & 16.7 & 609.3 \\
\hline 511 & $8 / 42008$ & 125 &
\end{tabular}

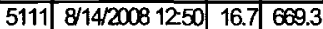

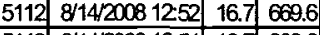

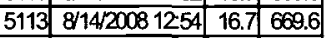

\begin{tabular}{|l|l|l|l|}
\hline 5114 & $8 / 14 / 20081256$ & 16.7 & 669.9 \\
\hline
\end{tabular}

\begin{tabular}{|lll|l|l|}
\hline 5115 & $8 / 14 / 2008$ & 1258 & 16.7 & 670.7 \\
\hline
\end{tabular}

\begin{tabular}{lllll|}
\hline 5116 & $8 / 14 / 2008$ & $13: 00$ & 16.7 & 671.3 \\
\hline
\end{tabular}

\begin{tabular}{|l|l|l|l|}
\hline 5117 & $8 / 14 / 2008$ 13:02 & 16.7 & 671.1 \\
\hline
\end{tabular}

\begin{tabular}{|l|l|l|l|}
\hline 5118 & $8 / 14 / 200813: 04$ & 16.7 & 671.2 \\
\hline
\end{tabular}

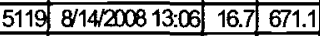

\begin{tabular}{|l|l|l|l|}
\hline 5120 & $8 / 14 / 2008$ 13:08 & 16.7 & 671 \\
\hline
\end{tabular}

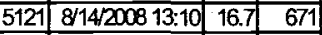

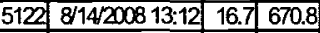

\begin{tabular}{|l|l|l|l|l|}
\hline 5123 & $814 / 2000$ & $13: 14$ & 16.7 & 670.6 \\
\hline
\end{tabular}

\begin{tabular}{|l|l|l|l|}
\hline 5124 & $8 / 14 / 200813: 16$ & 16.7 & 670.1 \\
\hline
\end{tabular}

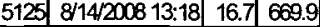

\begin{tabular}{|l|l|l|l|}
\hline 5126 & $8 / 14 / 2008$ 13:20 & 16.7 & 670.1 \\
\hline
\end{tabular}

\begin{tabular}{|l|l|l|l|}
\hline 5127 & $8 / 14 / 200813: 22$ & 16.7 & 670.4 \\
\hline 5
\end{tabular}

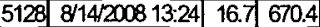

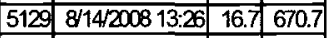

\begin{tabular}{|l|l|l|l|}
\hline 5130 & $8 / 14 / 2008$ & $13: 28$ & 16.7 \\
\hline
\end{tabular}

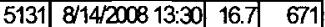

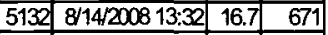

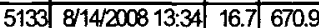

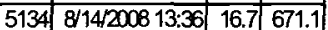

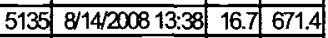

\begin{tabular}{ll|l|l|l|}
\hline 5136 & $8114 / 2008$ & $13: 40$ & 16.7 & 671.4 \\
\hline
\end{tabular}

\begin{tabular}{|lllll|}
\hline 5137 & $8 / 14 / 2008$ & $13: 42$ & 16.7 & 671.5 \\
\hline
\end{tabular}

\begin{tabular}{|l|l|l|l|}
\hline 5138 & $8 / 14 / 200813: 44$ & 16.7 & 671.5 \\
\hline
\end{tabular}

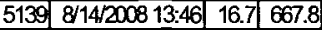

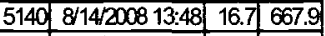

\begin{tabular}{|l|l|l|l|l|}
\hline 5141 & $8 / 14 / 200813: 50$ & 16.7 & 667.9 \\
\hline
\end{tabular}

\begin{tabular}{|l|l|l|l|l|}
\hline 5142 & $8 / 14 / 2008$ & $13: 52$ & 16.7 & 667.8 \\
\hline
\end{tabular}

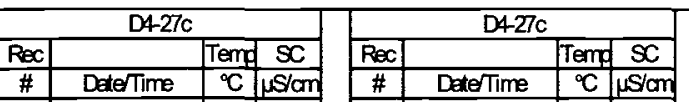

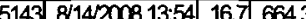 \\ \begin{tabular}{|l|l|l|l|}
\hline 5144 & $8 / 142000813: 56$ & 16.7 & 658.7 \\
\hline
\end{tabular}

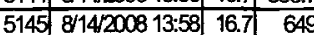

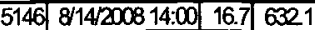

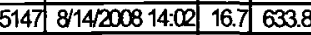

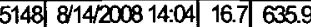 \begin{tabular}{lllll}
5149 & $814 / 2008$ & $14: 06$ & 16.7 & 637.1 \\
\hline
\end{tabular} \begin{tabular}{lllll}
5150 & $8 / 14 / 2008$ & $14: 08$ & 16.7 & 638.1 \\
\hline
\end{tabular} \begin{tabular}{l|l|l|l|}
5151 & $814 / 200814: 10$ & 16.7 & 638.6 \\
\hline
\end{tabular} \\ \begin{tabular}{|c|c|c|c|}
\hline$\#$ & Dade/Time & ${ }^{\circ} \mathrm{C}$ & $\mu \mathrm{S} / \mathrm{cm}$ \\
\hline 5212 & $8 / 14 / 200816: 12$ & 16.7 & 664.8 \\
\hline 5213 & $8 / 14200816.11$ & 16.7 & 6065 \\
\hline
\end{tabular} \begin{tabular}{|l|l|l|l|l|}
\hline 5213 & $8 / 14 / 200816: 14$ & 16.7 & 665.5 \\
\hline
\end{tabular} \begin{tabular}{|l|l|l|l|}
\hline 5214 & 8/14/2008 16:16 & 16.7 & 665.5 \\
\hline
\end{tabular}

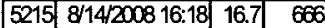 \begin{tabular}{|l|l|l|l|}
\hline $5216 / 14 / 200816: 20$ & 16.7 & 667.1 \\
\hline
\end{tabular}

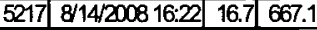 \begin{tabular}{|l|l|l|l|}
\hline 5218 & $8 / 14 / 200816: 24$ & 16.7 & 667 \\
\hline
\end{tabular}

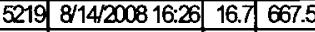

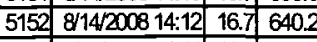
\begin{tabular}{llllll}
\hline 5153 & $8 / 14 / 2008$ & $14: 14$ & 16.7 & 641.5 \\
\hline
\end{tabular} \begin{tabular}{lllll}
5154 & $8 / 142008$ 14:16 & 16.7 & 643.1 \\
\hline
\end{tabular}

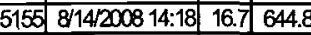
\begin{tabular}{l|l|l|l|}
\hline 5156 & $814 / 2008$ 14:20 & 16.7 & 645.8 \\
\hline
\end{tabular}

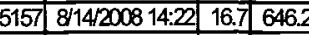

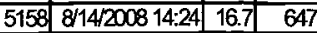

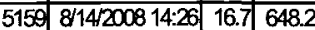

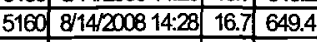

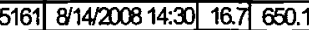
\begin{tabular}{|l|l|l|l|}
\hline 5162 & $8 / 14 / 2008$ & $14: 32$ & 16.7 \\
\hline
\end{tabular}

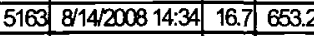
\begin{tabular}{|l|l|l|l|}
\hline 5164 & 8/14/2008 14:36 & 16.7 & 653.7 \\
\hline
\end{tabular} \begin{tabular}{|l|l|l|l|}
\hline 5165 & 811420008 14:38 & 16.7 & 654.4 \\
\hline
\end{tabular}

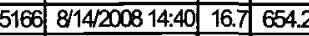
\begin{tabular}{l|l|l|l|l}
5167 & $8114 / 2008$ & $14: 42$ & 16.7 & 654.4 \\
\hline
\end{tabular}

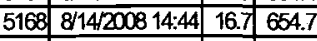
$\begin{array}{lllll}5169 & 8 / 1420008 & 14: 46 & 16.7 & 654.9\end{array}$

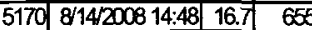

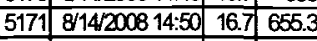
\begin{tabular}{lllll}
\hline 5172 & $8 / 14 / 2008$ & $14: 52$ & 16.7 & 655.3 \\
\hline
\end{tabular} \begin{tabular}{llllll}
5173 & $8 / 14 / 2008$ & $14: 54$ & 16.7 & 655.4 \\
\hline
\end{tabular} \begin{tabular}{lllll}
5174 & $8 / 142008$ & $14: 56$ & 16.7 & 655.5 \\
\hline
\end{tabular} \begin{tabular}{|l|l|l|l|}
\hline 5175 & $8 / 14 / 200814: 58$ & 16.7 & 655.4 \\
\hline
\end{tabular} 5176 8114:2008 15:00 16.7 655.6 \begin{tabular}{lll|l|l|}
5177 & 81142008 & $15: 02$ & 16.7 & 655.9 \\
\hline
\end{tabular} \begin{tabular}{l|l|l|l|}
\hline 5178 & $8 / 14 / 2008$ 15:04 & 16.7 & 656.3 \\
\hline
\end{tabular}

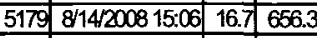

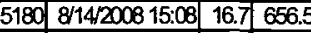
\begin{tabular}{|l|l|l|l|}
\hline 5181 & $8 / 14 / 2008$ 15:10 & 16.7 & 656.7 \\
\hline
\end{tabular}

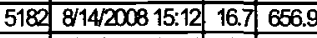
\begin{tabular}{l|l|l|l|l|}
\hline 5183 & $8 / 142008$ 15:14 & 16.7 & 657.1 \\
\hline
\end{tabular} \begin{tabular}{lllll}
5184 & $8 / 14 / 2008$ & $15: 16$ & 16.7 & 67.3 \\
\hline
\end{tabular} \begin{tabular}{ll|l|l|}
\hline 5185 & $814 / 2008$ 15:18 & 16.7 & 657.6 \\
\hline
\end{tabular} \begin{tabular}{l|l|l|l|}
\hline 5186 & $814 / 2008$ 15:20 & 16.7 & 658.1 \\
\hline
\end{tabular} \begin{tabular}{lllll}
5187 & $814 / 200815: 22$ & 16.7 & 658 \\
\hline
\end{tabular}

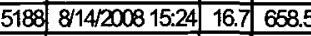

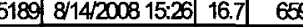
\begin{tabular}{l|l|l|l|}
55190 & $8 / 14200815: 28$ & 16.7 & 659.3 \\
\hline 5191 & 8114200815.30 & 16.7 & 659.9 \\
\hline
\end{tabular} \begin{tabular}{|l|l|l|l|}
\hline 5191 & $8 / 14 / 200815: 30$ & 16.7 & 659.6 \\
\hline 5192 & $8 / 14200815: 32$ & 16.7 & 659.8 \\
\hline
\end{tabular}

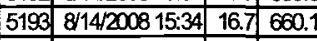
\begin{tabular}{l|l|l|l|}
5194 & $8 / 14 / 200815: 36$ & 16.7 & 660.6 \\
\hline
\end{tabular} \begin{tabular}{l|l|l|l|l|}
51965 & $8 / 14 / 200815: 38$ & 16.7 & 660.7 \\
\hline
\end{tabular} \begin{tabular}{l|l|l|l|}
\hline 5196 & $8 / 14 / 2008$ 15:40 & 16.7 & 660.9 \\
\hline
\end{tabular}

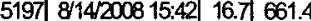

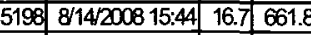

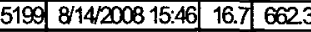

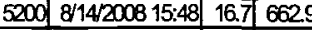

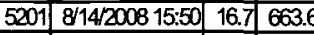

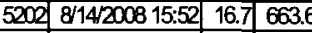

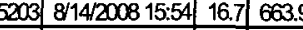

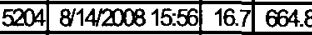

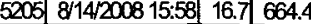
5206 8/14/2008 16:00 16.7 665.6

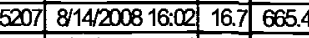
\begin{tabular}{|l|l|l|l|}
\hline 5208 & $8 / 14200816: 04$ & 16.7 & 666 \\
\hline
\end{tabular} \begin{tabular}{|l|l|l|l|}
\hline 5209 & $8 / 142000816: 06$ & 16.7 & 665.4 \\
\hline
\end{tabular}

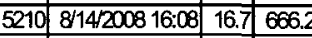
\begin{tabular}{|l|l|l|l|}
\hline 5211 & $8 / 14 / 200816: 10$ & 16.7 & 665.9 \\
\hline
\end{tabular}

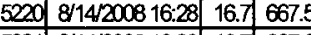
\begin{tabular}{lllll}
5221 & $8 / 14 / 2008$ & $16: 30$ & 16.7 & 667.6 \\
\hline
\end{tabular}

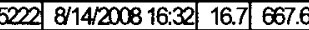

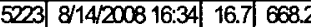

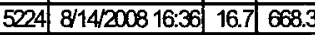
\begin{tabular}{|l|l|l|l|}
\hline 5225 & $81 / 4 / 200816: 38$ & 16.7 & 668.2 \\
\hline
\end{tabular}

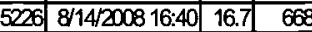

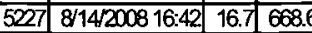
5228 8/14/2008 16:44 16.7 668.6

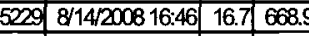

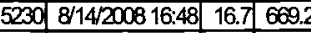
\begin{tabular}{|l|l|l|l|}
5231 & $8 / 14 / 200816: 50$ & 16.7 & 669.5 \\
\hline
\end{tabular} \begin{tabular}{|l|l|l|l|}
\hline 5232 & $8 / 14 / 200816: 52$ & 16.7 & 670.1 \\
\hline
\end{tabular} \begin{tabular}{l|l|l|l|l|}
5233 & $8 / 14 / 2008$ & $16: 54$ & 16.7 & 670.1 \\
\hline
\end{tabular}

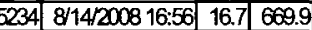

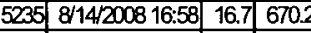

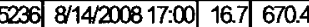
5237 8/14/2008 17:02 16.7 670.5 \begin{tabular}{|l|l|l|l|}
5233 & $8114 / 200817: 04$ & 16.7 & 670.5 \\
\hline
\end{tabular} \begin{tabular}{|l|l|l|l|l|}
\hline 5239 & $8 / 14 / 2008$ & $17: 06$ & 16.7 & 670.4 \\
\hline
\end{tabular} \begin{tabular}{|l|l|l|l|}
\hline 5240 & $8 / 14 / 200817: 08$ & 16.7 & 670.6 \\
\hline
\end{tabular} \begin{tabular}{|l|l|l|l|}
\hline 5241 & $8 / 14 / 200817: 10$ & 16.7 & 670.4 \\
\hline
\end{tabular} \begin{tabular}{|l|l|l|l|}
\hline 5242 & $8 / 14 / 200817: 12$ & 16.7 & 670.4 \\
\hline 5
\end{tabular}

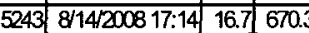
\begin{tabular}{|l|l|l|l|}
\hline 5244 & $8 / 14 / 200817: 16$ & 16.7 & 670.3 \\
\hline
\end{tabular} \begin{tabular}{l|l|l|l|}
5245 & $8 / 14 / 200817: 18$ & 16.7 & 670.1 \\
\hline
\end{tabular} \begin{tabular}{l|l|l|l|}
\hline 5246 & $8 / 14 / 200817: 20$ & 16.7 & 670.2 \\
\hline
\end{tabular} \begin{tabular}{lll|l|l|}
5247 & $8 / 14 / 200817: 22$ & 16.7 & 670.1 \\
\hline
\end{tabular} \begin{tabular}{|l|l|l|r|}
5248 & $8 / 14 / 200817: 24$ & 16.7 & 670 \\
\hline 5220 & $8 / 420091720$ & 167 & 6098 \\
\hline
\end{tabular}

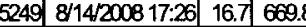

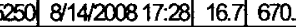
\begin{tabular}{|l|l|l|l|}
\hline 5251 & $8 / 14 / 200817: 30$ & 16.7 & 670.1 \\
\hline
\end{tabular} \begin{tabular}{|l|l|l|l|}
5252 & $8114 / 200817: 32$ & 16.7 & 670.2 \\
\hline
\end{tabular}

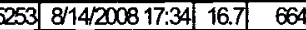
\begin{tabular}{lllll}
5254 & $8 / 14 / 2008$ & $17: 36$ & 16.7 & 664 \\
\hline
\end{tabular}

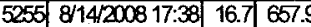
\begin{tabular}{l|l|l|l|}
\hline 5256 & $8 / 14 / 200817: 40$ & 16.7 & 658.2 \\
\hline
\end{tabular}

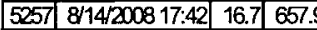
\begin{tabular}{|l|l|l|l|}
\hline 5258 & $8 / 14 / 200817: 44$ & 16.7 & 658.1 \\
\hline
\end{tabular} \begin{tabular}{|l|l|l|l|}
\hline 5259 & $8 / 14 / 200817: 46$ & 16.7 & 658.3 \\
\hline
\end{tabular} \begin{tabular}{|l|l|l|l|}
\hline 5260 & $8 / 14 / 200817: 48$ & 16.7 & 657.9 \\
\hline 500 & $1 / 200017.50$ & 167 & 65.8 \\
\hline
\end{tabular} \begin{tabular}{lll|l|l|}
5261 & $8 / 14 / 2008$ & $17: 50$ & 16.7 & 657 \\
\hline 5 & &
\end{tabular}

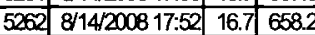

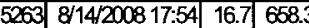
\begin{tabular}{|l|l|l|l|l|}
\hline 5264 & $8 / 14200817: 56$ & 16.7 & 658.5 \\
\hline
\end{tabular} \begin{tabular}{|l|l|l|l|}
52606 & $8 / 14200817.58$ & 16.7 & 658.8 \\
\hline
\end{tabular}

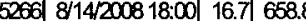
\begin{tabular}{|l|l|l|l|}
\hline 5267 & $8114 / 2008$ 18:02 & 16.7 & 659.2 \\
\hline
\end{tabular} \begin{tabular}{|l|l|l|l|}
\hline 5269 & $8 / 142000818: 06$ & 16.7 & 659.6 \\
\hline
\end{tabular}

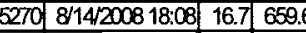
\begin{tabular}{|l|l|l|l|}
\hline 5271 & $8 / 14 / 200818: 10$ & 16.7 & 660 \\
\hline
\end{tabular} \begin{tabular}{lllll}
5272 & $8 / 14 / 2008$ & $18: 12$ & 16.7 & 660 \\
\hline
\end{tabular} \begin{tabular}{|l|l|l|l|}
\hline $5273 / 14 / 2008$ & $18: 14$ & 16.7 & 660 \\
\hline
\end{tabular}

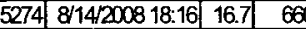

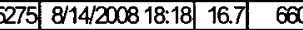

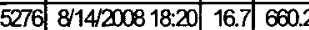

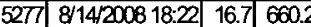
\begin{tabular}{|l|l|l|l|}
\hline 5278 & $8 / 14 / 200818: 24$ & 16.7 & 660.2 \\
\hline 5 & &
\end{tabular} \begin{tabular}{|l|l|l|l|}
5279 & $8 / 14 / 2008$ & $18: 26$ & 16.7 \\
\hline
\end{tabular}

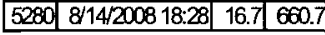

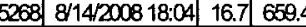

\section{\begin{tabular}{|c|c|c|c|}
\hline \multicolumn{3}{|c|}{ D427c } \\
\hline Roc & & Temp & SC \\
\hline$\#$ & DaterTime & ${ }^{\circ} \mathrm{C}$ & $\mu S / 0 m$ \\
\hline 5281 & $8 / 142008$ 18:30 & 16.7 & 660.9 \\
\hline
\end{tabular}}

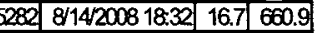

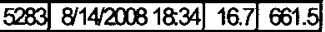

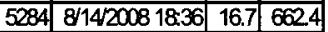

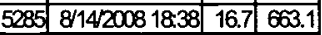

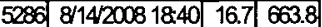

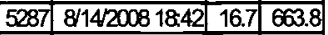

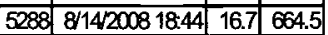

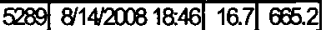

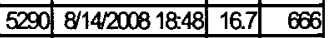

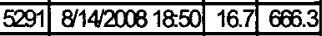

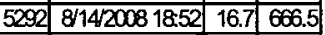

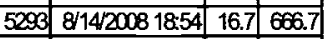

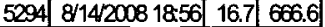

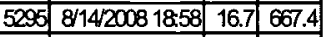

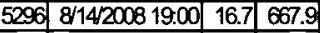

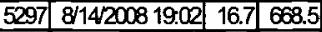

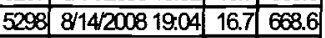

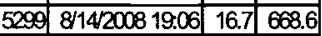

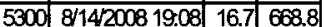
\begin{tabular}{|l|l|l|l|}
\hline 5301 & $8 / 14200819.10$ & 16.7 & 668.9 \\
\hline 5302
\end{tabular} \begin{tabular}{|l|l|l|l|}
5302 & $8 / 14 / 200819.12$ & 16.7 & 608.9 \\
\hline 5300 & $8 / 4200819.14$ & 16.7 & 68.8 \\
\hline
\end{tabular}

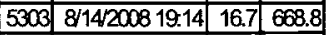
\begin{tabular}{|l|l|l|l|}
\hline 5304 & $8 / 14200819.16$ & 16.7 & 668.8 \\
\hline
\end{tabular} \begin{tabular}{|l|l|l|l|l|}
5306 & 81142008 & 19.18 & 16.7 & 668.6 \\
\hline
\end{tabular}

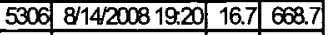

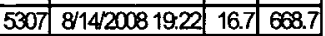

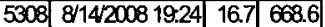
\begin{tabular}{|l|l|l|l|}
\hline 5309 & $8 / 14 / 200819.26$ & 16.7 & 668.7 \\
\hline 5310 & 81420081928 & 16.7 & 668.6 \\
\hline
\end{tabular}

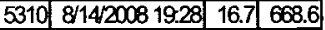

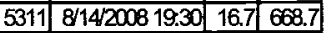

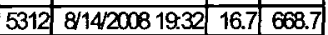

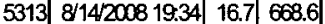

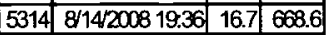

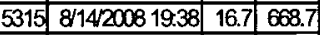

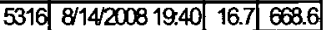
\begin{tabular}{|l|l|l|l|}
\hline 5317 & $8 / 142000819.42$ & 16.7 & 668.7 \\
\hline
\end{tabular}

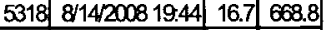
\begin{tabular}{|l|l|l|l|l|}
53319 & $8 / 142008$ & 19.46 & 16.7 & 668.6 \\
\hline
\end{tabular}

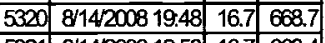

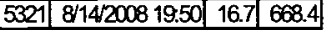

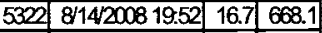

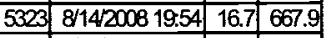
\begin{tabular}{|l|l|l|l|l|}
\hline 5324 & 8142000819.56 & 16.7 & 667.7 \\
\hline
\end{tabular}

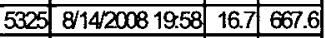
\begin{tabular}{|l|l|l|l|}
\hline 5326 & $8 / 142000820.00$ & 16.7 & 667.5 \\
\hline
\end{tabular} \begin{tabular}{|l|l|l|l|}
\hline 5327 & $8 / 14 / 200820002$ & 16.7 & 667.4 \\
\hline
\end{tabular} \begin{tabular}{|l|l|l|l|}
\hline 5328 & $8 / 14200820.04$ & 16.7 & 667.4 \\
\hline 5320 & $8 / 200820.06$ & 16.7 & 667.3 \\
\hline
\end{tabular} \begin{tabular}{|l|l|l|l|}
55220 & $8114200820: 06$ & 16.7 & 667.3 \\
\hline 5 & &
\end{tabular}

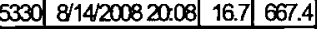
\begin{tabular}{|l|l|l|l|}
53331 & $8 / 14 / 200820.10$ & 16.7 & 667.5 \\
\hline
\end{tabular}

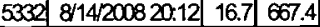
\begin{tabular}{l|l|l|l|}
53333 & 8114200820.14 & 16.7 & 667.4 \\
\hline
\end{tabular} \begin{tabular}{l|l|l|l|l|}
55334 & 8114200820.16 & 16.7 & 667.5 \\
\hline
\end{tabular} \begin{tabular}{|l|l|l|l|}
\hline 5335 & 8114200820.18 & 16.7 & 667.6 \\
\hline
\end{tabular} \begin{tabular}{|l|l|l|l|}
\hline 5336 & $8 / 14 / 200820.20$ & 16.7 & 667.6 \\
\hline 533 & $8 / 42008202$ & 16.7 & 667. \\
\hline
\end{tabular} \begin{tabular}{lllll}
5337 & $8 / 14200820.2$ & 16.7 & 667.6 \\
\hline
\end{tabular} \begin{tabular}{|l|l|l|l|}
\hline 5338 & $8114200820: 24$ & 16.7 & 667.9 \\
\hline
\end{tabular} \begin{tabular}{|l|l|l|l|}
\hline 5339 & $8 / 14 / 200820.26$ & 16.7 & 667.7 \\
\hline 5340 & $8 / 14200820.2$ & 16.7 & 667.7 \\
\hline
\end{tabular} \begin{tabular}{|l|l|l|l|l|}
53340 & $8142200820: 28$ & 16.7 & 667.7 \\
\hline 5
\end{tabular} \begin{tabular}{|l|l|l|l|}
55341 & 8144200820.30 & 16.7 & 667.7 \\
\hline
\end{tabular} \begin{tabular}{|l|l|l|l|}
5342 & 8114200820.32 & 16.7 & 668 \\
\hline 534 & 81420082034 & 16.7 & 607.8 \\
\hline
\end{tabular} \begin{tabular}{|l|l|l|l|}
\hline 5343 & 81142000820.34 & 16.7 & 667.8 \\
\hline
\end{tabular} \begin{tabular}{lllll}
5344 & 8114200820.36 & 16.7 & 668.1 \\
\hline
\end{tabular}

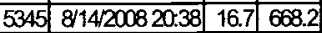
\begin{tabular}{|l|l|l|l|}
\hline 5346 & 8142200820.40 & 16.7 & 668.2 \\
\hline
\end{tabular} \begin{tabular}{|l|l|l|l|}
\hline 5347 & 8114200820.42 & 16.7 & 668.3 \\
\hline
\end{tabular} \begin{tabular}{|l|l|l|l|}
\hline 5348 & 81142008200.44 & 16.7 & 668.1 \\
\hline
\end{tabular} \begin{tabular}{|l|l|l|l|}
\hline 5349 & $8 / 14 / 200820.46$ & 16.8 & 667.5 \\
\hline
\end{tabular}

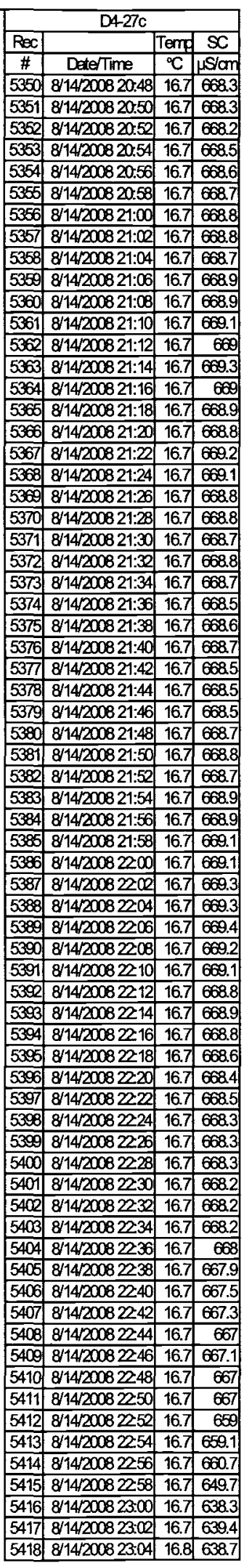

\begin{tabular}{|l|l|l|l|}
5351 & $8 / 14 / 200820.50$ & 16.7 & 668.3 \\
\hline
\end{tabular}

\begin{tabular}{lll} 
& \\
81420082052 & 16.7 & 6682 \\
\hline
\end{tabular}

\begin{tabular}{|l|l|l|l|}
\hline 5354 & $8 / 14 / 200820.56$ & 16.7 & 668.6 \\
\hline
\end{tabular} 1414200820581676687 \begin{tabular}{|l|l|l|l|}
5357 & $8 / 14 / 200821: 02$ & 16.7 & 668.8 \\
\hline
\end{tabular} \begin{tabular}{lllll} 
& $8 / 14 / 200821: 04$ & 16.7 & 6687 \\
\hline
\end{tabular} 6689 \begin{tabular}{|l|l|l|l|}
\hline 5361 & $8 / 14 / 200821: 10$ & 16.7 & 669.1 \\
\hline
\end{tabular} 53. \begin{tabular}{|l|l|l|l|}
\hline 5644 & $8 / 14 / 200821: 16$ & 16.7 & 660 \\
\hline
\end{tabular} \begin{tabular}{|l|l|l|}
\hline $00821: 18$ & 16.7 & 668.9 \\
\hline
\end{tabular} \begin{tabular}{|l|l|l|l|}
5367 & $8 / 14 / 200821: 22$ & 16.7 & 669.2 \\
\hline
\end{tabular} \begin{tabular}{llll}
5368 & $8 / 14 / 200821: 24$ & 16.7 & 669.1 \\
\hline
\end{tabular} \begin{tabular}{|l|l|l|l|}
\hline 572 & $8 / 14 / 200821: 32$ & 16.7 & 668.8 \\
\hline
\end{tabular} \begin{tabular}{|l|l|l|}
5375 & $8 / 14 / 200821: 38$ & 16.7 \\
\hline
\end{tabular} \begin{tabular}{|l|l|l|}
$814 / 200821: 40$ & 16.7 & 668.7 \\
\hline
\end{tabular} \begin{tabular}{|l|l|l|l|}
\hline 378 & $8 / 14 / 200821: 44$ & 16.7 & 668.5 \\
\hline
\end{tabular} \begin{tabular}{|l|l|l|l|}
\hline $3714 / 200821: 46$ & 16.7 & 668.5 \\
\hline
\end{tabular} \begin{tabular}{l|l|l|l|}
5381 & $8 / 14 / 200821: 50$ & 16.7 & 6688 \\
\hline
\end{tabular}

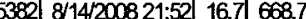
\begin{tabular}{|l|l|l|l|}
\hline 5384 & $8 / 14200821.56$ & 167 & 6689 \\
\hline
\end{tabular} 821:58 16.7669 .1 \begin{tabular}{|l|l|l|l|}
\hline 5387 & $8114 / 20082202$ & 16.7 & 669.3 \\
\hline
\end{tabular} 


\begin{tabular}{|c|c|c|c|c|c|c|c|c|c|c|c|c|c|c|c|c|c|c|c|}
\hline \multicolumn{4}{|c|}{ D427c } & \multicolumn{4}{|c|}{ D427c } & \multicolumn{4}{|c|}{$D 427 \mathrm{c}$} & & D4-27c & & & & D4-27c & & \\
\hline $\operatorname{Rec}$ & & end & SC & $\operatorname{Rec}$ & & & & $\operatorname{Rec}$ & & Tend & $\mathrm{SC}$ & Rec & & Tend & & $\operatorname{Rec}$ & & Termp & \\
\hline \# & DatefTime & & $\mu \mathrm{s} / \mathrm{cm}$ & $\#$ & DaterTime & ${ }^{\circ} \mathrm{C}$ & $\mu \mathrm{s} / \mathrm{am}$ & $\#$ & Dede/Time & ${ }^{\circ} \mathrm{C}$ & $\mathrm{H} / \mathrm{cm}$ & $\#$ & DeterTime & ${ }^{\circ} \mathrm{C}$ & $\mu \mathrm{S} / \mathrm{cm}$ & $\#$ & Date/Time & ${ }^{\circ} \mathrm{C}$ & $\mu \mathrm{s} / \mathrm{cm}$ \\
\hline 19 & $8 / 14 / 200823: 06$ & 16.7. & 699.6 & & $8 / 15 / 20081: 24$ & 16.7 & 659.8 & 5557 & $8 / 15 / 20083: 42$ & 16.7 & 669.3 & 5626 & $8 / 15 / 20086: 00$ & 16.7 & 667.6 & 5695 & 8/15/2008:18 & 16.7 & 669.1 \\
\hline 420 & $4 / 2008223: 08$ & 16.7 & 639.3 & 5489 & $8 / 15 / 20081: 26$ & 16.7 & 660 & 5558 & $8 / 15 / 20083: 44$ & 16.7 & 669.2 & 5627 & $8 / 15 / 20086: 02$ & 16.7 & 667.5 & 5696 & $8 / 15 / 20088: 20$ & 16.7 & 609 \\
\hline 421 & $8 / 14 / 200823: 10$ & & 639.3 & 5490 & $8 / 15 / 20081: 28$ & 16.8 & 650 & 5559 & $8 / 15 / 20083: 46$ & 16.7 & 669.4 & 5628 & $8 / 15 / 20086: 04$ & 16.7 & 667.6 & 5697 & & 16.7 & 668.8 \\
\hline 422 & $8 / 14 / 200823: 12$ & 16.7 & 639.4 & 5491 & $8 / 15 / 20081: 30$ & 16.7 & 660.3 & 5560 & & 16 त & 668.9 & 6629 & & 16.7 & 667.5 & 5698 & $8 / 15 / 20088: 24$ & 16.7 & \\
\hline 5423 & $8 / 14 / 200823: 14$ & 16.7 & 639.6 & 5492 & $8 / 15 / 20081: 32$ & 16.7 & 660.4 & 5561 & $8 / 15 / 20083: 50$ & 16.7 & 668.9 & 5630 & $8 / 15 / 20086: 08$ & 16.7 & 667.6 & 5699 & $8 / 15 / 20088: 26$ & 16.7 & 668.8 \\
\hline 424 & & 16.7 & & 5493 & & \begin{tabular}{|l|}
16.7 \\
\end{tabular} & 660.5 & 5562 & & 16.7 & & 5631 & & 16.7 & 667.6 & 5700 & $8 / 15 / 20088: 28$ & 16.7 & \\
\hline 5425 & $8 / 14 / 200823: 18$ & 16.7 & 639.8 & 5494 & $8 / 15 / 20081: 36$ & 16.7 & 600.6 & 5563 & 8/15/20083:54 & 16.7 & 668.9 & 5632 & $8 / 15 / 20086: 12$ & 16.7 & 667.5 & 5701 & $88: 30$ & 16.7 & 668.5 \\
\hline 5426 & $823: 20$ & 16.7 & 639.8 & 5495 & $8 / 15 / 20081: 38$ & \begin{tabular}{|l|}
16.7 \\
\end{tabular} & 600.9 & 5564 & $8 / 15 / 20083: 56$ & 16.7 & \begin{tabular}{|l|}
668.7 \\
\end{tabular} & 5633 & $8 / 15 / 20086: 14$ & \begin{tabular}{l|l|}
16.7 \\
\end{tabular} & 667.6 & 5702 & $088: 32$ & 16.7 & 668.6 \\
\hline 427] & $23: 22$ & 16.7 & 639.8 & 5496 & & 16.7 & 661.2 & 5565 & & & 668.6 & 5634 & & 16.7 & 667.5 & 703 & & 16.7 & \\
\hline 5428 & $823: 24$ & 16.7 & 640.1 & 5497 & $8 / 15 / 20081: 42$ & 16.7 & 661.6 & 5566 & $8 / 15 / 20084: 00$ & 16.7 & 668.8 & 5635 & $8 / 15 / 20086: 18$ & \begin{tabular}{l|l|}
16.7 \\
\end{tabular} & 667.6 & 5704 & $8 / 15 / 20088: 36$ & 16.7 & \begin{tabular}{|l|}
668.7 \\
\end{tabular} \\
\hline 5429 & $823: 26$ & 16.7 & 640.5 & 5498 & $8 / 15 / 20081: 44$ & 16.7 & 661.8 & 5567 & $8 / 15 / 20084: 02$ & 16.7 & 668.6 & 5636 & $8 / 15 / 20086: 20$ & 16.7 & 667.5 & 5705 & $8 / 15 / 20088: 38$ & 16.7 & 668.9 \\
\hline 3430 & $8 / 14 / 2$ & 16.7 & 640.5 & 5499 & $8 / 15 / 20081: 46$ & 16.7 & 662.1 & 5568 & $8 / 15 / 20084: 04$ & & 668.6 & 5637 & & 16.7 & 667.9 & 5706 & & 16.7 & \\
\hline 5431 & $823: 30$ & 16.7 & 640.4 & 5500 & $8 / 15 / 20081: 48$ & 16.7 & 662.5 & 5560 & $8 / 15 / 20084: 06$ & 16.7 & 668.6 & 5638 & $8 / 15 / 20086: 24$ & 16.7 & 668 & 5707 & $8 / 15 / 20088: 42$ & 16.7 & 669.2 \\
\hline 432 & $8 / 14 / 2$ & 16.7 & \begin{tabular}{|l|l|}
640.7 \\
\end{tabular} & 5501 & $81: 50$ & 16.7 & 663 & 5570 & $84: 08$ & 16.7 & 668.4 & 5639 & 08626 & 16.7 & 668 & 5708 & $38: 44$ & 16.7 & 669.1 \\
\hline 5433 & $23: 34$ & 16.7 & 641 & 5502 & $81: 52$ & 16.7 & 663.4 & 5571 & $84: 10$ & 16.7 & 668.5 & 5640 & $86-28$ & 16.7 & 667.9 & 5709 & & 16.7 & \\
\hline 2434 & $23: 36$ & 16.7 & 641.3 & 5503 & $8 / 15 / 20081: 54$ & 16.7 & 664.2 & 5572 & $84: 12$ & 16.7 & \begin{tabular}{|l|}
668.2 \\
\end{tabular} & 5641 & $36: 30$ & 16.7 & 668.2 & 5710 & $38: 48$ & 16.7 & 668.9 \\
\hline 40 & & 16.7 & & 5504 & & 16.7 & & 5573 & & & \begin{tabular}{|l|}
667.7 \\
\end{tabular} & 5642 & & \begin{tabular}{l|}
16.7 \\
\end{tabular} & 668 & 711 & & 16.7 & \\
\hline 5436 & $23: 40$ & 16.7 & 641.7 & 5505 & $8 / 15 / 20081: 58$ & 16.7 & 664.7 & 5574 & $84: 16$ & 16.7 & 668.1 & 5643 & $86: 34$ & 16.7 & 668 & 5712 & 8:52 & 16.7 & 668.6 \\
\hline 2437 & 23:42 & 16.7 & \begin{tabular}{|l|l|}
641.8 \\
\end{tabular} & 5506 & $8 / 15 / 20082: 00$ & 16.7 & 664.9 & 5575 & $084: 18$ & \begin{tabular}{|l|}
16.7 \\
\end{tabular} & \begin{tabular}{|l|}
668.1 \\
\end{tabular} & 5644 & $36: 36$ & 16.7 & 668.1 & 5713 & $8 / 15$ & 16.7 & 668.8 \\
\hline 5438 & $8 / 14 /$ & 16.7 & 641.8 & 5507 & & 16.7 & & 5576 & & 16.7 & \begin{tabular}{|l|}
667.6 \\
\end{tabular} & 5645 & & 16.7 & 668.3 & 714 & & 16.7 & \\
\hline 439 & 23:46 & 16.7 & 642 & 5508 & $82: 04$ & 16.7 & 665.2 & 5677 & 34:22 & 16.7 & 667.5 & 5646 & $86: 40$ & 16.7 & 668.6 & 5715 & $88: 58$ & 16.7 & 668.8 \\
\hline 440 & $8 / 14 / 2$ & 16.7 & 642 & 5509 & 3206 & 16.7 & 665.3 & 5578 & $84: 24$ & 16.7 & 667.4 & 5647 & $6: 42$ & 16.7 & 668.6 & 716 & 9.00 & 16.7 & 668.7 \\
\hline 441 & $8 / 14 / 2$ & 16.7 & 641.8 & 5510 & $32: 08$ & 16.7 & 665. & 5579 & $34: 26$ & \begin{tabular}{l|l|}
16.7 \\
\end{tabular} & 667.2 & 5648 & & \begin{tabular}{l|l|}
16.7 \\
\end{tabular} & 668.6 & 717 & & & \\
\hline 442 & $8 / 14 / 2$ & 16.7 & 641.9 & 5511 & 2210 & 16.7 & 665.7 & 5580 & 44:28 & $\begin{array}{l}16.7 \\
\end{array}$ & \begin{tabular}{|l}
667 \\
\end{tabular} & 5649 & $6: 46$ & \begin{tabular}{l|l}
16.7 \\
\end{tabular} & 668.4 & 718 & 9.04 & 16.7 & 668.4 \\
\hline 5443 & $8 / 14$ & 16.7 & 641.9 & & 212 & 16.7 & 666.1 & 5581 & & 16.7 & 667 & 5650 & & 16.7 & 668.4 & & & 16.7 & 668.6 \\
\hline 5444 & $8 / 14 /$ & $\begin{array}{c}6.7 \\
\end{array}$ & 641.9 & 5513 & $8 / 15 / 20$ & 16.7 & 666.2 & 5582 & & $\begin{array}{l}16.7 \\
\end{array}$ & \begin{tabular}{|l|l}
666.7 \\
\end{tabular} & 5651 & $36: 50$ & 16.7 & 668.4 & 5720 & 89.08 & 16.7 & 668.5 \\
\hline 445 & $3: 58$ & $\begin{array}{l}16.7 \\
\end{array}$ & 641.9 & 5614 & $8 / 15 / 2$ & $\begin{array}{l}16.7 \\
\end{array}$ & 666.2 & 5583 & $4: 34$ & 16.7 & 666.4 & 5652 & 6:52. & 16.7 & 668.5 & 721 & 9.10 & 16.7 & 668.6 \\
\hline 5446 & & 16.7 & \begin{tabular}{|l|l|}
641.7 \\
\end{tabular} & 5515 & $8 / 15 / 2$ & 16.7 & 666.3 & 5584 & & 16.7 & 666. & 6 & & \begin{tabular}{|c|}
16.7 \\
\end{tabular} & 668.7 & करा & & 16.7 & \\
\hline 5447 & & $\begin{array}{l}16.7 \\
\end{array}$ & 641.8 & 5516 & $8 / 15 / 2$ & $\begin{array}{l}16.7 \\
\end{array}$ & 666.6 & 5585 & 4:38 & \begin{tabular}{|l}
16.7 \\
\end{tabular} & 665.8 & 5654 & & 16.7 & 668.8 & 723 & 9.14 & 16.7 & 668.3 \\
\hline 5448 & & 16.7 & $\overline{6018}$ & 5517 & $2 \cdot 22$ & 16.7 & 666 & 5586 & & 16.7 & 665.1 & 5655 & & 16.7 & 668. & 5724 & & 16.8 & 667 \\
\hline 5449 & & $\begin{array}{l}16.7 \\
\end{array}$ & 641.9 & \begin{tabular}{|l|}
5518 \\
\end{tabular} & 32.24 & 16.7 & 666.8 & 5558 & 34:42 & $\overline{16.7}$ & 664.8 & 5656 & $87: 00$ & 16.7 & 668 & 5725 & 89.18 & 16.7 & 6684 \\
\hline 450 & & \begin{tabular}{c|}
16.7 \\
\end{tabular} & 641.6 & 5519 & $8 / 15 / 2$ & $\begin{array}{l}16.7 \\
\end{array}$ & 667 & 5588 & 4:44 & \begin{tabular}{|l|l}
16.7 \\
\end{tabular} & 664. & 5657 & $7: 02$ & 16.7 & 668. & 5726 & 9.20 & \begin{tabular}{l|l|}
16.7 \\
\end{tabular} & 668.4 \\
\hline 5451 & & 16.7 & 641.7 & 5520 & 228 & 16.8 & 666. & 5589 & & 16.7 & 664 & 6058 & & \begin{tabular}{|l|}
16.7 \\
\end{tabular} & 668 & 727 & & \begin{tabular}{|c|}
16.7 \\
\end{tabular} & 668.3 \\
\hline 5452 & & 16.7 & 641.7 & 5521 & & 16.7 & 667. & 5590 & & 16.7 & 664 & 5659 & & 16.7 & 668 & 728 & & 16.7 & 6686 \\
\hline 5453 & & 16.7 & 641. & 5522 & & 16.7 & 667 & 5591 & & 16.7 & 664 & 6060 & & \begin{tabular}{l|l}
6.7 \\
\end{tabular} & 668 & 729 & 9.26 & 16.7 & 668.4 \\
\hline 5454 & & $\begin{array}{l}16.7 \\
\end{array}$ & 641.9 & 5523 & 2.34 & $\begin{array}{l}16.7 \\
\end{array}$ & 667.8 & 5592 & $4: 52$ & 16.7 & 664 & 56661 & $8 / 15$ & 16.7 & 668 & 5730 & 9.28 & 16.7 & 668.3 \\
\hline 5455 & & 16.7 & \begin{tabular}{|l|l|}
642 \\
\end{tabular} & 5524 & 236 & 16.7 & 667.7 & 5593 & 4:54 & \begin{tabular}{|l|l|}
16.7 \\
\end{tabular} & 664.3 & 5662 & & $\begin{array}{l}16.7 \\
\end{array}$ & 66 & 5731 & & 16.7 & 668.2 \\
\hline 5456 & & 16.7 & 642 & 5525 & 238 & 16.7 & 66 & 5594 & & 16.7 & 66 & 5663 & & 16.7 & 668 & 570 & 9.32 & 16.7 & 668.3 \\
\hline 5457 & & $\begin{array}{l}16.7 \\
\end{array}$ & & 5526 & & 16.7 & 668.2 & 5595 & & 16.7 & & 5664 & & \begin{tabular}{l|l|}
16.7 \\
\end{tabular} & 667 & 5733 & 39.34 & 16.7 & 668.2 \\
\hline 4458 & & $\begin{array}{l}16.7 \\
\end{array}$ & 643 & \begin{tabular}{|c|c|}
5527 \\
\end{tabular} & & 16.7 & 668 & 5506 & & \begin{tabular}{|l|l}
16.7 \\
\end{tabular} & 66 & 5665 & & \begin{tabular}{|l|}
16.7 \\
\end{tabular} & 668 & 734 & 9.36 & 16.7 & 668.2 \\
\hline 5459 & & \begin{tabular}{l|l|}
16.7 \\
\end{tabular} & 644.2 & 5528 & $8 / 15 / 2$ & 16.7 & 668.6 & 5597 & $5: 02$ & \begin{tabular}{|l|}
16.7 \\
\end{tabular} & 663.5 & 5666 & $7: 20$ & $\begin{array}{l}16.7 \\
\end{array}$ & 667. & 5735 & & 16.7 & 668.3 \\
\hline 5460 & & \begin{tabular}{|c|}
16.7 \\
\end{tabular} & 645 & 5529 & 246 & 16.7 & 668.8 & 5598 & & \begin{tabular}{|l|}
16.7 \\
\end{tabular} & 663.5 & 5667 & & $\begin{array}{l}16.7 \\
\end{array}$ & & 5736 & & 16.7 & 668.3 \\
\hline 5461 & & $\begin{array}{l}16.7 \\
\end{array}$ & 646.2 & 5530 & $2: 48$ & $\begin{array}{l}16.7 \\
\end{array}$ & 668.8 & 5509 & & 16.7 & 663 & 5668 & $7: 24$ & 16.7 & 668 & & & 16.7 & 668.3 \\
\hline$\pi 9$ & & 16.7 & & 5531 & & \begin{tabular}{|l|}
16.7 \\
\end{tabular} & $6 \approx$ & 5600 & & 16.7 & 663 & 5669 & & \begin{tabular}{l|l|}
16.7 \\
\end{tabular} & 66 & 5738 & 9.44 & 16.7 & 668.3 \\
\hline 5463 & & 16.7 & 648.7 & & & \begin{tabular}{|l|}
16.7 \\
\end{tabular} & 669.1 & 5601 & & & & 6670 & & $\begin{array}{l}16.7 \\
\end{array}$ & 668 & & & 16.7 & 668.4 \\
\hline 5464 & & \begin{tabular}{c|}
16.7 \\
\end{tabular} & 650 & \begin{tabular}{|l|l|}
5533 \\
\end{tabular} & $8 / 15 / 2$ & $\begin{array}{l}16.7 \\
\end{array}$ & 669 & 5602 & $5: 12$ & 16.7 & 663.7 & 5671 & & $\begin{array}{l}16.7 \\
\end{array}$ & 668 & $\overline{774}$ & 9.48 & 16.7 & 668.4 \\
\hline 5465 & & $\begin{array}{l}16.7 \\
\end{array}$ & 651.5 & 5534 & & 16.7 & 669.1 & 5603 & & \begin{tabular}{|l|}
16.7 \\
\end{tabular} & 664 & 5672 & & 16.7 & & & & 16. & 668 \\
\hline 5466 & & \begin{tabular}{|c|}
16.7 \\
\end{tabular} & 652 & 5535 & 258 & \begin{tabular}{|l|l}
16.7 \\
\end{tabular} & 66 & 5604 & & \begin{tabular}{|l|l}
16.7 \\
\end{tabular} & 664. & 5673 & & 16.7 & 66 & & & 16.7 & 668.5 \\
\hline 5467. & & \begin{tabular}{|l|}
16.7 \\
\end{tabular} & & 5536 & & 16.7 & 60 & 5600 & & 16.7 & 664 & 5674 & & \begin{tabular}{|c|}
16.7 \\
\end{tabular} & 66 & & 9.54 & 16.7 & 668.8 \\
\hline 5468 & & \begin{tabular}{|l|}
16.7 \\
\end{tabular} & & 5537 & & 16.7 & 668 & 5606 & & & & & & 16.7 & & & & 16. & \\
\hline 5469 & & 16.7 & 65 & 5538 & & 16.7 & 669.2 & 5607 & & 16.7 & 664. & 5676 & & 16.7 & 668 & 745 & & 16.7 & 668.9 \\
\hline 5470 & & 16.7 & & 5539 & & 16.7 & 668. & 5608 & & 16.7 & 66 & 5677 & & 16.7 & & & & 16.7 & 609 \\
\hline 5471 & & 16.7 & 658. & 5640 & & 16.7 & 668 & 5609 & & 16.7 & 664 & 6678 & & 16.7 & & & & 16.7 & 668.7 \\
\hline 5472 & & 16.7 & 66 & 5541 & & \begin{tabular}{|l|}
16.7 \\
\end{tabular} & 668.8 & 5610 & & 16.7 & 66 & 5679 & & \begin{tabular}{ll|}
16.7 \\
\end{tabular} & & & & 16.7 & 668.8 \\
\hline 5473 & & \begin{tabular}{|l|}
16.7 \\
\end{tabular} & & & & \begin{tabular}{|l|}
16.7 \\
\end{tabular} & & 5611 & & & & 5680 & & 16.7 & & & & 16.7 & \\
\hline 5474 & 0.56 & 16.7 & 659. & \begin{tabular}{|l|}
5543 \\
\end{tabular} & 3:14 & 16.7 & 668.9 & 5612 & & 16.7 & 665. & 5681 & & 16.7 & 66 & 750 & 0.08 & 16.7 & 668.4 \\
\hline 5475 & & 167 & & & & \begin{tabular}{|l|}
16.7 \\
\end{tabular} & 669 & 5613 & & 16.7 & 66 & 5682 & & \begin{tabular}{l|l|}
16.7 \\
\end{tabular} & & 51 & & 16.7 & 668.4 \\
\hline 5476 & & \begin{tabular}{|l|}
16.7 \\
\end{tabular} & & 5545 & & \begin{tabular}{|l|}
16.7 \\
\end{tabular} & 669. & 5614 & & & 66 & & & $\begin{array}{l}16.7 \\
\end{array}$ & & & & & \\
\hline 5477 & & 16.7 & 660 & 5546 & & 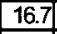 & 669. & 5615 & & 16.7 & 666 & 5684 & & $\begin{array}{l}16.7 \\
\end{array}$ & 66 & 53 & 0.14 & 16.7 & 668.8 \\
\hline 5478 & & 16.7 & & & & & & & & & 667.1 & 5685 & & & & & & & 6684 \\
\hline 5479 & $1: 06$ & 16.7 & 660.6 & 5548 & 33:24 & 16.7 & 669.3 & 5617 & & 16.7 & 667 & 5606 & & \begin{tabular}{l|l|}
16.7 \\
\end{tabular} & 66 & 5755 & 10:18 & 16.7 & 668 \\
\hline 5480 & & \begin{tabular}{|l|}
16.7 \\
\end{tabular} & 660. & 5549 & & \begin{tabular}{|l|}
16.7 \\
\end{tabular} & 669.5 & 5618 & & 16.7 & 667 & 5687 & & $\begin{array}{l}16.7 \\
\end{array}$ & & & & 16.7 & 668.2 \\
\hline 5481 & & 16.7 & 660. & & & 16 & & & & 16.7 & & 5688 & & & & & & & \\
\hline 5482 & & 16.7 & 660 & 5651 & $8 / 15 / 20083: 30$ & 16.7 & 669. & 5620 & $5: 48$ & 16.7 & 667.4 & 5680 & & 16.7 & 668 & 5758 & $10: 24$ & 16.7 & 667.7 \\
\hline 5483 & & \begin{tabular}{|l|}
16.7 \\
\end{tabular} & & & & & & 5621 & & 16.7 & 667.5 & 5690 & & 16.7 & & & & 16 & \\
\hline 5484 & 1:16 & 16.7 & 659.4 & 5553 & 8/15/20083:34 & \begin{tabular}{|l|l|}
16.7 \\
\end{tabular} & 669.4 & 5622 & & 16.7 & 667 & 5691 & 8:10 & 16.7 & 668 & 5760 & $10: 28$ & 16.7 & 667.4 \\
\hline 5485 & & \begin{tabular}{|l|}
16.7 \\
\end{tabular} & 659. & 5554 & $8 / 15 / 2$ & \begin{tabular}{|l|}
16.7 \\
\end{tabular} & 669. & 5623 & $5: 54$ & 16.7 & 667. & 5692 & & \begin{tabular}{|l|}
16.7 \\
\end{tabular} & 668 & 5761 & 10.30 & 16.7 & 667.3 \\
\hline 5486 & & \begin{tabular}{|l|}
16.7 \\
\end{tabular} & 659 & 5555 & $8 / 15 / 2$ & 10.1 & 669. & 5624 & & \begin{tabular}{|l|}
16.7 \\
\end{tabular} & 667. & 5693 & & 16.7 & 1002 & 5762 & & 16.7 & 667.5 \\
\hline 5487] & $81 \cdot 22$ & \begin{tabular}{|l|}
16.7 \\
\end{tabular} & 659.6 & 5556 & $8 / 15 / 20$ & \begin{tabular}{|l|}
16.7 \\
\end{tabular} & 669.1 & 5625 & 85:58 & 16.7 & 667.6 & 5694 & $8: 16$ & 16.8 & 669.1 & 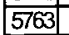 & 10.34 & & $\pi$ \\
\hline
\end{tabular}




\begin{tabular}{|c|c|c|c|c|c|c|c|c|c|c|c|c|c|c|c|c|c|c|c|}
\hline \multicolumn{4}{|c|}{ D427c } & \multicolumn{4}{|c|}{$0427 \mathrm{c}$} & \multicolumn{4}{|c|}{$D 427 \mathrm{c}$} & & D427c & & & & D427c & & \\
\hline Rec & & Temp & $\mathrm{SC}$ & \begin{tabular}{|l|l}
$\operatorname{Rec}$ \\
\end{tabular} & & Temp & $\mathrm{SC}$ & $\mathrm{Rex}$ & & & & Rec & & & $\mathrm{SC}$ & Rec & & Temp & $S C$ \\
\hline$\#$ & Date/Time & ${ }^{\circ} \mathrm{C}$ & $\mu \mathrm{S} / \mathrm{cm}$ & $\#$ & Dateflime & \begin{tabular}{|l|}
${ }^{\circ} \mathrm{C}$ \\
\end{tabular} & $\mathrm{s} / \mathrm{cm}$ & $\#$ & Dater/Time & ${ }^{\circ} \mathrm{C}$ & $\mu \mathrm{s} / \mathrm{cm}$ & \# & Date/Time & ${ }^{\circ} \mathrm{C}$ & $\mu \mathrm{S} / \mathrm{cm}$ & $\#$ & Date/Time & & $\mu \mathrm{s} / \mathrm{cm}$ \\
\hline 5764 & $8 / 15 / 200810.36$ & & 667.7 & $\frac{5833}{5094}$ & $8 / 1520001254$ & \begin{tabular}{|l|}
16.7 \\
1167 \\
\end{tabular} & \begin{tabular}{|l|l|}
653.3 \\
6523
\end{tabular} & & & & & & & & & & & & \\
\hline 5765 & $8 / 15 / 200810.38$ & 16.7 & 667.9 & & & 16.7 & 6523 & & & & & & & & & & & & \\
\hline 5766 & $8 / 15 / 200810: 40$ & & & 5835 & $8 / 15 / 20081258$ & \begin{tabular}{|l|}
16.7 \\
\end{tabular} & 6525 & & & & & & & & & & & & \\
\hline 5767 & $8 / 15 / 200810.42$ & & 668.4 & 5836 & & \begin{tabular}{|l|}
16.7 \\
\end{tabular} & 652 & & & & & & & & & & & & \\
\hline 5768 & $8 / 15 / 200010,44$ & 16.7 & 669 & 5837 & $8 / 15 / 2008$ 13:02 & \begin{tabular}{|l|}
16.7 \\
\end{tabular} & 651.8 & & & & & & & & & & & & \\
\hline 5769 & $8 / 15 / 200810: 46$ & 16.7 & 668.9 & 5838 & 8/15/2008 13:0 & \begin{tabular}{|l|}
16.7 \\
\end{tabular} & 651.8 & & & & & & & & & & & & \\
\hline 5770 & $8 / 15 / 200810.48$ & 16.7 & 669.1 & 5839 & $8 / 15 / 200813: 00$ & \begin{tabular}{|l|}
16.7 \\
\end{tabular} & 651.4 & & & & & & & & & - & & & \\
\hline 5771 & $8 / 15 / 200810.50$ & 16.7 & 660 & 5840 & $8 / 15 / 200813: 06$ & \begin{tabular}{|l|l|}
16.7 \\
\end{tabular} & 651.5 & & & & & & & & & & & & \\
\hline 5772 & $8 / 15 / 200810.52$ & $\begin{array}{ll}16.7 \\
\end{array}$ & 609.1 & 5841 & 8/15/2008 13:10 & 16.7 & 651.4 & & & & & & & & & & & & \\
\hline 5773 & $8 / 15 / 200610.54$ & & 669.2 & 5842 & $8 / 15 / 2008 \uparrow 3: 12$ & \begin{tabular}{|l|}
16.7 \\
\end{tabular} & 651.1 & & & & & & & & & & & & \\
\hline 5774 & $8 / 15 / 200810: 56$ & & & & $8 / 15 / 2008$ 13:14 & \begin{tabular}{|l|}
16.7 \\
\end{tabular} & & & & & & & & & & & & & \\
\hline 5775 & $8 / 15 / 200010.58$ & & 669.2 & 5844 & $8 / 15 / 2008$ 13:16 & \begin{tabular}{|l|}
16.7 \\
\end{tabular} & 650.5 & & & & & & & & & & & & \\
\hline 5776 & $8 / 15 / 200811: 00$ & 16.7 & 669.6 & & & & & & & & & & & & & & & & \\
\hline $5 \pi \pi$ & $8 / 15 / 200811: 02$ & 16.7 & 669.6 & & & & & & & & & & & & & & & & \\
\hline 5778 & $8 / 15 / 2008$ 11:04 & 16.7 & 669.6 & E & & $\square$ & & & & & & & & & & & & & \\
\hline 5779 & $8 / 15 / 200811: 06$ & & 669.4 & & & & & & & & & & & & & & & & \\
\hline 5780 & $8 / 15 / 2008$ 11:08 & & 609.4 & & & & & & & & & & & & & & & & \\
\hline 5781 & 8/15/2008 11:10 & & 669.4 & & & & & & & & & & & & & 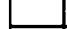 & & & \\
\hline 5782 & $8 / 15 / 2008$ 11:12 & 16.7 & 669.5 & & & & & & & & & & & & & & & & \\
\hline 5783 & 8/15/2008 11:14 & 16.7 & 669.8 & & & & & & & & & & & & & & & & \\
\hline 5784 & 8/15/2008 11:16 & 16.7 & 669.8 & & & & & & & & & & & & & & & & \\
\hline 5785 & 8/15/2008 11:18 & 16.7 & 669.9 & & & & & & & & & & & & & & & & \\
\hline 5786 & $8 / 15 / 200811: 20$ & 16.7 & 670.1 & - & & & & & & & & & & & & & & & \\
\hline 5787 & $8 / 15 / 200811: 22$ & 16.7 & 670.1 & & & & & & & & & & & & & & & & \\
\hline 5788 & $8 / 15 / 200811: 24$ & 16.7 & 670 & - & & & & & & & & & & & & & & & \\
\hline 5789 & 8/15/2008 11:26 & 16.7 & 670.9 & E & & & & & & & & & & & & & & & \\
\hline 5590 & 8/15/2008 11:28 & \begin{tabular}{|l|}
16.7 \\
\end{tabular} & 664.6 & & & & & & & & & & & & & & & & \\
\hline 5791 & $8 / 15 / 200811: 30$ & 16.7 & 666.9 & & & & & - & & & & -1 & & & & - & & & \\
\hline 5792 & $8 / 15 / 200811: 32$ & 16.7 & 660 & & & & & - & & & & & & & & & & & \\
\hline 5793 & $8 / 15 / 200811: 34$ & 16.7 & 665.3 & & & & & & & & & & & & & & & & \\
\hline 5794 & $8 / 15 / 200811: 36$ & 16.7 & 665.4 & & & & & 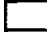 & & & & & & & & & & & \\
\hline 5795 & $8 / 15 / 200811: 38$ & 16.7 & 666.3 & & & & & & & & & & & & & & & & \\
\hline 5796 & $8 / 15 / 2008$ 11:40 & \begin{tabular}{|l|}
16.7 \\
\end{tabular} & 665.8 & & & & & & & & & & & & & - & & & \\
\hline 5797 & $8 / 15 / 2008$ 11:42 & \begin{tabular}{|l|l|}
16.7 \\
\end{tabular} & 606.2 & & & & & & & & & & & & & & & & \\
\hline 5798 & $8 / 15 / 200811: 44$ & 16.7 & 669.2 & & & & & & & & & & & & & & & & \\
\hline 5799 & $8 / 15 / 200811: 46$ & \begin{tabular}{|c|c|}
16.7 \\
\end{tabular} & 660.2 & & & & & & & & & & & & & & & & \\
\hline $580 \mathrm{at}$ & $8 / 15 / 200811: 48$ & \begin{tabular}{|c|c|}
16.7 \\
\end{tabular} & 656.3 & 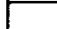 & & & & & & & & & & & & & & & \\
\hline 5801 & $8 / 15 / 2008$ 11:50 & \begin{tabular}{|c|}
16.7 \\
\end{tabular} & 664.9 & & & & & & & & & & & & & & & & \\
\hline 5802 & $8 / 15 / 2008$ 11:52 & 16.7 & 669.6 & & & & & & & & & & & & & & & & \\
\hline 5803 & $8 / 15 / 2008$ 11:54 & 16.8 & 666.9 & & & & & & & & & & & & & & & & \\
\hline 5804 & $8 / 15 / 2008$ 11:56 & 16.7 & 6625 & & & & & & & & & & & & & & & & \\
\hline 5805 & $8 / 15 / 200811: 58$ & \begin{tabular}{|l|}
16.7 \\
\end{tabular} & 659.3 & & & & & & & & & & & & & & & & \\
\hline 5806 & $8 / 15 / 20081200$ & 16.7 & $\begin{array}{ll}648.6 \\
\end{array}$ & & & & 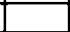 & 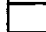 & & - & & 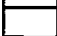 & & & - & 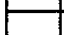 & & - & \\
\hline 5807 & $8 / 15 / 20081202$ & 16.7 & 6522 & & & & & & & & & & & & & & & & \\
\hline 5808 & $8 / 15 / 20081204$ & $\begin{array}{lll}16.7 & & \\
\end{array}$ & & 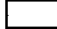 & & & & & & & & & & & 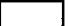 & 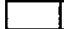 & & & \\
\hline 5809 & $8115 / 20081206$ & $16.7 \mid$ & 652.8 & & & & & & & & & & & & & & & & \\
\hline 5810 & $8 / 15 / 20081208$ & \begin{tabular}{|c|c|}
16.7 \\
\end{tabular} & 649.5 & & & & & & & & & & & & & & & & \\
\hline 5811 & $8 / 15 / 20081210$ & \begin{tabular}{|c|c|}
16.7 \\
\end{tabular} & 650.3 & & & & & & & & & & & & & & & & \\
\hline 5812 & $8 / 15 / 20081212$ & \begin{tabular}{|l|l|}
16.7 \\
\end{tabular} & 649.4 & & & & & & & & & & & & & & & & \\
\hline 5813 & $8 / 15 / 20081214$ & & & & & & & & & & & & & & & & & & \\
\hline 5814 & $8 / 1520081216$ & & 648.3 & 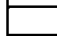 & & & & & & & & & & & 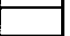 & & & & \\
\hline 5815 & $8 / 15 / 20081218$ & 16.7 & 648.3 & & & 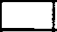 & & & & & & & & & & & & & \\
\hline 5816 & $8 / 15 / 20081220$ & 16.7 & & & & & & & & & & & & & 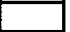 & & & & \\
\hline 5817 & $8 / 15 / 20081222$ & 16.7 & 648 & & & 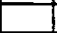 & - & 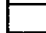 & & 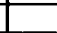 & & 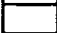 & & & - & 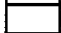 & & & \\
\hline 5818 & $8 / 15220081224$ & $\mid \begin{array}{l}\mid 16.7 \\
\end{array}$ & 648.3 & & & & & & & & & - & & & & & & & \\
\hline 5819 & $8 / 15 / 20081226$ & \begin{tabular}{|c|c|}
16.7 \\
\end{tabular} & 648.6 & & & & & & & & & 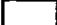 & & & & & & & \\
\hline 5820 & $8 / 15 / 20081228$ & \begin{tabular}{|c|c|}
16.7 \\
\end{tabular} & 649.6 & & & & & & & & & 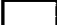 & & & & & & & \\
\hline 5821$]$ & $8 / 15 / 20081230$ & & 6524 & & & & & & & & & & & & & & & & \\
\hline 5822 & $8 / 152000812 ; 32$ & & 650.1 & & & & & - & & & & - & & & & & & & - \\
\hline 5823] & $8 / 15 / 20081234$ & \begin{tabular}{|c|c|}
16.7 \\
\end{tabular} & 650.7 & - & & - & & - & & & & - & & & - & - & & 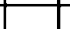 & \\
\hline 5824 & $8 / 15 / 20081236$ & 16.7 & 648.9 & & & & & & & & & & & & & & & & \\
\hline 5825 & $8 / 15 / 20081238$ & 16.7 & 647.6 & & & & & 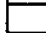 & & & & & & & & & & & \\
\hline 5826 & $8 / 15 / 20081240$ & 16.7 & 648.1 & 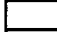 & & & & & & & & & & & 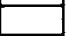 & 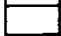 & & & 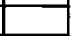 \\
\hline 5827 & $8 / 1520081242$ & \begin{tabular}{|c|}
16.7 \\
\end{tabular} & 646.9 & & & & & & & & & & & & 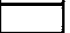 & 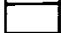 & & 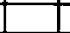 & \\
\hline 5828 & $8 / 15 / 20081244$ & 16.7 & 647.7 & & & & & 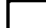 & & & & 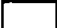 & & & 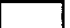 & - & & & \\
\hline 5829 & $8 / 15 / 20081246$ & \begin{tabular}{|c|c|}
16.7 \\
\end{tabular} & 646.8 & & & & & & & & & & & & & - & & & \\
\hline 5830 & $8 / 15 / 20081248$ & 16.7 & 648.9 & & & & & & & & & - & & & & - & & & \\
\hline & $8 / 15 / 20081$ & & 651.9 & & & & & & & & & & & & & - & & & \\
\hline 832 & $8 / 15 / 20081252$ & 16.7 & 650.2 & & & & & & & & & & & & 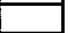 & 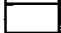 & & & \\
\hline
\end{tabular}




\begin{tabular}{|c|c|c|c|}
\hline \multicolumn{4}{|c|}{ D4-27p } \\
\hline $\operatorname{Rec}$ & & Pres & Temp \\
\hline$\#$ & Date/Time & psi & ${ }^{\circ} \mathrm{C}$ \\
\hline 1 & $8 / 7 / 2008$ 10:30 & 1.502 & 17.3 \\
\hline 2 & $8 / 7 / 200810: 32$ & 1.504 & 17.4 \\
\hline 3 & $8 / 7 / 200810: 34$ & 1.504 & 17.1 \\
\hline 4 & $8 / 7 / 2008$ 10:36 & 1.503 & 16.9 \\
\hline 5 & $8 / 7 / 200810: 38$ & 1.503 & 16.9 \\
\hline 6 & $8 / 7 / 200810: 40$ & 1.503 & 16.9 \\
\hline 7 & $8 / 7 / 200810: 42$ & 1.502 & 16.9 \\
\hline 8 & $8 / 7 / 200810: 44$ & 1.502 & 16.9 \\
\hline 9 & $8 / 7 / 200810: 46$ & 1.502 & 16.9 \\
\hline 10 & $8 / 7 / 200810: 48$ & 1.502 & 16.9 \\
\hline 11 & $8 / 7 / 200810: 50$ & 1.502 & 16.9 \\
\hline 12 & $8 / 7 / 200810: 52$ & 1.502 & 16.9 \\
\hline 13 & $8 / 7 / 200810: 54$ & 1.501 & 16.9 \\
\hline 14 & $8 / 7 / 200810: 56$ & 1.501 & 16.9 \\
\hline 15 & $8 / 7 / 200810: 58$ & 1.501 & 16.9 \\
\hline 16 & $8 / 7 / 200811: 00$ & 1.5 & 16.9 \\
\hline 17 & $8 / 7 / 2008$ 11:02 & 1.5 & 16.9 \\
\hline 18 & $8 / 7 / 200811: 04$ & 1.5 & 16.9 \\
\hline 19 & $8 / 7 / 200811: 06$ & 1.5 & 16.9 \\
\hline 20 & $8 / 7 / 200811: 08$ & 1.5 & 16.9 \\
\hline 21 & $8 / 7 / 2008$ 11:10 & 1.5 & 16.9 \\
\hline 22 & $8 / 7 / 200811: 12$ & 1.5 & 16.9 \\
\hline 23 & $8 / 7 / 200811: 14$ & 1.5 & 16.9 \\
\hline 24 & $8 / 7 / 200811: 16$ & 1.5 & 16.9 \\
\hline 25 & $8 / 7 / 200811: 18$ & 1.501 & 16.9 \\
\hline 26 & $8 / 7 / 200811: 20$ & 1.501 & 16.9 \\
\hline 27 & $8 / 7 / 200811: 22$ & 1.501 & 16.9 \\
\hline 28 & $8 / 7 / 200811: 24$ & 1.502 & 16.9 \\
\hline 29 & $8 / 7 / 200811: 26$ & 1.502 & 16.9 \\
\hline 30 & $8 / 7 / 200811: 28$ & 1.502 & 16.9 \\
\hline 31 & $8 / 7 / 2008$ 11:30 & 1.501 & 16.9 \\
\hline 32 & $8 / 7 / 2008$ 11:32 & 1.502 & 16.9 \\
\hline 33 & $8 / 7 / 200811: 34$ & 1.502 & 16.9 \\
\hline 34 & $8 / 7 / 200811: 36$ & 1.503 & 16.9 \\
\hline 35 & $8 / 7 / 200811: 38$ & 1.502 & 16.9 \\
\hline 36 & $8 / 7 / 200811: 40$ & 1.503 & 16.9 \\
\hline 37 & $8 / 7 / 200811: 42$ & 1.502 & 16.9 \\
\hline 38 & $8 / 7 / 2008$ 11:44 & 1.503 & 16.9 \\
\hline 39 & $8 / 7 / 2008$ 11:46 & 1.504 & 16.9 \\
\hline 40 & $8 / 7 / 200811: 48$ & 1.504 & 16.9 \\
\hline 41 & $8 / 7 / 200811: 50$ & 1.504 & 16.9 \\
\hline 42 & $8 / 7 / 2008$ 11:52 & 1.503 & 16.9 \\
\hline 43 & $8 / 7 / 2008$ 11:54 & 1.501 & 16.9 \\
\hline 44 & $8 / 7 / 200811: 56$ & 1.502 & 16.9 \\
\hline 45 & $8 / 7 / 200811: 58$ & 1.503 & 16.9 \\
\hline 46 & $8 / 7 / 2008$ 12:00 & 1.504 & 16.9 \\
\hline 47 & $8 / 7 / 200812: 02$ & 1.504 & 16.9 \\
\hline 48 & $8 / 7 / 200812: 04$ & 1.503 & 16.9 \\
\hline 49 & $8 / 7 / 2008$ 12:06 & 1.504 & 16.9 \\
\hline 50 & $8 / 7 / 2008$ 12:08 & 1.504 & 16.9 \\
\hline 51 & $8 / 7 / 200812: 10$ & 1.506 & 16.9 \\
\hline 52 & $8 / 7 / 2008$ 12:12 & 1.506 & 16.9 \\
\hline 53 & $8 / 7 / 2008$ 12:14 & 1.506 & 16.9 \\
\hline 54 & $8 / 7 / 200812: 16$ & 1.506 & 16.9 \\
\hline 55 & $8 / 7 / 200812: 18$ & 1.506 & 16.9 \\
\hline 56 & $8 / 7 / 200812: 20$ & 1.505 & 16.9 \\
\hline 57 & $8 / 7 / 200812: 22$ & 1.504 & 16.9 \\
\hline 58 & $8 / 7 / 200812: 24$ & 1.504 & 16.9 \\
\hline 59 & $8 / 7 / 2008$ 12:26 & 1.504 & 16.9 \\
\hline 60 & $8 / 7 / 200812: 28$ & 1.503 & 16.9 \\
\hline 61 & $8 / 7 / 2008$ 12:30 & 1.502 & 16.9 \\
\hline 62 & $8 / 7 / 200812: 32$ & 1.502 & 16.9 \\
\hline 63 & $8 \sqrt{7 / 2008} 12: 34$ & 1.502 & 16.9 \\
\hline 64 & $8 / 7 / 2008$ 12:36 & 1.503 & 16.9 \\
\hline 65 & $8 / 7 / 200812: 38$ & 1.505 & 16.9 \\
\hline 66 & $8 / 7 / 200812: 40$ & 1.504 & 16.9 \\
\hline 67 & $8 / 7 / 200812: 42$ & 1.505 & 16.9 \\
\hline
\end{tabular}

\begin{tabular}{|c|c|c|c|}
\hline \multicolumn{4}{|c|}{$D 4-27 p$} \\
\hline Rec & & Pres & emp \\
\hline$\#$ & Date/Time & psi & \\
\hline 68 & $87 / 200812: 44$ & $\frac{p 04}{1.504}$ & \\
\hline & 7/2008 12:46 & 1.504 & 16. \\
\hline 70 & 12008 12:48 & 1.505 & 16. \\
\hline 71 & 72008 12:50 & 1.504 & 16. \\
\hline$\overline{72}$ & $3 \pi / 200812: 52$ & 1.506 & \\
\hline 73 & $87 / 2008$ 12:54 & 1.506 & 16 . \\
\hline 74 & $7 / 2008$ 12:56 & 1.505 & 16. \\
\hline 75 & $8 / 7 / 200812: 58$ & 1.505 & 16. \\
\hline$\overline{76}$ & $8 / 7 / 200813: 00$ & 1.505 & 16. \\
\hline 77 & $8 / 7 / 200813: 02$ & 1.505 & 16. \\
\hline 78 & 72008 13:04 & 1.506 & 16. \\
\hline 79 & $8 / 7 / 200813: 06$ & 1.505 & 16. \\
\hline 80 & $8 / 7 / 200813: 08$ & 1.507 & 16. \\
\hline 81 & $8 / 7 / 2008$ 13:10 & 1.506 & \\
\hline 82 & V7/2008 13:12 & 1.506 & \\
\hline 83 & $8 / 7 / 2008$ 13:14 & 1.504 & \\
\hline 84 & $87 / 200813: 16$ & 1.505 & 16. \\
\hline 85 & $8 / 7 / 2008$ 13:18 & 1.506 & 16. \\
\hline 86 & $8 / 7 / 200813: 20$ & 1.508 & \\
\hline 87 & $8 / 7 / 200813: 2$ & 1.509 & \\
\hline 88 & $87 / 2008$ 13:24 & 1.51 & 16 \\
\hline 89 & $8 / 7 / 200813: 26$ & 1.505 & $\frac{16}{16}$ \\
\hline 90 & $8 / 7 / 200813: 28$ & 1.509 & \\
\hline 91 & /7/2008 13:30 & 1.508 & \\
\hline 92 & $8 / 7 / 2008$ 13:32 & 1.507 & 16. \\
\hline 93 & $8 / 7 / 2008$ 13:34 & 1.508 & $\frac{\pi}{16}$ \\
\hline 94 & & 1.509 & \\
\hline 95 & $\sqrt{7 / 2008}$ & 1.512 & \\
\hline 96 & $87 / 2008$ 13:40 & 1.513 & \\
\hline 97 & $8 / 7 / 200813: 42$ & 1.515 & 16 \\
\hline & & & \\
\hline 99 & & 1.512 & \\
\hline 100 & $87 / 2008$ 13:48 & 1.511 & \\
\hline 101 & $87 / 2008$ & 1.511 & \\
\hline & $8 / 7200$ & 1.512 & \\
\hline 103 & & 1.5 & \\
\hline 104 & $8 / 7 / 2008$ 13:56 & 1.51 & \\
\hline 105 & $7 / 2008$ 13:58 & 1.512 & \\
\hline 106 & $87 / 2008$ & 1.512 & \\
\hline 107 & & 1.514 & \\
\hline 108 & 1200 & 1.512 & \\
\hline 109 & $87 / 2004$ & 1.512 & \\
\hline 110 & $87 / 200$ & 1.511 & \\
\hline 111 & & 1.509 & \\
\hline 112 & & 1.508 & 6 \\
\hline 113 & $8 / 7 / 2008$ 14:14 & 1.508 & \\
\hline 114 & $87 / 200$ & 1.507 & \\
\hline 115 & $87 / 2008$ & 1.508 & \\
\hline 1 & & 1.509 & \\
\hline 11 & 2 & 1.509 & \\
\hline 118 & $87 / 200$ & & \\
\hline 110 & & & \\
\hline 120 & $7 / 2008$ & 1.509 & \\
\hline 121 & & 1.511 & \\
\hline$\overline{122}+>$ & $87 / 200$ & & \\
\hline 123 & $8 / 7 / 200814$ & 1.511 & \\
\hline 124 & $8 / 7200814: 36$ & 1.512 & \\
\hline$\overline{125}$ & 710008 & 1.512 & \\
\hline$\overline{12}$ & & & \\
\hline 127 & $8 / 7 / 2008$ 14:42 & 1.511 & \\
\hline 128 & $8 / 7 / 2008$ 14:44 & 1.511 & \\
\hline 129 & 72008 & 1.512 & \\
\hline $17 \div 2+$ & & & \\
\hline 131 & $877 / 2008$ & 1.511 & \\
\hline 132 & $87 / 2008$ 14:52 & 1.511 & \\
\hline & $87 / 200814: 54$ & 1.512 & 16 \\
\hline & & & \\
\hline
\end{tabular}

\begin{tabular}{|c|c|c|c|}
\hline \multicolumn{4}{|c|}{$D 4-27 p$} \\
\hline $\operatorname{Rec}$ & & Pres & Temp \\
\hline$\#$ & Date/Time & psi & \\
\hline 135 & $8 / 7 / 200814: 58$ & 1.513 & $16.9>\mathrm{l}$ \\
\hline 136 & $87 / 200815: 00$ & $\mid 1.514$ & $\begin{array}{l}16.9 \\
\end{array}$ \\
\hline 137 & $8 / 7 / 200815: 02$ & 1.515 & 16.9 \\
\hline 138 & $8 / 7 / 200815: 04$ & 1.514 & 16.9 \\
\hline 139 & $8 / 7 / 200815: 06$ & 1.513 & 16.9 \\
\hline 140 & $8 / 1200815: 08$ & 1.513 & 16.9 \\
\hline 141 & $8 / 7 / 200815: 10$ & 1.512 & 16.9 \\
\hline 142 & $8 / 7 / 2008$ 15:12 & 1.513 & 16.9 \\
\hline 143 & $8 / 7 / 2008$ 15:14 & 1.514 & 16.9 \\
\hline 144 & $8 / 7200815: 16$ & 1.515 & 16.9 \\
\hline 145 & $8 / 7 / 200815: 18$ & 1.514 & \\
\hline 146 & $8 / 7 / 200815: 20$ & & 16.9 \\
\hline 147 & $8 / 7 / 200815: 22$ & 1.515 & 16.9 \\
\hline 148 & $8 / / 200815: 24$ & 1.514 & 16.9 \\
\hline 149 & $87 / 2008$ 15:26 & 1.513 & \\
\hline 150 & $8 / 7 / 2008$ 15:28 & 1.513 & 16.9 \\
\hline 151 & $8 / 7 / 2008$ 15:30 & 1.513 & 16.9 \\
\hline 152 & $8 / 7 / 2008$ 15:32 & 1.514 & 16.9 \\
\hline 153 & $8 / 7 / 200815: 34$ & 1.515 & 16.9 \\
\hline 154 & $8 / 7 / 2008$ 15:36 & 1.517 & 16.9 \\
\hline 155 & $8 / / 200815: 38$ & 1.517 & 16.9 \\
\hline 156 & $8 / 7200815: 40$ & 1.516 & 16.9 \\
\hline 157 & $8 / 7 / 200815: 42$ & 1.515 & 16.9 \\
\hline 158 & $8 / 7 / 200815: 44$ & 1.514 & 16.9 \\
\hline 159 & $8 / 7 / 200815: 46$ & 1.513 & 16.9 \\
\hline 160 & $8 / 7 / 2008$ 15:48 & 1.514 & 16.9 \\
\hline 161 & $8 / 7 / 200815: 50$ & 1.514 & 16.9 \\
\hline 162 & $87 / 12008 \quad 15: 52$ & 1.513 & 16.9 \\
\hline 163 & $8 / 7 / 2008$ 15:54 & 1.513 & 16.9 \\
\hline 164 & $8 / 7 / 2008$ 15:56 & 1.514 & 16.9 \\
\hline 165 & $8 / 7 / 2008$ 15:58 & 1.514 & 16.9 \\
\hline 166 & $8 / 7 / 200816: 00$ & 1.514 & 16.9 \\
\hline 167 & $8 / 7 / 2008$ 16:02 & 1.513 & 16.9 \\
\hline 168 & $8 / 7 / 200816: 04$ & 1.514 & 16.9 \\
\hline 169 & $8 / 7 / 2008$ 16:06 & 7.514 & 16.9 \\
\hline 170 & $8 / 7 / 2008$ 16:08 & 1.514 & 16.9 \\
\hline 171 & $8 / 7 / 2008$ 16:10 & 1.514 & 16.9 \\
\hline 172 & $8 / 7 / 2008$ 16:12 & 1.512 & 16.9 \\
\hline 173 & $8 / 7200816: 14$ & 1.512 & 16.9 \\
\hline 174 & $8 / 7 / 2008$ 16:16 & 1.513 & 16.9 \\
\hline 175 & $8 / 7 / 2008$ 16:18 & 1.512 & 16.9 \\
\hline 176 & $8 / 7 / 2008$ 16:20 & 1.511 & 16.9 \\
\hline 177 & $8 / 7 / 200816: 22$ & 1.512 & 16.9 \\
\hline 178 & $8 / 7 / 2008$ 16:24 & 1.51 & 16.9 \\
\hline 179 & $8 / 7 / 200816: 26$ & 1.511 & 16.9 \\
\hline 180 & $87 / 2008$ 16:28 & 1.511 & \\
\hline 181 & $8 / 7 / 200816: 30$ & 1.511 & \\
\hline 182 & $8 / 7 / 200816: 32$ & 1.511 & 16.9 \\
\hline 183 & $8 / 7 / 200816: 34$ & 1.511 & 16.9 \\
\hline 184 & $8 / 7 / 200816: 36$ & 1.512 & 16.9 \\
\hline 185 & $8 / 7 / 200816: 38$ & 1.512 & 16.9 \\
\hline 186 & $8 / 7 / 200816: 40$ & 1.513 & 16.9 \\
\hline 187 & $8 / 7 / 2008$ 16:42 & 1.513 & 16.9 \\
\hline 188 & $8 / 7 / 200816: 44$ & 1.513 & 16.9 \\
\hline 189 & $8 / 7 / 200816: 46$ & 1.513 & 16.9 \\
\hline 190 & $8 / 7 / 2008$ 16:48 & 1.513 & 16.9 \\
\hline 191 & $8 / 7 / 200816: 50$ & 1.513 & 16.9 \\
\hline 192 & $8 / 7 / 200816: 52$ & 1.512 & 16.9 \\
\hline 193 & $8 / 7 / 200816: 54$ & 1.512 & \\
\hline 194 & $8 / 7 / 200816: 56$ & 1.512 & 16.9 \\
\hline 195 & $8 / 7 / 200816: 58$ & 1.512 & 16.9 \\
\hline 196 & $8 / 7 / 200817: 00$ & 1.513 & 16.9 \\
\hline 197. & $8 / 7 / 200817: 02$ & 1.513 & 1 \\
\hline 198 & $8 / 7 / 2008$ 17:04 & 1.513 & 16.9 \\
\hline 199 & $87 / 1200817: 06$ & 1.514 & 16.9 \\
\hline 200 & $87 / 200817: 08$ & $1.514 \mid$ & 16.9 \\
\hline & & 1.514 & 16.9 \\
\hline
\end{tabular}




\begin{tabular}{|c|c|c|c|}
\hline \multicolumn{4}{|c|}{$04-27 p$} \\
\hline $\operatorname{Rec}$ & & Pres & Temp \\
\hline$\#$ & Date/Time & psi & ${ }^{\circ} \mathrm{C}$ \\
\hline 269 & $87 / 2008$ 19:26 & 1.514 & 16.9 \\
\hline 270 & $8 / 7 / 200819: 28$ & 1.514 & 16.9 \\
\hline 271 & $87 / 2008$ 19:30 & 1.513 & 16.9 \\
\hline 272 & $8 / 7 / 2008$ 19:32 & 1.514 & 16.9 \\
\hline 273 & $8 / 7 / 200819: 34$ & 1.515 & 16.9 \\
\hline 274 & $8 / 7 / 200819: 36$ & 1.515 & 16.9 \\
\hline 275 & $8 / 7 / 2008$ 19:38 & 1.514 & 16.9 \\
\hline 276 & $87 / 200819: 40$ & 1.514 & 16.9 \\
\hline 277 & $8 / 7 / 200819: 42$ & 1.514 & 16.9 \\
\hline 278 & $8 / 7 / 2008$ 19:44 & 1.515 & 16.9 \\
\hline 279 & $8 / 7 / 200819: 46$ & 1.514 & 16.9 \\
\hline 280 & $8 / 7 / 2008 \quad 19: 48$ & 1.514 & 16.9 \\
\hline 281 & $8 / 7 / 2008$ 19:50 & 1.513 & 16.9 \\
\hline 282 & $8 / 7 / 2008$ 19:52 & 1.514 & 16.9 \\
\hline 283 & $8 / 7 / 200819: 54$ & 1.513 & 16.9 \\
\hline 284 & $8 / 7 / 200819: 56$ & 1.513 & 16.9 \\
\hline 285 & $8 / 7 / 200819: 58$ & 1.512 & 16.9 \\
\hline 286 & $8 / 7 / 200820: 00$ & 1.512 & 16.9 \\
\hline 287 & $8 / 7 / 200820: 02$ & 1.512 & 16.9 \\
\hline 288 & $8 / 7 / 200820: 04$ & 1.513 & 16.9 \\
\hline 289 & $8 / 7 / 200820: 06$ & 1.513 & 16.9 \\
\hline 290 & $8 / 7 / 200820: 08$ & 1.514 & 16.9 \\
\hline 291 & $8 / 7 / 200820: 10$ & 1.513 & 16.9 \\
\hline 292 & $820: 12$ & 1.513 & 16.9 \\
\hline 293 & $8 / 7 / 200820: 14$ & 1.512 & 16.9 \\
\hline 294 & $8 / 7 / 200820: 16$ & 1.511 & 16.9 \\
\hline 295 & $320: 18$ & 1.512 & 16.9 \\
\hline 296 & $8 / 7 / 200820: 20$ & 1.512 & 16.9 \\
\hline 297 & $8 / 7 / 200820: 22$ & 1.512 & 16.9 \\
\hline 298 & $87 / 20$ & 1.513 & 16.9 \\
\hline 299 & $320: 26$ & 1.512 & 16.9 \\
\hline 300 & $8 / 7 / 200820: 28$ & 1.512 & 16.9 \\
\hline 301 & $87 / 20$ & 1.511 & 16.9 \\
\hline 302 & $8 / 7 / 200820: 32$ & 1.51 & 16.9 \\
\hline 303 & $8 / 7 / 200820: 34$ & 1.509 & 16.9 \\
\hline 304 & $820: 36$ & 1.508 & 16.9 \\
\hline 305 & $8 / 7 / 20$ & 1.507 & 16.9 \\
\hline 306 & $8 / 7200820: 40$ & 1.507 & 16.9 \\
\hline 307 & $820: 42$ & 1.509 & 16.9 \\
\hline 308 & $20: 44$ & 1.508 & 16.9 \\
\hline 309 & $820: 46$ & 1.507 & 16.9 \\
\hline 310 & $8 \overline{20: 48}$ & 1.507 & 16.9 \\
\hline 311 & $8 / 7 / 20$ & 1.507 & 16.9 \\
\hline 312 & $820: 52$ & 1.507 & 16.9 \\
\hline 313 & $320: 54$ & 1.508 & 16.9 \\
\hline$\overline{314}$ & $20: 56$ & 1.508 & 16.9 \\
\hline 315 & $8 / 720$ & 1.509 & 16.9 \\
\hline 316 & $8 / 7 / 20 x$ & 1.508 & 16.9 \\
\hline 317 & & 1.508 & 16.8 \\
\hline 318 & $21: 04$ & 1.508 & 16.9 \\
\hline 319 & $8 / 7 / 20$ & 1.508 & 16.9 \\
\hline 320 & $21: 08$ & 1.508 & 16.9 \\
\hline 321 & $8 / 7 / 20$ & 1.508 & 16.9 \\
\hline 322 & $8 / 7 / 20$ & 1.508 & 16.9 \\
\hline 323 & & 1.51 & 110 \\
\hline 324 & $8 / 7 / 20$ & 1.508 & 16.9 \\
\hline 325 & $8 / 7 / 20$ & 1.508 & 16.9 \\
\hline 326 & $8 / 7 / 20$ & 1.508 & 16.9 \\
\hline 327 & $8 / 7 / 20$ & 1.509 & 16.9 \\
\hline 328 & $8 / 7 / 200821: 24$ & 1.509 & 16.9 \\
\hline 329 & $8 / 7 / 200$ & 1.509 & 16.9 \\
\hline 330 & $8 / 120$ & 1.51 & 16.9 \\
\hline 331 & $8 / 7 / 200821: 30$ & 1.51 & 16.9 \\
\hline 332 & $8 / 7 / 200821: 32$ & 1.51 & 16.9 \\
\hline 333 & $8 / 7 / 200821: 34$ & 1.509 & 16.9 \\
\hline 334 & $8 / 7 / 200821: 36$ & 1.509 & 16.9 \\
\hline 335 & $8 / 7 / 200821: 38$ & 1.508 & 16. \\
\hline
\end{tabular}

\begin{tabular}{|c|c|c|c|}
\hline \multicolumn{4}{|c|}{ D4-27p } \\
\hline $\operatorname{Rec}$ & & Pres & Temp \\
\hline \# & Date/Time & psi & ${ }^{\circ} \mathrm{C}$ \\
\hline 336 & $87 / 2008$ 21:40 & 1.509 & 16.9 \\
\hline 337 & $87 / 2008$ 21:42 & 1.509 & 16.9 \\
\hline 338 & $8 / 7 / 200821: 44$ & 1.51 & 16.9 \\
\hline 339 & $87 / 2008$ 21:46 & 1.511 & 16.9 \\
\hline 340 & $87 / 2008$ 21:48 & 1.509 & 16.9 \\
\hline 341 & $87 / 200821: 50$ & 1.509 & 16.9 \\
\hline 342 & $8 / 7 / 2008$ 21:52 & 1.509 & 16.9 \\
\hline 343 & $8 / 7 / 200821: 54$ & 1.51 & 16.9 \\
\hline 344 & $87 / 200821: 56$ & 1.509 & 16.9 \\
\hline 345 & $87 / 200821: 58$ & 1.509 & 16.9 \\
\hline 346 & $8 / 7 / 200822: 00$ & 1.508 & 16.9 \\
\hline 347 & $8 / 7 / 200822: 02$ & 1.507 & 16.9 \\
\hline 348 & $87 / 2008$ 22:04 & 1.507 & 16.9 \\
\hline 349 & $87 / 200822: 06$ & 1.508 & 16.9 \\
\hline 350 & $8 / 7 / 200822: 08$ & 1.508 & 16.9 \\
\hline 351 & $8 / 7 / 200822: 10$ & 1.509 & 16.9 \\
\hline 352 & $8 / 7 / 200822: 12$ & 1.508 & 16.9 \\
\hline 353 & $8 / 7 / 200822: 14$ & 1.509 & 16.9 \\
\hline 354 & $8 / 7 / 2008$ 22:16 & 1.509 & 16.9 \\
\hline 355 & $8 / 7 / 200822: 18$ & 1.508 & 16.9 \\
\hline 356 & $87 / 200822: 20$ & 1.506 & 16.9 \\
\hline 357 & $8 / 7 / 200822: 22$ & 1.506 & 16.9 \\
\hline 358 & $87 / 2008$ 22:24 & 1.508 & 16.9 \\
\hline 359 & $87 / 200822: 26$ & 1.507 & 16.9 \\
\hline 360 & $8 / 7 / 200822: 28$ & 1.508 & 16.9 \\
\hline 361 & $8 / 7 / 200822: 30$ & 1.508 & 16.9 \\
\hline 362 & $8 / 7 / 200822: 32$ & 1.508 & 16.9 \\
\hline 363 & $8 / 7 / 200822: 34$ & 1.507 & 16.9 \\
\hline 364 & $8 / 8 / 2008$ 22:34 & 1.508 & 16.9 \\
\hline 365 & $8 / 9 / 200822: 34$ & 1.508 & 16.9 \\
\hline 366 & $8 / 10 / 200822: 34$ & 1.508 & 16.9 \\
\hline 367 & $8 / 11 / 200822: 34$ & 1.508 & 16.9 \\
\hline 368 & $8 / 12 / 200822: 34$ & 1.509 & 16.9 \\
\hline 369 & $8 / 13 / 200822: 34$ & 1.509 & 16.9 \\
\hline 370 & 8/14/2008 22:34 & 1.509 & 16.9 \\
\hline 371 & $8 / 15 / 200822: 34$ & 1.509 & 16.9 \\
\hline 372 & $8 / 16 / 200822: 34$ & 1.509 & 16.9 \\
\hline 373 & $8 / 17 / 2008$ 22:34 & 1.509 & 16.9 \\
\hline 374 & $1 / 18 / 200822: 34$ & 1.508 & 16.9 \\
\hline 375 & 8/19/2008 22:34 & 1.509 & 16.9 \\
\hline 376 & $8 / 20 / 200822: 34$ & 1.509 & 16.9 \\
\hline 377 & $8 / 21 / 200822: 34$ & 1.509 & 16.9 \\
\hline 378 & $8 / 22 / 200822: 34$ & 1.509 & 16.9 \\
\hline 379 & $8 / 23 / 200822: 34$ & 1.508 & 16.9 \\
\hline 380 & $8 / 24 / 200822: 34$ & 1.508 & 16.9 \\
\hline 381 & $8 / 25 / 200822: 34$ & 1.509 & 16.9 \\
\hline 382 & $8 / 26 / 200822: 34$ & 1.511 & 16.9 \\
\hline 383 & $8 / 27 / 200822: 34$ & 1.511 & 16.9 \\
\hline 384 & $8 / 28 / 200822: 34$ & 1.509 & 16.9 \\
\hline 385 & $8 / 29 / 200822: 34$ & 1.509 & 16.9 \\
\hline 386 & $8 / 30 / 200822: 34$ & 1.509 & 16.9 \\
\hline 387 & $8 / 31 / 200822: 34$ & 1.51 & 16.9 \\
\hline 388 & $9 / 1 / 200822: 34$ & 1.51 & 16.9 \\
\hline 389 & $9 / 2 / 200822: 34$ & 1.51 & 16.9 \\
\hline 390 & $9 / 3 / 200822: 34$ & 1.511 & 16.9 \\
\hline 391 & 9/4/2008 22:34 & 1.51 & 16.9 \\
\hline 392 & 9/5/2008 22:34 & 1.511 & 16.9 \\
\hline 393 & $9 / 6 / 200822: 34$ & 1.512 & 16.9 \\
\hline 394 & $9 / 7 / 200822: 34$ & 1.511 & 16.9 \\
\hline 395 & $9 / 8 / 200822: 34$ & 1.51 & 16.9 \\
\hline 396 & $9 / 9 / 200822: 34$ & 1.51 & \\
\hline 397 & 9/10/2008 22:34 & 1.511 & 16.9 \\
\hline 398 & $9 / 11 / 200822: 34$ & 1.51 & 16.9 \\
\hline 399 & $9 / 12 / 200822: 34$ & 1.509 & 16.9 \\
\hline 400 & 9/13/2008 22:34 & 1.509 & 16.9 \\
\hline 401 & 9/14/2008 22:34 & 1.509 & 16.9 \\
\hline 402 & 9/15/2008 22:34 & 1.509 & 16.9 \\
\hline
\end{tabular}

\begin{tabular}{|c|c|c|c|}
\hline \multicolumn{4}{|c|}{ D4-27p } \\
\hline $\operatorname{Rec}$ & & Pres & Temp \\
\hline$\#$ & Date/Time & $p s i$ & ${ }^{\circ} \mathrm{C}$ \\
\hline 403 & $8 / 7 / 200823: 54$ & 1.508 & 16.9 \\
\hline 404 & $87 / 2008$ 23:56 & 1.507 & 16.9 \\
\hline 405 & $87 / 200823: 58$ & 1.506 & 16.9 \\
\hline 406 & $8 / 8 / 20080: 00$ & 1.506 & 16.9 \\
\hline 407 & $8 / 8 / 20080: 02$ & 1.506 & 16.9 \\
\hline 408 & $8 / 8 / 20080: 04$ & 1.506 & 16.9 \\
\hline 409 & $8 / 8 / 20080: 06$ & 1.505 & 16.9 \\
\hline 410 & $8 / 8 / 20080: 08$ & 1.505 & 16.9 \\
\hline 411 & $8 / 8 / 20080: 10$ & 1.506 & 16.9 \\
\hline 412 & $8 / 8 / 20080: 12$ & 1.506 & 16.9 \\
\hline 413 & $8 / 8 / 20080: 14$ & 1.506 & 160 \\
\hline 414 & $8 / 8 / 20080: 16$ & 1.506 & 16.9 \\
\hline 415 & $8 / 8 / 20080: 18$ & 1.506 & 16.9 \\
\hline 416 & $8 / 8 / 20080: 20$ & 1.504 & 16.9 \\
\hline 417 & $8 / 8 / 20080: 22$ & 1.506 & 16.9 \\
\hline 418 & $8 / 8 / 20080: 24$ & 1.506 & 16.9 \\
\hline 419 & $8 / 8 / 20080: 26$ & 1.508 & 16.9 \\
\hline 420 & $8 / 8 / 20080: 28$ & 1.508 & 16. \\
\hline 421 & $8 / 8 / 20080: 30$ & 1.506 & 16.9 \\
\hline 422 & $8 / 8 / 20080: 32$ & 1.505 & 16.9 \\
\hline 423 & $8 / 8 / 20080: 34$ & 1.504 & 16.9 \\
\hline 424 & $8 / 8 / 20080: 36$ & 1.506 & 16.9 \\
\hline 425 & $8 / 8 / 20080: 38$ & 1.505 & 16.9 \\
\hline 426 & $8 / 8 / 20080: 40$ & 1.505 & 16.9 \\
\hline 427 & $8 / 8 / 20080: 42$ & 1.505 & 16. \\
\hline 428 & $8 / 8 / 20080: 44$ & 1.504 & 16.9 \\
\hline 429 & $8 / 8 / 20080: 46$ & 1.505 & 16.9 \\
\hline 430 & $8 / 8 / 20080: 48$ & 1.506 & 16. \\
\hline 431 & $8 / 8 / 20080: 50$ & 1.506 & 16.9 \\
\hline 432 & $8 / 8 / 20080: 52$ & 1.506 & 16.9 \\
\hline 433 & $8 / 8 / 20080: 54$ & 1.506 & 16. \\
\hline 434 & $8 / 8 / 20080: 56$ & 1.506 & 16.9 \\
\hline 435 & $8 / 8 / 20080: 58$ & 1.506 & 16. \\
\hline 436 & $8 / 8 / 20081: 00$ & 1.506 & 16. \\
\hline 437 & $8 / 8 / 20081: 02$ & 1.506 & 16. \\
\hline 438 & $8 / 8 / 20081: 04$ & 1.505 & 16. \\
\hline 439 & $8 / 8 / 20081: 06$ & 1.506 & 16. \\
\hline 440 & $8 / 8 / 20081: 08$ & 1.506 & 16.9 \\
\hline 441 & $8 / 8 / 20081: 10$ & 1.507 & 16.9 \\
\hline 442 & $8 / 8 / 20081: 12$ & 1.506 & 16.9 \\
\hline 443 & $8 / 8 / 20081: 14$ & 1.506 & 16. \\
\hline 444 & $8 / 8 / 20081: 16$ & 1.507 & 16. \\
\hline 445 & $8 / 8 / 20081: 18$ & 1.507 & 16.9 \\
\hline 446 & $8 / 8 / 20081: 20$ & 1.506 & 16. \\
\hline 447 & $8 / 8 / 2008$ 1:22 & 1.505 & 16. \\
\hline 448 & $8 / 8 / 20081: 24$ & 1.506 & 16.9 \\
\hline 449 & $8 / 8 / 20081: 26$ & 1.507 & 16.9 \\
\hline 450 & $8 / 8 / 2008$ 1:28 & 1.507 & 16.8 \\
\hline 451 & $8 / 8 / 20081: 30$ & 1.506 & 16. \\
\hline 452 & $8 / 8 / 20081: 32$ & 1.506 & 16. \\
\hline 453 & $8 / 8 / 20081: 34$ & 1.505 & 16. \\
\hline 454 & $8 / 8 / 20081: 36$ & 1.505 & 16. \\
\hline 455 & $8 / 8 / 20081: 38$ & 1.504 & 16. \\
\hline 456 & $8 / 8 / 20081: 40$ & 1.504 & 16. \\
\hline 457 & $8 / 8 / 20081: 42$ & 1.504 & 16. \\
\hline 458 & $8 / 8 / 20081: 44$ & 1.504 & 16. \\
\hline 459 & $8 / 8 / 20081: 46$ & 1.504 & 16. \\
\hline 460 & $8 / 8 / 20081: 48$ & 1.505 & 16. \\
\hline 461 & $8 / 8 / 20081: 50$ & 1.505 & 16. \\
\hline 462 & $8 / 8 / 20081: 52$ & 1.504 & 16. \\
\hline 463 & $8 / 8 / 20081: 54$ & 1.504 & 16. \\
\hline 464 & $8 / 8 / 20081: 56$ & 1.504 & 16. \\
\hline 465 & $8 / 8 / 20081: 58$ & 1.504 & 16. \\
\hline 466 & $8 / 8 / 20082: 00$ & 1.504 & 16. \\
\hline 467 & $8 / 8 / 20082: 02$ & 1.505 & 16.9 \\
\hline 468 & $8 / 8 / 20082: 04$ & 1.504 & 16.9 \\
\hline 469 & $8 / 8 / 20082: 06$ & 1.505 & 16. \\
\hline
\end{tabular}

\begin{tabular}{|c|c|c|c|}
\hline \multicolumn{4}{|c|}{ D4-27p } \\
\hline $\operatorname{Rec}$ & & Pres & Temp \\
\hline$\#$ & Date/Time & psi & ${ }^{\circ} \mathrm{C}$ \\
\hline 470 & $8 / 8 / 20082: 08$ & 1.506 & 16.9 \\
\hline 471 & $8 / 8 / 20082: 10$ & 1.505 & 16.9 \\
\hline 472 & $8 / 8 / 20082: 12$ & 1.506 & 16.9 \\
\hline 473 & $8 / 8 / 20082: 14$ & 1.506 & 16.9 \\
\hline 474 & $8 / 8 / 20082: 16$ & 1.506 & 16.9 \\
\hline 475 & $8 / 8 / 20082: 18$ & 1.505 & 16.9 \\
\hline 476 & $8 / 8 / 20082: 20$ & 1.504 & 16.9 \\
\hline 477 & $8 / 8 / 2008$ 2:22 & 1.504 & 16.9 \\
\hline 478 & $8 / 8 / 20082: 24$ & 1.504 & 16.9 \\
\hline 479 & $8 / 8 / 20082: 26$ & 1.505 & 16.9 \\
\hline 480 & $8 / 8 / 20082: 28$ & 1.506 & 16.9 \\
\hline 481 & $8 / 8 / 20082: 30$ & 1.505 & 16.9 \\
\hline 482 & $8 / 8 / 20082: 32$ & 1.504 & 16.9 \\
\hline 483 & $8 / 8 / 20082: 34$ & 1.505 & 16.9 \\
\hline 484 & $8 / 8 / 20082: 36$ & 1.505 & 16.9 \\
\hline 485 & $8 / 8 / 20082: 38$ & 1.505 & 16.9 \\
\hline 486 & $8 / 8 / 20082: 40$ & 1.505 & 16.9 \\
\hline 487 & $8 / 8 / 20082: 42$ & 1.504 & 16.9 \\
\hline 488 & $8 / 8 / 20082: 44$ & 1.503 & 16.9 \\
\hline 489 & $8 / 8 / 20082: 46$ & 1.502 & 16.9 \\
\hline 490 & $8 / 8 / 20082: 48$ & 1.501 & 16.9 \\
\hline 491 & $8 / 8 / 20082: 50$ & 1.501 & 16.9 \\
\hline 492 & $8 / 8 / 20082: 52$ & 1.5 & 16.9 \\
\hline 493 & $8 / 8 / 20082: 54$ & 1.501 & 16.9 \\
\hline 494 & $8 / 8 / 20082: 56$ & 1.502 & 16.9 \\
\hline 495 & $8 / 8 / 20082: 58$ & 1.503 & 16.9 \\
\hline 496 & $8 / 8 / 20083: 00$ & 1.504 & 16.9 \\
\hline 497 & $8 / 8 / 20083: 02$ & 1.504 & 16.9 \\
\hline 498 & $8 / 8 / 20083: 04$ & 1.504 & 16.9 \\
\hline 499 & $8 / 8 / 20083: 06$ & 1.504 & 16.9 \\
\hline 500 & $8 / 8 / 20083: 08$ & 1.504 & 16.9 \\
\hline 501 & $8 / 8 / 20083: 10$ & 1.504 & 16.9 \\
\hline 502 & $8 / 8 / 20083: 12$ & 1.503 & 16.9 \\
\hline 503 & $8 / 8 / 20083: 14$ & 1.504 & 16.9 \\
\hline 504 & $8 / 8 / 20083: 16$ & 1.503 & 16.9 \\
\hline 505 & $8 / 8 / 20083: 18$ & 1.504 & 16.9 \\
\hline 506 & $8 / 8 / 20083: 20$ & 1.504 & 16.9 \\
\hline 507 & $8 / 8 / 20083: 22$ & 1.503 & 16.9 \\
\hline 508 & $8 / 8 / 20083: 24$ & 1.502 & 16.9 \\
\hline 509 & $8 / 8 / 20083: 26$ & 1.503 & 16.9 \\
\hline 510 & $8 / 8 / 20083: 28$ & 1.503 & 16.9 \\
\hline 511 & $8 / 8 / 20083: 30$ & 1.502 & 16.9 \\
\hline 512 & $8 / 8 / 20083: 32$ & 1.503 & 16.9 \\
\hline 513 & $8 / 8 / 20083: 34$ & 1.503 & 16.9 \\
\hline 514 & $8 / 8 / 20083: 36$ & 1.502 & 16.9 \\
\hline 515 & $8 / 8 / 20083: 38$ & 1.502 & 16.9 \\
\hline 516 & $8 / 8 / 20083: 40$ & 1.501 & $\overline{16.9}$ \\
\hline 517 & $8 / 8 / 20083: 42$ & 1.5 & 16.9 \\
\hline 518 & $8 / 8 / 20083: 44$ & 1.5 & 16.9 \\
\hline 519 & $8 / 8 / 20083: 46$ & 1.502 & $\overline{16.9}$ \\
\hline 520 & $8 / 8 / 20083: 48$ & 1.503 & 16.9 \\
\hline 521 & $8 / 8 / 200$ & 1.503 & 16.9 \\
\hline 522 & $8 / 8 / 20083: 52$ & 1.503 & 16.9 \\
\hline 523 & $8 / 8 / 20083: 54$ & 1.502 & 16.9 \\
\hline 524 & $8 / 8 / 20083: 56$ & 1.502 & 16.9 \\
\hline 525 & $8 / 8 / 20083: 58$ & 1.5 & 16.9 \\
\hline 526 & $8 / 8 / 20084: 00$ & 1.5 & 16.9 \\
\hline 527 & 8/8/2008 4:02 & 1.501 & 16.9 \\
\hline 528 & $8 / 8 / 20084: 04$ & 1.501 & 16.9 \\
\hline 529 & $8 / 8 / 20084: 06$ & 1.502 & 16.9 \\
\hline 530 & $8 / 8 / 2008$ 4:08 & 1.502 & 16.9 \\
\hline 531 & $8 / 8 / 20084: 10$ & 1.501 & 16.9 \\
\hline 532 & $8 / 8 / 20084: 12$ & 1.5 & 16.9 \\
\hline 533 & 8/8/2008 4:14 & 1.5 & 16.9 \\
\hline 534 & $8 / 8 / 20084: 16$ & 1.502 & 16.9 \\
\hline$\overline{535}$ & $8 / 8 / 20084: 18$ & 1.501 & 16.9 \\
\hline 536 & $8 / 8 / 20084: 20$ & 1.501 & 16.9 \\
\hline
\end{tabular}


DOE/RL-2009-35, REV. 0

\begin{tabular}{|c|c|c|c|c|c|c|c|c|c|c|c|c|c|c|c|}
\hline \multicolumn{4}{|c|}{ D4-27p } & \multicolumn{4}{|c|}{ D4-27p } & \multicolumn{4}{|c|}{ D4-27p } & \multicolumn{4}{|c|}{ D4-27p } \\
\hline $\operatorname{Rec}$ & & Pres & Temp & $\operatorname{Rec}$ & & Pres & Temp & $\operatorname{Rec}$ & & Pres & Temp & $\operatorname{Rec}$ & & Pres & Temp \\
\hline$\#$ & Date/Time & psi & ${ }^{\circ} \mathrm{C}$ & $\#$ & Date/Time & psi & ${ }^{\circ} \mathrm{C}$ & $\#$ & Date/Time & psi & ${ }^{\circ} \mathrm{C}$ & $\#$ & Date/Time & psi & ${ }^{\circ} \mathrm{C}$ \\
\hline 537 & $8 / 8 / 20084: 22$ & 1.501 & 16.9 & 604 & $8 / 8 / 20086: 36$ & 1.496 & 16.9 & 671 & $8 / 8 / 20088: 50$ & 1.491 & 16.9 & 738 & $8 / 8 / 200811: 04$ & 1.492 & 16.9 \\
\hline 538 & $3 / 20084: 24$ & 1.5 & 16.9 & 605 & $8 / 8 / 20086: 38$ & 1.498 & 16.9 & 672 & $8 / 8 / 20088: 52$ & 1.491 & 16.9 & 739 & $8 / 8 / 200811: 06$ & 1.491 & 16.9 \\
\hline 539 & $8 / 8 / 20084: 26$ & 1.499 & 16.9 & 606 & $8 / 8 / 20086: 40$ & 1.498 & 16.9 & 673 & $8 / 8 / 20088: 54$ & 1.491 & 16.9 & 740 & $8 / 8 / 200811: 08$ & 1.49 & 16.9 \\
\hline 540 & $8 / 8 / 20084: 28$ & 1.499 & 16.9 & 607 & $8 / 8 / 20086: 42$ & 1.498 & 16.9 & 674 & $8 / 8 / 20088: 56$ & 1.492 & 16.9 & 741 & $8 / 8 / 200811: 10$ & 1.491 & 16.9 \\
\hline 541 & $3 / 20084: 30$ & 1.499 & 16.9 & 608 & $8 / 8 / 20086: 44$ & 1.498 & 16.9 & 675 & $8 / 8 / 20088: 58$ & 1.492 & 16.9 & 742 & $8 / 8 / 200811: 12$ & 1.49 & 16.9 \\
\hline 542 & $8 / 20084: 32$ & 1.5 & 16.9 & 609 & $8 / 8 / 20086: 46$ & 1.499 & 16.9 & 676 & $8 / 8 / 20089: 00$ & 1.491 & 16.9 & 743 & $8 / 8 / 2008$ 11:14 & 1.49 & 17.3 \\
\hline 543 & $8 / 20084: 34$ & 1.499 & 16.9 & 610 & $8 / 8 / 20086: 48$ & 1.498 & 16.9 & 677 & $8 / 8 / 20089: 02$ & 1.49 & 16.9 & 744 & $8 / 8 / 200811: 16$ & 1.491 & 17 \\
\hline 544 & $8 / 20084: 36$ & 1.501 & 16.9 & 611 & $8 / 8 / 20086: 50$ & 1.498 & 16.9 & 678 & $8 / 8 / 20089: 04$ & 1.49 & 16.9 & 745 & $8 / 8 / 2008$ 11:18 & 1.49 & 16.9 \\
\hline 545 & $8 / 20084: 38$ & 1.5 & 16.9 & 612 & $8 / 8 / 20086: 52$ & 1.495 & 16.9 & 679 & $8 / 8 / 20089: 06$ & 1.491 & 16.9 & 746 & $8 / 8 / 200811: 20$ & 1.491 & 16.9 \\
\hline 546 & $8 / 8 / 20084: 40$ & 1.5 & 16.9 & 613 & $8 / 8 / 20086: 54$ & 1.492 & 16.9 & 680 & $8 / 8 / 20089: 08$ & 1.494 & 16.9 & 747 & $8 / 8 / 200811: 22$ & 1.491 & 16.9 \\
\hline 547 & $8 / 8 / 20084: 42$ & 1.5 & 16.9 & 614 & $8 / 8 / 20086: 56$ & 1.489 & 16.9 & 681 & $8 / 8 / 20089: 10$ & 1.495 & 16.9 & 748 & $8 / 8 / 200811: 24$ & 1.49 & 16.9 \\
\hline 548 & $3 / 20084: 44$ & 1.501 & 16.9 & 615 & $8 / 8 / 20086: 58$ & 1.488 & 16.9 & 682 & $8 / 8 / 20089: 12$ & 1.494 & 16.9 & 749 & $8 / 8 / 200811: 26$ & 1.491 & 16.9 \\
\hline 549 & $8 / 20084: 46$ & 1.501 & 16.9 & 616 & $8 / 8 / 20087: 00$ & 1.491 & 16.9 & 683 & $8 / 8 / 20089: 14$ & 1.493 & 16.9 & 750 & $8 / 8 / 200811: 28$ & 1.49 & 16.9 \\
\hline 550 & $8 / 20084: 48$ & 1.502 & 16.9 & 617 & $8 / 8 / 20087: 02$ & 1.492 & 16.9 & 684 & $8 / 8 / 20089: 16$ & 1.492 & 16.9 & 751 & $8 / 8 / 200811: 30$ & 1.491 & 16.9 \\
\hline 551 & $3 / 20084: 50$ & 1.501 & 16.9 & 618 & $8 / 8 / 20087: 04$ & 1.492 & 16.9 & 685 & $8 / 8 / 20089: 18$ & 1.492 & 16.9 & 752 & $8 / 8 / 2008$ 11:32 & 1.491 & 16.9 \\
\hline 552 & $3 / 20084: 52$ & 1.501 & 16.9 & 619 & $8 / 8 / 20087: 06$ & 1.492 & 16.9 & 686 & $8 / 8 / 20089: 20$ & 1.489 & 16.9 & 753 & $8 / 8 / 200811: 34$ & 1.491 & 16.9 \\
\hline 553 & $8 / 20084: 54$ & 1.501 & 16.9 & 620 & $8 / 8 / 20087: 08$ & 1.493 & 16.9 & 687 & $8 / 8 / 20089: 22$ & $1 . \overline{487}$ & 16.9 & 754 & $8 / 8 / 200811: 36$ & 1.491 & 16.9 \\
\hline 554 & $3 / 20084: 56$ & 1.501 & 16.9 & 621 & $8 / 8 / 20087: 10$ & 1.494 & 16.9 & 688 & $8 / 8 / 20089: 24$ & 1.487 & 16.9 & 755 & $8 / 8 / 200811: 38$ & 1.49 & 16.9 \\
\hline 555 & $8 / 20084: 58$ & 1.501 & 16.9 & 622 & $8 / 8 / 20087: 12$ & 1.495 & 16.9 & 689 & $8 / 8 / 20089: 26$ & 1.488 & 16.9 & 756 & $8 / 8 / 200811: 40$ & 1.491 & 16.9 \\
\hline 556 & $8 / 8 / 20085: 00$ & 1.5 & 16.9 & 623 & $8 / 8 / 20087: 14$ & 1.497 & 16.9 & 690 & $8 / 8 / 20089: 28$ & 1.489 & 16.9 & 757 & $8 / 8 / 2008$ 11:42 & 1.49 & 16.9 \\
\hline 557 & $8 / 20085: 02$ & 1.499 & 16.9 & 624 & $8 / 8 / 20087: 16$ & 1.497 & 16.9 & 691 & $8 / 8 / 20089: 30$ & 1.49 & 16.8 & 758 & $8 / 8 / 2008$ 11:44 & 1.49 & 16.9 \\
\hline 558 & $3 / 20085: 04$ & 1.498 & 16.9 & 625 & $8 / 8 / 20087: 18$ & 1.496 & 16.9 & 692 & $8 / 8 / 20089: 32$ & 1.491 & 16.9 & 759 & $8 / 8 / 200811: 46$ & 1.49 & 16.9 \\
\hline 559 & $8 / 20085: 06$ & 1.498 & 16.9 & 626 & $8 / 8 / 20087: 20$ & 1.495 & 16.9 & 693 & $8 / 8 / 20089: 34$ & 1.492 & 16.9 & 760 & $8 / 8 / 2008$ 11:48 & 1.49 & 16.9 \\
\hline 560 & $8 / 20085: 08$ & 1.498 & 16.9 & 627 & $8 / 8 / 20087: 22$ & 1.495 & 16.9 & 694 & $8 / 8 / 20089: 36$ & 1.493 & 16.8 & 761 & $8 / 8 / 2008$ 11:50 & 1.49 & 16.9 \\
\hline 561 & $3 / 20085: 10$ & 1.5 & 16.9 & 628 & $8 / 8 / 20087: 24$ & 1.495 & 16.9 & 695 & $8 / 8 / 20089: 38$ & 1.494 & 16. & 762 & $8 / 8 / 2008$ 11:52 & 1.491 & 16.9 \\
\hline 562 & $8 / 8 / 20085: 12$ & 1.501 & 16.9 & 629 & $8 / 8 / 20087: 26$ & 1.495 & 16.9 & 696 & $8 / 8 / 20089: 40$ & 1.493 & 16.8 & 763 & $8 / 8 / 2008$ 11:54 & 1.491 & 16.9 \\
\hline 563 & $8 / 20085: 14$ & 1.5 & 16.9 & 630 & $8 / 8 / 20087: 28$ & 1.495 & 16.9 & 697 & $8 / 8 / 20089: 42$ & 1.491 & 16. & 764 & $0811: 56$ & 1.491 & 16.9 \\
\hline 564 & $3 / 20085: 16$ & 1.5 & 16.9 & 631 & $8 / 8 / 20087: 30$ & 1.494 & 16.9 & 698 & $8 / 8 / 20089: 44$ & 1.491 & 16 & 765 & $8 / 8 / 2008$ 11:58 & 1.49 & 16.9 \\
\hline 565 & $8 / 20085: 18$ & 1.5 & 16.9 & 632 & $8 / 8 / 20087: 32$ & 1.495 & 16.9 & 699 & $8 / 8 / 20089: 46$ & 1.492 & 16 & 766 & $8 / 8 / 200812: 00$ & 1.491 & 16.9 \\
\hline 566 & $8 / 8 / 20085: 20$ & 1.5 & 16.9 & 633 & $8 / 8 / 20087: 34$ & 1.495 & 16.9 & 700 & $8 / 8 / 20089: 48$ & 1.493 & 16. & 767 & $8 / 8 / 200812: 02$ & 1.489 & 16.9 \\
\hline 567 & $3 / 20085: 22$ & 1.5 & 16.9 & 634 & $8 / 8 / 200$ & 1.496 & 16.9 & 701 & $8 / 8 / 20089: 50$ & 1.495 & 16. & 768 & $812: 04$ & 1.49 & 16.9 \\
\hline 568 & $8 / 20085: 24$ & 1.5 & 16.9 & 635 & $8 / 8 / 20087: 38$ & 1.495 & 16.9 & 702 & $8 / 8 / 20089: 52$ & 1.494 & 16. & 769 & $8 / 8 / 200812: 06$ & 1.49 & 16.9 \\
\hline 569 & $8 / 20085: 26$ & 1.5 & 16.9 & 636 & $8 / 8 / 20087: 40$ & 1.494 & 16.9 & 703 & $8 / 8 / 20089: 54$ & 1.494 & 16. & 770 & 08 12:08 & 1.49 & 16.9 \\
\hline 570 & $3 / 20085: 28$ & 1.5 & 16.9 & 637 & $8 / 8 / 200$ & 1.495 & 16.9 & 704 & $8 / 8 / 20089: 56$ & 1.494 & 16. & 771 & $0812: 10$ & 1.49 & 16.9 \\
\hline 571 & $8 / 20085: 30$ & 1.5 & 16.9 & 638 & $8 / 8 / 20087: 44$ & 1.495 & 16.9 & 705 & $8 / 8 / 20089: 58$ & 1.493 & 16. & 772 & $0812: 12$ & 1.49 & 16.9 \\
\hline 572 & $8 / 20085: 32$ & 1.5 & 16.9 & 639 & $8 / 8 / 20087: 46$ & 1.496 & 16.9 & 706 & $8 / 8 / 2008 \quad 10: 00$ & 1.492 & 16. & 773 & $2812: 14$ & 1.489 & 16.9 \\
\hline 573 & $3 / 20085: 34$ & 1.499 & 16.9 & 640 & $8 / 8 / 20$ & 1.496 & 16.9 & 707 & $8 / 8 / 200$ & 1.493 & 16. & 774 & $812: 16$ & 1.49 & 16.9 \\
\hline 574 & $8 / 8 / 20085: 36$ & 1.499 & 16.9 & 641 & $8 / 8 / 20087: 50$ & 1.496 & 16.9 & 708 & $8 / 8 / 200810: 04$ & 1.493 & 16. & 775 & $3812: 18$ & 1.49 & 16.9 \\
\hline 575 & $8 / 8 / 20085: 38$ & 1.498 & 16.9 & 642 & $8 / 8 / 20087: 52$ & 1.494 & 16.9 & 709 & $8 / 8 / 2008$ 10:06 & 1.493 & 16. & 776 & $812: 20$ & 1.49 & 16.9 \\
\hline 576 & $8 / 20085: 40$ & 1.497 & 16.9 & 643 & $37: 54$ & 1.495 & 16.9 & 710 & $8 / 8 / 200$ & 1.493 & 16. & 777 & $812: 22$ & 1.49 & 16.9 \\
\hline 577 & $8 / 20085: 42$ & 1.499 & 16.9 & 644 & $8 / 8 / 200$ & 1.495 & 16.9 & 711 & $8 / 8 / 2008$ 10:10 & 1.493 & 16. & 778 & $812: 24$ & 1.491 & 16.9 \\
\hline 578 & $3 / 20085: 44$ & 1.499 & 16.9 & 645 & $8 / 8 / 20$ & 1.494 & 16. & 712 & $8 / 8 / 200$ & 1.494 & $1 \overline{16}$ & 779 & $0812: 26$ & 1.49 & 16.9 \\
\hline 579 & $3 / 20085: 46$ & 1.499 & 16.9 & 646 & $8 / 8 / 20$ & 1.493 & 16.8 & 713 & $8 / 8 / 200$ & 1.494 & 16. & 780 & $812: 28$ & 1.49 & 16.9 \\
\hline 580 & $3 / 20085: 48$ & 1.499 & 16.9 & 647 & $8 / 20088: 02$ & 1.491 & 16. & 714 & $8 / 2008$ 10:16 & 1.494 & 16. & 781 & $8 / 8 / 200812: 30$ & 1.49 & 16.9 \\
\hline 581 & $3 / 20085: 50$ & 1.497 & 16.9 & 648 & $8 / 8 / 20$ & 1.492 & 16. & 715 & $8 / 8 / 2008$ & 1.493 & 16 & 782 & $312: 32$ & 1.489 & 16.9 \\
\hline 582 & $8 / 20085: 52$ & 1.497 & 16.9 & 649 & $8 / 8 / 20$ & 1.493 & 16. & 716 & $8 / 8 / 200$ & 1.493 & 16. & 783 & $312: 34$ & 1.49 & 16.9 \\
\hline 583 & $8 / 20085: 54$ & 1.498 & 16.9 & 650 & $8 / 8 / 20088: 08$ & 1.495 & 16 . & 717 & $8 / 8 / 2008$ 10:22 & 1.492 & 16. & 784 & $8 / 8 / 200812: 36$ & 1.49 & 16.9 \\
\hline 584 & $3 / 20085: 56$ & 1.498 & 16.9 & 651 & $8 / 8 / 20088: 10$ & 1.495 & 16. & 718 & $8 / 8 / 2008$ 10:24 & 1.492 & 16 & 785 & $812: 38$ & 1.49 & 16.9 \\
\hline 585 & $/ / 20085: 58$ & 1.497 & 16.9 & 652 & $8 / 8 / 20$ & 1.496 & 16. & 719 & $8 / 8 / 200810: 26$ & 1.491 & 16 & 786 & $8 \longdiv { 1 2 : 4 0 }$ & 1.49 & 16.9 \\
\hline 586 & $/ / 20086: 00$ & 1.497 & 16.9 & 653 & $8 / 8 / 20088: 14$ & 1.495 & 16. & 720 & $8 / 8 / 2008$ 10:28 & 1.491 & 16. & 787 & $8 / 8 / 2008$ 12:42 & 1.49 & 16.9 \\
\hline 587 & & 1.498 & 16.9 & 654 & $8 / 8 / 20$ & 1.496 & 16. & 721 & $8 / 8 / 200$ & 1.491 & 16. & 788 & $812: 44$ & 1.491 & 16.9 \\
\hline 588 & $6: 04$ & 1.498 & 16.9 & 655 & $8: 18$ & 1.495 & 16. & 722 & $810: 32$ & 1.491 & 16 & 789 & 812:46 & 1.491 & 16.9 \\
\hline 589 & $3 / 20086: 06$ & 1.498 & 16.9 & 656 & $8 / 8 / 20088: 20$ & 1.494 & 16. & 723 & $8 / 8 / 2008$ 10:34 & 1.491 & 16 & 790 & $812: 48$ & 1.49 & 16.9 \\
\hline 590 & $8 / 20086: 08$ & 1.497 & 16.9 & 657 & $8 / 8 / 20$ & 1.494 & 16. & 724 & $8 / 8 / 200$ & 1.49 & 16 & 791 & $812: 50$ & 1.491 & 16.9 \\
\hline 591 & & 1.498 & 16.9 & 658 & & 1.493 & 16. & 725 & & 1.491 & & 792 & 312:52 & 1.488 & 16.9 \\
\hline 592 & $8 / 8 / 20086: 12$ & 1.498 & 16.9 & 659 & $8 / 8 / 20088: 26$ & 1.493 & 16.9 & 726 & $8 / 8 / 2008 \quad 10: 40$ & 1.491 & 16. & 793 & $3812: 54$ & 1.489 & 16.9 \\
\hline 593 & $8 / 8 / 20086: 14$ & 1.499 & 16.9 & 660 & $8 / 8 / 20$ & 1.493 & 16. & 727 & $8 / 8 / 2008 \quad 10: 42$ & 1.492 & 16. & 794 & $812: 56$ & 1.489 & 16.9 \\
\hline 594 & $3 / 20086: 16$ & 1.499 & 16.9 & 661 & $38: 30$ & 1.493 & 16. & 728 & $3 / 8 / 2008 \quad 10: 44$ & 1.492 & 16 & 795 & $8812: 58$ & 1.489 & 16.9 \\
\hline 595 & $8 / 8 / 20086: 18$ & 1.498 & 16.9 & 662 & $8 / 8 / 20088: 32$ & 1.493 & 16.9 & 729 & $8 / 8 / 2008$ 10:46 & 1.493 & 16. & 796 & $8 / 8 / 2008$ 13:00 & 1.49 & 16.9 \\
\hline 596 & 8/8/2008 6:20 & 1.496 & 16.9 & 663 & $8 / 8 / 20088: 34$ & 1.491 & 16.0 & 730 & $8 / 8 / 2008 \quad 10: 48$ & 1.492 & 16.9 & 797 & $8 / 8 / 2008$ 13:02 & 1.488 & 16.9 \\
\hline 597 & & 1.496 & 16.9 & 664 & & 1.49 & 16. & 731 & $8 / 8 / 2008$ 10:50 & 1.492 & 16. & 798 & $8 / 8 / 200813: 04$ & 1.488 & 16.9 \\
\hline 598 & $8 / 8 / 20086: 24$ & 1.496 & 16.9 & 665 & $8 / 8 / 20088: 38$ & 1.491 & 16.9 & 732 & $8 / 200810: 52$ & 1.491 & 16. & 799 & $8 / 8 / 2008+13: 06$ & 1.489 & 16.9 \\
\hline 599 & $8 / 8 / 20086: 26$ & 1.497 & 16.9 & 666 & $8 / 8 / 20088: 40$ & 1.491 & 16.9 & 733 & $8 / 8 / 2008$ 10:54 & 1.492 & 16.9 & 800 & $8 / 8 / 200813: 08$ & 1.488 & 16.9 \\
\hline 600 & $8 / 8 / 20086: 28$ & 1.497 & 16.9 & 667 & $8 / 8 / 20088: 42$ & 1.493 & 16. & 734 & $8 / 8 / 200810: 56$ & 1.491 & 16.9 & 801 & $8 / 8 / 200813: 10$ & 1.487 & 16.9 \\
\hline 601 & $8 / 8 / 20086: 30$ & 1.498 & 16.9 & 668 & $8 / 8 / 20088: 44$ & 1.493 & 16. & 735 & $3 / 8 / 200810: 58$ & 1.491 & 16. & 802 & $8 / 8 / 200813: 12$ & 1.488 & 16.9 \\
\hline 602 & $8 / 8 / 20086: 32$ & 1.497 & 16.9 & 669 & $8 / 8 / 20088: 46$ & 1.493 & 16.9 & 736 & $8 / 8 / 200811: 00$ & 1.492 & 16.9 & 803 & $8 / 8 / 2008$ 13:14 & 1.488 & 16.9 \\
\hline 603 & $8 / 8 / 20086: 34$ & 1.497 & 16.9 & 670 & $8 / 8 / 20088: 48$ & 1.493 & 16.9 & 737 & $8 / 8 / 200811: 02$ & 1.491 & 16.9 & 804 & $8 / 8 / 200813: 16$ & 1.49 & 16.9 \\
\hline
\end{tabular}


DOE/RL-2009-35, REV. 0

\begin{tabular}{|c|c|c|c|}
\hline \multicolumn{4}{|c|}{ D4-27p } \\
\hline $\operatorname{Rec}$ & & Pres & Temp \\
\hline \# & DaterTime & psi & ${ }^{\circ} \mathrm{C}$ \\
\hline 805 & $8 / 8 / 2008$ 13:18 & 1.489 & 16.9 \\
\hline 806 & $8 / 8 / 200813: 20$ & 1.489 & 16.9 \\
\hline 807 & $8 / 8 / 2008$ 13:22 & 1.488 & 16.9 \\
\hline 808 & $8 / 8 / 2008$ 13:24 & 1.49 & 16.9 \\
\hline 809 & $8 / 8 / 200813: 26$ & 1.488 & 16.9 \\
\hline 810 & $8 / 8 / 200813: 28$ & 1.489 & 16.9 \\
\hline 811 & $8 / 8 / 200813: 30$ & 1.489 & 16.9 \\
\hline 812 & $8 / 8 / 200813: 32$ & 1.49 & 16.9 \\
\hline 813 & $8 / 8 / 200813: 34$ & 1.489 & 16.9 \\
\hline 814 & $8 / 8 / 200813: 36$ & 1.49 & 16.9 \\
\hline 815 & $8 / 8 / 200813: 38$ & 1.49 & 16.9 \\
\hline 816 & $8 / 8 / 2008$ 13:40 & 1.488 & 16.9 \\
\hline 817 & $8 / 8 / 2008$ 13:42 & 1.489 & 16.9 \\
\hline 818 & $8 / 8 / 2008$ 13:44 & 1.488 & 16.9 \\
\hline 819 & $8 / 8 / 200813: 46$ & 1.487 & 16.9 \\
\hline 820 & $8 / 8 / 2008$ 13:48 & 1.488 & 16.9 \\
\hline 821 & $8 / 8 / 200813: 50$ & 1.488 & 16.9 \\
\hline 822 & $8 / 8 / 2008$ 13:52 & 1.488 & 16.9 \\
\hline 823 & $8 / 8 / 200813: 54$ & 1.488 & 16.9 \\
\hline 824 & $8 / 8 / 200813: 56$ & 1.488 & 16.9 \\
\hline 825 & $8 / 8 / 200813: 58$ & 1.49 & 16.9 \\
\hline 826 & $8 / 8 / 200$ & 1.489 & 16.9 \\
\hline 827 & $8 / 8 / 2008$ 14:02 & 1.488 & 16.9 \\
\hline 828 & $8 / 8 / 2008$ 14:04 & 1.49 & 16.9 \\
\hline 829 & 14:06 & 1.488 & 16.9 \\
\hline 830 & $8 / 8 / 2008$ 14:08 & 1.489 & 16.9 \\
\hline 831 & $8 / 8 / 2008$ 14:10 & 1.488 & 16.9 \\
\hline 832 & $8 / 8 / 20$ & 1.488 & 16.9 \\
\hline 833 & $8 / 8 / 20$ & 1.488 & 16.9 \\
\hline 834 & $8 / 8 / 200814: 16$ & 1.488 & 16. \\
\hline 835 & $8 / 8 / 2008$ 14:18 & 1.488 & 16.9 \\
\hline 836 & $8 / 8 / 20$ & 1.488 & 16.9 \\
\hline 837 & $8 / 8 / 20$ & 1.488 & 16.9 \\
\hline 838 & $814: 24$ & 1.488 & 16.9 \\
\hline 839 & $8 / 8 / 20$ & 1.488 & 16.9 \\
\hline 840 & $8 / 8 / 20$ & 1.487 & 16.9 \\
\hline 841 & $8 / 8 / 2008$ 14:30 & 1.489 & 16. \\
\hline 842 & $8 / 8 / 2008$ 14:32 & 1.487 & 16. \\
\hline 843 & $8 / 8 / 20$ & 1.487 & 16. \\
\hline 844 & $814: 36$ & 1.489 & 16. \\
\hline 845 & $8 / 8 / 200814: 38$ & 1.488 & 16. \\
\hline 846 & $8 / 8 / 2008 \quad 14: 40$ & 1.488 & 16.8 \\
\hline 847 & 4:42 & 1.489 & 16.9 \\
\hline 848 & $8 / 8 / 2008$ 14:44 & 1.488 & 16.9 \\
\hline 849 & $8 / 8 / 2008$ 14:46 & 1.488 & $16 . \mathrm{C}$ \\
\hline 850 & $8 / 8 / 20$ & 1.488 & 16.9 \\
\hline 851 & $8 / 8 / 20$ & 1.487 & 16.8 \\
\hline 852 & $8 / 8 / 20$ & 1.487 & 16. \\
\hline 853 & $8 / 8 / 20$ & 1.487 & 16.9 \\
\hline 854 & & 1.488 & 16.9 \\
\hline 855 & $8 / 8 / 2008$ 14:58 & 1.487 & 16.9 \\
\hline 856 & $8 / 8 / 2008$ 15:00 & 1.488 & 16.9 \\
\hline 857 & :02 & 1.487 & 16.9 \\
\hline 858 & $8 / 8 / 200815: 04$ & 1.487 & 16.9 \\
\hline 859 & $8 / 8 / 200815: 06$ & 1.488 & 16.9 \\
\hline 860 & $8 / 8 / 200815: 08$ & 1.488 & 16.9 \\
\hline 861 & & 1.488 & 16.9 \\
\hline 862 & $15: 12$ & 1.488 & 16.9 \\
\hline 863 & $8 / 8 / 2008$ 15:14 & 1.488 & 16.9 \\
\hline 864 & $8 / 8 / 200815: 16$ & 1.488 & 16.9 \\
\hline 865 & $8 / 8 / 200815: 18$ & 1.488 & 16.9 \\
\hline 866 & $8 / 8 / 2008$ 15:20 & 1.488 & 16.9 \\
\hline 867 & $8 / 8 / 200815: 22$ & 1.488 & 16.9 \\
\hline 868 & $8 / 8 / 2008$ 15:24 & 1.489 & 16.9 \\
\hline 869 & $8 / 8 / 2008$ 15:26 & 1.488 & 16.9 \\
\hline 870 & $8 / 8 / 200815: 28$ & 1.489 & 16.9 \\
\hline 871 & $8 / 8 / 2008$ 15:30 & 1.49 & 16.9 \\
\hline
\end{tabular}

\begin{tabular}{|c|c|c|c|}
\hline \multicolumn{4}{|c|}{ D4-27p } \\
\hline $\operatorname{Rec}$ & & Pres & Temp \\
\hline$\#$ & DaterTime & psi & ${ }^{\circ} \mathrm{C}$ \\
\hline 872 & $8 / 8 / 2008$ 15:32 & 1.488 & 16. \\
\hline 873 & $8 / 8 / 2008$ 15:34 & 1.49 & 16. \\
\hline 874 & $8 / 8 / 2008$ 15:36 & 1.489 & 16 \\
\hline 875 & $8 / 8 / 2008$ 15:38 & 1.49 & 16. \\
\hline 876 & $8 / 8 / 2008$ 15:40 & 1.49 & 16. \\
\hline 877 & $8 / 8 / 200815: 42$ & 1.488 & 16 \\
\hline 878 & $8 / 8 / 2008$ 15:44 & 1.49 & 16 \\
\hline 879 & $8 / 8 / 200815: 46$ & 1.489 & 16 \\
\hline 880 & $8 / 8 / 200815: 48$ & 1.49 & 16. \\
\hline 881 & $8 / 8 / 2008$ 15:50 & 1.489 & 16 \\
\hline 882 & $8 / 8 / 2008$ 15:52 & 1.489 & 16. \\
\hline 883 & $8 / 8 / 2008$ 15:54 & 1.49 & 16. \\
\hline 884 & $8 / 8 / 200815: 56$ & 1.49 & 16. \\
\hline 885 & $8 / 8 / 200815: 58$ & 1.49 & 16. \\
\hline 886 & $8 / 8 / 200816: 00$ & 1.491 & 16. \\
\hline 887 & $8 / 8 / 200816: 02$ & 1.49 & 16. \\
\hline 888 & $8 / 8 / 200816: 04$ & 1.49 & 16. \\
\hline 889 & $8 / 8 / 200816: 06$ & 1.489 & 16. \\
\hline 890 & $8 / 8 / 200816: 08$ & 1.488 & 16. \\
\hline 891 & $8 / 8 / 200816: 10$ & 1.487 & 16 . \\
\hline 892 & $816: 12$ & 1.493 & 16. \\
\hline 893 & $8 / 8 / 200816: 14$ & 1.503 & 16. \\
\hline 894 & $8 / 8 / 200816: 16$ & 1.511 & 16. \\
\hline 895 & $8 / 8 / 2008$ 16:18 & 1.516 & 16. \\
\hline 896 & $8 / 8 / 200$ & 1.52 & 16. \\
\hline 897 & $8 / 8 / 2008$ 16:22 & 1.523 & 16. \\
\hline 898 & $8 / 8 / 200816: 24$ & 1.526 & 16. \\
\hline 899 & $8 / 8 / 200816: 26$ & 1.527 & 16. \\
\hline 900 & $8 / 8 / 200816: 28$ & 1.53 & 16. \\
\hline 901 & $8 / 8 / 200816: 30$ & 1.531 & 16. \\
\hline 902 & $8 / 8 / 200816: 32$ & 1.532 & 16. \\
\hline 903 & $16: 34$ & 1.533 & 16. \\
\hline 904 & $8 / 8 / 2008$ 16:36 & 1.534 & 16. \\
\hline 905 & $8 / 8 / 200816: 38$ & 1.536 & 16. \\
\hline 906 & $8 / 8 / 2008$ 16:40 & 1.538 & 16. \\
\hline 907 & $8 / 8 / 2008$ 16:42 & 1.539 & 16. \\
\hline 908 & $8 / 8 / 200816: 44$ & 1.54 & 16. \\
\hline 909 & $8 / 200816: 46$ & 1.54 & 16. \\
\hline 910 & $8 / 8 / 2008 \quad 16: 48$ & 1.541 & 16. \\
\hline 911 & $8 / 8 / 200816: 50$ & 1.541 & 16. \\
\hline 912 & $8 / 8 / 2008$ 16:52 & 1.542 & 16. \\
\hline 913 & $8 / 8 / 200816: 54$ & 1.543 & 16. \\
\hline 914 & $816: 56$ & 1.544 & 16. \\
\hline 915 & $8 / 8 / 200816: 58$ & 1.544 & 16. \\
\hline 916 & $8 / 8 / 2008$ 17:00 & 1.544 & 16. \\
\hline 917 & 117:02 & 1.545 & 16. \\
\hline 918 & $8 / 8 / 2008 \quad 17: 04$ & 1.546 & 16. \\
\hline 919 & $8 / 8 / 200817: 06$ & 1.547 & 16. \\
\hline 920 & 17:08 & 1.548 & 16. \\
\hline 921 & $317: 10$ & 1.549 & 16 \\
\hline 922 & $8 / 8 / 2008$ 17:12 & 1.55 & 16. \\
\hline 923 & $8 / 8 / 2008$ 17:14 & 1.55 & 16. \\
\hline 924 & & 1.55 & 16 \\
\hline 925 & $8 / 8 / 200817: 18$ & 1.55 & 16 \\
\hline 926 & $8 / 8 / 2008$ 17:20 & 1.55 & 16 . \\
\hline 927 & $8 / 8 / 2008$ 17:22 & 1.55 & 16. \\
\hline 928 & $8 / 8 / 2008$ 17:24 & 1.551 & 16. \\
\hline 929 & $8 / 8 / 2008$ 17:26 & 1.551 & 16 \\
\hline 930 & $8 / 8 / 200817: 28$ & 1.551 & 16. \\
\hline 931 & $8 / 8 / 200817: 30$ & 1.552 & 16. \\
\hline 932 & $8 / 8 / 2008$ 17:32 & 1.552 & 16 \\
\hline 933 & $8 / 8 / 200817: 34$ & 1.553 & 16. \\
\hline 934 & $8 / 8 / 2008$ 17:36 & 1.553 & 16. \\
\hline 935 & $8 / 8 / 2008 \quad 17: 38$ & 1.552 & 16 \\
\hline 936 & $8 / 8 / 2008$ 17:40 & 1.552 & 16 \\
\hline 937 & $8 / 8 / 2008$ 17:42 & 1.554 & 16 \\
\hline 938 & $8 / 8 / 2008$ 17:44 & 1.554 & 76. \\
\hline
\end{tabular}

\begin{tabular}{|c|c|c|c|}
\hline \multicolumn{4}{|c|}{$D 4-27 p$} \\
\hline Rec & & Pres & Temp \\
\hline$\#$ & DaterTime & psi & ${ }^{\circ} \mathrm{C}$ \\
\hline 939 & $8 / 8 / 2008$ 17:46 & 1.555 & 16.9 \\
\hline 940 & $8 / 8 / 2008$ 17:48 & 1.556 & 16.9 \\
\hline 941 & $8 / 8 / 2008$ 17:50 & 1.556 & 16.9 \\
\hline 942 & $8 / 8 / 2008$ 17:52 & 1.557 & 16.9 \\
\hline 943 & $8 / 8 / 2008$ 17:54 & 1.558 & 16.9 \\
\hline 944 & $8 / 8 / 2008$ 17:56 & 1.558 & 16.9 \\
\hline 945 & $8 / 8 / 2008$ 17:58 & 1.559 & 16.9 \\
\hline 946 & $8 / 8 / 200818: 00$ & 1.559 & 16.9 \\
\hline 947 & $8 / 8 / 200818: 02$ & 1.558 & 16.9 \\
\hline 948 & $8 / 8 / 2008$ 18:04 & 1.558 & 16.9 \\
\hline 949 & $8 / 8 / 2008$ 18:06 & 1.558 & 16.9 \\
\hline 950 & $8 / 8 / 2008$ 18:08 & 1.559 & 16.9 \\
\hline 951 & $8 / 8 / 200818: 10$ & 1.56 & 16.9 \\
\hline 952 & $8 / 8 / 2008$ 18:12 & 1.561 & 16.9 \\
\hline 953 & $8 / 8 / 2008$ 18:14 & 1.561 & 16.9 \\
\hline 954 & $8 / 8 / 2008$ 18:16 & 1.559 & 16.9 \\
\hline 955 & $8 / 8 / 200818: 18$ & 1.557 & 16.9 \\
\hline 956 & $8 / 8 / 200818: 20$ & 1.556 & 16.9 \\
\hline 957 & $8 / 8 / 2008$ 18:22 & 1.556 & 16.9 \\
\hline 958 & $8 / 8 / 2008$ 18:24 & 1.555 & 16.9 \\
\hline 959 & $8 / 8 / 2008$ 18:26 & 1.549 & 16.9 \\
\hline 960 & $8 / 8 / 2008$ 18:28 & 1.558 & 16.9 \\
\hline 961 & $8 / 8 / 2008$ 18:30 & 1.557 & 16.9 \\
\hline 962 & $8 / 8 / 2008$ 18:32 & 1.558 & 16.9 \\
\hline 963 & $8 / 8 / 2008$ 18:34 & 1.547 & 16.9 \\
\hline 964 & $8 / 8 / 2008 \quad 18: 36$ & 1.547 & 16.9 \\
\hline 965 & $8 / 8 / 2008$ 18:38 & 1.536 & 16.9 \\
\hline 966 & $8 / 8 / 200818: 40$ & 1.527 & 16.9 \\
\hline 967 & $8 / 8 / 2008 \quad 18: 42$ & 1.524 & 16.9 \\
\hline 968 & $8 / 8 / 2008$ 18:44 & 1.522 & 16.9 \\
\hline 969 & $8 / 8 / 200818: 46$ & 1.519 & 16.9 \\
\hline 970 & $8 / 8 / 2008$ 18:48 & 1.517 & 16.9 \\
\hline 971 & $8 / 8 / 2008$ 18:50 & 1.517 & 16.9 \\
\hline 972 & $8 / 8 / 2008$ 18:52 & 1.52 & 16.9 \\
\hline 973 & $8 / 8 / 2008$ 18:54 & 1.523 & 16.9 \\
\hline 974 & $8 / 8 / 2008$ 18:56 & 1.523 & 16.9 \\
\hline 975 & $8 / 8 / 2008$ 18:58 & 1.524 & $\overline{16.9}$ \\
\hline 976 & $8 / 8 / 2008$ 19:00 & 1.525 & 16.9 \\
\hline 977 & $8 / 8 / 2008$ 19:02 & 1.526 & 16.9 \\
\hline 978 & $8 / 8 / 2008$ 19:04 & 1.526 & 16.9 \\
\hline 979 & $8 / 8 / 2008$ 19:06 & 1.525 & 16. \\
\hline 980 & $8 / 8 / 2008$ 19:08 & 1.524 & 16.9 \\
\hline 981 & $8 / 8 / 2008$ 19:10 & 1.521 & 16.9 \\
\hline 982 & $8 / 8 / 2008 \quad 19: 12$ & 1.519 & 16.9 \\
\hline 983 & $8 / 8 / 2008$ 19:14 & 1.518 & 16.9 \\
\hline 984 & $8 / 200819: 16$ & 1.517 & 16.9 \\
\hline 985 & $8 / 8 / 2008$ 19:18 & 1.516 & 16.9 \\
\hline 986 & $8 / 8 / 2008$ 19:20 & 1.518 & 17.1 \\
\hline 987 & $3 / 2008$ 19:22 & 1.518 & 17.1 \\
\hline 988 & $3 / 2008$ 19:24 & 1.516 & 16.9 \\
\hline 989 & $8 / 8 / 2008$ 19:26 & 1.515 & 16.9 \\
\hline 990 & $8 / 8 / 2008$ 19:28 & 1.512 & 16.9 \\
\hline 991 & $8 / 8 / 2008$ 19:30 & 1.511 & 16.9 \\
\hline 992 & $8 / 8 / 2008$ 19:32 & 1.509 & 16.9 \\
\hline 993 & $8 / 8 / 2008$ 19:34 & 1.508 & 16.9 \\
\hline 994 & $8 / 8 / 2008$ 19:36 & 1.508 & 16.9 \\
\hline 995 & $8 / 8 / 2008$ 19:38 & 1.509 & 16.9 \\
\hline 996 & $8 / 8 / 2008$ 19:40 & 1.511 & 16.9 \\
\hline 997 & $8 / 8 / 2008$ 19:42 & 1.511 & 16.9 \\
\hline 998 & $8 / 8 / 2008$ 19:44 & 1.511 & 16.9 \\
\hline 999 & $8 / 8 / 2008$ 19:46 & 1.511 & 16.9 \\
\hline 1000 & $8 / 8 / 2008$ 19:48 & 1.51 & 16.9 \\
\hline 1001 & $8 / 8 / 2008$ 19:50 & 1.51 & 16.9 \\
\hline 02 & $8 / 8 / 2008$ 19:52 & 1.51 & 16.9 \\
\hline 1003 & $8 / 8 / 2008$ 19:54 & 1.51 & 16.9 \\
\hline 1004 & $8 / 8 / 2008$ 19:56 & 1.509 & 16.9 \\
\hline 1005 & $8 / 8 / 2008$ 19:58 & 1.51 & 16.9 \\
\hline
\end{tabular}

\begin{tabular}{|c|c|c|c|}
\hline \multicolumn{4}{|c|}{ D4-27p } \\
\hline $\operatorname{Rec}$ & & Pres & Temp \\
\hline$\#$ & Date/Time & psi & ${ }^{\circ} \mathrm{C}$ \\
\hline 1006 & $8 / 8 / 200820: 00$ & 1.509 & 16.9 \\
\hline 1007 & $8 / 8 / 200820: 02$ & 1.509 & 16.9 \\
\hline 1008 & $8 / 8 / 200820: 04$ & 1.508 & 16.9 \\
\hline 1009 & $8 / 8 / 200820: 06$ & 1.506 & 16.9 \\
\hline 1010 & $8 / 8 / 200820: 08$ & 1.505 & 16.9 \\
\hline 1011 & $8 / 8 / 200820: 10$ & 1.52 & 16.9 \\
\hline 1012 & $8 / 8 / 200820: 12$ & 1.53 & 16.9 \\
\hline 1013 & $8 / 8 / 200820: 14$ & 1.536 & 16.9 \\
\hline 1014 & $8 / 8 / 200820: 16$ & 1.539 & 16.9 \\
\hline 1015 & $8 / 8 / 200820: 18$ & 1.529 & 16.9 \\
\hline 1016 & $8 / 8 / 200820: 20$ & 1.521 & 16.9 \\
\hline 1017 & $8 / 8 / 200820: 22$ & 1.517 & 16.9 \\
\hline 1018 & $8 / 8 / 200820: 24$ & 1.516 & 16.9 \\
\hline 1019 & $8 / 8 / 200820: 26$ & 1.514 & 16.9 \\
\hline 1020 & $8 / 8 / 200820: 28$ & 1.514 & 16.9 \\
\hline 1021 & $8 / 8 / 200820: 30$ & 1.514 & 16.9 \\
\hline 1022 & $8 / 8 / 200820: 32$ & 1.514 & 16.9 \\
\hline 1023 & $8 / 8 / 200820: 34$ & 1.513 & 16.9 \\
\hline 1024 & $8 / 8 / 200820: 36$ & 1.512 & 16.9 \\
\hline 1025 & $8 / 8 / 200820: 38$ & 1.512 & 16.9 \\
\hline 1026 & $8 / 8 / 200820: 40$ & 1.52 & 16.9 \\
\hline 1027 & 8/8/2008 20:42 & 1.53 & 16.9 \\
\hline 1028 & $8 / 8 / 200820: 44$ & 1.534 & 16.9 \\
\hline 1029 & $8 / 8 / 200820: 46$ & 1.536 & 16.9 \\
\hline 1030 & $8 / 8 / 200820: 48$ & 1.538 & 16.9 \\
\hline 1031 & $8 / 8 / 200820: 50$ & 1.539 & 16.9 \\
\hline 1032 & $8 / 8 / 200820: 52$ & 1.54 & 16.9 \\
\hline 1033 & $8 / 8 / 200820: 54$ & 1.54 & 16.9 \\
\hline 1034 & $8 / 8 / 200820: 56$ & 1.541 & 16.9 \\
\hline 1035 & $8 / 8 / 200820: 58$ & 1.542 & 16.9 \\
\hline 1036 & $8 / 8 / 200821: 00$ & 1.543 & 16.9 \\
\hline 1037 & $8 / 8 / 200821: 02$ & 1.543 & 16.9 \\
\hline 1038 & $8 / 8 / 200821: 04$ & 1.544 & 16.9 \\
\hline 1039 & 8/8/2008 21:06 & 1.544 & 16.9 \\
\hline 1040 & $8 / 8 / 200821: 08$ & 1.545 & 16.9 \\
\hline 1041 & $8 / 8 / 200821: 10$ & 1.545 & 17.3 \\
\hline$\overline{1042}$ & 8/8/2008 21:12 & 1.545 & 17.5 \\
\hline 1043 & $8 / 8 / 200821: 14$ & 1.546 & 17.3 \\
\hline$\overline{1044}$ & $8 / 8 / 200821: 16$ & 1.546 & 17 \\
\hline 1045 & $8 / 8 / 200821: 18$ & 1.546 & 16.9 \\
\hline 1046 & $8 / 8 / 200821: 20$ & 1.546 & 16.9 \\
\hline 1047 & $8 / 8 / 200821: 22$ & 1.548 & 16.9 \\
\hline 1048 & $8 / 8 / 200821: 24$ & 1.55 & 16.9 \\
\hline 1049 & $8 / 8 / 200821: 26$ & 1.551 & 16.9 \\
\hline 1050 & $8 / 8 / 200821: 28$ & 1.551 & 16.9 \\
\hline 1051 & $8 / 8 / 200821: 30$ & 1.551 & 16.9 \\
\hline 1052 & $8 / 8 / 200821: 32$ & 1.552 & 16.9 \\
\hline 1053 & $8 / 8 / 200821: 34$ & 1.552 & 16.9 \\
\hline 1054 & $8 / 8 / 200821: 36$ & 1.552 & 16.9 \\
\hline 1055 & $8 / 8 / 200821: 38$ & 1.552 & 16.9 \\
\hline 1056 & $8 / 8 / 200821: 40$ & 1.552 & 16.9 \\
\hline 1057 & $8 / 8 / 200821: 42$ & 1.552 & $\overline{16.9}$ \\
\hline 1058 & $8 / 8 / 200821: 44$ & 1.551 & 16.9 \\
\hline 1059 & $8 / 8 / 2008$ 21:46 & 1.552 & 16.9 \\
\hline 1060 & $8 / 8 / 200821: 48$ & 1.552 & 16.9 \\
\hline 1061 & $8 / 8 / 200821: 50$ & 1.553 & 16.9 \\
\hline 1062 & $8 / 8 / 200821: 52$ & 1.553 & 16.9 \\
\hline 1063 & $8 / 8 / 200821: 54$ & 1.552 & 16.9 \\
\hline 1064 & $8 / 8 / 200821: 56$ & 1.554 & 16.9 \\
\hline 1065 & $8 / 8 / 200821: 58$ & 1.554 & 16.9 \\
\hline 1066 & $8 / 8 / 200822: 00$ & 1,556 & 16.9 \\
\hline 1067 & $8 / 8 / 200822: 02$ & 1.556 & 16.9 \\
\hline 1068 & $8 / 8 / 200822: 04$ & 1.558 & 16.9 \\
\hline 1069 & $8 / 8 / 200822: 06$ & 1.559 & 16.9 \\
\hline 1070 & $8 / 8 / 200822: 08$ & 1.559 & 16.9 \\
\hline 1071 & $8 / 8 / 200822: 10$ & 1.558 & 16.9 \\
\hline 1072 & $8 / 8 / 200822: 12$ & 1.559 & 16.9 \\
\hline
\end{tabular}


DOE/RL-2009-35, REV. 0

\begin{tabular}{|c|c|c|c|c|c|c|c|c|c|c|c|c|c|c|c|}
\hline \multicolumn{4}{|c|}{$D 4-27 p$} & \multicolumn{4}{|c|}{ D4-27p } & \multicolumn{4}{|c|}{ D4-27p } & \multicolumn{4}{|c|}{ D4-27p } \\
\hline $\operatorname{Rec}$ & & Pres & Temp & $\operatorname{Rec}$ & & Pres & Temp & $\operatorname{Rec}$ & & Pres & Temp & $\operatorname{Rec}$ & & Pres & Temp \\
\hline$\#$ & Date/Time & psi & ${ }^{\circ} \mathrm{C}$ & \# & Date/Time & $\mathrm{psi}$ & ${ }^{\circ} \mathrm{C}$ & $\#$ & Date/Time & psi & ${ }^{\circ} \mathrm{C}$ & $\#$ & Date/Time & psi & ${ }^{\circ} \mathrm{C}$ \\
\hline 1073 & $8 / 8 / 200822: 14$ & 1.558 & 16.9 & 1140 & $8 / 9 / 20080: 28$ & 1.55 & 16.9 & 1207 & $8 / 9 / 20082: 42$ & 1.566 & 16.9 & 1274 & $8 / 9 / 20084: 56$ & 1.575 & 16.9 \\
\hline 1074 & $8 / 8 / 2008$ 22:16 & 1.559 & 16.9 & 1141 & $8 / 9 / 20080: 30$ & 1.558 & 16.9 & 1208 & $8 / 9 / 20082: 44$ & 1.568 & 16.9 & 1275 & $8 / 9 / 20084: 58$ & 1.575 & 16.9 \\
\hline 1075 & $8 / 8 / 2008$ 22:18 & 1.56 & 16.9 & 1142 & $8 / 9 / 20080: 32$ & 1.559 & 16.9 & 1209 & $8 / 9 / 20082: 46$ & 1.568 & 16.9 & 1276 & $8 / 9 / 20085: 00$ & 1.574 & 16.9 \\
\hline 1076 & $8 / 8 / 2008$ 22:20 & 1.56 & 16.9 & 1143 & $8 / 9 / 20080: 34$ & 1.56 & 16.9 & 1210 & $8 / 9 / 20082: 48$ & 1.576 & 16.9 & $12 \pi 7$ & $8 / 9 / 20085: 02$ & 1.574 & 16.9 \\
\hline 1077 & $8 / 8 / 200822: 22$ & 1.56 & 16.9 & 1144 & $8 / 9 / 20080: 36$ & 1.56 & 16.9 & 1211 & $8 / 9 / 2008$ 2:50 & 1.569 & 16.9 & 1278 & $8 / 9 / 20085: 04$ & 1.574 & 16.9 \\
\hline 1078 & $8 / 8 / 200822: 24$ & 1.56 & 16.9 & 1145 & $8 / 9 / 20080: 38$ & 1.559 & 16.9 & 1212 & $8 / 9 / 20082: 52$ & 1.57 & 16.9 & 1279 & $8 / 9 / 20085: 06$ & 1.569 & 16.9 \\
\hline 1079 & $8 / 8 / 200822: 26$ & 1.56 & 16.9 & 1146 & $8 / 9 / 20080: 40$ & 1.56 & 16.9 & 1213 & $8 / 9 / 20082: 54$ & 1.57 & 16.9 & 1280 & $8 / 9 / 20085: 08$ & 1.559 & 16.9 \\
\hline 1080 & $8 / 8 / 200822: 28$ & 1.56 & 16.9 & 1147 & $8 / 9 / 20080: 42$ & 1.561 & 16.9 & 1214 & $8 / 9 / 20082: 56$ & 1.569 & 16.9 & 1281 & $8 / 9 / 20085: 10$ & 1.552 & $16 . \overline{9}$ \\
\hline 1081 & 8/8/2008 22:30 & 1.56 & 16.9 & 1148 & $8 / 9 / 20080: 44$ & 1.56 & 16.9 & 1215 & $8 / 9 / 20082: 58$ & 1.554 & 16.9 & 1282 & $8 / 9 / 20085: 12$ & 1.549 & 16.9 \\
\hline 1082 & $8 / 8 / 2008$ 22:32 & 1.561 & 16.9 & 1149 & $8 / 9 / 20080: 46$ & 1.56 & 16.9 & 1216 & $8 / 9 / 20083: 00$ & 1.514 & 16.9 & 1283 & $8 / 9 / 20085: 14$ & 1.547 & 16.9 \\
\hline 1083 & $8 / 8 / 200822: 34$ & 1.561 & 16.9 & 1150 & $8 / 9 / 20080: 48$ & 1.56 & 16.9 & 1217 & $8 / 9 / 20083: 02$ & 1.567 & 16.9 & 1284 & $8 / 9 / 20085: 16$ & 1.546 & 16.9 \\
\hline 1084 & $8 / 8 / 200822: 36$ & 1.561 & 16.9 & 1151 & $8 / 9 / 20080: 50$ & 1.562 & 16.9 & 1218 & $8 / 9 / 20083: 04$ & 1.57 & 16.9 & 1285 & $8 / 9 / 20085: 18$ & 1.546 & 16.9 \\
\hline 1085 & $8 / 8 / 2008$ 22:38 & 1.562 & 16.9 & 1152 & $8 / 9 / 20080: 52$ & 1.562 & 16.9 & 1219 & $8 / 9 / 20083: 06$ & 1.571 & 16.9 & 1286 & $8 / 9 / 20085: 20$ & 1.544 & 16.9 \\
\hline 1086 & $8 / 8 / 200822: 40$ & 1.562 & 16.9 & 1153 & $8 / 9 / 20080: 54$ & 1.562 & 16.9 & 1220 & $8 / 9 / 20083: 08$ & 1.571 & 16.9 & 1287 & $8 / 9 / 20085: 22$ & 1.542 & 16.9 \\
\hline 1087 & $8 / 8 / 200822: 42$ & 1.562 & 16.9 & 1154 & $8 / 9 / 20080: 56$ & 1.562 & 16.9 & 1221 & $8 / 9 / 20083: 10$ & 1.571 & 16.9 & 1288 & $8 / 9 / 20085: 24$ & 1.544 & 16.9 \\
\hline 1088 & $8 / 8 / 2008$ 22:44 & 1.562 & 16.9 & 1155 & $8 / 9 / 20080: 58$ & 1.562 & 16.9 & 1222 & $8 / 9 / 20083: 12$ & 1.571 & 16.9 & 1289 & $8 / 9 / 20085: 26$ & 1.554 & 16.9 \\
\hline 1089 & $8 / 8 / 2008$ 22:46 & 1.562 & 16.9 & 1156 & $8 / 9 / 20081: 00$ & 1.563 & 16.9 & 1223 & $8 / 9 / 20083: 14$ & 1.57 & 16.9 & 1290 & $8 / 9 / 20085: 28$ & 1.56 & 16.9 \\
\hline 1090 & $8 / 8 / 200822: 48$ & 1.561 & 16.9 & 1157 & $8 / 9 / 20081: 02$ & 1.562 & 16.9 & 1224 & $8 / 9 / 20083: 16$ & 1.57 & 16.9 & 1291 & $8 / 9 / 20085: 30$ & 1.563 & 16.9 \\
\hline 1091 & $8 / 8 / 200822: 50$ & 1.562 & 16.9 & 1158 & $8 / 9 / 20081: 04$ & 1.563 & 16.9 & 1225 & $8 / 9 / 20083: 18$ & 1.571 & 16.9 & 1292 & $8 / 9 / 20085: 32$ & 1.566 & 16.9 \\
\hline 1092 & $8 / 8 / 200822: 52$ & 1.563 & 16.9 & 1159 & $8 / 9 / 20081: 06$ & 1.562 & 16.9 & 1226 & $8 / 9 / 20083: 20$ & 1.57 & 16.9 & 1293 & $8 / 9 / 20085: 34$ & 1.567 & 16.9 \\
\hline 1093 & $8 / 8 / 2008$ 22:54 & 1.564 & 16.9 & 1160 & $8 / 9 / 20081: 08$ & 1.562 & 16.9 & 1227 & $8 / 9 / 20083: 22$ & 1.571 & 16.9 & 1294 & $8 / 9 / 20085: 36$ & 1.57 & 16.9 \\
\hline 1094 & $8 / 8 / 200822: 56$ & 1.564 & 16.9 & 1161 & $8 / 9 / 20081: 10$ & 1.563 & 16.9 & 1228 & $8 / 9 / 20083: 24$ & 1.571 & 16.9 & 1295 & $8 / 9 / 20085: 38$ & 1.57 & 16.9 \\
\hline 1095 & $8 / 8 / 200822: 58$ & 1.555 & 16.9 & 1162 & $8 / 9 / 20081: 12$ & 1.562 & 16.9 & 1229 & $8 / 9 / 20083: 26$ & 1.571 & 16.9 & 1296 & $8 / 9 / 20085: 40$ & 1.571 & 16.9 \\
\hline 1096 & $8 / 8 / 200823: 00$ & 1.545 & 16.9 & 1163 & $8 / 9 / 2008$ 1:14 & 1.562 & 16.9 & 1230 & $8 / 9 / 20083: 28$ & 1.571 & 16.9 & 1297 & $8 / 9 / 20085: 42$ & 1.571 & 16.9 \\
\hline 1097 & $8 / 8 / 200823: 02$ & 1.539 & 16.9 & 1164 & $8 / 9 / 2008$ 1:16 & 1.563 & 16.9 & 1231 & $8 / 9 / 20083: 30$ & 1.572 & 16.9 & 1298 & $8 / 9 / 20085: 44$ & 1.573 & 16.9 \\
\hline 1098 & $8 / 8 / 2008$ 23:04 & 1.535 & 16.9 & 1165 & $8 / 9 / 20081: 18$ & 1.563 & 16.9 & 1232 & $8 / 9 / 20083: 32$ & 1.571 & 16.9 & 1299 & $8 / 9 / 20085: 46$ & 1.574 & 16.9 \\
\hline 1099 & $8 / 8 / 200823: 06$ & 1.532 & 16.9 & 1166 & $8 / 9 / 20081: 20$ & 1.564 & 16.9 & 1233 & $8 / 9 / 20083: 34$ & 1.571 & 17.4 & 1300 & $8 / 9 / 20085: 48$ & 1.573 & 16.9 \\
\hline 1100 & $8 / 8 / 200823: 08$ & 1.531 & 16.9 & 1167 & $8 / 9 / 2008$ 1:22 & 1.565 & 16.9 & 1234 & $8 / 9 / 20083: 36$ & 1.573 & 17.1 & 1301 & $8 / 9 / 20085: 50$ & 1.573 & 16.9 \\
\hline 1101 & $8 / 8 / 200823: 10$ & 1.529 & 16.9 & 1168 & $8 / 9 / 20081: 24$ & 1.566 & 16.9 & 1235 & $8 / 9 / 20083: 38$ & 1.573 & 17 & 1302 & $8 / 9 / 20085: 52$ & 1.573 & 16.9 \\
\hline 1102 & $8 / 8 / 200823: 12$ & 1.527 & 16.9 & 1169 & $8 / 9 / 20081: 26$ & 1.568 & 16.9 & 1236 & $8 / 9 / 20083: 40$ & 1.572 & 16.9 & 1303 & $8 / 9 / 20085: 54$ & 1.574 & 16.9 \\
\hline 1103 & $8 / 8 / 200823: 14$ & 1.527 & 16.9 & 1170 & $8 / 9 / 20081: 28$ & 1.568 & 16.9 & 1237 & $8 / 9 / 20083: 42$ & 1.573 & 16.9 & 1304 & $8 / 9 / 20085: 56$ & 1.574 & 16.9 \\
\hline 1104 & $8 / 8 / 200823: 16$ & 1.526 & 16.9 & 1171 & $8 / 9 / 20081: 30$ & 1.568 & 16.9 & 1238 & $8 / 9 / 20083: 44$ & 1.574 & 16.9 & 1305 & $8 / 9 / 20085: 58$ & 1.574 & 16.9 \\
\hline 1105 & $8 / 8 / 200823: 18$ & 1.526 & 16.9 & 1172 & $8 / 9 / 20081: 32$ & 1.567 & 16.9 & 1239 & $8 / 9 / 20083: 46$ & 1.57 & 16.9 & 1306 & $8 / 9 / 20086: 00$ & 1.574 & 16.9 \\
\hline 1106 & $8 / 8 / 200823: 20$ & 1.525 & 16.9 & 1173 & $8 / 9 / 20081: 34$ & 1.567 & 16.9 & 1240 & $8 / 9 / 20083: 48$ & 1.57 & 16.9 & 1307 & $8 / 9 / 20086: 02$ & 1.574 & 16.9 \\
\hline 1107 & $8 / 8 / 200823: 22$ & 1.524 & 16.9 & 1174 & $8 / 9 / 2008$ 1:36 & 1.566 & 16.9 & 1241 & $8 / 9 / 20083: 50$ & 1.571 & 16.9 & 1308 & $8 / 9 / 20086: 04$ & 1.575 & 16.9 \\
\hline 1108 & $8 / 8 / 200823: 24$ & 1.522 & 16.9 & 1175 & $8 / 9 / 20081: 38$ & 1.569 & 16.9 & 1242 & $8 / 9 / 20083: 52$ & 1.573 & 16.9 & 1309 & $8 / 9 / 20086: 06$ & 1.576 & 16.9 \\
\hline 1109 & $8 / 8 / 200823: 26$ & 1.522 & 16.9 & 1176 & $8 / 9 / 2008$ 1:40 & 1.57 & 16.9 & 1243 & $8 / 9 / 20083: 54$ & 1.575 & 16.9 & 1310 & $8 / 9 / 20086: 08$ & 1.577 & 16.9 \\
\hline 1110 & $8 / 8 / 200823: 28$ & 1.521 & 16.9 & 1177 & $8 / 9 / 2008$ 1:42 & 1.571 & 16.9 & 1244 & $8 / 9 / 20083: 56$ & 1.574 & 16.9 & 1311 & $8 / 9 / 20086: 10$ & 1.577 & 16.9 \\
\hline 1111 & $8 / 8 / 200823: 30$ & 1.521 & 16.9 & 1178 & $8 / 9 / 20081: 44$ & 1.572 & 16.9 & 1245 & $8 / 9 / 20083: 58$ & 1.574 & 16.9 & 1312 & $8 / 9 / 20086: 12$ & 1.577 & 16.9 \\
\hline 1112 & $8 / 8 / 200823: 32$ & 1.522 & 16.9 & 1179 & $8 / 9 / 20081: 46$ & 1.57 & 16.9 & 1246 & $8 / 9 / 20084: 00$ & 1.574 & 16.9 & 1313 & $8 / 9 / 20086: 14$ & 1.578 & 16.9 \\
\hline 1113 & $8 / 8 / 200823: 34$ & 1.524 & 16.9 & 1180 & $8 / 9 / 20081: 48$ & 1.569 & 16.9 & 1247 & $8 / 9 / 20084: 02$ & 1.575 & 16.9 & 1314 & $8 / 9 / 20086: 16$ & 1.579 & 16.9 \\
\hline 1114 & $8 / 8 / 200823: 36$ & 1.522 & 16.9 & 1181 & $8 / 9 / 20081: 50$ & 1.569 & 16.9 & 1248 & $8 / 9 / 2008$ 4:04 & 1.575 & 16.9 & 1315 & $8 / 9 / 20086: 18$ & 1.578 & 16.9 \\
\hline 1115 & $8 / 8 / 200823: 38$ & 1.521 & 16.9 & 1182 & $8 / 9 / 20081: 52$ & 1.568 & 16.9 & 1249 & $8 / 9 / 20084: 06$ & 1.576 & 16.9 & 1316 & $8 / 9 / 20086: 20$ & 1.579 & 17.1 \\
\hline 1116 & $8 / 8 / 200823: 40$ & 1.52 & 16.9 & 1183 & $8 / 9 / 20081: 54$ & 1.568 & 16.9 & 1250 & $8 / 9 / 20084: 08$ & 1.575 & 16.9 & 1317 & $8 / 9 / 20086: 22$ & 1.579 & 17 \\
\hline 1117 & $8 / 8 / 200823: 42$ & 1.519 & 16.9 & 1184 & $8 / 9 / 20081: 56$ & 1.568 & 16.9 & 1251 & $8 / 9 / 20084: 10$ & 1.576 & 16.9 & 1318 & $8 / 9 / 20086: 24$ & 1.579 & 16.9 \\
\hline 1118 & $8 / 8 / 200823: 44$ & 1.517 & 16.9 & 1185 & $8 / 9 / 20081: 58$ & 1.568 & 76.9 & 1252 & $8 / 9 / 20084: 12$ & 1.576 & 16.9 & 1319 & $8 / 9 / 20086: 26$ & 1.579 & 16.9 \\
\hline 1119 & $8 / 8 / 200823: 46$ & 1.516 & 16.9 & 1186 & $8 / 9 / 20082: 00$ & 1.569 & 16.9 & 1253 & $8 / 9 / 20084: 14$ & 1.575 & 16.9 & 1320 & $8 / 9 / 20086: 28$ & 1.579 & 16.9 \\
\hline 1120 & $8 / 8 / 200823: 48$ & 1.53 & 16.9 & 1187 & 8/9/2008 2:02 & 1.569 & 16.9 & 1254 & $8 / 9 / 20084: 16$ & 1.576 & 16.9 & 1321 & $8 / 9 / 20086: 30$ & 1.579 & 16.9 \\
\hline 1121 & $8 / 8 / 200823: 50$ & 1.539 & 16.9 & 1188 & $8 / 9 / 2008$ 2:04 & 1.568 & 16.9 & 1255 & $8 / 9 / 20084: 18$ & 1.575 & 16.9 & 1322 & $8 / 9 / 20086: 32$ & 1.58 & 16.9 \\
\hline 1122 & $8 / 8 / 200823: 52$ & 1.543 & 16.9 & 1189. & $8 / 9 / 20082: 06$ & 1.567 & 16.9 & 1256 & $8 / 9 / 20084: 20$ & 1.576 & 16.9 & 1323 & $8 / 9 / 20086: 34$ & 1.58 & 16.9 \\
\hline 1123 & $8 / 8 / 200823: 54$ & 1.545 & 16.9 & 1190 & $8 / 9 / 20082: 08$ & 1.563 & 16.9 & 1257 & $8 / 9 / 20084: 22$ & 1.576 & 16.9 & 1324 & $8 / 9 / 20086: 36$ & 1.581 & 16.9 \\
\hline 1124| & $8 / 8 / 200823: 56$ & 1.546 & 16.9 & 1191 & $8 / 9 / 20082: 10$ & 1.553 & 16.9 & 1258 & $8 / 9 / 20084: 24$ & 1.575 & 16.9 & 1325 & $8 / 9 / 20086: 38$ & 1.58 & 16.9 \\
\hline 1125 & $8 / 8 / 200823: 58$ & 1.547 & 16.9 & 1192 & $8 / 9 / 20082: 12$ & 1.547 & 16.9 & 1259 & $8 / 9 / 20084: 26$ & 1.576 & 16.9 & 1326 & $8 / 9 / 20086: 40$ & 1.581 & 16.9 \\
\hline 1126 & $8 / 9 / 20080: 00$ & 1.549 & 16.9 & 1193 & $8 / 9 / 20082: 14$ & 1.543 & 16.9 & 1260 & $8 / 9 / 20084: 28$ & 1.576 & 16.9 & 1327 & $8 / 9 / 20086: 42$ & 1.582 & 16.9 \\
\hline 1127 & $8 / 9 / 20080: 02$ & 1.551 & 16.9 & 1194 & $8 / 9 / 20082: 16$ & 1.541 & 16.9 & 1261 & $8 / 9 / 20084: 30$ & 1.577 & 16.9 & 1328 & $89 / 20086: 44$ & 1.58 & 16.9 \\
\hline 1128 & $8 / 9 / 20080: 04$ & 1.552 & 16.9 & 1195 & $8 / 9 / 20082: 18$ & 1.539 & 16.9 & 1262 & $8 / 9 / 20084: 32$ & 1.577 & 16.9 & 1329 & $8 / 9 / 20086: 46$ & 1.581 & 16.9 \\
\hline 1129 & $8 / 9 / 20080: 06$ & 1.553 & 16.9 & 1196 & $8 / 9 / 20082: 20$ & 1.537 & 16.9 & 1263 & $8 / 9 / 20084: 34$ & 1.577 & 16.9 & 1330 & $8 / 9 / 20086: 48$ & 1.58 & 16.9 \\
\hline 1130 & $8 / 9 / 20080: 08$ & 1.552 & 16.9 & 1197| & $8 / 9 / 20082: 22$ & 1.538 & 16.9 & 1264 & $8 / 9 / 20084: 36$ & 1.577 & 16.9 & 1331 & $8 / 9 / 20086: 50$ & 1.579 & 16.9 \\
\hline 1131 & $8 / 9 / 20080: 10$ & 1.553 & 16.9 & 1198 & $8 / 9 / 20082: 24$ & 1.546 & 16.9 & 1265 & $8 / 9 / 20084: 38$ & $1.5 \pi$ & 16.9 & 1332 & $8 / 9 / 20086: 52$ & 1.581 & 16.9 \\
\hline 1132 & $8 / 9 / 20080: 12$ & 1.554 & 16.9 & 1199 & $8 / 9 / 20082: 26$ & 1.553 & 16.9 & 1266 & $8 / 9 / 20084: 40$ & 1.577 & 16.9 & 1333 & $8 / 9 / 20086: 54$ & 1.548 & 16.9 \\
\hline 1133 & $8 / 9 / 20080: 14$ & 1.555 & 16.9 & 1200 & $8 / 9 / 20082: 28$ & 1.557 & 16.9 & 1267 & $8 / 9 / 20084: 42$ & 1.578 & 16.9 & 1334 & $8 / 9 / 20086: 56$ & 1.576 & 16.9 \\
\hline 1134 & $8 / 9 / 20080: 16$ & 1.554 & 16.9 & 1201 & $8 / 9 / 20082: 30$ & 1.56 & 16.9 & 1268 & $8 / 9 / 20084: 44$ & 1.578 & 16.9 & 1335 & $8 / 9 / 20086: 58$ & 1.577 & 16.9 \\
\hline 1135 & $8 / 9 / 20080: 18$ & 1.555 & 16.9 & 1202 & $8 / 9 / 2008$ 2:32 & 1.562 & 16.9 & 1269 & $8 / 9 / 20084: 46$ & 1.578 & 16.9 & 1336 & $8 / 9 / 20087: 00$ & 1.578 & 16.9 \\
\hline 1136 & $8 / 9 / 20080: 20$ & 1.554 & 16.9 & 1203 & $8 / 9 / 20082: 34$ & 1.562 & 16.9 & 1270 & $8 / 9 / 20084: 48$ & 1.578 & 16.9 & 1337 & $8 / 9 / 20087: 02$ & 1.579 & 16.9 \\
\hline 1137 & $8 / 9 / 20080: 22$ & 1.555 & 16.9 & 1204 & $8 / 9 / 20082: 36$ & 1.564 & 16.9 & 1271 & $8 / 9 / 20084: 50$ & 1.578 & 16.9 & 1338 & $8 / 9 / 20087: 04$ & 1.58 & 16.9 \\
\hline 1138 & $8 / 9 / 20080: 24$ & 1.556 & 16.9 & 1205 & $8 / 9 / 20082: 38$ & 1.566 & 16.9 & 1272 & $8 / 9 / 20084: 52$ & 1.578 & 16.9 & 1339 & $8 / 9 / 20087: 06$ & 1.581 & 16.9 \\
\hline 1139 & $8 / 9 / 20080: 26$ & 1.557 & 16.9 & 1206 & $8 / 9 / 20082: 40$ & 1.565 & 16.9 & 1273 & $8 / 9 / 20084: 54$ & $1.5 \pi$ & 16.9 & 1340 & $8 / 9 / 20087: 08$ & 1.58 & 16.9 \\
\hline
\end{tabular}




\begin{tabular}{|c|c|c|c|c|c|c|c|c|c|c|c|c|c|c|c|}
\hline \multicolumn{4}{|c|}{ D4-27p } & \multicolumn{4}{|c|}{$D 4-27 p$} & \multicolumn{4}{|c|}{ D4-27p } & \multicolumn{4}{|c|}{ D4-27p } \\
\hline $\operatorname{Rec}$ & & Pres & Temp & $\operatorname{Rec}$ & & Pres & Temp & Rec & & Pres & Temp & $\operatorname{Rec}$ & & Pres & Temp \\
\hline$\#$ & Date/Time & psi & ${ }^{\circ} \mathrm{C}$ & $\#$ & Date/Time & psi & ${ }^{\circ} \mathrm{C}$ & $\#$ & Date/Time & psi & ${ }^{\circ} \mathrm{C}$ & $\#$ & Date/Time & psi & ${ }^{\circ} \mathrm{C}$ \\
\hline 1341 & $8 / 9 / 20087: 10$ & 1.578 & 16.9 & 1408 & $8 / 9 / 20089: 24$ & 1.555 & 16.9 & 1475 & $8 / 9 / 2008$ 11:38 & 1.592 & 16.9 & 1542 & $8 / 9 / 2008$ 13:52 & 1.564 & 16.9 \\
\hline 1342 & $8 / 9 / 20087: 12$ & 1.578 & 16.9 & 1409 & 8/9/2008 9:26 & 1.564 & 16.9 & 1476 & $8 / 9 / 2008$ 11:40 & 1.592 & 16.9 & 1543 & $8 / 9 / 2008$ 13:54 & 1.566 & 16.9 \\
\hline 1343 & $8 / 9 / 20087: 14$ & 1.579 & 16.9 & 1410 & $8 / 9 / 20089: 28$ & 1.569 & 16.9 & 1477 & $8 / 9 / 2008$ 11:42 & 1.592 & 16.9 & 1544 & $8 / 9 / 200813: 56$ & 1.613 & 16.9 \\
\hline 1344 & $8 / 9 / 20087: 16$ & 1.579 & 16.9 & 1411 & $8 / 9 / 20089: 30$ & 1.572 & 16.9 & 1478 & $8 / 9 / 2008$ 11:44 & 1.593 & 16.9 & 1545 & $8 / 9 / 2008$ 13:58 & 1.593 & 16.9 \\
\hline 1345 & $8 / 9 / 20087: 18$ & 1.58 & 16.9 & 1412 & $8 / 9 / 20089: 32$ & 1.575 & 16.9 & 1479 & $8 / 9 / 2008$ 11:46 & 1.591 & 16.9 & 1546 & $8 / 9 / 2008$ 14:00 & 1.595 & 16.9 \\
\hline 1346 & $8 / 9 / 20087: 20$ & 1.58 & 16.9 & 1413 & $8 / 9 / 20089: 34$ & 1.576 & 16.9 & 1480 & $8 / 9 / 2008$ 11:48 & 1.592 & 16.9 & 1547 & $8 / 9 / 2008$ 14:02 & 1.594 & 16.9 \\
\hline 1347 & $8 / 9 / 20087: 22$ & 1.579 & 16.9 & 1414 & $8 / 9 / 20089: 36$ & 1.576 & 16.9 & 1481 & $8 / 9 / 2008$ 11:50 & 1.592 & 16.9 & 1548 & $8 / 9 / 2008$ 14:04 & 1.594 & 16.9 \\
\hline 1348 & $8 / 9 / 20087: 24$ & 1.581 & 16.9 & 1415 & $8 / 9 / 20089: 38$ & 1.576 & 16.9 & 1482 & $8 / 9 / 2008$ 11:52 & 1.591 & 16.9 & 1549 & $8 / 9 / 2008$ 14:06 & 1.594 & 16.9 \\
\hline 1349 & $8 / 9 / 20087: 26$ & 1.582 & 16.9 & 1416 & $8 / 9 / 20089: 40$ & 1.577 & 16.9 & 1483 & $8 / 9 / 2008$ 11:54 & 1.589 & 16.9 & 1550 & $8 / 9 / 2008$ 14:08 & 1.595 & 16.9 \\
\hline 1350 & $8 / 9 / 20087: 28$ & 1.582 & 16.9 & 1417 & $8 / 9 / 20089: 42$ & 1.578 & 16.9 & 1484 & 8/9/2008 11:56 & 1.584 & 16.9 & 1551 & 8/9/2008 14:10 & 1.595 & 16.9 \\
\hline 1351 & $8 / 9 / 20087: 30$ & 1.581 & 16.9 & 1418 & $8 / 9 / 20089: 44$ & 1.578 & 16.9 & 1485 & $8 / 9 / 2008$ 11:58 & 1.575 & 16.9 & 1552 & $8 / 9 / 2008$ 14:12 & 1.594 & 16.9 \\
\hline 1352 & $8 / 9 / 20087: 32$ & 1.581 & 16.9 & 1419 & $8 / 9 / 20089: 46$ & 1.58 & 16.9 & 1486 & $8 / 9 / 2008$ 12:00 & 1.568 & 16.9 & 1553 & $8 / 9 / 2008$ 14:14 & 1.596 & 16.9 \\
\hline 1353 & $8 / 9 / 20087: 34$ & 1.58 & 16.9 & 1420 & 8/9/2008 9:48 & 1.581 & 16.9 & 1487 & $8 / 9 / 2008$ 12:02 & 1.565 & 16.9 & 1554 & $8 / 9 / 2008$ 14:16 & 1.596 & 16.9 \\
\hline 1354 & $8 / 9 / 20087: 36$ & 1.581 & 16.9 & 1421 & $8 / 9 / 20089: 50$ & 1.58 & 16.9 & 1488 & $8 / 9 / 2008$ 12:04 & 1.563 & 16.9 & 1555 & $8 / 9 / 2008$ 14:18 & 1.597 & 16.9 \\
\hline 1355 & $8 / 9 / 20087: 38$ & 1.581 & 16.9 & 1422 & $8 / 9 / 20089: 52$ & 1.58 & 16.9 & 1489 & $8 / 9 / 2008$ 12:06 & 1.561 & 16.9 & 1556 & $8 / 9 / 200814: 20$ & 1.598 & 16.9 \\
\hline 1356 & $8 / 9 / 20087: 40$ & 1.582 & 16.9 & 1423 & $8 / 9 / 20089: 54$ & 1.58 & 16.9 & 1490 & $8 / 9 / 2008$ 12:08 & 1.563 & 16.9 & 1557 & $8 / 9 / 2008$ 14:22 & 1.597 & 16.9 \\
\hline 1357 & $8 / 9 / 20087: 42$ & 1.58 & 16.9 & 1424 & $8 / 9 / 20089: 56$ & 1.58 & 16.9 & 1491 & 8/9/2008 12:10 & 1.573 & 16.9 & 1558 & $8 / 9 / 2008$ 14:24 & 1.597 & 16.9 \\
\hline 1358 & $8 / 9 / 20087: 44$ & 1.578 & 16.9 & 1425 & $8 / 9 / 20089: 58$ & 1.58 & 16.9 & 1492 & $8 / 9 / 2008$ 12:12 & 1.579 & 16.9 & 1559 & $8 / 9 / 200814: 26$ & 1.597 & 16.9 \\
\hline 1359 & $8 / 9 / 20087: 46$ & 1.579 & 16.9 & 1426 & $8 / 9 / 200810: 00$ & 1.58 & 16.9 & 1493 & $8 / 9 / 2008$ 12:14 & 1.581 & 16.9 & 1560 & $8 / 9 / 200814: 28$ & 1.597 & 16.9 \\
\hline 1360 & $8 / 9 / 20087: 48$ & 1.58 & 16.9 & 1427 & $8 / 9 / 200810: 02$ & 1.581 & 16.9 & 1494 & $8 / 9 / 2008$ 12:16 & 1.584 & 16.9 & 1561 & $8 / 9 / 2008$ 14:30 & 1.596 & 16.9 \\
\hline 1361 & $8 / 9 / 20087: 50$ & 1.582 & 16.9 & 1428 & $8 / 9 / 2008$ 10:04 & 1.582 & 16.9 & 1495 & 8/9/2008 12:18 & 1.586 & 16.9 & 1562 & $8 / 9 / 2008$ 14:32 & 1.597 & 16.9 \\
\hline 1362 & $8 / 9 / 20087: 52$ & 1.582 & 16.9 & 1429 & $8 / 9 / 2008$ 10:06 & 1.581 & 16.9 & 1496 & $8 / 9 / 2008$ 12:20 & 1.586 & 17.3 & 1563 & $8 / 9 / 2008$ 14:34 & 1.596 & 16.9 \\
\hline 1363 & $8 / 9 / 20087: 54$ & 1.581 & 16.9 & 1430 & $8 / 9 / 2008$ 10:08 & 1.582 & 16.9 & 1497 & $8 / 9 / 2008$ 12:22 & 1.588 & 17.5 & 1564 & $8 / 9 / 2008$ 14:36 & 1.597 & 16.9 \\
\hline 1364 & $8 / 9 / 20087: 56$ & 1.582 & 16.9 & 1431 & $8 / 9 / 2008$ 10:10 & 1.582 & 16.9 & 1498 & $8 / 9 / 2008 \quad 12: 24$ & 1.588 & 17.6 & 1565 & $8 / 9 / 200814: 38$ & 1.597 & 16.9 \\
\hline 1365 & $8 / 9 / 20087: 58$ & 1.583 & 16.9 & 1432 & $8 / 9 / 2008$ 10:12 & 1.582 & 16.9 & 1499 & $8 / 9 / 2008$ 12:26 & 1.593 & 17.1 & 1566 & $8 / 9 / 2008$ 14:40 & 1.596 & 16.9 \\
\hline 1366 & $8 / 9 / 20$ & 1.582 & 16.9 & 1433 & $8 / 9 / 2008$ 10:14 & 1.582 & 16.9 & 1500 & $8 / 9 / 200812: 28$ & 1.589 & 17 & 1567 & $8 / 9 / 2008 \quad 14: 42$ & 1.596 & 16.9 \\
\hline 1367 & $8 / 9 / 20088: 02$ & 1.582 & 16.9 & 1434 & $8 / 9 / 2008$ 10:16 & 1.582 & 16.9 & 1501 & $8 / 9 / 2008$ 12:30 & 1.589 & 16.9 & 1568 & $8 / 9 / 2008 \quad 14: 44$ & 1.596 & 16.9 \\
\hline 1368 & $8 / 9 / 20088: 04$ & 1.583 & 16.9 & 1435 & $8 / 9 / 2008$ 10:18 & 1.582 & 16.9 & 1502 & $8 / 9 / 2008$ 12:32 & 1.589 & 16.9 & 1569 & $8 / 9 / 2008$ 14:46 & 1.596 & 16.9 \\
\hline 1369 & $8 / 9 / 20088: 06$ & 1.583 & 16.9 & 1436 & $8 / 9 / 2008 \quad 10: 20$ & 1.581 & 16.9 & 1503 & $8 / 9 / 2008 \quad 12: 34$ & 1.59 & 16.9 & 1570 & $8 / 9 / 2008$ 14:48 & 1.596 & 16.9 \\
\hline 1370 & $8 / 9 / 20088: 08$ & 1.581 & 16.9 & 1437 & $8 / 9 / 2008$ 10:22 & 1.581 & 16.9 & 1504 & $8 / 9 / 2008$ 12:36 & 1.591 & 16.9 & 1571 & $8 / 9 / 2008$ 14:50 & 1.597 & 16.9 \\
\hline 1371 & 8/9/20088:10 & 1.58 & 16.9 & 1438 & $8 / 9 / 2008 \quad 10: 24$ & 1.581 & 16.9 & 1505 & 8/9/2008 12:38 & 1.59 & 16.9 & 1572 & $8 / 9 / 2008$ 14:52 & 1.596 & 16.9 \\
\hline 1372 & $8 / 9 / 20088: 12$ & 1.581 & 16.9 & 1439 & $8 / 9 / 2008$ 10:26 & 1.582 & 16.9 & 1506 & $8 / 9 / 2008$ 12:40 & 1.59 & 16.9 & 1573 & $8 / 9 / 2008 \quad 14: 54$ & 1.596 & 16.9 \\
\hline 1373 & $8 / 9 / 20088: 14$ & 1.581 & 16.9 & 1440 & $8 / 9 / 2008$ 10:28 & 1.583 & 16.9 & 1507 & $8 / 9 / 2008$ 12:42 & 1.591 & 16.9 & 1574 & $8 / 9 / 2008$ 14:56 & 1.595 & 16.9 \\
\hline 1374 & 8/9/20088:16 & 1.582 & 16.9 & 1441 & $8 / 9 / 2008$ 10:30 & 1.582 & 16.9 & 1508 & $8 / 9 / 2008$ 12:44 & 1.591 & 16.9 & 1575 & $8 / 9 / 2008$ 14:58 & 1.585 & 16.9 \\
\hline 1375 & $8 / 9 / 20088: 18$ & 1.582 & 16.9 & 1442 & $8 / 9 / 2008$ 10:32 & 1.588 & 16.9 & 1509 & $8 / 9 / 2008$ 12:46 & 1.591 & 16.9 & 1576 & $8 / 9 / 2008$ 15:00 & 1.57 & 16.9 \\
\hline 1376 & $8 / 9 / 2$ & 1.581 & 16.9 & 1443 & $8 / 9 / 2008$ 10:34 & 1.588 & 16.9 & 1510 & $8 / 9 / 2008$ 12:48 & 1.591 & 16.9 & 1577 & $8 / 9 / 2008$ 15:02 & 1.573 & 16.9 \\
\hline 1377 & $8 / 9 / 20$ & 1.58 & 16.9 & 1444 & $8 / 9 / 2008$ 10:36 & 1.588 & 16.9 & 1511 & $8 / 9 / 2008$ 12:50 & 1.592 & 16.9 & 1578 & $8 / 9 / 2008$ 15:04 & 1.571 & 16.9 \\
\hline 1378 & $8 / 9 / 20088: 24$ & 1.578 & 16.9 & 1445 & $8 / 9 / 200810: 38$ & 1.589 & 16.9 & 1512 & $8 / 9 / 2008$ 12:52 & 1.593 & 16.9 & 1579 & $8 / 9 / 2008$ 15:06 & 1.572 & 16.9 \\
\hline 1379 & $8 / 9 / 20088: 26$ & 1.579 & 16.9 & 1446 & $8 / 9 / 200810: 40$ & 1.588 & 16.9 & 4513 & $8 / 9 / 2008$ 12:54 & 1.593 & 16.9 & 1580 & $8 / 9 / 2008$ 15:08 & 1.579 & 16.9 \\
\hline 1380 & $8 / 9 / 2$ & 1.581 & 16.9 & 1447 & $8 / 9 / 2008 \quad 10: 42$ & 1.589 & 16.9 & 1514 & $8 / 9 / 2008 \quad 12: 56$ & 1.592 & 16.9 & 1581 & $8 / 9 / 2008$ 15:10 & 1.585 & 16.9 \\
\hline 1381 & $8 / 9 / 20$ & 1.582 & 16.9 & 1448 & $8 / 9 / 2008 \quad 10: 44$ & 1.588 & 16.9 & 1515 & $8 / 9 / 2008$ 12:58 & 1.592 & 16.9 & 1582 & $8 / 9 / 2008 \quad 15: 12$ & 1.589 & 16.9 \\
\hline 1382 & $8 / 9 / 20088: 32$ & 1.584 & 16.9 & 1449 & $8 / 9 / 2008$ 10:46 & 1.588 & 16.9 & 1516 & $8 / 9 / 2008$ 13:00 & 1.592 & 16.9 & 1583 & $8 / 9 / 2008$ 15:14 & 1.589 & 16.9 \\
\hline 1383 & $8 / 9 / 20$ & 1.585 & 16.9 & 1450 & $8 \overline{10: 48}$ & 1.588 & 16.9 & 1517 & $313: 02$ & 1.592 & 16.9 & 1584 & $3 / 2008$ 15:16 & 1.59 & 16.9 \\
\hline 1384 & $8 / 9 / 20$ & 1.586 & 16.9 & 1451 & $8 / 9 / 2008$ 10:50 & 1.588 & 16.9 & 1518 & $8 / 9 / 2008$ 13:04 & 1.592 & 16.9 & 1585 & $8 / 9 / 2008$ 15:18 & 1.591 & 16.9 \\
\hline 1385 & 8/9/20088:38 & 1.587 & 16.9 & 1452 & $8 / 9 / 2008$ 10:52 & 1.588 & 16.9 & 1519 & $8 / 9 / 2008$ 13:06 & 1.592 & 16.9 & 1586 & $8 / 9 / 2008$ 15:20 & 1.592 & 16.9 \\
\hline 1386 & $8 / 9 / 20088: 40$ & 1.585 & 16.9 & 1453 & $8 / 9 / 200810: 54$ & 1.589 & 16.9 & 1520 & $8 / 9 / 2008$ 13:08 & 1.592 & 16.9 & 1587 & $8 / 9 / 2008$ 15:22 & 1.592 & 16.9 \\
\hline 1387 & $8 / 9 / 20$ & 1.585 & 16.9 & 1454 & $8 / 9 / 2008 \quad 10: 56$ & 1.59 & 16.9 & 1521 & $8 / 9 / 200$ & 1.592 & 16.9 & 1588 & $8 / 9 / 2008$ 15:24 & 1.592 & 16.9 \\
\hline 1388 & $8 / 9 / 20$ & 1.584 & 16.9 & 1455 & $8 / 9 / 200810: 58$ & 1.59 & 16.9 & 1522 & $8 / 9 / 2008$ 13:12 & 1.593 & 16.9 & 1589 & $8 / 9 / 200815: 26$ & 1.592 & 16.9 \\
\hline 1389 & $8 / 9 / 20088: 46$ & 1.583 & 16.9 & 1456 & 8/9/2008 11:00 & 1.59 & 16.9 & 1523 & $8 / 9 / 2008$ 13:14 & 1.593 & 16.9 & 1590 & $8 / 9 / 200815: 28$ & 1.593 & 16.9 \\
\hline 1390 & $8 / 9 / 20088: 48$ & 1.582 & 16.9 & 1457 & $8 / 9 / 2008$ 11:02 & 1.589 & 16.9 & 1524 & $8 / 9 / 2008$ 13:16 & 7.594 & 16.9 & 1591 & $0815: 30$ & 1.594 & 16.9 \\
\hline 1391 & $8 / 9 / 20088: 50$ & 1.582 & 16.9 & 1458 & $8 / 9 / 2008$ 11:04 & 1.59 & 16.9 & 1525 & 8/9/2008 13:18 & 1.595 & 16.9 & 1592 & $8 / 9 / 200815: 32$ & 1.594 & 16.9 \\
\hline 1392 & $8 / 9 / 20088: 52$ & 1.583 & 16.9 & 1459 & $89 / 2008$ 11:06 & 1.589 & 16.9 & 1526 & $8 / 9 / 2008$ 13:20 & 1.596 & 16.9 & 1593 & $8 / 9 / 2008$ 15:34 & 1.595 & 16.9 \\
\hline 1393 & $8 / 9 / 20088: 54$ & 1.584 & 16.9 & 1460 & $8 / 9 / 200811: 08$ & 1.59 & 16.9 & 1527 & 8/9/2008 13:22 & 1.594 & 16.9 & 1594 & $8 / 9 / 2008$ 15:36 & 1.594 & 16.9 \\
\hline 1394 & $8 / 9 / 20088: 56$ & 1.584 & 16.9 & 1461 & $8 / 9 / 2008$ 11:10 & 1.589 & 16.9 & 1528 & $8 / 9 / 2008$ 13:24 & 1.593 & 16.9 & 1595 & $8 / 9 / 200815: 38$ & 1.594 & 16.9 \\
\hline 1395 & $8 / 9 / 20088: 58$ & 1.582 & 16.9 & 1462 & $8 / 9 / 2008$ 11:12 & 1.59 & 16.9 & 1529 & $8 / 9 / 2008$ 13:26 & 1.591 & 16.9 & 1596 & $8 / 9 / 200815: 40$ & 1.575 & 16.9 \\
\hline 1396 & $8 / 9 / 20089: 00$ & 1.582 & 16.9 & 1463 & $8 / 9 / 2008 \quad 11: 14$ & 1.589 & 16.9 & 1530 & $8 / 9 / 2008$ 13:28 & 1.594 & 16.9 & 1597 & $8 / 9 / 200815: 42$ & 1.591 & 16.9 \\
\hline 1397 & $8 / 9 / 20089: 02$ & 1.582 & 16.9 & 1464 & $8 / 9 / 200811: 16$ & 1.59 & 16.9 & 1531 & $8 / 9 / 2008 \overline{13: 30}$ & 1.594 & 16.9 & 1598 & $8 / 9 / 2008$ 15:44 & 1.596 & 16.9 \\
\hline 1398 & $8 / 9 / 20089: 04$ & 1.583 & 16.9 & 1465 & $8 / 9 / 2008+1: 18$ & 1.59 & 16.9 & 1532 & $8 / 9 / 2008$ 13:32 & 1.594 & 16.9 & 1599 & $8 / 9 / 2008$ 15:46 & 1.596 & 16.9 \\
\hline 1399 & $8 / 9 / 20089: 06$ & 1.584 & 16.9 & 1466 & $8 / 9 / 200811: 20$ & 1.59 & 16.9 & 1533 & $8 / 9 / 2008$ 13:34 & 1.595 & 16.9 & 1600 & $8 / 9 / 2008$ 15:48 & 1.595 & 16.9 \\
\hline 1400 & $8 / 9 / 20089: 08$ & 1.585 & 16.9 & 1467 & $8 / 9 / 2008+1: 22$ & 1.591 & 16.9 & 1534 & 8/9/2008 13:36 & 1.596 & 16.9 & 1601 & $8 / 9 / 200815: 50$ & 1.597 & 16.9 \\
\hline 1401 & $8 / 9 / 20089: 10$ & 1.576 & 16.9 & 1468 & $8 / 9 / 200811: 24$ & 1.59 & 16.9 & 1535 & $8 / 9 / 200813: 38$ & 1.597 & 16.9 & 1602 & $8 / 9 / 200815: 52$ & 1.597 & 16.9 \\
\hline 1402 & $8 / 9 / 20089: 12$ & 1.568 & 16.9 & 1469 & $8 / 9 / 2008 \quad 11: 26$ & 1.591 & 16.9 & 1536 & $8 / 9 / 2008$ 13:40 & 1.596 & 16.9 & 1603 & $8 / 9 / 2008 \quad 15: 54$ & 1.596 & 16.9 \\
\hline 1403 & $8 / 9 / 20089: 14$ & 1.561 & 16.9 & 1470 & $8 / 9 / 2008 \quad 11: 28$ & 1.591 & 16.9 & 1537 & $8 / 9 / 2008$ 13:42 & 1.597 & 16.9 & 1604 & $8 / 9 / 200815: 56$ & 1.595 & 16.9 \\
\hline 1404 & 8/9/2008 9:16 & 1.559 & 16.9 & 1471 & $8 / 9 / 2008$ 11:30 & 1.591 & 16.9 & 1538 & $8 / 9 / 2008$ 13:44 & 1.596 & 16.9 & 1605 & $8 / 9 / 200815: 58$ & 1.595 & 16.9 \\
\hline 1405 & 8/9/2008 9:18 & 1.556 & 16.9 & 1472 & $8 / 9 / 2008$ 11:32 & 1.591 & 16.9 & 1539 & $8 / 9 / 2008$ 13:46 & 1.56 & 16.9 & 1606 & $8 / 9 / 200816: 00$ & 1.596 & 16.9 \\
\hline 1406 & $8 / 9 / 20089: 20$ & 1.496 & 16.9 & 1473 & $8 / 9 / 2008$ 11:34 & 1.592 & 16.9 & 1540 & $8 / 9 / 2008$ 13:48 & 1.569 & 16.9 & 1607 & $8 / 9 / 2008$ 16:02 & 1.595 & 16.9 \\
\hline 1407 & $8 / 9 / 20089: 22$ & 1.547 & 16.9 & 1474 & $8 / 9 / 2008+11: 36$ & 1.592 & 16.9 & 1541 & $8 / 9 / 2008$ 13:50 & 1.564 & 16.9 & 1608 & 8/9/2008 16:04 & 1.595 & 16.9 \\
\hline
\end{tabular}


DOE/RL-2009-35, REV. 0

\begin{tabular}{|c|c|c|c|}
\hline \multicolumn{4}{|c|}{ D4-27p } \\
\hline $\operatorname{Rec}$ & & Pres & Temp \\
\hline$\#$ & Date/Time & psi & ${ }^{\circ} \mathrm{C}$ \\
\hline 1609 & $8 / 9 / 200816: 06$ & 1.596 & 16.9 \\
\hline 1610 & $8 / 9 / 2008$ 16:08 & 1.594 & 16.9 \\
\hline 1611 & $8 / 9 / 200816: 10$ & 1.595 & 16.9 \\
\hline 1612 & $8 / 9 / 2008$ 16:12 & 1.595 & 16.9 \\
\hline 1613 & $8 / 9 / 2008$ 16:14 & 1.596 & 16.9 \\
\hline 1614 & $8 / 9 / 2008$ 16:16 & 1.597 & 16.9 \\
\hline 1615 & $8 / 9 / 2008$ 16:18 & 1.597 & 16.9 \\
\hline 1616 & $8 / 9 / 200816: 20$ & 1.597 & 16.9 \\
\hline 1617 & $8 / 9 / 200816: 22$ & 1.598 & 16.9 \\
\hline 1618 & $8 / 9 / 200816.24$ & 1.598 & 16.9 \\
\hline 1619 & $8 / 9 / 200816: 26$ & 1.598 & 16.9 \\
\hline 1620 & $8 / 9 / 200816: 28$ & 1.598 & 17.1 \\
\hline 1621 & $8 / 9 / 2008$ 16:30 & 1.6 & 17.2 \\
\hline 1622 & $8 / 9 / 2008$ 16:32 & 1.599 & 17 \\
\hline 1623 & $9 / 200816: 34$ & 1.598 & 16.9 \\
\hline 1624 & $8 / 9 / 2008$ 16:36 & 1.598 & 16.9 \\
\hline 1625 & $8 / 9 / 200816: 38$ & 1.599 & 16.9 \\
\hline 1626 & $8 / 9 / 200816: 40$ & 1.599 & 16.9 \\
\hline 1627 & $8 / 9 / 2008$ 16:42 & 1.598 & 16.9 \\
\hline 1628 & $8 / 9 / 200816: 44$ & 1.598 & 16.9 \\
\hline 1629 & $8 / 9 / 200816: 46$ & 1.598 & 16.9 \\
\hline 1630 & $8 / 9 / 200816: 48$ & 1.599 & 16.9 \\
\hline 1631 & $8 / 9 / 2008$ 16:50 & 1.598 & 16.9 \\
\hline 1632 & $8 / 9 / 200816: 52$ & 1.599 & 16.9 \\
\hline 1633 & $816: 54$ & 1.598 & 16.9 \\
\hline 1634 & $0816: 56$ & 1.599 & 16.9 \\
\hline 1635 & $8 / 9 / 2008$ 16:58 & 1.599 & 16.9 \\
\hline 1636 & $8 / 9 / 2008$ 17:00 & 1.599 & 16.9 \\
\hline 1637 & 08 17:02 & 1.6 & 16.9 \\
\hline 1638 & $8 / 9 / 2008$ 17:04 & 1.6 & 16.9 \\
\hline 1639 & $8 / 9 / 2008$ 17:06 & 1.6 & 16.9 \\
\hline 1640 & $8 / 9 / 2008$ 17:08 & 1.601 & 16.9 \\
\hline 1641 & $3 / 9 / 2008$ 17:10 & 1.6 & 16.9 \\
\hline 1642 & 008 17:12 & 1.599 & 16.9 \\
\hline 1643 & 308 17:14 & 1.599 & 16.9 \\
\hline 1644 & $8 / 9 / 2008 \quad 17: 16$ & 1.599 & 16.9 \\
\hline 1645 & $8 / 9 / 2008$ 17:18 & 1.6 & 16.9 \\
\hline 1646 & $8 / 9 / 2008$ 17:20 & 1.6 & 16.9 \\
\hline 1647 & $8 / 9 / 2008$ 17:22 & 1.598 & 16.9 \\
\hline 1648 & 17:24 & 1.6 & 16.9 \\
\hline 1649 & $8 / 9 / 2008$ 17:26 & 1.598 & 16.9 \\
\hline 1650 & $8 / 9 / 2008$ 17:28 & 1.572 & 16.9 \\
\hline 1651 & 17:30 & 1.601 & 16.9 \\
\hline 1652 & $8 / 9 / 2008$ 17:32 & 1.585 & 16.9 \\
\hline 1653 & $8 / 9 / 2008$ 17:34 & 1.578 & 16.9 \\
\hline 1654 & $817: 36$ & 1.597 & 16.9 \\
\hline 1655 & 317:38 & 1.598 & 16.9 \\
\hline 1656 & $8 / 9 / 2008 \quad 17: 40$ & 1.599 & 16.9 \\
\hline 1657 & $8 / 9 / 2008$ 17:42 & 1.6 & 16.9 \\
\hline 1658 & $817: 44$ & 1.599 & 16.9 \\
\hline 1659 & $8 / 9 / 2008$ 17:46 & 1.594 & 16.9 \\
\hline 1660 & $8 / 9 / 2008$ 17:48 & 1.589 & 16.9 \\
\hline 1661 & $8 / 9 / 2008$ 17:50 & 1.583 & 16.9 \\
\hline 1662 & $8 / 9 / 2008$ 17:52 & 1.578 & 16.9 \\
\hline 1663 & $8 / 9 / 2008$ 17:54 & 1.574 & 16.9 \\
\hline 1664 & $8 / 9 / 2008$ 17:56 & 1.57 & 16.9 \\
\hline 1665 & $19 / 2008$ 17:58 & 1.568 & 16.9 \\
\hline 1666 & $8 / 9 / 2008$ 18:00 & 1.567 & 16.9 \\
\hline 1667 & $8 / 9 / 2008$ 18:02 & 1.568 & 16.9 \\
\hline 1668 & $8 / 9 / 2008$ 18:04 & 1.577 & 16.9 \\
\hline 1669 & $8 / 9 / 2008$ 18:06 & 1.583 & 16.9 \\
\hline 1670 & $8 / 9 / 2008$ 18:08 & 1.588 & 16.9 \\
\hline 1671 & $8 / 9 / 2008$ 18:10 & 1.589 & 16.9 \\
\hline 1672 & $8 / 9 / 2008$ 18:12 & 1.59 & 16.9 \\
\hline 1673 & $8 / 9 / 2008$ 18:14 & 1.589 & 16.9 \\
\hline 1674 & 8/9/2008 18:16 & 1.591 & 16.9 \\
\hline 1675 & 8/9/2008 18:18 & 1.594 & 16. \\
\hline
\end{tabular}

\begin{tabular}{|c|c|c|c|}
\hline \multicolumn{4}{|c|}{ D4-27p } \\
\hline $\operatorname{Rec}$ & & Pres & Temp \\
\hline$\#$ & Date-Time & psi & ${ }^{\circ} \mathrm{C}$ \\
\hline 1676 & $8 / 9 / 2008$ 18:20 & 1.594 & $\overline{16.9}$ \\
\hline 1677 & $8 / 9 / 2008$ 18:22 & 1.594 & 16.9 \\
\hline 1678 & $8 / 9 / 2008$ 18:24 & 1.594 & 16.9 \\
\hline 1679 & $8 / 9 / 200818: 26$ & 1.594 & 16.9 \\
\hline 1680 & $8 / 9 / 2008$ 18:28 & 1.595 & 16.9 \\
\hline 1681 & $89 / 2008$ 18:30 & 1.595 & 16.9 \\
\hline 1682 & $8 / 9 / 200818: 32$ & 1.595 & 16.9 \\
\hline 1683 & $8 / 9 / 200818: 34$ & 1.596 & 16.9 \\
\hline 1684 & $8 / 9 / 200818: 36$ & 1.594 & 16.9 \\
\hline 1685 & $8 / 9 / 2008$ 18:38 & 1.594 & 16.9 \\
\hline 1686 & $8 / 9 / 2008$ 18:40 & 1.595 & 16.9 \\
\hline 1687 & $8 / 9 / 2008$ 18:42 & 1.594 & 16.9 \\
\hline 1688 & $8 / 9 / 2008$ 18:44 & 1.596 & 16.9 \\
\hline 1689 & $8 / 9 / 200818: 46$ & 1.596 & 16.9 \\
\hline 1690 & $8 / 9 / 200818: 48$ & 1.596 & 16.9 \\
\hline 1691 & $8 / 9 / 200818: 50$ & 1.596 & 16.9 \\
\hline 1692 & $8 / 9 / 200818: 52$ & 1.596 & 16.9 \\
\hline 1693 & $8 / 9 / 200818: 54$ & 1.595 & 16.9 \\
\hline 1694 & $8 / 9 / 200818: 56$ & 1.597 & 16.9 \\
\hline 1695 & $8 / 9 / 200818: 58$ & 1.596 & 16.9 \\
\hline 1696 & $8 / 9 / 200819: 00$ & 1.596 & 16.9 \\
\hline 1697 & $8 / 9 / 200819: 02$ & 1.596 & 16.9 \\
\hline 1698 & $8 / 9 / 2008$ 19:04 & 1.594 & 16.9 \\
\hline 1699 & $8 / 9 / 2008$ 19:06 & 1.595 & 16.9 \\
\hline 1700 & $8 / 9 / 200819: 08$ & 1.595 & 16. \\
\hline 1701 & $8 / 9 / 2008$ 19:10 & 1.595 & 16.5 \\
\hline 1702 & $8819: 12$ & 1.595 & 16. \\
\hline 1703 & $819: 14$ & 1.596 & 16. \\
\hline 1704 & $8 / 9 / 2008$ 19:16 & 1.595 & 16. \\
\hline 1705 & $8 / 9 / 2008$ 19:18 & 1.596 & 16. \\
\hline 1706 & $319: 20$ & 1.596 & 16. \\
\hline 1707 & 819:22 & 1.595 & 16. \\
\hline 1708 & $8 / 9 / 2008$ 19:24 & 1.595 & 16. \\
\hline 1709 & $819: 26$ & 1.596 & 16.9 \\
\hline 1710 & $8 / 9 / 200819.28$ & 1.597 & 16. \\
\hline 1711 & $8 / 9 / 2008$ 19:30 & 1.596 & 16. \\
\hline 1712 & $3819: 32$ & 1.597 & 16. \\
\hline 1713 & $819: 34$ & 1.597 & 16. \\
\hline 1714 & $819: 36$ & 1.596 & 16. \\
\hline 1715 & $8 / 9 / 200819: 38$ & 1.596 & 16. \\
\hline 1716 & $8 / 9 / 200819: 40$ & 1.595 & 16. \\
\hline 1717 & $319: 42$ & 1.595 & 16. \\
\hline 1718 & $8 / 9 / 2008$ 19:44 & 1.594 & 16. \\
\hline 1719 & $8 / 9 / 2008$ 19:46 & 1.594 & 16. \\
\hline 1720 & $319: 48$ & 1.594 & 16. \\
\hline 1721 & $819: 50$ & 1.593 & 16. \\
\hline 1722 & $8 / 9 / 200819: 52$ & 1.594 & 16. \\
\hline 1723 & $819: 54$ & 1.594 & 16. \\
\hline 1724 & $8 / 9 / 2008$ 19:56 & 1.595 & 16. \\
\hline 1725 & $8 / 9 / 2008$ 19:58 & 1.594 & 16. \\
\hline 1726 & $8 / 9 / 200820: 00$ & 1.594 & 16. \\
\hline 1727 & $320: 02$ & 1.594 & 16. \\
\hline 1728 & $820: 04$ & 1.593 & 16. \\
\hline 1729 & $8 / 9 / 200820: 06$ & 1.593 & 16. \\
\hline 1730 & $8 / 9 / 200820: 08$ & 1.593 & 16. \\
\hline 1731 & $3820: 10$ & 1.594 & 168 \\
\hline 1732 & $8 / 9 / 200820: 12$ & 1.594 & 16. \\
\hline 1733 & 8/9/2008 20:14 & 1.596 & 16. \\
\hline 1734 & $8 / 9 / 200820: 16$ & 1.596 & 16. \\
\hline 1735 & $8 / 9 / 200820: 18$ & 1.595 & 16. \\
\hline 1736 & 8/9/2008 20:20 & 1.594 & 16. \\
\hline 1737 & $8 / 9 / 200820: 22$ & 1.594 & 16.9 \\
\hline 1738 & $8 / 9 / 200820: 24$ & 1.593 & 16.9 \\
\hline 1739 & $8 / 9 / 200820: 26$ & 1.592 & 16.8 \\
\hline 1740 & 8/9/2008 20:28 & 1.593 & 16. \\
\hline 1741 & $8 / 9 / 200820: 30$ & 1.592 & 16.9 \\
\hline 1742 & $8 / 9 / 200820: 32$ & 1.593 & 16.9 \\
\hline
\end{tabular}

\begin{tabular}{|c|c|c|c|}
\hline \multicolumn{4}{|c|}{ D4-27p } \\
\hline $\operatorname{Rec}$ & & Pres & Temp \\
\hline$\#$ & Date/Time & psi & ${ }^{\circ} \mathrm{C}$ \\
\hline 1743 & $8 / 9 / 200820: 34$ & 1.592 & 16.9 \\
\hline 1744 & $8 / 9 / 200820: 36$ & 1.592 & 16.9 \\
\hline 1745 & $8 / 9 / 200820: 38$ & 1.592 & 16.9 \\
\hline 1746 & $8 / 9 / 200820: 40$ & 1.592 & 16.9 \\
\hline 1747 & $8 / 9 / 200820: 42$ & 1.592 & 16.9 \\
\hline 1748 & $8 / 9 / 200820: 44$ & 1.592 & 16.9 \\
\hline 1749 & $8 / 9 / 200820: 46$ & 1.592 & 16.9 \\
\hline 1750 & $8 / 9 / 200820: 48$ & 1.589 & 16.9 \\
\hline 1751 & $8 / 9 / 200820: 50$ & 1.584 & 16.9 \\
\hline 1752 & $8 / 9 / 200820: 52$ & 1.578 & 16.9 \\
\hline 1753 & $8 / 9 / 200820: 54$ & 1.573 & 16.9 \\
\hline 1754 & $8 / 9 / 200820: 56$ & 1.569 & 16.9 \\
\hline 1755 & $8 / 9 / 200820: 58$ & 1.564 & 16.9 \\
\hline 1756 & $8 / 9 / 200821: 00$ & 1.562 & 16.9 \\
\hline 1757 & $8 / 9 / 200821: 02$ & 1.559 & 16.9 \\
\hline 1758 & $8 / 9 / 200821: 04$ & 1.558 & 16.9 \\
\hline 1759 & $8 / 9 / 200821: 06$ & 1.557 & 16.9 \\
\hline 1760 & $8 / 9 / 200821: 08$ & 1.558 & 16.9 \\
\hline 1761 & $8 / 9 / 200821: 10$ & 1.57 & 16.9 \\
\hline 1762 & $8 / 9 / 200821: 12$ & 1.577 & 16.9 \\
\hline 1763 & $8 / 9 / 200821: 14$ & 1.581 & 16.9 \\
\hline 1764 & $8 / 9 / 200821: 16$ & 1.583 & 16.9 \\
\hline 1765 & $8 / 9 / 200821: 18$ & 1.585 & 16.9 \\
\hline 1766 & $8 / 9 / 200821: 20$ & 1.585 & 16.9 \\
\hline 1767 & $8 / 9 / 200821: 22$ & 1.587 & 16.9 \\
\hline 1768 & $8 / 9 / 200821: 24$ & 1.587 & 16.9 \\
\hline 1769 & $8 / 9 / 200821: 26$ & 1.585 & 16.9 \\
\hline 1770 & $8 / 9 / 200821: 28$ & 1.585 & 16.9 \\
\hline 1771 & $8 / 9 / 200821: 30$ & 1.586 & 16.9 \\
\hline 1772 & $8 / 9 / 200821: 32$ & 1.587 & 16.9 \\
\hline 1773 & $8 / 9 / 200821: 34$ & 1.587 & 16.9 \\
\hline 1774 & $8 / 9 / 200821: 36$ & 1.586 & 16.9 \\
\hline 1775 & $8 / 9 / 200821: 38$ & 1.586 & 16.9 \\
\hline 1776 & $8 / 9 / 200821: 40$ & 1.587 & 16.9 \\
\hline $17 \pi$ & $8 / 9 / 200821: 42$ & 1.587 & 16.9 \\
\hline 1778 & $8 / 9 / 200821: 44$ & 1.587 & 16.9 \\
\hline 1779 & $8 / 9 / 200821: 46$ & 1.587 & 16.9 \\
\hline 1780 & $8 / 9 / 200821: 48$ & 1.587 & 16.9 \\
\hline 1781 & $8 / 9 / 200821: 50$ & 1.587 & 16.9 \\
\hline 1782 & $8 / 9 / 200821: 52$ & 1.587 & 16.9 \\
\hline 1783 & $8 / 9 / 200821: 54$ & 1.589 & 16.9 \\
\hline 1784 & $8 / 9 / 200821: 56$ & 1.589 & 16.9 \\
\hline 1785 & $8 / 9 / 200821: 58$ & 1.589 & 16.9 \\
\hline 1786 & $822: 00$ & 1.589 & 16.9 \\
\hline 1787 & $8 / 9 / 200822: 02$ & 1.591 & 16.9 \\
\hline 1788 & $8 / 9 / 200822: 04$ & 1.591 & 16.9 \\
\hline 1789 & $8 / 9 / 200822: 06$ & 1.59 & 16.9 \\
\hline 1790 & $8 / 9 / 200822: 08$ & 1.59 & 16.9 \\
\hline 1791 & $8 / 9 / 200822: 10$ & 1.591 & 16.9 \\
\hline 1792 & $8 / 9 / 200822: 12$ & 1.591 & 16.9 \\
\hline 1793 & $8 / 9 / 2008$ 22:14 & 1.591 & 16.9 \\
\hline 1794 & $8 / 9 / 2008$ 22:16 & 1.59 & 16.9 \\
\hline 1795 & $8 / 9 / 200822: 18$ & 1.589 & 16.9 \\
\hline 1796 & $8 / 9 / 200822: 20$ & 1.59 & 16.9 \\
\hline 1797 & $8 / 9 / 200822: 22$ & 1.59 & 16.9 \\
\hline 1798 & $8 / 9 / 200822: 24$ & 1.59 & 16.9 \\
\hline 1799 & $8 / 9 / 200822: 26$ & 1.59 & 16.9 \\
\hline 1800 & $8 / 9 / 200822: 28$ & 1.591 & 16.9 \\
\hline 1801 & $8 / 9 / 200822: 30$ & 1.591 & 16.9 \\
\hline 1802 & $8 / 9 / 200822: 32$ & 1.59 & 16.9 \\
\hline 1803 & $8 / 9 / 200822: 34$ & 1.591 & 16.9 \\
\hline 1804 & $8 / 9 / 200822: 36$ & 1.59 & 16.9 \\
\hline 1805 & $8 / 9 / 2008$ 22:38 & 1.591 & 16.9 \\
\hline 1806 & $8 / 9 / 2008$ 22:40 & 1.59 & 16.9 \\
\hline 1807 & 8/9/2008 22:42 & 1.589 & 16.9 \\
\hline 1808 & $8 / 9 / 200822: 44$ & 1.589 & 16.9 \\
\hline 1809 & $8 / 9 / 200822: 46$ & 1.588 & 16.9 \\
\hline
\end{tabular}

\begin{tabular}{|c|c|c|c|}
\hline \multicolumn{4}{|c|}{ D4-27p } \\
\hline $\operatorname{Rec}$ & & Pres & Temp \\
\hline \# & DateTime & psi & ${ }^{\circ} \mathrm{C}$ \\
\hline 1810 & $8 / 9 / 200822: 48$ & 1.589 & 16.9 \\
\hline 1811 & $9 / 200822: 50$ & 1.591 & 16.9 \\
\hline 1812 & $8 / 9 / 200822: 52$ & 1.543 & 16.9 \\
\hline 1813 & $8 / 9 / 200822: 54$ & 1.537 & 16.9 \\
\hline 1814 & $8 / 9 / 200822: 56$ & 1.584 & 16.9 \\
\hline 1815 & $8 / 9 / 200822: 58$ & 1.587 & 16.9 \\
\hline 1816 & $8 / 9 / 200823: 00$ & 1.587 & 16.9 \\
\hline 1817 & $8 / 9 / 200823: 02$ & 1.587 & 16.9 \\
\hline 1818 & $8 / 9 / 200823: 04$ & 1.588 & 16.9 \\
\hline 1819 & $9 / 200823: 06$ & 1.588 & 16.9 \\
\hline 1820 & $8 / 9 / 200823: 08$ & 1.588 & 16.9 \\
\hline 1821 & $8 / 9 / 200823: 10$ & 1.589 & 16.9 \\
\hline 1822 & $8 / 9 / 2008$ 23:12 & 1.589 & 16.9 \\
\hline 1823 & $8 / 9 / 200823: 14$ & 1.59 & 16.9 \\
\hline 1824 & $8 / 9 / 200823: 16$ & 1.59 & 16.9 \\
\hline 1825 & $8 / 9 / 200823: 18$ & 1.59 & 16.9 \\
\hline 1826 & $8 / 9 / 200823: 20$ & 1.59 & 16.9 \\
\hline 1827 & $8 / 9 / 200823: 22$ & 1.589 & 16. \\
\hline 1828 & $8 / 9 / 200823: 24$ & 1.589 & 16.9 \\
\hline 1829 & $823: 26$ & 1.589 & 16.9 \\
\hline 1830 & $8 / 9 / 200823: 28$ & 1.589 & 16.9 \\
\hline 1831 & $8 / 9 / 200823: 30$ & 1.59 & 16. \\
\hline 1832 & $8 / 9 / 200823: 32$ & 1.59 & 16. \\
\hline 1833 & $823: 34$ & 1.59 & 16. \\
\hline 1834 & $8 / 9 / 200823: 36$ & 1.59 & 16. \\
\hline 1835 & $8 / 9 / 200823: 38$ & 1.591 & 16.9 \\
\hline 1836 & $823: 40$ & 1.591 & 16.9 \\
\hline 1837 & $19 / 200823: 42$ & 1.591 & 16. \\
\hline 1838 & $8 / 9 / 200823: 44$ & 1.59 & 16. \\
\hline 1839 & $823: 46$ & 1.59 & 16. \\
\hline 1840 & $823: 48$ & 1.589 & 16.5 \\
\hline 1841 & $8 / 9 / 200823: 50$ & 1.59 & 16.5 \\
\hline 1842 & $8 / 9 / 200823: 52$ & 1.586 & 16.8 \\
\hline 1843 & $9 / 200823: 54$ & 1.579 & 16.9 \\
\hline 1844 & $823: 56$ & 1.572 & 16.9 \\
\hline 1845 & $8 / 9 / 200823: 58$ & 1.568 & 16. \\
\hline 1846 & $8 / 10 / 20080: 00$ & 1.564 & 16. \\
\hline 1847 & $30: 02$ & 1.561 & $\overline{16 .}$ \\
\hline 1848 & $80: 04$ & 1.559 & 16. \\
\hline 1849 & $8 / 10 / 20080: 06$ & 1.558 & 16.9 \\
\hline 1850 & $10 / 20080: 08$ & 1.556 & 16.9 \\
\hline 1851 & $80: 10$ & 1.554 & 16. \\
\hline 1852 & $080: 12$ & 1.557 & 16. \\
\hline 1853 & $8 / 10 / 20080: 14$ & 1.567 & 16.9 \\
\hline 1854 & $0: 16$ & 1.573 & 16.9 \\
\hline 1855 & $10 / 20080: 18$ & 1.576 & 16. \\
\hline 1856 & $8 / 10 / 20080: 20$ & 1.578 & 16.8 \\
\hline 1857 & $80: 22$ & 1.58 & 16. \\
\hline 1858 & $0: 24$ & 1.58 & 16. \\
\hline 1859 & $10 / 20080: 26$ & 1.581 & 16. \\
\hline 1860 & $3 / 10 / 20080: 28$ & 1.581 & 16. \\
\hline 1861 & & 1.581 & 16. \\
\hline 1862 & $80: 32$ & 1.582 & $\overline{16}$ \\
\hline 1863 & $8 / 10 / 20080: 34$ & 1.583 & 16.9 \\
\hline 1864 & $080: 36$ & 1.584 & 16. \\
\hline 1865 & $080: 38$ & 1.584 & 16. \\
\hline 1866 & $8 / 10 / 20080: 40$ & 1.585 & $\overline{16 .}$ \\
\hline 1867 & $8 / 10 / 20080: 42$ & 1.585 & 16. \\
\hline 1868 & $10 / 20080: 44$ & 1.585 & 16. \\
\hline 1869 & $10 / 20080: 46$ & 1.585 & 16. \\
\hline 1870 & $8 / 10 / 20080: 48$ & 1.585 & 16.9 \\
\hline 1871 & $8 / 10 / 20080: 50$ & 1.584 & 16.9 \\
\hline 1872 & $10 / 20080: 52$ & 1.585 & 16. \\
\hline 1873 & $10 / 20080: 54$ & 1.586 & 16. \\
\hline 1874 & $10 / 20080: 56$ & 1.587 & 16. \\
\hline 1875 & $10 / 20080: 58$ & 1.586 & 16.9 \\
\hline 1876 & $8 / 10 / 20081: 00$ & 1.587 & 16.9 \\
\hline
\end{tabular}




\begin{tabular}{|c|c|c|c|c|c|c|c|c|c|c|c|c|c|c|c|}
\hline \multicolumn{4}{|c|}{ D4-27p } & \multicolumn{4}{|c|}{ D4-27p } & \multicolumn{4}{|c|}{ D4-27p } & \multicolumn{4}{|c|}{ D4-27p } \\
\hline $\operatorname{Rec}$ & & Pres & Temp & $\operatorname{Rec}$ & & Pres & Temp & $\operatorname{Rec}$ & & Pres & Temp & $\operatorname{Rec}$ & & Pres & Temp \\
\hline$\#$ & Date/Time & psi & ${ }^{\circ} \mathrm{C}$ & $\#$ & Date/Time & psi & ${ }^{\circ} \mathrm{C}$ & $\#$ & Date/Time & psi & ${ }^{\circ} \mathrm{C}$ & $\#$ & Date/Time & psi & ${ }^{\circ} \mathrm{C}$ \\
\hline 1877 & $8 / 10 / 20081: 02$ & 1.587 & 16.9 & 1944 & $8 / 10 / 20083: 16$ & 1.586 & 16.9 & 2011 & $8 / 10 / 20085: 30$ & 1.596 & 16.9 & 2078 & $8 / 10 / 20087: 44$ & 1.594 & 16.9 \\
\hline 1878 & $10 / 20081: 04$ & 1.586 & 16.9 & 1945 & & 1.586 & 16.9 & 2012 & $8 / 10 / 20085: 32$ & 1.596 & 16.9 & 2079 & & 1.594 & 16.9 \\
\hline 1879 & $10 / 20081: 06$ & 1.587 & 16.9 & 1946 & $8 / 10 / 20083: 20$ & 1.587 & 16.9 & 2013 & $8 / 10 / 20085: 34$ & 1.596 & 16.9 & 2080 & $8 / 10 / 20087: 48$ & 1.594 & 16.9 \\
\hline 1880 & $8 / 10 / 20081: 08$ & 1.586 & 16.9 & 1947 & $8 / 10 / 20083: 22$ & 1.587 & 16.9 & 2014 & $8 / 10 / 20085: 36$ & 1.596 & 16.9 & 2081 & $8 / 10 / 20087: 50$ & 1.594 & 16.9 \\
\hline 1881 & $8 / 10 / 20081: 10$ & 1.586 & 16.9 & 1948 & $8 / 10 / 20083: 24$ & 1.587 & 16.9 & 2015 & $8 / 10 / 20085: 38$ & 1.596 & 16.9 & 2082 & $8 / 10 / 20087: 52$ & 1.594 & 16.9 \\
\hline 1882 & $8 / 10 / 2008$ 1:12 & 1.587 & 16.9 & 1949 & $8 / 10 / 20083: 26$ & 1.587 & 16.9 & 2016 & $8 / 10 / 20085: 40$ & 1.595 & 16.9 & 2083 & $8 / 10 / 20087: 54$ & 1.594 & 16.9 \\
\hline 1883 & $8 / 10 / 2008$ 1:14 & 1.587 & 16.9 & 1950 & $8 / 10 / 20083: 28$ & 1.588 & 16.9 & 2017 & $8 / 10 / 20085: 42$ & 1.596 & 16.9 & 2084 & $8 / 10 / 20087: 56$ & 1.594 & 16.9 \\
\hline 1884 & $8 / 10 / 20081: 16$ & 1.587 & 16.9 & 1951 & $8 / 10 / 20083: 30$ & 1.589 & 16.9 & 2018 & $8 / 10 / 20085: 44$ & 1.596 & 16.9 & 2085 & $8 / 10 / 20087: 58$ & 1.594 & 16.9 \\
\hline 1885 & $8 / 10 / 20081: 18$ & 1.587 & 16.9 & 1952 & $8 / 10 / 2008$ 3:32 & 1.588 & 17.4 & 2019 & $8 / 10 / 20085: 46$ & 1.597 & 16.9 & 2086 & $8 / 10 / 20088: 00$ & 1.595 & 16.9 \\
\hline 1886 & $8 / 10 / 20081: 20$ & 1.588 & 16.9 & 1953 & $8 / 10 / 20083: 34$ & 1.591 & 17.3 & 2020 & $8 / 10 / 20085: 48$ & 1.592 & 16.9 & 2087 & $8 / 10 / 20088: 02$ & 1.596 & 16.9 \\
\hline 1887 & $8 / 10 / 20081: 22$ & 1.587 & 16.9 & 1954 & $8 / 10 / 20083: 36$ & 1.59 & 17 & 2021 & $8 / 10 / 20085: 50$ & 1.585 & 16.9 & 2088 & $8 / 10 / 20088: 04$ & 1.595 & 16.9 \\
\hline 1888 & $8 / 10 / 20081: 24$ & 1.587 & 16.9 & 1955 & $8 / 10 / 20083: 38$ & 1.59 & 16.9 & 2022 & $8 / 10 / 20085: 52$ & 1.578 & 16.9 & 2089 & $8 / 10 / 20088: 06$ & 1.596 & 16.9 \\
\hline 1889 & $8 / 10 / 20081: 26$ & 1.588 & 16.9 & 1956 & $8 / 10 / 20083: 40$ & 1.589 & 16.9 & 2023 & $8 / 10 / 20085: 54$ & 1.573 & 16.9 & 2090 & $8 / 10 / 20088: 08$ & 1.596 & 16.9 \\
\hline 1890 & $8 / 10 / 2008$ 1:28 & 1.588 & 16.9 & 1957 & $8 / 10 / 20083: 42$ & 1.59 & 16.9 & 2024 & $8 / 10 / 20085: 56$ & 1.57 & 16.9 & 2091 & $8 / 10 / 20088: 10$ & 1.595 & 16.9 \\
\hline 1891 & $8 / 10 / 2008$ 1:30 & 1.588 & 16.9 & 1958 & $3: 44$ & 1.591 & 16.9 & 2025 & $8 / 10 / 20085: 58$ & 1.525 & 16.9 & 2092 & $8 / 10 / 20088: 12$ & 1.596 & 16.9 \\
\hline 1892 & $8 / 10 / 20081: 32$ & 1.589 & 16.9 & 1959 & $33: 46$ & 1.591 & 16.9 & 2026 & $8 / 10 / 20086: 00$ & 1.524 & 16.9 & 2093 & $8 / 10 / 20088: 14$ & 1.595 & 16.9 \\
\hline 1893 & $8 / 10 / 2008$ 1:34 & 1.589 & 16.9 & 1960 & $8 / 10 / 20083: 48$ & 1.59 & 16.9 & 2027 & $8 / 10 / 20086: 02$ & 1.562 & 16.9 & 2094 & $8 / 10 / 20088: 16$ & 1.595 & 16.9 \\
\hline 1894 & $8 / 10 / 20081: 36$ & 1.589 & 16.9 & 1961 & $3: 50$ & 1.589 & 16.9 & 2028 & $8 / 10 / 20086: 04$ & 1.564 & 16.9 & 2095 & $8 / 10 / 20088: 18$ & 1.595 & 16.9 \\
\hline 1895 & $8 / 10 / 20081: 38$ & 1.588 & 16.9 & 1962 & & 1.59 & 16.9 & 2029 & $8 / 10 / 20086: 06$ & 1.562 & 16.9 & 2096 & $8 / 10 / 20088: 20$ & 1.595 & 16.9 \\
\hline 1896 & $8 / 10 / 20081: 40$ & 1.543 & 16.9 & 1963 & $8 / 10 / 20083: 54$ & 1.59 & 16.9 & 2030 & $8 / 10 / 20086: 08$ & 1.573 & 16.9 & 2097 & $8 / 10 / 20088: 22$ & 1.596 & 16.9 \\
\hline 1897 & $8 / 10 / 20081: 42$ & 1.584 & 16.9 & 1964 & $8 / 10 / 20083: 56$ & 1.591 & 16.9 & 2031 & $8 / 10 / 20$ & 1.577 & 16.9 & 2098 & $88: 24$ & 1.596 & 16.9 \\
\hline 1898 & $8 / 40 / 20081: 44$ & 1.587 & 16.9 & 1965 & $3: 58$ & 1.592 & 16.9 & 2032 & $8 / 10 / 20086: 12$ & 1.581 & 16.9 & 2099 & $088: 26$ & 1.595 & 16.9 \\
\hline 1899 & $8 / 10 / 20081: 46$ & 1.589 & 16.9 & 1966 & $84: 00$ & 1.591 & 16.9 & 2033 & $8 / 10 / 20086: 14$ & 1.585 & 16.9 & 2100 & $088: 28$ & 1.596 & 16.9 \\
\hline 1900 & $8 / 10 / 20081: 48$ & 1.589 & 16.9 & 1967 & $8 / 10 / 20084: 02$ & 1.592 & 16.9 & 2034 & $8 / 10 / 2$ & 1.586 & 16.9 & 2101 & $38: 30$ & 1.596 & 16.9 \\
\hline 1901 & $8 / 10 / 20081: 50$ & 1.59 & 16.9 & 1968 & 4:04 & 1.591 & 16.9 & 2035 & $8 / 10 / 2$ & 1.587 & 16.9 & 2102 & & 1.596 & 16.9 \\
\hline 1902 & $8 / 10 / 20081: 52$ & 1.59 & 16.9 & 1969 & $34: 06$ & 1.591 & 16.9 & 2036 & $8 / 10 / 20086: 20$ & 1.588 & 16.9 & 2103 & $88: 34$ & 1.597 & 16.9 \\
\hline 1903 & $8 / 10 / 20081: 54$ & 1.591 & 16.9 & 1970 & $84: 08$ & 1.592 & 16.9 & 2037 & $8 / 10 / 20086: 22$ & 1.589 & 16. & 2104 & $88: 36$ & 1.597 & 16.9 \\
\hline 1904 & 1:56 & 1.591 & 16.9 & 1971 & 4:10 & 1.592 & 16.9 & 2038 & $8 / 10 /$ & 1.589 & 16. & 2105 & $8: 38$ & 1.597 & 16.9 \\
\hline 1905 & $8 / 10 / 20081: 58$ & 1.592 & 16.9 & 1972 & $8 / 10 / 20084: 12$ & 1.592 & 16.9 & 2039 & $8 / 10 / 20$ & 1.589 & 16.9 & 2106 & 38:40 & 1.596 & 16.9 \\
\hline 1906 & $8 / 10 / 20082: 00$ & 1.591 & 16.9 & 1973 & $8 / 10 / 20084: 14$ & 1.591 & 16.9 & 2040 & $8 / 10 / 20086: 28$ & 1.591 & 16.9 & 2107 & $38: 42$ & 1.596 & 16.9 \\
\hline 1907 & $2: 02$ & 1.591 & 16.9 & 1974 & $4: 16$ & 1.592 & 16.9 & 2041 & & 1.59 & 17.2 & 2108 & $8: 44$ & 1.596 & 16.9 \\
\hline 1908 & $8 / 10 / 20082: 04$ & 1.591 & 16.9 & 1975 & $84: 18$ & 1.592 & 16.9 & 2042 & $8 / 10 / 20$ & 1.592 & 17.1 & 2109 & $8: 46$ & 1.597 & 16.9 \\
\hline 1909 & $8 / 10 / 20082: 06$ & 1.591 & 16.9 & 1976 & $84: 20$ & 1.593 & 16.9 & 2043 & $8 / 10 / 20$ & 1.591 & 17 & 2110 & $8: 48$ & 1.597 & 16.9 \\
\hline 1910 & & 1.59 & 16. & 1977 & $4: 22$ & 1.594 & 16.9 & 2044 & & 1.592 & 16.9 & 2111 & 8:50 & 1.593 & 16.9 \\
\hline 1911 & $2: 10$ & 1.59 & 16.9 & 1978 & $4: 24$ & 1.595 & 16.9 & 2045 & $8 / 10 / 2$ & 1.592 & 16.9 & 2112 & $8: 52$ & 1.584 & 16.9 \\
\hline 1912 & $8 / 10 / 20082: 12$ & 1.591 & 16.9 & 1979 & $84: 26$ & 1.595 & 16.9 & 2046 & $8 / 10 / 20$ & 1.593 & 16.9 & 2113 & $88: 54$ & 1.58 & 16.9 \\
\hline 1913 & & 1.591 & 16. & 1980 & $4: 28$ & 1.595 & 16.9 & 2047 & & 1.593 & 16.9 & 2114 & & 1.576 & 16.9 \\
\hline 1914 & & 1.591 & 16. & 198 & 4:30 & 1.595 & 16.9 & 2048 & $8 / 10$ & 1.592 & 16. & 2115 & $8: 58$ & 1.572 & 16.9 \\
\hline 1915 & $8 / 10 / 20082: 18$ & 1.592 & 16.9 & 1982 & $4: 32$ & 1.595 & 16. & 2049 & $8 / 10 /$ & 1.591 & 16.9 & 2116 & $89: 00$ & 1.569 & 16.9 \\
\hline 1916 & & 1.591 & 16. & 1983 & & 1.595 & 16. & 2050 & & 1.591 & 16.9 & 2117 & & 1.568 & 16.9 \\
\hline 1917 & & 1.591 & 16 & 198 & & 1.595 & 16. & 2051 & & 1.591 & 16 & 2118 & & 1.566 & 16.9 \\
\hline 1918 & $10 / 20082: 24$ & 1.591 & 16. & 1985 & $4: 38$ & 1.594 & 16.9 & 2052 & $8 / 10 /$ & 1.591 & 16. & 2119 & $89: 06$ & 1.567 & 16.9 \\
\hline 1919 & & 1.59 & 16. & 1986 & & 1.595 & 16.9 & 2053 & & 1.592 & 16. & 2120 & & 1.576 & 16.9 \\
\hline 1920 & & 1.59 & 16 & 198 & & 1.596 & 16. & 2054 & & 1.592 & 16 & 2121 & $9: 10$ & 1.58 & 16.9 \\
\hline 1921 & & 1.59 & 16. & 1988 & $4: 44$ & 1.597 & 16.9 & 2055 & $8 / 11$ & 1.592 & 16. & 2122 & $39: 12$ & 1.584 & 16.9 \\
\hline 1922 & & 1.59 & 16. & 1989 & & 1.596 & 16.9 & 2056 & & 1.592 & 16. & 2123 & & 1.585 & 16.9 \\
\hline 1923 & & 1.59 & 16 & 199 & & 1.596 & 16.9 & 2057 & & 1.592 & 16. & 2124 & & 1.586 & 16.9 \\
\hline 1924 & 10/2008 2:36 & 1.591 & 16. & 1991 & $4: 50$ & 1.598 & 16.9 & 2058 & $7: 04$ & 1.552 & 16.9 & 2125 & 9:18 & 1.587 & 16.9 \\
\hline 1925 & & 1.592 & 16. & 1992 & & 1.597 & 16.9 & 2059 & & 1.545 & 16.9 & 212 & & 1.587 & 16.9 \\
\hline 1926 & & 1.592 & 16. & 195 & & 1.596 & 16.9 & 2060 & & 1.544 & 16.9 & 2127 & & 1.588 & 16.9 \\
\hline 1927 & $8 / 10 / 2008$ 2:42 & 1.592 & 16. & 1994 & $4: 56$ & 1.595 & 16.9 & 2061 & 7:10 & 1.543 & 16.9 & 2128 & $9: 24$ & 1.589 & 16.9 \\
\hline 1928 & & 1.592 & 16. & 1995 & & 1.595 & 16.9 & 2062 & & 1.54 & 16.9 & 2129 & & 1.59 & 16.9 \\
\hline 1929 & & 1.592 & 16 . & & & 1.594 & 16.9 & 2063 & & 1.61 & 16.9 & 2130 & & 1.591 & 16.9 \\
\hline 1930 & $8 / 10 / 20082: 48$ & 1.592 & 16. & 1997 & $35: 02$ & 1.594 & 16.9 & 2064 & $7: 16$ & 1.686 & 16.9 & 2131 & 9:30 & 1.59 & 16.9 \\
\hline 1931 & & 1.587 & 16. & 195 & & 1.594 & 16.9 & 2065 & & 1.696 & 16.9 & & & 1.59 & 16.9 \\
\hline 1932 & & 1.579 & & & & 1.594 & 16.9 & 2066 & & 1.647 & & 213 & & 1.591 & 16.9 \\
\hline 1933 & $10 / 20082: 54$ & 1.572 & 16.9 & 2000 & & 1.594 & 16.9 & 2067 & $7: 22$ & 1.603 & 16.9 & 2134 & $39: 36$ & 1.59 & 16.9 \\
\hline 1934 & $0 / 20082: 56$ & 1.569 & 16. & 2001 & & 1.595 & 16.9 & 2068 & & 1.598 & 16.9 & & & 1.591 & 16.9 \\
\hline 1935 & & 1.565 & & & & & & 2069 & & & & $213 x$ & & 1.591 & 16.9 \\
\hline 1936 & $10 / 20083: 00$ & 1.563 & 16.9 & 200 & 5:14 & 1.595 & 16.9 & 2070 & $7: 28$ & 1.596 & 16.9 & 2137 & $89: 42$ & 1.591 & 16.9 \\
\hline 1937 & $10 / 20083: 02$ & 1.562 & 16.9 & 2004 & $85: 16$ & 1.596 & 16.9 & 2071 & $8 / 10 / 20087: 30$ & 1.597 & 16.9 & 2138 & $8 / 10 / 20089: 44$ & 1.592 & 16.9 \\
\hline 1938 & & 1.56 & 16.9 & 2005 & & 1.596 & 16.9 & 2072 & & & & 2139 & & 1.592 & \\
\hline 1939 & $083: 06$ & 1.567 & 16.9 & 2006 & & 1.596 & 16.9 & 2073 & $77: 34$ & 1.596 & 16.9 & 2140 & $89: 48$ & 1.593 & 16.9 \\
\hline 1940 & $8 / 10 / 20083: 08$ & 1.575 & 16.9 & 2007 & $10 / 20085: 22$ & 1.596 & 16.9 & 2074 & $8 / 10 / 20087: 36$ & 1.596 & 16.9 & 2141 & $8 / 10 / 20089: 50$ & 1.593 & 16.9 \\
\hline 1941 & $10 / 20083: 10$ & 1.579 & 16.9 & 2008 & & 1.596 & 16.9 & 2075 & & 1.596 & 16.9 & 2142 & & 1.594 & 16.9 \\
\hline 1942 & & 1.582 & 16.9 & 2009 & & 1.596 & 16.9 & 2076 & $8 / 10 / 20087: 40$ & 1.596 & 16.9 & 2143 & $0089: 54$ & 1.594 & 16.9 \\
\hline 1943 & $8 / 10 / 2008$ 3:14 & 1.584 & 16.9 & 2010 & $8 / 10 / 20085: 28$ & 1.596 & 16.9 & 2077 & $8 / 10 / 20087: 42$ & 1.595 & 16.9 & 2144 & $8 / 10 / 20089: 56$ & 1.595 & 16.9 \\
\hline
\end{tabular}




\begin{tabular}{|c|c|c|c|}
\hline \multicolumn{4}{|c|}{ D4-27p } \\
\hline Rec & & Pres & Temp \\
\hline$\#$ & Date/Time & $p s i$ & ${ }^{\circ} \mathrm{C}$ \\
\hline 2145 & $8 / 10 / 20089: 58$ & 1.595 & 16.9 \\
\hline 2146 & $8 / 10 / 2008$ 10:00 & 1.595 & 16.9 \\
\hline 2147 & $8 / 10 / 2008$ 10:02 & 1.595 & 16.9 \\
\hline 2148 & $8 / 10 / 2008$ 10:04 & 1.594 & 16.9 \\
\hline 2149 & $8 / 10 / 2008$ 10:06 & 1.594 & 16.9 \\
\hline 2150 & $8 / 10 / 2008$ 10:08 & 1.594 & 16.9 \\
\hline 2151 & $8 / 10 / 2008$ 10:10 & 1.595 & 16.9 \\
\hline 2152 & $8 / 10 / 2008$ 10:12 & 1.595 & 16.9 \\
\hline 2153 & $8 / 10 / 2008$ 10:14 & 1.595 & 16.9 \\
\hline 2154 & $8 / 10 / 200810: 16$ & 1.593 & 16.9 \\
\hline 2155 & $8 / 10 / 2008$ 10:18 & 1.594 & 16.9 \\
\hline 2156 & $8 / 10 / 200810: 20$ & 1.595 & 16.9 \\
\hline 2157 & $8 / 10 / 2008$ 10:22 & 1.595 & 16.9 \\
\hline 2158 & $8 / 10 / 2008$ 10:24 & 1.595 & 16.9 \\
\hline 2159 & $8 / 10 / 200810: 26$ & 1.594 & 16.9 \\
\hline 2160 & $8 / 10 / 2008$ 10:28 & 1.595 & 16.9 \\
\hline 2161 & $8 / 10 / 2008$ 10:30 & 1.594 & 16.9 \\
\hline 2162 & $8 / 10 / 2008$ 10:32 & 1.595 & 16.9 \\
\hline 2163 & $8 / 10 / 2008$ 10:34 & 1.561 & 16.9 \\
\hline 2164 & $8 / 10 / 200810: 36$ & 1.593 & 16.9 \\
\hline 2165 & $8 / 10 / 2008$ 10:38 & 1.593 & 16.9 \\
\hline 2166 & $8 / 10 / 2008$ 10:40 & 1.594 & 17.3 \\
\hline 2167 & $8 / 10 / 200810: 42$ & 1.596 & 17.3 \\
\hline 2168 & $8 / 10 / 2008$ 10:44 & 1.595 & 17.1 \\
\hline 2169 & $8 / 10 / 2008$ 10:46 & 1.594 & 17.3 \\
\hline 2170 & $8 / 10 / 200810: 48$ & 1.595 & 17.1 \\
\hline 2171 & $8 / 10 / 200810: 50$ & 1.592 & 16.9 \\
\hline 2172 & $8 / 10 / 2008$ 10:52 & 1.594 & 16.9 \\
\hline 2173 & $8 / 10 / 2008$ 10:54 & 1.595 & 16.9 \\
\hline 2174 & $8 / 10 / 200810: 56$ & 1.595 & 16.9 \\
\hline 2175 & $8 / 10 / 200810: 58$ & 1.595 & 16.9 \\
\hline 2176 & $8 / 10 / 200811: 00$ & 1.595 & 16.9 \\
\hline 2177 & $8 / 10 / 200811: 02$ & 1.595 & 16.9 \\
\hline 2178 & $8 / 10 / 200811: 04$ & 1.595 & 16.9 \\
\hline 2179 & $8 / 10 / 200811: 06$ & 1.596 & 16.9 \\
\hline 2180 & $8 / 10 / 200811: 08$ & 1.595 & 16.9 \\
\hline 2181 & $8 / 10 / 200811: 10$ & 1.596 & 16.9 \\
\hline 2182 & $8 / 10 / 200811: 12$ & 1.596 & $\overline{16.9}$ \\
\hline 2183 & $8 / 10 / 200811: 14$ & 1.595 & 16.9 \\
\hline 2184 & $8 / 10 / 200811: 16$ & 1.596 & 16.9 \\
\hline 2185 & $8 / 10 / 200811: 18$ & 1.598 & 16.9 \\
\hline 2186 & $8 / 10 / 200811: 20$ & 1.597 & 16.9 \\
\hline 2187 & $8 / 10 / 200811: 22$ & 1.598 & 16.9 \\
\hline 2188 & $8 / 10 / 2008$ 11:24 & 1.598 & 16.9 \\
\hline 2189 & $8 / 10 / 200811: 26$ & 1.598 & 16.9 \\
\hline 2190 & $8 / 10 / 200811: 28$ & 1.598 & 16.9 \\
\hline 2191 & $8 / 10 / 200811: 30$ & 1.598 & 16.9 \\
\hline 2192 & $8 / 10 / 200811: 32$ & 1.597 & 16.9 \\
\hline 2193 & $8 / 10 / 200811: 34$ & 1.598 & 16.9 \\
\hline 2194 & $8 / 10 / 200811: 36$ & 1.597 & 16.9 \\
\hline 2195 & $8 / 10 / 200811: 38$ & 1.598 & 16.9 \\
\hline 2196 & $8 / 10 / 200811: 40$ & 1.598 & 16.9 \\
\hline 2197 & $8 / 10 / 200811: 42$ & 1.598 & 16.9 \\
\hline 2198 & $8 / 10 / 200811: 44$ & 1.597 & 16.9 \\
\hline 2199 & $8 / 10 / 200811: 46$ & 1.598 & 16.9 \\
\hline 2200 & $8 / 10 / 200811: 48$ & 1.597 & 16.9 \\
\hline 2201 & $8 / 10 / 2008$ 11:50 & 1.591 & 16.9 \\
\hline 2202 & $8 / 10 / 2008$ 11:52 & 1.584 & 16.9 \\
\hline 2203 & $8 / 10 / 200811: 54$ & 1.578 & 16.9 \\
\hline 2204 & $8 / 10 / 200811: 56$ & 1.576 & 16.9 \\
\hline 2205 & $8 / 10 / 200811: 58$ & 1.573 & 16.9 \\
\hline 2206 & $8 / 10 / 200812: 00$ & 1.572 & 16.9 \\
\hline 2207 & $8 / 10 / 200812: 02$ & 1.57 & 16.9 \\
\hline 2208 & $8 / 10 / 200812: 04$ & 1.575 & 16.9 \\
\hline 2209 & $8 / 10 / 2008$ 12:06 & 1.581 & 16.9 \\
\hline 2210 & $8 / 10 / 200812: 08$ & 1.587 & 16.9 \\
\hline 2211 & $8 / 10 / 200812: 10$ & 1.589 & 16.9 \\
\hline
\end{tabular}

\begin{tabular}{|c|c|c|c|}
\hline \multicolumn{4}{|c|}{ D4-27p } \\
\hline $\operatorname{Rec}$ & & Pres & Temp \\
\hline \# & Date/Time & psi & ${ }^{\circ} \mathrm{C}$ \\
\hline 2212 & $8 / 10 / 200812: 12$ & 1.591 & 16.9 \\
\hline 2213 & $8 / 10 / 2008$ 12:14 & 1.592 & 16.9 \\
\hline 2214 & $10 / 2008$ 12:16 & 1.591 & 16.9 \\
\hline 2215 & $8 / 10 / 200812: 18$ & 1.592 & 16.9 \\
\hline 2216 & $8 / 10 / 200812: 20$ & 1.593 & 16.9 \\
\hline 2217 & $8 / 10 / 200812: 22$ & 1.592 & 16.9 \\
\hline 2218 & $8 / 10 / 2008$ 12:24 & 1.592 & 16.9 \\
\hline 2219 & $8 / 10 / 2008$ 12:26 & 1.592 & 16.9 \\
\hline 2220 & $8 / 10 / 2008$ 12:28 & 1.593 & 16.9 \\
\hline 2221 & $312: 30$ & 1.594 & \\
\hline 2222 & $8 / 10 / 20$ & 1.594 & 16.9 \\
\hline 2223 & $8 / 10 / 20$ & 1.594 & 16.9 \\
\hline 2224 & $8 / 10 / 2$ & 1.595 & 16.9 \\
\hline 2225 & $8 / 10 / 2$ & 1.594 & 16.9 \\
\hline 2226 & $8 / 10 / 2$ & 1.594 & 16.9 \\
\hline 2227 & $8 / 10 / 2$ & 1.595 & 16.9 \\
\hline 2228 & $12: 44$ & 1.594 & 16.9 \\
\hline 2229 & $12: 46$ & 1.595 & 16.9 \\
\hline 2230 & $8 / 10 / 2$ & 1.596 & 16.9 \\
\hline 2231 & $312: 50$ & 1.597 & 16.9 \\
\hline 2232 & $2: 52$ & 1.597 & 16.9 \\
\hline 2233 & $2: 54$ & 1.597 & 16.9 \\
\hline 2234 & $8 / 10 / 2$ & 1.597 & 16.8 \\
\hline 2235 & $12: 58$ & 1.596 & 16.9 \\
\hline 2236 & $13: 00$ & 1.597 & 16.9 \\
\hline 2237 & & 1.597 & 16.9 \\
\hline 2238 & $8 / 10 / 2008$ 13:04 & 1.597 & 16.9 \\
\hline 2239 & $13: 06$ & 1.598 & 16.9 \\
\hline 2240 & $3: 08$ & 1.598 & 16.9 \\
\hline 2241 & $13: 10$ & 1.598 & 16.9 \\
\hline 2242 & & 1.598 & 16.9 \\
\hline 2243 & $\overline{3: 14}$ & 1.597 & 16.9 \\
\hline 2244 & & 1.598 & 16.9 \\
\hline 2245 & $13: 18$ & 1.598 & 16.9 \\
\hline 2246 & & 1.598 & 16.9 \\
\hline 2247 & & 1.597 & 16.9 \\
\hline 2248 & & 1.598 & 16.9 \\
\hline 2249 & $813: 26$ & 1.598 & 16.9 \\
\hline 2250 & & 1.598 & 16.9 \\
\hline 2251 & $13: 30$ & 1.596 & 16.9 \\
\hline 2252 & 3:32 & 1.597 & 16.9 \\
\hline 2253 & & 1.597 & 16.9 \\
\hline 2254 & & 1.598 & 16.9 \\
\hline 2255 & & 1.597 & 16.9 \\
\hline 2256 & $13: 40$ & 1.598 & 16.9 \\
\hline 2257 & & 1.598 & 16.9 \\
\hline 2258 & & 1.59 & 16.9 \\
\hline 2259 & & 1.598 & 16.9 \\
\hline 2260 & & 1.597 & 16.9 \\
\hline 2261 & & 1.597 & 16.9 \\
\hline 2262 & & 1.597 & 16. \\
\hline 2263 & & 1.599 & 16.9 \\
\hline 2264 & & 1.598 & 16.9 \\
\hline 2265 & & 1.59 & 16.9 \\
\hline 2266 & $14: 00$ & 1.597 & 16.9 \\
\hline 2267 & 14:02 & 1.599 & 16.9 \\
\hline 2268 & & 1.599 & 16.9 \\
\hline 2269 & & 1.598 & 190 \\
\hline 2270 & 314:08 & 1,599 & 16.9 \\
\hline 2271 & & 1.6 & 16.9 \\
\hline 2272 & & 1.6 & 16.9 \\
\hline 2273 & 14:14 & 1.6 & 16.9 \\
\hline 2274 & $8 / 10 / 2008$ 14:16 & 1.601 & 16.9 \\
\hline 2275 & $0814: 18$ & 1.6 & 16.9 \\
\hline 2276 & & 1.6 & 16.9 \\
\hline 2277 & $814: 22$ & 1.601 & 16.9 \\
\hline 2278 & $8 / 10 / 2008$ 14:24 & 1.601 & 16.9 \\
\hline
\end{tabular}

\begin{tabular}{|c|c|c|c|}
\hline \multicolumn{4}{|c|}{ D4-27p } \\
\hline $\operatorname{Rec}$ & & Pres & Temp \\
\hline$\#$ & DaterTime & psi & ${ }^{\circ} \mathrm{C}$ \\
\hline 2279 & $8 / 10 / 200814: 26$ & 1.602 & 16.9 \\
\hline 2280 & $8 / 10 / 2008$ 14:28 & 1.6 & 16.9 \\
\hline 2281 & $8 / 10 / 200814: 30$ & 1.601 & 16.9 \\
\hline 2282 & $8 / 10 / 200814: 32$ & 1.601 & 16.9 \\
\hline 2283 & $8 / 10 / 2008$ 14:34 & 1.575 & 16.9 \\
\hline 2284 & $8 / 10 / 2008$ 14:36 & 1.601 & 16. \\
\hline 2285 & $8 / 10 / 200814: 38$ & 1.601 & 16.9 \\
\hline 2286 & $8 / 10 / 200814: 40$ & 1.6 & 16.9 \\
\hline 2287 & $8 / 10 / 200814: 42$ & 1.602 & 16.9 \\
\hline 2288 & $8 / 10 / 200814: 44$ & 1.601 & 16.9 \\
\hline 2289 & $8 / 10 / 200814: 46$ & 1.599 & 16.9 \\
\hline 2290 & $8 / 10 / 200814: 48$ & 1.595 & 16.9 \\
\hline 2291 & $8 / 10 / 200814: 50$ & 1.587 & $16 !$ \\
\hline 2292 & $8 / 10 / 200814: 52$ & 1.582 & 16. \\
\hline 2293 & $8 / 10 / 200814: 54$ & 1.579 & 16.8 \\
\hline 2294 & $8 / 10 / 200814: 56$ & 1.577 & 16.9 \\
\hline 2295 & $8 / 10$ & 1.575 & 16.9 \\
\hline 2296 & $30815: 00$ & 1.574 & 16. \\
\hline 2297 & $8 / 10 / 200815: 02$ & 1.572 & 16.9 \\
\hline 2298 & $8 / 10 / 200815: 04$ & 1.571 & 16. \\
\hline 2299 & $8 / 10$ & 1.573 & 16. \\
\hline 2300 & 08 15:08 & 1.581 & 16. \\
\hline 2301 & $8 / 10 / 200815: 10$ & 1.587 & 16. \\
\hline 2302 & & 1.591 & 16. \\
\hline 2303 & $8 / 10$ & 1.593 & 16. \\
\hline 2304 & 15:16 & 1.593 & 16. \\
\hline 2305 & $15: 18$ & 1.593 & 16. \\
\hline 2306 & $8 / 1$ & 1.593 & 16. \\
\hline 2307 & & 1.593 & 16. \\
\hline 2308 & $8 / 10 / 20$ & 1.594 & 16.8 \\
\hline 2309 & & 1.595 & 16. \\
\hline 2310 & & 1.596 & 16. \\
\hline 2311 & $8 / 10 /$ & 1.596 & 16. \\
\hline 2312 & $8 / 10 / 200815: 32$ & 1.596 & 16. \\
\hline 2313 & & 1.597 & 16. \\
\hline 2314 & $8 / 10$ & 1.596 & 16. \\
\hline 2315 & $8 / 10$ & 1.596 & 16. \\
\hline 2316 & & 1.597 & 16. \\
\hline 2317 & & 1.597 & 16. \\
\hline 2318 & & 1.596 & 16 . \\
\hline 2319 & $15: 46$ & 1.596 & 16.8 \\
\hline 2320 & & 1.598 & 16 . \\
\hline 2321 & $8 / 1$ & 1.598 & 16. \\
\hline 2322 & $15: 52$ & 1.598 & 16 . \\
\hline 2323 & & 1.599 & 16. \\
\hline 2324 & & 1.598 & 16 \\
\hline 2325 & & 1.598 & 16 . \\
\hline 2326 & $16: 00$ & 1.598 & 16 . \\
\hline 2327 & & 1.599 & 16 . \\
\hline 2328 & & 7.598 & 16. \\
\hline 2329 & 88 16:06 & 1.599 & 16. \\
\hline 2330 & & 1.599 & 16. \\
\hline 2331 & & 1.599 & \\
\hline 2332 & & 1.598 & 16. \\
\hline 2333 & & 1.598 & 16. \\
\hline 2334 & & 1.598 & 16. \\
\hline 2335 & & 1.599 & 19 \\
\hline 2336 & $816: 20$ & 1.599 & 16 . \\
\hline 2337 & $8816: 22$ & 1.6 & 16.9 \\
\hline 2338 & & 1.6 & 16. \\
\hline 2339 & & 1.6 & \\
\hline 2340 & $8 / 10 / 200816: 28$ & 1.601 & 16. \\
\hline 2341 & & 1.6 & 16 . \\
\hline 2342 & & 1.6 & 16 . \\
\hline 2343 & & 1.6 & 16. \\
\hline 2344 & $8 / 10 / 2008$ 16:36 & 1.6 & 16.9 \\
\hline 2345 & $8 / 10 / 200816: 38$ & 1.602 & $\overline{16}$ \\
\hline
\end{tabular}

\begin{tabular}{|c|c|c|c|}
\hline \multicolumn{4}{|c|}{ D4-27p } \\
\hline $\operatorname{Rec}$ & & Pres & Temp \\
\hline$\#$ & Date/Time & psi & ${ }^{\circ} \mathrm{C}$ \\
\hline 2346 & $8 / 10 / 200816: 40$ & 1.601 & 16.9 \\
\hline 2347 & $8 / 10 / 200816: 42$ & 1.6 & 16.9 \\
\hline 2348 & $8 / 10 / 200816: 44$ & 1.6 & 16.9 \\
\hline 2349 & $8 / 10 / 200816: 46$ & 1.599 & 16.9 \\
\hline 2350 & $8 / 10 / 200816: 48$ & 1.6 & 16.9 \\
\hline 2351 & $8 / 10 / 200816: 50$ & 1.6 & 16.9 \\
\hline 2352 & $8 / 10 / 200816: 52$ & 1.6 & 16.9 \\
\hline 2353 & $8 / 10 / 200816: 54$ & 1.601 & 16.9 \\
\hline 2354 & $8 / 10 / 200816: 56$ & 1.6 & 16.9 \\
\hline 2355 & $8 / 10 / 200816: 58$ & 1.601 & 16.9 \\
\hline 2356 & $8 / 10 / 200817: 00$ & 1.601 & 16.9 \\
\hline 2357 & $8 / 10 / 200817: 02$ & 1.601 & 16.9 \\
\hline 2358 & $8 / 10 / 200817: 04$ & 1.601 & 16.9 \\
\hline 2359 & $8 / 10 / 200817: 06$ & 1.602 & 16.9 \\
\hline 2360 & $8 / 10 / 200817: 08$ & 1.602 & 16.9 \\
\hline 2361 & $8 / 10 / 200817: 10$ & 1.601 & 16.9 \\
\hline 2362 & $8 / 10 / 200817: 12$ & 1.602 & 16.9 \\
\hline 2363 & $8 / 10 / 200817: 14$ & 1.601 & 16.9 \\
\hline 2364 & $8 / 10 / 200817: 16$ & 1.601 & 16.9 \\
\hline 2365 & $8 / 10 / 200817: 18$ & 1.602 & 16.9 \\
\hline 2366 & $8 / 10 / 200817: 20$ & 1.6 & 16.9 \\
\hline 2367 & $8 / 10 / 200817: 22$ & 1.599 & 16.9 \\
\hline 2368 & $8 / 10 / 200817: 24$ & 1.6 & 16.9 \\
\hline 2369 & $8 / 10 / 200817: 26$ & 1.599 & 16.9 \\
\hline 2370 & $8 / 10 / 200817: 28$ & 1.582 & 16.9 \\
\hline 2371 & $8 / 10 / 200817: 30$ & 1.61 & 16.9 \\
\hline 2372 & $8 / 10 / 200817: 32$ & 1.6 & 16.9 \\
\hline 2373 & $8 / 10 / 200817: 34$ & 1.596 & 16.9 \\
\hline 2374 & $8 / 10 / 200817: 36$ & 1.599 & 16.9 \\
\hline 2375 & $8 / 10 / 2008$ 17:38 & 1.6 & 16.9 \\
\hline 2376 & $8 / 10 / 200817: 40$ & 1.601 & 16.9 \\
\hline 2377 & $8 / 10 / 2008$ 17:42 & 1.602 & 16.9 \\
\hline 2378 & $8 / 10 / 2008$ 17:44 & 1.602 & 16.9 \\
\hline 2379 & $8 / 10 / 200817: 46$ & 1.599 & 16.9 \\
\hline 2380 & $8 / 10 / 200817: 48$ & 1.594 & 16.9 \\
\hline 2381 & $8 / 10 / 200817: 50$ & 1.587 & 16.9 \\
\hline 2382 & $8 / 10 / 200817: 52$ & 1.589 & 16.9 \\
\hline 2383 & $8 / 10 / 200817: 54$ & 1.593 & 16.9 \\
\hline 2384 & $8 / 10 / 200817: 56$ & 1.595 & 16.9 \\
\hline 2385 & $8 / 10 / 200817: 58$ & 1.597 & 16.9 \\
\hline 2386 & $8 / 10 / 200818: 00$ & 1.597 & 16.9 \\
\hline 2387 & $8 / 10 / 200818: 02$ & 1.6 & 16.9 \\
\hline 2388 & $8 / 10 / 2008$ 18:04 & 1.6 & 16.9 \\
\hline 2389 & $8 / 10 / 2008$ 18:06 & 1.6 & 16.9 \\
\hline 2390 & $8 / 10 / 200818: 08$ & 1.601 & 16.9 \\
\hline 2391 & $8 / 10 / 200818: 10$ & 1.601 & 16.9 \\
\hline 2392 & $8 / 10 / 200818: 12$ & 1.602 & 16.9 \\
\hline 2393 & $8 / 10 / 200818: 14$ & 1.601 & 16.9 \\
\hline 2394 & $8 / 10 / 200818: 16$ & 1.601 & 16.9 \\
\hline 2395 & $8 / 10 / 200818: 18$ & 1.602 & 16.9 \\
\hline 2396 & $8 / 10 / 200818: 20$ & 1.601 & 16.9 \\
\hline 2397 & $8 / 10 / 200818: 22$ & 1.601 & 16.9 \\
\hline 2398 & $8 / 10 / 200818: 24$ & 1.6 & 16.9 \\
\hline 2399 & $8 / 10 / 2008$ 18:26 & 1.601 & 16.9 \\
\hline 2400 & $8 / 10 / 200818: 28$ & 1.6 & 16.9 \\
\hline 2401 & $8 / 10 / 200818: 30$ & 1.601 & 16.9 \\
\hline 2402 & $8 / 10 / 200818: 32$ & 1.601 & 16.9 \\
\hline 2403 & $8 / 10 / 200818: 34$ & 1.6 & 16.9 \\
\hline 2404 & $8 / 10 / 200818: 36$ & 1.601 & 16.9 \\
\hline 2405 & $8 / 10 / 200818: 38$ & 1.601 & 16.9 \\
\hline 2406 & $8 / 10 / 200818: 40$ & 1.602 & 16.9 \\
\hline 2407 & $8 / 10 / 200818: 42$ & 1.602 & 16.9 \\
\hline 2408 & $8 / 10 / 200818: 44$ & 1.601 & 16.9 \\
\hline 2409 & $8 / 10 / 200818: 46$ & 1.6 & 16.9 \\
\hline 2410 & $8 / 10 / 200818: 48$ & 1.601 & 16.9 \\
\hline 2411 & $8 / 10 / 200818: 50$ & 1.601 & 16.9 \\
\hline 2412 & $8 / 10 / 200818: 52$ & 1.603 & 16.9 \\
\hline
\end{tabular}




\begin{tabular}{|c|c|c|c|}
\hline \multicolumn{4}{|c|}{ D4-27p } \\
\hline $\operatorname{Rec}$ & & Pres & Temp \\
\hline \# & Date/Time & psi & ${ }^{\circ} \mathrm{C}$ \\
\hline 2413 & $8 / 10 / 2008$ 18:54 & 1.603 & 16.9 \\
\hline 2414 & $8 / 10 / 200818: 56$ & 1.603 & 16.9 \\
\hline 2415 & $8 / 10 / 200818: 58$ & 1.602 & 16.9 \\
\hline 2416 & $8 / 10 / 2008$ 19:00 & 1.602 & 16.9 \\
\hline 2417 & $8 / 10 / 2008$ 19:02 & 1.603 & 16.9 \\
\hline 2418 & $8 / 10 / 2008$ 19:04 & 1.602 & 16.9 \\
\hline 2419 & $8 / 10 / 200819: 06$ & 1.602 & 16.9 \\
\hline 2420 & $8 / 10 / 200819: 08$ & 1.603 & 16.9 \\
\hline 2421 & $8 / 10 / 2008$ 19:10 & 1.602 & 16.9 \\
\hline 2422 & $8 / 10 / 2008$ 19:12 & 1.602 & 16.9 \\
\hline 2423 & $8 / 10 / 2008$ 19:14 & 1.602 & 16.9 \\
\hline 2424 & $8 / 10 / 200819: 16$ & 1.603 & 16.9 \\
\hline 2425 & $8 / 10 / 2008$ 19:18 & 1.602 & 16.9 \\
\hline 2426 & $8 / 10 / 200819: 20$ & 1.601 & 16.9 \\
\hline 2427 & $8 / 10 / 200819: 22$ & 1.601 & 16.9 \\
\hline 2428 & $8 / 10 / 200819: 24$ & 1.601 & 16.9 \\
\hline 2429 & $8 / 10 / 2008$ 19:26 & 1.602 & 16.9 \\
\hline 2430 & $8 / 10 / 2008$ 19:28 & 1.603 & 16.9 \\
\hline 2431 & $8 / 10 / 2008$ 19:30 & 1.602 & 16.9 \\
\hline 2432 & $8 / 10 / 200819: 32$ & 1.601 & 16.9 \\
\hline 2433 & $8 / 10 / 2008$ 19:34 & 1.602 & 16.9 \\
\hline 2434 & $8 / 10 / 2008$ 19:36 & 1.603 & 16.9 \\
\hline 2435 & $8 / 10 / 200819: 38$ & 1.6 & 16.9 \\
\hline 2436 & $8 / 10 / 200819: 40$ & 1.602 & 16.9 \\
\hline 2437 & $8 / 10 / 2008$ 19:42 & 1.601 & 16.9 \\
\hline 2438 & $8 / 10 / 200819: 44$ & 1.602 & 16.9 \\
\hline 2439 & $8 / 10 / 2008$ 19:46 & 1.601 & 16.9 \\
\hline 2440 & $8 / 10 / 200819: 48$ & 1.602 & 16.9 \\
\hline 2441 & $8 / 10 / 200819: 50$ & 1.601 & 16.9 \\
\hline 2442 & $8 / 10 / 200819: 52$ & 1.601 & 16.9 \\
\hline 2443 & $8 / 10 / 200819: 54$ & 1.602 & 16.9 \\
\hline 2444 & $8 / 10 / 200819: 56$ & 1.6 & 16.9 \\
\hline 2445 & $8 / 10 / 200819: 58$ & 1.602 & 16.9 \\
\hline 2446 & $8 / 10 / 200820: 00$ & 1.601 & 16.9 \\
\hline 2447 & $8 / 10 / 200820: 02$ & 1.602 & 16.9 \\
\hline 2448 & $8 / 10 / 200820: 04$ & 1.601 & 16.9 \\
\hline 2449 & $8 / 10 / 200820: 06$ & 1.602 & 16.9 \\
\hline 2450 & $8 / 10 / 200820: 08$ & 1.6 & 16.9 \\
\hline 2451 & $8 / 10 / 200820: 10$ & 1.6 & 16.9 \\
\hline 2452 & $8 / 10 / 200820: 12$ & 1.602 & 16.9 \\
\hline 2453 & $8 / 10 / 200820: 14$ & 1.601 & 16.9 \\
\hline 2454 & $8 / 10 / 200820: 16$ & 1.602 & 16.9 \\
\hline 2455 & $8 / 10 / 200820: 18$ & 1.601 & 16.9 \\
\hline 2456 & $8 / 10 / 200820: 20$ & 1.602 & 16.9 \\
\hline 2457 & $8 / 10 / 200820: 22$ & 1.601 & 16.9 \\
\hline 2458 & $8 / 10 / 200820: 24$ & 1.601 & 16.9 \\
\hline 2459 & $8 / 10 / 200820: 26$ & 1.602 & 16.9 \\
\hline 2460 & $8 / 10 / 200820: 28$ & 1.601 & 16.9 \\
\hline 2461 & $8 / 10 / 200820: 30$ & 1.602 & 16.9 \\
\hline 2462 & $8 / 10 / 200820: 32$ & 1.598 & 16.9 \\
\hline 2463 & $8 / 10 / 200820: 34$ & 1.593 & 16.9 \\
\hline 2464 & $8 / 10 / 200820: 36$ & 1.59 & 16.9 \\
\hline 2465 & $8 / 10 / 200820: 38$ & 1.586 & 16.9 \\
\hline 2466 & $8 / 10 / 200820: 40$ & 1.582 & 16.9 \\
\hline 2467 & $8 / 10 / 200820: 42$ & 1.578 & 16.9 \\
\hline 2468 & $8 / 10 / 200820: 44$ & 1.575 & 16.9 \\
\hline 2469 & $8 / 10 / 200820: 46$ & 1.573 & 16.9 \\
\hline 2470 & $8 / 10 / 200820: 48$ & 1.57 & 16.9 \\
\hline 2471 & $8 / 10 / 200820: 50$ & 1.57 & 16.9 \\
\hline 2472 & $8 / 10 / 200820: 52$ & 1.569 & 16.9 \\
\hline 2473 & $8 / 10 / 200820: 54$ & 1.568 & 16.9 \\
\hline 2474 & $8 / 10 / 200820: 56$ & 1.568 & 16.9 \\
\hline 2475 & $8 / 10 / 200820: 58$ & 1.565 & 16.9 \\
\hline 2476 & $8 / 10 / 200821: 00$ & 1.563 & 16.9 \\
\hline 2477 & $8 / 10 / 200821: 02$ & 1.563 & 16.9 \\
\hline 2478 & $8 / 10 / 200821: 04$ & 1.562 & 16.9 \\
\hline 2479 & $8 / 10 / 200821: 06$ & 1.562 & 16.9 \\
\hline
\end{tabular}

\begin{tabular}{|c|c|c|c|}
\hline \multicolumn{4}{|c|}{ D4-27p } \\
\hline $\operatorname{Rec}$ & & Pres & Temp \\
\hline$\#$ & Date/Time & psi & ${ }^{\circ} \mathrm{C}$ \\
\hline 2480 & $8 / 10 / 200821: 08$ & 1.561 & 16.9 \\
\hline 2481 & $8 / 10 / 200821: 10$ & 1.56 & 16.9 \\
\hline 2482 & $110 / 200821: 12$ & 1.558 & 16.9 \\
\hline 2483 & $110 / 200821: 14$ & 1.558 & 16.9 \\
\hline 2484 & $8 / 10 / 200821: 16$ & 1.557 & 16.9 \\
\hline 2485 & $8 / 10 / 200821: 18$ & 1.562 & 16.9 \\
\hline 2486 & $8 / 10 / 200821: 20$ & 1.572 & 16.9 \\
\hline 2487 & $10 / 200821: 22$ & 1.577 & 169 \\
\hline 2488 & $8 / 10 / 200821: 24$ & 1.579 & 16.9 \\
\hline 2489 & $10 / 200821: 26$ & 1.583 & 16.9 \\
\hline 2490 & $321: 28$ & 1.586 & \\
\hline 2491 & $8 / 10 / 200821: 30$ & 1.586 & 16.9 \\
\hline 2492 & $10 / 200821: 32$ & 1.585 & 16.9 \\
\hline 2493 & $21: 34$ & 1.587 & 16.9 \\
\hline 2494 & $21: 36$ & 1.588 & $16 . \mathrm{c}$ \\
\hline 2495 & $321: 38$ & 1.589 & 16.9 \\
\hline 2496 & $1: 40$ & 1.588 & \\
\hline 2497 & $21: 42$ & 1.589 & 16.9 \\
\hline 2498 & $21: 44$ & 1.59 & 16.9 \\
\hline 2499 & & 1.589 & 16.9 \\
\hline 2500 & $1: 48$ & 1.59 & 16.9 \\
\hline 2501 & $21: 50$ & 1.59 & 16.9 \\
\hline 2502 & & 1.59 & 16.9 \\
\hline 2503 & $1: 54$ & 1.591 & 16. \\
\hline 2504 & $1: 56$ & 1.591 & 16.9 \\
\hline 2505 & $1: 58$ & 1.592 & 16. \\
\hline 2506 & $2: 00$ & 1.592 & 16. \\
\hline 2507 & $22: 02$ & 1.591 & 16. \\
\hline 2508 & $2: 04$ & 1.592 & 16. \\
\hline 2509 & $22: 06$ & 1.593 & 16. \\
\hline 2510 & $22: 08$ & 1.593 & 16. \\
\hline 2511 & $2: 10$ & 1.592 & 16. \\
\hline 2512 & $22: 12$ & 1.592 & 16.9 \\
\hline 2513 & 322:14 & 1.591 & 16. \\
\hline 2514 & $2: 16$ & 1.591 & 16. \\
\hline 2515 & $2: 18$ & 1.591 & 16. \\
\hline 2516 & $22: 20$ & 1.591 & 16. \\
\hline 2517 & & 1.591 & 16. \\
\hline 2518 & $2: 24$ & 1.591 & 16. \\
\hline 2519 & $22: 26$ & 1.592 & 16. \\
\hline 2520 & & 1.593 & 16. \\
\hline 2521 & $2: 30$ & 1.593 & 16 \\
\hline 2522 & $2: 32$ & 1.593 & 16. \\
\hline 2523 & & 1.594 & 16. \\
\hline 2524 & $2: 36$ & 1.594 & 16 \\
\hline 2525 & $22: 38$ & 1.594 & 16. \\
\hline 2526 & & 1.595 & 16. \\
\hline 2527 & $2: 42$ & 1.594 & 16. \\
\hline 2528 & $22: 44$ & 1.595 & 16. \\
\hline 2529 & & 1.595 & 16. \\
\hline 2530 & & 1.595 & 16. \\
\hline 2531 & $22: 50$ & 1.596 & 16. \\
\hline 2532 & & 1.596 & 16. \\
\hline 2533 & $2: 54$ & 1.596 & 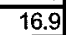 \\
\hline 2534 & $22: 56$ & 1.595 & 16 \\
\hline 2535 & $22: 58$ & 1.595 & 16. \\
\hline 2536 & $23: 00$ & 1.563 & \\
\hline 2537 & $23: 02$ & 1.551 & 16 \\
\hline 2538 & & 1.552 & 16 \\
\hline 2539 & & 1.594 & \\
\hline 2540 & 23:08: & 1.594 & 16. \\
\hline 2541 & $23: 10$ & 1.595 & 16. \\
\hline 2542 & & 1.596 & \\
\hline 2543 & $110 / 200823: 14$ & 1.596 & 16 \\
\hline 2544 & $23: 16$ & 1.596 & 16. \\
\hline 2545 & & 1.596 & 16. \\
\hline 2546 & $8 / 10 / 200823: 20$ & 1.597 & 1 \\
\hline
\end{tabular}

\begin{tabular}{|c|c|c|c|}
\hline \multicolumn{4}{|c|}{ D4-27p } \\
\hline Rec & & Pres & Temp \\
\hline$\#$ & Date/Time & psi & ${ }^{\circ} \mathrm{C}$ \\
\hline 2547 & $8 / 10 / 200823: 22$ & 1.597 & 16.9 \\
\hline 2548 & $8 / 10 / 200823: 24$ & 1.596 & 16.9 \\
\hline 2549 & $8 / 10 / 200823: 26$ & 1.596 & 16.9 \\
\hline 2550 & $8 / 10 / 200823: 28$ & 1.596 & 16.9 \\
\hline 2551 & $8 / 10 / 200823: 30$ & 1.597 & 16.9 \\
\hline 2552 & $8 / 10 / 200823: 32$ & 1.599 & 16.9 \\
\hline 2553 & $8 / 10 / 200823: 34$ & 1.598 & 16.9 \\
\hline 2554 & $8 / 10 / 200823: 36$ & 1.599 & 16.9 \\
\hline 2555 & $8 / 10 / 200823: 38$ & 1.598 & 16.9 \\
\hline 2556 & $8 / 10 / 200823: 40$ & 1.599 & 16.9 \\
\hline 2557 & $8 / 10 / 200823: 42$ & 1.599 & 16.9 \\
\hline 2558 & $8 / 10 / 200823: 44$ & 1.599 & 16.9 \\
\hline 2559 & $8 / 10 / 200823: 46$ & 1.599 & 16.9 \\
\hline 2560 & $8 / 10 / 200823: 48$ & 1.599 & 16.9 \\
\hline 2561 & $8 / 10 / 200823: 50$ & 1.6 & 16.9 \\
\hline 2562 & $8 / 10 / 200823: 52$ & 1.6 & 16.9 \\
\hline 2563 & $8 / 10 / 200823: 54$ & 1.6 & 16.9 \\
\hline 2564 & $8 / 10 / 200823: 56$ & 1.597 & 16.9 \\
\hline 2565 & $0823: 58$ & 1.592 & 16.9 \\
\hline 2566 & $1 / 20080: 00$ & 1.584 & 16.9 \\
\hline 2567 & $8 / 11 / 20080: 02$ & 1.579 & 16.9 \\
\hline 2568 & $20080: 04$ & 1.576 & 16.9 \\
\hline 2569 & $1 / 20080: 06$ & 1.573 & 16.9 \\
\hline 2570 & $11 / 20080: 08$ & 1.571 & 16.9 \\
\hline 2571 & $0080: 10$ & 1.569 & 16.9 \\
\hline 2572 & $20080: 12$ & 1.574 & 16.9 \\
\hline 2573 & $20080: 14$ & 1.58 & 16. \\
\hline 2574 & $0080: 16$ & 1.585 & 16.9 \\
\hline 2575 & $0080: 18$ & 1.588 & 16.8 \\
\hline 2576 & $11 / 20080: 20$ & 1.589 & 16.9 \\
\hline 2577 & $20080: 22$ & 1.59 & 16. \\
\hline 2578 & $1080: 24$ & 1.59 & 16. \\
\hline 2579 & $0080: 26$ & 1.59 & 16. \\
\hline 2580 & $0080: 28$ & 1.588 & 16 . \\
\hline 2581 & $080: 30$ & 1.617 & 16. \\
\hline 2582 & $00080: 32$ & 1.584 & $16 !$ \\
\hline 2583 & $080: 34$ & 1.592 & 16. \\
\hline 2584 & $080: 36$ & 1.593 & 16. \\
\hline 2585 & $20080: 38$ & 1.593 & 16. \\
\hline 2586 & $0080: 40$ & 1.594 & 16. \\
\hline 2587 & $080: 42$ & 1.594 & 16. \\
\hline 2588 & $0080: 44$ & 1.595 & $16 !$ \\
\hline 2589 & $0080: 46$ & 1.595 & 16. \\
\hline 2590 & $0080: 48$ & 1.596 & 16. \\
\hline 2591 & $1 / 20080: 50$ & 1.595 & 16. \\
\hline 2592 & $080: 52$ & 1.595 & 16. \\
\hline 2593 & $080: 54$ & 1.595 & $\overline{16}$ \\
\hline 2594 & $0080: 56$ & 1.595 & 16.5 \\
\hline 2595 & & 1.595 & 16. \\
\hline 2596 & $081: 00$ & 1.595 & 16 \\
\hline 2597 & 008 1:02 & 1.596 & 16. \\
\hline 2598 & $081: 04$ & 1.598 & 16. \\
\hline 2599 & $881: 06$ & 1.598 & 16 \\
\hline 2600 & $.0081: 08$ & 1.597 & 16.9 \\
\hline 2601 & $0081: 10$ & 1.597 & 16. \\
\hline 2602 & 008 1:12 & 1.598 & \\
\hline 2603 & $0081: 14$ & 1.598 & 16. \\
\hline 2604 & $0081: 16$ & 1.599 & 16. \\
\hline 2605 & 008 1:18 & 1.598 & \\
\hline 2606 & $120081: 20$ & 1.598 & 16.9 \\
\hline 2607 & $20081: 22$ & 1.599 & 16. \\
\hline 2608 & $0081: 24$ & 1.598 & \\
\hline 2609 & $0081: 26$ & 1.599 & 16. \\
\hline 2610 & $8 / 11 / 20081: 28$ & 1.599 & 16.9 \\
\hline 2611 & $8 / 11 / 20081: 30$ & 1.599 & 16.9 \\
\hline 2612 & $8 / 11 / 20081: 32$ & 1.598 & 16 \\
\hline 2613 & $8 / 11 / 20081: 34$ & 1.598 & 16 \\
\hline
\end{tabular}

\begin{tabular}{|c|c|c|c|}
\hline \multicolumn{4}{|c|}{ D4-27p } \\
\hline $\operatorname{Rec}$ & & Pres & Temp \\
\hline$\#$ & Date/Time & psi & ${ }^{\circ} \mathrm{C}$ \\
\hline 2614 & $8 / 11 / 20081: 36$ & 1.598 & 16.9 \\
\hline 2615 & $8 / 11 / 20081: 38$ & 1.597 & 16.9 \\
\hline 2616 & $8 / 11 / 20081: 40$ & 1.598 & 16.9 \\
\hline 2617 & $8 / 11 / 20081: 42$ & 1.598 & 16.9 \\
\hline 2618 & $8 / 11 / 20081: 44$ & 1.598 & 16.9 \\
\hline 2619 & $8 / 11 / 20081: 46$ & 1.599 & 16.9 \\
\hline 2620 & $8 / 11 / 20081: 48$ & 1.599 & 16.9 \\
\hline 2621 & $8 / 11 / 20081: 50$ & 1.599 & 16.9 \\
\hline 2622 & $8 / 11 / 20081: 52$ & 1.601 & 16.9 \\
\hline 2623 & $8 / 11 / 20081: 54$ & 1.6 & 16.9 \\
\hline 2624 & $8 / 11 / 20081: 56$ & 1.6 & 16.9 \\
\hline 2625 & $8 / 11 / 20081: 58$ & 1.6 & 16.9 \\
\hline 2626 & $8 / 11 / 20082: 00$ & 1.6 & 16.9 \\
\hline 2627 & $8 / 11 / 20082: 02$ & 1.599 & 16.9 \\
\hline 2628 & $8 / 11 / 20082: 04$ & 1.599 & 16.9 \\
\hline 2629 & $8 / 11 / 20082: 06$ & 1.599 & 16.9 \\
\hline 2630 & $8 / 11 / 20082: 08$ & 1.598 & 16.9 \\
\hline 2631 & $8 / 11 / 20082: 10$ & 1.6 & 16.9 \\
\hline 2632 & $8 / 11 / 20082: 12$ & 1.6 & 16.9 \\
\hline 2633 & $8 / 11 / 20082: 14$ & 1.6 & 16.9 \\
\hline 2634 & $8 / 11 / 20082: 16$ & 1.601 & 16.9 \\
\hline 2635 & $8 / 11 / 20082: 18$ & 1.601 & 16.9 \\
\hline 2636 & $8 / 11 / 20082: 20$ & 1.601 & 16.9 \\
\hline 2637 & $8 / 11 / 20082: 22$ & 1.6 & 16.9 \\
\hline 2638 & $8 / 11 / 20082: 24$ & 1.601 & 16.9 \\
\hline 2639 & $8 / 11 / 20082: 26$ & 1.6 & 16.9 \\
\hline 2640 & $8 / 11 / 20082: 28$ & 1.6 & 16.9 \\
\hline 2641 & $8 / 11 / 20082: 30$ & 1.6 & 16.9 \\
\hline 2642 & $8 / 11 / 20082: 32$ & 1.6 & 16.9 \\
\hline 2643 & $8 / 11 / 20082: 34$ & 1.6 & 16.9 \\
\hline 2644 & $8 / 11 / 20082: 36$ & 1.6 & 16.9 \\
\hline 2645 & $8 / 11 / 20082: 38$ & 1.601 & 16.9 \\
\hline 2646 & $8 / 11 / 20082: 40$ & 1.601 & 16.9 \\
\hline 2647 & $8 / 11 / 20082: 42$ & 1.601 & 16.9 \\
\hline 2648 & $8 / 11 / 20082: 44$ & 1.602 & 16.9 \\
\hline 2649 & $8 / 11 / 20082: 46$ & 1.602 & 16.9 \\
\hline 2650 & $8 / 11 / 20082: 48$ & 1.602 & 16.9 \\
\hline 2651 & $8 / 11 / 20082: 50$ & 1.601 & 16.9 \\
\hline 2652 & $8 / 11 / 20082: 52$ & 1.597 & 16.9 \\
\hline 2653 & $8 / 11 / 20082: 54$ & 1.589 & 16.9 \\
\hline 2654 & $8 / 11 / 20082: 56$ & 1.584 & 16.9 \\
\hline 2655 & $8 / 11 / 20082: 58$ & 1.578 & 16.9 \\
\hline 2656 & $8 / 11 / 20083: 00$ & 1.581 & 16.9 \\
\hline 2657 & $8 / 11 / 20083: 02$ & 1.587 & 16.9 \\
\hline 2658 & $8 / 11 / 20083: 04$ & 1.591 & 16.9 \\
\hline 2659 & $8 / 11 / 20083: 06$ & 1.593 & 16.9 \\
\hline 2660 & $8 / 11 / 20083: 08$ & 1.595 & 16.9 \\
\hline 2661 & $8 / 11 / 20083: 10$ & 1.595 & 16.9 \\
\hline 2662 & $8 / 11 / 20083: 12$ & 1.596 & 16.9 \\
\hline 2663 & $8 / 11 / 20083: 14$ & 1.596 & 16.9 \\
\hline 2664 & $8 / 11 / 20083: 16$ & 1.597 & 16.9 \\
\hline 2665 & $8 / 11 / 20083: 18$ & 1.598 & 16.9 \\
\hline 2666 & $8 / 11 / 20083: 20$ & 1.598 & 16.9 \\
\hline 2667 & $8 / 11 / 20083: 22$ & 1.599 & 16.9 \\
\hline 2668 & $8 / 11 / 20083: 24$ & 1.598 & 16.9 \\
\hline 2669 & $8 / 11 / 20083: 26$ & 1.599 & 16.9 \\
\hline 2670 & $8 / 11 / 20083: 28$ & 1.598 & 16.9 \\
\hline 2671 & $8 / 11 / 20083: 30$ & 1.599 & 16.9 \\
\hline 2672 & $8 / 11 / 20083: 32$ & 1.598 & 16.9 \\
\hline 2673 & $8 / 11 / 20083: 34$ & 1.599 & 16.9 \\
\hline 2674 & $8 / 11 / 20083: 36$ & 1.599 & 16.9 \\
\hline 2675 & $8 / 11 / 20083: 38$ & 1.599 & 16.9 \\
\hline 2676 & $8 / 11 / 20083: 40$ & 1.599 & 16.9 \\
\hline 2677 & $8 / 11 / 20083: 42$ & 1.599 & 16.9 \\
\hline 2678 & $8 / 11 / 20083: 44$ & 1.6 & 16.9 \\
\hline 2679 & $8 / 11 / 20083: 46$ & 1.6 & 16.9 \\
\hline 2680 & $8 / 11 / 20083: 48$ & 1.6 & 16.9 \\
\hline
\end{tabular}




\begin{tabular}{|c|c|c|c|}
\hline \multicolumn{4}{|c|}{ D4-27p } \\
\hline $\operatorname{Rec}$ & & Pres & Temp \\
\hline \# & Date/Time & psi & ${ }^{\circ} \mathrm{C}$ \\
\hline 2681 & $8 / 11 / 20083: 50$ & 1.6 & 16.9 \\
\hline 2682 & $8 / 11 / 20083: 52$ & 1.6 & 16.9 \\
\hline 2683 & $8 / 11 / 20083: 54$ & 1.601 & 16.9 \\
\hline 2684 & $8 / 11 / 20083: 56$ & 1.602 & 16.9 \\
\hline 2685 & $8 / 11 / 20083: 58$ & 1.602 & 16.9 \\
\hline 2686 & $8 / 11 / 20084: 00$ & 1.602 & 16.9 \\
\hline 2687 & $8 / 11 / 20084: 02$ & 1.603 & 16.9 \\
\hline 2688 & $8 / 11 / 20084: 04$ & 1.602 & 16.9 \\
\hline 2689 & $8 / 11 / 20084: 06$ & 1.602 & 16.9 \\
\hline 2690 & $8 / 11 / 20084: 08$ & 1.602 & 16.9 \\
\hline 2691 & $8 / 11 / 20084: 10$ & 1.602 & 16.9 \\
\hline 2692 & $8 / 11 / 20084: 12$ & 1.6 & 16.9 \\
\hline 2693 & $8 / 11 / 20084: 14$ & 1.602 & 16.9 \\
\hline 2694 & $8 / 11 / 20084: 16$ & 1.602 & 16.9 \\
\hline 2695 & $8 / 11 / 20084: 18$ & 1.602 & 16.9 \\
\hline 2696 & $8 / 11 / 20084: 20$ & 1.601 & 16.9 \\
\hline 2697 & $8 / 11 / 20084: 22$ & 1.601 & 16.9 \\
\hline 2698 & $8 / 11 / 20084: 24$ & 1.581 & 16.9 \\
\hline 2699 & $8 / 11 / 20084: 26$ & 1.628 & 16.9 \\
\hline 2700 & $8 / 11 / 20084: 28$ & 1.603 & 16.9 \\
\hline 2701 & $8 / 11 / 20084: 30$ & 1.6 & 16.9 \\
\hline 2702 & $8 / 11 / 20084: 32$ & 1.6 & 16.9 \\
\hline 2703 & $8 / 11 / 20084: 34$ & 1.6 & 16.9 \\
\hline 2704 & $8 / 11 / 20084: 36$ & 1.603 & 16.9 \\
\hline 2705 & $8 / 11 / 20084: 38$ & 1.613 & 16.9 \\
\hline 2706 & $8 / 11 / 20084: 40$ & 1.601 & 16.9 \\
\hline 2707 & $8 / 11 / 20084: 42$ & 1.601 & 16.9 \\
\hline 2708 & $8 / 11 / 20084: 44$ & 1.603 & 16.9 \\
\hline 2709 & $8 / 11 / 20084: 46$ & 1.599 & 16.9 \\
\hline 2710 & $8 / 11 / 20084: 48$ & 1.6 & 16.9 \\
\hline 2711 & $8 / 11 / 20084: 50$ & 1.607 & 16.9 \\
\hline 2712 & $8 / 11 / 20084: 52$ & 1.608 & 17 \\
\hline 2713 & $8 / 11 / 20084: 54$ & 1.604 & 16.9 \\
\hline 2714 & $8 / 11 / 20084: 56$ & 1.602 & 17 \\
\hline 2715 & $8 / 11 / 20084: 58$ & 1.603 & 16.9 \\
\hline 2716 & $8 / 11 / 20085: 00$ & 1.603 & 17 \\
\hline 2717 & $8 / 11 / 20085: 02$ & 1.604 & 17 \\
\hline 2718 & $8 / 11 / 20085: 04$ & 1.604 & 16.9 \\
\hline 2719 & $8 / 11 / 20085: 06$ & 1.603 & 16.9 \\
\hline 2720 & $8 / 11 / 20085: 08$ & 1.602 & 16.9 \\
\hline 2721 & $8 / 11 / 20085: 10$ & 1.601 & 16.9 \\
\hline 2722 & $8 / 11 / 20085: 12$ & 1.601 & 16.9 \\
\hline 2723 & $8 / 11 / 20085: 14$ & 1.6 & 16.9 \\
\hline 2724 & $8 / 11 / 20085: 16$ & 1.601 & 16.9 \\
\hline 2725 & $8 / 11 / 20085: 18$ & 1.601 & 16.9 \\
\hline 2726 & $8 / 11 / 20085: 20$ & 1.602 & 16.9 \\
\hline 2727 & $8 / 11 / 20085: 22$ & 1.604 & 16.9 \\
\hline 2728 & $8 / 11 / 20085: 24$ & 1.603 & 16.9 \\
\hline 2729 & $8 / 11 / 20085: 26$ & 1.602 & 16.9 \\
\hline 2730 & $8 / 11 / 20085: 28$ & 1.602 & 16.9 \\
\hline 2731 & $8 / 11 / 20085: 30$ & 1.602 & 16.9 \\
\hline 2732 & $8 / 11 / 20085: 32$ & 1.601 & 16.9 \\
\hline 2733 & $8 / 11 / 20085: 34$ & 1.6 & 16.9 \\
\hline 2734 & $8 / 11 / 20085: 36$ & 1.593 & 16.9 \\
\hline 2735 & $8 / 11 / 20085: 38$ & 1.588 & 16.9 \\
\hline 2736 & $8 / 11 / 20085: 40$ & 1.585 & 16.9 \\
\hline $27 \overline{37}$ & $8 / 11 / 20085: 42$ & 1.582 & 16.9 \\
\hline 2738 & $8 / 11 / 20085: 44$ & 1.58 & 16.9 \\
\hline 2739 & $8 / 11 / 20085: 46$ & 1.578 & 16.9 \\
\hline 2740 & $8 / 11 / 20085: 48$ & 1.575 & 16.9 \\
\hline 2741 & $811 / 20085: 50$ & 1.572 & 16.9 \\
\hline 2742 & $8 / 11 / 20085: 52$ & 1.571 & 16.9 \\
\hline 2743 & $8 / 11 / 20085: 54$ & 1.57 & 16.9 \\
\hline 2744 & $8 / 11 / 20085: 56$ & 1.572 & 16.9 \\
\hline 2745 & $8 / 11 / 20085: 58$ & 1.58 & 16.9 \\
\hline 2746 & $8 / 11 / 20086: 00$ & 1.585 & 16.9 \\
\hline 2747 & $8 / 11 / 20086: 02$ & 1.589 & 16.9 \\
\hline
\end{tabular}

\begin{tabular}{|c|c|c|c|}
\hline \multicolumn{4}{|c|}{$D 4-27 p$} \\
\hline $\operatorname{Rec}$ & & Pres & Temp \\
\hline$\#$ & Date/Time & psi & ${ }^{\circ} \mathrm{C}$ \\
\hline 2748 & $8 / 11 / 20086: 04$ & 1.59 & 16.9 \\
\hline 2749 & $111 / 20086: 06$ & 1.59 & 16.9 \\
\hline 2750 & $8 / 11 / 20086: 08$ & 1.591 & 16.9 \\
\hline 2751 & $8 / 11 / 20086: 10$ & 1.592 & 16.9 \\
\hline 2752 & $8 / 11 / 20086: 12$ & 1.593 & 16.9 \\
\hline 2753 & $8 / 11 / 20086: 14$ & 1.593 & 16.9 \\
\hline 2754 & $8 / 11 / 20086: 16$ & 1.593 & 16.9 \\
\hline 2755 & $8 / 11 / 20086: 18$ & 1.593 & 16.9 \\
\hline 2756 & $8 / 11 / 20086: 20$ & 1.593 & 16.9 \\
\hline 2757 & $8 / 11 / 20086: 22$ & 1.594 & 16.9 \\
\hline 2758 & $8 / 11 / 20086: 24$ & 1.594 & 16.9 \\
\hline 2759 & $8 / 11 / 20086: 26$ & 1.595 & 16.9 \\
\hline 2760 & $8 / 11 / 20086: 28$ & 1.596 & 16.9 \\
\hline 2761 & $8 / 11 / 20086: 30$ & 1.597 & 16.8 \\
\hline 2762 & $8 / 11 / 20086: 32$ & 1.596 & 16.9 \\
\hline 2763 & $8 / 11 / 20086: 34$ & 1.595 & 16.9 \\
\hline 2764 & $20086: 36$ & 1.595 & 16.9 \\
\hline 2765 & $8 / 11 / 20086: 38$ & 1.593 & 16.8 \\
\hline 2766 & $8 / 11 / 20086: 40$ & 1.594 & 16.9 \\
\hline $\begin{array}{ll}2767 \\
\end{array}$ & $086: 42$ & 1.594 & 16.9 \\
\hline 2768 & $086: 44$ & 1.595 & 16.9 \\
\hline 2769 & $8 / 11 / 20086: 46$ & 1.595 & 16.9 \\
\hline 2770 & $8 / 11 / 20086: 48$ & 1.595 & 16.9 \\
\hline 2771 & $086: 50$ & 1.596 & 16.9 \\
\hline 2772 & $8 / 11 / 20086: 52$ & 1.595 & 16.9 \\
\hline 2773 & $8 / 11 / 20086: 54$ & 1.595 & 16.8 \\
\hline 2774 & $886: 56$ & 1.595 & 16.8 \\
\hline 2775 & $086: 58$ & 1.594 & 16.8 \\
\hline 2776 & $8 / 11 / 20087: 00$ & 1.594 & 16.8 \\
\hline 2777 & $8 / 11 / 20087: 02$ & 1.593 & 16.8 \\
\hline 2778 & $87: 04$ & 1.595 & 16.8 \\
\hline 2779 & $087: 06$ & 1.595 & 16.9 \\
\hline 2780 & $8 / 11 / 20087: 08$ & 1.596 & 16.9 \\
\hline 2781 & $0087: 10$ & 1.596 & 16.8 \\
\hline 2782 & $887: 12$ & 1.596 & 16.9 \\
\hline 2783 & $087: 14$ & 1.597 & 16.0 \\
\hline 2784 & $0087: 16$ & 1.597 & 16.5 \\
\hline 2785 & $87: 18$ & 1.597 & 16.9 \\
\hline 2786 & $887: 20$ & 1.597 & 16.8 \\
\hline 2787 & $087: 22$ & 1.597 & 16.8 \\
\hline 2788 & $087: 24$ & 1.598 & 16.8 \\
\hline 2789 & $37: 26$ & 1.597 & 16.8 \\
\hline 2790 & $87: 28$ & 1.598 & 16.8 \\
\hline 2791 & $887: 30$ & 1.598 & 16.8 \\
\hline 2792 & $87: 32$ & 1.599 & 16.8 \\
\hline 2793 & $887: 34$ & 1.599 & 16.8 \\
\hline 2794 & $0087: 36$ & 1.6 & 16.8 \\
\hline 2795 & $0087: 38$ & 1.599 & 17.3 \\
\hline 2796 & $87: 40$ & 1.6 & 17.1 \\
\hline 2797 & $887: 42$ & 1.6 & 17.1 \\
\hline 2798 & $887: 44$ & 1.599 & 16.8 \\
\hline 2799 & $87: 46$ & 1.598 & 16.9 \\
\hline 2800 & $887: 48$ & 1.598 & 16.9 \\
\hline 2801 & $8 / 11 / 20087: 50$ & 1.599 & 16.9 \\
\hline 2802 & $087: 52$ & 1.6 & 16.9 \\
\hline 2803 & $87: 54$ & 1.6 & 16.9 \\
\hline 2804 & $087: 56$ & 1.6 & 16.5 \\
\hline 2805 & $087: 58$ & 1.599 & 16.9 \\
\hline 2806 & $088: 00$ & 1.6 & 16.8 \\
\hline 2807 & & 1.599 & \\
\hline 2808 & $0088: 04$ & 1.6 & 16.8 \\
\hline 2809 & $8 / 11 / 20088: 06$ & 1.599 & 16.9 \\
\hline 2810 & $8 / 11 / 20088: 08$ & 1.599 & 16.5 \\
\hline 2811 & $088: 10$ & 1.6 & 16.9 \\
\hline 2812 & $120088: 12$ & 1.601 & 16.8 \\
\hline 2813 & $8 / 11 / 20088: 14$ & 1.601 & 16.9 \\
\hline 2814 & $8 / 11 / 20088: 16$ & 1.601 & 16. \\
\hline
\end{tabular}

\begin{tabular}{|c|c|c|c|}
\hline \multicolumn{4}{|c|}{ D4-27p } \\
\hline $\operatorname{Rec}$ & & Pres & $\operatorname{emp}$ \\
\hline \# & Date-Time & psi & ${ }^{\circ} \mathrm{C}$ \\
\hline 2815 & 8/11/2008 8:18 & 1.601 & 16.9 \\
\hline 2816 & $8 / 11 / 20088: 20$ & 1.601 & 16.9 \\
\hline 2817 & $8 / 11 / 20088: 22$ & 1.601 & 16.9 \\
\hline 2818 & $8 / 11 / 20088: 24$ & 1.601 & 16.9 \\
\hline 2819 & $8 / 11 / 20088: 26$ & 1.601 & 16.9 \\
\hline 2820 & $8 / 11 / 20088: 28$ & 1.601 & 16.9 \\
\hline 2821 & $8 / 11 / 20088: 30$ & 1.6 & 16.9 \\
\hline 2822 & $8 / 11 / 20088: 32$ & 1.602 & 16.9 \\
\hline 2823 & $8 / 11 / 20088: 34$ & 1.601 & 16.9 \\
\hline 2824 & $8 / 11 / 20088: 36$ & 1.601 & 16.9 \\
\hline 2825 & $8 / 11 / 2008$ 8:38 & 1.599 & 16.9 \\
\hline 2826 & $8 / 11 / 2008$ 8:40 & 1.593 & 16.9 \\
\hline 2827 & $8 / 11 / 20088: 42$ & 1.589 & 16.9 \\
\hline 2828 & $8 / 11 / 20088: 44$ & 1.589 & 16.9 \\
\hline 2829 & $8 / 11 / 20088: 46$ & 1.593 & 16.9 \\
\hline 2830 & $8 / 11 / 20088: 48$ & 1.595 & 16.9 \\
\hline 2831 & $8 / 11 / 20088: 50$ & 1.597 & 16.9 \\
\hline 2832 & $8 / 11 / 20088: 52$ & 1.597 & 16.9 \\
\hline 2833 & $8 / 11 / 20088: 54$ & 1.598 & 16.9 \\
\hline 2834 & $8 / 11 / 20088: 56$ & 1.599 & 16.9 \\
\hline 2835 & $8 / 11 / 20088: 58$ & 1.6 & 16.9 \\
\hline 2836 & 008 9:00 & 1.6 & 16.9 \\
\hline 2837 & $1089: 02$ & 1.601 & 16.9 \\
\hline 2838 & $11 / 20089: 04$ & 1.6 & 16.9 \\
\hline 2839 & $8 / 11 / 20089: 06$ & 1.6 & $\overline{16.9}$ \\
\hline 2840 & $0089: 08$ & 1.6 & 16.9 \\
\hline 2841 & $1089: 10$ & 1.602 & 16.9 \\
\hline 2842 & 11/20089:12 & 1.601 & 16.9 \\
\hline 2843 & $8 / 11 / 20089: 14$ & 1.602 & 16.9 \\
\hline 2844 & $089: 16$ & 1.602 & 16.9 \\
\hline 2845 & $3089: 18$ & 1.602 & 16.9 \\
\hline 2846 & $11 / 20089: 20$ & 1.602 & $\overline{16.9}$ \\
\hline 2847 & $0089: 22$ & 1.603 & $\overline{16.9}$ \\
\hline 2848 & 089:24 & 1.603 & 16.9 \\
\hline 2849 & $89: 26$ & 1.602 & 16.9 \\
\hline 2850 & $8 / 11 / 20089: 28$ & 1.603 & 16.9 \\
\hline 2851 & $11 / 20089: 30$ & 1.602 & 16.9 \\
\hline 2852 & $39: 32$ & 1.603 & 16.9 \\
\hline 2853 & 008 9:34 & 1.603 & 16.9 \\
\hline 2854 & $8 / 11 / 20089: 36$ & 1.603 & 16.9 \\
\hline 2855 & $9: 38$ & 1.603 & 16.9 \\
\hline 2856 & $11 / 20089: 40$ & 1.603 & 16.9 \\
\hline 2857 & $8 / 11 / 20089: 42$ & 1.603 & 16.9 \\
\hline 2858 & $89: 44$ & 1.603 & 16.9 \\
\hline 2859 & $39: 46$ & 1.603 & 16.9 \\
\hline 2860 & $11 / 20089: 48$ & 1.603 & $\overline{16.9}$ \\
\hline 2861 & $089: 50$ & 1.604 & $\overline{16.9}$ \\
\hline 2862 & & 1.60 & 16.9 \\
\hline 2863 & $089: 54$ & 1.602 & 16.9 \\
\hline 2864 & $0089: 56$ & 1.602 & 16.9 \\
\hline 2865 & $0089: 58$ & 1.602 & 16.9 \\
\hline 2866 & 1/2008 10:00 & 1.603 & 16.9 \\
\hline 2867 & $1 / 2008$ 10:02 & 1.603 & $\overline{16.9}$ \\
\hline 2868 & 08 10:04 & 1.604 & 16.9 \\
\hline 2869 & & 1.604 & 16.9 \\
\hline 2870 & $8810: 08$ & 1.605 & 16.9 \\
\hline 2871 & 08 10:10 & 1.604 & 16.9 \\
\hline 2872 & $8810: 12$ & 1.604 & 16.9 \\
\hline 2873 & & 1.603 & 16.9 \\
\hline 2874 & $0810: 16$ & 1.604 & 16.9 \\
\hline 2875 & $11 / 2008$ 10:18 & 1.605 & 16.9 \\
\hline 2876 & $11 / 2008$ 10:20 & 1.604 & 16.9 \\
\hline 2877 & $11 / 2008$ 10:22 & 1.604 & 16.9 \\
\hline 2878 & $11 / 2008$ 10:24 & 1.605 & 16.6 \\
\hline 2879 & 11/2008 10:26 & 1.605 & 16.9 \\
\hline 2880 & $8 / 11 / 2008$ 10:28 & 1.605 & 16.9 \\
\hline 2881 & $8 / 11 / 2008$ 10:30 & 1.605 & \\
\hline
\end{tabular}

\begin{tabular}{|c|c|c|c|}
\hline \multicolumn{4}{|c|}{$\overline{D 4-27 p}$} \\
\hline $\operatorname{Rec}$ & & Pres & Temp \\
\hline$\#$ & Date/Time & psi & ${ }^{\circ} \mathrm{C}$ \\
\hline 2882 & $8 / 11 / 2008$ 10:32 & 1.606 & \\
\hline 2883 & $8 / 11 / 2008$ 10:34 & 1.606 & 16. \\
\hline 2884 & $8 / 11 / 2008$ 10:36 & 1.606 & 16.9 \\
\hline 2885 & $8 / 11 / 2008$ 10:38 & 1.606 & 16.9 \\
\hline 2886 & $8 / 11 / 2008$ 10:40 & 1.607 & \\
\hline 2887 & $8 / 11 / 2008$ 10:42 & 1.606 & 16. \\
\hline 2888 & $8 / 11 / 2008$ 10:44 & 1.605 & 16.9 \\
\hline 2889 & $8 / 11 / 2008$ 10:46 & 1.606 & 16.8 \\
\hline 2890 & $8 / 11 / 2008$ 10:48 & 1.607 & 16. \\
\hline 2891 & $8 / 11 / 2008$ 10:50 & 1.607 & $\overline{16.9}$ \\
\hline 2892 & $8 / 11 / 2008$ 10:52 & 1.608 & $\overline{16.9}$ \\
\hline 2893 & $8 / 11 / 200810: 54$ & 1.607 & 16.9 \\
\hline 2894 & $8 / 11 / 2008$ 10:56 & 1.608 & 16. \\
\hline 2895 & $8 / 11 / 2008$ 10:58 & 1.608 & 16.9 \\
\hline 2896 & $8 / 11 / 200811: 00$ & 1.608 & 16.9 \\
\hline 2897 & $0811: 02$ & 1.606 & 16. \\
\hline 2898 & $200811: 04$ & 1.606 & 16.9 \\
\hline 2899 & $8 / 11 / 2008$ 11:06 & 1.607 & 16.9 \\
\hline 2900 & 8/11/2008 11:08 & 1.607 & 16.5 \\
\hline 2901 & $0811: 10$ & 1.607 & 16. \\
\hline 2902 & 008 11:12 & 1.607 & 16. \\
\hline 2903 & 2008 11:14 & 1.608 & 16. \\
\hline 2904 & $0811: 16$ & 1.608 & 16. \\
\hline 2905 & $0811: 18$ & 1.609 & 16. \\
\hline 2906 & $0811: 20$ & 1.609 & 16.9 \\
\hline 2907 & $0811: 22$ & 1.609 & 16.5 \\
\hline 2908 & $811: 24$ & 1.609 & 16.9 \\
\hline 2909 & $811: 26$ & 1.605 & 16. \\
\hline 2910 & $8 / 11 / 2008$ 11:28 & 1.6 & 16.9 \\
\hline 2911 & $811: 30$ & 1.595 & 16.9 \\
\hline 2912 & $0811: 32$ & 1.598 & $\overline{16 .}$ \\
\hline 2913 & $8 / 11 / 2008$ 11:34 & 1.6 & $\overline{16.8}$ \\
\hline 2914 & 11/2008 11:36 & 1.603 & 16. \\
\hline 2915 & $811: 38$ & 1.603 & $\overline{16 .}$. \\
\hline 2916 & $0811: 40$ & 1.604 & 16. \\
\hline 2917 & $0811: 42$ & 1.606 & 16.5 \\
\hline 2918 & $811: 44$ & 1.605 & 16.5 \\
\hline 2919 & $311: 46$ & 1.606 & 16.5 \\
\hline 2920 & $811: 48$ & 1.607 & 16. \\
\hline 2921 & $8 / 11 / 200811: 50$ & 1.608 & 16.9 \\
\hline 2922 & $811: 52$ & 1.608 & 16. \\
\hline 2923 & $8811: 54$ & 1.609 & 16. \\
\hline 2924 & $00811: 56$ & 1.609 & 16.9 \\
\hline 2925 & $811: 58$ & 1.609 & 16.8 \\
\hline 2926 & $12: 00$ & 1.61 & 16. \\
\hline 2927 & $812: 02$ & 1.609 & 16. \\
\hline 2928 & $812: 04$ & 1.609 & 16.8 \\
\hline 2929 & 8 12:06 & 1.61 & 16. \\
\hline 2930 & $812: 08$ & 1.609 & 16. \\
\hline 2931 & $0812: 10$ & 1.61 & 16. \\
\hline 2932 & $0812: 12$ & 1.61 & 16.5 \\
\hline 2933 & $812: 14$ & 1.611 & 16. \\
\hline 2934 & $0812: 16$ & 1.611 & 16.5 \\
\hline 2935 & $8812: 18$ & 1.61 & 16.5 \\
\hline 2936 & $3812: 20$ & 1.61 & 16. \\
\hline 2937 & $812: 22$ & 1.611 & 16. \\
\hline 2938 & 08 12:24 & 1.608 & 16. \\
\hline 2939 & $0812: 26$ & 1.609 & 16.9 \\
\hline 2940 & $3812: 28$ & 1.61 & 16. \\
\hline 2941 & $0812: 30$ & 1.611 & 16. \\
\hline 2942 & $0812: 32$ & 1.611 & 16.8 \\
\hline 2943 & 11/2008 12:34 & 1.611 & 16. \\
\hline 2944 & 11/2008 12:36 & & 16. \\
\hline 2945 & $111 / 200812: 38$ & 1.611 & 16.5 \\
\hline 2946 & $8 / 11 / 2008$ 12:40 & 1.612 & 16. \\
\hline 2947 & $8 / 11 / 2008$ 12:42 & 1.612 & 16. \\
\hline 2948 & $8 / 11 / 2008$ 12:44 & 1.612 & \\
\hline
\end{tabular}




\begin{tabular}{|c|c|c|c|}
\hline \multicolumn{4}{|c|}{ D4-27p } \\
\hline $\operatorname{Rec}$ & & Pres & Temp \\
\hline \# & Date/Time & psi & ${ }^{\circ} \mathrm{C}$ \\
\hline 2949 & $8 / 11 / 200812: 46$ & 1.612 & 16.9 \\
\hline 2950 & $8 / 11 / 200812: 48$ & 1.613 & 17.1 \\
\hline 2951 & $8 / 11 / 2008$ 12:50 & 1.613 & 17 \\
\hline 2952 & $8 / 11 / 2008$ 12:52 & 1.613 & 16.9 \\
\hline 2953 & $8 / 11 / 2008$ 12:54 & 1.613 & 16.9 \\
\hline 2954 & $8 / 11 / 200812: 56$ & 1.613 & 16.9 \\
\hline 2955 & $8 / 11 / 2008$ 12:58 & 1.613 & 16.9 \\
\hline 2956 & 8/11/2008 13:00 & 1.613 & 16.9 \\
\hline 2957 & 8/11/2008 13:02 & 1.614 & 16.9 \\
\hline 2958 & $8 / 11 / 2008$ 13:04 & 1.615 & 16.9 \\
\hline 2959 & $8 / 11 / 2008$ 13:06 & 1.615 & 16.9 \\
\hline 2960 & $8 / 11 / 200813: 08$ & 1.614 & 16.9 \\
\hline 2961 & $8 / 11 / 200813: 10$ & 1.614 & 16.9 \\
\hline 2962 & 8/11/2008 13:12 & 1.614 & 16.9 \\
\hline 2963 & 8/11/2008 13:14 & 1.613 & 16.9 \\
\hline 2964 & 8/11/2008 13:16 & 1.614 & 16.9 \\
\hline 2965 & $8 / 11 / 200813: 18$ & 1.614 & 16.9 \\
\hline 2966 & $8 / 11 / 2008$ 13:20 & 1.614 & 16.9 \\
\hline 2967 & $8 / 11 / 200813: 22$ & 1.614 & 16.9 \\
\hline 2968 & $8 / 11 / 2008$ 13:24 & 1.614 & 16.9 \\
\hline 2969 & $8 / 11 / 200813: 26$ & 1.614 & 16.9 \\
\hline 2970 & $8 / 11 / 200813: 28$ & 1.614 & 16.9 \\
\hline 2971 & $8 / 11 / 200813: 30$ & 1.614 & 16.9 \\
\hline 2972 & 8/11/2008 13:32 & 1.614 & 16.9 \\
\hline 2973 & $8 / 11 / 200813: 34$ & 1.614 & 16.9 \\
\hline 2974 & 8/11/2008 13:36 & 1.613 & 16.9 \\
\hline 2975 & $8 / 11 / 2008$ 13:38 & 1.613 & 16.9 \\
\hline 2976 & 8/11/2008 13:40 & 1.614 & 16.9 \\
\hline 2977 & $8 / 11 / 200813: 42$ & 1.615 & 16.9 \\
\hline 2978 & $8 / 11 / 2008$ 13:44 & 1.614 & 16.9 \\
\hline 2979 & 8/11/2008 13:46 & 1.615 & 16.9 \\
\hline 2980 & $8 / 11 / 2008$ 13:48 & 1.615 & 16.9 \\
\hline 2981 & 8/11/2008 13:50 & 1.616 & 16.9 \\
\hline 2982 & 8/11/2008 13:52 & 1.616 & 16.9 \\
\hline 2983 & $8 / 11 / 2008$ 13:54 & 1.616 & 16.9 \\
\hline 2984 & 8/11/2008 13:56 & 1.616 & 16.9 \\
\hline 2985 & $8 / 11 / 2008$ 13:58 & 1.617 & 16.9 \\
\hline 2986 & 8/11/2008 14:00 & 1.616 & 16.9 \\
\hline 2987 & 8/11/2008 14:02 & 1.616 & 16.9 \\
\hline 2988 & $8 / 11 / 2008$ 14:04 & 1.616 & 16.9 \\
\hline 2989 & $8 / 11 / 200814: 06$ & 1.616 & 16.9 \\
\hline 2990 & $8 / 11 / 2008$ 14:08 & 1.617 & 16.9 \\
\hline 2991 & $8 / 11 / 2008$ 14:10 & 1.617 & 16.9 \\
\hline 2992 & $8 / 11 / 200814: 12$ & 1.613 & 16.9 \\
\hline 2993 & $8 / 11 / 2008$ 14:14 & 1.605 & 16.9 \\
\hline 2994 & $8 / 11 / 2008$ 14:16 & 1.601 & 16.9 \\
\hline 2995 & $8 / 11 / 2008$ 14:18 & 1.602 & 16.9 \\
\hline 2996 & $8 / 11 / 200814: 20$ & 1.607 & 16.9 \\
\hline 2997 & $8 / 11 / 2008$ 14:22 & 1.61 & 16.9 \\
\hline 2998 & $8 / 11 / 2008$ 14:24 & 1.613 & 16.9 \\
\hline 2999 & $8 / 11 / 2008$ 14:26 & 1.613 & 16.9 \\
\hline 3000 & $8 / 11 / 200814: 28$ & 1.613 & 16.9 \\
\hline 3001 & $8 / 11 / 200814: 3$ & 1.614 & 16.9 \\
\hline 3002 & $8 / 11 / 200814: 32$ & 1.615 & 16.9 \\
\hline 3003 & $8 / 11 / 2008$ 14:34 & 1.615 & 16.9 \\
\hline 3004 & $8 / 11 / 200814: 36$ & 1.614 & 16.9 \\
\hline 3005 & $8 / 11 / 200814: 38$ & 1.614 & 16.9 \\
\hline 3006 & $8 / 11 / 2008$ 14:40 & 1.615 & 16.9 \\
\hline 3007 & $8 / 11 / 2008$ 14:42 & 1.615 & 16.9 \\
\hline 3008 & $8 / 11 / 2008$ 14:44 & 1.615 & 16.9 \\
\hline 3009 & $8 / 11 / 200814: 46$ & 1.615 & 16.9 \\
\hline 3010 & $8 / 11 / 200814: 48$ & 1.617 & 16.9 \\
\hline 3011 & $8 / 11 / 200814: 50$ & 1.616 & 16.9 \\
\hline 3012 & $8 / 11 / 2008$ 14:52 & 1.618 & 16.9 \\
\hline 3013 & $8 / 11 / 2008$ 14:54 & 1.617 & 16.9 \\
\hline 3014 & $8 / 11 / 200814: 56$ & 1.619 & 16.9 \\
\hline 3015 & $8 / 11 / 200814: 58$ & 1.618 & 16.9 \\
\hline
\end{tabular}

\begin{tabular}{|c|c|c|c|}
\hline \multicolumn{4}{|c|}{ D4-27p } \\
\hline $\operatorname{Rec}$ & & Pres & Temp \\
\hline \# & DaterTime & psi & ${ }^{\circ} \mathrm{C}$ \\
\hline 3016 & $8 / 11 / 2008$ 15:00 & 1.617 & 16.9 \\
\hline 3017 & $8 / 11 / 200815: 02$ & 1.617 & 16.9 \\
\hline 3018 & $8 / 11 / 200815: 04$ & 1.619 & 16.9 \\
\hline 3019 & $8 / 11 / 2008$ 15:06 & 1.619 & 16.9 \\
\hline 3020 & $8 / 11 / 2008$ 15:08 & 1.618 & 16.9 \\
\hline 3021 & $8 / 11 / 200815: 10$ & 1.619 & 16.9 \\
\hline 3022 & $8 / 11 / 200815: 12$ & 1.619 & 16.9 \\
\hline 3023 & $8 / 11 / 200815: 14$ & 1.619 & 16.9 \\
\hline 3024 & $8 / 11 / 200815: 16$ & 1.619 & 16.9 \\
\hline 3025 & $8 / 11 / 200815: 18$ & 1.618 & 16.9 \\
\hline 3026 & $8 / 11 / 200815: 20$ & 1.619 & 16.9 \\
\hline 3027 & $8 / 11 / 200815: 22$ & 1.619 & 16.9 \\
\hline 3028 & $8 / 11 / 2008$ 15:24 & 1.619 & 16.9 \\
\hline 3029 & $8 / 11 / 200815: 26$ & 1.619 & 16.9 \\
\hline 3030 & $8 / 11 / 200815: 28$ & 1.62 & 16.9 \\
\hline 3031 & $8 / 11 / 200815: 30$ & 1.619 & 16.9 \\
\hline 3032 & $8 / 11 / 200815: 32$ & 1.62 & 16.9 \\
\hline 3033 & $8 / 11 / 2008$ 15:34 & 1.62 & 16.9 \\
\hline 3034 & $8 / 11 / 200815: 36$ & 1.619 & 16.9 \\
\hline 3035 & $8 / 11 / 2008$ 15:38 & 1.619 & 16.9 \\
\hline 3036 & $8 / 11 / 200815: 40$ & 1.623 & 16.9 \\
\hline 3037 & $8 / 11 / 2008$ 15:42 & 1.619 & 16.9 \\
\hline 3038 & $8 / 11 / 2008$ 15:44 & 1.621 & 16.9 \\
\hline 3039 & $8 / 11 / 200815: 46$ & 1.62 & 16.9 \\
\hline 3040 & $8 / 11 / 2008$ 15:48 & 1.621 & 16.9 \\
\hline 3041 & $8 / 11 / 200815: 50$ & 1.621 & 16.9 \\
\hline 3042 & $8 / 11 / 200815: 52$ & 1.621 & 16.9 \\
\hline 3043 & $8 / 11 / 200815: 54$ & 1.62 & 16.9 \\
\hline 3044 & $8 / 11 / 200815: 56$ & 1.621 & 16.9 \\
\hline 3045 & $8 / 11 / 2008$ 15:58 & 1.622 & 16.9 \\
\hline 3046 & $8 / 11 / 2008$ 16:00 & 1.622 & 16.9 \\
\hline 3047 & $8 / 11 / 200816: 02$ & 1.622 & 16.9 \\
\hline 3048 & $8 / 11 / 2008$ 16:04 & 1.622 & 16.9 \\
\hline 3049 & $8 / 11 / 200816: 06$ & 1.621 & 16.9 \\
\hline 3050 & $8 / 11 / 200816: 08$ & 1.622 & 16.9 \\
\hline 3051 & $8 / 11 / 200816: 10$ & 1.622 & 16.9 \\
\hline 3052 & $8 / 11 / 200816: 12$ & 1.622 & 16.9 \\
\hline 3053 & $8 / 11 / 200816: 14$ & 1.622 & 16.9 \\
\hline 3054 & $8 / 11 / 200816: 16$ & 1.622 & 16.9 \\
\hline 3055 & $8 / 11 / 200816: 18$ & 1.622 & 16.9 \\
\hline 3056 & $8 / 11 / 200816: 20$ & 1.622 & 16.9 \\
\hline 3057 & $8 / 11 / 200816: 22$ & 1.623 & 16.9 \\
\hline 3058 & $8 / 11 / 200816: 24$ & 1.624 & 16.9 \\
\hline 3059 & $8 / 11 / 200816: 26$ & 1.622 & 16.9 \\
\hline 3060 & $8 / 11 / 200816: 28$ & 1.623 & 16.9 \\
\hline 3061 & $8 / 11 / 200816: 30$ & 1.623 & 16.9 \\
\hline 3062 & $8 / 11 / 200816: 32$ & 1.622 & 16.9 \\
\hline 3063 & $8 / 11 / 200816: 34$ & 1.623 & 16.9 \\
\hline 3064 & $8 / 11 / 200816: 36$ & 1.622 & 16.9 \\
\hline 3065 & $8 / 11 / 200816: 38$ & 1.623 & 16.9 \\
\hline 3066 & $8 / 11 / 200816: 40$ & 1.624 & 16.9 \\
\hline 3067 & $8 / 11 / 200816: 42$ & 1.623 & 16.9 \\
\hline 3068 & $8 / 11 / 200816: 44$ & 1.624 & 16.9 \\
\hline 3069 & $8 / 11 / 200816: 46$ & 1.622 & 17.2 \\
\hline 3070 & $8 / 11 / 200816: 48$ & 1.623 & 17.5 \\
\hline 3071 & $8 / 11 / 200816: 50$ & 1.623 & 17.6 \\
\hline 3072 & $8 / 11 / 200816: 52$ & 1.624 & 17.3 \\
\hline 3073 & $8 / 11 / 200816: 54$ & 1.624 & 17.1 \\
\hline 3074 & $8 / 11 / 200816: 56$ & 1.621 & 17.4 \\
\hline 3075 & $8 / 11 / 200816: 58$ & 1.619 & 17.1 \\
\hline 3076 & $8 / 11 / 2008$ 17:00 & 1.612 & 17 \\
\hline 3077 & $8 / 11 / 2008$ 17:02 & 1.609 & 16.9 \\
\hline 3078 & $8 / 11 / 2008$ 17:04 & 1.614 & 16.9 \\
\hline 3079 & $8 / 11 / 200817: 06$ & 1.617 & 16.9 \\
\hline 3080 & $8 / 11 / 2008$ 17:08 & 1.62 & 16.9 \\
\hline 3081 & $8 / 11 / 2008$ 17:10 & 1.621 & 16.9 \\
\hline 3082 & $8 / 11 / 2008$ 17:12 & 1.623 & 16.9 \\
\hline
\end{tabular}

\begin{tabular}{|c|c|c|c|}
\hline \multicolumn{4}{|c|}{ D4-27p } \\
\hline $\operatorname{Rec}$ & & Pres & Temp \\
\hline$\#$ & Date/Time & psi & ${ }^{\circ} \mathrm{C}$ \\
\hline 3083 & $8 / 11 / 2008$ 17:14 & 1.623 & 16.9 \\
\hline 3084 & $3 / 11 / 2008 \quad 17: 16$ & 1.624 & 16.9 \\
\hline 3085 & $11 / 200817: 18$ & 1.624 & 16.9 \\
\hline 3086 & $11 / 2008$ 17:20 & 1.623 & 16.9 \\
\hline 3087 & & & 16.9 \\
\hline 3088 & $8 / 11 / 200817: 24$ & 1.622 & 16.9 \\
\hline 3089 & $8 / 11 / 2008$ 17:26 & 1.623 & 16.9 \\
\hline 3090 & & 1.623 & 16.9 \\
\hline 3091 & $11 / 2008$ 17:30 & 1.624 & $\overline{169}$ \\
\hline 3092 & $8 / 11 / 2008$ 17:32 & 1.624 & 16.9 \\
\hline 3093 & $11 / 200817: 34$ & 1.623 & 16.9 \\
\hline 3094 & & 1.624 & 16.9 \\
\hline 3095 & 17:38 & 1.624 & 16.9 \\
\hline 3096 & 17:40 & 1.624 & 16.9 \\
\hline 3097 & & 1.625 & 16.9 \\
\hline 3098 & $17: 44$ & 1.625 & 16.9 \\
\hline 3099 & $817: 46$ & 1.625 & 16.9 \\
\hline 3100 & & 1.626 & 16.9 \\
\hline 3101 & & 1.626 & 16.9 \\
\hline 3102 & $7: 52$ & 1.625 & 16.9 \\
\hline 3103 & & 1.625 & 16.9 \\
\hline 3104 & & 1.625 & 16.9 \\
\hline 3105 & & 1.624 & 16.9 \\
\hline 3106 & & 1.624 & 16.9 \\
\hline 3107 & & 1.626 & 16.9 \\
\hline 3108 & & 1.626 & $\overline{16.9}$ \\
\hline 3109 & & 1.626 & 16.9 \\
\hline 3110 & & 1.626 & 16.9 \\
\hline 3111 & & 1.626 & 16.9 \\
\hline 3112 & & 1.626 & 16.9 \\
\hline 3113 & & 1.625 & 16.9 \\
\hline 3114 & & 1.625 & 16.9 \\
\hline 3115 & & 1.625 & 16.9 \\
\hline 3116 & & 1.625 & 16.9 \\
\hline 3117 & & 1.625 & 16.9 \\
\hline 3118 & & 1.626 & 16.9 \\
\hline 3119 & & 1.625 & 16.9 \\
\hline 3120 & & 1.625 & 16.9 \\
\hline 3121 & & 1.625 & 16.9 \\
\hline 3122 & & 1.626 & 16.9 \\
\hline 3123 & & 1.626 & 16.9 \\
\hline 3124 & & 1.626 & 16.9 \\
\hline 3125 & & 1.626 & 16.9 \\
\hline 3126 & & 1.626 & 16.9 \\
\hline 3127 & & 1.627 & 16.9 \\
\hline 3128 & & 1.627 & 16.9 \\
\hline 3129 & & 1.626 & 160 \\
\hline 3130 & & 1.627 & 16.9 \\
\hline 3131 & & 1.627 & 16.9 \\
\hline 3132 & & 1.625 & 160 \\
\hline 3133 & & 1.625 & 16.9 \\
\hline 3134 & & 1.626 & 160 \\
\hline 3135 & & 1.626 & 160 \\
\hline 3136 & $9: 00$ & 1.626 & 16.9 \\
\hline 3137 & & 1.626 & 16.9 \\
\hline 3138 & & 1.626 & \\
\hline 3139 & & 1.626 & 16.9 \\
\hline 3140 & & 1.625 & 16.9 \\
\hline 3141 & & 1.626 & \\
\hline 3142 & 19:12 & 1.626 & 16.9 \\
\hline 3143 & & 1.626 & 10.9 \\
\hline 3144 & & 1.626 & \\
\hline 3145 & 19:18 & 1.626 & \\
\hline 3146 & 3 19:20 & 1.627 & \\
\hline 3147 & & 1.626 & \\
\hline 3148 & & 1.626 & \\
\hline 3149 & $819: 26$ & 1.627 & 76. \\
\hline
\end{tabular}

\begin{tabular}{|c|c|c|c|}
\hline \multicolumn{4}{|c|}{ D4-27p } \\
\hline $\operatorname{Rec}$ & & Pres & Temp \\
\hline$\#$ & Date/Time & psi & ${ }^{\circ} \mathrm{C}$ \\
\hline 3150 & $8 / 11 / 2008$ 19:28 & 1.626 & 16.9 \\
\hline 3151 & $8 / 11 / 2008$ 19:30 & 1.626 & 16.9 \\
\hline 3152 & 8/11/2008 19:32 & 1.626 & 16.9 \\
\hline 3153 & $8 / 11 / 2008$ 19:34 & 1.627 & 16.9 \\
\hline 3154 & 8/11/2008 19:36 & 1.627 & 16.9 \\
\hline 3155 & 8/11/2008 19:38 & 1.626 & 16.9 \\
\hline 3156 & $8 / 11 / 2008$ 19:40 & 1.627 & 16.9 \\
\hline 3157 & $8 / 11 / 2008$ 19:42 & 1.624 & 16.9 \\
\hline 3158 & $8 / 11 / 2008$ 19:44 & 1.622 & 16.9 \\
\hline 3159 & 8/11/2008 19:46 & 1.617 & 16.9 \\
\hline 3160 & $8 / 11 / 2008$ 19:48 & 1.61 & 16.9 \\
\hline 3161 & 8/11/2008 19:50 & 1.605 & 16.9 \\
\hline 3162 & $8 / 11 / 2008$ 19:52 & 1.602 & 16.9 \\
\hline 3163 & $8 / 11 / 2008$ 19:54 & 1.6 & 16.9 \\
\hline 3164 & $8 / 11 / 2008$ 19:56 & 1.607 & 16.9 \\
\hline 3165 & 8/11/2008 19:58 & 1.612 & 16.9 \\
\hline 3166 & $8 / 11 / 200820: 00$ & 1.616 & 16.9 \\
\hline 3167 & 8/11/2008 20:02 & 1.618 & 16.9 \\
\hline 3168 & $8 / 11 / 200820: 04$ & 1.619 & 16.9 \\
\hline 3169 & 8/11/2008 20:06 & 1.62 & 16.9 \\
\hline 3170 & $8 / 11 / 200820: 08$ & 1.621 & 16.9 \\
\hline 3171 & $8 / 11 / 200820: 10$ & 1.621 & 16.9 \\
\hline 3172 & 8/11/2008 20:12 & 1.621 & 16.9 \\
\hline 3173 & $8 / 11 / 200820: 14$ & 1.622 & 16.9 \\
\hline 3174 & 8/11/2008 20:16 & 1.622 & 16.9 \\
\hline 3175 & 8/11/2008 20:18 & 1.622 & 16.9 \\
\hline 3176 & $8 / 11 / 200820: 20$ & 1.622 & 16.9 \\
\hline 3177 & $8 / 11 / 200820: 22$ & 1.622 & 16.9 \\
\hline 3178 & $8 / 11 / 200820: 24$ & 1.622 & 16.9 \\
\hline 3179 & $8 / 11 / 200820: 26$ & 1.622 & 16.9 \\
\hline 3180 & $8 / 11 / 200820: 28$ & 1.622 & 16.9 \\
\hline 3181 & $8 / 11 / 200820: 30$ & 1.622 & 16.9 \\
\hline 3182 & $8 / 11 / 200820: 32$ & 1.622 & 16.9 \\
\hline 3183 & $8 / 11 / 200820: 34$ & 1.622 & 16.9 \\
\hline 3184 & 8/11/2008 20:36 & 1.622 & 16.9 \\
\hline 3185 & $8 / 11 / 200820: 38$ & 1.622 & 16.9 \\
\hline 3186 & $8 / 11 / 200820: 40$ & 1.622 & 16.9 \\
\hline 3187 & $8 / 11 / 200820: 42$ & 1.622 & 16.9 \\
\hline 3188 & $8 / 11 / 2008$ 20:44 & 1.621 & 16.9 \\
\hline 3189 & $8 / 11 / 200820: 46$ & 1.621 & 16.9 \\
\hline 3190 & $8 / 11 / 200820: 48$ & 1.621 & 16.9 \\
\hline 3191 & $8 / 11 / 200820: 50$ & 1.62 & 16.9 \\
\hline 3192 & $8 / 11 / 200820: 52$ & 1.621 & 16.9 \\
\hline 3193 & $8 / 11 / 200820: 54$ & 1.621 & 16.9 \\
\hline 3194 & $8 / 11 / 200820: 56$ & 1.622 & 16.9 \\
\hline 3195 & $8 / 11 / 200820: 58$ & 1.621 & 16.9 \\
\hline 3196 & $8 / 11 / 200821: 00$ & 1.601 & 16.9 \\
\hline 3197 & $8 / 11 / 200821: 02$ & 1.621 & 16.9 \\
\hline 3198 & $8 / 11 / 200821: 04$ & 1.623 & 16.9 \\
\hline 3199 & $8 / 11 / 200821: 06$ & 1.622 & 16.9 \\
\hline 3200 & $8 / 11 / 200821: 08$ & 1.621 & 16.9 \\
\hline 3201 & $8 / 11 / 200821: 10$ & 1.622 & 16.9 \\
\hline 3202 & $8 / 11 / 200821: 12$ & 1.622 & 16.9 \\
\hline 3203 & $8 / 11 / 200821: 14$ & 1.622 & 16.9 \\
\hline 3204 & $8 / 11 / 200821: 16$ & 1.621 & 16.9 \\
\hline 3205 & $8 / 11 / 200821: 18$ & 1.622 & 16.9 \\
\hline 3206 & $8 / 11 / 200821: 20$ & 1.622 & 16.9 \\
\hline 3207 & $8 / 11 / 200821: 22$ & 1.622 & 16.9 \\
\hline 3208 & $8 / 11 / 200821: 24$ & 1.623 & 16.9 \\
\hline 3209 & $8 / 11 / 200821: 26$ & 1.623 & 16.9 \\
\hline 3210 & $8 / 11 / 200821: 28$ & 1.622 & 16.9 \\
\hline 3211 & $8 / 11 / 200821: 30$ & 1.623 & 16.9 \\
\hline$\overline{3212}$ & $8 / 11 / 200821: 32$ & 1.623 & 16.9 \\
\hline 3213 & $8 / 11 / 200821: 34$ & 1.623 & 16.9 \\
\hline 3214 & $8 / 11 / 200821: 36$ & 1.622 & 16.9 \\
\hline 3215 & $8 / 11 / 200821: 38$ & 1.622 & 16.9 \\
\hline 3216 & $8 / 11 / 200821: 40$ & 1.622 & 16.9 \\
\hline
\end{tabular}




\begin{tabular}{|c|c|c|c|}
\hline \multicolumn{4}{|c|}{ D4-27p } \\
\hline $\operatorname{Rec}$ & & Pres & Temp \\
\hline$\#$ & Date/Time & psi & ${ }^{\circ} \mathrm{C}$ \\
\hline 3217 & $8 / 11 / 200821: 42$ & 1.621 & 16.9 \\
\hline 3218 & $8 / 11 / 200821: 44$ & 1.623 & 16.9 \\
\hline 3219 & $8 / 11 / 200821: 46$ & 1.622 & 16.9 \\
\hline 3220 & $8 / 11 / 200821: 48$ & 1.623 & 16.9 \\
\hline 3221 & $8 / 11 / 200821: 50$ & 1.623 & 16.9 \\
\hline 3222 & $8 / 11 / 200821: 52$ & 1.622 & 16.9 \\
\hline 3223 & $8 / 11 / 200821: 54$ & 1.623 & 16.9 \\
\hline 3224 & $8 / 11 / 200821: 56$ & 1.623 & 16.9 \\
\hline 3225 & $8 / 11 / 200821: 58$ & 1.623 & 16.9 \\
\hline 3226 & $8 / 11 / 200822: 00$ & 1.623 & 16.9 \\
\hline 3227 & $8 / 11 / 200822: 02$ & 1.622 & 16.9 \\
\hline 3228 & $8 / 11 / 200822: 04$ & 1.622 & 16.9 \\
\hline 3229 & $8 / 11 / 200822: 06$ & 1.622 & 16.9 \\
\hline 3230 & $8 / 11 / 200822: 08$ & 1.623 & 16.9 \\
\hline 3231 & $8 / 11 / 200822: 10$ & 1.622 & 16.9 \\
\hline 3232 & $8 / 11 / 200822: 12$ & 1.623 & 16.9 \\
\hline 3233 & $8 / 11 / 200822: 14$ & 1.623 & 16.9 \\
\hline 3234 & $8 / 11 / 200822: 16$ & 1.623 & 16.9 \\
\hline 3235 & $8 / 11 / 200822: 18$ & 1.624 & 16.9 \\
\hline 3236 & $8 / 11 / 200822: 20$ & 1.624 & 16.9 \\
\hline 3237 & $8 / 11 / 200822: 22$ & 1.623 & 16.9 \\
\hline 3238 & $8 / 11 / 200822: 24$ & 1.623 & 16.9 \\
\hline 3239 & $8 / 11 / 200822: 26$ & 1.622 & 16.9 \\
\hline 3240 & $8 / 11 / 200822: 28$ & 1.623 & 16.9 \\
\hline 3241 & $8 / 11 / 200822: 30$ & 1.623 & 16.9 \\
\hline 3242 & $8 / 11 / 200822: 32$ & 1.624 & 16.9 \\
\hline 3243 & $8 / 11 / 200822: 34$ & 1.624 & 16.9 \\
\hline 3244 & $8 / 11 / 200822: 36$ & 1.624 & 16.9 \\
\hline 3245 & $8 / 11 / 200822: 38$ & 1.621 & 16.9 \\
\hline 3246 & $8 / 11 / 200822: 40$ & 1.618 & 16.9 \\
\hline 3247 & $8 / 11 / 200822: 42$ & 1.614 & 16.9 \\
\hline 3248 & $8 / 11 / 200822: 44$ & 1.61 & 16.9 \\
\hline 3249 & $8 / 11 / 200822: 46$ & 1.607 & 16.9 \\
\hline 3250 & $8 / 11 / 200822: 48$ & 1.603 & 16.9 \\
\hline 3251 & $8 / 11 / 200822: 50$ & 1.599 & 16.9 \\
\hline 3252 & $8 / 11 / 200822: 52$ & 1.596 & 16.9 \\
\hline 3253 & $8 / 11 / 200822: 54$ & 1.594 & 16.9 \\
\hline 3254 & $8 / 11 / 200822: 56$ & 1.593 & 16.9 \\
\hline 3255 & $8 / 11 / 200822: 58$ & 1.59 & 16.9 \\
\hline 3256 & $8 / 11 / 200823: 00$ & 1.589 & 16.9 \\
\hline 3257 & $8 / 11 / 200823: 02$ & 1.589 & 16.9 \\
\hline 3258 & $8 / 11 / 200823: 04$ & 1.596 & 16.9 \\
\hline 3259 & $8 / 11 / 200823: 06$ & 1.603 & 16.9 \\
\hline 3260 & $8 / 11 / 200823: 08$ & 1.608 & 16.9 \\
\hline 3261 & $8 / 11 / 200823: 10$ & 1.611 & 16.9 \\
\hline 3262 & $8 / 11 / 200823: 12$ & 1.613 & 16.9 \\
\hline 3263 & $8 / 11 / 200823: 14$ & 1.614 & 16.9 \\
\hline 3264 & $8 / 11 / 200823: 16$ & 1.615 & 16.9 \\
\hline 3265 & $8 / 11 / 200823: 18$ & 1.615 & 16.9 \\
\hline 3266 & $8 / 11 / 200823: 20$ & 1.615 & 16.9 \\
\hline 3267 & $8 / 11 / 200823: 22$ & 1.615 & 16.9 \\
\hline 3268 & $8 / 11 / 200823: 24$ & 1.615 & 16.9 \\
\hline 3269 & $8 / 11 / 200823: 26$ & 1.616 & 16.9 \\
\hline 3270 & $8 / 11 / 200823: 28$ & 1.616 & 16.9 \\
\hline 3271 & $8 / 11 / 200823: 30$ & 1.616 & 16.9 \\
\hline 3272 & $8 / 11 / 200823: 32$ & 1.616 & 16.9 \\
\hline 3273 & $8 / 11 / 200823: 34$ & 1.617 & 16.9 \\
\hline 3274 & $8 / 11 / 200823: 36$ & 1.616 & 16.9 \\
\hline 3275 & $8 / 11 / 200823: 38$ & 1.617 & 16.9 \\
\hline 3276 & $8 / 11 / 200823: 40$ & 1.617 & 16.9 \\
\hline 3277 & $8 / 11 / 200823: 42$ & 1.618 & 16.9 \\
\hline 3278 & $8 / 11 / 200823: 44$ & 1.618 & 16.9 \\
\hline 3279 & $8 / 11 / 200823: 46$ & 1.618 & 16.9 \\
\hline 3280 & $8 / 11 / 200823: 48$ & 1.617 & 16.9 \\
\hline 3281 & $8 / 11 / 200823: 50$ & 1.618 & 16.9 \\
\hline 3282 & $8 / 11 / 200823: 52$ & 1.618 & 16.9 \\
\hline 3283 & $8 / 11 / 200823: 54$ & 1.618 & 16.9 \\
\hline & & & \\
\hline & & & \\
\hline
\end{tabular}

\begin{tabular}{|c|c|c|c|}
\hline \multicolumn{4}{|c|}{ D4-27p } \\
\hline $\operatorname{Rec}$ & & Pres & Temp \\
\hline$\#$ & DaterTime & psi & ${ }^{\circ} \mathrm{C}$ \\
\hline 3284 & $8 / 11 / 200823: 56$ & 1.618 & 16.9 \\
\hline 3285 & $8 / 11 / 2008$ 23:58 & 1.618 & 16.9 \\
\hline 3286 & $8 / 12 / 20080: 00$ & 1.618 & 16.9 \\
\hline 3287 & $8 / 12 / 20080: 02$ & 1.618 & 16.9 \\
\hline 3288 & $8 / 12 / 20080: 04$ & 1.618 & 16.9 \\
\hline 3289 & $8 / 12 / 20080: 06$ & 1.618 & 16.9 \\
\hline 3290 & $8 / 12 / 20080: 08$ & 1.618 & 16.9 \\
\hline 3291 & $8 / 12 / 20080: 10$ & 1.619 & 16.9 \\
\hline 3292 & $8 / 12 / 20080: 12$ & 1.618 & $\overline{16.9}$ \\
\hline 3293 & $8 / 12 / 20080: 14$ & 1.618 & 17.1 \\
\hline 3294 & $8 / 12 / 20080: 16$ & 1.619 & 17.1 \\
\hline 3295 & $8 / 12 / 20080: 18$ & 1.619 & 17 \\
\hline 3296 & $8 / 12 / 20080: 20$ & 1.62 & 16.9 \\
\hline 3297 & $8 / 12 / 20080: 22$ & 1.62 & 16.9 \\
\hline 3298 & $8 / 12 / 20080: 24$ & 1.619 & 16.9 \\
\hline 3299 & $8 / 12 / 20080: 26$ & 1.62 & 16.9 \\
\hline 3300 & $8 / 12 / 20080: 28$ & 1.62 & 16.9 \\
\hline$\overline{3301}$ & $8 / 12 / 20080: 30$ & 1.62 & 16.9 \\
\hline 3302 & $8 / 12 / 20080: 32$ & 1.62 & 16.9 \\
\hline 3303 & $8 / 12 / 20080: 34$ & 1.621 & 16.9 \\
\hline 3304 & $8 / 12 / 20080: 36$ & 1.62 & 16.9 \\
\hline$\overline{3305}$ & $8 / 12 / 20080: 38$ & 1.616 & 16.9 \\
\hline 3306 & $8 / 12 / 20080: 40$ & 1.62 & 16.9 \\
\hline 3307 & $8 / 12 / 20080: 42$ & 1.619 & 16.9 \\
\hline 3308 & $8 / 12 / 20080: 44$ & 1.619 & 16.9 \\
\hline 3309 & $8 / 12 / 20080: 46$ & 1.62 & 16.9 \\
\hline 3310 & $8 / 12 / 20080: 48$ & 1.62 & 16.9 \\
\hline 3311 & $8 / 12 / 20080: 50$ & 1.619 & 16.9 \\
\hline 3312 & $8 / 12 / 20080: 52$ & 1.619 & 16.9 \\
\hline 3313 & $8 / 12 / 20080: 54$ & 1.619 & 16.9 \\
\hline 3314 & $8 / 12 / 20080: 56$ & 1.62 & 16.9 \\
\hline 3315 & $8 / 12 / 20080: 58$ & 1.62 & 16.9 \\
\hline 3316 & $8 / 12 / 20081: 00$ & 1.62 & 16.9 \\
\hline$\overline{3317}$ & $8 / 12 / 20081: 02$ & 1.62 & 16.9 \\
\hline 3318 & $8 / 12 / 20081: 04$ & 1.62 & 16.9 \\
\hline 3319 & $8 / 12 / 20081: 06$ & 1.62 & 16.9 \\
\hline 3320 & $8 / 12 / 20081: 08$ & 1.62 & 16.9 \\
\hline 3321 & $8 / 12 / 20081: 10$ & 1.62 & 16.9 \\
\hline$\overline{3322}$ & $8 / 12 / 20081: 12$ & 1.62 & 16.9 \\
\hline 3323 & $8 / 12 / 20081: 14$ & 1.619 & 16.9 \\
\hline 3324 & $8 / 12 / 20081: 16$ & 1.619 & 16.9 \\
\hline 3325 & $8 / 12 / 20081: 18$ & 1.619 & 16.9 \\
\hline$\overline{3326}$ & $8 / 12 / 20081: 20$ & 1.62 & 16.9 \\
\hline$\overline{3327}$ & $8 / 12 / 20081: 22$ & 1.62 & 16.9 \\
\hline 3328 & $8 / 12 / 20081: 24$ & 1.62 & 16.9 \\
\hline 3329 & $8 / 12 / 20081: 26$ & 1.621 & 16.9 \\
\hline$\overline{3330}$ & $8 / 12 / 20081: 28$ & 1.621 & 16.9 \\
\hline$\overline{3331}$ & $8 / 12 / 20081: 30$ & 1.62 & 16.9 \\
\hline$\overline{3332}$ & $8 / 12 / 20081: 32$ & 1.62 & $\overline{16.9}$ \\
\hline 3333 & $8 / 12 / 20081: 34$ & 1.62 & 16.9 \\
\hline 3334 & $8 / 12 / 20081: 36$ & 1.621 & 16.9 \\
\hline 3335 & $8 / 12 / 20081: 38$ & 1.622 & 16.9 \\
\hline 3336 & $8 / 12 / 20081: 40$ & 1.622 & 16.9 \\
\hline 3337 & $8 / 12 / 20081: 42$ & 1.619 & 16.9 \\
\hline 3338 & $8 / 12 / 20081: 44$ & 1.615 & 16.9 \\
\hline 3339 & $8 / 12 / 20081: 46$ & 1.609 & 16.9 \\
\hline 3340 & $8 / 12 / 20081: 48$ & 1.603 & 16.9 \\
\hline$\overline{3341}$ & $8 / 12 / 20081: 50$ & 1.6 & 16.9 \\
\hline 3342 & $8 / 12 / 20081: 52$ & 1.6 & 16.9 \\
\hline 3343 & $8 / 12 / 20081: 54$ & 1.605 & 16.9 \\
\hline 3344 & $8 / 12 / 20081: 56$ & 1.609 & 16.9 \\
\hline$\overline{3345}$ & $8 / 12 / 20081: 58$ & 1.612 & 16.9 \\
\hline 3346 & $8 / 12 / 20082: 00$ & 1.613 & 16.9 \\
\hline 3347 & $8 / 12 / 20082: 02$ & 1.616 & 16.9 \\
\hline 3348 & $8 / 12 / 20082: 04$ & 1.616 & 16.9 \\
\hline$\overline{3349}$ & $8 / 12 / 20082: 06$ & 1.617 & 16.9 \\
\hline 3350 & $8 / 12 / 20082: 08$ & 1.617 & 16.9 \\
\hline & & & \\
\hline & & & \\
\hline
\end{tabular}

\begin{tabular}{|c|c|c|c|}
\hline \multicolumn{4}{|c|}{ D4-27p } \\
\hline Rec & & Pres & Temp \\
\hline \# & Date/Time & psi & ${ }^{\circ} \mathrm{C}$ \\
\hline 3351 & $8 / 12 / 20082: 10$ & 1.617 & 16.9 \\
\hline 3352 & $8 / 12 / 20082: 12$ & 1.618 & 16.9 \\
\hline 3353 & $8 / 12 / 20082: 14$ & 1.617 & 16.9 \\
\hline 3354 & $8 / 12 / 20082: 16$ & 1.618 & 16.9 \\
\hline 3355 & $8 / 12 / 20082: 18$ & 1.618 & 16.9 \\
\hline 3356 & $8 / 12 / 20082: 20$ & 1.618 & 16.9 \\
\hline 3357 & $8 / 12 / 20082: 22$ & 1.618 & $\overline{16.9}$ \\
\hline 3358 & $8 / 12 / 20082: 24$ & 1.619 & 16.9 \\
\hline 3359 & $8 / 12 / 20082: 26$ & 1.619 & 16.9 \\
\hline 3360 & $8 / 12 / 20082: 28$ & 1.619 & 16.9 \\
\hline 3361 & $8 / 12 / 20082: 30$ & 1.619 & 16.9 \\
\hline 3362 & $8 / 12 / 20082: 32$ & 1.619 & 16.9 \\
\hline 3363 & $8 / 12 / 20082: 34$ & 1.619 & 16.9 \\
\hline 3364 & $8 / 12 / 20082: 36$ & 1.619 & 16.9 \\
\hline 3365 & $8 / 12 / 20082: 38$ & 1.619 & 16.9 \\
\hline 3366 & $8 / 12 / 20082: 40$ & 1.618 & 16.9 \\
\hline 3367 & $2 / 20082: 42$ & 1.619 & $\overline{16.9}$ \\
\hline 3368 & $8 / 12 / 20082: 44$ & 1.619 & 16.9 \\
\hline 3369 & $8 / 12 / 20082: 46$ & 1.619 & 16.9 \\
\hline 3370 & $8 / 12 / 20082: 48$ & 1.619 & 16.9 \\
\hline 3371 & $\sqrt{20082: 50}$ & 1.62 & 16.9 \\
\hline 3372 & $2 / 20082: 52$ & 1.62 & 16.9 \\
\hline 3373 & $8 / 12 / 20082: 54$ & 1.62 & 16.9 \\
\hline 3374 & $\sqrt{20082: 56}$ & 1.62 & 16.9 \\
\hline 3375 & $20082: 58$ & 1.62 & 16.9 \\
\hline 3376 & $/ 20083: 00$ & 1.62 & 16.9 \\
\hline 3377 & $8 / 12 / 20083: 02$ & 1.619 & 16.9 \\
\hline 3378 & $8 / 12 / 20083: 04$ & 1.62 & 16.9 \\
\hline 3379 & $120083: 06$ & 1.619 & 16.9 \\
\hline 3380 & $3: 08$ & 1.619 & 16.9 \\
\hline 3381 & $8 / 12 / 20083: 10$ & 1.619 & 16.9 \\
\hline 3382 & $8 / 12 / 20083: 12$ & 1.619 & 16.9 \\
\hline 3383 & $8 / 12 / 20083: 14$ & 1.619 & $16 . \mathrm{C}$ \\
\hline 3384 & $3: 16$ & 1.619 & 16.9 \\
\hline 3385 & $8 / 12 / 20083: 18$ & 1.619 & 16.9 \\
\hline 3386 & $8 / 12 / 20083: 20$ & 1.619 & 16.9 \\
\hline 3387 & $8 / 12 / 20083: 22$ & 1.619 & 16.9 \\
\hline 3388 & $3: 24$ & 1.618 & 16.9 \\
\hline 3389 & $1 / 20083: 26$ & 1.618 & 16.9 \\
\hline 3390 & $8 / 12 / 20083: 28$ & 1.62 & 16.9 \\
\hline 3391 & $8 / 12 / 20083: 30$ & 1.62 & 16.9 \\
\hline 3392 & $0083: 32$ & 1.619 & 16.9 \\
\hline 3393 & $20083: 34$ & 1.618 & 16.9 \\
\hline 3394 & $8 / 12 / 20083: 36$ & 1.619 & 16.9 \\
\hline 3395 & $8 / 12 / 20083: 38$ & 1.619 & 16.9 \\
\hline 3396 & $20083: 40$ & 1.619 & 16.9 \\
\hline 3397 & $120083: 42$ & 1.62 & 16.9 \\
\hline 3398 & $8 / 12 / 20083: 44$ & 1.62 & 16.9 \\
\hline 3399 & $8 / 12 / 20083: 46$ & 1.619 & 16.9 \\
\hline 3400 & $8 / 12 / 20083: 48$ & 1.619 & 16.9 \\
\hline 3401 & $20083: 50$ & 1.619 & 16.9 \\
\hline 3402 & $8 / 12 / 20083: 52$ & 1.618 & 16.9 \\
\hline 3403 & $8 / 12 / 20083: 54$ & 1.619 & 16.9 \\
\hline 3404 & $8 / 12 / 20083: 56$ & 1.619 & 16.9 \\
\hline 3405 & $8 / 12 / 20083: 58$ & 1.62 & 16.9 \\
\hline 3406 & $2 / 20084: 00$ & 1.62 & 16.9 \\
\hline 3407 & $8 / 12 / 20084: 02$ & 1.621 & 16.9 \\
\hline 3408 & $8 / 12 / 20084: 04$ & 1.62 & 16.9 \\
\hline 3409 & $8 / 12 / 20084: 06$ & 1.62 & 16.9 \\
\hline 3410 & $8 / 12 / 20084: 08$ & 1.62 & 16.9 \\
\hline 3411 & $8 / 12 / 20084: 10$ & 1.619 & 16.9 \\
\hline 3412 & $8 / 12 / 20084: 12$ & 1.619 & 16.9 \\
\hline 3413 & $8 / 12 / 20084: 14$ & 1.619 & 16.9 \\
\hline 3414 & $8 / 12 / 20084: 16$ & 1.619 & 16.9 \\
\hline 3415 & $8 / 12 / 20084: 18$ & 1.619 & 16.9 \\
\hline 3416 & $8 / 12 / 20084: 20$ & 1.619 & 16.9 \\
\hline 3417 & $8 / 12 / 20084: 22$ & 1.62 & 16.9 \\
\hline & & & \\
\hline & & & \\
\hline
\end{tabular}

\begin{tabular}{|c|c|c|c|}
\hline \multicolumn{4}{|c|}{ D4-27p } \\
\hline & & Pres & \\
\hline & DaterT & & \\
\hline & $8 / 12 / 20084: 2$ & & \\
\hline 3419 & $8 / 12 / 20084: 26$ & 1.62 & 16. \\
\hline 3420 & $12 / 20084: 28$ & 1.62 & 16. \\
\hline 3421 & $8 / 12 / 20084: 30$ & 1.62 & 16. \\
\hline & $8 / 12 / 20084: 32$ & 1.616 & \\
\hline 3423 & $8 / 12 / 20084: 34$ & 1.609 & 16.9 \\
\hline 3424 & $8 / 12 / 20084: 36$ & 1.603 & 16.8 \\
\hline 3425 & $8 / 12 / 20084: 38$ & & $16 !$ \\
\hline 3426 & $8 / 12 / 20084: 40$ & 1.608 & 16.9 \\
\hline 3427 & 12/2008 4:42 & 1.612 & \\
\hline 3428 & $12 / 20084: 44$ & 1.613 & $\overline{16.5}$ \\
\hline & $8 / 12 / 20084: 46$ & 1.614 & 16. \\
\hline 3430 & $8 / 12 / 20084: 48$ & & 16. \\
\hline & $8 / 12 / 20084: 50$ & & \\
\hline 3432 & $8 / 12 / 20084: 52$ & & \\
\hline 3433 & $8 / 12 / 20084: 54$ & & \\
\hline 3434 & $8 / 12 / 20084: 56$ & 1.616 & 16. \\
\hline 3435 & $8 / 12 / 20084: 58$ & 1.616 & \\
\hline 3436 & $8 / 12 / 20085: 00$ & 1.617 & 16. \\
\hline 3437 & $2 / 20085: 02$ & 1.617 & $16 !$ \\
\hline 3438 & $8 / 12 / 20085: 04$ & & \\
\hline & 8/12/2008 5:06 & & \\
\hline 3440 & $8 / 12 / 20085: 08$ & & \\
\hline 3441 & $8 / 12 / 20085: 10$ & & \\
\hline 3442 & $8 / 12 / 20085: 12$ & & 16. \\
\hline 3443 & $8 / 12 / 20085: 14$ & 1.616 & 16. \\
\hline 3444 & $8 / 12 / 20085: 16$ & 1.615 & 16. \\
\hline 3445 & $8 / 12 / 20085: 18$ & 1.615 & \\
\hline 3446 & & & \\
\hline 3447 & $8 / 12 / 20085: 22$ & 1.61 & \\
\hline 3448 & $2 / 20085: 24$ & 1.616 & \\
\hline 3449 & $8 / 12 / 20085: 26$ & 1.616 & \\
\hline 3450 & $8 / 12 / 20085: 28$ & 1.616 & 16.5 \\
\hline 3451 & $8 / 12 / 20085: 30$ & 1.615 & \\
\hline 3452 & $8 / 12 / 20085: 32$ & & \\
\hline 3453 & $8 / 12 / 20085: 34$ & 1.616 & 17. \\
\hline 3454 & $2 / 20085: 36$ & 1.616 & \\
\hline 3455 & $2 / 20085 \cdot 38$ & 1.616 & $16 ! 5>>$ \\
\hline 3456 & & & \\
\hline 3457 & & 1.6 & \\
\hline 3458 & 2/2008 5:44 & 1.616 & 16. \\
\hline 3459 & 2/20085:46 & 1.617 & 16. \\
\hline 3460 & 2/2008 5:48 & & \\
\hline 3461 & 8 & & \\
\hline 3462 & & & \\
\hline 3463 & $\overline{2 / 20}$ & & \\
\hline 3464 & $2 / 20085: 56$ & 1.617 & \\
\hline 3465 & & 1.61 & 16.5 \\
\hline 3466 & $8 / 12 / 21$ & 1.67 & \\
\hline 3467. & & & \\
\hline 3468 & & $1.6 \mathrm{P}>\mathrm{l}$ & \\
\hline 3469 & & 1.6 & \\
\hline 3470 & & $\overline{1.61}$ & \\
\hline 3471 & & 1.6 & \\
\hline 3472 & & & \\
\hline 3473 & & & \\
\hline 3474 & & 1.616 & \\
\hline 3475 & $8 / 12 / 20$ & 1.616 & \\
\hline 76 & $8 / 12 / 20086: 20$ & 1.616 & \\
\hline 3477 & 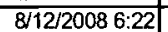 & & \\
\hline 3478 & 24 & 1.616 & \\
\hline 3479 & & 1.61 & \\
\hline 3480 & & $\overline{1.6}$ & \\
\hline & & & \\
\hline & & & \\
\hline 3483 & & & \\
\hline 3484 & & 1.616 & \\
\hline 3485 & $8 / 12 / 20$ & 1.615 & 6. \\
\hline 2486 & $8 / 12 / 20086: 40$ & 1.616 & 16.9 \\
\hline
\end{tabular}


DOE/RL-2009-35, REV. 0

\begin{tabular}{|c|c|c|c|c|c|c|c|c|c|c|c|c|c|c|c|}
\hline \multicolumn{4}{|c|}{ D4-27p } & \multicolumn{4}{|c|}{ D4-27p } & \multicolumn{4}{|c|}{$D 4-27 p$} & \multicolumn{4}{|c|}{$04-27 p$} \\
\hline $\operatorname{Rec}$ & & Pres & Temp & $\operatorname{Rec}$ & & Pres & Temp & $\operatorname{Rec}$ & & Pres & Temp & $\operatorname{Rec}$ & & Pres & Temp \\
\hline$\#$ & DaterTime & psi & ${ }^{\circ} \mathrm{C}$ & $\#$ & Date/Time & psi & ${ }^{\circ} \mathrm{C}$ & \# & Date/Time & psi & ${ }^{\circ} \mathrm{C}$ & $\#$ & DaterTime & $\mathrm{psi}$ & ${ }^{\circ} \mathrm{C}$ \\
\hline 3487 & $8 / 12 / 20086: 42$ & 1.617 & 16.9 & 3556 & $8 / 12 / 20089: 00$ & 1.614 & 16.9 & 3625 & $8 / 12 / 2008$ 11:18 & 1.615 & 16.9 & 3694 & $8 / 12200813: 36$ & 1.619 & 16.9 \\
\hline 3488 & $8 / 12 / 20086: 44$ & 1.616 & 16.9 & 3557 & $8 / 12 / 20089: 02$ & 1.614 & 16.9 & 3626 & $8 / 12200811: 20$ & 1.615 & 16.9 & 3695 & $8 / 12 / 2008$ 13:38 & 1.62 & 16.9 \\
\hline 3489 & $8 / 12 / 20086: 46$ & 1.617 & 16.9 & 3558 & $8 / 12 / 20089: 04$ & 1.613 & 16.9 & 3627 & $8 / 12 / 200811: 2$ & 1.615 & 16.9 & 3696 & $8 / 122008$ 13:40 & 1.619 & 16.9 \\
\hline 3490 & $8 / 12 / 20086: 48$ & 1.616 & 16.9 & 3559 & $8 / 12 / 20089: 06$ & 1.613 & 16.9 & 3628 & $8 / 12 / 200811: 24$ & 1.615 & 16.9 & 3697 & $8 / 12200813: 42$ & 1.619 & 16.9 \\
\hline 3491 & $8 / 12 / 20086: 50$ & 1.616 & 16.9 & 3560 & $8 / 12 / 20089: 08$ & 1.614 & 16.9 & 3629 & $8 / 12 / 200811: 26$ & 1.615 & 16.9 & 3698 & $8 / 12 / 2008$ 13:44 & 1.618 & 16.9 \\
\hline 3492 & $8 / 12 / 20086: 52$ & 1.616 & 16.9 & 3561 & $8 / 12 / 20089: 10$ & 1.614 & 16.9 & 3630 & $8 / 12 / 2008$ 11:28 & 1.615 & 16.9 & 3699 & $8 / 12 / 2008$ 13:46 & 1.619 & 16.9 \\
\hline 3493 & $8 / 12 / 20086: 54$ & 1.617 & 16.9 & 3562 & $8 / 12 / 20089: 12$ & 1.614 & 16.9 & 3631 & $8 / 12 / 2008$ 11:30 & 1.615 & 16.9 & 3700 & $8 / 12200813: 48$ & 1.619 & 16.9 \\
\hline 3494 & $8 / 12 / 20086: 56$ & 1.616 & 16.9 & 3563 & 8/12/20089:14 & 1.614 & 16.9 & 3632 & 8/12/2008 11:32 & 1.616 & 16.9 & 3701 & $8 / 12200813: 50$ & 1.619 & 16.9 \\
\hline 3495 & $8 / 12 / 20086: 58$ & 1.616 & 16.9 & 3564 & 8/12/20089:16 & 1.614 & 16.9 & 3633 & $8 / 12 / 2008$ 11:34 & 1.616 & 16.9 & 3702 & $8 / 12 / 200813: 52$ & 1.619 & 16.9 \\
\hline 3496 & $8 / 12220087: 00$ & 1.616 & 16.9 & 3565 & $8 / 12 / 20089: 18$ & 1.614 & 16.9 & 3634 & $8 / 12 / 200811: 36$ & 1.616 & 16.9 & 3703 & $8 / 12200813: 54$ & 1.619 & 16.9 \\
\hline 3497 & $8 / 12 / 20087: 02$ & 1.616 & 16.9 & 3566 & $8 / 12 / 20089: 20$ & 1.614 & 16.9 & 3635 & $8 / 12 / 200811: 38$ & 1.57 & 16.9 & 3704 & $8 / 12200813: 56$ & 1.619 & 16.9 \\
\hline 3498 & $8 / 12 / 20087: 04$ & 1.617 & 16.9 & 3567 & $8 / 12 / 20089: 22$ & 1.614 & 16.9 & 3636 & $8 / 12 / 200811: 40$ & 1.616 & 16.9 & 3705 & $8 / 12 / 200813: 58$ & 1.62 & 16.9 \\
\hline 3499 & $8 / 12 / 20087: 06$ & 1.617 & 16.9 & 3568 & $8 / 12 / 20089: 24$ & 1.615 & 16.9 & 3637 & $8 / 12 / 200811: 42$ & 1.616 & 16.9 & 3706 & $8 / 12 / 200814: 00$ & 1.62 & 16.9 \\
\hline 3500 & $8 / 12 / 20087: 08$ & 1.616 & 16.9 & 3569 & $8 / 12 / 20089: 26$ & 1.616 & 16.9 & 3638 & $8 / 12 / 2008$ 11:44 & 1.617 & 16.9 & 3707 & $8 / 12 / 2008$ 14:02 & 1.62 & 16.9 \\
\hline 3501 & $8 / 12 / 20087: 10$ & 1.616 & 16.9 & 3570 & $8 / 12 / 20089: 28$ & 1.615 & 16.9 & 3639 & $8 / 12 / 2008$ 11:46 & 1.617 & 16.9 & 3708 & $8 / 122008$ 14:04 & 1.62 & 16.9 \\
\hline 3502 & $8 / 12 / 20087: 12$ & 1.615 & 16.9 & 3571 & $8 / 12 / 20089: 30$ & 1.614 & 16.9 & 3640 & $8 / 12 / 200811: 48$ & 1.617 & 16.9 & 3709 & $8 / 122008$ 14:06 & 1.62 & 16.9 \\
\hline 3503 & $8 / 12 / 20087: 14$ & 1.616 & 16.9 & 3572 & $8 / 12 / 20089: 32$ & 1.614 & 16.9 & 3641 & $8 / 12 / 200811: 50$ & 1.617 & 16.9 & 3710 & $8 / 12 / 2008$ 14:08 & 1.621 & 16.9 \\
\hline 3504 & $8 / 12 / 20087: 16$ & 1.616 & 16.9 & 3573 & $8 / 12 / 20089: 34$ & 1.613 & 16.9 & 3642 & $8 / 12 / 2000111: 52$ & 1.617 & 16.9 & 3711 & $8 / 12 / 200814: 10$ & 1.621 & 16.9 \\
\hline 3505 & $8 / 12 / 20087: 18$ & 1.616 & 16.9 & 3574 & $8 / 12 / 20089: 36$ & 1.613 & 16.9 & 3643 & $8 / 12 / 200811: 54$ & 1.617 & 16.9 & 3712 & $8 / 12 / 200814: 12$ & 1.621 & 16.9 \\
\hline 3506 & $8 / 12 / 20087: 20$ & 1.615 & 16.9 & 3575 & $8 / 12 / 20089: 38$ & 1.613 & 16.9 & 3644 & $8 / 12 / 200811: 56$ & 1.617 & 16.9 & 3713 & $8 / 12 / 200814: 14$ & 1.622 & 16.9 \\
\hline 3507 & $8 / 12 / 20087: 22$ & 1.613 & 16.9 & 3576 & $8 / 12 / 20089: 40$ & 1.613 & 16.9 & 3645 & $8 / 12 / 2008$ 11:58 & 1.618 & 16.9 & 3714 & $8 / 12 / 2008$ 14:16 & 1.62 & 16.9 \\
\hline 3508 & $8 / 12 / 20087: 24$ & 1.61 & 16.9 & 3577 & $8 / 12 / 20089: 42$ & 1.613 & 16.9 & 3646 & $8 / 12 / 200812: 00$ & 1.618 & 16.9 & 3715 & $8 / 122008$ 14:18 & 1.62 & 16.9 \\
\hline 3509 & $8 / 12 / 20087: 26$ & 1.606 & 16.9 & 3578 & $8 / 12 / 20089: 44$ & 1.612 & 16.9 & 3647 & $8 / 12 / 2008$ 12:02 & 1.617 & 16.9 & 3716 & $8 / 12 / 200814: 20$ & 7.62 & 16.9 \\
\hline 3510 & $8 / 12 / 20087: 28$ & 1.601 & 16.9 & 3579 & $8 / 12 / 20089: 46$ & 1.614 & 17.1 & 3648 & $8 / 12 / 2008$ 12:04 & 1.617 & 16.9 & 3717 & $8 / 12 / 2008$ 14:22 & 1.621 & 16.9 \\
\hline 3511 & $8 / 12 / 20087: 30$ & 1.598 & 16.9 & 3580 & $8 / 12 / 20089: 48$ & 1.612 & 17 & 3649 & $8 / 12 / 200812: 06$ & 1.617 & 16.9 & 3718 & $8 / 12 / 200814: 24$ & 1.62 & 16.9 \\
\hline 3512 & $8 / 12 / 20087: 32$ & 1.594 & 16.9 & 3581 & $8 / 12 / 20089: 50$ & 1.614 & 16.9 & 3650 & $8 / 12 / 2008$ 12:08 & 1.616 & 16.9 & 3719 & $8 / 12 / 200814: 26$ & 1.621 & 16.9 \\
\hline 3513 & $8 / 1220087: 34$ & 1.591 & 16.9 & 3582 & $8 / 12 / 20089: 52$ & 1.614 & 16.9 & 3651 & $8 / 12 / 2008$ 12:10 & 1.618 & 16.9 & 3720 & $8 / 12 / 200814: 28$ & 1.621 & 16.9 \\
\hline 3514 & $8 / 12 / 20087: 36$ & 1.589 & 16.9 & 3583 & $8 / 12 / 20089: 54$ & 1.615 & 16.9 & 3652 & $8 / 12 / 2008$ 12:12 & 1.616 & 16.9 & 3721 & $8 / 12 / 200814: 30$ & 1.62 & 16.9 \\
\hline 3515 & $8 / 12220087: 38$ & 1.591 & 16.9 & 3584 & $8 / 12 / 20089: 56$ & 1.614 & 16.9 & 3653 & $8 / 12 / 2008$ 12:14 & 1.616 & 16.9 & 372 & $8 / 12200814: 32$ & 1.621 & 16.9 \\
\hline 3516 & $8 / 1220087: 40$ & 1.597 & 16.9 & 3585 & $8 / 12 / 20089: 58$ & 1.614 & 16.9 & 3654 & $8 / 12 / 200812: 16$ & 1.616 & 16.9 & 3723 & $8 / 12 / 200814: 34$ & 1.622 & 16.9 \\
\hline 3517 & $8 / 12 / 20087: 42$ & 1.601 & 16.9 & 3586 & $8 / 12 / 2008$ 10:00 & 1.614 & 16.9 & 3655 & $8 / 12 / 2008$ 12:18 & 1.618 & 16.9 & 3724 & $8 / 122008$ 14:36 & 1.622 & 16.9 \\
\hline 3518 & $8 / 1220087: 44$ & 1.604 & 16.9 & 3587 & $8 / 12 / 200810: 02$ & 1.614 & 16.9 & 3656 & $8 / 12 / 200812: 20$ & 1.618 & 16.9 & 3725 & $8 / 12 / 200814: 38$ & 1.623 & 16.9 \\
\hline 3519 & $8 / 12220087: 46$ & 1.605 & 16.9 & 3588 & $8 / 12 / 2008$ 10:04 & 1.615 & 16.9 & 3657 & $8 / 12 / 2008$ 12:22 & 1.618 & 16.9 & 3726 & $8 / 12 / 2008$ 14:40 & 1.622 & 16.9 \\
\hline 3520 & $8 / 12 / 20087: 48$ & 1.607 & 16.9 & 3589 & $8 / 12 / 200810: 06$ & 1.614 & 16.9 & 3658 & $8 / 12 / 200812: 24$ & 1.618 & 16.9 & 3727 & $8 / 12 / 200814: 42$ & 1.622 & 16.9 \\
\hline 3521 & $8 / 12 / 20087: 50$ & 1.608 & 16.9 & 3590 & $8 / 12 / 200810: 08$ & 1.614 & 16.9 & 3659 & $8 / 12 / 200812: 26$ & 1.619 & 16.9 & 3728 & $8 / 12 / 200814: 44$ & 1.621 & 16.9 \\
\hline 3522 & $8 / 12 / 20087: 52$ & 1.608 & 16.9 & 3591 & $8 / 12 / 200810: 10$ & 1.614 & 16.9 & 3660 & $8 / 12 / 200812: 28$ & 1.618 & 16.9 & 3729 & $8 / 12 / 200814: 46$ & 1.622 & 16.9 \\
\hline 3523 & $8 / 12 / 20087: 54$ & 1.609 & 16.9 & 3592 & $8 / 12 / 2008$ 10:12 & 1.613 & 16.9 & 3661 & $8 / 12 / 200812: 30$ & 1.619 & 16.9 & 3730 & $8 / 12 / 2008$ 14:48 & 1.622 & 16.9 \\
\hline 3524 & $8 / 12 / 20087: 56$ & 1.61 & 16.9 & 3593 & $8 / 12 / 2008$ 10:14 & 1.613 & 16.9 & 3662 & $8 / 12 / 2008$ 12:32 & 1.618 & 16.9 & 3731 & $8 / 12 / 2008$ 14:50 & 1.622 & 16.9 \\
\hline 3525 & $8 / 12 / 20087: 58$ & 1.608 & 16.9 & 3594 & $8 / 12 / 2008$ 10:16 & 1.614 & 16.9 & 3663 & $8 / 12 / 200812: 34$ & 1.619 & 16.9 & 3732 & $8 / 12 / 200$ & 1.622 & 16.9 \\
\hline 3526 & $8 / 12 / 20088: 00$ & 1.609 & 16.9 & 3595 & $8 / 12 / 200810: 18$ & 1.613 & 16.9 & 3664 & $8 / 12 / 200812: 36$ & 1.618 & 16.9 & 3733 & $8 / 12 / 200814: 54$ & 1.623 & 16.9 \\
\hline 3527 & $8 / 1220088: 02$ & 1.61 & 16.9 & 3596 & $8 / 12 / 200810: 20$ & 1.611 & 16.9 & 3665 & $8 / 12 / 200812: 38$ & 1.618 & 16.9 & 3734 & $8 / 12 / 200814: 56$ & 1.624 & 16.9 \\
\hline 3528 & $8 / 1220088: 04$ & 1.61 & 16.9 & 3597 & $8 / 12 / 200810: 22$ & 1.607 & 16.9 & 3666 & $8 / 12 / 200812: 40$ & 1.619 & 16.9 & 3735 & $8 / 12 / 2008$ 14:58 & 1.622 & 16.9 \\
\hline 3529 & $8 / 12 / 20088: 06$ & 1.61 & 16.9 & 3598 & $8 / 12 / 200810: 24$ & 1.602 & 16.9 & 3667 & $8 / 12 / 2008$ 12:42 & 1.619 & 16.9 & 3736 & $8 / 12 / 200815: 00$ & 1.623 & 16.9 \\
\hline 3530 & & 1.611 & 16.9 & 3599 & $8 / 12 / 200810: 26$ & 1.603 & 16.9 & 3668 & $8 / 12 / 200812: 44$ & 1.618 & 17.2 & 3737 & $8 / 12 / 20$ & 1.623 & 16.9 \\
\hline 3531 & $8 / 12 / 20$ & 1.612 & 16.9 & 3600 & $8 / 12 / 200810: 28$ & 1.606 & 16.9 & 3669 & $8 / 12 / 200812: 46$ & 1.619 & 17 & 3738 & $8 / 12 / 200815: 04$ & 1.623 & 16.9 \\
\hline 3532 & $8 / 12 / 200$ & 1.611 & 16.9 & 3601 & $8 / 12 / 2008$ 10:30 & 1.607 & 16.9 & 3670 & $8 / 12 / 200812: 48$ & 1.617 & 16.9 & 3739 & $8 / 122200815: 06$ & 1.623 & 16.9 \\
\hline 3533 & $8 / 12 / 200$ & 1.612 & 16.9 & 3602 & $8 / 12 / 2008$ 10:32 & 1.609 & 16.9 & 3671 & $8 / 12 / 200812 \cdot 50$ & 1.617 & 16.9 & 3740 & $8 / 12 / 20 x$ & 1.624 & 16.9 \\
\hline 3534 & $8 / 12 / 20088: 16$ & 1.611 & 16.9 & 3603 & $8 / 12 / 2008$ 10:34 & 1.611 & 16.9 & 3672 & $8 / 12 / 2008$ 12:52 & 1.618 & 16. & 3741 & $8 / 12 / 2008$ 15:10 & 1.623 & 16.9 \\
\hline 3535 & & 1.611 & 16.9 & 3604 & $8 / 12 / 2008$ 10:36 & 1.611 & 16.9 & 3673 & $8 / 12 / 200812: 54$ & 1.618 & 16. & 3742 & 15:12 & 1.622 & 16.9 \\
\hline 3536 & $8 / 12$ & 1.612 & 16.9 & 3605 & $8 / 12 / 2008$ 10:38 & 1.612 & 16.9 & 3674 & $8 / 12 / 200812: 56$ & 1.618 & 16. & 3743 & $8 / 12 / 2008$ 15:14 & 1.622 & 16.9 \\
\hline 3537 & $8 / 1220088: 22$ & 1.612 & 16.9 & 3606 & $8 / 12 / 200810: 40$ & 1.612 & 16.9 & 3675 & $8 / 12 / 200812: 58$ & 1.618 & 16. & 3744 & $8 / 12 / 2008$ 15:16 & 1.622 & 16.9 \\
\hline 3538 & $8 / 12 / 200$ & 1.611 & 16.9 & 3607 & $8 / 12 / 2008$ 10:42 & 1.613 & 16.9 & 3676 & $8 / 12 / 200813: 00$ & 1.618 & 16. & 3745 & $8 / 12 / 200$ & 1.623 & 16.9 \\
\hline 3539 & $8 / 12 / 20088: 26$ & 1.612 & 16.9 & 3608 & $8 / 12 / 2008$ 10:44 & 1.612 & 16.9 & 3677 & $8 / 12 / 200813: 02$ & 1.618 & 16. & 3746 & $8 / 12 / 2008$ 15:20 & 1.623 & 16.9 \\
\hline 3540 & $8 / 12$ & 1.611 & 16.9 & 3609 & $8 / 12 / 2008$ 10:46 & 1.613 & 16.9 & 3678 & $8 / 12 / 200813: 04$ & 1.618 & 16. & 3747 & $15: 22$ & 1.622 & 16.9 \\
\hline 3541 & $8 / 12$ & 1.612 & 16.9 & 3610 & $8 / 12 / 200810: 48$ & 1.613 & 16.9 & 3679 & $8 / 12 / 200813: 06$ & 1.618 & & 3748 & $8 / 12 / 200815: 24$ & 1.623 & 16.9 \\
\hline 3542 & $8 / 12 / 20088: 32$ & 1.611 & 16.9 & 3611 & $8 / 12 / 2008$ 10:50 & 1.613 & 16.9 & 3680 & $8 / 12 / 200813: 08$ & 1.615 & 16. & 3749 & $8 / 12 / 200815: 26$ & 1.624 & 16.9 \\
\hline 3543 & & 1.612 & 16.9 & 3612 & $8 / 12 / 2008$ 10:52 & 1.613 & 16.9 & 3681 & $8 / 12 / 2008$ 13:10 & 1.612 & 16. & 3750 & $8 / 12 / 2008$ 15:28 & 1.623 & 16.9 \\
\hline 3544 & 8/12/2008 8:36 & 1.613 & 16.9 & 3613 & $8 / 12 / 200810: 54$ & 1.613 & 16.9 & 3682 & $8 / 12 / 2008$ 13:12 & 1.607 & 16.8 & 3751 & $8 / 12 / 200815: 30$ & 1.614 & 16.9 \\
\hline 3545 & $8 / 12 / 20088: 38$ & 1.613 & 16.9 & 3614 & $8 / 12 / 200810: 56$ & 1.613 & 16.9 & 3683 & $8 / 12 / 200813: 14$ & 1.609 & 16. & 3752 & $8 / 12 / 20$ & 1.623 & 16.9 \\
\hline 3546 & $8 / 12 / 2$ & 1.613 & 16.9 & 3615 & $8 / 12 / 200810: 58$ & 1.613 & 16.9 & 3684 & $8 / 12 / 200813: 16$ & 1.613 & 16 & 3753 & $8 / 12 / 20$ & 1.621 & 16.9 \\
\hline 3547 & $8 / 12 / 20088: 42$ & 1.613 & 16.9 & 3616 & $8 / 12 / 2008$ 11:00 & 1.614 & 16.9 & 3685 & $8 / 12 / 2008$ 13:18 & 1.613 & 16.9 & 3754 & $8 / 12 / 2008$ 15:36 & 1.625 & 16.9 \\
\hline 3548 & $8 / 1220088: 44$ & 1.614 & 16.9 & 3617 & $8 / 12 / 2008$ 11:02 & 1.614 & 16.9 & 3686 & $8 / 12 / 200813: 20$ & 1.615 & 16.9 & 3755 & $8 / 12 / 200815 \cdot 38$ & 1.625 & 16.9 \\
\hline 3549 & $8 / 12 / 20088: 46$ & 1.614 & 16.9 & 3618 & $8 / 12 / 2008$ 11:04 & 1.615 & 16.9 & 3687 & $8 / 12 / 2008$ 13:22 & 1.617 & 16. & 3756 & $8 / 12 / 200815: 40$ & 1.625 & 16.9 \\
\hline 3550 & $8 / 12 / 20088: 48$ & 1.613 & 16.9 & 3619 & $8 / 12 / 2008$ 11:06 & 1.614 & 16.9 & 3688 & $8 / 12 / 200813: 24$ & 1.616 & 16. & 3757 & $8 / 12 / 2008$ 15:42 & 1.626 & 16.9 \\
\hline 3551 & $8 / 12 / 20088: 50$ & 1.613 & 16.9 & 3620 & $8 / 12 / 2008$ 11:08 & 1.614 & 16.9 & 3689 & $8 / 12 / 200813: 26$ & 1.617 & 16. & 3758 & $8 / 12 / 200815: 44$ & 1.626 & 16.9 \\
\hline 3552 & $8 / 12 / 20088: 52$ & 1.613 & 16.9 & 3621 & $8 / 12 / 2008+1: 10$ & 1.614 & 16.9 & 3690 & $8 / 12 / 200813: 28$ & 1.617 & 16. & 3759 & $8 / 12 / 200815: 46$ & 1.626 & 16.9 \\
\hline 3553 & $8 / 12 / 20088: 54$ & 1.614 & 16.9 & 3622 & $8 / 12 / 2008$ 11:12 & 1.614 & 16.9 & 3691 & $8 / 12 / 200813: 30$ & 1.616 & 16 . & 3760 & $8 / 12200815: 48$ & 1.626 & 16.9 \\
\hline 3554 & $8 / 1220088: 56$ & 1.613 & 16.9 & 3623 & $8 / 12 / 2008$ 11:14 & 1.614 & 16.9 & 3692 & $8 / 12 / 2008$ 13:32 & 1.618 & 16. & 3761 & $8 / 12200815: 50$ & 1.625 & 16.9 \\
\hline 3555 & $8 / 1220088: 58$ & 1.613 & 16.9 & 3624 & $8 / 12 / 200811: 16$ & 1.615 & 16.9 & 3693 & $8 / 12 / 200813: 34$ & 1.618 & 16.9 & 3762 & $8 / 12 / 200815: 52$ & 1.623 & 16.9 \\
\hline
\end{tabular}


DOE/RL-2009-35, REV. 0

\begin{tabular}{|c|c|c|c|}
\hline \multicolumn{4}{|c|}{$D 4-27 p$} \\
\hline $\operatorname{Rec}$ & & Pres & Temp \\
\hline \# & Date/Time & psi & ${ }^{\circ} \mathrm{C}$ \\
\hline 3763 & $8 / 12 / 200815: 54$ & 1.619 & 16.9 \\
\hline 3764 & $8 / 12 / 200815: 56$ & 1.616 & 16.9 \\
\hline 3765 & $8 / 12 / 200815: 58$ & 1.617 & 16.9 \\
\hline 3766 & $8 / 12 / 200816: 00$ & 1.619 & 16.9 \\
\hline 3767 & $8 / 12 / 200816: 02$ & 1.621 & 16.9 \\
\hline 3768 & $8 / 12 / 2008$ 16:04 & 1.622 & 16.9 \\
\hline 3769 & $8 / 12 / 2008$ 16:06 & 1.623 & 16.9 \\
\hline 3770 & $8 / 12 / 200816: 08$ & 1.622 & 16.9 \\
\hline 3771 & $8 / 12 / 200816: 10$ & 1.623 & 16.9 \\
\hline 3772 & $8 / 12 / 200816: 12$ & 1.623 & 16.9 \\
\hline 3773 & $8 / 12 / 2008$ 16:14 & 1.624 & 16.9 \\
\hline 3774 & $8 / 12 / 2008$ 16:16 & 1.623 & 16.9 \\
\hline 3775 & $8 / 12 / 200816: 18$ & 1.624 & 16.9 \\
\hline 3776 & $8 / 12 / 200816: 20$ & 1.624 & 16.9 \\
\hline $37 \pi$ & $8 / 12 / 200816: 22$ & 1.624 & 16.9 \\
\hline 3778 & $8 / 12 / 200816: 24$ & 1.624 & 16.9 \\
\hline 3779 & $8 / 12 / 200816: 26$ & 1.624 & 16.9 \\
\hline 3780 & $8 / 12 / 200816: 28$ & 1.624 & 16.9 \\
\hline 3781 & $8 / 12 / 200816: 30$ & 1.625 & 16.9 \\
\hline 3782 & $8 / 12 / 200816: 32$ & 1.625 & 16.9 \\
\hline 3783 & $8 / 12 / 200816: 34$ & 1.625 & 16.9 \\
\hline 3784 & $8 / 12 / 200816: 36$ & 1.624 & 16.9 \\
\hline 3785 & $8 / 12 / 200816: 38$ & 1.626 & 16.9 \\
\hline 3786 & $8 / 12 / 200816: 40$ & 1.625 & 16.9 \\
\hline 3787 & $8 / 12 / 200816: 42$ & 1.626 & 16.9 \\
\hline 3788 & $8 / 12 / 2008$ 16:44 & 1.627 & 16.9 \\
\hline 3789 & $8 / 12 / 2008$ 16:46 & 1.626 & 16.9 \\
\hline 3790 & $8 / 12 / 2008$ 16:48 & 1.626 & 16.5 \\
\hline 3791 & $8 / 12 / 2008$ 16:50 & 1.625 & 16.9 \\
\hline 3792 & $8 / 12 / 200816: 52$ & 1.625 & 16.9 \\
\hline 3793 & $8 / 12 / 2008$ 16:54 & 1.624 & 16.9 \\
\hline 3794 & $8 / 12 / 2008$ 16:56 & 1.626 & 16.9 \\
\hline 3795 & $8 / 12 / 200816: 58$ & 1.626 & 16.9 \\
\hline 3796 & $8 / 12 / 2008$ 17:00 & 1.626 & 16.9 \\
\hline 3797 & $8 / 12 / 2008$ 17:02 & 1.626 & 16.9 \\
\hline 3798 & $8 / 12 / 200817: 04$ & 1.626 & 16.9 \\
\hline 3799 & $8 / 12 / 2008$ 17:06 & 1.627 & 16.9 \\
\hline 3800 & $8 / 12 / 2008$ 17:08 & 1.626 & 16.9 \\
\hline 3801 & $8 / 12 / 2008$ 17:10 & 1.628 & 16.9 \\
\hline 3802 & $8 / 12 / 2008$ 17:12 & 9.627 & $\overline{17.4}$ \\
\hline 3803 & $8 / 12 / 200817: 14$ & 1.626 & 17.1 \\
\hline 3804 & $8 / 12 / 2008$ 17:16 & 1.626 & 17 \\
\hline 3805 & $8 / 12 / 2008$ & 1.626 & 16.9 \\
\hline 3806 & $8 / 12 / 2008$ 17:20 & 1.626 & 16.9 \\
\hline 3807 & $8 / 12 / 2008$ 17:22 & 1.627 & 16.5 \\
\hline 3808 & $8 / 12 / 2008$ & 1.627. & 16.9 \\
\hline 3809 & $8 / 12 / 200817: 26$ & 9.626 & 16.9 \\
\hline 3810 & $8 / 12 / 2008$ 17:28 & 9.626 & 16.9 \\
\hline 3811 & $8 / 12 / 2008$ 17:30 & 1.626 & 16.9 \\
\hline 3812 & $8 / 12 / 2008$ 17:32 & 1.626 & 16.9 \\
\hline 3813 & $8 / 12 / 2008$ & 1.627 & 16.9 \\
\hline 3814 & $8 / 12 / 2008$ & 1.627 & 16.9 \\
\hline 3815 & $8 / 12 / 200817: 38$ & 1.628 & 16.9 \\
\hline 3816 & $8 / 12 / 2008$ & 1.627. & 16.9 \\
\hline 3817 & $8 / 12 / 2008$ 17:42 & 1.627 & 16.9 \\
\hline 3818 & $8 / 12 / 2008$ 17:44 & 1.627 & 16.9 \\
\hline 3819 & $8 / 12 / 200817: 46$ & 7.627 & 16.9 \\
\hline 3820 & $8 / 12 / 2008$ 17:48 & 1.628 & 16.9 \\
\hline 3821 & $8 / 12 / 2008$ 17:50 & 1.627 & 16.9 \\
\hline 3822 & $8 / 12 / 2008$ 17:52 & 1.627 & 16.9 \\
\hline 3823 & $8 / 12 / 2008$ 17:54 & 1.626 & 16.9 \\
\hline 3824 & $8 / 12 / 2008$ 17:56 & 1.626 & 16.9 \\
\hline 3825 & $8 / 122008$ 17:58 & 1.626 & 16.9 \\
\hline 3826 & $8 / 12 / 2008$ 18:00 & 1.627 & 16.9 \\
\hline 3827 & $8 / 122200818: 02$ & 1.628 & 16.9 \\
\hline 3828 & $8 / 12 / 2008$ 18:04 & 1.628 & 16.9 \\
\hline 3829 & $8 / 12 / 200818: 06$ & 1.626 & 16.9 \\
\hline 3830 & $8 / 12 / 200818: 08$ & 1.627 & 16.9 \\
\hline 3831 & $8 / 12 / 200818: 10$ & 1.627 & 16. \\
\hline
\end{tabular}

\begin{tabular}{|c|c|c|c|}
\hline \multicolumn{4}{|c|}{$D 4-27 p$} \\
\hline $\operatorname{Rec}$ & & Pres & Temp \\
\hline$\#$ & DateTime & $p s i$ & ${ }^{\circ} \mathrm{C}$ \\
\hline 3832 & 8/12/2008 18:12 & 1.627 & 16.9 \\
\hline 3833 & $8 / 12 / 200818: 14$ & 1.627 & 16.9 \\
\hline 3834 & $8 / 12 / 200818: 16$ & 1.627 & 16.9 \\
\hline 3835 & $8 / 12 / 2008$ 18:18 & 1.627 & 16.9 \\
\hline 3836 & $8 / 12 / 2008$ 18:20 & 1.627 & 16.9 \\
\hline 3837 & $8 / 12 / 200818: 22$ & 1.627 & 16.9 \\
\hline 3838 & $8 / 12 / 2008$ 18:24 & 1.627 & 16.9 \\
\hline 3839 & $8 / 12 / 200818: 26$ & 1.627 & 16.9 \\
\hline 3840 & $8 / 12 / 200818: 28$ & 1.627 & 16.9 \\
\hline 3841 & $8 / 12 / 200818: 30$ & 1.627 & 16.9 \\
\hline 3842 & $8 / 12 / 200818: 32$ & 1.628 & 16.9 \\
\hline 3843 & $8 / 12 / 200818: 34$ & 1.628 & 16.9 \\
\hline 3844 & $8 / 12 / 2008$ 18:36 & 1.628 & 16.9 \\
\hline 3845 & $8 / 12 / 200818: 38$ & 1.625 & 16.9 \\
\hline 3846 & $8 / 12 / 200818: 40$ & 1.621 & 16.9 \\
\hline 3847 & $8 / 12 / 200818: 42$ & 1.618 & 16.9 \\
\hline 3848 & $8 / 12 / 200818: 44$ & 1.619 & 16.9 \\
\hline 3849 & $8 / 12 / 200818: 46$ & 1.622 & 16.9 \\
\hline 3850 & $8 / 12 / 200818: 48$ & 1.623 & 16.9 \\
\hline 3851 & $8 / 12 / 200818: 50$ & 1.623 & 16.9 \\
\hline 3852 & $8 / 12 / 200818: 52$ & 1.625 & 16.9 \\
\hline 3853 & $8 / 12 / 200818: 54$ & 1.625 & 16.9 \\
\hline 3854 & $8 / 12 / 200818: 56$ & 1.625 & 16.9 \\
\hline 3855 & $8 / 12 / 200818: 58$ & 1.625 & 16.9 \\
\hline 3856 & $8 / 12 / 200819: 00$ & 1.626 & 16.9 \\
\hline 3857 & $8 / 12 / 200819: 02$ & 1.625 & 16.9 \\
\hline 3858 & $8 / 12 / 200819: 04$ & 1.626 & 16.9 \\
\hline 3859 & $8 / 12 / 200819.06$ & 1.626 & 16.9 \\
\hline 3860 & $8 / 12 / 200819: 08$ & 1.626 & 16.9 \\
\hline 3861 & $8 / 12 / 200819: 10$ & 1.626 & 16.9 \\
\hline 3862 & $8 / 12 / 200819.12$ & 1.627 & 16.9 \\
\hline 3863 & $8 / 12 / 200819.14$ & 1.625 & 16.9 \\
\hline 3864 & $8 / 12 / 200819: 16$ & 1.626 & 16.9 \\
\hline 3865 & $8 / 12 / 200819.18$ & 1.626 & 16.9 \\
\hline 3866 & $8 / 12 / 200819.20$ & 1.626 & 16.9 \\
\hline 3867 & $8 / 12 / 200819.22$ & 1.627 & 16.9 \\
\hline 3868 & $8 / 12 / 200819.24$ & 1.627 & 16.9 \\
\hline 3869 & $8 / 12 / 200819.26$ & 1.626 & 16.9 \\
\hline 3870 & $8 / 12 / 200819.28$ & 1.626 & 16.9 \\
\hline 3871 & $8 / 12 / 200819.30$ & 1.626 & 16.9 \\
\hline 3872 & $8 / 12 / 200819.32$ & 1.625 & 16.9 \\
\hline 3873 & $8 / 12 / 200819.34$ & 1.626 & 16.9 \\
\hline 3874 & $8 / 12 / 200819.36$ & 1.626 & 16.9 \\
\hline 3875 & $8 / 12 / 200819: 38$ & 1.624 & 16.9 \\
\hline 3876 & $8 / 12 / 200819: 40$ & 1.625 & 16.9 \\
\hline 3877 & $8 / 12 / 200819: 42$ & 1.629 & 16.9 \\
\hline 3878 & $8 / 12 / 200819.44$ & 1.619 & 16.9 \\
\hline 3879 & $8 / 12 / 200819.46$ & 1.625 & 16.9 \\
\hline 3880 & $8 / 12 / 200819: 48$ & 1.625 & 16.9 \\
\hline 3881 & $8 / 12 / 2000819.50$ & 1.625 & 16.9 \\
\hline 3882 & $8 / 12 / 200819.52$ & 1.625 & 16.9 \\
\hline 3883 & $8 / 12 / 200819: 54$ & 1.625 & 16.9 \\
\hline 3884 & $8 / 12 / 200819.56$ & 1.624 & 16.9 \\
\hline 3885 & $8 / 12 / 200819.58$ & 1.625 & 16.9 \\
\hline 3886 & $8 / 12 / 200820: 00$ & 1.624 & 16.9 \\
\hline 3887 & $8 / 12 / 200820: 02$ & 1.625 & 16.9 \\
\hline 3888 & $8 / 12 / 200820: 04$ & 1.625 & 16.9 \\
\hline 3889 & $8 / 12 / 200820: 06$ & 1.625 & 16.9 \\
\hline 3890 & $8 / 12 / 200820: 08$ & 1.624 & 16.9 \\
\hline 3891 & $8 / 12 / 200820: 10$ & 1.624 & 16.9 \\
\hline 3892 & $8 / 12 / 200820.12$ & 1.624 & 16.9 \\
\hline 3893 & $8 / 12 / 200820: 14$ & 1.624 & 16.9 \\
\hline 3894 & $8 / 12 / 200820: 16$ & 1.625 & 16.9 \\
\hline 3895 & $8 / 12 / 200820: 18$ & 1.625 & 16.9 \\
\hline 3896 & $8 / 12 / 200820.20$ & 1.625 & 16.9 \\
\hline 3697 & $8 / 12 / 200820.22$ & 1.625 & 16.9 \\
\hline 3898 & $8 / 12 / 200820: 24$ & 1.626 & 16.9 \\
\hline 3890 & $8 / 12 / 200820: 26$ & 1.626 & 16.9 \\
\hline 3900 & $8 / 12 / 200820: 28$ & 1.625 & 16.9 \\
\hline
\end{tabular}

\begin{tabular}{|c|c|c|c|}
\hline \multicolumn{4}{|c|}{ D427p } \\
\hline $\mathrm{Rec}$ & & Pres & Temp \\
\hline \# & Date/Time & psi & ${ }^{\circ} \mathrm{C}$ \\
\hline 3901 & $8 / 12 / 200820: 30$ & 1.625 & 16.9 \\
\hline 3902 & $8 / 12 / 200820: 32$ & 1.625 & 16.9 \\
\hline 3903 & $8 / 12 / 200820: 34$ & 1.625 & 16.9 \\
\hline 3904 & $8 / 12 / 200820: 36$ & 1.626 & 16.9 \\
\hline 3905 & $8 / 12 / 200820: 38$ & 1.626 & 16.9 \\
\hline 3906 & $8 / 12 / 200820: 40$ & 1.625 & 16.9 \\
\hline 3907 & $8 / 12 / 200820: 42$ & 1.624 & 16.9 \\
\hline 3908 & $8 / 12 / 200820: 44$ & 1.625 & 16.9 \\
\hline 3909 & $8 / 12 / 200820: 46$ & 1.626 & 16.9 \\
\hline 3910 & $8 / 12 / 200820: 48$ & 1.625 & 16.9 \\
\hline 3911 & $8 / 12 / 200820: 50$ & 1.625 & 16.9 \\
\hline 3912 & $8 / 12 / 200820: 52$ & 1.625 & 16.9 \\
\hline 3913 & $8 / 12 / 200820: 54$ & 1.624 & 16.9 \\
\hline 3914 & $8 / 12 / 200820: 56$ & 1.625 & 16.9 \\
\hline 3915 & $8 / 12 / 200820.58$ & 1.625 & 16.9 \\
\hline 3916 & $8 / 12 / 200821: 00$ & 1.625 & 16.9 \\
\hline 3917 & $8 / 12 / 200821: 02$ & 1.626 & 16.9 \\
\hline 3918 & $8 / 12 / 200821: 04$ & 1.626 & 16.9 \\
\hline 3919 & $8 / 12 / 200821: 06$ & 1.626 & 16.9 \\
\hline 3920 & $8 / 12 / 200821: 08$ & 1.626 & 16.9 \\
\hline 3921 & $8 / 12 / 200821: 10$ & 1.626 & 16.9 \\
\hline 3922 & $8 / 12 / 200821: 12$ & 1.626 & 16. \\
\hline 3923 & $8 / 12 / 200821: 14$ & 1.626 & 16.5 \\
\hline 3924 & $8 / 12 / 200821: 16$ & 1.626 & 16. \\
\hline 3925 & $8 / 12 / 200821: 18$ & 1.626 & 16. \\
\hline 3926 & $8 / 12 / 200821: 20$ & 1.626 & 16.9 \\
\hline 3927 & $8 / 12 / 200821: 22$ & 1.627 & 16. \\
\hline 3928 & $8 / 12 / 200821: 24$ & 1.626 & 16. \\
\hline 3929 & $8 / 12 / 200821: 26$ & 1.626 & 16. \\
\hline 3930 & $8 / 12 / 200821: 28$ & 1.623 & 16. \\
\hline 3931 & $8 / 12 / 200821: 30$ & 1.62 & 16.9 \\
\hline 3932 & $8 / 12 / 200821: 32$ & 1.615 & 16.9 \\
\hline 3933 & $8 / 12 / 200821: 34$ & 1.612 & 16. \\
\hline 3934 & $8 / 12 / 200821: 36$ & 1.614 & 16. \\
\hline 3935 & $8 / 12 / 200$ & 1.617 & 16. \\
\hline 3936 & $8 / 12 / 200821: 40$ & 1.619 & 16. \\
\hline 3937 & $8 / 12 / 200821: 42$ & 1.62 & 16. \\
\hline 3938 & $8 / 12 / 200$ & 1.621 & 16. \\
\hline 3939 & $8 / 12 / 200821: 46$ & 1.622 & 16. \\
\hline 3940 & $8 / 12 / 200821: 48$ & 1.622 & 16. \\
\hline 3941 & $8 / 12 / 200$ & 1.624 & 16. \\
\hline 3942 & $8 / 12 / 200821: 52$ & 1.624 & 16.5 \\
\hline 3943 & $8 / 12 / 200821: 54$ & 1.625 & 16. \\
\hline 3944 & $8 / 12 / 200821: 56$ & 1.624 & 16. \\
\hline 3945 & $8 / 12 / 200821: 58$ & 1.624 & 16. \\
\hline 3946 & $8 / 12 / 200$ & 1.625 & 16. \\
\hline 3947 & $8 / 12 / 200822: 02$ & 1.625 & 16. \\
\hline 3948 & $8 / 12 / 200$ & 1.624 & 16. \\
\hline 3949 & 322:06 & 1.625 & 16. \\
\hline 3950 & $8 / 12 / 200$ & 1.625 & 16. \\
\hline 3951 & $22: 10$ & 1.625 & 16. \\
\hline 3952 & $8 / 12 / 200$ & 1.624 & 16. \\
\hline 3953 & $8 / 12 / 200822: 14$ & 1.625 & 16. \\
\hline 3954 & $8 / 12 / 200$ & 1.624 & 16. \\
\hline 3955 & $8 / 12 / 200$ & 1.625 & 16. \\
\hline 3956 & $8 / 12 / 200822: 20$ & 1.625 & 17. \\
\hline 3957 & $8 / 12 / 200822: 22$ & 1.625 & 17. \\
\hline 3958 & $22: 24$ & 1.626 & \\
\hline 3959 & $8 / 12 / 200822: 26$ & 1.625 & 16. \\
\hline 3960 & $8 / 12 / 200822: 28$ & 1.625 & 16. \\
\hline 3961 & $8 / 12 / 200822: 30$ & 1.625 & 16. \\
\hline 3962 & $8 / 12 / 200822: 32$ & 1.626 & 16. \\
\hline 3963 & $8 / 12 / 200822: 34$ & 1.626 & 16.5 \\
\hline 3964 & $8 / 12 / 200822: 36$ & 1.625 & $\overline{16 .}$ \\
\hline 3965 & $8 / 12 / 200822: 38$ & 1.624 & 16.9 \\
\hline 3966 & $8 / 12 / 200822: 40$ & 1.623 & 16.9 \\
\hline 3967 & $8 / 12 / 200822: 42$ & 1.624 & 16.9 \\
\hline 3968 & $8 / 12 / 200822: 44$ & 1.623 & 16.9 \\
\hline 3969 & $8 / 12 / 200822: 46$ & 1.625 & 16. \\
\hline
\end{tabular}

\begin{tabular}{|c|c|c|c|}
\hline \multicolumn{4}{|c|}{ D427p } \\
\hline $\operatorname{ReC}$ & & Pres & Termp \\
\hline \# & Date/Time & psi & ${ }^{\circ} \mathrm{C}$ \\
\hline 3970 & $8 / 12 / 200822: 48$ & 1.624 & 16.9 \\
\hline 3971 & $8 / 122200822: 50$ & 1.624 & 16.9 \\
\hline 3972 & $8 / 12 / 200822: 52$ & 1.624 & 16.9 \\
\hline 3973 & $8 / 12200822: 54$ & 1.624 & 16.9 \\
\hline 3974 & $8 / 12 / 200822: 56$ & 1.624 & 16.9 \\
\hline 3975 & $8 / 12200822: 58$ & 1.623 & 16.9 \\
\hline 3976 & $8 / 12200823: 00$ & 1.624 & 16.9 \\
\hline 3977 & $8 / 12200823: 02$ & 1.624 & 16.9 \\
\hline 3978 & $8 / 12 / 200823: 04$ & 1.624 & 16.9 \\
\hline 3979 & $8 / 12200823: 06$ & 1.624 & 16.9 \\
\hline 3980 & $8 / 12 / 200823: 08$ & 1.624 & 16.9 \\
\hline 3981 & $8 / 12 / 200823: 10$ & 1.623 & 16.9 \\
\hline 3982 & $8 / 12 / 200823: 12$ & 1.624 & 16.9 \\
\hline 3983 & $8 / 12 / 200823: 14$ & 1.624 & 16.9 \\
\hline 3984 & $8 / 12 / 200823: 16$ & 1.625 & 16.9 \\
\hline 3985 & $8 / 12 / 200823: 18$ & 1.625 & 16.9 \\
\hline 3986 & $8 / 121200823: 20$ & 1.625 & 16.9 \\
\hline 3987 & $8 / 12200823: 22$ & 1.625 & 16.9 \\
\hline 3988 & $8 / 12200823: 24$ & 1.624 & 16.9 \\
\hline 3989 & $8 / 12 / 200823: 26$ & 1.596 & 16.9 \\
\hline 3990 & $8 / 12 / 200823: 28$ & 1.624 & 16.9 \\
\hline 3991 & $8 / 12200823: 30$ & 1.625 & 16.9 \\
\hline 3992 & $8 / 12 / 200823: 32$ & 1.625 & 16.9 \\
\hline 3993 & $8 / 12 / 200823: 34$ & 1.625 & 16.9 \\
\hline 3994 & $8 / 12 / 200823: 36$ & 1.626 & 16.9 \\
\hline 3995 & $8 / 12 / 200823: 38$ & 1.625 & 16.9 \\
\hline 3996 & $8 / 12 / 200823: 40$ & 1.626 & 16.9 \\
\hline 3997 & $8 / 12 / 200823: 42$ & 1.626 & 16.9 \\
\hline 3998 & $8 / 12 / 200823: 44$ & 1.627 & 16.9 \\
\hline 3999 & $8 / 12 / 200823: 46$ & 1.627 & 16.9 \\
\hline 4000 & $8 / 12 / 200823: 48$ & 1.626 & 16.9 \\
\hline 4001 & $8 / 12 / 200823: 50$ & 1.627 & 16.9 \\
\hline 4002 & $8 / 12 / 200823: 52$ & 1.628 & 16.9 \\
\hline 4003 & $8 / 12 / 200823: 54$ & 1.627 & 16.9 \\
\hline 4004 & $8 / 12 / 200823: 56$ & 1.625 & 16.9 \\
\hline 4005 & $8 / 12 / 200823: 58$ & 1.626 & 16.9 \\
\hline 4006 & $8 / 13 / 20080: 00$ & 1.626 & 16.9 \\
\hline 4007 & $8 / 13 / 20080: 02$ & 1.625 & 16.9 \\
\hline 4008 & $8 / 13 / 20080: 04$ & 1.625 & 16.9 \\
\hline 4009 & $8 / 13 / 20080,06$ & 1.625 & 16.9 \\
\hline 4010 & $8 / 13 / 20080: 08$ & 1.627 & 16.9 \\
\hline 4011 & $8 / 13 / 20080.10$ & 1.626 & 16.9 \\
\hline 4012 & $8 / 13 / 20080: 12$ & 1.625 & 16.9 \\
\hline 4013 & $8 / 13 / 20080: 14$ & 1.625 & 16.9 \\
\hline 4014 & $8 / 13 / 20080: 16$ & 1.62 & 16.9 \\
\hline 4015 & $8 / 13 / 20080.18$ & 1.615 & 16.9 \\
\hline 4016 & $8 / 13 / 20080: 20$ & 1.611 & 16.9 \\
\hline 4017 & $8 / 13 / 20080: 22$ & 1.611 & 16.9 \\
\hline 4018 & $8 / 13 / 20080.24$ & 1.613 & 16.9 \\
\hline 4019 & $8 / 13 / 20080: 26$ & 1.616 & 16.9 \\
\hline 4020 & $8 / 13 / 20080: 28$ & 1.617 & 16.9 \\
\hline 4021 & $8 / 13 / 20080: 30$ & 1.619 & 16.9 \\
\hline 4022 & $8 / 13 / 20080.32$ & 1.62 & 16.9 \\
\hline 4023 & $8 / 13 / 20080: 34$ & 1.622 & 16.9 \\
\hline 4024 & $8 / 13 / 20080.36$ & 1.623 & 16.9 \\
\hline 4025 & $8 / 13 / 20080: 38$ & 1.622 & 16.9 \\
\hline 4026 & $8 / 13 / 20080: 40$ & 1.623 & 16.9 \\
\hline 4027 & $8 / 13 / 20080: 42$ & 1.623 & 16.9 \\
\hline 4028 & $8 / 13 / 20080: 44$ & 1.624 & 16.9 \\
\hline 4029 & $8 / 13 / 20080: 46$ & 1.624 & 16.9 \\
\hline 4030 & $8 / 13 / 20080: 48$ & 1.625 & 16.9 \\
\hline 4031 & $8 / 13 / 20080: 50$ & 1.624 & 16.9 \\
\hline 4032 & $8 / 13 / 20080.52$ & 1.624 & 16.9 \\
\hline 4033 & $8 / 13 / 20080: 54$ & 1.624 & 16.9 \\
\hline 4034 & $8 / 13 / 20080.56$ & 1.624 & 16.9 \\
\hline 4035 & $8 / 13 / 20080: 58$ & 1.624 & 16.9 \\
\hline 4036 & $8 / 13 / 20081: 00$ & 1.623 & 16.9 \\
\hline 4037 & $8 / 13 / 20081: 02$ & 1.623 & 16.9 \\
\hline 4038 & $8 / 13 / 20081: 04$ & 1.623 & 16.9 \\
\hline
\end{tabular}


DOE/RL-2009-35, REV. 0

\begin{tabular}{|c|c|c|c|c|c|c|c|c|c|c|c|c|c|c|c|}
\hline \multicolumn{4}{|c|}{ D4-27p } & \multicolumn{4}{|c|}{ D4-27p } & \multicolumn{4}{|c|}{ D4-27p } & \multicolumn{4}{|c|}{$D 427 p$} \\
\hline $\operatorname{Rec}$ & & Pres & Temp & $\operatorname{Rec}$ & & Pres & Temp & $\operatorname{Rec}$ & & Pres & Temp & $\operatorname{Rec}$ & & Pres & Ternp \\
\hline$\#$ & Date/Time & psi & ${ }^{\circ} \mathrm{C}$ & $\#$ & Date/Time & psi & ${ }^{\circ} \mathrm{C}$ & $\#$ & Date/Time & psi & ${ }^{\circ} \mathrm{C}$ & $\#$ & Date/Time & psi & ${ }^{\circ} \mathrm{C}$ \\
\hline 4039 & $8 / 13 / 20081: 06$ & 1.623 & 16.9 & 4108 & $8 / 13 / 20083: 24$ & 1.622 & 16.9 & 4177 & $8 / 13 / 20085: 42$ & 1.623 & 16.9 & 4246 & $8 / 13 / 20088: 00$ & 1.622 & 16.9 \\
\hline 4040 & $8 / 13 / 2008+: 08$ & 1.624 & 16.9 & 4109 & $8 / 13 / 20083: 26$ & 1.622 & 16.9 & 4178 & $8 / 13 / 20085: 44$ & 1.624 & 16.9 & 4247 & $8 / 13 / 20088: 02$ & 1.619 & 16.9 \\
\hline 4041 & $8 / 13 / 20081: 10$ & 1.624 & 16.9 & 4110 & $8 / 13 / 20083: 28$ & 1.621 & 16.9 & 4179 & $8 / 13 / 20085: 46$ & 1.624 & 16.9 & 4248 & $8 / 13 / 20088: 04$ & 1.622 & 16.9 \\
\hline 4042 & $8 / 13 / 20081: 12$ & 1.624 & 16.9 & 4111 & $8 / 13 / 20083: 30$ & 1.621 & 16.9 & 4180 & $8 / 13 / 20085: 48$ & 1.623 & 16.9 & 4249 & $8 / 13 / 20088: 06$ & 1.622 & 16.9 \\
\hline 4043 & $8 / 13 / 20081: 14$ & 1.624 & 16.9 & 4112 & $8 / 13 / 20083: 32$ & 1.62 & 16.9 & 4181 & $8 / 13 / 20085: 50$ & 1.624 & 16.9 & 4250 & $8 / 13 / 20088: 08$ & 1.621 & 16.9 \\
\hline 4044 & $8 / 13 / 20081: 16$ & 1.625 & 16.9 & 4113 & $8 / 13 / 20083: 34$ & 1.621 & 16.9 & 4182 & $8 / 13 / 20085: 52$ & 1.623 & 16.9 & 4251 & $8 / 13 / 20088: 10$ & 1.621 & 16.9 \\
\hline 4045 & $8 / 13 / 20081: 18$ & 1.624 & 16.9 & 4114 & $8 / 13 / 20083: 36$ & 1.621 & 16.9 & 4183 & $8 / 13 / 20085: 54$ & 1.622 & 16.9 & 4252 & $8 / 13 / 20088: 12$ & 1.62 & 16.9 \\
\hline 4046 & $8 / 13 / 20081: 20$ & 1.624 & 16.9 & 4115 & $8 / 13 / 20083: 38$ & 1.622 & 16.9 & 4184 & 8/13/20085:56 & 1.619 & 16.9 & 4253 & $8 / 13 / 20088: 14$ & 1.621 & 16.9 \\
\hline 4047 & $8 / 13 / 20081: 22$ & 1.625 & 16.9 & 4116 & $8 / 13 / 20083: 40$ & 1.621 & 16.9 & 4185 & $8 / 13 / 20085: 58$ & 1.615 & 16.9 & 4254 & $8 / 13 / 20088: 16$ & 1.622 & 16.9 \\
\hline 4048 & $8 / 13 / 20081: 24$ & 1.624 & 16.9 & 4117 & $8 / 13 / 20083: 42$ & 1.621 & 16.9 & 4186 & $8 / 13 / 20086: 00$ & 1.611 & 16.9 & 4255 & $8 / 13 / 20088: 18$ & 1.622 & 16.9 \\
\hline 4049 & $8 / 13 / 20081: 26$ & 1.624 & 16.9 & 4118 & $8 / 13 / 20083: 44$ & 1.622 & 16.9 & 4187 & $8 / 13 / 20086: 02$ & 1.611 & 16.9 & 4256 & $8 / 13 / 20088: 20$ & 1.621 & 16.9 \\
\hline 4050 & $8 / 13 / 20081: 28$ & 1.625 & 16.9 & 4119 & $8 / 13 / 20083: 46$ & 1.622 & 16.9 & 4188 & $8 / 13 / 20086: 04$ & 1.613 & 16.9 & 4257 & $8 / 13 / 20088: 22$ & 1.62 & 16.9 \\
\hline 4051 & $8 / 13 / 20081: 30$ & 1.625 & 16.9 & 4120 & $8 / 13 / 20083: 48$ & 1.623 & 16.9 & 4189 & $8 / 13 / 20086: 06$ & 1.616 & 16.9 & 4258 & $8 / 13 / 20088: 24$ & 1.62 & 16.9 \\
\hline 4052 & $8 / 13 / 20081: 32$ & 1.626 & 16.9 & 4121 & $8 / 13 / 20083: 50$ & 1.623 & 16.9 & 4190 & $8 / 13 / 20086: 08$ & 1.616 & 16.9 & 4259 & $8 / 13 / 20088: 26$ & 1.62 & 16.9 \\
\hline 4053 & $8 / 13 / 20081: 34$ & 1.625 & 16.9 & 4122 & $8 / 13 / 20083: 52$ & 1.623 & 16.9 & 4191 & $8 / 13 / 20086: 10$ & 1.616 & 16.9 & 4260 & $8 / 13 / 20088: 28$ & 1.619 & 16.9 \\
\hline 4054 & $8 / 13 / 20081: 36$ & 1.625 & 16.9 & 4123 & $8 / 13 / 20083: 54$ & 1.622 & 16.9 & 4192 & $8 / 13 / 20086: 12$ & 1.617 & 16.9 & 4261 & $8 / 13 / 20088: 30$ & 1.621 & 16.9 \\
\hline 4055 & & 1.626 & 16.9 & 4124 & $8 / 13 / 20083: 56$ & 1.623 & 16.9 & 4193 & $8 / 13 / 20086: 14$ & 1.619 & 16.9 & 4262 & $8 / 13 / 20088: 32$ & 1.62 & 16.9 \\
\hline 4056 & $1: 40$ & 1.625 & 16.9 & 4125 & $8 / 13 / 20083: 58$ & 1.622 & 16.9 & 4194 & $8 / 13 / 20086: 16$ & 1.618 & 16.9 & 4263 & $8 / 13 / 20088: 34$ & 1.621 & 16.9 \\
\hline 4057 & $8 / 13 / 20081: 42$ & 1.625 & 16.9 & 4126 & $8 / 13 / 20084: 00$ & 1.622 & 16.9 & 4195 & $8 / 13 / 20086: 18$ & 1.619 & 16.9 & 4264 & $8 / 13 / 20088: 36$ & 1.622 & 16.9 \\
\hline 4058 & $8 / 13 / 20081: 44$ & 1.625 & 16.9 & 4127 & $8 / 13 / 20084: 02$ & 1.622 & 16.9 & 4196 & $8 / 13 / 20086: 20$ & 1.619 & 16.9 & 4265 & $8 / 13 / 20088: 38$ & 1.622 & 16.9 \\
\hline 4059 & $8 / 13 / 20081: 46$ & 1.625 & 16.9 & 4128 & $8 / 13 / 20084: 04$ & 1.621 & 16.9 & 4197 & $8 / 13 / 20086: 22$ & 1.621 & 16.9 & 4266 & $8 / 13 / 20088: 40$ & 1.622 & 16.9 \\
\hline 4060 & $8 / 13 / 20081: 48$ & 1.625 & 16.9 & 4129 & $8 / 13 / 20084: 06$ & 1.621 & 16.9 & 4198 & $8 / 13 / 20086: 24$ & 1.62 & 16.9 & 4267 & $8 / 13 / 20088: 42$ & 1.621 & 16.9 \\
\hline 4061 & $8 / 13 / 20081: 50$ & 1.625 & 16.9 & 4130 & $8 / 13 / 20084: 08$ & 1.62 & 17.1 & 4199 & $8 / 13 / 20086: 26$ & 1.62 & 16.9 & 4268 & $8 / 13 / 20088: 44$ & 1.616 & 16.9 \\
\hline 4062 & $8 / 13 / 20081: 52$ & 1.625 & 16.9 & 4131 & $8 / 13 / 20084: 10$ & 1.62 & 17.4 & 4200 & $8 / 13 / 20086: 28$ & 1.62 & 16.9 & 4269 & $8 / 13 / 20088: 46$ & 1.611 & 16.9 \\
\hline 4063 & $8 / 13 / 20081: 54$ & 1.625 & 16.9 & 4132 & $8 / 13 / 20084: 12$ & 1.621 & 17.1 & 4201 & $8 / 13 / 20086: 30$ & 1.62 & 16.9 & 4270 & $8 / 13 / 20088: 48$ & 1.608 & 16.9 \\
\hline 4064 & $8 / 13 / 20081: 56$ & 1.624 & 16.9 & 4133 & $8 / 13 / 20084: 14$ & 1.621 & 16.9 & 4202 & $8 / 13 / 20086: 32$ & 1.619 & 16.9 & 4271 & $8 / 13 / 20088: 50$ & 1.608 & 16.9 \\
\hline 4065 & $8 / 13 / 20081: 58$ & 1.624 & 16.9 & 4134 & $8 / 13 / 20084: 16$ & 1.622 & 16.9 & 4203 & $8 / 13 / 20086: 34$ & 1.619 & 16.9 & 4272 & $8 / 13 / 20088: 52$ & 1.61 & 16.9 \\
\hline 4066 & $8 / 13 / 20082: 00$ & 1.625 & 16.9 & 4135 & $8 / 13 / 20084: 18$ & 1.622 & 16.9 & 4204 & $8 / 13 / 20086: 36$ & 1.619 & 16.9 & 4273 & $8 / 13 / 20088: 54$ & 1.613 & 16.9 \\
\hline 4067 & $8 / 13 / 20082: 02$ & 1.626 & 16.9 & 4136 & $8 / 13 / 20084: 20$ & 1.622 & 16.9 & 4205 & $8 / 13 / 20086: 38$ & 1.619 & 16.9 & 4274 & $8 / 13 / 20088: 56$ & 1.616 & 16.9 \\
\hline 4068 & $8 / 13 / 20082: 04$ & 1.626 & 16.9 & 4137 & $8 / 13 / 20084: 22$ & 1.622 & 16.9 & 4206 & $8 / 13 / 20086: 40$ & 1.619 & 16.9 & 4275 & $8 / 13 / 20088: 58$ & 1.616 & 16.9 \\
\hline 4069 & $8 / 13 / 20082: 06$ & 1.626 & 16.9 & 4138 & $8 / 13 / 20084: 24$ & 1.622 & 16.9 & 4207 & $8 / 13 / 20086: 42$ & 1.619 & 16.9 & 4276 & $8 / 13 / 20089: 00$ & 1.617 & 16.9 \\
\hline 4070 & $8 / 13 / 20082: 08$ & 1.627 & 16.9 & 4139 & $8 / 13 / 20084: 26$ & 1.623 & 16.9 & 4208 & $8 / 13 / 20086: 44$ & 1.62 & 16.9 & 4277 & $8 / 13 / 20089: 02$ & 1.617 & 16.9 \\
\hline 4071 & $8 / 13 / 2008$ 2:10 & 1.627 & 16.9 & 4140 & $8 / 13 / 20084: 28$ & 1.623 & 16.9 & 4209 & $8 / 13 / 20086: 46$ & 1.619 & 16.9 & 4278 & 8/13/2008 9:04 & 1.618 & 16.9 \\
\hline 4072 & $8 / 13 / 20082: 12$ & 1.626 & 16.9 & 4141 & $8 / 13 / 20084: 30$ & 1.624 & 16.9 & 4210 & $8 / 13 / 20086: 48$ & 1.62 & 16.9 & 4279 & $8 / 13 / 20089: 06$ & 1.618 & 16.9 \\
\hline 4073 & $8 / 13$ & 1.625 & 16.9 & 4142 & $8 / 13 / 20084: 32$ & 1.623 & 16.9 & 4211 & $8 / 13 / 20086: 50$ & 1.619 & 16.9 & 4280 & $8 / 13 / 20089: 08$ & 1.618 & 16.9 \\
\hline 4074 & $8 / 13 / 20082: 16$ & 1.626 & 16.9 & 4143 & $8 / 13 / 20084: 34$ & 1.624 & 16.9 & 4212 & $8 / 13 / 20086: 52$ & 1.62 & 16.9 & 4281 & $8 / 13 / 20089: 10$ & 1.618 & 16.9 \\
\hline 4075 & $8 / 13 / 20082: 18$ & 1.625 & 16.9 & 4144 & $8 / 13 / 20084: 36$ & 1.623 & 16.9 & 4213 & $8 / 13 / 20086: 54$ & 1.621 & 16.9 & 4282 & $8 / 13 / 20089: 12$ & 1.618 & 16.9 \\
\hline 4076 & $8 / 13 / 20082: 20$ & 1.625 & 16.9 & 4145 & $8 / 13 / 20084: 38$ & 1.622 & 16.9 & 4214 & $8 / 13 / 20086.56$ & 1.62 & 16.9 & 4283 & $8 / 13 / 20089: 14$ & 1.618 & 16.9 \\
\hline 4077 & $8 / 13 / 20082: 22$ & 1.626 & 16.9 & 4146 & $8 / 13 / 20084: 40$ & 1.623 & 16.9 & 4215 & $8 / 13 / 20086: 58$ & 1.621 & 16.9 & 4284 & $8 / 13 / 20089: 16$ & 1.619 & 16.9 \\
\hline 4078 & $8 / 13 / 20082: 24$ & 1.625 & 16.9 & 4147 & $8 / 13 / 20084: 42$ & 1.624 & 16.9 & 4216 & $8 / 13 / 20087: 00$ & 1.621 & 16.9 & 4285 & $8 / 13 / 20089: 18$ & 1.62 & 16.9 \\
\hline 4079 & $8 / 13 / 20082: 26$ & 1.625 & 16.9 & 4148 & $8 / 13 / 20084: 44$ & 1.623 & 16.9 & 4217 & $8 / 13 / 20087: 02$ & 1.619 & 17.3 & 4286 & $8 / 13 / 20089: 20$ & 1.62 & 16.9 \\
\hline 4080 & $8 / 13 / 20082: 28$ & 1.625 & 16.9 & 4149 & $8 / 13 / 20084: 46$ & 1.623 & 16.9 & 4218 & $8 / 13 / 20087: 04$ & 1.621 & 17.3 & 4287 & $8 / 13 / 20089: 22$ & 1.619 & 16.9 \\
\hline 4081 & $8 / 13 / 20082: 30$ & 1.624 & 16.9 & 4150 & $8 / 13 / 20084: 48$ & 1.623 & 16.9 & 4219 & $8 / 13 / 20087: 06$ & 1.619 & 17 & 4288 & $8 / 13 / 20089: 24$ & 1.62 & 16.9 \\
\hline 4082 & $8 / 13 / 20082: 32$ & 1.625 & 16.9 & 4151 & $8 / 13 / 20084: 50$ & 1.623 & 16.9 & 4220 & $8 / 13 / 20087: 08$ & 1.619 & 16.9 & 4289 & $0089: 26$ & 1.62 & 16.9 \\
\hline 4083 & $8 / 13 / 20082: 34$ & 1.625 & 16.9 & 4152 & $8 / 13 / 20084: 52$ & 1.622 & 16.9 & 4221 & $8 / 13 / 20087: 10$ & 1.62 & 16.9 & 4290 & $8 / 13 / 20089: 28$ & 1.621 & 16.9 \\
\hline 4084 & $8 / 13 / 20082: 36$ & 1.624 & 16.9 & 4153 & $8 / 13 / 20084: 54$ & 1.622 & 16.9 & 4222 & $8 / 13 / 20087: 12$ & 1.62 & 16.9 & 4291 & $8 / 13 / 20089: 30$ & 1.621 & 16.9 \\
\hline 4085 & $8 / 13 / 20082: 38$ & 1.626 & 16.9 & 4154 & $8 / 13 / 20084: 56$ & 1.623 & 16.9 & 4223 & $8 / 13 / 20087: 14$ & 1.62 & 16.9 & 4292 & $8 / 13 / 20089: 32$ & 1.62 & 16.9 \\
\hline 4086 & $8 / 13 / 20082: 40$ & 1.625 & 16.9 & 4155 & $8 / 13 / 20084: 58$ & 1.622 & 16.9 & 4224 & $8 / 43 / 20087: 16$ & 1.62 & 16.9 & 4293 & $8 / 13 / 20089: 34$ & 1.621 & 16.9 \\
\hline 4087 & $8 / 13 / 20082: 42$ & 1.625 & 16.9 & 4156 & $8 / 13 / 20085: 00$ & 1.624 & 16.9 & 4225 & $8 / 13 / 20087: 18$ & 1.621 & 16.9 & 4294 & $8 / 13 / 20089: 36$ & 1.621 & 16.9 \\
\hline 4088 & $8 / 13 / 20082: 44$ & 1.624 & 16.9 & 4157 & $8 / 13 / 20085: 02$ & 1.624 & 16.9 & 4226 & $8 / 13 / 20087: 20$ & 1.622 & 16.9 & 4295 & $8 / 13 / 20089: 38$ & 1.621 & 16.9 \\
\hline 4089 & $8 / 13 / 20082: 46$ & 1.625 & 16.9 & 4158 & $8 / 13 / 20085: 04$ & 1.624 & 16.9 & 4227 & $8 / 13 / 20087: 22$ & 1.622 & 16.9 & 4296 & $8 / 13 / 20089: 40$ & 1.621 & 16.9 \\
\hline 4090 & $8 / 13 / 20082: 48$ & 1.625 & 16.9 & 4159 & $8 / 13 / 20085: 06$ & 1.624 & 16.9 & 4228 & $8 / 13 / 20087: 24$ & 1.621 & 16.9 & 4297 & $8 / 13 / 20089: 42$ & 1.622 & 16.9 \\
\hline 4091 & $8 / 13 / 20082550$ & 1.625 & 16.9 & 4160 & $8 / 13 / 20085: 08$ & 1.623 & 16.9 & 4229 & $8 / 13 / 20087: 26$ & 1.621 & 16.9 & 4298 & $8 / 13 / 20089: 44$ & 1.622 & 16.9 \\
\hline 4092 & $8 / 13 / 20082: 52$ & 1.625 & 16.9 & 4161 & $8 / 13 / 20085: 10$ & 1.624 & 16.9 & 4230 & $8 / 13 / 20087: 28$ & 1.621 & 16.9 & 4299 & $8 / 13 / 20089: 46$ & 1.622 & 16.9 \\
\hline 4093 & $8 / 13 / 20082: 54$ & 1.625 & 16.9 & 4162 & $8 / 13 / 20085: 12$ & 1.623 & 16.9 & 4231 & $8 / 13 / 20087: 30$ & 1.621 & 16.9 & 4300 & $8 / 13 / 20089: 48$ & 1.622 & 16.9 \\
\hline 4094 & $8 / 13 / 20082: 56$ & 1.625 & 16.9 & 4163 & $8 / 13 / 20085: 14$ & 1.623 & 16.9 & 4232 & $8 / 13 / 20087: 32$ & 1.621 & 16.9 & 4301 & $8 / 13 / 20089: 50$ & 1.622 & 16.9 \\
\hline 4095 & $8 / 13 / 2008258$ & 1.624 & 16.9 & 4164 & $8 / 13 / 20085: 16$ & 1.623 & 16.9 & 4233 & $8 / 13 / 20087: 34$ & 1.622 & 16.9 & 4302 & $8 / 13 / 20089: 52$ & 1.622 & 16.9 \\
\hline 4096 & $8 / 13 / 20083: 00$ & 1.624 & 16.9 & 4165 & $8 / 13 / 20085: 18$ & 1.623 & 16.9 & 4234 & $8 / 13 / 20087: 36$ & 1.622 & 16.9 & 4303 & $8 / 13 / 20089: 54$ & 1.621 & 16.9 \\
\hline 4097 & $8 / 13 / 20083: 02$ & 1.624 & 16.9 & 4166 & $8 / 13 / 20085: 20$ & 1.624 & 16.9 & 4235 & $8 / 13 / 20087: 38$ & 1.622 & 16.9 & 4304 & $8 / 13 / 20089: 56$ & 1.621 & 16.9 \\
\hline 4098 & $8 / 13 / 20083: 04$ & 1.623 & 16.9 & 4167 & $8 / 13 / 20085: 22$ & 1.623 & 16.9 & 4236 & $8 / 13 / 20087: 40$ & 1.621 & 16.9 & 4305 & $8 / 13 / 20089: 58$ & 1.62 & 16.9 \\
\hline 4099 & $8 / 13 / 20083: 06$ & 1.619 & 16.9 & 4168 & $8 / 13 / 20085: 24$ & 1.622 & 16.9 & 4237 & $8 / 13 / 20087: 42$ & 1.621 & 16.9 & 4306 & $8 / 13 / 2008$ 10:00 & 1.621 & 16.9 \\
\hline 4100 & $8 / 13 / 20083: 08$ & 1.615 & 16.9 & 4169 & $8 / 13 / 20085: 26$ & 1.622 & 16.9 & 4238 & $8 / 13 / 20087: 44$ & 1.621 & 16.9 & 4307 & $8 / 13 / 2008$ 10:02 & 1.621 & 16.9 \\
\hline 4101 & $8 / 13 / 20083: 10$ & 1.611 & 16.9 & 4170 & $8 / 13 / 20085: 28$ & 1.622 & 16.9 & 4239 & $8 / 13 / 20087: 46$ & 1.621 & 16.9 & 4308 & $8 / 13 / 2008$ 10:04 & 1.622 & 16.9 \\
\hline 4102 & $8 / 13 / 20083: 12$ & 1.61 & 16.9 & 4171 & $8 / 13 / 20085: 30$ & 1.622 & 16.9 & 4240 & $8 / 13 / 20087: 48$ & 1.621 & 16.9 & 4309 & $8 / 13 / 2008$ 10:06 & 1.621 & 16.9 \\
\hline 4103 & $8 / 13 / 20083: 14$ & 1.614 & 16.9 & 4172 & $8 / 13 / 20085: 32$ & 1.622 & 16.9 & 4241 & $8 / 13 / 20087: 50$ & 1.621 & 16.9 & 4310 & $8 / 13 / 2008$ 10:08 & 1.622 & 16.9 \\
\hline 4104 & $8 / 13 / 20083: 16$ & 1.617 & 16.9 & 4173 & $8 / 13 / 20085: 34$ & 1.622 & 16.9 & 4242 & $8 / 13 / 20087: 52$ & 1.622 & 16.9 & 4311 & $8 / 13 / 2008$ 10:10 & 1.621 & 16.9 \\
\hline 4105 & $8 / 13 / 20083: 18$ & 1.619 & 16.9 & 4174 & $8 / 13 / 20085: 36$ & 1.622 & 16.9 & 4243 & $8 / 13 / 20087: 54$ & 1.622 & 16.9 & 4312 & $8 / 13 / 2008$ 10:12 & 1.622 & 16.9 \\
\hline 4106 & $8 / 13 / 20083: 20$ & 1.621 & 16.9 & 4175 & $8 / 13 / 20085: 38$ & 1.623 & 16.9 & 4244 & $8 / 13 / 20087: 56$ & 1.622 & 16.9 & 4313 & $8 / 13 / 2008$ 10:14 & 1.622 & 16.9 \\
\hline 4107 & $8 / 13 / 20083: 22$ & 1.621 & 16.9 & 4176 & $8 / 13 / 20085: 40$ & 1.623 & 16.9 & 4245 & $8 / 13 / 20087: 58$ & 1.622 & 16.9 & 4314 & $8 / 13 / 200810: 16$ & 1.622 & 16.9 \\
\hline
\end{tabular}




\begin{tabular}{|c|c|c|c|c|c|c|c|c|c|c|c|c|c|c|c|}
\hline \multicolumn{4}{|c|}{ D4-27p } & \multicolumn{4}{|c|}{ D4-27p } & \multicolumn{4}{|c|}{ D4-27p } & \multicolumn{4}{|c|}{ D427p } \\
\hline $\operatorname{Rec}$ & & Pres & Temp & Rec & & Pres & Temp & Rec & & Pres & Temp & Rec & & Pres & Temp \\
\hline$\#$ & Date/Time & psi & ${ }^{\circ} \mathrm{C}$ & $\#$ & Date/Time & psi & ${ }^{\circ} \mathrm{C}$ & $\#$ & Date/Time & psi & ${ }^{\circ} \mathrm{C}$ & $\#$ & Date/Time & psi & ${ }^{\circ} \mathrm{C}$ \\
\hline 4315 & $8 / 13 / 200810: 18$ & 1.622 & 16.9 & 4384 & $8 / 13 / 200812: 36$ & 1.625 & 16.9 & 4453 & $8 / 13 / 200814: 54$ & 1.627 & 16.9 & 4522 & $8 / 13 / 2008$ 17:12 & 1.625 & 16.9 \\
\hline 4316 & $8 / 13 / 200810: 20$ & 1.622 & 16.9 & 4385 & $8 / 13 / 2008$ 12:38 & 1.625 & 16.9 & 4454 & $8 / 13 / 200814: 56$ & 1.627 & 16.9 & 4523 & $8 / 13 / 200817: 14$ & 1.626 & 16.9 \\
\hline 4317 & $8 / 13 / 2008$ 10:22 & 1.622 & 16.9 & 4386 & $8 / 13 / 200812: 40$ & 1.626 & 16.9 & 4455 & $8 / 13 / 200814: 58$ & 1.628 & 16.9 & 4524 & $8 / 13 / 2008$ 17:16 & 1.628 & 16.9 \\
\hline 4318 & $8 / 13 / 200810: 24$ & 1.622 & 16.9 & 4387 & $8 / 13 / 2008$ 12:42 & 1.626 & 16.9 & 4456 & $8 / 13 / 2008$ 15:00 & 1.629 & 16.9 & 4525 & $8 / 13 / 200817: 18$ & 1.628 & 16.9 \\
\hline 4319 & $8 / 13 / 2008$ 10:26 & 1.622 & 16.9 & 4388 & $8 / 13 / 200812: 44$ & 1.626 & 16.9 & 4457 & $8 / 13 / 200815: 02$ & 1.628 & 16.9 & 4526 & $8 / 13 / 200817: 20$ & 1.629 & 16.9 \\
\hline 4320 & $8 / 13 / 2008$ 10:28 & 1.622 & 16.9 & 4389 & $8 / 13 / 2008$ 12:46 & 1.626 & 16.9 & 4458 & $8 / 13 / 2008$ 15:04 & 1.628 & 16.9 & 4527 & $8 / 13 / 200817: 22$ & 1.629 & 16.9 \\
\hline 4321 & $8 / 13 / 2008$ 10:30 & 1.622 & 16.9 & 4390 & $8 / 13 / 200812: 48$ & 1.626 & 16.9 & 4459 & $8 / 13 / 200815: 06$ & 1.628 & 16.9 & 4528 & $8 / 13 / 200817: 24$ & 1.629 & 16.9 \\
\hline 4322 & $8 / 13 / 2008$ 10:32 & 1.622 & 16.9 & 4391 & $8 / 13 / 2008$ 12:50 & 1.627 & 16.9 & 4460 & $8 / 13 / 2008$ 15:08 & 1.628 & 16.9 & 4529 & $8 / 13 / 2008$ 17:26 & 1.63 & 16.9 \\
\hline 4323 & $8 / 13 / 2008$ 10:34 & 1.623 & 16.9 & 4392 & $8 / 13 / 200812: 52$ & 1.626 & 16.9 & 4461 & $8 / 13 / 2008$ 15:10 & 1.627 & 16.9 & 4530 & $8 / 13 / 200817: 28$ & 1.629 & 16.9 \\
\hline 4324 & $8 / 13 / 200810: 36$ & 1.622 & 16.9 & 4393 & $8 / 13 / 200812: 54$ & 1.626 & 16.9 & 4462 & $8 / 13 / 2008$ 15:12 & 1.627 & 16.9 & 4531 & $8 / 13 / 200817: 30$ & 1.63 & 16.9 \\
\hline 4325 & $8 / 13 / 2008$ 10:38 & 1.622 & 16.9 & 4394 & $8 / 13 / 200812: 56$ & 1.626 & 16.9 & 4463 & $8 / 13 / 200815: 14$ & 1.628 & 16.9 & 4532 & $8 / 13 / 200817: 32$ & 1.631 & 16.9 \\
\hline 4326 & $8 / 13 / 200810: 40$ & 1.622 & 16.9 & 4395 & $8 / 13 / 200812: 58$ & 1.626 & 16.9 & 4464 & $8 / 13 / 200815: 16$ & 1.628 & 16.9 & 4533 & $8 / 13 / 200817: 34$ & 1.63 & 16.9 \\
\hline 4327 & $8 / 13 / 2008$ 10:42 & 1.622 & 16.9 & 4396 & $8 / 13 / 200813: 00$ & 1.626 & 16.9 & 4465 & $8 / 13 / 200815: 18$ & 1.629 & 16.9 & 4534 & $8 / 13 / 200817: 36$ & 1.631 & 16.9 \\
\hline 4328 & $8 / 13 / 200810: 44$ & 1.622 & 16.9 & 4397 & $8 / 13 / 200813: 02$ & 1.625 & 17.2 . & 4466 & $8 / 13 / 2008$ 15:20 & 1.629 & 16.9 & 4535 & $8 / 13 / 200817: 38$ & 1.631 & 16.9 \\
\hline 4329 & $8 / 13 / 2008$ 10:46 & 1.622 & 16.9 & 4398 & $8 / 13 / 200813: 04$ & 1.626 & 17 & 4467 & $8 / 13 / 2008$ 15:22 & 1.63 & 16.9 & 4536 & $8 / 13 / 200817: 40$ & 1.63 & 16.9 \\
\hline 4330 & $8 / 13 / 200810: 48$ & 1.622 & 16.9 & 4399 & $8 / 13 / 200813: 06$ & 1.627 & 16.9 & 4468 & $8 / 13 / 2008$ 15:24 & 1.63 & 16.9 & 4537 & $8 / 13 / 2008$ 17:42 & 1.631 & 16.9 \\
\hline 4331 & $8 / 13 / 2008$ 10:50 & 1.622 & 16.9 & 4400 & $8 / 13 / 200813: 08$ & 1.626 & 16.9 & 4469 & $8 / 13 / 2008$ 15:26 & 1.63 & 16.9 & 4538 & $8 / 13 / 200817: 44$ & 1.631 & 16.9 \\
\hline 4332 & $8 / 13 / 2008$ 10:52 & 1.623 & 16.9 & 4401 & $8 / 13 / 2008+3: 10$ & 1.627 & 16.9 & 4470 & $8 / 13 / 200815: 28$ & 1.631 & 16.9 & 4539 & $8 / 13 / 200817: 46$ & 1.63 & 16.9 \\
\hline 4333 & $8 / 13 / 2008$ 10:54 & 1.623 & 16.9 & 4402 & $8 / 13 / 200813: 12$ & 1.627 & 16.9 & 4471 & $8 / 13 / 200815: 30$ & 1.63 & 16.9 & 4540 & $8 / 13 / 200817: 48$ & 1.63 & 16.9 \\
\hline 4334 & $8 / 13 / 200810: 56$ & 1.623 & 16.9 & 4403 & $8 / 13 / 200813: 14$ & 1.628 & 16.9 & 4472 & $8 / 13 / 2008$ 15:32 & 1.63 & 16.9 & 4541 & $8 / 13 / 200817: 50$ & 1.63 & 16.9 \\
\hline 4335 & $8 / 13 / 2008$ 10:58 & 1.623 & 16.9 & 4404 & $8 / 13 / 200813: 16$ & 1.628 & 16.9 & 4473 & $8 / 13 / 200815: 34$ & \begin{tabular}{l|l|}
1.63 \\
\end{tabular} & 16.9 & 4542 & $8 / 13 / 2008$ 17:52 & 1.63 & 16.9 \\
\hline 4336 & $8 / 13 / 2008$ 11:00 & 1.623 & 16.9 & 4405 & $8 / 13 / 2008$ 13:18 & 1.628 & 16.9 & 4474 & $8 / 13 / 200815: 36$ & 1.629 & 16.9 & 4543 & $8 / 13 / 200817: 54$ & 1.63 & 16.9 \\
\hline 4337 & $8 / 13 / 200811: 02$ & 1.623 & 16.9 & 4406 & $8 / 13 / 200813: 20$ & 1.628 & 16.9 & 4475 & $8 / 13 / 200815: 38$ & 1.629 & 16.9 & 4544 & $8 / 13 / 2008$ 17:56 & 1.63 & 16.9 \\
\hline 4338 & $8 / 13 / 200811: 04$ & 1.623 & 16.9 & 4407 & $8 / 13 / 200813: 22$ & 1.628 & 16.9 & 4476 & $8 / 13 / 200815: 40$ & 1.63 & 16.9 & 4545 & $8 / 13 / 200817: 58$ & 1.631 & 16.9 \\
\hline 4339 & $8 / 13 / 200811: 06$ & 1.623 & 16.9 & 4408 & $8 / 13 / 200813: 24$ & 1.628 & 16.9 & 4477 & $8 / 13 / 200815: 42$ & 1.629 & 16.9 & 4546 & $8 / 13 / 200818: 00$ & 1.631 & 16.9 \\
\hline 4340 & $8 / 13 / 200811: 08$ & 1.623 & 16.9 & 4409 & $8 / 13 / 2008$ 13:26 & 1.628 & 16.9 & 4478 & $8 / 13 / 200815: 44$ & 1.629 & 16.9 & 4547 & $8 / 13 / 200818: 02$ & 1.631 & 16.9 \\
\hline 4341 & $8 / 13 / 200811: 10$ & 1.623 & 16.9 & 4410 & $8 / 13 / 200813: 28$ & 1.628 & 16.9 & 4479 & $8 / 13 / 200815: 46$ & 1.63 & 16.9 & 4548 & $8 / 13 / 200818: 04$ & 1.63 & 16.9 \\
\hline 4342 & $8 / 13 / 2008$ 11:12 & 1.623 & 16.9 & 4411 & $8 / 13 / 200813: 30$ & 1.627 & 16.9 & 4480 & $8 / 13 / 200815: 48$ & 1.63 & 16.9 & 4549 & 308 18:06 & 1.631 & 16.9 \\
\hline 4343 & $8 / 13 / 200811: 14$ & 1.623 & 16.9 & 4412 & $8 / 13 / 200813: 32$ & 1.628 & 16.9 & 4481 & $8 / 13 / 200815: 50$ & 1.63 & 16.9 & 4550 & $8 / 13 / 200818: 08$ & 1.63 & 16.9 \\
\hline 4344 & $8 / 13 / 200811: 16$ & 1.624 & 16.9 & 4413 & $8 / 13 / 200813: 34$ & 1.628 & 16.9 & \begin{tabular}{l|l}
4482 \\
\end{tabular} & $8 / 13 / 200815: 52$ & 1.63 & 16.9 & 4551 & $8 / 13 / 200818: 10$ & 1.631 & 16.9 \\
\hline 4345 & $8 / 13 / 200811: 18$ & 1.623 & 16.9 & 4414 & $8 / 13 / 200813: 36$ & 1.628 & 16.9 & 4483 & $8 / 13 / 200815: 54$ & 1.63 & 16.9 & 4552 & $8 / 13 / 200818: 12$ & 1.631 & 16.9 \\
\hline 4346 & $8 / 13 / 200811: 20$ & 1.623 & 16.9 & 4415 & $8 / 13 / 200813: 38$ & 1.628 & 16.9 & 4484 & $8 / 13 / 200815: 56$ & 1.63 & 16.9 & 4553 & $8 / 13 / 200818: 14$ & 1.63 & 16.9 \\
\hline 4347 & $8 / 13 / 200811: 22$ & 1.623 & 16.9 & 4416 & $8 / 13 / 200813: 40$ & 1.628 & 16.9 & 4485 & $8 / 13 / 200815: 58$ & 1.63 & 16.9 & 4554 & $8 / 13 / 200818: 16$ & 1.631 & 16.9 \\
\hline 4348 & $8 / 13 / 2008$ 11:24 & 1.621 & 16.9 & 4417 & $8 / 13 / 200813: 42$ & 1.629 & 16.9 & 4486 & $8 / 13 / 200816: 00$ & 1.63 & 16.9 & 4555 & $8 / 13 / 2008$ 18:18 & 1.631 & 16.9 \\
\hline 4349 & $8 / 13 / 200811: 26$ & 1.619 & 16.9 & 4418 & $8 / 13 / 200813: 44$ & 1.629 & 16.9 & 4487 & $8 / 13 / 200816: 02$ & 1.63 & 16.9 & 4556 & $8 / 13 / 200818: 20$ & 1.631 & 16.9 \\
\hline 4350 & $8 / 13 / 2008$ 11:28 & 1.616 & 16.9 & 4419 & $8 / 13 / 200813: 46$ & 1.629 & 16.9 & \begin{tabular}{l|l|}
4488 \\
\end{tabular} & $8 / 13 / 200816: 04$ & 1.629 & 16.9 & 4557 & $318: 22$ & 1.631 & 16.9 \\
\hline 4351 & $8 / 13 / 200811: 30$ & 1.612 & 16.9 & 4420 & $8 / 13 / 200813: 48$ & 1.628 & 16.9 & 4489 & $8 / 13 / 200816: 06$ & 1.63 & 16.9 & 4558 & $8 / 13 / 200818: 24$ & 1.631 & 16.9 \\
\hline 4352 & $8 / 13 / 200811: 32$ & 1.613 & 16.9 & 4421 & $8 / 13 / 200813: 50$ & 1.628 & 16.9 & 4490 & $8 / 13 / 200816: 08$ & 1.63 & 16.9 & 4559 & $8 / 13 / 200818: 26$ & 1.631 & 16.9 \\
\hline 4353 & $8 / 13 / 200811: 34$ & 1.614 & 16.9 & 4422 & $8 / 13 / 200813: 52$ & 1.629 & 16.9 & 4491 & $8 / 13 / 200816: 10$ & 1.63 & 16.9 & 4560 & $8 / 13 / 200818: 28$ & 1.632 & 16.9 \\
\hline 4354 & $8 / 13 / 20$ & 1.618 & 16.9 & 4423 & $8 / 13 / 200813: 54$ & 1.628 & 16.9 & 4492 & $8 / 13 / 200816: 12$ & 1.63 & 16.9 & 4561 & $8: 30$ & 1.632 & 16.9 \\
\hline 4355 & $8 / 13 / 200811: 38$ & 1.619 & 16.9 & 4424 & $8 / 13 / 200813: 56$ & 1.628 & 16.9 & 4493 & $8 / 13 / 200816: 14$ & 1.629 & 16.9 & 4562 & $8 / 13 / 200818: 32$ & 1.631 & 16.9 \\
\hline 4356 & $8 / 13 / 200811: 40$ & 1.62 & 16.9 & 4425 & $8 / 13 / 200813: 58$ & 1.628 & 16.9 & 4494 & $8 / 13 / 200816: 16$ & 1.63 & 16.9 & 4563 & $8 / 13 / 200818: 34$ & 1.631 & 16.9 \\
\hline 4357 & $8 / 13 / 2008$ 11:42 & 1.621 & 16.9 & 4426 & $8 / 13 / 2008$ 14:00 & 1.628 & 16.9 & 4495 & $8 / 13 / 200816: 18$ & 1.63 & 16.9 & 4564 & $8 / 13 / 200818: 36$ & 1.632 & 16.9 \\
\hline 4358 & $8 / 13 /$ & 1.622 & 16.9 & 4427 & $8 / 13 / 200814: 02$ & 1.628 & 16.9 & 4496 & $8 / 13 / 200816: 20$ & 1.63 & 16.9 & 4565 & 18:38 & 1.632 & 16.9 \\
\hline 4359 & $8 / 13 / 200811: 46$ & 1.622 & 16.9 & 4428 & $8 / 13 / 200814: 04$ & 1.628 & 16.9 & 4497 & $8 / 13 / 200816: 22$ & 1.63 & 16.9 & 4566 & $8 / 13 / 200818: 40$ & 1.632 & 16.9 \\
\hline 4360 & $8 / 13 / 200811: 48$ & 1.621 & 16.9 & 4429 & $8 / 13 / 200814: 06$ & 1.629 & 16.9 & 4498 & $8 / 13 / 200816: 24$ & 1.63 & 16.9 & 4567 & $8 / 3 / 200818: 42$ & 1.632 & 16.9 \\
\hline 4361 & $8 / 13 / 200811: 50$ & 1.623 & 16.9 & 4430 & $8 / 13 / 2008$ 14:08 & 1.629 & 16.9 & 4499 & $8 / 13 / 200816: 26$ & 1.63 & 16.9 & 4568 & $8 / 13 / 200818: 44$ & 1.631 & 16.9 \\
\hline 4362 & $8 / 13 / 200811: 52$ & 1.623 & 16.9 & 4431 & $8 / 13 / 200814: 10$ & 1.629 & 16.9 & 4500 & $8 / 13 / 200816: 28$ & 1.63 & 16.9 & 4569 & $8 / 13 / 200818: 46$ & 1.632 & 16.9 \\
\hline 4363 & $8 / 13 / 200811: 54$ & 1.623 & 16.9 & 4432 & $8 / 13 / 200814: 12$ & 1.629 & 16.9 & 4501 & $8 / 13 / 200816: 30$ & 1.63 & 16.9 & 4570 & $8 / 13 / 200818: 48$ & 1.631 & 16.9 \\
\hline 4364 & $8 / 13 / 200811: 56$ & 1.624 & 16.9 & 4433 & $8 / 13 / 200814: 14$ & 1.629 & 16.9 & 4502 & $8 / 13 / 200816: 32$ & 1.63 & 16.9 & 4571 & $8 / 13 / 200818.50$ & 1.631 & 16.9 \\
\hline 4365 & $8 / 13 / 200811: 58$ & 1.623 & 16.9 & 4434 & $8 / 13 / 200814: 16$ & 1.629 & 16.9 & 4503 & $8 / 13 / 200816: 34$ & 1.631 & 16.9 & 4572 & $8 / 13 / 200818: 52$ & 1.63 & 16.9 \\
\hline 4366 & $8 / 13 / 200812: 00$ & 1.624 & 16.9 & 4435 & $8 / 13 / 200814: 18$ & 1.63 & 16.9 & 4504 & $8 / 13 / 200816: 36$ & 1.63 & 16.9 & 4573 & $8 / 13 / 2008$ 18:54 & 1.63 & 16.9 \\
\hline 4367 & $8 / 13 / 2008$ 12:02 & 1.623 & 16.9 & 4436 & $8 / 13 / 200814: 20$ & 1.63 & 16.9 & 4505 & $8 / 13 / 200816: 38$ & 1.63 & 16.9 & 4574 & $8 / 13 / 200818.56$ & 1.631 & 16.9 \\
\hline 4368 & $8 / 13 / 2008$ 12:04 & 1.624 & 16.9 & 4437 & $8 / 13 / 200814: 22$ & 1.626 & 16.9 & 4506 & $8 / 13 / 200816: 40$ & 1.631 & 16.9 & 4575 & $8 / 13 / 200818: 58$ & 1.63 & 16.9 \\
\hline 4369 & $8 / 13 / 200812: 06$ & 1.624 & 16.9 & 4438 & $8 / 13 / 200814: 24$ & 1.621 & 16.9 & 4507 & $8 / 13 / 200816: 42$ & 1.63 & 16.9 & 4576 & $8 / 13 / 200819: 00$ & 1.631 & 16.9 \\
\hline 4370 & $8 / 13 / 200812: 08$ & 1.624 & 16.9 & 4439 & $8 / 13 / 200814: 26$ & 1.619 & 16.9 & 4508 & $8 / 13 / 2008$ 16:44 & 1.629 & 16.9 & 4577 & $8 / 13 / 200819: 02$ & 1.631 & 16.9 \\
\hline 4371 & $8 / 13 / 2008$ 12:10 & 1.625 & 16.9 & 4440 & $8 / 13 / 200814: 28$ & 1.621 & 169 & 4509 & $8 / 13 / 200816: 46$ & 1.629 & 16.9 & 4578 & $8 / 13 / 200819: 04$ & 1.63 & 16.9 \\
\hline 4372 & $8 / 13 / 200812: 12$ & 1.625 & 16.9 & 4441 & $8 / 13 / 200814: 30$ & 1.623 & 16.9 & 4510 & $8 / 13 / 200816: 48$ & 1.629 & 16.9 & 4579 & $8 / 13 / 2008$ 19:06 & 1.631 & 16.9 \\
\hline 4373 & $8 / 13 / 200812: 14$ & 1.625 & 16.9 & 4442 & $8 / 13 / 200814: 32$ & 1.624 & 16.9 & 4511 & $8 / 13 / 200816: 50$ & 1.63 & 16.9 & 4580 & $8 / 13 / 200819: 08$ & 1.631 & 16.9 \\
\hline 4374 & $8 / 13 / 200812: 16$ & 1.625 & 16.9 & 4443 & $8 / 13 / 200814: 34$ & 1.625 & 16.9 & 4512 & $8 / 13 / 200816: 52$ & 1.631 & 16.9 & 4581 & $8 / 13 / 2008$ 19:10 & 1.631 & 16.9 \\
\hline 4375 & $8 / 13 / 2008$ 12:18 & 1.626 & 16.9 & 4444 & $8 / 13 / 200814: 36$ & 1.626 & 16.9 & 4513 & $8 / 13 / 2008$ 16:54 & 1.631 & 16.9 & 4582 & $8 / 13 / 2008$ 19:12 & 1.63 & 16.9 \\
\hline 4376 & $8 / 13 / 200812: 20$ & 1.625 & 16.9 & 4445 & $8 / 13 / 200814: 38$ & 1.627 & 16.9 & 4514 & $8 / 13 / 200816: 56$ & 1.63 & 16.9 & 4583 & $8 / 13 / 2008$ 19:14 & 1.631 & 16.9 \\
\hline 4377 & $8 / 13 / 200812: 22$ & 1.625 & 16.9 & 4446 & $8 / 13 / 200814: 40$ & 1.626 & 16.9 & 4515 & $8 / 13 / 200816: 58$ & 1.63 & 16.9 & 4584 & $8 / 13 / 2008$ 19:16 & 1.631 & 16.9 \\
\hline 4378 & $8 / 13 / 2008$ 12:24 & 1.626 & 16.9 & 4447| & $8 / 13 / 200814: 42$ & 1.627 & 16.9 & 4516 & $8 / 13 / 2008$ 17:00 & 1.631 & 16.9 & 4585 & $8 / 13 / 2008$ 19:18 & 1.63 & 16.9 \\
\hline 4379 & $8 / 13 / 200812: 26$ & 1.625 & 16.9 & 4448 & $8 / 13 / 200814: 44$ & 1.627 & 16.9 & 4517 & $8 / 13 / 2008$ 17:02 & 1.63 & 16.9 & 4586 & $8 / 13 / 200819: 20$ & 1.63 & 16.9 \\
\hline 4380 & $8 / 13 / 200812: 28$ & 1.625 & 16.9 & 4449 & $8 / 13 / 200814: 46$ & 1.627 & 16.9 & 4518 & $8 / 13 / 200817: 04$ & 1.631 & 16.9 & 4587 & $8 / 13 / 200819: 22$ & 1.63 & 16.9 \\
\hline 4381 & $8 / 13 / 2008$ 12:30 & 1.626 & 16.9 & 4450 & $8 / 13 / 200814: 48$ & 1.628 & 16.9 & 4519 & $8 / 13 / 200817: 06$ & 1.631 & 16.9 & 4588 & $8 / 13 / 200819: 24$ & 1.631 & 16.9 \\
\hline 4382 & $8 / 13 / 20081232$ & 1.625 & 16.9 & 4451 & $8 / 13 / 200814: 50$ & 1.628 & 16.9 & 4520 & $8 / 13 / 200817: 08$ & 1.629 & 16.9 & 4589 & $8 / 13 / 200819: 26$ & 1.63 & 16.9 \\
\hline 4383 & $8 / 13 / 2008$ 12:34 & 1.625 & 16.9 & 4452 & $8 / 13 / 200814: 52$ & 1.628 & 16.9 & 4521 & $8 / 13 / 2008$ 17:10 & 1.626 & 16.9 & 4590 & $8 / 13 / 2008$ 19:28 & 1.63 & 16.9 \\
\hline
\end{tabular}


DOE/RL-2009-35, REV. 0

\begin{tabular}{|c|c|c|c|}
\hline \multicolumn{4}{|c|}{$D 4-27 p$} \\
\hline $\operatorname{Rec}$ & & Pres & Temp \\
\hline \# & Date/Time & $\overline{p s i}$ & ${ }^{\circ} \mathrm{C}$ \\
\hline 4591 & $8 / 13 / 200819: 30$ & 1.63 & 16.9 \\
\hline 4592 & $8 / 13 / 200819: 32$ & 1.629 & 16.9 \\
\hline 4593 & $8 / 13 / 200819: 34$ & 1.63 & 16.9 \\
\hline 4594 & $8 / 13 / 200819: 36$ & 1.631 & 16.9 \\
\hline 4595 & $8 / 13 / 200819: 38$ & 1.631 & 16.9 \\
\hline 4596 & $8 / 13 / 200819: 40$ & 1.631 & 16.9 \\
\hline 4597 & $8 / 13 / 200819: 42$ & 1.631 & 16.9 \\
\hline 4598 & $8 / 13 / 200819: 44$ & 1.63 & 16.9 \\
\hline 4599 & $8 / 13 / 200819: 46$ & 1.63 & 16.9 \\
\hline 4600 & $8 / 13 / 200819: 48$ & 1.631 & 16.9 \\
\hline 4601 & $8 / 13 / 200819: 50$ & 1.63 & 16.9 \\
\hline 4602 & $8 / 13 / 200819: 52$ & 1.629 & 16.9 \\
\hline 4603 & $8 / 13 / 200819: 54$ & 1.629 & 16.9 \\
\hline 4604 & $8 / 13 / 200819: 56$ & 1.629 & 16.9 \\
\hline 4605 & $8 / 13 / 200819: 58$ & 1.625 & 17.1 \\
\hline 4606 & $8 / 13 / 200820: 00$ & 1.624 & 17 \\
\hline 4607 & $8 / 13 / 200820: 02$ & 1.622 & 16.9 \\
\hline 4608 & $8 / 13 / 200820: 04$ & 1.619 & 16.9 \\
\hline 4609 & $8 / 13 / 200820: 06$ & 1.615 & 16.9 \\
\hline 4610 & $8 / 13 / 200820: 08$ & 1.611 & 16.9 \\
\hline 4611 & $8 / 13 / 200820: 10$ & 1.613 & 16.9 \\
\hline 4612 & $8 / 13 / 200820: 12$ & 1.616 & 16.9 \\
\hline 4613 & $8 / 13 / 200820: 14$ & 1.619 & 16.9 \\
\hline 4614 & $8 / 13 / 200820: 16$ & 1.622 & 16.9 \\
\hline 4615 & $8 / 13 / 200820: 18$ & 1.623 & 16.9 \\
\hline 4616 & $8 / 13 / 200820: 20$ & 1.625 & 16.9 \\
\hline 4617 & $8 / 13 / 200820: 22$ & 1.625 & 16.9 \\
\hline 4618 & $8 / 13 / 200820: 24$ & 1.625 & 16.9 \\
\hline 4619 & $8 / 13 / 200820: 26$ & 1.625 & 16.9 \\
\hline 4620 & $8 / 13 / 200820: 28$ & 1.625 & 16.9 \\
\hline 4621 & $8 / 13 / 200820: 30$ & 1.625 & 16.9 \\
\hline 4622 & $8 / 13 / 200820: 32$ & 1.625 & 16.9 \\
\hline 4623 & $8 / 13 / 200820: 34$ & 1.624 & 16.9 \\
\hline 4624 & $8 / 13 / 200820: 36$ & 1.624 & 16.9 \\
\hline 4625 & $8 / 13 / 200820: 38$ & 1.624 & 16.9 \\
\hline 4626 & $8 / 13 / 200820: 40$ & 1.624 & 16.9 \\
\hline 4627 & $8 / 13 / 200820: 42$ & 7.624 & 16.9 \\
\hline 4628 & $8 / 13 / 200820: 44$ & 1.624 & 16.9 \\
\hline 4629 & $8 / 13 / 200820: 46$ & 1.625 & 16.9 \\
\hline 4630 & $8 / 13 / 200820: 48$ & 1.625 & 16.9 \\
\hline 4631 & $8 / 13 / 200820: 50$ & 1.625 & 16.9 \\
\hline 4632 & $8 / 13 / 200820: 52$ & 1.626 & 16.9 \\
\hline 4633 & $8 / 13 / 200820: 54$ & 1.625 & 16.9 \\
\hline 4634 & $8 / 13 / 200820: 56$ & 1.625 & 16.9 \\
\hline 4635 & $8 / 13 / 200820: 58$ & 1.625 & 16.9 \\
\hline 4636 & $8 / 13 / 200821: 00$ & 1.625 & 16.9 \\
\hline 4637 & $8 / 13 / 200821: 02$ & 1.625 & 16.9 \\
\hline 4638 & $8 / 13 / 200821: 04$ & 1.625 & 16.9 \\
\hline 4639 & $8 / 13 / 200821: 06$ & 1.626 & 16.9 \\
\hline 4640 & $8 / 13 / 200821: 08$ & 1.626 & 16.9 \\
\hline 4641 & $8 / 13 / 200821: 10$ & 1.626 & 16.9 \\
\hline 4642 & $8 / 13 / 200821: 12$ & 1.625 & 16.9 \\
\hline 4643 & $8 / 13 / 200821: 14$ & 1.627 & 16.9 \\
\hline 4644 & $8 / 13 / 200821: 16$ & 1.626 & 16.9 \\
\hline 4645 & $8 / 13 / 200821: 18$ & 1.627 & 16.9 \\
\hline 4646 & $8 / 13 / 200821: 20$ & 1.626 & 16.9 \\
\hline 4647 & $8 / 13 / 200821: 22$ & 1.624 & 16.9 \\
\hline 4648 & $8 / 13 / 200821: 24$ & 1.625 & 16.9 \\
\hline 4649 & $8 / 13 / 200821: 26$ & 1.624 & 16.9 \\
\hline 4650 & $8 / 13 / 200821: 28$ & 1.625 & 16.9 \\
\hline 4651 & $8 / 13 / 200821: 30$ & 1.625 & 16.9 \\
\hline 4652 & $8 / 13 / 200821: 32$ & 1.625 & 16.9 \\
\hline 4653 & $8 / 13 / 200821: 34$ & 1.625 & 16.9 \\
\hline 4654 & $8 / 13 / 200821: 36$ & 1.626 & 16.9 \\
\hline 4655 & $8 / 13 / 200821: 38$ & 1.625 & 16.9 \\
\hline 4656 & $8 / 13 / 200821: 40$ & 1.626 & 16.9 \\
\hline 4657 & $8 / 13 / 200821: 42$ & 1.626 & 16.9 \\
\hline 4658 & $8 / 13 / 200821: 44$ & 1.626 & 16.9 \\
\hline 4659 & $8 / 13 / 200821: 46$ & 1.625 & 16.9 \\
\hline
\end{tabular}

\begin{tabular}{|c|c|c|c|}
\hline \multicolumn{4}{|c|}{ D4-27p } \\
\hline $\operatorname{Rec}$ & & Pres & Temp \\
\hline$\#$ & DaterTime & $p s i$ & ${ }^{\circ} \mathrm{C}$ \\
\hline 4660 & $8 / 13 / 200821: 48$ & 1.626 & 16.9 \\
\hline 4661 & $8 / 13 / 200821: 50$ & 1.626 & 16.9 \\
\hline 4662 & $8 / 13 / 200821: 52$ & 1.626 & 16.9 \\
\hline 4663 & $813 / 200821: 54$ & 1.626 & 16.9 \\
\hline 4664 & $8 / 13 / 200821: 56$ & 1.626 & 16.9 \\
\hline 4665 & $8 / 13 / 200821: 58$ & 1.627 & 16.9 \\
\hline 4666 & $8 / 13 / 200822 \cdot 00$ & 1.627 & 16.9 \\
\hline 4667 & $8 / 13 / 200822: 02$ & 1.626 & 16.9 \\
\hline 4668 & $8 / 13 / 200822: 04$ & 1.624 & 16.9 \\
\hline 4669 & $8 / 13 / 200822: 06$ & 1.62 & 16.9 \\
\hline 4670 & $8 / 13 / 200822: 08$ & 1.616 & 16.9 \\
\hline 4671 & $8 / 13 / 200822: 10$ & 1.612 & 16.9 \\
\hline 4672 & $8 / 13 / 200822: 12$ & 1.61 & 17 \\
\hline 4673 & $8 / 13 / 200822: 14$ & 1.605 & 16.9 \\
\hline 4674 & $8 / 13 / 200822: 16$ & 1.604 & 16.9 \\
\hline 4675 & $8 / 13 / 200822: 18$ & 1.601 & 17.3 \\
\hline 4676 & $8 / 13 / 200822: 20$ & 1.6 & 17.3 \\
\hline 4677 & $8 / 13 / 200822: 22$ & 1.599 & 17 \\
\hline 4678 & $8 / 13 / 200822: 24$ & 1.597 & 16.9 \\
\hline 4679 & $8 / 13 / 200822: 26$ & 1.597 & 16.9 \\
\hline 4680 & $8 / 13 / 200822: 28$ & 1.596 & 16.9 \\
\hline 4681 & $8 / 13 / 200822: 30$ & 1.595 & 16.9 \\
\hline 4682 & $8 / 13 / 200822: 32$ & 1.593 & 16.9 \\
\hline 4683 & $8 / 13 / 200822: 34$ & 1.592 & 16.9 \\
\hline 4684 & $8 / 13 / 200822: 36$ & 1.591 & 16.9 \\
\hline 4685 & $8 / 13 / 200822: 38$ & 1.59 & 16.9 \\
\hline 4686 & $8 / 13 / 200822: 40$ & 1.59 & 16.9 \\
\hline 4687 & $8 / 13 / 200822: 42$ & 1.589 & 16.9 \\
\hline 4688 & $8 / 13 / 200822: 44$ & 1.589 & 16.9 \\
\hline 4689 & $8 / 13 / 200822: 46$ & 1.588 & 16.9 \\
\hline 4690 & $8 / 13 / 200822: 48$ & 1.588 & 16.9 \\
\hline 4691 & $8 / 13 / 200822: 50$ & 1.588 & 16.9 \\
\hline 4692 & $8 / 13 / 200822: 52$ & 1.587 & 16.9 \\
\hline 4693 & $8 / 13 / 20082254$ & 1.586 & 16.9 \\
\hline 4694 & $8113 / 200822: 56$ & 1.586 & 16.9 \\
\hline 4695 & $8 / 13 / 200822: 58$ & 1.585 & 16.9 \\
\hline 4696 & $8 / 13 / 200823: 00$ & 1.584 & 16.9 \\
\hline 4697 & $8 / 13 / 200823: 02$ & 1.582 & 16.9 \\
\hline 4698 & $8 / 13 / 200823: 04$ & 1.582 & 16.9 \\
\hline 4699 & $8 / 13 / 200823: 06$ & 1.581 & 16.9 \\
\hline 4700 & $8 / 13 / 200823: 08$ & 1.581 & 16.9 \\
\hline 4701 & $8 / 13 / 200823: 10$ & 1.581 & 16.9 \\
\hline 4702 & $8 / 13 / 200823: 12$ & 1.58 & 16.9 \\
\hline 4703 & $8 / 13 / 200823: 14$ & 1.579 & 16.9 \\
\hline 4704 & $8 / 13 / 200823: 16$ & 1.578 & 16.9 \\
\hline 4705 & $8 / 13 / 200823: 18$ & 1.577 & 16.9 \\
\hline 4706 & $8 / 13 / 200823: 20$ & 1.576 & 16.9 \\
\hline 4707 & $8 / 13 / 200823: 22$ & 1.576 & 16.9 \\
\hline 4708 & $8 / 13 / 200823: 24$ & 1.576 & 16.9 \\
\hline 4709 & $8 / 13 / 200823: 26$ & 1.575 & 16.9 \\
\hline 4710 & $8 / 13 / 200823: 28$ & 1.576 & 16.9 \\
\hline 4711 & $8 / 13 / 200823: 30$ & 1.574 & 16.9 \\
\hline 4712 & $8 / 13 / 200823: 32$ & 1.574 & 16.9 \\
\hline 4713 & $8 / 13 / 200823: 34$ & 1.574 & 16.9 \\
\hline 4714 & $8 / 13 / 200823: 36$ & 1.573 & 16.9 \\
\hline 4715 & $8 / 13 / 200823: 38$ & 1.572 & 16.9 \\
\hline 4716 & $8 / 13 / 200823: 40$ & 1.572 & 16.9 \\
\hline 4717 & $8 / 13 / 200823: 42$ & 1.572 & 16.9 \\
\hline 4718 & $8 / 13 / 200823: 44$ & 1.57 & 16.9 \\
\hline 4719 & $8 / 13 / 200823: 46$ & 1.57 & 16.9 \\
\hline 4720 & $8 / 13 / 200823: 48$ & 1.569 & 16.9 \\
\hline 4721 & $8 / 13 / 200823: 50$ & 1.569 & 16.9 \\
\hline 472 & $8 / 13 / 200823: 52$ & 1.568 & 16.9 \\
\hline 4723 & $8 / 13 / 200823: 54$ & 1.568 & 16.9 \\
\hline 4724 & $8 / 13 / 200823: 56$ & 1.568 & 16.9 \\
\hline 4725 & $8 / 13 / 200823: 58$ & 1.568 & 16.9 \\
\hline 4726 & $8 / 14 / 20080: 00$ & 1.567 & 16.9 \\
\hline 4727 & $8 / 14 / 20080: 02$ & 1.566 & 16.9 \\
\hline 4728 & $8 / 14 / 20080: 04$ & 1.566 & 16.9 \\
\hline
\end{tabular}

\begin{tabular}{|c|c|c|c|}
\hline \multicolumn{4}{|c|}{ D4-27p } \\
\hline $\operatorname{Rec}$ & & Pres & Temp \\
\hline \# & DateTime & psi & ${ }^{\circ} \mathrm{C}$ \\
\hline 4729 & $8 / 14 / 20080: 06$ & 1.565 & 16.9 \\
\hline 4730 & $8 / 14 / 20080: 08$ & 1.565 & 16.9 \\
\hline 4731 & $8 / 14 / 20080: 10$ & 1.564 & 16.9 \\
\hline 4732 & $8 / 14 / 20080: 12$ & 1.563 & 16.9 \\
\hline 4733 & $14 / 20080: 14$ & 1.563 & 16.9 \\
\hline 4734 & $8 / 14 / 20080: 16$ & 1.563 & 16.9 \\
\hline 4735 & $8 / 14 / 20080: 18$ & 1.562 & 16.9 \\
\hline 4736 & $8 / 14 / 20080: 20$ & 1.562 & 16.9 \\
\hline 4737 & $114 / 20080: 22$ & 1.561 & 16.9 \\
\hline 4738 & $8 / 14 / 20080: 24$ & 1.561 & 16.9 \\
\hline 4739 & $8 / 14 / 20080: 26$ & 1.561 & 16.9 \\
\hline 4740 & $1 / 4 / 20080: 28$ & 1.56 & 16.9 \\
\hline 4741 & $14 / 20080: 30$ & 1.56 & $16 . \overline{9}$ \\
\hline 4742 & $8 / 14 / 20080: 32$ & 1.559 & 16.9 \\
\hline 4743 & $8 / 14 / 20080: 34$ & 1.558 & 16.9 \\
\hline 4744 & $8 / 14 / 20080: 36$ & 1.558 & 16.9 \\
\hline 4745 & $20080: 38$ & 1.557 & 16.9 \\
\hline 4746 & $8 / 14 / 20080: 40$ & 1.557 & $16 . \overline{9}$ \\
\hline 4747 & $8 / 14 / 20080: 42$ & 1.557 & 16.9 \\
\hline 4748 & $8 / 14 / 20080: 44$ & 1.556 & 16.9 \\
\hline 4749 & $30: 46$ & 1.557 & 16.9 \\
\hline 4750 & $20080: 48$ & 1.557 & 16.9 \\
\hline 4751 & $8 / 14 / 20080: 50$ & 1.557 & 16.9 \\
\hline 4752 & $1 / 20080: 52$ & 1.556 & 16.9 \\
\hline 4753 & $0: 54$ & 1.557 & 16.9 \\
\hline 4754 & $0: 56$ & 1.555 & 16.9 \\
\hline 4755 & $8 / 14 / 20080: 58$ & 1.555 & 16.9 \\
\hline 4756 & $8 / 14 / 20081: 00$ & 1.555 & $\overline{16.9}$ \\
\hline 4757 & $1: 02$ & 1.554 & 16.9 \\
\hline 4758 & $1: 04$ & 1.553 & 16.9 \\
\hline 4759 & $8 / 14 / 20081: 06$ & 1.553 & 16.9 \\
\hline 4760 & $8 / 14 / 2008 t: 08$ & 1.553 & 16.9 \\
\hline 4761 & $31: 10$ & 1.553 & 16.9 \\
\hline 4762 & $1: 12$ & 1.551 & 16.9 \\
\hline 4763 & $8 / 14 / 20081: 14$ & 1.552 & 16.9 \\
\hline 4764 & $8 / 14 / 20081: 16$ & 1.551 & 16.9 \\
\hline 4765 & $31: 18$ & 1.55 & 16.9 \\
\hline 4766 & $1: 20$ & 1.55 & 16.9 \\
\hline 4767 & $81: 22$ & 1.549 & 16.9 \\
\hline 4768 & $/ 20081: 24$ & 1.549 & 16.9 \\
\hline 4769 & $31: 26$ & 1.548 & 16.9 \\
\hline 4770 & $1: 28$ & 1.547 & 16.9 \\
\hline 4771 & $31: 30$ & 1.548 & 16.9 \\
\hline 4772 & $8 / 14 / 20081: 32$ & 1.548 & 16.9 \\
\hline 4773 & $8 / 14 / 20081: 34$ & 1.548 & 16.9 \\
\hline 4774 & $1: 36$ & 1.547 & 16.9 \\
\hline 4775 & $1: 38$ & 1.546 & 16.9 \\
\hline 4776 & $4 / 20081: 40$ & 1.545 & 16.9 \\
\hline 4777 & $8 / 14 / 20081: 42$ & 1.545 & 16.9 \\
\hline 4778 & $31: 44$ & 1.545 & 16.9 \\
\hline 4779 & $1: 46$ & 1.545 & 16.9 \\
\hline $4 \overline{780}$ & $31: 48$ & 1.545 & 16.9 \\
\hline 4781 & $8 / 14 / 20081: 50$ & 1.545 & 16.9 \\
\hline 4782 & $8 / 14 / 20081: 52$ & 1.544 & 16.9 \\
\hline 4783 & $1: 54$ & 1.544 & 16.9 \\
\hline 4784 & $1: 56$ & 1.543 & 16.9 \\
\hline 4785 & $8 / 14 / 20081: 58$ & 1.543 & 16.9 \\
\hline 4786 & $8 / 14 / 20082: 00$ & 1.543 & 16.9 \\
\hline 4787 & $2: 02$ & 1.544 & 16.9 \\
\hline 4788 & $\overline{82: 04}$ & 1.543 & 16.9 \\
\hline 4789 & $8 / 14 / 200$ & $\overline{1.543}$ & 16.9 \\
\hline 4790 & $8 / 14 / 20082: 08$ & 1.541 & 16.9 \\
\hline 4791 & $8 / 14 / 20082: 10$ & 1.543 & 16.9 \\
\hline 4792 & $14 / 20082: 12$ & 1.495 & 16.9 \\
\hline 4793 & $8 / 14 / 20082: 14$ & 1.541 & 16.9 \\
\hline 4794 & $8 / 14 / 20082: 16$ & 1.541 & 16.9 \\
\hline 4795 & $8 / 14 / 20082: 18$ & 1.54 & 16.9 \\
\hline 4796 & $8 / 14 / 20082: 20$ & 1.54 & 16.9 \\
\hline 4797 & $8 / 14 / 20082: 22$ & 1.54 & 16.9 \\
\hline
\end{tabular}

\begin{tabular}{|c|c|c|c|}
\hline \multicolumn{4}{|c|}{ D427] } \\
\hline $\operatorname{Rec}$ & & Pres & \\
\hline$\#$ & DaterTime & psi & ${ }^{\circ} \mathrm{C}$ \\
\hline 4796 & $8 / 14 / 20082: 24$ & 1.54 & 16.9 \\
\hline 4799 & $8 / 14 / 20082: 26$ & 1.54 & $\overline{16.9}$ \\
\hline 4800 & $8 / 14 / 20082: 28$ & 1.54 & 16.9 \\
\hline 4801 & $8 / 14 / 20082: 30$ & & 16.9 \\
\hline 4802 & $8 / 14 / 20082 \cdot 32$ & 1.54 & 16: $>>$ \\
\hline 480 & $8 / 14 / 20082: 34$ & 1.539 & 16. \\
\hline 4804 & $8 / 14 / 20082: 36$ & 1.53 & \\
\hline 4805 & $8 / 14 / 20082: 38$ & 1.538 & 16. \\
\hline 4806 & $8 / 14 / 20082: 40$ & 1.538 & 16! \\
\hline 4807 & $8 / 1 / 420082: 42$ & $1.538>$ & 16.5 \\
\hline 4808 & $8 / 14 / 20082: 44$ & 1.537 & 16.8 \\
\hline 4809 & $8 / 14 / 20082: 46$ & 1.537 & 16. \\
\hline 4810 & $8 / 14 / 20082: 48$ & & 16. \\
\hline 481 & $8 / 14 / 20082: 50$ & 1.537 & 16. \\
\hline 481 & 8/14/2008 2:52 & 1.536 & 16. \\
\hline 48 & $8 / 14 / 20082: 54$ & 1.536 & 16. \\
\hline$\overline{4814}$ & 8/14/20082:56 & 1.535 & $\overline{16 !}$ \\
\hline 4815 & $8 / 14 / 20082: 58$ & 1.535 & 16. \\
\hline 4816 & $8 / 14 / 20083: 00$ & 1.534 & 16. \\
\hline 4817 & $8 / 14 / 20083: 02$ & 1.533 & 16. \\
\hline 4818 & $8 / 14 / 20083: 04$ & & 16. \\
\hline 4819 & $8 / 14 / 20083: 06$ & 1.533 & 16. \\
\hline 4820 & 8/14/20083:08 & 1.532 & $\overline{16 !}$ \\
\hline 4821 & 8/14/20083:10 & 1.532 & $\overline{16.5}>>$ \\
\hline & $8 / 14 / 20083: 12$ & 1.53 & 16. \\
\hline & & 1.53 & \\
\hline 482 & 8/14/20083:16 & 1.55 & 16. \\
\hline 4825 & 8/14/20083:18 & 1.53 & $\overline{16 !} 5$ \\
\hline 4826 & $8 / 14 / 20083: 20$ & 1.532 & 16. \\
\hline 4827 & $8 / 14 / 20083: 22$ & 1.532 & 16. \\
\hline 4828 & 8/14/20083:24 & 1.531 & 16. \\
\hline 482. & $8 / 14 / 20083: 26$ & 1.53 & 16. \\
\hline $483 \mathrm{C}$ & $8 / 14 / 20083: 28$ & 1.53 & 16. \\
\hline 483 & $8 / 14 / 20083: 30$ & 1.53 & 16 \\
\hline $48^{2}$ & $083: 32$ & 1.53 & 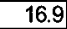 \\
\hline & & 1.529 & \\
\hline 48 & $0083: 36$ & 1.52. & 16. \\
\hline 48 & & 1.528 & 16! \\
\hline 48 & $83: 40$ & 1.527 & 16!: $>$ \\
\hline 483 & $8 / 14 / 20083: 42$ & 1.528 & 16. \\
\hline & $8 / 14 / 20083: 44$ & 1.526 & \\
\hline & $8 / 14 / 20083: 46$ & 1.528 & 16. \\
\hline 484 & $8 / 14 / 20083: 48$ & 1.527 & 16 . \\
\hline 484 & $8 / 14 / 20083: 50$ & 1.527 & 16. \\
\hline 48. & $8 / 14 / 2 / 2$ & 1.527 & \\
\hline 48 & & 1.526 & \\
\hline 484 & $8 / 14 / 2$ & 1.526 & \\
\hline 48 & $83: 58$ & 1.525 & \\
\hline 4846 & & 1.525 & \\
\hline 48 & $8 / 14 / 200 t$ & 1.525 & 16. \\
\hline & & 1.525 & 16. \\
\hline & & 1.525 & 16. \\
\hline & $8 /$ & 1.525 & \\
\hline & $8 / 14 / 20$ & 1.523 & 16. \\
\hline 485 & $8 / 14 / 2008$ & & 16. \\
\hline 4855 & $8 / 14 / 20084: 14$ & 1.524 & 16. \\
\hline 485 & $8 / 14 / 2 / 2$ & $\overline{1.524}$ & \\
\hline $48: 2-3$ & & & \\
\hline 48 & & & \\
\hline & & & \\
\hline & & 1.52 & \\
\hline & & 1.523 & \\
\hline 4860 & & 1.522 & $\overline{16 ! !}$ \\
\hline 486 & $8 / 14 / 20084: 30$ & 1.522 & 16.5 \\
\hline 4862 & $8 / 14 / 20084: 32$ & 1.522 & 16.5 \\
\hline 4863 & $8 / 14 / 20$ & 1502 & \\
\hline 4864 & $8 / 14 / 20$ & 1.52 & \\
\hline 4865 & $8 / 14 / 20084: 38$ & 1.521 & \\
\hline & & $\overline{1.52} \mathrm{Y}$ & \\
\hline
\end{tabular}




\begin{tabular}{|c|c|c|c|c|c|c|c|c|c|c|c|c|c|c|c|}
\hline \multicolumn{4}{|c|}{ D4-27p } & \multicolumn{4}{|c|}{ D4-27p } & \multicolumn{4}{|c|}{ D4-27p } & \multicolumn{4}{|c|}{ D4-27p } \\
\hline $\operatorname{Rec}$ & & Pres & Temp & Rec & & Pres & Temp & $\operatorname{Rec}$ & & Pres & Temp & $\operatorname{Rec}$ & & Pres & Temp \\
\hline$\#$ & Date/Time & psi & ${ }^{\circ} \mathrm{C}$ & $\#$ & Date/Time & psi & ${ }^{\circ} \mathrm{C}$ & $\#$ & DaterTime & psi & ${ }^{\circ} \mathrm{C}$ & $\#$ & Date-Time & psi & ${ }^{\circ} \mathrm{C}$ \\
\hline 4867 & $8 / 14 / 20084: 42$ & 1.52 & 16.9 & 4936 & $8 / 14 / 20087: 00$ & 1.504 & 16.9 & 5005 & $8 / 14 / 20089: 18$ & 1.495 & 16.9 & 5074 & $8 / 14 / 200811: 36$ & 1.487 & 16.9 \\
\hline 4868 & $8 / 14 / 20084: 44$ & 1.519 & 16.9 & 4937 & $8 / 14 / 20087: 02$ & 1.504 & 16.9 & 5006 & $8 / 14 / 20089: 20$ & 1.495 & 16.9 & 5075 & $8 / 14 / 200811: 38$ & 1.487 & 16.9 \\
\hline 4869 & $8 / 14 / 20084: 46$ & 1.519 & 16.9 & 4938 & $8 / 14 / 20087: 04$ & 1.505 & 16.9 & 5007 & $8 / 14 / 20089: 22$ & 1.495 & 16.9 & 5076 & $8 / 14 / 200811: 40$ & 1.486 & 16.9 \\
\hline 4870 & $8 / 14 / 20084: 48$ & 1.519 & 16.9 & 4939 & 8/14/2008 7:06 & 1.503 & 16.9 & 5008 & 8/14/2008 9:24 & 1.495 & 16.9 & 5077 & $8 / 14 / 200811: 42$ & 1.487 & 16.9 \\
\hline 4871 & $8 / 14 / 20084: 50$ & 1.519 & 16.9 & 4940 & 8/14/2008 7:08 & 1.503 & 16.9 & 5009 & $8 / 14 / 20089: 26$ & 1.495 & 16.9 & 5078 & $8 / 14 / 200811: 44$ & 1.486 & 16.9 \\
\hline 4872 & $8 / 14 / 20084: 52$ & 1.519 & 16.9 & 4941 & $8 / 14 / 20087: 10$ & 1.503 & 16.9 & 5010 & $8 / 14 / 20089: 28$ & 1.494 & 16.9 & 5079 & $8 / 14 / 200811: 46$ & 1.487 & 16.9 \\
\hline 4873 & $8 / 14 / 20084: 54$ & 1.519 & 16.9 & 4942 & $8 / 14 / 20087: 12$ & 1.503 & 16.9 & 5011 & $8 / 14 / 20089: 30$ & 1.494 & 16.9 & 5080 & $8 / 14 / 200811: 48$ & 1.486 & 16.9 \\
\hline 4874 & $8 / 14 / 20084: 56$ & 1.518 & 16.9 & 4943 & $8 / 14 / 20087: 14$ & 1.502 & 16.9 & 5012 & $8 / 14 / 20089: 32$ & 1.494 & 16.9 & 5081 & $8 / 14 / 200811: 50$ & 1.486 & 16.9 \\
\hline 4875 & $8 / 14 / 20084: 58$ & 1.518 & 16.9 & 4944 & $8 / 14 / 20087: 16$ & 1.503 & 16.9 & 5013 & $8 / 14 / 20089: 34$ & 1.496 & 16.9 & 5082 & $8 / 14 / 200811: 52$ & 1.486 & 16.9 \\
\hline 4876 & $8 / 14 / 20085: 00$ & 1.518 & 16.9 & 4945 & $8 / 14 / 20087: 18$ & 1.502 & 16.9 & 5014 & $8 / 14 / 20089: 36$ & 1.495 & 16.9 & 5083 & $8 / 14 / 200811: 54$ & 1.486 & 16.9 \\
\hline 4877 & $8 / 14 / 20085: 02$ & 1.518 & 16.9 & 4946 & $8 / 14 / 20087: 20$ & 1.503 & 16.9 & 5015 & $8 / 14 / 20089: 38$ & 1.494 & 16.9 & 5084 & $8 / 14 / 200811: 56$ & 1.486 & 16.9 \\
\hline 4878 & $8 / 14 / 20085: 04$ & 1.517 & 16.9 & 4947 & $8 / 14 / 20087: 22$ & 1.503 & 16.9 & 5016 & $8 / 14 / 20089: 40$ & 1.494 & 16.9 & 5085 & $8 / 14 / 200811: 58$ & 1.486 & 16.9 \\
\hline 4879 & $8 / 14 / 20085: 06$ & 1.516 & 16.9 & 4948 & $8 / 14 / 20087: 24$ & 1.503 & 16.9 & 5017 & $8 / 14 / 20089: 42$ & 1.494 & 16.9 & 5086 & $8 / 14 / 200812: 00$ & 1.486 & 16.9 \\
\hline 4880 & $8 / 14 / 20085: 08$ & 1.516 & 16.9 & 4949 & $8 / 14 / 20087: 26$ & 1.502 & 16.9 & 5018 & $8 / 14 / 20089: 44$ & 1.494 & 16.9 & 5087 & $8 / 14 / 2008$ 12:02 & 1.486 & 16.9 \\
\hline 4881 & $8 / 14 / 20085: 10$ & 1.516 & 16.9 & 4950 & $8 / 14 / 20087: 28$ & 1.501 & 16.9 & 5019 & $8 / 14 / 20089: 46$ & 1.493 & 16.9 & 5088 & $8 / 14 / 200812: 04$ & 1.485 & 16.9 \\
\hline 4882 & $8 / 14 / 20085: 12$ & 1.516 & 16.9 & 4951 & $8 / 14 / 20087: 30$ & 1.501 & 16.9 & 5020 & $8 / 14 / 20089: 48$ & 1.494 & 16.9 & 5089 & $8 / 14 / 200812: 06$ & 1.486 & 16.9 \\
\hline 4883 & $8 / 14 / 20085: 14$ & 1.516 & 16.9 & 4952 & $8 / 14 / 20087: 32$ & 1.501 & 16.9 & 5021 & $8 / 14 / 20089: 50$ & 1.493 & 16.9 & 5090 & $8 / 14 / 200812: 08$ & 1.486 & 16.9 \\
\hline 4884 & $8 / 14 / 20085: 16$ & 1.516 & 16.9 & 4953 & $8 / 14 / 20087: 34$ & 1.501 & 16.9 & 5022 & $8 / 14 / 20089: 52$ & 1.494 & 16.9 & 5091 & $8 / 14 / 200812: 10$ & 1.486 & 16.9 \\
\hline 4885 & $0085: 18$ & 1.516 & 16.9 & 4954 & $8 / 14 / 20087: 36$ & 1.501 & 16.9 & 5023 & $8 / 14 / 20089: 54$ & 1.493 & 16.9 & 5092 & $8 / 14 / 200812: 12$ & 1.485 & 16.9 \\
\hline 4886 & $8 / 14 / 20085: 20$ & 1.516 & 16.9 & 4955 & $8 / 14 / 20087: 38$ & 1.501 & 16.9 & 5024 & $8 / 14 / 20089: 56$ & 1.494 & 16.9 & 5093 & $8 / 14 / 2008$ 12:14 & 1.486 & 16.9 \\
\hline 4887 & $8 / 14 / 20085: 22$ & 1.516 & 16.9 & 4956 & $8 / 14 / 20087: 40$ & 1.502 & 16.9 & 5025 & $8 / 14 / 20089.58$ & 1.493 & 16.9 & 5094 & $8 / 44200812 ; 16$ & 1.486 & 16.9 \\
\hline 4888 & $85: 24$ & 1.515 & 16.9 & 4957 & $8 / 14 / 20087: 42$ & 1.501 & 16.9 & 5026 & $8 / 14 / 200810: 00$ & 1.493 & 16.9 & 5095 & 0008 12:18 & 1.485 & 16.9 \\
\hline 4889 & $8 / 14 / 20085: 26$ & 1.515 & 16.9 & 4958 & $8 / 14 / 20087: 44$ & 1.502 & 16.9 & 5027 & $8 / 14 / 2008$ 10:02 & 1.492 & 16.9 & 5096 & $8 / 14 / 200812: 20$ & 1.484 & 16.9 \\
\hline 4890 & $8 / 14 / 20085: 28$ & 1.514 & 16.9 & 4959 & $8 / 14 / 20087: 46$ & 1.501 & 16.9 & 5028 & $8 / 14 / 2008$ 10:04 & 1.492 & 16.9 & 5097 & $8 / 14 / 2008$ 12:22 & 1.485 & 16.9 \\
\hline 4891 & 8/14/20085:30 & 1.514 & 16.9 & 4960 & $8 / 14 / 20087: 48$ & 1.501 & 16.9 & 5029 & $8 / 14 / 2008$ 10:06 & 1.492 & 16.9 & 5098 & $3812: 24$ & 1.485 & 16.9 \\
\hline 4892 & $0085: 32$ & 1.514 & 16.9 & 4961 & $8 / 14 / 20087: 50$ & 1.501 & 16.9 & 5030 & $8 / 14 / 2008$ 10:08 & 1.492 & 16.9 & 5099 & $312: 26$ & 1.485 & 16.9 \\
\hline 4893 & 8/14/20085:34 & 1.514 & 16.9 & 4962 & $8 / 14 / 20087: 52$ & 1.501 & 16.9 & 5031 & $8 / 14 / 2008$ 10:10 & 1.491 & 16.9 & 5100 & $8 / 14 / 2008$ 12:28 & 1.485 & 16.9 \\
\hline 4894 & $8 / 14 / 20085: 36$ & 1.514 & 16.9 & 4963 & $8 / 14 / 20087: 54$ & 1.5 & 16.9 & 5032 & $8 / 14 / 2008$ 10:12 & 1.49 & 16.9 & 5101 & $8 / 14 / 200812: 30$ & 1.485 & 16.9 \\
\hline 4895 & $5: 38$ & 1.513 & 16.9 & 4964 & $8 / 14 / 20087: 56$ & 1.5 & 16.9 & 5033 & $8 / 14 / 2008$ 10:14 & 1.49 & 16.9 & 5102 & & 1.485 & 16.9 \\
\hline 4896 & $8 / 14 / 20085: 40$ & 1.513 & 16.9 & 4965 & $8 / 14 / 20087: 58$ & 1.499 & 16.9 & 5034 & $8 / 14 / 2008$ 10:16 & 1.491 & 16.9 & 5103 & $8 / 14 / 200812: 34$ & 1.485 & 16.9 \\
\hline 4897 & $8 / 14 / 20085: 42$ & 1.513 & 16.9 & 4966 & $8 / 14 / 20088: 00$ & 1.5 & 16.9 & 5035 & $8 / 14 / 2008$ 10:18 & 1.49 & 16.9 & 5104 & $8 / 14 / 200812: 36$ & 1.485 & 16.9 \\
\hline 4898 & $8 / 14 / 20085: 44$ & 1.513 & 16.9 & 4967 & $8 / 14 / 20088: 02$ & 1.5 & 16.9 & 5036 & $8 / 14 / 2008$ 10:20 & 1.49 & 16.9 & 5105 & $0812: 38$ & 1.485 & 16.9 \\
\hline 4899 & $8 / 14 / 20085: 46$ & 1.513 & 16.9 & 4968 & $8 / 14 / 20088: 04$ & 1.5 & 16.9 & 5037 & $8 / 14 / 200810: 22$ & 1.491 & 16.9 & 5106 & $312: 40$ & 9.484 & 16.9 \\
\hline 4900 & $8 / 14 / 20085: 48$ & 1.512 & 16.9 & 4969 & 8/14/20088:06 & 1.5 & 16.9 & 5038 & $8 / 14 / 2008$ 10:24 & 1.491 & 16.9 & 5107 & $8 / 14 / 200812: 42$ & 1.484 & 16.9 \\
\hline 4901 & $8 / 14 / 20085: 50$ & 1.512 & 16.9 & 4970 & $8 / 14 / 20088: 08$ & 1.5 & 16.9 & 5039 & $8 / 14 / 200810: 26$ & 1.491 & 16.9 & 5108 & $8 / 14 / 200812: 44$ & 1.483 & 16.9 \\
\hline 4902 & $8 / 14 / 20085: 52$ & 1.512 & 16.9 & 4971 & 8/14/20088:10 & 1.499 & 16.9 & 5040 & $8 / 14 / 2008$ 10:28 & 1.491 & 16.9 & 5109 & $812: 46$ & 1.483 & 16.9 \\
\hline 4903 & $8 / 14 / 20085: 54$ & 1.511 & 16.9 & 4972 & $8 / 14 / 20088: 12$ & 1.499 & 16.9 & 5041 & $8 / 14 / 2008$ 10:30 & 1.491 & 16.9 & 5110 & $8 / 14 / 200812: 48$ & 1.483 & 16.9 \\
\hline 4904 & $8 / 14 / 20085: 56$ & 1.511 & 16.9 & 4973 & $8 / 14 / 20088: 14$ & 1.498 & 16.9 & 5042 & $8 / 14 / 200810: 32$ & 1.49 & 16.9 & 5111 & $8 / 14 / 200812: 50$ & 1.484 & 16.9 \\
\hline 4905 & $8 / 14 / 20085: 58$ & 1.512 & 16.9 & 4974 & $8 / 14 / 20088: 16$ & 1.498 & 16.9 & 5043 & $8 / 14 / 200$ & 1.49 & 16.9 & 5112 & $12: 52$ & 1.484 & 16.9 \\
\hline 4906 & $8 / 14 / 20086: 00$ & 1.512 & 16.9 & 4975 & $8 / 14 / 20088: 18$ & 1.499 & 16.9 & 5044 & $8 / 14 / 200810: 36$ & 1.49 & 16.9 & 5113 & $8 / 14 / 200812: 54$ & 1.483 & 16.9 \\
\hline 4907 & $8 / 14 / 20086: 02$ & 1.511 & 16.9 & 4976 & $8 / 14 / 20088: 20$ & 1.498 & 17.3 & 5045 & $8 / 14 / 2008$ 10:38 & 1.49 & 16.9 & 5114 & $8 / 14 / 2008$ 12:56 & 1.484 & 16.9 \\
\hline 4908 & 8/14/20086:04 & 1.51 & 16.9 & 4977 & $8 / 14 / 20088: 22$ & 1.503 & 17.5 & 5046 & $8 / 14 / 2008$ 10:40 & 1.49 & 16.9 & 5115 & $8 / 14 / 200812: 58$ & 1.483 & 16.9 \\
\hline 4909 & $8 / 14 / 20086: 06$ & 1.51 & 16.9 & 4978 & $8 / 14 / 20088: 24$ & 1.498 & 17.1 & 5047 & $8 / 14 / 2008$ 10:42 & 1.49 & 16.9 & 5116 & $0813: 00$ & 1.483 & 16.9 \\
\hline 4910 & $8 / 14 / 20086: 08$ & 1.507 & 16.9 & 4979 & $8 / 14 / 20088: 26$ & 1.498 & 17 & 5048 & $8 / 14 / 200810: 44$ & 1.491 & 16.9 & 5117 & $8 / 14 / 200813: 02$ & 1.483 & 16.9 \\
\hline 4911 & $8 / 14 / 20086: 10$ & 1.51 & 16.9 & 4980 & $8 / 14 / 20088: 28$ & 1.497 & 16.9 & 5049 & $8 / 14 / 200810: 46$ & 1.49 & 16.9 & 5118 & $8 / 14 / 200813: 04$ & 1.483 & 16.9 \\
\hline 4912 & $8 / 14 / 2$ & 1.508 & 16.9 & 4981 & $8 / 14 / 20088: 30$ & 1.497 & 16.9 & 5050 & $8 / 14 / 200$ & 1.489 & 16.9 & 5119 & $13: 06$ & 1.483 & 16.9 \\
\hline 4913 & $8 / 14 / 20086: 14$ & 1.508 & 16.9 & 4982 & $8 / 14 / 20088: 32$ & 1.498 & 16.9 & 5051 & $8 / 14 / 200$ & 1.49 & 16.9 & 5120 & $13: 08$ & 1.483 & 16.9 \\
\hline 4914 & $8 / 14 / 20086: 16$ & 1.51 & 16.9 & 4983 & $8 / 14 / 20088: 34$ & 1.497 & 16.9 & 5052 & $8 / 14 / 200810: 52$ & 1.49 & 16.9 & 5121 & $8 / 14 / 200813: 10$ & 1.484 & 16.9 \\
\hline 4915 & $8 / 14 / 20086: 18$ & 1.509 & 16.9 & 4984 & $8 / 14 / 20088: 36$ & 1.496 & 16.9 & 5053 & $8 / 14 / 200810: 54$ & 1.491 & 16.9 & 5122 & $8 / 14 / 200813: 12$ & 1.483 & 16.9 \\
\hline 4916 & & 1.509 & 16.9 & 4985 & $8 / 14 / 20088: 38$ & 1.496 & 16.9 & 5054 & $8 / 14 / 200$ & 1.49 & 16.9 & 5123 & $13: 14$ & 1.484 & 16.9 \\
\hline 4917 & $8 / 14 / 20086: 22$ & 1.508 & 16.9 & 4986 & $8 / 14 / 20088: 40$ & 1.497 & 16.9 & 5055 & $8 / 14 / 200810.58$ & 1.49 & 16.9 & 5124 & $8 / 14 / 200813: 16$ & 1.481 & 17.2 \\
\hline 4918 & $8 / 14 / 20086: 24$ & 1.508 & 16.9 & 4987 & $8 / 14 / 20088: 42$ & 1.497 & 16.9 & 5056 & $8 / 14 / 200811: 00$ & 1.49 & 16.9 & 5125 & $8 / 14 / 200813: 18$ & 1.484 & 17.1 \\
\hline 4919 & $8 / 14 / 20086: 26$ & 1.508 & 16.9 & 4988 & $8 / 14 / 20088: 44$ & 1.497 & 16.9 & 5057 & $8 / 14 / 2008$ 11:02 & 1.49 & 16.9 & 5126 & $8 / 14 / 200813: 20$ & 1.484 & 17 \\
\hline 4920 & $8 / 14 / 20086.28$ & 1.508 & 16.9 & 4989 & $8 / 14 / 20088: 46$ & 1.497 & 16.9 & 5058 & $8 / 14 / 2008$ 11:04 & 1.49 & 16.9 & 5127 & $8 / 14 / 200$ & 1.483 & 16.9 \\
\hline 4921 & $8 / 14 / 20086: 30$ & 1.507 & 16.9 & 4990 & $8 / 14 / 20088: 48$ & 1.496 & 16.9 & 5059 & $8 / 14 / 200811: 06$ & 1.49 & 16.9 & 5128 & $8 / 14 / 200813: 24$ & 1.483 & 16.9 \\
\hline 4922 & $8 / 14 / 20086: 32$ & 1.507 & 46.9 & 4991 & $8 / 14 / 20088: 50$ & 1.496 & 16.9 & 5060 & $8 / 14 / 2008$ 11:08 & 1.491 & 16.9 & 5129 & $8 / 14 / 200813: 26$ & 1.483 & 16.9 \\
\hline 4923 & $8 / 14 / 20086: 34$ & 1.507 & 16.9 & 4992 & $8 / 14 / 20088: 52$ & 1.496 & 16.9 & 5061 & $8 / 14 / 200811: 10$ & 1.491 & 16.9 & 5130 & $8 / 14 / 200813: 28$ & 1.483 & 16.9 \\
\hline 4924 & $8 / 14 / 20086: 36$ & 1.506 & 16.9 & 4993 & $8 / 14 / 20088: 54$ & 1.496 & 16.9 & 5062 & $8 / 14 / 2008$ 11:12 & 1.49 & 16.9 & 5131 & $8 / 14 / 200813: 30$ & 1.483 & 16.9 \\
\hline 4925 & $8 / 14 / 20086: 38$ & 1.505 & 16.9 & 4994 & $8 / 14 / 20088: 56$ & 1.496 & 16.9 & 5063 & $8 / 14 / 2008$ 11:14 & 1.489 & 16.9 & 5132 & $8 / 14 / 200813: 32$ & 1.483 & 16.9 \\
\hline 4926 & $8 / 14 / 20086: 40$ & 1.505 & 16.9 & 4995 & $8 / 14 / 20088.58$ & 1.495 & 16.9 & 5064 & $8 / 14 / 2008$ 11:16 & 1.488 & 16.9 & 5133 & $8 / 14 / 200813: 34$ & 1.482 & 16.9 \\
\hline 4927 & $8 / 14 / 20086: 42$ & 1.505 & 16.9 & 4996 & $8 / 14 / 20089: 00$ & 1.496 & 16.9 & 5065 & $8 / 14 / 2008$ 11:18 & 1.489 & 16.9 & 5134 & $8 / 14 / 200813: 36$ & 1.482 & 16.9 \\
\hline 4928 & $8 / 14 / 20086: 44$ & 1.505 & 16.9 & 4997 & 8/14/20089:02 & 1.495 & 16.9 & 5066 & $8 / 14 / 200811: 20$ & 1.488 & 16.9 & 5135 & $8 / 14 / 200813: 38$ & 1.482 & 16.9 \\
\hline 4929 & $8 / 14 / 20086: 46$ & 1.504 & 16.9 & 4998 & $8 / 14 / 20089: 04$ & 1.495 & 16.9 & 5067 & $8 / 14 / 2008$ 11:22 & 1.488 & 16.9 & 5136 & $8 / 14 / 200813: 40$ & 1.482 & 16.9 \\
\hline 4930 & $8 / 14 / 20086: 48$ & 1.505 & 16.9 & 4999 & $8 / 14 / 20089: 06$ & 1.495 & 16.9 & 5068 & $8 / 14 / 200811: 24$ & 1.488 & 16.9 & 5137 & $8 / 14 / 200813: 42$ & 1.482 & 16.9 \\
\hline 4931 & $8 / 14 / 20086: 50$ & 1.505 & 16.9 & 5000 & $8 / 14 / 20089: 08$ & 1.495 & 16.9 & 5069 & $8 / 14 / 2008$ 11:26 & 1.487 & 16.9 & 5138 & $8 / 14 / 200813: 44$ & 1.482 & 16.9 \\
\hline 4932 & $8 / 14 / 20086: 52$ & 1.505 & 16.9 & 5001 & 8/14/2008 9:10 & 1.495 & 16.9 & 5070 & $8 / 14 / 2008$ 11:28 & 1.488 & 16.9 & 5139 & $8 / 14 / 200813: 46$ & 1.482 & 16.9 \\
\hline 4933 & $8 / 14 / 20086: 54$ & 1.504 & 16.9 & 5002 & $8 / 14 / 20089: 12$ & 1.495 & 16.9 & 5071 & $8 / 14 / 200811: 30$ & 1.487 & 16.9 & 5140 & $8 / 14 / 200813: 48$ & 1.482 & 16.9 \\
\hline 4934 & $8 / 14 / 20086: 56$ & 1.504 & 16.9 & 5003 & $8 / 14 / 20089: 14$ & 1.495 & 16.9 & 5072 & $8 / 14 / 2008$ 11:32 & 1.488 & 16.9 & 5141 & $8 / 14 / 200813: 50$ & 1.482 & 16.9 \\
\hline 4935 & $8 / 14 / 20086: 58$ & 1.504 & 16.9 & 5004 & $8 / 14 / 20089: 16$ & 1.496 & 16.9 & 5073 & $8 / 14 / 200811: 34$ & 1.488 & 16.9 & 5142 & $8 / 14 / 200813: 52$ & 1.482 & 16.9 \\
\hline
\end{tabular}




\begin{tabular}{|c|c|c|c|c|c|c|c|c|c|c|c|c|c|c|c|}
\hline \multicolumn{4}{|c|}{ D4-27p } & \multicolumn{4}{|c|}{ D427p } & \multicolumn{4}{|c|}{ D4-27p } & \multicolumn{4}{|c|}{ D4-27p } \\
\hline Rec & & Pres & Temp & Rec & & Pres & Temp & Rec & & Pres & Temp & Rec & & Pres & Temp \\
\hline$\#$ & DaterTime & psi & ${ }^{\circ} \mathrm{C}$ & $\#$ & Date/Time & psi & ${ }^{\circ} \mathrm{C}$ & $\#$ & Date/Time & psi & ${ }^{\circ} \mathrm{C}$ & $\#$ & Date/Time & psi & ${ }^{\circ} \mathrm{C}$ \\
\hline 5143 & $8 / 14 / 200813: 54$ & 1.482 & 16.9 & 5212 & $8 / 14 / 200816: 12$ & 1.476 & 16.9 & 5281 & $8 / 14 / 200818: 30$ & 1.472 & 16.9 & 5350 & $8 / 14 / 200820: 48$ & 1.467 & 16.9 \\
\hline 5144 & $8 / 14 / 200813: 56$ & 1.485 & 16.9 & 5213 & $8 / 14 / 2008$ 16:14 & 1.476 & 16.9 & 5282 & $8 / 14 / 200818: 32$ & 1.473 & 16.9 & 5351 & $8 / 14 / 200820: 50$ & 1.467 & 16.9 \\
\hline 5145 & $8 / 14 / 200813: 58$ & 1.482 & 16.9 & 5214 & $8 / 14 / 200816: 16$ & 1.476 & 16.9 & 5283 & $8 / 14 / 200818: 34$ & 1.472 & 16.9 & 5352 & $8 / 14 / 200820: 52$ & 1.466 & 16.9 \\
\hline 5146 & $8 / 14 / 200814: 00$ & 1.482 & 16.9 & 5215 & $8 / 14 / 200816: 18$ & 1.477 & 16.9 & 5284 & $8 / 14 / 200818: 36$ & 1.473 & 16.9 & 5353 & $8 / 14 / 200820: 54$ & 1.467 & 16.9 \\
\hline 5147 & $8 / 14 / 200814: 02$ & 1.483 & $\overline{16.9}$ & 5216 & $8 / 14 / 200816: 20$ & 1.476 & 16.9 & 5285 & $8 / 14 / 200818: 38$ & 1.473 & 16.9 & 5354 & $8 / 14 / 200820: 56$ & 1.467 & 16.9 \\
\hline 5148 & $8 / 14 / 200814: 04$ & 1.482 & 16.9 & 5217 & $8 / 14 / 200816: 22$ & 1.477 & 16.9 & 5286 & $8 / 14 / 200818: 40$ & 1.472 & 16.9 & 5355 & $8 / 14 / 200820: 58$ & 1.466 & 16.9 \\
\hline 5149 & $8 / 14 / 200814: 06$ & 1.482 & 16.9 & 5218 & $8 / 14 / 200816: 24$ & 1.477 & 16.9 & 5287 & $8 / 14 / 200818: 42$ & 1.472 & 16.9 & 5356 & $8 / 14 / 200821: 00$ & 1.466 & 16.9 \\
\hline 5150 & $8 / 14 / 200814: 08$ & 1.481 & 16.9 & 5219 & $8 / 14 / 200816: 26$ & 1.476 & 16.9 & 5288 & 8/14/2008 18:44 & 1.472 & 16.9 & 5357 & $8 / 14 / 200821: 02$ & 1.466 & 16.9 \\
\hline 5151 & $8 / 14 / 200814: 10$ & 1.481 & 16.9 & 5220 & $8 / 14 / 200816: 28$ & 1.476 & 16.9 & 5289 & $8 / 14 / 200818: 46$ & 1.472 & 16.9 & 5358 & $8 / 14 / 200821: 04$ & 1.467 & 16.9 \\
\hline 5152 & $8 / 14 / 200814: 12$ & 1.481 & 16.9 & 5221 & $8 / 14 / 200816: 30$ & 1.477 & 16.9 & 5290 & $8 / 14 / 200818: 48$ & 1.472 & 16.9 & 5359 & $8 / 14 / 200821: 06$ & 1.467 & 16.9 \\
\hline 5153 & $8 / 14 / 2008$ 14:14 & 1.482 & 16.9 & 522 & $8 / 14 / 200816: 32$ & 1.476 & 16.9 & 5291 & $8 / 14 / 200818: 50$ & 1.471 & 16.9 & 5360 & $8 / 14 / 200821: 08$ & 1.466 & 16.9 \\
\hline 5154 & $8 / 14 / 2008$ 14:16 & 1.481 & 16.9 & 5223 & $8 / 14 / 200816: 34$ & 1.477 & 16.9 & 5292 & $8 / 14 / 200818: 52$ & 1.471 & 16.9 & 5361 & $8 / 14 / 200821: 10$ & 1.466 & 16.9 \\
\hline 5155 & $8 / 14 / 200814: 18$ & 1.481 & 16.9 & 5224 & $8 / 14 / 200816: 36$ & 1.477 & 16.9 & 5293 & $8 / 14 / 200818: 54$ & 1.471 & 16.9 & 5362 & $8 / 14 / 200821: 12$ & 1.466 & 16.9 \\
\hline 5156 & $8 / 14 / 200814: 20$ & 1.48 & 16.9 & 5225 & $8 / 14 / 200816: 38$ & 1.477 & 16.9 & 5294 & $814 / 200818: 56$ & 1.472 & 16.9 & 5363 & $8 / 14 / 200821: 14$ & 1.466 & 16.9 \\
\hline 5157 & $8 / 14 / 200814: 22$ & 1.48 & 16.9 & 5226 & $8 / 14 / 200816: 40$ & 1.477 & 16.9 & 5295 & $8 / 14 / 200818.58$ & 1.472 & 16.9 & 5364 & 8/14/200821:16 & 1.466 & 16.9 \\
\hline 5158 & $8 / 14 / 200814: 24$ & 1.481 & 16.9 & 5227 & $8 / 14 / 200816: 42$ & 1.477 & 16.9 & 5296 & $8 / 14 / 200819: 00$ & 1.472 & 16.9 & 5365 & $8 / 14 / 200821: 18$ & 1.467 & 16.9 \\
\hline 5159 & $8 / 14 / 200814: 26$ & 1.481 & 16.9 & 5228 & $8 / 14 / 200816: 44$ & 1.478 & 16.9 & 5297 & $8 / 14 / 200819: 02$ & 1.472 & 16.9 & 5366 & $8 / 14 / 200821: 20$ & 1.467 & 16.9 \\
\hline 5160 & $14: 28$ & 1.481 & 16.9 & 5229 & $8 / 14 / 200816: 46$ & 1.477 & 16.9 & 5298 & $8 / 14 / 200819: 04$ & 1.471 & 16.9 & 5367 & $8 / 14 / 200821: 22$ & 1.465 & 16.9 \\
\hline 5161 & $8 / 14 / 200814: 30$ & 1.48 & 16.9 & 5230 & $8 / 14 / 200816: 48$ & 1.478 & 16.9 & 5299 & $8 / 14 / 200819.06$ & 1.472 & 16.9 & 5368 & $8 / 14 / 200821: 24$ & 1.465 & 16.9 \\
\hline 5162 & $8 / 14 / 2008$ 14:32 & 1.481 & 16.9 & 5231 & $8 / 14 / 200816: 50$ & 1.477 & 16.9 & 5300 & $8 / 14 / 200819: 08$ & 1.471 & 16.9 & 5369 & $8 / 14 / 200821: 26$ & 1.465 & 16.9 \\
\hline 5163 & $8 / 14 / 200814: 34$ & 1.481 & 16.9 & 5232 & $8 / 14 / 200816: 52$ & 1.476 & 16.9 & 5301 & $8 / 14 / 2008$ 19:10 & 1.471 & 16.9 & 5370 & $8 / 14 / 200821: 28$ & 1.465 & 16.9 \\
\hline 5164 & $8 / 14 / 200814: 36$ & 1.48 & 16.9 & 5233 & $8 / 14 / 200816: 54$ & 1.477 & 16.9 & 5302 & $8 / 14 / 200819: 12$ & 1.471 & 16.9 & 5371 & $821: 30$ & 1.466 & 16.9 \\
\hline 5165 & $8 / 14 / 200814: 38$ & 1.481 & 16.9 & 5234 & $8 / 14 / 200816: 56$ & 1.477 & 16.9 & 5303 & $8 / 14 / 2008$ 19:14 & 1.471 & 16.9 & 5372 & $8 / 14 / 200821: 32$ & 1.465 & 16.9 \\
\hline 5166 & $8 / 14 / 200814: 40$ & 1.481 & 16.9 & 5235 & $8 / 14 / 200816: 58$ & 1.476 & 16.9 & 5304 & $8 / 14 / 200819: 16$ & 1.472 & 16.9 & 5373 & $8 / 14 / 200821: 34$ & 1.465 & 16.9 \\
\hline 5167 & $8 / 14 / 200814: 42$ & 1.48 & 16.9 & 5236 & $8 / 14 / 200817: 00$ & 1.476 & 16.9 & 5305 & $814 / 200819: 18$ & 1.471 & 16.9 & 5374 & $8 / 14 / 200821: 36$ & 1.465 & 16.9 \\
\hline 5168 & $8 / 14 / 200814: 44$ & 1.48 & 16.9 & 5237 & $8 / 14 / 2008$ 17:02 & 1.476 & 16.9 & 5306 & $8 / 14 / 200819: 20$ & 1.471 & 16.9 & 5375 & $8 / 14 / 200821: 38$ & 1.465 & 16.9 \\
\hline 5169 & $8 / 14 / 200814: 46$ & 1.48 & 16.9 & 5238 & 8/14/2008 17:04 & 1.475 & 16.9 & 5307 & $8 / 14 / 2008$ 19:22 & 1.471 & 16.9 & 5376 & $8 / 14 / 200821: 40$ & 1.464 & 16.9 \\
\hline 5170 & $8 / 14 / 200814: 48$ & 1.48 & 16.9 & 5239 & $8 / 14 / 200817: 06$ & 1.475 & 16.9 & 5308 & $8 / 14 / 200819: 24$ & 1.471 & 16.9 & 5377 & $8 / 14 / 200821: 42$ & 1.465 & 16.9 \\
\hline 5171 & $8 / 14 / 200814: 50$ & 1.48 & 16.9 & 5240 & $8 / 14 / 200817: 08$ & 1.475 & 16.9 & 5309 & $8 / 14 / 200819: 26$ & 1.471 & 16.9 & 5378 & $8 / 14 / 200821: 44$ & 1.465 & 16.9 \\
\hline 5172 & $8 / 14 / 200814: 52$ & 1.481 & 16.9 & 5241 & $8 / 14 / 200817: 10$ & 1.476 & 16.9 & 5310 & $8 / 14 / 200819: 28$ & 1.471 & 16.9 & 5379 & $8 / 14 / 200821: 46$ & 1.465 & 16.9 \\
\hline 5173 & $14: 54$ & 1.48 & 16.9 & 5242 & $8 / 14 / 200817: 12$ & 1.476 & 16.9 & 5311 & 8/14/2008 19:30 & 1.471 & 16.9 & 5380 & $8 / 14 / 200821: 48$ & 1.465 & 16.9 \\
\hline 5174 & $8 / 14 / 200814: 56$ & 1.48 & 16.9 & 5243 & $8 / 14 / 2008$ 17:14 & 1.475 & 16.9 & 5312 & 8/14/2008 19:32 & 1.471 & 16.9 & 5381 & $8 / 14 / 200821: 50$ & 1.465 & 16.9 \\
\hline 5175 & $8 / 14 / 2008$ 14:58 & 1.479 & 16.9 & 5244 & $8 / 14 / 200817: 16$ & 1.476 & 16.9 & 5313 & $8 / 14 / 2008$ 19:34 & 1.471 & 16.9 & 5382 & $8 / 14 / 200821: 52$ & 1.465 & 16.9 \\
\hline 5176 & $8 / 14 / 200815: 00$ & 1.48 & 16.9 & 5245 & $8 / 14 / 200817: 18$ & 1.475 & 16.9 & 5314 & $8 / 14 / 200819: 36$ & 1.471 & 16.9 & 5383 & $8 / 14 / 200821: 54$ & 1.465 & 16.9 \\
\hline 5177 & $15: 02$ & 1.48 & 16.9 & 5246 & $8 / 14 / 200817: 20$ & 1.475 & 16.9 & 5315 & $8 / 14 / 200819: 38$ & 1.47 & 16.9 & 5384 & $8 / 14 / 200821: 56$ & 1.465 & 16.9 \\
\hline 5178 & $8 / 14 / 200815: 04$ & 1.479 & 16.9 & 5247 & $8 / 14 / 200817: 22$ & 1.475 & 16.9 & 5316 & $8 / 14 / 200819: 40$ & 1.47 & 16.9 & 5385 & $8 / 14 / 200821: 58$ & 1.465 & 16.9 \\
\hline 5179 & $8 / 14 / 200815: 06$ & 1.48 & 16.9 & 5248 & $8 / 14 / 200817: 24$ & 1.476 & 16.9 & 5317 & $8 / 14 / 200819: 42$ & 1.469 & 16.9 & 5386 & 8/14/2008 22:00 & 1.464 & 16.9 \\
\hline 5180 & $8 / 14 / 200815: 08$ & 1.479 & 16.9 & 5249 & $8 / 14 / 2008$ 17:26 & 1.475 & 16.9 & 5318 & $8 / 14 / 2008$ 19:44 & 1.47 & 16.9 & 5387 & $8 / 14 / 200822: 02$ & 1.464 & 16.9 \\
\hline 5181 & 8/14/2008 15:10 & 1.48 & 16.9 & 5250 & $8 / 14 / 200817: 28$ & 1.475 & 16.9 & 5319 & $8 / 14 / 200819: 46$ & 1.47 & 16.9 & 5388 & 8/14/2008 22:04 & 1.464 & 16.9 \\
\hline 5182 & $8 / 14 / 2008$ 15:12 & 1.48 & 16.9 & 5251 & $0817: 30$ & 1.474 & 16.9 & 5320 & $8 / 14 / 200819: 48$ & 1.47 & 16.9 & 5389 & $8 / 14 / 200822: 06$ & 1.466 & 16.9 \\
\hline 5183 & $8 / 14 / 200815: 14$ & 1.48 & 16.9 & 5252 & $8 / 14 / 2008$ 17:32 & 1.474 & 16.9 & 5321 & $8 / 14 / 200819: 50$ & 1.469 & 16.9 & 5390 & $8 / 14 / 200822: 08$ & 1.465 & 16.9 \\
\hline 5184 & $8 / 14 / 200815: 16$ & 1.48 & 16.9 & 5253 & $8 / 14 / 200817: 34$ & 1.475 & 16.9 & 5322 & $8 / 14 / 200819: 52$ & 1.469 & 16.9 & 5391 & 8/14/2008 22:10 & 1.464 & 16.9 \\
\hline 5185 & $8 / 14 / 200815: 18$ & 1.48 & 16.9 & 5254 & $8 / 14 / 200817: 36$ & 1.475 & 16.9 & 5323 & $8 / 14 / 200819: 54$ & 1.469 & 16.9 & 5392 & $8 / 14 / 200822: 12$ & 1.464 & 16.9 \\
\hline 5186 & $8 / 14 / 2008$ 15:20 & 1.48 & 16.9 & 5255 & 17:38 & 1.472 & 16.9 & 5324 & $19: 56$ & 1.469 & 16.9 & 5393 & $8 / 14 / 200822: 14$ & 1.463 & 16.9 \\
\hline 5187 & $8 / 14 / 2008$ 15:22 & 1.479 & 16.9 & 5256 & $8 / 14 / 200817: 40$ & 1.474 & 16.9 & 5325 & $8 / 14 / 200819: 58$ & 1.469 & 16.9 & 5394 & 8/14/2008 22:16 & 1.464 & 16.9 \\
\hline 5188 & $8 / 14 / 200815: 24$ & 1.479 & 16.9 & 5257 & $8 / 14 / 2008$ 17:42 & 1.474 & 16.9 & 5326 & $8 / 14 / 200820: 00$ & 1.469 & 16.9 & 5395 & $8 / 14 / 200822: 18$ & 1.464 & 16.9 \\
\hline 5189 & $8 / 14 / 200815: 26$ & 1.479 & 16.9 & 5258 & $8 / 14 / 2008$ 17:44 & 1.474 & 16.9 & 5327 & $8 / 14 / 200820: 02$ & 1.469 & 16.9 & 5396 & $8 / 14 / 200822: 20$ & 1.463 & 16.9 \\
\hline 5190 & $8 / 14 / 200815: 28$ & 1.479 & 16.9 & 5259 & $8 / 14 / 200817: 46$ & 1.474 & 16.9 & 5328 & $820: 04$ & 1.469 & 16.9 & 5397 & $0822: 22$ & 1.463 & 16.9 \\
\hline 5191 & $8 / 14 / 2008$ 15:30 & 1.479 & 16.9 & 5260 & $8 / 14 / 200817: 48$ & 1.474 & 16.9 & 5329 & $8 / 14 / 200820: 06$ & 1.469 & 16.9 & 5398 & $3822: 24$ & 1.463 & 16.9 \\
\hline 5192 & $8 / 14 / 200815: 32$ & 1.479 & 16.9 & 5261 & $8 / 14 / 200817: 50$ & 1.475 & 16.9 & 5330 & $8 / 14 / 200820: 08$ & 1.469 & 16.9 & 5399 & $8 / 14 / 200822: 26$ & 1.463 & 16.9 \\
\hline 5193 & $8 / 14 / 200815: 34$ & 1.478 & 16.9 & 5262 & $8 / 14 / 2008$ 17:52 & 1.475 & 16.9 & 5331 & $8 / 14 / 200820: 10$ & 1.469 & 16.9 & 5400 & $8 / 14 / 200822: 28$ & 1.464 & 16.9 \\
\hline 5194 & $8 / 14 / 200815: 36$ & 1.478 & 16.9 & 5263 & $8 / 14 / 200817: 54$ & 1.475 & 16.9 & 5332 & 8/14/2008 20:12 & 1.469 & 16.9 & 5401 & $8 / 14 / 200822: 30$ & 1.464 & 16.9 \\
\hline 5195 & $8 / 14 / 200815: 38$ & 1.478 & 16.9 & 5264 & $8 / 14 / 200817: 56$ & 1.474 & 16.9 & 5333 & $8 / 14 / 200820: 14$ & 1.469 & 16.9 & 5402 & $8 / 14 / 2008$ 22:32 & 1.463 & 16.9 \\
\hline 5196 & $8 / 14 / 200815: 40$ & 1.478 & 16.9 & 5265 & $8 / 14 / 200817: 58$ & 1.474 & 16.9 & 5334 & $8 / 14 / 200820: 16$ & 1.469 & 16.9 & 5403 & $8 / 14 / 200822: 34$ & 1.463 & 16.9 \\
\hline 5197 & $8 / 14 / 200815: 42$ & 1.478 & 16.9 & 5266 & $8 / 14 / 200818: 00$ & 1.474 & 16.9 & 5335 & $8 / 14 / 200820: 18$ & 1.468 & 16.9 & 5404 & $8 / 14 / 200822: 36$ & 1.463 & 16.9 \\
\hline 5198 & $8 / 14 / 200815: 44$ & 1.479 & 16.9 & 5267 & $8 / 14 / 200818: 02$ & 1.474 & 16.9 & 5336 & $8 / 14 / 200820: 20$ & 1.469 & 16.9 & 5405 & $8 / 14 / 200822: 38$ & 1.464 & 16.9 \\
\hline 5199 & & & 16.9 & 5268 & $8 / 14 / 200818: 04$ & 1.474 & 16.9 & 5337 & $8 / 14 / 200820: 22$ & 1.468 & 16.9 & 5406 & $8 / 14 / 200822: 40$ & 1.464 & 46.9 \\
\hline 5200 & $8 / 14 / 200815: 48$ & 1.478 & 16.9 & 5269 & $8 / 14 / 200818: 06$ & 1.473 & 16.9 & 5338 & $3820: 24$ & 1.468 & 16.9 & 5407 & $8 / 14 / 200822: 42$ & 1.464 & 16.9 \\
\hline 5201 & $8 / 14 / 200815: 50$ & 1.478 & 16.9 & 5270 & $8 / 14 / 200818: 08$ & 1.473 & 16.9 & 5339 & $8 / 14 / 200820: 26$ & 1.468 & 16.9 & 5408 & $8 / 14 / 200822: 44$ & 1.464 & 16.9 \\
\hline 5202 & $8 / 14 / 200815: 52$ & 1.478 & 16.9 & 5271 & $8 / 14 / 200818: 10$ & 1.474 & 16.9 & 5340 & $8 / 14 / 200820: 28$ & 1.468 & 16.9 & 5409 & $8 / 14 / 200822: 46$ & 1.464 & 16.9 \\
\hline 5203 & $8 / 14 / 200815: 54$ & 1.478 & 16.9 & 5272 & $8 / 14 / 200818: 12$ & 1.473 & 16.9 & 5341 & $8 / 14 / 200820: 30$ & 1.468 & 16.9 & 5410 & $8 / 14 / 200822: 48$ & 1.464 & 16.9 \\
\hline 5204 & $8 / 14 / 200815: 56$ & 1.479 & 16.9 & 5273 & $8 / 14 / 200818: 14$ & 1.473 & 16.9 & 5342 & $8 / 14 / 200820: 32$ & 1.467 & 16.9 & 5411 & $8 / 14 / 200822.50$ & 1.467 & 16.9 \\
\hline 5205 & $8 / 14 / 200815: 58$ & 1.477 & 16.9 & 5274 & $8 / 14 / 200818: 16$ & 1.473 & 16.9 & 5343 & $8 / 14 / 200820: 34$ & 1.467 & 16.9 & 5412 & $8 / 14 / 200822: 52$ & 1.463 & 16.9 \\
\hline 5206 & $8 / 14 / 200816: 00$ & 1.477 & 16.9 & 5275 & $8 / 14 / 200818: 18$ & 1.472 & 16.9 & 5344 & $8 / 14 / 200820: 36$ & 1.467 & 16.9 & 5413 & $8 / 14 / 200822: 54$ & 1.463 & 16.9 \\
\hline 5207 & $8 / 14 / 200816: 02$ & 1.478 & 16.9 & 5276 & $8 / 14 / 200818: 20$ & 1.473 & 16.9 & 5345 & $8 / 14 / 200820: 38$ & 1.467 & 16.9 & 5414 & $8 / 14 / 200822: 56$ & 1.462 & 16.9 \\
\hline 5208 & $8 / 14 / 200816: 04$ & 1.478 & 16.9 & 5277 & $8 / 14 / 200818: 22$ & 1.474 & 16.9 & 5346 & $8 / 14 / 200820: 40$ & 1.467 & 16.9 & 5415 & $8 / 14 / 200822: 58$ & 1.463 & 16.9 \\
\hline 5209 & $8 / 14 / 200816: 06$ & 1.478 & 16.9 & 5278 & $8 / 14 / 200818: 24$ & 1.473 & 16.9 & 5347 & $8 / 14 / 200820: 42$ & 1.467 & 16.9 & 5416 & $8 / 14 / 200823: 00$ & 1.463 & 16.9 \\
\hline 5210 & $8 / 14 / 200816: 08$ & 1.478 & 16.9 & 5279 & $8 / 14 / 200818: 26$ & 1.473 & 16.9 & 5348 & $8 / 14 / 200820: 44$ & 1.467 & 16.9 & 5417 & $8 / 14 / 200823: 02$ & 1.464 & 16.9 \\
\hline 5211 & $8 / 14 / 200816: 10$ & 1.477 & 16.9 & 5280 & $8 / 14 / 200818: 28$ & 1.472 & 16.9 & 5349 & $8 / 14 / 200820: 46$ & 1.467 & 16.9 & 5418 & $8 / 14 / 200823: 04$ & 1.463 & 16.9 \\
\hline
\end{tabular}




\begin{tabular}{|c|c|c|c|c|c|c|c|c|c|c|c|c|c|c|c|}
\hline \multicolumn{4}{|c|}{$0427 p$} & \multicolumn{4}{|c|}{ D4-27p } & \multicolumn{4}{|c|}{ D4-27p } & \multicolumn{4}{|c|}{ D427p } \\
\hline $\operatorname{Rec}$ & & Pres & Temp & $\operatorname{Rec}$ & & Pres & Termp & $\operatorname{Rec}$ & & Pres & Temp & $\operatorname{Rec}$ & & Pres & Temp \\
\hline \# & Date Time & psi & ${ }^{\circ} \mathrm{C}$ & $\#$ & Date-Time & psi & ${ }^{\circ} \mathrm{C}$ & $\#$ & Date/Time & psi & ${ }^{\circ} \mathrm{C}$ & $\#$ & Date/Time & psi & ${ }^{\circ} \mathrm{C}$ \\
\hline 5419 & $8 / 14 / 200823: 06$ & 1.463 & 16.9 & 5488 & $8 / 15 / 20081: 24$ & 1.458 & 16.9 & 5557 & $8 / 15 / 20083: 42$ & 1.452 & 16.9 & 5626 & $8 / 15 / 20086: 00$ & 1.444 & 16.9 \\
\hline 5420 & $8 / 14 / 200823: 08$ & 1.463 & 16.9 & 5489 & $8 / 15 / 20081: 26$ & 1.457 & 16.9 & 5558 & $8 / 15 / 20083: 44$ & 1.451 & 16.9 & 5627 & $8 / 15 / 20086: 02$ & 1.445 & 16.9 \\
\hline 5421 & $8 / 14 / 200823: 10$ & 1.463 & 16.9 & 5490 & $8 / 15 / 20081: 28$ & 1.456 & 16.9 & 5559 & $8 / 15 / 20083: 46$ & 1.452 & 16.9 & 5628 & $8 / 15 / 20086: 04$ & 1.444 & 16.9 \\
\hline 5422 & $8 / 14 / 200823: 1$ & 1.463 & 16.9 & 5491 & $8 / 15 / 20081: 30$ & 1.457 & 16.9 & 5560 & $8 / 15 / 20083: 48$ & 1.451 & 16.9 & 5629 & $8 / 15 / 20086: 06$ & 1.446 & 16.9 \\
\hline 5423 & $8 / 14 / 200823: 14$ & 1.463 & 16.9 & 5492 & $8 / 15 / 20081: 32$ & 1.457 & 16.9 & 5561 & $8 / 15 / 20083: 50$ & $1.45 t$ & 16.9 & 5630 & 8/15/20086:08 & 1.445 & 16.9 \\
\hline 5424 & $8 / 14 / 200823: 16$ & 1.462 & 16.9 & 5493 & $8 / 15 / 20081: 34$ & 1.457 & 16.9 & 5562 & $8 / 15 / 20083: 52$ & 1.451 & 16.9 & 5631 & $8 / 15 / 20086: 10$ & 1.444 & 16.9 \\
\hline 5425 & $8 / 14 / 200823: 18$ & 1.462 & 16.9 & 5494 & $8 / 15 / 20081: 36$ & 1.457 & 16.9 & 5563 & $8 / 15 / 20083: 54$ & 1.452 & 16.9 & 5632 & $8 / 15 / 20086: 12$ & 1.444 & 16.9 \\
\hline 5426 & $8 / 14 / 200823: 20$ & 1.462 & 16.9 & 5495 & $8 / 15 / 2008$ 1:38 & 1.457 & 16.9 & 5564 & $8 / 15 / 20083: 56$ & 1.451 & 16.9 & 5633 & $8 / 15 / 20086: 14$ & 1.445 & 16.9 \\
\hline 5427 & 8/14/200823:22 & 1.462 & 16.9 & 5496 & $8 / 15 / 20081: 40$ & 1.456 & 16.9 & 5565 & $8 / 15 / 20083: 58$ & 1.452 & 16.9 & 5634 & $8 / 15 / 20086: 16$ & 1.444 & 16.9 \\
\hline 5428 & $8 / 14 / 200823: 24$ & 1.462 & 16.9 & 5497 & $8 / 15 / 20081: 42$ & 1.457 & 16.9 & 5566 & $8 / 15 / 20084: 00$ & 1.451 & 16.9 & 5635 & $8 / 15 / 20086: 18$ & 1.445 & 16.9 \\
\hline 5429 & $8 / 14 / 200823: 26$ & 1.462 & 16.9 & 5498 & $8 / 15 / 20081: 44$ & 1.457 & 16.9 & 5567 & $8 / 15 / 20084: 02$ & 1.452 & 16.9 & 5636 & $8 / 15 / 20086: 20$ & 1.445 & 16.9 \\
\hline 5430 & $8 / 14 / 200823: 28$ & 1.462 & 16.9 & 5499 & $8 / 15 / 20081: 46$ & 1.456 & 16.9 & 5568 & $8 / 15 / 20084: 04$ & 1.452 & 16.9 & 5637 & $8 / 15 / 20086: 22$ & 1.445 & 16.9 \\
\hline 5431 & $8 / 14 / 200823: 30$ & 1.462 & 16.9 & 5500 & $8 / 15 / 20081: 48$ & 1.456 & 16.9 & 5569 & $8 / 15 / 20084: 06$ & 1.452 & 16.9 & 5638 & $8 / 15 / 20086: 24$ & 1.442 & 16.9 \\
\hline 5432 & $8 / 14 / 200823: 32$ & 1.462 & 16.9 & 5501 & $8 / 15 / 20081: 50$ & 1.457 & 16.9 & 5570 & $8 / 15 / 20084: 08$ & 1.451 & 16.9 & 5639 & $8 / 15 / 20086: 26$ & 1.444 & 16.9 \\
\hline 5433 & 8/14/200823:34 & 1.462 & 16.9 & 5502 & $8 / 15 / 20081: 52$ & 1.456 & 16.9 & 5571 & $8 \longdiv { 1 5 / 2 0 0 8 4 : 1 0 }$ & 1.452 & 16.9 & 5640 & $8 / 15 / 20086: 28$ & 1.444 & 16.9 \\
\hline 5434 & $8 / 14 / 200823: 36$ & 1.461 & 16.9 & 5503 & $8 / 15 / 20081: 54$ & 1.457 & 16.9 & 5572 & $8 / 15 / 20084: 12$ & 1.452 & 16.9 & 5641 & $8 / 15 / 20086: 30$ & 1.444 & 16.9 \\
\hline 5435 & $8 / 14 / 200823: 38$ & 1.461 & 16.9 & 5504 & $8 / 15 / 20081: 56$ & 1.457 & 16.9 & 5573 & $8 / 15 / 2008$ 4:14 & 1.451 & 16.9 & 5642 & $8 / 15 / 20086: 32$ & 1.444 & 16.9 \\
\hline 5436 & $8 / 14 / 200823: 40$ & 1.462 & 16.9 & 5505 & $8 / 15 / 20081: 58$ & 1.457 & 16.9 & 5574 & $8 / 15 / 20084: 16$ & 1.45 & 16.9 & 5643 & $8 / 15 / 20086: 34$ & 1.445 & 16.9 \\
\hline 5437 & $8 / 14 / 200823: 42$ & 1.462 & 16.9 & 5506 & $8 / 15 / 20082: 00$ & 1.457 & 16.9 & 5575 & $8 / 15 / 20084: 18$ & 1.451 & 16.9 & 5644 & $8 / 15 / 20086: 36$ & 1.442 & 16.9 \\
\hline 5438 & $8 / 14 / 200823: 44$ & 1.461 & 16.9 & 5507 & $8 / 15 / 20082: 02$ & 1.456 & 16.9 & 5576 & $8 / 15 / 20084: 20$ & 1.451 & 16.9 & 5645 & $8 / 15 / 20086: 38$ & 1.443 & 16.9 \\
\hline 5439 & $8 / 14 / 200823: 46$ & 1.461 & 16.9 & 5508 & $8 / 15 / 20082: 04$ & 1.456 & 16.9 & $55 \pi$ & $8 / 15 / 20084: 22$ & 1.452 & 16.9 & 5646 & $8 / 15 / 20086: 40$ & 1.444 & 16.9 \\
\hline 5440 & $8 / 14 / 200823: 48$ & 1.461 & 16.9 & 5509 & $8 / 15 / 20082: 06$ & 1.455 & 16.9 & 5578 & $8 / 15 / 20084: 24$ & 1.452 & 16.9 & 5647 & $8 / 15 / 20086: 42$ & 1.443 & 16.9 \\
\hline 5441 & $8 / 14 / 200823: 50$ & 1.461 & 16.9 & 5510 & $8 / 15 / 20082: 08$ & 1.456 & 16.9 & 5579 & $8 / 15 / 20084: 26$ & 1.452 & 16.9 & 5648 & $8 / 15 / 20086: 44$ & 1.443 & 16.9 \\
\hline 5442 & $8 / 14 / 200823: 52$ & 1.461 & 16.9 & 5511 & $8 / 15 / 20082: 10$ & 1.457 & 16.9 & 5580 & $8 / 15 / 20084: 28$ & 1.451 & 16.9 & 5649 & $8 / 15 / 20086: 46$ & 1.444 & 16.9 \\
\hline 5443 & $8 / 14 / 200823: 54$ & 1.46 & 16.9 & $55+2$ & $8 / 15 / 20082: 12$ & 1.456 & 16.9 & 5581 & $8 / 15 / 20084: 30$ & 1.452 & 16.9 & 5650 & $8 / 15 / 20086: 48$ & 1.443 & 16.9 \\
\hline 5444 & 8/14/2008 23:56 & 1.46 & 16.9 & 5513 & $8 / 15 / 20082: 14$ & 1.455 & 16.9 & 5582 & $8 / 15 / 20084: 32$ & 1.451 & 16.9 & 5651 & $8 / 15 / 20086: 50$ & 1.442 & 16.9 \\
\hline 5445 & $8 / 14 / 200823: 58$ & 1.46 & 16.9 & 5514 & 8/15/2008 2:16 & 1.455 & 16.9 & 5583 & $8 / 15 / 20084: 34$ & 1.451 & 16.9 & 5652 & $8 / 15 / 20086: 52$ & 1.443 & 16.9 \\
\hline 5446 & $8 / 15 / 20080: 00$ & 1.46 & 16.9 & 5515 & $8 / 15 / 20082: 18$ & 1.455 & 16.9 & 5584 & $8 / 15 / 20084: 36$ & 1.451 & 16.9 & 5653 & $8 / 15 / 20086: 54$ & 1.443 & 16.9 \\
\hline 5447 & $8 / 15 / 20080: 02$ & 1.46 & 16.9 & 5516 & $8 / 15 / 20082: 20$ & 1.455 & 16.9 & 5585 & $8 / 15 / 20084: 38$ & 1.45 & 16.9 & 5654 & $8 / 15 / 20086: 56$ & 1.442 & 16.9 \\
\hline 5448 & $8 / 15 / 20080: 04$ & 1.461 & 16.9 & 5517 & $8 / 15 / 20082: 22$ & 1.455 & 16.9 & 5586 & $8 / 15 / 20084: 40$ & 1.449 & 16.9 & 5655 & $8 / 15 / 20086: 58$ & 1.442 & 16.9 \\
\hline 5449 & $8 / 15 / 20080: 06$ & 1.461 & 16.9 & 5518 & $8 / 15 / 20082: 24$ & 1.455 & 16.9 & 5587 & $8 / 15 / 20084: 42$ & 1.448 & 16.9 & 5656 & $8 / 15 / 20087: 00$ & 1.442 & 16.9 \\
\hline 5450 & $8 / 15 / 20080: 08$ & 1.46 & 16.9 & 5519 & $8 / 15 / 20082: 26$ & 1.455 & 16.9 & 5588 & $8 / 15 / 20084: 44$ & 1.447 & 16.9 & 5657 & $8 / 15 / 20087: 02$ & 1.443 & 16.9 \\
\hline 5451 & $8 / 15 / 20080: 10$ & 1.46 & 16.9 & 5520 & $8 / 15 / 20082: 28$ & 1.455 & 16.9 & 5589 & $8 / 15 / 20084: 46$ & 1.447 & 16.9 & 5658 & $8 / 15 / 20087: 04$ & 1.443 & 16.9 \\
\hline 5452 & $8 / 15 / 20080: 12$ & 1.46 & 16.9 & 5521 & $8 / 15 / 20082: 30$ & 1.455 & 16.9 & 5590 & $8 / 15 / 20084: 48$ & 1.447 & 16.9 & 5659 & $8 / 15 / 20087: 06$ & 1.443 & 16.9 \\
\hline 5453 & $8 / 15 / 20080: 14$ & 1.459 & 16.9 & 5522 & $8 / 15 / 20082: 32$ & 1.454 & 16.9 & 5591 & $8 / 15 / 20084: 50$ & 1.447 & 16.9 & 5660 & $8 / 15 / 20087: 08$ & 1.444 & 16.9 \\
\hline 5454 & $8 / 15 / 20080: 16$ & 1.459 & 16.9 & 5523 & $8 / 15 / 20082: 34$ & 1.455 & 16.9 & 5592 & $8 / 15 / 20084: 52$ & 1.447 & 16.9 & 5661 & $8 / 15 / 20087: 10$ & 1.443 & 16.9 \\
\hline 5455 & $8 / 15 / 20080: 18$ & 1.46 & 16.9 & 5524 & $8 / 15 / 20082: 36$ & 1.455 & 16.9 & 5593 & $8 / 15 / 20084: 54$ & 1.448 & 16.9 & 5662 & $8 / 15 / 20087: 12$ & 1.443 & 16.9 \\
\hline 5456 & $8 / 15 / 20080: 20$ & 1.46 & 16.9 & 5525 & $8 / 15 / 20082: 38$ & 1.454 & 16.9 & 5594 & $8 / 15 / 20084: 56$ & 1.448 & 16.9 & 5663 & $8 / 15 / 20087: 14$ & 1.444 & 16.9 \\
\hline 5457 & $8 / 15 / 20080: 22$ & 1.46 & 16.9 & 5526 & 8/15/2008 2:40 & 1.454 & 16.9 & 5595 & $8 / 15 / 20084: 58$ & 1.448 & 16.9 & 5664 & $8 / 15 / 20087: 16$ & 1.442 & 16.9 \\
\hline 5458 & $8 / 15 / 20080: 24$ & 1.46 & 16.9 & 5527 & $8 / 15 / 20082: 42$ & 1.454 & 16.9 & 5596 & $8 / 15 / 20085: 00$ & 1.447 & 16.9 & 5665 & $8 / 15 / 20087: 18$ & 1.443 & 16.9 \\
\hline 5459 & $8 / 15 / 20080: 26$ & 1.461 & 16.9 & 5528 & $8 / 15 / 20082: 44$ & 1.454 & 16.9 & 5597 & $8 / 15 / 20085: 02$ & 1.45 & 16.9 & 5666 & 22008 7:20 & 1.442 & 16.9 \\
\hline 5460 & $8 / 15 / 20080: 28$ & 1.46 & 16.9 & 5529 & $8 / 15 / 20082: 46$ & 1.454 & 16.9 & 5598 & $8 / 15 / 20085: 04$ & 1.45 & 16.9 & 5667 & $8 / 15 / 20087: 22$ & 1.442 & 16.9 \\
\hline 5461 & $8 / 15 / 20080: 30$ & 1.46 & 16.9 & 5530 & $8 / 15 / 20082448$ & 1.455 & 16.9 & 5599 & $8 / 15 / 20085: 06$ & 1.447 & 16.9 & 5668 & $8 / 15 / 20087: 24$ & 1.442 & 16.9 \\
\hline 5462 & $8 / 15 / 20080: 32$ & 1.46 & 16.9 & 5531 & $8 / 15 / 20082: 50$ & 1.454 & 16.9 & 5600 & $8 / 15 / 20085: 08$ & 1.449 & 16.9 & 5669 & $8 / 15 / 20087: 26$ & 1.443 & 16.9 \\
\hline 5463 & $8 / 15 / 20080: 34$ & 1.46 & 16.9 & 5532 & $8 / 15 / 20082: 52$ & 1.454 & 16.9 & 5601 & $8 / 15 / 20085: 10$ & 1.447 & 16.9 & 5670 | & $8 / 15 / 20087: 28$ & 1.443 & 16.9 \\
\hline 5464 & $8 / 15 / 20080: 36$ & 1.459 & 16.9 & 5533 & $8 / 15 / 20082: 54$ & 1.455 & 16.9 & 5602 & $8 / 15 / 20085: 12$ & 1.447 & 16.9 & 5671 & $120087: 30$ & 1.442 & 16.9 \\
\hline 5465 & $8 / 15 / 20080: 38$ & 1.459 & 16.9 & 5534 & $8 / 15 / 2008256$ & 1.454 & 16.9 & 5603 & $8 / 15 / 20085: 14$ & 1.449 & 16.9 & 5672 & $8 / 15 / 20087: 32$ & 1.441 & 16.9 \\
\hline 5466 & $8 / 15 / 20080: 40$ & 1.458 & 16.9 & 5535 & $8 / 15 / 20082: 58$ & 1.454 & 16.9 & 5604 & $8 / 15 / 20085: 16$ & 1.447 & 16.9 & 5673 & $87: 34$ & 1.441 & 16.9 \\
\hline 5467 & $8 / 15 / 20080: 42$ & 1.458 & 16.9 & 5536 & $8 / 15 / 200$ & 1.454 & 16.9 & 5605 & $8 / 15 / 20085: 18$ & 1.447 & 16.9 & 5674 & $87: 36$ & 1.442 & 16.9 \\
\hline 5468 & $8 / 15 / 20080: 44$ & 1.459 & 16.9 & 5537 & $8 / 15 / 20083: 02$ & 1.454 & 16.9 & 5606 & $8 / 15 / 20085: 20$ & 1.448 & 16.9 & 5675 & $8 / 15 / 20087: 38$ & 1.442 & 16.9 \\
\hline 5469 & $8 / 15 / 20080: 46$ & 1.458 & 16.9 & 5538 & & 1.454 & 16.9 & 5607 & $8 / 15 / 20085: 22$ & 1.447 & 16.9 & 5676 & $87: 40$ & 1.443 & 16.9 \\
\hline 5470 & $8 / 15 / 20080: 48$ & 1.458 & 16.9 & 5539 & $8 / 15 / 20083: 06$ & 1.454 & 16.9 & 5608 & $8 / 15 / 20085: 24$ & 1.448 & 16. & 5677 & $8 / 15 / 20087: 42$ & 1.442 & 16.9 \\
\hline 5471 & $8 / 15 / 20080: 50$ & 1.458 & 16.9 & 5540 & $8 / 15 / 20083: 08$ & 1.454 & 16.9 & 5609 & $8 / 15 / 20085: 26$ & 1.447 & 16.9 & 5678 & $087: 44$ & 1.442 & 16.9 \\
\hline 5472 & $8 / 15 / 20080: 52$ & 1.458 & 16.9 & 5541 & $8 / 15 / 20083: 10$ & 1.453 & 16.9 & 5610 & $8 / 15 / 20085: 28$ & 1.446 & 16.5 & 5679 & $8 / 15 / 20087: 46$ & 1.442 & 16.9 \\
\hline 5473 & $8 / 15 / 20080: 54$ & 1.458 & 16.9 & 5542 & $8 / 15 / 20083: 12$ & 1.453 & 16.9 & 5611 & $8 / 15 / 20085: 30$ & 1.445 & 16.9 & 5680 & $8 / 15 / 20087: 48$ & 1.441 & 16.9 \\
\hline 5474 & $8 / 15 / 20080: 56$ & 1.458 & 16.9 & 5543 & $8 / 15 / 20083: 14$ & 1.452 & 16.9 & 5612 & $8 / 15 / 20085: 32$ & 1.447 & 16.9 & 5681 & $8 / 15 / 20087: 50$ & 1.441 & 16.9 \\
\hline 5475 & $8 / 15 / 20080: 58$ & 1.458 & 16.9 & 5544 & $8 / 15 / 20083: 16$ & 1.452 & 16.9 & 5613 & $8 / 15 / 20085: 34$ & 1.445 & 16.9 & 5682 & $8 / 15 / 20087: 52$ & 1.441 & 16.9 \\
\hline 5476 & $8 / 15 / 20081: 00$ & 1.459 & 16.9 & 5545 & $8 / 15 / 20083: 18$ & 1.453 & 16.9 & 5614 & $8 / 15 / 20085: 36$ & 1.446 & 16.9 & 5683 & $8 / 15 / 20087: 54$ & 1.441 & 16.9 \\
\hline 547 & $8 / 15 / 20081: 02$ & 1.459 & 16.9 & 5546 & $8 / 15 / 20083: 20$ & 1.451 & 16.9 & 5615 & $8 / 15 / 20085: 38$ & 1.446 & 16.5 & 5684 & $8 / 15 / 20087: 56$ & 1.443 & 16.9 \\
\hline 5478 & $8 / 15 / 2008$ 1:04 & 1.459 & 16.9 & 5547 & $8 / 15 / 20083: 22$ & 1.451 & 16.9 & 5616 & $8 / 15 / 20085: 40$ & 1.445 & $\overline{16.5}$ & 5685 & $8 / 15 / 20087: 58$ & 1.442 & 16.9 \\
\hline 5479 & $8 / 15 / 20081: 06$ & 1.459 & 16.9 & 5548 & $8 / 15 / 20083: 24$ & 1.451 & 16.9 & 5617 & $8 / 15 / 20085: 42$ & 1.445 & 16.8 & 5686 & $8 / 15 / 20088: 00$ & 1.442 & 16.9 \\
\hline 5480 & $8 / 15 / 20081: 08$ & 1.459 & 16.9 & 5549 & $8 / 15 / 20083: 26$ & 1.451 & 16.9 & 5618 & $8 / 15 / 20085: 44$ & 1.446 & 16.9 & 5687 & $8 / 15 / 20088: 02$ & 1.442 & 16.9 \\
\hline 5481 & $8 / 15 / 20081: 10$ & 1.458 & 16.9 & 5550 & 8/15/20083:28 & 1.452 & 16.9 & 5619 & $8 / 15 / 20085: 46$ & 1.446 & 16.9 & 5688 & $8 / 15 / 20088: 04$ & 1.442 & 16.9 \\
\hline 5482 & $8 / 15 / 2008$ 1:12 & 1.459 & 16.9 & 5551 & $8 / 15 / 20083: 30$ & 1.452 & 16.9 & 5620 & $8 / 15 / 20085: 48$ & 1.446 & 16.9 & 5689 & $8 / 15 / 20088: 06$ & 1.441 & 16.9 \\
\hline 5483 & $8 / 15 / 20081: 14$ & 1.456 & 16.9 & 5552 & 8/15/2008 3:32 & 1.452 & 16.9 & 5621 & $8 / 15 / 20085: 50$ & 1.448 & 16.9 & 5690 & $8 / 15 / 20088: 08$ & 1.439 & 16.9 \\
\hline 5484 & $8 / 15 / 20081: 16$ & 1.457 & 16.9 & 5553 & $8 / 15 / 20083: 34$ & 1.451 & 16.9 & 5622 & $8 / 15 / 20085: 52$ & 1.445 & 16.9 & 5691 & 8/15/2008 8:10 & 1.441 & 16.9 \\
\hline 5485 & $8 / 15 / 20081: 18$ & 1.458 & 16.9 & 5554 & $8 / 15 / 20083: 36$ & 1.452 & 16.9 & 5623 & $8 / 15 / 20085: 54$ & 1.446 & 16.9 & 5692 & $8 / 15 / 20088: 12$ & 1.442 & 16.9 \\
\hline 5486 & $8 / 15 / 20081: 20$ & 1.457 & 16.9 & 5555 & $8 / 15 / 20083: 38$ & 1.453 & 16.9 & 5624 & $8 / 15 / 20085: 56$ & 1.443 & 16.9 & 5693 & $8 / 15 / 20088: 14$ & 1.441 & 16.9 \\
\hline 5487 & $8 / 15 / 20081: 22$ & 1.458 & 16.9 & 5556 & $8 / 15 / 20083: 40$ & 1.452 & 16.9 & 5625 & $8 / 15 / 20085: 58$ & 1.443 & 16.9 & 5694 & $8 / 15 / 20088: 16$ & 1.44 & 16.9 \\
\hline
\end{tabular}


DOE/RL-2009-35, REV. 0

\begin{tabular}{|c|c|c|c|}
\hline \multicolumn{4}{|c|}{ D4-27p } \\
\hline $\operatorname{Rec}$ & & Pres & Temp \\
\hline$\#$ & Date/Time & psi & ${ }^{\circ} \mathrm{C}$ \\
\hline 5695 & $8 / 15 / 20088: 18$ & 1.44 & 16.9 \\
\hline 5696 & $8 / 15 / 20088: 20$ & 1.44 & 16.9 \\
\hline 5697 & $8 / 15 / 20088: 22$ & 1.44 & 16.9 \\
\hline 5698 & $8 / 15 / 20088: 24$ & 1.44 & 16.9 \\
\hline 5699 & $8 / 15 / 20088: 26$ & 1.438 & 16.9 \\
\hline 5700 & $8 / 15 / 20088: 28$ & 1.439 & 16.9 \\
\hline 5701 & $8 / 15 / 20088: 30$ & 1.44 & 16.9 \\
\hline 5702 & $8 / 15 / 20088: 32$ & 1.44 & 16.9 \\
\hline 5703 & $8 / 15 / 20088: 34$ & 1.441 & 16.9 \\
\hline 5704 & $8 / 15 / 20088: 36$ & 1.441 & 16.9 \\
\hline 5705 & $8 / 15 / 20088: 38$ & 1.44 & 16.9 \\
\hline 5706 & $8 / 15 / 20088: 40$ & 1.441 & 16.9 \\
\hline 5707 & $8 / 15 / 20088: 42$ & 1.44 & 16.9 \\
\hline 5708 & $8 / 15 / 20088: 44$ & 1.44 & 16.9 \\
\hline 5709 & $8 / 15 / 20088: 46$ & 1.44 & 16.9 \\
\hline 5710 & $8 / 15 / 20088: 48$ & 1.439 & 16.9 \\
\hline 5711 & $8 / 15 / 20088: 50$ & 1.441 & 16.9 \\
\hline 5712 & $8 / 15 / 20088: 52$ & 1.439 & 16.9 \\
\hline 5713 & $8 / 15 / 20088: 54$ & 1.44 & 16.9 \\
\hline 5714 & $8 / 15 / 20088: 56$ & 1.44 & 16.9 \\
\hline 5715 & $8 / 15 / 20088: 58$ & 1.44 & 16.9 \\
\hline 5716 & $8 / 15 / 20089: 00$ & 1.441 & 16.9 \\
\hline 5717 & $8 / 15 / 20089: 02$ & 1.44 & 16.9 \\
\hline 5718 & $8 / 15 / 20089: 04$ & 1.441 & 16.9 \\
\hline 5719 & $8 / 15 / 20089: 06$ & 1.44 & 16.9 \\
\hline 5720 & $8 / 15 / 20089: 08$ & 1.44 & 16.9 \\
\hline 5721 & $8 / 15 / 20089: 10$ & 1.44 & 16.9 \\
\hline 5722 & 8/15/20089:12 & 1.44 & 16.9 \\
\hline 5723 & $8 / 15 / 20089: 14$ & 1.44 & 16.9 \\
\hline 5724 & $8 / 15 / 20089: 16$ & 1.44 & 16.9 \\
\hline 5725 & $8 / 15 / 20089: 18$ & 1.44 & 16.9 \\
\hline 5726 & $8 / 15 / 20089: 20$ & 1.44 & 16.9 \\
\hline 5727 & $8 / 15 / 20089: 22$ & 1.439 & 16.9 \\
\hline 5728 & $8 / 15 / 20089: 24$ & 1.44 & 16.9 \\
\hline 5729 & $8 / 15 / 20089: 26$ & 1.439 & 16.9 \\
\hline 5730 & $8 / 15 / 20089: 28$ & 1.438 & 16.9 \\
\hline 5731 & $8 / 15 / 20089: 30$ & 1.438 & 16.9 \\
\hline 5732 & $8 / 15 / 20089: 32$ & 1.439 & 16.9 \\
\hline 5733 & $8 / 15 / 20089: 34$ & 1.438 & 16.9 \\
\hline 5734 & $8 / 15 / 20089: 36$ & 1.438 & 16.9 \\
\hline 5735 & $8 / 15 / 20089: 38$ & 1.438 & 16.9 \\
\hline 5736 & $8 / 15 / 20089: 40$ & 1.437 & 16.9 \\
\hline 5737 & $8 / 15 / 20089: 42$ & 1.437 & 16.9 \\
\hline 5738 & $8 / 15 / 20089: 44$ & 1.438 & 16.9 \\
\hline 5739 & $8 / 15 / 20089: 46$ & 1.438 & 16.9 \\
\hline 5740 & $8 / 15 / 20089: 48$ & 1.438 & 16.9 \\
\hline 5741 & $8 / 15 / 20089: 50$ & 1.438 & 16.9 \\
\hline 5742 & $8 / 15 / 20089: 52$ & 1.439 & 16.9 \\
\hline 5743 & $8 / 15 / 20089: 54$ & 1.438 & 16.9 \\
\hline 5744 & $8 / 15 / 20089: 56$ & 1.438 & 16.9 \\
\hline 5745 & $8 / 15 / 20089: 58$ & 1.438 & 16.9 \\
\hline 5746 & $8 / 15 / 2008$ 10:00 & 1.439 & 16.9 \\
\hline 5747 & $8 / 15 / 200810: 02$ & 1.438 & 16.9 \\
\hline 5748 & $8 / 15 / 2008$ 10:04 & 1.438 & 16.9 \\
\hline 5749 & $8 / 15 / 200810: 06$ & 1.439 & 16.9 \\
\hline 5750 & $8 / 15 / 2008$ 10:08 & 1.439 & 16.9 \\
\hline 5751 & $8 / 15 / 2008$ 10:10 & 1.439 & 16.9 \\
\hline 5752 & $8 / 15 / 2008$ 10:12 & 1.438 & 16.9 \\
\hline 5753 & $8 / 15 / 2008 \quad 10: 14$ & 1.439 & 16.9 \\
\hline 5754 & $8 / 15 / 2008$ 10:16 & 1.438 & 16.9 \\
\hline 5755 & $8 / 15 / 2008$ 10:18 & 1.439 & 16.9 \\
\hline 5756 & $8 / 15 / 2008$ 10:20 & 1.438 & 16.9 \\
\hline 5757 & $8 / 15 / 200810: 22$ & 1.438 & 16.9 \\
\hline 5758 & $8 / 15 / 2008$ 10:24 & 1.437 & 16.9 \\
\hline 5759 & $8 / 15 / 2008$ 10:26 & 1.438 & 16.9 \\
\hline 5760 & $8 / 15 / 2008$ 10:28 & 1.438 & 16.9 \\
\hline 5761 & $8 / 15 / 2008$ 10:30 & 1.437 & 16.9 \\
\hline 5762 & $8 / 15 / 2008$ 10:32 & 1.438 & 16.9 \\
\hline 5763 & $8 / 15 / 2008$ 10:34 & 1.438 & 16.9 \\
\hline
\end{tabular}

\begin{tabular}{|c|c|c|c|}
\hline \multicolumn{4}{|c|}{ D4-27p } \\
\hline $\operatorname{Rec}$ & & Pres & Temp \\
\hline \# & Date/Time & psi & ${ }^{\circ} \mathrm{C}$ \\
\hline 5764 & $8 / 15 / 200810: 36$ & 1.438 & 16.9 \\
\hline 5765 & $8 / 15 / 200810: 38$ & 1.438 & 16.8 \\
\hline 5766 & $8 / 15 / 200810: 40$ & 1.438 & 16.9 \\
\hline 5767 & $8 / 15 / 200810: 42$ & 1.437 & 16. \\
\hline 5768 & $8 / 15 / 200810: 44$ & 1.438 & 16. \\
\hline 5769 & $8 / 15 / 200810: 46$ & 1.438 & 16. \\
\hline 5770 & $8 / 15 / 2008$ 10:48 & 1.437 & 1 \\
\hline 5771 & $8 / 15 / 200810: 50$ & 1.438 & 16. \\
\hline 5772 & $8 / 15 / 200810: 52$ & 1.438 & 16. \\
\hline 5773 & $8 / 15 / 200810: 54$ & 1.437 & 16 \\
\hline 5774 & $8 / 15 / 200810: 56$ & 1.438 & 16. \\
\hline 5775 & $8 / 15 / 200810: 58$ & 1.436 & 16. \\
\hline 5776 & $8 / 15 / 200811: 00$ & 1.437 & 16. \\
\hline $57 \pi$ & $8 / 15 / 200811: 02$ & 1.437 & 16. \\
\hline 5778 & $8 / 15 / 200811: 04$ & 1.437 & 16. \\
\hline 5779 & $8 / 15 / 200811: 06$ & 1.437 & \\
\hline 5780 & $8 / 15 / 200811: 08$ & 1.437 & 16 \\
\hline 5781 & $8 / 15 / 200811: 10$ & 1.437 & 16. \\
\hline 5782 & $1 / 5 / 2008$ 11:12 & 1.438 & 16. \\
\hline 5783 & $8 / 15 / 200811: 14$ & 1.438 & 16. \\
\hline 5784 & $8 / 15 / 200811: 16$ & 1.438 & 16. \\
\hline 5785 & $8 / 15 / 2008$ 11:18 & 1.437 & \\
\hline 5786 & $8 / 15 / 200811: 20$ & 1.438 & 16. \\
\hline 5787 & $8 / 15 / 200811: 22$ & 1.438 & 16. \\
\hline 5788 & $8 / 15 / 2008$ 11:24 & 1.436 & 16. \\
\hline 5789 & $8 / 15 / 2008$ 11:26 & 1.436 & 16. \\
\hline 5790 & $8 / 15 / 2008$ 11:28 & 1.436 & 16. \\
\hline 5791 & $8 / 15 / 200811: 30$ & 1.437 & 16. \\
\hline 5792 & $8 / 15 / 200811: 32$ & 1.437 & 16. \\
\hline 5793 & $/ 15 / 2008 \quad 11: 34$ & 1.438 & 16 \\
\hline 5794 & $115 / 2008$ 11:36 & 1.436 & 16. \\
\hline 5795 & $8 / 15 / 200811: 38$ & 1.436 & 16 \\
\hline 5796 & $115 / 200$ & 1.436 & \\
\hline 5797 & $8 / 15 / 200811: 42$ & 1.436 & 16 \\
\hline 5798 & $115 / 2008$ 11:44 & 1.436 & 16 \\
\hline 5799 & $3 / 15 / 200811: 46$ & 1.436 & 16 \\
\hline 5800 & $8 / 15 / 200811: 48$ & 1.437 & 16 \\
\hline 5801 & $175 / 2008$ 11:50 & 1.437 & 16 \\
\hline 5802 & $3 / 15 / 2008$ 11:52 & 1.437 & 16 \\
\hline 5803 & $8 / 15 / 200811: 54$ & 1.436 & 16 \\
\hline 5804 & $115 / 2008$ & 1.437 & 16 \\
\hline 5805 & $1 / 15 / 200$ & 1.436 & 16 \\
\hline 5806 & $8 / 15 / 200$ & 1.437 & 16. \\
\hline 5807 & $1 / 15 / 200$ & 1.435 & $\overline{16}$ \\
\hline 5808 & $1 / 15 / 2008$ 12:04 & 1.436 & 16 \\
\hline 5809 & $8 / 15 / 2008$ 12:06 & 1.435 & 16 \\
\hline 5810 & 12:08 & 1.436 & 16 \\
\hline 5811 & $8 / 15 / 2008$ 12:10 & 1.436 & $\overline{16}$ \\
\hline 5812 & 12:12 & 1.436 & 16 \\
\hline 5813 & 12:14 & 1.436 & \\
\hline 5814 & $8 / 15 / 200812: 16$ & 1.435 & 16 \\
\hline 5815 & & 1.437 & 16 \\
\hline 5816 & $12: 20$ & 1.4 & \\
\hline 5817 & $8 / 15 / 200812: 22$ & 1.436 & 16 \\
\hline 5818 & $12: 24$ & 1.436 & 16 \\
\hline 5819 & $15 / 2008$ 12:26 & 1.434 & \\
\hline 5820 & $8 / 15 / 2008$ 12:28 & 1.435 & 16 \\
\hline 5821 & $15 / 200812: 30$ & 1.436 & 16 \\
\hline 5822 & 112:32 & 1.436 & \\
\hline 5823 & $8 / 15 / 200812: 34$ & 1.436 & 16 \\
\hline 5824 & $15 / 200812: 36$ & 1.434 & 16 \\
\hline 5825 & $15 / 200812: 38$ & 1.435 & \\
\hline 5826 & $15 / 2008 \quad 12: 40$ & 1.436 & 16 \\
\hline 5827 & $15 / 200812: 42$ & 1.436 & 16 \\
\hline 5828 & $15 / 2008$ 12:44 & 1.435 & \\
\hline 5829 & $8 / 15 / 2008$ 12:46 & 1.435 & 16 \\
\hline 5830 & $115 / 200812: 48$ & 1.435 & 16 \\
\hline 5831 & $15 / 200812: 50$ & 1.435 & \\
\hline 5832 & $8 / 15 / 2008$ 12:52 & 1.435 & 16 \\
\hline
\end{tabular}
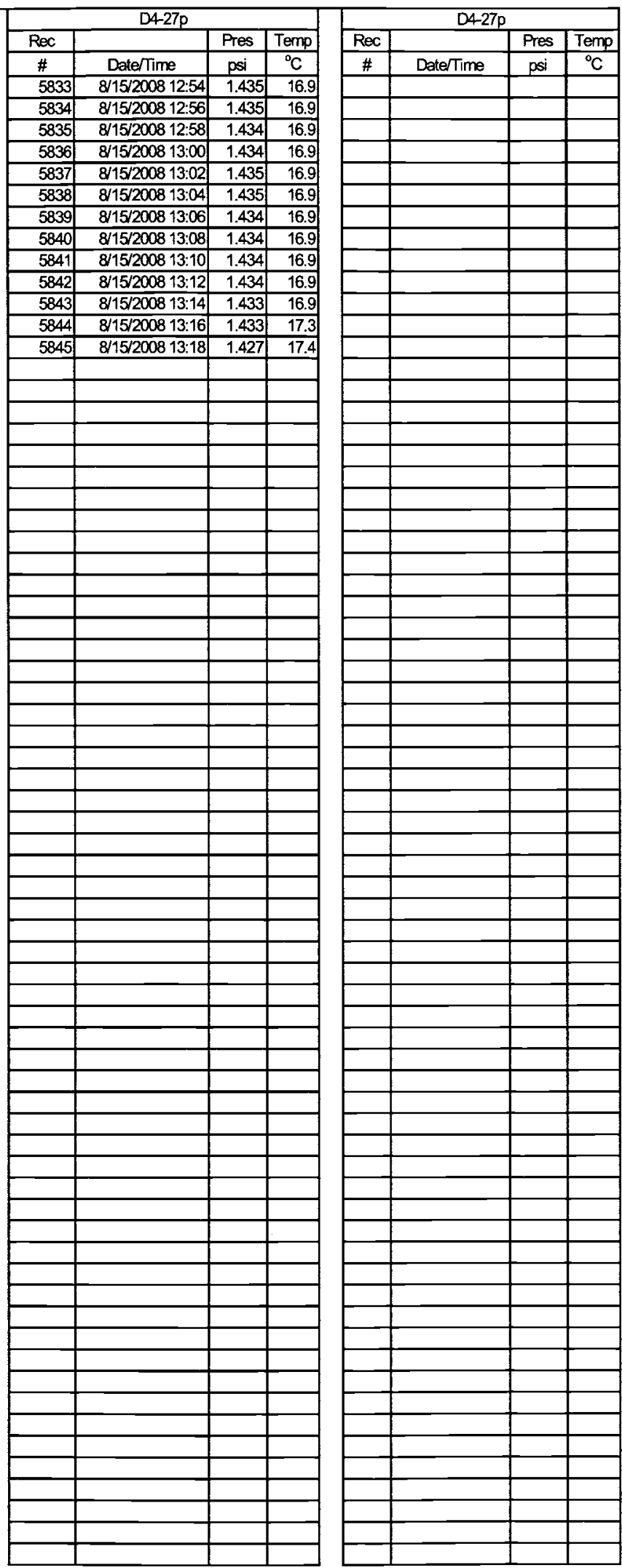


\begin{tabular}{|c|c|c|c|c|}
\hline \multicolumn{5}{|c|}{ D4-92c } \\
\hline $\operatorname{Rec}$ & & Adjusted & Temp & SC \\
\hline$\#$ & Date/Time & Date/Time & ${ }^{\circ} \mathrm{C}$ & $\mu \mathrm{S} / \mathrm{cm}$ \\
\hline 1 & $1 / 7 / 2008$ 10:04 & $8 / 7 / 2008$ 10:04 & \begin{tabular}{|l|}
16.8 \\
\end{tabular} & 706.6 \\
\hline 2 & 1/7/2008 10:06 & $8 / / 2008$ 10:06 & 16.8 & 706.1 \\
\hline 3 & $1 / 7 / 200810: 08$ & $8 / / 2008$ 10:08 & 16.8 & 706.6 \\
\hline 4 & 1/7/2008 10:10 & $8 / 7 / 2008$ 10:10 & 16.8 & 706.7 \\
\hline 5 & $1 / 7 / 2008$ 10:12 & $87 / 2008$ 10:12 & 16.8 & 706.8 \\
\hline 6 & $1 / 7 / 200810: 14$ & $8 / 7 / 2008$ 10:14 & 16.8 & 706.9 \\
\hline 7 & $1 / 7 / 2008$ 10:16 & $8 / 7 / 2008$ 10:16 & 16.8 & 706.8 \\
\hline 8 & $1 / 7 / 200810: 18$ & $8 / 7 / 2008$ 10:18 & 16.8 & 706.7 \\
\hline 9 & 1/7/2008 10:20 & $8 / 7 / 2008$ 10:20 & 16.8 & 706.5 \\
\hline 10 & $1 / 7 / 200810: 22$ & $8 / 7 / 200810: 22$ & 16.8 & 706.8 \\
\hline 11 & $1 / 7 / 200810: 24$ & $8 / / 2008$ 10:24 & 16.7 & 707 \\
\hline 12 & $1 / 7 / 200810: 26$ & $8 / 7 / 2008$ 10:26 & 16.7 & 707 \\
\hline 13 & $1 / 7 / 200810: 28$ & $8 / 72008$ 10:28 & 16.7 & 706.8 \\
\hline 14 & $1 / 7 / 200810: 30$ & $8 / 7 / 200810: 30$ & 16.8 & 706.7 \\
\hline 15 & $1 / 7 / 2008$ 10:32 & $8 / 7 / 2008$ 10:32 & 16.7 & 706.7 \\
\hline 16 & $1 / 7 / 200810: 34$ & $8 / 7 / 2008$ 10:34 & 16.7 & 706.6 \\
\hline 17 & $1 / 7 / 2008$ 10:36 & $8 / 7 / 2008$ 10:36 & 16.8 & 706.7 \\
\hline 18 & $1 / 7 / 2008$ 10:38 & $87 / 2008$ 10:38 & 16.7 & 706.7 \\
\hline 19 & $1 / 7 / 200810: 40$ & $8 / / 2008$ 10:40 & 16.8 & 706.7 \\
\hline 20 & $1 / 7 / 200810: 42$ & $8 / 7 / 2008$ 10:42 & 16.8 & 706.5 \\
\hline 21 & $1 / 7 / 200810: 44$ & $8 / 7 / 2008$ 10:44 & 16.8 & 706.8 \\
\hline 22 & $1 / 7 / 200810: 46$ & $8 / / 2008$ 10:46 & 16.8 & 706.9 \\
\hline 23 & $1 / 7 / 2008 \quad 10: 48$ & $8 / / 2008$ 10:48 & 16.8 & 706.7 \\
\hline 24 & $1 / 7 / 200810: 50$ & $8 / 7 / 2008$ 10:50 & 16.8 & 706.6 \\
\hline 25 & $1 / 7 / 200810: 52$ & $8 / 7 / 200810: 52$ & 16.8 & 706.8 \\
\hline 26 & $1 / 7 / 200810: 54$ & $8 / 7 / 2008 \quad 10: 54$ & 16.8 & 706.8 \\
\hline 27 & $1 / 7 / 2008 \quad 10: 56$ & $8 / 7 / 2008$ 10:56 & 16.8 & 706.8 \\
\hline 28 & $1 / 7 / 2008 \quad 10: 58$ & $8 / 7 / 2008$ 10:58 & 16.8 & 706.8 \\
\hline 29 & $1 / 7 / 200811: 00$ & $8 / 7 / 2008$ 11:00 & 16.8 & 706.8 \\
\hline 30 & $1 / 7 / 2008 \quad 11: 02$ & $8 / 7 / 2008$ 11:02 & 16.8 & 706.9 \\
\hline 31 & $1 / 7 / 2008$ 11:04 & $8 / 7 / 2008$ 11:04 & 16.7 & 707 \\
\hline 32 & 1/7/2008 11:06 & $8 / 7 / 2008$ 11:06 & 16.8 & 706.9 \\
\hline 33 & $1 / 7 / 200811: 08$ & $8 / / 2008$ 11:08 & 16.7 & 706.9 \\
\hline 34 & $1 / 7 / 200811: 10$ & $8 / / 2008$ 11:10 & 16.8 & 706.8 \\
\hline 35 & $1 / 7 / 2008$ 11:12 & $8 / 7 / 200811: 12$ & 16.8 & 706.9 \\
\hline 36 & $1 / 7 / 200811: 14$ & $8 / 7 / 2008$ 11:14 & 16.8 & 706.8 \\
\hline 37 & $1 / 7 / 200811: 16$ & $8 / 72008$ 11:16 & 16.7 & 707 \\
\hline 38 & 1/7/2008 11:18 & $8 / 7 / 2008$ 11:18 & 16.7 & 707.2 \\
\hline 39 & $1 / 7 / 200811: 20$ & $8 / 7 / 200811: 20$ & 16.7 & 707.2 \\
\hline 40 & 1/7/2008 11:22 & $8 / 7 / 2008$ 11:22 & 16.8 & 707 \\
\hline 41 & $1 / 7 / 200811: 24$ & $8 / 7 / 2008$ 11:24 & 16.7 & 707 \\
\hline 42 & $1 / 7 / 200811: 26$ & $8 / 7 / 2008$ 11:26 & 16.8 & 707 \\
\hline 43 & $1 / 7 / 200811: 28$ & $8 / 72008$ 11:28 & 16.8 & 706.9 \\
\hline 44 & $1 / 7 / 200811: 30$ & $8 / 7 / 2008$ 11:30 & 16.7 & 706.9 \\
\hline 45 & $1 / 7 / 200811: 32$ & $8 / 72008$ 11:32 & 16.7 & 706.9 \\
\hline 46 & $17 / 2008$ 11:34 & $8 / 7 / 200811: 34$ & 16.7 & 707 \\
\hline 47 & $1 / 7 / 200811: 36$ & $8 / 7 / 200811: 36$ & 16.8 & 706.9 \\
\hline 48 & $1 / 7 / 200811: 38$ & $8 / 7 / 200811: 38$ & 16.8 & 706.8 \\
\hline 49 & $1 / 7 / 200811: 40$ & $8 / 7 / 200811: 40$ & 16.7 & 707 \\
\hline 50 & $1 / 7 / 200811: 42$ & $8 / 7 / 2008$ 11:42 & 16.8 & 707 \\
\hline 51 & $1 / 7 / 200811: 44$ & $8 / / 2008$ 11:44 & 16.8 & 706.9 \\
\hline 52 & $1 / 7 / 200$ & $8 / 72008$ 11:46 & 16.8 & 706.9 \\
\hline 53 & $1 / 7 / 200811: 48$ & $8 / 7 / 200811: 48$ & 16.8 & 706.8 \\
\hline 54 & $1 / 7 / 200811: 50$ & $8 / 7 / 2008$ 11:50 & 16.8 & 706.8 \\
\hline 55 & $1 / 7 / 200811: 52$ & $8 / 7 / 200811: 52$ & 16.7 & 706.7 \\
\hline 56 & $1 / 7 / 200811: 54$ & $8 / 7 / 2008$ 11:54 & 16.8 & 706.7 \\
\hline 57 & $1 / 7 / 200811: 56$ & $8 / 7 / 2008$ 11:56 & 16.8 & 706.6 \\
\hline 58 & $1 / 7 / 2008$ 11:58 & $8 / 7 / 2008$ 11:58 & 16.8 & 706.7 \\
\hline 59 & $1 / 7 / 200812: 00$ & $8 / 7 / 200812: 00$ & 16.8 & 706.4 \\
\hline 60 & $1 / 7 / 200812: 02$ & $8 / 7 / 200812: 02$ & 16.7 & 706.8 \\
\hline 61 & $1 / 7 / 200812: 04$ & $8 / 7 / 2008$ 12:04 & 16.8 & 707.1 \\
\hline 62 & $1 / 7 / 2008 \quad 12: 06$ & $8 / 7 / 2008$ 12:06 & 16.8 & 706.9 \\
\hline 63 & $1 / 7 / 200812: 08$ & $8 / 7 / 2008$ 12:08 & 16.7 & 706.8 \\
\hline 64 & $1 / 7 / 200812: 10$ & $8 / 7 / 2008$ 12:10 & 16.8 & 706.8 \\
\hline 65 & $1 / 7 / 200812: 12$ & $8 / 7 / 2008$ 12:12 & 16.8 & 706.8 \\
\hline 66 & $1 / 7 / 200812: 14$ & $8 / 7 / 2008$ 12:14 & 16.8 & 707 \\
\hline 67 & $1 / 7 / 200812: 16$ & $8 / 7 / 2008$ 12:16 & 16.8 & 706.7 \\
\hline 68 & $1 / 7 / 200812: 18$ & $8 / 7 / 2008$ 12:18 & 16.8 & 706.7 \\
\hline
\end{tabular}

\begin{tabular}{|c|c|c|c|c|}
\hline \multicolumn{5}{|c|}{ D4-92c } \\
\hline $\operatorname{Rec}$ & & Adjusted & Temp & SC \\
\hline$\#$ & Date/Time & DaterTime & ${ }^{\circ} \mathrm{C}$ & $\mu \mathrm{S} / \mathrm{cm}$ \\
\hline 69 & $1 / 7 / 2008$ 12:20 & $8 / 7 / 2008$ 12:20 & 16.8 & 706.5 \\
\hline 70 & $1 / 7 / 200812: 22$ & $8 / 7 / 200812: 22$ & 16.8 & 706.8 \\
\hline 71 & $1 / 7 / 200812: 24$ & $8 / 7 / 2008$ 12:24 & 16.7 & 706.9 \\
\hline 72 & $1 / 7 / 200812: 26$ & $8 / 7 / 2008$ 12:26 & 16.8 & 706.8 \\
\hline 73 & $1 / 7 / 200812: 28$ & $8 / 7 / 200812: 28$ & 16.8 & 706.8 \\
\hline 74 & $1 / 7 / 200812: 30$ & $8 / 7 / 2008$ 12:30 & 16.8 & 706.9 \\
\hline 75 & 1/7/2008 12:32 & $8 / 7 / 2008$ 12:32 & 16.8 & 706.8 \\
\hline 76 & $1 / 7 / 200812 ; 34$ & $8 / 7 / 200812: 34$ & 16.7 & 707 \\
\hline 77 & $1 / 7 / 200812: 36$ & $8 / 7 / 2008$ 12:36 & 16.8 & 706.8 \\
\hline 78 & $1 / 7 / 200812: 38$ & $8 / 7 / 200812: 38$ & 16.8 & 706.8 \\
\hline 79 & $1 / 7 / 200812: 40$ & $8 / 7 / 200812: 40$ & 16.8 & 706.8 \\
\hline 80 & $1 / 7 / 200812: 42$ & $8 / 7200812: 42$ & 16.7 & 706.9 \\
\hline 81 & $1 / 7 / 200812: 44$ & $8 / 7 / 200812: 44$ & 16.7 & 706.8 \\
\hline 82 & $1 / 7 / 200812: 46$ & $8 / 7 / 2008$ 12:46 & 16.8 & 707 \\
\hline 83 & $1 / 7 / 200812: 48$ & $8 / 7 / 200812: 48$ & 16.8 & 706.9 \\
\hline 84 & $1 / 7 / 200812: 50$ & $8 / 7 / 200812: 50$ & 16.8 & 706.9 \\
\hline 85 & $1 / 7 / 200812: 52$ & $8 / 7 / 200812: 52$ & 16.8 & 706.8 \\
\hline 86 & $1 / 7 / 200812: 54$ & $8 / 7 / 200812: 54$ & 16.7 & 706.9 \\
\hline 87 & $1 / 7 / 20081256$ & $8 / 7 / 200812: 56$ & 16.7 & 707.1 \\
\hline 88 & $1 / 7 / 200812: 58$ & $8 / 7 / 200812: 58$ & 16.8 & 706.7 \\
\hline 89 & $1 / 7 / 200813: 00$ & $8 / 7 / 200813: 00$ & 16.7 & 706.9 \\
\hline 90 & $1 / 7 / 200813: 02$ & $8 / 7 / 200813: 02$ & 16.7 & 706.9 \\
\hline 91 & $1 / 7 / 200813: 04$ & $8 / 7 / 200813: 04$ & 16.8 & 706.5 \\
\hline 92 & 1/7/2008 13:06 & $8 / 7 / 200813: 06$ & 16.8 & 706.5 \\
\hline 93 & $1 / 7 / 200813: 08$ & $8 / 7 / 200813: 08$ & 16.8 & 706.5 \\
\hline 94 & 1/7/2008 13:10 & $8 / 7 / 200813: 10$ & 16.8 & 706.6 \\
\hline 95 & $1 / 7 / 200813: 12$ & $8 / 7 / 200813: 12$ & 16.7 & 706.7 \\
\hline 96 & $1 / 7 / 2008$ 13:14 & $8 / 7 / 2008$ 13:14 & 16.8 & 706.5 \\
\hline 97 & 1/7/2008 13:16 & $8 / 7 / 200813: 16$ & 16.8 & 706.8 \\
\hline 98 & $1 / 7 / 200813: 18$ & $8 / 7 / 200813: 18$ & 16.7 & 705.2 \\
\hline 99 & $1 / 7 / 200813: 20$ & $8 / 7 / 200813: 20$ & 16.7 & 705.5 \\
\hline 100 & $1 / 7 / 200813: 22$ & $8 / 7 / 200813: 22$ & 16.7 & 705.8 \\
\hline 101 & $1 / 7 / 200813: 24$ & $8 / 7 / 200813: 24$ & 16.8 & 706 \\
\hline 102 & $1 / 7 / 200813: 26$ & $8 / 7 / 200813: 26$ & 16.7 & 706.4 \\
\hline 103 & $1 / 7 / 200813: 28$ & $8 / 7 / 200813: 28$ & 16.8 & 706.3 \\
\hline 104 & $1 / 7 / 200813: 30$ & $8 / 7 / 200813: 30$ & 16.8 & 706.5 \\
\hline 105 & $1 / 7 / 200813: 32$ & $8 / 7 / 2008$ 13:32 & 16.7 & 706.6 \\
\hline 106 & $1 / 7 / 200813: 34$ & $8 / 7 / 2008$ 13:34 & 16.8 & 706.6 \\
\hline 107 & $1 / 7 / 2008$ 13:36 & $8 / 7 / 200813: 36$ & 16.7 & 706.7 \\
\hline 108 & $1 / 7 / 200813: 38$ & $8 / 7 / 2008$ 13:38 & 16.7 & 706.7 \\
\hline 109 & $1 / 7 / 200813: 40$ & $8 / 7 / 200813: 40$ & 16.8 & 706.8 \\
\hline 110 & $1 / 7 / 200813: 42$ & $8 / 7 / 200813: 42$ & 16.7 & 706.9 \\
\hline 111 & 1/7/2008 13:44 & $8 / 7 / 2008$ 13:44 & 16.7 & 706.9 \\
\hline 112 & $1 / 7 / 200813: 46$ & $8 / 7 / 200813: 46$ & 16.8 & 706.8 \\
\hline 113 & $1 / 7 / 200813: 48$ & $8 / 7 / 200813: 48$ & 16.8 & 707.2 \\
\hline 114 & $1 / 7 / 200813: 50$ & $8 / 7 / 200813: 50$ & 16.8 & 707.1 \\
\hline 115 & $1 / 7 / 200813: 52$ & $8 / 7 / 200813: 52$ & 16.8 & 707 \\
\hline 116 & $1 / 7 / 200813: 54$ & $8 / 7 / 200813: 54$ & 16.7 & 707 \\
\hline 117 & $1 / 7 / 200813: 56$ & $8 / 7 / 2008+3: 56$ & 16.7 & 707.2 \\
\hline 118 & $1 / 7 / 200813-58$ & $8 / 7200813: 58$ & 16.8 & 707 \\
\hline 119 & $1 / 7 / 200814: 00$ & $8 / 7 / 200814: 00$ & 16.7 & 707.2 \\
\hline 120 & $1 / 7 / 200814: 02$ & $8 / 7 / 200814: 02$ & 16.8 & 707 \\
\hline 121 & $1 / 7 / 200814: 04$ & $8 / 7 / 200814: 04$ & 16.7 & 707.1 \\
\hline 122 & $1 / 7 / 200814: 06$ & $8 / 7 / 200814: 06$ & 16.8 & 706.8 \\
\hline 123 & $1 / 7 / 200814: 08$ & $8 / 7 / 200814: 08$ & 16.8 & 707 \\
\hline 124 & 1/7/2008 14:10 & $8 / 7 / 200814: 10$ & 16.8 & 707 \\
\hline 125 & $1 / 7 / 2008$ 14:12 & $8 / 72008$ 14:12 & 16.8 & 707 \\
\hline 126 & $1 / 7 / 200814: 14$ & $8 / 7 / 2008$ 14:14 & 16.7 & 706.9 \\
\hline 127 & $1 / 7 / 2008$ 14:16 & $8 / 7 / 200814: 16$ & 16.7 & 707 \\
\hline 128 & $1 / 7 / 200814: 18$ & $8 / 7 / 200814: 18$ & 16.7 & 707 \\
\hline 129 & $1 / 7 / 200814: 20$ & $8 / 7 / 200814: 20$ & 16.7 & 706.9 \\
\hline 130 & $1 / 7 / 200814: 22$ & $8 / 7 / 2008$ 14:22 & 16.8 & 706.9 \\
\hline 131 & $1 / 7 / 200814: 24$ & $8 / 7 / 200814: 24$ & 16.7 & 706.8 \\
\hline 132 & $1 / 7 / 200814: 26$ & $8 / 7 / 2008$ 14:26 & 16.7 & 706.8 \\
\hline 133 & $1 / 7 / 200814: 28$ & $8 / 7 / 200814: 28$ & 16.8 & 706.8 \\
\hline 134 & $1 / 7 / 200814: 30$ & $8 / 7 / 2008$ 14:30 & 16.8 & 706.9 \\
\hline 135 & $1 / 7 / 2008$ 14:32 & $8 / 7 / 2008$ 14:32 & 16.7 & 707.1 \\
\hline 136 & $1 / 7 / 2008$ 14:34 & $8 / 7 / 2008$ 14:34 & 16.8 & 707.1 \\
\hline
\end{tabular}




\begin{tabular}{|c|c|c|c|c|}
\hline \multicolumn{5}{|c|}{ D4-92c } \\
\hline $\operatorname{Rec}$ & & Adjusted & Temp & $\mathrm{SC}$ \\
\hline$\#$ & Date/Time & Date/Time & ${ }^{\circ} \mathrm{C}$ & $\mu \mathrm{S} / \mathrm{cm}$ \\
\hline 205 & $1 / 7 / 200816: 52$ & $8 / 7 / 2008$ 16:52 & 16.7 & 708 \\
\hline 206 & $1 / 7 / 200816: 54$ & $87 / 2008$ 16:54 & 16.8 & 707.9 \\
\hline 207 & $1 / 7 / 200816: 56$ & $8 / 7 / 200816: 56$ & 16.7 & 707.9 \\
\hline 208 & $1 / 7 / 200816: 58$ & $8 / 7 / 200816: 58$ & 16.8 & 707.9 \\
\hline 209 & $1 / 7 / 2008$ 17:00 & $8 / 7 / 2008$ 17:00 & 16.7 & 708 \\
\hline 210 & $17 / 2008$ 17:02 & $8 / 7 / 2008$ 17:02 & 16.7 & 708 \\
\hline 211 & $1 / 7 / 2008$ 17:04 & $8 / 7 / 2008$ 17:04 & 16.8 & 708 \\
\hline 212 & $1 / 7 / 2008$ 17:06 & $8 / 7 / 2008+7: 06$ & 16.8 & 707.9 \\
\hline 213 & $1 / 7 / 200817: 08$ & $8 / 7 / 2008$ 17:08 & 16.7 & 708.2 \\
\hline 214 & $1 / 7 / 2008$ 17:10 & $8 / 7 / 2008$ 17:10 & \begin{tabular}{|c|}
16.7 \\
\end{tabular} & 708.2 \\
\hline 215 & $1 / 7 / 2008$ 17:12 & $8 / 7 / 2008$ 17:12 & 16.7 & 708.6 \\
\hline 216 & $1 / 7 / 2008$ 17:14 & $8 / 7 / 200817: 14$ & 16.8 & 708.4 \\
\hline 217 & $1 / 7 / 2008$ 17:16 & $8 / 7 / 2008$ 17:16 & \begin{tabular}{l|l}
16.7 \\
\end{tabular} & 708.5 \\
\hline 218 & $1 / 7 / 2008$ 17:18 & $8 / 7 / 2008$ 17:18 & 16.7 & 708.5 \\
\hline 219 & $1 / 7 / 2008$ 17:20 & $8 / 7 / 2008$ 17:20 & 16.8 & 708.3 \\
\hline 220 & 1/7/2008 17:22 & $8 / 7 / 200817: 22$ & 16.7 & 708.6 \\
\hline 221 & $1 / 7 / 2008$ 17:24 & $8 / 7 / 200817: 24$ & 16.7 & 708.6 \\
\hline 222 & $1 / 7 / 2008$ 17:26 & $8 / 7 / 2008$ 17:26 & 16.7 & 708.5 \\
\hline 223 & $1 / 7 / 2008$ 17:28 & $8 / 7 / 2008$ 17:28 & 16.7 & 708.5 \\
\hline 224 & $1 / 7 / 2008$ 17:30 & $8 / 7 / 200817: 30$ & 16.7 & 708.5 \\
\hline 225 & $1 / 7 / 2008$ 17:32 & $8 / 7 / 200817: 32$ & 16.8 & 708.3 \\
\hline 226 & $1 / 7 / 2008$ 17:34 & $8 / 7 / 2008$ 17:34 & 16.8 & 708.4 \\
\hline 227 & $1 / 7 / 2008$ 17:36 & $8 / 7 / 2008$ 17:36 & 16.7 & 708.4 \\
\hline 228 & $1 / 7 / 2008$ 17:38 & $8 / 7 / 2008$ 17:38 & 16.7 & 708.5 \\
\hline 229 & $1 / 7 / 2008$ 17:40 & $8 / 7 / 2008 \quad 17: 40$ & 16.7 & 708.5 \\
\hline 230 & 1/7/2008 17:42 & $8 / 7 / 2008$ 17:42 & 16.7 & 708.3 \\
\hline 231 & $1 / 7 / 2008$ 17:44 & $8 / 7 / 2008$ 17:44 & 16.7 & 708.3 \\
\hline 232 & $1 / 7 / 2008$ 17:46 & $8 / 7 / 2008$ 17:46 & 16.7 & 708.3 \\
\hline 233 & $1 / 7 / 2008$ 17:48 & $8 / 7 / 2008$ 17:48 & 16.7 & 708.4 \\
\hline 234 & $1 \pi / 200817: 50$ & $8 / 7 / 2008$ 17:50 & 16.8 & 708.2 \\
\hline 235 & $1 / 7 / 2008$ 17:52 & $8 / 7 / 2008$ 17:52 & 16.7 & 708.4 \\
\hline 236 & $1 / 7 / 200817: 54$ & $8 / 7 / 2008 \quad 17: 54$ & 16.7 & 708.2 \\
\hline 237 & $1 / 7 / 2008$ 17:56 & $8 / 7 / 2008$ 17:56 & 16.8 & 708.1 \\
\hline 238 & $1 / 7 / 200817: 58$ & $8 / 7 / 2008 \quad 17: 58$ & 16.7 & 708.2 \\
\hline 239 & $1 / 7 / 2008$ 18:00 & $8 / 7 / 200818: 00$ & 16.7 & 708.1 \\
\hline 240 & $1 / 7 / 2008$ 18:02 & $8 / 7 / 2008$ 18:02 & 16.8 & 708 \\
\hline 241 & $1 / 7 / 2008$ 18:04 & $8 / 7 / 2008$ 18:04 & 16.8 & 707.9 \\
\hline 242 & $1 / 7 / 2008$ 18:06 & $8 / 7 / 200818: 06$ & 16.7 & 708.2 \\
\hline 243 & $1 / 7 / 200818: 08$ & $8 / 7 / 2008$ 18:08 & 16.7 & 708.2 \\
\hline 244 & $1 / 7 / 2008$ 18:10 & $8 / 7 / 2008$ 18:10 & 16.7 & 708.1 \\
\hline 245 & 1/7/2008 18:12 & $8 / 7 / 200818: 12$ & 16.7 & 708.2 \\
\hline 246 & $1 / 7 / 2008$ 18:14 & $8 / / 2008$ 18:14 & 16.8 & 707.8 \\
\hline 247 & 1/7/2008 18:16 & $8 / 7 / 200818: 16$ & 16.7 & 708.1 \\
\hline 248 & $1 / 7 / 2008$ 18:18 & $8 / 7 / 2008$ 18:18 & 16.7 & 708.2 \\
\hline 249 & $1 / 7 / 2008$ 18:20 & $8 / 7 / 200818: 20$ & 16.7 & 708.1 \\
\hline 250 & $1 / 7 / 2008$ 18:22 & $87 / 200818: 22$ & 16.7 & 708 \\
\hline 251 & $1 / 7 / 2008$ 18:24 & $8 / 7 / 2008$ 18:24 & 16.7 & 708.1 \\
\hline 252 & $1 / 7 / 2008$ 18:26 & $8 / 7 / 200818: 26$ & 16.8 & 707.9 \\
\hline 253 & $1 / 7 / 2008$ 18:28 & $8 / 7 / 200818: 28$ & 16.7 & 708 \\
\hline 254 & $1 / 7 / 2008$ 18:30 & $8 / 7 / 200818: 30$ & 16.7 & 707.8 \\
\hline 255 & $1 / 7 / 2008$ 18:32 & $8 / 7 / 200818: 32$ & 16.7 & 708 \\
\hline 256 & $1 / 7 / 2008$ 18:34 & $8 / 7 / 200818: 34$ & 16.8 & 707.9 \\
\hline 257 & $1 / 7 / 2008$ 18:36 & $8 / 7 / 200818: 36$ & 16.7 & 708 \\
\hline 258 & $1 / 7 / 2008$ 18:38 & $8 / 7 / 200818: 38$ & 16.8 & 707.6 \\
\hline 259 & $1 / 7 / 2008$ 18:40 & $8 / 7 / 2008$ 18:40 & 16.7 & 707.8 \\
\hline 260 & $1 / 7 / 200818: 42$ & $8 / 7 / 200818: 42$ & 16.7 & 707.8 \\
\hline 261 & $1 / 7 / 200818: 44$ & $8 / 7 / 200818: 44$ & 16.8 & 707.7 \\
\hline 262 & $1 / 7 / 2008$ 18:46 & $87 / 200818: 46$ & 16.8 & 707.6 \\
\hline 263 & $1 / 7 / 200818: 48$ & $8 / 7 / 2008$ 18:48 & 16.7 & 707.6 \\
\hline 264 & $1 / 7 / 200818: 50$ & $8 / 7 / 200818: 50$ & 16.7 & 707.7 \\
\hline 265 & $1 / 7 / 200818: 52$ & $8 / 7 / 200818: 52$ & 16.7 & 707.6 \\
\hline 266 & $1 / 7 / 200818: 54$ & $87 / 2008$ 18:54 & 16.7 & 707.8 \\
\hline 267 & $1 / 7 / 200818: 56$ & $8 / 7 / 200818: 56$ & 16.8 & 707.7 \\
\hline 268 & $1 / 7 / 200818: 58$ & $8 / 7 / 2008$ 18:58 & 16.7 & 707.9 \\
\hline 269 & 1/7/2008 19:00 & $87 / 2008$ 19:00 & 16.7 & 707.8 \\
\hline 270 & $1 / 7 / 2008$ 19:02 & $8 / 7 / 2008$ 19:02 & 16.8 & 707.8 \\
\hline 271 & $17 / 2008$ 19:04 & $8 / 7 / 200819: 04$ & 16.8 & 707.7 \\
\hline 272 & 1/7/2008 19:06 & $8 / 7 / 2008$ 19:06 & $\begin{array}{ll}16.8 \\
\end{array}$ & 707.8 \\
\hline
\end{tabular}

\begin{tabular}{|c|c|c|c|c|}
\hline \multicolumn{5}{|c|}{ D4-92c } \\
\hline $\operatorname{Rec}$ & & Adjusted & Temp & \\
\hline$\#$ & Date/Time & Date/Time & ${ }^{\circ} \mathrm{C}$ & $\mu \mathrm{S} / \mathrm{cm}$ \\
\hline 273 & $1 / 7 / 2008$ 19:08 & $8 / 7 / 2008$ 19:08 & 16.7 & 707. \\
\hline 274 & $7 / 2008$ 19:10 & $8 / 7 / 200819: 10$ & 16.7 & \\
\hline 275 & $7 / 200819: 12$ & $8 / 7 / 2008$ 19:12 & 16.7 & \\
\hline 276 & $7 / 2008 \quad 19: 14$ & $8 / 7 / 2008$ 19:14 & 16.7 & 707. \\
\hline 277 & $7 / 2008$ 19:16 & $8 / 7 / 2008$ 19:16 & 16.8 & 707. \\
\hline 278 & $7 / 200819: 18$ & $8 / 7 / 2008$ 19:18 & 16.7 & \\
\hline 279 & $7 / 200819: 20$ & $8 / 7 / 2008$ 19:20 & 16.7 & 707. \\
\hline 280 & $1 / 7 / 200819: 22$ & $8 / 7 / 2008$ 19:22 & 16.7 & \\
\hline 281 & $1 / 7 / 200819: 24$ & $8 / 7 / 200819: 24$ & 16.7 & \\
\hline 282 & $1 / 7 / 200819: 26$ & $8 / 7 / 2008$ 19:26 & 16.7 & 707.8 \\
\hline 283 & $1 / 7 / 200819: 28$ & $8 / 7 / 2008$ 19:28 & 16.7 & 707.8 \\
\hline 284 & $1 / 7 / 200819: 30$ & $8 / 7 / 2008$ 19:30 & 16.8 & \\
\hline 285 & $\overline{7 / 200819: 32}$ & $819: 32$ & 16.7 & 707.8 \\
\hline 286 & $7 / 2008$ 19:34 & $819: 34$ & 16.8 & 707. \\
\hline 287 & $7 / 2008$ 19:36 & $8 / 7 / 20$ & 16.8 & \\
\hline 288 & $7 / 2008$ 19:38 & 319:38 & 16.7 & \\
\hline 289 & 19:40 & $19: 40$ & 16.7 & 707. \\
\hline 290 & 19:42 & $19: 42$ & & \\
\hline 291 & $7 / 200819: 44$ & $19: 44$ & 16.7 & \\
\hline 292 & $19: 46$ & $19: 46$ & 16.7 & 707. \\
\hline 293 & $7 / 20$ & $19: 48$ & 16.7 & \\
\hline 294 & $7 / 2008$ 19:50 & $19: 50$ & 16.8 & 707 . \\
\hline 295 & 19:52 & 19:52 & 16.7 & 707. \\
\hline 296 & 19:54 & 19:54 & 16.8 & 707. \\
\hline 297 & $7 / 200819: 56$ & 19:56 & 16.8 & \\
\hline 298 & $9: 58$ & 19:58 & 16.7 & 707 \\
\hline 299 & $20: 00$ & $\overline{20: 00}$ & 16.7 & 707 \\
\hline 300 & $7 / 200820: 02$ & $20: 02$ & 16. & \\
\hline 301 & $0: 04$ & $20: 04$ & 16. & 707 \\
\hline 302 & $20: 06$ & $20: 06$ & 16.8 & 707. \\
\hline 303 & & $20: 08$ & 16. & \\
\hline 304 & $7 / 20$ & $20: 10$ & 16.7 & 707 \\
\hline 305 & $0: 12$ & $20: 12$ & 16 & 707 \\
\hline 306 & & $20: 14$ & 16.8 & 707 \\
\hline 307 & & $20: 16$ & 16. & 707 \\
\hline 308 & & & 16.7 & 707. \\
\hline 309 & 20 & $20: 20$ & 16.7 & 707. \\
\hline 310 & & & 16. & 707. \\
\hline 311 & & & 16.7 & \\
\hline 312 & & $20: 26$ & 16.7 & 707 \\
\hline 313 & & & 16.8 & 707 \\
\hline 314 & & $20: 30$ & 16.8 & 707 \\
\hline 315 & & & 16.8 & 7 \\
\hline 316 & 34 & $20: 34$ & 16.8 & 707 \\
\hline 317 & & $20: 36$ & 16.7 & \\
\hline 318 & & $20: 38$ & 16.7 & 707 \\
\hline 319 & & $20: 40$ & 16.8 & 707 \\
\hline 320 & & & 16.8 & \\
\hline 321 & & 44 & 16.7 & 707 \\
\hline 322 & & & 16.7 & 707. \\
\hline 323 & & & 16.8 & \\
\hline 324 & & & 16 & 707 \\
\hline 325 & & $20: 52$ & 16.7 & \\
\hline 326 & & & 16.7 & \\
\hline 327 & 56 & $20: 56$ & 16.7 & \\
\hline 328 & & & 16.8 & \\
\hline 329 & & & 16.7 & \\
\hline 330 & & & 16.7 & \\
\hline 331 & & & 16 & \\
\hline 332 & & & & \\
\hline 333 & $7 / 200821: 08$ & $21: 08$ & 16.7 & 707 \\
\hline 334 & & & 16.7 & \\
\hline 335 & & & & \\
\hline 336 & 00021 & $21: 14$ & 16.7 & 101 \\
\hline 337 & & & 16.7 & \\
\hline 338 & & & 16.8 & 707 \\
\hline 339 & $1 / 7 / 200821: 20$ & $21: 20$ & 16.8 & \\
\hline 340 & & & 16.7 & \\
\hline
\end{tabular}

\begin{tabular}{|c|c|c|c|c|}
\hline \multicolumn{5}{|c|}{ D4-92c } \\
\hline $\operatorname{Rec}$ & & Adjusted & Temp & $\mathrm{SC}$ \\
\hline$\#$ & Date/Time & Date/Time & ${ }^{\circ} \mathrm{C}$ & $\mu \mathrm{S} / \mathrm{cm}$ \\
\hline 341 & $1 / 7 / 200821: 24$ & $8 / 7 / 2008$ 21:24 & 16.7 & 707.6 \\
\hline 342 & $1 / 7 / 200821: 26$ & $8 / 7 / 200821: 26$ & 16.7 & 707.6 \\
\hline 343 & $1 / 7 / 200821: 28$ & $8 / 7 / 200821: 28$ & 16.7 & 707.4 \\
\hline 344 & 1/7/200821:30 & $8 / 7 / 200821: 30$ & 16.8 & 707.3 \\
\hline 345 & $1 / 7 / 200821: 32$ & $8 / 7 / 200821: 32$ & 16.7 & 707.5 \\
\hline 346 & $1 / 7 / 200821: 34$ & $8 / 7 / 200821: 34$ & 16.7 & 707.2 \\
\hline 347 & $1 / 7 / 200821: 36$ & $8 / 7 / 200821: 36$ & 16.7 & 707.2 \\
\hline 348 & $1 / 7 / 200821: 38$ & $8 / 7 / 200821: 38$ & 16.8 & 707.2 \\
\hline 349 & $1 / 7 / 200821: 40$ & $8 / 7 / 200821: 40$ & 16.7 & 707.2 \\
\hline 350 & $1 / 7 / 200821: 42$ & $8 / 7 / 2008$ 21:42 & 16.7 & 707.1 \\
\hline 351 & $1 / 7 / 2008$ 21:44 & $8 / 7 / 200821: 44$ & 16.8 & 707 \\
\hline 352 & $1 / 7 / 200821: 46$ & $8 / 7 / 200821: 46$ & 16.7 & 707.1 \\
\hline 353 & $1 / 7 / 200821: 48$ & $8 / 7 / 200821: 48$ & 16.7 & 707.1 \\
\hline 354 & $1 / 7 / 200821: 50$ & $8 / 7 / 200821: 50$ & 16.7 & 707.1 \\
\hline 355 & $1 / 7 / 200821: 52$ & $8 / 7 / 200821: 52$ & 16.7 & 707.1 \\
\hline 356 & $1 / 7 / 200821: 54$ & $8 / 7 / 2008$ 21:54 & 16.7 & 707.2 \\
\hline 357 & $1 / 7 / 200821: 56$ & $8 / 7 / 2008$ 21:56 & 16.7 & 707 \\
\hline 358 & $1 / 7 / 200821: 58$ & $8 / 7 / 200821: 58$ & 16.7 & 707 \\
\hline 359 & $1 / 7 / 200822: 00$ & $8 / 7 / 200822: 00$ & 16.7 & 706.9 \\
\hline 360 & $1 / 7 / 200822: 02$ & $8 / 7 / 200822: 02$ & 16.7 & 707 \\
\hline 361 & 1/7/2008 22:04 & $8 / 7 / 2008$ 22:04 & 16.7 & 707 \\
\hline 362 & $1 / 7 / 200822: 06$ & $8 / 7 / 200822: 06$ & 16.7 & 706.8 \\
\hline 363 & $1 / 7 / 200822: 08$ & $8 / 7 / 200822: 08$ & 16.7 & 706.8 \\
\hline 364 & $1 / 7 / 200822: 10$ & $8 / 7 / 2008$ 22:10 & 16.8 & 706.7 \\
\hline 365 & 1/7/2008 22:12 & $8 / 7 / 2008$ 22:12 & 16.7 & 706.9 \\
\hline 366 & $1 / 7 / 2008$ 22:14 & $8 / 7 / 200822: 14$ & 16.8 & 706.7 \\
\hline 367 & 1/7/2008 22:16 & 8/7/2008 22:16 & 16.7 & 706.8 \\
\hline 368 & $1 / 7 / 200822: 18$ & $8 / 7 / 2008$ 22:18 & \begin{tabular}{l|l}
16.7 \\
\end{tabular} & 706.7 \\
\hline 369 & $1 / 7 / 200822: 20$ & $8 / 7 / 200822: 20$ & 16.7 & 706.7 \\
\hline 370 & $1 / 7 / 200822: 22$ & $8 / 7 / 200822: 22$ & 16.7 & 706.8 \\
\hline 371 & $1 / 7 / 200822: 24$ & $8 / 7 / 200822: 24$ & 16.8 & 706.8 \\
\hline 372 & $1 / 7 / 200822: 26$ & $8 / 7 / 200822: 26$ & 16.7 & 706.7 \\
\hline 373 & $1 / 7 / 200822: 28$ & $8 / 7 / 200822: 28$ & 16.8 & 706.5 \\
\hline 374 & $1 / 7 / 200822: 30$ & $8 / 7 / 200822: 30$ & 16.8 & 706.7 \\
\hline 375 & $1 / 7 / 200822: 32$ & $8 / 7 / 200822: 32$ & 16.7 & 706.6 \\
\hline 376 & $1 / 7 / 200822: 34$ & $8 / 7 / 2008$ 22:34 & 16.7 & 706.7 \\
\hline 377 & $1 / 7 / 200822: 36$ & $8 / 7 / 200822: 36$ & 16.7 & 706.8 \\
\hline 378 & $1 / 7 / 200822: 38$ & $8 / 7 / 200822: 38$ & 16.8 & 706.7 \\
\hline 379 & $1 / 7 / 200822: 40$ & $8 / 7 / 200822: 40$ & 16.7 & 706.8 \\
\hline 380 & $1 / 7 / 200822: 42$ & $8 / 7 / 200822: 42$ & 16.7 & 706.7 \\
\hline 381 & $1 / 7 / 200822: 44$ & $8 / 7 / 2008$ 22:44 & 16.7 & 706.8 \\
\hline 382 & 1/7/2008 22:46 & $8 / 7 / 200822: 46$ & 16.7 & 706.7 \\
\hline 383 & $1 / 7 / 200822: 48$ & $8 / 7 / 200822: 48$ & 16.7 & 706.7 \\
\hline 384 & $1 / 7 / 200822: 50$ & $8 / 7 / 200822: 50$ & 16.8 & 706.5 \\
\hline 385 & $1 / 7 / 200822: 52$ & $8 / 7 / 200822: 52$ & 16.7 & 706.8 \\
\hline 386 & $1 / 7 / 200822: 54$ & $8 / / 200822: 54$ & 16.8 & 706.5 \\
\hline 387 & $1 / 7 / 200822: 56$ & $8 / 7 / 2008$ 22:56 & 16.8 & 706.6 \\
\hline 388 & $1 / 7 / 200822: 58$ & $8 / 7 / 2008$ 22:58 & 16.7 & 706.7 \\
\hline 389 & $1 / 7 / 200823: 00$ & $8 / 7 / 200823: 00$ & 16.7 & 706.7 \\
\hline 390 & $1 / 7 / 200823: 02$ & $8 / 7 / 2008$ 23:02 & 16.7 & 706.8 \\
\hline 391 & $1 / 7 / 200823: 04$ & $8 / 7 / 2008$ 23:04 & 16.7 & 706.8 \\
\hline 392 & $1 / 7 / 200823: 06$ & $8 / 7 / 200823: 06$ & 16.7 & 706.9 \\
\hline 393 & $1 / 7 / 200823: 08$ & $8 / 7 / 200823: 08$ & 16.7 & 706.7 \\
\hline 394 & 1/7/2008 23:10 & $8 / 7 / 2008$ 23:10 & 16.7 & 706.6 \\
\hline 395 & $1 / 7 / 200823: 12$ & $8 / 7 / 2008$ 23:12 & 16.8 & 706.5 \\
\hline 396 & $1 / 7 / 200823: 14$ & $8 / 7 / 200823: 14$ & 16.7 & 706.7 \\
\hline 397 & 1/7/2008 23:16 & $8 / 7 / 2008$ 23:16 & 16.7 & 706.8 \\
\hline 398 & $1 / 7 / 200823: 18$ & $8 / 7 / 2008$ 23:18 & 16.8 & 706.5 \\
\hline 399 & $1 / 7 / 200823: 20$ & $8 / 7 / 200823: 20$ & 16.7 & 706.7 \\
\hline 400 & $1 / 7 / 200823: 22$ & $8 / 7 / 200823: 22$ & 16.7 & 706.8 \\
\hline 401 & $1 / 7 / 200823: 24$ & $8 / 7 / 200823: 24$ & 16.8 & 706.6 \\
\hline 402 & $1 / 7 / 200823: 26$ & $8 / 7 / 200823: 26$ & 16.7 & 706.8 \\
\hline 403 & $1 / 7 / 200823: 28$ & $8 / 7 / 200823: 28$ & 16.7 & 706.6 \\
\hline 404 & $1 / 7 / 200823: 30$ & $8 / 7 / 2008$ 23:30 & 16.8 & 706.4 \\
\hline 405 & $1 / 7 / 200823: 32$ & $8 / 7 / 200823: 32$ & 16.7 & 706.7 \\
\hline 406 & $1 / 7 / 200823: 34$ & $8 / 7 / 200823: 34$ & 16.7 & 706.7 \\
\hline 407 & $1 / 7 / 200823: 36$ & $8 / 7 / 200823: 36$ & 16.7 & 706.6 \\
\hline 408 & 1/7/2008 23:38 & $8 / 7 / 200823: 38$ & 16.7 & 706.5 \\
\hline
\end{tabular}




\begin{tabular}{|c|c|c|c|c|}
\hline \multicolumn{5}{|c|}{ D4-92c } \\
\hline $\operatorname{Rec}$ & & Adjusted & Temp & SC \\
\hline$\#$ & Date/Time & Date/Time & ${ }^{\circ} \mathrm{C}$ & $\mu \mathrm{S} / \mathrm{cm}$ \\
\hline 409 & $1 / 7 / 200823: 40$ & $8 / 7 / 200823: 40$ & 16.7 & 706.7 \\
\hline 410 & $1 / 7 / 200823: 42$ & $8 / 7 / 200823: 42$ & 16.7 & 706.6 \\
\hline 411 & $1 / 7 / 200823: 44$ & $8 / 7 / 200823: 44$ & 16.7 & 706.5 \\
\hline 412 & $1 / 7 / 200823: 46$ & $87 / 200823: 46$ & 16.7 & 706.5 \\
\hline 413 & $1 / 7 / 200823: 48$ & $8 / 7 / 200823: 48$ & 16.7 & 706.5 \\
\hline 414 & $1 / 7 / 200823: 50$ & $8 / 7 / 200823: 50$ & 16.7 & 706.6 \\
\hline 415 & $1 / 7 / 200823: 52$ & $8 / 7 / 200823: 52$ & 16.7 & 706.5 \\
\hline 416 & $1 / 7 / 200823: 54$ & $8 / 7 / 200823: 54$ & 16.7 & 706.7 \\
\hline 417 & $1 / 7 / 200823: 56$ & $8 / 7 / 200823: 56$ & 16.7 & 706.7 \\
\hline 418 & $1 / 7 / 200823: 58$ & $8 / 7 / 200823: 58$ & 16.7 & 706.5 \\
\hline 419 & $1 / 8 / 20080: 00$ & $8 / 8 / 20080: 00$ & 16.8 & 706.3 \\
\hline 420 & $1 / 8 / 20080: 02$ & $8 / 8 / 20080: 02$ & 16.7 & 706.9 \\
\hline 421 & $1 / 8 / 20080: 04$ & $8 / 8 / 20080: 04$ & 16.8 & 706.7 \\
\hline 422 & $1 / 8 / 20080: 06$ & $8 / 8 / 20080: 06$ & 16.8 & 706.6 \\
\hline 423 & $1 / 8 / 20080: 08$ & $8 / 8 / 20080: 08$ & 16.7 & 706.7 \\
\hline 424 & $1 / 8 / 20080: 10$ & $8 / 8 / 20080: 10$ & 16.7 & 706.7 \\
\hline 425 & $1 / 8 / 20080: 12$ & $8 / 8 / 20080: 12$ & 16.8 & 706.4 \\
\hline 426 & $1 / 8 / 20080: 14$ & $8 / 8 / 20080: 14$ & 16.7 & 706.5 \\
\hline 427 & $1 / 8 / 20080: 16$ & $8 / 8 / 20080: 16$ & 16.7 & 706.5 \\
\hline 428 & $1 / 8 / 20080: 18$ & $8 / 8 / 20080: 18$ & 16.7 & 706.5 \\
\hline 429 & $1 / 8 / 20080: 20$ & $8 / 8 / 20080: 20$ & 16.7 & 706.2 \\
\hline 430 & $1 / 8 / 20080: 22$ & $8 / 8 / 20080: 22$ & 16.7 & 706.3 \\
\hline 431 & $1 / 8 / 20080: 24$ & $8 / 8 / 20080: 24$ & 16.8 & 706.2 \\
\hline 432 & $1 / 8 / 20080: 26$ & $8 / 8 / 20080: 26$ & 16.7 & 706.5 \\
\hline 433 & $1 / 8 / 20080: 28$ & $8 / 8 / 20080: 28$ & 16.7 & 706.5 \\
\hline 434 & $1 / 8 / 20080: 30$ & $8 / 8 / 20080: 30$ & 16.8 & 706.5 \\
\hline 435 & $1 / 8 / 20080: 32$ & $8 / 8 / 20080: 32$ & 16.8 & 706.5 \\
\hline 436 & $1 / 8 / 20080: 34$ & $8 / 8 / 20080: 34$ & 16.8 & 706.7 \\
\hline 437 & $1 / 8 / 20080: 36$ & $8 / 8 / 20080: 36$ & 16.7 & 706.7 \\
\hline 438 & $1 / 8 / 20080: 38$ & $8 / 8 / 20080: 38$ & 16.7 & 706.8 \\
\hline 439 & $1 / 8 / 20080: 40$ & $8 / 8 / 20080: 40$ & 16.7 & 706.7 \\
\hline 440 & $1 / 8 / 20080: 42$ & $8 / 8 / 20080: 42$ & 16.7 & 706.7 \\
\hline 441 & $1 / 8 / 20080: 44$ & $8 / 8 / 20080: 44$ & 16.7 & 706.7 \\
\hline 442 & $1 / 8 / 20080: 46$ & $8 / 8 / 20080: 46$ & 16.8 & 706.7 \\
\hline 443 & $1 / 8 / 20080: 48$ & $8 / 8 / 20080: 48$ & 16.7 & 706.8 \\
\hline 444 & $1 / 8 / 20080: 50$ & $8 / 8 / 20080: 50$ & 16.7 & 706.7 \\
\hline 445 & $1 / 8 / 20080: 52$ & $8 / 8 / 20080: 52$ & 16.7 & 706.8 \\
\hline 446 & $1 / 8 / 20080: 54$ & $8 / 8 / 20080: 54$ & 16.7 & 706.7 \\
\hline 447 & $1 / 8 / 20080: 56$ & $8 / 8 / 20080: 56$ & 16.7 & 706.6 \\
\hline 448 & $1 / 8 / 20080: 58$ & $8 / 8 / 20080: 58$ & 16.7 & 706.7 \\
\hline 449 & $1 / 8 / 20081: 00$ & $8 / 8 / 20081: 00$ & 16.7 & 706.5 \\
\hline 450 & $1 / 8 / 20081: 02$ & $8 / 8 / 20081: 02$ & 16.7 & 706.5 \\
\hline 451 & $1 / 8 / 20081: 04$ & $8 / 8 / 20081: 04$ & 16.7 & 706.5 \\
\hline 452 & $1 / 8 / 20081: 06$ & $8 / 8 / 20081: 06$ & 16.7 & 706.4 \\
\hline 453 & $1 / 8 / 20081: 08$ & $8 / 8 / 20081: 08$ & 16.7 & 706.5 \\
\hline 454 & $1 / 8 / 20081: 10$ & $8 / 8 / 20081: 10$ & 16.8 & 706.4 \\
\hline 455 & $1 / 8 / 20081: 12$ & $8 / 8 / 20081: 12$ & 16.7 & 706.5 \\
\hline 456 & $1 / 8 / 20081: 14$ & $8 / 8 / 20081: 14$ & 16.7 & 706.5 \\
\hline 457 & 1/8/2008 1:16 & $8 / 8 / 20081: 16$ & 16.7 & 706.7 \\
\hline 458 & $1 / 8 / 20081: 18$ & $8 / 8 / 20081: 18$ & 16.7 & 706.4 \\
\hline 459 & $1 / 8 / 20081: 20$ & $8 / 8 / 20081: 20$ & 16.7 & 706.6 \\
\hline 460 & $1 / 8 / 20081: 22$ & $8 / 8 / 20081: 22$ & 16.7 & 706.4 \\
\hline 461 & $1 / 8 / 20081: 24$ & $8 / 8 / 20081: 24$ & 16.7 & 706.4 \\
\hline 462 & $1 / 8 / 20081: 26$ & $8 / 8 / 20081: 26$ & 16.7 & 706.2 \\
\hline 463 & $1 / 8 / 20081: 28$ & $8 / 8 / 20081: 28$ & 16.7 & 706.3 \\
\hline 464 & $1 / 8 / 20081: 30$ & $8 / 8 / 20081: 30$ & 16.7 & 706.3 \\
\hline 465 & $1 / 8 / 20081: 32$ & $8 / 8 / 20081: 32$ & 16.8 & 706.2 \\
\hline 466 & $1 / 8 / 20081: 34$ & $8 / 8 / 20081: 34$ & 16.7 & 706.4 \\
\hline 467 & $1 / 8 / 20081: 36$ & $8 / 8 / 20081: 36$ & 16.7 & 706.3 \\
\hline 468 & $1 / 8 / 20081: 38$ & $8 / 8 / 20081: 38$ & 16.7 & 706.2 \\
\hline 469 & $1 / 8 / 20081: 40$ & $8 / 8 / 20081: 40$ & 16.8 & 705.8 \\
\hline 470 & $1 / 8 / 20081: 42$ & $8 / 8 / 2008$ 1:42 & 16.7 & 706.2 \\
\hline 471 & $1 / 8 / 20081: 44$ & $8 / 8 / 20081: 44$ & 16.7 & 706.4 \\
\hline 472 & $1 / 8 / 20081: 46$ & $8 / 8 / 20081: 46$ & 16.7 & 706.1 \\
\hline 473 & $1 / 8 / 20081: 48$ & $8 / 8 / 20081: 48$ & 16.7 & 706 \\
\hline 474 & $1 / 8 / 20081: 50$ & $8 / 8 / 20081: 50$ & 16.7 & 706.2 \\
\hline 475 & $1 / 8 / 20081: 52$ & $8 / 8 / 20081: 52$ & 16.8 & 706 \\
\hline 476 & $1 / 8 / 20081: 54$ & $8 / 8 / 20081: 54$ & 16.8 & 706.1 \\
\hline
\end{tabular}

\begin{tabular}{|c|c|c|c|c|}
\hline \multicolumn{5}{|c|}{ D4-92C } \\
\hline Rec & & Adjusted & Temp & SC \\
\hline$\#$ & Date/Time & Date/Time & ${ }^{\circ} \mathrm{C}$ & $\mu \mathrm{S} / \mathrm{cm}$ \\
\hline 477 & $1 / 8 / 2008$ 1:56 & $8 / 8 / 20081: 56$ & 16.7 & 706.2 \\
\hline 78 & $3 / 20081: 58$ & $8 / 8 / 20081: 58$ & 16.7 & 706.3 \\
\hline 479 & 1/8/2008 2:00 & $8 / 8 / 20082: 00$ & 16.8 & 706 \\
\hline 480 & 1/8/2008 2:02 & $8 / 8 / 20082: 02$ & 16.8 & 706 \\
\hline 81 & 1/8/2008 2:04 & $8 / 8 / 20082: 04$ & 16.8 & 706 \\
\hline 482 & 1/8/20082:06 & $8 / 8 / 20082: 06$ & 16.7 & 706.2 \\
\hline 483 & 1/8/2008 2:08 & $8 / 8 / 20082: 08$ & 16.8 & 706.1 \\
\hline 484 & 1/8/2008 2:10 & 8/8/2008 2:10 & 16.8 & 706 \\
\hline 485 & 1/8/2008 2:12 & $8 / 8 / 20082: 12$ & 16.8 & 706.1 \\
\hline 486 & 1/8/2008 2:14 & $8 / 8 / 20082: 14$ & 16.8 & 706.2 \\
\hline 487 & 1/8/2008 2:16 & $8 / 8 / 20082: 16$ & 16.8 & \\
\hline 488 & 1/8/2008 2:18 & $8 / 8 / 20082: 18$ & 16.8 & $\overline{705.9}$ \\
\hline 489 & 1/8/2008 2:20 & $8 / 8 / 20082: 20$ & 16.8 & 706.1 \\
\hline 490 & $3 / 20082: 22$ & $8 / 8 / 20082: 22$ & 16.7 & 706 \\
\hline 491 & 1/8/2008 2:24 & $8 / 8 / 20082: 24$ & 16.7 & 706.1 \\
\hline 492 & 1/8/2008 2:26 & $8 / 8 / 20082: 26$ & 16.7 & 705.9 \\
\hline 493 & $8 / 20082228$ & $8 / 8 / 20082: 28$ & 16.7 & \\
\hline 494 & 1/8/2008 2:30 & $8 / 8 / 20082: 30$ & 16.7 & 706 \\
\hline 495 & $1 / 8 / 20082: 32$ & $8 / 8 / 20082: 32$ & 16.8 & 706 \\
\hline 496 & $3 / 20082: 34$ & $8 / 8 / 20082: 34$ & 16.7 & \\
\hline 497 & $1 / 8 / 20082: 36$ & $8 / 8 / 20082: 36$ & 16.8 & 706.2 \\
\hline 498 & $8 / 20082: 38$ & $8 / 8 / 20082: 38$ & 16.7 & 706.2 \\
\hline 499 & $8 / 20082: 40$ & $8 / 8 / 20082: 40$ & 16.7 & \\
\hline 500 & $1 / 8 / 20082: 42$ & $8 / 8 / 20082: 42$ & 16.7 & 706 \\
\hline 501 & $1 / 8 / 20082: 44$ & $8 / 8 / 20082: 44$ & 16.7 & 705.9 \\
\hline 502 & 1/8/2008 2:46 & $8 / 8 / 20082: 46$ & 16.7 & 705.9 \\
\hline 503 & $1 / 8 / 20082: 48$ & $8 / 8 / 20082: 48$ & 16.8 & 705.7 \\
\hline 504 & $3 / 2008$ 2:50 & $82: 50$ & 16.7 & 705.9 \\
\hline 505 & $1 / 8 / 20082: 52$ & $8 / 8 / 2008$ 2:52 & 16.8 & $\overline{705.4}$ \\
\hline 506 & 1/8/2008 2:54 & $8 / 8 / 20082: 54$ & 16.7 & 70 \\
\hline 507 & $82: 56$ & $82: 56$ & 16.7 & 705. \\
\hline 508 & $1 / 8 / 20082: 58$ & $8 / 8 / 20082: 58$ & 16.8 & 705. \\
\hline 509 & $8 / 20083: 00$ & $8 / 8 / 20083: 00$ & 16.8 & 70 \\
\hline 510 & $3: 02$ & 33:02 & 16.7 & 70 \\
\hline 511 & 1/8/2008 3:04 & $8 / 8 / 20083: 04$ & 16.7 & 705. \\
\hline 512 & $3 / 20083: 06$ & $8 / 20083: 06$ & 16.8 & 705. \\
\hline 513 & $3 / 20083: 08$ & $33: 08$ & 16.7 & 705 . \\
\hline 514 & $3 / 20083: 10$ & $3 / 20083: 10$ & 16.7 & 706.2 \\
\hline 515 & 3:12 & 3:12 & 16.7 & 706 . \\
\hline 516 & $3: 14$ & $3: 14$ & 16.7 & 706. \\
\hline 517 & $3: 16$ & $8 / 8 / 20083: 16$ & 16.7 & 706 . \\
\hline 518 & & & 16.8 & 706 . \\
\hline 519 & $3: 20$ & $3: 20$ & 16.7 & 706. \\
\hline 520 & & & 16.7 & 706 . \\
\hline 521 & $3: 24$ & $3: 24$ & 16.7 & 706 . \\
\hline 522 & $33: 26$ & $8 / 8 / 20083: 26$ & 16.7 & 706 . \\
\hline 523 & & & 16.7 & \\
\hline 524 & $3: 30$ & $3: 30$ & 16.8 & 706. \\
\hline 525 & $3: 32$ & $8 / 20083: 32$ & 16.7 & 706. \\
\hline 526 & & & 16.7 & \\
\hline 527 & & & 16.7 & 706. \\
\hline 528 & & 33:38 & 16.8 & 706. \\
\hline & & & 16.7 & 706 . \\
\hline 530 & $3: 42$ & $33: 42$ & 16.7 & 7 \\
\hline 531 & & & 16.7 & 706 . \\
\hline 532 & & $3: 46$ & 16.8 & \\
\hline 533 & $3: 48$ & $8 / 8 / 20083: 48$ & 16.8 & 705. \\
\hline 534 & & & 16.7 & \\
\hline 535 & & & 16.7 & \\
\hline 536 & $3: 54$ & $8 / 8 / 20083: 54$ & 16.7 & 705 . \\
\hline 537 & $3: 56$ & $8 / 8 / 20083: 56$ & 16.8 & 705. \\
\hline 538 & & $8 / 8 / 20083: 58$ & 16.8 & \\
\hline 539 & $20084: 00$ & $8 / 8 / 20084: 00$ & 16.7 & 705 \\
\hline 540 & $20084: 02$ & $8 / 8 / 20084: 02$ & 16.8 & 705 . \\
\hline 541 & $20084: 04$ & $8 / 8 / 20084: 04$ & 16.8 & 705 . \\
\hline 542 & 2008 4:06 & $8 / 8 / 20084: 06$ & 16.7 & 10 \\
\hline 543 & & $8 / 8 / 20084: 08$ & 16.8 & 706 \\
\hline 544 & & & & \\
\hline
\end{tabular}

\begin{tabular}{|c|c|c|c|c|}
\hline \\
\hline $\operatorname{Rec}$ & & Adjusted & Temp & $\mathrm{SC}$ \\
\hline$\#$ & Date/Time & Date/Time & ${ }^{\circ} \mathrm{C}$ & $\mu \mathrm{S} / \mathrm{cm}$ \\
\hline 545 & $1 / 8 / 20084: 12$ & $8 / 8 / 20084: 12$ & 16.7 & 706.1 \\
\hline 546 & $3 / 20084: 14$ & $3 / 20084: 14$ & 16.7 & 706 \\
\hline 547 & $8 / 20084: 16$ & $3 / 20084: 16$ & 16.7 & 706 \\
\hline 548 & 1/8/2008 4:18 & $8 / 8 / 20084: 18$ & 16.7 & 706.5 \\
\hline 549 & $1 / 8 / 20084: 20$ & $8 / 8 / 20084: 20$ & 16.7 & 706.2 \\
\hline 550 & $1 / 8 / 20084: 22$ & $8 / 8 / 20084: 22$ & 16.8 & 705.9 \\
\hline 551 & $1 / 8 / 20084: 24$ & $8 / 20084: 24$ & 16.8 & 705.4 \\
\hline 552 & 1/8/2008 4:26 & $8 / 8 / 20084: 26$ & 16.7 & 706 \\
\hline 553 & $8 / 20084: 28$ & $8 / 8 / 20084: 28$ & 16.7 & 706.1 \\
\hline 554 & 1/8/2008 4:30 & $8 / 8 / 20084: 30$ & 16.7 & 706.2 \\
\hline 555 & 1/8/2008 4:32 & $8 / 20084: 32$ & 16.7 & 706.1 \\
\hline 556 & $8 / 20084: 34$ & $34: 34$ & 16.8 & 705.8 \\
\hline 557 & 1/8/2008 4:36 & $8 / 8 / 20084: 36$ & 16.7 & 706 \\
\hline 558 & $1 / 8 / 20084: 38$ & $34: 38$ & 16.7 & 706 \\
\hline 559 & $8 / 20084: 40$ & $34: 40$ & 16.8 & \\
\hline 560 & $1 / 8 / 20084: 42$ & $8 / 8 / 20084: 42$ & 16.7 & 706.1 \\
\hline 561 & $8 / 20084: 44$ & $4: 44$ & 16.7 & 706 \\
\hline 562 & $8 / 20084: 46$ & $4: 46$ & 16.7 & 706 \\
\hline 563 & $8 / 20084: 48$ & $8 / 8 / 20084: 48$ & 16.7 & 705.9 \\
\hline 564 & $8 / 20084: 50$ & $8 / 8 / 20$ & 16.7 & 706.1 \\
\hline 565 & $8 / 20084: 52$ & 4:52 & 16.8 & 706 \\
\hline 566 & $8 / 20084: 54$ & 4:54 & 16.7 & 706 \\
\hline 567 & $4: 56$ & $4: 56$ & 16.7 & 706.1 \\
\hline 568 & $8 / 20084: 58$ & $4: 58$ & 16.7 & 7001 \\
\hline 569 & $8 / 20085: 00$ & $8 / 200$ & 16.8 & 705.7 \\
\hline 570 & 5:02 & $3 / 20$ & 16.7 & 706.2 \\
\hline 571 & $85: 04$ & $8 / 200$ & 16.7 & 706.1 \\
\hline 572 & & $5: 06$ & $\overline{16.8}$ & 706 \\
\hline 573 & & $8 / 20$ & 16.7 & 700 \\
\hline 574 & $5: 10$ & $8 / 8 / 200$ & 16.7 & 705.8 \\
\hline 575 & & $5: 12$ & 16.8 & 705.7 \\
\hline 576 & & $5: 14$ & 16.7 & 705.9 \\
\hline 577 & $5: 16$ & $5: 16$ & 16.7 & 705.9 \\
\hline 578 & & 18 & 16.7 & 705. \\
\hline 579 & $5: 20$ & $8 / 20$ & 16.7 & 705. \\
\hline 580 & & $8 / 8 / 200$ & 16.7 & 705.9 \\
\hline 581 & $5: 24$ & $5: 24$ & 16.7 & 705.8 \\
\hline 582 & $5: 26$ & $8 / 200$ & 16.7 & 705.8 \\
\hline 583 & & $8 / 8 / 20$ & 16.7 & 706 \\
\hline 584 & & $8 / 20$ & 16.7 & 705.9 \\
\hline 585 & & $8 / 20 x$ & 16.8 & 705.8 \\
\hline 586 & & & 16.8 & \\
\hline 587 & $5: 36$ & 36 & 16.8 & 706 \\
\hline 588 & & $5: 38$ & 16.8 & 700 \\
\hline 589 & & 40 & 16.8 & \\
\hline 590 & $5: 42$ & $8 / 8 / 200$ & 16.7 & 705.9 \\
\hline 591 & & & 16.7 & 705. \\
\hline 592 & & & & \\
\hline 593 & $5: 48$ & $\overline{48}$ & 16.7 & 705. \\
\hline 594 & & & 16.7 & 700. \\
\hline 595 & & & 16.8 & 7058 \\
\hline 596 & & $3 / 20$ & 16.7 & $25 \mathrm{c}>>$ \\
\hline 597 & & & 16.7 & 100. \\
\hline 598 & & $8 / 8 / 200$ & 167 & 7050 \\
\hline 599 & & 66:00 & & 705. \\
\hline 600 & & & 16.7 & \\
\hline 601 & & & & \\
\hline 602 & $6: 06$ & $8 / 8 / 200$ & 16.7 & 706 \\
\hline 603 & & & 16.7 & 706.1 \\
\hline 604 & & $8 / 8 / 200$ & & \\
\hline 605 & $86: 12$ & $8 / 8 / 20086: 12$ & 16.8 & 706 \\
\hline 606 & & & 16.7 & 706. \\
\hline 607 & हn & $8 / 200$ & & 706 \\
\hline 608 & $3 / 20086: 18$ & $8 / 8 / 20086: 18$ & 16.8 & 70 \\
\hline 609 & & & 16.7 & 70 \\
\hline 610 & & $8 / 20086.22$ & & \\
\hline 611 & 1/8/2008 6:24 & $8 / 8 / 20086: 24$ & 16.8 & \\
\hline & & $8 / 8 / 20086: 26$ & & 706. \\
\hline
\end{tabular}


DOE/RL-2009-35, REV. 0

\begin{tabular}{|c|c|c|c|c|}
\hline \multicolumn{5}{|c|}{$D 4-92 c$} \\
\hline $\operatorname{Rec}$ & & Adjusted & Temp & $\mathrm{SC}$ \\
\hline \# & Date/Time & DaterTime & ${ }^{\circ} \mathrm{C}$ & $\mu \mathrm{S} / \mathrm{cm}$ \\
\hline 613 & $1 / 8 / 20086: 28$ & $8 / 8 / 20086: 28$ & 16.7 & 706.2 \\
\hline 614 & 1/8/2008 6:30 & $8 / 8 / 20086: 30$ & 16.7 & 706.2 \\
\hline 615 & $3 / 20086: 32$ & $8 / 8 / 20086: 32$ & 16.7 & 706.1 \\
\hline 616 & 1/8/2008 6:34 & $8 / 8 / 20086: 34$ & 16.8 & 705.9 \\
\hline 617. & 1/8/2008 6:36 & $8 / 8 / 20086: 36$ & 16.8 & 706.1 \\
\hline 618 & $1 / 8 / 20086: 38$ & $8 / 8 / 20086: 38$ & 16.8 & 706 \\
\hline 619 & $1 / 8 / 20086: 40$ & $8 / 8 / 20086: 40$ & 16.7 & 706 \\
\hline 620 & $8 / 20086: 42$ & $8 / 8 / 20086: 42$ & 16.7 & 705.9 \\
\hline 621 & $1 / 8 / 20086: 44$ & $8 / 8 / 20086: 44$ & 16.7 & 706 \\
\hline 622 & 1/8/2008 6:46 & $8 / 8 / 20086: 46$ & 16.7 & 706.1 \\
\hline 623 & $1 / 8 / 20086: 48$ & $8 / 8 / 20086: 48$ & 16.7 & 706 \\
\hline 624 & 1/8/20086:50 & $8 / 8 / 20086: 50$ & 16.7 & 706.4 \\
\hline 625 & $1 / 8 / 20086: 52$ & $8 / 8 / 20086: 52$ & 16.7 & 706.6 \\
\hline 626 & $1 / 8 / 20086: 54$ & $8 / 8 / 20086: 54$ & 16.8 & 706.2 \\
\hline 627 & 1/8/2008 6:56 & $8 / 8 / 20086: 56$ & 16.7 & 706.5 \\
\hline 628 & $1 / 8 / 20086: 58$ & $8 / 8 / 20086: 58$ & 16.7 & 706.2 \\
\hline 629 & 1/8/2008 7:00 & $8 / 8 / 20087: 00$ & 16.7 & 706.2 \\
\hline 630 & 1/8/2008 7:02 & $8 / 8 / 20087: 02$ & 16.8 & 706 \\
\hline 631 & $8 / 20087: 04$ & $8 / 8 / 20087: 04$ & 16.8 & 706 \\
\hline 632 & $1 / 8 / 20087: 06$ & $8 / 8 / 20087: 06$ & 16.8 & 705.8 \\
\hline 633 & $887: 08$ & $8 / 8 / 20$ & 16.8 & 706.1 \\
\hline 634 & $287: 10$ & $8 / 8 / 20$ & 16.8 & 706 \\
\hline 635 & $887: 12$ & $8 / 8 / 20087: 12$ & 16.7 & 706.1 \\
\hline 636 & $887: 14$ & $8 / 8 / 2008.7: 14$ & 16.8 & 706.4 \\
\hline 637 & $087: 16$ & $8 / 8 / 20087: 16$ & 16.7 & 706.7 \\
\hline 638 & $7: 18$ & $8 / 8 / 20$ & 16.7 & 706.6 \\
\hline 639 & $7: 20$ & $8 / 8 / 20$ & 16.7 & 706.6 \\
\hline 640 & $7: 22$ & $8 / 8 / 20$ & 16.7 & 706.8 \\
\hline 641 & $7: 24$ & $8 / 8 / 20$ & 16.7 & 706.7 \\
\hline 642 & $087: 26$ & $8 / 8 / 20087: 26$ & 16.8 & 706.7 \\
\hline 643 & $7: 28$ & $8 / 8 / 20$ & 16.7 & 706.6 \\
\hline 644 & $7: 30$ & $8 / 8 / 20$ & 16.7 & 706.8 \\
\hline 645 & $7: 32$ & $8 / 8 / 20$ & 16.7 & 706.6 \\
\hline 646 & $7: 34$ & $8 / 8 / 20$ & 16.8 & 706.5 \\
\hline 647 & $7: 36$ & $8 / 8 / 20$ & 16.7 & 706.5 \\
\hline 648 & & $8 / 8 / 20$ & 16.7 & 706.5 \\
\hline 649 & 7:40 & $8 / 8 / 20$ & 16.7 & 706.5 \\
\hline 650 & $7: 42$ & $8 / 8 / 20$ & 16.7 & 706.3 \\
\hline 651 & & $8 / 8 / 20$ & 16.7 & 706.3 \\
\hline 652 & $7: 46$ & $8 / 8 / 200$ & 16.7 & 706.2 \\
\hline 653 & & & 16.7 & 706.4 \\
\hline 654 & $7: 50$ & $8 / 8 / 20$ & 16.8 & 706.3 \\
\hline 655 & $7: 52$ & $8 / 8 / 20$ & 16.7 & 706.4 \\
\hline 656 & & $8 / 8 / 20$ & 16.7 & 706.3 \\
\hline 657 & 7:56 & $88 / 20$ & 16.8 & 706.3 \\
\hline 658 & & & 16.7 & 706.8 \\
\hline 659 & & $8 / 8 / 20$ & 16.9 & 8.1 \\
\hline 660 & & $8 / 8 / 20$ & 17.5 & \\
\hline 661 & & $8 / 8 / 20$ & 18 & \\
\hline 662 & $8: 06$ & $8 / 8 / 20$ & 18.5 & \\
\hline 663 & & & 19 & \\
\hline 664 & & & 19.5 & 19 \\
\hline 665 & & & 20.1 & 2 \\
\hline 666 & & & 20.6 & 23 \\
\hline 667 & $8: 16$ & $8 / 8 / 2$ & 212 & 23 \\
\hline 668 & & & 21.8 & 24 \\
\hline 669 & & & 22.5 & 10 \\
\hline 670 & & & 23.8 & 11.8 \\
\hline 671 & & & 25.1 & 17 \\
\hline 672 & $38: 26$ & $8 / 8 / 200$ & 26.1 & 17 \\
\hline 673 & & $8 / 8 / 200$ & 27 & \\
\hline 674 & $38: 30$ & $8 / 8 / 20088: 30$ & 27.1 & 1.7 \\
\hline 675 & $8: 32$ & $8 / 8 / 200$ & 27.1 & 17 \\
\hline 676 & & & 271 & \\
\hline 677 & 1/8/2008 8:36 & $8 / 8 / 20$ & 27.3 & 17 \\
\hline 678 & & & 27.6 & 17 \\
\hline 679 & $1 / 8 / 20088: 40$ & $8 / 8 / 200$ & 27.9 & \\
\hline 680 & $1 / 8 / 20088: 42$ & $8 / 8 / 20088: 42$ & $<0$ & 8 \\
\hline
\end{tabular}

\begin{tabular}{|c|c|c|c|c|}
\hline \multicolumn{5}{|c|}{ D4-92c } \\
\hline $\operatorname{Rec}$ & & Adjusted & Temp & $\overline{S C}$ \\
\hline$\#$ & Date/Time & Date/Time & ${ }^{\circ} \mathrm{C}$ & $\mu \mathrm{S} / \mathrm{cm}$ \\
\hline 681 & $1 / 8 / 20088: 44$ & $8 / 8 / 20088: 44$ & 28.3 & 16 \\
\hline 682 & $1 / 8 / 20088: 46$ & $8 / 8 / 20088: 46$ & 28.5 & \\
\hline 683 & $1 / 8 / 20088: 48$ & $8 / 8 / 20088: 48$ & 28.6 & 1.6 \\
\hline 684 & $1 / 8 / 20088: 50$ & $8 / 8 / 20088: 50$ & 28.9 & 1.6 \\
\hline 685 & $1 / 8 / 20088: 52$ & $8 / 8 / 20088: 52$ & 29 & 1.6 \\
\hline 686 & $1 / 8 / 20088: 54$ & $8 / 8 / 20088: 54$ & 28.9 & 1.6 \\
\hline 687 & $1 / 8 / 20088: 56$ & $8 / 8 / 20088: 56$ & 27.6 & \\
\hline 688 & $1 / 8 / 20088: 58$ & $8 / 8 / 20088: 58$ & 18.4 & 516.3 \\
\hline 689 & $1 / 8 / 20089: 00$ & $8 / 8 / 20089: 00$ & 17.1 & 486.6 \\
\hline 690 & $1 / 8 / 20089: 02$ & 8/8/20089:02 & 16.9 & 441.1 \\
\hline 691 & $1 / 8 / 20089: 04$ & $8 / 8 / 20089: 04$ & 16.9 & 687 \\
\hline 692 & 1/8/2008 9:06 & $8 / 8 / 20089: 06$ & 16.9 & 687.6 \\
\hline 693 & $1 / 8 / 20089: 08$ & $8 / 8 / 20089: 08$ & 16.8 & 688.2 \\
\hline 694 & $1 / 8 / 20089: 10$ & $8 / 8 / 20089: 10$ & 16.8 & 688.7 \\
\hline 695 & $1 / 8 / 20089: 12$ & $8 / 8 / 20089: 12$ & 16.8 & 688.9 \\
\hline 696 & 1/8/20089:14 & $8 / 8 / 20089: 14$ & 16.8 & 689 \\
\hline 697 & 1/8/2008 9:16 & $8 / 8 / 20089: 16$ & 16.8 & 689.2 \\
\hline 698 & 1/8/20089:18 & $8 / 8 / 20089: 18$ & 16.8 & 689.3 \\
\hline 699 & 1/8/20089:20 & $8 / 8 / 20089: 20$ & 16.8 & 689.5 \\
\hline 700 & $1 / 8 / 20089: 22$ & $8 / 8 / 20089: 22$ & 16.8 & 689.8 \\
\hline 701 & $1 / 8 / 20089: 24$ & $8 / 8 / 20089: 24$ & 16.8 & 689.9 \\
\hline 702 & $1 / 8 / 20089: 26$ & $8 / 8 / 20089: 26$ & 16.8 & 689.9 \\
\hline 703 & $1 / 8 / 20089: 28$ & $8 / 8 / 20089: 28$ & 16.8 & 690.1 \\
\hline 704 & 1/8/20089:30 & $8 / 8 / 20089: 30$ & 16.8 & 690.3 \\
\hline 705 & $1 / 8 / 20089: 32$ & $8 / 8 / 20089: 32$ & 16.8 & 690.3 \\
\hline 706 & $1 / 8 / 20089: 34$ & $8 / 8 / 20089: 34$ & 16.8 & 690.3 \\
\hline 707 & 1/8/2008 9:36 & $8 / 8 / 20089: 36$ & 16.8 & 690.5 \\
\hline 708 & 1/8/20089:38 & $8 / 8 / 20089: 38$ & 16.8 & 690.6 \\
\hline 709 & 1/8/20089:40 & $8 / 8 / 20089: 40$ & 16.8 & 690.6 \\
\hline 710 & $1 / 8 / 20089: 42$ & $8 / 8 / 20089: 42$ & 16.8 & 690.6 \\
\hline 711 & $1 / 8 / 20089: 44$ & $8 / 8 / 20089: 44$ & 16.8 & 690.9 \\
\hline 712 & 1/8/20089:46 & $8 / 8 / 20089: 46$ & 16.8 & 691 \\
\hline 713 & $1 / 8 / 20089: 48$ & $8 / 8 / 20089: 48$ & 16.8 & 690.9 \\
\hline 714 & 1/8/20089:50 & $8 / 8 / 20089: 50$ & 16.8 & 690.9 \\
\hline 715 & 1/8/20089:52 & $8 / 8 / 20089: 52$ & 16.8 & 691 \\
\hline 716 & $1 / 8 / 20089: 54$ & $8 / 8 / 20089: 54$ & 16.8 & 691.1 \\
\hline 717 & $1 / 8 / 20089: 56$ & $8 / 8 / 20089: 56$ & 16.8 & 691.1 \\
\hline 718 & 1/8/20089:58 & $8 / 8 / 20089: 58$ & 16.8 & 691 \\
\hline 719 & 1/8/2008 10:00 & $8 / 8 / 200810: 00$ & 16.8 & 690.9 \\
\hline 720 & 1/8/2008 10:02 & $8 / 8 / 200810: 02$ & 16.8 & 691.1 \\
\hline 721 & 1/8/2008 10:04 & $8 / 8 / 200810: 04$ & 16.8 & 691.1 \\
\hline 722 & $1 / 8 / 2008$ 10:06 & $8 / 8 / 2008$ 10:06 & 16.8 & 691.4 \\
\hline 723 & $1 / 8 / 2008 \quad 10: 08$ & $8 / 8 / 200810: 08$ & 16.8 & 691.2 \\
\hline 724 & $1 / 8 / 2008$ 10:10 & $8 / 8 / 2008$ 10:10 & 16.8 & 691.4 \\
\hline 725 & 1/8/2008 10:12 & $8 / 8 / 200810: 12$ & 16.8 & 691.5 \\
\hline 726 & 1/8/2008 10:14 & $8 / 8 / 200810: 14$ & 16.8 & 690.9 \\
\hline 727 & 1/8/2008 10:16 & $8 / 8 / 2008$ 10:16 & 16.8 & 690.7 \\
\hline 728 & 1/8/2008 10:18 & $8 / 8 / 200810: 18$ & 16.8 & 690.5 \\
\hline 729 & 1/8/2008 10:20 & $8 / 8 / 2008$ 10:20 & 16.8 & 691 \\
\hline 730 & 1/8/2008 10:22 & $8 / 8 / 2008$ 10:22 & 16.8 & 691.2 \\
\hline 731 & 1/8/2008 10:24 & $8 / 8 / 200810: 24$ & 16.8 & 691.4 \\
\hline 732 & 1/8/2008 10:26 & $8 / 8 / 200810: 26$ & 16.8 & 691.6 \\
\hline 733 & $1 / 8 / 200810: 28$ & $8 / 8 / 200810: 28$ & 16.8 & 691.5 \\
\hline 734 & 1/8/2008 10:30 & $8 / 8 / 200810: 30$ & 16.8 & 691.7 \\
\hline 735 & 1/8/2008 10:32 & $8 / 8 / 200810: 32$ & 16.8 & 692 \\
\hline 736 & $1 / 8 / 200810: 34$ & $8 / 8 / 200810: 34$ & 16.8 & 692.2 \\
\hline 737 & 1/8/2008 10:36 & $8 / 8 / 2008$ 10:36 & 16.8 & 692.2 \\
\hline 738 & 1/8/2008 10:38 & $8 / 8 / 2008$ 10:38 & 16.8 & 692.2 \\
\hline 739 & $1 / 8 / 2008 \quad 10: 40$ & $8 / 8 / 2008$ 10:40 & 16.8 & 692.2 \\
\hline 740 & $1 / 8 / 200810: 42$ & $8 / 8 / 200810: 42$ & 16.8 & 692.5 \\
\hline 741 & 1/8/2008 10:44 & $8 / 8 / 2008$ 10:44 & 16.8 & 692.2 \\
\hline 742 & $1 / 8 / 2008$ 10:46 & $8 / 8 / 200810: 46$ & 16.8 & 692.6 \\
\hline 743 & $1 / 8 / 2008$ 10:48 & $8 / 8 / 200810: 48$ & 16.8 & 692.7 \\
\hline 744 & 1/8/2008 10:50 & $8 / 8 / 2008$ 10:50 & 16.8 & 692.6 \\
\hline 745 & $1 / 8 / 2008 \quad 10: 52$ & $8 / 8 / 200810: 52$ & 16.8 & 693.1 \\
\hline 746 & $1 / 8 / 2008 \quad 10: 54$ & $8 / 8 / 2008$ 10:54 & 16.8 & 693.1 \\
\hline 747 & $1 / 8 / 2008 \quad 10: 56$ & $8 / 8 / 200810: 56$ & 16.8 & 693.4 \\
\hline 748 & $1 / 8 / 200810: 58$ & $8 / 8 / 200810: 58$ & 16.8 & 693.7 \\
\hline
\end{tabular}

\begin{tabular}{|c|c|c|c|c|}
\hline \multicolumn{5}{|c|}{ D4-92c } \\
\hline $\operatorname{Rec}$ & & Adjusted & Temp & \\
\hline$\#$ & DateTime & Date-Time & ${ }^{\circ} \mathrm{C}$ & $\mu \mathrm{S} / \mathrm{cm}$ \\
\hline 749 & $1 / 8 / 200811: 00$ & $8 / 8 / 200811: 00$ & 16.8 & 693.6 \\
\hline 750 & $\sqrt{200811: 02}$ & $8 / 8 / 200811: 02$ & 16.8 & \\
\hline 751 & $\sqrt{200811: 04}$ & $8 / 8 / 2008$ 11:04 & 16.8 & 693.9 \\
\hline 752 & $\sqrt{200811: 06}$ & $8 / 8 / 2008$ 11:06 & 16.8 & \\
\hline 753 & $8 / 200811: 08$ & $8 / 8 / 200811: 08$ & 16.8 & 694.4 \\
\hline 754 & $3 / 200811: 10$ & $8 / 8 / 2008$ 11:10 & 16.8 & 694.4 \\
\hline 755 & $3 / 200811: 12$ & $8 / 8 / 200811: 12$ & 16.8 & \\
\hline 756 & $3 / 200811: 14$ & $8 / 8 / 2008$ 11:14 & 16.8 & 694.8 \\
\hline 757 & $8 / 200811: 16$ & $8 / 8 / 200811: 16$ & 16.8 & 694.7 \\
\hline 758 & $8 / 2008$ 11:18 & $8 / 8 / 2008$ 11:18 & 16.8 & 6948 \\
\hline 759 & $3 / 200811: 20$ & $8 / 8 / 2008$ 11:20 & 16.8 & 694.8 \\
\hline 760 & $3 / 2008$ 11:22 & $8 / 8 / 2008$ 11:22 & 16.8 & \\
\hline 761 & $3 / 2008$ 11:24 & $8 / 8 / 2008$ 11:24 & 16.8 & 69. \\
\hline 762 & $3 / 200811: 26$ & $8 / 8 / 200811: 26$ & 16.8 & 695.4 \\
\hline 763 & $11: 28$ & $8 / 8 / 200$ & 16.8 & \\
\hline 764 & $3 / 200811: 30$ & $8 / 8 / 2008$ 11:30 & 16.8 & 69 \\
\hline 765 & $11: 32$ & 11:32 & 16.8 & 695.7 \\
\hline 766 & $11: 34$ & 11:34 & 16.8 & 696.2 \\
\hline 767 & 1:36 & $11: 36$ & 16.8 & 696.1 \\
\hline 768 & $1: 38$ & $11: 38$ & 16.8 & \\
\hline 769 & $3 / 2008$ & $11: 40$ & 16.8 & 696.4 \\
\hline 770 & $1: 42$ & $11: 42$ & 16.8 & 696. \\
\hline 771 & & $11: 44$ & 16.8 & \\
\hline 772 & $1: 46$ & $11: 46$ & 16.8 & 696. \\
\hline 773 & $1: 48$ & 11:48 & 16.8 & 96. \\
\hline 774 & $3 / 200$ & $8 / 8 / 200$ & 16.8 & 696. \\
\hline 775 & & 1:52 & 16.8 & 696. \\
\hline 776 & 54 & $1: 54$ & 16.8 & \\
\hline 777 & & & 16.8 & 696. \\
\hline 778 & 58 & $1: 58$ & 16.8 & 696. \\
\hline 779 & 00 & $12: 00$ & 16.8 & 696. \\
\hline 780 & & 2:02 & 16.8 & 696. \\
\hline 781 & & $2: 04$ & 16.8 & 96 \\
\hline 782 & & $2: 06$ & 16.8 & 696. \\
\hline 783 & & & 16.8 & 696. \\
\hline 784 & 10 & $12: 10$ & 16.8 & 69 \\
\hline 785 & & & 16.8 & 696. \\
\hline 786 & & $12: 14$ & 16.8 & 696. \\
\hline 787 & & & 16.8 & \\
\hline 788 & & & 16.8 & 96 \\
\hline 789 & & $2: 20$ & 16.8 & 695 \\
\hline 790 & & & 16.8 & 695. \\
\hline 791 & & $2: 24$ & 16.8 & 695 \\
\hline 792 & & & 16.8 & 695. \\
\hline 793 & & & $\overline{16.8}$ & 695. \\
\hline 794 & & 12:30 & 16.8 & 69 \\
\hline 795 & & & 16.8 & 695. \\
\hline 796 & & & 16.8 & 695 \\
\hline 797 & & & 16.8 & 695 \\
\hline 798 & & 10 & 16.8 & \\
\hline 799 & & & 16.8 & 696 \\
\hline 800 & & & 16.8 & \\
\hline 801 & & & 16.8 & 696 \\
\hline 802 & & & 16.8 & 96. \\
\hline 803 & & & 168 & \\
\hline 804 & $2: 50$ & 12:50 & 16.8 & 696. \\
\hline 805 & & & 16.8 & \\
\hline 806 & & $12: 54$ & 16.8 & \\
\hline 807 & & & 16.8 & 050. \\
\hline 808 & & & 16.8 & \\
\hline 809 & $3: 00$ & $8 / 8 / 200$ & 16.8 & 097. \\
\hline 810 & & & 16.8 & \\
\hline 811 & & & 16.8 & \\
\hline 812 & & & 16.8 & \\
\hline 813 & & & & \\
\hline 814 & & $13: 10$ & 16.8 & 0 \\
\hline 815 & & $8 / 8 / 2008$ 13:12 & 16.8 & 698 \\
\hline & & & & \\
\hline
\end{tabular}


DOE/RL-2009-35, REV. 0

\begin{tabular}{|c|c|c|c|c|}
\hline \multicolumn{5}{|c|}{ D4-92c } \\
\hline $\operatorname{Rec}$ & & Adjusted & Temp & $\mathrm{SC}$ \\
\hline$\#$ & Date/Time & Date/Time & ${ }^{\circ} \mathrm{C}$ & $\mathrm{\mu S} / \mathrm{cm}$ \\
\hline 817 & 1/8/2008 13:16 & $8 / 8 / 200813: 16$ & 16.8 & 697.9 \\
\hline 818 & 1/8/2008 13:18 & $8 / 8 / 200813: 18$ & 16.8 & 698.2 \\
\hline 819 & 1/8/2008 13:20 & $8 / 8 / 200813: 20$ & 16.8 & 697.8 \\
\hline 820 & 1/8/2008 13:22 & $8 / 8 / 200813: 22$ & 16.8 & 697.9 \\
\hline 821 & $1 / 8 / 200813: 24$ & $8 / 8 / 200813: 24$ & 16.8 & 698 \\
\hline 822 & 1/8/2008 13:26 & $8 / 8 / 200813: 26$ & 16.8 & 697.9 \\
\hline 823 & 1/8/2008 13:28 & $8 / 8 / 200813: 28$ & 16.8 & 698 \\
\hline 824 & 1/8/2008 13:30 & $8 / 8 / 200813: 30$ & 16.8 & 697.9 \\
\hline 825 & $1 / 8 / 200813: 32$ & $8 / 8 / 200813: 32$ & 16.8 & 698.1 \\
\hline 826 & $1 / 8 / 200813: 34$ & $8 / 8 / 200813: 34$ & 16.8 & 698 \\
\hline 827 & $1 / 8 / 200813: 36$ & $8 / 8 / 200813: 36$ & 16.8 & 698 \\
\hline 828 & 1/8/2008 13:38 & $8 / 8 / 200813: 38$ & 16.8 & 698.1 \\
\hline 829 & $1 / 8 / 2008$ 13:40 & $8 / 8 / 200813: 40$ & 16.8 & 698.4 \\
\hline 830 & $1 / 8 / 200813: 42$ & $8 / 8 / 200813: 42$ & 16.8 & 698.4 \\
\hline 831 & $1 / 8 / 2008$ 13:44 & $8 / 8 / 200813: 44$ & 16.8 & 698.3 \\
\hline 832 & $1 / 8 / 200813: 46$ & $8 / 8 / 200813: 46$ & 16.8 & 698.3 \\
\hline 833 & $1 / 8 / 2008$ 13:48 & $8 / 8 / 200813: 48$ & 16.8 & 698.3 \\
\hline 834 & $1 / 8 / 200813: 50$ & $8 / 8 / 200813: 50$ & 16.8 & 698.2 \\
\hline 835 & $1 / 8 / 200813: 52$ & $8 / 8 / 2008+3: 52$ & 16.8 & 697.9 \\
\hline 836 & $1 / 8 / 2008$ 13:54 & $8 / 8 / 200813: 54$ & 16.8 & 698.3 \\
\hline 837 & $1 / 8 / 200813: 56$ & $8 / 8 / 2008+3: 56$ & 16.8 & 698.2 \\
\hline 838 & 1/8/2008 13:58 & $8 / 8 / 200813: 58$ & 16.8 & 698.1 \\
\hline 839 & 1/8/2008 14:00 & $8 / 8 / 200814: 00$ & 16.8 & 698 \\
\hline 840 & $1 / 8 / 200814: 02$ & $8 / 8 / 200814: 02$ & 16.8 & 698.1 \\
\hline 841 & $1 / 8 / 2008$ 14:04 & $8 / 8 / 2008$ 14:04 & 16.8 & 698.1 \\
\hline 842 & 1/8/2008 14:06 & $8 / 8 / 200814: 06$ & 16.8 & 698.1 \\
\hline 843 & 1/8/2008 14:08 & $8 / 8 / 200814: 08$ & 16.8 & 698.2 \\
\hline 844 & 1/8/2008 14:10 & $8 / 8 / 200814: 10$ & 16.8 & 698.1 \\
\hline 845 & 1/8/2008 14:12 & $8 / 8 / 200814: 12$ & 16.8 & 698.1 \\
\hline 846 & $1 / 8 / 2008$ 14:14 & $8 / 8 / 200814: 14$ & 16.8 & 698.2 \\
\hline 847 & 1/8/2008 14:16 & $8 / 8 / 200814: 16$ & 16.8 & 698.1 \\
\hline 848 & 1/8/2008 14:18 & $8 / 8 / 200814: 18$ & 16.8 & 698.3 \\
\hline 849 & $1 / 8 / 200814: 20$ & $8 / 8 / 200814: 20$ & 16.8 & 698.4 \\
\hline 850 & $1 / 8 / 2008$ 14:22 & $8 / 8 / 200814: 22$ & 16.8 & 698.6 \\
\hline 851 & 1/8/2008 14:24 & $8 / 8 / 200814: 24$ & 16.8 & 698.6 \\
\hline 852 & $1 / 8 / 200814: 26$ & $8 / 8 / 200814: 26$ & 16.8 & 698.4 \\
\hline 853 & 1/8/2008 14:28 & $8 / 8 / 200814: 28$ & 16.8 & 698.6 \\
\hline 854 & $1 / 8 / 200814: 30$ & $8 / 8 / 2008$ 14:30 & 16.8 & 698.6 \\
\hline 855 & $1 / 8 / 200814: 32$ & $8 / 8 / 200814: 32$ & 16.8 & 698.9 \\
\hline 856 & $1 / 8 / 200814: 34$ & $8 / 8 / 200814: 34$ & 16.8 & 698.7 \\
\hline 857 & 1/8/2008 14:36 & $8 / 8 / 200814: 36$ & 16.8 & 698.6 \\
\hline 858 & $1 / 8 / 200814: 38$ & $8 / 8 / 200814: 38$ & 16.8 & 698.4 \\
\hline 859 & $1 / 8 / 200814: 40$ & $8 / 8 / 200814: 40$ & 16.8 & 698.3 \\
\hline 860 & $1 / 8 / 2008$ 14:42 & $8 / 8 / 200814: 42$ & 16.8 & 698.3 \\
\hline 861 & 1/8/2008 14:44 & $8 / 8 / 200814: 44$ & 16.8 & 698.4 \\
\hline 862 & $1 / 8 / 2008$ 14:46 & $8 / 8 / 2008$ 14:46 & 16.8 & 698.2 \\
\hline 863 & $1 / 8 / 200814: 48$ & $8 / 8 / 200814: 48$ & 16.8 & 698.1 \\
\hline 864 & $1 / 8 / 2008$ 14:50 & $8 / 8 / 2008$ 14:50 & 16.8 & 698.2 \\
\hline 865 & $1 / 8 / 200814: 52$ & $8 / 8 / 200814: 52$ & 16.8 & 698.2 \\
\hline 866 & $1 / 8 / 200814: 54$ & $8 / 8 / 200814: 54$ & 16.8 & 698.4 \\
\hline 867 & $1 / 8 / 200814: 56$ & $8 / 8 / 200814: 56$ & 16.8 & 698.4 \\
\hline 868 & $1 / 8 / 200814: 58$ & $8 / 8 / 200814: 58$ & 16.8 & 698.5 \\
\hline 869 & $1 / 8 / 200815: 00$ & $8 / 8 / 200815: 00$ & 16.8 & 698.4 \\
\hline 870 & $1 / 8 / 2008$ 15:02 & $8 / 8 / 200815: 02$ & 16.8 & 698.2 \\
\hline 871 & $1 / 8 / 2008$ 15:04 & $8 / 8 / 200815: 04$ & 16.7 & 698.6 \\
\hline 872 & $1 / 8 / 200815: 06$ & $8 / 8 / 200815: 06$ & 16.8 & 698.6 \\
\hline 873 & $1 / 8 / 2008$ 15:08 & 8/8/2008 15:08 & 16.8 & 698.6 \\
\hline 874 & $1 / 8 / 2008$ 15:10 & $8 / 8 / 200815: 10$ & 16.8 & 698.6 \\
\hline 875 & 1/8/2008 15:12 & $8 / 8 / 200815: 12$ & 16.8 & 698.4 \\
\hline 876 & $1 / 8 / 2008$ 15:14 & $8 / 8 / 200815: 14$ & 16.8 & 698.5 \\
\hline 877 & $1 / 8 / 2008$ 15:16 & $8 / 8 / 200815: 16$ & 16.8 & 698.6 \\
\hline 878 & 1/8/2008 15:18 & $8 / 8 / 2008$ 15:18 & 16.7 & 698.6 \\
\hline 879 & 1/8/2008 15:20 & $8 / 8 / 2008$ 15:20 & 16.8 & 704.4 \\
\hline 880 & $1 / 8 / 2008$ 15:22 & $8 / 8 / 200815: 22$ & 16.8 & 704.6 \\
\hline 881 & 1/8/2008 15:24 & $8 / 8 / 200815: 24$ & 16.8 & 704.1 \\
\hline 882 & 1/8/2008 15:26 & $8 / 8 / 200815: 26$ & 16.8 & 703.3 \\
\hline 883 & $1 / 8 / 200815: 28$ & $8 / 8 / 200815: 28$ & 16.8 & 702.8 \\
\hline 884 & $1 / 8 / 200815: 30$ & $8 / 8 / 200815: 30$ & 16.8 & 702 \\
\hline
\end{tabular}

\begin{tabular}{|c|c|c|c|c|}
\hline \multicolumn{5}{|c|}{ D4-92C } \\
\hline $\operatorname{Rec}$ & & Adjusted & Temp & $\mathrm{SC}$ \\
\hline$\#$ & Date/Time & DaterTime & ${ }^{\circ} \mathrm{C}$ & $\mu \mathrm{S} / \mathrm{cm}$ \\
\hline 885 & $1 / 8 / 200815: 32$ & $8 / 8 / 200815: 32$ & 16.8 & 701.4 \\
\hline 886 & $1 / 8 / 200815: 34$ & $8 / 8 / 2008$ 15:34 & 16.8 & 701 \\
\hline 887 & 1/8/2008 15:36 & $8 / 8 / 200815: 36$ & 16.8 & 700.5 \\
\hline 888 & $1 / 8 / 200815: 38$ & $8 / 8 / 200815: 38$ & 16.8 & 700.2 \\
\hline 889 & $1 / 8 / 200815: 40$ & $8 / 8 / 200815: 40$ & 16.8 & 700.1 \\
\hline 890 & $1 / 8 / 200815: 42$ & $8 / 8 / 200815: 42$ & 16.8 & 699.6 \\
\hline 891 & $1 / 8 / 200815: 44$ & $8 / 8 / 200815: 44$ & 16.7 & 699.8 \\
\hline 892 & $1 / 8 / 200815: 46$ & $8 / 8 / 200815: 46$ & 16.8 & 699.4 \\
\hline 893 & $1 / 8 / 200815: 48$ & $8 / 8 / 200815: 48$ & 16.8 & 699.3 \\
\hline 894 & $1 / 8 / 200815: 50$ & $8 / 8 / 200815: 50$ & 16.8 & 699.2 \\
\hline 895 & $1 / 8 / 200815: 52$ & $8 / 8 / 200815: 52$ & 16.8 & 699 \\
\hline 896 & $1 / 8 / 200815: 54$ & $8 / 8 / 200815: 54$ & 16.8 & 698.9 \\
\hline 897 & $1 / 8 / 200815: 56$ & $8 / 8 / 200815: 56$ & 16.8 & 698.7 \\
\hline 898 & $1 / 8 / 200815: 58$ & $8 / 8 / 200815: 58$ & 16.7 & 698.9 \\
\hline 899 & 1/8/2008 16:00 & $8 / 8 / 200816: 00$ & 16.8 & 698.7 \\
\hline 900 & $1 / 8 / 200816: 02$ & $8 / 8 / 200816: 02$ & 16.8 & 698.7 \\
\hline 901 & $1 / 8 / 200816: 04$ & $8 / 8 / 200816: 04$ & 16.8 & 698.6 \\
\hline 902 & $1 / 8 / 200816: 06$ & $8 / 8 / 200816: 06$ & 16.8 & 698.7 \\
\hline 903 & $1 / 8 / 200816: 08$ & $8 / 8 / 200816: 08$ & 16.8 & 698.7 \\
\hline 904 & $1 / 8 / 200816: 10$ & $8 / 8 / 2008$ 16:10 & 16.8 & 698.7 \\
\hline 905 & $1 / 8 / 200816: 12$ & $8 / 8 / 200816: 12$ & 16.8 & 699 \\
\hline 906 & $1 / 8 / 200816: 14$ & $8 / 8 / 200816: 14$ & 16.8 & 699.5 \\
\hline 907 & 1/8/2008 16:16 & $8 / 8 / 200816: 16$ & 16.8 & 698.6 \\
\hline 908 & 1/8/2008 16:18 & 8/8/2008 16:18 & 16.7 & 697.5 \\
\hline 909 & 1/8/2008 16:20 & $8 / 8 / 200816: 20$ & 16.8 & 696.2 \\
\hline 910 & $1 / 8 / 200816: 22$ & $8 / 8 / 200816: 22$ & 16.7 & 695.8 \\
\hline 911 & $1 / 8 / 200816: 24$ & $8 / 8 / 200816: 24$ & 16.7 & 695.5 \\
\hline 912 & $1 / 8 / 200816: 26$ & $8 / 8 / 200816: 26$ & 16.7 & 695.7 \\
\hline 913 & $1 / 8 / 200816: 28$ & $8 / 8 / 200816: 28$ & 16.7 & 695.6 \\
\hline 914 & $1 / 8 / 200816: 30$ & $8 / 8 / 200816: 30$ & 16.7 & 695.6 \\
\hline 915 & $1 / 8 / 200816: 32$ & $8 / 8 / 200816: 32$ & 16.7 & 695.8 \\
\hline 916 & $1 / 8 / 200816: 34$ & $8 / 8 / 200816: 34$ & 16.7 & 695.9 \\
\hline 917 & $1 / 8 / 200816: 36$ & $8 / 8 / 200816: 36$ & 16.7 & 695.6 \\
\hline 918 & $1 / 8 / 200816: 38$ & $8 / 8 / 200816: 38$ & 16.8 & 695.2 \\
\hline 919 & 1/8/2008 16:40 & $8 / 8 / 200816: 40$ & 16.7 & 695.7 \\
\hline 920 & 1/8/2008 16:42 & $8 / 8 / 200816: 42$ & 16.7 & 695.5 \\
\hline 921 & $1 / 8 / 2008$ 16:44 & $8 / 8 / 200816: 44$ & $\begin{array}{ll}16.7 \\
\end{array}$ & 695.4 \\
\hline 922 & $1 / 8 / 200816: 46$ & $8 / 8 / 200816: 46$ & 16.7 & 695.4 \\
\hline 923 & $1 / 8 / 200816: 48$ & $8 / 8 / 200816: 48$ & 16.7 & 695.5 \\
\hline 924 & $1 / 8 / 200816: 50$ & $8 / 8 / 200816: 50$ & 16.7 & 695.5 \\
\hline 925 & $1 / 8 / 200816: 52$ & $8 / 8 / 200816: 52$ & 16.7 & 695.6 \\
\hline 926 & $1 / 8 / 200816: 54$ & $8 / 8 / 200816: 54$ & 16.7 & 695.8 \\
\hline 927 & $1 / 8 / 200816: 56$ & $8 / 8 / 200816: 56$ & 16.7 & 695.6 \\
\hline 928 & $1 / 8 / 200816: 58$ & $8 / 8 / 200816: 58$ & 16.7 & 695.6 \\
\hline 929 & 1/8/2008 17:00 & $8 / 8 / 200817: 00$ & 16.7 & 695.5 \\
\hline 930 & $1 / 8 / 200817: 02$ & $8 / 8 / 2008$ 17:02 & 16.7 & 695.6 \\
\hline 931 & $1 / 8 / 200817: 04$ & $8 / 8 / 200817: 04$ & 16.7 & 695.1 \\
\hline 932 & $1 / 8 / 200817: 06$ & $8 / 8 / 200817: 06$ & 16.7 & 694.8 \\
\hline 933 & $1 / 8 / 200817: 08$ & $8 / 8 / 200817: 08$ & 16.7 & 695.1 \\
\hline 934 & $1 / 8 / 200817: 10$ & $8 / 8 / 2008$ 17:10 & 16.7 & 695.4 \\
\hline 935 & $1 / 8 / 200817: 12$ & $8 / 8 / 200817: 12$ & 16.7 & 695.1 \\
\hline 936 & $1 / 8 / 200817: 14$ & $8 / 8 / 200817: 14$ & 16.7 & 695.3 \\
\hline 937 & $1 / 8 / 200817: 16$ & $8 / 8 / 200817: 16$ & 16.7 & 695.2 \\
\hline 938 & 1/8/2008 17:18 & $8 / 8 / 200817: 18$ & 16.7 & 695.2 \\
\hline 939 & $1 / 8 / 200817: 20$ & $8 / 8 / 200817: 20$ & 16.7 & 695.3 \\
\hline 940 & $1 / 8 / 200817: 22$ & $8 / 8 / 200817: 22$ & 16.7 & 694.1 \\
\hline 941 & $1 / 8 / 200817: 24$ & $8 / 8 / 200817: 24$ & 16.7 & 695 \\
\hline 942 & $1 / 8 / 200817: 26$ & $8 / 8 / 200817: 26$ & 16.7 & 695 \\
\hline 943 & $1 / 8 / 200817: 28$ & $8 / 8 / 200817: 28$ & 16.7 & 695.2 \\
\hline 944 & $1 / 8 / 200817: 30$ & $8 / 8 / 200817: 30$ & 16.7 & 695.2 \\
\hline 945 & $1 / 8 / 2008$ 17:32 & $8 / 8 / 200817: 32$ & 16.7 & 695.1 \\
\hline 946 & $1 / 8 / 2008$ 17:34 & $8 / 8 / 200817: 34$ & 16.7 & 695 \\
\hline 947 & $1 / 8 / 200817: 36$ & $8 / 8 / 200817: 36$ & 16.7 & 695.1 \\
\hline 948 & $1 / 8 / 200817: 38$ & $8 / 8 / 200817: 38$ & 16.7 & 695.1 \\
\hline 949 & 1/8/2008 17:40 & $8 / 8 / 200817: 40$ & 16.7 & 695.1 \\
\hline 950 & $1 / 8 / 200817: 42$ & $8 / 8 / 200817: 42$ & 16.7 & 695.1 \\
\hline 951 & $1 / 8 / 200817: 44$ & $8 / 8 / 200817: 44$ & 16.7 & 695.1 \\
\hline 952 & $1 / 8 / 200817: 46$ & $8 / 8 / 2008$ 17:46 & 16.7 & 694.6 \\
\hline
\end{tabular}

\begin{tabular}{|c|c|c|c|c|}
\hline \multicolumn{5}{|c|}{$D 4-92 c$} \\
\hline$R \in c$ & & Adjusted & Temp & $\mathrm{SC}$ \\
\hline$\#$ & Date/Time & Date/Time & ${ }^{\circ} \mathrm{C}$ & $\mu \mathrm{S} / \mathrm{cm}$ \\
\hline 953 & $1 / 8 / 200817: 48$ & $8 / 8 / 200817: 48$ & 16.7 & 694.6 \\
\hline 954 & $1 / 8 / 200817: 50$ & $8 / 8 / 200817: 50$ & 16.7 & 694.6 \\
\hline 955 & $1 / 8 / 200817: 52$ & $8 / 8 / 200817: 52$ & 16.7 & 694.6 \\
\hline 956 & 1/8/2008 17:54 & $8 / 8 / 2008$ 17:54 & 16.7 & 694.3 \\
\hline 957 & $1 / 8 / 200817: 56$ & $8 / 8 / 200817: 56$ & 16.7 & 694.8 \\
\hline 958 & $1 / 8 / 2008$ 17:58 & $8 / 8 / 200817: 58$ & 16.7 & 694.7 \\
\hline 959 & $1 / 8 / 2008$ 18:00 & $8 / 8 / 200818: 00$ & 16.7 & 694.6 \\
\hline 960 & $1 / 8 / 2008$ 18:02 & $8 / 8 / 200818: 02$ & 16.7 & 694.6 \\
\hline 961 & $1 / 8 / 2008$ 18:04 & $8 / 8 / 200818: 04$ & 16.7 & 694.8 \\
\hline 962 & $1 / 8 / 2008$ 18:06 & $8 / 8 / 2008$ 18:06 & 16.7 & 694.6 \\
\hline 963 & $1 / 8 / 2008$ 18:08 & $8 / 8 / 200818: 08$ & 16.7 & 694.6 \\
\hline 964 & 1/8/2008 18:10 & $8 / 8 / 200818: 10$ & 16.7 & 694.7 \\
\hline 965 & 1/8/2008 18:12 & $8 / 8 / 2008$ 18:12 & 16.7 & 694.3 \\
\hline 966 & 1/8/2008 18:14 & $8 / 8 / 2008$ 18:14 & 16.7 & 694.3 \\
\hline 967 & 1/8/2008 18:16 & $8 / 8 / 2008$ 18:16 & 16.7 & 694.3 \\
\hline 968 & 1/8/2008 18:18 & $8 / 8 / 200818: 18$ & 16.7 & 694.4 \\
\hline 969 & $1 / 8 / 200818: 20$ & $8 / 8 / 200818: 20$ & 16.7 & 694.4 \\
\hline 970 & $1 / 8 / 200818: 22$ & $8 / 8 / 200818: 22$ & 16.7 & 694.7 \\
\hline 971 & $1 / 8 / 200818: 24$ & $8 / 8 / 200818: 24$ & 16.7 & 694.6 \\
\hline 972 & $1 / 8 / 200818: 26$ & $8 / 8 / 200818: 26$ & 16.7 & 694.4 \\
\hline 973 & $1 / 8 / 200818: 28$ & $8 / 8 / 200818: 28$ & 16.7 & 694.2 \\
\hline 974 & 1/8/2008 18:30 & $8 / 8 / 200818: 30$ & 16.7 & 694.1 \\
\hline 975 & $1 / 8 / 200818: 32$ & $8 / 8 / 200818: 32$ & 16.7 & 693.9 \\
\hline 976 & $1 / 8 / 200818: 34$ & $8 / 8 / 200818: 34$ & 16.7 & 693.8 \\
\hline 977 & $1 / 8 / 200818: 36$ & $8 / 8 / 200818: 36$ & 16.7 & 693.8 \\
\hline 978 & $1 / 8 / 200818: 38$ & $8 / 8 / 200818: 38$ & 16.7 & 693.7 \\
\hline 979 & $1 / 8 / 200818: 40$ & $8 / 8 / 200818: 40$ & 16.7 & 693.9 \\
\hline 980 & $1 / 8 / 200818: 42$ & $8 / 8 / 200818: 42$ & 16.7 & 694 \\
\hline 981 & $1 / 8 / 200818: 44$ & $8 / 8 / 200818: 44$ & 16.7 & 694.1 \\
\hline 982 & $1 / 8 / 200818: 46$ & $8 / 8 / 200818: 46$ & 16.7 & 693.8 \\
\hline 983 & $1 / 8 / 200818: 48$ & $8 / 8 / 200818: 48$ & 16.7 & 693.9 \\
\hline 984 & $1 / 8 / 200818: 50$ & $8 / 8 / 200818: 50$ & 16.7 & 693.7 \\
\hline 985 & $1 / 8 / 2008$ 18:52 & $8 / 8 / 200818: 52$ & 16.7 & 693.5 \\
\hline 986 & $1 / 8 / 200818: 54$ & $8 / 8 / 200818: 54$ & 16.7 & 693.4 \\
\hline 987 & $1 / 8 / 2008 \quad 18: 56$ & $8 / 8 / 200818: 56$ & 16.7 & 693.3 \\
\hline 988 & 1/8/2008 18:58 & $8 / 8 / 200818: 58$ & 16.7 & 693.3 \\
\hline 989 & 1/8/2008 19:00 & $8 / 8 / 2008$ 19:00 & 16.7 & 693.1 \\
\hline 990 & 1/8/2008 19:02 & $8 / 8 / 2008$ 19:02 & 16.7 & 693.1 \\
\hline 991 & 1/8/2008 19:04 & $8 / 8 / 2008$ 19:04 & 16.7 & 693.1 \\
\hline 992 & 1/8/2008 19:06 & $8 / 8 / 200819: 06$ & 16.7 & 692.9 \\
\hline 993 & $1 / 8 / 200819: 08$ & $8 / 8 / 200819: 08$ & 16.7 & 693 \\
\hline 994 & 1/8/2008 19:10 & $8 / 8 / 200819: 10$ & 16.7 & 693.1 \\
\hline 995 & $1 / 8 / 2008$ 19:12 & $8 / 8 / 2008$ 19:12 & 16.7 & 693.2 \\
\hline 996 & 1/8/2008 19:14 & $8 / 8 / 200819: 14$ & 16.7 & 6924 \\
\hline 997 & 1/8/2008 19:16 & $8 / 8 / 2008$ 19:16 & 16.7 & 6927 \\
\hline 998 & 1/8/2008 19:18 & $8 / 8 / 2008$ 19:18 & 16.7 & 692.8 \\
\hline 999 & $1 / 8 / 200819: 20$ & $8 / 8 / 2008$ 19:20 & 16.7 & 693 \\
\hline 1000 & $1 / 8 / 200819: 22$ & $8 / 8 / 200819: 22$ & 16.7 & 692.8 \\
\hline 1001 & $1 / 8 / 200819: 24$ & $8 / 8 / 200819: 24$ & 16.7 & 693 \\
\hline 1002 & 1/8/2008 19:26 & $8 / 8 / 200819: 26$ & 16.7 & 693.1 \\
\hline 1003 & $1 / 8 / 200819: 28$ & $8 / 8 / 200819: 28$ & 16.7 & 693.1 \\
\hline 1004 & $1 / 8 / 200819: 30$ & $8 / 8 / 200819: 30$ & 16.7 & 693.1 \\
\hline 1005 & $1 / 8 / 200819: 32$ & $8 / 8 / 200819: 32$ & 16.7 & 693.3 \\
\hline 1006 & $1 / 8 / 2008$ 19:34 & $8 / 8 / 200819: 34$ & 16.7 & 693.3 \\
\hline 1007 & $1 / 8 / 200819: 36$ & $8 / 8 / 200819: 36$ & 16.7 & 693.3 \\
\hline 1008 & $1 / 8 / 200819: 38$ & $8 / 8 / 200819: 38$ & 16.7 & 693.2 \\
\hline 1009 & $1 / 8 / 200819: 40$ & $8 / 8 / 200819: 40$ & 16.7 & 693.3 \\
\hline 1010 & $1 / 8 / 200819: 42$ & $8 / 8 / 200819: 42$ & 16.7 & 693.3 \\
\hline 1011 & 1/8/2008 19:44 & $8 / 8 / 2008$ 19:44 & 16.7 & 693.3 \\
\hline 1012 & $1 / 8 / 200819: 46$ & $8 / 8 / 200819: 46$ & 16.7 & 693.1 \\
\hline 1013 & $1 / 8 / 200819: 48$ & $8 / 8 / 2008$ 19:48 & 16.7 & 693.3 \\
\hline 1014 & 1/8/2008 19:50 & $8 / 8 / 2008$ 19:50 & 16.7 & 693.3 \\
\hline 1015 & 1/8/2008 19:52 & $8 / 8 / 200819: 52$ & 16.7 & 693.1 \\
\hline 1016 & $1 / 8 / 200819: 54$ & $8 / 8 / 2008$ 19:54 & 16.7 & 693.1 \\
\hline 1017 & 1/8/2008 19:56 & $8 / 8 / 2008$ 19:56 & 16.7 & 693.1 \\
\hline 1018 & $1 / 8 / 200819: 58$ & $8 / 8 / 2008$ 19:58 & 16.7 & 693.3 \\
\hline 1019 & 1/8/2008 20:00 & $8 / 8 / 200820: 00$ & 16.7 & 693.2 \\
\hline 1020 & $1 / 8 / 200820: 02$ & $8 / 8 / 200820: 02$ & 16.7 & 693.3 \\
\hline
\end{tabular}


DOE/RL-2009-35, REV. 0

\begin{tabular}{|c|c|c|c|c|}
\hline \multicolumn{5}{|c|}{ D4-92c } \\
\hline $\operatorname{Rec}$ & & Adjusted & Temp & SC \\
\hline$\#$ & Date/Time & Date/Time & \begin{tabular}{ll|}
${ }^{\circ} \mathrm{C}$ \\
\end{tabular} & $\mu \mathrm{S} / \mathrm{cm}$ \\
\hline 1021 & $1 / 8 / 200820: 04$ & $8 / 8 / 200820: 04$ & 16.7 & 693.3 \\
\hline 1022 & $1 / 8 / 200820: 06$ & $8 / 8 / 200820: 06$ & 16.7 & 693 \\
\hline 1023 & $1 / 8 / 200820: 08$ & $8 / 8 / 200820: 08$ & 16.7 & \\
\hline 1024 & $1 / 8 / 200820: 10$ & $8 / 8 / 200820: 10$ & 16.7 & 693.3 \\
\hline 1025 & $1 / 8 / 200820: 12$ & $8 / 8 / 200820: 12$ & 16.7 & 693.1 \\
\hline 1026 & $1 / 8 / 200820: 14$ & $8 / 8 / 200820: 14$ & 16.7 & 693 \\
\hline 1027 & $1 / 8 / 200820: 16$ & $8 / 8 / 200820: 16$ & 16.7 & 692.6 \\
\hline 1028 & $1 / 8 / 200820: 18$ & $8 / 8 / 200820: 18$ & 16.7 & 692.2 \\
\hline 1029 & $1 / 8 / 200820: 20$ & $8 / 8 / 200820: 20$ & 16.7 & 692.1 \\
\hline 1030 & $1 / 8 / 200820: 22$ & $8 / 8 / 200820: 22$ & 16.7 & 692.3 \\
\hline 1031 & $1 / 8 / 200820: 24$ & $8 / 8 / 200820: 24$ & 16.7 & 692.2 \\
\hline 1032 & $1 / 8 / 200820: 26$ & $8 / 8 / 200820: 26$ & 16.7 & 692.6 \\
\hline 1033 & $1 / 8 / 200820: 28$ & $8 / 8 / 200820: 28$ & 16.7 & 692.6 \\
\hline 1034 & 1/8/2008 20:30 & $8 / 8 / 200820: 30$ & 16.7 & $\begin{array}{l}692.7 \\
\end{array}$ \\
\hline 1035 & $1 / 8 / 200820: 32$ & $8 / 8 / 200820: 32$ & 16.7 & 692.6 \\
\hline 1036 & $1 / 8 / 200820: 34$ & $8 / 8 / 200820: 34$ & 16.7 & 692.7 \\
\hline 1037 & 1/8/2008 20:36 & $8 / 8 / 200820: 36$ & 16.7 & 692.8 \\
\hline 1038 & $1 / 8 / 200820: 38$ & $8 / 8 / 200820: 38$ & 16.7 & 692.8 \\
\hline 1039 & $1 / 8 / 200820: 40$ & $8 / 8 / 200820: 40$ & 16.7 & 692.8 \\
\hline 1040 & $1 / 8 / 200820: 42$ & $8 / 8 / 200820: 42$ & 16.7 & 692.8 \\
\hline 1041 & $1 / 8 / 200820: 44$ & $8 / 8 / 200820: 44$ & 16.7 & 692.7 \\
\hline 1042 & $1 / 8 / 200820: 46$ & $8 / 8 / 200820: 46$ & 16.7 & 692.7 \\
\hline 1043 & $1 / 8 / 200820: 48$ & $8 / 8 / 200820: 48$ & 16.7 & 692.4 \\
\hline 1044 & $1 / 8 / 200820: 50$ & $8 / 8 / 200820: 50$ & 16.7 & 692.5 \\
\hline 1045 & $1 / 8 / 200820: 52$ & $8 / 8 / 200820: 52$ & 16.7 & 692.3 \\
\hline 1046 & $1 / 8 / 200820: 54$ & $8 / 8 / 200820: 54$ & 16.7 & 691.9 \\
\hline 1047 & $1 / 8 / 200820: 56$ & 8/8/2008 20:56 & 16.8 & 691.7 \\
\hline 1048 & $1 / 8 / 200820: 58$ & $8 / 8 / 200820: 58$ & 16.7 & 692.1 \\
\hline 1049 & $1 / 8 / 200821: 00$ & $8 / 8 / 200821: 00$ & 16.7 & 692 \\
\hline 1050 & $1 / 8 / 200821: 02$ & $8 / 8 / 200821: 02$ & 16.7 & 692 \\
\hline 1051 & $1 / 8 / 200821: 04$ & $8 / 8 / 200821: 04$ & 16.7 & 692.1 \\
\hline 1052 & $1 / 8 / 200821: 06$ & $8 / 8 / 200821: 06$ & 16.7 & 692.1 \\
\hline 1053 & $1 / 8 / 200821: 08$ & $8 / 8 / 200821: 08$ & 16.7 & 692.1 \\
\hline 1054 & $1 / 8 / 200821: 10$ & $8 / 8 / 200821: 10$ & 16.7 & 692.2 \\
\hline 1055 & $1 / 8 / 200821: 12$ & $8 / 8 / 200821: 12$ & 16.7 & 692.1 \\
\hline 1056 & $1 / 8 / 200821: 14$ & $8 / 8 / 200821: 14$ & 16.7 & 692.2 \\
\hline 1057 & $1 / 8 / 200821: 16$ & $8 / 8 / 200821: 16$ & 16.7 & 692 \\
\hline 1058 & $1 / 8 / 200821: 18$ & $8 / 8 / 200821: 18$ & 16.7 & 692 \\
\hline 1059 & $1 / 8 / 200821: 20$ & $8 / 8 / 200821: 20$ & 16.7 & 692.1 \\
\hline 1060 & $1 / 8 / 200821: 22$ & $8 / 8 / 200821: 22$ & 16.7 & 692.1 \\
\hline 1061 & $1 / 8 / 200821: 24$ & $8 / 8 / 200821: 24$ & 16.7 & 691.7 \\
\hline 1062 & $1 / 8 / 200821: 26$ & $8 / 8 / 200821: 26$ & 16.7 & 691.9 \\
\hline 1063 & $1 / 8 / 200$ & $8 / 8 / 200821: 28$ & 16.7 & 691.9 \\
\hline 1064 & $1 / 8 / 200$ & $8 / 8 / 200821: 30$ & 16.7 & 692.1 \\
\hline 1065 & $1 / 8 / 200821: 32$ & $8 / 8 / 200821: 32$ & 16.7 & 692.2 \\
\hline 1066 & $1 / 8 / 200821: 34$ & $8 / 8 / 200821: 34$ & 16.7 & 691.8 \\
\hline 1067 & $1 / 8 / 200821: 36$ & $8 / 8 / 200821: 36$ & 16.7 & 692 \\
\hline 1068 & $1 / 8 / 200821: 38$ & $8 / 8 / 200821: 38$ & 16.7 & 691.5 \\
\hline 1069 & $1 / 8 / 200821: 40$ & $8 / 8 / 200821: 40$ & 16.7 & 691.5 \\
\hline 1070 & $1 / 8 / 200821: 42$ & $8 / 8 / 200821: 42$ & 16.7 & 691.7 \\
\hline 1071 & $1 / 8 / 200$ & $8 / 8 / 200821: 44$ & 16.7 & 691.9 \\
\hline 1072 & $1 / 8 / 200821: 46$ & $8 / 8 / 200821: 46$ & 16.7 & 691.9 \\
\hline 1073 & $1 / 8 / 200821: 48$ & $8 / 8 / 200821: 48$ & 16.7 & 691.7 \\
\hline 1074 & $1 / 8 / 200821: 50$ & $8 / 8 / 200821: 50$ & 16.7 & 691.7 \\
\hline 1075 & $1 / 8 / 200821: 52$ & $8 / 8 / 200821: 52$ & 16.7 & 691.9 \\
\hline 1076 & 1/8/2008 21:54 & $8 / 8 / 200821: 54$ & 16.8 & 691.8 \\
\hline 1077 & $1 / 8 / 200821: 56$ & $8 / 8 / 200821: 56$ & 16.7 & 691.8 \\
\hline 1078 & $1 / 8 / 200821: 58$ & $8 / 8 / 200821: 58$ & 16.7 & 691.7 \\
\hline 1079 & $1 / 8 / 200822: 00$ & $8 / 8 / 200822: 00$ & 16.7 & 691.8 \\
\hline 1080 & $1 / 8 / 200822: 02$ & $8 / 8 / 200822: 02$ & 16.7 & 691.7 \\
\hline 1081 & $1 / 8 / 200822: 04$ & $8 / 8 / 200822: 04$ & 16.7 & 691.7 \\
\hline 1082 & $1 / 8 / 200822: 06$ & $8 / 8 / 200822: 06$ & 16.7 & 691.8 \\
\hline 1083 & $1 / 8 / 200822: 08$ & $8 / 8 / 200822: 08$ & 16.7 & 691.9 \\
\hline 1084 & $1 / 8 / 200822: 10$ & $8 / 8 / 200822: 10$ & 16.7 & 691.8 \\
\hline 1085 & 1/8/2008 22:12 & $8 / 8 / 200822: 12$ & 16.7 & 692.4 \\
\hline 1086 & 1/8/2008 22:14 & $8 / 8 / 200822: 14$ & $\begin{array}{ll}16.7 \\
\end{array}$ & 692.4 \\
\hline 1087 & 1/8/2008 22:16 & $8 / 8 / 200822: 16$ & 16.7 & 692.3 \\
\hline 1088 & 1/8/2008 22:18 & $8 / 8 / 200822: 18$ & 16.7 & 692.3 \\
\hline
\end{tabular}

\begin{tabular}{|c|c|c|c|c|}
\hline \multicolumn{5}{|c|}{ D4-92c } \\
\hline $\operatorname{Rec}$ & & Adjusted & Temp| & $\mathrm{SC}$ \\
\hline$\#$ & Date/Time & Date/Time & ${ }^{\circ} \mathrm{C}$ & $\mu \mathrm{S} / \mathrm{cm}$ \\
\hline 1089 & $1 / 8 / 200822: 20$ & $8 / 8 / 200822: 20$ & 16.7 & 692.4 \\
\hline 1090 & $1 / 8 / 200822: 22$ & $8 / 8 / 200822: 22$ & 16.7 & 692.4 \\
\hline 1091 & $1 / 8 / 200822: 24$ & $8 / 8 / 200822: 24$ & 16.7 & 692.4 \\
\hline 1092 & $1 / 8 / 200822: 26$ & $8 / 8 / 200822: 26$ & 16.7 & 692.5 \\
\hline 1093 & 1/8/2008 22:28 & $8 / 8 / 200822: 28$ & 16.7 & 692.7 \\
\hline 1094 & $1 / 8 / 200822: 30$ & $8 / 8 / 200822: 30$ & 16.7 & 692.9 \\
\hline 1095 & $1 / 8 / 200822: 32$ & $8 / 8 / 200822: 32$ & 16.7 & 692.6 \\
\hline 1096 & $1 / 8 / 200822: 34$ & $8 / 8 / 200822: 34$ & 16.7 & 692.6 \\
\hline 1097 & $1 / 8 / 200822: 36$ & $8 / 8 / 200822: 36$ & 16.7 & 692.7 \\
\hline 1098 & $1 / 8 / 200822: 38$ & $8 / 8 / 200822: 38$ & 16.7 & 692.6 \\
\hline 1099 & $1 / 8 / 200822: 40$ & $8 / 8 / 200822: 40$ & 16.7 & 692.7 \\
\hline 1100 & $1 / 8 / 200822: 42$ & $8 / 8 / 200822: 42$ & 16.7 & 692.6 \\
\hline 1101 & $1 / 8 / 200822: 44$ & $8 / 8 / 200822: 44$ & 16.7 & 692.7 \\
\hline 1102 & $1 / 8 / 200822: 46$ & $8 / 8 / 200822: 46$ & 16.7 & 692.5 \\
\hline 1103 & $1 / 8 / 200822: 48$ & $8 / 8 / 200822: 48$ & 16.7 & 692.8 \\
\hline 1104 & $1 / 8 / 200822: 50$ & $8 / 8 / 200822: 50$ & 16.7 & 692.7 \\
\hline 1105 & $1 / 8 / 200822: 52$ & $8 / 8 / 200822: 52$ & 16.7 & 692.8 \\
\hline 1106 & $1 / 8 / 200822: 54$ & $8 / 8 / 200822: 54$ & 16.7 & 692.9 \\
\hline 1107 & $1 / 8 / 200822: 56$ & $8 / 8 / 200822: 56$ & 16.7 & 692.9 \\
\hline 1108 & $1 / 8 / 200822: 58$ & $8 / 8 / 200822: 58$ & 16.7 & 692.8 \\
\hline 1109 & $1 / 8 / 200823: 00$ & $8 / 8 / 200823: 00$ & 16.7 & 693 \\
\hline 1110 & $1 / 8 / 200823: 02$ & $8 / 8 / 200823: 02$ & 16.8 & 692.9 \\
\hline 1111 & 1/8/2008 23:04 & $8 / 8 / 200823: 04$ & 16.7 & 693.4 \\
\hline 1112 & $1 / 8 / 200823: 06$ & $8 / 8 / 200823: 06$ & 16.7 & 693.1 \\
\hline 1113 & $1 / 8 / 200823: 08$ & $8 / 8 / 200823: 08$ & 16.7 & 693 \\
\hline 1114 & $1 / 8 / 200823: 10$ & $8 / 8 / 200823: 10$ & 16.7 & 693 \\
\hline 1115 & 1/8/2008 23:12 & $8 / 8 / 2008 \quad 23: 12$ & 16.7 & 693 \\
\hline 1116 & 1/8/2008 23:14 & $8 / 8 / 200823: 14$ & 16.7 & 693 \\
\hline 1117 & $1 / 8 / 200823: 16$ & $8 / 8 / 200823: 16$ & 16.7 & 693.3 \\
\hline 1118 & $1 / 8 / 200823: 18$ & $8 / 8 / 200823: 18$ & 16.7 & 693.1 \\
\hline 1119 & $1 / 8 / 200823: 20$ & $8 / 8 / 200823: 20$ & 16.7 & 693.1 \\
\hline 1120 & $1 / 8 / 200823: 22$ & $8 / 8 / 200823: 22$ & 16.7 & 693 \\
\hline 1121 & $1 / 8 / 200823: 24$ & $8 / 8 / 200823: 24$ & 16.7 & 693.2 \\
\hline 1122 & 1/8/2008 23:26 & $8 / 8 / 200823: 26$ & 16.7 & 693.1 \\
\hline 1123 & $1 / 8 / 200823: 28$ & $8 / 8 / 200823: 28$ & 16.7 & 693.2 \\
\hline 1124 & 1/8/2008 23:30 & $8 / 8 / 200823: 30$ & 16.7 & 693.4 \\
\hline 1125 & $1 / 8 / 200823: 32$ & $8 / 8 / 2008$ 23:32 & 16.7 & 693.3 \\
\hline 1126 & $1 / 8 / 200823: 34$ & $8 / 8 / 200823: 34$ & 16.8 & 693.5 \\
\hline 1127 & 1/8/2008 23:36 & $8 / 8 / 200823: 36$ & 16.7 & 693.5 \\
\hline 1128 & 1/8/2008 23:38 & $8 / 8 / 200823: 38$ & 16.7 & 693.7 \\
\hline 1129 & 1/8/2008 23:40 & $8 / 8 / 200823: 40$ & 16.7 & 693.8 \\
\hline 1130 & $1 / 8 / 200823: 42$ & $8 / 8 / 200823: 42$ & 16.8 & 693.9 \\
\hline 1131 & $1 / 8 / 200823: 44$ & $8 / 8 / 200823: 44$ & 16.7 & 693.9 \\
\hline 1132 & $1 / 8 / 200823: 46$ & $8 / 8 / 200823: 46$ & 16.8 & 694.1 \\
\hline 1133 & $1 / 8 / 200823: 48$ & $8 / 8 / 200823: 48$ & 16.8 & 694.9 \\
\hline 1134 & $1 / 8 / 200823: 50$ & $8 / 8 / 200823: 50$ & 16.8 & 695.2 \\
\hline 1135 & $1 / 8 / 200823: 52$ & $8 / 8 / 200823: 52$ & 16.8 & 695.6 \\
\hline 1136 & $1 / 8 / 200823: 54$ & $8 / 8 / 200823: 54$ & 16.7 & 695.7 \\
\hline 1137 & $1 / 8 / 200823: 56$ & $8 / 8 / 200823: 56$ & 16.8 & 695.6 \\
\hline 1138 & $1 / 8 / 200823: 58$ & $8 / 8 / 200823: 58$ & 16.8 & 695.6 \\
\hline 1139 & $1 / 9 / 20080 ; 00$ & $8 / 9 / 20080: 00$ & 16.8 & 695.4 \\
\hline 1140 & 1/9/2008 0:02 & $8 / 9 / 20080: 02$ & 16.8 & 697.1 \\
\hline 1141 & 1/9/2008 0:04 & $8 / 9 / 20080: 04$ & 16.8 & 696.9 \\
\hline 1142 & 1/9/2008 0:06 & $8 / 9 / 20080: 06$ & 16.8 & 696.4 \\
\hline 1143 & 1/9/2008 0:08 & $8 / 9 / 20080: 08$ & 16.8 & 696.4 \\
\hline 1144 & $1 / 9 / 20080: 10$ & 8/9/2008 0:10 & 16.8 & 696.4 \\
\hline 1145 & 1/9/2008 0:12 & $8 / 9 / 20080: 12$ & 16.8 & 696.1 \\
\hline 1146 & 1/9/2008 0:14 & $8 / 9 / 20080: 14$ & 16.8 & 697.1 \\
\hline 1147 & $1 / 9 / 20080: 16$ & $8 / 9 / 20080: 16$ & 16.7 & 695.1 \\
\hline 1148 & $1 / 9 / 20080: 18$ & $8 / 9 / 2008$ 0:18 & 16.8 & 694.8 \\
\hline 1149 & $1 / 9 / 20080: 20$ & $8 / 9 / 20080: 20$ & 16.8 & 694.6 \\
\hline 1150 & $1 / 9 / 20080: 22$ & $8 / 9 / 20080: 22$ & 16.8 & 695.1 \\
\hline 1151 & $1 / 9 / 20080: 24$ & $8 / 9 / 20080: 24$ & 16.8 & 695 \\
\hline 1152 & 1/9/2008 0:26 & $8 / 9 / 20080: 26$ & 16.8 & 695 \\
\hline 1153 & $1 / 9 / 20080: 28$ & $8 / 9 / 20080: 28$ & 16.8 & 695.3 \\
\hline 1154 & 1/9/20080:30 & $8 / 9 / 20080: 30$ & 16.8 & 696 \\
\hline 1155 & 1/9/2008 0:32 & $8 / 9 / 20080: 32$ & 16.8 & 699.2 \\
\hline 1156 & $1 / 9 / 20080: 34$ & $8 / 9 / 20080: 34$ & 16.8 & 714.4 \\
\hline
\end{tabular}

\begin{tabular}{|c|c|c|c|c|}
\hline \multicolumn{5}{|c|}{$04-928$} \\
\hline$\overline{\operatorname{Rec}}$ & & Adjusted & Temp & $\mathrm{SC}$ \\
\hline$\#$ & Date/Time & Date/Time & ${ }^{\circ} \mathrm{C}$ & $\mu \mathrm{S} / \mathrm{cm}$ \\
\hline 157 & 1/9/2008 0:36 & $8 / 9 / 20080: 36$ & 16.8 & 718.5 \\
\hline 58 & & $19 / 20080: 38$ & 16.8 & \\
\hline 159 & $1 / 9 / 20080: 40$ & $8 / 9 / 20080: 40$ & 16.8 & 696.7 \\
\hline 160 & $9 / 20080: 42$ & $8 / 9 / 20080: 42$ & 16.8 & 696.8 \\
\hline 161 & $9 / 20080: 44$ & $19 / 20080: 44$ & 16.8 & \\
\hline 162 & 1/9/2008 0:46 & $8 / 9 / 20080: 46$ & 16.8 & 697. \\
\hline 163 & $9 / 20080: 48$ & $8 / 9 / 20080: 48$ & 16.8 & 700.2 \\
\hline 164 & $1 / 9 / 20080: 50$ & 8/9/2008 0:50 & 16.8 & \\
\hline 165 & $1 / 9 / 20080: 52$ & $8 / 9 / 20080: 52$ & 16.8 & 704.4 \\
\hline 166 & $1 / 9 / 20080: 54$ & $8 / 9 / 20080: 54$ & 16.8 & 706.8 \\
\hline 167 & $1 / 9 / 20080: 56$ & $8 / 9 / 20080: 56$ & 16.8 & \\
\hline 1168 & $1 / 9 / 20080: 58$ & $8 / 9 / 2008$ 0:58 & 16.8 & 707.8 \\
\hline 1169 & 1/9/2008 1:00 & $8 / 9 / 20081: 00$ & 16.8 & 708.4 \\
\hline 170 & $9 / 20081: 02$ & $8 / 9 / 2008$ 1:02 & 16.8 & \\
\hline 1171 & 1/9/2008 1:04 & $8 / 9 / 20081: 04$ & 16.8 & 706 . \\
\hline 1172 & 1/9/2008 1:06 & $8 / 9 / 20081: 06$ & 16.8 & 707.6 \\
\hline 173 & 1/9/2008 1:08 & $8 / 9 / 20081: 08$ & 16.8 & \\
\hline 1174 & 1/9/2008 1:10 & $8 / 9 / 2008$ 1:10 & 16.8 & \\
\hline 1175 & 1/9/2008 1:12 & $8 / 9 / 20081: 12$ & 16.8 & 710.7 \\
\hline 1176 & $1 / 9 / 20081: 14$ & $8 / 9 / 2008$ 1:14 & 16.8 & \\
\hline 1177 & $1 / 9 / 20081: 16$ & $8 / 9 / 20081: 16$ & 16.8 & \\
\hline 1178 & $9 / 2008$ 1:18 & $8 / 9 / 20$ & 16.8 & 708.8 \\
\hline 1179 & 1/9/2008 1:20 & $8 / 9 / 20081: 20$ & 16.8 & \\
\hline 1180 & 1/9/2008 1:22 & $8 / 9 / 2008$ 1:22 & 16.8 & 705 \\
\hline 1181 & 24 & $1: 24$ & 16.8 & 712 \\
\hline 1182 & 1/9/2008 1:26 & $8 / 9 / 20$ & 16.8 & 711. \\
\hline 1183 & 1/9/2008 1:28 & $8 / 9 / 20$ & 16.8 & 712 \\
\hline 1184 & 30 & $1: 30$ & 16.8 & 710. \\
\hline 1185 & $1: 32$ & $81: 32$ & 16.8 & 12. \\
\hline 1186 & & $8 / 9 / 20$ & 16.8 & 713. \\
\hline 1187 & & & 16.8 & 713.2 \\
\hline 1188 & $1: 38$ & $8 / 9 / 20$ & 16.8 & 713. \\
\hline 1189 & & & 16.8 & 714 \\
\hline 1190 & $: 42$ & $1: 42$ & 16.8 & 715. \\
\hline 1191 & & $1: 44$ & 16.8 & 714 \\
\hline 1192 & & & 16.8 & 714 \\
\hline 1193 & 1:48 & $31: 48$ & 16.9 & 714. \\
\hline 1194 & & $31: 50$ & 16.8 & 714. \\
\hline 1195 & & & 16.8 & 71 \\
\hline 1196 & & & 16.8 & 714. \\
\hline 1197 & & $1: 56$ & 16.8 & 713. \\
\hline 1198 & & & 16.8 & 71 \\
\hline 1199 & & $2: 00$ & 16.8 & 715 \\
\hline 1200 & & & 16.8 & 716. \\
\hline 1201 & & $2: 04$ & 16.8 & 716 \\
\hline 1202 & & $82: 06$ & 16.8 & 716. \\
\hline & & & 16.8 & \\
\hline 1204 & & & 16.8 & 79 \\
\hline 1205 & & 2:12 & 16.8 & 710. \\
\hline 1206 & & & 16.9 & 711. \\
\hline 1207 & & & 16.8 & \\
\hline 1208 & & 82:18 & 16.9 & 704. \\
\hline 1209 & & & 16.9 & \\
\hline 1210 & & $32: 22$ & 16.8 & 699. \\
\hline 1211 & & $32: 24$ & 16.8 & 718. \\
\hline & & & & \\
\hline 121 & & 28 & 16.8 & 721. \\
\hline 1214 & & $32: 30$ & 16.8 & 721. \\
\hline & & & & \\
\hline & & $82: 34$ & 16.8 & \\
\hline 1217 & 2.50 & $8 / 9 / 20082: 36$ & 16.8 & 722. \\
\hline & & & & \\
\hline 1219 & $82: 40$ & $82: 40$ & 16.8 & 722. \\
\hline 1220 & & $8 / 9 / 20082: 42$ & 16.8 & 722. \\
\hline & & & & \\
\hline 1222 & $1 / 20082: 46$ & $8 / 9 / 20082: 46$ & 16.8 & 722. \\
\hline 1223 & $1 / 9 / 20082: 48$ & $8 / 9 / 20082: 48$ & 16.8 & 722 \\
\hline 1224 & $1 / 9 / 20082: 50$ & $8 / 9 / 20082: 50$ & & \\
\hline
\end{tabular}




\begin{tabular}{|c|c|c|c|c|}
\hline \multicolumn{5}{|c|}{ D4-92c } \\
\hline $\operatorname{Rec}$ & & Adjusted & Temp & $\mathrm{SC}$ \\
\hline$\#$ & Date/Time & Date/Time & ${ }^{\circ} \mathrm{C}$ & $\mu \mathrm{S} / \mathrm{cm}$ \\
\hline 1225 & 1/9/20082:52 & $8 / 9 / 2008$ 2:52 & 16.8 & 722.3 \\
\hline 1226 & 1/9/2008 2:54 & $8 / 9 / 20082: 54$ & 16.8 & 722.5 \\
\hline 1227 & 1/9/2008 2:56 & $8 / 9 / 20082.56$ & 16.8 & 722.3 \\
\hline 1228 & 1/9/20082:58 & $8 / 9 / 20082: 58$ & 16.8 & 722.6 \\
\hline 1229 & 1/9/2008 3:00 & $8 / 9 / 20083: 00$ & 16.8 & 722.3 \\
\hline 1230 & 1/9/2008 3:02 & $8 / 9 / 20083: 02$ & 16.8 & 722.5 \\
\hline 1231 & 1/9/2008 3:04 & $8 / 9 / 20083: 04$ & 16.8 & 722.3 \\
\hline 1232 & 1/9/2008 3:06 & $8 / 9 / 20083: 06$ & 16.8 & 722.2 \\
\hline 1233 & 1/9/2008 3:08 & $8 / 9 / 20083: 08$ & 16.8 & 722.4 \\
\hline 1234 & 1/9/20083:10 & $8 / 9 / 20083: 10$ & 16.8 & 722.2 \\
\hline 1235 & 1/9/2008 3:12 & $8 / 9 / 20083: 12$ & 16.8 & 722 \\
\hline 1236 & $1 / 9 / 20083: 14$ & $8 / 9 / 20083: 14$ & 16.8 & 721.9 \\
\hline 1237 & $1 / 9 / 20083: 16$ & $8 / 9 / 20083: 16$ & 16.8 & 721.8 \\
\hline 1238 & $1 / 9 / 20083: 18$ & $8 / 9 / 20083: 18$ & 16.8 & 721.8 \\
\hline 1239 & 1/9/2008 3:20 & $8 / 9 / 20083: 20$ & 16.8 & 722.2 \\
\hline 1240 & $1 / 9 / 20083: 22$ & $8 / 9 / 20083: 22$ & 16.8 & 721.2 \\
\hline 1241 & 1/9/2008 3:24 & $8 / 9 / 20083: 24$ & 16.8 & 720.6 \\
\hline 1242 & 1/9/2008 3:26 & $8 / 9 / 20083: 26$ & 16.8 & 721 \\
\hline 1243 & 1/9/20083:28 & $8 / 9 / 20083: 28$ & 16.8 & 721 \\
\hline 1244 & 1/9/20083:30 & $8 / 9 / 20083: 30$ & 16.8 & 721 \\
\hline 1245 & 1/9/20083:32 & $8 / 9 / 20083: 32$ & 16.8 & 720.8 \\
\hline 1246 & $1 / 9 / 20083: 34$ & $8 / 9 / 20083: 34$ & 16.8 & 721.1 \\
\hline 1247 & $1 / 9 / 20083: 36$ & $8 / 9 / 20083: 36$ & 16.8 & 721 \\
\hline 1248 & $1 / 9 / 20083: 38$ & $8 / 9 / 20083: 38$ & 16.8 & 720.9 \\
\hline 1249 & $1 / 9 / 20083: 40$ & $8 / 9 / 20083: 40$ & 16.8 & 720.9 \\
\hline 1250 & $1 / 9 / 20083: 42$ & $8 / 9 / 20083: 42$ & 16.8 & 720.7 \\
\hline 1251 & $1 / 9 / 20083: 44$ & $8 / 9 / 20083: 44$ & 16.8 & 719.8 \\
\hline 1252 & 1/9/20083:46 & $8 / 9 / 20083: 46$ & 16.8 & 720.3 \\
\hline 1253 & $1 / 9 / 20083: 48$ & $8 / 9 / 20083: 48$ & 16.8 & 720.2 \\
\hline 1254 & $1 / 9 / 20083: 50$ & $8 / 9 / 20083: 50$ & 16.8 & 719.8 \\
\hline 1255 & 1/9/2008 3:52 & $8 / 9 / 20083: 52$ & 16.8 & 719.7 \\
\hline 1256 & 1/9/2008 3:54 & $8 / 9 / 20083: 54$ & 16.8 & 719.9 \\
\hline 1257 & 1/9/2008 3:56 & $8 / 9 / 20083: 56$ & 16.8 & 718.4 \\
\hline 1258 & 1/9/2008 3:58 & $8 / 9 / 20083: 58$ & 16.8 & 718.5 \\
\hline 1259 & $1 / 9 / 20084: 00$ & $8 / 9 / 20084: 00$ & 16.8 & 714.3 \\
\hline 1260 & 1/9/20084:02 & $8 / 9 / 20084: 02$ & 16.8 & 718.2 \\
\hline 1261 & $1 / 9 / 20084: 04$ & $8 / 9 / 20084: 04$ & 16.8 & 715.5 \\
\hline 1262 & 1/9/2008 4:06 & $8 / 9 / 20084: 06$ & 16.8 & 714 \\
\hline 1263 & 1/9/20084:08 & $8 / 9 / 20084: 08$ & 16.8 & 713.2 \\
\hline 1264 & 1/9/20084:10 & $8 / 9 / 20084: 10$ & 16.8 & 710.8 \\
\hline 1265 & 1/9/20084:12 & $8 / 9 / 20084: 12$ & 16.8 & 713.1 \\
\hline 1266 & 1/9/20084:14 & $8 / 9 / 20084: 14$ & 16.8 & 711 \\
\hline 1267 & 1/9/20084:16 & $8 / 9 / 20084: 16$ & 16.8 & 690.3 \\
\hline 1268 & 1/9/20084:18 & $8 / 9 / 20084: 18$ & 16.8 & 690.8 \\
\hline 1269 & 1/9/20084:20 & $8 / 9 / 20084: 20$ & 16.8 & 699.6 \\
\hline 1270 & $1 / 9 / 20084: 22$ & $8 / 9 / 20084: 22$ & 16.8 & 701.1 \\
\hline 1271 & 1/9/2008 4:24 & $8 / 9 / 20084: 24$ & 16.8 & 709.6 \\
\hline 1272 & 1/9/20084:26 & $8 / 9 / 2008$ 4:26 & 16.8 & 701 \\
\hline 1273 & $1 / 9 / 20084: 28$ & $8 / 9 / 20084: 28$ & 16.8 & 704 \\
\hline 1274 & 1/9/20084:30 & $8 / 9 / 20084: 30$ & 16.8 & 705.2 \\
\hline 1275 & $1 / 9 / 20084: 32$ & $8 / 9 / 20084: 32$ & 16.8 & 706.8 \\
\hline 1276 & 1/9/2008 4:34 & $8 / 9 / 20084: 34$ & 16.8 & 712.5 \\
\hline 1277 & 1/9/2008 4:36 & $8 / 9 / 20084: 36$ & 16.8 & 706.1 \\
\hline 1278 & 1/9/2008 4:38 & $8 / 9 / 20084: 38$ & 16.8 & 705.1 \\
\hline 1279 & $1 / 9 / 20084: 40$ & $8 / 9 / 20084: 40$ & 16.8 & 705.1 \\
\hline 1280 & $1 / 9 / 20084: 42$ & $8 / 9 / 20084: 42$ & 16.8 & 695.4 \\
\hline 1281 & 1/9/20084:44 & $8 / 9 / 20084: 44$ & 16.8 & 696.8 \\
\hline 1282 & 1/9/20084:46 & $8 / 9 / 20084: 46$ & 16.8 & 692.2 \\
\hline 1283 & 1/9/20084:48 & $8 / 9 / 20084: 48$ & 16.8 & 687.1 \\
\hline 1284 & 1/9/20084:50 & $8 / 9 / 20084: 50$ & 16.8 & 686.2 \\
\hline 1285 & 1/9/20084:52 & $8 / 9 / 20084: 52$ & 16.8 & 697.3 \\
\hline 1286 & 1/9/20084:54 & $8 / 9 / 20084: 54$ & 16.8 & 700.6 \\
\hline 1287 & 1/9/20084:56 & $8 / 9 / 20084: 56$ & 16.8 & 692.4 \\
\hline 1288 & 1/9/2008 4:58 & $8 / 9 / 20084: 58$ & 16.8 & 691.9 \\
\hline 1289 & $1 / 9 / 20085: 00$ & $8 / 9 / 20085: 00$ & 16.8 & 687.1 \\
\hline 1290 & $1 / 9 / 20085: 02$ & $8 / 9 / 20085: 02$ & 16.8 & 688.7 \\
\hline 1291 & 1/9/20085:04 & $8 / 9 / 20085: 04$ & 16.8 & 689.9 \\
\hline 1292 & 1/9/20085:06 & $8 / 9 / 20085: 06$ & 16.8 & 677.3 \\
\hline
\end{tabular}

\begin{tabular}{|c|c|c|c|c|}
\hline \multicolumn{5}{|c|}{ D4-92c } \\
\hline $\operatorname{Rec}$ & & Adjusted & Temp & SC \\
\hline$\#$ & Date/Time & Date/Time & ${ }^{\circ} \mathrm{C}$ & $\mu \mathrm{S} / \mathrm{cm}$ \\
\hline 1293 & 1/9/20085:08 & $8 / 9 / 20085: 08$ & 16.8 & 671.1 \\
\hline 1294 & 1/9/20085:10 & $8 / 9 / 20085: 10$ & 16.8 & 668.8 \\
\hline 1295 & 1/9/2008 5:12 & $8 / 9 / 20085: 12$ & 16.9 & 667.9 \\
\hline 1296 & $1 / 9 / 20085: 14$ & $8 / 9 / 20085: 14$ & 16.9 & 665 \\
\hline 1297 & 1/9/20085:16 & $8 / 9 / 20085: 16$ & 16.9 & 662.8 \\
\hline 1298 & $1 / 9 / 20085: 18$ & 8/9/2008 5:18 & 16.9 & 656.1 \\
\hline 1299 & $1 / 9 / 20085: 20$ & $8 / 9 / 20085: 20$ & 16.9 & 645.7 \\
\hline 1300 & $1 / 9 / 20085: 22$ & $8 / 9 / 20085: 22$ & 16.9 & 642.9 \\
\hline 1301 & $1 / 9 / 20085: 24$ & $8 / 9 / 20085: 24$ & 16.9 & 633 \\
\hline 1302 & $1 / 9 / 20085: 26$ & $8 / 9 / 20085: 26$ & 16.9 & 702.5 \\
\hline 1303 & $1 / 9 / 20085: 28$ & $8 / 9 / 20085: 28$ & 16.9 & 716.8 \\
\hline 1304 & $1 / 9 / 20085: 30$ & $8 / 9 / 20085: 30$ & 16.9 & 718.4 \\
\hline 1305 & $1 / 9 / 20085: 32$ & 8/9/20085:32 & 16.9 & 670.3 \\
\hline 1306 & $1 / 9 / 20085: 34$ & $8 / 9 / 20085: 34$ & 17 & 664.6 \\
\hline 1307 & $1 / 9 / 20085: 36$ & 8/9/20085:36 & 17 & 664.8 \\
\hline 1308 & $1 / 9 / 20085: 38$ & $8 / 9 / 20085: 38$ & 17 & 662.1 \\
\hline 1309 & 1/9/20085:40 & $8 / 9 / 20085: 40$ & 17 & 656.3 \\
\hline 1310 & $1 / 9 / 20085: 42$ & $8 / 9 / 20085: 42$ & 17 & 655.7 \\
\hline 1311 & $1 / 9 / 20085: 44$ & $8 / 9 / 20085: 44$ & 17 & 656.6 \\
\hline 1312 & 1/9/20085:46 & $8 / 9 / 20085: 46$ & 17 & 659.1 \\
\hline 1313 & $1 / 9 / 20085: 48$ & $8 / 9 / 20085: 48$ & 16.9 & 660.7 \\
\hline 1314 & $1 / 9 / 20085: 50$ & $8 / 9 / 20085: 50$ & 16.9 & 666.5 \\
\hline 1315 & $1 / 9 / 20085: 52$ & $8 / 9 / 20085: 52$ & 16.9 & 672.4 \\
\hline 1316 & $1 / 9 / 20085: 54$ & $8 / 9 / 20085: 54$ & 16.9 & 677 \\
\hline 1317 & $1 / 9 / 20085: 56$ & $8 / 9 / 20085: 56$ & 16.9 & 675.7 \\
\hline 1318 & $1 / 9 / 20085: 58$ & $8 / 9 / 20085: 58$ & 16.9 & 678.7 \\
\hline 1319 & 1/9/2008 6:00 & $8 / 9 / 20086: 00$ & 16.9 & 678.8 \\
\hline 1320 & 1/9/2008 6:02 & $8 / 9 / 20086: 02$ & 16.9 & 679.2 \\
\hline 1321 & $1 / 9 / 20086: 04$ & 8/9/2008 6:04 & 16.9 & 679.7 \\
\hline 1322 & 1/9/2008 6:06 & $8 / 9 / 20086: 06$ & 16.9 & 678.8 \\
\hline 1323 & 1/9/2008 6:08 & $8 / 9 / 20086: 08$ & 16.9 & 682.1 \\
\hline 1324 & 1/9/2008 6:10 & $8 / 9 / 20086: 10$ & 16.9 & 684.3 \\
\hline 1325 & $1 / 9 / 20086: 12$ & $8 / 9 / 20086: 12$ & 16.9 & 687.4 \\
\hline 1326 & $1 / 9 / 20086: 14$ & $8 / 9 / 20086: 14$ & 16.9 & 686.8 \\
\hline 1327 & 1/9/2008 6:16 & $8 / 9 / 20086: 16$ & 16.9 & 688.4 \\
\hline 1328 & $1 / 9 / 20086: 18$ & $8 / 9 / 20086: 18$ & 16.9 & 690.9 \\
\hline 1329 & $1 / 9 / 20086: 20$ & $8 / 9 / 20086: 20$ & 16.9 & 692.5 \\
\hline 1330 & 1/9/20086:22 & $8 / 9 / 20086: 22$ & 16.9 & 691.5 \\
\hline 1331 & $1 / 9 / 20086: 24$ & $8 / 9 / 20086: 24$ & 16.9 & 690.5 \\
\hline 1332 & $1 / 9 / 20086: 26$ & $8 / 9 / 20086: 26$ & 16.9 & 687.9 \\
\hline 1333 & $1 / 9 / 20086: 28$ & $8 / 9 / 20086: 28$ & 16.9 & 685.1 \\
\hline 1334 & $1 / 9 / 20086: 30$ & $8 / 9 / 20086: 30$ & 16.9 & 691.9 \\
\hline 1335 & $1 / 9 / 20086: 32$ & $8 / 9 / 20086: 32$ & 16.9 & 691.6 \\
\hline 1336 & $1 / 9 / 20086: 34$ & $8 / 9 / 20086: 34$ & 16.9 & 691.3 \\
\hline 1337 & $1 / 9 / 20086: 36$ & 8/9/2008 6:36 & 16.9 & 676.3 \\
\hline 1338 & $1 / 9 / 20086: 38$ & $8 / 9 / 20086: 38$ & 16.9 & 674.4 \\
\hline 1339 & $1 / 9 / 20086: 40$ & $8 / 9 / 20086: 40$ & 16.9 & 678.1 \\
\hline 1340 & $1 / 9 / 20086: 42$ & $8 / 9 / 20086: 42$ & 16.9 & 673 \\
\hline 1341 & $1 / 9 / 20086: 44$ & $8 / 9 / 20086: 44$ & 16.9 & 680.7 \\
\hline 1342 & $1 / 9 / 20086: 46$ & $8 / 9 / 20086: 46$ & 16.9 & 673.8 \\
\hline 1343 & $1 / 9 / 20086: 48$ & $8 / 9 / 20086: 48$ & 17 & 668.3 \\
\hline 1344 & $1 / 9 / 20086: 50$ & $8 / 9 / 20086: 50$ & 17 & 671.6 \\
\hline 1345 & $1 / 9 / 20086: 52$ & $8 / 9 / 20086: 52$ & 17 & 676.4 \\
\hline 1346 & $1 / 9 / 20086: 54$ & $8 / 9 / 20086: 54$ & 17 & 679.1 \\
\hline 1347 & $1 / 9 / 20086: 56$ & $8 / 9 / 20086: 56$ & 17 & 669 \\
\hline 1348 & $1 / 9 / 20086: 58$ & $8 / 9 / 20086: 58$ & 17 & 669.4 \\
\hline 1349 & $1 / 9 / 20087: 00$ & $8 / 9 / 20087: 00$ & 17 & 667.6 \\
\hline 1350 & $1 / 9 / 20087: 02$ & $8 / 9 / 20087: 02$ & 17 & 666.5 \\
\hline 1351 & $1 / 9 / 20087: 04$ & $8 / 9 / 20087: 04$ & 17 & 675.1 \\
\hline 1352 & 1/9/2008 7:06 & $8 / 9 / 20087: 06$ & 17 & 663.5 \\
\hline 1353 & $1 / 9 / 20087: 08$ & $8 / 9 / 20087: 08$ & 17 & 662.6 \\
\hline 1354 & $1 / 9 / 20087: 10$ & $8 / 9 / 20087: 10$ & 17 & 667.4 \\
\hline 1355 & 1/9/2008 7:12 & $8 / 9 / 20087: 12$ & 17 & 666.2 \\
\hline 1356 & $1 / 9 / 20087: 14$ & $8 / 9 / 20087: 14$ & 17 & 667.2 \\
\hline 1357 & $1 / 9 / 20087: 16$ & $8 / 9 / 20087: 16$ & 17 & 657.9 \\
\hline 1358 & $1 / 9 / 20087: 18$ & $8 / 9 / 20087: 18$ & 17 & 657.8 \\
\hline 1359 & $1 / 9 / 20087: 20$ & $8 / 9 / 20087: 20$ & 17 & 647.6 \\
\hline 1360 & 1/9/2008 7:22 & $8 / 9 / 20087: 22$ & 17 & 654.3 \\
\hline
\end{tabular}

\begin{tabular}{|c|c|c|c|c|}
\hline \multicolumn{5}{|c|}{ D4-92c } \\
\hline $\operatorname{Rec}$ & & Adjusted & Temp & SC \\
\hline$\#$ & Date/Time & DaterTime & ${ }^{\circ} \mathrm{C}$ & $\mu \mathrm{S} / \mathrm{cm}$ \\
\hline 1361 & $9 / 20087: 24$ & $8 / 9 / 20087: 24$ & 17 & 653.8 \\
\hline 1362 & $9 / 20087: 26$ & $8 / 9 / 20087: 26$ & 17 & 661.8 \\
\hline 1363 & $9 / 20087: 28$ & $8 / 9 / 20087: 28$ & 17 & 658.2 \\
\hline 1364 & 1/9/2008 7:30 & $8 / 9 / 20087: 30$ & 17 & 651.4 \\
\hline 1365 & $1 / 9 / 20087: 32$ & $8 / 9 / 20087: 32$ & 17 & 655.9 \\
\hline 1366 & $9 / 20087: 34$ & $8 / 9 / 20087: 34$ & 17 & 660.1 \\
\hline 1367 & 1/9/2008 7:36 & $8 / 9 / 20087: 36$ & 17 & 654. \\
\hline 1368 & $1 / 9 / 20087: 38$ & $8 / 9 / 20087: 38$ & 17 & 650.8 \\
\hline 1369 & $1 / 9 / 20087: 40$ & $8 / 9 / 20087: 40$ & 17 & 648.8 \\
\hline 1370 & $1 / 9 / 20087: 42$ & $8 / 9 / 20087: 42$ & 17. & 647.2 \\
\hline 1371 & $37: 44$ & $8 / 9 / 20087: 44$ & 17 & 647.8 \\
\hline 1372 & $9 / 20087: 46$ & $8 / 9 / 20087: 46$ & 17 & 640.7 \\
\hline 1373 & $9 / 20087: 48$ & $8 / 9 / 20087: 48$ & 17 & 642 \\
\hline 1374 & $7: 50$ & $8 / 9 / 20087: 50$ & 17 & 642.9 \\
\hline 1375 & $7: 52$ & $8 / 9 / 20087: 52$ & 17 & 638.5 \\
\hline 1376 & $7: 54$ & $8 / 9 / 20087: 54$ & 17 & 643 \\
\hline 1377 & $7: 56$ & $8 / 9 / 20087: 56$ & 17.1 & 643.7 \\
\hline 1378 & $7: 58$ & $8 / 9 / 20087: 58$ & 17.1 & 64 \\
\hline 1379 & 38:00 & $8 / 9 / 20088: 00$ & 17.1 & 639 \\
\hline 1380 & $8: 02$ & $8 / 9 / 20$ & 17.1 & 639.8 \\
\hline 1381 & $8: 04$ & $8 / 9 / 20$ & 17.1 & 642 \\
\hline 1382 & $8: 06$ & $8 / 9 / 20088: 06$ & 17.1 & 634. \\
\hline 1383 & $3: 08$ & $8 / 9 / 20$ & 17.1 & 639.7 \\
\hline 1384 & $8: 10$ & $8 / 9 / 20$ & 17.1 & \\
\hline 1385 & & $8 / 9 / 2$ & 17.1 & 638.4 \\
\hline 1386 & $3: 14$ & $8 / 9 / 20$ & 17.1 & 634.3 \\
\hline 1387 & $8: 16$ & $8 / 9 / 20088: 16$ & 17.1 & 632.4 \\
\hline 1388 & & $8 / 9 / 2$ & 17.1 & 627.2 \\
\hline 1389 & $8: 20$ & $8 / 9 / 20$ & 17.1 & 627. \\
\hline 1390 & $8: 22$ & $8 / 9 / 20$ & 17.1 & 626. \\
\hline 1391 & & $8 / 9 / 2$ & 17.1 & 626. \\
\hline 1392 & $8: 26$ & $8 / 9 / 20$ & 17.1 & 652. \\
\hline 1393 & & $8 / 9 / 20$ & 17.2 & 58 \\
\hline 1394 & $3: 30$ & $8 / 9 / 2$ & 17.2 & 589. \\
\hline 1395 & $8: \overline{32}$ & $8 / 9 / 2$ & $\overline{17.2}$ & 589. \\
\hline 1396 & & & 17.2 & 590. \\
\hline 1397 & $: 36$ & $8 / 9 / 2$ & 17.2 & 593. \\
\hline 1398 & & $8 / 9 / 20$ & 17.2 & 59 \\
\hline 1399 & & $8 / 9 / 2$ & 17.1 & 601. \\
\hline 1400 & & $8 / 9 / 20$ & 17.1 & 603. \\
\hline 1401 & & $8 / 9 / 20$ & 17.1 & 604.2 \\
\hline 1402 & & $8: 46$ & $\overline{17.2}$ & 613. \\
\hline 1403 & $3: 48$ & $8: 48$ & 17.2 & 611. \\
\hline 1404 & & & & 610. \\
\hline 1405 & & $8 / 9 / 2$ & 17.2 & 611. \\
\hline 1406 & & $8 / 9 / 20$ & 17.2 & 610. \\
\hline 1407 & & & 17.2 & 61 \\
\hline 1408 & & $8: 58$ & 17.2 & 620. \\
\hline 1409 & $9: 00$ & $8 / 9 / 20$ & 17.2 & 620. \\
\hline 1410 & & & & 622. \\
\hline 1411 & & $9: 04$ & & 614 \\
\hline 1412 & & & 17.2 & 620. \\
\hline$\overline{1413}$ & & $8 / 9 / 2$ & & \\
\hline 1414 & & $8 / 9 / 20$ & 17.2 & 592.5 \\
\hline 1415 & & & 17.2 & 576.2 \\
\hline 1416 & & $8 / 9 / 2$ & & 573. \\
\hline 1417 & $9: 16$ & $8 / 9 / 20$ & 17.3 & 572. \\
\hline$\overline{1418}$ & & & & 571. \\
\hline 1419 & & & & 565. \\
\hline 1420 & & $8 / 9 / 20$ & 17.3 & 56 \\
\hline & & & & \\
\hline 1422 & & $8 / 9 / 20$ & & 572. \\
\hline 1423 & & $39: 28$ & 17.3 & 57 \\
\hline 1424 & & & & \\
\hline 1425 & $89: 32$ & $8 / 9 / 20089: 32$ & 17.3 & 592 \\
\hline 1426 & $39: 34$ & $8 / 9 / 20089: 34$ & 17.3 & 603 \\
\hline 1427 & $1 / 9 / 2$ & $8 / 9 / 20$ & & 60 \\
\hline & $1 / 9 / 200$ & $8 / 9 / 20089: 38$ & $\overline{17.3}$ & 621 \\
\hline
\end{tabular}




\begin{tabular}{|c|c|c|c|c|}
\hline \multicolumn{5}{|c|}{ D4-92c } \\
\hline $\operatorname{Rec}$ & & Adjusted & Temp & $\mathrm{SC}$ \\
\hline \# & Date/Time & Date/Time & ${ }^{\circ} \mathrm{C}$ & $\mu \mathrm{S} / \mathrm{cm}$ \\
\hline 1429 & $1 / 9 / 20089: 40$ & $8 / 9 / 20089: 40$ & 17.3 & 635.8 \\
\hline 1430 & 1/9/20089:42 & $8 / 9 / 20089: 42$ & 17.3 & 642.4 \\
\hline 1431 & t/9/20089:44 & $8 / 9 / 20089: 44$ & 17.3 & 633.2 \\
\hline 1432 & 1/9/20089:46 & $8 / 9 / 20089: 46$ & 17.3 & 629 \\
\hline 1433 & $1 / 9 / 20089: 48$ & $8 / 9 / 20089: 48$ & 17.3 & 630.9 \\
\hline 1434 & $1 / 9 / 20089: 50$ & $8 / 9 / 20089: 50$ & 17.3 & 538 \\
\hline 1435 & $1 / 9 / 20089: 52$ & $8 / 9 / 20089: 52$ & 17.3 & 612.6 \\
\hline 1436 & 1/9/20089:54 & $8 / 9 / 20089: 54$ & 17.3 & 638.2 \\
\hline 1437 & 1/9/20089:56 & $8 / 9 / 20089: 56$ & 17.3 & 589.7 \\
\hline 1438 & $1 / 9 / 20089: 58$ & $8 / 9 / 20089: 58$ & 17.3 & 626.6 \\
\hline 1439 & $1 / 9 / 200810: 00$ & $8 / 9 / 200810: 00$ & 17.3 & 626.3 \\
\hline 1440 & $1 / 9 / 200810: 02$ & $8 / 9 / 200810: 02$ & 17.4 & 628.5 \\
\hline 1441 & 1/9/2008 10:04 & $8 / 9 / 2008$ 10:04 & 17.4 & 626.3 \\
\hline 1442 & 1/9/2008 10:06 & $8 / 9 / 2008$ 10:06 & 17.4 & 624.2 \\
\hline 1443 & 1/9/2008 10:08 & $8 / 9 / 2008$ 10:08 & 17.5 & 624.5 \\
\hline 1444 & 1/9/2008 10:10 & $8 / 9 / 200810: 10$ & 17.5 & 591.3 \\
\hline 1445 & 1/9/2008 10:12 & $8 / 9 / 2008$ 10:12 & 17.5 & 607.9 \\
\hline 1446 & $1 / 9 / 2008$ 10:14 & $8 / 9 / 2008$ 10:14 & 17.5 & 613.5 \\
\hline 1447 & 1/9/2008 10:16 & $8 / 9 / 2008$ 10:16 & 17.5 & 603.7 \\
\hline 1448 & 1/9/2008 10:18 & $8 / 9 / 200810: 18$ & 17.5 & 599.7 \\
\hline 1449 & $1 / 9 / 200810: 20$ & $8 / 9 / 2008$ 10:20 & 17.6 & 591.3 \\
\hline 1450 & $1 / 9 / 200810: 22$ & $8 / 9 / 2008$ 10:22 & 17.6 & 587 \\
\hline 1451 & $1 / 9 / 200810: 24$ & $8 / 9 / 2008$ 10:24 & 17.6 & 556.6 \\
\hline 1452 & $1 / 9 / 200810: 26$ & $8 / 9 / 2008$ 10:26 & 17.6 & 549.6 \\
\hline 1453 & 1/9/2008 10:28 & $8 / 9 / 2008$ 10:28 & 17.6 & 565.7 \\
\hline 1454 & 1/9/2008 10:30 & $8 / 9 / 2008$ 10:30 & 17.6 & 568.6 \\
\hline 1455 & 1/9/2008 10:32 & $8 / 9 / 2008$ 10:32 & 17.6 & 566.3 \\
\hline 1456 & 1/9/2008 10:34 & $8 / 9 / 2008$ 10:34 & 17.6 & 560.3 \\
\hline 1457 & 1/9/2008 10:36 & $8 / 9 / 2008$ 10:36 & 17.6 & 553.9 \\
\hline 1458 & $1 / 9 / 2008$ 10:38 & $8 / 9 / 2008$ 10:38 & 17.6 & 547.3 \\
\hline 1459 & $1 / 9 / 200810: 40$ & $8 / 9 / 2008$ 10:40 & 17.6 & 535.1 \\
\hline 1460 & 1/9/2008 10:42 & $8 / 9 / 2008$ 10:42 & 17.7 & 533.9 \\
\hline 1461 & $1 / 9 / 2008 \quad 10: 44$ & $8 / 9 / 2008$ 10:44 & 17.7 & 524.4 \\
\hline 1462 & $1 / 9 / 2008 \quad 10: 46$ & $8 / 9 / 2008$ 10:46 & 17.7 & 526.4 \\
\hline 1463 & $1 / 9 / 200810: 48$ & $8 / 9 / 200810: 48$ & 17.7 & 518.9 \\
\hline 1464 & 1/9/2008 10:50 & $8 / 9 / 2008$ 10:50 & 17.7 & 517.6 \\
\hline 1465 & $1 / 9 / 200810: 52$ & $8 / 9 / 2008$ 10:52 & 17.7 & 510.9 \\
\hline 1466 & 1/9/2008 10:54 & $8 / 9 / 2008$ 10:54 & 17.7 & 511.5 \\
\hline 1467 & 1/9/2008 10:56 & $8 / 9 / 2008$ 10:56 & 17.7 & 509.6 \\
\hline 1468 & 1/9/2008 10:58 & $8 / 9 / 2008$ 10:58 & 17.7 & 502.9 \\
\hline 1469 & 1/9/2008 11:00 & $8 / 9 / 2008$ 11:00 & 17.8 & 502.9 \\
\hline 1470 & 1/9/2008 11:02 & $8 / 9 / 200811: 02$ & 17.8 & 501.7 \\
\hline 1471 & 1/9/2008 11:04 & $8 / 9 / 200811: 04$ & 17.7 & 498.1 \\
\hline 1472 & 1/9/2008 11:06 & $8 / 9 / 200811: 06$ & 17.8 & 493.8 \\
\hline 1473 & 1/9/2008 11:08 & $8 / 9 / 200811: 08$ & 17.8 & 498.7 \\
\hline 1474 & 1/9/2008 11:10 & $8 / 9 / 200811: 10$ & 17.7 & 492.6 \\
\hline 1475 & 1/9/2008 11:12 & $8 / 9 / 2008$ 11:12 & 17.8 & 487 \\
\hline 1476 & 1/9/2008 11:14 & $8 / 9 / 2008$ 11:14 & 17.8 & 491.7 \\
\hline 1477 & 1/9/2008 11:16 & 8/9/2008 11:16 & 17.8 & 494.2 \\
\hline 1478 & 1/9/2008 11:18 & $8 / 9 / 2008$ 11:18 & 17.8 & 490 \\
\hline 1479 & $1 / 9 / 2008$ 11:20 & $8 / 9 / 2008$ 11:20 & 17.8 & 490.9 \\
\hline 1480 & 1/9/2008 11:22 & $8 / 9 / 200811: 22$ & 17.8 & 493.8 \\
\hline 1481 & $1 / 9 / 2008$ 11:24 & $8 / 9 / 200811: 24$ & 17.8 & 493.7 \\
\hline 1482 & 1/9/2008 11:26 & $8 / 9 / 2008$ 11:26 & 17.8 & 497.9 \\
\hline 1483 & 1/9/2008 11:28 & $8 / 9 / 200811: 28$ & 17.8 & 492.4 \\
\hline 1484 & 1/9/2008 11:30 & $8 / 9 / 2008$ 11:30 & 17.8 & 493.9 \\
\hline 1485 & 1/9/2008 11:32 & $8 / 9 / 2008$ 11:32 & 17.8 & 490.9 \\
\hline 1486 & 1/9/2008 11:34 & $8 / 9 / 200811: 34$ & 17.8 & 492.1 \\
\hline 1487 & 1/9/2008 11:36 & $8 / 9 / 200811: 36$ & 17.8 & 487.3 \\
\hline 1488 & $1 / 9 / 2008$ 11:38 & $8 / 9 / 200811: 38$ & 17.8 & 486.9 \\
\hline 1489 & 1/9/2008 11:40 & $8 / 9 / 200811: 40$ & 17.8 & 486.8 \\
\hline 1490 & $1 / 9 / 200811: 42$ & $8 / 9 / 200811: 42$ & 17.8 & 486.2 \\
\hline 1491 & 1/9/2008 11:44 & $8 / 9 / 200811: 44$ & 17.8 & 486.7 \\
\hline 1492 & 1/9/2008 11:46 & $8 / 9 / 200811: 46$ & 17.8 & 484.4 \\
\hline 1493 & 1/9/2008 11:48 & $8 / 9 / 2008$ 11:48 & 17.8 & 483.8 \\
\hline 1494 & 1/9/2008 11:50 & $8 / 9 / 200811: 50$ & 17.8 & 482.9 \\
\hline 1495 & 1/9/2008 11:52 & $8 / 9 / 2008$ 11:52 & 17.8 & 482.1 \\
\hline 1496 & 1/9/2008 11:54 & $8 / 9 / 2008$ 11:54 & 17.9 & 481.2 \\
\hline
\end{tabular}

\begin{tabular}{|c|c|c|c|c|}
\hline \multicolumn{5}{|c|}{ D4-92c } \\
\hline $\operatorname{Rec}$ & & Adjusted & Temp & $\mathrm{SC}$ \\
\hline$\#$ & Date/Time & Date/Time & ${ }^{\circ} \mathrm{C}$ & $\mu \mathrm{S} / \mathrm{cm}$ \\
\hline 1497 & $1 / 9 / 200811: 56$ & $8 / 9 / 200811: 56$ & 17.9 & 476.5 \\
\hline 1498 & $1 / 9 / 200811: 58$ & $8 / 9 / 200811: 58$ & 17.9 & 473.1 \\
\hline 1499 & $1 / 9 / 200812: 00$ & $8 / 9 / 200812: 00$ & 18 & 465 \\
\hline 1500 & $1 / 9 / 200812: 02$ & $8 / 9 / 200812: 02$ & 18 & 471.7 \\
\hline 1501 & 1/9/2008 12:04 & $8 / 9 / 200812: 04$ & 18 & 473.2 \\
\hline 1502 & $1 / 9 / 200812: 06$ & $8 / 9 / 200812: 06$ & 18 & 481.5 \\
\hline 1503 & $1 / 9 / 200812: 08$ & $8 / 9 / 200812: 08$ & 18 & 476.2 \\
\hline 1504 & 1/9/2008 12:10 & $8 / 9 / 200812: 10$ & 18 & 478.4 \\
\hline 1505 & $1 / 9 / 200812: 12$ & $8 / 9 / 200812: 12$ & 18 & 479 \\
\hline 1506 & 1/9/2008 12:14 & $8 / 9 / 200812: 14$ & 17.9 & 478.4 \\
\hline 1507 & 1/9/2008 12:16 & $8 / 9 / 200812: 16$ & 17.9 & 479.4 \\
\hline 1508 & 1/9/2008 12:18 & $8 / 9 / 200812: 18$ & 17.9 & 478.3 \\
\hline 1509 & 1/9/2008 12:20 & $8 / 9 / 200812: 20$ & 17.9 & 477.9 \\
\hline 1510 & 1/9/2008 12:22 & $8 / 9 / 200812: 22$ & 17.9 & 477.1 \\
\hline 1511 & $1 / 9 / 200812: 24$ & $8 / 9 / 200812: 24$ & 17.9 & 476.8 \\
\hline 1512 & $1 / 9 / 200812: 26$ & $8 / 9 / 2008$ 12:26 & 17.9 & 476.3 \\
\hline 1513 & $1 / 9 / 200812: 28$ & $8 / 9 / 200812: 28$ & 17.9 & 475.5 \\
\hline 1514 & 1/9/2008 12:30 & $8 / 9 / 200812: 30$ & 17.9 & 473.8 \\
\hline 1515 & $1 / 9 / 200812: 32$ & $8 / 9 / 200812: 32$ & 17.9 & 472.4 \\
\hline 1516 & $1 / 9 / 200812: 34$ & $8 / 9 / 200812: 34$ & 17.9 & 472.5 \\
\hline 1517 & 1/9/2008 12:36 & $8 / 9 / 200812: 36$ & 18 & 472.2 \\
\hline 1518 & $1 / 9 / 200812: 38$ & $8 / 9 / 200812: 38$ & 17.9 & 471.2 \\
\hline 1519 & $1 / 9 / 200812: 40$ & $8 / 9 / 200812: 40$ & 18 & 470.4 \\
\hline 1520 & $1 / 9 / 2008+2: 42$ & $8 / 9 / 200812: 42$ & 18 & 469 \\
\hline 1521 & $1 / 9 / 2008 \quad 12: 44$ & $8 / 9 / 200812: 44$ & 18 & 468.1 \\
\hline 1522 & $1 / 9 / 200812: 46$ & $8 / 9 / 200812: 46$ & 18 & 467.7 \\
\hline 1523 & $1 / 9 / 200812: 48$ & $8 / 9 / 200812: 48$ & 18 & 467.6 \\
\hline 1524 & $1 / 9 / 200812: 50$ & $8 / 9 / 2008$ 12:50 & 18 & 466.5 \\
\hline 1525 & 1/9/2008 12:52 & $8 / 9 / 200812: 52$ & 18 & 465.8 \\
\hline 1526 & $1 / 9 / 200812: 54$ & $8 / 9 / 2008$ 12:54 & 18 & 465 \\
\hline 1527 & $1 / 9 / 200812: 56$ & $8 / 9 / 2008$ 12:56 & 18 & 463.7 \\
\hline 1528 & $1 / 9 / 200812: 58$ & $8 / 9 / 200812: 58$ & 18 & 463.3 \\
\hline 1529 & $1 / 9 / 2008+3: 00$ & $8 / 9 / 2008$ 13:00 & 18 & 462.6 \\
\hline 1530 & $1 / 9 / 200813: 02$ & $8 / 9 / 200813: 02$ & 18 & 461.4 \\
\hline 1531 & $1 / 9 / 200813: 04$ & $8 / 9 / 200813: 04$ & 18.1 & 460.7 \\
\hline 1532 & 1/9/2008 13:06 & $8 / 9 / 200813: 06$ & 18.1 & 459.5 \\
\hline 1533 & 1/9/2008 13:08 & $8 / 9 / 200813: 08$ & 18.1 & 459 \\
\hline 1534 & 1/9/2008 13:10 & $8 / 9 / 200813: 10$ & 18.1 & 458.5 \\
\hline 1535 & 1/9/2008 13:12 & $8 / 9 / 200813: 12$ & 18.1 & 458 \\
\hline 1536 & 1/9/2008 13:14 & $8 / 9 / 200813: 14$ & 18.1 & 457.2 \\
\hline 1537 & 1/9/2008 13:16 & $8 / 9 / 2008$ 13:16 & 18.1 & 457.2 \\
\hline 1538 & 1/9/2008 13:18 & $8 / 9 / 200813: 18$ & 18.1 & 455.3 \\
\hline 1539 & $1 / 9 / 200813: 20$ & $8 / 9 / 200813: 20$ & 18.1 & 454.9 \\
\hline 1540 & $1 / 9 / 200813: 22$ & $8 / 9 / 200813: 22$ & 18.1 & 454 \\
\hline 1541 & $1 / 9 / 200813: 24$ & $8 / 9 / 200813: 24$ & 18.1 & 453 \\
\hline 1542 & 1/9/2008 13:26 & $8 / 9 / 200813: 26$ & 18.1 & 452.8 \\
\hline 1543 & $1 / 9 / 200813: 28$ & $8 / 9 / 200813: 28$ & 18.1 & 451.7 \\
\hline 1544 & 1/9/2008 13:30 & $8 / 9 / 2008$ 13:30 & 18 & 463.4 \\
\hline 1545 & 1/9/2008 13:32 & $8 / 9 / 200813: 32$ & 18.1 & 449.6 \\
\hline 1546 & 1/9/2008 13:34 & $8 / 9 / 200813: 34$ & 18.1 & 451.9 \\
\hline 1547 & 1/9/2008 13:36 & $8 / 9 / 200813: 36$ & 18.1 & 458 \\
\hline 1548 & 1/9/2008 13:38 & $8 / 9 / 200813: 38$ & 18 & 455.7 \\
\hline 1549 & $1 / 9 / 2008$ 13:40 & $8 / 9 / 200813: 40$ & 18 & 460.7 \\
\hline 1550 & $1 / 9 / 2008$ 13:42 & $8 / 9 / 200813: 42$ & 18 & 460.9 \\
\hline 1551 & $1 / 9 / 2008 \quad 13: 44$ & $8 / 9 / 200813: 44$ & 18.1 & 442.6 \\
\hline 1552 & 1/9/2008 13:46 & $8 / 9 / 200813: 46$ & 18.1 & 440.8 \\
\hline 1553 & 1/9/2008 13:48 & $8 / 9 / 200813: 48$ & 18.1 & 455.2 \\
\hline 1554 & 1/9/2008 13:50 & $8 / 9 / 200813: 50$ & 18.1 & 453.9 \\
\hline 1555 & 1/9/2008 13:52 & $8 / 9 / 200813: 52$ & 18.1 & 454.8 \\
\hline 1556 & $1 / 9 / 2008$ 13:54 & $8 / 9 / 200813: 54$ & 18.2 & 453 \\
\hline 1557 & 1/9/2008 13:56 & $8 / 9 / 200813: 56$ & 18.2 & 452.8 \\
\hline 1558 & 1/9/2008 13:58 & $8 / 9 / 200813: 58$ & 18.2 & 451.1 \\
\hline 1559 & 1/9/2008 14:00 & $8 / 9 / 200814: 00$ & 18.2 & 450.7 \\
\hline 1560 & $1 / 9 / 2008$ 14:02 & $8 / 9 / 200814: 02$ & 18.2 & 448.7 \\
\hline 1561 & $1 / 9 / 2008 \quad 14: 04$ & $8 / 9 / 2008$ 14:04 & 18.3 & 446.7 \\
\hline 1562 & 1/9/2008 14:06 & $8 / 9 / 200814: 06$ & 18.3 & 447.3 \\
\hline 1563 & 1/9/2008 14:08 & $8 / 9 / 2008$ 14:08 & 18.3 & 445.7 \\
\hline 1564 & 1/9/2008 14:10 & $8 / 9 / 200814: 10$ & 18.3 & 448 \\
\hline
\end{tabular}

\begin{tabular}{|c|c|c|c|c|}
\hline \multicolumn{5}{|c|}{ D4-92c } \\
\hline $\operatorname{Rec}$ & & Adjusted & Temp & SC \\
\hline \# & Date/Time & Date/Time & ${ }^{\circ} \mathrm{C}$ & $\mu \mathrm{S} / \mathrm{cm}$ \\
\hline 1565 & $1 / 9 / 2008$ 14:12 & $8 / 9 / 2008$ 14:12 & 18.3 & 445.7 \\
\hline 1566 & 1/9/2008 14:14 & $8 / 9 / 2008$ 14:14 & 18.3 & 448.1 \\
\hline 1567 & $1 / 9 / 200814: 16$ & $8 / 9 / 200814: 16$ & 18.3 & 445 \\
\hline 1568 & $1 / 9 / 200814: 18$ & $8 / 9 / 200814: 18$ & 18.3 & 442.7 \\
\hline 1569 & $1 / 9 / 200814: 20$ & $8 / 9 / 2008$ 14:20 & 18.3 & 445 \\
\hline 1570 & $1 / 9 / 2008$ 14:22 & $8 / 9 / 2008$ 14:22 & 18.3 & 447.5 \\
\hline 1571 & $1 / 9 / 2008$ 14:24 & $8 / 9 / 2008$ 14:24 & 18.3 & 443.7 \\
\hline 1572 & $1 / 9 / 200814: 26$ & $8 / 9 / 200814: 26$ & 18.3 & 443.1 \\
\hline 1573 & $1 / 9 / 200814: 28$ & $8 / 9 / 2008$ 14:28 & 18.3 & 447.1 \\
\hline 1574 & $1 / 9 / 200814: 30$ & $8 / 9 / 2008$ 14:30 & 18.3 & 450 \\
\hline 1575 & $1 / 9 / 2008$ 14:32 & $8 / 9 / 2008$ 14:32 & 18.3 & 446.5 \\
\hline 1576 & $1 / 9 / 200814: 34$ & $8 / 9 / 2008$ 14:34 & 18.3 & 447.5 \\
\hline 1577 & $1 / 9 / 200814: 36$ & $8 / 9 / 200814: 36$ & 18.3 & 441.5 \\
\hline 1578 & $1 / 9 / 200814: 38$ & $8 / 9 / 2008$ 14:38 & 18.3 & 442.3 \\
\hline 1579 & $1 / 9 / 200814: 40$ & $8 / 9 / 200814: 40$ & 18.4 & 440.7 \\
\hline 1580 & $1 / 9 / 200814: 42$ & $8 / 9 / 200814: 42$ & 18.4 & 445.3 \\
\hline 1581 & $1 / 9 / 200814: 44$ & $8 / 9 / 2008$ 14:44 & 18.4 & 448.4 \\
\hline 1582 & 1/9/2008 14:46 & $8 / 9 / 2008$ 14:46 & 18.4 & 445.2 \\
\hline 1583 & $1 / 9 / 200814: 48$ & $8 / 9 / 2008$ 14:48 & 18.2 & 432.6 \\
\hline 1584 & $1 / 9 / 200814: 50$ & $8 / 9 / 2008$ 14:50 & 18.3 & 434.8 \\
\hline 1585 & $1 / 9 / 200814: 52$ & $8 / 9 / 200814: 52$ & 18.3 & 436.7 \\
\hline 1586 & $1 / 9 / 2008$ 14:54 & $8 / 9 / 2008$ 14:54 & 18.3 & 441.7 \\
\hline 1587 & $1 / 9 / 200814: 56$ & $8 / 9 / 2008 \quad 14: 56$ & 18.3 & 456.1 \\
\hline 1588 & $1 / 9 / 2008 \quad 14: 58$ & $8 / 9 / 200814: 58$ & 18.3 & 475.9 \\
\hline 1589 & $1 / 9 / 2008$ 15:00 & $8 / 9 / 200815: 00$ & 18.4 & 486.9 \\
\hline 1590 & $1 / 9 / 2008$ 15:02 & $8 / 9 / 200815: 02$ & 18.5 & 491.6 \\
\hline 1591 & $1 / 9 / 2008$ 15:04 & $8 / 9 / 2008$ 15:04 & 18.5 & 491.3 \\
\hline 1592 & $1 / 9 / 2008$ 15:06 & $8 / 9 / 200815: 06$ & 18.5 & 475.1 \\
\hline 1593 & 1/9/2008 15:08 & $8 / 9 / 2008$ 15:08 & 18.5 & 458 \\
\hline 1594 & $1 / 9 / 200815: 10$ & $8 / 9 / 200815: 10$ & 18.4 & 452.6 \\
\hline 1595 & 1/9/2008 15:12 & $8 / 9 / 2008$ 15:12 & 18.4 & 456.4 \\
\hline 1596 & $1 / 9 / 2008$ 15:14 & $8 / 9 / 2008$ 15:14 & 18.4 & 460.9 \\
\hline 1597 & 1/9/2008 15:16 & $8 / 9 / 200815: 16$ & 18.4 & 459.3 \\
\hline 1598 & $t / 9 / 2008$ 15:18 & $8 / 9 / 200815: 18$ & 18.4 & 453.2 \\
\hline 1599 & $1 / 9 / 200815: 20$ & $8 / 9 / 200815: 20$ & 18.4 & 452.7 \\
\hline 1600 & 1/9/2008 15:22 & $8 / 9 / 200815: 22$ & 18.4 & 456.2 \\
\hline 1601 & $1 / 9 / 2008$ 15:24 & $8 / 9 / 200815: 24$ & 18.4 & 461.5 \\
\hline 1602 & $1 / 9 / 200815: 26$ & $8 / 9 / 200815: 26$ & 18.4 & 451.4 \\
\hline 1603 & $1 / 9 / 2008$ 15:28 & $8 / 9 / 200815: 28$ & 18.4 & 456.7 \\
\hline 1604 & $1 / 9 / 2008$ 15:30 & $8 / 9 / 2008$ 15:30 & 18.5 & 449.6 \\
\hline 1605 & 1/9/2008 15:32 & $8 / 9 / 2008$ 15:32 & 18.5 & 450.2 \\
\hline 1606 & 1/9/2008 15:34 & $8 / 9 / 2008$ 15:34 & 18.4 & 451.3 \\
\hline 1607 & $1 / 9 / 20081$ & $8 / 9 / 2008$ 15:36 & 18.5 & 479.5 \\
\hline 1608 & 1/9/2008 15:38 & $8 / 9 / 200815: 38$ & 18.5 & 452.7 \\
\hline 1609 & $1 / 9 / 200815: 40$ & $8 / 9 / 200815: 40$ & 18.5 & 448.8 \\
\hline 1610 & $1 / 9 / 2008$ 15:42 & $8 / 9 / 200815: 42$ & 18.5 & 450.2 \\
\hline 1611 & $1 / 9 / 200815: 44$ & $8 / 9 / 200815: 44$ & 18.5 & 455.1 \\
\hline 1612 & $1 / 9 / 200815: 46$ & $8 / 9 / 2008$ 15:46 & 18.5 & 450.8 \\
\hline 1613 & $1 / 9 / 2008$ 15:48 & $8 / 9 / 2008$ 15:48 & 18.5 & 443.1 \\
\hline 1614 & 1/9/2008 15:50 & $8 / 9 / 200815: 50$ & 18.5 & 449.3 \\
\hline 1615 & 1/9/2008 15:52 & $8 / 9 / 2008$ 15:52 & 18.5 & 460 \\
\hline 1616 & $1 / 9 / 2008$ 15:54 & $8 / 9 / 2008$ 15:54 & 18.5 & 461.4 \\
\hline 1617 & $1 / 9 / 2008$ 15:56 & $8 / 9 / 2008$ 15:56 & 18.5 & 460.7 \\
\hline 1618 & $1 / 9 / 200815: 58$ & $8 / 9 / 2008+5: 58$ & 18.5 & 456.4 \\
\hline 1619 & $1 / 9 / 2008$ 16:00 & $8 / 9 / 2008$ 16:00 & 18.5 & 459.8 \\
\hline 1620 & 1/9/2008 16:02 & $8 / 9 / 2008$ 16:02 & 18.5 & 454.3 \\
\hline 1621 & 1/9/2008 16:04 & $8 / 9 / 2008$ 16:04 & 18.5 & 457.3 \\
\hline 1622 & 1/9/2008 16:06 & $8 / 9 / 200816: 06$ & 18.5 & 449.2 \\
\hline 1623 & 1/9/2008 16:08 & $8 / 9 / 2008$ 16:08 & 18.5 & 450.4 \\
\hline 1624 & 1/9/2008 16:10 & $8 / 9 / 200816: 10$ & 18.6 & 450.8 \\
\hline 1625 & 1/9/2008 16:12 & $8 / 9 / 2008$ 16:12 & 18.6 & 454.3 \\
\hline 1626 & 1/9/2008 16:14 & $8 / 9 / 2008$ 16:14 & 18.6 & 466 \\
\hline 1627 & 1/9/2008 16:16 & $8 / 9 / 200816: 16$ & 18.6 & 458.1 \\
\hline 1628 & 1/9/2008 16:18 & $8 / 9 / 200816: 18$ & 18.6 & 466.8 \\
\hline 1629 & $1 / 9 / 200816: 20$ & $8 / 9 / 200816: 20$ & 18.6 & 468.1 \\
\hline 1630 & $1 / 9 / 200816: 22$ & $8 / 9 / 2008$ 16:22 & 18.6 & 465.3 \\
\hline 1631 & $1 / 9 / 2008$ 16:24 & $8 / 9 / 2008$ 16:24 & 18.6 & 460.1 \\
\hline 1632 & $1 / 9 / 200816: 26$ & $8 / 9 / 200816: 26$ & 18.6 & 462.7 \\
\hline
\end{tabular}


DOE/RL-2009-35, REV. 0

\begin{tabular}{|c|c|c|c|c|}
\hline \multicolumn{5}{|c|}{ D4-92c } \\
\hline $\operatorname{Rec}$ & & Adjusted & Temp & $\mathrm{SC}$ \\
\hline$\#$ & Date/Time & Date/Time & ${ }^{\circ} \mathrm{C}$ & $\mu \mathrm{S} / \mathrm{cm}$ \\
\hline 1633 & $1 / 9 / 200816: 28$ & $8 / 9 / 2008$ 16:28 & 18.6 & 462.9 \\
\hline 1634 & 1/9/2008 16:30 & $8 / 9 / 200816: 30$ & 18.7 & 464.9 \\
\hline 1635 & 1/9/2008 16:32 & $8 / 9 / 2008$ 16:32 & 18.7 & 463.3 \\
\hline 1636 & $1 / 9 / 200816: 34$ & $8 / 9 / 2008$ 16:34 & 18.7 & 461.4 \\
\hline 1637 & 1/9/2008 16:36 & $8 / 9 / 2008$ 16:36 & 18.7 & 463.3 \\
\hline 1638 & 1/9/2008 16:38 & $8 / 9 / 200816: 38$ & 18.7 & 457.9 \\
\hline 1639 & $1 / 9 / 200816: 40$ & $8 / 9 / 2008$ 16:40 & 18.7 & 457.1 \\
\hline 1640 & $1 / 9 / 200816: 42$ & $8 / 9 / 2008$ 16:42 & 18.7 & 457.9 \\
\hline 1641 & $1 / 9 / 200816: 44$ & $8 / 9 / 2008$ 16:44 & 18.7 & 458.1 \\
\hline 1642 & $1 / 9 / 2008 \quad 16: 46$ & $8 / 9 / 200816: 46$ & 18.7 & 459.1 \\
\hline 1643 & $1 / 9 / 200816: 48$ & $8 / 9 / 2008$ 16:48 & 18.7 & 459.9 \\
\hline 1644 & 1/9/2008 16:50 & $8 / 9 / 200816: 50$ & 18.7 & 457.5 \\
\hline 1645 & $1 / 9 / 200816: 52$ & $8 / 9 / 2008$ 16:52 & 18.8 & 459.8 \\
\hline 1646 & $1 / 9 / 200816: 54$ & $8 / 9 / 200816: 54$ & 18.8 & 458.8 \\
\hline 1647 & $1 / 9 / 200816: 56$ & $8 / 9 / 200816: 56$ & 18.8 & 457.3 \\
\hline 1648 & $1 / 9 / 200816: 58$ & $8 / 9 / 2008$ 16:58 & 18.8 & 461.1 \\
\hline 1649 & 1/9/2008 17:00 & $8 / 9 / 200817: 00$ & 18.8 & 462.2 \\
\hline 1650 & 1/9/2008 17:02 & $8 / 9 / 2008$ 17:02 & 18.8 & 466.4 \\
\hline 1651 & $1 / 9 / 200817: 04$ & $8 / 9 / 200817: 04$ & 18.8 & 462.5 \\
\hline 1652 & 1/9/2008 17:06 & $8 / 9 / 2008$ 17:06 & 18.8 & 464.2 \\
\hline 1653 & 1/9/2008 17:08 & $8 / 9 / 200817: 08$ & 18.8 & 461.3 \\
\hline 1654 & $1 / 9 / 2008$ 17:10 & $8 / 9 / 200817: 10$ & 18.9 & 458.6 \\
\hline 1655 & $1 / 9 / 2008$ 17:12 & $8 / 9 / 2008$ 17:12 & 18.9 & 457.7 \\
\hline 1656 & $1 / 9 / 200817: 14$ & $8 / 9 / 200817: 14$ & 18.9 & 456.9 \\
\hline 1657 & $1 / 9 / 2008 \quad 17: 16$ & $8 / 9 / 200817: 16$ & 18.9 & 455.6 \\
\hline 1658 & $1 / 9 / 200817: 18$ & $8 / 9 / 2008$ 17:18 & 18.9 & 455.4 \\
\hline 1659 & $1 / 9 / 200817: 20$ & $8 / 9 / 2008$ 17:20 & 18.8 & 474.1 \\
\hline 1660 & $1 / 9 / 2008$ 17:22 & $8 / 9 / 200817: 22$ & 18.9 & 433.1 \\
\hline 1661 & $1 / 9 / 200817: 24$ & $8 / 9 / 2008$ 17:24 & 19 & 441.4 \\
\hline 1662 & 1/9/2008 17:26 & $8 / 9 / 2008$ 17:26 & 19 & 447 \\
\hline 1663 & $1 / 9 / 200817: 28$ & $8 / 9 / 2008$ 17:28 & 19 & 448.2 \\
\hline 1664 & $1 / 9 / 200817: 30$ & $8 / 9 / 200817: 30$ & 19 & 441.6 \\
\hline 1665 & $1 / 9 / 200817: 32$ & $8 / 9 / 2008$ 17:32 & 19 & 442.5 \\
\hline 1666 & $1 / 9 / 200817: 34$ & $8 / 9 / 2008$ 17:34 & 19 & 447.4 \\
\hline t667 & $1 / 9 / 200817: 36$ & $8 / 9 / 2008$ 17:36 & 19 & 447.8 \\
\hline 1668 & $1 / 9 / 200817: 38$ & $8 / 9 / 2008$ 17:38 & 19.1 & 446.1 \\
\hline 1669 & $1 / 9 / 2008 \quad 17: 40$ & $8 / 9 / 2008$ 17:40 & 19 & 447.9 \\
\hline 1670 & $1 / 9 / 2008 \quad 17: 42$ & $8 / 9 / 2008$ 17:42 & 19.1 & 447.4 \\
\hline 1671 & $1 / 9 / 200817: 44$ & $8 / 9 / 2008 \quad 17: 44$ & 19.1 & 450.6 \\
\hline 1672 & 1/9/2008 17:46 & $8 / 9 / 2008 \quad 17: 46$ & 19.1 & 489.1 \\
\hline 1673 & $1 / 9 / 2008 \quad 17: 48$ & $8 / 9 / 2008$ 17:48 & 19.2 & 498 \\
\hline 1674 & $1 / 9 / 2008 \quad 17: 50$ & $8 / 9 / 2008$ 17:50 & 19.2 & 524 \\
\hline 1675 & $1 / 9 / 200817: 52$ & $8 / 9 / 200817: 52$ & 19.3 & 531.2 \\
\hline 1676 & $1 / 9 / 2008 \quad 17: 54$ & $8 / 9 / 2008$ 17:54 & 19.4 & 532.8 \\
\hline 1677 & $1 / 9 / 2008 \quad 17: 56$ & $8 / 9 / 200017: 56$ & 19.4 & 533.1 \\
\hline 1678 & $1 / 9 / 200817: 58$ & $8 / 9 / 200817: 58$ & 19.4 & 533.6 \\
\hline 1679 & $1 / 9 / 200818: 00$ & $8 / 9 / 200818: 00$ & 19.4 & 531.2 \\
\hline 1680 & $1 / 9 / 2008$ 18:02 & $8 / 9 / 2008$ 18:02 & 19.4 & 527.5 \\
\hline 1681 & $1 / 9 / 200818: 04$ & $8 / 9 / 2008$ 18:04 & 19.3 & 485.1 \\
\hline 1682 & 1/9/2008 18:06 & 8/9/2008 18:06 & 19.2 & 412.5 \\
\hline 1683 & 1/9/2008 18:08 & 8/9/2008 18:08 & 19.1 & 406.3 \\
\hline 1684 & $1 / 9 / 2008$ 18:10 & $8 / 9 / 2008$ 18:10 & 19.2 & 494.2 \\
\hline 1685 & $1 / 9 / 200818: 12$ & $8 / 9 / 200818: 12$ & 19.3 & 494.6 \\
\hline 1686 & $1 / 9 / 200818: 14$ & $8 / 9 / 200818: 14$ & 19.3 & 480.9 \\
\hline 1687 & 1/9/2008 18:16 & $8 / 9 / 200818: 16$ & 19.2 & 467.3 \\
\hline 1688 & 1/9/2008 18:18 & $8 / 9 / 2008$ 18:18 & 19.2 & 428.7 \\
\hline 1689 & $1 / 9 / 200818: 20$ & $8 / 9 / 200818: 20$ & 19.2 & 440.8 \\
\hline 1690 & 1/9/2008 18:22 & $8 / 9 / 200818.22$ & 19.2 & 451.7 \\
\hline 1691 & $1 / 9 / 200818: 24$ & $8 / 9 / 200818: 24$ & 19.3 & 456.7 \\
\hline 1692 & $1 / 9 / 200818: 26$ & $8 / 9 / 200818: 26$ & 19.3 & 454.6 \\
\hline 1693 & $1 / 9 / 2008$ 18:28 & $8 / 9 / 2008$ 18:28 & 19.3 & 450.6 \\
\hline 1694 & $1 / 9 / 200818: 30$ & $8 / 9 / 2008$ 18:30 & 19.4 & 451.4 \\
\hline 1695 & 1/9/2008 18:32 & $8 / 9 / 200818: 32$ & 19.4 & 449.5 \\
\hline 1696 & $1 / 9 / 200818: 34$ & $8 / 9 / 200818: 34$ & 19.4 & 453.5 \\
\hline 1697 & $1 / 9 / 200818: 36$ & $8 / 9 / 200818: 36$ & 19.4 & 441.9 \\
\hline 1698 & $1 / 9 / 200818: 38$ & $8 / 9 / 2008$ 18:38 & 19.5 & 450.7 \\
\hline 1699 & $1 / 9 / 200818: 40$ & $8 / 9 / 2008$ 18:40 & 19.5 & 444.3 \\
\hline 1700 & $1 / 9 / 2008$ 18:42 & $8 / 9 / 2008$ 18:42 & 19.5 & 436.9 \\
\hline
\end{tabular}

\begin{tabular}{|c|c|c|c|c|}
\hline \multicolumn{5}{|c|}{ D492c } \\
\hline $\operatorname{Rec}$ & & Adjusted & Temp & $\mathrm{SC}$ \\
\hline$\#$ & Date/Time & DaterTime & ${ }^{\circ} \mathrm{C}$ & $\mu \mathrm{S} / \mathrm{cm}$ \\
\hline 1701 & 1/9/2008 18:44 & $8 / 9 / 2008$ 18:44 & 19.5 & 446.4 \\
\hline 1702 & 1/9/2008 18:46 & $8 / 9 / 200818: 46$ & 19.5 & 441.2 \\
\hline 1703 & $1 / 9 / 2008 \quad 18: 48$ & $8 / 9 / 200818: 48$ & 19.5 & 433.6 \\
\hline 1704 & $1 / 9 / 200818: 50$ & $8 / 9 / 200818: 50$ & 19.5 & 428.8 \\
\hline 1705 & $1 / 9 / 200818: 52$ & $8 / 9 / 200818: 52$ & 19.6 & 426.9 \\
\hline 1706 & $1 / 9 / 200818: 54$ & $8 / 9 / 2008$ 18:54 & 19.6 & 421.2 \\
\hline 1707 & $1 / 9 / 200818: 56$ & $8 / 9 / 2008$ 18:56 & 19.6 & 417.7 \\
\hline 1708 & $1 / 9 / 200818: 58$ & $8 / 9 / 200818: 58$ & 19.6 & 413.9 \\
\hline 1709 & $1 / 9 / 200819: 00$ & $8 / 9 / 200819: 00$ & 19.6 & 412.4 \\
\hline 1710 & $1 / 9 / 200819: 02$ & $8 / 9 / 200819: 02$ & 19.6 & 410.7 \\
\hline 1711 & $1 / 9 / 200819: 04$ & $8 / 9 / 200819: 04$ & 19.6 & 410.8 \\
\hline 1712 & $1 / 9 / 2008$ 19:06 & $8 / 9 / 2008$ 19:06 & 19.6 & 411.2 \\
\hline 1713 & $1 / 9 / 200819: 08$ & $8 / 9 / 200819: 08$ & 19.6 & 411.3 \\
\hline 1714 & 1/9/2008 19:10 & $8 / 9 / 200819: 10$ & 19.6 & 411.9 \\
\hline 1715 & $1 / 9 / 200819: 12$ & $8 / 9 / 200819: 12$ & 19.6 & 412.5 \\
\hline 1716 & $1 / 9 / 200819: 14$ & $8 / 9 / 200819: 14$ & 19.7 & 412.8 \\
\hline 1717 & $1 / 9 / 2008$ 19:16 & $8 / 9 / 200819: 16$ & 19.7 & 413.2 \\
\hline 1718 & 1/9/2008 19:18 & $8 / 9 / 2008$ 19:18 & 19.7 & 413.5 \\
\hline 1719 & 1/9/2008 19:20 & $8 / 9 / 2008$ 19:20 & 19.7 & 413.9 \\
\hline 1720 & $1 / 9 / 2008$ 19:22 & $8 / 9 / 200819: 22$ & 19.7 & 414.1 \\
\hline 1721 & $1 / 9 / 2008$ 19:24 & $8 / 9 / 2008$ 19:24 & 19.7 & 414.2 \\
\hline 1722 & 1/9/2008 19:26 & $8 / 9 / 2008$ 19:26 & 19.7 & 414.6 \\
\hline 1723 & 1/9/2008 19:28 & $8 / 9 / 2008$ 19:28 & 19.7 & 414.8 \\
\hline 1724 & $1 / 9 / 200819: 30$ & $8 / 9 / 200819: 30$ & 19.7 & 415 \\
\hline 1725 & 1/9/2008 19:32 & $8 / 9 / 200819: 32$ & 19.7 & 415.3 \\
\hline 1726 & $1 / 9 / 200819: 34$ & $8 / 9 / 200819: 34$ & 19.8 & 415.5 \\
\hline 1727 & 1/9/2008 19:36 & $8 / 9 / 200819: 36$ & 19.8 & 415.6 \\
\hline 1728 & $1 / 9 / 200819: 38$ & $8 / 9 / 200819: 38$ & 19.8 & 416.5 \\
\hline 1729 & $1 / 9 / 200819: 40$ & $8 / 9 / 2008$ 19:40 & 19.8 & 417.3 \\
\hline 1730 & 1/9/2008 19:42 & $8 / 9 / 2008$ 19:42 & 19.8 & 419.5 \\
\hline 1731 & 1/9/2008 19:44 & $8 / 9 / 2008$ 19:44 & 19.8 & 421.8 \\
\hline 1732 & $1 / 9 / 2008$ 19:46 & $8 / 9 / 200819: 46$ & 19.8 & 424.3 \\
\hline 1733 & $1 / 9 / 2008 \quad 19: 48$ & $8 / 9 / 2008$ 19:48 & 19.9 & 426.5 \\
\hline 1734 & $1 / 9 / 2008 \quad 19: 50$ & $8 / 9 / 200819: 50$ & 19.9 & 430.5 \\
\hline 1735 & 1/9/2008 19:52 & $8 / 9 / 2008$ 19:52 & 19.9 & 448.1 \\
\hline 1736 & $1 / 9 / 200819: 54$ & $8 / 9 / 200819: 54$ & 19.9 & 468.3 \\
\hline 1737 & 1/9/2008 19:56 & $8 / 9 / 200819: 56$ & 19.9 & 499.4 \\
\hline 1738 & $1 / 9 / 200819: 58$ & $8 / 9 / 200819: 58$ & 19.9 & 517.5 \\
\hline 1739 & $1 / 9 / 200820: 00$ & $8 / 9 / 200820: 00$ & 19.9 & 531.1 \\
\hline 1740 & $1 / 9 / 200820: 02$ & $8 / 9 / 200820: 02$ & 20 & 527.8 \\
\hline 1741 & $1 / 9 / 200820: 04$ & $8 / 9 / 200820: 04$ & 20 & 539.2 \\
\hline 1742 & 1/9/2008 20:06 & $8 / 9 / 200820: 06$ & 20 & 535.7 \\
\hline 1743 & $1 / 9 / 200820: 08$ & 8/9/2008 20:08 & 20 & 535.5 \\
\hline 1744 & 1/9/2008 20:10 & $8 / 9 / 200820: 10$ & 20 & 539.6 \\
\hline 1745 & $1 / 9 / 200820: 12$ & $8 / 9 / 200820: 12$ & 20 & 541.3 \\
\hline 1746 & $1 / 9 / 200820: 14$ & $8 / 9 / 200820: 14$ & 20 & 544.6 \\
\hline 1747 & 1/9/2008 20:16 & $8 / 9 / 200820: 16$ & 20.1 & 546.2 \\
\hline 1748 & $1 / 9 / 200820: 18$ & $8 / 9 / 200820: 18$ & 20.1 & 551.1 \\
\hline 1749 & $1 / 9 / 200820: 20$ & $8 / 9 / 200820: 20$ & 20.1 & 553.4 \\
\hline 1750 & $1 / 9 / 200820: 22$ & $8 / 9 / 200820: 22$ & 20.1 & 553.5 \\
\hline 1751 & $1 / 9 / 200820: 24$ & $8 / 9 / 200820: 24$ & 20.1 & 557.2 \\
\hline 1752 & 1/9/2008 20:26 & $8 / 9 / 200820: 26$ & 19.9 & 426.5 \\
\hline 1753 & $1 / 9 / 200820: 28$ & $8 / 9 / 200820: 28$ & 20.2 & 428.6 \\
\hline 1754 & $1 / 9 / 200820: 30$ & $8 / 9 / 200820: 30$ & 20.2 & 431.5 \\
\hline 1755 & $1 / 9 / 200820: 32$ & $8 / 9 / 200820: 32$ & 20.2 & 443.2 \\
\hline 1756 & $1 / 9 / 200820: 34$ & $8 / 9 / 200820: 34$ & 20.2 & 438.9 \\
\hline 1757 & $1 / 9 / 200820: 36$ & $8 / 9 / 200820: 36$ & 20.2 & 432.2 \\
\hline 1758 & $1 / 9 / 200820: 38$ & $8 / 9 / 200820: 38$ & 20.1 & 430.6 \\
\hline 1759 & $1 / 9 / 200820: 40$ & $8 / 9 / 200820: 40$ & 20.2 & 438.5 \\
\hline 1760 & $1 / 9 / 200820: 42$ & $8 / 9 / 200820: 42$ & 20.2 & 431.3 \\
\hline 1761 & 1/9/2008 20:44 & $8 / 9 / 200820: 44$ & 20.2 & 438.8 \\
\hline 1762 & $1 / 9 / 200820: 46$ & $8 / 9 / 200820: 46$ & 20.2 & 490.9 \\
\hline 1763 & $1 / 9 / 200820: 48$ & $8 / 9 / 200820: 48$ & 20.2 & 527.8 \\
\hline 1764 & $1 / 9 / 200820: 50$ & $8 / 9 / 200820: 50$ & 20.3 & 555.4 \\
\hline 1765 & $1 / 9 / 200820: 52$ & $8 / 9 / 200820: 52$ & 20.3 & 571.6 \\
\hline 1766 & $1 / 9 / 200820: 54$ & $8 / 9 / 200820: 54$ & 20.4 & 576.1 \\
\hline 1767 & $1 / 9 / 200820: 56$ & $8 / 9 / 200820: 56$ & 20.4 & 581,5 \\
\hline 1768 & $1 / 9 / 200820: 58$ & $8 / 9 / 200820: 58$ & 20.5 & 585.5 \\
\hline
\end{tabular}

\begin{tabular}{|c|c|c|c|c|}
\hline \multicolumn{5}{|c|}{ D4-92C } \\
\hline $\operatorname{Rec}$ & & Adjusted & Temp & SC \\
\hline$\#$ & Date/Time & DaterTime & ${ }^{\circ} \mathrm{C}$ & $\mu \mathrm{S} / \mathrm{cm}$ \\
\hline 1769 & 1/9/2008 21:00 & $8 / 9 / 200821: 00$ & 20.5 & 587.5 \\
\hline 1770 & $1 / 9 / 200821: 02$ & $8 / 9 / 200821: 02$ & 20.5 & 585.7 \\
\hline 1771 & $1 / 9 / 200821: 04$ & $8 / 9 / 200821: 04$ & 20.5 & 587.8 \\
\hline 1772 & 1/9/200821:06 & $8 / 9 / 200821: 06$ & 20.5 & 590.2 \\
\hline 1773 & 1/9/200821:08 & $8 / 9 / 200821: 08$ & 20.5 & 591 \\
\hline 1774 & 1/9/200821:10 & $8 / 9 / 200821: 10$ & 20.4 & 585.3 \\
\hline 1775 & 1/9/200821:12 & $8 / 9 / 200821: 12$ & 20.3 & 580.5 \\
\hline 1776 & 1/9/2008 21:14 & $8 / 9 / 200821: 14$ & 20.3 & 578.9 \\
\hline $17 \pi 7$ & 1/9/2008 21:16 & $8 / 9 / 200821: 16$ & 20.3 & 576.4 \\
\hline 1778 & 1/9/200821:18 & $8 / 9 / 200821: 18$ & 20.3 & 575 \\
\hline 1779 & 1/9/2008 21:20 & $8 / 9 / 200821: 20$ & 20.3 & 578.8 \\
\hline 1780 & 1/9/2008 21:22 & $8 / 9 / 200821: 22$ & 20.3 & 584.6 \\
\hline 1781 & 1/9/2008 21:24 & $8 / 9 / 200821: 24$ & 20.3 & 585.3 \\
\hline 1782 & 1/9/200821:26 & $8 / 9 / 200821: 26$ & 20.3 & 587.2 \\
\hline 1783 & 1/9/2008 21:28 & $8 / 9 / 200821: 28$ & 20.3 & 582.9 \\
\hline 1784 & 1/9/2008 21:30 & $8 / 9 / 200821: 30$ & 20.3 & 586.3 \\
\hline 1785 & $1 / 9 / 200821: 32$ & $8 / 9 / 200821: 32$ & 20.4 & 585.5 \\
\hline 1786 & 1/9/2008 21:34 & $8 / 9 / 200821: 34$ & 20.4 & 588.3 \\
\hline 1787 & 1/9/2008 21:36 & $8 / 9 / 200821: 36$ & 20.4 & 588.8 \\
\hline 1788 & 1/9/2008 21:38 & $8 / 9 / 200821: 38$ & 20.4 & 585.6 \\
\hline 1789 & 1/9/2008 21:40 & $8 / 9 / 200821: 40$ & 20.4 & 585.7 \\
\hline 1790 & 1/9/2008 21:42 & $8 / 9 / 200821: 42$ & 20.4 & 588.7 \\
\hline 1791 & 1/9/2008 21:44 & $8 / 9 / 200821: 44$ & 20.4 & 590.9 \\
\hline 1792 & 1/9/2008 21:46 & $8 / 9 / 200821: 46$ & 20.4 & 591.3 \\
\hline 1793 & 1/9/2008 21:48 & $8 / 9 / 200821: 48$ & 20.4 & 587 \\
\hline 1794 & $1 / 9 / 200821: 50$ & $8 / 9 / 200821: 50$ & 20.4 & 587 \\
\hline 1795 & $1 / 9 / 200821: 52$ & $8 / 9 / 200821: 52$ & 20.4 & 585.9 \\
\hline 1796 & $1 / 9 / 200821: 54$ & $8 / 9 / 200821: 54$ & 20.4 & 585.9 \\
\hline 1797 & $1 / 9 / 200821: 56$ & $8 / 9 / 200821: 56$ & 20.4 & 582.6 \\
\hline 1798 & 1/9/2008 21:58 & $8 / 9 / 200821: 58$ & 20.4 & 582.4 \\
\hline 1799 & 1/9/2008 22:00 & $8 / 9 / 2008$ 22:00 & 20.4 & 582 \\
\hline 1800 & 1/9/2008 22:02 & $8 / 9 / 200822: 02$ & 20.4 & 579.3 \\
\hline 1801 & 1/9/2008 22:04 & $8 / 9 / 200822: 04$ & 20.4 & 577.1 \\
\hline 1802 & 1/9/2008 22:06 & $8 / 9 / 200822: 06$ & 20.4 & 577.4 \\
\hline 1803 & 1/9/2008 22:08 & $8 / 9 / 2008$ 22:08 & 20.4 & 573.1 \\
\hline 1804 & 1/9/2008 22:10 & $8 / 9 / 200822: 10$ & 20.4 & 573.3 \\
\hline 1805 & $1 / 9 / 200822: 12$ & $8 / 9 / 2008 \quad 22: 12$ & 20.4 & 571.7 \\
\hline 1806 & 1/9/2008 22:14 & $8 / 9 / 200822: 14$ & 20.4 & 568.7 \\
\hline 1807 & 1/9/2008 22:16 & $8 / 9 / 200822: 16$ & 20.4 & 566.5 \\
\hline 1808 & 1/9/2008 22:18 & $8 / 9 / 200822: 18$ & 20.5 & 569 \\
\hline 1809 & $1 / 9 / 200822: 20$ & $8 / 9 / 200822: 20$ & 20.5 & 567.6 \\
\hline 1810 & $1 / 9 / 200822: 22$ & $8 / 9 / 2008$ 22:22 & 20.5 & 566.5 \\
\hline 1811 & 1/9/2008 22:24 & $8 / 9 / 2008$ 22:24 & 20.5 & 567.4 \\
\hline 1812 & 1/9/2008 22:26 & $8 / 9 / 200822: 26$ & 20.5 & 569.4 \\
\hline 1813 & $1 / 9 / 200822: 28$ & $8 / 9 / 200822: 28$ & 20.5 & 566.7 \\
\hline 1814 & $1 / 9 / 200822: 30$ & $8 / 9 / 200822: 30$ & 20.5 & 566.5 \\
\hline 1815 & 1/9/2008 22:32 & $8 / 9 / 200822: 32$ & 20.5 & 567.6 \\
\hline 1816 & $1 / 9 / 200822: 34$ & $8 / 9 / 200822: 34$ & 20.5 & 566.4 \\
\hline 1817 & 1/9/2008 22:36 & $8 / 9 / 200822: 36$ & 20.5 & 564.9 \\
\hline 1818 & 1/9/2008 22:38 & $8 / 9 / 200822: 38$ & 20.5 & 563.4 \\
\hline 1819 & 1/9/2008 22:40 & $8 / 9 / 200822: 40$ & 20.5 & 566 \\
\hline 1820 & 1/9/2008 22:42 & $8 / 9 / 2008$ 22:42 & 20.5 & 567.7 \\
\hline 1821 & 1/9/2008 22:44 & $8 / 9 / 200822: 44$ & 20.5 & 564.5 \\
\hline 1822 & 1/9/2008 22:46 & $8 / 9 / 200822: 46$ & 20.5 & 562.6 \\
\hline 1823 & 1/9/2008 22:48 & $8 / 9 / 200822: 48$ & 20.5 & 559.5 \\
\hline 1824 & 1/9/2008 22:50 & $8 / 9 / 200822: 50$ & 20.5 & 557.5 \\
\hline 1825 & 1/9/2008 22:52 & $8 / 9 / 200822: 52$ & 20.5 & 558.6 \\
\hline 1826 & $1 / 9 / 200822: 54$ & $8 / 9 / 200822: 54$ & 20.5 & 557.8 \\
\hline 1827 & 1/9/2008 22:56 & $8 / 9 / 200822: 56$ & 20.6 & 556.4 \\
\hline & $1 / 9 / 200822: 58$ & $8 / 9 / 200822: 58$ & 20.6 & 559.3 \\
\hline 1829 & 1/9/200823:00 & $8 / 9 / 200823: 00$ & 20.6 & 556.6 \\
\hline 1830 & 1/9/2008 23:02 & $8 / 9 / 200823: 02$ & 20.6 & 556.6 \\
\hline 1831 & $1 / 9 / 200823: 04$ & $8 / 9 / 200823: 04$ & 20.6 & 558.6 \\
\hline 1832 & 1/9/2008 23:06 & $8 / 9 / 200823: 06$ & 20.6 & 559.4 \\
\hline 1833 & 1/9/2008 23:08 & $8 / 9 / 200823: 08$ & 20.6 & 557.2 \\
\hline 1834 & 1/9/2008 23:10 & $8 / 9 / 200823: 10$ & 20.6 & 555.3 \\
\hline 1835 & 1/9/2008 23:12 & $8 / 9 / 200823: 12$ & 20.6 & 555.8 \\
\hline 1836 & 1/9/2008 23:14 & $8 / 9 / 200823: 14$ & 20.6 & 554.8 \\
\hline
\end{tabular}




\begin{tabular}{|c|c|c|c|c|c|c|c|c|c|}
\hline \multicolumn{5}{|c|}{ D4-92c } & \multicolumn{5}{|c|}{ D4-92c } \\
\hline $\operatorname{Rec}$ & & Adjusted & Temp & SC & Rec & & Adjusted & Temp & SC \\
\hline$\#$ & Date/Time & Date/Time & ${ }^{\circ} \mathrm{C}$ & $\mu \mathrm{S} / \mathrm{cm}$ & $\#$ & Date/Time & Date/Time & ${ }^{\circ} \mathrm{C}$ & $\mu \mathrm{S} / \mathrm{cm}$ \\
\hline 1837 & 1/9/2008 23:16 & $8 / 9 / 200823: 16$ & 20.6 & 552.5 & 1905 & $1 / 10 / 20081: 32$ & $8 / 10 / 20081: 32$ & 21.2 & 558.6 \\
\hline 1838 & $y / 2008$ 23:18 & $8 / 9 / 200823: 18$ & 20.6 & 548.5 & 1906 & $1 / 10 / 20081: 34$ & $8 / 10 / 20081: 34$ & 21.2 & 556.2 \\
\hline 1839 & $200823: 20$ & $8 / 9 / 200823: 20$ & 20.4 & 496.7 & 1907 & $1 / 10 / 20081: 36$ & $8 / 10 / 20081: 36$ & 21.2 & 539.5 \\
\hline 1840 & 1/9/2008 23:22 & $8 / 9 / 200823: 22$ & 20.1 & 518.2 & 1908 & $1 / 10 / 2008$ 1:38 & $8 / 10 / 20081: 38$ & 21.2 & 524.8 \\
\hline 1841 & $9 / 200823: 24$ & $8 / 9 / 200823: 24$ & 20.2 & 532.7 & 1909 & $1 / 10 / 20081: 40$ & $8 / 10 / 20081: 40$ & 21.2 & 543.4 \\
\hline 1842 & & $8 / 9 / 200823: 26$ & 20.2 & 530.8 & 1910 & $1 / 10 / 20081: 42$ & $8 / 10 / 20081: 42$ & 21.2 & 553.6 \\
\hline 1843 & $1 / 9 / 200823: 28$ & $8 / 9 / 200823: 28$ & 20.2 & 523.6 & 1911 & $1 / 10 / 20081: 44$ & $8 / 10 / 20081: 44$ & 21.3 & 561.8 \\
\hline 1844 & $9 / 200823: 30$ & $8 / 9 / 200823: 30$ & 20.6 & 542.9 & 1912 & $1 / 10 / 20081: 46$ & $8 / 10 / 20081: 46$ & 21.3 & 539 \\
\hline 1845 & & $8 / 9 / 200823: 32$ & 20.6 & 546.8 & 1913 & $1 / 10 / 20081: 48$ & $8 / 10 / 20081: 48$ & 21.3 & 560.3 \\
\hline 1846 & $1 / 9 / 200823: 34$ & $8 / 9 / 200823: 34$ & 20.5 & 548.3 & 1914 & $1 / 10 / 2008$ 1:50 & $8 / 10 / 20081: 50$ & 21.3 & 560.1 \\
\hline 1847 & 1/9/2008 23:36 & $8 / 9 / 200823: 36$ & 20.5 & 552.9 & 1915 & $1 / 10 / 20081: 52$ & $8 / 10 / 20081: 52$ & 21.3 & 562.6 \\
\hline 1848 & & $8 / 9 / 200$ & 20.5 & 558.2 & 1916 & $1 / 10 / 20081: 54$ & & 21.3 & 572.9 \\
\hline 1849 & $23: 40$ & $8 / 9 / 200823: 40$ & 20.5 & 557.8 & 1917 & $1 / 10 / 20081: 56$ & $8 / 10 / 20081: 56$ & 21.3 & 550.4 \\
\hline 1850 & $23: 42$ & $8 / 9 / 200823: 42$ & 20.5 & 554 & 1918 & $1 / 10 / 20081: 58$ & $8 / 10 / 20081: 58$ & 21.3 & 563.5 \\
\hline 1851 & & $8 / 9 / 200$ & 20.5 & 544.6 & 1919 & $1 / 10 / 200$ & 8/10/2008 2:00 & 21.3 & 575.2 \\
\hline 1852 & $23: 46$ & $8 / 9 / 200823: 46$ & 20.5 & 520.3 & 1920 & $1 / 10 / 20$ & $8 / 10 / 20082: 02$ & 21.3 & 575.6 \\
\hline 1853 & $23: 48$ & $8 / 9 / 200823: 48$ & 20.6 & 501.4 & 1921 & $1 / 10 / 20082: 04$ & $8 / 10 / 20082: 04$ & 21.3 & 572.4 \\
\hline 1854 & $23: 50$ & $8 / 9 / 200$ & 20.6 & 467.5 & 1922 & $1 / 10 / 20$ & $8 / 10 / 20082: 06$ & 21.3 & 580 \\
\hline 1855 & 23:52 & $8 / 9 / 200823: 52$ & 20.6 & 486.5 & 1923 & & $8 / 10 / 20082: 08$ & 21.3 & 577.2 \\
\hline 1856 & $23: 54$ & 8/9/2008 23:54 & 20.6 & 507.1 & 1924 & $1 / 10 / 2$ & $82: 10$ & 21.3 & 581.7 \\
\hline 1857 & $23: 56$ & $8 / 9 / 200$ & 20.7 & 529.5 & 1925 & $1 / 10 / 2$ & $8 / 10 / 20082: 12$ & 21.3 & 563.1 \\
\hline 1858 & 23:58 & $823: 58$ & 20.7 & 533.9 & 1926 & $1 / 10 / 2$ & $8 / 10 / 20082: 14$ & 21.3 & 579.4 \\
\hline 1859 & $0: 00$ & $8 / 10 / 20$ & 20.7 & 534.3 & 1927 & $1 / 10 / 2$ & $82: 16$ & 21.3 & 583.3 \\
\hline 1860 & & $8 / 10 / 2$ & 20.8 & 541.7 & 1928 & $1 / 10 / 2$ & $82: 18$ & 21.3 & 581.6 \\
\hline 1861 & $30: 04$ & $8 / 10 / 2$ & 20.8 & 548 & 1929 & $1 / 10 / 2$ & $8 / 10 / 20082: 20$ & 21.3 & 581.3 \\
\hline 1862 & & $8 / 10 / 2$ & 20.8 & 554.2 & 1930 & $1 / 10 / 2$ & $32: 22$ & 21.3 & 583.1 \\
\hline 1863 & & $8 / 10 / 2$ & 20.8 & 556.5 & 1931 & $1 / 10 / 2$ & $82: 24$ & 21.3 & 568.9 \\
\hline 1864 & $0: 10$ & $8 / 10 / 2$ & 20.9 & 558.7 & 1932 & $1 / 10 / 2$ & $8 / 10 / 20082: 26$ & 21.3 & 583.3 \\
\hline 1865 & $0: 12$ & $8 / 10$ & 20.8 & 548.7 & 1933 & $2: 28$ & $32: 28$ & 21.3 & 586.1 \\
\hline 1866 & & $8 / 10 / 2$ & 20.7 & 487.1 & 1934 & $32: 30$ & $82: 30$ & 21.3 & 581.8 \\
\hline 1867 & 30:16 & $30: 16$ & 20.7 & 480.4 & 1935 & $82: 32$ & $8 / 10 / 20082: 32$ & 21.3 & 591.3 \\
\hline 1868 & & 30:18 & 20.7 & 475 & 1936 & $2: 34$ & $2: 34$ & 21.3 & 559.1 \\
\hline 1869 & & $0: 20$ & 20.7 & 470. & 1937 & $2: 36$ & $32: 36$ & 21.3 & 551.8 \\
\hline 1870 & & $0: 22$ & 20.7 & 478.3 & 1938 & & $32: 38$ & 21.3 & 576.1 \\
\hline 1871 & & $0: 24$ & 20.7 & 477 & 1939 & $2: 40$ & $32: 40$ & 21.3 & 576.4 \\
\hline 1872 & & $8 / 10 / 2$ & 20.7 & 482. & 1940 & $32: 42$ & $32: 42$ & 21.3 & 559.8 \\
\hline 1873 & & & 20.7 & 510. & 1941 & $32: 44$ & $32: 44$ & 21.3 & 561.6 \\
\hline 1874 & & $0: 30$ & 20.7 & 505.7 & 1942 & $2: 46$ & $32: 46$ & 21.3 & 565.3 \\
\hline 1875 & & $8 / 10$ & 20.7 & 51 & 1943 & $2: 48$ & $2: 48$ & 21.3 & 585.6 \\
\hline 1876 & & & 20.7 & 508.9 & 1944 & & $2: 50$ & 21.4 & 577.4 \\
\hline 1877 & & & 20.7 & & 1945 & $2: 52$ & $32: 52$ & 21.4 & 577.9 \\
\hline 1878 & & $0: 38$ & 20.7 & 469.2 & 1946 & & $82: 54$ & 21.4 & 595.6 \\
\hline 1879 & & & 20.8 & 469.7 & 1947 & & $2: 56$ & 21.4 & 597.3 \\
\hline 1880 & & & 20.8 & & 1948 & $2: 58$ & $32: 58$ & 21.4 & 598.3 \\
\hline 1881 & & & 20.8 & 462.2 & 1949 & & $83: 00$ & 21.3 & 600.4 \\
\hline 1882 & & & 20.8 & & 350 & & & 21.3 & 595.6 \\
\hline 1883 & & & 20.8 & & 1951 & & & 21.1 & 570.8 \\
\hline 1884 & & & 20.8 & & 1952 & & & 21.1 & 569.5 \\
\hline 1885 & & & 20.8 & & & & & 21 & 564.6 \\
\hline 1886 & & $8 / 10$ & 20.8 & 475. & 1954 & $3: 10$ & $3: 10$ & 21 & 568.1 \\
\hline 1887 & & & 20.8 & & & & & 20.9 & 565.5 \\
\hline 1888 & & & 20.8 & & & & & 20.9 & 559.8 \\
\hline 1889 & & $31: 00$ & 20.9 & 51 & 1957 & $3: 16$ & $33: 16$ & 20.9 & 567.6 \\
\hline 1890 & & & 20.9 & 516 & & & & 21 & 567.4 \\
\hline 1891 & & & 20.9 & & & & & 21 & 559 \\
\hline 1892 & 1:06 & 1:06 & 20.9 & 532 & 1960 & $3: 22$ & $3: 22$ & 21 & 563.4 \\
\hline$\cdots$ & & & 21 & & & & & 21 & 557.1 \\
\hline 1894 & & & 21 & & & & & 21 & 553.1 \\
\hline 1895 & & & 21 & 556 & 1963 & & & 21.1 & 545.6 \\
\hline 1896 & & & 21 & & & & & & \\
\hline 1897 & & $8 / 10 / 2$ & 21 & & & $3: 32$ & $33: 32$ & 21.1 & 546.4 \\
\hline 1898 & & $1: 18$ & 21 & 545 & 1966 & & & 21.1 & 547.8 \\
\hline & & & 21 & & & & & 21.2 & 554.5 \\
\hline 1900 & $1: 22$ & $31: 22$ & 21.1 & 54 & 1968 & $83: 38$ & 8/10/20083:38 & 21.2 & 546 \\
\hline 1901 & & & 21.1 & & 1969 & $83: 40$ & $83: 40$ & 21.2 & 546.6 \\
\hline & & & 21.1 & & & & & 21.2 & 552.6 \\
\hline 1903 & $81: 28$ & $8 / 10 / 20$ & 21.1 & 549 & 1971 & $83: 44$ & $8 / 10 / 20083: 44$ & 21.2 & 543 \\
\hline 1904 & $881: 30$ & $081: 30$ & 21.2 & 566.2 & & $83: 46$ & $8 / 10 / 20083: 46$ & 21.2 & 54 \\
\hline
\end{tabular}

\begin{tabular}{|c|c|c|c|c|}
\hline \multicolumn{5}{|c|}{ D4-92C } \\
\hline Rec & & Adjusted & Temp & SC \\
\hline$\#$ & Date/Time & Date/Time & ${ }^{\circ} \mathrm{C}$ & $\mu \mathrm{S} / \mathrm{cm}$ \\
\hline 1973 & $1 / 10 / 20083: 48$ & $8 / 10 / 20083: 48$ & 21.2 & 555.7 \\
\hline 1974 & $1 / 10 / 20083: 50$ & $8 / 10 / 20083: 50$ & 21.2 & 545.9 \\
\hline 1975 & 1/10/2008 3:52 & $8 / 10 / 20083: 52$ & 21.2 & 554.5 \\
\hline 1976 & $1 / 10 / 20083: 54$ & $8 / 10 / 20083: 54$ & 21.2 & 556.8 \\
\hline 1977 & $1 / 10 / 20083: 56$ & $8 / 10 / 20083.56$ & 21.2 & 554.6 \\
\hline 1978 & $1 / 10 / 20083: 58$ & $8 / 10 / 20083: 58$ & 21.2 & 546.4 \\
\hline 1979 & $1 / 10 / 20084: 00$ & $8 / 10 / 20084: 00$ & 21.2 & 559 \\
\hline 1980 & $1 / 10 / 20084: 02$ & $8 / 10 / 2008$ 4:02 & 21.2 & 558.7 \\
\hline 1981 & $1 / 10 / 20084: 04$ & $8 / 10 / 20084: 04$ & 21.3 & 556.3 \\
\hline 1982 & $1 / 10 / 20084: 06$ & $8 / 10 / 20084: 06$ & 21.3 & 558.6 \\
\hline 1983 & $1 / 10 / 20084: 08$ & $8 / 10 / 20084: 08$ & 21.3 & 561.2 \\
\hline 1984 & $1 / 10 / 20084: 10$ & $8 / 10 / 20084: 10$ & 21.3 & 564.2 \\
\hline 1985 & $1 / 10 / 20084: 12$ & $8 / 10 / 20084: 12$ & 21.3 & 558.3 \\
\hline 1986 & $1 / 10 / 20084: 14$ & $8 / 10 / 20084: 14$ & 21.3 & 568.8 \\
\hline 1987 & $1 / 10 / 20084: 16$ & $8 / 10 / 20084: 16$ & 21.3 & 564 \\
\hline 1988 & $1 / 10 / 20084: 18$ & $8 / 10 / 20084: 18$ & 21.3 & 560.4 \\
\hline 1989 & $1 / 10 / 20084: 20$ & $8 / 10 / 20084: 20$ & 21.3 & 568.4 \\
\hline 1990 & $1 / 10 / 20084: 22$ & $8 / 10 / 20084: 22$ & 21.3 & 561.6 \\
\hline 1991 & $1 / 10 / 20084: 24$ & $8 / 10 / 20084: 24$ & 21.3 & 564 \\
\hline 1992 & $1 / 10 / 20084: 26$ & $8 / 10 / 20084: 26$ & 21.3 & 563.1 \\
\hline 1993 & $1 / 10 / 20084: 28$ & $8 / 10 / 20084: 28$ & 21.3 & 564.6 \\
\hline 1994 & $1 / 10 / 20084: 30$ & $8 / 10 / 20084: 30$ & 21.4 & 562.2 \\
\hline 1995 & $1 / 10 / 20084: 32$ & $8 / 10 / 20084: 32$ & 21.4 & 566.3 \\
\hline 1996 & $1 / 10 / 20084: 34$ & $8 / 10 / 20084: 34$ & 21.4 & 565.3 \\
\hline 1997 & $1 / 10 / 20084: 36$ & $8 / 10 / 20084: 36$ & 21.4 & 565.5 \\
\hline 1998 & $1 / 10 / 20084: 38$ & $8 / 10 / 20084: 38$ & 21.4 & 558.9 \\
\hline 1999 & $1 / 10 / 20084: 40$ & $8 / 10 / 20084: 40$ & 21.4 & 567.4 \\
\hline 2000 & $1 / 10 / 20084: 42$ & $8 / 10 / 20084: 42$ & 21.4 & 564.8 \\
\hline 2001 & $1 / 10 / 20084: 44$ & $8 / 10 / 20084: 44$ & 21.4 & 557.7 \\
\hline 2002 & $1 / 10 / 20084: 46$ & $8 / 10 / 20084: 46$ & 21.4 & 562.8 \\
\hline 2003 & $1 / 10 / 20084: 48$ & $8 / 10 / 20084: 48$ & 21.4 & 566.8 \\
\hline 2004 & $1 / 10 / 20084: 50$ & $8 / 10 / 20084: 50$ & 21.4 & 570.4 \\
\hline 2005 & $1 / 10 / 20084: 52$ & $8 / 10 / 20084: 52$ & 21.4 & 566.4 \\
\hline 2006 & $1 / 10 / 20084: 54$ & $8 / 10 / 20084: 54$ & 21.4 & 560.7 \\
\hline 2007 & $1 / 10 / 20084: 56$ & $8 / 10 / 20084: 56$ & 21.4 & 564.2 \\
\hline 2008 & $1 / 10 / 20084: 58$ & $8 / 10 / 20084: 58$ & 21.4 & 566.5 \\
\hline 2009 & $1 / 10 / 20085: 00$ & $8 / 10 / 20085: 00$ & 21.4 & 568.5 \\
\hline 2010 & $1 / 10 / 20085: 02$ & $8 / 10 / 20085: 02$ & 21.5 & 569 \\
\hline 2011 & $1 / 10 / 20085: 04$ & $8 / 10 / 20085: 04$ & 21.4 & 573 \\
\hline 2012 & $1 / 10 / 20085: 06$ & $8 / 10 / 20085: 06$ & 21.4 & 572 \\
\hline 2013 & $1 / 10 / 20085: 08$ & $8 / 10 / 20085: 08$ & 21.4 & 572.9 \\
\hline 2014 & $1 / 10 / 20085: 10$ & $8 / 10 / 20085: 10$ & 21.4 & 571.8 \\
\hline 2015 & $1 / 10 / 20085: 12$ & $8 / 10 / 20085: 12$ & 21.4 & 571.6 \\
\hline 2016 & $1 / 10 / 20085: 14$ & $8 / 10 / 20085: 14$ & 21.4 & 573.6 \\
\hline 2017 & $1 / 10 / 20085: 16$ & \begin{tabular}{|l|l|}
$8 / 10 / 20085: 16$ \\
\end{tabular} & 21.4 & 571.1 \\
\hline 2018 & $1 / 10 / 20085: 18$ & $8 / 10 / 20085: 18$ & 21.4 & 573.6 \\
\hline 2019 & $1 / 10 / 20085: 20$ & $8 / 10 / 20085: 20$ & 21.4 & 571.5 \\
\hline 2020 & $1 / 10 / 20085: 22$ & $8 / 10 / 20085: 22$ & 21.4 & 575.8 \\
\hline 2021 & $1 / 10 / 20085: 24$ & $8 / 10 / 20085: 24$ & 21.4 & 575.6 \\
\hline 2022 & $1 / 10 / 20085: 26$ & $8 / 10 / 20085: 26$ & 21.4 & 577.3 \\
\hline 2023 & $1 / 10 / 20085: 28$ & $8 / 10 / 20085: 28$ & 21.4 & 575.9 \\
\hline 2024 & $1 / 10 / 20085: 30$ & $8 / 10 / 20085: 30$ & 21.4 & 577 \\
\hline 2025 & $1 / 10 / 20085: 32$ & $8 / 10 / 20085: 32$ & 21.5 & 572.7 \\
\hline 2026 & $1 / 10 / 20085: 34$ & $8 / 10 / 20085: 34$ & 21.5 & 578 \\
\hline 2027 & $1 / 10 / 20085: 36$ & $8 / 10 / 20085: 36$ & 21.5 & 574.1 \\
\hline 2028 & $1 / 10 / 20085: 38$ & $8 / 10 / 20085: 38$ & 21.5 & 568.6 \\
\hline 2029 & $1 / 10 / 20085: 40$ & $8 / 10 / 20085: 40$ & 21.5 & 565.2 \\
\hline 2030 & $1 / 10 / 20085: 42$ & $8 / 10 / 20085: 42$ & 21.5 & 569.1 \\
\hline 2031 & $1 / 10 / 20085: 44$ & $8 / 10 / 20085: 44$ & 21.5 & 567.7 \\
\hline 2032 & $1 / 10 / 20085: 46$ & $8 / 10 / 20085: 46$ & 21.5 & 568.5 \\
\hline 2033 & $1 / 10 / 20085: 48$ & $8 / 10 / 20085: 48$ & 21.5 & 564.1 \\
\hline 2034 & $1 / 10 / 20085: 50$ & $8 / 10 / 20085: 50$ & 21.5 & 568.6 \\
\hline 2035 & $1 / 10 / 20085: 52$ & $8 / 10 / 20085: 52$ & 21.6 & 576.8 \\
\hline 2036 & $1 / 10 / 20085: 54$ & $8 / 10 / 20085: 54$ & 21.6 & 579.3 \\
\hline 2037 & $1 / 10 / 20085: 56$ & $8 / 10 / 20085: 56$ & 21.6 & 580.3 \\
\hline 2038 & $1 / 10 / 20085: 58$ & $8 / 10 / 20085: 58$ & 21.6 & 579.9 \\
\hline 2039 & $1 / 10 / 20086: 00$ & $8 / 10 / 20086: 00$ & 21.5 & 576.7 \\
\hline 2040 & $1 / 10 / 20086: 02$ & $8 / 10 / 20086: 02$ & 21.5 & 574 \\
\hline
\end{tabular}


DOE/RL-2009-35, REV. 0

\begin{tabular}{|c|c|c|c|c|}
\hline \multicolumn{5}{|c|}{$D 4-92 c$} \\
\hline $\operatorname{Rec}$ & & Adjusted & Temp & SC \\
\hline & Date/Time & Date/Time & ${ }^{\circ} \mathrm{C}$ & $\mu \mathrm{S} / \mathrm{cm}$ \\
\hline 2041 & 1/10/20086:04 & 8/10/20086:04 & 21.5 & 570.5 \\
\hline 2042 & 1/10/2008 6:06 & $8 / 10 / 20086: 06$ & 21.5 & 569.4 \\
\hline 2043 & \begin{tabular}{|c|}
$1 / 10 / 20086: 08$ \\
\end{tabular} & 8/10/20086:08 & 21.4 & 561.2 \\
\hline 2044 & \begin{tabular}{|l|}
$1 / 10 / 20086: 10$ \\
\end{tabular} & $8 / 10 / 20086: 10$ & 21.2 & 535.1 \\
\hline 2045 & $1 / 10 / 20086: 12$ & $8 / 10 / 20086: 12$ & 21.3 & 558.5 \\
\hline 2046 & \begin{tabular}{|l|}
$1 / 10 / 20086: 14$ \\
\end{tabular} & $8 / 10 / 20086: 14$ & 21.3 & 562.1 \\
\hline 2047 & |1/10/20086:16 & $8 / 10 / 20086: 16$ & 21.2 & 561.6 \\
\hline 2048 & 1/10/20086:18 & $8 / 10 / 20086: 18$ & 21.2 & 558.6 \\
\hline 2049 & $1 / 10 / 20086: 20$ & $8 / 10 / 20086: 20$ & 21.2 & 561.5 \\
\hline 2050 & $1 / 10 / 20086: 22$ & $8 / 10 / 20086: 22$ & 21.3 & 564 \\
\hline 2051 & $1 / 10 / 20086: 24$ & $8 / 10 / 20086: 24$ & 21.3 & 563.5 \\
\hline 2052 & 1/10/20086:26 & $8 / 10 / 20086: 26$ & 21.4 & 564 \\
\hline 2053 & $1 / 10 / 2$ & $8 / 10 / 20086: 28$ & 21.4 & 560.6 \\
\hline 2054 & 1/10/20086:30 & $8 / 10 / 20086: 30$ & 21.4 & 561.5 \\
\hline 2055 & $6: 32$ & $8 / 10 / 20086: 32$ & 21.4 & 563.5 \\
\hline 2056 & $1 / 10$ & $8 / 10 / 20$ & 21.4 & 569.1 \\
\hline 2057 & $1 / 10 / 200$ & $8 / 10 / 20$ & 21.4 & 567.4 \\
\hline 2058 & $1 / 10$ & $8 / 10 / 20$ & 21.4 & 569.9 \\
\hline 2059 & $1 / 10$ & $8 / 10 / 20$ & 21.4 & 570.9 \\
\hline 2060 & $1 / 10 / 2$ & $8 / 10 / 20086: 42$ & 21.5 & 573.7 \\
\hline 2061 & $6: 44$ & $8 / 10 / 2$ & 21.5 & 572.5 \\
\hline 2062 & & $8 / 10 / 20$ & 21.5 & 575.2 \\
\hline 2063 & $1 / 10 / 2$ & $8 / 10 / 20086: 48$ & 21.5 & 576.2 \\
\hline 2064 & & $8 / 10 / 2$ & 21.5 & 574.2 \\
\hline 2065 & $3: 52$ & $8 / 10 / 2$ & 21.5 & 578.8 \\
\hline 2066 & $1 / 10$ & $8 / 10 / 2$ & 21.5 & 577.4 \\
\hline 2067 & & $8 / 10 / 2$ & 21.5 & 579.8 \\
\hline 2068 & $1 / 10$ & $8 / 10 / 2$ & 21.5 & 579.1 \\
\hline 2069 & & $8 / 10 / 2$ & 21.5 & 580.9 \\
\hline 2070 & & $8 / 10 / 20$ & 21.5 & 580.5 \\
\hline 2071 & $1 / 10$ & $8 / 10 / 2$ & 21.5 & 580.7 \\
\hline 2072 & & $8 / 10 / 2$ & 21.5 & 581 \\
\hline 2073 & & $8 / 10 / 2$ & 21.5 & 580.7 \\
\hline 2074 & & $8 / 10 / 20$ & 21.5 & 581.8 \\
\hline 2075 & & $7: 12$ & 21.5 & 582.6 \\
\hline 2076 & & $8 / 10 / 20$ & 21.5 & 585.1 \\
\hline 2077 & & $8 / 10 / 20087: 16$ & 21.4 & 542.6 \\
\hline 2078 & & & 21.2 & 550.5 \\
\hline 2079 & & $8 / 10 / 2$ & 21.3 & 567.4 \\
\hline 2080 & & $8 / 10 / 2$ & 21.2 & 568.9 \\
\hline 2081 & & $77: 24$ & 21.3 & 570.5 \\
\hline 2082 & & $8 / 10 / 2$ & 21.4 & 573.8 \\
\hline 2083 & & $7: 28$ & 21.5 & 578.3 \\
\hline 2084 & & $8 / 10 / 2$ & 21.5 & 579.7 \\
\hline 2085 & & $8 / 10 / 2$ & 21.5 & 581.5 \\
\hline 2086 & & & 21.5 & 585.6 \\
\hline 2087 & & & 21.5 & 584.8 \\
\hline 2088 & & $8 / 10 / 20087: 38$ & 21.5 & 586.2 \\
\hline 2089 & & & 21.6 & 586.5 \\
\hline 2090 & & $37: 42$ & 21.6 & 588.2 \\
\hline 2091 & & $37: 44$ & 21.6 & 589.4 \\
\hline 2092 & & $37: 46$ & 21.6 & 589.8 \\
\hline 2093 & & $8 / 10 / 20$ & 21.5 & 584.9 \\
\hline 2094 & & & 21.5 & 582.9 \\
\hline 2095 & & & 21.5 & 585.7 \\
\hline 2096 & & $8 / 10 / 20087: 54$ & 21.5 & 586.3 \\
\hline 2097 & & & 21.5 & 589.7 \\
\hline 2098 & & $8 / 10 / 2$ & 21.6 & \\
\hline 2099 & & $8 / 10 / 20$ & 21.6 & 596.3 \\
\hline 2100 & & & 21.7 & \\
\hline 2101 & & 8:04 & 21.7 & 599.3 \\
\hline 2102 & & $8 / 10 / 20$ & 21.7 & 598.9 \\
\hline 2103 & & & 21.7 & \\
\hline 2104 & & $8 / 10 / 20088: 10$ & 21.7 & 599.3 \\
\hline 2105 & & $8 / 10 / 20$ & 21.7 & 600.4 \\
\hline 2106 & & & 21.7 & \\
\hline 2107 & $8: 16$ & $8 / 10 / 20088: 16$ & 21.8 & 602 \\
\hline 2108 & & & 21.8 & 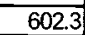 \\
\hline
\end{tabular}

\begin{tabular}{|c|c|c|c|c|}
\hline \multicolumn{5}{|c|}{$D 4-92 c$} \\
\hline Rec & & Adjusted & Temp & SC \\
\hline$\#$ & Date/Time & Date/Time & ${ }^{\circ} \mathrm{C}$ & $\mu \mathrm{S} / \mathrm{cm}$ \\
\hline 2109 & 1/10/2008 8:20 & $8 / 10 / 20088: 20$ & 21.8 & 603.5 \\
\hline 2110 & $1 / 10 / 20088: 22$ & $8 / 10 / 20088: 22$ & 21.8 & 602.8 \\
\hline 2111 & $1 / 10 / 20088: 24$ & $8 / 10 / 20088: 24$ & 21.8 & 605 \\
\hline 2112 & $1 / 10 / 20088: 26$ & $8 / 10 / 20088: 26$ & 21.8 & 606.1 \\
\hline 2113 & $1 / 10 / 20088: 28$ & $8 / 10 / 20088: 28$ & 21.8 & 604.5 \\
\hline 2114 & $1 / 10 / 20088: 30$ & $8 / 10 / 20088: 30$ & 21.8 & 605.8 \\
\hline 2115 & $1 / 10 / 20088: 32$ & $8 / 10 / 20088: 32$ & 21.9 & 606.6 \\
\hline 2116 & $1 / 10 / 20088: 34$ & $8 / 10 / 20088: 34$ & 21.9 & 608.4 \\
\hline 2117 & $1 / 10 / 20088: 36$ & $8 / 10 / 20088: 36$ & 21.9 & 608.7 \\
\hline 2118 & $1 / 10 / 20088: 38$ & $8 / 10 / 20088: 38$ & 21.9 & 608.8 \\
\hline 2119 & $1 / 10 / 20088: 40$ & $8 / 10 / 20088: 40$ & 21.9 & 609.5 \\
\hline 2120 & $1 / 10 / 20088: 42$ & $8 / 10 / 20088: 42$ & 21.9 & 609.6 \\
\hline 2121 & $1 / 10 / 20088: 44$ & $8 / 10 / 20088: 44$ & 21.9 & 609.8 \\
\hline $2+22$ & $1 / 10 / 20088: 46$ & $8 / 10 / 20088: 46$ & 21.9 & 613.1 \\
\hline 2123 & $1 / 10 / 20088: 48$ & $8 / 10 / 20088: 48$ & 21.9 & 614.2 \\
\hline 2124 & $1 / 10 / 20088: 50$ & $8 / 10 / 20088: 50$ & 21.9 & 609.4 \\
\hline 2125 & $1 / 10 / 20088: 52$ & $8 / 10 / 20088: 52$ & 21.9 & 609.6 \\
\hline 2126 & $1 / 10 / 20088: 54$ & $8 / 10 / 20088: 54$ & 21.8 & 603.8 \\
\hline 2127 & $1 / 10 / 20088: 56$ & $8 / 10 / 20088: 56$ & 21.8 & 596.6 \\
\hline 2128 & $1 / 10 / 20088: 58$ & $8 / 10 / 20088: 58$ & 21.8 & 593.1 \\
\hline 2129 & $1 / 10 / 20089: 00$ & $8 / 10 / 20089: 00$ & 21.8 & 589.3 \\
\hline 2130 & $1 / 10 / 20089: 02$ & $8 / 10 / 20089: 02$ & 21.8 & 587.7 \\
\hline 2131 & $1 / 10 / 20089: 04$ & $8 / 10 / 2008$ 9:04 & 21.8 & 586 \\
\hline 2132 & $1 / 10 / 20089: 06$ & 8/10/2008 9:06 & 21.7 & 585.1 \\
\hline 2133 & $1 / 10 / 20089: 08$ & $8 / 10 / 20089: 08$ & 21.7 & 585.7 \\
\hline 2134 & $1 / 10 / 20089: 10$ & $8 / 10 / 20089: 10$ & 21.6 & 585 \\
\hline 2135 & $1 / 10 / 20089: 12$ & $8 / 10 / 20089: 12$ & 21.7 & 581.3 \\
\hline 2136 & $1 / 10 / 20089: 14$ & $8 / 10 / 20089: 14$ & 21.8 & 581.1 \\
\hline 2137 & 1/10/2008 9:16 & $8 / 10 / 20089: 16$ & 21.8 & 580.2 \\
\hline 2138 & $1 / 10 / 20089: 18$ & 8/10/2008 9:18 & 21.8 & 583.7 \\
\hline 2139 & $1 / 10 / 20089: 20$ & $8 / 10 / 20089: 20$ & 21.8 & 582.6 \\
\hline 2140 & 1/10/2008 9:22 & $8 / 10 / 20089: 22$ & 21.7 & 584.4 \\
\hline 2141 & $1 / 10 / 20089: 24$ & $8 / 10 / 20089: 24$ & 21.8 & 585.4 \\
\hline 2142 & $1 / 10 / 200899: 26$ & $8 / 10 / 20089: 26$ & 21.7 & 587.7 \\
\hline 2143 & $1 / 10 / 20089: 28$ & $8 / 10 / 20089: 28$ & 21.7 & 588.4 \\
\hline 2144 & $1 / 10 / 20089: 30$ & $8 / 10 / 20089: 30$ & 21.7 & 588.4 \\
\hline 2145 & $1 / 10 / 20089: 32$ & $8 / 10 / 20089: 32$ & 21.8 & 590.1 \\
\hline 2146 & $1 / 10 / 20089: 34$ & $8 / 10 / 20089: 34$ & 21.7 & 591.1 \\
\hline 2147 & $1 / 10 / 20089: 36$ & 8/10/2008 9:36 & 21.8 & 593.2 \\
\hline 2148 & $1 / 10 / 20089: 38$ & $8 / 10 / 20089: 38$ & 21.7 & 591.3 \\
\hline 2149 & $1 / 10 / 20089: 40$ & $8 / 10 / 20089: 40$ & 21.8 & 589.8 \\
\hline 2150 & 1/10/2008 9:42 & 8/10/2008 9:42 & 21.8 & 592.7 \\
\hline 2151 & 1/10/2008 9:44 & $8 / 10 / 20089: 44$ & 21.8 & 594.9 \\
\hline 2152 & $1 / 10 / 20089: 46$ & $8 / 10 / 20089: 46$ & 21.8 & 594.3 \\
\hline 2153 & $1 / 10 / 20089: 48$ & $8 / 10 / 20089: 48$ & 21.8 & 594.2 \\
\hline 2154 & $1 / 10 / 20089: 50$ & $8 / 10 / 20089: 50$ & 21.8 & 597.6 \\
\hline 2155 & 1/10/2008 9:52 & 8/10/2008 9:52 & 21.8 & 598.3 \\
\hline 2156 & 1/10/20089:54 & $8 / 10 / 20089: 54$ & 21.8 & 597.8 \\
\hline 2157 & $1 / 10 / 20089: 56$ & $8 / 10 / 20089: 56$ & 21.8 & 600 \\
\hline 2158 & 1/10/20089:58 & $8 / 10 / 20089: 58$ & 21.9 & 601.8 \\
\hline 2159 & $1 / 10 / 200810: 00$ & 8/10/2008 10:00 & 21.9 & 603 \\
\hline 2160 & $1 / 10 / 2008$ 10:02 & $8 / 10 / 200810: 02$ & 21.9 & 603.3 \\
\hline 2161 & $1 / 10 / 200810: 04$ & $8 / 10 / 2008$ 10:04 & 21.9 & 604.5 \\
\hline 2162 & $1 / 10 / 2008$ 10:06 & $8 / 10 / 2008$ 10:06 & 21.9 & 604.5 \\
\hline 2163 & $1 / 10 / 2008$ 10:08 & $8 / 10 / 2008$ 10:08 & 22 & 605.4 \\
\hline 2164 & $1 / 10 / 200810: 10$ & $8 / 10 / 2008$ 10:10 & 22 & 607.4 \\
\hline 2165 & $1 / 10 / 2008$ 10:12 & $8 / 10 / 2008$ 10:12 & 22 & 608.8 \\
\hline 2166 & $1 / 10 / 2008$ 10:14 & $8 / 10 / 2008$ 10:14 & 22 & 607.7 \\
\hline 2167 & 1/10/2008 10:16 & $8 / 10 / 2008$ 10:16 & 22 & 608.2 \\
\hline 2168 & 1/10/2008 10:18 & $8 / 10 / 2008$ 10:18 & 22 & 610.2 \\
\hline 2169 & $1 / 10 / 2008$ 10:20 & $8 / 10 / 200810: 20$ & 22 & 609.4 \\
\hline 2170 & $1 / 10 / 2008$ 10:22 & $8 / 10 / 200810: 22$ & 22 & 609.7 \\
\hline 2171 & $1 / 10 / 2008$ 10:24 & $8 / 10 / 2008$ 10:24 & 21.9 & 567.8 \\
\hline 2172 & $1 / 10 / 2008$ t0:26 & $8 / 10 / 2008$ 10:26 & 21.8 & 599.8 \\
\hline 2173 & $1 / 10 / 2008$ 10:28 & $8 / 10 / 2008$ 10:28 & 21.8 & 602.3 \\
\hline 2174 & $1 / 10 / 200810: 30$ & $8 / 10 / 2008$ 10:30 & 21.8 & 609.2 \\
\hline 2175 & $1 / 10 / 200810: 32$ & \begin{tabular}{|l|}
$8 / 10 / 2008$ 10:32 \\
\end{tabular} & 21.9 & 616.8 \\
\hline 2176 & $1 / 10 / 2008$ t0:34 & $8 / 10 / 2008$ 10:34 & 22 & 614.2 \\
\hline
\end{tabular}

\begin{tabular}{|c|c|c|c|c|}
\hline \multicolumn{5}{|c|}{ D492c } \\
\hline $\operatorname{Rec}$ & & Adjusted & Temp & $\mathrm{SC}$ \\
\hline$\#$ & DaterTime & Date/Time & ${ }^{\circ} \mathrm{C}$ & $\mu \mathrm{S} / \mathrm{cm}$ \\
\hline 2177 & 1/10/2008 10:36 & $8 / 10 / 200810: 36$ & 22.1 & 613.1 \\
\hline 2178 & 1/10/2008 10:38 & $8 / 10 / 2008$ 10:38 & 22.1 & 615 \\
\hline 2179 & $1 / 10 / 2008$ 10:40 & $8 / 10 / 200810: 40$ & 22.1 & 613.1 \\
\hline 2180 & $1 / 10 / 2008$ 10:42 & $8 / 10 / 200810: 42$ & 22.1 & 612.7 \\
\hline 2181 & $1 / 10 / 2008$ 10:44 & $8 / 10 / 200810: 44$ & 22.1 & 614.8 \\
\hline 2182 & $1 / 10 / 200810: 46$ & $8 / 10 / 2008$ 10:46 & 22.1 & 616.2 \\
\hline 2183 & $1 / 10 / 200810: 48$ & $8 / 10 / 200810: 48$ & 22.1 & $6+4.8$ \\
\hline 2184 & $1 / 10 / 200810: 50$ & $8 / 10 / 200810: 50$ & 22.1 & 614.6 \\
\hline 2185 & $1 / 10 / 200810: 52$ & $8 / 10 / 200810: 52$ & 22.1 & 616.7 \\
\hline 2186 & $1 / 10 / 2008$ 10:54 & $8 / 10 / 200810: 54$ & 22.1 & 620 \\
\hline 2187 & 1/10/2008 10:56 & $8 / 10 / 2008$ 10:56 & 22.1 & 617.2 \\
\hline 2188 & $1 / 10 / 200810: 58$ & $8 / 10 / 200810: 58$ & 22.1 & 617.3 \\
\hline 2189 & 1/10/2008 11:00 & $8 / 10 / 200811: 00$ & 22.1 & 617.4 \\
\hline 2190 & $1 / 10 / 200811: 02$ & $8 / 10 / 200811: 02$ & 22.2 & 613.7 \\
\hline 2191 & $1 / 10 / 200811: 04$ & $8 / 10 / 200811: 04$ & 22.2 & 617.6 \\
\hline 2192 & $1 / 10 / 200811: 06$ & $8 / 10 / 200811: 06$ & 22.2 & 616.9 \\
\hline 2193 & $1 / 10 / 200811: 08$ & 8/10/2008 11:08 & 22.2 & 616.4 \\
\hline 2194 & 1/10/2008 11:10 & $8 / 10 / 200811: 10$ & 22.2 & 618.9 \\
\hline 2195 & 1/10/2008 11:12 & $8 / 10 / 200811: 12$ & 22.2 & 617 \\
\hline 2196 & 1/10/2008 11:14 & $8 / 10 / 200811: 14$ & 22.2 & 619.6 \\
\hline 2197 & 1/10/2008 11:16 & $8 / 10 / 200811: 16$ & 22.2 & 618.5 \\
\hline 2198 & $1 / 10 / 200811: 18$ & $8 / 10 / 200811: 18$ & 22.2 & 616.8 \\
\hline 2199 & $1 / 10 / 200811: 20$ & $8 / 10 / 200811: 20$ & 22.2 & 618.5 \\
\hline 2200 & $1 / 10 / 200811: 22$ & $8 / 10 / 200811: 22$ & 22.2 & 620.1 \\
\hline 2201 & $1 / 10 / 2008+11: 24$ & $8 / 10 / 200811: 24$ & 22.2 & 622.3 \\
\hline 2202 & $1 / 10 / 200811: 26$ & $8 / 10 / 200811: 26$ & 22.2 & 621.3 \\
\hline 2203 & $1 / 10 / 2008$ 11:28 & $8 / 10 / 200811: 28$ & 22.2 & 619.3 \\
\hline 2204 & $1 / 10 / 200811: 30$ & $8 / 10 / 200811: 30$ & 22.2 & 621.9 \\
\hline 2205 & 1/10/2008 11:32 & $8 / 10 / 200811: 32$ & 22.2 & 622.7 \\
\hline 2206 & 1/10/2008 11:34 & $8 / 10 / 200811: 34$ & 22.2 & 617.8 \\
\hline 2207 & $1 / 10 / 200811: 36$ & $8 / 10 / 200811: 36$ & 22.3 & 620.4 \\
\hline 2208 & $1 / 10 / 200811: 38$ & $8 / 10 / 200811: 38$ & 22.3 & 620.8 \\
\hline 2209 & $1 / 10 / 200811: 40$ & $8 / 10 / 200811: 40$ & 22.3 & 619.4 \\
\hline 2210 & $1 / 10 / 2008$ 11:42 & $8 / 10 / 200811: 42$ & 22.3 & 620.4 \\
\hline 2211 & $1 / 10 / 200811: 44$ & $8 / 10 / 200811: 44$ & 22.3 & 623.8 \\
\hline 2212 & $1 / 10 / 2008$ 11:46 & $8 / 10 / 2008+1: 46$ & 22.3 & 626.1 \\
\hline 2213 & $1 / 10 / 2008$ 11:48 & $8 / 10 / 200811: 48$ & 22.3 & 626.4 \\
\hline 2214 & $1 / 10 / 200811: 50$ & $8 / 10 / 200811: 50$ & 22.3 & 629.6 \\
\hline 2215 & $1 / 10 / 200811: 52$ & $8 / 10 / 200811: 52$ & 22.3 & 631.5 \\
\hline 2216 & $1 / 10 / 200811: 54$ & $8 / 10 / 200811: 54$ & 22.3 & 628.4 \\
\hline 2217 & $1 / 10 / 200811: 56$ & $8 / 10 / 200811: 56$ & 22.3 & 630.5 \\
\hline 2218 & $1 / 10 / 200811: 58$ & $8 / 10 / 200811: 58$ & 22.3 & 632.3 \\
\hline 2219 & $1 / 10 / 2008$ 12:00 & $8 / 10 / 200812: 00$ & 22.3 & 629.7 \\
\hline 2220 & $1 / 10 / 200812: 02$ & $8 / 10 / 200812: 02$ & 22.3 & 630.1 \\
\hline 2221 & $1 / 10 / 200812: 04$ & $8 / 10 / 200812: 04$ & 22.2 & 626.9 \\
\hline 2222 & $1 / 10 / 200812: 06$ & $8 / 10 / 200812: 06$ & 22.1 & 625.4 \\
\hline 2223 & $1 / 10 / 200812: 08$ & $8 / 10 / 200812: 08$ & 22.1 & 609.6 \\
\hline 2224 & $1 / 10 / 200812: 10$ & $8 / 10 / 200812: 10$ & 22.1 & 600.6 \\
\hline 2225 & $1 / 10 / 200812: 12$ & $8 / 10 / 200812: 12$ & 22.1 & 598.2 \\
\hline 2226 & $1 / 10 / 200812: 14$ & $8 / 10 / 200812: 14$ & 22.1 & 598.6 \\
\hline 2227 & 1/10/2008 12:16 & $8 / 10 / 200812: 16$ & 22.1 & 602 \\
\hline 2228 & 1/10/2008 12:18 & $8 / 10 / 200812: 18$ & 22.1 & 602.5 \\
\hline 2229 & $1 / 10 / 200812: 20$ & $8 / 10 / 200812: 20$ & 22.1 & 604.2 \\
\hline 2230 & $1 / 10 / 200812: 22$ & $8 / 10 / 200812: 22$ & 22.2 & 604.4 \\
\hline 2231 & $1 / 10 / 200812: 24$ & $8 / 10 / 200812: 24$ & 22.2 & 608 \\
\hline 2232 & $1 / 10 / 200812: 26$ & $8 / 10 / 200812: 26$ & 22.2 & 610.3 \\
\hline 2233 & $1 / 10 / 2008$ 12:28 & $8 / 10 / 200812: 28$ & 22.2 & 609.5 \\
\hline 2234 & $1 / 10 / 200812: 30$ & $8 / 10 / 200812: 30$ & 22.1 & 609.9 \\
\hline 2235 & $1 / 10 / 200812: 32$ & $8 / 10 / 200812: 32$ & 22.2 & 610.3 \\
\hline 2236 & $1 / 10 / 200812: 34$ & $8 / 10 / 200812: 34$ & 22.2 & 615 \\
\hline 2237 & $1 / 10 / 200812: 36$ & $8 / 10 / 200812: 36$ & 22.2 & 613.8 \\
\hline 2238 & $1 / 10 / 200812: 38$ & $8 / 10 / 200812: 38$ & 22.2 & 615.1 \\
\hline 2239 & $1 / 10 / 200812: 40$ & $8 / 10 / 200812: 40$ & 22.2 & 616.2 \\
\hline 2240 & $1 / 10 / 200812: 42$ & $8 / 10 / 2008112: 42$ & 22.2 & 615.1 \\
\hline 2241 & $1 / 10 / 200812: 44$ & $8 / 10 / 200812: 44$ & 22.2 & 617.1 \\
\hline 2242 & $1 / 10 / 200812: 46$ & $8 / 10 / 200812: 46$ & 22.2 & 617.5 \\
\hline 2243 & $1 / 10 / 200812: 48$ & $8 / 10 / 200812: 48$ & 22.2 & 617.5 \\
\hline 2244 & $1 / 10 / 200812: 50$ & $8 / 10 / 200812: 50$ & 22.3 & 617.9 \\
\hline
\end{tabular}




\begin{tabular}{|c|c|c|c|c|}
\hline \multicolumn{5}{|c|}{ D4-92c } \\
\hline $\operatorname{Rec}$ & & Adjusted & Temp & $\mathrm{SC}$ \\
\hline$\#$ & Dater/Time & Date/Time & ${ }^{\circ} \mathrm{C}$ & $\mu \mathrm{S} / \mathrm{cm}$ \\
\hline 2313 & $1 / 10 / 2008$ 15:08 & $8 / 10 / 200815: 08$ & 22.4 & 627.4 \\
\hline 2314 & $1 / 10 / 200815: 10$ & $8 / 10 / 200815: 10$ & 22.4 & 620.1 \\
\hline 2315 & $1 / 10 / 200815: 12$ & $8 / 10 / 2008$ 15:12 & 22.5 & 615.3 \\
\hline 2316 & 1/10/2008 15:14 & $8 / 10 / 200815: 14$ & 22.5 & 613.7 \\
\hline 2317 & 1/10/2008 15:16 & $8 / 10 / 2008$ 15:16 & 22.5 & 613.2 \\
\hline 2318 & $1 / 10 / 2008$ 15:18 & $8 / 10 / 200815: 18$ & 22.4 & 612 \\
\hline 2319 & $1 / 10 / 200815: 20$ & $8 / 10 / 200815: 20$ & 22.4 & 610.3 \\
\hline 2320 & $1 / 10 / 200815: 22$ & $8 / 10 / 200815: 22$ & 22.4 & 616.8 \\
\hline 2321 & $1 / 10 / 200815: 24$ & $8 / 10 / 2008$ 15:24 & 22.4 & 617.5 \\
\hline 2322 & 1/10/2008 15:26 & $8 / 10 / 2008$ 15:26 & 22.4 & 618.2 \\
\hline 2323 & 1/10/2008 15:28 & $8 / 10 / 2008$ 15:28 & 22.5 & 622.2 \\
\hline 2324 & 1/10/2008 15:30 & $8 / 10 / 200815: 30$ & 22.5 & 623.3 \\
\hline 2325 & $1 / 10 / 200815: 32$ & $8 / 10 / 2008$ 15:32 & 22.5 & 623.4 \\
\hline 2326 & $1 / 10 / 200815: 34$ & $8 / 10 / 200815: 34$ & 22.5 & 623.3 \\
\hline 2327 & 1/10/2008 15:36 & $8 / 10 / 200815: 36$ & 22.5 & 624.7 \\
\hline 2328 & $1 / 10 / 200815: 38$ & $8 / 10 / 200815: 38$ & 22.5 & 624.9 \\
\hline 2329 & 1/10/2008 15:40 & $8 / 10 / 200815: 40$ & 22.5 & 625.5 \\
\hline 2330 & $1 / 40 / 200815: 42$ & $8 / 10 / 2008$ 15:42 & 22.5 & 625.9 \\
\hline 2331 & $1 / 10 / 200815: 44$ & $8 / 10 / 200815: 44$ & 22.4 & 627.2 \\
\hline 2332 & $1 / 10 / 200815: 46$ & $8 / 10 / 200815: 46$ & 22.4 & 627.3 \\
\hline 2333 & $1 / 10 / 200815: 48$ & $8 / 10 / 200815: 48$ & 22.4 & 627.6 \\
\hline 2334 & 1/10/2008 15:50 & $8 / 10 / 200815: 50$ & 22.4 & 629.1 \\
\hline 2335 & 1/10/2008 15:52 & $8 / 10 / 200815: 52$ & 22.4 & 618.2 \\
\hline 2336 & $1 / 40 / 200815: 54$ & $8 / 10 / 200815: 54$ & 22.5 & 615 \\
\hline 2337 & 1/10/2008 15:56 & $8 / 10 / 200815: 56$ & 22.5 & 609.8 \\
\hline 2338 & $1 / 10 / 200815: 58$ & $8 / 10 / 2008$ 15:58 & 22.5 & 603.4 \\
\hline 2339 & 1/10/2008 16:00 & 8/10/2008 16:00 & 22.5 & 599.4 \\
\hline 2340 & 1/10/2008 16:02 & $8 / 10 / 200816: 02$ & 22.5 & 589.5 \\
\hline 2341 & 1/10/2008 16:04 & $8 / 10 / 200816: 04$ & 22.5 & 578.5 \\
\hline 2342 & 1/10/2008 16:06 & 8/10/2008 16:06 & 22.5 & 571.7 \\
\hline 2343 & 1/10/2008 16:08 & $8 / 10 / 2008$ 16:08 & 22.7 & 578.4 \\
\hline 2344 & $1 / 10 / 200816: 10$ & $8 / 10 / 200816: 10$ & 22.8 & 582.2 \\
\hline 2345 & $1 / 10 / 200816: 12$ & $8 / 10 / 2008$ 16:12 & 22.8 & 580.2 \\
\hline 2346 & $1 / 10 / 200816: 14$ & $8 / 10 / 200816: 14$ & 22.8 & 581.4 \\
\hline 2347 & 1/10/2008 16:16 & $8 / 10 / 200816: 16$ & 22.7 & 578.2 \\
\hline 2348 & 1/10/2008 16:18 & $8 / 10 / 200816: 18$ & 22.7 & 573.2 \\
\hline 2349 & 1/10/2008 16:20 & 8/10/2008 16:20 & 22.7 & 566.8 \\
\hline 2350 & $1 / 10 / 200816: 22$ & $8 / 10 / 200816: 22$ & 22.7 & 560.1 \\
\hline 2351 & 1/10/2008 16:24 & 8/10/2008 16:24 & 22.7 & 5529 \\
\hline 2352 & 1/10/2008 16:26 & 8/10/2008 16:26 & 22.7 & 551.6 \\
\hline 2353 & $1 / 10 / 200816: 28$ & $8 / 10 / 200816: 28$ & 22.7 & 548.7 \\
\hline 2354 & 1/10/2008 16:30 & $8 / 10 / 2008$ 16:30 & 22.8 & 547.1 \\
\hline 2355 & $1 / 10 / 200816: 32$ & $8 / 10 / 200816: 32$ & 22.8 & 543.5 \\
\hline 2356 & 1/10/2008 16:34 & $8 / 10 / 200816: 34$ & 228 & 540.7 \\
\hline 2357 & 1/10/2008 16:36 & $8 / 10 / 2008$ 16:36 & 22.8 & 538.6 \\
\hline 2358 & 1/10/2008 16:38 & $8 / 10 / 2008$ 16:38 & 22.8 & 536.2 \\
\hline 2359 & $1 / 10 / 200816: 40$ & $8 / 10 / 200816: 40$ & 22.8 & 533.8 \\
\hline 2360 & $1 / 10 / 2008$ 16:42 & \begin{tabular}{|l|}
$8 / 10 / 2008$ \\
\end{tabular} & 22.9 & 537.6 \\
\hline 2361 & $1 / 10 / 200816: 44$ & \begin{tabular}{|l|}
$8 / 10 / 2008$ 16:44 \\
\end{tabular} & 23.1 & 590.4 \\
\hline 2362 & 1/10/2008 16:46 & $8 / 10 / 200816: 46$ & 23.1 & 600.2 \\
\hline 2363 & 1/10/2008 16:48 & $8 / 10 / 200816: 48$ & 23.1 & 619.1 \\
\hline 2364 & 1/10/2008 16:50 & $8 / 10 / 200816: 50$ & 23.1 & 611.2 \\
\hline 2365 & 1/10/2008 16:52 & $8 / 10 / 200816: 52$ & 23 & 613.2 \\
\hline 2366 & 1/10/2008 16:54 & \begin{tabular}{|l|}
$8 / 10 / 2008$ \\
$16: 54$ \\
\end{tabular} & 23 & 612.6 \\
\hline 2367 & 1/10/2008 16:56 & $8 / 10 / 200816: 56$ & 23 & 628.5 \\
\hline 2368 & 1/190/2008 16:58 & \begin{tabular}{|l|}
$8 / 10 / 2008$ \\
$16: 58$ \\
\end{tabular} & 23 & 624.3 \\
\hline 2369 & 1/40/2008 17:00 & \begin{tabular}{|l|}
$8 / 10 / 2008$ 17:00 \\
\end{tabular} & 23 & 627.8 \\
\hline 2370 & 1/70/2008 17:02 & $8 / 10 / 200817: 02$ & 23 & 625.4 \\
\hline 2371 & 1/10/2008 17:04 & \begin{tabular}{|l|}
$8 / 10 / 200817: 04$ \\
\end{tabular} & 23 & 623.8 \\
\hline 2372 & 1/10/2008 17:06 & \begin{tabular}{|l|}
$8 / 10 / 200817: 06$ \\
\end{tabular} & 23 & 631.6 \\
\hline 2373 & 1/10/2008 17:08 & \begin{tabular}{|l|}
$8 / 10 / 2008$ 17:08 \\
\end{tabular} & 23 & 630.5 \\
\hline 2374 & $1 / 10 / 200817: 10$ & \begin{tabular}{|l|}
$8 / 10 / 2008$ \\
$17: 10$
\end{tabular} & 23 & 631.8 \\
\hline 2375 & 1/10/2008 17:12 & \begin{tabular}{|l|}
$8 / 10 / 2008$ \\
\end{tabular} & 23 & 629 \\
\hline 2376 & $1 / 10 / 200817: 14$ & \begin{tabular}{|l|}
$8 / 10 / 200817: 14$ \\
\end{tabular} & 23 & 628.1 \\
\hline 2377 & $1 / 10 / 200817: 16$ & \begin{tabular}{|l|}
$8 / 10 / 200817: 16$ \\
\end{tabular} & 23 & 638.2 \\
\hline 2378 & $1 / 10 / 2008$ 17:18 & \begin{tabular}{|l|}
$8 / 10 / 200817: 18$ \\
\end{tabular} & 22.9 & 590.1 \\
\hline 2379 & $1 / 10 / 200817: 20$ & \begin{tabular}{|l|}
$8 / 10 / 200817: 20$ \\
\end{tabular} & 22.7 & 629.4 \\
\hline 2380 & 1/10/2008 17:22 & \begin{tabular}{|l|}
$8 / 10 / 200817: 22$ \\
\end{tabular} & 22.7 & 633.9 \\
\hline
\end{tabular}

\begin{tabular}{|c|c|c|c|c|}
\hline \multicolumn{5}{|c|}{ D4-92C } \\
\hline $\operatorname{Rec}$ & & \begin{tabular}{|c|} 
Adjusted \\
\end{tabular} & Temp & SC \\
\hline$\#$ & Date/Time & Date/Time & \begin{tabular}{|l|l|}
${ }^{\circ} \mathrm{C}$ \\
\end{tabular} & $\mu \mathrm{S} / \mathrm{cm}$ \\
\hline 2381 & $1 / 10 / 200817: 24$ & 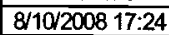 & 22.7 & 633.3 \\
\hline 2382 & $1 / 10 / 200817: 26$ & $8 / 10 / 2008 \quad 17: 26$ & 22.7 & 635.8 \\
\hline 2383 & $1 / 10 / 200817: 28$ & $8 / 10 / 2008$ 17:28 & 22.8 & 635.4 \\
\hline 2384 & $1 / 10 / 200817: 30$ & $8 / 10 / 2008$ 17:30 & 22.9 & 634.8 \\
\hline 2385 & $1 / 10 / 200817: 32$ & $8 / 10 / 200817: 32$ & 23 & 632.5 \\
\hline 2386 & $1 / 10 / 200817: 34$ & $8 / 10 / 2008$ 17:34 & 23 & 638.2 \\
\hline 2387 & $1 / 10 / 200817: 36$ & $8 / 10 / 200817: 36$ & 23 & 631.7 \\
\hline 2388 & $1 / 10 / 200817: 38$ & $8 / 10 / 200817: 38$ & 23 & 621.9 \\
\hline 2389 & $1 / 10 / 200817: 40$ & $8 / 10 / 2008$ 17:40 & 23 & 638.5 \\
\hline 2390 & $1 / 10 / 200817: 42$ & $8 / 10 / 200817: 42$ & 22.9 & 640.2 \\
\hline 2391 & $1 / 10 / 200817: 44$ & $8 / 10 / 2008$ 17:44 & 22.9 & 642.8 \\
\hline 2392 & $1 / 10 / 200817: 46$ & $8 / 10 / 200817: 46$ & 22.9 & 641 \\
\hline 2393 & $1 / 10 / 200817: 48$ & $8 / 10 / 200817: 48$ & 22.9 & 643.4 \\
\hline 2394 & $1 / 10 / 200817: 50$ & $8 / 10 / 200817: 50$ & 22.8 & 644 \\
\hline 2395 & $1 / 10 / 200817: 52$ & $8 / 10 / 200817: 52$ & 22.7 & 646 \\
\hline 2396 & $1 / 10 / 200817: 54$ & $8 / 10 / 200817: 54$ & 22.8 & 645.3 \\
\hline 2397 & 1/10/2008 17:56 & $8 / 10 / 200817: 56$ & 22.9 & 633.1 \\
\hline 2398 & $1 / 10 / 200817: 58$ & $8 / 10 / 200817: 58$ & 22.9 & 637.1 \\
\hline 2399 & $1 / 10 / 200818: 00$ & $8 / 10 / 200818: 00$ & 22.9 & 635.8 \\
\hline 2400 & $1 / 10 / 200818: 02$ & $8 / 10 / 200818: 02$ & 22.9 & 637.5 \\
\hline 2401 & $1 / 10 / 200818: 04$ & $8 / 10 / 200818: 04$ & 22.9 & 638.8 \\
\hline 2402 & $1 / 10 / 200818: 06$ & $8 / 10 / 200818: 06$ & 22.9 & 639.6 \\
\hline 2403 & $1 / 10 / 200818: 08$ & $8 / 10 / 200818: 08$ & 22.9 & 638.8 \\
\hline 2404 & $1 / 10 / 200818: 10$ & $8 / 10 / 200818: 10$ & 22.9 & 640.1 \\
\hline 2405 & 1/10/2008 18:12 & $8 / 10 / 200818: 12$ & 22.9 & 639.9 \\
\hline 2406 & $1 / 10 / 200818: 14$ & $8 / 10 / 200818: 14$ & 22.9 & 640.1 \\
\hline 2407 & 1/10/2008 18:16 & 8/10/2008 18:16 & 23 & 640 \\
\hline 2408 & $1 / 10 / 200818: 18$ & $8 / 10 / 200818: 18$ & 23 & 640.4 \\
\hline 2409 & $1 / 10 / 200818: 20$ & $8 / 10 / 200818: 20$ & 23 & 641.2 \\
\hline 2410 & $1 / 10 / 200818: 22$ & $8 / 10 / 200818: 22$ & 23 & 641.5 \\
\hline 2411 & 1/10/2008 18:24 & $8 / 10 / 200818: 24$ & 23 & 640.8 \\
\hline 2412 & $1 / 10 / 200818: 26$ & $8 / 10 / 200818: 26$ & 23 & 642.3 \\
\hline 2413 & $1 / 10 / 200818: 28$ & $8 / 10 / 200818: 28$ & 23 & 642.6 \\
\hline 2414 & $1 / 10 / 200818: 30$ & $8 / 10 / 200818: 30$ & 23 & 642.7 \\
\hline 2415 & $1 / 10 / 200818: 32$ & $8 / 10 / 200818: 32$ & 23 & 642.9 \\
\hline 2416 & $t / 10 / 200818: 34$ & $8 / 10 / 200818: 34$ & 23 & 642.1 \\
\hline 2417 & 1/10/2008 18:36 & $8 / 10 / 200818: 36$ & 23 & 642.2 \\
\hline 2418 & $1 / 10 / 200818: 38$ & $8 / 10 / 200818: 38$ & 23 & 643 \\
\hline 2419 & $1 / 10 / 200818: 40$ & $8 / 10 / 200818: 40$ & 23 & 641.8 \\
\hline 2420 & $1 / 10 / 200818: 42$ & $8 / 10 / 2008 \quad 18: 42$ & 23 & 642.5 \\
\hline 2421 & $1 / 10 / 200818: 44$ & $8 / 10 / 200818: 44$ & 23 & 642.2 \\
\hline 2422 & $1 / 10 / 200818: 46$ & $8 / 10 / 200818: 46$ & 23 & 642.2 \\
\hline 2423 & $1 / 10 / 200818: 48$ & $8 / 10 / 200818: 48$ & 23 & 641.8 \\
\hline 2424 & 1/10/2008 18:50 & $8 / 10 / 200818: 50$ & 23.1 & $\frac{642}{6}$ \\
\hline 2425 & $1 / 10 / 200818: 52$ & $8 / 10 / 200818: 52$ & 23 & 640.7 \\
\hline 2426 & $1 / 10 / 200818: 54$ & $8 / 10 / 200818: 54$ & 23 & 640 \\
\hline 2427 & $1 / 10 / 200818: 56$ & $8 / 10 / 200818: 56$ & 23 & 641.6 \\
\hline 2428 & 1/10/2008 18:58 & $8 / 10 / 200818: 58$ & 23 & 641.7 \\
\hline 2429 & 1/10/2008 19:00 & $8 / 10 / 200819: 00$ & 23.1 & 640.2 \\
\hline 2430 & 1/10/2008 19:02 & 8/10/2008 19:02 & 23.1 & 639 \\
\hline 2431 & $1 / 10 / 200819: 04$ & $8 / 10 / 200819: 04$ & 23.1 & 639.8 \\
\hline 2432 & $1 / 10 / 200819: 06$ & $8 / 10 / 2008$ 19:06 & 23.1 & 641.6 \\
\hline 2433 & $1 / 10 / 200819: 08$ & $8 / 10 / 200819: 08$ & 23 & 641.1 \\
\hline 2434 & $1 / 10 / 200819: 10$ & $8 / 10 / 200819: 10$ & 23.1 & 640.1 \\
\hline 2435 & $1 / 10 / 200819: 12$ & $8 / 10 / 200819: 12$ & 23.1 & 638.6 \\
\hline 2436 & $1 / 10 / 200819: 14$ & $8 / 10 / 2008$ 19:14 & 23.1 & 641.1 \\
\hline 2437 & $1 / 10 / 200819: 16$ & $8 / 10 / 2008$ 19:16 & 23.1 & 638.9 \\
\hline 2438 & $1 / 10 / 200819: 18$ & $8 / 10 / 200819: 18$ & 23.1 & 638.1 \\
\hline 2439 & $1 / 10 / 200819: 20$ & $8 / 10 / 200819: 20$ & 23.1 & 638.5 \\
\hline 2440 & $1 / 10 / 200819: 22$ & $8 / 10 / 200819: 22$ & 23.1 & 640.5 \\
\hline 2441 & $1 / 10 / 200819: 24$ & $8 / 10 / 2008$ 19:24 & 23.1 & 640.9 \\
\hline 2442 & $1 / 10 / 200819: 26$ & $8 / 10 / 200819: 26$ & 23.1 & 639.4 \\
\hline 2443 & $1 / 10 / 200819: 28$ & $8 / 10 / 2008$ 19:28 & 23.1 & 640.5 \\
\hline 2444 & $1 / 10 / 200819: 30$ & 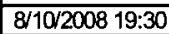 & 23.1 & 638.8 \\
\hline 2445 & $1 / 10 / 200819: 32$ & \begin{tabular}{|l|l}
$8 / 10 / 2008$ & $19: 32$ \\
\end{tabular} & 23.1 & 634.7 \\
\hline 2446 & $1 / 10 / 200819: 34$ & $8 / 10 / 200819: 34$ & 23.1 & 638.9 \\
\hline 2447 & $1 / 10 / 200819: 36$ & $8 / 10 / 2008$ 19:36 & 23.1 & 639.2 \\
\hline 2448 & $1 / 10 / 200819: 38$ & $8 / 10 / 2008$ 19:38 & 23.2 & 639.2 \\
\hline
\end{tabular}




\begin{tabular}{|c|c|c|c|c|}
\hline \multicolumn{5}{|c|}{ D4-92c } \\
\hline $\operatorname{Rec}$ & & Adjusted & Temp & SC \\
\hline$\#$ & Dater/Time & DaterTime & ${ }^{\circ} \mathrm{C}$ & $\mu \mathrm{S} / \mathrm{cm}$ \\
\hline 2449 & $1 / 10 / 200819: 40$ & $8 / 10 / 200819: 40$ & 23.2 & 639.9 \\
\hline 2450 & $1 / 10 / 200819: 42$ & $8 / 10 / 2008 \quad 19: 42$ & 23.2 & 636.6 \\
\hline 2451 & $1 / 10 / 200819: 44$ & $8 / 10 / 200819: 44$ & 23.2 & 636.7 \\
\hline 2452 & $1 / 10 / 200819: 46$ & $8 / 10 / 2008$ 19:46 & 23.2 & 636.5 \\
\hline 2453 & $1 / 10 / 2008 \quad 19: 48$ & $8 / 10 / 2008 \quad 19: 48$ & 23.2 & 637.4 \\
\hline 2454 & $1 / 10 / 2008$ 19:50 & $8 / 10 / 200819: 50$ & 23.2 & 638.6 \\
\hline 2455 & $1 / 10 / 2008$ 19:52 & $8 / 10 / 2008 \quad 19: 52$ & 23.2 & 635.4 \\
\hline 2456 & $1 / 10 / 2008$ 19:54 & $8 / 10 / 2008 \quad 19: 54$ & 23.2 & 640 \\
\hline 2457 & $1 / 10 / 200819: 56$ & $8 / 10 / 200819: 56$ & 23.2 & 636.6 \\
\hline 2458 & $1 / 10 / 2008$ 19:58 & $8 / 10 / 200819: 58$ & 23.2 & 636.1 \\
\hline 2459 & $1 / 10 / 200820: 00$ & $8 / 10 / 200820: 00$ & 23.2 & 637.5 \\
\hline 2460 & $1 / 10 / 200820: 02$ & $8 / 10 / 200820: 02$ & 23.2 & 641.3 \\
\hline 2461 & $1 / 10 / 200820: 04$ & $8 / 10 / 200820: 04$ & 23.2 & 638.9 \\
\hline 2462 & $1 / 10 / 200820: 06$ & $8 / 10 / 200820: 06$ & 23.2 & 639.2 \\
\hline 2463 & $1 / 10 / 200820: 08$ & $8 / 10 / 200820: 08$ & 23.2 & 636.9 \\
\hline 2464 & $1 / 10 / 200820: 10$ & $8 / 10 / 200820: 10$ & 23.3 & 640.2 \\
\hline 2465 & $1 / 10 / 200820: 12$ & $8 / 10 / 200820: 12$ & 23.3 & 636.7 \\
\hline 2466 & 1/10/2008 20:14 & $8 / 10 / 200820: 14$ & 23.3 & 637.5 \\
\hline 2467 & $1 / 10 / 200820: 16$ & $8 / 10 / 200820: 16$ & 23.3 & 633.1 \\
\hline 2468 & $1 / 10 / 200820: 18$ & $8 / 10 / 200820: 18$ & 23.3 & 631.3 \\
\hline 2469 & $1 / 10 / 200820: 20$ & $8 / 10 / 200820: 20$ & 23.3 & 634.6 \\
\hline 2470 & $1 / 10 / 200820: 22$ & $8 / 10 / 200820: 22$ & 23.3 & 631 \\
\hline 2471 & $1 / 10 / 200820: 24$ & $8 / 10 / 200820: 24$ & 23.3 & 628.8 \\
\hline 2472 & $1 / 10 / 200820: 26$ & $8 / 10 / 200820: 26$ & 23.3 & 627.7 \\
\hline 2473 & $1 / 10 / 200820: 28$ & $8 / 10 / 200820: 28$ & 23.3 & 625.6 \\
\hline 2474 & $1 / 10 / 200820: 30$ & $8 / 10 / 200820: 30$ & 23.3 & 629.5 \\
\hline 2475 & $1 / 10 / 200820: 32$ & $8 / 10 / 200820: 32$ & 23.3 & 628.1 \\
\hline 2476 & $1 / 10 / 200820: 34$ & $8 / 10 / 200820: 34$ & 22.9 & 555.9 \\
\hline 2477 & $1 / 10 / 200820: 36$ & $8 / 10 / 200820: 36$ & 23 & 617.1 \\
\hline 2478 & $1 / 10 / 200820: 38$ & $8 / 10 / 200820: 38$ & 23.1 & 627.1 \\
\hline 2479 & $1 / 10 / 200820: 40$ & $8 / 10 / 200820: 40$ & 23 & 631.8 \\
\hline 2480 & $1 / 10 / 200820: 42$ & $8 / 10 / 200820: 42$ & 23 & 633.9 \\
\hline 2481 & $1 / 10 / 200820: 44$ & $8 / 10 / 200820: 44$ & 23 & 633.3 \\
\hline 2482 & $1 / 10 / 200820: 46$ & $8 / 10 / 200820: 46$ & 23 & 629.9 \\
\hline 2483 & $1 / 10 / 200820: 48$ & $8 / 10 / 200820: 48$ & 23 & 627 \\
\hline 2484 & $1 / 10 / 200820: 50$ & $8 / 10 / 200820: 50$ & 23 & 625.5 \\
\hline 2485 & $1 / 10 / 200820: 52$ & \begin{tabular}{|l|}
$8 / 10 / 200820: 52$ \\
\end{tabular} & 23 & 623.9 \\
\hline 2486 & $1 / 10 / 200820: 54$ & \begin{tabular}{|l}
$8 / 10 / 200820: 54$ \\
\end{tabular} & 23 & 622.1 \\
\hline 2487 & $1 / 10 / 200820: 56$ & $8 / 10 / 200820: 56$ & 23 & 619.7 \\
\hline 2488 & $1 / 10 / 200820: 58$ & $8 / 10 / 200820: 58$ & 23 & 616.9 \\
\hline 2489 & 1/10/2008 21:00 & \begin{tabular}{|l|}
$8 / 10 / 200821: 00$ \\
\end{tabular} & 23 & 615.8 \\
\hline 2490 & $1 / 10 / 200821: 02$ & $8 / 10 / 200821: 02$ & 23 & 615.3 \\
\hline 2491 & $1 / 10 / 20$ & $821: 04$ & 23 & 615.7 \\
\hline 2492 & $1 / 10 / 200821: 06$ & $8 / 10 / 200821: 06$ & 23 & 615.9 \\
\hline 2493 & $1 / 10 / 200821: 08$ & $8 / 10 / 200821: 08$ & 22.9 & 616.7 \\
\hline 2494 & $1 / 10 / 200821: 10$ & $8 / 10 / 200821: 10$ & 22.9 & 617 \\
\hline 2495 & 1/10/2008 21:12 & $8 / 10 / 200821: 12$ & 22.9 & 616.4 \\
\hline 2496 & 1/10/2008 21:14 & $8 / 10 / 200821: 14$ & 22.9 & 614.2 \\
\hline 2497 & 1/10/200821:16 & \begin{tabular}{|l}
$8 / 10 / 200821: 16$ \\
\end{tabular} & 22.9 & 611.8 \\
\hline 2498 & $1 / 10 / 200821: 18$ & $8 / 10 / 200821: 18$ & 22.9 & 578 \\
\hline 2499 & $1 / 10 / 20$ & $8 / 10 / 200821: 20$ & 23 & 588.3 \\
\hline 2500 & $1 / 10 / 20$ & $8 / 10 / 20$ & 23 & 594.5 \\
\hline 2501 & $1 / 10 / 200821: 24$ & $8 / 10 / 200821: 24$ & 23.1 & 597.3 \\
\hline 2502 & $1 / 10 / 200821: 26$ & $8 / 10 / 200821: 26$ & 23 & 595.1 \\
\hline 2503 & $1 / 10 / 200821: 28$ & $8 / 10 / 200821: 28$ & 23 & 598.9 \\
\hline 2504 & $1 / 10 / 200821: 30$ & $8 / 10 / 200821: 30$ & 23 & 603.4 \\
\hline 2505 & $1 / 10 / 200821: 32$ & $8 / 10 / 200821: 32$ & 23 & 604.1 \\
\hline 2506 & $1 / 10 / 20$ & $8 / 10 / 200821: 34$ & 23 & 609.7 \\
\hline 2507 & $1 / 10 / 200821: 36$ & $8 / 10 / 200821: 36$ & 23 & 603.5 \\
\hline 2508 & $1 / 10 / 200821: 38$ & $8 / 10 / 200821: 38$ & 23 & 607.5 \\
\hline 2509 & $1 / 10 / 200821: 40$ & $8 / 10 / 200821: 40$ & 23 & 610.7 \\
\hline 2510 & $1 / 10 / 200821: 42$ & $8 / 10 / 200821: 42$ & 23 & 608.1 \\
\hline 2511 & $1 / 10 / 200821: 44$ & $8 / 10 / 200821: 44$ & 23 & 614.4 \\
\hline 2512 & $1 / 10 / 200821: 46$ & $8 / 10 / 200821: 46$ & 23.1 & 612.1 \\
\hline 2513 & $1 / 10 / 200821: 48$ & $8 / 10 / 200821: 48$ & 23 & 620.3 \\
\hline 2514 & $1 / 10 / 200821: 50$ & $8 / 10 / 200821: 50$ & 23 & 615.8 \\
\hline 2515 & $1 / 10 / 200821: 52$ & $8 / 10 / 200821: 52$ & 23 & 614.1 \\
\hline 2516 & $1 / 10 / 200821: 54$ & $8 / 10 / 200821: 54$ & 23.1 & 616.7 \\
\hline
\end{tabular}

\begin{tabular}{|c|c|c|c|c|}
\hline \multicolumn{5}{|c|}{ D4-92c } \\
\hline $\operatorname{Rec}$ & & Adjusted & & sc \\
\hline$\#$ & Date/Time & Date/Time & ${ }^{\circ} \mathrm{C}$ & $\mu \mathrm{S} / \mathrm{cm}$ \\
\hline 2585 & 1/11/2008 0:12 & $8 / 11 / 20080: 12$ & 23.2 & 638.4 \\
\hline & $1 / 11 / 20080: 14$ & $8 / 11 / 20080: 14$ & 23.2 & \\
\hline 2587 & 11/2008 0:16 & $8 / 11 / 20080: 16$ & 23.3 & \\
\hline 2588 & $1 / 11 / 20080: 18$ & $8 / 11 / 20080: 18$ & 23.4 & 618.9 \\
\hline 2589 & $1 / 11 / 20080: 20$ & $8 / 11 / 20080: 20$ & 23.3 & 618.9 \\
\hline 2590 & 1/11/2008 0:22 & $8 / 11 / 20080: 22$ & 23.4 & \\
\hline 2591 & $1 / 11 / 20080: 24$ & $8 / 11 / 20080: 24$ & 23.3 & 618.8 \\
\hline 2592 & $1 / 11 / 20080: 26$ & $8 / 11 / 20080: 26$ & 23.3 & 618.6 \\
\hline 2593 & $1 / 11 / 20080: 28$ & $8 / 11 / 200$ & 23.3 & \\
\hline 2594 & $1 / 11 / 20080: 30$ & $8 / 11 / 20080: 30$ & 23.3 & 619.1 \\
\hline 2595 & $1 / 11 / 20080: 32$ & $8 / 11 / 20080: 32$ & 23.3 & 621 \\
\hline 2596 & $1 / 11 / 20080: 34$ & $8 / 11 / 20 x$ & 23.3 & \\
\hline 2597 & $11 / 20080: 36$ & $8 / 11 / 20$ & 23.4 & 621.5 \\
\hline 2598 & $0: 38$ & $8 / 11 / 20$ & 23.4 & 622.4 \\
\hline 2599 & $0: 40$ & $8 / 11 / 20$ & 23.4 & \\
\hline 2600 & $1 / 11 / 2$ & $8 / 11 / 2$ & 23.4 & 631.5 \\
\hline 2601 & $0: 44$ & $8 / 11 / 2$ & 23.4 & 625.2 \\
\hline 2602 & & & 23.4 & \\
\hline 2603 & $1 / 11 / 2$ & $8 / 11 / 200$ & 23.3 & 625.2 \\
\hline 2604 & $0: 50$ & $8 / 11 / 2$ & 23.4 & 623 \\
\hline 2605 & $1 / 11 /$ & $8 / 11 / 20$ & 23.4 & 625.6 \\
\hline 2606 & $1 / 11 / 2$ & $8 / 11 / 20$ & 23.4 & 624 \\
\hline 2607 & $0: 56$ & $8 / 11$ & 23.4 & 626.8 \\
\hline 2608 & $1 / 111$ & $8 / 11 / 20$ & 23.4 & 625.8 \\
\hline 2609 & $881: 00$ & $1: 00$ & 23.4 & 625.8 \\
\hline 2610 & $1: 02$ & $: 02$ & 23.4 & 626.7 \\
\hline 2611 & & $8 / 11$ & 23.4 & \\
\hline 2612 & $1: 06$ & & 23.4 & 629.5 \\
\hline 2613 & & & 23.4 & 629.2 \\
\hline 2614 & & $: 10$ & 23.4 & \\
\hline 2615 & & & 23.4 & 630.8 \\
\hline 2616 & & & 23.4 & 628. \\
\hline 2617 & & & 23.4 & \\
\hline 2618 & & & 23.4 & 628.8 \\
\hline 2619 & & & 23. & 628.5 \\
\hline 2620 & & & 23.4 & 30.8 \\
\hline 2621 & & & 23.4 & 629. \\
\hline 2622 & & & 23.4 & 629.2 \\
\hline 2623 & & & 23.5 & 634.3 \\
\hline 2624 & & & 23.5 & 630.7 \\
\hline 2625 & & & 23.2 & 632. \\
\hline 2626 & & & 23.3 & 624. \\
\hline 2627 & & & 23.2 & 627. \\
\hline 2628 & & & 23 & 639.4 \\
\hline 2629 & & & 23.3 & 634. \\
\hline 2630 & & & 23.4 & 645 . \\
\hline 2631 & & & 23. & 643.6 \\
\hline 2632 & & & 23. & 647.2 \\
\hline 2633 & & & 23.5 & 646. \\
\hline 2634 & & & 23.5 & 638.7 \\
\hline 2635 & & & 23.4 & 639. \\
\hline 2636 & & & 23 & \\
\hline 2637 & & & 23.4 & 646. \\
\hline 2638 & & & 23.5 & \\
\hline 2639 & & & 23. & 64 \\
\hline 2640 & & & 23. & 642. \\
\hline 2641 & & & & \\
\hline 2642 & & & 23.5 & 649.1 \\
\hline 2643 & & & 23.5 & 65 \\
\hline 2644 & & & & \\
\hline 2645 & $2: 12$ & $32: 12$ & 23.5 & 656.2 \\
\hline 2646 & & & 23.5 & \\
\hline 2647 & & & & \\
\hline 2648 & $2: 18$ & $8 / 11 / 20082: 18$ & 23.5 & 649.4 \\
\hline 2649 & & & 23.5 & \\
\hline & & & 23.5 & \\
\hline 2651 & $882: 24$ & $8 / 11 / 20$ & 23.5 & \\
\hline 2652 & & & 23.5 & 669. \\
\hline
\end{tabular}


DOE/RL-2009-35, REV. 0

\begin{tabular}{|c|c|c|c|c|}
\hline \multicolumn{5}{|c|}{ D4-92c } \\
\hline Rec & & Adjusted & Temp & SC \\
\hline \# & Date/Time & Date/Time & ${ }^{\circ} \mathrm{C}$ & $\mu \mathrm{S} / \mathrm{cm}$ \\
\hline 2653 & 1/11/2008 2:28 & $8 / 11 / 20082: 28$ & 23.5 & 659.5 \\
\hline 2654 & 1/11/2008 2:30 & $8 / 11 / 20082: 30$ & 23.5 & 651.9 \\
\hline 2655 & 1/11/2008 2:32 & $8 / 11 / 20082: 32$ & 23.5 & 657.8 \\
\hline 2656 & 1/11/2008 2:34 & $8 / 11 / 20082: 34$ & 23.5 & 664 \\
\hline 2657 & 1/11/2008 2:36 & $8 / 11 / 20082: 36$ & 23.5 & 659.2 \\
\hline 2658 & 1/11/2008 2:38 & $8 / 11 / 20082: 38$ & 23.5 & 661.6 \\
\hline 2659 & 1/11/2008 2:40 & $8 / 11 / 20082: 40$ & 23.5 & 665.7 \\
\hline 2660 & 1/11/2008 2:42 & $8 / 11 / 20082: 42$ & 23.5 & 664.9 \\
\hline 2661 & 1/11/2008 2:44 & $8 / 11 / 20082: 44$ & 23.5 & 673.4 \\
\hline 2662 & 1/11/2008 2:46 & $8 / 11 / 20082: 46$ & 23.6 & 660.6 \\
\hline 2663 & $1 / 11 / 20082: 48$ & $8 / 11 / 20082: 48$ & 23.5 & 660 \\
\hline 2664 & $1 / 11 / 20082: 50$ & $8 / 11 / 20082: 50$ & 23.5 & 658.8 \\
\hline 2665 & 1/11/2008 2:52 & 8/11/2008 2:52 & 23.5 & 651.2 \\
\hline 2666 & 1/11/2008 2:54 & $8 / 11 / 20082: 54$ & 23.5 & 639.2 \\
\hline 2667 & 1/11/2008 2:56 & $8 / 11 / 20082: 56$ & 23.5 & 638.7 \\
\hline 2668 & 1/11/20082:58 & $8 / 11 / 20082: 58$ & 23.5 & 636.8 \\
\hline 2669 & 1/11/20083:00 & 8/11/20083:00 & 23.4 & 638.9 \\
\hline 2670 & 1/11/2008 3:02 & 8/11/2008 3:02 & 23.4 & 649.1 \\
\hline 2671 & 1/11/20083:04 & $8 / 11 / 20083: 04$ & 23.4 & 630 \\
\hline 2672 & 1/11/2008 3:06 & 8/11/2008 3:06 & 23.5 & 624 \\
\hline 2673 & 1/11/20083:08 & \begin{tabular}{|l|}
$8 / 11 / 20083: 08$ \\
\end{tabular} & 23.5 & 638 \\
\hline 2674 & 1/11/20083:10 & $8 / 11 / 20083: 10$ & 23.5 & 627.3 \\
\hline 2675 & 1/11/2008 3:12 & $8 / 11 / 20083: 12$ & 23.5 & 649 \\
\hline 2676 & 1/11/2008 3:14 & 8/11/2008 3:14 & 23.5 & 645.3 \\
\hline 2677 & 1/11/2008 3:16 & 8/11/2008 3:16 & 23.5 & 656.2 \\
\hline 2678 & 1/11/20083:18 & $8 / 11 / 20083: 18$ & 23.5 & 638.1 \\
\hline 2679 & 1/11/20083:20 & $8 / 11 / 20083: 20$ & 23.5 & 651.6 \\
\hline 2680 & 1/11/20083:22 & $8 / 11 / 20083: 22$ & 23.5 & 639.3 \\
\hline 2681 & 1/11/2008 3:24 & $8 / 11 / 20083: 24$ & 23.4 & 646.2 \\
\hline 2682 & 1/11/20083:26 & 8/11/2008 3:26 & 23.4 & 639 \\
\hline 2683 & $1 / 11 / 20083: 28$ & $8 / 11 / 20083: 28$ & 23.4 & 643.3 \\
\hline 2684 & 1/11/2008 3:30 & 8/11/2008 3:30 & 23.4 & 641.1 \\
\hline 2685 & 1/11/2008 3:32 & 8/11/2008 3:32 & 23.4 & 646.9 \\
\hline 2686 & 1/11/2008 3:34 & $8 / 11 / 20083: 34$ & 23.4 & 639.3 \\
\hline 2687 & $1 / 11 / 20083: 36$ & $8 / 11 / 20083: 36$ & 23.4 & 640.8 \\
\hline 2688 & 1/11/2008 3:38 & $8 / 11 / 20083: 38$ & 23.5 & 647.4 \\
\hline 2689 & $1 / 11 / 20083: 40$ & $8 / 11 / 20083: 40$ & 23.4 & 643.9 \\
\hline 2690 & $1 / 11 / 20083: 42$ & $8 / 11 / 20083: 42$ & 23.5 & 640.1 \\
\hline 2691 & $1 / 11 / 20083: 44$ & $8 / 11 / 20083: 44$ & 23.5 & 647 \\
\hline 2692 & 1/11/2008 3:46 & $8 / 11 / 20083: 46$ & 23.5 & 646.3 \\
\hline 2693 & 1/11/2008 3:48 & 8/11/2008 3:48 & 23.5 & 645.4 \\
\hline 2694 & 1/11/2008 3:50 & 8/11/2008 3:50 & 23.5 & 648.3 \\
\hline 2695 & 1/11/2008 3:52 & $8 / 11 / 20083: 52$ & 23.5 & 642.2 \\
\hline 2696 & $1 / 11 / 20083: 54$ & $8 / 11 / 20083: 54$ & 23.3 & 635.7 \\
\hline 2697 & 1/11/20083:56 & 8/11/2008 3:56 & 21.6 & 591.8 \\
\hline 2698 & $1 / 11 / 20083: 58$ & 8/11/2008 3:58 & 21.6 & 613.9 \\
\hline 2699 & $1 / 11 / 20084: 00$ & $8 / 11 / 20084: 00$ & 22.3 & 624.7 \\
\hline 2700 & 1/11/20084:02 & 8/11/2008 4:02 & 22,8 & 636.6 \\
\hline 2701 & 1/11/2008 4:04 & 8/11/2008 4:04 & 23.1 & 651.7 \\
\hline 2702 & 1/11/2008 4:06 & 8/11/2008 4:06 & 23.3 & 665.1 \\
\hline 2703 & 1/11/20084:08 & $8 / 11 / 20084: 08$ & 23.4 & 665.6 \\
\hline 2704 & 1/11/20084:10 & $8 / 11 / 20084: 10$ & 23.4 & 665.6 \\
\hline 2705 & 1/11/2008 4:12 & $8 / 11 / 20084: 12$ & 23.4 & 683.7 \\
\hline 2706 & 1/11/2008 4:14 & $8 / 11 / 20084: 14$ & 23.4 & 681.4 \\
\hline 2707 & 1/11/2008 4:16 & $8 / 11 / 20084: 16$ & 23.4 & 684.7 \\
\hline 2708 & 1/11/20084:18 & $8 / 11 / 20084: 18$ & 23.4 & 687.3 \\
\hline 2709 & 1/11/20084:20 & $8 / 11 / 20084: 20$ & 23.5 & 697.8 \\
\hline 2710 & $1 / 11 / 20084: 22$ & $8 / 11 / 20084: 22$ & 23.5 & 683.3 \\
\hline 2711 & 1/11/2008 4:24 & $8 / 11 / 20084: 24$ & 23.5 & 697.6 \\
\hline 2712 & 1/11/2008 4:26 & $8 / 11 / 20084: 26$ & 23.5 & 698 \\
\hline 2713 & $1 / 11 / 20084: 28$ & $8 / 11 / 20084: 28$ & 23.5 & 700 \\
\hline 2714 & 1/11/20084:30 & \begin{tabular}{|l|}
$8 / 11 / 20084: 30$ \\
\end{tabular} & 23.5 & 703.6 \\
\hline 2715 & 1/11/2008 4:32 & \begin{tabular}{|l|}
$8 / 11 / 20084: 32$ \\
\end{tabular} & 23.5 & 684 \\
\hline 2716 & $1 / 11 / 20084: 34$ & $8 / 11 / 20084: 34$ & 23.5 & 703.5 \\
\hline 2717 & 1/11/20084:36 & $8 / 11 / 20084: 36$ & 23.5 & 712.3 \\
\hline 2718 & 1/11/2008 4:38 & $8 / 11 / 20084: 38$ & 23.6 & 696.8 \\
\hline 2719 & $1 / 11 / 20084: 40$ & $8 / 11 / 20084: 40$ & 23.6 & 698.7 \\
\hline 2720 & $1 / 11 / 20084: 42$ & \begin{tabular}{|l|}
$8 / 11 / 20084: 42$ \\
\end{tabular} & 23.6 & 694.8 \\
\hline
\end{tabular}

\begin{tabular}{|c|c|c|c|c|}
\hline \multicolumn{5}{|c|}{ D4-92c } \\
\hline Rec & & Adjusted & Temp & SC \\
\hline$\#$ & Date/Time & Date/Time & ${ }^{\circ} \mathrm{C}$ & $\mu \mathrm{S} / \mathrm{cm}$ \\
\hline 2721 & 1/11/2008 4:44 & $8 / 11 / 20084: 44$ & 23.5 & 695.7 \\
\hline 2722 & $1 / 11 / 20084: 46$ & $8 / 11 / 20084: 46$ & 23.6 & 713.4 \\
\hline 2723 & $1 / 11 / 20084: 48$ & $8 / 11 / 20084: 48$ & 23.6 & 702.9 \\
\hline 2724 & $1 / 11 / 20084: 50$ & $8 / 11 / 20084: 50$ & 23.6 & 706.2 \\
\hline 2725 & $1 / 11 / 20084: 52$ & $8 / 11 / 20084: 52$ & 23.6 & 696.6 \\
\hline 2726 & $1 / 11 / 20084: 54$ & $8 / 11 / 20084: 54$ & 23.6 & 698.7 \\
\hline 2727 & $1 / 11 / 20084: 56$ & $8 / 11 / 20084: 56$ & 23.6 & 691.5 \\
\hline 2728 & $1 / 11 / 20084: 58$ & $8 / 11 / 20084: 58$ & 23.6 & 697.7 \\
\hline 2729 & $1 / 11 / 20085: 00$ & $8 / 11 / 20085: 00$ & 23.6 & 689.3 \\
\hline 2730 & 1/11/20085:02 & $8 / 11 / 20085: 02$ & 23.6 & 710.8 \\
\hline 2731 & $1 / 11 / 20085: 04$ & $8 / 11 / 20085: 04$ & 23.6 & 700.6 \\
\hline 2732 & 1/11/20085:06 & $8 / 11 / 20085: 06$ & 23.6 & 701.1 \\
\hline 2733 & $1 / 11 / 20085: 08$ & $8 / 11 / 20085: 08$ & 23.6 & 705.7 \\
\hline 2734 & 1/11/20085:10 & $8 / 11 / 20085: 10$ & 23.7 & 699.5 \\
\hline 2735 & 1/11/20085:12 & $8 / 11 / 20085: 12$ & 23.6 & 684.9 \\
\hline 2736 & $1 / 11 / 20085: 14$ & $8 / 11 / 20085: 14$ & 23.6 & 704.9 \\
\hline 2737 & 1/11/2008 5:16 & $8 / 11 / 20085: 16$ & 23.7 & 702.9 \\
\hline 2738 & $1 / 11 / 20085: 18$ & $8 / 11 / 20085: 18$ & 23.7 & 698.2 \\
\hline 2739 & $1 / 11 / 20085: 20$ & $8 / 11 / 20085: 20$ & 23.7 & 701.5 \\
\hline 2740 & 1/11/20085:22 & $8 / 11 / 20085: 22$ & 23.7 & 692.9 \\
\hline 2741 & $1 / 11 / 20085: 24$ & $8 / 11 / 20085: 24$ & 23.7 & 711.4 \\
\hline 2742 & $1 / 11 / 20085: 26$ & $8 / 11 / 20085: 26$ & 23.7 & 703.2 \\
\hline 2743 & $1 / 11 / 20085: 28$ & $8 / 11 / 20085: 28$ & 23.7 & 702.5 \\
\hline 2744 & $1 / 11 / 20085: 30$ & $8 / 11 / 20085: 30$ & 23.8 & 691.1 \\
\hline 2745 & $1 / 11 / 20085: 32$ & $8 / 11 / 20085: 32$ & 23.7 & 693.2 \\
\hline 2746 & $1 / 11 / 20085: 34$ & $8 / 11 / 20085: 34$ & 23.7 & 688.2 \\
\hline 2747 & $1 / 11 / 20085: 36$ & $8 / 11 / 20085: 36$ & 23.8 & 699.9 \\
\hline 2748 & $1 / 11 / 20085: 38$ & $8 / 11 / 20085: 38$ & 23.8 & 701.4 \\
\hline 2749 & $1 / 11 / 20085: 40$ & $8 / 11 / 20085: 40$ & 23.8 & 701.7 \\
\hline 2750 & $1 / 11 / 20085: 42$ & $8 / 11 / 20085: 42$ & 23.8 & 697.1 \\
\hline 2751 & $1 / 11 / 20085: 44$ & $8 / 11 / 20085: 44$ & 23.7 & 697.6 \\
\hline 2752 & $1 / 11 / 20085: 46$ & $8 / 11 / 20085: 46$ & 23.7 & 703.3 \\
\hline 2753 & $1 / 11 / 20085: 48$ & $8 / 11 / 20085: 48$ & 23.6 & 705.6 \\
\hline 2754 & $1 / 11 / 20085: 50$ & $8 / 11 / 20085: 50$ & 23.6 & 705.3 \\
\hline 2755 & $1 / 11 / 20085: 52$ & $8 / 11 / 20085: 52$ & 23.6 & 699.4 \\
\hline 2756 & $1 / 11 / 20085: 54$ & $8 / 11 / 20085: 54$ & 23.6 & 693.1 \\
\hline 2757 & $1 / 11 / 20085: 56$ & $8 / 11 / 20085: 56$ & 23.6 & 688 \\
\hline 2758 & $1 / 11 / 20085: 58$ & $8 / 11 / 20085: 58$ & 23.6 & 683.2 \\
\hline 2759 & $1 / 11 / 20086: 00$ & $8 / 11 / 20086: 00$ & 23.6 & 678.8 \\
\hline 2760 & $1 / 11 / 20086: 02$ & $8 / 11 / 20086: 02$ & 23.6 & 666.2 \\
\hline 2761 & 1/11/20086:04 & $8 / 11 / 20086: 04$ & 23.6 & 659.5 \\
\hline 2762 & 1/11/20086:06 & $8 / 11 / 20086: 06$ & 23.7 & 668.3 \\
\hline 2763 & 1/11/20086:08 & $8 / 11 / 20086: 08$ & 23.8 & 679 \\
\hline 2764 & 1/11/2008 6:10 & 8/11/2008 6:10 & 23.7 & 681.6 \\
\hline 2765 & 1/11/2008 6:12 & $8 / 11 / 20086: 12$ & 23.7 & 679.5 \\
\hline 2766 & 1/11/20086:14 & $8 / 11 / 20086: 14$ & 23.7 & 675.1 \\
\hline 2767 & 1/11/2008 6:16 & $8 / 11 / 20086: 16$ & 23.7 & 671.8 \\
\hline 2768 & $1 / 11 / 20086: 18$ & 8/11/2008 6:18 & 23.7 & 668.6 \\
\hline 2769 & $1 / 11 / 20086: 20$ & $8 / 11 / 20086: 20$ & 23.7 & 662.2 \\
\hline 2770 & $1 / 11 / 20086: 22$ & $8 / 11 / 20086: 22$ & 23.7 & 661.5 \\
\hline 2771 & 1/11/2008 6:24 & $8 / 11 / 20086: 24$ & 23.7 & 659.2 \\
\hline 2772 & $1 / 11 / 20086: 26$ & $8 / 11 / 20086: 26$ & 23.6 & 656.7 \\
\hline 2773 & $1 / 11 / 20086: 28$ & $8 / 11 / 20086: 28$ & 23.6 & 657.1 \\
\hline 2774 & $1 / 11 / 20086: 30$ & $8 / 11 / 20086: 30$ & 23.6 & 659 \\
\hline 2775 & 1/11/2008 6:32 & $8 / 11 / 20086: 32$ & 23.6 & 657 \\
\hline 2776 & $1 / 11 / 20086: 34$ & $8 / 11 / 20086: 34$ & 23.6 & 661.4 \\
\hline 2777 & 1/11/2008 6:36 & $8 / 11 / 20086: 36$ & 23.6 & 663.3 \\
\hline 2778 & $1 / 11 / 20086: 38$ & $8 / 11 / 20086: 38$ & 23.6 & 656.9 \\
\hline 2779 & 1/11/20086:40 & $8 / 11 / 20086: 40$ & 23.6 & 660.3 \\
\hline 2780 & 1/11/2008 6:42 & $8 / 11 / 20086: 42$ & 23.7 & 661.1 \\
\hline 2781 & $1 / 11 / 20086: 44$ & $8 / 11 / 20086: 44$ & 23.7 & 662.4 \\
\hline 2782 & $1 / 11 / 20086: 46$ & $8 / 11 / 20086: 46$ & 23.6 & 660.6 \\
\hline 2783 & $1 / 11 / 20086: 48$ & $8 / 11 / 20086: 48$ & 23.6 & 662.4 \\
\hline 2784 & $1 / 11 / 20086: 50$ & \begin{tabular}{|l|}
$8 / 11 / 20086: 50$ \\
\end{tabular} & 23.6 & 659.5 \\
\hline 2785 & $1 / 11 / 20086-52$ & $8 / 11 / 20086: 52$ & 23.6 & 656.2 \\
\hline 2786 & $1 / 11 / 20086: 54$ & $8 / 11 / 20086: 54$ & 23.6 & 657.4 \\
\hline 2787 & $1 / 11 / 20086: 56$ & \begin{tabular}{|l|}
$8 / 11 / 20086: 56$ \\
\end{tabular} & 23.6 & 658.1 \\
\hline 2788 & $1 / 11 / 20086: 58$ & $8 / 11 / 20086: 58$ & 23.6 & 661.8 \\
\hline
\end{tabular}

\begin{tabular}{|c|c|c|c|c|}
\hline \multicolumn{5}{|c|}{ D4-92c } \\
\hline $\operatorname{Rec}$ & & Adjusted & Temp & SC \\
\hline$\#$ & Date/Time & Date/Time & ${ }^{\circ} \mathrm{C}$ & $\mu \mathrm{S} / \mathrm{cm}$ \\
\hline 2789 & $1 / 11 / 20087: 00$ & $8 / 11 / 20087: 00$ & 23.6 & 658.4 \\
\hline 2790 & $1 / 11 / 20087: 02$ & $8 / 11 / 20087: 02$ & 23.7 & 658.8 \\
\hline 2791 & $1 / 11 / 20087: 04$ & $8 / 11 / 20087: 04$ & 23.7 & \\
\hline 2792 & $1 / 11 / 20087: 06$ & $8 / 11 / 20087: 06$ & 23.7 & 664 \\
\hline 2793 & $1 / 11 / 20087: 08$ & $8 / 11 / 20087: 08$ & 23.7 & 665.5 \\
\hline 2794 & $1 / 11 / 20087: 10$ & $8 / 11 / 20087: 10$ & 23.7 & \\
\hline 2795 & $1 / 11 / 20087: 12$ & $8 / 11 / 20087: 12$ & 23.7 & 663.6 \\
\hline 2796 & $1 / 11 / 20087: 14$ & $8 / 11 / 20087: 14$ & 23.7 & 661.1 \\
\hline 2797 & $1 / 11 / 20087: 16$ & $8 / 11 / 20087: 16$ & 23.6 & 665.9 \\
\hline 2798 & $1 / 11 / 20087: 18$ & $8 / 11 / 20087: 18$ & 23.6 & \\
\hline 2799 & $1 / 11 / 20087: 20$ & $8 / 11 / 20087: 20$ & 23.8 & 669. \\
\hline 2800 & $1 / 11 / 20087: 22$ & $8 / 11 / 20087: 22$ & 23.7 & 672.5 \\
\hline 2801 & $1 / 11 / 20087: 24$ & $8 / 11 / 20087: 24$ & 23.7 & 678.1 \\
\hline 2802 & $1 / 11 / 20087: 26$ & $8 / 11 / 20$ & 23.7 & \\
\hline 2803 & $1 / 11 / 20087: 28$ & $8 / 11 / 20087: 28$ & 23.7 & 666.7 \\
\hline 2804 & $\overline{0087: 30}$ & $8 / 11 / 20$ & 23.7 & 675.7 \\
\hline 2805 & $0087: 32$ & $8 / 11 / 20$ & 23.8 & 672.8 \\
\hline 2806 & $1 / 11 / 20087: 34$ & $8 / 11 / 20$ & 23.8 & \\
\hline 2807 & $1 / 11 / 20087: 36$ & $8 / 11 / 20$ & 23.8 & 665.4 \\
\hline 2808 & $1 / 11$ & $8 / 11 / 2$ & 23.8 & 678. \\
\hline 2809 & $1 / 11 / 2$ & $8 / 11 / 2$ & 23.8 & \\
\hline 2810 & $1 / 11 / 20087: 42$ & $8 / 11 / 20087: 42$ & 23.8 & 675.1 \\
\hline 2811 & $7: 44$ & $7: 44$ & 23.8 & 669.5 \\
\hline 2812 & $1 / 11 / 20087: 46$ & $8 / 11 / 20$ & 23.7 & \\
\hline 2813 & $1 / 11 / 20087: 48$ & $8 / 11 / 20$ & 23.7 & 669.2 \\
\hline 2814 & $1 / 11$ & $8 / 11$ & 23.7 & 685.5 \\
\hline 2815 & $87: 52$ & $7: 52$ & 23.8 & 83.4 \\
\hline 2816 & $1 / 11 / 20087: 54$ & $8 / 11 / 2$ & 23.8 & 81.7 \\
\hline 2817 & $1 / 111$ & $37: 56$ & 23.8 & 680. \\
\hline 2818 & $1 / 11$ & $7: 58$ & 23.8 & 677. \\
\hline 2819 & $1 / 11$ & $8: 00$ & 23. & 74. \\
\hline 2820 & $1 / 11$ & & 23.8 & 691. \\
\hline 2821 & $1 / 11$ & & 23.8 & 679. \\
\hline 2822 & $1 / 11 / 20$ & $8 / 11 / 2$ & 23.8 & 677. \\
\hline 2823 & $1 / 11 / 20$ & $8 / 11 / 20$ & 23.8 & 678.7 \\
\hline 2824 & $1 / 11$ & & 23.8 & 68 \\
\hline 2825 & $1 / 11$ & & 23. & 67 \\
\hline 2826 & $1 / 11$ & $8: 14$ & 23.8 & 673 \\
\hline 2827 & & & 23.8 & 683. \\
\hline 2828 & & & 23.7 & 680. \\
\hline 2829 & $1 / 111$ & $8: 20$ & 23.7 & 678. \\
\hline 2830 & & & 23.7 & 677. \\
\hline 2831 & $8: 24$ & & 23. & 676. \\
\hline 2832 & $8: 26$ & & 23. & 67 \\
\hline 2833 & & & 23.8 & 676. \\
\hline 2834 & & & 23.8 & 680. \\
\hline 2835 & & & 23. & 67 \\
\hline 2836 & $8: 34$ & & 23. & 682. \\
\hline 2837 & & & 23. & \\
\hline 2838 & $1 / 11$ & & 23.8 & 683. \\
\hline 2839 & $1 / 11$ & $\overline{8: 40}$ & 23.8 & 685. \\
\hline 2840 & & & 23.8 & \\
\hline 2841 & & & 23.8 & \\
\hline 2842 & $1 / 11$ & $8: 46$ & 23.8 & 683. \\
\hline 2843 & & & 23.8 & \\
\hline 2844 & & & 23.8 & \\
\hline 2845 & $8: 52$ & $8: 52$ & 23.7 & 683.3 \\
\hline 2846 & & & 23.7 & 685. \\
\hline 2847 & & & 23.7 & \\
\hline 2848 & $88: 58$ & $8 / 11 / 20$ & 23.8 & 684.8 \\
\hline 2849 & & & 23.7 & 688.2 \\
\hline 2850 & & & 23.7 & \\
\hline 2851 & $9: 04$ & $8 / 11 / 20$ & 23.7 & \\
\hline 2852 & $1 / 11 /$ & $8 / 11 / 20089: 06$ & 23.7 & 699 \\
\hline 2853 & & & 23.7 & 700. \\
\hline 2854 & & & & \\
\hline 2855 & 1/11/20089:12 & $8 / 11 / 20089: 12$ & 23.8 & 703 \\
\hline 2856 & & $8 / 11 / 20089: 14$ & 23.8 & 06. \\
\hline
\end{tabular}




\begin{tabular}{|c|c|c|c|c|}
\hline \multicolumn{5}{|c|}{ D4-92c } \\
\hline $\operatorname{Rec}$ & & Adjusted & Temp & SC \\
\hline$\#$ & Date/Time & Date/Time & ${ }^{\circ} \mathrm{C}$ & $\mu \mathrm{S} / \mathrm{cm}$ \\
\hline 2857 & 1/11/20089:16 & $8 / 11 / 20089: 16$ & 23.7 & 708 \\
\hline 2858 & $1 / 11 / 20089: 18$ & $8 / 11 / 20089: 18$ & 23.8 & 711.5 \\
\hline 2859 & 1/11/20089:20 & $8 / 11 / 20089: 20$ & 23.8 & 709.6 \\
\hline 2860 & 1/11/20089:22 & $8 / 11 / 20089: 22$ & 23.8 & 715 \\
\hline 2861 & $1 / 11 / 20089: 24$ & $8 / 11 / 20089: 24$ & 23.8 & 711.7 \\
\hline 2862 & $1 / 11 / 20089: 26$ & $8 / 11 / 20089: 26$ & 23.8 & 715.5 \\
\hline 2863 & $1 / 11 / 20089: 28$ & $8 / 11 / 20089: 28$ & 23.8 & 717 \\
\hline 2864 & 1/11/20089:30 & $8 / 11 / 20089: 30$ & 23.8 & 723.3 \\
\hline 2865 & $1 / 11 / 20089: 32$ & $8 / 11 / 20089: 32$ & 23.8 & 723.2 \\
\hline 2866 & $1 / 11 / 20089: 34$ & $8 / 11 / 20089: 34$ & 23.9 & 726.4 \\
\hline 2867 & $1 / 11 / 20089: 36$ & $8 / 11 / 20089: 36$ & 23.8 & 727.4 \\
\hline 2868 & $1 / 11 / 20089: 38$ & $8 / 11 / 20089: 38$ & 23.9 & 727.7 \\
\hline 2869 & 1/11/20089:40 & $8 / 11 / 20089: 40$ & 23.9 & 732 \\
\hline 2870 & $1 / 11 / 20089: 42$ & $8 / 11 / 20089: 42$ & 23.9 & 733.5 \\
\hline 2871 & $1 / 11 / 20089: 44$ & $8 / 11 / 20089: 44$ & 23.9 & 735.4 \\
\hline 2872 & $1 / 11 / 20089: 46$ & $8 / 11 / 20089: 46$ & 23.9 & 737.5 \\
\hline 2873 & $1 / 11 / 20089: 48$ & $8 / 11 / 20089: 48$ & 23.9 & 742.4 \\
\hline 2874 & $1 / 11 / 20089: 50$ & $8 / 11 / 20089: 50$ & 23.9 & 742.6 \\
\hline 2875 & $1 / 11 / 20089: 52$ & $8 / 11 / 20089: 52$ & 23.9 & 744.3 \\
\hline 2876 & $1 / 11 / 20089: 54$ & $8 / 11 / 20089: 54$ & 23.9 & 748.3 \\
\hline 2877 & $1 / 11 / 20089: 56$ & $8 / 11 / 20089: 56$ & 23.9 & 747.6 \\
\hline 2878 & $1 / 11 / 20089: 58$ & $8 / 11 / 20089: 58$ & 23.9 & 750.5 \\
\hline 2879 & 1/11/2008 10:00 & $8 / 11 / 200810: 00$ & 23.9 & 749.8 \\
\hline 2880 & 1/11/2008 10:02 & $8 / 11 / 200810: 02$ & 24 & 750 \\
\hline 2881 & $1 / 11 / 2008$ 10:04 & $8 / 11 / 200810: 04$ & 24 & 752.1 \\
\hline 2882 & 1/11/2008 10:06 & $8 / 11 / 200810: 06$ & 24 & 756.3 \\
\hline 2883 & $1 / 11 / 2008$ 10:08 & \begin{tabular}{|l}
$8 / 11 / 200810: 08$ \\
\end{tabular} & 24 & 757.6 \\
\hline 2884 & $1 / 11 / 200810: 10$ & $8 / 11 / 2008$ 10:10 & 24 & 761 \\
\hline 2885 & 1/11/2008 10:12 & $8 / 11 / 200810: 12$ & 24 & 762.9 \\
\hline 2886 & $1 / 11 / 200810: 14$ & $8 / 11 / 200810: 14$ & 24 & 763.7 \\
\hline 2887 & 1/11/2008 10:16 & $8 / 11 / 2008$ 10:16 & 24 & 768.1 \\
\hline 2888 & $1 / 11 / 200810: 18$ & $8 / 11 / 200810: 18$ & 24 & 764.6 \\
\hline 2889 & 1/11/2008 10:20 & $8 / 11 / 2008$ 10:20 & 24.1 & 769.6 \\
\hline 2890 & $1 / 11 / 2008 \quad 10: 22$ & $8 / 11 / 200810: 22$ & 24.1 & 768 \\
\hline 2891 & $1 / 11 / 200810: 24$ & $8 / 11 / 200810: 24$ & 24.1 & 773.3 \\
\hline 2892 & 1/11/2008 10:26 & $8 / 11 / 200810: 26$ & 24.1 & 772.9 \\
\hline 2893 & $1 / 11 / 200810: 28$ & $8 / 11 / 200810: 28$ & 24.1 & 772.9 \\
\hline 2894 & 1/11/2008 10:30 & $8 / 11 / 2008$ 10:30 & 24.1 & 777.3 \\
\hline 2895 & $1 / 11 / 2$ & $8 / 11 / 2008$ 10:32 & 24.1 & 775 \\
\hline 2896 & $1 / 11 / 200810: 34$ & $8 / 11 / 200810: 34$ & 24.1 & 780.3 \\
\hline 2897 & $1 / 11 / 2008$ 10:36 & $8 / 11 / 200810: 36$ & 24.1 & 780.6 \\
\hline 2898 & $1 / 11 / 200810: 38$ & $8 / 11 / 200810: 38$ & 24.1 & 781.5 \\
\hline 2899 & 1/11/2008 10:40 & $8 / 11 / 200810: 40$ & 24.1 & 783.4 \\
\hline 2900 & $1 / 11 / 2$ & $8 / 11 / 2008$ 10:42 & 24.2 & 783.8 \\
\hline 2901 & $1 / 11 / 20$ & $8 / 11 / 2008$ 10:44 & 24.2 & 786.6 \\
\hline 2902 & $1 / 11 / 200810: 46$ & $8 / 11 / 200810: 46$ & 24.2 & 789.5 \\
\hline 2903 & $1 / 11 / 200810: 48$ & $8 / 11 / 2008$ 10:48 & 24.2 & 793.2 \\
\hline 2904 & 1/11/2008 10:50 & \begin{tabular}{|l|l}
$8 / 11 / 200810: 50$ \\
\end{tabular} & 24.2 & 792.4 \\
\hline 2905 & $1 / 11 / 2$ & 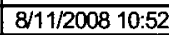 & 24.2 & 792.8 \\
\hline 2906 & 1/11/2008 10:54 & $8 / 11 / 2008 \quad 10: 54$ & 24.2 & 795 \\
\hline 2907 & $1 / 11 / 200810: 56$ & $8 / 11 / 200810: 56$ & 24.2 & 799.5 \\
\hline 2908 & $1 / 11 / 200810: 58$ & $8 / 11 / 200810: 58$ & 24.2 & 796.7 \\
\hline 2909 & 1/11/2008 11:00 & $8 / 11 / 2008$ 11:00 & 24.2 & 802.2 \\
\hline 2910 & $1 / 11 / 20$ & $8 / 11 / 2008$ 11:02 & 24.2 & 801.7 \\
\hline 2911 & $1 / 11 / 2$ & $8 / 11 / 200811: 04$ & 24.2 & 801.1 \\
\hline 2912 & 1/11/2008 11:06 & $8 / 11 / 2008$ 11:06 & 24.2 & 799.2 \\
\hline 2913 & $1 / 11 / 200811: 08$ & 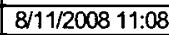 & 24.2 & 798.5 \\
\hline 2914 & 1/11/2008 11:10 & 8/11/2008 11:10 & 24.2 & 799.7 \\
\hline 2915 & 1/11/2008 11:12 & $8 / 11 / 2008$ 11:12 & 24.2 & 797.5 \\
\hline 2916 & & $8 / 11 / 200811: 14$ & 24.2 & 796 \\
\hline 2917 & 1/11/2008 11:16 & $8 / 11 / 200811: 16$ & 24.2 & 796.9 \\
\hline 2918 & 1/11/2008 11:18 & $8 / 11 / 200811: 18$ & 24.2 & 796.6 \\
\hline 2919 & 1/11/2008 11:20 & $8 / 11 / 200811: 20$ & 24.2 & 800.1 \\
\hline 2920 & 1/11/2008 11:22 & $8 / 11 / 2008$ 11:22 & 24.2 & 800.7 \\
\hline 2921 & 1/11/2008 11:24 & $8 / 11 / 2008$ 11:24 & 24.2 & 803.6 \\
\hline 2922 & 1/11/2008 11:26 & $8 / 11 / 200811: 26$ & 24.3 & 804.8 \\
\hline 2923 & 1/11/2008 11:28 & $8 / 11 / 200811: 28$ & 24.2 & 806.2 \\
\hline 2924 & $1 / 11 / 2008+11: 30$ & $8 / 1.1 / 200811: 30$ & 24.3 & 806.8 \\
\hline 2925 & $1 / 11 / 200811: 32$ & $8 / 11 / 2008$ 11:32 & 24.2 & 808.1 \\
\hline
\end{tabular}

\begin{tabular}{|c|c|c|c|c|}
\hline \multicolumn{5}{|c|}{$D 4-92 c$} \\
\hline $\operatorname{Rec}$ & & Adjusted & Temp & SC \\
\hline$\#$ & Date/Time & Date/Time & ${ }^{\circ} \mathrm{C}$ & $\mu \mathrm{S} / \mathrm{cm}$ \\
\hline 2926 & 1/11/2008 11:34 & 8/11/2008 11:34 & 24.3 & 811.5 \\
\hline 2927 & 1/11/2008 11:36 & $8 / 11 / 200811: 36$ & 24.4 & 813.3 \\
\hline 2928 & 1/11/2008 11:38 & $8 / 11 / 200811: 38$ & 24.4 & 813.9 \\
\hline 2929 & 1/11/2008 11:40 & $8 / 11 / 200811: 40$ & 24.4 & 818.1 \\
\hline 2930 & 1/11/12008 11:42 & $8 / 11 / 200811: 42$ & 24.4 & 814.3 \\
\hline 2931 & 1/11/2008 11:44 & $8 / 11 / 200811: 44$ & 24.4 & 817.8 \\
\hline 2932 & 1/11/2008 11:46 & $8 / 11 / 200811: 46$ & 24.4 & 813.1 \\
\hline 2933 & 1/11/2008 11:48 & $8 / 11 / 200811: 48$ & 24.4 & 816.5 \\
\hline 2934 & $1 / 11 / 200811: 50$ & $8 / 11 / 200811: 50$ & 24.3 & 814.6 \\
\hline 2935 & 1/11/2008 11:52 & $8 / 11 / 200811: 52$ & 24.3 & 814.8 \\
\hline 2936 & 1/11/2008 11:54 & $8 / 11 / 200811: 54$ & 24.3 & 813.7 \\
\hline 2937 & $1 / 11 / 200811: 56$ & $8 / 11 / 200811: 56$ & 24.3 & 816.5 \\
\hline 2938 & 1/11/2008 11:58 & $8 / 11 / 200811: 58$ & 24.4 & 817 \\
\hline 2939 & 1/11/2008 12:00 & $8 / 11 / 200812: 00$ & 24.4 & 818.9 \\
\hline 2940 & 1/11/2008 12:02 & $8 / 11 / 2008$ 12:02 & 24.4 & 817.7 \\
\hline 2941 & 1/11/2008 12:04 & $8 / 11 / 200812: 04$ & 24.4 & 819 \\
\hline 2942 & $1 / 11 / 200812: 06$ & $8 / 11 / 2008$ 12:06 & 24.4 & 817 \\
\hline 2943 & $1 / 11 / 200812: 08$ & $8 / 11 / 200812: 08$ & 24.4 & 820.3 \\
\hline 2944 & $1 / 11 / 200812: 10$ & $8 / 11 / 200812: 10$ & 24.4 & 821.2 \\
\hline 2945 & $1 / 11 / 200812: 12$ & $8 / 11 / 200812: 12$ & 24.4 & 821.6 \\
\hline 2946 & $1 / 11 / 200812: 14$ & $8 / 11 / 2008$ 12:14 & 24.4 & 820.4 \\
\hline 2947 & $1 / 11 / 200812: 16$ & $8 / 11 / 200812: 16$ & 24.5 & 822.9 \\
\hline 2948 & $1 / 11 / 200812: 18$ & $8 / 11 / 200812: 18$ & 24.5 & 822.6 \\
\hline 2949 & $1 / 11 / 200812: 20$ & $8 / 11 / 200812: 20$ & 24.5 & 822 \\
\hline 2950 & $1 / 11 / 200812: 22$ & $8 / 11 / 2008$ 12:22 & 24.5 & 825 \\
\hline 2951 & $1 / 11 / 200812: 24$ & $8 / 11 / 200812: 24$ & 24.5 & 823.4 \\
\hline 2952 & 1/11/2008 12:26 & 8/11/2008 12:26 & 24.5 & 824.6 \\
\hline 2953 & $1 / 11 / 200812: 28$ & $8 / 11 / 200812: 28$ & 24.5 & 821.6 \\
\hline 2954 & $1 / 11 / 200812: 30$ & $8 / 11 / 200812: 30$ & 24.5 & 823.9 \\
\hline 2955 & $1 / 11 / 200812: 32$ & $8 / 11 / 2008$ 12:32 & 24.5 & 825.4 \\
\hline 2956 & $1 / 11 / 200812: 34$ & $8 / 11 / 2008$ 12:34 & 24.5 & 825.9 \\
\hline 2957 & 1/11/2008 12:36 & $8 / 11 / 2008$ 12:36 & 24.5 & 824.1 \\
\hline 2958 & $1 / 11 / 200812: 38$ & $8 / 11 / 200812: 38$ & 24.6 & 826.1 \\
\hline 2959 & $1 / 11 / 200812: 40$ & $8 / 11 / 2008$ 12:40 & 24.5 & 825.4 \\
\hline 2960 & $1 / 11 / 200812: 42$ & $8 / 11 / 200812: 42$ & 24.6 & 825.3 \\
\hline 2961 & $1 / 11 / 200812: 44$ & $8 / 11 / 2008+2: 44$ & 24.6 & 827.5 \\
\hline 2962 & $1 / 11 / 200812: 46$ & $8 / 11 / 2008$ 12:46 & 24.6 & 828.8 \\
\hline 2963 & $1 / 11 / 200812: 48$ & $8 / 11 / 2008+2: 48$ & 24.6 & 829.3 \\
\hline 2964 & $1 / 11 / 200812: 50$ & $8 / 11 / 200812: 50$ & 24.6 & 828 \\
\hline 2965 & 1/11/2008 12:52 & $8 / 11 / 2008$ 12:52 & 24.6 & 829.6 \\
\hline 2966 & $1 / 11 / 200812: 54$ & $8 / 11 / 200812: 54$ & 24.6 & 827.8 \\
\hline 2967 & $1 / 11 / 200812: 56$ & $8 / 11 / 2008+2: 56$ & 24.6 & 829.6 \\
\hline 2968 & $1 / 11 / 200812: 58$ & $8 / 11 / 200812: 58$ & 24.7 & 831.3 \\
\hline 2969 & 1/11/2008 13:00 & $8 / 11 / 200813: 00$ & 24.7 & 829.3 \\
\hline 2970 & 1/11/2008 13:02 & 8/11/2008 13:02 & 24.7 & 828.7 \\
\hline 2971 & 1/11/2008 13:04 & $8 / 11 / 2008$ 13:04 & 24.7 & 830.2 \\
\hline 2972 & $1 / 11 / 200813: 06$ & $8 / 11 / 2008$ 13:06 & 24.7 & 831.1 \\
\hline 2973 & 1/11/2008 13:08 & $8 / 11 / 200813: 08$ & 24.7 & 832 \\
\hline 2974 & 1/11/2008 13:10 & $8 / 11 / 200813: 10$ & 24.7 & 835.7 \\
\hline 2975 & 1/11/2008 13:12 & $8 / 11 / 200813: 12$ & 24.7 & 830.9 \\
\hline 2976 & 1/11/2008 13:14 & 8/11/2008 13:14 & 24.7 & 830 \\
\hline 2977 & 1/11/2008 13:16 & $8 / 11 / 200813: 16$ & 24.7 & 829 \\
\hline 2978 & 1/11/2008 13:18 & $8 / 11 / 2008$ 13:18 & 24.7 & 826.6 \\
\hline 2979 & 1/11/2008 13:20 & $8 / 11 / 200813: 20$ & 24.7 & 826.5 \\
\hline 2980 & 1/11/2008 13:22 & 8/11/2008 13:22 & 24.7 & 821.8 \\
\hline 2981 & 1/111/2008 13:24 & $8 / 11 / 200813: 24$ & 24.7 & 827.5 \\
\hline 2982 & 1/11/2008 13:26 & $8 / 11 / 2008$ 13:26 & 24.7 & 822 \\
\hline 2983 & 1/11/2008 13:28 & $8 / 11 / 200813: 28$ & 24.7 & 828 \\
\hline 2984 & 1/11/2008 13:30 & $8 / 11 / 2008$ 13:30 & 24.8 & 827.6 \\
\hline 2985 & 1/11/2008 13:32 & $8 / 11 / 2008$ 13:32 & 24.8 & 827.8 \\
\hline 2986 & 1/11/2008 13:34 & $8 / 11 / 2008$ 13:34 & 24.8 & 827.8 \\
\hline 2987 & 1/11/2008 13:36 & $8 / 11 / 200813: 36$ & 24.8 & 829 \\
\hline 2988 & 1/11/2008 13:38 & $8 / 11 / 200813: 38$ & 24.8 & 832 \\
\hline 2989 & $1 / 11 / 200813: 40$ & $8 / 11 / 200813: 40$ & 24.8 & 831.4 \\
\hline 2990 & $1 / 11 / 2008$ 13:42 & $8 / 11 / 200813: 42$ & 24.8 & 832.6 \\
\hline 2991 & 1/11/2008 13:44 & $8 / 11 / 200813: 44$ & 24.8 & 834.3 \\
\hline 2992 & 1/11/2008 13:46 & $8 / 11 / 200813: 46$ & 24.9 & 836.7 \\
\hline 2993 & $1 / 11 / 200813: 48$ & $8 / 11 / 2008$ 13:48 & 24.9 & 838.5 \\
\hline 2994 & 1/11/2008 13:50 & $8 / 11 / 200813: 50$ & 24.9 & 841.2 \\
\hline
\end{tabular}

\begin{tabular}{|c|c|c|c|c|}
\hline \multicolumn{5}{|c|}{ D4-92C } \\
\hline $\operatorname{Rec}$ & & Adjusted & Temp & SC \\
\hline \# & Date/Time & Date/Time & ${ }^{\circ} \mathrm{C}$ & $\mu \mathrm{S} / \mathrm{cm}$ \\
\hline 2995 & $1 / 11 / 200813: 52$ & $8 / 11 / 200813: 52$ & 25 & \\
\hline 2996 & $1 / 11 / 200813: 54$ & $8 / 11 / 2008$ 13:54 & 25 & 848.1 \\
\hline 2997 & $1 / 11 / 200813: 56$ & $8 / 11 / 200813: 56$ & 25 & \\
\hline 2998 & $1 / 11 / 200813: 58$ & $8 / 11 / 200813: 58$ & 25.1 & 853.7 \\
\hline 2999 & $1 / 11 / 200814: 00$ & $8 / 11 / 200814: 00$ & 25.1 & 858.1 \\
\hline 3000 & $1 / 11 / 200814: 02$ & $8 / 11 / 2008$ 14:02 & 25.1 & 859.3 \\
\hline 3001 & $1 / 11 / 200814: 04$ & $8 / 11 / 200814: 04$ & 25.1 & 863 \\
\hline 3002 & $1 / 11 / 200814: 06$ & $8 / 11 / 200814: 06$ & 25.2 & 869.4 \\
\hline 3003 & $1 / 11 / 200814: 08$ & $8 / 11 / 200814: 08$ & 25.1 & 871.9 \\
\hline 3004 & $1 / 11 / 200814: 10$ & $8 / 11 / 2008$ 14:10 & 25.2 & 874 \\
\hline 3005 & $1 / 11 / 200814: 12$ & $8 / 11 / 20$ & & 877.5 \\
\hline 3006 & $1 / 11 / 20$ & $8 / 11 / 20$ & 25.2 & 877.3 \\
\hline 3007 & $814: 16$ & $8 / 11 / 2008$ 14:16 & 25.2 & 878.2 \\
\hline 3008 & $1 / 11 / 2$ & $8 / 11 / 20$ & 25.2 & \\
\hline 3009 & $814: 20$ & $8 / 11 / 20$ & 25.3 & 875.3 \\
\hline 3010 & $1 / 11 / 2$ & $8 / 11 / 2$ & 25.2 & 875.8 \\
\hline 3011 & $1 / 11 / 2$ & $8 / 11 / 2$ & 25.2 & \\
\hline 3012 & $1 / 11 / 2$ & $8 / 11 / 2$ & 25.2 & 878.5 \\
\hline 3013 & $1 / 11 / 2$ & $8 / 11 / 2$ & 25.2 & 875.2 \\
\hline 3014 & $1 / 11 / 2$ & $8 / 11 / 2$ & 25.2 & 877.4 \\
\hline 3015 & $1 / 11 / 2$ & $8 / 11 / 2$ & 25.2 & 875.2 \\
\hline 3016 & $1 / 11 / 2$ & $8 / 11 / 2$ & 25.2 & \\
\hline 3017 & $1 / 11 / 2$ & $8 / 11 / 2$ & 25.2 & 873.9 \\
\hline 3018 & $1 / 11$ & $8 / 11$ & 25.1 & 870.5 \\
\hline 3019 & $1 / 11$ & $8 / 11 /$ & 25.2 & \\
\hline 3020 & $1 / 11$ & $8 / 11 / 4$ & 25.1 & 866.6 \\
\hline 3021 & $1 / 11$ & $8 / 11 /$ & 25.1 & 889.6 \\
\hline 3022 & $1 / 11$ & $8 / 11 /$ & 25.1 & 881.3 \\
\hline 3023 & & $8 / 11 /$ & 25 & 857.8 \\
\hline 3024 & & $8 / 11 / 2$ & 25.1 & 866.7 \\
\hline 3025 & $1 / 11 /$ & $8 / 11 / 2$ & 25.1 & 853.5 \\
\hline 3026 & $1 / 11$ & $8 / 11$ & 25.1 & 858.2 \\
\hline 3027 & $1 / 11$ & $8 / 11$ & 25.1 & 861.5 \\
\hline 3028 & & $8 / 11 /$ & 25.2 & 861.7 \\
\hline 3029 & & $8 / 11 /$ & 25.2 & 866.6 \\
\hline 3030 & & $8 / 11 / 2$ & 25.3 & 869.9 \\
\hline 3031 & $1 / 11$ & $8 / 11$ & 25.3 & 870.4 \\
\hline 3032 & & $8 / 11$ & 25.3 & 874.5 \\
\hline 3033 & & & 25.3 & 876.1 \\
\hline 3034 & & $8 / 11$ & 25.3 & 873.3 \\
\hline 3035 & & $8 / 11$ & 25.4 & 878.2 \\
\hline 3036 & & & 25.4 & 883.7 \\
\hline 3037 & & $8 / 11$ & 25.4 & 891.1 \\
\hline 3038 & & & 25.5 & 898.9 \\
\hline 3039 & & & 25.6 & 906 \\
\hline 3040 & $1 / 111$ & $8 / 11 / 2$ & 25.7 & 906.8 \\
\hline 3041 & & & 25.7 & 909.3 \\
\hline 3042 & & & 25.8 & 922.6 \\
\hline 3043 & & & 25.8 & 918.5 \\
\hline 3044 & & & & 916.6 \\
\hline 3045 & $1 / 11$ & & 25.9 & 924.2 \\
\hline 3046 & & & 26 & 925.8 \\
\hline 3047 & & & 26.1 & 931.5 \\
\hline 3048 & & & 26.2 & 931.6 \\
\hline 3049 & & & & \\
\hline 3050 & $15: 42$ & $8 / 11 / 2$ & 26.3 & 936.6 \\
\hline 3051 & & & 26.3 & \\
\hline 3052 & & $8 / 11 / 2$ & 26.4 & \\
\hline 3053 & & $8 / 11 / 20$ & 26.4 & 940.7 \\
\hline 3054 & & & 26.4 & \\
\hline 3055 & $15: 52$ & $8 / 11 / 2$ & 26.5 & 947. \\
\hline 3056 & & & 26.5 & \\
\hline 3057 & & & 26.5 & \\
\hline 3058 & $315: 58$ & $8 / 11 / 2008$ 15:58 & 26.6 & 954.7 \\
\hline 3059 & & & 26.6 & \\
\hline 3060 & & & 26.6 & \\
\hline 3061 & & & 26.7 & 963 \\
\hline 3062 & & $8 / 11 / 2$ & 26.7 & \\
\hline & $816: 08$ & $8 / 11 / 200816: 08$ & 26.7 & Yll. \\
\hline
\end{tabular}




\begin{tabular}{|c|c|c|c|c|}
\hline \multicolumn{5}{|c|}{$D 4-92 c$} \\
\hline Rec & & Adjusted & Temp & $\mathrm{SC}$ \\
\hline \# & Date/Time & DaterTime & ${ }^{\circ} \mathrm{C}$ & $\mu \mathrm{S} / \mathrm{cm}$ \\
\hline 3064 & 1/11/2008 16:10 & \begin{tabular}{|l|l}
$8 / 11 / 200816: 10$ \\
\end{tabular} & 26.8 & 973.8 \\
\hline 3065 & 1/11/2008 16:12 & $8 / 11 / 200816: 12$ & 26.8 & 975.3 \\
\hline 3066 & $1 / 11 / 200816: 14$ & $8 / 11 / 200816: 14$ & 26.9 & 978.3 \\
\hline 3067 & 1/11/2008 16:16 & $8 / 11 / 200816: 16$ & 26.9 & 977.3 \\
\hline 3068 & $1 / 11 / 200816: 18$ & $8 / 11 / 2008$ 16:18 & 26.9 & 974.3 \\
\hline 3069 & 1/11/2008 16:20 & $8 / 11 / 2008$ 16:20 & 26.9 & 984.6 \\
\hline 3070 & 1/11/2008 16:22 & $8 / 11 / 2008$ 16:22 & 26.9 & 986.2 \\
\hline 3071 & $1 / 11 / 200816: 24$ & $8 / 11 / 200816: 24$ & 26.9 & 986 \\
\hline 3072 & 1/11/2008 16:26 & $8 / 11 / 200816: 26$ & 27 & 989.7 \\
\hline 3073 & $1 / 11 / 200816: 28$ & $8 / 11 / 200816: 28$ & 27 & 992.2 \\
\hline 3074 & $1 / 11 / 200816: 30$ & $8 / 11 / 200816: 30$ & 27 & 993.5 \\
\hline 3075 & 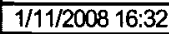 & $8 / 11 / 200816: 32$ & 27 & 996.2 \\
\hline 3076 & $1 / 11 / 200816: 34$ & $8 / 11 / 2008$ 16:34 & 27.1 & 997.6 \\
\hline 3077 & $1 / 11 / 200816: 36$ & $8 / 11 / 200816: 36$ & 27.1 & 1002 \\
\hline 3078 & 1/11/2008 16:38 & $8 / 11 / 2008$ 16:38 & 27.1 & 997.3 \\
\hline 3079 & $1 / 11 / 200816: 40$ & $8 / 11 / 200816: 40$ & 27 & 994.4 \\
\hline 3080 & $1 / 11 / 200816: 42$ & $8 / 11 / 200816: 42$ & 27 & 986 \\
\hline 3081 & $1 / 11 / 200816: 44$ & $8 / 11 / 200816: 44$ & 26.9 & 977.5 \\
\hline 3082 & $1 / 11 / 200816: 46$ & $8 / 11 / 200816: 46$ & 26.8 & 968.8 \\
\hline 3083 & $1 / 11 / 200816: 48$ & $8 / 11 / 200816: 48$ & 26.8 & 956.7 \\
\hline 3084 & $1 / 11 / 200816: 50$ & $8 / 11 / 200816: 50$ & 26.7 & 951 \\
\hline 3085 & $1 / 11 / 200816: 52$ & $8 / 11 / 200816: 52$ & 26.7 & 935.8 \\
\hline 3086 & $1 / 11 / 200816: 54$ & $8 / 11 / 200816: 54$ & 26.7 & 937.8 \\
\hline 3087 & 1/11/2008 16:56 & $8 / 11 / 200816: 56$ & 26.7 & 935.8 \\
\hline 3088 & $1 / 11 / 200816: 58$ & $8 / 11 / 200816: 58$ & 26.6 & 925.3 \\
\hline 3089 & $1 / 11 / 200817: 00$ & $8 / 11 / 200817: 00$ & 26.7 & 911.3 \\
\hline 3090 & 1/11/2008 17:02 & $8 / 11 / 200817: 02$ & 26.6 & 893.8 \\
\hline 3091 & 1/11/2008 17:04 & $8 / 11 / 2008$ 17:04 & 26.6 & 905.8 \\
\hline 3092 & 1/11/2008 17:06 & $8 / 11 / 200817: 06$ & 26.7 & 919.6 \\
\hline 3093 & 1/11/2008 17:08 & \begin{tabular}{|l|}
$8 / 11 / 200817: 08$ \\
\end{tabular} & 26.7 & 927.8 \\
\hline 3094 & $1 / 11 / 200817: 10$ & \begin{tabular}{|l|}
$8 / 11 / 200817: 10$ \\
\end{tabular} & 26.8 & 930.6 \\
\hline 3095 & $1 / 11 / 200817: 12$ & $8 / 11 / 200817: 12$ & 26.8 & 928.9 \\
\hline 3096 & $1 / 11 / 200817: 14$ & $8 / 11 / 2008$ 17:14 & 26.8 & 932.6 \\
\hline 3097 & $1 / 11 / 200817: 16$ & \begin{tabular}{|l|}
$8 / 11 / 200817: 16$ \\
\end{tabular} & 26.9 & 937.3 \\
\hline 3098 & $1 / 11 / 200817: 18$ & $8 / 11 / 200817: 18$ & 26.9 & 939.6 \\
\hline 3099 & $1 / 11 / 200817: 20$ & $8 / 11 / 200817: 20$ & 26.9 & 947 \\
\hline 3100 & 1/11/2008 17:22 & \begin{tabular}{|l|}
$8 / 11 / 200817: 22$ \\
\end{tabular} & 27 & 956.3 \\
\hline 3101 & $1 / 11 / 200817: 24$ & \begin{tabular}{|l|}
$8 / 11 / 200817: 24$ \\
\end{tabular} & 27 & 972.7 \\
\hline 3102 & $1 / 11 / 200817: 26$ & \begin{tabular}{|l|}
$8 / 11 / 200817: 26$ \\
\end{tabular} & 27.2 & 971.1 \\
\hline 3103 & $1 / 11 / 200817: 28$ & 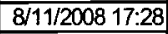 & 27.2 & 977 \\
\hline 3104 & $1 / 11 / 200817: 30$ & \begin{tabular}{|l|}
$8 / 11 / 2008$ \\
\end{tabular} & 27.2 & 979.5 \\
\hline 3105 & $1 / 11 / 200817: 32$ & \begin{tabular}{|l|}
$8 / 11 / 200817: 32$ \\
\end{tabular} & 27.2 & 981.6 \\
\hline 3106 & 1/11/2008 17:34 & 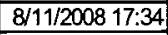 & 27.2 & 984.9 \\
\hline 3107 & $1 / 11 / 200817: 36$ & 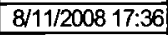 & 27.2 & 987.6 \\
\hline 3108 & $1 / 11 / 200817: 38$ & $8 / 11 / 200817: 38$ & 27.2 & 987.3 \\
\hline 3109 & $1 / 11 / 200817: 40$ & $8 / 11 / 200817: 40$ & 27.2 & 987.4 \\
\hline 3110 & $1 / 11 / 200817: 42$ & $8 / 11 / 2008$ 17:42 & 27.2 & 988.7 \\
\hline 3111 & $1 / 11 / 200817: 44$ & \begin{tabular}{|l|}
$8 / 11 / 200817: 44$ \\
\end{tabular} & 27.2 & 994.2 \\
\hline 3112 & 1/11/2008 17:46 & \begin{tabular}{|l|}
$8 / 11 / 200817: 46$ \\
\end{tabular} & 27.2 & 993 \\
\hline 3113 & 1/11/2008 17:48 & \begin{tabular}{|l|}
$8 / 11 / 200817: 48$ \\
\end{tabular} & 27.2 & 999.6 \\
\hline 3114 & $1 / 11 / 200817: 50$ & 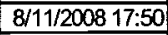 & 27.3 & 996.9 \\
\hline 3115 & $1 / 11 / 200817: 52$ & $8 / 11 / 200817: 52$ & 27.3 & 1001 \\
\hline 3116 & $1 / 11 / 200817: 54$ & $8 / 11 / 2008 \quad 17: 54$ & 27.3 & 1000.1 \\
\hline 3117 & $1 / 11 / 200817: 56$ & $8 / 11 / 200817: 56$ & 27.3 & 1001.2 \\
\hline 3118 & $1 / 11 / 200817: 58$ & \begin{tabular}{|l|}
$8 / 11 / 200817: 58$ \\
\end{tabular} & 27.3 & 1004.4 \\
\hline 3119 & 1/11/2008 18:00 & \begin{tabular}{|l|}
$8 / 11 / 200818: 00$ \\
\end{tabular} & 27.3 & 1004.8 \\
\hline 3120 & 1/11/2008 18:02 & \begin{tabular}{|l|}
$8 / 11 / 200818: 02$ \\
\end{tabular} & 27.3 & 1006.5 \\
\hline 3121 & 1/11/2008 18:04 & \begin{tabular}{|l|}
$8 / 11 / 2008$ 18:04 \\
\end{tabular} & 27.3 & 1006.2 \\
\hline 3122 & 1/11/2008 18:06 & 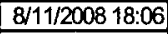 & 27.3 & 1006.6 \\
\hline 3123 & $1 / 11 / 200818: 08$ & $8 / 11 / 200818: 08$ & 27.3 & 1004.5 \\
\hline 3124 & 1/11/2008 18:10 & \begin{tabular}{|l|}
$8 / 11 / 200818: 10$ \\
\end{tabular} & 27.3 & 1007 \\
\hline 3125 & $1 / 11 / 200818: 12$ & $8 / 11 / 200818: 12$ & 27.3 & 1006 \\
\hline 3126 & 1/11/2008 18:14 & \begin{tabular}{|l|}
$8 / 11 / 200818: 14$ \\
\end{tabular} & 27.3 & 1006.6 \\
\hline 3127 & $1 / 11 / 200818: 16$ & 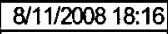 & 27.3 & 1006.6 \\
\hline 3128 & 1/11/2008 18:18 & 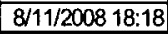 & 27.3 & 1007.6 \\
\hline 3129 & $1 / 11 / 200818: 20$ & $8 / 11 / 2008$ 18:20 & 27.3 & 1009.4 \\
\hline 3130 & 1/11/2008 18:22 & 8/11/2008 18:22 & 27.3 & 1010.6 \\
\hline 3131 & $1 / 11 / 200818: 24$ & \begin{tabular}{|l|}
$8 / 11 / 200818: 24$ \\
\end{tabular} & 27.3 & 993.1 \\
\hline 3132 & 1/11/2008 18:26 & 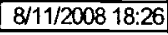 & 27.2 & 995.6 \\
\hline
\end{tabular}

\begin{tabular}{|c|c|c|c|c|}
\hline \multicolumn{5}{|c|}{ D4-92c } \\
\hline $\operatorname{Rec}$ & & Adjusted & Temp & SC \\
\hline$\#$ & DaterTime & Date/Time & ${ }^{\circ} \mathrm{C}$ & $\mu \mathrm{s} / \mathrm{cm}$ \\
\hline 3133 & $1 / 11 / 200818: 28$ & $8 / 11 / 200818: 28$ & 27.2 & 995.8 \\
\hline 3134 & 1/11/2008 18:30 & $8 / 11 / 200818: 30$ & 27.2 & 997.4 \\
\hline 3135 & 1/11/2008 18:32 & $8 / 11 / 2008$ 18:32 & 27.2 & 1002.8 \\
\hline 3136 & $1 / 11 / 200818: 34$ & $8 / 11 / 2008$ 18:34 & 27.3 & 1004.8 \\
\hline 3137 & 1/11/2008 18:36 & 8/11/2008 18:36 & 27.3 & 1005.2 \\
\hline 3138 & 1/11/2008 18:38 & 8/11/2008 18:38 & 27.3 & 1010.4 \\
\hline 3139 & 1/11/2008 18:40 & $8 / 11 / 200818: 40$ & 27.4 & 1012.4 \\
\hline 3140 & $1 / 11 / 200818: 42$ & 8/11/2008 18:42 & 27.4 & 1013.1 \\
\hline 3141 & 1/11/2008 18:44 & $8 / 11 / 2008$ 18:44 & 27.4 & 1016.1 \\
\hline 3142 & 1/11/2008 18:46 & $8 / 11 / 200818: 46$ & 27.4 & 1016.7 \\
\hline 3143 & $1 / 11 / 200818: 48$ & $8 / 11 / 200818: 48$ & 27.4 & 1019.7 \\
\hline 3144 & 1/11/2008 18:50 & $8 / 11 / 200818: 50$ & 27.5 & 1020.6 \\
\hline 3145 & $1 / 11 / 200818: 52$ & $8 / 11 / 200818: 52$ & 27.5 & 10223 \\
\hline 3146 & $1 / 11 / 200818: 54$ & $8 / 11 / 200818: 54$ & 27.5 & 1022.4 \\
\hline 3147 & 1/11/2008 18:56 & $8 / 11 / 200818: 56$ & 27.5 & 1023 \\
\hline 3148 & 1/11/2008 18:58 & $8 / 11 / 200818: 58$ & 27.5 & 1024.7 \\
\hline 3149 & 1/11/2008 19:00 & $8 / 11 / 200819: 00$ & 27.5 & 1025.4 \\
\hline 3150 & $1 / 11 / 200819: 02$ & $8 / 11 / 200819: 02$ & 27.5 & 1024.9 \\
\hline 3151 & 1/11/2008 19:04 & $8 / 11 / 2008$ 19:04 & 27.5 & 1026.4 \\
\hline 3152 & 1/11/2008 19:06 & 8/11/2008 19:06 & 27.5 & 1027 \\
\hline 3153 & $1 / 11 / 2008$ 19:08 & 8/11/2008 19:08 & 27.5 & 1027 \\
\hline 3154 & 1/11/2008 19:10 & $8 / 11 / 200819: 10$ & 27.5 & 1020.4 \\
\hline 3155 & 1/11/2008 19:12 & $8 / 11 / 200819: 12$ & 27.4 & 1015.2 \\
\hline 3156 & 1/111/2008 19:14 & $8 / 11 / 2008$ 19:14 & 27.4 & 1009.1 \\
\hline 3157 & 1/11/2008 19:16 & $8 / 11 / 200819: 16$ & 27.4 & 1008.4 \\
\hline 3158 & $1 / 11 / 2008$ 19:18 & 8/11/2008 19:18 & 27.3 & 1009.3 \\
\hline 3159 & $1 / 11 / 2008$ 19:20 & $8 / 11 / 200819: 20$ & 27.3 & 1007.7 \\
\hline 3160 & $1 / 11 / 200819.22$ & $8 / 11 / 200819: 22$ & 27.3 & 1002.8 \\
\hline 3161 & 1/11/2008 19:24 & $8 / 11 / 2008$ 19:24 & 27.3 & 1002.9 \\
\hline 3162 & 1/11/2008 19:26 & $8 / 11 / 200819: 26$ & 27.3 & 1001 \\
\hline 3163 & 1/11/2008 19:28 & $8 / 11 / 200819: 28$ & 27.3 & 999.1 \\
\hline 3164 & 1/11/2008 19:30 & $8 / 11 / 200819: 30$ & 27.4 & 997.7 \\
\hline 3165 & 1/11/2008 19:32 & $8 / 11 / 200819: 32$ & 27.3 & 999.4 \\
\hline 3166 & 1/11/2008 19:34 & $8 / 11 / 200819: 34$ & 27.4 & 1001.1 \\
\hline 3167 & 1/11/2008 19:36 & $8 / 11 / 2008$ 19:36 & 27.4 & 1003.4 \\
\hline 3168 & 1/11/2008 19:38 & $8 / 11 / 2008$ 19:38 & 27.4 & 1006.6 \\
\hline 3169 & $1 / 11 / 200819: 40$ & $8 / 11 / 2008$ 19:40 & 27.5 & 1013.3 \\
\hline 3170 & 1/11/2008 19:42 & $8 / 11 / 200819: 42$ & 27.5 & 1017.5 \\
\hline 3171 & $1 / 11 / 2008$ 19:44 & $8 / 11 / 2008$ 19:44 & 27.5 & 1023.2 \\
\hline 3172 & 1/11/2008 19:46 & $8 / 11 / 200819: 46$ & 27.6 & 1028.3 \\
\hline 3173 & $1 / 11 / 200819: 48$ & $8 / 11 / 200819: 48$ & 27.6 & 1026.7 \\
\hline 3174 & 1/11/2008 19:50 & $8 / 11 / 200819: 50$ & 27.5 & 1024.3 \\
\hline 3175 & 1/11/2008 19:52 & 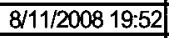 & 27.5 & 1022.4 \\
\hline 3176 & 1/11/2008 19:54 & $8 / 11 / 2008$ 19:54 & 27.4 & 1015.2 \\
\hline 3177 & 1/11/2008 19:56 & $8 / 11 / 2008$ 19:56 & 27.4 & 1015.3 \\
\hline 3178 & $1 / 11 / 2008$ 19:58 & $8 / 11 / 200819: 58$ & 27.4 & 1018.8 \\
\hline 3179 & 1/11/2008 20:00 & $8 / 11 / 200820: 00$ & 27.4 & 1014.1 \\
\hline 3180 & 1/11/2008 20:02 & \begin{tabular}{|l|}
$8 / 11 / 200820: 02$ \\
\end{tabular} & 27.3 & 1018.1 \\
\hline 3181 & 1/11/2008 20:04 & 8/11/200820:04 & 27.4 & 1022.7 \\
\hline 3182 & 1/11/200820:06 & 8/11/200820:06 & 27.4 & 1014.9 \\
\hline 3183 & 1/11/200820:08 & \begin{tabular}{|l|}
$8 / 11 / 200820: 08$ \\
\end{tabular} & 27.3 & 1015.8 \\
\hline 3184 & 1/11/2008 20:10 & 8/11/2008 20:10 & 27.3 & 1018.1 \\
\hline 3185 & 1/11/2008 20:12 & $8 / 11 / 200820: 12$ & 27.3 & 1017.3 \\
\hline 3186 & 1/11/2008 20:14 & $8 / 11 / 200820: 14$ & 27.3 & 1016.5 \\
\hline 3187 & 1/11/2008 20:16 & $8 / 11 / 200820: 16$ & 27.3 & 1017 \\
\hline 3188 & 1/11/2008 20:18 & 8/11/200820:18 & 27.3 & 1020.9 \\
\hline 3189 & 1/11/2008 20:20 & $8 / 11 / 200820: 20$ & 27.4 & 1022.8 \\
\hline 3190 & 1/11/200820:22 & 8/11/2008 20:22 & 27.4 & 1022.1 \\
\hline 3191 & 1/11/2008 20:24 & 8/11/2008 20:24 & 27.4 & 1024 \\
\hline 3192 & 1/11/200820:26 & 8/11/200820:26 & 27.4 & 1025.6 \\
\hline 3193 & $1 / 11 / 200820: 28$ & $8 / 11 / 200820: 28$ & 27.4 & 1025.2 \\
\hline 3194 & 1/11/2008 20:30 & $8 / 11 / 200820: 30$ & 27.4 & 1023.8 \\
\hline 3195 & 1/11/200820:32 & $8 / 11 / 200820: 32$ & 27.4 & 1023.2 \\
\hline 3196 & $1 / 11 / 200820: 34$ & $8 / 11 / 200820: 34$ & 27.3 & 1023 \\
\hline 3197 & 1/11/2008 20:36 & $8 / 11 / 200820: 36$ & 27.4 & 1022.9 \\
\hline 3198 & 1/11/2008 20:38 & $8 / 11 / 200820: 38$ & 27.4 & 1023.1 \\
\hline 3199 & $1 / 11 / 200820: 40$ & $8 / 11 / 200820: 40$ & 27.4 & 1023.2 \\
\hline 3200 & 1/11/2008 20:42 & 8/11/2008 20:42 & 27.4 & 1026.8 \\
\hline 3201 & 1/11/2008 20:44 & $8 / 11 / 200820: 44$ & 27.4 & 1021.7 \\
\hline
\end{tabular}

\begin{tabular}{|c|c|c|c|c|}
\hline \multicolumn{5}{|c|}{$D 4-92 c$} \\
\hline $\operatorname{Rec}$ & & \begin{tabular}{|l} 
Adjusted \\
\end{tabular} & Temp & SC \\
\hline$\#$ & Date/Time & Date/Time & ${ }^{\circ} \mathrm{C}$ & $\mu \mathrm{S} / \mathrm{cm}$ \\
\hline 3202 & $1 / 11 / 200820: 46$ & $8 / 11 / 200820: 46$ & 27.3 & 1015.7 \\
\hline 3203 & 1/11/2008 20:48 & $8 / 11 / 200820: 48$ & 27.3 & 1018.3 \\
\hline 3204 & 1/11/200820:50 & $8 / 11 / 200820: 50$ & 27.3 & 1021.5 \\
\hline 3205 & 1/11/2008 20:52 & $8 / 11 / 200820: 52$ & 27.3 & 1019.9 \\
\hline 3206 & $1 / 11 / 200820: 54$ & $8 / 11 / 200820: 54$ & 27.3 & 1022.2 \\
\hline 3207 & 1/11/2008 20:56 & 8/11/2008 20:56 & 27.3 & 1024.5 \\
\hline 3208 & 1/11/2008 20:58 & $8 / 11 / 200820: 58$ & 27.3 & 1026.7 \\
\hline 3209 & 1/11/2008 21:00 & 8/11/200821:00 & 27.3 & 1028.8 \\
\hline 3210 & 1/11/2008 21:02 & $8 / 11 / 200821: 02$ & 27.3 & 1030.7 \\
\hline 3211 & 1/11/2008 21:04 & 8/11/2008 21:04 & 27.3 & 1033.4 \\
\hline 3212 & 1/11/2008 21:06 & 8/11/2008 21:06 & 27.3 & 1033 \\
\hline 3213 & 1/11/200821:08 & $8 / 11 / 200821: 08$ & 27.3 & 1035.4 \\
\hline 3214 & 1/11/200821:10 & $8 / 11 / 200821: 10$ & 27.3 & 1036.9 \\
\hline 3215 & 1/11/2008 21:12 & $8 / 11 / 200821: 12$ & 27.3 & 1036.8 \\
\hline 3216 & 1/11/200821:14 & \begin{tabular}{|l|}
$8 / 11 / 200821: 14$ \\
\end{tabular} & 27.3 & 1038 \\
\hline 3217 & $1 / 11 / 200821: 16$ & $8 / 11 / 200821: 16$ & 27.3 & 1039.6 \\
\hline 3218 & 1/11/2008 21:18 & $8 / 11 / 200821: 18$ & 27.4 & 1040.5 \\
\hline 3219 & $1 / 11 / 200821: 20$ & $8 / 11 / 200821: 20$ & 27.3 & 1040.8 \\
\hline 3220 & 1/11/200821:22 & $8 / 11 / 200821: 22$ & 27.3 & 1042.5 \\
\hline 3221 & $1 / 11 / 200821: 24$ & $8 / 11 / 200821: 24$ & 27.3 & 1043.8 \\
\hline 3222 & 1/11/200821:26 & $8 / 11 / 200821: 26$ & 27.3 & 1044.4 \\
\hline 3223 & $1 / 11 / 200821: 28$ & $8 / 11 / 200821: 28$ & 27.4 & 1044.3 \\
\hline 3224 & 1/11/2008 21:30 & $8 / 11 / 200821: 30$ & 27.3 & 1045.7 \\
\hline 3225 & 1/11/2008 21:32 & 8/11/2008 21:32 & 27.3 & 1046.2 \\
\hline 3226 & 1/11/2008 21:34 & $8 / 11 / 200821: 34$ & 27.3 & 1049.2 \\
\hline 3227 & 1/11/200821:36 & $8 / 11 / 200821: 36$ & 27.3 & 1048.2 \\
\hline 3228 & 1/11/2008 21:38 & $8 / 11 / 200821: 38$ & 27.4 & 1049.1 \\
\hline 3229 & 1/11/200821:40 & $8 / 11 / 200821: 40$ & 27.3 & 1049.5 \\
\hline 3230 & $1 / 11 / 200821: 42$ & $8 / 11 / 200821: 42$ & 27.4 & 1051.7 \\
\hline 3231 & $1 / 11 / 200821: 44$ & $8 / 11 / 200821: 44$ & 27.4 & 1053.4 \\
\hline 3232 & 1/11/200821:46 & $8 / 11 / 200821: 46$ & 27.4 & 10526 \\
\hline 3233 & $1 / 11 / 200821: 48$ & $8 / 11 / 200821: 48$ & 27.4 & 1054.7 \\
\hline 3234 & 1/11/200821:50 & $8 / 11 / 200821: 50$ & 27.4 & 1054.9 \\
\hline 3235 & 1/11/2008 21:52 & $8 / 11 / 200821: 52$ & 27.4 & 1055.1 \\
\hline 3236 & 1/11/2008 21:54 & $8 / 11 / 200821: 54$ & 27.3 & 1055 \\
\hline 3237 & $1 / 11 / 200821: 56$ & $8 / 11 / 200821: 56$ & 27.3 & 1055.6 \\
\hline 3238 & 1/11/2008 21:58 & $8 / 11 / 200821: 58$ & 27.3 & 1058.3 \\
\hline 3239 & $1 / 11 / 200822: 00$ & 8/11/2008 22:00 & 27.4 & 1058.1 \\
\hline 3240 & 1/11/2008 22:02 & 8/11/2008 22:02 & 27.4 & 1059.1 \\
\hline 3241 & 1/11/2008 22:04 & 8/11/2008 22:04 & 27.4 & 1060.8 \\
\hline 3242 & 1/11/2008 22:06 & 8/11/2008 22:06 & 27.4 & 1062.3 \\
\hline 3243 & 1/11/2008 22:08 & $8 / 11 / 200822: 08$ & 27.4 & 1062.6 \\
\hline 3244 & 1/11/2008 22:10 & 8/11/2008 22:10 & 27.4 & 1063.9 \\
\hline 3245 & 1/11/2008 22:12 & $8 / 11 / 200822: 12$ & 27.4 & 1064.9 \\
\hline 3246 & 1/11/2008 22:14 & 8/11/2008 22:14 & 27.4 & 1066.1 \\
\hline 3247 & 1/11/2008 22:16 & $8 / 11 / 200822: 16$ & 27.4 & 1068.5 \\
\hline 3248 & 1/11/2008 22:18 & 8/11/2008 22:18 & 27.4 & 1067.7 \\
\hline 3249 & 1/11/2008 22:20 & $8 / 11 / 200822: 20$ & 27.4 & 1066.6 \\
\hline 3250 & $1 / 11 / 200822-22$ & 8/11/2008 22:22 & 27.4 & 1070.1 \\
\hline 3251 & 1/11/2008 22:24 & 8/11/2008 22:24 & 27.4 & 1069.1 \\
\hline 3252 & $1 / 11 / 200822: 26$ & $8 / 11 / 200822: 26$ & 27.4 & 1069.6 \\
\hline 3253 & $1 / 11 / 200822: 28$ & $8 / 11 / 200822: 28$ & 27.4 & 1069.6 \\
\hline 3254 & 1/11/2008 22:30 & $8 / 11 / 200822: 30$ & 27.4 & 1069.2 \\
\hline 3255 & $1 / 11 / 200822: 32$ & $8 / 11 / 200822: 32$ & 27.4 & 1069.7 \\
\hline 3256 & 1/111/2008 22:34 & $8 / 11 / 200822: 34$ & 27.4 & 1069.4 \\
\hline 3257 & $1 / 11 / 200822-36$ & $8 / 11 / 200822: 36$ & 27.4 & 1068.6 \\
\hline 3258 & 1/11/2008 22:38 & $8 / 11 / 200822: 38$ & 27.4 & 1073.1 \\
\hline 3259 & 1/11/2008 22:40 & $8 / 11 / 200822: 40$ & 27.4 & 1069.6 \\
\hline 3260 & $1 / 11 / 200822: 42$ & $8 / 11 / 200822: 42$ & 27.4 & 1069.3 \\
\hline 3261 & 1/11/2008 22:44 & $8 / 11 / 200822: 44$ & 27.4 & 1068.3 \\
\hline 3262 & $1 / 11 / 200822: 46$ & $8 / 11 / 200822: 46$ & 27.3 & 1067 \\
\hline 3263 & $1 / 11 / 200822: 48$ & $8 / 11 / 200822: 48$ & 27.3 & 1066.9 \\
\hline 3264 & 1/11/2008 22:50 & $8 / 11 / 200822: 50$ & 27.3 & 1065.9 \\
\hline 3265 & $1 / 11 / 200822: 52$ & $8 / 11 / 200822: 52$ & 27.2 & 1065.2 \\
\hline 3266 & $1 / 11 / 200822: 54$ & $8 / 11 / 200822: 54$ & 27.2 & 1063.1 \\
\hline 3267 & $1 / 11 / 200822: 56$ & $8 / 11 / 200822: 56$ & 27.2 & 1058.8 \\
\hline 3268 & $1 / 11 / 200822: 58$ & $8 / 11 / 200822: 58$ & 27.1 & 1057 \\
\hline 3269 & \begin{tabular}{|l|}
$1 / 11 / 200823: 00$ \\
\end{tabular} & $8 / 11 / 200823: 00$ & 27.1 & 1054.8 \\
\hline 3270 & 1/11/2008 23:02 & $8 / 11 / 200823: 02$ & 27 & 1053.3 \\
\hline
\end{tabular}




\begin{tabular}{|c|c|c|c|c|}
\hline \multicolumn{5}{|c|}{$D 4-92 c$} \\
\hline $\operatorname{Rec}$ & & Adjusted & Temp & SC \\
\hline$\#$ & Date/Time & Date/Time & ${ }^{\circ} \mathrm{C}$ & $\mu \mathrm{S} / \mathrm{cm}$ \\
\hline 3271 & 1/11/2008 23:04 & $8 / 11 / 200823: 04$ & 27 & 1050.7 \\
\hline 3272 & 1/11/200823:06 & $8 / 11 / 200823: 06$ & 27 & 1049.8 \\
\hline 3273 & 1/11/2008 23:08 & $8 / 11 / 200823: 08$ & 27 & 1049.2 \\
\hline 3274 & 1/11/2008 23:10 & 8/11/2008 23:10 & 27 & 1052.3 \\
\hline 3275 & 1/11/2008 23:12 & $8 / 11 / 200823: 12$ & 27 & 1050.4 \\
\hline 3276 & 1/11/2008 23:14 & 8/11/2008 23:14 & 27 & 1050.5 \\
\hline 3277 & 1/11/200823:16 & 8/11/2008 23:16 & 27 & 1051.1 \\
\hline 3278 & 1/11/2008 23:18 & $8 / 11 / 200823: 18$ & 27 & 1052.3 \\
\hline 3279 & 1/11/2008 23:20 & 8/11/2008 23:20 & 26.9 & 1053.7 \\
\hline 3280 & 1/11/2008 23:22 & $8 / 11 / 200823: 22$ & 26.9 & 1052.5 \\
\hline 3281 & 1/11/2008 23:24 & $8 / 11 / 200823: 24$ & 26.9 & 1053 \\
\hline 3282 & 1/11/2008 23:26 & $8 / 11 / 200823: 26$ & 27 & 1054.1 \\
\hline 3283 & 1/11/2008 23:28 & $8 / 11 / 200823: 28$ & 27 & 1054.9 \\
\hline$\overline{3284}$ & 1/11/200823:30 & $8 / 11 / 200823: 30$ & 27 & 1055.4 \\
\hline 3285 & 1/11/2008 23:32 & $8 / 11 / 200823: 32$ & 27 & 1056 \\
\hline 3286 & 1/11/2008 23:34 & $8 / 11 / 200823: 34$ & 27 & 1056.7 \\
\hline 3287 & $1 / 11 / 200823: 36$ & $8 / 11 / 200823: 36$ & 27 & 1057.3 \\
\hline 3288 & $1 / 11 / 200823: 38$ & $8 / 11 / 200823: 38$ & 27 & 1057.6 \\
\hline 3289 & $1 / 11 / 200823: 40$ & $8 / 11 / 200823: 40$ & 27 & 1058.8 \\
\hline 3290 & 1/11/200823:42 & $8 / 11 / 200823: 42$ & 27 & 1059.7 \\
\hline 3291 & $1 / 11 / 200823: 44$ & $8 / 11 / 200823: 44$ & 27 & 1060.6 \\
\hline 3292 & $1 / 11 / 200823: 46$ & 8/11/2008 23:46 & 26.9 & 1060.4 \\
\hline 3293 & $1 / 11 / 200823: 48$ & $8 / 11 / 200823: 48$ & 26.9 & 1061.5 \\
\hline 3294 & $823: 50$ & $8 / 11 / 200823: 50$ & 26.9 & 1062.4 \\
\hline 3295 & 1/11/2008 23:52 & $8 / 11 / 200823: 52$ & 26.9 & 1062.3 \\
\hline 3296 & 1/11/2008 23:54 & $8 / 11 / 200823: 54$ & 26.9 & 1062.1 \\
\hline 3297 & $323: 56$ & $8 / 11 / 200823: 56$ & 26.9 & 1063.9 \\
\hline 3298 & 1/11/2008 23:58 & $8 / 11 / 200823: 58$ & 26.9 & 1063.8 \\
\hline 3299 & $1 / 12 / 20080: 00$ & $8 / 12 / 20080: 00$ & 26.9 & 1063.9 \\
\hline 3300 & $80: 02$ & $8 / 12 / 20080: 02$ & 26.9 & 1063.3 \\
\hline 3301 & $1 / 12 / 20080: 04$ & $8 / 12 / 20080: 04$ & 26.8 & 1063.9 \\
\hline 3302 & $20080: 06$ & $8 / 12 / 20080: 06$ & 26.8 & 1063.6 \\
\hline 3303 & $180: 08$ & $8 / 12 / 20080: 08$ & 26.8 & 1064.1 \\
\hline 3304 & $1 / 12 / 20080: 10$ & $8 / 12 / 20080: 10$ & 26.8 & 1064.1 \\
\hline 3305 & $20080: 12$ & $8 / 12 / 20080: 12$ & 26.8 & 1064.3 \\
\hline 3306 & $080: 14$ & $8 / 12 / 20080: 14$ & 26.8 & 1064.6 \\
\hline 3307 & $1 / 12 / 20080: 16$ & $8 / 12 / 20080: 16$ & 26.8 & 1065.7 \\
\hline 3308 & $20080: 18$ & $8 / 12 / 20080: 18$ & 26.8 & 1065.8 \\
\hline 3309 & $80: 20$ & $8 / 12 / 20080: 20$ & 26.8 & 1066.3 \\
\hline 3310 & $1 / 12 / 20080: 22$ & $8 / 12 / 20080: 22$ & 26.8 & 1067.2 \\
\hline 3311 & $80: 24$ & $8 / 12 / 20080: 24$ & 26.8 & 1067.4 \\
\hline 3312 & $80: 26$ & $8 / 12 / 20080: 26$ & 26.8 & 1065.5 \\
\hline 3313 & $1 / 12 / 20080: 28$ & $8 / 12 / 20080: 28$ & 26.8 & 1059.5 \\
\hline 3314 & $30: 30$ & $8 / 12 / 20080: 30$ & 26.7 & 1060.3 \\
\hline 3315 & $1 / 12 / 20080: 32$ & $8 / 12 / 20080: 32$ & 26.7 & 1061.1 \\
\hline 3316 & $80: 34$ & $8 / 12 / 20080: 34$ & 26.7 & 1063.9 \\
\hline 3317 & $0: 36$ & $8 / 12 / 20080: 36$ & 26.7 & 1063.3 \\
\hline 3318 & $1 / 12 / 20080: 38$ & $8 / 12 / 20080: 38$ & 26.7 & 1065.2 \\
\hline 3319 & $0: 40$ & $8 / 12 / 20080: 40$ & 26.7 & 1066 \\
\hline 3320 & 30:42 & $8 / 12 / 20080: 42$ & 26.7 & 1066.9 \\
\hline 3321 & $80: 44$ & $8 / 12 / 20080: 44$ & 26.7 & 1066.7 \\
\hline 3322 & $80: 46$ & $8 / 12 / 20080: 46$ & 26.7 & 1068 \\
\hline 3323 & $80: 48$ & $8 / 12 / 20080: 48$ & 26.7 & 1069.2 \\
\hline 3324 & $1 / 12 / 20080: 50$ & $8 / 12 / 20080: 50$ & 26.7 & 1070.2 \\
\hline 3325 & $20080: 52$ & $8 / 12 / 20080: 52$ & 26.7 & 1071 \\
\hline 3326 & $80: 54$ & $8 / 12 / 20080: 54$ & 26.7 & 1071.9 \\
\hline 3327 & 1/12/2008 0:56 & $8 / 12 / 20080: 56$ & 26.7 & 1071.2 \\
\hline 3328 & $1 / 12 / 20080: 58$ & $8 / 12 / 20080: 58$ & 26.7 & 1072.9 \\
\hline 3329 & $81: 00$ & $8 / 12 / 20081: 00$ & 26.7 & 1074.3 \\
\hline 3330 & $1 / 12 / 20081: 02$ & $8 / 12 / 20081: 02$ & 26.7 & 1073.5 \\
\hline 3331 & & $8 / 12 / 20081: 04$ & 26.7 & 1074.3 \\
\hline 3332 & $20081: 06$ & $8 / 12 / 20081: 06$ & 26.7 & 1075.1 \\
\hline 3333 & $1 / 12 / 20081: 08$ & $8 / 12 / 2008$ 1:08 & 26.7 & 1076.8 \\
\hline 3334 & $1 / 12 / 20081: 10$ & $8 / 12 / 2008$ 1:10 & 26.7 & 1077.4 \\
\hline 3335 & $1 / 12 / 2008$ 1:12 & $8 / 12 / 2008$ 1:12 & 26.6 & 1077.9 \\
\hline 3336 & $1 / 12 / 20081: 14$ & $8 / 12 / 2008$ 1:14 & 26.7 & 1077.7 \\
\hline 3337 & $1 / 12 / 20081: 16$ & $8 / 12 / 2008$ 1:16 & 26.7 & 1077.4 \\
\hline 3338 & $1 / 12 / 20081: 18$ & $8 / 12 / 2008$ 1:18 & 26.6 & 1079 \\
\hline 3339 & $1 / 12 / 20081: 20$ & $8 / 12 / 20081: 20$ & 26.6 & 1079 \\
\hline
\end{tabular}

\begin{tabular}{|c|c|c|c|c|c|c|c|c|c|}
\hline \multicolumn{5}{|c|}{ D4-92c } & \multicolumn{5}{|c|}{$D 4-92 c$} \\
\hline $\operatorname{Rec}$ & & Adjusted & Temp & SC & $\operatorname{Rec}$ & & Adjusted & Temp & SC \\
\hline \# & Date/Time & Date/Time & ${ }^{\circ} \mathrm{C}$ & $\mu \mathrm{S} / \mathrm{cm}$ & \# & Date/Time & Date/Time & ${ }^{\circ} \mathrm{C}$ & $\mu \mathrm{S} / \mathrm{cm}$ \\
\hline 3340 & $1 / 12 / 20081: 22$ & $8 / 12 / 20081: 22$ & 26.6 & 1080 & 3409 & $1 / 12 / 20083: 40$ & $8 / 12 / 20083: 40$ & 26.1 & 1014 \\
\hline 3341 & $1 / 12 / 20081: 24$ & $8 / 12 / 20081: 24$ & 26.6 & 1078.8 & & & & 26.1 & \\
\hline 3342 & 1/12/2008 1:26 & $12 / 2008$ 1:26 & 26.6 & 1080.4 & 3411 & $1 / 12 / 20083: 44$ & $8 / 12 / 20083: 44$ & 26 & 1014.3 \\
\hline 3343 & $1 / 12 / 20081: 28$ & $12 / 2008$ 1:28 & 26.6 & 1080.4 & $\overline{3412}$ & 1/12/20083:46 & $112 / 20083: 46$ & 26 & 1014.1 \\
\hline 3344 & $1 / 12 / 200$ & & 26.6 & 1081.5 & & & & 26 & 10141 \\
\hline 3345 & $1 / 12 / 2008$ 1:32 & $12 / 20081: 32$ & 26.6 & 1083.5 & $\overline{3414}$ & $1 / 12 / 20083: 50$ & $8 / 12 / 20083: 50$ & 26 & 1014.9 \\
\hline 3346 & $1 / 12 / 20081: 34$ & $12 / 20081: 34$ & 26.6 & 1080.8 & 3415 & 1/12/20083:52 & $8 / 12 / 20083: 52$ & 26 & 1015.6 \\
\hline 3347 & $1 / 12 / 20$ & $1 / 2 / 20081: 36$ & 26.6 & 1078.2 & & & & 26 & \\
\hline 3348 & 1/12/2008 1:38 & $8 / 12 / 20081: 38$ & 26.6 & 1079.9 & 3417 & $1 / 12 / 20$ & $883: 56$ & 26 & $\begin{array}{l}1015.4 \\
\end{array}$ \\
\hline 3349 & 1/12/2008 1:40 & $/ 12 / 20081: 40$ & 26.6 & 1080.2 & 3418 & $1 / 12 / 20083: 58$ & $8 / 12 / 20083: 58$ & 26 & 1014 \\
\hline 3350 & $1 / 12 / 2$ & $8 / 12 / 20081: 42$ & 26.6 & 1079.2 & 3419 & $1 / 12 / 2$ & $84: 00$ & 26 & \\
\hline 3351 & $1 / 12 / 2$ & $8 / 12 / 2008$ 1:44 & 26.6 & 1078.2 & 3420 & $1 / 12 / 2$ & & 26 & 1015.7 \\
\hline 3352 & $1 / 12 / 20081: 46$ & $8 / 12 / 20081: 46$ & 26.6 & 1077.2 & 3421 & $1 / 12 / 20$ & $884: 04$ & 26 & 1016 \\
\hline 3353 & $1 / 12 / 2$ & $31: 48$ & 26.6 & 1075.6 & 3422 & $1 / 12 / 2$ & & 26 & 1015.8 \\
\hline 3354 & $1 / 12 / 2$ & 1:50 & 26.6 & 1075.3 & 3423 & $1 / 12 / 2$ & & 26 & \\
\hline 3355 & $1 / 12 / 20$ & $8 / 12 / 20081: 52$ & 26.5 & 1073.5 & 3424 & $1 / 12 / 2$ & $8 / 12 / 2$ & 26 & 1015.8 \\
\hline 3356 & $1 / 12 / 2$ & $1: 54$ & 26.5 & 1074.4 & 3425 & $1 / 12$ & & 26 & 1015.6 \\
\hline 3357 & $1 / 12 / 2$ & $8 / 12 / 20$ & 26.5 & 1073.6 & 3426 & & & 26 & \\
\hline 3358 & $1 / 12 / 20$ & $8 / 12 / 20081: 58$ & 26.5 & 1071.1 & 3427 & $1 / 12 / 2$ & $34: 16$ & 25.9 & 1016.3 \\
\hline 3359 & $1 / 12 / 2$ & $32: 00$ & 26.5 & 1069.5 & 3428 & & & 25.9 & 1012.9 \\
\hline 3360 & $1 / 12 / 2$ & $8 / 12 / 20$ & 26.5 & 1064 & 3429 & & & 25.9 & \\
\hline 3361 & $1 / 12 / 2$ & 8/12/2008 2:04 & 26.4 & 1061.5 & 3430 & & & 25.9 & 1010.2 \\
\hline 3362 & $1 / 12 / 2$ & $2: 06$ & 26.4 & 051.9 & 3431 & & $4: 24$ & 25.9 & 1009.7 \\
\hline 3363 & $1 / 12 / 2$ & $2: 08$ & 26.4 & 050.5 & 3432 & & 4:26 & 25.9 & \\
\hline 3364 & $1 / 12$ & $2: 10$ & 26.4 & 1048.3 & 3433 & & & 25.9 & 1009.5 \\
\hline 3365 & $1 / 12$ & 2:12 & 26.4 & 1041 & 3434 & $1 / 12$ & & 25.9 & 1009.8 \\
\hline 3366 & $1 / 12 /$ & $2: 14$ & 26.4 & 1039.7 & 3435 & & & 25.9 & \\
\hline 3367 & $1 / 12$ & $2: 16$ & 26.4 & 032.9 & 3436 & & & 25.9 & 1011. \\
\hline 3368 & $1 / 12$ & $2: 18$ & 26.4 & $\overline{331.6}$ & 3437 & & & 25.9 & 1012 \\
\hline 3369 & $1 / 12 / 2$ & $8 / 1$ & 26.4 & 032.9 & 3438 & & & 25.9 & 1010.8 \\
\hline 3370 & $1 / 12 / 2$ & & 26.4 & 102 & 3439 & & & 25.9 & \\
\hline 3371 & $1 / 12$ & $2: 24$ & 26.4 & 1025.7 & 3440 & & & 25.9 & \\
\hline 3372 & $1 / 12 /$ & $8 / 12$ & 26.4 & 1023 & 3441 & & $4: 44$ & 25.9 & 012. \\
\hline 3373 & & & 26.3 & 1020 & & & & 25.8 & \\
\hline 3374 & & 2:30 & 26.3 & 1022. & 3443 & & & 25.8 & \\
\hline 3375 & $1 / 12 /$ & 2:32 & 26.3 & & $\overline{3444}$ & & $4: 50$ & 25.8 & 1017 \\
\hline 3376 & $1 / 12 /$ & & 26.3 & & & & & 25.8 & \\
\hline 3377 & $1 / 12$ & $2: 36$ & 26.3 & $\overline{01}$ & 3446 & & & 25.8 & 1034. \\
\hline 3378 & $1 / 12$ & & 26.3 & 1018. & 3447 & & & 25.8 & \\
\hline 3379 & & & 26.3 & & & & & 25.8 & 1034. \\
\hline 3380 & & $2: 42$ & 26.3 & 101 & & & & 25.8 & 103 \\
\hline 3381 & & $2: 44$ & 26.2 & & 3450 & & & 25.8 & 1034. \\
\hline 3382 & & & 26.3 & & & & & 25.8 & 1035.5 \\
\hline 3383 & & & 26.2 & & & & & 25.8 & 1035. \\
\hline 3384 & & $2: 50$ & 26.2 & & 3453 & & & 25.8 & 10 \\
\hline 3385 & & & 26.2 & & & & & 25.8 & \\
\hline 3386 & & & 26.2 & & & & & 25.8 & 1035. \\
\hline 3387 & & & 26.2 & & & & & 25.8 & 1036. \\
\hline 3388 & & & 26.2 & & & & & 25.8 & 103 \\
\hline 3389 & & & 26.2 & & 3 & & & 25.8 & 1038.9 \\
\hline 3390 & & & 26.2 & & & & & 25.8 & \\
\hline 3391 & & & 26.2 & & & & & 25.8 & \\
\hline 3392 & & 3:06 & 26.2 & 101 & 3461 & & & 25.8 & 1037.9 \\
\hline 3393 & & & 26.2 & & & & & 25.8 & \\
\hline 3394 & & & 26.1 & & & & & 25.8 & \\
\hline 3395 & & $3: 12$ & 26.1 & & 3464 & & & 25.8 & 1039.4 \\
\hline 3396 & & & 26.1 & & & & & 25.8 & \\
\hline 3397 & & & 26.1 & & & & & 25.8 & \\
\hline 3398 & & $083: 18$ & 26.1 & & & & & 25.8 & \\
\hline 399 & & & 26.1 & & & & & 25.8 & \\
\hline 3400 & & & 26.1 & & & & & 25.8 & \\
\hline 3401 & $3: 24$ & $3: 24$ & 26.1 & 101 & & & & 25.8 & 1040. \\
\hline 3402 & & & 26.1 & & & & & 25.7 & \\
\hline 3403 & & & 26.1 & & & & & 25.7 & \\
\hline 3404 & $1 / 12 /$ & $33: 30$ & 26.1 & 101 & 3473 & $1 / 12 /$ & $85: 48$ & 25.7 & \\
\hline 405 & & & 26.1 & & & & & 25.7 & \\
\hline 3406 & & & 26.1 & & & & & 25.7 & \\
\hline 3407 & $1 / 12 / 2$ & $8 / 12$ & 26.1 & 101 & 34 & & $85: 54$ & 25.7 & 1042 \\
\hline 3408 & & $20083: 38$ & 26.1 & & & & & 25.7 & 1012 \\
\hline
\end{tabular}


DOE/RL-2009-35, REV. 0

\begin{tabular}{|c|c|c|c|c|}
\hline \multicolumn{5}{|c|}{$D 4-92 c$} \\
\hline $\operatorname{Rec}$ & & Adjusted & Temp & SC \\
\hline$\#$ & Date/Time & Date/Time & ${ }^{\circ} \mathrm{C}$ & $\mu \mathrm{S} / \mathrm{cm}$ \\
\hline 3478 & $1 / 12 / 20085: 58$ & $8 / 12 / 20085: 58$ & 25.7 & 1042.6 \\
\hline 3479 & $1 / 12 / 20086000$ & 8/12/2008 6:00 & 25.7 & 1042.8 \\
\hline 480 & $1 / 12 / 20086: 02$ & & 25.7 & 1043.3 \\
\hline 3481 & $1 / 12 / 20086: 04$ & $8 / 12 / 20086: 04$ & 25.7 & 1044.1 \\
\hline 3482 & $1 / 12 / 20086: 06$ & $8 / 12 / 20086: 06$ & 25.7 & 1043.8 \\
\hline 3483 & $1 / 12 / 20086: 08$ & $8 / 12 / 20086: 08$ & 25.7 & 1044.5 \\
\hline 484 & $1 / 12 / 20086: 10$ & $8 / 12 / 20086: 10$ & 25.7 & 1044.6 \\
\hline 3485 & $1 / 12 / 20086: 12$ & $8 / 12 / 20086: 12$ & 25.7 & \\
\hline 3486 & $1 / 12 / 20086: 14$ & $8 / 12 / 20086: 14$ & 25.7 & 1045.1 \\
\hline 3487 & 1/12/2008 6:16 & $8 / 12 / 20086: 16$ & 25.7 & 1045.7 \\
\hline & $1 / 12 / 20086: 18$ & $8 / 12 / 20086: 18$ & 25.7 & 1045.6 \\
\hline 3489 & 1/12/20086:20 & $8 / 12 / 20086: 20$ & 25.7 & 1045.3 \\
\hline 3490 & $1 / 12 / 20$ & $8 / 12 / 20086: 22$ & 25.7 & 1046.1 \\
\hline 3491 & $1 / 12 / 20$ & $8 / 12 / 20086: 24$ & 25.7 & \\
\hline 3492 & $1 / 12 / 20086: 26$ & $8 / 12 / 20086: 26$ & 25.7 & 1047.2 \\
\hline 3493 & $1 / 12 / 20$ & $8 / 12 / 20086: 28$ & 25.7 & 1047.3 \\
\hline 3494 & $1 / 12 / 20$ & $8 / 12 / 20086: 30$ & 25.7 & 1047.8 \\
\hline 3495 & $1 / 12 / 20$ & $8 / 12 / 20086: 32$ & 25.7 & 1047.8 \\
\hline 3496 & $1 / 12 / 20$ & $8 / 12 / 20$ & 25.6 & \\
\hline 3497 & $1 / 12 / 20086: 36$ & $8 / 12 / 20086: 36$ & 25.6 & 1048.3 \\
\hline 3498 & $1 / 12 / 2$ & $8 / 12 / 2$ & 25.7 & 1048.5 \\
\hline 3499 & $1 / 12 / 2$ & $8 / 12 / 2$ & 25.6 & \\
\hline 3500 & $1 / 12 / 20$ & $8 / 12 / 20086: 42$ & 25.6 & 1048.7 \\
\hline 3501 & $1 / 12 / 2$ & $8 / 12 / 20$ & 25.6 & 1049.2 \\
\hline 3502 & $1 / 12 / 20$ & $8 / 12 / 20086: 46$ & 25.6 & 1049.3 \\
\hline 3503 & $1 / 12 / 2$ & $8 / 12 / 2$ & 25.6 & 1049.9 \\
\hline 3504 & $1 / 12 / 2$ & $8 / 12 / 2$ & 25.6 & 1050.2 \\
\hline 3505 & $1 / 12 / 20$ & $8 / 12 / 20$ & 25.6 & 1050.2 \\
\hline 3506 & $1 / 12 / 2$ & $8 / 12 / 2$ & 25.6 & 1050.5 \\
\hline 3507 & $1 / 12 / 2$ & $8 / 12 / 2$ & 25.6 & 1050.7 \\
\hline 3508 & $1 / 12 / 2$ & $8 / 12 / 2$ & 25.6 & 1050 \\
\hline 3509 & $1 / 12 / 2$ & $8 / 12 / 2$ & 25.6 & 1050.9 \\
\hline 3510 & $1 / 12 / 2$ & $8 / 12 / 2$ & 25.6 & 1050.8 \\
\hline 3511 & $1 / 12 /$ & $8 / 12 / 2$ & 25.6 & 1051.4 \\
\hline 3512 & $1 / 12 / 2$ & $8 / 12 / 2$ & 25.6 & 1051.1 \\
\hline 3513 & $7: 08$ & $8 / 12 / 20$ & 25.6 & 1051.3 \\
\hline 3514 & $1 / 12$ & $8 / 12 /$ & 25.6 & 1051.5 \\
\hline 3515 & $1 / 12 / 20$ & $8 / 12 / 20$ & 25.6 & 1051.7 \\
\hline 3516 & & $8 / 12 / 20$ & 25.6 & 1051.8 \\
\hline 3517 & $1 / 12 / 2$ & $8 / 12 t$ & 25.6 & 10517 \\
\hline 3518 & $1 / 12 t$ & & 25.6 & \\
\hline 3519 & & $8 / 12$ & 25.6 & 1051.4 \\
\hline 3520 & $1 / 12 / 2$ & $8 / 12 / 2$ & 25.6 & 1050.7 \\
\hline 3521 & & & 25.6 & \\
\hline 3522 & 26 & $8 / 12 /$ & 25.6 & 1050.1 \\
\hline 3523 & $1 / 12 / 2$ & $8 / 12 / 2$ & 25.6 & 1048.7 \\
\hline 3524 & & $8 / 12 / 2$ & 25.6 & 1040 \\
\hline 3525 & 32 & $8 / 12 / 2$ & 25.6 & 1049.5 \\
\hline 3526 & & & 25.6 & \\
\hline 3527 & & $8 / 12 / 2$ & 25.6 & 10478 \\
\hline 3528 & 38 & $8 / 12 / 20$ & 25.6 & 1046.6 \\
\hline 3529 & & & 25.5 & \\
\hline 3530 & $7: 42$ & $8 / 12 / 200$ & 25.5 & 1048.3 \\
\hline 3531 & & & 25.5 & 1047.6 \\
\hline 3532 & & & 25.5 & 1018 \\
\hline 353 & & $8 / 12 / 2$ & 25.5 & 1047.9 \\
\hline 3534 & & & 25.5 & \\
\hline 3535 & & & 25.5 & 1048.2 \\
\hline 3536 & & & 25.5 & \\
\hline 3537 & & & 25.5 & \\
\hline 353 & $1 / 12 / 20$ & $8 / 12 / 200$ & 25.5 & 1049.6 \\
\hline 3539 & & & 25.5 & \\
\hline 3540 & $1 / 12 / 2$ & & 25.5 & \\
\hline 3541 & $1 / 12 / 20$ & $8 / 12 / 20088: 04$ & 25.5 & 1049.7 \\
\hline 3542 & & & 25.5 & \\
\hline 3543 & $1 / 12 / 20$ & $8 / 12 / 20088: 08$ & 25.5 & 1049.6 \\
\hline 3544 & & $8 / 12 / 20088: 10$ & 25.5 & 1048.8 \\
\hline 3545 & $1 / 12 / 20$ & $8 / 12 / 20088: 12$ & 25.5 & 1044.5 \\
\hline 3546 & $171 / 20$ & $8 / 12 / 20088: 14$ & 25.5 & 1045.7 \\
\hline
\end{tabular}

\begin{tabular}{|c|c|c|c|c|}
\hline \multicolumn{5}{|c|}{$D 4-92 c$} \\
\hline Rec & & Adjusted & Temp & SC \\
\hline \# & ate $/$ Time & Date-Time & ${ }^{\circ} \mathrm{C}$ & $\mathrm{S} / \mathrm{cm}$ \\
\hline 347 & $1 / 12 / 20088: 16$ & $8 / 12 / 20088: 16$ & 25.5 & \\
\hline 48 & $2 / 20088: 18$ & $/ 12 / 20088: 18$ & 25.5 & 1044. \\
\hline 49 & & $12 / 20088: 20$ & & \\
\hline 3550 & $2 / 20088: 22$ & $8 / 12 / 20088: 22$ & 25.5 & 1050 \\
\hline 551 & $2 / 20088: 24$ & $12 / 20088: 24$ & 25.5 & 1050. \\
\hline 552 & & & 25.5 & \\
\hline 3553 & $2 / 20088: 28$ & $8 / 12 / 20$ & 25.5 & 1051 \\
\hline 554 & $88: 30$ & $8 / 12 / 2$ & 25.5 & 1051 \\
\hline 55 & & & 25.5 & \\
\hline 556 & $2 / 20088: 34$ & $8 / 12 / 20088: 34$ & 25.5 & 1051. \\
\hline & & $8 / 12 / 20088: 36$ & 25.5 & \\
\hline 558 & $38: 38$ & $8 / 12 / 2$ & 25.5 & \\
\hline 3559 & $88: 40$ & $8: 40$ & 25.5 & 1053 \\
\hline 3560 & & & 25.5 & \\
\hline 3561 & $8: 44$ & $8 / 12 / 2$ & 25.5 & \\
\hline 3562 & $8: 46$ & $8 / 12 / 2$ & 25.5 & 1054 \\
\hline 3563 & & & & \\
\hline 3564 & $88: 50$ & $8: 50$ & 25.5 & 1055 \\
\hline & $8: 52$ & $8 / 12 / 2$ & 25.5 & 1056 \\
\hline 3566 & $8: 54$ & $8 / 12 / 2$ & 25.5 & \\
\hline 3567 & & & 25.5 & 1056 \\
\hline 3568 & & & 25.5 & \\
\hline 3569 & & $9: 00$ & 25.5 & \\
\hline 3570 & & & 25.5 & \\
\hline 3571 & & & 25.5 & \\
\hline 3572 & & $9: 06$ & 25.5 & \\
\hline 3573 & & & 25.5 & \\
\hline 3574 & $9: 10$ & & 25.5 & \\
\hline 3575 & & & 25.5 & \\
\hline 3576 & & & 25.5 & \\
\hline 3577 & $9: 16$ & $9: 16$ & 25.5 & \\
\hline 3578 & & & 25.5 & \\
\hline 3579 & & $9: 20$ & 25.5 & \\
\hline 3580 & & & 25.5 & \\
\hline 3581 & & & 25.5 & \\
\hline 3582 & & $9: 26$ & 25.5 & \\
\hline 3583 & & $9: 28$ & 25.5 & 10 \\
\hline 3584 & & $9: 30$ & 25.5 & \\
\hline 3585 & & & 25.5 & \\
\hline 3586 & & & 25.5 & 1062 \\
\hline 3587 & & & 25.5 & \\
\hline 3588 & & & 25.5 & \\
\hline 3589 & & & 25.5 & \\
\hline 3590 & & & 25.5 & \\
\hline 3591 & & & 25.5 & \\
\hline 3592 & & & 25.5 & \\
\hline 3593 & & & 25.5 & \\
\hline 3594 & & & 25.5 & \\
\hline 3595 & & & 25.5 & \\
\hline 3596 & & & 25.5 & \\
\hline 3597 & $9: 56$ & & 25.5 & 10 \\
\hline 3598 & & & 25.6 & \\
\hline 3599 & & & 25.5 & \\
\hline 3600 & & & 25.5 & \\
\hline 3601 & & & & \\
\hline 3602 & & & 25.5 & \\
\hline 3603 & & & 25.5 & \\
\hline 3604 & & & & \\
\hline 3605 & 12 & $8 / 12 / 200$ & 25.5 & \\
\hline & & & & \\
\hline 3607 & & & & \\
\hline 3608 & & & 25.5 & \\
\hline & & & & \\
\hline 3610 & $310: 22$ & 10:22 & 25.5 & 1002 \\
\hline & & & 25.6 & \\
\hline & & & 25.6 & \\
\hline 361 & & 1.20 & 25.7 & \\
\hline 3614 & $1 / 12 / 20$ & & 25.7 & \\
\hline & & & & \\
\hline
\end{tabular}

\begin{tabular}{|c|c|c|c|c|}
\hline \multicolumn{5}{|c|}{ D4-92c } \\
\hline $\operatorname{Rec}$ & & Adjusted & Temp & SC \\
\hline$\#$ & Date/Time & Date/Time & \begin{tabular}{|l|}
${ }^{\circ} \mathrm{C}$ \\
\end{tabular} & $\mu \mathrm{S} / \mathrm{cm}$ \\
\hline 3616 & 1/12/2008 10:34 & \begin{tabular}{|l|}
$8 / 12 / 2008$ 10:34 \\
\end{tabular} & 25.7 & 1063.9 \\
\hline 3617 & $1 / 12 / 200810: 36$ & 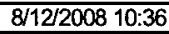 & 25.7 & 1072 \\
\hline 3618 & $1 / 12 / 2008$ 10:38 & \begin{tabular}{|ll}
$8 / 12 / 2008$ & $10: 38$ \\
\end{tabular} & 25.7 & 1078.6 \\
\hline 3619 & $1 / 12 / 200810: 40$ & $8 / 12 / 2008$ 10:40 & 25.8 & 1081.1 \\
\hline 3620 & $1 / 12 / 200810: 42$ & $8 / 12 / 2008$ 10:42 & 25.8 & 1082.7 \\
\hline 3621 & 1/12/2008 10:44 & $8 / 12 / 2008$ 10:44 & 25.9 & 1084 \\
\hline 3622 & 1/12/2008 10:46 & $8 / 12 / 2008$ 10:46 & 25.9 & 1086.5 \\
\hline 3623 & 1/12/2008 10:48 & $8 / 12 / 2008$ 10:48 & 25.9 & 1086.1 \\
\hline 3624 & 1/12/2008 10:50 & $8 / 12 / 2008$ 10:50 & 26 & 1086.3 \\
\hline 3625 & $1 / 12 / 200810: 52$ & $8 / 12 / 2008$ 10:52 & 26 & 1087.2 \\
\hline 3626 & $1 / 12 / 200810: 54$ & $8 / 12 / 2008$ 10:54 & 26 & 1088.3 \\
\hline 3627 & $1 / 12 / 200810: 56$ & $8 / 12 / 200810: 56$ & 26 & 1089.2 \\
\hline 3628 & $1 / 12 / 200810: 58$ & $8 / 12 / 2008 \quad 10: 58$ & 26.1 & 1090.4 \\
\hline 3629 & $1 / 12 / 200811: 00$ & $8 / 12 / 200811: 00$ & 26.1 & 1089.9 \\
\hline 3630 & 1/12/2008 11:02 & $8 / 12 / 200811: 02$ & 26.1 & 1089.5 \\
\hline 3631 & 1/12/2008 11:04 & $8 / 12 / 2008$ 11:04 & 26.1 & 1091.1 \\
\hline 3632 & $1 / 12 / 200811: 06$ & $8 / 12 / 2008$ 11:06 & 26.2 & 1091.7 \\
\hline 3633 & $1 / 12 / 200811: 08$ & $8 / 12 / 200811: 08$ & 26.2 & 1090.8 \\
\hline 3634 & $1 / 12 / 200811: 10$ & \begin{tabular}{|l|}
$8 / 12 / 200811: 10$ \\
\end{tabular} & 26.2 & 1091.4 \\
\hline 3635 & 1/12/2008 11:12 & $8 / 12 / 2008$ 11:12 & 26.2 & 1092.9 \\
\hline 3636 & 1/12/2008 11:14 & $8 / 12 / 2008$ 11:14 & 26.2 & 1092.1 \\
\hline 3637 & 1/12/2008 11:16 & $8 / 12 / 2008$ 11:16 & 26.3 & 1092.4 \\
\hline 3638 & 1/12/2008 11:18 & $8 / 12 / 2008$ 11:18 & 26.3 & 1092.6 \\
\hline 3639 & 1/12/2008 11:20 & $8 / 12 / 200811: 20$ & 26.3 & 1092.6 \\
\hline 3640 & $1 / 12 / 200811: 22$ & $8 / 12 / 2008$ 11:22 & 26.3 & 1093.5 \\
\hline 3641 & $1 / 12 / 200811: 24$ & $8 / 12 / 200811: 24$ & 26.3 & 1092.1 \\
\hline 3642 & $1 / 12 / 200811: 26$ & $8 / 12 / 2008$ 11:26 & 26.3 & 1092.8 \\
\hline 3643 & 1/12/2008 11:28 & $8 / 12 / 2008$ 11:28 & 26.3 & 1093.1 \\
\hline 3644 & $1 / 12 / 200811: 30$ & $8 / 12 / 2008 \quad 11: 30$ & 26.4 & 1093.3 \\
\hline 3645 & $1 / 12 / 200811: 32$ & $8 / 12 / 200811: 32$ & 26.4 & 1093.8 \\
\hline 3646 & $1 / 12 / 200811: 34$ & $8 / 12 / 200811: 34$ & 26.4 & 1093.7 \\
\hline 3647 & 1/12/2008 11:36 & $8 / 12 / 2008$ 11:36 & 26.4 & 1093.1 \\
\hline 3648 & 1/12/2008 11:38 & $8 / 12 / 2008$ 11:38 & 26.4 & 1094.8 \\
\hline 3649 & $1 / 12 / 200811: 40$ & $8 / 12 / 200811: 40$ & 26.5 & 1095.4 \\
\hline 3650 & $1 / 12 / 200811: 42$ & $8 / 12 / 2008 \quad 11: 42$ & 26.5 & 1095.2 \\
\hline 3651 & $1 / 12 / 200811: 44$ & $8 / 12 / 2008$ 11:44 & 26.5 & 1094.6 \\
\hline 3652 & $1 / 12 / 200811: 46$ & 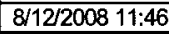 & 26.5 & 1095.4 \\
\hline 3653 & $1 / 12 / 200811: 48$ & $8 / 12 / 2008 \quad 11: 48$ & 26.5 & 1092.5 \\
\hline 3654 & $1 / 12 / 200811: 50$ & $8 / 12 / 200811: 50$ & 26.5 & 1093.2 \\
\hline 3655 & $1 / 12 / 200811: 52$ & $8 / 12 / 200811: 52$ & 26.5 & 1093.4 \\
\hline 3656 & 1/12/2008 11:54 & $8 / 12 / 200811: 54$ & 26.5 & 1092.5 \\
\hline 3657 & $1 / 12 / 200811: 56$ & $8 / 12 / 200811: 56$ & 26.5 & 1092.9 \\
\hline 3658 & $1 / 12 / 200811: 58$ & $8 / 12 / 2008 \quad 11: 58$ & 26.5 & 1094.3 \\
\hline 3659 & 1/12/2008 12:00 & $8 / 12 / 2008$ 12:00 & 26.6 & 1094.1 \\
\hline 3660 & 1/12/2008 12:02 & $8 / 12 / 2008$ 12:02 & 26.6 & 1093.7 \\
\hline 3661 & $1 / 12 / 200812: 04$ & $8 / 12 / 200812: 04$ & 26.6 & 1093.8 \\
\hline 3662 & $1 / 12 / 200812: 06$ & $8 / 12 / 2008 \quad 12: 06$ & 26.6 & 1094.1 \\
\hline 3663 & $1 / 12 / 200812: 08$ & \begin{tabular}{|l}
$8 / 12 / 2008$ 12:08 \\
\end{tabular} & 26.7 & 1093.7 \\
\hline 3664 & $1 / 12 / 200812: 10$ & \begin{tabular}{|l|}
$8 / 12 / 2008$ 12:10 \\
\end{tabular} & 26.7 & 1094.8 \\
\hline 3665 & 1/12/2008 12:12 & \begin{tabular}{|l}
$8 / 12 / 2008$ 12:12 \\
\end{tabular} & 26.7 & 1095 \\
\hline 3666 & $1 / 12 / 200812: 14$ & \begin{tabular}{|l}
$8 / 12 / 200812: 14$ \\
\end{tabular} & 26.7 & 1095.2 \\
\hline 3667 & $1 / 12 / 200812: 16$ & 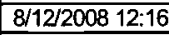 & 26.7 & 1095.1 \\
\hline 3668 & $1 / 12 / 200812: 18$ & $8 / 12 / 2008$ 12:18 & 26.7 & 1095.3 \\
\hline 3669 & $1 / 12 / 200812: 20$ & $8 / 12 / 2008$ 12:20 & 26.7 & 1097.3 \\
\hline 3670 & & $8 / 12 / 200812: 22$ & 26.7 & 1096.4 \\
\hline 3671 & $1 / 12 / 200812: 24$ & $\begin{array}{l}8 / 12 / 2008 \quad 12: 24 \\
\end{array}$ & 26.8 & 1097.5 \\
\hline 3672 & 1/12/2008 12:26 & $8 / 12 / 2008 \quad 12: 26$ & 26.8 & 1096.6 \\
\hline 3673 & $1 / 12 / 200812: 28$ & $8 / 12 / 2008$ 12:28 & 26.8 & 1097.6 \\
\hline 3674 & 1/12/2008 12:30 & \begin{tabular}{|l|l|l}
$8 / 12 / 2008$ & $12: 30$ \\
\end{tabular} & 26.8 & 1095.9 \\
\hline 3675 & 1/12/2008 12:32 & \begin{tabular}{|l}
$8 / 12 / 2008 \quad 12: 32$ \\
\end{tabular} & 26.8 & 1094.8 \\
\hline 3676 & $1 / 12 / 200812: 34$ & $8 / 12 / 2008 \quad 12: 34$ & 26.8 & 1095.3 \\
\hline 3677 & $1 / 12 / 200812: 36$ & $8 / 12 / 200812: 36$ & 26.8 & 1095.9 \\
\hline 3678 & $1 / 12 / 200812: 38$ & $8 / 12 / 2008 \quad 12: 38$ & 26.8 & 1096.8 \\
\hline 3679 & $1 / 12 / 200812: 40$ & $8 / 12 / 2008 \quad 12: 40$ & 26.8 & 1095.2 \\
\hline 3680 & $1 / 12 / 2008$ \{2:42 & \begin{tabular}{|l|l|}
$8 / 12 / 2008$ & $12: 42$ \\
\end{tabular} & 26.8 & 1094.8 \\
\hline 3681 & 1/12/2008 12:44 & 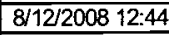 & 26.8 & 1099 \\
\hline 3682 & $1 / 12 / 200812: 46$ & \begin{tabular}{|l}
$8 / 12 / 200812: 46$ \\
\end{tabular} & 26.8 & 1097.2 \\
\hline 3683 & $1 / 12 / 200812: 48$ & 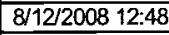 & 26.8 & 1097.3 \\
\hline 3684 & $1 / 12 / 200812: 50$ & $8 / 12 / 2008$ 12:50 & 26.8 & 1098.4 \\
\hline
\end{tabular}




\begin{tabular}{|c|c|c|c|c|}
\hline \multicolumn{5}{|c|}{ D4-92c } \\
\hline $\operatorname{Rec}$ & & Adjusted & Temp & SC \\
\hline$\#$ & Date/Time & Date/Time & ${ }^{\circ} \mathrm{C}$ & $\mu \mathrm{S} / \mathrm{cm}$ \\
\hline 3685 & $1 / 12 / 200812: 52$ & $8 / 12 / 200812: 52$ & 26.8 & .1098 .2 \\
\hline 3686 & $1 / 12 / 200812: 54$ & $8 / 12 / 200812: 54$ & 26.8 & 1100.1 \\
\hline 3687 & $1 / 12 / 200812: 56$ & $8 / 12 / 200812: 56$ & 27 & 1102.9 \\
\hline 3688 & $1 / 12 / 200812: 58$ & $8 / 12 / 200812: 58$ & 27 & 1102 \\
\hline 3689 & 1/12/2008 13:00 & 8/12/2008 13:00 & 27 & 1102.5 \\
\hline 3690 & $1 / 12 / 200813: 02$ & $8 / 12 / 200813: 02$ & 27 & 1103.3 \\
\hline 3691 & $1 / 12 / 200813: 04$ & $8 / 12 / 200813: 04$ & 27.1 & 1103.2 \\
\hline 3692 & 1/12/2008 13:06 & $8 / 12 / 200813: 06$ & 27.1 & 1104.8 \\
\hline 3693 & $1 / 12 / 200813: 08$ & $8 / 12 / 200813: 08$ & 27.1 & 1105.3 \\
\hline 3694 & $1 / 12 / 200813: 10$ & $8 / 12 / 200813: 10$ & 27.1 & 1104.8 \\
\hline 3695 & $1 / 12 / 2008$ 13:12 & $8 / 12 / 200813: 12$ & 27.1 & 1099.6 \\
\hline 3696 & $1 / 12 / 200813: 14$ & $8 / 12 / 200813: 14$ & 27.1 & 1101.8 \\
\hline 3697 & 1/12/2008 13:16 & 8/12/2008 13:16 & 27.1 & 1102.2 \\
\hline 3698 & $1 / 12 / 2008$ 13:18 & 8/12/2008 13:18 & 27.1 & 1101.7 \\
\hline 3699 & $1 / 12 / 200813: 20$ & $8 / 12 / 200813: 20$ & 27 & 1102.1 \\
\hline 3700 & $1 / 12 / 2008$ 13:22 & $8 / 12 / 200813: 22$ & 27 & 1102.1 \\
\hline 3701 & $1 / 12 / 200813: 24$ & $8 / 12 / 200813: 24$ & 27 & 1102 \\
\hline 3702 & $1 / 12 / 200813: 26$ & $8 / 12 / 200813: 26$ & 27.1 & 1099.1 \\
\hline 3703 & $1 / 12 / 200813: 28$ & $8 / 12 / 200813: 28$ & 27.1 & 1097 \\
\hline 3704 & 1/12/2008 13:30 & \begin{tabular}{|l|}
$8 / 12 / 2008$ \\
\end{tabular} & 27.1 & 1095.9 \\
\hline 3705 & $1 / 12 / 200813: 32$ & $8 / 12 / 200813: 32$ & 27.2 & 1094.4 \\
\hline 3706 & 1/12/2008 13:34 & $8 / 12 / 200813: 34$ & 27.2 & 1093.3 \\
\hline 3707 & 1/12/2008 13:36 & $8 / 12 / 200813: 36$ & 27.2 & 1092.4 \\
\hline 3708 & $1 / 12 / 200813: 38$ & $8 / 12 / 200813: 38$ & 27.2 & 1090.9 \\
\hline 3709 & $1 / 12 / 200813: 40$ & $8 / 12 / 200813: 40$ & 27.3 & 1090.3 \\
\hline 3710 & 1/12/2008 13:42 & $8 / 12 / 200813: 42$ & 27.3 & 1089.4 \\
\hline 3711 & $1 / 12 / 200813: 44$ & $8 / 12 / 2008$ 13:44 & 27.3 & 1088.6 \\
\hline 3712 & $1 / 12 / 200813: 46$ & $8 / 12 / 2008$ 13:46 & 27.2 & 1088.6 \\
\hline 3713 & $1 / 12 / 200813: 48$ & $8 / 12 / 200813: 48$ & 27.2 & 1088.2 \\
\hline 3714 & $1 / 12 / 200813: 50$ & $8 / 12 / 200813: 50$ & 27.3 & 1087.7 \\
\hline 3715 & $1 / 12 / 200813: 52$ & $8 / 12 / 200813: 52$ & 27.3 & 1087 \\
\hline 3716 & $1 / 12 / 200813: 54$ & $8 / 12 / 200813: 54$ & 27.3 & 1086.7 \\
\hline 3717 & $1 / 12 / 200813: 56$ & $8 / 12 / 200813: 56$ & 27.4 & 1085.7 \\
\hline 3718 & $1 / 12 / 200813: 58$ & $8 / 12 / 200813: 58$ & 27.4 & 1085.1 \\
\hline 3719 & $1 / 12 / 200814: 00$ & $8 / 12 / 200814: 00$ & 27.4 & 1086.4 \\
\hline 3720 & $1 / 12 / 200814: 02$ & $8 / 12 / 200814: 02$ & 27.4 & 1085.1 \\
\hline 3721 & $1 / 12 / 200814: 04$ & 8/12/2008 14:04 & 27.4 & 1085.6 \\
\hline 3722 & $1 / 12 / 200814: 06$ & $8 / 12 / 200814: 06$ & 27.4 & 1085.1 \\
\hline 3723 & $1 / 12 / 200814: 08$ & $8 / 12 / 200814: 08$ & 27.4 & 1084.7 \\
\hline 3724 & $1 / 12 / 200814: 10$ & $8 / 12 / 200814: 10$ & 27.4 & 1084.4 \\
\hline 3725 & $1 / 12 / 200814: 12$ & $8 / 12 / 200814: 12$ & 27.4 & 1084.6 \\
\hline 3726 & $1 / 12 / 200814: 14$ & $8 / 12 / 200814: 14$ & 27.5 & 1086.8 \\
\hline 3727 & 1/12/2008 14:16 & $8 / 12 / 200814: 16$ & 27.5 & 1085.4 \\
\hline 3728 & $1 / 12 / 200814: 18$ & $8 / 12 / 200814: 18$ & 27.5 & 1085.9 \\
\hline 3729 & $1 / 12 / 200814: 20$ & $8 / 12 / 200814: 20$ & 27.5 & 1085.6 \\
\hline 3730 & $1 / 12 / 200814: 22$ & $8 / 12 / 200814: 22$ & 27.5 & 1087.4 \\
\hline 3731 & $1 / 12 / 200814: 24$ & $8 / 12 / 200814: 24$ & 27.6 & 1086.1 \\
\hline 3732 & $1 / 12 / 200814: 26$ & $8 / 12 / 200814: 26$ & 27.6 & 1086.7 \\
\hline 3733 & $1 / 12 / 200$ & $8 / 12 / 200814: 28$ & 27.6 & 1086.3 \\
\hline 3734 & $1 / 12 / 200814: 30$ & $8 / 12 / 2008$ 14:30 & 27.6 & 1088.2 \\
\hline 3735 & $1 / 12 / 200814: 32$ & $8 / 12 / 2008$ 14:32 & 27.7 & 1087.5 \\
\hline 3736 & $1 / 12 / 200814: 34$ & $8 / 12 / 200814: 34$ & 27.7 & 1088.2 \\
\hline 3737 & $1 / 12 / 200814: 36$ & $8 / 12 / 200814: 36$ & 27.7 & 1087.3 \\
\hline 3738 & $1 / 12 / 200814: 38$ & $8 / 12 / 200814: 38$ & 27.7 & 1087.2 \\
\hline 3739 & $1 / 12 / 200814: 40$ & $8 / 12 / 2008$ 14:40 & 27.7 & 1088.6 \\
\hline 3740 & $1 / 12 / 200814: 42$ & $8 / 12 / 200814: 42$ & 27.7 & 1088.1 \\
\hline 3741 & \begin{tabular}{|l}
$1 / 12 / 200814: 44$ \\
\end{tabular} & $8 / 12 / 2008$ 14:44 & 27.8 & 1087.6 \\
\hline 3742 & $1 / 12 / 200814: 46$ & $8 / 12 / 200814: 46$ & 27.8 & 1089 \\
\hline 3743 & $1 / 12 / 200814: 48$ & $8 / 12 / 2008$ 14:48 & 27.8 & 1089.3 \\
\hline 3744 & $1 / 12 / 200814: 50$ & $8 / 12 / 2008$ 14:50 & 27.8 & 1090.4 \\
\hline 3745 & $1 / 12 / 200814: 52$ & $8 / 12 / 200814: 52$ & 27.8 & 1089.5 \\
\hline 3746 & $1 / 12 / 200814: 54$ & $8 / 12 / 200814: 54$ & 27.8 & 1089.9 \\
\hline 3747 & $1 / 12 / 200814: 56$ & $8 / 12 / 200814: 56$ & 27.9 & 1089.3 \\
\hline 3748 & $1 / 12 / 2008$ 14:58 & $8 / 12 / 200814: 58$ & 27.9 & 1089.2 \\
\hline 3749 & $1 / 12 / 2008$ 15:00 & $8 / 12 / 200815: 00$ & 27.9 & 1088.7 \\
\hline 3750 & $1 / 12 / 2008$ 15:02 & $8 / 12 / 200815: 02$ & 27.9 & 1089.2 \\
\hline 3751 & $1 / 12 / 200815: 04$ & $8 / 12 / 2008$ 15:04 & 27.9 & 1088.4 \\
\hline 3752 & $1 / 12 / 2008+5: 06$ & $8 / 12 / 200815: 06$ & 27.9 & 1089.9 \\
\hline 3753 & $1 / 12 / 200815: 08$ & $8 / 12 / 200815: 08$ & 27.9 & 1089.1 \\
\hline
\end{tabular}

\begin{tabular}{|c|c|c|c|c|c|c|c|c|c|}
\hline \multicolumn{5}{|c|}{ D4-92c } & \multicolumn{5}{|c|}{$D 4-92 C$} \\
\hline $\operatorname{Rec}$ & & Adjusted & Temp & SC & Rec & & Adjusted & Temp & SC \\
\hline \# & Date/Time & Date/Time & ${ }^{\circ} \mathrm{C}$ & $\mu \mathrm{S} / \mathrm{cm}$ & $\#$ & Date/Time & Date/Time & $\begin{array}{ll}{ }^{\circ} \mathrm{C} \\
\end{array}$ & $\mu S / \mathrm{cm}$ \\
\hline 3754 & $1 / 12 / 200815: 10$ & 8/12/2008 15:10 & 27.9 & 1090.9 & 382 & 1/12/2008 17:28 & \begin{tabular}{|l|}
$8 / 12 / 2008$ 17:28 \\
\end{tabular} & 28.7 & 1033 \\
\hline 3755 & 1/12/2008 15:12 & $8 / 12 / 200815: 12$ & 27.9 & 1089.5 & 3824 & $1 / 12 / 200817: 30$ & $8 / 12 / 2008$ 17:30 & 28.7 & 1033.2 \\
\hline 3756 & $1 / 12 / 200815: 14$ & $8 / 12 / 200815: 14$ & 27.9 & 1091.7 & 3825 & 1/12/2008 17:32 & $8 / 12 / 2008 \quad 17: 32$ & 28.7 & 1033.1 \\
\hline 3757 & 1/12/2008 15:16 & $8 / 12 / 200815: 16$ & 28 & 1090.6 & 3826 & $1 / 12 / 200817: 34$ & $8 / 12 / 2008$ 17:34 & 28.7 & 1032.7 \\
\hline 3758 & 1/12/2008 15:18 & $8 / 12 / 2008$ 15:18 & 28 & 1091.2 & 3827 & $1 / 12 / 200817: 36$ & $8 / 12 / 2008$ 17:36 & 28.8 & 1032.4 \\
\hline 3759 & $1 / 12 / 200815: 20$ & 8/12/2008 15:20 & 28 & 1091.6 & 3828 & $1 / 12 / 200817: 38$ & $8 / 12 / 2008$ 17:38 & 28.8 & 1032.7 \\
\hline 3760 & 1/12/2008 15:22 & $8 / 12 / 200815: 22$ & 28 & 1091.6 & 3829 & 1/12/2008 17:40 & $8 / 12 / 200817: 40$ & 28.8 & 1032.5 \\
\hline 3761 & $1 / 12 / 200815: 24$ & $8 / 12 / 200815: 24$ & 28.1 & 1091.7 & 3830 & $1 / 12 / 200817: 42$ & $8 / 12 / 2008$ 17:42 & 28.8 & 1032.2 \\
\hline 3762 & 1/12/2008 15:26 & $8 / 12 / 2008$ 15:26 & 28.1 & 1092.1 & 3831 & 1/12/2008 17:44 & $8 / 12 / 2008$ 17:44 & 28.8 & 1032 \\
\hline 3763 & 1/12/2008 15:28 & $8 / 12 / 200815: 28$ & 28.1 & 1092.2 & 3832 & 1/12/2008 17:46 & 8/12/2008 17:46 & 28.8 & 1032.4 \\
\hline 3764 & 1/12/2008 15:30 & $8 / 12 / 200815: 30$ & 28.1 & 1093.1 & 3833 & $1 / 12 / 200817: 48$ & $8 / 12 / 200817: 48$ & 28.8 & 1032.7 \\
\hline 3765 & 1/12/2008 15:32 & $8 / 12 / 200815: 32$ & 28.1 & 10927 & 3834 & $1 / 12 / 200817: 50$ & $8 / 12 / 200817: 50$ & 28.8 & 1032.4 \\
\hline 3766 & $1 / 12 / 200815: 34$ & $8 / 12 / 200815: 34$ & 28.1 & 1092.7 & 3835 & $1 / 12 / 200817: 52$ & $8 / 12 / 2008$ 17:52 & 28.8 & 1032.2 \\
\hline 3767 & 1/12/2008 15:36 & $8 / 12 / 200815: 36$ & 28.2 & 1093.6 & 3836 & $1 / 12 / 200817: 54$ & $8 / 12 / 200817: 54$ & 28.8 & 1032.4 \\
\hline 3768 & 1/12/2008 15:38 & $8 / 12 / 200815: 38$ & 28.2 & 1093.8 & 3837 & $1 / 12 / 2008$ 17:56 & $8 / 12 / 2008$ 17:56 & 28.8 & 1032.4 \\
\hline 3769 & 1/12/2008 15:40 & $8 / 12 / 200815: 40$ & 28.2 & 1091.2 & 3838 & 1/12/2008 17:58 & $8 / 12 / 200817: 58$ & 28.8 & 1032.1 \\
\hline 3770 & 1/12/2008 15:42 & $8 / 12 / 200815: 42$ & 28.2 & 1092 & 3839 & $1 / 12 / 200818: 00$ & $8 / 12 / 200818: 00$ & 28.8 & 1033.3 \\
\hline 3771 & 1/12/2008 15:44 & $8 / 12 / 2008$ 15:44 & 28.1 & 1093.2 & 3840 & 1/12/2008 18:02 & 8/12/2008 18:02 & 28.8 & 1033.1 \\
\hline 3772 & $1 / 12 / 200815: 46$ & $8 / 12 / 200815: 46$ & 28.1 & 1094.3 & 3841 & $1 / 12 / 200818: 04$ & $8 / 12 / 2008+8: 04$ & 28.8 & 1032.8 \\
\hline 3773 & 1/12/2008 15:48 & $8 / 12 / 200815: 48$ & 28.2 & 1094.5 & 3842 & $1 / 12 / 200818: 06$ & $8 / 12 / 200818: 06$ & 28.8 & 1032.8 \\
\hline 3774 & $1 / 12 / 200815: 50$ & $8 / 12 / 200815: 50$ & 28.2 & 1094.8 & 3843 & $1 / 12 / 200818: 08$ & $8 / 12 / 200818: 08$ & 28.7 & 1033.9 \\
\hline 3775 & 1/12/2008 15:52 & $8 / 12 / 200815: 52$ & 28.3 & 1094.6 & 3844 & $0818: 10$ & $8 / 12 / 200818: 10$ & 28.7 & 1034.1 \\
\hline 3776 & 1/12/2008 15:54 & $8 / 12 / 200815: 54$ & 28.3 & 1092.4 & 3845 & $1 / 12 / 20$ & 8/12/2008 18:12 & 28.7 & 1034.4 \\
\hline $37 \pi 7$ & $1 / 12 / 200815: 56$ & $8 / 12 / 200815: 56$ & 28.3 & 1092.1 & 3846 & $1 / 12 / 200818: 14$ & $8 / 12 / 200818: 14$ & 28.7 & 1033.9 \\
\hline 3778 & $1 / 12 / 200$ & $8 / 12 / 200815: 58$ & 28.2 & 1091.7 & 3847 & $1 / 12 / 20$ & $8 / 12 / 200818: 16$ & 28.7 & 1033.9 \\
\hline 3779 & 1/12/2008 16:00 & $8 / 12 / 200816: 00$ & 28.2 & 1090.9 & 3848 & $1 / 12 / 200818: 18$ & $8 / 12 / 200818: 18$ & 28.7 & 1034.4 \\
\hline 3780 & $1 / 12 / 2008$ & 8/12/2008 16:02 & 28.2 & 1088.4 & 3849 & $1 / 12 / 200818: 20$ & $8 / 12 / 200818: 20$ & 28.7 & 1037.5 \\
\hline 3781 & $1 / 12 / 200$ & $8 / 12 / 200816: 04$ & 28.2 & 1082.6 & 3850 & $1 / 12 / 20$ & $8 / 12 / 200818: 22$ & 28.7 & 1036.2 \\
\hline 3782 & $1 / 12 / 200$ & $8 / 12 / 200816: 06$ & 28.2 & 1080.6 & 3851 & $1 / 12 / 20$ & $8 / 12 / 2008$ 18:24 & 28.8 & 1040.2 \\
\hline 3783 & 1/12/2008 16:08 & $8 / 12 / 200816: 08$ & 28.2 & 1075.3 & 3852 & $1 / 12 / 200818: 26$ & $8 / 12 / 200818: 26$ & 28.9 & 1040.5 \\
\hline 3784 & $1 / 12 / 200816: 10$ & $8 / 12 / 200816: 10$ & 28.2 & 1067.4 & 3853 & $1 / 12 / 200818: 28$ & $8 / 12 / 200818: 28$ & 29 & 1040.9 \\
\hline 3785 & 1/12/2008 16:12 & $8 / 12 / 2008$ 16:12 & 28.2 & 1068.7 & 3854 & $1 / 12 / 200818: 30$ & $8 / 12 / 200818: 30$ & 29 & 1040.6 \\
\hline 3786 & 1/12/2008 16:14 & $8 / 12 / 200816: 14$ & 28.2 & 1067.2 & 3855 & $1 / 12 / 20$ & $8 / 12 / 200818: 32$ & 29 & 1041.2 \\
\hline 3787 & $1 / 12 / 200$ & 8/12/2008 16:16 & 28.2 & 1066.4 & 3856 & $1 / 12 / 20$ & $8 / 12 / 200818: 34$ & 29 & 1041.7 \\
\hline 3788 & $1 / 12 / 200$ & $8 / 12 / 200$ & 28.3 & 1053. & 3857 & $1 / 12 / 20$ & $8 / 12 / 200818: 36$ & 29 & 1042.1 \\
\hline 3789 & 1/12/2008 16:20 & \begin{tabular}{|l|}
$8 / 12 / 200816: 20$ \\
\end{tabular} & 28.4 & 1047.3 & 3858 & $1 / 12 / 200818: 38$ & $8 / 12 / 200818: 38$ & 29 & 1042.4 \\
\hline 3790 & $1 / 12 / 200816: 22$ & $8 / 12 / 200816: 22$ & 28.5 & 1043.9 & 3859 & $1 / 12 / 200818: 40$ & $8 / 12 / 200818: 40$ & 29 & 1042.8 \\
\hline 3791 & $1 / 12 / 200816: 24$ & $8 / 12 / 2008$ 16:24 & 28.5 & 1043 & 3860 & $1 / 12 / 2 C$ & $8 / 12 / 200818: 42$ & 29 & 1042.5 \\
\hline 3792 & $1 / 12 / 200$ & $8 / 12 / 200$ & 28.5 & 1042.5 & 3861 & $818: 44$ & $8 / 12 / 200818: 44$ & 29 & 1042.4 \\
\hline 3793 & $1 / 12 / 200$ & $8 / 12 / 200$ & 28.5 & 1041.3 & 3862 & 1/12/2008 18:46 & $8 / 12 / 200818: 46$ & 29 & 1041.7 \\
\hline 3794 & 1/12/2008 16:30 & $8 / 12 / 2008$ 16:30 & 28.5 & 1040.2 & 3863 & $1 / 12 / 20$ & $8 / 12 / 2008$ 18:48 & 29 & 1042.5 \\
\hline 3795 & 1/12/2008 16:32 & $8 / 12 / 200816: 32$ & 28.5 & 1039.1 & 3864 & $1 / 12 / 2$ & $8 / 12 / 20$ & 28.9 & 1042.7 \\
\hline 3796 & $1 / 12 / 200816: 34$ & $8 / 12 / 200$ & 28.5 & 1038.4 & 3865 & $1 / 12 / 20$ & $8 / 12 / 200818: 52$ & 28.9 & 1043.4 \\
\hline 3797 & $1 / 12 / 200$ & $8 / 12 / 200$ & 28.6 & 1037.6 & 3866 & $1 / 12 / 200818: 54$ & $8 / 12 / 200818: 54$ & 28.9 & 1053 \\
\hline 3798 & $1 / 12 / 200$ & $8 / 12 / 20 \mathrm{C}$ & 28.5 & 1037.9 & 3867 & $1 / 12 / 2$ & 8/12/2008 18:56 & 29 & 1055.9 \\
\hline 3799 & 1/12/2008 16:40 & $8 / 12 / 200816: 40$ & 28.6 & 1037.1 & 3868 & $1 / 12 / 20$ & $8 / 12 / 200818: 58$ & 29 & 1060.2 \\
\hline 3800 & $1 / 12 / 20$ & $8 / 12 / 20$ & 28.6 & 1036.5 & 3869 & & & 29 & 1060.5 \\
\hline 3801 & $1 / 12 / 200816: 44$ & $8 / 12 / 200$ & 28.6 & 1036.7 & 3870 & $1 / 12 / 2$ & $8 / 12 / 2008$ 19:02 & 29 & 1061.6 \\
\hline 3802 & $1 / 12 / 200$ & 8/12/2008 16:46 & 28.6 & 1036.2 & 3871 & $1 / 12 / 20$ & $8 / 12 / 200819: 04$ & 29 & 1062.2 \\
\hline 3803 & $1 / 12 / 2008$ & $8 / 12 / 200$ & 28.6 & 1035.9 & 3872 & $1 / 12 / 2$ & 8/12/2008 19:06 & 29 & 1062.7 \\
\hline 3804 & $1 / 12 / 200816: 50$ & 8/12/2008 16:50 & 28.6 & 1035.2 & 3873 & $1 / 12 / 20$ & $8 / 12 / 2008$ 19:08 & 29 & 1062.6 \\
\hline 3805 & $1 / 12 / 200$ & $8 / 12 / 20$ & 28.6 & 1034. & 3874 & & & 28.9 & 1064.3 \\
\hline 3806 & $1 / 12 / 200816: 54$ & \begin{tabular}{|l|}
$8 / 12 / 200816: 54$ \\
\end{tabular} & 28.6 & 1034. & 3875 & $1 / 12 / 20$ & $8 / 12 / 200819: 12$ & 28.9 & 1064.4 \\
\hline 3807 & $1 / 12 / 200816: 56$ & $8 / 12 / 200816: 56$ & 28.6 & 1034.5 & 3876 & $1 / 12 / 20$ & 8/12/2008 19:14 & 28.9 & 1064.9 \\
\hline 3808 & $1 / 12 / 200816: 58$ & $8 / 12 / 2008$ 16:58 & 28.6 & 1034.3 & 3877 & & & 28.9 & \\
\hline 3809 & $1 / 12 / 200817: 00$ & \begin{tabular}{|l|}
$8 / 12 / 200817: 00$ \\
\end{tabular} & 28.6 & 1034.3 & 3878 & $1 / 12 / 200819: 18$ & $8 / 12 / 2008$ 19:18 & 28.9 & 1066.8 \\
\hline 3810 & $1 / 12 / 200817: 02$ & \begin{tabular}{|l|l|}
$8 / 12 / 2008$ & $17: 02$ \\
\end{tabular} & 28.6 & 1034.3 & 3879 & $1 / 12 / 20$ & $8 / 12 / 2008$ 19:20 & 28.9 & 1067.2 \\
\hline 3811 & $1 / 12 / 200$ & $8 / 12 / 200$ & 28.7 & 1033.7 & 3880 & $1 / 12 / 20$ & $8 / 12 / 200$ & 28.9 & 1067.9 \\
\hline 3812 & $1 / 12 / 200817: 06$ & \begin{tabular}{|c|}
$8 / 12 / 2008$ \\
\end{tabular} & 28.7 & 1033.7 & 3881 & $1 / 12 / 200819: 24$ & $8 / 12 / 200819: 24$ & 28.9 & 1069.2 \\
\hline 3813 & $1 / 12 / 200817: 08$ & $8 / 12 / 2008$ 17:08 & 28.7 & 1033.4 & 3882 & $1 / 12 / 20$ & & 28.9 & \\
\hline 3814 & 1/12/2008 17:10 & $8 / 12 / 2008$ 17:10 & 28.7 & 1033.4 & 3883 & $1 / 12 / 2$ & $8 / 12 / 2008$ 19:28 & 28.9 & 1069.3 \\
\hline 3815 & $1 / 12 / 200817: 12$ & $8 / 12 / 2008$ 17:12 & 28.7 & 1033.4 & 3884 & $1 / 12 / 20$ & $8 / 12 / 200819: 30$ & 28.9 & 1069.3 \\
\hline 3816 & $1 / 12 / 200817: 14$ & \begin{tabular}{|l|}
$8 / 12 / 2008$ \\
\end{tabular} & 28.7 & 1033.1 & 3885 & $1 / 12 / 20$ & $8 / 12 / 2008$ 19:32 & 28.9 & 1068.7 \\
\hline 3817 & $1 / 12 / 200817: 16$ & \begin{tabular}{|l|}
$8 / 12 / 2008$ 17:16 \\
\end{tabular} & 28.7 & 1033 & 3886 & $1 / 12 / 200819: 34$ & $8 / 12 / 200819: 34$ & 28.9 & 1069 \\
\hline 3818 & 1/12/2008 17:18 & \begin{tabular}{|l|}
$8 / 12 / 2008$ 17:18 \\
\end{tabular} & 28.7 & 1034.7 & 3887 & 1/12/2008 19:36 & $8 / 12 / 2008$ 19:36 & 28.8 & 1067.7 \\
\hline 3819 & 1/12/2008 17:20 & \begin{tabular}{|l|}
$8 / 12 / 2008$ 17:20 \\
\end{tabular} & 28.7 & 1035.1 & 3888 & $1 / 12 / 20$ & $8 / 12 / 2008$ 19:38 & 28.8 & \\
\hline 3820 & $1 / 12 / 200817: 22$ & $8 / 12 / 2008$ 17:22 & 28.7 & 103 & 3889 & $1 / 12 / 20$ & $8 / 12 / 2008$ 19:40 & 28.8 & 1069.3 \\
\hline 3821 & $1 / 12 / 2008$ 17:24 & 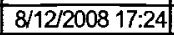 & 28.7 & 1034.1 & 3890 & $1 / 12 / 20$ & $8 / 12 / 2008$ 19:42 & 28.9 & 1069.7 \\
\hline 3822 & $1 / 12 / 200817: 26$ & $8 / 12 / 2008$ 17:26 & 28.7 & 1033.3 & 3891 & $1 / 12 / 2008+9: 44$ & $8 / 12 / 2008$ 19:44 & 28.8 & 1070.9 \\
\hline
\end{tabular}


DOE/RL-2009-35, REV. 0

\begin{tabular}{|c|c|c|c|c|}
\hline \multicolumn{5}{|c|}{ D4-92c } \\
\hline Rec & & Adjusted & Temp & SC \\
\hline$\#$ & Date/Time & Date/Time & ${ }^{\circ} \mathrm{C}$ & $\mu \mathrm{S} / \mathrm{cm}$ \\
\hline 3892 & 1/12/2008 19:46 & $8 / 12 / 200819: 46$ & 28.8 & 1070.2 \\
\hline 3893 & $1 / 12 / 200819: 48$ & $8 / 12 / 200819: 48$ & 28.8 & 1071.2 \\
\hline 3894 & $1 / 12 / 2008$ 19:50 & $8 / 12 / 200819: 50$ & 28.8 & 1071.4 \\
\hline 3895 & 1/12/2008 19:52 & $8 / 12 / 200819: 52$ & 28.8 & 1071.4 \\
\hline 3896 & 1/12/2008 19:54 & $8 / 12 / 200819: 54$ & 28.8 & 1070.3 \\
\hline 3897 & 1/12/2008 19:56 & $8 / 12 / 200819: 56$ & 28.8 & 1070.4 \\
\hline 3898 & 1/12/2008 19:58 & $8 / 12 / 200819: 58$ & 28.8 & 1070.9 \\
\hline 3899 & $1 / 12 / 200820: 00$ & $8 / 12 / 200820: 00$ & 28.8 & 1070 \\
\hline 3900 & $1 / 12 / 200820: 02$ & $8 / 12 / 200820: 02$ & 28.8 & 1072 \\
\hline 3901 & $1 / 12 / 200820: 04$ & $8 / 12 / 200820: 04$ & 28.8 & 1072.8 \\
\hline 3902 & $1 / 12 / 200820: 06$ & $8 / 12 / 200820: 06$ & 28.8 & 1073.4 \\
\hline 3903 & $1 / 12 / 200820: 08$ & $8 / 12 / 200820: 08$ & 28.8 & 1073.4 \\
\hline 3904 & $1 / 12 / 200820: 10$ & $8 / 12 / 200820: 10$ & 28.8 & 1073.8 \\
\hline 3905 & $1 / 12 / 200820: 12$ & $8 / 12 / 200820: 12$ & 28.8 & 1073.3 \\
\hline 3906 & $1 / 12 / 200820: 14$ & $8 / 12 / 200820: 14$ & 28.8 & 1073.4 \\
\hline 3907 & $1 / 12 / 200820: 16$ & 8/12/2008 20:16 & 28.8 & 1074 \\
\hline 3908 & 1/12/2008 20:18 & $8 / 12 / 200820: 18$ & 28.8 & 1074 \\
\hline 3909 & $1 / 12 / 200820: 20$ & $8 / 12 / 200820: 20$ & 28.8 & 1074.6 \\
\hline 3910 & $1 / 12 / 200820: 22$ & $8 / 12 / 200820: 22$ & 28.8 & 1074.8 \\
\hline 3911 & $1 / 12 / 200820: 24$ & $8 / 12 / 200820: 24$ & 28.8 & 1075.2 \\
\hline 3912 & $1 / 12 / 200820: 26$ & $8 / 12 / 200820: 26$ & 28.8 & 1075 \\
\hline 3913 & $1 / 12 / 200820: 28$ & $8 / 12 / 200820: 28$ & 28.8 & 1075.4 \\
\hline 3914 & $1 / 12 / 200820: 30$ & $8 / 12 / 200820: 30$ & 28.8 & 1075.3 \\
\hline 3915 & $1 / 12 / 200820: 32$ & $8 / 12 / 200820: 32$ & 28.8 & 1075.2 \\
\hline 3916 & $1 / 12 / 200820: 34$ & $8 / 12 / 200820: 34$ & 28.8 & 1075.2 \\
\hline 3917 & $1 / 12 / 200820: 36$ & $8 / 12 / 200820: 36$ & 28.8 & 1075.6 \\
\hline 3918 & $1 / 12 / 200820: 38$ & $8 / 12 / 200820: 38$ & 28.8 & 1076 \\
\hline 3919 & $1 / 12 / 200820: 40$ & $8 / 12 / 200820: 40$ & 28.8 & 1076.1 \\
\hline 3920 & $1 / 12 / 200820: 42$ & $8 / 12 / 200820: 42$ & 28.8 & 1075.8 \\
\hline 3921 & $1 / 12 / 200820: 44$ & $8 / 12 / 200820: 44$ & 28.8 & 1076.2 \\
\hline 3922 & $1 / 12 / 200820: 46$ & $8 / 12 / 200820: 46$ & 28.8 & 1076.4 \\
\hline 3923 & $1 / 12 / 200820: 48$ & $8 / 12 / 200820: 48$ & 28.8 & 1078.2 \\
\hline 3924 & $1 / 12 / 200820: 50$ & $8 / 12 / 200820: 50$ & 28.8 & 1076.8 \\
\hline 3925 & $1 / 12 / 200820: 52$ & $8 / 12 / 200820: 52$ & 28.8 & 1077.1 \\
\hline 3926 & 1/12/200820:54 & $8 / 12 / 200820: 54$ & 28.8 & 1076.6 \\
\hline 3927 & $1 / 12 / 200820: 56$ & $8 / 12 / 200820: 56$ & 28.8 & 1077.1 \\
\hline 3928 & $1 / 12 / 200820: 58$ & $8 / 12 / 200820: 58$ & 28.8 & 1077.4 \\
\hline 3929 & $1 / 12 / 200821: 00$ & $8 / 12 / 200821: 00$ & 28.8 & 1077.7 \\
\hline 3930 & $1 / 12 / 200821: 02$ & $8 / 12 / 200821: 02$ & 28.8 & 1077.9 \\
\hline 3931 & $1 / 12 / 200821: 04$ & $8 / 12 / 200821: 04$ & 28.8 & 1077.6 \\
\hline 3932 & 1/12/2008 21:06 & $8 / 12 / 200821: 06$ & 28.8 & 1077.9 \\
\hline 3933 & $1 / 12 / 200821: 08$ & $8 / 12 / 200821: 08$ & 28.8 & 1077.7 \\
\hline 3934 & $1 / 12 / 200821: 10$ & $8 / 12 / 200821: 10$ & 28.8 & 1077.9 \\
\hline 3935 & $1 / 12 / 200821: 12$ & $8 / 12 / 200821: 12$ & 28.8 & 1078.3 \\
\hline 3936 & 1/12/2008 21:14 & 8/12/2008 21:14 & 28.8 & 1077.9 \\
\hline 3937 & 1/12/2008 21:16 & $8 / 12 / 200821: 16$ & 28.8 & 1078.3 \\
\hline 3938 & $1 / 12 / 200821: 18$ & $8 / 12 / 200821: 18$ & 28.8 & 1078.3 \\
\hline 3939 & $1 / 12 / 200821: 20$ & $8 / 12 / 200821: 20$ & 28.8 & 1078.3 \\
\hline 3940 & $1 / 12 / 200821: 22$ & $8 / 12 / 200821: 22$ & 28.8 & 1078.4 \\
\hline 3941 & $1 / 12 / 200821: 24$ & $8 / 12 / 200821: 24$ & 28.8 & 1078 \\
\hline 3942 & 1/12/200821:26 & $8 / 12 / 200821: 26$ & 28.8 & 1077.7 \\
\hline 3943 & $1 / 12 / 200821: 28$ & $8 / 12 / 200821: 28$ & 28.8 & 1077.7 \\
\hline 3944 & $1 / 12 / 200821: 30$ & $8 / 12 / 200821: 30$ & 28.8 & 1076.9 \\
\hline 3945 & $1 / 12 / 200821: 32$ & $8 / 12 / 200821: 32$ & 28.8 & 1075.2 \\
\hline 3946 & $1 / 12 / 200821: 34$ & $8 / 12 / 200821: 34$ & 28.7 & 1075.7 \\
\hline 3947 & $1 / 12 / 200821: 36$ & 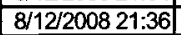 & 28.7 & 1075.6 \\
\hline 3948 & $1 / 12 / 200821: 38$ & $8 / 12 / 200821: 38$ & 28.7 & 1075.2 \\
\hline 3949 & $1 / 12 / 200821: 40$ & \begin{tabular}{|l|}
$8 / 12 / 200821: 40$ \\
\end{tabular} & 28.7 & 1074.7 \\
\hline 3950 & $1 / 12 / 200821: 42$ & $8 / 12 / 200821: 42$ & 28.6 & 1075.9 \\
\hline 3951 & $1 / 12 / 200821: 44$ & \begin{tabular}{|l|}
$8 / 12 / 200821: 44$ \\
\end{tabular} & 28.6 & 1076.8 \\
\hline 3952 & 1/12/2008 21:46 & \begin{tabular}{|l|}
$8 / 12 / 200821: 46$ \\
\end{tabular} & 28.6 & 1077.2 \\
\hline 3953 & $1 / 12 / 200821: 48$ & $8 / 12 / 200821: 48$ & 28.6 & 1079.4 \\
\hline 3954 & $1 / 12 / 200821: 50$ & \begin{tabular}{|l|}
$8 / 12 / 200821: 50$ \\
\end{tabular} & 28.5 & 1078.7 \\
\hline 3955 & $1 / 12 / 200821: 52$ & $8 / 12 / 200821: 52$ & 28.5 & 1077.8 \\
\hline 3956 & 1/12/2008 21:54 & \begin{tabular}{|l|}
$8 / 12 / 200821: 54$ \\
\end{tabular} & 28.5 & 1078.2 \\
\hline 3957 & $1 / 12 / 200821: 56$ & \begin{tabular}{|l|}
$8 / 12 / 200821: 56$ \\
\end{tabular} & 28.5 & 1077.9 \\
\hline 3958 & $1 / 12 / 200821: 58$ & \begin{tabular}{|l|}
$8 / 12 / 200821: 58$ \\
\end{tabular} & 28.5 & 1078.3 \\
\hline 3959 & 1/12/2008 22:00 & $8 / 12 / 200822: 00 \mid$ & 28.4 & 1079.1 \\
\hline 3960 & 1/12/2008 22:02 & \begin{tabular}{|l|}
$8 / 12 / 200822: 02$ \\
\end{tabular} & 28.4 & 1081.2 \\
\hline
\end{tabular}

\begin{tabular}{|c|c|c|c|c|}
\hline \multicolumn{5}{|c|}{ D4-92C } \\
\hline $\operatorname{Rec}$ & & Adjusted & Temp & \\
\hline$\#$ & Date/Time & Date/Time & ${ }^{\circ} \mathrm{C}$ & $\mu \mathrm{S} / \mathrm{cm}$ \\
\hline 961 & 1/12/200822:04 & $8 / 12 / 200822: 04$ & 28.4 & 1081 \\
\hline & & & & \\
\hline 3963 & $12 / 200822: 08$ & $8 / 12 / 200822: 08$ & 28.4 & 1083 \\
\hline 3964 & $1 / 12 / 200822: 10$ & $8 / 12 / 200822: 10$ & 28.4 & \\
\hline 3965 & $1 / 12 / 200822: 12$ & $8 / 12 / 200822: 12$ & 28.4 & \\
\hline 3966 & $12 / 200822: 14$ & $8 / 12 / 200822: 14$ & 28.4 & 1083. \\
\hline 3967 & & $8 / 12 / 200822: 16$ & & \\
\hline 3968 & 1/12/2008 22:18 & $8 / 12 / 200822: 18$ & 28.4 & 1083. \\
\hline 3969 & $12 / 200822: 20$ & $8 / 12 / 200822: 20$ & 28.4 & \\
\hline 3970 & & $8 / 12 / 200822: 22$ & & \\
\hline 3971 & $1 / 12 / 200$ & $8 / 12 / 200822: 24$ & 28.3 & 1084. \\
\hline 3972 & $1 / 12 / 20$ & $8 / 12 / 200822: 26$ & 28.3 & 1084. \\
\hline 3973 & $1 / 12 / 20$ & $8 / 12 / 20$ & 28.3 & \\
\hline 3974 & $1 / 12 / 20$ & $8 / 12 / 20$ & 28.3 & 1084. \\
\hline 3975 & ר & $8 / 12 / 20$ & & \\
\hline 3976 & $22: 34$ & $8 / 12 / 20$ & 28.3 & \\
\hline 3977 & $1 / 12 / 20$ & $8 / 12 / 20$ & 28.2 & 1085. \\
\hline 3978 & $1 / 12 / 20$ & $8 / 12 / 20$ & 28.2 & \\
\hline 3979 & $1 / 12 / 20$ & $8 / 12 / 200822: 40$ & 28.2 & 1086. \\
\hline 3980 & $1 / 12 / 20$ & $8 / 12 / 200822: 42$ & 28.2 & 1085. \\
\hline 3981 & $22: 44$ & $8 / 12 / 20$ & 28.2 & \\
\hline 3982 & $22: 46$ & $8 / 12 / 20$ & 28.2 & 1086 . \\
\hline 3983 & $22: 48$ & $822: 48$ & 28.2 & \\
\hline 3984 & $1 / 12 / 20$ & $8 / 12 / 200822: 50$ & 28.2 & \\
\hline 3985 & $1 / 12 / 2$ & $8 / 12 / 2$ & $\frac{20.2}{28.2}$ & 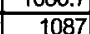 \\
\hline 3986 & $1 / 12 / 2$ & $8 / 12 / 2$ & 28.1 & \\
\hline 3987 & $22: 56$ & $22: 56$ & 28.1 & \\
\hline 3988 & $22: 58$ & $22: 58$ & 28.1 & 087 \\
\hline 3989 & $23: 00$ & $23: 00$ & 28.1 & \\
\hline 3990 & $23: 02$ & $23: 02$ & 28.1 & \\
\hline 3991 & & $23: 04$ & 28.1 & \\
\hline 3992 & & $323: 06$ & 28.1 & 1088 \\
\hline 3993 & 3.08 & $23: 08$ & 28.1 & 1088 \\
\hline 3994 & $3: 10$ & $23: 10$ & 28.1 & \\
\hline 3995 & & $23: 12$ & 28.1 & \\
\hline 3996 & & $23: 14$ & 28.1 & \\
\hline 3997 & & $8 / 12 / 200823: 16$ & 28.1 & 108 \\
\hline 3998 & & $23: 18$ & 28.1 & \\
\hline 3999 & $3: 20$ & $23: 20$ & 28 & 1089 \\
\hline 4000 & & $23: 22$ & 28 & \\
\hline 4001 & & $23: 24$ & 28 & 1089 \\
\hline 4002 & & $323: 26$ & 28 & 1089 \\
\hline & & $23: 28$ & 28 & 089 \\
\hline 4004 & & $23: 30$ & 28 & \\
\hline & & $8 / 12$ & 28 & \\
\hline 4006 & & $23: 34$ & 28 & 1090 \\
\hline & & $23: 36$ & 28 & \\
\hline & & & 28 & \\
\hline & & $23: 40$ & 28 & 1090. \\
\hline & & & 28 & \\
\hline 40 & & $8 / 12$ & 28 & \\
\hline 4012 & & $23: 46$ & 28 & \\
\hline & & & 28 & \\
\hline & & $8 / 12 / 2$ & 28 & \\
\hline & & & 28 & \\
\hline 4016 & & & 28 & \\
\hline 4017 & & $8 / 12 / 200823: 56$ & 28 & \\
\hline & & & & \\
\hline 401 & $0: 00$ & $80: 00$ & 27.9 & 1092 \\
\hline 402 & & & 27.9 & \\
\hline & & & 27.9 & \\
\hline 4022 & $\frac{\pi}{1}$ & $80: 06$ & 27.9 & 1093 \\
\hline & & & 27.9 & \\
\hline 4024 & & & 27.9 & \\
\hline 4025 & & $80: 12$ & 27.9 & \\
\hline$\overline{4 c}$ & & & 27.9 & \\
\hline 4027 & & $0: 16$ & 27.9 & \\
\hline & & & 27.9 & \\
\hline & & & & \\
\hline
\end{tabular}

\begin{tabular}{|c|c|c|c|c|}
\hline \multicolumn{5}{|c|}{ D4-92c } \\
\hline $\operatorname{Rec}$ & & Adjusted & Temp & $\mathrm{SC}$ \\
\hline$\#$ & Date/Time & DaterTime & ${ }^{\circ} \mathrm{C}$ & \\
\hline 4030 & $1 / 13 / 20080: 22$ & $8 / 13 / 20080: 22$ & 27.8 & 1091. \\
\hline & $1 / 13 / 20080: 24$ & $8 / 13 / 20080: 24$ & 27.8 & 1091.3 \\
\hline 4032 & & $8 / 13 / 20080: 26$ & 27.8 & \\
\hline 4033 & $1 / 13 / 20080: 28$ & $8 / 13 / 20080: 28$ & 27.8 & 1090.4 \\
\hline 4034 & $1 / 13 / 20080: 30$ & $8 / 13 / 20080: 30$ & 27.8 & 1089.2 \\
\hline 4035 & $1 / 13 / 20080: 32$ & $8 / 13 / 20080: 32$ & 27.7 & \\
\hline 4036 & $1 / 13 / 20080: 34$ & $8 / 13 / 20080: 34$ & 27.7 & 1088.7 \\
\hline 4037 & & $8 / 13 / 20080: 36$ & 27.8 & \\
\hline 4038 & $1 / 13 / 20080: 38$ & $8 / 13 / 20080: 38$ & 27.8 & 1086. \\
\hline 4039 & $1 / 13 / 20080: 40$ & $8 / 13 / 20080: 40$ & 27.8 & 1085.2 \\
\hline 4040 & & $8 / 13 / 20080: 42$ & & \\
\hline 4041 & $1 / 13 / 20080: 44$ & $8 / 13 / 20080: 44$ & 27.8 & 1084.7 \\
\hline 4042 & $1 / 13 / 20$ & $8 / 13 / 20$ & 27.8 & 1084.8 \\
\hline 4043 & $1 / 13 / 20$ & $8 / 13 / 20$ & 27.7 & \\
\hline 4044 & $1 / 13 / 20080: 50$ & $8 / 13 / 20$ & 27.7 & 1084. \\
\hline 4045 & $1 / 13 / 20$ & $8 / 13 / 2$ & 27.7 & 1083.6 \\
\hline 4046 & $1 / 13 / 20$ & $8 / 13 / 2$ & 27.7 & 1083. \\
\hline 4047 & $1 / 13 / 2$ & $8 / 13 / 20$ & 27.7 & 1084 \\
\hline 4048 & $1 / 13 / 2$ & $8 / 13 / 20$ & 27.6 & \\
\hline 4049 & $1 / 13 / 2$ & $8 / 13 / 20$ & 27.6 & 1083. \\
\hline 4050 & $1 / 13 / 2$ & $8 / 13 / 2$ & 27.6 & 1083.2 \\
\hline 4051 & $1 / 13 / 2$ & $8 / 13 / 2$ & 27.6 & \\
\hline 4052 & $1 / 13 / 2$ & $8 / 13 / 2$ & 27.6 & 1083. \\
\hline 4053 & & $8 / 13 / 2$ & & 1083.8 \\
\hline 4054 & $1 / 13 / 20$ & $8 / 13 / 2$ & 27.6 & 1081.7 \\
\hline 4055 & $1 / 13$ & $8 / 13$ & 27.6 & 1085.3 \\
\hline 4056 & & $8 / 13 / 2$ & 27.6 & 1083.5 \\
\hline 4057 & $1 / 13 / 2$ & $8 / 13 / 2$ & 27.6 & 1083.2 \\
\hline 4058 & $1 / 13$ & $8 / 13$ & 27.5 & 1084 \\
\hline 4059 & $1 / 13$ & $8 / 13$ & 27.5 & 1083 \\
\hline 4060 & & $8 / 13$ & 27.5 & 1084. \\
\hline 4061 & & $8 / 13 / 2$ & 27.5 & 108 \\
\hline 4062 & $1 / 13 / 2$ & $8 / 13 / 20$ & 27.5 & 1083.2 \\
\hline 4063 & & $8 / 13$ & 27.5 & 108 \\
\hline 4064 & & $8 / 13$ & 27.5 & 1083. \\
\hline 4065 & & & 27.5 & 1083.3 \\
\hline 4066 & & & 27.5 & 1082.9 \\
\hline 4067 & & $8 / 13 / 2$ & 27.4 & 1083 \\
\hline 4068 & & & 27.4 & 1083.3 \\
\hline 4069 & & $1: 40$ & 27.4 & 1083.2 \\
\hline 4070 & & & 27.4 & 1083.2 \\
\hline 4071 & & & 27.4 & 10836 \\
\hline 4072 & & $8 / 13 / 2$ & 27.4 & 1083.7 \\
\hline 4073 & & & 27.4 & 1083.6 \\
\hline 4074 & & $3 / 13$ & 27.4 & 1083. \\
\hline 4075 & & & 27.4 & 1082.8 \\
\hline 4076 & & & 27.4 & 10831 \\
\hline 4077 & $1 / 13 /$ & $8 / 13 / 2$ & 27.4 & 1083.2 \\
\hline 4078 & & & 27.4 & 1087 \\
\hline 4079 & & $2: 00$ & 27.4 & 1083.8 \\
\hline 4080 & & & 27.4 & \\
\hline 4081 & & & & \\
\hline 4082 & & $8 / 13 / 2$ & 27.4 & 1083.5 \\
\hline 4083 & & & & \\
\hline 4084 & & $8 / 13 / 2$ & 27.3 & 1083.6 \\
\hline 4085 & & & 27.3 & \\
\hline 408 & & & & \\
\hline 4087 & & $8 / 13 / 2$ & 27.3 & 1084.1 \\
\hline 4088 & & & 27.3 & \\
\hline 4089 & & \%1927 & 27 & 1084. \\
\hline 4090 & & & 27.3 & \\
\hline 4091 & & $8 / 13 / 2$ & 27.3 & 1085.1 \\
\hline 4092 & & $8 / 13 / 20$ & 27.3 & 1085 \\
\hline 4093 & & & 27.3 & 1085.7 \\
\hline 4094 & & $8 / 13 / 2$ & 27.3 & \\
\hline 4095 & & $8 / 13 / 20$ & 27.3 & 1085. \\
\hline 4096 & & $-1, \pi=0$ & 27.3 & \\
\hline 4097 & & $8 / 13 / 20082: 36$ & 27.3 & 1085. \\
\hline & & $8 / 13 / 20082: 38$ & 27.3 & 108 \\
\hline
\end{tabular}


DOE/RL-2009-35, REV. 0

\begin{tabular}{|c|c|c|c|c|}
\hline \multicolumn{5}{|c|}{ D4-92c } \\
\hline $\operatorname{Rec}$ & & Adjusted & Temp & SC \\
\hline$\#$ & Date/Time & Date/Time & ${ }^{\circ} \mathrm{C}$ & $\mu \mathrm{S} / \mathrm{cm}$ \\
\hline 4099 & $1 / 13 / 20082: 40$ & $8 / 13 / 20082: 40$ & 27.3 & 1085 . \\
\hline 100 & $1 / 13 / 20082: 42$ & $8 / 13 / 20082: 42$ & 27.3 & \\
\hline 101 & & $13 / 20082: 44$ & & \\
\hline 102 & $1 / 13 / 20082: 46$ & $8 / 13 / 20082: 46$ & 27.2 & 1085 \\
\hline 103 & $1 / 13 / 20082: 48$ & $8 / 13 / 20082: 48$ & 27.2 & 1086. \\
\hline 4104 & & & 27.2 & \\
\hline 4105 & $1 / 13 / 20082: 52$ & $8 / 13 / 20082: 52$ & 27.2 & 1086 \\
\hline 4106 & $082: 54$ & $8 / 13 / 20082: 54$ & 27.2 & 1086. \\
\hline 4107 & $1 / 13 / 20082: 56$ & $8 / 13 / 20082: 56$ & 27.2 & \\
\hline 4108 & $1 / 13 / 20082: 58$ & $8 / 13 / 20082: 58$ & 27.2 & 09 \\
\hline 4109 & $33: 00$ & $8 / 13 / 20$ & 27.2 & 1086.8 \\
\hline 4110 & & & 27.2 & \\
\hline 4111 & $083: 04$ & $8 / 13 / 20$ & 27.2 & 1086. \\
\hline 4112 & & & 27.2 & \\
\hline 4113 & $1 / 13 / 2$ & $8 / 13 / 20$ & 27.2 & \\
\hline 4114 & $083: 10$ & $83: 10$ & 27.2 & 1082. \\
\hline 4115 & & & 27.2 & \\
\hline 4116 & $83: 14$ & $8 / 13 / 2$ & 27.2 & \\
\hline 4117 & & & 27.2 & 1083. \\
\hline 4118 & & & 27.2 & \\
\hline 4119 & $1 / 13 / 2$ & $3: 20$ & 27.1 & 1079. \\
\hline 4120 & $3: 22$ & $3: 22$ & 27.1 & \\
\hline 4121 & & & 27.1 & \\
\hline 4122 & & & 27.1 & 1072. \\
\hline 4123 & & & 27.1 & \\
\hline 4124 & $1 / 13 / 2$ & & 27.1 & 1069. \\
\hline 4125 & & & 27.1 & 1065. \\
\hline 4126 & & & 27 & \\
\hline 4127 & & & 27 & 1062. \\
\hline 4128 & & & 27 & 1063 \\
\hline 4129 & & & 27 & \\
\hline 4130 & & & 27 & 1061. \\
\hline 4131 & & & 27 & 1058 \\
\hline 4132 & & & 21 & \\
\hline 4133 & & & 27 & 1058. \\
\hline 4134 & & & 26.9 & 1059 \\
\hline 4135 & & & 26.9 & 1058. \\
\hline 4136 & & & 26.9 & \\
\hline 4137 & & $3: 56$ & 26.9 & 1056 \\
\hline 4138 & & & 26.9 & 1056. \\
\hline 4139 & & & 26.9 & \\
\hline 4140 & & & 26.9 & \\
\hline 4141 & & & 26.9 & 1 \\
\hline 4142 & & & 26.9 & $\overline{1053}$ \\
\hline 414 & & & 26.9 & \\
\hline$\overline{414}$ & & & 26.9 & \\
\hline 4145 & & & 26.9 & 1054. \\
\hline 4146 & & & 26.9 & \\
\hline 4147 & & & 26.9 & 1052 \\
\hline 4148 & & & 26.9 & \\
\hline$\overline{414}$ & & & 26.9 & 1052 \\
\hline$\overline{415}$ & & & 26.5 & \\
\hline 415 & & & 26. & \\
\hline 415 & & & 26.9 & \\
\hline 415 & & & 26.9 & \\
\hline 41 & & & & \\
\hline 4155 & & & 26.8 & \\
\hline 415 & & & $26 . \overline{8}$ & \\
\hline 415 & & & 26.8 & \\
\hline 415 & & & 26.8 & \\
\hline 41 & & & & \\
\hline 4160 & $34: 42$ & $34: 42$ & 26.8 & 1000 \\
\hline 4161 & & & 26.8 & \\
\hline & & & & \\
\hline 41 & & & 26.8 & \\
\hline & & & 26.8 & \\
\hline 41 & & & & \\
\hline 4166 & & & 26.8 & \\
\hline & & & & \\
\hline
\end{tabular}

\begin{tabular}{|c|c|c|c|c|}
\hline \multicolumn{5}{|c|}{ D4-92c } \\
\hline$R e c$ & & Adjusted & Temp & \\
\hline$\#$ & Date/Time & Date/Time & ${ }^{\circ} \mathrm{C}$ & $\mu \mathrm{S} / \mathrm{cm}$ \\
\hline 4168 & $1 / 13 / 20084: 58$ & $8 / 13 / 20084: 58$ & 26.8 & 1050.3 \\
\hline 4169 & $3 / 20085: 00$ & $1 / 3 / 20085: 00$ & 26.8 & 0501 \\
\hline 4170 & & & 26.8 & \\
\hline 4171 & $85: 04$ & $/ 13 / 20085: 04$ & 26.8 & 1050.2 \\
\hline 172 & & & 26.8 & \\
\hline 4173 & $1 / 13 / 20085: 08$ & $8 / 13 / 20085: 08$ & 26.8 & 1050 . \\
\hline 4174 & $13 / 20085: 10$ & $8 / 13 / 20085: 10$ & 26.8 & 1050. \\
\hline 175 & & & 26.8 & \\
\hline 4176 & $13 / 20085: 14$ & $8 / 13 / 20085: 14$ & 26.7 & 1050. \\
\hline 4177 & $1 / 13 / 20085: 16$ & $8 / 13 / 20085: 16$ & 26.8 & 1049. \\
\hline 4178 & & & 26.7 & \\
\hline 4179 & $1 / 13 / 20085: 20$ & $8 / 13 / 20085: 20$ & 26.7 & 1050 \\
\hline 4180 & $5: 22$ & & 26.7 & 105 \\
\hline 4181 & & & 26.7 & \\
\hline 4182 & $35: 26$ & $8 / 13 / 20085: 26$ & 26.8 & 1049.1 \\
\hline 4183 & $5: 28$ & & 26.7 & \\
\hline 4184 & $5: 30$ & & 26.7 & 1050. \\
\hline 4185 & $5: 32$ & $085: 32$ & 26.7 & \\
\hline & & & & \\
\hline 4187 & $1 / 13 / 20$ & & 26.7 & 1050. \\
\hline 4188 & $1 / 13 /$ & & 26.7 & 1050. \\
\hline 4189 & & & 26.7 & \\
\hline 4190 & & $085: 42$ & 26.7 & 1050. \\
\hline 4191 & & $5: 44$ & 26.7 & 1052. \\
\hline 4192 & & & 26.7 & \\
\hline 4193 & & & 26.7 & 1050. \\
\hline 4194 & & & 26.7 & \\
\hline 4195 & $1 / 13 /$ & $35: 52$ & 26.7 & 1050. \\
\hline 4196 & & & 26.6 & 1050. \\
\hline 4197 & & & 26.6 & \\
\hline 4198 & & & 26.7 & 1050. \\
\hline 4199 & & & 26.6 & \\
\hline 4200 & & 6:02 & 26.6 & \\
\hline 4201 & & & 26.6 & 50. \\
\hline 4202 & & & 26.6 & 105 \\
\hline 4203 & & $6: 08$ & 26.6 & 1053. \\
\hline 4204 & & & 26.6 & 1053. \\
\hline 4205 & & & 26.6 & 1062. \\
\hline 4206 & & & 26.6 & \\
\hline 4207 & & & 26.6 & 1066 \\
\hline 4208 & & & 26.6 & 10 \\
\hline 4209 & & & 26.6 & 1069. \\
\hline 4210 & & & 26.6 & 1069 \\
\hline 4211 & & & 26.6 & \\
\hline 4212 & & & 26.6 & \\
\hline 4213 & & & 26.5 & 71. \\
\hline & & & 26.5 & \\
\hline 4215 & & $6: 32$ & 26.5 & 070 \\
\hline 4216 & & & 26.5 & 1073. \\
\hline & & & 26.5 & \\
\hline 4218 & & & 26.5 & \\
\hline & & & 26.5 & \\
\hline & & & 26.5 & \\
\hline 4221 & & & 26.5 & 1074. \\
\hline & & & 26.5 & \\
\hline & & & 26.5 & \\
\hline & & & 26.5 & \\
\hline 422 & & & & \\
\hline 4226 & & $086: 54$ & 26.5 & 1075. \\
\hline & & & 26.4 & \\
\hline 422 & & & 26.4 & \\
\hline & & & 26.4 & \\
\hline & & & 26.4 & \\
\hline 4231 & & $887: 04$ & 26.4 & 1077. \\
\hline & & & 26.4 & \\
\hline & & & 26.4 & \\
\hline & & $87: 10$ & 26.4 & \\
\hline & & & 26.4 & \\
\hline & & & & \\
\hline
\end{tabular}

\begin{tabular}{|c|c|c|c|c|}
\hline \multicolumn{5}{|c|}{ D4-92c } \\
\hline Rec & & Adjusted & Temp & $\mathrm{SC}$ \\
\hline$\#$ & Date/Time & Date/Time & ${ }^{\circ} \mathrm{C}$ & $\mu \mathrm{S} / \mathrm{cm}$ \\
\hline 4237 & $13 / 20087: 16$ & $8 / 13 / 20087: 16$ & 26.4 & 1077. \\
\hline & 700007 & $8 / 13 / 20087: 18$ & 26.4 & 1078. \\
\hline 239 & & & 26.4 & \\
\hline 4240 & $1 / 13 / 20087: 22$ & $8 / 13 / 20087: 22$ & 26.4 & 1078. \\
\hline 4241 & & $8 / 13 / 20087: 24$ & 26.4 & 1078.8 \\
\hline 4242 & & $8 / 13 / 20087: 26$ & 26.4 & 107 \\
\hline 4243 & $87: 28$ & $8 / 13 / 20087: 28$ & 26.4 & 1079.2 \\
\hline 4244 & & $8 / 13 / 20087: 30$ & 26.4 & 1079.2 \\
\hline 4245 & $37: 32$ & $8 / 13 / 20087: 32$ & 26.4 & \\
\hline 4246 & $87: 34$ & $8 / 13 / 20087: 34$ & 26.4 & 1079.8 \\
\hline 247 & & & & \\
\hline 4248 & $087: 38$ & $8 / 13 / 20087: 38$ & 26.4 & $1 \overline{08}$ \\
\hline 4249 & $87: 40$ & $8 / 13 / 20087: 40$ & 26.4 & 1080. \\
\hline 4250 & & & 26.4 & \\
\hline 4251 & $87: 44$ & $8 / 13 / 20087: 44$ & 26.4 & 1080. \\
\hline 4252 & $7: 46$ & $8 / 13 / 20$ & 26.4 & 1081. \\
\hline & & & & \\
\hline 4254 & & $8 / 13 / 20087: 50$ & 26.4 & 1080.8 \\
\hline 4255 & & $8 / 13 / 20$ & 26.4 & \\
\hline 4256 & & $8 / 13 / 20$ & 26.4 & \\
\hline 4257 & & $8 / 13 / 20$ & 26.4 & 1081 \\
\hline 4258 & & $8 / 13 / 2$ & 26.3 & \\
\hline 4259 & & $8 / 13 / 2$ & 26.4 & \\
\hline 4260 & & $8 / 13 / 2$ & 26.4 & 1081. \\
\hline & & & 26.3 & \\
\hline 4262 & & & 26.3 & 1081. \\
\hline & & & 26.3 & \\
\hline 4264 & & $8 / 13 / 20$ & 26.4 & \\
\hline 4265 & & $8: 12$ & 26.3 & 082. \\
\hline 4266 & & $88: 14$ & 26.3 & 1082. \\
\hline 4267 & & $8 / 13 / 200$ & 26.3 & 108 \\
\hline 4268 & & & 26.3 & 108 \\
\hline 4269 & & & 26.3 & 1083 \\
\hline 4270 & & & 26.3 & 1083. \\
\hline 4271 & & & 26.3 & \\
\hline 4272 & & & 26.3 & \\
\hline 4273 & & & 26.3 & 33. \\
\hline 4274 & & & 26.3 & \\
\hline & & & 26.3 & \\
\hline 427 & & & 26.3 & 1084 \\
\hline 4277 & & & 26.3 & 108 \\
\hline 4278 & & & 26.3 & \\
\hline 42 & & & 26.3 & \\
\hline 4280 & & & 26.3 & 1083 \\
\hline 428 & & & 26.3 & 1084 \\
\hline 428 & & & 26.3 & \\
\hline & & & 26.3 & \\
\hline 428 & & & 26.3 & \\
\hline 428 & & & 26.3 & 1080. \\
\hline & & & 26.3 & \\
\hline 4287 & & & 26.3 & \\
\hline & & & 26.3 & \\
\hline 4289 & & & 26.3 & \\
\hline 4290 & & & 26.3 & 1072. \\
\hline & & & 26.3 & \\
\hline 429 & & & 26.3 & \\
\hline 429 & & & 26.3 & \\
\hline 4294 & & & 26.3 & \\
\hline 4295 & & $9: 12$ & 26.3 & 1000 \\
\hline 4296 & & & 26.3 & \\
\hline 42 & & & 26.4 & \\
\hline 429 & & $8 / 13$ & 26.4 & \\
\hline 4299 & & & & \\
\hline 4300 & & & 26.4 & \\
\hline 4301 & & $9: 24$ & 26.4 & \\
\hline 430 & & & 26.4 & \\
\hline 4303 & & $13 / 20089: 28$ & 26.4 & \\
\hline 4304 & & & 26.4 & \\
\hline & & & & \\
\hline
\end{tabular}


DOE/RL-2009-35, REV. 0

\begin{tabular}{|c|c|c|c|c|}
\hline \multicolumn{5}{|c|}{$D 4-92 c$} \\
\hline $\operatorname{Rec}$ & & Adjusted & Temp & $\mathrm{SC}$ \\
\hline$\#$ & Date/Time & Date/Time & \begin{tabular}{|l|}
${ }^{\circ} \mathrm{C}$ \\
\end{tabular} & $\mu \mathrm{S} / \mathrm{cm}$ \\
\hline 4306 & $1 / 13 / 20089: 34$ & $8 / 13 / 20089: 34$ & 26.4 & 1061.9 \\
\hline 4307 & $1 / 13 / 20089: 36$ & $8 / 13 / 20089: 36$ & 26.4 & 1061.8 \\
\hline 4308 & $1 / 13 / 20089: 38$ & $8 / 13 / 20089: 38$ & 26.4 & 1061.7 \\
\hline 4309 & $1 / 13 / 20089: 40$ & $8 / 13 / 20089: 40$ & 26.4 & 1061.7 \\
\hline 4310 & $1 / 13 / 20089: 42$ & $8 / 13 / 20089: 42$ & 26.4 & 1061.6 \\
\hline 4311 & $1 / 13 / 20089: 44$ & $8 / 13 / 20089: 44$ & 26.4 & 1061.4 \\
\hline 4312 & $1 / 13 / 20089: 46$ & $8 / 13 / 20089: 46$ & 26.4 & 1061.6 \\
\hline 4313 & $1 / 13 / 20089: 48$ & $8 / 13 / 20089: 48$ & 26.4 & 1061.3 \\
\hline 4314 & $1 / 13 / 20089: 50$ & $8 / 13 / 20089: 50$ & 26.4 & 1061 \\
\hline 4315 & 1/13/20089:52 & $8 / 13 / 20089: 52$ & 26.4 & 1061 \\
\hline 4316 & $1 / 13 / 20089: 54$ & $8 / 13 / 20089: 54$ & 26.4 & 1061 \\
\hline 4317 & $1 / 13 / 20089: 56$ & $8 / 13 / 20089: 56$ & 26.4 & 1060.8 \\
\hline 4318 & $1 / 13 / 20089: 58$ & $8 / 13 / 20089: 58$ & 26.5 & 1059.8 \\
\hline 4319 & $1 / 13 / 2008$ 10:00 & $8 / 13 / 200810: 00$ & 26.4 & 1060.9 \\
\hline 4320 & $1 / 13 / 200810: 02$ & $8 / 13 / 200810: 02$ & 26.4 & 1060.6 \\
\hline 4321 & $1 / 13 / 200810: 04$ & $8 / 13 / 200810: 04$ & 26.4 & 1060.9 \\
\hline 4322 & 1/13/2008 10:06 & $8 / 13 / 200810: 06$ & 26.4 & 1061 \\
\hline 4323 & $1 / 13 / 200810: 08$ & $8 / 13 / 200810: 08$ & 26.4 & 1060.9 \\
\hline 4324 & 1/13/2008 10:10 & $8 / 13 / 200810: 10$ & 26.4 & 1060.8 \\
\hline 4325 & $1 / 13 / 200810: 12$ & $8 / 13 / 200810: 12$ & 26.4 & 1061.4 \\
\hline 4326 & $1 / 13 / 200810: 14$ & $8 / 13 / 200810: 14$ & 26.5 & 1060.9 \\
\hline 4327 & 1/13/2008 10:16 & $8 / 13 / 2008$ 10:16 & 26.4 & 1061 \\
\hline 4328 & $1 / 13 / 200810: 18$ & $8 / 13 / 200810: 18$ & 26.5 & 1061 \\
\hline 4329 & $1 / 13 / 2008$ 10:20 & $8 / 13 / 2008$ 10:20 & 26.5 & 1061.1 \\
\hline 4330 & $1 / 13 / 200810: 22$ & $8 / 13 / 200810: 22$ & 26.5 & 1061 \\
\hline 4331 & $1 / 13 / 2008$ 10:24 & $8 / 13 / 200810: 24$ & 26.5 & 1061.3 \\
\hline 4332 & $1 / 13 / 200810: 26$ & $8 / 13 / 200810: 26$ & 26.5 & 1061.1 \\
\hline 4333 & $1 / 13 / 200810: 28$ & $8 / 13 / 200810: 28$ & 26.5 & 1061.3 \\
\hline 4334 & $1 / 13 / 2008$ 10:30 & $8 / 13 / 2008$ 10:30 & 26.5 & 1061.2 \\
\hline 4335 & $1 / 13 / 2008$ 10:32 & $8 / 13 / 200810: 32$ & 26.5 & 1061.3 \\
\hline 4336 & $1 / 13 / 2008$ 10:34 & $8 / 13 / 200810: 34$ & 26.5 & 1061.3 \\
\hline 4337 & $1 / 13 / 2008$ 10:36 & $8 / 13 / 200810: 36$ & 26.5 & 1061.4 \\
\hline 4338 & $1 / 13 / 200810: 38$ & $8 / 13 / 200810: 38$ & 26.5 & 1061.4 \\
\hline 4339 & $1 / 13 / 200810: 40$ & $8 / 13 / 200810: 40$ & 26.5 & 1061.5 \\
\hline 4340 & 1/13/2008 10:42 & $8 / 13 / 200810: 42$ & 26.5 & 1061.4 \\
\hline 4341 & $1 / 13 / 200810: 44$ & $8 / 13 / 200810: 44$ & 26.5 & 1062 \\
\hline 4342 & $1 / 13 / 2008$ 10:46 & $8 / 13 / 200810: 46$ & 26.5 & 1061.7 \\
\hline 4343 & $1 / 13 / 200810: 48$ & $8 / 13 / 200810: 48$ & 26.5 & 1061.9 \\
\hline 4344 & $1 / 13 / 200810: 50$ & $8 / 13 / 200810: 50$ & 26.5 & 1060.9 \\
\hline 4345 & $1 / 13 / 200810: 52$ & $8 / 13 / 200810: 52$ & 26.5 & 1060.1 \\
\hline 4346 & $1 / 13 / 200810: 54$ & $8 / 13 / 200810: 54$ & 26.5 & 1059.5 \\
\hline 4347 & $1 / 13 / 200810: 56$ & $8 / 13 / 200810: 56$ & 26.5 & 1059.3 \\
\hline 4348 & $1 / 13 / 200810: 58$ & $8 / 13 / 200810: 58$ & 26.5 & 1057.7 \\
\hline 4349 & 1/13/2008 11:00 & $8 / 13 / 200811: 00$ & 26.5 & 1056.6 \\
\hline 4350 & 1/13/2008 11:02 & $8 / 13 / 2008$ 11:02 & 26.4 & 1056.8 \\
\hline 4351 & 1/13/2008 11:04 & $8 / 13 / 200811: 04$ & 26.4 & 1055.2 \\
\hline 4352 & 1/13/2008 11:06 & $8 / 13 / 200811: 06$ & 26.4 & 1054.6 \\
\hline 4353 & $1 / 13 / 200811: 08$ & $8 / 13 / 200811: 08$ & 26.4 & 1054.3 \\
\hline 4354 & $1 / 13 / 200811: 10$ & $8 / 13 / 200811: 10$ & 26.4 & 1054.3 \\
\hline 4355 & 1/13/2008 11:12 & $8 / 13 / 200811: 12$ & 26.4 & 1053.4 \\
\hline 4356 & 1/13/2008 11:14 & $8 / 13 / 200811: 14$ & 26.4 & 1053 \\
\hline 4357 & 1/13/2008 11:16 & $8 / 13 / 200811: 16$ & 26.4 & 1055.1 \\
\hline 4358 & 1/13/2008 11:18 & $8 / 13 / 200811: 18$ & 26.4 & 1054.2 \\
\hline 4359 & 1/13/2008 11:20 & $8 / 13 / 200811: 20$ & 26.4 & 1053.6 \\
\hline 4360 & 1/13/2008 11:22 & $8 / 13 / 200811: 22$ & 26.3 & 1053.9 \\
\hline 4361 & $1 / 13 / 200811: 24$ & $8 / 13 / 200811: 24$ & 26.3 & 1054.7 \\
\hline 4362 & 1/13/2008 11:26 & $8 / 13 / 200811: 26$ & 26.4 & 1055.9 \\
\hline 4363 & $1 / 13 / 200811: 28$ & $8 / 13 / 200811: 28$ & 26.5 & 1055.6 \\
\hline 4364 & 1/13/2008 11:30 & $8 / 13 / 200811: 30$ & 26.6 & 1054.6 \\
\hline 4365 & 1/13/2008 11:32 & $8 / 13 / 2008$ 11:32 & 26.7 & 1052.6 \\
\hline 4366 & 1/13/2008 11:34 & $8 / 13 / 200811: 34$ & 26.7 & 1052.7 \\
\hline 4367 & $1 / 13 / 200811: 36$ & $8 / 13 / 200811: 36$ & 26.6 & 1053.6 \\
\hline 4368 & $1 / 13 / 200811: 38$ & $8 / 13 / 200811: 38$ & 26.6 & 1053.6 \\
\hline 4369 & $1 / 13 / 200811: 40$ & $8 / 13 / 200811: 40$ & 26.6 & 1054.5 \\
\hline 4370 & $1 / 13 / 200811: 42$ & $8 / 13 / 200811: 42$ & 26.6 & 1058.7 \\
\hline 4371 & 1/13/2008 11:44 & $8 / 13 / 200811: 44$ & 26.7 & 1067.6 \\
\hline 4372 & $1 / 13 / 200811: 46$ & $8 / 13 / 200811: 46$ & 26.8 & 1072 \\
\hline 4373 & $1 / 13 / 200811: 48$ & $8 / 13 / 200811: 48$ & 26.9 & 1074.6 \\
\hline 4374 & $1 / 13 / 200811: 50$ & $8 / 13 / 200811: 50$ & 26.9 & 1075 \\
\hline
\end{tabular}

\begin{tabular}{|c|c|c|c|c|}
\hline \multicolumn{5}{|c|}{ D4-92c } \\
\hline $\operatorname{Rec}$ & & Adjusted & Temp & SC \\
\hline$\#$ & Date/Time & DaterTime & ${ }^{\circ} \mathrm{C}$ & $\mu \mathrm{S} / \mathrm{cm}$ \\
\hline 4375 & $1 / 13 / 200811: 52$ & \begin{tabular}{|l}
$8 / 13 / 200811: 52$ \\
\end{tabular} & 27 & \\
\hline 376 & $13 / 200811: 54$ & $8 / 13 / 2008$ 11:54 & 27 & 1077. \\
\hline & 1/13/2008 11:56 & \begin{tabular}{|l|}
$8 / 13 / 200811: 56$ \\
\end{tabular} & 27 & \\
\hline 378 & $811: 58$ & $8 / 13 / 200811: 58$ & 27 & \\
\hline 379 & $812: 00$ & \begin{tabular}{|l|l|l|l}
$8 / 13 / 2008: 00$ \\
\end{tabular} & 27.1 & 1079. \\
\hline & & & & \\
\hline 381 & $812: 04$ & $8 / 13 / 2008$ 12:04 & 27.1 & \\
\hline 382 & $1 / 13 / 20$ & $8 / 13 / 2008$ 12:06 & 27.1 & \\
\hline 383 & & 8/13/2008 12:08 & & \\
\hline 384 & $13 / 200812: 10$ & \begin{tabular}{|l|l|l|}
$8 / 13 / 200812: 10$ \\
\end{tabular} & 27.2 & 1081. \\
\hline & $12: 12$ & $8 / 13 / 200812: 12$ & 27.2 & \\
\hline 386 & 12:14 & $8 / 13 / 2008$ 12:14 & & \\
\hline 387 & $12: 16$ & 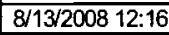 & 27.3 & 1082. \\
\hline & & & 27.3 & \\
\hline 4389 & $2: 20$ & $8 / 13 / 200812: 20$ & 27.4 & \\
\hline 4390 & $1 / 13 / 2$ & $8 / 13 / 200812: 22$ & 27.4 & 1085. \\
\hline & $1 / 13 /$ & & & \\
\hline 4392 & & $8 / 13 / 2008 \quad 12: 26$ & 27.4 & \\
\hline 4393 & $2: 28$ & $312: 28$ & 27.4 & \\
\hline 4394 & & & 27.5 & \\
\hline 4395 & $1 / 13$ & $8 / 13 / 2$ & 27.4 & 1084. \\
\hline 996 & 234 & $312: 34$ & 27.5 & \\
\hline 4397 & $: 36$ & $12: 36$ & 27.5 & \\
\hline 4398 & & $12: 38$ & 27.5 & \\
\hline & & $8 / 13 / 2$ & 27.5 & \\
\hline 4400 & & $0812 ; 42$ & 27.5 & \\
\hline 4401 & & $12: 44$ & 27.6 & \\
\hline 4402 & & $8 / 13 / 2$ & 27.6 & \\
\hline 4403 & & 12:48 & 27.6 & \\
\hline & & $12: 50$ & 27.6 & \\
\hline & & $12: 52$ & 27.6 & 1087. \\
\hline & & $12: 54$ & 27.6 & 1087. \\
\hline 4407 & & $12: 56$ & 27.6 & \\
\hline 4408 & & & 27.6 & 1087. \\
\hline & & & 27.7 & \\
\hline$\overline{44}$ & & $8 / 13 / 200$ & 27.6 & \\
\hline 4411 & & & 27.7 & \\
\hline 4412 & & & 27.7 & \\
\hline & & $13: 08$ & 27.7 & \\
\hline$\overline{4}$ & & & 27.7 & \\
\hline 4415 & & & 27.7 & \\
\hline & & & 27.7 & \\
\hline & & & 27.7 & \\
\hline & & & 27.7 & \\
\hline 44 & & & 27.8 & \\
\hline 4420 & & $13: 22$ & 27.8 & \\
\hline & & & 27.8 & \\
\hline 4 & & & 27.8 & \\
\hline & & $13: 28$ & 27.8 & \\
\hline 4 & & & 27.8 & \\
\hline 4425 & & 13:32 & 27.8 & 109 \\
\hline & & & 27.8 & \\
\hline & & & 27.8 & \\
\hline 4428 & & 13:38 & 27.8 & \\
\hline & & & & \\
\hline 4430 & & $\overline{13: 42}$ & 27.8 & \\
\hline & & & 27.9 & \\
\hline & & & 27 & \\
\hline & & $8 / 13 / 2008$ & 27.8 & \\
\hline & & & & \\
\hline & & $13: 52$ & 27.8 & \\
\hline & & & 27.8 & \\
\hline & & & 27.8 & \\
\hline & & $\sqrt{2008 ~ 13: 58}$ & 27.8 & \\
\hline & & & 27.8 & \\
\hline & & & & \\
\hline & & $8 / 13 / 2008 \quad 14: 04$ & 27.8 & \\
\hline & & & 27.7 & \\
\hline & & $9 / 1 / 2008+4 \cdot 09$ & & \\
\hline
\end{tabular}

\begin{tabular}{|c|c|c|c|c|}
\hline \multicolumn{5}{|c|}{ D4-92C } \\
\hline $\operatorname{Rec}$ & & \begin{tabular}{|l|} 
Adjusted \\
\end{tabular} & Temp & SC \\
\hline$\#$ & Date/Time & Date/Time & ${ }^{\circ} \mathrm{C}$ & $\mu \mathrm{S} / \mathrm{cm}$ \\
\hline 4444 & $1 / 13 / 2008$ 14:10 & $8 / 13 / 2008$ 14:10 & 27.7 & 1093.9 \\
\hline 4445 & 1/13/2008 14:12 & \begin{tabular}{|l}
$8 / 13 / 2008 \quad 14: 12$ \\
\end{tabular} & 27.8 & 1098.9 \\
\hline 4446 & $1 / 13 / 2008$ 14:14 & $8 / 13 / 2008$ 14:14 & 28 & 1099.1 \\
\hline 4447 & $1 / 13 / 200814: 16$ & $8 / 13 / 200814: 16$ & 28.1 & 1098.9 \\
\hline 4448 & 1/13/2008 14:18 & \begin{tabular}{|l}
$8 / 13 / 200814: 18$ \\
\end{tabular} & 28.1 & 1097.8 \\
\hline 4449 & $1 / 13 / 2008 \quad 14: 20$ & $8 / 13 / 200814: 20$ & 28.2 & 1099.2 \\
\hline 4450 & $1 / 13 / 2008$ 14:22 & $8 / 13 / 200814: 22$ & 28.2 & 1099.5 \\
\hline 4451 & $1 / 13 / 2008$ 14:24 & $8 / 13 / 2008$ 14:24 & 28.2 & 1100.5 \\
\hline 4452 & $1 / 13 / 2008$ 14:26 & $8 / 13 / 2008$ 14:26 & 28.1 & 1092.3 \\
\hline 4453 & $1 / 13 / 200814: 28$ & $8 / 13 / 2008$ 14:28 & 28.1 & 1094.3 \\
\hline 4454 & $1 / 13 / 200814: 30$ & $8 / 13 / 200814: 30$ & 28.1 & 1094.2 \\
\hline 4455 & $1 / 13 / 2008$ 14:32 & $8 / 13 / 2008$ 14:32 & 28.1 & 1094.3 \\
\hline 4456 & $1 / 13 / 2008$ 14:34 & $8 / 13 / 2008 \quad 14: 34$ & 28.1 & 1094.6 \\
\hline 4457 & $1 / 13 / 200814: 36$ & $8 / 13 / 2008 \quad 14: 36$ & 28 & 1093.4 \\
\hline 4458 & $1 / 13 / 200814: 38$ & $8 / 13 / 2008$ 14:38 & 28 & 1093.9 \\
\hline 4459 & $1 / 13 / 2008$ 14:40 & $8 / 13 / 200814: 40$ & 28.1 & 1097.9 \\
\hline 4460 & 1/13/2008 14:42 & $8 / 13 / 2008 \quad 14: 42$ & 28.3 & 1097.3 \\
\hline 4461 & $1 / 13 / 2008$ 14:44 & $8 / 13 / 2008$ 14:44 & 28.4 & 1096 \\
\hline 4462 & $1 / 13 / 200814: 46$ & $8 / 13 / 200814: 46$ & 28.4 & 1096.1 \\
\hline 4463 & $1 / 13 / 200814: 48$ & $8 / 13 / 200814: 48$ & 28.4 & 1096.4 \\
\hline 4464 & $1 / 13 / 2008 \quad 14: 50$ & $8 / 13 / 200814: 50$ & 28.5 & 1096 \\
\hline 4465 & $1 / 13 / 2008$ 14:52 & $8 / 13 / 200814: 52$ & 28.5 & 1096.5 \\
\hline 4466 & $1 / 13 / 2008$ 14:54 & $8 / 13 / 200814: 54$ & 28.5 & 1096 \\
\hline 4467 & $1 / 13 / 2008$ 14:56 & $8 / 13 / 2008 \quad 14: 56$ & 28.5 & 1095.7 \\
\hline 4468 & $1 / 13 / 200814: 58$ & $8 / 13 / 200814: 58$ & 28.5 & 1096.4 \\
\hline 4469 & $1 / 13 / 200815: 00$ & $8 / 13 / 200815: 00$ & 28.6 & 1096.5 \\
\hline 4470 & 1/13/2008 15:02 & \begin{tabular}{|l|l|l}
$8 / 13 / 200815: 02$ \\
\end{tabular} & 28.6 & 1096.1 \\
\hline 4471 & $1 / 13 / 2008$ 15:04 & $8 / 13 / 2008$ 15:04 & 28.6 & 1096.5 \\
\hline 4472 & $1 / 13 / 200815: 06$ & $8 / 13 / 200815: 06$ & 28.6 & 1098.7 \\
\hline 4473 & $1 / 13 / 200815: 08$ & \begin{tabular}{|l|l}
$8 / 13 / 2008$ & $15: 08$ \\
\end{tabular} & 28.6 & 1097.7 \\
\hline 4474 & $1 / 13 / 200815: 10$ & 8/13/2008 15:10 & 28.6 & 1097 \\
\hline 4475 & 1/13/2008 15:12 & 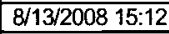 & 28.7 & 1097.5 \\
\hline 4476 & $1 / 13 / 2008$ 15:14 & \begin{tabular}{|l|}
$8 / 13 / 200815: 14$ \\
\end{tabular} & 28.7 & 1098.1 \\
\hline 4477 & 1/13/2008 15:16 & \begin{tabular}{|l|}
$8 / 13 / 200815: 16$ \\
\end{tabular} & 28.7 & 1097.3 \\
\hline 4478 & $1 / 13 / 200815: 18$ & $8 / 13 / 200815: 18$ & 28.7 & 1097.1 \\
\hline 4479 & $1 / 13 / 200815: 20$ & $8 / 13 / 2008$ 15:20 & 28.7 & 1097.1 \\
\hline 4480 & $1 / 13 / 200815: 22$ & $8 / 13 / 200815: 22$ & 28.7 & 1097.1 \\
\hline 4481 & $1 / 13 / 200815: 24$ & $8 / 13 / 2008 \quad 15: 24$ & 28.7 & 1097.3 \\
\hline 4482 & $1 / 13 / 200815: 26$ & 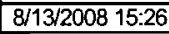 & 28.7 & 1096.1 \\
\hline 4483 & 1/13/2008 15:28 & $8 / 13 / 200815: 28$ & 28.7 & 1097.7 \\
\hline 4484 & 1/13/2008 15:30 & \begin{tabular}{|l|}
$8 / 13 / 200815: 30$ \\
\end{tabular} & 28.7 & 1096.4 \\
\hline 4485 & $1 / 13 / 2008$ 15:32 & \begin{tabular}{|l}
$8 / 13 / 2008 \quad 15: 32$ \\
\end{tabular} & 28.7 & 1096.1 \\
\hline 4486 & $1 / 13 / 2008+5: 34$ & $8 / 13 / 2008 \quad 15: 34$ & 28.7 & 1095.5 \\
\hline 4487 & $1 / 13 / 200815: 36$ & \begin{tabular}{|l|l|}
$8 / 13 / 2008 ~ 15: 36$ \\
\end{tabular} & 28.7 & 1097 \\
\hline 4488 & 1/13/2008 15:38 & \begin{tabular}{|l|}
$8 / 13 / 200815: 38$ \\
\end{tabular} & 28.7 & 1095.8 \\
\hline 4489 & $1 / 13 / 200815: 40$ & \begin{tabular}{|l|l|}
$8 / 13 / 200815: 40$ \\
\end{tabular} & 28.7 & 1098.6 \\
\hline 4490 & $1 / 13 / 2$ & $8 / 13 / 2008 \quad 15: 42$ & 28.7 & 1099.2 \\
\hline 4491 & $1 / 13 / 200815: 44$ & \begin{tabular}{|l|l|l}
$8 / 13 / 2008$ & $15: 44$ \\
\end{tabular} & 28.7 & 1098.9 \\
\hline 4492 & 1/13/2008 15:46 & \begin{tabular}{|l|l|l|}
$8 / 2008 \quad 15: 46$ \\
\end{tabular} & 28.7 & 1097.6 \\
\hline 4493 & $1 / 13 / 2008$ 15:48 & \begin{tabular}{|l|l}
$8 / 13 / 2008$ & $15: 48$ \\
\end{tabular} & 28.7 & 1098.8 \\
\hline 4494 & $1 / 13 / 200815: 50$ & \begin{tabular}{|l|}
$8 / 13 / 200815: 50$ \\
\end{tabular} & 28.8 & 1099.3 \\
\hline 4495 & $1 / 13 / 200815: 52$ & \begin{tabular}{|l|}
$8 / 13 / 200815: 52$ \\
\end{tabular} & 28.8 & 1100.3 \\
\hline 4496 & $1 / 13 / 200815: 54$ & $8 / 13 / 200815: 54$ & 28.9 & 1100.1 \\
\hline 4497 & $1 / 13 / 200815: 56$ & $8 / 13 / 200815: 56$ & 29 & 1100.8 \\
\hline 4498 & 1/13/2008 15:58 & $8 / 13 / 200815: 58$ & 29 & 1099.6 \\
\hline 4499 & $1 / 13 / 200816: 00$ & \begin{tabular}{|l|}
$8 / 13 / 200816: 00$ \\
\end{tabular} & 29 & 1100.9 \\
\hline 4500 & $1 / 13 / 200816: 02$ & $8 / 13 / 200816: 02$ & 29 & 1106.4 \\
\hline 4501 & $0816: 04$ & $8 / 13 / 200816: 04$ & 29 & 1105.4 \\
\hline 4502 & 1/13/2008 16:06 & \begin{tabular}{|l}
$8 / 13 / 200816: 06$ \\
\end{tabular} & 28.9 & 1103.9 \\
\hline 4503 & 1/13/2008 16:08 & 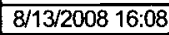 & 28.9 & 1103.8 \\
\hline 4504 & 1/13/2008 16:10 & 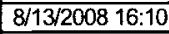 & 28.8 & 1104.4 \\
\hline 4505 & 1/13/2008 16:12 & $8 / 13 / 200816: 12$ & 28.9 & 1107.5 \\
\hline 4506 & & 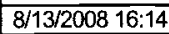 & 29.1 & 1108.3 \\
\hline 4507 & $1 / 13 / 200816: 16$ & 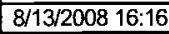 & 29.1 & 1107.6 \\
\hline 4508 & 1/13/2008 16:18 & \begin{tabular}{|l}
$8 / 13 / 200816: 18$ \\
\end{tabular} & 29.2 & 1107.8 \\
\hline 4509 & $1 / 13 / 200816: 20$ & \begin{tabular}{|l|}
$8 / 13 / 200816: 20$ \\
\end{tabular} & 29.2 & 1108.2 \\
\hline 4510 & $1 / 13 / 200816: 22$ & $8 / 13 / 200816: 22$ & 29.2 & 1107.7 \\
\hline 4511 & $1 / 13 / 2008$ 16:24 & \begin{tabular}{|l|}
$8 / 13 / 200816: 24$ \\
\end{tabular} & 29.1 & 1107.6 \\
\hline 4512 & $1 / 13 / 200816: 26$ & $8 / 13 / 200816: 26$ & 29.1 & 1108.2 \\
\hline
\end{tabular}


DOE/RL-2009-35, REV. 0

\begin{tabular}{|c|c|c|c|c|}
\hline \multicolumn{5}{|c|}{ D4-92c } \\
\hline $\operatorname{Rec}$ & & Adjusted & Temp & $\mathrm{SC}$ \\
\hline$\#$ & Date/Time & Date/Time & \begin{tabular}{|l|l|}
${ }^{\circ} \mathrm{C}$ \\
\end{tabular} & $\mu \mathrm{S} / \mathrm{cm}$ \\
\hline 4513 & $1 / 13 / 200816: 28$ & $8 / 13 / 200816: 28$ & 29.2 & 1106.9 \\
\hline 4514 & $1 / 13 / 200816: 30$ & $8 / 13 / 200816: 30$ & 29.2 & 1105.7 \\
\hline 4515 & $1 / 13 / 200816: 32$ & $8 / 13 / 200816: 32$ & 29.1 & 1108.1 \\
\hline 4516 & $1 / 13 / 200816: 34$ & $8 / 13 / 200816: 34$ & 29.1 & 1106.9 \\
\hline 4517 & $1 / 13 / 200816: 36$ & $8 / 13 / 200816: 36$ & 29.1 & 1106.4 \\
\hline 4518 & $1 / 13 / 200816: 38$ & $8 / 13 / 200816: 38$ & 29.1 & 1105.1 \\
\hline 4519 & $1 / 13 / 200816: 40$ & $8 / 13 / 200816: 40$ & 29.1 & 1106 \\
\hline$\frac{710}{4520}$ & $1 / 13 / 200816: 42$ & $8 / 13 / 200816: 42$ & 29 & 1104.6 \\
\hline 4521 & $1 / 13 / 200816: 44$ & $8 / 13 / 200816: 44$ & 29 & 1105.1 \\
\hline 4522 & 1/13/2008 16:46 & $8 / 13 / 200816: 46$ & 29 & 1109.9 \\
\hline 4523 & $1 / 13 / 200816: 48$ & $8 / 13 / 200816: 48$ & 29 & 1104 \\
\hline 4524 & $1 / 13 / 200816: 50$ & $8 / 13 / 200816: 50$ & 29 & 1103.7 \\
\hline 4525 & $1 / 13 / 2008+6: 52$ & $8 / 13 / 200816: 52$ & 28.9 & 1104.5 \\
\hline 4526 & $1 / 13 / 200816: 54$ & $8 / 13 / 200816: 54$ & 28.9 & 1104.7 \\
\hline 4527 & $1 / 13 / 2008$ 16:56 & $8 / 13 / 200816: 56$ & 28.8 & 1105.4 \\
\hline 4528 & $1 / 13 / 200816: 58$ & $8 / 13 / 200816: 58$ & 28.8 & \\
\hline 4529 & $1 / 13 / 2008 \quad 17: 00$ & $8 / 13 / 2008$ 17:00 & 29 & 1115.3 \\
\hline 4530 & $1 / 13 / 200817: 02$ & $8 / 13 / 200817: 02$ & 29.2 & 1115.2 \\
\hline 4531 & $1 / 13 / 2008$ 17:04 & $8 / 13 / 2008$ 17:04 & 29.3 & 1116.2 \\
\hline 4532 & $1 / 13 / 2008$ 17:06 & $8 / 13 / 200817: 06$ & 29.4 & 1116.2 \\
\hline 4533 & $1 / 13 / 2008$ 17:08 & $8 / 13 / 200817: 08$ & 29.4 & 1116.7 \\
\hline 4534 & $1 / 13 / 2008$ 17:10 & $8 / 13 / 200817: 10$ & 29.4 & 1107.6 \\
\hline 4535 & $1 / 13 / 2008$ 17:12 & $8 / 13 / 2008$ 17:12 & 29.4 & 1111.8 \\
\hline 4536 & $1 / 13 / 2008$ 17:14 & $8 / 13 / 2008$ 17:14 & 29.4 & 1110.7 \\
\hline 4537 & $1 / 13 / 200817: 16$ & $8 / 13 / 200817: 16$ & 29.4 & 1110.4 \\
\hline 4538 & $1 / 13 / 200817: 18$ & $8 / 13 / 2008 \quad 17: 18$ & 29.3 & 1110.2 \\
\hline 4539 & $1 / 13 / 2008$ 17:20 & $8 / 13 / 2008$ 17:20 & 29.3 & 1108 \\
\hline 4540 & $1 / 13 / 200817: 22$ & $8 / 13 / 2008$ 17:22 & 29.4 & 1097.2 \\
\hline 4541 & $1 / 13 / 200817: 24$ & $8 / 13 / 200817: 24$ & 29.5 & 1093 \\
\hline 4542 & 1/13/2008 17:26 & $8 / 13 / 200817: 26$ & 29.5 & 1090.1 \\
\hline 4543 & $1 / 13 / 200817: 28$ & $8 / 13 / 200817: 28$ & 29.5 & 1088.4 \\
\hline 4544 & $1 / 13 / 2008$ 17:30 & $8 / 13 / 200817: 30$ & 29.5 & 1085.6 \\
\hline 4545 & $1 / 13 / 200817: 32$ & $8 / 13 / 200817: 32$ & 29.5 & 1084.7 \\
\hline 4546 & $1 / 13 / 200817: 34$ & $8 / 13 / 200817: 34$ & 29.5 & 1082.7 \\
\hline 4547 & $1 / 13 / 200817: 36$ & $8 / 13 / 200817: 36$ & 29.5 & 1082.2 \\
\hline 4548 & $1 / 13 / 200817: 38$ & $8 / 13 / 200817: 38$ & 29.5 & 1081.6 \\
\hline 4549 & $1 / 13 / 200817: 40$ & $8 / 13 / 200817: 40$ & 29.5 & 1081.3 \\
\hline 4550 & $1 / 13 / 2008 \quad 17: 42$ & $8 / 13 / 200817: 42$ & 29.5 & 1079.3 \\
\hline 4551 & $1 / 13 / 200817: 44$ & $8 / 13 / 2008 \quad 17: 44$ & 29.5 & 1079.5 \\
\hline 4552 & $1 / 13 / 2008$ 17:46 & $8 / 13 / 200817: 46$ & 29.5 & 1078.5 \\
\hline 4553 & $1 / 13 / 200817: 48$ & $8 / 13 / 2008$ 17:48 & 29.5 & 1078.2 \\
\hline 4554 & $1 / 13 / 200817: 50$ & $8 / 13 / 200817: 50$ & 29.5 & 1078.5 \\
\hline 4555 & $1 / 13 / 200817: 52$ & $8 / 13 / 200817: 52$ & 29.5 & 1077.6 \\
\hline 4556 & $1 / 13 / 200817: 54$ & $8 / 13 / 2008$ 17:54 & 29.5 & 1077.1 \\
\hline 4557 & $1 / 13 / 200817: 56$ & $8 / 13 / 200817: 56$ & 29.5 & 1076.1 \\
\hline 4558 & $1 / 13 / 200817: 58$ & $8 / 13 / 2008 \quad 17: 58$ & 29.5 & 1076 \\
\hline 4559 & $1 / 13 / 2008$ 18:00 & $8 / 13 / 200818: 00$ & 29.5 & 1075.9 \\
\hline 4560 & $1 / 13 / 200818: 02$ & $8 / 13 / 200818: 02$ & 29.5 & 1074.7 \\
\hline 4561 & $1 / 13 / 200818: 04$ & $8 / 13 / 2008$ 18:04 & 29.5 & 1077.2 \\
\hline 4562 & $1 / 13 / 2008$ 18:06 & $8 / 13 / 200818: 06$ & 29.5 & 1075 \\
\hline 4563 & $1 / 13 / 200818: 08$ & $8 / 13 / 2008 \quad 18: 08$ & 29.5 & 1074.2 \\
\hline 4564 & $1 / 13 / 200818: 10$ & $8 / 13 / 2008$ 18:10 & 29.5 & 1073.8 \\
\hline 4565 & $1 / 13 / 20$ & $8 / 13 / 2008$ 18:12 & 29.5 & 1074 \\
\hline$\frac{7566}{4566}$ & $1 / 13 / 20$ & $8 / 13 / 200818: 14$ & 29.5 & 1074.3 \\
\hline 4567 & $1 / 13 / 200818: 16$ & $8 / 13 / 200818: 16$ & 29.5 & 1074 \\
\hline 4568 & $1 / 13 / 200818: 18$ & $8 / 13 / 200818: 18$ & 29.5 & 1073.6 \\
\hline 4569 & $1 / 13 / 200818: 20$ & $8 / 13 / 200818: 20$ & 29.5 & 1073.3 \\
\hline 4570 & $1 / 13 / 200818: 22$ & $8 / 13 / 200818: 22$ & 29.5 & 1073.6 \\
\hline 4571 & $1 / 13 / 200818: 24$ & $8 / 13 / 200818: 24$ & 29.5 & 1074.3 \\
\hline 4572 & $1 / 13 / 200818: 26$ & $8 / 13 / 2008$ 18:26 & 29.5 & 1073.7 \\
\hline 4573 & $1 / 13 / 200818: 28$ & $8 / 13 / 2008$ 18:28 & 29.6 & 1074.2 \\
\hline 4574 & 1/13/2008 18:30 & $8 / 13 / 200818: 30$ & 29.6 & 1074.5 \\
\hline 4575 & $1 / 13 / 200818: 32$ & $8 / 13 / 200818: 32$ & 29.6 & 1072.1 \\
\hline 4576 & $1 / 13 / 200818: 34$ & $8 / 13 / 200818: 34$ & 29.5 & 1073.4 \\
\hline 4577 & $1 / 13 / 200818: 36$ & $8 / 13 / 200818: 36$ & 29.6 & 1072.5 \\
\hline 4578 & $1 / 13 / 200818: 38$ & $8 / 13 / 200818: 38$ & 29.6 & 1073.1 \\
\hline 4579 & $1 / 13 / 200818: 40$ & $8 / 13 / 200818: 40$ & 29.6 & 1073.9 \\
\hline 4580 & $1 / 13 / 200818: 42$ & $8 / 13 / 200818: 42$ & 29.6 & 1073.4 \\
\hline 4581 & $1 / 13 / 200818: 44$ & $8 / 13 / 200818: 44$ & 29.6 & 1073.5 \\
\hline
\end{tabular}

\begin{tabular}{|c|c|c|c|c|}
\hline \multicolumn{5}{|c|}{ D4-92c } \\
\hline $\operatorname{Rec}$ & & Adjusted & & \\
\hline$\#$ & Date/Time & Date/Time & ${ }^{\circ} \mathrm{C}$ & $\mu \mathrm{S} / \mathrm{cm}$ \\
\hline 4582 & $1 / 13 / 2008$ 18:46 & $8 / 13 / 2008$ 18:46 & 29.6 & 1072.4 \\
\hline & $1 / 13 / 200818: 48$ & $8 / 13 / 200818: 48$ & & \\
\hline 4584 & $13 / 200818: 50$ & $8 / 13 / 200818: 50$ & 29.6 & 1073. \\
\hline 885 & $13 / 2008$ 18:52 & $8 / 13 / 2008$ 18:52 & 29.6 & 1072 \\
\hline 386 & & & 29.6 & \\
\hline 4587 & 1/13/2008 18:56 & $8 / 13 / 200818: 56$ & 29.6 & 1072.5 \\
\hline 4588 & 1/13/2008 18:58 & $8 / 13 / 200818: 58$ & 29.6 & \\
\hline 4589 & 1/13/2008 19:00 & 8/13/2008 19:00 & 29.6 & \\
\hline 4590 & 1/13/2008 19:02 & $8 / 13 / 200819: 02$ & 29.6 & 1071.5 \\
\hline & & & & \\
\hline 4592 & $13 / 200819: 06$ & $8 / 13 / 200819: 06$ & 29.5 & 1068. \\
\hline 4593 & 1/13/2008 19:08 & $8 / 13 / 2008$ 19:08 & 29.5 & 1072.4 \\
\hline & & & 29.4 & \\
\hline 4595 & 1/13/2008 19:12 & $8 / 13 / 2008$ 19:12 & 29.4 & 1071. \\
\hline 4596 & 19:14 & $8 / 13 / 200$ & 29.4 & 1073 \\
\hline 4597 & & & & \\
\hline 4598 & $0819: 18$ & $8 / 13 / 200819: 18$ & 29.5 & 1072.4 \\
\hline & & & & \\
\hline 4600 & $1 / 13 /$ & $8 / 13 / 20$ & 29.5 & \\
\hline 4601 & $19: 24$ & $8 / 13 / 20$ & 29.5 & 1071. \\
\hline 4602 & & & 29.5 & \\
\hline 4603 & $819: 28$ & $8 / 13 / 2008$ 19:28 & 29.5 & 1068. \\
\hline 4604 & $9: 30$ & $8 / 13 / 2$ & 29.5 & 1072. \\
\hline 4605 & $1 / 13$ & & 29.5 & \\
\hline 4606 & $1 / 13$ & $8 / 13 / 2$ & 29.5 & 1071. \\
\hline 4607 & & $8 / 13 / 20$ & 29.5 & \\
\hline 4608 & $1 / 13 /$ & $8 / 13 / 20$ & 29.6 & \\
\hline 4609 & $1 / 13$ & $8 / 13 / 2$ & 29.6 & 1075 . \\
\hline 4610 & & 19:42 & 29.5 & \\
\hline 4611 & & $19: 44$ & 29.4 & 1074. \\
\hline 4612 & & & 29.5 & \\
\hline 4613 & & $9: 48$ & 29.5 & \\
\hline 4614 & & & 29.5 & 1076. \\
\hline 4615 & & & 29.5 & 1074. \\
\hline 4616 & & $19: 54$ & 29.6 & 107 \\
\hline 4617 & & & 29.4 & 1073 \\
\hline 4618 & & 19:58 & 29.3 & 1075. \\
\hline 4619 & & & 29.2 & 1074. \\
\hline 4620 & & & 29 & 1074 \\
\hline 4621 & & $20: 04$ & 29.2 & \\
\hline & & & 29.6 & \\
\hline 4623 & & $0: 08$ & 29.6 & 1083 \\
\hline 4624 & & & 29.7 & \\
\hline 4625 & & & 29.7 & \\
\hline 4626 & & 20:14 & 29.7 & 1079. \\
\hline & & & 29.7 & \\
\hline 4628 & & & 29.6 & 1078 \\
\hline 4629 & & & 29.6 & \\
\hline 4630 & & & 29.6 & \\
\hline 4631 & & $20: 24$ & 29.7 & \\
\hline & & & & \\
\hline 4633 & & $20: 28$ & 29.9 & \\
\hline 4634 & & & 29.9 & \\
\hline 4635 & & & 30 & \\
\hline 4636 & & $20: 34$ & 29.9 & \\
\hline & & & & \\
\hline 4638 & & $20: 38$ & 29.9 & \\
\hline & & & 29.9 & \\
\hline 4640 & & & 29.9 & \\
\hline & & $320: 44$ & 29.9 & \\
\hline 4642 & & & & \\
\hline 4643 & & $8 / 13 / 200820: 48$ & 29.8 & 1074 \\
\hline & & $8 / 13 / 200$ & 29.8 & \\
\hline & & & 29.8 & \\
\hline 4646 & $820: 54$ & $8 / 13 / 200820: 54$ & 29.8 & 1073 \\
\hline & & & 29.8 & \\
\hline & & & 29.7 & \\
\hline & & $0<1.00$ & $\begin{array}{ll}29.7 \\
\end{array}$ & \\
\hline & & & & \\
\hline
\end{tabular}

\begin{tabular}{|c|c|c|c|c|}
\hline \multicolumn{5}{|c|}{ D4-92c } \\
\hline $\operatorname{Rec}$ & & Adjusted & Temp & SC \\
\hline$\#$ & Date/Time & Date/Time & ${ }^{\circ} \mathrm{C}$ & $\mu \mathrm{S} / \mathrm{cm}$ \\
\hline 4651 & 1/13/2008 21:04 & $8 / 13 / 200821: 04$ & 29.7 & 1074.1 \\
\hline 4652 & 1/13/2008 21:06 & $8 / 13 / 200821: 06$ & 29.7 & 1073.4 \\
\hline 4653 & 1/13/200821:08 & $8 / 13 / 200821: 08$ & 29.7 & 1074.1 \\
\hline 4654 & $1 / 13 / 200821: 10$ & $8 / 13 / 200821: 10$ & 29.7 & 1073.1 \\
\hline 4655 & 1/13/2008 21:12 & $8 / 13 / 200821: 12$ & 29.7 & 1074.1 \\
\hline 4656 & 1/13/2008 21:14 & $8 / 13 / 200821: 14$ & 29.7 & 1074.9 \\
\hline 4657 & 1/13/2008 21:16 & $8 / 13 / 200821: 16$ & 29.7 & 1075.1 \\
\hline 4658 & 1/13/200821:18 & $8 / 13 / 200821: 18$ & 29.6 & 1073.5 \\
\hline 4659 & 1/13/200821:20 & $8 / 13 / 200821: 20$ & 29.6 & 1073.1 \\
\hline 4660 & 1/13/2008 21:22 & $8 / 13 / 200821: 22$ & 29.6 & 1072.6 \\
\hline 4661 & $1 / 13 / 200821: 24$ & $8 / 13 / 200821: 24$ & 29.6 & 1073.1 \\
\hline 4662 & $1 / 13 / 200821: 26$ & $8 / 13 / 200821: 26$ & 29.6 & 1071.4 \\
\hline 4663 & 1/13/2008 21:28 & $8 / 13 / 200821: 28$ & 29.6 & 1074.2 \\
\hline 4664 & $1 / 13 / 200821: 30$ & $8 / 13 / 200821: 30$ & 29.5 & 1075.5 \\
\hline 4665 & 1/13/2008 21:32 & $8 / 13 / 200821: 32$ & 29.6 & 1073.2 \\
\hline 4666 & $1 / 13 / 200821: 34$ & $8 / 13 / 200821: 34$ & 29.5 & 1073 \\
\hline 4667 & 1/13/2008 21:36 & $8 / 13 / 200821: 36$ & 29.5 & 1073.8 \\
\hline 4668 & $1 / 13 / 200821: 38$ & $8 / 13 / 200821: 38$ & 29.5 & 1074.2 \\
\hline 4669 & $1 / 13 / 200821: 40$ & $8 / 13 / 200821: 40$ & 29.4 & 1075.5 \\
\hline 4670 & $1 / 13 / 200821: 42$ & $8 / 13 / 200821: 42$ & 29.4 & 1076.6 \\
\hline 4671 & $1 / 13 / 200821: 44$ & $8 / 13 / 200821: 44$ & 29.5 & 1072.4 \\
\hline 4672 & $1 / 13 / 200821: 46$ & $8 / 13 / 200821: 46$ & 29.4 & 1074.7 \\
\hline 4673 & $1 / 13 / 200821: 48$ & $8 / 13 / 200821: 48$ & 29.4 & 1075.8 \\
\hline 4674 & 1/13/2008 21:50 & $8 / 13 / 200821: 50$ & 29.4 & 1073.4 \\
\hline 4675 & $1 / 13 / 200821: 52$ & $8 / 13 / 200821: 52$ & 29.4 & 1072.3 \\
\hline 4676 & $1 / 13 / 200821: 54$ & $8 / 13 / 200821: 54$ & 29.4 & 1072.8 \\
\hline 4677 & $1 / 13 / 200821: 56$ & $8 / 13 / 200821: 56$ & 29.3 & 1073.1 \\
\hline 4678 & $1 / 13 / 200821: 58$ & $8 / 13 / 200821: 58$ & 29.3 & 1073.2 \\
\hline 4679 & $1 / 13 / 200822: 00$ & $8 / 13 / 200822: 00$ & 29.3 & 1072.9 \\
\hline 4680 & $1 / 13 / 200822: 02$ & $8 / 13 / 200822: 02$ & 29.3 & 1073.1 \\
\hline 4681 & 1/13/2008 22:04 & $8 / 13 / 200822: 04$ & 29.4 & 1075.8 \\
\hline 4682 & $1 / 13 / 200822: 06$ & $8 / 13 / 200822: 06$ & 29.5 & 1074.7 \\
\hline 4683 & $1 / 13 / 200822: 08$ & $8 / 13 / 200822: 08$ & 29.5 & 1074.3 \\
\hline 4684 & 1/13/2008 22:10 & $8 / 13 / 200822: 10$ & 29.6 & 1072.5 \\
\hline 4685 & $1 / 13 / 200822: 12$ & $8 / 13 / 200822: 12$ & 29.6 & 1071.7 \\
\hline 4686 & $1 / 13 / 200822: 14$ & $8 / 13 / 200822: 14$ & 29.5 & 1071.3 \\
\hline 4687 & 1/13/2008 22:16 & $8 / 13 / 200822: 16$ & 29.5 & 1071.3 \\
\hline 4688 & 1/13/2008 22:18 & $8 / 13 / 200822: 18$ & 29.4 & 1071 \\
\hline 4689 & $1 / 13 / 200822: 20$ & $8 / 13 / 200822: 20$ & 29.4 & 1069.2 \\
\hline 4690 & 1/13/2008 22:22 & $8 / 13 / 200822: 22$ & 29.4 & 1069.5 \\
\hline 4691 & $1 / 13 / 200822: 24$ & $8 / 13 / 20$ & 29.3 & 1068.3 \\
\hline 4692 & $1 / 13 / 2$ & $8 / 13 / 200822: 26$ & 29.2 & 1070.8 \\
\hline 4693 & $1 / 13 / 200822: 28$ & $8 / 13 / 200822: 28$ & 29.1 & 1069.8 \\
\hline 4694 & $1 / 13 / 200822: 30$ & $8 / 13 / 200822: 30$ & 29.1 & 1070.4 \\
\hline 4695 & $1 / 13 / 200822: 32$ & $8 / 13 / 200822: 32$ & 29 & 1068.3 \\
\hline 4696 & $1 / 13 / 200822: 34$ & $8 / 13 / 200822: 34$ & 29 & 1067.9 \\
\hline 4697 & $1 / 13 / 200822: 36$ & $8 / 13 / 200822: 36$ & 28.9 & 1067.1 \\
\hline 4698 & $1 / 13 / 200822: 38$ & $8 / 13 / 200822: 38$ & 28.9 & 1067.5 \\
\hline 4699 & $1 / 13 / 200822: 40$ & $8 / 13 / 200822: 40$ & 28.9 & 1067.7 \\
\hline 4700 & 1/13/2008 22:42 & $8 / 13 / 200822: 42$ & 28.8 & 1068.3 \\
\hline 4701 & $1 / 13 / 200822: 44$ & $8 / 13 / 200822: 44$ & 28.8 & 1067.5 \\
\hline 4702 & $1 / 13 / 200822: 46$ & $8 / 13 / 200822: 46$ & 28.8 & 1070.2 \\
\hline 4703 & $1 / 13 / 200822: 48$ & $8 / 13 / 200822: 48$ & 28.8 & 1069.1 \\
\hline 4704 & $1 / 13 / 200822: 50$ & $8 / 13 / 200822: 50$ & 28.7 & 1069.2 \\
\hline 4705 & 1/13/2008 22:52 & $8 / 13 / 200822: 52$ & 28.7 & 1069.3 \\
\hline 4706 & 1/13/2008 22:54 & $8822: 54$ & 28.7 & 1069.2 \\
\hline 4707 & $1 / 13 / 200822: 56$ & $8 / 13 / 200822: 56$ & 28.7 & 1068.8 \\
\hline 4708 & $1 / 13 / 200822: 58$ & $8 / 13 / 200822: 58$ & 28.7 & 1069.3 \\
\hline 4709 & 1/13/2008 23:00 & $8 / 13 / 200823: 00$ & 28.7 & 1069.4 \\
\hline 4710 & 1/13/2008 23:02 & $8 / 13 / 200823: 02$ & 28.7 & 1068.9 \\
\hline 4711 & 1/13/2008 23:04 & $8 / 13 / 200823: 04$ & 28.7 & 1068.4 \\
\hline 4712 & 1/13/2008 23:06 & $8 / 13 / 200823: 06$ & 28.7 & 1067.8 \\
\hline 4713 & 1/13/2008 23:08 & $8 / 13 / 200823: 08$ & 28.7 & 1067.3 \\
\hline 4714 & 1/13/2008 23:10 & $8 / 13 / 200823: 10$ & 28.7 & 1067.4 \\
\hline 4715 & $1 / 13 / 200823: 12$ & $8 / 13 / 200823: 12$ & 28.7 & 1066.8 \\
\hline 4716 & 1/13/2008 23:14 & $8 / 13 / 200823: 14$ & 28.7 & 1066.5 \\
\hline 4717 & 1/13/2008 23:16 & $8 / 13 / 200823: 16$ & 28.7 & 1066.4 \\
\hline 4718 & 1/13/2008 23:18 & $8 / 13 / 200823: 18$ & 28.7 & 1066.5 \\
\hline 4719 & 1/13/2008 23:20 & $8 / 13 / 200823: 20$ & 28.7 & 1066.8 \\
\hline
\end{tabular}




\begin{tabular}{|c|c|c|c|c|}
\hline \multicolumn{5}{|c|}{ D4-92c } \\
\hline $\operatorname{Rec}$ & & Adjusted & Temp & SC \\
\hline$\#$ & Date/Time & Date/Time & ${ }^{\circ} \mathrm{C}$ & $\mu \mathrm{S} / \mathrm{cm}$ \\
\hline 4720 & $1 / 13 / 200823: 22$ & $8 / 13 / 200823: 22$ & 28.6 & 1065.5 \\
\hline 4721 & $1 / 13 / 200823: 24$ & $8 / 13 / 200823: 24$ & 28.6 & 1065.5 \\
\hline 4722 & $1 / 13 / 200823: 26$ & $8 / 13 / 200823: 26$ & 28.6 & 1065.1 \\
\hline 4723 & 1/13/2008 23:28 & $8 / 13 / 200823: 28$ & 28.6 & 1065.1 \\
\hline 4724 & $1 / 13 / 200823: 30$ & $8 / 13 / 200823: 30$ & 28.7 & 1064.2 \\
\hline 4725 & $1 / 13 / 200823: 32$ & $8 / 13 / 200823: 32$ & 28.6 & 1065.2 \\
\hline 4726 & $1 / 13 / 200823: 34$ & $8 / 13 / 200823: 34$ & 28.6 & 1065.4 \\
\hline 4727 & $1 / 13 / 200823: 36$ & $8 / 13 / 200823: 36$ & 28.6 & 1064.7 \\
\hline 4728 & $1 / 13 / 200823: 38$ & $8 / 13 / 200823: 38$ & 28.6 & 1064.5 \\
\hline 4729 & $1 / 13 / 200823: 40$ & $8 / 13 / 200823: 40$ & 28.6 & 1064.6 \\
\hline 4730 & $1 / 13 / 200823: 42$ & $8 / 13 / 200823: 42$ & 28.5 & 1064.7 \\
\hline 4731 & $1 / 13 / 200823: 44$ & $8 / 13 / 200823: 44$ & 28.5 & 1064.6 \\
\hline 4732 & $1 / 13 / 200823: 46$ & $8 / 13 / 200823: 46$ & 28.5 & 1064.2 \\
\hline 4733 & $1 / 13 / 200823: 48$ & $8 / 13 / 200823: 48$ & 28.5 & 1064.2 \\
\hline 4734 & $1 / 13 / 200823: 50$ & $8 / 13 / 200823: 50$ & 28.6 & 1063.9 \\
\hline 4735 & $1 / 13 / 200823: 52$ & $8 / 13 / 200823: 52$ & 28.5 & 1063.9 \\
\hline 4736 & $1 / 13 / 200823: 54$ & $8 / 13 / 200823: 54$ & 28.5 & 1063.6 \\
\hline 4737 & $1 / 13 / 2$ & $8 / 13 / 200823: 56$ & 28.5 & 1063.4 \\
\hline 4738 & $1 / 13 / 200823: 58$ & $8 / 13 / 200823: 58$ & 28.5 & 1063.4 \\
\hline 4739 & $80: 00$ & $080: 00$ & 28.5 & 1063.4 \\
\hline $47 \overline{0}$ & $1 / 14 / 20080: 02$ & $8 / 14 / 20080: 02$ & 28.5 & 1063.4 \\
\hline 4741 & $1 / 14 / 20$ & $8 / 14 / 20080: 04$ & 28.4 & 1063.6 \\
\hline 4742 & $1 / 14$ & $080: 06$ & 28.5 & 1063.4 \\
\hline 4743 & $1 / 14$ & $80: 08$ & 28.4 & 1063.1 \\
\hline 4744 & 1/14/2008 0:10 & $8 / 14 / 20080: 10$ & 28.5 & 1062.5 \\
\hline 4745 & $1 / 14 / 20080: 12$ & $8 / 14 / 2008$ 0:12 & 28.4 & 1063.3 \\
\hline 4746 & $1 / 14 / 20$ & $80: 14$ & 28.4 & 1062.8 \\
\hline 4747 & $1 / 14$ & $080: 16$ & 28.4 & 1063 \\
\hline 4748 & $1 / 14 / 20080: 18$ & $8 / 14 / 20080: 18$ & 28.4 & 1063 \\
\hline 4749 & 1/14/2008 0:20 & $8 / 14 / 20080: 20$ & 28.4 & 1062.4 \\
\hline 4750 & $0: 22$ & $80: 22$ & 28.4 & 1062.5 \\
\hline 4751 & $1 / 14$ & $80: 24$ & 28.4 & 1062.3 \\
\hline 4752 & $1 / 14 /$ & $080: 26$ & 28.4 & 1062 \\
\hline 4753 & $80: 28$ & $080: 28$ & 28.4 & 1061.6 \\
\hline 4754 & $0: 30$ & $0: 30$ & 28.3 & 1061.7 \\
\hline 4755 & $1 / 14$ & $30: 32$ & 28.3 & 1061.5 \\
\hline 4756 & $1 / 14 / 2$ & $30: 34$ & 28.3 & 1061.7 \\
\hline 4757 & $1 / 14 / 2$ & & 28.3 & 1061.4 \\
\hline 4758 & $1 / 14 / 2$ & 38 & 28.3 & 1061.3 \\
\hline 4759 & $1 / 1$ & $0: 40$ & 28.4 & 1061.1 \\
\hline 4760 & & $30: 42$ & 28.4 & 1060.6 \\
\hline 4761 & $0: 44$ & $80: 44$ & 28.4 & 1060.8 \\
\hline 4762 & & $30: 46$ & 28.4 & 060.4 \\
\hline 4763 & & & 28.4 & 1060.5 \\
\hline 4764 & $1 / 14 / 2$ & $080: 50$ & 28.3 & 1060.5 \\
\hline 4765 & $80: 52$ & $080: 52$ & 28.3 & 1060.8 \\
\hline 4766 & & & 28.3 & 1060.7 \\
\hline 4767 & & & 28.3 & \\
\hline 4768 & $0: 58$ & $0: 58$ & 28.3 & 1060.3 \\
\hline 4769 & 1/14/2008 1:00 & $0081: 00$ & 28.3 & 1059.2 \\
\hline 4770 & $0081: 02$ & $081: 02$ & 28.3 & 1059.8 \\
\hline 4771 & & & 28.3 & 1059.9 \\
\hline 4772 & $1: 06$ & $1: 06$ & 28.3 & 1059.9 \\
\hline 4773 & $81: 08$ & $081: 08$ & 28.2 & 1060.5 \\
\hline 4774 & $81: 10$ & $081: 10$ & 28.2 & 1060 \\
\hline 4775 & & & 28.2 & 1060.2 \\
\hline 4776 & & & 28.2 & \\
\hline 4777 & $81: 16$ & $0081: 16$ & 28.2 & 1060.3 \\
\hline 4778 & $1 / 14 / 20081: 18$ & $081: 18$ & 28.2 & 1059.7 \\
\hline 4779 & $1 / 14 / 20081: 20$ & $081: 20$ & 28.2 & 1060.1 \\
\hline 4780 & & & 28.2 & 1059.7 \\
\hline 4781 & $1 / 14 / 2008 \uparrow: 24$ & $8 / 14 / 20081: 24$ & 28.2 & 1059.3 \\
\hline 4782 & $1 / 14 / 20081: 26$ & $8 / 14 / 20081: 26$ & 28.2 & 1059.1 \\
\hline 4783 & $1 / 14 / 20081: 28$ & $8 / 14 / 20081: 28$ & 28.2 & 1059 \\
\hline 4784 & $1 / 14 / 20081: 30$ & $8 / 14 / 20081: 30$ & 28.2 & 1058.9 \\
\hline 4785 & $1 / 14 / 2008$ t:32 & $8 / 14 / 20081: 32$ & 28.2 & 1058.8 \\
\hline 4786 & $1 / 14 / 20081: 34$ & $8 / 14 / 2008$ 1:34 & 28.1 & 1059.2 \\
\hline 4787 & 1/14/2008 1:36 & $8 / 14 / 20081: 36$ & 28.1 & 1058.7 \\
\hline 4788 & $1 / 14 / 20081: 38$ & $8 / 14 / 20081: 38$ & 28.1 & 1058.6 \\
\hline
\end{tabular}

\begin{tabular}{|c|c|c|c|c|}
\hline \multicolumn{5}{|c|}{ D4-92c } \\
\hline $\operatorname{Rec}$ & & Adjusted & Temp & SC \\
\hline$\#$ & Date/Time & Date/Time & ${ }^{\circ} \mathrm{C}$ & $\mu \mathrm{S} / \mathrm{cm}$ \\
\hline 4789 & $1 / 14 / 20081: 40$ & $8 / 14 / 20081: 40$ & 28.1 & 1058.7 \\
\hline 4790 & $1 / 14 / 20081: 42$ & $8 / 14 / 20081: 42$ & 28.1 & 1058.6 \\
\hline 4791 & $1 / 14 / 20081: 44$ & $8 / 14 / 20081: 44$ & 28.1 & \\
\hline 4792 & $14 / 20081: 46$ & $8 / 14 / 20081: 46$ & & 1058.5 \\
\hline 4793 & $081: 48$ & $8 / 14 / 20081: 48$ & 28.1 & 1057.9 \\
\hline 4794 & & $8 / 14 / 20081: 50$ & & 1057.8 \\
\hline 4795 & $1 / 14 / 20081: 52$ & $8 / 14 / 20081: 52$ & 28.1 & 1058 \\
\hline 4796 & $081: 54$ & $8 / 14 / 20081: 54$ & 28.1 & 1058 \\
\hline 4797 & $81: 56$ & $8 / 14 / 20081: 56$ & 28.1 & \\
\hline 4798 & $081: 58$ & $8 / 14 / 20081: 58$ & 28 & 1058.2 \\
\hline 4799 & $2: 00$ & $8 / 14 / 20082: 00$ & 28 & 1058.1 \\
\hline 4800 & $2: 02$ & $8 / 14 / 20082: 02$ & 28 & 1058 \\
\hline 4801 & $32: 04$ & $8 / 14 / 20082: 04$ & 28 & 1057.8 \\
\hline & $2 \cdot 0$ & $8 / 14 / 20082: 06$ & 28 & 1057.6 \\
\hline 4803 & $2: 08$ & $8 / 14 / 20082: 08$ & 28 & 1057. \\
\hline 4804 & $32: 10$ & $8 / 14 / 20082: 10$ & 28 & 1057.2 \\
\hline & $2: 12$ & $8 / 14 / 20082: 12$ & 28 & \\
\hline 4806 & $2: 14$ & $8 / 14 / 20082: 14$ & 28 & 1057.2 \\
\hline 4807 & $2: 16$ & $8 / 14 / 20082: 16$ & 28 & 1056.6 \\
\hline 4808 & & $8 / 14 / 20$ & 28 & 1060.7 \\
\hline 4809 & $2: 20$ & $8 / 14 / 20082: 20$ & 28 & 1059. \\
\hline 4810 & $2: 22$ & $8 / 14 / 20$ & 28 & 1061. \\
\hline 4811 & $2: 24$ & $8 / 14 / 20$ & 27.9 & 1057.6 \\
\hline 4812 & & $8 / 14 / 20$ & 27.8 & $105^{5}$ \\
\hline 4813 & & $8 / 14 / 2$ & 27.7 & 1055.2 \\
\hline 4814 & $2: 30$ & $8 / 14 / 20$ & 27.7 & 1055.2 \\
\hline 4815 & $2: 32$ & $8 / 14 / 2$ & 27.6 & 1055.1 \\
\hline 4816 & $2: 34$ & $8 / 14 / 2$ & 27.6 & 1054. \\
\hline 4817 & $1 / 12$ & $8 / 14 / 20$ & 27.6 & 1054.2 \\
\hline 4818 & & $8 / 14 / 2$ & 27.6 & 1054.7 \\
\hline 4819 & $2: 40$ & $8 / 14 / 2$ & 27.7 & \\
\hline 4820 & & & 27.7 & 1054.6 \\
\hline 4821 & $2: 44$ & $8 / 14 / 2$ & 27.7 & 1055. \\
\hline 4822 & $2: 4 \overline{6}$ & $8 / 14 / 2$ & 27.6 & 1054.7 \\
\hline 4823 & & $2: 48$ & 27.6 & 1054. \\
\hline 4824 & $2: 50$ & $8 / 14 / 2$ & 27.6 & 1054. \\
\hline 4825 & & & 27.6 & 1054. \\
\hline 4826 & & $2: 54$ & 27.6 & 1053.5 \\
\hline 4827 & & $2: 56$ & 27.6 & 1054.8 \\
\hline 4828 & & $2: 58$ & 27.6 & 1054. \\
\hline 4829 & & $3: 00$ & 27.5 & 1053.7 \\
\hline 4830 & & & 27.5 & \\
\hline 4831 & & & 27.5 & 1053. \\
\hline 4832 & & $3: 06$ & 27.5 & 1054 \\
\hline 4833 & & & 27.5 & 1053.8 \\
\hline 4834 & & $3: 10$ & 27.5 & 1053.5 \\
\hline & & & 27.5 & \\
\hline & & & 27.5 & 1053 \\
\hline & & & 27.5 & 1053. \\
\hline & & & 27.5 & 1053. \\
\hline 4839 & & $3: 20$ & 27.5 & 1053.8 \\
\hline 4840 & & & 27.5 & \\
\hline 4841 & & & 27.5 & \\
\hline 4842 & & & 27.5 & 1053. \\
\hline & & & 27.5 & \\
\hline 4844 & & 3:30 & 27.5 & \\
\hline & & & 27.5 & \\
\hline & & & & \\
\hline 4847 & & $8 / 14 / 2$ & 27.5 & 1053. \\
\hline & & & 27.5 & \\
\hline 4849 & & 8 & 27.6 & \\
\hline 4850 & & $83: 42$ & 27.6 & \\
\hline 4851 & & & & \\
\hline 4852 & $3: 46$ & $8 / 14 / 20083: 46$ & 27.6 & 1052.6 \\
\hline 4853 & & & 27.5 & 1053.2 \\
\hline 4854 & & & 27.5 & \\
\hline 4855 & & $8 / 14 / 20083: 52$ & 27.5 & 1052 \\
\hline 4856 & & & 27.6 & 105 \\
\hline & & & & \\
\hline
\end{tabular}

\begin{tabular}{|c|c|c|c|c|}
\hline \multicolumn{5}{|c|}{ D4-92c } \\
\hline $\operatorname{Rec}$ & & Adjusted & Temp & \\
\hline$\#$ & Date/Time & Date/Time & ${ }^{\circ} \mathrm{C}$ & $\mu \mathrm{S} / \mathrm{cm}$ \\
\hline & $1 / 14 / 20083: 58$ & $8 / 14 / 20083: 58$ & 27.6 & 1052.2 \\
\hline 4859 & $1 / 14 / 20084: 00$ & $8 / 14 / 20084: 00$ & 27.5 & 1052.9 \\
\hline 4860 & $1 / 14 / 20084: 02$ & $8 / 14 / 20084: 02$ & 27.5 & 1052.3 \\
\hline 4861 & & $8 / 14 / 20084: 04$ & 27.5 & 1052.4 \\
\hline 4862 & $1 / 14 / 20084: 06$ & $8 / 14 / 20084: 06$ & 27.5 & 1052.5 \\
\hline 4863 & $1 / 14 / 20$ & $8 / 14 / 20084: 08$ & 27.5 & \\
\hline 4864 & $1 / 14 / 20$ & $8 / 14 / 20084: 10$ & 27.5 & 1051.4 \\
\hline 4865 & $1 / 14 / 20$ & $8 / 14 / 20084: 12$ & 27.5 & 1052 \\
\hline 4866 & $1 / 14 / 20$ & $8 / 14 / 20084: 14$ & 27.5 & \\
\hline 4867 & $1 / 14 / 200$ & $8 / 14 / 20084: 16$ & 27.5 & 1051.8 \\
\hline 4868 & $1 / 14 / 20$ & $8 / 14 / 200$ & 27.5 & 1052.1 \\
\hline 4869 & $1 / 14 / 20$ & $8 / 14 / 200$ & 27.5 & 10517 \\
\hline 4870 & $1 / 14 / 200$ & $8 / 14 / 20084: 22$ & 27.5 & 1052.2 \\
\hline 4871 & $1 / 14 / 2$ & $8 / 14 / 20$ & 27.5 & 1051.6 \\
\hline 4872 & $1 / 14 / 20$ & $8 / 14 / 20$ & 27.5 & 1051.2 \\
\hline 4873 & $1 / 14 / 20$ & $8 / 14 / 200$ & 27.5 & 1050.8 \\
\hline 4874 & $1 / 14 / 2$ & $8 / 14 / 200$ & 27.5 & 1051.5 \\
\hline 4875 & $1 / 14 / 2$ & $8 / 14 / 20$ & 27.5 & 1051 \\
\hline 4876 & $1 / 14 / 2$ & $8 / 14 / 20$ & 27.5 & 1051.5 \\
\hline 4877 & $1 / 14 / 2$ & $8 / 14 / 20$ & 27.5 & \\
\hline 4878 & $1 / 14 / 20$ & $8 / 14 / 20$ & 27.5 & 1050.9 \\
\hline 4879 & $1 / 14 / 2$ & $8 / 14 / 20$ & 27.5 & 1050.6 \\
\hline 4880 & $1 / 14 / 2$ & $8 / 14 / 20$ & 27.5 & \\
\hline 4881 & $\overline{1 / 14 /}$ & $8 / 14 / 2$ & 27.5 & 1050.6 \\
\hline 4882 & $1 / 14 / 2$ & $8 / 14 / 20$ & 27.5 & 1050.5 \\
\hline 4883 & $1 / 14 / 2$ & $8 / 14 / 20$ & 27.5 & 1049.9 \\
\hline 4884 & $1 / 14 /$ & $8 / 14 / 2$ & 27.5 & 1050.1 \\
\hline 4885 & $1 / 14 \pi$ & $8 / 14 / 2$ & 27.5 & 1050.4 \\
\hline 4886 & $1 / 14 /$ & $8 / 14 / 2$ & 27.5 & 1049.9 \\
\hline 4887 & $\overline{1 / 14 /}$ & $8 / 14 / 2$ & 27.5 & 1050.6 \\
\hline 4888 & $1 / 14 / 2$ & $8 / 14 / 20$ & 27.5 & 1049.5 \\
\hline 4889 & & & 27.5 & 1049.8 \\
\hline 4890 & $1 / 14 /$ & $8 / 14$ & 27.5 & 1049.8 \\
\hline 4891 & $1 / 14 / 2$ & $8 / 14 / 20$ & 27.5 & 1049.7 \\
\hline 4892 & $1 / 14$ & $8 / 14 /$ & 27.5 & 1049.1 \\
\hline 4893 & $\overline{1 / 14 /}$ & $8 / 14 / 2$ & 27.5 & 1049.2 \\
\hline 4894 & & & 27.5 & 1049.9 \\
\hline 4895 & & & 27.5 & 1049.3 \\
\hline 4896 & $1 / 1$ & $8 / 14 / 20$ & 27.5 & 1048.6 \\
\hline 4897 & & & 27.5 & 1048.7 \\
\hline 4898 & $1 / 14$ & & 27.5 & 1048.6 \\
\hline 4899 & & & 27.5 & \\
\hline 4900 & & & 27.5 & 1048.2 \\
\hline 4901 & $1 / 14$ & & 27.5 & 1048.1 \\
\hline 4902 & & & 27.5 & 1048.4 \\
\hline 4903 & & & 27.5 & 1047.9 \\
\hline 4904 & & & 27.5 & 1047.9 \\
\hline 4905 & & & 27.4 & 10484 \\
\hline 4906 & & & 27.4 & 1047.7 \\
\hline 4907 & & & 27.4 & \\
\hline 4908 & & & 27.4 & 1048.5 \\
\hline 4909 & & & 27.4 & \\
\hline 4910 & & & 27.4 & 10483 \\
\hline 4911 & & & 27.4 & 1047.8 \\
\hline & & & 27.4 & \\
\hline 4913 & & & 27.5 & 1048 \\
\hline 4914 & & & 27.5 & 1047.9 \\
\hline 4915 & & & 27.4 & \\
\hline 4916 & $1 / 14$ & $8 / 14 / 20$ & 27.4 & 1047.8 \\
\hline 4917 & & & 27.4 & \\
\hline 4918 & & & 27.4 & \\
\hline 4919 & & $8 / 14 / 20$ & 27.4 & 1047.4 \\
\hline 4920 & & & 27.4 & \\
\hline 4921 & & $8 / 14 / 200$ & 27.4 & 1046.6 \\
\hline 4922 & $1 / 14 / 2$ & & 27.4 & 1046.6 \\
\hline 4923 & & & 27.4 & \\
\hline 4924 & & $8 / 14 / 20$ & 27.4 & 1045.8 \\
\hline 4925 & & & 27.4 & 1046.3 \\
\hline & & & & \\
\hline
\end{tabular}


DOE/RL-2009-35, REV. 0

\begin{tabular}{|c|c|c|c|c|}
\hline \multicolumn{5}{|c|}{ D4-92c } \\
\hline $\operatorname{Rec}$ & & Adjusted & Temp & \\
\hline$\#$ & Date/Time & Date/Time & ${ }^{\circ} \mathrm{C}$ & $\mu \mathrm{S} / \mathrm{cm}$ \\
\hline 4927 & 1/14/20086:16 & 8/14/20086:16 & 27.4 & 1045.8 \\
\hline 4928 & $1 / 14 / 20086: 18$ & $8 / 14 / 20086: 18$ & 27.4 & 1045.5 \\
\hline 4929 & $1 / 14 / 20086: 20$ & $8 / 14 / 20086: 20$ & 27.4 & 1047.4 \\
\hline 930 & $1 / 14 / 20086: 22$ & $8 / 14 / 20086: 22$ & 27.4 & 1046.3 \\
\hline 931 & $1 / 14 / 20086: 24$ & $8 / 14 / 20086: 24$ & 27.2 & 1046.1 \\
\hline 4932 & $1 / 14 / 20086: 26$ & $8 / 14 / 20086: 26$ & 27.1 & 1043.5 \\
\hline 4933 & $1 / 14 / 20086: 28$ & $8 / 14 / 20086: 28$ & 27.1 & 1043.8 \\
\hline 4934 & $1 / 14 / 20086: 30$ & 8/14/2008 6:30 & 27 & 1043.5 \\
\hline 4935 & $1 / 14 / 20086: 32$ & $8 / 14 / 20086: 32$ & 27 & 1041.8 \\
\hline 4936 & $1 / 14 / 20086: 34$ & $8 / 14 / 20086: 34$ & 27 & \\
\hline 4937 & 1/14/20086:36 & $8 / 14 / 20086: 36$ & 26.9 & 1041.4 \\
\hline 4938 & $1 / 14 / 20086: 38$ & $8 / 14 / 20086: 38$ & 26.9 & 1041.1 \\
\hline 4939 & $1 / 14 / 20086: 40$ & $8 / 14 / 20086: 40$ & 26.9 & 1041.5 \\
\hline 4940 & $1 / 14 / 20086: 42$ & $8 / 14 / 20086: 42$ & 26.9 & 1041 \\
\hline 4941 & $1 / 14 / 20086: 44$ & $8 / 14 / 20086: 44$ & 26.9 & 1039.2 \\
\hline 4942 & $1 / 14 / 20086: 46$ & $8 / 14 / 20086: 46$ & 26.9 & 1038.3 \\
\hline 4943 & $1 / 14 / 20086: 48$ & $8 / 14 / 20086: 48$ & 26.9 & 1035.6 \\
\hline 4944 & 1/14/20086:50 & $8 / 14 / 20086: 50$ & 26.9 & \\
\hline 4945 & $1 / 14 / 20086: 52$ & $8 / 14 / 20086: 52$ & 26.9 & 1053.2 \\
\hline 4946 & $086: 54$ & $8 / 14 / 20086: 54$ & 26.9 & 1053.2 \\
\hline 4947 & $1 / 14 / 2$ & $8 / 14 / 20$ & 26.9 & 1052.9 \\
\hline 4948 & 086.58 & $8 / 14 / 20086: 58$ & 26.9 & 1053.1 \\
\hline 4949 & $87: 00$ & $8 / 14 / 20$ & 26.9 & 1052.6 \\
\hline 4950 & $1 / 14 /$ & $8 / 14 / 20$ & 26.9 & 1052.3 \\
\hline 4951 & $1 / 14$ & $8 / 14 / 20$ & 26.9 & 1052.6 \\
\hline 4952 & $1 / 14$ & $8 / 14 / 2$ & 26.9 & 1054.4 \\
\hline 4953 & $87: 08$ & $8 / 14 / 20$ & 26.9 & 1055.7 \\
\hline 4954 & $1 / 14 / 2$ & $8 / 14 / 20087: 10$ & 27 & 1055.1 \\
\hline 4955 & $887: 12$ & $8 / 14 / 20 x$ & 26.9 & 1054.4 \\
\hline 4956 & 77:14 & $8 / 14 / 20$ & 26.9 & 1053.8 \\
\hline 4957 & $1 / 14$ & $8 / 14 / 2$ & 27 & 1052.6 \\
\hline 4958 & $1 / 14$ & $8 / 14 / 2$ & 27 & 1053.4 \\
\hline 4959 & $1 / 14$ & $8 / 14 / 2$ & 27 & 1052.9 \\
\hline 4960 & $1 / 14 /$ & $8 / 14 / 20$ & 27 & 1052.3 \\
\hline 4961 & $7: 24$ & $8 / 14 / 2$ & 27 & 1052.8 \\
\hline 4962 & $1 / 14$ & $37: 26$ & 27 & 1052.4 \\
\hline 4963 & $1 / 14$ & $87: 28$ & 27 & 1054.5 \\
\hline 4964 & $1 / 14$ & $8 / 14 / 20$ & 27 & 1052.9 \\
\hline 4965 & $1 / 14 / 4$ & $8 / 14 / 20$ & 27 & 1053.3 \\
\hline 4966 & & $8 / 14 / 20$ & 27 & 1052.5 \\
\hline 4967 & $7: 36$ & $8 / 14$ & 27 & 1052.7 \\
\hline 4968 & $1 / 14$ & $8 / 14 / 20$ & 27 & 1052.7 \\
\hline 4969 & & $8 / 14 / 2$ & 27 & 1052.2 \\
\hline 4970 & $7: 42$ & $8 / 14 / 20$ & 27 & 1051.9 \\
\hline 4971 & & $8 / 14 / 2$ & 27 & 1052.3 \\
\hline 4972 & $7: 46$ & $8 / 14 / 20$ & 27 & 1051.4 \\
\hline 4973 & & $8 / 14$ & 27 & 1051.7 \\
\hline 4974 & & & 27 & 1051.1 \\
\hline 4975 & $1 / 14$ & $8 / 14 / 20$ & 27 & 1051.6 \\
\hline 4976 & & $8 / 14 / 20$ & 27 & 1051.6 \\
\hline 4977 & $7: 56$ & $8 / 14 / 20$ & 27 & 1050.9 \\
\hline 4978 & & & 27 & \\
\hline 4979 & & $8 / 14$ & 27 & 1050.6 \\
\hline 4980 & $1 / 14$ & $8 / 14 / 20$ & 27 & 1050.8 \\
\hline 4981 & & & 27 & \\
\hline 4982 & & $8 / 14 / 2$ & 27 & 1050.8 \\
\hline 4983 & & $8 / 14 / 2$ & 27.1 & 1049.9 \\
\hline 4984 & & $8 / 14 / 2$ & 27.1 & \\
\hline 4985 & $1 / 14 / 2$ & $8 / 14 / 20088: 12$ & 27.1 & 1049.5 \\
\hline 4986 & & $8 / 14 / 20088: 14$ & 27.1 & \\
\hline 4987 & & $8 / 14 / 200$ & 27.1 & 1050.3 \\
\hline 4988 & & $8 / 14 / 200$ & 27 & 1050.2 \\
\hline 4989 & & $8 / 14 / 20$ & 27 & \\
\hline 4990 & $1 / 14$ & $8 / 14 / 20088: 22$ & 27 & 1049.6 \\
\hline 4991 & & $8 / 14 / 20088: 24$ & 27 & \\
\hline 4992 & $8: 26$ & $8 / 14 / 200$ & 27 & 1049.3 \\
\hline 4993 & $1 / 14 / 2$ & $8 / 14 / 20088: 28$ & 27 & 1049.1 \\
\hline 4994 & $1 / 14 / 2$ & $8 / 14 / 20088: 30$ & 27 & 1049.4 \\
\hline 4995 & 1/14/2008 8:32 & $8 / 14 / 20088: 32$ & 27 & 1049.1 \\
\hline
\end{tabular}

\begin{tabular}{|c|c|c|c|c|}
\hline \multicolumn{5}{|c|}{ D4-92C } \\
\hline$\overline{R e c}$ & & Adjusted & Temp & \\
\hline$\#$ & Date/Time & Date/Time & ${ }^{\circ} \mathrm{C}$ & $\mu \mathrm{S} / \mathrm{cm}$ \\
\hline 4996 & $1 / 14 / 20088: 34$ & $8 / 14 / 20088: 34$ & 2 & \\
\hline 997 & & & 27 & \\
\hline 1998 & $14 / 20088: 38$ & $8 / 14 / 20088: 38$ & 27 & 1048. \\
\hline 4999 & $14 / 20088: 40$ & $8 / 14 / 20088: 40$ & 27 & \\
\hline 5000 & 1/14/2008 8:42 & $8 / 14 / 20088: 42$ & 27 & 104 \\
\hline 5001 & $1 / 14 / 20088: 44$ & 8/14/2008 8:44 & 27 & 1049 \\
\hline 5002 & & 8/14/2008 8:46 & 27 & \\
\hline 5003 & 1/14/2008 8:48 & $8 / 14 / 20088: 48$ & 27.1 & 1048 \\
\hline 5004 & $14 / 20088: 50$ & $8 / 14 / 20088: 50$ & 27 & \\
\hline 5005 & & $8 / 14 / 20088: 52$ & 27 & \\
\hline 5006 & $0088: 54$ & $8 / 14 / 20088: 54$ & 27 & 1048. \\
\hline & & $8 / 14 / 20088: 56$ & 27 & \\
\hline 5008 & $1 / 14 / 20088: 58$ & $8 / 14 / 20088: 58$ & 27 & 1048 \\
\hline 5009 & $39: 00$ & $8 / 14 / 20089: 00$ & 27 & 1047 \\
\hline 5010 & & 8/14/20089:02 & 27 & \\
\hline 5011 & $089: 04$ & $8 / 14 / 20089: 04$ & 27 & 1047. \\
\hline 5012 & 9:06 & $8 / 14 / 20089: 06$ & 27 & 1048. \\
\hline 5013 & & & 27 & \\
\hline 5014 & 9:10 & $089: 10$ & 27 & 1048. \\
\hline 5015 & $9: 12$ & $89: 12$ & 27 & \\
\hline 5016 & $9: 14$ & $8 / 14 / 20$ & 27 & 1047 \\
\hline 5017 & $9: 16$ & $389: 16$ & 27 & 1047. \\
\hline 5018 & & $8 / 14 / 2$ & 27 & \\
\hline 5019 & $9: 20$ & $089: 20$ & 27 & 1047. \\
\hline 5020 & & $8 / 14 / 2$ & & \\
\hline 5021 & $9: 24$ & $8 / 14 / 2$ & 27.1 & \\
\hline 5022 & $9: 26$ & $8 / 14 / 20$ & 27 & 1046. \\
\hline 5023 & & $8 / 14 / 20$ & 27 & \\
\hline 5024 & $9: 30$ & $8 / 14 / 20$ & 27 & 1046. \\
\hline 5025 & & $8 / 14$ & 27 & 1047. \\
\hline 5026 & $: 34$ & $8 / 14 / 2$ & 27 & 1047 \\
\hline 5027 & & $8 / 14 / 2$ & 27 & 1047. \\
\hline 5028 & & $8 / 14 /$ & 27 & 104 \\
\hline 5029 & $9: 40$ & $8 / 14 /$ & 27 & 1047. \\
\hline 5030 & & $8 / 14$ & 27 & 1047 \\
\hline 5031 & & $8 / 14$ & 27 & 1047. \\
\hline 5032 & & & 27 & 1048. \\
\hline 5033 & & $8 / 14 / 2$ & 27 & 1044. \\
\hline 5034 & & $89: 50$ & 26.7 & 1040 \\
\hline 5035 & & $39: 52$ & 26.5 & 106 \\
\hline 5036 & & $8 / 14 /$ & 26.3 & 10 \\
\hline 5037 & & & 26.1 & 1066. \\
\hline 5038 & & $8 / 14 / 2$ & 26 & 1065. \\
\hline 5039 & & $8 / 14 / 2$ & 25.8 & \\
\hline 5040 & & $8 / 14 /$ & 25.8 & 1065 \\
\hline 5041 & & $8 / 14 / 2$ & 25.7 & 1064 \\
\hline 5042 & & & 25.6 & \\
\hline 5043 & & & 25.5 & 1061 \\
\hline 5044 & & & 25 & 1061 \\
\hline 5045 & & & 25. & 1060 \\
\hline 5046 & & 10:14 & 25.4 & 106 \\
\hline 5047 & & & 25.4 & \\
\hline 5048 & & & 25.4 & 1059 \\
\hline 5049 & & & 25.4 & 1057 \\
\hline 5050 & & & 25.4 & \\
\hline 5051 & & $10: 24$ & 25.4 & 1057. \\
\hline 5052 & & & & \\
\hline 5053 & & & 25.5 & \\
\hline 5054 & & & 25.6 & \\
\hline 5055 & & & 25.6 & \\
\hline 5056 & & $810: 34$ & 25.6 & 1057 \\
\hline 5057 & & & 25.6 & \\
\hline 5058 & & $810: 38$ & 25.7 & 10 \\
\hline 5059 & & & 25.7 & 1057 \\
\hline 5060 & & & 25.7 & \\
\hline 5061 & 10:44 & 8/14/2008 10:44 & 25.7 & 1057 \\
\hline 5062 & & & 25.8 & \\
\hline 5063 & & & 25.8 & 1057 \\
\hline 5064 & & $8 / 14 / 2008 \quad 10: 50$ & 25.8 & \\
\hline
\end{tabular}

\begin{tabular}{|c|c|c|c|c|}
\hline \multicolumn{5}{|c|}{ D4-92C } \\
\hline $\operatorname{Rec}$ & & Adjusted & Temp & \\
\hline$\#$ & Date/Time & Date/Time & ${ }^{\circ} \mathrm{C}$ & $\mu \mathrm{S} / \mathrm{cm}$ \\
\hline 5065 & 1/14/2008 10:52 & $8 / 14 / 200810: 52$ & 25.8 & \\
\hline & $14 / 200810: 54$ & $8 / 14 / 2008$ 10:54 & 25.8 & \\
\hline 5067 & $14 / 200810: 56$ & $8 / 14 / 2008$ 10:56 & 25.9 & 1056 \\
\hline & $14 / 200810: 58$ & $8 / 14 / 200810: 58$ & 25.9 & \\
\hline 5069 & 1/14/2008 11:00 & $8 / 14 / 200811: 00$ & 25.9 & \\
\hline 5070 & $1 / 14 / 200811: 02$ & $8 / 14 / 200811: 02$ & 25.9 & 1056. \\
\hline & 1/14/2008 11:04 & $8 / 14 / 2008$ 11:04 & 25.9 & \\
\hline 5072 & 1/14/2008 11:06 & $8 / 14 / 2008$ 11:06 & 25.9 & 1056. \\
\hline 5073 & 1/14/2008 11:08 & $8 / 14 / 2008$ 11:08 & 25.9 & 1056. \\
\hline 5074 & $1 / 14 / 200$ & $8 / 14 / 200811: 10$ & 26 & \\
\hline 5075 & $1 / 14 / 200811: 12$ & $8 / 14 / 200811: 12$ & 26 & 1055. \\
\hline & $811: 14$ & $8 / 14 / 2008$ 11:14 & 26 & \\
\hline 5077 & $1 / 14 / 2$ & $8 / 14 / 200811: 16$ & 26 & 1055 \\
\hline 5078 & $1 / 14 / 2$ & $8 / 14 / 200811: 18$ & 26 & 1056. \\
\hline 5079 & $11: 20$ & $8 / 14 / 2008$ 11:20 & 26.1 & \\
\hline 5080 & $1 / 14 / 2$ & $8 / 14 / 200811: 22$ & 26 & 1055. \\
\hline 5081 & $1 / 14 /$ & $8 / 14 / 2008$ 11:24 & 26.1 & 1055. \\
\hline 5082 & $1 / 14 / 2$ & $8 / 14 / 200811: 26$ & & \\
\hline 5083 & $1 / 14$ & $8 / 14 / 200811: 28$ & 26.1 & 1057. \\
\hline 5084 & & $8 / 14 / 200811: 30$ & 26.1 & \\
\hline 5085 & $1 / 14 / 2$ & $8 / 14 / 20$ & 26.1 & 1057. \\
\hline 5086 & $1 / 14 /$ & $8 / 14 / 2$ & 26.1 & 1056. \\
\hline 5087 & $1 / 14 /$ & $8 / 14 / 2$ & & \\
\hline 5088 & 114 & $8 / 14 / 2$ & 26.1 & 1056. \\
\hline 5089 & & $8 / 14 / 2$ & 26.1 & \\
\hline 5090 & $1 / 14 /$ & $11: 42$ & 26.1 & 1056. \\
\hline 5091 & $1 / 14$ & $8 / 14 /$ & 26.1 & 1056. \\
\hline 5092 & $1 / 14$ & $8 / 14 / 2$ & 26.2 & \\
\hline 5093 & $1 / 14 /$ & $8 / 14 / 2$ & 26.2 & 1056. \\
\hline 5094 & & $8 / 14 / 20$ & 26.2 & \\
\hline 5095 & $1 / 14 /$ & $8 / 14 / 200811: 52$ & 26.2 & 1055 \\
\hline 5096 & $1 / 14$ & $8 / 14 /$ & 26.3 & 105 \\
\hline 5097 & $1 / 14$ & $8 / 14 / 2$ & 26.2 & 1056 \\
\hline 5098 & & & 26.2 & 1055. \\
\hline 5099 & & $8 / 14 t$ & 26.2 & \\
\hline 5100 & & $8 / 14 / 2008$ 12:02 & 26.2 & 1056. \\
\hline 5101 & & & 26.3 & 055. \\
\hline 5102 & & $8 / 1$ & 26.3 & 055 . \\
\hline & & $8 / 1$ & 26.3 & \\
\hline 5104 & & $12: 10$ & 26.3 & 0 \\
\hline 5105 & & $12: 12$ & 26.3 & 1055. \\
\hline 5106 & & & 26.3 & 055 . \\
\hline 5107 & & $8 / 14$ & 26.3 & 055 \\
\hline 5108 & & $8 / 1$ & 26.3 & \\
\hline 5109 & & $12: 20$ & 26.3 & 1055 \\
\hline 5110 & & $12: 22$ & 26.3 & 1055. \\
\hline 5111 & & & 26.3 & \\
\hline 5112 & & $12: 26$ & 26.4 & 10 \\
\hline 5113 & & & 26.4 & \\
\hline 5114 & & & 26. & 1054 \\
\hline 5115 & & $12: 32$ & 26.4 & \\
\hline & & & & \\
\hline 5117 & & $0812: 36$ & 26.4 & 1055 \\
\hline 5118 & & $12: 38$ & 26.4 & \\
\hline & & & 26.4 & \\
\hline 5120 & & $12: 42$ & 26.4 & \\
\hline & & & & \\
\hline 5122 & & $1812: 46$ & 26.4 & \\
\hline 5123 & & $8 / 14 / 2008$ 12:48 & 26.4 & \\
\hline 5124 & & & 26.4 & \\
\hline 5125 & & $8 / 14 / 2008$ 12:52 & 26.4 & \\
\hline 5126 & & & 26.4 & \\
\hline 5127 & & $8 / 14 / 2008 \quad 12: 56$ & 26.4 & 1054 \\
\hline 5128 & & $8 / 14 / 200812: 58$ & 26.4 & \\
\hline & & $8 / 14 / 200813: 00$ & & \\
\hline 5130 & $1 / 14 /$ & $8 / 14 / 200813: 02$ & 26.5 & \\
\hline & & & 26.5 & \\
\hline 5132 & & $8 / 14 / 2008$ 13:06 & 26.5 & 1053 \\
\hline & & 8/14/2008 13:08 & & \\
\hline
\end{tabular}


DOE/RL-2009-35, REV. 0

\begin{tabular}{|c|c|c|c|c|}
\hline \multicolumn{5}{|c|}{ D4-92c } \\
\hline $\operatorname{Rec}$ & & Adjusted & Temp & SC \\
\hline$\#$ & Date/Time & Date/Time & ${ }^{\circ} \mathrm{C}$ & $\mu \mathrm{S} / \mathrm{cm}$ \\
\hline 134 & 1/14/2008 13:10 & 14/2008 13:10 & 26.5 & \\
\hline & 1/14/2008 13:12 & $14 / 2008$ 13:12 & 26.5 & 1054 \\
\hline & & $14 / 2008$ 13:14 & & \\
\hline 5137 & \begin{tabular}{|l|l|}
$1 / 14 / 200813: 16$ \\
\end{tabular} & $14 / 200813: 16$ & 26.5 & \\
\hline 5138 & \begin{tabular}{|l|}
$1 / 14 / 2008$ 13:18 \\
\end{tabular} & $8 / 14 / 2008$ 13:18 & 26.5 & \\
\hline 139 & 1/14/2008 13:20 & $8 / 14 / 2008$ 13:20 & 26.5 & \\
\hline 5140 & \begin{tabular}{|l|}
$1 / 14 / 200813: 22$ \\
\end{tabular} & $14 / 200813: 22$ & 26.5 & 1057. \\
\hline 5141 & \begin{tabular}{|l|}
$1 / 14 / 2008$ 13:24 \\
\end{tabular} & $14 / 2008$ 13:24 & 26.5 & \\
\hline 5142 & $1 / 14 / 200$ & $8 / 14 / 2008$ 13:26 & 26.5 & \\
\hline 5143 & $8813: 28$ & $8 / 14 / 200813: 28$ & 26.5 & 1054. \\
\hline & & $8 / 14 / 200813: 30$ & 26.5 & \\
\hline 5145 & \begin{tabular}{|l|}
$1 / 14 / 200813: 32$ \\
\end{tabular} & $8 / 14 / 2008$ 13:32 & 26.5 & \\
\hline 5146 & $8813: 34$ & $8 / 14 / 200813: 34$ & 26.5 & 1053. \\
\hline & & $8 / 14 / 20$ & 26.5 & \\
\hline 5148 & $813: 38$ & 13:38 & 26.5 & \\
\hline 5149 & $813: 40$ & $13: 40$ & 26.5 & \\
\hline & & $8 / 14 / 2$ & 26.5 & \\
\hline 5151 & $813: 44$ & $13: 44$ & 26.5 & 1052. \\
\hline 5152 & 13:46 & $8 / 14 / 2$ & & \\
\hline 5153 & $813: 48$ & $13: 48$ & 26.5 & \\
\hline 5154 & $813: 50$ & $8 / 14 / 2$ & 26.5 & 1052 \\
\hline & & $8 / 14 / 2$ & 26.5 & \\
\hline 5156 & & $13: 54$ & 26.5 & 1052. \\
\hline 5157 & 13:56 & $8 / 14 / 2$ & 26.5 & 1052. \\
\hline & $1 / 144$ & $8 / 14 / 2$ & 26.5 & \\
\hline 5159 & 14:00 & $8 / 14 / 2$ & 26.5 & 1051. \\
\hline 5160 & & $8 / 14 / 20$ & 26.5 & \\
\hline 5161 & & $14: 04$ & 26.6 & \\
\hline 5162 & 4:06 & 4:06 & 26.5 & 1051. \\
\hline 5163 & 14:08 & & 26.6 & \\
\hline 5164 & & $8 / 14 / 2$ & 26.5 & 1059 . \\
\hline 6 & 14:12 & & 26.3 & \\
\hline 66 & 14:14 & 4:14 & 26.2 & \\
\hline 5167 & & & 26.1 & 1059. \\
\hline 5168 & & & 6.1 & \\
\hline & & & 26.1 & \\
\hline 70 & 14:22 & & 26 & 1057 \\
\hline 5171 & $4: 24$ & & & \\
\hline & & & 26 & \\
\hline 5173 & & & 26 & \\
\hline & & & & \\
\hline & & & 26 & 1058 \\
\hline 5176 & & & & 1058 \\
\hline & & & 26.1 & \\
\hline$\pi$ & & & 26.1 & \\
\hline 5179 & & & 26.1 & \\
\hline & & & 6.1 & \\
\hline 5181 & & & & \\
\hline & & & 26.1 & \\
\hline 31 & & & 26. & \\
\hline 51 & & & 26.1 & \\
\hline & & & 26.1 & \\
\hline 5186 & & & 5.1 & \\
\hline 5187 & & & 2 & \\
\hline & & & & \\
\hline$\overline{5189}$ & & & 26.2 & \\
\hline 519 & & & 26.2 & \\
\hline 5191 & & & & \\
\hline 5192 & & & & \\
\hline 519 & & & & \\
\hline & 15:10 & $15: 10$ & 26.2 & \\
\hline & & & 26.2 & \\
\hline 5196 & & 15:14 & 26.2 & \\
\hline 5197 & & 15:16 & 26.2 & \\
\hline 5198 & & & 26.2 & \\
\hline 519 & & $15: 20$ & 26.2 & \\
\hline 5200 & & & 26.2 & \\
\hline 5201 & & & 26.2 & \\
\hline 5202 & & $8 / 14 / 200815 \cdot 26$ & & 00. \\
\hline
\end{tabular}

\begin{tabular}{|c|c|c|c|c|}
\hline \multicolumn{5}{|c|}{ D4-92c } \\
\hline $\operatorname{Rec}$ & & Adjusted & Temp & SC \\
\hline$\#$ & Date/Time & Date/Time & ${ }^{\circ} \mathrm{C}$ & $\mu \mathrm{S} / \mathrm{cm}$ \\
\hline 5203 & \begin{tabular}{|l|}
$1 / 14 / 200815: 28$ \\
\end{tabular} & $8 / 14 / 200815: 28$ & 26.2 & 1055.8 \\
\hline 5204 & 1/14/2008 15:30 & $8 / 14 / 2008$ 15:30 & 26.2 & 1057.6 \\
\hline 5205 & 1/14/2008 15:32 & $8 / 14 / 2008$ 15:32 & 26.3 & 1057.1 \\
\hline 5206 & 1/14/2008 15:34 & $8 / 14 / 2008$ 15:34 & 26.3 & 1056.3 \\
\hline 5207 & $1 / 14 / 200815: 36$ & $8 / 14 / 200815: 36$ & 26.3 & 1057 \\
\hline 5208 & $1 / 14 / 200815: 38$ & $8 / 14 / 200815: 38$ & 26.3 & 1057.2 \\
\hline 5209 & 1/14/2008 15:40 & $8 / 14 / 200815: 40$ & 26.3 & 1057.5 \\
\hline 5210 & $1 / 14 / 200815: 42$ & $8 / 14 / 2008$ 15:42 & 26.3 & 1056.7 \\
\hline 5211 & 1/14/2008 15:44 & $8 / 14 / 200815: 44$ & 26.3 & 1056.6 \\
\hline 5212 & $1 / 14 / 200815: 46$ & $8 / 14 / 200815: 46$ & 26.3 & 1056.6 \\
\hline 5213 & $1 / 14 / 200815: 48$ & $8 / 14 / 200815: 48$ & 26.3 & 1056.2 \\
\hline 5214 & $1 / 14 / 200815: 50$ & $8 / 14 / 200815: 50$ & 26.3 & 1056.8 \\
\hline 5215 & $1 / 14 / 200815: 52$ & $8 / 14 / 2008$ 15:52 & 26.3 & 1055.5 \\
\hline 5216 & $1 / 14 / 200815: 54$ & $8 / 14 / 2008$ 15:54 & 26.4 & 1056 \\
\hline 5217 & 1/14/2008 15:56 & $8 / 14 / 200815: 56$ & 26.3 & 1055.6 \\
\hline 5218 & $1 / 14 / 200815: 58$ & $8 / 14 / 200815: 58$ & 26.3 & 1055.5 \\
\hline 5219 & 1/14/2008 16:00 & $8 / 14 / 200816: 00$ & 26.3 & 1056 \\
\hline 5220 & 1/14/2008 16:02 & $8 / 14 / 200816: 02$ & 26.3 & 1055.7 \\
\hline 5221 & $1 / 14 / 2008$ 16:04 & $8 / 14 / 200816: 04$ & 26.3 & 1055.4 \\
\hline 5222 & 1/14/2008 16:06 & $8 / 14 / 200816: 06$ & 26.3 & 1055.2 \\
\hline 5223 & 1/144/2008 16:08 & $8 / 14 / 200816: 08$ & 26.3 & 1055.2 \\
\hline 5224 & 1/14/2008 16:10 & $8 / 14 / 2008$ 16:10 & 26.3 & 1056.3 \\
\hline 5225 & 1/14/2008 16:12 & $8 / 14 / 2008$ 16:12 & 26.3 & 1055.5 \\
\hline 5226 & $1 / 14 / 2008+6: 14$ & $8 / 14 / 2008$ 16:14 & 26.3 & 1054.8 \\
\hline 5227 & 1/14/2008 16:16 & $8 / 14 / 200816: 16$ & 26.3 & 1055.7 \\
\hline 5228 & $1 / 14 / 200816: 18$ & $8 / 14 / 2008$ 16:18 & 26.3 & 1055.6 \\
\hline 5229 & 1/14/2008 16:20 & $8 / 14 / 200816: 20$ & 26.3 & 1056 \\
\hline 5230 & 1/14/2008 16:22 & $8 / 14 / 200816: 22$ & 26.3 & 1055.4 \\
\hline 5231 & $1 / 14 / 200816: 24$ & \begin{tabular}{|l}
$8 / 14 / 200816: 24$ \\
\end{tabular} & 26.3 & 1054.9 \\
\hline 5232 & $1 / 14 / 200816: 26$ & $8 / 14 / 2008$ 16:26 & 26.4 & 1055.1 \\
\hline 5233 & $1 / 14 / 200816: 28$ & 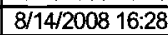 & 26.3 & 1055 \\
\hline 5234 & $1 / 14 / 200816: 30$ & 8/14/2008 16:30 & 26.3 & 1055.1 \\
\hline 5235 & $1 / 14 / 200816: 32$ & $8 / 14 / 200816: 32$ & 26.3 & 1054.9 \\
\hline 5236 & 1/14/2008 16:34 & \begin{tabular}{|l|}
$8 / 14 / 200816: 34$ \\
\end{tabular} & 26.4 & 1054.6 \\
\hline 5237 & $1 / 14 / 200816: 36$ & \begin{tabular}{|l}
$8 / 14 / 200816: 36$ \\
\end{tabular} & 26.4 & 1054.4 \\
\hline 5238 & $1 / 14 / 200816: 38$ & $8 / 14 / 2008$ 16:38 & 26.3 & 1054.9 \\
\hline 5239 & $1 / 14 / 200816: 40$ & \begin{tabular}{|l|}
$8 / 14 / 200816: 40$ \\
\end{tabular} & 26.4 & 1054.8 \\
\hline 5240 & $1 / 14 / 2008$ 16:42 & $8 / 14 / 2008$ 16:42 & 26.4 & 1054.7 \\
\hline 5241 & $1 / 14 / 200816: 44$ & $8 / 14 / 2008$ 16:44 & 26.4 & 1054.5 \\
\hline 5242 & 1/14/2008 16:46 & $8 / 14 / 200816: 46$ & 26.4 & 1056.1 \\
\hline 5243 & $1 / 14 / 2008$ 16:48 & $8 / 14 / 2008 \quad 16: 48$ & 26.4 & 1055.9 \\
\hline 5244 & 1/14/2008 16:50 & 8/14/2008 16:50 & 26.4 & 1055.5 \\
\hline 5245 & $1 / 14 / 200816: 52$ & $8 / 14 / 200816: 52$ & 26.4 & 1055.9 \\
\hline 5246 & $1 / 14 / 200816: 54$ & \begin{tabular}{|l|}
$8 / 14 / 200816: 54$ \\
\end{tabular} & 26.4 & 1055.5 \\
\hline 5247 & $1 / 14 / 2008$ 16:56 & 8/14/2008 16:56 & 26.4 & 1055.5 \\
\hline 5248 & $1 / 14 / 200816: 58$ & $8 / 14 / 200816: 58$ & 26.4 & 1055.6 \\
\hline 5249 & 1/14/2008 17:00 & $8 / 14 / 200817: 00$ & 26.4 & 1055.1 \\
\hline 5250 & $1 / 14 / 200817: 02$ & 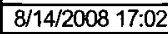 & 26.4 & 1055.5 \\
\hline 5251 & 1/144/2008 17:04 & 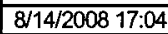 & 26.4 & 1055.2 \\
\hline 5252 & t/144/2008 17:06 & $8 / 14 / 2008 \quad 17: 06$ & 26.4 & 1055.3 \\
\hline 5253 & 1/14/2008 17:08 & $8 / 14 / 200817: 08$ & 26.4 & 1055.2 \\
\hline 5254 & 1/144/2008 17:10 & 8/14/2008 17:10 & 26.4 & 1054.7 \\
\hline 5255 & 1/14/2008 17:12 & $8 / 14 / 200817: 12$ & 26.4 & 1054.6 \\
\hline 5256 & $1 / 14 / 2008 \quad 17: 14$ & \begin{tabular}{|l|}
$8 / 14 / 2008$ 17:14 \\
\end{tabular} & 26.4 & 1054.3 \\
\hline 5257 & 1/14/2008 17:16 & $8 / 14 / 2008 \quad 17: 16$ & 26.4 & 1054.5 \\
\hline 5258 & 1/14/2008 17:18 & \begin{tabular}{|l}
$8 / 14 / 2008 \quad 17: 18$ \\
\end{tabular} & 26.4 & 1054.3 \\
\hline 5259 & $1 / 14 / 200817: 20$ & $8 / 14 / 200817: 20$ & 26.4 & 1053.6 \\
\hline 5260 & $1 / 14 / 200817: 22$ & \begin{tabular}{|l|}
$8 / 14 / 200817: 22$ \\
\end{tabular} & 26.4 & $1055 . \overline{6}$ \\
\hline 5261 & $1 / 14 / 2008$ 17:24 & \begin{tabular}{|l|}
$8 / 14 / 2008 \quad 17: 24$ \\
\end{tabular} & 26.4 & 1055.5 \\
\hline 5262 & 1/14/2008 17:26 & \begin{tabular}{|l|}
$8 / 14 / 200817: 26$ \\
\end{tabular} & 26.4 & 1055.3 \\
\hline 5263 & $1 / 14 / 2008$ 17:28 & \begin{tabular}{|l|}
$8 / 14 / 2008 \quad 17: 28$ \\
\end{tabular} & 26.4 & 1055.1 \\
\hline 5264 & $1 / 14 / 2008$ 17:30 & $8 / 14 / 2008 \quad 17: 30$ & 26.3 & 1070.4 \\
\hline 5265 & $1 / 14 / 200817: 32$ & $8 / 14 / 2008$ 17:32 & 26.4 & 1069.9 \\
\hline 5266 & $1 / 14 / 2008$ 17:34 & 8/14/2008 17:34 & 26.4 & 1069.3 \\
\hline 5267 & $1 / 14 / 2008$ 17:36 & \begin{tabular}{|l|l|}
$8 / 14 / 2008$ & $17: 36$ \\
\end{tabular} & 26.4 & 1070.2 \\
\hline 5268 & $1 / 14 / 2008$ 17:38 & \begin{tabular}{|l|l|l}
$8 / 14 / 2008$ & $17: 38$ \\
\end{tabular} & 26.3 & 1070.4 \\
\hline 5269 & $1 / 14 / 2008$ 17:40 & \begin{tabular}{|l|}
$8 / 14 / 2008 \quad 17: 40$ \\
\end{tabular} & 26.3 & 1069.9 \\
\hline 5270 & $1 / 14 / 200817: 42$ & \begin{tabular}{|l|}
$8 / 14 / 200817: 42$ \\
\end{tabular} & 26.3 & 1070.2 \\
\hline 5271 & \begin{tabular}{|l|}
$1 / 14 / 200817: 44$ \\
\end{tabular} & $8 / 14 / 200817: 44$ & 26.3 & 1070.7 \\
\hline
\end{tabular}

\begin{tabular}{|c|c|c|c|c|}
\hline \multicolumn{5}{|c|}{ D4-92c } \\
\hline $\operatorname{Rec}$ & & Adjusted & Temp & SC \\
\hline$\#$ & Date/Time & Date/Time & ${ }^{\circ} \mathrm{C}$ & $\mu \mathrm{S} / \mathrm{cm}$ \\
\hline 5272 & 1/14/2008 17:46 & $8 / 14 / 200817: 46$ & & \\
\hline 5273 & 1/14/2008 17:48 & $8 / 14 / 200817: 48$ & 26.4 & 1070. \\
\hline 274 & & $14 / 2008$ 17:50 & & \\
\hline 275 & $8817: 52$ & $8 / 14 / 2008$ 17:52 & 26.5 & 1068.7 \\
\hline 276 & 1/14/2008 17:54 & $8 / 14 / 2008$ 17:54 & 26.3 & 1066. \\
\hline & $1 / 14 / 2008$ 17:56 & $8 / 14 / 200817: 56$ & 26.1 & \\
\hline 278 & $1 / 14 / 200817: 58$ & $8 / 14 / 200817: 58$ & 26 & 1066.8 \\
\hline & 318:00 & $8 / 14 / 2008$ 18:00 & 25.9 & \\
\hline 5280 & $318: 02$ & 8/14/2008 18:02 & 25.9 & 1067.8 \\
\hline 281 & $818: 04$ & 8/14/2008 18:04 & 25.9 & 1067 \\
\hline & & 8/14/2008 18:06 & & \\
\hline 5283 & $318: 08$ & 8/14/2008 18:08 & 25.9 & 1067. \\
\hline 5284 & $18: 10$ & $8 / 14 / 20$ & 26 & 1066.8 \\
\hline & & 8/14/2008 18:12 & 26 & \\
\hline 286 & $818: 14$ & $8 / 14 / 2008$ 18:14 & 25.9 & 1066.2 \\
\hline 287 & 18:16 & $8 / 14 / 20$ & 26 & 1065.7 \\
\hline & & & 26 & \\
\hline 289 & $18: 20$ & $318: 20$ & 26 & 1065.1 \\
\hline & $18: 22$ & $8 / 14 / 20$ & 26 & \\
\hline 291 & 18:24 & $8 / 14 / 20$ & 26.1 & \\
\hline 992 & 18:26 & $18: 26$ & 26 & 1064.7 \\
\hline & $18: 28$ & & 26 & \\
\hline 294 & $18: 30$ & 18:30 & 26 & 1065.4 \\
\hline 295 & $18: 32$ & $8: 32$ & 26.1 & \\
\hline 296 & $18: 34$ & & 26.1 & \\
\hline 297 & $18: 36$ & $8 / 14 / 2$ & 26.1 & 1064. \\
\hline 298 & $8: 38$ & & 26.1 & \\
\hline & $18: 40$ & $18: 40$ & 26 & \\
\hline 300 & $48: 42$ & & 26 & 1064. \\
\hline 301 & $8: 44$ & & 26 & 1064. \\
\hline 02 & $18: 46$ & & 26 & 1064. \\
\hline 03 & $8: 48$ & & 26 & 1064. \\
\hline 5304 & 18:50 & & 26.1 & 1064. \\
\hline 5305 & & & 26.1 & \\
\hline 5306 & & & 26.1 & \\
\hline 307 & & & 26.1 & \\
\hline 08 & & & 26.1 & 1064. \\
\hline 5309 & 19:00 & & 26.2 & 1063. \\
\hline 5310 & & & 26. & \\
\hline 5311 & $9: 04$ & & 26.2 & 1063 \\
\hline 5312 & & & 26.1 & \\
\hline 5313 & & & 26.2 & 1063. \\
\hline 5314 & & & 26.2 & 1064. \\
\hline 315 & & & 26. & \\
\hline 5316 & & & 26.2 & \\
\hline 5317 & & & 26.2 & \\
\hline 318 & & & 26.2 & \\
\hline 5319 & & & 26.2 & \\
\hline 53 & & & 26. & \\
\hline 5.321 & & & 26.2 & \\
\hline 5322 & & & 26.2 & \\
\hline 23 & & & 26.2 & \\
\hline 5324 & & & 26.2 & 1064. \\
\hline 5325 & & & 26. & \\
\hline 5326 & & & 26. & \\
\hline 5327 & 19:36 & 19:36 & 26.1 & 1064. \\
\hline 5328 & & & 26.1 & \\
\hline 5329 & & & 26. & \\
\hline 5330 & & & 26. & \\
\hline 5331 & & & 26.2 & \\
\hline 5332 & & $19: 46$ & 26.2 & 1064. \\
\hline 5333 & & & 26.2 & \\
\hline 5334 & & & 26. & \\
\hline 5335 & $19: 52$ & 19:52 & 26.1 & \\
\hline 5336 & & & 26.2 & \\
\hline 5337 & & & 26.2 & \\
\hline 5338 & $19: 58$ & $819: 58$ & 26.2 & \\
\hline 5339 & & & 26.2 & \\
\hline & & & & \\
\hline
\end{tabular}


DOE/RL-2009-35, REV. 0

\begin{tabular}{|c|c|c|c|c|}
\hline \multicolumn{5}{|c|}{ D4-92c } \\
\hline $\operatorname{Rec}$ & & Adjusted & Temp & SC \\
\hline \# & Date Time & Date/Time & ${ }^{\circ} \mathrm{C}$ & $\mu \mathrm{S} / \mathrm{cm}$ \\
\hline 5341 & 1/14/200820:04 & $8 / 14 / 200820: 04$ & 26.3 & 1063.2 \\
\hline 5342 & 1/14/2008 20:06 & $8 / 14 / 200820: 06$ & 26.3 & 1059.8 \\
\hline 5343 & 1/14/2008 20:08 & $8 / 14 / 200820: 08$ & 26.2 & 1064 \\
\hline 5344 & 1/14/2008 20:10 & $8 / 14 / 200820: 10$ & 26.2 & 1063.7 \\
\hline 5345 & $1 / 14 / 200820: 12$ & $8 / 14 / 200820: 12$ & 26.2 & 1063.3 \\
\hline 5346 & 1/14/2008 20:14 & $8 / 14 / 200820: 14$ & 26.2 & 1062.7 \\
\hline 5347 & 1/14/200820:16 & $8 / 14 / 200820: 16$ & 26.2 & 1063 \\
\hline 5348 & 1/14/2008 20:18 & $8 / 14 / 200820: 18$ & 26.2 & 1063 \\
\hline 5349 & 1/14/200820:20 & $8 / 14 / 200820: 20$ & 26.2 & 1063 \\
\hline 5350 & 1/14/200820:22 & $8 / 14 / 200820: 22$ & 26.2 & 1063 \\
\hline 5351 & $1 / 14 / 200820: 24$ & $8 / 14 / 200820: 24$ & 26.2 & 1063.4 \\
\hline 5352 & $1 / 14 / 200820: 26$ & $8 / 14 / 200820: 26$ & 26.2 & 1063.1 \\
\hline 5353 & $1 / 14 / 200820: 28$ & $8 / 14 / 200820: 28$ & 26.2 & 1063.4 \\
\hline 5354 & $1 / 14 / 200820: 30$ & $8 / 14 / 200820: 30$ & 26.2 & 1063.4 \\
\hline 5355 & $1 / 14 / 200820: 32$ & $8 / 14 / 200820: 32$ & 26.2 & 1063.8 \\
\hline 5356 & 1/14/2008 20:34 & $8 / 14 / 200820: 34$ & 26.2 & 1064 \\
\hline 5357 & $1 / 14 / 200820: 36$ & 8/14/2008 20:36 & 26.2 & 1063.8 \\
\hline 5358 & $1 / 14 / 200820: 38$ & $8 / 14 / 200820: 38$ & 26.2 & 1063.4 \\
\hline 5359 & $1 / 14 / 200820: 40$ & $8 / 14 / 200820: 40$ & 26.2 & 1064 \\
\hline 5360 & 1/14/2008 20:42 & $8 / 14 / 200820: 42$ & 26.2 & 1064 \\
\hline 5361 & $1 / 14 / 200820: 44$ & $8 / 14 / 200820: 44$ & 26.2 & 1063.8 \\
\hline 5362 & $1 / 14 / 200820: 46$ & $8 / 14 / 200820: 46$ & 26.2 & 1063.5 \\
\hline 5363 & $1 / 14 / 200820: 48$ & $8 / 14 / 200820: 48$ & 26.2 & 1063 \\
\hline 5364 & $1 / 14 / 200820: 50$ & $8 / 14 / 200820: 50$ & 26.2 & 1063.2 \\
\hline 5365 & $1 / 14 / 200820: 52$ & $8 / 14 / 200820: 52$ & 26.2 & 1063.7 \\
\hline 5366 & $1 / 14 / 200820: 54$ & $8 / 14 / 200820: 54$ & 26.3 & 1063.2 \\
\hline 5367 & 1/14/200820:56 & $8 / 14 / 200820: 56$ & 26.3 & 1062.8 \\
\hline 5368 & $1 / 14 / 200820: 58$ & $8 / 14 / 200820: 58$ & 26.3 & 1063.1 \\
\hline 5369 & 1/14/2008 21:00 & $8 / 14 / 200821: 00$ & 26.3 & 1063.6 \\
\hline 5370 & 1/14/200821:02 & $8 / 14 / 200821: 02$ & 26.2 & 1063.7 \\
\hline 5371 & 1/14/2008 21:04 & $8 / 14 / 200821: 04$ & 26.2 & 1064 \\
\hline 5372 & 1/14/200821:06 & $8 / 14 / 200821: 06$ & 26.3 & 1063.2 \\
\hline 5373 & 1/14/2008 21:08 & $8 / 14 / 200821: 08$ & 26.3 & 1063.5 \\
\hline 5374 & 1/14/200821:10 & $8 / 14 / 200821: 10$ & 26.2 & 1063.8 \\
\hline 5375 & 1/14/2008 21:12 & $8 / 14 / 200821: 12$ & 26.2 & 1063.5 \\
\hline 5376 & $1 / 14 / 200821: 14$ & $8 / 14 / 200821: 14$ & 26.2 & 1064 \\
\hline 5377 & 1/14/2008 21:16 & $8 / 14 / 200821: 16$ & 26.2 & 1064.1 \\
\hline 5378 & 1/14/2008 21:18 & $8 / 14 / 200821: 18$ & 26.3 & 1063.5 \\
\hline 5379 & 1/14/2008 21:20 & $8 / 14 / 200821: 20$ & 26.3 & 1064.1 \\
\hline 5380 & 1/14/2008 21:22 & $8 / 14 / 200821: 22$ & 26.3 & 1063.9 \\
\hline 5381 & $1 / 14 / 200821: 24$ & $8 / 14 / 200821: 24$ & 26.3 & 1063.5 \\
\hline 5382 & $1 / 14 / 200821: 26$ & $8 / 14 / 200821: 26$ & 26.3 & 1063.9 \\
\hline 5383 & $1 / 14 / 200821: 28$ & $8 / 14 / 200821: 28$ & 26.3 & 1063.5 \\
\hline 5384 & $1 / 14 / 200821: 30$ & $8 / 14 / 200821: 30$ & 26.2 & 1064 \\
\hline 5385 & 1/14/2008 21:32 & $8 / 14 / 200821: 32$ & 26.2 & 1063.9 \\
\hline 5386 & $1 / 14 / 200821: 34$ & $8 / 14 / 200821: 34$ & 26.2 & 1063.8 \\
\hline 5387 & $1 / 14 / 200821: 36$ & $8 / 14 / 200821: 36$ & 26.2 & 1063.1 \\
\hline 5388 & 1/14/2008 21:38 & $8 / 14 / 200821: 38$ & 26.2 & 1063.3 \\
\hline 5389 & $1 / 14 / 200821: 40$ & \begin{tabular}{|l|}
$8 / 14 / 200821: 40$ \\
\end{tabular} & 26.2 & 1063 \\
\hline 5390 & 1/14/200821:42 & $8 / 14 / 200821: 42$ & 26.2 & 1063.2 \\
\hline 5391 & 1/14/2008 21:44 & $8 / 14 / 200821: 44$ & 26.2 & 1064.6 \\
\hline 5392 & $1 / 14 / 200821: 46$ & $8 / 14 / 200821: 46$ & 26.2 & 1063.5 \\
\hline 5393 & $1 / 14 / 200821: 48$ & $8 / 14 / 200821: 48$ & 26.2 & 1062.8 \\
\hline 5394 & $1 / 14 / 200821: 50$ & $8 / 14 / 200821: 50$ & 26.2 & 1063.1 \\
\hline 5395 & $1 / 14 / 200821: 52$ & $8 / 14 / 200821: 52$ & 26.2 & 1063.1 \\
\hline 5396 & $1 / 14 / 200821: 54$ & $8 / 14 / 200821: 54$ & 26.2 & 1063.3 \\
\hline 5397 & 1/14/200821:56 & $8 / 14 / 200821: 56$ & 26.2 & 1063.2 \\
\hline 5398 & $1 / 14 / 200821: 58$ & $8 / 14 / 200821: 58$ & 26.2 & 1062.9 \\
\hline 5399 & 1/14/2008 22:00 & \begin{tabular}{|l|l|}
$8 / 14 / 200822: 00$ \\
\end{tabular} & 26.2 & 1064.7 \\
\hline 5400 & 1/14/2008 22:02 & $8 / 14 / 200822: 02$ & 26.2 & 1062.8 \\
\hline 5401 & 1/14/2008 22:04 & $8 / 14 / 200822: 04$ & 26.2 & 1063.4 \\
\hline 5402 & 1/14/2008 22:06 & $8 / 14 / 200822: 06$ & 26.2 & 1063.4 \\
\hline 5403 & 1/14/2008 22:08 & $8 / 14 / 200822: 08$ & 26.2 & 1063.4 \\
\hline 5404 & $1 / 14 / 200822: 10$ & $8 / 14 / 200822: 10$ & 26.2 & 1062.9 \\
\hline 5405 & 1/14/2008 22:12 & $8 / 14 / 200822: 12$ & 26.2 & 1062.5 \\
\hline 5406 & 1/14/2008 22:14 & 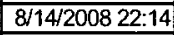 & 26.2 & 1063.1 \\
\hline 5407 & 1/14/2008 22:16 & 8/14/2008 22:16 & 26.3 & 1062.5 \\
\hline 5408 & 1/14/2008 22:18 & \begin{tabular}{|l|}
$8 / 14 / 200822: 18$ \\
\end{tabular} & 26.2 & 1063.2 \\
\hline 5409 & $1 / 14 / 200822: 20$ & \begin{tabular}{|l|}
$8 / 14 / 200822: 20$ \\
\end{tabular} & 26.2 & 1063.6 \\
\hline
\end{tabular}

\begin{tabular}{|c|c|c|c|c|}
\hline \multicolumn{5}{|c|}{ D4-92C } \\
\hline $\operatorname{Rec}$ & & Adjusted & & \\
\hline$\#$ & DaterTime & Date/Time & ${ }^{\circ} \mathrm{C}$ & $\mathrm{\mu S} / \mathrm{cm}$ \\
\hline 410 & 1/14/2008 22:22 & $8 / 14 / 200822: 22$ & 26.2 & \\
\hline 411 & & & & 1063.1 \\
\hline 5412 & $14 / 200822: 26$ & $8 / 14 / 200822: 26$ & 26.2 & \\
\hline 5413 & $1 / 14 / 200822: 28$ & $8 / 14 / 200822: 28$ & 26.2 & 1063 \\
\hline & $1 / 14 / 200822: 30$ & $8 / 14 / 200822: 30$ & 26.2 & \\
\hline 5415 & $1 / 14 / 200822: 32$ & $8 / 14 / 200822: 32$ & 26.2 & 1063. \\
\hline 5416 & $1 / 14 / 200822: 34$ & $8 / 14 / 200822: 34$ & & \\
\hline 17 & $1 / 14 / 200822: 36$ & $8 / 14 / 200822: 36$ & 26.2 & 1063. \\
\hline 418 & 1/14/2008 22:38 & $8 / 14 / 200822: 38$ & 26.2 & 106 \\
\hline & & $8 / 14 / 200822: 40$ & & \\
\hline 5420 & $1 / 14 / 200822: 42$ & $8 / 14 / 200822: 42$ & 26.2 & 1062. \\
\hline 5421 & $1 / 14 / 200822: 44$ & $8 / 14 / 200822: 44$ & 26.2 & 1062. \\
\hline & & $8 / 14 / 200822: 46$ & & \\
\hline 5423 & $1 / 14 / 200822: 48$ & $8 / 14 / 200822: 48$ & 26.2 & 1062 \\
\hline 5424 & $1 / 14 / 20$ & $8 / 14 / 200822: 50$ & 26.2 & 1062. \\
\hline & $1 / 14 / 20$ & $8 / 14 / 200822: 52$ & & \\
\hline 5426 & $1 / 14 / 200822: 54$ & $8 / 14 / 200822: 54$ & 26.2 & 1062. \\
\hline & $822: 56$ & $8 / 14 / 200822: 56$ & 26.2 & \\
\hline 5428 & $1 / 14 / 200822: 58$ & $8 / 14 / 200822 ; 58$ & 26.2 & \\
\hline 5429 & $1 / 14 / 200823: 00$ & 8/14/2008 23:00 & 26.2 & 1062. \\
\hline 130 & & & 26.2 & \\
\hline 5431 & $1 / 14 / 20$ & $823: 04$ & 26.2 & \\
\hline 5432 & $23: 06$ & $823: 06$ & 26.2 & 1066. \\
\hline 5433 & $1 / 14 / 2$ & & 26.2 & \\
\hline 5434 & $23: 10$ & $823: 10$ & 25.9 & 1061. \\
\hline 5435 & & & 25.9 & \\
\hline 5436 & $1 / 14 / 2$ & $823: 14$ & 25.7 & \\
\hline 5437 & $23: 16$ & $23: 16$ & 25.7 & 1064. \\
\hline 5438 & & $823: 18$ & 25.6 & \\
\hline 5439 & $23: 20$ & $823: 20$ & 25.7 & \\
\hline 5440 & $23: 22$ & $23: 22$ & 25.7 & \\
\hline 5441 & $23: 24$ & $23: 24$ & 25.7 & \\
\hline 5442 & $23: \overline{26}$ & $23: 26$ & 25.7 & 1061. \\
\hline 5443 & & $23: 28$ & 25. & \\
\hline 5444 & & $23: 30$ & 25.7 & \\
\hline 45 & $3: 32$ & $23: 32$ & 25.7 & 106 \\
\hline 5446 & $23: 34$ & $23: 34$ & 25.7 & \\
\hline 5447 & $23: 36$ & $23: 36$ & 25.7 & \\
\hline 5448 & & $23: 38$ & 25. & \\
\hline 5449 & $3: 40$ & $23: 40$ & 25.7 & \\
\hline 5450 & & $23: 42$ & 25.7 & \\
\hline 5451 & & $23: 44$ & 25.7 & \\
\hline 5452 & & $23: 46$ & 25.7 & 1063 \\
\hline 53 & & $23: 48$ & 25 & \\
\hline 5454 & $23: 50$ & $23: 50$ & 25.8 & \\
\hline 5455 & & & 25.8 & \\
\hline 5456 & & $23: 54$ & 25 . & \\
\hline 5457 & & $23: 56$ & 25.8 & \\
\hline 5458 & & $23: 58$ & 25.8 & \\
\hline 5459 & & $30: 00$ & 25.8 & \\
\hline & & & 25.8 & \\
\hline 546 & & & 25.8 & \\
\hline & & & 25. & \\
\hline 5463 & & & 25 & \\
\hline 5464 & & & 25.8 & \\
\hline & & & 25.8 & \\
\hline 466 & & & & \\
\hline & & & 25.8 & \\
\hline & & & & \\
\hline 5469 & $0: 20$ & $30: 20$ & 25.8 & \\
\hline & & & 25.8 & \\
\hline$\overline{5}$ & & & & \\
\hline 772 & & & 25.8 & \\
\hline & & & 25.8 & \\
\hline 474 & $0: 30$ & $8 / 15 / 20080: 30$ & & \\
\hline & & & 25.8 & \\
\hline & & & 25.8 & \\
\hline 5477 & $80: 36$ & $0080: 36$ & 25.8 & \\
\hline & & & & \\
\hline
\end{tabular}

\begin{tabular}{|c|c|c|c|c|}
\hline \multicolumn{5}{|c|}{ D4-92C } \\
\hline $\operatorname{Rec}$ & & Adjusted & Temp & SC \\
\hline$\#$ & Date/Time & DaterTime & ${ }^{\circ} \mathrm{C}$ & $\mu \mathrm{S} / \mathrm{cm}$ \\
\hline 479 & $1 / 15 / 20080: 40$ & $8 / 15 / 20080: 40$ & 25.9 & \\
\hline 5480 & $15 / 20080: 42$ & $8 / 15 / 20080: 42$ & 25.9 & 1065.6 \\
\hline & & $8 / 15 / 20080: 44$ & 25.9 & \\
\hline 5482 & $15 / 20080: 46$ & $8 / 15 / 20080: 46$ & 25.9 & 1065. \\
\hline 5483 & $5 / 20$ & $8 / 15 / 20080: 48$ & 25.9 & 1064.8 \\
\hline 5484 & & $8 / 15 / 20080: 50$ & 25.9 & \\
\hline 5485 & $1 / 15 / 20080: 52$ & $8 / 15 / 20080: 52$ & 25.9 & 1065.6 \\
\hline 5486 & $1 / 15 / 200$ & $8 / 15 / 20080: 54$ & 25.9 & 1065.4 \\
\hline 5487 & $1 / 15 / 200$ & $8 / 15 / 20080: 56$ & 25.9 & \\
\hline 5488 & $1 / 15 / 20080: 58$ & $8 / 15 / 20080: 58$ & 25.9 & 1065.5 \\
\hline 5489 & $1 / 15 / 20$ & $8 / 15 / 20081: 00$ & 25.9 & \\
\hline 5490 & $15 / 20$ & $8 / 15 / 20081: 02$ & 25.9 & 1066.4 \\
\hline 5491 & $1 / 15 / 20$ & $8 / 15 / 20081: 04$ & 25.9 & 1065.9 \\
\hline 5492 & $1 / 15 / 20$ & $8 / 15 / 20081: 06$ & 25.9 & 1065.8 \\
\hline 5493 & $1 / 15 / 200$ & $8 / 15 / 20081: 08$ & 25.9 & 106 \\
\hline 5494 & $1 / 15 / 20$ & $8 / 15 / 20081: 10$ & 25.9 & 1065.9 \\
\hline 5495 & $1 / 15 / 20$ & & 25.9 & \\
\hline 5496 & $1 / 15 / 20$ & $8 / 15 / 20081: 14$ & 25.9 & 1065.7 \\
\hline 5497 & $1 / 15 / 2$ & $8 / 15 / 20081: 16$ & 25.9 & 1065.9 \\
\hline 5498 & $1 / 15 / 2$ & $8 / 15 / 20081: 18$ & 25.9 & \\
\hline 5499 & $1 / 15 / 2 C$ & $8 / 15 / 20081: 20$ & 25.9 & 1065.7 \\
\hline 5500 & $1 / 15 / 20$ & $8 / 15 / 20081: 22$ & 25.9 & 1065.7 \\
\hline 5501 & $1 / 15 / 20$ & $8 / 15 / 20$ & 25.9 & $106 t$ \\
\hline 5502 & $1 / 15 / 2$ & $8 / 15 / 20$ & 25.9 & 1065.2 \\
\hline 5503 & $1 / 15 / 2$ & $8 / 15 / 20$ & 25.9 & \\
\hline 5504 & $1 / 15 / 20$ & $8 / 15 / 20081: 30$ & 25.9 & 1065. \\
\hline 5505 & $1 / 15 / 2$ & $8 / 15 / 2$ & 25.9 & 1065. \\
\hline 5506 & $1 / 15 / 2$ & $8 / 15 / 20$ & 26 & 1065. \\
\hline 5507 & & & 26 & 1065 . \\
\hline 5508 & $1 / 15 / 2$ & $8 / 15 / 2$ & 26 & \\
\hline 5509 & $1 / 15 / 2 C$ & $8 / 15 / 2$ & 26 & 1064. \\
\hline 5510 & $1 / 15$ & & 26 & 1065. \\
\hline 5511 & $1 / 15 / 2$ & $8 / 15 / 2$ & 26 & 1065. \\
\hline 5512 & & & 26 & 1065. \\
\hline 5513 & $1 / 15 / 2$ & $8 / 15 / 2$ & 26 & 1065. \\
\hline 5514 & $1 / 15 / 2$ & $8 / 15 / 200$ & 26 & 1065. \\
\hline 5515 & & & 26 & 1065. \\
\hline 5516 & & $8 / 15$ & 26 & 1065. \\
\hline 5517 & & & 26 & 1065. \\
\hline 518 & $1 / 15$ & & 26 & 1065. \\
\hline 5519 & & & $\underline{26}$ & 1065. \\
\hline 5520 & & & & 106 \\
\hline 5521 & & $8 / 1$ & & 106 \\
\hline 5522 & & & 26 & 1064. \\
\hline 623. & & & 26 & 1064. \\
\hline 5524 & & & & 1064. \\
\hline 5525 & & & & \\
\hline 5526 & & $8 / 15$ & & 1064 \\
\hline 5527 & & & 26 & \\
\hline 528 & & & 26 & 1065. \\
\hline 5529 & & & & 106 \\
\hline 5530 & & & & \\
\hline 5531 & & & & \\
\hline 632 & & $2: 26$ & 26 & \\
\hline 5533 & & & & \\
\hline 5534 & & $8 / 15 / 2$ & 26 & 1065. \\
\hline 5535 & & & & \\
\hline 5536 & & & & \\
\hline 5537 & & $2: 36$ & 26 & 1064. \\
\hline 538 & & & & \\
\hline 5539 & & & $t$ & \\
\hline 5540 & & & 26 & \\
\hline 5541 & & & & \\
\hline 5542 & & $82: 46$ & 26 & \\
\hline 5543 & & $8 / 15 / 2 C$ & 26 & \\
\hline 5544 & & & & \\
\hline 554 & & $8 / 15 / 20082: 52$ & 25.9 & \\
\hline 5546 & & $8 / 15 / 20082: 54$ & 26 & \\
\hline 554 & & $8 / 15 / 20082: 56$ & 26 & 1063 \\
\hline
\end{tabular}


DOE/RL-2009-35, REV. 0

\begin{tabular}{|c|c|c|c|c|}
\hline \multicolumn{5}{|c|}{$D 4-92 c$} \\
\hline $\operatorname{Rec}$ & & Adjusted & Temp & SC \\
\hline$\#$ & Date/Time & DaterTime & ${ }^{\circ} \mathrm{C}$ & $\mu \mathrm{S} / \mathrm{cm}$ \\
\hline 5548 & $1 / 15 / 20082: 58$ & $8 / 15 / 20082: 58$ & 26 & 1063.7 \\
\hline 5549 & 1/15/2008 3:00 & $8 / 15 / 20083: 00$ & 26 & 1063.7 \\
\hline 5550 & 1/15/2008 3:02 & $8 / 15 / 20083: 02$ & 25.9 & 1064.2 \\
\hline 5551 & 1/15/2008 3:04 & $8 / 15 / 20083: 04$ & 25.9 & 1064.7 \\
\hline 5552 & 1/15/2008 3:06 & $8 / 15 / 20083: 06$ & 25.9 & 1063.3 \\
\hline 5553 & 1/15/2008 3:08 & 8/15/2008 3:08 & 25.9 & 1063.3 \\
\hline 5554 & $1 / 15 / 20083: 10$ & $8 / 15 / 20083: 10$ & 25.9 & 1063.4 \\
\hline 5555 & $1 / 15 / 20083: 12$ & $8 / 15 / 20083: 12$ & 25.9 & 1063.5 \\
\hline 5556 & 1/15/2008 3:14 & $8 / 15 / 20083: 14$ & 25.9 & 1063.5 \\
\hline 5557 & 1/15/2008 3:16 & $8 / 15 / 20083: 16$ & 25.9 & 1063.5 \\
\hline 5558 & 1/15/2008 3:18 & $8 / 15 / 20083: 18$ & 25.9 & 1063.4 \\
\hline 5559 & $1 / 15 / 20083: 20$ & $8 / 15 / 20083: 20$ & 25.9 & 1063.9 \\
\hline 5560 & $1 / 15 / 20083: 22$ & $8 / 15 / 20083: 22$ & 25.9 & 1063.8 \\
\hline 5561 & $1 / 15 / 20083: 24$ & $8 / 15 / 20083: 24$ & 26 & 1063.8 \\
\hline 5562 & $1 / 15 / 20083: 26$ & $8 / 15 / 20083: 26$ & 26 & 1062.2 \\
\hline 5563 & $1 / 15 / 20083: 28$ & $8 / 15 / 20083: 28$ & 25.9 & 1062.9 \\
\hline 5564 & 1/15/2008 3:30 & $8 / 15 / 20083: 30$ & 25.9 & 1062.6 \\
\hline 5565 & $1 / 15 / 20083: 32$ & $8 / 15 / 20083: 32$ & 25.9 & 1063.1 \\
\hline 5566 & $1 / 15 / 20083: 34$ & $8 / 15 / 20083: 34$ & 25.9 & 1063 \\
\hline 5567 & $1 / 15 / 20083: 36$ & $8 / 15 / 20083: 36$ & 26 & 1063.2 \\
\hline 5568 & $1 / 15 / 20083: 38$ & $8 / 15 / 20083: 38$ & 26 & 1063.8 \\
\hline 5569 & $1 / 15 / 20083: 40$ & $8 / 15 / 20083: 40$ & 25.9 & 1063.4 \\
\hline 5570 & $1 / 15 / 20083: 42$ & $8 / 15 / 20083: 42$ & 26 & 1063.8 \\
\hline 5571 & $1 / 15 / 20083: 44$ & $8 / 15 / 20083: 44$ & 26 & 1063.8 \\
\hline 5572 & $1 / 15 / 20083: 46$ & $8 / 15 / 20083: 46$ & 26 & 1064 \\
\hline 5573 & $1 / 15 / 20083: 48$ & $8 / 15 / 20083: 48$ & 26 & 1063.5 \\
\hline 5574 & $1 / 15 / 20083: 50$ & $8 / 15 / 20083: 50$ & 26 & 1063.7 \\
\hline 5575 & $1 / 15 / 20083: 52$ & $8 / 15 / 20083: 52$ & 25.9 & 1063.8 \\
\hline 5576 & $1 / 15 / 20083: 54$ & $8 / 15 / 20083: 54$ & 26 & 1064.1 \\
\hline 5577 & 1/15/2008 3:56 & $8 / 15 / 20083: 56$ & 25.9 & 1064.3 \\
\hline 5578 & $1 / 15 / 20083: 58$ & $8 / 15 / 20083: 58$ & 26 & 1063.5 \\
\hline 5579 & $1 / 15 / 20084: 00$ & $8 / 15 / 20084: 00$ & 26 & 1063.8 \\
\hline 5580 & $1 / 15 / 20084: 02$ & $8 / 15 / 20084: 02$ & 26 & 1063.8 \\
\hline 5581 & 1/15/2008 4:04 & $8 / 15 / 20084: 04$ & 25.9 & 1063.9 \\
\hline 5582 & 1/15/2008 4:06 & $8 / 15 / 20084: 06$ & 26 & 1063.7 \\
\hline 5583 & $1 / 15 / 20084: 08$ & $8 / 15 / 20084: 08$ & 25.9 & 1063.6 \\
\hline 5584 & $1 / 15 / 20084: 10$ & $8 / 15 / 20084: 10$ & 25.9 & 1064 \\
\hline 5585 & $1 / 15 / 20084: 12$ & $8 / 15 / 20084: 12$ & 25.9 & 1064 \\
\hline 5586 & $1 / 15 / 20084: 14$ & $8 / 15 / 20084: 14$ & 25.9 & 1063.6 \\
\hline 5587 & $1 / 15 / 20084: 16$ & $8 / 15 / 20084: 16$ & 25.9 & 1063.4 \\
\hline 5588 & 1/15/2008 4:18 & $8 / 15 / 20084: 18$ & 25.9 & 1063.7 \\
\hline 5589 & $1 / 15 / 20084: 20$ & $8 / 15 / 20084: 20$ & 25.9 & 1063.5 \\
\hline 5590 & $1 / 15 / 20084: 22$ & $8 / 15 / 20084: 22$ & 25.9 & 1063.4 \\
\hline 5591 & $1 / 15 / 20084: 24$ & $8 / 15 / 20084: 24$ & 25.9 & 1064.1 \\
\hline 5592 & $1 / 15 / 20084: 26$ & $8 / 15 / 20084: 26$ & 26 & 1064.3 \\
\hline 5593 & $1 / 15 / 20084: 28$ & $8 / 15 / 20084: 28$ & 26 & 1063.7 \\
\hline 5594 & $1 / 15 / 20084: 30$ & $8 / 15 / 20084: 30$ & 26 & 1063.7 \\
\hline 5595 & $1 / 15 / 20084: 32$ & $8 / 15 / 20084: 32$ & 26 & 1063.9 \\
\hline 5596 & $1 / 15 / 20084: 34$ & $8 / 15 / 20084: 34$ & 26 & 1063.7 \\
\hline 5597 & $1 / 15 / 20084: 36$ & $8 / 15 / 20084: 36$ & 26 & 1063.1 \\
\hline 5598 & $1 / 15 / 20084: 38$ & $8 / 15 / 20084: 38$ & 26 & 1063.3 \\
\hline 5599 & $1 / 15 / 20084: 40$ & $8 / 15 / 20084: 40$ & 26 & 1063.6 \\
\hline 5600 & 1/15/2008 4:42 & $8 / 15 / 20084: 42$ & 26 & 1064 \\
\hline 5601 & $1 / 15 / 20084: 44$ & $8 / 15 / 20084: 44$ & 26 & 1063.8 \\
\hline 5602 & $1 / 15 / 20084: 46$ & $8 / 15 / 20084: 46$ & 26 & 1064.1 \\
\hline 5603 & $1 / 15 / 20084: 48$ & $8 / 15 / 20084: 48$ & 25.9 & 1064.4 \\
\hline 5604 & $1 / 15 / 20084: 50$ & $8 / 15 / 20084: 50$ & 26 & 1063.9 \\
\hline 5605 & $1 / 15 / 20084: 52$ & $8 / 15 / 20084: 52$ & 26 & 1063.2 \\
\hline 5606 & $1 / 15 / 20084: 54$ & $8 / 15 / 20084: 54$ & 26 & 1063.8 \\
\hline 5607 & 1/15/20084:56 & $8 / 15 / 20084: 56$ & 26 & 1064 \\
\hline 5608 & 1/15/2008 4:58 & $8 / 15 / 20084: 58$ & 26 & 1063.8 \\
\hline 5609 & $1 / 15 / 20085: 00$ & $8 / 15 / 20085: 00$ & 26 & 1063.9 \\
\hline 5610 & $1 / 15 / 20085: 02$ & 8/15/2008 5:02 & 26 & 1063.9 \\
\hline 5611 & $1 / 15 / 20085: 04$ & $8 / 15 / 20085: 04$ & 26 & 1063.7 \\
\hline 5612 & $1 / 15 / 20085: 06$ & $8 / 15 / 20085: 06$ & 26 & 1063.5 \\
\hline 5613 & $1 / 15 / 20085: 08$ & $8 / 15 / 20085: 08$ & 26 & 1063.5 \\
\hline 5614 & $1 / 15 / 20085: 10$ & $8 / 15 / 20085: 10$ & 25.9 & 1062.4 \\
\hline 5615 & $1 / 15 / 20085: 12$ & $8 / 15 / 20085: 12$ & 25.9 & 1063.5 \\
\hline 5616 & $1 / 15 / 20085: 14$ & & 25.9 & 1063.2 \\
\hline
\end{tabular}

\begin{tabular}{|c|c|c|c|c|}
\hline \multicolumn{5}{|c|}{ D4-92C } \\
\hline $\operatorname{Rec}$ & & Adjusted & Temp & SC \\
\hline$\#$ & Date/Time & Date/Time & ${ }^{\circ} \mathrm{C}$ & $\mu \mathrm{S} / \mathrm{cm}$ \\
\hline 5617 & 1/15/20085:16 & $8 / 15 / 20085: 16$ & 25.9 & 1062.7 \\
\hline 18 & $085: 18$ & $8 / 15 / 20085: 18$ & 25.9 & 1062.9 \\
\hline & & $8 / 15 / 20085: 20$ & & \\
\hline 5620 & $85: 22$ & $8 / 15 / 20085: 22$ & 25.9 & 1062. \\
\hline 5621 & $85: 24$ & $8 / 15 / 20085: 24$ & 25.9 & 1062 \\
\hline 222 & & $8 / 15 / 20085: 26$ & 25.9 & \\
\hline 5623 & $1 / 15 / 20085: 28$ & $8 / 15 / 20085: 28$ & 25.9 & 1062. \\
\hline 24 & $855: 30$ & $8 / 15 / 20085: 30$ & 25.9 & 1063 \\
\hline & $085: 32$ & $8 / 15 / 20085: 32$ & 25.9 & \\
\hline 26 & 1/15/2008 5:34 & $8 / 15 / 20085: 34$ & 25.9 & 1062.3 \\
\hline & $85: 36$ & $8 / 15 / 20085: 36$ & 25.9 & \\
\hline 5628 & $1 / 15 / 2$ & $8 / 15 / 20085: 38$ & 25.9 & 1058. \\
\hline 5629 & $1 / 15 / 2$ & $8 / 15 / 20085: 40$ & 25.8 & \\
\hline & & & 25.8 & \\
\hline 331 & $85: 44$ & $8 / 15 / 20085: 44$ & 25.9 & 1062.9 \\
\hline 5632 & $35: 46$ & $8 / 15 / 20085: 46$ & 25.9 & 1062.1 \\
\hline 5633 & & & & \\
\hline 5634 & $85: 50$ & $8 / 15 / 20085: 50$ & 25.9 & 1062. \\
\hline 5635 & $1 / 15 / 2$ & $8 / 15 / 20085: 52$ & 25.9 & 1062. \\
\hline 5636 & & $8 / 15 / 20085: 54$ & 25.9 & \\
\hline 5637 & $1 / 151$ & $8 / 15 / 20085: 56$ & 25.8 & 1062.5 \\
\hline 638 & & $8 / 15 / 20085: 58$ & 25.8 & \\
\hline 5639 & 151 & $115 / 20086: 00$ & 25.8 & \\
\hline 5640 & & & 25.9 & 1062. \\
\hline 5641 & 1 & $8 / 15 / 2$ & 25.8 & \\
\hline 5642 & & $8 / 15 / 20$ & 25.9 & 1061. \\
\hline 5643 & $1 / 15$ & $8 / 15 / 2$ & 25.9 & 1061. \\
\hline 5644 & $8: 10$ & $8 / 15 / 20$ & 25.9 & \\
\hline 5645 & & & 25.9 & 1061. \\
\hline 5646 & & $8 / 15 / 2$ & 25.9 & \\
\hline 5647 & & $8 / 15 / 2$ & 25.9 & \\
\hline 5648 & & & 25.9 & 1060 \\
\hline 5649 & & $8 / 15$ & 25.9 & \\
\hline 5650 & & & 25.9 & \\
\hline 5651 & & & 25.9 & \\
\hline 5652 & & $8 / 15$ & 25.9 & \\
\hline 5653 & & & 25.9 & 1061 \\
\hline 5654 & & & 25.9 & 1060 \\
\hline 5655 & & & 25.9 & \\
\hline 5656 & & & 25.8 & 1060 \\
\hline 5657 & & & 25.8 & \\
\hline 5658 & & & 25.8 & \\
\hline 5659 & & & 25.8 & \\
\hline 5660 & & & 25.8 & \\
\hline 5661 & & & 25.8 & 1060 \\
\hline 5662 & & & 25. & \\
\hline & & & 25.8 & \\
\hline 5664 & & & 25.8 & \\
\hline 5665 & & & 25.8 & \\
\hline 66 & & & 25.8 & \\
\hline 5667 & & & 25.8 & \\
\hline & & & 25.8 & \\
\hline 5669 & & & 25.8 & \\
\hline 5670 & & & 25.8 & \\
\hline 5671 & & & & \\
\hline 5672 & & $8 / 15 / 20087: 06$ & 25.9 & 10 \\
\hline 5673 & & & 25.9 & \\
\hline 5674 & & & & \\
\hline 5675 & & & 25.9 & \\
\hline & & & & \\
\hline 5677 & & & 25.9 & \\
\hline 5678 & & & 25.8 & \\
\hline & & & 25.8 & \\
\hline & & $87: 22$ & 25.8 & \\
\hline & & & 25.8 & \\
\hline 5 & & & & \\
\hline 5683 & & & 25.8 & \\
\hline 5684 & & & 25.8 & \\
\hline & & & & \\
\hline
\end{tabular}

\begin{tabular}{|c|c|c|c|c|}
\hline \multicolumn{5}{|c|}{$D 4-92 c$} \\
\hline $\operatorname{Rec}$ & & Adjusted & Temp & SC \\
\hline$\#$ & Date/Time & Date/Time & ${ }^{\circ} \mathrm{C}$ & $\mu \mathrm{S} / \mathrm{cm}$ \\
\hline 5686 & 1/15/20087:34 & $8 / 15 / 20087: 34$ & 25.8 & \\
\hline 5687 & $1 / 15 / 20087: 36$ & $8 / 15 / 20087: 36$ & 25.8 & 1061.4 \\
\hline 5688 & $115 / 200$ & $8 / 15 / 20087: 38$ & 25.8 & \\
\hline 5689 & $1 / 15 / 20087: 40$ & $8 / 15 / 20087: 40$ & 25.8 & 1061 \\
\hline 5690 & $1 / 15 / 20$ & $8 / 15 / 20087: 42$ & 25.8 & 1061. \\
\hline 5691 & & & 25.8 & \\
\hline 5692 & $1 / 15 / 20087: 46$ & $8 / 15 / 20087: 46$ & 25.8 & 1061.2 \\
\hline 5693 & $1 / 15 / 2$ & $8 / 15 / 20087: 48$ & 25.8 & \\
\hline 5694 & $77: 50$ & $8 / 15 / 20087: 50$ & 25.8 & \\
\hline 5695 & $1 / 15 / 20$ & $8 / 15 / 20087: 52$ & 25.8 & 1062.1 \\
\hline 5696 & $1 / 15 / 2$ & $8 / 15 / 20087: 54$ & 25.8 & \\
\hline 5697 & $1 / 15 / 2$ & $8 / 15 / 20087: 56$ & 25.9 & 1061. \\
\hline 5698 & $1 / 15 / 2$ & $8 / 15 / 20$ & 25.9 & 1062. \\
\hline 5699 & & & 25.9 & \\
\hline 5700 & $1 / 15 / 2$ & $8 / 15 / 20$ & 25.9 & 1061. \\
\hline 5701 & $1 / 15 / 2$ & $8 / 15 / 20$ & 25.8 & 1062. \\
\hline 5702 & $1 / 15 / 2$ & $8 / 15 / 20$ & 25.9 & \\
\hline 5703 & $1 / 15 / 2$ & $88: 08$ & 25.9 & 1062.4 \\
\hline 5704 & $1 / 15 / 2$ & $8 / 15 / 2$ & 25.9 & 1062.1 \\
\hline 5705 & $1 / 15 / 2$ & $8 / 15 / 2$ & 25.8 & \\
\hline 5706 & & $8 / 15 / 2$ & 25.9 & 1062. \\
\hline 5707 & & $8 / 15 / 2$ & 25.9 & \\
\hline 5708 & $\overline{11}$ & $8 / 15 / 2$ & 25.9 & 1061.7 \\
\hline 5709 & & $38: 20$ & 25.8 & 1061. \\
\hline 5710 & & $8 / 15 /$ & 25.8 & \\
\hline 5711 & & & 25.8 & 1061 \\
\hline 5712 & & $8 / 15$ & 25.8 & 1061 \\
\hline 5713 & & $8 / 15$ & 25. & \\
\hline 5714 & & & 25.8 & 1061. \\
\hline 5715 & & $8 / 15$ & 25.8 & \\
\hline 5716 & & & 25.8 & \\
\hline 5717 & & & 25.8 & 1061 \\
\hline 5718 & & $8 / 15$ & 25.8 & \\
\hline 5719 & & & 25.8 & \\
\hline 5720 & & & 25.8 & \\
\hline 5721 & & & 25.8 & \\
\hline 5722 & & & 25.8 & 1061 \\
\hline 5723 & & & 25.8 & \\
\hline 5724 & & & 25. & 1061 \\
\hline 5725 & & & 25. & \\
\hline 5726 & & & 25.8 & \\
\hline 5727 & & & 25.8 & \\
\hline 5728 & & & 25. & \\
\hline 5729 & & & 25.8 & \\
\hline 5730 & & & 25. & \\
\hline 5731 & & & 25.8 & \\
\hline 5732 & & & 25.8 & \\
\hline 5733 & & & 25.8 & \\
\hline 5734 & & & 25. & \\
\hline 5735 & & & 25. & \\
\hline 5736 & & & 25.8 & \\
\hline 5737 & & & 25.8 & \\
\hline 5738 & & & 25. & \\
\hline 5739 & & & 25. & \\
\hline 5740 & & & & \\
\hline 5741 & & $9: 24$ & 25.8 & 1000 \\
\hline 5742 & & & 25 & \\
\hline 5743 & & & 25. & \\
\hline 5744 & & & 25.8 & \\
\hline 5745 & & & & \\
\hline 5746 & & & 25.8 & \\
\hline 5747 & & & 25. & \\
\hline 5748 & & & & \\
\hline 5749 & & $8 / 15 / 2$ & 25.8 & 100 \\
\hline & & & & \\
\hline 575 & & & & \\
\hline 5752 & & & 25.7 & \\
\hline & & & 25.8 & \\
\hline & & $8 / 15 / 20089: 50$ & 25.8 & \\
\hline
\end{tabular}


DOE/RL-2009-35, REV. 0

\begin{tabular}{|c|c|c|c|c|}
\hline \multicolumn{5}{|c|}{ D4-92c } \\
\hline $\operatorname{Rec}$ & & Adjusted & Temp & SC \\
\hline$\#$ & DaterTime & Date/Time & ${ }^{\circ} \mathrm{C}$ & $\mu \mathrm{S} / \mathrm{cm}$ \\
\hline 5755 & $1 / 15 / 20089: 52$ & $8 / 15 / 20089: 52$ & 25.8 & 1060 \\
\hline 5756 & $1 / 15 / 20089: 54$ & $8 / 15 / 20089: 54$ & 25.8 & 1060.3 \\
\hline 5757 & $1 / 15 / 20089: 56$ & $8 / 15 / 20089: 56$ & 25.8 & 1060.8 \\
\hline 5758 & $1 / 15 / 20089: 58$ & $8 / 15 / 20089: 58$ & 25.8 & 1060.5 \\
\hline 5759 & 1/15/2008 10:00 & $8 / 15 / 2008$ 10:00 & 25.8 & 1060.9 \\
\hline 5760 & $1 / 15 / 2008$ 10:02 & $8 / 15 / 2008$ 10:02 & 25.8 & 1060 \\
\hline 5761 & 1/15/2008 10:04 & $8 / 15 / 2008$ 10:04 & 25.8 & 1062.6 \\
\hline 5762 & $1 / 15 / 2008$ 10:06 & $8 / 15 / 2008$ 10:06 & 25.7 & 1060 \\
\hline 5763 & $1 / 15 / 2008$ 10:08 & $8 / 15 / 200810: 08$ & 25.7 & 1060.4 \\
\hline 5764 & 1/15/2008 10:10 & $8 / 15 / 2008$ 10:10 & 25.7 & 1060.5 \\
\hline 5765 & $1 / 15 / 2008$ 10:12 & $8 / 15 / 2008 \quad 10: 12$ & 25.7 & 1060.6 \\
\hline 5766 & 1/15/2008 10:14 & $8 / 15 / 2008$ 10:14 & 25.7 & 1060.2 \\
\hline 5767 & $1 / 15 / 2008$ 10:16 & $8 / 15 / 2008$ 10:16 & 25.7 & 1060.7 \\
\hline 5768 & $1 / 15 / 2008$ 10:18 & $8 / 15 / 2008$ 10:18 & 25.7 & 1060.7 \\
\hline 5769 & $1 / 15 / 2008 \quad 10: 20$ & $8 / 15 / 200810: 20$ & 25.7 & 1061.7 \\
\hline 5770 & $1 / 15 / 2008$ 10:22 & $8 / 15 / 2008$ 10:22 & 25.7 & 1059.9 \\
\hline 5771 & $1 / 15 / 2008$ 10:24 & $8 / 15 / 2008$ 10:24 & 25.8 & 1059.7 \\
\hline 5772 & $1 / 15 / 2008$ 10:26 & $8 / 15 / 2008$ 10:26 & 25.7 & 1059.5 \\
\hline 5773 & $1 / 15 / 2008$ 10:28 & $8 / 15 / 2008$ 10:28 & 25.6 & 1059.2 \\
\hline 5774 & $1 / 15 / 2008 \quad 10: 30$ & $8 / 15 / 2008$ 10:30 & 25.6 & 1060 \\
\hline 5775 & 1/15/2008 10:32 & $8 / 15 / 2008$ 10:32 & 25.6 & 1059.6 \\
\hline 5776 & $1 / 15 / 2008 \quad 10: 34$ & $8 / 15 / 2008$ 10:34 & 25.6 & 1060.1 \\
\hline 5777 & 1/15/2008 10:36 & $8 / 15 / 2008$ 10:36 & 25.6 & 1060.5 \\
\hline 5778 & $1 / 15 / 2008$ 10:38 & $8 / 15 / 200810: 38$ & 25.6 & 1060 \\
\hline 5779 & 1/15/2008 10:40 & $8 / 15 / 2008$ 10:40 & 25.6 & 1060.1 \\
\hline 5780 & $1 / 15 / 2008$ 10:42 & $8 / 15 / 2008$ 10:42 & 25.6 & 1059.8 \\
\hline 5781 & $1 / 15 / 2008$ 10:44 & $8 / 15 / 2008 \quad 10: 44$ & 25.7 & 1059.9 \\
\hline 5782 & $1 / 15 / 2008$ 10:46 & $8 / 15 / 2008$ 10:46 & 25.6 & 1059.6 \\
\hline 5783 & $1 / 15 / 2008$ 10:48 & $8 / 15 / 2008 \quad 10: 48$ & 25.6 & 1059.9 \\
\hline 5784 & $1 / 15 / 2008 \quad 10: 50$ & $8 / 15 / 200810: 50$ & 25.7 & 1059.7 \\
\hline 5785 & $1 / 15 / 2008$ 10:52 & $8 / 15 / 2008$ 10:52 & 25.7 & 1060.1 \\
\hline 5786 & $1 / 15 / 2008 \quad 10: 54$ & $8 / 15 / 2008$ 10:54 & 25.6 & 1060.1 \\
\hline 5787 & $1 / 15 / 2008 \quad 10: 56$ & $8 / 15 / 2008$ 10:56 & 25.7 & 1059 \\
\hline 5788 & $1 / 15 / 2008 \quad 10: 58$ & $8 / 15 / 200810: 58$ & $\frac{25.6}{25.6}$ & 1059.9 \\
\hline 5789 & 1/1/5/2008 11:00 & $8 / 15 / 2008$ 11:00 & 25.7 & 1059.4 \\
\hline 5790 & $1 / 15 / 2008$ 11:02 & $8 / 15 / 2008$ 11:02 & 25.7 & 1060.1 \\
\hline 5791 & 1/15/2008 11:04 & $8 / 15 / 2008$ 11:04 & 25.7 & 1060.3 \\
\hline 5792 & $1 / 15 / 2008+1,06$ & $8 / 15 / 2008$ 11:06 & 25.7 & 1059.6 \\
\hline 5793 & $1 / 15 / 2008$ 11:08 & $8 / 15 / 2008$ 11:08 & 25.7 & 1060 \\
\hline 5794 & $1 / 15 / 2008+11: 10$ & $8 / 15 / 2008$ 11:10 & 25.7 & 1060.3 \\
\hline 5795 & $1 / 15 / 200811: 12$ & $8 / 15 / 2008$ 11:12 & 25.7 & 1059 \\
\hline 5796 & $1 / 15 / 2008 \quad 11: 14$ & $8 / 15 / 2008$ 11:14 & 25.7 & 1059.9 \\
\hline 5797 & $1 / 15 / 200811: 16$ & 8/15/2008 11:16 & 25.7 & 1059.1 \\
\hline 5798 & $1 / 15 / 2008$ 11:18 & $8 / 15 / 2008$ 11:18 & 25.6 & 1059.8 \\
\hline 5799 & $1 / 15 / 2008 \quad 11: 20$ & $8 / 15 / 200811: 20$ & 25.6 & 1059.5 \\
\hline 5800 & $1 / 15 / 2008 \quad 11: 22$ & $8 / 15 / 2008$ 11:22 & 25.6 & 1058.5 \\
\hline 5801 & $1 / 15 / 2008$ 11:24 & $8 / 15 / 2008$ 11:24 & 25.7 & 1059.9 \\
\hline 5802 & $1 / 15 / 200811: 26$ & $8 / 15 / 2008$ 11:26 & 25.7 & 1059.6 \\
\hline 5803 & $1 / 15 / 200811: 28$ & $8 / 15 / 200811: 28$ & 25.7 & 1059.3 \\
\hline 5804 & $1 / 15 / 2008$ 11:30 & $8 / 15 / 2008$ 11:30 & 25.7 & 1059.4 \\
\hline 5805 & $1 / 15 / 200811: 32$ & $8 / 15 / 2008$ 11:32 & 25.6 & 1059.2 \\
\hline 5806 & $1 / 15 / 200811: 34$ & $8 / 15 / 2008$ 11:34 & 25.6 & 1058.9 \\
\hline 5807 & $1 / 15 / 20$ & $8 / 15 / 2008$ 11:36 & 25.6 & 1059 \\
\hline 5808 & $1 / 15 / 20$ & $8 / 15 / 2008$ 11:38 & 25.6 & 1059.5 \\
\hline 5809 & $1 / 15 / 200$ & $8 / 15 / 2008$ 11:40 & 25.6 & 1059.5 \\
\hline 5810 & $1 / 15 / 2008$ 11:42 & $8 / 15 / 2008$ 11:42 & 25.6 & 1059.2 \\
\hline 5811 & $1 / 15 / 2008$ 11:44 & $8 / 15 / 2008$ 11:44 & 25.5 & 1067.1 \\
\hline 5812 & $1 / 15 / 2008$ 11:46 & $8 / 15 / 2008$ 11:46 & 25.4 & 1073.9 \\
\hline 5813 & $1 / 15 / 2008$ 11:48 & $8 / 15 / 2008$ 11:48 & 25 & 1074.5 \\
\hline 5814 & $1 / 15 / 200811: 50$ & $8 / 15 / 200811: 50$ & 25 & 1071.4 \\
\hline 5815 & $1 / 15 / 200811 ; 52$ & $8 / 15 / 2008$ 11:52 & 24.8 & 1070.8 \\
\hline 5816 & $1 / 15 / 200811: 54$ & $8 / 15 / 2008$ 11:54 & 24.8 & \\
\hline 5817 & $1 / 15 / 2008$ 11:56 & $8 / 15 / 2008$ 11:56 & 24.6 & 1067.3 \\
\hline 5818 & $1 / 15 / 200811: 58$ & $8 / 15 / 2008$ 11:58 & 24.5 & 1065.3 \\
\hline 5819 & $1 / 15 / 2008$ 12:00 & $8 / 15 / 2008$ 12:00 & 24.5 & 1065.6 \\
\hline 5820 & 1/15/2008 12:02 & $8 / 15 / 2008$ 12:02 & 24.5 & 1063.8 \\
\hline 5821 & $1 / 15 / 2008$ 12:04 & $8 / 15 / 2008$ 12:04 & 24.4 & 1069.3 \\
\hline 5822 & 1/15/2008 12:06 & $8 / 15 / 200812: 06$ & 24.3 & 1067.2 \\
\hline 5823 & $1 / 15 / 2008$ 12:08 & $8 / 15 / 2008$ 12:08 & 24.3 & 1066.9 \\
\hline 5824 & 1/15/2008 12:10 & $8 / 15 / 2008$ 12:10 & 24.3 & 1064.4 \\
\hline 5825 & 1/15/2008 12:12 & $8 / 15 / 2008$ 12:12 & 24.2 & 1063.9 \\
\hline 5826 & 1/15/2008 12:14 & $8 / 15 / 2008$ 12:14 & 24.3 & 1063.1 \\
\hline
\end{tabular}
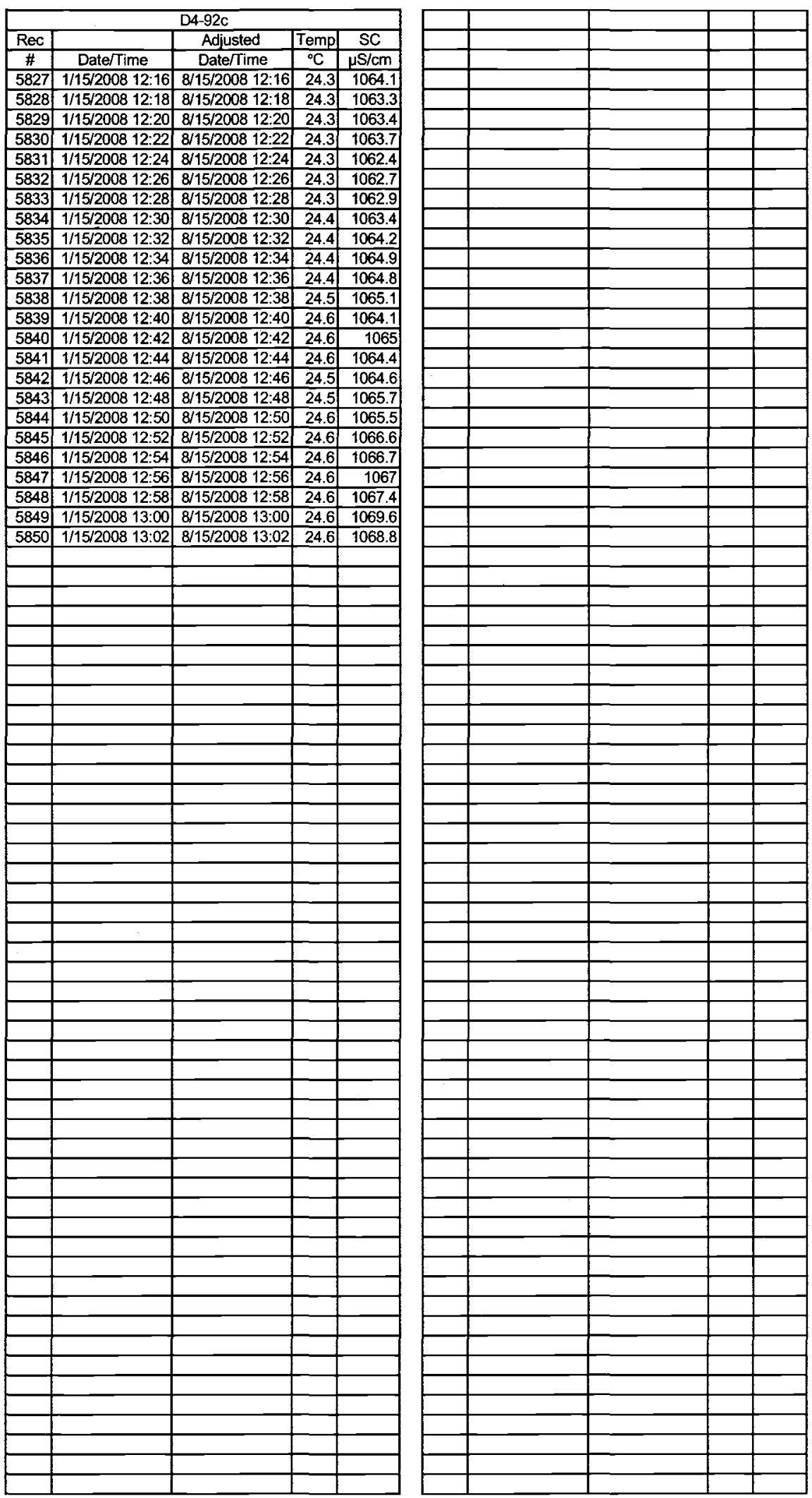


\begin{tabular}{|c|c|c|c|c|}
\hline \multicolumn{5}{|c|}{ D4990 } \\
\hline $\mathrm{ReC}$ & & Adusted & Pressure & Temp \\
\hline$\#$ & DeterTime & Deter Time & $p s i$ & ${ }^{\circ} \mathrm{C}$ \\
\hline 1 & $1 / 7 / 2008$ 10:04 & $87 / 2008$ 10:04 & 1.623 & 17.3 \\
\hline 2 & $1 / 7 / 200810.06$ & $871200810: 06$ & 1.623 & 17.3 \\
\hline 3 & $1 / 7 / 200810008$ & 8712008 10:08 & 1.23 & 17 \\
\hline 4 & $1 / 7200810.10$ & $87 / 200810: 10$ & 1.024 & 16.9 \\
\hline 5 & $1 / 7 / 2008$ 10:12 & $87 / 2008$ 10:12 & 1.624 & 16.9 \\
\hline 6 & $1 / 7 / 2008$ 10.14 & 8712008 10.14 & 1.624 & 16.9 \\
\hline 7 & $1 / 7200810.16$ & $87 / 200810: 16$ & 1.623 & 169 \\
\hline 8 & $1 / 7 / 2008$ 10.18 & $87 / 2008$ 10:18 & 1.623 & 16.9 \\
\hline 9 & $1 / 7200810220$ & 8712008 10:20 & 1.623 & 169 \\
\hline 10 & $1 / 7 / 2008$ 10:22 & 8712008 10:22 & 1.624 & 16.9 \\
\hline 11 & $1 / 7 / 2008$ 10:24 & $87 / 2008$ 10:24 & 1.624 & 169 \\
\hline 12 & $1 / 7 / 2008$ 10:26 & 871200810266 & 1.624 & 16.9 \\
\hline 13 & $1 / 7 / 2008$ 10:28 & $871200810: 28$ & 1.625 & 16.9 \\
\hline 14 & $1 / 7 / 200810.30$ & $87 / 200810: 30$ & 1.625 & 16.9 \\
\hline 15 & $1 / 7 / 2008$ 10:32 & 8712008 10:32 & 1.625 & 16.9 \\
\hline 调 & $1 / 72008$ 10:34 & $877200810-34$ & 1.025 & 16.9 \\
\hline 17 & $1 / 72008$ 10:36 & $872200810: 36$ & 1.625 & 16.9 \\
\hline 18 & $1 / 7200810.38$ & $877200810: 38$ & 1.624 & 16.9 \\
\hline 19 & $1 / 72008$ 10:40 & $871200810: 40$ & 1.024 & 16.9 \\
\hline 20 & $1 / 7 / 2008$ 10:42 & $87 / 2008$ 10:42 & 1.623 & 16.9 \\
\hline 21 & $1 / 72008$ 10:44 & $87 / 200810: 44$ & 1.623 & 16.9 \\
\hline 22 & $1 / 7 / 200810: 46$ & $877200810: 46$ & 1.623 & 169 \\
\hline 23 & $1 / 7 / 200810: 48$ & $87 / 2008$ 10:48 & 1.624 & 16.9 \\
\hline 24 & $1 / 7 / 200810: 50$ & 877200810.50 & 1.624 & 16.9 \\
\hline 25 & $1 / 7 / 200810.52$ & $87 / 2008$ 10:52 & 1.624 & 16.9 \\
\hline 26 & $17 / 200810: 54$ & $87 / 200810.54$ & 1.623 & 16.9 \\
\hline 27 & $1 / 7200810: 56$ & $87 / 200810: 56$ & 1.62 & 16.9 \\
\hline 28 & $1 / 7 / 200810.58$ & $87 / 200810: 58$ & 1.622 & 16.9 \\
\hline 20 & 1/72008 11:000 & 872008 11:00 & 1.62 & 16.9 \\
\hline 30 & 1/72008 11:02 & $877200811: 02$ & 1.621 & 16.9 \\
\hline 31 & $1 / 7200811: 04$ & $87 / 200811: 04$ & 1.621 & 16.9 \\
\hline 32 & $1 / 7200811: 06$ & $871200811: 06$ & 1.621 & 16.9 \\
\hline 33 & $1 / 7200811: 08$ & $877200811: 08$ & 1.621 & 16.9 \\
\hline 34 & 1/72008 11:10 & $877200811: 10$ & 1.621 & 16.9 \\
\hline 35 & 1/7/2008 11:12 & $87 / 200811: 12$ & 1.621 & 16.9 \\
\hline 36 & $1 / 7 / 2008$ 11:14 & $87 / 200811: 14$ & 1.621 & 16.9 \\
\hline 37 & $1 / 7200811: 16$ & $87 / 200811: 16$ & 1.621 & 16.9 \\
\hline 38 & $1 / 7200811: 18$ & $877200811: 18$ & 1.621 & 16.9 \\
\hline 39 & $1 / 7 / 200811: 20$ & $87 / 200811: 20$ & 1.621 & 16.9 \\
\hline 40 & $1 / 7200811: 22$ & $8712008+11: 22$ & 1.62 & 16.9 \\
\hline 41 & 1/72008 11:24 & $877200811: 24$ & 1.622 & 16.9 \\
\hline 42 & $1 / 7200811: 26$ & $87 / 200811: 26$ & 1.022 & 16.9 \\
\hline 43 & $1 / 7200811: 28$ & $87 / 200811: 28$ & 1.621 & 16.9 \\
\hline 44 & 1/7/2008 11:30 & $871200811: 30$ & 1.621 & 16.9 \\
\hline 45 & $1 / 7200811: 32$ & $87 / 200811: 32$ & 1.62 & 16.9 \\
\hline 46 & $1 / 72008$ 11:34 & $87 / 2008$ 11:34 & 1.62 & 16.9 \\
\hline 47 & $17 / 200811: 36$ & $87 / 200811: 36$ & 1.62 & 16.9 \\
\hline 48 & $1 / 7200811: 38$ & $87 / 200811: 38$ & 1.62 & 16.9 \\
\hline 49 & $17 / 200811: 40$ & 8772008 11:40 & 1.222 & 16.9 \\
\hline 50 & $17 / 200811: 42$ & $87 / 200811: 42$ & 1.622 & 16.9 \\
\hline 51 & $17 / 200811: 44$ & $877200811: 44$ & 1.623 & 16.9 \\
\hline 52 & $1 / 7200811: 46$ & 8712008 11:46 & 1.623 & 16.9 \\
\hline 53 & $1 / 7200811: 48$ & 8772008 11:48 & 1.624 & 16.9 \\
\hline 54 & $1 / 7200811: 50$ & $87 / 200811: 50$ & 1.623 & 16.9 \\
\hline जक & $1 / 7200811: 52$ & $87 / 200811: 52$ & 1.622 & 16.9 \\
\hline 56 & $1 / 7200811: 54$ & $87 / 2008$ 11:54 & 1.621 & 16.9 \\
\hline 57 & $1 / 7200811: 56$ & $87 / 200811: 56$ & 1.621 & 16.9 \\
\hline 58 & $1 / 7200811: 58$ & $87 / 200811: 58$ & 1.63 & 16.9 \\
\hline 50 & $1 / 720081200$ & $87 / 20081200$ & 1.623 & 16.9 \\
\hline 60 & $1 / 72008$ 1202 & $87 / 20081200$ & 1.623 & 16.9 \\
\hline 61 & $1 / 7 / 20081204$ & $87 / 20081204$ & 1.623 & 16.9 \\
\hline 62 & $17 / 2008$ १206 & $87 / 20081206$ & 1.623 & 16.9 \\
\hline 63 & $1 / 72008$ 1208 & 87720081208 & 1.624 & 16.9 \\
\hline 64 & $1 / 72008$ १₹10 & $87 / 20081210$ & 1.624 & 16.9 \\
\hline 65 & $1 / 720081212$ & $87 / 2008$ 1212 & 1.625 & 16.9 \\
\hline 66 & $1 / 7 / 20081214$ & $87 / 20081214$ & 1.625 & 16.9 \\
\hline 67 & $17 / 20081216$ & $87 / 20081216$ & 1.625 & 16.9 \\
\hline 68 & $1 / 7 / 2008$ 1218 & $87 / 20081218$ & 1.624 & 16.9 \\
\hline
\end{tabular}

\begin{tabular}{|c|c|c|c|c|}
\hline \multicolumn{5}{|c|}{ D4928 } \\
\hline$B x$ & & Aqusted & Pressurt & Temp \\
\hline$\#$ & Detertime & DetefTime & psi & ${ }^{\circ} \mathrm{C}$ \\
\hline @ & $1 / 7 / 2008+220$ & $87 / 20081220$ & 1.62 & 16.9 \\
\hline 70 & $17 / 20081222$ & 87720081222 & 1.623 & 16.9 \\
\hline 71 & $1 / 7200011224$ & $87 / 20081224$ & 1.62 & 16.9 \\
\hline 72 & $1 / 7 / 20081226$ & $87 / 20081226$ & 1.223 & 16.9 \\
\hline 73 & $17 / 20081228$ & $87 / 20081228$ & 1.621 & 16.9 \\
\hline 74 & $1 / 7 / 20081230$ & $8 / 7 / 20081230$ & 1.6 & 16.9 \\
\hline 75 & $1 / 7 / 20081232$ & $87 / 20081232$ & 1.621 & 169 \\
\hline 76 & $17 / 200081234$ & 87120081234 & 1.622 & 16.9 \\
\hline 777 & $1 / 7 / 20081236$ & $87 / 20081236$ & 1.22 & 16.9 \\
\hline 78 & $17 / 20081238$ & $87 / 20081233$ & 1.622 & 16.9 \\
\hline 79 & $17 / 720081240$ & $87 / 20081240$ & 1.223 & 16.9 \\
\hline 80 & $1 / 7 / 20081242$ & 87120081242 & 1.223 & 16.9 \\
\hline 81 & $17 / 20081244$ & 87120081244 & 1.623 & 16.9 \\
\hline 82 & $1 / 7 / 20081246$ & $87 / 20081246$ & 1.22 & 16.9 \\
\hline 83 & $17 / 20081248$ & 87120081248 & 1.62 & 16.9 \\
\hline 84 & $1 / 7 / 20081250$ & $87 / 20081250$ & 1.62 & 16.9 \\
\hline 86 & $1 / 7 / 20081252$ & 87120081252 & 1.623 & 16.9 \\
\hline 86 & $1 / 7 / 20081254$ & $87 / 20081254$ & 1.623 & 16.9 \\
\hline 87 & $1 / 7 / 20081256$ & $87 / 20081256$ & 1.622 & 16. \\
\hline 88 & $1 / 7 / 20081258$ & $87 / 20081258$ & 1.622 & 16.9 \\
\hline 89 & $1 / 7 / 2008$ & $13: 00$ & 1.622 & 169 \\
\hline 90 & $1 / 7 / 200813: 02$ & $87 / 200813: 02$ & $1 . \mathbb{2} 3$ & 165 \\
\hline 91 & $1 / 7 / 200813: 04$ & $87 / 2008$ 13:04 & 1.623 & 16.9 \\
\hline 92 & $1 / 7 / 200$ & $13: 06$ & 1.623 & 16.9 \\
\hline 93 & $1 / 7 / 200813: 06$ & $87 / 200813: 08$ & 1.624 & 16.5 \\
\hline 94 & $1 / 7 / 2008+13: 10$ & $87 / 200813: 10$ & 1.623 & 16.9 \\
\hline 96 & $1 / 7 / 200$ & $3: 12$ & 1.62 & 16.9 \\
\hline 96 & $1 / 7 / 200813: 14$ & $87 / 200813: 14$ & 1.621 & 16.9 \\
\hline 97 & $1 / 7 / 2008$ 13:16 & $87 / 200813: 16$ & 1.622 & 16.9 \\
\hline 98 & $1 / 7 / 200$ & 871 & 1.623 & 16.9 \\
\hline 99 & $1 / 7 / 2000$ & $13: 20$ & 1.623 & 16.9 \\
\hline 100 & 1/7/2008 13:22 & $87 / 2008$ 13:22 & 1.624 & 16.9 \\
\hline 101 & $1 / 7 / 200$ & $87 / 2$ & 1.625 & 16.9 \\
\hline 102 & $1 / 7 / 2008$ & $87 / 200813: 26$ & 1.625 & 16 . \\
\hline 103 & $1 / 7 / 200$ & $13: 28$ & 1.624 & 16. \\
\hline 104 & $1 / 7 / 20 x$ & 13:30 & 1.623 & 16.9 \\
\hline 105 & $1 / 7 / 2000$ & $87 / 200813: 32$ & 1.622 & 16.9 \\
\hline 106 & $1 / 7 / 2000$ & 313:34 & 1.624 & 16.9 \\
\hline 107 & $1 / 7 / 200$ & $3: 36$ & 1.626 & 16. \\
\hline 108 & $1 / 7 / 200$ & $13: 38$ & 1.628 & 16. \\
\hline 109 & $1 / 7 / 200$ & $813: 40$ & 1.629 & 169 \\
\hline 110 & $1 / 7 / 200$ & $13: 42$ & 1.629 & 16. \\
\hline 111 & $1 / 7 / 20$ & & 1.628 & 16. \\
\hline 112 & $1 / 7 / 200$ & 0813.46 & 1.627 & 16. \\
\hline 113 & $1 / 7 / 200$ & $13: 48$ & 1.627 & 16. \\
\hline 114 & 50 & & 1.625 & 16. \\
\hline 115 & $1 / 71200$ & $0813: 52$ & 1.626 & 16. \\
\hline 116 & $1 / 7 / 200$ & $13: 54$ & 1.626 & 16. \\
\hline 117 & & & 1.626 & 16. \\
\hline 118 & $1 / 7 / 200$ & $813: 58$ & 1.627 & 16 . \\
\hline 119 & $1 / 7 / 200$ & $87 / 20$ & 1.628 & 16. \\
\hline 120 & & & 1.628 & 16 \\
\hline 121 & $1 / 7 / 2008$ 14:04 & $87 / 200814: 04$ & 1.627 & 16 . \\
\hline 122 & 1/7/2008 14:06 & $87 / 2008$ 14:06 & 1.627 & 16 . \\
\hline 123 & & & 1.626 & 16 \\
\hline 124 & $17 / 20 x$ & $14: 10$ & 1.624 & 16 \\
\hline 125 & $1 / 7 / 2008$ 14:12 & $87 / 200814: 12$ & 1.624 & 16. \\
\hline 126 & $1 / 772008$ 14:14 & & 1.624 & 16. \\
\hline 127 & & & 1.623 & 16. \\
\hline 128 & $1 / 7 / 200814: 18$ & $87 / 200814: 18$ & 1.624 & 16. \\
\hline 129 & $1 / 7 / 200814: 20$ & $87 / 200814: 20$ & 1.624 & 16. \\
\hline 130 & & & 1.625 & \\
\hline 131 & $1 / 7 / 2008$ 14:24 & $87 / 200814: 24$ & 1.625 & 16. \\
\hline 132 & $1 / 7 / 2008$ 14:26 & $877200814: 26$ & 1.624 & 16. \\
\hline 133 & 1/7/2008 14:28 & $87 / 200814: 28$ & 1.624 & 16. \\
\hline 134 & 1/7/2008 14:30 & $87 / 200814: 30$ & 1.625 & \\
\hline 135 & $1 / 7 / 2008$ 14:32 & $87 / 200814: 32$ & 1.620 & 16. \\
\hline 136 & 1/7/2008 14:34 & $87 / 200814: 34$ & 1.628 & 16 \\
\hline
\end{tabular}

\begin{tabular}{|c|c|c|c|c|}
\hline \multicolumn{5}{|c|}{ D494 } \\
\hline $\mathrm{Pec}$ & & Adusted & Pressures & Termp \\
\hline \# & DateTime & DeterTime & psi & \\
\hline 137 & $1 / 7 / 2008$ 14:36 & $877200814: 36$ & 1.627 & 16.9 \\
\hline 138 & $1 / 7 / 2008$ 14:38 & $87 / 200814: 38$ & 1.62 & 16.9 \\
\hline 139 & $1 / 7 / 2008$ 14:40 & 8772008 14:40 & 1.626 & 16.9 \\
\hline 140 & $1 / 7 / 2008$ 14:42 & $87 / 2008$ 14:42 & 1.627 & 16.9 \\
\hline 141 & $1 / 7 / 2008$ 14:44 & $87 / 2008$ 14:44 & 1.627 & 16. \\
\hline 142 & $1 / 7 / 200814: 46$ & $87 / 2008$ 14:46 & 1.628 & 16.9 \\
\hline 143 & $1 / 7 / 2008$ 14:48 & $87 / 200814: 48$ & 1.627 & 16.9 \\
\hline 144 & $1 / 72008$ 14:50 & $87 / 2008$ 14:50 & 1.627 & 16. \\
\hline 145 & 1/72008 14:52 & 8772008 14:52 & 1.627 & 16.9 \\
\hline 146 & $1 / 7 / 2008$ 14:54 & $87 / 2008$ 14:54 & 1.627 & 16.9 \\
\hline 147 & $1 / 72008$ 14:56 & $87 / 2008$ 14:56 & 1.628 & 16 : \\
\hline 148 & $1 / 72008$ 14:58 & $87 / 2008$ 14:58 & 1.628 & 169 \\
\hline 149 & $1 / 7 / 2008$ 15:00 & $87 / 200815: 00$ & 1.620 & 16.9 \\
\hline 150 & $1 / 7 / 2008$ 15:02 & $87 / 200815: 02$ & 1.629 & 16.9 \\
\hline 151 & $1 / 7 / 2008$ ^5:04 & $87 / 2008$ 15:04 & 1.628 & 16. \\
\hline 152 & $1 / 7 / 2008$ 15:06 & $87 / 200815: 06$ & 1.628 & 16.9 \\
\hline 153 & $1 / 72008$ 15:08 & $87 / 200815: 08$ & 1.628 & 16. \\
\hline 154 & $1 / 7 / 200815: 10$ & $87 / 200815: 10$ & 1.628 & 16. \\
\hline 150 & $1 / 7 / 2008$ 15:12 & $87 / 2008$ 15:12 & 1.629 & 16 \\
\hline 156 & $1 / 7 / 2008$ 15:14 & $87 / 2008$ 15:14 & 1.63 & 16 . \\
\hline 15त्री & $1 / 7 / 200815: 16$ & $87 / 200815: 16$ & 1.63 & 16. \\
\hline 158 & $1 / 7200815: 18$ & $87 / 2008$ 15:18 & 1.63 & 16. \\
\hline 159 & $1 / 7 / 2008$ & $87 / 2008$ 15:20 & 1.631 & 16. \\
\hline 160 & $1 / 7200815: 22$ & $87 / 200815: 22$ & 1.63 & 16. \\
\hline 161 & $1 / 7 / 200815: 24$ & $87 / 2008$ 15:24 & 1.620 & 16.5 \\
\hline 16 & $1 / 72000$ & $87 / 2008$ 15:26 & 1.629 & 16. \\
\hline 163 & $1 / 7 / 200 x$ & $87 / 200815: 28$ & 1.627 & 16. \\
\hline 164 & $1 / 7200815: 30$ & $87 / 200815: 30$ & 1.628 & 16. \\
\hline 100 & $1 / 7200815: 32$ & $87 / 2008$ 15:32 & 1.629 & 16.5 \\
\hline 160 & $1 / 7 / 2008$ 15:34 & $87 / 200815: 34$ & 1.631 & 16 \\
\hline 167 & $17 / 2008$ 15:36 & $87 / 200815: 36$ & 1.631 & $\overline{16}$. \\
\hline 168 & $1 / 7 / 200$ & $87 / 200815: 38$ & 1.631 & 16. \\
\hline 169 & $1 / 7 / 200 x$ & $87 / 2008$ 15:40 & 1.631 & 16 . \\
\hline 170 & $1 / 7 / 2008$ 15:42 & $87 / 200815: 42$ & 1.63 & 16. \\
\hline 171 & $1 / 7 / 2008$ 15:44 & $871200815: 44$ & 1.629 & 16. \\
\hline 172 & $1 / 7 / 20$ & 871200 & 1.629 & 16. \\
\hline 173 & $1 / 7 / 2008$ 15:48 & $87 / 200815: 48$ & 1.63 & 16. \\
\hline 174 & $1 / 7 / 2008$ & $87 / 200815: 50$ & 1.629 & 16. \\
\hline 175 & $1 / 7 / 20$ & $87 / 20$ & 1.628 & 16. \\
\hline 176 & $1 / 7 / 200$ & $87 / 200$ & 1.620 & 16. \\
\hline 177 & $1 / 7 / 200815: 56$ & $877200815: 56$ & 1.620 & 16. \\
\hline 178 & $1 / 7 / 20$ & $87 / 20$ & 1.63 & 16. \\
\hline 179 & $1 / 7 / 200$ & $87 / 200$ & 1.620 & 16 \\
\hline 180 & $17 / 200816: 02$ & $87 / 2008$ 16:02 & 1.620 & 16. \\
\hline 181 & $1 / 7 / 200$ & $87 / 200$ & 1.629 & 16 \\
\hline 182 & $1 / 7200$ & $87 / 200816: 06$ & 1.63 & 16 \\
\hline 183 & $1 / 7 / 200816: 08$ & $87 / 2008$ 16:08 & 1.629 & 16. \\
\hline 184 & $1 / 7 / 200$ & $87 / 20$ & 1.63 & 16 \\
\hline 185 & $1 / 7 / 200$ & $87 / 200816: 12$ & 1.627 & 16 \\
\hline 186 & $1 / 7 / 200816: 14$ & $87 / 200816: 14$ & 1.628 & 16. \\
\hline 187 & $1 / 7 / 200$ & $87 / 200$ & 1.628 & 16 \\
\hline 188 & $1 / 7 / 200$ & $8 / 7 / 200$ & 1.628 & 16 \\
\hline 189 & $1 / 7 / 200816: 20$ & $8 / 7 / 200816: 20$ & 1.628 & 16. \\
\hline 190 & $1 / 7 / 2008$ 16:22 & $8 / 7 / 200$ & 1.627 & 16 \\
\hline 191 & $1 / 7 / 20$ & $8 / 7 / 200$ & 1.627 & \\
\hline 192 & $1 / 7 / 200816: 26$ & $87 / 200816: 26$ & 1.627 & 16. \\
\hline 193 & $1 / 7 / 200816: 28$ & $87 / 200$ & 1.627 & 16. \\
\hline 194 & $17 / 20$ & $87 / 200$ & 1.627 & \\
\hline 195 & $1 / 7 / 2008$ 16:32 & $871200816: 32$ & 1.627 & 16 \\
\hline 196 & $1 / 7 / 200816: 34$ & $871200816: 34$ & 1.627 & 16 . \\
\hline 197 & $1 / 7 / 200816: 36$ & $87 / 200816: 36$ & 1.628 & 16 \\
\hline 198 & $17 / 72008$ 16:38 & $877200816: 38$ & 1.62 & 16. \\
\hline 190 & $1 / 7 / 200816: 40$ & $87 / 200816: 40$ & 1.629 & 16. \\
\hline 200 & $1 / 7 / 2008$ 16:42 & $87 / 200816.42$ & 1.629 & 16. \\
\hline 201 & $1 / 7 / 200816.44$ & $877200816: 44$ & 1.628 & 16 \\
\hline 202 & $1 / 7 / 200816: 46$ & $87 / 2008$ 16:46 & 1.628 & 16. \\
\hline 203 & $17 / 20081648$ & $87 / 200816: 48$ & 1.628 & 16. \\
\hline 204 & $1 / 7 / 200816: 50$ & 8712008 16:50 & 1.620 & 16. \\
\hline
\end{tabular}




\begin{tabular}{|c|c|c|c|c|}
\hline \multicolumn{5}{|c|}{$D 4920$} \\
\hline$R \in C$ & & Adjusted & Fessurs & Temp \\
\hline$\#$ & DateTime & DateTime & psi & ${ }^{\circ} \mathrm{C}$ \\
\hline 205 & $1 / 7 / 200816: 52$ & $87 / 200816: 52$ & 1.628 & 16.9 \\
\hline 206 & $1 / 7200816: 54$ & $8 / 7 / 200816: 54$ & 1.627 & 16.9 \\
\hline 207 & $1 / 7 / 200816.56$ & $87 / 200816: 56$ & 1.628 & 16.9 \\
\hline 208 & $1 / 7 / 200816: 58$ & $87 / 200816: 58$ & 1.628 & 16.9 \\
\hline 200 & $1 / 7 / 200817: 00$ & $87 / 200817: 00$ & 1.620 & 16.9 \\
\hline 210 & $1 / 7 / 200817: 02$ & $87 / 200817: 02$ & 1.620 & 16.9 \\
\hline 211 & $1 / 7 / 2008$ 17:04 & $87 / 2008$ 17:04 & 1.63 & 16.9 \\
\hline 212 & $1 / 7 / 200817: 06$ & $87 / 200817: 06$ & 1.620 & 16.9 \\
\hline 213 & $1 / 7 / 200817: 08$ & $87 / 200817: 08$ & 1.629 & 16.9 \\
\hline 214 & $1 / 7 / 200817: 10$ & $87 / 200817: 10$ & 1.620 & 16.9 \\
\hline 215 & $1 / 7 / 200817: 12$ & $87 / 2008$ 17:12 & 1.620 & 16.9 \\
\hline 216 & $1 / 7 / 200817: 14$ & $87 / 200817: 14$ & 1.628 & 16.9 \\
\hline 217 & $1 / 7 / 2008$ 17:16 & $87 / 200817: 16$ & 1.628 & 16.9 \\
\hline 218 & $1 / 7 / 200817: 18$ & $87 / 200817: 18$ & 1.628 & 16.9 \\
\hline 219 & $1 / 7 / 200817: 20$ & $87 / 200817: 20$ & 1.627 & 16.9 \\
\hline 220 & $1 / 72008$ 17:22 & $87 / 200817: 22$ & 1.627 & 16.9 \\
\hline 221 & $1 / 72008$ 17:24 & $87 / 2008$ 17:24 & $1.62 \pi$ & 16.9 \\
\hline 222 & $1 / 7 / 200817: 26$ & $8 / 7 / 200817: 26$ & 1.62 & 16.9 \\
\hline 223 & $1 / 7 / 200817: 28$ & $8 / 72008$ 17:28 & $1.62 \pi$ & 16.9 \\
\hline 224 & $1 / 7 / 200817: 30$ & $87 / 200817: 30$ & 1.627 & 16.9 \\
\hline 225 & $1 / 7 / 200817: 32$ & $87 / 2008$ 17:32 & 1.627 & 16.9 \\
\hline 226 & $1 / 7 / 200817: 34$ & $87 / 2008$ 17:34 & 1.627 & 16.9 \\
\hline 227 & $1 / 7 / 200817: 36$ & $8 / 7200817: 36$ & 1.627 & 16.9 \\
\hline 228 & $1 / 7 / 200817: 38$ & $87 / 200817: 38$ & 1.629 & 16.9 \\
\hline 220 & $1 / 7 / 200817: 40$ & $87 / 200817: 40$ & 1.620 & 16.9 \\
\hline 230 & $1 / 7 / 200817: 42$ & $87 / 200817: 42$ & 1.620 & 16.9 \\
\hline 231 & $1 / 7 / 2008$ 17:44 & $87 / 2008$ 17:44 & 1.620 & 16.9 \\
\hline 232 & $1 / 7 / 200817: 46$ & $871200817: 46$ & 1.620 & 16.9 \\
\hline 233 & $1 / 7 / 2008$ 17:48 & $8 / 7200817: 48$ & 1.629 & 16.9 \\
\hline 234 & $1 / 7 / 2008$ 17:50 & $87 / 2008$ 17:50 & 1.628 & 16.9 \\
\hline 235 & $1 / 7 / 200817: 52$ & $87 / 2008$ 17:52 & 1.628 & 16.9 \\
\hline 236 & $1 / 7200817: 54$ & $87 / 2008$ 17:54 & 1.628 & 16.9 \\
\hline 237 & $1 / 7 / 200817: 56$ & $8 / 7200817: 56$ & 1.628 & 16.9 \\
\hline 238 & $1 / 7 / 2008$ 17:58 & $8 / 7200817: 58$ & 1.628 & 16.9 \\
\hline 239 & $1 / 7 / 200818: 00$ & $87 / 200818: 00$ & 1.628 & 16.9 \\
\hline 240 & $1 / 7 / 200818: 02$ & $8 / 7200818: 02$ & 1.628 & 16.9 \\
\hline 241 & $1 / 7 / 200818: 04$ & $87 / 200818: 04$ & 1.628 & 16.9 \\
\hline 242 & $1 / 7 / 200818: 06$ & $87 / 200818.06$ & 1.628 & 16.9 \\
\hline 243 & $1 / 7 / 200818: 08$ & $87 / 200818: 08$ & 1.620 & 16.9 \\
\hline 244 & 1/7/2008 18:10 & $87 / 200818: 10$ & 1.628 & 16.9 \\
\hline 245 & $1 / 72008$ 18:12 & $87 / 2008$ 18:12 & $1.62 \pi$ & 16.9 \\
\hline 246 & $1 / 7 / 20081814$ & $87 / 2008$ 18:14 & 1.627 & 16.9 \\
\hline 247 & $1 / 7 / 200818: 16$ & $87 / 2008$ 18:16 & 1.627 & 16.9 \\
\hline 248 & $1 / 7 / 2008$ 18:18 & $87 / 2008$ 18:18 & 1.627 & 16.9 \\
\hline 249 & $1 / 7 / 200818: 20$ & $87 / 200818: 20$ & 1.628 & 16.9 \\
\hline 250 & $1 / 7 / 200818: 22$ & $87 / 200818: 22$ & 1.628 & 16.9 \\
\hline 251 & $1 / 7 / 200818-24$ & $87 / 200818-24$ & 1.627 & 16.9 \\
\hline 252 & $1 / 7 / 2008$ 18:26 & $87 / 2008$ 18:26 & 1.627 & 16.9 \\
\hline 253 & $1 / 7 / 200818: 28$ & $87 / 200818: 28$ & 1.626 & 16.9 \\
\hline 254 & $1 / 7 / 200818-30$ & $87 / 200818: 30$ & 1.626 & 16.9 \\
\hline 256 & $1 / 7 / 200818: 32$ & $87 / 2008$ ^8:32 & 1.627 & 16.9 \\
\hline 256 & $1 / 7 / 2008$ 18:34 & $87 / 200818: 34$ & 1.627 & 16.9 \\
\hline 257 & $1 / 7 / 2008$ 18:36 & $87 / 200818: 36$ & 1.628 & 16.9 \\
\hline 258 & $1 / 7 / 2008$ 18:38 & $87 / 200818: 38$ & 1.628 & 16.9 \\
\hline 259 & $1 / 7 / 200818: 40$ & $87 / 2008$ 18:40 & 1.628 & 16.9 \\
\hline 260 & $1 / 7 / 2008$ 18:42 & $87 / 2008$ 18:42 & 1.620 & 16.9 \\
\hline 261 & $1 / 7 / 2008$ 18:44 & $87 / 2008$ 18:44 & 1.629 & 16.9 \\
\hline 262 & $1 / 7 / 200818: 46$ & $87 / 2008$ 18:46 & 1.620 & 16.9 \\
\hline 263 & $1 / 7200818: 48$ & $87 / 200818: 48$ & 1.6 & 16.9 \\
\hline 264 & $1 / 7 / 200818.50$ & $87 / 200818: 50$ & 1.63 & 16.9 \\
\hline 265 & $1 / 7 / 2008$ 18:52 & $87 / 2008$ 18:52 & 1.629 & 16.9 \\
\hline 266 & $1 / 7 / 200818.54$ & $87 / 200818: 54$ & 1.629 & 16.9 \\
\hline 267 & $1 / 7 / 200818: 56$ & $871200818: 56$ & 1.620 & 16.9 \\
\hline 268 & $1 / 7 / 200818: 58$ & $87 / 200818: 58$ & 1.63 & 16.9 \\
\hline 269 & $1 / 7 / 200819: 00$ & $8 / 7200819.00$ & 1.63 & 16.9 \\
\hline 270 & $1 / 7 / 2008$ 19:02 & $87 / 2006$ 19:02 & 1,631 & 16.9 \\
\hline 271 & $1 / 7 / 2008$ 19:04 & $877200619: 04$ & 1.63 & 16.9 \\
\hline 272 & $1 / 7 / 200819.06$ & $87 / 200819.06$ & 1.63 & 16.9 \\
\hline
\end{tabular}

\begin{tabular}{|c|c|c|c|c|}
\hline \multicolumn{5}{|c|}{ D4924 } \\
\hline $\mathrm{Pec}$ & & Adusted & Pressure & Temp \\
\hline$\#$ & DetêTime & Dete-Time & psi & ${ }^{\circ} \mathrm{C}$ \\
\hline 273 & $1 / 7 / 2008$ 19:08 & $87 / 200819: 08$ & 1.620 & 16.9 \\
\hline 274 & $1 / 7 / 2008$ 19:10 & 877200819.10 & 1.629 & 16.9 \\
\hline 275 & $1 / 7 / 200819.12$ & $87 / 200819.12$ & 1.629 & 16.9 \\
\hline 276 & $1 / 7 / 2008$ 19:14 & $87 / 200819.14$ & 1.629 & 16.9 \\
\hline 277 & $1 / 7 / 200819: 16$ & $87 / 200819.16$ & 1.620 & 16.9 \\
\hline 278 & $1 / 7 / 2008$ 19:18 & $87 / 200819.18$ & 1.629 & 16.9 \\
\hline 279 & $1 / 7 / 2008$ 19:20 & $87 / 2008$ 19:20 & 1.63 & 16.9 \\
\hline 280 & $1 / 7 / 200819: 22$ & $87 / 200819: 22$ & 1.63 & 16.9 \\
\hline 281 & $1 / 7 / 200819.24$ & 871200819.24 & 1.629 & 16.9 \\
\hline 282 & $1 / 7 / 200819.26$ & 877200819.26 & 1.620 & 16.9 \\
\hline 283 & $1 / 72008$ 19.28 & 877200819.28 & 1.629 & 16.9 \\
\hline 284 & $1 / 7 / 2008$ 19:30 & $87 / 200819.30$ & 1.629 & 16.9 \\
\hline 285 & $1 / 7 / 200819.32$ & $87 / 200819.32$ & 1.629 & 16.9 \\
\hline 286 & $1 / 7 / 2008$ 19:34 & $87 / 2008$ 19:34 & 1.63 & 16.9 \\
\hline 287 & $1 / 7 / 200819: 36$ & $87 / 200819.36$ & 1.63 & 16.9 \\
\hline 288 & $1 / 7 / 2008$ 19:38 & $87 / 200819: 38$ & 1.63 & 16.9 \\
\hline 289 & $1 / 7200819.40$ & $87 / 200819.40$ & 1.620 & 16.9 \\
\hline 290 & $1 / 7 / 2000$ 19.42 & $87 / 200819.42$ & 1.63 & 16.9 \\
\hline 291 & $1 / 7 / 2008$ 19:44 & $87 / 200819.44$ & 1.63 & 16.9 \\
\hline 292 & $1 / 7 / 200819.46$ & $87 / 200819.46$ & 1.63 & 16.9 \\
\hline 293 & $1 / 7 / 200819.48$ & $87 / 200819.48$ & 1.629 & 16.9 \\
\hline 294 & $17 / 200819.50$ & $877 / 200819.50$ & 1.620 & 16.9 \\
\hline 296 & $1 / 7 / 200819.52$ & $87 / 200819.52$ & 1.628 & 16.9 \\
\hline 296 & $1 / 7 / 200819.54$ & 877200819.54 & 1.628 & 16.9 \\
\hline 297 & $1 / 7 / 200819.56$ & 871200819.56 & 1.628 & 16.9 \\
\hline 298 & $1 / 7 / 200819: 58$ & $87 / 200819.58$ & 1.628 & 16.9 \\
\hline 299 & $1 / 7 / 200820: 00$ & $87 / 200820: 00$ & 1.628 & 16.9 \\
\hline 300 & $17 / 200820: 02$ & $87 / 200820: 02$ & 1.628 & 16.9 \\
\hline 301 & $17 / 200820: 04$ & $87 / 200820: 04$ & 1.628 & 16.9 \\
\hline 302 & $1 / 7 / 200820.06$ & $87 / 200820.06$ & 1.629 & 16.9 \\
\hline 303 & $1 / 7 / 200820: 08$ & $87 / 200820.08$ & 1.629 & 16.9 \\
\hline 304 & $1 / 7 / 200820: 10$ & $87 / 200820: 10$ & 1.628 & 16.9 \\
\hline 305 & $1 / 7 / 200820: 12$ & 877200820.12 & 1.628 & 16.9 \\
\hline 306 & $1 / 7 / 200820: 14$ & $87 / 200820: 14$ & 1.627 & 16.9 \\
\hline 307 & $1 / 7 / 200820: 16$ & $871200820: 16$ & 1.627 & 16.9 \\
\hline 308 & $1 / 7 / 200820: 18$ & $87 / 200820: 18$ & 1.627 & 16.9 \\
\hline 300 & $1 / 7 / 200820: 20$ & $877200820: 20$ & 1.627 & 16.9 \\
\hline 310 & $1 / 7 / 200820: 22$ & $87 / 200820: 22$ & 1.628 & 16.9 \\
\hline 311 & $1 / 7 / 200820: 24$ & $87 / 200820: 24$ & 1.628 & 16.9 \\
\hline 312 & $1 / 7 / 200820: 26$ & $87 / 200820: 26$ & 1.628 & 16.9 \\
\hline 313 & $1 / 7 / 200820228$ & $87 / 200820.28$ & 1.628 & 16.9 \\
\hline 314 & $1 / 7200820: 30$ & $87 / 200820.30$ & 1.627 & 16.9 \\
\hline 315 & $17 / 200820: 32$ & $877 / 200820.32$ & 1.626 & 16.9 \\
\hline 316 & $1 / 7 / 200820: 34$ & $87 / 200820.34$ & 1.625 & 16.9 \\
\hline 317 & $1 / 7 / 200820: 36$ & $87 / 200820.36$ & 1.624 & 16.9 \\
\hline 318 & $1 / 7 / 200820: 38$ & $87 / 200820.38$ & 1.623 & 16.9 \\
\hline 319 & $1 / 7 / 200820: 40$ & $87 / 200820.40$ & 1.624 & 16.9 \\
\hline 320 & $1 / 7200820: 42$ & $87 / 200820: 42$ & 1.624 & 16.9 \\
\hline 321 & $1 / 7 / 200820: 44$ & $87 / 200820.44$ & 1.624 & 16.9 \\
\hline 327 & $1 / 7 / 200820: 46$ & $87 / 200820.46$ & 1.623 & 16.9 \\
\hline 323 & $1 / 7 / 200820.48$ & $87 / 200820.48$ & 1.622 & 16.9 \\
\hline 324 & $1 / 7200820.50$ & $8 / 7 / 200820.50$ & 1.623 & 16.9 \\
\hline 325 & $1 / 7 / 200820.52$ & $877 / 200820.52$ & 1.624 & 16.9 \\
\hline 326 & $1 / 7 / 200820.54$ & $87 / 200820.54$ & 1.624 & 16.9 \\
\hline 327 & $1 / 7 / 200820.56$ & $8772000820: 56$ & 1.624 & 16.9 \\
\hline 328 & $1 / 7 / 200820.58$ & $87 / 200820.58$ & 1.624 & 16.9 \\
\hline 329 & 1/7/200821:00 & $87 / 200821: 00$ & 1.624 & 16.9 \\
\hline 330 & 1/7/2008 21:02 & $87 / 200821: 02$ & 1.624 & 16.9 \\
\hline 331 & 1/7/2008 21:04 & $87 / 200821: 04$ & 1.624 & 16.9 \\
\hline 332 & 1/7/2008 21:06 & $877200821: 06$ & 1.624 & 16.9 \\
\hline 333 & 1/7/2008 21:08 & $87 / 200821: 08$ & 1.623 & 16.9 \\
\hline 334 & $1 / 7 / 200821: 10$ & $8772000821: 10$ & 1.623 & 16.9 \\
\hline 335 & $1 / 7 / 200821: 12$ & $871200821: 12$ & 1.624 & 16.9 \\
\hline 336 & $1 / 7200821: 14$ & $87 / 200821: 14$ & 1.624 & 16.9 \\
\hline 337 & $1 / 7 / 200821: 16$ & $877200821: 16$ & 1.624 & 16.9 \\
\hline 338 & $1 / 7 / 200821: 18$ & $87 / 200821: 18$ & 1.623 & 16.9 \\
\hline 339 & $1 / 7 / 200821: 20$ & $877200821: 20$ & 1.624 & 16.9 \\
\hline 340 & $1 / 7 / 200821: 27$ & $87 / 2000821: 22$ & 1.624 & 16.9 \\
\hline
\end{tabular}

\begin{tabular}{|c|c|c|c|c|}
\hline \multicolumn{5}{|c|}{ D4928 } \\
\hline $\operatorname{Rec}$ & & Adusted & Pressurg & Temp \\
\hline$\#$ & Dete-Time & DetêTime & psi & ${ }^{\circ} \mathrm{C}$ \\
\hline 341 & $1 / 7 / 200821: 24$ & $871200821: 24$ & 1.625 & 16.9 \\
\hline 342 & $1 / 7 / 200821: 26$ & $87 / 200821: 26$ & 1.625 & 16.9 \\
\hline 343 & $1 / 7 / 200821: 28$ & $87 / 200821: 28$ & 1.625 & 16.9 \\
\hline 344 & $1 / 7 / 200821: 30$ & $87 / 200821: 30$ & 1.625 & 16.9 \\
\hline 345 & $1 / 7 / 200821: 32$ & $8 / 7200821: 32$ & 1.625 & 16.9 \\
\hline 346 & $1 / 7 / 200821: 34$ & $87 / 200821: 34$ & 1.625 & 16.9 \\
\hline 347 & $1 / 7 / 200821: 36$ & $87 / 200821: 36$ & 1.624 & 16.9 \\
\hline 348 & $1 / 7 / 200821: 38$ & $87 / 200821: 38$ & 1.624 & 16.9 \\
\hline 349 & $17 / 200821: 40$ & $877200821: 40$ & 1.624 & 16.9 \\
\hline 350 & $1 / 7 / 200821: 42$ & $87 / 200821: 42$ & 1.624 & 16.9 \\
\hline 351 & $1 / 7 / 200821: 44$ & $8 / 7200821: 44$ & 1.625 & 16.9 \\
\hline 352 & $1 / 7 / 200821: 46$ & $87 / 200821: 46$ & 1.625 & 16.9 \\
\hline 353 & $1 / 7 / 200821: 48$ & $871200821: 48$ & 1.624 & 16.9 \\
\hline 354 & $17 / 200821: 50$ & $87 / 200821: 50$ & 1.624 & 16.9 \\
\hline 355 & $1 / 7 / 200821: 52$ & $871200821: 52$ & 1.624 & 16.9 \\
\hline 356 & $1 / 7 / 200821: 54$ & $87 / 200821: 54$ & 1.624 & 16.9 \\
\hline 357 & $1 / 7 / 200821: 56$ & $871200821: 56$ & 1.624 & 16.9 \\
\hline 358 & $1 / 7 / 200821: 58$ & $87 / 200821: 58$ & 1.624 & 16.9 \\
\hline 359 & $1 / 7 / 20082200$ & 877200822200 & 1.623 & 16.9 \\
\hline 360 & $1 / 7 / 200822-02$ & $87 / 200822 \cdot 02$ & 1.623 & 16.9 \\
\hline 361 & $1 / 7 / 20082204$ & $87 / 200822-04$ & 1.623 & 16.9 \\
\hline $36^{2}$ & $1 / 7 / 200822206$ & $87 / 20082206$ & 1.623 & 16.9 \\
\hline 3 & $1 / 7 / 20082208$ & $87 / 200822: 08$ & 1.624 & 16.9 \\
\hline 364 & $1 / 7 / 20082210$ & $87 / 200822210$ & 1.624 & 16.9 \\
\hline 365 & $1 / 7 / 200822212$ & $87 / 200822: 12$ & 1.624 & 16.9 \\
\hline 366 & $1 / 7 / 20082214$ & $87 / 20082214$ & 1.624 & 16.9 \\
\hline 367 & $1 / 7 / 20082216$ & $87 / 20082216$ & 1.624 & 16.9 \\
\hline 368 & $1 / 7 / 200822 \div 18$ & $87 / 200822-18$ & 1.623 & 16.9 \\
\hline 369 & $1 / 7 / 20082220$ & $87 / 20082220$ & 1.622 & 16.9 \\
\hline 370 & $1 / 7 / 20082222$ & $87 / 200822-22$ & 1.622 & 16.9 \\
\hline 371 & $1 / 7 / 20082224$ & 87120082224 & 1.622 & 16.9 \\
\hline 372 & $1 / 7 / 20082226$ & 87120082226 & 1.623 & 16.9 \\
\hline 373 & $1 / 7 / 20082228$ & $87 / 20082228$ & 1.624 & 16.9 \\
\hline 374 & $1 / 7 / 200822230$ & $871200822: 30$ & 1.624 & 16.9 \\
\hline 375 & $1 / 7 / 20082232$ & 871200822232 & 1.623 & 16.9 \\
\hline 376 & $1 / 7 / 20082234$ & $87 / 20082234$ & 1.623 & 16.9 \\
\hline 377 & $1 / 7 / 200822236$ & 87120082236 & 1.623 & 16.9 \\
\hline 378 & $1 / 7 / 20082233$ & $87 / 20082238$ & 1.623 & 16.9 \\
\hline 379 & $1 / 7 / 20082240$ & $87 / 200822240$ & 1.624 & 16.9 \\
\hline 380 & $1 / 7 / 200822442$ & 87120082242 & 1.623 & 16.9 \\
\hline 381 & $1 / 7 / 20082244$ & $87 / 20082244$ & 1.624 & 16.9 \\
\hline 382 & $17 / 20082246$ & $87 / 20082246$ & 1.625 & 16.9 \\
\hline 383 & $1 / 720082248$ & $87 / 20082248$ & 1.625 & 16.9 \\
\hline 384 & $1 / 7 / 20082250$ & $87 / 20062250$ & 1.625 & 16.9 \\
\hline 385 & $1 / 7 / 20082252$ & 87120082252 & 1.625 & 16.9 \\
\hline 386 & $1 / 7 / 20082254$ & $87 / 20082254$ & 1.624 & 16.9 \\
\hline 387 & $1 / 7 / 20082256$ & $87 / 20082256$ & 1.624 & 16.9 \\
\hline 388 & $1 / 7 / 20082258$ & 87120082258 & 1.624 & 16.9 \\
\hline 389 & $1 / 7 / 200823: 00$ & $87 / 200823: 00$ & 1.625 & 16.9 \\
\hline 390 & $1 / 7 / 200823: 02$ & $871200823: 02$ & 1.624 & 16.9 \\
\hline 391 & $1 / 7 / 200823: 04$ & $871200823: 04$ & 1.624 & 16.9 \\
\hline 392 & $1 / 7 / 200823: 06$ & $87 / 200823: 06$ & 1.623 & 16.9 \\
\hline 393 & $1 / 7 / 200823: 08$ & $8 / 7200823: 08$ & 1.623 & 16.9 \\
\hline 394 & $17 / 200823: 10$ & $87 / 200823: 10$ & 1.624 & 16.9 \\
\hline 395 & $1 / 7 / 200823: 12$ & $87 / 200823: 12$ & 1.626 & 16.9 \\
\hline 396 & $1 / 7 / 200823: 14$ & $877200823: 14$ & 1.625 & 16.9 \\
\hline 397 & $1 / 7 / 200823: 16$ & $87 / 200823: 16$ & 1.624 & 16.9 \\
\hline 398 & $1 / 7 / 200823: 18$ & $8 / 7 / 200823: 18$ & 1.624 & 16.9 \\
\hline 399 & $1 / 7 / 200823: 20$ & $87 / 200823: 20$ & 1.624 & 16.9 \\
\hline 400 & $1 / 7 / 200823: 22$ & $87 / 200823: 22$ & 1.625 & 16.9 \\
\hline 401 & $1 / 7 / 200823: 24$ & $877 / 200823: 24$ & 1.625 & 169 \\
\hline 402 & $1 / 7 / 200825: 26$ & $87 / 200823: 26$ & 1.625 & 16.9 \\
\hline 403 & $1 / 7200823: 28$ & $87 / 200823: 28$ & 1.625 & 16.9 \\
\hline 404 & $1 / 7 / 200823: 30$ & $87 / 200823: 30$ & 1.626 & 16.9 \\
\hline 405 & $1 / 7 / 200823: 32$ & $87 / 200823: 32$ & 1.626 & 16.9 \\
\hline 406 & $1 / 7 / 200823: 34$ & $87 / 200823: 34$ & 1.627 & 16.9 \\
\hline 407 & $1 / 7 / 200823: 36$ & $87 / 200823: 36$ & 1.626 & 16.9 \\
\hline 408 & $1 / 7 / 200823: 38$ & $877 / 200823: 38$ & 1.626 & 16.9 \\
\hline
\end{tabular}




\begin{tabular}{|c|c|c|c|c|}
\hline \multicolumn{5}{|c|}{ D4-92p } \\
\hline $\operatorname{Rec}$ & & Adjusted & Pressure & Temp \\
\hline$\#$ & DeteTime & Date-Time & \begin{tabular}{|l|} 
psi \\
\end{tabular} & ${ }^{\circ} \mathrm{C}$ \\
\hline 409 & $1 / 7 / 200823: 40$ & $87 / 200823: 40$ & 1.625 & 16.9 \\
\hline 410 & $1 / 7 / 200823: 42$ & $87 / 2000823: 42$ & 1.625 & 16.9 \\
\hline 411 & $1 / 7 / 200823: 44$ & $871200823: 44$ & 1.625 & 16.9 \\
\hline 412 & $1 / 7 / 200823: 46$ & $87 / 200823: 46$ & 1.624 & 16.9 \\
\hline 413 & $1 / 7 / 200823: 48$ & $87 / 200823: 48$ & 1.624 & 16.9 \\
\hline 414 & $1 / 7 / 200823: 50$ & $87 / 200823: 50$ & 1.625 & 16.9 \\
\hline 415 & $1 / 7 / 200823: 52$ & $877 / 200823: 52$ & 1.625 & 16.9 \\
\hline 416 & $1 / 7 / 200823: 54$ & $8772000823: 54$ & 1.623 & 16.9 \\
\hline 417 & $1 / 7 / 200823: 56$ & $871200823: 56$ & 1.622 & 16.9 \\
\hline 418 & $1 / 7 / 200823: 58$ & $87 / 200823: 58$ & 1.622 & 16.9 \\
\hline 419 & $1 / 8 / 20080000$ & 8/8/20080:00 & 1.62 & 16.9 \\
\hline 420 & $1 / 8 / 20080: 02$ & $8 / 8 / 20080: 02$ & 1.623 & 16.9 \\
\hline 421 & $1 / 8 / 20080: 04$ & $8 / 8 / 20080: 04$ & 1.622 & 16.9 \\
\hline 422 & $1 / 8 / 20080.06$ & $88 / 20080: 06$ & 1.621 & 16.9 \\
\hline 423 & $1 / 8 / 20080.08$ & $8 / 8 / 20080: 08$ & 1.621 & 16.9 \\
\hline 424 & $1 / 8 / 20080: 10$ & 8/8/20080:10 & 1.621 & 16.9 \\
\hline 425 & $1 / 8 / 20080: 12$ & 8/8/20080:12 & 1.622 & 16.9 \\
\hline 426 & $1 / 8 / 20080: 14$ & $8 / 8 / 20080: 14$ & 1.621 & 16.9 \\
\hline 427 & $1 / 8 / 20080: 16$ & 8/8120080:16 & 1.62 & 16.9 \\
\hline 428 & 1/8/2008 0.18 & 8/8/20080:18 & 1.621 & 16.9 \\
\hline 429 & $1 / 8 / 20080.20$ & $8 / 8 / 20080: 20$ & 1.62 & 16.9 \\
\hline 430 & $1 / 8 / 20080.22$ & $8 / 8 / 20080: 22$ & 1.62 & 16.9 \\
\hline 431 & $1 / 8 / 20080.24$ & 8/8/20080:24 & 1.62 & 16.9 \\
\hline 432 & $1 / 8 / 20080.26$ & $8 / 8 / 20080: 26$ & 1.623 & 16.9 \\
\hline 433 & $1 / 8 / 20080: 28$ & $8 / 8 / 20080: 28$ & 1.623 & 16.9 \\
\hline 434 & $1 / 8 / 20080: 30$ & $8 / 8 / 20080: 30$ & 1.621 & 16.9 \\
\hline 435 & $1 / 8 / 20080.32$ & $8 / 8 / 20080: 32$ & 1.621 & 16.9 \\
\hline 436 & $1 / 8 / 20080.34$ & $8 / 8 / 20080: 34$ & 1.62 & 16.9 \\
\hline 437. & $1 / 8 / 20080: 36$ & $8 / 8 / 20080: 36$ & 1.621 & 16.9 \\
\hline 438 & $1 / 8 / 20080.38$ & $8 / 8 / 20080: 38$ & 1.62 & 16.9 \\
\hline 439 & $1 / 8 / 20080: 40$ & $8 / 8 / 20080: 40$ & 1.62 & 16.9 \\
\hline 440 & $1 / 8 / 20080.42$ & $8 / 820080-42$ & 1.621 & 16.9 \\
\hline 441 & $1 / 8 / 20080: 44$ & $8 / 8 / 20080: 44$ & 1.621 & 16.9 \\
\hline 442 & $1 / 8 / 20080: 46$ & $8 / 8 / 20080: 46$ & 1.621 & 16.9 \\
\hline 443 & $1 / 8 / 20080: 48$ & $8 / 8 / 20080: 48$ & 1.62 & 16.9 \\
\hline 444 & $1 / 8 / 20080.50$ & $8 / 8 / 20080: 50$ & 1.62 & 16.9 \\
\hline 445 & $1 / 8 / 20080.52$ & $8 / 820080: 52$ & 1.62 & 16.9 \\
\hline 446 & $1 / 8 / 20080.54$ & $8 / 8 / 20080: 54$ & 1.621 & 16.9 \\
\hline 447. & $1 / 8 / 20080: 56$ & $8 / 8 / 20080: 56$ & 1.62 & 16.9 \\
\hline 448 & $1 / 8 / 20080.58$ & $8 / 8 / 20080.58$ & 1.621 & 16.9 \\
\hline 449 & $1 / 8 / 20081: 00$ & $8 / 8 / 20081: 00$ & 1.621 & 16.9 \\
\hline 450 & 1/8/2008 1:02 & $88120081: 02$ & 1.621 & 16.9 \\
\hline 451 & 1/8/2008 1:04 & $88 / 20081: 04$ & 1.621 & 16.9 \\
\hline 452 & 1/8/2008 1:06 & $8 / 8 / 20081: 06$ & 1.621 & 16.9 \\
\hline 453 & 1/8/2008 1:08 & $8 / 8 / 20081: 08$ & 1.62 & 16.9 \\
\hline 454 & 1/8/2008 1:10 & $8 / 8 / 20081: 10$ & 1.62 & 16.9 \\
\hline 455 & 1/8/2008 1:12 & $8 / 8 / 20081: 12$ & 1.622 & 16.9 \\
\hline 456 & $1 / 8 / 2008$ 1:14 & $8 / 8 / 20081: 14$ & 1.62 & 16.9 \\
\hline 457 & 1/8/2008 1:16 & $8 / 8 / 20081: 16$ & 1.622 & 16.9 \\
\hline 458 & $1 / 8 / 2008$ 1:18 & $8 / 8 / 20081: 18$ & 1.622 & 16.9 \\
\hline 459 & 1/8/2008 1:20 & 8/8/2008 1:20 & 1.621 & 16.9 \\
\hline 460 & 1/8/2008 1:22 & $8 / 8 / 20081: 22$ & 1.62 & 16.9 \\
\hline 461 & 1/8/2008 1:24 & $8 / 820081: 24$ & 1.621 & 16.9 \\
\hline 462 & 1/8/2008 1:26 & $8 / 8 / 20081: 26$ & 1.623 & 16.9 \\
\hline 463 & 1/8/2008 1:28 & $8 / 8 / 20081: 28$ & 1.621 & 16.9 \\
\hline 464 & $1 / 8 / 20081: 30$ & $8 / 8 / 20081: 30$ & 1.621 & 16.9 \\
\hline 465 & 1/8/2008 1:32 & $8 / 8 / 20081: 32$ & 1.621 & 16.9 \\
\hline 466 & $1 / 8 / 20081: 34$ & $8 / 8 / 20081: 34$ & 1.62 & 16.9 \\
\hline 467 & 1/8/2008 1:36 & $8 / 8 / 20081: 36$ & 1.62 & 16.9 \\
\hline 468 & $1 / 8 / 20081: 38$ & $8 / 8 / 20081: 38$ & 1.62 & 16.9 \\
\hline 469 & $1 / 8 / 20081: 40$ & $8 / 8 / 20081: 40$ & 1.62 & 16.9 \\
\hline 470 & $1 / 8 / 20081: 42$ & $8 / 8 / 20081: 42$ & 1.619 & 16.9 \\
\hline 471 & $1 / 8 / 20081: 44$ & $8 / 8 / 20081: 44$ & 1.62 & 16.9 \\
\hline 472 & $1 / 8 / 20081: 46$ & $8 / 8 / 20081: 46$ & 1.62 & 16.9 \\
\hline 473 & $1 / 8 / 2008$ 1:48 & $8 / 8 / 2008$ 1:48 & 1.621 & 16.9 \\
\hline 474 & $1 / 8 / 2008$ 1:50 & $8 / 8 / 2008$ 1:50 & 1.62 & 16.9 \\
\hline 475 & 1/8/2008 1:52 & $8 / 8 / 20081: 52$ & 1.62 & 16.9 \\
\hline 476 & $1 / 8 / 20081: 54$ & $8 / 8 / 20081: 54$ & 1.62 & 16.9 \\
\hline
\end{tabular}

\begin{tabular}{|c|c|c|c|c|}
\hline \multicolumn{5}{|c|}{ D4920 } \\
\hline $\mathrm{Rec}$ & & Ad justed & Pressurs & Temr \\
\hline$\#$ & DeterTime & DeterTime & psi & \\
\hline $4 \pi$ & $1 / 8220081: 56$ & $8 / 8 / 20081: 56$ & 1.62 & 16. \\
\hline 478 & $1 / 8 / 20081: 58$ & $8 / 8 / 20081: 58$ & 1.619 & 16. \\
\hline 479 & $1 / 8 / 2008200$ & $8 / 8 / 20082: 00$ & 1.619 & \\
\hline 480 & $1 / 8 / 2008202$ & $8 / 8 / 20082: 02$ & 1.619 & 16. \\
\hline 481 & $1 / 8 / 2008204$ & $8 / 8 / 2008204$ & $1 . ळ 2$ & 16. \\
\hline 482 & $1 / 8 / 2008206$ & $8 / 8 / 20082: 06$ & 1.621 & 16. \\
\hline 483 & $1 / 8 / 2008208$ & $8 / 8 / 20082: 08$ & 1.621 & 16 \\
\hline 484 & $1 / 822008210$ & $8 / 8 / 20082: 10$ & 1.62 & 16. \\
\hline 485 & $1 / 8 / 20082: 12$ & $8 / 8 / 20082: 12$ & 1.621 & 16.9 \\
\hline 486 & $1 / 8 / 2008214$ & $8 / 8 / 20082: 14$ & 1.621 & 16.9 \\
\hline 487 & $1 / 820082: 16$ & $8 / 8 / 20082: 16$ & 1.62 & 16. \\
\hline 488 & $1 / 8220082: 18$ & $8 / 8 / 2008218$ & 1.62 & 16. \\
\hline 489 & $1 / 82008220$ & $8 / 8 / 20082: 20$ & 1.619 & 16 \\
\hline 490 & $1 / 8 / 20082222$ & $8 / 8 / 2008222$ & 1.619 & 16 \\
\hline 491 & $1 / 82008224$ & $8 / 8 / 2008224$ & 1.62 & 16. \\
\hline 492 & $1 / 8 / 2008226$ & $8 / 8 / 2008226$ & 1.621 & 16. \\
\hline 493 & $1 / 82008228$ & $8 / 8 / 20082: 28$ & 1.621 & 16. \\
\hline 494 & $1 / 82008230$ & $8 / 8 / 20082,30$ & 1.62 & 16 \\
\hline 495 & $1 / 82008232$ & $8 / 8 / 20082: 32$ & 1.62 & 16. \\
\hline 496 & $1 / 8 / 20082: 34$ & $8 / 8 / 20082 \cdot 34$ & 1.62 & 16. \\
\hline 497 & $1 / 82008236$ & $8 / 8 / 2008236$ & 1.62 & 16 \\
\hline 498 & $1 / 8 / 2008238$ & $8 / 8 / 2008238$ & 1.621 & 16. \\
\hline 499 & $1 / 8 / 200$ & $8 / 8 / 2008240$ & 1.621 & 16. \\
\hline 500 & $1 / 8 / 2008242$ & $8 / 8 / 2008242$ & 1.62 & 16. \\
\hline 501 & $1 / 82008244$ & $8 / 820082444$ & 1.618 & 16. \\
\hline 502 & $1 / 8200$ & $8 / 8 / 20082: 46$ & 1.617 & 16. \\
\hline 503 & $1 / 82008248$ & $8 / 8 / 20082: 48$ & 1.616 & 16. \\
\hline 504 & $1 / 82008250$ & $8 / 8 / 20082: 50$ & 1.616 & 16. \\
\hline 505 & $1 / 82008252$ & $8 / 8 / 2008252$ & 1.616 & 16. \\
\hline 506 & $1 / 82008254$ & $8 / 8 / 2008254$ & 1.617 & 16. \\
\hline 507. & $1 / 8 / 2008256$ & $8 / 8 / 2008256$ & 1.619 & 16. \\
\hline 508 & $1 / 8 / 200$ & $8 / 8 / 2008258$ & 1.619 & 16 \\
\hline 509 & $1 / 8200$ & $8 / 8 / 20083: 00$ & 1.02 & 16 \\
\hline 510 & $1 / 8200$ & $8 / 8 / 20083: 02$ & 1.62 & 16. \\
\hline 511 & $33: 04$ & $8 / 8 / 20083: 04$ & 1.62 & 16 \\
\hline 512 & $1 / 8 / 200$ & $8 / 8 / 20083: 06$ & 1.62 & 16 \\
\hline 513 & 1/8/20083:08 & $8 / 8 / 20083: 08$ & 1.619 & 16 \\
\hline 514 & 3:10 & $8 / 8 / 20083: 10$ & 1.619 & 16. \\
\hline 515 & $3: 12$ & $8 / 820083: 12$ & 1.619 & 16 \\
\hline 516 & 1/8/20083:14 & $8 / 8 / 20083: 14$ & 1.619 & 16 \\
\hline 517 & $820083: 16$ & $8 / 8 / 20083: 16$ & 1.619 & 16. \\
\hline 518 & 18 & $8 / 8 / 20083: 18$ & 1.619 & 16 \\
\hline 519 & $3: 20$ & $8 / 8 / 20083: 20$ & 1.619 & 16 \\
\hline 520 & 1/820083:22 & 8/8/20083:22 & 1.619 & 16 \\
\hline 521 & $3: 24$ & $8 / 8 / 20083: 24$ & 1.619 & 16 \\
\hline 522 & $3: 26$ & $8 / 8 / 20083: 26$ & 1.618 & 16 \\
\hline 523 & 1/820083:28 & $8 / 820083: 28$ & 1.618 & 16 \\
\hline 524 & 3:30 & $8 / 8 / 20083: 30$ & 1.618 & 16. \\
\hline 525 & $3: 32$ & $8 / 8 / 20083: 32$ & 1.618 & 16. \\
\hline 526 & $1 / 8 / 200$ & 8/8:20083:34 & 1.617 & 16 \\
\hline 527 & 3:36-3 & $8 / 8120083: 36$ & 1.617 & 16. \\
\hline 528 & 3:38 & $8 / 8 / 20083: 38$ & 1.617 & 16. \\
\hline 529 & 1/820083:40 & $8 / 8 / 20083: 40$ & 1.616 & 16 \\
\hline 530 & $1 / 8 / 200$ & $88 / 20083: 42$ & 1.615 & 16 \\
\hline 531 & $1 / 8 / 20$ & $8 / 8 / 20083: 44$ & 1.616 & 16. \\
\hline 532 & 1/82:20083:46 & $8 / 8 / 20083: 46$ & 1.617 & 16. \\
\hline 533 & $1 / 8 / 2000$ & $8 / 8 / 20083: 48$ & 1.619 & 16. \\
\hline 534 & $1 / 8 / 2000$ & $8 / 8 / 20083: 50$ & 1.619 & 16. \\
\hline 535 & $1 / 820083.52$ & $8 / 8 / 20083: 52$ & 1.618 & 16. \\
\hline 536 & 1/8/20083:54 & $8 / 820083: 54$ & 1.618 & 16 . \\
\hline 537 & $1 / 820083: 56$ & $8 / 8 / 2008356$ & 1.617 & 16. \\
\hline 538 & $1 / 820083: 58$ & $8 / 8 / 20083: 58$ & 1.617 & 16. \\
\hline 539 & 1/82008 4:00 & $8 / 820084: 00$ & 1.615 & 16. \\
\hline 540 & 1/820084:02 & $8 / 8 / 20084: 02$ & 1.616 & 16. \\
\hline 541 & 1/8/20084:04 & $8 / 8 / 20084: 04$ & 1.617 & 46. \\
\hline 542 & 1/8/20084:06 & $8 / 8 / 20084: 06$ & 1.617 & 16 . \\
\hline 543 & 1/8/20084:08 & $8 / 8 / 20084: 08$ & 1.617 & 16. \\
\hline 544 & 1/8/20084:10 & $8 / 8 / 20084: 10$ & 1.617 & $16 . \mathrm{C}$ \\
\hline
\end{tabular}

\begin{tabular}{|c|c|c|c|c|}
\hline \multicolumn{5}{|c|}{ D4989 } \\
\hline $\operatorname{Rec}$ & & Adjusted & Pressure & Temp \\
\hline$\#$ & Date/Time & Date-Time & \begin{tabular}{|l|}
$p s i$ \\
\end{tabular} & ${ }^{\circ} \mathrm{C}$ \\
\hline 545 & $1 / 820084: 12$ & $8 / 8 / 20084: 12$ & 1.615 & 16. \\
\hline 546 & 1/8/20084:14 & 8/8/20084:14 & 1.616 & 16.8 \\
\hline 547 & $1 / 8 / 20084: 16$ & $8 / 8 / 20084: 16$ & 1.616 & \\
\hline 548 & $1 / 820084: 18$ & $8 / 8 / 20084: 18$ & 1.616 & 16. \\
\hline 549 & $1 / 820084: 20$ & $8 / 8 / 20084: 20$ & 1.616 & 16.9 \\
\hline 550 & $1 / 8 / 20084: 22$ & $8 / 8 / 20084: 22$ & 1.616 & 16. \\
\hline 551 & $1 / 820084: 24$ & $8 / 820084: 24$ & 1.615 & 16. \\
\hline 552 & 1/8220084:26 & $8 / 8 / 20084: 26$ & 1.615 & 16 . \\
\hline 553 & 1/8/20084:28 & $8 / 8 / 20084: 28$ & 1.614 & 16. \\
\hline 554 & $1 / 820084: 30$ & $8 / 8 / 20084: 30$ & 1.615 & 16. \\
\hline 555 & $1 / 820084: 32$ & $8 / 820084: 32$ & 1.615 & $\overline{16}$ \\
\hline 556 & $1 / 8 / 20084: 34$ & $8 / 8 / 20084: 34$ & 1.616 & 16. \\
\hline 557 & $1 / 820084: 36$ & $8 / 8 / 20084: 36$ & 1.616 & 16.9 \\
\hline 558 & $1 / 8 / 20084: 38$ & $8 / 8 / 20084: 38$ & 1.615 & 110 \\
\hline 559 & $1 / 8 / 20084: 40$ & $8 / 8 / 20084: 40$ & 1.615 & 16.9 \\
\hline 560 & $1 / 8 / 20084: 42$ & $8 / 8 / 20084: 42$ & 1.616 & 16.9 \\
\hline 561 & $1 / 8 / 20084: 44$ & $8 / 8 / 20084: 44$ & 1.616 & 16.5 \\
\hline 562 & $1 / 820084: 46$ & $8 / 820084: 46$ & 1.616 & 16. \\
\hline 563 & $1 / 8 / 20084: 48$ & $8 / 8 / 20084: 48$ & 1.616 & 16. \\
\hline 564 & $1 / 8200084: 50$ & $8 / 8 / 20084: 50$ & 1.615 & 16.9 \\
\hline 565 & $1 / 8 / 20084: 52$ & $8 / 8 / 20084: 52$ & 1.616 & \\
\hline 566 & $1 / 8 / 20084: 54$ & $8 / 8 / 20084: 54$ & 1.616 & 16. \\
\hline 567 & $1 / 8 / 20084: 56$ & $8 / 8 / 20084: 56$ & 1.616 & 16.9 \\
\hline 568 & $1 / 8 / 20084: 58$ & $8 / 8 / 20084: 58$ & 1.616 & 16. \\
\hline 569 & $1 / 8 / 20085: 00$ & $8 / 8 / 20085: 00$ & 1.615 & 16.9 \\
\hline 570 & $1 / 820085: 02$ & $8 / 8 / 20085: 02$ & 1.614 & 16.9 \\
\hline 571 & $1 / 8 / 20085: 04$ & 8/8/20085:04 & 1.614 & 16. \\
\hline 572 & 1/820085:06 & $8 / 8 / 20085: 06$ & 1.614 & 16. \\
\hline 573 & $1 / 8 / 20085: 08$ & $8 / 820085: 08$ & 1.614 & 16.9 \\
\hline 574 & $1 / 8 / 200$ & $8 / 8 / 20085: 10$ & 1.615 & 16. \\
\hline 575 & $1 / 8 / 20085: 12$ & $8 / 8 / 20085: 12$ & 1.615 & 16.9 \\
\hline 576 & $1 / 8 / 20085: 14$ & $8 / 8 / 20085: 14$ & 1.615 & 16. \\
\hline $5 \pi 7$ & $1 / 82200$ & $85: 16$ & 1.615 & 16. \\
\hline 578 & $1 / 8 / 20085: 18$ & $8 / 8 / 20085: 18$ & 1.615 & 16. \\
\hline 579 & $1 / 820085: 20$ & $8 / 8 / 20085: 20$ & 1.615 & 16 \\
\hline 580 & $1 / 8 / 200$ & 35:22 & 1.615 & 16. \\
\hline 581 & $1 / 8 / 20085: 24$ & $8 / 820005: 24$ & 1.615 & 16. \\
\hline 582 & $1 / 8 / 20085: 26$ & $8 / 8 / 20085: 26$ & 1.615 & $16 .$. \\
\hline 583 & 8200 & $8 / 8 / 200$ & 1.615 & 16.9 \\
\hline 584 & $1 / 8 / 200$ & $5: 30$ & 1.615 & 16. \\
\hline 585 & $1 / 8200085: 32$ & $8 / 8 / 20085: 32$ & 1.614 & 16.9 \\
\hline 586 & $1 / 8 / 200$ & $8 / 8 / 2$ & 1.614 & 16. \\
\hline 587 & $1 / 8 / 200$ & $8 / 820085: 36$ & 1.613 & 16. \\
\hline 588 & $1 / 8200085: 38$ & $8 / 8220085: 38$ & 1.613 & 16.9 \\
\hline 589 & $1 / 8 / 200$ & $8 / 8 / 20085: 40$ & 1.613 & 16. \\
\hline 590 & $8 / 200$ & $8 / 8 / 2$ & 1.614 & 16. \\
\hline 591 & $1 / 8 / 20085: 44$ & $8 / 8 / 20085: 44$ & 1.614 & 16. \\
\hline 592 & 1/8/20085:46 & $8 / 8 / 20085: 46$ & 1.614 & 16.9 \\
\hline 593 & $1 / 8 / 200$ & $88 / 2$ & 1.613 & 1 \\
\hline 594 & $1 / 8 / 2008$ & $8 / 8 / 20085: 50$ & 1.613 & 16. \\
\hline 505 & $1 / 8 / 200$ & $8 / 8 / 20085: 52$ & 1.613 & 16. \\
\hline 596 & $1 / 8 / 200$ & $8 / 8 \sqrt{2}$ & 1.613 & 1 \\
\hline 597 & 1/8/20085:56 & $8 / 8 / 20085: 56$ & 1.613 & 16. \\
\hline 598 & $1 / 8 / 200$ & $8 / 820085: 58$ & 1.612 & 16. \\
\hline 599 & $1 / 8 / 200$ & 8/8/20086:00 & 1.612 & 16. \\
\hline 600 & 1/8/20086:02 & $8 / 8 / 20086: 02$ & 1.613 & 16 . \\
\hline 601 & $1 / 8 / 200$ & $8 / 8 / 20086: 04$ & 1.612 & 16. \\
\hline 602 & $1 / 8 / 200$ & $8 / 820086: 06$ & 1.613 & 16. \\
\hline 603 & $1 / 820086: 08$ & $8 / 8 / 20086: 08$ & 1.612 & 16. \\
\hline 604 & 1/8/20086-10 & $8820086: 10$ & 1.613 & 16. \\
\hline 605 & 1/8/2008 6:12 & $8820086: 12$ & 1.613 & 16. \\
\hline 606 & $1 / 8 / 20086: 14$ & $8 / 820086: 14$ & 1.614 & 16. \\
\hline 607 & 1/8/20086:16 & $8 / 820086: 16$ & 1.614 & 16. \\
\hline 608 & 1/8/2008 6:18 & $8 / 820086: 18$ & 1.612 & 16 . \\
\hline 609 & $1 / 8 / 20086: 20$ & 8/820086:20 & 1.612 & 16. \\
\hline 610 & $1 / 8 / 20086: 22$ & 8/8/20086:22 & 1.612 & 16 . \\
\hline 611 & 1/8/2008 6:24 & $8 / 820006: 24$ & 1.611 & 16. \\
\hline 612 & $1 / 8 / 20086: 26$ & $8 / 8 / 20086: 26$ & 1.612 & 16. \\
\hline
\end{tabular}


DOE/RL-2009-35, REV. 0

\begin{tabular}{|c|c|c|c|c|}
\hline \multicolumn{5}{|c|}{ D4-92p } \\
\hline $\mathrm{Bec}$ & & Adjusted & Pressure & Temp \\
\hline \# & DetelTime & Date/Time & \begin{tabular}{|l|}
$p s i$ \\
\end{tabular} & ${ }^{\circ} \mathrm{C}$ \\
\hline 613 & 1/8/20086:28 & $8 / 8 / 20086: 28$ & 1.612 & 16.9 \\
\hline 614 & $320086: 30$ & $8 / 820086: 30$ & 1.612 & 16.9 \\
\hline 615 & $820086: 32$ & $8 / 820086: 32$ & 1.612 & 16.9 \\
\hline 616 & $1 / 8 / 20086: 34$ & $8 / 820086: 34$ & 1.612 & 16.9 \\
\hline 617 & $1 / 820086: 36$ & $8 / 820086: 36$ & 1.612 & 16.9 \\
\hline 618 & $1 / 8 / 20086: 38$ & $8 / 820086: 38$ & 1.612 & 16.9 \\
\hline 619 & $1 / 8 / 20086: 40$ & $8 / 820086: 40$ & 1.613 & 16.9 \\
\hline 620 & $1 / 8 / 20086: 42$ & $8 / 820086: 42$ & 1.613 & 16.9 \\
\hline 621 & $1 / 8 / 20086: 44$ & $8 / 8 / 20086: 44$ & 1.613 & 16.9 \\
\hline 622 & $1 / 8 / 20086: 46$ & $8 / 820086: 46$ & 1.613 & 16.9 \\
\hline 623 & $1 / 8 / 20086: 48$ & $8 / 820086: 48$ & 1.613 & 16.9 \\
\hline 624 & 1/8/20086:50 & $8 / 820086: 50$ & 1.612 & 16.9 \\
\hline 625 & $1 / 8 / 20086.52$ & $8 / 200086.52$ & 1.61 & 16.8 \\
\hline 626 & $1 / 8 / 20086: 54$ & $8 / 820086: 54$ & 1.607 & 16.9 \\
\hline 627 & $1 / 820006656$ & $8 / 820086: 56$ & 1.605 & 16.9 \\
\hline 228 & $1 / 8 / 200$ & $8 / 8 / 20086: 58$ & 1.605 & 16.8 \\
\hline 629 & 1/8/2008 7:00 & $8 / 820087: 00$ & 1.607 & 16.9 \\
\hline 630 & $1 / 8 / 200$ & $8 / 8 / 20087: 02$ & 1.608 & 16.9 \\
\hline 61 & $1 / 8 / 200$ & $8 / 8 / 20087: 04$ & 1.608 & 16. \\
\hline 632 & 1/8/2008 7:06 & $8 / 820087: 06$ & 1.608 & 16.9 \\
\hline 63 & $1 / 8 / 200$ & $8 / 820087: 08$ & 1.608 & 16.0 \\
\hline 634 & $1 / 8 / 2000$ & $8820087: 10$ & 1.609 & 16 . \\
\hline 635 & $1 / 8 / 20087: 12$ & $8820087: 12$ & 1.611 & 16.9 \\
\hline 636 & $1 / 8200$ & $8 / 820087: 14$ & 1.611 & 16.9 \\
\hline 637 & $1 / 8 / 200$ & $8820087: 16$ & 1.612 & 16. \\
\hline 638 & $1 / 8 / 200$ & $8 / 20087: 18$ & 1.611 & 16.9 \\
\hline 639 & $1 / 8 / 20$ & $8 / 820087: 20$ & 1.61 & 16.9 \\
\hline 640 & $1 / 8 / 200$ & $8 / 8 / 20087: 22$ & 1.61 & 16. \\
\hline 641 & $1 / 8 / 200$ & $88 / 20087: 24$ & 1.61 & 16.9 \\
\hline 642 & $1 / 8 / 20$ & $88220087: 26$ & 1.61 & 16.5 \\
\hline 643 & $1 / 8200$ & $8 / 820087: 28$ & 1.61 & 16.8 \\
\hline 644 & $1 / 8 / 20$ & $8 / 820087: 30$ & 1.609 & 16.5 \\
\hline 645 & $1 / 8 / 20$ & $8820087: 32$ & 1.61 & 16.5 \\
\hline 646 & $1 / 8 / 20$ & $8820087: 34$ & 1.611 & 16.5 \\
\hline 647 & $1 / 8 / 20$ & $88: 20087: 36$ & 1.611 & 16 \\
\hline 648 & $1 / 8 / 20$ & $8 / 820087: 38$ & 1.61 & 16. \\
\hline 649 & $1 / 8 / 200$ & $8820087: 40$ & 1.609 & 16. \\
\hline 650 & $1 / 8 / 20$ & $8 / 820087: 42$ & 1.609 & 16.9 \\
\hline 651 & $1 / 8 / 20$ & $8 / 20087: 44$ & 1.61 & 16. \\
\hline 652 & $1 / 8 / 20$ & $8 / 820087: 46$ & 1.611 & 16.9 \\
\hline 653 & $1 / 8 / 20$ & $8 / 8 / 20087: 48$ & 1.61 & 16.8 \\
\hline 654 & $1 / 8 / 20$ & $8 / 820087: 50$ & 1.61 & 16. \\
\hline 655 & $1 / 8 / 20$ & $88 / 20087: 52$ & 1.609 & 16.0 \\
\hline 656 & $1 / 8 / 20$ & $8 / 820087: 54$ & 1.609 & 16. \\
\hline 607 & $1 / 8200$ & $8 / 820087: 56$ & 1.543 & 16.9 \\
\hline 658 & $1 / 8 / 20$ & $8 / 820087: 58$ & 1.609 & 16.5 \\
\hline 659 & & $820088: 00$ & 0.006 & 172 \\
\hline 660 & $1 / 8 / 20$ & $8: 02$ & 0.006 & 178 \\
\hline 661 & & 8:04 & 0.006 & 18.7 \\
\hline 662 & & $8: 06$ & 0.007 & 19.5 \\
\hline 663 & $1 / 8 / 20$ & $820088: 08$ & 0.008 & 20. \\
\hline 664 & & 8:10 & 0.008 & 209 \\
\hline 665 & $1 / 8 / 2$ & $8: 12$ & 0.000 & 21.6 \\
\hline 666 & $1 / 8 / 200$ & $820088: 14$ & 0.008 & 223 \\
\hline 667 & & & 0.007 & 23 \\
\hline 668 & & 18 & 0.000 & 239 \\
\hline 669 & $1 / 8 / 20$ & $8 / 20088: 20$ & 0.001 & 24.9 \\
\hline 670 & & & 0.003 & 26.8 \\
\hline 671 & & $820088: 24$ & 0.006 & 284 \\
\hline 672 & $1 / 8 / 200$ & $8 / 820088: 26$ & 0.007 & 29.6 \\
\hline 673 & & $8 / 20088.28$ & 0.011 & 306 \\
\hline 674 & $1 / 8 / 20$ & $820088: 30$ & 0.015 & 30.3 \\
\hline 675 & $1 / 8 / 2000$ & $8 / 20088: 32$ & 0.012 & 29.8 \\
\hline 676 & & $8 / 20088.34$ & 0.012 & 29.4 \\
\hline 677 & $1 / 8 / 20$ & $3 / 20088: 36$ & 0.01 & 294 \\
\hline 678 & $1 / 8 / 20088: 38$ & $8 / 20088: 38$ & 0009 & 29 \\
\hline 679 & & $820008: 40$ & 0.012 & 30.1 \\
\hline 680 & $1 / 8 / 20$ & $8 / 820088: 42$ & & 303 \\
\hline
\end{tabular}

\begin{tabular}{|c|c|c|c|c|}
\hline \multicolumn{5}{|c|}{4929} \\
\hline $\operatorname{Rec}$ & & Adjusted & Pressurg & Temp \\
\hline \# & Deter/ime & DeterTime & psi & ${ }^{\circ} \mathrm{C}$ \\
\hline 681 & $1 / 8 / 20088: 44$ & $8 / 8 / 20088: 44$ & 0.009 & 30.6 \\
\hline 682 & $1 / 8 / 20088: 46$ & $8 / 8 / 20088: 46$ & 0.011 & 30.7 \\
\hline 683 & $1 / 8 / 20088: 48$ & $88 / 20088: 48$ & 0.01 & 30.9 \\
\hline 684 & $1 / 8 / 20088: 50$ & $88120088: 50$ & 0.011 & 31 \\
\hline 685 & $1 / 8 / 20088.52$ & $8 / 820008: 52$ & 0.012 & 31.1 \\
\hline 686 & $1 / 8 / 20088.54$ & $8 / 820088: 54$ & 0.009 & 30.9 \\
\hline 687 & $1 / 8 / 20088.56$ & $8 / 820088: 56$ & 1.672 & 27.1 \\
\hline 688 & $1 / 8 / 20088: 58$ & $8820008: 58$ & 1.622 & 20.5 \\
\hline 689 & $1 / 8 / 20089: 00$ & $8 / 820089: 00$ & 1.615 & 18.1 \\
\hline 690 & $1 / 8 / 20089.02$ & $88 / 20089: 02$ & 1.611 & 17.4 \\
\hline 691 & $1 / 8 / 20089.04$ & $8 / 820089: 04$ & 1.61 & 17.2 \\
\hline 692 & $1 / 8 / 20089.06$ & 8820089.06 & 1.611 & 17.1 \\
\hline 693 & $1 / 8 / 20089.08$ & $88220089: 08$ & 1.612 & 17 \\
\hline 694 & $1 / 820089: 10$ & 88220089.10 & 1.612 & 17 \\
\hline 695 & 1/8/20089:12 & $8 / 820089.12$ & 1.611 & 17 \\
\hline 696 & $1 / 8 / 20089.14$ & $8 / 8 / 20089.14$ & 1.61 & 17 \\
\hline 697 & $1 / 8 / 20089: 16$ & $8 / 8 / 20089.16$ & 1.61 & 17 \\
\hline 698 & $1 / 8 / 20089.18$ & $8 / 8200099.18$ & 1.608 & 17 \\
\hline 699 & $1 / 8 / 20089: 20$ & $8 / 8 / 20089: 20$ & 1.606 & 17 \\
\hline 700 & $1 / 8 / 20089: 22$ & $8 / 8 / 20089: 22$ & 1.605 & 17 \\
\hline 701 & $1 / 8 / 20089.24$ & $8 / 8 / 20089: 24$ & 1.605 & 16.9 \\
\hline 702 & $1 / 8 / 20089: 26$ & $8 / 820089: 26$ & 1.605 & 17 \\
\hline 703 & $1 / 8 / 20089.28$ & 88120089.28 & 1.607 & 16.9 \\
\hline 704 & $1 / 8 / 20089.30$ & $8 / 820089: 30$ & 1.608 & 16.9 \\
\hline 706 & $1 / 8 / 20089.32$ & $8 / 8 / 20089: 32$ & 1.608 & 16.9 \\
\hline 706 & $1 / 8 / 20089.34$ & $88 / 20089.34$ & 1.609 & 16.9 \\
\hline 707 & $1 / 8220089.36$ & $8 / 8 / 20009.36$ & 1.61 & 16.9 \\
\hline 708 & $1 / 8 / 20089.38$ & $88 / 20089.38$ & 1.61 & 16.9 \\
\hline 709 & $1 / 8 / 20089: 40$ & $8 / 8220089: 40$ & 1.609 & 16.9 \\
\hline 710 & $1 / 8 / 20089: 42$ & $8 / 8 / 20089.42$ & 1.607 & 16.9 \\
\hline 711 & $1 / 8 / 20089: 44$ & $8 / 8 / 20089.44$ & 1.607 & 16.9 \\
\hline 712 & $1 / 8 / 20089: 46$ & $8 / 8 / 20089.46$ & 1.608 & 16.9 \\
\hline 713 & $1 / 8 / 20089.48$ & $8 / 8 / 20089.48$ & 1.61 & 16.9 \\
\hline 714 & $1 / 8 / 20089.50$ & $8 / 8 / 20089.50$ & 1.611 & 16.9 \\
\hline 715 & $1 / 8 / 20089: 52$ & 88820089.52 & 1.611 & 16.9 \\
\hline 716 & $1 / 8 / 20089.54$ & $8 / 820089.54$ & 1.61 & 16.9 \\
\hline 717 & $1 / 8 / 20089.56$ & $88 / 20089.56$ & 1.609 & 16.9 \\
\hline 718 & $1 / 8 / 20089.58$ & $8 / 8 / 20089.58$ & 1.609 & 16.9 \\
\hline 719 & $1 / 8 / 200810: 00$ & $8 / 8200810: 00$ & 1.608 & 16.9 \\
\hline 720 & $1 / 8 / 2008$ 10:02 & $8 / 8 / 200810: 02$ & 1.609 & 16.9 \\
\hline 721 & $1 / 8 / 200810: 04$ & $8 / 8 / 200810: 04$ & 1.609 & 16.9 \\
\hline 722 & $1 / 8 / 2008$ 10:06 & $8 / 8 / 200810: 06$ & 1.609 & 16.9 \\
\hline 723 & $1 / 8 / 2008$ 10:08 & $8 / 8 / 200810: 08$ & 1.609 & 16.9 \\
\hline 724 & 1/8/2008 10:10 & $8 / 8 / 2008$ 10:10 & 1.609 & 16.9 \\
\hline 725 & $1 / 8 / 2008$ 10.12 & $8 / 8 / 2008$ 10:12 & 1.61 & 16.9 \\
\hline 726 & 1/8/2008 10:14 & $8 / 82008$ 10:14 & 1.611 & 17.4 \\
\hline 727 & $1 / 8 / 2008$ 10:16 & $8 / 8 / 200810: 16$ & 1.611 & 17.4 \\
\hline 728 & $1 / 8 / 200810: 18$ & $8 / 8 / 200810: 18$ & 1.61 & 17.4 \\
\hline 729 & $1 / 8 / 2008$ 10:20 & $8 / 8 / 200810: 20$ & 1.609 & 17.1 \\
\hline 730 & $1 / 8 / 200810: 22$ & $8 / 8 / 200810: 22$ & 1.609 & 17 \\
\hline 731 & $1 / 8 / 200810: 24$ & $8 / 8 / 200810: 24$ & 1.608 & 17 \\
\hline 732 & $1 / 8 / 200810: 26$ & $8 / 8 / 200810.26$ & 1.608 & 16.9 \\
\hline 733 & $1 / 8 / 200810: 28$ & $8 / 8200810: 28$ & 1.608 & 16.9 \\
\hline 734 & $1 / 8 / 200810: 30$ & $8 / 8 / 200810: 30$ & 1.609 & 16.9 \\
\hline 735 & $1 / 8 / 2008$ 10:32 & $8 / 8200810.32$ & 1.608 & 16.9 \\
\hline 736 & $1 / 8 / 200810: 34$ & $8 / 8 / 200810: 34$ & 1.607 & 16.9 \\
\hline 737 & $1 / 8 / 200810: 36$ & $8 / 8 / 2008$ 10:36 & 1.608 & .16 .9 \\
\hline 738 & $1 / 8 / 200610: 38$ & $8 / 822008$ 10:38 & 1.608 & 16.9 \\
\hline 739 & $1 / 8 / 200810: 40$ & $88 / 200810: 40$ & 1.609 & 16.9 \\
\hline 740 & $1 / 8 / 200810: 42$ & $8 / 82200810: 42$ & 1.608 & 16.9 \\
\hline $741 \mid$ & $1 / 8 / 2008$ 10:44 & $8 / 8200810: 44$ & 1.609 & 16.9 \\
\hline 742 & $1 / 8 / 2008$ 10:46 & $8 / 8200810: 46$ & 1.61 & 16.9 \\
\hline 743 & $1 / 8 / 200810.48$ & $8 / 82008$ 10:48 & 1.609 & 16.9 \\
\hline 744 & $1 / 8200810: 50$ & $8 / 8200810.50$ & 1.609 & 16.9 \\
\hline 745 & $1 / 8 / 200810.52$ & $8 / 8200810: 52$ & 1.608 & 16.9 \\
\hline 746 & $1 / 8 / 200810.54$ & $8 / 8200810: 54$ & 1.608 & 16.9 \\
\hline 747 & $1 / 8 / 200810.56$ & $8 / 8 / 2008$ 10:56 & 1.608 & 16.9 \\
\hline 748 & $1 / 8 / 200810.58$ & $8 / 8 / 2008$ 10:58 & 1.608 & 16.9 \\
\hline
\end{tabular}

\begin{tabular}{|c|c|c|c|c|}
\hline \multicolumn{5}{|c|}{ D4-92p } \\
\hline Rec & & Adjusted & Pressune & $\overline{T e m p}$ \\
\hline$\#$ & DeterTime & DaterTime & psi & ${ }^{\circ} \mathrm{C}$ \\
\hline 749 & 1/8/2008 11:00 & 8/8/2008 11:00 & 1.608 & 16.9 \\
\hline 750 & 1/8/2008 11:02 & $8 / 8 / 2008$ 11:02 & 1.608 & 16.9 \\
\hline 751 & $1 / 8 / 200811: 04$ & $8 / 8 / 2008$ 11:04 & 1.608 & 16.9 \\
\hline 752 & $1 / 82008+1: 06$ & $8 / 8200811: 06$ & 1.608 & 16.9 \\
\hline 753 & $1 / 8200811: 08$ & $8 / 82008$ 11:08 & 1.608 & 16.9 \\
\hline 754 & $1 / 82200811: 10$ & $8 / 82008$ 11:10 & 1.607 & 16.9 \\
\hline 755 & 1/82008 11:12 & $8 / 82008$ 11:12 & 1.608 & 16.9 \\
\hline 756 & $1 / 8 / 2008$ 11:14 & $8 / 8 / 2008$ 11:14 & 1.607 & 16.9 \\
\hline 757 & 1/82008 11:16 & $8 / 8 / 2008$ 11:16 & 1.608 & 16.9 \\
\hline 758 & 1/8/2008 11:18 & $8 / 82008$ 11:18 & 1.607 & 16.9 \\
\hline 759 & 1/82008 11:20 & $8 / 82008$ 11:20 & 1.607 & 16.9 \\
\hline 760 & 1/8200811:22 & $8 / 82008$ 11:22 & 1.608 & 16.9 \\
\hline 761 & $1 / 8200811: 24$ & $8 / 82008$ 11:24 & 1.608 & 16.9 \\
\hline 762 & 1/8/2008 11:26 & $8 / 82008$ 11:26 & 1.607 & 16.9 \\
\hline 763 & 1/8/2008 11:28 & $8 / 82008$ 11:28 & 1.607 & 16.9 \\
\hline 764 & 1/8/2008 11:30 & $8 / 8 / 200811: 30$ & 1.607 & 16.9 \\
\hline 765 & 1/8/2008 11:32 & $8 / 8 / 2008$ 11:32 & 1.607 & 16.9 \\
\hline 766 & $1 / 8200811: 34$ & $8 / 8 / 2008$ 11:34 & 1.608 & 16.9 \\
\hline 767 & 1/8/200811:36 & $8 / 8 / 2008$ 11:36 & 1.608 & 16.9 \\
\hline 768 & $1 / 8 / 200811: 38$ & $8 / 8 / 200811: 38$ & 1.606 & 16.9 \\
\hline 769 & $1 / 8200811: 40$ & $8 / 8 / 2008$ 11:40 & 1.608 & 16.9 \\
\hline 770 & $1 / 8 / 200811: 42$ & $8 / 8200811: 42$ & 1.607 & 16.9 \\
\hline 771 & $1 / 8 / 200811: 44$ & $8 / 8200811: 44$ & 1.607 & 16.9 \\
\hline$\pi 72$ & 1/8/2008 11:46 & $8 / 8 / 2008$ 11:46 & 1.607 & 16.9 \\
\hline 773 & $1 / 8200811: 48$ & $8 / 8 / 200811: 48$ & 1.607 & 16.9 \\
\hline $7 \pi 4$ & $1 / 8 / 2008$ 11:50 & $8 / 82008$ 11:50 & 1.607 & 16.9 \\
\hline 775 & 1/8/2008 11:52 & $8 / 8 / 200811: 52$ & 1.607 & 16.9 \\
\hline 776 & $1 / 8200811: 54$ & $8 / 82008$ 11:54 & 1.608 & 16.9 \\
\hline$\pi 77$ & 1/8/2008 11:56 & $8 / 8 / 2008$ 11:56 & 1.607 & 16.9 \\
\hline 778 & 1/8/2008 11:58 & $8 / 8 / 2008$ 11:58 & 1.607 & 16.9 \\
\hline $7 \pi 9$ & $1 / 8 / 20081200$ & $8 / 8 / 2008+2000$ & 1.606 & 16.9 \\
\hline 780 & $1 / 8 / 200812: 02$ & $8 / 8 / 2008+2.02$ & 1.606 & 16.9 \\
\hline 781 & $1 / 8 / 20081204$ & $8 / 8 / 20081204$ & 1.607 & 16.9 \\
\hline 782 & $1 / 8 / 200812: 06$ & 88820081206 & 1.607 & 16.9 \\
\hline 783 & $1 / 8 / 20081208$ & $8 / 8 / 200812008$ & 1.607 & 16.9 \\
\hline 784 & 1/8/2008 12:10 & $8 / 8 / 200812: 10$ & 1.607 & 16.9 \\
\hline 785 & 1/8/2008 12:12 & $8 / 8 / 20081212$ & 1.607 & 16.9 \\
\hline 786 & 1/8/2008 12:14 & $8 / 8 / 200812: 14$ & 1.607 & 16.9 \\
\hline 787 & $1 / 8200812,16$ & $8 / 82008$ 12:16 & 1.606 & 16.9 \\
\hline 788 & 1/8/2008 12:18 & $8 / 8200812: 18$ & 1.607 & 16.9 \\
\hline 789 & $1 / 820001220$ & $8 / 820081220$ & 1.607 & 16.9 \\
\hline 790 & $1 / 8 / 20081222$ & $8 / 8 / 2008+2222$ & 1.607 & 16.9 \\
\hline 791 & $1 / 8220081224$ & $8 / 820081224$ & 1.607 & 16.9 \\
\hline 792 & $1 / 8 / 20081226$ & $8 / 820081226$ & 1.607 & 16.9 \\
\hline 793 & $1 / 8 / 200812: 28$ & $8 / 8200812: 28$ & 1.607 & 16.9 \\
\hline 794 & $1 / 8 / 20081230$ & $8 / 8 / 20081230$ & 1.607 & 16.9 \\
\hline 795 & 1/8/2008 12:32 & $8 / 8 / 200812 ; 32$ & 1.606 & 16.9 \\
\hline 796 & $1 / 8200812: 34$ & $8 / 8 / 200812334$ & 1.607 & 16.9 \\
\hline 797| & $1 / 8200012336$ & $8 / 8 / 20081236$ & 1.607 & 16.9 \\
\hline 798 & $1 / 8 / 2008+2338$ & $8 / 8 / 20081238$ & 1.607 & 16.9 \\
\hline 799 & $1 / 8 / 20081240$ & $8 / 8200812: 40$ & 1.607 & 16.9 \\
\hline 800 & $1 / 8 / 2008+242$ & $8 / 8 / 20081242$ & 1.607 & 16.9 \\
\hline 801 & $1 / 8 / 200812444$ & $8 / 8 / 20081244$ & 1.609 & 16.9 \\
\hline 802 & $1 / 8200812-46$ & $8 / 8 / 200812446$ & 1.608 & 16.9 \\
\hline 803 & $1 / 82008$ 1248 & 88820081248 & 1.608 & 16.9 \\
\hline 804 & $1 / 8 / 20081250$ & $8 / 8 / 20081250$ & 1.607 & 16.9 \\
\hline 805 & $1 / 8 / 20081252$ & $8 / 8 / 20081252$ & 1.606 & 16.9 \\
\hline 806 & $1 / 820081254$ & $8 / 8 / 20081254$ & 1.606 & 16.9 \\
\hline 807 & $1 / 8 / 20081256$ & $8 / 8 / 20081256$ & 1.606 & 16.9 \\
\hline 808 & $1 / 820081258$ & $8 / 8 / 20081258$ & 1.606 & 16.9 \\
\hline 800 & 1/8/2008 13:00 & $8 / 8 / 200813: 00$ & 1.607 & 16.9 \\
\hline 810 & 1/82008 13:02 & $8 / 8 / 2008$ 13:02 & 1.606 & 16.9 \\
\hline 811 & 1/82008 13:04 & $8 / 8 / 2008$ 13:04 & 1.606 & 16.9 \\
\hline 812 & 1/8/2008 13:06 & $8 / 8 / 200813: 06$ & 1.607 & 16.9 \\
\hline 813 & $1 / 8 / 200813: 08$ & $8 / 8 / 2008$ 13:08 & 1.606 & 16.9 \\
\hline 814 & 1/8/2008 13:10 & $8 / 8 / 200813: 10$ & 1.606 & 16.9 \\
\hline 815 & 1/8/2008 13:12 & $8 / 8 / 2008$ 13:12 & 1.606 & 16.9 \\
\hline 816 & 1/8/2008 13:14 & $8 / 8 / 2008$ 13:14 & 1.606 & 16.9 \\
\hline
\end{tabular}


DOE/RL-2009-35, REV. 0

\begin{tabular}{|c|c|c|c|c|c|c|c|c|c|}
\hline \multicolumn{5}{|c|}{ D4920 } & \multicolumn{5}{|c|}{ D4-92p } \\
\hline$\overline{P B C}$ & & Acjusted & Pressures & Tenp & $\operatorname{Rec}$ & & Adusted & Pressures & \\
\hline \# & DaterTime & Deter/Time & psi & ${ }^{\circ} \mathrm{C}$ & $\#$ & DeterTime & DeterTime & psi & ${ }^{\circ} \mathrm{C}$ \\
\hline 817 & $1 / 8 / 200813: 16$ & $8 / 8 / 2008$ 13:16 & 1.606 & 16.9 & 885 & $1 / 8 / 2008$ 15:32 & $8 / 8 / 200815: 32$ & 1.607 & 16.9 \\
\hline 818 & 1/8/2008 13:18 & $8 / 8 / 2008$ 13:18 & 1.606 & 16.9 & 886 & $1 / 82000815: 34$ & $8 / 8200815: 34$ & 1.607 & 16.9 \\
\hline 819 & 1/8/2008 13:20 & $8 / 822008$ 13:20 & 1.606 & 16.9 & 887 & $1 / 82200815: 36$ & $8 / 8 / 200815: 36$ & 1.607 & 16.9 \\
\hline 820 & 1/8/2008 13:22 & $8 / 8 / 2008$ 13:22 & 1.606 & 16.9 & 888 & $1 / 8 / 200815: 38$ & $8 / 8 / 200815: 38$ & 1.607 & 16.9 \\
\hline 821 & $1 / 8200813: 24$ & $88 / 2008$ 13:24 & 1.607 & 16.9 & 889 & $1 / 8200815: 40$ & $8 / 8 / 200815: 40$ & 1.607 & 16.9 \\
\hline 822 & 1/82008 13:26 & $8 / 8 / 200813: 26$ & 1.606 & 16.9 & 890 & $1 / 8 / 2008$ 15:42 & $8 / 8 / 200815: 42$ & 1.607 & 16.9 \\
\hline 823 & $1 / 82008+3: 28$ & $8 / 8 / 2008$ 13:28 & 1.606 & 16.9 & 891 & $1 / 8 / 2008$ 15:44 & $8 / 2000815: 44$ & 1.607 & 16.9 \\
\hline 824 & 1/82008 13:30 & 8882008 13:30 & 1.607 & 16.9 & 892 & $1 / 8200815: 46$ & $8 / 82008$ 15:46 & 1.607 & 16.9 \\
\hline 825 & 1/8/2008 13:32 & $8 / 82008$ 13:32 & 1.606 & 16.9 & 893 & $1 / 8200815: 48$ & $8 / 82008$ 15:48 & 1.607 & 16.9 \\
\hline 826 & $1 / 82008$ 13:34 & $88 / 2008$ 13:34 & 1.606 & 16.9 & 894 & $1 / 82200815: 50$ & $8 / 82008$ 15:50 & 1.607 & 16.9 \\
\hline 827 & $1 / 8200813: 36$ & $8 / 82008$ 13:36 & 1.606 & 16.9 & 896 & $1 / 8 / 200815: 52$ & $8 / 8 / 200815: 52$ & 1.606 & 16.9 \\
\hline 828 & $1 / 8200013: 38$ & $8 / 8200813: 38$ & 1.606 & 16.9 & 896 & $1 / 8 / 200815: 54$ & $8 / 8 / 200815: 54$ & 1.607 & 16.9 \\
\hline 829 & 1/822008 13:40 & $8 / 8 / 200813: 40$ & 1.606 & 16.9 & 897 & $1 / 8 / 200815: 56$ & $8 / 8200815: 56$ & 1.606 & 16.9 \\
\hline 830 & $1 / 8200813: 42$ & $8 / 82008$ 13:42 & 1.606 & 16.9 & 898 & $1 / 8 / 200815: 58$ & $8 / 8 / 200815: 58$ & 1.607 & 16.9 \\
\hline 831 & $1 / 8200813: 44$ & $8182000813: 44$ & 1.605 & 16.9 & 899 & $1 / 82000816: 00$ & $8 / 8 / 200816: 00$ & 1.607 & 16.9 \\
\hline 832 & 1/82008 13:46 & $8 / 8 / 2008$ 13:46 & 1.605 & 16.9 & 900 & $1 / 8 / 2008$ 16:02 & $8 / 8 / 2008$ 16:02 & 1.607 & 16.9 \\
\hline 833 & $1 / 8200013: 48$ & $8 / 8 / 2008$ 13:48 & 1.605 & 16.9 & 901 & $1 / 8 / 2008$ 16:04 & $8 / 8 / 2008$ 16:04 & 1.607 & 16.9 \\
\hline 834 & $1 / 82000813: 50$ & $8 / 8 / 2008$ 13:50 & 1.606 & 16.9 & 902 & $1 / 8200816: 06$ & $8 / 8 / 2000116: 06$ & 1.606 & 16.9 \\
\hline 835 & $1 / 8200813: 52$ & $8 / 8 / 200013: 52$ & 1.606 & 16.9 & 903 & $1 / 8 / 200816: 08$ & $8 / 8 / 200816: 08$ & 1.605 & 16.9 \\
\hline 836 & $1 / 8 / 200813: 54$ & $8 / 8 / 200813: 54$ & 1.605 & 16.9 & 904 & $1 / 8 / 200816: 10$ & $8 / 8 / 200816: 10$ & 1.605 & 16.9 \\
\hline 837 & $1 / 8200813: 56$ & $8 / 8200813: 56$ & 1.606 & 16.9 & 906 & $1 / 8200816: 12$ & $8 / 8 / 200816: 12$ & 1.634 & 16.9 \\
\hline 838 & $1 / 8200813: 58$ & $8 / 8 / 200813: 58$ & 1.606 & 16.9 & 906 & $1 / 8 / 200816: 14$ & $8 / 8 / 200816: 14$ & 1.659 & 16.9 \\
\hline 839 & $1 / 82008$ & $8 / 8 / 2008$ 14:00 & 1.606 & 16.9 & 907 & 1/820008 16:16 & $8 / 8 / 2008$ 16:16 & 1.68 & 16.9 \\
\hline 840 & 1/8:2008 14:02 & $8 / 82008$ 14:02 & 1.605 & 16.9 & 908 & $1 / 8 / 2008$ 16:18 & 8/8/2008 16:18 & 1.694 & 16.9 \\
\hline 841 & $1 / 82008$ 14:04 & $8 / 8 / 2008$ 14:04 & 1.605 & 16.9 & 909 & $1 / 8 / 2008$ 16:20 & $8 / 8200816: 20$ & 1.705 & 16.9 \\
\hline 842 & 1/82008 14:06 & $8 / 82008$ 14:06 & 1.605 & 16.9 & 910 & $1 / 8 / 200816: 22$ & $8 / 8 / 2008$ 16:22 & 1.713 & 16.9 \\
\hline 843 & 1/8/2008 14:08 & $8 / 8 / 2008$ 14:08 & 1.605 & 16.9 & 911 & $1 / 8 / 200816: 24$ & $8 / 8 / 200816: 24$ & 1.72 & 16.9 \\
\hline 844 & $1 / 820081$ & $8 / 82008$ 14:10 & 1.605 & 16.9 & 912 & $1 / 8 / 200816: 26$ & $8 / 8 / 200816: 26$ & 1.725 & 16.9 \\
\hline 845 & $1 / 8200814: 12$ & $8 / 8 / 2008$ 14:12 & 1.605 & 16.9 & 913 & $1 / 8 / 200816: 28$ & $8 / 8 / 200616: 28$ & 1.729 & 16.9 \\
\hline 846 & $1 / 8 / 200814: 14$ & $8 / 8200814: 14$ & 1.605 & 16.9 & 914 & $1 / 8 / 200816: 30$ & $8 / 8 / 200816: 30$ & 1.732 & 16.9 \\
\hline 847 & $1 / 8 / 2008$ & $8 / 822000$ & 1.605 & 16.9 & 915 & $1 / 8 / 200816: 32$ & $8 / 8 / 200816: 32$ & 1.736 & 16.9 \\
\hline 848 & $1 / 8200814: 18$ & $8 / 82008$ 14:18 & 1.605 & 16.9 & 916 & $1 / 8 / 200816: 34$ & $8 / 8 / 200816: 34$ & 1.738 & 16.9 \\
\hline 849 & $1 / 8200814: 20$ & $8 / 82008$ 14:20 & 1.605 & 16.9 & 917 & $1 / 8 / 200816: 36$ & $8 / 8 / 200816: 36$ & 1.74 & 16.9 \\
\hline 850 & $1 / 8 / 2008$ & $8 / 8 / 2000$ & 1.605 & 16.9 & 918 & $1 / 8 / 200816: 38$ & $8 / 8 / 200816: 38$ & 1.743 & 16.9 \\
\hline 851 & $1 / 82000$ & $8 / 8 / 2008$ 14:24 & 1.605 & 16.9 & 919 & $1 / 8200816: 40$ & $8 / 8 / 2008$ 16:40 & 1.746 & 16.9 \\
\hline 852 & $1 / 8 / 200$ & $8 / 82008$ & 1.605 & 16.9 & 920 & $1 / 8 / 2008$ 16:42 & $8 / 8 / 2008$ 16:42 & 1.748 & 16.9 \\
\hline 853 & $1 / 82200$ & $8 / 8 / 2008$ 14:28 & 1.605 & 16.9 & 921 & $1 / 8200816: 44$ & $8 / 8 / 200816: 44$ & 1.75 & 16.9 \\
\hline 854 & $1 / 8 / 200814: 30$ & $8 / 8 / 200814: 30$ & 1.605 & 16.9 & 922 & $1 / 82200816: 46$ & $8 / 8 / 200816: 46$ & 1.751 & 16.9 \\
\hline 856 & 1/8/2008 14:32 & $8 / 8 / 200$ & 1.604 & 16.9 & 923 & $1 / 8 / 2008 \quad 16: 48$ & $8 / 8 / 200816: 48$ & 1.753 & 16.9 \\
\hline 856 & $1 / 82200814: 34$ & $88 / 2008$ 14:34 & 1.604 & 16.9 & 924 & $1 / 8 / 200816: 50$ & $8 / 8 / 200816: 50$ & 1.753 & 16.9 \\
\hline 857 & $1 / 8200814: 36$ & $8 / 8 / 2008$ 14:36 & 1.605 & 16.9 & 925 & $1 / 8 / 200816: 52$ & $8 / 8 / 200816: 52$ & 1.756 & 16.9 \\
\hline 858 & 14:38 & $8 / 8 / 200$ & 1.605 & 16.9 & 926 & $1 / 8 / 200816: 54$ & $8 / 8 / 200816: 54$ & 1.757 & 16.9 \\
\hline 859 & $1 / 8200814: 40$ & $8 / 8200814: 40$ & 1.605 & 16.9 & 927 & $1 / 8 / 200816: 56$ & $8 / 8 / 200816: 56$ & 1.759 & 16.9 \\
\hline 860 & $1 / 82006$ & $8 / 82008$ 14:42 & 1.605 & 16.9 & 928 & $1 / 8 / 200816: 58$ & $8 / 82000816: 58$ & 1.76 & 16.9 \\
\hline 861 & $1 / 82000$ & $8 / 82000$ & 1.605 & 16.9 & 929 & $1 / 8 / 2008$ 17:00 & $8 / 8 / 200$ & 1.761 & 16.9 \\
\hline 862 & $1 / 8 / 200$ & $8 / 82000$ & 1.605 & 16.9 & 930 & 1/82008 17:02 & $8 / 82008$ 17:02 & 1.762 & 16.9 \\
\hline 863 & $1: 48$ & $8 / 8 / 2008$ 14:48 & 1.604 & 16.9 & 931 & $1 / 8 / 200817: 04$ & $8 / 8 / 200817: 04$ & 1.763 & 17.3 \\
\hline 864 & & $8 / 8 / 200$ & 1.604 & 16.9 & 932 & $1 / 8 / 2000$ & $8 / 8 / 20$ & 1.764 & 17.5 \\
\hline 865 & $1 / 8200814: 52$ & $8 / 82000814: 52$ & 1.604 & 16.9 & 933 & $1 / 8 / 200817: 08$ & $8 / 8 / 2000617: 08$ & 1.766 & 17.1 \\
\hline 866 & & $8 / 8 / 200$ & 1.604 & 16.9 & 934 & $1 / 8 / 200$ & $8 / 8 / 20$ & 1.767 & 16.9 \\
\hline 867 & 56 & $8 / 8200$ & 1.604 & 16.9 & 935 & $1 / 8200817: 12$ & $8 / 8 / 20$ & 1.766 & 16.9 \\
\hline 868 & $1 / 82200814: 58$ & $8 / 8 / 200814: 58$ & 1.604 & 16.9 & 936 & $1 / 8 / 2008$ 17:14 & $8 / 8 / 200817: 14$ & 1.766 & 16.9 \\
\hline 869 & $1 / 8 / 2008$ & $8 / 82000$ & 1.605 & 16.9 & 937 & $1 / 8 / 2008$ 17:16 & $8 / 8 / 20$ & 1.767 & 16.9 \\
\hline 870 & $1 / 8200$ & 882200 & 1.604 & 16.9 & 938 & $1 / 8 / 200817: 18$ & $8 / 8 / 2000817: 18$ & 1.767 & 16.9 \\
\hline 871 & $1 / 8 / 2008$ & 8882008 15:04 & 1.604 & 16.9 & 939 & $1 / 8 / 2008$ 17:20 & $8 / 8 / 200817: 20$ & 1.768 & 16.9 \\
\hline 872 & & $8 / 8 / 200$ & 1.604 & 16.9 & 940 & $1 / 8 / 200817: 22$ & $817: 2$ & 1.768 & 17.1 \\
\hline 873 & $1 / 82008$ & $8 / 8 / 2008$ & 1.604 & 16.5 & 941 & $1 / 8 / 200817: 24$ & $8 / 8 / 200817: 24$ & 1.769 & 16.5 \\
\hline 874 & $1 / 8 / 2008$ & $8 / 8 / 2008$ 15:10 & 1.605 & 16.5 & 942 & $1 / 8 / 2008$ 17:26 & $8 / 8 / 200817: 26$ & 1.77 & 16.5 \\
\hline 875 & & $8 / 8200815: 12$ & 1.605 & 16. & 943 & $1 / 8200817: 28$ & $8 / 8 / 200817: 28$ & 1.77 & 16.5 \\
\hline 876 & $1 / 8200815: 14$ & $8 / 8 / 2008$ 15:14 & 1.606 & 16.9 & 944 & $1 / 8 / 200817: 30$ & $8 / 8 / 2008+7: 30$ & 1.772 & 16.9 \\
\hline $8 \pi$ & 1/8/2008 15:16 & $8 / 8 / 2008$ 15:16 & 1.605 & 16.9 & 945 & $1 / 8 / 200817: 32$ & $8 / 8 / 2008$ 17:32 & $1.7 / 2$ & 16.5 \\
\hline 878 & 1/82008 15:18 & $8 / 8200815: 18$ & 1.605 & 16. & 946 & $1 / 8 / 2008$ 17:34 & $8 / 8 / 2008$ 17:34 & 1.773 & 16.9 \\
\hline 879 & 1/82008 15:20 & 8882008 15:20 & 1.606 & 16.9 & 947 & $1 / 8 / 200817: 36$ & $8 / 8 / 2008 \uparrow 7: 36$ & 1.773 & 76.9 \\
\hline 880 & 1/82008 15:22 & $8 / 8200815: 22$ & 1.606 & 16.9 & 948 & $1 / 8 / 200817: 38$ & $8 / 8 / 200817: 38$ & 1.774 & 16.9 \\
\hline 881 & $1 / 8200815: 24$ & $8 / 8 / 2008$ 15:24 & 1.606 & 16.5 & 949 & $1 / 8 / 200817: 40$ & $8 / 8 / 200817: 40$ & 1.774 & 16.9 \\
\hline 882 & 1/822008 15:26 & $8 / 8 / 200815: 26$ & 1.606 & 16.9 & 960 & $1 / 8 / 200817: 42$ & $8 / 8 / 200817: 42$ & 1.775 & 16.9 \\
\hline 883 & $1 / 82008$ 15:28 & $8 / 8 / 200815: 28$ & 1.607 & 16.9 & 951 & $1 / 822008$ 17:44 & $8 / 8 / 2008$ 17:44 & 1.776 & 16.9 \\
\hline 884 & 1/8/2008 15:30 & $8 / 8 / 2008$ 15:30 & 1.607 & 16. & 952 & $1 / 82000817: 46$ & $8 / 8 / 2008$ 17:46 & 1.776 & 16.9 \\
\hline
\end{tabular}

\begin{tabular}{|c|c|c|c|c|}
\hline \multicolumn{5}{|c|}{ D4920 } \\
\hline Rec & & Adjusted & Pressing & Temp \\
\hline \# & Date/Time & DaterTime & psi & ${ }^{\circ} \mathrm{C}$ \\
\hline 953 & $1 / 8 / 200817: 48$ & $8 / 8 / 2008$ 17:48 & $1.7 \pi$ & 16.9 \\
\hline 954 & $1 / 8200817: 50$ & $8 / 82008$ 17:50 & 1.779 & 16.9 \\
\hline 955 & $1 / 82008$ 17:52 & $8 / 8 / 2008$ 17:52 & 1.779 & 16.9 \\
\hline 956 & $1 / 8200817: 54$ & $8 / 8 / 2008$ 17:54 & 1.78 & 16.9 \\
\hline 957 & $1 / 8 / 200817: 56$ & $8 / 8 / 2008$ 17:56 & 1.781 & 16.9 \\
\hline 958 & $1 / 8 / 2008$ 17:58 & $8 / 8 / 2008$ 17:58 & 1.781 & 16.9 \\
\hline 959 & 1/8/2008 18:00 & $8 / 8 / 2008$ 18:00 & 1.781 & 16.9 \\
\hline 960 & 1/82008 18:02 & $8 / 8 / 2008$ 18:02 & 1.781 & 16.9 \\
\hline 961 & $1 / 82008$ 18:04 & $8 / 8 / 2008$ 18:04 & 1.781 & 16.9 \\
\hline 962 & 1/8/2008 18:06 & $8 / 8 / 200818: 06$ & 1.782 & 16.9 \\
\hline 963 & 1/82008 18:08 & $8 / 8 / 200818: 08$ & 1.783 & 16.9 \\
\hline 964 & 1/82008 18:10 & $8 / 8 / 2008$ 18:10 & 1.784 & 16.9 \\
\hline 965 & 1/8/2008 18:12 & $8 / 8 / 2008$ १8:12 & 1.783 & 17.3 \\
\hline 966 & $1 / 8 / 2008$ 18:14 & 8/8/2008 18:14 & 1.786 & 17 \\
\hline 967 & 1/8/2008 18:16 & $8 / 8 / 200818-16$ & 1.783 & 16.9 \\
\hline 968 & $1 / 8 / 2008$ 18:18 & $8 / 8 / 2008$ 18:18 & 1.782 & 16.9 \\
\hline 969 & $1 / 8 / 200818: 20$ & $8 / 8 / 2008$ 18:20 & 1.782 & 16.9 \\
\hline 970 & $1 / 8 / 2008$ 18:22 & $8 / 8 / 200818: 22$ & 1.781 & 16.9 \\
\hline 971 & $1 / 8 / 200818: 24$ & $8 / 8 / 2008 \quad 18: 24$ & 1.78 & 16.9 \\
\hline 972 & $1 / 8 / 2008$ 18:26 & $8 / 8 / 2008$ 18:26 & $1.7 \pi$ & 16.9 \\
\hline 973 & $1 / 8 / 200818: 28$ & $8 / 8 / 200818: 28$ & 1.786 & 16.9 \\
\hline 974 & 1/8/2008 18:30 & $8 / 82008$ 18:30 & 1.782 & 16.9 \\
\hline 975 & $1 / 8 / 200818: 32$ & $8 / 8 / 2008$ 18:32 & 1.788 & 16.9 \\
\hline 976 & $1 / 8 / 200818: 34$ & $8 / 8 / 2008$ 18:34 & 1.774 & 16.9 \\
\hline 977 & $1 / 8 / 2008$ 18:36 & $8 / 8 / 2008$ 18:36 & 1.757 & 16.9 \\
\hline 978 & $1 / 8 / 2008$ 18:38 & $8 / 8 / 2008$ 18:38 & 1.736 & 16.9 \\
\hline 979 & 1/8/2008 18:40 & $8 / 82008$ 18:40 & 1.725 & 16.9 \\
\hline 980 & 1/8/2008 18:42 & $8 / 8 / 2008$ 18:42 & 1.72 & 16.9 \\
\hline 981 & $1 / 8 / 200818: 44$ & $8 / 8 / 2008$ 18:44 & 1.715 & 16.9 \\
\hline 962 & $1 / 8 / 2008$ 18:46 & $8 / 8 / 200818: 46$ & 1.709 & 16.9 \\
\hline 983 & $1 / 8 / 200618: 48$ & $8 / 8 / 200818: 48$ & 1.704 & 16.9 \\
\hline 984 & $1 / 8 / 2008$ 18:50 & $8 / 8 / 2008$ 18:50 & 1.704 & 16.9 \\
\hline 985 & $1 / 8 / 200818: 52$ & $8 / 8 / 200818: 52$ & 1.705 & 16.9 \\
\hline 986 & $1 / 8 / 200818: 54$ & $8 / 8 / 2008$ 18:54 & 1.705 & 16.9 \\
\hline 987 & $1 / 8 / 200818: 56$ & $8 / 8 / 2008$ 18:56 & 1.703 & 16.9 \\
\hline 988 & $1 / 8 / 200818: 58$ & $8 / 8 / 2008$ 18:58 & 1.702 & 16.9 \\
\hline 969 & $1 / 82200819.00$ & $8 / 8 / 200819: 00$ & 1.701 & 16.9 \\
\hline 990 & 1/8/2008 19:02 & $8 / 8 / 200819: 02$ & 1.7 & 16.9 \\
\hline 991 & $1 / 8 / 200819.04$ & $8 / 8 / 2008$ 19:04 & 1.699 & 16.9 \\
\hline 992 & 1/8/2008 19:06 & $8 / 8 / 200819 \cdot 06$ & 1.696 & 16.9 \\
\hline 993 & $1 / 8 / 200819.08$ & $8 / 8 / 200819: 08$ & 1.693 & 16.9 \\
\hline 994 & $1 / 8 / 200819.10$ & $8 / 8 / 2008$ 19:10 & 1.691 & 16.9 \\
\hline 996 & $1 / 8 / 2008$ 19:12 & $8 / 8 / 2008$ 19:12 & 1.687 & 17 \\
\hline 996 & $1 / 8 / 2008$ 19:14 & $8 / 8 / 2008$ 19:14 & 1.685 & 17.4 \\
\hline 997 & $1 / 8 / 200819.16$ & $8 / 8 / 2008$ 19:16 & 1.684 & 17.1 \\
\hline 996 & $1 / 8 / 2008$ 19:18 & $8 / 8 / 2008$ 19:18 & 1.683 & 16.9 \\
\hline 999 & $1 / 8 / 200819.20$ & $8 / 8 / 2008$ 19:20 & 1.682 & 16.9 \\
\hline 1000 & $1 / 8 / 200819.22$ & $8 / 8 / 200819.22$ & 1.68 & 16.9 \\
\hline 1001 & $1 / 8 / 200819.24$ & $8 / 8 / 200819: 24$ & 1.678 & 16.9 \\
\hline 1002 & $1 / 8 / 200819.26$ & $8 / 8 / 200819: 26$ & 1.676 & 16.9 \\
\hline 1003 & $1 / 8 / 200819.28$ & $8 / 8 / 200819: 28$ & 1.673 & 16.9 \\
\hline 1004 & $1 / 8 / 200819.30$ & $8 / 8 / 2008$ 19:30 & 1.672 & 16.9 \\
\hline 1005 & $1 / 8 / 200819.32$ & $8 / 8 / 2008$ 19:32 & 1.67 & 16.9 \\
\hline 1006 & $1 / 8 / 200819.34$ & $8 / 8 / 200819.34$ & 1.668 & 16.9 \\
\hline 1007 & $1 / 8 / 2008$ 19.36 & $8 / 8 / 2008$ 19:36 & 1.668 & 16.9 \\
\hline 1008 & $1 / 8 / 2008$ 19:38 & $8 / 8 / 2008$ 19:38 & 1.669 & $\overline{16.9}$ \\
\hline 1009 & $1 / 8 / 200819.40$ & $8 / 8 / 200819: 40$ & 1.660 & 16.9 \\
\hline 1010 & $1 / 8 / 200819.42$ & $8 / 8 / 200819: 42$ & 1.669 & 16.9 \\
\hline 1011 & $1 / 8 / 200819.44$ & $888 / 200819: 44$ & 1.669 & 16.9 \\
\hline 1012 & $1 / 8 / 200819.46$ & $8 / 8 / 200819: 46$ & 1.667 & 16.9 \\
\hline 1013 & $1 / 8 / 200819: 48$ & $8 / 8 / 200819: 48$ & 1.666 & 16.9 \\
\hline 1014 & $1 / 8 / 200819.50$ & $8 / 8 / 200819: 50$ & 1.665 & 16.9 \\
\hline 1015 & $1 / 8 / 200819.52$ & $8 / 8 / 200819.52$ & 1.665 & 16.9 \\
\hline 1016 & $1 / 8 / 200819.54$ & $88 / 200819.54$ & 1.664 & 169 \\
\hline 1017 & $1 / 8 / 200819.56$ & $8 / 8200819: 56$ & 1.664 & 16.9 \\
\hline 1018 & $1 / 8 / 200819.58$ & $8 / 8 / 200819.58$ & 1.663 & 16.9 \\
\hline 1019 & 1/8/200820000 & $8 / 8 / 200820: 00$ & 1.662 & 16.9 \\
\hline 1020 & $1 / 8 / 200820.02$ & $8 / 8 / 200820: 02$ & 1.661 & 16.9 \\
\hline
\end{tabular}


DOE/RL-2009-35, REV. 0

\begin{tabular}{|c|c|c|c|c|}
\hline \multicolumn{5}{|c|}{04924} \\
\hline $\mathrm{ReC}$ & & Adusted & Pressure & Temp \\
\hline$\#$ & DeteTime & DateTime & psi & ${ }^{\circ} \mathrm{C}$ \\
\hline 1021 & 1/8/200820:04 & $8 / 8200820: 04$ & 1.66 & 16.9 \\
\hline 1002 & $1 / 8 / 200820: 06$ & $8 / 8200820: 06$ & 1.658 & 16.9 \\
\hline 1023 & $1 / 8 / 200820: 08$ & $8 / 8200820: 08$ & 1.658 & 16.9 \\
\hline 1024 & $1 / 8 / 200820: 10$ & $8 / 8200820.10$ & 1.696 & 16.9 \\
\hline 1025 & $1 / 8 / 200820: 12$ & $8 / 8200820: 12$ & 1.71 & 16.9 \\
\hline 1026 & $1 / 8 / 200820: 14$ & $8 / 8 / 200820: 14$ & 1.719 & 16.9 \\
\hline 1027 & $1 / 82200820-16$ & $8 / 8200820: 16$ & 1.724 & 16.9 \\
\hline 1028 & $1 / 8 / 200820.18$ & $8 / 8200820: 18$ & 1.695 & 16.9 \\
\hline 1029 & $1 / 8200820: 20$ & $8 / 8 / 200820: 20$ & 1.684 & 16.9 \\
\hline 1030 & $1 / 82000820.22$ & $8 / 820082022$ & 1.678 & 16.9 \\
\hline 1031 & $1 / 8 / 200820: 24$ & $8 / 8 / 200820: 24$ & 1.674 & 16.9 \\
\hline 1032 & 1/8/200820:26 & $8 / 82200820.26$ & 1.672 & 16.9 \\
\hline 1033 & $1 / 8 / 200820: 28$ & $8 / 8 / 200820: 28$ & 1.67 & 16.9 \\
\hline 1034 & $1 / 8 / 200820: 30$ & $8 / 8 / 200820: 30$ & 1.669 & 16.9 \\
\hline 1035 & $1 / 8200820: 32$ & $8 / 8 / 200820: 32$ & 1.668 & 16.9 \\
\hline 1036 & $1 / 8 / 200820: 34$ & $8 / 8 / 200820: 34$ & 1.666 & 16.9 \\
\hline 1037 & $1 / 8 / 200820: 36$ & $8 / 8200820: 36$ & 1.664 & 16.9 \\
\hline 1038 & $1 / 8 / 200820: 38$ & $8 / 82000820: 38$ & 1.663 & 16.9 \\
\hline 1039 & $1 / 8 / 200820: 40$ & $8 / 8 / 200820: 40$ & 1.692 & 16.9 \\
\hline 1040 & $1 / 8 / 200820.42$ & $8 / 8200820: 42$ & 1.708 & 16.9 \\
\hline 1041 & $1 / 8200820: 44$ & $8 / 8 / 200820: 44$ & 1.716 & 16.9 \\
\hline 1042 & $1 / 8 / 200820: 46$ & $8 / 8200820: 46$ & 1.721 & 16.9 \\
\hline 1043 & $1 / 8 / 200820: 48$ & $8 / 8200820: 48$ & 1.725 & 16.9 \\
\hline 1044 & $1 / 8200820.50$ & $8 / 8200820: 50$ & 1.728 & 16.9 \\
\hline 1045 & $1 / 8 / 200820.52$ & $8 / 8200820.52$ & 1.731 & 16.9 \\
\hline 1046 & $1 / 8 / 200820: 54$ & $8 / 82000820: 54$ & 1.732 & 17.3 \\
\hline 1047 & $1 / 8 / 200820.56$ & $8 / 8 / 200820: 56$ & 1.736 & 17 \\
\hline 1048 & $1 / 8 / 200820: 58$ & $8 / 8 / 200820.58$ & 1.738 & 16.9 \\
\hline 1049 & 1/8/200821:00 & $8 / 8 / 200821: 00$ & 1.74 & 16.9 \\
\hline 1050 & 1/8200821:02 & $8 / 8 / 200821: 02$ & 1.743 & 16.9 \\
\hline 1051 & 1/82000821:04 & $8 / 8 / 200821: 04$ & 1.744 & 16.9 \\
\hline 1052 & 1/8200821:06 & $8 / 81200821: 06$ & 1.746 & 16.9 \\
\hline 1053 & $1 / 8200821: 08$ & $8 / 8 / 200821: 08$ & 1.747 & 16.9 \\
\hline 1054 & $1 / 8 / 200821: 10$ & $8 / 8 / 200821: 10$ & 1.749 & 16.9 \\
\hline 1056 & $1 / 8 / 200821: 12$ & $8 / 8 / 200821: 12$ & 1.75 & 16.9 \\
\hline 1056 & $1 / 8200821: 14$ & $8 / 8 / 200821: 14$ & 1.751 & 16.9 \\
\hline 1057 & $1 / 8200821: 16$ & $8 / 8 / 200821: 16$ & 1.753 & 16.9 \\
\hline 1058 & 1/8/200821:18 & $8 / 8 / 200821: 18$ & 1.754 & 16.9 \\
\hline 1059 & 1/8/200821:20 & $8 / 8 / 200821: 20$ & 1.757 & 16.9 \\
\hline 1060 & $1 / 8200821: 22$ & $8 / 8 / 200821: 22$ & 1.750 & 17.1 \\
\hline 1061 & 1/8200821:24 & $8 / 8 / 200821: 24$ & 1.762 & 16.9 \\
\hline 1062 & 1/8/200821:26 & $8 / 8 / 200821: 26$ & 1.763 & 16.9 \\
\hline 1063 & 1/8/200821:28 & $8 / 8 / 200821: 28$ & 1.764 & $\overline{16.9}$ \\
\hline 1064 & $1 / 8 / 200821: 30$ & $8 / 82200821: 30$ & 1.765 & 16.9 \\
\hline 1065 & $1 / 8 / 200821: 32$ & $8 / 8 / 200821: 32$ & 1.766 & 16.9 \\
\hline 1006 & 1/8:200821:34 & $8 / 8 / 200821: 34$ & 1.768 & 16.9 \\
\hline 1067 & $1 / 8200821: 36$ & $8 / 8 / 200821: 36$ & 1.769 & 16.9 \\
\hline 1068 & 1/8200821:38 & $8 / 82200821: 38$ & 1.769 & 17.4 \\
\hline 1069 & $1 / 82200821: 40$ & $8 / 8200821: 40$ & 1.771 & 17.2 \\
\hline 1070 & 1/8/200821:42 & $8 / 8200821: 42$ & 1.771 & 17 \\
\hline 1071 & 1/8/200821:44 & $8 / 8 / 200821: 44$ & 1.771 & 16.9 \\
\hline 1072 & 1/8/200821:46 & $8 / 8 / 200821: 46$ & 1.773 & 16.9 \\
\hline 1073 & 1/8/200821:48 & $8 / 8200821: 48$ & 1.774 & 16.9 \\
\hline 1074 & $1 / 8 / 200821: 50$ & $8 / 8 / 200821: 50$ & 1.775 & 16.9 \\
\hline 1075 & $1 / 8 / 200821: 52$ & $8 / 8200821: 52$ & 1.775 & 16.9 \\
\hline 1076 & $1 / 8 / 200821: 54$ & $8 / 8 / 200821: 54$ & 1.774 & 16.9 \\
\hline $10 \pi$ & 1/8/200821:56 & $8 / 8 / 200821: 56$ & 1.77 & 16.9 \\
\hline 1078 & 1/8/200821:58 & $8 / 8200821: 58$ & 1.77 & 16.9 \\
\hline 1079 & 1/8200822:00 & 88220082200 & 1.778 & 16.9 \\
\hline 1080 & $1 / 8 / 200822-02$ & $8 / 8 / 20082202$ & 1.78 & 16.9 \\
\hline 1081 & $1 / 8 / 20082204$ & $8 / 8 / 20082204$ & 1.782 & 16.9 \\
\hline 1082 & 1/8/200822:06 & $8 / 82200822: 06$ & 1.783 & 16.9 \\
\hline 1083 & $1 / 8 / 20082208$ & $8 / 8 / 20082208$ & 1.783 & 16.9 \\
\hline 1084 & $1 / 8 / 200822-10$ & $8 / 820082210$ & 1.784 & 16.9 \\
\hline 7085 & $1 / 8200822: 12$ & $8 / 8 / 200822: 12$ & 1.784 & 16.9 \\
\hline 1086 & 1/8/200822:14 & $8 / 8 / 20082214$ & 1.784 & 16.9 \\
\hline 1087 & $1 / 820082216$ & $8 / 8 / 200822: 16$ & 1.786 & 16.9 \\
\hline 1088 & $1 / 8200822: 18$ & $8 / 8 / 20082218$ & 1.787 & 16.9 \\
\hline
\end{tabular}

\begin{tabular}{|c|c|c|c|c|}
\hline \multicolumn{5}{|c|}{ D4929 } \\
\hline $\mathrm{PeC}$ & & Aglusted & Pressure & Temp \\
\hline \# & DaterTime & DateTime & \begin{tabular}{|c|} 
psi \\
\end{tabular} & ${ }^{\circ} \mathrm{C}$ \\
\hline 1089 & $1 / 8 / 20082220$ & $8 / 8 / 20082220$ & 1.788 & 16.9 \\
\hline 1090 & $1 / 8 / 20082222$ & $8 / 8 / 20082222$ & 1.788 & 16.9 \\
\hline 1091 & $1 / 8 / 20082224$ & $8 / 8 / 20082224$ & 1.789 & 16.9 \\
\hline 1092 & 1/8/200822:26 & $8 / 8 / 20082226$ & 1.79 & 16.9 \\
\hline 1093 & $1 / 8 / 20082228$ & $8 / 8 / 20082228$ & 1.79 & 16.9 \\
\hline 1094 & $1 / 820082230$ & $8 / 8 / 20082230$ & 1.791 & 16.9 \\
\hline 1095 & 1/8/200822:32 & $8 / 8 / 20082232$ & 1.792 & 16.9 \\
\hline 1006 & 1/8/200822:34 & $8 / 8 / 20082234$ & 1.792 & 16.9 \\
\hline 1097 & 1/8/20082236 & $8 / 8 / 20082236$ & 1.793 & 16.9 \\
\hline 1008 & $1 / 8 / 200822: 38$ & $8 / 8 / 20082238$ & 1.794 & 16.9 \\
\hline 1000 & $1 / 8 / 20082240$ & $8 / 8 / 200822240$ & 1.794 & 16.9 \\
\hline 1100 & $1 / 8 / 20082242$ & $8 / 8 / 200822 \div 42$ & 1.795 & 16.9 \\
\hline 1101 & $1 / 8 / 20082244$ & $8 / 8 / 20082244$ & 1.795 & 16.9 \\
\hline 1102 & $1 / 820082246$ & $8 / 8 / 200822446$ & 1.795 & 16.9 \\
\hline 1103 & $1 / 8 / 20082248$ & $8 / 8 / 20082244$ & 1.796 & 16.9 \\
\hline 1104 & $1 / 8 / 20082250$ & $8 / 8 / 20082250$ & 1.797 & 16.9 \\
\hline 1105 & $1 / 8 / 20082252$ & $8 / 8 / 200822: 52$ & 1.798 & 16.9 \\
\hline 1106 & $1 / 8 / 20082254$ & $8 / 8 / 20082254$ & 1.799 & 16.9 \\
\hline 1107 & $1 / 8 / 20082256$ & $8 / 8 / 20082256$ & 1.801 & 16.9 \\
\hline 1108 & $1 / 8 / 20082258$ & $8 / 8 / 20082258$ & 1.771 & 16.9 \\
\hline 1109 & $1 / 8 / 200823: 00$ & $8 / 8 / 200823: 00$ & 1.757 & 16.9 \\
\hline 1110 & 1/8/200823:02 & $8 / 8 / 200823: 02$ & 1.746 & 16.9 \\
\hline 1111 & $1 / 8 / 200823: 04$ & $8 / 8 / 200823: 04$ & 1.739 & 16.9 \\
\hline 1112 & 1/8/200823:06 & $8 / 8 / 200823: 06$ & 1.734 & 16.9 \\
\hline 1113 & 1/8/2008 23:08 & $8 / 8 / 200823: 08$ & 1.729 & 16.9 \\
\hline 1114 & $1 / 8 / 200823: 10$ & $8 / 8 / 200823: 10$ & 1.725 & 16.9 \\
\hline 1115 & $1 / 8200823: 12$ & $8 / 8 / 200823: 12$ & 1.72 & 16.9 \\
\hline 1116 & $1 / 8 / 200823: 14$ & $8 / 8 / 200823: 14$ & 1.719 & 16.9 \\
\hline 1117 & $1 / 8 / 200823: 16$ & $8 / 8 / 200823: 16$ & 1.717 & 16.9 \\
\hline 1118 & 1/8/200823:18 & $8 / 8 / 200823: 18$ & 1.715 & 16.9 \\
\hline 1119 & 1/8/200823:20 & $8 / 8 / 200823: 20$ & 1.712 & 16.9 \\
\hline 1120 & 1/8/200823:22 & $8 / 8 / 200823: 22$ & 1.709 & 16.9 \\
\hline 1121 & $1 / 8 / 200823: 24$ & $8 / 8 / 200823: 24$ & 1.706 & 16.9 \\
\hline 1122 & 1/8/200823:26 & $8 / 8200823: 26$ & 1.705 & 16.9 \\
\hline 1123 & 1/8/200823:28 & $8 / 8 / 200823: 28$ & 1.703 & 16.9 \\
\hline 1124 & 1/8/200823:30 & $8 / 8 / 200823: 30$ & 1.702 & 16.9 \\
\hline 1125 & $1 / 8 / 200823: 32$ & $8 / 8 / 200823: 32$ & 1.701 & 16.9 \\
\hline 1126 & $1 / 82200823: 34$ & $8 / 8 / 200823: 34$ & 1.7 & 16.9 \\
\hline 1127 & $1 / 8 / 200823: 36$ & $8 / 8200823: 36$ & 1.699 & 16.9 \\
\hline 1128 & $1 / 8 / 200823: 38$ & $8 / 8 / 200823: 38$ & 1.697 & 16.9 \\
\hline 1120 & $1 / 8 / 200823: 40$ & $8 / 8 / 200822: 40$ & 1.694 & 16.9 \\
\hline 1130 & $1 / 8 / 200823: 42$ & $8 / 8 / 200823: 42$ & 1.691 & 16.9 \\
\hline 1131 & $1 / 8 / 200823: 44$ & $8 / 8 / 200823: 44$ & 1.689 & 16.9 \\
\hline 1132 & $1 / 8 / 200823: 46$ & $8 / 8 / 200823: 46$ & 1.69 & 16.9 \\
\hline 1133 & $1 / 8 / 200823: 48$ & $8 / 8 / 200823: 48$ & 1.723 & 16.9 \\
\hline 1134 & $1 / 8 / 200823: 50$ & $8 / 8 / 200823: 50$ & 1.737 & 16.9 \\
\hline 1135 & 1/8/200823:52 & $8 / 8 / 200823: 52$ & 1.744 & 16.9 \\
\hline 1136 & $1 / 8 / 200823: 54$ & $8 / 8 / 200823: 54$ & 1.749 & 16.9 \\
\hline 1137 & $1 / 8200823: 56$ & $8 / 8 / 200823: 56$ & 1.755 & 16.9 \\
\hline 1138 & 1/8/2008 23:58 & $8 / 8 / 200823: 58$ & 1.759 & 16.9 \\
\hline 1139 & $1 / 920080.00$ & $89 / 20080.00$ & 1.762 & 17.3 \\
\hline 1140 & $1 / 920080: 02$ & $89 / 20080: 02$ & 1.767 & 17.1 \\
\hline 1141 & $1 / 920080.04$ & $8 / 9 / 20080: 04$ & 1.77 & 17 \\
\hline 1142 & $1 / 920080: 06$ & $8 / 9 / 20080: 06$ & 1.773 & 16.9 \\
\hline 1143 & $1 / 9 / 20080.08$ & $8 / 920080: 08$ & 1.774 & 16.9 \\
\hline 1144 & 1/9/20080:10 & $89920080: 10$ & $1.7 \pi$ & 16.9 \\
\hline 1145 & 1/9/20080:12 & $89920080: 12$ & 1.779 & 17.1 \\
\hline 1146 & $1 / 9 / 20080: 14$ & $89 / 20080: 14$ & 1.781 & 16.9 \\
\hline 1147 & 1/920080:16 & $89 / 20080: 16$ & 1.785 & 16.9 \\
\hline 1148 & $1 / 920080: 18$ & $89 / 20080: 18$ & 1.784 & 16.9 \\
\hline 1149 & $19 / 20080: 20$ & $89 / 20080: 20$ & 1.785 & 16.9 \\
\hline 1150 & $1 / 9 / 20080.22$ & 8920080.22 & 1.785 & 16.9 \\
\hline 1151 & $1 / 9 / 20080.24$ & $8 / 9200080: 24$ & 1.788 & 16.9 \\
\hline 1152 & $1 / 920080.26$ & 89920080.26 & 1.751 & 16.9 \\
\hline 1153 & $1 / 9 / 20080.28$ & $89 / 20080: 28$ & $1, \pi$ & 16.9 \\
\hline 1154 & $1 / 920080: 30$ & 89920000.30 & 1.79 & 16.9 \\
\hline 1150 & $1 / 920080.32$ & 89920080.32 & 1.749 & 16.9 \\
\hline 1156 & $1 / 9 / 20080.34$ & 89920000.34 & 1.744 & 16.9 \\
\hline
\end{tabular}

\begin{tabular}{|c|c|c|c|c|}
\hline \multicolumn{5}{|c|}{ D492p } \\
\hline $\operatorname{Rec}$ & & Adusted & Fressure & Temp \\
\hline$\#$ & Dete/Time & DetedTme & psi & ${ }^{\circ} \mathrm{C}$ \\
\hline 1157 & $1 / 920080.36$ & 8920080.36 & 1.74 & 17 \\
\hline 1158 & 1/920080:38 & 89200080.38 & 1.94 & 16.9 \\
\hline 1159 & $1 / 9 / 20080: 40$ & $8920080: 40$ & 1.808 & 17 \\
\hline 1160 & $1 / 920080: 42$ & 89120080.42 & 1.801 & 16.9 \\
\hline 1161 & 1/9/20080:44 & $8920080: 44$ & 1.8 & 17 \\
\hline 1162 & $1 / 920080.46$ & $8 / 9 / 20080.46$ & 1.8 & 16.9 \\
\hline 1163 & $1 / 920080: 48$ & 8920080.48 & 1.8 & 16.9 \\
\hline 1164 & $1 / 920080.50$ & $89 / 20080: 50$ & 1.802 & 16.9 \\
\hline 1165 & $1 / 920080: 52$ & 8920080.52 & 1.803 & 16.9 \\
\hline 1166 & $1 / 920080.54$ & $8920080: 54$ & 1.803 & 16.9 \\
\hline 1167 & $1 / 920080.56$ & 8920080.56 & 1.804 & 16.9 \\
\hline 1168 & $1 / 9 / 20080.58$ & $89 / 20080.58$ & 1.804 & 16.9 \\
\hline 1169 & 1/920081:00 & $89 / 20081: 00$ & 1.806 & 17 \\
\hline 1170 & $1 / 920081: 02$ & $89920081: 02$ & 1.806 & 16.9 \\
\hline 1171 & $1 / 920081: 04$ & $89 / 20081: 04$ & 1.806 & 17 \\
\hline 1172 & 1/92008 1:06 & $89200081: 06$ & 1.806 & 16.9 \\
\hline 1173 & $1 / 920081: 08$ & $89920081: 08$ & 1.807 & 17 \\
\hline 1174 & $1 / 9 / 20081: 10$ & $89220081: 10$ & 1.808 & 17 \\
\hline 1175 & $1 / 920081: 12$ & $89 / 20081: 12$ & 1.808 & 17 \\
\hline 1176 & $1 / 92008$ 1:14 & $8 / 9 / 20081: 14$ & 1.808 & 17 \\
\hline 1177 & $1 / 92008$ 1:16 & $89200081: 16$ & 1.809 & 17 \\
\hline 1178 & $1 / 920081: 18$ & $89 / 20081: 18$ & 1.81 & 17 \\
\hline 1179 & $1 / 9 / 20081: 20$ & $89220081: 20$ & 1.812 & 17 \\
\hline 1180 & 1/9/2008 1:22 & $89 / 20081: 22$ & 1.813 & 17 \\
\hline 1481 & $1 / 9 / 20081: 24$ & $89 / 20081: 24$ & 1.814 & 17 \\
\hline 1182 & $1 / 9 / 20081: 26$ & $89120081: 26$ & 1.816 & 17 \\
\hline 1183 & $1 / 9 / 20081: 28$ & $89 / 20081: 28$ & 1.816 & 17 \\
\hline 1184 & $1 / 9 / 20081: 30$ & $89120081: 30$ & 1.816 & 17 \\
\hline 1185 & $1 / 9 / 20081: 32$ & $89200081: 32$ & 1.816 & 17 \\
\hline 1186 & $1 / 920081: 34$ & $8 / 9 / 20081: 34$ & 1.816 & 17 \\
\hline 1187 & $1 / 9 / 20081: 36$ & $89920081: 36$ & 1.817 & 17 \\
\hline 1188 & $1 / 9 / 20081: 38$ & $89 / 20081: 38$ & 1.818 & 17 \\
\hline 1180 & $1 / 9 / 20081: 40$ & $8 / 9 / 20081: 40$ & 1.821 & 17 \\
\hline 1190 & $1 / 9 / 20081: 42$ & $89 / 20081: 42$ & 1.82 & 17 \\
\hline 1191 & $1 / 9 / 20081: 44$ & $89 / 20081: 44$ & 1.822 & 17 \\
\hline 1192 & $1 / 9 / 20081: 46$ & $8920001: 46$ & 1.822 & 17 \\
\hline 1193 & $1 / 9 / 20081: 48$ & $8920081: 48$ & 1.822 & 17 \\
\hline 1194 & $1 / 9 / 20081: 50$ & $8 / 920001: 50$ & 1.82 & 17 \\
\hline 1195 & $1 / 9 / 2008$ 1:52 & $89920081: 52$ & 1.821 & 17 \\
\hline 1196 & $1 / 9 / 20081: 54$ & $89200081: 54$ & 1.821 & 17 \\
\hline 1197 & $1 / 9 / 20081: 56$ & $89920081: 56$ & 1.821 & 17 \\
\hline 1198 & $1 / 9 / 20081: 58$ & $89220081: 58$ & 1.822 & 17 \\
\hline 1199 & $1 / 92008200$ & 892008200 & 1.823 & 17 \\
\hline 1200 & $1 / 9 / 2008202$ & $819 / 20082002$ & 1.823 & 17 \\
\hline 1201 & $1 / 9 / 2008204$ & 8192008204 & 1.823 & 17 \\
\hline 1202 & $1 / 92008206$ & $89 / 2008206$ & 1.823 & 17 \\
\hline 1203 & $1 / 9 / 2008208$ & 8912008208 & 1.8 & 17 \\
\hline 1204 & $1 / 92008210$ & $8 / 9 / 2008210$ & 1.778 & 17 \\
\hline 1205 & $1 / 9 / 2008212$ & $89 / 2008212$ & 1.766 & 17 \\
\hline 1206 & $1 / 92008214$ & $89 / 2008214$ & 1.759 & 17 \\
\hline 1207 & $1 / 92008216$ & $89 / 2008216$ & 1.752 & 17 \\
\hline 1208 & $1 / 92008218$ & $8 / 9 / 2008218$ & 1.747 & 17 \\
\hline 1200 & $1 / 9 / 2008220$ & $8 / 9 / 2008220$ & 1.743 & 17 \\
\hline 1210 & $1 / 92008222$ & $89 / 2008222$ & 1.747 & 17 \\
\hline 1211 & $1 / 9 / 2008224$ & $89 / 2008224$ & 1.774 & 17 \\
\hline 1212 & $1 / 92008226$ & 8912008226 & 1.787 & 17 \\
\hline 1213 & $1 / 92008228$ & $89 / 2008228$ & 1.796 & 17 \\
\hline 1214 & $1 / 9 / 2008230$ & $89 / 2008230$ & 1.802 & 17 \\
\hline 1215 & $1 / 92008232$ & $89 / 2008232$ & 1.804 & 17 \\
\hline 1216 & $1 / 92008234$ & $89 / 2008234$ & 1.808 & 17 \\
\hline 1217 & $1 / 92008236$ & $89 / 2008236$ & 1.81 & 17 \\
\hline 1218 & $1 / 9 / 2008238$ & $89 / 2008238$ & 1.813 & 17 \\
\hline 1219 & $1 / 9 / 2008240$ & $89 / 2008240$ & 1.814 & 17 \\
\hline 1220 & $1 / 9 / 2008242$ & $89 / 2008242$ & 1.816 & 17 \\
\hline 1221 & $1 / 92008244$ & $89 / 2008244$ & 1.818 & 17 \\
\hline 1222 & $1 / 9 / 2008246$ & 8912008246 & 1.819 & 17 \\
\hline 1223 & $1 / 9 / 2008248$ & $89 / 20082-48$ & 1.821 & 17 \\
\hline 1224 & $1 / 9 / 2008250$ & $8 / 9 / 2008250$ & 1.822 & \\
\hline
\end{tabular}


DOE/RL-2009-35, REV. 0

\begin{tabular}{|c|c|c|c|c|}
\hline \multicolumn{5}{|c|}{ D492p } \\
\hline $\operatorname{Rec}$ & & Aqusted & Pressurf & Temp \\
\hline \# & DeterTime & Date-Time & psi & ${ }^{\circ} \mathrm{C}$ \\
\hline 1225 & $1 / 9 / 2008252$ & $89 / 2008252$ & 1.823 & 17 \\
\hline 1226 & $1 / 92008254$ & $8 / 92008254$ & 1.824 & 17 \\
\hline 1227 & $1 / 9 / 2008256$ & $8 / 920082556$ & 1.824 & 17 \\
\hline 1228 & $1 / 9 / 2008258$ & $8 / 9 / 2008258$ & 1.825 & 17 \\
\hline 1229 & 1/9/20083:00 & $8 / 9 / 20083: 00$ & 1.825 & 17 \\
\hline 1230 & 1/9/20083:02 & $8 / 9 / 20083: 02$ & 1.826 & 17 \\
\hline 1231 & 1/9/2008 3:04 & $8 / 9120083.04$ & 1.827 & 17 \\
\hline 1232 & 1/9/2008 3:06 & $89120083: 06$ & 1.828 & 17 \\
\hline 1233 & 1/9/20083:08 & $89 / 20083: 08$ & 1.828 & 17 \\
\hline 1234 & 1/9/20083:10 & 8/9/2008 3:10 & 1.829 & 17 \\
\hline 1235 & 1/9/2008 3:12 & $89 / 20083: 12$ & 1.83 & 16.9 \\
\hline 1236 & 1/9/20083:14 & $8 / 9 / 20083: 14$ & 1.83 & 17 \\
\hline 1237 & 1/9/20083:16 & $89 / 20083: 16$ & 1.83 & 17 \\
\hline 1238 & 1/9/2008 3:18 & $8 / 920083: 18$ & 1.83 & 16.9 \\
\hline 1239 & $1 / 9 / 20083: 20$ & $8 / 9 / 20083: 20$ & 1.831 & 17 \\
\hline 1240 & 1/9/20083:22 & $8 / 920083: 22$ & 1.832 & 17.1 \\
\hline 1241 & $1 / 9 / 20083: 24$ & $8 / 9 / 20083: 24$ & 1.832 & 17.5 \\
\hline 1242 & 1/9/20083:26 & $8 / 9 / 20083: 26$ & 1.833 & 17.1 \\
\hline 1243 & $1 / 9 / 20083: 28$ & $8 / 9 / 20083: 28$ & 1.833 & 17.1 \\
\hline 1244 & 1/9/2008 3:30 & $8 / 9 / 20083: 30$ & 1.834 & 17 \\
\hline 1245 & $1 / 9 / 2008$ 3:32 & $8 / 9 / 20083: 32$ & 1.834 & 17 \\
\hline 1246 & $1 / 9 / 20083: 34$ & $89120083: 34$ & 1.835 & 17 \\
\hline 1247 & $1 / 9 / 20083: 36$ & $8 / 9 / 20083: 36$ & 1.835 & 17 \\
\hline 1248 & $1 / 9 / 20083: 38$ & $8 / 920083: 38$ & 1.835 & 17 \\
\hline 1249 & $1 / 9 / 20083: 40$ & $8 / 9 / 20083: 40$ & 1.837 & 17 \\
\hline 1250 & 1/9/20083:42 & $8 / 9 / 20083: 42$ & 1.838 & 17 \\
\hline 1251 & $1 / 9 / 20083: 44$ & $8 / 9 / 20083: 44$ & 1.836 & 17 \\
\hline 1252 & $1 / 9 / 20083: 46$ & $8 / 9 / 20083: 46$ & 1.832 & 17 \\
\hline 1253 & $1 / 9 / 20083: 48$ & $8 / 9 / 20083: 48$ & 1.834 & 17 \\
\hline 1254 & $1 / 9 / 20083: 50$ & $89 / 20083: 50$ & 1.837 & 17 . \\
\hline 1255 & $1 / 9 / 20083: 52$ & $8 / 9 / 20083: 52$ & 1.838 & 17 \\
\hline 1256 & $1 / 9 / 20083: 54$ & $89: 20083: 54$ & 1.839 & 17 \\
\hline 1257 & $1 / 9 / 20083: 56$ & $8 / 920083: 56$ & 1.84 & 17 \\
\hline 1258 & 1/9/20083:58 & $8 / 9 / 20083: 58$ & 1.839 & 17 \\
\hline 1259 & 1/9/20084:00 & $8 / 9 / 20084: 00$ & 1.841 & 17 \\
\hline 1260 & 1/9/20084:02 & $8 / 9 / 20084: 02$ & 1.842 & 17 . \\
\hline 1261 & $1 / 9 / 20084: 04$ & $8 / 9 / 20084: 04$ & 1.842 & 17 \\
\hline 1262. & 1/9/20084:06 & $8 / 920084: 06$ & 1.843 & 17. \\
\hline 1263 & $1 / 9 / 20084: 08$ & $8 / 9 / 20084: 08$ & 1.843 & 17 \\
\hline 1264 & 1/9/20084:10 & $8 / 9 / 20084: 10$ & 1.844 & 17 . \\
\hline 1265 & $1 / 9 / 20084: 12$ & $89: 20084: 12$ & 1.845 & 17 \\
\hline 1266 & 1/9/20084:14 & $8 / 9 / 20084: 14$ & 1.844 & 17 \\
\hline 1267 & 1/9/20084:16 & $89 / 20084: 16$ & 1.844 & 17 . \\
\hline 1268 & 1/9/20084:18 & $8 / 9 / 20084: 18$ & 1.845 & 17. \\
\hline 1269 & $1 / 9 / 20084: 20$ & $8 / 9 / 20084: 20$ & 1.845 & 17 \\
\hline 1270 & 1/9/20084:22 & $8 / 9 / 20084: 22$ & 1.845 & 17 \\
\hline 1271 & $1 / 9 / 20084: 24$ & $8 / 920084: 24$ & 1.845 & 17 \\
\hline 1272 & $1 / 9 / 20084: 26$ & $8 / 9 / 20084: 26$ & 1.846 & 17 \\
\hline 1273 & 1/9/20084:28 & $8 / 9 / 20084: 28$ & 1.847 & 17. \\
\hline 1274 & 1/9/2008 4:30 & $8 / 9 / 20084: 30$ & 1.847 & 17 \\
\hline 1275 & 1/9/20084:32 & $8 / 920084: 32$ & 1.847 & 17. \\
\hline 1276 & $1 / 9 / 20084: 34$ & $89 / 20084: 34$ & 1.848 & 17 \\
\hline 1277 & 1/9/20084:36 & $8 / 920084: 36$ & 1.847 & 17 \\
\hline 1278 & $1 / 9 / 20084: 38$ & $8 / 920084: 38$ & 1.848 & 17 \\
\hline 1279 & $1 / 9 / 20084: 40$ & $8 / 920084: 40$ & 1.849 & 17 \\
\hline 1280 & $1 / 9 / 20084: 42$ & $8 / 9: 20084: 42$ & 1.849 & 17 \\
\hline 1281 & $1 / 9 / 20084: 44$ & $8 / 920084: 44$ & 1.85 & 17 \\
\hline 1282 & $1 / 920084: 46$ & $8 / 9120084: 46$ & 1.85 & 17 \\
\hline 1283 & 1/9/20084:48 & $8 / 920084: 48$ & 1.85 & 17. \\
\hline 1284 & 1/9/20084:50 & $8 / 9 / 20084: 50$ & 1.851 & 17 \\
\hline 1285 & $1 / 9 / 20084: 52$ & $8 / 9 / 20084: 52$ & 1.85 & 17 \\
\hline 1286 & $1 / 9 / 20084: 54$ & $8 / 9 / 20084: 54$ & 1.85 & 17 \\
\hline 1287 & 1/9/20084:56 & $8 / 9 / 20084: 56$ & \begin{tabular}{|l|l|}
5.848 \\
\end{tabular} & 17. \\
\hline 1288 & $1 / 9 / 20084: 58$ & $8 / 9 / 20084: 58$ & 1.848 & 17. \\
\hline 1289 & 1/9/20085:00 & $8 / 920085: 00$ & 1.848 & 17 \\
\hline 1290 & 1/9/20085:02 & $89920085: 02$ & 1.848 & 17 \\
\hline 1291 & 1/9/20085:04 & $8 / 9 / 20085: 04$ & 1.848 & 17 \\
\hline 1292 & 1/9/20085:06 & $89 / 20085: 06$ & \begin{tabular}{|l|}
1.822 \\
\end{tabular} & 17 \\
\hline
\end{tabular}

\begin{tabular}{|c|c|c|c|c|}
\hline \multicolumn{5}{|c|}{ D4-920 } \\
\hline $\operatorname{Rec}$ & & Adusted & Pressure & \\
\hline$\#$ & Date/Time & DaterTime & psi & ${ }^{\circ} \mathrm{C}$ \\
\hline 1293 & 1/9/20085:08 & $8 / 9 / 20085: 08$ & 1.798 & 17 \\
\hline 1294 & $1 / 920085: 10$ & $8 / 9 / 20085: 10$ & 1.785 & \\
\hline 1295 & 1/9/20085:12 & $8 / 9 / 20085: 12$ & 1.776 & 17 \\
\hline 1296 & 1/9/20085:14 & $8 / 920085: 14$ & 1.769 & 17.1 \\
\hline 1297 & 1/9/20085:16 & $8920085: 16$ & 1.765 & 17.1 \\
\hline 1298 & 1/9/20085:18 & $8 / 9 / 20085: 18$ & 1.76 & 17.1 \\
\hline 1299 & 1/9/20085:20 & $8 / 9 / 20085: 20$ & 1.756 & 17.1 \\
\hline 1300 & 1/920085:22 & $8 / 9 / 20085: 22$ & 1.751 & 17.1 \\
\hline 1301 & $1 / 9 / 20085: 24$ & $8920085: 24$ & 1.714 & 17.1 \\
\hline 1302 & $1 / 9 / 20085: 26$ & $89 / 20085: 26$ & 1.669 & 17.1 \\
\hline 1303 & 1/9/20085:28 & $89 / 20085: 28$ & 1.675 & 17.1 \\
\hline 1304 & 1/9/20085:30 & $8 / 9 / 20085: 30$ & 1.681 & 17.1 \\
\hline 1305 & 1/9/20085:32 & $8 / 9 / 20085: 32$ & 2109 & $\overline{17.4}$ \\
\hline 1306 & $1 / 9 / 20085: 34$ & $89 / 20085: 34$ & 1.847 & 17.7 \\
\hline 1307 & $1 / 9 / 20085: 36$ & $8 / 9 / 20085: 36$ & 1.83 & $\overline{17.3}$ \\
\hline 1308 & $1 / 9 / 20085: 38$ & $8 / 920085: 38$ & 1.829 & 17.2 \\
\hline 1309 & $1 / 9 / 20085: 40$ & $8 / 9 / 20085: 40$ & 1.83 & 17.2 \\
\hline 1310 & $1 / 9 / 20085: 42$ & $89 / 20085: 42$ & 1.832 & 17.1 \\
\hline 1311 & $1 / 9 / 20085: 44$ & $89 / 20085: 44$ & 1.834 & $\overline{17.3}$ \\
\hline 1312 & $1 / 9 / 20085: 46$ & $8 / 9 / 20085: 46$ & 1.836 & 17. \\
\hline 1313 & $1 / 9 / 20085: 48$ & $8 / 9120085: 48$ & 1.837 & 17.2 \\
\hline 1314 & 1/9/20085:50 & $8 / 9 / 20085: 50$ & 1.838 & 17.2 \\
\hline 1315 & 1/9/20085:52 & $8 / 9 / 20085: 52$ & 1.839 & 17. \\
\hline 1316 & $1 / 9 / 20085: 54$ & $8 / 9 / 20085: 54$ & 1.84 & 17. \\
\hline 1317 & $1 / 9 / 20085: 56$ & $8 / 9 / 20085: 56$ & 1.841 & 17.1 \\
\hline 1318 & $1 / 9 / 20085: 58$ & $89 / 20085: 58$ & 1.842 & 17. \\
\hline 1319 & $1 / 9 / 20086: 00$ & $8 / 9 / 20086: 00$ & 1.842 & 17. \\
\hline 1320 & 1/9/20086:02 & $8 / 9 / 20086: 02$ & 1.844 & 17. \\
\hline 1321 & $86: 04$ & $8 / 9 / 20086: 04$ & 1.846 & 17. \\
\hline 1322 & $1 / 9 / 20086: 06$ & $8 / 9 / 20086: 06$ & 1.848 & 17. \\
\hline 1323 & $1 / 9 / 20086: 08$ & $8 / 9 / 20086: 08$ & 1.849 & 17. \\
\hline 1324 & $86: 10$ & $8 / 9 / 20086: 10$ & 1.85 & 17. \\
\hline 1325 & $36: 12$ & $8 / 9 / 20086: 12$ & 1.851 & 17. \\
\hline 1326 & 1/9/20086:14 & $8 / 9 / 20086: 14$ & 1.852 & 17. \\
\hline 1327 & $1 / 9 / 20086: 16$ & $9 / 20086: 16$ & 1.853 & 17. \\
\hline 1328 & $6: 18$ & 36:18 & 1.853 & 17. \\
\hline 1329 & 1/9/20086:20 & $8 / 9 / 20086: 20$ & 1.253 & 17. \\
\hline 1330 & $1 / 9 / 20086: 22$ & $8 / 9 / 20086: 22$ & 1.854 & 17. \\
\hline 1331 & & & 1.855 & 17. \\
\hline 1332 & $6: 26$ & $86: 26$ & 1.855 & 17. \\
\hline 1333 & $1 / 9 / 20086: 28$ & $8 / 9 / 20086: 28$ & 1.855 & 17. \\
\hline 1334 & $6: 30$ & $8 / 9 / 20086: 30$ & 1.855 & 17. \\
\hline 1335 & $6: 32$ & $86: 32$ & 1.856 & 17. \\
\hline 1336 & $36: 34$ & $8 / 9 / 20086: 34$ & 1.857 & 17. \\
\hline 1337 & & & 1.857 & 17. \\
\hline 1338 & $6: 38$ & $8 / 920086: 38$ & 1.85 & 17. \\
\hline 1339 & $0086: 40$ & $89 / 20086: 40$ & 1.858 & 17. \\
\hline 1340 & & & 1.858 & 17. \\
\hline 1341 & $6: 44$ & $8 / 9 / 20086: 44$ & 1.858 & 17. \\
\hline 1342 & $086: 46$ & $8 / 9 / 20086: 46$ & 1.858 & 17. \\
\hline 1343 & $6: 48$ & $36: 48$ & 1.858 & 17. \\
\hline 1344 & & $86: 50$ & 1.859 & 17. \\
\hline 1345 & 886.52 & $8 / 920086: 52$ & 1.86 & 17. \\
\hline 1346 & 6:54 & $8 / 9 / 20086: 54$ & 1.859 & 17. \\
\hline 1347 & & & 1.859 & 17. \\
\hline 1348 & 86:58 & $8 / 9 / 20086: 58$ & 1.859 & 17. \\
\hline 1349 & 87:00 & $9920087: 00$ & 1.858 & 17. \\
\hline 1350 & & & 1.859 & 17. \\
\hline 1351 & $37: 04$ & $87: 04$ & 1.859 & 17. \\
\hline 1352 & $1 / 9 / 20087: 06$ & $8920087: 06$ & 1.86 & 17. \\
\hline 1353 & $7: 08$ & $89 / 20087: 08$ & 1.859 & 17. \\
\hline 1354 & & & 1.859 & \\
\hline 1355 & 1/9/2008 7:12 & $8 / 9 / 20087: 12$ & 1.859 & 17.2 \\
\hline 1356 & $1 / 9 / 20087: 14$ & $89 / 20087: 14$ & 1.859 & 17.2 \\
\hline 1357 & 1/9/2008 7:16 & $8 / 9 / 20087: 16$ & 1.86 & 17. \\
\hline 1358 & $1 / 9 / 20087: 18$ & $8 / 920087: 18$ & 1.861 & 17.2 \\
\hline 1350 & $1 / 920087: 20$ & $89 / 20087: 20$ & 1.861 & 17.2 \\
\hline 1360 & 1/9/2008 7:22 & $89120087: 22$ & 1.861 & 17. \\
\hline
\end{tabular}

\begin{tabular}{|c|c|c|c|c|}
\hline \multicolumn{5}{|c|}{$D 4920$} \\
\hline Rec & & Adusted & Pressure & Temp \\
\hline$\#$ & DaterTime & DaterTime & psi & ${ }^{\circ} \mathrm{C}$ \\
\hline 1361 & $1 / 9 / 20087: 24$ & 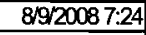 & 1.862 & 17.2 \\
\hline 1362 & 1/9/20087:26 & $89120087: 26$ & 1.863 & 17.3 \\
\hline 1363 & $1 / 9 / 20087: 28$ & $89 \sqrt{20087: 28}$ & 1.863 & 17.2 \\
\hline 1364 & $1 / 9 / 20087: 30$ & $89 / 20087730$ & 1.863 & 17.3 \\
\hline 1365 & 1/9/20087:32 & $89 / 20087: 32$ & 1.862 & 17.2 \\
\hline 1366 & $1 / 9 / 20087: 34$ & $89 / 20087734$ & 1.862 & 17.3 \\
\hline 1367 & $1 / 9 / 20087: 36$ & $89 / 20087: 36$ & 1.864 & 17.3 \\
\hline 1368 & $1 / 9 / 20087: 38$ & $89 / 20087: 38$ & 1.864 & 17.3 \\
\hline 1369 & 19/2008 7:40 & $89 / 20087: 40$ & 1.863 & 17.3 \\
\hline 1370 & $1 / 9 / 20087: 42$ & $89 \sqrt{200887: 42}$ & 1.863 & 17.3 \\
\hline 1371 & $1 / 9 / 20087: 44$ & $89 / 20087: 44$ & 1.862 & 17.3 \\
\hline 1372 & $1 / 9 / 20087: 46$ & $89 / 20087: 46$ & 1.862 & 17.3 \\
\hline 1373 & $1 / 9 / 20087: 48$ & $89 / 20087: 48$ & 1.864 & 17.3 \\
\hline 1374 & $1 / 9 / 20087: 50$ & $89 / 20087: 50$ & 1.865 & 17.3 \\
\hline 1375 & $1 / 9 / 20087: 52$ & $89 / 20087: 52$ & 1.864 & 17.3 \\
\hline 1376 & $1 / 9 / 20087: 54$ & $899200087: 54$ & 1.864 & 17.3 \\
\hline 1377 & $1 / 9 / 20087: 56$ & $89 / 20087: 56$ & 1.865 & 17.3 \\
\hline 1378 & $1 / 9 / 20087: 58$ & $89120087: 58$ & 1.866 & 17.4 \\
\hline 1379 & $1 / 9 / 20088: 00$ & $8 / 9 / 20088: 00$ & 1.865 & 17.4 \\
\hline 1380 & $1 / 9 / 20088.02$ & $89 / 20088: 02$ & 1.865 & 17.3 \\
\hline 1381 & $1 / 9 / 20088: 04$ & $89920088: 04$ & 1.866 & 17.4 \\
\hline 1382 & $1 / 9 / 20088: 06$ & $8 / 9 / 20088: 06$ & 1.866 & 17.4 \\
\hline 1383 & $1 / 9 / 20088: 08$ & $8 / 9 / 20088: 08$ & 1.865 & 17.4 \\
\hline 1384 & $1 / 9 / 20088: 10$ & $8 / 9 / 20088: 10$ & 1.863 & 17.4 \\
\hline 1385 & $1 / 9 / 20088: 12$ & $89 / 20088: 12$ & 1.865 & 17.4 \\
\hline 1386 & $1 / 9 / 20088: 14$ & $8 / 9 / 20088: 14$ & 1.865 & 17.4 \\
\hline 1387 & 1/9/20088:16 & $8 / 9 / 20088: 16$ & 1.866 & 17.4 \\
\hline 1388 & $1 / 9 / 20088: 18$ & $8 / 9 / 20088: 18$ & 1.866 & 17.4 \\
\hline 1389 & 1/9/2008 8:20 & $8 / 9 / 20088: 20$ & 1.865 & 17.4 \\
\hline 1390 & $1 / 9 / 20088: 22$ & $8 / 9 / 20088: 22$ & 1.863 & 17.4 \\
\hline 1391 & $1 / 9 / 20088: 24$ & $8 / 9 / 20088: 24$ & 1.863 & 17.4 \\
\hline 1392 & $1 / 9 / 20088.26$ & $8 / 9 / 20088: 26$ & 1.691 & 17.4 \\
\hline 1393 & $1 / 9 / 20088: 28$ & $8 / 9 / 20088: 28$ & 1.888 & 17.4 \\
\hline 1394 & $1 / 9 / 20088: 30$ & $8 / 9 / 20088: 30$ & 1.87 & 17.4 \\
\hline 1395 & $1 / 9 / 20088: 32$ & $89 / 20088: 32$ & 1.871 & 17.4 \\
\hline 1396 & $1 / 9 / 20088: 34$ & $89 / 20088: 34$ & 1.872 & 17.4 \\
\hline 1397 & $19 / 20088: 36$ & $8 / 9 / 20088: 36$ & 1.873 & 17.4 \\
\hline 1398 & $1 / 9 / 20088: 38$ & $89 / 20088: 38$ & 1.873 & 17.4 \\
\hline 1399 & $1 / 9 / 20088: 40$ & $8 / 9 / 20088: 40$ & 1.872 & 17.4 \\
\hline 1400 & $1 / 9 / 20088: 42$ & $8 / 9 / 20088: 42$ & 1.871 & 17.4 \\
\hline 1401 & 1/9/2008 8:44 & $89 / 20088: 44$ & 1.819 & 17.4 \\
\hline 1402 & $1 / 9 / 20088: 46$ & $8 / 9 / 20088: 46$ & 1.872 & 17.4 \\
\hline 1403 & $1 / 9 / 20088: 48$ & $8 / 9 / 20088: 48$ & 1.868 & 17.4 \\
\hline 1404 & $1 / 920088.50$ & $89 / 20088: 50$ & 1.869 & 17.4 \\
\hline 1405 & $1 / 9 / 20088: 52$ & $8 / 9 / 20088: 52$ & 1.869 & 17.4 \\
\hline 1406 & $1 / 9 / 20088.54$ & $8 / 9 / 20088: 54$ & 1.871 & 17.4 \\
\hline 1407 & $1 / 9 / 20088.56$ & $8 / 9 / 20088: 56$ & 1.872 & 17.4 \\
\hline 1408 & $1 / 9 / 20088: 58$ & $8 / 9 / 20088: 58$ & 1.871 & 17.4 \\
\hline 1409 & 1/9/20089:00 & $89 / 20089: 00$ & 1.871 & $17 . \overline{4}$ \\
\hline 1410 & 1/9/20089:02 & 89920089.02 & 1.871 & 17.4 \\
\hline 1411 & $1 / 9 / 20089.04$ & 8/9/20089:04 & 1.873 & 17.4 \\
\hline 1412 & $1 / 9 / 20089.06$ & $89 / 20089: 06$ & 1.874 & 17.4 \\
\hline 1413 & $1 / 9 / 20089.08$ & $89 / 20089: 08$ & 1.87 & 17.4 \\
\hline 1414 & $1 / 9 / 20089.10$ & $89 / 20089.10$ & 1.833 & 17.5 \\
\hline 1415 & $1 / 9 / 20089.12$ & $89120089: 12$ & 1.813 & 17.5 \\
\hline 1416 & $1 / 9 / 20089.14$ & $89920089: 14$ & 1.799 & 17.5 \\
\hline 1417 & $1 / 9 / 20089.16$ & $89 / 20089.16$ & 1.789 & 17.5 \\
\hline 1418 & 1/9/20089.18 & $89 / 20089: 18$ & 1.782 & 17.6 \\
\hline 1419 & $1 / 9 / 20089.20$ & $89 / 20089.20$ & 1.776 & 17.6 \\
\hline 1420 & 1/9/20089:22 & $89 / 20089: 22$ & 1.771 & 17.6 \\
\hline 1421 & $1 / 9 / 20089.24$ & $8 / 9 / 20089.24$ & 1.803 & 17.6 \\
\hline 1422 & $1 / 9 / 20089.26$ & $89 / 20089.26$ & 1.821 & 17.6 \\
\hline 1423 & 1/9/20089.28 & $8 / 9 / 20089.28$ & 1.831 & 17.6 \\
\hline 1424 & $1 / 9 / 20089.30$ & 8920089.30 & 1.837 & 17.6 \\
\hline 1425 & $1 / 9 / 20089.32$ & $89 / 20089.32$ & 1.842 & 17.6 \\
\hline 1426 & $1 / 9 / 20089.34$ & 89920089.34 & 1.845 & 17.6 \\
\hline 1427 & $1 / 9 / 20089.36$ & 89920089.36 & 1.848 & 17.6 \\
\hline 1428 & 1/9/20089.38 & 8920089.38 & 1.851 & 17.6 \\
\hline
\end{tabular}




\begin{tabular}{|c|c|c|c|c|}
\hline \multicolumn{5}{|c|}{$D 4920$} \\
\hline $\operatorname{Rec}$ & & Adusted & Pressure & Temp \\
\hline \# & Dade/Time & Deter/ime & \begin{tabular}{|l|} 
psi \\
\end{tabular} & ${ }^{\circ} \mathrm{C}$ \\
\hline 1429 & $1 / 9 / 20089: 40$ & 89.20089 .40 & 1.853 & 17.6 \\
\hline 1430 & $1 / 9 / 20089442$ & 89200089.42 & 1.850 & 17.6 \\
\hline 1431 & $1 / 9 / 2008944$ & 89200089.44 & 1.857 & 17.6 \\
\hline 1432 & $1 / 9 / 20089: 46$ & 8920089.46 & 1.858 & 17.6 \\
\hline 1433 & $1 / 9 / 20089: 48$ & 8920089.48 & 1.859 & 17.6 \\
\hline 1434 & 19920089.50 & 89920089.50 & 1.954 & 17.6 \\
\hline 1435 & $1 / 9 / 20089.52$ & 8920089.52 & 1.787 & 17.6 \\
\hline 1436 & $1 / 920089.54$ & 89200089.54 & 1.781 & 17.6 \\
\hline 1437| & $1 / 920089.56$ & 8920089.56 & 1.862 & 17.7 \\
\hline 1438 & $1 / 9 / 20089: 58$ & 89200089.58 & 1.868 & 17.7 \\
\hline 1439 & $1 / 9 / 2008$ 10:00 & $89.200810: 00$ & 1.799 & 17.7 \\
\hline 1440 & $192000810: 02$ & $89200010: 02$ & 1.797 & 17.8 \\
\hline 1441 & $1 / 9200810: 04$ & $89: 200810: 04$ & 1.793 & 17.8 \\
\hline 1442 & 1/920008 10:06 & 89200810.06 & 1.792 & 17.8 \\
\hline 1443 & $19 / 92008$ 10:08 & $899200810: 08$ & 1.792 & 17.9 \\
\hline 1444 & $19200810: 10$ & 892000810.10 & 1.792 & 17.9 \\
\hline 1445 & 1/92008 10:12 & 89.200810 .12 & 1.793 & 17.9 \\
\hline 1446 & $1 / 92008$ 10:14 & 89200810.14 & 1.793 & 17.9 \\
\hline 1447 & $19200810: 16$ & 899200810.46 & 1.792 & 17.9 \\
\hline 1448 & $1 / 9200810: 18$ & 892000810.18 & 1.791 & 17.9 \\
\hline 1449 & $1 / 9200810: 20$ & $8 / 9200810.20$ & 1.791 & 18 \\
\hline 1450 & $1 / 9200810: 22$ & 89200810.22 & 1.791 & 18 \\
\hline 1451 & $1 / 9200810.24$ & 892008 10.24 & 1.766 & 18 \\
\hline 1452 & 1/92008 10:26 & 89200810.26 & 1.868 & 17.9 \\
\hline 1453 & 1/92008 10:28 & 89200810.28 & 1.868 & 17.9 \\
\hline 1454 & $1 / 9200810: 30$ & 89200810.30 & 1.868 & 17.9 \\
\hline 1456 & $1 / 9200810: 32$ & 89200810.32 & 1.869 & 17.9 \\
\hline 1456 & $1 / 9200810: 34$ & 89200810.34 & 1.869 & 17.9 \\
\hline 1457 & $1 / 9200810: 36$ & 892000810.36 & 1.809 & 17.9 \\
\hline 1458 & $1 / 9200810: 38$ & 899200810.38 & 1.869 & 18 \\
\hline 1450 & $1 / 9200810: 40$ & 89200810.40 & 1.868 & 18 \\
\hline 1460 & $1 / 9200810.42$ & 899200810.42 & 1.868 & 18 \\
\hline 1461 & $1 / 92008$ 10:44 & 899200810.44 & 1.868 & 18 \\
\hline 1462 & $1 / 92008$ 10:46 & $89200810: 46$ & 1.868 & 18 \\
\hline 1463 & $1 / 92008$ 10:48 & 89200810.48 & 1.808 & 18 \\
\hline 1464 & $1 / 9200810: 50$ & 89200810.50 & 1.869 & 18 \\
\hline 1465 & $1 / 9200810.52$ & 892000810.52 & 1.869 & 181 \\
\hline 1466 & $1 / 92008$ 10:54 & 899200810.54 & 1.89 & 18.1 \\
\hline 1467 & $1 / 92008$ 10:56 & 892008 10.56 & 1.87 & 18.1 \\
\hline 1468 & $1 / 9200810: 58$ & 892000810.58 & 1.87 & 18.1 \\
\hline 1469 & 1/92008 11:00 & $892000811: 00$ & 1.87 & 18.1 \\
\hline 1470 & 1/92008 11:00 & $899200811: 02$ & 1.87 & 18.1 \\
\hline 1471 & 1/92008 11:04 & 8992008 11:04 & 1.87 & 18.1 \\
\hline 1472 & 1/92008 11:06 & $899200811: 06$ & 1.87 & 181 \\
\hline 1473 & 1/9200811:08 & $899200811: 08$ & 1.87 & 181 \\
\hline 1474 & $1 / 9200811: 10$ & 8992008 11:10 & 1.87 & 18.1 \\
\hline 1475 & 1/92008 11:12 & $899200811: 12$ & 1.87 & 18.1 \\
\hline 1476 & $1 / 9200811: 14$ & 8992008 11:14 & 1.87 & 18.1 \\
\hline 1477 & 1/92008 11:16 & $89200811: 16$ & 1.871 & 18.1 \\
\hline 1478 & $19200811: 18$ & 8922008 11:18 & 1.871 & 18.1 \\
\hline 1479 & 1/92008 11:20 & $899200811: 20$ & 1.871 & 18.1 \\
\hline 1480 & 1/92008 11:22 & $89200811: 2$ & 1.872 & 18.1 \\
\hline 1481 & $1 / 9200811: 24$ & $899200811: 24$ & 1.872 & 18.1 \\
\hline 1482 & $1 / 9200811: 26$ & $892000811: 26$ & 1.872 & 18.1 \\
\hline 1483 & $1 / 92008$ 11:28 & $89200811: 28$ & 1.872 & 18.1 \\
\hline 1484 & $1 / 9200811: 30$ & $89: 200811: 30$ & 1.872 & 18.1 \\
\hline 1485 & 1/92008 11:32 & $89: 200811: 32$ & 1.872 & 18.1 \\
\hline 1496 & $1 / 9200811: 34$ & $89: 2008$ 11:34 & 1.873 & 18.1 \\
\hline 1487 & $1 / 9200811: 36$ & $892000811: 36$ & 1.873 & 18.1 \\
\hline 1488 & 1/9200811:38 & $8 / 92000811: 38$ & 1.874 & 18.2 \\
\hline 1489 & $1 / 9200811: 40$ & $89: 200811: 40$ & 1.874 & 18.1 \\
\hline 1490 & 1/92008 11:42 & $89200811: 42$ & 1.874 & 18.1 \\
\hline 1491 & $1 / 92008$ 11:44 & $89: 2008$ 11:44 & 1.873 & 18.1 \\
\hline 1492 & $1 / 9200811: 46$ & $89: 2008$ 11:46 & 1.874 & 18.1 \\
\hline 1493 & 1/92008 11:48 & $89: 200811: 48$ & 1.873 & 18.1 \\
\hline 1494 & $1 / 9200811: 50$ & $89 / 200811: 50$ & 1.873 & 18.2 \\
\hline 1496 & $1 / 9 / 200811: 52$ & $89 / 200811: 52$ & 1.871 & 18.2 \\
\hline 1496 & $1 / 9200811: 54$ & $8 / 9 / 200811: 54$ & 1.861 & 18.2 \\
\hline
\end{tabular}

\begin{tabular}{|c|c|c|c|c|}
\hline \multicolumn{5}{|c|}{ D4920 } \\
\hline $\operatorname{Rox}$ & & Agusted & Pressure & Tentp \\
\hline$\#$ & DaeTime & DedefTime & psi & ${ }^{\circ} \mathrm{C}$ \\
\hline 1497 & $19 / 200811: 56$ & $89200811: 56$ & 1.846 & 18.2 \\
\hline 1498 & $1 / 9 / 200811: 58$ & $89200811: 58$ & 1.826 & 18.3 \\
\hline 1499 & $1 / 9 / 20081200$ & 8920081200 & 1.813 & 18.3 \\
\hline 1500 & $1 / 920081202$ & 8920081202 & 1.803 & 18.3 \\
\hline 1501 & $1 / 9 / 20081204$ & 89920081204 & 1.795 & 18.3 \\
\hline 1502 & $1 / 9 / 20081206$ & $8 / 920081206$ & 1.789 & 18.3 \\
\hline 1503 & $1 / 9 / 20081208$ & $8 / 920081208$ & 1.808 & 18.3 \\
\hline 1504 & $1 / 9 / 200812: 10$ & 8920081210 & 1.827 & 18.6 \\
\hline 1505 & $1 / 9200812: 12$ & $891200812: 12$ & 1.839 & 18.4 \\
\hline 1506 & $1 / 9 / 20081214$ & $89 / 20081214$ & 1.844 & 18.3 \\
\hline 1507 & $1 / 920081216$ & 8920081216 & 1.847 & 18.3 \\
\hline 1508 & $19 / 20081218$ & 8920081218 & 1.851 & 18.3 \\
\hline 1509 & $1 / 9 / 20081220$ & $8 / 920081220$ & 1.853 & 18.3 \\
\hline 1510 & $1 / 9 / 20081222$ & 8920081222 & 1.854 & 18.3 \\
\hline 1511 & $1 / 9 / 2008$ १224 & 8920081224 & 1.856 & 18.3 \\
\hline 1512 & $19 / 20081226$ & $8 / 920081226$ & 1.858 & 18.3 \\
\hline 1513 & $1 / 9 / 20081228$ & 8920081228 & 1.858 & 18.3 \\
\hline 1514 & $1 / 9 / 20081230$ & $8 / 920081230$ & 1.850 & 18.3 \\
\hline 1515 & $19 / 2008$ †2:32 & $8 / 920081232$ & 1.859 & 18.3 \\
\hline 1516 & $1 / 92008 \uparrow 234$ & $8 / 9 / 20081234$ & 1.86 & 18.3 \\
\hline 1517 & $1 / 920081236$ & 81920081236 & 1.861 & 18.3 \\
\hline 1518 & $1 / 9 / 200812-38$ & 8920081238 & 1.861 & 18.3 \\
\hline 1519 & $1 / 9 / 200812,40$ & 8920081240 & 1.86 & 18.3 \\
\hline 1520 & $1 / 9 / 20081242$ & 89920081242 & 1.861 & 18.3 \\
\hline 1521 & $1 / 9 / 20081244$ & 89200081244 & 1.862 & 18.3 \\
\hline 1522 & $1 / 9 / 20081246$ & 89200812,46 & 1.862 & 18.3 \\
\hline 1523 & $1 / 920081248$ & 899200812,48 & 1.863 & 18.3 \\
\hline 1524 & $1 / 9 / 20081250$ & 8920081250 & 1.864 & 18.3 \\
\hline 1525 & $1 / 9 / 20081252$ & 899200812552 & 1.864 & 18.4 \\
\hline 1526 & $19 / 20081254$ & 89920081254 & 1.865 & $\overline{18.4}$ \\
\hline 1527 & $1 / 920081256$ & 8920081256 & 1.864 & 18.4 \\
\hline 1528 & $1 / 9 / 20081258$ & $8 / 920081258$ & 1.864 & 18.4 \\
\hline 1529 & 1/9/2008 13:00 & $89200813: 00$ & 1.864 & 18.4 \\
\hline 1530 & 1/9/2008 13:02 & $89200813: 02$ & 1.864 & 18.4 \\
\hline 1531 & 1/9/2008 13:04 & $8 / 9200813: 04$ & 1.865 & 18.4 \\
\hline 1532 & $1 / 9200813: 06$ & $89200813: 06$ & 1.865 & 18.4 \\
\hline 1533 & $1 / 9200813: 08$ & $8 / 9200813: 08$ & 1.864 & 18.4 \\
\hline 1534 & 19/2008 13:10 & $89200813: 10$ & 1.865 & 18.4 \\
\hline 1535 & 1/9/2008 13:12 & 892008 13:12 & 1.866 & 18.4 \\
\hline 1536 & 1/9/2008 13:14 & $8 / 9 / 2008$ 13:14 & 1.866 & 18.4 \\
\hline 1537 & 19200813:16 & $8 / 9200813: 16$ & 1.867 & 18.4 \\
\hline 1538 & 19/2008 13:18 & $892000813: 18$ & 1.868 & 18.4 \\
\hline 1539 & $1 / 9200813: 20$ & 8920081320 & 1.87 & 18.5 \\
\hline 1540 & 1/9200813:22 & $89 / 200813: 22$ & 1.868 & 18.4 \\
\hline 1541 & 1/9/2008 13:24 & $892200813: 24$ & 1.867 & 18.4 \\
\hline 1542 & 19/2008 13:26 & $8 / 92008$ 13:26 & 1.866 & 18.4 \\
\hline 1543 & 1/9/2008 13:28 & $89200813: 28$ & 1.867 & 18.5 \\
\hline 1544 & $1 / 9 / 200813: 30$ & $89: 200813: 30$ & 1.862 & 18.4 \\
\hline 1545 & 1/9/2008 13:32 & $892000813: 32$ & 1.868 & $\overline{18.4}$ \\
\hline 1546 & $1 / 9 / 2008$ 13:34 & 8992008 13:34 & 1.869 & 18.4 \\
\hline 1547 & 19/2008 13:36 & $892000813: 36$ & 1.786 & 18.4 \\
\hline 1548 & $1 / 9 / 200813: 38$ & $8 / 92008$ 13:38 & 1.771 & 18.4 \\
\hline 1549 & $19 / 200813: 40$ & $8 / 9200813: 40$ & 1.769 & 18.4 \\
\hline 1550 & $1 / 9 / 2008$ 13:42 & $8 / 9 / 2008$ 13:42 & 1.768 & 18.4 \\
\hline 1551 & $1 / 9200813: 44$ & $8 / 9 / 200813: 44$ & 1.869 & 18.4 \\
\hline 1552 & $1 / 9 / 200813: 46$ & $89200813: 46$ & 1.866 & 18.4 \\
\hline 1563 & $19 / 200813: 48$ & $892000813: 48$ & 1.867 & 18.4 \\
\hline 1554 & $19 / 200813: 50$ & $892000813: 50$ & 1.867 & 18.4 \\
\hline 1555 & $1 / 9200813: 52$ & $8 / 9 / 200813: 52$ & 1.867 & 18.5 \\
\hline 1556 & $19 / 200813: 54$ & $892000813: 54$ & 1.869 & 18.5 \\
\hline 1507 & $19 / 200813: 56$ & $8 / 9 / 200813: 56$ & 1.87 & 18.6 \\
\hline 1558 & $1 / 9 / 2008+3: 58$ & $819200813: 58$ & 1.87 & 18.6 \\
\hline 1559 & $1 / 9 / 200814: 00$ & $8 / 920008$ 14:00 & 1.869 & 18.6 \\
\hline 1560 & $1 / 9 / 200814: 02$ & $8 / 9 / 2008$ 14:02 & 1.669 & 18.6 \\
\hline 1561 & $1 / 9 / 200814: 04$ & $899200814: 04$ & \begin{tabular}{|l|}
1.8609 \\
\end{tabular} & 18.6 \\
\hline 1562 & 1/9:2008 14:06 & $8 / 92008$ 14:06 & 1.869 & 18.6 \\
\hline 1563 & 1/9/2008 14:08 & $8 / 9 / 200814: 08$ & 1.87 & 18.6 \\
\hline 1564 & 1/9/2008 14:10 & 892008 14:10 & 1.87 & 18.6 \\
\hline
\end{tabular}

\begin{tabular}{|c|c|c|c|c|}
\hline \multicolumn{5}{|c|}{ D4920 } \\
\hline $\mathrm{Pec}$ & & Acjusted & Pressure & Termp \\
\hline$\#$ & DeteTime & DeteTime & \begin{tabular}{|l|}
$p s i$ \\
\end{tabular} & ${ }^{\circ} \mathrm{C}$ \\
\hline 1565 & 1/9/2008 14:12 & $8 / 9 / 2008$ 14:12 & 1.869 & 18.6 \\
\hline 1566 & $1 / 9 / 2008$ 14:14 & $89 / 2008$ 14:14 & 1.869 & 18.6 \\
\hline 1567 & 1/9/2008 14:16 & 8920008 14:16 & 1.871 & 18.6 \\
\hline 1568 & 1/9/2008 14:18 & $8 / 9 / 2008$ 14:18 & 1.871 & 18.6 \\
\hline 1569 & $1 / 9 / 200814: 20$ & $892000814: 20$ & 1.871 & 18.6 \\
\hline 1570 & 1/9:2008 14:22 & $89 / 200814: 2$ & 1.872 & 18.6 \\
\hline 1571 & $19 / 2008$ 14:24 & 8920008 14:24 & 1.871 & 18.6 \\
\hline 1572 & $1 / 9 / 2008$ 14:26 & $89 / 2008$ 14:26 & 1.87 & 18.7 \\
\hline 1573 & $1 / 9 / 200814: 28$ & $89 / 2008$ 14:28 & 1.87 & 18.7 \\
\hline 1574 & $1 / 9 / 200814: 30$ & $8992000814: 30$ & 1.87 & 18.7 \\
\hline 1575 & $1 / 9 / 200814: 32$ & $89 / 2008$ 14:32 & 1.87 & 18.6 \\
\hline 1576 & 1/9/2008 14:34 & $89 / 2008$ 14:34 & 1.87 & 18.6 \\
\hline $15 \pi$ & 1/9/2008 14:36 & $89 / 2008$ 14:36 & 1.871 & 18.7 \\
\hline 1578 & $1 / 9 / 2008$ 14:38 & $89 / 2008$ 14:38 & 1.872 & 18.8 \\
\hline 1579 & $1 / 92000814: 40$ & $89200814: 40$ & 1.871 & 18.7 \\
\hline 1580 & $1 / 9 / 200814: 42$ & $8 / 9 / 2008$ 14:42 & 1.87 & 18.7 \\
\hline 1581 & $1 / 9 / 2008$ 14:44 & 892008 14:44 & 1.87 & 18.8 \\
\hline 1582 & $1 / 9 / 2008$ 14:46 & $8 / 9 / 2008$ 14:46 & 1.789 & 18.8 \\
\hline 1583 & $1 / 9 / 2008$ 14:48 & $89 / 200814: 48$ & 1.843 & 18.7 \\
\hline 1584 & $1 / 9 / 200814: 50$ & $8 / 92008$ 14:50 & 1.862 & 18.6 \\
\hline 1585 & $1 / 9 / 2008$ 14:52 & 8992008 14:52 & 1.866 & 18.6 \\
\hline 1586 & $1 / 9 / 2008$ 14:54 & 892008 14:54 & 1.869 & 18.6 \\
\hline 1587 & $1 / 92008$ 14:56 & $89 / 2008$ 14:56 & 1.86 & 18.6 \\
\hline 1588 & $1 / 9 / 200814: 58$ & $89200814: 58$ & 1.83 & 18.7 \\
\hline 1589 & $19 / 9200815000$ & $892000815: 00$ & 1.812 & 18.7 \\
\hline 1590 & $1 / 9 / 200815: 02$ & 892000815002 & 1.806 & 18.8 \\
\hline 1591 & $1 / 9 / 200815: 04$ & $8 / 9 / 2008$ 15:04 & 1.796 & 18.8 \\
\hline 1592 & $199200815: 06$ & $892000815: 06$ & 1.813 & 18.9 \\
\hline 1593 & $1 / 9200815: 08$ & $8 / 9 / 200815: 08$ & 1.835 & 18.9 \\
\hline 1594 & $1 / 9 / 200815: 10$ & $89 / 200815: 10$ & 1.844 & 18.8 \\
\hline 1595 & $1 / 9 / 2008$ 15:12 & 892008 15:12 & 1.852 & 18.8 \\
\hline 1596 & $1 / 9 / 200815: 14$ & $8 / 9 / 200815: 14$ & 1.855 & 18.8 \\
\hline 1597 & $19 / 200815: 16$ & $89 / 200815: 16$ & 1.858 & 18.8 \\
\hline 1598 & $1 / 9200815: 18$ & $8 / 9200815: 18$ & 1.861 & 18.8 \\
\hline 1509 & 1/9/2008 15:20 & $89 / 200815: 20$ & 1.862 & 18.8 \\
\hline 1600 & $1 / 9 / 200815: 22$ & $89200815: 22$ & 1.864 & 18.8 \\
\hline 1601 & 1/9/2008 15:24 & 892008 15:24 & 1.864 & 18.8 \\
\hline 1602 & $1 / 9 / 200815: 26$ & 892008 15:26 & 1.865 & 18.8 \\
\hline 1603 & $1 / 9 / 200815: 28$ & $89 / 2008$ 15:28 & 1.865 & 18.8 \\
\hline 1604 & $19 / 200815: 30$ & $89200815: 30$ & 1.867 & 18.9 \\
\hline 1606 & 1/9/2008 15:32 & $8 / 9 / 200815: 32$ & 1.868 & 18.9 \\
\hline 1606 & 1/9/2008 15:34 & $8 / 9 / 200815: 34$ & 1.879 & 18.8 \\
\hline 1607 & $1 / 9200815: 36$ & 8920081536 & 1.869 & 18.8 \\
\hline 1608 & $1 / 9 / 200815: 38$ & $8 / 9200815: 38$ & 1.87 & 18.9 \\
\hline 1609 & $1 / 9 / 200815: 40$ & $89 / 200815: 40$ & 1.871 & 19.2 \\
\hline 1610 & $1 / 9 / 2008$ 15:42 & $89 / 2008$ 15:42 & 1.872 & 19.1 \\
\hline 1611 & $1 / 9 / 200815: 44$ & $89 / 200815: 44$ & 1.873 & 18.9 \\
\hline 1612 & $1 / 9 / 200815: 46$ & $89 / 200815: 46$ & 1.874 & 18.9 \\
\hline 1613 & $1 / 9 / 200815: 48$ & $89200815: 48$ & 1.873 & 18.9 \\
\hline 1614 & $1 / 9 / 200815: 50$ & $89200815: 50$ & 1.875 & 18.9 \\
\hline 1615 & $1 / 9 / 200815: 52$ & $8 / 9 / 200815: 52$ & 1.874 & 18.9 \\
\hline 1616 & $1 / 9 / 200815: 54$ & $8 / 9 / 200815: 54$ & 1.874 & 18.9 \\
\hline $16+7$ & $1 / 9 / 200815: 56$ & $8 / 9 / 200815: 56$ & 1.875 & 18.9 \\
\hline 1618 & $1 / 9 / 200815: 58$ & $8 / 9 / 200815: 58$ & 1.875 & 18.9 \\
\hline 1619 & $1 / 9200816: 00$ & $89 / 200816: 00$ & 1.876 & 18.9 \\
\hline 1620 & 1/9/2008 16:02 & $8 / 9 / 200816: 02$ & 1.875 & 18.9 \\
\hline 1621 & 1/9/2008 16:04 & $8 / 9 / 200816: 04$ & 1.875 & 18.9 \\
\hline 1622 & 1/9/2008 16:06 & $89 / 200816.06$ & 1.876 & 18.9 \\
\hline 1623 & $1 / 9 / 200816: 08$ & $8 / 9 / 200816: 08$ & 1.877 & 18.9 \\
\hline 1624 & $1 / 9 / 200816: 10$ & $89 / 200816: 10$ & 1.876 & 19 \\
\hline 1625 & $1 / 9 / 2008$ 16:12 & $8 / 9200816: 12$ & 1.876 & 18.9 \\
\hline 1626 & $1 / 9 / 200816: 14$ & $8 / 9 / 200816: 14$ & 1.878 & 19 \\
\hline 1627 & $1 / 9 / 2008$ 16:16 & $89 / 2008+6: 16$ & 1.878 & 19 \\
\hline 1628 & $1 / 9 / 200816: 18$ & $8 / 9 / 200816: 18$ & 1.879 & 19 \\
\hline 1620 & $1 / 9 / 200816: 20$ & $892000816: 20$ & 1.88 & 19 \\
\hline 1630 & $1 / 9 / 20081622$ & $89 / 200816 \cdot 22$ & 1.881 & 19 \\
\hline 1631 & $1 / 9 / 2008$ 16:24 & $8 / 9 / 2008$ 16:24 & 1.88 & 19.4 \\
\hline 1632 & $1 / 9 / 200816: 26$ & $89 / 200816: 26$ & 1.882 & 19.1 \\
\hline
\end{tabular}


DOE/RL-2009-35, REV. 0

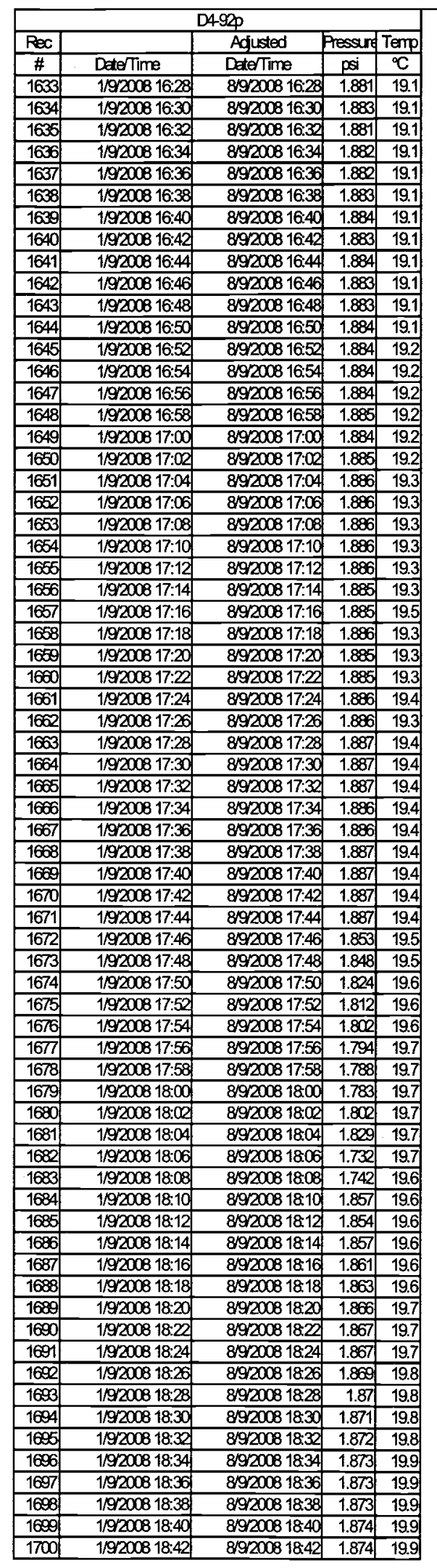

\begin{tabular}{|c|c|c|c|c|}
\hline \multicolumn{5}{|c|}{ D4920 } \\
\hline $\mathrm{REC}$ & & Adusted & Fressurf & Temp \\
\hline \# & Dete/Time & Dete/Time & psi & ${ }^{\circ} \mathrm{C}$ \\
\hline 1701 & $1 / 92008$ 18:44 & 8992008 18:44 & 1.875 & 19.9 \\
\hline 1700 & $1 / 9200818: 46$ & $899200818: 46$ & 1.877 & 19.9 \\
\hline 1703 & $1 / 9200818: 48$ & $899200818: 48$ & 1.877 & 19.9 \\
\hline 1704 & $1 / 9200818: 50$ & $89 / 200818: 50$ & 1.878 & 19.9 \\
\hline 1705 & $1 / 9200818: 52$ & $899200818: 52$ & 1.878 & 19.9 \\
\hline 1706 & 199200818.54 & $89 / 200818: 54$ & 1.879 & 19.9 \\
\hline 1707 & $1 / 9200818: 56$ & 891200818.56 & 1.879 & 19.9 \\
\hline 1708 & $1 / 9200818: 58$ & $892000818: 58$ & 1.879 & 19.9 \\
\hline 1709 & $1 / 9 / 200819: 00$ & $89 / 200819.00$ & 1.879 & 19.9 \\
\hline 1710 & $1 / 9200819.02$ & 899200819.02 & 1.881 & 19.9 \\
\hline 1711 & $1 / 920081904$ & 89200819.04 & 1.88 & 19.9 \\
\hline 1712 & $19,9200819.06$ & 89200819.06 & 1.88 & 19.9 \\
\hline 1713 & 199200819.08 & 89200819.08 & 1.88 & 19.9 \\
\hline 1714 & $1 / 9200819.10$ & 899200819.10 & 1.88 & 20 \\
\hline 1715 & $1 / 9200819.12$ & 899200819.12 & 1.88 & 20 \\
\hline 1716 & $1 / 9200819.14$ & 899200819.14 & 1.881 & 20 \\
\hline 1717 & $1 / 9200819.16$ & 8992008 19.16 & 1.881 & 20 \\
\hline 1718 & $1 / 9200819.18$ & 89200819.18 & 1.881 & 20 \\
\hline 1719 & $1 / 9200819.20$ & 89200819.20 & 1.882 & 20.1 \\
\hline 1720 & $1 / 9200819.22$ & 89.200819 .22 & 1.881 & 20.1 \\
\hline 1721 & $1 / 9 / 200819.24$ & 899200819.24 & 1.881 & 20.1 \\
\hline 1722 & $19 / 200819: 26$ & $89 / 200819.26$ & 1.882 & 20 \\
\hline 1723 & $1 / 9200819.28$ & 899200819.28 & 1.882 & 20.1 \\
\hline 1724 & $1 / 9200819.30$ & 899200819.30 & 1.883 & 20.1 \\
\hline 1725 & 199200819.32 & $8 / 9200819.32$ & 1.883 & 20.1 \\
\hline 1726 & $1 / 9200819.34$ & 89200819.34 & 1.883 & 20.1 \\
\hline 1727 & $1 / 9200819.36$ & $89 / 200819.36$ & 1.883 & 20.1 \\
\hline 1728 & $1 / 9200819.38$ & 899200819.38 & 1.883 & 20.1 \\
\hline 1729 & $1 / 9200819: 40$ & 89.200819 .40 & 1.882 & 20.1 \\
\hline 1730 & $1 / 9200819.42$ & $89 / 200819.42$ & 1.882 & 20.2 \\
\hline 1731 & $1 / 9200819.44$ & 899200819.44 & 1.882 & 20.2 \\
\hline 1732 & $1 / 9200819.46$ & $89 / 200819.46$ & 1.882 & 20.2 \\
\hline 1733 & $1 / 9200819.48$ & 899200819.48 & 1.882 & 20.2 \\
\hline 1734 & $1 / 9200819.50$ & 899200819.50 & 1.883 & 20.3 \\
\hline 1735 & $1 / 9200819.52$ & 899200819.52 & 1.883 & 20.3 \\
\hline 1736 & $1 / 9200819.54$ & 89200819.54 & 1.883 & 20.3 \\
\hline 1737 & $1 / 9200819.56$ & 892000819.56 & 1.884 & 20.5 \\
\hline 1738 & $1 / 9200819.58$ & 892000819.58 & 1.884 & 20.4 \\
\hline 1739 & $1 / 9200820: 00$ & $89 / 200820: 00$ & 1.884 & 20.3 \\
\hline 1740 & $1 / 9200820: 02$ & $899200820: 02$ & 1.884 & 20.3 \\
\hline 1741 & $1 / 9 / 200820: 04$ & $89 / 200820: 04$ & 1.884 & 20.3 \\
\hline 1742 & 1/9200820:06 & $89: 200820: 06$ & 1.883 & 20.3 \\
\hline 1743 & $1 / 9200820: 08$ & $89200820: 08$ & 1.884 & 20.4 \\
\hline 1744 & $1 / 9200820.10$ & $899200820: 10$ & 1.885 & 20.4 \\
\hline 1745 & $1 / 9200820: 12$ & $89200820: 12$ & 1.885 & 20.4 \\
\hline 1746 & $1 / 9200820: 14$ & $89200820: 14$ & 1.884 & 20.4 \\
\hline 1747 & $199200820: 16$ & $89200820: 16$ & 1.885 & 20.4 \\
\hline 1748 & $1 / 9 / 200820: 18$ & $89200820: 18$ & 1.885 & 20.4 \\
\hline 1749 & 1/9/200820:20 & $89200820: 20$ & 1.884 & 20.4 \\
\hline 1750 & $1 / 9 / 200820: 22$ & 899200820.22 & 1.883 & 20.4 \\
\hline 1751 & $1 / 9 / 200820: 24$ & 89200820.24 & 1.883 & 20.4 \\
\hline 1752 & $1 / 9200820.26$ & 899200820.26 & 1.894 & 20.5 \\
\hline 1753 & $1 / 9200820.28$ & 89200820.28 & 1.88 & 20.6 \\
\hline 1754 & $1 / 9200820.30$ & 89200820.30 & 1.883 & 20.6 \\
\hline 1755 & $1 / 91200820.32$ & 89200820.32 & 1.884 & 20.6 \\
\hline 1756 & $1 / 9200820.34$ & 89200820.34 & 1.884 & 20.6 \\
\hline 1757 & $1 / 9200820.36$ & $89 / 200820: 36$ & 1.885 & 20.5 \\
\hline 1758 & $1 / 9200820.38$ & $89200820: 38$ & 1.885 & 20.5 \\
\hline 1759 & $1 / 9200820$ & $899200820: 40$ & 1.886 & 20.5 \\
\hline 1760 & $1 / 9 / 200820.42$ & $892000820: 42$ & 1.886 & 20.5 \\
\hline 1761 & $1 / 9 / 200820: 44$ & $89200820: 44$ & 1.886 & 20.6 \\
\hline $17 \sqrt[2]{2}$ & $1 / 9200820446$ & 89200820.46 & 1.886 & 20.6 \\
\hline 1763 & $1 / 9 / 200820.48$ & $89 / 200820: 48$ & 1.87 & 20.6 \\
\hline 1764 & $1 / 9200820.50$ & 89200820.50 & 1.853 & 20.6 \\
\hline 1765 & $1 / 9200820: 52$ & 89200820.52 & 1.831 & 20.7 \\
\hline 1766 & $1,9200820.54$ & 89200820.54 & 1.819 & 20.7 \\
\hline 1767. & $1 / 9200820.56$ & 89200820.56 & 1.806 & 20.8 \\
\hline 1768 & $1 / 9200820.58$ & $89200820: 58$ & \begin{tabular}{|l|l|}
3 & 1.7966 \\
\end{tabular} & 20.8 \\
\hline
\end{tabular}

\begin{tabular}{|c|c|c|c|c|}
\hline \multicolumn{5}{|c|}{ D4924 } \\
\hline$R A C$ & & Adusted & Pressure & Tem \\
\hline$\#$ & DeteTime & Dete/Time & psi & ${ }^{\circ} \mathrm{C}$ \\
\hline 1769 & $1 / 9 / 200821: 00$ & $899200821: 00$ & 1.788 & 20. \\
\hline 1770 & 1/9/200821:02 & $89200821: 02$ & 1.781 & $\overline{20}$ \\
\hline 1771 & $1 / 9 / 200821: 04$ & $89 / 200821: 04$ & $1.7 \pi$ & 20. \\
\hline $17 \pi 2$ & $1 / 9 / 200821: 06$ & $89 / 200821: 06$ & 1.774 & $x^{2}$ \\
\hline 1773 & $1 / 9200821: 08$ & $89 / 200821: 08$ & 1.799 & 20 \\
\hline 1774 & $1 / 9200821: 10$ & $89 / 200821: 10$ & 1.824 & 20. \\
\hline 1775 & 1/9200821:12 & $89 / 200821: 12$ & 1.835 & 20. \\
\hline 1776 & $1 / 9200821: 14$ & $89 / 200821: 14$ & 1.842 & 20. \\
\hline $17 \pi$ & 1/9200821:16 & $89 / 200821: 16$ & 1.847 & 20. \\
\hline 1778 & $1 / 92000821: 18$ & $89200821: 18$ & 1.85 & 20 . \\
\hline 1779 & 1/92000821:20 & $89: 200821: 20$ & 1.853 & 20. \\
\hline 1780 & 1/9200821:22 & $89 / 200821: 22$ & 1.856 & 20 \\
\hline 1781 & 1/9200821:24 & $89 / 200821: 24$ & 1.85 & 20. \\
\hline 1782 & 1/9200821:26 & $89 / 200821: 26$ & 1.858 & 20. \\
\hline 1783 & $1 / 9200821: 28$ & $89200821: 28$ & 1.859 & 20 \\
\hline 1784 & $1 / 9 / 200821: 30$ & $8 / 9200021: 30$ & 1.86 & 20 . \\
\hline 1785 & 1/9200821:32 & $89 / 200821: 32$ & 1.862 & 20. \\
\hline 1786 & $1 / 9 / 200821: 34$ & $89 / 200821: 34$ & 1.86 & \\
\hline 1787 & 19/2008 21:36 & $892000821: 36$ & 1.863 & 20 . \\
\hline 1788 & 1/9/200821:38 & $8 / 9200821: 38$ & 1.864 & 20. \\
\hline 1789 & $1 / 9 / 200$ & $8 / 9 / 200821: 40$ & 1.865 & 20. \\
\hline 1790 & $1 / 9 / 200821: 42$ & $89200821: 42$ & 1.866 & 20 \\
\hline 1791 & $1 / 9200821: 44$ & $89 / 200821: 44$ & 1.867 & 20. \\
\hline 1792 & $1 / 9 / 20$ & $89 / 200821: 46$ & 1.867 & 20. \\
\hline 1793 & $1 / 9200821: 48$ & $89 / 200821: 48$ & 1.868 & 20 \\
\hline 1794 & $1 / 9 / 20$ & $89 / 200821: 50$ & 1.87 & 20. \\
\hline 1795 & $1 / 9 / 20$ & $8 / 9 / 200821: 52$ & 1.871 & 20 \\
\hline 1796 & $1 / 9200821: 54$ & $89 / 200821: 54$ & 1.872 & 20 \\
\hline 1797 & $1 / 9 / 200821: 56$ & $89 / 200821: 56$ & 1.873 & 20. \\
\hline 1798 & $1 / 9 / 20$ & $821: 58$ & 1.874 & 20. \\
\hline 1799 & $1 / 9200$ & $89 / 20082200$ & 1.874 & 20 \\
\hline 1800 & $1 / 9 / 200822002$ & $89 / 20082202$ & 1.875 & 20 \\
\hline 1801 & $1 / 9 / 20$ & $89 / 200822204$ & 1.876 & 20. \\
\hline 1802 & $1 / 9 / 20$ & $89 / 20082206$ & 1.876 & 20 \\
\hline 1803 & $1 / 9200$ & $89 / 20082208$ & 1.876 & 20 \\
\hline 1804 & & 8920082210 & 1.87 & 20 \\
\hline 1805 & 212 & 82212 & 1.878 & 20 \\
\hline 1806 & $1 / 920082214$ & $89 / 20082214$ & 1.877 & 20 \\
\hline 1807| & & 8920082216 & 1.876 & 20 \\
\hline 1808 & 218 & 8920 & 1.877 & 20 \\
\hline 1809 & $1 / 9 / 20$ & $8 / 920082220$ & 1.878 & 20 \\
\hline 1810 & 222 & $89 / 20082222$ & 1.879 & 20 \\
\hline 1811 & 224 & 32224 & 1.879 & 20 \\
\hline 1812 & 2226 & $89 / 20082226$ & 1.88 & 20 \\
\hline 1813 & 228 & $89 / 20082228$ & 1.88 & 20 \\
\hline 1814 & & 32230 & 1.879 & 20 \\
\hline 1815 & 232 & 82232 & 1.88 & 20 \\
\hline 1816 & $1 / 9 / 20$ & 32234 & 1.88 & 20 \\
\hline 1817 & & 32236 & 1.88 & 20 \\
\hline 1818 & 238 & 82238 & 1.88 & 20 \\
\hline 1819 & 240 & 82240 & 1.881 & 20 \\
\hline 1820 & & & 1.88 & \\
\hline 4821 & 244 & 82244 & 1.88 & 20 \\
\hline 1822 & $1 / 9 / 200$ & 89200082246 & 1.879 & 20 \\
\hline 1823 & & 9920082248 & 1.881 & 20 \\
\hline 1824 & 250 & 82250 & 1.881 & \\
\hline 1825 & $1 / 920082252$ & $89 / 20082252$ & 1.882 & 20 \\
\hline 1826 & 2254 & 4920082254 & 1.881 & \\
\hline 1827 & & $9 / 20082256$ & 1.881 & \\
\hline 1828 & $1 / 9200$ & 89200082258 & 1.881 & 20 \\
\hline 1829 & 23500 & 9920082300 & 1.881 & 20 \\
\hline 1830 & & 8920082302 & 1.881 & \\
\hline 1831 & $1 / 920$ & $892000823: 04$ & 1.881 & 20 \\
\hline 1832 & $1 / 920082306$ & 9920082306 & 1.882 & 20 \\
\hline 1833 & 2508 & 9200023.08 & 1.882 & 20 \\
\hline 1834 & $1 / 9 / 200$ & 920082310 & 1.882 & \\
\hline 1835 & $1 / 9 / 200$ & $89200823: 12$ & 1.882 & 20 \\
\hline 1836 & $1 / 9 / 20082314$ & $89 / 200823: 14$ & 1.883 & \\
\hline
\end{tabular}




\begin{tabular}{|c|c|c|c|c|}
\hline \multicolumn{5}{|c|}{ D492p } \\
\hline $\operatorname{Rec}$ & & Adjusted & Pressurs & Temp \\
\hline$\#$ & DeterTime & DateTime & psi & ${ }^{\circ} \mathrm{C}$ \\
\hline 1837 & $1 / 9 / 200823: 16$ & $8 / 9200823: 16$ & 1.883 & 20.9 \\
\hline 1838 & $1 / 9200823: 18$ & $8 / 9200823: 18$ & 1.884 & 20.9 \\
\hline 1839 & 1/9/200823:20 & $8 / 9 / 200823: 20$ & 1.633 & 20.9 \\
\hline 1840 & $1 / 9200823-22$ & $8 / 9 / 200823: 22$ & 1.856 & 20.6 \\
\hline 1841 & $1 / 9200823: 24$ & $8 / 9 / 200823: 24$ & 1.869 & 20.4 \\
\hline 1842 & 1/9200823:26 & $89 / 200823: 26$ & 1.879 & 20.4 \\
\hline 1843 & 1/9200823:28 & $8 / 9 / 200823: 28$ & 1.82 & 20.4 \\
\hline 1844 & 1/9200823:30 & $8 / 9 / 200823: 30$ & 1.888 & 20.6 \\
\hline 1845 & 1/9200823:32 & $899200823: 32$ & 1.885 & 20.8 \\
\hline 1846 & 1/9200823:34 & $8 / 9 / 200823: 34$ & 1.885 & 20.8 \\
\hline 1847 & 1/9/200823:36 & $89200823: 36$ & 1.887 & 20.8 \\
\hline 1848 & 1/9200823:38 & $89 / 200823: 38$ & 1.886 & 20.8 \\
\hline 1849 & $1 / 9 / 200823: 40$ & $8 / 9 / 200823: 40$ & 1.884 & 20.8 \\
\hline 1850 & $1 / 9200823: 42$ & $8 / 9 / 200823: 42$ & 1.882 & 20.8 \\
\hline 1851 & $1 / 9200823: 44$ & $8 / 9 / 200823: 44$ & 1.882 & 20.8 \\
\hline 1852 & $1 / 9 / 200823: 46$ & $8 / 9 / 200823: 46$ & 1.883 & 20.9 \\
\hline 1853 & $1 / 9200823: 48$ & $8 / 9 / 200823: 48$ & 1.884 & 20.9 \\
\hline 1854 & $1 / 9 / 200823: 50$ & $8 / 9 / 200823: 50$ & 1.885 & 20.9 \\
\hline 1855 & $1 / 9 / 200823: 52$ & $8 / 9 / 200823: 52$ & 1.863 & 20.9 \\
\hline 1856 & $1 / 9 / 200823: 54$ & $8 / 9 / 200823: 54$ & 1.838 & 20.9 \\
\hline 1857 & $1 / 9200823: 56$ & $8 / 9 / 200823: 56$ & 1.818 & 21 \\
\hline 1858 & $1 / 9 / 200823: 58$ & $8 / 9200823: 58$ & 1.812 & 21 \\
\hline 1859 & $1 / 10 / 20080: 00$ & $8 / 1020080: 00$ & 1.798 & 21 \\
\hline 1860 & $1 / 1020080: 02$ & $8 / 1 \alpha 20080: 02$ & 1.79 & 21.1 \\
\hline 1861 & $1 / 10 / 20080: 04$ & $8 / 10 / 20080: 04$ & 1.784 & 21.1 \\
\hline 1862 & 1/10/20080:06 & $8 / 1020080: 06$ & 1.778 & 21.1 \\
\hline 1863 & $1 / 10 / 20080: 08$ & $8 / 10 / 20080: 08$ & 1.774 & 21.1 \\
\hline 1864 & 1/10200080:10 & $8 / 1020080: 10$ & 1.77 & 21.1 \\
\hline 1865 & 1/1020080:12 & $8 / 10 / 20080: 12$ & 1.796 & 21.1 \\
\hline 1866 & $1 / 1020000: 14$ & $8 / 1020080.14$ & 1.82 & 21.1 \\
\hline 1867 & $1 / 1020000: 16$ & $8 / 10 / 20080: 16$ & 1.835 & 21.1 \\
\hline 1868 & $1 / 10 / 20080: 18$ & $8 / 10 / 20080: 18$ & 1.842 & 21.1 \\
\hline 1869 & $1 / 10 / 20080: 20$ & $8 / 10 / 20080: 20$ & 1.848 & 21.1 \\
\hline 1870 & $1 / 10 / 20080: 22$ & $8 / 10 / 20080: 22$ & 1.852 & 21.1 \\
\hline 1871 & $1 / 10 / 20080.24$ & $8 / 10 / 20080: 24$ & 1.854 & 21.1 \\
\hline 1872 & $1 / 1020000: 26$ & $8 / 10 / 20080: 26$ & 1,85 & 21.1 \\
\hline 1873 & $1 / 1020080.28$ & $8 / 1020080: 28$ & 1.858 & 21.1 \\
\hline 1874 & $1 / 1020080: 30$ & $8 / 1020080: 30$ & 1.86 & 21.1 \\
\hline 1875 & $1 / 10 / 20$ & $8 / 1020080.32$ & 1.862 & 21.1 \\
\hline 1876 & $1 / 1020000: 34$ & $8 / 1020080: 34$ & 1.864 & 21.1 \\
\hline 1877 & $1 / 10200080: 36$ & $8 / 1020080: 36$ & 1.866 & 21.1 \\
\hline 1878 & $1 / 10 / 20$ & $8 / 10 / 20080.38$ & 1.867 & 21.1 \\
\hline 1879 & $1 / 10 / 20080: 40$ & $8 / 1020080: 40$ & 1.868 & 21.1 \\
\hline 1880 & $1 / 10 / 20080: 42$ & $8 / 1020080: 42$ & 1.869 & 21.1 \\
\hline 1881 & $1 / 10 / 20$ & $8 / 10 / 20080: 44$ & 1.87 & 21.1 \\
\hline 1882 & $1 / 10 / 20080: 46$ & $8 / 10 / 20080: 46$ & 1.871 & 21.1 \\
\hline 1883 & $1 / 10 / 20080: 48$ & $8 / 10 / 20080: 48$ & 1.872 & 21.1 \\
\hline 1884 & $1 / 10 / 20080.50$ & $8 / 1 \alpha 20080: 50$ & 1.872 & 21.1 \\
\hline 1885 & $1 / 10 / 20000: 52$ & $8 / 1020080: 52$ & 1.874 & 21.1 \\
\hline 1886 & $1 / 10 / 20080: 54$ & $8 / 10 / 20080: 54$ & 1.875 & 21.1 \\
\hline 1887| & $1 / 10 / 20080.56$ & $8 / 1020080: 56$ & 1.876 & 21.2 \\
\hline 1888 & $1 / 10 / 20000: 58$ & $8 / 1020080: 58$ & 1.877 & 21.2 \\
\hline 1889 & 1/10/2008 1:00 & $8 / 102008$ 1:00 & 1.878 & 21.2 \\
\hline 1890 & 1/10/2008 1:02 & $8 / 1020081: 02$ & 1.878 & 21.3 \\
\hline 1891 & 1/10/2008 1:04 & $8 / 1020081: 04$ & 1.879 & 21.3 \\
\hline 1892 & 1/102008 1:06 & $8 / 1020081: 06$ & 1.88 & 21.3 \\
\hline 1893 & 1/10/2008 1:08 & $8 / 1020081: 08$ & 1.88 & 21.3 \\
\hline 1894 & 1/10/20081:10 & $8 / 1020081: 10$ & 1.88 & 21.3 \\
\hline 1895 & 1/10/2008 1:12 & $8 / 1020081: 12$ & 1.881 & 21.3 \\
\hline 1896 & 1/10/2008 1:14 & $8 / 1020081: 14$ & 1.882 & 21,3 \\
\hline 1897 & 1/10/2008 1:16 & $811020081: 16$ & 1.882 & 21.3 \\
\hline 1898 & $1 / 1020081: 18$ & $8 / 1020081: 18$ & 1.883 & 21.3 \\
\hline 1890 & 1/10/2008 1:20 & $8 / 1020081: 20$ & 1.883 & 21.4 \\
\hline 1900 & 1/102008 1:22 & $8 / 1020081: 22$ & 1.883 & 21.4 \\
\hline 1901 & 1/10/2008 1:24 & $8 / 10 / 20081: 24$ & 1.883 & 21.4 \\
\hline 1902 & 1/10/2008 1:26 & 8/1020081:26 & 1.884 & 21.4 \\
\hline 1903 & 1/10/2008 1:28 & $8 / 1020081: 28$ & 1.885 & 21.4 \\
\hline 1904 & $1 / 10 / 20081: 30$ & $8 / 1 / 20081: 30$ & 1.886 & 21.0 \\
\hline
\end{tabular}

\begin{tabular}{|c|c|c|c|c|}
\hline \multicolumn{5}{|c|}{ D4920 } \\
\hline Rec & & Adjusted & & \\
\hline \# & Dete-Time & DaterTime & $\mathrm{psi}$ & ${ }^{\circ} \mathrm{C}$ \\
\hline 1905 & $1 / 102008$ 1:32 & $8 / 1020081: 32$ & 1.886 & 21.5 \\
\hline 1906 & 1/102008 1:34 & $8 / 1020081: 34$ & 1.886 & \\
\hline 1907 & $1020081: 36$ & $1020081: 36$ & 1.886 & 21 \\
\hline 1908 & $1020081: 38$ & 102008 1:38 & 1.885 & 21.6 \\
\hline 1909 & $1020081: 40$ & $8 / 1020081: 40$ & 1.886 & \\
\hline 1910 & $1020081: 42$ & $8 / 10 / 20081: 42$ & 1.887 & \\
\hline 1911 & 1/102008 1:44 & $8 / 1020081: 44$ & 1.888 & 21. \\
\hline 1912 & $0200081: 46$ & $8 / 10 / 20081: 46$ & 1.888 & $\angle 1.6$ \\
\hline 1913 & $0 / 20081: 48$ & $8 / 1020081: 48$ & 1.888 & \\
\hline 1914 & $1 / 1020081: 50$ & $8 / 10200081: 50$ & 1.889 & 21. \\
\hline 1915 & 102008 1:52 & $8 / 1020081: 52$ & 1.889 & 21.6 \\
\hline 1916 & $81: 54$ & $8 / 1020081: 54$ & 1.89 & \\
\hline 1917 & $0001: 56$ & $8 / 1020081: 56$ & 1.89 & 21. \\
\hline 1918 & $1020001: 58$ & $8 / 1020081: 58$ & 1.891 & 21.6 \\
\hline 1919 & 8200 & $8 / 1020082: 00$ & 1.891 & 21.6 \\
\hline 1920 & & $811020082: 02$ & 1.89 & \\
\hline 1921 & 8204 & $8 / 10200082: 04$ & 1.89 & 21.6 \\
\hline 1922 & & $8 / 10 / 20082: 06$ & 1.89 & 21.6 \\
\hline 1923 & & $8 / 102008208$ & 1.889 & \\
\hline 1924 & 8210 & $8 / 1020082: 10$ & 1.89 & 21.6 \\
\hline 1925 & & $8 / 102008212$ & 1.89 & 21.6 \\
\hline 1926 & & $8 / 10 / 20$ & 1.891 & \\
\hline 1927. & 216 & $8 / 10 / 200$ & 1.891 & 21. \\
\hline 1928 & & $8 / 10 / 20$ & 1.89 & 21. \\
\hline 1929 & & $8 / 10 / 2$ & 1.891 & 21. \\
\hline 1930 & & $8 / 102$ & 1.891 & 21. \\
\hline 1931 & & $32: 24$ & 1.89 & 21. \\
\hline 1932 & & $8 / 102$ & 1.889 & 21. \\
\hline 1933 & & $8 / 10 / 20082: 28$ & 1.89 & 21. \\
\hline 1934 & & & 1.889 & 21.6 \\
\hline 1935 & & & 1.888 & 21. \\
\hline 1936 & & $8 / 10 / 200$ & 1.888 & 22 \\
\hline 1937 & & $8 / 102008236$ & 1.891 & 21. \\
\hline 1938 & & 2.38 & 1.891 & 21. \\
\hline 1939 & & $10 / 2008240$ & 1.892 & \\
\hline 1940 & & $8 / 10 / 20082: 42$ & 1.891 & 21. \\
\hline 1941 & & $2: 44$ & 1.891 & 21. \\
\hline 1942 & & & 1.892 & 21. \\
\hline 1943 & & $8 / 10 / 2008248$ & 1.89 & 21. \\
\hline 1944 & & & 1.864 & 21. \\
\hline 1945 & & & 1.839 & 21. \\
\hline 1946 & & $8 / 1020082: 54$ & 1.821 & 21. \\
\hline 1947 & & & 1.81 & 21. \\
\hline 1948 & & & 1.8 & 21 \\
\hline 1949 & & $8 / 1020083: 00$ & 1.794 & 21. \\
\hline 1950 & & & 1.6 & 21. \\
\hline 1951 & & $33: 04$ & 1.776 & \\
\hline 1952 & & $8 / 1020083: 06$ & 1.815 & 21. \\
\hline 1953 & & & 1.836 & 21. \\
\hline 1954 & & & 1.847 & \\
\hline 1955 & & & 1.854 & 21. \\
\hline 1956 & & & 1.858 & \\
\hline 1957 & & 16 & 1.862 & \\
\hline 1958 & & $3: 18$ & 1.865 & 21 \\
\hline 1959 & & & 1.867 & \\
\hline 1960 & & & 1.866 & \\
\hline 1961 & & $8 / 1020083: 24$ & 1.868 & 21. \\
\hline 1962 & & & 1.869 & 21. \\
\hline & & & & \\
\hline 1964 & & $1020083: 30$ & 1.874 & 21. \\
\hline 1965 & & & 1.876 & 21. \\
\hline & & & & \\
\hline 1967 & & $8 / 1020083: 36$ & 1.878 & 21. \\
\hline 1968 & & $8 / 1020083: 38$ & 1.878 & \\
\hline & & & & \\
\hline 1970 & & $8 / 1020003: 42$ & 1.879 & \\
\hline 1971 & & $8 / 1020083: 44$ & 1.881 & \\
\hline & & & & \\
\hline
\end{tabular}

\begin{tabular}{|c|c|c|c|c|}
\hline \\
\hline $\operatorname{Rec}$ & & Agusted & Fessurt & Temp \\
\hline$\#$ & Dete/Time & DaterTime & psi & \\
\hline 1973 & 1/1020083:48 & $8 / 10 / 20083-48$ & 1.882 & 21.4 \\
\hline 1974 & $1020083: 50$ & $8 / 10 / 20083: 50$ & 1.882 & 21.4 \\
\hline 1975 & 10200083.52 & $8 / 10 / 20083: 52$ & & \\
\hline 1976 & $1 / 1020083: 54$ & $8 / 10220083554$ & 1.884 & 21. \\
\hline 1977 & $1 / 1020083: 56$ & $8110 / 2008356$ & 1.885 & 21.4 \\
\hline 1978 & $10200083: 58$ & $8 / 102008355$ & 1.885 & 21.5 \\
\hline 1979 & $1 / 1020084: 00$ & 8/102008 4:00 & 1.886 & 21. \\
\hline 1980 & 1/102008 4:02 & $8 / 10 / 20084: 02$ & 1.886 & 21. \\
\hline 1981 & $10200084: 04$ & $811020084: 04$ & 1.887 & 21. \\
\hline 1982 & $1020084: 06$ & $8 / 10 / 20084: 06$ & 1.887 & 21. \\
\hline 1983 & $10200084: 08$ & $811020084: 08$ & 1.887 & 21. \\
\hline 1984 & 10/20084:10 & 8/10/20084:10 & 1.888 & 21. \\
\hline 1985 & $1020084: 12$ & $8 / 10 / 20084: 12$ & & 21. \\
\hline 1986 & $1 / 1020084: 14$ & $8 / 10 / 20084: 14$ & 1.888 & 21.5 \\
\hline 1987 & $1 / 1020084: 16$ & $8 / 10 / 20084: 16$ & 1.880 & 21. \\
\hline 1988 & $1 / 10 / 20084: 18$ & $8 / 1020084: 18$ & 1.80 & \\
\hline 1969 & $1 / 10 / 20084: 20$ & $8 / 10 / 20084: 20$ & 1.891 & 21. \\
\hline 1990 & 10:20084:22 & $8 / 10 / 20084: 22$ & 1.892 & 21. \\
\hline 1991 & 34:24 & $8 / 10 / 20084: 24$ & 1.893 & 21.5 \\
\hline 1992 & 34:26 & $8 / 1020084: 26$ & 1.893 & 21.8 \\
\hline 1993 & $1 / 1020084: 28$ & $8 / 10 / 20084: 28$ & 1.894 & 21. \\
\hline 1994 & 34:30 & & 1.894 & 21. \\
\hline 1995 & & $8 / 10$ & 1.894 & \\
\hline 1996 & $10 / 20084: 34$ & $084: 34$ & 1.894 & 21. \\
\hline 1997 & $4: 36$ & & 1.895 & 21. \\
\hline 1998 & & $8 / 10$ & 1.896 & \\
\hline 1999 & $34: 40$ & $8 / 10$ & 1.896 & 21. \\
\hline 2000 & 4:42 & & 1.898 & 21. \\
\hline 2001 & $4: 44$ & & 1.899 & 21. \\
\hline 2002 & 84:46 & $8 / 10$ & 1.899 & 21. \\
\hline 2003 & & & 1.899 & 21. \\
\hline 2004 & & & 1.9 & 21. \\
\hline 2005 & 44:52 & $8 / 10$ & 1.9 & 21. \\
\hline 2006 & & & 1.899 & 21. \\
\hline 2007 & & & 1.898 & 21.7 \\
\hline 2008 & $10 / 20084: 58$ & $8 / 10$ & 1.898 & 21. \\
\hline 2009 & & & 1.898 & 21. \\
\hline 2010 & & & 1.898 & 21.7 \\
\hline 2011 & & & 1.898 & 21.7 \\
\hline 2012 & & & 1.899 & 21. \\
\hline 2013 & & & 1.899 & 21. \\
\hline 2014 & & & 1.899 & 21. \\
\hline 2015 & & $5: 12$ & 1.9 & 21. \\
\hline 2016 & & & 1.901 & 21. \\
\hline 2017 & & & 1.901 & 21, \\
\hline 2018 & & & 1.902 & 21. \\
\hline 2019 & & & 1.902 & 21.7 \\
\hline 2020 & & & 1.902 & 21.7 \\
\hline 2021 & & & 1.902 & \\
\hline 2022 & & & 1.902 & 21.7 \\
\hline 2023 & & & 1.902 & \\
\hline 2024 & & & 1.903 & 21.8 \\
\hline 2025 & & & 1.903 & 21.8 \\
\hline 2026 & & & 1.903 & \\
\hline 2027 & & & 1.903 & \\
\hline 2028 & & & 1.903 & $\overline{218}+>$ \\
\hline 2029 & $35: 40$ & & 1.903 & \\
\hline 2030 & & & 1.904 & \\
\hline 2031 & & & 1.904 & \\
\hline 2032 & 85:46 & & 1.903 & \\
\hline 2033 & $35: 48$ & $5: 48$ & 1.885 & 21.8 \\
\hline 2034 & & & 1.852 & \\
\hline 2035 & & & 1.834 & \\
\hline 2036 & $85: 54$ & $885: 54$ & 1.821 & 21. \\
\hline 2037 & & & 1.811 & \\
\hline$m$ nी & & & - & \\
\hline 339 & 6600 & 600 & 1.797 & \\
\hline & $1 / 14<600.04$ & 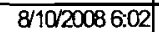 & 1.791 & \\
\hline
\end{tabular}


DOE/RL-2009-35, REV. 0

\begin{tabular}{|c|c|c|c|c|}
\hline \multicolumn{5}{|c|}{$D 4924$} \\
\hline Rec & & Adusted & Pressure & Ternp \\
\hline \# & DeterTime & DateTime & psi & ${ }^{\circ} \mathrm{C}$ \\
\hline 2041 & $1 / 1020086: 04$ & $8 / 10 / 20086: 04$ & 1.787 & 21.7 \\
\hline 2042 & $1 / 10200086: 06$ & $8 / 10 / 20086: 06$ & 1.79 & 21.7 \\
\hline 2043 & $1 / 1020086: 08$ & $8 / 1020086: 08$ & 1.65 & 21.7 \\
\hline 2044 & $10 / 20086: 10$ & $8 / 10 / 20086: 10$ & 1.916 & 21.7 \\
\hline 2045 & $1 / 1020086: 12$ & $8 / 10 / 20086: 12$ & 1.846 & 21.5 \\
\hline 2046 & $1 / 1020086: 14$ & $8 / 10 / 20086: 14$ & 1.855 & 21.4 \\
\hline 2047 & $10 / 20086: 16$ & $8 / 10 / 20086: 16$ & 1.861 & \\
\hline 2048 & 1/10/20086:18 & 8/10/20086:18 & 1.864 & 21.4 \\
\hline 2049 & $1 / 10 / 20086: 20$ & $8 / 1020086: 20$ & 1.868 & 21.4 \\
\hline 2050 & $1020086: 22$ & $8 / 10 / 20086: 22$ & 1.87 & 21.7 \\
\hline 2051 & & $8 / 1020086: 24$ & 1.873 & 21.9 \\
\hline 2052 & $1 / 10 / 20086: 26$ & $8 / 1020086: 26$ & 1.875 & 21.7 \\
\hline 2053 & 102008628 & $8 / 10220086: 28$ & 1.87 & 21.6 \\
\hline 2054 & $1020086: 30$ & $8 / 1020086: 30$ & 1.87 & \\
\hline 2050 & $1020086: 32$ & $8 / 10 / 20086: 32$ & 1.879 & 21.7 \\
\hline 2056 & $10 r 20086: 34$ & $8 / 10 / 20086: 34$ & 1.881 & 21.7 \\
\hline 2057 & 6.36 & $8 / 10 / 20086: 36$ & 1.883 & 21.7 \\
\hline 2058 & & $8 / 10200$ & 1.884 & \\
\hline 2069 & $1020086: 40$ & $8 / 1020086: 40$ & 1.884 & 21.7 \\
\hline 2060 & 36.42 & $8 / 1020$ & 1.885 & 21.7 \\
\hline 2061 & & $8 / 1020$ & 1.885 & \\
\hline 2002 & $6: 46$ & $8 / 1020$ & 1.882 & 21.7 \\
\hline 2063 & & $8 / 10 / 20086: 48$ & 1.885 & 21.7 \\
\hline 2064 & & $8 / 10 / 20$ & 1.887 & \\
\hline 2065 & 66:52 & $8 / 1020$ & 1.888 & 21.7 \\
\hline 2066 & & $8 / 10 / 20$ & 1.889 & 21.8 \\
\hline 2067 & & $8 / 102$ & 1.889 & 21.7 \\
\hline 2068 & $1020086: 58$ & $8 / 10 / 20086: 58$ & 1.89 & 21. \\
\hline 2069 & $10200087: 00$ & $8 / 10 / 20087: 00$ & 1.89 & 21.8 \\
\hline 2070 & & $8 / 102$ & 1.891 & 21. \\
\hline 2071 & & $8 / 102$ & 1.892 & \\
\hline 2072 & $10 / 20087: 06$ & $8 / 1020087: 06$ & 1.892 & 21 \\
\hline 2073 & & $8 / 102$ & 1.892 & 21.7 \\
\hline 2074 & & $7: 10$ & 1.892 & 21. \\
\hline 2075 & $7: 12$ & 811020 & 1.892 & \\
\hline 2076 & & $8 / 10 / 2$ & 1.892 & 21.8 \\
\hline 207 & & $7: 16$ & 1.725 & 21.8 \\
\hline 2078 & $7: 18$ & $8 / 1020$ & 1.734 & 21. \\
\hline 2079 & & & 1.687 & 21. \\
\hline 2080 & & $7: 22$ & 1.894 & 21. \\
\hline 2081 & & $87: 24$ & 1.896 & 21.4 \\
\hline 2082 & & $8 / 1020$ & 1.897 & 21. \\
\hline 2083 & & $7: 28$ & 1.898 & 21. \\
\hline 2084 & & $7: 30$ & 1.899 & 21. \\
\hline 2085 & & $8 / 102$ & 1.9 & 21. \\
\hline 2086 & & $7: 34$ & 1.9 & 21. \\
\hline 2087 & & $7: 36$ & 1.9 & 21. \\
\hline 2088 & & $8 / 102$ & 1.901 & 21. \\
\hline 2089 & & & 1.9 & 21. \\
\hline 2090 & & $7: 42$ & 1.9 & 21. \\
\hline 2091 & & $77: 44$ & 1.9 & 21. \\
\hline 2092 & & & 1.899 & 21. \\
\hline 2093 & & $77: 48$ & 1.741 & 21. \\
\hline 2094 & & $87: 50$ & 1.903 & 21. \\
\hline 2005 & & & 1.9 & $\overline{21}$. \\
\hline 2096 & & & 1.9 & 21 \\
\hline 2097 & & $8 / 10 / 20087: 56$ & 1.9 & 21.7 \\
\hline 2008 & & & 1.901 & 21.8 \\
\hline 2009 & & & 1.902 & \\
\hline 2100 & & $8 / 1020088: 02$ & 1.902 & 21 . \\
\hline 2101 & & $8 / 1020$ & 1.903 & 21. \\
\hline 2102 & & & 1.903 & 21. \\
\hline 2103 & & $8 / 10 / 20088.08$ & 1.904 & 21.5 \\
\hline 2104 & & 88.10 & 1.904 & 21.9 \\
\hline 105 & & 88:12 & 1.904 & 21.9 \\
\hline 2106 & & $8 / 1020$ & 1.904 & \\
\hline 2107 & $8: 16$ & $8 / 10 / 20088: 16$ & 1.904 & 21 \\
\hline 2108 & 88:18 & $8 / 10 / 20088: 18$ & 1.905 & \\
\hline
\end{tabular}

\begin{tabular}{|c|c|c|c|c|}
\hline \multicolumn{5}{|c|}{ D4920 } \\
\hline $\operatorname{Rec}$ & & Adusted & Pressure & Temp \\
\hline$\#$ & Dete/Time & DeterTime & \begin{tabular}{|l|}
$p s i$ \\
\end{tabular} & ${ }^{\circ} \mathrm{C}$ \\
\hline 2109 & $1 / 10 / 20088: 20$ & $8 / 10 / 20088: 20$ & 1.906 & 21.9 \\
\hline 2110 & $1 / 1020088.22$ & $8 / 10 / 20088: 22$ & 1.905 & 22 \\
\hline 2111 & $1 / 1020088: 24$ & $8 / 10220088: 24$ & 1.905 & 22 \\
\hline 2112 & 1/102008 8:26 & $8 / 10200088: 26$ & 1.905 & 22 \\
\hline 2113 & $1 / 1020088: 28$ & $8 / 1020088: 28$ & 1.905 & 22 \\
\hline 2114 & $1 / 1020008: 30$ & $8 / 10 / 20088: 30$ & 1.906 & 221 \\
\hline 2115 & $1 / 10 / 20088: 32$ & $8 / 1020008: 32$ & 1.907 & 22.1 \\
\hline 2116 & $1 / 10 / 20088: 34$ & $8 / 10220088: 34$ & 1.907 & 22.1 \\
\hline 2117 & $1 / 1020088.36$ & $8 / 1020088: 36$ & 1.908 & 221 \\
\hline 2118 & 1/10/20088:38 & $8 / 10200088: 38$ & 1.908 & 22.1 \\
\hline 2119 & $1 / 102008840$ & $8 / 10220088: 40$ & 1.908 & 221 \\
\hline 2120 & $1 / 10 / 20088.42$ & $8 / 1020088: 42$ & 1.908 & 221 \\
\hline 2121 & $1 / 1020088: 44$ & $8 / 1020088: 44$ & 1.908 & 22.1 \\
\hline 2122 & $1 / 10 / 20088446$ & $8 / 10 / 20088: 46$ & 1.909 & 222 \\
\hline 2123 & $1 / 1020088: 48$ & $8 / 1020088448$ & 1.91 & 222 \\
\hline 2124 & $1 / 10 / 20088.50$ & $8 / 102008850$ & 1.877 & 221 \\
\hline 2125 & 1/10/2008 8:52 & $8 / 1020088: 52$ & 1.852 & 22 \\
\hline 2126 & 1/10/20088:54 & $8 / 1020088: 54$ & 1.845 & 21.9 \\
\hline 2127 & $1 / 1020088.56$ & $8 / 1020088: 56$ & 1,826 & 21.9 \\
\hline 2128 & $1 / 1020088: 58$ & $8 / 1020088.58$ & 1.815 & 21.9 \\
\hline 2129 & $1 / 1020089.00$ & $8 / 1020089.00$ & 1.807 & 21.9 \\
\hline 2130 & 1/10/20089:02 & $8 / 1020089.02$ & 1.801 & 21.9 \\
\hline 2131 & $1 / 10 / 20089.04$ & $8 / 1020089.04$ & 1.795 & 21.9 \\
\hline 2132 & $1 / 1020089.06$ & 8110220089.06 & 1.813 & 21.9 \\
\hline 2133 & 1/10/20089:08 & $8 / 10220089.08$ & 1.849 & 21.9 \\
\hline 2134 & $1 / 10 / 20089.10$ & $8 / 1020089.10$ & 1.863 & 21.9 \\
\hline 213 - & $1 / 1020089.12$ & $8 / 1020089.12$ & 1.871 & 21.9 \\
\hline 2136 & 1/1020089:14 & $8 / 1020089.14$ & 1.87 & 22 \\
\hline 2137 & 1/1020089-16 & $8 / 1020089.16$ & 1.88 & 22 \\
\hline 2138 & 1/10/20089.18 & $8 / 1020089.18$ & 1.883 & 22 \\
\hline 2139 & $1 / 10720089: 20$ & 811020089.20 & 1.885 & 22 \\
\hline 2140 & $1 / 1020089-22$ & $8 / 10200089.22$ & 1.889 & 21.9 \\
\hline 2141 & $1 / 10 / 20089.24$ & $8 / 1020089.24$ & 1.891 & 22 \\
\hline 2142 & 1/10/20089.26 & $8 / 1020089.26$ & 1.893 & 21.9 \\
\hline 2143 & $1 / 1020089.28$ & $8 / 1020089.28$ & 1.895 & 21.9 \\
\hline 2144 & 1/10/20089:30 & 811020089.30 & 1.896 & 21.9 \\
\hline 2145 & $1 / 1020089.32$ & $8 / 1020089.32$ & 1.897 & 21.9 \\
\hline 2146 & 1/10/20089.34 & $8 / 10120089.34$ & 1.898 & 22 \\
\hline 2147 & 1/10/20089.36 & $8 / 1020089.36$ & 1.9 & 21.9 \\
\hline 2148 & $1 / 1020089.38$ & $8 / 1020009938$ & 1.901 & 22 \\
\hline 2149 & $1 / 10 / 20089.40$ & $8 / 1020089.40$ & 1.902 & 22 \\
\hline 2150 & 1/1020089.42 & $8 / 1020089.42$ & 1.903 & 22 \\
\hline 2151 & 1/10/20089:44 & 811020089.44 & 1.904 & 22 \\
\hline 2152 & $1 / 102008946$ & $8 / 1020089.46$ & 1.905 & 22 \\
\hline 2153 & $1 / 10 / 2008948$ & 811020089.48 & 1.906 & 22 \\
\hline 2154 & $1 / 10 / 2008950$ & 81020089.50 & 1.908 & 22 \\
\hline 2156 & $1 / 10 / 20089.52$ & $8 / 1020089.52$ & 1.909 & 22 \\
\hline 2156 & $1 / 10 / 20089.54$ & $8 / 1020089.54$ & 1.91 & 22 \\
\hline 2157 & $1 / 10 / 20089.56$ & $8 / 1020089.56$ & 1.911 & 221 \\
\hline 2158 & $1 / 10 / 20089.58$ & $8 / 1020089.58$ & 1.911 & 221 \\
\hline 2159 & 1/10/2008 10:00 & $8 / 10200810: 00$ & 1.911 & 221 \\
\hline 2160 & 1/10/2008 10:02 & $8 / 102000810.02$ & 1.911 & 221 \\
\hline 2161 & 1/10/2008 10:04 & $8 / 102000110: 04$ & 1.912 & 22.1 \\
\hline 2162 & 1/10/2008 10:06 & $8 / 10 / 200810.06$ & 1.913 & 22.1 \\
\hline 2163 & 1/10/2008 10:08 & $8 / 10200810.08$ & 1.913 & 222 \\
\hline 2164 & 1/10/2008 10:10 & $8 / 10 / 200810: 10$ & 1.913 & 222 \\
\hline 2165 & 1/102008 10:12 & $8 / 10200810.12$ & 1.914 & 222 \\
\hline 2166 & 1/10/2008 10:14 & $8 / 10 / 200810: 14$ & 1.913 & 222 \\
\hline 2167 & 1/10/2008 10:16 & $8 / 10 / 200810.16$ & 1.913 & 222 \\
\hline 2168 & 1/10/2008 10:18 & $8 / 10 / 200810.18$ & 1.914 & 222 \\
\hline 2169 & 1/10/2008 10:20 & $8 / 10 / 200810: 20$ & 1.914 & 222 \\
\hline 2170 & 1/10/2008 10:22 & $8 / 10 / 200810.22$ & 1.914 & 223 \\
\hline 2171 & 1/10/2008 10:24 & $8 / 10 / 200810.24$ & 1.684 & 223 \\
\hline 2172 & 1/10/2008 10:26 & $8 / 10 / 200810.26$ & 1.909 & 221 \\
\hline 2173 & 1/10/2008 10:28 & $8 / 10 / 200810: 28$ & \begin{tabular}{|l|l|}
3.912 \\
\end{tabular} & \\
\hline 2174 & $1 / 102008$ 10:30 & $8 / 102200810.30$ & 1.915 & 224 \\
\hline 2175 & 1/10/2008 10:32 & $8 / 10200810.32$ & 1.916 & 223 \\
\hline 2176 & 1/10:2008 10:34 & $8 / 10 / 200810.34$ & 1.915 & 223 \\
\hline
\end{tabular}

\begin{tabular}{|c|c|c|c|c|}
\hline \multicolumn{5}{|c|}{ D492p } \\
\hline $\operatorname{Rec}$ & & Adjusted & Pressures & Temp \\
\hline$\#$ & DateTime & Dete/Time & psi & ${ }^{\circ} \mathrm{C}$ \\
\hline 2177 & $1 / 10 / 200810.36$ & $8 / 102000810: 36$ & 1.915 & 223 \\
\hline 2178 & $1 / 10 / 200810: 38$ & $8 / 102008$ 10:38 & 1.915 & 223 \\
\hline 2179 & $1 / 100200810: 40$ & $8 / 10200810: 40$ & 1.916 & $\overline{223}$ \\
\hline 2180 & $1 / 10 / 200810: 42$ & $8 / 10 / 2008$ 10:42 & 1.916 & 223 \\
\hline 2181 & $1 / 10 / 200810: 44$ & $8 / 102008$ 10:44 & 1.917 & 223 \\
\hline 2182 & $1 / 10 / 200810: 46$ & $8 / 10 / 200810: 46$ & 1.917 & $\overline{223}$ \\
\hline 2183 & $1 / 10 / 200810: 48$ & $8 / 10 / 200810: 48$ & 1.917 & 223 \\
\hline 2184 & $1 / 10 / 200810.50$ & $8 / 101200810: 50$ & 1.916 & 223 \\
\hline 2185 & $1 / 10200810: 52$ & $8 / 10 / 2008$ 10:52 & 1.917 & 223 \\
\hline 2186 & $1 / 10 / 200810: 54$ & $8 / 10200810: 54$ & 1.917 & 223 \\
\hline 2187 & $1 / 10200810.56$ & $8 / 102008$ 10:56 & 1.918 & 223 \\
\hline 2188 & $1 / 40 / 200810: 58$ & $8 / 102000110.58$ & 1.918 & 223 \\
\hline 2189 & 1/10/2008 11:00 & $8 / 102008611: 00$ & 1.918 & $\overline{223}$ \\
\hline 2190 & 1/10/2008 11:02 & $8 / 10200811: 02$ & 1.918 & 223 \\
\hline 2191 & 1/102008 11:04 & $8 / 10200811: 04$ & 1.918 & 223 \\
\hline 2192 & 1/102008 11:06 & $8 / 10102008$ 11:06 & 1.919 & 224 \\
\hline 2193 & 1/10/2008 11:08 & $8 / 10 / 2008$ 11:08 & 1.918 & 224 \\
\hline 2194 & 1/102008 11:10 & $8 / 10200811: 10$ & 1.919 & 22.4 \\
\hline 2195 & 1/102008 11:12 & 81102008 11:12 & 1.919 & 224 \\
\hline 2196 & 1/102008 11:14 & 81102008 11:14 & 1.919 & 224 \\
\hline 2197 & 1/102008 11:16 & $8 / 10 / 200811: 16$ & 1.92 & 224 \\
\hline 2198 & 1/10/2008 11:18 & $8 / 102008$ 11:18 & 1.921 & 224 \\
\hline 2199 & 1/10/2008 11:20 & 81102008 11:20 & 1.921 & 224 \\
\hline 2200 & 1/102008 11:22 & $8 / 102008$ 11:22 & 1.922 & 224 \\
\hline 2201 & $1 / 10 / 200811: 24$ & $8 / 10200811: 24$ & 1.922 & 22.4 \\
\hline 2202 & 1/102008 11:26 & $8 / 102008$ 11:26 & 1.922 & 224 \\
\hline 2203 & $1 / 102008$ 11:28 & $8 / 10 / 2008$ 11:28 & 1.921 & 224 \\
\hline 2204 & $1 / 10200811: 30$ & $8 / 102008$ 11:30 & 1.921 & 22.4 \\
\hline 2205 & $1 / 10200811: 32$ & $8 / 10 / 2008$ 11:32 & 1.92 & $\overline{224}$ \\
\hline 2206 & 1/102008 11:34 & $8 / 102008$ 11:34 & 1.92 & 224 \\
\hline 2207 & $1 / 102200811: 36$ & $8 / 10200811: 36$ & 1.92 & 225 \\
\hline 2208 & 1/102008 11:38 & $8 / 10200811: 38$ & 1.921 & 225 \\
\hline 2209 & $1 / 102008$ 11:40 & $8 / 10 / 2008$ 11:40 & 1.921 & 225 \\
\hline 2210 & $1 / 10200811: 42$ & $8 / 10 / 2008$ 11:42 & 1.921 & 225 \\
\hline 2211 & $1 / 102000811: 44$ & $8 / 102008$ 11:44 & 1.92 & 225 \\
\hline 2212 & $1 / 10200811: 46$ & $8 / 10 / 200811: 46$ & 1.92 & 225 \\
\hline 2213 & $1 / 10200811: 48$ & $8 / 10200811: 48$ & 1.919 & 225 \\
\hline 2214 & $1 / 102000811: 50$ & $8 / 10200811: 50$ & 1.878 & 225 \\
\hline 215 & $1 / 10200811: 52$ & $8 / 102008$ 11:52 & 1.855 & 225 \\
\hline 2216 & $1 / 102008$ 11:54 & $8 / 102008$ 11:54 & 1.839 & 226 \\
\hline 2217 & $1 / 102000811: 56$ & $8 / 10200811: 56$ & 1.828 & 225 \\
\hline 2218 & $1 / 102200811: 58$ & $8 / 10200811: 58$ & 1.82 & 225 \\
\hline 2219 & $1 / 1020081200$ & $8 / 10 / 200812: 00$ & 1.815 & 224 \\
\hline 2200 & $1 / 1020081202$ & $8 / 1020081202$ & 1.800 & 224 \\
\hline $2 m 21$ & $1 / 1020081204$ & $8 / 10 / 20081204$ & 1.847 & 223 \\
\hline 2222 & $1 / 1020081206$ & $8 / 1020081206$ & 1.866 & 223 \\
\hline 2223 & $1 / 1020081208$ & $8 / 1020081208$ & 1.878 & 223 \\
\hline 2224 & $1 / 10200812: 10$ & $8 / 102008$ 12:10 & 1.885 & 223 \\
\hline 2225 & $1 / 1020081212$ & $8 / 102008$ 12:12 & 1.889 & 223 \\
\hline 2226 & $1 / 10200812: 14$ & $8 / 10200812: 14$ & 1.893 & 224 \\
\hline 2227 & $1 / 1020081216$ & $8 / 10 / 200812: 16$ & 1.894 & 224 \\
\hline 2228 & $1 / 1020081218$ & $8 / 1020081218$ & 1.896 & 223 \\
\hline 220 & $1 / 1020081220$ & $8 / 10 / 20081220$ & 1.897 & 224 \\
\hline 2230 & $1 / 1020081222$ & $8 / 1020081222$ & 1.898 & $\overline{224}$ \\
\hline 2231 & $1 / 1020081224$ & $8 / 10 / 20081224$ & 1.9 & $\overline{224}$ \\
\hline 2232 & $1 / 102008$ 1226 & $8 / 10 / 20081226$ & 1.901 & 224 \\
\hline 2233 & $1 / 1020081228$ & $8 / 10 / 20081228$ & 1.904 & 224 \\
\hline 2234 & $1 / 1020081230$ & $8 / 10 / 20081230$ & 1.905 & 224 \\
\hline 2235 & $1 / 10 / 20081232$ & $8 / 10 / 20081232$ & 1.906 & 224 \\
\hline 2236 & $1 / 1020001234$ & $8 / 1020081234$ & 1.907 & 224 \\
\hline 2237 & $1 / 1020001236$ & $8 / 10 / 20081236$ & 1.907 & 224 \\
\hline 2238 & $1 / 10220081238$ & $8 / 1020081238$ & 1.908 & $\overline{224}$ \\
\hline 2239 & $1 / 1020081240$ & $8 / 10 / 20081240$ & 1.909 & 224 \\
\hline 2240 & $1 / 1020081242$ & $8 / 1020081242$ & 1.91 & 224 \\
\hline 2241 & $1 / 102008$ 12444 & $8 / 1020081244$ & 1.91 & $\overline{224}$ \\
\hline 2242 & $1 / 1020081246$ & $8 / 10220081246$ & 1.912 & 224 \\
\hline 2243 & $1 / 1020081248$ & $8 / 10 / 20081248$ & 7.912 & 224 \\
\hline 224 & $1 / 10 / 20081250$ & $8 / 10120081250$ & 1.914 & $\overline{224}$ \\
\hline
\end{tabular}




\begin{tabular}{|c|c|c|c|c|}
\hline \multicolumn{5}{|c|}{ D4929 } \\
\hline $\mathrm{PeC}$ & & Aqusted & Pressurs & Temp \\
\hline$\#$ & DeteTime & Date/Time & psi & \\
\hline 2245 & $1 / 10 / 20081252$ & $8 / 10220081252$ & 1.914 & 224 \\
\hline 2246 & $1 / 10 / 20081254$ & $8 / 1020081254$ & 1.915 & 224 \\
\hline 2247 & $1 / 102008$ 12:56 & 81020081256 & 1.915 & 224 \\
\hline 2248 & $1 / 1020081258$ & 81020081258 & 1.914 & 225 \\
\hline 2249 & $1 / 102008$ 13:00 & $810: 200813: 00$ & 1.916 & 225 \\
\hline 2250 & $1 / 102008$ 13:02 & $8 / 10200813: 02$ & 1.917 & 22.5 \\
\hline 2251 & $1 / 102008$ 13:04 & $8 / 10200813: 04$ & 1.918 & 225 \\
\hline 2252 & 1/102008 13:06 & 81102200813.06 & 1.918 & 225 \\
\hline 2253 & $1 / 102008$ 13:08 & $8 / 10200813.08$ & 1.919 & 225 \\
\hline 2254 & $1 / 102008$ 13:10 & $8 / 102000813: 10$ & 1.918 & 226 \\
\hline 2255 & $1 / 10 / 2008$ 13:12 & $8 / 102000$ 13:12 & 1.918 & 226 \\
\hline 2256 & $1 / 102008$ 13:14 & $8 / 102000813: 14$ & 1.918 & 226 \\
\hline 225 & $1 / 102000813: 16$ & $8 / 10 / 200813: 16$ & 1.918 & 226 \\
\hline 2258 & 1/10/2008 13:18 & $81102000113: 18$ & 1.918 & 226 \\
\hline 2259 & $1 / 40 / 200813: 20$ & $8 / 102000813: 20$ & 1.919 & 226 \\
\hline 2260 & $1 / 10200813: 22$ & $8110200013: 2$ & 1.918 & 226 \\
\hline 2261 & $1 / 102008$ 13:24 & $8 / 102000813: 24$ & 1.919 & 226 \\
\hline 2262 & $1 / 10200813: 26$ & $8 / 102000813: 26$ & 1.919 & 226 \\
\hline 2263 & $1 / 102008$ 13:28 & $8 / 10200813: 28$ & 1.919 & 226 \\
\hline 2264 & $1 / 102008$ 13:30 & $8 / 102008$ 13:30 & 1.919 & 226 \\
\hline 2265 & $1 / 1022008$ 13:32 & $8 / 10200813: 32$ & 1.72 & 226 \\
\hline 2266 & $1 / 102008$ 13:34 & $8 / 10200813344$ & 1.914 & 225 \\
\hline 2267 & $1 / 102008$ 13:36 & $8110200813: 36$ & 1.916 & 224 \\
\hline 2268 & $1 / 1012008$ 13:38 & 8102000813338 & 1.918 & 224 \\
\hline 2269 & $1 / 402008$ 13:40 & 8110200813440 & 1.919 & 225 \\
\hline 2270 & $1 / 10 / 200813: 42$ & $8 / 10 / 20081344$ & 1.92 & 226 \\
\hline 2271 & $1 / 10200813: 44$ & $8 / 10200813: 44$ & 1.921 & 226 \\
\hline 2272 & $1 / 102008$ 13:46 & $8 / 10200013: 46$ & 1.921 & 226 \\
\hline 273 & $1 / 10200813: 48$ & $8 / 102200813 ; 48$ & 1.92 & 227 \\
\hline 2274 & $1 / 10200813: 50$ & $8 / 1020081355$ & 1.921 & 227 \\
\hline 275 & $1 / 10200813: 52$ & $8 / 10200813.52$ & 1.921 & 227 \\
\hline 2276 & $1 / 102008$ 13:54 & 8110200813.54 & 1.922 & 228 \\
\hline $22 \pi$ & $1 / 102008$ 13:56 & $8 / 102200813.56$ & 1.921 & 228 \\
\hline 2278 & $1 / 10200813: 58$ & $8 / 102000813.58$ & 1.922 & 228 \\
\hline $22 \pi$ & 1/10/2008 14:00 & $8 / 102008$ 14:00 & 1.922 & 228 \\
\hline 2280 & $1 / 10200814: 02$ & $8 / 102008$ 14:02 & 1.923 & 228 \\
\hline 2281 & 1/10:2008 14:04 & $8 / 102008$ 14:04 & 1.923 & 228 \\
\hline 2282 & $1 / 10 / 2008$ 14:06 & $8 / 10200814: 06$ & 1.923 & 228 \\
\hline 2283 & $1 / 102008$ 14:06 & $8 / 10200014: 08$ & 1.923 & 228 \\
\hline 2284 & 1/10/2008 14:10 & $8 / 102000814: 10$ & 1.923 & 22.8 \\
\hline 2285 & 1/10/2008 14:12 & $8 / 10200814: 12$ & 1.923 & 228 \\
\hline 2286 & 1/10/2008 14:14 & $8 / 102008$ 14:14 & 1.924 & 228 \\
\hline 2287 & 1/102008 14:16 & 8/10/2008 14:16 & 1.925 & 228 \\
\hline 2288 & $1 / 102008$ 14:18 & $8 / 102008$ 14:18 & 1.925 & 22.8 \\
\hline 2280 & 1/10/2008 14:20 & $8 / 102008$ 14:20 & 1.925 & 228 \\
\hline 2290 & $1 / 10 / 200814: 22$ & $8 / 102000814: 22$ & 1.925 & 228 \\
\hline 2291 & $1 / 10 / 2008$ 14:24 & $8 / 102000814: 24$ & 1.926 & 228 \\
\hline 2292 & 1/10:2008 14:26 & $8 / 102008$ 14:26 & 1.926 & 228 \\
\hline 2293 & 1/10:2008 14:28 & $8 / 10200814: 28$ & 1.926 & 228 \\
\hline 2294 & $1 / 10200814: 30$ & $8 / 10200814: 30$ & 1.925 & 228 \\
\hline 2295 & $1 / 102008$ 14:32 & $8 / 102008$ 14:32 & 1.926 & 228 \\
\hline 2296 & $1 / 10200814: 34$ & $8 / 102008$ 14:34 & 1.926 & 229 \\
\hline 2297 & $1 / 10200814: 36$ & $8 / 102008$ 14:36 & 1.926 & 229 \\
\hline 2298 & $1 / 10200814: 38$ & $8 / 102000814: 38$ & 1.926 & 229 \\
\hline 2299 & $1 / 10 / 2008$ 14:40 & $8 / 10200814: 40$ & 1.927 & 229 \\
\hline 2300 & $1 / 10 / 2008$ 14:42 & $8 / 102008$ 14:42 & 1.927 & 229 \\
\hline 2301 & $1 / 10200814: 44$ & $8 / 10 / 200814: 44$ & 1.925 & 229 \\
\hline 2302 & 1/102008 14:46 & $8 / 10200014: 46$ & 1.914 & 23 \\
\hline 2303 & $1 / 102008$ 14:48 & $8 / 102008$ 14:48 & 1.892 & 23 \\
\hline 2304 & $1 / 102008$ 14:50 & $8 / 102000614: 50$ & 1.868 & 23 \\
\hline 2305 & $1 / 102008$ 14:52 & $8 / 10200814: 52$ & 1.853 & 23.1 \\
\hline 2306 & $1 / 10: 2008$ 14:54 & $8 / 102008$ 14:54 & 1.841 & \\
\hline 2307 & $1 / 10: 2008$ 14:56 & $8 / 102000814: 56$ & 1.833 & 229 \\
\hline 2308 & $1 / 10 / 2008$ 14:58 & $8 / 10 / 200814: 58$ & 1.826 & 228 \\
\hline 2309 & 1/10/2008 15:00 & $8 / 102000815: 00$ & 1.82 & 228 \\
\hline 2310 & $1 / 10: 2008$ 15:02 & $8 / 102008$ 15:02 & 1.815 & 228 \\
\hline 2311 & 1/10/2008 15:04 & $8 / 10200815: 04$ & 1.81 & 227 \\
\hline 2312 & $1 / 10200815: 06$ & $81102000815: 06$ & 1.831 & 226 \\
\hline
\end{tabular}

\begin{tabular}{|c|c|c|c|c|}
\hline \multicolumn{5}{|c|}{ D4-920 } \\
\hline $\operatorname{Rec}$ & & Adjusted & Pressurt & Temp \\
\hline$\#$ & Date/Time & DaterTime & psi & ${ }^{\circ} \mathrm{C}$ \\
\hline 2313 & $1 / 10200815: 08$ & $8 / 10200815: 08$ & 1.855 & 226 \\
\hline 2314 & 1/10/2008 15:10 & $8 / 10200815: 10$ & 1.868 & 226 \\
\hline 2315 & 1/10/2008 15:12 & $8 / 10200815: 12$ & 1.877 & 227 \\
\hline 2316 & 1/10/2008 15:14 & $8 / 102000815: 14$ & 1.882 & 226 \\
\hline 2317 & 1/10/2008 15:16 & $8 / 10200815: 16$ & 1.887 & 226 \\
\hline 2318 & 1/10/20008 15:18 & $8 / 10200815: 18$ & 1.89 & 226 \\
\hline 2319 & $1 / 102008$ 15:20 & $8 / 10200815: 20$ & 1.893 & 226 \\
\hline 2320 & $1 / 10200815: 22$ & $8 / 10200815: 22$ & 1.894 & 226 \\
\hline 2321 & $1 / 102000815: 24$ & $8 / 102000815: 24$ & 1.895 & 226 \\
\hline 2322 & $1 / 10200815: 26$ & $8 / 102000815: 26$ & 1.896 & 226 \\
\hline 2323 & 1/1020008 15:28 & $8 / 10200815: 28$ & 1.898 & 26 \\
\hline 2324 & $1 / 10200815: 30$ & $8 / 102000815: 30$ & 1.899 & 227 \\
\hline 2325 & $1 / 10200815: 32$ & $8 / 10200815: 32$ & 1.901 & $\overline{227}$ \\
\hline 2326 & $1 / 10 / 200815: 34$ & $8 / 102000815: 34$ & 1.902 & 227 \\
\hline 2327 & $1 / 102000815: 36$ & $8 / 10200815: 36$ & 1.903 & 228 \\
\hline 2328 & $1 / 10200815: 38$ & $8 / 10200815: 38$ & 1.903 & 28 \\
\hline 2320 & $1 / 10200815: 40$ & $8 / 10 / 200815: 40$ & 1.906 & 227 \\
\hline 2330 & $1 / 10200815: 42$ & $8 / 10200815: 42$ & 1.906 & 227 \\
\hline 2331 & $1 / 10200815: 44$ & $8 / 10200815: 44$ & 1.907 & 227 \\
\hline 2332 & $1 / 10 / 200815: 46$ & $8 / 10200815: 46$ & 1.908 & 226 \\
\hline 2333 & $1 / 10200815: 48$ & $8 / 10200815: 48$ & 1.91 & 226 \\
\hline 2334 & $1 / 10200815: 50$ & $8 / 10200815: 50$ & 1.91 & 226 \\
\hline 2335 & $1 / 10200815: 52$ & $8 / 10200815: 52$ & 1.911 & 227 \\
\hline 2336 & $1 / 10 / 200815: 54$ & $8 / 10200815: 54$ & 1.912 & 227 \\
\hline 2337 & $1 / 102008$ 15:56 & $8 / 10200815: 56$ & 1.913 & 227 \\
\hline 2338 & $1 / 10200815: 58$ & $8 / 10200815: 58$ & 1.913 & 27 \\
\hline 2339 & $1 / 10 / 200816: 00$ & $8 / 10 / 200816: 00$ & 1.913 & 227 \\
\hline 2340 & $1 / 10 / 200816: 02$ & $8 / 10200816: 02$ & 1.915 & 227 \\
\hline 2341 & $1 / 102000816: 04$ & $8 / 102008$ 16:04 & 1.916 & 227 \\
\hline 2342 & $1 / 10200816: 06$ & $8 / 10200816: 06$ & 1.916 & 228 \\
\hline 2343 & $1 / 10200816: 08$ & $8 / 10200816: 08$ & 1.916 & 229 \\
\hline 2344 & 1/102008 16:10 & $8 / 10200816: 10$ & 1.917 & 23 \\
\hline 2345 & 1/102008 16:12 & $8 / 10200816: 12$ & 1.916 & 23 \\
\hline 2346 & $1 / 102008$ 16:14 & $8 / 10200816: 14$ & 1.917 & 23 \\
\hline 2347 & 1/102008 16:16 & $8 / 10200816: 16$ & 1.917 & 229 \\
\hline 2348 & 1/1902008 16:18 & $8 / 10 / 200816: 18$ & 1.918 & 229 \\
\hline 2349 & $1 / 40200816: 20$ & $8 / 10200816: 20$ & 1.919 & 229 \\
\hline 2350 & $1 / 10200816: 22$ & $8 / 10200816: 22$ & 1.919 & 229 \\
\hline 2351 & $1 / 102000816: 24$ & $8 / 10 / 200816: 24$ & 1.92 & 220 \\
\hline 2352 & $1 / 102000816: 26$ & $8 / 10 / 200816: 26$ & 1.92 & 23 \\
\hline 2353 & $1 / 10200816: 28$ & $8 / 10200816: 28$ & 1.921 & 23 \\
\hline 2354 & $1 / 10 / 200816: 30$ & $8 / 10200816: 30$ & 1.92 & 23 \\
\hline 2355 & 1/102008 16:32 & $8 / 10200816: 32$ & 1.92 & 23.1 \\
\hline 2356 & $1 / 102000816: 34$ & $8 / 10200816: 34$ & 1.921 & 23.1 \\
\hline 2367 & $1 / 10200816: 36$ & $8 / 10200816: 36$ & 1.922 & 23.1 \\
\hline 2358 & $1 / 102000816: 38$ & $8 / 10200816: 38$ & 1.902 & 23.1 \\
\hline 2350 & $1 / 10200816: 40$ & $8 / 10200816: 40$ & 1.922 & 23.1 \\
\hline 2360 & $1 / 102000816: 42$ & $8 / 10200016: 42$ & 1.92 & 23.1 \\
\hline 2361 & $1 / 4 \alpha 200816: 44$ & $8 / 102000116: 44$ & 1.921 & 23.3 \\
\hline 2362 & $1 / 142000816: 46$ & $8 / 10200816: 46$ & 1.92 & 23.3 \\
\hline 2363 & $1 / 10200816: 48$ & $8 / 10200816: 48$ & 1.92 & 23.3 \\
\hline 2364 & $1 / 402008$ 16:50 & $8 / 10200816: 50$ & 1.921 & 23.3 \\
\hline 2365 & $1 / 102000816: 52$ & $8 / 10200816: 52$ & 1.92 & 23.3 \\
\hline 2366 & 1/102008 16:54 & $8 / 10200816: 54$ & 1.92 & 23.3 \\
\hline 2367 & $1 / 10 / 200816: 56$ & $8 / 10 / 200816: 56$ & 1.922 & 23.3 \\
\hline 2368 & $1 / 10 / 200816: 58$ & $8 / 10 / 200816: 58$ & 1.922 & 23.2 \\
\hline 2369 & $1 / 10 / 200817: 00$ & $8 / 10200817: 00$ & 1.922 & 23.2 \\
\hline 2370 & $1 / 10200817: 02$ & $8 / 10200817: 02$ & 1.902 & 23.2 \\
\hline 2371 & $1 / 10200817: 04$ & $8 / 10200817: 04$ & 1.923 & 23.2 \\
\hline 2372 & $1 / 102000817: 06$ & $8 / 10200817: 06$ & 1.923 & 23.2 \\
\hline 2373 & $1 / 100200817: 08$ & $8 / 10200817: 08$ & 1.924 & 23.2 \\
\hline 2374 & 1/10/2008 17:10 & $8 / 10200817: 10$ & 1.923 & 23.2 \\
\hline 2375 & $1 / 10200817: 12$ & $8 / 102000817: 12$ & 1.924 & 23.2 \\
\hline 2376 & $1 / 10 / 200817: 14$ & $8 / 10200817: 14$ & 1.924 & 23.3 \\
\hline 237 & 1/102000 17:16 & $8 / 10200817: 16$ & 1.923 & 23.2 \\
\hline 2378 & $1 / 10200817: 18$ & $8 / 10200817: 18$ & 1.676 & 23.3 \\
\hline 2379 & $1 / 10200817 \cdot 20$ & $8 / 10200817: 20$ & 1915 & 231 \\
\hline 2380 & $1 / 102000817: 22$ & $8 / 10200817: 22$ & 1.92 & 229 \\
\hline
\end{tabular}

\begin{tabular}{|c|c|c|c|c|}
\hline \multicolumn{5}{|c|}{$D 492 p$} \\
\hline$R e c$ & & Adjusted & Pressurs & \\
\hline$\#$ & DateTime & DateTime & psi & ${ }^{\circ} \mathrm{C}$ \\
\hline 2381 & $1 / 10200017: 24$ & $8 / 10200817: 24$ & 1.922 & 22 \\
\hline 2382 & $1 / 10200817: 26$ & $8 / 102008$ 17:26 & 1.923 & \\
\hline 2383 & d2008 17:28 & $8 / 102008$ 17:28 & 1.924 & \\
\hline 2384 & $1 / 10 / 200817: 30$ & $8 / 1072008$ 17:30 & 1.923 & $\overline{2}$ \\
\hline 2385 & $107200817: 32$ & $8 / 10 / 200817: 32$ & 1.921 & \\
\hline 2386 & 102006 17:34 & $8 / 102008$ 17:34 & 1.921 & \\
\hline 2387 & 102006 17:36 & $8 / 107200817: 36$ & 1.922 & 23. \\
\hline 2388 & $10200017: 38$ & $8 / 102000617: 38$ & 1.923 & \\
\hline 2389 & 1022008 17:40 & $8 / 10200617: 40$ & 1.924 & \\
\hline 2390 & $1 / 1002006$ 17:42 & $8 / 102008$ 17:42 & 1.925 & 23. \\
\hline 2391 & 77:44 & $8 / 1072008$ 17:44 & 1.925 & 23. \\
\hline 2392 & & $8 / 102008$ 17:46 & 1.909 & \\
\hline 2393 & 102000 17:48 & 81102008 17:48 & 1.881 & 23. \\
\hline 2394 & 50 & $8 / 10 / 2008$ 17:50 & 1.861 & 23. \\
\hline 2395 & & $8 / 10200817: 52$ & & \\
\hline 2396 & 1022008 17:54 & $8 / 10200817: 54$ & 1.899 & \\
\hline 2397 & & $8 / 102008$ 17:56 & 1.905 & 23. \\
\hline 2396 & & $8 / 10200817: 58$ & & \\
\hline 2399 & $18: 00$ & $8 / 102008$ 18:00 & 1.911 & 23. \\
\hline 2400 & & 811020 & 1.913 & 23. \\
\hline 2401 & & $8 / 1020$ & 1.914 & 23. \\
\hline 2402 & & 8110200 & 1.915 & 2 \\
\hline 2403 & & $8 / 107200$ & 1.916 & \\
\hline 2404 & & $8 / 10220$ & 1.917 & 23 \\
\hline 2405 & & $8 / 10200$ & 1.918 & 23. \\
\hline 2406 & & $8 / 10 / 2$ & 1.918 & 23. \\
\hline 2407 & & $8 / 102$ & 1.918 & 23 \\
\hline 2408 & & $8 / 102$ & 1.918 & 23. \\
\hline 2409 & & & 1.919 & 23. \\
\hline 2410 & & & 1.92 & 23 \\
\hline 2411 & & & 1.921 & 23. \\
\hline 2412 & & & 1.921 & 23 \\
\hline 2413 & & $8 / 10 / 2$ & 1.922 & 23. \\
\hline 2414 & & & 1.922 & 23 \\
\hline 2415 & & & 1.923 & $\overline{23}$ \\
\hline 2416 & & $18: 34$ & 1.922 & 23 \\
\hline 2417 & & & 1.923 & 23 \\
\hline 2418 & & & 1.923 & 23 \\
\hline 2419 & & & 1.924 & 23 \\
\hline 2420 & & & 1.924 & 23 \\
\hline 2421 & & & 1.924 & \\
\hline 2422 & & & 1.923 & 23 \\
\hline 2423 & & & 1.923 & 2 \\
\hline 2424 & & & 1.924 & 5 \\
\hline 2425 & & & 1.925 & $\overline{23}$ \\
\hline 2426 & & & 1.925 & $x$ \\
\hline 2427 & & & 1.926 & 23 \\
\hline 2428 & & & 1.925 & 2 \\
\hline 2429 & & & 1.925 & \\
\hline 2430 & & & 1.925 & 2 \\
\hline 2431 & & & 1.925 & \\
\hline 2432 & & & 1.926 & \\
\hline 2433 & & & 1.926 & \\
\hline 2434 & & & 1.926 & \\
\hline 2435 & & & 1.926 & 23 \\
\hline 2436 & & & 1.926 & \\
\hline 2437 & & & & \\
\hline 2438 & & 319.18 & 1.926 & 23 \\
\hline 2439 & & & 1.925 & \\
\hline 2440 & & & 1.925 & \\
\hline 2441 & 19.24 & $8 / 102000819.24$ & 1.925 & $\Delta$ \\
\hline 2442 & & & 1.926 & \\
\hline 2443 & & & 1.926 & \\
\hline 2444 & 19.30 & $8 / 10200819: 30$ & 1.926 & 23 \\
\hline 2445 & & & 1.926 & \\
\hline 2446 & & & 1.926 & \\
\hline 2447 & & $8 / 10200819: 36$ & 1.927 & 23 \\
\hline 2448 & 19.38 & $8 / 10200819: 38$ & 1.926 & \\
\hline
\end{tabular}


DOE/RL-2009-35, REV. 0

\begin{tabular}{|c|c|c|c|c|}
\hline \multicolumn{5}{|c|}{ D4920 } \\
\hline$\overline{F e c}$ & & Adjusted & Pressure & Temp \\
\hline \# & Deter/ime & Dete/Time & \begin{tabular}{|l|}
$p s i$ \\
\end{tabular} & \\
\hline 2449 & $1 / 102000819.40$ & $8 / 10200819.40$ & 1.927 & 23.3 \\
\hline 2450 & 1/10/2008 19.42 & $8 / 1020008$ 19.42 & 1.926 & 23.4 \\
\hline 2451 & $1 / 10200819.44$ & $8 / 10200819.44$ & 1.927 & 23.3 \\
\hline 2452 & $1 / 10 / 200819.46$ & $8 / 102000819.46$ & 1.926 & 23.3 \\
\hline 2453 & $1 / 10200819.48$ & $8 / 10200819: 48$ & 1.926 & 23.3 \\
\hline 2454 & $1 / 10200819.50$ & $8 / 10200819.50$ & 1.926 & 23.3 \\
\hline 2456 & $1 / 10200819.52$ & $8 / 10200819.52$ & 1.926 & 23.4 \\
\hline 2456 & $1 / 10200819.54$ & $8 / 10200819: 54$ & 1.926 & 23.4 \\
\hline 2457 & $1 / 10200819.56$ & $8 / 10200819.56$ & 1.926 & 23.4 \\
\hline 2458 & $1 / 10 / 200819.58$ & $8 / 10200819.58$ & 1.927 & 23.4 \\
\hline 2459 & 1/10/200820:00 & $8 / 10200820: 00$ & 1.927 & 23.4 \\
\hline 2460 & $1 / 10 / 200820: 02$ & $8 / 10200820: 02$ & 1.927 & 23.4 \\
\hline 2461 & $1 / 10200820: 04$ & $8 / 10 / 200820: 04$ & 1.927 & 23.4 \\
\hline 2462 & $1 / 10200820: 06$ & $8 / 10 / 200820: 06$ & 1.927 & 23.4 \\
\hline 2463 & $1 / 10 / 200820.08$ & $8 / 10200820: 08$ & 1.928 & 23.4 \\
\hline 2464 & $1 / 10 / 200820: 10$ & $8 / 10 / 200820: 10$ & 1.927 & 23.4 \\
\hline 2465 & 1/10/200820:12 & $8 / 10 / 200820: 12$ & 1.920 & 23.4 \\
\hline 2466 & $1 / 10 / 200820: 14$ & $8 / 10 / 200820: 14$ & 1.929 & 23.5 \\
\hline 2467 & 1/10/200820:16 & $8 / 10200820: 16$ & 1.928 & 23.4 \\
\hline 2468 & 1/10/200820:18 & $8 / 10 / 200820: 18$ & 1.928 & 23.5 \\
\hline 2469 & $1 / 10 / 200820: 20$ & $8 / 10200820: 20$ & 1.929 & 23.5 \\
\hline 2470 & $1 / 10 / 200820: 22$ & $8 / 10200020: 22$ & 1.929 & 23.5 \\
\hline 2471 & $1 / 10 / 200820: 24$ & $8 / 10200020.24$ & 1.93 & 23.5 \\
\hline 2472 & $1 / 10 / 200820: 26$ & $8 / 10200020: 26$ & 1.93 & 23.5 \\
\hline 2473 & 1/10/2008 20:28 & $8 / 10200020.28$ & 1.93 & 23.5 \\
\hline 2474 & $1 / 10 / 200820: 30$ & $8 / 10200820: 30$ & 1.927 & 23.5 \\
\hline 2475 & $1 / 10200820: 32$ & $8 / 10 / 200820: 32$ & 1.866 & 23.5 \\
\hline 2476 & $1 / 10200820: 34$ & $8 / 10 / 200820.34$ & 1.995 & 23.5 \\
\hline 2477 & $1 / 10 / 200820: 36$ & $8 / 10 / 200820.36$ & 1.879 & 23.3 \\
\hline 2478 & $1 / 10 / 200820: 38$ & $8 / 10200020.38$ & 1.866 & 23.3 \\
\hline 2479 & $1 / 10 / 200820: 40$ & $8 / 102200820: 40$ & 1.852 & 23.3 \\
\hline 2480 & $1 / 10 / 200820: 42$ & $8 / 10200020: 42$ & 1.84 & 23.3 \\
\hline 2481 & $1 / 102000820: 44$ & $8 / 102000820: 44$ & 1.832 & 23.3 \\
\hline 2482 & 1/10/2008 20:46 & $8 / 10200020: 46$ & 1.825 & 23.3 \\
\hline 2483 & $1 / 10 / 200820: 48$ & $8 / 10 / 200820: 48$ & 1.819 & 23.3 \\
\hline 2484 & $1 / 10200820: 50$ & $8 / 10200820.50$ & 1.815 & 23.3 \\
\hline 2486 & $1 / 102000820: 52$ & $8 / 10^{\prime 200820: 52}$ & 1.811 & 23.3 \\
\hline 2486 & $1 / 10 / 200820: 54$ & $8 / 10200020.54$ & 1.807 & 23.3 \\
\hline 2487 & $1 / 10200820: 56$ & $8 / 102000820.56$ & 1.802 & 23.3 \\
\hline 2488 & $1 / 10200820: 58$ & $8 / 102000820: 58$ & 1.8 & 23.3 \\
\hline 2489 & 1/10/200821:00 & $8 / 102200821: 00$ & 1.796 & 23.2 \\
\hline 2490 & $1 / 10 / 200821: 02$ & $8 / 10200821: 02$ & 1.793 & 23.2 \\
\hline 2491 & $1 / 10 / 20$ & $8 / 10200821: 04$ & 1.788 & 23.2 \\
\hline 2498 & 1/10/200821:06 & $8 / 101200821: 06$ & 1.787 & 23.1 \\
\hline 2493 & 1/10/200821:08 & $8 / 102200821: 08$ & 1.784 & 23.1 \\
\hline 2494 & 1/10/200821:10 & $8 / 10200821: 10$ & 1.781 & 23.1 \\
\hline 2495 & 1/10/200821:12 & $8 / 10200821: 12$ & 1.778 & 23.1 \\
\hline 2496 & 1/10/200821:14 & $8 / 102000821: 14$ & $1.7 \pi$ & 23.1 \\
\hline 2497 & 1/10/200821:16 & $8 / 102200821: 16$ & 1.775 & 23.1 \\
\hline 2498 & $1 / 10 / 200821: 18$ & $8 / 102200821: 18$ & 1.802 & 23.1 \\
\hline 2499 & 1/10/200821:20 & $8 / 10 / 200821: 20$ & 1.826 & 23.1 \\
\hline 2500 & 321:22 & $8 / 10200821: 22$ & 1.845 & 23.2 \\
\hline 2501 & $821: 24$ & $8 / 10 / 200821: 24$ & 1.854 & 23.2 \\
\hline 2502 & 1/10/200821:26 & $8 / 10200821: 26$ & 1.86 & 23.2 \\
\hline 2503 & $1 / 10200821: 28$ & $8 / 10200821: 28$ & 1.865 & 23.1 \\
\hline 2504 & $321: 30$ & $8 / 10200821: 30$ & 1.869 & 23.2 \\
\hline 2506 & 1/10/2008 21:32 & $8 / 10200821: 32$ & 1.872 & 23.1 \\
\hline 2506 & 1/10/200821:34 & $8 / 10200021: 34$ & 1.876 & 23.2 \\
\hline 2507 & 1/10/200821:36 & $8110200821: 36$ & 1.878 & 23.2 \\
\hline 2508 & 1/10/200821:38 & $8 / 10200821: 38$ & 1.881 & 23.2 \\
\hline 2500 & $1 / 10200821: 40$ & $8 / 10200821: 40$ & 1.883 & 23.2 \\
\hline 2510 & 1/10/200821:42 & $8 / 10200821: 42$ & 1.884 & 23.2 \\
\hline 2511 & 1/10/200821:44 & $8 / 10200821: 44$ & 1.885 & 23.2 \\
\hline 2512 & $1 / 10200821: 46$ & $8110200821: 46$ & 1.887 & 23.2 \\
\hline 2513 & 1/10/2008 21:48 & $8 / 10200821: 48$ & 1.889 & 23.2 \\
\hline 2514 & 1/10/200821:50 & $81102200821: 50$ & 1.89 & 23.2 \\
\hline 2515 & 1/10/200821:52 & $8110200821: 52$ & 1.892 & 23.2 \\
\hline 2516 & $1 / 10 / 200821: 54$ & $8 / 10200821 \cdot 54$ & 1.893 & 23.2 \\
\hline
\end{tabular}

\begin{tabular}{|c|c|c|c|c|}
\hline \multicolumn{5}{|c|}{04929} \\
\hline $\mathrm{ReC}$ & & Aqusted & Pressure & Temp \\
\hline$\#$ & Dake-Time & Dete/Time & \begin{tabular}{|l|}
$p s i$ \\
\end{tabular} & ${ }^{\circ} \mathrm{C}$ \\
\hline 2517 & 1/10/200821:56 & $8 / 10200821: 56$ & 1.894 & 23.2 \\
\hline 2518 & 1/10/200821:58 & $8 / 102000821: 58$ & 1.895 & 23.2 \\
\hline 2519 & $1 / 10200822200$ & $8 / 10200082200$ & 1.896 & 23.3 \\
\hline 2520 & $1 / 10200822,02$ & $8 / 10200022002$ & 1.897 & 23.3 \\
\hline 2521 & $1 / 10 / 20082204$ & $8 / 1020082204$ & 1.898 & 23.3 \\
\hline 2522 & $1 / 10200822206$ & $8 / 1020082206$ & 1.9 & 23.3 \\
\hline 2523 & $1 / 10 / 200822208$ & $8 / 102200822208$ & 1.901 & 23.3 \\
\hline 2524 & $1 / 1022008$ 2210 & $8 / 1020082210$ & 1.901 & 23.3 \\
\hline 2525 & $1 / 1020082212$ & $8 / 1020082212$ & 1.9 & 23.3 \\
\hline 2526 & $1 / 10 / 200822-14$ & $8 / 1020082214$ & 1.9 & 23.3 \\
\hline 2527 & $1 / 10200822-16$ & $8 / 1020082216$ & 1.901 & 23.3 \\
\hline 2528 & $1 / 10200822-18$ & 81020082218 & 1.902 & 23.3 \\
\hline 2520 & $1 / 1020082220$ & $8 / 1020082220$ & 1.902 & 23.3 \\
\hline 2530 & $1 / 1020082222$ & $8 / 1020082222$ & 1.903 & 23.3 \\
\hline 2531 & $1 / 1020082224$ & $8 / 1020002224$ & 1.904 & 23.3 \\
\hline 2532 & $1 / 10220082226$ & $8 / 1020082226$ & 1.905 & 23.3 \\
\hline 2533 & $1 / 10220082228$ & 811020082228 & 1.906 & 23.3 \\
\hline 2534 & $1 / 10 / 20082230$ & 811020082230 & 1.906 & 23.4 \\
\hline 2535 & $1 / 10 / 20082232$ & $8 / 1020082232$ & 1.907 & 23.4 \\
\hline 2536 & $1 / 10 / 20082234$ & $8 / 10200022: 34$ & 1.908 & 23.4 \\
\hline 2537 & $1 / 10 / 200822236$ & 811020082236 & 1.909 & 23.4 \\
\hline 2538 & $1 / 1020082238$ & $8 / 10200822: 38$ & 1.909 & 23.4 \\
\hline 2539 & $1 / 1020082240$ & 811020082240 & 1.91 & 23.4 \\
\hline 2540 & $1 / 10 / 20082242$ & $8 / 10200822442$ & 1.911 & 23.4 \\
\hline 2541 & $1 / 10 / 20082244$ & $8 / 10 / 20082244$ & 1.912 & 23.4 \\
\hline 2542 & $1 / 1020082246$ & 811020082246 & 1.912 & 23.4 \\
\hline 2543 & $1 / 10 / 20082248$ & $8 / 10 / 200822: 48$ & 1.913 & 23.4 \\
\hline 2544 & $1 / 10 / 20082250$ & 811020082250 & 1.913 & 23.4 \\
\hline 2545 & $1 / 1020002252$ & $8 / 10200822: 52$ & 1.914 & 23.4 \\
\hline 2546 & $1 / 1020082254$ & $8 / 10200022554$ & 1.913 & 23.4 \\
\hline 2547 & 32256 & $8 / 10 / 20082256$ & 1.913 & 23.4 \\
\hline 2548 & $1 / 10 / 20082258$ & $8 / 10 / 20082258$ & 1.914 & 23.4 \\
\hline 2549 & $1 / 10200823: 00$ & $8 / 102200823: 00$ & 1.915 & 23.4 \\
\hline 2550 & $323: 02$ & $8 / 10200023: 02$ & 1.914 & 23.5 \\
\hline 2551 & $1 / 10 / 200823: 04$ & $8 / 10200823: 04$ & 1.915 & 23.5 \\
\hline 2552 & 1/10/200823:06 & $8 / 10200823: 06$ & 1.916 & 23.5 \\
\hline 2553 & 1/102008 Z3:08 & $8 / 10200823: 08$ & 1.916 & 23.4 \\
\hline 2554 & 1/102008 23:10 & $8823: 10$ & 1.917 & 23.5 \\
\hline 2555 & 1/10/2008:23:12 & $8 / 10 / 200823: 12$ & 1.917 & 23.5 \\
\hline 2556 & $1 / 10 / 200823: 14$ & $8 / 10200823: 14$ & 1.918 & 23.4 \\
\hline 2557 & 1/10/2008 23:16 & $8 / 10200823: 16$ & 1.917 & 23.5 \\
\hline 2558 & 1/10/2008 23:18 & $8 / 10 / 200823: 18$ & 1.917 & 23.5 \\
\hline 2559 & $1 / 10200823: 20$ & $8 / 10200823: 20$ & 1.918 & 23.5 \\
\hline 2560 & $823: 2$ & $8 / 10200823: 22$ & 1.919 & 23.5 \\
\hline 2561 & $1 / 10 / 200823: 24$ & $8 / 10 / 200823: 24$ & 1.918 & 23.5 \\
\hline 2562 & $000823: 26$ & $8 / 10 / 200823: 26$ & 1.919 & 23.5 \\
\hline 2563 & $00823: 28$ & $323: 28$ & 1.919 & 23.5 \\
\hline 2564 & 1/10:2008 23:30 & $8 / 10200823: 30$ & 1.92 & 23.6 \\
\hline 2565 & $1 / 10 / 200823: 32$ & $8 / 10200823: 32$ & 1.921 & 23.6 \\
\hline 2566 & $323: 34$ & 323:34 & 1.922 & 23.6 \\
\hline 2567 & 1/10/2008 23:36 & $8 / 10200823: 36$ & 1.922 & 23.6 \\
\hline 2568 & 1/40/2008 23:38 & $8 / 10200823: 38$ & 1.922 & 23.6 \\
\hline 2569 & 1/10/2008 23:40 & $8 / 10200823: 40$ & 1.923 & 23.6 \\
\hline 2570 & 1/10/2008 23:42 & $8 / 10200823: 42$ & 1.923 & 23.6 \\
\hline 2571 & 1/10/2008 23:44 & $8 / 10200823: 44$ & 1.923 & 23.6 \\
\hline 2572 & 1/102008 23:46 & $8 / 10200823: 46$ & 1.923 & 23.6 \\
\hline 2573 & $1 / 10200823: 48$ & $8 / 10200823: 48$ & 1.923 & 23.6 \\
\hline 2574 & 1/10/2008 23:50 & $8 / 10200823: 50$ & 1.925 & 23.6 \\
\hline 2575 & $1 / 10 / 200823: 52$ & $8 / 10200823: 52$ & 1.925 & 23.6 \\
\hline $25 / 6$ & 1/102008 23:54 & $8 / 10200823: 54$ & 1.924 & 23.6 \\
\hline $25 \pi$ & $1 / 1020082356$ & $8 / 10200823: 56$ & 1.906 & 23.6 \\
\hline 2578 & 1/102008 23:58 & $8 / 10200823: 58$ & 1.881 & 23.6 \\
\hline 2579 & $1 / 11 / 20080.00$ & $8 / 11 / 20080: 00$ & 1.858 & 23.6 \\
\hline 2580 & $1 / 11 / 20080.02$ & $8 / 11 / 20080: 02$ & 1.842 & 23.6 \\
\hline 2581 & 1/11/20080:04 & $8 / 11 / 20080: 04$ & 1.83 & 23.6 \\
\hline 2582 & $1 / 11 / 20080: 06$ & $8 / 11 / 20080.06$ & 1.822 & 23.6 \\
\hline 2583 & 1/11/20080:08 & $8 / 11 / 20080: 08$ & 1.815 & 23.5 \\
\hline 2584 & 1/11/20080:10 & $8 / 11 / 20080.10$ & 1.81 & 23.4 \\
\hline
\end{tabular}

\begin{tabular}{|c|c|c|c|c|}
\hline \multicolumn{5}{|c|}{0499} \\
\hline Rec & & Adusted & Pressurf & \\
\hline \# & DateTime & DaterTime & psi & ${ }^{\circ} \mathrm{C}$ \\
\hline 2585 & $1 / 11 / 20080: 12$ & $8 / 11 / 20080: 12$ & 1.846 & $\overline{23}$ \\
\hline 2586 & 1/11/20080:14 & $8 / 11 / 20080: 14$ & 1.866 & 23. \\
\hline 2587 & 1/11/20080:16 & $8 / 11 / 20080: 16$ & 1.878 & 23.4 \\
\hline 2588 & 1/11/20080.18 & $8 / 11 / 20080: 18$ & 1.885 & 23. \\
\hline 2589 & 1/11/20080:20 & $8 / 11 / 20080.20$ & 1.888 & $\overline{23.4}$ \\
\hline 2590 & $1 / 11 / 2008022$ & $8 / 11 / 20080: 22$ & 1.891 & 23.4 \\
\hline 2591 & $1 / 11 / 20080: 24$ & $8 / 11 / 20080: 24$ & 1.894 & $\overline{23.4}$ \\
\hline 2592 & $1 / 11 / 20080.26$ & $8 / 11 / 20080: 26$ & 1.895 & 23.4 \\
\hline 2593 & $1 / 11 / 20080.28$ & $8 / 11 / 20080: 28$ & 1.897 & 23.4 \\
\hline 2594 & $1 / 11 / 20080: 30$ & $8 / 11 / 20080: 30$ & 1.898 & 23.4 \\
\hline 2595 & $1 / 11 / 20080.32$ & $8 / 11 / 20080: 32$ & 1.9 & 23.4 \\
\hline 2596 & $1 / 11 / 20080.34$ & $8 / 11 / 20080: 34$ & 1.902 & 23.4 \\
\hline 2597 & $1 / 11 / 20080: 36$ & $8 / 11 / 20080: 36$ & 1.902 & $\overline{23.4}$ \\
\hline 2598 & $1 / 11 / 20080: 38$ & $8 / 11 / 20080: 38$ & 1.904 & 23 \\
\hline 2599 & $1 / 11 / 20080: 40$ & $8 / 11 / 20080: 40$ & 1.905 & 23.5 \\
\hline 2600 & $1 / 11 / 20080.42$ & $8 / 11 / 20080: 42$ & 1.906 & 23.4 \\
\hline 2601 & $1 / 11 / 20080: 44$ & $8 / 11 / 20080: 44$ & 1.907 & 23.4 \\
\hline 2602 & $1 / 11 / 20080: 46$ & $8 / 11 / 20080: 46$ & 1.908 & 3.5 \\
\hline 2603 & $1 / 11 / 20080: 48$ & $8 / 11 / 20080: 48$ & 1.908 & 23.4 \\
\hline 2604 & 0.50 & 20080.50 & 1.909 & 23.5 \\
\hline 2605 & $1 / 11 / 20080: 52$ & $8 / 11 / 20080: 52$ & 1.91 & 3.5 \\
\hline 2606 & & $8 / 11 / 20080.54$ & 1.91 & 23.5 \\
\hline 2607 & & $20080: 56$ & 1.91 & \\
\hline 2608 & $11 / 20080: 58$ & 20080.58 & 1.911 & 23 \\
\hline 2600 & 1/11/2008 1:00 & $8 / 11 / 20081: 00$ & 1.912 & 23.5 \\
\hline 2610 & & $20081: 02$ & 1.913 & 23. \\
\hline 2611 & & & 1.913 & 23 \\
\hline 2612 & $1 / 11 / 20081: 06$ & $8 / 11 / 20081: 06$ & 1.913 & 23.5 \\
\hline 2613 & & $0081: 08$ & 1.913 & 23. \\
\hline 2614 & & $0081: 10$ & 1.913 & 23. \\
\hline 2615 & 1/11/20081:12 & 2008 1:12 & 1.915 & 23. \\
\hline 2616 & & 2008 1:14 & 1.917 & 23. \\
\hline 2617 & & $0081: 16$ & 1.917 & 23. \\
\hline 2618 & $20081: 18$ & $8 / 11 / 20081: 18$ & 1.917 & 23. \\
\hline 2619 & & $8 / 11 / 20081: 20$ & 1.918 & 23 \\
\hline 2620 & & $1: 2$ & 1.918 & 23. \\
\hline 2621 & & $31: 24$ & 1.918 & 23 \\
\hline 2622 & & $20081: 26$ & 1.919 & 23. \\
\hline 2623 & & $1: 28$ & 1.919 & 23 \\
\hline 2624 & & & 1.919 & 23. \\
\hline 2625 & 1:32 & $8 / 11 / 20081: 32$ & 1.925 & 23. \\
\hline 2626 & & & 1.949 & 23 \\
\hline 2627 & & & 1.919 & 23 \\
\hline 2628 & & $8 / 11 / 20081: 38$ & 1.919 & 23 \\
\hline 2629 & & $20081: 40$ & 1.919 & 23 \\
\hline 2630 & & & 1.919 & 23 \\
\hline 2631 & & $81: 44$ & 1.92 & 23 \\
\hline 2632 & & & 1.92 & 23 \\
\hline 2633 & & & 1.921 & 23 \\
\hline 2634 & & $20081: 50$ & 1.921 & 23 \\
\hline 2635 & & & 1.922 & 23 \\
\hline 2636 & & & 1.922 & 23 \\
\hline 2637 & & $81: 56$ & 1.923 & 23 \\
\hline 2638 & & $81: 58$ & 1.923 & 23 \\
\hline 2639 & & & 1.922 & $\overline{23}$ \\
\hline 2640 & & & 1.922 & \\
\hline 2641 & 204 & $20082: 04$ & 1.922 & \\
\hline 2642 & & & 1.922 & \\
\hline 2643 & & & 1.92 & \\
\hline 2644 & 08210 & 2008210 & 1.921 & 23 \\
\hline 2645 & & & 1.923 & 23 \\
\hline 2646 & & & 1.923 & \\
\hline 2647 & $1 / 11 / 2008216$ & $8 / 11 / 2008216$ & 1.924 & 23 \\
\hline 2648 & & $8 / 11 / 20082: 18$ & 1.924 & 23 \\
\hline 2649 & & & 1.924 & 23 \\
\hline 2650 & $1 / 11 / 2008222$ & $8 / 11 / 2008222$ & 1.924 & 23 \\
\hline 2651 & $1 / 11 / 2008224$ & $8 / 11 / 2008224$ & 1.925 & 23 \\
\hline 2652 & 1/11/20082:26 & $8 / 11 / 2008226$ & 1.925 & 23 \\
\hline
\end{tabular}




\begin{tabular}{|c|c|c|c|c|}
\hline \multicolumn{5}{|c|}{ D4920 } \\
\hline $\operatorname{Rec}$ & & Adjusted & Pressurt & Temp \\
\hline$\#$ & Date-Time & Dater/ime & psi & ${ }^{\circ} \mathrm{C}$ \\
\hline 2653 & $1 / 11 / 20082 \cdot 28$ & $8 / 11 / 20082: 28$ & 1.925 & 23.6 \\
\hline 2654 & $1 / 11 / 2008230$ & $8 / 11 / 20082 ; 30$ & 1.925 & 23.6 \\
\hline 2655 & 1/1/1/2008 2:32 & $8 / 11 / 20082: 32$ & 1.925 & 23.6 \\
\hline 2656 & 1/11/20082:34 & $8 / 11 / 20082: 34$ & 1.925 & 23.7 \\
\hline 2657 & 1/11/20082:36 & $8 / 11 / 20082: 36$ & 1.925 & 23.7 \\
\hline 2658 & 1/11/20082:38 & $8 / 11 / 20082: 38$ & 1.926 & 23.7 \\
\hline 2659 & $1 / 11 / 20082: 40$ & $8 / 11 / 20082: 40$ & 1.926 & 23.8 \\
\hline 2660 & 1/11/20082:42 & $8 / 11 / 20082442$ & 1.927 & 23.8 \\
\hline 2661 & $1 / 11 / 20082: 44$ & $8 / 11 / 20082: 44$ & 1.928 & 23.8 \\
\hline 2662 & $1 / 11 / 20082446$ & $8 / 11 / 20082: 46$ & 1.928 & 23.8 \\
\hline 2663 & $1 / 11 / 20082448$ & $8 / 11 / 20082: 48$ & 1.928 & 23.8 \\
\hline 2664 & $1 / 11 / 20082550$ & $8 / 11 / 20082: 50$ & 1.918 & 23.7 \\
\hline 2665 & $1 / 11 / 20082: 52$ & $8 / 11 / 20082: 52$ & 1.898 & 23.7 \\
\hline 2666 & $1 / 11 / 20082554$ & $8 / 11 / 20082: 54$ & 1.87 & 23.7 \\
\hline 2667 & $1 / 11 / 2008256$ & $8 / 11 / 20082: 56$ & 1.853 & 23.6 \\
\hline 2668 & $1 / 11 / 2008258$ & $8 / 11 / 2008258$ & 1.84 & 23.7 \\
\hline 2669 & $1 / 11 / 20083: 00$ & $8 / 11 / 20083: 00$ & 1.862 & 23.6 \\
\hline 2670 & $1 / 11 / 20083: 02$ & $8 / 11 / 20083: 02$ & 1.883 & 23.6 \\
\hline 2671 & 1/11/20083:04 & $8 / 11 / 20083: 04$ & 1.892 & 23.6 \\
\hline 2672 & 1/11/20083:06 & $8 / 11 / 20083: 06$ & 1.898 & 23.6 \\
\hline 2673 & $1 / 11 / 20083: 08$ & $8 / 11 / 20083: 08$ & 1.901 & 23.6 \\
\hline 2674 & 1/11/2008 3:10 & $8 / 11 / 20083: 10$ & 1.904 & 23.6 \\
\hline 2675 & 1/11/20083:12 & $8 / 11 / 20083: 12$ & 1.905 & 23.6 \\
\hline 2676 & 1/11/2008 3:14 & $8 / 11 / 20083: 14$ & 1.906 & 23.6 \\
\hline 267 & 1/11/2008 3:16 & $8 / 11 / 20083: 16$ & 1.908 & 23.6 \\
\hline 2678 & 1/11/2008 3:18 & $8 / 11 / 20083: 18$ & 1.908 & 23.6 \\
\hline 2679 & 1/11/2008 3:20 & $8 / 11 / 20083: 20$ & 1.909 & 23.6 \\
\hline 2680 & $1 / 11 / 20083: 22$ & $8 / 11 / 20083: 22$ & 1.911 & 23.6 \\
\hline 2681 & 1/11/20083:24 & $8 / 11 / 20083: 24$ & 1.911 & 23.6 \\
\hline 2682 & $1 / 11 / 20083: 26$ & $8 / 11 / 20083: 26$ & 1.912 & 23.6 \\
\hline 2683 & 1/11/2008 3:28 & $8 / 11 / 20083: 28$ & 1.912 & 23.6 \\
\hline 2684 & 1/11/20083:30 & $8 / 11 / 20083: 30$ & 1.913 & 23.6 \\
\hline 2685 & 1/11/2008 3:32 & $8 / 11 / 20083: 32$ & 1.913 & 23.6 \\
\hline 2686 & 1/11/20083:34 & $8 / 11 / 20083: 34$ & 1.913 & 23.6 \\
\hline 2687 & 1/11/2008 3:36 & $8 / 11 / 20083: 36$ & 1.913 & 23.6 \\
\hline 2688 & $1 / 11 / 20083: 38$ & $8 / 11 / 20083: 38$ & 1.914 & 23.6 \\
\hline 2689 & $1 / 11 / 20083: 40$ & $8 / 11 / 20083: 40$ & 1.914 & 23.6 \\
\hline 2690 & 1/11/20083:42 & $8 / 11 / 20083: 42$ & 1.915 & 23.6 \\
\hline 2691 & $1 / 11 / 20083: 44$ & $8 / 11 / 20083: 44$ & 1.916 & 23.6 \\
\hline 2692 & $1 / 11 / 20083: 46$ & $8 / 11 / 20083: 46$ & 1.916 & 23.6 \\
\hline 2693 & $1 / 11 / 20083: 48$ & $8 / 11 / 20083: 48$ & 1.916 & 23.6 \\
\hline 2694 & $1 / 11 / 20083: 50$ & $8 / 11 / 20083: 50$ & 1.917 & 23.6 \\
\hline 2695 & $1 / 11 / 20083: 52$ & $8 / 11 / 20083: 52$ & 1.774 & 23.6 \\
\hline 2696 & $1 / 11 / 20083: 54$ & $8 / 11 / 20083: 54$ & 2337 & 23.5 \\
\hline 2697 & 1/11/20083:56 & $8 / 11 / 20083: 56$ & 1.987 & 225 \\
\hline 2698 & $1 / 11 / 20083: 58$ & $8 / 11 / 20083: 58$ & 1.94 & 22.4 \\
\hline 2699 & 1/11/20084:00 & $8 / 11 / 20084: 00$ & 1.93 & 22.8 \\
\hline 2700 & 1/111/20084:02 & $8 / 11 / 20084: 02$ & 1.926 & 23.1 \\
\hline 2701 & 1/11/20084:04 & $8 / 11 / 20084: 04$ & 1.924 & 23.3 \\
\hline 2702 & 1/11/20084:06 & $8 / 11 / 20084: 06$ & 1.924 & 23.4 \\
\hline 2703 & 1/11/20084:08 & $8 / 11 / 20084: 08$ & 1.923 & 23.6 \\
\hline 2704 & $1 / 11 / 20084: 10$ & $8 / 11 / 20084: 10$ & 1.924 & 23.9 \\
\hline 2705 & 1/11/20084:12 & $8 / 11 / 20084: 12$ & 1.923 & 23.6 \\
\hline 2706 & $1 / 11 / 20084: 14$ & $8 / 11 / 20084: 14$ & 1.923 & 23.6 \\
\hline 2707 & 1/11/20084:16 & $8 / 11 / 20084: 16$ & 1.924 & 23.6 \\
\hline 2708 & $1 / 11 / 20084: 18$ & $8 / 11 / 20084: 18$ & 1.924 & 23.6 \\
\hline 2709 & 1/11/20084:20 & $8 / 11 / 20084: 20$ & 1.923 & 23.6 \\
\hline 2710 & 1/11/20084:22 & $8 / 11 / 20084: 22$ & 1.923 & 23.6 \\
\hline 2711 & 1/11/20084:24 & $8 / 11 / 20084: 24$ & 1.923 & 23.6 \\
\hline 2712 & 1/11/20084:26 & $8 / 11 / 20084: 26$ & 1.923 & 23.6 \\
\hline 2713 & 1/11/20084:28 & $8 / 11 / 20084: 28$ & 1.923 & 23.6 \\
\hline 2714 & $1 / 11 / 20084: 30$ & $8 / 11 / 20084: 30$ & 1.923 & 23.6 \\
\hline 2715 & 1/11/20084:32 & $8 / 11 / 20084: 32$ & 1.923 & 23.7 \\
\hline 2716 & 1/11/20084:34 & $8 / 11 / 20084: 34$ & 1.923 & 23.7 \\
\hline 2717 & 1/11/20084:36 & $8 / 11 / 20084: 36$ & 1.924 & 23.7 \\
\hline 2718 & 1/11/20084:38 & $8 / 11 / 20084: 38$ & 1.924 & 23.7 \\
\hline 2719 & $1 / 11 / 20084: 40$ & $8 / 11 / 20084: 40$ & 1.924 & 23.8 \\
\hline 2720 & $1 / 11 / 20084: 42$ & $8 / 11 / 20084: 42$ & 1.924 & 23.8 \\
\hline
\end{tabular}

\begin{tabular}{|c|c|c|c|c|}
\hline \multicolumn{5}{|c|}{ D4-92p } \\
\hline $\operatorname{Rec}$ & & Adjusted & Pressure & Temp \\
\hline$\#$ & Date/Time & DaterTime & psi & ${ }^{\circ} \mathrm{C}$ \\
\hline 2789 & $1 / 11 / 20087: 00$ & $8 / 11 / 20087: 00$ & 1.908 & 23.9 \\
\hline 2790 & $1 / 11 / 20087: 02$ & $8 / 11 / 20087: 02$ & 1.907 & 23.9 \\
\hline 2791 & $1 / 11 / 20087: 04$ & $8 / 11 / 20087: 04$ & 1.909 & 23.9 \\
\hline 2792 & $1 / 11 / 20087: 06$ & $8 / 11 / 20087: 06$ & 1.911 & 23.9 \\
\hline 2793 & $1 / 11 / 20087: 08$ & $8 / 11 / 20087: 08$ & 1.913 & 23.9 \\
\hline 2794 & 1/11/2008 7:10 & $8 / 11 / 20087: 10$ & 1.91 & 23.9 \\
\hline 2795 & $1 / 11 / 20087: 12$ & $8 / 11 / 20087: 12$ & 1.911 & 23.9 \\
\hline 2796 & $1 / 11 / 20087: 14$ & $8 / 11 / 20087: 14$ & 1.913 & 23.9 \\
\hline 2797 & 1/11/2008 7:16 & $8 / 11 / 20087: 16$ & 1.914 & 23.9 \\
\hline 2798 & 1/11/2008 7:18 & $8 / 11 / 20087: 18$ & 1.914 & 23.8 \\
\hline 2799 & $1 / 11 / 20087: 20$ & $8 / 11 / 20087: 20$ & 1.916 & 23.9 \\
\hline 2800 & $1 / 11 / 20087: 22$ & $8 / 11 / 20087: 22$ & 1.917 & 23.9 \\
\hline 2801 & $1 / 11 / 20087: 24$ & $8 / 11 / 20087: 24$ & 1.918 & 23.9 \\
\hline 2802 & 1/11/2008 7:26 & $8 / 11 / 20087: 26$ & 1.919 & 23.9 \\
\hline 2803 & 1/11/2008 7:28 & $8 / 11 / 20087: 28$ & 1.919 & 23.9 \\
\hline 2804 & $1 / 11 / 20087: 30$ & $8 / 11 / 20087: 30$ & 1.92 & 23.9 \\
\hline 2805 & $1 / 11 / 20087: 32$ & $8 / 11 / 20087: 32$ & 1.921 & 23.9 \\
\hline 2806 & $1 / 11 / 20087: 34$ & $8 / 11 / 20087: 34$ & 1.922 & 24 \\
\hline 2807 & $1 / 11 / 20087: 36$ & $8 / 11 / 20087: 36$ & 1.922 & 23.9 \\
\hline 2808 & $1 / 11 / 20087: 38$ & $8 / 11 / 20087: 38$ & 1.922 & 24 \\
\hline 2809 & $1 / 11 / 20087: 40$ & $8 / 11 / 20087: 40$ & 1.921 & 24 \\
\hline 2810 & $1 / 11 / 20087: 42$ & $8 / 11 / 20087: 42$ & 1.921 & 23.9 \\
\hline 2811 & $1 / 11 / 20087: 44$ & $8 / 11 / 20087: 44$ & 1.92 & 23.9 \\
\hline 2812 & $1 / 11 / 20087: 46$ & $8 / 11 / 20087: 46$ & 1.921 & 23.9 \\
\hline 2813 & $1 / 11 / 20087: 48$ & $8 / 11 / 20087: 48$ & 1.923 & 23.9 \\
\hline 2814 & $1 / 11 / 20087: 50$ & $8 / 11 / 20087: 50$ & 1.923 & 23.9 \\
\hline 2815 & $1 / 11 / 20087: 52$ & $8 / 11 / 20087: 52$ & 1.924 & 23.9 \\
\hline 2816 & $1 / 11 / 20087: 54$ & $8 / 11 / 20087: 54$ & 1.926 & 23.9 \\
\hline 2817 & $1 / 11 / 20087: 56$ & $8 / 11 / 20087: 56$ & 1.926 & 23.9 \\
\hline 2818 & $1 / 11 / 20087: 58$ & $8 / 11 / 20087: 58$ & 1.927 & 23.9 \\
\hline 2819 & $1 / 11 / 20088: 00$ & $8 / 11 / 20088: 00$ & 1.927 & 23.9 \\
\hline 2820 & $1 / 11 / 20088.02$ & $8 / 11 / 20088: 02$ & 1.927 & 23.9 \\
\hline 2821 & $1 / 11 / 20088: 04$ & $8 / 11 / 20088: 04$ & 1.927 & 24 \\
\hline 2822 & $1 / 11 / 20088: 06$ & $8 / 11 / 20088: 06$ & 1.927 & 24 \\
\hline 2823 & $1 / 11 / 20088: 08$ & $8 / 11 / 20088: 08$ & 1.928 & 24 \\
\hline 2824 & 1/11/2008 8:10 & $8 / 11 / 20088: 10$ & 1.929 & 23.9 \\
\hline 2825 & 1/11/2008 8:12 & $8 / 11 / 20088: 12$ & 1.929 & 24.2 \\
\hline 2826 & $1 / 11 / 20088: 14$ & $8 / 11 / 20088: 14$ & 1.93 & 24.3 \\
\hline 2827 & 1/11/2008 8:16 & $8 / 11 / 20088: 16$ & 1.931 & 24.1 \\
\hline 2828 & $1 / 11 / 20088: 18$ & $8 / 11 / 20088: 18$ & 1.931 & 23.9 \\
\hline 2829 & $1 / 11 / 20088: 20$ & $8 / 11 / 20088: 20$ & 1.931 & 23.9 \\
\hline 2830 & $1 / 11 / 20088: 22$ & $8 / 11 / 20088: 22$ & 1.931 & 23.9 \\
\hline 2831 & $1 / 11 / 20088: 24$ & $8 / 11 / 20088: 24$ & 1.931 & 23.9 \\
\hline 2832 & $1 / 11 / 20088: 26$ & $8 / 11 / 20088: 26$ & 1.931 & 23.9 \\
\hline 2833 & $1 / 11 / 20088: 28$ & $8 / 11 / 20088: 28$ & 1.931 & 23.9 \\
\hline 2834 & 1/11/2008 8:30 & $8 / 11 / 20088: 30$ & 1.932 & 23.9 \\
\hline 2835 & $1 / 11 / 20088: 32$ & $8 / 11 / 20088: 32$ & 1.932 & 23.9 \\
\hline 2836 & 1/11/2008 8:34 & $8 / 11 / 20088: 34$ & 1.932 & 23.9 \\
\hline 2837 & $1 / 11 / 20088: 36$ & $8 / 11 / 20088: 36$ & 1.932 & 23.9 \\
\hline 2838 & $1 / 11 / 20088: 38$ & $8 / 11 / 20088: 38$ & 1.914 & 23.9 \\
\hline 2839 & $1 / 11 / 20088: 40$ & $8 / 11 / 20088: 40$ & 1.887 & 23.9 \\
\hline 2840 & $1 / 11 / 20088: 42$ & $8 / 11 / 20088: 42$ & 1.869 & 23.9 \\
\hline 2841 & $1 / 11 / 20088: 44$ & $8 / 11 / 20088: 44$ & 1.881 & 23.9 \\
\hline 2842 & $1 / 11 / 20088: 46$ & $8 / 11 / 20088: 46$ & 1.9 & 23.9 \\
\hline 2843 & $1 / 11 / 20088: 48$ & $8 / 11 / 20088: 48$ & 1.911 & 23.9 \\
\hline 2844 & $1 / 11 / 20088: 50$ & $8 / 11 / 20088: 50$ & 1.917 & 23.9 \\
\hline 2845 & $1 / 11 / 20088: 52$ & $8 / 11 / 20088: 52$ & 1.92 & 23.9 \\
\hline 2846 & $1 / 11 / 20088: 54$ & $8 / 11 / 20088: 54$ & 1.922 & 23.9 \\
\hline 2847 & $1 / 11 / 20088: 56$ & $8 / 11 / 20088: 56$ & 1.924 & 23.9 \\
\hline 2848 & $1 / 11 / 20088: 58$ & $8 / 11 / 20088: 58$ & 1.925 & 23.9 \\
\hline 2849 & $1 / 11 / 20089000$ & $8 / 11 / 20089.00$ & 1.926 & 23.9 \\
\hline 2850 & $1 / 11 / 20089.02$ & $8 / 11 / 20089: 02$ & 1.927 & 23.9 \\
\hline 2851 & $1 / 11 / 20089.04$ & $8 / 11 / 20089: 04$ & 1.927 & 23.9 \\
\hline 2852 & $1 / 11 / 20089.06$ & $8 / 11 / 20089: 06$ & 1.928 & 23.9 \\
\hline 2853 & $1 / 11 / 20089.08$ & $8 / 11 / 20089.08$ & 1.929 & 23.9 \\
\hline 2854 & 1/11/2008 9:10 & $8 / 11 / 20069: 10$ & 1.93 & 23.9 \\
\hline 2855 & $1 / 11 / 20089: 12$ & $8 / 11 / 20089: 12$ & 1.931 & 23.9 \\
\hline 2856 & $1 / 11 / 20089,14$ & $8 / 11 / 20089: 14$ & 1.931 & 23.9 \\
\hline
\end{tabular}




\begin{tabular}{|c|c|c|c|c|}
\hline \multicolumn{5}{|c|}{ D4920 } \\
\hline 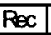 & & Adjusted & Pressure & Temp \\
\hline$\#$ & Dater/Time & DaterTime & psi & ${ }^{\circ} \mathrm{C}$ \\
\hline 2857 & $1 / 11 / 20089.16$ & $8 / 11 / 20089.16$ & 1.931 & 23.9 \\
\hline 2858 & $1 / 11 / 20089.18$ & $8 / 11 / 20089.18$ & 1.932 & \\
\hline 2859 & $1 / 11 / 20089.20$ & $8 / 11 / 20089: 20$ & 1.932 & 23.9 \\
\hline 2860 & $1 / 11 / 2008922$ & $8 / 11 / 2008922$ & 1.933 & 23.9 \\
\hline 2861 & $1 / 11 / 20089.24$ & $8 / 11 / 20089: 24$ & 1.933 & 23.9 \\
\hline 2862 & $1 / 11 / 20089.26$ & $8 / 11 / 20089: 26$ & 1.933 & 23.9 \\
\hline 2863 & $1 / 11 / 20089.28$ & $8 / 11 / 20089: 28$ & 1.933 & 23.9 \\
\hline 2864 & $11 / 20089.30$ & $8 / 11 / 20089: 30$ & 1.923 & 24 \\
\hline 2865 & $1 / 11 / 20089.32$ & $8 / 11 / 20089.32$ & 1.934 & 23.9 \\
\hline 2866 & $11 / 20089.34$ & $8 / 11 / 20089.34$ & 1.934 & \\
\hline 2867 & 1120089.36 & $8 / 11 / 20089.36$ & 1.933 & 24 \\
\hline 2068 & $1 / 11 / 20089.38$ & $8 / 11 / 20089.38$ & 1.934 & 24 \\
\hline 2869 & $11 / 20089: 40$ & $8 / 11 / 20089: 40$ & 1.934 & 24 \\
\hline 280 & $1 / 11 / 20089.42$ & $8 / 11 / 20089.42$ & 1.934 & 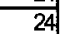 \\
\hline 2871 & $1 / 11 / 20089.44$ & $8 / 11 / 20089.44$ & 1.935 & 24.1 \\
\hline 2872 & $11 / 20089.46$ & $8 / 11 / 20089.46$ & 1.935 & \\
\hline 2873 & $1 / 11 / 20089.48$ & $8 / 11 / 20089.48$ & 1.935 & 24.1 \\
\hline 2874 & & $8 / 11 / 20089: 50$ & 1.935 & 24.1 \\
\hline 2875 & $1 / 11 / 20089.52$ & $8 / 11 / 20089.52$ & 1.935 & 24.1 \\
\hline 2876 & $1 / 1120089.54$ & $8 / 11 / 2008954$ & 1.935 & 24.1 \\
\hline 287 & & $8 / 11 / 20089.56$ & 1.935 & \\
\hline 2878 & $11 / 20089.58$ & $8 / 11 / 20089.58$ & 1.935 & 24.1 \\
\hline 2879 & 0810,00 & $8 / 11 / 200810: 00$ & 1.935 & 24.1 \\
\hline 2880 & 0810,02 & $8 / 11 / 200810: 02$ & 1.936 & 24.1 \\
\hline 2881 & 0810.04 & $8 / 11 / 200810: 04$ & 1.936 & 24.1 \\
\hline 2882 & & $8 / 11 / 200810: 06$ & 1.936 & 24.1 \\
\hline 2883 & 12008 10:08 & $8 / 11 / 200810: 08$ & 1.936 & 24.1 \\
\hline 2884 & 10.10 & $8 / 11 / 2008$ 10:10 & 1.937 & 24.1 \\
\hline 2885 & $1 / 200810.12$ & $8 / 11 / 200810: 12$ & 1.937 & 24. \\
\hline 2836 & $1 / 2008$ 10:14 & $8 / 11 / 2008$ 10:14 & 1.936 & 24.1 \\
\hline 2887 & $1 / 11 / 200810: 16$ & 8/11/2008 10:16 & 1.937 & 24. \\
\hline 2888 & $1 / 11 / 200810.18$ & $8 / 11 / 200810-18$ & 1.937 & 24. \\
\hline 2389 & $10: 20$ & $8 / 1 / 200810: 20$ & 1.937 & 24. \\
\hline 2890 & $1 / 200810.22$ & $8 / 11 / 200810: 22$ & 1.937 & 24.2 \\
\hline 2891 & & $8 / 11 / 200810: 24$ & 1.936 & 24.2 \\
\hline 2892 & $1 / 200810: 26$ & $8 / 11 / 200810: 26$ & 1.937 & 24. \\
\hline 2893 & $1 / 200810: 28$ & $8 / 11 / 200810-28$ & 1.937 & 24.2 \\
\hline 2894 & & 308 10:30 & 1.938 & 24. \\
\hline 239 & 0.32 & $8 / 11 / 200810-32$ & 1.937 & 24 \\
\hline 2896 & & $1 / 2008$ 10:34 & 1.938 & 24. \\
\hline 2897 & & 008 10:36 & 1.938 & 24. \\
\hline 2898 & $11 / 200810.38$ & $8 / 11 / 200810: 38$ & 1.938 & 24. \\
\hline 2899 & & $8 / 11 / 200810-40$ & 1.938 & 24 \\
\hline 2000 & 0.42 & $8 / 11 / 200810: 42$ & 1.938 & 24. \\
\hline 2901 & & $1 / 200810: 44$ & 1.938 & 24. \\
\hline 2902 & & $10: 46$ & 1.938 & 24 \\
\hline 2903 & & $11 / 200810: 48$ & 1.938 & 24. \\
\hline 2004 & & & 1.939 & 24. \\
\hline 2905 & & $8 / 11 / 200810.52$ & 1.938 & 24 \\
\hline 2906 & & 10.54 & 1.937 & 24. \\
\hline 2907 & & & 1.938 & 24. \\
\hline 2908 & & & 1.938 & 24. \\
\hline 2909 & & & 1.937 & 24. \\
\hline 2910 & & 11:02 & 1.937 & 24 \\
\hline 2911 & & & 1.936 & 24. \\
\hline 2912 & & & 1.937 & 24. \\
\hline 2913 & & 11:08 & 1.937 & 24. \\
\hline 2914 & & & 1.938 & 24. \\
\hline 2915 & 1/11/2008 11:12 & $8 / 11 / 200811: 12$ & 1.938 & 24. \\
\hline 2916 & & & 1.938 & 24. \\
\hline 2917 & & & 1.939 & 24. \\
\hline 2018 & $11 / 2008$ 11:18 & $8 / 11 / 200811: 18$ & 1.94 & 24. \\
\hline 2919 & & 8/11/2008 11:20 & 1.941 & 24. \\
\hline 2920 & $11 / 2008$ 11:22 & $8 / 11 / 200811: 22$ & 1.94 & 24. \\
\hline 2921 & $1 / 11 / 2008$ 11:24 & $8 / 11 / 200811: 24$ & 1.94 & 24. \\
\hline 2922 & $11 / 200811: 26$ & $8 / 11 / 200811: 26$ & 1.92 & 24. \\
\hline 2923 & $1 / 2008$ 11:28 & $8 / 11 / 200811 \cdot 28$ & 1.89 & 24 \\
\hline 2024 & $1 / 11 / 200811: 30$ & $8 / 11 / 200811: 30$ & 1.88 & 24 \\
\hline 2925 & $1 / 11 / 200811: 32$ & $8 / 11 / 200811: 32$ & 1.904 & \\
\hline
\end{tabular}

\begin{tabular}{|c|c|c|c|c|}
\hline \multicolumn{5}{|c|}{ D4-929 } \\
\hline $\operatorname{Rec}$ & & Adiusted & Pressura & \\
\hline$\#$ & DaterTime & DaterTime & psi & ${ }^{\circ} \mathrm{C}$ \\
\hline 2926 & 1/11/2008 11:34 & $8 / 11 / 200811: 34$ & 1.915 & 24.4 \\
\hline 2927 & 1/111/2008 11:36 & $8 / 11 / 200811: 36$ & 1.921 & \\
\hline 2928 & $1 / 11 / 200811: 38$ & $8 / 11 / 200811: 38$ & 1.925 & 24.4 \\
\hline 2029 & $1 / 11 / 200811: 40$ & $8 / 11 / 200811: 40$ & 1.927 & \\
\hline 2930 & 1/11/2008 11:42 & $8 / 11 / 200811: 42$ & 1.920 & \\
\hline 2931 & 1/11/2008 11:44 & $8 / 11 / 200811: 44$ & 1.931 & 24. \\
\hline 2932 & 1/11/2008 11:46 & $8 / 11 / 2008$ 11:46 & 1.932 & 24.5 \\
\hline 2933 & 1/11/2008 11:48 & $8 / 11 / 200811: 48$ & & \\
\hline 2934 & 1/11/2008 11:50 & $8 / 11 / 200811: 50$ & 1.934 & 24.5 \\
\hline 2035 & $1 / 11 / 2008$ 11:52 & $8 / 11 / 200811: 52$ & 1.935 & \\
\hline 2936 & $1 / 11 / 200811: 54$ & $0811: 54$ & 1.935 & 24.5 \\
\hline 2937 & $1 / 11 / 200811: 56$ & $30811: 56$ & 1.936 & 24.5 \\
\hline 2938 & & & 1.936 & \\
\hline 2939 & $1 / 11 / 20081200$ & & 1.937 & 24.6 \\
\hline 2940 & $1 / 11 / 20081202$ & 1202 & 1.937 & 24.6 \\
\hline 2041 & $1 / 11 / 20081204$ & 1204 & & \\
\hline 2942 & $1 / 11 / 20081206$ & $8 / 11 / 20081206$ & 1.938 & 24.6 \\
\hline 2043 & $11 / 20081200$ & & 1.938 & 24.6 \\
\hline 2044 & $11 / 20081210$ & 1210 & 1.939 & 24 \\
\hline 2045 & $1 / 11 / 200812: 12$ & $8 / 11$ & 1.939 & 24.6 \\
\hline 2946 & & $2 \cdot 14$ & 1.94 & \\
\hline 2047 & 1/11/2008 12:16 & & 1.94 & 24.6 \\
\hline 2948 & 218 & & 1.94 & 24.6 \\
\hline 2949 & 1220 & & 1.94 & \\
\hline 2050 & & & 1.94 & 24.9 \\
\hline 2051 & & & 1.939 & 24.8 \\
\hline 2952 & $11 / 20081226$ & $2: 26$ & 1.94 & $24 . \varepsilon$ \\
\hline 2953 & 1228 & & 1.94 & 24.7 \\
\hline 2054 & 230 & & 1.941 & \\
\hline 2956 & & & 1.942 & 24.7 \\
\hline 2056 & & & 1.942 & 24.7 \\
\hline 2957) & 236 & 1236 & 1.942 & 24.7 \\
\hline 2058 & 38 & & 1.943 & 24.8 \\
\hline 2059 & 240 & & 1.943 & 24.8 \\
\hline 2960 & & & 1.943 & 24.8 \\
\hline 2061 & & & 1.944 & 24.8 \\
\hline 2064 & $11 / 20081246$ & 1246 & 1.944 & 24. \\
\hline 2063 & & & 1.944 & 24.8 \\
\hline 2064 & & & 1.945 & 24.8 \\
\hline 2060 & & & 1.946 & 25.1 \\
\hline 2060 & & & 1.945 & 24.5 \\
\hline 2967 & 1256 & 1256 & 1.945 & 24.8 \\
\hline 2068 & & & 1.945 & 24.8 \\
\hline 2069 & & & 1.945 & 24.8 \\
\hline 290 & & & 1.946 & 24.8 \\
\hline 2971 & & & 1.948 & \\
\hline 2972 & & & 1.947 & 24. \\
\hline 2973 & & & 1.947 & 24. \\
\hline 2974 & & & 1.947 & 30 \\
\hline 2975 & & & 1.948 & \\
\hline 2976 & & & 1.948 & \\
\hline 2977 & & $13: 16$ & 1.948 & 24. \\
\hline 2978 & & & 1.948 & \\
\hline 2979 & & & 1.948 & \\
\hline 2980 & & & 1.948 & \\
\hline 2981 & & & 1.948 & \\
\hline 2982 & $13: 26$ & $13: 26$ & 1.948 & 24. \\
\hline 2083 & & & 1.948 & 24. \\
\hline 2084 & & & 1.948 & \\
\hline 2986 & & & 1.948 & \\
\hline 2086 & & & 1.948 & \\
\hline 2987 & $13: 36$ & $200813: 36$ & 1.948 & 24. \\
\hline 2988 & & & 1.949 & 24. \\
\hline 2089 & & & 1.95 & \\
\hline 2090 & $11 / 200813: 42$ & $8 / 1 / 200813: 42$ & 1.951 & \\
\hline 2991 & & & 1.951 & \\
\hline 2992 & & $111 / 200813.46$ & 1.961 & 2 \\
\hline 2993 & & $8 / 11 / 2000813: 48$ & 1.951 & 25.1 \\
\hline 2094 & & $8 / 11 / 200813: 50$ & 1.952 & \\
\hline
\end{tabular}

\begin{tabular}{|c|c|c|c|c|}
\hline \multicolumn{5}{|c|}{ D492p } \\
\hline $\mathrm{ReC}$ & & Adusted & Pressurs & \\
\hline$\#$ & DateTime & Dater/me & psi & \\
\hline 2996 & $1 / 11 / 200813: 52$ & $8 / 11 / 200813: 52$ & 1.953 & 25.1 \\
\hline 2906 & $1 / 11 / 200813.54$ & $8 / 11 / 200813: 54$ & 1.953 & \\
\hline 2997 & $1 / 11 / 200813: 56$ & $8 / 11 / 200813: 56$ & 1.963 & 25.2 \\
\hline 2998 & $1 / 11 / 200813.58$ & $8 / 11 / 200813: 58$ & 1.963 & 25.2 \\
\hline 2999 & $1 / 11 / 200814: 00$ & $8 / 11 / 200814: 00$ & 1.954 & \\
\hline 3000 & $1 / 11 / 2008+4: 02$ & $8 / 11 / 2008$ 14:02 & 1.95 & 25 \\
\hline 3001 & $1 / 11 / 200814: 04$ & $8 / 11 / 2008$ 14:04 & 1.964 & 25. \\
\hline 3002 & $11 / 2008$ 14:06 & $8 / 11 / 2008$ 14:06 & 1.964 & 25.3 \\
\hline 3003 & 1/11/2008 14:08 & $8 / 11 / 2008$ 14:08 & 1.964 & 25 \\
\hline 3004 & $11 / 2008$ 14:10 & $8 / 11 / 200814: 10$ & 1.961 & 25 \\
\hline 3005 & $0814: 12$ & $8 / 11 / 2008+4: 12$ & 1.919 & 25 . \\
\hline 3006 & 08 14:14 & $8 / 11 / 200814: 14$ & 1.898 & 25. \\
\hline 3007 & $314: 16$ & $8 / 11 / 200814: 16$ & & \\
\hline 3008 & $0814: 18$ & $8 / 11 / 2008$ 14:18 & 1.902 & \\
\hline 3000 & $8814: 20$ & $8 / 11 / 200814: 20$ & 1.918 & 25 \\
\hline 3010 & & $8 / 11 / 200814: 22$ & 1.926 & \\
\hline 3011 & $814: 24$ & $8 / 11 / 200814: 24$ & 1.902 & \\
\hline 3012 & $14: 26$ & 8/11/2008 14:26 & 1.934 & \\
\hline 3013 & $14: 28$ & $8 / 11 / 200814: 28$ & 1.906 & 25 \\
\hline 3014 & $14: 30$ & $8 / 11 / 200814: 30$ & 1.938 & 25. \\
\hline 3015 & & $8 / 11 / 200814: 32$ & 1.969 & \\
\hline 3016 & $814: 34$ & $8 / 11 / 200814: 34$ & 1.94 & 25. \\
\hline 3017 & $14: 36$ & $8 / 11 / 200814: 36$ & 1.94 & 2 \\
\hline 3018 & & $8 / 11 / 200$ & 1.94 & \\
\hline 3019 & $4: 40$ & $8 / 11 / 2008$ & 1.941 & 25 . \\
\hline 3020 & $14: 42$ & $8 / 11 / 200814: 42$ & 1.892 & 25 . \\
\hline 3021 & 314:44 & $8 / 11 / 200814: 44$ & 1.943 & \\
\hline 3022 & $14: 46$ & $8 / 11 / 200814: 46$ & 1.946 & 25. \\
\hline 3023 & 14:48 & $8 / 11 / 2008$ 14:48 & 1.94 & \\
\hline 3024 & 14:50 & $8 / 11 / 200814: 50$ & 1.947 & 25 . \\
\hline 3025 & & $8 / 11 / 200814: 52$ & 1.799 & \\
\hline 3026 & $814: 54$ & $8 / 11 / 2008$ 14:54 & 1.949 & \\
\hline 3027 & $14: 56$ & $8 / 11 / 200814: 56$ & 1.951 & 25 . \\
\hline 3028 & & $8 / 11 / 200$ & 1.952 & \\
\hline 3029 & & & 1.952 & 25. \\
\hline 3000 & & $5: 02$ & 1.953 & 25 \\
\hline 3031 & & $8 / 11 / 200815: 04$ & 1.953 & \\
\hline 3032 & & & 1.953 & 25 \\
\hline 3003 & & & 1.907 & \\
\hline 3034 & $15: 10$ & $5: 10$ & 1.958 & 25 \\
\hline 3006 & & & 1.96 & \\
\hline 3036 & $5: 14$ & $15: 14$ & 1.96 & 25. \\
\hline 3037 & & & 1.969 & 25. \\
\hline 3038 & & 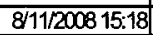 & 1.950 & 25. \\
\hline 3039 & & $75: 20$ & 1.96 & 25 \\
\hline 3040 & & & 1.961 & \\
\hline 3041 & & $5: 24$ & 1.962 & 25 . \\
\hline 3042 & & & 1.962 & 25. \\
\hline 3043 & & & 1.963 & \\
\hline 3044 & & $15: 30$ & 1.963 & 26. \\
\hline 3045 & & & 1.963 & \\
\hline 3046 & & $315: 34$ & 1.964 & 26. \\
\hline 3047 & & & 1.965 & 26. \\
\hline 3048 & & & 1.965 & \\
\hline 3049 & & $15: 40$ & 1.965 & 26. \\
\hline 3050 & & & 1.965 & \\
\hline 3051 & $15: 44$ & $8 / 11 / 200815: 44$ & 1.965 & 26 \\
\hline 3052 & & & 1.966 & \\
\hline 3053 & $5: 48$ & $15: 48$ & 1.966 & \\
\hline 3054 & & $8 / 11 / 200815: 50$ & 1.967 & \\
\hline $305 x$ & & & 1.966 & \\
\hline 3056 & $315: 54$ & $8 / 11 / 200815: 54$ & 1.967 & 26. \\
\hline 3057 & & & 1.967 & \\
\hline 3058 & & $8 / 11 / 200815.58$ & 1.967 & \\
\hline 3050 & $1 / 11 / 200816: 00$ & $8 / 11 / 200816: 00$ & 1.968 & \\
\hline 3060 & & & 1.968 & \\
\hline 3061 & & $8 / 11 / 200816: 04$ & 1.969 & \\
\hline 3062 & $8816: 06$ & $8 / 11 / 200016: 06$ & 1.968 & 26 \\
\hline 3063 & $1 / 11 / 200816: 08$ & & & \\
\hline
\end{tabular}


DOE/RL-2009-35, REV. 0

\begin{tabular}{|c|c|c|c|c|}
\hline \multicolumn{5}{|c|}{ D492p } \\
\hline $\mathrm{ReC}$ & & Adjusted & Pressum & Termp \\
\hline$\#$ & DaterTime & Date/Time & \begin{tabular}{|l|}
$p s i$ \\
\end{tabular} & \\
\hline 3064 & 1/11/2008 16:10 & $8 / 11 / 200816: 10$ & 1.968 & 26.9 \\
\hline 3065 & $1 / 11 / 200816: 12$ & $8 / 11 / 2008$ 16:11 & 1.968 & 26.9 \\
\hline 3066 & $1 / 11 / 200816: 14$ & $8 / 11 / 2008$ 16:14 & 1.969 & 27 \\
\hline 3067 & $1 / 11 / 200816: 16$ & $8 / 11 / 2008$ 16:16 & 1.969 & 27 \\
\hline 3068 & V/11/2008 16:18 & $8 / 11 / 2008$ 16:18 & 1.97 & 27 \\
\hline 3069 & $1 / 11 / 200816: 20$ & $8 / 11 / 200816: 20$ & 1.97 & 27.1 \\
\hline 3070 & $1 / 11 / 2008$ 16:22 & $8 / 11 / 200816: 22$ & 1.97 & 27.1 \\
\hline 3071 & $1 / 11 / 2008$ 16:24 & $8 / 11 / 200816: 24$ & 1.97 & 27.1 \\
\hline 3072 & $1 / 11 / 2008$ 16:26 & $8 / 11 / 200816: 26$ & 1.97 & 27.1 \\
\hline 3073 & $1 / 11 / 200816: 28$ & $8 / 11 / 200816: 28$ & 1.97 & 27.1 \\
\hline 3074 & $1 / 11 / 200816: 30$ & $8 / 11 / 200816: 30$ & 1.971 & 27.1 \\
\hline 3075 & $1 / 11 / 200816: 32$ & $8 / 11 / 2008$ 16:32 & 1.971 & 27.2 \\
\hline 3076 & $1 / 11 / 200816: 34$ & $8 / 11 / 200816: 34$ & 1.972 & 27.2 \\
\hline 3077 & $1 / 11 / 200816: 36$ & $8 / 11 / 2008$ 16:36 & 1.969 & 27.2 \\
\hline 3078 & $1 / 11 / 200816: 38$ & $8 / 11 / 200816: 38$ & 1.966 & 27.3 \\
\hline 3079 & $1 / 11 / 200816: 40$ & $8 / 11 / 2008$ 16:40 & 1.965 & 27.1 \\
\hline 3080 & $1 / 11 / 200816: 42$ & $8 / 11 / 200816: 42$ & 1.965 & 27.1 \\
\hline 3081 & $1 / 11 / 200816: 44$ & $8 / 11 / 2008$ 16:44 & 1.966 & 27.1 \\
\hline 3082 & $1 / 11 / 200816 \cdot 46$ & $8 / 11 / 200816: 46$ & 1.967 & 26.9 \\
\hline 3083 & $1 / 11 / 200816: 48$ & $8 / 11 / 200816: 48$ & 1.967 & 26.9 \\
\hline 3084 & $1 / 11 / 200816.50$ & $8 / 11 / 200816: 50$ & 1.969 & 26.9 \\
\hline 3085 & $1 / 11 / 200816: 52$ & $8 / 11 / 200816: 52$ & 1.968 & 26.8 \\
\hline 3086 & $1 / 11 / 200816.54$ & $8 / 11 / 200816: 54$ & 1.969 & 26.8 \\
\hline 3087 & $1 / 11 / 200816.56$ & $8 / 11 / 200816: 56$ & 1.96 & 26.8 \\
\hline 3088 & $1 / 11 / 200816.58$ & $8 / 11 / 200816: 58$ & 1.932 & 26.8 \\
\hline 3089 & 1/11/2008 17:00 & 8/11/2008 17:00 & 1.902 & 26.8 \\
\hline 3090 & 1/11/2008 17:02 & $8 / 11 / 2008$ 17:0R & 1.914 & 26.7 \\
\hline 3091 & $1 / 11 / 2008$ 17:04 & $8 / 11 / 2008$ 17:04 & 1.931 & 26.9 \\
\hline 3092 & $1 / 11 / 200817: 06$ & $8 / 11 / 2008$ 17:06 & 1.942 & 26.9 \\
\hline 3093 & $1 / 11 / 200817: 08$ & $8 / 11 / 2008$ 17:08 & 1.947 & 26.9 \\
\hline 3094 & $1 / 11 / 200817: 10$ & $8 / 11 / 2008$ 17:10 & 1.948 & 26.9 \\
\hline 3095 & 1/11/2008 17:12 & $8 / 11 / 200817: 12$ & 1.949 & 26.9 \\
\hline 3096 & 1/11/2008 17:14 & $8 / 11 / 2008$ 17:14 & 1.951 & 26.9 \\
\hline 3097 & $1 / 11 / 200817: 16$ & $8 / 11 / 200817: 16$ & 1.953 & 27 \\
\hline 3098 & 1/11/2008 17:18 & $8 / 11 / 200817: 18$ & 1.954 & 27 \\
\hline 3009 & 1/11/2008 17:20 & 8/11/2008 17:20 & 1.954 & 27.1 \\
\hline 3100 & 1/11/2008 17:22 & $8 / 11 / 200817: 22$ & 1.955 & 27.2 \\
\hline 3101 & $1 / 11 / 2008$ 17:24 & $8 / 11 / 2008$ 17:24 & 1.956 & 27.3 \\
\hline 3102 & 1/11/2008 17:26 & $8 / 11 / 200817: 26$ & 1.957 & 27.3 \\
\hline 3103 & $1 / 11 / 2008$ 17:28 & $8 / 11 / 200817: 28$ & 1.958 & 27.3 \\
\hline 3104 & $1 / 11 / 200817: 30$ & $8 / 11 / 200817: 30$ & 1.950 & 27.3 \\
\hline 3105 & $1 / 11 / 2008$ 17:32 & $8 / 11 / 200817: 32$ & 1.950 & 27.3 \\
\hline 3106 & $1 / 11 / 2008$ 17:34 & $8 / 11 / 200817: 34$ & 1.96 & 27.4 \\
\hline 3107 & $1 / 11 / 200817: 36$ & $8 / 11 / 200817: 36$ & 1.96 & 27.4 \\
\hline 3108 & $1 / 11 / 2008$ 17:38 & $8 / 11 / 2006$ 17:38 & 1.961 & 27.4 \\
\hline 3109 & 1/11/2008 17:40 & $8 / 11 / 200817: 40$ & 1.961 & 27.4 \\
\hline 3110 & $1 / 11 / 2008$ 17:42 & $8 / 11 / 2008$ 17:42 & 1.962 & 27.4 \\
\hline 3111 & $1 / 11 / 2008$ 17:44 & $8 / 11 / 200817: 44$ & 1.962 & 27.4 \\
\hline 3112 & $1 / 11 / 2008$ 17:46 & $8 / 11 / 2008$ 17:46 & 1.962 & 27.4 \\
\hline 3113 & $1 / 11 / 2008$ 17:48 & $8 / 11 / 200817: 48$ & 1.963 & 27.4 \\
\hline 3114 & $1 / 11 / 200817: 50$ & $8 / 11 / 200817: 50$ & 1.964 & 27.4 \\
\hline 3115 & 1/11/2008 17:52 & $8 / 11 / 200817: 52$ & 1.965 & 27.4 \\
\hline 3116 & $1 / 11 / 2008$ 17:54 & $8 / 11 / 200817: 54$ & 1.964 & 27.4 \\
\hline 3117 & $1 / 11 / 2008$ 17:56 & $8 / 11 / 2008$ 17:56 & 1.964 & 27.4 \\
\hline 3118 & $1 / 11 / 2008$ 17:58 & $8 / 11 / 200817: 58$ & 1.964 & 27.4 \\
\hline 3119 & $1 / 11 / 200818: 00$ & $8 / 11 / 2008$ 18:00 & 1.966 & 27.4 \\
\hline 3120 & $1 / 11 / 200818.02$ & $8 / 11 / 200818: 02$ & 1.965 & 27.4 \\
\hline 3121 & $1 / 11 / 200818: 04$ & $8 / 11 / 200818: 04$ & 1.966 & 27.4 \\
\hline 3122 & 1/11/2008 18:06 & $8 / 11 / 200818: 06$ & 1.965 & 27.4 \\
\hline 3123 & $1 / 11 / 200818: 08$ & $8 / 11 / 200818: 08$ & 1.967 & 27.4 \\
\hline$\frac{3124}{3124}$ & $1 / 11 / 200818: 10$ & $8 / 11 / 200818: 10$ & 1.967 & 27.4 \\
\hline 3125 & $1 / 11 / 200818: 12$ & $8 / 11 / 200818: 12$ & 1.967 & 27.4 \\
\hline 3126 & 1/11/2008 18:14 & $8 / 11 / 200818: 14$ & 1.967 & 27.4 \\
\hline 3127 & $1 / 11 / 200818: 16$ & $8 / 11 / 200818: 16$ & 1.968 & 27.4 \\
\hline 3128 & 1/11/2008 18:18 & $8 / 11 / 200818: 18$ & 1.969 & 27.5 \\
\hline 3129 & $1 / 11 / 200818: 20$ & $8 / 11 / 200818: 20$ & 1.968 & 275 \\
\hline 3130 & $1 / 11 / 200818-22$ & $8 / 11 / 200818: 22$ & 1.97 & 27.5 \\
\hline 3131 & $1 / 11 / 200818: 24$ & $8 / 11 / 200818: 24$ & 1.963 & 27.4 \\
\hline 3132 & $1 / 11 / 200818: 26$ & $8 / 11 / 200818: 26$ & 1.95 & 27.4 \\
\hline
\end{tabular}

\begin{tabular}{|c|c|c|c|c|}
\hline \multicolumn{5}{|c|}{ D4920 } \\
\hline Rec & & Adusted & Pressurf & Tem \\
\hline$\#$ & Date'Time & Date/Time & $p s i$ & ${ }^{\circ}$ \\
\hline 3133 & 1/11/2008 18:28 & $8 / 11 / 200818: 28$ & 1.967 & \\
\hline 3134 & 11/2008 18:30 & $8 / 11 / 200818: 30$ & 1.97 & 27 \\
\hline 3135 & & $8 / 11 / 200818: 32$ & 1.97 & \\
\hline 3136 & 1/11/2008 18:34 & $8 / 11 / 200818: 34$ & 1.97 & 27. \\
\hline 3137 & $1 / 11 / 200818: 36$ & $8 / 11 / 200818: 36$ & 1.969 & \\
\hline 3138 & $1 / 11 / 200818: 38$ & $8 / 11 / 200818: 38$ & 1.97 & 27. \\
\hline 3139 & $1 / 11 / 2008$ 18:40 & $8 / 11 / 2008$ 18:40 & 1.971 & 27.5 \\
\hline 3140 & $1 / 11 / 200818: 42$ & $8 / 11 / 200818: 42$ & 1.972 & \\
\hline 3141 & $1 / 11 / 2008$ 18:44 & $8 / 11 / 200818: 44$ & 1.972 & 27 \\
\hline 3142 & $1 / 11 / 200818: 46$ & $8 / 11 / 200818: 46$ & 1.972 & 27.6 \\
\hline 3143 & $1 / 11 / 200818: 48$ & $8 / 11 / 200818: 48$ & 1.972 & 27.6 \\
\hline 3144 & $1 / 11 / 200818.50$ & $8 / 11 / 200818: 50$ & 1.972 & 27. \\
\hline 3145 & $1 / 11 / 2008$ 18:52 & $200818: 52$ & 1.973 & 27.8 \\
\hline 3146 & & $0818: 54$ & 1.973 & 27 \\
\hline 3147 & 1/11/2008 18:56 & 200818.56 & 1.974 & 27.6 \\
\hline 3148 & $1 / 11 / 200818: 58$ & $0818: 58$ & 1.974 & \\
\hline 3149 & 1/11/2008 19:00 & 08 19:00 & 1.974 & 27. \\
\hline 3150 & $1 / 11 / 2008$ 19:02 & 0819.02 & 1.974 & 27.6 \\
\hline 3151 & $1 / 11 / 200819.04$ & $819: 04$ & 1.973 & \\
\hline 3152 & $1 / 11 / 200819.06$ & 00819.06 & 1.973 & 27 \\
\hline 3153 & $8 \overline{19.08}$ & 819.08 & 1.973 & 27. \\
\hline 3154 & 19:10 & 319.10 & 1.973 & 27. \\
\hline 3155 & 819.12 & 819.12 & 1.974 & 27.6 \\
\hline 3156 & 19.14 & 199.14 & 1.974 & 27.6 \\
\hline 3157 & 19.16 & 319.16 & 1.974 & \\
\hline 3158 & 19.18 & 319.18 & 1.974 & 27. \\
\hline 3159 & $19: 20$ & 319.20 & 1.974 & 27. \\
\hline 3160 & $19: 2$ & 319.22 & 1.974 & 27. \\
\hline 3161 & 19.24 & 19.24 & 1.975 & 27. \\
\hline 3162 & 19.26 & 19.26 & 1.974 & \\
\hline 3163 & & 19.28 & 1.975 & 27. \\
\hline 3164 & 19.30 & 319.30 & 1.976 & \\
\hline 3165 & $19: 32$ & 319.32 & 1.977 & 27. \\
\hline 3166 & & 19:34 & 1.977 & \\
\hline 3167 & 19:36 & 19.36 & 1.977 & \\
\hline 3168 & & & 1.978 & 27 \\
\hline $31 \%$ & & 19.40 & 1.978 & \\
\hline 3170 & & 19.42 & 1.963 & \\
\hline 3171 & 19.44 & 19.44 & 1.948 & \\
\hline 3172 & 19.46 & & 1.914 & \\
\hline 3173 & & & 1.891 & 27. \\
\hline 3174 & & & 1.878 & \\
\hline 3175 & 19.52 & 19.52 & 1.867 & 27. \\
\hline 3176 & & 19.54 & 1.874 & \\
\hline $317 \pi$ & & & 1.904 & \\
\hline 3178 & & & 1.92 & 27 \\
\hline 3179 & & & 1.932 & \\
\hline 3180 & $00: 02$ & $200-02$ & 1.939 & 27 \\
\hline 3181 & & & & \\
\hline 3182 & & $20: 06$ & 1.945 & \\
\hline 3183 & & & 1.948 & \\
\hline 3184 & & & 1.949 & \\
\hline 3185 & 20.12 & & 1.95 & \\
\hline 3186 & & & & \\
\hline 3187 & & & 1.953 & \\
\hline 3188 & & & 1.954 & \\
\hline 3189 & & & 1.955 & \\
\hline 3190 & & $20: 22$ & 1.956 & \\
\hline 3191 & & & & \\
\hline 3192 & $20: 26$ & $20: 26$ & 1.958 & $2 t$ \\
\hline 3193 & & & 1.962 & \\
\hline 3194 & & & 1.962 & \\
\hline 3195 & 820.32 & $820: 32$ & 1.961 & 21 \\
\hline 3196 & & & 1.962 & \\
\hline 31977) & & & 1.962 & \\
\hline 3198 & 0820.38 & 0820.38 & 1.963 & 27 \\
\hline 3199 & & & & \\
\hline 3200 & $11 / 200820: 42$ & 200820.42 & 1.876 & \\
\hline 3201 & $11 / 200820.44$ & & & \\
\hline
\end{tabular}

\begin{tabular}{|c|c|c|c|c|}
\hline \multicolumn{5}{|c|}{ D492p } \\
\hline$R \otimes C$ & & Adjusted & Pressurs & Tent \\
\hline$\#$ & DaterTime & DaterTime & psi & \\
\hline 3202 & $1 / 11 / 200820: 46$ & $8 / 11 / 200820: 46$ & 1.956 & \\
\hline 3203 & $11 / 200820: 48$ & $8 / 11 / 200820: 48$ & 1.963 & \\
\hline 3204 & & & & \\
\hline 3205 & $1 / 11 / 200820: 52$ & $8 / 11 / 200820.52$ & 1.962 & 27.4 \\
\hline 3206 & $1 / 11 / 200820: 54$ & $8 / 11 / 200820.54$ & 1.963 & \\
\hline 3207 & $1 / 11 / 200820.56$ & & 1.964 & \\
\hline 3208 & $11 / 200820.58$ & $8 / 11 / 200820: 58$ & 1.965 & 27. \\
\hline 3209 & $11 / 200821: 00$ & & & \\
\hline 3210 & 1/11/2008 21:02 & $8 / 11 / 200821: 02$ & 1.966 & \\
\hline 3211 & 1/11/2008 21:04 & $8 / 11 / 200821: 04$ & 1.967 & 27. \\
\hline 3212 & $11 / 200821: 06$ & $8 / 11 / 200821: 06$ & 1.967 & \\
\hline 3213 & 1/11/2008 21:08 & 8/11/200821:08 & 1.967 & 27.4 \\
\hline 3214 & 11/2008 21:10 & $00821: 10$ & 1.968 & \\
\hline 3215 & 11/2008 21:12 & $0821: 12$ & 1.968 & \\
\hline 3216 & $1 / 200821: 14$ & $8 / 11 / 200821: 14$ & 1.969 & 27. \\
\hline 3217 & 21:16 & $821: 16$ & 1.969 & \\
\hline 3218 & 11/2008 21:18 & $821: 18$ & 1.969 & 27 \\
\hline 3219 & $21: 20$ & $321: 20$ & 1.969 & \\
\hline 3220 & 21:22 & & 1.97 & \\
\hline 3221 & 1/11/200821:24 & $0821: 24$ & 1.97 & 27.5 \\
\hline 322 & $21: 26$ & $321: 26$ & 1.971 & \\
\hline 3223 & $21: 28$ & $321: 28$ & 1.971 & \\
\hline 3224 & $21: 30$ & $21: 30$ & 1.972 & 27 \\
\hline 3225 & & & 1.972 & \\
\hline 3226 & $21: 34$ & 321:34 & 1.972 & 7. \\
\hline 3227 & 36 & $21: 36$ & 1.971 & 27 \\
\hline 3228 & & $21: 38$ & 1.971 & \\
\hline 3229 & & $21: 40$ & 1.972 & \\
\hline 3230 & & & 1.972 & \\
\hline 3231 & $21: 44$ & $21: 44$ & 1.972 & \\
\hline 3232 & 1:46 & 21:46 & 1.973 & \\
\hline 3233 & & 1:48 & 1.973 & \\
\hline 3234 & & $21: 50$ & 1.974 & \\
\hline 3235 & & $21: 52$ & 1.974 & \\
\hline 3236 & $21: 54$ & $21: 54$ & 1.974 & 7 \\
\hline 3237 & & $21: 56$ & 1.975 & \\
\hline 3238 & & & 1.975 & \\
\hline 3239 & & 2200 & 1.975 & \\
\hline 3240 & & & 1.975 & 27 \\
\hline 3241 & 22.04 & 2204 & 1.976 & 27 \\
\hline 3242 & & & 1.977 & \\
\hline 3243 & 208 & 2208 & 1.977 & \\
\hline 3244 & 210 & $22: 10$ & 1.977 & \\
\hline 3245 & & 2212 & 1.978 & \\
\hline 3246 & 214 & 2214 & 1.978 & \\
\hline 3247 & & $22: 16$ & 1.979 & \\
\hline 3248 & $2: 18$ & 2218 & 1.979 & \\
\hline 3249 & & 220 & 1.98 & \\
\hline 3250 & & & 1.981 & \\
\hline 3251 & 22.24 & & 1.98 & \\
\hline 3252 & & & 1.979 & \\
\hline 3253 & $22: 28$ & & 1.979 & \\
\hline 3254 & & & 1.98 & \\
\hline 3255 & & & 1.98 & \\
\hline 3256 & 2234 & 32234 & 1.981 & 27 \\
\hline 3257 & & & 1.985 & \\
\hline 3258 & 2238 & 2238 & 1.961 & \\
\hline 3259 & & & 1.942 & \\
\hline 3260 & & & 1.925 & \\
\hline 3261 & 2244 & 82244 & 1.91 & \\
\hline 3262 & & & 1.891 & \\
\hline 3263 & & & 1878 & \\
\hline 3264 & 82250 & 82250 & 1.869 & \\
\hline 3265 & & & 1.861 & \\
\hline 3266 & $11 / 200822: 54$ & 282254 & 1.856 & 27 \\
\hline 3267 & 32256 & & 1.85 & \\
\hline 3268 & 32258 & 322.58 & 1.846 & \\
\hline 3269 & 11/2008 23:00 & $08<5: 00$ & 1.842 & \\
\hline 3270 & $11 / 200823: 02$ & & 1.846 & \\
\hline
\end{tabular}




\begin{tabular}{|c|c|c|c|c|}
\hline \multicolumn{5}{|c|}{ D4928 } \\
\hline $\mathrm{ReC}$ & & Adjusted & Pressure & Temp \\
\hline$\#$ & DaterTime & Dete-Time & psi & ${ }^{\circ} \mathrm{C}$ \\
\hline 3271 & 1/11/2008 23:04 & $8 / 11 / 200823: 04$ & 1.885 & 27.1 \\
\hline 3272 & $1 / 11 / 200823: 06$ & $8 / 11 / 200823: 06$ & 1.907 & 27.1 \\
\hline 3273 & 1/11/200823:08 & $8 / 11 / 200823: 08$ & 1.919 & 27.1 \\
\hline 3274 & $1 / 11 / 200823: 10$ & $8 / 11 / 200823: 10$ & 1.927 & 27.1 \\
\hline 3275 & 1/111/2008 23:12 & $8 / 11 / 200823: 12$ & 1.932 & 27.1 \\
\hline 3276 & 1/11/200823:14 & $8 / 11 / 200823: 14$ & 1.937 & 27.1 \\
\hline 327 & $1 / 11 / 200823: 16$ & 8/11/200823:16 & 1.94 & 27.1 \\
\hline 3278 & $1 / 11 / 200823: 18$ & 8/11/200823:18 & 1.942 & 27.1 \\
\hline 3279 & 1/111/200823:20 & $8 / 11 / 200823: 20$ & 1.944 & 27.1 \\
\hline 3280 & $1 / 11 / 200823: 22$ & $8 / 11 / 200823: 22$ & 1.946 & 27.1 \\
\hline 3281 & $1 / 11 / 200823: 24$ & $8 / 11 / 200823: 24$ & 1.948 & 27.1 \\
\hline 3282 & 1/11/200823:26 & $8 / 11 / 200823: 26$ & 1.949 & 27.1 \\
\hline 3283 & 1/11/200823:28 & $8 / 11 / 200823: 28$ & 1.951 & 27.1 \\
\hline 3284 & $1 / 11 / 200823: 30$ & $8 / 11 / 200823: 30$ & 1.953 & 27.1 \\
\hline 3285 & 1/11/200823:32 & $8 / 11 / 200823: 32$ & 1.954 & 27.1 \\
\hline 3286 & 1/11/200823:34 & $8 / 11 / 200823: 34$ & 1.955 & 27.1 \\
\hline 3287 & 1/11/200823:36 & $8 / 11 / 200823: 36$ & 1.956 & 27.1 \\
\hline 3288 & 1/11/200823:38 & $000823: 38$ & 1.959 & 27.1 \\
\hline 3289 & $1 / 11 / 200823: 40$ & $000823: 40$ & 1.96 & 27.1 \\
\hline 3290 & 1/11/200823:42 & $200823: 42$ & 1.962 & 27.1 \\
\hline 3291 & $1 / 11 / 200823: 44$ & $200823: 44$ & 1.962 & 27.1 \\
\hline 3292 & $1 / 11 / 200823: 46$ & $200823: 46$ & 1.963 & 27.1 \\
\hline 3293 & $1 / 11 / 200823: 48$ & $200823: 48$ & 1.964 & 27.1 \\
\hline 3294 & $1 / 11 / 200823: 50$ & $200823: 50$ & 1.964 & 27.6 \\
\hline 3295 & $1 / 11 / 200823: 52$ & $200823: 52$ & 1.966 & 27.1 \\
\hline 3296 & $1 / 11 / 200823: 54$ & $200823: 54$ & 1.966 & 27.3 \\
\hline 3297 & $1 / 11 / 200823: 56$ & $2823: 56$ & 1.965 & 27.1 \\
\hline 3298 & $1 / 11 / 200823: 58$ & $200823: 58$ & 1.967 & 27.1 \\
\hline 3299 & 1/12/20080:00 & 0080.00 & 1.967 & 27 \\
\hline 3300 & $1 / 12 / 20080: 02$ & 0080.02 & 1.967 & 27 \\
\hline 3301 & 1/1220000:04 & $0080: 04$ & 1.968 & 27 \\
\hline 3302 & 80.06 & 080.06 & 1.969 & 26.9 \\
\hline 3303 & $80: 08$ & $20080: 08$ & 1.97 & 26.9 \\
\hline 3304 & $1 / 1220080: 10$ & $8 / 12 / 20080: 10$ & 1.97 & 26.9 \\
\hline 3305 & $30: 12$ & 80.12 & 1.971 & 26.9 \\
\hline 3306 & $1 / 12200080: 14$ & $080: 14$ & 1.971 & 26.9 \\
\hline 3307 & 1/1220080:16 & $8 / 12 / 20080: 16$ & 1.972 & 26.9 \\
\hline 3308 & $0: 18$ & $80: 18$ & 1.972 & 26.9 \\
\hline 3309 & $1 / 12 / 200$ & $080: 20$ & 1.973 & 26.9 \\
\hline 3310 & $1 / 1220080.22$ & $8 / 12 / 20080: 22$ & 1.974 & 26.9 \\
\hline 3311 & 0.24 & 30:24 & 1.975 & 26.9 \\
\hline 3312 & $1 / 1220080.26$ & 80.26 & 1.816 & 26.9 \\
\hline 3313 & 0.28 & 80.28 & 1.972 & 26.9 \\
\hline 3314 & 0.30 & $80: 30$ & 1.975 & 26.8 \\
\hline 3315 & $20080: 32$ & $080: 32$ & 1.976 & 26.8 \\
\hline 3316 & & 30:34 & 1.976 & 26.8 \\
\hline 3317 & 0.36 & $80: 36$ & 1.977 & 26.8 \\
\hline 3318 & 20080.38 & $2 / 20080: 38$ & 1.977 & 26.8 \\
\hline 3319 & & & 1.978 & 26.8 \\
\hline 3320 & 30.42 & $08: 0: 42$ & 1.978 & 26.8 \\
\hline 3321 & $1 / 12 / 20080.44$ & $2,20080: 44$ & 1.978 & 26.8 \\
\hline 3322 & & $20080: 46$ & 1.979 & 26.8 \\
\hline 3323 & $20080: 48$ & $080: 48$ & 1.979 & 26.8 \\
\hline 3324 & 0.50 & $8: 50$ & 1.979 & 26.8 \\
\hline 3325 & & & 1.979 & 26.8 \\
\hline 3326 & 20080.54 & 20080.54 & 1.98 & 26.8 \\
\hline 3327 & 20080.56 & 80.56 & 1.981 & 26.8 \\
\hline 3328 & & & 1.981 & 26.8 \\
\hline 3329 & $20081: 00$ & $0081: 00$ & 1.982 & 26.8 \\
\hline 3330 & $20081: 02$ & $081: 02$ & 1.983 & 26.8 \\
\hline 3331 & & & 1.983 & 26.8 \\
\hline 3332 & 1/12/2008 1:06 & $8 / 12 / 20081: 06$ & 1.982 & 26.8 \\
\hline 3333 & $20081: 08$ & $220081: 08$ & 1.983 & 26.8 \\
\hline 3334 & $5001: 10$ & $2 / 20081: 10$ & 1.983 & 26.8 \\
\hline 3335 & $1 / 12 / 20081: 12$ & $8 / 12 / 2008$ 1:12 & 1.983 & 26.8 \\
\hline 3336 & 1/12/2008 1:14 & $8 / 12 / 2008$ 1:14 & 1.983 & 26.8 \\
\hline 3337 & $1 / 1220081: 16$ & $8 / 12 / 20081: 16$ & 1.984 & 26.8 \\
\hline 3338 & 1/12/2008 1:18 & $8 / 12 / 2008$ 1:18 & 1.984 & 26.8 \\
\hline 3339 & 1/12/2008 1:20 & $8 / 12 / 20081: 20$ & 1.984 & 26.8 \\
\hline
\end{tabular}

\begin{tabular}{|c|c|c|c|c|}
\hline \multicolumn{5}{|c|}{$04-929$} \\
\hline $\mathrm{ReC}$ & & Adjusted & Pressure & Temp \\
\hline$\#$ & Date/Time & DaterTime & $p s i$ & ${ }^{\circ} \mathrm{C}$ \\
\hline 3340 & $1 / 12 / 20081: 22$ & $8 / 12 / 20081: 22$ & 1.984 & 26.8 \\
\hline 3341 & $1 / 12 / 20081: 24$ & $8 / 12 / 20081: 24$ & 1.985 & 26.8 \\
\hline 3342 & $1 / 12 / 20081: 26$ & $8 / 1220081: 26$ & 1.986 & 26.8 \\
\hline 3343 & $1 / 12 / 20081: 28$ & $8 / 12 / 20081: 28$ & 1.987 & 26.8 \\
\hline 3344 & 1/12/2008 1:30 & $8 / 12 / 20081: 30$ & 1.986 & 26.8 \\
\hline 3345 & $1 / 12 / 20081: 32$ & $8 / 12 / 20081: 32$ & 1.985 & 26.7 \\
\hline 3346 & $1 / 12 / 20081: 34$ & $8 / 12 / 20081: 34$ & 1.985 & 26.7 \\
\hline 3347 & 1/12/2008 1:36 & $8 / 12 / 20081: 36$ & 1.986 & 26.7 \\
\hline 3348 & 1/12/2008 1:38 & $8 / 12 / 20081: 38$ & 1.987 & 26.7 \\
\hline 3349 & 1/12/2008 1:40 & $8 / 12 / 20081: 40$ & 1.984 & 26.7 \\
\hline 3350 & 1/12/2008 1:42 & $8 / 12 / 20081: 42$ & 1.965 & 26.7 \\
\hline 3351 & 1/12/2008 1:44 & $8 / 12 / 20081: 44$ & 1.923 & 26.7 \\
\hline 3352 & $1 / 12 / 20081: 46$ & $8 / 12 / 20081: 46$ & 1.898 & 26.7 \\
\hline 3353 & $1 / 12 / 20081: 48$ & $8 / 12 / 20081: 48$ & 1.88 & 26.7 \\
\hline 3354 & $1 / 12 / 20081: 50$ & $8 / 12 / 20081: 50$ & 1.868 & 26.7 \\
\hline 3355 & $1 / 12 / 20081: 52$ & $8 / 12 / 2008$ 1:52 & 1.891 & 26.6 \\
\hline 3356 & $1 / 12 / 20081: 54$ & $8 / 12 / 20081: 54$ & 1.92 & 26.6 \\
\hline 3357 & $1 / 12 / 20081: 56$ & $8 / 12 / 20081: 56$ & 1.936 & 26.6 \\
\hline 3358 & $1 / 12 / 20081: 58$ & $8 / 12 / 20081: 58$ & 1.945 & 26.6 \\
\hline 3359 & $1 / 122008200$ & $8 / 12 / 20082: 00$ & 1.951 & 26.6 \\
\hline 3360 & $1 / 12 / 2008202$ & $8 / 12 / 20082002$ & 1.954 & 26.6 \\
\hline 3361 & $1 / 12 / 2008204$ & $8 / 12 / 20082: 04$ & 1.956 & 26.6 \\
\hline 3362 & $1 / 12 / 2008206$ & $8 / 12 / 20082006$ & 1.957 & 26.6 \\
\hline 3363 & $1 / 12 / 2008208$ & $8 / 12 / 2008208$ & 1.959 & 26.6 \\
\hline 3364 & $1 / 12 / 2008210$ & $8 / 12 / 20082: 10$ & 1.961 & 26.6 \\
\hline 3365 & $1 / 12 / 2008212$ & $8 / 12 / 20082: 12$ & 1.962 & 26.5 \\
\hline 3366 & $1 / 12 / 20082,14$ & $8 / 12 / 20082: 14$ & 1.962 & 26.5 \\
\hline 3367 & 1/12/20082:16 & $8 / 12 / 20082: 16$ & 1.963 & 26.5 \\
\hline 3368 & $1 / 12 / 20082: 18$ & $8 / 12 / 20082: 18$ & 1.964 & 26.5 \\
\hline 3369 & $1 / 12 / 2008220$ & $8 / 12 / 2008220$ & 1.965 & 26.5 \\
\hline 3370 & $1 / 12 / 2008222$ & $8 / 12 / 20082: 2$ & 1.966 & 26.5 \\
\hline 3371 & $1 / 12 / 2008224$ & $8 / 12 / 2008224$ & 1.967 & 26.4 \\
\hline 3372 & $1 / 12 / 20082226$ & $8 / 12 / 20082: 26$ & 1.968 & 26.4 \\
\hline 3373 & $1 / 12 / 2008228$ & $8 / 12 / 20082: 28$ & 1.969 & 26.4 \\
\hline 3374 & $1 / 12 / 2008230$ & $8 / 12 / 2008230$ & 1.969 & 26.4 \\
\hline 3375 & $1 / 12 / 2008232$ & $8 / 12 / 20082: 32$ & 1.969 & 26.4 \\
\hline 3376 & $1 / 12 / 2008234$ & $8 / 12 / 20082-34$ & 1.97 & 26.4 \\
\hline 3377 & $1 /\{2 / 2008236$ & $8 / 12 / 20082336$ & 1.97 & 26.4 \\
\hline 3378 & $1 / 12 / 2008238$ & $8 / 12 / 20082: 38$ & 1.97 & 26.4 \\
\hline 3379 & $1 / 12 / 2008240$ & $8 / 12 / 20082: 40$ & 1.971 & 26.4 \\
\hline 3380 & $1 / 12 / 2008242$ & $8 / 12 / 20082: 42$ & 1.972 & 26.4 \\
\hline 3381 & $1 / 12 / 2008244$ & $8 / 12 / 20082: 44$ & 1.974 & 26.4 \\
\hline 3382 & $1 / 12 / 2008246$ & $8 / 72 / 20082: 46$ & 1.975 & 26.4 \\
\hline 3383 & $1 / 12 / 2008248$ & $8 / 12 / 20082: 48$ & 1.975 & 26.4 \\
\hline 3384 & $1 / 12 / 2008250$ & $8 / 12 / 2008250$ & 1.975 & 26.3 \\
\hline 3385 & $1 / 12 / 2008252$ & $8 / 12 / 2008252$ & 1.976 & 26.3 \\
\hline 3386 & $1 / 12 / 2008254$ & $8 / 12 / 2008254$ & 1.976 & 26.3 \\
\hline 3387 & $1 / 12 / 2008256$ & $8 / 12 / 20082556$ & 1.976 & 26.3 \\
\hline 3388 & $1 / 12 / 2008258$ & $8 / 12 / 20082: 58$ & 1.977 & 26.3 \\
\hline 3389 & 1/12/20083:00 & $8 / 12 / 20083: 00$ & 1.977 & 26.3 \\
\hline 3390 & 1/12/20083:02 & $8 / 12 / 20083: 02$ & 1.977 & 26.3 \\
\hline 3391 & 1/12/2008 3:04 & $8 / 12 / 20083: 04$ & 1.977 & 26.3 \\
\hline 3392 & $1 / 12 / 20083: 06$ & $8 / 12 / 20083: 06$ & 1.977 & 26.3 \\
\hline 3393 & $1 / 12 / 20083: 08$ & $8 / 12 / 20083: 08$ & 1.977 & 26.3 \\
\hline 3394 & 1/12/20083:10 & $8 / 12 / 20083: 10$ & 1.978 & 26.3 \\
\hline 3395 & 1/12/20083:12 & $8 / 12 / 20083: 12$ & 1.979 & 26.3 \\
\hline 3396 & 1/12/20083:14 & $8 / 12 / 20083: 14$ & 1.979 & 26.2 \\
\hline 3397 & 1/12/20083:16 & $8 / 12 / 20083: 16$ & 1.98 & 26.3 \\
\hline 3398 & 1/12/2008 3:18 & $8 / 12 / 20083: 18$ & 1.98 & 26.3 \\
\hline 3399 & 1/12/20083:20 & $8 / 12 / 20083: 20$ & 1.98 & 26.3 \\
\hline 3400 & $1 / 12 / 20083: 22$ & $8 / 12 / 20083: 22$ & 1.98 & 26.2 \\
\hline 3401 & $1 / 12 / 20083: 24$ & $8 / 12 / 20083: 24$ & 1.98 & 26.2 \\
\hline 3402 & $1 / 12 / 20083: 26$ & $8 / 12 / 20083: 26$ & 1.981 & 26.2 \\
\hline 3403 & $1 / 12 / 20083: 28$ & $8 / 12 / 20083: 28$ & 1.982 & 26.2 \\
\hline 3404 & 1/12/20083:30 & 8/12/20083:30 & 1.982 & 26.2 \\
\hline 3405 & $1 / 12 / 20083: 32$ & $8 / 12 / 20083: 32$ & 1.981 & 26.2 \\
\hline 3406 & $1 / 12 / 20083: 34$ & $8 / 12 / 20083: 34$ & 1.981 & 26.2 \\
\hline 3407 & $1 / 12 / 20083: 36$ & $8 / 12 / 20083: 36$ & 1.982 & 26.2 \\
\hline 3408 & 1/12/20083:38 & $8 / 12 / 20083: 38$ & 1.983 & 26.2 \\
\hline
\end{tabular}

\begin{tabular}{|c|c|c|c|c|}
\hline \multicolumn{5}{|c|}{ D492p } \\
\hline Rec & & Adjusted & Fressure 7 & Temp \\
\hline$\#$ & Date/Time & Dete/Time & psi & ${ }^{\circ} \mathrm{C}$ \\
\hline 3409 & $1 / 12 / 20083: 40$ & $8 / 12 / 20083: 40$ & 1.983 & 26.1 \\
\hline 3410 & $1 / 12 / 20083: 42$ & $8 / 12 / 20083: 42$ & 1.983 & 26.1 \\
\hline 3411 & $1 / 12 / 20083: 44$ & $8 / 12 / 20083: 44$ & 1.984 & 26.1 \\
\hline 3412 & $1 / 12 / 20083: 46$ & $8 / 12 / 20083: 46$ & 1.984 & 26.1 \\
\hline 3413 & $1 / 12 / 20083: 48$ & $8 / 12 / 20083: 48$ & 1.984 & 26.1 \\
\hline 3414 & $1 / 12 / 20083: 50$ & $8 / 12 / 20083: 50$ & 1.984 & 26.1 \\
\hline 3415 & 1/12/20083:52 & $8 / 12 / 20083: 52$ & 1.984 & 26.1 \\
\hline 3416 & 1/12/20083:54 & $8 / 12 / 20083: 54$ & 1.984 & 26.1 \\
\hline 3417 & 1/12/20083:56 & $8 / 12 / 20083: 56$ & 1.985 & 26.1 \\
\hline 3418 & 1/12/20083:58 & $8 / 12 / 20083: 58$ & 1.986 & 26.1 \\
\hline 3419 & 1/12/20084:00 & $8 / 12 / 20084: 00$ & 1.987 & 26.1 \\
\hline 3420 & 1/12/20084:02 & $8 / 12 / 20084: 02$ & 1.988 & 26.1 \\
\hline 3421 & 1/12/20084:04 & $8 / 12 / 2008$ 4:04 & 1.988 & 26.1 \\
\hline 3422 & 1/12/20084:06 & $8 / 12 / 20084: 06$ & 1.988 & 26.1 \\
\hline 3423 & $1 / 12 / 20084: 08$ & $8 / 12 / 20084: 08$ & 1.988 & 26.1 \\
\hline 3424 & 1/12/20084:10 & $8 / 12 / 20084: 10$ & 1.988 & 26.1 \\
\hline 3425 & $1 / 12 / 20084: 12$ & $8 / 12 / 20084: 12$ & 1.988 & 26.1 \\
\hline 3426 & $1 / 12 / 20084: 14$ & $8 / 12 / 20084: 14$ & 1.988 & 26.1 \\
\hline 3427 & $1 / 12 / 20084: 16$ & $8 / 12200084: 16$ & 1.919 & 26.1 \\
\hline 3428 & $1 / 12 / 20084: 18$ & $8 / 12 / 20084: 18$ & 1.984 & 26.1 \\
\hline 3429 & $1 / 12 / 20084: 20$ & $8 / 1220084: 20$ & 1.994 & 26.1 \\
\hline 3430 & $1 / 12 / 20084: 22$ & $8 / 12 / 20084: 22$ & 1.977 & 26 \\
\hline 3431 & $1 / 12 / 20084: 24$ & $8 / 12 / 20084: 24$ & 1.987 & 26.1 \\
\hline 3432 & 1/12/20084:26 & $8 / 12 / 20084: 26$ & 1.988 & 26.1 \\
\hline 3433 & $1 / 12 / 20084: 28$ & $8 / 12 / 20084: 28$ & 1.988 & 26 \\
\hline 3434 & $1 / 12 / 20084: 30$ & $8 / 12 / 20084: 30$ & 1.986 & 26 \\
\hline 3435 & $1 / 12 / 20084: 32$ & $8 / 12 / 20084: 3$ & 1.945 & 26 \\
\hline 3436 & $1 / 12 / 20084: 34$ & $8 / 12 / 20084: 34$ & 1.911 & 26 \\
\hline 3437 & 1/12/20084:36 & $8 / 12 / 20084: 36$ & 1.889 & 26 \\
\hline 3438 & 1/12/20084:38 & $8 / 12 / 20084: 38$ & 1.912 & 26 \\
\hline 3439 & $1 / 12 / 20084: 40$ & $8 / 12 / 20084: 40$ & 1.931 & 26 \\
\hline 3440 & $1 / 12 / 20064: 42$ & $8 / 12 / 20084: 42$ & 1.94 & 26 \\
\hline 3441 & $1 / 12 / 20084: 44$ & $8 / 12 / 20084: 44$ & 1.952 & 25.9 \\
\hline 3442 & $1 / 12 / 20084: 46$ & $8 / 12 / 20084: 46$ & 1.963 & 25.9 \\
\hline 3443 & 1/12/2008 4:48 & $8 / 12 / 20084: 48$ & 1.968 & 25.9 \\
\hline 3444 & $1 / 12 / 20084: 50$ & $8 / 12 / 20084: 50$ & 1.97 & 25.9 \\
\hline 3445 & $1 / 12 / 20084: 52$ & $8 / 12 / 20084: 52$ & 1.971 & 25.9 \\
\hline 3446 & 1/1/2/20084:54 & $8 / 12 / 20084: 54$ & 1.97 & 25.9 \\
\hline 3447 & $1 / 12 / 20084: 56$ & $8 / 12 / 20084: 56$ & 1.971 & 25.9 \\
\hline 3448 & $1 / 12 / 20084: 58$ & $8 / 12 / 20084: 58$ & 1.971 & 25.9 \\
\hline 3449 & 1/12/20085:00 & $8 / 12 / 20085: 00$ & 1.973 & 25.9 \\
\hline 3450 & $1 / 12 / 20085: 02$ & $8 / 12 / 20085: 02$ & 1.975 & 25.9 \\
\hline 3451 & 1/12/20085:04 & $8 / 12 / 20085: 04$ & 1.977 & 25.9 \\
\hline 3452 & $1 / 12 / 20085: 06$ & $8 / 12 / 20085: 06$ & 1.978 & 25.9 \\
\hline 3453 & $1 / 12 / 20085: 08$ & $8 / 12 / 20085: 08$ & 1.978 & 25.9 \\
\hline 3454 & $1 / 12 / 20085: 10$ & $8 / 12 / 20085: 10$ & 1.979 & 25.9 \\
\hline 3455 & 1/12/20085:12 & $8 / 12 / 20085: 12$ & 1.979 & 25.9 \\
\hline 3456 & 1/12/20085:14 & $8 / 12 / 20085: 14$ & 1.979 & 25.9 \\
\hline 3457 & 1/12/20085:16 & $8 / 12 / 20085: 16$ & 1.98 & 25.9 \\
\hline 3458 & 1/12/20085:18 & $8 / 12 / 20085: 18$ & 1.979 & 26.3 \\
\hline 3459 & $1 / 42 / 20085: 20$ & $8 / 12 / 20085: 20$ & 1.98 & 26.4 \\
\hline 3460 & 1/12/20085:22 & $8 / 12 / 20085: 2$ & 1.981 & 26 \\
\hline 3461 & $1 / 12 / 20085: 24$ & $8 / 12 / 20085: 24$ & 1.982 & 25.9 \\
\hline 3462 & $1 / 12 / 20085: 26$ & $8 / 12 / 20085: 26$ & 1.983 & 25.9 \\
\hline 3463 & $1 / 12 / 20085: 28$ & $8 / 12 / 20085: 28$ & 1.983 & 25.9 \\
\hline 3464 & $1 / 12 / 20085: 30$ & $8 / 12 / 20085: 30$ & 1.983 & 25.9 \\
\hline 3465 & 1/12/20085:32 & $8 / 12 / 20085: 32$ & 1.983 & 25.9 \\
\hline 3466 & 1/12/2008 5:34 & $8 / 12 / 20085: 34$ & 1.985 & 25.9 \\
\hline 3467 & 1/12/20085:36 & $8 / 12 / 20085: 36$ & 1.985 & 25.9 \\
\hline 3468 & 1/12/20085:38 & $8 / 12 / 20085: 38$ & 1.985 & 25.9 \\
\hline 3469 & $1 / 12 / 20085: 40$ & $8 / 12 / 20085: 40$ & 1.985 & 25.9 \\
\hline 3470 & $1 / 12 / 20065: 42$ & $8 / 12 / 20085: 42$ & 1.986 & 25.9 \\
\hline 3471 & $1 / 12 / 20085: 44$ & $8 / 12 / 20085: 44$ & 1.986 & 25.9 \\
\hline 3472 & $1 / 12 / 20065: 46$ & $8 / 12 / 20085: 46$ & 1.986 & 25.9 \\
\hline 3473 & $1 / 12 / 20085: 48$ & $8 / 12 / 20085: 48$ & 1.987 & 25.8 \\
\hline 3474 & $1 / 12 / 20085: 50$ & $8 / 12 / 20085: 50$ & 1.987 & 25.8 \\
\hline 3475 & $1 / 12 / 20085: 52$ & $8 / 12 / 20085: 52$ & 1.987 & 25.8 \\
\hline 3476 & $1 / 12 / 20085: 54$ & $8 / 12 / 20085: 54$ & 1.988 & 25.9 \\
\hline $34 \pi$ & 1/12/20085:56 & $8 / 12 / 20085: 56$ & 1.988 & 25.8 \\
\hline
\end{tabular}


DOE/RL-2009-35, REV. 0

\begin{tabular}{|c|c|c|c|c|}
\hline \multicolumn{5}{|c|}{ D492p } \\
\hline Rec & & Adjusted & Pressurg & Temp \\
\hline$\#$ & DaterTime & DaterTime & psi & ${ }^{\circ} \mathrm{C}$ \\
\hline 3478 & $2 / 20085: 58$ & $8 / 12 / 20085: 58$ & 1.989 & \\
\hline 3479 & $2 / 20086: 00$ & $8 / 12 / 20086: 00$ & 1.989 & \\
\hline 3480 & $2 / 20086: 02$ & $8 / 12 / 20086002$ & 1.991 & \\
\hline 3481 & $2 / 20086: 04$ & $8 / 12 / 20086: 04$ & 1.991 & \\
\hline 3482 & $2 / 20086: 06$ & $8 / 12 / 20086: 06$ & 1.991 & 25 . \\
\hline 3483 & $2 / 20086: 08$ & $8 / 1220086: 08$ & 1.99 & \\
\hline 3484 & $12 / 20086: 10$ & $8 / 12 / 20086: 10$ & 1.99 & 25 \\
\hline 3485 & $2 / 20086: 12$ & $8 / 12 / 20086: 12$ & 1.989 & \\
\hline 3436 & $2 / 20086: 14$ & $8 / 12 / 20086: 14$ & 1.99 & \\
\hline 3487 & $12120086: 16$ & $8 / 12 / 20086: 16$ & 1.991 & 25. \\
\hline 3488 & $2 / 20086: 18$ & $8 / 12 / 20086: 18$ & 1.991 & $\Delta$. \\
\hline 3489 & $86: 20$ & $8 / 12 / 20086: 20$ & 1.991 & \\
\hline 3490 & $2 / 20086: 22$ & $8 / 12 / 20086: 22$ & 1.991 & 25. \\
\hline 3491 & $6: 24$ & $8 / 12 / 20086: 24$ & 1.99 & \\
\hline 3492 & $6: 26$ & $8 / 12 / 20086: 26$ & 1.991 & 25 \\
\hline 3493 & $86: 28$ & $8 / 12 / 2008628$ & 1.991 & 25. \\
\hline 3494 & 6:30 & $8 / 12 / 20086: 30$ & 1.991 & \\
\hline 3495 & 6.32 & $8 / 12 / 20086: 32$ & 1.991 & $\overline{25}$ \\
\hline 3496 & $6: 34$ & $8 / 12 / 20086: 34$ & 1.991 & 25. \\
\hline 3497 & & $8 / 12 / 20086: 36$ & 1.992 & \\
\hline 3498 & $2 / 20086: 38$ & $8 / 12 / 20086: 38$ & 1.992 & \\
\hline 3499 & $6: 40$ & $8 / 12 / 20086: 40$ & 1.992 & \\
\hline 3500 & $6: 42$ & $8 / 12 / 20086: 42$ & 1.992 & \\
\hline 3501 & & $8 / 12 / 20086: 44$ & 1.992 & 2 \\
\hline 3502 & & $8 / 12 / 20086: 46$ & 1.993 & \\
\hline 3503 & $36: 48$ & $8 / 12 / 20086: 48$ & 1.993 & \\
\hline 3504 & & $8 / 12 / 20$ & 1.992 & 25. \\
\hline 3505 & $6: 52$ & $8 / 12 / 20086: 52$ & 1.993 & \\
\hline 3506 & & $8 / 12 / 20086: 54$ & 1.993 & 25 \\
\hline 3507 & & $8 / 12 / 20$ & 1.993 & \\
\hline 3508 & 6:58 & $8 / 12 / 20086: 58$ & 1.994 & \\
\hline 3509 & & $8 / 12 / 200$ & 1.994 & 25. \\
\hline 3510 & & $8 / 12 / 20087: 02$ & 1.994 & \\
\hline 3511 & $37: 04$ & $8 / 12 / 20087: 04$ & 1.996 & \\
\hline 3512 & & $8 / 12 / 20$ & 1.996 & \\
\hline 3513 & 7:08 & $8 / 12 / 20$ & 1.995 & \\
\hline 3514 & & $37: 10$ & 1.994 & 20. \\
\hline 3515 & & $8 / 12 / 20$ & 1.994 & \\
\hline 3516 & $7: 14$ & $8 / 12 / 20087: 14$ & 1.995 & \\
\hline 3517 & & $312 / 20$ & 1.995 & \\
\hline 3518 & 7:18 & $112 / 200$ & 1.996 & \\
\hline 3519 & & & 1.993 & \\
\hline 3520 & & $77: 22$ & 1.962 & \\
\hline 3521 & & $8 / 12 / 20$ & 1.945 & \\
\hline 3522 & & & 1.918 & \\
\hline 3523 & & $7: 28$ & 1.893 & \\
\hline 3524 & & & 1.874 & \\
\hline 3525 & & & 1.861 & \\
\hline 3526 & $7: 34$ & $8 / 12 / 20$ & 1.853 & \\
\hline 3527 & & & 1.846 & \\
\hline 3528 & & $12 / 20$ & 1.892 & \\
\hline 3529 & & & 1.926 & \\
\hline 3530 & & & 1.945 & \\
\hline 3531 & & $112 / 200$ & 1.957 & \\
\hline 3532 & & & 1.963 & \\
\hline 3633 & & $7: 48$ & 1.968 & \\
\hline 3634 & & & 1.972 & \\
\hline 3535 & & & 1.974 & \\
\hline 3536 & $1 / 12 / 20$ & $8 / 12 / 20087: 54$ & 1.975 & \\
\hline 3537 & & & 1.975 & \\
\hline 3538 & & $12 / 20$ & 1.978 & \\
\hline 3539 & & $112 / 20088: 00$ & 1.979 & \\
\hline 3540 & & $12 / 20088: 02$ & 1.98 & \\
\hline 3541 & $1 / 12 / 20$ & $8 / 12 / 20088: 04$ & 1.981 & \\
\hline 3542 & $1 / 12 / 20$ & $8 / 12 / 20088: 06$ & 1.982 & \\
\hline 3543 & & $8 / 12 / 20088: 08$ & 1.983 & \\
\hline 3544 & $38: 10$ & 8/12/20088:10 & 1.997 & \\
\hline 3545 & & $8 / 12 / 20088: 12$ & 1.977 & \\
\hline 3546 & & $8 / 12 / 20088: 14$ & & \\
\hline
\end{tabular}

\begin{tabular}{|c|c|c|c|c|}
\hline \multicolumn{5}{|c|}{ D4920 } \\
\hline $\mathrm{Rec}$ & & Adjusted & Pressure & Temp \\
\hline$\#$ & DaterTime & DateTime & $\mathrm{psi}$ & ${ }^{\circ} \mathrm{C}$ \\
\hline 3547 & $1 / 12 / 20088: 16$ & $8 / 12 / 20088: 16$ & 1.972 & 25.6 \\
\hline 3548 & $1 / 12 / 20088: 18$ & $8 / 12 / 20088: 18$ & 1.982 & 25.6 \\
\hline 3549 & $1 / 12 / 20088: 20$ & $8 / 12 / 20088: 20$ & 1.983 & 25.6 \\
\hline 3550 & 1/1220088:22 & $8 / 12 / 20088: 22$ & 1.984 & 25.6 \\
\hline 3551 & $1 / 12 / 20088: 24$ & $8 / 12 / 20088: 24$ & 1.984 & 25.6 \\
\hline 3552 & $1 / 12 / 20088: 26$ & $8 / 12 / 20088: 26$ & 1.986 & 25.6 \\
\hline 3553 & $1 / 12 / 20088: 28$ & $8 / 12 / 20088: 28$ & 1.987 & 25.6 \\
\hline 3554 & $1 / 12 / 20088: 30$ & $8 / 12 / 20088: 30$ & 1.987 & 25.8 \\
\hline 3555 & 1/12/20088:32 & $8 / 12 / 20088: 32$ & 1.988 & 25.6 \\
\hline 3556 & 1/12/2008 8:34 & $8 / 12 / 20088: 34$ & 1.989 & 25.6 \\
\hline 3557 & $1 / 12 / 20088: 36$ & $8 / 12 / 20088: 36$ & 1.99 & 25.6 \\
\hline 3558 & $1 / 1220088: 38$ & $8 / 12 / 20088: 38$ & 1.992 & 25.6 \\
\hline 3550 & $1 / 12 / 20088: 40$ & $8 / 12 / 20088: 40$ & 1.994 & 25.8 \\
\hline 3560 & $1 / 12 / 20088: 42$ & $8 / 12 / 20088: 42$ & 1.994 & 25.7 \\
\hline 3561 & $1 / 12 / 20088: 44$ & $8 / 12 / 20088: 44$ & 1.995 & 25.6 \\
\hline 3562 & $1 / 1220088: 46$ & 8/12/20088:46 & 1.991 & 25.6 \\
\hline 3563 & $1 / 12 / 20088: 48$ & $8 / 12 / 20088: 48$ & 1.969 & 25.6 \\
\hline 3564 & $1 / 12 / 20088: 50$ & $8 / 12 / 20088: 50$ & 1.996 & 25.6 \\
\hline 3565 & $1 / 12 / 20088: 52$ & $8 / 12 / 20088: 52$ & 1.996 & 25.6 \\
\hline 3566 & $1 / 12 / 20088: 54$ & $8 / 12 / 20088: 54$ & 1.997 & 25.6 \\
\hline 3567 & $1 / 1220088: 56$ & $8 / 12 / 20088: 56$ & 1.998 & 25.6 \\
\hline 3568 & $1 / 12 / 20088: 58$ & $8 / 12 / 20088: 58$ & 1.999 & 25.6 \\
\hline 3569 & $1 / 12 / 20089.00$ & $8 / 12 / 20089: 00$ & 1.998 & 25.6 \\
\hline 3570 & $1 / 12 / 20089: 02$ & $8 / 12 / 20089: 02$ & 1.999 & 25.6 \\
\hline 3571 & $1 / 12 / 20089: 04$ & $8 / 12 / 20089: 04$ & 2 & 25.6 \\
\hline $3 \overline{72}$ & $1 / 12 / 20089.06$ & $8 / 12 / 20089: 06$ & 2 & 25.6 \\
\hline 3573 & $1 / 12 / 20089: 08$ & $8 / 12 / 20089: 08$ & 1.999 & 25.6 \\
\hline 3574 & $1 / 12 / 20089.10$ & $8 / 12 / 20089 \cdot 10$ & 1.999 & 25.6 \\
\hline 3575 & $1 / 12 / 20089: 12$ & $8 / 12 / 20089: 12$ & 2 & 25.6 \\
\hline 3576 & $1 / 12 / 20089.14$ & $8 / 12 / 20089: 14$ & 2 & 25.6 \\
\hline $35 \pi$ & $1 / 12 / 20089: 16$ & $8 / 12 / 20089: 16$ & 2 & 25.6 \\
\hline 3578 & $1 / 12 / 20089.18$ & $8 / 12 / 20089: 18$ & 2001 & 25.6 \\
\hline 3579 & $1 / 12 / 20089.20$ & $8 / 12 / 20089: 20$ & 2002 & 25.6 \\
\hline 3580 & $1 / 12 / 20089.22$ & $8 / 12 / 20089 \cdot 22$ & 2002 & 25.6 \\
\hline 3581 & $1 / 12 / 20089: 24$ & $8 / 12 / 20089: 24$ & 2.003 & 25.6 \\
\hline 3582 & $1 / 12220089: 26$ & $8 / 12 / 20089.26$ & 2004 & 25.6 \\
\hline 3583 & $1 / 12 / 20089.28$ & $8 / 12 / 20089: 28$ & 2003 & 25.6 \\
\hline 3584 & $1 / 12 / 20089.30$ & $8 / 12 / 20089: 30$ & 2003 & 25.6 \\
\hline 3585 & $1 / 12 / 20089.32$ & $8 / 12 / 20089: 32$ & 2003 & 25.6 \\
\hline 3586 & $1 / 12 / 20089.34$ & $8 / 12 / 20089: 34$ & 2003 & 25.6 \\
\hline 3587 & $1 / 12220089: 36$ & $8 / 12 / 20089: 36$ & 2003 & 25.6 \\
\hline 3588 & $1 / 12 / 20089.38$ & $8 / 12 / 20089.38$ & 2003 & 25.6 \\
\hline 3589 & $1 / 12 / 20089.40$ & $8 / 12 / 20089: 40$ & 2003 & 25.6 \\
\hline 3590 & $1 / 12 / 20089: 42$ & $8 / 12 / 20089: 42$ & 2004 & 25.6 \\
\hline 3591 & $1 / 12220089: 44$ & $8 / 12 / 20089: 44$ & 2004 & 25.6 \\
\hline 3592 & $1 / 12 / 20089.46$ & $8 / 12 / 20089.46$ & 2005 & 25.6 \\
\hline 3593 & $1 / 12 / 20089.48$ & $8 / 12 / 20089: 48$ & 2006 & 25.6 \\
\hline 3594 & $1 / 12 / 20089.50$ & $8 / 12 / 20089: 50$ & 2006 & 25.6 \\
\hline 3595 & $1 / 12 / 20089.52$ & $8 / 12 / 20089: 52$ & 2006 & 25.6 \\
\hline 3506 & $1 / 12 / 20089.54$ & $8 / 12 / 20089554$ & 2007 & 25.6 \\
\hline 3597 & 1/12/20089:56 & $8 / 12 / 20089.56$ & 2007 & 25.6 \\
\hline 3598 & $1 / 12 / 20089.58$ & $8 / 12 / 20089.58$ & 2004 & 25.6 \\
\hline 3599 & 1/12/2008 10:00 & $8 / 12 / 200810: 00$ & 2001 & 25.6 \\
\hline 3600 & $1 / 12 / 2008$ t0:02 & $8 / 12 / 2008$ 10:02 & 1.999 & 25.9 \\
\hline 3601 & $1 / 12 / 2008$ 10:04 & $8 / 12 / 200810: 04$ & 1.999 & 26.2 \\
\hline 3602 & 1/12/2008 10:06 & $8 / 12 / 200810-06$ & 1.999 & 26.3 \\
\hline 3603 & 1/12/2008 10:08 & $8 / 12 / 200810: 08$ & 1.999 & 26.3 \\
\hline 3604 & $1 / 12 / 200810: 10$ & $8 / 12 / 2008$ 10:10 & 2.001 & 26.3 \\
\hline 3605 & 1/12/2008 10:12 & $8 / 12 / 2008$ 10:12 & 2002 & 26.3 \\
\hline 3606 & $1 / 12 / 200810: 14$ & $8 / 12 / 200810: 14$ & 2003 & 26.3 \\
\hline 3607 & 1/12/2008 10:16 & 8/12/2008 10:16 & 2.004 & 26.4 \\
\hline 3608 & 1/12/2008 10:18 & $8 / 12 / 2008$ 10:18 & 2002 & 26 \\
\hline 3600 & $1 / 12 / 200810: 20$ & $8 / 12 / 200810: 20$ & 1.98 & 26.1 \\
\hline 3610 & $1 / 12 / 200810: 22$ & $8 / 12 / 200810: 22$ & 1.953 & 26.1 \\
\hline 3611 & $1 / 12 / 200810: 24$ & $8 / 12 / 200810: 24$ & 1.919 & 26.3 \\
\hline 3612 & $1 / 12 / 200810-26$ & $8 / 12 / 200810: 26$ & 1.955 & 25.9 \\
\hline 3613 & $1 / 12 / 200810 \cdot 28$ & $8 / 12 / 200810: 28$ & 1.976 & 25.9 \\
\hline 3614 & $1 / 12 / 200810: 30$ & $8 / 12 / 2008$ 10:30 & \begin{tabular}{|l|}
1.987 \\
\end{tabular} & 25.8 \\
\hline 3615 & 1/12/2008 10:32 & $8 / 12 / 2008$ 10:32 & 1.992 & 25.8 \\
\hline
\end{tabular}

\begin{tabular}{|c|c|c|c|c|}
\hline \multicolumn{5}{|c|}{ D4-920 } \\
\hline $\operatorname{Rec}$ & & Adjusted & Pressurg & Temp \\
\hline$\#$ & Date/Time & DaterTime & psi & ${ }^{\circ} \mathrm{C}$ \\
\hline 3616 & 1/12/2008 10:34 & $8 / 12 / 200810: 34$ & 1.994 & 25.8 \\
\hline 3617 & $1 / 12 / 2008$ 10:36 & $8 / 12 / 200810: 36$ & 1.996 & 25.8 \\
\hline 3618 & 1/12/2008 10:38 & $8 / 12 / 200810.38$ & 1.998 & 25.9 \\
\hline 3619 & $1 / 122000810: 40$ & $8 / 12 / 200810: 40$ & 1.999 & 25.9 \\
\hline 3620 & $1 / 12 / 200810: 42$ & $8 / 12 / 200810: 42$ & 2.002 & 25.9 \\
\hline 3621 & $1 / 12 / 200810: 44$ & $8 / 12 / 200810: 44$ & 2003 & 26 \\
\hline 3622 & $1 / 12 / 200810: 46$ & $8 / 12 / 200810: 46$ & 2004 & 26 \\
\hline 3623 & $1 / 12 / 200810: 48$ & $8 / 12 / 200810: 48$ & 2006 & 26.1 \\
\hline 3624 & $1 / 12 / 200810: 50$ & $8 / 12 / 200810: 50$ & 2007 & 26.1 \\
\hline 3625 & $1 / 12 / 200810: 52$ & $8 / 12 / 200810.52$ & 2.008 & 26.1 \\
\hline 3626 & $1 / 12 / 200810: 54$ & $8 / 12 / 200810: 54$ & 2009 & 26.1 \\
\hline 3627 & $1 / 12 / 200810: 56$ & $8 / 12 / 200810: 56$ & 2.009 & 26.4 \\
\hline 3628 & $1 / 12 / 200810: 58$ & $8 / 12 / 200810: 58$ & 2011 & 26.3 \\
\hline 3629 & 1/12/2008 11:00 & $8 / 12 / 200811: 00$ & 2.012 & 26.3 \\
\hline 3630 & 1/12/2008 11:02 & $8 / 12200811: 02$ & 2013 & 26.3 \\
\hline 3631 & 1/12/2008 11:04 & $8 / 12 / 200811: 04$ & 2.013 & 26.3 \\
\hline 3632 & 1/12/2008 11:06 & $8 / 12 / 200811: 06$ & 2.014 & 26.6 \\
\hline 3633 & 1/12/2008 11:08 & $8 / 12 / 200811: 08$ & 2014 & 26.4 \\
\hline 3634 & 1/12/2008 11:10 & $8 / 12 / 200811: 10$ & 2.015 & 26.4 \\
\hline 3635 & $1 / 12 / 200811: 12$ & $8 / 12 / 200811: 12$ & 2014 & 26.4 \\
\hline 3636 & $1 / 122000811: 14$ & $8 / 12 / 200811: 14$ & 2012 & 26.4 \\
\hline 3637 & 1/12/2008 11:16 & $8 / 12 / 200811: 16$ & 2013 & 26.4 \\
\hline 3638 & 1/12/2008 11:18 & $8 / 12 / 200811: 18$ & 2.014 & 26.4 \\
\hline 3639 & 1/12/2008 11:20 & $8 / 12 / 200811: 20$ & 2.015 & 26.4 \\
\hline 3640 & 1/12/2008 11:22 & $8 / 12 / 200811: 22$ & 2017 & 26.4 \\
\hline 3641 & 1/12/2008 11:24 & $8 / 12 / 200811: 24$ & 2017 & 26.5 \\
\hline 3642 & 1/12/2008 11:26 & $8 / 12 / 200811: 26$ & 2.017 & 26.4 \\
\hline 3643 & $1 / 12 / 200811: 28$ & $8 / 12 / 200811: 28$ & 2.017 & 26.4 \\
\hline 3644 & $1 / 12 / 200811: 30$ & $8 / 12 / 200811: 30$ & 2.019 & 26.5 \\
\hline 3645 & 1/12/2008 11:32 & $8 / 12 / 200811: 32$ & 202 & 26.6 \\
\hline 3646 & 1/12/2008 11:34 & $8 / 12 / 200811: 34$ & 202 & 26.5 \\
\hline 3647 & 1/12/2008 11:36 & $8 / 12 / 200811: 36$ & 2.021 & 26.6 \\
\hline 3648 & $1 / 12 / 200811: 38$ & $8 / 12 / 200811: 38$ & 2022 & 27.1 \\
\hline 3649 & $1 / 12 / 200811: 40$ & $8 / 12 / 200811: 40$ & 2.023 & 27 \\
\hline 3650 & 1/12/2008 11:42 & $8 / 12 / 200811: 42$ & 2.023 & 26.8 \\
\hline 3651 & 1/12/2008.11:44 & $8 / 12 / 200811: 44$ & 2023 & 26.7 \\
\hline 3652 & 1/12/2008 11:46 & $8 / 12 / 2008$ 11:46 & 2.024 & 26.6 \\
\hline 3653 & 1/12/2008 11:48 & $8 / 12 / 200811: 48$ & 1.963 & 26.6 \\
\hline 3654 & $1 / 12 / 200811: 50$ & $8 / 12 / 200811: 50$ & 2.013 & 26.6 \\
\hline 3655 & $1 / 12 / 2008$ 11:52 & $8 / 12 / 200811: 52$ & 2019 & 26.6 \\
\hline 3656 & $1 / 12200811: 54$ & $8 / 12 / 200811: 54$ & 2.02 & 26.6 \\
\hline 3657 & 1/12/2008 11:56 & $8 / 12 / 200811: 56$ & 2.021 & 26.6 \\
\hline 3658 & $1 / 12 / 200811: 58$ & $8 / 12 / 200811: 58$ & 2.02 & 26.7 \\
\hline 3659 & $1 / 12 / 200812: 00$ & $8 / 12 / 20081200$ & 2.018 & 26.8 \\
\hline 3660 & 1/12/2008 12:02 & $8 / 12 / 20081202$ & 2.018 & 26.8 \\
\hline 3661 & $1 / 12 / 2008$ 12:04 & $8 / 12 / 20081204$ & 2.007 & 26.8 \\
\hline 3662 & 1/12/2008 12:06 & $8 / 12 / 20081206$ & 2.021 & 26.8 \\
\hline 3663 & $1 / 12 / 20081208$ & $8 / 12 / 20081208$ & 2.022 & 26.8 \\
\hline 3664 & $1 / 12 / 200812: 10$ & $8 / 12 / 200812: 10$ & 2023 & 26.8 \\
\hline 3665 & $1 / 12 / 200812: 12$ & $8 / 12 / 200812: 12$ & 2.022 & 26.8 \\
\hline 3666 & $1 / 122008$ 12:14 & $8 / 12 / 200812: 14$ & 2.024 & 26.8 \\
\hline 3667 & 1/12/2008 12:16 & $8 / 12 / 20081216$ & 2.024 & 26.8 \\
\hline 3668 & $1 / 12 / 200812: 18$ & $8 / 12 / 200812: 18$ & 2.025 & 26.8 \\
\hline 3669 & $1 / 12 / 200812: 20$ & $8 / 12 / 200812: 20$ & 2.026 & 26.9 \\
\hline 3670 & 1/12/2008 12:22 & $8 / 12 / 20081222$ & 2.027 & 26.9 \\
\hline 3671 & 1/12/2008 12:24 & $8 / 12 / 2008$ 12:24 & 2020 & 26.9 \\
\hline 3672 & 1/12/2008 12:26 & $8 / 12 / 200812: 26$ & 203 & 26.9 \\
\hline 3673 & & $8 / 12 / 200812: 28$ & 203 & 26.9 \\
\hline 3674 & $1 / 12 / 2008$ 12:30 & $8 / 12 / 200812: 30$ & 2028 & 26.9 \\
\hline 3675 & $1 / 12 / 200812: 32$ & $8 / 12 / 200812: 32$ & 2028 & 26.9 \\
\hline 3676 & 1/12/2008 12:34 & $8 / 12 / 200812: 34$ & 2.029 & 26.9 \\
\hline 3677 & $1 / 12 / 200812,36$ & $8 / 12 / 20081236$ & 203 & 26.9 \\
\hline 3678 & 1/12/200812:38 & $8 / 12200812: 38$ & 2029 & 26.9 \\
\hline 3679 & $1 / 12 / 2008+2: 40$ & $8 / 12 / 200812: 40$ & 2.033 & 26.9 \\
\hline 3680 & $1 / 12 / 200812442$ & $8 / 12 / 200812: 42$ & 2033 & 26.9 \\
\hline 3681 & $1 / 12 / 200812444$ & $8 / 12 / 200812: 44$ & 2.033 & 26.9 \\
\hline 3682. & $1 / 12200812: 46$ & $8 / 12 / 200812: 46$ & 2.033 & 27.1 \\
\hline 3683 & $1 / 12 / 200812: 48$ & $8 / 12 / 200812: 48$ & 2032 & 27.1 \\
\hline 3684 & $1 / 12 / 200812: 50$ & $8 / 12 / 20081250$ & 2033 & 27.3 \\
\hline
\end{tabular}




\begin{tabular}{|c|c|c|c|c|}
\hline \multicolumn{5}{|c|}{ D492p } \\
\hline Rec & & Adusted & Pressure & Temp \\
\hline$\#$ & Date/Time & DaterTime & psi & ${ }^{\circ} \mathrm{C}$ \\
\hline 3685 & $1 / 12 / 20081252$ & $8 / 12 / 20081252$ & 2003 & 27.1 \\
\hline 3686 & $1 / 12 / 200812: 54$ & $8 / 12 / 20081254$ & 2034 & 27.1 \\
\hline 3687 & $1 / 12 / 20081256$ & $8 / 2 / 20081256$ & 2034 & 27.5 \\
\hline 3688 & $1 / 12 / 200812-58$ & $8 / 12 / 20081258$ & 2.035 & 27.2 \\
\hline 3689 & $1 / 12 / 200813: 00$ & $8 / 12 / 200813: 00$ & 2.034 & 27.2 \\
\hline 3600 & $1 / 12 / 200813: 02$ & $8 / 12 / 200813: 02$ & 2.036 & 27.2 \\
\hline 3691 & $1 / 12 / 200813: 04$ & $8 / 12 / 200813: 04$ & 2.036 & 27.2 \\
\hline 3692 & $1 / 12 / 200813: 06$ & $8 / 12 / 200813: 06$ & 2029 & 27.2 \\
\hline 3693 & $1 / 12 / 200813: 08$ & $812 / 200813: 08$ & 2001 & 27.3 \\
\hline 3694 & $1 / 12 / 200813: 10$ & $8 / 12 / 200813: 10$ & 1.949 & 27.3 \\
\hline 3696 & $1 / 12 / 200813: 12$ & $8 / 12 / 200813: 12$ & 1.953 & 27.3 \\
\hline 3696 & $1 / 12 / 2008$ 13:14 & $8 / 12 / 20081314$ & 1.984 & 27.2 \\
\hline 3697 & $1 / 12 / 200813: 16$ & $812 / 200813: 16$ & 2006 & 27.2 \\
\hline 3698 & $1 / 12 / 200813: 18$ & $8 / 12 / 200813: 18$ & 2013 & 27.4 \\
\hline 3099 & $1 / 12200013: 20$ & $8 / 12 / 200813: 20$ & 2016 & 27.3 \\
\hline 3700 & $1 / 12 / 200813: 22$ & $8 / 12 / 200813: 22$ & 20 & 27.2 \\
\hline 3701 & $1 / 12 / 200813: 24$ & $8 / 12 / 20081324$ & 2021 & 27.2 \\
\hline 3702 & $1 / 12 / 200813: 26$ & $8 / 12 / 200813: 26$ & 2023 & 27.3 \\
\hline 3703 & $1 / 12 / 200813: 28$ & $8 / 12 / 200813: 28$ & 2026 & 27.3 \\
\hline 3704 & $1 / 12 / 200813: 30$ & $8 / 12 / 20081330$ & 2.026 & 27.3 \\
\hline 3705 & 1/12/2008 13:32 & $8 / 12 / 20081332$ & 2.027 & 27.3 \\
\hline 3706 & $1 / 12 / 200813: 34$ & $8 / 12 / 20081334$ & 2029 & 27.3 \\
\hline 3707 & $1 / 12 / 200813: 36$ & $8 / 12 / 200813: 36$ & 2020 & 27.3 \\
\hline 3708 & $1 / 122000813: 38$ & $8 / 12 / 200813: 38$ & 2.031 & 27.4 \\
\hline 3709 & $1 / 12 / 200813: 40$ & $8 / 2 / 200813: 40$ & 2033 & 27.4 \\
\hline 3710 & $1 / 12 / 200813: 42$ & $8 / 12 / 200813: 42$ & 2034 & 27.4 \\
\hline 3711 & $1 / 12 / 200813: 44$ & $8 / 12 / 200813: 44$ & 2.037 & 27.4 \\
\hline 3712 & $1 / 12 / 200813: 46$ & $812 / 200813: 46$ & 2037 & 27.4 \\
\hline 3713 & $1 / 12 / 200813: 48$ & $8 / 12 / 200813: 48$ & 2.037 & 27.4 \\
\hline 3714 & $1 / 12 / 200813: 50$ & $812 / 20081350$ & 2037 & 27.4 \\
\hline 3715 & $1 / 12 / 200813: 52$ & $8 / 12 / 200813.52$ & 2037 & 27.4 \\
\hline 3716 & 1/12/2008 13:54 & $8 / 12 / 200813: 54$ & 204 & 27.5 \\
\hline 3717 & $1 / 12 / 200813: 56$ & $8 / 12 / 200813: 56$ & 2.041 & 27.5 \\
\hline 3718 & $1 / 12 / 200813: 58$ & $8 / 12 / 200813: 58$ & 2.04 & 27.5 \\
\hline 3719 & $1 / 12 / 200814: 00$ & $8 / 12 / 200814: 00$ & 2.04 & 27.5 \\
\hline 3720 & $1 / 12 / 200814: 02$ & $8 / 12 / 2008$ 14:02 & 2042 & 27.5 \\
\hline 3721 & $1 / 12 / 200814: 04$ & $8 / 12 / 200814: 04$ & 2042 & 27.5 \\
\hline 372 & $1 / 122000814: 06$ & $8122200814: 06$ & 2044 & 27.6 \\
\hline 3723 & $1 / 12 / 200814: 08$ & $8 / 12 / 2008$ 14:08 & 2045 & 27.6 \\
\hline 3724 & $1 / 12 / 200814: 10$ & $8 / 12200814: 10$ & 2.044 & 27.6 \\
\hline 3725 & $1 / 12 / 200814: 12$ & $8 / 12 / 2008$ 14:12 & 2.047 & 27.6 \\
\hline 3726 & $1 / 12 / 200814: 14$ & $8 / 12 / 2008$ 14:14 & 2051 & 27.6 \\
\hline 3727 & $1 / 12 / 200814: 16$ & $8 / 12 / 200814: 16$ & 2052 & 27.6 \\
\hline 3728 & $1 / 12 / 200814: 18$ & $8 / 12 / 200814: 18$ & 2052 & 27.6 \\
\hline 3729 & $1 / 12 / 200814: 20$ & $8 / 12 / 200814: 20$ & 2051 & 27.6 \\
\hline 3730 & $1 / 12 / 200814: 22$ & $8 / 12 / 200814: 22$ & 2053 & 27.7 \\
\hline 3731 & $1 / 12 / 200814: 24$ & $8 / 12 / 200814: 24$ & 2054 & 27.7 \\
\hline 3732 & $1 / 12 / 200814: 26$ & $8 / 2 / 200814: 26$ & 2055 & 27.8 \\
\hline 3733 & $1 / 12 / 2008$ 14:28 & $812 / 200814: 28$ & 2056 & 27.8 \\
\hline 3734 & $1 / 12 / 200814: 30$ & $8 / 12 / 200814: 30$ & 2056 & 27.8 \\
\hline 3735 & $1 / 12 / 200814: 32$ & $812 / 2008$ 14:32 & 2056 & 27.8 \\
\hline 3736 & $1 / 12 / 200814: 34$ & $8 / 12 / 200814: 34$ & 2056 & 27.8 \\
\hline 3737 & $1 / 12200814: 36$ & $8 / 12200814: 36$ & 2056 & 27.8 \\
\hline 3738 & $1 / 12 / 200814: 38$ & $8 / 122000814: 38$ & 2056 & 27.9 \\
\hline 3739 & $1 / 12 / 200814: 40$ & $8 / 12 / 200814: 40$ & 2057 & 27.9 \\
\hline 3740 & $1 / 12 / 200814: 42$ & $8 / 12 / 200814: 42$ & 2057 & 27.9 \\
\hline 3741 & $1 / 12 / 200814: 44$ & $8 / 12 / 200814: 44$ & 2057 & 27.9 \\
\hline 3742 & $1 / 12 / 200814: 46$ & $8 / 12 / 200814: 46$ & 2058 & 27.9 \\
\hline 3743 & $1 / 12 / 200814: 48$ & $8 / 2 / 200814: 48$ & 2061 & 27.9 \\
\hline 3744 & $1 / 12 / 200814: 50$ & $8 / 12 / 200814: 50$ & 2.06 & 28.3 \\
\hline 3745 & $1 / 12 / 200814: 52$ & $8 / 12 / 200814: 52$ & 2.06 & 28 \\
\hline 3746 & $1 / 12 / 200814: 54$ & $812 / 200814: 54$ & 2.061 & 28 \\
\hline 3747 & $1 / 12 / 200814: 56$ & $8 / 12 / 200814: 56$ & 2061 & 28 \\
\hline 3748 & $1 / 12 / 200814: 58$ & $8 / 2 / 200814: 58$ & 206 & 28 \\
\hline 3749 & $1 / 12 / 200815: 00$ & $812 / 200815: 00$ & 2.06 & 28 \\
\hline 3750 & $1 / 12 / 200815: 02$ & $8 / 12 / 200815: 02$ & 2061 & 28 \\
\hline 3751 & $1 / 12200815: 04$ & $8 / 12200815: 04$ & 2063 & 28 \\
\hline 3752 & 1/12/2008 15:06 & $8 / 12 / 200815: 06$ & 2064 & 28.1 \\
\hline 3753 & $1 / 12 / 200815: 08$ & $8 / 12200815: 08$ & 2066 & 28.1 \\
\hline
\end{tabular}

\begin{tabular}{|c|c|c|c|c|}
\hline \multicolumn{5}{|c|}{ D49920 } \\
\hline Rec & & Adjusted & Pressurt & Temp \\
\hline$\#$ & DeterTime & DaterTime & psi & ${ }^{\circ} \mathrm{C}$ \\
\hline 3754 & 1/12/2008 15:10 & 8/12/2008 15:10 & 2064 & 28.1 \\
\hline 3756 & 1/12/2008 15:12 & $8 / 12 / 2008$ 15:12 & 2064 & 28.1 \\
\hline 3756 & 1/12/2008 15:14 & $8 / 12 / 2008$ 15:14 & 2065 & 28.1 \\
\hline 375 & $1 / 12 / 2008$ 15:16 & $8 / 12 / 2008$ 15:16 & 2.066 & 28.1 \\
\hline 3758 & $1 / 12 / 200815: 18$ & $8 / 12 / 200815: 18$ & 2066 & 28.1 \\
\hline 3759 & $1 / 12 / 200815: 20$ & $8 / 12 / 200815: 20$ & 2008 & 28.1 \\
\hline 3760 & $1 / 12 / 200815 \cdot 22$ & $8 / 12 / 200815: 22$ & 2008 & 28.2 \\
\hline 3761 & $1 / 12 / 200815 \cdot 24$ & $8 / 12 / 200815: 24$ & 2000 & 28.2 \\
\hline 3762 & $1 / 12 / 200815: 26$ & $8 / 12 / 2008$ 15:26 & 207 & 28.2 \\
\hline 3763 & 1/12/2008 15:28 & $8 / 12 / 200815: 28$ & 207 & 28.2 \\
\hline 3764 & 1/12/2008 15:30 & $8 / 12 / 2008$ 15:30 & 207 & 28.3 \\
\hline 3765 & 1/12/2008 15:32 & $8 / 12 / 2008$ 15:32 & 207 & 28.3 \\
\hline $37 \times 6$ & $1 / 12 / 200815: 34$ & $8 / 12 / 200815: 34$ & 2071 & 28.3 \\
\hline 3767| & $1 / 12 / 200815: 36$ & $8 / 12 / 200815: 36$ & 2073 & 28.3 \\
\hline 3768 & $1 / 12 / 200815: 38$ & $8 / 12 / 2008$ 15:38 & 2073 & 28.3 \\
\hline 3769 & $1 / 12 / 200815: 40$ & $8 / 122200815: 40$ & 2019 & 28.3 \\
\hline 3770 & $1 / 12 / 200815: 42$ & $8 / 12 / 2008$ 15:42 & 2065 & 28.3 \\
\hline 377 & $1 / 12 / 200815: 44$ & $8 / 12 / 200815: 44$ & 2068 & 28.4 \\
\hline $37 / 2$ & 1/12/2008 15:46 & $8 / 12 / 2008$ 15:46 & 2068 & 28.8 \\
\hline 3773 & 1/12/2008 15:48 & $8 / 12 / 2008$ 15:48 & 2006 & 28.4 \\
\hline 3774 & $1 / 12 / 200815: 50$ & $8 / 12 / 200815: 50$ & 2009 & 28.4 \\
\hline 3775 & $1 / 12 / 200815: 52$ & $8 / 12 / 200815.52$ & 2006 & 28.4 \\
\hline 3776 & $1 / 12 / 200815: 54$ & $8 / 12 / 200815: 54$ & 1.978 & 28.4 \\
\hline $37 \pi$ & $1 / 12 / 200815: 56$ & $8 / 12 / 2008$ 15:56 & 2001 & 28.7 \\
\hline 3778 & 1/12/2008 15:58 & $8 / 12 / 200815: 58$ & 2033 & 28.4 \\
\hline 3779 & $1 / 12 / 200816.00$ & $8 / 12 / 200816: 00$ & 2048 & 28.4 \\
\hline 3780 & $1 / 12 / 200816: 02$ & $8 / 12 / 200816: 02$ & 2055 & 28.4 \\
\hline 3781 & $1 / 12 / 200816: 04$ & $8 / 12 / 200816: 04$ & 2059 & 28.3 \\
\hline 3782 & 1/12/2008 16:06 & $8 / 12 / 200816: 06$ & 2062 & 28.4 \\
\hline 378 & 1/12/2008 16:08 & $8 / 12200816: 08$ & 2064 & 28.3 \\
\hline 3784 & 1/12/2008 16:10 & $8 / 122008$ 16:10 & 2071 & 28.4 \\
\hline 3785 & 1/12/2008 16:12 & $8 / 12 / 200816: 12$ & 2072 & 28.4 \\
\hline 3786 & $1 / 12 / 200816: 14$ & $8 / 12 / 200816: 14$ & 2.073 & 28.4 \\
\hline 3787 & 1/12/2008 16:16 & $8 / 12 / 200816: 16$ & 2074 & 28.4 \\
\hline 3788 & 1/12/2008 16:18 & $8 / 12 / 2008$ 16:18 & 2074 & 28.4 \\
\hline 3789 & $1 / 12 / 200816: 20$ & $8 / 12 / 200816: 20$ & 2075 & 28.5 \\
\hline 3790 & 1/12/200816:22 & $8 / 12 / 200816: 22$ & 2076 & 28.6 \\
\hline 3791 & $1 / 12 / 200816: 24$ & $8 / 12 / 200816: 24$ & 2077 & 28.6 \\
\hline 3792 & $1 / 12 / 200816: 26$ & $8 / 12 / 200816: 26$ & 2.077 & 28.6 \\
\hline 3793 & 1/12/2008 16:28 & $8 / 12 / 200816: 28$ & 208 & 28.6 \\
\hline 3794 & $1 / 12 / 200816: 30$ & $8 / 12 / 200816: 30$ & 208 & 28.6 \\
\hline 3796 & $1 / 12 / 200816: 32$ & $8 / 12 / 200816: 32$ & 2081 & 28.6 \\
\hline 3796 & 1/12/2008 16:34 & $8 / 12 / 200816: 34$ & 2082 & 28.7 \\
\hline 3797 & $1 / 12 / 200816: 36$ & $8 / 12200016: 36$ & 2081 & 28.7 \\
\hline 3796 & 1/12/2008 16:38 & $8 / 12200816: 38$ & 2081 & 28.7 \\
\hline 3799 & $1 / 12 / 200816: 40$ & $8 / 12 / 200816: 40$ & 2084 & 28.7 \\
\hline 3800 & $1 / 12 / 200816442$ & $8 / 12 / 200816: 42$ & 2084 & 28.7 \\
\hline 3801 & $1 / 12 / 200816: 44$ & $8 / 12 / 200816: 44$ & 2084 & 28.7 \\
\hline 3802 & 1/12/2008 16:46 & $8 / 12 / 200816: 46$ & 2085 & 28.7 \\
\hline 3803 & $1 / 12 / 200816: 48$ & $8 / 12 / 200816: 48$ & 2086 & 28.8 \\
\hline 3804 & $1 / 12 / 200816: 50$ & $8 / 12 / 2008$ 16:50 & 2006 & 28.8 \\
\hline 3805 & $1 / 12 / 200816: 52$ & $8 / 12 / 200816: 52$ & 2085 & \\
\hline 3806 & $1 / 12 / 200816: 54$ & $8 / 12200816: 54$ & 2085 & 28.8 \\
\hline 3807 & $1 / 12 / 200816: 56$ & $8 / 12 / 200816: 56$ & 2086 & 28.8 \\
\hline 3808 & $1 / 12 / 200816: 58$ & $8 / 12 / 200816: 58$ & 2.086 & \\
\hline 3809 & $1 / 12 / 200817: 00$ & $8 / 12 / 2008$ 17:00 & 2087 & 28.8 \\
\hline 3810 & 1/12/2008 17:02 & $8 / 12 / 200817: 02$ & 2087 & 28.8 \\
\hline 3811 & 1/12/2008 17:04 & $8 / 12200817: 04$ & 2087 & 28.8 \\
\hline 3812 & 1/12/2008 17:06 & $8 / 12 / 2008$ 17:06 & 2088 & 28.8 \\
\hline 3813 & 1/12/2008 17:08 & $8 / 12 / 200817: 08$ & 2009 & 28.8 \\
\hline 3814 & $1 / 12 / 200817: 10$ & $8 / 12 / 2008$ 17:10 & 2009 & 28.9 \\
\hline 3815 & 1/12/2008 17:12 & $8 / 12 / 2008$ 17:12 & 2089 & 28.8 \\
\hline 3816 & 1/12/2008 17:14 & $8 / 12 / 200817: 14$ & 209 & 28.9 \\
\hline 3817 & 1/12/200817:16 & $8 / 12 / 2008$ 17:16 & 2.09 & 28.8 \\
\hline 3818 & 1/12/200817:18 & $8 / 12 / 200817: 18$ & 200 & 29.2 \\
\hline 3819 & 1/12/2008 17:20 & $8 / 12 / 200817: 20$ & 2001 & 29.4 \\
\hline 3820 & 1/12/2008 17:22 & $8 / 12 / 200817: 2$ & 2094 & 29.2 \\
\hline 3821 & $1 / 12 / 200817: 24$ & $8 / 12 / 200817: 24$ & 2093 & 28.9 \\
\hline 3822 & 1/12/2008 17:26 & $8 / 12 / 200817: 26$ & 2.092 & 28.9 \\
\hline
\end{tabular}

\begin{tabular}{|c|c|c|c|c|}
\hline \multicolumn{5}{|c|}{ D4-92p } \\
\hline$R \in C$ & & Acjusted & Pressure & Temp \\
\hline$\#$ & DateTime & Date/Time & psi & ${ }^{\circ} \mathrm{C}$ \\
\hline 3823 & $1 / 12 / 200817: 28$ & $8 / 12 / 2008$ 17:28 & 2003 & 28.9 \\
\hline 3824 & 1/12/2008 17:30 & $8 / 12 / 200817: 30$ & 2003 & 28.9 \\
\hline 3825 & $1 / 12 / 200817: 32$ & $8 / 12 / 200817: 32$ & 2004 & 28.9 \\
\hline 3826 & 1/12/2008 17:34 & $8 / 12 / 200817: 34$ & 2005 & 28.9 \\
\hline 3827 & 1/12/2008 17:36 & $8 / 12 / 200817: 36$ & 2006 & 28.9 \\
\hline 3828 & 1/12/2008 17:38 & $8 / 12 / 200817: 38$ & 2005 & 28.9 \\
\hline 3829 & $1 / 12 / 2008$ 17:40 & $8 / 12 / 2008$ 17:40 & 2006 & 28.9 \\
\hline 3830 & $1 / 12 / 2008$ 17:42 & $8 / 12 / 200017: 42$ & 2005 & 28.9 \\
\hline 3831 & $1 / 12 / 2008$ 17:44 & $8112 / 2008$ 17:44 & 2096 & 28.9 \\
\hline 3832 & $1 / 12 / 2008$ 17:46 & $8 / 12 / 200817: 46$ & 2.006 & 28.9 \\
\hline 3833 & $1 / 12 / 2008$ 17:48 & $8 / 12 / 200817: 48$ & 2005 & 28.9 \\
\hline 3834 & $1 / 12 / 2008$ 17:50 & $8 / 12 / 200817: 50$ & 2006 & 28.9 \\
\hline 3835 & 1/12/2008 17:52 & $8 / 12 / 2008$ 17:52 & 2094 & 28.9 \\
\hline 3836 & $1 / 12 / 200817: 54$ & $8 / 12 / 2008$ 17:54 & 2006 & 29 \\
\hline 3837 & $1 / 12 / 2008$ 17:56 & $8 / 12 / 200817: 56$ & 2003 & 28.9 \\
\hline 3838 & $1 / 12 / 200817: 58$ & $8 / 12 / 2008$ 17:58 & 2089 & 28.9 \\
\hline 3839 & 1/12/2008 18:00 & $8 / 12 / 200818: 00$ & 209 & 29.1 \\
\hline 3840 & $1 / 12200818: 02$ & $8 / 12 / 200818: 02$ & 2.091 & 29 \\
\hline 3841 & $1 / 12 / 200818.04$ & 8112200818.04 & 2.094 & 28.9 \\
\hline 3942 & $1 / 12 / 200818: 06$ & $8 / 12 / 200818: 06$ & 2006 & 28.9 \\
\hline 3843 & $1 / 12 / 2008$ 18:08 & $8 / 12 / 2008$ 18:08 & 2007 & 28.9 \\
\hline 3844 & 1/12/2008 18:10 & $8 / 12 / 200818: 10$ & 2009 & 28.9 \\
\hline 3845 & $1 / 12 / 200818: 12$ & $8 / 12 / 200818: 12$ & 2008 & 28.9 \\
\hline 3346 & $1 / 122008$ 18:14 & $8 / 12 / 200818: 14$ & 2009 & 28.9 \\
\hline 3847 & 1/12/2008 18:16 & $8 / 12 / 2008$ 18:16 & 21 & 28.9 \\
\hline 3848 & $1 / 12 / 200818: 18$ & $8 / 12 / 200818: 18$ & 2.101 & 28.9 \\
\hline 3849 & 1/12/2008 18:20 & $8 / 12 / 200818: 20$ & 2.101 & 29.2 \\
\hline 3850 & $1 / 12200818: 22$ & $8 / 12 / 200818: 22$ & 2102 & 29 \\
\hline 3851 & $1 / 12 / 200818: 24$ & $8 / 12 / 200818: 24$ & 2101 & 29 \\
\hline 3852 & $1 / 12 / 200818: 26$ & $8 / 12 / 200818: 26$ & 2105 & 29.1 \\
\hline 3853 & 1/12/2008 18:28 & $8 / 12 / 200818 \cdot 28$ & 2107 & 29.1 \\
\hline 3854 & $1 / 12 / 200818: 30$ & $8 / 12 / 2008$ 18:30 & 2108 & 29.1 \\
\hline 3355 & $1 / 12 / 200818: 32$ & $8 / 12 / 2008$ 18:32 & 2,108 & 29.1 \\
\hline 3856 & 1/12/2008 18:34 & $8 / 12 / 200818: 34$ & 2.109 & 29.1 \\
\hline उ850 & 1/12/2008 18:36 & $8 / 12 / 200818: 36$ & 2103 & 29.1 \\
\hline 3858 & 1/12/2008 18:38 & $8 / 12 / 200818: 38$ & 2052 & 29.1 \\
\hline 3859 & $1 / 12 / 200818: 40$ & $8 / 12 / 2008$ 18:40 & 2005 & 29.1 \\
\hline 3860 & $1 / 12 / 200818: 42$ & $8 / 12 / 200818: 42$ & 2021 & 29.1 \\
\hline 3861 & $1 / 12 / 200818: 44$ & $8 / 12 / 200818: 44$ & 206 & 29.1 \\
\hline 3862 & $1 / 12 / 2008$ 18:46 & $8 / 12 / 200818: 46$ & 2079 & 29.1 \\
\hline 3863 & $1 / 12 / 2008$ 18:48 & $8 / 12 / 200818: 48$ & 2.086 & 29 \\
\hline 3864 & $1 / 12 / 200818: 50$ & $8 / 12 / 200818: 50$ & 2091 & 29 \\
\hline 3865 & 1/12/2008 18:52 & $8 / 1 / 200818.52$ & 2094 & 29 \\
\hline 3306 & $1 / 12 / 200818: 54$ & $8 / 12 / 200818: 54$ & 2006 & 29.3 \\
\hline 3867 & $1 / 12 / 200818: 56$ & $8 / 12 / 200818: 56$ & 2006 & 29.1 \\
\hline 3968 & 1/12/2008 18:58 & $8 / 12 / 200818: 58$ & 2.098 & 29.1 \\
\hline 3869 & 1/12/2008 19:00 & $8 / 12 / 200819.00$ & 21 & 29.1 \\
\hline 3870 & 1/12/2008 19:C2 & $8 / 12 / 2008$ 19:02 & 2101 & 20.1 \\
\hline 3871 & $1 / 12200819.04$ & $8 / 12 / 200819: 04$ & 2103 & 29.1 \\
\hline 3872 & 1/12/2008 19:06 & $8 / 2 / 2008$ 19:06 & 2105 & 29.1 \\
\hline 3873 & $1 / 12 / 200819.08$ & $8 / 12 / 200819: 08$ & 2106 & 29 \\
\hline 3874 & $1 / 12 / 200819.10$ & $8 / 12200819.10$ & 2107 & 29 \\
\hline 3875 & $1 / 12 / 2008$ 19:12 & $8 / 12 / 200819.12$ & 2108 & 29 \\
\hline 3876 & $1 / 122008$ 19:14 & $8 / 12 / 200819: 14$ & 2109 & 29 \\
\hline 3877 & $1 / 12 / 200819: 16$ & 8/12/2008 19:16 & 2109 & 29 \\
\hline 3878 & 1/12/2008 19:18 & $8 / 12 / 200819: 18$ & 211 & \\
\hline 3879 & $1 / 12 / 200819: 20$ & $8 / 12 / 2008$ 19:20 & 2111 & 28.9 \\
\hline 3880 & $1 / 12 / 2008$ 19:22 & $8 / 12 / 200819.22$ & 2113 & 28.9 \\
\hline 3881 & $1 / 12 / 200849.24$ & $8 / 12 / 200819.24$ & 2114 & 29.3 \\
\hline 3882 & $1 / 12 / 200819.26$ & $8 / 12 / 200819: 26$ & 2114 & 29 \\
\hline 3883 & 1/12/2008 19:28 & $8 / 12 / 200819: 28$ & 2114 & 29 \\
\hline 3884 & $1 / 12 / 200819.30$ & $8 / 12 / 200819.30$ & 2.114 & 29 \\
\hline 3885 & $1 / 12 / 200819.32$ & $8 / 12 / 200819.32$ & 2115 & 28.9 \\
\hline 3886 & $1 / 12 / 200819.34$ & $8 / 12 / 2008$ 19.34 & 2.116 & 28.9 \\
\hline 3887 & $1 / 12 / 200819.36$ & $8 / 12 / 2008+9: 36$ & 2118 & 28.9 \\
\hline 3888 & $1 / 12 / 200819.38$ & $8 / 12 / 200819.38$ & 2118 & 28.9 \\
\hline 3889 & $1 / 12 / 200819.40$ & $8 / 12 / 200819: 40$ & 2119 & 28.9 \\
\hline 3890 & $1 / 12 / 200819.42$ & $8 / 12 / 2008$ 19:42 & 2119 & 28.9 \\
\hline 3891 & $1 / 12 / 200819: 44$ & $8 / 12 / 2008$ 19:44 & 212 & 28.9 \\
\hline
\end{tabular}


DOE/RL-2009-35, REV. 0

\begin{tabular}{|c|c|c|c|c|}
\hline \multicolumn{5}{|c|}{$D 4920$} \\
\hline $\mathrm{FeC}$ & & Agjusted & Pressure & \\
\hline$\#$ & DaterTime & DeteTime & psi & ${ }^{\circ} \mathrm{C}$ \\
\hline 3892 & $1 / 12 / 20081946$ & $8 / 12 / 200819: 46$ & 2119 & 28.9 \\
\hline 3893 & $1 / 12 / 200819.48$ & $8 / 12 / 200819: 48$ & & \\
\hline 3894 & $1 / 12 / 200819.50$ & $8 / 12 / 200819: 50$ & 2.12 & 28.9 \\
\hline 3896 & $1 / 12 / 200819.52$ & $8 / 12 / 200819.52$ & 2121 & 28.9 \\
\hline 3896 & $1 / 12 / 200819.54$ & $8 / 12 / 200819.54$ & 2.068 & 28.9 \\
\hline 3897 & $1 / 12 / 200819.56$ & $8 / 12 / 200819.56$ & 2.115 & 28.9 \\
\hline 3898 & $1 / 12 / 200819.58$ & $8 / 12 / 200819.58$ & 211 & 28.9 \\
\hline 3899 & $1 / 12 / 200820: 00$ & $8 / 12 / 200820: 00$ & 2117 & 28.9 \\
\hline 3900 & $1 / 12 / 200820.02$ & $8 / 12 / 200820: 02$ & 2.118 & 28.9 \\
\hline 3901 & $1 / 12 / 200820: 04$ & $8 / 12 / 200820: 04$ & 2119 & 28.9 \\
\hline 3902 & $1 / 12 / 200820: 06$ & $8 / 12 / 200820: 06$ & 2.12 & 28.9 \\
\hline 3903 & $1 / 12 / 200820: 08$ & $8 / 12 / 200820: 08$ & 2.121 & 28.9 \\
\hline 3904 & $1 / 12 / 200820: 10$ & 8/12/2008 20:10 & 2.12 & \\
\hline 3906 & $1 / 12 / 200820: 12$ & $8 / 12 / 200820: 12$ & 212 & 28.9 \\
\hline 3906 & $1 / 12 / 200820: 14$ & $8 / 12 / 200820: 14$ & 2121 & 28.9 \\
\hline 3907 & 1/12/2008 20:16 & $8 / 12 / 200820: 16$ & 212 & 28.9 \\
\hline 3908 & $1 / 12 / 200820: 18$ & $8 / 12 / 200820: 18$ & 2.123 & 28.9 \\
\hline 3909 & $1 / 12 / 200820: 20$ & $8 / 12 / 200820: 20$ & 2.123 & \\
\hline 3910 & $1 / 12 / 200820 \cdot 22$ & $8 / 12 / 200820 \cdot 22$ & 2.112 & 28.9 \\
\hline 3911 & $1 / 12 / 200820: 24$ & $8 / 12 / 200820: 24$ & 2123 & 28.9 \\
\hline 3912 & 1/12/200820:26 & $8 / 12 / 200820: 26$ & 2.125 & \\
\hline 3913 & $1 / 12 / 200820: 28$ & $8 / 12 / 200820: 28$ & 2124 & 28.9 \\
\hline 3914 & $1 / 12 / 200820: 30$ & $8 / 12 / 200820: 30$ & 2.123 & 28.9 \\
\hline 3915 & $1 / 12 / 200820: 32$ & $8 / 12 / 200820: 32$ & 2.125 & 28. \\
\hline 3916 & $1 / 12200820: 34$ & $8 / 12 / 200820: 34$ & 2126 & 28.9 \\
\hline 3917 & $1 / 12 / 200820: 36$ & $8 / 12 / 200820: 36$ & 2.126 & 28.9 \\
\hline 3918 & $1 / 12 / 200820.38$ & $8 / 122200820.38$ & 2127 & 28.9 \\
\hline 3919 & $1 / 12200820.40$ & $8 / 12 / 200820: 40$ & 2125 & 28.9 \\
\hline 3920 & $1 / 12 / 200820.42$ & $8 / 12 / 200820: 42$ & 2127 & 28.9 \\
\hline 3921 & $1 / 12200820: 44$ & $8 / 12 / 200820 ; 44$ & 2127 & 28.9 \\
\hline 3922 & $1 / 12 / 200820: 46$ & $8 / 122200820: 46$ & 2.127 & 28.9 \\
\hline 3923 & $1 / 122000820: 48$ & $8 / 12 / 200820: 48$ & 2.128 & 29.3 \\
\hline 3924 & $1 / 12 / 200820.50$ & $8 / 12 / 200820.50$ & 2.13 & 28.9 \\
\hline 3925 & $1 / 12 / 200820.52$ & $8 / 12 / 200820.52$ & 2.128 & 28.5 \\
\hline 3926 & $1 / 12 / 200820.54$ & $8 / 12 / 200820: 54$ & 2.129 & 28.9 \\
\hline 3927 & $1 / 12 / 200820.56$ & $8 / 12 / 200820: 56$ & 2.129 & 29.3 \\
\hline 3928 & $1 / 12200820: 58$ & $8 / 12 / 200820.58$ & 213 & 28.9 \\
\hline 3929 & 1/12/2008 21:00 & $8 / 12 / 200821: 00$ & 2.13 & 28.9 \\
\hline 3930 & $1 / 12 / 200821: 02$ & $8 / 12200821: 02$ & 213 & 28.9 \\
\hline 3931 & $1 / 12 / 200821: 04$ & $8 / 12 / 200821: 04$ & 2,131 & 28.9 \\
\hline 3932 & 1/12/200821:06 & $8 / 12 / 200821: 06$ & 2131 & 28.9 \\
\hline 3933 & $1 / 12 / 200821: 08$ & $8 / 12 / 200821: 08$ & 2,132 & 28.9 \\
\hline 3934 & $1 / 12 / 200821: 10$ & $8 / 12 / 200821: 10$ & 2.133 & 28.9 \\
\hline 3935 & $1 / 12 / 200821: 12$ & $8 / 12 / 200821: 12$ & 2.133 & 28.9 \\
\hline 3936 & 1/12/2008 21:14 & $8 / 12200821: 14$ & 2.136 & 28.9 \\
\hline 3937 & 1/12/2008 21:16 & $8 / 12 / 200821: 16$ & 2135 & 28.9 \\
\hline 3938 & $1 / 12 / 200821: 18$ & $8 / 12200821: 18$ & 2.136 & 28.9 \\
\hline 3939 & 1/12/200821:20 & $8 / 12 / 200821: 20$ & 2.136 & 28.9 \\
\hline 3940 & 1/12/200821:22 & $8 / 12 / 200821: 22$ & 2.137 & 28.9 \\
\hline 3941. & $1 / 122200821: 24$ & $8 / 12 / 200821: 24$ & 2.137 & 28.9 \\
\hline 3942 & 1/12/200821:26 & $8 / 12 / 200821: 26$ & 213 & 28.9 \\
\hline 3943 & 1/12/2008 21:28 & $8 / 12 / 200821: 28$ & 2003 & 28.9 \\
\hline 3944 & $1 / 12 / 200821: 30$ & $8 / 12 / 200821: 30$ & 2.027 & 28.9 \\
\hline 3945 & 1/12/2008 21:32 & $8 / 12 / 200821: 32$ & 1.98 & 28.9 \\
\hline 3946 & $1 / 12 / 200821: 34$ & $8 / 12 / 200821: 34$ & 2018 & 28.9 \\
\hline 3947 & $1 / 12 / 200821: 36$ & $8 / 12 / 200821: 36$ & 2.073 & 28.9 \\
\hline 3948 & 1/12/2008 21:38 & $8 / 12200821: 38$ & 2005 & 28.9 \\
\hline 3949 & $1 / 12 / 200821: 40$ & $8 / 12 / 200821: 40$ & 2.106 & 28.8 \\
\hline 3950 & $1 / 12 / 200821: 42$ & $8 / 12 / 200821: 42$ & 2.113 & 28.8 \\
\hline 3951 & $1 / 12 / 200821: 44$ & $8 / 12 / 200821: 44$ & 2.117 & 28.8 \\
\hline 3952 & $1 / 12 / 200821: 46$ & $8 / 12200821: 46$ & 2.12 & 28.8 \\
\hline 3953 & $1 / 12 / 200821: 48$ & $8 / 12 / 200821: 48$ & 2117 & 28.7 \\
\hline 3954 & $1 / 12 / 200821: 50$ & $8 / 12 / 200821: 50$ & 2.115 & 28.7 \\
\hline 3955 & $1 / 12 / 200821: 52$ & $8 / 12 / 200821: 52$ & 2.117 & 28.7 \\
\hline 3056 & $1 / 12 / 200821: 54$ & $8 / 12200021: 54$ & 2.121 & 286 \\
\hline 3957 & 1/12/200821:56 & $8 / 12200821: 56$ & 2.123 & 28.6 \\
\hline 3958 & $1 / 12 / 200821: 58$ & $8 / 12 / 200821: 58$ & 2126 & 28.6 \\
\hline 3950 & $1 / 12 / 200822: 00$ & $8 / 12 / 20082200$ & 2127 & 28.6 \\
\hline 3960 & $1 / 12 / 200822: 02$ & $8112 / 200822: 02$ & 2.133 & 29 \\
\hline
\end{tabular}

\begin{tabular}{|c|c|c|c|c|}
\hline \multicolumn{5}{|c|}{$04-924$} \\
\hline $\mathrm{BAC}$ & & Adjusted & Fressure & Temp \\
\hline$\#$ & DaterTime & Deter/ime & psi & ${ }^{\circ} \mathrm{C}$ \\
\hline 3961 & $1 / 12 / 20082204$ & $8 / 12 / 20082204$ & 2134 & 29.1 \\
\hline 3962 & 1/12/2008 22:06 & $8 / 12 / 20082206$ & 2.137 & 28.8 \\
\hline 3963 & $1 / 12 / 200822: 08$ & $8 / 12 / 20082208$ & 2.136 & 28.6 \\
\hline 3964 & $1 / 12 / 200822: 10$ & $8 / 12 / 200822: 10$ & 2.136 & 28.6 \\
\hline 3965 & 1/12/200822:12 & $8 / 12 / 200822: 12$ & 2.137 & 28.6 \\
\hline 3966 & 1/12/200822:14 & $8 / 12 / 20082214$ & 2137 & 28.6 \\
\hline 3967 & 1/12/200822:16 & $8 / 12 / 200822: 16$ & 2.138 & 28.5 \\
\hline 3968 & $1 / 12 / 20082218$ & $8 / 12 / 20082218$ & 2138 & 28.5 \\
\hline 3960 & $1 / 12 / 20082220$ & $8 / 12200022220$ & 2139 & 28.4 \\
\hline 3970 & $1 / 12 / 20082222$ & $8 / 12200822: 22$ & 2.139 & 28.5 \\
\hline 3971 & $1 / 12 / 200822: 24$ & $8 / 12200822: 24$ & 2.14 & 28.4 \\
\hline 3972 & $1 / 12 / 20082226$ & $8 / 12 / 200822: 26$ & 2142 & 28.4 \\
\hline 3973 & $1 / 12 / 20082228$ & $8 / 12 / 20082228$ & 2142 & 28.4 \\
\hline 3974 & $1 / 12 / 200822,30$ & $8 / 12 / 20082230$ & 2144 & 28.4 \\
\hline 3975 & $1 / 12 / 20082232$ & $8 / 12 / 200822332$ & 2.145 & 28.4 \\
\hline 3976 & $1 / 12 / 20082234$ & $8 / 12 / 20082234$ & 2.146 & 28.4 \\
\hline 3977 & $1 / 12 / 20082236$ & $8 / 12 / 20082236$ & 2147 & 28.4 \\
\hline 3978 & 1/12/2008 22:38 & $8 / 12 / 200822: 38$ & 2149 & 28.3 \\
\hline 3979 & $1 / 12 / 200822 ; 40$ & $8 / 12 / 200822440$ & 215 & 28.3 \\
\hline 3980 & $1 / 12200822442$ & $8 / 12200822: 42$ & 2151 & 28.3 \\
\hline 3961 & $1 / 12 / 200822444$ & $8 / 12 / 200822: 44$ & 2.152 & 28.3 \\
\hline 3962 & $1 / 12 / 200822446$ & $8 / 12 / 20082246$ & 2.152 & 28.3 \\
\hline 3963 & $1 / 12 / 200822448$ & $8 / 12 / 200822448$ & 2152 & 28.3 \\
\hline 3984 & $1 / 12 / 20082250$ & $8 / 12 / 20082250$ & 2.152 & 28.3 \\
\hline 3985 & $1 / 12 / 200822552$ & $8 / 12 / 200822552$ & 2.153 & 28.3 \\
\hline 3986 & 1/12/2008 22:54 & $8 / 12 / 200822: 54$ & 2.154 & 28.3 \\
\hline 3987 & $1 / 12 / 20082256$ & $8 / 12 / 20082256$ & 2.153 & 28.3 \\
\hline 3988 & $1 / 12 / 20082258$ & 811220002258 & 2.154 & 28.3 \\
\hline 3989 & 1/12/200823:00 & $8 / 12 / 200823: 00$ & 2154 & 28.3 \\
\hline 3990 & $1 / 12 / 200823: 02$ & $8 / 12 / 200823: 02$ & 2154 & 28.2 \\
\hline 3991 & 1/12/2008 23:04 & $8 / 12 / 200823: 04$ & 2154 & 28.3 \\
\hline 3992 & 1/12/200823:06 & $8 / 12 / 200823: 06$ & 2154 & 28.2 \\
\hline 3993 & 1/12/2008 23:08 & $8 / 12 / 200823: 08$ & 2.156 & 28.2 \\
\hline 3994 & 1/12/2008 23:10 & $8 / 12 / 200823: 10$ & 2.158 & 28.2 \\
\hline 3996 & 1/12/2008 23:12 & $8 / 12 / 200823: 12$ & 2.157 & 28.2 \\
\hline 3996 & 1/12/2008 23:14 & $8 / 12 / 200823: 14$ & 2157 & 28.2 \\
\hline 3997 & 1/12/200823:16 & $8 / 12 / 200823: 16$ & 2.159 & 28.2 \\
\hline 3998 & 1/12/2008 23:18 & $8 / 12 / 200823: 18$ & 2162 & 28.2 \\
\hline 3999 & 1/12/2008 23:20 & $8 / 12 / 200823: 20$ & 2.162 & 28.2 \\
\hline 4000 & 1/12/2008 23:22 & $8 / 12 / 200823: 22$ & 2162 & 28.1 \\
\hline 4001 & $1 / 12 / 200823: 24$ & $8 / 12 / 200823: 24$ & 216 & 28.1 \\
\hline 4002 & $1 / 12 / 200823: 26$ & $8 / 12 / 200823: 26$ & 2.10 & 28.1 \\
\hline 4003 & 1/12/200823:28 & $8 / 12 / 200823: 28$ & 2162 & 28.1 \\
\hline 4004 & 1/12/2008 23:30 & $8 / 12 / 200823: 30$ & 2164 & 28.1 \\
\hline 4005 & 1/12/2008 23:32 & $8 / 12 / 200823: 32$ & 2164 & 28.1 \\
\hline 4006 & 1/12/200823:34 & $8 / 12 / 200823: 34$ & 2164 & 28.1 \\
\hline 4007 & $1 / 12 / 200823: 36$ & $8 / 12 / 200823: 36$ & 2165 & 28.1 \\
\hline 4008 & 1/12/200823:38 & $8 / 12 / 200823: 38$ & 2.165 & 28.1 \\
\hline 4000 & $1 / 12 / 200823: 40$ & $8 / 12 / 200823: 40$ & 2166 & 28.1 \\
\hline 4010 & 1/12/2008 23:42 & $8 / 12 / 200823: 42$ & 2166 & 28.3 \\
\hline 4011 & 1/12/2008 23:44 & $8 / 12 / 200823: 44$ & 2168 & 28.3 \\
\hline 4012 & $1 / 12 / 200823: 46$ & $8 / 12 / 200823: 46$ & 2169 & 28.1 \\
\hline 4013 & $1 / 12 / 200823: 48$ & $8 / 12 / 200823: 48$ & 2169 & 28.1 \\
\hline 4014 & 1/12/2008 23:50 & $8 / 12 / 200823: 50$ & 2.171 & 28.1 \\
\hline 4015 & $1 / 12 / 200823: 52$ & $8 / 12 / 200823: 52$ & 2.17 & 28.1 \\
\hline 4016 & $1 / 12 / 200823: 54$ & $8 / 12 / 200823: 54$ & 2.192 & 28.1 \\
\hline 4017 & $1 / 12 / 200823: 56$ & $8 / 12 / 200823: 56$ & 2.106 & 28.1 \\
\hline 4018 & $1 / 12 / 200823: 58$ & $8 / 12 / 200823: 58$ & 2.001 & 28.1 \\
\hline 4019 & $1 / 13 / 20080: 00$ & $8 / 13 / 20080: 00$ & 2.144 & 28.1 \\
\hline 4020 & 1/13/20080:02 & $8 / 13 / 20080: 02$ & 2.165 & 28.1 \\
\hline 4021 & $1 / 13 / 20080: 04$ & $8 / 13 / 20080: 04$ & 2166 & 28.1 \\
\hline 4022 & $1 / 13 / 20080: 06$ & $8 / 13 / 20080: 06$ & 2166 & 28.1 \\
\hline 4023 & $1 / 13 / 20080: 08$ & $8 / 13 / 20080: 08$ & 2.168 & 28.1 \\
\hline 4024 & $1 / 13 / 20080.10$ & $8 / 13 / 20080: 10$ & 2166 & 28 \\
\hline 4025 & 1/13/20080:12 & $8 / 13 / 20080.12$ & 2157 & \\
\hline 4026 & $1 / 13 / 20080.14$ & $8 / 13 / 20080: 14$ & 2111 & \\
\hline 4027 & $1 / 13 / 20080.16$ & $8 / 13 / 20080: 16$ & 2.051 & 28 \\
\hline 4028 & 1/13/20080:18 & $8 / 13 / 20080.18$ & & 28 \\
\hline 4029 & $1 / 13 / 20080: 20$ & $8 / 13 / 20080.20$ & 1.962 & 28 \\
\hline
\end{tabular}

\begin{tabular}{|c|c|c|c|c|}
\hline \multicolumn{5}{|c|}{ D4920 } \\
\hline $\mathrm{Pec}$ & & Adjusted & Pressure & Termp \\
\hline$\#$ & DaterTime & DaterTme & psi & ${ }^{\circ} \mathrm{C}$ \\
\hline 4030 & $1 / 13 / 20080.22$ & $8 / 13 / 20080: 22$ & 2.053 & \\
\hline 4031 & $1 / 13 / 20080.24$ & $8 / 13 / 20080: 24$ & 2112 & 27.9 \\
\hline 4032 & $1 / 13 / 20080.26$ & $8 / 13 / 20080: 26$ & 2133 & 27.9 \\
\hline 4033 & $13 / 20080: 28$ & $8 / 13 / 20080.28$ & 2146 & 27.9 \\
\hline 4034 & $1 / 13 / 20080.30$ & $8 / 13 / 20080: 30$ & 2.154 & 27.9 \\
\hline 4035 & $1 / 13 / 20080.32$ & $8 / 13 / 20080: 32$ & 2161 & 27.9 \\
\hline 4006 & $1 / 13 / 20080: 34$ & $8 / 13 / 20080: 34$ & 2.166 & 27.9 \\
\hline 4037 & $1 / 13 / 20080.36$ & $8 / 13 / 20080: 36$ & 2166 & 27.9 \\
\hline 4038 & & $8 / 13 / 20080: 38$ & 2168 & 27.9 \\
\hline 4009 & $1 / 13 / 20080.40$ & $8 / 13 / 20080.40$ & 2169 & 27.9 \\
\hline 4040 & 20080.42 & $8 / 13 / 20080: 42$ & 2172 & 27.9 \\
\hline 4041 & & $8 / 13 / 20$ & 2174 & 27.9 \\
\hline 4042 & $1 / 13 / 20080.46$ & $8 / 13 / 20080.46$ & 2.174 & 27.9 \\
\hline 4043 & & $8 / 13 / 2$ & 2.174 & 27.9 \\
\hline 4044 & & $8 / 13 / 2$ & 2177 & 27.8 \\
\hline 4045 & & $8 / 13 / 2$ & 2179 & 27.8 \\
\hline 4046 & & $8 / 13 / 2$ & 2182 & 27.8 \\
\hline 4047 & $30: 56$ & $8 / 13 / 20080.56$ & 2183 & 27.8 \\
\hline 4048 & & $8 / 13$ & 2184 & 27.8 \\
\hline 4049 & & $8 / 13$ & 2184 & 27.8 \\
\hline 4050 & $881: 02$ & $8 / 13 / 20081: 02$ & 2.186 & 27.8 \\
\hline 4051 & & $8 / 13 /$ & 2187 & 27.8 \\
\hline 4052 & & $8 / 13$ & 2187 & 27.8 \\
\hline 4053 & & & 2189 & 27.7 \\
\hline 4054 & & $8 / 13$ & 2191 & 27.7 \\
\hline 4055 & 31:12 & $8 / 13 / 2008$ 1:12 & 2189 & 28 \\
\hline 4056 & & $8 / 13$ & 2191 & 27.8 \\
\hline 405 & & $8 / 13$ & 2191 & 27.7 \\
\hline 4058 & & & 2192 & 27.6 \\
\hline 4059 & & $8 / 13$ & 2192 & 27.6 \\
\hline 4060 & $1: 22$ & $8 / 13 / 2$ & 2193 & 27.6 \\
\hline 4061 & & $8 / 13$ & 2.195 & 27.6 \\
\hline 4062 & & $8 / 13$ & 2.194 & 27.6 \\
\hline 4063 & & & 2194 & 27.6 \\
\hline 4064 & & & 2195 & 27.6 \\
\hline 4065 & & $8 / 13 / 2$ & 2197 & 27.6 \\
\hline 4066 & & & 2199 & 27.6 \\
\hline 4067 & & & 22 & 27.6 \\
\hline 4068 & & & 2.2 & 27.6 \\
\hline 4069 & & & 2201 & 27.5 \\
\hline 4070 & & $8 / 13$ & 2204 & 27.5 \\
\hline 4071 & & & 2205 & 27.5 \\
\hline 4072 & & & 2204 & 27.5 \\
\hline 4073 & & $8 / 13$ & 2203 & 27.5 \\
\hline 4074 & & & 2204 & 27.5 \\
\hline 4075 & & & 2204 & 27.5 \\
\hline 4076 & & & 2206 & 27.5 \\
\hline 407 & & & 221 & 27.5 \\
\hline 4078 & & & 221 & 27.4 \\
\hline 4079 & & & 221 & 27.5 \\
\hline 4080 & & & 2200 & 27.4 \\
\hline 4081 & & & 2208 & 27.4 \\
\hline 4082 & & & 221 & 27.4 \\
\hline 4083 & & & 2211 & 27.4 \\
\hline 4084 & & & 2211 & 274 \\
\hline 4085 & $32: 12$ & $8 / 13$ & 2.211 & 27.4 \\
\hline 4086 & & & 2212 & 27.4 \\
\hline 4087 & & & 2214 & 27.4 \\
\hline 4088 & & & 2.214 & 27.4 \\
\hline 4089 & & & & 27.4 \\
\hline 4090 & 3222 & $8 / 13 / 2$ & 2214 & 27.6 \\
\hline 4091 & & & 2216 & 27.6 \\
\hline 4092 & & 8226 & 2215 & 2 \\
\hline 4093 & & $8 / 13 / 2008228$ & 2216 & 27.4 \\
\hline 4094 & & & 2.216 & 27.4 \\
\hline 4095 & 3232 & $8 / 13 / 2008232$ & 2217 & 27.4 \\
\hline 4006 & & & 2217 & 27.4 \\
\hline 4097 & & & 2219 & \\
\hline 4098 & $1 / 13 / 20082: 38$ & $8 / 13 / 20082: 38$ & 2.221 & 21. \\
\hline
\end{tabular}




\begin{tabular}{|c|c|c|c|c|}
\hline \multicolumn{5}{|c|}{ D4-92p } \\
\hline $\operatorname{Rec}$ & & Acjusted & Pressure & Temp \\
\hline$\#$ & Date/Time & Date-Time & psi & ${ }^{\circ} \mathrm{C}$ \\
\hline 4099 & $1 / 13 / 2008240$ & $8 / 13 / 2008240$ & 222 & 27.4 \\
\hline 4100 & $1 / 13 / 2008242$ & $8 / 13 / 2008242$ & 2224 & 27.4 \\
\hline 4101 & $1 / 13 / 2008244$ & $8 / 13 / 2008244$ & 2223 & 27.4 \\
\hline 4102 & $1 / 13 / 20082446$ & $8 / 13 / 2008246$ & 2223 & 27.4 \\
\hline 4103 & $1 / 13 / 20082448$ & $8 / 13 / 2008248$ & 2224 & 27.4 \\
\hline 4104 & $1 / 13 / 2008250$ & $8 / 13 / 2008250$ & 2225 & 27.3 \\
\hline 4105 & $1 / 13 / 2008255$ & $8 / 13 / 2008252$ & 2225 & 27.3 \\
\hline 4106 & $1 / 13 / 2008254$ & $8 / 13 / 2008254$ & 2224 & 27.3 \\
\hline 4107 & $1 / 13 / 2008256$ & $8 / 13 / 2008256$ & 2.224 & 27.3 \\
\hline 4108 & $1 / 13 / 2008258$ & $8 / 13 / 2008258$ & 2.226 & 27.3 \\
\hline 4109 & 1/13/20083:00 & $8 / 13 / 20083: 00$ & 2.222 & 27.3 \\
\hline 4110 & 1/13/20083:02 & $8 / 13 / 20083: 02$ & 22 & 27.3 \\
\hline 4111 & 1/13/2008 3:04 & $8 / 13 / 20083: 04$ & 2187 & 27.3 \\
\hline 4112 & 1/13/20083:06 & $8 / 13 / 20083: 06$ & 2105 & 27.3 \\
\hline 4113 & 1/13/20083:08 & $8 / 13 / 20083: 08$ & 2047 & 27.3 \\
\hline 4114 & 1/13/20083:10 & 8/13/2008 3:10 & 2.005 & 27.3 \\
\hline 4115 & 1/13/20083:12 & $8 / 13 / 20083: 12$ & 2.082 & 27.3 \\
\hline 4116 & 1/13/20083:14 & $8 / 13 / 20083: 14$ & 2.152 & 27.3 \\
\hline 4117 & 1/13/20083:16 & 8/13/2008 3:16 & 2183 & 27.3 \\
\hline 4118 & 1/13/20083:18 & $8 / 13 / 20083: 18$ & 2.201 & 27.6 \\
\hline 4119 & $1 / 13 / 20083: 20$ & $8 / 13 / 20083: 20$ & 2207 & 27.4 \\
\hline 4120 & 1/13/20083:22 & $8 / 13 / 20083: 22$ & 2215 & 27.3 \\
\hline 4121 & 1/13/20083:24 & $8 / 13 / 20083: 24$ & 2.219 & 27.3 \\
\hline 4122 & 1/13/20083:26 & $8 / 13 / 20083: 26$ & 2.223 & 27.3 \\
\hline 4123 & $1 / 13 / 20083: 28$ & $8 / 13 / 20083: 28$ & 2.225 & 27.2 \\
\hline 4124 & $1 / 13 / 20083: 30$ & $8 / 13 / 20083: 30$ & 2.226 & 27.2 \\
\hline 4125 & 1/13/20083:32 & $8 / 13 / 20083: 32$ & 2.227 & 27.2 \\
\hline 4126 & 1/13/20083:34 & $8 / 13 / 20083: 34$ & 223 & 27.1 \\
\hline 4127 & 1/13/20083:36 & $8 / 13 / 20083: 36$ & 2.234 & 27.1 \\
\hline 4128 & 1/13/20083:38 & $8 / 13 / 20083: 38$ & 2.235 & 27.1 \\
\hline 4129 & $1 / 13 / 20083: 40$ & $8 / 13 / 20083: 40$ & 2.236 & 27.1 \\
\hline 4130 & 1/13/20083:42 & $8 / 13 / 20083: 42$ & 2237 & 27.1 \\
\hline 4131 & 1/13/20083:44 & $8 / 13 / 20083: 44$ & 2.252 & 27.1 \\
\hline 4132 & 1/13/20083:46 & $8 / 13 / 20083: 46$ & 2.156 & 27.1 \\
\hline 4133 & $1 / 13 / 20083: 48$ & $8 / 13 / 20083: 48$ & 2.221 & 27.1 \\
\hline 4134 & $1 / 13 / 20083: 50$ & $8 / 13 / 20083: 50$ & 2.24 & 27.1 \\
\hline 4135 & $1 / 13 / 20083: 52$ & $8 / 13 / 20083: 52$ & 2.245 & 27.1 \\
\hline 4136 & $1 / 13 / 20083: 54$ & $8 / 13 / 20083: 54$ & 2246 & 27.1 \\
\hline 4137 & $1 / 13 / 20083: 56$ & $8 / 13 / 20083: 56$ & 2246 & 27.1 \\
\hline 4138 & 1/13/20083:58 & $8 / 13 / 20083: 58$ & 2236 & 27.5 \\
\hline 4139 & $1 / 13 / 20084: 00$ & $8 / 13 / 20084: 00$ & 2.236 & 27.2 \\
\hline 4140 & 1/13/20084:02 & $8 / 13 / 2008$ 4:02 & 2.245 & 27.1 \\
\hline 4141 & 1/13/20084:04 & $8 / 13 / 20084: 04$ & 2.245 & 27.1 \\
\hline 4142 & 1/13/20084:06 & $8 / 13 / 20084: 06$ & 2247 & 27.1 \\
\hline 4143 & 1/13/20084:08 & $8 / 13 / 20084: 08$ & 2247 & 27.1 \\
\hline 4144 & 1/13/20084:10 & $8 / 13 / 20084: 10$ & 2.251 & 27 \\
\hline 4145 & $1 / 13 / 20084: 12$ & $8 / 13 / 20084: 12$ & 2.252 & 27.3 \\
\hline 4146 & 1/13/20084:14 & $8 / 13 / 2008$ 4:14 & 2.253 & 27.6 \\
\hline 4147 & $1 / 13 / 20084: 16$ & $8 / 13 / 20084: 16$ & 2254 & 27.6 \\
\hline 4148 & 1/13/20084:18 & $8 / 13 / 20084: 18$ & 2257 & 27.2 \\
\hline 4149 & $1 / 13 / 20084: 20$ & $8 / 13 / 20084: 20$ & 2258 & 27.1 \\
\hline 4150 & 1/13/20084:22 & $8 / 13 / 20084: 22$ & 2261 & 27 \\
\hline 4151 & $1 / 13 / 20084: 24$ & $8 / 13 / 20084: 24$ & 2.263 & 27 \\
\hline 4152 & 1/13/20084:26 & $8 / 13 / 20084: 26$ & 2.264 & 26.9 \\
\hline 4153 & $1 / 13 / 20084: 28$ & $8 / 13 / 20084: 28$ & 2.265 & 26.9 \\
\hline 4154 & $1 / 13 / 20084: 30$ & $8 / 13 / 20084: 30$ & 2.266 & 26.9 \\
\hline 4155 & $1 / 13 / 20084: 32$ & $8 / 13 / 20084: 32$ & 2267 & 26.9 \\
\hline 4156 & $1 / 13 / 20084: 34$ & $8 / 13 / 20084: 34$ & 2266 & 26.9 \\
\hline 4157 & $1 / 13 / 20084: 36$ & $8 / 13 / 20084: 36$ & 2267 & 26.9 \\
\hline 4158 & $1 / 13 / 20084: 38$ & $8 / 13 / 20084: 38$ & 2.267 & 26.9 \\
\hline 4159 & $1 / 13 / 20084: 40$ & $8 / 13 / 20084: 40$ & 2266 & 26.9 \\
\hline 4160 & $1 / 13 / 20084: 42$ & $8 / 13 / 20084: 42$ & 2268 & 26.9 \\
\hline 4161 & $1 / 13 / 20084: 44$ & $8 / 13 / 20084: 44$ & 2269 & 26.9 \\
\hline 4162 & $1 / 13 / 20084: 46$ & $8 / 13 / 20084: 46$ & 2269 & 26.9 \\
\hline 4163 & $1 / 13 / 20084: 48$ & $8 / 13 / 20084: 48$ & 2271 & 26.9 \\
\hline 4164 & $1 / 13 / 20084: 50$ & $8 / 13 / 20084: 50$ & 2273 & 26.9 \\
\hline 4165 & $1 / 13 / 20084: 52$ & $8 / 13 / 20084: 52$ & 2.271 & 26.9 \\
\hline 4166 & $1 / 13200084: 54$ & $8 / 13 / 20084: 54$ & 2.271 & 26.9 \\
\hline 4167 & $1 / 13 / 20084: 56$ & $8 / 13 / 20084: 56$ & 2.272 & 26.9 \\
\hline
\end{tabular}

\begin{tabular}{|c|c|c|c|c|}
\hline \multicolumn{5}{|c|}{ D4-92p } \\
\hline $\operatorname{Rec}$ & & Adjusted & Pressure & Temp \\
\hline$\#$ & Date-Time & DaterTime & \begin{tabular}{|l|}
$p s i$ \\
\end{tabular} & \\
\hline 4168 & $1 / 13 / 20084: 58$ & $8 / 13 / 20084: 58$ & 2.273 & 26.9 \\
\hline 4169 & $1 / 13 / 20085: 00$ & $8 / 13 / 20085: 00$ & 2275 & 26.9 \\
\hline 4170 & $1 / 13 / 20085: 02$ & $8 / 13 / 20085: 02$ & 2275 & 26.9 \\
\hline 4171 & $1 / 13 / 20085: 04$ & $8 / 13 / 20085: 04$ & 2.275 & 26.9 \\
\hline 4172 & $1 / 13 / 20085: 06$ & $8 / 13 / 20085: 06$ & 2.276 & 26.9 \\
\hline 4173 & $1 / 13 / 20085: 08$ & $8 / 13 / 20085: 08$ & 2.276 & 26.9 \\
\hline 4174 & 1/13/20085:10 & $8 / 13 / 20085: 10$ & 2.27 & 26.9 \\
\hline 4175 & $1 / 13 / 20085: 12$ & $8 / 13 / 20085: 12$ & 2.277 & 26.9 \\
\hline 4176 & $1 / 13 / 20085: 14$ & $8 / 13 / 20085: 14$ & 2.279 & 26.9 \\
\hline $41 \pi$ & 1/13/20085:16 & $8 / 13 / 20085: 16$ & 2.279 & 26.8 \\
\hline 4178 & 1/13/20085:18 & $8 / 13 / 20085: 18$ & 2.28 & 26.8 \\
\hline 4179 & $1 / 13 / 20085: 20$ & $8 / 13 / 20085: 20$ & 2.283 & 26.9 \\
\hline 4180 & $1 / 13 / 20085: 22$ & $8 / 13 / 20085: 22$ & 2.284 & 26.8 \\
\hline 4181 & $1 / 13 / 20085: 24$ & $8 / 13 / 20085: 24$ & 2.284 & 26.8 \\
\hline 4182 & $1 / 13 / 20085: 26$ & $8 / 13 / 20085: 26$ & 2.285 & 26.8 \\
\hline 4183 & $1 / 13 / 20085: 28$ & $8 / 13 / 20085: 28$ & 2.284 & 26.8 \\
\hline 4184 & $1 / 13 / 20085: 30$ & $8 / 13 / 20085: 30$ & 2.285 & 26.8 \\
\hline 4185 & $1 / 13 / 20085: 32$ & $8 / 13 / 20085: 32$ & 2.285 & 26.8 \\
\hline 4186 & 1/13/20085:34 & $8 / 13 / 20085: 34$ & 2.286 & 26.8 \\
\hline 4187 & $1 / 13 / 20085: 36$ & $8 / 13 / 20085: 36$ & 2.287 & 26.8 \\
\hline 4188 & $1 / 13 / 20085: 38$ & $8 / 13 / 20085: 38$ & 229 & 26.8 \\
\hline 4189 & $1 / 13 / 20085: 40$ & $8 / 13 / 20085: 40$ & 2.289 & 26.8 \\
\hline 4190 & $1 / 13 / 20085: 42$ & $8 / 13 / 20085: 42$ & 2.291 & 26.8 \\
\hline 4191 & $1 / 13 / 20085: 44$ & $8 / 13 / 20085: 44$ & 2.291 & 27.2 \\
\hline 4192 & $1 / 13 / 20085: 46$ & $8 / 13 / 20085: 46$ & 2.294 & 26.9 \\
\hline 4193 & $1 / 13 / 20085: 48$ & $8 / 13 / 20085: 48$ & 2.293 & 26.8 \\
\hline 4194 & $1 / 13 / 20085550$ & $8 / 13 / 20085: 50$ & 2.291 & 26.8 \\
\hline 4195 & $1 / 13 / 20085552$ & $8 / 13 / 20085: 52$ & 2.280 & 26.8 \\
\hline 4196 & $1 / 13 / 20085554$ & $8 / 13 / 20085: 54$ & 2.251 & 26.8 \\
\hline 4197 & $1 / 13 / 20085: 56$ & $8 / 13 / 20085: 56$ & 2.157 & 26.8 \\
\hline 4198 & $1 / 13 / 20085: 58$ & $8 / 13 / 20085: 58$ & 2.089 & 26.8 \\
\hline 4199 & $1 / 13 / 20086: 00$ & $8 / 13 / 20086: 00$ & 2102 & 27 \\
\hline 4200 & $1 / 13 / 20086: 02$ & $8 / 13 / 20086: 02$ & 2.189 & 26.9 \\
\hline 4201 & $1 / 13 / 20086: 04$ & $8 / 13 / 20086: 04$ & 2.248 & 26.8 \\
\hline 4202 & $1 / 13 / 20086: 06$ & $8 / 13 / 20086: 06$ & 2271 & 27.1 \\
\hline 4203 & $1 / 13 / 20086: 08$ & $8 / 1320086: 08$ & 2.279 & 27.1 \\
\hline 4204 & $1 / 13 / 20086: 10$ & $8 / 13 / 20086: 10$ & 2285 & 27.2 \\
\hline 4205 & $1 / 13 / 20086: 12$ & $8 / 13 / 20086: 12$ & 2.293 & 27.1 \\
\hline 4206 & $1 / 13 / 20086: 14$ & $8 / 13 / 20086: 14$ & 23 & 27.1 \\
\hline 4207 & 1/13/20086:16 & $8 / 13 / 20086: 16$ & 2.302 & 27.3 \\
\hline 4208 & $1 / 13 / 20086: 18$ & $8 / 13 / 20086: 18$ & 2.304 & 26.9 \\
\hline 4209 & $1 / 13 / 20086: 20$ & $8 / 13 / 20086: 20$ & 2.309 & 26.8 \\
\hline 4210 & $1 / 13 / 20086: 22$ & $8 / 13 / 20086: 22$ & 2.314 & 26.7 \\
\hline 4211 & $1 / 13 / 20086: 24$ & $8 / 13 / 20086: 24$ & 2.315 & 26.7 \\
\hline 4212 & $1 / 13 / 20086: 26$ & $8 / 13 / 20086: 26$ & 2.316 & 26.7 \\
\hline 4213 & $1 / 13 / 20086: 28$ & $8 / 13 / 20086: 28$ & 2.318 & 26.7 \\
\hline 4214 & $1 / 13 / 20086: 30$ & $8 / 13 / 20086: 30$ & 2.319 & 26.6 \\
\hline 4215 & $1 / 13 / 20086: 32$ & $8 / 13 / 20086: 32$ & 2.32 & 26.6 \\
\hline 4216 & $1 / 13 / 20086: 34$ & $8 / 13 / 20086: 34$ & 2.321 & 26.6 \\
\hline 4217 & $1 / 13 / 20086: 36$ & $8 / 13 / 20086: 36$ & 2.319 & 26.6 \\
\hline 4218 & $1 / 13 / 20086: 38$ & $8 / 13 / 20086: 38$ & 2.319 & 26.6 \\
\hline 4219 & $1 / 13 / 20086: 40$ & $8 / 13 / 20086: 40$ & 2.319 & 26.6 \\
\hline 4220 & $1 / 13 / 20086: 42$ & $8 / 13 / 20086: 42$ & 232 & 26.6 \\
\hline 4221 & $1 / 13 / 20086: 44$ & $8 / 13 / 20086: 44$ & 2.323 & 26.6 \\
\hline 4222 & $1 / 13 / 20086: 46$ & $8 / 13 / 20086: 46$ & 2.326 & 26.6 \\
\hline 4223 & $1 / 13 / 20086: 48$ & $8 / 13 / 20086: 48$ & 2.329 & 26.6 \\
\hline 4224 & $1 / 13 / 20086: 50$ & $8 / 13 / 20086: 50$ & 2.331 & 26.6 \\
\hline 4225 & $1 / 13 / 20086: 52$ & $8 / 13 / 20086: 52$ & 2.333 & 26.6 \\
\hline 4226 & $1 / 13 / 20086: 54$ & $8 / 13 / 20086: 54$ & 2.335 & 26.6 \\
\hline 4227 & $1 / 13 / 20086: 56$ & $8 / 13 / 20086: 56$ & 2.337 & 26.6 \\
\hline 4228 & $1 / 13 / 20086.58$ & $8 / 13 / 20086: 58$ & 2.339 & 26.6 \\
\hline 4229 & $1 / 13 / 20087: 00$ & $8 / 13 / 20087: 00$ & 2.339 & 26.6 \\
\hline 4230 & $1 / 13 / 20087: 02$ & $8 / 13 / 20087: 02$ & 234 & 26.6 \\
\hline 4231 & $1 / 13 / 20087: 04$ & $8 / 13 / 20087: 04$ & 2.343 & 26.6 \\
\hline 4232 & $1 / 13 / 20087: 06$ & $8 / 13 / 20087: 06$ & 2.348 & 26.5 \\
\hline 4233 & $1 / 13 / 20087: 08$ & $8 / 13 / 20087: 08$ & 2.349 & 26.5 \\
\hline 4234 & $1 / 13 / 20087: 10$ & $8 / 13 / 20087: 10$ & 2.348 & 26.5 \\
\hline 4235 & $1 / 13 / 20087: 12$ & $8 / 13 / 20087: 12$ & 2.347 & 26.5 \\
\hline 4236 & $1 / 13 / 20087: 14$ & $8 / 13 / 20087: 14$ & 2.347 & 26.5 \\
\hline
\end{tabular}

\begin{tabular}{|c|c|c|c|c|}
\hline \multicolumn{5}{|c|}{ D4-92p } \\
\hline Rec & & Adjusted & Pressure & Temp \\
\hline$\#$ & DatéTime & DaterTime & \begin{tabular}{|l|} 
psi \\
\end{tabular} & ${ }^{\circ} \mathrm{C}$ \\
\hline 4237 & $1 / 13 / 20087: 16$ & $8 / 13 / 20087: 16$ & 2347 & 26.5 \\
\hline 4238 & $1 / 13 / 20087: 18$ & $8 / 13 / 20087: 18$ & 2347 & 26.5 \\
\hline 4239 & $1 / 13 / 20087: 20$ & $8 / 13 / 20087: 20$ & 2348 & 26.5 \\
\hline 4240 & $1 / 13 / 20087: 22$ & $8 / 13 / 20087: 22$ & 2351 & 26.5 \\
\hline 4241 & $1 / 13 / 20087: 24$ & $8 / 13 / 20087: 24$ & 2351 & 26.5 \\
\hline 4242 & 1/13/2008 7:26 & $8 / 13 / 20087: 26$ & 2351 & 26.5 \\
\hline 4243 & $1 / 13 / 20087: 28$ & $8 / 13 / 20087: 28$ & 2351 & 26.5 \\
\hline 4244 & $1 / 13 / 20087: 30$ & $8 / 13 / 20087: 30$ & 2354 & 26.5 \\
\hline 4245 & 1/13/20087:32 & $8 / 13 / 2008$ 7:32 & 2357 & 26.5 \\
\hline 4246 & $1 / 13 / 20087: 34$ & $8 / 13 / 20087: 34$ & 236 & 26.5 \\
\hline 4247 & $1 / 13 / 20087: 36$ & $8 / 13 / 20087: 36$ & 2.362 & 26.5 \\
\hline 4248 & $1 / 13 / 20087: 38$ & $8 / 13 / 20087: 38$ & 2.362 & 26.5 \\
\hline 4249 & $1 / 13 / 20087: 40$ & $8 / 13 / 20087: 40$ & 2.361 & 26.4 \\
\hline 4250 & $1 / 13 / 20087: 42$ & $8 / 13 / 2008$ 7:42 & 2361 & 26.5 \\
\hline 4251 & $1 / 13 / 20087: 44$ & $8 / 13 / 20087: 44$ & 2.362 & 26.5 \\
\hline 4252 & $1 / 13 / 20087: 46$ & $8 / 13 / 20087: 46$ & 2363 & 26.5 \\
\hline 4253 & 1/13/20087:48 & $8 / 13 / 20087: 48$ & 2.363 & 26.5 \\
\hline 4254 & 1/13/20087:50 & $8 / 13 / 20087: 50$ & 2364 & 26.4 \\
\hline 4255 & $1 / 13 / 20087: 52$ & $8 / 13 / 20087: 52$ & 2.366 & 26.4 \\
\hline 4256 & $1 / 13 / 20087: 54$ & $8 / 43 / 20087: 54$ & 2368 & 26.4 \\
\hline 4257 & $1 / 13 / 20087: 56$ & $8 / 13 / 20087: 56$ & 2368 & 26.4 \\
\hline 4258 & $1 / 13 / 20087: 58$ & $8 / 13 / 20087: 58$ & 2369 & 26.4 \\
\hline 4259 & $1 / 13 / 20088: 00$ & $8 / 13 / 20088: 00$ & 2369 & 26.4 \\
\hline 4260 & $1 / 13 / 20088: 02$ & $8 / 13 / 20088: 02$ & 2.374 & 26.4 \\
\hline 4261 & $1 / 13 / 20088: 04$ & $8 / 13 / 20088: 04$ & 2.375 & 26.4 \\
\hline 4262 & 1/13/20088:06 & $8 / 13 / 20088: 06$ & 2375 & 26.4 \\
\hline 4263 & 1/13/2008 8:08 & $8 / 13 / 20088: 08$ & 2375 & 26.4 \\
\hline 4264 & 1/13/20088:10 & $8 / 13 / 20088: 10$ & 2376 & 26.4 \\
\hline 4265 & 1/13/20088:12 & $8 / 13 / 20088: 12$ & 2376 & 26.4 \\
\hline 4266 & 1/13/20088:14 & $8 / 13 / 20088: 14$ & 2.376 & 26.4 \\
\hline 4267 & 1/13/20088:16 & $8 / 13 / 20088: 16$ & 2.378 & 26.4 \\
\hline 4268 & 1/13/2008 8:18 & $8 / 13 / 20088: 18$ & 2.379 & 26.4 \\
\hline 4269 & $1 / 13 / 20088: 20$ & $8 / 13 / 20088: 20$ & 2382 & 26.4 \\
\hline 4270 & $1 / 13 / 20088: 22$ & $8 / 13 / 20088: 22$ & 2384 & 26.4 \\
\hline 4271 & $1 / 13 / 20088: 24$ & $8 / 13 / 20088: 24$ & 2385 & 26.4 \\
\hline 4272 & $1 / 13 / 20088: 26$ & $8 / 13 / 20088: 26$ & 2384 & 26.4 \\
\hline 4273 & $1 / 13 / 20088: 28$ & $8 / 13 / 20088: 28$ & 2385 & 26.4 \\
\hline 4274 & $1 / 13 / 20088: 30$ & $8 / 13 / 20088: 30$ & 2387 & 26.4 \\
\hline 4275 & 1/13/2008 8:32 & $8 / 13 / 20088: 32$ & 2389 & 26.4 \\
\hline 4276 & 1/13/2008 8:34 & $8 / 13 / 20088: 34$ & 2.39 & 26.4 \\
\hline 4277 & 1/13/2008 8:36 & $8 / 13 / 20088: 36$ & 2391 & 26.4 \\
\hline 4278 & 1/13/2008 8:38 & $8 / 13 / 20088: 38$ & 2.3 & 26.8 \\
\hline 4279 & 1/13/20088:40 & $8 / 13 / 20088: 40$ & 2361 & 26.5 \\
\hline 4280 & 1/13/2008 8:42 & $8 / 13 / 2008$ 8:42 & 2207 & 26.4 \\
\hline 4281 & 1/13/20088:44 & $8 / 13 / 20088: 44$ & 2186 & 26.4 \\
\hline 4282 & $1 / 13 / 20088: 46$ & $8 / 13 / 20088: 46$ & 2.049 & 26.4 \\
\hline 4283 & $1 / 13 / 20088: 48$ & $8 / 13 / 20088: 48$ & 2047 & 26.4 \\
\hline 4284 & $1 / 13 / 20088: 50$ & $8 / 13 / 20088: 50$ & 2181 & 26.4 \\
\hline 4285 & $1 / 13 / 20088: 52$ & $8 / 13 / 20088: 52$ & 2.298 & 26.4 \\
\hline 4286 & $1 / 13 / 20088: 54$ & $8 / 13 / 20088: 54$ & 2357 & 26.4 \\
\hline 4287 & $1 / 13 / 20088: 56$ & $8 / 13 / 20088.56$ & 2382 & 26.4 \\
\hline 4288 & $1 / 13 / 20088: 58$ & $8 / 13 / 20088: 58$ & 2.393 & 26.4 \\
\hline 4289 & $1 / 13 / 20089: 00$ & $8 / 13 / 20089.00$ & 2.385 & 26.4 \\
\hline 4290 & $1 / 13 / 20089.02$ & $8 / 13 / 20089: 02$ & 2404 & 26.4 \\
\hline 4291 & $1 / 13 / 20089: 04$ & $8 / 13 / 20089: 04$ & 2389 & 26.4 \\
\hline 4292 & $1 / 13 / 20089: 06$ & $8 / 13 / 20089.06$ & 2.387 & 26.4 \\
\hline 4293 & $1 / 13 / 20089.08$ & $8 / 13 / 20089.08$ & 2.376 & 26.4 \\
\hline 4294 & 1/13/20089:10 & $8 / 13 / 20089: 10$ & 2399 & 26.4 \\
\hline 4295 & 1/13/20089.12 & $8 / 13 / 20089.12$ & 2.404 & 26.4 \\
\hline 4296 & 1/13/20089:14 & $8 / 13 / 20089.14$ & 2.411 & 26.4 \\
\hline 4297 & 1/13/20089:16 & $8 / 13 / 20089: 16$ & 2.417 & 26.5 \\
\hline 4298 & 1/13/20089.18 & $8 / 13 / 20089: 18$ & 2419 & 26.4 \\
\hline 4299 & $1 / 13 / 20089: 20$ & $8 / 13 / 20089.20$ & 2422 & 26.5 \\
\hline 4300 & 1/13/20089:22 & $8 / 13 / 20089.22$ & 2423 & 26.5 \\
\hline 4301 & 1/13/20089.24 & $8 / 13 / 20089.24$ & 2424 & 26.5 \\
\hline 4302 & $1 / 13 / 20089: 26$ & $8 / 13 / 20089: 26$ & 2426 & 26.5 \\
\hline 4303 & 1/13/20089:28 & $8 / 13 / 20089: 28$ & 2427 & 26.5 \\
\hline 4304 & 1/13/20089:30 & $8 / 13 / 20089: 30$ & 2428 & 26.5 \\
\hline 4305 & $1 / 13 / 20089.32$ & $8 / 13 / 20089.32$ & 2429 & 26.8 \\
\hline
\end{tabular}


DOE/RL-2009-35, REV. 0

\begin{tabular}{|c|c|c|c|c|}
\hline \multicolumn{5}{|c|}{$D 4920$} \\
\hline $\mathrm{Bec}$ & & Acjusted & Pressure & Tem \\
\hline \# & DaterTime & DeteTime & & \\
\hline 4306 & 1/13/20089:34 & $8 / 13 / 20089.34$ & 2429 & 2 \\
\hline 4307 & $1 / 13 / 20089: 36$ & $8 / 13 / 20089.36$ & 2431 & \\
\hline 4308 & $1 / 13 / 20089.38$ & & 2434 & 26 \\
\hline 4309 & $1 / 13 / 20089.40$ & $8 / 13 / 20089.40$ & 2436 & 26.5 \\
\hline 4310 & $1 / 13 / 20089.42$ & & 2437 & \\
\hline 4311 & $1 / 13 / 20089.44$ & $8 / 13 / 20089.44$ & 2438 & 26.5 \\
\hline 4312 & $1 / 13 / 20089.46$ & $8 / 13 / 20089.46$ & 2439 & 26.5 \\
\hline 4313 & $1 / 13 / 20089.48$ & $8 / 13 / 20089.48$ & 2441 & 26.5 \\
\hline 4314 & $1 / 13 / 20089.50$ & $8 / 13 / 20089.50$ & 2441 & 26.5 \\
\hline 4315 & $1 / 13 / 20089.52$ & $8 / 13 / 20089.52$ & 2443 & 26.5 \\
\hline 4316 & $1 / 13 / 20089.54$ & $8 / 13 / 20089.54$ & 2443 & 26.5 \\
\hline 4317 & $1 / 13 / 20089.56$ & $8 / 13 / 2008956$ & 2444 & 26.5 \\
\hline 4318 & $1 / 13 / 20089.58$ & $8 / 13 / 20089.58$ & 2443 & \\
\hline 4319 & 1/13/2008 10:00 & $8 / 13 / 2008$ 10:00 & 2444 & 26 . \\
\hline 4320 & $13 / 200810: 02$ & $8 / 13 / 2008$ 10:02 & 2446 & 26.6 \\
\hline 4321 & 1320008 10:04 & $8 / 13 / 200810.04$ & 2445 & \\
\hline 4322 & $1 / 13 / 200810: 06$ & $8 / 13 / 200810.06$ & 2446 & 26.6 \\
\hline 4323 & $1 / 13 / 200810: 08$ & $8 / 13 / 200810: 08$ & 2448 & 26.6 \\
\hline 4324 & $1 / 13 / 200810: 10$ & $8 / 13 / 2008$ 10:10 & 2449 & $\pi$ \\
\hline 4325 & $1 / 13 / 200810: 12$ & $8 / 13 / 200810: 12$ & 2451 & 26. \\
\hline 4326 & $1 / 13 / 200810: 14$ & $8 / 13 / 2008$ 10:14 & 2452 & 26.6 \\
\hline 4327 & $113 / 200810: 16$ & $8 / 13 / 2008$ 10:16 & 2452 & 26.6 \\
\hline 4328 & 10.18 & $8 / 13 / 200810: 18$ & 2453 & 26.6 \\
\hline 4329 & $10: 20$ & $8 / 13 / 2008$ 10:20 & 2455 & \\
\hline 4330 & 10:22 & $8 / 13 / 200810.22$ & 2456 & 26. \\
\hline 4331 & & $8 / 13 / 200810.24$ & 2457 & 26. \\
\hline 4332 & $10: 26$ & $13 / 2008+10: 26$ & 2458 & 26. \\
\hline 4333 & 10.28 & $00810: 28$ & 2450 & 26.6 \\
\hline 4334 & $10: 30$ & 00810.30 & 246 & 26. \\
\hline 4335 & 10.32 & 008 10:32 & 2461 & 26. \\
\hline 4336 & 10.34 & 810.34 & 2462 & 26. \\
\hline 4337 & & $810: 36$ & 2462 & $\overline{\underline{x}}$ \\
\hline 4338 & & $10: 38$ & 2462 & 26. \\
\hline 4330 & & $10: 40$ & 2462 & 26 \\
\hline 4340 & & $10: 42$ & 2463 & 26.6 \\
\hline 4341 & 0.44 & 810.44 & 2463 & 26. \\
\hline 4342 & & 190:46 & 2463 & 26. \\
\hline 4343 & & & 2456 & 26. \\
\hline 4344 & & & 2438 & 26. \\
\hline 4345 & & 10.52 & 2432 & 26 . \\
\hline 4346 & & 10.54 & 2437 & 26 . \\
\hline 4347 & & $810: 56$ & 2445 & 26. \\
\hline 4348 & & & 2456 & 26. \\
\hline 4349 & & & 246 & 26. \\
\hline 4350 & & & 2469 & 26 \\
\hline & & & 2476 & 26 \\
\hline 4352 & & & 2481 & 26. \\
\hline 4363 & & & 2487 & \\
\hline 4354 & & & 2488 & 26 \\
\hline 4355 & & & 2491 & 26 \\
\hline 4356 & & & 2495 & \\
\hline 4357 & & & 25 & 26 \\
\hline 4358 & & & 2505 & \\
\hline 4359 & & $0811: 20$ & 251 & 26 \\
\hline 4360 & & & 2512 & 26 \\
\hline 4361 & & & 2464 & \\
\hline 4362 & & & 2396 & 26 \\
\hline 4363 & & & 229 & \\
\hline 4364 & & $8 / 13 / 2008+1: 30$ & 2227 & 26 \\
\hline 4365 & & & 2307 & 26 \\
\hline 4366 & & & 2412 & \\
\hline 4367 & $1 / 13 / 20$ & & 2.49 & 26 \\
\hline & & & 2527 & \\
\hline 4369 & $1 / 13 / 2$ & $13 / 200811: 40$ & 2537 & 20 \\
\hline 4370 & & & 2538 & \\
\hline 4371 & & & 2538 & \\
\hline 4372 & $1 / 13 / 200811: 46$ & $8 / 13 / 2008$ 11:46 & 254 & 26 \\
\hline 4373 & $1 / 13 / 200$ & & 2543 & \\
\hline & $1 / 13 / 200811: 50$ & $8 / 13 / 200811: 50$ & & \\
\hline
\end{tabular}

\begin{tabular}{|c|c|c|c|c|}
\hline \multicolumn{5}{|c|}{$D 4-92 p$} \\
\hline Rec & & Adusted & & \\
\hline$\#$ & DeterTime & DateTime & psi & ${ }^{\circ} \mathrm{C}$ \\
\hline 4375 & $1 / 13 / 200811: 52$ & $8 / 13 / 200811: 52$ & 2549 & \\
\hline 4376 & $1 / 13 / 200811: 54$ & $8 / 13200811: 54$ & 2554 & \\
\hline 4377 & $1 / 13 / 200811: 56$ & $8 / 13200811: 56$ & 2558 & 27 \\
\hline 4378 & $1 / 13 / 2008$ 11:58 & $8 / 13 / 200811: 58$ & 2579 & \\
\hline 4379 & $1 / 13 / 20081200$ & $8 / 13 / 20081200$ & 2474 & 27. \\
\hline 4380 & $1 / 13 / 20081202$ & $8 / 13 / 200812002$ & 2536 & 27.3 \\
\hline 4381 & $1 / 13 / 20081204$ & $8 / 13 / 200812: 04$ & 2557 & \\
\hline 4382 & $1 / 13 / 20081206$ & $8 / 1320081206$ & 2566 & 27. \\
\hline 4383 & $1 / 13 / 20081208$ & $8 / 13 / 200812 \cdot 08$ & 2571 & \\
\hline 4384 & $1 / 13 / 20081210$ & $8 / 13 / 200812: 10$ & 2575 & 27.3 \\
\hline 4385 & $1 / 13 / 20081212$ & $8 / 13 / 200812: 12$ & 2584 & 27.4 \\
\hline 4386 & $1 / 13 / 20081214$ & $8 / 1320081214$ & 2579 & 27. \\
\hline 4387 & $1 / 13 / 20081216$ & $8 / 13 / 200812: 16$ & 2585 & 274 \\
\hline 4388 & $3 / 20081218$ & $8 / 13 / 20081218$ & 2587 & 27.4 \\
\hline 4389 & $3 / 20081220$ & $8 / 1320081220$ & 2588 & \\
\hline 4390 & $3 / 20081222$ & $8 / 13 / 20081222$ & 2588 & 27 \\
\hline 4391 & 1224 & $8 / 13 / 20081224$ & 2589 & 27.6 \\
\hline 4392 & & $8 / 13 / 200812226$ & 2591 & \\
\hline 4393 & 320081228 & $8 / 13 / 20081228$ & 2593 & 27.6 \\
\hline 4394 & & $8 / 13 / 20081230$ & 2597 & \\
\hline 4395 & 1232 & 811320081233 & 2598 & 27 \\
\hline 4396 & & $8 / 1320081234$ & 26 & 27. \\
\hline 4397 & & $8113 / 20081236$ & 26 & 27. \\
\hline 4398 & & $8 / 13 / 20081238$ & 2.601 & \\
\hline 4399 & & $8 / 1320081240$ & 2598 & 27 \\
\hline 4400 & & $8 / 13 / 20081242$ & 2.596 & 27 \\
\hline 4401 & & $8 / 13 / 20081244$ & 2596 & 27. \\
\hline 4402 & & $8 / 13 / 20081246$ & 2596 & 27. \\
\hline 4403 & 1248 & $8 / 13 / 20081248$ & 2599 & \\
\hline 4404 & & $8 / 13 / 20081250$ & 26 & 20. \\
\hline 4405 & & $8 / 13 / 20081255$ & 2.601 & \\
\hline 4406 & & $8 / 13 / 20081254$ & 2602 & 27. \\
\hline 4407 & & $8 / 13 / 20081256$ & 2600 & 27 \\
\hline 4408 & & $8 / 13 / 20081258$ & 2604 & 27.8 \\
\hline 4400 & & $8 / 13 / 2$ & 2.606 & \\
\hline 4410 & & $8 / 13 / 200813: 02$ & 2600 & \\
\hline 4411 & & $8 / 13 / 200813: 04$ & 2611 & 27. \\
\hline 4412 & & $813: 06$ & 2614 & 27. \\
\hline 4413 & & $8 / 13 / 200813: 08$ & 2615 & \\
\hline 4414 & & & 2616 & 27. \\
\hline 4415 & & 13:12 & 2.617 & 27. \\
\hline 4416 & & $8 / 13 / 200813: 14$ & 2.618 & \\
\hline 4417 & & $8 / 13 / 200813: 16$ & 2619 & \\
\hline 4418 & & $8 / 13 / 200813: 18$ & 262 & 27 \\
\hline 4419 & & & 2621 & \\
\hline 4420 & & $3: 22$ & 2.62 & \\
\hline 4421 & & $8 / 13 / 2008$ & 2.624 & 27 \\
\hline 4422 & & & 2625 & \\
\hline 4423 & & $13: 28$ & 2.626 & 27 \\
\hline 4424 & & & 2.626 & 27 \\
\hline 4425 & & $313: 32$ & 2628 & 27 \\
\hline 4426 & & & 2631 & 27 \\
\hline 4427) & & & 2632 & \\
\hline 4428 & & $13: 38$ & 2.634 & 27. \\
\hline 442 & & & 2635 & \\
\hline 4430 & & $8 / 13 / 200813: 42$ & 2.634 & \\
\hline 4431 & & $8 / 13 / 200813: 44$ & 2.629 & \\
\hline 4432 & & & 2626 & \\
\hline 4433 & & $8 / 13 / 200813: 48$ & 2628 & 27 \\
\hline 4434 & & & 2631 & \\
\hline 4435 & 13:52 & $8 / 13 / 200813: 52$ & 2636 & \\
\hline 4436 & & $8 / 13 / 20081354$ & 2.639 & \\
\hline 4437 & & $8 / 13 / 20$ & 2644 & \\
\hline 4438 & $13: 58$ & $8 / 13 / 200813: 58$ & 2648 & 28 \\
\hline & & & 2651 & \\
\hline 4440 & $1 / 13 / 200814: 02$ & $8 / 13 / 2008$ 14:02 & 266 & \\
\hline 4441 & $1 / 13 / 200814: 04$ & $8 / 13 / 200814: 04$ & 2653 & \\
\hline 4442 & & $8 / 13 / 2008$ 14:06 & 2655 & \\
\hline 4443 & 1/13/2008 14:08 & $8 / 13 / 2008$ 14:06 & 2.656 & \\
\hline
\end{tabular}

\begin{tabular}{|c|c|c|c|c|}
\hline \multicolumn{5}{|c|}{ D4-920 } \\
\hline $\mathrm{R} \theta \mathrm{C}$ & & Agiusted & Pressurt & \\
\hline$\#$ & Dede/Time & DeterTime & psi & ${ }^{\circ} \mathrm{C}$ \\
\hline 4444 & $1 / 13 / 200814: 10$ & $8 / 13 / 200814: 10$ & 2659 & 28. \\
\hline 4445 & 1/13/2008 14:12 & $8 / 13 / 200814: 11$ & 2661 & \\
\hline 4446 & $1 / 13 / 2008$ 14:14 & $8 / 13 / 200814: 14$ & 2663 & \\
\hline 4447 & $13 / 200814: 16$ & $8 / 13 / 200814: 16$ & 2665 & \\
\hline 4448 & $13200814: 18$ & $8 / 13 / 200814: 18$ & 2668 & \\
\hline 4449 & 1/13/2008 14:20 & $8 / 13 / 200814: 20$ & 2645 & \\
\hline 4450 & $1 / 13 \sqrt{2000814: 22}$ & $8 / 13 / 200814: 22$ & & \\
\hline 4451 & $1 / 13 / 200814: 24$ & $8 / 13 / 200814: 24$ & 2371 & \\
\hline 4452 & $1 / 13 / 200814: 26$ & $8 / 13 / 200814: 26$ & 2428 & \\
\hline 4453 & $13 / 2008$ 14:28 & $8 / 13 / 200814: 28$ & 2545 & \\
\hline 4454 & $1 / 13 / 200814: 30$ & $8 / 13 / 200814: 30$ & 2625 & \\
\hline 4455 & $1 / 13 / 200814: 32$ & $8 / 13 / 200814: 32$ & 2667 & \\
\hline 4456 & $13 / 200814: 34$ & $8 / 13 / 200814: 34$ & 2689 & \\
\hline 4457 & $1 / 13 / 200814: 36$ & $8 / 13 / 200814: 36$ & 27 & 28. \\
\hline 4458 & $13 / 200814: 38$ & $8 / 13 / 200814: 38$ & 2706 & \\
\hline 4450 & $13 / 200814: 40$ & $8 / 13 / 200814: 40$ & 2711 & \\
\hline 4460 & $1 / 13 / 200814: 42$ & $8 / 13 / 200814: 42$ & 2714 & \\
\hline 4461 & $13200814: 44$ & $8 / 13 / 2008$ 14:44 & & \\
\hline 4462 & $13 / 2008$ 14:46 & $8 / 13 / 200814: 46$ & 2719 & 28. \\
\hline 4463 & $13 / 200814: 48$ & $8 / 13 / 200814: 48$ & 272 & \\
\hline 4464 & $13 / 200814: 50$ & $8 / 13 / 200814: 50$ & 272 & \\
\hline 4465 & $132000814: 52$ & $8 / 13 / 200814: 52$ & 2725 & 28. \\
\hline 4466 & $13200814: 54$ & $8 / 13 / 200814: 54$ & 2727 & \\
\hline 4467 & $13 / 200814: 56$ & $8 / 13 / 200814: 56$ & 2728 & 28. \\
\hline 4468 & 314:58 & $814: 58$ & 273 & \\
\hline 4469 & $15: 00$ & $8 / 13 / 20$ & 2732 & \\
\hline 4470 & 15:02 & $8 / 13 / 2$ & 2734 & \\
\hline 4471 & $15: 04$ & $8 / 13 / 200815: 04$ & 2735 & \\
\hline 4472 & 15:06 & $8 / 13 / 200815: 06$ & 2736 & 28. \\
\hline 4473 & 08 & $8 / 13 / 2$ & 2739 & 28 \\
\hline 4474 & 15:10 & $8 / 13 / 2$ & 2741 & \\
\hline 4475 & & $8 / 13 / 2$ & 274 & 28. \\
\hline 4476 & $15: 14$ & $8 / 13 / 200815: 14$ & 2742 & \\
\hline 4477 & $15: 16$ & $8 / 13 / 200815: 16$ & 2742 & \\
\hline 4478 & 15:18 & $8 / 13 / 2$ & 2743 & \\
\hline 4479 & 320 & $8 / 13 / 2$ & 2744 & 28 \\
\hline 4480 & & & 2743 & 28. \\
\hline 4481 & & $15: 24$ & 2741 & 28 \\
\hline 4482 & $15: 26$ & $8 / 13 / 200815: 26$ & 2741 & 28. \\
\hline 4483 & & $8 / 13 / 2$ & 2742 & 29 \\
\hline 4484 & 30 & $15: 30$ & 2744 & 28 \\
\hline 4485 & & & 2747 & 2 \\
\hline 4486 & & $5: 34$ & $274 c$ & \\
\hline 4487 & $15: 36$ & $8 / 13 / 2$ & 2751 & 28 \\
\hline 4488 & & & 2753 & \\
\hline 4489 & & $15: 40$ & 2753 & 28 \\
\hline 4490 & & & 2.754 & 2. \\
\hline 4491 & & & 2756 & \\
\hline 4492 & $15: 46$ & $8 / 13 / 20$ & 2.76 & 28. \\
\hline 4493 & & & 2761 & 28 \\
\hline 4494 & 315:50 & $315: 50$ & 2761 & \\
\hline 4496 & & & 2762 & 28 \\
\hline 4496 & & & 2763 & \\
\hline 4497 & $15: 56$ & $315: 56$ & 2765 & 29. \\
\hline 4498 & & & 2765 & \\
\hline 4499 & 16:00 & 31600 & 2785 & 29 \\
\hline 4500 & & & 2683 & 29 \\
\hline 4501 & & & 2731 & 29 \\
\hline 4502 & $316: 06$ & $8 / 13 / 20$ & 2757 & 29 . \\
\hline 4503 & & & 2771 & \\
\hline 4504 & $1 / 2008$ 16:10 & $8 / 13 / 200816: 10$ & $2 \pi 77$ & 2 \\
\hline 4505 & & $8 / 13 / 2$ & 2781 & \\
\hline 4506 & & & & \\
\hline 4507 & $13 / 200816: 16$ & $8 / 13 / 200816: 16$ & 2783 & 29. \\
\hline 4508 & & & 2784 & \\
\hline 4509 & $1 / 13 / 200816: 20$ & $8 / 13 / 200816: 20$ & 2785 & 29. \\
\hline 4510 & $13 / 2008$ 16:22 & $8 / 13 / 200816: 22$ & 2787 & \\
\hline 4511 & $13 / 200816: 24$ & $8 / 13 / 200816: 24$ & 2785 & \\
\hline 4512 & $3 / 200816: 26$ & $8 / 13 / 200816: 26$ & 2785 & \\
\hline
\end{tabular}


DOE/RL-2009-35, REV. 0

\begin{tabular}{|c|c|c|c|c|}
\hline \multicolumn{5}{|c|}{ D4-920 } \\
\hline $\operatorname{Rec}$ & & Aqusted & Pressure & $\overline{\text { Temp }}$ \\
\hline$\#$ & DateTime & Date/Time & psi & \\
\hline 4513 & $1 / 13 / 200816: 28$ & $8 / 13 / 200816: 28$ & 2775 & 29.3 \\
\hline 4514 & $1 / 13 / 2008$ 16:30 & $8 / 13 / 200816: 30$ & $2 \pi 7$ & 29.3 \\
\hline 4515 & 1/13/2008 16:32 & $8 / 13 / 200816: 32$ & 2778 & \\
\hline 4516 & $1 / 13 / 200816: 34$ & $8 / 13 / 2008$ 16:34 & 2782 & 29.3 \\
\hline 4517 & $1 / 13 / 200816: 36$ & $8 / 13 / 200816: 36$ & 2784 & 29.3 \\
\hline 4518 & $1 / 13 / 2008$ 16:38 & $8 / 13 / 200816: 38$ & 2787 & 29.2 \\
\hline 4519 & $1 / 13 / 200816: 40$ & $8 / 13 / 200816: 40$ & 2789 & 29.2 \\
\hline 4520 & $1 / 13 / 2008$ 16:42 & $8 / 13 / 200816: 42$ & 2794 & 29.2 \\
\hline 4521 & $1 / 13 / 2008$ 16:44 & $8 / 132000816: 44$ & 2799 & 29.1 \\
\hline 4522 & $1 / 13 / 2008$ 16:46 & $8 / 13 / 200816: 46$ & 2803 & 29.1 \\
\hline 4523 & $1 / 13 / 2008$ 16:48 & $8 / 13 / 200816: 48$ & 2808 & 29.1 \\
\hline 4524 & $1 / 13 / 2008$ 16:50 & $8 / 13200016: 50$ & 2813 & 29.2 \\
\hline 4525 & $1 / 13 / 2008$ 16:52 & $8 / 13 / 200816: 52$ & 2817 & 29.1 \\
\hline 4526 & $1 / 13 / 2008$ 16:54 & $8 / 13 / 200816: 54$ & 282 & 29 \\
\hline 4527 & $1 / 13 / 2008$ 16:56 & $8 / 13 / 200816: 56$ & 2822 & 28.9 \\
\hline 4528 & $1 / 13 / 2008$ 16:58 & $8 / 13 / 200816: 58$ & 2823 & 29.1 \\
\hline 4520 & $1 / 13 / 2008$ 17:00 & $8 / 132000817: 00$ & 2825 & 29.3 \\
\hline 4530 & 1/13/2008 17:02 & $8 / 13 / 2008$ 17:02 & 2826 & 29.4 \\
\hline 4531 & $1 / 13 / 2008$ 17:04 & $8 / 13 / 2008$ 17:04 & 2827 & 29.8 \\
\hline 4532 & $1 / 13 / 200817: 06$ & $8 / 13 / 2008$ 17:06 & 2819 & 29.6 \\
\hline 4533 & $1 / 13 / 2008$ 17:08 & $8 / 13 / 200817: 08$ & 2679 & 29.6 \\
\hline 4534 & 1/13/2008 17:10 & $8 / 13 / 2008$ 17:10 & 2624 & 29.6 \\
\hline 4535 & $1 / 13 / 2008$ 17:12 & $8 / 13 / 2008$ 17:12 & 2692 & 29.5 \\
\hline 4536 & 1/13/2008 17:14 & $8 / 13 / 200817: 14$ & 2751 & 29.5 \\
\hline 4537 & 1/13/2008 17:16 & $8 / 13200817: 16$ & 2788 & 29.5 \\
\hline 4538 & 1/13/2008 17:18 & $8 / 13 / 2008$ 17:18 & 281 & 29.5 \\
\hline 4539 & $1 / 13 / 200817: 20$ & $8 / 13 / 200817: 20$ & 2822 & 29.5 \\
\hline 4540 & 1/13/2008 17:22 & $8 / 13 / 200817: 22$ & 2832 & 29.6 \\
\hline 4541 & $1 / 13 / 200817: 24$ & $8 / 13 / 200817: 24$ & 2839 & 29.7 \\
\hline 4542 & $1 / 13 / 200817: 26$ & $8 / 13 / 200817: 26$ & 2844 & 29.6 \\
\hline 4543 & 1/13/2008 17:28 & $8 / 13200817: 28$ & 2846 & 29.7 \\
\hline 4544 & $1 / 13 / 2008$ 17:30 & $8 / 13200817: 30$ & 285 & 29.7 \\
\hline 4545 & 1/13/2008 17:32 & $8 / 13 / 200817: 32$ & 2851 & 29.7 \\
\hline 4546 & $1 / 13 / 2008$ 17:34 & $8 / 13 / 200817: 34$ & 2852 & 29.7 \\
\hline 4547 & $1 / 13 / 2008$ 17:36 & $8 / 13200817: 36$ & 2853 & 29.7 \\
\hline 4548 & $1 / 13 / 2008$ 17:38 & $8 / 13 / 200817: 38$ & 2856 & 29.6 \\
\hline 4549 & $1 / 13 / 2008$ 17:40 & $8 / 13 / 200817: 40$ & 285 & 29.7 \\
\hline 4550 & 1/13/2008 17:42 & $8 / 13200817: 42$ & 2859 & 29.6 \\
\hline 4551 & 1/13/2008 17:44 & $8 / 13 / 200817: 44$ & 2861 & 29.7 \\
\hline 4552 & $1 / 13 / 2008$ 17:46 & $8 / 13 / 200817: 46$ & 286 & 29.6 \\
\hline 4553 & $1 / 13 / 2008$ 17:48 & $8 / 13 / 200017: 48$ & 286 & 29.7 \\
\hline 4554 & $1 / 13 / 200817: 50$ & $8 / 13 / 2008$ 17:50 & 2861 & 29.6 \\
\hline 4555 & 1/13/2008 17:52 & $8 / 13 / 2008$ 17:52 & 2863 & 29.6 \\
\hline 4556 & $1 / 13 / 2008$ 17:54 & $8 / 13 / 200817: 54$ & 2863 & 29.6 \\
\hline 455 . & $1 / 13 / 2008$ 17:56 & $8 / 13 / 200817: 56$ & 2864 & 29.6 \\
\hline 4558 & 1/132008 17:58 & $8 / 13 / 200817: 58$ & 2867 & 29.6 \\
\hline 4559 & 1/13/2008 18:00 & $8 / 13 / 200818: 00$ & 2866 & 29.7 \\
\hline 4560 & $1 / 13 / 200818: 02$ & $8 / 13 / 200818: 02$ & 2866 & 29.7 \\
\hline 4561 & $1 / 13 / 2008$ 18:04 & $8 / 13 / 200818: 04$ & 2806 & 29.8 \\
\hline 4562 & 1/13/2008 18:06 & $8 / 13 / 200818: 06$ & 2868 & 29.8 \\
\hline 4563 & 1/13/2008 18:08 & $8 / 13 / 200818: 06$ & 2868 & 29.7 \\
\hline 4564 & $1 / 13 / 2008$ 18:10 & $8 / 13 / 200818: 10$ & 287 & 29.7 \\
\hline 4566 & $1 / 13 / 2008$ 18:12 & $8 / 13 / 200818: 12$ & 2872 & 29.7 \\
\hline 4566 & $1 / 13 / 2008$ 18:14 & $8 / 13 / 200818: 14$ & 2872 & 29.7 \\
\hline 4567 & $1 / 13 / 2008$ 18:16 & $8 / 13 / 200818: 16$ & 2.874 & 29.7 \\
\hline 4568 & 1/13/2008 18:18 & $8 / 13 / 2008$ 18:18 & 2876 & 29. \\
\hline 4569 & 1/13/2008 18:20 & $8 / 13 / 200818: 20$ & 2878 & 29.7 \\
\hline $45 \pi 0$ & 1/13/2008 18:22 & $8 / 13 / 200818: 22$ & 2878 & 29.7 \\
\hline 4571 & 1/13/2008 18:24 & $8 / 13 / 200818.24$ & 2881 & 29.7 \\
\hline 4572 & $1 / 13 / 200818: 26$ & $8 / 13 / 200818: 26$ & 2882 & 29.7 \\
\hline 4573 & $1 / 13 / 200818: 28$ & $8 / 13 / 200818: 28$ & 2883 & 29.8 \\
\hline 4574 & $1 / 13 / 200818: 30$ & $8 / 13 / 200818: 30$ & 2884 & 29.8 \\
\hline 4575 & $1 / 13 / 200818: 32$ & $8 / 13 / 200818: 32$ & 2886 & 29.8 \\
\hline 4576 & $1 / 13 / 200818: 34$ & $8 / 13 / 200818: 34$ & 2887 & 29.8 \\
\hline $45 \pi$ & $1 / 13 / 200818: 36$ & $8 / 13 / 200818: 36$ & 2891 & 29.8 \\
\hline 4578 & $1 / 13 / 2008$ 18:38 & $8 / 13 / 200818: 38$ & 2896 & 29.8 \\
\hline 4579 & $1 / 13 / 200818: 40$ & $8 / 13 / 20081840$ & 2894 & 29.8 \\
\hline 4580 & 1/13/2008 18:42 & $8 / 13 / 20081842$ & 2896 & 29.8 \\
\hline 4581 & $1 / 13 / 2008$ 18:44 & $8 / 13 / 20081844$ & 2896 & 29.8 \\
\hline
\end{tabular}

\begin{tabular}{|c|c|c|c|c|}
\hline \multicolumn{5}{|c|}{$D 4-994$} \\
\hline ReC & & Adjusted & Pressure & Temp \\
\hline$\#$ & Dete/Time & DaterTime & psi & ${ }^{\circ} \mathrm{C}$ \\
\hline 4582 & $1 / 13 / 200818: 46$ & $8 / 13 / 2008$ 18:46 & 2899 & 29.8 \\
\hline 4583 & $1 / 13 / 200818: 48$ & $8 / 13 / 200818: 48$ & 2901 & 20.8 \\
\hline 4584 & $1 / 13 / 200818: 50$ & $8 / 13 / 200818: 50$ & 2903 & 29.8 \\
\hline 4585 & $1 / 13 / 200818: 52$ & $8 / 13 / 200818: 52$ & 2906 & 29.8 \\
\hline 4586 & $1 / 13 / 200818: 54$ & $8 / 13 / 200018: 54$ & 2907 & 29.8 \\
\hline 4587 & $1 / 13 / 200818: 56$ & $8 / 13 / 200818: 56$ & 2908 & 29.8 \\
\hline 4588 & $1 / 13 / 200818: 58$ & $8 / 13 / 200018: 58$ & 2900 & 29.8 \\
\hline 4589 & $1 / 13 / 20081900$ & $8 / 13 / 200819.00$ & 2909 & 29.8 \\
\hline 4590 & $1 / 13 / 200819.02$ & $8 / 13 / 200819: 02$ & 291 & 29.8 \\
\hline 4591 & $1 / 13 / 200819.04$ & $8 / 13 / 2008$ 19:04 & 2911 & 20.7 \\
\hline 4592 & $1 / 13 / 200819.06$ & $8 / 13 / 2008$ 19:06 & 2914 & 29.7 \\
\hline 4593 & $1 / 13 / 200819.08$ & $8 / 13 / 2008$ 19:08 & 2916 & 29.7 \\
\hline 4594 & $1 / 13 / 200819: 10$ & $8 / 13 / 200819: 10$ & 2919 & 29.6 \\
\hline 4596 & $1 / 13 / 200819.12$ & $8 / 13 / 2008$ 19.12 & 2923 & 29.6 \\
\hline 4596 & $1 / 13 / 200819: 14$ & $8 / 13 / 200819.14$ & 2927 & 29.8 \\
\hline 4597 & $1 / 13 / 200819.16$ & $8 / 13 / 200819: 16$ & 2928 & 29.7 \\
\hline 4598 & $1 / 13 / 200819.18$ & $8 / 13 / 200819: 18$ & 2928 & 29.6 \\
\hline 4599 & $1 / 13 / 200819.20$ & $8 / 13200819: 20$ & 2928 & 29.6 \\
\hline 4600 & $1 / 13 / 200819: 22$ & $8 / 13 / 200819.22$ & 2928 & 20.6 \\
\hline 4601 & $1 / 13 / 200819.24$ & $8 / 13 / 200819.24$ & 2931 & 29.6 \\
\hline 4602 & $1 / 13 / 200819: 26$ & $8 / 13200819.26$ & 2934 & 29.6 \\
\hline 4603 & $1 / 13 / 200819.28$ & $8 / 13 / 200819: 28$ & 2937 & 29.6 \\
\hline 4604 & $1 / 13 / 2008$ 19:30 & $8 / 13 / 200819.30$ & 2939 & 29.7 \\
\hline 4605 & $1 / 13 / 200819: 32$ & $8 / 13 / 200819.32$ & 2939 & 29.7 \\
\hline 4606 & $1 / 13 / 200819.34$ & $8 / 13 / 200819.34$ & 2941 & 29.7 \\
\hline 4607 & $1 / 13 / 200819.36$ & $8 / 13 / 200819: 36$ & 2946 & 29.7 \\
\hline 4608 & $1 / 13 / 200819.38$ & $8 / 13 / 2008$ 19:38 & 295 & 29.7 \\
\hline 4609 & $1 / 13 / 200819: 40$ & $8 / 13 / 200819.40$ & 2953 & 29.7 \\
\hline 4610 & 1/13/2008 19:42 & $8 / 13 / 2008$ 19:42 & 2829 & 20.6 \\
\hline 4611 & $1 / 13 / 2008$ 19:44 & $8 / 13 / 200819: 44$ & 2891 & 29.6 \\
\hline 4612 & $1 / 13 / 200819.46$ & $8 / 13 / 200819: 46$ & 2928 & 30 \\
\hline 4613 & $1 / 13 / 200819.48$ & $8 / 13 / 200819-48$ & 2949 & 20.7 \\
\hline 4614 & $1 / 13 / 200819.50$ & $8 / 13 / 200819.50$ & 2962 & 29.7 \\
\hline 4615 & $1 / 13 / 200819.52$ & $8 / 13 / 200819.52$ & 2964 & 29.6 \\
\hline 4616 & $1 / 13 / 200819.54$ & $8 / 13 / 200819-54$ & 2952 & 29.6 \\
\hline 4617 & $1 / 13 / 200819.56$ & $8 / 13 / 200819: 56$ & 2901 & 29.6 \\
\hline 4618 & $1 / 13 / 200819.58$ & $8 / 13 / 200819.58$ & 2826 & 29.4 \\
\hline 4619 & $1 / 13 / 200820.00$ & $8 / 13 / 200820-00$ & 2761 & 29.4 \\
\hline 4620 & 1/13/200820:02 & $8 / 13 / 200820: 02$ & 2693 & 29.5 \\
\hline 4621 & 1/13/2008 20:04 & $8 / 13 / 200820: 04$ & 2617 & 29.8 \\
\hline 4622 & 1/13/2008 20:06 & $8 / 13 / 200820: 06$ & 2542 & 29.9 \\
\hline 4623 & $1 / 13 / 200820: 08$ & $8 / 13 / 200820: 08$ & 2482 & 29.9 \\
\hline 4624 & $1 / 13 / 200820.10$ & $8 / 13 / 200820: 10$ & 2542 & 29.9 \\
\hline 4625 & $1 / 13 / 200820: 12$ & $8 / 13 / 200820: 12$ & 2688 & 30 \\
\hline 4626 & 1/13/200820:14 & $8 / 13 / 200820: 14$ & 2821 & 29.9 \\
\hline 4627 & $1 / 13 / 200820-16$ & $8 / 13 / 200820: 16$ & 2905 & 29.8 \\
\hline 4628 & 1/13/200820:18 & $8 / 13 / 200820: 18$ & 2947 & 29.8 \\
\hline 4629 & 1/13/200820:20 & $8 / 13 / 200820: 20$ & 2963 & 29.8 \\
\hline 4630 & $1 / 13 / 200820 \cdot 22$ & $8 / 13 / 200820: 22$ & 2968 & 29.9 \\
\hline 4631 & $1 / 13 / 200820: 24$ & $8 / 13 / 200820: 24$ & 2967 & 30 \\
\hline 4632 & $1 / 13 / 200820.26$ & $8 / 13 / 200820: 26$ & 2909 & 30.1 \\
\hline 4633 & $1 / 13 / 200820.28$ & $8 / 13 / 200820: 28$ & 297 & 30.1 \\
\hline 4634 & $1 / 13 / 200820: 30$ & $8 / 13 / 200820: 30$ & 2971 & 30.1 \\
\hline 4635 & $1 / 13 / 200820-32$ & $8 / 13 / 200820: 32$ & 2972 & 30.1 \\
\hline 4636 & 1/13/200820:34 & $8 / 13 / 200820: 34$ & 2972 & 30.1 \\
\hline 4637 & 1/13/2008 20:36 & $8 / 13 / 200820: 36$ & 2975 & 30.4 \\
\hline 4638 & 1/13/200820:38 & $8 / 13 / 200820: 38$ & 2976 & 30.1 \\
\hline 4639 & $1 / 13 / 200620: 40$ & $8 / 13 / 200820: 40$ & 2976 & 30.1 \\
\hline 4640 & $1 / 13 / 200820: 42$ & $8 / 13 / 200820: 42$ & 2977 & 30.3 \\
\hline 4641 & $1 / 13 / 200820: 44$ & $8 / 13 / 200820: 44$ & 2978 & 30.1 \\
\hline 4642 & $1 / 13 / 200820: 46$ & $8 / 13 / 200820: 46$ & 2981 & 30.1 \\
\hline 4643 & $1 / 13 / 200820: 48$ & $8 / 13 / 200820: 48$ & 2984 & 30 \\
\hline 4644 & $1 / 13 / 200820-50$ & $8 / 13 / 200820: 50$ & 2987 & 29.9 \\
\hline 4645 & $1 / 13 / 200820-52$ & $8 / 13 / 200820: 52$ & 2991 & 29.9 \\
\hline 4646 & $1 / 13 / 200820-54$ & $8 / 13 / 200820: 54$ & 2992 & 29.9 \\
\hline 4647 & $1 / 13 / 200820.56$ & $8 / 13 / 200820: 56$ & 2992 & 29.9 \\
\hline 4648 & $1 / 13 / 200820.58$ & $8 / 13 / 200820: 58$ & 2994 & 30.1 \\
\hline 4649 & 1/13/200821:00 & $8 / 13 / 200821: 00$ & 2995 & 29.9 \\
\hline 4650 & 1/13/200821:02 & 8/13/200821:02 & 2996 & 29.9 \\
\hline
\end{tabular}

\begin{tabular}{|c|c|c|c|c|}
\hline \multicolumn{5}{|c|}{$D 4929$} \\
\hline $\mathrm{Rec}$ & & Adjusted & Tessure & \\
\hline$\#$ & Dete/Time & DaterTime & $p s i$ & \\
\hline 4651 & 1/13/200821:04 & $8 / 13 / 200821: 04$ & 2998 & \\
\hline 4652 & 1/13/200821:06 & $8 / 13 / 200821: 06$ & 2999 & \\
\hline 4653 & 1/13/200821:08 & $8 / 13 / 200821: 08$ & & \\
\hline 4654 & $13200821: 10$ & $8 / 13 / 200821: 10$ & 3.001 & 29 \\
\hline 4656 & 1/13/200821:12 & $8 / 13 / 200821: 12$ & 3.004 & $\underline{\underline{z}}$ \\
\hline 4656 & 1/13/200821:14 & $8 / 13 / 200821: 14$ & 3.004 & \\
\hline 465 & $13 / 200821: 16$ & $8 / 13 / 200821: 16$ & 3.004 & \\
\hline 4658 & 1/13/200821:18 & $8 / 13 / 200821: 18$ & 3.008 & \\
\hline 4659 & $132000821: 20$ & $8 / 13 / 200821: 20$ & 3.011 & 29.8 \\
\hline 4660 & $13 / 200821: 22$ & $8 / 13 / 200821: 22$ & 3.011 & \\
\hline 4661 & $1 / 13 / 200821: 24$ & $8 / 13 / 200821: 24$ & 3.01 & 29.8 \\
\hline 4662 & $13 / 200021: 26$ & $8 / 13 / 200821: 26$ & 3.01 & 29.8 \\
\hline 4663 & $13 / 200821: 28$ & $8 / 13 / 200821: 28$ & 3.009 & \\
\hline 4664 & $13 / 2000821: 30$ & $8 / 13 / 200821: 30$ & 3.009 & 30.1 \\
\hline 4665 & $13 / 200821: 32$ & $8 / 13 / 200821: 32$ & 3.012 & 29.8 \\
\hline 4666 & $1: 34$ & $8 / 13 / 200821: 34$ & 3.015 & \\
\hline 4667 & $13 / 200821: 36$ & $8 / 13 / 200821: 36$ & 3.02 & 29.7 \\
\hline 4668 & $13 / 2008$ & $8 / 13 / 200821: 38$ & 3024 & 29.7 \\
\hline 4669 & $21: 40$ & $8 / 13 / 200821: 40$ & 3.027 & \\
\hline 4670 & $13 / 200821: 42$ & $8 / 13 / 200821: 42$ & 3.026 & 29.7 \\
\hline 4671 & $21: 44$ & $8 / 13 / 200821: 44$ & 3.028 & 29 \\
\hline 4672 & 21:46 & $8 / 13 / 200821: 46$ & 3.031 & \\
\hline 4673 & $13 / 200821: 48$ & $8 / 13 / 200821: 48$ & 3.032 & 29. \\
\hline 4674 & 50 & $8 / 13 / 200$ & 3.034 & \\
\hline 4675 & $13 / 200821: 52$ & $8 / 13 / 200821: 52$ & 3.006 & \\
\hline 4676 & $3 / 200821: 54$ & $8 / 13 / 200821: 54$ & 3.039 & 29 . \\
\hline 4677 & 21:56 & $21: 56$ & 3.042 & 29 \\
\hline 4678 & $21: 58$ & $113 / 200$ & 3.045 & 29 \\
\hline 4679 & & $13 / 20082200$ & 3.049 & 29. \\
\hline 4680 & & 2202 & 3.005 & 20. \\
\hline 4681 & 204 & $8 / 13 / 20$ & 2918 & 29 \\
\hline 4682 & & $8 / 13 / 20$ & 2742 & 22 . \\
\hline 4683 & & 82208 & 2597 & 22 \\
\hline 4684 & 2210 & $8 / 13 / 20082210$ & 248 & 29 \\
\hline 4685 & & $8 / 13 / 200822: 12$ & 2385 & 29. \\
\hline 4686 & & $113 / 20082214$ & 2311 & 29. \\
\hline 4687 & 2216 & $8 / 13 / 2008 \cdot 22: 16$ & 2254 & 29 \\
\hline 4688 & 2218 & 82218 & 221 & 29. \\
\hline 4689 & & 2220 & 2176 & 20. \\
\hline 4690 & & $8 / 13 / 20082222$ & 2151 & 29. \\
\hline 4691 & & 2224 & 2005 & 29 \\
\hline 4692 & & 2226 & 2017 & 29 \\
\hline 4693 & & 82228 & 2005 & 20. \\
\hline 4694 & & & 2009 & 20 \\
\hline 4695 & & & 2031 & 29 \\
\hline 4696 & & 2234 & 2029 & 29 \\
\hline 4697 & & & 2027 & 29. \\
\hline 4698 & & 2238 & 2024 & \\
\hline 4699 & & & 202 & 28. \\
\hline 4700 & & & 2015 & \\
\hline 4701 & & $113 / 20082244$ & 2011 & 28. \\
\hline 4702 & & & 2005 & \\
\hline 4703 & & 248 & & \\
\hline 4704 & & 82250 & 1.994 & 28. \\
\hline 4705 & & & 1.989 & \\
\hline 4706 & & 2254 & 1.984 & 28 \\
\hline 4707 & 2256 & 82256 & 1.979 & 28 \\
\hline 4708 & & & 1.974 & \\
\hline 4709 & & $23: 00$ & 1.969 & 28 \\
\hline 4710 & & 32302 & 1.963 & 28 \\
\hline 4711 & & & 1.95 & \\
\hline 4712 & $3: 06$ & $8 / 13 / 200823: 06$ & 1.952 & 28 \\
\hline 4713 & & 823:08 & 1.948 & 28 \\
\hline 4714 & & & 1.943 & \\
\hline 4715 & $23: 12$ & $8 / 13 / 200823: 12$ & 1.938 & 28. \\
\hline 4716 & $13 / 200823: 14$ & $8 / 13 / 200823: 14$ & 1.933 & 28. \\
\hline 4717 & & & 1.928 & \\
\hline 4718 & $13 / 200823: 18$ & $8 / 13 / 200825: 18$ & 1.924 & 28. \\
\hline 4719 & $1 / 13 / 200823: 20$ & $8 / 13 / 200823: 20$ & 1.918 & 28 \\
\hline
\end{tabular}




\begin{tabular}{|c|c|c|c|c|}
\hline \multicolumn{5}{|c|}{ D4920 } \\
\hline $\operatorname{Rec}$ & & Adjusted & Pressure & Temp \\
\hline$\#$ & Date/Time & Date/Time & psi & $\infty$ \\
\hline 4720 & 1/13/200823:22 & $8 / 13 / 200823: 22$ & 1.914 & 28.8 \\
\hline 4721 & $1 / 13 / 200823: 24$ & $8 / 13 / 200823: 24$ & 1.91 & 28.8 \\
\hline 4722 & $1 / 13 / 200823: 26$ & $8 / 13200823: 26$ & 1.907 & 28.9 \\
\hline 4723 & $1 / 13 / 200823: 28$ & $8 / 13 / 200823: 28$ & 1.903 & 28.9 \\
\hline 4724 & 1/13/200823:30 & $8 / 13 / 200823: 30$ & 1.9 & 28.8 \\
\hline 4725 & $1 / 13 / 200823: 32$ & $8 / 13 / 200823: 32$ & 1.897 & 28.8 \\
\hline 4726 & $1 / 13 / 200823.34$ & $8 / 13 / 200823: 34$ & 1.893 & 28.8 \\
\hline 4727 & 1/13/200823:36 & $8 / 13 / 200823: 36$ & 1.891 & 28.8 \\
\hline 4728 & $1 / 13 / 200823: 38$ & $8 / 13 / 200822: 38$ & 1.888 & 28.8 \\
\hline 4729 & $1 / 13 / 200823: 40$ & $8 / 13 / 200823: 40$ & 1.886 & 28.8 \\
\hline 4730 & $1 / 13 / 200823: 42$ & $8 / 13 / 200823: 42$ & 1.882 & 28.7 \\
\hline 4731 & $1 / 13 / 200823: 44$ & $8 / 13 / 200823: 44$ & 1.878 & 28.7 \\
\hline 4732 & $1 / 13 / 200823: 46$ & $8 / 13 / 200823: 46$ & 1.876 & 28.7 \\
\hline 4733 & $1 / 13 / 200823: 48$ & $8 / 13 / 200823: 48$ & 1.872 & 28.7 \\
\hline 4734 & $1 / 13 / 200823.50$ & $8 / 13 / 200823: 50$ & 1.87 & 28.8 \\
\hline 4735 & $1 / 13 / 200823: 52$ & $8 / 13 / 200823: 52$ & 1.868 & 28.8 \\
\hline 4736 & 1/13/200823:54 & $8 / 13 / 200823: 54$ & 1.866 & 28.7 \\
\hline 4737 & $1 / 13 / 200823: 56$ & $8 / 13 / 200823: 56$ & 1.864 & 28.6 \\
\hline 4738 & $1 / 13 / 200823: 58$ & $8 / 13 / 200823: 58$ & 1.862 & 28.6 \\
\hline 4739 & $1 / 14 / 20080000$ & $8 / 14 / 20080.00$ & 1.859 & 28.6 \\
\hline 4740 & 1/14/20080:02 & $8 / 14 / 20080.02$ & 1.857 & 28.6 \\
\hline 4741 & $1 / 14 / 20080.04$ & $8 / 14 / 20080: 04$ & 1.855 & 28.6 \\
\hline 4742 & $1 / 14 / 20080: 06$ & $8 / 14 / 20080: 06$ & 1.853 & 28.6 \\
\hline 4743 & $1 / 14 / 20080: 08$ & $8 / 14 / 20080.08$ & 1.851 & 28.6 \\
\hline 4744 & 1/14/20080:10 & $8 / 14 / 20080: 90$ & 1.849 & 28.6 \\
\hline 4745 & $1 / 14 / 20080: 12$ & $8 / 14 / 20080: 12$ & 1.847 & 28.6 \\
\hline 4746 & 1/14/20080:14 & $8 / 14 / 20080: 14$ & 1.845 & 28.6 \\
\hline 4747 & 1/14/20080:16 & $8 / 14 / 20080: 16$ & 1.843 & 28.6 \\
\hline 4748 & $1 / 14 / 20080: 18$ & $8 / 14 / 20080: 18$ & 1.842 & 28.6 \\
\hline 4749 & $1 / 14 / 20080.20$ & $8 / 14 / 20080: 20$ & 1.84 & 28.6 \\
\hline 4750 & $1 / 14 / 20080: 2$ & $8 / 14 / 20080: 22$ & 1.838 & 28.6 \\
\hline 4751 & $1 / 14 / 20080.24$ & $8 / 14 / 20080: 24$ & 1.837 & 28.6 \\
\hline 4752 & $1 / 14 / 20080: 26$ & $8 / 14 / 20080.26$ & 1.836 & 28.5 \\
\hline 4753 & $1 / 14 / 20080: 28$ & $8 / 14 / 20080.28$ & 1.836 & 28.5 \\
\hline 4754 & $1 / 14 / 20080.30$ & $8 / 14 / 20080.30$ & 1.833 & 28.5 \\
\hline 4755 & $1 / 14 / 20080: 32$ & $8 / 14 / 20080.32$ & 1.832 & 28.5 \\
\hline 4756 & $1 / 14 / 20080.34$ & $8 / 14 / 200000.34$ & 1.831 & 28.6 \\
\hline 4757 & $1 / 14 / 200000.36$ & $8 / 14 / 20000036$ & 1.828 & 28.5 \\
\hline 4758 & $1 / 14 / 20080.38$ & $8 / 14 / 20080.38$ & 1.826 & 286 \\
\hline 4759 & $1 / 14 / 20080.40$ & $8 / 14 / 20080040$ & 1.824 & 28.6 \\
\hline 4760 & $1 / 14 / 20080: 42$ & $8 / 14 / 20080.42$ & 1.823 & 28.6 \\
\hline 4761 & $1 / 14 / 20080.44$ & $8 / 14 / 20080.44$ & 1.821 & 28.6 \\
\hline 4762 & $1 / 14 / 20080.46$ & $8 / 14 / 20060: 46$ & 1.82 & 28.6 \\
\hline 4763 & $1 / 14 / 20080.48$ & $8 / 14 / 20080.48$ & 1.819 & 28.6 \\
\hline 4764 & $1 / 14 / 20080: 50$ & $8 / 14 / 20080.50$ & 1.817 & 28.5 \\
\hline 4765 & $1 / 14 / 20080.52$ & $8 / 14 / 20080.52$ & 1.816 & 28.5 \\
\hline 4766 & 1/14/2008 0:54 & $8 / 14 / 20080: 54$ & 1.815 & 28.5 \\
\hline 4767 & $1 / 14 / 20080.56$ & $8 / 14 / 20080.56$ & 1.814 & 28.5 \\
\hline 4768 & $1 / 14 / 20080.58$ & $8 / 14 / 20080.58$ & 1.813 & 28.4 \\
\hline 4769 & 1/14/2008 1:00 & $8 / 14 / 20081: 00$ & 1.812 & 28.5 \\
\hline 4770 & 1/14/2008 1:02 & $8 / 14 / 2008$ 1:02 & 1.812 & 28.5 \\
\hline 4771 & 1/14/2008 1:04 & $8 / 14 / 2008$ 1:04 & 1.811 & 28.4 \\
\hline 4772 & $1 / 14 / 20081: 06$ & $8 / 14 / 20081: 06$ & 1.81 & 28.4 \\
\hline 4773 & 1/14/2008 1:08 & $8 / 14 / 20081: 08$ & 1.809 & 28.4 \\
\hline 4774 & $1 / 14 / 2008$ 1:10 & 8/14/2008 1:10 & 1.808 & 28.4 \\
\hline 4775 & 1/14/2008 1:12 & $8 / 14 / 2008$ 1:12 & 1.806 & 28.4 \\
\hline 4776 & $1 / 14 / 20081: 14$ & $8 / 14 / 20081: 14$ & 1.805 & \\
\hline $4 \pi 7$ & 1/14/2008 1:16 & $8 / 14 / 2008$ 1:16 & 1.804 & 28.4 \\
\hline 4778 & 1/14/2008 1:18 & $8 / 14 / 2008$ 1:18 & 1.803 & \\
\hline 4779 & $1 / 14 / 20081: 20$ & $8 / 14 / 20081: 20$ & 1.801 & 28.4 \\
\hline 4780 & 1/14/2008 1:22 & $8 / 14 / 20081: 22$ & 1.801 & 28.4 \\
\hline 4781 & $1 / 14 / 20081: 24$ & $8 / 14 / 20081: 24$ & 1.799 & 28.4 \\
\hline 4782 & $1 / 14 / 20081: 26$ & $8 / 14 / 20081: 26$ & 1.798 & 28.4 \\
\hline 4783 & 1/14/2008 1:28 & $8 / 14 / 2008$ 1:28 & 1.797 & 28.4 \\
\hline 4784 & 1/14/2008 1:30 & 8/14/2008 1:30 & 1.796 & 28.4 \\
\hline 4785 & $1 / 14 / 20081: 32$ & $8 / 14 / 20081: 32$ & 1.795 & 28.3 \\
\hline 4786 & 1/14/2008 1:34 & $8 / 14 / 2008$ 1:34 & 1.794 & 28.3 \\
\hline 4787 & $1 / 14 / 2008$ 1:36 & $8 / 14 / 20081: 36$ & 1,793 & \\
\hline 4788 & 1/14/2008 1:38 & $8 / 14 / 20081: 38$ & 1.792 & \\
\hline
\end{tabular}

\begin{tabular}{|c|c|c|c|c|}
\hline \multicolumn{5}{|c|}{$D 4-929$} \\
\hline $\operatorname{Rec}$ & & Acjusted & Pressun & \\
\hline$\#$ & Date/Time & DaterTime & psi & \\
\hline 4789 & $1 / 14 / 20081: 40$ & $8 / 14 / 20081: 40$ & 1.791 & \\
\hline 4790 & 1/14/2008 1:42 & $8 / 14 / 20081: 42$ & 1.70 & \\
\hline 4791 & $1 / 14 / 20081: 44$ & $8 / 14 / 20081: 44$ & 1.70 & \\
\hline 4792 & 1/14/2008 1:46 & $8 / 14 / 20081: 46$ & 1.789 & 28 \\
\hline 4793 & 1/14/20081:48 & $8 / 14 / 20081: 48$ & & \\
\hline 4794 & 1/14/2008 1:50 & $8 / 14 / 20081: 50$ & 1.787 & \\
\hline 4795 & $4 / 20081: 52$ & $8 / 14 / 20081: 52$ & 1.786 & \\
\hline 4796 & & $8 / 14 / 20081: 54$ & & \\
\hline 4797 & $1 / 14 / 20081: 56$ & $8 / 14 / 20081: 56$ & 1.784 & \\
\hline 4798 & $4 / 20081: 58$ & $8 / 14 / 20081: 58$ & 1.783 & \\
\hline 4799 & & $8 / 14 / 20082: 00$ & & \\
\hline 4800 & $1 / 14 / 2008202$ & $8 / 14 / 20082 \cdot 02$ & 1.781 & 28 \\
\hline 4801 & $4 / 2008204$ & $8 / 14 / 20082: 04$ & 1.781 & \\
\hline 4802 & & $8 / 14 / 2008206$ & 1.778 & \\
\hline 4803 & 3208 & $8 / 14 / 2008200$ & $1.7 \pi$ & 28 \\
\hline 4804 & & $8 / 14 / 2008210$ & 1.778 & 28. \\
\hline 4805 & & $882: 12$ & 1.776 & \\
\hline 4806 & 3214 & $8 / 14 / 2008214$ & 1.775 & $\overline{28}$ \\
\hline 4807 & & $82: 16$ & 1.775 & 28. \\
\hline 4808 & & $8 / 14 / 20$ & 1.774 & \\
\hline 4809 & & $8 / 14 / 2008220$ & 1.774 & 28.2 \\
\hline 4810 & & & 1.603 & 28. \\
\hline 4811 & & $8 / 14$ & 1.636 & \\
\hline 4812 & & & 1.652 & \\
\hline 4813 & & 3228 & 1.66 & \\
\hline 4814 & 230 & 3230 & 1.661 & \\
\hline 4815 & & & 1.67 & 27. \\
\hline 4816 & & & 1.685 & 27. \\
\hline 4817 & & & 1.680 & \\
\hline 4818 & & & 1.694 & 27. \\
\hline 4819 & & & 1.702 & 27. \\
\hline 4820 & & $8 / 14 / 20082: 42$ & 1.708 & 27 \\
\hline 4821 & & & 1.713 & 27. \\
\hline 4822 & & & 1.718 & 27. \\
\hline 4823 & & & 1.721 & 27. \\
\hline 4824 & & $32: 50$ & 1.724 & 27 \\
\hline 4825 & & 3252 & 1.727 & 27. \\
\hline 4826 & & & 1.728 & 27 \\
\hline 4827 & & & 1.73 & 27 \\
\hline 4828 & & & 1.73 & \\
\hline 4829 & & & 1.73 & 27. \\
\hline 4830 & & & 1.731 & 27 \\
\hline 4831 & & & 1.731 & 27 \\
\hline 4832 & & & 1.732 & 27 \\
\hline 4833 & & & 1.732 & 27 \\
\hline 4834 & & & 1.733 & 27. \\
\hline 4835 & & & 1.733 & \\
\hline 4836 & & & 1.733 & 27 \\
\hline 4837 & & & 1.733 & 27. \\
\hline 4838 & & & 1.733 & 27 \\
\hline 4839 & & & 1.734 & 27. \\
\hline 4840 & & & 1.734 & \\
\hline 4841 & & & 1.734 & \\
\hline 4842 & & & 1.734 & 27. \\
\hline 4843 & & & 1.734 & \\
\hline 4844 & $3: 30$ & & 1.734 & 27. \\
\hline 4845 & & & 1.734 & \\
\hline 4846 & & & 1.733 & \\
\hline 4847 & & & 1.733 & 27. \\
\hline 4848 & & & 1.733 & \\
\hline 4849 & & & & \\
\hline 4850 & & & 1.732 & \\
\hline 4851 & & & 1.732 & \\
\hline 4852 & 3:46 & $8 / 14 / 20083: 46$ & 1.732 & 27. \\
\hline 4853 & & $8 / 14 / 20083: 48$ & 1.732 & 27. \\
\hline 4854 & & & 1.732 & \\
\hline 4855 & $3: 52$ & & 7.13 & \\
\hline 4856 & & & 1.731 & \\
\hline & & $8 / 14 / 20083: 56$ & & \\
\hline
\end{tabular}

\begin{tabular}{|c|c|c|c|c|}
\hline \multicolumn{5}{|c|}{$D 4920$} \\
\hline Rec & & Agusted & Pressure & \\
\hline$\#$ & Date/Time & DaterTime & psi & \\
\hline 4858 & $1 / 14 / 20083: 58$ & $8 / 14 / 20003: 58$ & 1.73 & \\
\hline 4859 & $1 / 14 / 20084: 00$ & 8/14/20084:00 & 1.729 & 27.7 \\
\hline 4860 & 1/14/2008 4:02 & 8/14/20084:02 & 1.729 & \\
\hline 4861 & $14 / 20084: 04$ & $8 / 14 / 2008$ 4:04 & 1.729 & 27.7 \\
\hline 4862 & $1 / 14 / 20084: 06$ & $8 / 14 / 20084: 06$ & 1.729 & 27.7 \\
\hline 4863 & 1/14/20084:08 & $8 / 14 / 20084: 08$ & 1.729 & 27.7 \\
\hline 4864 & $14 / 20084: 10$ & $8 / 14 / 20084: 10$ & 1.728 & 27.7 \\
\hline 4866 & $14 / 20084: 12$ & $8 / 14 / 20084: 12$ & 1.728 & 27.7 \\
\hline 4866 & $14 / 20084: 14$ & $8 / 14 / 2008$ 4:14 & 1.728 & \\
\hline 4867 & 14/2008 4:16 & $8 / 14 / 20084: 16$ & 1.728 & \\
\hline 4868 & $4 / 20084: 18$ & 8/14/2008 4:18 & 1.727 & 27.7 \\
\hline 4869 & & & 1.726 & \\
\hline 4870 & 14/20084:20 & $8 / 14 / 20084: 22$ & 1.726 & 27. \\
\hline 4871 & $0084: 24$ & 8/14/2008 4:24 & 1.726 & 27. \\
\hline 4872 & & & 1.726 & \\
\hline 4873 & $4: 28$ & $84: 28$ & 1.725 & 27. \\
\hline 4874 & & $8 / 14$ & 1.725 & 27.7 \\
\hline 4875 & & $8 / 14$ & 1.724 & \\
\hline 4876 & $4: 34$ & $8 / 14$ & 1.724 & 27. \\
\hline 4877 & & $8 / 14$ & 1.723 & 27.7 \\
\hline 4878 & & & 1.723 & \\
\hline 4879 & $4: 40$ & $34: 40$ & 1.722 & 27.8 \\
\hline 4880 & & & 1.721 & 27.7 \\
\hline 4881 & & & 1.72 & \\
\hline 4882 & & & 1.72 & 27.7 \\
\hline 4883 & & $8 / 14$ & 1.719 & 27.7 \\
\hline 4884 & & & 1.719 & \\
\hline 4885 & & & 1.719 & 27. \\
\hline 4886 & & & 1.719 & \\
\hline 4887 & & & 1.718 & 27. \\
\hline 4888 & & & 1.718 & 27.7 \\
\hline 4889 & & & 1.717 & 27. \\
\hline 4890 & & $8 / 14$ & 1.716 & 27.8 \\
\hline 4891 & & & 1.716 & 27. \\
\hline 4892 & & & 1.715 & 27. \\
\hline 4893 & & & 1.715 & 27. \\
\hline 4894 & & & 1.714 & 27. \\
\hline 4896 & & & 1.714 & 27. \\
\hline 4896 & & & 1.714 & 27. \\
\hline 4897 & & & 1.714 & \\
\hline 4898 & & & 1.714 & $\overline{2}$ \\
\hline 4899 & & & 1.714 & 27. \\
\hline 4900 & & & 1.714 & \\
\hline 4901 & & & 1.713 & 27.8 \\
\hline 4902 & & & 1.713 & 27. \\
\hline 4903 & & & 1.713 & 27 \\
\hline 4904 & & & 1.712 & \\
\hline 4905 & & & 1.711 & \\
\hline 4906 & & & 1.711 & \\
\hline 4907 & & & 1.711 & \\
\hline 4908 & & & 1.71 & \\
\hline 4909 & & & 1.71 & 27. \\
\hline 4910 & & & 1.709 & \\
\hline 4911 & & & 1.708 & \\
\hline 4912 & & & 1.708 & 27. \\
\hline 4913 & & & 1.707 & \\
\hline 4914 & & & 1.707 & \\
\hline 4915 & & & 1.707 & \\
\hline 4916 & & & & \\
\hline 4917 & & & 1.707 & \\
\hline 4918 & & & 1.707 & \\
\hline 4919 & & & 1.706 & \\
\hline 4920 & & $8 / 14 \pi$ & 1.706 & \\
\hline 492 & & & & \\
\hline 4922 & & & 1.705 & 27. \\
\hline 4923 & & & 1.705 & \\
\hline & & & 1.704 & \\
\hline 4925 & & $6: 12$ & 1.704 & 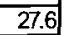 \\
\hline & 1/14/20086:14 & $8 / 14 / 20086: 14$ & 1.704 & \\
\hline
\end{tabular}


DOE/RL-2009-35, REV. 0

\begin{tabular}{|c|c|c|c|c|}
\hline \multicolumn{5}{|c|}{04.99} \\
\hline $\mathrm{Pac}$ & & Adusted & Pressur & Terpp \\
\hline$\#$ & Dede/Time & DeterTime & psi & ${ }^{\circ} \mathrm{C}$ \\
\hline 4927 & $1 / 14 / 20086: 16$ & $8 / 14 / 20086: 16$ & 1.704 & 27.6 \\
\hline 4928 & $1 / 14 / 20086: 18$ & $8 / 14 / 20086.18$ & 1.703 & 27.6 \\
\hline 49029 & $1 / 14 / 20086: 20$ & $8 / 14 / 20086: 20$ & 1.523 & 27.6 \\
\hline 4930 & $1 / 14 / 20086: 22$ & $8 / 14 / 20086 \cdot 22$ & 1.571 & 27.6 \\
\hline 4931 & $1 / 14 / 20086: 24$ & $8 / 1420086: 24$ & 1.584 & 27.4 \\
\hline 4932 & $1 / 14 / 20086: 26$ & $8 / 1420086: 26$ & 1.594 & 27. \\
\hline 4993 & $1 / 14 / 2008628$ & $8 / 14 / 20086: 28$ & 1.601 & 27. \\
\hline 4934 & $1 / 14 / 20086.30$ & $8 / 14 / 20086.30$ & 1.607 & 27.2 \\
\hline 4935 & $1 / 14 / 2008632$ & $8 / 14 / 20086.32$ & 1.612 & 27.1 \\
\hline 4906 & $1 / 14 / 20086: 34$ & $8 / 14 / 20086: 34$ & 1.604 & 27. \\
\hline 4937 & $1 / 14 / 2008636$ & $8 / 14 / 20086.36$ & 1.628 & 27. \\
\hline 4938 & $1 / 14 / 20086: 38$ & $8 / 142000633$ & 1.626 & 27. \\
\hline 4939 & $1 / 14 / 20086440$ & $8 / 14 / 20086: 40$ & 1.629 & 27. \\
\hline 4940 & $1 / 14 / 20086: 42$ & $8 / 1420086442$ & 1.632 & 27. \\
\hline 4941 & $1 / 14 / 2008$ & $8 / 1420086,44$ & 1.635 & 27. \\
\hline 4942 & $1 / 14 / 2008$ & $8 / 14 / 20086.46$ & 1.637 & 27. \\
\hline 4943 & $1 / 14 / 20086: 48$ & $8 / 14 / 2008648$ & 1.64 & 27. \\
\hline 4944 & $1 / 14 / 20086.50$ & $8 / 14 / 20086: 50$ & 1.643 & 27.1 \\
\hline 4945 & $1 / 14 /$ & $8 / 14 / 20086: 52$ & 1.645 & 27.1 \\
\hline 4946 & $1 / 14 /$ & $8 / 14 / 20086: 54$ & 1.647 & 27. \\
\hline 4947 & $1 / 14 / 2$ & $8 / 14 / 20086: 56$ & 1.649 & 27. \\
\hline 4948 & $1 / 14 / 20086.58$ & $8 / 14 / 20086.58$ & 1.65 & 27 \\
\hline 4949 & $1 / 14 /$ & $8 / 14 / 20087: 00$ & 1.652 & 27. \\
\hline 4050 & $1 / 14$ & $8 / 14 / 20087: 02$ & 1.654 & 27. \\
\hline 4951 & & $8 / 14 / 20087: 04$ & 1.655 & 27. \\
\hline 4952 & $1 / 14 / 200$ & $8 / 14 / 20087: 06$ & 1.655 & 27. \\
\hline 4963 & & $8 / 1420087: 08$ & 1.658 & 27.8 \\
\hline 4954 & & $8 / 1420087: 10$ & 1.650 & 27. \\
\hline 4966 & & 8/14/20087:12 & 1.60 & 27. \\
\hline 4966 & $1 / 14 / 20087: 14$ & 8/14/20087:14 & 1.66 & 27. \\
\hline 4957 & 1/14/20087:16 & 8/14/20087:16 & 1.661 & 27. \\
\hline 4958 & & $37: 18$ & 1.62 & 27. \\
\hline 4969 & & $87: 20$ & 1.663 & 27. \\
\hline 4960 & & $8 / 14 / 20087: 22$ & 1.664 & 27. \\
\hline 4961 & $1 / 14 /$ & $8 / 14 / 20087: 24$ & 1.664 & $273^{2}$ \\
\hline 4962 & & & 1.665 & 27. \\
\hline 4963 & & $37: 28$ & 1.667 & 27. \\
\hline 4964 & & $37: 30$ & 1.667 & 27. \\
\hline 4965 & $1 / 14 / 2$ & $8 / 14 / 20087: 32$ & 1.668 & 27. \\
\hline 4966 & & & 1.668 & 27. \\
\hline 4967 & & & 1.668 & 27. \\
\hline 4968 & & & 1.669 & 27. \\
\hline 4969 & $1 / 14 / 20087: 40$ & $8 / 14 / 20087: 40$ & 1.669 & 27. \\
\hline 4970 & & $8 / 14 / 20087: 42$ & 1.67 & 27. \\
\hline 4971 & & $37: 44$ & 1.669 & 27. \\
\hline 4972 & & & 1.67 & 27. \\
\hline 4973 & & $8 / 14 / 20087: 48$ & 1.67 & 27. \\
\hline 4974 & & & 1.67 & 27. \\
\hline 4975 & & & 1.671 & 27. \\
\hline 4976 & & $77: 54$ & 1.672 & 27. \\
\hline 4977 & & $8 / 14 / 20087: 56$ & 1.672 & 27. \\
\hline 4978 & & & 1.672 & 27. \\
\hline 4979 & & & 1.672 & 27. \\
\hline 4980 & & & 1.672 & 27. \\
\hline 4981 & $1 / 14 / 200$ & $8 / 14 / 2008804$ & 1.672 & 27. \\
\hline 4982 & & & 1.672 & 27. \\
\hline 4983 & & & 1.672 & 27. \\
\hline 4984 & & & 1.672 & 27. \\
\hline 4905 & $1 / 14 / 20$ & $8 / 14 / 2008: 12$ & 1.672 & 27. \\
\hline 4906 & $1 / 14 / 20$ & $8 / 14 / 2008814$ & 1.672 & 27. \\
\hline 4987 & & & 1.672 & 27. \\
\hline 4988 & & & 1.672 & 27. \\
\hline 4909 & 20 & $8 / 14 / 2008820$ & 1.672 & 27. \\
\hline 4990 & $1 / 14 / 2$ & $8 / 14 / 20088: 22$ & 1.673 & 27. \\
\hline 4991 & $1 / 14 / 20088: 24$ & $8 / 14 / 20088: 24$ & 1.673 & 27. \\
\hline 4992 & & $8 / 14 / 2008826$ & 1.672 & 27. \\
\hline & & $8 / 14 / 2008828$ & 1.672 & 27. \\
\hline 4994 & $1 / 14 / 20088: 30$ & $8 / 14 / 20088: 30$ & 1.672 & 27. \\
\hline 4995 & $1 / 14 / 20088: 32$ & $8 / 14 / 20088: 32$ & 1.672 & 21. \\
\hline
\end{tabular}

\begin{tabular}{|c|c|c|c|c|}
\hline \multicolumn{5}{|c|}{ D4-949 } \\
\hline $\mathrm{R} \in \mathrm{C}$ & & Adusted & Pressure & Temp \\
\hline$\#$ & Dete/Time & Deterime & psi & ${ }^{\circ} \mathrm{C}$ \\
\hline 4996 & 1/14/20088:34 & $8 / 14 / 20088: 34$ & 1.671 & 27.4 \\
\hline 4997 & 1/14/20088:36 & $8 / 14 / 20088: 36$ & 1.672 & 27.3 \\
\hline 4998 & $1 / 14 / 20088: 38$ & $8 / 14 / 20088: 38$ & 1.672 & 27.3 \\
\hline 4999 & $1 / 14 / 2008840$ & $8 / 14 / 2008840$ & 1.672 & 27.3 \\
\hline 5000 & 1/14/2008842 & $8 / 14 / 20088: 42$ & 1.672 & 27.3 \\
\hline 5001 & 1/14/20088:44 & $8 / 14 / 2008844$ & 1.672 & 27.3 \\
\hline 5000 & $1 / 14 / 20088: 46$ & $8 / 14 / 2008846$ & 1.671 & 27.3 \\
\hline 5003 & $1 / 14 / 2008848$ & $8 / 14 / 2008848$ & 1.671 & 27.3 \\
\hline 5004 & $1 / 14 / 20088.50$ & $8 / 14 / 20088.50$ & 1.671 & 27.3 \\
\hline 5005 & $1 / 14 / 2008852$ & $8 / 14 / 20088: 52$ & 1.67 & 27.3 \\
\hline 5006 & $1 / 142008854$ & $8 / 142008854$ & 1.67 & 27.3 \\
\hline 5007 & $1 / 14 / 2008856$ & $8 / 14 / 20088.56$ & 1.67 & 27.3 \\
\hline 5008 & $1 / 14 / 2008858$ & $8 / 14 / 2008858$ & 1.671 & 27.3 \\
\hline 5009 & $1 / 14 / 20089.00$ & $8 / 14 / 20089.00$ & 1.67 & 27.3 \\
\hline 5010 & 1/14/20089:02 & $8 / 14 / 20089.02$ & 1.67 & 27.3 \\
\hline 5011 & $1 / 14 / 20089.04$ & $8 / 14 / 20089.04$ & 1.67 & 27.3 \\
\hline 5012 & $1 / 14 / 20089.06$ & $8 / 14 / 20089.06$ & 1.67 & 27.3 \\
\hline 5013 & $1 / 14 / 20089.08$ & $8 / 14 / 20089.08$ & 1.669 & 27.3 \\
\hline 5014 & $1 / 14 / 20089.10$ & $8 / 14 / 20089.10$ & 1.669 & 27.3 \\
\hline 5015 & $1 / 14 / 20089.12$ & $8 / 14 / 20089.12$ & 1.669 & 27.3 \\
\hline 5016 & $1 / 14 / 20089.14$ & $8 / 14 / 20089 \cdot 14$ & 1.669 & 27.3 \\
\hline 5017 & $1 / 14 / 20089.16$ & $8 / 14 / 20089.16$ & 1.669 & 27.3 \\
\hline 5018 & $1 / 1420009.18$ & $8 / 14 / 20089.18$ & 1.669 & 27.3 \\
\hline 5019 & $1 / 14 / 20089.20$ & $8 / 14 / 20089: 20$ & 1.669 & 27.3 \\
\hline 5000 & 1/14/20089.22 & $8 / 14 / 20089 \cdot 22$ & 1.669 & 27.3 \\
\hline 5021 & $1 / 14 / 20089.24$ & $8 / 14 / 20089.24$ & 1.668 & 27.3 \\
\hline 5020 & $1 / 1420089.26$ & $8 / 14 / 20089: 26$ & 1.668 & 27.3 \\
\hline 5023 & $1 / 1420089.28$ & $8 / 14 / 20089.28$ & 1.668 & 27.3 \\
\hline 5024 & $1 / 14 / 20089.30$ & $8 / 14 / 20089.30$ & 1.668 & 27.3 \\
\hline 5005 & $1 / 14 / 20089.32$ & $8 / 142008932$ & 1.668 & 27.3 \\
\hline 5026 & $1 / 1420089.34$ & $8 / 14 / 20089.34$ & 1.668 & 27.3 \\
\hline 5027 & $1 / 14 / 20089.36$ & $8 / 14 / 20089: 36$ & 1.668 & 27.3 \\
\hline 5028 & $1 / 14 / 20089.38$ & $8 / 14 / 20089.38$ & 1.608 & 27.3 \\
\hline 5020 & $1 / 14 / 20089.40$ & $8 / 14 / 20089: 40$ & 1.668 & 27.3 \\
\hline 5030 & $1 / 1420089.42$ & $8 / 14 / 2008942$ & 1.668 & 27.3 \\
\hline 5031 & $1 / 1420089.44$ & $8 / 14 / 20089: 44$ & 1.668 & 27.3 \\
\hline 5032 & $1 / 14 / 20089.46$ & $8 / 14 / 20089: 46$ & 1.668 & 27.3 \\
\hline 5033 & $1 / 14 / 20089.48$ & $8 / 14 / 20089: 48$ & 1.526 & 27.2 \\
\hline 5034 & $1 / 14 / 20089.50$ & $8 / 14 / 20089.50$ & 1.541 & 27 \\
\hline 5035 & 1/14/20089.52 & $8 / 14 / 20089.52$ & 1.414 & 26.8 \\
\hline 5036 & $1 / 14 / 20089.54$ & $8 / 14 / 20089.54$ & 1.445 & 26.6 \\
\hline 5037 & $1 / 1420089.56$ & $8 / 14 / 2008956$ & 1.345 & 26.4 \\
\hline 5038 & $1 / 14 / 20089.58$ & $8 / 14 / 20089.58$ & 1.409 & 26.2 \\
\hline 5039 & $1 / 14 / 200810: 00$ & $8 / 14 / 200810: 00$ & 1.303 & 26.1 \\
\hline 5040 & $1 / 14 / 200810: 02$ & $8 / 14 / 200810: 02$ & 1.349 & 25.9 \\
\hline 5041 & $1 / 14 / 200810: 04$ & $8 / 14 / 200810: 04$ & 1.363 & 25.9 \\
\hline 5042 & 1/14/2008 10.06 & $8 / 14 / 200810: 06$ & 1.416 & 25.8 \\
\hline 5043 & $1 / 14200810.08$ & $8 / 14200810.08$ & 1.435 & 25.8 \\
\hline 5044 & $1 / 14 / 200810.10$ & $8 / 14 / 200810.10$ & 1.447 & 25.7 \\
\hline 5045 & $1 / 14 / 200810.12$ & $8 / 14 / 200810.12$ & 1.469 & 25.6 \\
\hline 5046 & $1 / 14 / 200810: 14$ & $8 / 14 / 200810: 14$ & 1.482 & 25.6 \\
\hline 5047 & $1 / 14 / 200810.16$ & $8 / 14 / 200810: 16$ & 1.494 & 25.6 \\
\hline 5048 & $1 / 14 / 200810.18$ & $8 / 14 / 200810: 18$ & 1.505 & 25.6 \\
\hline 5049 & $1 / 14200810: 20$ & $8 / 14 / 200810: 20$ & 1.514 & 25.6 \\
\hline 5050 & 1/14/2008 10:22 & $8 / 14 / 200810: 22$ & 1.523 & 25.6 \\
\hline 5051 & $1 / 14 / 200810.24$ & $8 / 14 / 2008$ 10:24 & 1.532 & 25.7 \\
\hline 5052 & $1 / 14 / 200810: 26$ & $8 / 14 / 200810: 26$ & 1.539 & 25.8 \\
\hline 5053 & $1 / 14 / 200810.28$ & $8 / 14 / 2008$ 10:28 & 1.545 & 25.8 \\
\hline 5054 & $1 / 14 / 200810.30$ & $8 / 14 / 200810: 30$ & 1.551 & 25.8 \\
\hline 5056 & $1 / 14 / 200810.32$ & $8 / 14 / 200810: 32$ & 1.507 & 25.8 \\
\hline 5056 & $1 / 14 / 200810.34$ & $8 / 14 / 200810: 34$ & 1.562 & 25.9 \\
\hline 5057 & $1 / 14 / 200810: 36$ & $8 / 14200810: 36$ & 1.566 & 25.9 \\
\hline 5058 & $1 / 14200810.38$ & $8 / 142008$ 10:38 & 1.571 & 25.9 \\
\hline 5059 & $1 / 14 / 200810: 40$ & $8 / 14 / 200810: 40$ & 1.575 & 25.9 \\
\hline 5060 & $1 / 14 / 200810.42$ & $8 / 14 / 200810: 42$ & 1.579 & 25.9 \\
\hline 5061 & $1 / 14 / 200810.44$ & $8 / 14 / 200810: 44$ & 1.582 & 26 \\
\hline 5062 & $1 / 1420081046$ & $8 / 14 / 200810: 46$ & 1.586 & 26 \\
\hline 506 & $1 / 14 / 200810: 48$ & $8 / 14 / 2008$ to:48 & 1.59 & 26 \\
\hline 5064 & $1 / 14 / 200810.50$ & $8 / 14 / 200810: 50$ & 1.509 & 26 \\
\hline
\end{tabular}

\begin{tabular}{|c|c|c|c|c|}
\hline \multicolumn{5}{|c|}{ D4990 } \\
\hline $\operatorname{Rec}$ & & Aciusted & Pessure & Temp \\
\hline$\#$ & Date/Tirme & Dade/Time & psi & ${ }^{\circ} \mathrm{C}$ \\
\hline 5065 & $1 / 142008$ 10.52 & $8 / 14200810: 52$ & 1.595 & 26 \\
\hline 5066 & $1 / 14 / 200810.54$ & $8 / 14200810.54$ & 1.598 & 26.1 \\
\hline 5067 & $1 / 14 / 200810.56$ & $8 / 14 / 200810.56$ & 1.602 & 26.1 \\
\hline 5068 & $1 / 14 / 200810.58$ & $8 / 14 / 200810.58$ & 1.604 & 26.1 \\
\hline 5069 & 1/14/2008 11:00 & 8/14/2008 11:00 & 1.607 & 26.1 \\
\hline 5070 & 1/14/2008 11:02 & $8 / 14 / 200811: 02$ & 1.609 & 26.1 \\
\hline 5071 & 1/14/2008 11:04 & $8 / 14 / 200811: 04$ & 1.612 & 26.2 \\
\hline 5072 & 1/14/2008 11:06 & $8 / 14 / 200811: 06$ & 1.614 & 26.2 \\
\hline 5073 & 1/14/2008 11:08 & $8 / 142000811: 08$ & 1.616 & 26.2 \\
\hline 5074 & 1/142008 11:10 & $8 / 14 / 200811: 10$ & 1.618 & 26.2 \\
\hline 5075 & 1/14/2008 11:12 & $8 / 14200811: 12$ & $1 . ळ 2$ & 26.3 \\
\hline 5076 & 1/14/2008 11:14 & $8 / 14 / 200011: 14$ & 1.621 & 26.3 \\
\hline 507 & 1/14/2008 11:16 & 8/14/200811:16 & 1.623 & 26.3 \\
\hline 5078 & 1/14/2008 11:18 & 8/14/200811:18 & 1.624 & 263 \\
\hline 5079 & 1/14/200811:20 & 8/14/200811:20 & 1.626 & 26.3 \\
\hline 5080 & 1/14/2008 11:22 & $8 / 14200011: 22$ & 1.627 & 26.3 \\
\hline 5081 & 1/14/2008 11:24 & $8 / 14 / 200811: 24$ & 1.628 & 26.3 \\
\hline 5082 & 1/14/2008 11:26 & $8 / 14 / 200811: 26$ & 1.629 & 26.3 \\
\hline 5083 & 1/14/2008 11:28 & $8 / 142008.11: 28$ & 1.63 & 26.3 \\
\hline 5084 & 1/14/2008 11:30 & $8 / 14200811: 30$ & 1.631 & 26.3 \\
\hline 5086 & 1/14/2008 11:32 & $8 / 14 / 200811: 32$ & 1.632 & 26.3 \\
\hline 5006 & 1/14/2008 11:34 & $8 / 14 / 200811: 34$ & 1.633 & 26.4 \\
\hline 5087 & 1/14/2008 11:36 & $8 / 14 / 200811: 36$ & 1.634 & 26.4 \\
\hline 5088 & 1/14/2008 11:38 & $8 / 14 / 200811: 38$ & 1.636 & 26.4 \\
\hline 5089 & 1/14/2008 11:40 & $8 / 14 / 200811: 40$ & 1.636 & 26.4 \\
\hline 5090 & $1 / 14 / 2008$ 11:42 & $8 / 14 / 200811: 42$ & 1.637 & 26.4 \\
\hline 5091 & $1 / 14 / 200811: 44$ & $8 / 14 / 200811: 44$ & 1.638 & 26.4 \\
\hline 5092 & 1/14/2008 11:46 & $8 / 14200811: 46$ & 1.638 & 26.4 \\
\hline 5093 & 1/14/2008 11:48 & $8 / 14200811: 48$ & 1.639 & 26.4 \\
\hline 5094 & $1 / 14 / 200811: 50$ & $8 / 14 / 200811: 50$ & 1.64 & 26.4 \\
\hline 5096 & 1/14/2008 11:52 & $8 / 14 / 200811: 52$ & 1.64 & 26.4 \\
\hline 5096 & 1/14/2008 11:54 & $8 / 14 / 200811: 54$ & 1.641 & 26.5 \\
\hline 5097 & $1 / 14 / 200811: 56$ & $8 / 14 / 200811: 50$ & 1.641 & 26.5 \\
\hline 5008 & $1 / 14 / 200811: 58$ & $8 / 14 / 200811: 58$ & 1.641 & 265 \\
\hline 5090 & $1 / 14 / 20081200$ & $8 / 14 / 20081200$ & 1.642 & 26.5 \\
\hline 5100 & $1 / 14 / 20081202$ & $8 / 14 / 20081200$ & 1.642 & 26.5 \\
\hline 5101 & $1 / 14 / 20081204$ & $8 / 14 / 20081204$ & 1.642 & 26.5 \\
\hline 5102 & $1 / 14 / 20081206$ & $8 / 1420081206$ & 1.643 & 26.5 \\
\hline 5103 & $1 / 14 / 20081208$ & $8 / 14 / 20081208$ & 1.643 & 26.5 \\
\hline 5104 & $1 / 14 / 200812: 10$ & $8 / 14 / 20081210$ & 1.644 & 26.6 \\
\hline 5106 & $1 / 14 / 20081212$ & $8 / 14 / 20081212$ & 1.644 & 26.6 \\
\hline 5106 & 1/14/200812:14 & $8 / 1420081214$ & 1.644 & 26.6 \\
\hline 5107 & $1 / 14 / 20081216$ & $8 / 1420081216$ & 1.645 & 26.6 \\
\hline 5108 & $1 / 14 / 20081218$ & $8 / 1420081218$ & 1.645 & 26.6 \\
\hline 5100 & $1 / 14 / 20081220$ & $8 / 1420081220$ & 1.645 & 26.6 \\
\hline 5110 & $1 / 14 / 2008+222$ & $8 / 142008122$ & 1.645 & 26.6 \\
\hline 5111 & $1 / 14 / 20081224$ & $8 / 14 / 20081224$ & 1.646 & 26.6 \\
\hline 5112 & $1 / 14 / 20081226$ & $8 / 14 / 20081226$ & 1.646 & 26.6 \\
\hline 5113 & $1 / 14 / 20081228$ & $8 / 14 / 20081228$ & 1.646 & 26.6 \\
\hline 5114 & $1 / 1420081230$ & $8 / 1420081230$ & 1.646 & 26.7 \\
\hline 5115 & $1 / 14 / 20081232$ & $8 / 14 / 20081232$ & 1.646 & 26.7 \\
\hline 5116 & $1 / 14 / 20081234$ & $8 / 14 / 20081234$ & 1.647 & 26.7 \\
\hline 5117 & $1 / 14 / 20081236$ & 81420001236 & 1.647 & 26.7 \\
\hline 5118 & $1 / 14 / 20081238$ & $8 / 1420081238$ & 1.647 & 266 \\
\hline 5119 & $1 / 14 / 20081240$ & $8 / 14 / 20081240$ & 1.647 & 26.7 \\
\hline 5120 & $1 / 14 / 20081242$ & $8 / 1420081242$ & 1.647 & 26.7 \\
\hline 5121 & $1 / 14 / 20081244$ & $8 / 14 / 20081244$ & 1.647 & 26.7 \\
\hline 5122 & $1 / 14 / 20081246$ & $8 / 14 / 20081246$ & 1.647 & 26.7 \\
\hline 5123 & $1 / 14 / 20081248$ & $8 / 14 / 20081248$ & 1.647 & 26.7 \\
\hline 5124 & $1 / 14 / 20081250$ & $8 / 14 / 20081250$ & 1.647 & 26.7 \\
\hline 5125 & $1 / 14 / 20081252$ & $8 / 14 / 20081252$ & 1.647 & 26.7 \\
\hline 5126 & $1 / 14 / 20081254$ & $8 / 14 / 20081254$ & 1.647 & 26.7 \\
\hline 5127 & $1 / 14 / 20081256$ & $8 / 1420081256$ & 1.647 & 26.7 \\
\hline 5128 & $1 / 1420081258$ & $8 / 14 / 20081258$ & 1.647 & 26.7 \\
\hline 5129 & $1 / 14 / 200813: 00$ & $8 / 14 / 200813,00$ & 1.647 & 26.8 \\
\hline 5130 & 1/14/2008 13:02 & $8 / 14 / 200813: 02$ & 1.647 & 26.8 \\
\hline 5131 & $7 / 14 / 200813: 04$ & $8 / 1420081304$ & 1.647 & 26.8 \\
\hline 5132 & 1/14/2008 13:06 & $8 / 14 / 200813.06$ & 1.647 & 26.8 \\
\hline 5133 & $1 / 14 / 200813: 08$ & $8 / 14 / 200813: 08$ & 1.647 & 26.8 \\
\hline
\end{tabular}


DOE/RL-2009-35, REV. 0

\begin{tabular}{|c|c|c|c|c|}
\hline \multicolumn{5}{|c|}{ D4929 } \\
\hline $\mathrm{Rec}$ & & Acjusted & Pressure & Temp \\
\hline$\#$ & DeterTime & Dete/Time & psi & ${ }^{\circ} \mathrm{C}$ \\
\hline 5134 & $1 / 14 / 200813: 10$ & $8 / 14 / 200813: 10$ & 1.647 & 26.8 \\
\hline 5135 & $1 / 14 / 200813: 12$ & $8 / 14 / 200813: 12$ & 1.647 & 26.8 \\
\hline 5136 & $1 / 14 / 2008$ 13:14 & $8 / 14 / 2008$ 13:14 & 1.647 & 26.8 \\
\hline 5137 & $1 / 14 / 200813: 16$ & $8 / 14 / 200813: 16$ & 1.647 & 26.8 \\
\hline 5138 & $1 / 14 / 200813: 18$ & $8 / 14 / 200813: 18$ & 1.647 & 26.8 \\
\hline 5139 & $1 / 14 / 200813: 20$ & $8 / 14 / 200813: 20$ & 1.647 & 27 \\
\hline 5140 & $1 / 14 / 200813: 22$ & $8 / 14 / 20081322$ & 1.647 & 27.3 \\
\hline 5141 & $1 / 14 / 200813: 24$ & $8 / 14 / 20081324$ & 1.648 & 27.4 \\
\hline 5142 & $1 / 14 / 200813: 26$ & $8 / 14 / 200813: 26$ & 1.648 & 26.9 \\
\hline 5143 & $1 / 14 / 200813: 28$ & $8 / 14 / 2008$ 13:28 & 1.648 & 26.8 \\
\hline 5144 & $1 / 14 / 200813: 30$ & $8 / 14 / 20061330$ & 1.647 & 26.8 \\
\hline 5145 & $1 / 14 / 200813: 32$ & $8 / 14 / 200813: 32$ & 1.647 & 26.8 \\
\hline 5146 & 1/14/2008 13:34 & $8 / 14 / 200813: 34$ & 1.647 & 26.8 \\
\hline 5147 & $1 / 14 / 200813: 36$ & $8 / 14 / 200813: 36$ & 1.647 & 26.8 \\
\hline 5148 & $1 / 14 / 2008$ 13:38 & $8 / 14 / 200813: 38$ & 1.647 & 26.8 \\
\hline 5149 & $1 / 14 / 200813: 40$ & $8 / 14 / 200813: 40$ & 1.647 & 26.8 \\
\hline 5150 & $1 / 14 / 2008$ 13:42 & $8 / 14 / 200813: 42$ & 1.647 & 26.8 \\
\hline 5151 & $1 / 14 / 200813: 44$ & $8 / 14 / 200813: 44$ & 1.647 & 26.8 \\
\hline 5152 & $1 / 14 / 200813: 46$ & $8 / 14 / 200813: 46$ & 1.647 & 26.8 \\
\hline 5153 & $1 / 14 / 200813: 48$ & $8 / 14 / 200813: 48$ & 1.646 & 26.8 \\
\hline 5154 & $1 / 14 / 200813: 50$ & $8 / 14 / 200813: 50$ & 1.646 & 26.8 \\
\hline 5155 & $1 / 14 / 200813: 52$ & $8 / 14 / 200813: 52$ & 1.646 & 26.8 \\
\hline 5156 & $1 / 14 / 200813: 54$ & $8 / 14 / 20081354$ & 1.646 & 26.8 \\
\hline 5157 & $1 / 14 / 200813: 56$ & $8 / 14 / 200813-56$ & 1.646 & 26.8 \\
\hline 5158 & $1 / 14 / 200813: 58$ & $8 / 14 / 200813: 58$ & 1.646 & 26.8 \\
\hline 5159 & $1 / 14 / 200814: 00$ & $8 / 14 / 200814: 00$ & 1.647 & 26.8 \\
\hline 5160 & $1 / 14 / 200814: 02$ & $8 / 14 / 2008$ 14:02 & 1.646 & 26.8 \\
\hline 5161 & $1 / 14 / 200814: 04$ & $8 / 14 / 2008$ 14:04 & 1.646 & 26.8 \\
\hline 5162 & $1 / 14 / 200814: 06$ & $8 / 14 / 2008$ 14:06 & 1.667 & 26.8 \\
\hline 5163 & 1/14/2008 14:08 & $8 / 14 / 200814: 08$ & 1.507 & 26.8 \\
\hline 5164 & 1/14/2008 14:10 & $8 / 14 / 200814: 10$ & 1.531 & 26.7 \\
\hline 5165 & $1 / 14 / 200814: 12$ & $8 / 14 / 200814: 12$ & 1.544 & 26.5 \\
\hline 516 & 1/14/2008 14:14 & $8 / 14 / 2008$ 14:14 & 1.554 & 26.4 \\
\hline 5167 & 1/14/2008 14:16 & $8 / 14 / 200814: 16$ & 1.561 & 26.4 \\
\hline 5168 & 1/14/2008 14:18 & $8 / 14 / 2008$ 14:18 & 1.568 & 26.6 \\
\hline $51 ळ$ & $1 / 14 / 200814: 20$ & $8 / 14 / 200814: 20$ & 1.591 & 26.8 \\
\hline 5170 & $1 / 14 / 200814: 22$ & $8 / 14 / 200814: 22$ & 1.579 & 26.6 \\
\hline 5171 & $1 / 14 / 200814: 24$ & $8 / 14 / 200814: 24$ & 1.581 & 26.7 \\
\hline 5172 & $1 / 14 / 200814: 26$ & $8 / 14 / 200814: 26$ & 1.586 & 26.5 \\
\hline 5173 & $1 / 14 / 200814: 28$ & $8 / 14 / 200814: 28$ & 1.589 & 26.3 \\
\hline 5174 & 1/14/2008 14:30 & $8 / 14 / 2008$ 14:30 & 1.592 & 26.4 \\
\hline 5175 & $1 / 14 / 200814: 32$ & $8 / 14 / 200814: 32$ & 1.595 & 26.4 \\
\hline 5176 & $1 / 14 / 200814: 34$ & $8 / 14 / 200014: 34$ & 1.598 & 26.3 \\
\hline 5177 & $1 / 14 / 200814: 36$ & $8 / 14 / 200814: 36$ & 1.6 & 26.3 \\
\hline 5178 & $1 / 14 / 200814: 38$ & $8 / 14 / 200814: 38$ & 1.602 & 26.3 \\
\hline 5179 & $1 / 14 / 200814: 40$ & $8 / 14 / 200814: 40$ & 1.604 & 26.4 \\
\hline 5180 & $1 / 14 / 200814: 42$ & $8 / 14 / 200814: 42$ & 1.607 & 26.4 \\
\hline 5181 & $1 / 14 / 200814: 44$ & $8 / 14 / 200814: 44$ & 1.008 & 26.4 \\
\hline 518 & $1 / 14 / 200814: 46$ & $8 / 14 / 200814: 46$ & 1.61 & 26.4 \\
\hline 5183 & $1 / 14 / 200814: 48$ & $8 / 14 / 200814: 48$ & 1.611 & 26.4 \\
\hline 5184 & $1 / 14 / 200814: 50$ & $8 / 14 / 200814: 50$ & 1.612 & 26.4 \\
\hline 5185 & $1 / 14 / 200814: 52$ & $8 / 14 / 200814: 52$ & 1.614 & 26.4 \\
\hline 5186 & $1 / 14 / 200814: 54$ & $8 / 14 / 200814: 54$ & 1.615 & 26.4 \\
\hline 5187 & $1 / 14 / 200814: 56$ & $8 / 14 / 200814: 56$ & 1.616 & 26.4 \\
\hline 518 & $1 / 14 / 200814: 58$ & $8 / 14 / 200814: 58$ & 1.617 & 26.4 \\
\hline 5189 & $1 / 14 / 200815: 00$ & $8 / 14 / 200815: 00$ & 1.618 & 26.4 \\
\hline 5190 & $1 / 14 / 200815: 02$ & $8 / 14 / 200815: 02$ & 1.619 & 26.4 \\
\hline 5191 & $1 / 14 / 200815: 04$ & $8 / 14 / 200815: 04$ & $1 . \tilde{2}$ & 26.4 \\
\hline 5192 & 1/14/2008 15:06 & $8 / 14 / 200815: 06$ & 1.621 & 26.4 \\
\hline 5193 & $1 / 14 / 200815: 08$ & $8 / 14 / 200815: 08$ & 1.621 & 26.4 \\
\hline 5194 & $1 / 14 / 200815: 10$ & $8 / 14 / 200815: 10$ & 1.622 & 26.4 \\
\hline 5195 & $1 / 14 / 200815: 12$ & $8 / 14 / 200815: 12$ & 1.62 & 26.4 \\
\hline 5196 & $1 / 14 / 200815: 14$ & $8 / 14 / 200815: 14$ & 1.62 & 26.4 \\
\hline 5197 & $1 / 14 / 200815: 16$ & $8 / 14 / 2008$ 15:16 & 1.623 & 26.4 \\
\hline 5198 & $1 / 14 / 200815: 18$ & $8 / 14 / 200815: 18$ & 1.624 & 26.4 \\
\hline 519 & $1 / 14 / 200815: 20$ & $8 / 14 / 200815: 20$ & 1.625 & 26.4 \\
\hline 5200 & $1 / 14 / 200815: 22$ & $814 / 200815: 22$ & 1.625 & 26.4 \\
\hline 5201 & $1 / 14 / 2008$ 15:24 & $8 / 14 / 2008+5: 24$ & 1.626 & 26.4 \\
\hline 5202 & $1 / 14 / 200815: 26$ & $8 / 14 / 200815: 26$ & 1.626 & 26.4 \\
\hline
\end{tabular}

\begin{tabular}{|c|c|c|c|c|}
\hline \\
\hline $\operatorname{Rec}$ & & Adjusted & Fressen & \\
\hline$\#$ & Date/Time & Date-Time & psi & \\
\hline & 1/14/2008 15:28 & $8 / 14 / 200815: 28$ & 1.62 & 26.4 \\
\hline & & $8 / 14 / 2008$ 15:30 & 1.62 & 26.5 \\
\hline & & & 1.62 & \\
\hline & & $8 / 14 / 200815: 34$ & 1.62 & \\
\hline 2007 & 1/14/200815:36 & $8 / 14 / 200815: 36$ & 1.62 & \\
\hline & $1 / 14 / 200815538$ & $8 / 14 / 200815: 38$ & 1.62 & \\
\hline & $1 / 14 / 200815: 40$ & $8 / 14200815 ; 40$ & 1.62 & $26.6 \div>$ \\
\hline 210 & $\mid 142008$ 15:42 & $8 / 14 / 200815: 42$ & 1.62 & 26.6 \\
\hline 5211] & 1/14/2008 15:44 & $8 / 14 / 200815: 44$ & 1.62 & \\
\hline & 1/14/2008 15:46 & $8 / 14 / 200815: 46$ & 1.62 & \\
\hline 5213 & & & & \\
\hline 5214 & 1/14/2008 15:50 & $8 / 14 / 200815: 50$ & 1.6 & 26. \\
\hline 5215 & 1/14/2008 15:52 & $8 / 14 / 200815: 52$ & 1.62 & \\
\hline 5216 & $1 / 14 / 200815: 54$ & $8 / 14200815: 54$ & 1.62 & \\
\hline 5217 & $4 / 200815: 56$ & $8 / 14 / 200815: 56$ & 1.6 & \\
\hline 5218 & & & 1.63 & \\
\hline 5219 & $00816: 00$ & 8/14/2008 16:00 & 1.63 & 26. \\
\hline 5220 & 1/14/2008 16:02 & $8 / 14 / 200816: 02$ & & \\
\hline 5221 & 1/14/2008 16:04 & $8 / 14 / 200816: 04$ & & \\
\hline & $1 / 14 / 200816: 06$ & $8 / 14 / 2008$ 16:06 & 1.0 & 26. \\
\hline 5223 & $1 / 14 / 200816: 08$ & $8 / 14 / 200816: 08$ & 1.63 & \\
\hline 5224 & 1/14/2008 16:10 & 8/14/2008 16:10 & 1.63 & 26.1 \\
\hline & 08 16:12 & $8 / 14 / 200816: 12$ & 1.63 & \\
\hline 26 & & & 1.63 & \\
\hline 27 & & & 1.63 & 26. \\
\hline & $4 / 2008$ 16:18 & $8 / 14 / 200816: 18$ & $1 . ळ$ & 26.6 \\
\hline & $1 / 14 / 200816: 20$ & $8 / 14200816: 20$ & $1.0 x$ & \\
\hline 5230 & $1 / 14 / 200816: 22$ & $8 / 14 / 200816: 2$ & 1.6 & 26. \\
\hline 5231 & 1/14/2008 16:24 & $8 / 14 / 200816: 24$ & 1.63 & \\
\hline 5232 & 1/14/2008 16:26 & $8 / 14 / 200816: 26$ & 1.63 & \\
\hline & 1/14/2008 16:28 & $8 / 14 / 200816: 28$ & 1.03 & 26. \\
\hline 5234 & & $8 / 14 / 200816: 30$ & 1.63 & \\
\hline & & & & \\
\hline 5236 & & & 1.6 & 26.6 \\
\hline 5237 & & & 1.63 & 26.6 \\
\hline & & $8 / 14 / 200816: 38$ & 1.63 & 26.6 \\
\hline 5239 & 1/14/2008 16:40 & $8 / 14 / 200816: 40$ & 1.63 & \\
\hline 5240 & $1 / 14 / 200816$ & $14: 2008$ 16:42 & $1 . \varpi$ & \\
\hline 5241 & $1 / 14 / 200816$ & $14200816: 44$ & & \\
\hline 5242 & & $8 / 1420081$ & 1.6 & \\
\hline & & $8 / 14 / 200816: 48$ & 1.63 & 26. \\
\hline 5244 & & & 1.63 & 26.7 \\
\hline & & & & 26.7 \\
\hline 5246] & & & & \\
\hline 5247 & & & & \\
\hline 5248 & & & 1.6 & \\
\hline $5249 \mid$ & & & 1.63 & \\
\hline & & & 1.63 & \\
\hline 5251 & & & & \\
\hline 5252 & & $8 / 14 / 200$ & 1.63 & \\
\hline & & & 1.63 & $26.7>>$ \\
\hline 5254 & & & 1.63 & \\
\hline & & & & $26.7-7>3$ \\
\hline 5256 & & & & 26.7 \\
\hline & & & & \\
\hline & & & $\overline{1.6}$ & \\
\hline & & & 1.63 & \\
\hline 5260 & & & $1.6 x$ & 26.7 \\
\hline 5261 & & $8 / 14 / 200$ & $1.0 x$ & \\
\hline 5262 & 1/14/2008 & $8 / 14 / 200$ & 1.635 & \\
\hline 526 & & $8 / 14 / 200817: 28$ & $1.6 x$ & \\
\hline 5264 & & $7: 30$ & $16 x$ & 26.6 \\
\hline & & & & \\
\hline 5206 & & & & \\
\hline & & & & \\
\hline & & & & \\
\hline 5269 & & $8 / 14 / 2$ & $1.6 x$ & \\
\hline 5270 & & $8 / 14 / 20 x$ & 1.63 & 266 \\
\hline 527 & $\mid 1 / 14 / 200817: 44$ & $8 / 14200817: 44$ & 1.633 & 26.6 \\
\hline
\end{tabular}

\begin{tabular}{|c|c|c|c|c|}
\hline \\
\hline $\mathrm{Rec}$ & & Adjusted & Pressurt & Temp \\
\hline$\#$ & Dete-Time & DateTime & $\mathrm{psi}$ & ${ }^{\circ} \mathrm{C}$ \\
\hline & 1/14/2008 17:46 & $8 / 14 / 200817: 46$ & 1.633 & 26.6 \\
\hline 5273 & $1 / 14 / 200817: 48$ & & 1.633 & \\
\hline 5274 & $1 / 14 / 200817: 50$ & $8 / 14 / 200817: 50$ & 1.633 & 26.6 \\
\hline 5275 & $1 / 14 / 200817: 52$ & $8 / 14 / 2008$ 17:52 & 1.494 & \\
\hline 5276 & 1/14/2008 17:54 & 8/14/2008 17:54 & 1.517 & 26.4 \\
\hline $52 \pi 7$ & 1/14/2008 17:56 & $8 / 142008$ 17:56 & 1.528 & 26.3 \\
\hline 5278 & $1 / 14 / 2008$ 17:58 & $8 / 14 / 200817: 58$ & 1.536 & 26.1 \\
\hline 5279 & 1/1/4/2008 18:00 & 8/14/2008 18:00 & 1.523 & 26.1 \\
\hline 5280 & 1/1/4/2008 18:02 & 8/14/2008 18:02 & 1.546 & 26.1 \\
\hline 5281 & & & 1.551 & 26.1 \\
\hline & 1/14/2008 18:06 & & & \\
\hline & $\mid \overline{1 / 14 / 200818: 006}$ & $8 / 14 / 2008$ 18:08 & 1.56 & \\
\hline 5284 & $\overline{1 / 14 / 200818: 10}$ & $8 / 14 / 2008$ 18:10 & 1.564 & 26.1 \\
\hline 5285 & 1/14/2008 18:12 & $8 / 14 / 200818: 12$ & 1.567 & 26.1 \\
\hline 5286 & $1 / 14 / 2008$ 18:14 & $8 / 14 / 2008$ 18:14 & 1.57 & \\
\hline & $\begin{array}{l}1 / 4 / 2008 \text { 18:16 } \\
\end{array}$ & $8 / 14 / 2008$ 18:16 & & 26.2 \\
\hline 5288 & $1 / 14 / 200818: 18$ & 8/14/2008 18:18| & 1.576 & \\
\hline 5289 & 1/14/2008 18:20 & 8/14/2008 18:20 & & \\
\hline 5290 & $1 / 14 / 200818: 22$ & $8 / 14 / 200818: 22$ & 1.592 & \\
\hline 5221 & $1 / 14 / 200818: 24$ & $8 / 14 / 200818: 24$ & 1.585 & 26.3 \\
\hline & $1 / 14 / 2008$ 18:26 & $8 / 14 / 200818: 26$ & 1.586 & 26.2 \\
\hline & $1 / 14 / 200818: 28$ & $8 / 14 / 200818: 28$ & 1.528 & 26.2 \\
\hline 5294 & 1/14/2008 18:30 & $8 / 14 / 2008$ 18:30 & 1.59 & $26.3 .3>3$ \\
\hline & $\overline{1 / 14 / 2008} 18: 32$ & $8 / 14 / 2008$ 18:32 & & \\
\hline & $\overline{1 / 14 / 2008} 18: 34$ & $8 / 14 / 200818: 34$ & 1.593 & \\
\hline 5297 & 1/14/2008 18:36 & 8/14/2008 18:36 & 1.595 & 26. \\
\hline 5298 & 1/1/4/2008 18:38 & $8 / 14 / 2008$ 18:38 & & 26.3 \\
\hline & $1 / 14 / 2008$ 18:40 & $8 / 14 / 2008$ 18:40 & 1.598 & 26.3 \\
\hline 5300 & $1 / 14 / 2008$ 18:42 & $8 / 14 / 2008$ 18:42 & 1.599 & \\
\hline & $1 / 14 / 2008$ 18:44 & $8 / 14 / 200818: 44$ & 1.6 & 26.3 \\
\hline 5302 & $1 / 14 / 200818: 46$ & $8 / 14 / 200818: 46$ & 1.601 & \\
\hline & 1/14/2008 18:48 & $8 / 14 / 2008$ 18:48 & 1.002 & \\
\hline & 1/1/4/20081 & $8 / 14200$ & 1.603 & \\
\hline 5305 & $1 / 14 / 200818: 52$ & $8 / 14 / 200818: 52$ & 1.604 & 26. \\
\hline 5306 & $1 / 14 / 200818.54$ & $8 / 142008$ 18:54 & 1.605 & 26. \\
\hline 53077 & 1/14/2008 18:56 & 8/14/2008 18:56 & & \\
\hline 5308 & 1/14/2008 18:58 & 8/14/2008 18:58 & & \\
\hline & $1 / 14 / 200819.00$ & $0819: 00$ & & \\
\hline 5310 & $1 / 14 / 200819.02$ & $8 / 14 / 2008$ 19:02 & 1.009 & 26.4 \\
\hline 5311 & $1 / 14 / 2008$ 19:04 & $8 / 14 / 200819: 04$ & 1.609 & \\
\hline 5312 & 1/14/2008 19:06 & $8 / 14 / 200819.06$ & 1.61 & 26.4 \\
\hline 5313 & & & 1.61 & \\
\hline 5314 & $1 / 14 / 200819.10$ & $8 / 14 / 2008$ 19:10 & 1.61 & 26. \\
\hline & $1 / 14 / 200819: 12$ & $8 / 14 / 2008$ 19:12 & 1.61 & \\
\hline & 1/14/2008 19:14 & $8 / 14 / 200819: 14$ & 1.611 & \\
\hline 5317| & $1 / 14 / 200819.16$ & $8 / 14200819: 16$ & 1.612 & \\
\hline & $1 / 14 / 200819.18$ & & & \\
\hline & $1 / 14 / 200819.20$ & $8 / 14 / 2008$ 19:20 & 1.613 & \\
\hline 5320 & $1 / 14 / 200819.22$ & & 1.614 & \\
\hline & $1 / 14 / 200819.24$ & $8 / 14 / 200819: 24$ & 1.614 & \\
\hline & $1 / 14 / 200819.26$ & $8 / 14 / 200819$ & 1.615 & 26.4 \\
\hline & & & 1.615 & \\
\hline & 1/114/20 & & 1.616 & \\
\hline & $1 / 1 / 4 / 200819.32$ & & & \\
\hline & & & & \\
\hline & $1 / 14 / 200819: 36$ & & & \\
\hline 5328] & $1 / 14 / 20$ & & & \\
\hline & $1 / 14 / 200819.40$ & $8 / 14 / 200819: 40$ & 1.618 & 26.4 \\
\hline & $1 / 14 / 2008$ 19:42 & $8 / 14 / 2008$ 19:42 & 1.618 & \\
\hline & $1 / 14 / 200819: 44$ & $8 / 14 / 2008$ 19:44 & 1.617 & 26.4 \\
\hline 53 & $1 / 14 / 200819.46$ & $8 / 142008$ 19:46 & 1.617 & 26.4 \\
\hline & 1/14/2008 19.48 & 8/14/2008 & 1.617 & \\
\hline & 1/144/20 & & & \\
\hline & 1/14/2008 19 & & & \\
\hline 533 & $\overline{t / 14 / 20 x}$ & & & \\
\hline & $\overline{1 / 14 / 20}$ & & & \\
\hline 5338 & $1 / 14 / 200819$ & $8 / 1420$ & 1.617 & \\
\hline 5339 & $1 / 14 / 200820: 00$ & $8 / 14 / 200820: 00$ & 1.617 & 26.4 \\
\hline & & 8/14/200820:c2 & \begin{tabular}{l|l}
1.617 \\
\end{tabular} & 26.4 \\
\hline
\end{tabular}


DOE/RL-2009-35, REV. 0

\begin{tabular}{|c|c|c|c|c|}
\hline \multicolumn{5}{|c|}{$D 4-92 p$} \\
\hline $\operatorname{Rec}$ & & Adusted & Pressure & Temp \\
\hline$\#$ & \begin{tabular}{|l|} 
Date/Time \\
\end{tabular} & DaterTime & \begin{tabular}{|l|} 
psi \\
\end{tabular} & ${ }^{\circ} \mathrm{C}$ \\
\hline 5341 & $1 / 14 / 200820: 04$ & $8 / 14 / 200820: 04$ & 1.618 & 26.4 \\
\hline 5342 & 1/14/2008 20:06 & $8 / 14 / 200820: 06$ & 1.617 & 26.4 \\
\hline 5343 & $1 / 14 / 200820.08$ & $8 / 14200820: 08$ & 1.618 & 26.4 \\
\hline 5344 & 1/14/200820:10 & $8 / 14 / 200820: 10$ & 1.618 & 26.4 \\
\hline 5345 & 1/14/200820:12 & $8 / 14 / 200820: 12$ & 1.619 & 26.5 \\
\hline 5346 & 1/14/2008 20:14 & $8 / 14 / 200820: 14$ & 1.619 & 26.5 \\
\hline 5347 & 1/14/200820:16 & $8 / 14 / 200820: 16$ & 1.619 & 26.5 \\
\hline 5348 & $1 / 14 / 200820: 18$ & $8 / 14 / 200820: 18$ & 1.619 & 26.5 \\
\hline 5349 & $1 / 14 / 200820: 20$ & $8 / 14 / 200820.20$ & 1.619 & 26.5 \\
\hline 5350 & $1 / 14 / 200820: 22$ & $8 / 14 / 200820: 22$ & 1.619 & 26.4 \\
\hline 5351 & $1 / 14 / 200820: 24$ & $8 / 14 / 200820.24$ & 1.62 & 26.4 \\
\hline 5352 & 1/14/200820:26 & $8 / 14 / 200820 \cdot 26$ & 1.62 & 26.4 \\
\hline 5353 & 1/14/200820:28 & $8 / 14 / 200820: 28$ & 1.62 & 26.4 \\
\hline 5354 & 1/14/2008 20:30 & $8 / 14 / 200820: 30$ & 1.62 & 26.4 \\
\hline 5355 & $1 / 14 / 200820: 32$ & $8 / 14 / 200820: 32$ & 1.62 & 26.4 \\
\hline 5356 & 1/14/2008 20:34 & $8 / 14 / 200820: 34$ & 1.62 & 26.4 \\
\hline 5357 & $1 / 14 / 200820: 36$ & $8 / 14 / 200820: 36$ & 1.62 & 26.4 \\
\hline 5358 & 1/14/200820:38 & $8 / 14 / 200820: 38$ & 1.62 & 26.4 \\
\hline 5359 & $1 / 14 / 200820: 40$ & $8 / 14 / 200820: 40$ & 1.62 & 26.4 \\
\hline 5360 & $1 / 14 / 200820: 42$ & $8 / 14 / 200820: 42$ & 1.62 & 26.4 \\
\hline 5361 & $1 / 14 / 200820: 44$ & $8 / 14 / 200820: 44$ & 1.62 & 26.5 \\
\hline 5362 & $1 / 14 / 200820: 46$ & $8 / 14 / 200820: 46$ & 1.62 & 26.5 \\
\hline 5363 & $1 / 14 / 200820: 48$ & $8 / 14 / 200820: 48$ & 1.62 & 26.5 \\
\hline 5364 & $1 / 14 / 200820.50$ & $8 / 14 / 200820.50$ & 1.62 & 26.4 \\
\hline 5365 & $1 / 14 / 200820: 52$ & $8 / 14 / 200820.52$ & 1.619 & 26.5 \\
\hline 5366 & $1 / 14 / 200820: 54$ & $8 / 14 / 200820: 54$ & 1.62 & 26.6 \\
\hline 5367 & $1 / 14 / 200820: 56$ & $8 / 14 / 200820: 56$ & 1.62 & 26.5 \\
\hline 5368 & $1 / 14 / 200820: 58$ & $8 / 14 / 200820: 58$ & 1.62 & 26.5 \\
\hline 5369 & 1/14/200821:00 & $8 / 14 / 200821: 00$ & 1.62 & 26.5 \\
\hline 5370 & 1/14/200821:02 & $8 / 14 / 200821: 02$ & 1.62 & 26.5 \\
\hline 5371 & $1 / 14 / 200821: 04$ & $8 / 14 / 200821: 04$ & 1.62 & 26.5 \\
\hline 5372 & 1/14/200821:06 & $8 / 14 / 200821: 06$ & 1.62 & 26.5 \\
\hline 5373 & $1 / 14 / 200821: 08$ & $8 / 14 / 200821: 08$ & 1.62 & 26.5 \\
\hline 5374 & 1/14/200821:10 & $8 / 14 / 200821: 1$ & 1.621 & 26.5 \\
\hline 5375 & 1/14/200821:12 & $8 / 14 / 200821: 12$ & 1.62 & 26.5 \\
\hline 5376 & 1/14/200821:14 & $8 / 14 / 200821: 14$ & 1.62 & 26.5 \\
\hline $53 \pi$ & 1/14/200821:16 & $8 / 14 / 200821: 16$ & 1.62 & 26.4 \\
\hline 5378 & $1 / 14 / 200821: 18$ & $8 / 14 / 200821: 18$ & 1.62 & 26.5 \\
\hline 5379 & 1/14/200821:20 & $8 / 14 / 200821: 20$ & 1.62 & 26.5 \\
\hline 5380 & $1 / 14 / 200821: 22$ & $8 / 14 / 200821: 22$ & 1.619 & 26.5 \\
\hline 5381 & $1 / 14 / 200821: 24$ & $8 / 14 / 200821: 24$ & 1.619 & 26.5 \\
\hline 5382 & $1 / 14 / 200821: 26$ & 8/14/200821:26 & 1.619 & 26.5 \\
\hline 5383 & 1/14/200821:28 & $8 / 14 / 200821: 28$ & 1.62 & 26.5 \\
\hline 5384 & 1/14/200821:30 & $8 / 14 / 200821: 30$ & 1.62 & 26.5 \\
\hline 5385 & 1/14/200821:32 & $8 / 14 / 200821: 32$ & 1.62 & 26.5 \\
\hline 5386 & 1/14/200821:34 & $8 / 14 / 200821: 34$ & 1.62 & 26.5 \\
\hline 5387 & 1/14/2008 21:36 & $8 / 14 / 200821: 36$ & 1.619 & 26.5 \\
\hline 5388 & $1 / 14 / 200821: 38$ & $8 / 14 / 200821: 38$ & 1.619 & 26.5 \\
\hline 5389 & 1/14/200821:40 & $8 / 14 / 200821: 40$ & 1.619 & 26.5 \\
\hline 5390 & $1 / 14 / 200821: 42$ & $8 / 14 / 200821: 42$ & 1.619 & 26.5 \\
\hline 5391 & 1/14/2008 21:44 & $8 / 14 / 200821: 44$ & 1.62 & 26.5 \\
\hline 5392 & 1/14/2008 21:46 & $8 / 14 / 200821: 46$ & 1.619 & 26.4 \\
\hline 5393 & $1 / 14 / 200821: 48$ & $8 / 14 / 200821: 48$ & 1.619 & 26.4 \\
\hline 5394 & $1 / 14 / 200821: 50$ & $8 / 14 / 200821: 50$ & 1.619 & 26.4 \\
\hline 5396 & $1 / 14 / 200821: 52$ & & 1.618 & 26.5 \\
\hline 5396 & $1 / 14 / 200821: 54$ & $8 / 14 / 200821: 54$ & 1.618 & 26.5 \\
\hline 5397 & 1/14/200821:56 & $8 / 14 / 200821: 56$ & 1.618 & 26.4 \\
\hline 5398 & $1 / 14 / 200821: 58$ & $8 / 14 / 200821: 58$ & 1.617 & 26.5 \\
\hline 5399 & $1 / 14 / 20082200$ & $8 / 14 / 20082200$ & 1.616 & 26.4 \\
\hline 5400 & $1 / 14 / 200822002$ & $8 / 14 / 20082202$ & 1.616 & 26.4 \\
\hline 5401 & $1 / 14 / 200822=04$ & $8 / 14 / 200822: 04$ & 1.616 & 26.4 \\
\hline 5402 & $1 / 14 / 20082206$ & $8 / 14 / 200822: 06$ & 1.616 & 26.4 \\
\hline 5403 & $1 / 14 / 200822: 08$ & $8 / 14 / 200822: 08$ & 1.616 & 26.4 \\
\hline 5404 & $1 / 14 / 20082210$ & $8 / 14 / 200822: 10$ & 1.616 & 26.4 \\
\hline 5405 & $1 / 14 / 20082212$ & $8 / 14 / 200822: 12$ & 1.616 & 26.4 \\
\hline 5406 & $1 / 14 / 200822: 14$ & $8 / 14 / 200822: 14$ & 1.616 & 26.4 \\
\hline 5407 & 1/14/2008 22:16 & $8 / 14 / 200822: 16$ & 1.616 & 26.4 \\
\hline 5408 & $1 / 14 / 20082218$ & 8/14/2008 22:18 & 1.615 & 26.4 \\
\hline 5409 & $1 / 14 / 20082220$ & $8 / 14 / 200822-20$ & 1.616 & 26.4 \\
\hline
\end{tabular}

\begin{tabular}{|c|c|c|c|c|}
\hline \multicolumn{5}{|c|}{ D4-92p } \\
\hline $\mathrm{ReC}$ & & Adusted & Pressure & Temp \\
\hline$\#$ & DedeTime & Date/Time & psi & ${ }^{\circ} \mathrm{C}$ \\
\hline 5410 & 1/14/2008 22:22 & $8 / 14 / 200822: 22$ & 1.616 & 26.4 \\
\hline 5411 & $1 / 14 / 200822=24$ & $8 / 14 / 200822224$ & 1.616 & 26.4 \\
\hline 5412 & $1 / 14 / 200822226$ & $8 / 14 / 200822: 26$ & 1.616 & 26.4 \\
\hline 5413 & $1 / 14 / 200822-28$ & $8 / 14 / 20082228$ & 1.616 & 26.4 \\
\hline 5414 & $1 / 14 / 20082230$ & $8 / 14 / 200822330$ & 1.616 & 26.4 \\
\hline 5415 & $1 / 14 / 200822 \div 32$ & $8 / 14 / 200822: 32$ & 1.615 & 26.4 \\
\hline 5416 & $1 / 14 / 200822: 34$ & $8 / 14 / 20082234$ & 1.615 & 26.4 \\
\hline 5417 & $1 / 14 / 200822336$ & $814 / 20082236$ & 1.615 & 26.4 \\
\hline 5418 & $1 / 14 / 200822=38$ & $8 / 14 / 200822: 38$ & 1.616 & 26.4 \\
\hline 5419 & $1 / 14 / 200822440$ & $8 / 14 / 200822: 40$ & 1.616 & 26.4 \\
\hline 5420 & $1 / 14 / 200822-42$ & $8 / 14 / 200822: 42$ & 1.616 & 26.4 \\
\hline 5421 & $1 / 14 / 20082244$ & $8 / 14 / 20082244$ & 1.616 & 26.4 \\
\hline 5422 & $1 / 14 / 20082246$ & $8 / 14 / 200822: 46$ & 1.616 & 26.4 \\
\hline 5423 & $1 / 14 / 200822: 48$ & $8 / 14 / 200822: 48$ & 1.616 & 26.5 \\
\hline 5424 & $1 / 14 / 20082250$ & $8 / 14 / 200822: 50$ & 1.617 & 26.5 \\
\hline 5425 & $1 / 14 / 200822-52$ & $8 / 14 / 200822: 52$ & 1.616 & 26.4 \\
\hline 5426 & $1 / 14 / 20082254$ & $8 / 14 / 200822: 54$ & 1.616 & 26.5 \\
\hline 5427 & $1 / 14 / 200822: 56$ & $8 / 14 / 200822: 56$ & 1.616 & 26.5 \\
\hline 5428 & $1 / 14 / 20082258$ & $8 / 14 / 200822: 58$ & 1.616 & 26.5 \\
\hline 5420 & 1/14/200823:00 & $8 / 14 / 200823: 00$ & 1.616 & 26.5 \\
\hline 5430 & 1/14/2008 23:02 & 8/14/2008 23:02 & 1.615 & 26.4 \\
\hline 5431 & $1 / 14 / 200823: 04$ & $8 / 14 / 200823: 04$ & 1.615 & 26.4 \\
\hline 5432 & $1 / 14 / 200823: 06$ & $8 / 14 / 200823: 06$ & 1.616 & 26.5 \\
\hline 5433 & $1 / 14 / 200823: 08$ & $8 / 14 / 200823: 08$ & 1.624 & 26.5 \\
\hline 5434 & 1/14/200823:10 & $8 / 14 / 200823: 10$ & 1.491 & 26.3 \\
\hline 5435 & 1/14/2008 23:12 & $8 / 14 / 200823: 12$ & 1.506 & 26.1 \\
\hline 5436 & $1 / 14 / 200823: 14$ & $8 / 14 / 200823: 14$ & 1.52 & 25.9 \\
\hline 5437 & 1/14/2008 23:16 & $8 / 14 / 200823: 16$ & 1.511 & 25.8 \\
\hline 5438 & $1 / 14 / 200823: 18$ & $8 / 14 / 200823: 18$ & 1.517 & 25.8 \\
\hline 5439 & 1/14/200823:20 & 8/14/2008 23:20 & 1.533 & 25.8 \\
\hline 5440 & $1 / 14 / 200823: 22$ & $8 / 14 / 200823: 22$ & 1.538 & 25.8 \\
\hline 5441 & $1 / 14 / 200823: 24$ & $8 / 14 / 200823: 24$ & 1.542 & 25.8 \\
\hline 5442 & $1 / 14 / 200823: 26$ & $8 / 14 / 200823: 26$ & 1.547 & 25.9 \\
\hline 5443 & $1 / 14 / 200823: 28$ & $8 / 14 / 200823: 28$ & 1.55 & 25.9 \\
\hline 5444 & $1 / 14 / 200823: 30$ & $8 / 14 / 200823: 30$ & 1.553 & 25.9 \\
\hline 5445 & $1 / 14 / 200823: 32$ & $8 / 14 / 200823: 32$ & 1.556 & 25.9 \\
\hline 5446 & 1/14/200823:34 & $8 / 14 / 200823: 34$ & 1.559 & 25.9 \\
\hline 5447 & 1/14/2008 23:36 & $8 / 14 / 200823: 36$ & 1.561 & 25.9 \\
\hline 5448 & $1 / 14 / 200823: 38$ & $8 / 14 / 200823: 38$ & 1.563 & 25.9 \\
\hline 5449 & $1 / 14 / 200823: 40$ & $8 / 14 / 200823: 40$ & 1.565 & 25.9 \\
\hline 5450 & $1 / 14 / 200823: 42$ & $8 / 14 / 200823: 42$ & 1.568 & 25.9 \\
\hline 5451 & $1 / 14 / 200823: 44$ & $8 / 14 / 200823: 44$ & 1.57 & 25.9 \\
\hline 5452 & $1 / 14 / 200823: 46$ & $8 / 14 / 200823: 46$ & 1.571 & 25.9 \\
\hline 5453 & $1 / 14 / 200823: 48$ & $8 / 14 / 200823: 48$ & 1.574 & 26 \\
\hline 5454 & $1 / 14 / 200823: 50$ & $8 / 14 / 200823: 50$ & 1.575 & 26 \\
\hline 5455 & $1 / 14 / 200823: 52$ & $8 / 14 / 200823: 52$ & 1.577 & 26 \\
\hline 5456 & $1 / 14 / 200823: 54$ & $8 / 14 / 200823: 54$ & 1.578 & 26 \\
\hline 5457 & $1 / 14 / 200823: 56$ & $8 / 14 / 200823: 56$ & 1.579 & 26 \\
\hline 5458 & $1 / 14 / 200823: 58$ & $8 / 14 / 200823: 58$ & 1.581 & 26 \\
\hline 5450 & $1 / 15 / 20080: 00$ & $8 / 15 / 20080: 00$ & 1.582 & 26 \\
\hline 5460 & 1/15/20080:02 & $8 / 15 / 20080: 02$ & 1.583 & 26 \\
\hline 5461 & 1/15/20080:04 & $8 / 15 / 20080: 04$ & 1.584 & 26.1 \\
\hline 5462 & 1/15/20080:06 & $8 / 15 / 20080: 06$ & 1.585 & 26.1 \\
\hline 5463 & 1/15/20080:08 & $8 / 15 / 20080: 08$ & 1.586 & 26.1 \\
\hline 5464 & $1 / 15 / 20080: 10$ & $8 / 15 / 20080: 10$ & 1.587 & 26.1 \\
\hline 5465 & $1 / 15 / 20080: 12$ & $8 / 15 / 20080.12$ & 1.586 & 26.1 \\
\hline 5466 & 1/15/20080:14 & $8 / 15 / 20080: 14$ & 1.587 & 26.1 \\
\hline 5467 & 1/15/20080:16 & $8 / 15 / 20080: 16$ & 1.587 & 26.1 \\
\hline 5468 & $1 / 15 / 20080: 18$ & $8 / 15 / 20080.18$ & 1.589 & 26 \\
\hline 5469 & 1/15/20080:20 & $8 / 15 / 20080: 20$ & 1.589 & 26.1 \\
\hline 5470 & 1/15/20080:22 & $8 / 15 / 20080: 22$ & 1.591 & 26.1 \\
\hline 5471 & 1/15/20080:24 & $8 / 15 / 20080: 24$ & 1.591 & 26.1 \\
\hline 5472 & 1/15/20080:26 & $8 / 15 / 20080.26$ & 1.592 & 26.1 \\
\hline 5473 & $1 / 15 / 20080: 28$ & $8 / 15 / 20080: 28$ & 1.593 & 26.1 \\
\hline 5474 & $1 / 15 / 20080: 30$ & $8 / 15 / 20080: 30$ & 1.594 & 26.1 \\
\hline 5475 & 1/15/20080:32 & $8 / 15 / 20080: 32$ & 1.595 & 26.1 \\
\hline 5476 & 1/15/20080:34 & $8 / 15 / 20080.34$ & 1.595 & 26.1 \\
\hline 5477 & 1/15/20080:36 & $8 / 15 / 20080: 36$ & 1.505 & 26.1 \\
\hline 5478 & $1 / 15 / 20080: 38$ & $8 / 15 / 20080.38$ & 1.595 & 26.1 \\
\hline
\end{tabular}

\begin{tabular}{|c|c|c|c|c|}
\hline \multicolumn{5}{|c|}{ D492p } \\
\hline $\mathrm{ReC}$ & & Adjusted & Pressure & \\
\hline \# & Date-Time & DaterTme & psi & \\
\hline 5479 & $1 / 15 / 20080: 40$ & $8 / 15 / 20080: 40$ & 1.596 & \\
\hline 5480 & $1 / 15 / 20080: 42$ & $8 / 15 / 20080: 42$ & 1.597 & \\
\hline 5481 & $1 / 15 / 20080.44$ & $8 / 15 / 20080: 44$ & 1.597 & 26.1 \\
\hline 5482 & $1 / 15 / 20080: 46$ & $8 / 15 / 20080: 46$ & 1.598 & 26.1 \\
\hline 5483 & $1 / 15 / 20080: 48$ & $8 / 15 / 20080: 48$ & 1.599 & \\
\hline 5484 & $1 / 15 / 20080.50$ & $8 / 15 / 20080.50$ & 1.599 & 26 \\
\hline 5485 & $1 / 15 / 20080: 52$ & $8 / 15 / 20080: 52$ & 1.599 & \\
\hline 5486 & $1 / 15 / 20080: 54$ & $8 / 15 / 20080: 54$ & 1.6 & \\
\hline 5487 & $1 / 15 / 20080: 56$ & $8 / 15 / 20080.56$ & 1.601 & 26.1 \\
\hline 5488 & $1 / 15 / 20080.58$ & $8 / 15 / 20080.58$ & 1.601 & 26.1 \\
\hline 5489 & 1/15/2008 1:00 & 8/15/2008 1:00 & 1.601 & \\
\hline 5490 & 1/15/2008 1:02 & $8 / 15 / 2008$ 1:02 & 1.601 & 26.1 \\
\hline 5491 & $1 / 15 / 2008$ & $8 / 15 / 20081: 04$ & 1.602 & \\
\hline 5492 & $15 / 20081: 06$ & $8 / 15 / 20081: 06$ & 1.602 & \\
\hline 5493 & $15 / 20081: 08$ & $8 / 15 / 20081: 08$ & 1.603 & 26.2 \\
\hline 5494 & $15 / 200$ & $8 / 15 / 20081: 10$ & 1.603 & \\
\hline 5495 & 1/15/2008 1:12 & $8 / 15 / 2008$ 1:12 & 1.504 & \\
\hline 5496 & $15 / 200$ & $81: 14$ & 1.604 & \\
\hline 5497 & 155200 & $881: 16$ & 1.604 & \\
\hline 5498 & $15 / 20081: 18$ & $8 / 15 / 20081: 18$ & 1.605 & 26.2 \\
\hline 5499 & $15 / 200$ & & 1.605 & \\
\hline 5500 & $15 / 200$ & $0081: 22$ & 1.605 & \\
\hline 5501 & $15 / 20$ & $81: 24$ & 1.605 & 26.2 \\
\hline 5502 & $15 / 200$ & $8 / 15 / 20081: 26$ & 1.606 & \\
\hline 5503 & $15 / 200$ & $8 / 15 / 20081: 28$ & 1.506 & 26 . \\
\hline 5504 & $15 / 20$ & 1:30 & 1.606 & 26. \\
\hline 5505 & $15 / 20$ & $1: 32$ & 1.606 & 26. \\
\hline 5506 & $15 / 200$ & & 1.606 & 26. \\
\hline 5507 & $15 / 200$ & $1: 36$ & 1.606 & 26 . \\
\hline 5508 & 38 & 1:38 & 1.606 & 26. \\
\hline 5509 & 40 & & 1.606 & 26. \\
\hline 5510 & 42 & & 1.606 & 26. \\
\hline 5511 & 44 & $1: 44$ & 1.607 & 26 . \\
\hline 5512 & & & 1.607 & 26. \\
\hline 5513 & $15 / 200$ & $8 / 15 / 2$ & 1.607 & 26. \\
\hline 5514 & & & 1.607 & 26 . \\
\hline 5515 & 52 & & 1.607 & 26. \\
\hline 5516 & & $8 / 15 / 20081: 54$ & 1.607 & 26. \\
\hline 5517| & & & 1.606 & 26. \\
\hline 5518 & 8 & & 1.606 & 26. \\
\hline 5519 & & & 1.606 & 26. \\
\hline 5520 & & 202 & 1.607 & 26 \\
\hline 5521 & & & 1.607 & \\
\hline 5522 & & & 1.607 & 26 \\
\hline 5523 & $5 / 200$ & & 1.606 & 26 . \\
\hline 5524 & & & 1.606 & 26 . \\
\hline 5625 & & & 1.606 & \\
\hline 5526 & & & 1.606 & 26. \\
\hline 5527 & & & 1.606 & \\
\hline 5528 & & 218 & 1.606 & 26. \\
\hline 5529 & & & 1.606 & 26. \\
\hline 5530 & & & 1.607 & \\
\hline 5531 & & 224 & 1.606 & 26 . \\
\hline 5532 & & & 1.606 & \\
\hline 5533 & & & 1.606 & \\
\hline 5534 & & & 1.605 & \\
\hline 5535 & & & 1.605 & \\
\hline 5536 & & 8234 & 1.505 & 26. \\
\hline 5537 & & & 1.605 & \\
\hline 5538 & $15 / 200$ & & 1.604 & \\
\hline 5539 & & & 1.604 & \\
\hline 5540 & & & 1.605 & \\
\hline 5541 & 244 & 82244 & 1.605 & 26. \\
\hline 5542 & & & 1.606 & \\
\hline 5543 & & & 1.605 & \\
\hline 5544 & $1 / 15 / 2008250$ & $8 / 15 / 2008255$ & 1.605 & 26. \\
\hline 5 & & & 1.605 & \\
\hline 5546 & $1 / 15 / 2008254$ & $8 / 15 / 20082: 54$ & 1.605 & 26 \\
\hline 5547 & $1 / 15 / 2008256$ & $8 / 15 / 2008256$ & 1.606 & \\
\hline
\end{tabular}


DOE/RL-2009-35, REV. 0

\begin{tabular}{|c|c|c|c|c|}
\hline \multicolumn{5}{|c|}{ D492p } \\
\hline $\operatorname{Rec}$ & & Adusted & Pressure & Temp \\
\hline$\#$ & Date-Time & Date/Time & psi & ${ }^{\circ} \mathrm{C}$ \\
\hline 5548 & $1 / 15 / 20082: 58$ & $8 / 15 / 2008258$ & 1.605 & 26.3 \\
\hline 5549 & 1/15/2008 3:00 & $8 / 15 / 20083: 00$ & 1.604 & 26.3 \\
\hline 5550 & $1 / 15 / 20083: 02$ & $8 / 15 / 20083: 02$ & 1.604 & 26.3 \\
\hline 5551 & $1 / 15 / 20083: 04$ & $8 / 15 / 20083: 04$ & 1.604 & 26.2 \\
\hline 5552 & $1 / 15 / 20083: 06$ & $8 / 15 / 20083: 06$ & 1.604 & 26.2 \\
\hline 5553 & $1 / 15 / 20083: 08$ & $8 / 15 / 20083: 08$ & 1.604 & 26.2 \\
\hline 5554 & $1 / 15 / 20083: 10$ & $8 / 15 / 20083: 10$ & 1.604 & 26.2 \\
\hline 5555 & $1 / 15 / 20083: 12$ & $8 / 15 / 20083: 12$ & 1.604 & 26.2 \\
\hline 5556 & $1 / 15 / 20083: 14$ & $8 / 15 / 20083: 14$ & 1.604 & 26.2 \\
\hline 5557 & $1 / 15 / 20083: 16$ & $8 / 15 / 20083: 16$ & 1.603 & 26.2 \\
\hline 5558 & $1 / 15 / 20083: 18$ & $8 / 15 / 20083: 18$ & 1.603 & 26.2 \\
\hline 5559 & $1 / 15 / 20083: 20$ & $8 / 15 / 20083: 20$ & 1.603 & 26.2 \\
\hline 5560 & $1 / 15 / 20083: 22$ & $8 / 15 / 20083: 22$ & 1.603 & 26.1 \\
\hline 5561 & $1 / 15 / 20083: 24$ & $8 / 15 / 20083: 24$ & 1.602 & 26.1 \\
\hline 5562 & $1 / 15 / 20083: 26$ & $8 / 15 / 20083: 26$ & 1.601 & 26.2 \\
\hline 5563 & $1 / 15 / 20083: 28$ & $8 / 15 / 20083: 28$ & 1.602 & 26.2 \\
\hline 5564 & $1 / 15 / 20083: 30$ & $8 / 15 / 20083: 30$ & 1.601 & 26.2 \\
\hline 5565 & $1 / 15 / 20083: 32$ & $8 / 15 / 20083: 32$ & 1.601 & 26.2 \\
\hline 5566 & $1 / 15 / 20083: 34$ & $8 / 15 / 20083: 34$ & 1.601 & 26.2 \\
\hline 5567 & $1 / 15 / 20083: 36$ & $8 / 15 / 2008336$ & 1.601 & 26.2 \\
\hline 5568 & 1/15/20083:38 & $8 / 15 / 20083: 38$ & 1.601 & 26.2 \\
\hline 5569 & $1 / 15 / 20083: 40$ & $8 / 15 / 20083: 40$ & 1.602 & 26.2 \\
\hline 5570 & $1 / 15 / 20083: 42$ & $8 / 15 / 20083: 42$ & 1.602 & 26.1 \\
\hline 5571 & $1 / 15 / 20083: 44$ & $8 / 15 / 20083: 44$ & 1.602 & 26.2 \\
\hline 5572 & $1 / 15 / 20083: 46$ & $8 / 15 / 20083: 46$ & 1.602 & 26.2 \\
\hline 5573 & $1 / 15 / 20083: 48$ & $8 / 15 / 20083: 48$ & 1.601 & 26.2 \\
\hline 5574 & $1 / 15 / 20083: 50$ & $8 / 15 / 20083: 50$ & 1.602 & 26.2 \\
\hline 5575 & $1 / 15 / 20083: 52$ & $8 / 15 / 20083: 52$ & 1.602 & 26.2 \\
\hline 5576 & $1 / 15 / 20083.54$ & $8 / 15 / 20083: 54$ & 1.601 & 26.2 \\
\hline 5577 & $1 / 15 / 20083.56$ & $8 / 15 / 20083: 56$ & 1.601 & 26.2 \\
\hline 5578 & $1 / 15 / 20083: 58$ & $8 / 15 / 20083: 58$ & 1.601 & 26.2 \\
\hline 5579 & $1 / 15 / 20084: 00$ & $8 / 15 / 20084: 00$ & 1.601 & 26.2 \\
\hline 5580 & $1 / 15 / 20084: 02$ & $8 / 15 / 20084: 02$ & 1.601 & 26.2 \\
\hline 5581 & $1 / 15 / 20084: 04$ & $8 / 15 / 20084: 04$ & 1.601 & 26.2 \\
\hline 5582 & $1 / 15 / 20084: 06$ & $8 / 15 / 20084: 06$ & 1.601 & 26.2 \\
\hline 5583 & $1 / 15 / 20084: 08$ & $8 / 15 / 20084: 08$ & 1.601 & 26.2 \\
\hline 5584 & $1 / 15 / 20084: 10$ & $8 / 15 / 20084: 10$ & 1.601 & 26.2 \\
\hline 5585 & $1 / 15 / 20084: 12$ & $8 / 15 / 20084: 12$ & 1.601 & 26.2 \\
\hline 5586 & $1 / 15 / 20084: 14$ & $8 / 15 / 20084: 14$ & 1.601 & 26.2 \\
\hline 5587 & $1 / 15 / 20084: 16$ & $8 / 15 / 20084: 16$ & 1.601 & 26.3 \\
\hline 5588 & $1 / 15 / 20084: 18$ & $8 / 15 / 20084: 18$ & 1.601 & 26.2 \\
\hline 5589 & $1 / 15 / 20084: 20$ & $8 / 15 / 20084: 20$ & 1.602 & $26 . \overline{3}$ \\
\hline 5590 & $1 / 15 / 20084: 22$ & $8 / 15 / 20084: 22$ & 1.602 & 26.2 \\
\hline 5591 & $1 / 15 / 20084: 24$ & $8 / 15 / 20084: 24$ & 1.602 & 26.3 \\
\hline 5592 & $1 / 15 / 20084: 26$ & $8 / 15 / 20084: 26$ & 1.602 & 26.3 \\
\hline 5593 & 1/15/20084:28 & $8 / 15 / 20084: 28$ & 1.602 & 26.3 \\
\hline 5594 & $1 / 15 / 20084: 30$ & $8 / 15 / 20084: 30$ & 1.603 & 26.3 \\
\hline 5595 & $1 / 15 / 20084: 32$ & $8 / 15 / 20084: 32$ & 1.602 & 26.3 \\
\hline 5596 & $1 / 15 / 20084: 34$ & $8 / 15 / 20084: 34$ & 1.602 & 26.3 \\
\hline 5597 & $1 / 15 / 20084: 36$ & $8 / 15 / 20084: 36$ & 1.602 & 26.3 \\
\hline 5598 & $1 / 15 / 20084: 38$ & $8 / 15 / 20084: 38$ & 1.602 & 26.3 \\
\hline 5599 & $1 / 15 / 20084: 40$ & $8 / 15 / 20084: 40$ & 1.602 & 26.3 \\
\hline 5600 & $1 / 15 / 20084: 42$ & $8 / 15 / 20084: 42$ & 1.601 & 26.2 \\
\hline 5601 & $1 / 15 / 20084: 44$ & $8 / 15 / 20084: 44$ & 1.601 & 26.2 \\
\hline 5602 & $1 / 15 / 20084: 46$ & $8 / 15 / 20084: 46$ & 1.601 & 26.2 \\
\hline 5603 & $t / 15 / 20084: 48$ & $8 / 15 / 20084: 48$ & 1.601 & 26.2 \\
\hline 5604 & $1 / 15 / 20084: 50$ & $8 / 15 / 20084: 50$ & 1.6 & 26.2 \\
\hline 5605 & $1 / 15 / 20084: 52$ & $8 / 15 / 20084: 52$ & 1.6 & 26.2 \\
\hline 5606 & $1 / 15 / 20084: 54$ & $8 / 15 / 20084: 54$ & 1.601 & 26.2 \\
\hline 5607 & $1 / 15 / 20084: 56$ & $8 / 15 / 20084: 56$ & 1.601 & 26.2 \\
\hline 5608 & $1 / 15 / 20084: 58$ & $8 / 15 / 20084: 58$ & 1.601 & 26.2 \\
\hline 5609 & $1 / 15 / 20085: 00$ & $8 / 15 / 20085: 00$ & 1.601 & 26.2 \\
\hline 5610 & $1 / 15 / 20085: 02$ & $8 / 15 / 20085: 02$ & 1.602 & 26.2 \\
\hline 5611 & $1 / 15 / 20085: 04$ & $8 / 15 / 20085: 04$ & 1.602 & 26.2 \\
\hline 5612 & 1/15/20085:06 & $8 / 15 / 20085: 06$ & 1.602 & 26.2 \\
\hline 5613 & $1 / 15 / 20085: 08$ & $8 / 15 / 20085: 08$ & 1.601 & 26.3 \\
\hline 5614 & $1 / 15 / 20085: 10$ & $8 / 15 / 20085: 10$ & 1.601 & 26.2 \\
\hline 5615 & $1 / 15 / 20085: 12$ & $8 / 15 / 20085: 12$ & 1.6 & 26.2 \\
\hline 5616 & 1/15/2008 5:14 & $8 / 15 / 20085: 14$ & 1.6 & 26.1 \\
\hline
\end{tabular}

\begin{tabular}{|c|c|c|c|c|}
\hline \multicolumn{5}{|c|}{$492 p$} \\
\hline$R e C$ & & Adjusted & Pressure & \\
\hline$\#$ & DaterTime & Date/Time & psi & \\
\hline 5617 & 1/15/20085:16 & $8 / 15 / 20085: 16$ & 1.6 & 2 \\
\hline 5618 & 1/15/20085:18 & $8 / 15 / 20085: 18$ & 1.6 & \\
\hline 5619 & $15 / 20085: 20$ & $3 / 15 / 20085: 20$ & 1.6 & \\
\hline 5620 & $1 / 15 / 20085: 22$ & $8 / 15 / 20085: 22$ & 1.6 & $\overline{2}$ \\
\hline 5621 & $1 / 15 / 20085: 24$ & $8 / 15 / 20085: 24$ & 1.599 & \\
\hline 5622 & $1 / 15 / 20085: 26$ & $8 / 15 / 20085: 26$ & 1.599 & \\
\hline 5623 & $1 / 15 / 20085: 28$ & $8 / 15 / 20085: 28$ & 1.598 & $\overline{2}$ \\
\hline 5624 & $1 / 15 / 20085: 30$ & $8 / 15 / 20085: 30$ & 1.599 & 26. \\
\hline 5625 & $115 / 20085: 32$ & $8 / 15 / 20085: 32$ & 1.598 & \\
\hline 5626 & $1 / 15 / 20085: 34$ & $8 / 15 / 20085: 34$ & 1.598 & $\overline{2}$ \\
\hline 5627 & $1 / 15 / 20085: 36$ & $8 / 15 / 20085: 36$ & 1.598 & 26 \\
\hline 5628 & $115 / 20085: 38$ & $8 / 15 / 20085: 38$ & 1.598 & \\
\hline 5629 & $1 / 15 / 20085: 40$ & $8 / 15 / 20085: 40$ & 1.597 & \\
\hline 5630 & $1 / 15 / 20085: 42$ & $8 / 15 / 20085: 42$ & 1.598 & 26 . \\
\hline 5631 & $115 / 20085: 44$ & $8 / 15 / 20085: 44$ & 1.598 & \\
\hline 5632 & $15 / 20085: 46$ & $8 / 15 / 20085: 46$ & 1.598 & \\
\hline 5633 & $1 / 15 / 20085: 48$ & $8 / 15 / 20$ & 1.597 & 26 \\
\hline 5634 & $15 / 20085: 50$ & $8 / 15 / 20$ & 1.598 & \\
\hline 5635 & $15 / 20085: 52$ & $8 / 15 / 20$ & 1.598 & \\
\hline 5636 & $1 / 15 / 20085: 54$ & $8 / 15 / 20$ & 1.598 & \\
\hline 5637 & $15 / 20085: 56$ & $8 / 15 / 20$ & 1.597 & \\
\hline 5638 & $15 / 20085: 58$ & $8 / 15 / 20$ & 1.597 & \\
\hline 5639 & $15 / 20086: 00$ & $8 / 15 / 20$ & 1.597 & 26. \\
\hline 5640 & $15 / 20086: 02$ & $3 / 15 / 20$ & 1.597 & \\
\hline 5641 & $15 / 20086: 04$ & $8 / 15 / 20$ & 1.597 & \\
\hline 5642 & $15 / 20086: 06$ & $8 / 15 / 2$ & 1.596 & 26 \\
\hline 5643 & $15 / 20086: 08$ & $8 / 15 / 2$ & 1.595 & \\
\hline 5644 & $15 / 20086: 10$ & $8 / 15 / 2$ & 1.594 & $\underline{2}$ \\
\hline 5645 & $36: 12$ & $8 / 15 / 2$ & 1.594 & 26 \\
\hline 5646 & $86: 14$ & $8 / 15 / 20$ & 1.593 & 26 \\
\hline 5647 & $15 / 20086: 16$ & $8 / 15 / 20$ & 1.593 & 2 \\
\hline 5648 & $15 / 20086: 18$ & $8 / 15 / 2$ & 1.593 & 26 \\
\hline 5649 & $36: 20$ & $8 / 15 / 2$ & 1.593 & 26 \\
\hline 5650 & & $8 / 15 / 2$ & 1.592 & \\
\hline 5651 & $6: 24$ & $8 / 15 / 2$ & 1.592 & 26 \\
\hline 5652 & $86: 26$ & $8 / 15 \sqrt{2}$ & 1.592 & 26 \\
\hline 5653 & $20086: 28$ & $8 / 15 / 20$ & 1.592 & $\overline{2}$ \\
\hline 5654 & $6: 30$ & $8 / 15 / 2$ & 1.592 & 2 \\
\hline 5655 & $520086: 32$ & $8 / 15 / 2$ & 1.591 & 2 \\
\hline 5656 & & $8 / 15 / 2$ & 1.591 & 2 \\
\hline 5657 & & $: 36$ & 1.591 & 2 \\
\hline 5658 & $120086: 38$ & $115 / 2$ & 1.592 & 26 \\
\hline 5659 & $6: 40$ & $8 / 15 / 2$ & 1.592 & 2 \\
\hline 5660 & & $: 42$ & 1.592 & \\
\hline 5661 & $86: 44$ & $8 / 15 / 20$ & 1.593 & 26 . \\
\hline 5662 & $6: 46$ & 3:46 & 1.593 & \\
\hline 5663 & & $6: 48$ & 1.593 & $\overline{26}$ \\
\hline 5664 & $15 / 20086: 50$ & $8 / 15 / 2$ & 1.593 & 26 \\
\hline 5665 & & & 1.593 & $\overline{2}$ \\
\hline 5666 & & $6: 54$ & 1.593 & 2 \\
\hline 5667 & $66: 56$ & $8 / 15 / 20$ & 1.593 & 26 \\
\hline 5668 & & & 1.593 & 2 \\
\hline 5669 & $37: 00$ & $7: 00$ & 1.593 & \\
\hline 5670 & $20087: 02$ & $8 / 15 / 20087: 02$ & 1.593 & \\
\hline 5671 & & & 1.593 & 26 \\
\hline 5672 & 17 & $7: 06$ & 1.592 & 26 \\
\hline 5673 & $15 / 20087: 08$ & $87: 08$ & 1.593 & $2 x$ \\
\hline 5674 & & & 1.593 & \\
\hline 5675 & & & 1.593 & 26 \\
\hline 5676 & $15 / 20087: 14$ & $8 / 15 / 20087: 14$ & 1.593 & 26 \\
\hline 5677 & & $87: 16$ & 1.593 & \\
\hline 5678 & $120087: 18$ & $8 / 15 / 20$ & 1.592 & 26 \\
\hline 5679 & $15 / 20087: 20$ & $8 / 15 / 20087: 20$ & 1.591 & \\
\hline 5680 & & $8 / 15 / 20087: 22$ & 1.591 & \\
\hline 5681 & $5 / 20087: 24$ & $87: 24$ & 1.591 & 26 \\
\hline 5682 & $19 / 20087: 26$ & $3 / 15 / 20087: 26$ & 1.591 & \\
\hline 5683 & & & 1.591 & 26 \\
\hline 5684 & $15 / 20087: 30$ & $8 / 15 / 20087: 30$ & 1.591 & \\
\hline 5685 & $15 / 20087: 32$ & $8 / 15 / 20087: 32$ & 1.59 & 20 \\
\hline
\end{tabular}

\begin{tabular}{|c|c|c|c|c|}
\hline \multicolumn{5}{|c|}{ D4-920 } \\
\hline Rec & & Adjusted & Pressurt & Temp \\
\hline$\#$ & Date/Time & Dater/Time & psi & ${ }^{\circ} \mathrm{C}$ \\
\hline 5686 & 1/15/20087:34 & $8 / 15 / 20087: 34$ & 1.59 & 26.1 \\
\hline 5687 & 1/15/20087:36 & $8 / 15 / 20087: 36$ & 1.59 & 26.1 \\
\hline 5688 & 1/15/20087:38 & $8 / 15 / 20087: 38$ & 1.589 & 26.1 \\
\hline 5689 & $1 / 15 / 20087: 40$ & $8 / 15 / 20087: 40$ & 1.589 & 26.1 \\
\hline 5690 & 1/15/20087:42 & $8 / 15 / 20087: 42$ & 1.59 & 26.1 \\
\hline 5691 & $1 / 15 / 20087: 44$ & $8 / 15 / 20087: 44$ & 1.589 & 26.1 \\
\hline 5692 & $1 / 15 / 20087: 46$ & $8 / 15 / 20087: 46$ & 1.59 & 26.1 \\
\hline 5693 & $1 / 15 / 20087: 48$ & $8 / 15 / 20087: 48$ & 1.59 & 26.1 \\
\hline 5694 & $1 / 15 / 20087: 50$ & $8 / 15 / 20087: 50$ & 1.59 & 26.1 \\
\hline 5695 & $1 / 15 / 20087: 52$ & $8 / 15 / 20087: 52$ & 1.59 & 26.1 \\
\hline 5696 & $1 / 15 / 20087: 54$ & $8 / 15 / 20087: 54$ & 1.59 & 26.1 \\
\hline 5697 & $1 / 15 / 20087: 56$ & $8 / 15 / 20087: 56$ & 1.59 & 26.1 \\
\hline 5698 & $1 / 15 / 20087: 58$ & $8 / 15 / 20087: 58$ & 1.59 & 26.1 \\
\hline 5699 & 1/15/2008 8:00 & $8 / 15 / 20088: 00$ & 1.50 & 26.1 \\
\hline 5700 & $1 / 15 / 20088: 02$ & $8 / 15 / 20088: 02$ & 1.591 & 26.1 \\
\hline 5701 & $1 / 15 / 20088: 04$ & $8 / 15 / 20088: 04$ & 1.591 & 26.1 \\
\hline 5702 & $1 / 15 / 20088: 06$ & $8 / 15 / 20088: 06$ & 1.591 & 26.1 \\
\hline 5703 & 1/15/20088:08 & $8 / 15 / 20088: 08$ & 1.59 & 26.1 \\
\hline 5704 & 1/15/20088:10 & $8 / 15 / 20088: 10$ & 1.59 & 26.1 \\
\hline 5705 & 1/15/20088:12 & $8 / 15 / 20088: 12$ & 1.59 & 26.1 \\
\hline 5706 & 1/15/20088:14 & $8 / 15 / 20088: 14$ & 1.59 & 26.1 \\
\hline 5707 & 1/15/20088:16 & $8 / 15 / 20088: 16$ & 1.589 & 26.1 \\
\hline 5708 & 1/15/20088:18 & $8 / 15 / 20088: 18$ & 1.588 & 26.1 \\
\hline 5709 & 1/15/20088:20 & $8 / 15 / 20088: 20$ & 1.587 & 26.1 \\
\hline 5710 & 1/15/20088:22 & $8 / 15 / 20088: 22$ & 1.588 & 26 \\
\hline 5711 & 1/15/20088:24 & $8 / 15 / 20088: 24$ & 1.588 & 26 \\
\hline 5712 & 1/15/20088:26 & $8 / 15 / 20088: 26$ & 1.587 & 26 \\
\hline 5713 & $1 / 15 / 20088: 28$ & $8 / 15 / 20088: 28$ & 1.587 & 26 \\
\hline 5714 & $1 / 15 / 20088: 30$ & $8 / 15 / 20088: 30$ & 1.587 & 26 \\
\hline 5715 & 1/15/2008 8:32 & $8 / 15 / 20088: 32$ & 1.588 & 26.1 \\
\hline 5716 & 1/15/2008 8:34 & $8 / 15 / 20088: 34$ & 1.589 & 26 \\
\hline 5717 & 1/15/20088:36 & $8 / 15 / 20088: 36$ & 1.589 & 26.1 \\
\hline 5718 & $1 / 15 / 20088: 38$ & $8 / 15 / 20088: 38$ & 1.588 & 26 \\
\hline 5719 & $1 / 15 / 20088: 40$ & $8 / 15 / 20088: 40$ & 1.588 & 26.1 \\
\hline 5720 & $1 / 15 / 20088: 42$ & $8 / 15 / 20088: 42$ & 1.587 & 26 \\
\hline 5721 & $1 / 15 / 20088: 44$ & $8 / 15 / 20088: 44$ & 1.586 & 26 \\
\hline 5722 & 1/15/20088:46 & $8 / 15 / 20088: 46$ & 1.585 & 26 \\
\hline 5723 & $1 / 15 / 20088: 48$ & $8 / 15 / 20088: 48$ & 1.586 & 26 \\
\hline 5724 & $1 / 15 / 20088: 50$ & $8 / 15 / 20088: 50$ & 1.586 & 26.1 \\
\hline 5725 & $1 / 15 / 20088: 52$ & $8 / 15 / 20088: 52$ & 1.586 & 26.1 \\
\hline 5726 & $1 / 15 / 20088: 54$ & $8 / 15 / 20088: 54$ & 1.587 & 26.1 \\
\hline 5727 & $1 / 15 / 20088: 56$ & $8 / 15 / 20088: 56$ & 1.586 & 26.1 \\
\hline 5728 & $1 / 15 / 20088: 58$ & $8 / 15 / 20088: 58$ & 1.586 & 26 \\
\hline 5729 & 1/15/20089:00 & $8 / 15 / 20089: 00$ & 1.586 & 26 \\
\hline 5730 & 1/15/20089:02 & $8 / 15 / 20089.02$ & 1.587 & 26 \\
\hline 5731 & 1/15/20089:04 & $8 / 15 / 20089: 04$ & 1.587 & 26 \\
\hline 5732 & 1/15/20089:06 & $8 / 15 / 20089.06$ & 1.587 & 26 \\
\hline 5733 & $1 / 15 / 20089: 08$ & $8 / 1 5 \longdiv { 2 0 0 8 9 : 0 8 }$ & 1.588 & 26.1 \\
\hline 5734 & $1 / 15 / 20089: 10$ & $8 / 15 / 20089: 10$ & 1.587 & 26.1 \\
\hline 5735 & 1/15/20089:12 & $8 / 15 / 20089: 12$ & 1.588 & 26 \\
\hline 5736 & 1/15/20089:14 & $8 / 15 / 20089: 14$ & 1.587 & 26 \\
\hline 5737 & $1 / 15 / 20089.16$ & $8 / 15 / 20089: 16$ & 1.588 & 26.1 \\
\hline 5738 & 1/15/20089:18 & $8 / 15 / 20089: 18$ & 1.587 & 26 \\
\hline 5739 & 1/15/20089.20 & $8 / 15 / 20089.20$ & 1.588 & 26.1 \\
\hline 5740 & 1/15/20089:22 & $8 / 15 / 20089.22$ & 1.588 & 26.1 \\
\hline 5741 & $1 / 15 / 20089: 24$ & $8 / 15 / 20089.24$ & 1.587 & 26.1 \\
\hline 5742 & 1/15/20089:26 & $8 / 15 / 20089.26$ & 1.587 & 26.1 \\
\hline 5743 & $1 / 15 / 20089: 28$ & $8 / 15 / 20089: 28$ & 1.588 & 26 \\
\hline 5744 & 1/15/20089:30 & $8 / 15 / 20089: 30$ & 1.587 & 26.1 \\
\hline 5745 & $1 / 15 / 20089: 32$ & $8 / 15 / 20089.32$ & 1.587 & 26 \\
\hline 5746 & $1 / 15 / 20089: 34$ & $8 / 15 / 20089.34$ & 1.587 & 26.1 \\
\hline 5747 & 1/15/20089:36 & $8 / 15 / 20089: 36$ & 1.588 & 26.1 \\
\hline 5748 & 1/15/20089:38 & $8 / 15 / 20089.38$ & 1.588 & 26.1 \\
\hline 5749 & $1 / 15 / 20089: 40$ & $8 / 15 / 20089.40$ & 1.587 & 26 \\
\hline 5750 & 1/15/20089:42 & $8 / 15 / 20089: 42$ & 1.587 & 26 \\
\hline 5751 & 1/15/20089:44 & $8 / 15 / 20089.44$ & 1.587 & 26 \\
\hline 5752 & $1 / 15 / 20089: 46$ & $8 / 15 / 20089: 46$ & 1.587 & 26 \\
\hline 5753 & 1/15/20089:48 & $8 / 15 / 20089: 48$ & 1.587 & 26 \\
\hline 5754 & $1 / 15 / 20089.50$ & $8 / 15 / 20089: 50$ & 1.587 & 26 \\
\hline
\end{tabular}


DOE/RL-2009-35, REV. 0

\begin{tabular}{|c|c|c|c|c|}
\hline \multicolumn{5}{|c|}{$24-92 p$} \\
\hline $\mathrm{Rec}$ & & Adjusted & Pressure & Temp \\
\hline$\#$ & Date/Time & Date/Time & psi & ${ }^{\circ} \mathrm{C}$ \\
\hline 5755 & $1 / 15 / 20089.52$ & $8 / 15 / 2008952$ & 1.586 & 26 \\
\hline 5756 & $1 / 15 / 20089.54$ & $8 / 15 / 20089.54$ & 1.586 & 26 \\
\hline 5757 & $1 / 15 / 20089.56$ & $8 / 15 / 20089.56$ & 1.586 & 26 \\
\hline 5758 & $1 / 1 5 \longdiv { 2 0 0 8 9 . 5 8 }$ & $8 / 1520089.58$ & 1.586 & 26 \\
\hline 5759 & $1 / 15200810.00$ & $815 / 200810,00$ & 1.587 & 26 \\
\hline 5760 & $1 / 15 / 200810.02$ & $8 / 15200810.02$ & 1.587 & 26 \\
\hline 5761 & $1 / 15 / 2008$ 10.04 & $8 / 15 / 200810.04$ & 1.586 & 26 \\
\hline 5762 & $1 / 15 / 200810.06$ & $8 / 1520081006$ & 1.586 & 26 \\
\hline 5763 & $1 / 15 / 200810.08$ & $8 / 15 / 200810.08$ & 1.586 & 26 \\
\hline 5764 & $1 / 15 / 200810.10$ & $8 / 15 / 200810: 10$ & 1.587 & 25.9 \\
\hline 5765 & $1 / 15 / 200810.12$ & $8 / 15 / 200810.12$ & 1.587 & 26 \\
\hline 5766 & $1 / 15 / 200810: 14$ & $8 / 15 / 200810.14$ & 1.587 & 25.9 \\
\hline 5767 & $1 / 15 / 2008$ 10:16 & $8 / 15 / 200810.16$ & 1.587 & 25.9 \\
\hline 5768 & $1 / 15 / 200810: 18$ & $8 / 15 / 200810.18$ & 1.587 & 25.9 \\
\hline 5769 & $1 / 15 / 200810: 20$ & $8 / 15 / 200810.20$ & 1.586 & 25.9 \\
\hline $5 / 70$ & $1 / 15 / 200810.22$ & $8 / 15 / 200810.22$ & 1.586 & 25.9 \\
\hline 577 & $1 / 15 / 200810.24$ & $8 / 15 / 200810.24$ & 1.587 & 25.9 \\
\hline 5772 & $1 / 15 / 200810.26$ & $8 / 15 / 200810.26$ & 1.587 & 25.9 \\
\hline 5773 & $1 / 15 / 200810-28$ & $8 / 15 / 200810.28$ & 1.586 & 25.9 \\
\hline 5774 & $1 / 15 / 2008$ 10:30 & $8 / 15 / 200810: 30$ & 1.586 & 25.9 \\
\hline 5775 & $1 / 15 / 200810.32$ & $8 / 15 / 200810.32$ & 1.586 & 25.8 \\
\hline 5776 & $1 / 15200810.34$ & $8 / 15 / 200810: 34$ & 1.585 & 25.8 \\
\hline $5 / 77$ & $1 / 15 / 200810.36$ & $8 / 15 / 200810.36$ & 1.585 & 25.8 \\
\hline 5778 & $1 / 15 / 200810.38$ & $8 / 15 / 200810: 38$ & 1.585 & 25.8 \\
\hline $5 / 79$ & $1 / 15 / 200810.40$ & $8 / 15 / 200810: 40$ & 1.585 & 25.8 \\
\hline 5780 & $1 / 15 / 200810.42$ & $8 / 15 / 200810: 42$ & 1.584 & 25.9 \\
\hline $5 / 81$ & $1 / 15 / 200810.44$ & $8 / 15 / 200810.44$ & 1.585 & 25.9 \\
\hline 5782 & $1 / 15 / 2008$ 10.46 & $8 / 15 / 200810.46$ & 1.585 & 25.8 \\
\hline 5783 & $1 / 15200810.48$ & $8 / 15 / 200810.48$ & 1.585 & 25.9 \\
\hline 5784 & $1 / 15 / 200010.50$ & $8 / 15 / 200810.50$ & 1.586 & 25.9 \\
\hline 5785 & $1 / 15 / 2008$ 10.52 & $8 / 15 / 200810.52$ & 1.586 & 25.9 \\
\hline 5786 & $1 / 15 / 200810.54$ & $8 / 15 / 200810.54$ & 9.586 & 25.9 \\
\hline 5787 & $1 / 15 / 200810.56$ & $8 / 15 / 200810.56$ & 1.585 & 25.9 \\
\hline 5788 & $1 / 15 / 200810.58$ & $8 / 15 / 200810.58$ & 1.585 & 25.9 \\
\hline 5789 & $1 / 15 / 200811: 00$ & $8 / 15 / 2008$ 11:00 & 1.586 & 25.9 \\
\hline 5790 & $1 / 15 / 200811: 02$ & $8 / 15 / 200811: 02$ & 1.586 & 25.9 \\
\hline 5791 & $1 / 15 / 200811: 04$ & $8 / 15 / 200811: 04$ & 1.586 & 25.9 \\
\hline $5 / 92$ & $1 / 15 / 200811: 06$ & $8 / 15200811: 06$ & 1.585 & 25.9 \\
\hline $5 / 93$ & $1 / 15 / 200811: 08$ & $8 / 15 / 200811: 08$ & 1.58 列 & 25.9 \\
\hline 5794 & $1 / 15 / 200811: 10$ & $8 / 15 / 200811: 10$ & 1.587 & 25.9 \\
\hline 5795 & $1 / 15 / 200811: 12$ & $8 / 15200811: 12$ & 1.588 & 25.9 \\
\hline $5 / 96$ & $1 / 15 / 200811: 14$ & $8 / 15 / 200811: 14$ & 1.587 & 25.9 \\
\hline 5797 & 1/15/2008 11:16 & $8 / 15 / 2008$ 11:16 & 1.586 & 25.9 \\
\hline 5798 & 1/15/2008 11:18 & $8 / 15 / 200811: 18$ & 1.586 & 25.8 \\
\hline 579 & $1 / 15 / 200811: 20$ & $8 / 15 / 200811: 20$ & 1.586 & 25.8 \\
\hline 5800 & $1 / 15 / 200811: 22$ & $8 / 15 / 200811: 22$ & 1.585 & 25.8 \\
\hline 5801 & $1 / 152000811: 24$ & $8 / 15200811: 24$ & 1.586 & 25.8 \\
\hline 5802 & $1 / 15 / 200811: 26$ & $8 / 15 / 200811: 26$ & 1.586 & 25.8 \\
\hline 5803 & $1 / 15 / 200811: 28$ & $8 / 15 / 200811: 28$ & 1.586 & 25.8 \\
\hline 5804 & $1 / 15200811: 30$ & $8 / 15 / 200811: 30$ & 1.587 & 25.8 \\
\hline 5805 & $1 / 15 / 200811: 32$ & $8 / 15 / 200811: 32$ & 1.586 & 25.8 \\
\hline 5806 & $1 / 15 / 200811: 34$ & $8 / 15 / 200811: 34$ & 1.586 & 25.8 \\
\hline 5807 & $1 / 15 / 200811: 36$ & $8 / 15200811: 36$ & 1.585 & 25.8 \\
\hline 5808 & $1 / 15 / 200811: 38$ & $8 / 15 / 200811: 38$ & 1.586 & 25.8 \\
\hline 5809 & $1 / 15 / 200811: 40$ & $8 / 15 / 200811: 40$ & 1.586 & 25.8 \\
\hline 5810 & $1 / 15 / 200811: 42$ & $8 / 15200811: 42$ & 1.587 & 25.9 \\
\hline 5811 & $1 / 15 / 200811: 44$ & $8 / 15 / 200811: 44$ & 1.521 & 25.8 \\
\hline 5812 & $1 / 15 / 200811: 46$ & $8 / 15 / 200811: 46$ & 1.452 & 25.6 \\
\hline 5813 & $1 / 15 / 200811: 48$ & $8 / 15 / 200811: 48$ & 1.328 & 25.4 \\
\hline 5814 & $1 / 15 / 200811: 50$ & $8 / 15 / 200811: 50$ & 1.374 & 25.2 \\
\hline 5815 & $1 / 15 / 200811.52$ & 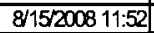 & 1.265 & 25.1 \\
\hline 5816 & $1 / 15 / 200811: 54$ & $8 / 15 / 200811: 54$ & 1.306 & 24.9 \\
\hline 5817 & $1 / 15200811: 56$ & $8 / 15200811: 56$ & 1.34 & 24.8 \\
\hline 5818 & $1 / 15200811.58$ & $8 / 15200811: 58$ & 1.363 & 24.7 \\
\hline 5819 & $1 / 15 / 20081200$ & $8 / 15 / 20081200$ & 1.378 & 24.6 \\
\hline 5820 & $1 / 15 / 20081202$ & $8 / 15 / 20081202$ & 1.39 & 24.6 \\
\hline 5821 & $1 / 15 / 200812: 04$ & $8 / 15 / 20081204$ & 1.277 & 24.5 \\
\hline 5822 & $1 / 15 / 200812-06$ & $8 / 15200812 \cdot 06$ & 1.309 & 24.4 \\
\hline 5823 & $1 / 15 / 20081208$ & $8 / 15 / 20081208$ & 1.331 & 24.4 \\
\hline 5824 & $1 / 15 / 200812: 10$ & $8 / 1 5 \longdiv { 2 0 0 8 1 2 1 0 }$ & 1.347 & 24.4 \\
\hline 5825 & $1 / 15 / 200812: 12$ & $8 / 15200812: 12$ & 1.362 & 24.4 \\
\hline 5826 & $1 / 15 / 200812-14$ & $8 / 15 / 20081214$ & 1.374 & 24.4 \\
\hline
\end{tabular}
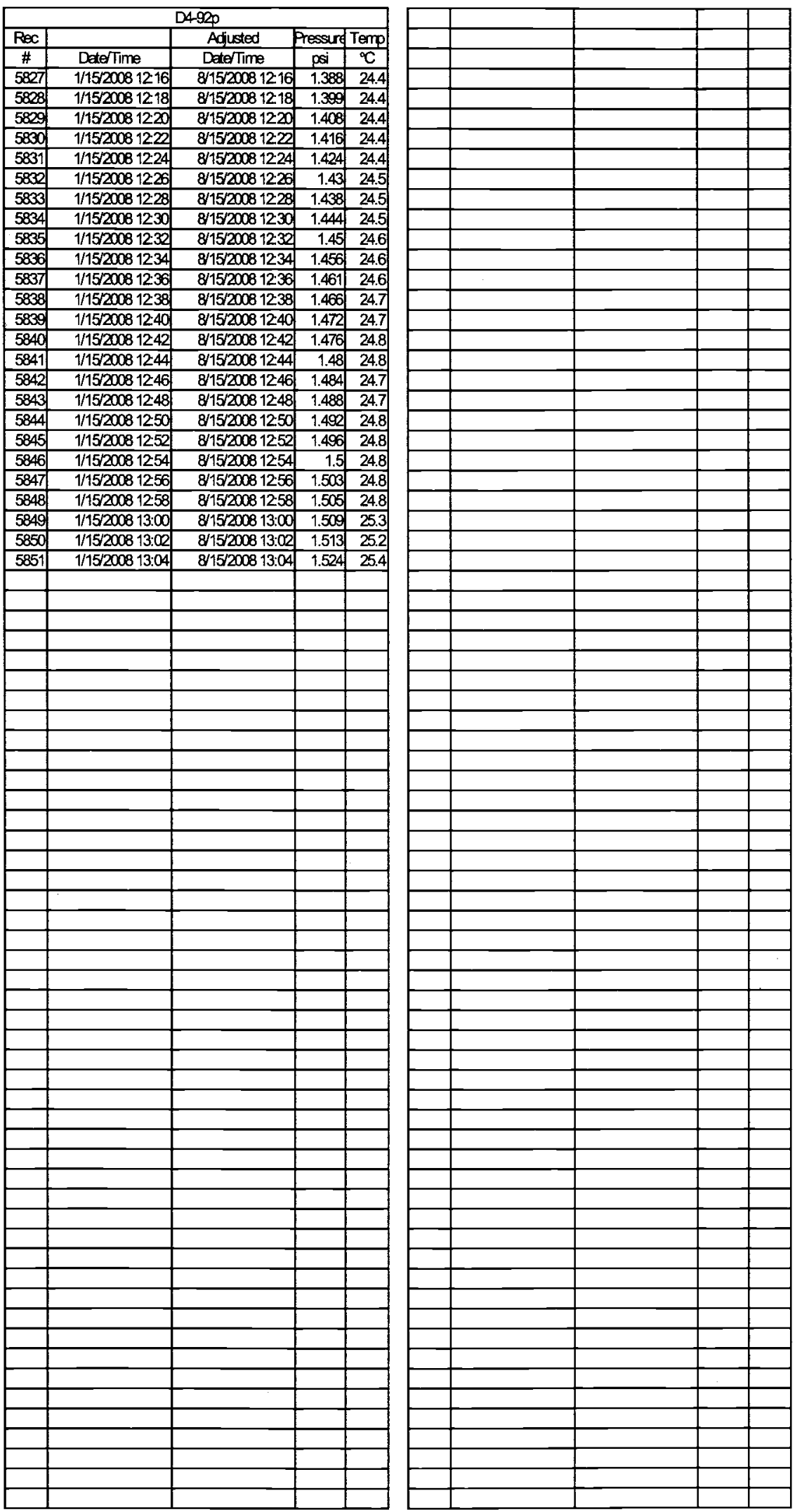
DOE/RL-2009-35, REV. 0

\begin{tabular}{|c|c|c|c|c|}
\hline \multicolumn{5}{|c|}{ D4-93c } \\
\hline $\operatorname{Rec}$ & & Adusted & Temp & $S \mathrm{~S}$ \\
\hline$\#$ & DateTime & DeterTime & $\alpha$ & $\mu \mathrm{S} / \mathrm{am}$ \\
\hline & & & & \\
\hline & $1 / 7 / 20089.53$ & $87 / 20089.53$ & 16.7 & 569.3 \\
\hline 2 & $1 / 7 / 20089.56$ & $87 / 20089.55$ & 16.7 & 568.3 \\
\hline 3 & $1 / 7 / 20089.57$ & $87 / 20089: 57$ & 16.7 & 564.7 \\
\hline 4 & $1 / 7 / 20089.59$ & $87 / 20089.59$ & 16.7 & 564.4 \\
\hline 5 & $1 / 7 / 2008$ 10:01 & $8 / 72008$ 10:01 & 16.7 & 564.4 \\
\hline 6 & $1 / 72008$ 10:03 & $87 / 200810: 03$ & 16.7 & 503 \\
\hline 7 & $17 / 2008$ 10:05 & $87 / 200810: 05$ & 16.7 & 5629 \\
\hline 8 & $1 / 7 / 2008$ 10:07 & $87 / 200810: 07$ & 16.7 & 563.3 \\
\hline 9 & $1 / 7 / 200810: 09$ & $87 / 200810.09$ & 16.7 & 563.3 \\
\hline 10 & $1 / 7 / 2008$ 10:11 & $87 / 200810: 11$ & 16.7 & 563.9 \\
\hline 11: & $1 / 7 / 2008$ 10:13 & $8 / 7200810: 13$ & 16.7 & 564.3 \\
\hline 12 & $1 / 7 / 2008$ 10:15 & $87 / 2008$ 10:15 & 16.7 & 564.5 \\
\hline 13 & $1 / 7 / 200810.17$ & $87 / 200810: 17$ & 16.7 & 564.4 \\
\hline 14 & $1 / 7 / 2008$ 10:19 & $87 / 2008$ 10:19 & 16.7 & 564.6 \\
\hline 15 & $1 / 7 / 2008$ 10:21 & $877 / 2008$ 10.21 & 16.7 & 564.4 \\
\hline 16 & $1 / 7 / 2008$ 10:23 & $87 / 200810: 23$ & 16.7 & 564 \\
\hline 17 & $1 / 7 / 2008$ 10:25 & $87 / 2008$ 10:25 & 16.7 & 564.2 \\
\hline 18 & $1 / 7 / 2008$ 10:27 & $8 / 7 / 200810: 27$ & 16.7 & 564.3 \\
\hline 19 & $1 / 72008$ 10:29 & $8 / 7200810.29$ & 16.7 & 564.5 \\
\hline 20 & $1 / 7 / 200810: 31$ & $8 / 7200810.31$ & 16.7 & 564.6 \\
\hline 21 & $1 / 7 / 2008$ 10:33 & $87 / 200010.33$ & 16.7 & 564.4 \\
\hline 22 & $1 / 7 / 200810.35$ & $87 / 2000810.35$ & 16.7 & 564.6 \\
\hline 23. & $1 / 7 / 200810: 37$ & $87 / 200810: 37$ & 16.7 & 564.1 \\
\hline 24 & $1 / 7 / 200810: 39$ & $87 / 2008$ 10:39 & 16.7 & 563.2 \\
\hline 25 & $17 / 2008 \quad 10: 41$ & $87 / 200810: 41$ & 16.7 & 562.8 \\
\hline 26 & $1 / 7 / 200810.43$ & $87 / 200810: 43$ & 16.7 & 5626 \\
\hline 27 & $1 / 7 / 2008 \quad 10: 45$ & $87 / 200810.45$ & 16.7 & 562 \\
\hline 28 & $1 / 7 / 200810.47$ & $87 / 2008$ 10:47 & 16.7 & 561 \\
\hline 29 & $1 / 7 / 2008$ 10:49 & $87 / 200810: 49$ & 16.7 & 560.8 \\
\hline 30 & $1 / 7 / 2008$ 10:51 & $87 / 2008$ 10:51 & $\begin{array}{l}16.7 \\
\end{array}$ & 560.5 \\
\hline 31 & $1 / 7 / 200810.53$ & $87 / 200810: 53$ & 16.7 & 560.3 \\
\hline 32 & $1 / 7 / 200810: 56$ & $87 / 200810: 56$ & (16.7 & 560.2 \\
\hline 33 & $1 / 7 / 200810: 57$ & $87 / 2000810: 57$ & 16.7 & 560.6 \\
\hline 34 & $1 / 7 / 200810.59$ & $8772000810: 59$ & 16.7 & 561.2 \\
\hline 35 & $1 / 7 / 2008$ 11:01 & $8 / 7 / 2008$ 11:01 & 16.7 & 561.5 \\
\hline 36 & $1 / 7 / 200811: 03$ & $87 / 200811: 03$ & 16.7 & 561.3 \\
\hline 37 & $1 / 7 / 200811: 05$ & $87 / 2008$ 11:05 & 16.7 & 561.5 \\
\hline 38 & $17 / 2008$ 11:07 & $87 / 200811: 07$ & 16.7 & 561.4 \\
\hline 39 & $1 / 7 / 200811: 09$ & $87 / 2008$ 11:00 & 16.7 & 561.6 \\
\hline 40 & $1 / 7 / 2008$ 11:11 & $87 / 2008$ 11:11 & 16.7 & 561.6 \\
\hline 41 & $1 / 7 / 2008$ 11:13 & $87 / 2008$ 11:13 & 16.7 & 561.5 \\
\hline 42 & $1 / 7 / 200811: 15$ & 8772008 11:15 & 16.7 & 561.6 \\
\hline 43 & $1 / 7 / 2008$ 11:17 & $87 / 2008$ 11:17 & 16.7 & 562.2 \\
\hline 44 & 1/7/2008 11:19 & $87 / 2008$ 11:19 & \begin{tabular}{|c|}
16.7 \\
\end{tabular} & 5623 \\
\hline 45 & $1 / 7 / 200811: 21$ & $87 / 200811: 21$ & 16.7 & 561.6 \\
\hline 46 & $1 / 7 / 2008$ 11:23 & $8 / 7 / 200811: 23$ & 16.7 & 561.2 \\
\hline 47 & $17 / 200811: 25$ & $87 / 2008$ 11:25 & $\begin{array}{l}16.7 \\
\end{array}$ & 561.2 \\
\hline 48 & $1 / 7 / 2008$ 11:27 & $87 / 2008$ 11:27 & 16.7 & 561.3 \\
\hline 49 & $17 / 200811: 29$ & $8772000811: 29$ & 16.7 & 560.9 \\
\hline 50 & $1 / 7 / 2008$ 11:31 & $87 / 2008$ 11:31 & 16.7 & 560.4 \\
\hline 51 & $1 / 7 / 2008$ 11:33 & $87 / 200811: 33$ & 16.7 & 559.8 \\
\hline 52 & $1 / 7 / 2008$ 11:35 & $8 / 7 / 2008$ 11:35 & 16.7 & 559.8 \\
\hline 53 & 1/7/2008 11:37 & $8 / 7 / 2008$ 11:37 & 16.7 & 559.6 \\
\hline 54 & $1 / 7 / 200811: 39$ & $8 / 7200811: 39$ & 16.7 & 559.2 \\
\hline 55 & $1 / 7 / 2008$ 11:41 & $87 / 2008$ 11:41 & 16.7 & 558.7 \\
\hline 56 & $1 / 7 / 200811: 43$ & $87 / 2008$ 11:43 & 16.7 & 558.2 \\
\hline 57 & $1 / 7 / 200811: 45$ & 8712008 11:45 & 16.7 & 557.8 \\
\hline 58 & $1 / 7 / 200811: 47$ & $87 / 2008$ 11:47 & 16.7 & 557.4 \\
\hline 59 & $1 / 7 / 200811: 49$ & 8772008 11:49 & 16.7 & 567 \\
\hline 60 & $17 / 2008$ 11:51 & $8 / 7 / 2008$ 11:51 & 16.7 & 556.9 \\
\hline 61 & $1 / 7 / 200811: 53$ & $87 / 2008 \quad 11: 53$ & 16.7 & 507 \\
\hline 6 & $1 / 7 / 200811: 56$ & $87 / 2008$ 11:56 & 16.7 & 556.9 \\
\hline 6 & $1 / 7 / 200811: 57$ & $87 / 2008$ 11:57 & 16.7 & 556.6 \\
\hline 64 & $1 / 7 / 200811: 59$ & $87 / 2008$ 11:59 & 16.7 & 556.6 \\
\hline 65 & $1 / 7 / 20081201$ & $8 / 720081201$ & 16.7 & 556.4 \\
\hline 66 & $1 / 720081203$ & $8 / 7 / 20081203$ & 16.7 & 556.2 \\
\hline 67 & $1 / 7 / 200812: 05$ & $87 / 20081205$ & 16.7 & 556 \\
\hline 68 & $1 / 7 / 20081207$ & $87 / 200812: 07$ & 16.7 & 556 \\
\hline
\end{tabular}

\begin{tabular}{|c|c|c|c|c|}
\hline \multicolumn{5}{|c|}{$\mathrm{D} 493 \mathrm{C}$} \\
\hline $\mathrm{R} x \mathrm{C}$ & & Aclusted & Terrp & $\mathrm{SC}$ \\
\hline \# & Date/Time & DeterTime & $\infty$ & $\mu \mathrm{s} / \mathrm{cm}$ \\
\hline 69 & $17 / 20081200$ & $87 / 20081209$ & 16.7 & \\
\hline 70 & $7 / 20081211$ & $87 / 2008$ 12:11 & 16.7 & 55 \\
\hline 71 & $1 / 7 / 20081213$ & $87 / 200812: 13$ & 16.7 & 556.1 \\
\hline 72 & $1 / 7 / 2008$ 12:15 & 87120081215 & 16.7 & 556.2 \\
\hline 73 & $1 / 7 / 20081217$ & $87 / 20081217$ & 16.7 & 556.2 \\
\hline 74 & $17 / 20081219$ & $8 / 720081219$ & 16.7 & 556. \\
\hline 75 & $17 / 20081221$ & $87 / 20081221$ & 16.7 & 556.3 \\
\hline 76 & $1 / 7 / 20081223$ & $8 / 7 / 20081223$ & 16.7 & 556.3 \\
\hline$\pi$ & $17 / 20081225$ & $87 / 20081225$ & 16.7 & 556. \\
\hline 78 & $1 / 7 / 200812227$ & $87 / 20081227$ & 16.7 & 556.2 \\
\hline 79 & $17 / 20081220$ & $8 / 7120081229$ & 16.7 & 556.3 \\
\hline 80 & $1 / 7 / 20081231$ & $8 / 7 / 20081231$ & 16.7 & 55 \\
\hline 81 & $1 / 7 / 20081233$ & $8 / 7 / 20081233$ & 16.7 & 555. \\
\hline 82 & $1 / 7 / 20081235$ & $87 / 20081235$ & 16.7 & 555. \\
\hline 83 & $1 / 7 / 20081237$ & $87 / 200812 \cdot 37$ & 16.7 & 555. \\
\hline 84 & $7 / 20081239$ & $87 / 200812: 39$ & 16.7 & 555.2 \\
\hline 85 & $1 / 7 / 200812441$ & $87 / 20081241$ & 16.7 & 555. \\
\hline 86 & $1 / 7 / 20081243$ & $87 / 20081243$ & 16.7 & 555. \\
\hline 87 & $7 / 200812: 45$ & $8 / 7120081245$ & 16.7 & 555.4 \\
\hline 88 & $1 / 7 / 20081247$ & $87 / 20081247$ & 16.7 & 555.3 \\
\hline 89 & $1 / 7 / 20081249$ & $8 / 7 / 20081249$ & $\begin{array}{ll}16.7 \\
\end{array}$ & 555. \\
\hline 90 & $7 / 20081251$ & $87 / 20081251$ & 16.7 & 555.3 \\
\hline 91 & $1 / 7 / 200$ & $8 / 7 / 200$ & 16.7 & 555.1 \\
\hline 92 & $1 / 7 / 20081255$ & $87 / 20081255$ & 16.7 & 55 \\
\hline 93 & $1 / 7 / 20081257$ & $87 / 200$ & 16.7 & 555.2 \\
\hline 94 & $1 / 7 / 20081259$ & $87 / 200$ & 16.7 & 555.4 \\
\hline 95 & $1 / 7 / 2008$ 13:01 & $87 / 2008$ 13:01 & 16.7 & 555.5 \\
\hline 96 & $1 / 7 / 200813: 03$ & $87 / 2000$ & 16.7 & 555. \\
\hline 97 & $1 / 7 / 2008$ 13:05 & $87 / 200813: 05$ & 16.7 & 554. \\
\hline 98 & $1 / 7 / 2008$ 13:07 & $8 / 7200813: 07$ & 16.7 & 554. \\
\hline 99 & 09 & $87 / 20$ & 16.7 & 554. \\
\hline 100 & $1 / 7 / 200$ & $8 / 1200$ & 16.7 & 554. \\
\hline 101 & $1 / 7 / 200 x$ & $87 / 2006$ & 16.7 & 554.1 \\
\hline 102 & 15 & $87 / 200$ & 16.7 & 553. \\
\hline 103 & $7 / 200$ & $8 / 7200$ & 16.7 & 55 \\
\hline 104 & & 877200 & 16. & 55 \\
\hline 105 & 21 & $87 / 20$ & 16.7 & 552 \\
\hline 106 & $7 / 200$ & $87 / 200$ & 16.7 & 552 \\
\hline 107 & & $87 / 200$ & & 552 \\
\hline 108 & 3:27 & $87 / 200$ & $\overline{6.7}$ & 551. \\
\hline 109 & $3: 29$ & 871200 & 16.7 & 550. \\
\hline 110 & & $87 / 200$ & 16.7 & 550. \\
\hline 111 & 7120 & $8 / 7 / 20$ & 167 & 550. \\
\hline 112 & 3:35 & 87120 & 16.7 & 55 \\
\hline 113 & & & 16.7 & 549. \\
\hline 114 & 120 & $87 / 120$ & 6.7 & 549. \\
\hline 115 & & & 16.7 & 549. \\
\hline 116 & & & 16.7 & 54 \\
\hline 117 & 45 & $87 / 200$ & & 548. \\
\hline 118 & & & $\underline{6 .}$ & 548. \\
\hline 119 & & $87 / 200$ & & 547. \\
\hline 120 & 351 & 877200 & 16. & 54 \\
\hline 121 & 1 & & 16.7 & 546. \\
\hline 122 & 11 & $87 / 2008$ & 16.7 & \\
\hline 123 & 13:57 & $87 / 2000$ & 16.7 & 546. \\
\hline 124 & & & 6.7 & 546 \\
\hline 125 & & & & \\
\hline 126 & $7 / 2008$ 14:03 & $87 / 2008$ & 16.7 & 545 \\
\hline 127. & & & & 545 \\
\hline 128 & 12008 14:07 & $87 / 2008$ & & \\
\hline 129 & 14:09 & $87 / 2006$ & 16.7 & 545. \\
\hline 130 & & & 10.1 & 545. \\
\hline 131 & 14:13 & $87 / 200$ & & 545. \\
\hline 132 & 712008 14:15 & $87 / 2008$ 14:15 & 16.7 & 54 \\
\hline 133 & & & 16.7 & 544. \\
\hline 134 & & $87 / 2008$ 14:19 & & \\
\hline 135 & & $8 / 7 / 2008$ 14:21 & 10.1 & \\
\hline 136 & & $87 / 2000$ & 16. & 5 \\
\hline & & & & \\
\hline
\end{tabular}

\begin{tabular}{|c|c|c|c|c|}
\hline \multicolumn{5}{|c|}{ D493c } \\
\hline $\operatorname{Rec}$ & & Agjusted & Ternp & SC \\
\hline$\#$ & Daterlime & DeterTime & $\alpha C$ & $\mu \mathrm{S} / \mathrm{am}$ \\
\hline 138 & $17 / 7200814: 27$ & $8 / 7 / 2008$ 14:27 & 16.7 & 545.2 \\
\hline 139 & $1 / 7 / 200814: 29$ & $8 / 7 / 200814: 29$ & 16.7 & 545.3 \\
\hline 140 & $1 / 7 / 2008$ 14:31 & $87 / 2008$ 14:31 & 16.7 & 545.3 \\
\hline 141 & $1 / 7 / 200814: 33$ & $87 / 2008$ 14:33 & 16.7 & 545.3 \\
\hline 142 & $1 / 7 / 200814: 35$ & $87 / 2008$ 14:35 & 16.7 & 545.2 \\
\hline 143 & $1 / 7 / 2008$ 14:37 & $87 / 2008$ 14:37 & 16.7 & 544.8 \\
\hline 144 & $1 / 7 / 200814: 39$ & $87 / 2008$ 14:39 & 16.7 & 544.7 \\
\hline 145 & $1 / 7 / 200814: 41$ & $87 / 2008$ 14:41 & 16.7 & 544.3 \\
\hline 146 & $1 / 7 / 200814: 43$ & $87 / 2008$ 14:43 & 16.7 & 544.3 \\
\hline 147 & $1 / 7 / 2008$ 14:45 & $87 / 200814: 45$ & 16.7 & 544.2 \\
\hline 148 & $1 / 7 / 200814: 47$ & $87 / 2008$ 14:47 & 16.7 & 544.2 \\
\hline 149 & $1 / 7 / 200814: 49$ & $87 / 2008$ 14:49 & 16.7 & 544.2 \\
\hline 150 & $1 / 7 / 2008$ 14:51 & $8 / 7 / 2008$ 14:51 & 16.7 & 544.1 \\
\hline 151 & $1 / 7 / 2008$ 14:53 & $8 / 7 / 200814: 53$ & 16.7 & 544 \\
\hline 152 & $1 / 7 / 200814: 55$ & $8 / 7 / 2008$ 14:55 & 16.7 & 543.8 \\
\hline 153 & $1 / 7 / 2008$ 14:57 & $87 / 2008$ 14:57 & 16.7 & 543.7 \\
\hline 154 & $17 / 2008$ 14:59 & $87 / 200814: 59$ & 16.7 & 543.4 \\
\hline 155 & 1/7/2008 15:01 & $8 / 72008$ 15:01 & 16.7 & $\overline{543.4}$ \\
\hline 156 & $1 / 7 / 200815: 03$ & $87 / 2008$ 15:03 & 16.7 & 543.1 \\
\hline 157 & 1//72008 15:05 & $8 / 7 / 2008$ 15:06 & 16.7 & 543 \\
\hline 158 & 1/7/2008 15:07 & $8 / 12008$ 15:07 & 16.7 & 5427 \\
\hline 159 & $1 / 7 / 200815: 09$ & $8 / 7 / 200815: 09$ & 16.7 & 5425 \\
\hline 160 & $1 / 7 / 2008$ & $8 / 7 / 200$ & 16.7 & 5422 \\
\hline 161 & $1 / 7 / 200815: 13$ & $8 / 7 / 2008$ 15:13 & 16.7 & $\overline{541.8}$ \\
\hline 162 & 1/7/2008 15:15 & $87 / 2008$ 15:15 & 16.7 & 541.7 \\
\hline 163 & $1 / 7 / 2008$ & $87 / 200$ & 16.7 & 541.5 \\
\hline 164 & $1 / 7 / 200815: 19$ & $87 / 200815: 19$ & 16.7 & 541. \\
\hline 165 & $1 / 7 / 2008$ & $87 / 2008$ 15:21 & 16.7 & 540.9 \\
\hline 166 & 1/7/2008 15:23 & $8 / 7 / 2008$ 15:23 & 16.7 & 540.5 \\
\hline 167 & $17 / 200$ & $87 / 2008$ 15:25 & 16.7 & 540.5 \\
\hline 168 & $1 / 7 / 2008$ & $8 / 7 / 200$ & 16.7 & 540.2 \\
\hline 169 & $1 / 7 / 200815: 29$ & $8 / 72008$ 15:29 & 16.7 & 540.2 \\
\hline 170 & $1 / 7 / 2008$ & $8 / 72000$ & 16.7 & 539.9 \\
\hline 171 & $1 / 7 / 200$ & $87 / 200$ & 16.7 & 539.7 \\
\hline 172 & 1/7/2008 15:35 & $8 / 7200$ & 16.7 & 539.6 \\
\hline 173 & $9 / 7 / 200815: 37$ & $8 / 7 / 2008$ 15:37 & 16.7 & 539.4 \\
\hline 174 & $1 / 7 / 200$ & $87 / 200$ & 16.7 & 539.5 \\
\hline 175 & $1 / 7 / 200$ & $87 / 200$ & 16.7 & 539.3 \\
\hline 176 & $1 / 7 / 200$ & $87 / 200$ & 16.7 & 539.3 \\
\hline 177 & $1 / 7 / 2000$ & $87 / 200$ & 16.7 & 539.1 \\
\hline 178 & $17 / 2008$ & $8 / 7200$ & 16.7 & 539.2 \\
\hline 179 & $17 / 200$ & $87 / 200$ & 16.7 & 538.9 \\
\hline 180 & $1 / 7 / 200$ & $87 / 20$ & 16.7 & 538.8 \\
\hline 181 & $1 / 7 / 200815: 53$ & $8 / 7 / 2008$ 15:53 & 16.7 & 538.8 \\
\hline 182 & $1 / 7 / 200$ & $8 / 7 / 20$ & 16.7 & 538.6 \\
\hline 183 & $1 / 7 / 200$ & $8 / 7 / 200$ & 16.7 & 538 \\
\hline 184 & $1 / 7 / 200$ & $87 / 200$ & 16.7 & 537.8 \\
\hline 185 & $17 / 200$ & $87 / 20$ & 16.7 & 537.8 \\
\hline 186 & $1 / 7 / 200$ & $87 / 20$ & 16.7 & 537.8 \\
\hline 187 & 1/7/2008 16:05 & $8 \pi / 2008$ 16:05 & 16.7 & 537.7 \\
\hline 188 & $1 / 7 / 2008$ & $87 / 2008$ 16:07 & 16.7 & 537.5 \\
\hline 189 & 1/7/2008 16:09 & $8 / 7 / 200816: 09$ & 16.7 & 537.2 \\
\hline 190 & $1 / 7 / 2000$ & $87 / 200$ & 16.7 & 537.3 \\
\hline 191 & & $87 / 200$ & 16.7 & 537.2 \\
\hline 192 & $177 / 200$ & $87 / 12008$ 16:15 & 16.7 & 537.3 \\
\hline 193 & $1 / 7 / 2000$ & $87 / 20$ & 16.7 & 537.3 \\
\hline 194 & 1/7/2008 16:19 & $87 / 200$ & 16.7 & 537.2 \\
\hline 195 & 1/7/2008 16:21 & $87 / 20$ & 16.7 & 537.1 \\
\hline 196 & $1 \pi / 200$ & 8712008 16:23 & 16.7 & 537.1 \\
\hline 197 & $17 / 200$ & $87 / 200816: 25$ & & 537.1 \\
\hline 198 & 1/7/2008 16:27 & $8 / 7 / 200816: 27$ & 16.7 & 537 \\
\hline 199 & $1 / 7 / 200816: 29$ & $8 / 12008$ 16:29 & 16.7 & 537.1 \\
\hline 200 & $1 / 7 / 2008$ 16:31 & $8 / 72008$ 16:31 & 16.7 & 53 \\
\hline 201 & 1/7/2008 16:33 & 87/2008 16:33 & 16.7 & 536.9 \\
\hline 202 & 17/2008 16:35 & $8 / 7200816: 35$ & 16.7 & 536.7 \\
\hline 203 & $1 / 7 / 200816: 37$ & $87 / 2008$ 16:37 & 16.7 & 536. \\
\hline 204 & 1/7/2008 16:39 & $8 / 7 / 2008$ 16:39 & 16.7 & 53 \\
\hline 205 & $1 / 7 / 200816: 41$ & $8 / 72008$ 16:41 & 16.7 & 53 \\
\hline 206 & $1 / 7 / 200816: 43$ & $87 / 200816: 43$ & 16.7 & 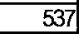 \\
\hline
\end{tabular}


DOE/RL-2009-35, REV. 0

\begin{tabular}{|c|c|c|c|c|}
\hline \multicolumn{5}{|c|}{$D 493 \mathrm{c}$} \\
\hline $\mathrm{Rec}$ & & Adjusted & Termp & $\mathrm{SC}$ \\
\hline$\#$ & DaterTime & DateTime & 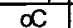 & $\mu \mathrm{S} / \mathrm{cm}$ \\
\hline 207 & $1 / 7 / 200816: 45$ & $87 / 200816: 45$ & 16.7 & 536.9 \\
\hline 208 & $1 / 7 / 200816: 47$ & $87 / 200816: 47$ & 16.7 & 536.9 \\
\hline 200 & $1 / 7 / 200816: 49$ & $87 / 200816: 49$ & 16.7 & 536.9 \\
\hline 210 & $1 / 7 / 200816: 51$ & $87 / 200816: 51$ & 16.7 & 536.9 \\
\hline 211 & $1 / 7 / 200816: 53$ & $87 / 200816: 53$ & 16.7 & 536.9 \\
\hline 212 & $1 / 7 / 20081655$ & $87 / 200816: 55$ & 16.7 & 536.8 \\
\hline 213 & $1 / 7 / 200816: 57$ & $87 / 200816: 57$ & 16.7 & 536.7 \\
\hline 214 & $1 / 7 / 200816.59$ & $8 / 200816: 59$ & 16.7 & 536.4 \\
\hline 215 & $1 / 7 / 200817: 01$ & $87 / 200817: 01$ & 16.7 & 536.1 \\
\hline 216 & $1 / 7 / 200817: 03$ & $87 / 200817: 03$ & 16.7 & 536.2 \\
\hline 217 & $1 / 7 / 200817: 05$ & $87 / 200817: 05$ & 16.7 & 536.1 \\
\hline 218 & $1 / 7 / 200817: 07$ & $87 / 2008$ 17:07 & 16.7 & 536.2 \\
\hline 219 & $1 / 7 / 200817: 09$ & $87 / 2008$ 17:09 & 16.7 & 536 \\
\hline 220 & $1 / 7 / 200817: 11$ & $87 / 2008$ 17:11 & 16.7 & 535.9 \\
\hline 221 & $1 / 7 / 200817: 13$ & $8 / 7 / 200817: 13$ & 16.7 & 535.8 \\
\hline 222 & $1 / 7 / 200817: 15$ & $87 / 200817: 15$ & 16.7 & 535.9 \\
\hline 223 & $1 / 7 / 200817: 17$ & $87 / 2008$ 17:17 & 16.7 & 536 \\
\hline 224 & $1 / 7 / 200817: 19$ & $87 / 200817: 19$ & 16.7 & 536.1 \\
\hline 225 & $1 / 7 / 200817: 21$ & $87 / 200817: 21$ & 16.7 & 535.9 \\
\hline 226 & $1 / 7 / 200817: 23$ & $8 / 7 / 200817: 23$ & 16.7 & 536.1 \\
\hline 227 & $1 / 7 / 200817: 25$ & $8 / 7 / 200817: 25$ & 16.7 & 536.2 \\
\hline 228 & $1 / 7 / 200817: 27$ & $87 / 200817: 27$ & 16.7 & 536.1 \\
\hline 229 & $1 / 7 / 200817: 29$ & $8 / 7 / 200817: 29$ & 16.7 & 536.3 \\
\hline 230 & $1 / 7 / 200817: 31$ & $87 / 200817: 31$ & 16.7 & 536.2 \\
\hline 231 & $1 / 7 / 200817: 33$ & $87 / 200817: 33$ & 16.7 & 536.2 \\
\hline 232 & $1 / 7 / 200817: 35$ & $87 / 200817: 35$ & 16.7 & 536.7 \\
\hline 233 & $1 / 7 / 200817: 37$ & $8 / 7 / 200817: 37$ & 16.7 & 536.8 \\
\hline 234 & $1 / 7 / 200817: 39$ & $87 / 200817: 39$ & 16.7 & 536.9 \\
\hline 235 & $1 / 7 / 200817: 41$ & $87 / 200817: 41$ & 16.7 & 537 \\
\hline 236 & $1 / 7 / 200817: 43$ & $8 / 200017: 43$ & 16.7 & 537.2 \\
\hline 237 & $1 / 7 / 2008$ 17:45 & $8 / 7 / 200817: 45$ & 16.7 & 5372 \\
\hline 238 & $1 / 7 / 200817: 47$ & $87 / 200817: 47$ & 16.7 & 537.3 \\
\hline 239 & $1 / 7 / 200817: 49$ & $877 / 200817: 49$ & 16.7 & 537.2 \\
\hline 240 & $1 / 7 / 200817: 51$ & $8 / 7 / 200817: 51$ & 16.7 & 537.3 \\
\hline 241 & $1 / 7 / 200817: 53$ & $87 / 200817: 53$ & 16.7 & 536.9 \\
\hline 242 & $1 / 7 / 200817: 55$ & $87 / 200817: 55$ & 16.7 & 536.7 \\
\hline 243 & $1 / 7 / 200817: 57$ & $87 / 2008$ 17:57 & 16.7 & 536.8 \\
\hline 244 & $1 / 7 / 200817: 59$ & $8 / 7 / 200817: 59$ & 16.7 & 536.5 \\
\hline 245 & $1 / 7 / 200818: 01$ & $87 / 200818: 01$ & 16.7 & 536.5 \\
\hline 246 & 1/7/2008 18:03 & $87 / 200818: 03$ & 16.7 & 536.4 \\
\hline 247 & $1 / 7 / 200818: 05$ & $87 / 200818: 05$ & 16.7 & 536 \\
\hline 248 & $1 / 7 / 200818: 07$ & $87 / 200818: 07$ & 16.7 & 535.7 \\
\hline 249 & $1 / 7 / 200818: 09$ & $87 / 200818: 09$ & 16.7 & 536.5 \\
\hline 250 & $1 / 7 / 200818: 11$ & $87 / 200818: 11$ & 16.7 & 535.4 \\
\hline 251 & $1 / 7 / 200818: 13$ & $87 / 200818: 13$ & 16.7 & 535.3 \\
\hline 252 & $1 / 7 / 200818: 15$ & $87 / 200818: 15$ & 16.7 & 535.1 \\
\hline 253 & $1 / 7 / 200818: 17$ & $87 / 200818: 17$ & 16.7 & 534.9 \\
\hline 254 & $1 / 7 / 200818: 19$ & $87 / 200818: 19$ & 16.7 & 534.9 \\
\hline 255 & $1 / 7 / 200818: 21$ & $87 / 200818: 21$ & 16.7 & 534.7 \\
\hline 256 & $1 / 7 / 200818: 23$ & $87 / 200818: 23$ & 16.7 & 534.7 \\
\hline 257 & $1 / 7 / 200818: 25$ & $87 / 200818: 25$ & 16.7 & 534.5 \\
\hline 258 & $1 / 7 / 200818: 27$ & $8 / 7 / 200818: 27$ & 16.7 & 534.5 \\
\hline 259 & $1 / 7 / 200818: 29$ & $87 / 200818: 29$ & 16.7 & 534.3 \\
\hline 260 & $1 / 7 / 200818: 31$ & $8 / 7 / 200818: 31$ & 16.7 & 534.4 \\
\hline 261 & $1 / 7 / 200818: 33$ & $87 / 200818: 33$ & 16.7 & 534.1 \\
\hline 262 & $1 / 7 / 200818: 35$ & $87 / 200818: 35$ & 16.7 & 534.1 \\
\hline 263 & $1 / 7 / 200818: 37$ & $87 / 200818: 37$ & 16.7 & 534.2 \\
\hline 264 & $1 / 7 / 200818: 39$ & $87 / 200818: 39$ & 16.7 & 534 \\
\hline 265 & $1 / 7 / 200818: 41$ & $8 / 7 / 200818: 41$ & 16.7 & 533.9 \\
\hline 266 & $1 / 7 / 200818: 43$ & $8 / 7 / 200818: 43$ & 16.7 & 533.9 \\
\hline 267 & $1 / 7 / 200818: 45$ & $87 / 200818: 45$ & 16.7 & 533.9 \\
\hline 268 & $1 / 7 / 200818: 47$ & $87 / 200818: 47$ & 16.7 & 534 \\
\hline 269 & $1 / 7 / 200818: 49$ & $877 / 200818: 40$ & 16.7 & 533.9 \\
\hline 270 & $1 / 7 / 200818: 51$ & $87 / 200818: 51$ & 16.7 & 533.9 \\
\hline 271 & $1 / 7 / 200818: 53$ & $87 / 200818: 53$ & 16.7 & 533.9 \\
\hline 272 & $1 / 7 / 200818: 55$ & $87 / 200818: 55$ & 16.7 & 533.9 \\
\hline 273 & $1 / 7 / 200818: 57$ & $87 / 200818: 57$ & 16.7 & 533.9 \\
\hline 274 & $1 / 7 / 200818: 59$ & $8 / 7 / 200818.59$ & 16.7 & 533.9 \\
\hline 275 & $1 / 7 / 200819.01$ & $87 / 200819.01$ & 16.7 & 533.8 \\
\hline
\end{tabular}

\begin{tabular}{|c|c|c|c|c|}
\hline \multicolumn{5}{|c|}{ D4-93c } \\
\hline $\mathrm{ReC}$ & & Adjusted & Temp & SC \\
\hline \# & DaterTime & DaterTime & $\alpha$ & $\mu \mathrm{s} / \mathrm{cm}$ \\
\hline 276 & 1/7/2008 19:03 & $87 / 200819: 03$ & 16.7 & 533.8 \\
\hline $2 \pi 7$ & $1 / 7 / 200819,05$ & $8 / 7 / 200819: 05$ & 16.7 & 533.8 \\
\hline 278 & $1 / 7 / 2008$ 19:07 & $87 / 200819.07$ & 16.7 & 533.8 \\
\hline 279 & $1 / 7 / 200819.00$ & $87 / 200819.09$ & 16.7 & 533.8 \\
\hline 280 & $1 / 7 / 2008$ 19.11 & $8 / 7 / 200819.11$ & 16.7 & 533.8 \\
\hline 281 & 1/7/2008 19:13 & $87 / 200819.13$ & 16.7 & 533.6 \\
\hline 282 & $1 / 7 / 2008$ 19:15 & $87 / 200819.15$ & 16.7 & 533.6 \\
\hline 283 & $1 / 7 / 200819.17$ & $87 / 200819.17$ & 16.7 & 533.5 \\
\hline 284 & $1 / 7 / 2008$ 19:19 & 871200819.19 & 16.7 & 533.5 \\
\hline 285 & $1 / 7 / 200819: 21$ & $87 / 200819.21$ & 16.7 & 533.6 \\
\hline 286 & $1 / 7 / 200819: 23$ & $87 / 200819: 23$ & 16.7 & 533.5 \\
\hline 287 & $1 / 7 / 200819.25$ & $87 / 200819: 25$ & 16.7 & 533.6 \\
\hline 288 & $1 / 7 / 200819: 27$ & $87 / 200819.27$ & 16.7 & 533.5 \\
\hline 289 & $1 / 7 / 200819.29$ & $8 / 7 / 200819.29$ & 16.7 & 533.7 \\
\hline 290 & $1 / 7 / 200819.31$ & $8 / 7 / 200819.31$ & 16.7 & 533.7 \\
\hline 291 & $1 / 7 / 200819.33$ & $87 / 200819.33$ & 16.7 & 533.8 \\
\hline 292 & $1 / 7 / 200819.35$ & $87 / 200819,35$ & 16.7 & 533.9 \\
\hline 293 & $1 / 7 / 2008$ 19:37 & $87 / 200819.37$ & 16.7 & 533.7 \\
\hline 294 & $1 / 7 / 200819.39$ & $87 / 200819.39$ & 16.7 & 533.6 \\
\hline 296 & $1 / 7 / 20081944$ & $87 / 200819.41$ & 16.7 & 533.6 \\
\hline 296 & $1 / 7 / 200819.43$ & $87 / 200819.43$ & $\begin{array}{ll}16.7 \\
\end{array}$ & 533.6 \\
\hline 297 & $1 / 7 / 200819.45$ & $87 / 200819.45$ & 16.7 & 533.6 \\
\hline 298 & $1 / 7 / 200819: 47$ & $87 / 200819.47$ & 16.7 & 533.8 \\
\hline 299 & $1 / 7 / 200819: 49$ & 877200819.49 & 16.7 & 533.7 \\
\hline 300 & $1 / 7 / 200819.51$ & $87 / 200819.51$ & 16.7 & 533.7 \\
\hline 301 & $1 / 7 / 200819.53$ & 877200819.53 & 16.7 & 533.8 \\
\hline 302 & $1 / 7 / 200819.55$ & $87 / 200819.55$ & 16.7 & 533.7 \\
\hline 303 & $1 / 7 / 200819: 57$ & $87 / 200819.57$ & 16.7 & 533.7 \\
\hline 304 & $1 / 7 / 200819: 59$ & $87 / 200819.59$ & 16.7 & 533.6 \\
\hline 305 & $1 / 7 / 200820: 01$ & $87 / 200820: 01$ & 16.7 & 533.5 \\
\hline 306 & $1 / 7 / 200820: 03$ & $87 / 200820: 03$ & 16.7 & 533.6 \\
\hline 307 & $1 / 7 / 200820: 06$ & $87 / 200820: 05$ & 16.7 & 533.5 \\
\hline 308 & $1 / 7 / 200820: 07$ & $87 / 200820.07$ & $\begin{array}{ll}16.7 \\
\end{array}$ & 533.5 \\
\hline 309 & $1 / 7 / 200820: 09$ & $87 / 200820: 00$ & 16.7 & 533.1 \\
\hline 310 & $1 / 7 / 200820: 11$ & $87 / 200820: 11$ & 16.7 & 533.2 \\
\hline 311 & $1 / 7 / 200820.13$ & $87 / 200820: 13$ & 16.7 & 533 \\
\hline 312 & $1 / 7 / 200820.15$ & $87 / 200820: 15$ & 16.7 & 533.1 \\
\hline 313 & $1 / 7 / 200820.17$ & $87 / 200820: 17$ & 16.7 & 5329 \\
\hline 314 & $1 / 7 / 200820.19$ & $8 / 7 / 200820.19$ & 16.7 & 532.9 \\
\hline 315 & $1 / 7 / 200820: 21$ & $8 / 7 / 200820.21$ & 16.7 & 533 \\
\hline 316 & $1 / 7 / 200820: 23$ & $8 / 7 / 200820: 23$ & 16.7 & 532.9 \\
\hline 317 & $1 / 7 / 200820: 25$ & 877200820.25 & 16.7 & 532.9 \\
\hline 318 & $1 / 7 / 200820.27$ & $87 / 200820.27$ & 16.7 & 532.7 \\
\hline 319 & $1 / 7 / 200820.20$ & $87 / 200820.20$ & 16.7 & 532.7 \\
\hline 320 & $1 / 7 / 200820: 31$ & $877 / 200820.31$ & 16.7 & 532.6 \\
\hline 321 & $1 / 7 / 200820: 33$ & $87 / 200820: 33$ & 16.7 & 532.5 \\
\hline 322 & $1 / 7 / 200820: 35$ & $87 / 200820.35$ & 16.7 & 532.4 \\
\hline 323 & $1 / 7 / 200820: 37$ & $87 / 200820.37$ & 16.7 & 532.2 \\
\hline 324 & $1 / 7 / 200820: 39$ & $87 / 200820.39$ & 16.7 & 532 \\
\hline 325 & $1 / 7 / 200820: 41$ & $8 / 7 / 200820: 41$ & 16.7 & 531.9 \\
\hline 326 & $1 / 7 / 200820: 43$ & $87 / 200820: 43$ & 16.7 & 531.8 \\
\hline 327 & $1 / 7 / 200820.45$ & $87 / 200820.45$ & 16.7 & 531.7 \\
\hline 328 & $1 / 7 / 200820.47$ & $87 / 200820: 47$ & 16.7 & 531.7 \\
\hline 329 & $1 / 7 / 200820: 49$ & $87 / 200820.49$ & 16.7 & 531.9 \\
\hline 330 & $1 / 7 / 200820: 51$ & $87 / 200820.51$ & 16.7 & $\begin{array}{ll}531.7 \\
\end{array}$ \\
\hline 331 & $1 / 7 / 200820.53$ & $87 / 200820.53$ & 16.7 & 531.5 \\
\hline 332 & $1 / 7 / 200820.55$ & $87 / 200820.55$ & 16.7 & 531.6 \\
\hline 333 & $1 / 7 / 200820.57$ & $87 / 200820.57$ & 16.7 & 531.7 \\
\hline 334 & $1 / 7 / 200820.59$ & $87 / 1200820.59$ & 16.7 & 531.2 \\
\hline 335 & $1 / 7 / 200821: 01$ & $8 / 7 / 200821: 01$ & 16.7 & 531.6 \\
\hline 336 & $1 / 7 / 200821: 03$ & $877 / 200821: 03$ & 16.7 & 531.6 \\
\hline 337 & $1 / 7 / 200821: 05$ & $87 / 200821: 05$ & 16.7 & 531.5 \\
\hline 338 & 1/7/200821:07 & $87 / 200821: 07$ & 16.7 & 531.6 \\
\hline 339 & 1/7/200821:09 & $877 / 200821: 09$ & 16.7 & 531.5 \\
\hline 340 & $1 / 7 / 200821: 11$ & $877200821: 11$ & 16.7 & 531.2 \\
\hline 341 & $1 / 7 / 200821: 13$ & $8 / 7 / 200821: 13$ & $\begin{array}{ll}16.7 \\
\end{array}$ & 531.4 \\
\hline 342 & $1 / 7 / 200821: 15$ & $87 / 200821: 15$ & 16.7 & 531.3 \\
\hline 343 & 1/7/200821:17 & $8 / 7 / 200821: 17$ & 16.7 & 531.3 \\
\hline 344 & 1/7/200821:19 & $87 / 200821: 19$ & 16.7 & 531.2 \\
\hline
\end{tabular}

\begin{tabular}{|c|c|c|c|c|}
\hline \multicolumn{5}{|c|}{ D4-93c } \\
\hline $\operatorname{Rec}$ & & Adjusted & Temp & SC \\
\hline$\#$ & Date/Time & Dater/Time & $\infty$ & $\mu \mathrm{S} / \mathrm{cm}$ \\
\hline 345 & 1/7/200821:21 & $87 / 200821: 21$ & 16.7 & 531.4 \\
\hline 346 & $1 / 7 / 200821: 23$ & $87 / 200821: 23$ & 16.7 & 531.4 \\
\hline 347 & 1/7/200821:25 & $87 / 200821: 25$ & 16.7 & 531.4 \\
\hline 348 & $1 / 7 / 200821: 27$ & $87 / 200821: 27$ & 16.7 & 531.4 \\
\hline 349 & 1/7/200821:29 & $87 / 200821: 29$ & 16.7 & 531.4 \\
\hline 350 & $1 / 7200821: 31$ & $87 / 200821: 31$ & 16.7 & 531.5 \\
\hline 351 & $1 / 7 / 200821: 33$ & $87 / 1200821: 33$ & 16.7 & 531.3 \\
\hline 352 & $1 / 7 / 200821: 35$ & $87 / 1200821: 35$ & 16.7 & 531.7 \\
\hline 353 & $1 / 7 / 200821: 37$ & $87 / 200821: 37$ & 16.7 & 532 \\
\hline 354 & $1 / 7 / 200821: 39$ & $8 / 7 / 200821: 39$ & 16.7 & 531.7 \\
\hline 355 & $1 / 7 / 200821: 41$ & $8 / 7200821: 41$ & 16.7 & 531.9 \\
\hline 356 & 1/7/200821:43 & $87 / 200821: 43$ & 16.7 & 531.8 \\
\hline 357 & $1 / 7 / 200821: 45$ & $87 / 200821: 45$ & 16.7 & 531.8 \\
\hline 358 & $1 / 7 / 200821: 47$ & $87 / 200821: 47$ & 16.7 & 531.9 \\
\hline 359 & 1/7/200821:49 & $87 / 200821: 49$ & 16.7 & 531.8 \\
\hline 360 & 1/7/200821:51 & $87 / 200821: 51$ & 16.7 & 532 \\
\hline 361 & $1 / 7 / 200821: 53$ & $871200821: 53$ & 16.7 & 531.9 \\
\hline 362 & $1 / 7 / 200821: 55$ & $87 / 200821: 55$ & 16.7 & 5321 \\
\hline 363 & 1/7/200821:57 & $871200821: 57$ & 16.7 & 532 \\
\hline 364 & 1/7/2008 21:59 & $8 / 7 / 200821: 59$ & 16.7 & 532. \\
\hline 365 & $1 / 7 / 200822: 01$ & $87 / 20082201$ & 16.7 & 532 \\
\hline 366 & $1 / 7 / 20082203$ & $87 / 200822: 03$ & 16.7 & 532 \\
\hline 367 & $17 / 200822205$ & $87 / 20082205$ & 16.7 & 532 \\
\hline 368 & $1 / 7 / 200822: 07$ & $87 / 200822: 07$ & 16.7 & 531.9 \\
\hline 369 & $1 / 7 / 20082200$ & $8 / 7 / 200822: 09$ & 16.7 & 531.9 \\
\hline 370 & $1 / 7 / 200822: 11$ & $87 / 200822: 11$ & 16.7 & 532 \\
\hline 371 & 1/7/200822:13 & $87 / 200822: 13$ & 16.7 & 531.9 \\
\hline 372 & $1 / 7 / 200822: 15$ & $87 / 200822: 15$ & 16.7 & 531.9 \\
\hline 373 & $1 / 7 / 200822: 17$ & $8 / 7 / 200822: 17$ & $\begin{array}{l}16.7 \\
\end{array}$ & 531.7 \\
\hline 374 & $1 / 7 / 200822: 19$ & $87 / 200822: 19$ & 16.7 & 531.5 \\
\hline 375 & $1 / 71200822: 21$ & $87 / 200822: 21$ & 16.7 & 531.4 \\
\hline 376 & 1/7/200822:23 & $87 / 200822: 23$ & 16.7 & 531.5 \\
\hline 377 & 1/7/200822:25 & $87 / 200822225$ & 16.7 & 531.4 \\
\hline 378 & $1 / 7 / 200822: 27$ & $87 / 200822: 27$ & 16.7 & 531.3 \\
\hline 379 & $1 / 7 / 20082229$ & $87 / 200822: 20$ & 16.7 & 531.5 \\
\hline 380 & $1 / 7 / 200822331$ & $87 / 200822: 31$ & 16.7 & 531.4 \\
\hline 381 & $1 / 7 / 200822: 33$ & $87 / 200822: 33$ & 16.7 & 531.5 \\
\hline 382 & $1 / 7 / 200822335$ & $87 / 20082235$ & 16.7 & 531.4 \\
\hline 383 & $1 / 7 / 200822: 37$ & $871200822: 37$ & 16.7 & 531.6 \\
\hline 384 & $1 / 7 / 200822: 39$ & $8 / 720082239$ & 16.7 & 531.1 \\
\hline 385 & 1/7/200822:41 & $87 / 200822: 41$ & 16.7 & 530.9 \\
\hline 386 & $1 / 7 / 200822: 43$ & $87 / 200822443$ & 16.7 & 531.7 \\
\hline 387 & $1 / 7 / 200822: 45$ & $87 / 200822: 45$ & 16.7 & 532.6 \\
\hline 388 & $1 / 7 / 20082247$ & $87 / 20082247$ & 16.7 & 533.3 \\
\hline 389 & $1 / 7 / 200822,49$ & $87 / 20082249$ & 16.7 & 533.9 \\
\hline 390 & $1 / 7 / 200822551$ & $87 / 20082251$ & 16.7 & 534.8 \\
\hline 391 & $1 / 7 / 200822: 53$ & $87 / 20082255$ & 16.7 & 535.6 \\
\hline 392 & $1 / 7 / 200822: 55$ & $87 / 20082255$ & 16.7 & 536.1 \\
\hline 393 & $1 / 7 / 200822: 57$ & $87 / 20082257$ & 16.7 & 536.8 \\
\hline 394 & $1 / 7 / 200822: 59$ & $87 / 20082250$ & 16.7 & 536.9 \\
\hline 395 & $1 / 7 / 200823: 01$ & $87 / 200823: 01$ & 16.7 & 537.2 \\
\hline 396 & $1 / 7 / 200823: 03$ & $87 / 200823: 03$ & 16.7 & 537.4 \\
\hline 397 & 1/7/200823:05 & $871200823: 05$ & 16.7 & 537.4 \\
\hline 398 & $1 / 7 / 200823: 07$ & $87 / 200823: 07$ & 16.7 & 537.5 \\
\hline 399 & 1/7/200823:09 & $87 / 200823: 09$ & 16.7 & 537.3 \\
\hline 400 & $1 / 7 / 200823: 11$ & $87 / 200823: 11$ & 16.7 & 537.1 \\
\hline 401 & $1 / 7 / 200823: 13$ & $87 / 200823: 13$ & 16.7 & 537.2 \\
\hline 402 & 1/7/200823:15 & $87 / 200823: 15$ & 16.7 & 537 \\
\hline 403 & $1 / 7 / 200823: 17$ & $87 / 200823: 17$ & 16.7 & 537.1 \\
\hline 404 & 1/7/200823:19 & $87 / 200823: 19$ & 16.7 & 537.2 \\
\hline 405 & $1 / 7 / 200823: 21$ & $87 / 200823: 21$ & 16.7 & 536.6 \\
\hline 406 & 1/7/200823:23 & $87 / 200823: 23$ & 16.7 & 535.4 \\
\hline 407 & 1/7/200823:25 & 87/200823:25 & 16.7 & 534.6 \\
\hline 408 & 1/7/200823:27 & $8 / 7 / 200823: 27$ & 16.7 & 533.6 \\
\hline 409 & 1/7/200823:29 & $87 / 200823: 29$ & 16.7 & 533.3 \\
\hline 410 & 1/7/200823:31 & $87 / 200823: 31$ & 16.7 & 533.2 \\
\hline 411 & $1 / 7 / 200823: 33$ & $87 / 1200823: 33$ & 16.7 & 533.2 \\
\hline 412 & $1 / 7 / 200823: 35$ & $87 / 200823: 35$ & 16.7 & 533.1 \\
\hline 413 & $1 / 7 / 200823: 37$ & $877 / 200823: 37$ & 16.7 & 533.2 \\
\hline
\end{tabular}




\begin{tabular}{|c|c|c|c|c|}
\hline \multicolumn{5}{|c|}{$D 493 c$} \\
\hline $\operatorname{Rec}$ & & Adjusted & Temp & $\mathrm{SC}$ \\
\hline$\#$ & Dete/Time & Date/Time & $\alpha C$ & $\mu \mathrm{S} / \mathrm{cm}$ \\
\hline 414 & $1 / 7 / 200823: 39$ & $8 / 7 / 200823: 39$ & 16.7 & 533.1 \\
\hline 415 & $1 / 7 / 200823: 41$ & $8 / 7 / 200823: 41$ & 16.7 & 533 \\
\hline 416 & $1 / 7 / 200823: 43$ & $8 / 7 / 200823: 43$ & 16.7 & 533.2 \\
\hline 417 & $1 / 7 / 200823: 45$ & $8 / 71200823: 45$ & 16.7 & 533.1 \\
\hline 418 & $1 / 7 / 200823: 47$ & $8 / 7 / 200823: 47$ & 16.7 & 533.2 \\
\hline 419 & $1 / 7 / 200823: 49$ & $8 / 7 / 200823: 49$ & 16.7 & 533.2 \\
\hline 420 & $1 / 7 / 200823: 51$ & $8 / 7 / 200823: 51$ & 16.7 & 533.3 \\
\hline 421 & $1 / 7 / 200823: 53$ & $8 / 7 / 200823: 53$ & 16.7 & 533.4 \\
\hline 422 & $1 / 7 / 200823: 55$ & $8 / 7 / 200823: 55$ & 16.7 & 533.4 \\
\hline 423 & $1 / 7 / 200823: 57$ & $8 / 7 / 200823: 57$ & 16.7 & 533.3 \\
\hline 424 & $1 / 7 / 200823: 59$ & $877 / 200823: 59$ & 16.7 & 533.4 \\
\hline 425 & $1 / 8 / 20080: 01$ & $8 / 8 / 20080: 01$ & 16.7 & 533.4 \\
\hline 426 & $1 / 8 / 20080: 03$ & $8 / 8 / 20080: 03$ & 16.7 & 533.5 \\
\hline 427 & $1 / 8 / 20080: 05$ & $8 / 8 / 20080: 05$ & 16.7 & 533.5 \\
\hline 428 & $1 / 8 / 20080: 07$ & $8 / 8 / 20080: 07$ & 16.7 & 533.4 \\
\hline 429 & 1/8/20080:09 & $8 / 820080: 09$ & 16.7 & 533.6 \\
\hline 430 & 1/8/20080:11 & $8 / 8 / 20080: 11$ & 16.7 & 533.5 \\
\hline 431 & 1/8/20080:13 & $8 / 8 / 20080: 13$ & 16.7 & 533.7 \\
\hline 432 & 1/8/20080:15 & $8 / 8 / 20080: 15$ & 16.7 & 533.6 \\
\hline 433 & 1/8/20080:17 & $8 / 8 / 20080: 17$ & 16.7 & 533.9 \\
\hline 434 & 1/8/20080:19 & $8 / 8 / 20080: 19$ & 16.7 & 533.8 \\
\hline 435 & $1 / 8 / 20080.21$ & $8 / 8 / 20080: 21$ & 16.7 & 533.8 \\
\hline 436 & $1 / 8 / 20080: 23$ & $8 / 8 / 20080: 23$ & 16.7 & 534.1 \\
\hline 437 & $1 / 8 / 20080.25$ & $8 / 8 / 20080: 25$ & 16.7 & 534.2 \\
\hline 438 & $1 / 8 / 20080: 27$ & $8 / 8 / 20080: 27$ & 16.7 & 534.1 \\
\hline 439 & $1 / 8 / 20080: 29$ & $8 / 8 / 20080: 29$ & 16.7 & 534.5 \\
\hline 440 & $1 / 8 / 20080: 31$ & $8 / 8 / 20080.31$ & 16.7 & 534.6 \\
\hline 441 & $1 / 8 / 20080: 33$ & $8 / 8 / 20080.33$ & 16.7 & 534.7 \\
\hline 442 & $1 / 8 / 20080: 35$ & $8 / 8 / 20080: 35$ & 16.7 & 534.6 \\
\hline 443 & 1/8/20080:37 & $8 / 8 / 20080: 37$ & 16.7 & 534.4 \\
\hline 444 & $1 / 8 / 20080: 39$ & $8 / 8 / 20080: 39$ & 16.7 & 534.1 \\
\hline 445 & 1/8/20080:41 & $8 / 8 / 20080: 41$ & 16.7 & 534.2 \\
\hline 446 & $1 / 8 / 20080: 43$ & $8 / 8 / 20080: 43$ & 16.7 & 534.1 \\
\hline 447 & $1 / 8 / 20080: 45$ & $8 / 8 / 20080: 45$ & 16.7 & 533.9 \\
\hline 448 & 1/8/20080:47 & $8 / 8 / 20080: 47$ & 16.7 & 533.4 \\
\hline 449 & $1 / 8 / 20080: 49$ & $8 / 8 / 20080: 49$ & 16.7 & 533.1 \\
\hline 450 & 1/8/20080:51 & $8 / 8 / 20080: 51$ & 16.7 & 5326 \\
\hline 451 & $1 / 8 / 20080: 53$ & $8 / 8 / 20080: 53$ & 16.7 & 5325 \\
\hline 452 & $1 / 8 / 20080: 55$ & $8 / 8 / 20080: 55$ & 16.7 & 5323 \\
\hline 453 & $1 / 8 / 20080: 57$ & $8 / 8 / 20080: 57$ & 16.7 & 5323 \\
\hline 454 & $1 / 8 / 20080: 59$ & $8 / 8 / 20080: 59$ & 16.7 & 5323 \\
\hline 455 & 1/8/2008 1:01 & $8 / 8 / 20081: 01$ & 16.7 & 532.1 \\
\hline 456 & 1/8/20081:03 & $8 / 8 / 20081: 03$ & 16.7 & 532.2 \\
\hline 457 & 1/8/20081:05 & $8 / 8 / 20081: 05$ & 16.7 & 532 \\
\hline 458 & $1 / 8 / 20081: 07$ & $8 / 8 / 200081007$ & 16.7 & 531.6 \\
\hline 459 & $1 / 8 / 20081: 09$ & $8 / 8 / 20081: 09$ & 16.7 & 531.8 \\
\hline 460 & 1/8/2008 1:11 & $8 / 8 / 20081: 11$ & 16.7 & 5323 \\
\hline 461 & $1 / 8 / 20081: 13$ & $8 / 8 / 2008$ :113 & 16.7 & 533.1 \\
\hline 462 & $1 / 8 / 20081: 15$ & $8 / 8 / 20081: 15$ & 16.7 & 533.7 \\
\hline 463 & 1/8/2008 1:17 & $8 / 8 / 2008$ 1:17 & 16.7 & 534.1 \\
\hline 464 & $1 / 8 / 20081: 19$ & $8 / 8 / 2008$ 1:19 & 16.7 & 534.4 \\
\hline 465 & $1 / 8 / 20081: 21$ & $8 / 8 / 2008$ 1:21 & 16.7 & 534.6 \\
\hline 466 & $1 / 8 / 20081: 23$ & $8 / 8 / 20081: 23$ & 16.7 & 534.7 \\
\hline 467 & $1 / 8 / 20081: 25$ & $8 / 8 / 20081: 25$ & 16.7 & 534.6 \\
\hline 468 & $1 / 8 / 20081: 27$ & $8 / 8 / 20081: 27$ & 16.7 & 534.8 \\
\hline 469 & $1 / 8 / 20081: 29$ & $8 / 8 / 20081: 29$ & 16.7 & 534.8 \\
\hline 470 & $1 / 8 / 2008$ 1:31 & $8 / 8 / 2008$ 1:31 & 16.7 & 535 \\
\hline 471 & $1 / 8 / 20081: 33$ & $8 / 8 / 20081: 33$ & 16.7 & 535.1 \\
\hline 472 & $1 / 8 / 20081: 35$ & $8 / 8 / 2008$ 1:35 & 16.7 & 535 \\
\hline 473 & $1 / 8 / 20081: 37$ & $8 / 8 / 20081: 37$ & 16.7 & 535.1 \\
\hline 474 & $1 / 8 / 20081: 39$ & $8 / 8 / 20081: 39$ & 16.7 & 535.3 \\
\hline 475 & $1 / 8 / 2008$ 1:41 & $8 / 8 / 20081: 41$ & 16.7 & 535.2 \\
\hline 476 & $1 / 8 / 20081: 43$ & $8 / 8 / 20081: 43$ & 16.7 & 535.3 \\
\hline 477 & $1 / 8 / 20081: 45$ & $8 / 8 / 20084: 45$ & 16.7 & 535.1 \\
\hline 478 & $1 / 8 / 20081: 47$ & $8 / 8 / 20081: 47$ & 16.7 & 535 \\
\hline 479 & $1 / 8 / 20081: 49$ & $8 / 8 / 20081: 49$ & 16.7 & 535 \\
\hline 480 & 1/8/2008 1:51 & $8 / 8 / 2008$ 1:51 & 16.7 & 535.1 \\
\hline 481 & $1 / 8 / 20081: 53$ & $8 / 8 / 20081: 53$ & 16.7 & 535.5 \\
\hline 482 & $1 / 8 / 20081: 55$ & $8 / 8 / 2008$ 1:55 & 16.7 & 535.7 \\
\hline
\end{tabular}

\begin{tabular}{|c|c|c|c|c|}
\hline \multicolumn{5}{|c|}{$D 4-93 c$} \\
\hline $\operatorname{Rec}$ & & Adjusted & Temp & $\mathrm{SC}$ \\
\hline$\#$ & Date/Time & Date/Time & $\alpha$ & $\mu \mathrm{S} / \mathrm{cm}$ \\
\hline 483 & $1 / 8 / 20081: 57$ & $8 / 8 / 20081: 57$ & 16.7 & 536.1 \\
\hline 484 & $1 / 8 / 20081: 59$ & $8 / 8 / 20081: 59$ & 16.7 & 536.3 \\
\hline 485 & $1 / 8 / 2008201$ & $8 / 8 / 20082: 01$ & 16.7 & 536.4 \\
\hline 486 & $1 / 8 / 2008203$ & $8 / 8 / 20082: 03$ & 16.7 & 536.5 \\
\hline 487 & $1 / 8 / 2008205$ & $8 / 8 / 20082: 05$ & 16.7 & 536.7 \\
\hline 488 & $1 / 8 / 20082: 07$ & $8 / 8 / 20082: 07$ & 16.7 & 536.9 \\
\hline 489 & $1 / 8 / 20082.09$ & $8 / 8 / 20082: 09$ & 16.7 & 537.2 \\
\hline 490 & $1 / 8 / 20082: 11$ & $8 / 8 / 20082: 11$ & 16.7 & 537.3 \\
\hline 491 & $1 / 8 / 2008213$ & $8 / 8 / 20082: 13$ & 16.7 & 537.4 \\
\hline 492 & $1 / 8 / 20082: 15$ & $8 / 8 / 20082: 15$ & 16.7 & 537.5 \\
\hline 493 & $1 / 8 / 2008217$ & $8 / 8 / 20082: 17$ & 16.7 & 537.6 \\
\hline 494 & $1 / 820082: 19$ & $8 / 8 / 20082: 19$ & 16.7 & 537.8 \\
\hline 495 & $1 / 8 / 20082221$ & $8 / 8 / 20082: 21$ & 16.7 & 537.8 \\
\hline 496 & $1 / 8 / 20082: 23$ & $8 / 8 / 2008223$ & 16.7 & 537.8 \\
\hline 497 & $1 / 8 / 20082: 25$ & $8 / 8 / 2008225$ & 16.7 & 537.8 \\
\hline 498 & $1 / 8 / 20082: 27$ & $8 / 8 / 20082: 27$ & 16.7 & 537.7 \\
\hline 499 & $1 / 820082: 29$ & $8 / 8 / 20082229$ & 16.7 & 537.8 \\
\hline 500 & $1 / 8 / 20082: 31$ & $8 / 8 / 20082: 31$ & 16.7 & 537.8 \\
\hline 501 & $1 / 8 / 20082: 33$ & $8 / 8 / 20082: 33$ & 16.7 & 537.9 \\
\hline 502 & $1 / 8 / 20082: 35$ & $8 / 8 / 200$ & 16.7 & 537.9 \\
\hline 503 & $1 / 8 / 20082: 37$ & $8 / 8 / 20082: 37$ & 16.7 & 537.9 \\
\hline 504 & $1 / 8 / 20082: 39$ & $8 / 8 / 20082: 39$ & 16.7 & 538.1 \\
\hline 505 & $1 / 8 / 20082: 41$ & $8 / 8 / 20$ & 16.7 & 538.1 \\
\hline 506 & $1 / 8 / 20082: 43$ & $8 / 8 / 20$ & 16.7 & 538.4 \\
\hline 507 & $1 / 8 / 20082: 45$ & $8 / 8 / 20082: 45$ & 16.7 & 538.3 \\
\hline 508 & $1 / 8 / 2008247$ & $8 / 8 / 20$ & 16.7 & 538.5 \\
\hline 509 & $1 / 8 / 2008249$ & $8 / 8 / 20$ & 16.7 & 538.7 \\
\hline 510 & $1 / 82008251$ & $8 / 8 / 20082: 51$ & \begin{tabular}{l|l}
16.7 \\
\end{tabular} & 538.5 \\
\hline 511 & $1 / 8 / 20$ & $8 / 8 / 20$ & 16.7 & 538.8 \\
\hline 512 & $1 / 8 / 20082555$ & $8 / 8 / 20082: 55$ & 16.7 & 538.8 \\
\hline 513 & $1 / 8 / 20082: 57$ & $8 / 8 / 2008257$ & 16.7 & 538.8 \\
\hline 514 & $1 / 8 / 2008259$ & $8 / 8 / 200$ & 16.7 & 538.9 \\
\hline 515 & 1/8/20083:01 & $8 / 8 / 20083: 01$ & 16.7 & 539 \\
\hline 516 & $83: 03$ & $8 / 8 / 20083: 03$ & 16.7 & 538.8 \\
\hline 517 & $1 / 8 / 20083: 05$ & $8 / 8 / 20083: 05$ & 16.7 & 538.8 \\
\hline 518 & $1 / 8200$ & $8 / 8 / 20$ & 16.7 & 53 \\
\hline 519 & 3:09 & $8 / 8 / 20$ & 16.7 & 538.9 \\
\hline 520 & $1 / 8 / 20$ & $8 / 8 / 20$ & 16.7 & 539.1 \\
\hline 521 & $1 / 8 / 200$ & $8 / 8 / 20$ & 16.7 & 539 \\
\hline 522 & $1 / 8 / 20$ & $8 / 8 / 20$ & 16.7 & 539.1 \\
\hline 523 & $1 / 8 / 200$ & $8 / 8 / 20$ & 16.7 & 539.2 \\
\hline 524 & $1 / 8 / 200$ & $8 / 820083: 19$ & 16.7 & 539.1 \\
\hline 525 & 3:21 & $8 / 8 / 20$ & 16.7 & 539.1 \\
\hline 526 & $1 / 8 / 200$ & $8 / 820$ & 16.7 & 539.2 \\
\hline 527] & $1 / 8 / 200$ & $8 / 8 / 20083: 25$ & 16.7 & 539.4 \\
\hline 528 & 27 & 3.27 & 16.7 & 539.4 \\
\hline 529 & $1 / 8 / 200$ & $8 / 8 / 200$ & 16.7 & 539.5 \\
\hline 530 & & $8 / 8 / 2$ & 16.7 & 539.6 \\
\hline 531 & 33 & $8 / 8 / 20$ & 16.7 & \\
\hline 532 & $1 / 8 / 20$ & $8 / 8 / 20 x$ & 16.7 & 540.1 \\
\hline 533 & 3:37 & $8 / 8 / 200$ & 16.7 & 540.3 \\
\hline 534 & $1 / 8 / 20$ & $8 / 8 / 20$ & 16.7 & 540.3 \\
\hline 535 & $1 / 8 / 200$ & $8 / 820083: 41$ & 16.7 & 540.3 \\
\hline 536 & & & 16.7 & 540.3 \\
\hline 537 & $1 / 8 / 20$ & $8 / 8 / 20$ & & 540.2 \\
\hline 538 & 3:47 & $8 / 8 / 200$ & 16.7 & 539.8 \\
\hline 539 & & & 16.7 & 539.4 \\
\hline 540 & $1 / 8 / 20$ & $8 / 8 / 200$ & 16.7 & 533 \\
\hline 541 & $8 / 20$ & $8 / 8 / 20083: 53$ & \begin{tabular}{|c|}
16.7 \\
\end{tabular} & 540.1 \\
\hline 542 & 55 & $8 / 8 / 20083: 55$ & 16.7 & 542.2 \\
\hline 543 & $1 / 8 / 20$ & $8 / 8 / 20083: 57$ & 16.7 & 54 \\
\hline 544 & 1/8/20083:59 & $8 / 8 / 20083: 59$ & 16.7 & 546.3 \\
\hline 545 & & & 16.7 & 546. \\
\hline 546 & $1 / 8 / 20$ & $8 / 8 / 20084: 03$ & \begin{tabular}{|c|}
16.7 \\
\end{tabular} & $\overline{546.4}$ \\
\hline 547 & $1 / 820084: 05$ & $8 / 8 / 20084: 05$ & 16.7 & 545.4 \\
\hline 548 & & & & 544.5 \\
\hline 549 & $1 / 8 / 20084: 09$ & $8 / 8 / 20084: 09$ & 16.7 & 544.1 \\
\hline 550 & 1/8/20084:11 & 8/8/20084:11 & 16.7 & 544. \\
\hline 551 & $1 / 8 / 20084: 13$ & $8 / 8 / 20084: 13$ & \begin{tabular}{l|l|}
16.7 \\
\end{tabular} & 545. \\
\hline
\end{tabular}

\begin{tabular}{|c|c|c|c|c|}
\hline \multicolumn{5}{|c|}{$D 493 c$} \\
\hline $\operatorname{Rec}$ & & Adusted & Temp & SC \\
\hline$\#$ & Date/Time & Date/Time & $\alpha$ & $\mu \mathrm{S} / \mathrm{mm}$ \\
\hline 552 & $1 / 8 / 20084: 15$ & $8 / 8 / 20084: 15$ & 16.7 & 546.4 \\
\hline 553 & 1/8/20084:17 & $8 / 8 / 20084: 17$ & 16.7 & 550.5 \\
\hline 554 & 1/8/20084:19 & $8 / 8 / 20084: 19$ & 16.7 & 5521 \\
\hline 556 & $1 / 8 / 20084: 21$ & $8 / 8 / 20084: 21$ & 16.7 & 553.8 \\
\hline 556 & $1 / 8 / 20084: 23$ & $8 / 8 / 20084: 23$ & 16.7 & 556 \\
\hline 557 & $1 / 8 / 20084: 25$ & $8 / 8 / 20084: 25$ & 16.7 & 556.7 \\
\hline 558 & 1/8/20084:27 & $8 / 8 / 20084: 27$ & 16.7 & 558.1 \\
\hline 559 & $1 / 8 / 20084: 29$ & $8 / 8 / 20084: 29$ & 16.7 & 557.7 \\
\hline 560 & $1 / 8 / 20084: 31$ & $8 / 8 / 20084: 31$ & 16.7 & 556.4 \\
\hline 561 & $1 / 8 / 20084: 33$ & $8 / 8 / 20084: 33$ & 16.7 & 557.9 \\
\hline 562 & $1 / 8 / 20084: 35$ & $8 / 8 / 20084: 35$ & 16.7 & 559.7 \\
\hline 563 & $1 / 8 / 20084: 37$ & $8 / 8 / 20084: 37$ & 16.7 & 557.6 \\
\hline 564 & $1 / 8 / 20084: 39$ & $8 / 8 / 20084: 39$ & 16.7 & 559.9 \\
\hline 565 & $1 / 8 / 20084: 41$ & $8 / 8 / 20084: 41$ & 16.7 & 559.3 \\
\hline 566 & $1 / 8 / 20084: 43$ & $8 / 8 / 20084: 43$ & 16.7 & 557.9 \\
\hline 567 & $1 / 8 / 20084: 45$ & $8 / 8 / 20084: 45$ & 16.7 & 558.6 \\
\hline 568 & $1 / 8 / 20084: 47$ & $8 / 8 / 20084: 47$ & 16.7 & 558 \\
\hline 569 & 1/8/20084:49 & $8 / 8 / 20084: 49$ & 16.7 & 5624 \\
\hline 570 & $1 / 8 / 20084: 51$ & $8 / 8 / 20084: 51$ & 16.7 & 560.8 \\
\hline 571 & $1 / 8 / 20084: 53$ & $8 / 8 / 20084: 53$ & 16.7 & 557.2 \\
\hline 572 & 1/8/20084:55 & $8 / 8 / 20084: 55$ & 16.7 & 558.8 \\
\hline 573 & $1 / 8 / 20084: 57$ & $8 / 8 / 20084: 57$ & 16.7 & 560.4 \\
\hline 574 & $1 / 8 / 20084: 59$ & $8 / 8 / 20084: 59$ & 16.7 & 561 \\
\hline 575 & 1/8/20085:01 & $8 / 8 / 20085: 01$ & 16.7 & 561 \\
\hline 576 & 1/8/20085:03 & $8 / 8 / 20085: 03$ & 16.7 & 558.6 \\
\hline 577 & $1 / 8 / 20085: 05$ & $8 / 8 / 20085: 05$ & 16.7 & 557.8 \\
\hline 578 & $1 / 8 / 20085: 07$ & $8 / 8 / 20085: 07$ & 16.7 & 555.5 \\
\hline 579 & $1 / 8 / 20085: 09$ & $8 / 8 / 20085: 09$ & 16.7 & 552.1 \\
\hline 580 & $1 / 8 / 20085: 11$ & $8 / 8 / 20085: 11$ & 16.7 & 552 \\
\hline 581 & 1/8/20085:13 & $8 / 8 / 20085: 13$ & 16.7 & 552 \\
\hline 582 & 1/8/20085:15 & $8 / 8 / 20085: 15$ & 16.7 & 559.4 \\
\hline 583 & 1/8/20085:17 & $8 / 8 / 20085: 17$ & 16.7 & 560.3 \\
\hline 584 & 1/8/20085:19 & $8 / 8 / 20085: 19$ & 16.7 & 558.1 \\
\hline 585 & $1 / 8 / 20085: 21$ & $8 / 8 / 20085: 21$ & 16.7 & 556.1 \\
\hline 586 & $1 / 8 / 20085: 23$ & $8 / 8 / 20085: 23$ & 16.7 & 560 \\
\hline 587 & $1 / 8 / 20085: 25$ & $8 / 8 / 20085: 25$ & 16.7 & 560.4 \\
\hline 588 & 1/8/20085:27 & $8 / 8 / 20085: 27$ & 16.7 & 556.7 \\
\hline 589 & $1 / 8 / 20085: 29$ & $8 / 8 / 20085: 29$ & 16.7 & 554.6 \\
\hline 590 & 1/8/20085:31 & $8 / 8 / 20085: 31$ & 16.7 & 554.5 \\
\hline 591 & $1 / 8 / 20085: 33$ & $8 / 8 / 20085: 33$ & 16.7 & 553.9 \\
\hline 592 & $1 / 8 / 20085: 35$ & $8 / 8 / 20085: 35$ & 16.7 & 553 \\
\hline 593 & $1 / 820085: 37$ & $8 / 8 / 20085: 37$ & 16.7 & 552.6 \\
\hline 594 & 1/8/20085:39 & $8 / 8 / 20085: 39$ & 16.7 & 552.8 \\
\hline 596 & 1/8/20085:41 & $8 / 8 / 20085: 41$ & 16.7 & 5566.7 \\
\hline 596 & $1 / 8 / 20085: 43$ & $8 / 8 / 20085: 43$ & 16.7 & 561.9 \\
\hline 597 & 1/8/20085:45 & $8 / 8 / 20085: 45$ & 16.7 & 557.8 \\
\hline 598 & $1 / 8 / 20085: 47$ & $8 / 8 / 20085: 47$ & \begin{tabular}{l|l|}
16.7 \\
\end{tabular} & 562.2 \\
\hline 599 & $1 / 8 / 20085: 49$ & $8 / 8 / 20085: 49$ & 16.7 & 560.1 \\
\hline 600 & $1 / 8 / 20085: 51$ & $8 / 8 / 20085: 51$ & 16.7 & 563.1 \\
\hline 601 & $1 / 8 / 20085: 53$ & $8 / 8 / 20085: 53$ & 16.7 & 561 \\
\hline 602 & 1/8/20085:55 & $8 / 8 / 20085: 55$ & 16.7 & 560.8 \\
\hline 603 & 1/8/20085:57 & $8 / 8 / 20085: 57$ & 16.7 & 557.4 \\
\hline 604 & $1 / 8 / 20085: 59$ & $8 / 8 / 20085: 59$ & 16.7 & 555.8 \\
\hline 605 & 1/8/20086:01 & 8/8/20086:01 & 16.7 & 551.8 \\
\hline 606 & $1 / 8 / 20086: 03$ & $8 / 8 / 20086: 03$ & 16.7 & 550.4 \\
\hline 607 & $1 / 8 / 20086: 05$ & $8 / 8 / 20086: 05$ & 16.7 & 552.1 \\
\hline 608 & 1/8/20086:07 & $8 / 8 / 20086: 07$ & 16.7 & 553.8 \\
\hline 609 & $1 / 8 / 20086: 09$ & $8 / 8 / 20086: 09$ & 16.7 & 553.4 \\
\hline 610 & $1 / 8 / 20086: 11$ & $8 / 820086: 11$ & 16.7 & 559.6 \\
\hline 611 & $1 / 8 / 20086:\{3$ & $8 / 8 / 20086: 13$ & 16.7 & 562.9 \\
\hline 612 & 1/8/20086:15 & $8 / 8 / 20086: 15$ & \begin{tabular}{ll|}
16.7 \\
\end{tabular} & 565.5 \\
\hline 613 & 1/8/20086:17 & 8/8/20086:17 & 16.7 & 564.4 \\
\hline 614 & 1/8/20086:19 & $8 / 8 / 20086: 19$ & \begin{tabular}{|c|}
16.7 \\
\end{tabular} & 566 \\
\hline 615 & $1 / 8 / 20086: 21$ & $8 / 8 / 20086: 21$ & 16.7 & 566.2 \\
\hline 616 & $1 / 8 / 20086: 23$ & $8 / 8 / 20086: 23$ & 16.7 & 565.9 \\
\hline 617 & $1 / 8 / 20086: 25$ & $8 / 8 / 20086: 25$ & $\begin{array}{l}16.7 \\
\end{array}$ & 565.3 \\
\hline 618 & $1 / 8 / 20086: 27$ & $8 / 8 / 20086: 27$ & 16.7 & 562.3 \\
\hline 619 & $1 / 8 / 20086: 20$ & $8 / 8 / 20086: 20$ & 16.7 & 563.9 \\
\hline 620 & 1/8/2008 6:31 & $8 / 8 / 20086: 31$ & 16.7 & 562.9 \\
\hline
\end{tabular}


DOE/RL-2009-35, REV. 0

\begin{tabular}{|c|c|c|c|c|}
\hline \multicolumn{5}{|c|}{ D4-93c } \\
\hline Rec & & Agjusted & Temp & SC \\
\hline$\#$ & Date/Time & DateTime & $\alpha C$ & $\mu \mathrm{s} / \mathrm{am}$ \\
\hline 621 & $1 / 8 / 20086: 33$ & $8 / 8 / 20086: 33$ & 16.7 & 567.2 \\
\hline 62 & $1 / 820086: 35$ & $8 / 8 / 20086: 35$ & 16.7 & 561.8 \\
\hline 623 & $1 / 820086: 37$ & $8 / 200086: 37$ & 16.7 & 563.1 \\
\hline 624 & $1 / 8220086: 39$ & $8 / 8 / 20086: 39$ & 16.7 & 557.7 \\
\hline 625 & $1 / 8 / 20086: 41$ & $8 / 8 / 20086: 41$ & $\begin{array}{ll}16.7 \\
\end{array}$ & 557.7 \\
\hline 626 & $1 / 8 / 20086: 43$ & $8 / 8 / 20086: 43$ & 16.7 & 559.6 \\
\hline 627 & $1 / 820086: 45$ & $8 / 8 / 20086: 45$ & 16.7 & 564.6 \\
\hline 628 & $1 / 820086: 47$ & $8 / 8 / 20086: 47$ & 16.7 & 561.1 \\
\hline 629 & $1 / 8 / 20086: 49$ & $8 / 820086: 49$ & 16.7 & 558.9 \\
\hline 630 & $1 / 8 / 20086: 51$ & $8 / 8 / 20086: 51$ & 16.7 & 557.4 \\
\hline 631 & $1 / 8 / 20086: 53$ & $8 / 820086: 53$ & 16.7 & 556.9 \\
\hline 632 & $1 / 820086: 55$ & $8 / 8 / 20086: 55$ & 16.7 & 556.7 \\
\hline 633 & $1 / 8 / 20086: 57$ & $8 / 820086: 5$ & 96.7 & 556.5 \\
\hline 634 & $1 / 8 / 20086: 59$ & $8 / 8 / 20086: 59$ & 16.7 & 557.1 \\
\hline 635 & $1 / 8 / 20087: 01$ & $8 / 8 / 20087: 01$ & 16.7 & 559.7 \\
\hline 636 & $1 / 8 / 20087: 03$ & $8 / 8 / 20087: 03$ & 16.7 & 559.5 \\
\hline 637 & $1 / 8 / 20087: 05$ & $88 / 20087: 05$ & 16.7 & 561.2 \\
\hline 638 & 1/820087:07 & $8 / 820087: 07$ & 16.7 & 561.8 \\
\hline 639 & $1 / 820087: 09$ & $8 / 8 / 20087: 09$ & 16.7 & 565.2 \\
\hline 640 & 1/8/20087:11 & $8 / 8 / 20087: 11$ & 16.7 & 569 \\
\hline 641 & $1 / 8 / 20087: 13$ & $8 / 8 / 20087: 13$ & 16.7 & 563.8 \\
\hline 642 & $1 / 8 / 20087: 15$ & $8 / 8 / 20087: 15$ & 16.7 & 5629 \\
\hline 643 & $1 / 8 / 20087: 17$ & $8 / 8 / 20087: 17$ & 16.7 & 564.7 \\
\hline 644 & $1 / 8 / 20087: 19$ & $8 / 820087: 19$ & 16.7 & 561.6 \\
\hline 645 & $1 / 8 / 20087: 21$ & $8 / 8 / 20087: 21$ & $\begin{array}{ll}16.7 \\
\end{array}$ & 560.7 \\
\hline 646 & 1/8/20087:23 & $8 / 8 / 20087: 23$ & $\begin{array}{ll}16.7 \\
\end{array}$ & 561.4 \\
\hline 647 & $1 / 820087.25$ & $8 / 8 / 20087: 25$ & 16.7 & 560.9 \\
\hline 648 & $1 / 8 / 20087: 27$ & $8 / 8 / 20087: 27$ & 16.7 & 561.8 \\
\hline 649 & $1 / 8 / 20087: 29$ & $8 / 8 / 20087: 29$ & 16.7 & 558.9 \\
\hline 650 & $1 / 820087: 31$ & $8 / 8 / 20087: 31$ & 16.7 & 559.1 \\
\hline 651 & $1 / 8 / 20087: 33$ & $8 / 8 / 20087: 33$ & 16.7 & 559 \\
\hline 652 & $1 / 8 / 20087: 35$ & $88820087: 35$ & 16.7 & 558.8 \\
\hline 653 & $1 / 8 / 20087: 37$ & $8 / 8 / 20087: 37$ & 16.7 & 558.4 \\
\hline 654 & $1 / 8 / 20087: 39$ & $8 / 8 / 20087: 39$ & 16.7 & 559.9 \\
\hline 655 & $1 / 8 / 20087: 41$ & $8 / 8 / 20087: 41$ & 16.7 & 560 \\
\hline 666 & $1 / 8 / 20087: 43$ & $8 / 8 / 20087: 43$ & 16.7 & 558.2 \\
\hline 657 & 1/8/20087:45 & $8 / 820087: 45$ & 16.7 & 557.9 \\
\hline 658 & $1 / 8 / 20087: 47$ & $8 / 8 / 20087: 47$ & 16.7 & 557.9 \\
\hline 659 & $1 / 8 / 20087: 49$ & $8 / 8 / 20087: 49$ & 16.7 & 558 \\
\hline 660 & $1 / 8 / 20087: 51$ & $8 / 8 / 20087: 51$ & 16.7 & 557.7 \\
\hline 661 & $1 / 820087: 53$ & $8 / 8 / 20087: 53$ & 16.7 & 557.6 \\
\hline 662 & $1 / 8 / 20087: 56$ & $8 / 8 / 20087: 55$ & 16.7 & 558.5 \\
\hline 663 & $1 / 8 / 20087: 57$ & $8 / 8 / 20087: 57$ & 16.7 & 558.3 \\
\hline 664 & $1 / 8 / 20087: 59$ & $8 / 8 / 20087: 59$ & 16.7 & 558.3 \\
\hline 665 & $1 / 820088: 01$ & $8 / 8 / 20088: 01$ & 16.7 & 558.4 \\
\hline 666 & $1 / 8220088: 03$ & $8 / 8 / 20088: 03$ & 16.7 & 559.3 \\
\hline 667 & $1 / 8 / 20088: 05$ & $8 / 8 / 20088: 05$ & 16.7 & 558.5 \\
\hline 668 & 1/8/20088:07 & $8 / 8 / 20088: 07$ & 16.7 & 558.2 \\
\hline 669 & $1 / 8 / 20088: 09$ & $8 / 8 / 20088: 09$ & 16.7 & 558.1 \\
\hline 670 & $1 / 8 / 20088: 11$ & $8 / 8 / 20088: 11$ & 16.7 & 558.2 \\
\hline 671 & $1 / 8 / 20088: 13$ & $8 / 8 / 20088: 13$ & 16.7 & 560 \\
\hline 672 & 1/8/20088:15 & $8 / 8 / 20088: 15$ & 16.7 & 561 \\
\hline 673 & 1/8/20088:17 & $8 / 8 / 20088: 17$ & 16.7 & 560 \\
\hline 674 & 1/8/20088:19 & $8 / 8 / 20088: 19$ & 16.7 & 559.8 \\
\hline 675 & $1 / 8 / 20088: 21$ & $8 / 8 / 20088: 21$ & 16.7 & 560.5 \\
\hline 676 & $1 / 8 / 20088: 23$ & $8 / 8 / 20088: 23$ & 16.7 & 559.9 \\
\hline 677 & $1 / 820088: 25$ & $8 / 8 / 20088: 25$ & 16.7 & 558.9 \\
\hline 678 & $1 / 8 / 20088: 27$ & $8 / 8 / 20088: 27$ & 16.7 & 558.7 \\
\hline 679 & $1 / 8 / 20088: 29$ & $8 / 8 / 20088: 29$ & 16.7 & 557.3 \\
\hline 680 & $1 / 8 / 20088: 31$ & $8 / 8 / 20088: 31$ & 16.7 & 557.3 \\
\hline 681 & $1 / 8 / 20088: 33$ & $8 / 820088: 33$ & 16.7 & 558.7 \\
\hline 682 & 1/8/20088:35 & $8 / 8 / 20088: 35$ & 16.7 & 558.9 \\
\hline 683 & $1 / 8 / 20088: 37$ & $8 / 8 / 20088: 37$ & 16.7 & 559 \\
\hline 684 & $1 / 8 / 20088: 39$ & $8 / 820088: 39$ & 16.7 & 559.2 \\
\hline 685 & $1 / 8 / 20088: 41$ & $8 / 8 / 20088: 41$ & 16.7 & 560.4 \\
\hline 686 & $1 / 8 / 20088: 43$ & $8 / 8 / 20088: 43$ & 16.7 & 557.7 \\
\hline 687 & $1 / 8 / 20088: 45$ & $8 / 8 / 20088: 45$ & 16.7 & 558.6 \\
\hline 688 & $1 / 8 / 20088: 47$ & 8/8/2008 8:47 & 16.7 & 569.2 \\
\hline 689 & $1 / 8 / 20088: 49$ & $8 / 8 / 20088: 49$ & 16.7 & 557.3 \\
\hline
\end{tabular}

\begin{tabular}{|c|c|c|c|c|}
\hline \multicolumn{5}{|c|}{$D 4-93 \mathrm{C}$} \\
\hline $\operatorname{Rec}$ & & Adiusted & Temp & $\mathrm{SC}$ \\
\hline$\#$ & DateTime & DaterTime & $\infty$ & $\mu \mathrm{S} / \mathrm{cm}$ \\
\hline 690 & $1 / 8 / 20088: 51$ & $8 / 8 / 20088: 51$ & 16.7 & 557 \\
\hline 691 & $1 / 8 / 20088: 53$ & $8 / 8 / 20088: 53$ & 16.7 & 557.5 \\
\hline 692 & $1 / 8 / 20088.55$ & $8 / 8 / 20088: 55$ & 16.7 & 558.7 \\
\hline 693 & $1 / 8 / 20088: 57$ & 8/8:2008 8:57 & 16.7 & 559.7 \\
\hline 694 & $1 / 8 / 20088: 59$ & $8 / 8 / 20088: 50$ & 16.7 & 560.4 \\
\hline 695 & $1 / 8 / 20089: 01$ & $8 / 8 / 20089.01$ & 16.7 & 558.9 \\
\hline 696 & $1 / 8 / 20089: 03$ & $8 / 8 / 20089: 03$ & 16.7 & 559.5 \\
\hline 697 & $1 / 8 / 20089: 05$ & $8 / 8 / 20089.05$ & 16.7 & 559.4 \\
\hline 698 & $1 / 8 / 20089: 07$ & $8 / 8 / 20089.07$ & 16.7 & 558.7 \\
\hline 699 & $1 / 8 / 20089.09$ & $8 / 8 / 20089.09$ & 16.7 & 559.6 \\
\hline 700 & $1 / 8 / 20089.11$ & $8 / 8 / 20089.11$ & 16.7 & 5627 \\
\hline 701 & $\overline{1 / 8 / 20089.13}$ & $8 / 8 / 20089.13$ & 16.7 & 563.9 \\
\hline 702 & $1 / 820089.15$ & $8 / 8 / 20089.15$ & 16.7 & 562 \\
\hline 703 & $1 / 8 / 20089.17$ & $8 / 8 / 20089.17$ & 16.7 & 560.6 \\
\hline 704 & $1 / 8 / 20089.19$ & $8 / 8 / 20089: 19$ & 16.7 & 559.6 \\
\hline 705 & $1 / 8 / 20089.21$ & $8 / 8220089.21$ & 16.7 & 561.9 \\
\hline 706 & $1 / 8 / 20089.23$ & $8 / 8 / 20089.23$ & 16.7 & 561.4 \\
\hline 707 & $1 / 8 / 20089.25$ & $8 / 8 / 20089.25$ & 16.7 & 561 \\
\hline 708 & $1 / 8 / 20089.27$ & $8 / 8 / 20089.27$ & 16.7 & 561 \\
\hline 709 & $1 / 8 / 20089.29$ & $8 / 8 / 20089.29$ & 16.7 & 560.9 \\
\hline 710 & $1 / 8 / 20089.31$ & $8 / 8 / 20089.31$ & 16.7 & 561.4 \\
\hline 711 & $1 / 8 / 20089: 33$ & $8 / 8 / 20089: 33$ & 16.7 & 562.2 \\
\hline 712 & $1 / 8 / 20089.35$ & $8 / 8 / 20089: 35$ & 16.7 & 5625 \\
\hline 713 & $1 / 8 / 20089.37$ & $8 / 8 / 20089.37$ & 16.7 & 563.9 \\
\hline 714 & $1 / 8 / 20089.39$ & $8 / 8 / 20089.39$ & 16.7 & 564 \\
\hline 715 & $1 / 8 / 20089.41$ & $8 / 8 / 20089.41$ & 16.7 & 5623 \\
\hline 716 & $1 / 8 / 20089.43$ & $8 / 8 / 20089.43$ & \begin{tabular}{ll|}
16.7 \\
\end{tabular} & 563 \\
\hline 717 & $1 / 8 / 20089.45$ & $8 / 8 / 20089: 45$ & 16.7 & 563.4 \\
\hline 718 & $1 / 8 / 20089: 47$ & $8 / 8 / 20089: 47$ & 16.7 & 563.6 \\
\hline 719 & $1 / 8 / 20089.49$ & $8 / 8 / 20089.49$ & 16.7 & 563.8 \\
\hline 720 & $1 / 8 / 20089.51$ & $8 / 8 / 20089.51$ & 16.7. & 562 \\
\hline 721 & $1 / 8 / 20089.53$ & $8 / 8 / 20089.53$ & 16.7 & 5628 \\
\hline 722 & $1 / 8 / 20089.55$ & $8 / 8 / 20089.55$ & 16.7 & 5623 \\
\hline 723 & $1 / 8 / 20089.57$ & $8 / 8 / 20089: 57$ & 16.7 & 561.7 \\
\hline 724 & $1 / 8 / 20089.59$ & $8 / 8 / 20089.59$ & 16.7 & 562 \\
\hline 725 & $1 / 8 / 200810: 01$ & $8 / 8 / 2008$ 10:01 & 16.7 & 561.8 \\
\hline 726 & 1/8/2008 10:03 & $8 / 8200810: 03$ & 16.7 & 562.1 \\
\hline 727 & $1 / 8200810: 05$ & $8 / 8 / 200810: 05$ & 16.7 & 561.6 \\
\hline 728 & $1 / 8 / 200810.07$ & $8 / 8 / 2008$ 10:07 & 16.7 & 561 \\
\hline 729 & $1 / 8 / 200810: 09$ & $8 / 8 / 200810: 09$ & 16.7 & 559.6 \\
\hline 730 & $1 / 8 / 200810: 11$ & $8 / 8 / 2008$ 10:11 & 16.7 & 560.5 \\
\hline 731 & $1 / 8 / 200810: 13$ & $8 / 8200810: 13$ & 16.7 & 559.9 \\
\hline 732 & $1 / 8 / 200810.15$ & $8 / 8 / 200810: 15$ & 16.7 & 560.4 \\
\hline 733 & $1 / 8 / 200810.17$ & $8 / 8 / 2008$ 10:17 & 16.7 & 560.7 \\
\hline 734 & $\cdot 1 / 8 / 200810: 19$ & $8 / 8 / 2008$ 10:19 & 16.7 & 559.9 \\
\hline 735 & $1 / 8 / 200810: 21$ & $8 / 8 / 2008$ 10:21 & 16.7 & 558.7 \\
\hline 736 & $1 / 8 / 200810.23$ & $8 / 8 / 200810: 23$ & 16.7 & 559 \\
\hline 737 & $1 / 8 / 200810.25$ & $8 / 8 / 2008$ 10.25 & 16.7 & 559.8 \\
\hline 738 & $1 / 8 / 200810.27$ & $8 / 8 / 2008$ 10:27 & 16.7 & 560.4 \\
\hline 739 & $1 / 8 / 200810: 29$ & $8 / 8 / 2008$ 10:20 & 16.7 & 559.8 \\
\hline 740 & $1 / 8 / 200810: 31$ & $88 / 200810: 31$ & 16.7 & 560.3 \\
\hline 741 & $1 / 8 / 200810: 33$ & $8 / 8 / 200810: 33$ & 16.7 & 560.4 \\
\hline 742 & $1 / 8 / 200810: 35$ & $8 / 8 / 2008$ 10:35 & 16.7 & 560.4 \\
\hline 743 & $1 / 8 / 2008$ 10:37 & $8 / 8 / 2008$ 10.37 & 16.7 & 560.7 \\
\hline 744 & $1 / 8 / 200810: 39$ & $8 / 8 / 2008$ 10:39 & 16.7 & 559.8 \\
\hline 745 & $1 / 8 / 200810: 41$ & $8 / 8 / 200810: 41$ & 16.7 & 560.4 \\
\hline 746 & $1 / 8 / 200810: 43$ & $8 / 8200810.43$ & 16.7 & 560.2 \\
\hline 747 & $1 / 8 / 200810: 45$ & $8 / 8 / 2008$ 10:45 & 16.7 & 560.4 \\
\hline 748 & $1 / 8 / 200810: 47$ & $8 / 8 / 2008$ 10:47 & 16.7 & 560.7 \\
\hline 749 & $1 / 8 / 200810: 49$ & $8 / 8 / 200810: 49$ & 16.7 & 560.6 \\
\hline 750 & $1 / 8 / 200810: 51$ & $8 / 8 / 200810.51$ & 16.7 & 560.4 \\
\hline 751 & $1 / 8 / 200810.53$ & $8 / 8200810.53$ & 16.7 & 559.7 \\
\hline 752 & $1 / 8 / 200810.55$ & $8 / 8 / 2008$ 10.55 & 16.7 & 560.3 \\
\hline 753 & $1 / 8 / 200810: 57$ & $8 / 8 / 200810.57$ & 16.7 & 560.5 \\
\hline 754 & $1 / 8 / 200810: 59$ & $8 / 8 / 2008$ 10:59 & 16.7 & 560.5 \\
\hline 755 & $1 / 8 / 2008$ 11:01 & $8 / 8 / 2008$ 11:01 & 16.7 & 560.5 \\
\hline 756 & $1 / 8 / 200811: 03$ & $8 / 8 / 200811: 03$ & 16.7 & 559.9 \\
\hline 757 & $1 / 8 / 2008$ 11:05 & $8 / 8 / 2008$ 11:05 & 16.7 & 559.3 \\
\hline 758 & $1 / 8 / 2008$ 11:07 & 8/8/2008 11:07 & 16.7 & 559.3 \\
\hline
\end{tabular}

\begin{tabular}{|c|c|c|c|c|}
\hline \multicolumn{5}{|c|}{ D493C } \\
\hline $\operatorname{Rec}$ & & Adjusted & Termp & $\mathrm{SC}$ \\
\hline$\#$ & DaterTime & DaterTime & $\alpha C$ & $\mu \mathrm{S} / \mathrm{cm}$ \\
\hline 750 & 1/8/2008 11:09 & $8 / 8 / 200811: 09$ & 16.7 & 559.5 \\
\hline 760 & $1 / 8 / 200811: 11$ & $8 / 8 / 2008+1: 11$ & 16.7 & 560.1 \\
\hline 761 & 1/8/2008 11:13 & $8 / 8 / 2008$ 11:13 & 16.7 & 560.5 \\
\hline $7 \sqrt{2}$ & 1/8/2008 11:15 & $8 / 8 / 2008$ 11:15 & 16.7 & 561.4 \\
\hline $7 \sqrt{6}$ & 1/8/2008 11:17 & $8 / 8 / 2008$ 11:17 & 16.7 & 561.3 \\
\hline 764 & 1/8/2008 11:19 & $8 / 8 / 2008$ 11:19 & 16.7 & 560.9 \\
\hline 765 & $1 / 8 / 2008$ 11:21 & $8 / 8 / 2008$ 11:21 & 16.7 & 560.8 \\
\hline 766 & $1 / 8 / 200811: 23$ & $8 / 8 / 200811: 23$ & 16.7 & 561.9 \\
\hline 767 & 1/8/2008 11:25 & $8 / 8 / 200811: 25$ & 16.7 & 561.8 \\
\hline 768 & $1 / 8 / 200811: 27$ & $8 / 8 / 200811: 27$ & 16.7 & 561.1 \\
\hline 769 & 1/8/2008 11:29 & $8 / 8 / 2008$ 11:29 & 16.7 & 560.7 \\
\hline 770 & 1/8/2008 11:31 & $8 / 8 / 2008$ 11:31 & 16.7 & 561.7 \\
\hline 771 & $1 / 8 / 200811: 33$ & $8 / 8 / 2008$ 11:33 & \begin{tabular}{l|l|}
16.7 \\
\end{tabular} & 561.3 \\
\hline 772 & 1/8/2008 11:35 & $8 / 8 / 2008$ 11:35 & 16.7 & 561.5 \\
\hline 773 & $1 / 8 / 200811: 37$ & $8 / 8 / 2008$ 11:37 & 16.7 & 560.4 \\
\hline 774 & $1 / 8 / 200811: 39$ & $8 / 8 / 200811: 39$ & 16.7 & 559.5 \\
\hline 775 & $1 / 8 / 200811: 41$ & $8 / 8 / 2008$ 11:41 & 16.7 & 559.9 \\
\hline 776 & 1/8/2008 11:43 & $8 / 8 / 200811: 43$ & 16.7 & 560.6 \\
\hline $7 \pi$ & 1/8/2008 11:45 & $8 / 8 / 2008$ 11:45 & 16.7 & 560.9 \\
\hline 778 & 1/8/2008 11:47 & $8 / 8 / 2008$ 11:47 & \begin{tabular}{l|l|}
16.7 \\
\end{tabular} & 560.9 \\
\hline 779 & $1 / 8 / 2008$ 11:49 & $8 / 8 / 2008$ 11:49 & 16.7 & 561.7 \\
\hline 780 & $1 / 8 / 200811: 51$ & $8 / 8 / 200811: 51$ & 16.7 & 561.3 \\
\hline 781 & $1 / 8 / 200811: 53$ & $8 / 8 / 200811: 53$ & 16.7 & 559.9 \\
\hline 782 & $1 / 8 / 200811: 55$ & $8 / 8 / 200811: 55$ & 16.7 & 560.5 \\
\hline 783 & 1/8/2008 11:57 & $8 / 8 / 2008$ 11:57 & 16.7 & 561.1 \\
\hline 784 & 1/8/2008 11:59 & $8 / 8 / 2008$ 11:59 & 16.7 & 560.6 \\
\hline 785 & 1/8/2008 1201 & $8 / 8 / 200812: 01$ & \begin{tabular}{c|c|}
16.7 \\
\end{tabular} & 558.5 \\
\hline 786 & $1 / 8 / 20081203$ & $8 / 8 / 200812: 03$ & 16.7 & 559.3 \\
\hline 787 & $1 / 8 / 20081205$ & $8 / 8 / 20081205$ & 16.7 & 560 \\
\hline 788 & $1 / 8 / 200812: 07$ & $8 / 8 / 200812: 07$ & 16.7 & 560.9 \\
\hline 789 & 1/8/2008 12:09 & $8 / 8 / 20081209$ & \begin{tabular}{l|l|}
16.7 \\
\end{tabular} & 562.4 \\
\hline 790 & $1 / 8 / 200812: 11$ & $8 / 8 / 200812: 11$ & 16.7 & 561.2 \\
\hline 791 & $1 / 8 / 20081213$ & $8 / 8 / 20081213$ & 16.7 & 561.5 \\
\hline 792 & $1 / 8 / 200812: 15$ & $8 / 8 / 200812: 15$ & 16.7 & 561.7 \\
\hline 793 & $1 / 8 / 200812: 17$ & $8 / 8 / 200812: 17$ & 16.7 & 560.7 \\
\hline 794 & $1 / 8 / 20081219$ & $8 / 8 / 200812: 19$ & 16.7 & 561 \\
\hline 795 & $1 / 8 / 20081221$ & $8 / 8 / 2008$ 12:21 & 16.7 & 561.8 \\
\hline 796 & $1 / 8 / 20081223$ & $8 / 8 / 20081223$ & 16.7 & 562.4 \\
\hline 797 & $1 / 8 / 20081225$ & $8 / 8 / 20081225$ & 16.7 & 561.5 \\
\hline 798 & $1 / 8 / 2008$ 12:27 & $8 / 8 / 200812227$ & 16.7 & 5625 \\
\hline 799 & $1 / 8 / 20081220$ & $8 / 8 / 20081229$ & 16.7 & 562.3 \\
\hline 800 & $1 / 8 / 200812331$ & $8 / 8 / 2008$ 12:31 & 16.7 & 561.5 \\
\hline 801 & 1/8/2008 1233 & $8 / 8 / 20081233$ & 16.7 & 560.8 \\
\hline 802 & $1 / 8 / 200812335$ & $8 / 8 / 200812: 35$ & 16.7 & 560.7 \\
\hline 803 & $1 / 8 / 200812337$ & $8 / 8 / 200812337$ & 16.7 & 561.6 \\
\hline 804 & $1 / 8 / 200812 ; 39$ & $8 / 8 / 200812: 39$ & 16.7 & 561.9 \\
\hline 805 & $1 / 8 / 20081241$ & $8 / 8 / 200812: 41$ & 16.7 & 561.3 \\
\hline 806 & $1 / 8 / 20081243$ & $8 / 8 / 20081243$ & 16.7 & 560.8 \\
\hline 807 & $1 / 8 / 20081245$ & $8 / 8 / 20081245$ & 16.7 & 559.9 \\
\hline 808 & $1 / 8 / 200812477$ & $8 / 8 / 200812: 47$ & 16.7 & 558.5 \\
\hline 809 & $1 / 8 / 20081249$ & $8 / 82200812449$ & 16.7 & 558.8 \\
\hline 810 & $1 / 8 / 200812: 51$ & $8 / 820081251$ & 16.7 & 561.4 \\
\hline 811 & $1 / 8 / 20081253$ & $8 / 8 / 20081253$ & 16.7 & 561.4 \\
\hline 812 & $1 / 8 / 20081255$ & $8 / 8 / 200812-55$ & 16.7 & 561.4 \\
\hline 813 & 1/8/2008 12:57 & $8 / 8 / 2008$ 12:57 & 16.7 & 561.2 \\
\hline 814 & $1 / 8 / 20081259$ & $8 / 8 / 20081259$ & 16.7 & 561.1 \\
\hline 815 & 1/8/2008 13:01 & $8 / 8 / 2008$ 13:01 & \begin{tabular}{|c|}
16.7 \\
\end{tabular} & 560.6 \\
\hline 816 & 1/8/2008 13:03 & $8 / 8 / 200813: 03$ & 16.7 & 560.7 \\
\hline 817 & $1 / 8 / 2008$ 13:05 & $8 / 8 / 2008+3: 05$ & \begin{tabular}{|c|}
16.7 \\
\end{tabular} & 560.2 \\
\hline 818 & $1 / 8 / 2008$ 13:07 & $8 / 8 / 2008$ 13:07 & 16.7 & 559.7 \\
\hline 819 & $1 / 8 / 200813: 09$ & $8 / 8 / 2008$ 13:09 & 16.7 & 559.4 \\
\hline 820 & 1/8/2008 13:11 & $8 / 8 / 2008$ 13:11 & \begin{tabular}{l|l|}
16.7 \\
\end{tabular} & 5622 \\
\hline 821 & 1/8/2008 13:13 & $8 / 8 / 2008$ 13:13 & 16.7 & 562 \\
\hline 822 & 1/8/2008 13:15 & $8 / 8 / 2008$ १3:15 & 16.7 & 560.8 \\
\hline 823 & $1 / 8 / 2008$ 13:17 & $8 / 8 / 2008$ 13:17 & 16.7 & 560.6 \\
\hline 824 & 1/8/2008 13:19 & 8/8/2008 13:19 & 16.7 & 560.7 \\
\hline 825 & $1 / 8 / 2008$ 13:21 & $8 / 8 / 2008$ 13:21 & 16.7 & 560.9 \\
\hline 826 & 1/8/2008 13:23 & $8 / 8 / 200813: 23$ & 16.7 & 561.5 \\
\hline 827 & 1/8/2008 13:25 & $8 / 8 / 2008$ 13:25 & 16.7 & 561.1 \\
\hline
\end{tabular}




\begin{tabular}{|c|c|c|c|c|}
\hline \multicolumn{5}{|c|}{ D4-93c } \\
\hline$R A C$ & & Adusted & Temp & $\mathrm{SC}$ \\
\hline \# & Date/Time & Date/Time & $\alpha C$ & $\mu \mathrm{S} / \mathrm{am}$ \\
\hline 828 & 1/8/2008 13:27 & $8 / 8200813: 27$ & 16.7 & 559.7 \\
\hline 829 & $1 / 8200813: 29$ & $8 / 200813: 29$ & 16.7 & 559.1 \\
\hline 830 & $1 / 8 / 200813: 31$ & $8 / 8 / 200813: 31$ & 16.7 & 559.4 \\
\hline 831 & 1/8/2008 13:33 & $8 / 8 / 200813: 33$ & 16.7 & 561.1 \\
\hline 832 & $1 / 8 / 200813: 35$ & $8 / 8 / 200813: 35$ & 16.7 & 561.5 \\
\hline 833 & $1 / 8 / 200813: 37$ & $8 / 8 / 200813: 37$ & 16.7 & 561.5 \\
\hline 834 & 1/8/2008 13:39 & $8 / 8 / 200813: 39$ & 16.7 & 560.4 \\
\hline 835 & $1 / 8 / 200813: 41$ & $8 / 8 / 200813: 41$ & 16.7 & 559.6 \\
\hline 836 & $1 / 8 / 200813: 43$ & $8 / 8 / 200813: 43$ & 16.7 & 560.2 \\
\hline 837 & $1 / 8 / 200813: 45$ & $8 / 8 / 200813: 45$ & 16.7 & 561.9 \\
\hline 838 & $1 / 8 / 200813: 47$ & $8 / 8 / 200813: 47$ & 16.7 & 561.8 \\
\hline 839 & $1 / 8 / 200813: 49$ & $8 / 2000813: 49$ & 16.7 & 561.4 \\
\hline 840 & $1 / 8 / 200813.51$ & $8 / 8 / 2008$ 13:51 & 16.7 & 561.7 \\
\hline 841 & $1 / 8 / 2008$ 13:53 & $8 / 8 / 200813: 53$ & 16.7 & 559.7 \\
\hline 842 & $1 / 8 / 200813: 55$ & $8 / 8 / 200813: 55$ & 16.7 & 559.3 \\
\hline 843 & $1 / 8 / 200813: 57$ & $8 / 8 / 200813: 57$ & 16.7 & 559.8 \\
\hline 844 & 1/8/2008 13:59 & $8 / 8200813: 59$ & 16.7 & 561 \\
\hline 845 & $1 / 8 / 200814: 01$ & $8 / 8200814: 01$ & 16.7 & 560.3 \\
\hline 846 & $1 / 8 / 200814: 03$ & 8/8/2008 14:03 & 16.7 & 561 \\
\hline 847 & $1 / 8 / 200814: 05$ & $8 / 8 / 200814: 05$ & 16.7 & 561.5 \\
\hline 848 & $1 / 8 / 200814: 07$ & 8/8/2008 14:07 & 16.7 & 559.5 \\
\hline 849 & $1 / 8 / 200814: 09$ & $8 / 8 / 200814: 09$ & 16.7 & 558.9 \\
\hline 850 & $1 / 8 / 2008$ 14:11 & $8 / 8 / 200814: 11$ & 16.7 & 559.6 \\
\hline 851 & $1 / 8 / 200814: 13$ & $8 / 8 / 200814: 13$ & 16.7 & 560.4 \\
\hline 852 & $1 / 8 / 200814: 15$ & $8 / 8 / 200814: 15$ & 16.7 & 561.1 \\
\hline 853 & $1 / 8 / 200814: 17$ & $8 / 8 / 200814: 17$ & 16.7 & 560.3 \\
\hline 854 & $1 / 8 / 200814: 19$ & $8 / 8 / 200814: 19$ & 16.7 & 559.9 \\
\hline 855 & $1 / 8 / 200814: 21$ & $8 / 8 / 200814: 21$ & 16.7 & 560.2 \\
\hline 856 & $1 / 8 / 200814: 23$ & $8 / 8 / 200814: 23$ & 16.7 & 560.2 \\
\hline 857 & $1 / 8 / 200814: 25$ & $8 / 8 / 200814: 25$ & 16.7 & 559.6 \\
\hline 858 & $1 / 8 / 200814: 27$ & $8 / 8 / 2008$ 14:27 & 16.7 & 560.5 \\
\hline 859 & $1 / 8 / 200814: 29$ & $8 / 8200814: 29$ & 16.7 & 5021 \\
\hline 860 & $1 / 8 / 200814: 31$ & $8 / 8 / 200814: 31$ & 16.7 & 561.5 \\
\hline 861 & $1 / 8 / 200814: 33$ & $8 / 8 / 200814: 33$ & 16.7 & 559.9 \\
\hline 82 & $1 / 8 / 200814: 35$ & $8 / 8 / 2008$ 14:35 & 16.7 & 560.7 \\
\hline 863 & 1/8/2008 14:37 & $8 / 8 / 2008$ 14:37 & 16.7 & 561.5 \\
\hline 864 & $1 / 8 / 200814: 39$ & $8 / 8 / 200814: 39$ & 16.7 & 5624 \\
\hline 865 & $1 / 8 / 200814: 41$ & $8 / 8 / 200814: 41$ & 16.7 & 561.4 \\
\hline 866 & $1 / 8 / 200814: 43$ & $8 / 8 / 200814: 43$ & 16.7 & 5625 \\
\hline 867 & $1 / 8 / 200814: 45$ & $8 / 8 / 200814: 45$ & 16.7 & 563.4 \\
\hline 868 & $1 / 8 / 200814: 47$ & $8 / 8200814: 47$ & 16.7 & 5623 \\
\hline 869 & $1 / 8 / 200814: 49$ & $8 / 8 / 200814: 49$ & 16.7 & 561.7 \\
\hline 870 & $1 / 8 / 200814: 51$ & $8 / 8 / 2008$ 14:51 & 16.7 & 561.9 \\
\hline 871 & $1 / 8 / 200814: 53$ & $8 / 8 / 200814: 53$ & 16.7 & 561.9 \\
\hline 872 & $1 / 8 / 200814: 55$ & $8 / 8 / 200814: 55$ & 16.7 & 560.7 \\
\hline 873 & $1 / 8 / 200814: 57$ & $8 / 8 / 200814: 57$ & 16.7 & 560.7 \\
\hline 874 & $1 / 8 / 200814: 50$ & $8 / 8 / 200814: 59$ & 16.7 & 560.8 \\
\hline 875 & $1 / 8 / 200815: 01$ & $8 / 8 / 2008$ 15:01 & 16.7 & 562 \\
\hline 876 & 1/8/2008 15:03 & $8 / 8 / 200815: 03$ & 16.7 & 561.7 \\
\hline 877 & $1 / 8 / 200815: 05$ & $8 / 8 / 2008$ 15:05 & 16.7 & 561.1 \\
\hline 878 & $1 / 8 / 200815: 07$ & $8 / 8 / 200815: 07$ & 16.7 & 561.7 \\
\hline 879 & $1 / 8 / 200815: 09$ & $8 / 8 / 200815: 09$ & 16.7 & 560.9 \\
\hline 880 & $1 / 8 / 200815: 11$ & $8 / 82008$ 15:11 & 16.7 & 561.3 \\
\hline 881 & $1 / 8 / 200815: 13$ & $8 / 82008$ 15:13 & 16.7 & 561.5 \\
\hline 882 & 1/8/2008 15:15 & $8 / 8 / 200815: 15$ & 16.7 & 561.8 \\
\hline 883 & 1/8/2008 15:17 & $8 / 8 / 200815: 17$ & 16.7 & 561.4 \\
\hline 884 & $1 / 8 / 200815: 19$ & $8 / 8 / 200815: 19$ & 16.7 & 561.2 \\
\hline 885 & $1 / 8 / 200815: 21$ & $8 / 8200815: 21$ & 16.7 & 5626 \\
\hline 886 & $1 / 8 / 200815: 23$ & $8 / 8 / 200815: 23$ & 16.7 & 581.7 \\
\hline 887 & $1 / 8 / 200815: 25$ & $8 / 8 / 2008$ 15:25 & 16.7 & 5723 \\
\hline 888 & $1 / 8 / 200815: 27$ & $8 / 8 / 200815: 27$ & 16.7 & 563.4 \\
\hline 889 & 1/8/2008 15:29 & $8 / 8200815: 29$ & 16.7 & 561.1 \\
\hline 890 & $1 / 8 / 200815: 31$ & $8 / 8 / 200815: 31$ & 16.7 & 559.7 \\
\hline 891 & $1 / 8 / 200815: 33$ & $8 / 8 / 200815: 33$ & 16.7 & 559.4 \\
\hline 892 & $1 / 8 / 200815: 35$ & $8 / 8 / 200815: 35$ & 16.7 & 559.3 \\
\hline 893 & $1 / 8 / 200815: 37$ & $8 / 8 / 200815-37$ & 16.7 & 559.5 \\
\hline 894 & 1/8/2008 15:39 & 8/8/2008 15:39 & 16.7 & 559.6 \\
\hline 895 & $1 / 8 / 200815: 41$ & $8 / 8 / 200815: 41$ & 16.7 & 560.1 \\
\hline 896 & $1 / 8 / 200815: 43$ & $8 / 200815: 43$ & 16.7 & 560 \\
\hline
\end{tabular}

\begin{tabular}{|c|c|c|c|c|}
\hline \multicolumn{5}{|c|}{ D493c } \\
\hline $\mathrm{ReC}$ & & Aciusted & Temp & $\mathrm{SC}$ \\
\hline$\#$ & Dete/Time & DaterTime & $\alpha C$ & HSIom \\
\hline 897 & $1 / 8 / 200815: 45$ & $8 / 8 / 200815: 45$ & 16.7 & 560.3 \\
\hline 898 & $1 / 8 / 200815: 47$ & $8 / 8200815: 47$ & 16.7 & 560.5 \\
\hline 899 & $1 / 8200815: 49$ & $8 / 8 / 200815: 49$ & 16.7 & 559.9 \\
\hline 900 & $1 / 8 / 200815: 51$ & $8 / 8 / 200815.51$ & 16.7 & 559.5 \\
\hline 901 & $1 / 8 / 200815: 53$ & $8 / 8 / 200815: 53$ & 16.7 & 558.9 \\
\hline 902 & $1 / 8 / 200815: 55$ & $8 / 8 / 200815: 55$ & 16.7 & 559.8 \\
\hline 903 & $1 / 8 / 200815: 57$ & $8 / 8 / 200815: 57$ & 16.7 & 559.4 \\
\hline 904 & $1 / 8 / 200815: 59$ & $8 / 8200815: 59$ & 16.7 & 559.5 \\
\hline 905 & $1 / 8 / 200816: 01$ & $8 / 8 / 200816: 01$ & 16.7 & 559.3 \\
\hline 906 & $1 / 8 / 200816: 03$ & $8 / 8 / 200816: 03$ & 16.7 & 559.3 \\
\hline 907 & $1 / 8 / 200816: 05$ & $8 / 8 / 200816: 05$ & 16.7 & 559.4 \\
\hline 908 & $1 / 8 / 200816: 07$ & $8 / 8 / 200816: 07$ & 16.7 & 558.9 \\
\hline 909 & $1 / 8 / 200816: 09$ & $8 / 8200816: 09$ & 16.7 & 559.2 \\
\hline 910 & $1 / 8200816: 11$ & $8 / 8 / 200816: 11$ & 16.7 & 558.3 \\
\hline 911 & $1 / 8 / 200816: 13$ & $8 / 8200816: 13$ & 16.7 & 555.1 \\
\hline 912 & 1/82008 16:15 & $8 / 8 / 200816: 15$ & 16.7 & 565.1 \\
\hline 913 & $1 / 8 / 200816: 17$ & $8 / 8 / 20081617$ & 16.7 & 557.3 \\
\hline 914 & $1 / 8 / 200816: 19$ & $8 / 8 / 200816: 19$ & 16.7 & 557.5 \\
\hline 915 & $1 / 8 / 200816: 21$ & $8 / 8 / 200816: 21$ & 16.7 & 556.7 \\
\hline 916 & $1 / 8 / 20081623$ & $8 / 8 / 20081623$ & 16.7 & 544.3 \\
\hline 917 & $1 / 8 / 20081625$ & $8 / 8 / 200816: 25$ & 16.7 & 543.2 \\
\hline 918 & $1 / 8 / 200816: 27$ & $8 / 8 / 200816: 27$ & 16.7 & 537.5 \\
\hline 919 & $1 / 8 / 200816: 29$ & $8 / 8 / 200816: 29$ & 16.7 & 536.1 \\
\hline 920 & $1 / 8 / 200816: 31$ & $8 / 8 / 200816: 31$ & 16.7 & 536.6 \\
\hline 921 & 1/8/2008 16:33 & $8 / 8 / 200816: 33$ & 16.7 & 536.4 \\
\hline 922 & $1 / 8 / 200816: 35$ & $8 / 8 / 200816: 35$ & 16.7 & 537.8 \\
\hline 923 & $1 / 8 / 200816: 37$ & $8 / 8 / 200816: 37$ & 16.7 & 542.1 \\
\hline 924 & $1 / 8 / 200816: 39$ & $8 / 8 / 200816: 39$ & 16.7 & 541.5 \\
\hline 925 & $1 / 8200816: 41$ & $88200816: 41$ & 16.7 & 545.6 \\
\hline 926 & $1 / 8 / 200816: 43$ & $88 / 200816.43$ & 16.7 & 5423 \\
\hline 927 & $1 / 8 / 200816: 45$ & $8 / 8 / 200816: 45$ & 16.7 & 543.7 \\
\hline 928 & $1 / 8 / 200816: 47$ & $8 / 8 / 200816: 47$ & 16.7 & 5428 \\
\hline 929 & $1 / 8 / 200816: 49$ & $8 / 8 / 200816: 49$ & 16.7 & 5428 \\
\hline 930 & $1 / 8 / 200816: 51$ & $8 / 8 / 200816: 51$ & 16.7 & 543.8 \\
\hline 931 & $1 / 8 / 200816: 53$ & $8 / 8 / 200816: 53$ & 16.7 & 542.5 \\
\hline 932 & $1 / 8 / 200816: 55$ & $8 / 8 / 200816: 55$ & 16.7 & 541.9 \\
\hline 933 & $1 / 8 / 200816.57$ & $8 / 8 / 200816: 57$ & 16.7 & 543 \\
\hline 934 & $1 / 8 / 200816: 59$ & $8 / 8 / 200816: 59$ & 16.7 & 540.4 \\
\hline 935 & $1 / 8 / 200817: 01$ & $8 / 8 / 200817: 01$ & 16.7 & 538.9 \\
\hline 936 & 1/8/2008 17:03 & $8 / 8 / 200817: 03$ & 16.7 & 537 \\
\hline 937 & $1 / 8 / 200817: 05$ & $8 / 8 / 200817: 05$ & 16.7 & 535 \\
\hline 938 & $1 / 8 / 200817: 07$ & $8 / 8 / 2008$ 17:07 & 16.7 & 533.1 \\
\hline 939 & $1 / 8 / 200817: 09$ & $8 / 8 / 200817: 09$ & 16.7 & 5329 \\
\hline 940 & 1/8/2008 17:11 & $8 / 8 / 200817: 11$ & 16.7 & 531.3 \\
\hline 941 & $1 / 8 / 200817: 13$ & $8 / 8200817: 13$ & 16.7 & 529.7 \\
\hline 942 & 1/8/2008 17:15 & $8 / 8 / 200817: 15$ & 16.7 & 529.4 \\
\hline 943 & $1 / 8 / 200817: 17$ & $8 / 8 / 200817: 17$ & 16.7 & 524.8 \\
\hline 944 & $1 / 8 / 200817: 19$ & $8 / 8 / 200817: 19$ & 16.7 & 5228 \\
\hline 945 & $1 / 8 / 2008$ 17:21 & $8 / 8 / 2008$ 17:21 & 16.7 & 525.6 \\
\hline 946 & $1 / 8 / 200817: 23$ & $8 / 8200817: 23$ & 16.7 & 521.8 \\
\hline 947 & $1 / 8 / 200817: 25$ & $8 / 8 / 200817: 25$ & 16.7 & 523 \\
\hline 948 & $1 / 8 / 2008$ 17:27 & $8 / 82008$ 17:27 & 16.7 & 518.9 \\
\hline 949 & 1/8/2008 17:29 & $8 / 8 / 2008$ 17:29 & 16.7 & 516.1 \\
\hline 950 & $1 / 8 / 2008$ 17:31 & $8 / 8 / 200817: 31$ & 16.7 & 516.7 \\
\hline 951 & 1/8/2008 17:33 & $8 / 2000817: 33$ & 16.8 & 515.1 \\
\hline 952 & $1 / 8 / 200817: 35$ & $8 / 8 / 200817: 35$ & 16.8 & 515 \\
\hline 953 & $1 / 8 / 200817 ; 37$ & $8 / 8 / 2008$ 17:37 & 16.8 & 516 \\
\hline 954 & $1 / 8 / 200817: 39$ & $8 / 8 / 200817: 39$ & 16.8 & 514.4 \\
\hline 955 & $1 / 8 / 200817: 41$ & $88 / 200817: 41$ & 16.8 & 514.4 \\
\hline 956 & $1 / 8 / 200817: 43$ & $8 / 8200817: 43$ & 16.8 & 514.1 \\
\hline 957 & $1 / 8 / 200817: 45$ & $8 / 8200817: 45$ & 16.8 & 513.8 \\
\hline 958 & $1 / 8 / 200817: 47$ & $8 / 8 / 200817: 47$ & 16.8 & 514.2 \\
\hline 959 & $1 / 8200817: 49$ & $8 / 8 / 2008$ 17:49 & 16.8 & 514.3 \\
\hline 960 & $1 / 8 / 200817: 51$ & $8 / 8 / 2008$ 17:51 & 16.8 & 513.6 \\
\hline 961 & $1 / 8 / 200817: 53$ & $8 / 8 / 200817: 53$ & 16.8 & 513.6 \\
\hline 902 & $1 / 8 / 200817: 55$ & $8 / 8 / 200817: 55$ & 16.8 & 512.8 \\
\hline 963 & $1 / 8 / 200817: 57$ & $8 / 8 / 2008$ 17:57 & 16.9 & 5121 \\
\hline 964 & $1 / 8 / 200817: 59$ & $8 / 8 / 200817: 59$ & 16.9 & 511.5 \\
\hline 965 & $1 / 8 / 200818: 01$ & $8 / 8 / 200818: 01$ & 16.9 & 511.6 \\
\hline
\end{tabular}

\begin{tabular}{|c|c|c|c|c|}
\hline \multicolumn{5}{|c|}{ D4.93c } \\
\hline Rec & & Adusted & Temp & $\mathrm{SC}$ \\
\hline & Dater/Time & DaterTime & $\propto \mathrm{C}$ & HSam \\
\hline 966 & $1 / 8200818: 0$ & $88 / 2000818: 0$ & 16.9 & \\
\hline 967 & 1/822008 18:06 & $882000818: 05$ & 16.9 & 511.2 \\
\hline 968 & $1 / 82000818: 07$ & $8 / 8 / 200818: 07$ & 16.9 & 511.4 \\
\hline 969 & $1 / 8200018: 09$ & $8 / 82000818: 09$ & 16.9 & 511.8 \\
\hline 970 & 1/82008 18:11 & $8 / 8200818: 11$ & 16.9 & \\
\hline 971 & 1/82008 18:13 & $8 / 8200818: 13$ & $\overline{16.9}$ & 510.6 \\
\hline 972 & $1 / 82200818: 15$ & $882200818: 15$ & 16.9 & 503.2 \\
\hline 973 & 1/8/2008 18:17 & $8 / 82008$ 18:17 & 16.9 & $507 .$. \\
\hline 974 & $1 / 82008$ 18:15 & $882200818: 19$ & 16.9 & 508. \\
\hline 975 & $1 / 82000618: 21$ & $8 / 82006$ 18:21 & 17 & 508. \\
\hline 976 & $1 / 82000818: 23$ & $8 / 8 / 200818: 23$ & 17 & \\
\hline 97 & $1 / 82000818: 25$ & $8 / 8200818: 25$ & 17 & 508.1 \\
\hline 978 & $1 / 8200018: 27$ & $8182000818: 27$ & 17 & 507.5 \\
\hline 979 & $1 / 82000818: 20$ & $8 / 8200818: 20$ & 17 & 507.6 \\
\hline 980 & $1 / 8200818: 31$ & $8 / 8200818: 31$ & 17 & 507.5 \\
\hline 981 & 2008 & $8 / 8200818: 33$ & 17 & \\
\hline 982 & 182000818.35 & $8 / 8200818: 35$ & $\overline{17}$ & \\
\hline 983 & $1 / 8200818: 37$ & $8 / 2200818: 37$ & & \\
\hline 984 & $1 / 8 / 200818: 39$ & $8 / 8 / 200818: 39$ & 17 & 506.1 \\
\hline 925 & 1/8/2008 18:41 & $8 / 8 / 200818: 41$ & $\mid$\begin{tabular}{|c|}
17 \\
\end{tabular} & \\
\hline 986 & $1 / 82000818: 43$ & $8 / 8 / 200818: 43$ & 17 & 507.3 \\
\hline 987| & $1 / 8 / 200818: 45$ & $8 / 8 / 200818: 45$ & 17 & 507.8 \\
\hline 988 & 320008 & $8 / 8 / 200818: 47$ & 16.9 & 5125 \\
\hline 989 & $1 / 8 / 2008$ 18:49 & $8 / 8 / 200818: 49$ & 16.9 & 509.5 \\
\hline 990 & 1/8/2008 18:51 & $8 / 8 / 200818: 51$ & 16.9 & 511.7 \\
\hline 991 & $1 / 8 / 200818: 53$ & $8 / 8 / 200818: 53$ & 16.9 & 511.6 \\
\hline 992 & $1 / 8 / 200818: 55$ & $8 / 8 / 2008$ 18:55 & 16.9 & 511.6 \\
\hline 993 & $1 / 8 / 2008$ 18:57 & $8 / 8 / 200818: 57$ & 16.9 & 511.2 \\
\hline 994 & 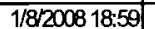 & $8 / 8 / 200818.59$ & 16.9 & \\
\hline 995 & $1 / 82008$ & $8 / 8200819.01$ & 16.9 & 511.2 \\
\hline 996 & /2008 19:03 & $8 / 82008$ 19:003 & 16.9 & $\begin{array}{l}511.1 \\
51\end{array}$ \\
\hline 9971 & $1 / 8 / 200819.05$ & $8 / 8 / 200819.05$ & 16.9 & \\
\hline 998 & 1/8/2008 19:07 & $8 / 8 / 200819: 07$ & 16.9 & 510.6 \\
\hline 999 & $1 / 8 / 200819.09$ & $8 / 8 / 200819.09$ & 16.9 & 510.2 \\
\hline 10000 & $3 / 2008$ 19:11 & $8 / 8 / 200819.11$ & 16.9 & \\
\hline 1001 & $1 / 8 / 200819: 13$ & $8 / 8 / 200819: 13$ & 16.9 & 510.6 \\
\hline 1002 & $1 / 8 / 200$ & $8 / 8 / 200819.15$ & 16.9 & 509.7 \\
\hline 1003 & 32008 19:17 & $8 / 82008$ 19:17 & 16.8 & 503 \\
\hline 1004 & $1 / 8 / 2008$ 19:19 & $8 / 8 / 200819.19$ & & \\
\hline 1005 & $1 / 8 / 2008$ 19:21 & $8 / 8 / 200819.21$ & 16.8 & 508.8 \\
\hline 1006 & $1 / 8 / 200819.23$ & $8 / 8 / 2008$ 19.23 & 16.9 & 508.4 \\
\hline & $1 / 8 / 2008$ & $8 / 8 / 2008$ 19.25 & 16.8 & \\
\hline 1008 & $1 / 8 / 2008$ 19.27 & $8 / 8200819.27$ & 16.8 & 508.6 \\
\hline $\mid 1009$ & & $8 / 8 / 200819.29$ & 16.8 & 508.6 \\
\hline 1010 & $1 / 8200$ & $4200819: 31$ & $16.8 \mathrm{C}>\mathrm{s}$ & 508.4 \\
\hline $\mid 1011$ & 200819 & $8 / 8200819933$ & 16.8 & 508. \\
\hline 1012 & $1 / 8 / 2008$ & $\sqrt{2000819: 35}$ & $16.8 \mathrm{P}>\mathrm{C}$ & 508. \\
\hline 1013 & $1 / 820008$ 19:37 & $8 / 82008$ 19:37| & $16.8 \mathrm{Y}>\mathrm{C}$ & 507.7 \\
\hline 1014 & $1 / 820001$ & $8 / 8200819: 39$ & 16.8 & 507.7 \\
\hline 1015 & $1 / 82000819: 41$ & $8 / 8200819: 41$ & 16.8 & 507.7 \\
\hline 1016 & $1 / 8 / 200819: 43$ & $8 / 8 / 200819: 43$ & 16.8 & 507.7 \\
\hline 1017 & 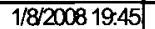 & $8 / 8200819445$ & 16.8 & 508 \\
\hline 1018 & & & 16.8 & 507.8 \\
\hline 1019 & 1/82008 19:49 & $881200819: 49$ & $16.8 \mathrm{r}>\mathrm{l}$ & 507. \\
\hline 102 & & $200819: 51$ & $16.8 \mathrm{r}$ & 507.6 \\
\hline 1021 & $1 / 8 / 2000$ & 8/8/2008 19:53 & 16.8 & 507. \\
\hline 1022 & 1/8/2008 19: & $8820081 \mathrm{~s}$ & 16.8 & 507.9 \\
\hline 1023 & $1 / 820008$ 19:57 & $8 / 8200819: 57$ & 16.8 & 507.7 \\
\hline 1024 & $1 / 8 / 200819.59$ & $8 / 8 / 200819.59$ & 16.8 & 507.6 \\
\hline & $1 / 8200820: 01$ & $88200820: 01$ & 16.8 & 507.7 \\
\hline 1026 & 1/820008 & & $16 . \varepsilon$ & 507. \\
\hline & & 8822008 & $\overline{16 . \varepsilon}$ & \\
\hline & & & 16.8 & \\
\hline 1025 & $1 / 8 / 20$ & & 16.8 & \\
\hline 1030 & $1 / 82000820: 11$ & $8 / 8200820: 11$ & 16.8 & 512 \\
\hline$\overline{103}$ & $1 / 8200820: 13$ & $881200820: 13$ & 16.8 & 511.2 \\
\hline & 1/8/20008? & 4 & 168 & \\
\hline & $1 / 82008$ & $818200820: 17$ & 16.8 & 13. \\
\hline & & & & \\
\hline
\end{tabular}


DOE/RL-2009-35, REV. 0

\begin{tabular}{|c|c|c|c|c|}
\hline \multicolumn{5}{|c|}{ D493c } \\
\hline $\operatorname{Rec}$ & & Adjusted & Temp & SC \\
\hline$\#$ & DaterTime & DaterTime & $\alpha$ & $\mu \mathrm{s} / \mathrm{am}$ \\
\hline 1035 & $1 / 8 / 200820: 21$ & $8 / 8 / 200820: 21$ & 16.8 & $5+3.3$ \\
\hline 1036 & $1 / 8200820: 23$ & $8 / 8 / 200820: 23$ & 16.8 & 512.6 \\
\hline 1037 & $1 / 8 / 200820: 25$ & $8 / 82200820: 25$ & 16.8 & 511.9 \\
\hline 1038 & $1 / 8 / 200820: 27$ & $8 / 8200820: 27$ & 16.8 & 511.7 \\
\hline 1039 & $1 / 8200820: 20$ & $8 / 8 / 200820: 29$ & 16.8 & 510.9 \\
\hline 1040 & $1 / 8 / 200820: 31$ & $8 / 8 / 200820: 31$ & 16.8 & 510.9 \\
\hline 1041 & $1 / 8 / 200820: 33$ & $8 / 8 / 200820: 33$ & 16.8 & 510.7 \\
\hline 1042 & $1 / 8 / 200820: 35$ & $8 / 8 / 200820: 35$ & 16.8 & \\
\hline 1043 & $1 / 8 / 200820: 37$ & $8 / 8 / 200820: 37$ & 16.8 & 509.8 \\
\hline 1044 & $1 / 8 / 200820: 39$ & $8 / 8 / 200820: 39$ & 16.8 & 510.2 \\
\hline 1045 & $1 / 8 / 200820: 41$ & $8 / 8 / 200820: 41$ & 16.8 & 512.9 \\
\hline 1046 & $1 / 8 / 200820: 43$ & $88 / 200820: 43$ & 16.8 & 515.7 \\
\hline 1047 & $1 / 8 / 200820: 45$ & $8 / 8 / 200820: 45$ & 16.8 & 513.8 \\
\hline 1048 & $1 / 8 / 200820: 47$ & $8 / 8 / 200820: 47$ & 16.8 & 513.2 \\
\hline 1049 & $1 / 8 / 200820: 49$ & $8 / 8 / 200820: 49$ & 16.8 & 512.4 \\
\hline 1050 & $1 / 8 / 200820: 51$ & $8 / 8 / 200820: 51$ & 16.8 & 508.9 \\
\hline 1051 & $1 / 8 / 200820: 53$ & $8 / 8 / 200820: 53$ & 16.8 & 507.1 \\
\hline 1052 & $1 / 8 / 200820: 55$ & $8 / 8200820: 55$ & 16.9 & 506.7 \\
\hline 1053 & 1/82008 20:57 & $8 / 8 / 200820: 57$ & 16.9 & 507.1 \\
\hline 1054 & $1 / 8 / 200820: 59$ & $8 / 8 / 200820: 59$ & 16.9 & 506.2 \\
\hline 1055 & 1/8/200821:01 & 8/8/200821:01 & 16.9 & 505.5 \\
\hline 1056 & $1 / 8 / 200821: 03$ & 8/8/200821:03 & 16.9 & 504.7 \\
\hline 105 & 1/8/2008 21:05 & $8 / 8 / 200821: 05$ & 16.9 & 505.4 \\
\hline 1058 & $1 / 8 / 200821: 07$ & 8/8/200821:07 & 16.9 & 503.8 \\
\hline 1059 & $1 / 8 / 200821: 09$ & $8 / 8200821: 09$ & 16.9 & 502.7 \\
\hline 1060 & 1/8/200821:11 & $8 / 8 / 200821: 11$ & 16.9 & 500.4 \\
\hline 1061 & $1 / 8 / 200821: 13$ & $8 / 8 / 200821: 13$ & 16.9 & 498.9 \\
\hline 1062 & $1 / 8 / 200821: 15$ & $8 / 8 / 200821: 15$ & 16.9 & 497.6 \\
\hline 1063 & 1/8/200821:17 & $8 / 8 / 200821: 17$ & 17 & 496.7 \\
\hline 1064 & 1/8/200821:19 & $8 / 8 / 200821: 19$ & 17 & 496.8 \\
\hline 1065 & $1 / 8 / 200821: 21$ & $8 / 8 / 200821: 21$ & 17 & 487.8 \\
\hline 1066 & 1/8/200821:23 & $8 / 8 / 200821: 23$ & 17 & 493.7 \\
\hline 1067 & 1/8/200821:25 & $8 / 8 / 200821: 25$ & 17 & 494.3 \\
\hline 1068 & $1 / 8 / 200821: 27$ & $8 / 8 / 200821: 27$ & 17.1 & 494.3 \\
\hline 1069 & $1 / 8 / 200821: 29$ & $8 / 8 / 200821: 29$ & 17.1 & 494.3 \\
\hline 1070 & 1/8/200821:31 & $8 / 8 / 200821: 31$ & 17.1 & 494.1 \\
\hline 1071 & 1/8/200821:33 & $8 / 8200821: 33$ & 17.1 & 493.5 \\
\hline 1072 & 1/8/200821:35 & $8 / 8 / 200821: 35$ & 17.1 & 493.4 \\
\hline 1073 & $1 / 8 / 200821: 37$ & $8 / 8 / 200821: 37$ & 17.2 & 493.3 \\
\hline 1074 & 1/8/200821:39 & $8 / 8 / 200821: 39$ & 17.2 & 493.3 \\
\hline 1075 & $1 / 8 / 200821: 41$ & $8 / 8 / 200821: 41$ & 17.2 & 486.2 \\
\hline 1076 & $1 / 8 / 200821: 43$ & $88 / 200821: 43$ & 17.2 & 489.9 \\
\hline 1077 & $1 / 8 / 200821: 45$ & $8 / 8 / 200821: 45$ & 17.2 & 491.2 \\
\hline 1078 & 1/8/200821:47 & $8 / 8 / 200821: 47$ & 17.2 & 492 \\
\hline 1079 & $1 / 8 / 200821: 49$ & $8 / 8 / 200821: 49$ & 17.2 & 490.5 \\
\hline 1080 & $1 / 8 / 200821: 51$ & $8 / 8 / 200821: 51$ & 17.2 & 492 \\
\hline 1081 & $1 / 8 / 200821: 53$ & $8 / 8 / 200821: 53$ & 17.3 & 492.2 \\
\hline 1082 & 1/8/200821:55 & $8 / 8 / 200821: 55$ & 17.3 & 492.4 \\
\hline 1083 & 1/8/200821:57 & $8 / 8 / 200821: 57$ & 17.3 & 492.8 \\
\hline 1084 & $1 / 8 / 200821: 59$ & $8 / 8 / 200821: 59$ & 17.3 & 492.8 \\
\hline 1085 & $1 / 8 / 200822: 01$ & $8 / 8 / 200822=01$ & 17.3 & 492.5 \\
\hline 1086 & 1/8/200822:03 & $8 / 8 / 200822: 03$ & 17.3 & 492.5 \\
\hline 1087 & 1/8/200822:05 & $8 / 8 / 200822: 05$ & 17.3 & 492.7 \\
\hline 1088 & $1 / 8 / 200822: 07$ & $8 / 8 / 200822: 07$ & 17.3 & 491.7 \\
\hline 1089 & $1 / 8 / 200822: 09$ & $8 / 8 / 200822: 09$ & 17.3 & 492.3 \\
\hline 1090 & $1 / 8 / 200822: 11$ & $8 / 8 / 200822=11$ & 17.3 & 492.4 \\
\hline 1091 & 1/8/200822:13 & $8 / 8 / 200822: 13$ & 17.4 & 492.8 \\
\hline 1092 & 1/8/2008 22:15 & $8 / 8 / 200822: 15$ & 17.4 & 492.6 \\
\hline 1093 & 1/8/200822:17 & $8 / 8 / 200822: 17$ & 17.4 & 492.8 \\
\hline 1094 & 1/8/200822:19 & $8 / 8 / 200822: 19$ & 17.4 & 492.8 \\
\hline 1095 & $1 / 8 / 200822: 21$ & $8 / 8 / 200822-21$ & 17.4 & 492.7 \\
\hline 1096 & 1/8/200822:23 & $8 / 8 / 200822: 23$ & 17.4 & 4926 \\
\hline 1097 & 1/8/2008 22:25 & $8 / 8 / 200822: 25$ & 17.4 & 492.9 \\
\hline 1098 & 1/8/200822:27 & $8 / 8 / 200822: 27$ & 17.4 & 492.8 \\
\hline 1099 & $1 / 8 / 200822: 29$ & $8 / 8 / 200822: 29$ & 17.4 & 492.6 \\
\hline 1100 & $1 / 8 / 200822: 31$ & $8 / 8 / 200822: 31$ & 17.5 & 492.6 \\
\hline 1101 & 1/8/200822:33 & $8 / 8 / 200822: 33$ & 17.5 & 493 \\
\hline 1102 & 1/8/2008 22:35 & $8 / 8 / 200822=35$ & 17.5 & 492.9 \\
\hline 1103 & 1/8/200822:37 & $8 / 8 / 200822: 37$ & 17.5 & 4929 \\
\hline
\end{tabular}

\begin{tabular}{|c|c|c|c|c|}
\hline \multicolumn{5}{|c|}{ D4-93c } \\
\hline $\operatorname{Rec}$ & & Adjusted & Temp & SC \\
\hline$\#$ & DaterTime & Date/Time & $\alpha$ & $\mu \mathrm{S} / \mathrm{cm}$ \\
\hline 1104 & $1 / 8 / 20082233$ & $8 / 8 / 200822: 39$ & 17.5 & 492.9 \\
\hline 1105 & $1 / 820082241$ & $8 / 8 / 200822: 41$ & 17.5 & 492.4 \\
\hline 1106 & $1 / 8 / 200822: 43$ & $8 / 8 / 200822: 43$ & 17.5 & 492.8 \\
\hline 1107 & $1 / 8 / 20082245$ & $8 / 8 / 200822: 45$ & 17.5 & 492.9 \\
\hline 1108 & $1 / 8 / 20082247$ & $8 / 8 / 200822: 47$ & 77.5 & 4927 \\
\hline 1109 & $1 / 8 / 200822249$ & $8 / 8 / 200822: 49$ & 17.5 & 492.7 \\
\hline 1110 & $1 / 8 / 200822551$ & $8 / 8 / 200822: 51$ & 17.6 & 492.8 \\
\hline 1111 & $1 / 8200822553$ & $8 / 8 / 200822: 53$ & 17.6 & 492.8 \\
\hline 1112 & $1 / 8 / 200822255$ & $8 / 8 / 200822: 55$ & 17.6 & 492.5 \\
\hline 1113 & $1 / 8 / 20082255$ & $8 / 82200822: 57$ & 17.6 & 492.5 \\
\hline 1114 & $1 / 8 / 200822: 59$ & $8 / 8 / 200822: 59$ & 17.4 & 484.9 \\
\hline 1115 & 1/8/200823:01 & $8 / 8 / 200823: 01$ & 17.4 & 489.4 \\
\hline 1116 & $1 / 8 / 200823: 03$ & $8 / 8 / 200823: 03$ & 17.2 & 487.5 \\
\hline 1117 & 1/8/200823:05 & $8 / 8 / 200823: 05$ & 17.2 & 487.9 \\
\hline 1118 & $1 / 8 / 200823: 07$ & $8 / 8 / 200823: 07$ & 17.2 & 487.3 \\
\hline 1119 & $1 / 8200823: 09$ & $8 / 8 / 2008 \times 23: 09$ & 172 & 487.6 \\
\hline 1120 & 1/8/2008 23:11 & $8 / 8 / 200823: 11$ & 17.2 & 487.6 \\
\hline 1121 & $1 / 8200823: 13$ & $8 / 8 / 200823: 13$ & 17.3 & 487.3 \\
\hline 1122 & $1 / 8 / 200823: 15$ & 8/8/200823:15 & 17.4 & 487.1 \\
\hline 11123 & $1 / 8 / 200823: 17$ & 8/8/200823:17 & 17.4 & 487.6 \\
\hline 1124 & $1 / 8 / 200823: 19$ & $8 / 8 / 200823: 19$ & 17.5 & 489.8 \\
\hline 1125 & $1 / 82200823: 21$ & $8 / 8 / 200823: 21$ & 17.6 & 497.7 \\
\hline 1126 & $1 / 8 / 200823: 23$ & $8 / 8 / 200823: 23$ & 17.7 & 516.4 \\
\hline 1127 & $1 / 8 / 200823: 25$ & $8 / 8 / 200823: 25$ & 17.7 & 518.2 \\
\hline 1128 & $1 / 8 / 200823: 27$ & 8/8/2008 23:27 & 17.8 & 526.1 \\
\hline 1129 & $1 / 82200823: 29$ & $8 / 8 / 200823: 29$ & 17.8 & 530.9 \\
\hline 1130 & $1 / 8 / 200823: 31$ & $8 / 8 / 200823: 31$ & 17.9 & 520.6 \\
\hline 1131 & $1 / 8 / 200823: 33$ & $8 / 8 / 200823: 33$ & 17.9 & 494.9 \\
\hline 1132 & $1 / 8 / 200823: 35$ & $8 / 8 / 200823: 35$ & 17.9 & 494.7 \\
\hline 1133 & $1 / 82200823: 37$ & $8 / 8 / 200823: 37$ & 17.9 & 493.4 \\
\hline 1134 & $1 / 82200823: 39$ & $8 / 8 / 200823: 39$ & 18 & 493.9 \\
\hline 1135 & $1 / 8 / 200823: 41$ & $8 / 8 / 200823: 41$ & 18 & 489.5 \\
\hline 1136 & $1 / 8 / 200$ & $8 / 8 / 200823: 43$ & 18 & 487.1 \\
\hline 1137 & $1 / 82200823: 45$ & $8 / 8 / 200823: 45$ & 18 & 488.3 \\
\hline 1138 & $1 / 8 / 200823: 47$ & $8 / 8 / 200823: 47$ & 18 & 496.1 \\
\hline 1139 & $1 / 8200823: 49$ & $8 / 8 / 200823: 49$ & 18 & 522 \\
\hline 1140 & $1 / 8 / 200823551$ & $8 / 8 / 200823: 51$ & 17.9 & 533.5 \\
\hline 1141 & $1 / 8 / 200823: 53$ & $8 / 8 / 200823: 53$ & 17.8 & 532.2 \\
\hline 1142 & $1 / 8 / 200823: 55$ & $8 / 8 / 200823: 55$ & 17.8 & 533 \\
\hline 1143 & $1 / 8 / 200$ & $8 / 8 / 200823: 57$ & 17.7 & 520.3 \\
\hline 1144 & $1 / 8 / 200823: 59$ & $8 / 8 / 200823: 59$ & 17.6 & 507.8 \\
\hline 1145 & $1 / 9 / 20080001$ & 8/9/2008 0:01 & 17.5 & 503.9 \\
\hline 1146 & $1 / 9 / 20080: 03$ & $8 / 9 / 20080: 03$ & 17.5 & 496.5 \\
\hline 1147 & $1 / 9 / 20080: 05$ & $8 / 9 / 20080: 05$ & 17.5 & 499.4 \\
\hline 1148 & $1 / 9 / 20080: 07$ & $8 / 9 / 20080: 07$ & 17.5 & 492.5 \\
\hline 1149 & 1/9/20080:00 & $8 / 9 / 20080: 09$ & 17.5 & 494.6 \\
\hline 1150 & 1/9/2008 0:11 & $8 / 920080: 11$ & 17.5 & 489.5 \\
\hline 1151 & $0: 13$ & $8 / 9 / 200$ & 17.5 & 491.2 \\
\hline 1152 & $1 / 9 / 20080: 15$ & $8 / 9 / 20080: 15$ & 17.5 & 488.9 \\
\hline 1153 & $1 / 9 / 20080: 17$ & $8 / 9 / 20080: 17$ & 17.4 & 487.7 \\
\hline 1154 & $1 / 9 / 20080: 19$ & $8 / 9 / 20080: 19$ & 17.5 & 486.4 \\
\hline 1155 & $20080: 21$ & $89 / 20080: 21$ & 17.5 & 486.4 \\
\hline 1156 & & $8 / 9 / 20080: 23$ & 17.5 & 486.2 \\
\hline 1157. & $1 / 9 / 20080: 25$ & $8 / 9 / 20080: 25$ & 17.5 & 486.1 \\
\hline 1158 & $1 / 9 / 20080: 27$ & $8 / 9 / 20080: 27$ & 17.5 & 486.2 \\
\hline 1159 & & $8 / 9 / 20080: 29$ & 17.5 & 486.4 \\
\hline 1160 & $920080: 31$ & $89 / 20080: 31$ & 17.5 & 486.3 \\
\hline 1161 & & $8 / 9 / 20080: 33$ & 17.5 & 486.2 \\
\hline 1162 & $1 / 9 / 20080: 35$ & $8 / 9 / 20080: 35$ & 17.5 & 485.8 \\
\hline 1163 & $1 / 9 / 20080: 37$ & $8 / 9 / 20080: 37$ & 17.5 & 486.3 \\
\hline 1164 & $9 / 20080: 39$ & $8 / 9 / 20080: 39$ & 17.5 & 486.2 \\
\hline 1165 & $1 / 920080: 41$ & $8 / 920080: 41$ & 17.5 & 486 \\
\hline 1166 & $1 / 9 / 20080-43$ & $8 / 9 / 20080: 43$ & 17.5 & 486 \\
\hline 1167 & $1 / 9 / 20080: 45$ & $8 / 9 / 20080: 45$ & 17.6 & 486.4 \\
\hline 1168 & $1 / 9 / 20080: 47$ & $8 / 9 / 20080: 47$ & 17.6 & 486.5 \\
\hline 1169 & $1 / 9 / 20080: 49$ & $8 / 9 / 20080: 49$ & 17.6 & 486.4 \\
\hline 1170 & $1 / 9 / 20080: 51$ & $8 / 9 / 20080: 51$ & 17.6 & 486.6 \\
\hline 1171 & $1 / 9 / 20080.53$ & $89 / 20080: 53$ & 17.6 & 486.8 \\
\hline 1172 & $1 / 9 / 20080: 55$ & $8 / 9 / 20080: 55$ & 17.6 & 487.1 \\
\hline
\end{tabular}

\begin{tabular}{|c|c|c|c|c|}
\hline \multicolumn{5}{|c|}{ D4-93c } \\
\hline$\overline{R e c}$ & & Adjusted & Temp & $\mathrm{SC}$ \\
\hline$\#$ & DaterTime & Dater/Time & $\infty$ & $\mu \mathrm{S} / \mathrm{am}$ \\
\hline 1173 & $1 / 9 / 20080: 57$ & $8 / 9 / 20080: 57$ & 17.6 & 486.7 \\
\hline 1174 & $1 / 9 / 20080: 59$ & $8 / 920080.59$ & 17.7 & 486.8 \\
\hline 1175 & $1 / 9 / 20081: 01$ & $8 / 92008$ 1:01 & 17.7 & 486.7 \\
\hline 1176 & $1 / 9 / 20081: 03$ & $8 / 9 / 20081: 03$ & \begin{tabular}{l|l|}
17.7 \\
\end{tabular} & 487.6 \\
\hline 1177 & $1 / 9 / 20081: 05$ & $8 / 920081: 05$ & 17.7 & 486.9 \\
\hline 1178 & $1 / 9 / 20081: 07$ & $8 / 9 / 2008$ 1:07 & \begin{tabular}{|c|}
17.7 \\
\end{tabular} & 489.2 \\
\hline 1179 & $1 / 9 / 20081: 09$ & $8 / 9 / 20081: 09$ & 17.7 & 486.8 \\
\hline 1180 & $1 / 9 / 20081: 11$ & $8 / 920081: 11$ & 17.7 & 488.7 \\
\hline 1181 & $1 / 9 / 20081: 13$ & $8 / 9 / 20081: 13$ & 17.8 & 487.1 \\
\hline 1182 & 1/9/2008 1:15 & $8 / 92008$ 1:15 & 17.8 & 486.6 \\
\hline 1183 & $1 / 920081: 17$ & $8 / 92008$ 1:17 & 17.8 & 486.2 \\
\hline 1184 & 1/92008 1:19 & $8 / 9 / 2008$ 1:19 & 17.8 & 487.6 \\
\hline 1185 & $1 / 9 / 20081: 21$ & $89: 20081: 21$ & 17.8 & 486.7 \\
\hline 1186 & $1 / 9 / 20081: 23$ & $8 / 92008$ 1:23 & 17.8 & 487.5 \\
\hline 1187 & $1 / 9 / 20081: 25$ & $8 / 9 / 20081: 25$ & 17.8 & 488.1 \\
\hline 1188 & $1 / 9 / 20081: 27$ & $8 / 920081: 27$ & 17.9 & 486.3 \\
\hline 1189 & $1 / 9 / 20081: 29$ & $8 / 9 / 20081: 20$ & 17.9 & 485.7 \\
\hline 1190 & $1 / 9 / 20081: 31$ & $8 / 9 / 2008$ 1:31 & 17.9 & 485 \\
\hline 1191 & $1 / 9 / 20081: 33$ & $8 / 920081: 33$ & 17.9 & 485.1 \\
\hline 1192 & $1 / 9 / 20081: 35$ & $8 / 9 / 2008$ 1:35 & 17.9 & 486.7 \\
\hline 1193 & $1 / 9 / 20081: 37$ & $8 / 9 / 2008$ 1:37 & 18 & 486.4 \\
\hline 1194 & $1 / 9 / 20081: 39$ & $8 / 920081: 39$ & 18 & 484.6 \\
\hline 1195 & $1 / 9 / 20081: 41$ & $8 / 920081: 41$ & 18 & 484.2 \\
\hline 1196 & $1 / 9 / 20081: 43$ & $8 / 92008$ 1:43 & 18 & 483.3 \\
\hline 1197 & $1 / 920081: 45$ & $8 / 9 / 20081: 45$ & 18 & 482.8 \\
\hline 1198 & 1/9/2008 1:47 & $8 / 92008$ 1:47 & 18 & 482.2 \\
\hline 1199 & $1 / 9 / 20081: 49$ & $8 / 9 / 20081: 49$ & 18 & 482.6 \\
\hline 1200 & $1 / 9 / 20081: 51$ & $8 / 9 / 2008$ 1:51 & 18 & 4821 \\
\hline 1201 & $1 / 9 / 20081: 53$ & $8 / 9 / 20081: 53$ & 18 & 482.1 \\
\hline 1202 & $1 / 9 / 20081: 55$ & $8 / 92008$ 1:55 & 18.1 & 481.2 \\
\hline 1203 & $1 / 9 / 20081: 57$ & $8 / 9 / 2008$ 1:57 & 18.1 & 482 \\
\hline 1204 & $1 / 9 / 20081: 59$ & $8 / 9 / 20081: 59$ & 18.1 & 481.6 \\
\hline 1205 & $1 / 9 / 20082: 01$ & $8 / 9 / 20082: 01$ & 18.1 & 481.9 \\
\hline 1206 & $1 / 9 / 20082: 03$ & $8 / 9 / 20082: 03$ & 18.1 & 481.5 \\
\hline 1207 & $1 / 9 / 20082: 05$ & $8 / 9 / 20082: 05$ & 18.1 & 481.2 \\
\hline 1208 & 1/9/2008 2:07 & $8 / 9 / 2008207$ & 18.2 & 482 \\
\hline 1209 & 1/9/20082:00 & $8 / 9 / 20082: 09$ & 18.4 & 494.6 \\
\hline 1210 & 1/9/2008 2:11 & $8 / 9 / 20082: 11$ & 18.9 & 549.2 \\
\hline 1211 & 1/9/2008 2:13 & $8 / 9 / 20082: 13$ & 19.3 & 552.6 \\
\hline 1212 & 1/9/2008 2:15 & $8 / 9 / 20082: 15$ & 19.5 & 556.7 \\
\hline 1213 & 1/9/2008 2:17 & $8 / 9 / 20082: 17$ & 19.7 & 556.7 \\
\hline 1214 & 1/9/2008 2:19 & $8 / 9 / 20082: 19$ & 19.8 & 547.3 \\
\hline 1215 & $1 / 920082: 21$ & $8 / 9 / 20082: 21$ & 19.9 & 548 \\
\hline 1216 & 1/9/2008 2:23 & $8 / 9 / 20082: 23$ & 20 & 540.9 \\
\hline 1217 & 1/9/2008 2:25 & $8 / 9 / 20082: 25$ & 20 & 541.8 \\
\hline 1218 & 1/9/2008 2:27 & $8 / 9 / 20082: 27$ & 19.9 & 534.5 \\
\hline 1219 & 1/9/2008 2:29 & $8 / 9 / 20082: 29$ & 19.8 & 536.2 \\
\hline 1220 & 1/92008 2:31 & $8 / 9 / 2008231$ & 19.7 & 536.2 \\
\hline 1221 & 1/9/2008 2:33 & $8 / 9 / 20082: 33$ & 19.6 & 536.7 \\
\hline 1222 & $1 / 9 / 20082: 35$ & $8 / 9 / 20082: 35$ & 19.5 & 524.2 \\
\hline 1223 & $1 / 9 / 20082: 37$ & $8 / 9 / 20082: 37$ & 19.3 & 517.5 \\
\hline 1224 & 1/9/2008 2:39 & $8 / 9 / 20082: 39$ & 19.2 & 502.3 \\
\hline 1225 & $1 / 9 / 20082: 41$ & $8 / 9 / 20082: 41$ & 19 & 493.5 \\
\hline 1226 & $1 / 9 / 20082: 43$ & $8 / 9 / 20082: 43$ & 18.9 & 487 \\
\hline 1227 & $1 / 9 / 20082: 45$ & $8 / 9 / 20082: 45$ & 18.8 & 491.2 \\
\hline 1228 & $1 / 9 / 20082: 47$ & $8 / 9 / 20082: 47$ & 18.8 & 498 \\
\hline 1229 & $1 / 9 / 20082: 49$ & $8 / 9 / 20082: 49$ & 18.7 & 484.7 \\
\hline 1230 & $1 / 9 / 20082: 51$ & $8 / 9 / 20082: 51$ & 18.6 & 485 \\
\hline 1231 & $1 / 9 / 2008253$ & $8 / 9 / 20082: 53$ & 18.6 & 493 \\
\hline 1232 & $1 / 9 / 20082: 55$ & $8 / 9 / 20082: 55$ & 18.6 & 491.6 \\
\hline 1233 & 1/9/2008 2:57 & $8 / 9 / 20082: 57$ & 18.6 & 485.4 \\
\hline 1234 & $1 / 9 / 20082.59$ & $8 / 9 / 20082: 59$ & 18.5 & 480.1 \\
\hline 1235 & 1/920083:01 & $8 / 9 / 20083: 01$ & 18.5 & 479.2 \\
\hline 1236 & $1 / 9 / 20083: 03$ & $8 / 9 / 20083: 03$ & 18.6 & 482.8 \\
\hline 1237 & 1/9/2008 3:05 & $8 / 9 / 20083: 05$ & 18.7 & 479.2 \\
\hline 1238 & $1 / 920083: 07$ & $8 / 9 / 20083: 07$ & 18.7 & 486.3 \\
\hline 1239 & $1 / 9 / 20083: 09$ & $8 / 9 / 20083: 09$ & 18.8 & 480.8 \\
\hline 1240 & 1/9/20083:11 & 8/9/20083:11 & 19 & 475.4 \\
\hline 1241| & 1/9/20083:13 & $8 / 9 / 20083: 13$ & 19.2 & 478.4 \\
\hline
\end{tabular}




\begin{tabular}{|c|c|c|c|c|}
\hline \multicolumn{5}{|c|}{ D4-93c } \\
\hline Rec & & Adjusted & Termp & SC \\
\hline$\#$ & Date/Time & Date/Time & $\alpha$ & $\mu \mathrm{S} / \mathrm{cm}$ \\
\hline 1242 & $1 / 9 / 20083: 15$ & $8 / 9 / 20083: 15$ & 19.4 & 481.9 \\
\hline 1243 & 1/9/20083:17 & $89 / 20083: 17$ & 19.6 & 484.1 \\
\hline 1244 & $1 / 9 / 20083: 19$ & $8 / 9 / 20083: 19$ & 19.7 & 491.8 \\
\hline 1245 & $1 / 920083.21$ & $8 / 9 / 20083.21$ & 19.8 & 499.2 \\
\hline 1246 & $1 / 920083: 23$ & $8 / 9 / 20083: 23$ & 19.9 & 513.6 \\
\hline 1247 & 1/9/20083:25 & $89 / 20083: 25$ & 20 & 514.8 \\
\hline 1248 & 1/9/20083:27 & $89 / 20083: 27$ & 20.1 & 545.9 \\
\hline 1249 & $1 / 9 / 20083: 20$ & $8 / 9 / 20083: 29$ & 20.4 & 570.2 \\
\hline 1250 & $1 / 9 / 20083: 31$ & $8 / 9 / 20083: 31$ & 20.1 & 509.8 \\
\hline 1251 & 1/9/2008 3:33 & $8 / 9 / 20083: 33$ & 20.1 & 509.2 \\
\hline 1252 & $1 / 9 / 20083: 35$ & $8 / 9 / 20083: 35$ & 20.2 & 523.7 \\
\hline 1253 & $1 / 9 / 20083: 37$ & $8 / 9 / 20083: 37$ & 20.4 & 537.2 \\
\hline 1254 & 1/9/20083:39 & $8 / 9 / 20083: 39$ & 20.5 & 534.4 \\
\hline 1255 & $1 / 9 / 20083: 41$ & $8 / 9 / 20083: 41$ & 20.6 & 551.7 \\
\hline 1256 & $1 / 9 / 20083: 43$ & $8 / 9 / 20083: 43$ & 20.6 & 549.9 \\
\hline 1257 & $1 / 9 / 20083: 45$ & $8 / 9 / 20083: 45$ & 20.7 & 552.3 \\
\hline 1258 & $1 / 9 / 20083: 47$ & $8 / 9 / 20083: 47$ & 20.7 & 568.5 \\
\hline 1259 & $1 / 920083: 49$ & $89220083: 49$ & 20.8 & 564.3 \\
\hline 1260 & $1 / 920083: 51$ & $8 / 9 / 20083: 51$ & 20.8 & 570.3 \\
\hline 1261 & $1 / 9 / 20083: 53$ & $8 / 9 / 20083: 53$ & 20.8 & 596.9 \\
\hline 1262 & $1 / 9 / 20083: 55$ & $8 / 9 / 20083: 55$ & 20.9 & 585.1 \\
\hline 1263 & $1 / 9 / 20083: 57$ & $8 / 9 / 20083: 57$ & 20.9 & 584.8 \\
\hline 1264 & 1/9/2008 3:59 & $8 / 920083.59$ & 20.8 & 569.9 \\
\hline 1265 & $1 / 920084: 01$ & $8 / 9 / 20084: 01$ & 20.6 & 511 \\
\hline 1266 & $1 / 9 / 20084: 03$ & $8 / 920084: 03$ & 20.7 & 533.1 \\
\hline 1267 & 1/9/2008 4:05 & $8 / 9 / 20084: 05$ & 20.9 & 571.1 \\
\hline 1268 & $1 / 9 / 20084: 07$ & $8 / 9 / 20084: 07$ & 21 & 575.1 \\
\hline 1269 & 1/9/2008 4:09 & $8 / 9 / 20084: 09$ & 21.1 & 582.8 \\
\hline 1270 & $1 / 920084: 11$ & $8 / 9 / 20084: 11$ & 20.6 & 517.9 \\
\hline 1271 & 1/9/20084:13 & $8 / 920084: 13$ & 20.7 & 518.8 \\
\hline 1272 & 1/9/20084:15 & $8 / 9 / 20084: 15$ & 20.8 & 561 \\
\hline 1273 & 1/9/2008 4:17 & $8 / 9 / 20084: 17$ & 21.1 & 579.2 \\
\hline 1274 & $1 / 9 / 20084: 19$ & $8 / 9 / 20084: 19$ & 21.2 & 574.6 \\
\hline 1275 & $1 / 920084: 21$ & $8 / 9 / 20084: 21$ & 21.2 & 573.5 \\
\hline 1276 & $1 / 9 / 20084: 23$ & $8 / 9 / 20084: 23$ & 21.2 & 573 \\
\hline 1277 & $1 / 9 / 20084: 25$ & $8 / 9 / 20084: 25$ & 21.1 & 537.2 \\
\hline 1278 & $1 / 9 / 20084: 27$ & $8 / 9 / 20084: 27$ & 20.9 & 521.8 \\
\hline 1279 & $1 / 9 / 20084: 29$ & $8 / 9 / 20084: 29$ & 21.1 & 572.5 \\
\hline 1280 & $1 / 9 / 20084: 31$ & $8 / 9 / 20084: 31$ & 21.3 & 573.2 \\
\hline 1281 & 1/9/2008 4:33 & $8 / 9 / 20084: 33$ & 21.2 & 517.5 \\
\hline 1282 & $1 / 920084: 35$ & $8 / 9 / 20084: 35$ & 21.1 & 507.3 \\
\hline 1283 & $1 / 9 / 20084: 37$ & $8 / 9 / 20084: 37$ & 21.1 & 492.6 \\
\hline 1284 & $1 / 9 / 20084: 39$ & $8 / 9 / 20084: 39$ & 21.2 & 492.8 \\
\hline 1285 & $1 / 9 / 20084: 41$ & $8 / 9 / 20084: 41 \mid$ & 21.2 & 506.3 \\
\hline 1286 & $1 / 9 / 20084: 43$ & $8 / 9 / 20084: 43$ & 21.2 & 547.7 \\
\hline 1287 & $1 / 9 / 20084: 45$ & $8 / 9 / 20084: 45$ & 21.3 & 544.3 \\
\hline 1288 & $1 / 9 / 20084: 47$ & $8 / 9 / 20084: 47$ & 21.3 & 562.2 \\
\hline 1289 & $1 / 9 / 20084: 49$ & $8 / 9 / 20084: 49$ & 21.4 & 560.6 \\
\hline 1290 & $1 / 9 / 20084: 51$ & $8 / 9 / 20084: 51$ & 21.4 & 559.1 \\
\hline 1291 & $1 / 9 / 20084: 53$ & $8 / 9 / 20084: 53$ & 21.5 & 565.1 \\
\hline 1292 & 1/9/2008 4:55 & $8 / 9 / 20084: 55$ & 21.4 & 544.2 \\
\hline 1293 & $1 / 9 / 20084: 57$ & $899 / 20084: 57$ & 21.5 & 550.5 \\
\hline 1294 & $1 / 9 / 20084: 59$ & $8 / 9 / 20084: 50$ & 21.5 & 567.9 \\
\hline 1295 & 1/9/2008 5:01 & $8 / 9 / 20085: 01$ & 21.6 & 572.9 \\
\hline 1296 & 1/9/20085:03 & $8 / 9 / 20085: 03$ & 21.6 & 561.1 \\
\hline 1297 & 1/9/20085:05 & $8 / 9 / 20085: 05$ & 21.6 & 512 \\
\hline 1298 & $1 / 9 / 20085: 07$ & $8 / 9 / 20085: 07$ & 21.6 & 542.7 \\
\hline 1299 & $1 / 9 / 20085: 09$ & $8 / 9 / 20085: 09$ & 21.7 & 587.3 \\
\hline 1300 & $1 / 9 / 20085: 11$ & $8 / 9 / 20085: 11$ & 21.7 & 592.9 \\
\hline 1301 & 1/9/20085:13 & $8 / 920085: 13$ & 21.8 & 593.7 \\
\hline 1302 & 1/9/2008 5:15 & $8 / 920085: 15$ & 21.9 & 593.8 \\
\hline 1303 & t/92008 5:17 & $8 / 9 / 20085: 17$ & 21.9 & 590.9 \\
\hline 1304 & 1/9/20085:19 & $8 / 9 / 20085: 19$ & 21.8 & 577.6 \\
\hline 1305 & $1 / 9 / 20085: 21$ & $8 / 9 / 20085: 21$ & 21.8 & 576.3 \\
\hline 1306 & $1 / 9 / 20085: 23$ & $8 / 9 / 20085: 23$ & 21.7 & 573.5 \\
\hline 1307 & $1 / 9 / 20085: 25$ & $8 / 9 / 20085: 25$ & 21.7 & 569.9 \\
\hline 1308 & $1 / 9 / 20085: 27$ & $8 / 9 / 20085: 27$ & 21.6 & 568.1 \\
\hline 1309 & 1/9/20085:29 & $8 / 9 / 20085: 29$ & 21.7 & 581.7 \\
\hline 1310 & 1/9/20085:31 & $8 / 9720085: 31$ & 21.9 & 576.6 \\
\hline
\end{tabular}

\begin{tabular}{|c|c|c|c|c|}
\hline \multicolumn{5}{|c|}{$\overline{D 493 c}$} \\
\hline $\operatorname{Rec}$ & & Adjusted & Termp & $\mathrm{SC}$ \\
\hline$\#$ & Date-Time & Dater/Time & $\alpha$ & $\mu \mathrm{S} / \mathrm{cm}$ \\
\hline 1311 & $1 / 9 / 20085: 33$ & $8 / 9 / 20085: 33$ & 22 & 576. \\
\hline 1312 & $1 / 9 / 20085: 35$ & $8 / 9 / 20085: 35$ & 224 & 573. \\
\hline 1313 & $1 / 9 / 20085: 37$ & $8 / 920085: 37$ & 225 & 567.6 \\
\hline 1314 & $1 / 9 / 20085: 39$ & $8 / 920085: 39$ & 22.3 & \\
\hline 1315 & $1 / 9 / 20085: 41$ & $8 / 9 / 20085: 41$ & 22.6 & 557 \\
\hline 1316 & $1 / 9 / 20085: 43$ & $8 / 9 / 20085: 43$ & 23.6 & 549. \\
\hline 1317 & $1 / 9 / 20085: 45$ & $8 / 9 / 20085: 45$ & 24.4 & \\
\hline 1318 & $1 / 9 / 20085: 47$ & $8 / 9 / 20085: 47$ & 24.4 & 536 \\
\hline 1319 & 1/9/20085:49 & $8920085: 49$ & 23.9 & 536. \\
\hline 1320 & 1/9/20085:51 & $8 / 9 / 20085: 51$ & 23.6 & \\
\hline 1321 & $1 / 9 / 20085: 53$ & $8 / 920085: 53$ & 23.5 & 533.1 \\
\hline 1322 & $1 / 9 / 20085: 55$ & $8 / 920085: 55$ & 23.1 & 519.1 \\
\hline 1323 & $1 / 9 / 20085: 57$ & $8 / 920085: 57$ & 22.9 & 506. \\
\hline 1324 & $1 / 9 / 20085: 59$ & $8 / 9 / 20085: 59$ & 21.9 & 486.7 \\
\hline 1325 & $1 / 9 / 20086: 01$ & $8 / 9 / 20086: 01$ & 21.6 & \\
\hline 1326 & $1 / 9 / 20086: 03$ & $8 / 9 / 20086: 03$ & 21.3 & 483 \\
\hline 1327 & 1/9/2008 6:05 & $8 / 9 / 20086: 05$ & 21.4 & 485. \\
\hline 1328 & $1 / 9 / 20086: 07$ & $8 / 920086: 07$ & 21.2 & \\
\hline 1329 & $1 / 9 / 20086: 09$ & $8 / 9 / 20086: 09$ & 21.1 & 48 \\
\hline 1330 & $1 / 9 / 200$ & $8 / 9 / 20086: 11$ & 21.2 & 482 \\
\hline 1331 & $1 / 9 / 200$ & $8 / 9 / 20086: 13$ & 21.1 & \\
\hline 1332 & $1 / 9 / 20086: 15$ & $8 / 9 / 20086: 15$ & 20.7 & 485.2 \\
\hline 1333 & $1 / 9 / 20086: 17$ & $8 / 9 / 20086: 17$ & 20.5 & 476.8 \\
\hline 1334 & 1/9/20086:19 & $8 / 9 / 20086: 19$ & 20.4 & 477. \\
\hline 1335 & $1 / 9 / 200$ & $8 / 9 / 20086: 21$ & 20.3 & 477. \\
\hline 1336 & $6: 23$ & $8 / 920086: 23$ & 20.2 & 476 \\
\hline 1337 & $9 / 20086: 25$ & $8 / 9 / 20086: 25$ & 20.1 & 476. \\
\hline 1338 & $6: 27$ & $8 / 9 / 20086: 27$ & 20 & 476 \\
\hline 1339 & $1 / 9 / 200$ & $8 / 920086: 29$ & 19.9 & 476 \\
\hline 1340 & $1 / 9 / 200$ & $8 / 920086.31$ & 19.9 & 476. \\
\hline 1341 & 6:33 & $8 / 9 / 20086: 33$ & 19.8 & 476. \\
\hline 1342 & $120086: 35$ & $8 / 9 / 20086: 35$ & 19.8 & 476 \\
\hline 1343 & 37 & $8 / 920086: 37$ & 19.8 & 476 \\
\hline 1344 & $6: 39$ & $8 / 920086: 39$ & 19.8 & 478. \\
\hline 1345 & & $8 / 9 / 20086: 41$ & 19.8 & 477 \\
\hline 1346 & 6.43 & $8 / 920086: 43$ & 19.8 & 477. \\
\hline 1347 & $0: 45$ & $8 / 920086: 45$ & 19.8 & 477. \\
\hline 1348 & 47 & $8 / 9 / 20086: 47$ & 19.8 & 476. \\
\hline 1349 & 49 & $8 / 9 / 20086: 49$ & 19.8 & 474 \\
\hline 1350 & & $8 / 9 / 20086: 51$ & 19.8 & 473. \\
\hline 1351 & 53 & $8 / 9 / 20086: 53$ & 19.7 & 469 \\
\hline 1352 & 36.55 & 89920086.55 & 19.8 & 46 \\
\hline 1353 & & $8 / 9 / 20086: 57$ & 19.8 & 464 \\
\hline 1354 & 59 & $8 / 9 / 20086: 59$ & 19.8 & 462 \\
\hline 1355 & 01 & $8 / 9 / 20087: 01$ & 19.8 & 46 \\
\hline 1356 & & $8 / 9 / 20087: 03$ & 19.8 & 464 \\
\hline 1357 & $7: 05$ & $8 / 920087: 05$ & 19.8 & 465 \\
\hline 1358 & & $8 / 9 / 200$ & 19.8 & 464 \\
\hline 1359 & 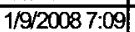 & $8 / 9 / 20$ & 19.8 & 464 \\
\hline 1360 & 11 & $8 / 9 / 20087: 11$ & 19.8 & 464 \\
\hline 1361 & & $8 / 920087: 13$ & 19.7 & 463. \\
\hline 1362 & $7: 15$ & $8 / 920087: 15$ & 19.7 & 463 \\
\hline 1363 & & & 19.7 & 462 \\
\hline 1364 & & $8 / 9 / 20087: 19$ & 19.7 & 461 \\
\hline 1365 & 21 & $8 / 9 / 20087: 21$ & 19.7 & 460 \\
\hline 366 & & & 19.6 & 459 \\
\hline 1367 & 25 & $8 / 920087: 25$ & 19.6 & 458 \\
\hline 1368 & & & 19.6 & 458 \\
\hline 1369 & & $8 / 9 / 20087: 29$ & 19.6 & \\
\hline 1370 & $7: 31$ & $8 / 9 / 20087: 31$ & 19.5 & 458. \\
\hline 1371 & & & 19.5 & 457 \\
\hline 1372 & $1 /$ & $8 / 9 / 20087: 35$ & 19.5 & 456 \\
\hline 1373 & $7: 37$ & $8 / 9 / 20087: 37$ & 19.5 & 455 \\
\hline 1374 & & $8 / 9 / 20087: 39$ & 19.5 & 454 \\
\hline 1375 & $1 / 9 / 20087: 41$ & $8 / 9 / 20087: 41$ & 19.5 & 453. \\
\hline 1376 & $1 / 9 / 20087: 43$ & $8 / 9 / 20087: 43$ & 19.5 & 453 \\
\hline & & $8 / 9 / 20087: 45$ & 19.5 & 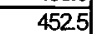 \\
\hline 1378 & $1 / 9 / 20087: 47$ & $8 / 920087: 47$ & 19.5 & 451 \\
\hline 1379 & $1 / 9 / 20087: 49$ & $8 / 920087: 49$ & 19.5 & \\
\hline
\end{tabular}

\begin{tabular}{|c|c|c|c|c|}
\hline \multicolumn{5}{|c|}{$D 4-93 c$} \\
\hline $\operatorname{Rec}$ & & Acjusted & Temp & $\mathrm{SC}$ \\
\hline$\#$ & Date-Time & DaterTime & $\alpha$ & $\mu \mathrm{S} / \mathrm{cm}$ \\
\hline 1380 & $1 / 9 / 20087: 51$ & $8 / 9 / 20087: 51$ & 19.5 & 450.1 \\
\hline 1381 & $1 / 9 / 20087: 53$ & $8 / 9 / 20087: 53$ & 19.5 & 450.1 \\
\hline 1382 & $1 / 9 / 20087: 55$ & $8 / 9 / 20087755$ & 19.6 & 449.9 \\
\hline 1383 & 1/920087:57 & $8 / 9 / 20087: 57$ & 19.6 & 449.8 \\
\hline 1384 & 1/9/20087:59 & $8 / 9 / 20087: 59$ & 19.6 & 448.9 \\
\hline 1385 & $1 / 9 / 20088: 01$ & $8 / 9 / 20088: 01$ & 19.6 & 449 \\
\hline 1386 & 1/9/20088:03 & $8 / 9 / 20088: 03$ & 19.7 & 448 \\
\hline 1387 & $1 / 9 / 20088: 05$ & $8 / 9 / 20088: 05$ & 19.7 & 448.1 \\
\hline 1388 & $1 / 9 / 20088: 07$ & $8 / 9 / 20088: 07$ & 19.8 & 447.1 \\
\hline 1389 & $1 / 920088: 09$ & $8 / 9 / 20088: 09$ & 19.8 & 446.5 \\
\hline 1390 & 1/9/20088:11 & $8 / 9 / 20088: 11$ & 19.9 & 445.5 \\
\hline 1391 & 1/9/20088:13 & $8 / 9 / 20088: 13$ & 20 & 443.9 \\
\hline 1392 & 1/9/20088:15 & 8/9/20088:15 & 20.1 & 442.9 \\
\hline 1393 & 1/9/20088:17 & $8 / 9 / 20088: 17$ & 20.2 & 441.1 \\
\hline 1394 & 1/9/2008 8:19 & $8 / 9 / 20088: 19$ & 20.3 & 440.7 \\
\hline 1395 & $1 / 9 / 20088: 21$ & $8 / 9 / 20088: 21$ & 20.5 & 439.3 \\
\hline 1396 & $1 / 9 / 20088: 23$ & $8 / 9 / 20088: 23$ & 20.6 & 437.7 \\
\hline 1397| & $1 / 9 / 20088.25$ & $8 / 9 / 20088: 25$ & 20.9 & 436.1 \\
\hline 1398 & $1 / 9 / 20088: 27$ & $8 / 9 / 20088: 27$ & 21.1 & 434.8 \\
\hline 1399 & $1 / 9 / 20088: 29$ & $8 / 9 / 20088: 29$ & 21.5 & 433.8 \\
\hline 1400 & 1/9/20088:31 & $8 / 9 / 20088: 31$ & 21.6 & 432.8 \\
\hline 1401 & $1 / 9 / 20088: 33$ & $8 / 9 / 20088: 33$ & 21.6 & 433.3 \\
\hline 1402 & $1 / 9 / 20088: 35$ & $8 / 9 / 20088: 35$ & 21.5 & 433.3 \\
\hline 1403 & 1/9/2008 8:37 & $8 / 9 / 20088: 37$ & 24.4 & 500.5 \\
\hline 1404 & $1 / 9 / 20088: 39$ & $8 / 9 / 20088: 39$ & 23.8 & 455.7 \\
\hline 1405 & $1 / 9 / 20088: 41$ & $8 / 9 / 20088: 41$ & 228 & 426.6 \\
\hline 1406 & $1 / 9 / 20088: 43$ & $8 / 9 / 20088: 43$ & 19.7 & 445.3 \\
\hline 1407 & $1 / 9 / 20088: 45$ & $8 / 9 / 20088: 45$ & 19.3 & 448.2 \\
\hline 1408 & $1 / 9 / 20088: 47$ & $8 / 9 / 20088: 47$ & 19.2 & 450.2 \\
\hline 1409 & 1/9/20088:49 & $8 / 9 / 20088: 49$ & 19.2 & 450.5 \\
\hline 1410 & 1/9/2008 8:51 & $8 / 9 / 20088: 51$ & 19.3 & 449.9 \\
\hline 1411 & $1 / 9 / 20088: 53$ & $8 / 9 / 20088: 53$ & 19.3 & 450.4 \\
\hline 1412 & 1/9/2008 8:55 & $8 / 9 / 20088: 55$ & 21.9 & 459.4 \\
\hline 1413 & $1 / 9 / 20088: 57$ & $8 / 9 / 20088: 57$ & 22.2 & 478 \\
\hline 1414 & $1 / 9 / 20088: 59$ & $8 / 9 / 20088: 59$ & 21.8 & 475.1 \\
\hline 1415 & 1/9/20089:01 & $8 / 9 / 20089.01$ & 21.6 & 457.4 \\
\hline 1416 & $1 / 9 / 20089.03$ & $8 / 9 / 20089: 03$ & 21.3 & 454.5 \\
\hline 1417 & $1 / 9 / 20089.05$ & $8 / 9 / 20089: 05$ & 21 & 432.8 \\
\hline 1418 & $1 / 9 / 20089.07$ & $8 / 9 / 20089: 07$ & 20.5 & 440.4 \\
\hline 1419 & $1 / 9 / 20089: 09$ & $8 / 9 / 20089: 09$ & 24 & 550.1 \\
\hline 1420 & $1 / 920089.11$ & $8 / 9 / 20089: 11$ & 26 & 545 \\
\hline 1421 & $1 / 9 / 20089.13$ & $8 / 9 / 20089: 13$ & 25.8 & 546.3 \\
\hline 1422 & $1 / 9 / 20089: 15$ & $8 / 9 / 20089.15$ & 25.5 & 545.8 \\
\hline 1423 & $1 / 9 / 20089.17$ & $8 / 9 / 20089: 17$ & 25.1 & 545.5 \\
\hline 1424 & $1 / 9 / 20089.19$ & $8 / 9 / 20089: 19$ & 24.9 & 543.8 \\
\hline 1425 & $1 / 9 / 20089.21$ & $8 / 9 / 20089: 21$ & 24.7 & 542 \\
\hline 1426 & $1 / 9 / 20089.23$ & $8 / 9 / 20089: 23$ & 24.5 & 540 \\
\hline 1427 & $1 / 9 / 20089.25$ & $8 / 9 / 20089: 25$ & 24.4 & 541 \\
\hline 1428 & $1 / 9 / 20089.27$ & $8 / 9 / 20089.27$ & 24.4 & 541.4 \\
\hline 1429 & $1 / 9 / 20089.29$ & $8 / 9 / 20089: 29$ & 24.4 & 539.9 \\
\hline 1430 & 1/9/20089:31 & $8 / 9 / 20089: 31$ & 24.3 & 539 \\
\hline 1431 & $1 / 9 / 20089.33$ & $8 / 9 / 20089: 33$ & 24.2 & 539.7 \\
\hline 1432 & $1 / 9 / 20089.35$ & $8 / 9 / 20089: 35$ & 24 & 539 \\
\hline 1433 & 1/9/20089.37 & $8 / 9 / 20089: 37$ & 23.9 & 537.5 \\
\hline 1434 & $1 / 9 / 20089.39$ & $8 / 9 / 20089: 39$ & 23.7 & 537.1 \\
\hline 1435 & $1 / 9 / 20089: 41$ & $8 / 9 / 20089: 41$ & 23.4 & 536.4 \\
\hline 1436 & $1 / 9 / 20089: 43$ & $8 / 9 / 20089: 43$ & 23.3 & 536.1 \\
\hline 1437 & $1 / 9 / 20089.45$ & $8 / 9 / 20089: 45$ & 23 & 535.9 \\
\hline 1438 & $1 / 9 / 20089.47$ & $8 / 9 / 20089: 47$ & 22.8 & 534.7 \\
\hline 1439 & $1 / 9 / 20089.49$ & $8 / 9 / 20089: 49$ & 22.6 & 531.1 \\
\hline 1440 & $1 / 9 / 20089.51$ & $8 / 9 / 20089: 51$ & 22.4 & 522.7 \\
\hline 1441 & $1 / 920089.53$ & $8 / 2 / 20089: 53$ & 22.2 & 519 \\
\hline 1442 & 1/9/20089.55 & $8 / 9 / 20089: 55$ & 22 & 514.9 \\
\hline 1443 & $1 / 9 / 20089.57$ & 8/9/20089:57 & 21.7 & 504.1 \\
\hline 1444 & $1 / 9 / 20089.59$ & $8 / 9 / 20089: 59$ & 21.5 & 502.2 \\
\hline 1445 & $1 / 9 / 200810.01$ & $8 / 9 / 2008$ 10:01 & 21.2 & 500.8 \\
\hline 1446 & $1 / 9 / 200810.03$ & $8 / 9 / 2008$ 10:03 & 21 & 499.8 \\
\hline 1447 & 1/9/2008 10:05 & $8 / 9 / 2008$ 10:05 & 20.8 & 494.1 \\
\hline 1448 & 1/9/2008 10:07 & $8 / 9 / 2008$ 10:07 & 20.7 & 484.7 \\
\hline
\end{tabular}




\begin{tabular}{|c|c|c|c|c|}
\hline \multicolumn{5}{|c|}{ D493c } \\
\hline $\operatorname{Rec}$ & & Adjusted & Temp & SC \\
\hline$\#$ & Date-Time & DaterTime & $\alpha$ & $\mu \mathrm{s} / \mathrm{cm}$ \\
\hline 1449 & $1 / 9 / 2008$ 10:09 & $8 / 9 / 2008$ 10:09 & 20.5 & 4728 \\
\hline 1450 & 1/9/2008 10:11 & 8/9/2008 10:11 & 20.4 & 470.9 \\
\hline 1451 & $1 / 9 / 200810: 13$ & $8 / 9 / 2008$ 10:13 & 20.3 & 469.3 \\
\hline 1452 & $1 / 9 / 2008$ 10:15 & 8/9/2008 10:15 & 20.2 & 466 \\
\hline 1453 & 1/9/2008 10:17 & $8 / 9 / 2008$ 10:17 & 20.1 & 460 \\
\hline 1454 & 1/9/2008 10:19 & $8 / 9 / 2008$ 10:19 & 20 & 457.9 \\
\hline 1455 & $1 / 9 / 2008$ 10:21 & $8 / 9 / 2008$ 10:21 & 20 & 457.2 \\
\hline 1456 & $1 / 9 / 200810: 23$ & $8 / 9 / 200810: 23$ & 19.9 & 455.3 \\
\hline 1457 & $1 / 9200810.25$ & $8 / 9 / 2008$ 10:25 & 19.8 & 453.7 \\
\hline 1458 & $1 / 9 / 2008$ 10:27 & $8 / 9 / 200810: 27$ & 19.8 & 451.5 \\
\hline 1459 & $1 / 9 / 2008$ 10:29 & $8 / 9 / 2008$ 10:29 & 19.7 & 449.6 \\
\hline 1460 & 1/9/2008 10:31 & $8 / 9 / 2008$ 10:31 & 19.7 & 449.2 \\
\hline 1461 & $1 / 9 / 200810: 33$ & $8 / 9 / 200810: 33$ & 19.6 & 448.2 \\
\hline 1462 & $1 / 9 / 200810: 35$ & $8 / 9 / 2008$ 10:35 & 19.6 & 447.8 \\
\hline 1463 & $1 / 9 / 200810: 37$ & $8 / 9 / 2008$ 10:37 & 19.5 & 447.2 \\
\hline 1464 & $1 / 9 / 2008$ 10:39 & $89 / 2008$ 10:39 & 19.5 & 447.6 \\
\hline 1465 & $1 / 9 / 200810: 41$ & $8 / 9 / 2008$ 10:41 & 19.5 & 447.4 \\
\hline 1466 & $1 / 9 / 200810: 43$ & $8 / 9 / 200810: 43$ & 19.5 & 447.9 \\
\hline 1467 & $1 / 9 / 2008$ 10:45 & $8 / 9 / 2008$ 10:45 & 19.4 & 446.7 \\
\hline 1468 & $1 / 9 / 200810: 47$ & 8892008 10:47 & 19.4 & 446.2 \\
\hline 1469 & 1/9/2008 10:49 & $8 / 9 / 200810: 49$ & 19.4 & 446.4 \\
\hline 1470 & $1 / 9 / 2008$ 10:51 & $8 / 9 / 2008$ 10:51 & 19.4 & 446.4 \\
\hline 1471 & $1 / 9 / 200810: 53$ & $8 / 9 / 200810: 53$ & 19.4 & 446.9 \\
\hline 1472 & $1 / 9 / 200810: 55$ & $89 / 2008$ 10:55 & 19.4 & 447.9 \\
\hline 1473 & $1 / 9 / 200810.57$ & $8 / 9 / 2008$ 10:57 & 19.4 & 449.2 \\
\hline 1474 & $1 / 9 / 200810: 59$ & $8 / 9 / 200810: 59$ & 19.4 & 450.9 \\
\hline 1475 & $1 / 9 / 2008$ 11:01 & $8 / 9 / 2008$ 11:01 & 19.4 & 450.9 \\
\hline 1476 & $1 / 9 / 200811: 03$ & $8 / 9 / 200811: 03$ & 19.4 & 451.8 \\
\hline 1477 & 1/9/2008 11:05 & $8 / 9 / 2008$ 11:06 & 19.4 & 451.8 \\
\hline 1478 & $1 / 9 / 200811: 07$ & 8/9/2008 11:07 & 19.4 & 451.9 \\
\hline 1479 & $1 / 9 / 200811: 09$ & $8 / 9 / 2008$ 11:09 & 19.4 & 451.9 \\
\hline 1480 & 1/9/2008 11:11 & $8 / 9 / 2008$ 11:11 & 19.4 & 453.3 \\
\hline 1481 & 1/9/2008 11:13 & $8 / 9 / 2008$ 11:13 & 19.5 & 452.9 \\
\hline 1482 & 1/9/2008 11:15 & $8 / 9 / 2008$ 11:15 & 19.5 & 453.1 \\
\hline 1483 & 1/9/2008 11:17 & $8 / 9 / 2008$ 11:17 & 19.6 & 452.9 \\
\hline 1484 & 1/9/2008 11:19 & $8 / 9 / 2008$ 11:19 & 19.7 & 453.9 \\
\hline 1485 & $1 / 9 / 200811: 21$ & $8 / 9 / 2008$ 11:21 & 19.9 & 454 \\
\hline 1486 & 1/9/2008 11:23 & 8/9/2008 11:23 & 20.1 & 453.1 \\
\hline 1487 & $1 / 9 / 200811: 25$ & $8 / 9 / 200811: 25$ & 20.3 & 453.3 \\
\hline 7488 & 1/9/2008 11:27 & $8 / 9 / 200811: 27$ & 20.5 & 453.9 \\
\hline 1489 & $1 / 9 / 200811: 29$ & $8 / 9 / 2008$ 11:29 & 20.8 & 454.3 \\
\hline 1490 & 1/9/2008 11:31 & $8 / 9 / 2008$ 11:31 & 21 & 455.5 \\
\hline 1491 & $1 / 9 / 200811: 33$ & $8 / 9 / 2008$ 11:33 & 21.3 & 458.3 \\
\hline 1492 & $1 / 9 / 200811: 35$ & $8 / 9 / 200811: 35$ & 21.6 & 462.4 \\
\hline 1493 & 1/9/2008 11:37 & $8 / 9 / 2008$ 11:37 & 21.9 & 470 \\
\hline 1494 & 1/9/2008 11:39 & $8 / 9 / 2008$ 11:39 & 22.1 & 477.1 \\
\hline 1495 & $1 / 9 / 200811: 41$ & $8 / 9 / 2008$ 11:41 & 22.3 & 490.5 \\
\hline 1496 & $1 / 9 / 200811: 43$ & $8 / 9 / 2008$ 11:43 & 22.5 & 537.9 \\
\hline 1497 & $1 / 9 / 2008$ 11:45 & $8 / 9200811: 45$ & 22.6 & 577.7 \\
\hline 1498 & 1/9/2008 11:47 & $8 / 9 / 200811: 47$ & 22.8 & 659.8 \\
\hline 1499 & $1 / 9 / 200811: 49$ & $8 / 9 / 200811: 49$ & 22.8 & 644.3 \\
\hline 1500 & 1/9/2008 11:51 & $8 / 9 / 2008$ 11:51 & 22.3 & 4929 \\
\hline 1501 & 1/9/2008 11:53 & $8 / 9 / 2008$ 11:53 & 19.8 & 466 \\
\hline 1502 & $1 / 9 / 2008$ 11:55 & $8 / 9 / 2008$ 11:55 & 19.4 & 464.6 \\
\hline 1503 & $1 / 9 / 2008$ 11:57 & $8 / 9 / 2008$ 11:57 & 21.7 & 5627 \\
\hline 1504 & $1 / 9 / 2008$ 11:59 & $89200811: 59$ & 23 & 651.9 \\
\hline 1505 & $1 / 9 / 2008$ 12:01 & $8 / 9 / 20081201$ & 23.2 & 665 \\
\hline 1506 & 1/9/2008 12:03 & $8 / 9 / 200812: 03$ & 23.2 & 671.4 \\
\hline 1507 & 1/9/2008 12:05 & $8 / 9 / 2008$ 12:05 & 23.1 & 671.4 \\
\hline 1508 & 1/9/2008 12:07 & $89 / 2008$ 12:07 & 23.1 & 670.1 \\
\hline 1509 & $1 / 9 / 200812: 09$ & $89 / 200812: 09$ & 23 & 673.8 \\
\hline 1510 & $1 / 9 / 200812: 11$ & $8 / 9 / 200812: 11$ & 23 & 672.2 \\
\hline 1511 & $1 / 9 / 200812: 13$ & $89 / 200812: 13$ & 23 & 668.7 \\
\hline 1512 & $1 / 9 / 200812: 15$ & $89 / 200812: 15$ & 229 & 666.8 \\
\hline 1513 & $1 / 9 / 200812: 17$ & $8 / 9 / 200812: 17$ & 22.8 & 663.6 \\
\hline 1514 & $1 / 9 / 200812: 19$ & $8 / 9 / 200812: 19$ & 22.6 & 661.1 \\
\hline 1515 & $1 / 9 / 2008$ 12:21 & $8 / 9 / 2008$ 12:21 & 22.4 & 655 \\
\hline 1516 & $1 / 9 / 200812: 23$ & $8 / 9 / 2008$ 12:23 & 22.2 & 647.6 \\
\hline 1517 & 1/9/2008 12:25 & $8 / 9 / 200812: 25$ & & 641.5 \\
\hline
\end{tabular}

\begin{tabular}{|c|c|c|c|c|}
\hline \multicolumn{5}{|c|}{ D4-93c } \\
\hline $\operatorname{Rec}$ & & Adisted & Temp & SC \\
\hline$\#$ & Date/Time & Daterime & $\infty$ & $\mu \mathrm{S} / \mathrm{cm}$ \\
\hline 1518 & $1 / 9 / 2008$ 12:27 & $8 / 9 / 20081227$ & 21.8 & 637.1 \\
\hline 1519 & $1 / 9 / 20081229$ & 89920081229 & 21.5 & 633.5 \\
\hline 1520 & $1 / 9 / 2008$ 12:31 & $8 / 9 / 20081231$ & 21.3 & 629.7 \\
\hline 1521 & $1 / 9 / 200812: 33$ & $8 / 920081233$ & 21.2 & 619.5 \\
\hline 1522 & $1 / 9 / 200812: 35$ & $8 / 9200812: 35$ & 20.9 & 595 \\
\hline 1523 & 1/9/2008 12:37 & 8992008 12:37 & 20.7 & 573.4 \\
\hline 1524 & $1 / 9 / 20081239$ & $8 / 920081239$ & 20.5 & 554.3 \\
\hline 1525 & $1 / 9 / 2008 \quad 1244$ & $8 / 9 / 2008$ 1241 & 20.3 & 539.7 \\
\hline 1526 & $1 / 9 / 2008 \quad 12: 43$ & $8 / 9 / 20081243$ & 20.2 & 529.8 \\
\hline 1527 & $1 / 9 / 200812: 45$ & $8 / 9 / 20081245$ & 20.1 & 521.6 \\
\hline 1528 & 1/9/2008 12:47 & $8 / 92008$ 12:47 & 20 & 514.6 \\
\hline 1529 & $1 / 920081249$ & $8 / 920081249$ & 19.9 & 509 \\
\hline 1530 & $1 / 9 / 200812: 51$ & $8 / 9 / 20081251$ & 19.9 & 503.3 \\
\hline 1531 & $1 / 9 / 200812: 53$ & $8 / 9 / 200812: 53$ & 19.9 & 500.1 \\
\hline 1532 & $1 / 9 / 200812555$ & $8 / 9200812: 55$ & 19.8 & 499.8 \\
\hline 1533 & $1 / 9 / 200812: 57$ & $8 / 9 / 2008$ 12:57 & 19.8 & 497.4 \\
\hline 1534 & $1 / 920081259$ & $8 / 9 / 200812: 59$ & 19.8 & 4925 \\
\hline 1535 & $1 / 9 / 2008$ 13:01 & $8 / 9 / 2008$ 13:01 & 19.7 & 485 \\
\hline 1536 & $1 / 9 / 200813: 03$ & $8 / 9 / 2008$ 13:03 & 19.7 & 484.8 \\
\hline 1537 & $1 / 9 / 200813: 05$ & $89 / 2008$ 13:06 & 19.7 & 483.9 \\
\hline 1538 & $1 / 9 / 200813: 07$ & 8/9/2008 13:07 & 19.7 & 481.7 \\
\hline 1539 & $1 / 9 / 200813: 09$ & $8 / 9 / 200813: 09$ & 19.7 & 479.8 \\
\hline 1540 & $1 / 9 / 200813: 11$ & $8 / 9 / 2008$ 13:11 & 19.7 & 474.5 \\
\hline 1541 & $1 / 9 / 200813: 13$ & 8/9/2008 13:13 & 19.6 & 472.3 \\
\hline 1542 & 1/9/2008 13:15 & $8 / 9 r 2008$ 13:15 & 19.6 & 472.9 \\
\hline 1543 & $1 / 9 / 2008$ 13:17 & $8 / 9 / 2008$ 13:17 & 19.6 & 472.3 \\
\hline 1544 & $1 / 9 / 2008$ 13:19 & $8 / 9 / 2008$ 13:19 & 19.6 & 472.2 \\
\hline 1545 & $1 / 9 / 2008$ 13:21 & $8 / 92008$ 13:21 & 19.6 & 470.8 \\
\hline 1546 & 1/9/2008 13:23 & $8 / 9 / 200813: 23$ & 19.6 & 470.9 \\
\hline 1547 & $1 / 9 / 2008$ 13:25 & $8 / 9 / 2008 \quad 13: 25$ & 19.6 & 470.7 \\
\hline 1548 & $1 / 9 / 2008$ 13:27 & $8 / 9 / 2008$ 13:27 & 19.6 & 468.6 \\
\hline 1549 & $1 / 9 / 2008$ 13:29 & $8 / 9200813: 29$ & 19.5 & 469.6 \\
\hline 1550 & $1 / 9 / 200813: 31$ & $8 / 9 / 2008$ 13:31 & 19.6 & 468.7 \\
\hline 1551 & $1 / 9 / 200813: 33$ & $8 / 9 / 200813: 33$ & 19.6 & 468.5 \\
\hline 1552 & $1 / 9 / 200813: 35$ & $8 / 9 / 2008$ 13:35 & 19.6 & 468 \\
\hline 1553 & $1 / 9 / 2008$ 13:37 & $8 / 9 / 2008$ 13:37 & 19.6 & 467.8 \\
\hline 1554 & 1/9/2008 13:39 & $8 / 9 / 2008$ 13:39 & 19.6 & 467.8 \\
\hline 1555 & 1/9/2008 13:41 & $8 / 9 / 2008$ 13:41 & 19.6 & 466.5 \\
\hline 1556 & $1 / 9 / 200813: 43$ & $8 / 9 / 200813: 43$ & 19.6 & 466 \\
\hline 1557 & $1 / 9 / 2008$ 13:45 & $8 / 9 / 2008$ 13:45 & 19.6 & 466.7 \\
\hline 1558 & $1 / 9200813: 47$ & $8 / 9 / 200813: 47$ & 19.6 & 466 \\
\hline 1559 & $1 / 9 / 200813: 49$ & $8 / 9 / 2008$ 13:49 & 19.6 & 465.4 \\
\hline 1560 & $1 / 9 / 200813: 51$ & $8 / 9 / 200813: 51$ & 19.6 & 466.9 \\
\hline 1561 & 1/9/2008 13:53 & $8 / 9 / 200813: 53$ & 19.6 & 464.8 \\
\hline 1562 & 1/9/2008 13:55 & $8 / 9 / 200813: 55$ & 19.6 & 469.4 \\
\hline 1563 & $1 / 9 / 200813: 57$ & $8 / 9 / 200813: 57$ & 19.6 & 465 \\
\hline 1564 & $1 / 9 / 200813: 59$ & $8 / 9 / 200813: 59$ & 19.7 & 470.9 \\
\hline 1565 & $1 / 9 / 200814: 01$ & $8 / 9 / 2008$ 14:01 & 19.7 & 463.9 \\
\hline 1566 & 1/9/2008 14:03 & $8 / 9 / 2008$ 14:03 & 19.7 & 464.2 \\
\hline 1567 & $1 / 9 / 2008$ 14:05 & $8 / 9 / 200814: 05$ & 19.7 & 461.5 \\
\hline 1568 & $1 / 9 / 2008$ 14:07 & $8 / 9 / 2008$ 14:07 & 19.7 & 461.4 \\
\hline 1569 & $1 / 9 / 2008$ 14:09 & $8 / 9 / 200814: 09$ & 19.7 & 459.9 \\
\hline 1570 & $1 / 92008$ 14:11 & $8 / 9 / 2008$ 14:11 & 19.7 & 458.3 \\
\hline 1571 & $1 / 9 / 200814: 13$ & $8 / 9 / 2008$ 14:13 & 19.7 & 456.5 \\
\hline 1572 & 1/9/2008 14:15 & $8 / 9 / 2008$ 14:15 & 19.7 & 456 \\
\hline 1573 & 1/9/2008 14:17 & $8 / 9 / 2008$ 14:17 & 19.7 & 455.8 \\
\hline 1574 & $1 / 9 / 200814: 19$ & $8 / 9 / 2008$ 14:19 & 19.7 & 457.5 \\
\hline 1575 & 1/9/2008 14:21 & $8 / 9 / 2008$ 14:21 & 19.7 & 456.8 \\
\hline 1576 & $1 / 9 / 2008$ 14:23 & $8 / 9 / 200814: 23$ & 19.7 & 457.3 \\
\hline 157 & $1 / 9 / 2008$ 14:25 & $8 / 9 / 2008$ 14:25 & 19.7 & 455.4 \\
\hline 1578 & $1 / 9 / 2008$ 14:27 & $8 / 9 / 2008$ 14:27 & 19.7 & 457.9 \\
\hline 1579 & $1 / 9 / 200814: 29$ & $8 / 9 / 200814: 29$ & 19.7 & 456.9 \\
\hline 1580 & $1 / 9 / 2008$ 14:31 & $8 / 9 / 2008$ 14:31 & 19.8 & 456.3 \\
\hline 1581 & $1 / 9 / 2008 \quad 14: 33$ & $8 / 9 / 2008$ 14:33 & 19.8 & 456.5 \\
\hline 1582 & $1 / 9 / 2008$ 14:35 & $8 / 9 / 2008$ 14:35 & 19.8 & 456.1 \\
\hline 1583 & $1 / 9 / 2008$ 14:37 & $8 / 9 / 2008$ 14:37 & 19.8 & 455.4 \\
\hline 1584 & $1 / 9 / 200814: 39$ & $8 / 9 / 200814: 39$ & 19.8 & 455.7 \\
\hline 1585 & $1 / 92008$ 14:41 & $8 / 9 / 200814: 41$ & 19.9 & 455 . \\
\hline 1586 & 1/9/2008 14:43 & $8 / 9 / 200814: 43$ & 19.9 & 454.9 \\
\hline
\end{tabular}

\begin{tabular}{|c|c|c|c|c|}
\hline \multicolumn{5}{|c|}{ D4-93c } \\
\hline $\operatorname{Rec}$ & & Adjusted & Temp & SC \\
\hline$\#$ & DaterTime & DaterTime & $\alpha$ & $\mu \mathrm{S} / \mathrm{cm}$ \\
\hline 1587 & $1 / 9 / 2008$ 14:45 & $8 / 9 / 200814: 45$ & 19.9 & 453.9 \\
\hline 1588 & $1 / 9 / 200814: 47$ & $8 / 9 / 200814: 47$ & 19.9 & 453.5 \\
\hline 1589 & $1 / 9 / 2008 \quad 14: 49$ & $8 / 912008$ 14:49 & 19.9 & 452.9 \\
\hline 1590 & $1 / 9 / 2008$ 14:51 & $8 / 9 / 200814: 51$ & 20 & 451.8 \\
\hline 1591 & $1 / 9 / 200814: 53$ & $89 / 200814: 53$ & 20 & 451.1 \\
\hline 1592 & $1 / 9 / 200814: 55$ & $8 / 9 / 2008$ 14:55 & 20 & 451 \\
\hline 1593 & $1 / 9 / 200814: 57$ & $8 / 9 / 2008$ 14:57 & 22 & $\overline{621.6}$ \\
\hline 1594 & $1 / 9 / 2008$ 14:59 & $8 / 9 / 2008$ 14:59 & 23.1 & 640.3 \\
\hline 1595 & $1 / 9 / 2008$ 15:01 & $8 / 9 / 2008$ 15:01 & 23.2 & 640.3 \\
\hline 1596 & $1 / 9 / 200815: 03$ & $8 / 9 / 2008$ 15:03 & 23.2 & 639.5 \\
\hline 1597 & 1/9/2008 15:05 & $8 / 9 / 2008$ 15:05 & 23.2 & 635.7 \\
\hline 1598 & 1/9/2008 15:07 & $8 / 9 / 2008$ 15:07 & 23.2 & 633.5 \\
\hline 1599 & 1/9/2008 15:09 & $8 / 9200815: 09$ & 23.2 & 634.2 \\
\hline 1600 & $1 / 9 / 2008$ 15:11 & $8 / 9 / 2008$ 15:11 & 23.1 & 634.1 \\
\hline 1601 & $1 / 9 / 2008$ 15:13 & $8 / 9 / 2008$ 15:13 & 22.9 & 634.8 \\
\hline 1602 & 1/9/2008 15:15 & 892008 15:15 & 226 & 632.9 \\
\hline 1603 & $1 / 9 / 2008$ 15:17 & $8 / 9 / 2008$ 15:17 & 22.3 & 626.8 \\
\hline 1604 & $1 / 9 / 200815: 19$ & 8/9/2008 15:19 & 22 & 613.4 \\
\hline 1605 & 1/9/2008 15:21 & $8 / 9 / 2008$ 15:21 & 21.7 & 602 \\
\hline 1606 & 1/9/2008 15:23 & $8 / 9 / 2008$ 15:23 & 21.3 & 593.4 \\
\hline 1607 & $1 / 9 / 2008$ 15:25 & $8 / 9 / 2008$ 15:25 & 20.6 & 546 \\
\hline 1608 & $1 / 9 / 2008$ 15:27 & $8 / 9 / 2008$ 15:27 & 20.1 & 508.8 \\
\hline 1609 & $1 / 9 / 2008$ 15:29 & $8 / 9 / 2008$ 15:29 & 20.5 & 513.4 \\
\hline 1610 & $1 / 9 / 2008$ 15:31 & $8 / 9 / 2008$ 15:31 & 20.7 & 468.1 \\
\hline 1611 & $1 / 9 / 200815: 33$ & $8 / 9 / 2008$ 15:33 & 20.4 & 456.7 \\
\hline 1612 & $1 / 9 / 2008$ 15:35 & $8 / 9 / 2008$ 15:35 & 20.2 & 446 \\
\hline 1613 & $1 / 9 / 2008$ 15:37 & $8 / 9 / 2008$ 15:37 & 20.1 & 445 \\
\hline 1614 & $1 / 9 / 200815: 39$ & $8 / 9 / 2008$ 15:39 & 20 & 444.7 \\
\hline 1615 & $1 / 9 / 2008$ 15:41 & $8 / 9 / 2008$ 15:41 & 20 & 444.8 \\
\hline 1616 & $1 / 9 / 200815: 43$ & $8 / 9 / 200815: 43$ & 20 & 445.5 \\
\hline 1617 & $1 / 9 / 200815: 45$ & $8 / 9 / 2008$ 15:45 & 20 & 448 \\
\hline 1618 & $1 / 9 / 200815: 47$ & $8 / 9 / 2008$ 15:47 & 20 & 447.4 \\
\hline 1619 & $1 / 9 / 2008$ 15:49 & $8 / 9 / 2008$ 15:49 & 20 & 446.7 \\
\hline 1620 & $1 / 9 / 200815: 51$ & $8 / 9 / 2008$ 15:51 & 20 & 449.2 \\
\hline 1621 & $1 / 9 / 200815: 53$ & $8 / 9 / 200815: 53$ & 20 & 450.5 \\
\hline 1622 & 1/9/2008 15:55 & $8 / 9 / 2008$ 15:55 & 20 & 449.4 \\
\hline 1623 & $1 / 9 / 2008$ 15:57 & $89 / 2008$ 15:57 & 20 & 449.2 \\
\hline 1624 & $1 / 9 / 200815: 59$ & $8 / 9 / 2008$ 15:59 & 20.1 & 448.2 \\
\hline 1625 & $1 / 9 / 2008$ 16:01 & $8 / 9 / 2008$ 16:01 & 20.1 & 449.9 \\
\hline 1626 & $1 / 9 / 2008$ 16:03 & $8 / 9 / 200816: 03$ & 20.1 & 449.7 \\
\hline 1627 & 1/9/2008 16:05 & $8 / 9 / 2008$ 16:05 & 20.1 & 446.9 \\
\hline 1628 & 1/9/2008 16:07 & 8/9/2008 16:07 & 20.1 & 447.4 \\
\hline 1629 & 1/9/2008 16:09 & $8 / 9 / 200816: 09$ & 20.1 & 446.5 \\
\hline 1630 & 1/9/2008 16:11 & $8 / 9 / 2008$ 16:11 & 20.1 & 447 \\
\hline 1631 & 1/9/2008 16:13 & 8/9/2008 16:13 & 20.2 & 447.3 \\
\hline 1632 & 1/9/2008 16:15 & $8 / 9 / 2008$ 16:15 & 20.2 & 447.2 \\
\hline 1633 & 1/9/2008 16:17 & 8/9/2008 16:17 & 20.2 & 448.6 \\
\hline 1634 & 1/9/2008 16:19 & $8 / 9 / 2008$ 16:19 & 20.3 & 449 \\
\hline 1635 & 1/9/2008 16:21 & $8 / 9 / 2008$ 16:21 & 20.3 & 448.9 \\
\hline 1636 & $1 / 9 / 2008$ 16:23 & $8 / 9 / 200816: 23$ & 20.4 & 449.4 \\
\hline 1637 & 1/9/2008 16:25 & $8 / 9 / 2008$ 16:25 & 20.5 & 443.6 \\
\hline 1638 & $1 / 9 / 2008$ 16:27 & $8 / 9 / 200816: 27$ & 20.7 & 442.7 \\
\hline 1639 & $1 / 92000816: 29$ & $8 / 9 / 200816: 29$ & 20.9 & 440.7 \\
\hline 1640 & 1/9/2008 16:31 & $8 / 9 / 2008$ 16:31 & 21 & 440.8 \\
\hline 1641 & $1 / 9 / 200816: 33$ & $8 / 9 / 200816: 33$ & 21.2 & 440.3 \\
\hline 1642 & $1 / 9 / 2008$ 16:35 & $8 / 9 / 2008$ 16:35 & 21.4 & 445.8 \\
\hline 1643 & $1 / 9 / 2008$ 16:37 & 8/9/2008 16:37 & 21.7 & 448.5 \\
\hline 1644 & $1 / 9 / 2008$ 16:39 & $8 / 9 / 2008$ 16:39 & 22 & 452.5 \\
\hline 1645 & $1 / 9 / 2008$ 16:41 & $8 / 9 / 200816: 41$ & 22.2 & 452.8 \\
\hline 1646 & 1/9/2008 16:43 & $8 / 9 / 200816: 43$ & 22.5 & 452.1 \\
\hline 1647 & $1 / 9 / 2008$ 16:45 & $8 / 9 / 2008 \quad 16: 45$ & 22.7 & 475.5 \\
\hline 1648 & $1 / 9 / 200816: 47$ & $8 / 9 / 2008$ 16:47 & 22.8 & 510.6 \\
\hline 1649 & $1 / 9 / 2008+6: 49$ & $8 / 9 / 200816: 49$ & 22.9 & 530.3 \\
\hline 1650 & 1/9/2008 16:51 & $8 / 9 / 2008$ 16:51 & 23 & 555.4 \\
\hline 1651 & 1/9/2008 16:53 & $8 / 9 / 200816: 53$ & 23.1 & 556.8 \\
\hline 1652 & $1 / 9 / 200816: 55$ & $8 / 9 / 2008$ 16:55 & 23.2 & 564.6 \\
\hline 1653 & $1 / 9 / 200816: 57$ & $8 / 9 / 200816: 57$ & 23.2 & 565.3 \\
\hline 1654 & 1/9/2008 16:59 & $8 / 9 / 200816: 59$ & 23.2 & 569.3 \\
\hline 1655 & 1/9/2008 17:01 & $8 / 9 / 2008$ 17:01 & 23.2 & 565.3 \\
\hline
\end{tabular}




\begin{tabular}{|c|c|c|c|c|}
\hline \multicolumn{5}{|c|}{$D 493 c$} \\
\hline $\mathrm{Rec}$ & & Adusted & Temp & $\overline{S C}$ \\
\hline$\#$ & Date/Time & Dater/ime & $\alpha C$ & psiom \\
\hline 1656 & 1/92008 17:03 & 892008 17:03 & 23.2 & 564.6 \\
\hline 1657 & $1 / 9200817: 05$ & $892000817: 05$ & 23.3 & 564.6 \\
\hline 1658 & 1/92008 17:07 & $89 / 2008$ 17:07 & 23.3 & 563.8 \\
\hline 1659 & $1 / 9200817: 00$ & 8920008 17:09 & 23.3 & 567.8 \\
\hline 1660 & $1 / 9200817: 11$ & 8920008 17:11 & 23.3 & 565.2 \\
\hline 1661 & $1 / 9200817: 13$ & 8912008 17:13 & 23.3 & 563.2 \\
\hline 1662 & $1 / 9200817: 15$ & 892008 17:15 & 23.3 & 562 \\
\hline 1663 & $1 / 92008$ 17:17 & $89 / 2008$ 17:17 & 23.3 & 564 \\
\hline 1664 & $1 / 9200817: 19$ & 8992008 17:19 & 23.4 & 567.1 \\
\hline 1605 & $1 / 9200817: 21$ & $89 / 2008$ 17:21 & 23.4 & 574 \\
\hline 1606 & $1 / 9200817: 23$ & $89 / 2008$ 17:23 & 23.4 & 578.6 \\
\hline 1667 & $1 / 9200817: 25$ & $89 / 2008$ 17:25 & 23.4 & 5828 \\
\hline 1668 & $1 / 9 / 200817: 27$ & $89 / 2008$ 17:27 & 23.5 & 583 \\
\hline 1609 & $1 / 9200817: 20$ & $8 / 9 / 2008$ 17:29 & 23.5 & 583.1 \\
\hline 1670 & $1 / 9200817: 31$ & 892008 17:31 & 23.5 & 585.8 \\
\hline 1671 & $1 / 92008$ 17:33 & 8992008 17:33 & 23.5 & 587.5 \\
\hline 1672 & 1/920008 17:35 & $89 / 2008$ 17:35 & 236 & 591.1 \\
\hline 1673 & $1 / 920008$ 17:37 & 8992008 17:37 & 23.6 & 595.8 \\
\hline 1674 & 1/92008 17:39 & 892008 17:39 & 23.6 & 592.3 \\
\hline 1675 & $1 / 9200817: 41$ & $89 / 2008$ 17:41 & 23.7 & 586.9 \\
\hline 1676 & $1 / 9 / 200817: 43$ & 892008 17:43 & 23.7 & 590.5 \\
\hline $16 \pi$ & $1 / 97200817: 45$ & $89 / 2008$ 17:45 & 23.7 & 598.5 \\
\hline 1678 & $1920200817: 47$ & $89 / 2008$ 17:47 & 23.8 & 597 \\
\hline 1679 & 1992008 17:49 & $89 / 2008$ 17:49 & 239 & 606.5 \\
\hline 1680 & $1 / 92008$ 17:51 & 892008 17:51 & 23.9 & 609.7 \\
\hline 1681 & $1 / 92008$ 17:53 & 892008 17:53 & 23.9 & 610.5 \\
\hline 1682 & 1/9/2008 17:56 & 892008 17:55 & 23.9 & 611.2 \\
\hline 1683 & $1 / 9 / 200817: 57$ & 8992008 17:57 & 24 & 610.5 \\
\hline 1684 & $1 / 9200817: 59$ & $899200817: 59$ & 24 & 609.6 \\
\hline 1685 & $1 / 9200818: 01$ & $89 / 200818.01$ & 24 & 608.1 \\
\hline 1686 & $1 / 9200818: 03$ & $8 / 9 / 2008$ 18:03 & 23.9 & 607.4 \\
\hline 1687 & $1 / 9200818: 05$ & $89 / 2008$ 18:05 & 23.9 & 605.6 \\
\hline 1688 & $1 / 9200818: 07$ & 892008 18:07 & 23.8 & 604.6 \\
\hline 1689 & $192000818: 09$ & $892000818: 09$ & 23.6 & 6025 \\
\hline 1690 & $1 / 92008$ 18.11 & 892000 18:11 & 23.3 & 600.1 \\
\hline 1691 & 1/9/200818:13 & $89200818: 13$ & 229 & 591.8 \\
\hline 1692 & $19 / 900818: 15$ & $89 / 200818: 15$ & 225 & 583.1 \\
\hline 1693 & $1 / 9 / 200818: 17$ & $89 / 2008$ 18:17 & 221 & 567.8 \\
\hline 1694 & $1 / 9200818: 19$ & $89200018: 19$ & 21.6 & 539.2 \\
\hline 1605 & 1/92008 18:21 & $89 / 2008$ 18:21 & 21.2 & 530 \\
\hline 1696 & 1/9/2008 18:23 & $89 / 200818: 23$ & 20.9 & 517.7 \\
\hline 1697 & $1 / 9 / 200818: 25$ & $8912008+8: 25$ & 20.8 & 469.9 \\
\hline 1696 & $199200818: 27$ & $89200818: 27$ & 20.7 & 457.7 \\
\hline 1690 & $1 / 9 / 200818: 20$ & $89200818: 29$ & 20.8 & 448.6 \\
\hline 1700 & $1 / 9 / 200818: 31$ & $89 / 200818: 31$ & 20.8 & 444.5 \\
\hline 1701 & $1 / 9200818: 33$ & $89 / 2008$ 18:33 & 20.7 & 4426 \\
\hline 1702 & $1 / 9200818.35$ & $89 / 200818: 35$ & 20.7 & 442.2 \\
\hline 1703 & $1 / 9200818.37$ & $89200818: 37$ & 20.6 & 4427 \\
\hline 1704 & 1/92008 18:39 & $89200818: 39$ & 20.6 & 444.6 \\
\hline 1705 & 1/9/200818:41 & $8 / 92008$ 18:41 & 20.5 & 451 \\
\hline 1706 & 1/92008 18:43 & $89 / 200818: 43$ & 20.4 & 447 \\
\hline 1707 & $1 / 9200818: 45$ & $892000818: 45$ & 20.4 & 4424 \\
\hline 1708 & $1 / 9200818: 47$ & 892008 18:47 & 20.5 & 440.6 \\
\hline 1700 & $199200818: 49$ & $89200818: 49$ & 20.6 & 439.1 \\
\hline 1710 & $1 / 9 / 200818.51$ & $89 / 2008$ 18:51 & 20.6 & 439.5 \\
\hline 1711 & $1 / 9200818: 53$ & $89200818: 53$ & 20.7 & 445.5 \\
\hline 1712 & $1 / 9200818.55$ & $89200818: 55$ & 20.7 & 441.3 \\
\hline 1713 & $1 / 9200818: 57$ & 892008 18:57 & 20.7 & 440.6 \\
\hline 1714 & $1 / 9200818: 59$ & $89200818: 59$ & 20.7 & 440.7 \\
\hline 1715 & 1/9/2008 19:01 & 892008 19:01 & 20.7 & 440.4 \\
\hline 1716 & $1 / 9200819.03$ & $89 / 200819.03$ & 20.7 & 439.9 \\
\hline 1717 & $1 / 9200819.05$ & 891200819.06 & 20.7 & 438.9 \\
\hline 1718 & 1/92008 19.07 & $8 / 9200819.07$ & 20.7 & 439.3 \\
\hline 1719 & $1 / 9200819.09$ & $89 / 200819: 09$ & 20.7 & 438.8 \\
\hline 1720 & $1 / 9 / 200819: 11$ & $8 / 9 / 2008$ 19:11 & 20.7 & 438.7 \\
\hline 1721 & $1 / 9200819.13$ & 899200819.13 & 20.8 & 438.1 \\
\hline 1722 & $1 / 9200819.15$ & $89 / 2008$ 19:15 & 20.8 & 438 \\
\hline 1723 & $1 / 9200819.17$ & $89 / 2008$ 19.17 & 20.8 & 438.1 \\
\hline 1724 & $1 / 9 / 200819.19$ & $8 / 9 / 200819: 19$ & 20.8 & 437.4 \\
\hline
\end{tabular}

\begin{tabular}{|c|c|c|c|c|}
\hline \multicolumn{5}{|c|}{$D 493 \mathrm{C}$} \\
\hline $\mathrm{Rec}$ & & Adusted & Temp & $\mathrm{SC}$ \\
\hline$\#$ & Dater/ime & Date/Time & $\alpha$ & $\mu \mathrm{s} / \mathrm{am}$ \\
\hline 1725 & $1992008 \quad 19.21$ & $89200819: 21$ & 20,8 & \\
\hline 1726- & 9200819.23 & 9200819.23 & 20.8 & 43 \\
\hline 1727 & 92008 19.25 & 89200819.25 & 20.8 & 436 \\
\hline 1728 & 9200819.27 & 899200819.27 & 20.8 & \\
\hline 1720 & $1 / 92008$ 19:29 & 89200819.29 & 20.9 & 435 \\
\hline 1730 & $1 / 9200819.31$ & 89200819.31 & 20.9 & 436 \\
\hline 1731 & $1 / 9200819.33$ & 899200819.33 & 20.9 & \\
\hline 1732 & 9200819.35 & 89200819.35 & 20.9 & 435 \\
\hline 1733 & $1 / 92008$ 19.37 & 8992008 19:37 & 20.9 & 4 \\
\hline 1734 & 9200819.39 & 89200819.39 & 20.9 & 434 \\
\hline 1735 & 9200019.41 & $8 / 9 / 200819.41$ & 20.9 & \\
\hline 1736 & $1 / 9200819: 43$ & 89200819.43 & 20.9 & 434 \\
\hline 1737 & $1 / 9 / 200819.45$ & 89200819.45 & 21 & 434. \\
\hline 1738 & 19.47 & 892200 & 21 & 434 \\
\hline 1739 & 19.49 & 892200 & 21 & \\
\hline 1740 & 9200819.51 & $8 / 9200819.51$ & 21 & 433. \\
\hline 1741 & 819.53 & $89 / 200$ & 21 & 4 \\
\hline 1742 & 19.55 & 891200 & 21 & \\
\hline 1743 & 92000819.57 & 899200819.5 & 21 & 438 \\
\hline 1744 & 9200819.59 & 89200819.59 & 21 & 432 \\
\hline 1745 & $20: 01$ & 8920 & 21 & 432 \\
\hline 1746 & 200.03 & 89200 & 21.1 & 432 \\
\hline 1747 & 20.05 & $89200820: 05$ & 21.1 & 4 \\
\hline 1748 & 00.07 & 20.07 & 21.1 & 4 \\
\hline 1749 & 20.09 & 320.09 & 21.1 & \\
\hline 1750 & $320: 11$ & $89200820: 11$ & 21.1 & 432 \\
\hline 1751 & $200: 13$ & $8 / 9 \sqrt{2}$ & 21.1 & 432 \\
\hline 1752 & $20: 15$ & $899200820: 15$ & 21.1 & 432 \\
\hline 1753 & 20:17 & $899200820: 17$ & 21.2 & 132 \\
\hline 1754 & 00.19 & $20: 19$ & 21.2 & 432 \\
\hline 1756 & 0.21 & 20.21 & 21.2 & 432 \\
\hline 1756 & & $20: 23$ & 21.2 & 32 \\
\hline 1757 & $20: 25$ & 20.25 & 21.2 & 432 \\
\hline 1758 & $20: 27$ & 20.27 & 21.2 & 432 \\
\hline 1759 & 0.20 & 20.20 & 21.2 & 432 \\
\hline 1760 & 20:31 & & 21.2 & 432 \\
\hline 1761 & 0.33 & 89 & 21.2 & 432 \\
\hline 1762 & 20.35 & 892 & 21.3 & 432 \\
\hline $17 \sqrt[3]{3}$ & $20: 37$ & 20.37 & 21.3 & 432 \\
\hline 1764 & & & 21.3 & 432 \\
\hline 1766 & 20.41 & $20: 41$ & 21.3 & 432 \\
\hline 1766 & $20: 43$ & $20: 43$ & 21.3 & 432 \\
\hline 1767 & $00: 45$ & $20: 45$ & 21.2 & 432 \\
\hline 1768 & $20: 47$ & 20.47 & 21.2 & 433. \\
\hline 1769 & $20: 49$ & $20: 49$ & 21.2 & 434. \\
\hline 1770 & & & 21.9 & 456 \\
\hline 1771 & & 20.53 & 23.4 & 513 \\
\hline $17 \pi 2$ & & 20.56 & 23.6 & 544 \\
\hline 1773 & & & 23.7 & 558 \\
\hline $17 \pi 4$ & & 20.59 & 23.7 & 56 \\
\hline 1775 & & & 23.8 & 564 \\
\hline 1776 & & & 23.8 & 567 \\
\hline $17 \pi$ & & 89 & 23.8 & 56 \\
\hline 1778 & $21: 07$ & 8912 & 23.8 & 567 \\
\hline 1779 & & & 23.8 & 558 \\
\hline 1780 & & & 23.6 & 56 \\
\hline 1781 & 21:13 & 321:13 & 23.3 & 570 \\
\hline 1782 & & & 229 & 568 \\
\hline 1783 & & & 225 & \\
\hline 1784 & 21:19 & 21:19 & 21.9 & 532 \\
\hline 1785 & & & 21.4 & 516 \\
\hline 1786 & & & 21.1 & 507 \\
\hline 1787 & & & 20.9 & 4 \\
\hline 1788 & 821:27 & $89 / 200821: 27$ & 20.9 & $44^{2}$ \\
\hline 1789 & & & 21 & 437 \\
\hline & & & 21.1 & \\
\hline 1791 & $0821: 33$ & $89200821: 33$ & 21.1 & 48 \\
\hline 1792 & & & 21.1 & 43 \\
\hline & & & & \\
\hline
\end{tabular}




\begin{tabular}{|c|c|c|c|c|}
\hline \multicolumn{5}{|c|}{ D493c } \\
\hline $\operatorname{Rec}$ & & Adjusted & Temp & SC \\
\hline \# & DeterTime & Dete/Time & $\infty$ & $\mu \mathrm{S} / \mathrm{cm}$ \\
\hline 1863 & $1 / 9 / 200823: 5$ & $89 / 200823: 57$ & 24.1 & 604.5 \\
\hline 1864 & $1 / 9 / 200823.50$ & $8 / 9200823: 59$ & 24.2 & 524.8 \\
\hline 1865 & $1 / 1020080: 01$ & $8 / 10 / 20080: 01$ & 24.2 & 631.6 \\
\hline 1806 & 1/10:20080:03 & $8 / 10 / 20080: 03$ & 24.2 & 631.7 \\
\hline 1867 & $1 / 10200080: 05$ & $8 / 10 / 20080: 05$ & 24.2 & 630.5 \\
\hline 1868 & $1 / 10200080: 07$ & $8 / 10 / 20080: 07$ & 24.2 & 628 \\
\hline 1869 & 1/1020080:09 & $8 / 10 / 20080: 09$ & 24.2 & 628 \\
\hline 1870 & $1 / 10 / 20080.11$ & $8110 / 20080: 11$ & 24.2 & 630.1 \\
\hline 1871 & $1 / 1020080: 13$ & 8/10/2008 0:13 & 24.2 & 630.3 \\
\hline 1872 & $1 / 10200000.15$ & $8 / 10 / 20080: 15$ & 24 & 6321 \\
\hline 1873 & $1 / 10 / 200000: 17$ & 8/10/20080:17 & 23.8 & $\approx 28.3$ \\
\hline 1874 & 1/10/20080:19 & 8/10/20080:19 & 23.5 & 619.2 \\
\hline 1875 & $1 / 10 / 20080.21$ & $8 / 10 / 20080: 21$ & 23.2 & 608 \\
\hline 1876 & $1 / 10 / 20080: 23$ & $8 / 10 / 20080: 23$ & 229 & 590.6 \\
\hline 1877 & $1 / 10 / 20080.25$ & $8 / 10 / 20080: 25$ & 226 & 568.5 \\
\hline 1878 & $1 / 10 / 20080.27$ & $8 / 10 / 20080: 27$ & 224 & 546.3 \\
\hline 1879 & $1 / 1020080: 29$ & $8 / 10 / 20080: 29$ & 222 & 516.3 \\
\hline 1880 & $1 / 10 / 20080: 31$ & $8 / 10 / 20080: 31$ & 22 & 505.2 \\
\hline 1881 & $1 / 10 / 20080.33$ & $8 / 10 / 20080: 33$ & 21.9 & 4826 \\
\hline 1882 & $1 / 10200000.35$ & $8 / 10 / 20080.35$ & 21.9 & 477.4 \\
\hline 1883 & $1 / 10 / 20080: 37$ & $8 / 10 / 20080: 37$ & 21.8 & 4821 \\
\hline 1884 & $1 / 10 / 20080.39$ & $8 / 10 / 20080: 39$ & 21.8 & 454.3 \\
\hline 1885 & $1 / 10 / 20080.41$ & $8 / 10 / 2008$ 0:41 & 21.8 & 430.3 \\
\hline 1886 & $1 / 10 / 20080: 43$ & $8 / 10 / 2008$ 0:43 & 21.8 & 424.7 \\
\hline 1887 & $1 / 10 / 20080: 45$ & $8 / 10 / 20080: 45$ & 21.8 & 4226 \\
\hline 1888 & $1 / 10 / 20080: 47$ & 8/10/20080:47 & 21.8 & 421.8 \\
\hline 1889 & $1 / 10200080.49$ & $8 / 10 / 20080: 49$ & 21.8 & 421 \\
\hline 1890 & $1 / 10 / 20080: 51$ & $8 / 10 / 20080: 51$ & 21.8 & 420.8 \\
\hline 1891 & $1 / 1020080: 53$ & $8 / 10 / 20080: 53$ & 21.8 & 420.4 \\
\hline 1892 & $1 / 10200080.55$ & $8 / 10 / 20080: 55$ & 21.8 & 420.2 \\
\hline 1893 & $1 / 10 / 20080: 5$ & $8 / 10 / 20080: 57$ & 21.8 & 420.3 \\
\hline 1894 & $1 / 1020080: 59$ & $8 / 10 / 20080: 59$ & 21.8 & 419.9 \\
\hline 1895 & $1 / 10 / 20081: 01$ & $8 / 10 / 20081: 01$ & 21.8. & 419.9 \\
\hline 1896 & $1 / 10 / 20081: 03$ & $8 / 10 / 20081: 03$ & 21.8 & 419.9 \\
\hline 1897 & $1 / 10 / 20081: 05$ & $8 / 10 / 20081: 05$ & 21.8 & 419.5 \\
\hline 1898 & $1 / 1020081: 07$ & $8 / 10 / 20081: 07$ & 21.8 & 419.3 \\
\hline 1899 & $1 / 10 / 20081: 09$ & $8 / 10 / 20081: 09$ & 21.9 & 418.7 \\
\hline 1900 & $1 / 10 / 20081: 11$ & $8 / 10 / 20081: 11$ & 21.8 & 419.2 \\
\hline 1901 & 1/10/20081:13 & $8 / 10 / 20081: 13$ & 21.8 & 419 \\
\hline 1902 & $1 / 10 / 20081: 15$ & $8 / 10 / 20081: 15$ & 21.9 & 418.6 \\
\hline 1903 & $1 / 10 / 20081: 17$ & $8 / 10 / 20081: 17$ & 21.9 & 418.7 \\
\hline 1904 & $1 / 10 / 20081: 19$ & $8 / 10 / 2008$ 1:19 & 21.9 & 418.3 \\
\hline 1905 & $1 / 10 / 20081: 21$ & $8 / 10 / 20081: 21$ & 21.9 & 418.3 \\
\hline 1906 & $1 / 1020081: 23$ & $8 / 10 / 20081: 23$ & 21.9 & 418.3 \\
\hline 1907 & $1 / 10 / 20081: 25$ & $8 / 10 / 20081: 25$ & 21.9 & 418.4 \\
\hline 1908 & $1 / 10 / 20081: 27$ & $8 / 10 / 20081: 27$ & 21.9 & 418.4 \\
\hline 1900 & $1 / 10 / 20081: 20$ & $8 / 10 / 20081: 29$ & 21.9 & 418.1 \\
\hline 1910 & $1 / 10 / 20081: 31$ & $8 / 10 / 20081: 31$ & 22 & 418 \\
\hline 1911 & $1 / 10 / 20081: 33$ & $8 / 10 / 20081: 33$ & 22 & 418.9 \\
\hline 1912 & $1 / 10 / 20081: 35$ & $8 / 10 / 20081: 35$ & 22 & 420.4 \\
\hline 1913 & $1 / 10 / 20081: 37$ & $8 / 10 / 20081: 37$ & 22 & 420.4 \\
\hline 1914 & $1 / 10 / 20081: 39$ & $8 / 10 / 20081: 39$ & 221 & 4229 \\
\hline 1915 & $1 / 10 / 20081: 41$ & $8 / 10 / 20081: 41$ & 221 & 422 \\
\hline 1916 & $1 / 10 / 20081: 43$ & $8 / 10 / 20081: 43$ & 221 & 421.4 \\
\hline 1917 & $1 / 1 0 / 2 0 0 8 \longdiv { 1 : 4 5 }$ & $8 / 10 / 20081: 45$ & 222 & 4226 \\
\hline 1918 & $1 / 10 / 20081: 47$ & $8 / 10 / 20081: 47$ & 222 & 4227 \\
\hline 1919 & 1/10/20081:49 & $8 / 10 / 2008$ 1:49 & 222 & 427.4 \\
\hline 1920 & 1/10/2008 1:51 & $8 / 10 / 20081: 51$ & 222 & 425 \\
\hline 1921 & $1 / 10 / 20081: 53$ & $8 / 10 / 20081: 53$ & 222 & 424.1 \\
\hline 1922 & $1 / 1020081: 55$ & $8 / 10 / 20081: 55$ & 22.3 & 425.9 \\
\hline 1923 & $1 / 1020081: 5$ & $8 / 10 / 20081: 57$ & 224 & 428.5 \\
\hline 1924 & $1 / 10 / 20081: 59$ & $8 / 10 / 20081: 59$ & 224 & 434.4 \\
\hline 1925 & 1/10/20082:01 & $8 / 10 / 20082: 01$ & 22.3 & 433.1 \\
\hline 1926 & $1 / 10 / 2008203$ & $8 / 10 / 20082003$ & 224 & 425.9 \\
\hline 1927 & $1 / 102008206$ & $8 / 10 / 2008205$ & 224 & 425.4 \\
\hline 1928 & $1 / 1020082: 07$ & $8 / 10 / 20082: 07$ & 225 & 430.3 \\
\hline 1929 & $1 / 1022008209$ & $8 / 10 / 20082: 09$ & 225 & 432.5 \\
\hline 1930 & $1 / 10 / 2008211$ & $8 / 10 / 20082: 11$ & 226 & 437.9 \\
\hline 1931 & $1 / 10 / 2008213$ & $8 / 10 / 20082: 13$ & 226 & 434.9 \\
\hline
\end{tabular}

\begin{tabular}{|c|c|c|c|c|c|c|c|c|c|}
\hline \multicolumn{5}{|c|}{$D 4-93 c$} & \multicolumn{5}{|c|}{$D 493 c$} \\
\hline Pec & & Aglusted & Terrp & SC & $\mathrm{Rec}$ & & Adjusted & Temp & $\mathrm{SC}$ \\
\hline$\#$ & Date/Time & DateTime & $\infty$ & $\mu \mathrm{S} / \mathrm{am}$ & $\#$ & Dete/Time & DaterTime & $\infty$ & $\mu \mathrm{S} / \mathrm{cm}$ \\
\hline 1932 & $1 / 102008215$ & $8 / 10 / 2008215$ & 226 & 429.3 & 2001 & $1 / 10 / 20084: 33$ & $8 / 10 / 20084: 33$ & 23.6 & 561.7 \\
\hline 1933 & $1 / 102008217$ & $8 / 10 / 20082: 17$ & 228 & 474.9 & 2000 & $1 / 10 / 20084: 35$ & $8 / 10 / 20084: 35$ & 23.7 & 551.4 \\
\hline 1934 & 1/10/20082:19 & $8 / 10 / 20082: 19$ & 226 & 431.2 & 2003 & $1 / 10 / 20084: 37$ & $8 / 1020084: 37$ & 23.7 & 575.1 \\
\hline 1935 & $1 / 10 / 2008221$ & $8 / 1020082: 21$ & 225 & 431.3 & 2004 & $1 / 10 / 20084: 39$ & $8 / 10 / 20084: 39$ & 23.6 & 539.8 \\
\hline 1936 & $1 / 102008223$ & $8 / 1020082223$ & 226 & 427.1 & 2005 & $1 / 1020084: 41$ & $8 / 1020084: 41$ & 23.5 & 540 \\
\hline 1937 & $1 / 1020008225$ & $8 / 102008225$ & 227 & 439.1 & 2006 & $1 / 10 / 20084: 43$ & $8 / 1020084: 43$ & 23.7 & 580.1 \\
\hline 1938 & $1 / 1022008227$ & $8 / 10 / 2008227$ & 227 & 446 & 2007 & $1 / 10 / 20084: 45$ & $8 / 10 / 20084: 45$ & 23.8 & 580.1 \\
\hline 1939 & $1 / 10 / 2008229$ & $8 / 10 / 20082: 29$ & 226 & 435 & 2008 & $1 / 10 / 20084: 47$ & $8 / 10 / 20084: 47$ & 23.7 & 500.4 \\
\hline 1940 & $1 / 1020002231$ & $8 / 1020082231$ & 226 & 431.6 & 2000 & $1 / 10 / 20084: 49$ & $8 / 10 / 20084: 49$ & 23.7 & 581 \\
\hline 1941 & $1 / 102008233$ & $8 / 1020082233$ & 225 & 4329 & 2010 & $1 / 10 / 20084: 51$ & $8 / 10 / 20084: 51$ & 23.7 & $5 \pi$ \\
\hline 1942 & $1 / 102008235$ & $8 / 10 / 2008235$ & 226 & 438.2 & 2011 & $1 / 10200084: 53$ & \begin{tabular}{|l|l|}
$8 / 1020084: 53$ \\
\end{tabular} & 23.6 & 560.7 \\
\hline 1943 & $1 / 10 / 2008237$ & $8 / 10 / 20082: 37$ & 22.5 & 427.9 & 2012 & $1 / 10 / 20084: 55$ & $8 / 10 / 20084: 55$ & 23.6 & 536.1 \\
\hline 1944 & $1 / 10 / 2008239$ & $8 / 10 / 2008239$ & 226 & 431.8 & 2013 & $1 / 1020084: 57$ & $8 / 10 / 20084: 57$ & 23.4 & 512.2 \\
\hline 1945 & $1 / 10 / 2008241$ & $8 / 102008241$ & 23 & 478.8 & 2014 & $1 / 10 / 20084: 59$ & $8 / 10 / 20084: 59$ & 23.7 & 528.3 \\
\hline 1946 & $1 / 10 / 2008243$ & $8 / 102008243$ & 23.6 & 507.1 & 2015 & $1 / 1020085: 01$ & $8 / 10 / 20085: 01$ & 23.7 & 513.9 \\
\hline 1947 & $1 / 10 / 2008245$ & $8 / 1020008245$ & 23.4 & 527.1 & 2016 & $1 / 10 / 20085: 03$ & $8 / 10 / 20085: 03$ & 23.6 & 547.5 \\
\hline 1948 & $1 / 10 / 2008247$ & $8 / 10 / 2008247$ & 23.4 & 560 & 2017 & $1 / 10 / 20085: 05$ & $8 / 1020085: 05$ & 23.6 & 545.7 \\
\hline 1949 & $1 / 10 / 2008249$ & $8 / 102008249$ & 23.5 & 558.1 & 2018 & $1 / 10 / 20085: 07$ & $8 / 10 / 20085: 07$ & 23.7 & 551.5 \\
\hline 1950 & $1 / 10 / 2008251$ & $8 / 10 / 2008251$ & 23.8 & 578.7 & 2019 & $1 / 10 / 20085: 09$ & $8 / 1020085: 09$ & 23.7 & 579.6 \\
\hline 1951 & $1 / 10 / 2008253$ & 81102008253 & 24.1 & 596.1 & 20020 & $1 / 10 / 20085: 11$ & $8 / 1020085: 11$ & 23.7 & 552.1 \\
\hline 1952 & $1 / 10 / 2008255$ & $8 / 10 / 2008255$ & 24.5 & 681 & 2021 & $1 / 10 / 20085: 13$ & $8 / 10 / 20085: 13$ & 23.6 & 539.3 \\
\hline 1953 & $1 / 10 / 2008257$ & $8 / 10 / 2008257$ & 24.7 & 714.4 & 2022 & $1 / 10 / 20085: 15$ & $8 / 10 / 20085: 15$ & 23.6 & 534.8 \\
\hline 1954 & $1 / 10 / 2008250$ & $8 / 10 / 2008259$ & 24.8 & 744.6 & 2003 & $1 / 10 / 20085: 17$ & $8 / 10 / 20085: 17$ & 23.6 & 546.8 \\
\hline 1955 & 1/10/20083:01 & $8 / 1020083: 01$ & 24.8 & 750.6 & 2024 & $1 / 1020085: 19$ & $8 / 10 / 20085: 19$ & 23.7 & 518.2 \\
\hline 1956 & $1 / 1020$ & $8 / 10 / 20083: 03$ & 24.8 & 749 & 2025 & $1 / 1020085: 21$ & $8 / 10 / 20085: 21$ & 23.5 & 533.9 \\
\hline 1957 & $1 / 10 / 20$ & $8 / 10 / 20083: 05$ & 24.9 & 7421 & 20026 & $1 / 10 / 20085: 23$ & $8 / 10 / 20085: 23$ & 23.7 & 528.8 \\
\hline 1958 & $1 / 10 / 20083: 07$ & $8 / 10 / 20083: 07$ & 24.7 & 749.5 & 20027 & $1 / 1020085: 25$ & $8 / 10 / 20085: 25$ & 23.5 & 525.9 \\
\hline 1950 & $1 / 10 / 20083: 09$ & $8 / 1020083: 09$ & 24.4 & 747.2 & 2028 & $1 / 1020085: 27$ & $8 / 10 / 20085: 27$ & 23.5 & 515 \\
\hline 1960 & $1 / 1020$ & $8 / 10: 20083: 11$ & 24.1 & 731.1 & 2029 & $1 / 1020085: 29$ & $8 / 10 / 20085: 20$ & 23.6 & 538.8 \\
\hline 1961 & $1 / 10200$ & $8 / 10 / 20083: 13$ & 23.7 & 678.8 & 20030 & $1 / 10 / 20085: 31$ & $8 / 10 / 20085: 31$ & 23.5 & 513.6 \\
\hline 1962 & 1/10/2008 3:15 & $8 / 10 / 20083: 15$ & 23.2 & 603.4 & 2031 & $1 / 10 / 20085: 33$ & $8 / 10 / 20085: 33$ & 23.5 & 507.2 \\
\hline 1963 & 1/10/2008 3:17 & $8 / 10 / 20083: 17$ & 228 & 536 & 20032 & $1 / 10 / 20085: 35$ & $8 / 10 / 20085: 35$ & 23.6 & 497.1 \\
\hline 1964 & $1 / 1020$ & $8 / 10 / 20083: 19$ & 22.5 & 494.1 & 2003 & 1/10/20085:37 & $8 / 10 / 20085: 37$ & 23.6 & 498.4 \\
\hline 1965 & $1 / 10 / 20083: 21$ & $8 / 1020083: 21$ & 23 & 510. & 2034 & $1 / 10 / 20085: 39$ & $8 / 1020085: 39$ & 23.6 & 499.3 \\
\hline 1966 & $1 / 10 / 20083: 23$ & $8 / 10 / 20083: 23$ & 24.1 & 535.2 & 2035 & $1 / 10 / 20085: 41$ & $8 / 1020085: 41$ & 23.7 & 501 \\
\hline 1967. & 1/10/20083:25 & $8 / 10 / 20083: 25$ & 24 & 5028 & 2003 & $1 / 10 / 20085: 43$ & $8 / 1020085: 43$ & 23.7 & 519 \\
\hline 1968 & $1 / 10 / 20$ & $8 / 10 / 20083: 27$ & 23.7 & 5024 & 20037 & $1 / 10 / 20085: 45$ & $8 / 10 / 20085: 45$ & 23.7 & 533.1 \\
\hline 1969 & $1 / 10 / 20$ & $8 / 10 / 20083: 29$ & 23.5 & 511.5 & 2038 & $1 / 1020085: 47$ & \begin{tabular}{|l|}
$8 / 10 / 20085: 47$ \\
\end{tabular} & 23.8 & 573.1 \\
\hline 1970 & 1/10/2008 3:31 & $8 / 1020083: 31$ & 23.4 & 500. & 2039 & $1 / 1020085: 49$ & $8 / 10 / 20085: 49$ & 24.4 & 775.8 \\
\hline 1971 & $1 / 1020083: 33$ & $8 / 10 / 20083: 33$ & 23.2 & 480.6 & 2040 & $1 / 10 / 20085: 51$ & $8 / 10 / 20085: 51$ & 24.7 & 811.4 \\
\hline 1972 & $1 / 10 / 20083: 35$ & $8 / 10 / 2008$ 3:35 & 23.1 & 4727 & 2041 & $1 / 10 / 20085: 53$ & $8 / 10 / 20085: 53$ & 24.8 & 839 \\
\hline 1973 & $1 / 10 / 2$ & $8 / 10: 2008$ 3:37 & 23 & 453.5 & 2042 & $1 / 10 / 2$ & $8 / 10 / 20085: 55$ & 24.8 & 841.4 \\
\hline 1974 & $1 / 10 / 20$ & $8 / 10 / 20083: 39$ & 228 & 442 & 2043 & $1 / 10 / 20085: 57$ & $8 / 10 / 20085: 57$ & 24.8 & 8429 \\
\hline 1975 & $1 / 10 / 20083: 41$ & $8 / 10 / 20083: 41$ & 228 & 435.5 & 2044 & $1 / 10 \overline{20085: 59}$ & $8 / 10 / 20085: 59$ & 24.8 & 843.7 \\
\hline 1976 & $1 / 10 / 20083: 43$ & $8 / 10 / 20083: 43$ & 229 & 433 & 2045 & $1 / 1020086: 01$ & $8 / 10 / 20086: 01$ & 24.8 & 842 \\
\hline 1977 & $1 / 102$ & $8 / 1020083: 45$ & 229 & 433.9 & 2046 & $1 / 102$ & $8 / 102$ & 24.8 & 841.5 \\
\hline 1978 & $1 / 1020083: 47$ & $8 / 10 / 20083: 47$ & 23.1 & 444. & 2047 & $1 / 1020086: 05$ & $8 / 10 / 20086: 05$ & 24.9 & 837.1 \\
\hline 1979 & $1 / 10 / 20083: 49$ & $8 / 10 / 20083: 49$ & 23.3 & 450.8 & 2048 & $1 / 10 / 20086: 07$ & $8 / 1020006: 07$ & 24.9 & 836 \\
\hline 1980 & 1/10/2008 3:51 & $8 / 1020083: 51$ & 23.2 & 433.7 & 2049 & $1 / 10 / 200$ & $8 / 10720086: 09$ & 24.7 & 837.8 \\
\hline 1981 & $1 / 1 \alpha^{\prime 2}$ & $8 / 10 / 20083: 53$ & 23.5 & 433.9 & 2050 & $1 / 10200$ & $8 / 10 \sqrt{2}$ & 24.6 & 832.9 \\
\hline 1982 & $1 / 10 / 20$ & $8 / 10 / 20083: 55$ & 23.4 & 44 & 2051 & $1 / 10 / 20086: 13$ & $8 / 1020086: 13$ & 24.5 & 819.1 \\
\hline 1983 & $1 / 40 / 20083: 5$ & $8 / 1020083: 57$ & 23.8 & 486.9 & 2052 & 1/10/20086:15 & $8 / 1020086: 15$ & 24.3 & 797.1 \\
\hline 1984 & 1/10/20083:59 & $8 / 10 / 20083: 59$ & 23.8 & 5523 & 2053 & $1 / 1020086: 17$ & $8 / 10 / 20086: 17$ & 24.1 & 755.5 \\
\hline 1985 & $1 / 1 \alpha^{\prime 2}$ & 8/102008 4:01 & 23.6 & 491.4 & 2054 & & $8 / 1020$ & 23.8 & 684.1 \\
\hline 1986 & $1 / 10 / 2$ & $8 / 10 / 20084: 03$ & 23.7 & 554. & 2055 & $1 / 10 / 20$ & $8 / 10220086: 21$ & 23.6 & 609.6 \\
\hline 1987 & 1/10/20084:05 & $8 / 10 / 20084: 05$ & 23.7 & 550.3 & 2056 & $1 / 10 / 20086: 23$ & $8 / 10 / 20086: 23$ & 24 & 551.6 \\
\hline 1988 & 1/10/2008 4:07 & $8 / 10 / 20084: 07$ & 236 & 547.7 & 2007 & $1 / 1020086.25$ & $8 / 10 / 20086: 25$ & 23.9 & 599 \\
\hline 1989 & $1 / 10 / 2$ & $8 / 10 / 20084: 09$ & 23.6 & 518 & 2058 & $1 / 102008$ & $8 / 10 / 20086: 27$ & 23.9 & 631.3 \\
\hline 1990 & $1 / 10 / 2$ & $8 / 10 / 20084: 11$ & 23.7 & 557.7 & 2050 & $1 / 10 / 2008$ & $8 / 1020086: 29$ & 23.8 & 615.4 \\
\hline 1991 & 1/10/20084:13 & $8 / 10 / 20084: 13$ & 23.6 & 540.6 & 2060 & $1 / 1020086: 31$ & $8 / 1020086: 31$ & 24 & 525.4 \\
\hline 1992 & $1 / 10 / 20084: 15$ & $8 / 10 / 20084: 15$ & 23.6 & 541.4 & 2061 & $1 / 10 / 20086: 33$ & $8 / 10 / 20086: 33$ & 24.1 & 529.5 \\
\hline 1993 & 1/10/2008 4:17 & $8 / 10 / 20084: 17$ & 23.7 & 538.7 & 2062 & $1 / 10 / 20086: 35$ & $8 / 10 / 20086: 35$ & 23.8 & 484.7 \\
\hline 1994 & 1/10/2008 4:19 & $8 / 10 / 20084: 19$ & 23.7 & 565 ? & 2063 & $1 / 10 / 20086: 37$ & $8 / 10 / 20086: 37$ & 23.6 & 518.2 \\
\hline 1996 & $1 / 10 / 20084: 21$ & \begin{tabular}{|l|}
$8 / 1020084: 21$ \\
\end{tabular} & 23.7 & 565.5 & 2064 & $1 / 10 / 20086.39$ & $8 / 10 / 20086: 39$ & 23.6 & 531.8 \\
\hline 1996 & 1/10:2008 4:23 & $8 / 10 / 20084: 23$ & 23.7 & 586.9 & 2066 & $1 / 10 / 20086: 41$ & $8 / 1020086: 41$ & 23.5 & 506.2 \\
\hline 1997 & $1 / 10 / 20084: 25$ & $8 / 1020084: 25$ & 23.7 & 568.2 & 2066 & $1 / 10 / 20086: 43$ & $8 / 10 / 20086: 43$ & 23.4 & 505 \\
\hline 1998 & $1 / 10 / 20084: 27$ & 8/10/20084:27 & 23.8 & 556. & 2067 & $1 / 10 / 20086: 45$ & $8 / 10 / 20086: 45$ & 23.4 & 514.9 \\
\hline 1999 & $1 / 10 / 20084: 29$ & $8 / 10 / 20084: 29$ & 23.7 & 567.7 & 2068 & $1 / 10 / 20086: 47$ & $8 / 10 / 20086: 47$ & 23.4 & 526.5 \\
\hline 2000 & & $8 / 10 / 20084: 31$ & 23.7 & 561.7 & 2069 & $1 / 10 / 20086: 49$ & $8 / 10 / 20086: 49$ & 23.4 & 513.4 \\
\hline
\end{tabular}




\begin{tabular}{|c|c|c|c|c|}
\hline \multicolumn{5}{|c|}{ D4-93C } \\
\hline $\mathrm{Fec}$ & & Adiusted & Temp & $S C$ \\
\hline$\#$ & DateTime & DetoTime & 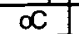 & $\mu \mathrm{S} / \mathrm{cm}$ \\
\hline 2070 & $1 / 1020086.51$ & $8 / 1020086: 51$ & 23.3 & 506.4 \\
\hline 2071 & $1 / 1020086.53$ & $8 / 1020086: 53$ & 23.3 & 496.5 \\
\hline 2072 & $1 / 1020086.55$ & $8 / 1020086: 55$ & 23.2 & 484.1 \\
\hline 2073 & $1 / 1020008655$ & $8 / 1020086: 57$ & 23.2 & 469.9 \\
\hline 2074 & $1 / 102008659$ & $8 / 1020006: 59$ & 23.2 & 479.7 \\
\hline 2075 & $1 / 1020087: 01$ & 8/1020087:01 & 23.2 & 464.1 \\
\hline 2076 & 1/102008 7:03 & $8 / 1020007703$ & 23.3 & 504.4 \\
\hline 207 & $1 / 1020087: 05$ & $8 / 1020087: 05$ & 23.3 & 507.7 \\
\hline 2078 & 1/1020087:07 & 8/1020087:07 & 23.5 & 514.4 \\
\hline 2079 & $1 / 1020087: 09$ & $8 / 1020087: 09$ & 23.5 & 511.7 \\
\hline 2080 & $1 / 1020087: 11$ & $8 / 10 / 20087: 11$ & 23.5 & 527.3 \\
\hline 2081 & $1 / 10200$ & $8 / 10200077: 13$ & 23.4 & 543.1 \\
\hline 2062 & $1 / 10200$ & 8/1020087:15 & 23.5 & 530.8 \\
\hline 2083 & $1 / 10200$ & $8 / 1020087: 17$ & 23.5 & 547.9 \\
\hline 2084 & 1/10200087:19 & $8 / 1020087: 19$ & 23.6 & 587.5 \\
\hline 2005 & $1 / 1020$ & $8 / 10 / 20087: 21$ & 23.6 & 515.7 \\
\hline 2006 & $1 / 1020$ & $8 / 10 / 20087: 23$ & 23.6 & 568.6 \\
\hline 2087 & $1 / 102$ & $8 / 1020087: 25$ & 23.6 & 604.2 \\
\hline 2088 & $1 / 1020$ & $8 / 10220067: 27$ & 23.7 & 533.3 \\
\hline 2089 & $1 / 102$ & $8 / 1020087: 20$ & 23.7 & 620.4 \\
\hline 2090 & $1 / 102$ & $8 / 10200$ & 23.6 & 626.5 \\
\hline 2091 & $1 / 10$ & $8 / 1020$ & 23.7 & 576.5 \\
\hline 2098 & $1 / 1020$ & $8 / 10 / 20087: 35$ & 23.7 & $\approx 23.9$ \\
\hline 2093 & $1 / 1020$ & $8 / 1020087: 37$ & 23.7 & 589.4 \\
\hline 2094 & $1 / 10$ & $8 / 102$ & 23.7 & 585.3 \\
\hline 2095 & $1 / 10 / 2$ & $8 / 10 \alpha$ & 23.7 & 590.9 \\
\hline 2096 & $1 / 102$ & $8 / 1020087: 43$ & 23.7 & 5821 \\
\hline 2007 & $1 / 1020$ & $8 / 1020087: 45$ & 23.8 & 594.6 \\
\hline 2098 & $1 / 10$ & $8 / 1020$ & 23.7 & 608.2 \\
\hline 2009 & $1 / 1 \alpha$ & $8 / 1020$ & 23.7 & 607.6 \\
\hline 2100 & $1 / 1 \alpha_{2}$ & $8 / 10 / 20$ & 23.8 & 592.9 \\
\hline 2101 & $1 / 1020$ & $8 / 1020087: 53$ & 23.8 & 5724 \\
\hline 2102 & $1 / 1020$ & $8 / 102200$ & 23.8 & 607.8 \\
\hline 2103 & & $8 / 102$ & 23.8 & 583.5 \\
\hline 2104 & & $8 / 10 / 2$ & 23.7 & 576 \\
\hline 2105 & $1 / 102$ & $8 / 1020088: 01$ & 23.7 & 593.7 \\
\hline 2106 & $1 / 102$ & $8 / 1020088: 03$ & 23.7 & 5826 \\
\hline 2107 & & $8 / 102$ & 23.7 & 593 \\
\hline 2108 & $1 / 10$ & $8 / 102$ & 23.8 & 564.1 \\
\hline 2100 & $1 / 10$ & $8 / 1020088: 09$ & 23.7 & $5 \pi .4$ \\
\hline 2110 & & $8 / 102008811$ & 23.7 & 571.2 \\
\hline 2111 & & $8 / 102$ & 23.7 & $\overline{571.3}$ \\
\hline 2112 & & $8 / 102$ & 23.7 & 596.4 \\
\hline 2113 & & $811020088: 17$ & 23.7 & 5626 \\
\hline 2114 & & $8 / 1020088: 19$ & 23.7 & 615.8 \\
\hline 2115 & & $8 / 102$ & 23.7 & 580.1 \\
\hline 2116 & & $8 / 102$ & 23.7 & 586.5 \\
\hline 2117 & $1 / 102$ & $8 / 10 / 20088: 25$ & 23.6 & 544.8 \\
\hline 2118 & & $8 / 1020088: 27$ & 23.7 & 565.7 \\
\hline 2119 & & & 23.7 & $5 / 22$ \\
\hline 2120 & & $8 / 102$ & 23.7 & 613.3 \\
\hline 2121 & & $8 / 1020088: 33$ & 23.9 & 633.7 \\
\hline 212 & & $8 / 102200$ & 23.9 & 661. \\
\hline 2123 & & & 23.9 & $\overline{641.2}$ \\
\hline 2124 & & $8 / 102$ & 24 & 660.1 \\
\hline 2125 & & $8^{\prime} 1022$ & 23.9 & 656 \\
\hline 2126 & & $81020088: 43$ & 23.8 & 608.9 \\
\hline 2127 & & $811020088: 45$ & 23.8 & 601.7 \\
\hline 2128 & & & 23.7 & 586.7 \\
\hline 2129 & & $8 / 1020$ & 23.7 & 568.8 \\
\hline 2130 & & $8 / 10 / 20088: 51$ & 24.1 & 779.5 \\
\hline 2131 & $1 / 10$ & $8 / 1020088: 53$ & 24.4 & $\overline{824.1}$ \\
\hline 2132 & & $8 / 1020088.55$ & 24.5 & 846.9 \\
\hline 2133 & & $8 / 1020088: 57$ & 24.6 & 859.6 \\
\hline 2134 & & $8 / 10 / 20088: 59$ & 24.5 & 855.1 \\
\hline 2135 & $1 / 1020089.01$ & $8 / 10 / 20089.01$ & 24.6 & 854.3 \\
\hline 2136 & & $8 / 10 / 20089=03$ & 24.6 & 850.5 \\
\hline 213त्ती & & $8 / 1020089.05$ & 24.6 & 845.5 \\
\hline & & $8 / 1020$ & 24.6 & \\
\hline
\end{tabular}

\begin{tabular}{|c|c|c|c|c|}
\hline \multicolumn{5}{|c|}{ D493C } \\
\hline $\operatorname{Rec}$ & & Adusted & Tertp & $S$ \\
\hline \# & DateTime & DaterTime & $O C$ & $\mu \mathrm{s} / \mathrm{m}$ \\
\hline 2139 & 1/1020089.00 & $8 / 1020089.09$ & 24.5 & 834.8 \\
\hline 2140 & $1 / 10200099.11$ & $8 / 1020089.11$ & 24.4 & 831 \\
\hline 2141 & $1 / 1020069.13$ & $8 / 10220089.13$ & 24.4 & 824.2 \\
\hline 2142 & $1 / 1020089.15$ & $8 / 1020089.15$ & 24.4 & 797.9 \\
\hline 2143 & $1 / 1020009.17$ & $8 / 10 / 20089.17$ & 25.1 & 751 \\
\hline 2144 & 1/1020089.19 & $8 / 1020089.19$ & 25.6 & 725.2 \\
\hline 2145 & $1 / 1020089.21$ & $8 / 1020089.21$ & 25.3 & 705.7 \\
\hline 2146 & $1 / 1020069.23$ & $8 / 1020089.23$ & 25.1 & 6722 \\
\hline 2147 & $1 / 1020089.25$ & $8 / 1020089.25$ & 24.8 & 6721 \\
\hline 2148 & $1 / 1020009.27$ & $8 / 1020089.27$ & 24.6 & 657.3 \\
\hline 2149 & 1/1020089.20 & $8 / 10 / 20089: 20$ & 24.5 & 653.4 \\
\hline 2150 & $1 / 1020089.31$ & $8 / 10 / 20089: 31$ & 24.4 & 630 \\
\hline 2151 & $1 / 1020089.33$ & $8 / 10 / 20089.33$ & 24.8 & 7222 \\
\hline 2152 & $1 / 1020089.35$ & $8 / 10 / 20089.35$ & 25.1 & 773.4 \\
\hline 2153 & $1 / 1020089.37$ & $8 / 1020089.37$ & 25.1 & 734.7 \\
\hline 2154 & $1 / 1020089.39$ & $8 / 1020089.39$ & 24.9 & 697 \\
\hline 2155 & $1 / 1020089.41$ & $8 / 1020089.41$ & 24.7 & 724.3 \\
\hline 2156 & $1 / 10200089.43$ & $8 / 1020089.43$ & 24.7 & 687.2 \\
\hline 2157 & $1 / 1020009945$ & $8 / 10 / 20089.45$ & 24.6 & 698 \\
\hline 2158 & $1 / 1020009.47$ & $8 / 1020009.47$ & 24.6 & 813.6 \\
\hline 2159 & $1 / 1020089.49$ & $8 / 1020089.49$ & 24.7 & 838.8 \\
\hline 2160 & $1 / 1020089.51$ & $8 / 1020089.51$ & 24.7 & 853.6 \\
\hline 2161 & $1 / 1020089.53$ & $8 / 10 / 20089.53$ & 24.7 & 859.1 \\
\hline 2162 & $1 / 1020089.55$ & $8 / 1020089.55$ & 24.7 & 861.1 \\
\hline 2163 & $1 / 10 / 20089.57$ & $8 / 1020089.57$ & 24.7 & 861.4 \\
\hline 2164 & $1 / 1020089.59$ & $8 / 10 / 20089.59$ & 24.7 & 860.6 \\
\hline 2165 & $1 / 102008$ 10:01 & $810^{\prime 2000810.01}$ & 24.7 & 859 \\
\hline 2166 & $1 / 10200810: 03$ & $8 / 10200010.03$ & 24.7 & 857.7 \\
\hline 2167 & $1 / 10200810.05$ & $8 / 10200010: 05$ & 24.7 & 855.8 \\
\hline 2168 & 1/102008 10.07 & $8 / 10 / 2008$ 10:07 & 24.7 & 856.3 \\
\hline 2169 & $1 / 10 / 200810-00$ & $8 / 102008$ 10:09 & 24.7 & 855.9 \\
\hline 2170 & 1/10/2008 10:11 & $8 / 10 / 2008$ 10:11 & 24.7 & 855.3 \\
\hline 2171 & $1 / 10 / 2008$ 10:13 & $8 / 10200810: 13$ & 24.7 & 855 \\
\hline 2172 & 1/10/200810:15 & $8 / 10200010: 15$ & 24.7 & 854.5 \\
\hline 2173 & 1/10/2008 10:17 & $8 / 10 / 200810.17$ & 24.7 & 854.1 \\
\hline 2174 & $1 / 10 / 200810-19$ & $8 / 10200010 \cdot 19$ & 24.7 & 853.6 \\
\hline 2175 & 1/102008 10:21 & $8 / 102000810.21$ & 24.7 & 8528 \\
\hline 2176 & $1 / 10200810: 23$ & $8 / 10200810.23$ & 24.7 & 8525 \\
\hline $217 \pi$ & $1 / 10200810: 25$ & $8 / 102008$ 10:25 & 24.7 & 852 \\
\hline 2178 & $1 / 102000810: 27$ & $8 / 10200010: 27$ & 24.7 & 851.4 \\
\hline 2179 & $1 / 10200810.29$ & 8110200010.20 & 24.7 & 851.4 \\
\hline 2180 & $1 / 10200010.31$ & $8 / 10200810.31$ & 24.7 & 851.5 \\
\hline 2181 & $1 / 102000810.33$ & $8 / 102000810.33$ & 24.7 & 851.7 \\
\hline 2182 & $1 / 10200810.35$ & $8 / 102008$ 10:35 & 24.7 & 851.9 \\
\hline 2183 & $1 / 102008$ 10.37 & $8 / 1 \alpha 200810: 37$ & 24.7 & 851.8 \\
\hline 2184 & $1 / 102000810.39$ & $8 / 10200810: 39$ & 24.7 & 852.1 \\
\hline 2185 & $1 / 10200810.41$ & $8 / 10: 2008$ 10:41 & 24.7 & 851.6 \\
\hline 2186 & $1 / 10200010.43$ & $8 / 102000$ 10:43 & 24.7 & 851.9 \\
\hline 2187 & $1 / 10 / 200810.45$ & 81102000 10:45 & 24.7 & 8522 \\
\hline 2188 & $1 / 102000810.47$ & $8 / 102000810: 47$ & 24.7 & 8524 \\
\hline 2189 & $1 / 102000810.49$ & $8 / 102008$ 10:49 & 24.7 & 8525 \\
\hline 2190 & $1 / 10 / 20$ & $8 / 10200810: 51$ & 24.7 & 8525 \\
\hline 2191 & $1 / 10 / 200810.53$ & $8 / 10200010.53$ & 24.7 & 8529 \\
\hline 2192 & $1 / 10 / 200810.50$ & $8 / 10200810.55$ & 24.7 & 8528 \\
\hline 2193 & $1 / 10200010.5$ & $8 / 10200810: 5$ & 24.7 & 853.1 \\
\hline 2194 & $1 / 102000810.59$ & $8 / 102000810.59$ & 24.7 & 853.2 \\
\hline 2195 & 1/102008 11:01 & $8 / 10200811: 01$ & 24.7 & 853.1 \\
\hline 2196 & 1/102008 11:03 & $8 / 10200811: 03$ & 24.8 & 8524 \\
\hline 2197 & $1 / 10 / 200811: 06$ & $8 / 10200811: 05$ & 24.8 & 8525 \\
\hline 2198 & 1/102008 11:07 & $8 / 10200011: 07$ & 24.8 & 8524 \\
\hline 2199 & 1/1020008 11:09 & $8 / 10 / 200811: 09$ & 24.8 & 8525 \\
\hline 2200 & 1/102008 11:11 & $8110200811: 11$ & 24.8 & 8523 \\
\hline 2201 & 1/10/2008 11:13 & $8 / 10200811: 13$ & 24.8 & 8522 \\
\hline 2202 & $1 / 10200811: 15$ & $8 / 10200811: 15$ & 24.8 & 851.8 \\
\hline 2203 & $1 / 10 / 2008+11: 17$ & $8 / 10200811: 17$ & 24.8 & 851.3 \\
\hline 2204 & $1 / 10200811: 19$ & $8 / 10200811: 19$ & 24.8 & 850.8 \\
\hline 2205 & $1 / 102000811: 21$ & $8 / 12200811: 21$ & 24.8 & 850.3 \\
\hline 2206 & $1 / 10200811: 23$ & $8 / 10200811: 23$ & 24.8 & 850.5 \\
\hline 2207 & 1/102008 11:25 & $8110200811: 25$ & 24.8 & 850.4 \\
\hline
\end{tabular}

\begin{tabular}{|c|c|c|c|c|}
\hline \multicolumn{5}{|c|}{$D 493 \mathrm{c}$} \\
\hline $\mathrm{ReC}$ & & Adiusted & Temp & 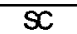 \\
\hline$\#$ & Datertime & Date/Time & $\propto$ & \\
\hline 2008 & 1/102008 11:27 & $8 / 10200811: 27$ & 24.8 & 850.2 \\
\hline 2200 & 1/10/2008 11:20 & $8 / 10200811: 29$ & 24.8 & $844^{\circ}$ \\
\hline 2210 & $\mid$\begin{tabular}{|l|}
$1 / 10200811: 31$ \\
\end{tabular} & $8 / 102008$ 11:31 & 24.8 & 847.7 \\
\hline 2211 & 1/10/2008 11:33 & $8102000811: 33$ & 24.8 & 846. \\
\hline 2212 & 1/102008 11:35 & $8 / 10200811: 35$ & 24.8 & 846 \\
\hline 2213 & 1/102000 11:37 & $8 / 102200811: 37$ & 24.8 & 848 \\
\hline 2214 & 1/102008 11:39 & $8110200811: 39$ & 24.8 & 8423 \\
\hline 2215 & 1/10/2008 11:41 & $8 / 10200811: 41$ & 24.8 & 840.6 \\
\hline 2216 & 1/102008 11:43 & $8 / 1022008$ 11:43 & 24.7 & \\
\hline 2217 & 1/10/2008 11:45 & $8 / 10200811: 45$ & 24.7 & 821. \\
\hline 2218 & $1 / 1020008$ 11:47 & $8 / 10200811: 47$ & 24.7 & 820. \\
\hline 2219 & $1 / 102008$ 11:49 & $8 / 10200811: 49$ & 24.8 & 853.5 \\
\hline 200 & $1 / 102200811: 51$ & $8 / 10 / 2008$ 11:51 & 24.8 & \\
\hline 2221 & $1 / 10 / 200811: 53$ & $8 / 1020$ & 24.8 & \\
\hline 2202 & $1 / 1028$ & $8 / 102200811: 55$ & 24.8 & 828 \\
\hline 2223 & 1/102008 11:50 & $8 / 10200811: 57$ & 24.8 & 808 . \\
\hline 2224 & $1 / 102008$ 11:59 & $8110200811: 50$ & 24.8 & 808. \\
\hline 2225 & $1 / 1022$ & $8 / 102 x$ & 24.8 & 80 \\
\hline 2226 & $1 / 102$ & $8 / 102$ & 24.8 & \\
\hline 2227 & $1 / 102 x$ & $8 / 10 / 20$ & 24.8 & 808 \\
\hline 2228 & $1 / 102$ & $8 / 1020081207$ & 24.8 & 807. \\
\hline 220 & $1 / 10 / 2$ & $8 / 102$ & 24.8 & 785. \\
\hline 2230 & $1 / 1012$ & $8 / 1020$ & 24.8 & \\
\hline 2231 & $1 / 10 / 2$ & $8 / 10 / 2$ & 24.8 & 774 \\
\hline 2232 & $1 / 102$ & $8 / 1020081215$ & 24.8 & 783. \\
\hline 2233 & $1 / 10$ & $8 / 102$ & 24.8 & 787. \\
\hline 2234 & $1 / 10 / 2$ & $8 / 10^{2}$ & 24.8 & 794. \\
\hline 2236 & $1 / 102$ & 31221 & 24.8 & \\
\hline 2236 & $1 / 102$ & 81223 & 24.8 & 80 \\
\hline 2237 & $1 / 102$ & $8 / 10 / 2$ & 24.8 & 813. \\
\hline 2238 & $1 / 10$ & $8 / 10$ & 24.8 & 819 \\
\hline 2239 & $1 / 102$ & $8 / 10^{2}$ & 24.8 & 820 \\
\hline 2240 & $1 / 10$ & $8 / 10$ & 24.8 & 828. \\
\hline 2241 & $1 / 10$ & 31233 & 24.9 & 832 \\
\hline 2242 & & $8 / 10$ & 24.9 & 839 \\
\hline 2243 & $1 / 10 /$ & $8 / 10$ & 24.9 & 847 \\
\hline 2244 & $1 / 102$ & 81239 & 24.9 & 852 \\
\hline 2245 & $1 / 10 / 2$ & 81241 & 25 & 859. \\
\hline 2246 & & $8 / 10$ & 25 & 863. \\
\hline 2247 & $1 / 10$ & 1245 & 25.1 & 864 \\
\hline 2248 & $1 / 10$ & 1247 & 251 & 866 \\
\hline 2249 & $1 / 10$ & 31249 & 25.1 & 866. \\
\hline 2250 & $1 / 10$ & $8 / 10$ & 25.1 & 865 \\
\hline 2251 & & $8 / 10$ & 25.2 & 865 \\
\hline 2252 & & 1255 & 252 & 865. \\
\hline 2253 & 1257 & 31257 & 26.7 & 833. \\
\hline 2254 & & 1259 & 25.7 & \\
\hline 2255 & & $8 / 10$ & 25.6 & 849 \\
\hline 2256 & 13:03 & $8 / 10$ & 254 & 837. \\
\hline 2257 & & $8 / 1 \alpha$ & 254 & 840 \\
\hline 2258 & & $8 / 10$ & 25.4 & 839 \\
\hline 2259 & & & 25.4 & \\
\hline 2260 & & $8 / 10$ & 25.4 & 351 \\
\hline 2261 & 13:13 & $2813: 13$ & 25.4 & 851. \\
\hline 2262 & & $8 / 10$ & 25.4 & 850 \\
\hline 2263 & & & 25.4 & \\
\hline 2264 & & $8 / 10$ & 25.5 & \\
\hline 2265 & & 0813.21 & 25.5 & 848 \\
\hline 2266 & $13: 23$ & 813.23 & 25.5 & 848 \\
\hline 2267 & & $13: 25$ & 25.5 & 848 \\
\hline 2268 & 13:27 & 13.27 & 25.5 & \\
\hline 2269 & & 1329 & 25.5 & \\
\hline 2270 & $813: 31$ & 8133.31 & 25.5 & 846 \\
\hline 2271 & $1 / 1 \alpha^{2}$ & $8 / 10$ & 25.6 & 846 \\
\hline 2272 & $13: 35$ & 810 & 25.6 & \\
\hline 2273 & 13:37 & $8 / 10$ & 25.6 & \\
\hline 2274 & 813:39 & $8 / 10^{\prime 2}$ & 25.6 & 844 \\
\hline 2275 & 313:41 & $8 / 10 / 20081341$ & 25.6 & 843 \\
\hline 2276 & & $8 / 1020081343$ & 25.6 & 842 \\
\hline
\end{tabular}




\begin{tabular}{|c|c|c|c|c|}
\hline \multicolumn{5}{|c|}{$D 4-93 c$} \\
\hline $\operatorname{Rec}$ & & Adjusted & Temp & $\mathrm{SC}$ \\
\hline$\#$ & Date/Time & Date/Time & $\alpha$ & $\mu \mathrm{S} / \mathrm{cm}$ \\
\hline 2277 & 1/10/2008 13:45 & $8 / 10200813: 45$ & 25.6 & 841.7 \\
\hline 2278 & $1 / 10200813: 47$ & $8 / 10200813: 47$ & 25.7 & 840.5 \\
\hline 2279 & $1 / 10200813: 49$ & $8 / 10200813: 49$ & 25.7 & 840 \\
\hline 2280 & 1/10/2008 13:51 & $8 / 102008$ 13:51 & 25.7 & 838.8 \\
\hline 2281 & $1 / 10200813: 53$ & $8 / 102008$ 13:53 & 25.7 & 838 \\
\hline 2282 & $1 / 10 / 200813: 55$ & $8 / 10 / 200813: 56$ & 25.7 & 836.9 \\
\hline 2283 & $1 / 102000813: 57$ & $8 / 10200813: 57$ & 25.7 & 836.5 \\
\hline 2284 & $1 / 10200813.59$ & $8 / 10200813: 59$ & 25.7 & 835.9 \\
\hline 2285 & $1 / 102008$ 14:01 & $8 / 10200814: 01$ & 25.7 & 835.5 \\
\hline 2286 & $1 / 10 / 2008$ 14:03 & $8 / 10 / 200814: 03$ & 25.7 & 835.1 \\
\hline 2287 & $1 / 10200814: 05$ & $8 / 10 / 200814: 05$ & 25.7 & 835.1 \\
\hline 2288 & 1/10/2008 14:07 & $8 / 10 / 200814: 07$ & 25.7 & 834.3 \\
\hline 2289 & $1 / 102200814: 09$ & $8 / 10 / 200814: 09$ & 25.8 & 833.9 \\
\hline 2290 & 1/10/2008 14:11 & $8 / 102000814: 11$ & 25.8 & 833.1 \\
\hline 2291 & 1/10/2008 14:13 & $8 / 10200814: 13$ & 25.8 & 830.8 \\
\hline 2292 & $1 / 10 / 200814: 15$ & $8 / 10 / 200814: 15$ & 25.8 & 829 \\
\hline 2293 & $1 / 10 / 200814: 17$ & $8 / 10 / 200814: 17$ & 25.8 & 829.1 \\
\hline 2294 & 1/10/2008 14:19 & $8 / 10 / 200814: 19$ & 25.8 & 831.7 \\
\hline 2295 & $1 / 10 / 2008$ 14:21 & $8 / 10 / 200814: 21$ & 25.8 & 8328 \\
\hline 2296 & 1/10/2008 14:23 & $8 / 10 / 200814: 23$ & 25.8 & 833.6 \\
\hline 2297 & $1 / 10 / 200814: 25$ & $8 / 10200814: 25$ & 25.8 & 833 \\
\hline 2298 & 1/10/2008 14:27 & $8 / 10200814: 27$ & 25.8 & 834.1 \\
\hline 2299 & $1 / 10 / 2008$ 14:29 & $8 / 10 / 200814: 29$ & 25.8 & 834.5 \\
\hline 2300 & 1/10/2008 14:31 & $8 / 10 / 2008$ 14:31 & 25.8 & 834.5 \\
\hline 2301 & $1 / 10 / 200814: 33$ & $8 / 10 / 200814: 33$ & 25.9 & 831.9 \\
\hline 2302 & $1 / 1020008$ 14:33 & $8 / 10 / 200814: 35$ & 25.9 & 831.5 \\
\hline 2303 & $1 / 10 / 2008$ 14:37 & $8 / 10 / 200814: 37$ & 25.9 & 831 \\
\hline 2304 & $1 / 102000814: 39$ & $8 / 10 / 200814: 39$ & 25.9 & 829.9 \\
\hline 2305 & $1 / 10 / 200814: 41$ & $8 / 10 / 200814: 41$ & 25.9 & 829.4 \\
\hline 2306 & $1 / 10 / 200814: 43$ & $8 / 10 / 200814: 43$ & 25.9 & 828.1 \\
\hline 2307 & $1 / 10 / 200814: 45$ & $8 / 10 / 200814: 45$ & 26 & 825.5 \\
\hline 2308 & $1 / 10 / 2008$ 14:47 & $8 / 10 / 200814: 47$ & 26 & 8221 \\
\hline 2309 & $1 / 10200814: 49$ & $8 / 10200814: 49$ & 26 & 813 \\
\hline 2310 & $1 / 102008$ 14:51 & $8 / 10 / 200814: 51$ & 26 & 804.9 \\
\hline 2311 & $1 / 10 / 2008$ 14:53 & $8 / 10 / 200814: 53$ & 26 & 794.1 \\
\hline 2312 & $1 / 10200814: 55$ & $8 / 10 / 200814: 55$ & 25.9 & 779.4 \\
\hline 2313 & 1/102008 14:57 & $8 / 10 / 200814: 57$ & 25.9 & 770.8 \\
\hline 2314 & $1 / 10 / 2008 \quad 14: 59$ & $8 / 10 / 200814: 59$ & 25.9 & 770.4 \\
\hline 2315 & $1 / 10 / 200815: 01$ & $8 / 10 / 200815: 01$ & 25.9 & 769.7 \\
\hline 2316 & $1 / 10 / 200815: 03$ & $8 / 10 / 200815: 03$ & 25.9 & 767.6 \\
\hline 2317 & $1 / 10 / 200815: 05$ & $8 / 10 / 200815: 05$ & 25.9 & 765 \\
\hline 2318 & $1 / 10 / 2008$ 15:07 & $8 / 10 / 200815: 07$ & 25.9 & 765.7 \\
\hline 2319 & $1 / 10 / 200815: 09$ & $8 / 10 / 200815: 09$ & 25.9 & 765.8 \\
\hline 2320 & $1 / 10 / 200815: 11$ & $8 / 10 / 200815: 11$ & 25.8 & 755.5 \\
\hline 2321 & $1 / 10 / 2008$ 15:13 & $8 / 10 / 2008$ 15:13 & 25.8 & 747.2 \\
\hline 2322 & $1 / 10200815: 15$ & 8/10/2008 15:15 & 25.8 & 7522 \\
\hline 2323 & 1/10/2008 15:17 & $8 / 10 / 200815: 17$ & 25.8 & 761.1 \\
\hline 2324 & 1/10/2008 15:19 & $8 / 10 / 200815: 19$ & 25.7 & 770.4 \\
\hline 2325 & $1 / 10 / 200815: 21$ & $8 / 10 / 200815: 21$ & 25.7 & 774.5 \\
\hline 2326 & $1 / 10 / 200815: 23$ & $8 / 10 / 200815: 23$ & 25.7 & $7 \pi .4$ \\
\hline 2327 & $1 / 10 / 200015: 25$ & $8 / 10200815: 25$ & 25.6 & $\pi 7$ \\
\hline 2328 & $1 / 10 / 2008$ 15:27 & $8 / 10200815: 27$ & 25.9 & 857.5 \\
\hline 2329 & $1 / 10 / 200815: 29$ & $8 / 10200815: 29$ & 26 & 859.4 \\
\hline 2330 & $1 / 10200815: 31$ & $8 / 10 / 200815: 31$ & 26 & 869.7 \\
\hline 2331 & 1/10/2008 15:33 & $8 / 10 / 200815: 33$ & 26.1 & 872.9 \\
\hline 2332 & $1 / 10 / 200815: 35$ & $8 / 10 / 200815: 35$ & 26.1 & 874.2 \\
\hline 2333 & $1 / 10 / 2008$ 15:37 & $8 / 10 / 200815: 37$ & 26.1 & 876.1 \\
\hline 2334 & $1 / 10 / 200815: 39$ & $8 / 10 / 200815: 39$ & 26.1 & 877.9 \\
\hline 2335 & 1/10/2008 15:41 & $8 / 10 / 200815: 41$ & 26.1 & 876 \\
\hline 2336 & $1 / 10 / 200815: 43$ & $8 / 10 / 200815: 43$ & 26.1 & 876 \\
\hline 2337 & $1 / 10 / 200815: 45$ & $8 / 10200815: 45$ & 26.1 & 876 \\
\hline 2338 & $1 / 10 / 200815: 47$ & $8 / 10200815: 47$ & 26.1 & 876.5 \\
\hline 2339 & $1 / 10 / 200815: 49$ & $8 / 10200815: 49$ & 26.2 & 8725 \\
\hline 2340 & $1 / 10 / 2008$ 15:51 & $8 / 10 / 200815: 51$ & 26.3 & 871.4 \\
\hline 2341 & $1 / 10 / 2008$ 15:53 & $8 / 10200815: 53$ & 26.3 & 870 \\
\hline 2342 & $1 / 10 / 200815: 55$ & $8 / 10 / 200815: 55$ & 26.3 & 867.1 \\
\hline 2343 & $1 / 10 / 200815: 57$ & 8/10/2008 15:57 & 26.3 & 864.8 \\
\hline 2344 & $1 / 10 / 200815: 59$ & $8 / 10 / 200815: 59$ & 26.3 & 860.5 \\
\hline 2345 & 1/10/2008 16:01 & $8 / 10 / 200816: 01$ & 26.3 & 858.7 \\
\hline
\end{tabular}

\begin{tabular}{|c|c|c|c|c|c|c|c|c|c|}
\hline \multicolumn{5}{|c|}{$D 4-93 c$} & \multicolumn{5}{|c|}{ D4-93c } \\
\hline $\operatorname{Rec}$ & & Adisted & Ternp & SC & Rec & & Aciusted & Temp & SC \\
\hline$\#$ & Deter/ime & DaterTime & $\alpha$ & $\mu \mathrm{s} / \mathrm{cm}$ & $\#$ & Date/Time & Date/Time & $\alpha$ & $\mu \mathrm{S} / \mathrm{cm}$ \\
\hline 2346 & 1/10/2008 16:03 & $8 / 102008$ 16:03 & 26.3 & 856.5 & 2415 & 1/10/2008 18:21 & $8 / 102008$ 18:21 & 27.1 & 903.7 \\
\hline 2347 & 1/10/2008 16:05 & \begin{tabular}{|l|}
$8 / 10 / 2008$ 16:05 \\
\end{tabular} & 26.3 & 849.2 & 2416 & 1/10/2008 18:23 & $8 / 10 / 200818: 23$ & 27.1 & 905.1 \\
\hline 2348 & 1/10/2008 16:07 & \begin{tabular}{|l|}
$8 / 10 / 2008$ 16:07 \\
\end{tabular} & 26.3 & 851.3 & 2417 & 1/10/2008 18:25 & $8 / 10 / 2008$ 18:25 & 27.1 & 905.4 \\
\hline 2349 & 1/10/2008 16:09 & $8 / 10 / 200816: 09$ & 26.3 & 849.5 & 2418 & 1/10/2008 18:27 & 8/10/2008 18:27 & 27.1 & 906.4 \\
\hline 2350 & 1/10/2008 16:11 & \begin{tabular}{|l|}
$8 / 10 / 2008$ 16:11 \\
\end{tabular} & 26.3 & 846.6 & 2419 & $1 / 10200018: 29$ & $8 / 10 / 200818: 29$ & 27.2 & 907.1 \\
\hline 2351 & 1/10/2008 16:13 & $8 / 10 / 200816: 13$ & 26.3 & 845.7 & 2420 & $1 / 10 / 200818: 31$ & $8 / 10 / 2008$ 18:31 & 27.1 & 907.9 \\
\hline 2352 & 1/10/2008 16:15 & \begin{tabular}{|l|}
$8 / 102008$ 16:15 \\
\end{tabular} & 26.3 & 843 & 2421 & $1 / 10200018: 33$ & $8 / 10 / 200818: 33$ & 27.1 & 907.5 \\
\hline 2353 & 1/10/2008 16:17 & \begin{tabular}{|l|}
$8 / 10 / 200816: 17$ \\
\end{tabular} & 26.4 & 841.2 & 2422 & 1/10/2008 18:35 & $8 / 10200818: 35$ & 27.1 & 907.5 \\
\hline 2354 & 1/10/2008 16:19 & 8/10/2008 16:19 & 26.4 & 839 & 2423 & 1/102008 18:37 & $8 / 10 / 2008$ 18:37 & 27.2 & 905.9 \\
\hline 2355 & 1/10/2008 16:21 & $8 / 10 / 200816: 21$ & 26.4 & 834.5 & 2424 & 1/1020008 18:39 & $8 / 10 / 200818: 39$ & 27.2 & 905.5 \\
\hline 2356 & $1 / 10 / 200816: 23$ & $8 / 10 / 200816: 23$ & 26.4 & 8326 & 2425 & $1 / 102000818: 41$ & $8 / 10 / 2008$ 18:41 & 27.2 & 905.1 \\
\hline 2357 & $1 / 10 / 200816: 25$ & \begin{tabular}{|l|}
$8 / 10 / 200816: 25$ \\
\end{tabular} & 26.4 & 824.9 & 2426 & $1 / 10 / 200818: 43$ & $8 / 10 / 200818: 43$ & 27.2 & 905.3 \\
\hline 2358 & $1 / 10 / 20$ & \begin{tabular}{|l|}
$8 / 10 / 200816: 27$ \\
\end{tabular} & 26.4 & 823.3 & 2427 & $1 / 10200018: 45$ & $8 / 10 / 200818: 45$ & 27.2 & 904.8 \\
\hline 2359 & $1 / 10 / 200816: 29$ & \begin{tabular}{|l|}
$8 / 10 / 200016: 29$ \\
\end{tabular} & 26.4 & 823.2 & 2428 & $1 / 10200818: 47$ & $8 / 10 / 200818: 47$ & 27.2 & 903.1 \\
\hline 2360 & $1 / 10 / 2$ & \begin{tabular}{|l|}
$8 / 10 / 200816: 31$ \\
\end{tabular} & 26.4 & 824.7 & 2429 & $1 / 10 / 2$ & $8 / 10 / 20$ & 27.2 & 903 \\
\hline 2361 & $1 / 10 / 2$ & $8 / 10 / 200$ & 26.4 & 828.2 & 2430 & $1 / 10 / 2$ & $8 / 10 / 200$ & 27.2 & \\
\hline 2362 & 816:35 & \begin{tabular}{|l|}
$8 / 10 / 200816: 35$ \\
\end{tabular} & 26.4 & 828.1 & 2431 & $818: 53$ & $8 / 10 / 200818: 53$ & 27.2 & 899.4 \\
\hline 2363 & 316:37 & \begin{tabular}{|l|}
$8 / 10 / 200816: 37$ \\
\end{tabular} & 26.4 & 824 & 2432 & $1 / 10 / 2$ & $8 / 10 / 200818: 55$ & 27.2 & 900 \\
\hline 2364 & $1 / 10 / 2$ & $8 / 10 / 200$ & 26.4 & 823.6 & 2433 & $1 / 10 / 2$ & $8 / 10 / 2008$ 18:57 & 27.2 & 900 \\
\hline 2365 & $1 / 10 / 2$ & \begin{tabular}{|l|}
$8 / 10 / 200816: 41$ \\
\end{tabular} & 26.4 & 8227 & 2434 & $1 / 10 / 2$ & $8 / 10 / 200818: 59$ & 27.2 & 899.3 \\
\hline 2366 & $1 / 102$ & \begin{tabular}{|l|}
$8 / 10 / 200816: 43$ \\
\end{tabular} & 26.5 & 825.4 & 2435 & $1 / 10 / 2$ & $8 / 10 / 200$ & 27.2 & 899.2 \\
\hline 2367 & $1 / 10 / 2$ & \begin{tabular}{|l|}
$8 / 1 \alpha 200816: 45$ \\
\end{tabular} & 26.5 & 837.4 & 2436 & $1 / 10 / 2$ & $8 / 10 / 200$ & 27.2 & 898.1 \\
\hline 2368 & $1 / 10 / 2$ & \begin{tabular}{|l|}
$8 / 10 / 200816: 47$ \\
\end{tabular} & 26.5 & 8422 & 2437 & $1 / 10 / 2$ & $8 / 102200819.05$ & 27.2 & 898.1 \\
\hline 2369 & $1 / 10$ & $8 / 10 / 20$ & 26.5 & 842 & 2438 & $1 / 10 / 2$ & $8 / 10 \sqrt{2}$ & 27.2 & 897.3 \\
\hline 2370 & $1 / 10 / 2$ & $8 / 10 / 20$ & 26.6 & 848 & 2439 & $1 / 10 / 2$ & $8 / 10 / 200819: 09$ & 27.2 & 896.6 \\
\hline 2371 & $1 / 10 / 2$ & $8 / 10 / 200$ & 26.4 & 846.5 & 2440 & $1 / 10 / 2$ & $8 / 10 / 200819.11$ & 27.2 & 896.3 \\
\hline 2372 & $1 / 10$ & $8 / 10 / 20$ & 26.7 & 8424 & 2441 & $1 / 10 / 2$ & $8 / 10 / 20$ & 27.2 & 895.4 \\
\hline 2373 & $1 / 10 / 2$ & $8 / 10 / 2008$ 16:57 & 26.6 & 837.3 & 2442 & $1 / 10 / 2$ & $8 / 10 / 200819: 15$ & 27.1 & 895.7 \\
\hline 2374 & $1 / 10 / 2$ & $8 / 10 / 200816: 59$ & 26.5 & 835.9 & 2443 & 88 19:17 & $8 / 10 / 2008$ 19:17 & 27.1 & 896.5 \\
\hline 2375 & $1 / 10$ & $8 / 1 \alpha / 20$ & 26.5 & 830.6 & 2444 & 19.19 & $8 / 1012$ & 27.1 & 895.5 \\
\hline 2376 & $1 / 10 / 2$ & $8 / 10 / 20$ & 26.7 & 893.1 & 2445 & 19.21 & $8 / 1 \alpha / 2$ & 27.2 & 895.8 \\
\hline 237 & $1 / 10 / 2$ & $8 / 10 / 200$ & 26.7 & 880.4 & 2446 & $1 / 10 / 2$ & 819.23 & 27.2 & 894.7 \\
\hline 2378 & $1 / 110$ & 8110120 & 26.7 & 869. & 2447 & 19.25 & $8 / 10 / 2$ & 27.1 & 894.6 \\
\hline 2379 & $1 / 10$ & $8 / 10 / 20$ & 26.7 & 867.5 & 2448 & $1 / 10$ & $8 / 102$ & 27.1 & 894.5 \\
\hline 2380 & & $8 / 10 / 20$ & 26.8 & 86 & 2449 & & 19.29 & 27.1 & 893.5 \\
\hline 2381 & $1 / 10$ & $8 / 10 / 20$ & 26.8 & 8723 & 2450 & $1 / 1002$ & $8 / 10 / 2$ & 27.2 & 893.7 \\
\hline 2382 & $1 / 10$ & $8 / 10 / 20$ & 26.8 & 871.2 & 2451 & 19.33 & $8 / 10 / 20$ & 27.1 & 892.4 \\
\hline 2383 & & $8 / 10 / 20$ & 26.8 & 870. & 2452 & & 19.35 & 27.1 & 892 \\
\hline 2384 & $1 / 10$ & $8 / 10 / 20$ & 26.8 & 8722 & 2453 & $1 / 10$ & $8 / 10 / 2$ & 27.1 & 891.5 \\
\hline 2385 & $1 / 10$ & $8 / 10 / 20$ & 26.9 & 871.4 & 2454 & $1 / 10$ & $8 / 10 / 2$ & 27.1 & 893.6 \\
\hline 2386 & & $8 / 10 / 20$ & 26.8 & 873 & 2455 & & $19: 41$ & 27.1 & 8929 \\
\hline 2387 & $1 / 10$ & $8 / 10 / 20$ & 26.9 & 873.4 & 2456 & $1 / 10$ & $8 / 10 / 2$ & 27.1 & 892.6 \\
\hline 2388 & & $8 / 10 / 20$ & 26.9 & 876.1 & 2457 & $19: 45$ & 19.45 & 27.1 & 892. \\
\hline 2389 & & $8 / 10 / 2$ & 26.9 & 875.5 & 2458 & & 19.47 & 27.1 & $\overline{890.8}$ \\
\hline 2390 & $7: 31$ & $8 / 10 / 2$ & 26.9 & 876. & 2459 & $1 / 10$ & $8 / 1 \alpha^{\prime 2}$ & 27.1 & 892. \\
\hline 2391 & & $8 / 10$ & 26.9 & 873.7 & 2460 & $19: 51$ & $8 / 10 / 2$ & 27.1 & 891.7 \\
\hline 2392 & & $8 / 10 / 2$ & 26.9 & 873.1 & 2461 & & & 27.1 & 892.3 \\
\hline 2393 & \begin{tabular}{|l|}
$1 / 10$ \\
\end{tabular} & $8 / 10 / 20$ & 26.9 & 873 & 2462 & $1 /$ & $8 / 10 / 2$ & 27.1 & 891.5 \\
\hline 2394 & $1 / 10$ & $8 / 10 / 20$ & 26.9 & 873. & 2463 & & 19.57 & 27.1 & 890 \\
\hline 2395 & & $8 / 10 / 20$ & 26.9 & 874. & 2464 & & $8 / 1 \alpha$ & 27.1 & 8 \\
\hline 2396 & & $8 / 10 / 20$ & 26.9 & 875. & 2465 & 20:01 & $8 / 10 / 2$ & 27.1 & 8921 \\
\hline 2397 & & $8 / 10 / 20$ & 26.9 & 875. & 2466 & & $8 / 10$ & 27.1 & 892.6 \\
\hline 2398 & & $8 / 10 / 20$ & 26.9 & 876. & 2467 & & 20:05 & 27.1 & 891.8 \\
\hline 2399 & 17:49 & $8 / 10 / 20$ & \begin{tabular}{|l|}
27 \\
\end{tabular} & 873.3 & 2468 & $20: 07$ & 20:07 & 27.1 & 891.7 \\
\hline 2400 & & & 27 & 876 & 2469 & & $20: 09$ & 27.1 & \\
\hline 2401 & & $8 / 10 / 20$ & 27 & & 2470 & & $8 / 10 / 2$ & 27.1 & $\overline{8923}$ \\
\hline 2402 & $17: 55$ & $8 / 10 / 200$ & 27 & 864.8 & 2471 & $20: 13$ & $820: 13$ & 27.1 & 8924 \\
\hline 2403 & & & 27 & & 2472 & & & 27.1 & 890. \\
\hline 2404 & & $8 / 10 / 2$ & 27 & 848 & 2473 & & $20: 17$ & 27.1 & 889.5 \\
\hline 2405 & $1 / 10$ & $8 / 10 / 20$ & 26.9 & 850.7 & 2474 & $820: 19$ & $820: 19$ & 27.1 & 890.0 \\
\hline 2406 & & $8 / 10 / 200$ & 26.9 & 852. & 2475 & & & 27.1 & 891.3 \\
\hline 2407 & & $8 / 1 \alpha / 20$ & 27 & 870 . & & & $320: 23$ & 27.1 & 893.8 \\
\hline 2408 & \begin{tabular}{|l|l}
$1 / 10$ \\
\end{tabular} & \begin{tabular}{|l|}
$8 / 10 / 200818: 07$ \\
\end{tabular} & 27. & 874. & 2477 & 820.25 & $8 / 10 / 200820.25$ & 27.1 & 8925 \\
\hline 2409 & & \begin{tabular}{|l|}
$8 / 10 / 2008$ \\
$18: 09$ \\
\end{tabular} & 27 & 880. & 2478 & & & 27.1 & 891.3 \\
\hline 2410 & & $8 / 10 / 20$ & & & 2479 & & 820.29 & 27.1 & \\
\hline 2411 & $1 / 10$ & \begin{tabular}{|l|}
$8 / 102008$ 18:13 \\
\end{tabular} & 27.1 & 891. & 2480 & 1/10/200820:31 & $8 / 10 / 200820: 31$ & 27.1 & 886.3 \\
\hline 2412 & & $8 / 10 / 2008$ 18:15 & 27.1 & 894. & 2481 & & $8 / 10 / 200820: 33$ & 27.1 & 884.2 \\
\hline 2413 & & 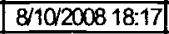 & 27.1 & 899. & 2482 & $8820: 35$ & $8 / 10 / 200820: 35$ & 27.1 & 877.9 \\
\hline 2414 & $1 / 10 / 2$ & $8 / 102008$ 18:19 & 27.1 & 902.2 & 2483 & 1/10/200820:37 & $8 / 10 / 200820: 37$ & 27.1 & 872.5 \\
\hline
\end{tabular}




\begin{tabular}{|c|c|c|c|c|}
\hline \multicolumn{5}{|c|}{ D498c } \\
\hline $\mathrm{PEC}$ & & Aqusted & Temp & $S C$ \\
\hline \# & DeterTime & DateTime & $\infty$ & $\mu \mathrm{Som}$ \\
\hline 2484 & $1 / 10200820: 39$ & $8 / 10200020039$ & 27.1 & 859.7 \\
\hline 2485 & $1 / 10200820.41$ & $8 / 10200020: 41$ & 27.1 & 856.7 \\
\hline 2486 & $1 / 10200820: 43$ & $8 / 102000820.43$ & 27.1 & 855.3 \\
\hline 2487 & $1 / 10200820: 45$ & $8 / 10200820.45$ & 27 & 8529 \\
\hline 2488 & $1 / 10200820: 47$ & $8 / 10200820.47$ & 27 & 8524 \\
\hline 2489 & $1 / 10200820: 49$ & $8 / 10200820: 49$ & 27 & 849.4 \\
\hline 2490 & $1 / 102200820.51$ & $8 / 10200820.51$ & 27 & 848.3 \\
\hline 2491 & $1 / 10200820.53$ & $8 / 10200820.53$ & 27 & 849.5 \\
\hline 2498 & 1/10/2008 20:50 & $8 / 10200020.55$ & 27 & 849.5 \\
\hline 2493 & $1 / 10200820: 57$ & $8 / 10200820.5$ & 27 & 845 \\
\hline 2494 & $1 / 10200820.59$ & $8 / 10200020.59$ & 27 & 833.9 \\
\hline 2496 & 1/10200821:01 & $8 / 10200821: 01$ & 28.2 & 805.1 \\
\hline 2496 & 1/102008 21:03 & $810200021: 03$ & 28.2 & 825.5 \\
\hline 2497 & 1/10200821:06 & $8 / 10200821: 05$ & 27.7 & 823.1 \\
\hline 2498 & 1/102008 21:07 & $8 / 10200821: 07$ & 27.4 & 824.1 \\
\hline 2499 & 1/102000 21:09 & 8/10200821:09 & 27.4 & 829.6 \\
\hline 2500 & 1/10/200821:11 & $8 / 10200821: 11$ & 27.3 & 830.9 \\
\hline 2501 & 1/102008 21:13 & \begin{tabular}{|c|}
$8 / 10200821: 13$ \\
\end{tabular} & 27.2 & 831 \\
\hline 2502 & 1/102008 21:15 & $8 / 10200821: 15$ & 27.2 & $\overline{834}$ \\
\hline 2503 & 1/10200821:17 & $8 / 10200821: 17$ & 27.1 & 837 \\
\hline 2504 & 1/102008 21:19 & $8 / 102000821: 19$ & 27.1 & 837.4 \\
\hline 2505 & 1/10/200821:21 & $8 / 10200821: 21$ & 27 & 839.6 \\
\hline 2506 & $1 / 10200821: 23$ & $8 / 102000821: 23$ & 26.9 & 841.1 \\
\hline 2507 & 1/10/200821:25 & $8 / 10 / 200821: 25$ & 26.9 & 842 \\
\hline 2508 & 1/10200821:27 & $8110200821: 27$ & 27 & 825.1 \\
\hline 2509 & 1/102008 21:29 & $8 / 10200821: 20$ & 27 & 815.9 \\
\hline 2510 & 1/10200821:31 & $8 / 10200821: 31$ & 27 & 816.1 \\
\hline 2511 & 1/10200821:33 & $8110200821: 33$ & 27 & 824 \\
\hline 2512 & 1/10/2008 21:30 & $8 / 10200821: 35$ & 27 & 834.6 \\
\hline 2513 & $1 / 10200821: 37$ & $8 / 10200821: 37$ & 27 & 838.6 \\
\hline 2514 & 1/10200821:39 & $8 / 10 / 200821: 39$ & 27 & 845.2 \\
\hline 2515 & 1/10/200821:41 & $8 / 10200821: 41$ & 27.1 & 861.2 \\
\hline 2516 & $1 / 10200821: 43$ & $8 / 10200021: 43$ & 27.1 & 881.2 \\
\hline 2517 & $1 / 102000821: 45$ & $8 / 10200821: 45$ & 27.1 & 894.6 \\
\hline 2518 & $1 / 10200821: 47$ & $8 / 10200021: 47$ & 27.1 & 901.7 \\
\hline 2519 & 1/10:2008 21:49 & 8/10:2008 21:49 & 27.1 & 907.3 \\
\hline 2520 & $1 / 102000821: 51$ & $8 / 10200821: 51$ & 27.1 & 911.2 \\
\hline 2521 & $1 / 10200821: 53$ & $8 / 102000821: 53$ & 27.1 & 914 \\
\hline 2522 & 1/102008 21:55 & $8 / 10200821: 56$ & 27.1 & 917.3 \\
\hline 2523 & 1/102000821:57 & 8/10200821:50 & 27.1 & 918.2 \\
\hline 2524 & 1/102008 21:59 & $8110200821: 59$ & 27.1 & 919 \\
\hline 2525 & $1 / 1020082201$ & 811020082201 & 27.1 & 919.3 \\
\hline 2526 & $1 / 10200822200$ & $8 / 10200822203$ & 27.1 & 919.6 \\
\hline 2527 & $1 / 1020082206$ & 811020082205 & 27.1 & 918.6 \\
\hline 2528 & $1 / 102200822.07$ & 811020082207 & 27.1 & 919.1 \\
\hline 2529 & 1/10200822:09 & $8 / 10200822,09$ & 27 & 918.2 \\
\hline 2530 & $1 / 1020082211$ & $8 / 1020082211$ & 27.1 & 917.4 \\
\hline 2531 & $1 / 1020082213$ & $8 / 1020082213$ & 27 & 917.6 \\
\hline 2532 & $1 / 1020082215$ & $8 / 1020082215$ & 27 & 917.7 \\
\hline 2533 & $1 / 102000822: 17$ & $8 / 10200822: 17$ & 27. & 916.9 \\
\hline 2534 & $1 / 102200822: 19$ & $8 / 1020082219$ & 27 & 914.4 \\
\hline 2535 & $1 / 10 / 200822: 21$ & 811020082221 & 27 & 915.9 \\
\hline 2536 & $1 / 1020082223$ & $8 / 1020082223$ & 27 & 914.1 \\
\hline 2537 & 1/10200082225 & $8 / 1020082225$ & 26.9 & 914.2 \\
\hline 2538 & $1 / 1020082227$ & $8 / 1020082227$ & 26.9 & 913.3 \\
\hline 2539 & $1 / 1020082220$ & $8 / 1020082220$ & 26.9 & 9127 \\
\hline 2540 & $1 / 1020082231$ & $8 / 102008223$ & 26.9 & 911.4 \\
\hline 2541 & $1 / 10220082233$ & $8 / 1020002233$ & 26.9 & 910.7 \\
\hline 2542 & $1 / 1020082235$ & $8 / 10 / 200822335$ & 26.9 & 909.8 \\
\hline 2543 & 1/102008 22:37 & 811020002237 & 26.9 & $\begin{array}{l}908.7 \\
\end{array}$ \\
\hline 2544 & $1 / 1020082239$ & $8 / 10200082239$ & 26.9 & 908.1 \\
\hline 2545 & $1 / 10200822241$ & $8 / 10200022241$ & 26.9 & 907.6 \\
\hline 2546 & $1 / 10200822243$ & $8 / 1020082243$ & 26.9 & 905.1 \\
\hline 2547 & $1 / 10200082245$ & $8 / 1020082245$ & 26.8 & 904.1 \\
\hline 2548 & $1 / 1020082247$ & $8 / 10200822<47$ & 26.8 & 904.3 \\
\hline 2549 & $1 / 10200822-49$ & 811020082249 & 26.8 & 9029 \\
\hline 2550 & $1 / 1020082251$ & $8 / 1020082251$ & 26.8 & 901.9 \\
\hline 2551 & $1 / 1020082225$ & 811020082253 & 26.8 & 900.2 \\
\hline 2552 & $1 / 1020082255$ & $8 / 1020082255$ & 26.8 & 900 \\
\hline
\end{tabular}

\begin{tabular}{|c|c|c|c|c|}
\hline \multicolumn{5}{|c|}{$D 493 c$} \\
\hline $\mathrm{P}_{\mathrm{B} C}$ & & Agusted & Temp & $\mathrm{SC}$ \\
\hline$\#$ & Date/Time & DaterTime & $\alpha$ & HSIam \\
\hline 2553 & $1 / 1020082257$ & $8 / 102008225$ & 26.8 & 899.4 \\
\hline 2564 & $1 / 1020082259$ & $8 / 10220082250$ & 26.8 & 899.1 \\
\hline 2565 & $1 / 10200823001$ & $8 / 10200823: 01$ & 26.8 & 897.7 \\
\hline 2556 & 1/10/200823:03 & 8/102008 23:03 & 26.8 & 898.4 \\
\hline 2557 & 1/10/200823:05 & $8 / 10200823: 06$ & 26.8 & 896.5 \\
\hline 2558 & $1 / 1020082307$ & $8 / 10200323: 07$ & 26.8 & 896.9 \\
\hline 2559 & $1 / 10 / 200823.09$ & $8 / 102000323: 09$ & 26.7 & 897.1 \\
\hline 2560 & $1 / 10220082311$ & $8 / 10200023: 11$ & 26.7 & 895.5 \\
\hline 2561 & $1 / 10200825: 13$ & $8 / 10200823: 13$ & 26.7 & 894.9 \\
\hline 2552 & 1/10200823:15 & $8 / 10200823: 15$ & 26.7 & 894.3 \\
\hline 2563 & 1/10/200823:17 & $8 / 10 / 200823: 17$ & 26.7 & 894.4 \\
\hline 2564 & $1 / 10 / 20082319$ & $8 / 10 / 200823: 19$ & 26.7 & 893.5 \\
\hline 2565 & $1 / 1020082321$ & $8 / 10 / 200823: 21$ & 26.7 & 893.2 \\
\hline 2566 & $1 / 10200823: 23$ & $8 / 10200823: 23$ & 26.7 & 8921 \\
\hline 2567 & $1 / 10200823: 25$ & $8 / 10200823: 25$ & 26.7 & 8926 \\
\hline 2568 & $1 / 10 / 200823 \cdot 27$ & $8 / 10200823: 27$ & 26.7 & 891.3 \\
\hline 2569 & $1 / 1020082329$ & $8 / 101200823: 29$ & 26.7 & 890.6 \\
\hline 2570 & $1 / 10 / 200823: 31$ & $8 / 10200823: 31$ & 26.6 & 890 \\
\hline 2571 & $1 / 10200823.33$ & $8 / 10200023: 33$ & 26.6 & 888.8 \\
\hline 2572 & $1 / 10 / 200823.35$ & $8 / 10200823: 35$ & 26.6 & 888.7 \\
\hline 2573 & $1 / 10200823 \cdot 37$ & $8 / 10200823: 37$ & 26.6 & 888.4 \\
\hline 2574 & $1 / 10 / 20082339$ & $8 / 10200023: 39$ & 26.6 & 887.5 \\
\hline 2575 & $1 / 10 / 200823441$ & $8 / 10 / 200823: 41$ & 266 & 886.1 \\
\hline 2576 & $1 / 10200823: 43$ & $8 / 10 / 200823: 43$ & 26.6 & 884.9 \\
\hline $25 \pi$ & $1 / 1020082344$ & $8 / 10200823: 45$ & 26.6 & 883.6 \\
\hline 2578 & $1 / 10200823-47$ & $8 / 10200823: 47$ & 26.6 & 8823 \\
\hline 2579 & $1 / 102200823: 49$ & $8 / 10200823: 49$ & 26.6 & 879.8 \\
\hline 2580 & $1 / 1020082351$ & $8 / 10200823: 51$ & 26.6 & 877.7 \\
\hline 2581 & $1 / 10 / 200823: 53$ & $8 / 10200823: 53$ & 26.6 & 877.2 \\
\hline 2582 & $1 / 10200823: 56$ & $8 / 10200823: 55$ & 26.5 & 876.6 \\
\hline 2583 & $1 / 10 / 200823: 57$ & $8 / 10200823: 5$ & 26.5 & 874.9 \\
\hline 2584 & $1 / 10 / 200823: 59$ & $8 / 102000823: 59$ & 26.5 & 867.4 \\
\hline 2585 & $1 / 11 / 20080.01$ & $8 / 11 / 20080: 01$ & 26.5 & 854.5 \\
\hline 2506 & $1 / 11 / 20080: 03$ & $8 / 11 / 20080: 03$ & 26.5 & 8328 \\
\hline 2587 & $1 / 11 / 20080005$ & $8 / 11 / 20080.05$ & 26.5 & 833.8 \\
\hline 2588 & 1/11/20080-07 & $8 / 11 / 20080.07$ & 26.5 & 829.9 \\
\hline 2589 & $1 / 11 / 2008000$ & $8 / 11 / 20080: 00$ & 26.5 & 827.4 \\
\hline 2590 & $1 / 11 / 20080.11$ & $8 / 11 / 20080: 11$ & 26.5 & 831.2 \\
\hline 2591 & $1 / 11 / 20080.13$ & $8 / 11 / 20080: 13$ & 26.5 & 833.4 \\
\hline 2592 & $1 / 11 / 20080.15$ & $8 / 11 / 20000.15$ & 26.5 & 835.5 \\
\hline 2503 & $1 / 11 / 20080.17$ & $8 / 11 / 20080.17$ & 26.5 & 836.7 \\
\hline 2594 & 1/11/20080:19 & $8 / 11 / 20080: 19$ & 26.5 & 834.5 \\
\hline 2596 & $1 / 11 / 20080.21$ & $8 / 11 / 20080: 21$ & 26.4 & 837.2 \\
\hline 2596 & $1 / 11 / 20080: 23$ & $8 / 11 / 20080: 23$ & 26.4 & 846.2 \\
\hline 2597 & 1/11/20080.25 & $8 / 11 / 20080: 25$ & 26.4 & 849.1 \\
\hline 2598 & $1 / 11 / 20080.27$ & $8 / 11 / 20080.27$ & 26.4 & 857.2 \\
\hline 2509 & $1 / 11 / 20080.29$ & $8 / 11 / 20080.29$ & 26.5 & 863.7 \\
\hline 2600 & $1 / 11 / 20080.31$ & $8 / 11 / 20080: 31$ & 26.5 & 8623 \\
\hline 2601 & $1 / 11 / 20080.33$ & $8 / 11 / 20080.33$ & 26.5 & 865.8 \\
\hline 2600 & $1 / 11 / 20080.35$ & $8 / 11 / 20080: 35$ & 26.5 & 881.4 \\
\hline 2603 & $1 / 11 / 20080.37$ & $8 / 11 / 20080: 37$ & 26.5 & 890.1 \\
\hline 2604 & $1 / 11 / 20080.39$ & $8 / 11 / 20080: 39$ & 26.5 & 898.2 \\
\hline 2605 & $1 / 11 / 20080.41$ & $8 / 11 / 20080: 41$ & 26.5 & 902 \\
\hline 2606 & $1 / 11 / 20080.43$ & $8 / 11 / 20080.43$ & 26.5 & 9022 \\
\hline 2607 & $1 / 11 / 20080.45$ & $8 / 11 / 20080.45$ & 26.5 & 9027 \\
\hline 2608 & $1 / 11 / 20080.47$ & $8 / 11 / 20080.47$ & 26.5 & 901.8 \\
\hline 2609 & $1 / 11 / 20080.49$ & $8 / 11 / 20080: 49$ & 26.5 & 899.9 \\
\hline 2610 & $1 / 11 / 20080.51$ & $8 / 11 / 20080.51$ & 26.5 & 894.5 \\
\hline 2611 & $1 / 11 / 20080.53$ & $8 / 11 / 20080: 53$ & 26.5 & 890.9 \\
\hline 2612 & $1 / 11 / 20080.55$ & $8 / 11 / 20080.56$ & 26.4 & 886.5 \\
\hline 2613 & $1 / 11 / 20080.57$ & $8 / 11 / 20080.57$ & 26.4 & 8826 \\
\hline 2614 & $1 / 11 / 20080.50$ & $8 / 11 / 20080.59$ & 26.4 & 879.3 \\
\hline 2615 & 1/11/2008 1:01 & $8 / 11 / 20081: 01$ & 26.4 & 878.5 \\
\hline 2616 & 1/11/2008 1:03 & $8 / 11 / 20081: 03$ & 26.4 & 875.8 \\
\hline 2617 & 1/11/2008 1:05 & $8 / 11 / 20081: 06$ & 26.3 & 875.5 \\
\hline 2618 & $1 / 11 / 20081: 07$ & $8 / 11 / 20081: 07$ & 26.3 & 875.5 \\
\hline 2619 & 1/11/2008 1:09 & $8 / 11 / 20081: 09$ & 26.3 & 875.5 \\
\hline 2620 & 1/11/2008 1:11 & $8 / 11 / 20081: 11$ & 26.3 & 876.9 \\
\hline 2621 & 1/11/2008 1:13 & $8 / 11 / 20081: 13$ & 26.2 & 878.3 \\
\hline
\end{tabular}

\begin{tabular}{|c|c|c|c|c|}
\hline \multicolumn{5}{|c|}{$D 493 \mathrm{C}$} \\
\hline $\operatorname{Roc}$ & & Adusted & Temp & $\mathrm{SC}$ \\
\hline \# & DateTime & Dater/ime & $\propto$ & psicm \\
\hline 262 & 1/11/2008 1:15 & $8 / 11 / 2008$ 1:15 & 26.2 & 879.6 \\
\hline $2 \sqrt[23]{3}$ & $1 / 11 / 2008$ 1:17 & $8 / 11 / 2008$ 1:17 & 262 & 8823 \\
\hline 2624 & 1/11/2008 1:19 & $8 / 11 / 20081: 19$ & 26.2 & 884.7 \\
\hline 2625 & $1 / 11 / 20081: 21$ & $8 / 11 / 20081: 21$ & 261 & 886.3 \\
\hline 2626 & $1 / 11 / 20081: 23$ & 8/11/2008 1:23 & 26.1 & 888.4 \\
\hline 2627 & $1 / 11 / 20081: 25$ & $8 / 11 / 20081: 25$ & 26.1 & 890.2 \\
\hline 2628 & $1 / 11 / 20081: 27$ & $8 / 11 / 2008$ 1:27 & 26.1 & 8922 \\
\hline 2629 & $1 / 11 / 20081: 29$ & $8 / 11 / 20081: 29$ & 26.1 & 8904 \\
\hline 2630 & $1 / 11 / 20081: 31$ & $8 / 11 / 20081: 31$ & 26.1 & 894.6 \\
\hline 2631 & $1 / 11 / 20081: 33$ & $8 / 11 / 20081: 33$ & 26 & 896.5 \\
\hline 2632 & $1 / 11 / 20081: 35$ & $8 / 11 / 20081: 35$ & 26 & 897.9 \\
\hline 2633 & 1/11/2008 1:37 & $8 / 11 / 20081: 37$ & 26 & 899.3 \\
\hline 2634 & $1 / 11 / 20081: 39$ & $8 / 11 / 20081: 39$ & 26 & 900.9 \\
\hline 2635 & $1 / 11 / 2008$ 1:41 & $8 / 11 / 2008$ 1:41 & 26 & 903.1 \\
\hline 2636 & $1 / 11 / 20081: 43$ & $8 / 11 / 20081: 43$ & 26 & 9038 \\
\hline 2637 & $1 / 11 / 20081: 45$ & $8 / 11 / 2008$ 1:45 & 26 & 905 \\
\hline 2638 & 1/11/20081:47 & $8 / 11 / 20081: 47$ & 26 & 906.9 \\
\hline 2639 & $1 / 11 / 2008$ 1:49 & $8 / 11 / 2008$ 1:49 & 25.9 & 908.5 \\
\hline 2640 & $1 / 11 / 20081: 51$ & \begin{tabular}{|l|l|}
$8 / 11 / 20081: 51$ \\
\end{tabular} & 25.9 & 909.8 \\
\hline 2641 & 1/11/2008 1:53 & $8 / 11 / 20081: 53$ & 25.9 & 911 \\
\hline 2642 & $1 / 11 / 20081: 56$ & $8 / 11 / 2008$ 1:50 & 25.9 & 9124 \\
\hline 2643 & $1 / 11 / 20081: 57$ & $8 / 11 / 20081: 57$ & 25.9 & 9122 \\
\hline 2644 & $1 / 11 / 20081: 59$ & $8 / 11 / 20081: 59$ & 25.9 & 9127 \\
\hline 2645 & $1 / 11 / 2008201$ & $8 / 11 / 2008201$ & 25.9 & 913.1 \\
\hline 2646 & $1 / 11 / 2008203$ & $8 / 11 / 2008203$ & 25.9 & 9123 \\
\hline 2647 & $1 / 11 / 2008205$ & $8 / 11 / 2008205 \mid$ & 25.9 & 912 \\
\hline 2648 & $1 / 11 / 2008207$ & $8 / 11 / 2006207$ & 262 & 890.1 \\
\hline 2649 & $1 / 11 / 2008200$ & $8 / 11 / 2008200$ & 26.1 & 899.5 \\
\hline 2650 & $1 / 11 / 2008211$ & $8 / 11 / 2008211$ & 26.1 & 901.9 \\
\hline 2651 & $1 / 11 / 20$ & $8 / 11 / 2008213$ & 26 & 9023 \\
\hline 2652 & $1 / 11 / 2008215$ & $8 / 11 / 2008215$ & 25.9 & 898.4 \\
\hline 2653 & $1 / 11 / 2008217$ & $8 / 11 / 2008217$ & 25.8 & 938.6 \\
\hline 2654 & $1 / 11 / 2008219$ & $8 / 11 / 2008219$ & 25.8 & 945 \\
\hline 26्5 & $1 / 11 / 2008221$ & $8 / 11 / 2008227$ & 25.8 & 939.1 \\
\hline 2656 & $1 / 11 / 20$ & $8 / 11 / 2008223$ & 25.8 & 935.5 \\
\hline 265 & $1 / 11 / 20$ & $8 / 11 / 2008225$ & 25.8 & 9324 \\
\hline 2658 & $1 / 11 / 2008227$ & $8 / 11 / 20002227$ & 25.8 & 929.8 \\
\hline 2659 & $1 / 11 / 2008220$ & $8 / 11 / 2008229$ & 25.8 & 929.4 \\
\hline 2660 & $1 / 11 / 2008231$ & $8 / 11 / 2008231$ & 258 & 928.2 \\
\hline 2661 & $1 / 11 / 2008233$ & $8 / 11 / 2008233$ & 25.8 & 927.3 \\
\hline 2662 & $1 / 11 / 2008236$ & $8 / 11 / 2008235$ & 25.8 & 926.5 \\
\hline 2663 & $1 / 11 / 2008237$ & $8 / 11 / 2008237$ & 25.8 & 925.2 \\
\hline 2664 & $1 / 11 / 2008239$ & $8 / 11 / 2008239$ & 25.8 & 925.7 \\
\hline 2665 & $1 / 11 / 2008241$ & $8 / 11 / 2008241$ & 25.7 & 925.6 \\
\hline 2606 & $1 / 11 / 2008243$ & $8 / 11 / 2008243$ & 257 & 924.3 \\
\hline 2667 & $1 / 11 / 2008245$ & $8 / 11 / 2008245$ & 257 & 925.9 \\
\hline 2668 & $1 / 11 / 200$ & $8 / 11 / 2008247$ & 25.7 & 925. \\
\hline 2669 & $1 / 11 / 2008249$ & $8 / 11 / 2008249$ & 25.7 & 927.5 \\
\hline $25 \pi 0$ & $1 / 11 / 2008251$ & $8 / 11 / 2008251$ & 25.7 & 931.2 \\
\hline 2571 & $1 / 11 / 2008253$ & $8 / 11 / 2008253$ & 25.7 & 923.5 \\
\hline 2672 & $1 / 11 / 2$ & $8 / 11 / 2008255$ & 25.7 & 914.7 \\
\hline 2673 & $1 / 11 / 2008257$ & $8 / 11 / 200825$ & 25.7 & 904.2 \\
\hline 2674 & $1 / 11 / 2008259$ & $8 / 11 / 2008259$ & 25.7 & 9025 \\
\hline 2675 & $1 / 11 / 20083.01$ & $8 / 11 / 20083: 01$ & 25.7 & 904.7 \\
\hline $26 \pi 6$ & & $8 / 11 / 20083: 03$ & 25.7 & 9056 \\
\hline 2677 & $1 / 11 / 2$ & $8 / 11 / 200083.05$ & 25.7 & 907.3 \\
\hline 2678 & $1 / 11 / 20083.07$ & $8 / 11 / 20083.07$ & 25.7 & 908 \\
\hline 2679 & $1 / 11 / 20083: 00$ & $8 / 11 / 2008300$ & 25.7 & 910.8 \\
\hline 2680 & $1 / 11 / 20$ & \begin{tabular}{|l|l|}
$8 / 11 / 20083: 11$ \\
\end{tabular} & 25.7 & 915 \\
\hline 2681 & $1 / 11 / 2$ & $8 / 11 / 20083: 13$ & 25.7 & 917 \\
\hline 2682 & 1/11/20083:15 & $8 / 11 / 20083: 15$ & 25.7 & 950.8 \\
\hline 2683 & $1 / 11 / 20083.17$ & $8 / 11 / 20083-17$ & 25.7 & 968.1 \\
\hline 2684 & $1 / 11 / 20083-19$ & \begin{tabular}{|l|l|}
$8 / 1 / 20083: 19$ \\
\end{tabular} & 25.7 & 977.2 \\
\hline 2685 & $1 / 11 / 20$ & $8 / 11 / 20083221$ & 258 & 9781 \\
\hline 2686 & $1 / 11 / 20083.23$ & $8 / 11 / 20083: 23$ & 25.8 & 971.9 \\
\hline 2687 & $1 / 11 / 20083.25$ & $8 / 11 / 20083225$ & 25.8 & $\begin{array}{l}964.7 \\
\end{array}$ \\
\hline 2688 & 1/11/20083:27, & 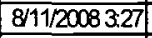 & 25.8 & 961.6 \\
\hline 2689 & $1 / 11 / 2008322$ & $8 / 11 / 20083: 29$ & 25.7 & 963.3 \\
\hline 2690 & $1 / 11 / 20083: 31$ & $8 / 11 / 20083331$ & 25.7 & 960.4 \\
\hline
\end{tabular}




\begin{tabular}{|c|c|c|c|c|}
\hline \multicolumn{5}{|c|}{$D 493 c$} \\
\hline Rec & & Adjusted & Temp & $\mathrm{SC}$ \\
\hline$\#$ & Date/Time & DeterTime & $\infty$ & $\mu \mathrm{s} / \mathrm{cm}$ \\
\hline 2091 & $1 / 11 / 20083 \cdot 33$ & $8 / 11 / 20083: 33$ & 25.7 & 969.4 \\
\hline 2692 & $1 / 11 / 20083: 35$ & $8 / 11 / 20083: 35$ & 25.7 & 9727 \\
\hline 2693 & $1 / 11 / 20083: 37$ & $8 / 11 / 20083: 37$ & 25.7 & 975. \\
\hline 2694 & $1 / 11 / 20083: 39$ & $8 / 11 / 20083: 39$ & 25.7 & 977.2 \\
\hline 2696 & $1 / 11 / 20083: 41$ & $8 / 11 / 20083: 41$ & 25.6 & 978.9 \\
\hline 2696 & $1 / 11 / 20083: 43$ & $8 / 11 / 20083.43$ & 25.6 & 979.8 \\
\hline 2697 & $1 / 11 / 20083: 45$ & $8 / 11 / 20083: 45$ & 25.6 & 980 \\
\hline 2698 & $1 / 11 / 20083: 47$ & $8 / 11 / 20083: 47$ & 25.6 & 978 \\
\hline 2699 & $1 / 11 / 20083: 49$ & $8 / 11 / 20083: 49$ & 25.6 & 978.2 \\
\hline 2700 & $1 / 11 / 20083: 51$ & $8 / 11 / 20083: 51$ & 25.6 & 977.8 \\
\hline 2701 & $1 / 11 / 20083.53$ & $8 / 11 / 20083.53$ & 25.6 & 977.7 \\
\hline 270 & $1 / 11 / 20083.55$ & $8 / 11 / 20083.55$ & 25.5 & 977.7 \\
\hline 2703 & $1 / 11 / 20083: 57$ & $8 / 11 / 20083: 5$ & 25.5 & 978 \\
\hline 2704 & $1 / 11 / 20083: 59$ & $8 / 11 / 20083: 59$ & 25.5 & 979 \\
\hline 2705 & $1 / 11 / 20084: 01$ & $8 / 11 / 20084: 01$ & 25.5 & 979.9 \\
\hline 2706 & $1 / 111 / 200$ & $8 / 11 / 20084: 03$ & 25.5 & 980.4 \\
\hline 2707 & $1 / 11 / 2$ & $8 / 11 / 20084: 05$ & 25.5 & 981. \\
\hline 2708 & $1 / 11 / 200$ & $8 / 11 / 20084: 07$ & 25.5 & 981.7 \\
\hline 2709 & $1 / 11 / 2$ & $8 / 11 / 20084: 09$ & 25.5 & 981.9 \\
\hline 2710 & $1 / 11$ & 8/11/2008 4:11 & 25.5 & 9821 \\
\hline 2711 & $1 / 11$ & $8 / 11 / 20084: 13$ & 25.5 & 98 \\
\hline 2712 & $1 / 11 / 2$ & $8 / 11 / 20084: 15$ & 25.4 & 980.2 \\
\hline 2713 & $1 / 11 / 2$ & $8 / 11 / 20084: 17$ & 25.4 & 980.1 \\
\hline 2714 & $1 / 11$ & $8 / 11 / 200$ & 25.4 & 981. \\
\hline 2715 & $1 / 111$ & $8 / 11 / 200$ & 25.4 & 980. \\
\hline 2716 & $1 / 11 / 2008$ & $8 / 11 / 20084: 23$ & 25.4 & 9623 \\
\hline 2717 & 1/11/20084:25 & $8 / 11 / 20084: 25$ & 25.4 & 981.3 \\
\hline 2718 & $1 / 11$ & $8 / 11 / 200$ & 25.4 & 980. \\
\hline 2719 & $1 / 11$ & $8 / 11 / 20$ & 25.4 & 980. \\
\hline 2720 & $1 / 11 / 2$ & $8 / 11 / 20084: 31$ & 25.4 & 980.4 \\
\hline 2721 & $1 / 11 / 20084: 33$ & $8 / 11 / 20084: 33$ & 25.4 & 980.8 \\
\hline 2722 & $1 / 11$ & $8 / 11 / 20$ & 25.4 & 980. \\
\hline 2723 & $1 / 11$ & $8 / 11 / 2$ & 25.4 & 980 \\
\hline 2724 & $1 / 11 / 20084: 30$ & $8 / 11 / 20084: 39$ & 25.4 & 981. \\
\hline 2725 & $1 / 11 / 2008 \overline{4: 41}$ & $8 / 11 / 20084: 41$ & 25.4 & 981.6 \\
\hline 2726 & $1 / 11$ & $8 / 11 / 20$ & 25.4 & 98 \\
\hline 2727 & $1 / 11 /$ & $8 / 11 / 20$ & 25.3 & 98 \\
\hline 2728 & $1 / 11$ & $8 / 11 / 20084: 47$ & 25.3 & 983. \\
\hline 272 & $1 / 11 /$ & $8 / 11 / 20084: 49$ & 25.3 & 983. \\
\hline 2730 & & $8 / 11 / 2$ & 25.3 & 983. \\
\hline 2731 & $\mid 1 / 11$ & $8 / 11 / 2$ & 25.3 & 983. \\
\hline 2732 & $1 / 11 / 2$ & $8 / 11 / 20084: 55$ & 25.3 & 963. \\
\hline 2733 & $1 / 11 /$ & $8 / 11 / 20084: 57$ & 25.3 & 984.5 \\
\hline 2734 & & $8 / 11 / 2 x$ & 25.3 & 985. \\
\hline 2735 & & $8 / 11 / 2$ & 25.3 & 983. \\
\hline 2736 & $1 / 11 / 2$ & $8 / 11 / 20085: 03$ & 25.3 & 985. \\
\hline 2737 & $1 / 11 / 2$ & $8 / 11 / 20085: 05$ & 25.3 & 985. \\
\hline 2738 & & $8 / 11 / 2$ & 25.3 & 986. \\
\hline 2739 & & $8 / 11$ & 25.3 & 98 \\
\hline 2740 & $1 / 11 /$ & $8 / 11 / 20085: 11$ & 25.3 & 987. \\
\hline 2741 & & $8 / 31 / 20085: 13$ & 25.3 & 988. \\
\hline 2742 & & & 25.2 & 986. \\
\hline 2743 & & $8 / 11 / 2$ & 25.2 & 98 \\
\hline 2744 & $1 / 11 /$ & $8 / 11 / 20085: 19$ & 25.2 & 986.8 \\
\hline 2745 & $1 / 11$ & $8 / 11 / 20085: 21$ & 25.2 & 985.4 \\
\hline 2746 & & & 25.2 & 98 \\
\hline 2747 & & $8 / 11 / 20$ & 25.2 & 98 \\
\hline 2748 & $1 / 11$ & $8 / 11 / 20085: 27$ & 25.2 & 98 \\
\hline 2749 & $1 / 11 /$ & $8 / 11 / 20085: 29$ & 25.2 & 985. \\
\hline 2750 & & & 25.2 & 984. \\
\hline 2751 & & $8 / 11 / 20$ & 25.2 & \\
\hline 2752 & $1 / 111$ & $8 / 11 / 20085: 35$ & 25.6 & 956. \\
\hline 2753 & $1 / 11 / 20085: 37$ & $8 / 11 / 20085: 37$ & 23.6 & 632 \\
\hline 2754 & & & 19 & 606. \\
\hline 275 & & $8 / 11 / 20085: 41$ & 18.4 & 598. \\
\hline 2756 & 1/11/20085:43 & $8 / 11 / 20085: 43$ & 18.2 & 59 \\
\hline 2757 & $1 / 11 / 20085: 45$ & $8 / 11 / 20085: 45$ & 19.3 & 63 \\
\hline 2758 & $1 / 11 / 20085: 47$ & $8 / 11 / 20085: 47$ & 21.3 & 656. \\
\hline 2759 & $1 / 11 / 20085: 49$ & $8 / 11 / 20085: 49$ & 21.7 & 68 \\
\hline
\end{tabular}

\begin{tabular}{|c|c|c|c|c|}
\hline \multicolumn{5}{|c|}{$D 493 c$} \\
\hline $\operatorname{Rec}$ & & Adiusted & Temp & SC \\
\hline \# & DEteTTime & DeterTime & $\alpha$ & $\mu \mathrm{s} / \mathrm{cm}$ \\
\hline 2760 & $1 / 11 / 20085: 51$ & $8 / 11 / 20085: 51$ & 215 & 6808 \\
\hline 2761 & $1 / 11 / 20085: 53$ & $8 / 11 / 20085: 53$ & 217 & 694.9 \\
\hline $27 \sqrt{2}$ & $1 / 11 / 20085: 55$ & $8 / 11 / 20085: 50$ & 219 & 698 \\
\hline $27 \sqrt[3]{3}$ & $1 / 11 / 20085: 57$ & $8 / 11 / 20085: 57$ & 2 & 690.3 \\
\hline 2764 & $1 / 11 / 20085: 59$ & $8 / 11 / 20085.59$ & 221 & 696.9 \\
\hline 2765 & 1/11/20086:01 & $8 / 11 / 20086: 01$ & 222 & 6967 \\
\hline 2766 & 1/11/20086:03 & $8 / 11 / 20086: 03$ & 222 & 700.5 \\
\hline 2767 & 1/11/20086:05 & $8 / 11 / 20086.05$ & 223 & 707 \\
\hline 2768 & $1 / 11 / 20$ & $8 / 11 / 20086: 07$ & 225 & 780 \\
\hline 2769 & $1 / 11 / 20086: 09$ & $8 / 11 / 20086: 09$ & 231 & 857.5 \\
\hline 2770 & $1 / 11 / 2$ & $8 / 11 / 20086: 11$ & 23.5 & 890.1 \\
\hline 2771 & $1 / 11 / 20086: 13$ & $8 / 11 / 20086: 13$ & 239 & 906.8 \\
\hline 2772 & $1 / 11 / 20086: 15$ & $8 / 11 / 20086: 15$ & 24.2 & 921.5 \\
\hline 2773 & $1 / 11 / 2$ & $8 / 11 / 20086: 17$ & 24.4 & 928.6 \\
\hline 2774 & $1 / 11 / 2$ & $8 / 11 / 20086: 19$ & 24.5 & 928.4 \\
\hline 2775 & $1 / 11 / 2$ & $8 / 11 / 20086: 21$ & 24.6 & 928.3 \\
\hline 2776 & 1/11/20086:23 & $8 / 11 / 20086: 23$ & 24.6 & 931.1 \\
\hline 277 & $1 / 11 / 2$ & $8 / 11 / 200$ & 24.6 & 936.6 \\
\hline 2778 & $1 / 11 / 2$ & $8 / 11 / 200$ & 24.7 & \\
\hline 2779 & $1 / 11 / 2$ & $8 / 11 / 20086: 29$ & 24.7 & 9422 \\
\hline 2780 & $1 / 11 / 2$ & $8 / 11 / 20086: 31$ & 24.7 & 946.6 \\
\hline 2781 & $1 / 11 /$ & $8 / 11 / 20$ & 24.8 & 946.5 \\
\hline 2782 & $1 / 11 /$ & $8 / 11 / 20$ & 24.8 & 9 \\
\hline 2783 & $1 / 11 /$ & $8 / 11 / 20086: 37$ & 24.8 & 947.2 \\
\hline 2784 & $1 / 11 / 2$ & $8 / 11 / 20086: 39$ & 24.8 & 948.1 \\
\hline 2785 & $1 / 11 /$ & $8 / 11 / 20$ & 24.8 & 947.6 \\
\hline 2786 & $1 / 11 /$ & $8 / 11 / 20$ & 24.8 & 947.8 \\
\hline 2787 & $1 / 11 /$ & $8 / 11 / 20$ & 24.8 & 948. \\
\hline 2788 & $1 / 11 /$ & $8 / 11 / 20$ & 24.8 & 948.7 \\
\hline 2789 & $1 / 11$ & $8 / 11 / 2$ & 24.9 & 947.5 \\
\hline 2790 & $1 / 11 / 2$ & $8 / 11 / 20$ & 24.9 & 947.4 \\
\hline 2791 & $1 / 11$ & $8 / 11 / 20$ & 24.9 & 947.5 \\
\hline 2792 & $1 / 11 / 2$ & $8 / 11 / 20086.55$ & 24.9 & 947.3 \\
\hline 2793 & $1 / 11 / 2$ & $8 / 11 / 20086.57$ & 24.9 & 946.6 \\
\hline 2794 & & $8 / 11$ & 24.9 & 946. \\
\hline 2795 & $1 / 1$ & $8 / 11 / 2$ & 24.9 & 946. \\
\hline 2796 & $1 / 11 / 2$ & $8 / 11 / 20087: 03$ & 24.9 & 945.8 \\
\hline 2797 & $1 / 11 / 2$ & $8 / 11 / 20087: 05$ & 24.9 & 945.7 \\
\hline 2798 & $1 / 11$ & & 24.9 & 945.5 \\
\hline 2799 & $1 / 111$ & $8 / 11$ & 24.9 & 945. \\
\hline 2800 & $1 / 11 / 2$ & $8 / 11 / 20087: 11$ & 24.9 & 945.2 \\
\hline 2801 & $1 / 11 / 2$ & $8 / 11 / 20087: 13$ & 24.9 & 944.5 \\
\hline 2802 & & & 24.9 & 943.5 \\
\hline 2803 & $1 / 11$ & $8 / 11 / 2$ & 24.9 & 943. \\
\hline 2804 & $1 / 11 /$ & $8 / 11 / 20087: 19$ & 24.9 & 9422 \\
\hline 2805 & & $8 / 11 / 20087: 21$ & 24.9 & 941.8 \\
\hline 2806 & & & 24.9 & 940.7 \\
\hline 2807 & $1 / 11$ & $8 / 11 / 2$ & 24.8 & 909.1 \\
\hline 2808 & & $8 / 11 / 20$ & 24.9 & 938. \\
\hline 2800 & $1 / 11$ & $8 / 11 / 20$ & 24.8 & 938.4 \\
\hline 2810 & & & 24.9 & 938. \\
\hline 2811 & $\overline{1 / 11}$ & $8 / 11 / 2$ & 24.8 & 938. \\
\hline 2812 & & $8 / 11 / 20087: 35$ & 24.8 & 938.5 \\
\hline 2813 & & & 24.8 & 938.5 \\
\hline 2814 & & & 24.8 & 909.2 \\
\hline 2815 & & $8 / 11 / 2$ & 24.8 & 938.6 \\
\hline 2816 & $1 / 11$ & $8 / 11 / 20087: 43$ & 24.8 & 93 \\
\hline 2817 & & $8 / 11 / 20087: 45$ & 24.8 & 939.2 \\
\hline 2818 & & & 24.8 & 939. \\
\hline 2819 & & $8 / 11 / 20$ & 24.8 & \\
\hline 2820 & $1 / 11$ & $8 / 11 / 20087: 51$ & 24.8 & 939.3 \\
\hline 2821 & $1 / 11 / 2$ & $8 / 11 / 20087: 53$ & 24.8 & 936. \\
\hline 2822 & & $8 / 11 / 20087: 55$ & 24.8 & 936. \\
\hline 2823 & & & 24.8 & \\
\hline 2824 & & $8 / 11 / 20087: 59$ & 24.8 & 937.6 \\
\hline 2825 & $1 / 11 / 20088: 01$ & $8 / 11 / 20088: 01$ & 24.8 & 938.3 \\
\hline 2826 & & $8 / 11 / 20088: 03$ & 24.8 & 940. \\
\hline 2827 & & $8 / 11 / 20088: 05$ & 24.8 & 940. \\
\hline 2828 & & $8 / 11 / 20088: 07$ & 24.8 & 941. \\
\hline
\end{tabular}

\begin{tabular}{|c|c|c|c|c|}
\hline \multicolumn{5}{|c|}{$D 493 c$} \\
\hline Pec & & Adiusted & Termp & SC \\
\hline$\#$ & DeterTime & DeterTime & $\alpha$ & $\mu \mathrm{s} / \mathrm{cm}$ \\
\hline 2829 & $1 / 11 / 20088: 09$ & $8 / 11 / 20088: 09$ & 24.8 & 941 \\
\hline 2830 & 1/11/20088:11 & $8 / 11 / 20088: 11$ & 24.8 & 941.3 \\
\hline 2831 & 1/11/20088:13 & $8 / 11 / 20088: 13$ & 24.8 & 943.3 \\
\hline 2832 & 1/11/2008 8:15 & $8 / 11 / 20088: 15$ & 24.8 & 942 \\
\hline 2833 & 1/11/20088:17 & $8 / 11 / 2008: 17$ & 24.8 & 9427 \\
\hline 2834 & $1 / 11 / 20088: 19$ & 8/11/20088:19 & 24.8 & 9427 \\
\hline 2835 & $1 / 11 / 20088: 21$ & $8 / 11 / 20088: 21$ & 24.8 & 9427 \\
\hline 2836 & $1 / 11 / 20088: 23$ & $8 / 11 / 20088: 23$ & 24.8 & 9428 \\
\hline 2837 & 1/11/20088:25 & $8 / 11 / 20088: 25$ & 24.8 & 9424 \\
\hline 2838 & 1/11/20088:27 & $8 / 11 / 20088: 27$ & 24.8 & 9429 \\
\hline 2839 & 1/11/20088:20 & $8 / 11 / 20088: 20$ & 24.8 & 9426 \\
\hline 2840 & $1 / 11 / 20088: 31$ & $8 / 11 / 20088: 31$ & 24.8 & 943.9 \\
\hline 2841 & $1 / 11 / 20088: 33$ & $8 / 11 / 20088: 33$ & 24.8 & 944.9 \\
\hline 2842 & $1 / 11 / 20088: 35$ & $8 / 11 / 20088: 35$ & 24.8 & 943.9 \\
\hline 2843 & $1 / 11 / 20088.37$ & $8 / 11 / 20088: 37$ & 24.8 & 9427 \\
\hline 2844 & $1 / 11 / 20088: 39$ & $8 / 11 / 20088: 39$ & 24.8 & 944.7 \\
\hline 2845 & $1 / 11 / 20088: 41$ & $8 / 11 / 20088: 41$ & 24.8 & 939.6 \\
\hline 2846 & $1 / 11 / 20088: 43$ & $8 / 11 / 20088: 43$ & 24.8 & 924.8 \\
\hline 2847 & $1 / 11 / 20088: 45$ & $8 / 11 / 20088: 45$ & 24.8 & 926 \\
\hline 2848 & $1 / 11 / 20088: 47$ & $8 / 11 / 20088: 47$ & 24.8 & 927.5 \\
\hline 2849 & $1 / 11 / 20088.49$ & $8 / 11 / 20088449$ & 24.8 & 928.9 \\
\hline 2850 & 1/11/20088:51 & $8 / 11 / 20088: 51$ & 24.8 & 935.6 \\
\hline 2851 & $1 / 11 / 20088: 53$ & $8 / 11 / 20088: 53$ & 24.8 & 9422 \\
\hline 2852 & $1 / 11 / 20088: 55$ & $8 / 11 / 20088: 55$ & 24.8 & 9423 \\
\hline 2853 & 1/11/20088:57 & $8 / 11 / 20088: 57$ & 24.8 & 9429 \\
\hline 2854 & $1 / 11 / 2008859$ & $8 / 11 / 20088: 59$ & 24.8 & 976.2 \\
\hline 2856 & 1/11/20089.01 & $8 / 11 / 20089.01$ & 24.8 & 971.5 \\
\hline 2856 & $1 / 11 / 20089.03$ & $8 / 11 / 20089.03$ & 24.8 & 965 \\
\hline 2857 & $1 / 11 / 20089.05$ & $8 / 11 / 20089.05$ & 24.8 & 964.1 \\
\hline 2858 & 1/11/20089:07 & $8 / 11 / 20089.07$ & 24.8 & 964.3 \\
\hline 2859 & $1 / 11 / 20089.00$ & $8 / 11 / 20089: 09$ & 24.8 & 964.6 \\
\hline 2860 & $1 / 11 / 20089.11$ & $8 / 11 / 20089.11$ & 24.8 & 964.8 \\
\hline 2861 & 1/11/20089:13 & $8 / 11 / 20089.13$ & 24.8 & 964.6 \\
\hline 2862 & 1/11/20089:15 & $8 / 11 / 20089.15$ & 24.8 & 964.2 \\
\hline 2863 & 1/11/20089:17 & $8 / 11 / 20089.17$ & 24.8 & 9629 \\
\hline 2864 & $1 / 11 / 20089.19$ & $8 / 11 / 20089.19$ & 24.8 & 9624 \\
\hline 2865 & $1 / 11 / 20089.21$ & $8 / 11 / 20089.21$ & 24.8 & 961.4 \\
\hline 2866 & $1 / 11 / 20089.23$ & $8 / 11 / 20089.23$ & 24.8 & 960.1 \\
\hline 2867 & $1 / 11 / 20089.25$ & $8 / 11 / 20089.25$ & 24.8 & 958.1 \\
\hline 2868 & $1 / 11 / 20089: 27$ & $8 / 11 / 20089.27$ & 24.8 & 956 \\
\hline 2869 & $1 / 11 / 20089: 29$ & $8 / 11 / 20089.29$ & 24.8 & 954.4 \\
\hline 2870 & $1 / 11 / 20089.31$ & $8 / 11 / 20089.31$ & 24.8 & 953.8 \\
\hline 2871 & $1 / 11 / 20089.33$ & $8 / 11 / 20089.33$ & 24.8 & 9526 \\
\hline 2872 & $1 / 11 / 20089.35$ & $8 / 11 / 20089.35$ & 24.8 & 953.1 \\
\hline 2873 & $1 / 11 / 20089.37$ & $8 / 11 / 20089.37$ & 24.8 & 953.3 \\
\hline 2874 & $1 / 11 / 20089.39$ & $8 / 11 / 20089.39$ & 24.8 & 9524 \\
\hline 2875 & $1 / 11 / 20089.41$ & $8 / 11 / 20089.41$ & 24.8 & 9528 \\
\hline 2876 & $1 / 11 / 20089.43$ & $8 / 11 / 20089.43$ & 24.8 & 9528 \\
\hline 2877 & $1 / 11 / 20089.45$ & $8 / 11 / 20089.45$ & 24.8 & 963.5 \\
\hline 2878 & $1 / 11 / 20089.47$ & $8 / 11 / 20089.47$ & 24.8 & 953.1 \\
\hline 2879 & $1 / 11 / 20089.49$ & $8 / 11 / 20089.49$ & 24.8 & 963.4 \\
\hline 2880 & $1 / 11 / 20089.51$ & $8 / 11 / 20089.51$ & 24.9 & 954.3 \\
\hline 2881 & $1 / 11 / 20089.53$ & $8 / 11 / 20089.53$ & 24.9 & 953.3 \\
\hline 2882 & $1 / 11 / 20089.55$ & $8 / 11 / 20089.55$ & 24.9 & 954.7 \\
\hline 2883 & $1 / 11 / 20089.57$ & $8 / 11 / 20089.57$ & 24.9 & 954.7 \\
\hline 2884 & $1 / 11 / 20089.50$ & $8 / 11 / 20089.59$ & 24.9 & 955.3 \\
\hline 2885 & $1 / 11 / 200810: 01$ & $8 / 11 / 200810: 01$ & 24.9 & 954.4 \\
\hline 2886 & $1 / 11 / 200810.03$ & $8 / 11 / 2008$ 10:03 & 24.9 & 954.6 \\
\hline 2887 & $1 / 11 / 2008$ 10:05 & $8 / 11 / 200810.05$ & 24.9 & 955.1 \\
\hline 2888 & $1 / 11 / 200810: 07$ & $8 / 11 / 200810: 07$ & 24.9 & 955.3 \\
\hline 2889 & $1 / 11 / 200810: 08$ & $8 / 11 / 200810: 09$ & 24.9 & 955.7 \\
\hline 2890 & 1/11/2008 10.11 & $8 / 11 / 2008$ 10.11 & 24.9 & 955.7 \\
\hline 2891 & $1 / 11 / 200810.13$ & $8 / 11 / 200810.13$ & 24.9 & 955.4 \\
\hline 2892 & $1 / 11 / 200810.15$ & $8 / 11 / 200810.15$ & 24.9 & 954.3 \\
\hline 2893 & $1 / 11 / 200810: 17$ & $8 / 11 / 200810.17$ & 24.9 & 963.7 \\
\hline 2894 & $1 / 11 / 2008$ 10:19 & $8 / 11 / 200810: 19$ & 24.9 & 953.2 \\
\hline 2895 & $1 / 11 / 200810: 21$ & $8 / 11 / 200810.21$ & 24.9 & 9524 \\
\hline 2896 & $1 / 11 / 200810: 23$ & $8 / 11 / 200810.23$ & 24.9 & 950.7 \\
\hline 2897 & $1 / 11 / 200810.25$ & $8 / 11 / 200810.25$ & 24.9 & 951.4 \\
\hline
\end{tabular}


DOE/RL-2009-35, REV. 0

\begin{tabular}{|c|c|c|c|c|}
\hline \multicolumn{5}{|c|}{$D 4-93 c$} \\
\hline $\mathrm{Rec}$ & & Agusted & Temp & SC \\
\hline$\#$ & DeterTime & DeterTime & $\alpha$ & $\mu \mathrm{scm}$ \\
\hline 2898 & $1 / 11 / 200810: 27$ & $8 / 11 / 2000810.27$ & 24.9 & 951.5 \\
\hline 2899 & $1 / 11 / 200810-29$ & $8 / 11 / 200810: 29$ & 24.9 & 9522 \\
\hline 2900 & \begin{tabular}{|l|}
$1 / 11 / 200810: 31$ \\
\end{tabular} & $8 / 11 / 200810.31$ & 25 & 951.8 \\
\hline 2901 & $1 / 11 / 200810: 33$ & $8 / 11 / 200810: 33$ & 24.9 & 951.3 \\
\hline 2902 & $1 / 11 / 200810: 35$ & $8 / 11 / 200810.35$ & 25 & 953.3 \\
\hline 2903 & 1/11/2008 10:37 & $8 / 11 / 200810.37$ & 25 & 953.9 \\
\hline 2904 & $1 / 11 / 200810: 39$ & $8 / 11 / 200810.39$ & 25 & 9528 \\
\hline 2005 & 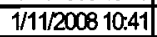 & $8 / 11 / 2008$ 10:41 & 25 & 9521 \\
\hline 2906 & $1 / 11 / 2008$ 10:43 & $8 / 11 / 200810: 43$ & 25 & 954.2 \\
\hline 2907 & \begin{tabular}{|l|}
$1 / 11 / 200810: 45$ \\
\end{tabular} & $8 / 11 / 200810: 45$ & 25 & 954.7 \\
\hline 2908 & $1 / 11 / 2008$ 10:47 & $8 / 11 / 2008$ 10:47 & 25 & 953.8 \\
\hline 2900 & $1 / 11 / 200810: 49$ & $8 / 11 / 200810: 49$ & 25 & 955.7 \\
\hline 2010 & $1 / 11 / 200810: 51$ & $8 / 11 / 2008$ 10:51 & 25 & 955.6 \\
\hline 2911 & $1 / 11 / 200810: 53$ & $8 / 11 / 200810: 53$ & 25 & 956 \\
\hline 2912 & $1 / 11 / 200810: 55$ & $8 / 11 / 200810.55$ & 25 & 956.4 \\
\hline 2913 & $1 / 11 / 200810: 57$ & $8 / 11 / 200810: 57$ & 25 & 955 \\
\hline 2914 & $1 / 11 / 200810: 59$ & $8 / 11 / 200810.59$ & 25 & 965.3 \\
\hline 2915 & 1/11/2008 11:01 & $8 / 11 / 200811: 01$ & 25 & 955.2 \\
\hline 2916 & 1/11/2008 11:03 & $8 / 11 / 200811: 03$ & 25 & 955.9 \\
\hline 2917 & \begin{tabular}{|l|}
$1 / 11 / 200811: 05$ \\
\end{tabular} & $8 / 11 / 200811: 06$ & 25 & 907.6 \\
\hline 2918 & 1/11/2008 11:07 & $8 / 11 / 2008$ 11:07 & 25.1 & 956.4 \\
\hline 2919 & 1/11/2008 11:00 & $8 / 11 / 200811: 09$ & 25 & 958 \\
\hline 2920 & 1/11/2008 11:11 & $8 / 11 / 2008$ 11:11 & 25 & 958.8 \\
\hline 2921 & 1/11/200811:13 & $8 / 11 / 200811: 13$ & 25 & 959.1 \\
\hline 2922 & \begin{tabular}{|l|}
$1 / 11 / 200811: 15$ \\
\end{tabular} & $8 / 11 / 2008$ 11:15 & 25 & 969.6 \\
\hline 2923 & 1/11/2008 11:17 & $8 / 11 / 200811: 17$ & 25 & 969.4 \\
\hline 2924 & 1/11/2008 11:19 & $8 / 11 / 200811: 19$ & 25 & 964.1 \\
\hline 2925 & 1/11/2008 11:21 & $8 / 11 / 200811: 21$ & 25.1 & 965.9 \\
\hline 2926 & 1/11/2008 11:23 & $8 / 11 / 200811: 23$ & 25.1 & 967.2 \\
\hline 2927 & \begin{tabular}{|c|}
$1 / 11 / 200811: 25$ \\
\end{tabular} & $8 / 11 / 200811: 25$ & 25.1 & 969.5 \\
\hline 2928 & $1 / 11 / 200811: 27$ & $8 / 11 / 200811: 27$ & 25.1 & 973.8 \\
\hline 2929 & $1 / 11 / 200811: 29$ & $8 / 11 / 200811: 29$ & 25.1 & 970.5 \\
\hline 2930 & 1/11/2008 11:31 & $8 / 11 / 200811: 31$ & 25.1 & 9524 \\
\hline 2931 & 1/11/2008 11:33 & $8 / 11 / 200811: 33$ & 25.1 & 941.8 \\
\hline 2932 & \begin{tabular}{|c|}
$1 / 11 / 200811: 35$ \\
\end{tabular} & $8 / 11 / 200811: 35$ & 25.1 & 943.9 \\
\hline 2933 & $1 / 11 / 200811: 37$ & $8 / 11 / 200811: 37$ & 25.1 & 946.1 \\
\hline 2934 & 1/11/2008 11:39 & 8/11/2008 11:39 & 25.1 & 947.7 \\
\hline 2935 & 1/11/2008 11:41 & $8 / 11 / 200811: 41$ & 25.1 & 948.6 \\
\hline 2936 & $1 / 11 / 200811: 43$ & $8 / 11 / 200811: 43$ & 25.1 & 950.2 \\
\hline 2937 & 1/11/2008 11:45 & $8 / 11 / 200811: 45$ & 25.1 & 950.3 \\
\hline 2938 & 1/11/2008 11:47 & $8 / 11 / 200811: 47$ & 25.1 & 974.7 \\
\hline 2939 & 1/11/2008 11:49 & $8 / 11 / 200811: 49$ & 25.2 & 974.7 \\
\hline 2940 & \begin{tabular}{|l|}
$1 / 11 / 200811: 51$ \\
\end{tabular} & $8 / 11 / 2008$ 11:51 & 25.2 & 975.7 \\
\hline 2941 & $1 / 11 / 200811: 53$ & $8 / 11 / 200811: 53$ & 25.2 & 975.4 \\
\hline 2942 & $1 / 11 / 200811: 55$ & $8 / 11 / 200811: 50$ & 25.2 & 976.4 \\
\hline 2943 & \begin{tabular}{|l|}
$1 / 11 / 200811: 57$ \\
\end{tabular} & $8 / 11 / 2008$ 11:57 & 25.2 & 976.1 \\
\hline 2944 & 1/11/200811:59 & 8/11/2000 11:50 & 25.2 & 976.3 \\
\hline 2945 & $1 / 11 / 20081201$ & $8 / 11 / 20081201$ & 25.3 & 975.3 \\
\hline 2946 & $1 / 11 / 200812003$ & $8 / 11 / 20081200$ & 25.3 & 976.1 \\
\hline 2947 & 1/11/2008 12:05 & $8 / 11 / 20081206$ & 25.3 & 975.7 \\
\hline 2948 & \begin{tabular}{|l|}
$1 / 11 / 200812007$ \\
\end{tabular} & $8 / 11 / 20081207$ & 25.3 & 974.9 \\
\hline 2949 & $1 / 11 / 20081200$ & $8 / 11 / 20081200$ & 25.3 & 973.9 \\
\hline 2950 & 1/11/2008 12:11 & $8 / 11 / 20081211$ & 25.3 & 9726 \\
\hline 2951 & 1/11/200812:13 & $8 / 11 / 20081213$ & 25.3 & 970.7 \\
\hline 2952 & $1 / 11 / 20081215$ & $8 / 11 / 20081215$ & 25.3 & 970 \\
\hline 2953 & $1 / 11 / 20081217$ & $8 / 11 / 20081217$ & 25.3 & 968.5 \\
\hline 2954 & \begin{tabular}{|l|}
$1 / 11 / 20081219$ \\
\end{tabular} & $8 / 11 / 20081219$ & 25.3 & 965.9 \\
\hline 2955 & $1 / 11 / 20081221$ & $8 / 11 / 20081221$ & 25.4 & 961.7 \\
\hline 2956 & $1 / 11 / 20081223$ & $8 / 11 / 20001223$ & 25.4 & 960.5 \\
\hline 2957 & $1 / 11 / 20081225$ & $8 / 11 / 20001225$ & 25.4 & 969.5 \\
\hline 2958 & $1 / 11 / 20081227$ & $8 / 11 / 20081227$ & 25.4 & 961 \\
\hline 2059 & $1 / 11 / 20081229$ & $8 / 11 / 20001220$ & 25.4 & 960.7 \\
\hline 2960 & $1 / 11 / 20081231$ & $8 / 11 / 20081231$ & 25.4 & 968.7 \\
\hline 2961 & 1/11/200812:33 & $8 / 11 / 20081233$ & 25.4 & 968.5 \\
\hline 2962 & 1/11/2008 1235 & $8 / 11 / 20081236$ & 25.4 & 958.1 \\
\hline 2963 & $1 / 11 / 20081237$ & $8 / 11 / 200812: 37$ & 25.4 & 95.7 \\
\hline 2964 & $1 / 11 / 200812: 39$ & $8 / 11 / 20081239$ & 25.4 & 957.6 \\
\hline 2965 & $1 / 11 / 20081241$ & $8 / 11 / 20081241$ & 25.4 & 967.2 \\
\hline 2966 & $1 / 11 / 20081243$ & $8 / 11 / 20081243$ & 25.5 & 966.9 \\
\hline
\end{tabular}

\begin{tabular}{|c|c|c|c|c|}
\hline \multicolumn{5}{|c|}{$D 4-93 c$} \\
\hline$R_{\theta C}$ & & Adjusted & Temp & $\mathrm{SC}$ \\
\hline$\#$ & Date/Time & Date/Time & $\alpha C$ & $\mu \mathrm{s} / \mathrm{cm}$ \\
\hline 2967 & $1 / 11 / 20081245$ & $8 / 11 / 200812 \div 45$ & 25.5 & 965.8 \\
\hline 2968 & $1 / 11 / 20081247$ & $8 / 11 / 20081247$ & 25.5 & 956.6 \\
\hline 2969 & $1 / 11 / 20081249$ & $8 / 11 / 20081249$ & 25.5 & 956.7 \\
\hline 2970 & $1 / 11 / 20081251$ & $8 / 11 / 20081251$ & 25.5 & 965. \\
\hline 2971 & 1/11/2008 1253 & $8 / 11 / 20081253$ & 25.5 & 956. \\
\hline 2972 & $1 / 11 / 20081255$ & $8 / 11 / 20081255$ & 25.6 & 954.8 \\
\hline 2973 & $1 / 11 / 20081257$ & $8 / 11 / 20081257$ & 25.6 & \\
\hline 2974 & $1 / 11 / 20081259$ & $8 / 11 / 20081259$ & 25.6 & 965. \\
\hline 2975 & 1/11/2008 13:01 & $8 / 11 / 200813: 01$ & 25.6 & 955.6 \\
\hline 2976 & $1 / 11 / 200813: 03$ & $8 / 11 / 2008$ 13:03 & 25.6 & 955.1 \\
\hline 297 & 1/11/2008 13:05 & $8 / 11 / 200813: 05$ & 25.6 & 957. \\
\hline 2978 & 1/11/2008 13:07 & $8 / 11 / 2008$ 13:07 & 25.7 & 955.6 \\
\hline 2979 & 1/11/2008 13:09 & $8 / 11 / 2008$ 13:09 & 25.7 & 954.1 \\
\hline 2980 & 1/11/2008 13:11 & $8 / 11 / 200813: 11$ & 25.7 & 954 \\
\hline 2981 & 1/11/2008 13:13 & $8 / 11 / 200813: 13$ & 25.7 & 955. \\
\hline 2962 & $1 / 11 / 200813: 15$ & $8 / 11 / 200813: 15$ & 25.7 & 955.8 \\
\hline 2983 & $1 / 11 / 20$ & $813: 17$ & 25.7 & क5.1 \\
\hline 2984 & $1 / 11 / 20$ & $813: 19$ & 25.7 & \\
\hline 2985 & $1 / 11 / 20$ & & 25.7 & 95 \\
\hline 2906 & $1 / 11 / 200013: 23$ & $313: 23$ & 25.7 & 966.7 \\
\hline 2987 & $1 / 11 / 2$ & 13:25 & 25.6 & 956.8 \\
\hline 2988 & $1 / 11 / 2$ & $8 / 11 / 2$ & 25.6 & 957. \\
\hline 2989 & $1 / 11 / 2$ & 13:29 & 25.7 & 96 \\
\hline 2990 & 3:31 & 13:31 & 25.7 & 96 \\
\hline 2991 & $3: 33$ & 13:33 & 25.8 & 961. \\
\hline 2992 & $1 / 11 / 2$ & 13:35 & 25.8 & 961. \\
\hline 2993 & $1 / 11 /$ & 13:37 & 25.8 & 960. \\
\hline 2994 & $1 / 11 / 2$ & 13:39 & 25.8 & \\
\hline 2995 & $1 / 11 / 2$ & $8 / 11 / 20$ & 25.9 & \\
\hline 2906 & & 13:43 & 25.9 & 96 \\
\hline 2997 & & 13:45 & 25.9 & 960. \\
\hline 2996 & & 13:47 & 25.9 & \\
\hline 2009 & & 13:49 & 25.9 & 959. \\
\hline 3000 & & $13: 51$ & 25.9 & 960. \\
\hline 3001 & $3: 53$ & 13:53 & 25.9 & 960. \\
\hline 3002 & & 13:55 & 25.9 & \\
\hline 3003 & & & 26 & 962 \\
\hline 3004 & & & 26 & 962 \\
\hline 3005 & & $814: 01$ & 26 & 962 \\
\hline 3006 & & & 26 & 962 \\
\hline 3007 & & 14:05 & 26 & 963. \\
\hline 3008 & & 14:07 & 26 & 963. \\
\hline 3009 & & & 26 & 963. \\
\hline 3010 & & & 26 & 964. \\
\hline 3011 & & & 26 & 961. \\
\hline 3012 & & & 26 & 957 \\
\hline 3013 & & & 26.1 & 935 \\
\hline 3014 & & & 26.1 & 931. \\
\hline 3015 & & & 26.1 & 935. \\
\hline 3016 & & & 26.1 & \\
\hline 3017 & & 314:25 & 26.1 & 937. \\
\hline 3018 & & & 26 & 938. \\
\hline$\overline{3019}$ & & & 26 & 939. \\
\hline 3020 & & $14: 31$ & 26 & \\
\hline 3021 & & & 25.9 & 940. \\
\hline 3022 & & & 25.9 & \\
\hline 3023 & & 14:37 & 25.9 & \\
\hline 3024 & & & 26 & \\
\hline 3025 & & & 26.1 & \\
\hline 3026 & & 14:43 & 26.1 & \\
\hline 3027 & & 14:45 & 26.1 & \\
\hline 3028 & & & 26.2 & \\
\hline 3020 & & & & \\
\hline 3030 & 14:51 & $814: 51$ & 26.2 & 985. \\
\hline 3031 & & & 26.2 & \\
\hline 3032 & & & 26.2 & \\
\hline 3033 & & $8 / 11 / 2008$ 14:57 & 26.3 & \\
\hline 3034 & & 08 14:59 & 26.2 & \\
\hline & & & & \\
\hline
\end{tabular}

\begin{tabular}{|c|c|c|c|c|}
\hline \multicolumn{5}{|c|}{$D 4.93 c$} \\
\hline$R e C$ & & Adjusted & Temp & $\mathrm{SC}$ \\
\hline \# & Daterlime & Dete/Time & $\alpha$ & $\mathrm{HS} / \mathrm{cm}$ \\
\hline 3036 & 1/111/2008 15:03 & $8 / 11 / 200815: 03$ & 26.2 & 9829 \\
\hline 3037 & 1/11/2008 15:05 & $8 / 11 / 200815: 05$ & 26.2 & 983 \\
\hline 3038 & $1 / 111200815: 07$ & $8 / 11 / 2008$ 15:07 & 26.2 & 983.2 \\
\hline 3039 & 1/11/2008 15:09 & $8 / 11 / 200815: 09$ & 26.2 & 9822 \\
\hline 3040 & 1/1112008 15:11 & $8 / 11 / 200815: 11$ & 26.2 & 9824 \\
\hline 3041 & 1/1112008 15:13 & $8 / 11 / 2008$ 15:13 & 26.3 & 981.3 \\
\hline 3042 & 1/11/2008 15:15 & $8 / 11 / 2008$ 15:15 & 26.3 & $9 \overline{77.7}$ \\
\hline 3043 & 1/11/2008 15:17 & $8 / 11 / 2008$ 15:17 & 26.3 & 977 \\
\hline 3044 & $1 / 11 / 200815: 19$ & $8 / 11 / 200815: 19$ & 26.3 & 975.4 \\
\hline 3045 & $1 / 11 / 200815: 21$ & $8 / 11 / 200015: 21$ & 26.3 & 974.5 \\
\hline 3046 & $1 / 11 / 200815: 23$ & $8 / 11 / 200815: 23$ & 26.3 & 973 \\
\hline 3047 & $1 / 11 / 200815: 25$ & $8 / 11 / 200815: 25$ & 26.3 & 9724 \\
\hline 3048 & $1 / 11 / 200815: 27$ & $8 / 11 / 200815: 27$ & 26.4 & 970.6 \\
\hline 3049 & $1 / 11 / 200815: 29$ & $8 / 11 / 200815: 29$ & 26.3 & 970.3 \\
\hline 3050 & 1/11/2008 15:31 & $8 / 11 / 200815: 31$ & 26.4 & 909 \\
\hline 3051 & 1/11/2008 15:33 & $8 / 11 / 200815: 33$ & 26.4 & 966.3 \\
\hline 3052 & 1/11/2008 15:35 & $8 / 11 / 200815: 35$ & 26.4 & 965.2 \\
\hline 3053 & 1/11/2008 15:37 & 8/11/2008 15:37 & 26.4 & 969.8 \\
\hline 3054 & $1 / 11 / 200815: 39$ & $8 / 11 / 200815: 39$ & 26.5 & 958.9 \\
\hline 3055 & 1/11/2008 15:41 & $8 / 11 / 200815: 41$ & 26.5 & 958.9 \\
\hline 3056 & $1 / 11 / 200815: 43$ & $8 / 11 / 200815: 43$ & 26.4 & 969.9 \\
\hline 3057 & $1 / 11 / 200815: 45$ & $8 / 11 / 200815: 45$ & 26.4 & 962.5 \\
\hline 3058 & $1 / 11 / 200815: 47$ & $8 / 11 / 200815: 47$ & 26.4 & 968 \\
\hline 3059 & 1/11/2008 15:49 & $8 / 11 / 200815: 49$ & 26.5 & 966.1 \\
\hline 3060 & $1 / 11 / 200815: 51$ & $8 / 11 / 200815: 51$ & 26.6 & 962.1 \\
\hline 3061 & $1 / 11 / 200815: 53$ & $8 / 11 / 200815: 53$ & 26.6 & 965.3 \\
\hline 3062 & $1 / 11 / 200815: 56$ & $8 / 11 / 20081555$ & 26.6 & 967.8 \\
\hline 3063 & 1/11/2008 15:5 & $8 / 11 / 200815: 57$ & 26.6 & 966 \\
\hline 3064 & $1 / 11 / 200815: 50$ & $8 / 11 / 200815: 59$ & 26.5 & 964.6 \\
\hline 3065 & 1/11/2008 16:01 & 8/11/2008 16:01 & 26.5 & 966.8 \\
\hline 3066 & 1/11/2008 16:03 & $8 / 11 / 200816: 03$ & 26.5 & 964.4 \\
\hline 3067 & 1/11/2008 16:05 & $8 / 11 / 200816: 06$ & 26.5 & 960.7 \\
\hline 3068 & 1/11/200816:07 & 8/11/2008 16:07 & 26.5 & 961.7 \\
\hline 3069 & $1 / 11 / 200816: 00$ & $8 / 11 / 2008$ 16:09 & 26.5 & 958.8 \\
\hline 3070 & $1 / 11 / 200816: 11$ & $8 / 11 / 2008$ 16:11 & 26.6 & 960.1 \\
\hline 3071 & $1 / 11 / 200816: 13$ & $8 / 11 / 200816: 13$ & 26.6 & 958.2 \\
\hline 3072 & 1/11/2008 16:15 & $8 / 11 / 200816: 15$ & 26.6 & 958.7 \\
\hline 3073 & 1/11/2008 16:17 & $8 / 11 / 2008$ 16:17 & 26.6 & 957.3 \\
\hline 3074 & $1 / 11 / 200816: 19$ & $8 / 11 / 2008$ 16:19 & 26.6 & 960.8 \\
\hline 3075 & $1 / 11 / 200816: 21$ & $8 / 11 / 200816: 21$ & 26.6 & 956.2 \\
\hline 3076 & $1 / 11 / 200816: 23$ & $8 / 11 / 200816: 23$ & 26.6 & 956.8 \\
\hline 3077 & 1/11/2008 16:25 & \begin{tabular}{|l|l|}
$8 / 11 / 200816: 25$ \\
\end{tabular} & 26.6 & 958.3 \\
\hline 3078 & 1/11/2008 16:27 & $8 / 11 / 200816: 27$ & 26.6 & 955.1 \\
\hline 3079 & $1 / 11 / 200816: 20$ & 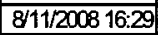 & 26.6 & 968.9 \\
\hline 3080 & 1/11/2008 16:31 & $8 / 11 / 200816: 31$ & 26.6 & 960.7 \\
\hline 3081 & 1/11/2008 16:33 & $8 / 11 / 200816: 33$ & 26.7 & 966.5 \\
\hline 3062 & 1/11/2008 16:33 & $8 / 11 / 200816: 35$ & 26.7 & 962.2 \\
\hline 3083 & 1/11/2008 16:37 & $8 / 11 / 200816: 37$ & 26.7 & 964.6 \\
\hline 3084 & 1/11/2008 16:30 & 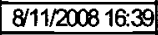 & 26.7 & 963.3 \\
\hline 3085 & 1/11/2008 16:41 & $8 / 11 / 2008$ 16:41 & 26.7 & 964.1 \\
\hline 3086 & $1 / 11 / 200816: 43$ & \begin{tabular}{|l|}
$8 / 11 / 2008$ 16:43 \\
\end{tabular} & 26.8 & 960.9 \\
\hline 3087 & 1/11/2008 16:45 & $8 / 11 / 200816: 45$ & 26.8 & 956.8 \\
\hline 3088 & $1 / 11 / 2008$ 16:47 & $8 / 11 / 200816: 47$ & 26.8 & 955.9 \\
\hline 3089 & $1 / 11 / 200816: 49$ & 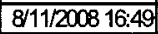 & 26.8 & 957.4 \\
\hline 3090 & $1 / 11 / 200816: 51$ & $8 / 11 / 200816: 51$ & 26.7 & 954.2 \\
\hline 3091 & \begin{tabular}{|l|}
$1 / 11 / 200816: 53$ \\
\end{tabular} & \begin{tabular}{|l}
$8 / 11 / 200816: 53$ \\
\end{tabular} & 26.7 & 955.9 \\
\hline 3092 & $1 / 11 / 200816: 56$ & $8 / 11 / 200816: 56$ & 26.7 & 956.4 \\
\hline 3093 & $1 / 11 / 2008$ 16:5 & $8 / 11 / 200816: 5$ & 26.6 & 957.7 \\
\hline 3094 & $1 / 11 / 200816: 59$ & $8 / 11 / 200816.59$ & 26.7 & 956.1 \\
\hline 3005 & 1/11/2008 17:01 & $8 / 11 / 2008$ 17:01 & 26.7 & 955.3 \\
\hline 3096 & 1/11/2008 17:03 & 8/11/2008 17:03 & 26.6 & 953.4 \\
\hline 3097 & 1/11/2008 17:05 & \begin{tabular}{|l|}
$8 / 11 / 200817: 05$ \\
\end{tabular} & 26.5 & 954 \\
\hline 3096 & 1/11/2008 17:07 & $8 / 11 / 2008$ 17:07 & 26.6 & 947.4 \\
\hline 3099 & 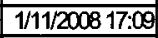 & $8 / 11 / 200817: 09$ & 26.7 & 946.8 \\
\hline 3100 & 1/11/2008 17:11 & \begin{tabular}{|l|l|}
$8 / 1 / 2008$ 17:11 \\
\end{tabular} & 26.6 & 948.3 \\
\hline 3101 & 1/11/2008 17:13 & \begin{tabular}{|l|}
$8 / 11 / 200817: 13$ \\
\end{tabular} & 26.6 & 948.3 \\
\hline 3102 & 1/11/2008 17:15 & $8 / 11 / 200817: 15$ & 26.6 & 950.2 \\
\hline 3103 & 1/11/2008 17:17 & $8 / 11 / 200817: 17$ & 26.5 & 949.9 \\
\hline 3104 & 1/11/2008 17:19 & $8 / 11 / 200817: 19$ & 26.5 & 951.6 \\
\hline
\end{tabular}


DOE/RL-2009-35, REV. 0

\begin{tabular}{|c|c|c|c|c|}
\hline \multicolumn{5}{|c|}{ D493c } \\
\hline Rec & & Adusted & Temp & $\mathrm{SC}$ \\
\hline$\#$ & Dete/Time & Dete/Time & $\propto$ & $\mu \mathrm{s} / \mathrm{cm}$ \\
\hline 3105 & 1/11/2008 17:21 & $8 / 11 / 2008$ 17:21 & 264 & 962 \\
\hline 3106 & 1/11/2008 17:23 & $8 / 11 / 200817: 23$ & 264 & \\
\hline 107 & $1 / 11 / 2008$ 17:25 & $8 / 11 / 200817: 25$ & 26.3 & \\
\hline 3108 & 1/11/2008 17:27| & $8 / 11 / 2000$ 17:27 & 26.5 & 993 \\
\hline 3109 & $1 / 11 / 200817: 29$ & $8 / 11 / 200817: 29$ & 265 & \\
\hline 3110 & $1 / 11 / 200017: 31$ & $8 / 11 / 200817: 31$ & 26.6 & 992 \\
\hline 3111 & 1/11/2008 17:33 & $8 / 11 / 200817: 33$ & 267 & $995:$ \\
\hline 3112 & 1/111/2008 17:36 & $8 / 11 / 200817: 30$ & 26.8 & $994 !$ \\
\hline 3113 & $1 / 11 / 2008$ 17:37 & $8 / 11 / 200017: 37$ & 26.9 & \\
\hline 3114 & $1 / 11 / 2008$ & $8 / 11 / 200817: 39$ & 26.9 & \\
\hline 3115 & $1 / 11 / 20$ & $8 / 11 / 200817: 41$ & 27 & 992 \\
\hline 3116 & $1 / 11 / 200817: 43$ & $8 / 11 / 200017: 43$ & 27.2 & 973 \\
\hline 3117 & $1 / 11 / 200817: 45$ & $8 / 11 / 200817: 45$ & 27.2 & 975. \\
\hline 3118 & $1 / 11 / 20$ & $8 / 11 / 200817: 47$ & 27.2 & 979. \\
\hline 3119 & $1 / 11 / 200$ & $8 / 11 / 2008$ & 27.2 & 979 \\
\hline $3+20$ & $1 / 11 / 200$ & $8 / 11 / 200017: 51$ & 27.2 & \\
\hline 3121 & $1 / 11 / 20$ & $8 / 11 / 2008$ 17:53 & 27.2 & 978. \\
\hline 3122 & 1/11/2008 17:56 & $8 / 11 / 200817: 56$ & 27.2 & 978 \\
\hline 3123 & 1/11/2008 17:57 & $8 / 11 / 200817: 57$ & 27.1 & 979. \\
\hline 3124 & $1 / 11 / 2 x$ & $8 / 11 / 2006$ & 27.1 & 978. \\
\hline 3125 & $1 / 11 / 2 x$ & $8 / 11 / 2008$ & 27.1 & 980 \\
\hline 3126 & $1 / 11 / 2$ & $8 / 11 / 200$ & 27 & 990. \\
\hline 3127 & $1 / 11 / 2008$ & $8 / 11 / 20081806$ & 27 & 10024 \\
\hline 3128 & 1/11/2008 18:07 & $8 / 11 / 200818.07$ & 27.1 & 1001.6 \\
\hline 3129 & $1 / 11 / 2$ & $8 / 11 / 20$ & 27.2 & 999.5 \\
\hline 3130 & $1 / 11 / 2$ & $8 / 11 / 20$ & 27.2 & 99 \\
\hline 3131 & $1 / 11 / 2$ & $8 / 11 / 200$ & 27.2 & 995 \\
\hline 3132 & $1 / 11 / 200$ & $8 / 11 / 200818: 15$ & 27.2 & 997.4 \\
\hline 3133 & $1 / 11 / 2008$ 1817 & $8 / 11 / 200818: 17$ & 272 & 99 \\
\hline 3134 & $1 / 11 / 2$ & $8 / 11 / 20$ & 27.3 & 996. \\
\hline 3135 & $1 / 11 / 2$ & $8 / 11 / 20$ & 27.2 & 998. \\
\hline 3136 & $1 / 11 / 2$ & $8 / 11 / 200$ & 27.2 & 994 \\
\hline 3137 & $1 / 11 / 2 x$ & $8 / 11 / 200818.25$ & 272 & 993 \\
\hline 3138 & $1 / 11 / 2 x$ & $8 / 11 / 200818: 27$ & 272 & 998. \\
\hline 3139 & $1 / 11 / 2 x$ & $8 / 11 / 200818: 29$ & 272 & 990.7 \\
\hline 3140 & $1 / 11 / 2$ & $8 / 11 / 2$ & 27.2 & 996. \\
\hline 3141 & $1 / 11 / 2$ & $8 / 11 / 20$ & 27.2 & 992 \\
\hline 3142 & $1 / 11 / 2$ & $8 / 11 / 200$ & 27.1 & 996. \\
\hline 3143 & $1 / 11 / 20081837$ & $8 / 11 / 200818: 37$ & 27.1 & 998 \\
\hline 3144 & $1 / 11 / 200818: 39$ & $8 / 11 / 200818: 39$ & 27.1 & 993. \\
\hline 3145 & $1 / 11 /$ & $8 / 11 /$ & 27.1 & 994. \\
\hline 3146 & $1 / 111 / 2$ & $8 / 11 / 20$ & 27.1 & 996 \\
\hline 3147 & $1 / 11 / 2$ & $8 / 11 / 2008$ & 27.1 & 996. \\
\hline 3148 & $1 / 111 / 20$ & $8 / 11 / 20081844$ & 27.1 & 99 \\
\hline 3149 & $1 / 11 / 20$ & $8 / 11 / 200818: 49$ & 27.2 & 999. \\
\hline 3150 & $1 / 11 / 2$ & $8 / 111$ & 272 & 990 \\
\hline 3151 & $1 / 11 / 2$ & $8 / 11 / 200818.53$ & 27.2 & 1002 \\
\hline 3152 & $1 / 111 / 2$ & $8 / 11 / 20$ & 27.2 & 99 \\
\hline 3153 & $1 / 111 / 2$ & $8111 / 2008$ 18.57 & 27.2 & 1001. \\
\hline 3154 & & $8 / 11 / 200818.59$ & 27.3 & 990 \\
\hline 3156 & & & 27.3 & 1001. \\
\hline 3156 & $1 / 11 / 2$ & $8 / 11 / 20$ & 27.3 & 1001. \\
\hline 3157 & $1 / 11 / 20$ & $8 / 11 / 2008$ & 27.3 & 1003 \\
\hline 3158 & $1 / 11 / 20$ & $8 / 11 / 200$ & 27.3 & 1002 \\
\hline 3159 & & $8 / 11 / 200$ & 27.3 & 1003 \\
\hline 316 & & & 27.3 & 10 \\
\hline 3161 & & & 27.3 & 990 \\
\hline 3162 & $1 / 1112$ & 8/11/2000 19:15 & 27.4 & 997. \\
\hline 3163 & $1 / 11 / 2$ & $8 / 11 / 200019.17$ & 27.4 & 996 \\
\hline 3164 & & $8 / 11 / 200819.19$ & 27.4 & 993 \\
\hline 3165 & & & 27.3 & 996 \\
\hline 316 & & $8 / 11 / 200$ & 27.3 & \\
\hline 3167 & & $8 / 11 / 200$ & 27.3 & \\
\hline 3168 & $\sqrt{111 / 2}$ & $8111 / 200819.27$ & 27.2 & 994. \\
\hline 3169 & $1 / 11 / 20$ & $8 / 11 / 200819.29$ & 27.3 & 995. \\
\hline 317 & $1 / 1112$ & $8111 / 200819.31$ & 27.2 & 997 \\
\hline 317 & $1 / 11 / 2$ & $8 / 11 / 200819: 33$ & 27.2 & 998 \\
\hline 3172 & & $8 / 11 / 200819.35$ & 27.2 & \\
\hline 3173 & 819.37 & $8 / 11 / 200819.37$ & 27.2 & $998:$ \\
\hline
\end{tabular}

\begin{tabular}{|c|c|c|c|c|}
\hline \multicolumn{5}{|c|}{ D493c } \\
\hline $\mathrm{Pec}$ & & Adiusted & Temp & SC \\
\hline \# & Deter/Time & DeterTime & $\propto$ & HSlam \\
\hline 3174 & $1 / 11 / 200819.39$ & $8 / 11 / 200819: 39$ & 27.1 & 996.8 \\
\hline 3175 & $1 / 11 / 200819.41$ & \begin{tabular}{|l|l|}
$811 / 200819.41$ \\
\end{tabular} & 27.1 & 996.5 \\
\hline 3176 & $1 / 11 / 200819.43$ & $8 / 11 / 2008$ 19.43 & 2र्ता & 995.8 \\
\hline 3177 & $1 / 11 / 200819.45$ & $8 / 11 / 200819: 45$ & 27 & 1013.9 \\
\hline 3178 & $1 / 11 / 200819.47$ & $8 / 11 / 200819.47$ & 27.2 & 1025.4 \\
\hline 3179 & $1 / 11 / 200819.49$ & $8 / 11 / 200819: 49$ & 27.3 & 1019 \\
\hline 3180 & $1 / 11 / 200819.51$ & $8 / 11 / 200819.51$ & 27.3 & 1010.6 \\
\hline 3181 & $1 / 11 / 200819.53$ & $8 / 11 / 200819.53$ & 27.4 & 9623 \\
\hline 3182 & $1 / 11 / 200819.56$ & $8 / 11 / 200819.55$ & 27.5 & 978.7 \\
\hline 3183 & 1/11/2008 19.55 & $8 / 11 / 200819: 57$ & 27.4 & 978.4 \\
\hline 3184 & 1/11/2008 19.59 & $8 / 11 / 200819.59$ & 27.4 & 975.6 \\
\hline 3185 & $1 / 11 / 200820.01$ & $8 / 11 / 200820: 01$ & 27.3 & 974.1 \\
\hline 3186 & $1 / 11 / 200820.03$ & $8 / 11 / 200820.03$ & 27.3 & 9721 \\
\hline 3187 & $1 / 11 / 200820.05$ & $8 / 11 / 200820: 05$ & 27.3 & 971.2 \\
\hline 3188 & 1/11/200820.07 & $8 / 11 / 200820: 07$ & 27.2 & 971.7 \\
\hline 3189 & $1 / 11 / 200820.00$ & $8 / 11 / 200820: 09$ & 27.2 & 973.2 \\
\hline 3190 & $1 / 11 / 20082011$ & $8 / 11 / 200820: 11$ & 27.1 & 974.5 \\
\hline 3191 & $1 / 11 / 200020013$ & $8 / 11 / 200820.13$ & 27.1 & 975.8 \\
\hline 3192 & 1/11/200820:15 & $8 / 11 / 200820: 15$ & 27 & 977.2 \\
\hline 3193 & $1 / 11 / 200820 \cdot 17$ & $8 / 11 / 200820: 17$ & 26.9 & 9782 \\
\hline 3194 & $1 / 11 / 200820,19$ & $8 / 11 / 200820: 19$ & 27 & 963.5 \\
\hline 3196 & $1 / 11 / 200820.21$ & $8 / 11 / 200820: 21$ & 27.2 & 990.2 \\
\hline 3196 & $1 / 11 / 200820.23$ & $8 / 11 / 200820: 23$ & 27.3 & 995.6 \\
\hline 3197 & $1 / 11 / 200820.25$ & $8 / 11 / 200820: 25$ & 27.3 & 925 \\
\hline 3198 & $1 / 11 / 200820.27$ & $8 / 11 / 200820227$ & 27.3 & 991.6 \\
\hline 3199 & $1 / 11 / 200820: 20$ & $8 / 11 / 200820: 29$ & 27.3 & 997.7 \\
\hline 3200 & $1 / 11 / 200820.31$ & $8 / 11 / 200820: 31$ & 27.3 & 997.8 \\
\hline 3201 & $1 / 11 / 200020.33$ & $8 / 11 / 200820: 33$ & 27.3 & 998.7 \\
\hline 3200 & $1 / 11 / 200820.36$ & $8 / 11 / 200820336$ & 27.3 & 10026 \\
\hline 3203 & $1 / 11 / 200820 \cdot 37$ & $8 / 11 / 200820: 37$ & 27.3 & 100 \\
\hline 3204 & $1 / 11 / 200820.39$ & $8 / 11 / 200820: 39$ & 27.3 & 1000.2 \\
\hline 3205 & $1 / 11 / 200820.41$ & $8 / 11 / 200820: 41$ & 27.3 & 1010.5 \\
\hline 3206 & $1 / 11 / 200820.43$ & $8 / 11 / 200820: 43$ & 27.3 & 1009.3 \\
\hline 3207 & $1 / 11 / 200820: 45$ & $8 / 11 / 200820: 45$ & 27.3 & 1008. \\
\hline 3208 & $1 / 11 / 200820447$ & $8 / 11 / 200820: 47$ & 27.3 & 10087 \\
\hline 3009 & $1 / 11 / 200820,49$ & $8 / 11 / 200820: 49$ & 27.2 & 1009.8 \\
\hline 3210 & $1 / 11 / 200820.51$ & $8 / 11 / 200820051$ & 27.2 & 1008 \\
\hline 3211 & $1 / 11 / 200820: 53$ & $8 / 11 / 200820: 53$ & 27.2 & 1008.2 \\
\hline 3212 & $1 / 11 / 20002055$ & $8 / 11 / 20082055$ & 27.2 & 1006.3 \\
\hline 3213 & 1/11/200820:57 & $8 / 11 / 200820: 5$ & 27.1 & 1008 \\
\hline 3214 & 1/11/200820.50 & $8 / 11 / 20082005$ & 27.1 & 1005. \\
\hline 3215 & 1/11/200821:01 & 8/11/200821:01 & 27.1 & 1008.5 \\
\hline 3216 & 1/11/200821:03 & $8 / 11 / 200821: 03$ & 27.1 & $10 \div 0.1$ \\
\hline 3217 & 1/11/200821:06 & $8 / 11 / 200821: 05$ & 27.1 & 1011 \\
\hline 3218 & 1/11/200821:07 & $8 / 11 / 200821: 07$ & 27.1 & 10122 \\
\hline 3219 & 1/11/200821:09 & $8 / 11 / 200821: 09$ & 27.1 & 1011 \\
\hline 3220 & 1/11/200821:11 & $8 / 11 / 200821: 11$ & 27.1 & 1014.1 \\
\hline 3221 & 1/11/200821:13 & $8 / 11 / 200821: 13$ & 27.1 & 1011 \\
\hline 3222 & 1/11/200821:15 & $8 / 11 / 200821: 15$ & 27.1 & 1013.7 \\
\hline 3223 & 1/11/200821:17 & $8 / 11 / 200821: 17$ & 27.1 & 1016.4 \\
\hline 3224 & 1/11/200821:19 & $8 / 11 / 200821: 19$ & 27.1 & 1013.8 \\
\hline 3225 & 1/11/200821:21 & $8 / 11 / 200821: 21$ & 27.1 & 10138 \\
\hline 3226 & 1/11/200821:23 & $8 / 11 / 200821: 23$ & 27.1 & 1016.6 \\
\hline $322 \pi$ & 1/11/200821:25 & 8/11/200821:25 & 27 & 1015.1 \\
\hline 3228 & $1 / 11 / 200821: 27$ & $8 / 11 / 200821: 27$ & 27 & 1016 \\
\hline 3220 & 1/11/200821:29 & 8/11/200821:29 & 27 & 1014.8 \\
\hline 3230 & 1/11/200821:31 & $8 / 11 / 200821: 31$ & 27 & 1016.7 \\
\hline 3231 & 1/11/200821:33 & $8 / 11 / 200821: 33$ & 27 & 1006.8 \\
\hline 3232 & 1/11/200821:35 & $8 / 11 / 200821: 35$ & 27.6 & 10155 \\
\hline 3233 & 1/11/200821:37 & $8 / 11 / 200821: 37$ & 27.5 & 10126 \\
\hline 3234 & 1/11/200821:30 & $8 / 11 / 200821: 39$ & 27.5 & 10125 \\
\hline 3235 & 1/11/200821:41 & $8 / 11 / 200821: 41$ & 27.4 & 1011.7 \\
\hline 3236 & 1/11/200821:43 & $8 / 11 / 200821: 43$ & 27.4 & 1011.7 \\
\hline 3237 & 1/11/200821:45 & $8 / 11 / 200821: 45$ & 27.4 & 1011 \\
\hline 3238 & 1/11/200821:47 & $8 / 11 / 200821: 47$ & 27.3 & 1011.3 \\
\hline 3239 & 1/11/200821:49 & $8 / 11 / 200821: 49$ & 27.3 & 10125 \\
\hline 3240 & 1/11/200821:51 & $8 / 11 / 200821: 51$ & 27.2 & 1011.7 \\
\hline 3241 & 1/11/200821:53 & $8 / 11 / 200821: 53$ & 27.2 & 10124 \\
\hline & & $8 / 11 / 200821: 55$ & 27.2 & 1020.7 \\
\hline
\end{tabular}

\begin{tabular}{|c|c|c|c|c|}
\hline \multicolumn{5}{|c|}{$D 493 \mathrm{C}$} \\
\hline $\mathrm{Pec}$ & & Adisted & Temp & SC \\
\hline$\#$ & Date/Time & DaterTime & $\alpha$ & $\mu \mathrm{sqm}$ \\
\hline 3243 & $1 / 11 / 200821: 5$ & $8 / 11 / 200821: 5$ & 27.3 & 10302 \\
\hline 3244 & $1 / 11 / 200821: 59$ & $8 / 11 / 200821: 59$ & 27.3 & \\
\hline 3245 & $11 / 20082201$ & $8 / 11 / 20082201$ & 27.3 & 1038 \\
\hline 3246 & $322 \alpha$ & $8 / 11 / 20082203$ & 27.4 & 1009 \\
\hline 3247 & $11 / 20082205$ & $8 / 11 / 20082206$ & 27.4 & 1044 \\
\hline 3248 & $1 / 11 / 20082207$ & $8 / 11 / 20082207$ & 27.4 & 1047 \\
\hline 3249 & $1 / 11 / 20$ & $8 / 11 / 20082209$ & 27.4 & 1049. \\
\hline 3250 & 2211 & $8 / 11 / 200822: 11$ & 27.5 & \\
\hline 3251 & 2213 & $8 / 11 / 20082213$ & 27.5 & 1048 \\
\hline 3252 & $1 / 11 / 2$ & $8 / 11 / 20082215$ & 27.5 & 1050 \\
\hline 3253 & $1 / 11 / 20082217$ & $8 / 11 / 20082217$ & 27.5 & 1050. \\
\hline 3254 & $1 / 11 / 20082219$ & $8 / 11 / 20082219$ & 27.5 & 1052 \\
\hline 3255 & $1 / 11 / 2$ & $8 / 11 / 20082221$ & 27.4 & 1062 \\
\hline 3256 & $1 / 11 / 2$ & $8 / 11 / 20082223$ & 27.5 & 1053 \\
\hline 3257 & $1 / 11 / 2$ & 82225 & 27.5 & \\
\hline 3258 & $1 / 11 / 2$ & $8 / 11 / 20082227$ & 27.5 & 1064 \\
\hline 3259 & $1 / 11 / 2$ & $8 / 11 / 20082229$ & 27.5 & 1055. \\
\hline 3260 & $1 / 11 /$ & 32231 & 27.5 & 1056. \\
\hline 3261 & 233 & 2233 & 27.4 & 106 \\
\hline 3262 & 236 & 2235 & 27.4 & 1057 \\
\hline 3263 & $1 / 111 / 2$ & 82237 & 27.5 & \\
\hline 3264 & 2239 & 82239 & 27.5 & 1057 \\
\hline 3265 & $\overline{2241}$ & 82241 & 27.5 & 1056 \\
\hline 3266 & & 82243 & 27.5 & 1057 \\
\hline 3267 & & 82245 & 27.5 & 105 \\
\hline 3268 & & 2247 & 27.5 & 1056 \\
\hline 3269 & 2249 & 2249 & 27.5 & 1047 \\
\hline 3270 & & 32251 & 27.5 & 1040 \\
\hline 3271 & & 2253 & 27.5 & 1037 \\
\hline 3272 & & 2255 & 27.4 & 1034 \\
\hline 3273 & 257 & 2257 & 27.4 & 1028 \\
\hline 3274 & & 2259 & 27.3 & 1027 \\
\hline 3275 & & $23: 01$ & 27.3 & 1024 \\
\hline 3276 & & $23: 03$ & 27.2 & 1023 \\
\hline 3277 & & 2305 & 272 & 1019 \\
\hline 3278 & & 2307 & 27.2 & 1012 \\
\hline 3279 & & 2309 & 27.1 & 1011 \\
\hline 3280 & & $823: 11$ & 27.1 & 1009 \\
\hline 3281 & & $823: 13$ & 27.1 & 1006 \\
\hline 3282 & & 2315 & 27.1 & 1008 \\
\hline 3283 & & $23: 17$ & 27.1 & 1011 \\
\hline 3284 & & $23: 19$ & 27 & 1010 \\
\hline 3285 & & $23: 21$ & चर्जा & 1011 \\
\hline 3286 & & 23.23 & 26.9 & 1012 \\
\hline 3287 & & & 26.9 & \\
\hline 3288 & & $23: 27$ & 26.8 & 1014 \\
\hline 3239 & & $23: 29$ & 26.9 & 006 \\
\hline 3290 & & $23: 31$ & 27.1 & 1001 \\
\hline 3291 & & $23: 3$ & 27.2 & 990 \\
\hline 3292 & & & 27.2 & \\
\hline 3293 & & 2337 & 27.3 & \\
\hline 3294 & & $23: 39$ & 27.3 & 1001 \\
\hline 3296 & & 823:41 & 27.3 & 1006 \\
\hline 3296 & & & 27.3 & 1009 \\
\hline 32977 & & & 27.3 & 1010 \\
\hline 3296 & & & 27.2 & \\
\hline 3290 & & & 27.2 & 1011 \\
\hline 3300 & & 823:51 & 27.1 & 1014 \\
\hline 3301 & & 823.53 & 27.1 & 1015 \\
\hline 3302 & & & 27.1 & 10 \\
\hline 3003 & & & 27.1 & \\
\hline 3304 & & $23: 59$ & 27.1 & \\
\hline 3306 & & 80.01 & 27.1 & \\
\hline 3306 & & 220000003 & 27.1 & 1025 \\
\hline 3307 & & & 27.1 & \\
\hline 3308 & & & 27.2 & \\
\hline 3309 & & & & \\
\hline 310 & & & 27.2 & \\
\hline & $1 / 12 / 20080.13$ & $8 / 1220080.13$ & 27.2 & tor \\
\hline
\end{tabular}




\begin{tabular}{|c|c|c|c|c|}
\hline \multicolumn{5}{|c|}{ D4-93c } \\
\hline $\operatorname{Rec}$ & & Adusted & Temp & $\mathrm{SC}$ \\
\hline \# & Date-Time & Deter/Time & $\alpha$ & $\mu \mathrm{s} / \mathrm{cm}$ \\
\hline 3312 & $1 / 12 / 20080: 15$ & $8 / 12 / 20080: 15$ & 27.2 & 1031.6 \\
\hline 3313 & $1 / 12 / 20080: 17$ & $8 / 12 / 20080: 17$ & 27.1 & 1030.7 \\
\hline 3314 & 1/12/20080:19 & $8 / 12 / 20080: 19$ & 27.1 & 1034.8 \\
\hline 3315 & $1 / 12 / 20080: 21$ & $8 / 12 / 20080.21$ & 27.1 & 1035.3 \\
\hline 3316 & $1 / 12 / 20080: 23$ & $8 / 12 / 20080.23$ & 27.1 & 10323 \\
\hline 3317 & $1 / 12 / 20080.25$ & $8 / 12 / 20080: 25$ & 27 & 1037.8 \\
\hline 3318 & $1 / 12 / 20080: 27$ & $8 / 1220080: 27$ & 27 & 1032.8 \\
\hline 3319 & $1 / 12 / 20080: 29$ & $8 / 12 / 20080: 29$ & 26.9 & 1032.9 \\
\hline 3320 & $1 / 12 / 20080: 31$ & $8 / 12 / 20080: 31$ & 26.9 & 1035.4 \\
\hline 3321 & $1 / 12 / 20080: 33$ & $8 / 12 / 20080: 33$ & 26.8 & 1031.4 \\
\hline 3322 & $1 / 12 / 20080.35$ & $8 / 12 / 20080: 35$ & 26.8 & 1031.6 \\
\hline 3323 & $1 / 12 / 20080.37$ & $8 / 12 / 20080: 37$ & 26.8 & 1035.6 \\
\hline 3324 & $1 / 12 / 20080.39$ & $8 / 12 / 20080.39$ & 26.8 & 1037.4 \\
\hline 3325 & $1 / 12220080: 41$ & $8 / 12 / 20080.41$ & 26.9 & 1040 \\
\hline 3326 & $1 / 12 / 20080: 43$ & $8 / 12 / 20080: 43$ & 26.9 & 1043.6 \\
\hline 3327 & $1 / 12 / 20080.45$ & $8 / 12 / 20080.45$ & 26.9 & 1044.8 \\
\hline 3328 & $1 / 12 / 20080: 47$ & $8 / 12 / 20080: 47$ & 27 & 1046.6 \\
\hline 3329 & $1 / 12 / 20080.49$ & $8 / 12 / 20080: 49$ & 27 & 1047.2 \\
\hline 3330 & $1 / 12 / 20080.51$ & $8 / 12 / 20080.51$ & 27 & 1048.9 \\
\hline 3331 & $1 / 12 / 20080: 53$ & $8 / 12 / 20080: 53$ & 27 & 1049.8 \\
\hline 3332 & $1 / 12 / 20080: 55$ & $8 / 12 / 20080: 55$ & 27 & 1050.7 \\
\hline 3333 & $1 / 12 / 20080: 57$ & $8 / 12 / 20080: 57$ & 27 & 1051.1 \\
\hline 3334 & $1 / 12 / 20080: 59$ & $8 / 12 / 20080.59$ & 27 & 1050.8 \\
\hline 3335 & $1 / 12 / 20081: 01$ & $8 / 12 / 20081: 01$ & 27 & 1052.1 \\
\hline 3336 & $1 / 12 / 20081: 03$ & $8 / 12 / 20081: 03$ & 27 & 10523 \\
\hline 3337 & $1 / 12 / 20081: 05$ & $8 / 12 / 20081: 05$ & 27 & 1052.7 \\
\hline 3338 & 1/12/2008 1:07 & $8 / 12 / 20081: 07$ & 27 & 1053.3 \\
\hline 3339 & 1/12/2008 1:09 & $8 / 12 / 20081: 09$ & 27 & 1053 \\
\hline 3340 & $1 / 12 / 2008$ 1:11 & $8 / 12 / 20081: 11$ & 27 & 1052.2 \\
\hline 3341 & $1 / 12 / 20081: 13$ & $8 / 2 / 20081: 13$ & 27 & 1052.6 \\
\hline 3342 & $1 / 12 / 20081: 15$ & $8 / 12 / 20081: 15$ & 27 & 1052.4 \\
\hline 3343 & $1 / 12 / 20081: 17$ & $8 / 12 / 20081: 17$ & 27 & 1052 \\
\hline 3344 & $1 / 12 / 2008$ 1:19 & $8 / 12 / 20081: 19$ & 27 & 1031.2 \\
\hline 3345 & $1 / 12 / 20081: 21$ & $8 / 12 / 20081: 21$ & 27 & 1031.7 \\
\hline 3346 & $1 / 12 / 20081: 23$ & $8 / 12 / 20081: 23$ & 27 & 1030.7 \\
\hline 3347 & 1/12/2008 1:25 & $8 / 12 / 20081: 25$ & 27 & 1030.1 \\
\hline 3348 & 1/12/2008 1:27 & $8 / 12 / 20081: 27$ & 26.9 & 1030.9 \\
\hline 3349 & 1/12/2008 1:29 & $8 / 12 / 20081: 29$ & 26.9 & 1030.8 \\
\hline 3350 & $1 / 12 / 20081: 31$ & $8 / 12 / 20081: 31$ & 26.9 & 1030.5 \\
\hline 3351 & $1 / 12 / 20081: 33$ & $8 / 12 / 20081: 33$ & 26.8 & 1029.2 \\
\hline 3352 & $1 / 12 / 20081: 35$ & $8 / 12 / 20081: 35$ & 26.8 & 1030.6 \\
\hline 3353 & $1 / 12 / 20081: 37$ & $8 / 12 / 20081: 37$ & 26.7 & 1029.8 \\
\hline 3354 & $1 / 12 / 20081: 39$ & $8 / 12 / 20081: 39$ & 26.8 & 1027.9 \\
\hline 3355 & $1 / 12 / 20081: 41$ & $8 / 12 / 20081: 41$ & 26.8 & 1024.9 \\
\hline 3356 & $1 / 12 / 20081: 43$ & $8 / 12 / 20081: 43$ & 26.8 & 1024.3 \\
\hline 3357 & $1 / 12 / 20081: 45$ & $8 / 12 / 20081: 45$ & 26.8 & 1031.3 \\
\hline 3358 & $1 / 12 / 20081: 47$ & $8 / 12 / 20081: 47$ & 26.8 & 1034.2 \\
\hline 3359 & $1 / 12 / 20081: 49$ & $8 / 12 / 20081: 49$ & 26.8 & 1035.6 \\
\hline 3360 & $1 / 12 / 20081: 51$ & $8 / 12 / 20081: 51$ & 26.8 & 1035.4 \\
\hline 3361 & $1 / 12 / 20081: 53$ & $8 / 12 / 20081: 53$ & 26.8 & 1033.4 \\
\hline 3362 & $1 / 12 / 20081: 55$ & $8 / 12 / 20081: 55$ & 26.8 & 1027 \\
\hline 3363 & $1 / 12 / 20081: 57$ & $8 / 12 / 20081: 57$ & 26.8 & 1023.3 \\
\hline 3364 & $1 / 12 / 20081: 59$ & $8 / 12 / 20081: 59$ & 26.8 & 1021.3 \\
\hline 3365 & $1 / 12 / 2008201$ & $8 / 12 / 2008201$ & 26.7 & 1019.8 \\
\hline 3366 & $1 / 12 / 20082: 03$ & $8 / 12 / 2008203$ & 26.7 & 1016.8 \\
\hline 3367 & 1/12/20082:05 & $8 / 12 / 2008205$ & 26.7 & 1017 \\
\hline 3368 & 1/12/20082:07 & $8 / 12 / 20082: 07$ & 26.7 & 1017 \\
\hline 3369 & $1 / 12 / 20082: 09$ & $8 / 12 / 2008200$ & 26.7 & 1017.2 \\
\hline 3370 & $1 / 12 / 20082 \cdot 11$ & $8 / 12 / 20082: 11$ & 26.6 & 1018 \\
\hline 3371 & $1 / 12 / 20082: 13$ & $8 / 12 / 2008213$ & 26.6 & 1017.8 \\
\hline 3372 & $1 / 12 / 20082: 15$ & $8 / 12 / 2008215$ & 26.6 & 1018.3 \\
\hline 3373 & $1 / 12 / 20082: 17$ & $8 / 12 / 20082: 17$ & 26.6 & 1019 \\
\hline 3374 & $1 / 12 / 2008219$ & $8 / 12 / 20082: 19$ & 26.7 & 997.2 \\
\hline 3375 & $1 / 12 / 20082221$ & $8 / 12 / 2008221$ & 26.7 & 997.8 \\
\hline 3376 & $1 / 12 / 2008223$ & $8 / 12 / 20082: 23$ & 26.7 & 996.2 \\
\hline 3377 & $1 / 12 / 20082225$ & $8 / 12 / 2008225$ & 26.8 & 995.4 \\
\hline 3378 & $1 / 12 / 2008227$ & $8 / 12 / 20082: 27$ & 26.7 & 996.1 \\
\hline 3379 & $1 / 12 / 2008222$ & $8 / 12 / 20082.29$ & 26.7 & 996.9 \\
\hline 3380 & $1 / 1220082.31$ & $8 / 12 / 20082: 31$ & 26.7 & 996.1 \\
\hline
\end{tabular}

\begin{tabular}{|c|c|c|c|c|}
\hline \multicolumn{5}{|c|}{ D4-93C } \\
\hline $\mathrm{Rec}$ & & Agjusted & Temp & SC \\
\hline$\#$ & DateTime & Dete/Time & $\propto$ & $\mu \mathrm{S} / \mathrm{cm}$ \\
\hline 3381 & $1 / 12 / 2008233$ & $8 / 12 / 2008233$ & 26.7 & 996.3 \\
\hline 3382 & $1 / 12 / 2008235$ & $8 / 12 / 20082: 35$ & 26.7 & \\
\hline 3383 & $1 / 12 / 2008237$ & $8 / 12 / 20082: 37$ & 26.7 & 996.6 \\
\hline 3384 & $1 / 12 / 2008239$ & $8 / 12 / 2008239$ & 26.7 & 996.3 \\
\hline 3385 & $1 / 12 / 2008241$ & $8 / 12 / 2008241$ & 26.7 & \\
\hline 3386 & $1 / 12 / 2008243$ & $8 / 12 / 2008243$ & 26.7 & 995.6 \\
\hline 3387 & $1 / 12 / 2008244$ & $8 / 12 / 20082: 45$ & 26.7 & 996.2 \\
\hline 3388 & $1 / 12 / 2008247$ & $8 / 12 / 2008247$ & 26.6 & 995.8 \\
\hline 3389 & $1 / 12 / 20$ & $8 / 12 / 2008249$ & 26.6 & 995.8 \\
\hline 3390 & $1 / 12 / 20$ & $8 / 12 / 20082: 51$ & $26 . \overline{6}$ & 99 \\
\hline 3391 & $1 / 12 / 20$ & $8 / 1220008253$ & 26.6 & 996.2 \\
\hline 3392 & 32.55 & $8 / 12 / 20082: 55$ & 26.6 & 995.7 \\
\hline 3393 & $1 / 12 / 2$ & $8 / 12 / 20082: 57$ & 26.6 & 995.7 \\
\hline 3394 & $1 / 12 / 2$ & $8 / 12 / 20082: 59$ & 26.5 & 99 \\
\hline 3395 & $1 / 12 / 20$ & 8/12/20083:01 & 26.5 & 99 \\
\hline 3396 & $1 / 12 / 2$ & $8 / 12 / 20083: 03$ & 26.5 & 995.5 \\
\hline 3397 & $1 / 12 / 2$ & $8 / 12 / 20083: 05$ & 26.5 & 995.2 \\
\hline 3398 & $1 / 12 / 2$ & $8 / 12 / 20083: 07$ & 26.5 & 995.2 \\
\hline 3399 & $1 / 12 / 2$ & $8 / 12 / 20083: 09$ & 26.5 & 995.5 \\
\hline 3400 & $1 / 12 / 2$ & $8 / 12 / 20083: 11$ & 26.5 & 995.4 \\
\hline 3401 & $1 / 12 / 2$ & $8 / 12 / 20083: 13$ & 26.4 & 995.9 \\
\hline 3402 & $1 / 12 / 2$ & $8 / 12 / 20083: 15$ & 26.4 & 996 \\
\hline 3403 & $1 / 12 / 2$ & $8 / 12 / 20083: 17$ & 26.4 & 996.2 \\
\hline 3404 & $1 / 12 / 2$ & $8 / 12 / 20083: 19$ & 26.4 & 995.9 \\
\hline 3405 & $1 / 12 / 2$ & $8 / 12 / 20083: 21$ & 26.4 & 996 \\
\hline 3406 & $1 / 12 / 2$ & $8 / 12 / 20083: 23$ & 26.3 & 996.3 \\
\hline 3407 & $1 / 12 / 2$ & $8 / 12 / 20083: 25$ & 26.3 & 996.7 \\
\hline 3408 & $1 / 12 / 2$ & $8 / 12 / 20083: 27$ & 26.3 & 996 \\
\hline 3409 & $1 / 12 / 2$ & $8 / 12 / 20083: 29$ & 26.3 & 996 \\
\hline 3410 & $1 / 12 / 2$ & $8 / 12 / 20083: 31$ & 26.4 & 995.2 \\
\hline 3411 & $1 / 12$ & $8 / 12 / 200$ & 26.4 & 995.1 \\
\hline 3412 & $1 / 12 /$ & $8 / 12 / 200$ & 26.4 & 993.5 \\
\hline 3413 & $1 / 12 / 2$ & $8 / 12 / 20083: 37$ & 26.4 & 994.1 \\
\hline 3414 & & $8 / 12 / 20083: 39$ & 26.4 & 993.6 \\
\hline 3415 & $1 / 12 / 2$ & $8 / 12 / 20$ & 26.5 & 992.5 \\
\hline 3416 & $1 / 12 / 2$ & $8 / 12 / 20083: 43$ & 26.5 & 9929 \\
\hline 3417 & $1 / 12 / 2$ & $8 / 12 / 20083: 45$ & 26.5 & 992.9 \\
\hline 3418 & $1 / 12$ & $8 / 12 / 20$ & 26.5 & 992.2 \\
\hline 3419 & $1 / 12 /$ & $8 / 12 / 20$ & 26.5 & 992 \\
\hline 3420 & $1 / 12 / 2$ & $8 / 12 / 20083: 51$ & 26.5 & 991.8 \\
\hline 3421 & & $8 / 12 / 20083: 53$ & 26.5 & 991.6 \\
\hline 3422 & $1 / 12 / 2$ & $8 / 12 / 20$ & 26.5 & 991.7 \\
\hline 3423 & $1 / 12 / 2$ & $8 / 12 / 200$ & 26.5 & 991.5 \\
\hline 3424 & & $8 / 12 / 200$ & 26.5 & 99 \\
\hline 3425 & $1 / 12$ & $8 / 12 / 2$ & 26.5 & 990.6 \\
\hline 3426 & $1 / 12$ & $8 / 12 / 20$ & 26.5 & 991.5 \\
\hline 3427 & & $8 / 12 / 20084: 05$ & 26.5 & 990.7 \\
\hline 3428 & & & 26.4 & 990 \\
\hline 3429 & & $8 / 12 / 20$ & 26.4 & 990 \\
\hline 3430 & $1 / 12 / 2$ & $8 / 12 / 20$ & 26.4 & 989.8 \\
\hline 3431 & & $8 / 12 / 20$ & 26.5 & 989.1 \\
\hline 3432 & & & 26.4 & 98 \\
\hline 3433 & $1 / 12 /$ & $8 / 12 / 20$ & 26.4 & 989.1 \\
\hline 3434 & & $8 / 12 / 20$ & 26.4 & 988.5 \\
\hline 3435 & & $8 / 12 / 20$ & 26.4 & 968.6 \\
\hline 3436 & & $8 / 12 / 20$ & 26.4 & 987.7 \\
\hline 3437 & $1 / 12 / 2$ & $8 / 12 / 20084: 25$ & 26.4 & 987.2 \\
\hline 3438 & $1 / 12 / 2$ & $8 / 12220084: 27$ & 26.4 & 986.5 \\
\hline 3439 & $1 / 12 / 2$ & $8 / 1220084: 29$ & 26.4 & 986 \\
\hline 3440 & & $8 / 12 / 20084: 31$ & 26.4 & $982 \mathrm{C}$ \\
\hline 3441 & $1 / 12 / 2$ & $8 / 12 / 20084: 33$ & 26.3 & 980.5 \\
\hline 3442 & & $8 / 12 / 20084: 35$ & 26.3 & 980.4 \\
\hline 3443 & & & 26.3 & 979.2 \\
\hline 3444 & & $8 / 12 / 20084: 39$ & 26.3 & 980.7 \\
\hline 3445 & $1 / 12 / 2$ & $8 / 12 / 20084: 41$ & 26.3 & 97 \\
\hline 3446 & & $8 / 12 / 20084: 43$ & 26.3 & 971.5 \\
\hline 3447 & & & 26.2 & 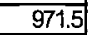 \\
\hline 3448 & $1 / 12 / 2$ & $8 / 12 / 20084: 47$ & 26.2 & 966.1 \\
\hline 3449 & & $8 / 12 / 20084: 49$ & 26.2 & 96 \\
\hline
\end{tabular}


DOE/RL-2009-35, REV. 0

\begin{tabular}{|c|c|c|c|c|}
\hline \multicolumn{5}{|c|}{ D4-96c } \\
\hline ReC & & Acjusted & Temp & $\overline{S C}$ \\
\hline$\#$ & Date/Time & Dete-Time & $\alpha C$ & $\mu \mathrm{S} / \mathrm{con}$ \\
\hline 3519 & $1 / 12 / 20087: 00$ & $8 / 12 / 20087: 09$ & 26 & 1018.1 \\
\hline 3520 & $1 / 12 / 20087: 11$ & $8 / 12 / 20087: 11$ & 26 & 1018.7 \\
\hline 3521 & $1 / 12 / 20087: 13$ & $8 / 12 / 20087: 13$ & 26 & 1018.5 \\
\hline 3522 & 1/12/20087:15 & $8 / 1220087: 15$ & 26 & 1018.7 \\
\hline 3523 & 1/12/20087:17 & $8 / 12 / 20087: 17$ & 26 & 1018.6 \\
\hline 3524 & $1 / 12 / 20087: 19$ & $8 / 12200087: 19$ & 26 & 1018.1 \\
\hline 3525 & $1 / 12 / 20087: 21$ & $8 / 12 / 20087: 21$ & 26 & 1018.1 \\
\hline 3526 & $1 / 12 / 20087: 23$ & $8 / 12 / 20087: 23$ & 26 & 1017.9 \\
\hline 3527 & 1/12/20087:25 & $8 / 12 / 20087: 25$ & 26 & 1018.2 \\
\hline 3528 & $1 / 12 / 20087: 27$ & $8 / 12 / 20087: 27$ & 25.9 & 1018.4 \\
\hline 3529 & $1 / 12 / 20087: 29$ & $8 / 12 / 20087: 29$ & 25.9 & 1017.9 \\
\hline 3530 & $1 / 12 / 20087: 31$ & $8 / 12 / 20087: 31$ & 25.9 & 1017.8 \\
\hline 3531 & $1 / 12 / 20087: 33$ & $8 / 12 / 20087: 33$ & 25.9 & 1017.4 \\
\hline 3532 & 1/12/20087:35 & $8 / 12 / 20087: 35$ & 25.9 & 1008.1 \\
\hline 3533 & $1 / 1220087: 37$ & $8 / 12 / 20087: 37$ & 25.9 & 1008.5 \\
\hline 3534 & $1 / 12 / 20087: 39$ & $8 / 12 / 20087: 39$ & 25.9 & 1007.6 \\
\hline 3535 & $1 / \uparrow 2 / 200$ & $8 / 12 / 20087: 41$ & 25.9 & 1004.2 \\
\hline 3536 & $1 / 12 / 200$ & $8 / 12 / 20087: 43$ & 25.9 & \\
\hline 3537 & $1 / 12 / 20087: 46$ & $8 / 12 / 20087: 45$ & 25.8 & 996.2 \\
\hline 3538 & 1/12/20087:47 & \begin{tabular}{|l|l|}
$8 / 12 / 20087: 47$ \\
\end{tabular} & 25.8 & $9 x$ \\
\hline 3539 & $1 / 12 / 20$ & $8 / 12 / 20087: 49$ & 25.8 & 993.4 \\
\hline 3540 & $1 / 12 / 200$ & $8 / 12 / 20087: 51$ & 25.8 & 9926 \\
\hline 3541 & $1 / 12 / 200$ & $8 / 12 / 20087: 53$ & 25.7 & 993.8 \\
\hline 3542 & $1 / 12 / 2$ & $8 / 12 / 20087: 55$ & 25.7 & 993.6 \\
\hline 3543 & $1 / 12 / 20$ & $8 / 12 / 20087: 57$ & 25.7 & 993.5 \\
\hline 3544 & $1 / 12 / 20087: 59$ & $8 / 12 / 20087: 59$ & 25.7 & 994.1 \\
\hline 3545 & $1 / 12 / 2$ & $8 / 12200$ & 25.7 & $99 x$ \\
\hline 3546 & $1 / 12 / 2$ & $8 / 12 / 20088: 03$ & 25.6 & 998 \\
\hline 3547 & & $8 / 12 / 20088: 05$ & 25.6 & 996.3 \\
\hline 3548 & $1 / 12 / 20$ & $8 / 12 / 20088: 07$ & 25.6 & 996. \\
\hline 3549 & $1 / 12 / 2$ & $8 / 12 / 20088: 09$ & 25.6 & 993.8 \\
\hline 3550 & $1 / 12 / 20$ & $8 / 12 / 20088: 11$ & 25.7 & 991.1 \\
\hline 3551 & $1 / 12 / 2$ & $8 / 12 / 20088: 13$ & 25.8 & 99 \\
\hline 3552 & $1 / 12 / 2$ & $8 / 12 / 200$ & 25.8 & 990.2 \\
\hline 3553 & $1 / 12 /$ & $8 / 12 / 20088: 17$ & 25.8 & 9925 \\
\hline 3654 & $1 / 12 / 2$ & $8 / 12 / 20088: 19$ & 25.8 & 994.3 \\
\hline 3556 & $1 / 12$ & $8 / 12 / 2$ & 25.8 & 993.5 \\
\hline 3556 & $1 / 12$ & $8 / 12 / 20088: 23$ & 25.8 & 994.1 \\
\hline 3557 & & $8 / 12 / 20088: 25$ & 25.8 & 995.4 \\
\hline 3558 & & $8 / 12 / 20$ & 25.8 & 996.4 \\
\hline 3559 & $1 / 12$ & $8 / 12$ & 25.8 & 998.1 \\
\hline 3560 & $1 / 12 / 2$ & $8 / 12$ & 25.8 & 99 \\
\hline 3561 & & & 25.7 & 99 \\
\hline 3562 & $1 / 12 / 2$ & $8 / 12 / 200$ & 25.7 & 996.2 \\
\hline 356 & $1 / 12 / 2$ & $8 / 12 / 2$ & 25.7 & 997.4 \\
\hline 3564 & & & 25.7 & 996.7 \\
\hline 3565 & & 8 & 25.7 & $997^{2} \quad 3$ \\
\hline 3566 & & $\overline{12 \pi}$ & 25.7 & 998.2 \\
\hline 3567 & & & 25.7 & 1001.8 \\
\hline 3568 & & $8 / 12$ & 25.8 & 1005. \\
\hline 3509 & & $8: 49$ & 25.8 & 1006.6 \\
\hline $35 \pi 0$ & & $88: 51$ & 25.8 & 1006.8 \\
\hline 3571 & & $8 / 12 /$ & 25.8 & 1007.2 \\
\hline 3572 & & $8 / 12 / 20088: 56$ & 25.9 & 1007.7 \\
\hline 3573 & & \begin{tabular}{|l|l|}
$812 / 20088: 57$ \\
\end{tabular} & 25.9 & 1008.2 \\
\hline 3574 & & & 25.9 & \\
\hline 3575 & & $8 / 12 / 200$ & 25.9 & 1007.4 \\
\hline 3576 & $1 / 12 / 2008$ & $8 / 12 / 20089.03$ & 25.9 & 1007.3 \\
\hline $35 \pi$ & & $8 / 12 / 20089.05$ & 25.9 & 1006.6 \\
\hline 3578 & & & 25.9 & \\
\hline 3579 & $1 / 12 / 200$ & $8 / 12 / 20089.09$ & 25.9 & 1007.3 \\
\hline 3580 & & $8 / 12 / 20089.11$ & 25.8 & 1006.5 \\
\hline 3581 & & & 25.8 & \\
\hline 3582 & & $8 / 12 / 20089.15$ & 25.8 & 1005.8 \\
\hline 3583 & $1 / 12 / 200$ & $8 / 12 / 20089.17$ & 25.8 & 1006.2 \\
\hline 3584 & $1 / 12 / 20089.19$ & $8 / 12 / 20089.19$ & 25.8 & 1005.1 \\
\hline 3585 & & 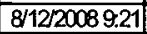 & 25.8 & 1004. \\
\hline 3586 & $1 / 12 / 20$ & $8 / 12 / 20089.23$ & 25.8 & 1005 \\
\hline & & a & 25.8 & \\
\hline
\end{tabular}

\begin{tabular}{|c|c|c|c|c|}
\hline \multicolumn{5}{|c|}{ D493C } \\
\hline $\mathrm{ReC}$ & & Agusted & Terrp & $\mathrm{SC}$ \\
\hline \# & DeteTime & Date/Time & $\propto$ & $\mu \mathrm{S} / \mathrm{cm}$ \\
\hline 3588 & $1 / 12 / 20089.27$ & $8 / 12 / 20089.27$ & 25.8 & 1005. \\
\hline 3589 & $1 / 12 / 20089.29$ & $8 / 1220089: 29$ & 25.8 & 1005 . \\
\hline 3590 & $1 / 12220089.31$ & $8 / 1220089.31$ & 25.8 & \\
\hline 3591 & $1 / 12 / 20089.33$ & $8 / 12 / 20089.33$ & 25.8 & \\
\hline 3592 & $1 / 12 / 20089.35$ & $8 / 1220089.35$ & 25.8 & 100 \\
\hline 3593 & $1 / 12 / 20089.37$ & $8 / 1220089.37$ & 25.8 & 1008 \\
\hline 3594 & $1 / 12 / 20089: 39$ & $8 / 1220089.39$ & 25.8 & \\
\hline 3595 & $1 / 12 / 20089,41$ & $8 / 12 / 20089.41$ & 25.7 & \\
\hline 3506 & $1 / 12 / 20089.43$ & $8 / 12 / 20089,43$ & 25.7 & \\
\hline 3597| & $1 / 12 / 20089.45$ & $8 / 12 / 20089.45$ & 25.7 & \\
\hline 3598 & $1 / 12 / 20089: 47$ & $8 / 12200089.47$ & 25.7 & \\
\hline 3599 & $1 / 12 / 20089.49$ & $8 / 12 / 20089.49$ & 25.7 & 1010 \\
\hline 3600 & $1 / 12 / 20089.51$ & $8 / 1220089.51$ & 25.7 & 1011. \\
\hline 3601 & 1220089.53 & $8 / 12 / 20089.53$ & 25.7 & \\
\hline 3600 & $12 / 20089.55$ & & 25.7 & \\
\hline 3603 & $1 / 12 / 20089.57$ & 89.5 & 25.7 & \\
\hline 3604 & $1 / 12 / 20089.59$ & 89.59 & 25.7 & 1012 \\
\hline 3606 & $1 / 122200810.01$ & $8 / 12 / 2$ & 25.7 & \\
\hline 3606 & 1/122008 10:03 & $8 / 12 / 2$ & 25.7 & \\
\hline 3607 & $1 / 12200810: 05$ & 310.05 & 25.7 & 1010 \\
\hline 3608 & $1 / 12 / 20$ & 10:07 & 25.7 & \\
\hline 3609 & $1 / 12 / 2008$ 10:09 & $8 / 12$ & 25.7 & \\
\hline 3610 & $1 / 12 / 200810: 11$ & 10:11 & 25.7 & \\
\hline 3611 & $1 / 12 / 2$ & $8 / 12$ & 25.7 & 11. \\
\hline 3612 & $10: 15$ & $8 / 122$ & 25.7 & \\
\hline 3613 & $1 / 12 / 2008$ 10:17 & 10:17 & 25.6 & 19. \\
\hline 3614 & $1 / 12 / 2$ & $8 / 12$ & 25.6 & 0 \\
\hline 3615 & $1 / 12 / 200$ & 10:21 & 25.6 & \\
\hline 3616 & $1 / 12 / 200$ & $10: 23$ & 25.6 & \\
\hline 3617 & $1 / 12 / 2$ & 10.25 & 25.6 & \\
\hline 3618 & $1 / 122$ & $8 / 12$ & 25 & \\
\hline 3619 & & $8 / 12$ & 25 & \\
\hline 3620 & & & 25.5 & \\
\hline 3621 & $1 / 12 / 2$ & $8 / 12$ & 25. & \\
\hline 362 & $1 / 12 / 2$ & $8 / 12$ & 25 & 05. \\
\hline 3623 & & 10.37 & 25 & 1005 . \\
\hline 3624 & & & 25 & 100 \\
\hline 3625 & $1 / 12 /$ & & 25 & 05. \\
\hline 3626 & & 310.43 & 25 . & 1005 \\
\hline 3627 & & & 25 & 1005 \\
\hline 3628 & $1 / 12$ & & 25. & 1005 \\
\hline 3620 & & 10:49 & 25 . & 100 \\
\hline 3630 & & & 25 & 1006 \\
\hline 3631 & & & 25 & 100 \\
\hline 3632 & & & 25 & 1006 \\
\hline 3633 & & & 25. & \\
\hline 3634 & & & 25 & 013 \\
\hline 3635 & & & 25. & 101 \\
\hline 3636 & & & 25. & \\
\hline 3637 & & & 25 & \\
\hline 3638 & & & 25. & 1018 \\
\hline 3639 & & & 25 & \\
\hline 3640 & & & & \\
\hline 3641 & & & 25. & \\
\hline 3642 & & & 25 & \\
\hline 3643 & & & 25 & \\
\hline 3644 & & & 25 & \\
\hline 3645 & & 812 & 25.6 & \\
\hline 3646 & & & 25.6 & \\
\hline 3647 & & & 25 & \\
\hline 3648 & & $8811: 27$ & 25.6 & 702 \\
\hline 3649 & & & 25 & \\
\hline 3650 & & & 25 & \\
\hline 3651 & $1 / 1220$ & $8 / 12 / 200811: 33$ & 25.6 & 1031 \\
\hline 3652 & & & 25.6 & \\
\hline 3653 & & & 25 & \\
\hline 3654 & & $81122200811: 30$ & 25.6 & \\
\hline 3650 & & 8112 & 25.6 & \\
\hline & & & & \\
\hline
\end{tabular}

\begin{tabular}{|c|c|c|c|c|}
\hline \multicolumn{5}{|c|}{ D493c } \\
\hline$P x$ & & Adjusted & Temp & $S C$ \\
\hline \# & Dater/ime & Dete/Time & $\alpha$ & $\mathrm{H} / \mathrm{sm}$ \\
\hline 3657 & 1/12/2008 11:45 & $8 / 12 / 200811: 45$ & 25.6 & 1035 \\
\hline 3658 & $1 / 122008$ 11:47 & \begin{tabular}{|l|l|}
$8 / 122008$ 11:47 \\
\end{tabular} & 25.6 & 1005.8 \\
\hline 3659 & 1/12/2008 11:49 & $8 / 12 / 200811: 49$ & 25.6 & 1036.4 \\
\hline 3660 & $1 / 122008$ 11:51 & $8 / 12 / 2008$ 11:51 & 25.6 & 1007.5 \\
\hline 3661 & $1 / 12200811: 53$ & $8 / 122200811: 53$ & 25.6 & 1038.5 \\
\hline 3662 & $1 / 12 / 2008$ 11:55 & $8 / 12 / 200811: 55$ & 25.6 & 1040 \\
\hline 3663 & 1/12/2008 11:57 & $8 / 12 / 200811: 5$ & 25.6 & 1041.1 \\
\hline 3664 & $1 / 12 / 200811: 59$ & $8 / 12 / 200811: 59$ & 25.7 & 1041.6 \\
\hline 3665 & $1 / 12 / 20081201$ & $8 / 12 / 20081201$ & 25.7 & 10425 \\
\hline 3666 & $1 / 12 / 20081203$ & $8 / 12 / 20081203$ & 25.7 & 1044.1 \\
\hline 3667 & $1 / 12 / 20081205$ & $8 / 12 / 200812005$ & 25.8 & 1038.5 \\
\hline 3668 & $1 / 12 / 20081207$ & $8 / 12 / 20081207$ & 25.8 & 1038 \\
\hline 3669 & $1 / 12200081200$ & $8 / 1220081209$ & 25.7 & 1036.5 \\
\hline 3670 & $1 / 12 / 20081211$ & $8 / 12 / 20081211$ & 25.7 & 1036.1 \\
\hline 3671 & $1 / 12 / 20081213$ & $8 / 122200812: 13$ & 25.7 & 1036 \\
\hline 3672 & $1 / 12 / 200812-15$ & $8 / 12 / 20081215$ & 25.7 & 1036.2 \\
\hline 3673 & 1/12/2008 12:17 & \begin{tabular}{|l|l|}
$8 / 2200812: 17$ \\
\end{tabular} & 25.7 & 1035.5 \\
\hline 3674 & $1 / 12 / 20081219$ & $8 / 12 / 20081219$ & 25.7 & 1034.9 \\
\hline 3675 & $1 / 12 / 20081221$ & $8 / 12 / 20081221$ & 25.6 & 1034.7 \\
\hline 3676 & $1 / 12 / 20081223$ & $8 / 12 / 20081223$ & 25.6 & 1034 \\
\hline 3677 & $1 / 12220081225$ & $8 / 12220081225$ & 25.6 & 1034.6 \\
\hline 3678 & $1 / 12 / 20081227$ & $8 / 12 / 20081227$ & 25.6 & 1034.6 \\
\hline 3679 & $1 / 1220081229$ & $8 / 12 / 200812: 29$ & 25.5 & 1033.6 \\
\hline 3680 & $1 / 12 / 20081231$ & $8 / 12 / 200812331$ & 25.5 & 1033.9 \\
\hline 3681 & $1 / 12 / 20081233$ & $8 / 1220081233$ & 25.5 & 1034 \\
\hline 3682 & $1 / 12 / 20081235$ & $8 / 12 / 20081235$ & 25.5 & 1034.7 \\
\hline 3683 & $1 / 12 / 20081237$ & $8 / 1220081237$ & 25.5 & 1038.9 \\
\hline 3684 & $1 / 12 / 20081239$ & $8 / 1220081239$ & 25.6 & 1040.4 \\
\hline 3685 & $1 / 12 / 2008$ १2-41 & $8 / 12 / 20081241$ & 25.8 & 1039.5 \\
\hline 3686 & $1 / 12 / 20081243$ & \begin{tabular}{|l|l|}
$8 / 12 / 20081244$ \\
\end{tabular} & 25.9 & 10429 \\
\hline 3687 & $1 / 12 / 20081245$ & $8 / 12 / 20081245$ & 25.9 & 1045.4 \\
\hline 3688 & $1 / 12 / 2008$ १२47 & $8 / 12 / 20081247$ & 25.9 & 1044 \\
\hline 3689 & $1 / 12 / 20081249$ & $8 / 12 / 20081249$ & 25.9 & 1044.4 \\
\hline 3690 & $1 / 12 / 20081251$ & $8 / 12 / 20081251$ & 25.9 & 1045.5 \\
\hline 3691 & $1 / 12 / 20081253$ & $8 / 12 / 20081253$ & 25.9 & 1046.2 \\
\hline 3692 & $1 / 12 / 20081255$ & $8 / 12 / 20081255$ & 25.9 & 1045.4 \\
\hline 3693 & $1 / 12 / 20081257$ & $8 / 12 / 20081255$ & 25.9 & 1046 \\
\hline 3694 & $1 / 12 / 20081250$ & $8 / 12220081259$ & 25.9 & 1045.5 \\
\hline 3695 & 1/12/2008 13:01 & $8 / 12 / 200813: 01$ & 25.8 & 1045.4 \\
\hline 3696 & $1 / 12 / 200813: 03$ & $8 / 12200813: 03$ & 25.8 & 1045.1 \\
\hline 3697 & $1 / 12 / 200813: 05$ & $8 / 12200813: 05$ & 25.8 & 1045.8 \\
\hline 3698 & $1 / 12 / 200813: 07$ & $8 / 12 / 200813: 07$ & 25.8 & 1046.4 \\
\hline 3699 & 1/12/2008 13:09 & \begin{tabular}{|l}
$1 / 122200813: 09$ \\
\end{tabular} & 25.8 & 1047 \\
\hline 3700 & $1 / 12 / 2008$ 13:11 & $8 / 12 / 200813: 11$ & 25.8 & 1047.5 \\
\hline 3701 & 1/12/2008 13:13 & $8 / 12 / 200813: 13$ & 25.8 & 1048.4 \\
\hline 3702 & 1/12/2008 13:15 & 8/12/2008 13:15 & 25.8 & 1048.2 \\
\hline 3703 & 1/12/2008 13:17 & $8 / 12 / 200813: 17$ & 25.8 & 1047.2 \\
\hline 3704 & 1/12/2008 13:19 & $8 / 12 / 2008$ 13:19 & 25.7 & 1048.3 \\
\hline 3705 & $1 / 12 / 200813: 21$ & 8/12/2008 13:21 & 25.9 & 1049.2 \\
\hline 3706 & $1 / 12 / 200813: 23$ & $8 / 12 / 200813: 23$ & 26 & 1049.2 \\
\hline 3707 & $1 / 12 / 200813: 25$ & $8 / 12 / 200813: 25$ & 26 & 1048.4 \\
\hline 3708 & 1/12/2008 13:27 & $8 / 12 / 200813: 27$ & 26 & 1048.4 \\
\hline 3709 & $1 / 12 / 200813-29$ & $8 / 12 / 200813: 29$ & 26 & 1048.5 \\
\hline 3710 & 1/12/2008 13:31 & $8 / 12 / 200813: 31$ & 26 & 1048.1 \\
\hline 3711 & $1 / 12 / 200813: 33$ & $8 / 122200813: 33$ & 26 & 1047.2 \\
\hline 3712 & 1/12/2008 13:35 & $8 / 122200813: 35$ & 25.9 & 1048.3 \\
\hline 3713 & 1/12/2008 13:37 & $8 / 12 / 200813: 37$ & 25.9 & 1048.3 \\
\hline 3714 & $1 / 12 / 2008$ 13-39 & $8 / 12 / 200813: 39$ & 25.9 & 1049.6 \\
\hline 3715 & $1 / 12 / 200813: 41$ & $8 / 12 / 200813: 41$ & 25.9 & 1049.1 \\
\hline 3716 & $1 / 12 / 200813: 43$ & $8 / 12 / 200813: 43$ & 25.9 & 1049.1 \\
\hline 3717 & $1 / 12 / 2008$ 13:45 & $8 / 122200813: 45$ & 25.9 & 1046.4 \\
\hline 3718 & $1 / 12 / 2008$ 13:47 & $8 / 12 / 200813: 47$ & 26 & 1045 \\
\hline 3719 & $1 / 12 / 200813: 49$ & $8 / 12200813: 49$ & 26 & 1044 \\
\hline 3720 & $1 / 12 / 200813-51$ & $8 / 12 / 200813: 51$ & 26 & 1043.2 \\
\hline 3721 & $1 / 12 / 200813: 53$ & $8 / 12 / 200813: 53$ & 26 & 1043.2 \\
\hline 3722 & $1 / 12 / 200813: 55$ & $8 / 12 / 200813: 55$ & 26 & 1043.5 \\
\hline 3723 & $1 / 12 / 200813: 57$ & $8 / 12 / 200813: 57$ & 26 & 10427 \\
\hline 3724 & $1 / 12 / 200813: 50$ & $8 / 122200813: 59$ & 26 & 1043.2 \\
\hline 3725 & $1 / 12 / 2008$ 14:01 & $8 / 122200814: 01$ & 26 & 1043.1 \\
\hline
\end{tabular}


DOE/RL-2009-35, REV. 0

\begin{tabular}{|c|c|c|c|c|}
\hline \multicolumn{5}{|c|}{ D4.93c } \\
\hline $\mathrm{Fec}$ & & Adusted & Temp & $S C$ \\
\hline$\#$ & Dater/ime & DaterTime & $\alpha$ & $\mu \mathrm{s} / \mathrm{cm}$ \\
\hline 3726 & 1/12/2008 14:03 & $8 / 122008$ 14:03 & 26 & 10426 \\
\hline 3727 & 1/12/2008 14:05 & $8 / 12 / 2008$ 14:05 & 26 & 1043.2 \\
\hline 3728 & 1/12/2008 14:07 & $8 / 1220008$ 14:07 & 25.9 & 1043.9 \\
\hline 3720 & 1/12/2008 14:09 & 81122008 14:09 & 25.9 & 10427 \\
\hline 3730 & $1 / 122200814: 11$ & $8 / 12 / 2008$ 14:11 & 25.9 & 1042.8 \\
\hline 3731 & 1/12/2008 14:13 & $8 / 1220008$ 14:13 & 26 & 10432 \\
\hline 3732 & $1 / 12 / 200814: 15$ & $8 / 122008$ 14:15 & 26 & 1043 \\
\hline 3733 & V/12/2008 14:17 & $8 / 12 / 2008$ 14:17 & 26 & 10426 \\
\hline 3734 & $1 / 12 / 2008$ 14:19 & $8 / 12 / 2008$ 44:19 & 26 & 10426 \\
\hline 3735 & $1 / 12 / 2008$ 14:21 & $8 / 12 / 2008$ 14:21 & 26 & 10425 \\
\hline 3736 & 1/12/2008 14:23 & $8 / 122008$ 14:23 & 26 & 1044 \\
\hline 3737 & $1 / 12 / 200814: 25$ & $8 / 12 / 2008$ 14:25 & 26 & 10427 \\
\hline 3738 & 1/12/2008 14:27 & $8 / 12 / 2008$ 14:27 & 25.9 & 1043.1 \\
\hline 3739 & 1/12/2008 14:20 & $8 / 122008$ 14:20 & 25.9 & 1043.9 \\
\hline 3740 & $1 / 12 / 2008$ 14:31 & $8 / 12 / 2008$ 14:31 & 25.9 & 1043.5 \\
\hline 3741 & 1/12/2008 14:33 & $8 / 12 / 200814: 33$ & 26 & 1043.2 \\
\hline 3742 & 1/12/2008 14:35 & $8 / 12 / 200814: 35$ & 26 & 1044 \\
\hline 3743 & $1 / 12 / 2008$ 14:37 & $8 / 122000814: 37$ & 26 & 10429 \\
\hline 3744 & $1 / 12 / 200814: 39$ & $8 / 122200814: 39$ & 26 & 1043.4 \\
\hline 3745 & $1 / 12 / 200814: 41$ & $8 / 12 / 200814: 41$ & 26 & 1043.1 \\
\hline 3746 & $1 / 12 / 200814: 43$ & $8 / 12 / 200814: 43$ & 26 & 1043.4 \\
\hline 3747 & $1 / 12 / 200814: 45$ & $8 / 12 / 2008$ 14:45 & 26.1 & 1043 \\
\hline 3748 & 1/12/2008 14:47 & $8 / 12 / 2008$ 14:47 & 26 & 1043.1 \\
\hline 3749 & $1 / 12 / 200814: 49$ & $8 / 12 / 2008$ 14:49 & 26 & 10423 \\
\hline 3750 & $1 / 12 / 200814: 51$ & $8 / 12 / 2008$ 14:51 & 26 & 1041.3 \\
\hline 3751 & $1 / 12 / 200814: 53$ & $8 / 12 / 200814: 53$ & 26 & 10423 \\
\hline 3752 & 1/12/2008 14:55 & $8 / 12 / 200814: 55$ & 26 & 1043.2 \\
\hline 3753 & 1/12/2008 14:57 & 8/12/2008 14:57 & 26.1 & 10422 \\
\hline 3754 & $1 / 12 / 200814: 59$ & $8 / 12 / 200814: 59$ & 26.1 & 10425 \\
\hline 3750 & 1/12/2008 15:01 & $8 / 12 / 200815: 01$ & 26.1 & 1041.7 \\
\hline 3756 & 1/12/2008 15:03 & $8 / 12 / 200815: 03$ & 26.1 & 10426 \\
\hline 3757 & 1/12/2008 15:05 & $8 / 12 / 200815: 05$ & 261 & 1042 \\
\hline 3758 & 1/12/2008 15:07 & $8 / 12 / 2008$ 15:07 & 26.1 & 10423 \\
\hline 3759 & $1 / 12 / 200815: 09$ & $8 / 12 / 200815: 09$ & 26.1 & 1041.9 \\
\hline 3760 & 1/12/2008 15:11 & $8 / 12 / 2008$ 15:11 & 26.1 & 1041.3 \\
\hline 3761 & $1 / 12 / 200815: 13$ & $8 / 1222008$ 15:13 & 26.2 & 1040.2 \\
\hline 3762 & $1 / 12 / 2008$ 15:15 & $8 / 12200815: 15$ & 26.2 & 1039.9 \\
\hline 376 & $1 / 12 / 2008$ 15:17 & $8 / 12 / 2008$ 15:17 & 26.2 & 1039.3 \\
\hline 3764 & $1 / 12 / 200815: 19$ & $8 / 12 / 2008$ 15:19 & 26.2 & 1040.5 \\
\hline 3765 & $1 / 12 / 200815: 21$ & $8 / 12 / 200815: 21$ & 26.2 & 1040 \\
\hline 376 & 1/12/2008 15:23 & $8 / 12 / 200815: 23$ & 26.2 & 1039.2 \\
\hline 3767 & $1 / 12 / 200815: 25$ & $8 / 12 / 2008$ 15:25 & 26.2 & 1040.1 \\
\hline 3768 & \begin{tabular}{|l|}
$1 / 122200815: 27$ \\
\end{tabular} & $8 / 12 / 200815 \cdot 27$ & 26.1 & 1040.3 \\
\hline 3769 & 1/12/200815:20 & $8 / 12 / 200815: 20$ & 26.1 & 1041.4 \\
\hline $37 \pi 0$ & \begin{tabular}{|l|l|}
$1 / 12200815: 31$ \\
\end{tabular} & $8 / 12 / 200815: 31$ & 26.1 & 1040.6 \\
\hline 3771 & $1 / 12 / 200815: 33$ & $8 / 12 / 200815: 33$ & 26.1 & 1040.5 \\
\hline $37 / 2$ & \begin{tabular}{|l|}
$1 / 12 / 200815: 35$ \\
\end{tabular} & $8 / 12 / 200815: 35$ & 26 & 1041.2 \\
\hline 3773 & \begin{tabular}{|l|l|}
$1 / 12 / 200815: 37$ \\
\end{tabular} & $8 / 12 / 2008$ 15:37 & 26 & 1041.3 \\
\hline 3774 & $1 / 12 / 200815: 39$ & $8 / 12 / 200815: 39$ & 26. & 1041.7 \\
\hline 3775 & \begin{tabular}{|l|l|}
$1 / 12200815: 41$ \\
\end{tabular} & $8 / 12 / 2008$ 15:44 & 26 & 1040.9 \\
\hline $37 / 6$ & $1 / 12 / 200815: 43$ & $8 / 127200815: 43$ & 26 & 1041 \\
\hline $3 \pi m$ & $1 / 12 / 200815: 45$ & $8 / 127200815: 45$ & 26 & 1040.4 \\
\hline 3778 & 1/12/2008 15:47 & $8 / 12 / 2008$ १5:47 & 26.1 & 1040.1 \\
\hline 3779 & $1 / 12 / 200815: 49$ & $8 / 12 / 2008$ 15:49 & 26.6 & 1037.3 \\
\hline 3780 & $1 / 12 / 200815: 51$ & $8 / 12 / 2008$ 15:51 & 26.5 & 1034.4 \\
\hline 3781 & $1 / 12 / 200815: 53$ & $8 / 12 / 2008+5: 53$ & 26.4 & 1035.8 \\
\hline 3782 & $1 / 12 / 200815: 56$ & $8 / 12 / 2006$ 15:55 & 26.4 & 10326 \\
\hline 3783 & $1 / 12 / 200815: 57$ & $8 / 12 / 2008$ 15:57 & 26.3 & 1033.2 \\
\hline 3784 & $1 / 12 / 200015: 59$ & $8 / 12 / 2008$ 15:59 & 26.3 & 10326 \\
\hline 3785 & 1/12/2008 16:01 & $8 / 12 / 2008$ 16:01 & 26.2 & 10327 \\
\hline 3786 & $1 / 12 / 200816003$ & $8 / 12 / 2008$ 16:03 & 26.2 & 1032 \\
\hline 3787 & $1 / 12 / 2008$ 16:05 & $8 / 12 / 200816: 05$ & 26.2 & 1029.9 \\
\hline 3788 & 1/12/2008 16:07 & $8 / 12 / 200816: 07$ & 26.1 & 1030.5 \\
\hline 3789 & 1/12/2008 16:09 & $8 / 12 / 2008$ 16:09 & 26.1 & 1029.2 \\
\hline 3790 & $\mid 1 / 12 / 200816: 11$ & $8 / 12 / 2008$ 16:11 & 26.1 & 1030.3 \\
\hline 3791 & 1/12/2008 16:13 & $8 / 12 / 200816: 13$ & 26 & 1029.6 \\
\hline 3792 & 1/12/2008 16:15 & $8 / 12 / 200816: 15$ & 26 & 1029.9 \\
\hline 3793 & $1 / 12 / 200816: 17$ & $8 / 12 / 2008$ 16:17 & 25.9 & 1030.5 \\
\hline & 1/12/2008 16:19 & 8/12/2008 16:19 & 25.9 & \\
\hline
\end{tabular}

\begin{tabular}{|c|c|c|c|c|}
\hline \multicolumn{5}{|c|}{ D4-93c } \\
\hline $\operatorname{Roc}$ & & Agusted & Temp & $\mathrm{SC}$ \\
\hline$\#$ & Date/Time & DeterTime & $\propto$ & $\mu \mathrm{s} / \mathrm{m}$ \\
\hline 3796 & $1 / 12 / 20081621$ & $8 / 122200816: 21$ & 25.8 & 1030.2 \\
\hline 3796 & $1 / 12 / 200816.23$ & $8 / 12 / 200816: 23$ & 25.8 & 1029.4 \\
\hline 3797 & $1 / 12 / 20081625$ & $8 / 12 / 200816: 25$ & 25.7 & 1029.7 \\
\hline 3798 & 1/12/2008 16.27 & $8 / 122200816: 27$ & 25.7 & 1030.2 \\
\hline 3799 & 1/12/2008 1620 & $8 / 122200816: 29$ & 25.7 & 1030.5 \\
\hline 3800 & 1/12/2008 16:31 & $8 / 122200816: 31$ & 25.7 & 1030.2 \\
\hline 3801 & $1 / 12 / 200816: 33$ & $8 / 12200816: 33$ & 25.9 & 1023.5 \\
\hline 3802 & $1 / 12 / 200816.35$ & $8 / 12200816: 35$ & 25.9 & 1020.8 \\
\hline 3803 & 1/12/2008 16:37 & $8 / 12 / 200816: 37$ & 26 & 1017.3 \\
\hline 3804 & 1/12/2008 16:39 & $8 / 12200816: 39$ & 26.1 & 1014.1 \\
\hline 3805 & $1 / 12 / 200816: 41$ & $8 / 12200816: 41$ & 26.1 & 1010 \\
\hline 3906 & $1 / 12 / 200816: 43$ & $8 / 12 / 200816: 43$ & 26.2 & 1005.4 \\
\hline 3807 & $1 / 12 / 200816: 45$ & $8 / 12200016: 45$ & 26.2 & 1003.4 \\
\hline 3808 & $1 / 12 / 20081647$ & $8 / 12 / 200816: 47$ & 26.3 & 1003.1 \\
\hline 3800 & $1 / 12 / 20081649$ & $8 / 12 / 200816: 49$ & 26.3 & 1001.8 \\
\hline 3810 & $1 / 12 / 200816: 51$ & $8 / 12 / 200816: 51$ & 26.3 & 10024 \\
\hline 3811 & $1 / 122000816.53$ & $8 / 12 / 200816: 53$ & 26.3 & 1000.5 \\
\hline 3812 & $1 / 12 / 200816.55$ & $8 / 12 / 200816: 56$ & 26.3 & 1000.2 \\
\hline 3813 & 1/12/2008 16.57 & $8 / 12 / 2008$ 16:57 & 26.3 & 999.6 \\
\hline 3814 & $1 / 12 / 200816.59$ & $8 / 12 / 200816: 59$ & 26.3 & 999.2 \\
\hline 3815 & 1/12/2008 17:01 & $8 / 12 / 2008$ 17:01 & 26.3 & 99.1 \\
\hline 3816 & 1/12/2008 17:03 & $8 / 12 / 200817: 03$ & 26.3 & 996.7 \\
\hline 3817 & 1/12/2008 17:06 & $8 / 121200817: 06$ & 26.4 & 997.3 \\
\hline 3818 & $1 / 12 / 2008$ 17:07 & $8 / 12 / 200817: 07$ & 26.4 & 996.1 \\
\hline 3819 & $1 / 12 / 200817: 09$ & $8 / 12 / 2008$ 17:09 & 26.4 & 995.5 \\
\hline 3820 & 1/12/2008 17:11 & $8 / 12 / 2008$ 17:11 & 26.4 & 996.6 \\
\hline 3821 & 1/12/2008 17:13 & $8 / 12 / 2008$ 17:13 & 26.4 & 994.9 \\
\hline 3822 & 1/12/2008 17:15 & $8 / 12 / 2008$ 17:15 & 26.4 & 994.4 \\
\hline 3823 & 1/12/2008 17:17 & $8 / 1220008$ 17:17 & 26.4 & 993.5 \\
\hline 3824 & 1/12/2008 17:19 & $8 / 12 / 2008$ 17:19 & 26.4 & 991.1 \\
\hline 3825 & $1 / 12 / 200817: 21$ & $8 / 12 / 2008$ 17:21 & 26.4 & 991 \\
\hline 3826 & 1/12/2008 17:23 & $8 / 12 / 200817: 23$ & 26.4 & 990.4 \\
\hline 3827 & 1/12/2008 17:25 & $8 / 12 / 200817: 25$ & 26.4 & 9922 \\
\hline 3828 & $1 / 1222008$ 17:27 & $8 / 12 / 200817: 27$ & 26.4 & 991.1 \\
\hline 3829 & $1 / 12 / 200817: 29$ & $8 / 12 / 200817: 29$ & 26.4 & 991.4 \\
\hline 3830 & 1/1222008 17:31 & $8 / 122008$ 17:31 & 26.4 & 991.2 \\
\hline 3831 & $1 / 12 / 200817: 33$ & $8 / 12 / 2008$ 17:33 & 26.5 & 990.7 \\
\hline 3832 & $1 / 122200817: 35$ & $8 / 12 / 2008$ 17:35 & 26.5 & 990.4 \\
\hline 3833 & $1 / 12 / 2008$ 17:37 & $8 / 12 / 200817: 37$ & 26.5 & 969.5 \\
\hline 3834 & $1 / 12 / 200817: 39$ & $8 / 12200817: 39$ & 26.5 & 969.9 \\
\hline 3835 & $1 / 1222008$ 17:41 & $8 / 122000817: 41$ & 26.5 & 969.5 \\
\hline 3836 & $1 / 1222008$ 17:43 & $8 / 12 / 2008$ 17:43 & 26.5 & 969.7 \\
\hline 3837 & $1 / 12 / 2008$ 17:45 & $8 / 12 / 200817: 45$ & 26.5 & 969.5 \\
\hline 3838 & $1 / 12 / 200817: 47$ & $8 / 12 / 200817: 47$ & 26.5 & 989.5 \\
\hline 3839 & $1 / 12 / 200817: 49$ & $8 / 12 / 2008$ 17:49 & 26.5 & 988.4 \\
\hline 3840 & $1 / 12 / 200817: 51$ & $8 / 12 / 2008$ 17:51 & 26.5 & 968.9 \\
\hline 3841 & $1 / 12 / 200817: 53$ & $8 / 12 / 2008$ 17:53 & 26.5 & 968.1 \\
\hline 3842 & $1 / 12 / 2008$ 17:56 & $8 / 12 / 2008$ 17:56 & 26.5 & 987.8 \\
\hline 3843 & 1/12/2008 17:57 & $8 / 12 / 2008$ 17:57 & 26.5 & 968.3 \\
\hline 3844 & $1 / 12 / 200817: 59$ & $8 / 12 / 200817: 59$ & 26.5 & 987.8 \\
\hline 3845 & $1 / 12 / 20081801$ & $8 / 12 / 2008$ 18:01 & 26.5 & 987.2 \\
\hline 3846 & $1 / 12 / 20081803$ & $8 / 122000818: 03$ & 26.6 & 968.1 \\
\hline 3847 & $1 / 12 / 20081805$ & $8 / 12 / 200818: 06$ & 26.8 & 987.3 \\
\hline 3848 & $1 / 122200818: 07$ & $8 / 12 / 200818: 07$ & 26.8 & 963.7 \\
\hline 3849 & $1 / 12 / 200818: 09$ & $8 / 12 / 200818: 09$ & 26.7 & 906.3 \\
\hline 3850 & $1 / 12 / 200818: 11$ & $8 / 12 / 2008$ 18:11 & 26.7 & 906.3 \\
\hline 3851 & $1 / 12 / 200818: 13$ & $8 / 12 / 200818: 13$ & 26.6 & 966.9 \\
\hline 3852 & $1 / 12 / 200818 \cdot 15$ & $8 / 12 / 200818: 15$ & 26.5 & 966.1 \\
\hline 3853 & $1 / 12 / 200818: 17$ & $8 / 1220008$ 18:17 & 26.4 & 987.5 \\
\hline 3854 & $1 / 12 / 200818: 19$ & $8 / 12 / 200818: 19$ & 26.5 & 987.3 \\
\hline 3855 & $1 / 12 / 200818.21$ & $8 / 12 / 200818: 21$ & 26.3 & 968.6 \\
\hline 3856 & $1 / 12 / 200818: 23$ & $8 / 12 / 200818: 23$ & 26.3 & 987.3 \\
\hline 3857 & $1 / 12 / 200818.25$ & $8 / 121200818: 25$ & 26.3 & 966.3 \\
\hline 3858 & $1 / 12 / 20081827$ & $8 / 12200818: 27$ & 26.3 & 987.9 \\
\hline 3859 & $1 / 122000818.29$ & $8 / 12 / 200818: 29$ & 26.3 & 988 \\
\hline 3860 & 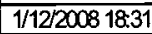 & $8 / 12 / 2008$ 18:31 & 26.2 & 968.1 \\
\hline 3861 & \begin{tabular}{|l}
$1 / 12200818: 33$ \\
\end{tabular} & $8 / 12200818: 33$ & 26.2 & 987.7 \\
\hline 3962 & $1 / 12 / 20081835$ & $8 / 12 / 200818: 35$ & 26.1 & 969.8 \\
\hline 3863 & $1 / 12 / 20081837$ & $8 / 12 / 200818: 37$ & & 969.4 \\
\hline
\end{tabular}

\begin{tabular}{|c|c|c|c|c|}
\hline \multicolumn{5}{|c|}{ D493c } \\
\hline $\operatorname{Rec}$ & & Adusted & Temp & $S C$ \\
\hline$\#$ & Date/Time & Date/Time & $\alpha$ & $\mu \mathrm{sicm}$ \\
\hline 3864 & $1 / 12 / 200818: 39$ & $8 / 12 / 200818.39$ & 26 & \\
\hline 860 & $1 / 12 / 200818: 41$ & $8 / 12 / 200818: 41$ & 25.9 & 991 \\
\hline 3866 & $1 / 12 / 200818: 43$ & \begin{tabular}{|l|l|}
$/ 12 / 200818: 43$ \\
\end{tabular} & 25.8 & 991 \\
\hline 3867 & $1 / 12 / 200818: 45$ & $8 / 12 / 200818: 45$ & 25.8 & \\
\hline 3968 & $1 / 12 / 200818: 47$ & $8 / 12 / 200818: 47$ & 25.7 & \\
\hline 369 & $1 / 12 / 200818: 49$ & $8 / 12 / 200818: 49$ & 25.9 & 998 \\
\hline 3870 & $1 / 12 / 200818.51$ & $8 / 12 / 200818.51$ & 26.2 & 992 \\
\hline 3871 & & \begin{tabular}{|c|}
$8 / 12 / 200818: 53$ \\
\end{tabular} & 26.3 & \\
\hline 3872 & $1 / 12 / 200818: 55$ & \begin{tabular}{|c|}
$8 / 12 / 200818: 55$ \\
\end{tabular} & 26.2 & \\
\hline 3873 & $1 / 12 / 200818: 5$ & $8 / 12 / 200818: 57$ & 26.1 & 985. \\
\hline 3874 & $1 / 12 / 200$ & $8 / 12 / 200818: 50$ & 26.1 & 980 \\
\hline 3875 & $1 / 12 / 200$ & $8 / 12 / 200$ & 26 & \\
\hline 3876 & $1 / 12 / 20$ & $8 / 12 / 200019: 03$ & 25.9 & \\
\hline 3877 & $1 / 12 / 20$ & $8 / 12 / 200819.05$ & 25.9 & 989. \\
\hline 3878 & $1 / 12 / 20$ & $8 / 12 / 200$ & 25.8 & \\
\hline 3879 & $1 / 12 / 20$ & $8 / 12 / 200819.09$ & 25.7 & 980 \\
\hline 3880 & 1/12/2008 19:11 & $8 / \nmid 2 / 2008$ 19:11 & 25.7 & 990. \\
\hline 3881 & $1 / 12 / 20$ & $8 / 12 / 20$ & 25.9 & 990. \\
\hline 3882 & $1 / 12 / 20$ & $8 / 12 / 20$ & 25.9 & \\
\hline 3883 & $1 / 12 / 2$ & $8 / 12 / 200819: 17$ & 26 & 990. \\
\hline 3884 & $1 / 12 / 2$ & $8 / 12 / 20$ & 26.1 & 989. \\
\hline 3880 & $1 / 12 / 2$ & $8 / 12 / 20$ & 26.2 & 989 \\
\hline 3806 & $1 / 12 / 2$ & $8 / 12 / 20$ & 26.2 & \\
\hline 3887 & $1 / 12 / 2$ & $8 / 12 / 20$ & 26.2 & 988 \\
\hline 3888 & $1 / 12 / 2$ & $8 / 12 / 20$ & 26.3 & 989 \\
\hline 3889 & $1 / 12 / 2$ & $8 / 12 / 2$ & 26. & 988 \\
\hline 3890 & $1 / 12 / 2$ & $8 / 12 / 20$ & 26.3 & 991. \\
\hline 3891 & $1 / 12 /$ & $8 / 12 / 2$ & 26.2 & 991. \\
\hline 3892 & $1 / 12 / 20$ & $8 / 12 / 200819.35$ & 26.3 & 9 \\
\hline 3896 & $1 / 12 / 20$ & $8 / 12 / 200819.37$ & 26.3 & 991. \\
\hline 3894 & $1 / 12 /$ & $8 / 12 / 2$ & 26.3 & 994 \\
\hline 3896 & $1 / 12 / 2$ & $8 / 12 / 2$ & 26.4 & 996 \\
\hline 3896 & & $8 / 12 / 2$ & 26.4 & 99 \\
\hline 3897 & $1 / 12$ & $8 / 12 / 2$ & 26.4 & 996 \\
\hline 3898 & $1 / 12 /$ & $8112 / 2$ & 26. & 998 \\
\hline 3899 & $1 / 12$ & $8 / 12 / 2$ & 26. & 100 \\
\hline 3900 & & $8 / 12 / 2$ & 26.5 & \\
\hline 3901 & 12 & $8 / 12 / 2$ & 26.5 & 1000 \\
\hline 3902 & $1 / 12 /$ & $8 / 12 / 2$ & 26. & 1001 \\
\hline 3903 & & $8 / 12 / 2$ & 26.5 & 100 \\
\hline 3904 & & $8 / 12 / 2$ & 27.1 & 1021 \\
\hline 3906 & $12 \pi$ & $8 / 12 / 2$ & 27. & 1010 \\
\hline 3906 & & $8 / 12 / 2$ & 26. & 100 \\
\hline 3907 & & $8 / 12 / 2$ & 26.8 & 1002 \\
\hline 3908 & $1 / 12$ & $1 / 12 / 2$ & 26 & 1005 \\
\hline 3900 & & $8 / 12 / 2$ & 26.7 & 1006. \\
\hline 3910 & & $8 / 12 / 2$ & 26.7 & 1004 \\
\hline 3911 & $\overline{12 \pi}$ & $8 / 12 / 2$ & 26. & 1903 \\
\hline 3912 & & $8 / 12 / 2$ & 26.6 & 9000.8 \\
\hline 3913 & & & 26. & \\
\hline 3914 & & $8 / 12 / 2$ & 26. & \\
\hline 3915 & & $8 / 12 / 2$ & 26.5 & 1021. \\
\hline 3916 & & & 27.5 & 1015 \\
\hline 3917 & & & 27. & \\
\hline 3918 & & $20: 27$ & 27.3 & 1011. \\
\hline 3919 & & $8 / 12 / 20$ & 27.2 & 10 \\
\hline 3920 & & & 27.2 & \\
\hline 3921 & & $8 / 12 / 2$ & 27. & \\
\hline 3922 & $1 / 12 / 2$ & $8 / 12 / 20$ & 27.1 & 10 \\
\hline 3923 & & & 27 & \\
\hline 3924 & & & 26.9 & \\
\hline 3925 & $1 / 12 / 2$ & $8 / 12 / 200$ & 26.8 & 7000 \\
\hline 3926 & & $8 / 12 / 20$ & 26.8 & \\
\hline 3927 & & & 26. & \\
\hline 3928 & & $8 / 12 / 200820: 47$ & 26.7 & Twor \\
\hline 3929 & & $8 / 12 / 200820: 49$ & 26.7 & \\
\hline 3930 & & $8 / 12 / 200820: 51$ & 26.6 & \\
\hline & & & 26.7 & \\
\hline & AWO 4.50 & 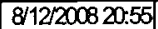 & 26.7 & \\
\hline
\end{tabular}




\begin{tabular}{|c|c|c|c|c|}
\hline \multicolumn{5}{|c|}{$D 4-93 c$} \\
\hline $\mathrm{REC}$ & & Adusted & Temp & $S C$ \\
\hline$\#$ & Dete/Time & \begin{tabular}{|l|} 
DeterTime \\
\end{tabular} & $\infty$ & $\mu \mathrm{S} / \mathrm{cm}$ \\
\hline 3933 & $1 / 12 / 200820.5$ & $8 / 12 / 200820.5$ & 26.8 & 1004 \\
\hline 3934 & $1 / 12 / 200820.59$ & $8 / 12 / 200820.50$ & 26.8 & 1004.1 \\
\hline 3035 & 1/12/200821:01 & $8 / 12 / 200821: 01$ & 26.9 & 1004.5 \\
\hline 3936 & 1/12/200821:03 & $8 / 12 / 200821: 03$ & 27 & 1004 \\
\hline 3937 & 1/12/200821:06 & $8 / 12 / 200821: 06$ & 27 & 1003 \\
\hline 3938 & 1/122000821:07 & $8 / 12200821: 07$ & 27 & 1000.1 \\
\hline 3909 & $1 / 12200821: 09$ & $8112200821: 09$ & 2रा & 1004.3 \\
\hline 3940 & 1/12/200821:11 & $8 / 12 / 200821: 11$ & 27 & 1003.9 \\
\hline 3941 & 1/122200821:13 & $8 / 12 / 200821: 13$ & 27.1 & 1004 \\
\hline 3942 & 1/12/200821:15 & $8 / 12 / 200821: 15$ & 27 & 1005.6 \\
\hline 3943 & 1/12/200821:17 & $8 / 12 / 200821: 17$ & 27 & 1004.8 \\
\hline 3944 & 1/12/200821:19 & $8 / 12 / 200821: 19$ & 27 & 1006.1 \\
\hline 3946 & 1/12/200821:21 & $8 / 12 / 200821: 21$ & 27 & 1006.7 \\
\hline 3946 & $1 / 12 / 200821: 23$ & $8 / 12 / 200821: 23$ & 27 & 1007.1 \\
\hline 3947 & $1 / 12200021: 25$ & $8 / 12 / 200821: 25$ & 2ता & 1008.2 \\
\hline 3948 & $1 / 12 / 200821: 27$ & $8 / 12200821: 27$ & 27) & 1009.6 \\
\hline 3949 & $1 / 12200021: 29$ & $8 / 12 / 200821: 20$ & 27- & 1011.1 \\
\hline 3050 & $1 / 12200821: 31$ & $8 / 12 / 200821: 31$ & 27 & 1010.8 \\
\hline 3951 & $1 / 12 / 200821: 33$ & $8 / 122000821: 33$ & 27 & 1010.4 \\
\hline 3952 & 1/12/200821:35 & $8 / 12 / 200821: 35$ & 27 & 1010.5 \\
\hline 3953 & 1/12/200821:37 & $8 / 122000821: 37$ & 27 & 10121 \\
\hline 3964 & 1/12/200821:39 & $8 / 12 / 200821: 39$ & 27.2 & 1008.2 \\
\hline 3956 & $1 / 12200821: 41$ & $8 / 12200821: 41$ & 27.1 & 1001.8 \\
\hline 3956 & $1 / 12200821: 43$ & $8 / 12200821: 43$ & 26.9 & 1004 \\
\hline 3957 & $1 / 12 / 200821: 45$ & $8 / 12 / 200821: 45$ & 27 & 1000.9 \\
\hline 3968 & 1/12200821:47 & $8 / 12200821: 47$ & 26.9 & 997.5 \\
\hline 3950 & $1 / 12200821: 49$ & $8 / 12 / 200821: 49$ & 26.8 & 997.5 \\
\hline 3960 & $1 / 12 / 200821: 51$ & $8 / 12200821: 51$ & 26.7 & 998.2 \\
\hline 3961 & $1 / 12200021: 53$ & $8 / 122000821: 53$ & 26.7 & 997.1 \\
\hline 3962 & $1 / 12 / 200821: 56$ & $8 / 12200821: 55$ & 26.6 & 998.3 \\
\hline 3963 & $1 / 12 / 200821: 57$ & $8 / 121200021: 57$ & 26.5 & 998.3 \\
\hline 3964 & $1 / 12 / 200821: 50$ & $8 / 12200021: 50$ & 26.4 & 998.9 \\
\hline 3965 & $1 / 12 / 20082201$ & $8 / 1220082201$ & 26.3 & 997 \\
\hline 3966 & $1 / 12 / 20082203$ & $8 / 12 / 200822: 03$ & 26.2 & 995.4 \\
\hline 3967 & $1 / 12 / 200082205$ & $8 / 12200022205$ & 26.3 & 997.3 \\
\hline 3968 & $1 / 12 / 20082207$ & $8 / 1220002207$ & 26.4 & 997.8 \\
\hline 3969 & $1 / 12 / 20082200$ & $8 / 12220082200$ & 26.5 & 998.6 \\
\hline 3970 & $1 / 12 / 20082211$ & $8 / 12200082211$ & 26.6 & 995.5 \\
\hline 3971 & $1 / 12 / 200822113$ & $8 / 12200822: 13$ & 26.6 & 993.3 \\
\hline 3972 & $1 / 12 / 20082215$ & $8 / 12200022115$ & 26.6 & 9926 \\
\hline 3973 & $1 / 12 / 200822: 17$ & $8 / 12 / 20082217$ & 26.6 & 993.1 \\
\hline 3974 & $1 / 12 / 200022219$ & $8 / 12200822: 19$ & 26.6 & 995 \\
\hline 3975 & $1 / 12 / 20082221$ & $8 / 1220002221$ & 26.6 & 995.3 \\
\hline 3976 & $1 / 1220082223$ & $8 / 12200082223$ & 26.6 & 997.2 \\
\hline 3977 & $1 / 1220082225$ & $8 / 12200082225$ & 26.7 & 998.4 \\
\hline 3978 & $1 / 12200082227$ & $8 / 12 / 20082227$ & 26.7 & 997.8 \\
\hline 3970 & $1 / 1220082220$ & $8 / 12120082229$ & 26.7 & 998.4 \\
\hline 3980 & $1 / 12 / 20082231$ & $8 / 12 / 200022231$ & 26.7 & 998.7 \\
\hline 3981 & $1 / 12200082233$ & $8 / 12 / 20082233$ & 26.7 & 999.7 \\
\hline 3982 & $1 / 12 / 20082235$ & $8 / 1220082235$ & 26.8 & 10023 \\
\hline 3983 & $1 / 12 / 200822: 37$ & $8 / 1220082237$ & 26.8 & 1002.3 \\
\hline 3984 & $1 / 12 / 20082230$ & $8 / 12 / 20082239$ & 26.8 & 1002.2 \\
\hline 3985 & $1 / 12 / 20082241$ & $8 / 1220082241$ & 26.8 & 1003.1 \\
\hline 3986 & $1 / 1220082243$ & $8 / 12 / 20082243$ & 26.8 & 1004.1 \\
\hline 3987 & $1 / 1220082245$ & $8 / 12 / 20082245$ & 26.8 & 1004.5 \\
\hline 3988 & $1 / 12 / 20082247$ & $8 / 1220082247$ & 26.8 & 1006.7 \\
\hline 3989 & $1 / 1220082249$ & $8 / 12 / 200822449$ & 26.8 & 1007.6 \\
\hline 3990 & $1 / 12 / 20082251$ & $812 / 20082251$ & 26.8 & 1009.9 \\
\hline 3991 & $1 / 12220082253$ & $8 / 12 / 20082253$ & 26.8 & 1007.9 \\
\hline 3992 & $1 / 12 / 200022255$ & $8 / 12 / 20082255$ & 26.8 & 1011.3 \\
\hline 3993 & $1 / 12200082257$ & $8 / 122008225$ & 26.8 & 10121 \\
\hline 3994 & $1 / 12 / 20082250$ & $8 / 12 / 20082259$ & 26.9 & 1013.8 \\
\hline 390 & $1 / 12 / 200823: 01$ & $8 / 12 / 200823: 01$ & 26.9 & 1014.8 \\
\hline 3996 & $1 / 12 / 200823: 03$ & $8 / 12 / 200823: 03$ & 26.9 & 1015.2 \\
\hline 3997 & $1 / 12 / 200823: 05$ & $8 / 12200823: 05$ & 26.9 & 1014.8 \\
\hline 3998 & $1 / 12 / 200823: 07$ & $8 / 12 / 200823: 07$ & 26.9 & 1016.2 \\
\hline 3999 & $1 / 12 / 200823: 00$ & $8 / 12 / 200823: 09$ & 26.9 & 1018.7 \\
\hline 4000 & 1/12/200823:11 & $8 / 12 / 200823: 11$ & 26.9 & 1019.1 \\
\hline 4001 & $1 / 12 / 200823: 13$ & $8 / 12200823: 13$ & 27 & 1019.1 \\
\hline
\end{tabular}

\begin{tabular}{|c|c|c|c|c|}
\hline \multicolumn{5}{|c|}{$D 4.93 c$} \\
\hline Rec & & Adusted & Termp & $S C$ \\
\hline$\#$ & DaterTime & DaterTime & $\infty$ & $\mu \mathrm{s} / \mathrm{am}$ \\
\hline 4002 & 1/12/200823:15 & $8 / 12 / 200823: 15$ & 27 & 1020. \\
\hline 4003 & 1/12/200823:17 & $8 / 12200823: 17$ & 27 & 1021.8 \\
\hline 4004 & $1 / 12 / 200823: 19$ & $8 / 12 / 200823: 19$ & 27 & 1022 \\
\hline 4005 & $1 / 12 / 200823: 21$ & $8 / 12 / 200823: 21$ & 27 & 102 \\
\hline 4006 & $1 / 12 / 200823: 23$ & $8 / 122200823.23$ & 27 & \\
\hline 4007 & $1 / 12 / 200823: 25$ & $8 / 12 / 200823: 25$ & 27 & 1024 \\
\hline 4008 & $1 / 12 / 200823: 27$ & $8 / 12200823: 27$ & 27 & 1024 \\
\hline 4009 & $1 / 12200823: 29$ & $8 / 12200823: 20$ & 27 & 1025.8 \\
\hline 4010 & $1 / 12 / 200823: 31$ & $8 / 122000823: 31$ & 27 & 1025.7 \\
\hline 4011 & $1 / 12 / 200823: 33$ & $8 / 12200823: 33$ & 27.1 & 1025. \\
\hline 4012 & 1/12/200823:35 & $8 / 12 / 200823: 35$ & 27.1 & 1027 \\
\hline 4013 & $1 / 12 / 200823.37$ & 8/12/200823:37 & 27.1 & 102 \\
\hline 4014 & $1 / 12 / 200$ & $8 / 12 / 200823: 39$ & 27.1 & 1027. \\
\hline 4015 & $1 / 12 / 20$ & $8 / 12 / 200823.41$ & 27.1 & \\
\hline 4016 & $1 / 12 / 200823: 43$ & $8 / 12 / 200823: 43$ & 27.1 & 1027 \\
\hline 4017 & $1 / 12 / 200823: 45$ & $8 / 12 / 200823: 45$ & 27.1 & 1028. \\
\hline 4018 & $1 / 12 / 2$ & $8 / 12200$ & 27.1 & 1028. \\
\hline 4019 & $1 / 12 / 2$ & $8 / 12 / 20$ & 27.1 & \\
\hline 4020 & $1 / 12 / 2$ & $8 / 12 / 20$ & 27.1 & 1030 \\
\hline 4021 & $1 / 12 / 20$ & $8 / 12 / 20$ & 27.1 & 1030 \\
\hline 4002 & $1 / 12 / 2$ & $8 / 12 / 20$ & 27.1 & 7030 \\
\hline 4023 & $1 / 12 / 2$ & $8 / 12 / 20$ & 27.1 & \\
\hline 4024 & 1212 & $8 / 12 / 200$ & 27.1 & 1032 \\
\hline 4025 & $1 / 13$ & $8 / 13 / 2$ & 27.1 & 1032 \\
\hline 4026 & & $8 / 13 / 2$ & 27.1 & 10 \\
\hline 4027. & 0.05 & $8 / 13 / 2$ & 27.1 & \\
\hline 4028 & & $8 / 13 / 20$ & 27.2 & 1033 \\
\hline 4020 & & $8 / 13$ & 27.1 & 1035 \\
\hline 4030 & & $8 / 13 / 2$ & 27.1 & 1034 \\
\hline 4031 & & $8 / 13 / 2$ & 27.1 & 1034 \\
\hline 4032 & & $8 / 13 / 2$ & 27.1 & 1035 \\
\hline 4033 & & & 27.2 & 1035 \\
\hline 4034 & & & 27.1 & \\
\hline 40035 & & 0.21 & 27.5 & \\
\hline 4036 & & 23 & 27.4 & 1016 \\
\hline 4037 & & .25 & 27.3 & 1012 \\
\hline 4038 & & & 27.2 & 1010 \\
\hline 4039 & & & 27.2 & \\
\hline 4040 & & & 27.1 & 1006 \\
\hline 4041 & & & 27 & 10 \\
\hline 4042 & & & 26.9 & 1006 \\
\hline 4043 & & & 26.9 & \\
\hline 4044 & & & 26.9 & 1005 \\
\hline 4045 & & & 26.8 & 10 \\
\hline 4046 & & $8 / 13 / 2$ & 26.7 & 1000 \\
\hline 4047 & & & 26.7 & 1007 \\
\hline 4048 & & & 26.6 & 1007 \\
\hline 4049 & & & 26.6 & 1008 \\
\hline 4050 & & & 26.5 & 10 \\
\hline 251 & & & 26.4 & 1007 \\
\hline 4052 & & & 26.4 & 1007 \\
\hline 4053 & & & 26.3 & 1007 \\
\hline 4054 & & & 26.3 & \\
\hline 4065 & & & 26.2 & \\
\hline 4056 & & $31: 03$ & 26.2 & 1008 \\
\hline 4057 & & & 26.2 & 1008 \\
\hline & & & 26.2 & \\
\hline 4059 & & & 26.3 & \\
\hline 4060 & & & 26.4 & 1014 \\
\hline 4061 & & & 26.5 & \\
\hline & & & & \\
\hline 4063 & & & 26.7 & \\
\hline 4064 & $1: 19$ & $8 / 13 / 20081: 19$ & 26.8 & \\
\hline & & & 26.9 & \\
\hline & & & 26.9 & \\
\hline 4067 & $81: 2^{2}$ & $8 / 13 / 20081: 25$ & 27 & 7022 \\
\hline 068 & $1 / 13 / 2$ & $8 / 13 / 20081: 27$ & 27 & 1026 \\
\hline & & & 27 & \\
\hline & & & & \\
\hline
\end{tabular}

\begin{tabular}{|c|c|c|c|c|}
\hline \multicolumn{5}{|c|}{$D 493 c$} \\
\hline $\operatorname{ReC}$ & & Adusted & Termp & SC \\
\hline$\#$ & Deter/Time & Daterime & $\propto$ & $\mu \mathrm{S} / \mathrm{cm}$ \\
\hline 4071 & $1 / 13 / 20081: 33$ & $8 / 13 / 20081: 33$ & 27.1 & 1027.9 \\
\hline 4072 & $1 / 13 / 20081: 35$ & $8 / 13 / 20081: 35$ & 27.1 & 1028.1 \\
\hline 4073 & $1 / 13 / 2008$ 1:37 & $8 / 13 / 2008$ 1:37 & 27.1 & 1028.6 \\
\hline 4074 & $1 / 13 / 20081: 39$ & $8 / 13 / 20081: 39$ & 27.1 & 1008.3 \\
\hline 4075 & 1/13/2008 1:41 & $8 / 13 / 20081: 41$ & 27.1 & 1008.8 \\
\hline 4076 & $1 / 13 / 2008$ 1:43 & $8 / 13 / 2008$ 1:43 & 27.1 & 1028.4 \\
\hline 4077 & $1 / 13 / 20081: 45$ & $8 / 13 / 2008$ 1:45 & 27 & 1028.7 \\
\hline 4078 & $1 / 13 / 2008$ 1:47 & $8 / 13 / 2008+4: 47$ & 27 & 1029.3 \\
\hline 4079 & 1/13/2008 1:49 & $8 / 13 / 2008$ 1:40 & 27 & 1029.8 \\
\hline 4080 & $1 / 13 / 20081: 51$ & $8 / 13 / 2008$ 1:51 & 27 & 1029.4 \\
\hline 4081 & $1 / 13 / 20081: 53$ & $8 / 13 / 20061: 53$ & 27 & 1029.9 \\
\hline 4082 & $1 / 13 / 20081: 55$ & $8 / 13 / 200061: 55$ & 27 & 1002.5 \\
\hline 4083 & $1 / 13 / 200$ & $8 / 13 / 20081: 57$ & 27 & 1029.8 \\
\hline 4084 & $1 / 13 / 20$ & $8 / 13 / 20081: 59$ & 27 & 1030.3 \\
\hline 4085 & 1/13/20082:01 & \begin{tabular}{|l|l|}
$8 / 2008201$ \\
\end{tabular} & 27 & 1030.5 \\
\hline 4086 & $1 / 13 / 20082003$ & $8 / 13 / 20082: 03$ & 27 & 1030.6 \\
\hline 4087 & $1 / 13 / 2 x$ & $8 / 13 / 2008205$ & 27. & 1030.3 \\
\hline 4088 & $1 / 13 / 2$ & $8 / 13 / 2008207$ & 27 & 1030.2 \\
\hline 4089 & $1 / 13 / 20$ & $8 / 13 / 2008200$ & 27 & 1031 \\
\hline 4090 & $1 / 13 / 2$ & $8 / 13 / 2008211$ & 27 & 1030.6 \\
\hline 4091 & $1 / 13 / 2$ & $8 / 13 / 2008213$ & 27 & 1031.4 \\
\hline 4092 & $1 / 13 / 2$ & $8 / 13 / 2008215$ & 27 & 1031.7 \\
\hline 4093 & $1 / 13 / 2$ & $8 / 13 / 2008217$ & 27 & 1031.4 \\
\hline 4094 & $1 / 13 / 2$ & $8 / 13 / 200$ & 27 & 1032 \\
\hline 4095 & $1 / 13 / 20$ & 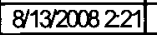 & 27 & 1031.6 \\
\hline 4096 & $1 / 13 / 2$ & $8 / 13 / 2008223$ & 27 & 1030.2 \\
\hline 4097 & $1 / 13 / 20$ & $8 / 13 / 2008225$ & 27 & 1030.7 \\
\hline 4098 & $1 / 13 / 2$ & $8 / 13 / 20$ & 27 & 1030.4 \\
\hline 4099 & $1 / 13 / 2$ & $8 / 13 / 2008220$ & 27 & 1032 \\
\hline 4100 & $1 / 13 / 2$ & $8 / 13 / 2008231$ & 27 & 1031.4 \\
\hline 4101 & $1 / 13 / 2$ & $8 / 13 / 200$ & 27 & 1031.8 \\
\hline 4102 & $1 / 13 / 2$ & $8 / 13 / 200$ & 27 & 10325 \\
\hline 4103 & $1 / 13 / 20$ & $8 / 13 / 20082237$ & 27 & 10321 \\
\hline 4104 & $1 / 13 / 20$ & $8 / 13 / 2008239$ & 27 & 100325 \\
\hline 4105 & $1 / 13 / 2$ & $8 / 13 / 20$ & 27 & 10323 \\
\hline 4106 & $1 / 13 / 20$ & $8 / 13 / 2008243$ & 27 & 10325 \\
\hline 4107 & $1 / 13 / 2$ & $8 / 13 / 2008245$ & 27 & 1033.7 \\
\hline 4108 & $1 / 13 / 2$ & $8 / 13 / 2008247$ & 27 & 10329 \\
\hline 4109 & $1 / 13 /$ & $8 / 13 / 20$ & 27 & 1033 \\
\hline 4110 & $1 / 13 / 2$ & $8 / 13 / 2008251$ & 27 & 1033.8 \\
\hline 4111 & $1 / 13 / 2$ & $8 / 13 / 2008253$ & 27 & 1031.4 \\
\hline 4112 & $1 / 13 / 2$ & $8 / 13 / 2008256$ & 27 & 1034.2 \\
\hline 4113 & $1 / 13 / 2$ & $8 / 13 / 2008257$ & 27 & 1034.2 \\
\hline 4114 & $1 / 13 / 20$ & $8 / 13 / 2008259$ & 27 & 1034.6 \\
\hline 4115 & $1 / 13 / 2$ & $8 / 13 / 20083: 01$ & 27 & 1035.2 \\
\hline 4116 & & $8 / 13 / 20$ & 27 & 1034.8 \\
\hline 4117 & $1 / 13 / 2$ & $8 / 13 / 20083: 05$ & 27 & 1034.8 \\
\hline 4118 & $1 / 13 / 20$ & $8 / 13 / 20083: 07 \mid$ & 27 & 1036.2 \\
\hline & & $8 / 13 / 20$ & 27 & 1035.5 \\
\hline 4120 & $1 / 13 / 2$ & $8 / 13 / 20083: 11$ & 27 & 1035.9 \\
\hline 4121 & $1 / 13 / 20$ & $8 / 13 / 20083: 13$ & 27 & 1036.1 \\
\hline 4122 & $1 / 13$ & $8 / 13 / 20083: 15$ & 27.1 & 1027.9 \\
\hline 4123 & & $8 / 13 / 20$ & 27 & 10284 \\
\hline 4124 & $1 / 13 / 20$ & 8/13/2008 3:19 & 26.8 & 1027.7 \\
\hline 4125 & 1/13/20083:21 & $8 / 13 / 20083: 21$ & 26.7 & 1026.4 \\
\hline 4126 & $1 / 13 / 2$ & $8 / 13 / 20083: 23$ & 26.7 & 1024.1 \\
\hline 4127 & $1 / 13 / 2$ & $8 / 13 / 20083: 25$ & 26.6 & 1023.2 \\
\hline 4128 & $1 / 13 / 2$ & $8 / 13 / 20083: 27$ & 26.5 & 10228 \\
\hline 4129 & 1/13/20083:20 & $8 / 13 / 20083: 29$ & 26.4 & 1023.1 \\
\hline 4130 & $1 / 13 / 2$ & $8 / 13 / 20083: 31$ & 26.4 & 10228 \\
\hline 4131 & & $8 / 13 / 20083: 33$ & 26.3 & 1023.1 \\
\hline 4132 & 883:35 & $8 / 13 / 20083: 36$ & 26.2 & 10227 \\
\hline 4133 & 083:37 & 8/13/20083:37 & 26.2 & 10221 \\
\hline 413 & $1 / 13 / 2$ & $8 / 13 / 20083: 39$ & 26.1 & 1023.4 \\
\hline & $1 / 13 / 2$ & $8 / 13 / 20083: 41$ & 26 & 1023 \\
\hline 4136 & $1 / 13 / 20083.43$ & $8 / 13 / 20083: 43$ & 26.1 & 1019.9 \\
\hline 4137 & 1/13/20083:45 & $8 / 13 / 20083: 45$ & 26.3 & 1018.7 \\
\hline 4138 & 1/13/20083:47 & $8 / 13 / 20083: 47$ & 26.3 & 1017.1 \\
\hline & & & 26.4 & \\
\hline
\end{tabular}




\begin{tabular}{|c|c|c|c|c|}
\hline \multicolumn{5}{|c|}{$D 493 c$} \\
\hline $\mathrm{Rec}$ & & Adusted & Temp & $\overline{S C}$ \\
\hline$\#$ & DaterTime & DaterTime & $\alpha$ & $\mu \mathrm{S} / \mathrm{am}$ \\
\hline 4140 & $1 / 13 / 20083551$ & $8 / 13 / 20083: 51$ & 26.5 & 1014.3 \\
\hline 4141 & $1 / 1320083: 53$ & $8 / 13 / 20083.53$ & 26.5 & 1013.3 \\
\hline 4142 & $1 / 13 / 20083: 56$ & $8 / 13 / 20083.55$ & 26.5 & 1013 \\
\hline 4143 & $1 / 13 / 20083: 57$ & $8 / 13 / 20083: 57$ & 26.5 & 1009.7 \\
\hline 4144 & $1 / 13 / 20083: 59$ & $8 / 13 / 20083: 59$ & 27 & 1006.7 \\
\hline 4145 & $1 / 13 / 20084: 01$ & \begin{tabular}{|l|}
$813 / 20084: 01$ \\
\end{tabular} & 27 & 1003.7 \\
\hline 4146 & $1 / 13 / 20084: 03$ & $8 / 13 / 20084: 03$ & 26.9 & 1003.9 \\
\hline 4147 & $1 / 1320084: 05$ & $8 / 13 / 20084: 05$ & 26.9 & 1003. \\
\hline 4148 & $1 / 13 / 20084: 07$ & $8 / 13 / 20084: 07$ & 26.9 & 1003.4 \\
\hline 4149 & $1 / 13 / 20084: 09$ & $8 / 13 / 20084: 09$ & 26.8 & 1003.8 \\
\hline 4150 & $1 / 13 / 20084: 11$ & $8 / 13 / 20084: 11$ & 26.8 & \\
\hline 4151 & $1 / 13 / 20084: 13$ & $8 / 13 / 20084: 13$ & 26.8 & 1001.5 \\
\hline 4152 & $1 / 13 / 20084: 15$ & $8 / 13 / 20084: 15$ & 26.7 & 999.5 \\
\hline 4153 & $1 / 13 / 20084: 17$ & $8 / 13 / 20084: 17$ & 26.6 & 1001.3 \\
\hline 4154 & 1/13/2008 4:19 & $8 / 13 / 20084: 19$ & 26.6 & \\
\hline 4155 & $1 / 13 / 20084: 21$ & $8 / 13 / 20084: 21$ & 26.5 & 10025 \\
\hline 4156 & $1 / 13 / 20084: 23$ & $8 / 13 / 20084: 23$ & 26.5 & 1003.3 \\
\hline 4157 & $1 / 13 / 20084: 25$ & $8 / 13 / 20084: 25$ & 26.4 & \\
\hline 4158 & $1 / 13 / 20084: 27$ & $8 / 13 / 20084: 27$ & 26.4 & 1003. \\
\hline 4159 & $1 / 13 / 20084: 29$ & $8 / 13 / 20084: 20$ & 26.3 & 1003.2 \\
\hline 4160 & $1 / 13 / 20084: 31$ & $8 / 13 / 2$ & 26.3 & 1003.9 \\
\hline 4161 & $1 / 13 / 20084: 33$ & $8 / 13 / 2$ & 26.3 & 1004. \\
\hline 4162 & $1 / 13 / 20084: 33$ & $8 / 13 / 20084: 35$ & 26.3 & 1004.7 \\
\hline 4163 & 1/13/20084:37 & $8 / 13 / 2$ & 26.3 & 1004.5 \\
\hline 4164 & $1 / 13 / 20084: 39$ & $8 / 13 / 2$ & 26.3 & 1006 . \\
\hline 4165 & $1 / 13 / 20084: 41$ & $8 / 13 / 2$ & 26.4 & 1007.4 \\
\hline 4166 & $1 / 13 / 20084: 43$ & $8 / 13 / 2$ & 26.4 & 1007 \\
\hline 4167 & $1 / 13 / 20084: 45$ & $8 / 13 / 2$ & 26.5 & 1006.7 \\
\hline 4168 & $1 / 13 / 20084: 47$ & $8113 / 2$ & 26.6 & 1004. \\
\hline 4169 & $1 / 13 / 20084: 49$ & $8 / 13 / 2$ & 26.6 & 1005.8 \\
\hline 4170 & \begin{tabular}{|c|}
$1 / 13 / 20084: 51$ \\
\end{tabular} & $8 / 13 / 2$ & 26.7 & 1004. \\
\hline 4171 & $1 / 13 / 20084: 53$ & $8 / 13 / 2$ & 26.7 & 1002 \\
\hline 4172 & $1 / 1320084: 55$ & 氞 $8113 / 20$ & 26.7 & 10027 \\
\hline 4173 & $1 / 13 / 200$ & $8 / 13$ & 26.7 & 1002 \\
\hline 4174 & $1 / 13 / 200$ & $8 / 13 / 2$ & 26.7 & 1001 . \\
\hline 4175 & $\begin{array}{l}1 / 13 / 2006 \\
\end{array}$ & 8/13/2008 5:01 & 26.7 & 1001.5 \\
\hline 4176 & $1 / 13 / 2008$ & $8 / 13$ & 26.7 & 1001.5 \\
\hline 4177 & $1 / 13 / 200$ & $8 / 13$ & 26.7 & 1000 . \\
\hline 4178 & $1 / 13 / 20085: 07$ & $8 / 13 / 2$ & 26.7 & 1001.2 \\
\hline 4179 & $1 / 13 / 20085: 09$ & $8 / 13 / 2$ & 26.7 & 1001.4 \\
\hline 4180 & $1 / 13 / 20$ & $8 / 13 / 2$ & 26.7 & 100 \\
\hline 4181 & $1 / 13 / 20085: 13$ & $8 / 13 / 2$ & 26.7 & 1001. \\
\hline 4182 & & $8 / 13 / 2$ & 26.7 & 1001. \\
\hline 4183 & & $8 / 13$ & 26.7 & 1000 . \\
\hline 4184 & $1 / 13 / 2$ & $8 / 13$ & 26.7 & 1001. \\
\hline 4185 & $5: 21$ & $8 / 13$ & 26.7 & 1001. \\
\hline & & & 26.7 & 1000. \\
\hline 4187 & $5: 25$ & $8 / 13 / 2$ & 26.7 & 1000. \\
\hline 4188 & $1 / 13 / 20$ & $8 / 13$ & 26.7 & 1000. \\
\hline 4189 & & & 26.7 & 1000. \\
\hline 4190 & & $8 / 13$ & 26.7 & 1000. \\
\hline 4191 & $1 / 13 / 20085: 33$ & $\begin{array}{ll}8 / 13 / 2 \\
\end{array}$ & 26.7 & 1001.5 \\
\hline 4192 & & & 26.7 & 1001. \\
\hline 4193 & & $8 / 13$ & 26.7 & 1000.7 \\
\hline 4194 & $1 / 13 / 20085: 39$ & $8 / 13 / 20085: 39$ & 26.7 & 1002.5 \\
\hline 4195 & & $8 / 13 / 20085: 41$ & 26.7 & 1001.1 \\
\hline 4196 & & & 26.7 & 999. \\
\hline 4197 & $1 / 13 / 20085445$ & $8 / 13 / 2$ & 26.7 & 999.1 \\
\hline 4198 & & $8 / 13 / 2$ & 26.7 & 999.2 \\
\hline 4199 & & & 26.7 & 1000.1 \\
\hline 4200 & 35.51 & $085: 51$ & 26.7 & 1000.5 \\
\hline 4201 & $1 / 13 / 200$ & $8 / 13 / 20085: 53$ & 26.7 & 1000.1 \\
\hline 4202 & & $8 / 13 / 20085: 56$ & 26.7 & 999. \\
\hline 4203 & & $8 / 13 / 20085: 57$ & 26.7 & 999. \\
\hline 4204 & $1 / 13 / 20085559$ & $8 / 13 / 20085: 50$ & 26.6 & 999 \\
\hline 4205 & 1/13/20086:01 & $8 / 13 / 20086: 01$ & 26.6 & 909.2 \\
\hline 4206 & & & 26.6 & 998.6 \\
\hline 4207 & 1/13/20086:05 & $8 / 13 / 20086: 06$ & 26.7 & 994.7 \\
\hline 4208 & $1 / 13 / 20086: 07$ & $8 / 13 / 20086: 07$ & 26.5 & 994. \\
\hline
\end{tabular}

\begin{tabular}{|c|c|c|c|c|}
\hline \multicolumn{5}{|c|}{ D493C } \\
\hline $\operatorname{ReC}$ & & Adjusted & Terpp & SC \\
\hline \# & Date-Time & DaterTime & $\alpha$ & $\mu \mathrm{S} / \mathrm{cm}$ \\
\hline 4209 & $1 / 13 / 20086: 09$ & $8 / 13 / 2008609$ & 26.5 & \\
\hline 4210 & $1 / 13 / 20086: 11$ & 8/13/20086:11 & 264 & 990.4 \\
\hline 4211 & 1/13/20086:13 & 8/13/20086:13 & 26.3 & 9926 \\
\hline 4212 & 1/13/20086:15 & $8 / 13 / 20086: 15$ & 26.3 & 969.7 \\
\hline 4213 & 1/13/20086:17 & $8 / 13 / 20086: 17$ & 26.3 & 991.1 \\
\hline 4214 & 1/13/20086:19 & $8 / 13 / 20086: 19$ & 26.2 & 9921 \\
\hline 4215 & 1/13/20086:21 & $8 / 13 / 20086: 21$ & 26.1 & 993.7 \\
\hline 4216 & $1 / 13 / 200$ & $8 / 13 / 20086: 23$ & 26.1 & 995.1 \\
\hline 4217 & 1/13/20086:25 & $8 / 13 / 20086: 25$ & 26 & 994.3 \\
\hline 4218 & $1 / 13 / 20086: 27$ & $8 / 13 / 20086: 27$ & 25.9 & 994.7 \\
\hline 4219 & $1 / 13 / 20$ & 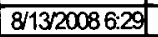 & 25.9 & 995.2 \\
\hline 4220 & $1 / 13 / 20$ & $8 / 13 / 20086: 31$ & 25.9 & 995.4 \\
\hline 4221 & $1 / 13 / 200$ & $8 / 13 / 20086: 33$ & 25.9 & 998 \\
\hline 4222 & $1 / 13 / 20$ & $8 / 13 / 20086: 35$ & 26 & 999.5 \\
\hline 4223 & $1 / 13 / 2$ & $8 / 13 / 20086: 37$ & 26.1 & \\
\hline 4224 & $1 / 13 / 2$ & $8 / 13 / 20086: 39$ & 26.2 & 1002 \\
\hline 4225 & $1 / 13 / 20$ & $8 / 13 / 20086: 41$ & 26.2 & 10027 \\
\hline 4226 & $1 / 13 / 2$ & $8 / 13 / 20086: 43$ & 26.2 & 10027 \\
\hline 4227 & $1 / 13 / 2$ & $8 / 13 / 20086: 45$ & 26.3 & \\
\hline 4228 & $1 / 13 / x$ & $8 / 13 / 20086: 47$ & 26.3 & 1005 \\
\hline 4229 & $1 / 13 / 2$ & $8 / 13 / 20086: 49$ & 26.3 & 1006 . \\
\hline 4230 & $1 / 13 / 2$ & $8 / 13 / 20086: 51$ & 26.3 & 1007 \\
\hline 4231 & $1 / 13 / 2$ & $8 / 13 / 20086: 53$ & 26.3 & 1008. \\
\hline 4232 & $1 / 13 / 2$ & $8 / 13 / 20086: 55$ & 26.2 & 1007. \\
\hline 4233 & t/13kt & $8 / 13 / 20$ & 26.3 & 1008 \\
\hline 4234 & $1 / 13 / 2$ & $8 / 13 / 200$ & 26.3 & $100 \%$. \\
\hline 4235 & $1 / 13 / 2$ & \begin{tabular}{|l|}
$8 / 13 / 20087: 01$ \\
\end{tabular} & 26.3 & 1008. \\
\hline 4236 & $1 / 13 / 2$ & $8 / 13 / 20$ & 26.3 & 1010. \\
\hline 4237 & $1 / 13 / 2$ & $8 / 13 / 200$ & 26.3 & 1010. \\
\hline 4238 & $1 / 13 / 2$ & $8 / 13 / 200$ & 26.3 & 4011. \\
\hline 4239 & $1 / 13 /$ & $8 / 13 / 20$ & 26.3 & 101 \\
\hline 4240 & $1 / 13 / 2$ & $8 / 13 / 20$ & 26.3 & 1012 \\
\hline 4241 & $1 / 13$ & $8 / 13 / 200$ & 26.3 & 1013. \\
\hline 4242 & & $8 / 13200$ & 26.3 & 1013. \\
\hline 4243 & $1 / 13$ & $8 / 13$ & 26.3 & 1014. \\
\hline 4244 & $1 / 13$ & $8 / 13 / 2$ & 26.3 & 101 \\
\hline 4245 & & $8 / 13 / 20$ & 26.3 & 1016. \\
\hline 4246 & & & 26.3 & \\
\hline 4247 & & $8 / 13 / 20$ & 26.3 & \\
\hline 4248 & & $8 / 13 / 20087: 27$ & 26.4 & 1018. \\
\hline 4249 & & $8 / 13 / 2$ & 26.4 & \\
\hline 4250 & & $8 / 13 / 2$ & 264 & 1019 . \\
\hline 4251 & & $8 / 13 / 20$ & 26.4 & 102 \\
\hline 4252 & & & 26.4 & 1019. \\
\hline 4253 & & $8 / 13 / 2$ & 26. & \\
\hline 4254 & & $8 / 13 / 2$ & 26. & 102 \\
\hline 4255 & & & 26. & 1021. \\
\hline 4256 & & $8 / 13$ & 26 . & \\
\hline 4257 & & $8 / 13 / 20$ & 26.3 & \\
\hline 4258 & & & 26.3 & \\
\hline (n) & & $8 / 13 / 20$ & 26.3 & \\
\hline 4260 & & $8 / 13 / 20$ & 26. & \\
\hline 4261 & & & 26.3 & \\
\hline & & & 26.4 & \\
\hline 4263 & & $8 / 13 / 20$ & 26 & \\
\hline 4264 & & $8 / 13 / 20087: 59$ & 26.4 & \\
\hline 4265 & & & 26.4 & \\
\hline 426 & & $8 / 13 / 20$ & 26 & \\
\hline 4267 & & $8 / 13 / 20$ & 26.4 & $10<0$ \\
\hline 4268 & & & 26.4 & \\
\hline 4269 & & & 26 . & \\
\hline 4270 & & $8 / 13 / 200$ & 26.4 & 1025. \\
\hline 4271 & & & 26.4 & \\
\hline 4272 & & & 26.4 & \\
\hline 4273 & & 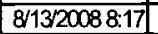 & 26.4 & \\
\hline 4274 & & $8 / 13 / 20088: 19$ & 26.4 & \\
\hline 4275 & & & 26.4 & \\
\hline 4276 & & & 26.4 & \\
\hline 427 & $1 / 73 / 20088.20$ & $8 / 73 / 20088.25$ & 20.4 & IU⿺辶. \\
\hline
\end{tabular}

\begin{tabular}{|c|c|c|c|c|}
\hline \multicolumn{5}{|c|}{ D4-93c } \\
\hline $\operatorname{Rec}$ & & Adiusted & Temp & SC \\
\hline \# & Date/Time & Deter/ime & $\infty$ & $\mu \mathrm{S} / \mathrm{cm}$ \\
\hline 4278 & 1/13/20088:27 & $8 / 13 / 20088: 27$ & 26.4 & 1027.9 \\
\hline 4279 & 1/13/20088.20 & $8 / 13 / 20088.29$ & 26.4 & 1029.7 \\
\hline 4280 & 1/13/20088:31 & $8 / 13 / 20088: 31$ & 26.4 & 1029.1 \\
\hline 4281 & 1/13/20088:33 & $8 / 13 / 20088: 33$ & 26.4 & 1029 \\
\hline 4282 & $1 / 13 / 20088: 35$ & $8 / 13 / 20088: 35$ & 26.4 & 1002.1 \\
\hline 4283 & $1 / 13 / 20088.37$ & $8 / 13 / 2008837$ & 26.4 & 1027.2 \\
\hline 4284 & 1/1320088:39 & $8 / 13 / 20088: 30$ & 26.4 & 1028.4 \\
\hline 4285 & 1/13/20088:41 & $8 / 13 / 20088: 41$ & 26.4 & 1028.9 \\
\hline 4206 & $1 / 13 / 20088: 43$ & $8 / 13 / 20088: 43$ & 26.4 & 1029.3 \\
\hline 4287 & $1 / 13 / 20088: 45$ & $8 / 13 / 20088: 45$ & 26.4 & 1029.2 \\
\hline 4288 & $1 / 13 / 20088: 47$ & $8 / 13 / 2008847$ & 26.4 & 1029.3 \\
\hline 4289 & $1 / 13 / 20088: 49$ & $8 / 13 / 20088: 49$ & 26.4 & 1028 \\
\hline 4290 & $1 / 13 / 20088.51$ & $8 / 13 / 20088: 51$ & 26.3 & 1029.1 \\
\hline 4291 & $1 / 13 / 2008$ 8:53 & $8 / 13 / 20088: 53$ & 26.4 & 1024.3 \\
\hline 4292 & $1 / 13 / 20088.55$ & $8 / 13 / 20088: 56$ & 26.3 & 1021.3 \\
\hline 4293 & $1 / 13 / 20088: 57$ & $8 / 13 / 20088: 57$ & 26.2 & 1020.9 \\
\hline 4294 & $1 / 13 / 20088.59$ & $8 / 13 / 20088: 59$ & 26.2 & 1020 \\
\hline 4296 & $1 / 13 / 20089.01$ & $8 / 13 / 20089.01$ & 26.4 & 1009.3 \\
\hline 4296 & 1/13/20089:03 & $8 / 13 / 20089.03$ & 26.4 & 1007.2 \\
\hline 4297 & 1/13/20089.05 & $8 / 13 / 20089.05$ & 26.4 & 1003.4 \\
\hline 4298 & 1/13/20089.07 & $8 / 13 / 20089.07$ & 26.4 & 1001.1 \\
\hline 4299 & 1/13/20089:09 & $8 / 13 / 20089.09$ & 26.4 & 1001.2 \\
\hline 4300 & $1 / 13 / 20089.11$ & $8 / 13 / 20089.11$ & 26.4 & 1000.6 \\
\hline 4301 & 1/13/20089:13 & $8 / 13 / 20089.13$ & 26.4 & 10021 \\
\hline 4302 & $1 / 13 / 20089.15$ & $8 / 13 / 20089.15$ & 26.4 & 1001.5 \\
\hline 4303 & 1/13/20089.17 & $8 / 13 / 20089.17$ & 26.4 & 1001.6 \\
\hline 4304 & 1/13/20089:19 & $8 / 13 / 20089.19$ & 26.4 & 1001.7 \\
\hline 4305 & $1 / 13 / 20089.21$ & $8 / 13 / 20089.21$ & 26.4 & 1001.9 \\
\hline 4306 & $1 / 13 / 20089.23$ & $8 / 13 / 20089.23$ & 26.3 & 10023 \\
\hline 4307 & $1 / 13 / 20089.25$ & $8 / 13 / 20089.25$ & 26.3 & 1003.1 \\
\hline 4308 & $1 / 13 / 20089.27$ & $8 / 1320089.27$ & 26.3 & 1003 \\
\hline 4309 & $1 / 1320089.29$ & $8 / 13 / 20089.29$ & 26.3 & 10028 \\
\hline 4310 & 1/13/20089.31 & $8 / 1320089.31$ & 26.2 & 1001.4 \\
\hline 4311 & $1 / 13 / 20089.33$ & $8 / 13 / 20089.33$ & 26.2 & 1001.4 \\
\hline 4312 & $1 / 13 / 20089.35$ & $8 / 13 / 20089.35$ & 26.3 & 1001.8 \\
\hline 4313 & 1/13/20089.37 & $8 / 13 / 20089.37$ & 26.3 & 1002.9 \\
\hline 4314 & 1/13/20089.39 & $8 / 13 / 20089.39$ & 26.3 & 1002.8 \\
\hline 4315 & $1 / 13 / 20089.41$ & $8 / 1320089.41$ & 26.3 & 1003.3 \\
\hline 4316 & $1 / 13 / 20089443$ & $8 / 13 / 20089.43$ & 26.3 & 10027 \\
\hline 4317 & $1 / 13 / 20089.45$ & $8 / 1320089.45$ & 26.3 & 1003.4 \\
\hline 4318 & $1 / 13 / 20089.47$ & $8 / 13 / 20089.47$ & 26.3 & 1003.9 \\
\hline 4319 & $1 / 13 / 20089.49$ & $8 / 13 / 20089.49$ & 26.3 & 1004.1 \\
\hline 4320 & $1 / 13 / 20089.51$ & $8 / 13 / 20089.51$ & 26.3 & 1004 \\
\hline 4321 & $1 / 13 / 20089.53$ & 811320089.53 & 26.3 & 1004 \\
\hline 4322 & $1 / 13 / 20089: 55$ & $8 / 13 / 20089.56$ & 26.3 & 1004.5 \\
\hline 4323 & 1/13/20089.57 & $8 / 13 / 20089.57$ & 26.3 & 1004.9 \\
\hline 4324 & $1 / 13 / 20089.59$ & $8 / 13 / 20089.59$ & 26.3 & 1006.3 \\
\hline 4325 & $1 / 13 / 200810.01$ & $8 / 13 / 2008$ 10:01 & 26.3 & 1006.2 \\
\hline 4326 & $1 / 13 / 200810: 03$ & $8 / 13200810: 03$ & 26.3 & 1006.5 \\
\hline 4327 & $1 / 13 / 200810.05$ & $8 / 13 / 200810.05$ & 26.3 & 1006.5 \\
\hline 4328 & 1/13/2008 t0:07 & $8 / 13 / 2008$ 10.07 & 26.3 & 1006.6 \\
\hline 4329 & $1 / 13 / 200810: 09$ & $8 / 13 / 200810: 09$ & 26.3 & 1006.3 \\
\hline 4330 & $1 / 13 / 2008$ 10:11 & $8 / 13 / 200810.11$ & 263 & 1007.2 \\
\hline 4331 & $1 / 13 / 200810: 13$ & $8 / 13 / 200810: 13$ & 26.3 & 1006.9 \\
\hline 4332 & $1 / 43 / 200810: 15$ & $8 / 13 / 2008$ 10:15 & 26.3 & 1008 \\
\hline 4333 & $1 / \uparrow 3 / 200810: 17$ & $8 / 13 / 200810: 17$ & 26.3 & 1007.5 \\
\hline 4334 & 1/13/2008 10:19 & $8 / 13 / 200810: 19$ & 26.3 & 1007.4 \\
\hline 4335 & $1 / 13 / 200810: 21$ & $8 / 13 / 200810.21$ & 26.3 & 1007.1 \\
\hline 4336 & $1 / 13 / 200810: 23$ & $8 / 13 / 200810: 23$ & 26.3 & 1008 \\
\hline 4333 & $1 / 13 / 200810: 25$ & $8 / 13 / 200810.25$ & 263 & 1007.7 \\
\hline 4338 & $1 / 13 / 200810.27$ & $8 / 13 / 200810.27$ & 26.3 & 1007.1 \\
\hline 4339 & $1 / 13 / 200810.29$ & $8 / 13 / 200810.20$ & 26.3 & 1007.4 \\
\hline 4340 & $1 / 13 / 2008$ 10:31 & $8 / 13 / 200810.31$ & 26.3 & 1007.7 \\
\hline 4341 & 1/13/2008 10:33 & $8 / 13 / 200810.33$ & 26.3 & 10086 \\
\hline 4342 & $1 / 13 / 200810: 35$ & $8 / 13200810.35$ & 26.3 & 1008.2 \\
\hline 4343 & 1/13/2008 10:37 & $8 / 13200810: 37$ & 26.3 & 1008.3 \\
\hline 4344 & $1 / 13 / 200810: 39$ & $8 / 13 / 200810.39$ & 26.3 & 1008.4 \\
\hline 4345 & $1 / 13 / 200810: 41$ & $8 / 13 / 200810.41$ & 263 & 1008.1 \\
\hline 4346 & $1 / 13 / 200810: 43$ & $8 / 13 / 200810.43$ & 26.3 & 700.5 \\
\hline
\end{tabular}




\begin{tabular}{|c|c|c|c|c|}
\hline \multicolumn{5}{|c|}{ D4-93C } \\
\hline $\mathrm{Pec}$ & & Adusted & Termp & $\mathrm{SC}$ \\
\hline$\#$ & DaterTime & DaterTime & $\propto$ & $\mu S / d m$ \\
\hline 4347 & $1 / 13 / 200810.45$ & $8 / 13 / 200810.45$ & 26.3 & 1007.7 \\
\hline 4348 & $1 / 13 / 200810.47$ & $8 / 13 / 200810.47$ & 26.3 & 1008.1 \\
\hline 4349 & $1 / 13 / 200810.49$ & $8 / 13 / 200810: 49$ & 26.3 & 1008.5 \\
\hline 4350 & $1 / 13 / 200810.51$ & $8 / 13 / 200810.51$ & 26.3 & 1008.6 \\
\hline 4351 & $1 / 13 / 200810.53$ & $8 / 132000810.53$ & 26.3 & 1005.9 \\
\hline 4352 & $1 / 13 / 200810.56$ & $8 / 13 / 200810.55$ & 26.3 & 1006.4 \\
\hline 4353 & $1 / 13 / 200810.57$ & $8 / 13 / 200810: 50$ & 26.3 & 1006.9 \\
\hline 4354 & $1 / 13 / 200810.59$ & $8 / 13 / 200810.59$ & 26.3 & 1007.1 \\
\hline 4355 & 1/13/2008 11:01 & $8 / 13 / 200811: 01$ & 26.3 & 1005.1 \\
\hline 4356 & 1/13/2008 11:04 & $8 / 13 / 200811: 03$ & 26.2 & 1004.6 \\
\hline 435 & 1/13/2008 11:05 & $8 / 13 / 200811: 05$ & 261 & 1004.1 \\
\hline 4358 & 1/13/2008 11:07 & $8 / 13 / 2008$ 11:07 & 26.1 & 1000.7 \\
\hline 4359 & 1/13/2008 11:09 & $8 / 13 / 200811: 09$ & 26 & 1004.2 \\
\hline 4360 & 1/13/2008 11:11 & $8 / 13 / 200811: 11$ & 26 & 1003.5 \\
\hline 4361 & 1/13/2008 11:13 & $8 / 13200811: 13$ & 26. & 10025 \\
\hline $43 \pi$ & $1 / 13 / 2008$ 11:15 & $8 / 132008$ 11:15 & 25.9 & 10028 \\
\hline 4363 & 1/13/2008 11:17 & $8 / 13 / 200811: 17$ & 26 & 998.5 \\
\hline 4364 & 1/13/2008 11:19 & $8 / 13 / 200811: 19$ & 25.9 & 1001.2 \\
\hline 4365 & $1 / 13200811: 21$ & $8 / 13 / 200811: 21$ & 25.9 & 1000.5 \\
\hline 4306 & 1/13/2008 11:23 & $8 / 13 / 200811: 23$ & 25.9 & 999.5 \\
\hline 4367 & 1/13/2008 11:25 & $8 / 13 / 200811: 25$ & 25.9 & 1000.3 \\
\hline 4368 & 1/13/2008 11:27 & $8 / 13 / 2008$ 11:27 & 25.9 & 999 \\
\hline 4360 & $1 / 13 / 200811: 29$ & $8 / 13 / 200811: 20$ & 25.8 & 1001 \\
\hline 4370 & $1 / 13 / 2008$ 11:31 & $8 / 13 / 200811: 31$ & 25.8 & 1000.3 \\
\hline 4371 & $1 / 13 / 200811: 33$ & $8 / 13 / 200811: 33$ & 25.8 & 999.7 \\
\hline 4372 & 1/13/2008 11:35 & $8 / 13 / 200811: 35$ & 25.8 & 1001.7 \\
\hline 4373 & $1 / 13 / 2008$ 11:37 & $8 / 13 / 200811: 37$ & 25.9 & 999.6 \\
\hline 4374 & V13/2008 11:39 & $8 / 13 / 200811: 39$ & 25.9 & 999.8 \\
\hline 4375 & $1 / 3 / 200811: 41$ & $8 / 13 / 200811: 41$ & 25.9 & 996.3 \\
\hline 4376 & $1 / 13 / 200811: 43$ & $8 / 13 / 2008$ 11:43 & 25.9 & 998.2 \\
\hline $43 \pi$ & $1 / 13 / 200811: 45$ & $8 / 13 / 200811: 45$ & 25.8 & 998.5 \\
\hline 4378 & $1 / 13 / 2008$ 11:47 & $8 / 13 / 2008$ 11:47 & 25.8 & 998.3 \\
\hline 4379 & $1 / 13 / 200811: 49$ & $8 / 13 / 200811: 49$ & 25.8 & 990 \\
\hline 4380 & V/13/2008 11:51 & $8 / 13 / 200811: 51$ & 25.7 & 998.4 \\
\hline 4381 & $1 / 13 / 200811: 53$ & $8 / 13 / 200811: 53$ & 25.7 & 1000.1 \\
\hline 4382 & $1 / 13 / 200811: 55$ & $8 / 13 / 200811: 55$ & 25.7 & 999.5 \\
\hline 4383 & $1 / 13 / 2008$ 11:57 & $8 / 13 / 2008$ 11:57 & 25.6 & 990.3 \\
\hline 4384 & $1 / 13 / 200811: 59$ & $8 / 13 / 200811: 59$ & 25.6 & 996.3 \\
\hline 4385 & $1 / 13 / 20081201$ & $8 / 13 / 20081201$ & 25.6 & 996.3 \\
\hline 4306 & $1 / 13 / 200812003$ & $8 / 13 / 20081203$ & 25.6 & 998 \\
\hline 4387 & $1 / 13 / 20081205$ & $8 / 13 / 20081205$ & 25.5 & 998 \\
\hline 4388 & $1 / 13 / 20081207$ & $8 / 13 / 20081207$ & 25.6 & 1000.3 \\
\hline 4389 & $1 / 1320081209$ & $8 / 13 / 20081209$ & 25.7 & 1003.6 \\
\hline 4390 & $1 / 13 / 20081211$ & $8 / 13 / 20061211$ & 25.9 & 1006 \\
\hline 4391 & $1 / 13 / 20081213$ & $8 / 13 / 20081213$ & 26.3 & 1018.2 \\
\hline 4392 & $1 / 13 / 20081215$ & $8 / 13 / 20081215$ & 26.3 & 1013.8 \\
\hline 4393 & $1 / 13 / 20081217$ & $8 / 13 / 20081217$ & 26.3 & 1016.2 \\
\hline 4394 & $1 / 13 / 20081219$ & $8 / 13 / 20081219$ & 26.3 & 1016.3 \\
\hline 4395 & $1 / 13 / 20081221$ & $8 / 13 / 20081221$ & 26.3 & 1015 \\
\hline 4396 & $1 / 13 / 20081223$ & $8 / 13 / 20081223$ & 26.3 & 1014.4 \\
\hline 4397. & $1 / 13 / 20081225$ & $8 / 13 / 20081225$ & 26.3 & 1014 \\
\hline 4398 & $1 / 13 / 20081227$ & $8 / 13 / 20081227$ & 26.2 & 1014.9 \\
\hline 4390 & $1 / 13 / 2008+220$ & $8 / 13 / 20081229$ & 26.2 & 1015 \\
\hline 4400 & $1 / 13 / 20081231$ & $8 / 13 / 20081231$ & 26.2 & 1015.4 \\
\hline 4401 & $1 / 13 / 20081233$ & $8 / 13 / 20081233$ & 26.1 & 1014.9 \\
\hline 4402 & $1 / 13 / 20081235$ & $8 / 13 / 20081235$ & 26.1 & 1014.2 \\
\hline 4403 & $1 / 1320081237$ & $8 / 13 / 20081237$ & 26.1 & 1013.9 \\
\hline 4404 & $1 / 13 / 20081239$ & $8 / 13 / 20081239$ & 26 & t014.7 \\
\hline 4405 & $1 / 13 / 20081241$ & $8 / 13 / 20081241$ & 26. & 1013.9 \\
\hline 4406 & $1 / 13 / 20081243$ & $8 / 13 / 20081244$ & 26. & 1014.3 \\
\hline 4407 & $1 / 13 / 20081245$ & $8 / 13 / 20081245$ & 26 & 1014.7 \\
\hline 4408 & $1 / 13 / 20081247$ & $8 / 13 / 20081247$ & 26 & $10 \nmid 5.3$ \\
\hline 4409 & $1 / 13 / 20081249$ & $8 / 13 / 200812449$ & 25.9 & 1015.5 \\
\hline 4410 & $1 / 13 / 20081251$ & $8 / 13 / 20081251$ & 25.9 & 1015.9 \\
\hline 4411 & $1 / 13 / 20081253$ & $8 / 13 / 20081253$ & 25.9 & 1015.6 \\
\hline 4412 & $1 / 13 / 20081255$ & $8 / 13 / 20081255$ & 25.9 & 1016.3 \\
\hline 4413 & $1 / 13 / 20081250$ & $8 / 13 / 2008125$ & 26 & 1021.8 \\
\hline 4414 & $1 / 13 / 20081259$ & $8 / 13 / 20081259$ & 26.1 & 1022 \\
\hline 4415 & $1 / 13 / 200813: 01$ & $8 / 13 / 200813: 01$ & 26.1 & 10224 \\
\hline
\end{tabular}

\begin{tabular}{|c|c|c|c|c|}
\hline \multicolumn{5}{|c|}{ D493c } \\
\hline$R \in C$ & & Adusted & Temp & $\mathrm{SC}$ \\
\hline$\#$ & DeteTime & DaterTime & $\propto C$ & pS/om \\
\hline 4416 & $1 / 13 / 200813: 00$ & $8 / 13 / 200813: 03$ & 26.1 & 10226 \\
\hline 4417 & $1 / 13 / 200813.05$ & $8 / 13 / 2008$ 13:05 & 26.2 & 1023.6 \\
\hline 4418 & $1 / 13 / 200813.07$ & $8 / 13 / 200813: 07$ & 26.2 & 1026 \\
\hline 4419 & $1 / 13 / 200813: 09$ & $8 / 13 / 200813: 00$ & 26.2 & 1023.3 \\
\hline 4420 & $1 / 13 / 200813: 11$ & $8 / 132008$ 13:11 & 26.2 & 1024 \\
\hline 4421 & 1/13/2008 13:13 & $8 / 13 / 200813: 13$ & 26.3 & 1005.7 \\
\hline 4422 & $1 / 13200813: 15$ & $8 / 13 / 2008$ 13:15 & 26.3 & 1026.5 \\
\hline 4423 & $1 / 13 / 200813: 17$ & $8 / 13 / 2008$ 13:17 & 26.3 & 1026.8 \\
\hline 4424 & $1 / 13 / 200813.19$ & $8 / 13 / 2008$ 13:19 & 26.3 & 1027.9 \\
\hline 4425 & $1 / 13 / 20081321$ & $8 / 13 / 200813: 21$ & 26.4 & 1027.3 \\
\hline 4426 & $1 / 13 / 20081323$ & $8 / 13 / 200813: 2$ & 26.4 & 1027.9 \\
\hline 4427 & $1 / 13 / 20081325$ & $8 / 13 / 200813: 25$ & 26.4 & 1028.7 \\
\hline 4428 & 1/13/2008 13:27 & $8 / 13 / 200813: 27$ & 26.3 & 1028.6 \\
\hline 4429 & $1 / 13 / 20081329$ & $8 / 13200813: 20$ & 26.3 & 1029.9 \\
\hline 4430 & $1 / 13 / 200813: 31$ & $8 / 132000813: 31$ & 26.3 & 1031.3 \\
\hline 4431 & 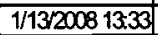 & $8 / 13 / 200813: 33$ & 26.4 & 1030.6 \\
\hline 4432 & $1 / 13 / 200813: 35$ & $8 / 13200813: 35$ & 26.4 & 1030.8 \\
\hline 4433 & 1/13/2008 13:37 & $8 / 13 / 2008$ 13:37 & 26.4 & 1031.8 \\
\hline 4434 & $1 / 13 / 200813.39$ & $8 / 13 / 200813: 39$ & 26.4 & 1031.7 \\
\hline 4436 & $1 / 13 / 200813.41$ & $8 / 13200813: 41$ & 26.5 & 1031.9 \\
\hline 4436 & $1 / 13 / 200813443$ & $8 / 13 / 200813: 43$ & 26.5 & 10329 \\
\hline 4437 & $1 / 13 / 200813: 45$ & $8 / 13 / 200813: 45$ & 26.5 & 1032.1 \\
\hline 4438 & $1 / 13 / 200813: 47$ & $8 / 13 / 2008$ 13:47 & 26.5 & 10325 \\
\hline 4439 & $1 / 1320081344$ & $8 / 13 / 200813: 49$ & 26.5 & 1030.6 \\
\hline 4440 & $1 / 13 / 20081351$ & $8 / 13 / 2008$ 13:51 & 26.5 & 1031.2 \\
\hline 4441 & $1 / 13 / 20081353$ & $8 / 13 / 2008$ 13:53 & 26.6 & 1034.2 \\
\hline 4442 & 1/13/2008 13:50 & $8 / 13 / 200813: 55$ & 26.8 & 10323 \\
\hline 4443 & $1 / 13 / 20081357$ & $8 / 13 / 200813: 5$ & 26.7 & 10329 \\
\hline 4444 & $1 / 13 / 200813.59$ & $8 / 13 / 200813: 50$ & 26.7 & 1028.3 \\
\hline 4445 & $1 / 132008$ 14:01 & $8 / 13 / 2008$ 14:01 & 26.6 & 1027.2 \\
\hline 4446 & $1 / 13 / 200814: 03$ & $8 / 13 / 2008$ 14:03 & 26.5 & 1031 \\
\hline 4447 & $1 / 13 / 200814: 05$ & $8 / 13 / 2008$ 14:05 & 26.5 & 1028.7 \\
\hline 4448 & $1 / 13 / 200814: 07$ & $8 / 13 / 2008$ 14:07 & 26.5 & 1026.6 \\
\hline 4449 & $1 / 13 / 200814: 00$ & $8 / 13 / 2008$ 14:00 & 26.4 & 1028.2 \\
\hline 4450 & $1 / 13 / 200814: 11$ & $8 / 132008$ 14:11 & 26.4 & 1028.5 \\
\hline 4451 & $1 / 13 / 200814: 13$ & $8 / 13 / 200814: 13$ & 26.4 & 1028.1 \\
\hline 4452 & $1 / 13 / 200814: 15$ & $8 / 1322008$ 14:15 & 26.3 & 1026.2 \\
\hline 4453 & $1 / 13 / 200814: 17$ & $8 / 132008$ 14:17 & 26.3 & 1028.5 \\
\hline 4454 & $1 / 13 / 200814: 19$ & $8 / 13 / 2008$ 14:19 & 26.2 & 1028 \\
\hline 4455 & 1/13/2008 14:21 & $8 / 13 / 2008$ 14:21 & 26.1 & 1027.9 \\
\hline 4456 & 1/13/2008 14:23 & $8 / 13 / 200814: 23$ & 26.1 & 1026.7 \\
\hline 4457 & 1/13/2008 14:25 & $8 / 13 / 2008$ 14:25 & 26 & 1025.5 \\
\hline 4458 & $1 / 13 / 2008$ 14:27 & $8 / 13 / 2008$ 14:27 & 25.9 & 1026.4 \\
\hline 4459 & 1/13/2008 14:20 & $8 / 13 / 200814: 20$ & 26.1 & 1000.1 \\
\hline 4400 & 1/13/2008 14:31 & \begin{tabular}{|l|l|}
$8 / 13 / 2008$ 14:31 \\
\end{tabular} & 26.4 & 1027.7 \\
\hline 4461 & 1/13/2008 14:33 & $8 / 13 / 2008$ 14:33 & 26.3 & 1028.3 \\
\hline 4462 & 1/13/2008 14:36 & $8 / 13 / 200814: 35$ & 26.3 & 1020 \\
\hline 443 & 1/13/2008 14:37 & $8 / 13 / 2008$ 14:37 & 26.3 & 1027 \\
\hline 4464 & $1 / 13 / 200814: 39$ & $8 / 13 / 2008$ 14:39 & 26.2 & 1025.9 \\
\hline 4465 & 1/13/2008 14:41 & $8 / 13 / 2008$ 14:41 & 26.2 & 1026.7 \\
\hline 4466 & 1/13/2008 14:43 & $8 / 13 / 2008$ 14:43 & 26.1 & 1027.9 \\
\hline 4467 & $1 / 13 / 200814: 45$ & $8 / 13200814: 45$ & 26.1 & 1027 \\
\hline 4468 & $1 / 13 / 2008$ 14:47 & $8 / 13 / 2008$ 14:47 & 26 & 1026 \\
\hline 4409 & 1/13/2008 14:49 & $8 / 13 / 2008$ 14:49 & 26 & 1027.3 \\
\hline 4470 & 1/13/2008 14:51 & $8 / 13 / 2008$ 14:51 & 25.9 & 1027.6 \\
\hline 4471 & 1/13/2008 14:50 & $8 / 13 / 2008$ 14:53 & 25.9 & 1026.8 \\
\hline 4472 & 1/13/2008 14:55 & $8 / 13 / 2008$ 14:56 & 25.8 & 1028.4 \\
\hline 4473 & 1/13/2008 14:57 & $8 / 13 / 2008$ 14:57 & 25.8 & 1026.8 \\
\hline 4474 & 1/13/2008 14:50 & $8 / 13 / 2008$ 14:59 & 25.8 & 1027.7 \\
\hline 4475 & 1/13/2008 15:01 & 8/13/2008 15:01 & 25.8 & 1027.6 \\
\hline 4476 & 1/13/2008 15:03 & $8 / 13 / 2008$ 15:03 & 26 & 1028.8 \\
\hline 4477 & 1/13/2008 15:06 & $8 / 13 / 200815.05$ & 26.1 & 1029.6 \\
\hline 4478 & t/13/2008 15:07 & $8 / 13 / 2008$ 15:07 & 26.1 & 1023.6 \\
\hline 4479 & 1/13/2008 15:09 & $8 / 13 / 2008$ 15:09 & 26.2 & 1027 \\
\hline 4480 & $1 / 13 / 200815: 11$ & $8 / 13 / 200815: 11$ & 26.2 & 1028.1 \\
\hline 4481 & 1/13/2008 15:13 & $8 / 13 / 200815: 13$ & 26.3 & 1000 \\
\hline 4482 & 1/13/2008 15:15 & $8 / 13 / 200815: 15$ & 26.3 & 1028.9 \\
\hline 4483 & 1/13/2008 15:17 & $8 / 13 / 2008$ 15:17 & 26.3 & 1030.1 \\
\hline & & & 26.3 & \\
\hline
\end{tabular}

\begin{tabular}{|c|c|c|c|c|}
\hline \multicolumn{5}{|c|}{$D 493 C$} \\
\hline $\operatorname{Rec}$ & & Agiusted & Temp & $\mathrm{SC}$ \\
\hline$\#$ & DaterTime & DeterTime & $\propto$ & HS/m \\
\hline 4485 & $1 / 13 / 2008$ 15:21 & $8 / 13 / 200815: 21$ & 26.3 & 1031.4 \\
\hline 4486 & $1 / 13 / 200815: 23$ & $8 / 13 / 200815: 23$ & 26.3 & 1031.1 \\
\hline 4487 & 1/13/2008 15:25 & $8 / 13 / 200815: 25$ & 26.4 & 1030.5 \\
\hline 4488 & $1 / 13 / 200815: 27$ & $8 / 13 / 200815: 27$ & 26.4 & 1031.3 \\
\hline 4489 & $1 / 13 / 200815: 29$ & $8 / 13 / 200815: 20$ & 26.5 & 1028.8 \\
\hline 4490 & $1 / 13 / 2008$ 15:31 & $8 / 13 / 200815: 31$ & 26.5 & 1030.6 \\
\hline 4491 & $1 / 13 / 2008$ 15:33 & $8 / 13 / 200815: 33$ & 26.6 & 1030.6 \\
\hline 4492 & 1/13/2008 15:35 & $8 / 13 / 200815: 35$ & 26.7 & 1030.7 \\
\hline 4496 & $1 / 13 / 2008$ 15:37 & $8 / 13 / 2008$ 15:37 & 26.9 & 1036.8 \\
\hline 4494 & $1 / 13 / 200815: 39$ & $8 / 13 / 200815: 39$ & 26.9 & 1031.7 \\
\hline 4496 & $1 / 13 / 200815: 41$ & $8 / 13 / 200815: 41$ & 27 & 1035.2 \\
\hline 4496 & 1/13/200815:43 & $8 / 13 / 200815: 43$ & 26.9 & 1034.3 \\
\hline 4497 & $1 / 13 / 200815: 45$ & $8 / 13 / 200815: 45$ & 26.9 & 1033.8 \\
\hline 4498 & $1 / 13 / 200815: 47$ & $8 / 13 / 2008$ 15:47 & 26.7 & 10026.7 \\
\hline 4490 & $1 / 13 / 20081549$ & $8 / 13200815-49$ & 26.7 & 10328 \\
\hline 4500 & $1 / 13 / 200815: 51$ & $8 / 13 / 200815: 51$ & 26.8 & 1034.3 \\
\hline 4501 & $1 / 13 / 200815: 53$ & $8 / 13 / 200815: 53$ & 26.8 & 1035.8 \\
\hline 4502 & $1 / 13 / 2008$ 15:56 & $8 / 13 / 2008$ 15:55 & 26.7 & 1027.6 \\
\hline 4503 & $1 / 13 / 2008$ 15:57 & $8 / 13 / 200815: 57$ & 26.4 & 1028.6 \\
\hline 4504 & 1/13/200815:59 & $8 / 13 / 200815: 59$ & 26.3 & 1028 \\
\hline 4505 & $1 / 13 / 200816: 01$ & $8 / 13 / 2008$ 16:01 & 26.2 & 1031.2 \\
\hline 4506 & $1 / 13 / 200816: 03$ & 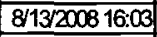 & 26.2 & 1029.4 \\
\hline 4507 & $1 / 13 / 200816: 05$ & $8 / 13 / 200816: 05$ & 26.2 & 1028.8 \\
\hline 4508 & $1 / 13 / 200816: 07$ & $8 / 13 / 2008$ 16:07 & 26.1 & 1029.8 \\
\hline 4509 & $1 / 13 / 200816: 09$ & \begin{tabular}{|l|}
$8 / 13 / 200816: 09$ \\
\end{tabular} & 26.1 & 1031.2 \\
\hline 4510 & 1/13/2008 16:11 & $8 / 13 / 2008$ 16:11 & 26.1 & 1031.4 \\
\hline 4511 & 1/13/2008 16:13 & $8 / 13 / 200816: 13$ & 26 & 1032.3 \\
\hline 4512 & $1 / 13 / 200816: 15$ & $8 / 13 / 200816: 15$ & 26 & 1033.8 \\
\hline 4513 & 1/13/2008 16:17 & $8 / 13 / 200816: 17$ & 26 & 1034.4 \\
\hline 4514 & $1 / 13 / 200816: 19$ & 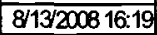 & 26.1 & 1033.8 \\
\hline 4515 & $1 / 13 / 200816: 21$ & $8 / 13 / 2008$ 16:21 & 26.1 & 1034.7 \\
\hline 4516 & $1 / 13 / 200816: 23$ & $8 / 13 / 200816: 23$ & 26.2 & 1036 \\
\hline 4517 & $1 / 13 / 200816: 25$ & $8 / 13 / 200816: 25$ & 26.3 & 1034.8 \\
\hline 4518 & $1 / 13 / 200816: 27$ & $8 / 13 / 200816: 27$ & 26.4 & 1036.3 \\
\hline 4519 & $1 / 13 / 200816: 20$ & $8 / 13 / 200816: 20$ & 27.4 & 1046.9 \\
\hline 4520 & 1/13/2008 16:31 & $8 / 13 / 2008$ 16:31 & 27.6 & 1034.7 \\
\hline 4521 & $1 / 13 / 200816: 33$ & $8 / 13 / 2008$ 16:33 & 27.6 & 1031.4 \\
\hline 4522 & $1 / 13 / 200816: 35$ & $8 / 13 / 2008$ 16:36 & 27.5 & 1034.9 \\
\hline 4523 & 1/13/2008 16:37 & $8 / 13 / 200816: 37$ & 27.4 & 1031.8 \\
\hline 4524 & $1 / 13 / 200816: 39$ & $8 / 13 / 200816: 39$ & 27.3 & 1033 \\
\hline 4525 & $1 / 13 / 200816: 41$ & $8 / 13 / 200816: 41$ & 27,1 & 1034.3 \\
\hline 4526 & $1 / 13 / 200816: 43$ & $8 / 13 / 200816: 43$ & 27.1 & 1036.4 \\
\hline 4527 & $1 / 13 / 200816: 45$ & $8 / 13 / 200816: 45$ & 27.1 & 1035.4 \\
\hline 4528 & $1 / 13 / 200816: 47$ & $8 / 13 / 200816: 47$ & 26.9 & 1030.7 \\
\hline 4529 & $1 / 13 / 200816: 49$ & $8 / 13 / 200816: 49$ & 26.9 & 1034.3 \\
\hline 4530 & 1/13/2008 16:51 & $8 / 13 / 200816: 51$ & 26.9 & 1034.4 \\
\hline 4531 & $1 / 13 / 200816: 53$ & $8 / 13 / 200816: 53$ & 26.9 & 1034.2 \\
\hline 4532 & $1 / 13 / 200816: 55$ & $8 / 13 / 200816: 56$ & 26.9 & 1033.4 \\
\hline 4533 & $1 / 13 / 200816: 57$ & $8 / 13 / 200816: 5$ & 26.8 & 1034.5 \\
\hline 4534 & $1 / 13 / 200816: 59$ & $8 / 13 / 200816: 59$ & 26.7 & 1033.2 \\
\hline 4535 & 1/13/2008 17:01 & $8 / 13 / 200817: 01$ & 26.7 & 10329 \\
\hline 4536 & 1/13/2008 17:03 & $8 / 13 / 200817: 03$ & 26.6 & 1029 \\
\hline 4537 & $1 / 13 / 2008$ 17:05 & $8 / 13 / 200817: 05$ & 26.5 & 1031.3 \\
\hline 4538 & $1 / 13 / 2008$ 17:07 & $8 / 13: 2008$ 17:07 & 26.5 & 10322 \\
\hline 4539 & $1 / 13 / 200817: 09$ & $8 / 13 / 2008$ 17:09 & 26.4 & 1030.4 \\
\hline 4540 & $1 / 13 / 2008$ 17:11 & $8 / 13 / 2008$ 17:11 & 26.4 & 10327 \\
\hline 4541 & $1 / 13 / 200817: 13$ & $8 / 13 / 2008$ 17:13 & 26.3 & 10327 \\
\hline 4542 & 1/13/2008 17:15 & $8 / 13 / 200817: 15$ & 26.2 & 1031.5 \\
\hline 4543 & 1/13/2008 17:17 & $8 / 132008$ 17:17 & 26.1 & 1031.9 \\
\hline 4544 & $1 / 13 / 200817: 19$ & $8 / 13 / 200817: 19$ & 26.1 & 10324 \\
\hline 4545 & $1 / 13 / 200817: 21$ & $8 / 13 / 2008$ 17:21 & 26.2 & 1035.6 \\
\hline 4546 & 1/13/2008 17:23 & $8 / 13 / 200817: 23$ & 26.3 & 1037.3 \\
\hline 4547 & 1/13/2008 17:25 & $8 / 13 / 200817: 25$ & 26.4 & 1034.6 \\
\hline 4548 & 1/13/2008 17:27 & $8 / 13 / 200817: 27$ & 26.4 & 1035.5 \\
\hline 4549 & $1 / 13 / 200817: 29$ & $8 / 13 / 200817: 29$ & 26.3 & 10326 \\
\hline 4550 & $1 / 13 / 200817: 31$ & $8 / 13 / 2008$ 17:31 & 26.2 & 1034 \\
\hline 4551 & $1 / 13 / 200817: 33$ & $8 / 13 / 2008$ 17:33 & 26.1 & 10326 \\
\hline 4552 & 1/13/2008 17:35 & $8 / 13 / 2008$ 17:35 & 26.1 & 10326 \\
\hline & & & & \\
\hline
\end{tabular}




\begin{tabular}{|c|c|c|c|c|}
\hline \multicolumn{5}{|c|}{ D493c } \\
\hline $\operatorname{Rec}$ & & Agjusted & Temp & $S C$ \\
\hline \# & DaterTime & DateTime & $\propto$ & jsiam \\
\hline 4554 & $1 / 13 / 200817: 39$ & $8 / 13 / 200817: 39$ & 26 & 1033.7 \\
\hline 4550 & $1 / 13 / 200817: 41$ & $8 / 13 / 2008$ 17:41 & 26 & 1033.8 \\
\hline 4566 & $1 / 13 / 200817: 43$ & $8 / 13 / 200817: 43$ & 26.2 & 1031.9 \\
\hline 4567 & $1 / 13200817: 45$ & $8 / 13 / 2008$ 17:45 & 26.6 & 1030 \\
\hline 4558 & $1 / 13 / 200817: 47$ & $8 / 13 / 200817: 47$ & 26.7 & 1031.1 \\
\hline 4559 & $1 / 13 / 2008$ 17:49 & $8 / 13 / 2008$ 17:49 & 26.7 & 1027.7 \\
\hline 4560 & $1 / 13 / 2008$ 17:51 & $8 / 13 / 2008$ 17:51 & 26.8 & 1028.5 \\
\hline 4561 & $1 / 13 / 200817: 53$ & $8 / 13 / 200817: 53$ & 26.9 & 1026.6 \\
\hline 4562 & $1 / 13200817: 55$ & $8 / 13 / 2008$ 17:55 & 26.9 & 1026.8 \\
\hline 4563 & $1 / 13 / 2008$ 17:57 & $8 / 13 / 2008$ 17:57 & 26.9 & 1026.5 \\
\hline 4564 & $1 / 132008$ 17:59 & $8 / 13 / 2008$ 17:59 & 26.9 & 1026.1 \\
\hline 4565 & $1 / 132000818: 01$ & $8 / 13 / 2008$ 18:01 & 26.9 & 1024.8 \\
\hline 4566 & $1 / 13 / 200818: 03$ & $8 / 13 / 200818: 03$ & 27 & 1024.5 \\
\hline 4567 & 1/13/2008 18:05 & $8 / 132000818: 05$ & 27 & 1020.2 \\
\hline 4568 & $1 / 13 / 200818: 07$ & 8/132008 18:07| & 27) & 1020.8 \\
\hline 4509 & $1 / 13 / 2008$ 18:00 & $8 / 13 / 200818: 00$ & 27 & 1020.6 \\
\hline 4570 & $1 / 13 / 2008$ 18:11 & $8 / 13 / 200818: 11$ & 27.1 & 1019.3 \\
\hline 4571 & $1 / 13 / 200818: 13$ & $8 / 13 / 200818: 13$ & 27 & 1018.2 \\
\hline 452 & $1 / 13200018: 15$ & $8 / 13 / 2008$ 18:15 & 27.1 & 1017.7 \\
\hline 4573 & $1 / 13 / 200818: 17$ & $8 / 13 / 200818: 17$ & 27 & 1018.2 \\
\hline 4574 & $1 / 13 / 2008$ 18:19 & $8 / 13 / 200818: 19$ & 27 & 1017.8 \\
\hline $45 \% 5$ & $1 / 13 / 2008$ 18:21 & $8 / 13 / 200818: 21$ & 26.9 & 1017.4 \\
\hline 4576 & $1 / 13 / 200818: 23$ & $8 / 13 / 200818: 23$ & 26.8 & 1016.7 \\
\hline $45 \pi 7$ & $1 / 132000818.25$ & $8 / 13 / 200818: 25$ & 26.8 & 1017.9 \\
\hline 4578 & $1 / 132000818.27$ & $8 / 13 / 200818.27$ & 26.8 & 1016 \\
\hline $45 \times 9$ & $1 / 13 / 200818: 29$ & $8 / 13 / 200818: 29$ & 26.8 & 1016.4 \\
\hline 4580 & 1/13/2008 18:31 & $8 / 13 / 2008$ 18:31 & 26.7 & 1017 \\
\hline 4581 & $1 / 13 / 200818: 33$ & $8 / 13 / 200818: 33$ & 26.8 & 1016.1 \\
\hline 4582 & $1 / 13 / 200818.35$ & $8 / 132000818: 35$ & 26.9 & 1015.2 \\
\hline 4583 & $1 / 13200818.37$ & $8 / 13 / 200818: 37$ & 26.9 & 1014.3 \\
\hline 4584 & $1 / 13 / 200818.39$ & $8 / 13 / 200818: 39$ & 26.8 & 1014.4 \\
\hline 4586 & \begin{tabular}{|c|}
$1 / 13 / 2008$ \\
\end{tabular} & $8 / 13 / 2008$ 18:41 & 26.9 & 1015.2 \\
\hline 4586 & $1 / 13 / 20081843$ & $8 / 132000818: 43$ & 26.9 & 1013.8 \\
\hline 4587 & $1 / 13 / 200818445$ & $8 / 13 / 2008$ 18:45 & 26.9 & 10136 \\
\hline 4588 & $1 / 13 / 20081844$ & $8 / 13 / 200818: 47$ & 27 & 1012.4 \\
\hline 4589 & $1 / 13200018: 49$ & $8 / 13 / 200018: 49$ & 26.9 & 10128 \\
\hline 4590 & $1 / 13 / 200818: 51$ & \begin{tabular}{|l|l|}
$8 / 200818: 51$ \\
\end{tabular} & 26.9 & 10129 \\
\hline 4591 & \begin{tabular}{|l|}
$1 / 13 / 200818: 53$ \\
\end{tabular} & $8 / 13200818: 53$ & 27 & 1010.5 \\
\hline 4592 & $1 / 132000818.56$ & $8 / 13 / 2008$ 18:55 & 27 & 10129 \\
\hline 4593 & 1/13/2008 18:57 & $8 / 13 / 2008$ 18:57 & 27 & 1013.2 \\
\hline 4594 & \begin{tabular}{|l|}
$1 / 13 / 200818: 50$ \\
\end{tabular} & $8 / 13200018: 59$ & 27.1 & 1010.6 \\
\hline 4506 & $1 / 13 / 200819.01$ & $8 / 13200819.01$ & 27.1 & 1009.2 \\
\hline 4506 & $1 / 13 / 200819.03$ & $8 / 13 / 200819.03$ & 27.1 & 1009.3 \\
\hline 4597 & \begin{tabular}{|l|l|}
$1 / 13 / 200819.06$ \\
\end{tabular} & $8 / 13 / 200819.06$ & 27.2 & 1010.2 \\
\hline 4596 & $1 / 13 / 200819.07$ & $8 / 13 / 200819.07$ & 27.2 & 1010.3 \\
\hline 4599 & $1 / 13200819.00$ & $8 / 13 / 200819: 09$ & 27.3 & 1008.7 \\
\hline 4600 & \begin{tabular}{|l|l|}
$1 / 1200089.11$ \\
\end{tabular} & 8/132008 19:11 & 27.4 & 1010.2 \\
\hline 4601 & $1 / 13 / 200819.13$ & \begin{tabular}{|l|l|}
$8 / 200819: 13$ \\
\end{tabular} & 27.5 & 1005.4 \\
\hline 4602 & $1 / 13 / 200819.15$ & 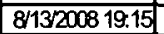 & 27.5 & 1008.1 \\
\hline 4603 & $1 / 13 / 200819.17$ & $8 / 132000819: 17$ & 27.6 & 1010.5 \\
\hline 4604 & $1 / 13 / 200019.19$ & 8/13/200819:19 & 27.4 & 1010.2 \\
\hline 4606 & 1/13/2008 19.21 & $8 / 13 / 200819.21$ & 27.1 & 1010 \\
\hline 4606 & $1 / 13200819.23$ & $8 / 132008$ 19:23 & 26.9 & 10027 \\
\hline 4607 & $1 / 13200819.25$ & $8 / 13 / 200819.25$ & 26.7 & 1008.2 \\
\hline 4608 & $1 / 13 / 200819.27$ & $8 / 13 / 200819.27$ & 26.6 & 1005.6 \\
\hline 4600 & 1/13/2008 19:29 & $8 / 13 / 200819.29$ & 26.6 & 1004.1 \\
\hline 4610 & $1 / 13 / 200819.31$ & $8 / 13 / 200819.31$ & 26.9 & 1004.1 \\
\hline 4611 & $1 / 13 / 200019.33$ & $8 / 13200819.33$ & 27.1 & 1007.2 \\
\hline 4612 & $1 / 13 / 200819.35$ & $8 / 13 / 200819.35$ & 27 & 1008.6 \\
\hline 4613 & $1 / 13200819.37$ & $8 / 13 / 2008$ 19:37 & 27.1 & 10007.9 \\
\hline 4614 & $1 / 13 / 200819.39$ & $8 / 13 / 2008$ 19.39 & 27.2 & 1000 \\
\hline 4615 & \begin{tabular}{|l|l|}
$1 / 132008$ & 19.41 \\
\end{tabular} & $8 / 13200819.41$ & 27.1 & 1007.9 \\
\hline 4616 & $1 / 13 / 200819.43$ & $8 / 13 / 200819: 43$ & 27 & 1009.6 \\
\hline 4617 & $1 / 13 / 200819.45$ & $8 / 13 / 200819.45$ & 27.1 & 1006.6 \\
\hline 4618 & $1 / 13 / 2008$ 19:47 & $8 / 13 / 200819: 47$ & 27.1 & 1007.4 \\
\hline 4619 & $1 / 13 / 200819.49$ & $8 / 13 / 200819.49$ & 27 & 10128 \\
\hline 4620 & \begin{tabular}{|l|l|}
$1 / 13 / 200819.51$ \\
\end{tabular} & $8 / 13200819.51$ & 27.2 & 10084 \\
\hline 4621 & 1/132008 19.53 & $8 / 13 / 200819.53$ & 27.3 & 1009.8 \\
\hline 4622 & $1 / 13 / 200819.56$ & $8 / 13 / 200819.55$ & 27.2 & 1020.5 \\
\hline
\end{tabular}

\begin{tabular}{|c|c|c|c|c|}
\hline \multicolumn{5}{|c|}{ D493C } \\
\hline $\operatorname{Rec}$ & & Adusted & Temp & $\mathrm{SC}$ \\
\hline$\#$ & DeterTime & Deter/Time & $\infty$ & $\mu \mathrm{s} / \mathrm{cm}$ \\
\hline 4623 & $1 / 13 / 200819.5$ & $8 / 13 / 2008$ 19.57 & 27.5 & 10129 \\
\hline 4624 & $1 / 13 / 200819.59$ & $8 / 13 / 200819.59$ & 27.4 & 1013.8 \\
\hline 4625 & $1 / 13 / 200820001$ & $8 / 13 / 200820: 01$ & 27.4 & 1012.1 \\
\hline 4626 & $1 / 13 / 200820: 03$ & $8 / 13200820: 03$ & 27.3 & 1010.2 \\
\hline 4627 & $1 / 13 / 20082005$ & 8113200820.05 & 27.4 & 1010.6 \\
\hline 4628 & $1 / 13200820: 0$ & $8 / 13200820: 07$ & 27.3 & 1008.9 \\
\hline 4629 & $1 / 13 / 20082000$ & $8 / 13 / 200820: 00$ & 27.2 & 1009.1 \\
\hline 4630 & $1 / 13 / 200820.11$ & $8 / 13 / 200820: 11$ & 27.1 & 1007.8 \\
\hline 4631 & $1 / 13 / 20082013$ & $8 / 13 / 200820: 13$ & 27.2 & 1008.4 \\
\hline 4632 & $1 / 13 / 200820: 15$ & $8 / 13 / 200820: 15$ & 27.2 & 1010.4 \\
\hline 4633 & $1 / 13 / 200820: 17$ & $8 / 13200820: 17$ & 27.2 & 1007.2 \\
\hline 4634 & $1 / 13 / 200820: 19$ & $8 / 13 / 200820: 19$ & 27.1 & 1008.5 \\
\hline 4635 & $1 / 13 / 200820: 21$ & $8 / 13200820: 21$ & 27.2 & 1008.2 \\
\hline 4636 & $1 / 13 / 200820: 23$ & $8 / 13 / 200820: 23$ & 27.1 & 1007.5 \\
\hline 4637 & $1 / 13 / 200820: 25$ & $8 / 13 / 200820: 25$ & 27 & 1006.7 \\
\hline 4638 & $1 / 13 / 200820: 27$ & $8 / 13 / 200820: 27$ & 27 & 1007.1 \\
\hline 4639 & $1 / 13 / 200820: 29$ & $8 / 13 / 200820: 20$ & 26.9 & 1008.8 \\
\hline 4640 & $1 / 13 / 200820: 31$ & $8 / 13 / 200820: 31$ & 26.9 & 1007.1 \\
\hline 4641 & 1/13/2008 20:33 & $8 / 13 / 200820.33$ & 26.8 & 1007.9 \\
\hline 4642 & $1 / 13 / 200820.35$ & $81132200820: 35$ & 26.7 & 1003.8 \\
\hline 4643 & $1 / 13 / 2008200.37$ & $8 / 13 / 200820: 37$ & 26.7 & 1005.1 \\
\hline 4644 & $1 / 13 / 200820: 39$ & $8 / 13 / 200820039$ & 26.6 & 1005.3 \\
\hline 4645 & $1 / 13 / 200820: 41$ & $8 / 13 / 200820: 41$ & 26.6 & 10021 \\
\hline 4646 & $1 / 13 / 200820: 43$ & $8 / 13 / 200820: 43$ & 26.6 & 1004.1 \\
\hline 4647 & $1 / 13 / 200820.45$ & $8 / 13200820-45$ & 26.5 & 1006 \\
\hline 4648 & $1 / 13 / 200820.47$ & \begin{tabular}{|l|}
$8 / 13 / 200820: 47$ \\
\end{tabular} & 26.5 & 1005.7 \\
\hline 4649 & $1 / 13 / 200820: 49$ & $8 / 13 / 200820: 49$ & 26.5 & 1006.9 \\
\hline 4650 & $1 / 13 / 200820.51$ & 8/13/2008 20:51 & 26.5 & 1007.2 \\
\hline 4651 & $1 / 13 / 2008$ 20:53 & $8 / 13 / 200820.53$ & 26.5 & 1007.7 \\
\hline 4652 & $1 / 13 / 200820.56$ & $8 / 13 / 200820: 55$ & 26.4 & 1007.7 \\
\hline 4653 & $1 / 13 / 200820: 5$ & $8 / 13 / 200820: 57$ & 26.5 & 1003.4 \\
\hline 4654 & $1 / 13 / 200820.59$ & $8 / 13 / 200820.59$ & 26.6 & 1005.8 \\
\hline 4655 & 1/13/200821:01 & $8 / 13 / 200821: 01$ & री & 1007.2 \\
\hline 4656 & 1/13/200821:03 & $8 / 13200821: 03$ & 27.2 & 1006.6 \\
\hline 4607 & 1/13/200821:06 & $8 / 13200821: 05$ & 27.2 & 1006.2 \\
\hline 4658 & $1 / 13 / 200821: 07$ & $8 / 13200821: 07$ & 27.2 & 1007.1 \\
\hline 4659 & 1/13/200821:09 & $8113200821: 00$ & 27.3 & 1006.1 \\
\hline 4660 & 1/13/200821:11 & $8 / 13 / 200821: 11$ & 27.3 & 1007.7 \\
\hline 4661 & $1 / 13 / 200821: 13$ & $8 / 13 / 200821: 13$ & 27.3 & 1008.6 \\
\hline 4662 & $1 / 13 / 200821: 15$ & $8 / 13200821: 15$ & 27.3 & 1007.4 \\
\hline 4663 & 1/13/200821:17 & $813200821: 17$ & 27.3 & 1004.4 \\
\hline 4664 & $1 / 13 / 200821: 19$ & $8 / 13 / 200821: 19$ & 27.3 & 1005.9 \\
\hline 4665 & 1/13/200821:21 & $8 / 13 / 200821: 21$ & 27.3 & 1006.6 \\
\hline 4666 & 1/13/200821:23 & $8 / 13 / 200821 \cdot 23$ & 27.2 & 1006.2 \\
\hline 4667 & 1/13/200821:25 & $8 / 13 / 200821: 25$ & 27.3 & 1007.3 \\
\hline 4668 & 1/13/200821:27 & $8 / 13 / 200821: 27$ & 27.4 & 1008.5 \\
\hline 4609 & 1/13/200821:29 & $8 / 13 / 200821: 29$ & 27.5 & 998.5 \\
\hline 4670 & $1 / 13 / 200821: 31$ & $8 / 13 / 200821: 31$ & 27.4 & 10023 \\
\hline 4671 & 1/13/200821:33 & $8 / 13 / 200821: 33$ & 27.5 & 1000.3 \\
\hline 4672 & $1 / 13 / 200821: 35$ & $8 / 13200821: 35$ & 27.4 & 1007.6 \\
\hline 4673 & $1 / 13 / 200821: 37$ & $8 / 13 / 200821: 37$ & 27.6 & 1007.1 \\
\hline 4674 & 1/13/200821:39 & $8 / 13200821: 30$ & 27.8 & 1009.8 \\
\hline 4675 & $1 / 13 / 200821: 41$ & $8 / 13 / 200821: 41$ & 27.7 & 1009.4 \\
\hline 4676 & $1 / 13 / 200821: 43$ & $8 / 13 / 200821: 43$ & 27.7 & 1009.5 \\
\hline $46 \pi$ & $1 / 13 / 200821: 45$ & $8 / 13 / 200821: 45$ & 27.7 & 1008.8 \\
\hline 4678 & $1 / 13 / 200821: 47$ & $8 / 13 / 200821: 47$ & 27.6 & 1008.5 \\
\hline 4679 & 1/13/200821:49 & $8 / 13 / 200821: 49$ & 27.7 & 1010.3 \\
\hline 4680 & 1/13/2008 21:51 & $8 / 13 / 200821: 51$ & 27.6 & 1011.7 \\
\hline 4681 & $1 / 13 / 200821: 53$ & $8 / 13 / 200821: 53$ & 27.6 & 1009.4 \\
\hline 4682 & $1 / 132200821: 56$ & $8 / 13 / 200821: 55$ & 27.6 & 1009.8 \\
\hline 4683 & $1 / 13 / 200821: 5$ & $8 / 13 / 200821: 57$ & 27.7 & 1000 \\
\hline 4684 & $1 / 13 / 200821: 59$ & $8113200821: 59$ & 27.6 & 1009.6 \\
\hline 4685 & $1 / 13 / 20082201$ & $8 / 13200822: 01$ & 27.6 & 1010.2 \\
\hline 4606 & $1 / 13 / 20082203$ & $8 / 13 / 20082203$ & 27.6 & 1008.8 \\
\hline 4687 & $1 / 13 / 20082205$ & $8 / 1320082205$ & 27.5 & 1007.8 \\
\hline 4688 & $1 / 13 / 20082207$ & $8 / 13 / 20082207$ & 27.5 & 1008.4 \\
\hline 4689 & $1 / 13 / 20082200$ & $813 / 20082200$ & 27.4 & 1008 \\
\hline 4690 & $1 / 13 / 20082211$ & $8 / 13 / 2008$ 22 11 & 27.4 & 1008.2 \\
\hline 4691 & $1 / 13 / 20082213$ & $813 / 20082213$ & 27.3 & 1008.3 \\
\hline
\end{tabular}

\begin{tabular}{|c|c|c|c|c|}
\hline \multicolumn{5}{|c|}{$D 4-98 \mathrm{C}$} \\
\hline $\mathrm{REC}$ & & Adusted & Temp & $\mathrm{SC}$ \\
\hline$\#$ & Dater/ime & Date/Time & $\alpha$ & psom \\
\hline 4692 & $1 / 13 / 20082215$ & $8 / 13 / 20082215$ & 27.2 & 1009.3 \\
\hline 4693 & $1 / 13 / 20082217$ & $8 / 13 / 20082217$ & 27.2 & 1007.5 \\
\hline 4694 & $1 / 13 / 200822 \div 19$ & $8 / 1320082219$ & 27.1 & 1009.7 \\
\hline 4696 & $1 / 13 / 20082221$ & $8 / 13 / 200822221$ & 27.1 & 1008.8 \\
\hline 4696 & $1 / 13 / 20082220$ & $8 / 13 / 20082223$ & 27 & 1008.6 \\
\hline 4697 & $1 / 13 / 20082225$ & $8 / 13 / 20082225$ & 27 & 1007.8 \\
\hline 4698 & $1 / 13 / 20082227$ & $8 / 1320082227$ & 26.9 & 1003.7 \\
\hline 4629 & $1 / 13 / 2008222$ & $8 / 13 / 200822 \cdot 29$ & 27 & 1007.4 \\
\hline 4700 & $1 / 13 / 20082231$ & $8 / 13 / 20082231$ & 27 & 1005.4 \\
\hline 4701 & $1 / 13 / 2008223$ & $8 / 1320082233$ & 28.1 & 1004.3 \\
\hline 4702 & $1 / 13 / 20082235$ & $8 / 1320082236$ & 28 & 1007.8 \\
\hline 4703 & $1 / 13 / 20082237$ & $8 / 13 / 20082237$ & 27.8 & 1007.2 \\
\hline 4704 & $1 / 13 / 20082239$ & $8 / 13 / 20082239$ & 27.8 & 1004.3 \\
\hline 4705 & $1 / 13 / 20082241$ & $8 / 13 / 20082244$ & 27.8 & 1006.4 \\
\hline 4706 & $1 / 13 / 20082244$ & $8 / 13 / 20082243$ & 27.7 & 1005.9 \\
\hline 4707 & $1 / 13 / 20082245$ & $8 / 13220082245$ & 27.6 & 1001.7 \\
\hline 4708 & $1 / 13 / 20082247$ & $8 / 13 / 200822: 47$ & 27.5 & 1004.5 \\
\hline 4709 & $1 / 13 / 20082240$ & $8 / 13 / 20082249$ & 27.5 & 1004.5 \\
\hline 4710 & $1 / 43 / 20082251$ & $8 / 13 / 20082251$ & 27.4 & 1004.5 \\
\hline 4711 & $1 / 13 / 2008225$ & $8 / 1320082253$ & 27.4 & 1004.8 \\
\hline 4712 & $1 / 13 / 20082255$ & $8 / 13 / 20082250$ & 27.4 & 1007.8 \\
\hline 4713 & $1 / 13 / 2008225$ & $8 / 13 / 2008225$ & 27.3 & 1004.8 \\
\hline 4714 & $1 / 13 / 2008225$ & $8 / 13 / 20082259$ & 27.3 & 1006.3 \\
\hline 4715 & $1 / 13 / 2008223: 01$ & $8 / 13 / 200823: 01$ & 27.2 & 1004.3 \\
\hline 4716 & $1 / 13 / 200823: 00$ & $8 / 13 / 200823: 03$ & 27.2 & 1006.7 \\
\hline 4717 & 1/13/200823:06 & \begin{tabular}{|l|}
$8 / 13 / 200823: 06$ \\
\end{tabular} & 27.1 & 1004.1 \\
\hline 4718 & $1 / 13 / 200823: 07$ & $8 / 13200823: 07$ & 27.1 & 1004.8 \\
\hline 4719 & $1 / 13 / 200823: 08$ & $8 / 13 / 200823: 09$ & 27 & 1004.9 \\
\hline 4720 & 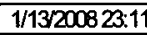 & $8 / 13 / 200823: 11$ & 26.9 & 1005.2 \\
\hline 4721 & $1 / 13 / 200823: 13$ & $8 / 13200823: 13$ & 26.9 & 1004.9 \\
\hline 4722 & $1 / 13 / 200822: 15$ & $8 / 13 / 200823: 15$ & 26.9 & 1003.5 \\
\hline 4723 & $1 / 13 / 200823: 17$ & \begin{tabular}{|l|}
$8 / 13 / 200823: 17$ \\
\end{tabular} & 26.9 & 1006.3 \\
\hline 4724 & $1 / 13 / 200823: 19$ & $8 / 13 / 200823: 19$ & 26.8 & 1005.7 \\
\hline 4725 & $1 / 13 / 200823: 21$ & $8 / 13 / 200823: 21$ & 26.7 & 1005.5 \\
\hline 4726 & $1 / 13 / 200823: 22$ & $8 / 13 / 200823: 23$ & 26.7 & 1005.9 \\
\hline 4727 & $1 / 13 / 200823: 25$ & $8 / 13200823: 25$ & 26.7 & 1008.3 \\
\hline 4728 & $1 / 13 / 200823: 2$ & $8 / 13 / 200823: 27$ & 26.7 & 1007.2 \\
\hline 4729 & $1 / 13 / 200823: 2$ & $8 / 13 / 200823: 29$ & 26.7 & 1007.4 \\
\hline 4730 & $1 / 13 / 200823: 31$ & $8 / 13 / 200823: 31$ & 26.7 & 1007.1 \\
\hline 4731 & $1 / 13 / 200823: 33$ & $8 / 13 / 200823: 33$ & 26.7 & 1007.6 \\
\hline 4732 & $1 / 13 / 200823: 36$ & $8 / 13 / 200823: 35$ & 26.7 & 1008 \\
\hline 4733 & $1 / 13 / 200823: 37$ & $8 / 13200823: 37$ & 26.7 & 1007.4 \\
\hline 4734 & $1 / 13 / 200823: 3$ & \begin{tabular}{|l|}
$8 / 13 / 200823: 39$ \\
\end{tabular} & 26.8 & 1008.1 \\
\hline 4735 & $1 / 13 / 200823: 4$ & $8 / 13 / 200823: 41$ & 26.8 & 1007 \\
\hline 4736 & $1 / 13 / 200823: 4^{12}$ & $8 / 13 / 200823: 43$ & 26.7 & 1007.3 \\
\hline 4737 & $1 / 13 / 200823: 45$ & $8 / 13200823: 45$ & 26.7 & 1006.9 \\
\hline 4738 & $1 / 13 / 200823: 47$ & $8 / 13200823: 47$ & 26.7 & 1008.6 \\
\hline 4739 & $1 / 13200823: 40$ & $8 / 13 / 200823: 49$ & 26.7 & 1006.6 \\
\hline 4740 & $1 / 13 / 200823: 51$ & $8 / 13 / 200823: 51$ & 26.7 & 1006.5 \\
\hline 4741 & $1 / 13 / 200823: 5$ & $8 / 13 / 200823: 53$ & 26.7 & 10066 \\
\hline 4742 & $1 / 13 / 200823: 55$ & $8 / 132200823: 56$ & 26.7 & 1006 \\
\hline 4743 & $1 / 13 / 200823: 5$ & $8 / 13 / 200823: 57$ & 26.7 & 10065 \\
\hline 4744 & $1 / 13 / 200823.50$ & $8 / 132008$ 23:59 & 26.7 & 1005 \\
\hline 4745 & $1 / 14 / 20080.01$ & $8 / 14 / 20080: 01$ & 26.7 & 10061 \\
\hline 4746 & $1 / 14 / 20080: 00$ & $8 / 14 / 20080: 03$ & 26.6 & 1005.2 \\
\hline 4747 & $1 / 14 / 20080.05$ & $8 / 14 / 20080.06$ & 26.6 & 1005.2 \\
\hline 4748 & $1 / 14 / 20080: 07$ & $8 / 14 / 20080: 07$ & 26.6 & 1005.1 \\
\hline 4749 & $1 / 14 / 2008000$ & $8 / 1420080: 09$ & 26.6 & 1004.5 \\
\hline 4750 & $1 / 1420080.11$ & $8 / 14 / 20080: 11$ & 26.6 & 1004.7 \\
\hline 4751 & $1 / 14 / 20080: 13$ & 8/14/20080:13 & 26.6 & 10039 \\
\hline 4752 & $1 / 14 / 20080.15$ & $8 / 14 / 20080: 15$ & 26.6 & 10023 \\
\hline 4753 & $1 / 14 / 20080: 17$ & $8 / 1420080: 17$ & 26.6 & 10028 \\
\hline 4754 & $1 / 14 / 20080.19$ & $8 / 14 / 20080: 19$ & 26.5 & 10021 \\
\hline 4755 & $1 / 14 / 20080.21$ & $8 / 1420080: 21$ & 26.5 & 10029 \\
\hline 4756 & $1 / 14 / 20080: 23$ & $8 / 14 / 20080.23$ & 26.5 & 10029 \\
\hline 4757 & $1 / 14 / 20080.25$ & $8 / 14 / 20080.25$ & 26.5 & 1000.8 \\
\hline 4758 & $1 / 14 / 20080.27$ & $8 / 14 / 20080.27$ & 26.5 & 1000.4 \\
\hline 4759 & $1 / 14 / 20080.20$ & $8 / 14 / 20080: 29$ & 26.5 & 1000.5 \\
\hline 4760 & $1 / 14 / 20080: 31$ & $8 / 14 / 20080: 31$ & 26.5 & 999.9 \\
\hline
\end{tabular}




\begin{tabular}{|c|c|c|c|c|}
\hline \multicolumn{5}{|c|}{$D 493 c$} \\
\hline Rec & & Adusted & Temp & SC \\
\hline$\#$ & DaterTime & DaterTime & $\propto$ & $\mu \mathrm{s} / \mathrm{cm}$ \\
\hline 4761 & $1 / 14 / 20080: 33$ & $8 / 14 / 20080.33$ & 26.5 & 999. \\
\hline 4762 & $1 / 14 / 20080: 35$ & $8 / 14 / 20080: 35$ & 26.5 & 1000 \\
\hline 4763 & $1 / 14 / 20080: 37$ & $8 / 14 / 20080: 37$ & 26.5 & 998.5 \\
\hline 4764 & 1/14/20080:39 & $8 / 14 / 20080.39$ & 26.5 & \\
\hline 4765 & $1 / 14 / 20080.41$ & $8 / 14 / 20080: 41$ & 26.4 & 999. \\
\hline 4766 & $1 / 14 / 20080: 43$ & $8 / 14 / 20080: 43$ & 26.4 & 99 \\
\hline 4767 & $1 / 1420080.45$ & $8 / 14 / 20080.45$ & 26.4 & 997. \\
\hline 4768 & $1 / 14 / 20080: 47$ & $8 / 14 / 20080: 47$ & 26.5 & 996. \\
\hline 476 & $1 / 14 / 20080: 49$ & $8 / 14 / 20080: 49$ & 26.5 & 997. \\
\hline $47 \pi$ & $1 / 14 / 20080: 51$ & $8 / 14 / 20080: 51$ & 26.5 & 99 \\
\hline 4771 & $1 / 14 / 20080.53$ & $8 / 14 / 20080.53$ & 26.5 & 995 \\
\hline 4772 & $1 / 14 / 20080.55$ & $8 / 14 / 20080: 55$ & 26.4 & 995. \\
\hline 4773 & $1 / 14 / 20080: 57$ & $8 / 14 / 20000.57$ & 26.4 & 996. \\
\hline 4774 & $1 / 14 / 20080.50$ & $8 / 14 / 20080.59$ & 26.4 & 99 \\
\hline 4775 & $1 / 14 / 20$ & $8 / 14 / 200$ & 26.4 & 995. \\
\hline 4776 & $1 / 14 / 20$ & $8 / 14 / 20081: 03$ & 26.4 & 994. \\
\hline $47 \pi$ & $1 / 14 / 2$ & $8 / 14 / 20081: 05$ & 26.4 & 995 \\
\hline 4778 & 1/14/2008 1:07 & $8 / 14 / 20081: 07$ & 26.4 & 994 \\
\hline $47 \pi 9$ & 1/14/2008 1:09 & $8 / 14 / 20081: 09$ & 26.4 & 992 \\
\hline 4780 & $1 / 14 / 2$ & $8 / 14 / 2$ & 26.3 & 994. \\
\hline 4781 & $1 / 14 / 20$ & $8 / 14 / 2$ & 26.4 & 993 \\
\hline 4782 & $1 / 14$ & $8 / 14 / 20$ & 26.4 & 993. \\
\hline 4783 & $1 / 14 / 200$ & $8 / 14 / 20081: 17$ & 26.4 & \\
\hline 4784 & $1 / 14 / 2008$ 1:19 & 8/14/20081:19 & 26.3 & 993. \\
\hline 4785 & $1 / 14$ & $1: 21$ & 26.3 & 990. \\
\hline 4786 & $1 / 14$ & $8 / 14 /$ & 26.4 & 99 \\
\hline 4787 & $1 / 14 / 2$ & $8 / 14 / 20$ & 26.4 & 969. \\
\hline 4788 & $1 / 14 / 20$ & $8 / 14 / 20081: 27$ & 26.3 & 969. \\
\hline 4789 & $1 / 14 / 200$ & $8 / 14 / 20081: 29$ & 26.3 & 990. \\
\hline 4790 & $1 / 14$ & $8 / 14$ & 26.3 & 990. \\
\hline 4791 & $1 / 14 / 2$ & $8 / 14 / 20$ & 26.3 & 969 \\
\hline 4792 & $1 / 14$ & $8 / 14 / 2$ & 26.3 & 990 \\
\hline 4793 & 1/14/20081:37 & $8 / 14 / 20081: 37$ & 26.3 & \\
\hline 4794 & 1/14/20081:39 & $8 / 14 / 20081: 39$ & 26.2 & 969. \\
\hline 4796 & $1 / 14$ & 1:41 & 26.2 & 969. \\
\hline 4796 & $1 / 14 / 2$ & $8 / 14 / 2$ & 26.2 & 969. \\
\hline 4797 & $1 / 14$ & $8 / 14 / 20081: 45$ & 26.2 & 980 \\
\hline 4798 & $1 / 14 / 20$ & $8 / 14 / 20081: 47$ & 26.2 & 969. \\
\hline 4799 & $1 / 14 / 20$ & $8 / 14 / 20081: 49$ & 26.3 & 986 . \\
\hline 4800 & $1 / 14$ & 1:51 & 26.3 & 987. \\
\hline 4801 & $1 / 14$ & 8114 & 26.3 & 968 \\
\hline 4802 & $1 / 14$ & $8 / 14 / 20081: 55$ & 26.2 & 967 \\
\hline 4803 & $1 / 14 / 20081: 5$ & $8 / 14 / 20081: 57$ & 26.2 & 98 \\
\hline 4804 & $1 / 14 / 20081: 59$ & $8 / 14 / 20081: 50$ & 26.2 & 9 \\
\hline 305 & $1 / 14$ & 8201 & 26.2 & 987 \\
\hline 4806 & $1 / 14 / 2$ & $8 / 14 / 2008203$ & 26.2 & 987 \\
\hline 4807 & $1 / 14$ & $8 / 14 / 2008205$ & 26.2 & 987 \\
\hline 4808 & $1 / 14 / 20$ & $8 / 14 / 20082007$ & 26.1 & 987 \\
\hline 4809 & $1 / 14$ & 2008209 & 26.2 & 986 \\
\hline 4810 & & $2: 11$ & 26.1 & \\
\hline & & 8213 & 26.1 & \\
\hline 4812 & $1 / 14 / 2008215$ & $8 / 14 / 2008215$ & 26.1 & 985 \\
\hline 4813 & $1 / 14 / 20082: 17$ & $8 / 14 / 2008217$ & 26.1 & 986 \\
\hline 4814 & & 8219 & 26.1 & 965 \\
\hline 4815 & $1 / 14$ & 221 & 26.3 & 984 \\
\hline 4816 & $1 / 14$ & 008223 & 26.2 & 984 \\
\hline 4817 & $1 / 14 / 20$ & $8 / 14 / 2008225$ & 26.1 & 984 \\
\hline 4818 & $1 / 14 / 2$ & $8 / 14 / 20082: 27$ & 26.1 & 985 \\
\hline 4819 & $1 / 14 / 2$ & $8 / 14 / 20082229$ & 26.1 & 98 \\
\hline 320 & $1 / 14 / 2$ & $8 / 14 / 2008233$ & 26.7 & 968 \\
\hline 4821 & & $8 / 14 / 2008233$ & 25.3 & \\
\hline 4822 & $1 / 14 / 2008235$ & $8 / 14 / 2008235$ & 25.4 & 9 \\
\hline 4823 & $1 / 14 / 20082.37$ & $8 / 14 / 2008237$ & 25.7 & 937 \\
\hline 4824 & $1 / 14 / 20$ & $8 / 14 / 20082: 39$ & 25.8 & 9 \\
\hline 4825 & $1 / 14 / 20082: 41$ & $8 / 14 / 2008241$ & 25.9 & $\overline{9}$ \\
\hline 4826 & & $8 / 14 / 2008243$ & 25.9 & \\
\hline 4827 & $1 / 14 / 2008245$ & $8 / 14 / 2008245$ & 25.9 & 943 \\
\hline 4828 & $1 / 14 / 2008247$ & $8 / 14 / 2008247$ & 25.8 & \\
\hline 4829 & $1 / 14 / 2008249$ & $8 / 14 / 2008249$ & 25.8 & \\
\hline
\end{tabular}

\begin{tabular}{|c|c|c|c|c|}
\hline \multicolumn{5}{|c|}{ D493c } \\
\hline $\mathrm{Rec}$ & & Adusted & Temp & $S C$ \\
\hline$\#$ & DeterTime & DaterTime & $\infty$ & $\mu \mathrm{S} / \mathrm{am}$ \\
\hline 4830 & $1 / 14 / 2008251$ & $8 / 14 / 2008251$ & 25.7 & 9425 \\
\hline 4831 & $1 / 142008253$ & $8 / 14 / 2008253$ & 25.7 & 943 \\
\hline 4832 & $1 / 14 / 2008255$ & $8 / 14 / 2008255$ & 25.7 & 943 \\
\hline 4833 & $1 / 14 / 2008257$ & $8 / 14 / 2008257$ & 25.6 & 943.7 \\
\hline 4834 & $1 / 14 / 2008259$ & $8 / 14 / 2008259$ & 25.6 & 9425 \\
\hline 4835 & $1 / 14 / 20083: 01$ & $8 / 14 / 20083: 01$ & 25.6 & 941.1 \\
\hline 4836 & $1 / 14 / 20083: 03$ & $8 / 14 / 20083: 03$ & 25.5 & 9421 \\
\hline 4837 & $1 / 14 / 2008305$ & $8 / 14 / 20083: 05$ & 25.5 & 9427 \\
\hline 4838 & $1 / 14 / 20083: 07$ & $8 / 14 / 20083: 07$ & 25.4 & 943.5 \\
\hline 4839 & $1 / 14 / 20083: 09$ & $8 / 14 / 20083: 09$ & 25.4 & 943.3 \\
\hline 4840 & $1 / 14 / 20083: 11$ & 8/14/20083:11 & 25.4 & 944.2 \\
\hline 4841 & $1 / 14 / 20083: 13$ & $8 / 14 / 20083: 13$ & 25.4 & 944.2 \\
\hline 4842 & $1 / 14 / 20083: 15$ & $8 / 14 / 20083: 15$ & 25.5 & 944.1 \\
\hline 4843 & 1/14/20083:17 & $8 / 14 / 20083: 17$ & 255 & 944.1 \\
\hline 4844 & $1 / 14 / 20083: 19$ & 8/14/20083:19 & 25.5 & 944.9 \\
\hline 4845 & $1 / 14 / 20083: 21$ & $8 / 14 / 20083: 21$ & 25.5 & 944.5 \\
\hline 4846 & $1 / 14 / 20083.23$ & $8 / 14 / 20083: 23$ & 25.5 & 945.7 \\
\hline 4847 & 1/14/20083:25 & $8 / 14 / 20083: 25$ & 25.5 & 944.4 \\
\hline 4848 & $1 / 14 / 20083: 27$ & $8 / 14 / 20083: 27$ & 25.6 & 944.6 \\
\hline 4849 & $1 / 14 / 2008322$ & $8 / 14 / 20083: 29$ & 25.6 & 943.8 \\
\hline 4850 & $1 / 14 / 20083331$ & $8 / 14 / 20083: 31$ & 25.6 & 944.1 \\
\hline 4851 & $1 / 14 / 20083: 33$ & $8 / 14 / 20083: 33$ & 25.6 & 944.1 \\
\hline 4852 & $1 / 14 / 20083: 35$ & $8 / 14 / 20083: 35$ & 25.7 & 944 \\
\hline 4853 & $1 / 14 / 20083: 37$ & $8 / 14 / 20083: 37$ & 25.7 & 943.4 \\
\hline 4854 & $1 / 14 / 20083.39$ & $8 / 14 / 20083: 39$ & 25.7 & 943.8 \\
\hline 4855 & $1 / 14 / 20083: 41$ & $8 / 14 / 20083: 41$ & 25.7 & 944.3 \\
\hline 4856 & $1 / 14 / 20083: 43$ & $8 / 14 / 20083: 43$ & 25.7 & 943.8 \\
\hline 4857 & $1 / 14 / 20083.45$ & $8 / 14 / 20083: 45$ & 25.7 & 944.1 \\
\hline 4858 & $1 / 14 / 20083447$ & $8 / 14 / 20083: 47$ & 25.7 & 944.2 \\
\hline 4859 & $1 / 14 / 20083: 49$ & $8 / 14 / 20083: 49$ & 25.7 & 944.6 \\
\hline 4860 & $1 / 14 / 20083: 51$ & $8 / 14 / 20083: 51$ & 25.7 & 944.6 \\
\hline 4861 & $1 / 14 / 20083.53$ & $8 / 14 / 20083: 53$ & 25.7 & 943.9 \\
\hline 4862 & $1 / 14 / 20083.55$ & $8 / 14 / 20083: 50$ & 25.7 & 944.1 \\
\hline 4863 & $1 / 14 / 20083.57$ & $8 / 14 / 20083: 57$ & 25.6 & 941.9 \\
\hline 4864 & $1 / 14 / 20083.59$ & $8 / 14 / 20083.59$ & 25.7 & 944.8 \\
\hline 4865 & $1 / 14 / 20084: 01$ & $8 / 14 / 20084: 01$ & 25.7 & 944.8 \\
\hline 4866 & 1/14/20084:03 & $8 / 14 / 20084: 03$ & 25.7 & 944.9 \\
\hline 4867 & $1 / 14 / 20084: 05$ & $8 / 14 / 20084: 05$ & 25.7 & 944.5 \\
\hline 4868 & $1 / 14 / 20084: 07$ & $8 / 14 / 20084: 07$ & 25.6 & 944.5 \\
\hline 4869 & $1 / 14 / 20084: 09$ & $8 / 14 / 20084: 09$ & 25.6 & 945.1 \\
\hline 4870 & 1/14/20084:11 & $8 / 14 / 20084: 11$ & 25.6 & 944.9 \\
\hline 4871 & 1/14/20084:13 & $8 / 14 / 20084: 13$ & 25.6 & 945 \\
\hline 4872 & $1 / 14 / 20084: 15$ & $8 / 14 / 20084: 15$ & 257 & 944.9 \\
\hline 4873 & 1/14/20084:17 & $8 / 14 / 20084: 17$ & 25.7 & 943.8 \\
\hline 4874 & $1 / 14 / 20084: 19$ & $8 / 14 / 20084: 19$ & 25.7 & 944.9 \\
\hline 4875 & $1 / 14 / 20084: 21$ & $8 / 14 / 20084: 21$ & 25.6 & 944.3 \\
\hline 4876 & $1 / 14 / 20084: 23$ & $8 / 14 / 20084: 23$ & 256 & 945 \\
\hline 4877 & $1 / 14 / 20084: 25$ & $8 / 14 / 20084: 25$ & 25.6 & 944.6 \\
\hline 4878 & $1 / 14 / 20084: 27$ & $8 / 14 / 20084: 27$ & 25.6 & 944.9 \\
\hline 4879 & $1 / 14 / 20084: 29$ & $8 / 14 / 20084: 29$ & 25.6 & 944.4 \\
\hline 4880 & $1 / 14 / 20084: 31$ & $8 / 14 / 20084: 31$ & 25.6 & 943.9 \\
\hline 4881 & $1 / 14 / 20084: 33$ & $8 / 14 / 20084: 33$ & 25.6 & 944.5 \\
\hline 4882 & $1 / 14 / 20084: 35$ & $8 / 14 / 20084: 35$ & 25.6 & 944.3 \\
\hline 4883 & $1 / 14 / 20084: 37$ & $8 / 14 / 20084: 37$ & 25.6 & 944.9 \\
\hline 4884 & $1 / 14 / 20084: 39$ & $8 / 14 / 20084: 39$ & 25.6 & 942 \\
\hline 4885 & $1 / 14 / 20084: 41$ & $8 / 14 / 20084: 41$ & 25.6 & 943.9 \\
\hline 4886 & $1 / 14 / 20084: 43$ & $8 / 14 / 20084: 43$ & 25.6 & 944.6 \\
\hline 4887 & $1 / 14 / 20084: 45$ & $8 / 14 / 20084: 45$ & 25.6 & 9425 \\
\hline 4888 & $1 / 14 / 20084: 47$ & $8 / 14 / 20084: 47$ & 25.7 & 944.6 \\
\hline 4889 & $1 / 14 / 20084: 49$ & $8 / 1420084: 49$ & 25.6 & 943.5 \\
\hline 4890 & $1 / 14 / 20084: 51$ & $8 / 14 / 20084: 51$ & 25.6 & 944.5 \\
\hline 4891 & $1 / 14 / 20084: 53$ & $8 / 14 / 20084: 53$ & 25.6 & 944.9 \\
\hline 4898 & $1 / 14 / 20084: 55$ & $8 / 14 / 20084: 55$ & 25.6 & 944.8 \\
\hline 4893 & $1 / 14 / 20084: 57$ & $8 / 14 / 20084: 57$ & 25.6 & 944.9 \\
\hline 4894 & $1 / 14 / 20084: 59$ & $8 / 14 / 20084: 50$ & 25.6 & 944.5 \\
\hline 4896 & $1 / 14 / 20085: 01$ & $8 / 14 / 20085: 01$ & 25.6 & 944.5 \\
\hline 4896 & $1 / 14 / 20085: 03$ & $8 / 14 / 20085: 03$ & 25.6 & 944.6 \\
\hline 4897 & $1 / 14 / 20085: 05$ & $8 / 14 / 20085: 05$ & 25.6 & 944.7 \\
\hline 4898 & $1 / 14 / 20085: 07$ & $8 / 14 / 20085: 07$ & 25.6 & 944.7 \\
\hline
\end{tabular}

\begin{tabular}{|c|c|c|c|c|}
\hline \multicolumn{5}{|c|}{$D 4-93 c$} \\
\hline $\mathrm{Pec}$ & & Adjusted & Terp & SC \\
\hline \# & DaterTime & DaterTime & $\propto$ & $\mu \mathrm{s} / \mathrm{cm}$ \\
\hline 4899 & $1 / 14 / 20085: 09$ & $8 / 1420085: 09$ & 25.6 & 9456 \\
\hline 4900 & 1/14/20085:1 & $8 / 14 / 20085: 11$ & 25.6 & 944.7 \\
\hline 4901 & $1 / 14 / 20085: 13$ & $8 / 14 / 20085: 13$ & 25.6 & 944.6 \\
\hline 4902 & 1/14/20085:15 & $8 / 14 / 20085: 15$ & 25.6 & 944.5 \\
\hline 4903 & 1/14/20085:17 & $8 / 14 / 20085: 17$ & 25.9 & 941.4 \\
\hline 4904 & $1 / 14 / 20085: 19$ & $8 / 14 / 20085: 19$ & 25.8 & 941.8 \\
\hline 4905 & $1 / 14 / 20085: 21$ & $8 / 14 / 20085: 21$ & 259 & 943.9 \\
\hline 4906 & $1 / 14 \sqrt{20085: 23}$ & $8 / 14 / 20085: 23$ & 25.9 & 945.5 \\
\hline 4907 & $1 / 1420085: 25$ & $8 / 1420085: 25$ & 25.9 & 945.3 \\
\hline 4908 & $1 / 14 / 20085: 27$ & $8 / 14 / 20085: 27$ & 25.9 & 944.2 \\
\hline 4909 & $1 / 14 / 20085: 29$ & $8 / 14 / 20085: 29$ & 25.8 & 945 \\
\hline 4910 & 1/14/20085:31 & $8 / 14 / 20085: 31$ & 25.8 & 944.8 \\
\hline 4911 & $1 / 14 / 20085: 33$ & 8/14/20085:33 & 25.8 & 944.8 \\
\hline 4912 & $1 / 14 / 20085: 35$ & $8 / 14 / 20085: 35$ & 25.8 & 944.6 \\
\hline 4913 & $1 / 14 / 20085: 37$ & $8 / 1420085: 37$ & 25.7 & 945.1 \\
\hline 4914 & $1 / 14 / 20085: 39$ & $8 / 14 / 20085: 39$ & 25.7 & 944.8 \\
\hline 4915 & $1 / 14 / 20085441$ & $8 / 14 / 20085: 41$ & 25.7 & 945 \\
\hline 4916 & $1 / 14 / 20085: 43$ & $8 / 14 / 20085: 43$ & 25.7 & 944.7 \\
\hline 4917 & $1 / 14 / 20085445$ & $8 / 14 / 20085: 45$ & 25.7 & 944.7 \\
\hline 4918 & $1 / 14 / 2008544$ & $8 / 14 / 20085: 47$ & 25.7 & 945.2 \\
\hline 4919 & $1 / 14 / 20085: 49$ & $8 / 14 / 20085: 49$ & 25.7 & 945.2 \\
\hline 4920 & $1 / 14 / 20085: 51$ & $8 / 14 / 20085: 51$ & 25.7 & 945.1 \\
\hline 4921 & $1 / 14 / 20085: 53$ & $8 / 14 / 20085: 53$ & 25.7 & 944.8 \\
\hline 4922 & $1 / 14 / 2008555$ & $8 / 14 / 20085: 55$ & 25.7 & 945.2 \\
\hline 4923 & $1 / 14 / 20085: 57$ & $8 / 1420085: 57$ & 25.7 & 944.4 \\
\hline 4924 & $1 / 14 / 20085: 59$ & $8 / 14 / 20085: 50$ & 25.7 & 944.3 \\
\hline 4925 & $1 / 14 / 20086: 01$ & $8 / 14 / 20086: 01$ & 25.7 & 944.7 \\
\hline 4926 & $1 / 14 / 20086003$ & $8 / 14 / 20086: 03$ & 25.8 & 943.5 \\
\hline 4927 & $1 / 14 / 20086: 05$ & $8 / 14 / 20086: 05$ & 25.8 & 9443 \\
\hline 4928 & $1 / 14 / 20086: 07$ & $8 / 14 / 20086: 07$ & 25.8 & 944.6 \\
\hline 4929 & $1 / 14 / 20086: 00$ & $8 / 14 / 20086: 09$ & 25.7 & 944.1 \\
\hline 4930 & 1/14/20086:11 & $8 / 14 / 20086: 11$ & 25.7 & 944 \\
\hline 4931 & t/14/20086:13 & $8 / 14 / 20086: 13$ & 25.6 & 944.7 \\
\hline 4932 & $1 / 14 / 20086: 15$ & $8 / 1420086: 15$ & 25.6 & 944.8 \\
\hline 4933 & $1 / 14 / 20086: 17$ & $8 / 14 / 20086: 17$ & 256 & 943.5 \\
\hline 4934 & 1/14/20086:19 & $8 / 14 / 20086: 19$ & 25.6 & 943.7 \\
\hline 4935 & $1 / 14 / 20086: 21$ & $8 / 14 / 20086: 21$ & 25.5 & 9427 \\
\hline 4936 & $1 / 14 / 20086: 23$ & $8 / 14 / 20086: 23$ & 25.6 & 944.6 \\
\hline 4937 & $1 / 14 / 20086: 25$ & $8 / 14 / 20086: 25$ & 25.7 & 944.4 \\
\hline 4938 & $1 / 14 / 20086.27$ & $8 / 14 / 20086: 27$ & 25.7 & 9428 \\
\hline 4939 & $1 / 1420086: 29$ & $8 / 1420086: 20$ & 25.7 & 945.5 \\
\hline 4940 & $1 / 14 / 20086: 31$ & $8 / 14 / 20086: 31$ & 25.7 & 945 \\
\hline 4941 & $1 / 14 / 20086: 33$ & $8 / 14 / 20086: 33$ & 25.8 & 945 \\
\hline 4942 & $1 / 14 / 20086: 35$ & $8 / 14 / 20086: 35$ & 26.2 & 946.6 \\
\hline 4943 & $1 / 14 / 20086: 37$ & $8 / 14 / 20086: 37$ & 25.9 & 961.1 \\
\hline 4944 & $1 / 14 / 20086: 39$ & $8 / 14 / 20086: 39$ & 25.9 & 961.4 \\
\hline 4945 & $1 / 14 / 20086: 41$ & $8 / 14 / 20086: 41$ & 25.8 & 963.5 \\
\hline 4946 & $1 / 14 / 20086443$ & $8 / 14 / 20086: 43$ & 25.7 & 963.3 \\
\hline 4947 & $1 / 14 / 20086: 45$ & $8 / 14 / 20086: 45$ & 25.7 & 964.7 \\
\hline 4948 & $1 / 14 / 20086: 47$ & $8 / 14 / 20086: 47$ & 25.7 & 964.9 \\
\hline 4949 & $1 / 14 / 20086: 49$ & $8 / 14 / 20086: 49$ & 25.7 & 964.6 \\
\hline 4950 & $1 / 14 / 20086551$ & $8 / 14 / 20086: 51$ & 25.6 & 965.3 \\
\hline 4051 & $1 / 14 / 20086: 53$ & $8 / 14 / 20086: 53$ & 25.6 & 964.9 \\
\hline 4952 & $1 / 14 / 20086: 55$ & $8 / 14 / 20066: 55$ & 25.6 & 966.4 \\
\hline 4953 & $1 / 14 / 20086: 57$ & $8 / 14 / 20086: 57$ & 25.5 & 964.7 \\
\hline 4954 & $1 / 14 / 20086: 59$ & $8 / 14 / 20086.59$ & 25.5 & 965.8 \\
\hline 4955 & $1 / 14 / 20087: 01$ & $8 / 14 / 20087: 01$ & 25.5 & 965.1 \\
\hline 4956 & $1 / 14 / 20087: 03$ & $8 / 14 / 20087: 03$ & 25.4 & 965.1 \\
\hline 4957 & $1 / 14 / 20087: 06$ & $8 / 14 / 20087: 05$ & 25.4 & 962 \\
\hline 4058 & $1 / 14 / 20087: 07$ & $8 / 14 / 20087: 07$ & 25.4 & 961.2 \\
\hline 4950 & 1/14/2008 7:09 & $8 / 14 / 20087: 09$ & 25.4 & 960.5 \\
\hline 4980 & $1 / 14 / 20087: 11$ & $8 / 14 / 20087: 11$ & 25.3 & 964.3 \\
\hline 4961 & 1/14/20087:13 & $8 / 14 / 20087: 13$ & 25.3 & 963.5 \\
\hline 4962 & $1 / 14 / 20087: 15$ & $8 / 14 / 20087: 15$ & 25.3 & 964.4 \\
\hline 4963 & $1 / 14 / 20087: 17$ & $8 / 14 / 20087: 17$ & 25.3 & 964.5 \\
\hline 4964 & $1 / 14 / 20087: 19$ & $8 / 14 / 20087: 19$ & 25.3 & 965.5 \\
\hline 4965 & 1/14/20087:21 & $8 / 1420087: 21$ & 25.2 & 967.2 \\
\hline 4966 & $1 / 1420087: 23$ & $8 / 14 / 20087: 23$ & 25.2 & 966.1 \\
\hline 4967 & 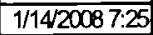 & $8 / 14 / 20087: 25$ & 25.2 & 966.8 \\
\hline
\end{tabular}


DOE/RL-2009-35, REV. 0

\begin{tabular}{|c|c|c|c|c|}
\hline \multicolumn{5}{|c|}{ D4-93c } \\
\hline Rec & & Adusted & Temp & $S C$ \\
\hline$\#$ & Date/Time & Date/Time & $\alpha$ & $\mu \mathrm{S} / \mathrm{cm}$ \\
\hline 4968 & 1/14/20087:27 & $8 / 14 / 20087: 27$ & 25.2 & 963.1 \\
\hline 4969 & $1 / 14 / 20087: 29$ & $8 / 14 / 20087: 29$ & 25.2 & 966.9 \\
\hline 4970 & $1 / 14 / 20087: 31$ & $8 / 14 / 20087: 31$ & 25.2 & 967.8 \\
\hline 4971 & $1 / 14 / 20087: 33$ & 8/14/20087:33 & 25.2 & 967.8 \\
\hline 4972 & $1 / 14 / 20087: 35$ & $8 / 14 / 20087: 35$ & 25.2 & \\
\hline 4973 & $1 / 14 / 20087: 37$ & $8 / 14 / 20087: 37$ & 25.2 & 968.6 \\
\hline 4974 & $1 / 14 / 20087: 39$ & 8/14/20087:39 & 25.2 & 969.3 \\
\hline 4975 & $1 / 14 / 20087: 41$ & $8 / 14 / 20087: 41$ & 25.2 & 970.2 \\
\hline 4976 & $1 / 14 / 20087: 43$ & $8 / 14 / 20087: 43$ & 25.2 & 969.9 \\
\hline 4977 & $1 / 14 / 20087: 45$ & $8 / 14 / 20087: 45$ & 25.1 & 969.9 \\
\hline 4978 & $1 / 14 / 20087: 47$ & $8 / 14 / 20087: 47$ & 25.2 & 969.7 \\
\hline 4979 & $1 / 14 / 2$ & $8 / 14 / 20087: 49$ & 25.1 & 969.8 \\
\hline 4980 & $1 / 14 / 2$ & $8 / 14 / 20087: 51$ & 25.1 & 971 \\
\hline 4981 & $1 / 14 / 2$ & $8 / 14 / 20087: 53$ & 25.1 & 970.5 \\
\hline 4982 & $1 / 14 / 2$ & $8 / 14 / 20087: 55$ & 25.1 & 970.4 \\
\hline 4983 & $1 / 14 / 2$ & $8 / 14 / 20087: 57$ & 25.1 & \\
\hline 4984 & $1 / 14 / 2$ & $8 / 14 / 20087: 59$ & 25.1 & 971. \\
\hline 4985 & $1 / 14 / 2$ & 8/14/2008 8:01 & 25.1 & 971.3 \\
\hline 4986 & $1 / 14 / 2$ & $8 / 14 / 200$ & 25.1 & 971.9 \\
\hline 4987 & $1 / 14 / 2$ & $8 / 14 / 20088: 05$ & 25.1 & 972 \\
\hline 4988 & $1 / 14 / 2$ & $8 / 14 / 20088: 07$ & 25.1 & 971.9 \\
\hline 4989 & $1 / 14 / 2$ & $8 / 14 / 20$ & 25 & 9726 \\
\hline 4990 & $1 / 14$ & $8 / 14 / 20$ & 25.1 & \\
\hline 4991 & $1 / 14 / 2$ & $8 / 14 / 20$ & 25.1 & 974.8 \\
\hline 4992 & $1 / 14 / 2$ & \begin{tabular}{|l|}
$8 / 14 / 20$ \\
\end{tabular} & 25.1 & 975.5 \\
\hline 4993 & $1 / 14 /$ & $8 / 14 / 20$ & 25.1 & 975.2 \\
\hline 4994 & $1 / 14 / 2$ & $8 / 14 / 200$ & 25.1 & 975. \\
\hline 4995 & $1 / 14 / 2$ & $8 / 14 / 2000$ & 25.1 & 976.8 \\
\hline 4996 & $1 / 14 / 2$ & $8 / 14 / 20$ & 25.1 & 976.7 \\
\hline 4997 & $1 / 14 / 2$ & 8/14/20088:25 & 25.2 & 976. \\
\hline 4998 & $1 / 14 / 2$ & 8/14/20088:27 & 25.2 & 976. \\
\hline 4999 & $1 / 14$ & $8 / 14 / 20$ & 25.2 & 976. \\
\hline 5000 & $1 / 14$ & $8 / 14 / 20$ & 25.2 & 976. \\
\hline 5001 & $1 / 14$ & $8 / 14 / 200$ & 25.2 & 97 \\
\hline 5002 & 1/14/ & $8 / 14 / 20$ & 25.2 & 975.6 \\
\hline 5003 & $1 / 14 /$ & $8 / 14 / 20$ & 25.2 & 976. \\
\hline 5004 & $1 / 14 / 2$ & 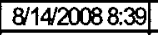 & 25.2 & 97 \\
\hline 5005 & $1 / 14 / 2$ & $8 / 14 / 200$ & 25.3 & 976. \\
\hline 5006 & $1 / 14$ & $8 / 14 / 2$ & 25.3 & 976. \\
\hline 5007 & $1 / 14$ & $8 / 14 / 20$ & 25.3 & 975. \\
\hline 5008 & $1 / 14$ & $8 / 14 / 20$ & 25.2 & 976.4 \\
\hline 5009 & & $8 / 14 / 2$ & 25.2 & 976. \\
\hline 5010 & & $8 / 14 / 20$ & 25.2 & 976. \\
\hline 5011 & $1 / 14$ & $8 / 14 / 20$ & 25.2 & 976.8 \\
\hline 5012 & & $8 / 14 / 20$ & 25.2 & 976. \\
\hline 5013 & & & 25.2 & 976. \\
\hline 5014 & $1 / 14$ & $8 / 14 / 20$ & 25.2 & 977.3 \\
\hline 5015 & & & 25.2 & 976.7 \\
\hline 5016 & & $8 / 14 / 20$ & 25.2 & 976. \\
\hline 5017 & $1 / 14 / 2$ & 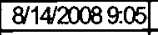 & 25.2 & 97 \\
\hline 5018 & & $8 / 14 / 200$ & 25.2 & 977. \\
\hline 5019 & & $8 / 14 / 20$ & 25.2 & 976. \\
\hline 5020 & $1 / 14 / 2$ & \begin{tabular}{|l|}
$8 / 14 / 20089: 11$ \\
\end{tabular} & 25.2 & 977. \\
\hline 5021 & & & 25.2 & 977. \\
\hline 5022 & & & 25.2 & \\
\hline 5023 & $1 / 14$ & $8 / 14 / 200$ & 25.2 & 977. \\
\hline 5024 & $1 / 14 / 2$ & $8 / 14 / 200$ & 25.2 & 977. \\
\hline 5025 & & $8 / 14 / 200$ & 25.2 & 977. \\
\hline 5026 & & $8 / 14 / 200$ & 25.2 & 976.5 \\
\hline 5027 & $1 / 14 / 20$ & 8/14/20089-25 & 25.2 & 978.1 \\
\hline 5028 & & $8 / 14 / 200$ & 25.2 & \\
\hline 5029 & & $8 / 14 / 20$ & 25.2 & 97. \\
\hline 5030 & $1 / 14 / 20$ & $8 / 14 / 20089.31$ & 25.2 & 97. \\
\hline 5031 & $1 / 14 / 20$ & 8/14/20089:33 & 25.2 & 976.2 \\
\hline 5032 & 39.35 & 8/14/20089:35 & 25.2 & 977. \\
\hline 5033 & $1 / 14 / 2$ & 8/14/20089:37 & 25.2 & 977. \\
\hline 5034 & 1/14/20089.39 & 8/14/20089:39 & 25.2 & \\
\hline 5035 & $1 / 14 / 20089: 41$ & $8 / 14 / 20089: 41$ & 25.3 & 97 \\
\hline 5036 & $1 / 14 / 20$ & $8 / 14 / 20089.43$ & 25.3 & 978.5 \\
\hline
\end{tabular}

\begin{tabular}{|c|c|c|c|c|}
\hline \multicolumn{5}{|c|}{$D 4-93 c$} \\
\hline $\operatorname{Rec}$ & & Adiusted & Temp & SC \\
\hline$\#$ & DaterTime & Date-Time & $\propto$ & $\mu \mathrm{S} / \mathrm{cm}$ \\
\hline 5037 & 1/14/20089:45 & $8 / 14 / 20089.45$ & 25.4 & 977.6 \\
\hline 5038 & 1/14/20089.47 & 8/14/20089:47 & 25.3 & 977.7 \\
\hline 5039 & $1 / 14 / 20089.49$ & $8 / 14 / 20089.49$ & 25.3 & 978 \\
\hline 5040 & 1/14/20089.51 & $8 / 14 / 20089: 51$ & 25.3 & 977.8 \\
\hline 5041 & $1 / 14 / 20089.53$ & $8 / 14 / 20089.53$ & 25.3 & 977.5 \\
\hline 5042 & 1/14/20089.55 & $8 / 14 / 20089.55$ & 25.3 & 978.8 \\
\hline 5043 & 1/14/20089.57 & $8 / 14 / 20089.57$ & 25.3 & 978.2 \\
\hline 5044 & 1/14/20089.59 & $8 / 14 / 20089.59$ & 25.3 & 978.2 \\
\hline 5045 & 1/14/2008 10:01 & 8/14/2008 10:01 & 25.3 & 978.5 \\
\hline 5046 & 1/14/2008 10:03 & 8/14/2008 10:03 & 25.3 & 978.8 \\
\hline 5047 & 1/14/2008 10:05 & 8/14/2008 10:05 & 25.5 & 988.9 \\
\hline 5048 & 1/14/2008 10:07 & 8/14/2008 10:07 & 26 & 984.9 \\
\hline 5049 & $1 / 14 / 200810: 09$ & $8 / 14 / 200810: 09$ & 25.8 & 6.5 \\
\hline 5050 & 1/14/2008 10:11 & $8 / 14 / 200810: 11$ & 25.5 & 968 \\
\hline 5051 & 1/14/2008 10:13 & 8/14/2008 10:13 & 25.4 & 970 \\
\hline 5052 & 1/14/2008 10:15 & \begin{tabular}{|l|}
$8 / 14 / 200810: 15$ \\
\end{tabular} & 25.4 & 967.6 \\
\hline 5053 & 1/14/2008 10:17 & \begin{tabular}{|l|}
$8 / 14 / 200810: 17$ \\
\end{tabular} & 25.3 & 963.6 \\
\hline 5054 & 1/14/2008 10:19 & \begin{tabular}{|l|}
$8 / 14 / 200810: 19$ \\
\end{tabular} & 25.3 & 961.6 \\
\hline 5055 & 1/14/2008 10:21 & \begin{tabular}{|l|}
$8 / 14 / 2008$ 10:21 \\
\end{tabular} & 25.3 & 960.2 \\
\hline 5056 & $1 / 14 / 200810: 23$ & $8 / 14 / 200810: 23$ & 25.3 & 958 \\
\hline 5057 & 1/14/2008 10:25 & \begin{tabular}{|l|}
$8 / 14 / 2008$ 10:25 \\
\end{tabular} & 25.3 & 958.6 \\
\hline 5058 & 1/14/2008 10:27 & 8/14/2008 10:27 & 25.3 & 956.3 \\
\hline 5059 & $1 / 14 / 200810: 29$ & $8 / 14 / 200810: 29$ & 25.3 & 955.1 \\
\hline 5060 & 1/14/2008 10:31 & 8/14/2008 10:31 & 25.2 & 952.4 \\
\hline 5061 & 1/14/2008 10:33 & $8 / 14 / 2008$ 10:33 & 25.2 & 9522 \\
\hline 5062 & $1 / 14 / 200810.35$ & $8 / 14 / 2008$ 10:35 & 25.2 & 949.9 \\
\hline 5063 & 1/14/2008 10:37 & \begin{tabular}{|l|l|}
$8 / 14 / 2008$ 10:37 \\
\end{tabular} & 25.2 & 948.9 \\
\hline 5064 & 1/14/2008 10:39 & $8 / 14 / 200810: 39$ & 25.2 & 945.8 \\
\hline 5065 & 1/14/2008 10:41 & 8/14/2008 10:41 & 25.1 & 947.7 \\
\hline 5066 & $1 / 14 / 200810: 43$ & 8/14/2008 10:43 & 25.1 & 946.5 \\
\hline 5067 & 1/14/2008 10:45 & $8 / 14 / 2008$ 10:45 & 25.1 & 946.4 \\
\hline 5068 & 1/14/2008 10:47 & 8/14/2008 10:47 & 25.1 & 944.9 \\
\hline 5069 & $1 / 14 / 200810.49$ & 8/14/2008 10:49 & 25.1 & 945.6 \\
\hline 5070 & 1/14/2008 10:51 & 8/14/2008 10:51 & 25.1 & 947.7 \\
\hline 5071 & 1/14/2008 10:53 & $8 / 14 / 200810: 53$ & 25.1 & 944.8 \\
\hline 5072 & 1/14/2008 10.55 & $8 / 14 / 200810.55$ & 25 & 945.4 \\
\hline 5073 & 1/14/2008 10:57 & 8/14/2008 10:57 & 25 & 944.3 \\
\hline 5074 & 810.59 & 8/14/2008 10:59 & 25 & 944.1 \\
\hline 5075 & 1/14/2008 11:01 & 8/14/2008 11:01 & 25 & 944.2 \\
\hline 5076 & 1/14/2008 11:03 & 8/14/2008 11:03 & 25 & 944.3 \\
\hline 5077 & 1/14/2008 11:05 & \begin{tabular}{|l|}
$8 / 14 / 200811: 05$ \\
\end{tabular} & 25 & 946.9 \\
\hline 5078 & 1/14/2008 11:07 & \begin{tabular}{|l|}
$8 / 14 / 2008$ 11:07 \\
\end{tabular} & 24.9 & 955.9 \\
\hline 5079 & 1/14/2008 11:09 & \begin{tabular}{|l|}
$8 / 14 / 200811: 09$ \\
\end{tabular} & 24.9 & 954 \\
\hline 5080 & 1/14/2008 11:11 & \begin{tabular}{|l|}
$8 / 14 / 2008$ 11:11 \\
\end{tabular} & 24.9 & 954.2 \\
\hline 5081 & 1/14/2008 11:13 & \begin{tabular}{|l|}
$8 / 14 / 200811: 13$ \\
\end{tabular} & 24.9 & 953.6 \\
\hline 5082 & 1/14/2008 11:15 & \begin{tabular}{|l|l|}
$8 / 14 / 200811: 15$ \\
\end{tabular} & 24.9 & 9528 \\
\hline 5083 & 1/14/2008 11:17 & \begin{tabular}{|l|}
$8 / 14 / 200811: 17$ \\
\end{tabular} & 24.8 & 953 \\
\hline 5084 & 1/14/2008 11:19 & \begin{tabular}{|l|}
$8 / 14 / 200811: 19$ \\
\end{tabular} & 24.8 & 951.5 \\
\hline 5085 & 1/14/2008 11:21 & $8 / 14 / 200811: 21$ & 24.8 & 952.1 \\
\hline 5086 & 1/14/2008 11:23 & $8 / 14 / 200811: 23$ & 24.8 & 951.8 \\
\hline 5087 & 1/14/2008 11:25 & \begin{tabular}{|l|}
$8 / 14 / 200811: 25$ \\
\end{tabular} & 24.8 & 951.4 \\
\hline 5088 & 1/14/2008 11:27 & $8 / 14 / 200811: 27$ & 24.8 & 951 \\
\hline 5089 & 1/14/2008 11:29 & 8/14/2008 11:20 & 24.7 & 950.6 \\
\hline 5090 & 1/14/2008 11:31 & 8/14/2008 11:31 & 24.7 & 952.6 \\
\hline 5001 & 1/14/2008 11:33 & $8 / 14 / 200811: 33$ & 24.7 & 952.3 \\
\hline 5092 & 1/14/2008 11:35 & 8/14/2008 11:35 & 24.7 & 9522 \\
\hline 5093 & 1/14/2008 11:37 & \begin{tabular}{|l|l|}
$8 / 14 / 200811: 37$ \\
\end{tabular} & 24.7 & 9521 \\
\hline 5094 & 1/14/2008 11:30 & 8/14/2008 11:39 & 24.7 & 951.6 \\
\hline 5095 & 1/14/2008 11:41 & \begin{tabular}{|l|}
$8 / 14 / 200811: 41$ \\
\end{tabular} & 24.7 & 951.3 \\
\hline 5006 & 1/14/2008 11:43 & $8 / 14 / 200811: 43$ & 24.7 & 951.4 \\
\hline 5097 & 1/14/2008 11:45 & \begin{tabular}{|l|}
$8 / 14 / 200811: 45$ \\
\end{tabular} & 24.8 & 955.8 \\
\hline 5098 & 1/14/2008 11:47 & 8/14/2008 11:47 & 24.8 & 955.9 \\
\hline 5099 & 1/14/2008 11:49 & \begin{tabular}{|l|}
$8 / 14 / 200811: 49$ \\
\end{tabular} & 24.8 & 957.2 \\
\hline 5100 & 1/14/2008 11:51 & \begin{tabular}{|l|}
$8 / 14 / 200811: 51$ \\
\end{tabular} & 24.7 & 958.2 \\
\hline 5101 & 1/14/2008 11:53 & \begin{tabular}{|l|}
$8 / 14 / 200811: 53$ \\
\end{tabular} & 24.7 & 957 \\
\hline 5102 & 1/14/2008 11:55 & 8/14/2008 11:56 & 24.7 & 956.1 \\
\hline 5103 & 1/14/2008 11:57 & \begin{tabular}{|l|}
$8 / 14 / 200811: 57$ \\
\end{tabular} & 24.7 & 956.6 \\
\hline 5104 & 1/14/2008 11:59 & 8/14/2008 11:59 & 24.7 & 954.8 \\
\hline 5105 & T/74/2UUS TZ:UT & $8 / 14 / 200872: 01$ & 24.7 & \\
\hline
\end{tabular}

\begin{tabular}{|c|c|c|c|c|}
\hline \multicolumn{5}{|c|}{$\overline{D 493 C}$} \\
\hline $\operatorname{Rec}$ & & Adjusted & Temp & SC \\
\hline$\#$ & Date/Time & Date/Time & $O C$ & $\mu \mathrm{S} / \mathrm{cm}$ \\
\hline 5106 & $1 / 14 / 20081203$ & $8 / 14 / 200812-03$ & 24.7 & 955.5 \\
\hline 5107 & 1/14/2008 12005 & $8 / 14 / 20081205$ & 24.8 & 955.5 \\
\hline 5108 & $1 / 14 / 2008$ 1207 & $8 / 14 / 20081207$ & 24.8 & 966.4 \\
\hline 5109 & $1 / 14 / 20081209$ & $8 / 14 / 20081209$ & 24.8 & 966.4 \\
\hline 5110 & 1/14/2008 12:11 & 8/14/2008 12:11 & 24.8 & 956.6 \\
\hline 5111 & $1 / 14 / 20081213$ & $8 / 14 / 2008$ 12:13 & 24.8 & 957.4 \\
\hline 5112 & $1 / 14 / 20081215$ & 8/14/2008 12:15 & 24.8 & 956.9 \\
\hline 5113 & $1 / 14 / 20081217$ & $8 / 14 / 2008$ 12:17 & 24.8 & 957.3 \\
\hline 5114 & $1 / 14 / 2008$ 12:19 & $8 / 14 / 200812: 19$ & 24.8 & 957.1 \\
\hline 5115 & $1 / 14 / 20081221$ & $8 / 14 / 2008$ 12:21 & 24.8 & 95 \\
\hline 5116 & $1 / 14 / 20081223$ & $8 / 14 / 20081223$ & 24.7 & 957 \\
\hline 5117 & $1 / 14 / 20081225$ & $8 / 14 / 200812: 25$ & 24.7 & 957.4 \\
\hline 5118 & $1 / 14 / 20081227$ & $8 / 14 / 200812 \cdot 27$ & 24.7 & 958.8 \\
\hline 5119 & $1 / 14 / 20081229$ & $8 / 14 / 200812: 29$ & 24.7 & 959 \\
\hline 5120 & $1 / 14 / 20081231$ & $8 / 14 / 20081231$ & 24.7 & 950.3 \\
\hline 5121 & $1 / 14 / 20081233$ & $8 / 14 / 2008+233$ & 24.7 & 959.1 \\
\hline 5122 & $1 / 14 / 20081235$ & $8 / 14 / 200812: 35$ & 24.7 & 958.7 \\
\hline 5123 & 1/14/2008 1237 & $8 / 14 / 200812: 37$ & 24.7 & 958.6 \\
\hline 5124 & $1 / 14 / 20081239$ & $8 / 14 / 20081239$ & 24.7 & 950.2 \\
\hline 5125 & $1 / 14 / 20081241$ & $8 / 14 / 20081241$ & 24.7 & 958.4 \\
\hline 5126 & $1 / 14 / 20081243$ & $8 / 14 / 20081243$ & 24.7 & 958.2 \\
\hline 5127 & $1 / 14 / 20081244$ & $8 / 14 / 20081245$ & 24.7 & 959 \\
\hline 5128 & 1/14/20081247 & $8 / 14 / 200812: 47$ & 24.7 & 958.9 \\
\hline 5129 & $1 / 14 / 20081249$ & $8 / 14 / 20081244$ & 24.7 & 958 \\
\hline 5130 & $1 / 14 / 20081251$ & $8 / 14 / 20081251$ & 24.7 & 958.5 \\
\hline 5131 & $1 / 14 / 20081253$ & $8 / 14 / 200812: 53$ & 24.7 & 958 \\
\hline 5132 & $1 / 14 / 20081255$ & $8 / 14 / 20081255$ & 24.6 & 958.5 \\
\hline 5133 & $1 / 14 / 20081257$ & $8 / 14 / 200812: 57$ & 24.7 & 957.8 \\
\hline 5134 & $1 / 14 / 20081259$ & $8 / 14 / 20081259$ & 24.7 & 957.5 \\
\hline 5135 & 1/14/2008 13:01 & $8 / 14 / 2008$ 13:01 & 24.7 & 97.7 \\
\hline 5136 & $1 / 14 / 200813: 03$ & 8/14/2008 13:03 & 24.7 & 958 \\
\hline 5137 & 1/14/2008 13:05 & 8/14/2008 13:05 & 24.7 & 957.8 \\
\hline 5138 & $1 / 14 / 2008$ 13:07 & 8/14/2008 13:07 & 24.6 & 957.6 \\
\hline 5139 & $1 / 14 / 200813: 09$ & $8 / 14 / 200813: 09$ & 24.7 & 957 \\
\hline 5140 & 1/14/2008 13:11 & $8 / 14 / 2008$ 13:11 & 24.7 & 957.3 \\
\hline 5141 & $1 / 14 / 200813: 13$ & 8/14/2008 13:13 & 24.7 & 97.5 \\
\hline 5142 & 1/14/2008 13:15 & $8 / 14 / 2008$ 13:15 & 24.7 & 956.2 \\
\hline 5143 & 1/14/2008 13:17 & 8/14/2008 13:17 & 24.6 & 966.7 \\
\hline 5144 & $1 / 14 / 2008$ 13:19 & 8/14/2008 13:19 & 24.6 & 956.5 \\
\hline 5145 & $1 / 14 / 200813: 21$ & $8 / 14 / 200813: 21$ & 24.6 & 952.5 \\
\hline 5146 & 1/14/2008 13:23 & $8 / 14 / 200813: 23$ & 24.6 & 952 \\
\hline 5147 & 1/14/2008 13-25 & $8 / 14 / 200813: 25$ & 24.6 & 952.7 \\
\hline 5148 & $1 / 14 / 200813: 27$ & $8 / 14 / 200813: 27$ & 24.7 & 953.5 \\
\hline 5149 & $1 / 14 / 200813-29$ & $8 / 14 / 200813: 29$ & 24.7 & 953.5 \\
\hline 5150 & 1/14/2008 13:31 & $8 / 14 / 200813: 31$ & 24.7 & 953.8 \\
\hline 5151 & 1/14/2008 13:33 & 8/14/2008 13:33 & 24.7 & 9527 \\
\hline 5152 & 1/14/2008 13:35 & 8/14/2008 13:35 & 24.8 & 954.1 \\
\hline 5153 & 1/14/2008 13:37 & $8 / 14 / 200813: 37$ & 24.8 & 954.7 \\
\hline 5154 & 1/14/2008 13:39 & $8 / 14 / 200813: 39$ & 24.8 & 956.3 \\
\hline 5155 & $1 / 14 / 200813: 41$ & $8 / 14 / 2008$ 13:41 & 24.7 & 955.5 \\
\hline 5156 & 1/14/2008 13:43 & $8 / 14 / 2008$ 13:43 & 24.7 & 955.4 \\
\hline 5157 & 1/14/2008 13:45 & $8 / 14 / 2008$ 13:45 & 24.7 & 953.7 \\
\hline 5158 & $1 / 14 / 200813: 47$ & $8 / 14 / 2008$ 13:47 & 24.6 & 955 \\
\hline 5159 & $1 / 14 / 2008$ 13:49 & $8 / 14 / 200813: 49$ & 24.6 & 954.9 \\
\hline 5160 & $1 / 14 / 200813: 51$ & $\mid 8 / 14 / 200813: 51$ & 24.6 & 955.4 \\
\hline 5161 & $1 / 14 / 2008$ 13:53 & $8 / 14 / 200813: 53$ & 24.6 & 955.3 \\
\hline 5162 & $1 / 14 / 200813: 55$ & $8 / 14 / 200813: 55$ & 24.6 & 955.1 \\
\hline 5163 & $1 / 14 / 2008$ 13:57 & $8 / 14 / 2008$ 13:57 & 24.6 & 955.1 \\
\hline 5164 & $1 / 14 / 200813: 59$ & $8 / 14 / 200813: 59$ & 24.6 & 955.2 \\
\hline 5165 & 1/14/2008 14:01 & 8/14/2008 14:01 & 24.6 & 955.7 \\
\hline 5166 & 1/14/2008 14:03 & 8/14/2008 14:03 & 24.6 & 955.5 \\
\hline 5167 & 1/14/2008 14:05 & $8 / 14 / 2008$ 14:05 & 24.6 & 955.3 \\
\hline 5168 & 1/14/2008 14:07 & $8 / 14 / 2008$ 14:07 & 24.6 & 955.3 \\
\hline 5469 & 1/14/2008 14:09 & $8 / 14 / 2008$ 14:09 & 24.6 & 954.9 \\
\hline 5170 & 1/14/2008 14:11 & $8 / 14 / 2008$ 14:11 & 24.6 & 955.9 \\
\hline 5171 & 1/14/2008 14:13 & $8 / 14 / 2008$ 14:13 & 24.6 & 955.8 \\
\hline 5172 & 1/14/2008 14:15 & 8/14/2008 14:15 & 24.6 & 956 \\
\hline 5173 & 1/14/2008 14:17 & $8 / 14 / 2008$ 14:17 & 24.6 & 951.4 \\
\hline & & & 24.6 & 505.1 \\
\hline
\end{tabular}


DOE/RL-2009-35, REV. 0

\begin{tabular}{|c|c|c|c|c|}
\hline \multicolumn{5}{|c|}{$D 4-93 c$} \\
\hline$R A C$ & & Adjusted & Tenp & SC \\
\hline$\#$ & DaterTime & Date/Time & $\infty$ & $\mu \mathrm{s} / \mathrm{cm}$ \\
\hline 5175 & $1 / 14 / 200814: 21$ & $8 / 14 / 200014: 21$ & 25 & 980.2 \\
\hline 5176 & 1/14/2008 14:23 & $8 / 14 / 200814: 23$ & 25.7 & 975.4 \\
\hline 5177 & 1/14/2008 14:25 & $8 / 14 / 2008$ 14:25 & 25.6 & 977.6 \\
\hline 5178 & $1 / 14 / 200814: 27$ & $8 / 14 / 200814: 27$ & 25.4 & 980.3 \\
\hline 5179 & $1 / 14 / 200814: 29$ & $8 / 14200814: 29$ & 25.3 & 979.7 \\
\hline 5180 & $1 / 14 / 200814: 31$ & $8 / 14 / 2008$ 14:31 & 25.2 & 980.9 \\
\hline 5181 & $1 / 14 / 200814: 33$ & $8 / 14 / 200814: 33$ & 25.3 & 980.2 \\
\hline 5182 & $1 / 14 / 200814: 35$ & $8 / 14 / 2008$ 14:35 & 25.2 & 980.8 \\
\hline 5183 & 1/14/2008 14:37 & $8 / 14 / 2008$ 14:37 & 25.2 & 980.7 \\
\hline 5184 & 1/14/2008 14:39 & $8 / 14 / 200814: 39$ & 25.1 & 981.8 \\
\hline 5185 & $1 / 14 / 200814: 41$ & $8 / 14 / 2008$ 14:41 & 25.1 & 982 \\
\hline 5186 & $1 / 14 / 200814: 43$ & $8 / 14: 200814: 43$ & 25 & 981.5 \\
\hline 5187 & $1 / 14 / 200814: 45$ & $8 / 14 / 2008$ 14:45 & 25 & 9824 \\
\hline 5188 & $1 / 14 / 200814: 47$ & $8 / 14 / 2008$ 14:47 & 25 & 981.9 \\
\hline 5189 & $1 / 14 / 200814: 49$ & $8 / 14 / 200814: 49$ & 24.9 & 9827 \\
\hline 5190 & $1 / 14 / 200814: 51$ & $8 / 14 / 2008$ 14:51 & 24.9 & 982 \\
\hline 5191 & $1 / 14 / 200814: 53$ & $8 / 14 / 200814: 53$ & 24.9 & 981.9 \\
\hline 5192 & 1/14/2008 14:56 & $8 / 14 / 200814: 56$ & 24.8 & 981 \\
\hline 5193 & $1 / 14 / 200814: 5$ & $8 / 14 / 200814: 57$ & 24.8 & 980.8 \\
\hline 5194 & $1 / 14 / 200814: 59$ & $8 / 14 / 200814: 59$ & 24.8 & 981.4 \\
\hline 5195 & $1 / 14 / 200815: 01$ & $8 / 14 / 200815: 01$ & 24.8 & 980.7 \\
\hline 5196 & 1/14/2008 15:03 & $8 / 14 / 200815: 03$ & 24.7 & 980.9 \\
\hline 5197 & $1 / 14 / 200815: 05$ & $8 / 14 / 200815: 05$ & 24.7 & 981.1 \\
\hline 5198 & 1/14/2008 15:07 & $8 / 14 / 200015: 07$ & 24.7 & 981.1 \\
\hline 5199 & $1 / 14 / 200815: 09$ & $8 / 14 / 200815: 00$ & 24.7 & 981.9 \\
\hline 5200 & 1/14/2008 15:11 & $8 / 14 / 200015: 11$ & 24.7 & 981.1 \\
\hline 5201 & 1/14/2008 15:13 & $8 / 14 / 200015: 13$ & 24.7 & 981.4 \\
\hline 5202 & 1/14/2008 15:15 & $8 / 14 / 200815: 15$ & 24.7 & 990.1 \\
\hline 5203 & 1/14/2008 15:17 & $8 / 14 / 200015: 17$ & 24.7 & 981.3 \\
\hline 5204 & 1/14/200815:19 & $8 / 14 / 200815: 19$ & 24.7 & 980.7 \\
\hline 5205 & $1 / 14 / 200815: 21$ & $8 / 14 / 2008$ 15:21 & 24.7 & 980.5 \\
\hline 5206 & 1/14/2008 15:23 & $8 / 14 / 200815: 23$ & 24.7 & 980.8 \\
\hline 5207 & 1/14/2008 15:25 & $8 / 14 / 200815: 25$ & 24.7 & 975.5 \\
\hline 5208 & $1 / 14 / 200815: 27$ & $8 / 14 / 200815: 27$ & 24.7 & 980.2 \\
\hline 5209 & $1 / 14 / 200815: 29$ & $8 / 14 / 200815: 29$ & 24.7 & 977.2 \\
\hline 5210 & $1 / 14 / 200815: 31$ & $8 / 14 / 200815: 31$ & 24.7 & 979.3 \\
\hline 5211 & $1 / 14 / 200815: 33$ & $8 / 14 / 200815: 33$ & 24.7 & 980.8 \\
\hline 5212 & 1/14/2008 15:35 & $8 / 14 / 200015: 35$ & 24.7 & 978.2 \\
\hline 5213 & 1/14/2008 15:37 & $8 / 14 / 200015: 37$ & 24.7 & 980.9 \\
\hline 5214 & 1/14/2008 15:39 & $8 / 14 / 200815: 39$ & 24.7 & 980.5 \\
\hline 5215 & 1/14/2008 15:41 & $8 / 14 / 200815: 41$ & 24.7 & 979.8 \\
\hline 5216 & 1/14/2008 15:43 & $8 / 14 / 200815: 43$ & 24.7 & 979.5 \\
\hline 5217 & 1/14/2008 15:45 & $8 / 14 / 200815: 45$ & 24.7 & 980.6 \\
\hline 5218 & 1/14/2008 15:47 & $8 / 14 / 200815: 47$ & 24.7 & 980 \\
\hline 5219 & $1 / 14 / 200815: 49$ & $8 / 14 / 200815: 49$ & 24.7 & 979.9 \\
\hline 5220 & 1/14/2008 15:51 & $8 / 14 / 200815551$ & 24.7 & 980.5 \\
\hline 5221 & $1 / 14 / 200815: 53$ & $8 / 14 / 200815: 53$ & 24.7 & 980.3 \\
\hline 5222 & $1 / 14 / 200815: 55$ & $8 / 14 / 200815: 55$ & 24.7 & 978.4 \\
\hline 5223 & $1 / 14 / 200815: 57$ & $8 / 14 / 200815: 57$ & 24.8 & 979.4 \\
\hline 5224 & $1 / 14 / 200815: 59$ & $8 / 14 / 200815: 59$ & 24.7 & 978.4 \\
\hline 5225 & $1 / 14 / 200816: 01$ & $8 / 14 / 200816: 01$ & 24.8 & 980.4 \\
\hline 5226 & $1 / 14 / 200816: 03$ & $8 / 14 / 200816: 03$ & 24.8 & 977.9 \\
\hline 5227 & 1/14/2008 16:05 & $8 / 14 / 200016: 05$ & 24.7 & 977.1 \\
\hline 5228 & $1 / 14 / 200816: 07$ & $8 / 14 / 200016: 07$ & 24.7 & 977.4 \\
\hline 5229 & 1/14/2008 16:09 & $8 / 14 / 200816: 09$ & 24.7 & 978.9 \\
\hline 5230 & $1 / 14 / 200816: 11$ & $8 / 14 / 200816: 11$ & 24.7 & 978.3 \\
\hline 5231 & $1 / 14 / 200816: 13$ & $8 / 14 / 200816: 13$ & 24.7 & 974.9 \\
\hline 5232 & $1 / 14 / 200816: 15$ & $8 / 14 / 200816: 15$ & 24.7 & 977.1 \\
\hline 5233 & $1 / 14 / 200816: 17$ & $8 / 14 / 200016: 17$ & 24.8 & 978.4 \\
\hline 5234 & 1/14/2008 16:19 & $8 / 14 / 200816: 19$ & 24.8 & 978.9 \\
\hline 5235 & 1/14/2008 16:21 & $8 / 14 / 200816: 21$ & 24.8 & 980.7 \\
\hline 5236 & $1 / 14 / 200816.23$ & $8 / 14 / 200816: 23$ & 24.7 & 980.2 \\
\hline 5237 & $1 / 14 / 200816.25$ & $8 / 14 / 200816: 25$ & 24.7 & 979.6 \\
\hline 5238 & $1 / 14 / 200816: 27$ & $8 / 14 / 200816: 27$ & 24.7 & 976.2 \\
\hline 5239 & 1/14/2008 16:29 & $8 / 14 / 200816: 29$ & 24.7 & 976.5 \\
\hline 5240 & 1/14/2008 16:31 & $8 / 14 / 200816: 31$ & 24.7 & 979.3 \\
\hline 5241 & 1/14/2008 16:33 & $8 / 14 / 200816: 33$ & 24.7 & 977 \\
\hline 5242 & 1/14/2008 16:35 & $8 / 14 / 200816: 35$ & 24.7 & 978.7 \\
\hline 5243 & 1/14/2008 16:37 & $8 / 14 / 200816: 37$ & 24.7 & 978.2 \\
\hline
\end{tabular}

\begin{tabular}{|c|c|c|c|c|}
\hline \multicolumn{5}{|c|}{$D 493 c$} \\
\hline $\mathrm{Rec}$ & & Adjusted & Temp & SC \\
\hline$\#$ & DaterTime & Date/Time & $\alpha$ & $\mu S / c m$ \\
\hline 5244 & $1 / 14 / 200816: 39$ & $8 / 14 / 200816: 39$ & 24.7 & \\
\hline 5245 & $1 / 14 / 200816: 41$ & $8 / 14200816: 41$ & 24.7 & 977 \\
\hline 5246 & $1 / 14 / 200816: 43$ & $8 / 14 / 200816: 43$ & 24.7 & 97 \\
\hline 5247 & $1 / 14 / 200816: 45$ & $8 / 14 / 200816: 45$ & 24.7 & 976.7 \\
\hline 5248 & $1 / 14 / 200816: 47$ & $8 / 14 / 200816: 47$ & 24.7 & \\
\hline 5249 & $1 / 14 / 200816: 49$ & $8 / 14 / 200816: 49$ & 24.7 & 975 \\
\hline 5250 & 1/14/2008 16:51 & $8 / 14 / 200816: 51$ & 24.8 & 978 \\
\hline 5251 & $1 / 14 / 20$ & $8 / 14200816: 53$ & 24.8 & \\
\hline 5252 & $1 / 14 / 200$ & $8 / 14 / 200816: 55$ & 24.8 & \\
\hline 5253 & $1 / 14 / 200816: 57$ & $8 / 14200816.57$ & 24.8 & 977 \\
\hline 5254 & $1 / 14 / 200816.59$ & $8 / 14 / 200816: 59$ & 24.8 & 973.5 \\
\hline 5255 & $1 / 14 / 20$ & 317:01 & 24.8 & 975.1 \\
\hline 5256 & $1 / 14 / 20$ & 17:03 & 24.8 & 97 \\
\hline 5257 & $1 / 14 / 200$ & $8 / 14 / 2008$ 17:05 & 24.8 & 977. \\
\hline 5258 & 1/14/2008 17:07 & $8 / 14 / 2008$ 17:07 & 24.8 & 970. \\
\hline 5259 & $1 / 142$ & 17:09 & 24.8 & 976. \\
\hline 5260 & $1 / 14 / 2$ & 17:11 & 24.8 & \\
\hline 5261 & $1 / 14 / 2$ & 817:13 & 24.7 & 97 \\
\hline 5262 & $1 / 14 / 20$ & $200817: 15$ & 24.7 & 977 \\
\hline 5263 & $1 / 14 /$ & 17:17 & 24.7 & 975. \\
\hline 5264 & $1 / 14 / 2$ & 17:19 & 24.7 & \\
\hline 5265 & 17:21 & 317:21 & 24.7 & 977. \\
\hline 5266 & $1 / 142$ & 17:23 & 24.7 & 975. \\
\hline 5267 & $1 / 14 / 2$ & 17:25: & 24.9 & $9 \pi$. \\
\hline 5268 & $77: 27$ & $17: 27$ & 25 & \\
\hline 5269 & $17: 29$ & $17: 29$ & 25 & 979. \\
\hline 5270 & $1 / 14 / 2$ & & 25.1 & 976. \\
\hline 5271 & $\frac{1 / 14 / 2}{2}$ & 17:33 & 25.1 & $9 \overline{7}$. \\
\hline 5272 & $1 / 14 / 2$ & 17:35 & 25.1 & \\
\hline 5273 & $\frac{1 / 14 / 2}{2}$ & & 25.1 & 978. \\
\hline 5274 & $1 / 14$ & & 25 & 978. \\
\hline 5275 & & & 25 & 977 \\
\hline 5276 & & $17: 43$ & 25 & \\
\hline $52 \pi 7$ & & & 25 & 978. \\
\hline 5278 & $1 / 14$ & 7:47 & 25 & 978. \\
\hline 5279 & & & 25 & \\
\hline 5280 & $1 / 142$ & $17: 51$ & 24.9 & 976. \\
\hline 5281 & & & 24.9 & 973 \\
\hline 5282 & & & 25 & 976. \\
\hline 5283 & $1 / 14 / 2$ & 17:57 & 25.1 & 97 \\
\hline 5284 & & & 25 & \\
\hline 5285 & & & 25.4 & 974 \\
\hline 5286 & & & 25.3 & 974. \\
\hline 5287 & & 18:05 & 25.2 & 775. \\
\hline 5288 & & & 25.2 & $\overline{776}$ \\
\hline 5289 & & & 25.2 & 972 \\
\hline 5290 & & & 25.1 & 974. \\
\hline 5291 & & & 25.1 & 975 \\
\hline 5292 & & & 25.1 & 977 \\
\hline 5293 & & & 25 & 975 . \\
\hline 5294 & & & 25 & 973 \\
\hline 5295 & & & 25 & 974 \\
\hline 5296 & & & 24.9 & \\
\hline 5297 & & $18: 25$ & 24.9 & 973. \\
\hline 5298 & & & 24.9 & 973 \\
\hline 99 & & & 24.9 & 973 \\
\hline 5300 & & & 24.9 & \\
\hline 5301 & & 18:33 & 24.8 & 971 \\
\hline 5302 & & & 24.8 & $\overline{972}$ \\
\hline 303 & & & 24.8 & 972 \\
\hline 5304 & & & & \\
\hline 5305 & 8:41 & $18: 41$ & 24.8 & 972 \\
\hline 306 & & & 24.7 & 972 \\
\hline 307 & & & & \\
\hline 308 & 18:47 & $818: 47$ & 4.7. & \\
\hline 5309 & $1 / 14 / 2$ & $8818: 49$ & 24.7 & \\
\hline 5310 & & 18:51 & 24.7 & 971 \\
\hline 5311 & & & 24.6 & \\
\hline 5312 & 318:55 & $8 / 14 / 200818: 55$ & 24.7 & \\
\hline
\end{tabular}

\begin{tabular}{|c|c|c|c|c|}
\hline \multicolumn{5}{|c|}{ D4938 } \\
\hline Pec & & Adusted & Temp & $\mathrm{SC}$ \\
\hline$\#$ & Date/ime & DeterTine & $\infty$ & $\mu \mathrm{s} / \mathrm{cm}$ \\
\hline 5313 & 1/14/2008 18:57 & 8/14/2008 18:5 & 24.7 & \\
\hline$\overline{314}$ & $1 / 14 / 200818: 59$ & 8/14/2008 18.59 & 24.7 & 971.5 \\
\hline 315 & 1/14/2008 19:01 & 8/14/2008 19:01 & 24.7 & 971.3 \\
\hline 316 & $14 / 200819.03$ & 8/14/2008 19:03 & 24.7 & 971. \\
\hline 317 & $14 / 200819.05$ & \begin{tabular}{|l|}
$8 / 14 / 200819.05$ \\
\end{tabular} & 24.6 & 970. \\
\hline 318 & $14 / 2008$ 19:07 & \begin{tabular}{|l|}
$8 / 14 / 200819: 07$ \\
\end{tabular} & 24.7 & 972 \\
\hline$\overline{5319}$ & $1 / 14 / 200819.09$ & \begin{tabular}{|l|}
$8 / 14 / 2008$ \\
$19: 09$
\end{tabular} & 24.7 & 970.8 \\
\hline 5320 & $1 / 14 / 2008$ 19:11 & \begin{tabular}{|l|}
$8 / 14 / 200819.11$ \\
\end{tabular} & 24.7 & 971.8 \\
\hline 321 & $14 / 200819: 13$ & \begin{tabular}{|l|}
$8 / 14 / 200819.13$ \\
\end{tabular} & 24.7 & \\
\hline 322 & $1 / 14 / 2008$ 19.15 & \begin{tabular}{|l|}
$8 / 4 / 200819.15$ \\
\end{tabular} & 24.7 & \\
\hline 5323 & 1/14/2008 19.17 & \begin{tabular}{|l|}
$8 / 14 / 200819.17$ \\
\end{tabular} & 24.7 & 971.3 \\
\hline 5324 & 1/14/2008 19:19 & $8 / 14 / 200819: 19$ & 24.7 & $970 .$. \\
\hline 3325 & $1 / 14 / 2008$ 19:21 & $8 / 14 / 200819.21$ & 24.8 & \\
\hline 5326 & $1 / 14 / 200819: 23$ & $8 / 14 / 200819.23$ & 24.8 & \\
\hline 5327 & $14 / 2008+19.25$ & \begin{tabular}{|l|}
$8 / 14 / 200819.25$ \\
\end{tabular} & 24.8 & 969.4 \\
\hline 5328 & $1 / 14 / 200$ & $8 / 14 / 20$ & 24.8 & 971.8 \\
\hline 5329 & $1 / 14 / 20$ & $8 / 14 / 20$ & 24.8 & 971.6 \\
\hline 5330 & 19.31 & $8 / 14 / 20$ & 24.8 & 965.7 \\
\hline 5331 & $14 / 200819.33$ & $8 / 14 / 20$ & 24.8 & 971.2 \\
\hline 5332 & $1 / 14 / 20$ & $8 / 14 / 20$ & 24.9 & $\overline{971.0}$ \\
\hline 5333 & $1 / 14 / 20$ & $8 / 14 / 20$ & 24.9 & 971.9 \\
\hline 5334 & 19.39 & $8 / 14 / 20$ & 25 & 974.4 \\
\hline 5335 & $1 / 14 / 20$ & 19.41 & 25 & 971 \\
\hline 5336 & $1 / 14 / 2$ & $19: 43$ & 24.9 & 971. \\
\hline 5337 & $19: 45$ & 19.45 & 24.9 & 970. \\
\hline 5338 & $14 / 20$ & 19.47 & 24.9 & 969.8 \\
\hline 5339 & $1 / 14 / 2$ & 19.49 & 24.9 & 970 \\
\hline 340 & 9.51 & 19.51 & 24.8 & 970. \\
\hline 5341 & 9.53 & $8 / 14 / 20$ & 24.8 & 969. \\
\hline$\overline{5342}$ & 19.55 & 819.55 & 24.8 & 968.6 \\
\hline 5343 & 9.57 & & 24.8 & 968.9 \\
\hline 5344 & 9.59 & $8 / 14$ & 24.8 & 969. \\
\hline 5345 & 0.01 & $20: 01$ & 24.8 & 969. \\
\hline 346 & 20.03 & & 24 & 968. \\
\hline 347 & 3.05 & & 24.8 & 969. \\
\hline 5348 & $: 07$ & $8 / 14$ & 24.8 & 967. \\
\hline 5349 & & 20.09 & 24.8 & 968.1 \\
\hline 5350 & & & 24.9 & 969. \\
\hline 351 & & & 24.9 & 96 \\
\hline 5352 & & & 24.9 & 969. \\
\hline 5353 & & & 24.8 & 968. \\
\hline 354 & & & 24.9 & 967. \\
\hline 356 & 0.21 & 0.21 & 24.8 & $\overline{9 x}$ \\
\hline 5356 & & & 24. & 969. \\
\hline 535 & & & 24.8 & 968. \\
\hline 5358 & & & 24.8 & 966 \\
\hline 5359 & & & 24. & 967 \\
\hline 5360 & & & 24.9 & 968. \\
\hline 5361 & & & 24.9 & 968 \\
\hline 5362 & & & 24.9 & 966 \\
\hline 5363 & $1 / 14$ & 0.37 & 24.9 & 966. \\
\hline 364 & & & 24.8 & 966 \\
\hline & & & 24.8 & 9 \\
\hline 5366 & & & 24.8 & 963 \\
\hline 5367 & & & 24.9 & 967. \\
\hline 368 & & & 25 & 967 \\
\hline 20 & & & & \\
\hline 370 & & 20.51 & 25 & 968. \\
\hline 5371 & & $8 / 14$ & 25 & 967 \\
\hline & & & 25 & 967 \\
\hline & & & & \\
\hline 5374 & 20.50 & 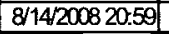 & 25.1 & 966. \\
\hline 5375 & & & 25.1 & 501 \\
\hline 376 & & & 25 & \\
\hline & & & 25 & \\
\hline 5378 & 1/14/2008 21:07 & \begin{tabular}{|l|}
$8 / 14 / 200821: 07$ \\
\end{tabular} & 25 & 967. \\
\hline $20 / 9$ & $1 / 14 / 200$ & \begin{tabular}{|l|}
$8 / 14 / 200821: 09$ \\
\end{tabular} & 25 & \\
\hline 5380 & & & 25 & 966. \\
\hline & & & 25 & $90 \%$ \\
\hline
\end{tabular}




\begin{tabular}{|c|c|c|c|c|}
\hline \multicolumn{5}{|c|}{ D4-93c } \\
\hline $\mathrm{Rec}$ & & Adjusted & Temp & $\mathrm{SC}$ \\
\hline$\#$ & $\begin{array}{l}\text { Date/Time } \\
\end{array}$ & DaterTime & $O C$ & $\mu \mathrm{S} / \mathrm{cm}$ \\
\hline 538 & 1/14/200821:15 & $8 / 14 / 200821: 15$ & 25 & 966.7 \\
\hline 5383 & 1/14/200821:17 & $8 / 14 / 200821: 17$ & 25 & 966.7 \\
\hline 5384 & 1/14/200821:19 & $8 / 14 / 200821: 19$ & 25 & 966.9 \\
\hline 5385 & $1 / 14 / 200821: 21$ & $8 / 14 / 200821: 21$ & 25 & 966.6 \\
\hline 5386 & 1/14/200821:23 & 8/14/200821:23 & 25 & 966.3 \\
\hline 5387 & 1/14/200821:25 & $8 / 14 / 200821: 25$ & 25 & 967.7 \\
\hline 5388 & 1/14/200821:27 & 8/14/200821:27 & 25 & 966.9 \\
\hline 5389 & 1/14/200821:29 & $8 / 14 / 200821: 29$ & 25 & 966.6 \\
\hline 5390 & 1/14/200821:31 & $8 / 14 / 200821: 31$ & 25 & 967.1 \\
\hline 5391 & 1/14/200821:33 & $8 / 14 / 200821: 33$ & 25 & 965.3 \\
\hline 5392 & 1/14/200821:35 & 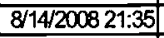 & 25.1 & 966 \\
\hline 5393 & 1/14/200821:37 & $8 / 14 / 200821: 37$ & 25.1 & 966.2 \\
\hline 5394 & 1/14/200821:39 & 8/14/200821:39 & 25 & 966.8 \\
\hline 5395 & 1/14/200821:41 & 8/14/200821:41 & 25 & 965.8 \\
\hline 5396 & 1/14/200821:43 & 8/14/2008 21:43 & 25 & 967 \\
\hline 5397 & $1 / 14 / 200821: 45$ & 8/14/200821:45 & 25.1 & 965.8 \\
\hline 5398 & 1/14/200821:47 & $8 / 14 / 200821: 47$ & 25 & 964.9 \\
\hline 5399 & 1/14/200821:49 & $8 / 14 / 200821: 49$ & 25 & 965.3 \\
\hline 5400 & 1/14/200821:51 & 8/14/2008 21:51 & 25 & 964 \\
\hline 5401 & $1 / 14 / 200821: 53$ & 8/14/2008 21:53 & 25.1 & 963.7 \\
\hline 5402 & 1/14/200821:55 & 8/14/2008 21:55 & 25.1 & 964.5 \\
\hline 5403 & 1/14/200821:57 & $8 / 14 / 200821: 57$ & 25 & 964 \\
\hline 5404 & $1 / 14 / 200821: 59$ & $8 / 14 / 200821: 59$ & 25 & 965.1 \\
\hline 5405 & $1 / 14 / 200822: 01$ & $8 / 14 / 200822: 01$ & 25 & 964.8 \\
\hline 5406 & $1 / 14 / 200822-03$ & 8/14/200822:03 & 25 & 963.4 \\
\hline 5407 & 1/14/200822:05 & $8 / 14 / 20082205$ & 25 & 964.5 \\
\hline 5408 & 1/14/200822:07 & 8/14/2008 22:07 & 25 & 964.8 \\
\hline 5409 & 1/14/200822:09 & $8 / 14 / 200822209$ & 25 & 964.4 \\
\hline 5410 & 1/14/2008 22:11 & $8 / 14 / 200822: 11$ & 25 & 964.3 \\
\hline 5411 & $1 / 14 / 200822: 13$ & $8 / 14 / 200822: 13$ & 25 & 964.3 \\
\hline 5412 & $1 / 14 / 200822: 15$ & 8/14/2008 22:15 & 25 & 964.1 \\
\hline 5413 & 1/14/200822:17 & 8/14/2008 22:17 & 25 & 964.5 \\
\hline 5414 & 1/14/200822:19 & 8/14/2008 22:19 & 25 & 963.3 \\
\hline 5415 & 1/14/2008 22:21 & $8 / 14 / 200822221$ & 25 & 963.4 \\
\hline 5416 & $1 / 14 / 200822: 23$ & $8 / 14 / 20082223$ & 25 & 963.6 \\
\hline 5417 & 1/14/2008 22:25 & $8 / 14 / 200822: 25$ & 25 & 963.9 \\
\hline 5418 & $1 / 14 / 200822: 27$ & $8 / 14 / 200822 \cdot 27$ & 25 & 963.1 \\
\hline 5419 & 1/14/200822:29 & $8 / 14 / 20082229$ & 25 & 961.5 \\
\hline 5420 & 1/14/200822:31 & $8 / 14 / 200822231$ & 25 & 9627 \\
\hline 5421 & 1/14/2008 22:33 & $8 / 14 / 20082233$ & 25 & 963 \\
\hline 5422 & 1/14/2008 22:35 & $8 / 14 / 20082235$ & 25 & 963.1 \\
\hline 5423 & $1 / 14 / 200822: 37$ & $8 / 14 / 200822337$ & 25 & 963.8 \\
\hline 5424 & 1/14/200822:39 & $8 / 14 / 200822-39$ & 25 & 963.5 \\
\hline 5425 & $1 / 14 / 200822-41$ & $8 / 14 / 20082241$ & 25 & 9628 \\
\hline 5426 & $1 / 14 / 200822: 43$ & $8 / 14 / 20082243$ & 25 & 9627 \\
\hline 5427 & 1/144/2008 22:45 & $8 / 14 / 200822445$ & 25 & 963 \\
\hline 5428 & $1 / 14 / 200822: 47$ & $8 / 14 / 20082247$ & 25 & 9628 \\
\hline 5429 & $1 / 14 / 200822: 49$ & $8 / 14 / 200822-49$ & 25 & 963 \\
\hline 5430 & 1/14/2008 22:51 & $8 / 14 / 20082255$ & 25 & 962.5 \\
\hline 5431 & 1/14/2008 22:53 & $8 / 14 / 200822: 53$ & 25 & 963.2 \\
\hline 5432 & 1/14/2008 22:55 & $8 / 14 / 20082255$ & 25 & 964.2 \\
\hline 5433 & $1 / 14 / 200822: 57$ & $8 / 14 / 200822-57$ & 24.9 & 961.8 \\
\hline 5434 & $1 / 14 / 200822: 59$ & $8 / 14 / 20082255$ & 24.9 & 962.1 \\
\hline 5435 & $1 / 14 / 200823: 01$ & 8/14/2008 23:01 & 25 & 961.9 \\
\hline 5436 & $1 / 14 / 200823: 03$ & $8 / 14 / 200823: 03$ & 25 & 962.2 \\
\hline 5437 & 1/14/2008 23:05 & $8 / 14 / 200823: 05$ & 25 & 9621 \\
\hline 5438 & 1/14/2008 23:07 & 8/14/200823:07 & 25 & 9629 \\
\hline 5439 & 1/14/2008 23:09 & 8/14/2008 23:09 & 25 & 9628 \\
\hline 5440 & 1/14/2008 23:11 & $8 / 14 / 200823: 11$ & 25.1 & 966.2 \\
\hline 5441 & 1/14/2008 23:13 & $8 / 14 / 200823: 13$ & 25.2 & 964.2 \\
\hline 5442 & 1/14/2008 23:15 & 8/14/2008 23:15 & 25.1 & 977 \\
\hline 5443 & 1/14/2008 23:17 & $8 / 14 / 200823.17$ & 25 & 977.9 \\
\hline 5444 & 1/14/200823:19 & 8/14/2008 23:19 & 25 & 983.1 \\
\hline 5445 & 1/14/200823:21 & $8 / 14 / 200823: 21$ & 25 & 9829 \\
\hline 5446 & $1 / 14 / 200823: 23$ & $8 / 14 / 200823: 23$ & 25 & 983 \\
\hline 5447 & $1 / 14 / 200823: 25$ & $8 / 14 / 200823: 25$ & 25 & 981.6 \\
\hline 5448 & 1/14/2008 23:27 & $8 / 14 / 200823: 27$ & 24.9 & 980.1 \\
\hline 5449 & $1 / 14 / 200823: 29$ & 8/14/2008 23:29 & 24.9 & 980.2 \\
\hline 5450 & $1 / 14 / 200823: 31$ & 8/14/2008 23:31 & 24.9 & 980.3 \\
\hline
\end{tabular}

\begin{tabular}{|c|c|c|c|c|}
\hline \multicolumn{5}{|c|}{ D493c } \\
\hline $\operatorname{Rec}$ & & Adjusted & Temp & SC \\
\hline$\#$ & DaterTime & DaterTime & $O C$ & $\mu \mathrm{S} / \mathrm{cm}$ \\
\hline 5451 & 1/14/200823:33 & $8 / 14 / 200823: 33$ & 24.9 & 978.9 \\
\hline 5452 & $1 / 14 / 200823: 35$ & $8 / 14 / 200823: 35$ & 24.8 & 978.8 \\
\hline 5453 & 1/14/200823:37 & $8 / 14 / 200823: 37$ & 24.8 & 977.6 \\
\hline 5454 & 1/14/200823:39 & $8 / 14 / 200823: 39$ & 24.8 & 978.2 \\
\hline 5455 & 1/14/2008 23:41 & $8 / 14 / 200823: 41$ & 24.8 & 977.6 \\
\hline 5456 & $1 / 14 / 200823: 43$ & $8 / 14 / 200823: 43$ & 24.7 & 975.7 \\
\hline 5457 & 1/14/200823:45 & $8 / 14 / 200823: 4$ & 24.7 & 975.9 \\
\hline 5458 & $1 / 14 / 200823: 47$ & $8 / 14 / 200823: 47$ & 24.7 & 974.1 \\
\hline 5459 & $1 / 14 / 200823: 49$ & $8 / 14 / 200823: 49$ & 24.7 & 974.4 \\
\hline 5460 & 1/14/2008 23:51 & $8 / 14 / 200823: 51$ & 24.6 & 973.4 \\
\hline 5461 & 1/14/200823:53 & $8 / 14 / 200023: 53$ & 24.6 & 974.1 \\
\hline 5462 & 1/14/200823:55 & $8 / 14 / 200823: 55$ & 24.6 & 973.7 \\
\hline 5463 & $1 / 14 / 200823: 57$ & $8 / 14 / 200823: 57$ & 24.6 & 972.7 \\
\hline 5464 & 1/14/2008 23:59 & $8 / 14 / 200823: 59$ & 24.6 & 973.3 \\
\hline 5465 & $1 / 15 / 20080: 01$ & 8/15/20080:01 & 24.5 & 971.7 \\
\hline 5466 & $1 / 15 / 20080: 03$ & $8 / 15 / 20080: 03$ & 24.5 & 972.5 \\
\hline 5467 & $1 / 15 / 20080: 05$ & $8 / 15 / 20080: 05$ & 24.5 & 972.4 \\
\hline 5468 & $1 / 15 / 20080: 07$ & $8 / 15 / 20080: 07$ & 24.5 & 972 \\
\hline 5469 & $1 / 15 / 20080: 09$ & $8 / 15 / 20080: 09$ & 24.4 & 971.7 \\
\hline 5470 & 1/15/2008 0:11 & $8 / 15 / 20080: 11$ & 24.4 & 971.1 \\
\hline 5471 & $1 / 15 / 20080: 13$ & 8/15/20080:13 & 24.4 & 971.8 \\
\hline 5472 & $1 / 15 / 20080: 15$ & $8 / 15 / 20080: 15$ & 24.4 & 972.3 \\
\hline 5473 & $1 / 15 / 20080: 17$ & $8 / 15 / 20080: 17$ & 24.4 & 972.2 \\
\hline 5474 & $1 / 15 / 20080: 19$ & $8 / 15 / 20080: 19$ & 24.4 & 972.4 \\
\hline 5475 & $1 / 15 / 20080: 21$ & $8 / 15 / 20080: 21$ & 24.4 & 972.2 \\
\hline 5476 & $1 / 15 / 20080: 23$ & $8 / 15 / 20080: 23$ & 24.4 & 973 \\
\hline $54 \pi 7$ & 1/15/20080:25 & $8 / 15 / 20080: 25$ & 24.5 & 973 \\
\hline 5478 & $1 / 15 / 20080: 27$ & $8 / 15 / 20080: 27$ & 24.5 & 972 \\
\hline 5479 & $1 / 15 / 20080: 29$ & $8 / 15 / 20080: 29$ & 24.5 & 972.2 \\
\hline 5480 & $1 / 15 / 20080: 31$ & $8 / 15 / 20080: 31$ & 24.5 & 972.9 \\
\hline 5481 & 1/15/20080:33 & $8 / 15 / 20080: 33$ & 24.5 & 973.4 \\
\hline 5482 & 1/15/20080:35 & $8 / 15 / 20080: 35$ & 24.5 & 971.6 \\
\hline 5483 & $1 / 15 / 20080: 37$ & $8 / 15 / 20080: 37$ & 24.5 & 971.8 \\
\hline 5484 & $1 / 15 / 20080: 39$ & $8 / 15 / 20080: 39$ & 24.5 & 971.8 \\
\hline 5485 & $1 / 15 / 20080: 41$ & $8 / 15 / 20080: 41$ & 24.4 & 972.6 \\
\hline 5486 & $1 / 15 / 20080: 43$ & $8 / 15 / 20080: 43$ & 24.4 & 972.6 \\
\hline 5487 & $1 / 15 / 20080: 45$ & $8 / 15 / 20080: 45$ & 24.4 & 970 \\
\hline 5488 & $1 / 15 / 20080: 47$ & $8 / 15 / 20080.47$ & 24.5 & 971.4 \\
\hline 5489 & $1 / 15 / 20080: 49$ & $8 / 15 / 20080: 49$ & 24.5 & 969.5 \\
\hline 5490 & $1 / 15 / 20080: 51$ & $8 / 15 / 20080.51$ & 24.4 & 970.5 \\
\hline 5491 & $1 / 15 / 20080: 53$ & $8 / 15 / 20080: 53$ & 24.5 & 970.5 \\
\hline 5492 & $1 / 15 / 20080: 55$ & $8 / 15 / 20080.55$ & 24.4 & 971.2 \\
\hline 5493 & 1/15/2008 0:57 & $8 / 15 / 20080.57$ & 24.5 & 970.3 \\
\hline 5494 & 1/15/2008 0:59 & $8 / 15 / 20080.59$ & 24.5 & 971.6 \\
\hline 5495 & $1 / 15 / 2008$ 1:01 & $8 / 15 / 2008$ 1:01 & 24.5 & 971.1 \\
\hline 5496 & $1 / 15 / 20081: 03$ & $8 / 15 / 2008$ 1:03 & 24.5 & 972 \\
\hline 5497 & 1/15/2008 1:05 & $8 / 15 / 20081: 05$ & 24.5 & 971.7 \\
\hline 5498 & 1/15/2008 1:07 & $8 / 15 / 20081: 07$ & 24.5 & 971.4 \\
\hline 5499 & $0081: 09$ & $8 / 15 / 20081: 09$ & 24.5 & 972.1 \\
\hline 5500 & $1 / 15 / 2008$ 1:11 & $8 / 15 / 2008$ 1:11 & 24.5 & 971.8 \\
\hline 5501 & $1 / 15 / 20081: 13$ & $8 / 15 / 20081: 13$ & 24.5 & 971.6 \\
\hline 5502 & 1/15/2008 1:15 & $8 / 15 / 2008$ 1:15 & 24.5 & 972 \\
\hline 5503 & 1/15/2008 1:17 & $8 / 15 / 20081: 17$ & 24.5 & 971.6 \\
\hline 5504 & 1/15/2008 1:19 & $8 / 15 / 20081: 19$ & 24.5 & 972.3 \\
\hline 5505 & $1 / 15 / 20081: 21$ & $8 / 15 / 2008$ 1:21 & 24.5 & 972.3 \\
\hline 5506 & 1/15/2008 1:23 & $8 / 15 / 20081: 23$ & 24.5 & 972.9 \\
\hline 5507 & $1 / 15 / 20081: 25$ & $8 / 15 / 20081: 25$ & 24.5 & 973.4 \\
\hline 5508 & $1 / 15 / 20081: 27$ & $8 / 15 / 20081: 27$ & 24.5 & 973.2 \\
\hline 5509 & 1/15/2008 1:29 & $8 / 15 / 20081: 29$ & 24.5 & 972.8 \\
\hline 5510 & $1 / 15 / 20081: 31$ & $8 / 15 / 20081: 31$ & 24.5 & 970.9 \\
\hline 5511 & $1 / 15 / 20081: 33$ & $8 / 15 / 20081: 33$ & 24.5 & 972.4 \\
\hline 5512 & $1 / 15 / 20081: 35$ & $8 / 15 / 20081: 35$ & 24.5 & 972.7 \\
\hline 5513 & $1 / 15 / 2008$ 1:37 & $8 / 15 / 20081: 37$ & 24.5 & 971.8 \\
\hline 5514 & $1 / 15 / 20081: 39$ & $8 / 15 / 20081: 39$ & 24.5 & 970.6 \\
\hline 5515 & $1 / 15 / 20081: 41$ & $8 / 15 / 20081: 41$ & 24.5 & 971.1 \\
\hline 5516 & $1 / 15 / 20081: 43$ & $8 / 15 / 20081: 43$ & 24.5 & 971.1 \\
\hline 5517 & $1 / 15 / 2008 \quad 1: 45$ & $8 / 15 / 20081: 45$ & 24.5 & 971.7 \\
\hline 5518 & $1 / 15 / 20081: 47$ & $8 / 15 / 20081: 47$ & 24.5 & 970.2 \\
\hline 5519 & 1/15/2008 1:49 & $8 / 15 / 20081: 49$ & 24.4 & 972.3 \\
\hline
\end{tabular}

\begin{tabular}{|c|c|c|c|c|}
\hline \multicolumn{5}{|c|}{ D4-93c } \\
\hline $\operatorname{Rec}$ & & Adjusted & Temp & SC \\
\hline$\#$ & Dater/ime & Date/Time & $\alpha$ & $\mu \mathrm{s} / \mathrm{cm}$ \\
\hline 5520 & $1 / 15 / 20081: 51$ & $8 / 15 / 2008$ 1:51 & 24.5 & 972.3 \\
\hline 5521 & $1 / 15 / 20081: 53$ & $8 / 15 / 20081: 53$ & 24.6 & 9724 \\
\hline 5522 & & $8 / 15 / 20081: 55$ & 24.5 & 968.7 \\
\hline 5523 & $1 / 15 / 20081: 57$ & $8 / 15 / 20081: 57$ & 24.5 & 970.7 \\
\hline 5524 & $1 / 15 / 20081: 59$ & $8 / 15 / 20081: 59$ & 24.5 & 971.5 \\
\hline 5525 & $1 / 15 / 20082: 01$ & $8 / 15 / 2008201$ & 24.5 & 972 \\
\hline 5526 & $1 / 15 / 20082: 03$ & $8 / 15 / 20082: 03$ & 24.5 & 971.2 \\
\hline 5527 & 1/15/20082:05 & $8 / 15 / 2008205$ & 24.5 & 971.7 \\
\hline 5528 & 1/15/20082:07 & $8 / 15 / 20082: 07$ & 24.5 & 970.6 \\
\hline 5529 & $1 / 15 / 20082009$ & $|8 / 15 / 20082: 09|$ & 24.5 & 971.4 \\
\hline 5530 & $1 / 15 / 20082: 11$ & $8 / 15 / 20082: 11$ & 24.5 & 970.4 \\
\hline 5531 & $1 / 15 / 20082: 13$ & $8 / 15 / 20082: 13$ & 24.5 & 971.3 \\
\hline 5532 & $1 / 15 / 20082: 15$ & $8 / 15 / 20082: 15$ & 24.5 & 970.1 \\
\hline 5533 & 1/15/20082:17 & $8 / 15 / 20082: 17$ & 24.5 & \\
\hline 5534 & $1 / 15 / 20082: 19$ & $8 / 15 / 20082: 19$ & 24.6 & 971.5 \\
\hline 5535 & $1 / 15 / 20$ & $8 / 15 / 20082: 21$ & 24.5 & 971.8 \\
\hline 5536 & $1 / 15 / 20082: 23$ & $8 / 15 / 20082: 23$ & 24.5 & 969.7 \\
\hline 5537 & $1 / 15 / 200$ & $8 / 15 / 20082: 25$ & 24.5 & 969.9 \\
\hline 5538 & $1 / 15 / 20082: 27$ & \begin{tabular}{|c|}
$8 / 15 / 20082: 27$ \\
\end{tabular} & 24.5 & \\
\hline 5539 & $1 / 15 / 20082: 29$ & $8 / 15 / 20082: 29$ & 24.5 & 971.5 \\
\hline 5540 & $1 / 15 / 20$ & $8 / 15 / 20082: 31$ & 24.5 & 970.9 \\
\hline 5541 & $1 / 15 / 20$ & $8 / 15 / 20082: 33$ & 24.6 & 970. \\
\hline 5542 & $1 / 15 / 20$ & $8 / 15 / 20082: 35$ & 24.6 & 970.8 \\
\hline 5543 & $1 / 15 / 20$ & $8 / 15 / 20082: 37$ & 24.6 & 969.6 \\
\hline 5544 & $1 / 15 / 20082: 39$ & $8 / 15 / 20082: 39$ & 24.6 & 971.3 \\
\hline 5545 & $1 / 15 / 2$ & $8 / 15 / 20$ & 24.6 & 969.5 \\
\hline 5546 & $1 / 15 / 2$ & $8 / 15 / 20$ & 24.6 & 971.3 \\
\hline 5547 & $1 / 15 / 2$ & $8 / 15 / 20$ & 24.6 & 971.4 \\
\hline 5548 & $1 / 15 / 200$ & $8 / 15 / 20082: 47$ & 24.6 & 97 \\
\hline 5549 & $1 / 15 / 200$ & $8 / 15 / 20082: 49$ & 24.6 & 970.8 \\
\hline 5550 & $1 / 15 / 2$ & $8 / 15 / 20$ & 24.6 & 97 \\
\hline 5551 & $1 / 15 / 2$ & $8 / 15 / 20$ & 24.6 & 971 \\
\hline 5552 & $1 / 15 / 2$ & $8 / 15 / 20$ & 24.6 & 970. \\
\hline 5553 & $1 / 15 / 2$ & $8 / 15 / 20$ & 24.6 & 970. \\
\hline 5554 & & $8 / 15 / 20$ & 24.6 & 97 \\
\hline 5555 & $1 / 15$ & $8 / 15 / 20$ & 24.6 & 969. \\
\hline 5556 & $1 / 15$ & $8 / 15 / 20$ & 24.6 & 97 \\
\hline 5557 & & $8 / 15 / 2$ & 24.7 & 969 . \\
\hline 5558 & & $8 / 15 / 20$ & 24.7 & 968. \\
\hline 5559 & $1 / 15$ & $8 / 15 / 20$ & 24.7 & 970. \\
\hline 5560 & & $8 / 15 / 20$ & 24.7 & 970. \\
\hline 5561 & $1 / 15$ & $8 / 15 / 20$ & 24.7 & 970. \\
\hline 5562 & & $8 / 15 / 20$ & 24. & 970. \\
\hline 5563 & & $8 / 15 / 20$ & 24.6 & 969. \\
\hline 5564 & & $8 / 15 / 20$ & 24.7 & 969. \\
\hline 5565 & & & 24.8 & 971. \\
\hline 5566 & & $8 / 15 / 20$ & 24.8 & 970. \\
\hline 5567 & & $8 / 15 / 2$ & 24.8 & 972. \\
\hline 5568 & & \begin{tabular}{|l|}
$8 / 15 / 2$ \\
\end{tabular} & 24. & \\
\hline 5569 & & $8 / 15 / 20$ & 24. & 971. \\
\hline 5570 & & $8 / 15 / 20$ & 24. & 971. \\
\hline 5571 & & $8 / 15 / 20$ & 24.9 & 970. \\
\hline 5572 & & & 24.9 & 971. \\
\hline 5573 & & $8 / 15 / 2$ & 24. & \\
\hline 5574 & & $8 / 15 / 20$ & 24. & 968. \\
\hline & & $8 / 15 / 20$ & 24. & 971. \\
\hline 5576 & & $8 / 15 / 20$ & 24.8 & 96 \\
\hline 5577 & & & 24.8 & \\
\hline 5578 & & $8 / 15 / 20$ & 24.8 & \\
\hline 5579 & & $8 / 15 / 20$ & 24.8 & 968. \\
\hline & & $8 / 15 / 20$ & 24.8 & \\
\hline 5581 & $1 / 15$ & $8 / 15 / 20083.53$ & 24.8 & 969 \\
\hline 5582 & & $8 / 15 / 200$ & 24.8 & 969. \\
\hline 5583 & & \begin{tabular}{|l|}
$8 / 15 / 20$ \\
\end{tabular} & 24.8 & \\
\hline 5584 & $1 / 15 / 2$ & $\begin{array}{l}8 / 15 / 200 \\
\end{array}$ & 24.8 & 968.2 \\
\hline 5585 & & $8 / 15 / 200$ & 24.8 & \\
\hline 5586 & $1 / 15 / 20084: 03$ & \begin{tabular}{|l|}
$8 / 15 / 20084: 03$ \\
\end{tabular} & 24.9 & 970. \\
\hline 5587 & $1 / 15 / 20084: 05$ & \begin{tabular}{|l|}
$8 / 15 / 20084: 05$ \\
\end{tabular} & 24.9 & 969 \\
\hline 5588 & & \begin{tabular}{|c|}
$8 / 15 / 20084: 07$ \\
\end{tabular} & 24.9 & \\
\hline
\end{tabular}


DOE/RL-2009-35, REV. 0

\begin{tabular}{|c|c|c|c|c|}
\hline \multicolumn{5}{|c|}{ D493c } \\
\hline $\operatorname{Rec}$ & & Agusted & Temp & SC \\
\hline$\#$ & DaterTime & Date/Time & $\propto$ & $\mu \mathrm{s} / \mathrm{cm}$ \\
\hline 5589 & $1 / 15 / 20084: 09$ & $8 / 15 / 20084: 09$ & 24.9 & 968.7 \\
\hline 5590 & $1 / 15 / 20084: 11$ & $8 / 15 / 20084: 11$ & 24.9 & 969.3 \\
\hline 5591 & $1 / 15 / 20084: 13$ & $8 / 15 / 20084: 13$ & 24.9 & \\
\hline 5592 & $1 / 15 / 20084: 15$ & $8 / 15 / 20084: 15$ & 24.9 & 970.4 \\
\hline 5593 & $1 / 15 / 20084: 17$ & $8 / 15 / 20084: 17$ & 24.9 & 969. \\
\hline 5594 & 1/15/2008 4:19 & 8/15/2008 4:19 & 24.9 & 968.9 \\
\hline 5595 & $1 / 15 / 20084: 21$ & $8 / 15 / 20084: 21$ & 24.9 & \\
\hline 5596 & 1/15/2008 4:23 & $8 / 15 / 20084: 23$ & 24.9 & 969.4 \\
\hline 5597 & $1 / 15 / 20084: 25$ & $8 / 15 / 20084: 25$ & 24.9 & 970.1 \\
\hline 5598 & 1/15/20084:27 & $8 / 15 / 20084: 27$ & 25 & \\
\hline 5599 & 1/15/20084:29 & $8 / 15 / 20084: 29$ & 24.9 & \\
\hline 5600 & 1/15/20084:31 & $8 / 15 / 20084: 31$ & 24.9 & 909 \\
\hline 5601 & $1 / 15 / 20084: 33$ & $8 / 15 / 20084: 33$ & 24.9 & 971.6 \\
\hline 5602 & $1 / 15 / 20084: 35$ & $8 / 15 / 20084: 35$ & 25 & \\
\hline 5603 & $1 / 15 / 20084: 37$ & $8 / 15 / 20084: 37$ & 25 & 971. \\
\hline 5604 & $1 / 15 / 20084: 39$ & $8 / 15 / 20084: 39$ & 25 & 971.5 \\
\hline 5605 & $1 / 15 / 200$ & $8 / 15 / 20084: 41$ & 25 & 970. \\
\hline 5606 & $1 / 1520084: 43$ & $8 / 1520084: 43$ & 25 & 970. \\
\hline 5607 & $1 / 15 / 20084: 45$ & $8 / 15 / 20084: 45$ & 25 & 971.2 \\
\hline 5608 & $1 / 15 / 20$ & $8 / 15 / 200$ & 25 & 970 \\
\hline 5600 & $1 / 15 / 20$ & $8 / 15 / 200$ & 25 & \\
\hline 5610 & $1 / 15 / 20$ & $8 / 15 / 20084: 51$ & 25 & 970.2 \\
\hline 5611 & $1 / 15 / 20$ & $8 / 15 / 200$ & 25 & 970. \\
\hline 5612 & $1 / 15 / 20$ & $8 / 15 / 200$ & 25 & \\
\hline 5613 & $1 / 15 / 20$ & $8 / 15 / 20$ & 25 & 971. \\
\hline 5614 & $1 / 15 / 20$ & $8 / 15 / 200$ & 24.9 & 972 \\
\hline 5615 & $1 / 15 / 2$ & $8 / 15 / 20$ & 24.9 & 971. \\
\hline 5616 & $1 / 15 / 200$ & $8 / 15 / 20$ & 24.9 & 971. \\
\hline 5617 & $1 / 15 / 20085: 05$ & $8 / 15 / 20085: 05$ & 24.9 & 971.8 \\
\hline 5618 & & $8 / 15 / 2$ & 24.9 & 972 \\
\hline 5619 & $1 / 15 / 20$ & $8 / 15 / 20085: 09$ & 24. & 971. \\
\hline 5620 & & $8 / 15 / 20085: 11$ & 24.9 & 971. \\
\hline 5621 & 13 & $8 / 15 / 2$ & 24.8 & 970. \\
\hline 5622 & 15 & $8 / 15 / 2$ & 24.9 & 969. \\
\hline 5623 & & $8 / 15 / 20085: 17$ & 24.8 & 970. \\
\hline 5624 & & $8 / 15 / 2$ & 24.8 & 971. \\
\hline 5625 & & $8 / 15 / 2$ & 24. & 970. \\
\hline 5626 & 23 & $8 / 15 / 20$ & 24.9 & 969. \\
\hline 5627 & & $8 / 15 / 20$ & 24.9 & 970. \\
\hline 5628 & 27 & $8 / 15 / 20$ & 24.9 & 971. \\
\hline 5620 & $5: 29$ & $8 / 15 / 2$ & 24. & 970. \\
\hline 5630 & & & 24. & 971. \\
\hline 531 & & $8 / 15 / 2$ & 24. & 971 \\
\hline 5632 & $5: 35$ & $8 / 15 / 20$ & 24 & 970. \\
\hline 5633 & & & 24 & 971. \\
\hline 63 & & & 24. & 97 \\
\hline 5635 & $5: 41$ & $8 / 15 / 2$ & 24 & 970. \\
\hline 5636 & & & 24.8 & 970. \\
\hline 5031 & & & 24.9 & 973 \\
\hline 5638 & & $5: 47$ & 25 & 972 \\
\hline 5639 & & & 25 & 971. \\
\hline 5640 & & & 24.9 & \\
\hline 5641 & & $8 / 15 / 2$ & 24.9 & 972 \\
\hline 5642 & & $8 / 15$ & 24.9 & 972 \\
\hline 5643 & & & 24.9 & \\
\hline 5644 & & $8 / 15 / 20$ & 24.9 & \\
\hline 5645 & & $8 / 15 / 20$ & 24.9 & 972 \\
\hline 5646 & & & 24.9 & 971 \\
\hline 5647 & & & 24.9 & \\
\hline 5648 & & $8 / 15 / 20086: 07$ & 24.9 & 971 \\
\hline 5649 & & & 24.9 & 971 \\
\hline 5650 & & & & \\
\hline 5651 & & $8 / 15 / 20086: 13$ & 24.9 & 971 \\
\hline 5652 & & $8 / 15 / 20086: 15$ & 24.9 & \\
\hline 5653 & & & 24.9 & 971 \\
\hline 5654 & & $8 / 15 / 20086: 19$ & 24.9 & \\
\hline 5655 & & $8 / 15 / 20$ & 24.9 & \\
\hline 5656 & & & 24.8 & 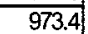 \\
\hline & & & & \\
\hline
\end{tabular}

\begin{tabular}{|c|c|c|c|c|}
\hline \multicolumn{5}{|c|}{$D 493 \mathrm{c}$} \\
\hline Rec & & Adisted & Temp & SC \\
\hline$\#$ & Date/Time & Date/Time & $\propto$ & $\mu \mathrm{S} / \mathrm{cm}$ \\
\hline 5658 & 1/15/20086:27 & $8 / 15 / 20086: 27$ & 24.8 & 989.8 \\
\hline 5659 & $1 / 15 / 20086: 29$ & $8 / 15 / 20086: 29$ & 24.8 & 989.2 \\
\hline 5660 & 1/15/20086:31 & $8 / 15 / 20086: 31$ & 24.9 & 989.6 \\
\hline 5661 & 1/15/20086:33 & $8 / 15 / 20086: 33$ & 24.9 & 990.4 \\
\hline 5662 & 1/15/20086:35 & $8 / 15 / 20086: 35$ & 24.9 & 99 \\
\hline 5663 & 1/15/20086:37 & $8 / 15 / 20086: 37$ & 24.9 & 989.6 \\
\hline 5664 & 1/15/20086:39 & $8 / 15 / 20086: 39$ & 24.9 & 990.5 \\
\hline 5665 & $1 / 15 / 20086: 41$ & $8 / 15 / 20086: 41$ & 24.9 & 99 \\
\hline 5666 & $1 / 15 / 20086: 43$ & $8 / 15 / 20086: 43$ & 24.9 & 990. \\
\hline 5667 & $1 / 15 / 20086: 45$ & $8 / 15 / 20086: 45$ & 24.9 & 990.9 \\
\hline 5668 & $1 / 15 / 20$ & $8 / 15 / 20086: 47$ & 24.9 & 990.5 \\
\hline 5669 & $1 / 15 / 20$ & $8 / 15 / 20086: 49$ & 24.9 & 989.5 \\
\hline 5670 & $1 / 15 / 20$ & $8 / 15 / 20086: 51$ & 24.9 & 990. \\
\hline 5671 & $1 / 15 / 20$ & $8 / 15 / 20086: 53$ & 24.9 & 989.2 \\
\hline 5672 & $1 / 15 / 20$ & $8 / 15 / 20086: 56$ & 24.8 & 989.7 \\
\hline 5673 & 1/15/20086:57 & $8 / 15 / 20086: 5$ & 24.8 & 99 \\
\hline 5674 & 1/15/20086:59 & $8 / 15 / 20086: 59$ & 24.9 & 989.3 \\
\hline 5675 & $1 / 15 / 2$ & $8 / 15 / 20087: 01$ & 24.8 & 991.2 \\
\hline 5676 & $1 / 15 / 2$ & $8 / 15 / 20087: 03$ & 24.9 & 988. \\
\hline 567 & $1 / 15 / 20$ & $8 / 15 / 20087: 05$ & 24.9 & 989.4 \\
\hline 5678 & $1 / 15 / 2$ & 8/15/2008 7:07 & 24.9 & 980 \\
\hline 5679 & $1 / 15 / 2$ & $8 / 15 / 20087: 09$ & 24.8 & 99 \\
\hline 5680 & $1 / 15 / 2$ & $8 / 15 / 20087: 11$ & 24.8 & 989.8 \\
\hline 5681 & $1 / 15 / 2$ & $8 / 15 / 200$ & 24.8 & 980 \\
\hline 5682 & $1 / 15 / 2$ & $8 / 15 / 20087: 15$ & 24.8 & 989.7 \\
\hline 5683 & $1 / 15 / 2$ & $8 / 15 / 20087: 17$ & 24.9 & 990. \\
\hline 5684 & $1 / 15 / 2$ & $8 / 15 / 20087: 19$ & 24.9 & 989. \\
\hline 5685 & $1 / 15$ & $8 / 15 / 200$ & 24.9 & 989.2 \\
\hline 5686 & $1 / 15 / 2$ & $8 / 15 / 20$ & 24.9 & 98 \\
\hline 5687 & $1 / 15 / 2$ & $8 / 15 / 20$ & 24.8 & 988 \\
\hline 5688 & & $8 / 15 / 20$ & 24.8 & 987.7 \\
\hline 5689 & $1 / 15 / 2$ & $8 / 15 / 20087: 29$ & 24.8 & 987.8 \\
\hline 5690 & $1 / 15 / 20$ & $8 / 15 / 20087: 31$ & 24.8 & $9 \overline{88.5}$ \\
\hline 5691 & $1 / 15$ & $8 / 15 / 2$ & 24.8 & 988.5 \\
\hline 5692 & $1 / 15$ & $8 / 15 / 2$ & 24.8 & 989. \\
\hline 5693 & & $8 / 15 / 200$ & 24.8 & 989.5 \\
\hline 5694 & & $8 / 15 / 2$ & 24.9 & 989 \\
\hline 5695 & 41 & $8 / 15 / 2$ & 24.9 & 989.7 \\
\hline 5696 & $1 / 15 / 2$ & $8 / 15 / 20$ & 24.9 & 989.5 \\
\hline 5697 & & $8 / 15 / 20$ & 24.9 & 989. \\
\hline 5698 & $: 47$ & $8 / 15 / 20$ & 24.9 & 990.2 \\
\hline 5699 & $1 / 15 / 2$ & $8 / 15 / 20$ & 24.9 & 989.7 \\
\hline 5700 & & & 24.9 & 99 \\
\hline 5701 & & $8 / 15 / 2$ & 24.9 & 988.5 \\
\hline 5702 & & $8 / 15 / 2$ & 24.8 & 989.7 \\
\hline 5703 & & $8 / 15$ & 24.8 & 989. \\
\hline 5704 & & $8 / 15 / 2$ & 24.8 & 988.8 \\
\hline 5705 & $1 / 1$ & $8 / 15 / 2$ & 24.9 & 989. \\
\hline 5706 & & & 24.9 & 988. \\
\hline 5707 & & & 24.8 & 989. \\
\hline 5708 & & $8 / 15 / 2$ & 24.8 & 989. \\
\hline 5709 & & $8 / 15$ & 24.8 & 988.7 \\
\hline 5710 & & & 24.8 & \\
\hline 5711 & & $8 / 15 / 2$ & 24.8 & 988. \\
\hline 5712 & & $8 / 15$ & 24.8 & 988. \\
\hline 5713 & & & 24.8 & 988. \\
\hline 5714 & & $8 / 15 / 2$ & & 988. \\
\hline 5715 & & $8 / 15 / 20088: 21$ & 24.9 & 990.6 \\
\hline 5716 & & & 24.9 & 989. \\
\hline 5717 & & $8 / 15 / 20088: 25$ & & \\
\hline 5718 & & $8 / 15 / 20088: 27$ & 24.9 & 989. \\
\hline 5719 & & & 24.9 & 989. \\
\hline 5720 & & & 24.9 & 989.2 \\
\hline 5721 & & $8 / 15 / 20088: 33$ & 24.9 & \\
\hline 572 & & $8 / 15 / 20088: 35$ & 24.9 & 989.8 \\
\hline 5723 & & $8 / 15 / 20088: 37$ & 24.9 & 989. \\
\hline 5724 & & & $20 \mathrm{~d}$ & \\
\hline 5725 & & $8 / 15 / 2$ & 24.9 & 50 \\
\hline & & & & \\
\hline
\end{tabular}

\begin{tabular}{|c|c|c|c|c|}
\hline \multicolumn{5}{|c|}{ D4-93c } \\
\hline Rec & & Adjusted & Temp & SC \\
\hline$\#$ & Date/Time & Date/Time & $\infty$ & $\mu \mathrm{S} / \mathrm{cm}$ \\
\hline 5727 & $1 / 15 / 20088: 45$ & $8 / 15 / 20088: 45$ & 24.9 & 988.7 \\
\hline 5728 & $1 / 15 / 20088: 47$ & $8 / 15 / 20088: 47$ & 24.9 & 988.8 \\
\hline 5729 & $1 / 15 / 20088: 49$ & $8 / 15 / 20088: 49$ & 24.9 & 988.1 \\
\hline 5730 & $1 / 15 / 20088: 51$ & $8 / 15 / 20088: 51$ & 24.9 & 989 \\
\hline 5731 & $1 / 15 / 20088: 53$ & $8 / 15 / 20088: 53$ & 24.9 & 988.7 \\
\hline 5732 & $1 / 15 / 20088: 55$ & $8 / 15 / 20088: 55$ & 24.9 & 989.4 \\
\hline 5733 & 1/15/2008 8:57 & $8 / 15 / 20088: 57$ & 24.9 & 988.6 \\
\hline 5734 & $1 / 15 / 20088.59$ & $8 / 15 / 20088: 59$ & 24.9 & 988.7 \\
\hline 5735 & $1 / 15 / 20089: 01$ & $8 / 15 / 20089: 01$ & 24.9 & 988.5 \\
\hline 5736 & 1/15/20089:03 & $8 / 15 / 20089.03$ & 24.9 & 988.6 \\
\hline 5737 & 1/15/20089:05 & $8 / 15 / 20089.05$ & 24.9 & 988.7 \\
\hline 5738 & 1/15/20089.07 & $8 / 15 / 20089.07$ & 24.9 & 988.7 \\
\hline 5739 & $1 / 15 / 20089: 09$ & $8 / 15 / 20089: 09$ & 24.9 & 988.3 \\
\hline 5740 & 1/15/20089:11 & $8 / 15 / 20089.11$ & 24.9 & 989.2 \\
\hline 5741 & 1/15/20089:13 & $8 / 15 / 20089.13$ & 24.9 & 989 \\
\hline 5742 & 1/15/20089.15 & $8 / 15 / 20089: 15$ & 24.8 & 988.2 \\
\hline 574 & $1 / 15 / 20089.17$ & $8 / 15 / 20089.17$ & 24.8 & 988.5 \\
\hline 5744 & 1/15/20089:19 & $8 / 15 / 20089: 19$ & 24.8 & 989.4 \\
\hline 5745 & $1 / 15 / 20089.21$ & $8 / 15 / 20089.21$ & 24.9 & 989.2 \\
\hline 5746 & $1 / 15 / 20089: 23$ & $8 / 15 / 20089: 23$ & 24.9 & 988.1 \\
\hline 5747 & $1 / 15 / 20089.25$ & $8 / 15 / 20089.25$ & 24.8 & 988.8 \\
\hline 5748 & $1 / 15 / 20089.27$ & $8 / 15 / 20089.27$ & 24.9 & 988.7 \\
\hline 5749 & $1 / 15 / 20089: 29$ & $8 / 15 / 20089: 29$ & 24.9 & 988.9 \\
\hline 5750 & 1/15/20089.31 & $8 / 15 / 20089.31$ & 24.9 & 988.3 \\
\hline 5751 & $1 / 15 / 20089.33$ & $8 / 15 / 20089.33$ & 24.9 & 989 \\
\hline 5752 & 1/15/20089.35 & $8 / 15 / 20089.35$ & 25 & 985 \\
\hline 5753 & 1/15/20089:37 & $8 / 15 / 20089: 37$ & 24.9 & 986 \\
\hline 5754 & $1 / 15 / 20089: 39$ & $8 / 15 / 20089.39$ & 24.7 & 987 \\
\hline 5755 & $1 / 15 / 20089: 41$ & $8 / 15 / 20089.41$ & 24.7 & 986 \\
\hline 5756 & $1 / 15 / 20089.43$ & $8 / 15 / 20089.43$ & 24.7 & 987.1 \\
\hline 5757 & 1/15/20089:45 & $8 / 15 / 20089.45$ & 24.7 & 989.4 \\
\hline 5758 & $1 / 15 / 20089.47$ & $8 / 15 / 20089: 47$ & 24.7 & 989.9 \\
\hline 5759 & $1 / 15 / 20089.49$ & $8 / 15 / 20089: 49$ & 24.7 & 988.7 \\
\hline 5760 & 1/15/20089:51 & $8 / 15 / 20089.51$ & 24.7 & 989.6 \\
\hline 5761 & $1 / 15 / 20089: 53$ & $8 / 15 / 20089.53$ & 24.7 & 989.5 \\
\hline 5762 & $1 / 15 / 20089.55$ & $8 / 15 / 20089.55$ & 24.8 & 989.9 \\
\hline 5763 & 1/15/20089:57 & $8 / 15 / 20089: 57$ & 24.8 & 990 \\
\hline 5764 & $1 / 15 / 20089.59$ & $8 / 15 / 20089.59$ & 24.8 & 990.7 \\
\hline 5765 & 1/15/2008 10:01 & $8 / 15 / 200810: 01$ & 24.8 & 989.6 \\
\hline 5766 & $1 / 15 / 200810: 03$ & $8 / 15 / 200810: 03$ & 24.8 & 990.2 \\
\hline 5767 & 1/15/2008 10:05 & $8 / 15 / 2008$ 10:05 & 24.8 & 990.7 \\
\hline 5768 & $1 / 15 / 200810: 07$ & $8 / 15 / 200810: 07$ & 24.8 & 990.1 \\
\hline 5769 & $1 / 15 / 2008$ 10:09 & $8 / 15 / 200810: 09$ & 24.8 & 990.4 \\
\hline 5770 & 1/15/2008 10:11 & $8 / 15 / 200810: 11$ & 24.8 & 991.2 \\
\hline 5771 & $1 / 15 / 200810: 13$ & $8 / 15 / 200810: 13$ & 24.9 & 990.1 \\
\hline 5772 & 1/15/2008 10:15 & $8 / 15 / 200810: 15$ & 24.9 & 990 \\
\hline 5773 & 1/15/2008 10:17 & $8 / 15 / 200810: 17$ & 24.8 & 991.1 \\
\hline 5774 & 1/15/2008 10:19 & $8 / 15 / 2008$ 10:19 & 24.9 & 991.2 \\
\hline 5775 & $1 / 15 / 200810: 21$ & $8 / 15 / 2008$ t0:21 & 24.9 & 990.3 \\
\hline 5776 & $1 / 15 / 200810: 23$ & $8 / 15 / 200810: 23$ & 24.9 & 990.5 \\
\hline $5 \pi 7$ & $1 / 15 / 2008$ 10:25 & $8 / 15 / 200810: 25$ & 24.8 & 991.3 \\
\hline 5778 & $1 / 15 / 200810: 27$ & $8 / 15 / 200810: 27$ & 24.9 & 991.1 \\
\hline 5779 & 1/15/2008 10:29 & $8 / 15 / 200810: 29$ & 24.7 & 990.2 \\
\hline 5780 & 1/15/2008 10:31 & $8 / 15 / 2008$ 10:31 & 24.7 & 989 \\
\hline 5781 & $1 / 15 / 200810: 33$ & $8 / 15 / 200810: 33$ & 24.7 & 989.4 \\
\hline 5782 & $1 / 15 / 2008$ 10:35 & $8 / 15 / 200810: 35$ & 24.7 & 989.8 \\
\hline 5783 & $1 / 15 / 2008$ 10:37 & $8 / 15 / 200810: 37$ & 24.6 & 990.2 \\
\hline 5784 & $1 / 15 / 200810: 39$ & $8 / 15 / 200810: 39$ & 24.7 & 991.2 \\
\hline 5785 & $1 / 15 / 2008$ 10:41 & $8 / 15 / 2008$ 10:41 & 24.6 & 9928 \\
\hline 5786 & $1 / 15 / 200810: 43$ & $8 / 15 / 2008$ 10:43 & 24.6 & 9923 \\
\hline 5787 & $1 / 15 / 200810: 45$ & $8 / 15 / 200810: 45$ & 24.6 & 991.9 \\
\hline 5788 & $1 / 15 / 2008$ 10:47 & $8 / 15 / 2008$ 10:47 & 24.6 & 992 \\
\hline 5789 & $1 / 15 / 200810: 49$ & $8 / 15 / 2008$ 10:49 & 24.6 & 993.2 \\
\hline 5790 & $1 / 15 / 2008$ 10:51 & $8 / 15 / 200810: 51$ & 24.6 & 993.1 \\
\hline 5791 & $1 / 15 / 2008$ 10:53 & 8/15/2008 10:53 & 24.7 & 992.5 \\
\hline 5792 & $1 / 15 / 2008$ 10:55 & $8 / 15 / 200810: 55$ & \begin{tabular}{l|l|}
24.7 \\
\end{tabular} & 992.9 \\
\hline 5793 & $1 / 15 / 200810: 57$ & $8 / 15 / 200810: 57$ & 24.8 & 992.2 \\
\hline 5794 & $1 / 15 / 200810: 59$ & $8 / 15 / 200810: 59$ & 24.7 & 993.6 \\
\hline & & 8/15/2008 11:01 & 24.8 & 991.1 \\
\hline
\end{tabular}




\begin{tabular}{|c|c|c|c|c|}
\hline \multicolumn{5}{|c|}{ D4-93C } \\
\hline $\operatorname{Rec}$ & & Adusted & Temp & $S C$ \\
\hline \# & Date/Time & Date/Time & $\alpha C$ & $\mu \mathrm{s} / \mathrm{om}$ \\
\hline 5796 & 1/15/2008 11:03 & \begin{tabular}{|l|}
$8 / 15 / 200811: 03$ \\
\end{tabular} & 24.7 & 993 \\
\hline 5797 & 1/15/2008 11:05 & $8 / 15 / 2008$ 11:05 & 24.8 & 993.4 \\
\hline 5798 & 1/15/2008 11:07 & \begin{tabular}{|l|}
$8 / 15 / 2008$ 11:07 \\
\end{tabular} & 24.8 & 991.2 \\
\hline 5799 & 1/15/2008 11:09 & $8 / 15 / 200811: 09$ & 24.8 & 990.9 \\
\hline 5800 & 1/15/2008 11:11 & 8/15/2008 11:11 & 24.7 & 992.1 \\
\hline 5801 & 1/15/2008 11:13 & $8 / 15 / 200811: 13$ & 24.7 & 9924 \\
\hline 5902 & 1/15/2008 11:15 & 8/15/2008 11:15 & 24.8 & 991.7 \\
\hline 5803 & 1/15/2008 11:17 & \begin{tabular}{|l|}
$8 / 15 / 200811: 17$ \\
\end{tabular} & 24.8 & 9921 \\
\hline 5804 & 1/15/2008 11:19 & \begin{tabular}{|l|}
$8 / 15 / 200811: 19$ \\
\end{tabular} & 24.8 & 9925 \\
\hline 5805 & 1/15/2008 11:21 & \begin{tabular}{|l|}
$8 / 15 / 200811: 21$ \\
\end{tabular} & 24.7 & 9924 \\
\hline 5806 & 1/15/2008 11:23 & $8 / 15 / 200811: 23$ & 24.7 & 991.8 \\
\hline 5807 & 1/15/2008 11:25 & $8 / 15 / 200811: 25$ & 24.7 & 9922 \\
\hline 5808 & 1/15/2008 11:27 & 8/15/2008 11:27 & 24.7 & 9928 \\
\hline 5809 & 1/15/2008 11:29 & $8 / 15 / 200811: 29$ & 24.7 & 9923 \\
\hline 5810 & 1/15/2008 11:31 & \begin{tabular}{|l|}
$8 / 15 / 200811: 31$ \\
\end{tabular} & 24.7 & 993.2 \\
\hline 5811 & 1/15/2008 11:33 & \begin{tabular}{|l|}
$8 / 15 / 200811: 33$ \\
\end{tabular} & 24.8 & 9927 \\
\hline 5812 & 1/15/2008 11:35 & $8 / 15 / 200811: 35$ & 24.8 & 992.7 \\
\hline 5813 & 1/15/2008 11:37 & \begin{tabular}{|l|l|}
$8 / 15200811: 37$ \\
\end{tabular} & 24.8 & 9924 \\
\hline 5814 & 1/15/2008 11:39 & $8 / 15 / 200811: 39$ & 24.8 & 993.4 \\
\hline 5815 & 1/15/2008 11:41 & $8 / 15 / 200811: 41$ & 24.8 & 993.7 \\
\hline 5816 & $1 / 15 / 200$ & $8 / 15 / 200811: 43$ & 24.8 & 987.5 \\
\hline 5817 & 1/15/2008 11:45 & $8 / 15 / 2008$ 11:45 & 25 & 999.5 \\
\hline 5818 & 1/15/2008 11:47 & $8 / 15 / 2008+1: 47$ & 24.9 & 1008.7 \\
\hline 5819 & 1/15/2008 11:49 & \begin{tabular}{|l|}
$8 / 15 / 200811: 49$ \\
\end{tabular} & 24.8 & 1010 \\
\hline 5820 & $1 / 15 / 2008$ & $8 / 15 / 2008$ 11:51 & 24.8 & 1008 \\
\hline 5821 & $1 / 15 / 200811: 53$ & $8 / 15 / 200811: 53$ & 24.8 & 1009.4 \\
\hline 5822 & 1/15/2008 11:55 & $8 / 15 / 200811: 55$ & 24.8 & 1007.3 \\
\hline 5823 & $1 / 15 / 2000$ & $8 / 15 / 200811: 57$ & 24.8 & 1005.7 \\
\hline 5824 & $1 / 15 / 20$ & \begin{tabular}{|l|l|}
$8 / 15 / 200811: 59$ \\
\end{tabular} & 24.8 & 1005.8 \\
\hline 5825 & $1 / 15 / 20$ & \begin{tabular}{|l|}
$8 / 15 / 200812001$ \\
\end{tabular} & 24.8 & 10023 \\
\hline 5826 & $1 / 15 / 200$ & $8 / 15 / 200812: 03$ & 24.8 & 1000.2 \\
\hline 5827 & $1 / 15 / 200812: 05$ & $8 / 15 / 20081205$ & 24.7 & 999.1 \\
\hline 5828 & $1 / 15 / 200812: 07$ & $8 / 15 / 20081207$ & 24.7 & 1000.2 \\
\hline 5829 & $1 / 15 / 20081209$ & $8 / 15 / 20081209$ & 24.7 & 999.4 \\
\hline 5830 & $1 / 15 / 200$ & $8 / 15 / 20081211$ & 24.7 & 997.3 \\
\hline 5831 & $1 / 15 / 200812: 13$ & $8 / 15 / 20081213$ & 24.7 & 997 \\
\hline 5832 & $1 / 15 / 20081215$ & $8 / 15 / 20081215$ & 24.6 & 994.6 \\
\hline 5833 & 1/15/2008 12:17 & $8 / 15 / 200812: 17$ & 24.6 & 994.4 \\
\hline 5834 & $1 / 15 / 20$ & $8 / 15 / 20081219$ & 24.6 & 993.2 \\
\hline 5835 & $1 / 15 / 20081221$ & \begin{tabular}{|l|l|}
$8 / 15 / 20081221$ \\
\end{tabular} & 24.5 & 994.1 \\
\hline 5836 & 1/15/2008 12:23 & $8 / 15 / 20081223$ & 24.5 & 9924 \\
\hline 5837 & $1 / 15 / 20$ & $8 / 15 / 20081225$ & 24.5 & 991.2 \\
\hline 5838 & $1 / 15 / 20081227$ & $8 / 15 / 20081227$ & 24.5 & 9921 \\
\hline 5839 & $1 / 15 / 20081229$ & $8 / 15 / 20081229$ & 24.4 & 990.9 \\
\hline 5840 & $1 / 15 / 200812 ; 31$ & $8 / 15 / 20081231$ & 24.4 & 989.8 \\
\hline 5841 & $1 / 15 / 20$ & $8 / 15 / 20081233$ & 24.4 & 990.3 \\
\hline 5842 & $1 / 15 / 20$ & $8 / 15 / 20081235$ & 24.4 & 989.2 \\
\hline 5843 & 1/15/200812:37 & \begin{tabular}{|l|}
$8 / 15 / 20081237$ \\
\end{tabular} & 24.3 & 989.6 \\
\hline 5844 & $1 / 15 / 200812 ; 39$ & $8 / 15 / 20081239$ & 24.3 & 989.2 \\
\hline 5845 & $1 / 15 / 2008$ & $8 / 15 / 20081241$ & 24.3 & 989.3 \\
\hline 5846 & $1 / 15 / 200812: 43$ & $8 / 15 / 20081243$ & 24.3 & 989.3 \\
\hline 5847 & $1 / 15 / 20081245$ & $8 / 15 / 20081245$ & 24.3 & 990.2 \\
\hline 5848 & 1/15/200812477 & $8 / 15 / 20081247$ & 24.3 & 990.3 \\
\hline 5849 & $1 / 15 / 20$ & $8 / 15 / 20081249$ & 24.3 & 969.6 \\
\hline 5850 & $1 / 15 / 20081251$ & $8 / 15 / 20081251$ & 24.2 & 990.1 \\
\hline 5851 & $1 / 15 / 20081253$ & $8 / 15 / 20081253$ & 24.2 & 989.8 \\
\hline 5852 & $1 / 15 / 200812556$ & $8 / 15 / 20081255$ & 24.2 & 990.7 \\
\hline 5853 & $1 / 15 / 20081257$ & \begin{tabular}{|l|l|}
$8 / 15 / 20081257$ \\
\end{tabular} & 24.2 & 989.2 \\
\hline 5854 & $1 / 15 / 20081259$ & \begin{tabular}{|l|l|}
$8 / 1520081259$ \\
\end{tabular} & 24.2 & 984.4 \\
\hline 5855 & 1/15/2008 13:01 & \begin{tabular}{|l|l|}
$8 / 15 / 200813: 01$ \\
\end{tabular} & 24.3 & 983.8 \\
\hline 5856 & $1 / 15 / 200813: 03$ & $8 / 15 / 200813: 03$ & 24.3 & 989.2 \\
\hline
\end{tabular}
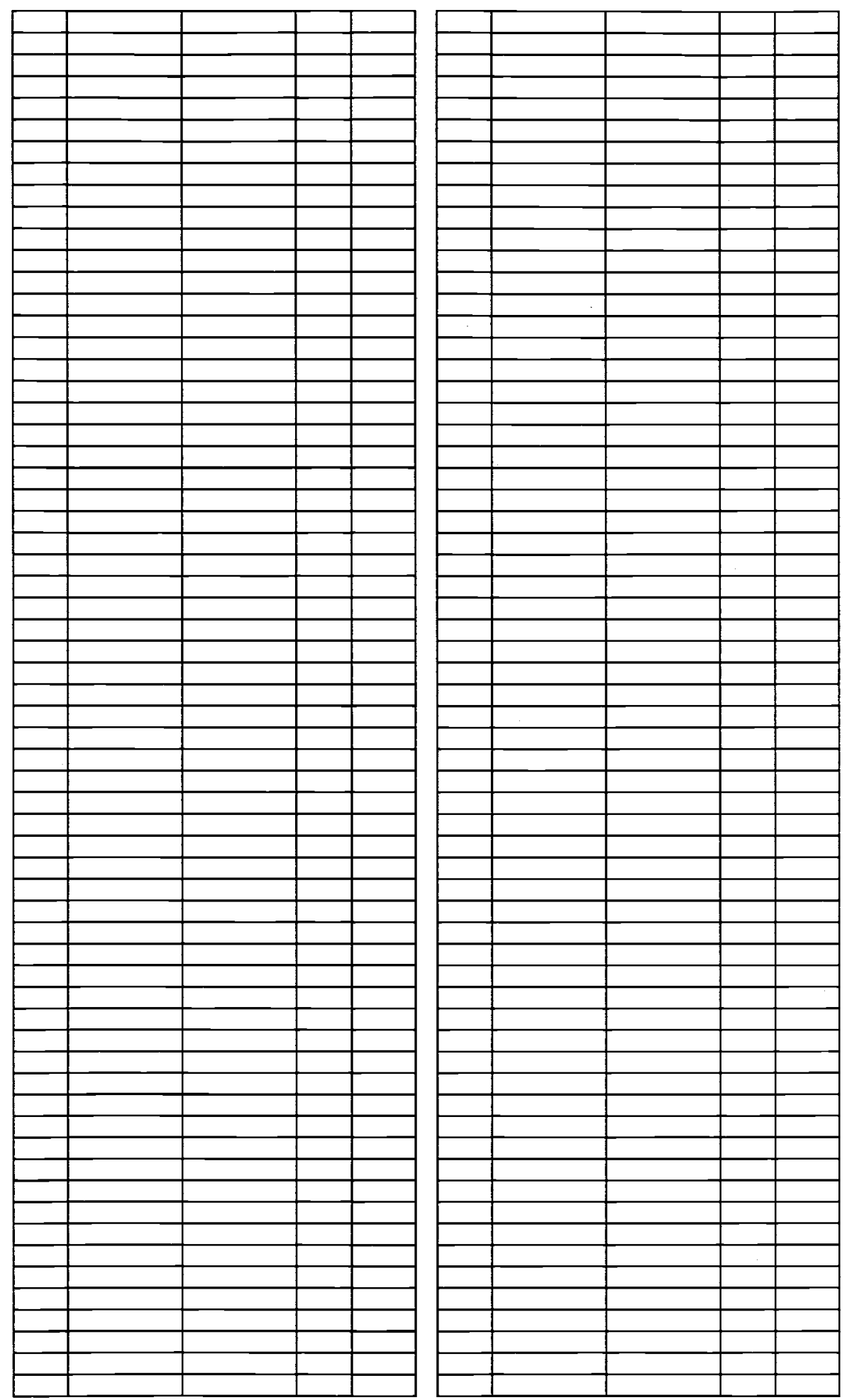
DOE/RL-2009-35, REV. 0

\begin{tabular}{|c|c|c|c|c|}
\hline \multicolumn{5}{|c|}{$D 4-93 p$} \\
\hline Rec & & Adjusted & \begin{tabular}{|l|} 
Pressure \\
\end{tabular} & Temp \\
\hline \# & Date/Time & DaterTime & \begin{tabular}{|c|}
$p s i$ \\
\end{tabular} & ${ }^{\circ} \mathrm{C}$ \\
\hline & $17 / 20089.50$ & $87120089: 50$ & 1.875 & 17.4 \\
\hline 2 & $1 / 7 / 20089.52$ & $87 / 20089.52$ & 1.875 & 17.5 \\
\hline 3 & $1 / 7 / 20089.54$ & $87 / 20089.54$ & 1.876 & 17.3 \\
\hline 4 & $1 / 7 / 20089: 56$ & $87 / 20089.56$ & 1.876 & 17.1 \\
\hline 5 & $1 / 7 / 20089.58$ & $8 / 7 / 20089.58$ & 1.876 & 16.9 \\
\hline 6 & 1/7/2008 10:00 & $8 / 7 / 200810: 00$ & 1.875 & 16.9 \\
\hline 7 & $1 / 7 / 200810: 02$ & $8 / 7 / 2008$ 10:02 & 1.876 & 16.9 \\
\hline 8 & $1 / 7 / 2008$ 10:04 & $87 / 200810: 04$ & 1.876 & 16.9 \\
\hline 9 & $1 / 7 / 2008$ 10:06 & $87 / 200810: 06$ & 1.875 & 16.9 \\
\hline 10 & $1 / 7 / 200810: 08$ & $87 / 2008$ 10:08 & 1.876 & 16.9 \\
\hline 11 & 1/7/2008 10:10 & $8 / 7 / 2008$ 10:10 & 1.877 & 16.9 \\
\hline 12 & 1/7/2008 10:12 & $87 / 2008$ 10:12 & 1.877 & $\overline{16.9}$ \\
\hline 13 & $1 / 7 / 200810: 14$ & $87 / 2008$ 10:14 & 1.877 & 16.9 \\
\hline 14 & 1/7/2008 10:16 & $87 / 2008$ 10:16 & 1.876 & 16.9 \\
\hline 15 & $1 / 7 / 2008$ 10:18 & $87 / 2008$ 10:18 & 1.876 & 16.9 \\
\hline 16 & $1 / 7 / 200810: 20$ & $87 / 2008$ 10:20 & 1.877 & 16.9 \\
\hline 17 & $1 / 7 / 200810: 22$ & $87 / 2008$ 10:22 & 1.877 & 16.9 \\
\hline 18 & $1 / 7 / 2008$ 10:24 & $87 / 2008$ 10:24 & 1.878 & 16.9 \\
\hline 19 & $1 / 7 / 2008$ 10:26 & $87 / 2008$ 10:26 & 1.878 & $\overline{16.9}$ \\
\hline 20 & $1 / 7 / 2008$ 10:28 & $87 / 2008$ 10:28 & 1.878 & 16.9 \\
\hline 21 & $1 / 7 / 2008$ 10:30 & $8 / 7 / 2008$ 10:30 & 1.878 & 16.9 \\
\hline 22 & $1 / 7 / 2008$ 10:32 & $87 / 2008$ 10:32 & 1.878 & 16.9 \\
\hline 23 & $1 / 7 / 2008$ 10:34 & $8 / 7 / 200810: 34$ & 1.878 & 16.9 \\
\hline 24 & $1 / 7 / 2008$ 10:36 & $87 / 2008$ 10:36 & 1.878 & $\overline{16.9}$ \\
\hline 25 & $1 / 7 / 2008$ 10:38 & $87 / 2008$ 10:38 & 1.878 & 16.9 \\
\hline 26 & $1 / 7 / 200810: 40$ & $8 / 7 / 2008$ 10:40 & 1.877 & 16.9 \\
\hline 27 & $1 / 7 / 200810: 42$ & $8 / 7 / 2008$ 10:42 & 1.877 & 16.9 \\
\hline 28 & $1 / 7 / 200810: 44$ & $87 / 2008$ 10:44 & 1.877 & 16.9 \\
\hline 29 & $1 / 7 / 200810: 46$ & $8 / 7 / 2008$ 10:46 & 1.87 & 16.5 \\
\hline 30 & $1 / 7 / 200810: 48$ & $8 / 7 / 2008$ 10:48 & 1.877 & 16.0 \\
\hline 31 & $1 / 7 / 2008$ 10:50 & $8 / 7 / 2008$ 10:50 & 1.878 & 16.9 \\
\hline 32. & $17 / 2008$ 10:52 & $8 / 7 / 2008$ 10:52 & 1.878 & 16.9 \\
\hline 33 & $1 / 7 / 2008$ 10:54 & $87 / 2008$ 10:54 & 1.877 & 16.9 \\
\hline 34 & $1 / 7 / 200810.56$ & $8 / 7 / 2008$ 10:56 & 1.876 & 16.9 \\
\hline 35 & $1 / 7 / 2008$ 10:58 & $8 / 7 / 2008$ 10:58 & 1.876 & 16.9 \\
\hline 36 & 1/7/2008 11:00 & $8 / 7 / 2008$ 11:00 & 1.876 & 16.9 \\
\hline 37 & $17 / 200811: 02$ & $87 / 2008$ 11:02 & 1.876 & 16.9 \\
\hline 38) & $1 / 7 / 200811: 04$ & $87 / 2008$ 11:04 & 1.876 & 16.9 \\
\hline 39 & $1 / 7 / 2008$ 11:06 & $8 / 7 / 2008$ 11:06 & 1.876 & 16.9 \\
\hline 40 & 1/7/2008 11:08 & $8 / 7 / 2008$ 11:08 & 1.876 & 16.9 \\
\hline 41 & $1 / 7 / 200811: 10$ & $8 / 7 / 2008$ 11:10 & 1.875 & 16.9 \\
\hline 42 & $1 / 7 / 2008$ 11:12 & $8 / 72008$ 11:12 & 1.876 & 16. \\
\hline 43 & $1 / 7 / 2008$ 11:14 & $87 / 2008$ 11:14 & 1.876 & 16.9 \\
\hline 44 & $1 / 7 / 200811: 16$ & $87 / 200811: 16$ & 1.876 & 16.9 \\
\hline 45 & $1 / 7 / 200811: 18$ & $8 / 7 / 200811: 18$ & 1.87 & 16.5 \\
\hline 46 & $1 / 7 / 200811: 20$ & $8 / 7 / 200811: 20$ & 1.877 & 16. \\
\hline 47 & $1 / 7 / 200811: 2$ & $8 / 7 / 200811: 22$ & 1.877 & 16.9 \\
\hline 48 & $1 / 7 / 200811: 24$ & $8 / 7 / 2008$ 11:24 & 1.878 & 16.9 \\
\hline 49 & 1/7/2008 11:26 & $8 / 7 / 2008$ 11:26 & 1.877 & 16.9 \\
\hline 50 & 1/7/2008 11:28 & $8 / 7200811: 28$ & 1.877 & 16.9 \\
\hline 51 & $17 / 200811: 30$ & $87 / 200811: 30$ & 1.877 & 16.9 \\
\hline 52 & $1 / 7 / 200811: 32$ & $8 / 7 / 2008+11: 32$ & 1.878 & 16.9 \\
\hline 53 & $1 / 7 / 200811: 34$ & $8 / 7 / 200811: 34$ & 1.878 & 16. \\
\hline 54 & $1 / 7 / 200811: 36$ & $8 / 7 / 200811: 36$ & 1.878 & 16.9 \\
\hline 56 & $1 / 7 / 200811: 38$ & $8 / 7 / 200811: 38$ & 1.878 & 16.9 \\
\hline 56 & $1 / 7 / 200811: 40$ & $8 / 7 / 200811: 40$ & 1.878 & 16.9 \\
\hline 57 & 1/7/2008 11:42 & $8 / 7 / 2008$ 11:42 & 1.878 & 16.9 \\
\hline 58 & 1/7/200811:44 & $8 / 7 / 2008$ 11:44 & 1.879 & 16. \\
\hline 59 & $1 / 7 / 200811: 46$ & $8 / 7 / 200811: 46$ & 1.879 & 16.9 \\
\hline 60 & $1 / 7 / 200811: 48$ & $8 / 7 / 200811: 48$ & 1.88 & 16.9 \\
\hline 61 & $1 / 7 / 200811: 50$ & $8 / 7 / 200811: 50$ & 1.879 & 16.9 \\
\hline 62 & $1 / 7 / 200811: 52$ & $8 / 7 / 2008$ 11:52 & 1.878 & 16.9 \\
\hline 6 & $1 / 7 / 200811: 54$ & $8 / 7 / 2008$ 11:54 & 1.877 & 16.9 \\
\hline 64 & 1/7/200811:56 & $87 / 2008$ 11:56 & 1.878 & 16.9 \\
\hline 65 & $1 / 7 / 200811: 58$ & $8 / 7 / 200811: 58$ & 1.879 & 16.9 \\
\hline 66 & $1 / 7 / 200812: 00$ & $8 / 7 / 200812: 00$ & 1.88 & 16.9 \\
\hline 67 & $1 / 7 / 200812.02$ & $8 / 7 / 20081202$ & 1.88 & 16.9 \\
\hline 68 & $1 / 7 / 2008$ 12:04 & $8 / 7 / 2008$ 12:04 & 1.88 & 16.9 \\
\hline
\end{tabular}

\begin{tabular}{|c|c|c|c|c|}
\hline \multicolumn{5}{|c|}{ D4-93p } \\
\hline $\operatorname{Rec}$ & & Adjusted & Pressure & Temp \\
\hline$\#$ & Date/Time & DaterTime & psi & ${ }^{\circ} \mathrm{C}$ \\
\hline 69 & $1 / 7 / 20081206$ & $87 / 200812.06$ & 1.879 & 16.9 \\
\hline 70 & $1 / 7 / 20081208$ & $87 / 200812: 08$ & 1.88 & 16.9 \\
\hline 71 & $1 / 7 / 20081210$ & $8 / 7 / 200812: 10$ & 1.881 & 16.9 \\
\hline 72 & $1 / 7 / 2008$ 12:12 & $8 / 7 / 2008$ 12:12 & 1.882 & 16.9 \\
\hline 73 & $1 / 7 / 200812: 14$ & $87 / 2008+2: 14$ & 1.882 & 16.9 \\
\hline 74 & $1 / 7 / 2008$ 12:16 & $87 / 200812: 16$ & 1.882 & 16.9 \\
\hline 75 & $1 / 7 / 200812: 18$ & $8 / 7 / 200812: 18$ & 1.881 & 16.9 \\
\hline 76 & $1 / 7 / 20081220$ & $87 / 20081220$ & 1.88 & 16.9 \\
\hline $7 \pi$ & $1 / 7 / 200812: 22$ & $87 / 200812: 22$ & 1.88 & 16.9 \\
\hline 78 & $1 / 7 / 200812: 24$ & $8 / 7 / 200812: 24$ & 1.88 & 16.9 \\
\hline 79 & $1 / 7 / 20081226$ & $8 / 7 / 200812: 26$ & 1.88 & 16.9 \\
\hline 80 & $1 / 7 / 2008$ 12:28 & $8 / 7 / 200812: 28$ & 1.879 & 16.9 \\
\hline 81 & $1 / 7 / 200812: 30$ & $87 / 200812: 30$ & 1.877 & 16.9 \\
\hline 82 & $1 / 7 / 200812: 32$ & $87 / 200812: 32$ & 1.878 & 16.9 \\
\hline 83 & $1 / 7 / 200812: 34$ & $8 / 7 / 200812: 34$ & 1.879 & 16.9 \\
\hline 84 & $1 / 7 / 200812: 36$ & $87 / 20081236$ & 1.879 & 16.9 \\
\hline 85 & $1 / 7 / 20081238$ & $8 / 7 / 200812: 38$ & 1.88 & 16.9 \\
\hline 86 & $1 / 7200812: 40$ & $8 / 7200812: 40$ & 1.88 & 16.9 \\
\hline 87 & $1 / 7 / 200812: 42$ & $87 / 200812: 42$ & 1.88 & 16.9 \\
\hline 88 & $1 / 7 / 200812: 44$ & $8 / 7 / 200812: 44$ & 1.88 & 16.9 \\
\hline 89 & $1 / 7 / 200812: 46$ & $87 / 20081246$ & 1.88 & 16.9 \\
\hline 90 & $1 / 7 / 200812: 48$ & $8 / 7 / 20081248$ & 1.88 & 16.9 \\
\hline 91 & $1 / 7 / 200812550$ & $8 / 7 / 200812: 50$ & 1.88 & 16.9 \\
\hline 92 & $1 / 7 / 200812: 52$ & $8 / 7 / 200812: 52$ & 1.881 & 16.9 \\
\hline 93 & $1 / 7 / 200812: 54$ & $8 / 7 / 20081254$ & 1.882 & 16.9 \\
\hline 94 & $1 / 7 / 20081256$ & $8 / 720081256$ & 1.881 & 16.9 \\
\hline 95 & $1 / 7 / 20081258$ & $8 / 7 / 200812: 58$ & 1.88 & 16.9 \\
\hline 96 & $1 / 7 / 2008+3: 00$ & $87 / 200813: 00$ & 1.881 & 16.9 \\
\hline 97 & $1 / 7 / 200813: 02$ & $8 / 7 / 200813: 02$ & 1.881 & 16.9 \\
\hline 98 & $1 / 7 / 200813: 04$ & $87 / 200813: 04$ & 1.881 & 16.9 \\
\hline 99 & $1 / 7 / 200813: 06$ & $8 / 7 / 200813: 06$ & 1.882 & 16.9 \\
\hline 100 & $1 / 7 / 200813: 08$ & $87 / 200813: 08$ & 1.882 & 16.9 \\
\hline 101 & $1 / 7 / 200813: 10$ & $87 / 200813: 10$ & 1.882 & 16.9 \\
\hline 102 & $1 / 7 / 2008$ 13:12 & $8 / 7 / 2008$ 13:12 & 1.881 & 16.9 \\
\hline 103 & $1 / 7 / 200813: 14$ & $8 / 7 / 200813: 14$ & 1.88 & 16.9 \\
\hline 104 & $1 / 7 / 200813: 16$ & $8 / 7 / 200813: 16$ & 1.881 & 16.9 \\
\hline 105 & $1 / 7 / 200813: 18$ & $8 / 7 / 200813: 18$ & 1.881 & 16.9 \\
\hline 106 & $1 / 7 / 2008$ 13:20 & $8 / 7 / 200813: 20$ & 1.882 & 16.9 \\
\hline 107 & $1 / 7 / 200813: 22$ & $87 / 200813: 22$ & 1.883 & 16.9 \\
\hline 108 & $1 / 7 / 2008$ 13:24 & $8 / 7 / 200813: 24$ & 1.834 & 16.9 \\
\hline 109 & $1 / 7 / 200813: 26$ & $8 / 7 / 200813: 26$ & 1.834 & 16.9 \\
\hline 110 & $1 / 7 / 200813: 28$ & $8 / 7 / 200813: 28$ & 1.883 & 16.9 \\
\hline 111 & $1 / 7 / 200813: 30$ & $8 / 7 / 2008$ 13:30 & 1.882 & 16.9 \\
\hline 112 & $1 / 7 / 200813: 32$ & $8 / 7 / 200813: 32$ & 1.881 & 16.9 \\
\hline 113 & $1 / 7 / 2008$ 13:34 & $8 / 7 / 200813: 34$ & 1.883 & 16.9 \\
\hline 114 & $1 / 7200813: 36$ & $8 / 7 / 200813: 36$ & 1.885 & 16.9 \\
\hline 115 & $1 / 7 / 2008$ 13:38 & $8 / 7 / 200813: 38$ & 1.887 & 16.9 \\
\hline 116 & $1 / 7 / 2008$ 13:40 & $8 / 7 / 200813: 40$ & 1.889 & 16.9 \\
\hline 117 & $1 / 7 / 200813: 42$ & $8 / 7 / 200813: 42$ & 1.889 & 16.9 \\
\hline 118 & $1 / 7 / 200813: 44$ & $8 / 7 / 2008$ 13:44 & 1.888 & 16.9 \\
\hline 119 & $17 / 200813: 46$ & $87 / 200813: 46$ & 1.886 & 16.9 \\
\hline 120 & $1 / 7 / 200813: 48$ & $87 / 200813: 48$ & 1.886 & 16.9 \\
\hline 121 & $1 / 7 / 2008$ 13:50 & $87 / 200813: 50$ & 1.886 & 16.9 \\
\hline 122 & $1 / 7 / 2008$ 13:52 & $8 / 7 / 200813: 52$ & 1.887 & 16.9 \\
\hline 123 & $1 / 7 / 200813: 54$ & $87 / 200813: 54$ & 1.886 & 16.9 \\
\hline 124 & $1 / 7 / 2008$ 13:56 & $8 / 7 / 200813: 56$ & 1.886 & 16.9 \\
\hline 125 & $1 / 7 / 200813: 58$ & $8 / 7 / 2008+3: 58$ & 1.887 & 16.9 \\
\hline 126 & $1 / 7 / 2008$ 14:00 & $8 / 7 / 2008$ 14:00 & 1.888 & 16.9 \\
\hline 127 & $1 / 7 / 2008$ 14:02 & $87 / 2008$ 14:02 & 1.888 & 16.9 \\
\hline 128 & $1 / 7 / 2008$ 14:04 & $87 / 2008$ 14:04 & 1.888 & 16.9 \\
\hline 129 & $1 / 7 / 2008$ 14:06 & $8 / 72008$ 14:06 & 1.887 & 16.9 \\
\hline 130 & 1/7/2008 14:08 & $87 / 2008$ 14:08 & 1.886 & 16.9 \\
\hline 131 & $1 / 7 / 2008$ 14:10 & $87 / 2008$ 14:10 & 1.886 & 16.9 \\
\hline 132 & $1 / 7 / 2008$ 14:12 & $87 / 2008$ 14:12 & 1.885 & 16.9 \\
\hline 133 & $1 / 7 / 2008$ 14:14 & $87 / 2008+4: 14$ & 1.885 & 16.9 \\
\hline 134 & $1 / 7 / 200814: 16$ & $87 / 2008$ 14:16 & 1.884 & 16.9 \\
\hline 135 & $1 / 7 / 2008$ 14:18 & $8 / 7 / 2008$ 14:18 & 1.884 & 16.9 \\
\hline 136 & $1 / 7 / 2008$ 14:20 & $8 / 7 / 200814: 20$ & 1.885 & 16.9 \\
\hline
\end{tabular}

\begin{tabular}{|c|c|c|c|c|}
\hline \multicolumn{5}{|c|}{ D4-93p } \\
\hline $\operatorname{Rec}$ & & Agjusted & Pressure & Temp \\
\hline$\#$ & Date/Time & Date/Time & psi & ${ }^{\circ} \mathrm{C}$ \\
\hline 137 & $1 / 7 / 200814: 22$ & $8 / 7 / 2008$ 14:22 & 1.896 & 16.9 \\
\hline 138 & $1 / 7 / 2008$ 14:24 & $8 / 7 / 2008$ 14:24 & 1.886 & 16.9 \\
\hline 139 & $1 / 7 / 2008$ 14:26 & $8 / 7 / 2008$ 14:26 & 1.885 & 16.9 \\
\hline 140 & $1 / 7 / 2008$ 14:28 & $8 / 7 / 200814: 28$ & 1.886 & 16.9 \\
\hline 141 & $1 / 7 / 2008$ 14:30 & $8 / 7 / 2008$ 14:30 & 1.887 & 16.9 \\
\hline 142 & $1 / 7 / 200814: 32$ & $8 / 7 / 2008$ 14:32 & 1.888 & 16.9 \\
\hline 143 & $1 / 7 / 200814: 34$ & $8 / 7 / 2008$ 14:34 & 1.889 & 16.9 \\
\hline 144 & $1 / 7 / 2008$ 14:36 & $8 / 7 / 2008$ 14:36 & 1.888 & 16.9 \\
\hline 145 & $1 / 7 / 2008$ 14:38 & $8 / 7 / 2008$ 14:38 & 1.889 & 16.9 \\
\hline 146 & $1 / 7 / 200814: 40$ & $8 / 7 / 200814: 40$ & 1.887 & 16.9 \\
\hline 147 & $1 / 7 / 2008$ 14:42 & $8 / 7 / 2008$ 14:42 & 1.888 & 16.9 \\
\hline 148 & $1 / 7 / 200814: 44$ & $8 / 7 / 2008$ 14:44 & 1.888 & 16.9 \\
\hline 149 & $1 / 7 / 200814: 46$ & $8 / 7 / 2008$ 14:46 & 1.889 & 16.9 \\
\hline 150 & $1 / 7 / 200814: 48$ & $8 / 7 / 200814: 48$ & 1.888 & 16.9 \\
\hline 151 & $1 / 7 / 2008$ 14:50 & $8 / 7 / 2008$ 14:50 & 1.888 & 16.9 \\
\hline 152 & $1 / 7 / 2008$ 14:52 & $8 / 7 / 2008$ 14:52 & 1.888 & 16.9 \\
\hline 153 & $1 / 7 / 2008$ 14:54 & $87 / 2008$ 14:54 & 1.889 & 16.9 \\
\hline 154 & $1 / 7 / 200814: 56$ & $87 / 200814: 56$ & 1.889 & 16.9 \\
\hline 155 & $1 / 7 / 2008$ 14:58 & $8 / 7 / 200814: 58$ & 1.891 & 16.9 \\
\hline 156 & $1 / 7 / 2008$ 15:00 & $87 / 2008$ 15:00 & 1.891 & 16.9 \\
\hline 157 & $1 / 7 / 200815: 02$ & $8 / 7 / 2008$ 15:02 & 1.891 & 16.9 \\
\hline 158 & $1 / 7 / 2008$ 15:04 & $8 / 7 / 200815: 04$ & 1.891 & 16.9 \\
\hline 159 & $1 / 7 / 200815: 06$ & $8 / 7 / 200815: 06$ & 1.89 & 16.9 \\
\hline 160 & $1 / 7 / 2008$ 15:08 & $8 / 7 / 200815: 08$ & 1.89 & 16.9 \\
\hline 161 & $1 / 7 / 2008$ 15:10 & $87 / 200815: 10$ & 1.89 & 16.9 \\
\hline 162 & $1 / 7 / 200815: 12$ & $8 / 7 / 2008$ 15:12 & 1.891 & 16.9 \\
\hline 163 & $1 / 7 / 200815: 14$ & $8 / 7 / 2008$ 15:14 & 1.892 & 16.9 \\
\hline 164 & $1 / 7 / 200815: 16$ & $87 / 200815: 16$ & 1.892 & 16.9 \\
\hline 165 & $1 / 7 / 200815: 18$ & $87 / 200815: 18$ & 1.892 & 16.9 \\
\hline 166 & $1 / 7 / 2008$ 15:20 & $8 / 7 / 2008$ 15:20 & 1.893 & 16.9 \\
\hline 167 & $1 / 7 / 2008$ 15:22 & $8 / 7 / 200815: 22$ & 1.892 & 16.9 \\
\hline 168 & $1 / 7 / 2008$ 15:24 & $87 / 200815: 24$ & 1.892 & 16.9 \\
\hline 169 & $1 / 7 / 2008$ 15:26 & $87 / 2008$ 15:26 & 1.891 & 16.9 \\
\hline 170 & $1 / 7 / 200815: 28$ & $87 / 200815: 28$ & 1.891 & 16.9 \\
\hline 171 & 1/7/2008 15:30 & $8 / 7 / 200815: 30$ & 1.891 & 16.9 \\
\hline 172 & $1 / 7 / 200815: 32$ & $8 / 7 / 200815: 32$ & 1.892 & 16.9 \\
\hline 173 & $1 / 7 / 2008$ 15:34 & $877 / 2008$ 15:34 & 1.893 & 16.9 \\
\hline 174 & $1 / 7 / 2008$ 15:36 & $87 / 2008$ 15:36 & 1.894 & 16.9 \\
\hline 175 & $1 / 7 / 200815: 38$ & $8 / 7 / 200815: 38$ & 1.894 & 16.9 \\
\hline 176 & $1 / 7 / 200815: 40$ & $8 / 7 / 200815: 40$ & 1.894 & 16.9 \\
\hline 177 & $1 / 7 / 2008$ 15:42 & $8 / 7 / 200815: 42$ & 1.893 & 16.9 \\
\hline 178 & $1 / 7 / 2008$ 15:44 & $87 / 2008$ 15:44 & 1.892 & 16.9 \\
\hline 179 & $1 / 7 / 200815: 46$ & $8 / 7 / 200815: 46$ & 1.891 & 16.9 \\
\hline 180 & $1 / 7 / 2008$ 15:48 & $8 / 7 / 200815: 48$ & 1.892 & 16.9 \\
\hline 181 & $1 / 7 / 200815: 50$ & $87 / 200815: 50$ & 1.892 & 16.9 \\
\hline 182 & $1 / 7 / 2008$ 15:52 & $87 / 200815: 52$ & 1.891 & 16.9 \\
\hline 183 & $1 / 7 / 2008$ 15:54 & $8 / 7 / 200815: 54$ & 1.891 & 16.9 \\
\hline 184 & $1 / 7 / 200815: 56$ & $87 / 200815: 56$ & 1.892 & 16.9 \\
\hline 185 & $1 / 7 / 200815: 58$ & $87 / 200815: 58$ & 1.893 & 16.9 \\
\hline 186 & 1/7/2008 16:00 & $8 / 7 / 200816: 00$ & 1.893 & 16.9 \\
\hline 187 & $1 / 7 / 200816: 02$ & $87 / 200816: 02$ & 1.892 & 16.9 \\
\hline 188 & $1 / 7 / 2008$ 16:04 & $87 / 200816: 04$ & 1.892 & 16.9 \\
\hline 189 & $1 / 7 / 200816: 06$ & $87 / 200816: 06$ & 1.892 & 16.9 \\
\hline 190 & $1 / 7 / 200816: 08$ & $87 / 2008$ 16:08 & 1.892 & 16.9 \\
\hline 191 & $1 / 7 / 2008$ 16:10 & $87 / 200816: 10$ & 1.892 & 16.9 \\
\hline 192 & $1 / 7 / 2008$ 16:12 & $87 / 2008$ 16:12 & 1.891 & 16.9 \\
\hline 193 & 1/7/2008 16:14 & $87 / 2008$ 16:14 & 1.89 & 16.9 \\
\hline 194 & $1 / 7 / 200816: 16$ & $8 / 7 / 2008$ 16:16 & 1.89 & 16.9 \\
\hline 195 & $1 / 7 / 2008$ 16:18 & $8 / 7 / 200816: 18$ & 1.891 & 16.9 \\
\hline 196 & $1 / 7 / 2008$ 16:20 & $8 / 7 / 200816: 20$ & 1.891 & 16.9 \\
\hline 197 & $1 / 7 / 200816: 22$ & $87 / 200816: 22$ & 1.89 & 16.9 \\
\hline 198 & $1 / 7 / 200816: 24$ & $87 / 200816: 24$ & 1.89 & 16.9 \\
\hline 199 & $1 / 7 / 2008$ 16:26 & $8 / 7 / 200816: 26$ & 1.89 & 16.9 \\
\hline 200 & $1 / 7 / 200816: 28$ & $87 / 200816: 28$ & 1.89 & 16.9 \\
\hline 201 & $1 / 7 / 200816: 30$ & $8 / 7 / 200816: 30$ & 1.891 & 16.9 \\
\hline 202 & $1 / 7 / 2008$ 16:32 & $87 / 200816: 32$ & 1.89 & 16.9 \\
\hline 203 & $1 / 7 / 2008$ 16:34 & $8 / 7 / 200816: 34$ & 1.891 & 16.9 \\
\hline 204 & $1 / 7 / 2008$ 16:36 & $87 / 200816: 36$ & 1.891 & 16.9 \\
\hline
\end{tabular}




\begin{tabular}{|c|c|c|c|c|}
\hline \multicolumn{5}{|c|}{ D4-93p } \\
\hline $\operatorname{Rec}$ & & Adjusted & Pressure & Temp \\
\hline$\#$ & Date/Time & Date-Time & psi & ${ }^{\circ} \mathrm{C}$ \\
\hline 205 & $1 / 7 / 200816: 38$ & $87 / 2008$ 16:38 & 1.891 & 16.9 \\
\hline 206 & $1 / 7 / 200816: 40$ & $8 / 7 / 2008$ 16:40 & 1.892 & 16.9 \\
\hline 207 & $1 / 7 / 200816: 42$ & $87 / 2008$ 16:42 & 1.892 & 16.9 \\
\hline 208 & $1 / 7 / 200816: 44$ & $87 / 2008$ 16:44 & 1.891 & 16.9 \\
\hline 209 & $1 / 7 / 200816: 46$ & $87 / 200816: 46$ & 1.892 & 16.9 \\
\hline 210 & $1 / 7 / 200816: 48$ & $87 / 2008$ 16:48 & 1.892 & 16.9 \\
\hline 211 & $1 / 7 / 200816: 50$ & $87 / 2008$ 16:50 & 1.892 & 16.9 \\
\hline 212 & $1 / 7 / 200816: 52$ & $8 / 7 / 2008$ 16:52 & 1.891 & 16.9 \\
\hline 213 & $1 / 7 / 200816: 54$ & $8 / 7 / 2008$ 16:54 & 1.891 & 16.9 \\
\hline 214 & $1 / 7 / 200816: 56$ & $87 / 2008$ 16:56 & 1.891 & 16.9 \\
\hline 215 & $1 / 7 / 200816: 58$ & $8 / 7 / 2008$ 16:58 & 1.891 & 16.9 \\
\hline 216 & $1 / 7 / 200817: 00$ & $8 / 7 / 2008$ 17:00 & 1.892 & 16.9 \\
\hline 217 & 1/7/2008 17:02 & $87 / 2008$ 17:02 & 1.892 & 16.9 \\
\hline 218 & $1 / 7 / 2008$ 17:04 & $87 / 2008$ 17:04 & 1.893 & 16.9 \\
\hline 219 & $1 / 7 / 200817: 06$ & $8 / 7 / 2008$ 17:06 & 1.893 & 16.9 \\
\hline 220 & $1 / 7 / 2008$ 17:08 & $87 / 2008$ 17:08 & 1.893 & 16.9 \\
\hline 221 & $1 / 7 / 2008$ 17:10 & $877 / 2008$ 17:10 & 1.893 & 16.9 \\
\hline 22 & $1 / 7 / 2008$ 17:12 & $87 / 2008$ 17:12 & 1.892 & 16.9 \\
\hline 223 & $1 / 7 / 2008$ 17:14 & $87 / 2008$ 17:14 & 1.891 & 16.9 \\
\hline 224 & 1/7/2008 17:16 & $87 / 2008$ 17:16 & 1.891 & 16.9 \\
\hline 225 & $1 / 7 / 2008$ 17:18 & $87 / 2008$ 17:18 & 1.891 & 16.9 \\
\hline 226 & $1 / 7 / 2008$ 17:20 & $87 / 2008$ 17:20 & 1.891 & 16.9 \\
\hline 227 & $1 / 7 / 2008$ 17:22 & $8 / 7 / 200817: 22$ & 1.891 & 16.9 \\
\hline 228 & $1 / 7 / 2008$ 17:24 & $8 / 72008$ 17:24 & 1.891 & 16.9 \\
\hline 229 & $1 / 7 / 200817: 26$ & $87 / 2008$ 17:26 & 1.891 & 16.9 \\
\hline 230 & $1 / 7 / 200817: 28$ & $8 / 7 / 2008$ 17:28 & 1.89 & 16.9 \\
\hline 231 & $1 / 7 / 2008$ 17:30 & $87 / 2008$ 17:30 & 1.89 & 16.9 \\
\hline 232 & $1 / 7 / 2008$ 17:32 & $87 / 2008$ 17:32 & 1.89 & 16.9 \\
\hline 233 & $1 / 7 / 200817: 34$ & $87 / 2008$ 17:34 & 1.89 & 16.9 \\
\hline 234 & $1 / 7 / 200817: 36$ & $87 / 2008$ 17:36 & 1.891 & 16.9 \\
\hline 235 & $1 / 7 / 200817: 38$ & $87 / 200817: 38$ & 1.892 & 16.9 \\
\hline 236 & $1 / 7 / 200817: 40$ & $87 / 2008$ 17:40 & 1.893 & 16.9 \\
\hline 237 & $1 / 7 / 2008$ 17:42 & $8 / 72008$ 17:42 & 1.893 & 16.9 \\
\hline 238 & $1 / 7 / 200817: 44$ & $87 / 2008$ 17:44 & 1.893 & 16.9 \\
\hline 239 & $1 / 7 / 200817: 46$ & $87 / 2008$ 17:46 & 1.893 & 16.9 \\
\hline 240 & $1 / 7 / 200817: 48$ & $87 / 2008 \quad 17: 48$ & 1.893 & 16.9 \\
\hline 241 & $1 / 7 / 200817: 50$ & $87 / 2008$ 17:50 & 1.892 & 16.9 \\
\hline 242 & $1 / 7 / 2008$ 17:52 & $8 / 7 / 2008$ 17:52 & 1.892 & 16.9 \\
\hline 243 & $1 / 7 / 200817: 54$ & $87 / 2008$ 17:54 & 1.892 & 16.9 \\
\hline 244 & $1 / 7 / 200817: 56$ & $87 / 2008$ 17:56 & 1.891 & 16.9 \\
\hline 245 & $1 / 7 / 200817: 58$ & $87 / 2008$ 17:58 & 1.891 & 16.9 \\
\hline 246 & $1 / 7 / 200818: 00$ & $87 / 2008$ 18:00 & 1.892 & 16.9 \\
\hline 247 & $1 / 7 / 200818: 02$ & $87 / 2008$ 18:02 & 1.892 & 16.9 \\
\hline 248 & $1 / 7 / 200818: 04$ & $87 / 2008$ 18:04 & 1.892 & 16.9 \\
\hline 249 & $1 / 7 / 200818: 06$ & $87 / 2008$ 18:06 & 1.892 & 16.9 \\
\hline 250 & $1 / 7 / 200818: 08$ & $87 / 2008$ 18:08 & 1.892 & 16.9 \\
\hline 251 & $1 / 7 / 200818: 10$ & $8 / 7 / 2008$ 18:10 & 1.892 & 16.9 \\
\hline 252 & $1 / 7 / 200818: 12$ & $8 / 7 / 2008$ 18:12 & 1.892 & 16.9 \\
\hline 253 & $1 / 7 / 200818: 14$ & $87 / 2008$ 18:14 & 1.891 & 16.9 \\
\hline 254 & $1 / 7 / 200818: 16$ & $87 / 2008$ 18:16 & 1.891 & 16.9 \\
\hline 255 & $1 / 7 / 200818: 18$ & $87 / 2008$ 18:18 & 1.892 & 16.9 \\
\hline 256 & $1 / 7 / 200818: 20$ & $87 / 2008$ 18:20 & 1.891 & 16.9 \\
\hline 257 & $1 / 7 / 200818: 22$ & $87 / 2008$ 18:22 & 1.892 & 16.9 \\
\hline 258 & $1 / 7 / 2008$ 18:24 & $87 / 2008$ 18:24 & 1.891 & 16.9 \\
\hline 259 & $1 / 7 / 200818: 26$ & $87 / 2008$ 18:26 & 1.89 & 16.9 \\
\hline 260 & $1 / 7 / 200818: 28$ & $87 / 2008$ 18:28 & 1.89 & 16.9 \\
\hline 261 & $1 / 7 / 2008$ 18:30 & $87 / 2008$ 18:30 & 1.89 & 16.9 \\
\hline 262 & $1 / 7 / 200818: 32$ & $8 / 7 / 2008$ 18:32 & 1.891 & 16.9 \\
\hline 263 & $1 / 7 / 200818: 34$ & $8 / 7 / 2008$ 18:34 & 1.891 & 16.9 \\
\hline 264 & $1 / 7 / 2008$ 18:36 & $87 / 2008$ 18:36 & 1.892 & 16.9 \\
\hline 265 & $1 / 7 / 200818: 38$ & $87 / 2008$ 18:38 & 1.892 & 16.9 \\
\hline 266 & $1 / 7 / 200818: 40$ & $87 / 2008$ 18:40 & 1.892 & 16.9 \\
\hline 267 & $1 / 7 / 200818: 42$ & $87 / 2008$ 18:42 & 1.893 & 16.9 \\
\hline 268 & $1 / 7 / 200818: 44$ & $8 / 7 / 2008$ 18:44 & 1.893 & 16.9 \\
\hline 269 & $1 / 7 / 200818: 46$ & $87 / 2008$ 18:46 & 1.893 & 16.9 \\
\hline 270 & $1 / 7 / 200818: 48$ & $87 / 2008$ 18:48 & 1.893 & 16.9 \\
\hline 271 & $1 / 7 / 2008$ 18:50 & $87 / 2008$ 18:50 & 1.893 & 16.9 \\
\hline 272 & $1 / 7 / 2008$ 18:52 & $87 / 2008$ 18:52 & 1.893 & 16.9 \\
\hline
\end{tabular}

\begin{tabular}{|c|c|c|c|c|}
\hline \multicolumn{5}{|c|}{$D 4-930$} \\
\hline $\operatorname{Rec}$ & & Adusted & Pressure & Temp \\
\hline$\#$ & DaterTime & Date/Time & psi & ${ }^{\circ} \mathrm{C}$ \\
\hline 273 & $1 / 7 / 200818: 54$ & $87 / 200818: 54$ & 1.893 & 16.9 \\
\hline 274 & $1 / 7 / 200818: 56$ & $87 / 200818: 56$ & 1.893 & 16.9 \\
\hline 275 & $1 / 7 / 200818: 58$ & $877200818: 58$ & 1.893 & 16.9 \\
\hline 276 & $1 / 7 / 200819: 00$ & $8 / 7 / 200819: 00$ & $1 . \overline{894}$ & 16.9 \\
\hline $2 \pi 7$ & $1 / 7 / 200819.02$ & $87 / 200819: 02$ & 1.893 & 16.9 \\
\hline 278 & $1 / 7 / 200819.04$ & $87 / 200819: 04$ & 1.894 & 16.9 \\
\hline 279 & $1 / 7 / 200819: 06$ & $87 / 2008$ 19:06 & 1.894 & 16.9 \\
\hline 280 & $1 / 7 / 200819: 08$ & $8 / 7 / 200819: 08$ & 1.893 & 16.9 \\
\hline 281 & $1 / 7 / 2008$ 19:10 & $87 / 200819: 10$ & 1.893 & 16.9 \\
\hline 282 & $1 / 7 / 200819.12$ & $87 / 2008$ 19:12 & 1.893 & 16.9 \\
\hline 283 & $1 / 7 / 2008$ 19:14 & $87 / 2008$ 19:14 & 1.892 & 16.9 \\
\hline 284 & $1 / 7 / 200819.16$ & $87 / 200819: 16$ & 1.893 & 16.9 \\
\hline 285 & $1 / 7 / 200819: 18$ & $87 / 200819: 18$ & 1.893 & 16.9 \\
\hline 286 & $1 / 7 / 200819.20$ & $87 / 200819: 20$ & 1.893 & 16.9 \\
\hline 287 & $1 / 7 / 200819: 22$ & $87 / 200819: 22$ & 1.893 & $\overline{16.9}$ \\
\hline 288 & $1 / 7 / 200819.24$ & $87 / 200819.24$ & 1.893 & 16.9 \\
\hline 289 & $1 / 7 / 200819.26$ & $8 / 7200819: 26$ & 1.893 & 16.9 \\
\hline 290 & $1 / 7 / 200819.28$ & $877 / 200819: 28$ & $1 . \overline{893}$ & 16.9 \\
\hline 291 & $1 / 7 / 200819.30$ & $8 / 7 / 2008$ 19:30 & 1.893 & 16.9 \\
\hline 292 & $1 / 7 / 2008$ 19:32 & $87 / 2008$ 19.32 & 1.893 & 16.9 \\
\hline 293 & $1 / 7 / 200819.34$ & $87 / 200819.34$ & 1.893 & 16.9 \\
\hline 294 & $1 / 7 / 200819.36$ & $8 / 7 / 2008$ 19:36 & 1.893 & 16.9 \\
\hline 295 & $1 / 7 / 200819: 38$ & $8 / 7 / 200819: 38$ & 1.894 & 16.9 \\
\hline 296 & $1 / 7 / 200819.40$ & $8 / 7 / 200819: 40$ & 1.893 & 16.9 \\
\hline 297 & $1 / 7 / 200819.42$ & $87 / 2008$ 19:42 & 1.893 & 16.9 \\
\hline 298 & $1 / 7 / 200819.44$ & $8 / 7 / 2008$ 19:44 & 1.894 & 16.9 \\
\hline 299 & $1 / 7 / 200819: 46$ & $8 / 7 / 200819: 46$ & 1.893 & 16.9 \\
\hline 300 & $1 / 7 / 200819: 48$ & $8 / 7 / 200819: 48$ & 1.893 & 16.9 \\
\hline 301 & $1 / 7 / 2008 \quad 19.50$ & $87 / 2008$ 19:50 & 1.893 & 16.9 \\
\hline 302 & $1 / 7 / 200819.52$ & $8 / 7 / 200819: 52$ & 1.892 & 16.9 \\
\hline 303 & $1 / 7 / 200819: 54$ & $8 / 7 / 2008$ 19:54 & 1.892 & 16.9 \\
\hline 304 & $1 / 7 / 200819.56$ & $87 / 200819: 56$ & 1.892 & 16.9 \\
\hline 305 & $1 / 7 / 200819.58$ & $87 / 200819.58$ & 1.891 & 16.9 \\
\hline 306 & $1 / 7 / 200820.00$ & $8 / 7 / 200820: 00$ & 1.891 & 16.9 \\
\hline 307 & $1 / 7 / 200820: 02$ & $8 / 7 / 200820: 02$ & 1.892 & 16.9 \\
\hline 308 & $1 / 7 / 200820: 04$ & $8 / 7 / 200820: 04$ & 1.892 & 16.9 \\
\hline 309 & $1 / 7 / 200820: 06$ & $8 / 7 / 200820: 06$ & 1.893 & 16.9 \\
\hline 310 & $1 / 7 / 200820.08$ & $8 / 7 / 200820: 08$ & 1.893 & 16.9 \\
\hline 311 & $1 / 7 / 200820: 10$ & $8 / 7 / 200820: 10$ & 1.892 & 16.9 \\
\hline 312 & $1 / 7 / 200820: 12$ & $87 / 200820: 12$ & 1.891 & 16.9 \\
\hline 313 & $1 / 7 / 200820: 14$ & $8 / 7 / 200820: 14$ & 1.89 & 16.9 \\
\hline 314 & $1 / 7 / 200820: 16$ & $8 / 7 / 200820: 16$ & 1.89 & 16.8 \\
\hline 315 & $1 / 7 / 200820: 18$ & $8 / 7 / 200820: 18$ & 1.89 & 16.9 \\
\hline 316 & $1 / 7 / 200820.20$ & $87 / 200820: 20$ & 1.89 & 16.8 \\
\hline 317 & $1 / 7 / 200820.22$ & $8 / 7 / 200820: 22$ & 1.891 & 16.9 \\
\hline 318 & $1 / 7 / 200820: 24$ & $87 / 200820: 24$ & 1.892 & 16.9 \\
\hline 319 & $1 / 7 / 200820: 26$ & $8 / 7 / 200820: 26$ & 1.891 & 16.9 \\
\hline 320 & $1 / 7 / 200820: 28$ & $8 / 7 / 200820: 28$ & 1.891 & 16.9 \\
\hline 321 & $1 / 7 / 200820: 30$ & $8 / 7 / 200820.30$ & 1.891 & 16.9 \\
\hline 322 & $1 / 7 / 200820.32$ & $87 / 200820: 32$ & 1.89 & 16.8 \\
\hline 323 & $1 / 7 / 200820.34$ & $8 / 7 / 200820: 34$ & 1.889 & 16.9 \\
\hline 324 & $1 / 7 / 200820.36$ & $8 / 7200820: 36$ & 1.887 & 16.0 \\
\hline 325 & $1 / 7 / 200820.38$ & $87 / 200820: 38$ & 1.886 & 16.9 \\
\hline 326 & $1 / 7 / 200820: 40$ & $8 / 7 / 200820: 40$ & 1.887 & 16.9 \\
\hline 327 & $1 / 7 / 200820: 42$ & $87 / 200820: 42$ & 1.888 & 16.9 \\
\hline 328 & $1 / 7 / 200820: 44$ & $87 / 200820: 44$ & 1.887 & 16.9 \\
\hline 329 & $1 / 7 / 200820: 46$ & $8 / 7 / 200820: 46$ & 1.887 & 16.9 \\
\hline 330 & $1 / 7 / 200820.48$ & $8 / 7 / 200820: 48$ & 1.886 & 16.9 \\
\hline 331 & $1 / 7 / 200820.50$ & $8 / 7200820: 50$ & 1.886 & 16.9 \\
\hline 332 & $1 / 7 / 200820.52$ & $87 / 200820: 52$ & 1.887 & 16.9 \\
\hline 333 & $1 / 7 / 200820.54$ & $8 / 7 / 200820: 54$ & 1.887 & 16.9 \\
\hline 334 & $1 / 7 / 200820.56$ & $8 / 7 / 200820: 56$ & 1.888 & 16.9 \\
\hline 335 & $1 / 7 / 200820.58$ & $8 / 7 / 200820: 58$ & 1.887 & 16.9 \\
\hline 336 & $1 / 7 / 200821: 00$ & $8 / 7 / 200821: 00$ & 1.887 & 16.9 \\
\hline 337 & 1/7/200821:02 & $8 / 7 / 200821: 02$ & 1.887 & 16.9 \\
\hline 338 & $1 / 7 / 200821: 04$ & $87 / 200821: 04$ & 1.887 & 16.9 \\
\hline 339 & $1 / 7 / 200821: 06$ & $8 / 7 / 200821: 06$ & 1.887 & 16.9 \\
\hline 340 & $1 / 7 / 200821: 08$ & $87 / 200821: 08$ & 1.887 & 16.9 \\
\hline
\end{tabular}

\begin{tabular}{|c|c|c|c|c|}
\hline \multicolumn{5}{|c|}{ D4-930 } \\
\hline Rec & & Adusted & Pressure & Temp \\
\hline$\#$ & Date/Time & Dete/Time & psi & ${ }^{\circ} \mathrm{C}$ \\
\hline 341 & $1 / 7 / 200821: 10$ & $87 / 200821: 10$ & 1.886 & 16.9 \\
\hline 342 & $1 / 7 / 200821: 12$ & $8 / 7 / 200821: 12$ & 1.888 & 16.9 \\
\hline 343 & $1 / 7 / 200821: 14$ & $8 / 7 / 200821: 14$ & 1.888 & 16.9 \\
\hline 344 & $1 / 7 / 200821: 16$ & $87 / 200821: 16$ & 1.887 & 16.9 \\
\hline 345 & 1/7/200821:18 & $8 / 7 / 200821: 18$ & 1.887 & 16.9 \\
\hline 346 & $1 / 7 / 200821: 20$ & $8 / 7 / 200821: 20$ & 1.887 & 16.9 \\
\hline 347 & $1 / 7 / 200821: 22$ & $87 / 200821: 22$ & 1.888 & 16.9 \\
\hline 348 & $1 / 7 / 200821: 24$ & $87 / 200821: 24$ & 1.888 & 16.9 \\
\hline 349 & $1 / 7 / 200821: 26$ & $87 / 200821: 26$ & 1.888 & 16.9 \\
\hline 350 & $1 / 7 / 200821: 28$ & $87 / 200821: 28$ & 1.889 & 16.9 \\
\hline 351 & $1 / 7 / 200821: 30$ & $87 / 200821: 30$ & 1.889 & 16.9 \\
\hline 352 & $1 / 7 / 200821: 32$ & $87 / 200821: 32$ & 1.888 & 16.9 \\
\hline 353 & $1 / 7 / 200821: 34$ & $8 / 7 / 200821: 34$ & 1.888 & 16.9 \\
\hline 354 & $1 / 7 / 200821: 36$ & $8 / 7 / 200821: 36$ & 1.888 & 16.9 \\
\hline 355 & $1 / 7 / 200821: 38$ & $8 / 7 / 200821: 38$ & 1.887 & 16.9 \\
\hline 356 & $1 / 7 / 200821: 40$ & $877 / 200821: 40$ & 1.887 & 16.9 \\
\hline 357. & $1 / 7 / 200821: 42$ & $87 / 200821: 42$ & 1.887 & 16.9 \\
\hline 358 & $1 / 7 / 200821: 44$ & $8 / 7 / 200821: 44$ & 1.888 & 16.9 \\
\hline 359 & $1 / 7 / 200821: 46$ & $87 / 200821: 46$ & 1.888 & 16.9 \\
\hline 360 & $1 / 7 / 200821: 48$ & $87 / 200821: 48$ & 1.888 & 16.9 \\
\hline 361 & $1 / 7 / 200821: 50$ & $87 / 200821: 50$ & 1.887 & 16.9 \\
\hline 362 & $1 / 7 / 200821: 52$ & $8 / 7 / 200821: 52$ & 1.888 & 16.9 \\
\hline 363 & $1 / 7 / 200821: 54$ & $8 / 7200821: 54$ & 1.888 & 16.9 \\
\hline 364 & $1 / 7 / 200821: 56$ & $8 / 7 / 200821: 56$ & 1.888 & 16.9 \\
\hline 365 & $1 / 7 / 200821: 58$ & $8 / 7 / 200821: 58$ & 1.887 & 16.9 \\
\hline 366 & $1 / 7 / 20082200$ & $87 / 20082200$ & 1.887 & 16.9 \\
\hline 367. & $1 / 7 / 20082202$ & $8 / 7 / 200822: 02$ & 1.886 & 16.9 \\
\hline 368 & $1 / 7 / 20082204$ & $8 / 7 / 200822: 04$ & 1.886 & 16.9 \\
\hline 369 & $17 / 20082206$ & $8 / 7 / 200822: 06$ & 1.886 & 16.9 \\
\hline 370 & $1 / 7 / 20082208$ & $8 / 7 / 200822208$ & 1.887 & 16.9 \\
\hline 371 & $1 / 7 / 20082210$ & $87 / 200822: 10$ & 1.887 & 16.9 \\
\hline 372 & $1 / 7 / 200822: 12$ & $8 / 7 / 20082212$ & 1.888 & 16.9 \\
\hline 373 & $1 / 7 / 200822: 14$ & $8 / 7 / 200822: 14$ & 1.887 & 16.9 \\
\hline 374 & $1 / 7 / 20082216$ & $87 / 200822: 16$ & 1.887 & 16.9 \\
\hline 375 & $1 / 7 / 20082218$ & $87 / 200822: 18$ & 1.887 & 16.9 \\
\hline 376 & $1 / 7 / 20082220$ & $87 / 200822: 20$ & 1.885 & 16.9 \\
\hline 377 & $1 / 7 / 20082222$ & $87 / 200822 \cdot 22$ & 1.825 & 16.9 \\
\hline 378 & $1 / 7 / 200822224$ & $8 / 7 / 200822: 24$ & 1.885 & 16.9 \\
\hline 379 & $1 / 7 / 20082226$ & $8 / 7 / 20082226$ & 1.886 & 16.9 \\
\hline 380 & $1 / 7 / 200822228$ & $8 / 7 / 200822: 28$ & 1.886 & 16.9 \\
\hline 381 & $1 / 7 / 200822,30$ & $87 / 200822: 30$ & 1.887 & 16.9 \\
\hline 382 & $1 / 7 / 20082232$ & $8 / 7 / 200822: 32$ & 1.886 & 16.9 \\
\hline 383 & $1 / 7 / 20082234$ & $8 / 7 / 200822: 34$ & 1.885 & 16.9 \\
\hline 384 & $1 / 7 / 20082236$ & $8 / 7 / 20082236$ & 1.886 & 16.9 \\
\hline 385 & $1 / 7 / 20082238$ & $8 / 7 / 200822338$ & 1.886 & 16.9 \\
\hline 386 & $1 / 7 / 20082240$ & $87 / 20082240$ & 1.886 & 16.9 \\
\hline 387 & $1 / 7 / 200822: 42$ & $8 / 7 / 200822: 42$ & 1.886 & 16.9 \\
\hline 388 & $1 / 7 / 200822244$ & $8 / 7 / 200822: 44$ & 1.888 & 16.9 \\
\hline 389 & $1 / 7 / 20082246$ & $87 / 200822: 46$ & 1.888 & 16.9 \\
\hline 390 & $17 / 20082248$ & $8 / 7 / 200822: 48$ & 1.888 & 16.9 \\
\hline 391 & $1 / 7 / 20082250$ & $8 / 7 / 200822=50$ & 1.888 & 16.9 \\
\hline 392 & $1 / 7 / 20082252$ & $8 / 7 / 200822552$ & 1.887 & 16.9 \\
\hline 393 & $1 / 7 / 20082254$ & $8 / 7 / 20082254$ & 1.887 & 16.9 \\
\hline 394 & $1 / 7 / 200822556$ & $87 / 200822556$ & 1.887 & 16.9 \\
\hline 395 & $1 / 7 / 20082258$ & $8 / 7 / 20082258$ & 1.887 & 16.9 \\
\hline 396 & $1 / 7 / 200823: 00$ & $8 / 7 / 200823: 00$ & 1.888 & 16.9 \\
\hline 397 & $1 / 7 / 200823: 02$ & $8 / 7 / 200823: 02$ & 1.887 & 16.9 \\
\hline 398 & 1/7/2008 23:04 & $8 / 7 / 200823: 04$ & 1.887 & 16.9 \\
\hline 399 & $1 / 7 / 200823: 06$ & $8 / 7 / 200823: 06$ & 1.887 & 16.9 \\
\hline 400 & $1 / 7 / 200823: 08$ & $8 / 7 / 200823: 08$ & 1.886 & 16.9 \\
\hline 401 & $1 / 7 / 200823: 10$ & $8 / 1200823: 10$ & 1.887 & 16.9 \\
\hline 402 & $1 / 7 / 200823: 12$ & $8 / 7200823: 12$ & 1.839 & 16.9 \\
\hline 403) & 1/7/200823:14 & $8 / 7 / 200823: 14$ & 1.889 & 16.9 \\
\hline 404 & $1 / 7 / 200823: 16$ & $8 / 7200823: 16$ & 1.888 & 16.9 \\
\hline 405 & $1 / 7 / 200823: 18$ & $8 / 7 / 200823: 18$ & 1.887 & 16.9 \\
\hline 406 & $1 / 7 / 200823: 20$ & $8 / 7 / 200823: 20$ & 1.887 & 16.9 \\
\hline 407 & $1 / 7 / 200823: 22$ & $8 / 7 / 200823: 22$ & 1.888 & 16.9 \\
\hline 408 & $1 / 7 / 200823: 24$ & $87 / 200823: 24$ & 1.888 & 16.9 \\
\hline
\end{tabular}


DOE/RL-2009-35, REV. 0

\begin{tabular}{|c|c|c|c|c|}
\hline \multicolumn{5}{|c|}{ D4-93p } \\
\hline $\operatorname{Rec}$ & & Acjusted & Pressure & Temp \\
\hline$\#$ & Date/Time & DaterTime & psi & ${ }^{\circ} \mathrm{C}$ \\
\hline 409 & $1 / 7 / 200823: 26$ & $8 / 7 / 200823: 26$ & 1.88 & 16.9 \\
\hline 410 & $1 / 7 / 200823: 28$ & $8 / 7 / 200823: 28$ & 1.888 & 16.9 \\
\hline 411 & $1 / 7 / 200823: 30$ & $8 / 7 / 200823: 30$ & 1.88 & 16.9 \\
\hline 412 & $1 / 7 / 200823: 32$ & $8 / 7 / 200823: 32$ & 1.89 & 16.9 \\
\hline 413 & $1 / 7 / 200823: 34$ & $8 / 7 / 200823: 34$ & 1.89 & 16.9 \\
\hline 414 & $1 / 7 / 200823: 36$ & $8 / 7 / 200823: 36$ & 1.89 & 16.9 \\
\hline 415 & $1 / 7 / 200823: 38$ & $8 / 7 / 200823: 38$ & 1.889 & 16.9 \\
\hline 416 & $1 / 7 / 200823: 40$ & $87 / 200823: 40$ & 1.88 & 16.9 \\
\hline 417 & $1 / 7 / 200823: 42$ & $87 / 200823: 42$ & 1.888 & 16.9 \\
\hline 418 & $1 / 7 / 200823: 44$ & $8 / 7 / 200823: 44$ & 1.888 & 16.9 \\
\hline 419 & $1 / 7 / 200823: 46$ & $8 / 7 / 200823: 46$ & 1.887 & 16.9 \\
\hline 420 & $1 / 7 / 200823: 48$ & $8 / 7 / 200823: 48$ & 1.887 & 16.9 \\
\hline 421 & $1 / 7 / 200823: 50$ & $8 / 7 / 200823: 50$ & 1.888 & 16.9 \\
\hline 422 & $1 / 7 / 200823: 52$ & $8 / 7 / 200823: 52$ & 1.887 & 16.9 \\
\hline 423 & $1 / 7 / 200823: 54$ & $8 / 7200823: 54$ & 1.886 & 16.9 \\
\hline 424 & $1 / 7 / 200823: 56$ & $8 / 7 / 200823: 56$ & 1.885 & 16.9 \\
\hline 425 & $1 / 7 / 2008$ Z3:58 & $87 / 200823: 58$ & 1.885 & 16.9 \\
\hline 426 & $1 / 8 / 20080: 00$ & $8 / 8 / 20080: 00$ & 1.885 & 16.9 \\
\hline 427 & $1 / 8 / 20080: 02$ & $8 / 8 / 20080: 02$ & 1.885 & 16.9 \\
\hline 428 & $1 / 8 / 20080: 04$ & $8 / 8 / 20080: 04$ & 1.885 & 16.9 \\
\hline 429 & $1 / 8 / 20080: 06$ & $8 / 8 / 20080: 06$ & 1.884 & 16.9 \\
\hline 430 & $1 / 8 / 20080: 08$ & $8 / 8 / 20080: 08$ & 1.884 & 16.9 \\
\hline 431 & $1 / 8 / 20080: 10$ & $8 / 8 / 20080: 10$ & 1.884 & 16.9 \\
\hline 432 & $1 / 8 / 20080: 12$ & $8 / 8 / 20080: 12$ & 1.884 & 16.9 \\
\hline 433 & $1 / 8 / 20080: 14$ & $8 / 8 / 20080: 14$ & 1.884 & 16.9 \\
\hline 434 & 1/8/20080:16 & $8 / 8 / 20080: 16$ & 1.884 & 16.9 \\
\hline 435 & $1 / 8 / 20080: 18$ & $8 / 8 / 20080: 18$ & 1.884 & 16.9 \\
\hline 436 & $1 / 8 / 20080: 20$ & $8 / 8 / 20080: 20$ & 1.883 & 16.9 \\
\hline 437 & $1 / 8 / 20080: 22$ & $8 / 8 / 20080: 22$ & 1.883 & 16.9 \\
\hline 438 & $1 / 8 / 20080: 24$ & $8 / 8 / 20080: 24$ & 1.885 & 16.9 \\
\hline 439 & $1 / 8 / 20080: 26$ & $8 / 8 / 20080: 26$ & 1.886 & 16.9 \\
\hline 440 & $1 / 8220080: 28$ & $8 / 8 / 20080: 28$ & 1.886 & 16.9 \\
\hline 441 & $1 / 8 / 20080: 30$ & $8 / 8 / 20080: 30$ & 1.884 & 16.9 \\
\hline 442 & $1 / 8 / 20080: 32$ & $8 / 8 / 20080: 32$ & 1.883 & 16.9 \\
\hline 443 & $1 / 8 / 20080: 34$ & $8 / 8 / 20080: 34$ & 1.883 & 16.9 \\
\hline 444 & $1 / 8 / 20080: 36$ & $8 / 8 / 20080: 36$ & 1.883 & 16.9 \\
\hline 445 & $1 / 8 / 20080: 38$ & $8 / 8 / 20080: 38$ & 1.883 & 16.9 \\
\hline 446 & $1 / 8 / 20080: 40$ & $8 / 8 / 20080: 40$ & 1.882 & 16.9 \\
\hline 447 & $1 / 8 / 20080: 42$ & $8 / 8 / 20080: 42$ & 1.883 & 16.9 \\
\hline 448 & $1 / 8 / 20080: 44$ & $8 / 8 / 20080: 44$ & 1.883 & 16.9 \\
\hline 449 & $1 / 8 / 20080: 46$ & $8 / 8 / 20080: 46$ & 1.883 & 16.9 \\
\hline 450 & $1 / 8 / 20080: 48$ & $8 / 8 / 20080: 48$ & 1.884 & 16.9 \\
\hline 451 & $1 / 8 / 20080: 50$ & $8 / 8 / 20080: 50$ & 1.885 & 16.9 \\
\hline 452 & $1 / 8 / 20080: 52$ & $8 / 8 / 20080: 52$ & 1.884 & 16.9 \\
\hline 453 & $1 / 8 / 20080: 54$ & $8 / 8 / 20080: 54$ & 1.884 & 16.9 \\
\hline 454 & $1 / 8 / 20080: 56$ & $8 / 8 / 20080: 56$ & 1.884 & 16.9 \\
\hline 455 & $1 / 8 / 20080: 58$ & $8 / 8 / 20080: 58$ & 1.884 & 16.9 \\
\hline 456 & $1 / 8 / 20081: 00$ & $8 / 8 / 20081: 00$ & 1.883 & 16.9 \\
\hline 457 & $1 / 8 / 20081: 02$ & $8 / 8 / 20081: 02$ & 1.884 & 16.9 \\
\hline 458 & $1 / 8 / 20081: 04$ & $8 / 8 / 20081: 04$ & 1.884 & 16.9 \\
\hline 459 & $1 / 8 / 20081: 06$ & $8 / 8 / 20081: 06$ & 1.884 & 16.9 \\
\hline 460 & $1 / 8 / 20081: 08$ & $8 / 8 / 20081: 08$ & 1.884 & 16.9 \\
\hline 461 & 1/8/2008 1:10 & $8 / 8 / 2008$ 1:10 & 1.885 & 16.9 \\
\hline 462 & 1/8/20081:12 & $8 / 8 / 20081: 12$ & 1.884 & 16.9 \\
\hline 463 & $1 / 8 / 2008$ 1:14 & $8 / 8 / 2008$ t:14 & 1.884 & 16.9 \\
\hline 464 & $1 / 8 / 20081: 16$ & $8 / 8 / 20081: 16$ & 1.885 & 16.9 \\
\hline 465 & $1 / 8 / 20081: 18$ & $8 / 8 / 20081: 18$ & 1.885 & 16.9 \\
\hline 466 & $1 / 8 / 20081: 20$ & $8 / 8 / 20081: 20$ & 1.884 & 16.9 \\
\hline 467 & $1 / 8 / 20081: 22$ & $8 / 8 / 20081: 22$ & 1.883 & 16.9 \\
\hline 468 & $1 / 8 / 20081: 24$ & $8 / 8 / 20081: 24$ & 1.884 & 16.9 \\
\hline 469 & 1/8/20081:26 & $8 / 8 / 20081: 26$ & 1.885 & 16.9 \\
\hline 470 & $1 / 8 / 20081: 28$ & $8 / 8 / 20081: 28$ & 1.884 & 16.9 \\
\hline 471 & 1/8/2008 1:30 & $8 / 8 / 20081: 30$ & 1.883 & 16.9 \\
\hline 472 & $1 / 8 / 20081: 32$ & $8 / 8 / 20081: 32$ & 1.884 & 16.9 \\
\hline 473 & 1/8/2008 1:34 & $8 / 8 / 20081: 34$ & 1.883 & 16.9 \\
\hline 474 & 1/8/2008 1:36 & $8 / 8 / 20081: 36$ & 1.882 & 16.9 \\
\hline 475 & $1 / 8 / 20081: 38$ & $8 / 8 / 20081: 38$ & 1.882 & 16.9 \\
\hline 476 & $1 / 8 / 20081: 40$ & $8 / 8 / 20081: 40$ & 1.882 & 16.9 \\
\hline
\end{tabular}

\begin{tabular}{|c|c|c|c|c|}
\hline \multicolumn{5}{|c|}{ D493p } \\
\hline $\operatorname{Rec}$ & & Adjusted & Pressure & Temp \\
\hline \# & Date/Time & Date/Time & psi & ${ }^{\circ} \mathrm{C}$ \\
\hline 477 & $1 / 8 / 20081: 42$ & $8 / 8 / 20081: 42$ & 1.882 & 16.9 \\
\hline 78 & $8 / 20081: 44$ & $8 / 8 / 20081: 44$ & 1.882 & \\
\hline 479 & $1 / 8 / 20081: 46$ & $8 / 8 / 20081: 46$ & 1.882 & 16.9 \\
\hline 480 & $1 / 8 / 20081: 48$ & $8 / 8 / 20081: 48$ & 1.883 & 16.9 \\
\hline 481 & $1 / 8 / 20081: 50$ & $8 / 8 / 20081: 50$ & 1.882 & 16.9 \\
\hline 482 & $1 / 8 / 20081: 52$ & $8 / 8 / 20081: 52$ & 1.882 & 16.9 \\
\hline 483 & $1 / 8 / 20081: 54$ & $8 / 820081: 54$ & 1.882 & 16.9 \\
\hline 484 & $1 / 8 / 20081: 56$ & $8 / 8 / 20081: 56$ & 1.882 & 16.9 \\
\hline 485 & $1 / 8 / 20081: 58$ & $8 / 8 / 20081: 58$ & 1.881 & 16.9 \\
\hline 486 & 1/8/20082:00 & 8/8/2008 2:00 & 1.881 & 16.9 \\
\hline 487 & $8 / 20082: 02$ & $8 / 8 / 20082: 02$ & 1.882 & 16.9 \\
\hline 488 & $1 / 8 / 20082: 04$ & $8 / 8 / 2008$ 2:04 & 1.882 & 16.9 \\
\hline 489 & 1/8/20082:06 & $8 / 8 / 20082: 06$ & 1.883 & 16.9 \\
\hline 490 & $8 / 20082: 08$ & $8 / 8 / 20082: 08$ & 1.883 & 16.9 \\
\hline 491 & $1 / 8 / 20082: 10$ & $8 / 8 / 20082: 10$ & 1.883 & 16.9 \\
\hline 492 & 1/8/20082:12 & $8 / 8 / 20082: 12$ & 1.883 & 16.9 \\
\hline 493 & $8 / 20082: 14$ & $8 / 8 / 200$ & 1.883 & 16.9 \\
\hline 494 & 1/8/20082:16 & $8 / 8 / 20082: 16$ & 1.883 & 16.8 \\
\hline 495 & 1/8/20082:18 & $8 / 8 / 20082: 18$ & 1.882 & 16.9 \\
\hline 496 & $1 / 8 / 20082: 20$ & $8 / 8 / 200$ & 1.882 & 16.9 \\
\hline 497 & $1 / 8 / 20082: 22$ & $8 / 8 / 20082: 22$ & 1.882 & 16.8 \\
\hline 498 & $3 / 20082: 24$ & $8 / 8 / 200$ & 1.882 & 16.9 \\
\hline 499 & $2: 26$ & $8 / 8 / 200$ & 1.883 & 16.9 \\
\hline 500 & $8 / 20082: 28$ & $8 / 8 / 20$ & 1.883 & 16.9 \\
\hline 501 & $1 / 8 / 200$ & $8 / 8 / 20$ & 1.882 & 16.9 \\
\hline 502 & $8 / 20082: 32$ & $8 / 8 / 20082: 32$ & 1.882 & 16.8 \\
\hline 503 & $120082: 34$ & $8 / 8 / 20082: 34$ & 1.882 & $\frac{10.9}{16.9}$ \\
\hline 504 & $1 / 8 / 20$ & $8 / 8 / 20$ & 1.882 & 16.9 \\
\hline 505 & $1 / 8 / 20082: 38$ & $8 / 8 / 20082: 38$ & 1.883 & 16. \\
\hline 506 & $8 / 20082: 40$ & $8 / 8 / 20082: 40$ & 1.883 & 16.9 \\
\hline 507 & $2: 42$ & $8 / 8 / 20$ & 1.882 & 16. \\
\hline 508 & $3 / 20082: 44$ & $8 / 8 / 200$ & 1.881 & 16. \\
\hline 509 & $120082: 46$ & $8 / 8 / 200$ & 1.88 & 16. \\
\hline 510 & 48 & $8 / 8 / 20$ & 1.879 & 16. \\
\hline 511 & $2: 50$ & $8 / 8 / 20$ & 1.878 & 16. \\
\hline 512 & $2: 52$ & $8 / 8 / 20$ & 1.878 & 16. \\
\hline 513 & $2: 54$ & $8 / 8 / 200$ & 1.879 & 16. \\
\hline 514 & $2: 56$ & $8 / 8 / 200$ & 1.879 & 16. \\
\hline 515 & 2.58 & $8 / 8 / 20$ & 1.881 & 16. \\
\hline 516 & $3: 00$ & $8 / 8 / 200$ & 1.881 & 16. \\
\hline 517 & $3 / 20083: 02$ & $8 / 8 / 200$ & 1.882 & 16. \\
\hline 518 & & & 1.882 & 16. \\
\hline 519 & 06 & $8 / 8 / 20$ & 1.881 & 16. \\
\hline 520 & $3: 08$ & $8 / 8 / 20$ & 1.881 & $\frac{10.8}{16 .}$ \\
\hline 521 & $3: 10$ & & 1.881 & 16. \\
\hline 522 & & $8 / 8 / 20$ & 1.881 & 16. \\
\hline 523 & $3: 14$ & $8 / 8 / 20$ & 1.881 & 16. \\
\hline 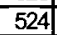 & & & 1.881 & 16. \\
\hline 525 & $3: 18$ & $8 / 8 / 200$ & 1.881 & 16. \\
\hline 526 & & $8 / 8 / 20$ & 1.881 & 16. \\
\hline 527 & 22 & & 1.881 & \\
\hline 528 & $3: 24$ & $8 / 8 / 20$ & 1.88 & 16. \\
\hline 529 & & & 1.88 & 16. \\
\hline 530 & & $8 / 8 / 20$ & 1.88 & \\
\hline 531 & 3:30 & $8 / 8 / 200$ & 1.88 & 16. \\
\hline 532 & & & 1.88 & 16. \\
\hline 533 & 34 & $8 / 8 / 20$ & 1.88 & 16. \\
\hline 534 & $3: 36$ & $8 / 8 / 200$ & 1.88 & 16. \\
\hline 535 & & & 1.879 & 16. \\
\hline 536 & $3: 40$ & $8 / 8 / 200$ & 1.878 & \\
\hline 537 & $3: 42$ & $8 / 8 / 20083: 42$ & 1.878 & 16. \\
\hline 538 & & & 1.878 & 16. \\
\hline 539 & $3: 46$ & $8 / 8200$ & 1.879 & 16. \\
\hline 540 & $1 / 8 / 20083: 48$ & $8 / 8 / 20083: 48$ & 1.881 & 16. \\
\hline 4 & & $8 / 8 / 20083: 50$ & 1.88 & 16.9 \\
\hline 542 & 120083.52 & $8 / 8 / 20083: 52$ & 1.88 & \\
\hline 543 & $1 / 8 / 20083: 54$ & $8 / 8 / 20083: 54$ & 1.88 & 16. \\
\hline 544 & $1 / 8 / 20083: 56$ & $8 / 8 / 20083: 56$ & 1.879 & 16. \\
\hline
\end{tabular}

\begin{tabular}{|c|c|c|c|c|}
\hline \multicolumn{5}{|c|}{ D4-93p } \\
\hline $\operatorname{Rec}$ & & Adjusted & Pressure & Temp \\
\hline$\#$ & Date/Time & DaterTime & $p s i$ & ${ }^{\circ} \mathrm{C}$ \\
\hline 545 & $1 / 8 / 20083: 58$ & $8 / 20083: 58$ & 1.878 & 16.9 \\
\hline 546 & $1 / 8 / 20084: 00$ & $8 / 20084: 00$ & 1.877 & 16.9 \\
\hline 547 & $8 / 20084: 02$ & $3 / 20084: 02$ & 1.878 & 16.9 \\
\hline 548 & $1 / 8 / 20084: 04$ & $3 / 20084: 04$ & 1.879 & 16.9 \\
\hline 549 & $1 / 8 / 20084: 06$ & $8 / 20084: 06$ & 1.879 & 16.9 \\
\hline 550 & $1 / 8 / 20084: 08$ & $18 / 20084: 08$ & 1.879 & 16.9 \\
\hline 551 & $1 / 8 / 20084: 10$ & $8 / 8 / 20084: 10$ & 1.879 & 16. \\
\hline 552 & $1 / 8 / 20084: 12$ & $8 / 8 / 20084: 12$ & 1.878 & 16.9 \\
\hline 553 & $1 / 8 / 20084: 14$ & $8 / 8 / 20084: 14$ & 1.87 & 16.9 \\
\hline 554 & $1 / 8 / 20084: 16$ & $8 / 8 / 20084: 16$ & 1.878 & 16. \\
\hline 555 & $1 / 8 / 20084: 18$ & $8 / 8 / 20084: 18$ & 1.879 & 16.9 \\
\hline 556 & $1 / 8 / 20084: 20$ & $18 / 20084: 20$ & 1.878 & \\
\hline 557 & $1 / 8 / 20084: 22$ & $8 / 8 / 20084: 22$ & 1.878 & 16. \\
\hline 558 & $1 / 8 / 20084: 24$ & $8 / 8 / 20084: 24$ & $1.8 \pi$ & 16.9 \\
\hline 559 & $8 / 20084: 26$ & $8 / 8 / 20084: 26$ & 1.877 & 16.9 \\
\hline 560 & $1 / 8 / 20084: 28$ & $8 / 8 / 20084: 28$ & 1.876 & 16. \\
\hline 561 & $1 / 8 / 20084: 30$ & $8 / 8 / 20084: 30$ & 1.876 & 16.9 \\
\hline 562 & $1 / 8 / 2008$ & $84: 32$ & 1.877 & \\
\hline 563 & $8 / 20084: 34$ & $84: 34$ & 1.877 & 16. \\
\hline 564 & $1 / 8 / 20084: 36$ & $84: 36$ & 1.877 & 16. \\
\hline 565 & $1 / 8 / 2008$ & $84: 38$ & 1.877 & 16. \\
\hline 566 & $1 / 8 / 20084: 40$ & $84: 40$ & 1.877 & 16. \\
\hline 567 & $8 / 20084: 42$ & $84: 42$ & 1.878 & 16. \\
\hline 568 & $8 / 20084: 44$ & 34:44 & 1.878 & 16. \\
\hline 569 & $1 / 8 / 20084: 46$ & 34:46 & 1.877 & 16. \\
\hline 570 & $1 / 8 / 20084: 48$ & 34:48 & 1.877 & 16. \\
\hline 571 & $1 / 8 / 20084: 50$ & $34: 50$ & 1.877 & 16. \\
\hline 572 & $1 / 8 / 20084: 52$ & 34:52 & 1.87 & 16.9 \\
\hline 573 & $4: 54$ & 4:54 & 1.877 & 16.8 \\
\hline 574 & $8 / 20084: 56$ & $84: 56$ & 1.877 & 16. \\
\hline 575 & $8 / 20084: 58$ & $084: 58$ & 1.878 & 16.9 \\
\hline 576 & $5: 00$ & $5: 00$ & 1.876 & 16. \\
\hline 577 & $5: 02$ & $35: 02$ & 1.876 & 16. \\
\hline 578 & $5: 04$ & & 1.875 & 16. \\
\hline 579 & $5: 06$ & $5: 06$ & 1.875 & 16. \\
\hline 580 & $1 / 8 / 200$ & 5:08 & 1.876 & 16. \\
\hline 581 & $5: 10$ & $5: 10$ & 1.877 & 16. \\
\hline 582 & $5: 12$ & 12 & 1.87 & 16. \\
\hline 583 & $5: 14$ & $5: 14$ & 1.877 & 16. \\
\hline 584 & $5: 16$ & $: 16$ & 1.876 & 16. \\
\hline 585 & $3 / 20$ & $: 18$ & 1.876 & 16. \\
\hline 586 & $8 / 20$ & $35: 20$ & 1.876 & 16. \\
\hline 587 & $8 / 20$ & $5: 22$ & 1.877 & 16. \\
\hline 588 & 24 & $5: 24$ & 1.87 & 16. \\
\hline 589 & $1 / 8 / 200$ & $85: 26$ & 1.877 & 16. \\
\hline 590 & & & 1.877 & 16. \\
\hline 591 & $5: 30$ & $5: 30$ & 1.877 & 16. \\
\hline 592 & $5: 32$ & $35: 32$ & 1.876 & 16. \\
\hline 593 & & & 1.875 & 16. \\
\hline 594 & 36 & $5: 36$ & 1.875 & 16. \\
\hline 595 & 38 & & 1.874 & 16. \\
\hline 596 & & & 1.875 & \\
\hline 597 & $1 / 8 / 200$ & $35: 42$ & 1.875 & 16: \\
\hline 598 & & & 1.875 & 16. \\
\hline 599 & $5: 46$ & 35:46 & 1.875 & \\
\hline 600 & $1 / 8 / 200$ & $8 / 8 / 20085: 48$ & 1.874 & 16. \\
\hline 601 & & & 1.874 & 16. \\
\hline 602 & $5: 52$ & $5: 52$ & 1.874 & \\
\hline 603 & $5: 54$ & $5: 54$ & 1.875 & 16. \\
\hline 604 & & & 1.874 & \\
\hline 605 & $5: 58$ & $5: 58$ & 1.874 & \\
\hline 606 & $6: 00$ & $86: 00$ & 1.874 & 16. \\
\hline 607 & & & 1.874 & 16 \\
\hline 608 & $6: 04$ & $6: 04$ & 1.874 & \\
\hline 609 & $8 / 20086: 06$ & $8 / 2008$ 6:06 & 1.874 & 16. \\
\hline 610 & & $8 / 20086: 08$ & 1.874 & 16. \\
\hline 611 & & & 1.874 & \\
\hline 612 & $1 / 8 / 20086: 12$ & $8 / 8 / 20086: 12$ & 1.874 & \\
\hline
\end{tabular}




\begin{tabular}{|c|c|c|c|c|}
\hline \multicolumn{5}{|c|}{ D493p } \\
\hline $\mathrm{Rec}$ & & Acjusted & Pressure & Temp \\
\hline \# & Dete/Time & DeteTime & psi & ${ }^{\circ} \mathrm{C}$ \\
\hline 613 & $1 / 8 / 20086: 14$ & $8 / 8 / 20086: 14$ & 1.875 & 16.9 \\
\hline 614 & 1/8/20086:16 & $8 / 8 / 20086: 16$ & 1.875 & 16.9 \\
\hline 615 & 1/820086:18 & $8 / 8 / 20086: 18$ & 1.874 & 16.9 \\
\hline 616 & $1 / 8 / 20086: 20$ & $8 / 8 / 20086: 20$ & 1.873 & 16.9 \\
\hline 617 & $1 / 8 / 20086: 22$ & $8 / 8 / 20086: 22$ & 1.873 & 16.9 \\
\hline 618 & 1/8/20086:24 & $8 / 820086: 24$ & 1.873 & 16.9 \\
\hline 619 & $1 / 8 / 20086: 26$ & $8 / 8 / 20086: 26$ & 1.873 & 16. \\
\hline 620 & $1 / 8 / 20086: 28$ & $8 / 8 / 20086: 28$ & 1.873 & 16. \\
\hline 621 & $1 / 8 / 20086: 30$ & $8 / 8 / 20086: 30$ & 1.873 & 16.9 \\
\hline 622 & $1 / 8 / 20086: 32$ & $8 / 8 / 20086: 32$ & 1.874 & 16.9 \\
\hline 623 & $1 / 8 / 20086: 34$ & $8 / 8 / 20086: 34$ & 1.873 & 16.9 \\
\hline 624 & $1 / 8 / 20086: 36$ & $8 / 8 / 20086: 36$ & 1.873 & 16. \\
\hline 625 & $1 / 8 / 20086: 38$ & $8 / 8 / 20086: 38$ & 1.873 & 16. \\
\hline 626 & $1 / 8 / 20086: 40$ & $8 / 8 / 20086: 40$ & 1.874 & 16.9 \\
\hline 627 & $1 / 8 / 20086: 42$ & $8 / 8 / 20086: 42$ & 1.874 & 16.9 \\
\hline 628 & $1 / 8 / 200$ & $8 / 8 / 20086: 44$ & 1.874 & 16.9 \\
\hline 629 & $6: 46$ & $8 / 8 / 20086: 46$ & 1.874 & 16.0 \\
\hline 630 & $1 / 8 / 20086: 48$ & $8 / 8 / 20086: 48$ & 1.874 & 16. \\
\hline 631 & $1 / 8 / 20086: 50$ & $8 / 8 / 20086.50$ & 1.874 & 16. \\
\hline 632 & $1 / 8 / 20086: 52$ & $8 / 8 / 20086: 52$ & 1.87 & 16.9 \\
\hline 63 & $1 / 8 / 200$ & $8 / 8 / 20086: 54$ & 1.866 & 16.9 \\
\hline 634 & $1 / 8 / 200$ & $8 / 8 / 20086: 56$ & 1.865 & 16.9 \\
\hline 635 & $1 / 8 / 200$ & $8 / 8 / 20086: 58$ & 1.864 & 16.9 \\
\hline 636 & $1 / 8 / 20087: 00$ & $8 / 8 / 20087: 00$ & 1.866 & 16. \\
\hline 637 & $1 / 8 / 20087: 02$ & $8 / 8 / 20087: 02$ & 1.867 & 16. \\
\hline 638 & $37: 04$ & $8 / 8 / 20087: 04$ & 1.867 & 16. \\
\hline 639 & $7: 06$ & $8 / 8 / 20087: 06$ & 1.868 & 16.5 \\
\hline 640 & $7: 08$ & $8 / 8 / 20087: 08$ & 1.868 & 16. \\
\hline 641 & $1 / 8 / 20087: 10$ & $8 / 8 / 20087: 10$ & 1.869 & 16. \\
\hline 642 & $1 / 8 / 20087: 12$ & $8 / 8 / 20087: 12$ & 1.87 & 16. \\
\hline 643 & $7: 14$ & $8 / 8 / 200$ & 1.871 & 16. \\
\hline 644 & $7: 16$ & $8 / 8 / 200$ & 1.871 & 16. \\
\hline 645 & $77: 18$ & $8 / 8 / 20087: 18$ & 1.872 & 16. \\
\hline 646 & $37: 20$ & $8 / 820087: 20$ & 1.87 & 16. \\
\hline 647 & $87: 2$ & $8 / 820087: 22$ & 1.87 & 16. \\
\hline 648 & & $8 / 8 / 200$ & 1.87 & 16. \\
\hline 649 & & $8 / 8 / 200$ & 1.87 & 16. \\
\hline 650 & $7: 28$ & $8 / 8 / 20087: 28$ & 1.869 & 16. \\
\hline 651 & $7: 30$ & $8 / 8 / 200$ & 1.869 & 16. \\
\hline 652 & $1 / 8 / 20087: 32$ & $8 / 8 / 20087: 32$ & 1.87 & 16. \\
\hline 653 & & $3 / 8 / 200$ & 1.87 & 16. \\
\hline 654 & & $3 / 8200$ & 1.871 & 16. \\
\hline 655 & $87: 38$ & $8 / 8 / 20087: 38$ & 1.87 & 16. \\
\hline 656 & $1 / 8 / 20087: 40$ & $8 / 8 / 20087: 40$ & 1.869 & 16.8 \\
\hline 657 & $87: 42$ & $8 / 8 / 20087: 42$ & 1.869 & $\overline{16.5}$ \\
\hline 658 & & $8 / 20$ & 1.87 & 16. \\
\hline 659 & $7: 46$ & $3 / 8 / 200$ & 1.871 & 16. \\
\hline 660 & $37: 48$ & $8 / 8 / 20087: 48$ & 1.87 & 16. \\
\hline 661 & 7750 & $8 / 8 / 20087: 50$ & 1.87 & 16.9 \\
\hline 662 & & $8 / 820087: 52$ & 1.869 & 16. \\
\hline 663 & & 8200 & 1.869 & $\overline{16 .}$ \\
\hline 664 & $7: 56$ & $3 / 8 / 200$ & 1.869 & 16. \\
\hline 665 & $87: 58$ & $8 / 8 / 20087: 58$ & 1.868 & 16. \\
\hline 666 & $8: 00$ & 8/8/20088:00 & 1.867 & 16.9 \\
\hline 667 & & $18 / 200$ & 1.866 & 16. \\
\hline 668 & & $8 / 8 / 200$ & 1.867 & 16.5 \\
\hline 669 & & $8 / 8 / 20088: 06$ & 1.868 & 16.9 \\
\hline 670 & $38: 08$ & $8 / 8 / 20088: 08$ & 1.869 & 16.9 \\
\hline 671 & $1 / 8 / 20$ & $88 / 20088: 10$ & 1.871 & 16.9 \\
\hline 672 & $8: 12$ & $8 / 8 / 20088: 12$ & 1.871 & 16. \\
\hline 673 & & $8 / 8 / 20088: 14$ & 1.871 & 16.9 \\
\hline 674 & & $8 / 8 / 20088: 16$ & 1.87 & 16.9 \\
\hline 675 & $88: 18$ & $8 / 820088: 18$ & 1.869 & 16.9 \\
\hline 676 & $38: 20$ & $8 / 8 / 20088: 20$ & 1.868 & 16.9 \\
\hline 67 & $88: 22$ & $8 / 820088: 22$ & 1.868 & $\overline{16 !}$ \\
\hline 678 & $38: 24$ & $8 / 8 / 20088: 24$ & 1.868 & 16.9 \\
\hline 679 & $8 / 20088: 26$ & $8 / 8 / 20088: 26$ & 1.868 & 16.9 \\
\hline 680 & $1 / 8 / 20088: 28$ & $8 / 8 / 20088: 28$ & 1.867 & 16. \\
\hline
\end{tabular}

\begin{tabular}{|c|c|c|c|c|}
\hline \multicolumn{5}{|c|}{ D4-93p } \\
\hline $\operatorname{Rec}$ & & Adjusted & Pressure & Temp \\
\hline$\#$ & Dater/lime & Date/Time & psi & ${ }^{\circ} \mathrm{C}$ \\
\hline 681 & 1/8/20088:30 & $8 / 8 / 20088: 30$ & 1.867 & 16.9 \\
\hline 682 & $1 / 8 / 20088: 32$ & $8 / 8 / 20088: 32$ & 1.866 & 16.9 \\
\hline 683 & 1/8/20088:34 & $8 / 8 / 20088: 34$ & 1.866 & 16.9 \\
\hline 684 & $1 / 8 / 20088: 36$ & $8 / 8 / 20088: 36$ & 1.865 & 16.9 \\
\hline 685 & $1 / 8 / 20088: 38$ & $8 / 8 / 20088: 38$ & 1.865 & 16.9 \\
\hline 686 & $1 / 8 / 20088: 40$ & $8 / 8 / 20088: 40$ & 1.866 & 16.9 \\
\hline 687 & $1 / 8 / 20088: 42$ & $8 / 8 / 20088: 42$ & 1.867 & 16.9 \\
\hline 688 & 1/8/20088:44 & $8 / 8 / 20088: 44$ & 1.868 & 16.9 \\
\hline 689 & $1 / 8 / 20088: 46$ & $8 / 8 / 20088: 46$ & 1.868 & 16.9 \\
\hline 690 & $1 / 8 / 20088: 48$ & $8 / 8 / 20088: 48$ & 1.867 & 16.9 \\
\hline 691 & $1 / 8 / 20088: 50$ & $8 / 8 / 20088: 50$ & 1.866 & 16.9 \\
\hline 692 & 1/8/20088:52 & $8 / 8 / 20088: 52$ & 1.865 & 16.9 \\
\hline 693 & $1 / 8 / 20088: 54$ & $8 / 8 / 20088: 54$ & 1.865 & 16.9 \\
\hline 694 & 1/8/2008 8:56 & $8 / 8 / 20088: 56$ & 1.866 & 16.9 \\
\hline 695 & 1/8/20088:58 & $8 / 8 / 20088: 58$ & 1.866 & 16.9 \\
\hline 696 & $1 / 8 / 20089.00$ & $8 / 820089.00$ & 1.865 & 16.9 \\
\hline 697 & $1 / 8 / 20089: 02$ & $8 / 8 / 20089.02$ & 1.864 & 16.9 \\
\hline 698 & $1 / 8 / 20089.04$ & $8 / 820089.04$ & 1.864 & 16.9 \\
\hline 699 & 1/8/20089.06 & $8 / 8 / 20089.06$ & 1.866 & 16.9 \\
\hline 700 & $1 / 8 / 20089.08$ & $8 / 8 / 20089.08$ & 1.868 & 16.9 \\
\hline 701 & $1 / 8 / 20089: 10$ & $8 / 8 / 20089.10$ & 1.869 & 16.9 \\
\hline 702 & $1 / 8 / 20089.12$ & $8 / 8 / 20089.12$ & 1.868 & 16.9 \\
\hline 703 & $1 / 8 / 20089: 14$ & $8 / 8 / 20089.14$ & 1.867 & 16.9 \\
\hline 704 & $1 / 820089.16$ & $8 / 820089.16$ & 1.867 & 16.9 \\
\hline 705 & $1 / 8 / 20089.18$ & $8 / 8 / 20089.18$ & 1.866 & 16.9 \\
\hline 706 & $1 / 8 / 20089.20$ & $8 / 8 / 20089.20$ & 1.864 & 16.9 \\
\hline 707 & $1 / 820089.22$ & $8 / 820089.22$ & 1.862 & 16.9 \\
\hline 708 & $1 / 8 / 20089.24$ & $8 / 8 / 20089.24$ & 1.863 & 16.9 \\
\hline 700 & $1 / 8 / 20089.26$ & $8 / 8 / 20089.26$ & 1.863 & 16.9 \\
\hline 710 & $1 / 8 / 20089.28$ & $8 / 8 / 20089.28$ & 1.864 & 16.9 \\
\hline 711 & 1/8/20089.30 & $8 / 8 / 20089.30$ & 1.865 & 16.9 \\
\hline 712 & $1 / 8 / 20089.32$ & $8 / 8 / 20089.32$ & 1.866 & 16.9 \\
\hline 713 & $1 / 8 / 20089.34$ & $8 / 8 / 20089.34$ & 1.866 & 16.9 \\
\hline 714 & $1 / 8 / 2008936$ & $8 / 8 / 20089.36$ & 1.867 & 16.9 \\
\hline 715 & $1 / 8 / 20089.38$ & $8 / 820089.38$ & 1.868 & 16.9 \\
\hline 716 & $1 / 8 / 20089.40$ & $8 / 8 / 20089.40$ & 1.866 & 16.9 \\
\hline 717 & $1 / 8 / 20089.42$ & $8 / 8 / 20089.42$ & 1.865 & 16.9 \\
\hline 718 & $1 / 820089.44$ & $8 / 8 / 20089.44$ & 1.865 & 16.9 \\
\hline 719 & $1 / 8 / 20089.46$ & $8 / 8 / 20089.46$ & 1.866 & 16.9 \\
\hline 720 & $1 / 8 / 20089.48$ & $8 / 8 / 20089.48$ & 1.868 & 16.9 \\
\hline 721 & $1 / 8 / 20089.50$ & $8 / 820089.50$ & 1.869 & 16.9 \\
\hline 722 & $1 / 8 / 20089.52$ & $8 / 8 / 20089.52$ & 1.868 & 16.9 \\
\hline 723 & $1 / 8 / 20089.54$ & $8 / 8 / 20089.54$ & 1.868 & 16.9 \\
\hline 724 & $1 / 8 / 20089.56$ & $8 / 820089.56$ & 1.867 & 17.1 \\
\hline 725 & $1 / 8 / 20089.58$ & $8 / 8 / 20089.58$ & 1.867 & 17.5 \\
\hline 726 & $1 / 8 / 200810: 00$ & $8 / 8 / 2008$ 10:00 & 1.867 & 17.3 \\
\hline 727 & $1 / 8 / 200810: 02$ & $8 / 8 / 200810: 02$ & 1.868 & 17.1 \\
\hline 728 & $1 / 8 / 200810: 04$ & $8 / 8 / 2008$ 10:04 & 1.867 & 17.2 \\
\hline 729 & $1 / 8 / 200810: 06$ & $8 / 8 / 200810: 06$ & 1.868 & 17.1 \\
\hline 730 & $1 / 8 / 2008$ 10:08 & $8 / 8 / 2008$ 10:08 & 1.868 & 17.3 \\
\hline 731 & 1/8/2008 10:10 & $8 / 8 / 2008$ 10:10 & 1.868 & 17.1 \\
\hline 732 & $1 / 8 / 2008$ 10:12 & $8 / 8 / 2008$ 10:12 & 1.868 & 16.9 \\
\hline 733 & 1/8/2008 10:14 & $8 / 8 / 2008$ 10.14 & 1.868 & 16.9 \\
\hline 734 & $1 / 8 / 200810.16$ & $8 / 8 / 200810: 16$ & 1.867 & 16.9 \\
\hline 735 & $1 / 8 / 2008$ 10:18 & $8 / 8 / 200810: 18$ & 1.867 & 16.9 \\
\hline 736 & $1 / 8 / 200810: 20$ & $8 / 8 / 200810: 20$ & 1.867 & 16.9 \\
\hline 737 & $1 / 8 / 200810: 22$ & $8 / 8 / 2008$ 10:22 & 1.866 & 16.9 \\
\hline 738 & $1 / 8 / 200810.24$ & $8 / 82008$ 10:24 & 1.865 & 16.9 \\
\hline 739 & $1 / 8 / 200810: 26$ & $8 / 8 / 2008$ 10:26 & 1.865 & 16.9 \\
\hline 740 & $1 / 8 / 200810: 28$ & $8 / 8 / 200810: 28$ & 1.865 & 16.9 \\
\hline 741 & $1 / 8 / 200810: 30$ & $88 / 2008$ 10:30 & 1.865 & 16.9 \\
\hline 742 & $1 / 8 / 2008$ 10:32 & $8 / 8 / 200810: 32$ & 1.865 & 16.9 \\
\hline 743 & $1 / 8 / 2008$ 10:34 & $8 / 8 / 2008$ 10:34 & 1.864 & 16.9 \\
\hline 744 & $1 / 8 / 200810: 36$ & $8 / 8 / 2008$ 10:36 & 1.864 & 16.9 \\
\hline 745 & $1 / 8 / 200810.38$ & $8 / 8 / 200810: 38$ & 1.865 & 16.9 \\
\hline 746 & $1 / 8 / 200810: 40$ & $8 / 8 / 2008$ 10:40 & 1.866 & 16.9 \\
\hline 747 & $1 / 8 / 200810: 42$ & $8 / 8 / 2008$ 10:42 & 1.866 & 16.9 \\
\hline 748 & $1 / 8 / 2008$ 10:44 & $8 / 8 / 2008$ 10:44 & 1.866 & 16.9 \\
\hline
\end{tabular}

\begin{tabular}{|c|c|c|c|c|}
\hline \multicolumn{5}{|c|}{$04-93 p$} \\
\hline $\operatorname{Rec}$ & & Adjusted & Pressure & Temp \\
\hline$\#$ & Date/Time & DeterTime & psi & ${ }^{\circ} \mathrm{C}$ \\
\hline 749 & $1 / 8 / 2008$ 10:46 & $8 / 8 / 2008$ 10:46 & 1.867 & 16.9 \\
\hline 750 & $1 / 8 / 2008$ 10:48 & $8 / 8 / 200810: 48$ & 1.867 & 16.9 \\
\hline 751 & $1 / 8 / 200810: 50$ & $8 / 8200810: 50$ & 1.866 & 16.9 \\
\hline 752 & $1 / 8 / 200810: 52$ & $8 / 8 / 200810.52$ & 1.865 & 16.9 \\
\hline 753 & $1 / 8 / 200810: 54$ & $8 / 8 / 200810: 54$ & 1.866 & 16.9 \\
\hline 754 & $1 / 8 / 200810: 56$ & $8 / 8 / 2008$ 10.56 & 1.866 & 16.9 \\
\hline 755 & $1 / 8 / 2008$ 10:58 & $8 / 8 / 2008$ 10:58 & 1.865 & 16.9 \\
\hline 756 & 1/8/2008 11:00 & $8 / 8 / 200811: 00$ & 1.865 & 16.9 \\
\hline 757 & 1/8/2008 11:02 & $8 / 8 / 200811: 02$ & 1.866 & $\overline{16.9}$ \\
\hline 758 & 1/8/2008 11:04 & $8 / 8 / 200811: 04$ & 1.866 & 16.9 \\
\hline 759 & 1/8/2008 11:06 & $8 / 8 / 200811: 06$ & 1.866 & 16.9 \\
\hline 760 & 1/8/200811:08 & $8 / 8 / 2008$ 11:08 & 1.865 & 16.9 \\
\hline 761 & 1/8/2008 11:10 & $8 / 8 / 2008$ 11:10 & 1.864 & 16.9 \\
\hline 762 & 1/8/2008 11:12 & $8 / 8 / 200811: 12$ & 1.865 & 16.9 \\
\hline 763 & 1/8/2008 1t:14 & $8 / 8 / 200811: 14$ & 1.865 & 16.9 \\
\hline 764 & 1/8/2008 11:16 & $8 / 8 / 200811: 16$ & 1.865 & 16.9 \\
\hline 765 & 1/8/2008 11:18 & $8 / 8 / 200811: 18$ & 1.865 & 16.9 \\
\hline 766 & 1/8/2008 11:20 & $8 / 8 / 200811: 20$ & 1.865 & 16.9 \\
\hline 767 & 1/8/200811:22 & $8 / 8 / 200811: 22$ & 1.865 & 16.9 \\
\hline 768 & 1/8/2008 11:24 & $8 / 8 / 200811: 24$ & 1.865 & 16.9 \\
\hline 769 & 1/8/2008 11:26 & $8 / 8 / 200811: 26$ & 1.865 & 16.9 \\
\hline 770 & 1/8/2008 11:28 & $8 / 8 / 200811: 28$ & 1.865 & 16.9 \\
\hline$\pi 1$ & $1 / 8 / 200811: 30$ & $8 / 8 / 200811: 30$ & 1.865 & $\overline{16.9}$ \\
\hline$\pi 2$ & 1/8/2008 11:32 & $8 / 8 / 200811: 32$ & 1.865 & 16.9 \\
\hline 773 & 1/8/2008 11:34 & $8 / 8 / 200811: 34$ & 1.866 & 16.9 \\
\hline 774 & 1/8/2008 11:36 & $8 / 8 / 200811: 36$ & 1.865 & 16.9 \\
\hline 775 & 1/8/2008 11:38 & $8 / 8 / 200811: 38$ & 1.865 & $\overline{16.9}$ \\
\hline 776 & $1 / 8 / 2008$ 11:40 & $8 / 8 / 200811: 40$ & 1.865 & 16.9 \\
\hline $7 \pi$ & $1 / 8 / 200811: 42$ & $8 / 8 / 200811: 42$ & 1.865 & 16.9 \\
\hline 778 & $1 / 8 / 2008$ 11:44 & $8 / 8 / 200811: 44$ & 1.865 & 16.9 \\
\hline $7 \pi 9$ & $1 / 8 / 200811: 46$ & $8 / 8 / 200811: 46$ & 1.865 & 16.9 \\
\hline 780 & 1/8/2008 11:48 & $8 / 8 / 2008$ 11:48 & 1.865 & 16.9 \\
\hline 781 & 1/8/2008 11:50 & $8 / 8 / 200811: 50$ & 1.865 & 16.9 \\
\hline 782 & 1/8/2008 11:52 & $8 / 8 / 200811: 52$ & 1.866 & 16.9 \\
\hline 783 & $1 / 8 / 200811: 54$ & $8 / 8 / 200811: 54$ & 1.866 & 16.9 \\
\hline 784 & $1 / 8 / 200811: 56$ & $8 / 8 / 200811: 56$ & 1.865 & 16.9 \\
\hline 785 & 1/8/2008 11:58 & $8 / 8 / 200811: 58$ & 1.866 & 16.9 \\
\hline 786 & 1/8/2008 12:00 & $8 / 8 / 200812: 00$ & 1.865 & 16.9 \\
\hline 787 & $1 / 8 / 200812: 02$ & $8 / 8 / 2008$ 12:02 & 1.864 & 16.9 \\
\hline 788 & $1 / 8 / 200812: 04$ & $8 / 8 / 200812: 04$ & 1.865 & 16.9 \\
\hline 789 & $1 / 8 / 200812: 06$ & $8 / 8 / 200812: 06$ & 1.865 & 16.9 \\
\hline 790 & 1/8/2008 12:08 & $8 / 8 / 2008$ 12:08 & 1.865 & 16.9 \\
\hline 791 & $1 / 8 / 20081210$ & $8 / 8 / 200812: 10$ & 1.865 & 16.9 \\
\hline 792 & $1 / 8 / 200812: 12$ & $8 / 8 / 200812: 12$ & 1.865 & 16.9 \\
\hline 793 & 1/8/2008 12:14 & $8 / 8 / 2008$ 12:14 & 1.865 & 16.9 \\
\hline 794 & $1 / 8 / 2008$ 12:16 & $8 / 8200812: 16$ & 1.865 & 16.9 \\
\hline 795 & $1 / 8 / 200812: 18$ & $8 / 8 / 200812: 18$ & 1.865 & 16.9 \\
\hline 796 & $1 / 8 / 20081220$ & $8 / 8 / 200812: 20$ & 1.865 & 16.9 \\
\hline 797 & $1 / 8 / 20081222$ & $8 / 8 / 20081222$ & 1.865 & 16.9 \\
\hline 798 & 1/8/200812:24 & $8 / 8 / 2008$ 12:24 & 1.865 & 16.9 \\
\hline 799 & $1 / 8 / 20081226$ & $8 / 8 / 20081226$ & 1.865 & 16.9 \\
\hline 800 & $1 / 8 / 200812: 28$ & $8 / 8 / 200812: 28$ & 1.866 & 16.9 \\
\hline 801 & $1 / 8 / 20081230$ & $8 / 8 / 20081230$ & 1.865 & 16.9 \\
\hline 802 & 1/8/2008 12:32 & $8 / 8 / 200812: 32$ & 1.865 & 16.9 \\
\hline 803 & $1 / 8 / 200812344$ & $8 / 8 / 200812: 34$ & 1.865 & 16.9 \\
\hline 804 & $1 / 8 / 200812: 36$ & $8 / 8 / 200812: 36$ & 1.865 & 16.9 \\
\hline 805 & 1/8/2008 12:38 & $8 / 8 / 2008$ 12:38 & 1.865 & 16.9 \\
\hline 806 & $1 / 8 / 200812: 40$ & $8 / 8 / 200812: 40$ & 1.865 & 16.9 \\
\hline 807 & $1 / 8 / 200812442$ & $8 / 8 / 200812442$ & 1.866 & 16.9 \\
\hline 808 & $1 / 8 / 20081244$ & $8 / 8 / 200812: 44$ & 1.866 & 16.9 \\
\hline 809 & $1 / 8 / 2008+2: 46$ & $8 / 8 / 200812: 46$ & 1.866 & 16.9 \\
\hline 810 & $1 / 8 / 20081248$ & $8 / 8200812: 48$ & 1.866 & 16.9 \\
\hline 811 & $1 / 8 / 20081250$ & $8 / 8 / 200812: 50$ & 1.865 & 16.9 \\
\hline 812 & $1 / 8 / 20081252$ & $8 / 8 / 20081252$ & 1.864 & 16.9 \\
\hline 813 & $1 / 8 / 20081254$ & $8 / 8 / 2008$ 12:54 & 1.865 & 16.9 \\
\hline 814 & $1 / 8 / 20081256$ & $8 / 8 / 200812: 56$ & 1.864 & 16.9 \\
\hline 815 & $1 / 8 / 20081258$ & $8 / 8 / 200812: 58$ & 1.865 & 16.9 \\
\hline 816 & $1 / 8 / 200813: 00$ & $8 / 8 / 200813: 00$ & 1.865 & 16.9 \\
\hline
\end{tabular}




\begin{tabular}{|c|c|c|c|c|}
\hline \multicolumn{5}{|c|}{ D493p } \\
\hline$\overline{R e c}$ & & Agisted & \begin{tabular}{|l|} 
Pressure \\
\end{tabular} & Temp \\
\hline$\#$ & DeterTime & DeteTTime & psi & ${ }^{\circ} \mathrm{C}$ \\
\hline 817 & 1/8/2008 13:02 & $8 / 8 / 200813: 02$ & 1.864 & 16.9 \\
\hline 818 & $1 / 8 / 2008$ 13:04 & $8 / 8 / 2008$ 13:04 & 1.864 & 16.9 \\
\hline 819 & $1 / 8 / 2008$ 13:06 & $8 / 8 / 200813: 06$ & 1.865 & 16.9 \\
\hline 820 & $1 / 8 / 200813: 08$ & $8 / 8 / 2008$ 13:08 & 1.864 & 16.9 \\
\hline 821 & $1 / 8 / 200813: 10$ & $8 / 8 / 200813: 10$ & 1.864 & 16.9 \\
\hline 822 & 1/8/2008 13:12 & $8 / 8 / 2008$ 13:12 & 1.864 & 16.9 \\
\hline 823 & $1 / 8 / 2008$ 13:14 & $8 / 8 / 2008$ 13:14 & 1.864 & 16.9 \\
\hline 824 & 1/8/2008 13:16 & $8 / 82200813: 16$ & 1.865 & 16.9 \\
\hline 825 & $1 / 8 / 200813: 18$ & $8 / 8 / 2008$ 13:18 & 1.865 & 16.9 \\
\hline 826 & $1 / 8 / 200813: 20$ & $8 / 8200813: 20$ & 1.865 & 16.9 \\
\hline 827 & 1/8/2008 13:22 & $8 / 8 / 200813: 22$ & 1.865 & 16.9 \\
\hline 828 & $1 / 8 / 2008$ 13:24 & $8 / 8200813: 24$ & 1.866 & 16.9 \\
\hline 829 & $1 / 82200813: 26$ & $8 / 8 / 200813: 26$ & 1.865 & 16.9 \\
\hline 830 & $1 / 8 / 200813: 28$ & $8 / 8 / 200813: 28$ & 1.865 & 16.9 \\
\hline 831 & $1 / 8 / 2008$ 13:30 & $8 / 8 / 2008$ 13:30 & 1.865 & 16.9 \\
\hline 832 & $1 / 8 / 2008$ 13:32 & $8 / 8 / 200813: 32$ & 1.866 & 16.9 \\
\hline 833 & 1/8/2008 13:34 & $8 / 8 / 200813: 34$ & 1.865 & 16.9 \\
\hline 834 & $1 / 8 / 200813: 36$ & $8 / 8 / 200813: 36$ & 1.865 & 16.9 \\
\hline 835 & 1/8/2008 13:38 & $8 / 8 / 200813: 38$ & 1.865 & 16.9 \\
\hline 836 & $1 / 8 / 200813: 40$ & $8 / 8 / 200813: 40$ & 1.865 & 16.9 \\
\hline 837 & $1 / 8 / 200813: 42$ & $8 / 8 / 200813: 42$ & 1.865 & 16.9 \\
\hline 838 & $1 / 8 / 200813: 44$ & $8 / 8 / 200813: 44$ & 1.864 & 16.9 \\
\hline 839 & $1 / 8 / 2008$ 13:46 & $8 / 8 / 200813: 46$ & 1.864 & 16.9 \\
\hline 840 & $1 / 8 / 2008$ 13:48 & $8 / 8 / 200813: 48$ & 1.864 & 16.9 \\
\hline 841 & $1 / 8 / 200813: 50$ & $8 / 8 / 200813: 50$ & 1.865 & 16.9 \\
\hline 842 & 1/8/2008 13:52 & $8 / 8 / 2000813: 52$ & 1.865 & 16.9 \\
\hline 843 & $1 / 8 / 2008$ 13:54 & $8 / 8 / 200813: 54$ & 1.865 & 16.9 \\
\hline 844 & $1 / 8 / 200813: 56$ & $8 / 8 / 200813: 56$ & 1.865 & 16.9 \\
\hline 845 & $1 / 8200813: 58$ & $8 / 8 / 200813: 58$ & 1.866 & 16.9 \\
\hline 846 & 1/8/2008 14:00 & $8 / 8 / 200814: 00$ & 1.865 & 16.9 \\
\hline 847 & $1 / 8 / 200814: 02$ & $8 / 8 / 2008$ 14:02 & 1.865 & 16.9 \\
\hline 848 & 1/8/2008 14:04 & $8 / 8 / 200814: 04$ & 1.865 & 16.9 \\
\hline 849 & $1 / 8 / 2008$ 14:06 & $8 / 8 / 200814: 06$ & 1.865 & 16.9 \\
\hline 850 & 1/822008 14:08 & $8 / 8 / 200814: 08$ & 1.865 & 16.9 \\
\hline 851 & $1 / 8 / 200814: 10$ & $8 / 8 / 200814: 10$ & 1.865 & 16.9 \\
\hline 852 & 1/8/2008 14:12 & $8 / 8 / 2008$ 14:12 & 1.865 & 16.9 \\
\hline 853 & 1/8/2008 14:14 & $8 / 8 / 2008$ 14:14 & 1.865 & $\overline{16.9}$ \\
\hline 854 & 1/8/2008 14:16 & $8 / 8 / 200814: 16$ & 1.865 & 16.9 \\
\hline 855 & 1/8/2008 14:18 & $8 / 8 / 2008$ 14:18 & 1.865 & 16.9 \\
\hline 856 & $1 / 8 / 200814: 20$ & $8 / 8 / 2008$ 14:20 & 1.865 & 16.9 \\
\hline 857 & 1/8/2008 14:22 & $8 / 8 / 200814: 2$ & 1.865 & 16.9 \\
\hline 858 & $1 / 8 / 200814: 24$ & $8 / 8 / 2008$ 14:24 & 1.865 & 16.9 \\
\hline 859 & 1/8/2008 14:26 & $8 / 8 / 2008$ 14:26 & 1.865 & 16.9 \\
\hline 860 & 1/8/2008 14:28 & $8 / 8 / 2008$ 14:28 & 1.865 & 16.9 \\
\hline 861 & 1/8/2008 14:30 & $8 / 8 / 200814: 30$ & 1.865 & 16.9 \\
\hline 862 & 1/8/2008 14:32 & $8 / 8 / 2008$ 14:32 & 1.864 & 16.9 \\
\hline 863 & $1 / 8 / 200814: 34$ & $8 / 8 / 2008$ 14:34 & 1.864 & 16.9 \\
\hline 864 & $1 / 8 / 200814: 36$ & $8 / 8 / 200814: 36$ & 1.865 & 16.9 \\
\hline 865 & $1 / 8 / 200814: 38$ & $8 / 8 / 200814: 38$ & 1.866 & 16.9 \\
\hline 866 & 1/8/2008 14:40 & $8 / 8 / 200814: 40$ & 1.865 & 16.9 \\
\hline 867 & $1 / 8 / 200814: 42$ & $8 / 8 / 2008$ 14:42 & 1.865 & 16.9 \\
\hline 868 & $1 / 8 / 2008$ 14:44 & $8 / 8 / 200814: 44$ & 1.866 & 16.9 \\
\hline 869 & $1 / 8 / 200814: 46$ & $8 / 8 / 2008$ 14:46 & 1.866 & 16.9 \\
\hline 870 & 1/8/2008 14:48 & $8 / 8 / 2008$ 14:48 & 1.864 & 16.9 \\
\hline 871 & $1 / 8 / 200814: 50$ & $8 / 8 / 200814: 50$ & 1.865 & 16.9 \\
\hline 872 & $1 / 8 / 200814: 52$ & $8 / 8 / 200814: 52$ & 1.865 & 16.9 \\
\hline 873 & $1 / 8 / 200814: 54$ & $8 / 8 / 2008$ 14:54 & 1.865 & 16.9 \\
\hline 874 & $1 / 8 / 200814: 56$ & $8 / 8 / 200814: 56$ & 1.865 & 16.9 \\
\hline 875 & $1 / 8 / 200814: 58$ & $8 / 8 / 2008$ 14:58 & 1.865 & 16.9 \\
\hline 876 & 1/8/2008 15:00 & $8 / 8 / 2008$ 15:00 & 1.865 & 16.9 \\
\hline 877 & $1 / 8 / 200815: 02$ & $8 / 8 / 2008$ 15:C2 & 1.865 & 16.9 \\
\hline 878 & $1 / 8200815: 04$ & $8 / 8 / 200815: 04$ & 1.865 & 16.9 \\
\hline 879 & 1/8/2008 15:06 & $8 / 8200815: 06$ & 1.865 & 16.9 \\
\hline 880 & $1 / 8 / 200815: 08$ & $8 / 8 / 200815: 08$ & 1.865 & 16.9 \\
\hline 881 & $1 / 8 / 200815: 10$ & $8 / 8 / 200815: 10$ & 1.865 & 16.9 \\
\hline 882 & 1/8/2008 15:12 & $8 / 8 / 2008$ 15:12 & 1.866 & 16.9 \\
\hline 883 & $1 / 8 / 200815: 14$ & $8 / 8 / 200815: 14$ & 1.867 & 16.9 \\
\hline 884 & $1 / 8 / 200815: 16$ & $8 / 8 / 200815: 16$ & 1.866 & 16.9 \\
\hline
\end{tabular}

\begin{tabular}{|c|c|c|c|c|}
\hline \multicolumn{5}{|c|}{ D493p } \\
\hline $\mathrm{Rec}$ & & Adusted & Pressure & Termp \\
\hline$\#$ & Deter Time & DaterTime & $p s i$ & ${ }^{\circ} \mathrm{C}$ \\
\hline 885 & $1 / 8 / 200815: 18$ & $8 / 8 / 200815: 18$ & 1.866 & 16.9 \\
\hline 886 & 1/8/2008 15:20 & $8 / 8 / 200815: 20$ & 1.866 & 16.9 \\
\hline 887 & $1 / 8 / 200815: 22$ & $8 / 8200815: 22$ & 1.866 & 16.9 \\
\hline 888 & $1 / 8 / 200815: 24$ & $8 / 8 / 2008$ 15:24 & 1.868 & $\overline{16.9}$ \\
\hline 889 & $1 / 8 / 200815: 26$ & $8 / 82000815: 26$ & 1.860 & 16.9 \\
\hline 890 & $1 / 8 / 200815: 28$ & $8 / 8 / 2008$ 15:28 & 1.87 & 16.9 \\
\hline 891 & 1/8/2008 15:30 & $8 / 8 / 2008$ 15:30 & 1.869 & 16.9 \\
\hline 892 & $1 / 8 / 200815: 32$ & $8 / 8 / 200815: 32$ & 1.869 & 16.9 \\
\hline 893 & 1/8/2008 15:34 & $88 / 200815: 34$ & 1.869 & 16.9 \\
\hline 894 & $1 / 8 / 200815: 36$ & $8 / 8 / 2008$ 15:36 & 1.87 & 16.9 \\
\hline 896 & $1 / 8 / 200815: 38$ & $88 / 200815: 38$ & 1.869 & $\overline{16.9}$ \\
\hline 896 & $1 / 8 / 200815: 40$ & $8 / 8 / 2008$ 15:40 & 1.869 & $\overline{16.9}$ \\
\hline 897 & $1 / 8 / 200815: 42$ & $8 / 8 / 2008$ 15:42 & 1.869 & 16.9 \\
\hline 898 & $1 / 8 / 200815: 44$ & $8 / 8 / 2008 \quad 15: 44$ & 1.87 & 16.9 \\
\hline 899 & $1 / 8 / 200815: 46$ & $8 / 8 / 200815: 46$ & 1.869 & 16.9 \\
\hline 900 & $1 / 8 / 200815: 48$ & $8 / 8 / 2008$ 15:48 & 1.869 & 16.9 \\
\hline 901 & $1 / 8 / 200815: 50$ & $8 / 8 / 200815: 50$ & 1.869 & 16.9 \\
\hline 902 & 1/8/2008 15:52 & $8 / 8 / 200815: 52$ & 1.869 & 16.9 \\
\hline 903 & $1 / 8 / 200815: 54$ & $8 / 8 / 200815: 54$ & 1.869 & 16.9 \\
\hline 904 & $1 / 8 / 2008$ 15:56 & $8 / 8 / 200815: 56$ & 1.869 & 16.9 \\
\hline 905 & $1 / 8 / 200815: 58$ & $8 / 8 / 200815: 58$ & 1.869 & 16.9 \\
\hline 906 & $1 / 8 / 200816: 00$ & $8 / 8 / 200816: 00$ & 1.87 & 16.9 \\
\hline 907 & 1/8/2008 16:02 & $8 / 8 / 200816: 02$ & 1.87 & 16.9 \\
\hline 908 & 1/8/2008 16:04 & $8 / 8 / 2008$ 16:04 & 1.869 & 16.9 \\
\hline 900 & 1/8/2008 16:06 & $8 / 8 / 200816: 06$ & 1.868 & 16.9 \\
\hline 910 & $1 / 8 / 200816: 08$ & $8 / 8 / 200816: 08$ & 1.868 & 16.9 \\
\hline 911 & 1/8/200816:10 & 8/8/2008 16:10 & 1.867 & 16.9 \\
\hline 912 & $1 / 8 / 200816: 12$ & $8 / 8 / 200816: 12$ & 1.915 & 16.9 \\
\hline 913 & 1/8/2008 16:14 & $8 / 8 / 2008$ 16:14 & 1.95 & 16.9 \\
\hline 914 & 1/8/2008 16:16 & $8 / 8 / 200816: 16$ & 1.972 & 16.9 \\
\hline 915 & $1 / 8 / 2008$ 16:18 & $8 / 8 / 200816: 18$ & 1.983 & 16.9 \\
\hline 916 & $1 / 8 / 200816: 20$ & $888 / 200816: 20$ & 1.99 & 16.9 \\
\hline 917 & 1/8/2008 16:22 & $8 / 8 / 200816: 22$ & 1.996 & 16.9 \\
\hline 918 & $1 / 8 / 200816: 24$ & $8 / 8 / 200816: 24$ & 2001 & 16.9 \\
\hline 919 & $1 / 8 / 200816: 26$ & $8 / 8 / 2008$ 16:26 & 2003 & 16.9 \\
\hline 920 & 1/8/2008 16:28 & $8 / 8 / 200816: 28$ & 2006 & 16.9 \\
\hline 921 & 1/8/2008 16:30 & $8 / 8 / 200816: 30$ & 2007 & 16.8 \\
\hline 922 & 1/82008 16:32 & $8 / 8 / 200816: 32$ & 2009 & $\overline{16.9}$ \\
\hline 923 & $1 / 8 / 2008$ 16:34 & $8 / 8 / 2008$ 16:34 & 2012 & 16.9 \\
\hline 924 & 1/8/2008 16:36 & $8 / 8 / 200816: 36$ & 2013 & 16.9 \\
\hline 925 & 1/8/2008 16:38 & $8 / 8 / 200816: 38$ & 2016 & 16.9 \\
\hline 926 & $1 / 8 / 200816: 40$ & $8 / 8 / 200816: 40$ & 2018 & 16.9 \\
\hline 927 & $1 / 8 / 200816: 42$ & $8 / 8 / 200816: 42$ & 202 & 16.8 \\
\hline 928 & 1/8/2008 16:44 & $8 / 8 / 2008$ 16:44 & 2.022 & 16.8 \\
\hline 929 & $1 / 8 / 200816: 46$ & $8 / 8 / 2008$ 16:46 & 2023 & 16.9 \\
\hline 930 & $1 / 8 / 200816: 48$ & $8 / 8 / 2008$ 16:48 & 2025 & 16.9 \\
\hline 931 & $1 / 8 / 200816: 50$ & $8 / 8 / 200816: 50$ & 2.026 & 16.9 \\
\hline 932 & $1 / 8 / 200816: 52$ & $8 / 8 / 2008$ 16:52 & 2028 & 16.9 \\
\hline 933 & $1 / 8 / 200816: 54$ & $8 / 8 / 2008$ 16:54 & 2031 & 16.8 \\
\hline 934 & $1 / 8 / 200816: 56$ & $8 / 8 / 2008$ 16:56 & 2.032 & 16.8 \\
\hline 935 & $1 / 8 / 200816: 58$ & $8 / 8 / 2008$ 16:58 & 2003 & 16.9 \\
\hline 936 & 1/8/2008 17:00 & $8 / 8 / 2008$ 17:00 & 2034 & 16.8 \\
\hline 937 & 1/82008 17:02 & $8 / 8 / 200817: 02$ & 2035 & 16.9 \\
\hline 938 & 1/8/2008 17:04 & $8 / 8 / 200817: 04$ & 2.036 & 16.9 \\
\hline 939 & $1 / 8200817: 06$ & $8 / 8 / 2008$ 17:06 & 2003 & 16.9 \\
\hline 940 & $1 / 8 / 200817: 08$ & $8 / 8 / 200817: 08$ & 204 & 16.9 \\
\hline 941 & $1 / 8 / 200817: 10$ & $8 / 8 / 200817: 10$ & 2041 & 16.9 \\
\hline 942 & 1/8/2008 17:12 & $8 / 8 / 2008$ 17:12 & 2.042 & 16.9 \\
\hline 943 & $1 / 8 / 2008$ 17:14 & $8 / 8 / 200817: 14$ & 2042 & 16.9 \\
\hline 944 & $1 / 8 / 200817: 16$ & $8 / 8 / 200817: 16$ & 2043 & 16.9 \\
\hline 945 & $1 / 8 / 200817: 18$ & $8 / 8 / 2008$ 17:18 & 2045 & 16.9 \\
\hline 946 & $1 / 8 / 200817: 20$ & $8 / 8 / 2008$ 17:20 & 2.046 & 16.9 \\
\hline 947 & 1/8/2008 17:22 & $8 / 8 / 200817: 2$ & 2046 & 16.9 \\
\hline 948 & $1 / 8 / 200817: 24$ & $8 / 8 / 2008$ 17:24 & 2048 & 16.9 \\
\hline 949 & $1 / 8 / 200817: 26$ & $8 / 8 / 2008$ 17:26 & 2048 & 17.4 \\
\hline 950 & $1 / 8 / 2008$ 17:28 & $8 / 8 / 200817: 28$ & 2051 & 17.3 \\
\hline 961 & $1 / 8 / 200817: 30$ & $8 / 8 / 200817: 30$ & 2062 & 17.1 \\
\hline 952 & 1/8/2008 17:32 & $8 / 8 / 200817: 32$ & 2.053 & 17 \\
\hline
\end{tabular}

\begin{tabular}{|c|c|c|c|c|}
\hline \multicolumn{5}{|c|}{ D493p } \\
\hline $\mathrm{Rec}$ & & Adusted & Pressure & Temp \\
\hline$\#$ & DaterTime & DeterTime & psi & ${ }^{\circ} \mathrm{C}$ \\
\hline 953 & $1 / 8 / 200817: 34$ & $8 / 8 / 2008$ 17:34 & 2.054 & 17 \\
\hline 954 & $1 / 8 / 200817: 36$ & $8 / 822008$ 17:36 & 2056 & 17 \\
\hline 955 & $1 / 8 / 200817: 38$ & $8 / 8 / 2008$ 17:38 & 2057 & 17 \\
\hline 956 & $1 / 8200817: 40$ & $8 / 82008$ 17:40 & 2058 & 17 \\
\hline 957 & $1 / 8 / 200817: 42$ & $8 / 8 / 2008$ 17:42 & 2059 & 17 \\
\hline 958 & $1 / 8 / 200817: 44$ & $8 / 8 / 2008$ 17:44 & 2061 & 17 \\
\hline 959 & $1 / 8 / 200817: 46$ & $8 / 82008$ 17:46 & 2062 & 17 \\
\hline 960 & $1 / 8 / 2008 \uparrow 7: 48$ & $8 / 82008$ 17:48 & 2064 & 17. \\
\hline 961 & $1 / 8 / 200817: 50$ & $8 / 8 / 2008$ 17:50 & 2066 & 17. \\
\hline 962 & $1 / 8 / 200817: 52$ & $8 / 8 / 2008$ 17:52 & 2067 & 17. \\
\hline 963 & $1 / 8 / 200817: 54$ & $8 / 8 / 2008$ 17:54 & 2068 & 17. \\
\hline 964 & $1 / 8 / 200817: 56$ & $8 / 8200817: 56$ & 2069 & 17. \\
\hline 965 & $1 / 8 / 200817: 58$ & $8 / 8 / 2008$ 17:58 & 2.07 & 17. \\
\hline 966 & $1 / 8200818: 00$ & $8 / 8 / 200818: 00$ & 2071 & 17. \\
\hline 967 & $1 / 8 / 2008$ 18:02 & $8 / 8 / 2008$ 18:02 & 2071 & 17. \\
\hline 968 & $1 / 8 / 200818: 04$ & $8 / 8 / 2008$ 18:04 & 2072 & 17. \\
\hline 960 & $1 / 8 / 200818: 06$ & $8 / 82008$ 18:06 & 2073 & 17. \\
\hline 970 & $1 / 8200818: 08$ & $8 / 8 / 2008$ 18:08 & 2075 & 17. \\
\hline 971 & $1 / 8 / 200818: 10$ & $8 / 8 / 2008$ 18:10 & 2076 & 17.1 \\
\hline 972 & $1 / 8 / 200818: 12$ & $8 / 8 / 2008$ 18:12 & 2077 & 17. \\
\hline 973 & $1 / 8 / 200818: 14$ & $8 / 8 / 2008$ 18:14 & 2076 & 17.6 \\
\hline 974 & $1 / 8 / 200818: 16$ & $8 / 8 / 2008$ 18:16 & 2076 & 17.4 \\
\hline 975 & $1 / 8 / 200818: 18$ & $8 / 8200818: 18$ & 2074 & 17.3 \\
\hline 976 & $1 / 8 / 200818: 20$ & $8 / 8 / 200818: 20$ & 2075 & 17.2 \\
\hline 97 & $1 / 8 / 200818: 22$ & $8 / 8 / 200818: 22$ & 2075 & 17.2 \\
\hline 978 & $1 / 8 / 200818: 24$ & $8 / 8 / 2008$ 18:24 & 2075 & 17.2 \\
\hline 979 & $1 / 8 / 200818: 26$ & $8 / 8 / 2008$ 18:26 & 2072 & 17.2 \\
\hline 980 & $1 / 8200818: 28$ & $8 / 82008$ 18:28 & 2082 & 17.2 \\
\hline 981 & $1 / 8 / 200818: 30$ & $8 / 8 / 2008$ 18:30 & 2078 & 17.3 \\
\hline 982 & $1 / 8 / 200818: 32$ & $8 / 8 / 2008$ 18:32 & 2087 & 17.3 \\
\hline 983 & $1 / 8 / 200818: 34$ & $8 / 8 / 200818: 34$ & 2073 & 17.3 \\
\hline 984 & $1 / 8 / 200818: 36$ & $8 / 8 / 200818: 36$ & 2033 & 17.3 \\
\hline 985 & $1 / 8 / 200818: 38$ & $8 / 8 / 200818: 38$ & 2013 & 17.3 \\
\hline 986 & $1 / 8 / 200818: 40$ & $8 / 8 / 2008$ 18:40 & 2 & 17.3 \\
\hline 987 & $1 / 8 / 200818: 42$ & $8 / 8 / 2008$ 18:42 & 1.99 & 17.3 \\
\hline 988 & $1 / 8 / 200818: 44$ & $8 / 8 / 2008$ 18:44 & 1.98 & 17.2 \\
\hline 989 & $1 / 8 / 200818: 46$ & $8 / 8 / 2008$ 18:46 & 1.969 & 17. \\
\hline 990 & $1 / 8 / 200818: 48$ & $8 / 8 / 2008$ 18:48 & 1.959 & 17. \\
\hline 991 & $1 / 8 / 2008 \div 8: 50$ & $8 / 8 / 200818: 50$ & 1.95 & 17. \\
\hline 992 & $1 / 8 / 200818: 52$ & $8 / 8 / 2008$ 18:52 & 1.956 & 17. \\
\hline 993 & $1 / 8 / 200818: 54$ & $8 / 8 / 2008$ 18:54 & 1.953 & 17.1 \\
\hline 994 & $1 / 8 / 200818: 56$ & $8 / 8 / 2008$ 18:56 & 1.948 & 17. \\
\hline 995 & $1 / 8 / 200818.58$ & $8 / 8 / 200818.58$ & 1.945 & 17. \\
\hline 996 & $1 / 8 / 200819.00$ & $8 / 8 / 200819.00$ & 1.944 & 17. \\
\hline 997 & $1 / 8200819.02$ & $8 / 8 / 200819.02$ & 1.943 & 17. \\
\hline 998 & $1 / 8200819.04$ & $88 / 200819.04$ & 1.941 & 17. \\
\hline 999 & $1 / 8200819: 06$ & $8 / 8 / 200819: 06$ & 1.938 & 17. \\
\hline 1000 & $1 / 8 / 200819: 08$ & $8 / 8 / 200819.08$ & 1.935 & 17. \\
\hline 1001 & $1 / 8 / 200819.10$ & $8 / 8 / 200819.10$ & 1.931 & 17.1 \\
\hline 1002 & $1 / 8 / 200819.12$ & $8 / 8 / 2008$ 19.12 & 1.927 & 17. \\
\hline 1003 & $1 / 8 / 200819.14$ & $8 / 82008$ 19.14 & 1.924 & 17. \\
\hline 1004 & $1 / 8 / 200819: 16$ & $8 / 8 / 200819: 16$ & 1.921 & 17.4 \\
\hline 1005 & $1 / 8 / 200819: 18$ & $8 / 8200819.18$ & 1.921 & 17.3 \\
\hline 1006 & $1 / 8 / 200819: 20$ & $8 / 8 / 200819: 20$ & 1.92 & 17.1 \\
\hline 1007 & $1 / 8 / 200819: 22$ & $8 / 8 / 200819: 22$ & 1.918 & 17. \\
\hline 1008 & $1 / 8 / 200819: 24$ & $8 / 8 / 200819.24$ & 1.917 & 17. \\
\hline 1009 & $1 / 8 / 200819.26$ & $8 / 8 / 200819.26$ & 1.915 & 17. \\
\hline 1010 & $1 / 8 / 200819.28$ & $8 / 8 / 200819.28$ & 1.912 & 17. \\
\hline 1011 & $1 / 8 / 200819: 30$ & $8 / 8 / 2008$ 19:30 & 1.911 & 17.1 \\
\hline 1012 & $1 / 8 / 200819: 32$ & $8 / 8 / 200819.32$ & 1.908 & 17.1 \\
\hline 1013 & $1 / 8 / 200819.34$ & $8 / 8 / 200819.34$ & 1.907 & 17.1 \\
\hline 1014 & $1 / 8 / 200819.36$ & $8 / 8 / 200819.36$ & 1.907 & 17. \\
\hline 1015 & $1 / 8200819.38$ & $8 / 8 / 200819.38$ & 1.908 & $\overline{17.1}$ \\
\hline 1016 & $1 / 8 / 200819.40$ & $8 / 8 / 200819,40$ & 1.908 & 17.1 \\
\hline 1017 & $1 / 8 / 200819: 42$ & $8 / 8 / 200819.42$ & 1.908 & 17.1 \\
\hline 1018 & $1 / 8 / 200819: 44$ & $8 / 8 / 200819: 44$ & 1.908 & 17.1 \\
\hline 1019 & $1 / 8 / 200819.46$ & $8 / 8 / 2008 \quad 19: 46$ & 1.907 & 17.1 \\
\hline 1020 & $1 / 8 / 200819.48$ & $8 / 8 / 200819.48$ & 1.906 & 17.1 \\
\hline
\end{tabular}




\begin{tabular}{|c|c|c|c|c|}
\hline \multicolumn{5}{|c|}{ D4-93p } \\
\hline$R e c$ & & Adiusted & Pressure & Temp \\
\hline$\#$ & Date/Time & DaterTime & psi & ${ }^{\circ} \mathrm{C}$ \\
\hline 1021 & $1 / 8 / 200819.50$ & $8 / 8 / 2008$ 19:50 & 1.906 & 17 \\
\hline 1022 & $1 / 8 / 200819.52$ & $8 / 82200819: 52$ & 1.905 & 17.1 \\
\hline 1023 & $1 / 8 / 200819.54$ & $8 / 8 / 2008$ 19:54 & 1.905 & 17.1 \\
\hline 1024 & $1 / 8 / 200819.56$ & $8 / 8 / 200819: 56$ & 1.905 & 17.1 \\
\hline 1025 & $1 / 8 / 200819.58$ & $8 / 8 / 2008$ 19:58 & 1.904 & 17.1 \\
\hline 1026 & $1 / 8 / 200820: 00$ & $8 / 8 / 200820: 00$ & 1.904 & 17.1 \\
\hline 1027 & 1/8/2008 20:02 & $8 / 8 / 200820: 02$ & 1.903 & 17.1 \\
\hline 1028 & $1 / 8 / 200820: 04$ & $8 / 8 / 200820: 04$ & 1.901 & 17.1 \\
\hline 1029 & $1 / 8 / 200820.06$ & $8 / 8 / 200820: 06$ & 1.9 & 17.1 \\
\hline 1030 & $1 / 8 / 200820.08$ & $8 / 8 / 200820: 08$ & 1.911 & 17.1 \\
\hline 1031 & 1/8/2008 20:10 & $8 / 8 / 200820.10$ & 1.986 & 17.1 \\
\hline 1032 & $1 / 8 / 200820: 12$ & $8 / 8 / 200820: 12$ & 2007 & 17.1 \\
\hline 1033 & $1 / 8 / 200820: 14$ & $8 / 8 / 200820: 14$ & 2013 & 17.1 \\
\hline 1034 & $1 / 8 / 200820: 16$ & $8 / 8 / 200820: 16$ & 2006 & 17.1 \\
\hline 1035 & $1 / 8 / 200820: 18$ & $8 / 8 / 200820: 18$ & 1.95 & 17.1 \\
\hline 1036 & $1 / 8 / 200820: 20$ & $8 / 8 / 200820: 20$ & 1.936 & 17.1 \\
\hline 1037 & 1/8/2008 20:22 & $8 / 8 / 200820: 22$ & 1.926 & 17.1 \\
\hline 1038 & $1 / 8 / 200820: 24$ & $8 / 8 / 200820: 24$ & 1.92 & 17.1 \\
\hline 1039 & $1 / 8 / 200820: 26$ & $8 / 8 / 200820: 26$ & 1.916 & 17.1 \\
\hline 1040 & $1 / 8 / 200820.28$ & $8 / 8 / 200820: 28$ & 1.914 & 17.1 \\
\hline 1041 & $1 / 8 / 200$ & $8 / 8 / 200820: 30$ & 1.913 & 17.1 \\
\hline 1042 & $1 / 8 / 200820.32$ & $8 / 8 / 200820: 32$ & 1.911 & 17.1 \\
\hline 1043 & $1 / 8 / 200820.34$ & $8 / 8 / 200820: 34$ & 1.91 & 17 \\
\hline 1044 & $1 / 8 / 200820.36$ & $8 / 8 / 200820: 36$ & 1.908 & 17 \\
\hline 1045 & $1 / 8 / 200$ & $8 / 8 / 200820: 38$ & 1.907 & 17 \\
\hline 1046 & $1 / 8 / 200820.40$ & $8 / 8 / 200820.40$ & 1.973 & 17.1 \\
\hline 1047 & $1 / 8 / 200820.42$ & $8 / 8 / 200820.42$ & 1.999 & 17.1 \\
\hline 1048 & $1 / 8 / 200820: 44$ & $8 / 8 / 200820: 44$ & 201 & 17.1 \\
\hline 1049 & $1 / 8 / 200$ & $8 / 8 / 200820: 46$ & 2012 & 17.1 \\
\hline 1050 & $1 / 8 / 20$ & $8 / 8 / 200820: 48$ & 2018 & 17.1 \\
\hline 1051 & $1 / 8 / 200820.50$ & $8 / 8 / 200820.50$ & 2022 & 17 \\
\hline 1052 & $1 / 8 / 200820.52$ & $8 / 8 / 200820.52$ & 2025 & 17.4 \\
\hline 1053 & $1 / 8 / 20$ & $8 / 8 / 200$ & 2031 & 17.1 \\
\hline 1054 & $1 / 8 / 200820.56$ & $8 / 8 / 200820: 56$ & 2035 & 17.1 \\
\hline 1055 & $1 / 8 / 200820: 58$ & $8 / 8 / 200820.58$ & 2037 & 17.1 \\
\hline 1056 & 1/8/2008 21:00 & $8 / 8 / 200821: 00$ & 2039 & 17.1 \\
\hline 105 ? & $1 / 8 / 200821: 02$ & $8 / 8 / 200821: 02$ & 2043 & 17.1 \\
\hline 1058 & $1 / 8 / 200821: 04$ & $8 / 8 / 200821: 04$ & 2043 & 17.1 \\
\hline 1059 & $1 / 8 / 200821: 06$ & $8 / 8 / 200821: 06$ & 2046 & 17.1 \\
\hline 1060 & 1/8/2008 21:08 & $8 / 8 / 200821: 08$ & 2048 & 17.1 \\
\hline 1061 & $1 / 8 / 200821: 10$ & $8 / 8 / 200821: 10$ & 205 & 17.1 \\
\hline 1062 & $1 / 8 / 20$ & $8 / 8 / 200$ & 2051 & 17.1 \\
\hline 1063 & 1/8/200821:14 & $8 / 8 / 200821: 14$ & 2.053 & 17.1 \\
\hline 1064 & 1/8/2008 21:16 & $8 / 8 / 200821: 16$ & 2054 & 17.2 \\
\hline 1065 & 1/8/200821:18 & 8/8/200821:18 & 2056 & 17.2 \\
\hline 1066 & $1 / 8 / 2$ & $8 / 8 / 20$ & 2059 & 17.4 \\
\hline 1067 & $1 / 8 / 20$ & $8 / 8 / 200821: 22$ & 2065 & 17.5 \\
\hline 1068 & $1 / 8 / 200821: 24$ & $8 / 8 / 200821: 24$ & 2067 & 17.3 \\
\hline 1069 & 1/8/200821:26 & $8 / 8 / 200821: 26$ & 2069 & 17.3 \\
\hline 1070 & 1/8/2008 21:28 & $8 / 8 / 200821: 28$ & 2071 & 17.3 \\
\hline 1071 & 1/8/2008 21:30 & $8 / 8 / 200821: 30$ & 2.073 & 17.3 \\
\hline 1072 & 1/8/2008 21:32 & $8 / 8 / 200821: 32$ & 2074 & 17.3 \\
\hline 1073 & $1 / 8 / 200821: 34$ & $8 / 8 / 200821: 34$ & 2076 & 17.3 \\
\hline 1074 & 1/8/2008 21:36 & $8 / 8 / 200821: 36$ & 2077 & 17.4 \\
\hline 1075 & $1 / 8 / 200821: 38$ & $8 / 8 / 200821: 38$ & 2078 & 17.4 \\
\hline 1076 & $1 / 8 / 200821: 40$ & $8 / 8 / 200821: 40$ & 207 & 17.6 \\
\hline 1077 & $1 / 8 / 200821: 42$ & $8 / 8 / 200821: 42$ & 2078 & 18 \\
\hline 1078 & $1 / 8 / 200821: 44$ & $8 / 8 / 200821: 44$ & 2081 & 17.6 \\
\hline 1079 & $1 / 8 / 200821: 46$ & $818 / 200821: 46$ & 2081 & 17.5 \\
\hline 1080 & $1 / 8 / 200821: 48$ & $8 / 8 / 200821: 48$ & 2082 & 17.6 \\
\hline 1081 & $1 / 8 / 200821: 50$ & $8 / 8 / 200821: 50$ & 2084 & 17.5 \\
\hline 1082 & 1/8/200821:52 & $8 / 8 / 200821: 52$ & 2083 & 17.5 \\
\hline 1083 & $1 / 8 / 200821: 54$ & $8 / 8 / 200821: 54$ & 2083 & 17.5 \\
\hline 1084 & $1 / 8 / 200821: 56$ & $8 / 8 / 200821: 56$ & 2087 & 17.5 \\
\hline 1085 & $1 / 8 / 200821: 58$ & $8 / 8 / 200821: 58$ & 2086 & 17.5 \\
\hline 1086 & $1 / 8 / 20082200$ & $8 / 8 / 200822200$ & 2087 & 17.5 \\
\hline 1087 & $1 / 8 / 20082202$ & $8 / 8 / 200822 \cdot 02$ & 2089 & 17.5 \\
\hline 1088 & $1 / 8 / 200822,04$ & $8 / 8 / 200822: 04$ & 2091 & 17.5 \\
\hline
\end{tabular}

\begin{tabular}{|c|c|c|c|c|}
\hline \multicolumn{5}{|c|}{$D 4-93 p$} \\
\hline $\operatorname{Rec}$ & & Adjusted & Pressure & Temp \\
\hline$\#$ & Date/Time & DaterTime & psi & ${ }^{\circ} \mathrm{C}$ \\
\hline 1089 & $1 / 8 / 200822: 06$ & $8 / 8 / 200822: 06$ & 2091 & 17.7 \\
\hline 1090 & 1/8/200822:08 & $8 / 8 / 2008$ 22:08 & 2.091 & 17.6 \\
\hline 1091 & 1/8/200822:10 & $8 / 8 / 200822: 10$ & 2091 & 17.6 \\
\hline 1092 & 1/8/2008 22:12 & $8 / 8 / 200822: 12$ & 2092 & 17.6 \\
\hline 1003 & $1 / 8 / 200822: 14$ & $8 / 8 / 20082214$ & 2092 & 17.6 \\
\hline 1094 & $1 / 8 / 200822-16$ & $8 / 8 / 200822: 16$ & 2093 & 17.6 \\
\hline 1095 & $1 / 8 / 200822: 18$ & $8 / 8 / 200822: 18$ & 2094 & 17.6 \\
\hline 1096 & $1 / 8 / 20082220$ & $8 / 8 / 200822220$ & 2.094 & 17.6 \\
\hline 1097 & $1 / 8 / 20082222$ & $8 / 8200822: 22$ & 2094 & 17.6 \\
\hline 1098 & $1 / 8 / 200822: 24$ & $8 / 8 / 200822: 24$ & 2095 & $\overline{17.6}$ \\
\hline 1099 & 1/8/200822:26 & $8 / 8 / 2008222.26$ & 2.095 & $\overline{17.6}$ \\
\hline 1100 & 1/8/2008 22:28 & $8 / 8 / 200822: 28$ & 2096 & $\overline{17.6}$ \\
\hline 1101 & $1 / 8 / 200822: 30$ & $8 / 8 / 200822: 30$ & 2096 & 17.7 \\
\hline 1102 & $1 / 8 / 200822: 32$ & $8 / 8 / 200822: 32$ & 2097 & 17.7 \\
\hline 1103 & 1/8/200822:34 & $8 / 8 / 200822: 34$ & 2.097 & 17.7 \\
\hline 1104 & 1/8/200822:36 & $8 / 8 / 200822: 36$ & 2.098 & 17.7 \\
\hline 1105 & $1 / 8 / 200822: 38$ & $8 / 8 / 200822: 38$ & 2.098 & 17.7 \\
\hline 1106 & $1 / 8 / 200822: 40$ & $8 / 8 / 200822: 40$ & 2.099 & 17.7 \\
\hline 1107 & $1 / 8 / 200822: 42$ & $8 / 8 / 200822442$ & 2099 & 17.7 \\
\hline 1108 & 1/8/2008 22:44 & $8 / 8200822: 44$ & 2.099 & 17.8 \\
\hline 1109 & 1/8/2008 22:46 & $8 / 8 / 200822: 46$ & 2099 & 17.8 \\
\hline 1110 & $1 / 8 / 200822.48$ & $8 / 8 / 200822448$ & 21 & 17.7 \\
\hline 1111 & $1 / 8 / 20082250$ & $8 / 8 / 200822: 50$ & 2.101 & 17.7 \\
\hline 1112 & $1 / 8 / 200822: 52$ & $8 / 8 / 200822552$ & 2102 & 17.6 \\
\hline 1113 & $1 / 8 / 200822: 54$ & $8 / 8 / 20082254$ & 2103 & 17.6 \\
\hline 1114 & $1 / 8 / 200822: 56$ & $8 / 8 / 200822: 56$ & 2103 & 17.6 \\
\hline 1115 & $1 / 8 / 200822: 58$ & $8 / 8 / 200822: 58$ & 2056 & 17.6 \\
\hline 1116 & 1/8/2008 23:00 & $8 / 8 / 200823: 00$ & 204 & 17.5 \\
\hline 1117 & $1 / 8 / 200823: 02$ & $8 / 8 / 200823: 02$ & 2.029 & $\overline{17.4}$ \\
\hline 1118 & $1 / 8 / 200823: 04$ & $8 / 8 / 200823: 04$ & 2.02 & 17.4 \\
\hline 1119 & $1 / 8 / 200823: 06$ & $8 / 8 / 200823: 06$ & 2.012 & 17.4 \\
\hline 1120 & 1/8/200823:08 & $8 / 8 / 200823: 08$ & 2.004 & $\overline{17.4}$ \\
\hline 1121 & 1/8/200823:10 & $8 / 8 / 200823: 10$ & 1.997 & $\overline{17.4}$ \\
\hline 1122 & 1/8/2008 23:12 & $8 / 8 / 200823: 12$ & 1.99 & $\overline{17.4}$ \\
\hline 1123 & $1 / 8 / 200823: 14$ & $8 / 8 / 200823: 14$ & 1.982 & 17.6 \\
\hline 1124 & 1/8/2008 23:16 & $8 / 8 / 200823: 16$ & 1.976 & 17.6 \\
\hline 1125 & 1/8/200823:18 & $8 / 8 / 200823: 18$ & 1.971 & 17.8 \\
\hline 1126 & 1/8/200823:20 & $8 / 8200823: 20$ & 1.967 & 17.8 \\
\hline 1127 & 1/8/2008 23:22 & $8 / 8 / 200823: 22$ & 1.962 & 17.9 \\
\hline 1128 & $1 / 8 / 200823: 24$ & $8 / 8 / 200823: 24$ & 1.958 & 17.9 \\
\hline 1129 & $1 / 8 / 200823: 26$ & $8 / 8 / 200823: 26$ & 1.955 & 18 \\
\hline 1130 & $1 / 8 / 200823: 28$ & $8 / 8 / 200823: 28$ & 1.95 & 18 \\
\hline 1131 & 1/8/200823:30 & $8 / 8 / 200823: 30$ & 1.948 & 18.1 \\
\hline 1132 & 1/8/200823:32 & $8 / 8 / 200823: 32$ & 1.946 & 18.1 \\
\hline 1133 & $1 / 8 / 200823: 34$ & $8 / 8200823: 34$ & 1.946 & 18.2 \\
\hline 1134 & $1 / 8 / 200823: 36$ & $8 / 8 / 200823: 36$ & 1.944 & 18.2 \\
\hline 1135 & $1 / 8 / 200823: 38$ & $8 / 8 / 200823: 38$ & 1.942 & 18.3 \\
\hline 1136 & $1 / 8 / 200823: 40$ & $8 / 8200823: 40$ & 1.939 & 18.3 \\
\hline 1137 & $1 / 8 / 200823: 42$ & $8 / 8 / 200823: 42$ & 1.936 & 18.3 \\
\hline 1138 & $1 / 8 / 200823: 44$ & $8 / 8 / 200823: 44$ & 1.934 & 18.3 \\
\hline 1139 & $1 / 8 / 200823: 46$ & $8 / 8 / 200823: 46$ & 1.944 & 18.3 \\
\hline 1140 & $1 / 8 / 200823: 48$ & $8 / 8 / 200823: 48$ & 2003 & 18.3 \\
\hline 1141 & $1 / 8 / 200823: 50$ & $8 / 8 / 200823: 50$ & 2.017 & 18.3 \\
\hline 1142 & $1 / 8 / 200823: 52$ & $8 / 8 / 200823: 52$ & 2026 & 18.1 \\
\hline 1143 & $1 / 8 / 200823: 54$ & $8 / 8 / 200823: 54$ & 2034 & 18.1 \\
\hline 1144 & $1 / 8 / 200823: 56$ & $8 / 8 / 200823: 56$ & 2041 & 18.3 \\
\hline 1145 & $1 / 8 / 200823: 58$ & $8 / 8 / 200823: 58$ & 2047 & 18.3 \\
\hline 1146 & $1 / 9 / 20080: 00$ & $8 / 9 / 20080: 00$ & 2053 & 17.9 \\
\hline 1147 & 1/9/2008 0:02 & $8 / 920080: 02$ & 2.05 & 17.8 \\
\hline 1148 & $1 / 9 / 20080: 04$ & $8 / 9 / 20080: 04$ & 2062 & 17.7 \\
\hline 1149 & $1 / 9 / 20080: 06$ & $8 / 9 / 2008006$ & 2067 & 17.7 \\
\hline 1150 & $1 / 9 / 20080.08$ & $8 / 9 / 2008000$ & 207 & 17.7 \\
\hline 1151 & 1/9/20080:10 & $8 / 9 / 20080: 10$ & 2073 & 17.6 \\
\hline 1152 & $1 / 9 / 20080: 12$ & $8 / 9 / 20080.12$ & 2.077 & 17.6 \\
\hline 1153 & $1 / 9 / 20080: 14$ & $8 / 9 / 20000: 14$ & 2079 & 17.6 \\
\hline 1154 & $1 / 9 / 20080: 16$ & $8 / 920080: 16$ & 2.081 & 17.6 \\
\hline 1155 & $1 / 9 / 20080: 18$ & $8 / 920080: 18$ & 2.083 & 17.6 \\
\hline 1156 & $1 / 9 / 20080: 20$ & $8 / 9 / 20080: 20$ & 2.084 & 17.6 \\
\hline
\end{tabular}

\begin{tabular}{|c|c|c|c|c|}
\hline \multicolumn{5}{|c|}{ D4-93p } \\
\hline $\operatorname{Rec}$ & & Acjusted & Pressure & Temp \\
\hline \# & DaterTime & Date-Time & psi & ${ }^{\circ} \mathrm{C}$ \\
\hline 115 & $1 / 9 / 20080: 22$ & $9 / 20080: 22$ & 2087 & 17.7 \\
\hline 1158 & 120080.24 & $9 / 20080: 24$ & 2088 & \\
\hline 1159 & $\sqrt{20080.26}$ & $9 / 20080.26$ & 209 & 17.7 \\
\hline 1160 & $820080: 28$ & $8 / 9 / 20080: 28$ & 2.091 & 17.7 \\
\hline 1161 & 1/9/20080:30 & $8 / 9 / 20080: 30$ & 2097 & 17.7 \\
\hline 1162 & $3 / 20080: 32$ & $8 / 9 / 20080: 32$ & 2095 & 17.7 \\
\hline 1163 & $3 / 20080: 34$ & $8 / 9 / 20080: 34$ & 2096 & \\
\hline 1164 & $120080: 36$ & $8 / 9 / 20080: 36$ & 2096 & 17. \\
\hline 1165 & $9 / 20080: 38$ & $8 / 9 / 20080: 38$ & 2097 & 17.8 \\
\hline 1166 & $1 / 9 / 20080: 40$ & $8 / 9 / 20080: 40$ & 2098 & 17.8 \\
\hline 1167 & $30: 42$ & $8 / 9 / 20080: 42$ & 2.1 & $\overline{17.8}$ \\
\hline 1168 & $9 / 20080: 44$ & $89 / 20080: 44$ & 2101 & $\overline{17.8}$ \\
\hline 1169 & $3 / 20080: 46$ & $8 / 9 / 20080: 46$ & 2.101 & 17. \\
\hline 1170 & $9 / 20080.48$ & $8 / 9 / 2000$ & 2102 & 17. \\
\hline 1171 & $3 / 20080.50$ & $8 / 9 / 20080.50$ & 2103 & $\overline{17.8}$ \\
\hline 1172 & .52 & $8 / 9 / 200$ & 2.105 & $\overline{17.8}$ \\
\hline 1173 & 54 & $8 / 9 / 200$ & 2106 & \\
\hline 1174 & $0: 56$ & $8 / 91200$ & 2106 & 17. \\
\hline 1175 & $9 / 20080: 58$ & $8 / 9 / 200$ & 2.106 & 17.9 \\
\hline 1176 & 31:00 & $8 / 9 / 2000$ & 2107 & 17.9 \\
\hline 1177 & 02 & $8 / 9 / 20$ & 2109 & 17.9 \\
\hline 1178 & & $1: 04$ & 2.109 & 17. \\
\hline 1179 & 1:06 & $89 / 200$ & 2109 & 17. \\
\hline 1180 & 1:08 & $9 / 20081: 08$ & 2.111 & 17.9 \\
\hline 1181 & & 10 & 2.111 & 18 \\
\hline 1182 & $: 12$ & $8 / 9 / 20$ & 2.111 & 18. \\
\hline 1183 & 11:14 & $89 / 20$ & 2.111 & 18. \\
\hline 1184 & $9 / 2008$ 1:16 & $8 / 9 / 20081: 16$ & 2.111 & 18. \\
\hline 1185 & 18 & $89 / 20$ & 2.113 & 18. \\
\hline 1186 & 20 & $8 / 9 / 20$ & 2.113 & 18. \\
\hline 1187 & & $8 / 9 / 20$ & 2115 & 18. \\
\hline 1188 & $81: 24$ & $89 / 20$ & 2.116 & 18. \\
\hline 1189 & & $89 / 20$ & 2.117 & 18. \\
\hline 1190 & & 28 & 2117 & 18. \\
\hline 1191 & & 30 & 2117 & 18. \\
\hline 1192 & & $1: 32$ & 2.117 & 18.2 \\
\hline 1193 & & & 2.117 & 18. \\
\hline 1194 & & & 2.118 & 18. \\
\hline 1195 & & 38 & 2.119 & 18. \\
\hline 1196 & & $1: 40$ & 2.121 & 18. \\
\hline 1197 & & $8 / 9 / 200$ & 2122 & 18. \\
\hline 1198 & & $: 44$ & 2122 & 18. \\
\hline 1199 & & 46 & 2.122 & 18. \\
\hline 1200 & & 48 & 2.122 & 48. \\
\hline 1201 & 1:50 & & 2.122 & 18. \\
\hline 1202 & & & 2.12 & 18. \\
\hline 1203 & & $8 / 9 / 20$ & 2.122 & 18. \\
\hline 1204 & & $9 \sqrt{20}$ & 2.122 & 18. \\
\hline 1205 & $1: 58$ & $8 / 9 / 20$ & 2.123 & 18. \\
\hline 1206 & & & 2.124 & 18. \\
\hline 1207 & & 02 & 2.124 & 18. \\
\hline 1208 & & 04 & 2.124 & 18. \\
\hline 1209 & 206 & $8 / 9 / 20$ & 2.124 & 18. \\
\hline 1210 & & & 2.089 & 18. \\
\hline 1211 & & & 2.067 & \\
\hline 1212 & & 212 & 2052 & \\
\hline 1213 & 214 & $2: 14$ & 2.042 & 19. \\
\hline 1214 & 216 & $2: 16$ & 2.034 & 19 . \\
\hline 1215 & & & 2.026 & 19. \\
\hline 1216 & & & & $x$ \\
\hline 1217 & $2 \cdot 22$ & $89 / 200$ & 2029 & $n$ \\
\hline 1218 & $1 / 9 / 20$ & $8 / 9 / 20082: 24$ & 2.063 & 20. \\
\hline 1219 & & & 2079 & 20. \\
\hline 1220 & & & 2.088 & 20 . \\
\hline 1221 & & & 2094 & \\
\hline 1222 & $1 / 9 / 2008232$ & $8 / 9 / 20082: 32$ & 2.098 & 2 \\
\hline 1223 & $1 / 9 / 2008234$ & & 21 & \\
\hline 1224 & $1 / 9 / 2008 \approx 36$ & $8 / 9 / 20082: 36$ & 2.104 & \\
\hline
\end{tabular}




\begin{tabular}{|c|c|c|c|c|}
\hline \multicolumn{5}{|c|}{ D493p } \\
\hline $\operatorname{Rec}$ & & Adjusted & \begin{tabular}{|l|} 
Pressure \\
\end{tabular} & Temp \\
\hline$\#$ & Date/Time & Date/Time & \begin{tabular}{|c|}
$p s i$ \\
\end{tabular} & ${ }^{\circ} \mathrm{C}$ \\
\hline 1225 & $1 / 9 / 2008238$ & $8 / 9 / 20082: 38$ & 2106 & 19.7 \\
\hline 1226 & $1 / 9 / 2008240$ & $8 / 9 / 20082: 40$ & 2108 & 19.6 \\
\hline 1227 & $1 / 9 / 2008242$ & $8 / 9 / 20082: 42$ & 2111 & 19.4 \\
\hline 1228 & $1 / 9 / 20082 ; 44$ & $8 / 9 / 2008244$ & 2114 & 19.4 \\
\hline 1229 & $1 / 9 / 2008246$ & $8 / 9 / 20082: 46$ & 2115 & 19.3 \\
\hline 1230 & $1 / 9 / 2008248$ & $8 / 9 / 2008248$ & 2117 & 19.3 \\
\hline 1231 & $1 / 9 / 20082: 50$ & $8 / 9 / 2008250$ & 2119 & 19.2 \\
\hline 1232 & $1 / 9 / 2008252$ & $8 / 9 / 2008252$ & 212 & 19.2 \\
\hline 1233 & $1 / 9 / 2008254$ & $8 / 9 / 2008254$ & 2.121 & 19.2 \\
\hline 1234 & $1 / 9 / 20082: 56$ & $8 / 9 / 2008256$ & 2.122 & 19.3 \\
\hline 1235 & $1 / 9 / 2008258$ & $8 / 9 / 2008258$ & 2124 & 19.4 \\
\hline 1236 & $1 / 9 / 20083: 00$ & $8 / 9 / 20083: 00$ & 2.124 & 19.6 \\
\hline 1237 & $1 / 9 / 20083: 02$ & $8 / 9 / 20083: 02$ & 2126 & 19.8 \\
\hline 1238 & $1 / 9 / 20083: 04$ & $8 / 9 / 20083: 04$ & 2128 & 20 \\
\hline 1239 & $1 / 9 / 20083: 06$ & $8 / 9 / 20083: 06$ & 2.129 & 20.1 \\
\hline 1240 & $1 / 9 / 20083: 08$ & $8 / 9 / 20083: 08$ & 2129 & 20.2 \\
\hline 1241 & $1 / 9 / 20083: 10$ & 8/9/20083:10 & 2.131 & 20.3 \\
\hline 1242 & 1/9/20083:12 & $8 / 9 / 20083: 12$ & 2.132 & 20.3 \\
\hline 1243 & 1/9/2008 3:14 & $8 / 9 / 20083: 14$ & 2131 & 20.3 \\
\hline 1244 & $1 / 9 / 20083: 16$ & $8 / 9 / 20083: 16$ & 2132 & 20.4 \\
\hline 1245 & 1/9/20083:18 & $8 / 9 / 20083: 18$ & 2.133 & 20.4 \\
\hline 1246 & $1 / 9 / 20003: 20$ & $8 / 9 / 20083: 20$ & 2132 & 21 \\
\hline 1247 & $1 / 9 / 20083: 22$ & $8 / 9 / 20083: 22$ & 2.134 & 20.7 \\
\hline 1248 & $1 / 9 / 20083: 24$ & $8 / 9 / 20083: 24$ & 2.135 & 20.6 \\
\hline 1249 & $1 / 9 / 20083: 26$ & $8 / 9 / 20083: 26$ & 2.135 & 20.6 \\
\hline 1250 & $1 / 9 / 20083: 28$ & $8 / 9 / 20083: 28$ & 2136 & 20.7 \\
\hline 1251 & 1/9/20083:30 & $8 / 9 / 20083: 30$ & 2.137 & 20.8 \\
\hline 1252 & $1 / 9 / 20083: 32$ & $8 / 9 / 20083: 32$ & 2.137 & 20.8 \\
\hline 1253 & 1/9/20083:34 & $8 / 9 / 20083: 34$ & 2137 & 20.8 \\
\hline 1254 & 1/9/20083:36 & $8 / 9 / 20083: 36$ & 2138 & 20.8 \\
\hline 1255 & 1/9/20083:38 & $8 / 9 / 20083: 38$ & 2.138 & 20.9 \\
\hline 1256 & $1 / 9 / 20083: 40$ & $8 / 9 / 20083: 40$ & 2139 & 20.9 \\
\hline 125 & $1 / 9 / 20083: 42$ & $8 / 9 / 20083: 42$ & 2.139 & 21 \\
\hline 1258 & $1 / 9 / 20083: 44$ & $8 / 9 / 20083: 44$ & 2.134 & 21 \\
\hline 1259 & $1 / 9 / 20083: 46$ & $8 / 9 / 20083: 46$ & 2.133 & 21.1 \\
\hline 1260 & $1 / 9 / 20083: 48$ & $8 / 9 / 20083: 48$ & 2.132 & 21.1 \\
\hline 1261 & $1 / 9 / 20083: 50$ & $8 / 9 / 20083: 50$ & 2134 & 21.1 \\
\hline 1262 & $1 / 9 / 20083: 52$ & $8 / 9 / 20083: 52$ & 2129 & 21.1 \\
\hline 1263 & $1 / 9 / 20083: 54$ & $8 / 9 / 20083: 54$ & 2139 & 21.1 \\
\hline 1264 & 1/9/2008 3:56 & $8 / 9 / 20083: 56$ & 2.138 & 21.2 \\
\hline 1265 & $1 / 9 / 20083: 58$ & $8 / 9 / 20083: 58$ & 2.173 & 21.2 \\
\hline 1266 & 1/9/20084:00 & $8 / 9 / 20084: 00$ & 2.142 & 21.2 \\
\hline 1267 & $1 / 9 / 20084: 02$ & $8 / 9 / 20084: 02$ & 2.143 & 21.2 \\
\hline 1268 & $1 / 9 / 20084: 04$ & $8 / 9 / 20084: 04$ & 2.106 & 21.3 \\
\hline 1269 & $1 / 9 / 20084: 06$ & $8 / 9 / 20084: 06$ & 2.144 & 21.3 \\
\hline 1270 & $1 / 9 / 20084: 08$ & $8 / 9 / 20084: 08$ & 2145 & 21.4 \\
\hline 1271 & $1 / 9 / 20084: 10$ & $8 / 9 / 20084: 10$ & 2155 & 21.4 \\
\hline 1272 & $1 / 9 / 20084: 12$ & $8 / 9 / 20084: 12$ & 2.146 & 21.3 \\
\hline 1273 & $1 / 9 / 20084: 14$ & $8 / 9 / 20084: 14$ & 2.146 & 21.3 \\
\hline 1274 & 1/9/20084:46 & $8 / 9 / 20084: 16$ & 2.145 & 21.3 \\
\hline 1275 & $1 / 9 / 20084: 18$ & $8 / 9 / 20084: 18$ & 2.145 & 21.4 \\
\hline 1276 & $1 / 9 / 20084: 20$ & $8 / 9 / 20084: 20$ & 2.147 & 21.4 \\
\hline $12 \pi$ & $1 / 9 / 20084: 22$ & $8 / 9 / 20084: 22$ & 2147 & 21.4 \\
\hline 1278 & $1 / 9 / 20084: 24$ & $8 / 9 / 20084: 24$ & 2.183 & 21.5 \\
\hline 1279 & $1 / 9 / 20084: 26$ & $8 / 9 / 20084: 26$ & 2.148 & 21.5 \\
\hline 1280 & $1 / 9 / 20084: 28$ & $8 / 9 / 20084: 28$ & 2.145 & 21.5 \\
\hline 1281 & $1 / 9 / 20084: 30$ & $8 / 9 / 20084: 30$ & 2.148 & 21.5 \\
\hline 1282 & $1 / 9 / 20084: 32$ & $8 / 9 / 20084: 32$ & 2.139 & 21.6 \\
\hline 1283 & $1 / 9 / 20084: 34$ & $8 / 9 / 20084: 34$ & 2.151 & 21.5 \\
\hline 1284 & $1 / 9 / 20084: 36$ & $8 / 9 / 20084: 36$ & 2149 & 21.6 \\
\hline 1285 & $1 / 9 / 20084: 38$ & $8 / 9 / 20084: 38$ & 2.15 & 21.6 \\
\hline 1286 & $1 / 9 / 20084: 40$ & $8 / 9 / 20084: 40$ & 2.151 & 21.6 \\
\hline 1287 & $1 / 9 / 20084: 42$ & $8 / 9 / 20084: 42$ & 2.151 & 21.5 \\
\hline 1288 & $1 / 9 / 20084: 44$ & $8 / 9 / 20084: 44$ & 2.153 & 21.6 \\
\hline 1289 & $1 / 9 / 20084: 46$ & $8 / 9 / 20084: 46$ & 2.156 & 21.6 \\
\hline 1290 & $1 / 9 / 20084: 48$ & $8 / 9 / 20084: 48$ & 215 & 21.6 \\
\hline 1291 & $1 / 9 / 20084: 50$ & $8 / 9 / 20084: 50$ & 215 & 21.6 \\
\hline 1292 & $1 / 9 / 20084: 52$ & $8 / 9 / 20084: 52$ & 2.15 & 21.7 \\
\hline
\end{tabular}

\begin{tabular}{|c|c|c|c|c|}
\hline \multicolumn{5}{|c|}{ D493p } \\
\hline $\operatorname{Rec}$ & & Adjusted & Pressure & Ternp \\
\hline$\#$ & Date/Time & DaterTime & $\mathrm{psi}$ & ${ }^{\circ} \mathrm{C}$ \\
\hline 1293 & $1 / 9 / 20084: 54$ & $8 / 9 / 20084: 54$ & 2.15 & 21.8 \\
\hline 1294 & $1 / 9 / 20084: 56$ & $8 / 9 / 20084: 56$ & 2.15 & 21.7 \\
\hline 1295 & $1 / 9 / 20084: 58$ & $8 / 9 / 20084: 58$ & 2.15 & 21.8 \\
\hline 1296 & $1 / 9 / 20085: 00$ & $8 / 9 / 20085: 00$ & 214 & 21.8 \\
\hline 1297 & 1/9/20085:02 & $8 / 9 / 20085: 02$ & 2.149 & 21.8 \\
\hline 1298 & $1 / 9 / 20085: 04$ & $8 / 9 / 20085: 04$ & 2.15 & 21.8 \\
\hline 1299 & 1/9/20085:06 & $8 / 9 / 20085: 06$ & 2115 & 21.8 \\
\hline 1300 & $1 / 9 / 20085: 08$ & $8 / 9 / 20085: 08$ & 2088 & 21.9 \\
\hline 1301 & 1/9/20085:10 & $8 / 9 / 20085: 10$ & 2.073 & 21.9 \\
\hline 1302 & $1 / 9 / 20085: 12$ & $8 / 9 / 20085: 12$ & 2119 & 22 \\
\hline 1303 & $1 / 9 / 20085: 14$ & $8 / 9 / 20085: 14$ & 1.995 & 22.1 \\
\hline 1304 & 1/9/20085:16 & $8 / 9 / 20085: 16$ & 2.042 & 22.1 \\
\hline 1305 & 1/9/20085:18 & $8 / 9 / 20085: 18$ & 2.047 & 22.1 \\
\hline 1306 & 1/9/20085:20 & $8 / 9 / 20085: 20$ & 2.026 & 22 \\
\hline 1307 & 1/9/20085:22 & $8 / 9 / 20085: 22$ & 2.015 & 21.9 \\
\hline 1308 & $1 / 9 / 20085: 24$ & $8 / 9 / 20085: 24$ & 2.048 & 21.9 \\
\hline 1309 & 1/9/20085:26 & $8 / 9 / 20085: 26$ & 2.084 & 21.9 \\
\hline 1310 & 1/9/20085:28 & $8 / 9 / 20085: 28$ & 2.103 & 21.8 \\
\hline 1311 & 1/9/20085:30 & $8 / 9 / 20085: 30$ & 2106 & 21.9 \\
\hline 1312 & $1 / 9 / 20085: 32$ & $8 / 9 / 20085: 32$ & 2.11 & 22 \\
\hline 1313 & $1 / 9 / 20085: 34$ & $8 / 9 / 20085: 34$ & 2115 & 22.2 \\
\hline 1314 & $1 / 9 / 20085: 36$ & $8 / 9 / 20085: 36$ & 2158 & $\overline{22.4}$ \\
\hline 1315 & $1 / 9 / 20085: 38$ & $8 / 9 / 20085: 38$ & 2.183 & 22.4 \\
\hline 1316 & $1 / 9 / 20085: 40$ & $8 / 9 / 20085: 40$ & 2.121 & 22.4 \\
\hline 1317 & $1 / 9 / 20085: 42$ & $8 / 9 / 20085: 42$ & 2.119 & 22.7 \\
\hline 1318 & $1 / 9 / 20085: 44$ & $8 / 9 / 20085: 44$ & 2.122 & 23.4 \\
\hline 1319 & $1 / 9 / 20085: 46$ & $8 / 9 / 20085: 46$ & 2.132 & 24.1 \\
\hline 1320 & $1 / 9 / 20085: 48$ & $8 / 9 / 20085: 48$ & 2.131 & 24.3 \\
\hline 1321 & $1 / 9 / 20085: 50$ & $8 / 9 / 20085: 50$ & 2.133 & 23.9 \\
\hline 1322 & 1/9/20085:52 & $8 / 9 / 20085: 52$ & 2.133 & 23.8 \\
\hline 1323 & $1 / 9 / 20085: 54$ & $8 / 9 / 20085: 54$ & 2136 & 23.7 \\
\hline 1324 & 1/9/20085:56 & $8 / 9 / 20085: 56$ & 2.144 & 23.5 \\
\hline 1325 & $1 / 9 / 20085: 58$ & $8 / 9 / 20085: 58$ & 2.135 & 23.4 \\
\hline 1326 & 1/9/20086:00 & $8 / 9 / 20086: 00$ & 2.128 & 23.2 \\
\hline 1327 & 1/9/20086:02 & $8 / 9 / 20086: 02$ & 2.141 & 22.8 \\
\hline 1328 & $1 / 9 / 20086: 04$ & $8 / 9 / 20086: 04$ & 2.144 & 22.5 \\
\hline 1329 & $1 / 9 / 20086: 06$ & $8 / 9 / 20086: 06$ & 2142 & 22.5 \\
\hline 1330 & 1/9/20086:08 & $8 / 9 / 20086: 08$ & 2195 & 22.2 \\
\hline 1331 & $1 / 9 / 20086: 10$ & $8 / 9 / 20086: 10$ & 2.146 & 22.6 \\
\hline 1332 & 1/9/2008 6:12 & $8 / 9 / 20086: 12$ & 2.148 & 22.5 \\
\hline 1333 & 1/9/20086:14 & $8 / 9 / 20086: 14$ & 2099 & 22.4 \\
\hline 1334 & 1/9/2008 6:16 & $8 / 9 / 20086: 16$ & 2.147 & 21.8 \\
\hline 1335 & 1/9/2008 6:18 & $8 / 9 / 20086: 18$ & 2.145 & 21.8 \\
\hline 1336 & $1 / 9 / 20086: 20$ & $8 / 9 / 20086: 20$ & 2.148 & 21.6 \\
\hline 1337 & $1 / 9 / 20086: 22$ & $8 / 9 / 20086: 22$ & 2.149 & 21.6 \\
\hline 1338 & $1 / 9 / 20086: 24$ & $8 / 9 / 20086: 24$ & 2.15 & 21.6 \\
\hline 1339 & 1/9/20086:26 & $8 / 9 / 20086: 26$ & 2151 & 21.6 \\
\hline 1340 & 1/9/20086:28 & $8 / 9 / 20086: 28$ & 2.151 & 21.5 \\
\hline 1341 & 1/9/20086:30 & $8 / 9 / 20086: 30$ & 2.152 & 21.4 \\
\hline 1342 & 1/9/2008 6:32 & $8 / 9 / 20086: 32$ & 2.152 & 21.4 \\
\hline 1343 & $1 / 9 / 20086: 34$ & $8 / 9 / 20086: 34$ & 2154 & 21.4 \\
\hline 1344 & 1/9/2008 6:36 & $8 / 9 / 20086: 36$ & 2154 & 21.5 \\
\hline 1345 & 1/9/2008 6:38 & $8 / 9 / 20086: 38$ & 2.154 & 21.6 \\
\hline 1346 & 1/9/2008 6:40 & $8 / 9 / 20086: 40$ & 2155 & 21.8 \\
\hline 1347 & $1 / 9 / 20086: 42$ & $8 / 9 / 20086: 42$ & 2155 & 21.8 \\
\hline 1348 & 1/9/20086:44 & $8 / 9 / 20086: 44$ & 2155 & 21.9 \\
\hline 1349 & 1/9/2008 6:46 & $8 / 9 / 20086: 46$ & 2.156 & 22 \\
\hline 1350 & $1 / 9 / 20086: 48$ & $8 / 9 / 20086: 48$ & 2155 & 22.1 \\
\hline 1351 & $1 / 9 / 20086: 50$ & $8 / 9 / 20086: 50$ & 2157 & 22.2 \\
\hline 1352 & 1/9/20086:52 & $8 / 9 / 20086: 52$ & 2157 & 22.3 \\
\hline 1353 & 1/9/20086:54 & $8 / 9 / 20086: 54$ & 2158 & 22.4 \\
\hline 1354 & 1/9/20086:56 & $8 / 9 / 20086: 56$ & 215 & 22.4 \\
\hline 1355 & $1 / 9 / 20086: 58$ & $8 / 9 / 20086: 58$ & 2156 & 22.6 \\
\hline 1356 & $1 / 9 / 20087: 00$ & $8 / 9 / 20087: 00$ & 2156 & 22.6 \\
\hline 1357 & $1 / 9 / 20087: 02$ & $8 / 9 / 20087: 02$ & 2157 & 22.8 \\
\hline 1358 & 1/9/2008 7:04 & $8 / 9 / 20087: 04$ & 2.158 & 22.8 \\
\hline 1359 & 1/9/2008 7:06 & $8 / 9 / 20087: 06$ & 2158 & 22.8 \\
\hline 1360 & 1/9/20087:08 & $8 / 9 / 20087: 08$ & 2157 & 22.8 \\
\hline
\end{tabular}

\begin{tabular}{|c|c|c|c|c|}
\hline \multicolumn{5}{|c|}{ D493p } \\
\hline $\operatorname{Rec}$ & & Adjusted & Pressure & Temp \\
\hline$\#$ & Date/Time & Date/Time & psi & ${ }^{\circ} \mathrm{C}$ \\
\hline 1361 & $1 / 9 / 20087: 10$ & $8 / 9 / 20087: 10$ & 2.15 & 228 \\
\hline 1362 & $1 / 9 / 20087: 12$ & $8 / 9 / 20087: 12$ & 2.15 & 229 \\
\hline 1363 & $1 / 9 / 20087: 14$ & $8 / 9 / 20087: 14$ & 2.156 & 22.9 \\
\hline 1364 & 1/9/2008 7:16 & $8 / 9 / 20087: 16$ & 2.158 & 23 \\
\hline 1365 & $1 / 9 / 20087: 18$ & $8 / 9 / 20087: 18$ & 2.159 & 23.1 \\
\hline 1366 & $1 / 9 / 20087: 20$ & $8 / 9 / 20087: 20$ & 2.158 & 23 \\
\hline 1367 & $1 / 9 / 20087: 22$ & $8 / 9 / 20087: 22$ & 2.158 & 23 \\
\hline 1368 & $1 / 9 / 20087: 24$ & $8 / 9 / 20087: 24$ & 2.159 & 23 \\
\hline 1369 & $1 / 9 / 20087: 26$ & $8 / 9 / 20087: 26$ & 216 & 23 \\
\hline 1370 & $1 / 9 / 20087: 28$ & $8 / 9 / 20087: 28$ & 2.16 & 23.1 \\
\hline 1371 & $1 / 9 / 20087: 30$ & $8 / 9 / 20087: 30$ & 2.159 & 23.1 \\
\hline 1372 & $1 / 9 / 20087: 32$ & $8 / 9 / 20087: 32$ & 2.158 & 23.1 \\
\hline 1373 & $1 / 9 / 20087: 34$ & $8 / 9 / 20087: 34$ & 2.16 & 23.3 \\
\hline 1374 & $1 / 9 / 20087: 36$ & $8 / 9 / 20087: 36$ & 2.16 & 23.4 \\
\hline 1375 & $1 / 9 / 20087: 38$ & $8 / 9 / 20087: 38$ & 2.16 & 23.6 \\
\hline 1376 & $1 / 9 / 20087: 40$ & $8 / 9 / 20087: 40$ & 216 & 23.8 \\
\hline 1377 & $1 / 9 / 20087: 42$ & $8 / 9 / 20087: 42$ & 216 & 23.9 \\
\hline 1378 & $1 / 9 / 20087: 44$ & $8 / 9 / 20087: 44$ & 2.159 & 24.1 \\
\hline 1379 & $1 / 9 / 20087: 46$ & $8 / 9 / 20087: 46$ & 216 & 24.3 \\
\hline 1380 & $1 / 9 / 20087: 48$ & $8 / 9 / 20087: 48$ & 2.162 & $\overline{24.4}$ \\
\hline 1381 & $1 / 9 / 20087: 50$ & $8 / 9 / 20087: 50$ & 2.163 & 24.7 \\
\hline 1382 & $1 / 9 / 20087: 52$ & $8 / 9 / 20087: 52$ & 2.163 & 24.9 \\
\hline 1383 & $1 / 9 / 20087: 54$ & $8 / 9 / 20087: 54$ & 2.164 & 25.1 \\
\hline 1384 & 1/9/2008 7:56 & $8 / 9 / 20087: 56$ & 2165 & 25.2 \\
\hline 1385 & $1 / 9 / 20087: 58$ & $8 / 9 / 20087: 58$ & 2.166 & $\overline{25.4}$ \\
\hline 1386 & 1/9/2008 8:00 & $8 / 9 / 20088: 00$ & 2.165 & 25.6 \\
\hline 1387 & $1 / 9 / 20088: 02$ & $8 / 9 / 20088: 02$ & 2.166 & 25.7 \\
\hline 1388 & $1 / 9 / 20088: 04$ & $8 / 9 / 20088: 04$ & 2.166 & 25.8 \\
\hline 1389 & 1/9/20088:06 & $8 / 9 / 20088: 06$ & 2.168 & 25.9 \\
\hline 1390 & $1 / 9 / 20088: 08$ & $8 / 9 / 20088: 08$ & 2.166 & 26.1 \\
\hline 1391 & $1 / 9 / 20088: 10$ & $8 / 9 / 20088: 10$ & 2.165 & 26.1 \\
\hline 1392 & $1 / 9 / 20088: 12$ & $8 / 9 / 20088: 12$ & 2.166 & 26.3 \\
\hline 1393 & $1 / 9 / 20088: 14$ & $8 / 9 / 20088: 14$ & 2.167 & 26.4 \\
\hline 1394 & $1 / 9 / 20088: 16$ & $8 / 9 / 20088: 16$ & 2.167 & 26.5 \\
\hline 1395 & $1 / 9 / 20088: 18$ & $8 / 9 / 20088: 18$ & 2.167 & 26.6 \\
\hline 1396 & $1 / 9 / 20088: 20$ & $8 / 9 / 20088: 20$ & 2.168 & 26.7 \\
\hline 1397 & 1/9/20088:22 & $8 / 9 / 20088: 22$ & 2.166 & 26.8 \\
\hline 1398 & $1 / 9 / 20088: 24$ & $8 / 9 / 20088: 24$ & 2.166 & 26.9 \\
\hline 1399 & $1 / 9 / 20088: 26$ & $8 / 9 / 20088: 26$ & 2.167 & 26.9 \\
\hline 1400 & 1/9/20088:28 & $8 / 9 / 20088: 28$ & 2.169 & 27.1 \\
\hline 1401 & $1 / 9 / 20088: 30$ & $8 / 9 / 20088: 30$ & 2.17 & 27.1 \\
\hline 1402 & 1/9/20088:32 & $8 / 9 / 20088: 32$ & 2.171 & 27.2 \\
\hline 1403 & 1/9/20088:34 & $8 / 9 / 20088: 34$ & 2.172 & 27.3 \\
\hline 1404 & 1/9/2008 8:36 & $8 / 9 / 20088: 36$ & 2.181 & 27.3 \\
\hline 1405 & $1 / 9 / 20088: 38$ & $8 / 9 / 20088: 38$ & 2.173 & 27.4 \\
\hline 1406 & $1 / 9 / 20088: 40$ & $8 / 9 / 20088: 40$ & 2.172 & 27.5 \\
\hline 1407 & $1 / 9 / 20088: 42$ & $8 / 9 / 20088: 42$ & 2.155 & 24.8 \\
\hline 1408 & $1 / 9 / 20088: 44$ & $8 / 9 / 20088: 44$ & 2.149 & 21.7 \\
\hline 1409 & $1 / 9 / 20088: 46$ & $8 / 9 / 20088: 46$ & 2.147 & 20.1 \\
\hline 1410 & $1 / 9 / 20088: 48$ & $8 / 9 / 20088: 48$ & 2.083 & 19.7 \\
\hline 1411 & $1 / 9 / 20088: 50$ & $8 / 9 / 20088: 50$ & 2.098 & 20.4 \\
\hline 1412 & $1 / 9 / 20088: 52$ & $8 / 9 / 20088: 52$ & 2.121 & 19.9 \\
\hline 1413 & $1 / 9 / 20088: 54$ & $8 / 9 / 20088: 54$ & 2.172 & 20.6 \\
\hline 1414 & $1 / 9 / 20088: 56$ & $8 / 9 / 20088: 56$ & 2.164 & 23.8 \\
\hline 1415 & $1 / 9 / 20088: 58$ & $8 / 9 / 20088: 58$ & 2.165 & 24.8 \\
\hline 1416 & $1 / 9 / 20089: 00$ & $8 / 9 / 20089: 00$ & 2.166 & 25 \\
\hline 1417 & $1 / 9 / 20089.02$ & $8 / 9 / 20089: 02$ & 2.167 & 25.2 \\
\hline 1418 & $1 / 9 / 20089: 04$ & $8 / 9 / 20089: 04$ & 2.168 & 25.6 \\
\hline 1419 & 1/9/20089:06 & $8 / 9 / 20089.06$ & 2.169 & 25.7 \\
\hline 1420 & 1/9/20089:08 & $8 / 9 / 20089: 08$ & 2.159 & 26.1 \\
\hline 1421 & $1 / 9 / 20089.10$ & $8 / 9 / 20089: 10$ & 2.117 & 26.4 \\
\hline 1422 & $1 / 9 / 20089.12$ & $8 / 9 / 20089.12$ & 2.097 & 26.3 \\
\hline 1423 & $1 / 9 / 20089.14$ & $8 / 9 / 20089.14$ & 2.084 & 25.8 \\
\hline 1424 & 1/9/20089:16 & $8 / 9 / 20089: 16$ & 2.074 & 25.4 \\
\hline 1425 & $1 / 9 / 20089.18$ & $8 / 9 / 20089.18$ & 2.062 & 25.2 \\
\hline 1426 & $1 / 9 / 20089: 20$ & $8 / 9 / 20089.20$ & 2.053 & 24.9 \\
\hline 1427 & $1 / 9 / 20089.22$ & $8 / 9 / 20089.22$ & 2.044 & 24.8 \\
\hline 1428 & $1 / 9 / 20089: 24$ & $8 / 9 / 20089.24$ & 2089 & 24.6 \\
\hline
\end{tabular}


DOE/RL-2009-35, REV. 0

\begin{tabular}{|c|c|c|c|c|}
\hline \multicolumn{5}{|c|}{ D4-93p } \\
\hline $\operatorname{Rec}$ & & Adjusted & Pressure & Temp \\
\hline$\#$ & DaterTime & Date/Time & $p s i$ & ${ }^{\circ} \mathrm{C}$ \\
\hline 1429 & 1/9/20089:26 & $8 / 9 / 20089: 26$ & 2.109 & 24.6 \\
\hline 1430 & $1 / 9 / 20089.28$ & $8 / 9 / 20089: 28$ & 2.118 & 24.5 \\
\hline 1431 & $1 / 9 / 20089: 30$ & 8/9/2008 9:30 & 2.123 & 24.5 \\
\hline 1432 & $1 / 9 / 20089: 32$ & $8 / 9 / 20089932$ & 2.129 & 24.5 \\
\hline 1433 & $1 / 9 / 20089.34$ & $8 / 9 / 20089: 34$ & 2132 & 24.4 \\
\hline 1434 & $1 / 9 / 20089.36$ & $8 / 9 / 20089: 36$ & 2133 & 24.3 \\
\hline 1435 & $1 / 9 / 20089.38$ & $8 / 9 / 20089: 38$ & 2135 & 24.2 \\
\hline 1436 & $1 / 9 / 20089: 40$ & $8 / 9 / 20089: 40$ & 2139 & 24.1 \\
\hline 1437 & $1 / 9 / 20089: 42$ & $8 / 9 / 20089: 42$ & 2141 & 23.9 \\
\hline 1438 & $1 / 9 / 20089.44$ & $8 / 9 / 20089: 44$ & 2144 & 23.8 \\
\hline 1439 & $1 / 9 / 20089.46$ & $8 / 9 / 20089: 46$ & 2146 & 23.6 \\
\hline 1440 & $1 / 9 / 20089.48$ & $8 / 9 / 20089: 48$ & 2,147 & 23.5 \\
\hline 1441 & $1 / 9 / 20089: 50$ & $8 / 9 / 20089: 50$ & 2147 & 23.3 \\
\hline 1442 & $1 / 9 / 20089.52$ & $8 / 9 / 20089: 52$ & 2.148 & 23.2 \\
\hline 1443 & $1 / 9 / 20089.54$ & $8 / 9 / 20089: 54$ & 2148 & 23.1 \\
\hline 1444 & $1 / 9 / 20089: 56$ & $8 / 9 / 20089: 56$ & 2149 & 22.9 \\
\hline 1445 & $1 / 9 / 20089.58$ & $8 / 9 / 20089: 58$ & 2.15 & 22.8 \\
\hline 1446 & $1 / 1 / 200810: 00$ & $8 / 9 / 200810: 00$ & 2.152 & 22.8 \\
\hline 1447 & $1 / 9 / 200810: 02$ & $8 / 9 / 200810: 02$ & 2154 & 226 \\
\hline 1448 & $1 / 9 / 200810: 04$ & $8 / 9 / 200810: 04$ & 2.154 & 22.5 \\
\hline 1449 & $1 / 9 / 200810: 06$ & $8 / 9 / 2008$ 10:06 & 2.155 & 22.4 \\
\hline 1450 & $1 / 9 / 200810: 08$ & $8 / 9 / 2008$ 10:08 & 2156 & $\overline{224}$ \\
\hline 1451 & $1 / 9 / 2008$ 10:10 & $8 / 9 / 200810: 10$ & 2156 & 224 \\
\hline 1452 & 1/9/2008 10:12 & $8 / 9 / 2008$ 10:12 & 2.157 & 224 \\
\hline 1453 & $1 / 9 / 200810: 14$ & $8 / 9 / 2008$ 10:14 & 2.157 & 224 \\
\hline 1454 & 1/9/2008 10:16 & $8 / 9 / 2008$ 10:16 & 2157 & 224 \\
\hline 1455 & 1/9/2008 10:18 & $8 / 9 / 200810: 18$ & 2157 & 224 \\
\hline 1456 & $1 / 9 / 200810: 20$ & $8 / 9 / 200810: 20$ & 2.156 & 224 \\
\hline 1457 & $1 / 9 / 200810: 22$ & $8 / 9 / 2008$ 10:22 & 2156 & 22.4 \\
\hline 1458 & $1 / 9 / 200810: 24$ & $8 / 9 / 2008$ 10:24 & 2157 & 22.3 \\
\hline 1459 & $1 / 9 / 200810: 26$ & $8 / 9 / 2008$ 10:26 & 2.159 & 22.2 \\
\hline 1460 & $1 / 9 / 200810: 28$ & $8 / 9 / 200810: 28$ & 2.16 & 22 \\
\hline 1461 & $1 / 9 / 200810: 30$ & $8 / 9 / 2008$ 10:30 & 2.16 & 21.9 \\
\hline 1462 & $1 / 9 / 200810: 32$ & $8 / 9 / 2008$ 10:32 & 2.161 & 21.7 \\
\hline 1463 & $1 / 9 / 200810: 34$ & $8 / 9 / 2008$ 10:34 & 2161 & 21.6 \\
\hline 1464 & $1 / 9 / 200810: 36$ & $8 / 9 / 200810: 36$ & 2.161 & 21.6 \\
\hline 1465 & $1 / 9 / 200810: 38$ & $8 / 9 / 200810: 38$ & 2.161 & 21.6 \\
\hline 1466 & $1 / 9 / 200810: 40$ & $8 / 9 / 200810: 40$ & 2161 & 21.6 \\
\hline 1467 & $1 / 9 / 200810: 42$ & $8 / 9 / 200810: 42$ & 2162 & 21.6 \\
\hline 1468 & $1 / 9 / 2008$ 10:44 & $8 / 9 / 200810: 44$ & 2162 & 21.6 \\
\hline 1469 & $1 / 9 / 200810: 46$ & $8 / 9 / 2008$ 10:46 & 2162 & 21.8 \\
\hline 1470 & $1 / 9 / 200810: 48$ & $8 / 9 / 200810: 48$ & 2163 & 21.8 \\
\hline 1471 & $1 / 9 / 200810: 50$ & $8 / 9 / 2008$ 10:50 & 2.163 & 21.9 \\
\hline 1472 & $1 / 9 / 200810: 52$ & $8 / 9 / 2008$ 10:52 & 2.164 & 22 \\
\hline 1473 & $1 / 9 / 200810: 54$ & $8 / 9 / 200810: 54$ & 2166 & 22.1 \\
\hline 1474 & $1 / 9 / 200810: 56$ & $8 / 9 / 2008$ 10:56 & 2166 & 22.2 \\
\hline 1475 & $1 / 9 / 200810.58$ & $8 / 9 / 2008$ 10:58 & 2.167 & 221 \\
\hline 1476 & $1 / 9 / 200811: 00$ & $8 / 9 / 200811: 00$ & 2167 & 221 \\
\hline 1477 & $1 / 9 / 200811: 02$ & $8 / 9 / 200811: 02$ & 2.167 & 221 \\
\hline 1478 & $1 / 9 / 2008$ 11:04 & $8 / 9 / 200811: 04$ & 2.168 & 22.3 \\
\hline 1479 & 1/9/2008 11:06 & $8 / 9 / 2008$ 11:06 & 2.169 & 22.4 \\
\hline 1480 & 1/9/2008 11:08 & $8 / 9 / 2008$ 11:08 & 2.169 & 225 \\
\hline 1481 & $1 / 9 / 200811: 10$ & $8 / 9 / 2008$ 11:10 & 2169 & 228 \\
\hline 1482 & $1 / 9 / 200811: 12$ & $8 / 9 / 2008$ 11:12 & 2.17 & 229 \\
\hline 1483 & $1 / 9 / 200811: 14$ & $8 / 9 / 2008$ 11:14 & 2.171 & 22.9 \\
\hline 1484 & 1/9/2008 11:16 & $8 / 9 / 200811: 16$ & 2.173 & 23.1 \\
\hline 1485 & 1/9/2008 11:18 & $8 / 9 / 2008$ 11:18 & 2173 & 23.1 \\
\hline 1486 & $1 / 9 / 200811: 20$ & $8 / 9 / 200811: 20$ & 2174 & 23.1 \\
\hline 1487 & 1/9/2008 11:22 & $8 / 9 / 2008$ 11:22 & 2174 & 23.2 \\
\hline 1488 & $1 / 9 / 200811: 24$ & $8 / 9 / 2008$ 11:24 & 2174 & 23.2 \\
\hline 1489 & 1/9/2008 11:26 & $8 / 9 / 2008$ 11:26 & 2175 & 23.3 \\
\hline 1490 & 1/9/2008 11:28 & $8 / 9 / 2008$ 11:28 & 2.175 & 23.3 \\
\hline 1491 & $1 / 9 / 200811: 30$ & $8 / 9 / 2008$ 11:30 & 2175 & 23.3 \\
\hline 1492 & $1 / 9 / 200811: 32$ & $8 / 9 / 2008$ 11:32 & 2175 & 23.3 \\
\hline 1493 & $1 / 9 / 2008$ 11:34 & $8 / 9 / 2008$ 11:34 & 2177 & 23.3 \\
\hline 1494 & 1/9/2008 11:36 & $8 / 9 / 2008$ 11:36 & 2.176 & 23.3 \\
\hline 1495 & $1 / 9 / 200811: 38$ & $8 / 9 / 200811: 38$ & 2.177 & 23.3 \\
\hline 1496 & $1 / 9 / 200811: 40$ & $8 / 9 / 2008$ 11:40 & 2176 & 23.3 \\
\hline
\end{tabular}

\begin{tabular}{|c|c|c|c|c|}
\hline \multicolumn{5}{|c|}{ D4-93p } \\
\hline Rec & & Adjusted & Pressure & Tem \\
\hline$\#$ & Date/Time & Date/Time & psi & \\
\hline 1497 & 1/9/2008 11:42 & $8 / 9 / 2008$ 11:42 & 2.177 & \\
\hline 1498 & $9 / 2008$ 11:44 & $8 / 9 / 2008$ 11:44 & & \\
\hline 1499 & $\sqrt{2000811: 46}$ & $8 / 9 / 2008$ 11:46 & 2177 & \\
\hline 1500 & 1/9/2008 11:48 & $8 / 9 / 2008$ 11:48 & 2.177 & \\
\hline 1501 & $9 / 2008+1: 50$ & $8 / 9 / 200811: 50$ & & \\
\hline 502 & 32008 11:52 & $8 / 9 / 200811: 52$ & 2.154 & \\
\hline 1503 & $1 / 9 / 2008 \quad 11: 54$ & $8 / 9 / 2008$ 11:54 & 2077 & 20 \\
\hline 1504 & $9 / 200811: 56$ & $8 / 9 / 200811: 56$ & 2127 & 20. \\
\hline 1505 & $9 / 200811: 58$ & $8 / 9 / 200811: 58$ & 2099 & \\
\hline 1506 & $9 / 200812 ; 00$ & $8 / 9 / 200812: 00$ & 2086 & 23. \\
\hline 1507 & $12: 02$ & $8 / 9 / 200812: 02$ & 2.074 & \\
\hline 1508 & $12: 04$ & $8 / 9 / 200$ & 2064 & \\
\hline 1509 & $1 / 9 / 200812: 06$ & $8 / 9 / 200812: 06$ & 2.055 & 23. \\
\hline 1510 & $12: 08$ & $8 / 9 / 200$ & 2.1 & 20 \\
\hline 1511 & $12: 10$ & $8 / 9 / 200$ & 2.123 & \\
\hline 1512 & 1/9/2008 12:12 & $8 / 9 / 200812: 12$ & 2.133 & 23. \\
\hline 1513 & $12: 14$ & $8 / 9 / 20$ & 2.138 & \\
\hline 1514 & $12: 16$ & $8 / 9 / 20$ & 2143 & \\
\hline 1515 & $12: 18$ & $8 / 9 / 20$ & 2147 & 23. \\
\hline 1516 & $12: 20$ & $8 / 9 / 20$ & 2.149 & 22. \\
\hline 1517 & 222 & $8 / 9 / 2$ & 2.151 & \\
\hline 1518 & $2: 24$ & $8 / 9 / 2$ & 2.152 & 22. \\
\hline 1519 & & $8 / 9 / 2$ & 2155 & 22 \\
\hline 1520 & $2: 28$ & $12: 28$ & 2156 & \\
\hline 1521 & $2: 30$ & $8 / 9 / 20$ & 2159 & 22. \\
\hline 1522 & & $8 / 9 / 2$ & 2.159 & \\
\hline 1523 & $312: 34$ & $8 / 9 / 20$ & 2.161 & 21. \\
\hline 1524 & $2: 36$ & $8 / 9 / 2$ & 2162 & 21. \\
\hline 1525 & $2 \cdot 38$ & $8 / 9 / 20$ & 2163 & 21. \\
\hline 1526 & 12:40 & $8 / 9 / 20$ & 2164 & 21 \\
\hline 1527 & 42 & $8 / 9 / 2$ & 2164 & 21 \\
\hline 1528 & $2: 44$ & $8 / 9 / 2$ & 2165 & 21. \\
\hline 1529 & $2: 46$ & $8 / 9 / 2$ & 2.166 & 20. \\
\hline 7530 & $2: 48$ & $8 / 9 / 2$ & 2.167 & 20. \\
\hline 1531 & $2: 50$ & $8 / 9 / 2$ & 2.168 & 20. \\
\hline 1532 & & $8 / 9 / 2$ & 2.168 & 20 . \\
\hline 1533 & & $2: 54$ & 2.169 & \\
\hline 1534 & $12: 56$ & $8 / 9 / 200812: 56$ & 2169 & 20 \\
\hline 1535 & & $8 / 9 / 2$ & 2.169 & 20 \\
\hline 1536 & & $9 / 20$ & 2.17 & 20 \\
\hline 1537 & & $8 / 9 / 20$ & 217 & \\
\hline 1538 & & & 2.171 & \\
\hline 1539 & & $8 / 9 / 2$ & 2171 & 20 \\
\hline 1540 & & & 2.171 & \\
\hline 1541 & & $8 / 9 / 2$ & 2173 & \\
\hline 1542 & & $8 / 9 / 2$ & 2.173 & \\
\hline 1543 & & & 2.173 & \\
\hline 1544 & & & 2.174 & \\
\hline 1545 & 3:18 & $8 / 9 / 20$ & 2.175 & 20 \\
\hline 1546 & & & 2.176 & \\
\hline 1547 & & $8 / 9 / 2$ & 2.175 & \\
\hline 1548 & & & 2.174 & \\
\hline 1549 & & & 217 & \\
\hline 1550 & & $8 / 9 / 20$ & 2.175 & \\
\hline 1551 & & & 2.176 & \\
\hline 1552 & & & 2.177 & \\
\hline 1553 & $3: 34$ & $8 / 9 / 20$ & 2178 & 20 . \\
\hline 1554 & & & 2.179 & \\
\hline 1555 & & $8 / 9 / 2$ & & \\
\hline 1556 & 40 & $8 / 9 / 20$ & 2178 & \\
\hline 1557 & & & 2178 & \\
\hline 1558 & & $8 / 9 / 20$ & 2178 & \\
\hline 1559 & 22008 13:46 & $8 / 9 / 200813: 46$ & 2.177 & \\
\hline 1560 & & & & \\
\hline 1561 & 13:50 & $8 / 9 / 200813: 50$ & 2.178 & 21 \\
\hline 1562 & 13:52 & $8 / 9 / 200813: 52$ & 218 & \\
\hline 1563 & & $8 / 9 / 200$ & 2,182 & \\
\hline 1564 & $1 / 9 / 200813: 56$ & $8 / 9 / 200813: 56$ & 2182 & $2 z$ \\
\hline
\end{tabular}

\begin{tabular}{|c|c|c|c|c|}
\hline \multicolumn{5}{|c|}{ D4-93p } \\
\hline Rec & & Adjusted & Pressure & Temp \\
\hline$\#$ & Date/Time & Date/Time & $p s i$ & ${ }^{\circ} \mathrm{C}$ \\
\hline 1565 & 1/9/2008 13:58 & $8 / 9 / 200813: 58$ & 2,181 & 222 \\
\hline 1566 & 1/92008 14:00 & $8 / 9 / 2008$ 14:00 & 2.181 & 223 \\
\hline 1567 & 1/9/2008 14:02 & $8 / 9 / 2008$ 14:02 & 2.18 & 22.3 \\
\hline 1568 & 1/9/2008 14:04 & $8 / 9 / 2008$ 14:04 & 2182 & 22.3 \\
\hline 1569 & $1 / 9 / 200814: 06$ & $819 / 2008$ 14:06 & 2.182 & 22.4 \\
\hline 1570 & $1 / 9 / 2008$ 14:08 & $89 / 200814: 08$ & 2182 & 223 \\
\hline 1571 & 1/9/2008 14:10 & $89 / 2008$ 14:10 & 2.182 & 224 \\
\hline 1572 & $1 / 9 / 2008$ 14:12 & $8 / 9 / 200814: 12$ & 2.183 & 223 \\
\hline 1573 & 1/9/2008 14:14 & 8/9/2008 14:14 & 2182 & 221 \\
\hline 1574 & 1/9/2008 14:16 & $8 / 9 / 2008$ 14:16 & 2183 & 21.8 \\
\hline 1575 & $1 / 9 / 200814: 18$ & $8 / 9 / 2008$ 14:18 & 2.183 & 21.6 \\
\hline 1576 & $1 / 9 / 200814: 20$ & $8 / 9 / 2008$ 14:20 & 2.184 & 21.4 \\
\hline 1577 & 1/9/2008 14:22 & $8 / 9 / 2008$ 14:22 & 2.185 & 21.1 \\
\hline 1578 & $1 / 9 / 200814: 24$ & $8 / 9 / 200814: 24$ & 2.184 & 20.9 \\
\hline 1579 & $1 / 9 / 200814: 26$ & $8 / 9 / 200814: 26$ & 2.184 & 20.9 \\
\hline 1580 & $1 / 9 / 200814: 28$ & $8 / 9 / 2008$ 14:28 & 2185 & 20.8 \\
\hline 1581 & 1/9/2008 14:30 & $8 / 9 / 2008$ 14:30 & 2185 & 20.8 \\
\hline 1582 & $1 / 9 / 2008$ 14:32 & $8 / 9 / 200814: 32$ & 2.186 & 20.9 \\
\hline 1583 & 1/9/2008 14:34 & $8 / 9 / 2008$ 14:34 & 2.185 & 21 \\
\hline 1584 & $1 / 9 / 200814: 36$ & $8 / 9 / 2008$ 14:36 & 2.187 & 21.2 \\
\hline 1585 & 1/9/2008 14:38 & $8 / 9 / 200814: 38$ & 2.188 & 21.4 \\
\hline 1586 & 1/9/2008 14:40 & $8 / 9 / 2008$ 14:40 & 2.187 & 21.7 \\
\hline 1587 & $1 / 9 / 200814: 42$ & $8 / 9 / 200814: 42$ & 2.187 & 21.9 \\
\hline 1588 & $1 / 9 / 2008 \quad 14: 44$ & $8 / 9 / 2008$ 14:44 & 2187 & 22.1 \\
\hline 1589 & $1 / 9 / 200814: 46$ & $8 / 9 / 200814: 46$ & 2.188 & 22.3 \\
\hline 1590 & $1 / 9 / 200814: 48$ & $8 / 9 / 200814: 48$ & 2.187 & 224 \\
\hline 1591 & $1 / 9 / 200814: 50$ & $8 / 9 / 200814: 50$ & 2188 & 22.6 \\
\hline 1592 & $1 / 9 / 2008$ 14:52 & $8 / 9 / 2008$ 14:52 & 2.188 & 228 \\
\hline 1593 & $1 / 9 / 200814: 54$ & $8 / 9 / 200814: 54$ & 2.188 & 22.9 \\
\hline 1594 & $1 / 9 / 200814: 56$ & $8 / 9 / 200814: 56$ & 2.153 & 23 \\
\hline 1595 & $1 / 9 / 2008$ 14:58 & $8 / 9 / 2008$ 14:58 & 2.11 & 23.3 \\
\hline 1596 & $1 / 9 / 2008$ 15:00 & $8 / 9 / 200815: 00$ & 2.089 & 23.4 \\
\hline 1597 & 1/9/2008 15:02 & $8 / 9 / 2008$ 15:02 & 2.09 & 23.4 \\
\hline 1598 & 1/9/2008 15:04 & $8 / 9 / 2008$ 15:04 & 2.069 & 23.4 \\
\hline 1599 & 1/9/2008 15:06 & $8 / 9 / 2008$ 15:06 & 2115 & 23.4 \\
\hline 1600 & $1 / 9 / 200815: 08$ & $8 / 9 / 200815: 08$ & $2+37$ & 23.4 \\
\hline 1601 & $1 / 9 / 200815: 10$ & $8 / 9 / 2008$ 15:10 & 2147 & 23.4 \\
\hline 1602 & $1 / 9 / 200815: 12$ & $8 / 9 / 2008$ 15:12 & 2.154 & 23.3 \\
\hline 1603 & 1/9/2008 15:14 & $8 / 9 / 2008$ 15:14 & 2158 & 23.2 \\
\hline 1604 & $1 / 9 / 200815: 16$ & 8/9/2008 15:16 & 2.16 & 23 \\
\hline 1605 & $1 / 9 / 200815: 18$ & $8 / 9 / 200815: 18$ & 2165 & 22.7 \\
\hline 1606 & 1/9/2008 15:20 & $8 / 9 / 2008$ 15:20 & 2.167 & 22.4 \\
\hline 1607 & $1 / 9 / 200815: 22$ & $8 / 9 / 200815: 22$ & 2.17 & 22.3 \\
\hline 1608 & 1/9/2008 15:24 & $89 / 2008$ 15:24 & 2.134 & 21.9 \\
\hline 1609 & 1/9/2008 15:26 & $8 / 9 / 2008$ 15:26 & 2.14 & 21.1 \\
\hline 1610 & $1 / 9 / 200815: 28$ & $8 / 9 / 2008$ 15:28 & 2.259 & 20.6 \\
\hline 1611 & $1 / 9 / 2008$ 15:30 & $8 / 9 / 2008$ 15:30 & 2177 & 21.2 \\
\hline 1612 & $1 / 9 / 200815: 32$ & $8 / 9 / 2008$ 15:32 & 2.178 & 21.1 \\
\hline 1613 & $1 / 9 / 200815: 34$ & $8 / 9 / 200815: 34$ & 2.179 & 20.8 \\
\hline 1614 & $1 / 9 / 2008$ 15:36 & $8 / 9 / 2008$ 15:36 & 2.18 & 20.7 \\
\hline 1615 & $1 / 9 / 200815: 38$ & $8 / 9 / 200815: 38$ & 2.182 & 20.6 \\
\hline 1616 & 1/9/2008 15:40 & $8 / 9 / 200815: 40$ & 2183 & 20.6 \\
\hline 1617 & $1 / 9 / 200815: 42$ & $8 / 9 / 2008$ 15:42 & 2.183 & 20.6 \\
\hline 1618 & $1 / 9 / 200815: 44$ & $8 / 9 / 2008$ 15:44 & 2.183 & 20.5 \\
\hline 1619 & $1 / 9 / 200815: 46$ & $8 / 9 / 2008$ 15:46 & 2185 & 20.5 \\
\hline 1620 & $1 / 9 / 200815: 48$ & $8 / 9 / 2008$ 15:48 & 2186 & 20.5 \\
\hline 1621 & $1 / 9 / 200815: 50$ & $8 / 9 / 200815: 50$ & 2188 & 20.5 \\
\hline 1622 & $1 / 9 / 2008$ 15:52 & $8 / 9 / 2008$ 15:52 & 2.186 & 20.5 \\
\hline 1623 & $1 / 9 / 200815: 54$ & $8 / 9 / 2008$ 15:54 & 2.188 & 20.6 \\
\hline 1624 & $1 / 9 / 200815: 56$ & $8 / 9200815: 56$ & 2.188 & 20.6 \\
\hline 1625 & $1 / 9 / 200815: 58$ & $8 / 9 / 200815: 58$ & 2.189 & 20.8 \\
\hline 1626 & 1/9/2008 16:00 & $8 / 9 / 2008$ 16:00 & 2.191 & 72 \\
\hline 1627 & 1/9/2008 16:02 & $8 / 9 / 2008$ 16:02 & 2.19 & 21.2 \\
\hline 1628 & $1 / 9 / 2008 \quad 16: 04$ & $8 / 9 / 2008$ 16:04 & 2191 & 21.5 \\
\hline 1629 & 1/9/2008 16:06 & $8 / 9 / 200816: 06$ & 2.192 & 21.8 \\
\hline 1630 & $1 / 9 / 200816: 08$ & $8 / 9 / 200816: 08$ & 2.193 & 221 \\
\hline 1631 & $1 / 9 / 200816: 10$ & $8 / 9 / 200816: 10$ & 2.193 & 22.4 \\
\hline 1632 & $1 / 9 / 200816: 12$ & $8 / 9 / 2008$ 16:12 & 2,196 & 226 \\
\hline
\end{tabular}




\begin{tabular}{|c|c|c|c|c|}
\hline \multicolumn{5}{|c|}{ D4-93p } \\
\hline $\operatorname{Rex}$ & & Adjusted & Pressure & Temp \\
\hline$\#$ & Date/Time & Date/Time & psi & ${ }^{\circ} \mathrm{C}$ \\
\hline 1633 & $1 / 9 / 200816: 14$ & $8 / 9 / 2008$ 16:14 & 2.197 & 22.9 \\
\hline 1634 & 1/9/2008 16:16 & $8 / 9 / 200816: 16$ & 2.199 & 23.1 \\
\hline 1635 & 1/9/2008 16:18 & $8 / 9 / 200816: 18$ & 2.199 & 23.2 \\
\hline 1636 & $1 / 9 / 200816: 20$ & $8 / 9 / 200816: 20$ & 2.201 & 23.3 \\
\hline 1637 & $1 / 9 / 200816: 22$ & $8 / 9 / 200816: 22$ & 2.201 & 23.3 \\
\hline 1638 & $1 / 9 / 200816: 24$ & $8 / 9 / 200816: 24$ & 2.202 & 23.4 \\
\hline 1639 & $1 / 9 / 200816: 26$ & $8 / 9 / 200816: 26$ & 2.204 & 23.6 \\
\hline 1640 & $1 / 9 / 200816: 28$ & $8 / 9 / 200816: 28$ & 2202 & 23.5 \\
\hline 1641 & $1 / 9 / 200816: 30$ & $8 / 9 / 200816: 30$ & 2.204 & 23.4 \\
\hline 1642 & $1 / 9 / 200816: 32$ & $8 / 9 / 200816: 32$ & 2.204 & 23.4 \\
\hline 1643 & $1 / 9 / 200816: 34$ & $8 / 9 / 200816: 34$ & 2.203 & 23.4 \\
\hline 1644 & $1 / 9 / 200816: 36$ & $8 / 9 / 200816: 36$ & 2.205 & 23.4 \\
\hline 1645 & 1/9/2008 16:38 & $8 / 9 / 200816: 38$ & 2.204 & 23.4 \\
\hline 1646 & $1 / 9 / 200816: 40$ & $8 / 9 / 200816: 40$ & 2.208 & 23.4 \\
\hline 1647 & $1 / 9 / 200816: 42$ & $8 / 9 / 200816: 42$ & 2.208 & 23.4 \\
\hline 1648 & $1 / 9 / 200816: 44$ & $8 / 9 / 200816: 44$ & 2.209 & 23.4 \\
\hline 1649 & $1 / 9 / 200816: 46$ & $8 / 9 / 200816: 46$ & 2.208 & 23.5 \\
\hline 1650 & $1 / 9 / 200816: 48$ & $8 / 9 / 200816: 48$ & 2.208 & 23.5 \\
\hline 1651 & $1 / 9 / 200816: 50$ & $8 / 9 / 200816: 50$ & 2.209 & 23.5 \\
\hline 1652 & 1/9/2008 16:52 & $8 / 9 / 200816: 52$ & 2.209 & 23.5 \\
\hline 1653 & $1 / 9 / 200816: 54$ & $8 / 9 / 200816: 54$ & 2.21 & 23.5 \\
\hline 1654 & $1 / 9 / 200816: 56$ & $8 / 9 / 200816: 56$ & 2.208 & 23.5 \\
\hline 1655 & $1 / 9 / 200816: 58$ & $8 / 9200816: 58$ & 2.208 & 23.5 \\
\hline 1656 & $1 / 9 / 200817: 00$ & $8 / 9 / 200817: 00$ & 2.21 & 23.5 \\
\hline 1657 & $1 / 9 / 200817: 02$ & $8 / 9200817: 02$ & 2.209 & 23.5 \\
\hline 1658 & $1 / 9 / 200817: 04$ & $8 / 9 / 200817: 04$ & 2.209 & 23.5 \\
\hline 1659 & $1 / 9 / 200817: 06$ & $8 / 9 / 200817: 06$ & 2.21 & 23.5 \\
\hline 1660 & $1 / 9 / 200817: 08$ & $8 / 9 / 200817: 08$ & 2.21 & 23.5 \\
\hline 1661 & $1 / 9 / 200817: 10$ & $8 / 9 / 200817: 10$ & 2.21 & 23.5 \\
\hline 1662 & $1 / 9 / 200817: 12$ & $8 / 9 / 200817: 12$ & 2.21 & 23.5 \\
\hline 1663 & $1 / 9 / 200817: 14$ & $8 / 9 / 200817: 14$ & 2.209 & 23.6 \\
\hline 1664 & $1 / 9 / 200817: 16$ & $8 / 9 / 200817: 16$ & 2.209 & 23.6 \\
\hline 1665 & 1/9/2008 17:18 & $8 / 9 / 200817: 18$ & 2.208 & 23.6 \\
\hline 1666 & 1/9/2008 17:20 & $8 / 9 / 200817: 20$ & 2.208 & 23.6 \\
\hline 1667 & $817: 2$ & $8 / 9 / 200817: 22$ & 2.208 & 23.6 \\
\hline 1668 & $1 / 9 / 200817: 24$ & $8 / 9 / 200817: 24$ & 2.208 & 23.6 \\
\hline 1669 & $1 / 9 / 200817: 26$ & $8 / 9 / 200817: 26$ & 2.208 & 23.7 \\
\hline 1670 & $1 / 9 / 200817: 28$ & $8 / 9 / 200817: 28$ & 2.208 & 23.7 \\
\hline 1671 & $1 / 9 / 200817: 30$ & $8 / 9 / 200817: 30$ & 2.21 & 23.7 \\
\hline 1672 & $1 / 9 / 200817: 32$ & $8 / 9 / 200817: 32$ & 2.209 & 23.8 \\
\hline 1673 & $1 / 9 / 200817: 34$ & $8 / 9 / 200817: 34$ & 2.209 & 23.8 \\
\hline 1674 & $1 / 9 / 200817: 36$ & $8 / 9 / 200817: 36$ & 2.209 & 23.8 \\
\hline 1675 & $1 / 9 / 200817: 38$ & $8 / 9 / 200817: 38$ & 2.209 & 23.8 \\
\hline 1676 & $1 / 9 / 200817: 40$ & $8 / 9 / 200817: 40$ & 2.21 & 23.9 \\
\hline 1677 & $1 / 9 / 200817: 42$ & $8 / 9 / 2008$ 17:42 & 2.209 & 23.9 \\
\hline 1678 & $1 / 9 / 200817: 44$ & $8 / 9 / 200817: 44$ & 2.211 & 23.9 \\
\hline 1679 & $1 / 9 / 200817: 46$ & $8 / 9 / 200817: 46$ & 2.138 & 23.9 \\
\hline 1680 & $1 / 9 / 200817: 48$ & $8 / 9200817: 48$ & 2.13 & 24 \\
\hline 1681 & $1 / 9 / 200817: 50$ & $8 / 9 / 200817: 50$ & 2.097 & 24.1 \\
\hline 1682 & $1 / 9 / 200817: 52$ & $8 / 9 / 200817: 52$ & 2.083 & 24.1 \\
\hline 1683 & $1 / 9 / 200817: 54$ & $8 / 9 / 200817: 54$ & 2.072 & 24.1 \\
\hline 1684 & $1 / 9 / 200817: 56$ & $8 / 9 / 200817: 56$ & 2.064 & 24.1 \\
\hline 1685 & $1 / 9 / 200817: 58$ & $8 / 9 / 200817: 58$ & 2.057 & 24.1 \\
\hline 1686 & $1 / 9 / 200818: 00$ & $8 / 9 / 200818: 00$ & 2.05 & 24.1 \\
\hline 1687 & 1/9/2008 18:02 & $8 / 9 / 200818: 02$ & 2.1 & 24.1 \\
\hline 1688 & $1 / 9 / 200818: 04$ & $8 / 9 / 200818: 04$ & 2.129 & 24.1 \\
\hline 1689 & $1 / 9 / 200818: 06$ & $8 / 9 / 200818: 06$ & 2.141 & 24.1 \\
\hline 1690 & $1 / 9 / 200818: 08$ & $8 / 9 / 200818: 08$ & 2.148 & 24.1 \\
\hline 1691 & 1/9/2008 18:10 & $8 / 9 / 200818: 10$ & 2.152 & 23.8 \\
\hline 1692 & $1 / 9 / 200818: 12$ & $8 / 9 / 200818: 12$ & 2.156 & 23.6 \\
\hline 1693 & $1 / 9 / 200818: 14$ & $8 / 9 / 200818: 14$ & 2.16 & 23.2 \\
\hline 1694 & $1 / 9 / 200818: 16$ & $8 / 9 / 200818: 16$ & 2.163 & 22.9 \\
\hline 1695 & $1 / 9 / 200818: 18$ & $8 / 9 / 200818: 18$ & 2.166 & 22.4 \\
\hline 1696 & $1 / 9 / 200818: 20$ & $8 / 9 / 200818: 20$ & 2.168 & 22.1 \\
\hline 1697 & 1/9/2008 18:22 & $8 / 9 / 200818: 22$ & 2.085 & 21.6 \\
\hline 1698 & $1 / 9 / 200818: 24$ & $8 / 9 / 200818: 24$ & 2.15 & 21.3 \\
\hline 1699 & $1 / 9 / 200818: 26$ & $8 / 9 / 200818: 26$ & 2.245 & 21 \\
\hline 1700 & $1 / 9 / 200818: 28$ & $8 / 9 / 200818: 28$ & 2.174 & 21.1 \\
\hline
\end{tabular}

\begin{tabular}{|c|c|c|c|c|}
\hline \multicolumn{5}{|c|}{ D4-93p } \\
\hline Rec & & Adjusted & Pressure| & Temp \\
\hline$\#$ & Date/Time & DaterTime & psi & ${ }^{\circ} \mathrm{C}$ \\
\hline 1701 & 1/9/2008 18:30 & 8/9/2008 18:30 & 2.173 & 21.1 \\
\hline 1702 & 1/9/2008 18:33 & $8 / 9 / 2008$ 18:32 & 2.174 & 21.1 \\
\hline 1703 & 1/9/2008 18:34 & 8/9/2008 18:34 & 2.175 & 21 \\
\hline 1704 & 1/9/2008 18:36 & $8 / 9 / 2008$ 18:36 & 2176 & \\
\hline 1705 & $1 / 9 / 200818: 38$ & $8 / 9 / 200818: 38$ & 2.176 & 20.9 \\
\hline 1706 & $1 / 9 / 200818: 40$ & $8 / 9 / 200818: 40$ & 2.176 & 20.8 \\
\hline 1707 & $1 / 9 / 200818: 42$ & $8 / 9 / 200818: 42$ & 2.178 & 20.8 \\
\hline 1708 & $1 / 9 / 200818: 44$ & $8 / 9 / 200818: 44$ & 2.178 & 20.6 \\
\hline 1709 & 1/9/2008 18:46 & $8 / 9 / 200818: 46$ & 2.179 & 20.6 \\
\hline 1710 & $1 / 9 / 2008$ 18:48 & $8 / 9 / 200818: 48$ & 2.178 & 20.7 \\
\hline 1711 & $1 / 9 / 200818: 50$ & $8 / 9 / 200818: 50$ & 2.18 & 20.8 \\
\hline 1712 & 1/9/2008 18:52 & 8/9/2008 18:52 & 2.181 & 20.8 \\
\hline 1713 & 1/9/2008 18:54 & $8 / 9 / 200818: 54$ & 2.181 & 20.8 \\
\hline 1714 & 1/9/2008 18:56 & $8 / 9 / 200818: 56$ & 2.181 & 20.8 \\
\hline 1715 & $1 / 9 / 200818: 58$ & $8 / 9 / 200818: 58$ & 2.182 & 20.9 \\
\hline 1716 & 1/9/2008 19:00 & 8/9/2008 19:00 & 2.182 & 20.9 \\
\hline 1717 & $1 / 9 / 2008$ 19:02 & $8 / 9 / 2008$ 19:02 & 2.182 & 20.9 \\
\hline 1718 & $1 / 9 / 2008$ 19:04 & $8 / 9 / 200819: 04$ & 2.182 & 20.9 \\
\hline 1719 & 1/9/2008 19:06 & $8 / 9 / 200819: 06$ & 2.182 & 20.9 \\
\hline 1720 & 1/9/2008 19:08 & $8 / 9 / 200819: 08$ & 2.184 & 20.9 \\
\hline 1721 & $1 / 9 / 2008$ 19:10 & $8 / 9 / 2008$ 19:10 & 2.183 & 20.9 \\
\hline 1722 & 1/9/2008 19:12 & $8 / 9 / 200819: 12$ & 2.183 & 20.9 \\
\hline 1723 & 1/9/2008 19:14 & $8 / 9 / 2008$ 19:14 & 2.184 & 20.9 \\
\hline 1724 & 1/9/2008 19:16 & $8 / 9 / 200819: 16$ & 2.184 & 20.9 \\
\hline 1725 & $1 / 9 / 200819: 18$ & $8 / 9 / 200819: 18$ & 2.184 & 20.9 \\
\hline 1726 & $1 / 9 / 2008$ 19:20 & $8 / 9 / 200819: 20$ & 2.184 & 21 \\
\hline 1727 & 1/9/2008 19:22 & $8 / 9 / 2008$ 19:22 & 2.184 & 21 \\
\hline 1728 & 1/9/2008 19:24 & $8 / 9 / 2008$ 19:24 & 2.185 & 21 \\
\hline 1729 & $1 / 9 / 2008$ 19:26 & $8 / 9 / 2008$ 19:26 & 2.186 & 21 \\
\hline 1730 & $1 / 9 / 200819: 28$ & $8 / 9 / 200819: 28$ & 2.187 & 21 \\
\hline 1731 & 1/9/2008 19:30 & $8 / 9 / 2008$ 19:30 & 2.187 & 21 \\
\hline 1732 & 1/9/2008 19:32 & $8 / 9 / 2008$ 19:32 & 2.187 & 21 \\
\hline 1733 & $1 / 9 / 2008$ 19:34 & $8 / 9 / 200819: 34$ & 2188 & 21.1 \\
\hline 1734 & 1/9/2008 19:36 & $8 / 9 / 2008$ 19:36 & 2.187 & 21.1 \\
\hline 1735 & 1/9/2008 19:38 & $8 / 9 / 200819: 38$ & 2.187 & 21.1 \\
\hline 1736 & $1 / 9 / 200819: 40$ & $8 / 9 / 200819: 40$ & 2.188 & 21.1 \\
\hline 1737 & 1/9/2008 19:42 & $8 / 9 / 200819: 42$ & 2.187 & 21.1 \\
\hline 1738 & $1 / 9 / 2008$ 19:44 & $8 / 9 / 2008$ 19:44 & 2.187 & 21.1 \\
\hline 1739 & $1 / 9 / 2008$ 19:46 & $8 / 9 / 2008$ 19:46 & 2.186 & 21.1 \\
\hline 1740 & $1 / 9 / 200819: 48$ & $8 / 9 / 200819: 48$ & 2.187 & 21.1 \\
\hline 1741 & $1 / 9 / 200819: 50$ & $8 / 9 / 2008$ 19:50 & 2.188 & 21.1 \\
\hline 1742 & $1 / 9 / 200819: 52$ & $8 / 9 / 200819: 52$ & 2.187 & 21.1 \\
\hline 1743 & $1 / 9 / 200819: 54$ & $8 / 9 / 2008$ 19:54 & 2.188 & 21.3 \\
\hline 1744 & $1 / 9 / 200819: 56$ & $8 / 9 / 2008$ 19:56 & 2.188 & 21.3 \\
\hline 1745 & $1 / 9 / 200819: 58$ & $8 / 9 / 200819: 58$ & 2.188 & 21.2 \\
\hline 1746 & $1 / 9 / 200820: 00$ & $8 / 9 / 200820: 00$ & 2.188 & 21.2 \\
\hline 1747 & $1 / 9 / 200820: 02$ & $8 / 9 / 200820: 02$ & 2.188 & 21.3 \\
\hline 1748 & $1 / 9 / 200820: 04$ & $8 / 9 / 200820: 04$ & 2.188 & 21.2 \\
\hline 1749 & $1 / 9 / 200820: 06$ & $8 / 9 / 200820: 06$ & 2.187 & 21.3 \\
\hline 1750 & $1 / 9 / 200820: 08$ & $8 / 9 / 200820: 08$ & 2.187 & 21.3 \\
\hline 1751 & 1/9/2008 20:10 & $8 / 9 / 200820: 10$ & 2.188 & 21.3 \\
\hline 1752 & 1/9/2008 20:12 & $8 / 9 / 200820: 12$ & 2.189 & 21.3 \\
\hline 1753 & $1 / 9 / 200820: 14$ & 8/9/2008 20:14 & 2.19 & 21.3 \\
\hline 1754 & 1/9/2008 20:16 & $8 / 9 / 200820: 16$ & 2.19 & 21.3 \\
\hline 1755 & 1/9/2008 20:18 & $8 / 9 / 200820: 18$ & 2.189 & 21.3 \\
\hline 1756 & 1/9/2008 20:20 & $8 / 9 / 200820: 20$ & 2.189 & 21.3 \\
\hline 1757 & 1/9/2008 20:22 & $8 / 9 / 200820: 22$ & 2.189 & 21.4 \\
\hline 1758 & $1 / 9 / 200820: 24$ & $8 / 9 / 200820: 24$ & 2.19 & 21.4 \\
\hline 1759 & $1 / 9 / 200820: 26$ & $8 / 9 / 200820: 26$ & 2.188 & 21.4 \\
\hline 1760 & 1/9/2008 20:28 & $8 / 9 / 200820: 28$ & 2.19 & 21.4 \\
\hline 1761 & 1/9/2008 20:30 & $8 / 9 / 200820: 30$ & 2.191 & 21.4 \\
\hline 1762 & 1/9/2008 20:32 & $8 / 9 / 200820: 32$ & 2.191 & 21.4 \\
\hline 1763 & $1 / 9 / 200820: 34$ & $8 / 9 / 200820: 34$ & 2.191 & 21.4 \\
\hline 1764 & 1/9/2008 20:36 & $8 / 9 / 200820: 36$ & 2.19 & 21.4 \\
\hline 1765 & 1/9/2008 20:38 & $8 / 9 / 200820: 38$ & 2.191 & 21.4 \\
\hline 1766 & 1/9/2008 20:40 & $8 / 9 / 200820: 40$ & 2.192 & 21.4 \\
\hline 1767 & 1/9/2008 20:42 & $8 / 9 / 200820: 42$ & 2.191 & 21.4 \\
\hline 1768 & $1 / 9 / 200820: 44$ & $8 / 9 / 200820: 44$ & 2.19 & 21.4 \\
\hline
\end{tabular}

\begin{tabular}{|c|c|c|c|c|}
\hline \multicolumn{5}{|c|}{ D4-93p } \\
\hline $\operatorname{Rec}$ & & Adjusted & Pressure & Temp \\
\hline$\#$ & DaterTime & \begin{tabular}{l|l|} 
Date/Time \\
\end{tabular} & psi & ${ }^{\circ} \mathrm{C}$ \\
\hline 1769 & $1 / 9 / 200820: 46$ & $8 / 9 / 200820: 46$ & 2.19 & 21.4 \\
\hline 1770 & $1 / 9 / 200820: 48$ & $8 / 9 / 200820: 48$ & 2.15 & 21.4 \\
\hline 1771 & 1/9/200820:50 & $8 / 9 / 200820: 50$ & 2.123 & 21.9 \\
\hline 1772 & $1 / 9 / 200820: 52$ & $8 / 9 / 200820: 52$ & 2.088 & 23.1 \\
\hline 1773 & 1/9/2008 20:54 & $8 / 9 / 200820: 54$ & 2.075 & 23.6 \\
\hline 1774 & $1 / 9 / 200820: 56$ & $8 / 9 / 200820: 56$ & 2.062 & 23.8 \\
\hline 1775 & $1 / 9 / 200820: 58$ & $8 / 9 / 200820: 58$ & 2.052 & 23.9 \\
\hline 1776 & 1/9/2008 21:00 & $8 / 9 / 200821: 00$ & 2.045 & 23.9 \\
\hline 1777 & 1/9/200821:02 & $8 / 9 / 200821: 02$ & 2.039 & 23.9 \\
\hline 1778 & 1/9/200821:04 & $8 / 9 / 200821: 04$ & 2.033 & 23.9 \\
\hline 1779 & $1 / 9 / 200821: 06$ & $8 / 9 / 200821: 06$ & 2.028 & 23.9 \\
\hline 1780 & 1/9/2008 21:08 & $8 / 9 / 200821: 08$ & 2.085 & 23.9 \\
\hline 1781 & 1/9/200821:10 & $8 / 9 / 200821: 10$ & 2.124 & 23.9 \\
\hline 1782 & $1 / 9 / 200821: 12$ & $8 / 9 / 200821: 12$ & 2.141 & 23.8 \\
\hline 1783 & 1/9/200821:14 & $8 / 9 / 200821: 14$ & 2.149 & 23.5 \\
\hline 1784 & 1/9/200821:16 & $8 / 9 / 200821: 16$ & 2.154 & 23.2 \\
\hline 1785 & $1 / 9 / 200821: 18$ & $8 / 9 / 200821: 18$ & 2.158 & 22.8 \\
\hline 1786 & 1/9/200821:20 & $8 / 9 / 200821: 20$ & 2.161 & 22.4 \\
\hline 1787 & 1/9/2008 21:22 & $8 / 9 / 200821: 22$ & 2.163 & 21.8 \\
\hline 1788 & $1 / 9 / 200821: 24$ & $8 / 9 / 200821: 24$ & 2.165 & 21.4 \\
\hline 1789 & 1/9/200821:26 & 8/9/2008 21:26 & 2.166 & 21.2 \\
\hline 1790 & 1/9/200821:28 & $8 / 9 / 200821: 28$ & 2.167 & 21.1 \\
\hline 1791 & 1/9/200821:30 & $8 / 9 / 200821: 30$ & 2.169 & 21.2 \\
\hline 1792 & $1 / 9 / 200821: 32$ & $8 / 9 / 200821: 32$ & 2.171 & 21.3 \\
\hline 1793 & $1 / 9 / 200821: 34$ & $8 / 9 / 200821: 34$ & 2.172 & 21.3 \\
\hline 1794 & $1 / 9 / 200821: 36$ & $8 / 9 / 200821: 36$ & 2.172 & 21.3 \\
\hline 1795 & 1/9/200821:38 & $89 / 200821: 38$ & 2.173 & 21.3 \\
\hline 1796 & $1 / 9 / 200821: 40$ & $8 / 9 / 200821: 40$ & 2.174 & 21.3 \\
\hline 1797 & 1/9/200821:42 & $8 / 9 / 200821: 42$ & 2.175 & $\overline{21.4}$ \\
\hline 1798 & $1 / 9 / 200821: 44$ & $8 / 9 / 200821: 44$ & 2.174 & 21.4 \\
\hline 1799 & $1 / 9 / 200821: 46$ & $8 / 9 / 200821: 46$ & 2.175 & 21.4 \\
\hline 1800 & 1/9/200821:48 & $8 / 9 / 200821: 48$ & 2.175 & 21.4 \\
\hline 1801 & 1/9/200821:50 & $8 / 9 / 200821: 50$ & 2.176 & 21.4 \\
\hline 1802 & $1 / 9 / 200821: 52$ & $8 / 9 / 200821: 52$ & 2.177 & 21.5 \\
\hline 1803 & $1 / 9 / 200821: 54$ & $8 / 9 / 200821: 54$ & 2.178 & 21.5 \\
\hline 1804 & $1 / 9 / 200821: 56$ & $8 / 9 / 200821: 56$ & 2.178 & 21.5 \\
\hline 1805 & $1 / 9 / 200821: 58$ & $8 / 9 / 200821: 58$ & 2.18 & 21.5 \\
\hline 1806 & 1/9/200822:00 & 8/9/2008 22:00 & 2.18 & 21.5 \\
\hline 1807 & 1/9/2008 22:02 & $8 / 9 / 200822: 02$ & 2.181 & 21.5 \\
\hline 1808 & $1 / 9 / 200822: 04$ & $8 / 9 / 200822: 04$ & 2.183 & 21.5 \\
\hline 1809 & $1 / 9 / 200822: 06$ & $8 / 9 / 200822: 06$ & 2.183 & 21.6 \\
\hline 1810 & $1 / 9 / 200822: 08$ & $8 / 9 / 200822: 08$ & 2.185 & 21.6 \\
\hline 1811 & 1/9/2008 22:10 & 8/9/2008 22:10 & 2.186 & 21.6 \\
\hline 1812 & 1/9/200822:12 & $8 / 9 / 200822: 12$ & 2.186 & 21.6 \\
\hline 1813 & $1 / 9 / 200822: 14$ & $8 / 9 / 200822: 14$ & 2.185 & 21.6 \\
\hline 1814 & 1/9/2008 22:16 & $8 / 9 / 200822: 16$ & 2.186 & 21.6 \\
\hline 1815 & 1/9/2008 22:18 & $8 / 9 / 2008$ 22:18 & 2.187 & 21.6 \\
\hline 1816 & 1/9/2008 22:20 & $8 / 9 / 200822: 20$ & 2.187 & 21.6 \\
\hline 1817 & 1/9/2008 22:22 & $8 / 9 / 200822: 22$ & 2.188 & 21.6 \\
\hline 1818 & $1 / 9 / 200822: 24$ & $8 / 9 / 200822: 24$ & 2.19 & 21.6 \\
\hline 1819 & 1/9/2008 22:26 & $8 / 9 / 200822: 26$ & 2.19 & 21.6 \\
\hline 1820 & $1 / 9 / 200822: 28$ & $8 / 9 / 200822: 28$ & 2.191 & 21.6 \\
\hline 1821 & 1/9/200822:30 & $8 / 9 / 200822: 30$ & 2.191 & 21.6 \\
\hline 1822 & $1 / 9 / 200822: 32$ & $8 / 9 / 200822 ; 32$ & 2.192 & 21.6 \\
\hline 1823 & $1 / 9 / 200822: 34$ & $8 / 9 / 2008$ 22:34 & 2.192 & 21.6 \\
\hline 1824 & $1 / 9 / 200822: 36$ & $8 / 9 / 200822: 36$ & 2.192 & 21.6 \\
\hline 1825 & $1 / 9 / 200822: 38$ & $8 / 9 / 200822: 38$ & 2.192 & 21.6 \\
\hline 1826 & $1 / 9 / 200822: 40$ & $8 / 9 / 200822: 40$ & 2.194 & 21.7 \\
\hline 1827 & $1 / 9 / 200822: 42$ & $8 / 9 / 200822: 42$ & 2.193 & 21.7 \\
\hline 1828 & $1 / 9 / 200822: 44$ & $8 / 9 / 200822: 44$ & 2.193 & 21.7 \\
\hline 1829 & $1 / 9 / 200822: 46$ & $8 / 9 / 200822: 46$ & 2.192 & 21.7 \\
\hline 1830 & $1 / 9 / 200822: 48$ & $8 / 9 / 200822: 48$ & 2.194 & 21.7 \\
\hline 1831 & 1/9/2008 22:50 & $8 / 9 / 200822: 50$ & 2.195 & 21.8 \\
\hline 1832 & $1 / 9 / 200822: 52$ & $8 / 9 / 200822: 52$ & 2.196 & 21.8 \\
\hline 1833 & $1 / 9 / 200822: 54$ & $8 / 9 / 200822: 54$ & 2.195 & 21.8 \\
\hline 1834 & $1 / 9 / 200822: 56$ & $8 / 9 / 200822: 56$ & 2.195 & 21.8 \\
\hline 1835 & $1 / 9 / 200822: 58$ & $8 / 9 / 200822: 58$ & 2.195 & 21.8 \\
\hline 1836 & 1/9/200823:00 & $8 / 9 / 200823: 00$ & 2.196 & 21.8 \\
\hline
\end{tabular}




\begin{tabular}{|c|c|c|c|c|}
\hline \multicolumn{5}{|c|}{ D4-93p } \\
\hline Rec & & Adjusted & Pressure & Temp \\
\hline \# & Date/Time & Date/Time & psi & ${ }^{\circ} \mathrm{C}$ \\
\hline 1837 & $1 / 9 / 200823: 02$ & $8 / 9 / 200823: 02$ & 2.196 & 21.8 \\
\hline 1838 & $1 / 9 / 200823: 04$ & $8 / 9 / 2008$ 23:04 & 2.197 & 21.8 \\
\hline 1839 & $1 / 9 / 200823: 06$ & $8 / 9 / 200823: 06$ & 2.197 & 21.8 \\
\hline 1840 & $1 / 9 / 200823: 08$ & $8 / 9 / 200823: 08$ & 2.197 & 21.8 \\
\hline 1841 & 1/9/2008 23:10 & 8/9/2008 23:10 & 2.197 & 21.8 \\
\hline 1842 & 1/9/2008 23:12 & $8 / 9 / 200823: 12$ & 2.197 & 21.8 \\
\hline 1843 & 1/9/2008 23:14 & $8 / 9 / 200823: 14$ & 2.198 & 21.8 \\
\hline 1844 & 1/9/2008 23:16 & 8/9/2008 23:16 & 2.198 & 21.9 \\
\hline 1845 & 1/9/2008 23:18 & $8 / 9 / 200823: 18$ & 2.199 & 21.9 \\
\hline 1846 & 1/9/2008 23:20 & $8 / 9 / 200823: 20$ & 2.196 & 22.3 \\
\hline 1847 & $1 / 9 / 200823: 22$ & $8 / 9 / 200823: 22$ & 2.196 & 22.3 \\
\hline 1848 & 1/9/2008 23:24 & $8 / 9 / 200823: 24$ & 2.198 & 22.1 \\
\hline 1849 & $1 / 9 / 200823: 26$ & $8 / 9 / 200823: 26$ & 2.199 & 22 \\
\hline 1850 & $1 / 9 / 200823: 28$ & $8 / 9 / 200823: 28$ & 2.2 & 21.9 \\
\hline 1851 & $1 / 9 / 200823: 30$ & $8 / 9 / 200823: 30$ & 2.201 & 21.9 \\
\hline 1852 & $1 / 9 / 200823: 32$ & $8 / 9 / 2008$ 23:32 & 2.201 & 21.9 \\
\hline 1853 & 1/9/2008 23:34 & 8/9/2008 23:34 & 2.201 & 21.9 \\
\hline 1854 & $1 / 9 / 200823: 36$ & $8 / 9 / 200823: 36$ & 2.202 & 21.9 \\
\hline 1855 & $1 / 9 / 200823: 38$ & $8 / 9 / 2008$ 23:38 & 2.203 & 21.9 \\
\hline 1856 & $1 / 9 / 200823: 40$ & $8 / 9 / 200823: 40$ & 2.037 & 22 \\
\hline 1857 & $1 / 9 / 200823: 42$ & $8 / 9 / 200823: 42$ & 1.999 & 22.5 \\
\hline 1858 & $1 / 9 / 200823: 44$ & $8 / 9 / 2008 \quad 23: 44$ & 2.091 & 23.5 \\
\hline 1859 & $1 / 9 / 200823: 46$ & $8 / 9 / 200823: 46$ & 2.205 & 23.7 \\
\hline 1860 & $1 / 9 / 200823: 48$ & $8 / 9 / 200823: 48$ & 2.202 & 23.9 \\
\hline 1861 & $1 / 9 / 200823: 50$ & $8 / 9 / 200823: 50$ & 2.204 & 23.8 \\
\hline 1862 & $1 / 9 / 200823: 52$ & $8 / 9 / 2008$ 23:52 & 2.151 & 23.5 \\
\hline 1863 & $1 / 9 / 200823: 54$ & $8 / 9 / 2008 \quad 23: 54$ & 2.099 & $23 . \overline{8}$ \\
\hline 1864 & $1 / 9 / 200823: 56$ & $8 / 9 / 200823: 56$ & 2.067 & 24 \\
\hline 1865 & $1 / 9 / 200823: 58$ & 8/9/2008 23:58 & 2.064 & 24.2 \\
\hline 1866 & $1 / 10 / 20080: 00$ & $8 / 10 / 20080: 00$ & 2.047 & 24.3 \\
\hline 1867 & $1 / 10 / 20080: 02$ & $8 / 10 / 20080: 02$ & 2.039 & 24.3 \\
\hline 1868 & 1/10/2008 0:04 & $8 / 10 / 20080: 04$ & 2.032 & 24.4 \\
\hline 1869 & $1 / 10 / 20080: 06$ & $8 / 10 / 20080: 06$ & 2.025 & 24.4 \\
\hline 1870 & $1 / 10 / 20080: 08$ & $8 / 10 / 20080: 08$ & 2.019 & 24.4 \\
\hline 1871 & 1/10/2008 0:10 & $8 / 10 / 20080: 10$ & 2.015 & 24.4 \\
\hline 1872 & $1 / 10 / 20080: 12$ & $8 / 10 / 20080: 12$ & 2.074 & 24.4 \\
\hline 1873 & $1 / 10 / 20080: 14$ & $8 / 10 / 20080: 14$ & 2.118 & 24.3 \\
\hline 1874 & $1 / 10 / 20080: 16$ & $8 / 10 / 20080: 16$ & 2.138 & 24.2 \\
\hline 1875 & $1 / 10 / 20080: 18$ & $8 / 10 / 20080: 18$ & 2.151 & 24 \\
\hline 1876 & $1 / 10 / 20080: 20$ & $8 / 10 / 20080: 20$ & 2.162 & 23.8 \\
\hline 1877 & $1 / 10 / 20080: 22$ & $8 / 10 / 20080: 22$ & 2.169 & 23.6 \\
\hline 1878 & $1 / 10 / 20080: 24$ & $8 / 10 / 20080: 24$ & 2.174 & 23.3 \\
\hline 1879 & $1 / 10 / 20080: 26$ & $8 / 10 / 20080: 26$ & 2.178 & 23.1 \\
\hline 1880 & 1/10/2008 0:28 & $8 / 10 / 20080: 28$ & 2.18 & 22.8 \\
\hline 1881 & $1 / 10 / 20080: 30$ & $8 / 10 / 20080: 30$ & 2.183 & 22.6 \\
\hline 1882 & $1 / 10 / 20080: 32$ & $8 / 10 / 20080: 32$ & 2.186 & 22.4 \\
\hline 1883 & $1 / 10 / 20080: 34$ & $8 / 10 / 20080: 34$ & 2.189 & 22.4 \\
\hline 1884 & $1 / 10 / 20080: 36$ & $8 / 10 / 20080: 36$ & 2.19 & 22.3 \\
\hline 1885 & $1 / 10 / 20080: 38$ & $8 / 10 / 20080: 38$ & 2.192 & 22.3 \\
\hline 1886 & $1 / 10 / 20080: 40$ & $8 / 10 / 20080: 40$ & 2.194 & 22.2 \\
\hline 1887 & $1 / 10 / 20080: 42$ & $8 / 10 / 20080: 42$ & 2.195 & 22.1 \\
\hline 1888 & $1 / 10 / 20080: 44$ & $8 / 10 / 20080: 44$ & 2.196 & 22.1 \\
\hline 1889 & $1 / 10 / 20080: 46$ & $8 / 10 / 20080: 46$ & 2.197 & 22.1 \\
\hline 1890 & $4 / 10 / 20080: 48$ & $8 / 10 / 20080: 48$ & 2.198 & 22 \\
\hline 1891 & $1 / 10 / 20080: 50$ & $8 / 10 / 20080: 50$ & 2.198 & 22 \\
\hline 1892 & $1 / 10 / 20080: 52$ & $8 / 10 / 20080: 52$ & 2.2 & 22 \\
\hline 1893 & $1 / 10 / 20080: 54$ & $8 / 10 / 20080: 54$ & 2.201 & 22 \\
\hline 1894 & $1 / 10 / 20080: 56$ & $8 / 10 / 20080: 56$ & 2.202 & 22 \\
\hline 1895 & $1 / 10 / 20080: 58$ & $8 / 10 / 20080: 58$ & 2.203 & 22 \\
\hline 1896 & $1 / 10 / 20081: 00$ & $8 / 10 / 2008 \quad 1: 00$ & 2.203 & $\overline{22}$ \\
\hline 1897 & $1 / 10 / 20081: 02$ & $8 / 10 / 20081: 02$ & 2.204 & 22 \\
\hline 1898 & $1 / 10 / 20081: 04$ & $8 / 10 / 20081: 04$ & 2.204 & 22.1 \\
\hline 1899 & $1 / 10 / 20081: 06$ & $8 / 10 / 20081: 06$ & 2.205 & 22.1 \\
\hline 1900 & $1 / 10 / 20081: 08$ & $8 / 10 / 2008$ 1:08 & 2.205 & 22.1 \\
\hline 1901 & $1 / 10 / 2008$ 1:10 & $8 / 10 / 2008$ 1:10 & 2.206 & 22.1 \\
\hline 1902 & $1 / 10 / 20081: 12$ & $8 / 10 / 2008$ 1:12 & 2.206 & 22.1 \\
\hline 1903 & $1 / 10 / 20081: 14$ & $8 / 10 / 2008$ 1:14 & 2.207 & 22.1 \\
\hline 1904 & $1 / 10 / 20081: 16$ & $8 / 10 / 2008$ 4:16 & 2.208 & 22.1 \\
\hline
\end{tabular}

\begin{tabular}{|c|c|c|c|c|}
\hline \multicolumn{5}{|c|}{ D4-93p } \\
\hline Rec & & Adjusted & Pressure & Temp \\
\hline$\#$ & Date/Time & Date/Time & psi & ${ }^{\circ} \mathrm{C}$ \\
\hline 1905 & $1 / 10 / 20081: 18$ & $8 / 10 / 20081: 18$ & 2.208 & $\overline{22.2}$ \\
\hline 4906 & $1 / 10 / 20081: 20$ & $8 / 10 / 20081: 20$ & 2.208 & $\overline{22.2}$ \\
\hline 1907 & $1 / 10 / 20081: 22$ & $8 / 10 / 20081: 22$ & 2.209 & $\overline{22.2}$ \\
\hline 1908 & $1 / 10 / 20081: 24$ & $8 / 10 / 20081: 24$ & 2.209 & 22.3 \\
\hline 1909 & $1 / 10 / 20081: 26$ & $8 / 10 / 20081: 26$ & 2.21 & 22.3 \\
\hline 1910 & $1 / 10 / 20081: 28$ & $8 / 10 / 20081: 28$ & 2.211 & 22.3 \\
\hline 1911 & $1 / 10 / 20081: 30$ & $8 / 10 / 20081: 30$ & 2.212 & 22.3 \\
\hline 1912 & $1 / 10 / 20081: 32$ & $8 / 10 / 20081: 32$ & 2.213 & 22.4 \\
\hline 1913 & $1 / 10 / 20081: 34$ & $8 / 10 / 20081: 34$ & 2.213 & 22.4 \\
\hline 1914 & $1 / 10 / 20081: 36$ & $8 / 10 / 20081: 36$ & 2.213 & 22.4 \\
\hline 1915 & $1 / 10 / 20081: 38$ & $8 / 10 / 20081: 38$ & 2.213 & 22.4 \\
\hline 1916 & $1 / 10 / 20081: 40$ & $8 / 10 / 20081: 40$ & 2.213 & 22.4 \\
\hline 1917 & $1 / 10 / 20081: 42$ & $8 / 10 / 20081: 42$ & 2.214 & 22.4 \\
\hline 1918 & $81: 44$ & $8 / 10 / 20081: 44$ & 2.215 & 22.4 \\
\hline 1919 & $81: 46$ & $081: 46$ & 2.216 & 22.4 \\
\hline 1920 & $81: 48$ & $881: 48$ & 2.216 & 22.5 \\
\hline 1921 & $81: 50$ & $881: 50$ & 2.217 & 22.5 \\
\hline 1922 & $1: 52$ & $81: 52$ & 2.217 & 22.4 \\
\hline 1923 & $31: 54$ & $081: 54$ & 2.218 & 22.5 \\
\hline 1924 & $31: 56$ & $81: 56$ & 2.219 & 22.6 \\
\hline 1925 & $1: 58$ & $81: 58$ & 2.219 & 22.6 \\
\hline 1926 & $1 / 10$ & $32: 00$ & 2.219 & 22.7 \\
\hline 1927 & $2: 02$ & $82: 02$ & 2.219 & 22.7 \\
\hline 1928 & $1 / 10$ & $2: 04$ & 2.219 & 22.8 \\
\hline 1929 & $2: 06$ & $2: 06$ & 2.219 & 22.8 \\
\hline 1930 & $2: 08$ & $2: 08$ & 2.219 & 22.8 \\
\hline 1931 & $2: 10$ & $8 / 1$ & 2.22 & 22.9 \\
\hline 1932 & $2: 12$ & $2: 12$ & 2.22 & 22.9 \\
\hline 1933 & $2: 14$ & & 2.221 & $\overline{22.9}$ \\
\hline 1934 & $2: 16$ & $8 / 1$ & 2.22 & 23. \\
\hline 1935 & $2: 18$ & $2: 18$ & 2.221 & 23. \\
\hline 1936 & $2: 20$ & $2: 20$ & 2.221 & 23 \\
\hline 1937 & $2: 22$ & $2: 22$ & 2.221 & 23 \\
\hline 1938 & $2: 24$ & $32: 24$ & 2.221 & 23. \\
\hline 1939 & $2: 26$ & $32: 26$ & 2.221 & 23. \\
\hline 1940 & $2: 28$ & $2: 28$ & 2.22 & 23. \\
\hline 1941 & $2: 30$ & $2: 30$ & 2.222 & 23. \\
\hline 1942 & $82: 32$ & $32: 32$ & 2.221 & 23. \\
\hline 1943 & $2: 34$ & $2: 34$ & 2.221 & 23. \\
\hline 1944 & $82: 36$ & $82: 36$ & 2.223 & 23 \\
\hline 1945 & $82: 38$ & $32: 38$ & 2.223 & 23.6 \\
\hline 1946 & $82: 40$ & $82: 40$ & 2.227 & 24. \\
\hline 1947 & $82: 42$ & $32: 42$ & 2.226 & 23. \\
\hline 1948 & $2: 44$ & $2: 44$ & 2.226 & 23.8 \\
\hline 1949 & $2: 46$ & $2: 46$ & 2.226 & 23.7 \\
\hline 1950 & $2: 48$ & $2: 48$ & 2.216 & 23.7 \\
\hline 1951 & $2: 50$ & $2: 50$ & 2.152 & 23.8 \\
\hline 1952 & $2: 52$ & $32: 52$ & 2.107 & 2 \\
\hline 1953 & $2: 54$ & $82: 54$ & 2.075 & 24.3 \\
\hline 1954 & $2: 56$ & $82: 56$ & 2.062 & 24.6 \\
\hline 4955 & & & 2.051 & 24. \\
\hline 1956 & & & 2.044 & 24. \\
\hline 1957 & & & 2.038 & 24. \\
\hline 1958 & & & 2.032 & \\
\hline 1959 & & & 2.133 & 2 \\
\hline 1960 & $3: 08$ & & 2.163 & 24. \\
\hline 1961 & & & 2.175 & 24.6 \\
\hline 1962 & $83: 12$ & $8 / 10$ & 2.185 & 24. \\
\hline 1963 & $83: 14$ & $83: 14$ & 2.193 & 24. \\
\hline 1964 & $83: 16$ & $83: 16$ & 2.198 & 23. \\
\hline 1965 & $83: 18$ & $3: 18$ & 2.201 & 23 \\
\hline 1966 & $83: 20$ & $83: 20$ & 2.044 & 2 \\
\hline 1967 & $1 / 10 / 20083: 22$ & $083: 22$ & 2.326 & 23.8 \\
\hline 1968 & $083: 24$ & $83: 24$ & 2.211 & 24. \\
\hline 1969 & $1 / 10 / 20083: 26$ & $8 / 10 / 20083: 26$ & 2.213 & 2 \\
\hline 1970 & $1 / 10 / 20083: 28$ & $8 / 10 / 2008 \quad 3: 28$ & 2.213 & 23.8 \\
\hline 1971 & $083: 30$ & $8 / 10 / 20083: 30$ & 2.217 & 23.8 \\
\hline 1972 & $1 / 10 / 20083: 32$ & $8 / 10 / 20083: 32$ & 2.218 & 23. \\
\hline
\end{tabular}

\begin{tabular}{|c|c|c|c|c|}
\hline \multicolumn{5}{|c|}{ D4-93p } \\
\hline $\operatorname{Rec}$ & & Adjusted & Pressure & Temp \\
\hline$\#$ & Date/Time & Date/Time & psi & ${ }^{\circ} \mathrm{C}$ \\
\hline 1973 & $1 / 10 / 20083: 34$ & $8 / 10 / 20083: 34$ & 2.219 & 23.4 \\
\hline 1974 & $1 / 10 / 20083: 36$ & $8 / 10 / 20083: 36$ & 2.221 & 23.3 \\
\hline 1975 & $1 / 10 / 20083: 38$ & $8 / 10 / 20083: 38$ & 2.221 & 23.4 \\
\hline 1976 & $1 / 10 / 20083: 40$ & $8 / 10 / 20083: 40$ & 2.221 & 23.6 \\
\hline 1977 & $1 / 10 / 20083: 42$ & $8 / 10 / 20083: 42$ & 2.223 & 23.9 \\
\hline 1978 & $1 / 10 / 20083: 44$ & $8 / 10 / 20083: 44$ & 2.224 & 24.1 \\
\hline 1979 & $1 / 10 / 20083: 46$ & $8 / 10 / 20083: 46$ & 2.226 & 24.1 \\
\hline 1980 & $1 / 10 / 20083: 48$ & $8 / 10 / 20083: 48$ & 2.226 & 24.1 \\
\hline 1981 & $1 / 10 / 20083: 50$ & $8 / 10 / 20083: 50$ & 2.227 & 24.1 \\
\hline 1982 & $1 / 10 / 20083: 52$ & $8 / 10 / 20083: 52$ & 2.228 & 24.1 \\
\hline 1983 & $1 / 10 / 20083: 54$ & $8 / 10 / 20083: 54$ & 2.229 & 24.1 \\
\hline 1984 & $1 / 10 / 20083: 56$ & $8 / 10 / 20083: 56$ & 2.231 & 24.2 \\
\hline 1985 & $1 / 10 / 20083: 58$ & $8 / 10 / 20083: 58$ & 2.231 & 24.3 \\
\hline 1986 & $1 / 10 / 20084: 00$ & $8 / 10 / 20084: 00$ & 2.23 & 24 \\
\hline 1987 & $1 / 10 / 20084: 02$ & $8 / 10 / 20084: 02$ & 2.231 & 23.9 \\
\hline 1988 & $1 / 10 / 20084: 04$ & $8 / 10 / 20084: 04$ & 2.231 & 23.8 \\
\hline 1989 & $1 / 10 / 20084: 06$ & $8 / 10 / 20084: 06$ & 2.231 & 23.8 \\
\hline 1990 & $1 / 10 / 20084: 08$ & $8 / 10 / 20084: 08$ & 2.232 & 23.9 \\
\hline 1991 & $1 / 10 / 20084: 10$ & $8 / 10 / 20084: 10$ & 2.233 & 23.8 \\
\hline 1992 & $1 / 10 / 20084: 12$ & $8 / 40 / 20084: 12$ & 2.232 & 23.9 \\
\hline 1993 & $1 / 10 / 20084: 14$ & $8 / 10 / 20084: 14$ & 2.232 & 23.9 \\
\hline 1994 & $1 / 10 / 20084: 16$ & $8 / 10 / 20084: 16$ & 2.234 & 23.9 \\
\hline 1995 & $1 / 10 / 20084: 18$ & $8 / 10 / 20084: 18$ & 2.235 & 23.9 \\
\hline $19 \overline{96}$ & $1 / 10 / 20084: 20$ & $8 / 10 / 20084: 20$ & 2.234 & 23.9 \\
\hline 1997 & $1 / 10 / 20084: 22$ & $8 / 10 / 20084: 22$ & 2.235 & 23.9 \\
\hline 1998 & $1 / 10 / 20084: 24$ & $8 / 10 / 20084: 24$ & 2.237 & 23.9 \\
\hline 1999 & $1 / 10 / 20084: 26$ & $8 / 10 / 20084: 26$ & 2.238 & 24 \\
\hline 2000 & $1 / 10 / 20084: 28$ & $8 / 10 / 20084: 28$ & 2.238 & 23.9 \\
\hline 2001 & $1 / 10 / 20084: 30$ & $8 / 10 / 20084: 30$ & 2.238 & 23.9 \\
\hline $20 \overline{2}$ & $1 / 10 / 20084: 32$ & $8 / 10 / 20084: 32$ & 2.238 & 23.9 \\
\hline 2003 & $1 / 10 / 20084: 34$ & $8 / 10 / 20084: 34$ & 2.239 & 23.9 \\
\hline 2004 & $1 / 10 / 20084: 36$ & $8 / 10 / 20084: 36$ & 2.237 & 23.9 \\
\hline 2005 & $1 / 10 / 20084: 38$ & $8 / 10 / 20084: 38$ & 2.237 & 23.9 \\
\hline 2006 & $1 / 40 / 20084: 40$ & $8 / 10 / 20084: 40$ & 2.238 & 23.8 \\
\hline 2007 & $1 / 10 / 20084: 42$ & $8 / 10 / 20084: 42$ & 2.241 & 23.9 \\
\hline 2008 & $1 / 10 / 20084: 44$ & $8 / 10 / 20084: 44$ & 2.241 & 23.9 \\
\hline 2009 & $1 / 10 / 20084: 4 \overline{6}$ & $8 / 10 / 20084: 46$ & 2.241 & 23.9 \\
\hline 2010 & $1 / 10 / 20084: 48$ & $8 / 10 / 20084: 48$ & 2.241 & 23.8 \\
\hline 2011 & $1 / 10 / 20084: 50$ & $8 / 10 / 20084: 50$ & 2.241 & 23.9 \\
\hline 2012 & $1 / 10 / 20084: 52$ & $8 / 10 / 20084: 52$ & 2.24 & 23.9 \\
\hline 2013 & $1 / 10 / 20084: 54$ & $8 / 10 / 20084: 54$ & 2.24 & 23.9 \\
\hline 2014 & $1 / 10 / 20084: 56$ & $8 / 10 / 20084: 56$ & 2.239 & 23.7 \\
\hline 2015 & $1 / 10 / 20084: 58$ & $8 / 10 / 20084: 58$ & 2.239 & 23.9 \\
\hline 2016 & $1 / 10 / 20085: 00$ & $8 / 10 / 20085: 00$ & 2.239 & 23.9 \\
\hline 2017 & $1 / 10 / 20085: 02$ & $8 / 10 / 20085: 02$ & 2.239 & 23.9 \\
\hline 2018 & $1 / 10 / 20085: 04$ & $8 / 10 / 20085: 04$ & 2.241 & 23.8 \\
\hline 2019 & $1 / 10 / 20085: 06$ & $8 / 10 / 20085: 06$ & 2.24 & 23.8 \\
\hline 2020 & $1 / 10 / 20085: 08$ & $8 / 10 / 20085: 08$ & 2.241 & 23.8 \\
\hline 2021 & $1 / 10 / 20085: 10$ & $8 / 10 / 20085: 10$ & 2.241 & 23.8 \\
\hline 2022 & $1 / 10 / 20085: 12$ & $8 / 10 / 20085: 12$ & $\overline{2.242}$ & 23.8 \\
\hline 2023 & $1 / 10 / 20085: 14$ & $8 / 10 / 20085: 14$ & 2.242 & 23.8 \\
\hline 2024 & $1 / 10 / 20085: 16$ & $8 / 10 / 20085: 16$ & 2.243 & 23.8 \\
\hline 2025 & $1 / 10 / 20085: 18$ & $8 / 10 / 20085: 18$ & 2.243 & 23.8 \\
\hline 2026 & $1 / 10 / 20085: 20$ & $35: 20$ & 2.242 & 23.8 \\
\hline 2027 & $1 / 10 / 20$ & $8 / 10 / 20085: 22$ & 2.242 & 23.8 \\
\hline 2028 & $1 / 10 / 20085: 24$ & $8 / 10 / 20085: 24$ & 2.243 & 23.9 \\
\hline 2029 & $1 / 10 / 20085: 26$ & $8 / 10 / 20085: 26$ & 2.242 & 23.8 \\
\hline 2030 & $1 / 10 / 20085: 28$ & $8 / 10 / 20085: 28$ & 2.241 & 23.8 \\
\hline 2031 & $1 / 10 / 20085: 30$ & $8 / 10 / 20085: 30$ & 2.242 & 23.8 \\
\hline 2032 & $1 / 10 / 20085: 32$ & $8 / 10 / 20085: 32$ & 2.242 & 23.8 \\
\hline 2033 & $1 / 10 / 20085: 34$ & $8 / 10 / 20085: 34$ & 2.242 & 23.9 \\
\hline 2034 & $1 / 10 / 20085: 36$ & $8 / 10 / 20085: 36$ & 2.242 & 23.9 \\
\hline 2035 & $1 / 10 / 20085: 38$ & $8 / 10 / 20085: 38$ & 2.243 & 23.9 \\
\hline 2036 & $1 / 10 / 20085: 40$ & $8 / 10 / 20085: 40$ & 2.243 & 24. \\
\hline 2037 & $1 / 10 / 20085: 42$ & $8 / 10 / 20085: 42$ & 2.243 & 24.1 \\
\hline 2038 & $1 / 10 / 20085: 44$ & $8 / 10 / 20085: 44$ & 2.244 & 24.2 \\
\hline 2039 & $1 / 10 / 20085: 46$ & $8 / 10 / 20085: 46$ & 2.236 & 24.3 \\
\hline 2040 & $1 / 10 / 20085: 48$ & $8 / 10 / 20085: 48$ & 2.202 & 24.6 \\
\hline
\end{tabular}


DOE/RL-2009-35, REV. 0

\begin{tabular}{|c|c|c|c|c|}
\hline \multicolumn{5}{|c|}{ D493p } \\
\hline Rec & & Adjusted & Pressure & Temp \\
\hline$\#$ & DaterTime & Date/Time & psi & ${ }^{\circ} \mathrm{C}$ \\
\hline 2041 & $1 / 10 / 20085: 50$ & $8 / 10 / 2008$ 5:50 & 2119 & 24.9 \\
\hline 2042 & $1 / 10 / 20085: 52$ & 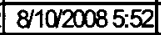 & 2087 & 24.9 \\
\hline 2043 & $1 / 10 / 2008554$ & $8 / 1020085: 54$ & 2072 & 24.9 \\
\hline 2044 & $1 / 1020085: 56$ & $8 / 1020085: 56$ & 2061 & 24.9 \\
\hline 2045 & $1 / 10 / 20085: 58$ & $8 / 1020085: 58$ & 2053 & 25 \\
\hline 2046 & $1 / 10 / 20086: 00$ & $8 / 10 / 20086: 00$ & 2046 & 25 \\
\hline 2047 & 1/10/20086:02 & $8 / 10 / 20086: 02$ & 2.04 & 25 \\
\hline 2048 & $1 / 10 / 20086: 04$ & $8 / 10 / 20086: 04$ & 2035 & 25 \\
\hline 2049 & $1 / 10 / 20$ & $8 / 10 / 20086: 06$ & 2063 & 25 \\
\hline 2050 & $1 / 10 / 200$ & $8 / 10 / 20086: 08$ & 216 & 25 \\
\hline 2051 & $1 / 10 / 200$ & 8/10:20086:10 & 2169 & 24.9 \\
\hline 2052 & $1 / 10 / 200$ & \begin{tabular}{|l|l|}
$80200: 12$ \\
\end{tabular} & 2189 & 24.8 \\
\hline 2053 & $1 / 10 / 2$ & $8 / 10 / 20086: 14$ & 2199 & 24.7 \\
\hline 2054 & $1 / 10 / 2$ & $8 / 10 / 20086: 16$ & 2206 & 24.6 \\
\hline 2055 & $1 / 10 / 20$ & $8 / 10 / 20086: 18$ & 2211 & 24.6 \\
\hline 2056 & $1 / 10 / 2$ & $8 / 10 / 20086: 20$ & 2214 & 24.6 \\
\hline 205 & $1 / 10 / 2$ & $8 / 102008622$ & 2218 & \\
\hline 2068 & $1 / 10 / 2$ & $8 / 10 / 20086: 24$ & 2.218 & 24.1 \\
\hline 2059 & $1 / 10 / 20$ & $8 / 10 / 20086: 26$ & 222 & 24.1 \\
\hline 2060 & $1 / 10 / 2$ & 81102200 & 2223 & 24.1 \\
\hline 2061 & $1 / 10 / 2$ & $8 / 10 / 200$ & 2058 & \\
\hline 2062 & $1 / 10 / 20$ & $8 / 10 / 20086: 32$ & 2237 & 23.8 \\
\hline 2063 & $1 / 10 / 20$ & $8 / 10 / 20086: 34$ & 2228 & 23.8 \\
\hline 2064 & $1 / 1 \alpha^{2}$ & $8 / 10 / 20$ & 2229 & 23.8 \\
\hline 2065 & $1 / 10 / 2$ & $8 / 10 / 200$ & 2229 & 23.8 \\
\hline 2066 & $1 / 10 / 2$ & $8 / 10 / 20086: 40$ & 2231 & 23.7 \\
\hline 2067 & $1 / 10 / 2$ & $8 / 10 / 200$ & 223 & 23.8 \\
\hline 206 & $1 / 10 / 2$ & $8 / 10 / 20$ & 2233 & 23.9 \\
\hline 2069 & $1 / 10 / 2$ & $8 / 10 / 20086: 46$ & 2216 & 23.7 \\
\hline 2070 & $1 / 10 / 20$ & $8 / 10 / 20086: 48$ & 2229 & 23.6 \\
\hline 2071 & $1 / 10$ & $8 / 10 / 20$ & 2232 & 23.6 \\
\hline 2072 & $1 / 10$ & $8 / 10 / 20$ & 2234 & 23.5 \\
\hline 2073 & $1 / 10 / 2$ & $8 / 10 / 20086: 54$ & 2235 & 23.4 \\
\hline 2074 & & $8 / 10 / 20086: 56$ & 2236 & 23.4 \\
\hline 2075 & & $8 / 10 / 20$ & 2237 & 23.3 \\
\hline 2076 & $1 / 10$ & $8 / 10 / 20$ & 2237 & 23.3 \\
\hline 207 & $1 / 10$ & $8 / 10 / 2008$ & 2238 & 23.4 \\
\hline 2078 & & $8 / 10200$ & 2239 & 23.5 \\
\hline 2075 & $1 / 10$ & $8 / 102$ & 2.24 & 23.7 \\
\hline 2080 & $1 / 10$ & $8 / 10 / 20$ & 2239 & 23.6 \\
\hline 2081 & $1 / 10 / 2$ & $8 / 10 / 20087: 10$ & 224 & 23.6 \\
\hline 2082 & & $8 / 10 / 2$ & 2239 & 23.6 \\
\hline 2083 & $1 / 10$ & $8 / 10 / 20$ & 2239 & 23.6 \\
\hline 2084 & $1 / 10 / 2$ & $8 / 10 / 20087: 16$ & 2242 & 23.7 \\
\hline 2085 & & $8 / 10 / 20087: 18$ & 2241 & 23.7 \\
\hline 208 & & $8 / 1 \alpha^{\prime}$ & 2243 & 23.8 \\
\hline 2087 & & $8 / 10 / 200$ & 2244 & 23.8 \\
\hline 2088 & & $8 / 10 / 200$ & 2245 & 23.8 \\
\hline 2089 & & & 2246 & 23.8 \\
\hline 2090 & & $8 / 10 / 20$ & 2247 & 23.8 \\
\hline 2091 & & $8 / 10 / 20$ & 2248 & 23.9 \\
\hline 2092 & & & 2249 & 23.9 \\
\hline 2093 & & $8 / 10 / 2$ & 2249 & 23.9 \\
\hline 2094 & & $8 / 10220$ & 2.25 & 23.9 \\
\hline 2095 & & $8 / 102200$ & 225 & 23.8 \\
\hline 2096 & & & 2248 & 23.8 \\
\hline 2097 & & $\sqrt{110}$ & 2248 & 23. \\
\hline 2098 & $1 / 10 / 2$ & $8 / 10 / 20087: 44$ & 2.25 & 23.9 \\
\hline 2099 & & $8 / 10 / 200$ & 2449 & 23.9 \\
\hline 2100 & & $8 / 10 / 20087: 48$ & 2249 & \\
\hline 2101 & $1 / 10 / 2$ & $8 / 10 / 20087: 50$ & 2249 & 23.0 \\
\hline 2102 & $1 / 10 / 20$ & $8 / 10 / 20087: 52$ & 2249 & 23.9 \\
\hline 2103 & & $8 / 10 / 20087: 54$ & 2.25 & 24 \\
\hline 210 & & & 2251 & \\
\hline 210 & $1 / 10 / 2$ & $8 / 10 / 20087: 58$ & 2251 & 23. \\
\hline 210 & & $8 / 10 / 20088: 00$ & 2.253 & 23. \\
\hline 2100 & & $8 / 10 / 20088: 02$ & 225 & 23. \\
\hline & & & 2253 & \\
\hline
\end{tabular}

\begin{tabular}{|c|c|c|c|c|}
\hline \multicolumn{5}{|c|}{ D4-93p } \\
\hline $\operatorname{Rec}$ & & Adjusted & ressure & Temp \\
\hline$\#$ & DaterTime & DaterTime & $p s i$ & ${ }^{\circ} \mathrm{C}$ \\
\hline 2109 & $1 / 10 / 20088: 06$ & $8 / 10 / 20088: 06$ & 2253 & \\
\hline 2110 & $1 / 1020088.08$ & 3/10/20088:08 & 2.254 & \\
\hline 2111 & 10/20088:10 & $8 / 10 / 20088: 10$ & 2254 & \\
\hline 2112 & $10 / 20088: 12$ & $8 / 10 / 20088: 12$ & 2.253 & \\
\hline 2113 & 1/10/2008 8:14 & $8 / 10 / 20088: 14$ & 2.254 & $\overline{23}$ \\
\hline 2114 & 1/10/20088:16 & $8 / 10 / 20088: 16$ & 2255 & 23 \\
\hline 2115 & $1 / 1020$ & $8 / 10 / 200$ & 2255 & 23 \\
\hline 2116 & $1 / 1020$ & $8 / 10 / 20088: 20$ & 2255 & \\
\hline 2117 & $1 / 10720088: 22$ & $8 / 10 / 20088: 22$ & 2255 & 23 \\
\hline 2118 & $1 / 10120088.24$ & $8 / 10 / 20088: 24$ & 2256 & 23 \\
\hline 2119 & $1 / 10 \sqrt{2}$ & $8 / 10 / 200$ & 2256 & 23 \\
\hline 2120 & $1 / 10 / 20$ & $8 / 10 / 20$ & 2256 & \\
\hline 2121 & $1 / 10 / 2 x$ & $8 / 10 / 20088: 30$ & 2256 & 23. \\
\hline 212 & $1 / 10 / 20088: 32$ & $8 / 10 / 20088: 32$ & 2.258 & \\
\hline 2123 & $1 / 102$ & $8 / 10 / 20$ & 2259 & \\
\hline 2124 & $1 / 102$ & $8 / 10 / 20$ & 226 & \\
\hline 2125 & $1 / 1 \alpha^{2}$ & $8 / 10 / 20$ & 2259 & 24 \\
\hline 2126 & $1 / 1 \alpha^{2}$ & $8 / 10 / 20$ & 2259 & 24. \\
\hline 2127 & $1 / 10$ & $8 / 10 / 20$ & 2.250 & 24. \\
\hline 2128 & $1 / 102$ & $8 / 1020$ & 2258 & 24 \\
\hline 2129 & $1 / 10 / 2$ & $8 / 10 / 200$ & 2258 & \\
\hline 2130 & $1 / 10$ & $8 / 10 / 20$ & 2257 & 23. \\
\hline 2131 & & $8 / 10 / 20$ & 2.158 & 23. \\
\hline 2132 & $1 / 10^{\prime 2}$ & $8 / 10 / 20$ & 2123 & 24 \\
\hline 2133 & $1 / 10 / 2$ & $8 / 10 / 20$ & 2105 & 24. \\
\hline 2134 & & $8 / 10 / 2$ & 2075 & 24. \\
\hline 2135 & & $\overline{8 / 10 / 2}$ & 2061 & 24 \\
\hline 2136 & $1 / 90$ & $8 / 10 / 20$ & 2.053 & 24 \\
\hline 2137 & $1 / 10$ & $8 / 10 / 20$ & 2047 & 24 \\
\hline 2138 & & $8 / 10 / 20$ & 204 & 24. \\
\hline 2139 & & $8 / 10 / 20$ & 2099 & 24 \\
\hline 2140 & $1 / 10 / 2$ & $8 / 10 / 20089.08$ & 2.179 & 24 \\
\hline 2141 & & $8 / 10 / 2$ & 2195 & 24 \\
\hline 2142 & & $8 / 10$ & 2.207 & 24 \\
\hline 2143 & & $8 / 10 / 200$ & 2215 & 24 \\
\hline 2144 & $1 / 102$ & $8 / 10 / 200$ & 2136 & 24 \\
\hline 2145 & & $8 / 10 / 2$ & 2167 & 24 \\
\hline 2146 & & $8 / 10 / 2$ & 2.349 & 24 \\
\hline 2147 & $1 / 10$ & $8 / 10 / 20$ & 224 & 25 \\
\hline 2148 & & $8 / 10 / 20$ & 2241 & 25 \\
\hline 2149 & & $8 / 10$ & 2244 & 24 \\
\hline 2150 & & $8 / 10 / 2$ & 2245 & 24 \\
\hline 2151 & & $8 / 10 / 2$ & 2247 & 24 \\
\hline 2152 & & & 214 & 24 \\
\hline 2153 & & $8 / 10$ & 2.189 & 24 \\
\hline 2154 & & $8 / 10 / 2$ & 2259 & 25 \\
\hline 2155 & & & 2258 & 25 \\
\hline 56 & & $8 / 10$ & 2259 & \\
\hline 2157 & & $\overline{110}$ & 226 & \\
\hline 2158 & & $8 / 10 / 20$ & 2262 & 24 \\
\hline 2159 & & & 2263 & 24 \\
\hline 160 & & $\overline{8}$ & 2265 & \\
\hline 2161 & & $8 / 10 / 2$ & 2266 & 24 \\
\hline 2162 & & & 2.268 & 24 \\
\hline 2163 & & & 227 & 24 \\
\hline 2164 & & & 2271 & \\
\hline 2165 & & $8 / 10 / 20$ & 2271 & 24 \\
\hline 2166 & & & 2272 & 24 \\
\hline 2167 & & & & \\
\hline 2168 & & $0: 04$ & 2273 & \\
\hline $216^{\circ}$ & & $10 / 2008$ 10:06 & 2274 & 24 \\
\hline & & & 2274 & \\
\hline & & & 2276 & \\
\hline 2172 & & 10/2008 10:12 & 2277 & 24 \\
\hline 2173 & & 110200810.14 & 2.277 & 24 \\
\hline 74 & & $110 / 200810.16$ & 221 & 24 \\
\hline 21 & & & 2278 & \\
\hline & & $8 / 10 / 200$ & 2279 & \\
\hline
\end{tabular}

\begin{tabular}{|c|c|c|c|c|}
\hline \multicolumn{5}{|c|}{ D4-93p } \\
\hline$R \in C$ & & Adjusted & Pressure & Temp \\
\hline \# & DaterTime & DaterTime & psi & ${ }^{\circ} \mathrm{C}$ \\
\hline 2177 & $1 / 10 / 200810: 22$ & $8 / 10 / 200810: 22$ & 2279 & 24.8 \\
\hline 2178 & $1 / 10 / 200810: 24$ & $8 / 107200810: 24$ & 2279 & 24.8 \\
\hline 2179 & $1 / 102000810: 26$ & $8 / 102200810: 26$ & 2279 & 24.8 \\
\hline 2180 & $1 / 10 / 200810.28$ & $8 / 102008$ 10:28 & 228 & 24.8 \\
\hline 2181 & $1 / 102000810: 30$ & $8 / 102008$ 10:30 & 2281 & 24.8 \\
\hline 2182 & $1 / 102008$ 10:32 & $8 / 1020006$ 10:32 & 2281 & 24.8 \\
\hline 2183 & $1 / 10 / 200810: 34$ & $8 / 10 / 200810.34$ & 2282 & 24.8 \\
\hline 2184 & $1 / 10 / 200810: 36$ & $8 / 102200810.36$ & 2281 & 24.9 \\
\hline 2185 & $1 / 10 / 200810.38$ & $8 / 10 / 2008$ 10:38 & 2282 & 24.9 \\
\hline 2186 & $1 / 10 / 200810.40$ & $8 / 10 / 2008$ 10:40 & 2283 & 24.8 \\
\hline 2187 & $1 / 10200810.42$ & $8 / 10 / 2008$ 10:42 & 2283 & 24.8 \\
\hline 2188 & $1 / 10 / 200810: 44$ & $8 / 10 / 200810: 44$ & 2284 & 24.9 \\
\hline 2189 & $1 / 10 / 200810: 46$ & $8 / 10 / 200810: 46$ & 2284 & 24.9 \\
\hline 2190 & $1 / 10 / 200810: 48$ & $8 / 10 / 200810: 48$ & 2284 & 24.9 \\
\hline 2191 & $1 / 1 \alpha / 200810.50$ & $8 / 10 / 200810.50$ & 2284 & 24.9 \\
\hline 2192 & $1 / 10 / 200810.52$ & $8 / 10 / 200810: 52$ & 2284 & 24.9 \\
\hline 2193 & $1 / 10 / 200810: 54$ & $8 / 10 / 200810: 54$ & 2285 & 24.9 \\
\hline 2194 & $1 / 10 / 200810.56$ & $8 / 10200810: 56$ & 2286 & 24.9 \\
\hline 2195 & $1 / 10200810.58$ & $8 / 10 / 2008$ 10:58 & 2287 & 24.9 \\
\hline 2196 & 1/10/2008 11:00 & $8 / 102200811: 00$ & 2287 & 24.9 \\
\hline 2197 & $1 / 10 / 200811: 02$ & $8 / 10 / 200811: 02$ & 2287 & 24.9 \\
\hline 2198 & $1 / 10 / 2008$ 11:04 & $8 / 10 / 200811: 04$ & 2287 & 24.9 \\
\hline 2199 & $1 / 10 / 200811: 06$ & $8 / 10 / 200811: 06$ & 2288 & 24.9 \\
\hline 2200 & $1 / 10 / 200811: 08$ & $8 / 10 / 200811: 08$ & 2288 & 24.9 \\
\hline 2201 & 1/10/2008 11:10 & $8 / 10 / 200811: 10$ & 2289 & 24.9 \\
\hline 202 & 1/10/2008 11:12 & $8 / 10 / 2008$ 11:12 & 2289 & 24.9 \\
\hline 2203 & 1/10/2008 11:14 & $8 / 10 / 200811: 14$ & 2289 & 24.9 \\
\hline 2204 & 1/10/2008 11:16 & $8 / 10 / 200811: 16$ & 2291 & 24.9 \\
\hline 2205 & 1/10/2008 11:18 & $8 / 10 / 2008$ 11:18 & 2.292 & 24.9 \\
\hline 2206 & 1/102008 11:20 & $8 / 10 / 2008$ 11:20 & 2292 & 24.9 \\
\hline 2207 & 1/102008 11:22 & $8 / 10 / 200811: 22$ & 2202 & 24.9 \\
\hline 2208 & $1 / 10 / 200811: 24$ & $8 / 10 / 200811: 24$ & 2293 & 24.9 \\
\hline 2209 & $1 / 10 / 200811: 26$ & $8 / 10 / 2008$ 11:26 & 2293 & 24.9 \\
\hline 2210 & 1/10/2008 11:28 & $8 / 102008$ 11:28 & 2295 & 24.9 \\
\hline 2211 & $1 / 10 / 200811: 30$ & $8 / 10 / 2008$ 11:30 & 2295 & 24.9 \\
\hline 2212 & 1/10/2008 11:32 & $8 / 10200811: 32$ & 2294 & 24.9 \\
\hline 2213 & 1/10/2008 11:34 & $8 / 10 / 2008$ 11:34 & 2295 & 24.9 \\
\hline 2214 & 1/10/2008 11:36 & $8 / 10 / 200811: 36$ & 22296 & 24.9 \\
\hline 2215 & 1/10/2008 11:38 & $8 / 10 / 200811: 38$ & 2298 & 24.9 \\
\hline 2216 & $1 / 10200811: 40$ & $8 / 10 / 200811: 40$ & 2299 & 24.9 \\
\hline 2217 & $1 / 10 / 2008$ 11:42 & $8 / 10 / 200811: 42$ & 2298 & 24.9 \\
\hline 2218 & $1 / 10 / 200811: 44$ & $8 / 10 / 2008$ 11:44 & 2298 & 24.9 \\
\hline 2219 & $1 / 10 / 200811: 46$ & $8 / 10 / 2008+1: 46$ & 2297 & 24.9 \\
\hline 2220 & $1 / 10 / 200811: 48$ & $8 / 10 / 200811: 48$ & 229 & 24.9 \\
\hline 2221 & $1 / 1 \alpha 200811: 50$ & $8 / 10 / 200811: 50$ & 2176 & 25 \\
\hline $2 m$ & $1 / 10 / 200811: 52$ & $8 / 102000$ 11:52 & 2122 & 25 \\
\hline 2223 & 1/10/2008 11:54 & $8 / 10200811: 54$ & 2006 & 25 \\
\hline 224 & $1 / 102008$ 11:56 & $8 / 10 / 2008$ 11:56 & 208 & 25 \\
\hline 2225 & $1 / 10 / 200811: 58$ & $8 / 102008$ 11:58 & 2071 & 25 \\
\hline 2226 & 1/10/2008 1200 & 8/10/2008 12:00 & 2064 & 24.9 \\
\hline 2227 & 1/10/2008 1202 & $8 / 10 / 200812: 02$ & 2059 & 25 \\
\hline 2228 & 1/10/2008 12:04 & $8 / 10200812: 04$ & 2175 & 24.9 \\
\hline 2229 & $1 / 10 / 20081206$ & $8 / 10 / 2008$ 12:06 & 2216 & 24.9 \\
\hline 2230 & $1 / 1020081208$ & $8 / 10 / 200812: 08$ & 2234 & 24.9 \\
\hline 2231 & $1 / 10 / 200812 \div 10$ & $8 / 10 / 20081210$ & 225 & 24.9 \\
\hline 2232 & $1 / 10 / 200812 \div 12$ & $8 / 10 / 200812: 12$ & 2261 & 24.9 \\
\hline 2233 & $1 / 10200012: 14$ & $8 / 10 / 200812: 14$ & 2268 & 24.9 \\
\hline 2234 & $1 / 10 / 200812: 16$ & $8 / 10 / 200812: 16$ & 2271 & 24.9 \\
\hline 2235 & $1 / 10 / 20081218$ & $8 / 10 / 20081218$ & 2275 & 24.9 \\
\hline 2236 & 1/102008 12:20 & $8 / 10 / 200812: 20$ & 2278 & 24.9 \\
\hline 2237 & $1 / 10 / 20081222$ & 8/10/2008 1222 & 2.281 & 24.9 \\
\hline 2238 & $1 / 10 / 200812: 24$ & $8 / 10200812: 24$ & 2282 & 24.9 \\
\hline 2239 & $1 / 1020081226$ & $8 / 10^{\prime 2} 20081226$ & 2284 & 24.9 \\
\hline 2240 & $1 / 10200812: 28$ & $8 / 10 / 20081228$ & 2.287 & 25 \\
\hline 2241 & $1 / 10 / 20081230$ & $8 / 10200812: 30$ & 2289 & 25 \\
\hline 224 & $1 / 1020081232$ & $8 / 10 / 20081232$ & 2291 & 25 \\
\hline 2243 & $1 / 1020081234$ & $8 / 1020001234$ & 2293 & 25 \\
\hline 2244 & $1 / 10 / 20081236$ & $8 / 1020081236$ & 2295 & 25.1 \\
\hline
\end{tabular}




\begin{tabular}{|c|c|c|c|c|}
\hline \multicolumn{5}{|c|}{ D4-93p } \\
\hline $\operatorname{Rec}$ & & Adjusted & Pressure & Termp \\
\hline$\#$ & DaterTime & Date/Time & psi & ${ }^{\circ} \mathrm{C}$ \\
\hline 2245 & $1 / 10 / 200812: 38$ & $8 / 10 / 2008$ 12:38 & 2.296 & 25.1 \\
\hline 2246 & $1 / 1020081240$ & $8 / 10 / 200812: 40$ & 2298 & 25.1 \\
\hline 2247 & $1 / 10 / 20081242$ & $8 / 10 / 200812: 42$ & 2298 & 25.2 \\
\hline 2248 & $1 / 10 / 20081244$ & $8 / 10 / 200812: 44$ & 2299 & 25.2 \\
\hline 2249 & $1 / 10 / 200812: 46$ & $8 / 10 / 200812: 46$ & 2301 & 25.3 \\
\hline 2250 & $1 / 10 / 20081248$ & $8 / 10 / 2008$ 12:48 & 2.303 & 25.3 \\
\hline 2251 & $1 / 10 / 200812: 50$ & $8 / 10 / 200812: 50$ & 2.304 & 25.3 \\
\hline 2252 & $1 / 10 / 200812: 52$ & $8 / 10 / 2008$ 12:52 & 2.305 & 25.3 \\
\hline 2253 & $1 / 10 / 200812: 54$ & $8 / 10 / 2008$ 12:54 & 2306 & 25.3 \\
\hline 2254 & $1 / 10 / 200812: 56$ & $8 / 10 / 200812: 56$ & 2.175 & 25.3 \\
\hline 2255 & $1 / 10 / 200812: 58$ & $8 / 10 / 200812: 58$ & 2.328 & 25.4 \\
\hline 2256 & $1 / 10 / 200813: 00$ & $8 / 10 / 2008$ 13:00 & 2.308 & 25.5 \\
\hline 2257 & $1 / 10 / 200813: 02$ & $8 / 10 / 2008$ 13:02 & 2309 & 26 \\
\hline 2258 & $1 / 10 / 200813: 04$ & $8 / 10 / 2008$ 13:04 & 2309 & 25.6 \\
\hline 2259 & $1 / 10 / 200813: 06$ & $8 / 10 / 2008$ 13:06 & 2309 & 25.6 \\
\hline 2260 & $1 / 10 / 200813: 08$ & $8 / 102008$ 13:08 & 2.31 & 25.6 \\
\hline 2261 & $1 / 10 / 200813: 10$ & $8 / 102008$ 13:10 & 2.31 & 25.6 \\
\hline 2262 & $1 / 10 / 200813: 12$ & $8 / 10 / 200813: 12$ & 2.311 & 25.6 \\
\hline 2263 & $1 / 10 / 200813: 14$ & $8 / 102008$ 13:14 & 2312 & 25.6 \\
\hline 2264 & 1/10/2008 13:16 & $8 / 10200813: 16$ & 2313 & 25.6 \\
\hline 2265 & $1 / 10 / 200813: 18$ & $8 / 10 / 200813: 18$ & 2314 & 25.6 \\
\hline 2266 & $1 / 10 / 2008$ 13:20 & $8 / 10 / 200813: 20$ & 2316 & 25.6 \\
\hline 2267 & $1 / 10 / 2008$ 13:22 & $8 / 10 / 20$ & 2.316 & 25.6 \\
\hline 2268 & 1/10/2008 13:24 & $8 / 10 / 200813: 24$ & 2.317 & 25.6 \\
\hline 2269 & $1 / 10 / 200813: 26$ & $8 / 10 / 200813: 26$ & 2.319 & 25.6 \\
\hline 2270 & 1/10/2008 13:28 & $8 / 10 / 200813: 28$ & 2.32 & 25.7 \\
\hline 2271 & $1 / 10 / 2008$ 13:30 & $8 / 10 / 200813: 30$ & 2.319 & 25.7 \\
\hline 2272 & $1 / 10 / 200813: 32$ & $8 / 10 / 200813: 32$ & 2.319 & 25.7 \\
\hline 2273 & $1 / 10 / 200813: 34$ & $8 / 102008$ 13:34 & 2.319 & 25.7 \\
\hline 2274 & $1 / 10 / 200813: 36$ & $8 / 10 / 200813: 36$ & 2.321 & 25.8 \\
\hline 2275 & $1 / 10 / 200$ & $8 / 10 / 200813: 38$ & 2.321 & 25.8 \\
\hline 2276 & $1 / 10 / 200813: 40$ & $8 / 10 / 200813: 40$ & 2.321 & 25.8 \\
\hline 2277 & $1 / 10 / 200813: 42$ & $8 / 10 / 200813: 42$ & 2.323 & 25.8 \\
\hline 2278 & $1 / 10 / 200$ & $8 / 10 / 200813: 44$ & 2.323 & 25.8 \\
\hline 2279 & $1 / 10 / 200813: 46$ & $8 / 10 / 200813: 46$ & 2.323 & 25.8 \\
\hline 2280 & $1 / 10 / 200813: 48$ & $8 / 10 / 200813: 48$ & 2.324 & 25.8 \\
\hline 2281 & $1 / 10 / 200813: 50$ & $8 / 10 / 200813: 50$ & 2.325 & 25.8 \\
\hline 2282 & $1 / 10 / 2008$ 13:52 & $8 / 10 / 200813: 52$ & 2.325 & 25.8 \\
\hline 2283 & $1 / 10 / 200813: 54$ & $8 / 10 / 200813: 54$ & 2.326 & 25.8 \\
\hline 2284 & $1 / 10 / 200813-56$ & $8 / 10 / 2008$ 13:56 & 2.327 & 25.8 \\
\hline 2285 & $1 / 10 / 200813: 58$ & $8 / 10 / 200813: 58$ & 2.327 & 25.9 \\
\hline 2286 & $1 / 10 / 2008$ 14:00 & $8 / 10 / 200814: 00$ & 2.328 & 25.9 \\
\hline 2287 & $1 / 10 / 200814: 02$ & $8 / 10 / 200814: 02$ & 2.328 & 25.9 \\
\hline 2288 & $1 / 10 / 200814: 04$ & $8 / 10 / 200814: 04$ & 2.328 & 25.9 \\
\hline 2289 & $1 / 10 / 2008$ 14:06 & $8 / 10 / 200814: 06$ & 2.329 & 25.9 \\
\hline 2290 & $1 / 10 / 200814: 08$ & $8 / 10 / 200814: 08$ & 2.331 & 25.9 \\
\hline 2291 & $1 / 10 / 200814: 10$ & $8 / 10 / 200814: 10$ & 2.333 & 25.9 \\
\hline 2292 & $1 / 10 / 2008$ 14:12 & $8 / 10200814: 12$ & 2.335 & 25.9 \\
\hline 2293 & 1/10/2008 14:14 & $8 / 10 / 200814: 14$ & 2.337 & 25.9 \\
\hline 2294 & $1 / 10 / 200814: 16$ & $8 / 102000814: 16$ & 2.341 & 25.9 \\
\hline 2295 & $1 / 10 / 2008$ 14:18 & $8 / 10 / 200814: 18$ & 2.342 & 25.9 \\
\hline 2296 & $1 / 10 / 200814: 20$ & $8 / 10 / 200814: 20$ & 2.343 & 25.9 \\
\hline 2297 & $1 / 10 / 200814: 22$ & $8 / 10 / 200814: 22$ & 2.344 & 25.9 \\
\hline 2298 & 1/10/2008 14:24 & $8 / 10 / 200814: 24$ & 2.345 & 25.9 \\
\hline 2299 & $1 / 10 / 200814: 26$ & $8 / 10 / 200814: 26$ & 2.346 & 25.9 \\
\hline 2300 & $1 / 10 / 2008$ 14:28 & $8 / 10 / 200814: 28$ & 2.345 & 25.9 \\
\hline 2301 & $1 / 10 / 2008$ 14:30 & $8 / 10 / 200814: 30$ & 2.345 & 26 \\
\hline 2302 & $1 / 10 / 200814: 32$ & $8 / 10 / 200814: 32$ & 2346 & 26 \\
\hline 2303 & $1 / 10 / 200814: 34$ & $8 / 10 / 200814: 34$ & 2346 & 26.1 \\
\hline 2304 & $1 / 40 / 200814: 36$ & $8 / 10 / 200814: 36$ & 2.346 & 26.1 \\
\hline 2305 & $1 / 10 / 200814: 38$ & $8 / 10 / 200814: 38$ & 2.347 & 26.1 \\
\hline 2306 & $1 / 10 / 200814: 40$ & $8 / 10 / 200814: 40$ & 2.348 & 26.1 \\
\hline 2307 & $1 / 10 / 200814: 42$ & $8 / 10 / 200814: 42$ & 2347 & 26.1 \\
\hline 2308 & $1 / 10 / 200814: 44$ & $8 / 10200814: 44$ & 2.339 & 26.1 \\
\hline 2309 & $1 / 10 / 200814: 46$ & $8 / 10 / 200814: 46$ & 2.295 & 26.1 \\
\hline 2310 & $1 / 10 / 200814: 48$ & $8 / 10 / 200814: 48$ & 2.232 & 26.1 \\
\hline 2311 & $1 / 10 / 200814: 50$ & $8 / 10 / 200814: 50$ & 2159 & 26.1 \\
\hline 2312 & $1 / 10 / 200814: 52$ & $8 / 10200814: 52$ & 2.119 & 26.1 \\
\hline
\end{tabular}

\begin{tabular}{|c|c|c|c|c|c|c|c|c|c|}
\hline \multicolumn{5}{|c|}{ D4-93p } & \multicolumn{5}{|c|}{ D4-93p } \\
\hline $\operatorname{Rec}$ & & Adjusted & Pressure & Temp & $\operatorname{Rec}$ & & Adjusted & Pressure & Temp \\
\hline$\#$ & Date/Time & Date/Time & psi & ${ }^{\circ} \mathrm{C}$ & $\#$ & Date/Time & Date-Time & $p s i$ & ${ }^{\circ} \mathrm{C}$ \\
\hline 2313 & 1/10/2008 14:54 & $8 / 10 / 2008$ 14:54 & 2,101 & 26.1 & 2381 & 1/10/2008 17:10 & $8 / 10 / 2008$ 17:10 & 2.368 & 26.9 \\
\hline 2314 & 1/10:2008 14:56 & $8 / 102008$ 14:56 & 2087 & 26.1 & 2382 & $1 / 10 / 2008$ 17:12 & $8 / 10 / 2008$ 17:12 & 2.37 & 26.9 \\
\hline $23+5$ & $1 / 10 / 200814: 58$ & $8 / 10 / 200814: 58$ & 2077 & 26.1 & 2383 & 1/10/2008 17:14 & $8 / 10 / 2008$ 17:14 & 2.37 & 26.9 \\
\hline 2316 & 1/10/2008 15:00 & $8 / 10 / 200815: 00$ & 2.07 & 26.1 & 2384 & 1/10/2008 17:16 & $8 / 10 / 2008$ 17:16 & 2.37 & 26.9 \\
\hline 2317 & 1/10/2008 15:02 & \begin{tabular}{|l|}
$8 / 10 / 200815: 02$ \\
\end{tabular} & 2064 & 26.1 & 2385 & 1/10/2008 17:18 & $8 / 10 / 2008$ 17:18 & 2369 & 26.9 \\
\hline 2318 & $1 / 10 / 2008$ 15:04 & \begin{tabular}{|l|}
$8 / 10 / 200815: 04$ \\
\end{tabular} & 2059 & 26 & 2386 & 1/10/2008 17:20 & $8 / 10 / 200817: 20$ & 2368 & 26.9 \\
\hline 2319 & $1 / 10 / 2008$ 15:06 & \begin{tabular}{|l|}
$8 / 10 / 200815: 06$ \\
\end{tabular} & 215 & 26 & 2387 & $1 / 10 / 200817: 22$ & $8 / 10 / 2008$ 17:22 & 2.369 & 26.9 \\
\hline 2320 & 1/10/2008 15:08 & \begin{tabular}{|l|l|}
$8 / 100815: 08$ \\
\end{tabular} & 2237 & 26 & 2388 & $1 / 10 / 2008$ 17:24 & $8 / 10 / 2008$ 17:24 & 2.37 & 27 \\
\hline 2321 & $1 / 10 / 2008$ 15:10 & \begin{tabular}{|l|}
$8 / 10 / 2008$ 15:10 \\
\end{tabular} & 2264 & 26 & 2389 & $1 / 10 / 200817: 26$ & $8 / 10 / 2008$ 17:26 & 2.37 & 27 \\
\hline 2322 & $1 / 10 / 2008$ 15:12 & $8 / 10 / 200815: 12$ & 2.281 & 26 & 2390 & 1/10/2008 17:28 & $8 / 10 / 2008$ 17:28 & 2371 & 27 \\
\hline 2323 & 1/10/2008 15:14 & \begin{tabular}{|l|}
$8 / 10 / 2008$ 15:14 \\
\end{tabular} & 2298 & 26 & 2391 & 1/10:2008 17:30 & $8 / 10 / 2008$ 17:30 & 2.373 & 27 \\
\hline 2324 & 1/10/2008 15:16 & $8 / 10 / 2008$ 15:16 & 2307 & 25.9 & 2392 & $1 / 10 / 2008$ 17:32 & $8 / 10 / 2008$ 17:32 & 2373 & 27.1 \\
\hline 2325 & 1/10/2008 15:18 & 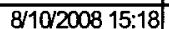 & 2.317 & 25.9 & 2393 & 1/10/2008 17:34 & $8 / 10 / 2008$ 17:34 & 2.372 & 27.1 \\
\hline 2326 & $1 / 10 / 200815: 20$ & \begin{tabular}{|l|}
$8 / 10 / 2008$ 15:20 \\
\end{tabular} & 2.321 & 25.9 & 2394 & 1/10/2008 17:36 & $8 / 10 / 200817: 36$ & 2.374 & 27.1 \\
\hline 2327 & 1/10/2008 15:22 & $8 / 10 / 2008$ 15:22 & 2.321 & 25.9 & 2395 & 1/10/2008 17:38 & 8/10/2008 17:38 & 2379 & 27.1 \\
\hline 2328 & 1/10/2008 15:24 & \begin{tabular}{|l|}
$8 / 10 / 2008$ 15:24 \\
\end{tabular} & 2319 & 25.8 & 2396 & 1/10/2008 17:40 & $8 / 10200817: 40$ & 2383 & 27 \\
\hline 2329 & 1/10/2008 15:26 & $8 / 10 / 200815: 26$ & 2319 & 25.9 & 2397 & 1/10/2008 17:42 & $8 / 10 / 2008$ 17:42 & 2385 & 27 \\
\hline 2330 & 1/10/2008 15:28 & $8 / 10 / 2008$ 15:28 & 232 & 26.1 & 2398 & 1/10/2008 17:44 & $8 / 10 / 200817: 44$ & 2384 & 27 \\
\hline 2331 & $1 / 10 / 200815: 30$ & $8 / 10 / 200815: 30$ & 2325 & 26.1 & 2399 & $1 / 10 / 2008$ 17:46 & $8 / 10 / 2008$ 17:46 & 2307 & 27 \\
\hline 2332 & 1/10/2008 15:32 & $8 / 10 / 2008$ 15:32 & 2328 & 26.2 & 2400 & $1 / 10 / 200817: 48$ & $8 / 10 / 2008$ 17:48 & 2.228 & 27.1 \\
\hline 2333 & $1 / 10 / 200815: 34$ & $8 / 10 / 200815: 34$ & 2331 & 26.2 & 2401 & $1 / 10 / 200817: 50$ & $8 / 10 / 200$ & 2.169 & 27.1 \\
\hline 2334 & $1 / 10 / 200815: 36$ & $8 / 10 / 200815: 36$ & 2334 & 26.2 & 2402 & $1 / 10 / 2008$ 17:52 & $8 / 10 / 2008$ 17:52 & 2286 & 27.1 \\
\hline 2335 & $1 / 10 / 200815: 38$ & $8 / 10 / 20$ & 2335 & 26.3 & 2403 & $817: 54$ & $8 / 10 / 20$ & 2322 & 27.1 \\
\hline 2336 & $1 / 10 / 200815: 40$ & $8 / 10 / 20$ & 2339 & 26.3 & 2404 & $1 / 10 / 20$ & $8 / 10 / 20$ & 2.349 & 27.1 \\
\hline 2337 & $1 / 10 / 2008$ 15:42 & $8 / 10 / 20$ & 2.34 & 26.3 & 2405 & $1 / 10 / 20$ & $8 / 10 / 20$ & 2.361 & 27.1 \\
\hline 2338 & $1 / 10 / 200$ & \begin{tabular}{|l|}
$8 / 10 / 200815: 44$ \\
\end{tabular} & 2341 & 26.3 & 2406 & $1 / 10 / 20$ & $8 / 10 / 20$ & 2366 & 27.1 \\
\hline 2339 & 1/10/2008 15:46 & \begin{tabular}{|l|}
$8 / 10 / 200815: 46$ \\
\end{tabular} & 2341 & 26.3 & 2407 & $1 / 1020$ & 818.02 & 2.369 & 27.1 \\
\hline 2340 & 1/10/2008 15:48 & $8 / 10 / 20$ & 2.341 & 26.4 & 2408 & $1 / 10 / 2$ & $8 / 10 / 20$ & 2371 & 27.1 \\
\hline 2341 & 1/10/2008 15:50 & $8 / 10 / 200$ & 2342 & 26.4 & 2409 & $1 / 10 / 20$ & \begin{tabular}{|l|}
$8 / 10 / 200818: 06$ \\
\end{tabular} & 2375 & 27.1 \\
\hline 2342 & 1/10/2008 15:52 & \begin{tabular}{|l|}
$8 / 10 / 200815: 52$ \\
\end{tabular} & 2342 & 26.4 & 2410 & $1 / 10 / 20$ & \begin{tabular}{|l|}
$8 / 10 / 200818: 08$ \\
\end{tabular} & 2.377 & 27.2 \\
\hline 2343 & $1 / 10 / 20$ & $8 / 10 / 2$ & 2344 & 26.4 & 2411 & $1 / 1 \alpha^{2}$ & $8 / 10 / 2$ & 2378 & 27.2 \\
\hline 2344 & $1 / 10 / 200815: 56$ & $8 / 10 / 20$ & 2.345 & 26.4 & 2412 & $318: 12$ & $8 / 10 / 2008$ 18:12 & 2.38 & 27.2 \\
\hline 2345 & $1 / 10 / 200815: 58$ & $8 / 10 / 200815: 58$ & 2345 & 26.4 & 2413 & 1/10/2008 18:14 & $8 / 10 / 200818: 14$ & 2382 & 27.2 \\
\hline 2346 & 1/10/2008 16:00 & $8 / 10 / 20$ & 2345 & 26.4 & 2414 & 318:16 & $8 / 10 / 20$ & 2383 & 27.2 \\
\hline 2347 & 1/10/2008 16:02 & $8 / 10 / 20$ & 2347 & 26.4 & 2415 & $318: 18$ & $8 / 10 / 20$ & 2.384 & 27.3 \\
\hline 2348 & $1 / 10 / 200816: 04$ & $8 / 10 / 20$ & 2348 & 26.4 & 2416 & 18:20 & $8 / 10 / 20$ & 2386 & 27.3 \\
\hline 2349 & $1 / 10 / 2$ & $8 / 10 / 2$ & 2348 & 26.4 & 2417 & $818: 22$ & \begin{tabular}{|l|l|}
$8 / 1000818: 22$ \\
\end{tabular} & 2.386 & 27.3 \\
\hline 2350 & $1 / 10 / 200816: 08$ & $8 / 10 / 2$ & 2349 & 26.4 & 2418 & 1/10/2008 18:24 & \begin{tabular}{|l|}
$8 / 10 / 2008$ 18:24 \\
\end{tabular} & 2.388 & 27.3 \\
\hline 2351 & $1 / 10 / 200$ & $8 / 10 / 2$ & 2.349 & 26.5 & 2419 & & $8 / 10 / 2$ & 2.388 & 27.3 \\
\hline 2352 & $1 / 10 / 20$ & $8 / 10 / 2$ & 2.349 & 26.5 & 2420 & $318: 28$ & \begin{tabular}{|l|}
$8 / 10 / 2008$ 18:28 \\
\end{tabular} & 2.388 & 27.3 \\
\hline 2353 & $1 / 10 / 20$ & \begin{tabular}{|c|}
$8 / 10200816: 14$ \\
\end{tabular} & 2.35 & 26.5 & 2421 & $318: 30$ & \begin{tabular}{|l|}
$8 / 10 / 200818: 30$ \\
\end{tabular} & 2389 & 27.3 \\
\hline 2354 & $1 / 10 / 20$ & $8 / 10 / 2$ & 235 & 26.5 & 2422 & & $8 / 10 / 2$ & 2.392 & 27.3 \\
\hline 2355 & $1 / 10 / 2$ & $8 / 10 / 2$ & 2.352 & 26.5 & 2423 & $18: 34$ & \begin{tabular}{|l|}
$8 / 10200818: 34$ \\
\end{tabular} & 2.391 & 27.3 \\
\hline 2356 & $816: 20$ & \begin{tabular}{|l|}
$8 / 10 / 200816: 20$ \\
\end{tabular} & 2.353 & 26.5 & 2424 & $00818: 36$ & \begin{tabular}{|l|}
$8 / 10 / 200818: 36$ \\
\end{tabular} & 2.393 & 27.3 \\
\hline 2357 & $16: 22$ & $8 / 10 / 2$ & 2353 & 26.5 & 2425 & 18:38 & $8 / 10 / 2$ & 2393 & 27.3 \\
\hline 2358 & 1/10/2008 16:24 & \begin{tabular}{|l|}
$8 / 10 / 200816: 24$ \\
\end{tabular} & 2.354 & 26.5 & 2426 & $0818: 40$ & $8 / 10 / 20$ & 2.396 & 27.3 \\
\hline 2359 & $16: 26$ & $8 / 10 / 2$ & 2355 & 26.5 & 2427 & & $8 / 10 / 2$ & 2.396 & 27.3 \\
\hline 2360 & $16: 28$ & $8 / 10 / 2$ & 2.355 & 26.5 & $242 \varepsilon$ & $8: 44$ & $8 / 10 / 20$ & 2397 & 27.3 \\
\hline 2361 & 1/10/2008 16:30 & $8 / 1020$ & 2.354 & 26.5 & 2429 & $0818: 46$ & $8 / 10 / 200818: 46$ & 2396 & 27.3 \\
\hline 2362 & $816: 32$ & $8 / 10 / 2$ & 2354 & 26.6 & 2430 & $18: 48$ & $8 / 10 / 2$ & 2398 & 27.3 \\
\hline 2363 & $16: 34$ & $8 / 10 / 2$ & 2.356 & 26.6 & 2431 & $1 / 10$ & $8 / 10 / 2$ & 2399 & 27.3 \\
\hline 2364 & $1 / 10 / 200816: 36$ & $8 / 10 / 2$ & 2.357 & 26.6 & 2432 & 18:52 & \begin{tabular}{|l|}
$8 / 10 / 200818: 52$ \\
\end{tabular} & 2.4 & 27.3 \\
\hline 2365 & $1 / 10 / 200816: 38$ & $8 / 10$ & 2.358 & 26.6 & 2433 & & $8 / 10 / 20$ & 2401 & 27.3 \\
\hline 2366 & $816: 40$ & \begin{tabular}{|l|l|}
$8 / 10 / 2$ \\
\end{tabular} & 2358 & 26.6 & & $818: 56$ & \begin{tabular}{|l|l|l}
$8 / 102008$ & $18: 56$ \\
\end{tabular} & 2402 & 27.3 \\
\hline 2367 & $1 / 10 / 200816: 42$ & $8 / 10 / 20$ & 2.357 & 26.6 & 2435 & $8: 58$ & \begin{tabular}{|l|}
$8 / 102008$ 18:58 \\
\end{tabular} & 2402 & 27.3 \\
\hline 2368 & 1/10/2008 16:44 & $8 / 10 / 22$ & 2.358 & 26. & & & \begin{tabular}{|l|}
$8 / 10 / 200819: 00$ \\
\end{tabular} & 2402 & 27.3 \\
\hline 2369 & 1/10/2008 16:46 & $8 / 10 / 2$ & 2358 & 26.6 & 2437 & $319: 02$ & $8 / 10 / 200819: 02$ & 2403 & 27.3 \\
\hline 2370 & 1/10/2008 16:48 & $8 / 10 / 20$ & 2.358 & 26.6 & 2438 & 19:04 & \begin{tabular}{|l|}
$8 / 10 / 200819: 04$ \\
\end{tabular} & 2403 & 27.3 \\
\hline 2371 & $1 / 10 / 200816: 50$ & $8 / 10 / 20$ & & 26.6 & 2439 & & $8 / 10 / 200819.06$ & 2403 & 27.3 \\
\hline 2372 & $1 / 10 / 200816: 52$ & \begin{tabular}{|c|}
$8 / 10 / 200816: 52$ \\
\end{tabular} & 2.187 & 26.7 & 2440 & $819: 08$ & \begin{tabular}{|l|l|}
$8 / 10200819: 08$ \\
\end{tabular} & 2403 & 27.3 \\
\hline 2373 & $1 / 10 / 200816: 54$ & $816: 54$ & 2363 & 26.7 & 2441 & $19: 10$ & 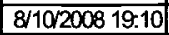 & 2.403 & 27.3 \\
\hline 2374 & $1 / 10 / 200816: 56$ & $8 / 10 / 20$ & 2361 & 26.8 & 2442 & $19: 12$ & \begin{tabular}{|l|}
$8 / 10 / 200819: 12$ \\
\end{tabular} & 2.403 & 27.3 \\
\hline 2375 & $1 / 10 / 200816: 58$ & \begin{tabular}{|l|}
$8 / 10 / 200816: 58$ \\
\end{tabular} & 2362 & 26.7 & 2443 & $1 / 10 / 200819: 14$ & \begin{tabular}{|l|l|}
$8 / 10 / 200819: 14$ \\
\end{tabular} & 2404 & 27.3 \\
\hline 2376 & 1/10/2008 17:00 & \begin{tabular}{|l|}
$8 / 10 / 2008$ 17:00 \\
\end{tabular} & 2361 & 26.7 & 2444 & $0819: 16$ & \begin{tabular}{|l|}
$8 / 10200819.16$ \\
\end{tabular} & 2.405 & 27.3 \\
\hline 2377 & $1 / 10 / 2008$ 17:02 & \begin{tabular}{|l|}
$8 / 10 / 200817: 02$ \\
\end{tabular} & 2363 & 26.8 & & $819: 18$ & \begin{tabular}{|l|}
$8 / 10200819: 18$ \\
\end{tabular} & 2404 & 27.3 \\
\hline 2378 & 1/10/2008 17:04 & \begin{tabular}{|l|}
$8 / 102008$ 17:04 \\
\end{tabular} & 2364 & 26. & 2446 & $1 / 10 / 200819.20$ & $8 / 10 / 200819.20$ & 2404 & 27.3 \\
\hline 2379 & 1/40/2008 17:06 & 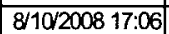 & 2366 & 26.9 & 2447 & 1/10/2008 19:22 & \begin{tabular}{|l|}
$8 / 10 / 200819.22$ \\
\end{tabular} & 2405 & 27.3 \\
\hline 2380 & 1/10/2008 17:08 & \begin{tabular}{|l|}
$8 / 10 / 200817: 08$ \\
\end{tabular} & 2.368 & 26.9 & 2448 & 1/102008 19:24 & \begin{tabular}{|l|}
$8 / 10 / 200819: 24$ \\
\end{tabular} & 2.406 & 27.3 \\
\hline
\end{tabular}




\begin{tabular}{|c|c|c|c|c|}
\hline \multicolumn{5}{|c|}{ D4-93o } \\
\hline $\operatorname{Rec}$ & & Adjusted & Pressure & Temp \\
\hline$\#$ & DaterTime & Date/Time & $p s i$ & ${ }^{\circ} \mathrm{C}$ \\
\hline 2449 & 1/10/2008 19:26 & $8 / 10 / 200819: 26$ & 2.406 & 27.3 \\
\hline 2450 & $1 / 10 / 2008$ 19:28 & $8 / 10 / 2008$ 19:28 & 2.405 & 27.3 \\
\hline 2451 & 1/10/2008 19:30 & $8 / 10 / 200819: 30$ & 2.408 & 27.3 \\
\hline 2452 & 1/10/2008 19:32 & $8 / 10 / 2008$ 19:32 & 2.408 & 27.3 \\
\hline 2453 & $1 / 10 / 2008$ 19:34 & $8 / 10 / 2008$ 19:34 & 2.407 & 27.3 \\
\hline 2454 & 1/10/2008 19:36 & $8 / 10 / 200819: 36$ & 2.408 & 27.3 \\
\hline 2455 & 1/10/2008 19:38 & $8 / 10 / 2008$ 19:38 & 2.408 & 27.3 \\
\hline 2456 & $1 / 10 / 2008$ 19:40 & $8 / 10 / 200819: 40$ & 2.408 & 27.3 \\
\hline 2457 & $1 / 10 / 2008$ 19:42 & $8 / 10 / 200819: 42$ & 2.408 & 27.3 \\
\hline 2458 & 1/10/2008 19:44 & $8 / 10 / 2008$ 19:44 & 2.41 & 27.3 \\
\hline 2459 & $1 / 10 / 200819: 46$ & $8 / 10 / 200819: 46$ & 2.408 & 27.3 \\
\hline 2460 & $1 / 10 / 200819: 48$ & $8 / 10 / 200819: 48$ & 2.409 & 27.3 \\
\hline 2461 & 1/10/2008 19:50 & $8 / 10 / 200819: 50$ & 2.409 & 27.3 \\
\hline 2462 & 1/10/2008 19:52 & $8 / 10 / 200819: 52$ & 2.409 & 27.3 \\
\hline 2463 & $1 / 10 / 2008+9: 54$ & $8 / 10 / 200819: 54$ & 2.409 & 27.3 \\
\hline 2464 & $1 / 10 / 200819.56$ & $8 / 10 / 2008$ 19:56 & 2.411 & 27.3 \\
\hline 2465 & $1 / 10 / 200819: 58$ & $8 / 10 / 200819: 58$ & 2.411 & 27.3 \\
\hline 2466 & $1 / 10 / 200820: 00$ & $8 / 10 / 200820: 00$ & 2.412 & 27.3 \\
\hline 2467 & $1 / 10 / 200820: 02$ & $8 / 10 / 200820: 02$ & 2.411 & 27.3 \\
\hline 2468 & $1 / 10 / 200820: 04$ & $8 / 10 / 200820: 04$ & 2.412 & 27.3 \\
\hline 2469 & 1/10/2008 20:06 & 8/10/2008 20:06 & 2.413 & 27.3 \\
\hline 2470 & 1/10/2008 20:08 & $8 / 10 / 200820: 08$ & 2.413 & 27.3 \\
\hline 2471 & $1 / 10 / 200820: 10$ & $8 / 10 / 200820: 10$ & 2.413 & 27.3 \\
\hline 2472 & $1 / 10 / 200820: 12$ & $8 / 10 / 200820: 12$ & 2.414 & 27.3 \\
\hline 2473 & $1 / 10 / 200820: 14$ & $8 / 10 / 200820: 14$ & 2.414 & 27.3 \\
\hline 2474 & 1/10/2008 20:16 & $8 / 10 / 200820: 16$ & 2.414 & 27.3 \\
\hline 2475 & 1/10/2008 20:18 & 8/10/2008 20:18 & 2.414 & 27.3 \\
\hline 2476 & $1 / 10 / 200820: 20$ & $8 / 10 / 200820: 20$ & 2.414 & 27.3 \\
\hline 2477 & $1 / 10 / 200820: 22$ & $8 / 10 / 200820: 22$ & 2.414 & 27.3 \\
\hline 2478 & $1 / 10 / 200820: 24$ & $8 / 10 / 200820: 24$ & 2.414 & 27.3 \\
\hline 2479 & $1 / 10 / 200820: 26$ & $8 / 10 / 200820: 26$ & 2.415 & 27.3 \\
\hline 2480 & $1 / 10 / 200820: 28$ & 8/10/2008 20:28 & 2.415 & $\frac{27.3}{27.3}$ \\
\hline 2481 & $1 / 10 / 200820: 30$ & $8 / 10 / 200820: 30$ & 2.398 & 27.3 \\
\hline 2482 & $1 / 10 / 200820: 32$ & $8 / 10 / 200820: 32$ & 2.317 & 27.3 \\
\hline 2483 & $1 / 10 / 200820: 34$ & $8 / 10 / 200820: 34$ & 2.283 & 27.3 \\
\hline 2484 & $1 / 10 / 200820: 36$ & $8 / 10 / 200820: 36$ & 2.24 & 27.3 \\
\hline 2485 & $1 / 10 / 200820: 38$ & $8 / 10 / 200820: 38$ & 2.193 & 27.3 \\
\hline 2486 & 1/10/2008 20:40 & $8 / 10 / 200820: 40$ & 2.142 & 27.3 \\
\hline 2487 & $1 / 10 / 200820: 42$ & 8/10/2008 20:42 & 2.108 & 27.2 \\
\hline 2488 & $1 / 10 / 200820: 44$ & $8 / 10 / 200820: 44$ & 2.089 & 27.2 \\
\hline 2489 & $1 / 10 / 200820: 46$ & $8 / 10 / 200820: 46$ & 2.078 & 27.2 \\
\hline 2490 & $1 / 10 / 200820: 48$ & $8 / 10 / 200820: 48$ & 2.07 & 27.2 \\
\hline 2491 & $1 / 10 / 200820: 50$ & $8 / 10 / 200820: 50$ & 2.064 & 27.1 \\
\hline 2492 & $1 / 10 / 200820: 52$ & 8/10/2008 20:52 & 2.057 & 27.2 \\
\hline 2493 & $1 / 10 / 200820: 54$ & $8 / 10 / 200820: 54$ & 2.052 & 27.1 \\
\hline 2494 & $1 / 10 / 200$ & $8 / 10 / 200820: 56$ & 2.047 & 27.1 \\
\hline 2495 & $1 / 10 / 200820: 58$ & $8 / 10 / 200820: 58$ & 2.043 & 27.1 \\
\hline 2496 & 1/10/2008 21:00 & 8/10/2008 21:00 & 1.924 & 27.1 \\
\hline 2497 & 1/10/200821:02 & $8 / 10 / 200821: 02$ & 2.019 & 27.8 \\
\hline 2498 & $1 / 10 / 20$ & $8 / 10 / 200821: 04$ & 2.084 & 27.7 \\
\hline 2499 & $1 / 10 / 200821: 06$ & $8 / 10 / 200821: 06$ & 2.018 & 27.6 \\
\hline 2500 & 1/10/2008 21:08 & 8/10/2008 21:08 & 2.02 & 27.6 \\
\hline 2501 & $1 / 10 / 200821: 10$ & $8 / 10 / 200821: 10$ & 2.018 & 27.5 \\
\hline 2502 & 1/10/200821:12 & $8 / 10 / 200821: 12$ & 2.015 & 27.4 \\
\hline 2503 & 1/10/2008 21:14 & $8 / 10 / 200821: 14$ & 2.013 & 27.4 \\
\hline 2504 & $1 / 10 / 200821: 16$ & $8 / 10 / 200821: 16$ & 2.011 & 27.3 \\
\hline 2505 & 1/10/200821:18 & $8 / 10 / 200821: 18$ & 2.159 & 27.3 \\
\hline 2506 & 1/10/200821:20 & $8 / 10 / 200821: 20$ & 2.246 & 27.3 \\
\hline 2507 & 1/10/200821:22 & $8 / 10 / 200821: 22$ & 2.28 & 27.2 \\
\hline 2508 & $1 / 10 / 200821: 24$ & $8 / 10 / 200821: 24$ & 2.299 & 27.1 \\
\hline 2509 & 1/10/200821:26 & $8 / 10 / 200821: 26$ & 2.315 & 27.1 \\
\hline 2510 & 1/10/200821:28 & $8 / 10 / 200821: 28$ & 2.33 & 27.2 \\
\hline 2511 & 1/10/2008 21:30 & $8 / 10 / 200821: 30$ & 2.344 & 27.2 \\
\hline 2512 & $1 / 10 / 200821: 32$ & $8 / 10 / 200821: 32$ & 2.353 & 27.2 \\
\hline 2513 & $1 / 10 / 200821: 34$ & $8 / 10 / 200821: 34$ & 2.362 & 27.2 \\
\hline 2514 & $1 / 10 / 200821: 36$ & $8 / 10 / 200821: 36$ & 2.367 & 27.2 \\
\hline 2515 & $1 / 10 / 200821: 38$ & $8 / 10 / 200821: 38$ & 2.372 & 27.2 \\
\hline 2516 & $1 / 10 / 200821: 40$ & $8 / 10 / 200821: 40$ & 2.375 & 27.2 \\
\hline
\end{tabular}

\begin{tabular}{|c|c|c|c|c|}
\hline \multicolumn{5}{|c|}{$D 4-93 p$} \\
\hline $\operatorname{Rec}$ & & Adjusted & Pressure & Temp \\
\hline$\#$ & Date-Time & DaterTime & psi & ${ }^{\circ} \mathrm{C}$ \\
\hline 2517 & $1 / 10 / 200821: 42$ & $8 / 10 / 200821: 42$ & 2.379 & 27.3 \\
\hline 2518 & 1/10/2008 21:44 & $8 / 10 / 200821: 44$ & 2.381 & 27.3 \\
\hline 2519 & 1/10/2008 21:46 & $8 / 10 / 200821: 46$ & 2.384 & 27.3 \\
\hline 2520 & 1/10/2008 21:48 & $8 / 10 / 200821: 48$ & 2.388 & 27.3 \\
\hline 2521 & $1 / 10 / 200821: 50$ & $8 / 10 / 200821: 50$ & 2.389 & 27.3 \\
\hline 2522 & 1/10/2008 21:52 & $8 / 10 / 200821: 52$ & 2.391 & 27.3 \\
\hline 2523 & $1 / 10 / 200821: 54$ & $8 / 10 / 200821: 54$ & 2.393 & 27.3 \\
\hline 2524 & 1/10/2008 21:56 & $8 / 10 / 200821: 56$ & 2.395 & 27.3 \\
\hline 2525 & 1/10/2008 21:58 & $8 / 10 / 200821: 58$ & 2.397 & 27.3 \\
\hline 2526 & 1/10/2008 22:00 & $8 / 10 / 200822: 00$ & 2.398 & 27.3 \\
\hline 2527 & 1/10/2008 22:02 & $8 / 10 / 200822: 02$ & 2.399 & 27.3 \\
\hline 2528 & $1 / 10 / 200822: 04$ & $8 / 10 / 200822: 04$ & 2.401 & 27.2 \\
\hline 2529 & $1 / 10 / 200822: 06$ & $8 / 10 / 200822: 06$ & 2.404 & 27.2 \\
\hline 2530 & 1/10/2008 22:08 & $8 / 10 / 200822: 08$ & 2.405 & 27.2 \\
\hline 2531 & 1/10/2008 22:10 & $8 / 10 / 200822: 10$ & 2.407 & 27.2 \\
\hline 2532 & 1/10/2008 22:12 & $8 / 10 / 200822: 12$ & 2.407 & 27.2 \\
\hline 2533 & 1/10/2008 22:14 & $8 / 10 / 200822: 14$ & 2.408 & 27.1 \\
\hline 2534 & 1/10/2008 22:16 & $8 / 10 / 200822: 16$ & 2.409 & 27.1 \\
\hline 2535 & 1/10/2008 22:18 & $8 / 10 / 200822: 18$ & 2.409 & 27.1 \\
\hline 2536 & 1/10/2008 22:20 & $8 / 10 / 200822: 20$ & 2.41 & 27.1 \\
\hline 2537 & 1/10/2008 22:22 & $8 / 10 / 200822: 22$ & 2.411 & 27.1 \\
\hline 2538 & $1 / 10 / 2008$ 22:24 & $8 / 10 / 200822: 24$ & 2.413 & 27.1 \\
\hline 2539 & $1 / 10 / 200822: 26$ & $8 / 10 / 200822: 26$ & 2.414 & 27.1 \\
\hline 2540 & 1/10/2008 22:28 & $8 / 10 / 200822: 28$ & 2.416 & 27.1 \\
\hline 2541 & 1/10/2008 22:30 & $8 / 10 / 200822: 30$ & 2.417 & 27.1 \\
\hline 2542 & 1/10/2008 22:32 & $8 / 10 / 200822: 32$ & 2.418 & 27.1 \\
\hline 2543 & 1/10/2008 22:34 & 8/10/2008 22:34 & 2.418 & 27.1 \\
\hline 2544 & 1/10/2008 22:36 & $8 / 10 / 200822: 36$ & 2.42 & 27.1 \\
\hline 2545 & $1 / 10 / 200822: 38$ & $8 / 1 \alpha 200822: 38$ & 2.421 & 27.1 \\
\hline 2546 & $1 / 10 / 200822: 40$ & $8 / 10 / 200822: 40$ & 2.421 & 27 \\
\hline 2547 & $1 / 10 / 200822: 42$ & $8 / 10 / 200822: 42$ & 2.423 & 27 \\
\hline 2548 & $1 / 10 / 200822: 44$ & $8 / 10 / 200822: 44$ & 2.424 & 27 \\
\hline 2549 & 9/10/2008 22:46 & $8 / 10 / 200822: 46$ & 2.425 & 27 \\
\hline 2550 & $1 / 10 / 200822: 48$ & $8 / 10 / 200822: 48$ & 2.425 & 27 \\
\hline 2551 & 1/10/2008 22:50 & $8 / 10 / 200822: 50$ & 2.427 & 26.9 \\
\hline 2552 & $1 / 10 / 200822: 52$ & $8 / 1 \alpha / 200822: 52$ & 2.427 & 26.9 \\
\hline 2553 & $1 / 10 / 200822: 54$ & $8 / 10 / 200822: 54$ & 2.428 & 26.9 \\
\hline 2554 & 1/10/200822:56 & $8 / 1 / 200822: 56$ & 2.429 & 26.9 \\
\hline 2555 & 1/10/2008 22:58 & $8 / 10 / 200822: 58$ & 2.429 & 26.9 \\
\hline 2556 & 1/10/200823:00 & $8 / 10 / 200823: 00$ & 2.43 & 26.9 \\
\hline 2557 & 1/10/2008 23:02 & $8 / 10 / 200823: 02$ & 2.43 & 26.9 \\
\hline 2558 & 1/10/2008 23:04 & 8/10/2008 23:04 & 2.432 & 26.9 \\
\hline 2559 & 1/10/2008 23:06 & 8/10/2008 23:06 & 2.433 & 26.9 \\
\hline 2560 & 1/10/2008 23:08 & $8 / 10 / 200823: 08$ & 2.433 & 26.9 \\
\hline 2561 & 1/10/2008 23:10 & $8 / 10 / 200823: 10$ & 2.434 & 26.9 \\
\hline 2562 & 1/10/2008 23:12 & $8 / 10 / 200823: 12$ & 2.435 & 26.9 \\
\hline 2563 & 1/10/2008 23:14 & 8/10/2008 23:14 & 2.436 & 26.9 \\
\hline 2564 & 1/10/2008 23:16 & $8 / 10 / 200823: 16$ & 2.435 & 26.9 \\
\hline 2565 & 1/10/2008 23:18 & $8 / 10 / 200823: 18$ & 2.435 & 26.9 \\
\hline 2566 & $1 / 10 / 200823: 20$ & $8 / 10 / 200823: 20$ & 2.436 & 26.8 \\
\hline 2567 & 1/10/200823:22 & $8 / 10 / 200823: 22$ & 2.437 & 26.8 \\
\hline 2568 & $1 / 10 / 200823: 24$ & $8 / 10 / 200823: 24$ & 2.438 & 26.8 \\
\hline 2569 & 1/10/2008 23:26 & $8 / 10 / 200823: 26$ & 2.438 & 26.8 \\
\hline 2570 & 1/10/2008 23:28 & $8 / 10 / 200823: 28$ & 2.439 & 26.8 \\
\hline 2571 & 1/10/2008 23:30 & $8 / 10 / 200823: 30$ & 2.441 & 26.8 \\
\hline 2572 & $1 / 10 / 200823: 32$ & $8 / 10 / 200823: 32$ & 2.442 & 26.8 \\
\hline 2573 & 1/10/2008 23:34 & $8 / 10 / 200823: 34$ & 2.443 & 26.8 \\
\hline 2574 & 1/10/2008 23:36 & $8 / 10 / 200823: 36$ & 2.444 & 26.8 \\
\hline 2575 & 1/10/2008 23:38 & $8 / 10 / 200823: 38$ & 2.445 & 26.8 \\
\hline 2576 & $1 / 10 / 200823: 40$ & $8 / 10 / 200823: 40$ & 2.446 & 26.8 \\
\hline 2577 & 1/10/2008 23:42 & $8 / 10 / 200823: 42$ & 2.446 & 26.8 \\
\hline 2578 & 1/10/2008 23:44 & $8 / 10 / 200823: 44$ & 2.446 & 26.8 \\
\hline 2579 & 1/10/2008 23:46 & $8 / 10 / 200823: 46$ & 2.446 & 26.8 \\
\hline 2580 & 1/10/2008 23:48 & $8 / 10 / 200823: 48$ & 2.447 & 26.8 \\
\hline 2581 & 1/10/2008 23:50 & $8 / 10 / 200823: 50$ & 2448 & 26.7 \\
\hline 2582 & $1 / 10 / 200823: 52$ & $8 / 10 / 200823: 52$ & 2.45 & 26.7 \\
\hline 2583 & 1/10/2008 23:54 & $8 / 10 / 200823: 54$ & 2.45 & 26.7 \\
\hline 2584 & 1/10/2008 23:56 & $8 / 10 / 200823: 56$ & 2.357 & 26.7 \\
\hline
\end{tabular}

\begin{tabular}{|c|c|c|c|c|}
\hline \multicolumn{5}{|c|}{ D4-93p } \\
\hline ReC & & Adjusted & Pressure & Temp \\
\hline$\#$ & Date-Time & Date/Time & $\mathrm{psi}$ & ${ }^{\circ} \mathrm{C}$ \\
\hline 2585 & $1 / 10 / 200823: 58$ & $8 / 10 / 200823: 58$ & 2.27 & 26.7 \\
\hline 2586 & $1 / 11 / 20080000$ & $8 / 11 / 20080: 00$ & 2.189 & 26.6 \\
\hline 2587 & 1/11/2008 0:02 & $8 / 11 / 20080: 02$ & 2.144 & 26.6 \\
\hline 2588 & $1 / 11 / 20080: 04$ & $8 / 11 / 20080: 04$ & 2.116 & 26.6 \\
\hline 2589 & $1 / 11 / 20080: 06$ & $8 / 11 / 20080: 06$ & 2.094 & 26.6 \\
\hline 2590 & $1 / 11 / 20080: 08$ & $8 / 11 / 20080: 08$ & 2.078 & 26.6 \\
\hline 2591 & 1/11/20080:10 & $8 / 11 / 20080: 10$ & 2.07 & 26.6 \\
\hline 2592 & 1/11/2008 0:12 & $8 / 11 / 20080: 12$ & 2.241 & 26.6 \\
\hline 2593 & $1 / 11 / 20080: 14$ & $8 / 11 / 20080: 14$ & 2.316 & 26.6 \\
\hline 2594 & 1/11/20080:16 & $8 / 11 / 20080: 16$ & 2.35 & 26.6 \\
\hline 2595 & 1/11/20080:18 & $8 / 11 / 20080: 18$ & 2.376 & 26.6 \\
\hline 2596 & $1 / 11 / 20080: 20$ & $8 / 11 / 20080: 20$ & 2.392 & 26.6 \\
\hline 2597 & $1 / 11 / 20080: 22$ & $8 / 11 / 20080: 22$ & 2.403 & 26.6 \\
\hline 2598 & $1 / 11 / 20080: 24$ & $8 / 11 / 20080: 24$ & 2.411 & 26.6 \\
\hline 2599 & 1/11/20080:26 & $8 / 11 / 20080: 26$ & 2.416 & 26.6 \\
\hline 2600 & $1 / 11 / 20080: 28$ & $8 / 11 / 20080: 28$ & 2.42 & 26.6 \\
\hline 2601 & 1/11/2008 0:30 & $8 / 11 / 20080: 30$ & 2.423 & 26.6 \\
\hline 2602 & $1 / 11 / 20080: 32$ & $8 / 11 / 20080: 32$ & 2.426 & 26.6 \\
\hline 2603 & 1/11/2008 0:34 & $8 / 11 / 20080: 34$ & 2.429 & 26.6 \\
\hline 2604 & 1/11/20080:36 & $8 / 11 / 20080: 36$ & 2.432 & 26.7 \\
\hline 2605 & 1/11/20080:38 & $8 / 11 / 20080: 38$ & 2.436 & 26.6 \\
\hline 2606 & $7 / 11 / 20080: 40$ & $8 / 11 / 20080: 40$ & 2.441 & 26.7 \\
\hline 2607 & $1 / 11 / 20080: 42$ & $8 / 11 / 20080: 42$ & 2.445 & 26.6 \\
\hline 2608 & $1 / 11 / 20080: 44$ & $8 / 11 / 20080: 44$ & 2.449 & 26.7 \\
\hline 2609 & $1 / 11 / 20080: 46$ & $8 / 11 / 20080: 46$ & 2.452 & 26.6 \\
\hline 2610 & $1 / 11 / 20080: 48$ & $8 / 11 / 20080: 48$ & 2.456 & 26.6 \\
\hline 2611 & 1/11/20080:50 & $8 / 11 / 20080: 50$ & 2.459 & 26.6 \\
\hline 2612 & 1/11/20080:52 & $8 / 11 / 20080: 52$ & 2.461 & 26.6 \\
\hline 2613 & $1 / 11 / 20080: 54$ & $8 / 11 / 20080: 54$ & 2.463 & 26.6 \\
\hline 2614 & $1 / 11 / 20080: 56$ & $8 / 11 / 20080: 56$ & 2.465 & 26.6 \\
\hline 2615 & $1 / 11 / 20080: 58$ & $8 / 11 / 20080: 58$ & 2.468 & 26.6 \\
\hline 2616 & 1/11/2008 1:00 & $8 / 11 / 20081: 00$ & 2.469 & 26.6 \\
\hline 2617 & 1/11/2008 1:02 & $8 / 11 / 2008$ 1:02 & 2.472 & 26.5 \\
\hline 2618 & 1/11/2008 1:04 & $8 / 11 / 20081: 04$ & 2.474 & 26.5 \\
\hline 2619 & $1 / 11 / 20081: 06$ & $8 / 11 / 20081: 06$ & 2.476 & 26.4 \\
\hline 2620 & $1 / 11 / 20081: 08$ & $8 / 11 / 20081: 08$ & 2.477 & 26.4 \\
\hline 2621 & 1/11/2008 1:10 & $8 / 11 / 20081: 10$ & 2.478 & 26.4 \\
\hline 2622 & 1/11/20081:12 & $8 / 11 / 2008$ 1:12 & 2.48 & 26.4 \\
\hline 2623 & $1 / 11 / 2008$ 1:14 & $8 / 11 / 2008$ 1:14 & 2.482 & 26.4 \\
\hline 2624 & 1/11/2008 1:16 & $8 / 11 / 20081: 16$ & 2.482 & 26.3 \\
\hline 2625 & 1/11/2008 1:18 & $8 / 11 / 2008$ 1:18 & 2.483 & 26.3 \\
\hline 2626 & $1 / 11 / 20081: 20$ & $8 / 11 / 20081: 20$ & 2.484 & 26.3 \\
\hline 2627 & 1/11/2008 1:22 & $8 / 11 / 20081: 22$ & 2.485 & 26.3 \\
\hline 2628 & 1/11/2008 1:24 & $8 / 11 / 20081: 24$ & 2.487 & 26.3 \\
\hline 2629 & $081: 26$ & $8 / 11 / 20081: 26$ & 2.488 & 26.3 \\
\hline 2630 & $1 / 11 / 20081: 28$ & $8 / 11 / 20081: 28$ & 2.488 & 26.3 \\
\hline 2631 & 1/11/2008 1:30 & $8 / 11 / 20081: 30$ & 2.489 & 26.2 \\
\hline 2632 & $1 / 11 / 20081: 32$ & $8 / 11 / 20081: 32$ & 2.489 & 26.2 \\
\hline 2633 & $1 / 11 / 2008$ 1:34 & $8 / 11 / 20081: 34$ & 2.489 & 26.2 \\
\hline 2634 & $1 / 11 / 20081: 36$ & $8 / 11 / 20081: 36$ & 2.489 & 26.2 \\
\hline 2635 & $1 / 11 / 20081: 38$ & $8 / 11 / 20081: 38$ & 249 & 26.1 \\
\hline 2636 & 1/11/2008 1:40 & $8 / 11 / 20081: 40$ & 249 & 26.1 \\
\hline 2637 & $1 / 11 / 20081: 42$ & $8 / 11 / 2008$ 1:42 & 2.491 & 26.1 \\
\hline 2638 & $1 / 11 / 20081: 44$ & $8 / 11 / 20081: 44$ & 2.492 & 26.1 \\
\hline 2639 & 1/11/2008 1:46 & $8 / 11 / 20081: 46$ & 2.492 & 26.1 \\
\hline 2640 & $1 / 11 / 20081: 48$ & $8 / 11 / 2008$ 1:48 & 2.493 & 26.1 \\
\hline 2641 & 1/11/2008 1:50 & $8 / 11 / 20081: 50$ & 2.493 & 26.1 \\
\hline 2642 & $1 / 11 / 20081: 52$ & $8 / 11 / 20081: 52$ & 2.494 & 26.1 \\
\hline 2643 & $1 / 11 / 20081: 54$ & $8 / 11 / 20081: 54$ & 2.495 & 26.1 \\
\hline 2644 & $1 / 11 / 20081: 56$ & $8 / 11 / 20081: 56$ & 2.496 & 26.1 \\
\hline 2645 & $1 / 11 / 20081: 58$ & $8 / 11 / 2008$ 1:58 & 2.496 & 26 \\
\hline 2646 & 1/11/20082:00 & $8 / 11 / 20082: 00$ & 2.496 & 26.1 \\
\hline 2647 & $1 / 11 / 20082: 02$ & $8 / 11 / 20082: 02$ & 2.497 & 26 \\
\hline 2648 & $1 / 11 / 20082: 04$ & $8 / 11 / 20082: 04$ & 2.497 & 26 \\
\hline 2649 & $1 / 11 / 20082: 06$ & $8 / 11 / 20082: 06$ & 2.166 & 26 \\
\hline 2650 & $1 / 11 / 20082: 08$ & $8 / 11 / 20082: 08$ & 2.494 & 26.1 \\
\hline 2651 & $1 / 11 / 20082: 10$ & $8 / 11 / 20082: 10$ & 2.506 & 26.1 \\
\hline 2652 & 1/11/2008 2:12 & $8 / 11 / 20082: 12$ & 2.507 & 26.1 \\
\hline
\end{tabular}




\begin{tabular}{|c|c|c|c|c|c|c|c|c|c|}
\hline \multicolumn{5}{|c|}{ D4-93p } & \multicolumn{5}{|c|}{ D493p } \\
\hline $\operatorname{Rec}$ & & Adjusted & Pressure & Temp & $\operatorname{Rec}$ & & Adjusted & Pressure & Temp \\
\hline$\#$ & DaterTime & Date/Time & psi & ${ }^{\circ} \mathrm{C}$ & \# & Date/Time & Date/Time & psi & ${ }^{\circ} \mathrm{C}$ \\
\hline 2653 & $1 / 11 / 20082: 14$ & $8 / 11 / 20082: 14$ & 2.505 & 26.1 & $27 \overline{21}$ & $1 / 11 / 20084: 30$ & $8 / 11 / 20084: 30$ & 2.553 & 25.5 \\
\hline 2654 & $11 / 20082: 16$ & $8 / 11 / 20082: 16$ & 2.505 & 26 & 272 & $1 / 11 / 20084: 32$ & $8 / 11 / 20084: 32$ & 2.552 & \\
\hline 2655 & $1 / 11 / 20082: 18$ & 8/11/20082:18 & 2.509 & 25.9 & 2723 & $1 / 11 / 20084: 34$ & $8 / 11 / 20084: 34$ & 2.553 & $\overline{25.6}$ \\
\hline 2656 & $1 / 11 / 20082: 20$ & $8 / 11 / 20082: 20$ & 2.512 & 25.9 & 2724 & $1 / 11 / 20084: 36$ & $8 / 11 / 20084: 36$ & 2.554 & 25 . \\
\hline 2657 & $1 / 11 / 20082: 22$ & $8 / 11 / 20082: 22$ & 2.514 & 25.9 & 2725 & $1 / 11 / 20084: 38$ & $8 / 11 / 20084: 38$ & 2.554 & 25.5 \\
\hline 2658 & $1 / 11 / 2$ & $8 / 11 / 20082: 24$ & 2.515 & 25.9 & 2726 & $1 / 11 / 20084: 40$ & $8 / 11 / 20084: 40$ & 2.555 & \\
\hline 2659 & $1 / 11 / 200$ & $8 / 11 / 20082: 26$ & 2.517 & 25.9 & 2727 & $1 / 11 / 20084: 42$ & $8 / 11 / 20084: 42$ & 2.556 & 25.5 \\
\hline 2660 & $1 / 11 / 20$ & $8 / 11 / 2008228$ & 2.518 & 25.9 & 2728 & $1 / 11 / 20084: 44$ & $8 / 11 / 20084: 44$ & 2.556 & 25.4 \\
\hline 2661 & $111 / 20082: 30$ & 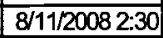 & 2.52 & 25.9 & 2729 & $1 / 11 / 20084: 46$ & $8 / 11 / 20084: 46$ & 2.557 & 25. \\
\hline 2662 & $1 / 11 /$ & $8 / 11 / 20082: 32$ & 252 & 25.9 & 2730 & $1 / 11 / 20084: 48$ & $8 / 11 / 20084: 48$ & 2,557 & 25.4 \\
\hline 2663 & $1 / 11 /$ & $8 / 11 / 20082: 34$ & 2.522 & 25.9 & 2731 & $1 / 11 /$ & $8 / 11 / 20084: 50$ & 2.558 & $25 . \overline{4}$ \\
\hline 2664 & $1 / 11 /$ & $8 / 11 / 20082: 36$ & 2.522 & 25.9 & 2732 & $84: 52$ & $8 / 11 / 20084: 52$ & 2.559 & 25.4 \\
\hline 2665 & $1 / 11 / 2$ & $8 / 11 / 20082: 38$ & 2.523 & 25.9 & 2733 & $1 / 11 /$ & $8 / 11 / 20084: 54$ & 2.56 & $\overline{25.4}$ \\
\hline 2666 & $1 / 11 / 20$ & $8 / 11 / 20082: 40$ & 2.524 & 25.9 & 2734 & $20084: 56$ & $8 / 11 / 20084: 56$ & 2.56 & 25.4 \\
\hline 2667 & $\overline{2: 42}$ & $8 / 11 / 20082: 42$ & 2.525 & 25.9 & 2735 & $34: 58$ & $8 / 11 / 20084: 58$ & 2.561 & $\overline{25.4}$ \\
\hline 2668 & $1 / 11 /$ & $8 / 11 / 20$ & 2.525 & 25.9 & 2736 & $5: 00$ & $8 / 11 / 20085: 00$ & 2.562 & 25.4 \\
\hline 2669 & $1 / 11 /$ & $11 / 20$ & 2.526 & 25.9 & 2737 & $1 / 11$ & $8 / 11 / 20085: 02$ & 2.562 & 25.4 \\
\hline 2670 & $1 / 11 /$ & $8 / 11 / 200$ & 2.526 & 25.9 & 2738 & $085: 04$ & $8 / 11 / 20085: 04$ & 2.562 & 25 . \\
\hline 2671 & $1 / 11 / 2$ & $8 / 11 / 20082: 50$ & 2.467 & 25.9 & 2739 & $1 / 11 / 20085: 06$ & $8 / 11 / 20085: 06$ & 2.562 & $\overline{25.4}$ \\
\hline 2672 & & $2: 52$ & 2.381 & 25.9 & 2740 & $5: 08$ & $8 / 11 / 2$ & 2.561 & 25.4 \\
\hline 2673 & & $2: 54$ & 2.259 & 25.8 & 2741 & $1 / 11$ & $8 / 11 / 2$ & 2.562 & \\
\hline 2674 & $1 / 11$ & $82: 56$ & 2.191 & 25.8 & 2742 & $1 / 11$ & $8 / 11 / 20085: 12$ & 2.563 & \\
\hline 2675 & $1 / 11 / 2$ & 8/11/2008 2:58 & 2.151 & 25.8 & 2743 & $285: 14$ & $8 / 11 / 20085: 14$ & 2.564 & 25.4 \\
\hline 2676 & $1 / 11$ & $3: 00$ & 2.275 & 25.8 & 2744 & & $8 / 11 / 2$ & 2.564 & 25. \\
\hline 2677 & & 02 & 2.367 & 25. & 2745 & & $8 / 11 / 2$ & 2.565 & 25.8 \\
\hline 2678 & $1 / 11 /$ & $8 / 11 / 20$ & 2.414 & 25.9 & 2746 & $1 / 11$ & $8 / 11 / 20$ & 2.566 & 25.4 \\
\hline 2679 & $1 / 11 /$ & $8 / 11 / 20083: 06$ & 2.445 & 25.8 & 2747 & $85: 22$ & $8 / 11 / 20085: 22$ & 2.567 & 25.4 \\
\hline 2680 & & $8 / 11 / 2$ & 2.463 & 25.8 & 2748 & & $8 / 11 / 2$ & 2.567 & 25. \\
\hline 2681 & $1 / 11$ & $8 / 11 /$ & 2.474 & 25. & 2749 & $1 / 1$ & $8 / 11 / 2$ & 2.566 & 25. \\
\hline 2682 & & $8 / 11 / 4$ & 2.486 & 25.9 & 2750 & & $8 / 11 / 2$ & 2.566 & 25. \\
\hline 2683 & $1 / 11 /$ & $8 / 11 / 20$ & 2.497 & 25.8 & 2751 & $5: 30$ & $8 / 11 / 200$ & 2.565 & 25.4 \\
\hline 2684 & & $8 / 11 / 2$ & 2.506 & 25.9 & 2752 & & $8 / 11 / 2$ & 2.565 & 25. \\
\hline 2685 & & & 2.511 & 25.9 & 2753 & & $8 / 11 / 2$ & 2.528 & 25. \\
\hline 2686 & & & 2.516 & 25. & 2754 & & & 2.148 & 25. \\
\hline 2687 & & $8 / 11 / 200$ & 2.519 & 25.9 & 2755 & $5: 38$ & $8 / 11 / 20085: 38$ & 2.723 & 23.5 \\
\hline 2688 & & & 2.522 & 25.9 & 2756 & & $8 / 11 / 20085: 40$ & 2.752 & 20 \\
\hline 2689 & & & 2.525 & 25. & 2757 & & $5: 42$ & 2.743 & 19. \\
\hline 2690 & & & 2.525 & 25 & 2758 & & & 2.553 & 18. \\
\hline 2691 & $1 / 11 /$ & & 2.528 & 25.9 & 2759 & $85: 46$ & $8 / 11 / 20$ & 1.862 & 19. \\
\hline 2692 & & $8 / 11 / 20$ & 2.529 & 25.9 & 2760 & & & & 208 \\
\hline 2693 & & & 2.531 & 25. & 2761 & & & 2.011 & 21. \\
\hline 2694 & & & 2.532 & 25. & 2762 & & & 2.058 & 21. \\
\hline 2695 & & & 2.533 & 25. & 2763 & & & 2.066 & 21. \\
\hline 2696 & & & 2.535 & 25. & 2764 & & & 2.213 & 2 \\
\hline 2697 & & & 2.536 & 25. & 2765 & & & 2.347 & 22 \\
\hline 2698 & & & 2.538 & 25 & 2766 & & & 2.41 & 22. \\
\hline 2699 & & & 2.538 & 25.8 & 2767 & & & 2.456 & 22. \\
\hline 2700 & & & 2.539 & 25.7 & 2768 & & & 2.484 & 22.4 \\
\hline 2701 & & & 254 & 25 & 2769 & & & 2.502 & 22. \\
\hline 2702 & & & & 25 & 2770 & & & .517 & 23. \\
\hline 2703 & & & & 25. & 2771 & & $6: 10$ & 2.527 & 23.6 \\
\hline 2704 & & & 2.547 & 25 & 2772 & & & 2.536 & 24 \\
\hline 2705 & & & & & 2773 & & & 2.544 & 24 \\
\hline 2706 & & & & & 2774 & & & 2.549 & 24. \\
\hline 2707 & & 4:02 & 2.547 & 25 . & 2775 & & $8 / 11 / 2$ & 2.554 & 24. \\
\hline 2708 & & & 2.547 & 25 . & 2776 & & & 2.557 & 24.7 \\
\hline 2709 & & & 2.548 & 25 & $27 \pi$ & & & & 24.8 \\
\hline 2710 & & & & & $277 \overline{8}$ & & & 2.565 & 24.8 \\
\hline 2711 & & & 2.548 & 25 . & & & $6: 26$ & 2.569 & 24. \\
\hline 2712 & $1 / 11$ & $4: 12$ & 2.548 & 25.8 & 2780 & $86: 28$ & $8 / 11 / 20086: 28$ & 2.572 & 24.9 \\
\hline 2713 & & & 2.55 & 26 . & 2781 & & & 2.576 & 24. \\
\hline 2714 & & & & 25 & & & & 2.578 & 24. \\
\hline 2715 & & & & & & & & 2.58 & \\
\hline 2716 & $4: 20$ & $8 / 11 / 20084: 20$ & 2.55 & 25.6 & 2784 & $36: 36$ & $8 / 11 / 20086: 36$ & 2.581 & 24.9 \\
\hline 2717 & $1 / 11 / 2$ & $8 / 11 / 200$ & 2.551 & 25. & 2785 & $36: 38$ & $8 / 11 / 20$ & 2.583 & 25 \\
\hline 2718 & & $8 / 11 / 20084: 24$ & 2.552 & 25 & 2786 & $886: 40$ & $8 / 11 / 20086: 40$ & 2.584 & \\
\hline 2719 & & & 2.552 & & 2787 & & & 2.586 & \\
\hline & $1 / 11 /$ & $8 / 11 / 20084: 28$ & 2.552 & 25.5 & 2788 & $886: 44$ & $8 / 11 / 20086: 44$ & 2.587 & \\
\hline
\end{tabular}

\begin{tabular}{|c|c|c|c|c|}
\hline \multicolumn{5}{|c|}{ D4-93p } \\
\hline $\operatorname{Rec}$ & & Adjusted & Pressure & Temp \\
\hline \# & Date/Time & Date/Time & psi & ${ }^{\circ} \mathrm{C}$ \\
\hline 2789 & $1 / 11 / 20086: 46$ & $8 / 11 / 20086: 46$ & 2.589 & 25 \\
\hline 2790 & $1 / 11 / 20086: 48$ & $8 / 11 / 20086: 48$ & 259 & 25 \\
\hline 2791 & 1/11/20086:50 & $8 / 11 / 20086: 50$ & 2.591 & 25 \\
\hline 2792 & 1/11/20086:52 & $8 / 11 / 20086: 52$ & 2.592 & 25 \\
\hline 2793 & $1 / 11 / 20086: 54$ & $8 / 11 / 20086: 54$ & 2.593 & 25 \\
\hline 2794 & $1 / 11 / 20086: 56$ & $8 / 11 / 20086: 56$ & 2.594 & 25.1 \\
\hline 2795 & $1 / 11 / 20086: 58$ & $8 / 11 / 20086: 58$ & 2.597 & 25 \\
\hline 2796 & $1 / 11 / 20087: 00$ & $8 / 11 / 20087: 00$ & 2.599 & 25.1 \\
\hline 2797 & $1 / 11 / 20087: 02$ & $8 / 11 / 20087: 02$ & 2.601 & 25 \\
\hline 2798 & $1 / 11 / 20087: 04$ & $8 / 11 / 20087: 04$ & 2.603 & 25 \\
\hline 2799 & $1 / 11 / 20087: 06$ & $8 / 11 / 20087: 06$ & 2.605 & 25 \\
\hline 2800 & $1 / 11 / 20087: 08$ & $8 / 11 / 20087: 08$ & 2.606 & 25 \\
\hline 2801 & $1 / 11 / 20087: 10$ & $8 / 11 / 20087: 10$ & 2.607 & 25 \\
\hline 2802 & $1 / 11 / 20087: 12$ & $8 / 11 / 20087: 12$ & 2.608 & 25 \\
\hline 2803 & $1 / 11 / 20087: 14$ & $8 / 11 / 20087: 14$ & 2.61 & 25 \\
\hline 2804 & $1 / 11 / 20087: 16$ & $8 / 11 / 20087: 16$ & 2.61 & 25 \\
\hline 2805 & $1 / 11 / 20087: 18$ & $8 / 11 / 20087: 18$ & 2.612 & 25 \\
\hline 2806 & $1 / 11 / 20087: 20$ & $8 / 11 / 20087: 20$ & 2.612 & 25 \\
\hline 2807 & $1 / 11 / 20087: 22$ & $8 / 11 / 20087: 22$ & 2.612 & 25 \\
\hline 2808 & $1 / 11 / 20087: 24$ & $8 / 11 / 20087: 24$ & 2.613 & 25 \\
\hline 2809 & $1 / 11 / 20087: 26$ & $8 / 11 / 20087: 26$ & 2.613 & 25 \\
\hline 2810 & $1 / 11 / 20087: 28$ & $8 / 11 / 20087: 28$ & 2.614 & 25 \\
\hline 2811 & $1 / 11 / 20087: 30$ & $8 / 11 / 20087: 30$ & 2.614 & 25 \\
\hline 2812 & $1 / 11 / 20087: 32$ & $8 / 11 / 20087: 32$ & 2.614 & 25 \\
\hline 2813 & $1 / 11 / 20087: 34$ & $8 / 11 / 20087: 34$ & 2.615 & 25 \\
\hline 2814 & $1 / 11 / 20087: 36$ & $8 / 11 / 20087: 36$ & 2.615 & 25 \\
\hline 2815 & $1 / 11 / 20087: 38$ & $8 / 11 / 20087: 38$ & 2.617 & 25 \\
\hline 2816 & $1 / 11 / 20087: 40$ & $8 / 11 / 20087: 40$ & 2.617 & 25 \\
\hline 2817 & $1 / 11 / 20087: 42$ & $8 / 11 / 20087: 42$ & 2.617 & 24.9 \\
\hline 2818 & $1 / 11 / 20087: 44$ & $8 / 11 / 20087: 44$ & 2.618 & 25 \\
\hline 2819 & $1 / 11 / 20087: 46$ & $8 / 11 / 20087: 46$ & 2.619 & 25 \\
\hline 2820 & $1 / 11 / 20087: 48$ & $8 / 11 / 20087: 48$ & 2.619 & 24.9 \\
\hline 2821 & $1 / 11 / 20087: 50$ & $8 / 11 / 20087: 50$ & 2.62 & 25 \\
\hline 2822 & $1 / 11 / 20087: 52$ & $8 / 11 / 20087: 52$ & 2.621 & 25.3 \\
\hline 2823 & $1 / 11 / 20087: 54$ & $8 / 11 / 20087: 54$ & 2.623 & 25.1 \\
\hline 2824 & $1 / 11 / 20087: 56$ & $8 / 11 / 20087: 56$ & 2.625 & 25 \\
\hline 2825 & $1 / 11 / 20087: 58$ & $8 / 11 / 20087: 58$ & 2.628 & 25 \\
\hline 2826 & $1 / 11 / 20088: 00$ & $8 / 11 / 20088: 00$ & 2.631 & 25.3 \\
\hline 2827 & $1 / 11 / 20088: 02$ & $8 / 11 / 20088: 02$ & 2.633 & 25.2 \\
\hline 2828 & $1 / 11 / 20088: 04$ & $8 / 11 / 20088: 04$ & 2.632 & 25.1 \\
\hline 2829 & $1 / 11 / 20088: 06$ & $8 / 11 / 20088: 06$ & 2.633 & 25 \\
\hline 2830 & 1/11/20088:08 & $8 / 11 / 20088: 08$ & 2.634 & 24.9 \\
\hline 2831 & $1 / 11 / 20088: 10$ & $8 / 11 / 20088: 10$ & 2.635 & 24.9 \\
\hline 2832 & $1 / 11 / 20088: 12$ & $8 / 11 / 20088: 12$ & 2.637 & 24.9 \\
\hline 2833 & $1 / 11 / 20088: 14$ & $8 / 11 / 20088: 14$ & 2.638 & 24.9 \\
\hline 2834 & 1/11/20088:16 & $8 / 11 / 20088: 16$ & 2.638 & 24.9 \\
\hline 2835 & 1/11/2008 8:18 & $8 / 11 / 20088: 18$ & 2.639 & 24.9 \\
\hline 2836 & 1/11/20088:20 & $8 / 11 / 20088: 20$ & 2.64 & 24.9 \\
\hline 2837 & 1/11/20088:22 & $8 / 11 / 20088: 22$ & 2.64 & 24.9 \\
\hline 2838 & $1 / 11 / 20088: 24$ & $8 / 11 / 20088: 24$ & 2.64 & 24.9 \\
\hline 2839 & $1 / 11 / 20088: 26$ & $8 / 11 / 20088: 26$ & 2.64 & 24.9 \\
\hline 2840 & 1/11/2008 8:28 & $8 / 11 / 20088: 28$ & 2.641 & 24.9 \\
\hline 2841 & $1 / 11 / 20088: 30$ & $8 / 11 / 20088: 30$ & 2.64 & 24.9 \\
\hline 2842 & $1 / 11 / 20088: 32$ & $8 / 11 / 20088: 32$ & 2.638 & 24.9 \\
\hline 2843 & 1/11/2008 8:34 & $8 / 11 / 20088: 34$ & 2.638 & 24.9 \\
\hline 2844 & 1/11/20088:36 & $8 / 11 / 20088: 36$ & 2.638 & 24.9 \\
\hline 2845 & 1/11/2008 8:38 & $8 / 11 / 20088: 38$ & 2.526 & 24.9 \\
\hline 2846 & $1 / 11 / 20088: 40$ & $8 / 11 / 20088: 40$ & 2.412 & 24.9 \\
\hline 2847 & $1 / 11 / 20088: 42$ & $8 / 11 / 20088: 42$ & 2.314 & 24.9 \\
\hline 2848 & $1 / 11 / 20088: 44$ & $8 / 11 / 20088: 44$ & 2.41 & 24.9 \\
\hline 2849 & $1 / 11 / 20088: 46$ & $8 / 11 / 20088: 46$ & 2.493 & 24.9 \\
\hline 2850 & $1 / 11 / 20088: 48$ & $8 / 11 / 20088: 48$ & 2.558 & 24.9 \\
\hline 2851 & 1/11/20088:50 & 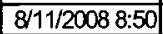 & 26 & 24.9 \\
\hline 2852 & 1/11/20088:52 & $8 / 11 / 20088: 52$ & 2.624 & 24.9 \\
\hline 2853 & 1/11/20088:54 & $8 / 11 / 20088: 54$ & 2.633 & 24.9 \\
\hline 2854 & 1/11/2008 8:56 & $8 / 11 / 20088: 56$ & 2.636 & 24.9 \\
\hline 2855 & 1/11/20088:58 & $8 / 11 / 20088: 58$ & 2.638 & 24.9 \\
\hline 2856 & 1/11/2008 9:00 & $8 / 11 / 20089.00$ & 2.641 & 24.9 \\
\hline
\end{tabular}


DOE/RL-2009-35, REV. 0

\begin{tabular}{|c|c|c|c|c|}
\hline \multicolumn{5}{|c|}{ D4-93p } \\
\hline $\operatorname{Rec}$ & & Adjusted & Pressure & Temp \\
\hline$\#$ & Date-Time & Date/Time & psi & ${ }^{\circ} \mathrm{C}$ \\
\hline 2857 & $1 / 11 / 20089.02$ & 8/11/20089:02 & 2.644 & 24.9 \\
\hline 2858 & $1 / 11 / 20089.04$ & $8 / 11 / 20089: 04$ & 2648 & 25 \\
\hline 2859 & $1 / 11 / 20089.06$ & $8 / 11 / 20089: 06$ & 2651 & 24.9 \\
\hline 2860 & 1/11/20089:08 & $8 / 11 / 20089: 08$ & 2.654 & 25 \\
\hline 2861 & 1/11/20089:10 & 8/11/20089:10 & 2657 & 24.9 \\
\hline 2862 & 1/11/20089:12 & 8/11/20089:12 & 2658 & 25 \\
\hline 2863 & 1/11/20089:14 & 8/11/20089:14 & 2.661 & 25 \\
\hline 2864 & 1/11/20089:16 & 8/11/2008 9:16 & 2.662 & 25 \\
\hline 2865 & 1/11/20089:18 & 8/11/2008 9:18 & 2.664 & 25 \\
\hline 2866 & 1/11/20089:20 & 8/11/20089:20 & 2.665 & 25 \\
\hline 2867 & $1 / 11 / 20089.22$ & $8 / 11 / 20089: 22$ & 2666 & 25 \\
\hline 2868 & 1/11/20089:24 & 8/11/2008 9:24 & 2668 & 25 \\
\hline 2869 & 1/11/20089:26 & 8/11/2008 9:26 & 2669 & 25 \\
\hline 2870 & 1/11/20089:28 & $8 / 11 / 20089: 28$ & 2.67 & 25 \\
\hline 2871 & 1/11/20089:30 & 8/11/20089:30 & 2671 & 25 \\
\hline 2872 & 1/11/20089:32 & 8/11/2008 9:32 & 2.672 & 25 \\
\hline 2873 & $1 / 11 / 20089.34$ & $8 / 11 / 20089: 34$ & 2673 & 25 \\
\hline 2874 & 1/11/20089:36 & $8 / 11 / 20089: 36$ & 2.674 & 25 \\
\hline 2875 & 1/11/20089:38 & $8 / 11 / 20089: 38$ & 2675 & 25 \\
\hline 2876 & $1 / 11 / 20089: 40$ & $8 / 11 / 20089: 40$ & 2.676 & 25 \\
\hline 2877 & 1/11/20089:42 & $8 / 11 / 20089: 42$ & 2677 & 25 \\
\hline 2878 & 1/11/20089:44 & $8 / 11 / 20089: 44$ & 2677 & 25 \\
\hline 2879 & 1/11/20089:46 & $8 / 11 / 20089: 46$ & 2678 & 25 \\
\hline 2880 & 1/11/20089:48 & 8/11/2008 9-48 & 2.679 & 25 \\
\hline 2881 & 1/11/20089:50 & 8/11/2008 9:50 & 2.68 & 25 \\
\hline 2882 & 1/11/20089.52 & 8/11/20089:52 & 2681 & 25 \\
\hline 2883 & 1/11/20089.54 & $8 / 11 / 20089: 54$ & 2.682 & 25 \\
\hline 2884 & $1 / 11 / 20089.56$ & $8 / 11 / 20089: 56$ & 2683 & 25 \\
\hline 2885 & $1 / 11 / 20089.58$ & $8 / 11 / 20089: 58$ & 2684 & 25 \\
\hline 2886 & 1/11/2008 10:00 & $8 / 11 / 200810: 00$ & 2.686 & 25 \\
\hline 2887 & 1/11/2008 10:02 & $8 / 11 / 200810: 02$ & 2.688 & 25 \\
\hline 2888 & 1/11/2008 10:04 & $8 / 11 / 200810: 04$ & 2689 & 25.1 \\
\hline 2889 & 1/11/2008 10:06 & $8 / 11 / 2008$ 10:06 & 2.69 & 25.1 \\
\hline 2890 & 1/11/2008 10:08 & 8/11/2008 10:08 & 2.69 & 25.1 \\
\hline 2891 & 1/11/2008 10:10 & $8 / 11 / 2008$ 10:10 & 2.691 & 25.1 \\
\hline 2892 & 1/11/2008 10:12 & 8/11/2008 10:12 & 2691 & 25.1 \\
\hline 2893 & 1/11/2008 10:14 & 8/11/2008 10:14 & 2.692 & 25.1 \\
\hline 2894 & 1/11/2008 10:16 & 8/11/2008 10:16 & 2693 & 25.1 \\
\hline 2895 & $0810: 18$ & 8/11/2008 10:18 & 2694 & 25.1 \\
\hline 2896 & $1 / 11 / 200810: 20$ & $8 / 11 / 200810: 20$ & 2694 & 25.1 \\
\hline 2897 & $1 / 11 / 200810: 22$ & $8 / 11 / 200810: 22$ & 2695 & 25.1 \\
\hline 2898 & 1/11/2008 10:24 & $8 / 11 / 2008$ 10:24 & 2696 & 25.1 \\
\hline 2899 & $1 / 11 / 200810: 26$ & $8 / 11 / 200810: 26$ & 2697 & 25.1 \\
\hline 2900 & $1 / 11 / 200810: 28$ & $8 / 11 / 200810: 28$ & 2.698 & 25.1 \\
\hline 2901 & 1/11/2008 10:30 & $8 / 11 / 2008$ 10:30 & 2698 & 25.1 \\
\hline 2902 & 1/11/2008 10:32 & 8/11/2008 10:32 & 2.7 & 25.1 \\
\hline 2903 & 1/11/2008 10:34 & 8/11/2008 10:34 & 2701 & 25.1 \\
\hline 2904 & $1 / 11 / 200810: 36$ & $8 / 11 / 2008$ 10:36 & 2701 & 25.1 \\
\hline 2905 & $1 / 11 / 200810: 38$ & $8 / 11 / 2008$ 10:38 & 2702 & 25.1 \\
\hline 2906 & $1 / 11 / 200810: 40$ & $8 / 11 / 200810: 40$ & 2702 & 25.1 \\
\hline 2907 & $1 / 11 / 200810: 42$ & $8 / 11 / 2008$ 10:42 & 2703 & 25.1 \\
\hline 2908 & $1 / 11 / 200810: 44$ & $8 / 11 / 200810: 44$ & 2703 & 25.1 \\
\hline 2909 & $1 / 11 / 200810: 46$ & $8 / 11 / 200810: 46$ & 2704 & 25.1 \\
\hline 2910 & $1 / 11 / 200810: 48$ & $8 / 11 / 2008$ 10:48 & 2705 & $\overline{25.1}$ \\
\hline 2911 & $1 / 11 / 200810: 50$ & 8/11/2008 10:50 & 2706 & 25.1 \\
\hline 2912 & 1/11/2008 10:52 & 8/11/2008 10:52 & 2.706 & 25.1 \\
\hline 2913 & 1/11/2008 10:54 & 8/11/2008 10:54 & 2.707 & 25.1 \\
\hline 2914 & $1 / 11 / 200810: 56$ & 8/11/2008 10:56 & 2708 & 25.1 \\
\hline 2915 & 1/11/2008 10:58 & 8/11/2008 10:58 & 2712 & 25.2 \\
\hline 2916 & 1/11/2008 11:00 & 8/11/2008 11:00 & 2715 & 25.2 \\
\hline 2917 & 1/11/200811:02 & $8 / 11 / 2008$ 11:02 & 2.716 & 25.1 \\
\hline 2918 & $1 / 11 / 200811: 04$ & $8 / 11 / 200811: 04$ & 2718 & 25.2 \\
\hline 2919 & 1/11/2008 11:06 & $8 / 11 / 2008$ 11:06 & 2.72 & 25.1 \\
\hline 2920 & 1/11/2008 11:08 & $8 / 11 / 200811: 08$ & 2721 & 25.2 \\
\hline 2921 & 1/11/2008 11:10 & $8 / 11 / 200811: 10$ & 2723 & 25.2 \\
\hline 2922 & 1/11/2008 11:12 & $8 / 11 / 200811: 12$ & 2723 & 25.1 \\
\hline 2923 & 1/11/2008 11:14 & $8 / 11 / 200811: 14$ & 2724 & 25.2 \\
\hline 2924 & 1/11/2008 11:16 & 8/11/2008 11:16 & 2724 & 25.2 \\
\hline 2925 & 1/11/2008 11:18 & 8/11/2008 11:18 & 2.724 & 25.2 \\
\hline
\end{tabular}

\begin{tabular}{|c|c|c|c|c|}
\hline \multicolumn{5}{|c|}{ D4-93p } \\
\hline $\operatorname{Rec}$ & & Adjusted & Pressure & Temp \\
\hline$\#$ & Date/Time & DaterTime & psi & ${ }^{\circ} \mathrm{C}$ \\
\hline 2926 & 1/11/2008 11:20 & $8 / 11 / 2008$ 11:20 & 2724 & 25.2 \\
\hline 2927 & $1 / 11 / 200811: 22$ & $8 / 11 / 200811: 22$ & 2724 & 25.3 \\
\hline 2928 & $1 / 11 / 200811: 24$ & $8 / 11 / 200811: 24$ & 2723 & 25.3 \\
\hline 2929 & 1/11/2008 11:26 & $8 / 11 / 2008$ 11:26 & 2.61 & 25.3 \\
\hline 2930 & 1/11/2008 11:28 & $8 / 11 / 2008$ 11:28 & 2458 & 25.3 \\
\hline 2931 & $1 / 11 / 200811: 30$ & $8 / 11 / 200811: 30$ & 2418 & 25.3 \\
\hline 2932 & 1/11/12008 11:32 & $8 / 11 / 2008$ 11:32 & 2535 & 25.3 \\
\hline 2933 & $1 / 11 / 200811: 34$ & $8 / 11 / 200811: 34$ & 2629 & 25.3 \\
\hline 2934 & 1/11/2008 11:36 & $8 / 11 / 2008$ 11:36 & 2.68 & 25.3 \\
\hline 2935 & 1/11/2008 11:38 & $8 / 11 / 200811: 38$ & 2697 & 25.3 \\
\hline 2936 & 1/11/2008 11:40 & $8 / 11 / 200811: 40$ & 2703 & 25.3 \\
\hline 2937 & $1 / 11 / 200811: 42$ & $8 / 11 / 200811: 42$ & 2706 & 25.3 \\
\hline 2938 & 1/11/2008 11:44 & $8 / 11 / 200811: 44$ & 2700 & 25.3 \\
\hline 2939 & 1/11/2008 11:46 & $8 / 11 / 200811: 46$ & 2711 & 25.3 \\
\hline 2940 & 1/11/2008 11:48 & $8 / 11 / 2008$ 11:48 & 2714 & 25.3 \\
\hline 2941 & $1 / 11 / 200811: 50$ & $8 / 11 / 200811: 50$ & 2718 & 25.3 \\
\hline 2942 & $1 / 11 / 200811: 52$ & $8 / 11 / 200811: 52$ & 2.72 & 25.4 \\
\hline 2943 & $1 / 11 / 200811: 54$ & $8 / 11 / 200811: 54$ & 2723 & 25.4 \\
\hline 2944 & $1 / 11 / 200811: 56$ & $8 / 11 / 200811: 56$ & 2726 & 25.4 \\
\hline 2945 & $1 / 11 / 200811: 58$ & $8 / 11 / 200811: 58$ & 2729 & 25.4 \\
\hline 2946 & $1 / 11 / 200812: 00$ & $8 / 11 / 200812: 00$ & 2.73 & 25.4 \\
\hline 2947 & $1 / 11 / 200812: 02$ & $8 / 11 / 200812: 02$ & 2732 & 25.4 \\
\hline 2948 & 1/11/2008 12:04 & $8 / 11 / 2008$ 12:04 & 2.733 & 25.4 \\
\hline 2949 & $1 / 11 / 200812: 06$ & $8 / 11 / 200812: 06$ & 2734 & 25.4 \\
\hline 2950 & $1 / 11 / 200812: 08$ & $8 / 11 / 200812: 08$ & 2736 & 25.4 \\
\hline 2951 & $1 / 11 / 200812: 10$ & $8 / 11 / 200812: 10$ & 2739 & 25.5 \\
\hline 2952 & $1 / 11 / 20081212$ & $8 / 11 / 200812: 12$ & 2.74 & 25.5 \\
\hline 2953 & $1 / 11 / 200812: 14$ & $8 / 11 / 2008$ 12:14 & 2.742 & 25.5 \\
\hline 2954 & $1 / 11 / 200812: 16$ & $8 / 11 / 200812: 16$ & 2743 & 25.5 \\
\hline 2955 & $1 / 11 / 200812: 18$ & $8 / 11 / 200812: 18$ & 2.744 & 25.6 \\
\hline 2956 & $1 / 11 / 200812: 20$ & $8 / 11 / 200812: 20$ & 2.744 & 25.8 \\
\hline 295 & $1 / 11 / 200812222$ & $8 / 11 / 200812: 22$ & 2.745 & 25.6 \\
\hline 2958 & $1 / 11 / 200812: 24$ & $8 / 11 / 2008$ 12:24 & 2746 & 25.6 \\
\hline 2959 & $1 / 11 / 20081226$ & $8 / 11 / 200812: 26$ & 2748 & 25.6 \\
\hline 2960 & $1 / 11 / 200812: 28$ & $8 / 11 / 200812: 28$ & 2749 & 25.6 \\
\hline 2961 & $1 / 11 / 20081230$ & $8 / 11 / 200812: 30$ & 2.75 & 25.6 \\
\hline 2962 & $1 / 11 / 20081232$ & $8 / 11 / 200812: 32$ & 2751 & 25.6 \\
\hline 2963 & $1 / 11 / 20081234$ & $8 / 11 / 200812: 34$ & 2752 & 25.6 \\
\hline 2964 & $1 / 11 / 200812: 36$ & $8 / 11 / 200812: 36$ & 2753 & 25.6 \\
\hline 2965 & $1 / 11 / 200812: 38$ & $8 / 11 / 200812: 38$ & 2754 & 25.6 \\
\hline 2966 & $1 / 11 / 200812: 40$ & $8 / 11 / 2008$ 12:40 & 2756 & 25.6 \\
\hline 2967 & $1 / 11 / 20081242$ & $8 / 11 / 200812: 42$ & 2.757 & 25.6 \\
\hline 2968 & $1 / 11 / 200812444$ & $8 / 11 / 200812: 44$ & 2758 & 25.6 \\
\hline 2969 & $1 / 11 / 20081246$ & $8 / 11 / 200812: 46$ & 2.759 & 25.7 \\
\hline 2970 & $1 / 11 / 200812448$ & $8 / 11 / 200812: 48$ & 2.759 & 25.7 \\
\hline 2971 & $1 / 11 / 200812: 50$ & $8 / 11 / 200812: 50$ & 2.76 & 25.7 \\
\hline 2972 & $1 / 11 / 200812: 52$ & 8/11/2008 12:52 & 2762 & 25.7 \\
\hline 2973 & $1 / 11 / 200812: 54$ & $8 / 11 / 2008$ 12:54 & 2763 & 25.9 \\
\hline 2974 & $1 / 11 / 20081256$ & $8 / 11 / 200812: 56$ & 2762 & 25.8 \\
\hline 2975 & $1 / 11 / 200812: 58$ & \begin{tabular}{|l|}
$8 / 11 / 200812: 58$ \\
\end{tabular} & 2763 & 25.8 \\
\hline 2976 & $1 / 11 / 200813: 00$ & 8/11/2008 13:00 & 2764 & 25.8 \\
\hline 297 & $1 / 11 / 200813: 02$ & $8 / 11 / 2008$ 13:02 & 2765 & 25.8 \\
\hline 2978 & $1 / 11 / 200813: 04$ & \begin{tabular}{|l|}
$8 / 11 / 200813: 04$ \\
\end{tabular} & 2766 & 25.8 \\
\hline 2979 & 1/11/2008 13:06 & 8/11/2008 13:06 & 2766 & 25.8 \\
\hline 2980 & $1 / 11 / 200813: 08$ & $8 / 11 / 2008$ 13:08 & 2.768 & 25.8 \\
\hline 2981 & 1/11/2008 13:10 & \begin{tabular}{|l|}
$8 / 11 / 200813: 10$ \\
\end{tabular} & 2769 & 25.9 \\
\hline 2982 & 1/11/2008 13:12 & \begin{tabular}{|l|}
$8 / 11 / 200813: 12$ \\
\end{tabular} & 2.771 & 25.9 \\
\hline 2983 & $1 / 11 / 200813: 14$ & \begin{tabular}{|l|}
$8 / 11 / 2008$ 13:14 \\
\end{tabular} & 2.773 & 25.9 \\
\hline 2984 & 1/11/2008 13:16 & \begin{tabular}{|l|}
$8 / 11 / 200813: 16$ \\
\end{tabular} & $2.7 / 4$ & 25.9 \\
\hline 2985 & $1 / 11 / 200813: 18$ & $8 / 11 / 200813: 18$ & 2774 & 25.9 \\
\hline 2986 & $1 / 11 / 200813: 20$ & 8/11/2008 13:20 & 2775 & 25.9 \\
\hline 2987 & $1 / 11 / 200813: 22$ & \begin{tabular}{|l|}
$8 / 11 / 200813: 22$ \\
\end{tabular} & 2776 & 25.9 \\
\hline 2988 & $1 / 11 / 200813: 24$ & \begin{tabular}{|l|}
$8 / 11 / 2008$ 13:24 \\
\end{tabular} & 2776 & 25.9 \\
\hline 2989 & $1 / 11 / 200813: 26$ & \begin{tabular}{|l|}
$8 / 11 / 200813: 26$ \\
\end{tabular} & 2.776 & 25.8 \\
\hline 2990 & $1 / 11 / 200813: 28$ & \begin{tabular}{|l|}
$8 / 11 / 200813: 28$ \\
\end{tabular} & 2776 & 25.8 \\
\hline 2991 & 1/11/2008 13:30 & \begin{tabular}{|l|}
$8 / 11 / 2008$ 13:30 \\
\end{tabular} & $2 \pi 78$ & 25.9 \\
\hline 2992 & 1/11/2008 13:32 & $8 / 11 / 2008$ 13:32 & 2.778 & 25.9 \\
\hline 2993 & $1 / 11 / 200813: 34$ & \begin{tabular}{|l|}
$8 / 11 / 200813: 34$ \\
\end{tabular} & 2.779 & 25.9 \\
\hline 2994 & $1 / 11 / 200813: 36$ & \begin{tabular}{|c|}
$8 / 11 / 200813: 36$ \\
\end{tabular} & 2.779 & 26 \\
\hline
\end{tabular}

\begin{tabular}{|c|c|c|c|c|}
\hline \multicolumn{5}{|c|}{ D4-93p } \\
\hline $\operatorname{Rec}$ & & Adjusted & Pressure & Temp \\
\hline \# & Date-Time & Date/Time & psi & ${ }^{\circ} \mathrm{C}$ \\
\hline 2995 & 1/11/2008 13:38 & \begin{tabular}{|l|}
$8 / 11 / 200813: 38$ \\
\end{tabular} & 2.78 & 26 \\
\hline 2996 & $1 / 11 / 200813: 40$ & \begin{tabular}{|l|}
$8 / 11 / 200813: 40$ \\
\end{tabular} & 2.78 & 26 \\
\hline 2997 & V/11/2008 13:42 & \begin{tabular}{|l|}
$8 / 11 / 200813: 42$ \\
\end{tabular} & 2781 & 26.1 \\
\hline 2998 & 1/11/2008 13:44 & $8 / 11 / 200813: 44$ & 2782 & 26.1 \\
\hline 2999 & 1/11/2008 13:46 & $8 / 11 / 200813: 46$ & 2782 & 26.1 \\
\hline 3000 & 1/11/2008 13:48 & \begin{tabular}{|l|}
$8 / 11 / 200813: 48$ \\
\end{tabular} & 2783 & 26.1 \\
\hline 3001 & 1/11/2008 13:50 & \begin{tabular}{|l|}
$8 / 11 / 2008$ 13:50 \\
\end{tabular} & 2783 & 26.1 \\
\hline 3002 & $1 / 11 / 200813: 52$ & \begin{tabular}{|l|}
$8 / 11 / 2008$ 13:52 \\
\end{tabular} & 2784 & 26.1 \\
\hline 3003 & 1/11/2008 13:54 & \begin{tabular}{|l|}
$8 / 11 / 200813: 54$ \\
\end{tabular} & 2784 & 26.1 \\
\hline 3004 & 1/11/2008 13:56 & \begin{tabular}{|l|}
$8 / 11 / 200813: 56$ \\
\end{tabular} & 2784 & 26.1 \\
\hline 3005 & 1/11/2008 13:58 & \begin{tabular}{|l|}
$8 / 11 / 200813: 58$ \\
\end{tabular} & 2784 & 26.1 \\
\hline 3006 & $1 / 11 / 200814: 00$ & \begin{tabular}{|l|}
$8 / 11 / 2008$ \\
\end{tabular} & 2785 & 26.1 \\
\hline 3007 & $1 / 11 / 200814: 02$ & \begin{tabular}{|c|}
$8 / 11 / 200814: 02$ \\
\end{tabular} & 2785 & 26.1 \\
\hline 3008 & $1 / 11 / 2008$ 14:04 & $8 / 11 / 2008$ 14:04 & 2.785 & $\overline{26.2}$ \\
\hline 3009 & $1 / 11 / 200814: 06$ & 8/11/2008 14:06 & 2.785 & 26.2 \\
\hline 3010 & $1 / 11 / 200814: 08$ & $8 / 11 / 2008$ 14:08 & 2786 & 26.2 \\
\hline 3011 & 1/11/2008 14:10 & $8 / 11 / 200814: 10$ & 2767 & 26.2 \\
\hline 3012 & 1/11/2008 14:12 & $8 / 11 / 200814: 12$ & 2.618 & 26.3 \\
\hline 3013 & 1/11/2008 14:14 & $8 / 11 / 200814: 14$ & 2475 & 26.3 \\
\hline 3014 & 1/11/2008 14:16 & \begin{tabular}{|l|}
$8 / 11 / 200814: 16$ \\
\end{tabular} & 2.393 & 26.3 \\
\hline 3015 & 1/11/2008 14:18 & \begin{tabular}{|l|}
$8 / 11 / 200814: 18$ \\
\end{tabular} & 2.528 & 26.3 \\
\hline 3016 & $1 / 11 / 200814: 20$ & $8 / 11 / 2008$ 14:20 & 2629 & 26.3 \\
\hline 3017 & $1 / 11 / 2008$ 14:22 & \begin{tabular}{|l|}
$8 / 11 / 2008$ 14:22 \\
\end{tabular} & 2.708 & 26.3 \\
\hline 3018 & $1 / 11 / 2008$ 14:24 & $8 / 11 / 2008$ 14:24 & 2.738 & 26.3 \\
\hline 3019 & $1 / 11 / 200814: 26$ & $8 / 11 / 2008$ 14:26 & 2.75 & 26.3 \\
\hline 3020 & $1 / 11 / 200814: 28$ & 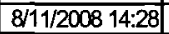 & 2756 & 26.2 \\
\hline 3021 & 1/11/2008 14:30 & \begin{tabular}{|l|}
$8 / 11 / 2008$ 14:30 \\
\end{tabular} & 2.76 & 26.1 \\
\hline 3022 & 1/11/2008 14:32 & $8 / 11 / 2008$ 14:32 & 2763 & 26.1 \\
\hline 3023 & $1 / 11 / 200814: 34$ & $8 / 11 / 200814: 34$ & 2765 & 26.1 \\
\hline 3024 & $1 / 11 / 200814: 36$ & \begin{tabular}{|l|}
$8 / 11 / 200814: 36$ \\
\end{tabular} & 2.767 & 26.1 \\
\hline 3025 & $1 / 11 / 200814: 38$ & \begin{tabular}{|l|}
$8 / 11 / 200814: 38$ \\
\end{tabular} & 2.771 & 26.2 \\
\hline 3026 & $1 / 11 / 200814: 40$ & $8 / 11 / 200814: 40$ & 2774 & 26.3 \\
\hline 3027 & $1 / 11 / 2008$ 14:42 & $8 / 11 / 2008$ 14:42 & 2778 & 26.3 \\
\hline 3028 & $1 / 11 / 200814: 44$ & $8 / 11 / 2008$ 14:44 & 2781 & 26.3 \\
\hline 3029 & $1 / 11 / 200814: 46$ & $8 / 11 / 2008$ 14:46 & 2783 & 26.3 \\
\hline 3030 & $1 / 11 / 200814: 48$ & \begin{tabular}{|l|}
$8 / 11 / 200814: 48$ \\
\end{tabular} & 2785 & 26.4 \\
\hline 3031 & $1 / 11 / 200814: 50$ & $8 / 11 / 200814: 50$ & 2.79 & 26.4 \\
\hline 3032 & 1/11/2008 14:52 & \begin{tabular}{|l|}
$8 / 11 / 200814: 52$ \\
\end{tabular} & 2795 & 26.4 \\
\hline 3033 & $1 / 11 / 2008$ 14:54 & \begin{tabular}{|l|l|}
$8 / 11 / 2008$ & $14: 54$ \\
\end{tabular} & 2.797 & 26.4 \\
\hline 3034 & $1 / 11 / 200814: 56$ & $8 / 11 / 200814: 56$ & 2799 & 26.4 \\
\hline 3035 & $1 / 11 / 200814: 58$ & \begin{tabular}{|l|}
$8 / 11 / 200814: 58$ \\
\end{tabular} & 2.802 & 26.4 \\
\hline 3036 & 1/11/2008 15:00 & 8/11/2008 15:00 & 2.802 & 26.4 \\
\hline 3037 & $1 / 11 / 2008$ 15:02 & $8 / 11 / 200815: 02$ & 2804 & 26.4 \\
\hline 3038 & 1/11/2008 15:04 & \begin{tabular}{|l|}
$8 / 11 / 2008$ 15:04 \\
\end{tabular} & 2.805 & 26.4 \\
\hline 3039 & 1/11/2008 15:06 & $8 / 11 / 200815: 06$ & 2.806 & 26.4 \\
\hline 3040 & 1/11/2008 15:08 & 8/11/2008 15:08 & 2808 & 26.4 \\
\hline 3041 & 1/11/2008 15:10 & \begin{tabular}{|l|}
$8 / 11 / 2008$ 15:10 \\
\end{tabular} & 2.809 & 26.4 \\
\hline 3042 & 1/11/2008 15:12 & \begin{tabular}{|l|}
$8 / 11 / 2008$ 15:12 \\
\end{tabular} & 2.81 & 26.4 \\
\hline 3043 & 1/11/2008 15:14 & \begin{tabular}{|l|}
$8 / 11 / 200815: 14$ \\
\end{tabular} & 2.811 & 26.4 \\
\hline 3044 & 1/11/2008 15:16 & \begin{tabular}{|l|}
$8 / 11 / 2008$ 15:16 \\
\end{tabular} & 2812 & 26.5 \\
\hline 3045 & 1/11/2008 15:18 & \begin{tabular}{|l|}
$8 / 11 / 200815: 18$ \\
\end{tabular} & 2812 & 26.5 \\
\hline 3046 & 1/11/2008 15:20 & \begin{tabular}{|l|}
$8 / 11 / 200815: 20$ \\
\end{tabular} & 2.813 & 26.5 \\
\hline 3047 & 1/11/2008 15:22 & $8 / 11 / 200815: 22$ & 2815 & 26.5 \\
\hline 3048 & $1 / 11 / 2008$ 15:24 & $8 / 11 / 2008$ 15:24 & 2815 & 26.5 \\
\hline 3049 & 1/11/2008 15:26 & \begin{tabular}{|l|}
$8 / 11 / 2008$ 15:26 \\
\end{tabular} & 2.816 & 26.6 \\
\hline 3050 & 1/11/2008 15:28 & $8 / 11 / 200815: 28$ & 2817 & 26.6 \\
\hline 3051 & 1/11/2008 15:30 & 8/11/2008 15:30 & 2.818 & 26.6 \\
\hline 3052 & $1 / 11 / 2008$ 15:32 & $8 / 11 / 2008$ 15:32 & 2954 & 26.6 \\
\hline 3053 & $1 / 11 / 2008$ 15:34 & $8 / 11 / 2008$ 15:34 & 2823 & 26.6 \\
\hline 3054 & 1/11/2008 15:36 & $8 / 11 / 2008$ 15:36 & 2818 & 26.6 \\
\hline 3055 & $1 / 11 / 200815: 38$ & $8 / 11 / 200815: 38$ & 2819 & 26.6 \\
\hline 3056 & 1/11/2008 15:40 & $8 / 11 / 200815: 40$ & 2.82 & 26.7 \\
\hline 3057 & $1 / 11 / 200815: 42$ & $8 / 11 / 200815: 42$ & 2.819 & 26.7 \\
\hline 3058 & $1 / 11 / 200815: 44$ & \begin{tabular}{|l|}
$8 / 11 / 200815: 44$ \\
\end{tabular} & 2.82 & 26.6 \\
\hline 3059 & $1 / 11 / 200815: 46$ & $8 / 11 / 2008$ 15:46 & 2821 & 26.6 \\
\hline 3060 & $1 / 11 / 200815: 48$ & \begin{tabular}{|l|l|}
$8 / 11 / 2008$ & $15: 48$ \\
\end{tabular} & 2822 & 26.7 \\
\hline 3061 & $1 / 11 / 200815: 50$ & \begin{tabular}{|l|l|}
$8 / 11 / 200815: 50$ \\
\end{tabular} & 2.823 & 26.7 \\
\hline 3062 & $1 / 11 / 200815: 52$ & $8 / 11 / 200815: 52$ & 2.824 & 26.8 \\
\hline 3063 & 1/11/2008 15:54 & \begin{tabular}{|l|}
$8 / 11 / 2008$ 15:54 \\
\end{tabular} & 2.824 & 26.8 \\
\hline
\end{tabular}




\begin{tabular}{|c|c|c|c|c|}
\hline \multicolumn{5}{|c|}{ D493p } \\
\hline $\operatorname{Rec}$ & & Adjusted & Pressure & Termp \\
\hline$\#$ & Date/Time & DaterTime & psi & ${ }^{\circ} \mathrm{C}$ \\
\hline 3064 & $1 / 11 / 200815: 56$ & $8 / 11 / 200815: 56$ & 2825 & 26.8 \\
\hline 3065 & $1 / 11 / 200815: 58$ & $8 / 11 / 200815: 58$ & 2826 & 26.7 \\
\hline 3066 & $1 / 11 / 200816: 00$ & $8 / 11 / 200816: 00$ & 2826 & 26.8 \\
\hline 3067 & $1 / 11 / 200816: 02$ & $8 / 11 / 200816: 02$ & 2827 & 26.8 \\
\hline 3068 & $1 / 11 / 200816: 04$ & $8 / 11 / 200816: 04$ & 2828 & 26.7 \\
\hline 3069 & $1 / 11 / 200816: 06$ & $8 / 11 / 200816: 06$ & 2829 & 26.7 \\
\hline 3070 & $1 / 11 / 200816: 08$ & $8 / 11 / 200816: 08$ & 2829 & 26.8 \\
\hline 3071 & $1 / 11 / 200816: 10$ & $8 / 11 / 200816: 10$ & 283 & 26.8 \\
\hline 3072 & $1 / 11 / 200816: 12$ & $8 / 11 / 200816: 12$ & 2831 & 26.8 \\
\hline 3073 & $1 / 11 / 200816: 14$ & $8 / 11 / 200816: 14$ & 2831 & 26.8 \\
\hline 3074 & $1 / 11 / 200816: 16$ & $8 / 11 / 200816: 16$ & 2831 & 26.8 \\
\hline 3075 & $1 / 11 / 200816: 18$ & $8 / 11 / 200816: 18$ & 2832 & 26.8 \\
\hline 3076 & $1 / 11 / 200816: 20$ & $8 / 11 / 200816: 20$ & 2.835 & 26.8 \\
\hline 3077 & $1 / 11 / 200816: 22$ & $8 / 11 / 200816: 22$ & 2835 & 26.8 \\
\hline 3078 & $1 / 11 / 200816: 24$ & $8 / 11 / 200816: 24$ & 2.835 & 26.8 \\
\hline 3079 & $1 / 11 / 200816: 26$ & $8 / 11 / 200816: 26$ & 2835 & 26.8 \\
\hline 3080 & $1 / 11 / 200816: 28$ & $8 / 11 / 200816: 28$ & 2836 & 26.8 \\
\hline 3081 & $1 / 11 / 200816: 30$ & $8 / 11 / 200816: 30$ & 2836 & 26.8 \\
\hline 3082 & $1 / 11 / 200816: 32$ & $8 / 11 / 200816: 32$ & 2837 & 26.8 \\
\hline 3083 & $1 / 11 / 200816: 34$ & $8 / 11 / 200816: 34$ & 2836 & 26.9 \\
\hline 3084 & $1 / 11 / 200816: 36$ & $8 / 11 / 200816: 36$ & 2836 & 26.9 \\
\hline 3085 & $1 / 11 / 200816: 38$ & $8 / 11 / 200816: 38$ & 2834 & 26.9 \\
\hline 3086 & $1 / 11 / 200816: 40$ & $8 / 11 / 200816: 40$ & 2835 & 26.9 \\
\hline 3087 & $1 / 11 / 200816: 42$ & $8 / 11 / 200816: 42$ & 2834 & 26.9 \\
\hline 3088 & $1 / 11 / 200816: 44$ & $8 / 11 / 200816: 44$ & 284 & 27 \\
\hline 3089 & $1 / 11 / 200816: 46$ & $8 / 11 / 200816: 46$ & 2845 & 27 \\
\hline 3090 & $1 / 11 / 200816: 48$ & $8 / 11 / 200816: 48$ & 2849 & 26.9 \\
\hline 3091 & $1 / 11 / 200816: 50$ & $8 / 11 / 200816: 50$ & 2855 & 26.9 \\
\hline 3092 & $1 / 11 / 200816: 52$ & $8 / 11 / 2008$ 16:52 & 2858 & 26.9 \\
\hline 3093 & $1 / 11 / 200816: 54$ & $8 / 11 / 200816: 54$ & 2862 & 26.8 \\
\hline 3094 & $1 / 11 / 200816: 56$ & $8 / 11 / 200816: 56$ & 2819 & 26.8 \\
\hline 3095 & $1 / 11 / 200816: 58$ & $8 / 11 / 200816: 58$ & 2714 & 26.8 \\
\hline 3096 & $1 / 11 / 200817: 00$ & $8 / 11 / 200817: 00$ & 2571 & 26.8 \\
\hline 3097 & $1 / 11 / 200817: 02$ & $8 / 11 / 200817: 02$ & 2595 & 27.1 \\
\hline 3098 & $1 / 11 / 200817: 04$ & $8 / 11 / 200817: 04$ & 2712 & 27.1 \\
\hline 3099 & 1/11/2008 17:06 & $8 / 11 / 200817: 06$ & 2781 & 26.8 \\
\hline 3100 & $1 / 11 / 200817: 08$ & $8 / 11 / 200817: 08$ & 2816 & 26.9 \\
\hline 3101 & $1 / 11 / 200$ & $8 / 11 / 2008$ 17:10 & 2831 & 26.8 \\
\hline 3102 & 1/11/2008 17:12 & $8 / 11 / 200817: 12$ & 2835 & 26.8 \\
\hline 3103 & $1 / 11 / 200817: 14$ & $8 / 11 / 2008$ 17:14 & 2836 & 26.8 \\
\hline 3104 & $1 / 11 / 200817: 16$ & $8 / 11 / 200817: 16$ & 2833 & 26.8 \\
\hline 3105 & $1 / 11 / 200817: 18$ & $8 / 11 / 2008$ 17:18 & 2832 & 26.7 \\
\hline 3106 & $1 / 11 / 200817: 20$ & $8 / 11 / 200817: 20$ & 2829 & 26.6 \\
\hline 3107 & $1 / 11 / 200817: 22$ & $8 / 11 / 200817: 22$ & 2827 & 26.6 \\
\hline 3108 & $1 / 11 / 200817: 24$ & $8 / 11 / 2008$ 17:24 & 2825 & 26.6 \\
\hline 3109 & $1 / 11 / 200817: 26$ & $8 / 11 / 2008$ 17:26 & 2824 & 26.7 \\
\hline 3110 & 1/111/2008 17:28 & $8 / 11 / 200817: 28$ & 2825 & 26.8 \\
\hline 3111 & $1 / 11 / 200817: 30$ & $8 / 11 / 200817: 30$ & 2827 & 26.9 \\
\hline 3112 & $1 / 11 / 200817: 32$ & $8 / 11 / 200817: 32$ & 2829 & 26.9 \\
\hline 3113 & $1 / 11 / 200817: 34$ & $8 / 11 / 200817: 34$ & 2.831 & 27 \\
\hline 3114 & 1/11/2008 17:36 & $8 / 11 / 200817: 36$ & 2832 & 27 \\
\hline 3115 & $1 / 11 / 200817: 38$ & $8 / 11 / 200817: 38$ & 2834 & 27.1 \\
\hline 3116 & $1 / 11 / 200817: 40$ & $8 / 11 / 200817: 40$ & 2836 & 27.1 \\
\hline 3117 & $1 / 11 / 200817: 42$ & $8 / 11 / 200817: 42$ & 2346 & 27.2 \\
\hline 3118 & $1 / 11 / 200817: 44$ & $8 / 11 / 200817: 44$ & 2763 & 27.3 \\
\hline 3119 & $1 / 11 / 200817: 46$ & $8 / 11 / 200817: 46$ & 2796 & 27.4 \\
\hline 3120 & $1 / 11 / 200817: 48$ & $8 / 11 / 200817: 48$ & 2897 & 27.4 \\
\hline 3121 & $1 / 11 / 200817: 50$ & $8 / 11 / 200817: 50$ & 2864 & 27.4 \\
\hline 3122 & $1 / 11 / 200817: 52$ & $8 / 11 / 200817: 52$ & 2863 & 27.4 \\
\hline 3123 & $1 / 11 / 200817: 54$ & $8 / 11 / 200817: 54$ & 2864 & 27.4 \\
\hline 3124 & $1 / 11 / 200817: 56$ & $8 / 11 / 200817: 56$ & 2864 & 27.3 \\
\hline 3125 & $1 / 11 / 200817: 58$ & $8 / 11 / 2008 \quad 17: 58$ & 2863 & 27.3 \\
\hline 3126 & $1 / 11 / 200818: 00$ & $8 / 11 / 2008$ 18:00 & 2862 & 27.3 \\
\hline 3127 & 1/11/2008 18:02 & $8 / 11 / 200818: 02$ & 2862 & 27.3 \\
\hline 3128 & $1 / 11 / 200818: 04$ & $8 / 11 / 2008$ 18:04 & 2863 & 27.3 \\
\hline 3129 & 1/11/2008 18:06 & $8 / 11 / 200818: 06$ & 2864 & 27.3 \\
\hline 3130 & 1/11/2008 18:08 & $8 / 11 / 200818: 08$ & 2867 & 27.4 \\
\hline 3131 & $1 / 11 / 200818: 10$ & $8 / 11 / 2008$ 18:10 & 2868 & 27.4 \\
\hline 3132 & $1 / 11 / 200818: 12$ & $8 / 11 / 2008$ 18:12 & 287 & 27.4 \\
\hline
\end{tabular}

\begin{tabular}{|c|c|c|c|c|}
\hline \multicolumn{5}{|c|}{ D4-93p } \\
\hline Rec & & Adjusted & Pressure & Temp \\
\hline \# & Date-Time & Date/Time & psi & ${ }^{\circ} \mathrm{C}$ \\
\hline 3133 & $1 / 11 / 200818: 14$ & $8 / 11 / 200818: 14$ & 2872 & $\overline{27.4}$ \\
\hline 3134 & $1 / 11 / 200818: 16$ & $8 / 11 / 200818: 16$ & 2873 & 27.4 \\
\hline 3135 & $1 / 11 / 200818: 18$ & $8 / 11 / 2008$ 18:18 & 2875 & 27.4 \\
\hline 3136 & $1 / 11 / 200818: 20$ & $8 / 11 / 200818: 20$ & 2876 & 27.4 \\
\hline 3137 & $1 / 11 / 200818: 22$ & $8 / 11 / 200818: 22$ & 2878 & 27.4 \\
\hline 3138 & $1 / 11 / 200818: 24$ & $8 / 11 / 200818: 24$ & 2.879 & $\overline{27.4}$ \\
\hline 3139 & $1 / 11 / 200818: 26$ & $8 / 11 / 200818: 26$ & 288 & 27.4 \\
\hline 3140 & $1 / 11 / 200818: 28$ & $8 / 11 / 200818: 28$ & 2881 & 27.4 \\
\hline 3141 & $1 / 11 / 200818: 30$ & $8 / 11 / 200818: 30$ & 2884 & 27.4 \\
\hline 3142 & $1 / 11 / 200818: 32$ & $8 / 11 / 200818: 32$ & 2885 & 27.4 \\
\hline 3143 & $1 / 11 / 200818: 34$ & $8 / 11 / 200818: 34$ & 2886 & 27.4 \\
\hline 3144 & 1/11/2008 18:36 & $8 / 11 / 200818: 36$ & 2888 & 27.4 \\
\hline 3145 & $1 / 11 / 200818: 38$ & $8 / 11 / 200818: 38$ & 2889 & 27.3 \\
\hline 3146 & $1 / 11 / 200818: 40$ & $8 / 11 / 200818: 40$ & 289 & 27.3 \\
\hline 3147 & $1 / 11 / 200818: 42$ & $8 / 11 / 200818: 42$ & 289 & 27.3 \\
\hline 3148 & $1 / 11 / 200818: 44$ & $8 / 11 / 200818: 44$ & 2891 & 27.3 \\
\hline 3149 & $1 / 11 / 200818: 46$ & $8 / 11 / 200818: 46$ & 2891 & 27.3 \\
\hline 3150 & $1 / 11 / 200818: 48$ & $8 / 11 / 200818: 48$ & 2892 & 27.4 \\
\hline 3151 & $1 / 11 / 200818: 50$ & $8 / 11 / 200818: 50$ & 2893 & 27.4 \\
\hline 3152 & 1/11/2008 18:52 & $8 / 11 / 200818: 52$ & 2894 & 27.4 \\
\hline 3153 & $1 / 11 / 2008$ 18:54 & $8 / 11 / 200818: 54$ & 2893 & 27.6 \\
\hline 3154 & $1 / 11 / 200818: 56$ & $8 / 11 / 200818: 56$ & 2895 & 27.6 \\
\hline 3156 & $1 / 11 / 200818: 58$ & $8 / 11 / 200818: 58$ & 2895 & 27.5 \\
\hline 3156 & $1 / 11 / 200819.00$ & $8 / 11 / 200819: 00$ & 2896 & $\overline{27.4}$ \\
\hline 3157 & $1 / 11 / 200819: 02$ & $8 / 11 / 2008$ 19:02 & 2897 & 27.4 \\
\hline 3158 & $1 / 11 / 200819.04$ & $8 / 11 / 2008$ 19:04 & 2897 & $2 \overline{27.4}$ \\
\hline 3159 & $1 / 11 / 200819.06$ & $8 / 11 / 200819-06$ & 2898 & 27.4 \\
\hline 3160 & $1 / 11 / 200819.08$ & $8 / 11 / 200819: 08$ & 2898 & 27.4 \\
\hline 3161 & $1 / 11 / 200819: 10$ & $8 / 11 / 200819: 10$ & 2899 & 27.4 \\
\hline 3162 & $1 / 11 / 200819: 12$ & $8 / 11 / 2008$ 19:12 & 2902 & 27.5 \\
\hline 3163 & $1 / 11 / 200819: 14$ & $8 / 11 / 2008$ 19:14 & 2907 & 27.6 \\
\hline 3164 & $1 / 11 / 200819.16$ & $8 / 11 / 200819: 16$ & 291 & 27.6 \\
\hline 3165 & $1 / 11 / 200819.18$ & $8 / 11 / 2008$ 19:18 & 2913 & 27.6 \\
\hline 3166 & $1 / 11 / 200819.20$ & $8 / 11 / 2008$ 19:20 & 2916 & 27.6 \\
\hline 3167 & $1 / 11 / 200819.22$ & $8 / 11 / 2008$ 19:22 & 2918 & 27.5 \\
\hline 3168 & $1 / 11 / 2008$ 19.24 & $8 / 11 / 2008$ 19:24 & 292 & 27.4 \\
\hline 3169 & $1 / 11 / 200819.26$ & $8 / 11 / 2008$ 19:26 & 2921 & 27.4 \\
\hline 3170 & $1 / 11 / 200819: 28$ & $8 / 11 / 200819: 28$ & 2926 & 27.4 \\
\hline 3171 & $1 / 11 / 200819.30$ & $8 / 11 / 200819: 30$ & 2926 & 27.4 \\
\hline 3172 & $1 / 11 / 200819: 32$ & $8 / 11 / 2008$ 19:32 & 2926 & 27.4 \\
\hline 3173 & $1 / 11 / 200819: 34$ & $8 / 11 / 2008$ 19:34 & 2926 & 27.4 \\
\hline 3174 & $1 / 11 / 200819: 36$ & $8 / 11 / 200819: 36$ & 2926 & 27.4 \\
\hline 3175 & $1 / 11 / 200819.38$ & $8 / 11 / 2008$ 19:38 & 2926 & 27.4 \\
\hline 3176 & $1 / 11 / 200819: 40$ & $8 / 11 / 200819: 40$ & 2926 & 27.3 \\
\hline 3177 & $1 / 11 / 200819.42$ & $8 / 11 / 200819.42$ & 2863 & 27.3 \\
\hline 3178 & $1 / 11 / 200819: 44$ & $8 / 11 / 200819.44$ & 281 & 27.3 \\
\hline 3179 & $1 / 11 / 200819.46$ & $8 / 11 / 200819.46$ & 2676 & 27.4 \\
\hline 3180 & $1 / 11 / 200819.48$ & $8 / 11 / 200819.48$ & 2546 & 27.5 \\
\hline 3181 & $1 / 11 / 200819.50$ & $8 / 11 / 200819.50$ & 2464 & 27.6 \\
\hline 3182 & $1 / 11 / 200819.52$ & $8 / 11 / 200819.52$ & 2412 & 27.6 \\
\hline 3183 & $1 / 11 / 200819.54$ & $8 / 11 / 200819-54$ & 2414 & 27.6 \\
\hline 3184 & $1 / 11 / 200819.56$ & $8 / 11 / 200819-56$ & 2574 & 27.6 \\
\hline 3185 & $1 / 11 / 200819.58$ & $8 / 11 / 200819.58$ & 2699 & 27.6 \\
\hline 3186 & $1 / 11 / 200820: 00$ & 8/11/2008 20:00 & 2806 & 27.6 \\
\hline 3187 & $1 / 11 / 200820: 02$ & $8 / 11 / 200820: 02$ & 2853 & 27.5 \\
\hline 3188 & $1 / 11 / 200820: 04$ & $8 / 11 / 200820: 04$ & 2.87 & 27.5 \\
\hline 3189 & 1/11/2008 20:06 & $8 / 11 / 200820: 06$ & 2878 & 27.4 \\
\hline 3190 & $1 / 11 / 200820: 08$ & 8/11/2008 20:08 & 288 & 27.4 \\
\hline 3191 & $1 / 11 / 200820: 10$ & $8 / 11 / 200820: 10$ & 2882 & 27.4 \\
\hline 3192 & $1 / 11 / 200820: 12$ & 8/11/2008 20:12 & 2883 & 27.3 \\
\hline 3193 & $1 / 11 / 200820: 14$ & $8 / 11 / 200820: 14$ & 2884 & 27.3 \\
\hline 3194 & $1 / 11 / 200820: 16$ & $8 / 11 / 200820: 16$ & 2886 & $\overline{27.2}$ \\
\hline 3196 & $1 / 11 / 200820: 18$ & 8/11/2008:20:18 & 2886 & 27.2 \\
\hline 3196 & $1 / 11 / 200820: 20$ & $8 / 11 / 200820: 20$ & 2888 & 27.4 \\
\hline 3197 & $1 / 11 / 200820.22$ & $8 / 11 / 200820: 22$ & 2892 & 27.5 \\
\hline 3198 & $1 / 11 / 200820: 24$ & $8 / 11 / 200820: 24$ & 2805 & 27.6 \\
\hline 3199 & $1 / 11 / 200820: 26$ & $8 / 11 / 200820: 26$ & 2899 & 27.6 \\
\hline 3200 & $1 / 11 / 200820.28$ & $8 / 11 / 200820: 28$ & 29 & 27.5 \\
\hline 3201 & $1 / 11 / 200820: 30$ & $8 / 11 / 200820: 30$ & 2902 & 27.5 \\
\hline
\end{tabular}




\begin{tabular}{|c|c|c|c|c|}
\hline \multicolumn{5}{|c|}{$D 4-93 p$} \\
\hline $\operatorname{Rec}$ & & Adjusted & Pressure & Temp \\
\hline \# & DateTime & Date/Time & psi & ${ }^{\circ} \mathrm{C}$ \\
\hline 3271 & $1 / 11 / 200822550$ & $8 / 11 / 200822 ; 50$ & 2498 & \\
\hline 3272 & $1 / 11 / 20082252$ & $8 / 11 / 200822552$ & 2459 & 27.6 \\
\hline 3273 & $1 / 11 / 20082254$ & $8 / 11 / 200822: 54$ & 2425 & 27.6 \\
\hline 3274 & $1 / 11 / 20082256$ & $8 / 11 / 200822: 56$ & 2389 & 27.6 \\
\hline 3275 & $1 / 11 / 20082258$ & $8 / 11 / 200822: 58$ & 2359 & \\
\hline 3276 & 1/11/2008 23:00 & 8/11/200823:00 & 2334 & 27.5 \\
\hline 3277 & 1/11/200823:02 & $8 / 11 / 200823: 02$ & 2.343 & 27.4 \\
\hline 3278 & $1 / 11 / 200823: 04$ & $8 / 11 / 200823: 04$ & 2.49 & $\overline{27.4}$ \\
\hline 3279 & $1 / 11 / 200823: 06$ & $8 / 11 / 200823: 06$ & 2.62 & 27.4 \\
\hline 3280 & 1/11/2008 23:08 & 8/11/200823:08 & 2765 & 27. \\
\hline 3281 & 1/11/200823:10 & $8 / 11 / 200823: 10$ & 2848 & 27.3 \\
\hline 3282 & $1 / 11 / 20$ & $8 / 11 / 200823: 12$ & 2882 & 27.3 \\
\hline 3283 & $1 / 11 / 20$ & 8/11/200823:14 & 2901 & 27. \\
\hline 3284 & $1 / 111 / 20$ & 8/11/200823:16 & 2.914 & 27. \\
\hline 3285 & 1/11/2008 23:18 & $8 / 11 / 200823: 18$ & 2921 & 27.2 \\
\hline 3286 & $1 / 11 / 2$ & $8 / 11 / 200$ & 2925 & 27.2 \\
\hline 3287 & $1 / 11 / 2$ & $8 / 11 / 200$ & 2927 & 27. \\
\hline 3288 & $1 / 11 / 2$ & $8 / 11 / 200823: 24$ & 2928 & 27. \\
\hline 3289 & $1 / 11 / 2$ & $8 / 11 / 200823: 26$ & 2928 & 27. \\
\hline 3290 & $1 / 11 / 2$ & $323: 28$ & 2.929 & 27. \\
\hline 3291 & $1 / 11 / 2$ & $8 / 11 / 200823: 30$ & 2933 & 27. \\
\hline 3292 & $1 / 11 / 2$ & 8/11/2008 23:32 & 2935 & 27. \\
\hline 3293 & $1 / 11 /$ & $8 / 11 / 2$ & 2939 & 27. \\
\hline$\overline{3294}$ & 3.36 & 323:36 & 2941 & 27. \\
\hline 3295 & $1 / 11 / 2$ & 8/11/200823:38 & 2.943 & 27. \\
\hline 3296 & $1 / 11 / 2$ & $8 / 11 / 200823: 40$ & 2945 & 27.4 \\
\hline 3297 & $\overline{1 / 11 /}$ & $323: 42$ & 2948 & 27. \\
\hline 3298 & $1 / 11 / 2$ & $8 / 11 / 200823: 44$ & 2.949 & 27. \\
\hline 3299 & $823: 46$ & $8 / 11 / 200823: 46$ & 2951 & 27.4 \\
\hline 3300 & $23: 48$ & $23: 48$ & 2953 & 27. \\
\hline 3301 & $1 / 11 / 4$ & $823: 50$ & 2954 & 27. \\
\hline 3302 & $1 / 11 / 2$ & $8 / 11 / 200823: 52$ & 2956 & 27.4 \\
\hline 3303 & $23: 54$ & 223:54 & 2956 & 27. \\
\hline 3304 & 3.56 & $23: 56$ & 2957 & 27. \\
\hline 3305 & $\overline{1 / 11 / 2}$ & $8 / 11 / 200823: 58$ & 2958 & 27.8 \\
\hline 3306 & $880: 00$ & $8 / 12 / 20080.00$ & 2.96 & 27.8 \\
\hline 3307 & & $30: 02$ & 2.96 & 27. \\
\hline 3308 & & 80.04 & 2961 & 27. \\
\hline 3309 & $0: 06$ & 880.06 & 2962 & 27.4 \\
\hline 3310 & & 880.08 & 2964 & 27. \\
\hline 3311 & $0: 10$ & $80: 10$ & 2965 & 27. \\
\hline 3312 & 0:12 & $8 / 12 / 20080: 12$ & 2966 & 27.3 \\
\hline 3313 & & $8 / 12 / 20080: 14$ & 2967 & 27. \\
\hline 3314 & & 30:16 & 2967 & 27. \\
\hline 3315 & $0: 18$ & $80: 18$ & 2968 & 27. \\
\hline 3316 & 30:20 & $8 / 12 / 20080: 20$ & 2969 & 27. \\
\hline 3317 & & $80: 22$ & 2.97 & 27. \\
\hline 3318 & & 80.24 & 2.97 & 27. \\
\hline 3319 & 0.26 & $8 / 12 / 20080.26$ & 2.972 & 27.2 \\
\hline 3320 & & & 2972 & 27.2 \\
\hline 3321 & & 30:30 & 2972 & 27. \\
\hline 3322 & 0.32 & 80.32 & 2.973 & 27. \\
\hline 3323 & & 0.34 & 2973 & 27. \\
\hline 3324 & & & 2.974 & 27. \\
\hline 3325 & & 80.38 & 2.974 & 27. \\
\hline 3326 & $0: 40$ & $8 / 12 / 20$ & 2974 & 27. \\
\hline 3327 & & & 2974 & 27. \\
\hline 3328 & & $80: 44$ & 2.975 & 27. \\
\hline 3329 & $30: 46$ & $8 / 12 / 20080: 46$ & 2975 & 27. \\
\hline 3330 & & $8 / 12 / 20$ & 2975 & 27. \\
\hline 3331 & & & 2975 & \\
\hline 3332 & & $8 / 12 / 20080: 52$ & 2975 & 27. \\
\hline 3333 & $1 / 12 / 20080.54$ & 8/12/20080:54 & 2975 & 27. \\
\hline 3334 & & $8 / 12 / 20080: 56$ & 2975 & 27.2 \\
\hline 3335 & & $8 / 12 / 20080.58$ & 2976 & \\
\hline 3336 & 281:00 & $8 / 12 / 20081: 00$ & 2976 & 27. \\
\hline 3337 & $81: 02$ & $8 / 12 / 20081: 02$ & 2.976 & 27.2 \\
\hline 3338 & $1 / 12 / 20081: 04$ & $8 / 12 / 2008$ 1:04 & 2977 & 27. \\
\hline 3339 & $1 / 12 / 20081: 06$ & $8 / 12 / 20081: 06$ & 2.97 & 27. \\
\hline
\end{tabular}

\begin{tabular}{|c|c|c|c|c|}
\hline \multicolumn{5}{|c|}{ D4-93p } \\
\hline $\operatorname{Rec}$ & & Adjusted & Pressure & Temp \\
\hline$\#$ & Date/Time & Date-Time & psi & ${ }^{\circ} \mathrm{C}$ \\
\hline 3340 & 1/12/2008 1:08 & $8 / 12 / 20081: 08$ & 2.977 & 27.2 \\
\hline 3341 & $1 / 12 / 20081: 10$ & $8 / 12 / 20081: 10$ & 2977 & 27.2 \\
\hline 3342 & $1 / 12 / 2008$ 1:12 & $8 / 12 / 2008$ 1:12 & 2977 & 27.2 \\
\hline 3343 & 1/12/2008 1:14 & $8 / 12 / 2008$ 1:14 & 2977 & 27.2 \\
\hline 3344 & 1/12/2008 1:16 & $8 / 12 / 2008$ 1:16 & 2977 & 27.2 \\
\hline 3345 & $1 / 12 / 2008$ 1:18 & $8 / 12 / 2008$ 1:18 & 2.556 & 27.2 \\
\hline 3346 & 1/12/2008 1:20 & $8 / 12 / 20081: 20$ & 2701 & 27.2 \\
\hline 3347 & 1/12/2008 1:22 & $8 / 12 / 20081: 22$ & 3.004 & 27.2 \\
\hline 3348 & $1 / 12 / 20081: 24$ & $8 / 12 / 20081: 24$ & 3.007 & 27.1 \\
\hline 3349 & 1/12/2008 1:26 & $8 / 12 / 20081: 26$ & 3.011 & 27.1 \\
\hline 3350 & $1 / 12 / 20081: 28$ & $8 / 12 / 20081: 28$ & 3.013 & 27.1 \\
\hline 3351 & 1/12/2008 1:30 & $8 / 12 / 20081: 30$ & 3.013 & 27.1 \\
\hline 3352 & $1 / 12 / 20081: 32$ & $8 / 12 / 20081: 32$ & 3.011 & 27 \\
\hline 3353 & 1/12/2008 1:34 & $8 / 12 / 20081: 34$ & 3.011 & 27 \\
\hline 3354 & $1 / 12 / 2008$ 1:36 & $8 / 12 / 20081: 36$ & 3.01 & 26.9 \\
\hline 3355 & $1 / 12 / 2008$ 1:38 & $8 / 12 / 20081: 38$ & 3.008 & 27 \\
\hline 3356 & $1 / 12 / 2008$ 1:40 & $8 / 12 / 20081: 40$ & 2997 & 27 \\
\hline 3357 & $1 / 12 / 20081: 42$ & $8 / 12 / 20081: 42$ & 2918 & 27 \\
\hline 3358 & $1 / 12 / 20081: 44$ & $8 / 12 / 20081: 44$ & 2.75 & 27 \\
\hline 3359 & $1 / \uparrow 2 / 2008$ 1:46 & $8 / 12 / 20081: 46$ & 2.62 & 27 \\
\hline 3360 & $1 / 12 / 2008$ 1:48 & $8 / 12 / 2008$ 1:48 & 2519 & 27 \\
\hline 3361 & $1 / 12 / 2008$ 1:50 & $8 / 12 / 20081: 50$ & 2452 & 27 \\
\hline 3362 & 1/12/2008 1:52 & $8 / 12 / 20081: 52$ & 2493 & 27 \\
\hline 3363 & $1 / 12 / 20081: 54$ & $8 / 12 / 20081: 54$ & 2.642 & 27 \\
\hline 3364 & 1/12/2008 1:56 & $8 / 12 / 20081: 56$ & 2.829 & 26.9 \\
\hline 3365 & 1/12/2008 1:58 & $8 / 12 / 20081: 58$ & 2.906 & 26.9 \\
\hline 3366 & 1/12/2008 2:00 & $8 / 12 / 20082: 00$ & 2.935 & 26.9 \\
\hline 3367 & 1/12/20082:02 & $8 / 12 / 2008202$ & 2.949 & 26.9 \\
\hline 3368 & 1/12/2008 2:04 & $8 / 12 / 20082: 04$ & 2.955 & 26.9 \\
\hline 3369 & $1 / 12 / 20082: 06$ & $8 / 12 / 20082: 06$ & 2959 & 26.9 \\
\hline 3370 & 1/12/2008208 & $8 / 12 / 20082: 08$ & 296 & 26.8 \\
\hline 3371 & $1 / 12 / 20082: 10$ & $8 / 12 / 20082: 10$ & 2961 & 26.8 \\
\hline 3372 & $1 / 12 / 20082: 12$ & $8 / 12 / 20082: 12$ & 2962 & 26.8 \\
\hline 3373 & $1 / 12 / 20082: 14$ & $8 / 12 / 20082: 14$ & 2963 & 26.8 \\
\hline 3374 & $1 / 12 / 20082: 16$ & $8 / 12 / 20082: 16$ & 2963 & 26.8 \\
\hline 3375 & $1 / 12 / 20082: 18$ & $8 / 12 / 20082: 18$ & 2966 & 26.8 \\
\hline 3376 & $1 / 12 / 20082: 20$ & $8 / 12 / 2008220$ & 2.968 & 26.9 \\
\hline 3377 & 1/12/20082:22 & $8 / 12 / 20082: 22$ & 2.97 & 26.9 \\
\hline 3378 & $1 / 12 / 20082: 24$ & $8 / 12 / 20082: 24$ & 2.972 & 26.9 \\
\hline 3379 & $1 / 12 / 20082: 26$ & $8 / 12 / 20082 \cdot 26$ & 2974 & 26.9 \\
\hline 3380 & $1 / 12 / 20082: 28$ & $8 / 12 / 20082: 28$ & 2976 & 26.9 \\
\hline 3381 & $1 / 12 / 20082: 30$ & $8 / 12 / 20082: 30$ & 2978 & 26.9 \\
\hline 3382 & $1 / 12 / 20082: 32$ & $8 / 12 / 20082 \cdot 32$ & 2979 & 26.9 \\
\hline 3383 & $1 / 12 / 20082: 34$ & $8 / 12 / 20082: 34$ & 2.98 & 26.9 \\
\hline 3384 & $1 / 12 / 20082 \cdot 36$ & $8 / 12 / 20082: 36$ & 2982 & 26.9 \\
\hline 3385 & $1 / 12 / 20082: 38$ & $8 / 12 / 20082: 38$ & 2983 & 26.9 \\
\hline 3386 & $1 / 12 / 20082: 40$ & $8 / 12 / 2008240$ & 2.986 & 26.9 \\
\hline 3387 & $1 / 12 / 20082: 42$ & $8 / 12 / 20082442$ & 299 & 26.8 \\
\hline 3388 & $1 / 12 / 20082: 44$ & $8 / 12 / 20082: 44$ & 2992 & 26.8 \\
\hline 3389 & 1/12/20082:46 & $8 / 12 / 20082: 46$ & 2.995 & 26.8 \\
\hline 3390 & 1/12/2008 2:48 & $8 / 12 / 20082: 48$ & 2.997 & 26.8 \\
\hline 3391 & $1 / 12 / 20082: 50$ & $8 / 12 / 2008250$ & 2.998 & 26.8 \\
\hline 3392 & 1/12/2008 2:52 & $8 / 12 / 20082: 52$ & 2.999 & 26.8 \\
\hline 3393 & $1 / 12 / 20082: 54$ & $8 / 12 / 20082: 54$ & & 26.8 \\
\hline 3394 & $1 / 12 / 20082-56$ & $8 / 12 / 20082: 56$ & 3.001 & 26.8 \\
\hline 3395 & 1/12/2008 2:58 & $8 / 12 / 20082: 58$ & 3.001 & 26.8 \\
\hline 3396 & 1/12/2008 3:00 & $8 / 12 / 20083: 00$ & 3.002 & 26.8 \\
\hline 3397 & $1 / 12 / 20083: 02$ & 8/12/2008 3:02 & 3.003 & 26.8 \\
\hline 3398 & $1 / 12 / 20083: 04$ & $8 / 12 / 20083: 04$ & 3.004 & 26.7 \\
\hline 3399 & $1 / 12 / 20083: 06$ & $8 / 12 / 20083: 06$ & 3.004 & 26.7 \\
\hline 3400 & 1/12/2008 3:08 & $8 / 12 / 20083: 08$ & 3.004 & 26.7 \\
\hline 3401 & 1/12/20083:10 & $8 / 12 / 20083: 10$ & 3.005 & 26.7 \\
\hline 3402 & 1/12/2008 3:12 & $8 / 12 / 20083: 12$ & 3.006 & 26.6 \\
\hline 3403 & 1/12/2008 3:14 & $8 / 12 / 20083: 14$ & 3.007 & 26.6 \\
\hline 3404 & 1/12/2008 3:16 & $8 / 12 / 20083: 16$ & 3.007 & 26.6 \\
\hline 3405 & 1/12/2008 3:18 & $8 / 12 / 20083: 18$ & 3.007 & 26.6 \\
\hline 3406 & 1/12/20083:20 & $8 / 12 / 20083: 20$ & 3.008 & 26.6 \\
\hline 3407 & 1/12/20083:22 & $8 / 12 / 20083: 22$ & 3.008 & 26.6 \\
\hline 3408 & $1 / 12 / 20083: 24$ & $8 / 12 / 20083: 24$ & 3.008 & 26.6 \\
\hline
\end{tabular}

\begin{tabular}{|c|c|c|c|c|}
\hline \multicolumn{5}{|c|}{ D493p } \\
\hline $\operatorname{Rec}$ & & Adjusted & Pressure & Temp \\
\hline$\#$ & Date/Time & DaterTime & psi & ${ }^{\circ} \mathrm{C}$ \\
\hline 3409 & $1 / 12 / 20083: 26$ & $8 / 12 / 20083: 26$ & 3.01 & 26.6 \\
\hline 3410 & $1 / 12 / 20083: 28$ & $8 / 12 / 20083: 28$ & 3.01 & 26.6 \\
\hline 3411 & 1/12/20083:30 & $8 / 12 / 20083: 30$ & 3.009 & 26.6 \\
\hline 3412 & $1 / 12 / 20083: 32$ & $8 / 12 / 20083: 32$ & 3.009 & 26.6 \\
\hline 3413 & $1 / 12 / 20083: 34$ & $8 / 12 / 20083: 34$ & 3.01 & 26.6 \\
\hline 3414 & $1 / 12 / 20083: 36$ & $8 / 12 / 20083: 36$ & 3.01 & 26.6 \\
\hline 3415 & 1/12/20083:38 & $8 / 12 / 20083: 38$ & 3.01 & 26.6 \\
\hline 3416 & $1 / 12 / 20083: 40$ & $8 / 12 / 20083: 40$ & 3.011 & 26.6 \\
\hline 3417 & $1 / 12 / 20083: 42$ & $8 / 12 / 20083: 42$ & 3.01 & 26.6 \\
\hline 3418 & $1 / 12 / 20083: 44$ & $8 / 12 / 20083: 44$ & 3.011 & 26.6 \\
\hline 3419 & $1 / 12 / 20083: 46$ & $8 / 12 / 20083: 46$ & 3.01 & 26.6 \\
\hline 3420 & $1 / 12 / 20083: 48$ & $8 / 12 / 20083: 48$ & 3.011 & 26.6 \\
\hline 3421 & $1 / 12 / 20083: 50$ & $8 / 12 / 20083: 50$ & 3.011 & 26.6 \\
\hline 3422 & 1/12/20083:52 & $8 / 12 / 20083: 52$ & 3.011 & 26.6 \\
\hline 3423 & $1 / 12 / 20083: 54$ & $8 / 12 / 20083: 54$ & 3.011 & 26.6 \\
\hline 3424 & $1 / 12 / 20083: 56$ & $8 / 12 / 20083: 56$ & 3.011 & 26.6 \\
\hline 3425 & $1 / 12 / 20083: 58$ & $8 / 12 / 20083: 58$ & 3.011 & 26.6 \\
\hline 3426 & $1 / 12 / 20084: 00$ & $8 / 12 / 20084: 00$ & 3.012 & 26.6 \\
\hline 3427 & $1 / 12 / 20084: 02$ & $8 / 12 / 20084: 02$ & 3.012 & 26.6 \\
\hline 3428 & $1 / 12 / 20084: 04$ & $8 / 12 / 20084: 04$ & 3.012 & 26.6 \\
\hline 3429 & 1/12/2008 4:06 & $8 / 12 / 20084: 06$ & 3.012 & 26.6 \\
\hline 3430 & $1 / 12 / 20084: 08$ & $8 / 12 / 20084: 08$ & 3.012 & 26.6 \\
\hline 3431 & $1 / 12 / 20084: 10$ & $8 / 12 / 20084: 10$ & 3.012 & 26.6 \\
\hline 3432 & 1/12/2008 4:12 & $8 / 12 / 20084: 12$ & 3.012 & 26.6 \\
\hline 3433 & $1 / 12 / 20084: 14$ & $8 / 12 / 20084: 14$ & 3.011 & 26.6 \\
\hline 3434 & $1 / 12 / 20084: 16$ & \begin{tabular}{|l|}
$8 / 12 / 20084: 16$ \\
\end{tabular} & 3.011 & 26.6 \\
\hline 3435 & 1/12/20084:18 & $8 / 12 / 20084: 18$ & 3.011 & 26.6 \\
\hline 3436 & $1 / 12 / 20084: 20$ & $8 / 12 / 20084: 20$ & 3.011 & 26.6 \\
\hline 3437 & $1 / 12 / 20084: 22$ & $8 / 12 / 20084: 22$ & 3.012 & 26.6 \\
\hline 3438 & $1 / 12 / 20084: 24$ & $8 / 12 / 20084: 24$ & 3.012 & 26.6 \\
\hline 3439 & $1 / 12 / 20084: 26$ & $8 / 12 / 20084: 26$ & 3.011 & 26.6 \\
\hline 3440 & $1 / 12 / 20084: 28$ & $8 / 12 / 20084: 28$ & 3.012 & 26.5 \\
\hline 3441 & 1/12/2008 4:30 & $8 / 12 / 20084: 30$ & 3.006 & 26.6 \\
\hline 3442 & $1 / 12 / 20084: 32$ & $8 / 12 / 20084: 32$ & 2.226 & 26.5 \\
\hline 3443 & $1 / 12 / 20084: 34$ & $8 / 12 / 20084: 34$ & 2.673 & 26.4 \\
\hline 3444 & $1 / 12 / 20084: 36$ & $8 / 12 / 20084: 36$ & 2574 & 26.4 \\
\hline 3445 & $1 / 12 / 20084: 38$ & $8 / 12 / 20084: 38$ & 2604 & 26.4 \\
\hline 3446 & $1 / 12 / 20084: 40$ & $8 / 12 / 20084: 40$ & 273 & 26.4 \\
\hline 3447 & $1 / 12 / 20084: 42$ & $8 / 12 / 20084: 42$ & 285 & 26.4 \\
\hline 3448 & $1 / 12 / 20084: 44$ & 8/12/20084:44 & 2.92 & 26.4 \\
\hline 3449 & $1 / 12 / 20084: 46$ & $8 / 12 / 20084: 46$ & 2.959 & 26.4 \\
\hline 3450 & $1 / 12 / 20084: 48$ & $8 / 12 / 20084: 48$ & 2989 & 26.4 \\
\hline 3451 & $1 / 12 / 20084: 50$ & $8 / 12 / 20084: 50$ & 3.009 & 26.3 \\
\hline 3452 & $1 / 12 / 20084: 52$ & $8 / 12 / 20084: 52$ & 3.018 & 26.3 \\
\hline 3453 & $1 / 12 / 20084: 54$ & $8 / 12 / 20084: 54$ & 3.02 & 26.3 \\
\hline 3454 & $1 / 12 / 20084: 56$ & $8 / 12 / 20084: 56$ & 3.02 & 26.3 \\
\hline 3455 & 1/12/2008 4:58 & $8 / 12 / 20084: 58$ & 3.02 & 26.3 \\
\hline 3456 & $1 / 12 / 20085: 00$ & $8 / 12 / 20085: 00$ & 3.02 & 26.3 \\
\hline 3457 & $1 / 12 / 20085: 02$ & $8 / 12 / 20085: 02$ & 3.021 & 26.3 \\
\hline 3458 & $1 / 12 / 20085: 04$ & $8 / 12 / 20085: 04$ & 3.022 & 26.2 \\
\hline 3459 & $1 / 12 / 20085: 06$ & $8 / 12 / 20085: 06$ & 3.023 & 26.2 \\
\hline 3460 & $1 / 12 / 20085: 08$ & $8 / 12 / 20085: 08$ & 3.024 & 26.2 \\
\hline 3461 & 1/12/20085:10 & $8 / 12 / 20085: 10$ & 3.024 & 26.1 \\
\hline 3462 & 1/12/20085:12 & $8 / 12 / 20085: 12$ & 3.023 & 26.8 \\
\hline 3463 & 1/12/20085:14 & $8 / 12 / 20085: 14$ & 3.024 & 26.8 \\
\hline 3464 & 1/12/20085:16 & $8 / 12 / 20085: 16$ & 3.025 & 26.4 \\
\hline 3465 & $1 / 12 / 20085: 18$ & $8 / 12 / 20085: 18$ & 3.025 & 26.3 \\
\hline 3466 & $1 / 12 / 20085: 20$ & $8 / 12 / 20085: 20$ & 3.025 & 26.3 \\
\hline 3467 & $1 / 12 / 20085: 22$ & $8 / 12 / 20085: 22$ & 3.025 & 26.3 \\
\hline 3468 & 1/12/20085:24 & $8 / 12 / 20085: 24$ & 3.026 & 26.3 \\
\hline 3469 & $1 / 12 / 20085: 26$ & $8 / 12 / 20085: 26$ & 3.026 & 26.3 \\
\hline 3470 & $1 / 12 / 20085: 28$ & $8 / 12 / 20085: 28$ & 3.026 & 26.3 \\
\hline 3471 & 1/12/2008 5:30 & $8 / 12 / 20085: 30$ & 3.027 & 26.3 \\
\hline 3472 & 1/12/2008 5:32 & $8 / 12 / 20085: 32$ & 3.028 & 26.3 \\
\hline 3473 & $1 / 12 / 20085: 34$ & $8 / 12 / 20085: 34$ & 3.028 & 26.3 \\
\hline 3474 & 1/12/20085:36 & $8 / 12 / 20085: 36$ & 3.029 & 26.3 \\
\hline 3475 & 1/12/20085:38 & $8 / 12 / 20085: 38$ & 3.029 & 26.3 \\
\hline 3476 & $1 / 12 / 20085: 40$ & $8 / 12 / 20085: 40$ & 3.029 & 26.3 \\
\hline 3477 & $1 / 12 / 20085: 42$ & $8 / 12 / 20085: 42$ & 3.03 & 26.3 \\
\hline
\end{tabular}


DOE/RL-2009-35, REV. 0

\begin{tabular}{|c|c|c|c|c|}
\hline \multicolumn{5}{|c|}{ D4-93p } \\
\hline $\operatorname{Rec}$ & & Adjusted & Pressure & Temp \\
\hline \# & Date/Time & Date/Time & psi & ${ }^{\circ} \mathrm{C}$ \\
\hline 3478 & $1 / 12 / 20085: 44$ & $8 / 12 / 20085: 44$ & 3.031 & 26.3 \\
\hline 3479 & $1 / 12 / 20085: 46$ & $8 / 12 / 20085: 46$ & 3.031 & 26.3 \\
\hline 3480 & $1 / 12 / 20085: 48$ & $8 / 12 / 20085: 48$ & 3.031 & 26.3 \\
\hline 3481 & $1 / 12 / 20085: 50$ & $8 / 12 / 20085: 50$ & 3.031 & 26.3 \\
\hline 3482 & $1 / 12 / 20085: 52$ & $8 / 12 / 20085: 52$ & 3.031 & 26.3 \\
\hline 3483 & $1 / 12 / 20085: 54$ & $8 / 12 / 20085: 54$ & 3.031 & 26.3 \\
\hline 3484 & $1 / 12 / 20085: 56$ & $8 / 12 / 20085: 56$ & 3.031 & 26.2 \\
\hline 3485 & $1 / 12 / 20085: 58$ & $8 / 12 / 20085: 58$ & 3.032 & 26.2 \\
\hline 3486 & $1 / 12 / 20086: 00$ & $8 / 12 / 20086: 00$ & 3.032 & 26.2 \\
\hline 3487 & $1 / 12 / 20086: 02$ & $8 / 12 / 20086: 02$ & 3.033 & 26.2 \\
\hline 3488 & $1 / 12 / 20086: 04$ & $8 / 12 / 20086: 04$ & 3.033 & 26.2 \\
\hline 3489 & $1 / 12 / 20086: 06$ & $8 / 12 / 20086: 06$ & 3.034 & 26.2 \\
\hline 3490 & $1 / 12 / 20086: 08$ & $8 / 12 / 20086: 08$ & 3.033 & 26.2 \\
\hline 3491 & $1 / 12 / 20086: 10$ & $8 / 12 / 20086: 10$ & 3.033 & 26.2 \\
\hline 3492 & $1 / 12 / 20086: 12$ & $8 / 12 / 20086: 12$ & 3.033 & 26.2 \\
\hline 3493 & $1 / 12 / 20086: 14$ & $8 / 12 / 20086: 14$ & 3.033 & 26.2 \\
\hline 3494 & $1 / 12 / 20086: 16$ & $8 / 12 / 20086: 16$ & 3.033 & 26.2 \\
\hline 3495 & 1/12/20086:18 & $8 / 12 / 20086: 18$ & 3.033 & 26.2 \\
\hline 3496 & $1 / 12 / 20086: 20$ & $8 / 12 / 20086: 20$ & 3.033 & 26.2 \\
\hline 3497 & $1 / 12 / 20086: 22$ & $8 / 12 / 20086: 22$ & 3.032 & 26.2 \\
\hline 3498 & $1 / 12 / 20086: 24$ & $8 / 12 / 20086: 24$ & 3.032 & 26.2 \\
\hline 3499 & $1 / 12 / 20086: 26$ & $8 / 12 / 20086: 26$ & 3.032 & 26.2 \\
\hline 3500 & $1 / 12 / 20086: 28$ & $8 / 12 / 20086: 28$ & 3.033 & 26.2 \\
\hline 3501 & $1 / 12 / 20086: 30$ & $8 / 12 / 20086: 30$ & 3.033 & 26.2 \\
\hline 3502 & $1 / 12 / 20086: 32$ & $8 / 12 / 20086: 32$ & 3.033 & 26.2 \\
\hline 3503 & $1 / 12 / 20086: 34$ & $8 / 12 / 20086: 34$ & 3.032 & 26.2 \\
\hline 3504 & $1 / 12 / 20086: 36$ & $8 / 12 / 20086: 36$ & 3.032 & 26.2 \\
\hline 3505 & $1 / 12 / 20086: 38$ & $8 / 12 / 20086: 38$ & 3.033 & 26.2 \\
\hline 3506 & $1 / 12 / 20086: 40$ & $8 / 12 / 20086: 40$ & 3.033 & 26.2 \\
\hline 3507 & $1 / 12 / 20086: 42$ & $8 / 12 / 20086: 42$ & 3.034 & 26.2 \\
\hline 3508 & $1 / 12 / 20086: 44$ & $8 / 12 / 20086: 44$ & 3.034 & 26.2 \\
\hline 3509 & $1 / 12 / 20086: 46$ & $8 / 12 / 20086: 46$ & 3.033 & 26.2 \\
\hline 3510 & $1 / 12 / 20086: 48$ & $8 / 12 / 20086: 48$ & 3.034 & 26.2 \\
\hline 3511 & $1 / 12 / 20086: 50$ & $8 / 12 / 20086: 50$ & 3.033 & 26.1 \\
\hline 3512 & 1/12/2008 6:52 & $8 / 12 / 20086: 52$ & 3.033 & 26.1 \\
\hline 3513 & $1 / 12 / 20086: 54$ & $8 / 12 / 20086: 54$ & 3.034 & 26.2 \\
\hline 3514 & $1 / 12 / 20086: 56$ & $8 / 12 / 20086: 56$ & 3.034 & 26.2 \\
\hline 3515 & $1 / 12 / 20086: 58$ & $8 / 12 / 20086: 58$ & 3.034 & 26.1 \\
\hline 3516 & 1/12/20087:00 & $8 / 12 / 20087: 00$ & 3.033 & 26.1 \\
\hline 3517 & $1 / 12 / 20087: 02$ & $8 / 12 / 20087: 02$ & 3.033 & 26.1 \\
\hline 3518 & $1 / 12 / 20087: 04$ & $8 / 12 / 20087: 04$ & 3.033 & 26.1 \\
\hline 3519 & $1 / 12 / 20087: 06$ & $8 / 12 / 20087: 06$ & 3.033 & 26.1 \\
\hline 3520 & $1 / 12 / 20087: 08$ & $8 / 12 / 20087: 08$ & 3.031 & 26.1 \\
\hline 3521 & $1 / 12 / 20087: 10$ & $8 / 12 / 20087: 10$ & 3.029 & 26.1 \\
\hline 3522 & $1 / 12 / 20087: 12$ & $8 / 12 / 20087: 12$ & 3.020 & 26.1 \\
\hline 3523 & $1 / 12 / 20087: 14$ & 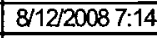 & 3.028 & 26.1 \\
\hline 3524 & $1 / 12 / 20087: 16$ & $8 / 12 / 20087: 16$ & 3.028 & 26.1 \\
\hline 3525 & $1 / 12 / 20087: 18$ & $8 / 12 / 20087: 18$ & 3.027 & 26.1 \\
\hline 3526 & $1 / 12 / 20087: 20$ & $8 / 12 / 20087: 20$ & 3.024 & 26.1 \\
\hline 3527 & $1 / 12 / 20087: 22$ & $8 / 12 / 20087: 22$ & 2945 & 26.1 \\
\hline 3528 & $1 / 12 / 20087: 24$ & $8 / 12 / 20087: 24$ & 2872 & 26.1 \\
\hline 3529 & $1 / 12 / 20087: 26$ & $8 / 12 / 20087: 26$ & 2772 & 26.1 \\
\hline 3530 & $1 / 12 / 20087: 28$ & $8 / 12 / 20087: 28$ & 2669 & 26.1 \\
\hline 3531 & $1 / 12 / 20087: 30$ & $8 / 12 / 20087: 30$ & 2583 & 26.1 \\
\hline 3532 & $1 / 12 / 20087: 32$ & $8 / 12 / 20087: 32$ & 2524 & 26.1 \\
\hline 3533 & $1 / 12 / 20087: 34$ & $8 / 12 / 20087: 34$ & 2.482 & 26.1 \\
\hline 3534 & $1 / 12 / 20087: 36$ & $8 / 12 / 20087: 36$ & 2449 & 26.1 \\
\hline 3535 & $1 / 12 / 20087: 38$ & $8 / 12 / 20087: 38$ & 2.51 & 26.1 \\
\hline 3536 & $1 / 12 / 20087: 40$ & $8 / 12 / 20087: 40$ & 2664 & 26 \\
\hline 3537 & $1 / 12 / 20087: 42$ & \begin{tabular}{|l}
$8 / 12 / 20087: 42$ \\
\end{tabular} & 2844 & 26 \\
\hline 3538 & $1 / 12 / 20087: 44$ & $8 / 12 / 20087: 44$ & 2.935 & 26 \\
\hline 3539 & $1 / 12 / 20087: 46$ & $8 / 12 / 20087: 46$ & 2978 & 26 \\
\hline 3540 & $1 / 12 / 20087: 48$ & $8 / 12 / 20087: 48$ & 2997 & 25.9 \\
\hline 3541 & $1 / 12 / 20087: 50$ & $8 / 12 / 20087: 50$ & 3.006 & 25.9 \\
\hline 3542 & $1 / 12 / 20087: 52$ & $8 / 12 / 20087: 52$ & 3.01 & 25.9 \\
\hline 3543 & $1 / 12 / 20087: 54$ & $8 / 12 / 20087: 54$ & 3.013 & 25.9 \\
\hline 3544 & $1 / 12 / 20087: 56$ & $8 / 12 / 20087: 56$ & 3.015 & 25.9 \\
\hline 3545 & $1 / 12 / 20087: 58$ & $8 / 12 / 20087: 58$ & 3.017 & 25.9 \\
\hline 3546 & $1 / 12 / 20088: 00$ & $8 / 12 / 20088: 00$ & 3.019 & 25.9 \\
\hline
\end{tabular}

\begin{tabular}{|c|c|c|c|c|}
\hline \multicolumn{5}{|c|}{ D4-93p } \\
\hline $\operatorname{Rec}$ & & $\begin{array}{l}\text { Adjusted } \\
\end{array}$ & Pressure & Temp \\
\hline \# & Date/Time & DaterTime & psi & ${ }^{\circ} \mathrm{C}$ \\
\hline 3547 & 1/12/20088:02 & $8 / 12 / 20088: 02$ & 3.021 & 25. \\
\hline 3548 & 1/12/2008 8:04 & $8 / 12 / 20088: 04$ & 3.024 & 25.8 \\
\hline 3549 & 1/12/2008 8:06 & $8 / 12 / 20088: 06$ & 3.025 & 25.8 \\
\hline 3550 & 1/12/20088:08 & $8 / 12 / 20088: 08$ & 3.026 & 25.8 \\
\hline 3551 & 1/12/20088:10 & $8 / 12 / 20088: 10$ & 3.027 & 25.9 \\
\hline 3552 & $1 / 12 / 20088: 12$ & $8 / 12 / 20088: 12$ & 3.029 & 26 \\
\hline 3553 & 1/12/2008 8:14 & $8 / 12 / 20088: 14$ & 3.03 & 26 \\
\hline 3554 & 1/12/20088:16 & $8 / 12 / 20088: 16$ & 3.033 & 26 \\
\hline 3555 & $1 / 12 / 20088: 18$ & $8 / 12 / 20088: 18$ & 3.033 & 26 \\
\hline 3556 & $1 / 12 / 20088: 20$ & $8 / 12 / 20088: 20$ & 3.035 & 2 \\
\hline 3557 & $1 / 1220088: 2$ & $8 / 12 / 20088: 22$ & 3.036 & 26 \\
\hline 3558 & $1 / 12 / 20088: 24$ & $8 / 12 / 20088: 24$ & 3.037 & 26 \\
\hline 3559 & $1 / 12 / 20088: 26$ & $8 / 12 / 20088: 26$ & $3.03 \overline{8}$ & 26 \\
\hline 3560 & $1 / 12 / 20088: 28$ & $8 / 12 / 20088: 28$ & 3.038 & 26 \\
\hline 3561 & $1 / 12 / 20088: 30$ & $8 / 12 / 20088: 30$ & 3.038 & 26.2 \\
\hline 3562 & $1 / 12 / 20088: 32$ & $8 / 12 / 20088: 32$ & 3.04 & 26 \\
\hline 3563 & $1 / 12 / 20088: 34$ & $8 / 12 / 20088: 34$ & 3.041 & 25.8 \\
\hline 3564 & 1/12/20088:36 & $8 / 12 / 20088: 36$ & 3.041 & 25.9 \\
\hline 3565 & 1/12/20088:38 & $8 / 12 / 20088: 38$ & 3.042 & 25.9 \\
\hline 3566 & 1/12/2008 8:40 & $8 / 12 / 20088: 40$ & 3.044 & 26. \\
\hline 3567 & $1 / 12 / 20088: 42$ & $8 / 12 / 20088: 42$ & 3.044 & 26 \\
\hline 3568 & 1/12/2008 8:44 & $8 / 12 / 20088: 44$ & 3.045 & 25.9 \\
\hline 3569 & $1 / 12 / 20088: 46$ & $8 / 12 / 20088: 46$ & 2.531 & 25.9 \\
\hline 3570 & $1 / 12 / 20088: 48$ & $8 / 12 / 20088: 48$ & 2.663 & 25. \\
\hline 3571 & $1 / 12 / 20088: 50$ & $8 / 12 / 20088: 50$ & 3.229 & 25. \\
\hline 3572 & $1 / 12 / 20088: 52$ & $8 / 12 / 20088: 52$ & 3.184 & 25.9 \\
\hline 3573 & $1 / 12 / 20088: 54$ & $8 / 12 / 20088: 54$ & 3.083 & 25.9 \\
\hline 3574 & $1 / 12 / 20088: 56$ & $8 / 12 / 20088: 56$ & 3.071 & 26 \\
\hline 3575 & $1 / 12 / 20088: 58$ & $8 / 12 / 20088: 58$ & 3.07 & 26 \\
\hline 3576 & 1/12/20089:00 & $8 / 12 / 20089=00$ & 3.069 & 26.1 \\
\hline 3577 & $1 / 12 / 20089: 02$ & $8 / 12 / 20089: 02$ & 3.068 & 26.1 \\
\hline 3578 & 1/12/20089:04 & $8 / 12 / 20089: 04$ & 3.067 & 26. \\
\hline 3579 & $1 / 12 / 20089: 06$ & $8 / 12 / 20089: 06$ & 3.067 & 26.1 \\
\hline 3580 & $1 / 12 / 200$ & $8 / 12 / 2$ & 3.064 & 26 \\
\hline 3581 & 1/12/20089:10 & $8 / 12 / 20089: 10$ & 3.062 & 26 \\
\hline 3582 & $1 / 12 / 20089: 12$ & $8 / 12 / 20089: 12$ & 3.062 & 25.9 \\
\hline 3583 & $1 / 12 / 20089: 14$ & $8 / 12 / 20089: 14$ & 3.063 & 25.9 \\
\hline 3584 & $1 / 12 / 200$ & $8 / 12 / 20$ & 3.062 & 25.9 \\
\hline 3585 & $1 / 12 / 20089: 18$ & $8 / 12 / 20089: 18$ & 3.062 & 25. \\
\hline 3586 & $1 / 12 / 20089: 20$ & $8 / 12 / 20089: 20$ & 3.063 & 25.9 \\
\hline 3587 & $1 / 12 / 20089: 2$ & $8 / 12 / 20089: 22$ & 3.064 & $25 !$ \\
\hline 3588 & $1 / 12 / 20089: 24$ & 8/12/20089:24 & 3.065 & 25. \\
\hline 3589 & 1/12/20089:26 & $8 / 12 / 200899-26$ & 3.065 & 25. \\
\hline 3590 & $1 / 12 / 20089: 28$ & $8 / 12 / 20089.28$ & 3.066 & 25.9 \\
\hline 3591 & 1/12/20089:30 & $8 / 12 / 2$ & 3.065 & 25.9 \\
\hline 3592 & 1/12/20089:32 & $8 / 12 / 20089: 32$ & 3.066 & 25 . \\
\hline 3593 & 1/12/20089:34 & $8 / 12 / 20089: 34$ & 3.066 & 25. \\
\hline 3594 & $1 / 12 / 200$ & $8 / 12 / 2$ & 3.067 & 25. \\
\hline 3595 & $1 / 12 / 200$ & $8 / 12 / 20089: 38$ & 3.067 & 25. \\
\hline 3596 & $1 / 12 / 20089: 40$ & $8 / 12 / 20089: 40$ & 3.068 & 25. \\
\hline 3597 & $1 / 12 / 20089: 42$ & $8 / 12 / 20089: 42$ & 3.068 & 25.9 \\
\hline 3598 & $1 / 12 / 20089: 44$ & $8 / 12 / 2$ & 3.068 & 25.9 \\
\hline 3599 & $1 / 12 / 20089: 46$ & $8 / 12 / 20089: 46$ & 3.069 & 25. \\
\hline 3600 & $1 / 12 / 20089: 48$ & $8 / 12 / 20089: 48$ & 3.069 & 25.9 \\
\hline 3601 & $1 / 12 / 20089: 50$ & $8 / 12 / 20089: 50$ & 3.07 & 25.9 \\
\hline 3602 & 1/12/20089:52 & $8 / 12 / 20089: 52$ & 3.071 & 25 . \\
\hline 3603 & 1/12/20089:54 & $8 / 12 / 20089: 54$ & 3.071 & 25 . \\
\hline 3604 & $1 / 12 / 20089: 56$ & $8 / 12 / 20089: 56$ & 3.072 & 25.9 \\
\hline 3605 & 1/12/20089:58 & $8 / 12 / 20089: 58$ & 3.068 & 25.8 \\
\hline 3606 & 1/12/2008 10:00 & 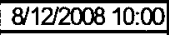 & 3.066 & 25. \\
\hline 3607 & 1/12/2008 10:02 & \begin{tabular}{|l|}
$8 / 12 / 200810: 02$ \\
\end{tabular} & 3.065 & 26. \\
\hline 3608 & 1/12/2008 10:04 & 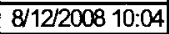 & 3.067 & 26.5 \\
\hline 3609 & \begin{tabular}{|l|}
$1 / 12 / 200810: 06$ \\
\end{tabular} & \begin{tabular}{|l|}
$8 / 12 / 2008$ 10:06 \\
\end{tabular} & 3.069 & 26.6 \\
\hline 3610 & 1/12/2008 10:08 & $8 / 12 / 200810: 08$ & 3.071 & 26. \\
\hline 3611 & \begin{tabular}{|l|}
$1 / 12 / 200810: 10$ \\
\end{tabular} & \begin{tabular}{|l|}
$8 / 12 / 2008$ 10:10 \\
\end{tabular} & 3.074 & 26.6 \\
\hline 3612 & 1/12/2008 10:12 & \begin{tabular}{|l|}
$8 / 12 / 2008$ 10:12 \\
\end{tabular} & 3.077 & 26.6 \\
\hline 3613 & $1 / 12 / 2008$ 10:14 & 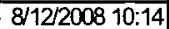 & 3.08 & 26. \\
\hline 3614 & $1 / 12 / 200810: 16$ & \begin{tabular}{|l|}
$8 / 12 / 2008$ 10:16 \\
\end{tabular} & 3.082 & 26.6 \\
\hline 3615 & \begin{tabular}{|l|}
$1 / 12 / 2008$ 10:18 \\
\end{tabular} & \begin{tabular}{|l|}
$8 / 12 / 2008$ 10:18 \\
\end{tabular} & 3.08 & 26.2 \\
\hline
\end{tabular}

\begin{tabular}{|c|c|c|c|c|}
\hline \multicolumn{5}{|c|}{ D4-93p } \\
\hline $\operatorname{Rec}$ & & Adjusted & Pressure & Temp \\
\hline$\#$ & Dater/ime & Date/Time & psi & ${ }^{\circ 0 \mathrm{C}}$ \\
\hline 3616 & 1/12/2008 10:20 & $8 / 12 / 2008$ 10:20 & 3.029 & 26.4 \\
\hline 3617 & $1 / 12 / 200810: 22$ & $8 / 12 / 200810: 22$ & 2.951 & 26.2 \\
\hline 3648 & $1 / 12 / 200810: 24$ & $8 / 12 / 2008$ 10:24 & 2.821 & 26.3 \\
\hline 3619 & $1 / 12 / 200810: 26$ & $8 / 12200810: 26$ & 2.871 & 25.9 \\
\hline 3620 & $1 / 12 / 200810: 28$ & $8 / 12 / 200810: 28$ & 2.966 & 25.8 \\
\hline 3621 & $1 / 12 / 200810: 30$ & $8 / 12 / 200810: 30$ & 3.023 & 25.8 \\
\hline 3622 & $1 / 12 / 200810: 32$ & $8 / 12 / 200810: 32$ & 3.056 & 25.8 \\
\hline 3623 & $1 / 12 / 200810: 34$ & $8 / 12 / 2008$ 10:34 & 3.074 & 25.7 \\
\hline 3624 & $1 / 12 / 200810: 36$ & $8 / 12 / 2008$ 10:36 & 3.082 & 25. \\
\hline 3625 & $1 / 12 / 2008$ 10:38 & $8 / 12 / 2008$ 10:38 & 3.085 & 25.7 \\
\hline 3626 & $1 / 12 / 200810: 40$ & $8 / 12 / 2008$ 10:40 & 3.086 & 25.7 \\
\hline 3627 & $1 / 12 / 200810: 42$ & $8 / 12 / 2008$ 10:42 & 3.087 & 25.7 \\
\hline 3628 & $1 / 12 / 200810: 44$ & $8 / 12 / 2008$ 10:44 & 3.088 & 25.7 \\
\hline 3629 & $1 / 12 / 200810: 46$ & $8 / 12 / 200810: 46$ & 3.088 & 25.6 \\
\hline 3630 & $1 / 12 / 200810: 48$ & $8 / 12 / 2008$ 10:48 & 3.089 & 25.6 \\
\hline 3631 & $1 / 12 / 200$ & $8 / 12 / 200810: 50$ & 3.089 & 25.6 \\
\hline 3632 & $1 / 12 / 200810-52$ & $8 / 12 / 200810: 52$ & 3.09 & 25.6 \\
\hline 3633 & 1/12/2008 10:54 & $8 / 12 / 200810: 54$ & 3.09 & 25.6 \\
\hline 3634 & $1 / 12 / 20$ & $8 / 12 / 20$ & 3.089 & 25.9 \\
\hline 3635 & $1 / 12 / 20$ & $8 / 12 / 20$ & 3.092 & 25.8 \\
\hline 3636 & $1 / 12 / 20$ & $8 / 12 / 20$ & 3.093 & 25.8 \\
\hline 3637 & $1 / 12 / 20$ & $8 / 12 / 20$ & 3.093 & 25.8 \\
\hline 3638 & $1 / 12 / 20$ & $8 / 12 / 20$ & 3.094 & 25.8 \\
\hline 3639 & $1 / 12 / 20$ & $8 / 12 / 20$ & 3.095 & 26.1 \\
\hline 3640 & $1 / 12 / 20$ & $8 / 12 / 20$ & 3.096 & 25.9 \\
\hline 3641 & $1 / 12 / 2$ & $8 / 12 / 20$ & 3.096 & 25.8 \\
\hline 3642 & $1 / 12 / 2$ & $8 / 12 / 20$ & 3.097 & 25.8 \\
\hline 3643 & $1 / 12 / 20$ & $8 / 12 / 20$ & 3.098 & 25.8 \\
\hline 3644 & 1/12/2008 11:16 & $8 / 12 / 200811: 16$ & 3.098 & 25.8 \\
\hline 3645 & $1 / 12 / 2$ & $8 / 12 / 20$ & 3.099 & 25.8 \\
\hline 3646 & $1 / 12 / 2$ & $8 / 12 / 20$ & 3.1 & 25.8 \\
\hline 3647 & $1 / 12 / 20$ & $8 / 1220$ & 3.1 & 25.8 \\
\hline 3648 & $1 / 12 / 200$ & $8 / 12 / 200811: 24$ & 3.101 & 25.8 \\
\hline 3649 & $1 / 12 / 2$ & $8 / 12 / 20$ & 3.101 & 25.8 \\
\hline 3650 & $1 / 12 / 2$ & $8 / 12 / 2$ & 3.102 & 25.8 \\
\hline 3651 & 1/12/2008 11:30 & \begin{tabular}{|l|}
$8 / 12 / 200811: 30$ \\
\end{tabular} & 3.102 & 25.8 \\
\hline 3652 & $1 / 12 / 200811: 32$ & $8 / 12 / 200811: 32$ & 3.103 & 25.8 \\
\hline 3653 & $1 / 12$ & $8 / 12 / 20$ & 3.103 & 25.8 \\
\hline 3654 & $1 / 12 / 2$ & $8 / 12 / 20$ & 3.104 & 25.8 \\
\hline 3655 & 1/12/2008 11:38 & $8 / 12 / 200811: 38$ & 3.105 & 26.2 \\
\hline 3656 & $1 / 12 / 2$ & $8 / 12 / 2$ & 3.106 & 26.3 \\
\hline 3657 & $1 / 12 / 20$ & $8 / 12 / 200$ & 3.105 & 25.9 \\
\hline 3658 & $1 / 12 / 20$ & $8 / 12 / 200811: 44$ & 3.106 & 25.8 \\
\hline 3659 & $1: 46$ & $8 / 12 / 20$ & 3.105 & 25.8 \\
\hline 3660 & $1 / 12 / 2$ & $8 / 12 / 20$ & 3.105 & 25.8 \\
\hline 3661 & $11: 50$ & $8 / 12 / 20$ & 3.104 & 25.8 \\
\hline 3662 & $1 / 12 / 200811: 52$ & $8 / 12 / 200$ & 3.104 & 25.8 \\
\hline 3663 & & $8 / 12 / 20$ & 3.105 & 25.8 \\
\hline 3664 & $1 / 12 / 20$ & $8 / 12 / 20$ & 3.104 & 25.8 \\
\hline 3665 & $1 / 12 / 200811: 58$ & $8 / 12 / 200811: 58$ & 3.104 & 25.8 \\
\hline 3666 & $1 / 12 / 20$ & $8 / 12 / 200$ & 3.105 & 25.8 \\
\hline 3667 & & $8 / 12 / 20$ & 3.105 & 25.8 \\
\hline 3668 & $1 / 12 / 2$ & $8 / 12 / 20$ & 223 & 25.9 \\
\hline 3669 & $1 / 12 / 200$ & $8 / 12 / 2008$ 12:06 & 3.092 & 25.9 \\
\hline 3670 & & $8 / 12 / 20$ & 3.131 & 25.9 \\
\hline 3671 & $1 / 12 / 2$ & $8 / 12 / 20$ & 3.143 & 25.9 \\
\hline 3672 & $1 / 12 / 200812: 12$ & $8 / 12 / 20$ & 3.147 & 25.9 \\
\hline 3673 & $1 / 12 / 20$ & $8 / 12 / 200812: 14$ & 3.148 & 25.9 \\
\hline 3674 & $1 / 12 / 20$ & $8 / 12 / 20$ & 3.147 & 25.9 \\
\hline 3675 & & \begin{tabular}{|l|}
$8 / 12 / 2008$ 12:18 \\
\end{tabular} & 3.146 & 25.9 \\
\hline 3676 & $1 / 12 / 200812: 20$ & $8 / 12 / 200812: 20$ & 3.146 & 25.8 \\
\hline 3677 & $1 / 12 / 200$ & 8/12/2008 12:22 & 3.145 & 25.8 \\
\hline 3678 & $312: 24$ & $8 / 12 / 2008$ 12:24 & 3.145 & 25.8 \\
\hline 3679 & $1 / 12 / 200812: 26$ & $8 / 12 / 200$ & 3.143 & 25.8 \\
\hline 3680 & $1 / 12 / 200812: 28$ & $8 / 12 / 200812: 28$ & 3.139 & 25.7 \\
\hline 3681 & $1 / 12 / 200812 ; 30$ & $8 / 12 / 200812: 30$ & 3.139 & 25.7 \\
\hline 3682 & $1 / 12 / 200812: 32$ & $8 / 12 / 2008$ 12:32 & 3.139 & 25.7 \\
\hline 3683 & $1 / 12 / 200812: 34$ & $8 / 12 / 200812: 34$ & 3.14 & 25.7 \\
\hline 3684 & $1 / 12 / 200812: 36$ & $8 / 12 / 200812: 36$ & 3.14 & 25.8 \\
\hline
\end{tabular}




\begin{tabular}{|c|c|c|c|c|}
\hline \multicolumn{5}{|c|}{ D493p } \\
\hline ReC & & Adjusted & Pressure & Temp \\
\hline$\#$ & Date/Time & Dater/Time & $\mathrm{psi}$ & ${ }^{\circ} \mathrm{C}$ \\
\hline 3685 & $1 / 12 / 200812: 38$ & 8/12/2008 12:38 & 3.142 & 25.9 \\
\hline 3686 & $1 / 12 / 20081240$ & $8 / 12 / 200812: 40$ & 3.143 & 25.9 \\
\hline 3687 & $1 / 12 / 200812442$ & $8 / 12 / 2008$ 12:42 & 3.145 & 26.1 \\
\hline 3688 & $1 / 12 / 20081244$ & $8 / 12 / 200812: 44$ & 3.145 & 26.1 \\
\hline 3689 & $1 / 12 / 200812446$ & $8 / 12 / 200812: 46$ & 3.147 & 26.1 \\
\hline 3690 & $1 / 12 / 20081248$ & $8 / 12 / 200812: 48$ & 3.149 & 26.3 \\
\hline 3691 & $1 / 12 / 20081250$ & $8 / 12 / 200812: 50$ & 3.149 & 26.4 \\
\hline 3692 & $1 / 12 / 20081255$ & $8 / 12 / 200812: 52$ & 3.149 & 26.2 \\
\hline 3693 & $1 / 12 / 20081254$ & $8 / 12 / 200812: 54$ & 3.15 & 26.1 \\
\hline 3694 & $1 / 12 / 20081256$ & $8 / 12 / 200812: 56$ & 3.15 & 26.4 \\
\hline 3695 & $1 / 12 / 20081258$ & $8 / 12 / 200812: 58$ & 3.152 & 26.2 \\
\hline 3696 & 1/12/2008 13:00 & 8/12/2008 13:00 & 3.151 & 26.1 \\
\hline 3697 & 1/12/2008 13:02 & 8/12/2008 13:02 & 3.151 & 26 \\
\hline 3698 & $1 / 12 / 200813: 04$ & $8 / 12 / 200813: 04$ & 3.151 & 26 \\
\hline 3699 & 1/12/2008 13:06 & 8/12/2008 13:06 & 3.134 & 26 \\
\hline 3700 & 1/12/2008 13:08 & 8/12/2008 13:08 & 3.046 & 26 \\
\hline 3701 & 1/12/2008 13:10 & $8 / 12 / 200813: 10$ & 2.881 & 25.9 \\
\hline 3702 & 1/12/2008 13:12 & 8/12/2008 13:12 & 2804 & 25.9 \\
\hline 3703 & 1/12/2008 13:14 & 8/12/2008 13:14 & 2935 & 25.9 \\
\hline 3704 & 1/12/2008 13:16 & 8/12/2008 13:16 & 3.03 & 25.9 \\
\hline 3705 & 1/12/2008 13:18 & 8/12/2008 13:18 & 3.084 & $\frac{26.3}{26.3}$ \\
\hline 3706 & 1/12/2008 13:20 & 8/12/2008 13:20 & 3.11 & 26.1 \\
\hline 3707 & $1 / 12 / 2008$ 13:22 & 8/12/2008 13:22 & 3.12 & 26.1 \\
\hline 3708 & $1 / 12 / 200813: 24$ & $8 / 12 / 200813: 24$ & 3.124 & 26.1 \\
\hline 3709 & 1/12/2008 13:26 & $8 / 12 / 200813: 26$ & 3.125 & 26.1 \\
\hline 3710 & $1 / 12 / 200813: 28$ & $8 / 12 / 2008$ 13:28 & 3.125 & 26.2 \\
\hline 3711 & $1 / 12 / 200813: 30$ & $8 / 12 / 200813: 30$ & 3.124 & 26.1 \\
\hline 3712 & $1 / 12 / 200813: 32$ & $8 / 12 / 200813: 32$ & 3.124 & 26.1 \\
\hline 3713 & $1 / 12 / 200813: 34$ & $8 / 12 / 200813: 34$ & 3.123 & 26.1 \\
\hline 3714 & 1/12/2008 13:36 & 8/12/2008 13:36 & 3.123 & 26.1 \\
\hline 3715 & 1/12/2008 13:38 & $8 / 12 / 200813: 38$ & 3.123 & 26.1 \\
\hline 3716 & $1 / 12 / 200813: 40$ & $8 / 12 / 2008$ 13:40 & 3.123 & 26 \\
\hline 3717 & $1 / 12 / 200813: 42$ & $8 / 12 / 200813: 42$ & 3.123 & 26.1 \\
\hline 3718 & $1 / 12 / 200813: 44$ & $8 / 12 / 200813: 44$ & 3.123 & 26.1 \\
\hline 3719 & $1 / 12 / 200813: 46$ & $8 / 12 / 200813: 46$ & 3.123 & 26.2 \\
\hline 3720 & $1 / 42 / 200813: 48$ & $8 / 12 / 200813: 48$ & 3.125 & 26.2 \\
\hline 3721 & $1 / 12 / 200813: 50$ & $8 / 12 / 200813: 50$ & 3.126 & 26.2 \\
\hline 3722 & $1 / 12 / 200813: 52$ & $8 / 12 / 200813: 52$ & 3.128 & 26.2 \\
\hline 3723 & $1 / 12 / 200813: 54$ & $8 / 12 / 200813: 54$ & 3.129 & 26.2 \\
\hline 3724 & $1 / 12 / 200813: 56$ & $8 / 12 / 200813: 56$ & 3.13 & 26.2 \\
\hline 3725 & 1/12/2008 13:58 & $8 / 12 / 200813: 58$ & 3.13 & 26.2 \\
\hline 3726 & $1 / 12 / 2008$ 14:00 & $8 / 12 / 200814: 00$ & 3.13 & 26.2 \\
\hline 3727 & 1/12/2008 14:02 & $8 / 12 / 200814: 02$ & 3.131 & 26.2 \\
\hline 3728 & $1 / 12 / 200814: 04$ & $8 / 12 / 200814: 04$ & 3.131 & 26.2 \\
\hline 3729 & 1/12/2008 14:06 & $8 / 12 / 200814: 06$ & 3.132 & 26.1 \\
\hline 3730 & 1/12/2008 14:08 & $8 / 12 / 200814: 08$ & 3.133 & 26.1 \\
\hline 3731 & $1 / 12 / 200$ & $8 / 12 / 200814: 10$ & 3.134 & 26.1 \\
\hline 3732 & 1/12/2008 14:12 & $8 / 12 / 200814: 12$ & 3.134 & 26.1 \\
\hline 3733 & 1/12/2008 14:14 & $8 / 12 / 200814: 14$ & 3.133 & 26.1 \\
\hline 3734 & 1/12/2008 14:16 & $8 / 12 / 200814: 16$ & 3.133 & 26.2 \\
\hline 3735 & 1/12/2008 14:18 & \begin{tabular}{|l|l|}
$8 / 12 / 200814: 18$ \\
\end{tabular} & 3.134 & 26.2 \\
\hline 3736 & 1/12/2008 14:20 & $8 / 12 / 200814: 20$ & 3.134 & 26.2 \\
\hline 3737 & 1/12/2008 14:22 & $8 / 12 / 200814: 22$ & 3.135 & 26.2 \\
\hline 3738 & $1 / 12 / 200814: 24$ & $8 / 12 / 200814: 24$ & 3.133 & 26.2 \\
\hline 3739 & $1 / 12 / 2008$ 14:26 & $8 / 12 / 200814: 26$ & 3.133 & 26.1 \\
\hline 3740 & 1/12/2008 14:28 & $8 / 12 / 200814: 28$ & 3.134 & 26.1 \\
\hline 3741 & $1 / 12 / 200814: 30$ & $8 / 12 / 200814: 30$ & 3.133 & 26.1 \\
\hline 3742 & 1/12/2008 14:32 & $8 / 12 / 2008$ 14:32 & 3.133 & 26.2 \\
\hline 3743 & 1/12/2008 14:34 & $8 / 12 / 200814: 34$ & 3.134 & 26.2 \\
\hline 3744 & $1 / 12 / 200814: 36$ & $8 / 12 / 200814: 36$ & 3.134 & 26.2 \\
\hline 3745 & $1 / 12 / 200814: 38$ & $8 / 12 / 200814: 38$ & 3.136 & 26.2 \\
\hline 3746 & $1 / 12 / 200814: 40$ & \begin{tabular}{|l|}
$8 / 12 / 2008$ \\
\end{tabular} & 3.136 & 26.2 \\
\hline 3747 & 1/12/2008 14:42 & \begin{tabular}{|l|}
$8 / 12 / 200814: 42$ \\
\end{tabular} & 3.137 & 26.3 \\
\hline 3748 & $1 / 12 / 2008$ 14:44 & $8 / 12 / 200814: 44$ & 3.138 & 26.3 \\
\hline 3749 & $1 / 12 / 2008$ 14:46 & $8 / 12 / 200814: 46$ & 3.14 & 26.3 \\
\hline 3750 & $1 / 12 / 2008$ 14:48 & \begin{tabular}{|l|}
$8 / 12 / 2008$ \\
\end{tabular} & 3.141 & 26.3 \\
\hline 3751 & $1 / 12 / 2008$ 14:50 & $8 / 12 / 200814: 50$ & 3.142 & 26.8 \\
\hline 3752 & $1 / 12 / 2008$ 14:52 & \begin{tabular}{|l|}
$8 / 12 / 200814: 52$ \\
\end{tabular} & 3.142 & 26.3 \\
\hline 3753 & $1 / 12 / 200814: 54$ & $8 / 12 / 200814: 54$ & 3.142 & 26.3 \\
\hline
\end{tabular}

\begin{tabular}{|c|c|c|c|c|}
\hline \multicolumn{5}{|c|}{ D493p } \\
\hline $\operatorname{Rec}$ & & Adjusted & Pressure & Termp \\
\hline \# & Date/Time & Date/Time & psi & ${ }^{\circ} \mathrm{C}$ \\
\hline 3754 & $1 / 12 / 200814: 56$ & 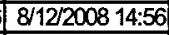 & 3.142 & 26.3 \\
\hline 3755 & $1 / 12 / 200814: 58$ & $8 / 12 / 2008$ 14:58 & 3.141 & 26.3 \\
\hline 3756 & $1 / 12 / 200815: 00$ & $8 / 12 / 200815: 00$ & 3.141 & 26.3 \\
\hline 3757 & 1/12/2008 15:02 & $8 / 12 / 2008$ 15:02 & 3.141 & 26.3 \\
\hline 3758 & 1/12/2008 15:04 & $8 / 12 / 2008$ 15:04 & 3.142 & 26.3 \\
\hline 3759 & 1/12/2008 15:06 & $8 / 12 / 200815: 06$ & 3.143 & 26.3 \\
\hline 3760 & 1/12/2008 15:08 & $8 / 12 / 200815: 08$ & 3.145 & 26.3 \\
\hline 3761 & $1 / 12 / 200815: 10$ & $8 / 12 / 2008$ 15:10 & 3.146 & 26.3 \\
\hline 3762 & $1 / 12 / 200815: 12$ & $8 / 12 / 2008$ 15:12 & 3.147 & 26.4 \\
\hline 3763 & $1 / 12 / 200815: 14$ & $8 / 12 / 2008$ 15:14 & 3.148 & 26.4 \\
\hline 3764 & 1/12/2008 15:16 & 8/12/2008 15:16 & 3.15 & 26.4 \\
\hline 3765 & 1/12/2008 15:18 & $8 / 12 / 200815: 18$ & 3.15 & 26.4 \\
\hline 3766 & 1/12/2008 15:20 & 8/12/2008 15:20 & 3.152 & 26.4 \\
\hline 3767 & 1/12/2008 15:22 & $8 / 12 / 200815: 22$ & 3.151 & 26.4 \\
\hline 3768 & 1/12/2008 15:24 & $8 / 12 / 2008$ 15:24 & 3.152 & 26.4 \\
\hline 3769 & 1/12/2008 15:26 & 8/12/2008 15:26 & 3.153 & 26.4 \\
\hline 3770 & $1 / 12 / 200815: 28$ & $8 / 12 / 200815: 28$ & 3.153 & 26.4 \\
\hline 3771 & $1 / 12 / 200815: 30$ & $8 / 12 / 200815: 30$ & 3.154 & 26.3 \\
\hline 3772 & 1/12/2008 15:32 & $8 / 12 / 2008$ 15:32 & 3.154 & 26.3 \\
\hline 3773 & 1/12/2008 15:34 & 8/12/2008 15:34 & 3.156 & 26.3 \\
\hline 3774 & 1/12/2008 15:36 & $8 / 12 / 200815: 36$ & 3.156 & 26.3 \\
\hline 3775 & 1/12/2008 15:38 & $8 / 12 / 200815: 38$ & 3.158 & 26.3 \\
\hline 3776 & $1 / 12 / 200815: 40$ & $8 / 12 / 2008$ 15:40 & 3.159 & 26.3 \\
\hline $37 \pi$ & $1 / 12 / 200815: 42$ & 8/12/2008 15:42 & 3.158 & 26.3 \\
\hline 3778 & 1/12/2008 15:44 & 8/12/2008 15:44 & 3.159 & 26.4 \\
\hline 3779 & $1 / 12 / 200815: 46$ & $8 / 12 / 2008$ 15:46 & 3.157 & 26.8 \\
\hline 3780 & $1 / 12 / 200815: 48$ & 8/12/2008 15:48 & 2536 & 26.4 \\
\hline 3781 & $1 / 12 / 200815: 50$ & $8 / 12 / 200815: 50$ & 3.08 & 26.7 \\
\hline 3782 & $1 / 12 / 200815: 52$ & $8 / 12 / 200815: 52$ & 3.086 & 26.6 \\
\hline 3783 & $1 / 12 / 200815: 54$ & $8 / 12 / 2008 \quad 15: 54$ & 2922 & 26.6 \\
\hline 3784 & 1/12/2008 15:56 & $8 / 12 / 200815: 56$ & 2.92 & 26.8 \\
\hline 3785 & 1/12/2008 15:58 & $8 / 12 / 200815: 58$ & 3.053 & 26.6 \\
\hline 3786 & $1 / 12 / 200816: 00$ & $8 / 12 / 200816: 00$ & 3.122 & 26.5 \\
\hline 3787 & $1 / 12 / 200816: 02$ & $8 / 12 / 200816: 02$ & 3.156 & 26.4 \\
\hline 3788 & $1 / 12 / 2008$ 16:04 & 8/12/2008 16:04 & 3.173 & 26.4 \\
\hline 3789 & $1 / 12 / 200816: 06$ & $8 / 12 / 200816: 06$ & 3.183 & 26.4 \\
\hline 3790 & $1 / 122000816: 08$ & $8 / 12 / 200816: 08$ & 3.189 & 26.3 \\
\hline 3791 & 1/12/2008 16:10 & $8 / 12 / 200816: 10$ & 3.192 & 26.3 \\
\hline 3792 & 1/12/2008 16:12 & $8 / 12 / 200816: 12$ & 3.195 & 26.3 \\
\hline 3793 & 1/12/2008 16:14 & 8/12/2008 16:14 & 3.197 & 26.2 \\
\hline 3794 & 1/12/2008 16:16 & $8 / 12 / 200816: 16$ & 3.198 & 26.1 \\
\hline 3795 & 1/12/2008 16:18 & $8 / 12 / 2008+6: 18$ & 3.199 & 26.1 \\
\hline 3796 & 1/12/2008 16:20 & $8 / 12 / 200816: 20$ & 3.199 & 26.1 \\
\hline 3797 & 1/12/2008 16:22 & 8/12/2008 16:22 & 3.199 & 26 \\
\hline 3798 & 1/12/2008 16:24 & $8 / 12 / 200816: 24$ & 3.199 & 26 \\
\hline 3799 & 1/12/2008 16:26 & $8 / 12 / 200816: 26$ & 3.199 & 25.9 \\
\hline 3800 & $1 / 122200816: 28$ & $8 / 12 / 200816: 28$ & 3.199 & 25.9 \\
\hline 3801 & 1/12/2008 16:30 & $8 / 12 / 200816: 30$ & 3.198 & 26 \\
\hline 3802 & 1/12/2008 16:32 & $8 / 12 / 200816: 32$ & 3.198 & 26.2 \\
\hline 3803 & $1 / 12 / 200816: 34$ & $8 / 12 / 200816: 34$ & 3.198 & 26.3 \\
\hline 3804 & $1 / 12 / 200816: 36$ & $8 / 12 / 200816: 36$ & 3.199 & 26.4 \\
\hline 3805 & 1/12/2008 16:38 & $8 / 12 / 2008$ 16:38 & 3.2 & 26.4 \\
\hline 3806 & $1 / 12 / 200816: 40$ & 8/12/2008 16:40 & 3.202 & 26.4 \\
\hline 3807 & 1/12/2008 16:42 & $8 / 12 / 200816: 42$ & 3.202 & 26.4 \\
\hline 3808 & 1/12/2008 16:44 & $8 / 12 / 200816: 44$ & 3.202 & 26.5 \\
\hline 3809 & 1/12/2008 16:46 & $8 / 12 / 200816: 46$ & 3.202 & 26.5 \\
\hline 3810 & 1/12/2008 16:48 & 8/12/2008 16:48 & 3.202 & 26.5 \\
\hline 3811 & 1/12/2008 16:50 & 8/12/2008 16:50 & 3.202 & 26.5 \\
\hline 3812 & 1/12/2008 16:52 & $8 / 12 / 200816: 52$ & 3.202 & 26.6 \\
\hline 3813 & 1/12/2008 16:54 & $8 / 12 / 200816: 54$ & 3.202 & 26.6 \\
\hline 3814 & $1 / 122200816: 56$ & 8/12/2008 16:56 & 3.202 & 26.6 \\
\hline 3815 & 1/12/2008 16:58 & $8 / 12 / 2008$ 16:58 & 3.202 & 26.6 \\
\hline 3816 & $1 / 12 / 2008+17: 00$ & $8 / 12 / 2008$ 17:00 & 3.203 & 26.6 \\
\hline 3817 & $1 / 12 / 200817: 02$ & $8 / 12 / 2008$ 17:02 & 3.203 & 26.6 \\
\hline 3818 & 1/12/2008 17:04 & $8 / 12 / 200817: 04$ & 3.202 & 26.6 \\
\hline 3819 & $1 / 12 / 200817: 06$ & $8 / 12 / 2008$ 17:06 & 3.203 & 26.6 \\
\hline 3820 & 1/12/2008 17:08 & $8 / 12 / 200817: 08$ & 3.202 & 26.6 \\
\hline 3821 & 1/12/2008 17:10 & $8 / 12 / 200817: 10$ & 3.202 & 26.6 \\
\hline 3822 & 1/12/2008 17:12 & $8 / 12 / 200817: 12$ & 3.202 & 26.6 \\
\hline
\end{tabular}

\begin{tabular}{|c|c|c|c|c|}
\hline \multicolumn{5}{|c|}{ D493p } \\
\hline $\operatorname{Rec}$ & & Adjusted & Pressure & Temp \\
\hline$\#$ & DateTime & Date/Time & psi & ${ }^{\circ} \mathrm{C}$ \\
\hline 3823 & 1/12/2008 17:14 & $8 / 12 / 2008$ 17:14 & 3.202 & 26.6 \\
\hline 3824 & 1/12/2008 17:16 & $8 / 12 / 2008$ 17:16 & 3.202 & 26.6 \\
\hline 3825 & 1/12/2008 17:18 & $8 / 12 / 2008$ 17:18 & 3.202 & 27 \\
\hline 3826 & 1/12/2008 17:20 & $8 / 12 / 2008$ 17:20 & 3.203 & 27.3 \\
\hline 3827 & 1/12/2008 17:22 & $8 / 12 / 2008$ 17:22 & 3.203 & 27.1 \\
\hline 3828 & $1 / 12 / 200817: 24$ & $8 / 12 / 2008$ 17:24 & 3.203 & 26.8 \\
\hline 3829 & 1/12/2008 17:26 & $8 / 12 / 200817: 26$ & 3.203 & 26.7 \\
\hline 3830 & $1 / 12 / 200817: 28$ & $8 / 12 / 200817: 28$ & 3.203 & 26.7 \\
\hline 3831 & $1 / 12 / 200817: 30$ & $8 / 12 / 200817: 30$ & 3.203 & 26.7 \\
\hline 3832 & $1 / 12 / 2008$ 17:32 & $8 / 12 / 2008$ 17:32 & 3.204 & 26.7 \\
\hline 3833 & 1/12/2008 17:34 & $8 / 12 / 2008$ 17:34 & 3.204 & 26.7 \\
\hline 3834 & 1/12/2008 17:36 & $8 / 12 / 200817: 36$ & 3.205 & 26.8 \\
\hline 3835 & 1/12/2008 17:38 & $8 / 12 / 2008$ 17:38 & 3.205 & 26.8 \\
\hline 3836 & 1/12/2008 17:40 & $8 / 12 / 200817: 40$ & 3.205 & 26.8 \\
\hline 3837 & 1/12/2008 17:42 & $8 / 12 / 2008$ 17:42 & 3.205 & 26.8 \\
\hline 3838 & 1/12/2008 17:44 & $8 / 12 / 2008$ 17:44 & 3.206 & 26.8 \\
\hline 3839 & 1/12/2008 17:46 & $8 / 12 / 2008$ 17:46 & 3.206 & 26.8 \\
\hline 3840 & 1/12/2008 17:48 & $8 / 12 / 2008$ 17:48 & 3.206 & 26.8 \\
\hline 3841 & 1/12/2008 17:50 & $8 / 12 / 2008$ 17:50 & 3.207 & 26.8 \\
\hline 3842 & $1 / 12 / 200817: 52$ & $8 / 12 / 2008$ 17:52 & 3.207 & 26.8 \\
\hline 3843 & $1 / 12 / 2008$ 17:54 & $8 / 12 / 2008$ 17:54 & 3.208 & 26.9 \\
\hline 3844 & $1 / 12 / 2008$ 17:56 & $8 / 12 / 2008$ 17:56 & 3.205 & 26.8 \\
\hline 3845 & $1 / 12 / 200817: 58$ & $8 / 12 / 2008$ 17:58 & 3.203 & 26.8 \\
\hline 3846 & 1/12/2008 18:00 & $8 / 12 / 2008$ 18:00 & 3.206 & 26.9 \\
\hline 3847 & 1/12/2008 18:02 & $8 / 12 / 200818: 02$ & 3.209 & 26.9 \\
\hline 3848 & 1/12/2008 18:04 & $8 / 12 / 2008$ 18:04 & 3.211 & 27 \\
\hline 3849 & 1/12/2008 18:06 & $8 / 12 / 200818: 06$ & 3.216 & 27.1 \\
\hline 3850 & $1 / 12 / 200818: 08$ & $8 / 12 / 200818: 08$ & 3.219 & 27 \\
\hline 3851 & 1/12/2008 18:10 & $8 / 12 / 2008$ 18:10 & 3.221 & 26.9 \\
\hline 3852 & 1/12/2008 18:12 & $8 / 12 / 2008$ 18:12 & 3.223 & 26.8 \\
\hline 3853 & 1/12/2008 18:14 & $8 / 12 / 2008$ 18:14 & 3.225 & 26.8 \\
\hline 3854 & 1/12/2008 18:16 & $8 / 12 / 2008$ 18:16 & 3.227 & 26.7 \\
\hline 3855 & 1/12/2008 18:18 & $8 / 12 / 200818: 18$ & 3.229 & 26.6 \\
\hline 3856 & $1 / 12 / 200818: 20$ & $8 / 12 / 2008$ 18:20 & 3.23 & 27 \\
\hline 3857 & 1/12/2008 18:22 & $8 / 12 / 2008$ 18:22 & 3.232 & 26.7 \\
\hline 3858 & 1/12/2008 18:24 & 8/12/2008 18:24 & 3.231 & 26.6 \\
\hline 3859 & $1 / 12 / 2008$ 18:26 & $8 / 12 / 2008$ 18:26 & 3.231 & 26.5 \\
\hline 3860 & 1/12/2008 18:28 & $8 / 12 / 2008$ 18:28 & 3.231 & 26.5 \\
\hline 3861 & 1/12/2008 18:30 & \begin{tabular}{|l|}
$8 / 12 / 200818: 30$ \\
\end{tabular} & 3.232 & 26.4 \\
\hline 3862 & 1/12/2008 18:32 & \begin{tabular}{|l|}
$8 / 12 / 200818: 32$ \\
\end{tabular} & 3.233 & 26.4 \\
\hline 3863 & 1/12/2008 18:34 & \begin{tabular}{|l|l|}
$8 / 12 / 200818: 34$ \\
\end{tabular} & 3.232 & 26.4 \\
\hline 3864 & 1/12/2008 18:36 & \begin{tabular}{|l|}
$8 / 12 / 200818: 36$ \\
\end{tabular} & 3.225 & 26.3 \\
\hline 3865 & 1/12/2008 18:38 & \begin{tabular}{|l|}
$8 / 12 / 2008$ 18:38 \\
\end{tabular} & 3.121 & 26.3 \\
\hline 3866 & 1/12/2008 18:40 & $8 / 12 / 200818: 40$ & 2966 & 26.2 \\
\hline 3867 & 1/12/2008 18:42 & \begin{tabular}{|l|}
$8 / 12 / 200818: 42$ \\
\end{tabular} & 2.935 & 26.1 \\
\hline 3868 & 1/12/2008 18:44 & $8 / 12 / 200818: 44$ & 3.051 & 26.1 \\
\hline 3869 & 1/12/2008 18:46 & \begin{tabular}{|l|}
$8 / 12 / 200818: 46$ \\
\end{tabular} & 3.131 & 26 \\
\hline 3870 & 1/12/2008 18:48 & \begin{tabular}{|l|}
$8 / 12 / 200818: 48$ \\
\end{tabular} & 3.178 & 26 \\
\hline 3871 & 1/12/2008 18:50 & $8 / 12 / 200818: 50$ & 3.205 & 26.3 \\
\hline 3872 & 1/12/2008 18:52 & \begin{tabular}{|l|}
$8 / 12 / 200818: 52$ \\
\end{tabular} & 3.22 & 26.4 \\
\hline 3873 & $1 / 12 / 200818: 54$ & \begin{tabular}{|l|}
$8 / 12 / 200818: 54$ \\
\end{tabular} & 3.228 & 26.8 \\
\hline 3874 & 1/12/2008 18:56 & \begin{tabular}{|l|}
$8 / 12 / 200818: 56$ \\
\end{tabular} & 3.232 & 26.6 \\
\hline 3875 & $1 / 12 / 2008$ 18:58 & \begin{tabular}{|l|}
$8 / 12 / 200818: 58$ \\
\end{tabular} & 3.234 & 26.4 \\
\hline 3876 & 1/12/2008 19:00 & \begin{tabular}{|l|}
$8 / 12 / 2008$ 19:00 \\
\end{tabular} & 3.236 & 26.3 \\
\hline 3877 & 1/12/2008 19:02 & \begin{tabular}{|l|}
$8 / 12 / 2008$ 19:02 \\
\end{tabular} & 3.237 & 26.2 \\
\hline 3878 & 1/12/2008 19:04 & \begin{tabular}{|l|}
$8 / 12 / 2008$ 19:04 \\
\end{tabular} & 3.238 & 26.1 \\
\hline 3879 & 1/12/2008 19:06 & \begin{tabular}{|l|l|}
$8 / 12 / 200819: 06$ \\
\end{tabular} & 3.238 & 26.1 \\
\hline 3880 & 1/12/2008 19:08 & \begin{tabular}{|l|l|}
$8 / 12 / 200819: 08$ \\
\end{tabular} & 3.237 & 26 \\
\hline 3881 & 1/12/2008 19:10 & \begin{tabular}{|l|}
$8 / 12 / 200819: 10$ \\
\end{tabular} & 3.237 & 26 \\
\hline 3882 & 1/12/2008 19:12 & \begin{tabular}{|l|}
$8 / 12 / 200819: 12$ \\
\end{tabular} & 3.238 & 26.3 \\
\hline 3883 & $1 / 12 / 200819: 14$ & \begin{tabular}{|l|}
$8 / 12 / 2008$ 19:14 \\
\end{tabular} & 3.238 & 26.4 \\
\hline 3884 & 1/12/2008 19:16 & $8 / 42 / 2008$ 19.16 & 3.238 & 26.4 \\
\hline 3885 & 1/12/2008 19:18 & \begin{tabular}{|l|}
$8 / 12 / 200819: 18$ \\
\end{tabular} & 3.238 & 26.4 \\
\hline 3886 & $1 / 12 / 200819: 20$ & \begin{tabular}{|l|l|}
$8 / 12 / 200819: 20$ \\
\end{tabular} & 3.239 & 26.4 \\
\hline 3887 & 1/12/2008 19:22 & \begin{tabular}{|l|}
$8 / 12 / 200819: 22$ \\
\end{tabular} & 3.239 & 26.5 \\
\hline 3888 & $1 / 12 / 200819: 24$ & \begin{tabular}{|l|}
$8 / 12 / 200819: 24$ \\
\end{tabular} & 3.242 & 26.8 \\
\hline 3889 & 1/12/2008 19:26 & $8 / 12 / 2008$ 19:26 & 3.241 & 26.6 \\
\hline 3890 & $1 / 12 / 200819: 28$ & \begin{tabular}{|l|l|}
$8 / 200819: 28$ \\
\end{tabular} & 3.241 & 26.6 \\
\hline 3891 & \begin{tabular}{|l|l|}
$1 / 12 / 200819.30$ \\
\end{tabular} & 8/12/2008 19:30 & 3.241 & 26.6 \\
\hline
\end{tabular}




\begin{tabular}{|c|c|c|c|c|}
\hline \multicolumn{5}{|c|}{ D4-93p } \\
\hline Rec & & Adjusted & Pressure & Temp \\
\hline$\#$ & Date/Time & DaterTime & psi & ${ }^{\circ} \mathrm{C}$ \\
\hline 3892 & $1 / 12 / 200819: 32$ & $8 / 12 / 2008$ 19:32 & 3.242 & 26.6 \\
\hline 3893 & $1 / 12 / 200819: 34$ & $8 / 12 / 200819: 34$ & 3.242 & 26.6 \\
\hline 3894 & $1 / 12 / 200819: 36$ & $8 / 12 / 200819: 36$ & 3.242 & 26.6 \\
\hline 3895 & $1 / 12 / 200819: 38$ & $8 / 12 / 200819: 38$ & 3.241 & 26.6 \\
\hline 3896 & $1 / 12 / 200819: 40$ & $8 / 12 / 200819: 40$ & 3.241 & 26.6 \\
\hline 3897 & $1 / 12 / 200819: 42$ & $8 / 12 / 200819: 42$ & 3.241 & 26.7 \\
\hline 3898 & $1 / 12 / 200819: 44$ & $8 / 12 / 200819: 44$ & 3.242 & 26.7 \\
\hline 3899 & $1 / 12 / 200819: 46$ & $8 / 12 / 200819: 46$ & 3.242 & 26.7 \\
\hline 3900 & $1 / 12 / 200819: 48$ & & 3.244 & 26.8 \\
\hline 3901 & $1 / 12 / 2008$ & $8 / 12 / 200819: 50$ & 3.243 & 26.8 \\
\hline 3902 & $1 / 12 / 200819: 52$ & $8 / 12 / 200819: 52$ & 3.244 & 26.8 \\
\hline 3903 & $1 / 12 / 2$ & $0819: 54$ & 3.243 & \\
\hline 3904 & $1 / 12 / 20$ & $0819: 56$ & 3.243 & 26.8 \\
\hline 3905 & $1 / 12 / 200819: 58$ & $8 / 12 / 200819: 58$ & & 26.8 \\
\hline 3906 & $1 / 12 / 2$ & $0820: 00$ & 3.146 & 27.3 \\
\hline 3907 & $1 / 12 / 2$ & $00820: 02$ & 3.235 & 27.3 \\
\hline 3908 & $1 / 12 / 2$ & $0820: 04$ & 3.267 & 27.1 \\
\hline 3909 & $1 / 12 / 20$ & & 3.278 & 27.1 \\
\hline 3910 & $1 / 12 / 2008$ & $8 / 12 / 200820: 08$ & 3.281 & 27 \\
\hline 3911 & $1 / 12 / 2$ & & 3.283 & 26.9 \\
\hline 3912 & $1 / 12 / 2$ & & 3.282 & 26.9 \\
\hline 3913 & $1 / 12 / 2$ & & 3.281 & 26.8 \\
\hline 3914 & $1 / 12 /$ & & 3.28 & 26.8 \\
\hline 3915 & $1 / 12 /$ & & 3.278 & 26.7 \\
\hline 3916 & $1 / 12 /$ & & 3.276 & 26.6 \\
\hline 3917 & $1 / 12 /$ & & 2.593 & 26.9 \\
\hline 3918 & $1 / 12 / 2$ & & 3.202 & 27.4 \\
\hline 3919 & $1 / 12 / 2$ & & 3.25 & 27.5 \\
\hline 3920 & 28 & & 3.275 & 27.4 \\
\hline 3921 & $1 / 12 /$ & & 3.284 & 27.4 \\
\hline 3922 & $1 / 12 / 2$ & & 3.287 & 27.4 \\
\hline 3923 & $1 / 1$ & & 3.288 & 27.3 \\
\hline 3924 & $1 / 12 /$ & & 3.287 & 27.3 \\
\hline 3925 & $1 / 12 /$ & & 3.286 & 27.3 \\
\hline 3926 & & & & 27.1 \\
\hline 3927 & $1 / 12 /$ & & 3.284 & 27.1 \\
\hline 3928 & $1 / 12 /$ & & 3.281 & 27 \\
\hline 3929 & $1 / 12 /$ & & 3.28 & 26.9 \\
\hline 3930 & $1 / 12 /$ & & 3.278 & 27.3 \\
\hline 3931 & $1 / 12 /$ & $0: 50$ & 3.277 & 27 \\
\hline 3932 & $1 / 12$ & & 3.275 & 27.1 \\
\hline 3933 & $0: 54$ & & 3.273 & 27.1 \\
\hline 3934 & $1 / 12 /$ & & 3.272 & 27.6 \\
\hline 3935 & $1 / 12$ & & 3.273 & 27.3 \\
\hline 3936 & & & 3.273 & 27.3 \\
\hline 3937 & $1 / 12 / 2$ & & 3.273 & 27.3 \\
\hline 3938 & $1 / 12$ & & 3.272 & 27.3 \\
\hline 3939 & & & 3.272 & 27.3 \\
\hline 3940 & $1 / 12 / 2$ & & 3.271 & 27.3 \\
\hline 3941 & $1 / 12 / 2$ & & 3.27 & 27.3 \\
\hline 3942 & & & 3.27 & 27.3 \\
\hline 3943 & & & 3.27 & 27.3 \\
\hline 3944 & & & & 27.3 \\
\hline 3945 & & & 3.271 & 27.3 \\
\hline 3946 & $1 / 12 / 2$ & & 3.271 & 27.3 \\
\hline 3947 & $1 / 12 /$ & & 3.27 & 27.3 \\
\hline 3948 & $1 / 12 / 2$ & & 3.271 & 27.3 \\
\hline 3949 & $1 / 12 / 2$ & & 3.261 & 27.3 \\
\hline 3950 & $1 / 12 / 20$ & & 3.178 & 27.3 \\
\hline 3951 & $1 / 12 / 2$ & & 3.025 & 27.3 \\
\hline 3952 & & & 2.869 & 27.3 \\
\hline 3953 & & & 2.867 & 27.3 \\
\hline 3954 & $1 / 12 / 2$ & & 3.021 & 27.3 \\
\hline 3955 & $1 / 12 / 2$ & & 3.121 & 27.3 \\
\hline 3956 & & & 3.181 & 27.3 \\
\hline 3957 & $1 / 12 / 200821: 42$ & & 3.215 & 27.3 \\
\hline 3958 & & & 3.235 & 27.2 \\
\hline 3959 & & & 3.247 & 27.1 \\
\hline 3960 & $1 / 12 / 200821: 48$ & $8 / 12 / 200821: 48$ & 3.256 & 27.1 \\
\hline
\end{tabular}

\begin{tabular}{|c|c|c|c|c|}
\hline \multicolumn{5}{|c|}{ D4-93p } \\
\hline $\operatorname{Rec}$ & & Adjusted & Pressure & Temp \\
\hline$\#$ & Date/Time & Date/Time & psi & ${ }^{\circ} \mathrm{C}$ \\
\hline 3961 & $1 / 12 / 200821: 50$ & $8 / 12 / 200821: 50$ & 3.262 & 27 \\
\hline 3962 & 1/12/200821:52 & $8 / 12 / 200821: 52$ & 3.267 & \\
\hline 3963 & 1/12/200821:54 & \begin{tabular}{|l|}
$8 / 12 / 200821: 54$ \\
\end{tabular} & 3.27 & 26.9 \\
\hline 3964 & 1/12/200821:56 & $8 / 12 / 200821: 56$ & 3.272 & 26.8 \\
\hline 3965 & 1/12/2008 21:58 & $8 / 12 / 200821: 58$ & 3.274 & 26.7 \\
\hline 3966 & 1/12/2008 22:00 & $8 / 12 / 200822: 00$ & 3.276 & 26.6 \\
\hline 3967 & 1/12/2008 22:02 & $8 / 12 / 200822: 02$ & 3.276 & 27.1 \\
\hline 3968 & 1/12/2008 22:04 & 8/12/2008 22:04 & 3.27 & 27.3 \\
\hline 3969 & 1/12/200822:06 & $8 / 12 / 200822: 06$ & 3.277 & 27.1 \\
\hline 3970 & $1 / 12 / 200822: 08$ & $8 / 12 / 200822: 08$ & 3.279 & 27 \\
\hline 3971 & 1/12/2008 22:10 & \begin{tabular}{|l|}
$8 / 12 / 200822: 10$ \\
\end{tabular} & 3.28 & 27 \\
\hline 3972 & $1 / 12 / 200$ & $8 / 12 / 200822: 12$ & 3.281 & 26.9 \\
\hline 3973 & $1 / 12 / 200$ & $8 / 12 / 200822: 14$ & 3.282 & 27 \\
\hline 3974 & $1 / 12 / 200822: 16$ & $8 / 12 / 200822: 16$ & 3.283 & 27 \\
\hline 3975 & 1/12/2008 22:18 & $8 / 12 / 200822: 18$ & 3.284 & 26.9 \\
\hline 3976 & $1 / 12 / 200$ & $8 / 12 / 200822: 20$ & 3.285 & 26.9 \\
\hline 3977 & $1 / 12 / 200$ & $8 / 12 / 200822: 22$ & 3.285 & 26.9 \\
\hline 3978 & 1/12/200822:24 & $8 / 12 / 200822: 24$ & 3.287 & 27 \\
\hline 3979 & $1 / 12 / 200$ & $8 / 12 / 200822: 26$ & 3.286 & 27 \\
\hline 3980 & $1 / 12 / 20$ & $8 / 12 / 20$ & 3.287 & 27 \\
\hline 3981 & $1 / 12 / 200$ & $8 / 12 / 200822: 30$ & 3.287 & 27.1 \\
\hline 3982 & $1 / 12 / 200$ & $8 / 12 / 200822: 32$ & 3.288 & 27.1 \\
\hline 3983 & $1 / 12 / 200$ & $8 / 12 / 200822: 34$ & 3.288 & 27.1 \\
\hline 3984 & $1 / 12 / 200$ & $8 / 12 / 20$ & 3.289 & 27.1 \\
\hline 3985 & $1 / 12 / 200$ & $8 / 12 / 20$ & 3.288 & 27.1 \\
\hline 3986 & $1 / 12 / 200$ & $8 / 12 / 20$ & 3.288 & 27.1 \\
\hline 3987 & $1 / 12 / 20$ & $8 / 12 / 200822: 42$ & 3.289 & 27.1 \\
\hline 3988 & $1 / 12 / 200822: 44$ & $8 / 12 / 200822: 44$ & 3.291 & 27.1 \\
\hline 3989 & $1 / 12 / 201$ & $8 / 12 / 20$ & 3.291 & 27.1 \\
\hline 3990 & $1 / 12 / 20$ & $8 / 12 / 20$ & 3.292 & 27.1 \\
\hline 3991 & 1/12/2008 22:50 & $8 / 12 / 200822: 50$ & 3.293 & 27.1 \\
\hline 3992 & $1 / 12 / 200$ & $8 / 12 / 20$ & 3.294 & 27.1 \\
\hline 3993 & $1 / 12 / 200$ & $8 / 12 / 20$ & 3.294 & 27.1 \\
\hline 3994 & $1 / 12 / 200$ & 8/12/2008 22:56 & 3.294 & 27.1 \\
\hline 3995 & $1 / 12 / 200$ & $8 / 12 / 200822: 58$ & 3.295 & 27.1 \\
\hline 3996 & $1 / 12 / 20$ & $8 / 12 / 20$ & 3.295 & 27.2 \\
\hline 3997 & $1 / 12 / 20$ & $8 / 12 / 20$ & 3.295 & 27.2 \\
\hline 3998 & $1 / 12 / 200$ & $8 / 12 / 200823: 04$ & 3.295 & 27.2 \\
\hline 3999 & $1 / 12 / 20$ & $8 / 12 / 20$ & 3.296 & 27.2 \\
\hline 4000 & $1 / 12 / 20$ & $8 / 12 / 20$ & 3.297 & $\overline{27.2}$ \\
\hline 4001 & $1 / 12 / 20$ & $8 / 12 / 200823: 10$ & 3.297 & 27.3 \\
\hline 4002 & $1 / 12 / 20$ & $8 / 12 / 20$ & 3.298 & 27.3 \\
\hline 4003 & $1 / 12 / 20$ & $8 / 12 / 20$ & 3.299 & 27.3 \\
\hline 4004 & $1 / 12 / 200$ & $8 / 12 / 200823: 16$ & 3.299 & 27.3 \\
\hline 4005 & $1 / 12 / 200$ & $8 / 12 / 200823: 18$ & 3.299 & 27.3 \\
\hline 4006 & $1 / 12 / 20$ & $8 / 12 / 20$ & 3.3 & 27.3 \\
\hline 4007 & $1 / 12 / 200$ & 8/12/2008 23:22 & 3.302 & 27.3 \\
\hline 4008 & $1 / 12 / 200$ & $8 / 12 / 200$ & 3.302 & 27.3 \\
\hline 4009 & $12 / 20$ & $8 / 12 / 20$ & 3.302 & 27.3 \\
\hline 4010 & $1 / 12 / 20$ & $8 / 12 / 20$ & 3.303 & 27.3 \\
\hline 4011 & $1 / 12 / 200$ & $8 / 12 / 20$ & 3.303 & 27.3 \\
\hline 4012 & $1 / 12 / 200$ & $23: 32$ & 3.304 & 27.3 \\
\hline 4013 & $1 / 12 / 200$ & $8 / 12 / 20$ & 3.304 & 27.4 \\
\hline 4014 & $1 / 12 / 200$ & $8 / 12 / 200823: 36$ & 3.305 & 27.3 \\
\hline 4015 & $1 / 12 / 20$ & $23: 38$ & 3.305 & 27.3 \\
\hline 4016 & $1 / 12 / 20$ & $8 / 12 / 20$ & 3.305 & 27.3 \\
\hline 4017 & 1/12/2008 23:42 & $8 / 12 / 200823: 42$ & 3.304 & 27.5 \\
\hline 4018 & $1 / 12 / 200$ & 8/12/2008 23:44 & 3.306 & 27.5 \\
\hline 4019 & $12 / 200$ & \begin{tabular}{|l|}
$8 / 12 / 200823: 46$ \\
\end{tabular} & 3.307 & 27.4 \\
\hline 4020 & 1/12/2008 23:48 & \begin{tabular}{|l|}
$8 / 12 / 200823: 48$ \\
\end{tabular} & 3.308 & 27.4 \\
\hline 4021 & 1/12/200823:50 & 8/12/2008 23:50 & 3.308 & 27.4 \\
\hline 4022 & 1/12/2008 23:52 & \begin{tabular}{|l|}
$8 / 12 / 200823: 52$ \\
\end{tabular} & 3.308 & 27.4 \\
\hline 4023 & $1 / 12 / 200$ & $8 / 12 / 20$ & 3.308 & 27.4 \\
\hline 4024 & 1/12/200823:56 & $8 / 12 / 2008$ 23:56 & 3.308 & 27.4 \\
\hline 4025 & 1/12/2008 23:58 & $8 / 12 / 200823: 58$ & 3.308 & 27.4 \\
\hline 4026 & $1 / 13 / 20$ & $8 / 13 / 20080: 00$ & 3.308 & 27.4 \\
\hline 4027 & 1/13/2008 0:02 & $8 / 13 / 20080: 02$ & 3.308 & 27.4 \\
\hline 4028 & $1 / 13 / 20080: 04$ & 8/13/2008 0:04 & 3.308 & 27.4 \\
\hline 4029 & 1/13/2008 0:06 & 8/13/2008 0:06 & 3.308 & 27.4 \\
\hline
\end{tabular}

\begin{tabular}{|c|c|c|c|c|}
\hline \multicolumn{5}{|c|}{ D4-93p } \\
\hline $\operatorname{Rec}$ & & Adjusted & Pressure & Temp \\
\hline \# & Date/Time & DaterTime & psi & ${ }^{\circ} \mathrm{C}$ \\
\hline 4030 & $1 / 13 / 20080: 08$ & $8 / 13 / 20080: 08$ & 3.309 & 27.4 \\
\hline 4031 & $1 / 13 / 20080: 10$ & $8 / 13 / 20080: 10$ & 3.309 & 27.4 \\
\hline 4032 & $1 / 13 / 20080: 12$ & $8 / 13 / 20080: 12$ & 3.299 & 27.4 \\
\hline 4033 & $1 / 13 / 20080: 14$ & $8 / 13 / 20080: 14$ & 3.221 & 27.4 \\
\hline 4034 & $1 / 13 / 20080: 16$ & $8 / 13 / 20080: 16$ & 3.071 & 27.4 \\
\hline 4035 & 1/13/2008 0:18 & $8 / 13 / 20080: 18$ & 2.918 & 27.4 \\
\hline 4036 & $1 / 13 / 20080: 20$ & $8 / 13 / 20080: 20$ & 2.205 & 27.4 \\
\hline 4037 & $1 / 13 / 20080: 22$ & $8 / 13 / 20080: 22$ & 2.617 & 27.6 \\
\hline 4038 & $1 / 13 / 20080: 24$ & $8 / 13 / 20080: 24$ & 2.965 & 27.6 \\
\hline 4039 & $1 / 13 / 20080: 26$ & $8 / 13 / 20080: 26$ & 3.151 & 27.5 \\
\hline 4040 & $1 / 13 / 20080: 28$ & $8 / 13 / 20080: 28$ & 3.242 & 27.4 \\
\hline 4041 & 1/13/2008 0:30 & \begin{tabular}{|l|}
$8 / 13 / 20080: 30$ \\
\end{tabular} & 3.282 & 27.3 \\
\hline 4042 & 1/13/2008 0:32 & $8 / 13 / 20080: 32$ & 3.302 & 27.3 \\
\hline 4043 & $1 / 13 / 20080: 34$ & $8 / 13 / 20080: 34$ & 3.314 & 27.2 \\
\hline 4044 & 1/13/2008 0:36 & $8 / 13 / 20080: 36$ & 3.323 & 27.1 \\
\hline 4045 & 1/13/20080:38 & $8 / 13 / 20080: 38$ & 3.33 & 27.1 \\
\hline 4046 & $1 / 13 / 20080: 40$ & $8 / 13 / 20080: 40$ & 3.335 & 27 \\
\hline 4047 & $1 / 13 / 20080: 42$ & $8 / 13 / 20080: 42$ & 3.338 & 27 \\
\hline 4048 & $1 / 13 / 20080: 44$ & $8 / 13 / 20080: 44$ & 3.342 & 26.9 \\
\hline 4049 & $1 / 13 / 20080: 46$ & $8 / 13 / 20080: 46$ & 3.345 & 26.9 \\
\hline 4050 & $1 / 13 / 20080: 48$ & $8 / 13 / 20080: 48$ & 3.346 & 26.8 \\
\hline 4051 & $1 / 13 / 20080: 50$ & $8 / 13 / 20080: 50$ & 3.348 & 26.8 \\
\hline 4052 & $1 / 13 / 20080: 52$ & $8 / 13 / 20080: 52$ & 3.349 & 26.7 \\
\hline 4053 & $1 / 13 / 20080: 54$ & $8 / 13 / 20080: 54$ & 3.351 & 26.6 \\
\hline 4054 & 1/13/2008 0:56 & $8 / 13 / 20080: 56$ & 3.352 & 26.6 \\
\hline 4055 & 1/13/2008 0:58 & $8 / 13 / 20080: 58$ & 3.352 & 26.5 \\
\hline 4056 & $1 / 13 / 20081: 00$ & $8 / 13 / 20081: 00$ & 3.354 & 26.5 \\
\hline 4057 & $1 / 13 / 20081: 02$ & $8 / 13 / 20081: 02$ & 3.354 & 26.5 \\
\hline 4058 & $1 / 13 / 20081: 04$ & $8 / 13 / 20081: 04$ & 3.354 & 26.5 \\
\hline 4059 & 1/13/2008 1:06 & $8 / 13 / 20081: 06$ & 3.355 & 26.6 \\
\hline 4060 & 1/13/2008 1:08 & $8 / 13 / 20081: 08$ & 3.356 & 26.8 \\
\hline 4061 & 1/13/2008 1:10 & $8 / 13 / 2008$ 1:10 & 3.356 & 26.8 \\
\hline 4062 & $1 / 13 / 20081: 12$ & $8 / 13 / 20081: 12$ & 3.356 & 27.3 \\
\hline 4063 & $1 / 13 / 20081: 14$ & $8 / 13 / 2008$ 1:14 & 3.357 & 27.1 \\
\hline 4064 & $1 / 13 / 20081: 16$ & $8 / 13 / 20081: 16$ & 3.358 & 27.1 \\
\hline 4065 & $1 / 13 / 20081: 18$ & $8 / 13 / 2008$ 1:18 & 3.358 & 27.1 \\
\hline 4066 & $1 / 13 / 20081: 20$ & $8 / 13 / 20081: 20$ & 3.358 & 27.1 \\
\hline 4067 & 1/13/2008 1:22 & $8 / 13 / 20081: 22$ & 3.358 & 27.2 \\
\hline 4068 & $1 / 13 / 20081: 24$ & $8 / 13 / 20081: 24$ & 3.358 & 27.3 \\
\hline 4069 & 1/13/2008 1:26 & $8 / 13 / 20081: 26$ & 3.359 & 27.3 \\
\hline 4070 & $1 / 13 / 20081: 28$ & $8 / 13 / 20081: 28$ & 3.36 & 27.3 \\
\hline 4071 & $1 / 13 / 20081: 30$ & $8 / 13 / 2008$ 1:30 & 3.36 & 27.4 \\
\hline 4072 & $1 / 13 / 20081: 32$ & $8 / 13 / 2008$ 1:32 & 3.36 & 27.4 \\
\hline 4073 & $1 / 13 / 20081: 34$ & $8 / 13 / 20081: 34$ & 3.362 & 27.4 \\
\hline 4074 & 1/13/2008 1:36 & $8 / 13 / 20081: 36$ & 3.362 & 27.4 \\
\hline 4075 & $1 / 13 / 20081: 38$ & $8 / 13 / 20081: 38$ & 3.362 & 27.4 \\
\hline 4076 & $1 / 13 / 20081: 40$ & $8 / 13 / 20081: 40$ & 3.363 & 27.3 \\
\hline 4077 & $1 / 13 / 20081: 42$ & $8 / 13 / 20081: 42$ & 3.364 & 27.3 \\
\hline 4078 & $1 / 13 / 20081: 44$ & $8 / 13 / 20081: 44$ & 3.364 & 27.3 \\
\hline 4079 & $1 / 13 / 20081: 46$ & $8 / 13 / 2008$ 1:46 & 3.365 & 27.3 \\
\hline 4080 & $1 / 13 / 20081: 48$ & $8 / 13 / 20081: 48$ & 3.366 & 27.3 \\
\hline 4081 & $1 / 13 / 20081: 50$ & $8 / 13 / 20081: 50$ & 3.366 & 27.3 \\
\hline 4082 & $1 / 13 / 20081: 52$ & 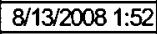 & 3.366 & 27.3 \\
\hline 4083 & $1 / 13 / 20081: 54$ & $8 / 13 / 20081: 54$ & 3.367 & 27.3 \\
\hline 4084 & $1 / 13 / 20081: 56$ & $8 / 13 / 2008$ 1:56 & 3.366 & 27.3 \\
\hline 4085 & $1 / 13 / 20081: 58$ & $8 / 13 / 2008$ 1:58 & 3.367 & 27.3 \\
\hline 4086 & $1 / 13 / 20082: 00$ & $8 / 13 / 20082: 00$ & 3.368 & 27.3 \\
\hline 4087 & $1 / 13 / 20082: 02$ & $8 / 13 / 20082: 02$ & 3.369 & 27.3 \\
\hline 4088 & 1/13/2008 2:04 & 8/13/2008:04 & 3.369 & 27.3 \\
\hline 4089 & 1/13/20082:06 & $8 / 13 / 20082: 06$ & 3.369 & 27.3 \\
\hline 4090 & 1/13/20082:08 & 8/13/20082:08 & 3.369 & 27.3 \\
\hline 4091 & 1/13/20082:10 & $8 / 13 / 20082: 10$ & 3.37 & 27.3 \\
\hline 4092 & $1 / 13 / 20082: 12$ & $8 / 13 / 20082: 12$ & 3.371 & 27.3 \\
\hline 4093 & 1/13/2008 2:14 & $8 / 13 / 20082: 14$ & 3.371 & 27.3 \\
\hline 4094 & 1/13/20082:16 & 8/13/2008 2:16 & 3.37 & 27.3 \\
\hline 4095 & $1 / 13 / 20082: 18$ & $8 / 13 / 20082: 18$ & 3.37 & 27.3 \\
\hline 4096 & 1/13/20082:20 & 8/13/2008 2:20 & 3.37 & 27.3 \\
\hline 4097 & $1 / 13 / 20082: 22$ & $8 / 13 / 20082: 22$ & 3.37 & 27.4 \\
\hline 4098 & $1 / 13 / 20082: 24$ & $8 / 13 / 20082: 24$ & 3.371 & 27.4 \\
\hline
\end{tabular}




\begin{tabular}{|c|c|c|c|c|}
\hline \multicolumn{5}{|c|}{ D4-93p } \\
\hline $\operatorname{Rec}$ & & Adjusted & Pressure & Temp \\
\hline$\#$ & Date/Time & Date/Time & psi & ${ }^{\circ} \mathrm{C}$ \\
\hline 4099 & $1 / 13 / 20082: 26$ & $8 / 13 / 20082: 26$ & 3.371 & 27.3 \\
\hline 4100 & $1 / 13 / 20082: 28$ & $8 / 13 / 20082 \cdot 28$ & 3.372 & 27.3 \\
\hline 4101 & $1 / 13 / 20082: 30$ & $8 / 13 / 20082: 30$ & 3.372 & 27.3 \\
\hline 4102 & $1 / 13 / 20082: 32$ & $8 / 13 / 20082: 32$ & 3.372 & 27.3 \\
\hline 4103 & $1 / 13 / 20082: 34$ & $8 / 13 / 20082: 34$ & 3.372 & 27.3 \\
\hline 4104 & $1 / 13 / 20082: 36$ & $8 / 13 / 20082: 36$ & 3.373 & 27.3 \\
\hline 4105 & $1 / 13 / 20082: 38$ & $8 / 13 / 20082: 38$ & 3.374 & 27.2 \\
\hline 4106 & $1 / 13 / 20082: 40$ & $8 / 13 / 20082: 40$ & 3.373 & 27.3 \\
\hline 4107 & $1 / 13 / 20082: 42$ & $8 / 13 / 20082: 42$ & 3.373 & 27.3 \\
\hline 4108 & $1 / 13 / 20082: 44$ & $8 / 13 / 20082: 44$ & 3.372 & 27.2 \\
\hline 4109 & $1 / 13 / 20082: 46$ & $8 / 13 / 20082: 46$ & 3.373 & 27.2 \\
\hline 4110 & $1 / 13 / 20082: 48$ & $8 / 13 / 20082: 48$ & 3.373 & 27.2 \\
\hline 4111 & $1 / 13 / 20082: 50$ & $8 / 13 / 20082: 50$ & 3.373 & 27.3 \\
\hline 4112 & $1 / 13 / 20082: 52$ & $8 / 13 / 20082: 52$ & 3.372 & 27.2 \\
\hline 4113 & $1 / 13 / 20082: 54$ & $8 / 13 / 20082: 54$ & 3.372 & 27.2 \\
\hline 4114 & $1 / 13 / 20082: 56$ & $8 / 13 / 20082: 56$ & 3.372 & 27.2 \\
\hline 4115 & $1 / 13 / 20082: 58$ & $8 / 13 / 20082: 58$ & 3.372 & 27.2 \\
\hline 4116 & 1/13/20083:00 & $8 / 13 / 20083: 00$ & 3.372 & 27.2 \\
\hline 4117 & $1 / 13 / 20083: 02$ & $8 / 13 / 20083: 02$ & 3.37 & 27.2 \\
\hline 4118 & 1/13/2008 3:04 & $8 / 13 / 20083: 04$ & 3.294 & 27.2 \\
\hline 4119 & $1 / 13 / 20083: 06$ & $8 / 13 / 20083: 06$ & 3.094 & 27.2 \\
\hline 4120 & $1 / 13 / 20083: 08$ & $8 / 13 / 20083: 08$ & 2.918 & 27.2 \\
\hline 4121 & 1/13/20083:10 & 8/13/2008 3:10 & 2.786 & 27.2 \\
\hline 4122 & $1 / 13 / 20083: 12$ & $83: 12$ & 2.874 & 27.2 \\
\hline 4123 & $1 / 13 / 20083: 14$ & $8 / 13 / 20083: 14$ & 3.058 & 27.2 \\
\hline 4124 & $1 / 13 / 20083: 16$ & $8 / 13 / 20083: 16$ & 3.185 & 27.2 \\
\hline 4125 & $1 / 13 / 20083: 18$ & 008 3:18 & 3.262 & 27.5 \\
\hline 4126 & $1 / 13 / 20083: 20$ & $83: 20$ & 3.304 & 27.1 \\
\hline 4127 & $1 / 13 / 20083: 22$ & $8 / 13 / 20083: 22$ & 3.328 & 27 \\
\hline 4128 & $1 / 13 / 20083: 24$ & $8 / 13 / 20083: 24$ & 3.342 & 26.9 \\
\hline 4129 & $1 / 13 / 20083: 26$ & $83: 26$ & 3.351 & 26.8 \\
\hline 4130 & $1 / 13 / 20083: 28$ & $8 / 13 / 20083: 28$ & 3.359 & 26.8 \\
\hline 4131 & 1/13/2008 3:30 & $8 / 13 / 20083: 30$ & 3.363 & 26.7 \\
\hline 4132 & $1 / 13 / 20083: 32$ & $883: 32$ & 3.367 & 26.6 \\
\hline 4133 & $1 / 13 / 20083: 34$ & $8 / 13 / 20083: 34$ & 3.37 & 26.6 \\
\hline 4134 & $1 / 13 / 20083: 36$ & $8 / 13 / 20083: 36$ & 3.372 & 26.4 \\
\hline 4135 & $1 / 13 / 20083: 38$ & $8 / 13 / 20083: 38$ & 3.374 & 26.4 \\
\hline 4136 & $1 / 13 / 20$ & $83: 40$ & 3.376 & 26.3 \\
\hline 4137 & $1 / 13 / 20083: 42$ & $883: 42$ & 3.378 & 26.5 \\
\hline 4138 & $1 / 13 / 20083: 44$ & $8 / 13 / 20083: 44$ & 3.381 & 26.7 \\
\hline 4139 & $1 / 13 / 20083: 46$ & $8 / 13 / 20083: 46$ & 3.383 & 26.8 \\
\hline 4140 & $1 / 13 / 20$ & $83: 48$ & 3.385 & 26.8 \\
\hline 4141 & $1 / 13 / 20083: 50$ & $3083: 50$ & 3.387 & 26.8 \\
\hline 4142 & $1 / 13 / 20083: 52$ & $8 / 13 / 20083: 52$ & 3.388 & 26.8 \\
\hline 4143 & $1 / 13 / 20083: 54$ & $33: 54$ & 3.39 & 26.8 \\
\hline 4144 & $1 / 13 / 20$ & $083: 56$ & 3.389 & 26.8 \\
\hline 4145 & $1 / 13 / 20083: 58$ & $8 / 13 / 20083: 58$ & 2.927 & 27.3 \\
\hline 4146 & 1/13/2008 4:00 & $084: 00$ & 2.317 & 27.3 \\
\hline 4147 & $1 / 13 / 2$ & $8 / 13 / 2$ & 3.258 & 27.2 \\
\hline 4148 & $1 / 13 / 20084: 04$ & $084: 04$ & 3.362 & 27.1 \\
\hline 4149 & $1 / 13 / 20084: 06$ & $084: 06$ & 3.398 & 27.1 \\
\hline 4150 & $1 / 13 / 20084: 08$ & $84: 08$ & 3.411 & 27 \\
\hline 4151 & $1 / 13 / 20$ & $8 / 13 / 2$ & 3.415 & 2 \\
\hline 4152 & 1/13/2008 4:12 & 8/13/2008 4:12 & 3.416 & 27.2 \\
\hline 4153 & $1 / 13 / 20084: 14$ & $8 / 13 / 20084: 14$ & 3.418 & 27.5 \\
\hline 4154 & $1 / 13 / 20084: 16$ & $8 / 13 / 20084: 16$ & 3.42 & 27.6 \\
\hline 4155 & 1/13/2008 4:18 & $8 / 13 / 20084: 18$ & 3.423 & 27.1 \\
\hline 4156 & $1 / 13 / 20084: 20$ & $8 / 13 / 20084: 20$ & 3.422 & 26.9 \\
\hline 4157 & $1 / 13 / 20084: 22$ & $884: 22$ & 3.422 & 26.8 \\
\hline 4158 & $1 / 13 / 20084: 24$ & $84: 24$ & 3.422 & 26.7 \\
\hline 4159 & $1 / 13 / 20084: 26$ & $8 / 13 / 20084: 26$ & 3.422 & 26.6 \\
\hline 4160 & $1 / 13 / 20084: 28$ & $8 / 13 / 20084: 28$ & 3.423 & 26.6 \\
\hline 4161 & 1/13/2008 4:30 & \begin{tabular}{|l|}
$8 / 13 / 20084: 30$ \\
\end{tabular} & 3.423 & 26.5 \\
\hline 4162 & $1 / 13 / 20084: 32$ & $8 / 13 / 20084: 32$ & 3.423 & 26.5 \\
\hline 4163 & 1/13/2008 4:34 & 8/13/2008 4:34 & 3.422 & 26.6 \\
\hline 4164 & 1/13/20084:36 & 8/13/2008 4:36 & 3.42 & 26.6 \\
\hline 4165 & $1 / 13 / 20084: 38$ & 8/13/2008 4:38 & 3.419 & 26.7 \\
\hline 4166 & 1/13/2008 4:40 & $8 / 13 / 20084: 40$ & 3.419 & 26.8 \\
\hline 4167 & $1 / 13 / 20084: 42$ & 8/13/2008 4:42 & 3.419 & 26.8 \\
\hline
\end{tabular}

\begin{tabular}{|c|c|c|c|c|}
\hline \multicolumn{5}{|c|}{ D4-93p } \\
\hline $\operatorname{Rec}$ & & Adjusted & Pressure & Temp \\
\hline$\#$ & Date/Time & Date/Time & psi & \\
\hline 4168 & $1 / 13 / 20084: 44$ & $8 / 13 / 20084: 44$ & 3.419 & 26.8 \\
\hline 4169 & $1 / 13 / 20084: 46$ & $8 / 13 / 20084: 46$ & 3.419 & 26.9 \\
\hline 4170 & $1 / 13 / 20084: 48$ & $8 / 13 / 20084: 48$ & 3.419 & 26.9 \\
\hline 4171 & $1 / 13 / 20084: 50$ & $8 / 13 / 20084: 50$ & 3.419 & 26.9 \\
\hline 4172 & $1 / 13 / 20084: 52$ & $8 / 13 / 20084: 52$ & 3.418 & 26.9 \\
\hline 4173 & $1 / 13 / 20084: 54$ & $8 / 13 / 20084: 54$ & 3.419 & 26.9 \\
\hline 4174 & $1 / 13 / 20084: 56$ & $8 / 13 / 20084: 56$ & 3.419 & 26.9 \\
\hline 4175 & $1 / 13 / 20084: 58$ & $8 / 13 / 20084: 58$ & 3.42 & 26.9 \\
\hline 4176 & $1 / 13 / 20085: 00$ & $8 / 13 / 20085: 00$ & 3.421 & 26.9 \\
\hline 4177 & $1 / 13 / 20085: 02$ & $8 / 13 / 20085: 02$ & 3.421 & 26.9 \\
\hline 4178 & $1 / 13 / 20085: 04$ & $8 / 13 / 20085: 04$ & 3.422 & 26.9 \\
\hline 4179 & $1 / 13 / 20085: 06$ & $8 / 13 / 20085: 06$ & 3.421 & 26.9 \\
\hline 4180 & 1/13/20085:08 & $8 / 13 / 20085: 08$ & 3.422 & 26.9 \\
\hline 4181 & $1 / 13 / 20085: 10$ & $8 / 13 / 20085: 10$ & 3.422 & 26.9 \\
\hline 4182 & $1 / 13 / 20085: 12$ & $8 / 13 / 20085: 12$ & 3.423 & 26.9 \\
\hline 4183 & $1 / 13 / 20085: 14$ & $8 / 13 / 20085: 14$ & 3.423 & 26.9 \\
\hline 4184 & $1 / 13 / 20085: 16$ & $8 / 13 / 20085: 16$ & 3.424 & 26.9 \\
\hline 4185 & $1 / 13 / 20085: 18$ & $8 / 13 / 20085: 18$ & 3.423 & 26.9 \\
\hline 4186 & $1 / 13 / 20085: 20$ & $8 / 13 / 20085: 20$ & 3.423 & 26.9 \\
\hline 4187 & $1 / 13 / 20085: 22$ & $8 / 13 / 20085: 22$ & 3.423 & 26.9 \\
\hline 4188 & $1 / 13 / 20085: 24$ & $8 / 13 / 20085: 24$ & 3.423 & 26.9 \\
\hline 4189 & $1 / 13 / 20085: 26$ & $8 / 13 / 20085: 26$ & 3.422 & 26.9 \\
\hline 4190 & $1 / 13 / 20085: 28$ & $8 / 13 / 20085: 28$ & 3.422 & 26.9 \\
\hline 4191 & 1/13/20085:30 & $8 / 13 / 20085: 30$ & 3.424 & 26.9 \\
\hline 4192 & $1 / 13 / 20085: 32$ & $8 / 13 / 20085: 32$ & 3.423 & 26.9 \\
\hline 4193 & $1 / 13 / 20085: 34$ & $8 / 13 / 20085: 34$ & 3.424 & 26.9 \\
\hline 4194 & $1 / 13 / 20085: 36$ & $8 / 13 / 20085: 36$ & 3.422 & 26.9 \\
\hline 4195 & $1 / 13 / 20085: 38$ & $8 / 13 / 20085: 38$ & 3.422 & 26.9 \\
\hline 4196 & $1 / 13 / 20085: 40$ & $8 / 13 / 20085: 40$ & 3.422 & 26.9 \\
\hline 4197 & $1 / 13 / 20085: 42$ & $8 / 13 / 20085: 42$ & 3.421 & 26.9 \\
\hline 4198 & $1 / 13 / 20085: 44$ & $8 / 13 / 20085: 44$ & 3.422 & 27.3 \\
\hline 4199 & $1 / 13 / 20085: 46$ & $8 / 13 / 20085: 46$ & 3.424 & 27 \\
\hline 4200 & $1 / 13 / 20085: 48$ & $8 / 13 / 20085: 48$ & 3.422 & 26.9 \\
\hline 4201 & $1 / 13 / 20085: 50$ & $8 / 13 / 20085: 50$ & 3.421 & 26.9 \\
\hline 4202 & $1 / 13 / 20085: 52$ & $8 / 13 / 20085: 52$ & 3.418 & 26.9 \\
\hline 4203 & $1 / 13 / 20085: 54$ & $8 / 13 / 20085: 54$ & 3.351 & 26.9 \\
\hline 4204 & $1 / 13 / 20085: 56$ & $8 / 13 / 20085: 56$ & 3.143 & 26.9 \\
\hline 4205 & $1 / 13 / 20$ & $8 / 13 / 20085: 58$ & 2.952 & 26.9 \\
\hline 4206 & $1 / 13 / 20086: 00$ & $8 / 13 / 20086: 00$ & 2.914 & 27 \\
\hline 4207 & $1 / 13 / 20086: 02$ & $8 / 13 / 20086: 02$ & 3.094 & 27 \\
\hline 4208 & $1 / 13 / 20086: 04$ & $8 / 13 / 20086: 04$ & 3.224 & 26.9 \\
\hline 4209 & $1 / 13 / 20$ & $8 / 13 / 20086: 06$ & 3.306 & 27.3 \\
\hline 4210 & $1 / 13 / 20086: 08$ & $8 / 13 / 20086: 08$ & 3.354 & 27.1 \\
\hline 4211 & $1 / 13 / 20086: 10$ & $8 / 13 / 20086: 10$ & 3.379 & 27.1 \\
\hline 4212 & $1 / 13 / 2$ & $8 / 13 / 20086: 12$ & 3.394 & 27.1 \\
\hline 4213 & $1 / 13 / 20086: 14$ & $8 / 13 / 20086: 14$ & 3.406 & 27 \\
\hline 4214 & $1 / 13 / 20086: 16$ & $8 / 13 / 20086: 16$ & 3.411 & 27 \\
\hline 4215 & $1 / 13 / 200$ & $8 / 13 / 20086: 18$ & 3.417 & 26.8 \\
\hline 4216 & $1 / 13 / 20086: 20$ & $8 / 13 / 20086: 20$ & 3.422 & 26.5 \\
\hline 4217 & $1 / 13 / 20086: 22$ & $8 / 13 / 20086: 22$ & 3.425 & 26.4 \\
\hline 4218 & $1 / 13 / 20086: 24$ & $8 / 13 / 20086: 24$ & 3.428 & 26.3 \\
\hline 4219 & & & 3.43 & 26.2 \\
\hline 4220 & $1 / 13 / 20086: 28$ & $8 / 13 / 20086: 28$ & 3.433 & 26.1 \\
\hline 4221 & 1/13/2008 6:30 & $8 / 13 / 20086: 30$ & 3.434 & 26.2 \\
\hline 4222 & $1 / 13 / 20086: 32$ & $8 / 13 / 20086: 32$ & 3.436 & 26.4 \\
\hline 4223 & $1 / 13 / 200$ & $8 / 13 / 20086: 34$ & 3.438 & 26.4 \\
\hline 4224 & $1 / 13 / 20086: 36$ & $8 / 13 / 20086: 36$ & 3.44 & 26.4 \\
\hline 4225 & $1 / 13 / 20086: 38$ & $8 / 13 / 20086: 38$ & 3.441 & 26.4 \\
\hline 4226 & $1 / 13 / 20086: 40$ & $8 / 13 / 20086: 40$ & 3.442 & 26.4 \\
\hline 4227 & $1 / 13 / 20086: 42$ & $8 / 13 / 20086: 42$ & 3.444 & 26.5 \\
\hline 4228 & $1 / 13 / 20086: 44$ & $8 / 13 / 20086: 44$ & 3.444 & 26.5 \\
\hline 4229 & $1 / 13 / 20086: 46$ & $8 / 13 / 20086: 46$ & 3.446 & 26.5 \\
\hline 4230 & $1 / 13 / 20086: 48$ & $8 / 13 / 20086: 48$ & 3.447 & 26.5 \\
\hline 4231 & $1 / 13 / 20086: 50$ & $8 / 13 / 20086: 50$ & 3.448 & 26.5 \\
\hline 4232 & $1 / 13 / 20086: 52$ & $8 / 13 / 20086.52$ & 3.449 & 26.5 \\
\hline 4233 & $1 / 13 / 20086: 54$ & $8 / 13 / 20086: 54$ & 3.45 & 26.5 \\
\hline 4234 & 1/13/20086:56 & $8 / 13 / 20086: 56$ & 3.452 & 26.5 \\
\hline 4235 & $1 / 13 / 20086: 58$ & $8 / 13 / 20086: 58$ & 3.452 & 26.5 \\
\hline 4236 & $1 / 13 / 20087: 00$ & $8 / 13 / 20087: 00$ & 3.453 & 26.5 \\
\hline
\end{tabular}

\begin{tabular}{|c|c|c|c|c|}
\hline \multicolumn{5}{|c|}{ D4-93p } \\
\hline $\operatorname{Rec}$ & & Adjusted & Pressure & Temp \\
\hline$\#$ & Date/Time & Date-Time & psi & \\
\hline 4237 & $1 / 13 / 20087: 02$ & $8 / 13 / 20087: 02$ & 3.454 & 26.5 \\
\hline 4238 & $1 / 13 / 20087: 04$ & $8 / 13 / 20087: 04$ & 3.454 & 26.5 \\
\hline 4239 & $1 / 13 / 20087: 06$ & $8 / 13 / 20087: 06$ & 3.454 & 26.5 \\
\hline 4240 & $1 / 13 / 20087: 08$ & 8/13/2008 7:08 & 3.454 & 26.5 \\
\hline 4241 & $1 / 13 / 20087: 10$ & $8 / 13 / 20087: 10$ & 3.454 & 26.5 \\
\hline 4242 & $1 / 13 / 20087: 12$ & $8 / 13 / 20087: 12$ & 3.454 & 26.5 \\
\hline 4243 & $1 / 13 / 20087: 14$ & 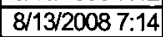 & 3.455 & 26.6 \\
\hline 4244 & $1 / 13 / 20087: 16$ & $8 / 13 / 20087: 16$ & 3.455 & 26.6 \\
\hline 4245 & $1 / 13 / 20087: 18$ & $8 / 13 / 20087: 18$ & 3.456 & 26.6 \\
\hline 4246 & $1 / 13 / 20087: 20$ & $8 / 13 / 20087: 20$ & 3.459 & 26.6 \\
\hline 4247 & $1 / 13 / 20087: 22$ & $8 / 13 / 20087: 22$ & 3.46 & 26.6 \\
\hline 4248 & $1 / 13 / 20087: 24$ & $8 / 13 / 20087: 24$ & 3.46 & 26.6 \\
\hline 4249 & $1 / 13 / 20087: 26$ & $8 / 13 / 20087: 26$ & 3.459 & 26.6 \\
\hline 4250 & $1 / 13 / 20087: 28$ & $8 / 13 / 20087: 28$ & 3.46 & 26.6 \\
\hline 4251 & $1 / 13 / 20087: 30$ & $8 / 13 / 20087: 30$ & 3.46 & 26.6 \\
\hline 4252 & $1 / 13 / 20087: 32$ & $8 / 13 / 20087: 32$ & 3.461 & 26.6 \\
\hline 4253 & $1 / 13 / 20087: 34$ & $8 / 13 / 20087: 34$ & 3.462 & 26.6 \\
\hline 4254 & $1 / 13 / 20087: 36$ & $8 / 13 / 20087: 36$ & 3.462 & 26.6 \\
\hline 4255 & $1 / 13 / 20087: 38$ & $8 / 13 / 20087: 38$ & 3.462 & 26.6 \\
\hline 4256 & $1 / 13 / 20087: 40$ & $8 / 13 / 20087: 40$ & 3.462 & 26.6 \\
\hline 4257 & $1 / 13 / 20087: 42$ & $8 / 13 / 20087: 42$ & 3.461 & 26.6 \\
\hline 4258 & 1/13/2008 7:44 & $8 / 13 / 20087: 44$ & 3.461 & 26.6 \\
\hline 4259 & $1 / 13 / 20087: 46$ & $8 / 13 / 20087: 46$ & 3.461 & 26.5 \\
\hline 4260 & $1 / 13 / 20087: 48$ & $8 / 13 / 20087: 48$ & 3.462 & 26.6 \\
\hline 4261 & $1 / 13 / 20087: 50$ & $8 / 13 / 20087: 50$ & 3.463 & 26.6 \\
\hline 4262 & $1 / 13 / 20087: 52$ & $8 / 13 / 20087: 52$ & 3.463 & 26.6 \\
\hline 4263 & $1 / 13 / 20087: 54$ & $8 / 13 / 20087: 54$ & 3.464 & 26.6 \\
\hline 4264 & $1 / 13 / 20087: 56$ & $8 / 13 / 20087: 56$ & 3.465 & 26.6 \\
\hline 4265 & $1 / 13 / 20087: 58$ & $8 / 13 / 20087: 58$ & 3.465 & 26.6 \\
\hline 4266 & $1 / 13 / 20088: 00$ & $8 / 13 / 20088: 00$ & 3.465 & 26.6 \\
\hline 4267 & $1 / 13 / 200$ & $8 / 13 / 20088: 02$ & 3.466 & 26.6 \\
\hline 4268 & $1 / 13 / 20088: 04$ & $8 / 13 / 20088: 04$ & 3.466 & 26.6 \\
\hline 4269 & $1 / 13 / 20088: 06$ & $8 / 13 / 20088: 06$ & 3.465 & 26.6 \\
\hline 4270 & $1 / 13 / 20088: 08$ & $8 / 13 / 20088: 08$ & 3.465 & 26.6 \\
\hline 4271 & $1 / 13 / 20088: 10$ & $8 / 13 / 20088: 10$ & 3.465 & 26.6 \\
\hline 4272 & $1 / 13 / 20088: 12$ & $8 / 13 / 20088: 12$ & 3.465 & 26.6 \\
\hline 4273 & $1 / 13 / 20088: 14$ & $8 / 13 / 20088: 14$ & 3.465 & 26.6 \\
\hline 4274 & $1 / 13 / 20088: 16$ & $8 / 13 / 20088: 16$ & 3.464 & 26.6 \\
\hline 4275 & $1 / 13 / 20088: 18$ & $8 / 13 / 20088: 18$ & 3.468 & 26.6 \\
\hline 4276 & $1 / 13 / 20088: 20$ & $8 / 13 / 20088: 20$ & 3.471 & 26.6 \\
\hline 4277 & $1 / 13 / 200$ & $8 / 13 / 20088: 22$ & 3.473 & 26.6 \\
\hline 4278 & $1 / 13 / 200$ & $8 / 13 / 20088: 24$ & 3.474 & 26.6 \\
\hline 4279 & $1 / 13 / 20088: 26$ & $8 / 13 / 20088: 26$ & 3.474 & 26.6 \\
\hline 4280 & $1 / 13 / 20088: 28$ & $8 / 13 / 20088: 28$ & 3.474 & 26.6 \\
\hline 4281 & $1 / 13 / 20088: 30$ & $8 / 13 / 20088: 30$ & 3.473 & 26.6 \\
\hline 4282 & $1 / 13 / 20088: 32$ & $8 / 13 / 20088: 32$ & 3.474 & 26.6 \\
\hline 4283 & $1 / 13 / 20088: 34$ & $8 / 13 / 20088: 34$ & 3.474 & 26.6 \\
\hline 4284 & $1 / 13 / 20088: 36$ & $8 / 13 / 20088: 36$ & 3.474 & 26.6 \\
\hline 4285 & $1 / 13 / 20088: 38$ & $8 / 13 / 20088: 38$ & 3.474 & 26.9 \\
\hline 4286 & $1 / 13 / 20088: 40$ & $8 / 13 / 20088: 40$ & 3.475 & 26.7 \\
\hline 4287 & $1 / 13 / 20088: 42$ & $8 / 13 / 20088: 42$ & 3.373 & 26.6 \\
\hline 4288 & $1 / 13 / 20088: 44$ & $8 / 13 / 20088: 44$ & 3.135 & 26.6 \\
\hline 4289 & $1 / 13 / 20088: 46$ & $8 / 13 / 20088: 46$ & 2.952 & 26.6 \\
\hline 4290 & $1 / 13 / 20088: 48$ & $8 / 13 / 20088: 48$ & 2.827 & 26.6 \\
\hline 4291 & $1 / 13 / 20088: 50$ & $8 / 13 / 20088: 50$ & 2.948 & 26.5 \\
\hline 4292 & $1 / 13 / 20088: 52$ & $8 / 13 / 20088: 52$ & 3.137 & 26.6 \\
\hline 4293 & $1 / 13 / 20088: 54$ & $8 / 13 / 20088: 54$ & 3.274 & 26.5 \\
\hline 4294 & $1 / 13 / 20088: 56$ & $8 / 13 / 20088: 56$ & 3.355 & 26.4 \\
\hline 4295 & $1 / 13 / 20088: 58$ & $8 / 13 / 20088: 58$ & 3.397 & 26.4 \\
\hline 4296 & $1 / 13 / 20089: 00$ & $8 / 13 / 20089: 00$ & 2.538 & 26.4 \\
\hline 4297 & $1 / 13 / 20089: 02$ & $8 / 13 / 20089: 02$ & 2.184 & 26.5 \\
\hline 4298 & $1 / 13 / 20089: 04$ & $8 / 13 / 20089: 04$ & 2.053 & 26.5 \\
\hline 4299 & 1/13/2008 9:06 & $8 / 13 / 20089: 06$ & 2.043 & 26.5 \\
\hline 4300 & $1 / 13 / 20089: 08$ & $8 / 13 / 20089: 08$ & 2.235 & 26.6 \\
\hline 4301 & 1/13/2008 9:10 & $8 / 13 / 20089: 10$ & 3.246 & 26.5 \\
\hline 4302 & 1/13/20089:12 & $8 / 13 / 20089: 12$ & 3.376 & 26.5 \\
\hline 4303 & $1 / 13 / 20089: 14$ & $8 / 13 / 20089: 14$ & 3.428 & 26.5 \\
\hline 4304 & 1/13/2008 9:16 & $8 / 13 / 20089: 16$ & 3.452 & 26.5 \\
\hline 4305 & $1 / 13 / 20089: 18$ & $8 / 13 / 20089: 18$ & 3.461 & 26.5 \\
\hline
\end{tabular}




\begin{tabular}{|c|c|c|c|c|}
\hline \multicolumn{5}{|c|}{ D4-93p } \\
\hline $\operatorname{Rec}$ & & Adjusted & Pressure & Temp \\
\hline$\#$ & Date/Time & Date/Time & psi & ${ }^{\circ} \mathrm{C}$ \\
\hline 4306 & $1 / 13 / 20089: 20$ & $8 / 13 / 20089: 20$ & 3.467 & 26.5 \\
\hline 4307 & $1 / 13 / 20089: 22$ & $8 / 13 / 20089: 22$ & 3.47 & 26.5 \\
\hline 4308 & $1 / 13 / 20089: 24$ & $8 / 13 / 20089: 24$ & 3.471 & 26.5 \\
\hline 4309 & 1/13/20089:26 & $8 / 13 / 20089: 26$ & 3.474 & 26.4 \\
\hline 4310 & $1 / 13 / 20089: 28$ & $8 / 13 / 20089.28$ & 3.476 & 26.4 \\
\hline 4311 & $1 / 13 / 20089: 30$ & $8 / 13 / 20089: 30$ & 3.478 & 26.4 \\
\hline 4312 & $1 / 13 / 20089: 32$ & $8 / 13 / 20089: 32$ & 3.479 & 26.8 \\
\hline 4313 & $1 / 13 / 20089: 34$ & $8 / 13 / 20089: 34$ & 3.481 & 26.5 \\
\hline 4314 & $1 / 13 / 20089: 36$ & $8 / 13 / 20089: 36$ & 3.482 & 26.5 \\
\hline 4315 & $1 / 13 / 20089: 38$ & $8 / 13 / 20089: 38$ & 3.483 & 26.5 \\
\hline 4316 & $1 / 13 / 20089: 40$ & $8 / 13 / 20089: 40$ & 3.484 & 26.4 \\
\hline 4317 & $1 / 13 / 20089: 42$ & $8 / 13 / 20089: 42$ & 3.485 & 26.4 \\
\hline 4318 & $1 / 13 / 20089: 44$ & $8 / 13 / 20089: 44$ & 3.485 & 26.4 \\
\hline 4319 & $1 / 13 / 20089: 46$ & $8 / 13 / 20089946$ & 3.485 & 26.5 \\
\hline 4320 & $1 / 13 / 20089: 48$ & $8 / 13 / 20089: 48$ & 3.484 & 26.5 \\
\hline 4321 & $1 / 13 / 20089: 50$ & $8 / 13 / 20089: 50$ & 3.482 & 26.4 \\
\hline 4322 & $1 / 13 / 20089: 52$ & $8 / 13 / 20089.52$ & 3.48 & 26.5 \\
\hline 4323 & $1 / 13 / 20089: 54$ & $8 / 13 / 20089: 54$ & 3.479 & 26.5 \\
\hline 4324 & $1 / 13 / 20089: 56$ & $8 / 13 / 20089: 56$ & 3.479 & 26.5 \\
\hline 4325 & $1 / 13 / 20089: 58$ & $8 / 13 / 20089: 58$ & 3.48 & 26.5 \\
\hline 4326 & $1 / 13 / 200810: 00$ & $8 / 13 / 200810: 00$ & 3.481 & 26.6 \\
\hline 4327 & $1 / 13 / 200810: 02$ & $8 / 13 / 200810: 02$ & 3.48 & 26.5 \\
\hline 4328 & $1 / 13 / 200810: 04$ & $8 / 13 / 2008$ 10:04 & 3.48 & 26.5 \\
\hline 4329 & 1/13/2008 10:06 & $8 / 13 / 2008$ 10:06 & 3.481 & 26.5 \\
\hline 4330 & $1 / 13 / 200810: 08$ & $8 / 13 / 200810: 08$ & 3.482 & 26.5 \\
\hline 4331 & 1/13/2008 10:10 & $8 / 13 / 2008$ 10:10 & 3.483 & 26.5 \\
\hline 4332 & $1 / 13 / 2008$ 10:12 & $8 / 13 / 2008$ 10:12 & 3.484 & 26.5 \\
\hline 4333 & $1 / 13 / 200810: 14$ & $8 / 13 / 2008$ 10:14 & 3.485 & 26.5 \\
\hline 4334 & 1/13/2008 10:16 & $8 / 13 / 2008$ 10:16 & 3.485 & 26.5 \\
\hline 4335 & $1 / 13 / 200810: 18$ & $8 / 13 / 2008$ 10:18 & 3.485 & 26.5 \\
\hline 4336 & $1 / 13 / 200810: 20$ & $8 / 13 / 200810: 20$ & 3.483 & 26.5 \\
\hline 4337 & $1 / 13 / 2008 \quad 10: 22$ & $8 / 13 / 200810: 22$ & 3.482 & 26.5 \\
\hline 4338 & $1 / 13 / 2008$ 10:24 & $8 / 13 / 200810: 24$ & 3.483 & 26.5 \\
\hline 4339 & $1 / 13 / 200810: 26$ & $8 / 13 / 200810: 26$ & 3.484 & 26.5 \\
\hline 4340 & $1 / 13 / 2008 \quad 10: 28$ & $8 / 13 / 200810: 28$ & 3.485 & 26.5 \\
\hline 4341 & $1 / 13 / 2008$ 10:30 & $8 / 13 / 200810: 30$ & 3.486 & 26.5 \\
\hline 4342 & $1 / 13 / 2008 \quad 10: 32$ & $8 / 13 / 200810: 32$ & 3.486 & 26.5 \\
\hline 4343 & $1 / 13 / 200810: 34$ & $8 / 13 / 200810: 34$ & 3.486 & 26.5 \\
\hline 4344 & $1 / 13 / 2008$ 10:36 & $8 / 13 / 200810: 36$ & 3.487 & 26.5 \\
\hline 4345 & $1 / 13 / 200$ & $8 / 13 / 2008$ 10:38 & 3.487 & 26.5 \\
\hline 4346 & $1 / 13 / 200810: 40$ & $8 / 13 / 200810: 40$ & 3.487 & 26.5 \\
\hline 4347 & $1 / 13 / 2008$ 10:42 & \begin{tabular}{|l|}
$8 / 13 / 2008$ 10:42 \\
\end{tabular} & 3.488 & 26.5 \\
\hline 4348 & $1 / 13 / 20$ & 8/13/2008 10:44 & 3.488 & 26.5 \\
\hline 4349 & $1 / 13 / 200810: 46$ & $8 / 13 / 2008$ 10:46 & 3.487 & 26.5 \\
\hline 4350 & \begin{tabular}{|l|l}
$1 / 13 / 2008 \quad 10: 48$ \\
\end{tabular} & $8 / 13 / 2008$ 10:48 & 3.481 & 26.5 \\
\hline 4351 & $1 / 13 / 200810: 50$ & $8 / 13 / 200810: 50$ & 3.477 & 26.5 \\
\hline 4352 & $1 / 13 / 200810: 52$ & $8 / 13 / 200810: 52$ & 3.479 & 26.5 \\
\hline 4353 & $1 / 13 / 200810: 54$ & $8 / 13 / 200810: 54$ & 3.484 & 26.8 \\
\hline 4354 & $1 / 13 / 200810: 56$ & 8/13/2008 10:56 & 3.491 & 26.6 \\
\hline 4355 & $1 / 13 / 200810: 58$ & $8 / 13 / 200810: 58$ & 3.498 & 26.5 \\
\hline 4356 & $1 / 13 / 200$ & $8 / 13 / 2008$ 11:00 & 3.505 & 26.5 \\
\hline 4357 & $1 / 13 / 200$ & $8 / 13 / 200811: 02$ & 3.506 & 26.4 \\
\hline 4358 & \begin{tabular}{|l|l|}
$1 / 13 / 200811: 04$ \\
\end{tabular} & $8 / 13 / 200811: 04$ & 3.509 & 26.4 \\
\hline 4359 & \begin{tabular}{|l|}
$1 / 13 / 200811: 06$ \\
\end{tabular} & $8 / 13 / 200811: 06$ & 3.511 & 26.3 \\
\hline 4360 & $1 / 13 / 20$ & $8 / 13 / 200811: 08$ & 3.514 & 26.3 \\
\hline 4361 & 1/13/2008 11:10 & $8 / 13 / 200811: 10$ & 3.517 & 26.2 \\
\hline 4362 & 1/13/2008 11:12 & $8 / 13 / 2008$ 11:12 & 3.521 & 26.1 \\
\hline 4363 & 1/13/2008 11:14 & $8 / 13 / 200811: 14$ & 3.524 & 26.1 \\
\hline 4364 & \begin{tabular}{|l|}
$1 / 13 / 200811: 16$ \\
\end{tabular} & 8/13/2008 11:16 & 3.528 & 26.1 \\
\hline 4365 & \begin{tabular}{|l|} 
1/13/2008 11:18 \\
\end{tabular} & 8/13/2008 11:18 & 3.53 & 26.3 \\
\hline 4366 & 1/13/2008 11:20 & $8 / 13 / 2008$ 11:20 & 3.532 & 26.2 \\
\hline 4367 & 1/13/2008 11:22 & 8/13/2008 11:22 & 3.531 & 26.1 \\
\hline 4368 & \begin{tabular}{|l|}
$1 / 13 / 2008$ \\
$11: 24$
\end{tabular} & $8 / 13 / 200811: 24$ & 3.434 & 26.1 \\
\hline 4369 & 1/13/2008 11:26 & 8/13/2008 11:26 & 3.304 & 26.1 \\
\hline 4370 & 1/13/2008 11:28 & 8/13/2008 11:28 & 3.114 & 26.1 \\
\hline 4371 & 1/13/2008 11:30 & $8 / 13 / 200811: 30$ & 2.97 & 26 \\
\hline 4372 & \begin{tabular}{|l|}
$1 / 13 / 2008$ \\
\end{tabular} & $8 / 13 / 200811: 32$ & 3.118 & 25.9 \\
\hline 4373 & 1/13/2008 11:34 & 8/13/2008 11:34 & 3.28 & 25.9 \\
\hline 4374 & $1 / 13 / 200811: 36$ & $8 / 13 / 200811: 36$ & 3.386 & 26 \\
\hline
\end{tabular}

\begin{tabular}{|c|c|c|c|c|}
\hline \multicolumn{5}{|c|}{ D4-93p } \\
\hline $\operatorname{Rec}$ & & Adjusted & Pressure & Temp \\
\hline$\#$ & Date/Time & DaterTime & psi & ${ }^{\circ} \mathrm{C}$ \\
\hline 4375 & 1/13/2008 11:38 & $8 / 13 / 200811: 38$ & 3.451 & 26.1 \\
\hline 4376 & $1 / 13 / 200811: 40$ & $8 / 13 / 200811: 40$ & 3.48 & 26.1 \\
\hline 4377 & $1 / 13 / 2008$ 11:42 & $8 / 13 / 200811: 42$ & 3.49 & 26.1 \\
\hline 4378 & 1/13/2008 11:44 & $8 / 13 / 200811: 44$ & 3.495 & 26 \\
\hline 4379 & 1/13/2008 11:46 & $8 / 13 / 200811: 46$ & 3.498 & 26 \\
\hline 4380 & 1/13/2008 11:48 & $8 / 13 / 200811: 48$ & 3.5 & 25.9 \\
\hline 4381 & $1 / 13 / 200811: 50$ & $8 / 13 / 200811: 50$ & 3.502 & 25.9 \\
\hline 4382 & 1/13/2008 11:52 & $8 / 13 / 200811: 52$ & 3.503 & 25.9 \\
\hline 4383 & 1/13/2008 11:54 & $8 / 13 / 200811: 54$ & 3.505 & 25.9 \\
\hline 4384 & 1/13/2008 11:56 & $8 / 13 / 200811: 56$ & 3.506 & 25.8 \\
\hline 4385 & 1/13/2008 11:58 & 8/13/2008 11:58 & 3.507 & 25.8 \\
\hline 4386 & 1/13/2008 12:00 & $8 / 13 / 2008$ 12:00 & 3.508 & 26.1 \\
\hline 4387 & 1/13/2008 12:02 & 8/13/2008 12:02 & 3.511 & 25.9 \\
\hline 4388 & 1/13/2008 12:04 & $8 / 13 / 200812: 04$ & 3.514 & 25.8 \\
\hline 4389 & 1/13/2008 12:06 & $8 / 13 / 200812: 06$ & 3.516 & 25.9 \\
\hline 4390 & 1/13/2008 12:08 & $8 / 13 / 200812: 08$ & 3.516 & 26.1 \\
\hline 4391 & 1/13/2008 12:10 & $8 / 13 / 200812: 10$ & 3.517 & 26.2 \\
\hline 4392 & $1 / 13 / 200812: 12$ & $8 / 13 / 2008$ 12:12 & 2805 & 26.2 \\
\hline 4393 & $1 / 13 / 200812: 14$ & $8 / 13 / 2008$ 12:14 & 3.487 & 26.5 \\
\hline 4394 & $1 / 13 / 200812: 16$ & $8 / 13 / 200812: 16$ & 3.526 & 26.5 \\
\hline 4395 & 1/13/2008 12:18 & \begin{tabular}{|l|}
$8 / 13 / 200812: 18$ \\
\end{tabular} & 3.538 & 26.5 \\
\hline 4396 & 1/13/2008 12:20 & $8 / 13 / 200812: 20$ & 3.54 & 26.5 \\
\hline 4397 & $1 / 13 / 200812: 22$ & $8 / 13 / 2008$ 12:22 & 3.54 & 26.7 \\
\hline 4398 & $1 / 13 / 200812: 24$ & $8 / 13 / 2008$ 12:24 & 3.542 & 26.6 \\
\hline 4399 & 1/13/2008 12:26 & $8 / 13 / 2008$ 12:26 & 3.543 & 26.4 \\
\hline 4400 & $1 / 13 / 200812: 28$ & $8 / 13 / 2008$ 12:28 & 3.543 & 26.4 \\
\hline 4401 & 1/13/2008 12:30 & \begin{tabular}{|l|}
$8 / 13 / 200812: 30$ \\
\end{tabular} & 3.543 & 26.4 \\
\hline 4402 & 1/13/2008 12:32 & \begin{tabular}{|l|}
$8 / 13 / 200812: 32$ \\
\end{tabular} & 3.541 & 26.3 \\
\hline 4403 & $1 / 13 / 200812: 34$ & \begin{tabular}{|l|}
$8 / 13 / 200812: 34$ \\
\end{tabular} & 3.54 & 26.3 \\
\hline 4404 & $1 / 13 / 200812: 36$ & 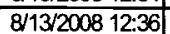 & 3.54 & 26.3 \\
\hline 4405 & $1 / 13 / 200812: 38$ & \begin{tabular}{|l|}
$8 / 13 / 200812: 38$ \\
\end{tabular} & 3.54 & 26.3 \\
\hline 4406 & 1/13/2008 12:40 & $8 / 13 / 2008$ 12:40 & 3.539 & 26.2 \\
\hline 4407 & $1 / 13 / 200812: 42$ & \begin{tabular}{|l|}
$8 / 13 / 200812: 42$ \\
\end{tabular} & 3.54 & 26.2 \\
\hline 4408 & $1 / 13 / 200812: 44$ & $8 / 13 / 200812: 44$ & 3.54 & 26.2 \\
\hline 4409 & $1 / 13 / 200812: 46$ & $8 / 13 / 200812: 46$ & 3.54 & 26.1 \\
\hline 4410 & $1 / 13 / 200812: 48$ & $8 / 13 / 2008$ 12:48 & 3.54 & 26.1 \\
\hline 4411 & $1 / 13 / 200812: 50$ & $8 / 13 / 2008$ 12:50 & 3.539 & 26.1 \\
\hline 4412 & $1 / 13 / 200812: 52$ & $8 / 13 / 2008$ 12:52 & 3.538 & 26.1 \\
\hline 4413 & $1 / 13 / 200812: 54$ & $8 / 13 / 200812: 54$ & 3.538 & 26.3 \\
\hline 4414 & $1 / 13 / 200812: 56$ & $8 / 13 / 200812: 56$ & 3.538 & 26.4 \\
\hline 4415 & $1 / 13 / 200812: 58$ & $8 / 13 / 200812558$ & 3.539 & 26.4 \\
\hline 4416 & $1 / 13 / 2008$ 13:00 & $8 / 13 / 2008$ 13:00 & 3.538 & 26.4 \\
\hline 4417 & 1/13/2008 13:02 & $8 / 13 / 200813: 02$ & 3.536 & 26.4 \\
\hline 4418 & 1/13/2008 13:04 & $8 / 13 / 200813: 04$ & 3.534 & 26.4 \\
\hline 4419 & 1/13/2008 13:06 & $8 / 13 / 200813: 06$ & 3.534 & 26.4 \\
\hline 4420 & $1 / 13 / 2008$ 13:08 & 8/13/2008 13:08 & 3.536 & 26.7 \\
\hline 4421 & $1 / 13 / 200813: 10$ & $8 / 13 / 2008$ 13:10 & 3.537 & 26.6 \\
\hline 4422 & 1/13/2008 13:12 & \begin{tabular}{|l|}
$8 / 13 / 2008$ 13:12 \\
\end{tabular} & 3.538 & 26.5 \\
\hline 4423 & 1/13/2008 13:14 & \begin{tabular}{|l|}
$8 / 13 / 2008$ 13:14 \\
\end{tabular} & 3.537 & 26.5 \\
\hline 4424 & 1/13/2008 13:16 & \begin{tabular}{|l|}
$8 / 13 / 2008$ 13:16 \\
\end{tabular} & 3.536 & 26.6 \\
\hline 4425 & $1 / 13 / 200$ & $8 / 13 / 2008$ 13:18 & 3.536 & 26.6 \\
\hline 4426 & $1 / 13 / 200813: 20$ & $8 / 13 / 2008$ 13:20 & 3.536 & 26.6 \\
\hline 4427 & 1/13/2008 13:22 & $8 / 13 / 2008$ 13:22 & 3.537 & 26.6 \\
\hline 4428 & $1 / 13 / 200813: 24$ & $8 / 13 / 2008$ 13:24 & 3.537 & 26.6 \\
\hline 4429 & 1/13/2008 13:26 & 8/13/2008 13:26 & 3.537 & 26.6 \\
\hline 4430 & $1 / 13 / 200813: 28$ & $8 / 13 / 200813: 28$ & 3.537 & 26.6 \\
\hline 4431 & 1/13/2008 13:30 & \begin{tabular}{|l|}
$8 / 13 / 2008$ 13:30 \\
\end{tabular} & 3.537 & 26.6 \\
\hline 4432 & 1/13/2008 13:32 & \begin{tabular}{|l|}
$8 / 13 / 2008$ \\
\end{tabular} & 3.537 & 26.6 \\
\hline 4433 & 1/13/2008 13:34 & $8 / 13 / 200813: 34$ & 3.537 & 26.6 \\
\hline 4434 & 1/13/2008 13:36 & $8 / 13 / 2008$ 13:36 & 3.538 & 26.6 \\
\hline 4435 & 1/13/2008 13:38 & 8/13/2008 13:38 & 3.538 & 26.7 \\
\hline 4436 & 1/13/2008 13:40 & \begin{tabular}{|l|}
$8 / 13 / 200813: 40$ \\
\end{tabular} & 3.539 & 26.7 \\
\hline 4437 & $1 / 13 / 2008$ 13:42 & \begin{tabular}{|l|}
$8 / 13 / 200813: 42$ \\
\end{tabular} & 3.536 & 26.7 \\
\hline 4438 & $1 / 13 / 2008$ 13:44 & $8 / 13 / 2008$ 13:44 & 3.534 & 26.7 \\
\hline 4439 & \begin{tabular}{|l|}
$1 / 13 / 200813: 46$ \\
\end{tabular} & \begin{tabular}{|l|}
$8 / 13 / 200813: 46$ \\
\end{tabular} & 3.535 & 26.8 \\
\hline 4440 & $1 / 13 / 200813: 48$ & $8 / 13 / 200813: 48$ & 3.539 & 26.8 \\
\hline 4441 & $1 / 13 / 200813: 50$ & \begin{tabular}{|l|}
$8 / 13 / 200813: 50$ \\
\end{tabular} & 3.544 & 27.2 \\
\hline 4442 & 1/13/2008 13:52 & \begin{tabular}{|l|}
$8 / 13 / 200813: 52$ \\
\end{tabular} & 3.549 & 26.9 \\
\hline 4443 & 1/13/2008 13:54 & \begin{tabular}{|l|}
$8 / 13 / 2008$ 13:54 \\
\end{tabular} & 3.551 & 26.9 \\
\hline
\end{tabular}

\begin{tabular}{|c|c|c|c|c|}
\hline \multicolumn{5}{|c|}{ D4-93p } \\
\hline $\operatorname{Rec}$ & & Adjusted & Pressure & Temp \\
\hline \# & Date/Time & Date/Time & psi & ${ }^{\circ} \mathrm{C}$ \\
\hline 4444 & $1 / 13 / 200813: 56$ & $8 / 13 / 200813: 56$ & 3.554 & 26.9 \\
\hline 4445 & $1 / 13 / 2008$ 13:58 & $8 / 13 / 2008$ 13:58 & 3.556 & 27.1 \\
\hline 4446 & $1 / 13 / 200814: 00$ & \begin{tabular}{|l|}
$8 / 13 / 2008$ \\
$14: 00$ \\
\end{tabular} & 3.556 & 26.9 \\
\hline 4447 & $1 / 13 / 2008$ 14:02 & \begin{tabular}{|l|}
$8 / 13 / 200814: 02$ \\
\end{tabular} & 3.558 & 26.8 \\
\hline 4448 & $1 / 13 / 2008$ 14:04 & \begin{tabular}{|l|}
$8 / 13 / 2008$ 14:04 \\
\end{tabular} & 3.558 & 26.8 \\
\hline 4449 & 1/13/2008 14:06 & 8/13/2008 14:06 & 3.559 & 26.7 \\
\hline 4450 & $1 / 13 / 2008$ 14:08 & \begin{tabular}{|l|}
$8 / 13 / 2008$ 14:08 \\
\end{tabular} & 3.559 & 27 \\
\hline 4451 & $1 / 13 / 2008$ 14:10 & 8/13/2008 14:10 & 3.56 & 26.8 \\
\hline 4452 & 1/13/2008 14:12 & $8 / 13 / 2008$ 14:12 & 3.559 & 26.7 \\
\hline 4453 & 1/13/2008 14:14 & \begin{tabular}{|l|}
$8 / 13 / 2008$ 14:14 \\
\end{tabular} & 3.558 & 26.6 \\
\hline 4454 & 1/13/2008 14:16 & $8 / 13 / 2008$ 14:16 & 3.558 & 26.5 \\
\hline 4455 & $1 / 13 / 2008$ 14:18 & $8 / 13 / 2008$ 14:18 & 3.557 & $\overline{26.4}$ \\
\hline 4456 & $1 / 13 / 200814: 20$ & $8 / 13 / 2008$ 14:20 & 3.515 & 26.4 \\
\hline 4457 & 1/13/2008 14:22 & $8 / 13 / 2008$ 14:22 & 3.212 & 26.4 \\
\hline 4458 & $1 / 13 / 2008$ 14:24 & \begin{tabular}{|l|}
$8 / 13 / 2008$ 14:24 \\
\end{tabular} & 2989 & 26.3 \\
\hline 4459 & 1/13/2008 14:26 & $8 / 13 / 2008$ 14:26 & 3.085 & 26.3 \\
\hline 4460 & $1 / 13 / 2008$ 14:28 & $8 / 13 / 2008$ 14:28 & 3.288 & 26.2 \\
\hline 4461 & $1 / 13 / 200814: 30$ & $8 / 13 / 2008$ 14:30 & 3.418 & 26.3 \\
\hline 4462 & $1 / 13 / 200814: 32$ & $8 / 13 / 2008$ 14:32 & 3.493 & 26.4 \\
\hline 4463 & $1 / 13 / 200814: 34$ & $8 / 13 / 2008$ 14:34 & 3.523 & 26.5 \\
\hline 4464 & $1 / 13 / 200814: 36$ & $8 / 13 / 200814: 36$ & 3.539 & 26.5 \\
\hline 4465 & $1 / 13 / 200814: 38$ & $8 / 13 / 200814: 38$ & 3.546 & 26.4 \\
\hline 4466 & $1 / 13 / 200814: 40$ & $8 / 13 / 2008$ 14:40 & 3.551 & 26.4 \\
\hline 4467 & $1 / 13 / 200814: 42$ & $8 / 13 / 200814: 42$ & 3.554 & 26.4 \\
\hline 4468 & $1 / 13 / 2008$ 14:44 & $8 / 13 / 2008$ 14:44 & 3.556 & 26.3 \\
\hline 4469 & $1 / 13 / 2008$ 14:46 & $8 / 13 / 2008$ 14:46 & 3.557 & 26.3 \\
\hline 4470 & $1 / 13 / 200814: 48$ & 8/13/2008 14:48 & 3.559 & 26.2 \\
\hline 4471 & $1 / 13 / 200814: 50$ & $8 / 13 / 200814: 50$ & 3.56 & 26.2 \\
\hline 4472 & $1 / 13 / 200814: 52$ & $8 / 13 / 200814: 52$ & 3.559 & 26.1 \\
\hline 4473 & $1 / 13 / 200814: 54$ & $8 / 13 / 2008$ 14:54 & 3.558 & 26.1 \\
\hline 4474 & $1 / 13 / 200814: 56$ & $8 / 13 / 2008$ 14:56 & 3.557 & 26.1 \\
\hline 4475 & $1 / 13 / 200814: 58$ & $8 / 13 / 200814: 58$ & 3.558 & 26 \\
\hline 4476 & $1 / 13 / 200815: 00$ & $8 / 13 / 200815: 00$ & 3.559 & 26.1 \\
\hline 4477 & $1 / 13 / 200815: 02$ & $8 / 13 / 200815: 02$ & 3.561 & 26.3 \\
\hline 4478 & $1 / 13 / 2008$ 15:04 & $8 / 13 / 200815: 04$ & 3.561 & 26.4 \\
\hline 4479 & $1 / 13 / 2008$ 15:06 & $8 / 13 / 200815: 06$ & 3.562 & 26.5 \\
\hline 4480 & 1/13/2008 15:08 & $8 / 13 / 200815: 08$ & 3.562 & 26.8 \\
\hline 4481 & $1 / 13 / 200815: 10$ & \begin{tabular}{|l|}
$8 / 13 / 200815: 10$ \\
\end{tabular} & 3.563 & 26.6 \\
\hline 4482 & 1/13/2008 15:12 & $8 / 13 / 200815: 12$ & 3.562 & 26.6 \\
\hline 4483 & $1 / 13 / 200815: 14$ & $8 / 13 / 2008$ 15:14 & 3.562 & 26.5 \\
\hline 4484 & 1/13/2008 15:16 & $8 / 13 / 2008$ 15:16 & 3.562 & 26.6 \\
\hline 4485 & 1/13/2008 15:18 & $8 / 13 / 200815: 18$ & 3.563 & 26.6 \\
\hline 4486 & $1 / 13 / 200815: 20$ & 8/13/2008 15:20 & 3.563 & 26.6 \\
\hline 4487 & $1 / 13 / 200815: 22$ & $8 / 13 / 200815: 22$ & 3.562 & 26.6 \\
\hline 4488 & $1 / 13 / 2008$ 15:24 & $8 / 13 / 200315: 24$ & 3.563 & 26.6 \\
\hline 4489 & $1 / 13 / 200815: 26$ & $8 / 13 / 2008$ 15:26 & 3.565 & 26.7 \\
\hline 4490 & $1 / 13 / 200815: 28$ & $8 / 13 / 200815: 28$ & 3.568 & 26.9 \\
\hline 4491 & $1 / 13 / 200815: 30$ & $8 / 13 / 2008$ 15:30 & 3.571 & 26.9 \\
\hline 4492 & $1 / 13 / 200815: 32$ & $8 / 13 / 200815: 32$ & 3.572 & 26.8 \\
\hline 4493 & $1 / 13 / 200815: 34$ & 8/13/2008 15:34 & 3.573 & 26.9 \\
\hline 4494 & $1 / 13 / 200815: 36$ & $8 / 13 / 200815: 36$ & 3.574 & 27 \\
\hline 4495 & 1/13/2008 15:38 & $8 / 13 / 200815: 38$ & 3.575 & 27.2 \\
\hline 4496 & $1 / 13 / 200815: 40$ & $8 / 13 / 2008$ 15:40 & 3.576 & 27.3 \\
\hline 4497 & $1 / 13 / 200815: 42$ & $8 / 13 / 2008$ 15:42 & 3.576 & 27.3 \\
\hline 4498 & $1 / 13 / 200815: 44$ & $8 / 13 / 200815: 44$ & 3.576 & 27.2 \\
\hline 4499 & $1 / 13 / 200815: 46$ & \begin{tabular}{|l|}
$8 / 13 / 200815: 46$ \\
\end{tabular} & 3.578 & 27.1 \\
\hline 4500 & $1 / 13 / 200815: 48$ & \begin{tabular}{|l|}
$8 / 13 / 200815: 48$ \\
\end{tabular} & 3.579 & 27.1 \\
\hline 4501 & $1 / 13 / 200815: 50$ & $8 / 13 / 200815: 50$ & 3.58 & 27 \\
\hline 4502 & $1 / 13 / 200815: 52$ & \begin{tabular}{|l|l|}
$8 / 13 / 200815: 52$ \\
\end{tabular} & 3.58 & 27 \\
\hline 4503 & $1 / 13 / 200815: 54$ & $8 / 13 / 2008$ 15:54 & 3.581 & 27 \\
\hline 4504 & $1 / 13 / 200815: 56$ & $8 / 13 / 200815: 56$ & 3.582 & 27 \\
\hline 4505 & $1 / 13 / 200815: 58$ & $8 / 13 / 200815: 58$ & 3.58 & 26.9 \\
\hline 4506 & $1 / 13 / 200816: 00$ & $8 / 13 / 200816: 00$ & 3.578 & 26.7 \\
\hline 4507 & $1 / 13 / 200816: 02$ & $8 / 13 / 200816: 02$ & 3.576 & 26.6 \\
\hline 4508 & $1 / 13 / 200816: 04$ & $8 / 13 / 2008$ 16:04 & 3.576 & 26.5 \\
\hline 4509 & $1 / 13 / 200816: 06$ & $8 / 13 / 200816: 06$ & 3.576 & 26.4 \\
\hline 4510 & $1 / 13 / 200816: 08$ & \begin{tabular}{|l|}
$8 / 13 / 2008$ \\
\end{tabular} & 3.577 & 26.4 \\
\hline 4511 & 1/13/2008 16:10 & $8 / 13 / 2008$ 16:10 & 3.578 & 26.4 \\
\hline 4512 & $1 / 13 / 200816: 12$ & $8 / 13 / 2008$ 16:12 & 3.578 & 26.4 \\
\hline
\end{tabular}




\begin{tabular}{|c|c|c|c|c|}
\hline \multicolumn{5}{|c|}{ D4-93p } \\
\hline $\operatorname{Rec}$ & & Adjusted & Pressure & Temp \\
\hline$\#$ & Date/Time & DaterTime & psi & ${ }^{\circ} \mathrm{C}$ \\
\hline 4513 & 1/13/2008 16:14 & \begin{tabular}{|l|}
$8 / 13 / 2008$ 16:14 \\
\end{tabular} & 3.577 & \\
\hline 4514 & 1/13/2008 16:16 & 8/13/2008 16:16 & 3.577 & 26.4 \\
\hline 4515 & 1/13/2008 16:18 & $8 / 13 / 2008$ 16:18 & 3.577 & 26.5 \\
\hline 4516 & 1/13/2008 16:20 & \begin{tabular}{|l|}
$8 / 13 / 200816: 20$ \\
\end{tabular} & 3.577 & 26.6 \\
\hline 4517 & $1 / 13 / 200816: 22$ & \begin{tabular}{|l|}
$8 / 13 / 200816: 22$ \\
\end{tabular} & 3.576 & 26.7 \\
\hline 4518 & $1 / 13 / 200816: 24$ & \begin{tabular}{|l|}
$8 / 13 / 200816: 24$ \\
\end{tabular} & 3.575 & 26.7 \\
\hline 4519 & $1 / 13 / 200816: 26$ & $8 / 13 / 2008$ 16:26 & 3.574 & 26.8 \\
\hline 4520 & $1 / 13 / 200816: 28$ & \begin{tabular}{|l|}
$8 / 13 / 200816: 28$ \\
\end{tabular} & 3.329 & 26.8 \\
\hline 4521 & $1 / 13 / 200816: 30$ & \begin{tabular}{|l|}
$8 / 13 / 200816: 30$ \\
\end{tabular} & 3.573 & 27.6 \\
\hline 4522 & $1 / 13 / 2008$ 16:32 & $8 / 13 / 2008$ 16:32 & 3.595 & 28.1 \\
\hline 4523 & 1/13/2008 16:34 & $8 / 13 / 200816: 34$ & 3.604 & 27.9 \\
\hline 4524 & $1 / 13 / 2008$ 16:36 & \begin{tabular}{|l|}
$8 / 13 / 2008$ 16:36 \\
\end{tabular} & 3.607 & 27.8 \\
\hline 4525 & $1 / 13 / 2008$ 16:38 & 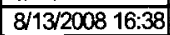 & 3.61 & 27.6 \\
\hline 4526 & $1 / 13 / 2008$ 16:40 & $8 / 13 / 200816: 40$ & 3.612 & 27.4 \\
\hline 4527 & $1 / 13 / 2008$ 16:42 & $8 / 13 / 200816: 42$ & 3.614 & 27.3 \\
\hline 4528 & 1/13/2008 16:44 & $8 / 13 / 2008$ 16:44 & 3.618 & 27.3 \\
\hline 4529 & $1 / 13 / 200$ & $8 / 13 / 200816: 46$ & 3.62 & 27.3 \\
\hline 4530 & $1 / 13 / 2008$ 16:48 & \begin{tabular}{|l|l|}
$8 / 13 / 2008$ & $16: 48$ \\
\end{tabular} & 3.622 & 27.1 \\
\hline 4531 & $1 / 13 / 200$ & \begin{tabular}{|l|}
$8 / 13 / 200816: 50$ \\
\end{tabular} & 3.623 & 27.1 \\
\hline 4532 & $1 / 13 / 200816: 52$ & $8 / 13 / 200816: 52$ & 3.623 & 27.1 \\
\hline 4533 & $1 / 13 / 200816: 54$ & $8 / 13 / 2008$ 16:54 & 3.623 & 27.1 \\
\hline 4534 & $1 / 13 / 20$ & \begin{tabular}{|l|}
$8 / 13 / 200816: 56$ \\
\end{tabular} & 3.623 & 27 \\
\hline 4535 & 1/13/2008 16:58 & \begin{tabular}{|l|l|}
$8 / 13 / 2008$ & $16: 58$ \\
\end{tabular} & 3.624 & 27 \\
\hline 4536 & $1 / 13 / 20$ & \begin{tabular}{|l|}
$8 / 13 / 2008 \quad 17: 00$ \\
\end{tabular} & 3.622 & 26.9 \\
\hline 4537 & $1 / 13 / 2008$ 17:02 & \begin{tabular}{|l|}
$8 / 13 / 2008 \quad 17: 02$ \\
\end{tabular} & 3.621 & 26.9 \\
\hline 4538 & $1 / 13 / 20$ & 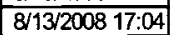 & 3.622 & 27.1 \\
\hline 4539 & $1 / 13 / 20$ & $8 / 13 / 200817: 06$ & 3.608 & 26.8 \\
\hline 4540 & $1 / 13 / 200817: 08$ & $8 / 13 / 200817: 08$ & 3.357 & 26.7 \\
\hline 4541 & $1 / 13 / 20$ & \begin{tabular}{|l|}
$8 / 13 / 2008$ 17:10 \\
\end{tabular} & 3.265 & 26.6 \\
\hline 4542 & $1 / 13 / 20$ & \begin{tabular}{|l|}
$8 / 13 / 2008$ 17:12 \\
\end{tabular} & 3.406 & 26.6 \\
\hline 4543 & $1 / 13 / 20$ & $8 / 13 / 2008$ 17:14 & 3.502 & 26.5 \\
\hline 4544 & $1 / 13 / 20$ & \begin{tabular}{|l|}
$8 / 13 / 2008$ 17:16 \\
\end{tabular} & 3.551 & 26.4 \\
\hline 4545 & 1/13/2008 17:18 & \begin{tabular}{|l|}
$8 / 13 / 2008$ 17:18 \\
\end{tabular} & 3.571 & 26.4 \\
\hline 4546 & 1/13/2008 17:20 & 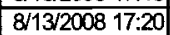 & 3.58 & 26.4 \\
\hline 4547 & $1 / 13 / 20$ & $8 / 13 / 2008 \quad 17: 22$ & 3.586 & 26.4 \\
\hline 4548 & $1 / 13 / 20$ & $8 / 13 / 2008$ 17:24 & 3.589 & 26.6 \\
\hline 4549 & $1 / 13 / 20$ & $8 / 13 / 2008$ 17:26 & 3.591 & 26.7 \\
\hline 4550 & $1 / 13 / 20$ & $8 / 13 / 2008$ 17:28 & 3.592 & 26.7 \\
\hline 4551 & $1 / 13 / 20$ & \begin{tabular}{|l|}
$8 / 13 / 200817: 30$ \\
\end{tabular} & 3.593 & 26.6 \\
\hline 4552 & $1 / 13 / 2008 \quad 17: 32$ & $8 / 13 / 2008$ 17:32 & 3.592 & 26.5 \\
\hline 4553 & $1 / 13 / 20$ & $8 / 13 / 20$ & 3.592 & 26.4 \\
\hline 4554 & $1 / 13 / 2$ & \begin{tabular}{|l|}
$8 / 13 / 2008 \quad 17: 36$ \\
\end{tabular} & 3.593 & 26.3 \\
\hline 4555 & $1 / 13 / 20$ & $0817: 38$ & 3.594 & 26.3 \\
\hline 4556 & $1 / 13 / 20$ & $8 / 13 / 20$ & 3.595 & 26.4 \\
\hline 4557 & $1 / 13 / 20$ & $8 / 13 / 2008$ 17:42 & 3.597 & 26.8 \\
\hline 4558 & $1 / 13 / 2$ & \begin{tabular}{|l|}
$8 / 13 / 2008 \quad 17: 44$ \\
\end{tabular} & 3.597 & 27.1 \\
\hline 4559 & $1 / 13 / 20$ & $8 / 13 / 20$ & 3.597 & 27.2 \\
\hline 4560 & $1 / 13 / 200$ & $8 / 13 / 2008$ 17:48 & 3.595 & 27.3 \\
\hline 4561 & & $8 / 13 / 200$ & 3.593 & 27.3 \\
\hline 4562 & $1 / 13 / 20$ & $8 / 13 / 2008$ 17:52 & 3.593 & 27.3 \\
\hline 4563 & $1 / 13 / 20$ & \begin{tabular}{|l|}
$8 / 13 / 2008$ \\
$17: 54$
\end{tabular} & 3.592 & 27.3 \\
\hline 4564 & $1 / 13 / 20$ & $8 / 13 / 2008$ 17:56 & 3.591 & 27.3 \\
\hline 4565 & $1 / 13 / 20$ & $8 / 13 / 200817: 58$ & 3.591 & 27.3 \\
\hline 4566 & $1 / 13 / 20$ & $8 / 13 / 2008$ 18:00 & 3.591 & 27.3 \\
\hline 4567 & $1 / 13 / 20$ & \begin{tabular}{|l|}
$8 / 13 / 200818: 02$ \\
\end{tabular} & 3.592 & 27.4 \\
\hline 4568 & & & & 27.4 \\
\hline 4569 & $1 / 13 / 2008$ 18:06 & \begin{tabular}{|l|}
$8 / 13 / 200818: 06$ \\
\end{tabular} & 3.592 & 27.7 \\
\hline 4570 & 1/13/2008 18:08 & $8 / 13 / 2008$ 18:08 & 3.592 & 27.6 \\
\hline 4571 & 1/13/2008 18:10 & \begin{tabular}{|l|}
$8 / 13 / 200818: 10$ \\
\end{tabular} & 3.593 & 27.5 \\
\hline 4572 & 1/13/2008 18:12 & 8/13/2008 18:12 & 3.594 & 27.5 \\
\hline 4573 & & \begin{tabular}{|l|}
$8 / 13 / 2008$ 18:14 \\
\end{tabular} & 3.594 & 27.5 \\
\hline 4574 & 1/13/2008 18:16 & $8 / 13 / 200818: 16$ & 3.593 & 27.6 \\
\hline 4575 & $1 / 13 / 200818: 18$ & $8 / 13 / 200818: 18$ & 3.593 & 27.5 \\
\hline 4576 & $1 / 13 / 2008$ 18:20 & $8 / 13 / 200818: 20$ & 3.593 & 27.5 \\
\hline 4577 & $1 / 13 / 200818: 22$ & \begin{tabular}{|l|}
$8 / 13 / 200818: 22$ \\
\end{tabular} & 3.595 & 27.5 \\
\hline 4578 & 1/13/2008 18:24 & $8 / 13 / 2008$ 18:24 & 3.595 & 27.5 \\
\hline 4579 & $1 / 13 / 200818: 26$ & $8 / 13 / 2008$ 18:26 & 3.597 & 27.4 \\
\hline 4580 & $1 / 13 / 200818: 28$ & $8 / 13 / 2008$ 18:28 & 3.597 & 27.4 \\
\hline 4581 & $1 / 13 / 200818: 30$ & $8 / 13 / 200818: 30$ & 3.596 & 27.4 \\
\hline
\end{tabular}

\begin{tabular}{|c|c|c|c|c|}
\hline \multicolumn{5}{|c|}{ D4-93p } \\
\hline $\operatorname{Rec}$ & & Adjusted & Pressure & Temp \\
\hline$\#$ & Date/Time & DaterTime & psi & \begin{tabular}{|l|}
${ }^{\circ} \mathrm{C}$ \\
\end{tabular} \\
\hline 4582 & 1/13/2008 18:32 & \begin{tabular}{|l|}
$8 / 13 / 200818: 32$ \\
\end{tabular} & 3.596 & 27.3 \\
\hline 4583 & $1 / 13 / 200818: 34$ & 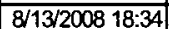 & 3.597 & 27.3 \\
\hline 4584 & $1 / 13 / 200818: 36$ & \begin{tabular}{|l|}
$8 / 13 / 200818: 36$ \\
\end{tabular} & 3.599 & 27.3 \\
\hline 4585 & $1 / 13 / 200818: 38$ & $8 / 13 / 200818: 38$ & 3.6 & 27.3 \\
\hline 4586 & $1 / 13 / 200818: 40$ & $8 / 13 / 200818: 40$ & 3.601 & 27.3 \\
\hline 4587 & $1 / 13 / 200818: 42$ & \begin{tabular}{|l|}
$8 / 13 / 200818: 42$ \\
\end{tabular} & 3.601 & 27.3 \\
\hline 4588 & 1/13/2008 18:44 & \begin{tabular}{|l|}
$8 / 13 / 200818: 44$ \\
\end{tabular} & 3.602 & 27.3 \\
\hline 4589 & 1/13/2008 18:46 & $8 / 13 / 200818: 46$ & 3.602 & 27.3 \\
\hline 4590 & $1 / 13 / 200818: 48$ & $8 / 13 / 200818: 48$ & 3.602 & 27.3 \\
\hline 4591 & 1/13/2008 18:50 & $8 / 13 / 200818: 50$ & 3.601 & 27.3 \\
\hline 4592 & 1/13/2008 18:52 & $8 / 13 / 200818: 52$ & 3.601 & 27.3 \\
\hline 4593 & $1 / 13 / 200818: 54$ & $8 / 13 / 200818: 54$ & 3.601 & 27.4 \\
\hline 4594 & $1 / 13 / 200818: 56$ & $8 / 13 / 200818: 56$ & 3.602 & 27.4 \\
\hline 4595 & 1/13/2008 18:58 & \begin{tabular}{|l|}
$8 / 13 / 2008$ \\
\end{tabular} & 3.604 & 27.4 \\
\hline 4596 & 1/13/2008 19:00 & \begin{tabular}{|l|}
$8 / 13 / 200819: 00$ \\
\end{tabular} & 3.605 & 27.4 \\
\hline 4597 & 1/13/2008 19:02 & \begin{tabular}{|l|}
$8 / 13 / 2008$ \\
$19: 02$
\end{tabular} & 3.605 & 27.4 \\
\hline 4598 & 1/13/2008 19:04 & \begin{tabular}{|l|}
$8 / 13 / 200819: 04$ \\
\end{tabular} & 3.604 & 27.4 \\
\hline 4599 & 1/13/2008 19:06 & \begin{tabular}{|l|}
$8 / 13 / 2008$ 19:06 \\
\end{tabular} & 3.605 & 27.6 \\
\hline 4600 & $1 / 13 / 200819: 08$ & $8 / 13 / 200819: 08$ & 3.606 & 27.6 \\
\hline 4601 & 1/13/2008 19:10 & $8 / 13 / 200819: 10$ & 3.608 & 27.6 \\
\hline 4602 & 1/13/2008 19:12 & \begin{tabular}{|l|}
$8 / 13 / 200819: 12$ \\
\end{tabular} & 3.611 & 27.8 \\
\hline 4603 & $1 / 13 / 200$ & \begin{tabular}{|l|}
$8 / 13 / 200819: 14$ \\
\end{tabular} & 3.615 & 28.1 \\
\hline 4604 & 1/13/2008 19:16 & $8 / 13 / 200819: 16$ & 3.616 & 28 \\
\hline 4605 & 1/13/2008 19:18 & $8 / 13 / 2008$ 19:18 & 3.617 & 28.1 \\
\hline 4606 & $1 / 13 / 20$ & $8 / 13 / 200819: 20$ & 3.617 & 28.1 \\
\hline 4607 & $1 / 13 / 200819: 22$ & $8 / 13 / 200819: 22$ & 3.618 & 27.9 \\
\hline 4608 & $1 / 13 / 20$ & $8 / 13 / 200819: 24$ & 3.619 & 27.9 \\
\hline 4609 & 1/13/2008 19:26 & $8 / 13 / 200819: 26$ & 3.619 & 27.7 \\
\hline 4610 & 1/13/2008 19:28 & \begin{tabular}{|l|}
$8 / 13 / 200819: 28$ \\
\end{tabular} & 3.62 & 27.4 \\
\hline 4611 & $1 / 13 / 20$ & \begin{tabular}{|l|}
$8 / 13 / 200819: 30$ \\
\end{tabular} & 3.62 & 27.3 \\
\hline 4612 & 1/13/2008 19:32 & $8 / 13 / 2008$ 19:32 & 3.621 & 27.4 \\
\hline 4613 & $1 / 13 / 200819: 34$ & \begin{tabular}{|l|}
$8 / 13 / 200819: 34$ \\
\end{tabular} & 3.623 & 27.4 \\
\hline 4614 & 1/13/2008 19:36 & $8 / 13 / 2008$ 19:36 & 3.625 & 27.4 \\
\hline 4615 & 1/13/2008 19:38 & $8 / 13 / 2008$ 19:38 & 3.625 & 27.4 \\
\hline 4616 & $1 / 13 / 2008$ 19:40 & $8 / 13 / 200819: 40$ & 3.627 & 27.4 \\
\hline $46+7$ & $1 / 13 / 20$ & $8 / 13 / 2008$ 19:42 & 3.627 & 27.3 \\
\hline 4618 & 1/13/2008 19:44 & \begin{tabular}{|l|}
$8 / 13 / 2008$ 19:44 \\
\end{tabular} & 3.627 & 27.3 \\
\hline 4619 & 1/13/2008 19:46 & $8 / 13 / 200819: 46$ & 3.628 & 27.8 \\
\hline 4620 & $1 / 13 / 2008$ 19:48 & \begin{tabular}{|l|}
$8 / 13 / 200819: 48$ \\
\end{tabular} & 3.631 & 27.4 \\
\hline 4621 & $1 / 13 / 200819: 50$ & \begin{tabular}{|l|}
$8 / 13 / 200819: 50$ \\
\end{tabular} & 3.635 & 27.4 \\
\hline 4622 & $1 / 13 / 2$ & $8 / 13 / 2008$ 19:52 & 3.193 & 27.4 \\
\hline 4623 & 1/13/2008 19:54 & $8 / 13 / 2008$ 19:54 & 3.522 & 27.5 \\
\hline 4624 & $1 / 13 / 200819: 56$ & $8 / 13 / 200819: 56$ & 3.528 & 27.5 \\
\hline 4625 & $1 / 13 / 200$ & $8 / 13 / 200819: 58$ & 3.467 & 27.6 \\
\hline 4626 & $1 / 13 / 200820: 00$ & $8 / 13 / 200820: 00$ & 3.371 & 27.6 \\
\hline 4627 & $1 / 13 / 2$ & $8 / 13 / 200820: 02$ & 3.259 & 27.6 \\
\hline 4628 & $1 / 13 / 2$ & $8 / 13 / 200820: 04$ & 3.162 & 27.6 \\
\hline 4629 & $1 / 13 / 200$ & $8 / 13 / 200820: 06$ & 3.078 & 27.5 \\
\hline 4630 & $1 / 13 / 200$ & $8 / 13 / 200820: 08$ & 3.013 & 27.4 \\
\hline 4631 & 1/13/2008 20:10 & $8 / 13 / 200820: 10$ & 3.109 & 27.4 \\
\hline 4632 & $1 / 13$ & $8 / 13 / 200820: 12$ & 3.268 & 27.6 \\
\hline 4633 & $1 / 13 / 2$ & $8 / 13 / 200820: 14$ & 3.402 & 27.4 \\
\hline 4634 & 1/13/2008 20:16 & $8 / 13 / 200820: 16$ & 3.487 & 27.4 \\
\hline 4635 & 1/13/2008 20:18 & $8 / 13 / 200820: 18$ & 3.547 & 27.4 \\
\hline 4636 & 1/13/2008 20:20 & \begin{tabular}{|l|}
$8 / 13 / 200820: 20$ \\
\end{tabular} & 3.59 & 27.3 \\
\hline 4637 & 1/13/2008 20:22 & \begin{tabular}{|l|}
$8 / 13 / 200820: 22$ \\
\end{tabular} & 3.609 & 27.3 \\
\hline 4638 & $1 / 13 / 20$ & \begin{tabular}{|l|}
$8 / 13 / 200820: 24$ \\
\end{tabular} & 3.619 & 27.3 \\
\hline 4639 & $1 / 13 / 200820: 26$ & $8 / 13 / 200820: 26$ & 3.626 & 27.2 \\
\hline 4640 & & $8 / 13 / 200820: 28$ & 3.63 & 27.1 \\
\hline 4641 & 1/13/2008 20:30 & \begin{tabular}{|l|}
$8 / 13 / 200820: 30$ \\
\end{tabular} & 3.632 & 27.1 \\
\hline 4642 & 1/13/2008 20:32 & \begin{tabular}{|l|}
$8 / 13 / 200820: 32$ \\
\end{tabular} & 3.632 & 27.1 \\
\hline 4643 & 1/13/2008 20:34 & 8/13/2008 20:34 & 3.632 & 27 \\
\hline 4644 & 1/13/2008 20:36 & \begin{tabular}{|l|}
$8 / 13 / 200820: 36$ \\
\end{tabular} & 3.629 & 27.3 \\
\hline 4645 & $1 / 13 / 200820: 38$ & $8 / 13 / 200820: 38$ & 3.628 & 27 \\
\hline 4646 & $1 / 13 / 200820: 40$ & \begin{tabular}{|l|}
$8 / 13 / 200820: 40$ \\
\end{tabular} & 3.626 & 26.9 \\
\hline 4647 & 1/13/2008 20:42 & \begin{tabular}{|l|}
$8 / 13 / 200820: 42$ \\
\end{tabular} & 3.627 & 27.1 \\
\hline 4648 & 1/13/2008 20:44 & \begin{tabular}{|l|}
$8 / 13 / 200820: 44$ \\
\end{tabular} & 3.627 & 26.9 \\
\hline 4649 & $1 / 13 / 200820 ; 46$ & \begin{tabular}{|l|}
$8 / 13 / 200820: 46$ \\
\end{tabular} & 3.631 & 26.8 \\
\hline 4650 & 1/13/2008 20:48 & \begin{tabular}{|l|}
$8 / 13 / 200820: 48$ \\
\end{tabular} & 3.635 & 26.7 \\
\hline
\end{tabular}

\begin{tabular}{|c|c|c|c|c|}
\hline \multicolumn{5}{|c|}{ D4-93p } \\
\hline $\operatorname{Rec}$ & & Adjusted & Pressure & Temp \\
\hline$\#$ & Date/Time & Dater/Time & psi & ${ }^{\circ} \mathrm{C}$ \\
\hline 4651 & $1 / 13 / 200820=50$ & $8 / 13 / 200820: 50$ & 3.638 & 26.7 \\
\hline 4652 & $1 / 13 / 200820: 52$ & $8 / 13 / 200820: 52$ & 3.638 & 26.7 \\
\hline 4653 & $1 / 13 / 200820: 54$ & $8 / 13 / 200820: 54$ & 3.64 & 26.7 \\
\hline 4654 & $1 / 13 / 200820: 56$ & $8 / 13 / 200820: 56$ & 3.64 & 26.9 \\
\hline 4655 & $1 / 13 / 200820: 58$ & $8 / 13 / 200820: 58$ & 3.64 & 27.5 \\
\hline 4656 & 1/13/2008 21:00 & $8 / 13 / 200821: 00$ & 3.64 & 27.6 \\
\hline 4657 & $1 / 13 / 200821: 02$ & $8 / 13 / 200821: 02$ & 3.639 & 27.6 \\
\hline 4658 & 1/13/200821:04 & $8 / 13 / 200821: 04$ & 3.639 & 27.6 \\
\hline 4659 & 1/13/200821:06 & $8 / 13 / 200821: 06$ & 3.639 & 27.6 \\
\hline 4660 & $1 / 13 / 200821: 08$ & $8 / 13 / 200821: 08$ & 3.639 & 27.6 \\
\hline 4661 & 1/13/200821:10 & $8 / 13 / 200821: 10$ & 3.64 & 27.6 \\
\hline 4662 & $1 / 13 / 200821: 12$ & $8 / 13 / 200821: 12$ & 3.64 & 27.6 \\
\hline 4663 & 1/13/200821:14 & $8 / 13 / 200821: 14$ & 3.639 & 27.6 \\
\hline 4664 & 1/13/2008 21:16 & $8 / 13 / 200821: 16$ & 3.637 & 27.8 \\
\hline 4665 & 1/13/2008 21:18 & $8 / 13 / 200821: 18$ & 3.64 & 27.8 \\
\hline 4666 & $1 / 13 / 200821: 20$ & $8 / 13 / 200821: 20$ & 3.641 & 27.6 \\
\hline 4667 & 1/13/2008 21:22 & $8 / 13 / 200821: 22$ & 3.64 & 27.6 \\
\hline 4668 & $1 / 13 / 200821: 24$ & $8 / 13 / 200821: 24$ & 3.637 & 27.6 \\
\hline 4669 & 1/13/200821:26 & $8 / 13 / 200821: 26$ & 3.636 & 27.6 \\
\hline 4670 & $1 / 13 / 200821: 28$ & $8 / 13 / 200821: 28$ & 3.637 & 27.8 \\
\hline 4671 & $1 / 13 / 200821: 30$ & $8 / 13 / 200821: 30$ & 3.637 & 28.4 \\
\hline 4672 & 1/13/200821:32 & $8 / 13 / 200821: 32$ & 3.64 & 28.1 \\
\hline 4673 & $1 / 13 / 200821: 34$ & $8 / 13 / 200821: 34$ & 3.644 & 28.1 \\
\hline 4674 & 1/13/200821:36 & $8 / 13 / 200821: 36$ & 3.646 & 27.9 \\
\hline 4675 & 1/13/200821:38 & $8 / 13 / 200821: 38$ & 3.648 & 27.9 \\
\hline 4676 & $1 / 13 / 200821: 40$ & $8 / 13 / 200821: 40$ & 3.649 & 28 \\
\hline 4677 & $1 / 13 / 200821: 42$ & $8 / 13 / 200821: 42$ & 3.647 & 28 \\
\hline 4678 & $1 / 13 / 200821: 44$ & $8 / 13 / 200821: 44$ & 3.648 & 27.9 \\
\hline 4679 & 1/13/200821:46 & $8 / 13 / 200821: 46$ & 3.65 & 27.9 \\
\hline 4680 & $1 / 13 / 200821: 48$ & $8 / 13 / 200821: 48$ & 3.651 & 27.9 \\
\hline 4681 & $1 / 13 / 200821: 50$ & $8 / 13 / 200821: 50$ & 3.652 & 27.9 \\
\hline 4682 & $1 / 13 / 200821: 52$ & $8 / 13 / 200821: 52$ & 3.654 & 27.8 \\
\hline 4683 & $1 / 13 / 200821: 54$ & $8 / 13 / 200821: 54$ & 3.657 & 27.9 \\
\hline 4684 & 1/13/2008 21:56 & $8 / 13 / 200821: 56$ & 3.659 & 27.9 \\
\hline 4685 & 1/13/2008 21:58 & $8 / 13 / 200821: 58$ & 3.66 & 27.9 \\
\hline 4686 & $1 / 13 / 200822: 00$ & $8 / 13 / 200822: 00$ & 3.662 & 27.9 \\
\hline 4687 & $1 / 13 / 200822: 02$ & $8 / 13 / 200822: 02$ & 3.64 & 27.8 \\
\hline 4688 & $1 / 13 / 200822: 04$ & $8 / 13 / 200822: 04$ & 3.483 & 27.8 \\
\hline 4689 & $1 / 13 / 200822: 06$ & 8/13/2008 22:06 & 3.211 & 27.8 \\
\hline 4690 & 1/13/2008 22:08 & $8 / 13 / 200822: 08$ & 3.014 & 27.6 \\
\hline 4691 & 1/13/2008 22:10 & $8 / 13 / 200822: 10$ & 2.884 & 27.6 \\
\hline 4692 & 1/13/2008 22:12 & $8 / 13 / 200822: 12$ & 2.795 & 27.5 \\
\hline 4693 & $1 / 13 / 20$ & $8 / 13 / 200822: 14$ & 2.737 & 27.5 \\
\hline 4694 & 1/13/2008 22:16 & $8 / 13 / 200822: 16$ & 2.694 & 27.4 \\
\hline 4695 & 1/13/2008 22:18 & $8 / 13 / 200822: 18$ & 2.662 & 27.4 \\
\hline 4696 & 1/13/2008 22:20 & $8 / 13 / 200822: 20$ & 2.634 & 27.3 \\
\hline 4697 & $1 / 13 / 200822: 22$ & $8 / 13 / 200822: 22$ & 2.611 & 27.3 \\
\hline 4698 & $1 / 13 / 200822: 24$ & $8 / 13 / 200822: 24$ & 2.586 & 27.2 \\
\hline 4699 & $1 / 13 / 200822: 26$ & $8 / 13 / 200822: 26$ & 2.565 & 27.3 \\
\hline 4700 & 1/13/2008 22:28 & $8 / 13 / 200822: 28$ & 2.545 & 27.7 \\
\hline 4701 & 1/13/200822:30 & $8 / 13 / 200822: 30$ & 2.53 & 27.9 \\
\hline 4702 & $1 / 13 / 200822: 32$ & $8 / 13 / 200822: 32$ & 2.517 & 27.8 \\
\hline 4703 & $1 / 13 / 200822: 34$ & $8 / 13 / 200822: 34$ & 2.239 & 28 \\
\hline 4704 & 1/13/2008 22:36 & $8 / 13 / 200822: 36$ & 2.262 & 28.1 \\
\hline 4705 & 1/13/2008 22:38 & $8 / 13 / 200822: 38$ & 2.295 & 28 \\
\hline 4706 & $1 / 13 / 200822: 40$ & $8 / 13 / 200822: 40$ & 2.319 & 28 \\
\hline 4707 & $1 / 13 / 200822: 42$ & $8 / 13 / 200822: 42$ & 2.337 & 27.9 \\
\hline 4708 & $1 / 13 / 200822: 44$ & $8 / 13 / 200822: 44$ & 2.352 & 27.9 \\
\hline 4709 & $1 / 13 / 200822: 46$ & $8 / 13 / 200822: 46$ & 2.365 & 28.3 \\
\hline 4710 & 1/13/2008 22:48 & $8 / 13 / 200822: 48$ & 2.375 & 27.9 \\
\hline 4711 & 1/13/2008 22:50 & $8 / 13 / 200822: 50$ & 2.385 & 27.8 \\
\hline 4712 & 1/13/2008 22:52 & $8 / 13 / 200822: 52$ & 2.394 & 27.6 \\
\hline 4713 & 1/13/2008 22:54 & $8 / 13 / 200822: 54$ & 2.403 & 27.6 \\
\hline 4714 & $1 / 13 / 200822: 56$ & $8 / 13 / 200822: 56$ & 2.41 & 27.5 \\
\hline 4715 & $1 / 13 / 200822: 58$ & $8 / 13 / 200822: 58$ & 2.417 & 27.4 \\
\hline 4716 & 1/13/2008 23:00 & $8 / 13 / 200823: 00$ & 2.422 & 27.4 \\
\hline 4717 & 1/13/2008 23:02 & $8 / 13 / 200823: 02$ & 2.427 & 27.4 \\
\hline 4718 & $1 / 13 / 200823: 04$ & $8 / 13 / 200823: 04$ & 2.431 & 27.3 \\
\hline 4719 & 1/13/2008 23:06 & $8 / 13 / 200823: 06$ & 2.433 & 27.3 \\
\hline
\end{tabular}




\begin{tabular}{|c|c|c|c|c|}
\hline \multicolumn{5}{|c|}{ D4-93p } \\
\hline $\operatorname{Rec}$ & & Adjusted & \begin{tabular}{l|} 
Pressure \\
\end{tabular} & Temp \\
\hline$\#$ & Date/Time & Date/Time & psi & ${ }^{\circ} \mathrm{C}$ \\
\hline 4720 & 1/13/2008 23:08 & $8 / 13 / 200823: 08$ & 2.436 & 27.2 \\
\hline 4721 & 1/13/2008 23:10 & $8 / 13 / 200823: 10$ & 2.437 & 27.2 \\
\hline 4722 & 1/13/2008 23:12 & $8 / 13 / 200823: 12$ & 2.437 & 27.1 \\
\hline 4723 & 1/13/2008 23:14 & 8/13/2008 23:14 & 2.436 & 27.1 \\
\hline 4724 & 1/13/2008 23:16 & $8 / 13 / 200823: 16$ & 2.436 & 27 \\
\hline 4725 & 1/13/2008 23:18 & $8 / 13 / 200823: 18$ & 2.434 & 27 \\
\hline 4726 & 1/13/2008 23:20 & $8 / 13 / 200823: 20$ & 2.434 & 26.9 \\
\hline 4727 & $1 / 13 / 200823: 22$ & $8 / 13 / 200823: 22$ & 2.432 & 26.9 \\
\hline 4728 & 1/13/2008 23:24 & $8 / 13 / 200823: 24$ & 2.43 & 27 \\
\hline 4729 & $1 / 13 / 200823: 26$ & 8/13/2008 23:26 & 2.427 & 27 \\
\hline 4730 & $1 / 13 / 200823: 28$ & $8 / 13 / 200823: 28$ & 2.425 & 27 \\
\hline 4731 & $1 / 13 / 200823: 30$ & $8 / 13 / 200823: 30$ & 2.422 & 27 \\
\hline 4732 & 1/13/2008 23:32 & $8 / 13 / 2008$ 23:32 & 2.42 & 27 \\
\hline 4733 & $1 / 13 / 200823: 34$ & $8 / 13 / 200823: 34$ & 2.417 & 27 \\
\hline 4734 & $1 / 13 / 20$ & $8 / 13 / 200823: 36$ & 2.413 & 26.9 \\
\hline 4735 & $1 / 13 / 20$ & $8 / 13 / 200823: 38$ & 2.412 & 27 \\
\hline 4736 & 1/13/2008 23:40 & $8 / 13 / 200823: 40$ & 2.408 & 27 \\
\hline 4737 & $1 / 13 / 20$ & $8 / 13 / 200823: 42$ & 2.408 & 27.1 \\
\hline 4738 & $1 / 13 / 20$ & $8 / 13 / 200823: 44$ & 2.405 & 27 \\
\hline 4739 & $1 / 13 / 20$ & $8 / 13 / 200823: 46$ & 2.403 & 27 \\
\hline 4740 & $1 / 13 / 20$ & $8 / 13 / 200823: 48$ & 2.4 & 27 \\
\hline 4741 & $1 / 13 / 20$ & $8 / 13 / 200823: 50$ & 2.398 & 27 \\
\hline 4742 & $1 / 13 / 20$ & $8 / 13 / 200823: 52$ & 2.395 & 26.9 \\
\hline 4743 & $1 / 13 / 20$ & $8 / 13 / 200823: 54$ & 2.393 & 26.9 \\
\hline 4744 & $1 / 13 / 2$ & $8 / 13 / 200823: 56$ & 2.39 & 27 \\
\hline 4745 & $1 / 13 / 20$ & $8 / 13 / 200823: 58$ & 2.388 & 26 . \\
\hline 4746 & $1 / 14 / 20080: 00$ & $8 / 14 / 20080: 00$ & 2.386 & 26.9 \\
\hline 4747 & $0: 02$ & $8 / 14 / 20$ & 2.383 & 26.9 \\
\hline 4748 & $1 / 14 / 20080: 04$ & $8 / 14 / 20080: 04$ & 2.38 & 26. \\
\hline 4749 & $1 / 14 / 20080: 06$ & $8 / 14 / 20080: 06$ & 2.378 & 26. \\
\hline 4750 & $0: 08$ & $8 / 14 / 20$ & 2.376 & 26 . \\
\hline 4751 & & $8 / 14 / 20080: 10$ & 2.373 & 26. \\
\hline 4752 & $88: 12$ & $8 / 14 / 20080: 12$ & 2.369 & 26. \\
\hline 4753 & & $8 / 14 / 20$ & 2.366 & 26. \\
\hline 4754 & & $8 / 14 / 20$ & 2.364 & 26 . \\
\hline 4755 & $0: 18$ & $8 / 14 / 20080: 18$ & 2.358 & 26.8 \\
\hline 4756 & $0: 20$ & $8 / 14 / 20080: 20$ & 2.351 & 26. \\
\hline 4757 & & $30: 22$ & 2.346 & 26. \\
\hline 4758 & $1 / 14$ & $8 / 14 / 20080: 24$ & 2.342 & 26. \\
\hline 4759 & $0: 26$ & $8 / 14 / 20080: 26$ & 2.34 & 26. \\
\hline 4760 & & $30: 28$ & 2.336 & 26. \\
\hline 4761 & & $8 / 14 / 2$ & 2.332 & 26. \\
\hline 4762 & & 30:32 & 2.328 & 26. \\
\hline 4763 & & $0: 34$ & 2.324 & 26. \\
\hline 4764 & & $8 / 14 / 20$ & 2.32 & 26. \\
\hline 4765 & & $8 / 14 / 20$ & 2.317 & 26. \\
\hline 4766 & & & 2.313 & 26. \\
\hline 4767 & & $0: 42$ & 2.311 & 26. \\
\hline 4768 & & $8 / 14 / 20$ & 2.309 & 26. \\
\hline 4769 & & $30: 46$ & 2.309 & 26. \\
\hline 4770 & & $0: 48$ & 2.307 & \\
\hline 4771 & $0: 50$ & $8 / 14 / 20$ & 2.306 & 26. \\
\hline 4772 & & & 2.303 & 26. \\
\hline 4773 & & $0: 54$ & 2.3 & \\
\hline 4774 & $0: 56$ & $8 / 14 / 20080: 56$ & 2.295 & 26. \\
\hline 4775 & & & 2.293 & 26. \\
\hline 4776 & & $81: 00$ & 2.291 & \\
\hline 4777 & $31: 02$ & $8 / 14 / 20081: 02$ & 2.288 & 26. \\
\hline 4778 & & & 2.285 & 26.7 \\
\hline 4779 & & $8 / 14 / 20081: 06$ & 2.284 & \\
\hline 4780 & $1: 08$ & $8 / 14 / 20081: 08$ & 2.282 & 26 \\
\hline 4781 & $1 / 14 / 2$ & $8 / 14 / 20081: 10$ & 2.281 & 26.7 \\
\hline 4782 & & & 2.279 & \\
\hline 4783 & & $8 / 14 / 20081: 14$ & 2.278 & 26. \\
\hline 4784 & $1: 16$ & $8 / 14 / 20081: 16$ & 2.277 & 26. \\
\hline 4785 & & $8 / 14 / 20081: 18$ & 2.275 & 26 . \\
\hline 4786 & & $881: 20$ & 2.274 & \\
\hline 4787 & $1 / 14 / 20081: 22$ & $8 / 14 / 20081: 22$ & 2.27 & 26.6 \\
\hline 4788 & $1 / 14 / 20081: 24$ & $8 / 14 / 20081: 24$ & 2.267 & \\
\hline
\end{tabular}

\begin{tabular}{|c|c|c|c|c|}
\hline \multicolumn{5}{|c|}{ D4-93p } \\
\hline $\operatorname{Rec}$ & & Adjusted & \begin{tabular}{l|} 
Pressure \\
\end{tabular} & Temp \\
\hline$\#$ & Date-Time & Date/Time & psi & ${ }^{\circ} \mathrm{C}$ \\
\hline 4789 & 1/14/2008 1:26 & $8 / 14 / 20081: 26$ & 2.265 & 26.7 \\
\hline 4790 & $1 / 14 / 20081: 28$ & $8 / 14 / 20081: 28$ & 2.262 & 26.6 \\
\hline 4791 & 1/14/2008 1:30 & $8 / 14 / 20081: 30$ & 2.259 & 26.6 \\
\hline 4792 & $1 / 14 / 20081: 32$ & $8 / 14 / 20081: 32$ & 2.256 & 26.6 \\
\hline 4793 & $1 / 14 / 20081: 34$ & $8 / 14 / 20081: 34$ & 2.255 & 26.6 \\
\hline 4794 & 1/14/2008 1:36 & $8 / 14 / 20081: 36$ & 2.252 & 26.6 \\
\hline 4795 & $1 / 14 / 20081: 38$ & $8 / 14 / 20081: 38$ & 2.249 & 26.6 \\
\hline 4796 & $1 / 14 / 20081: 40$ & $8 / 14 / 20081: 40$ & 2.245 & 26.6 \\
\hline \begin{tabular}{|l|}
4797 \\
\end{tabular} & 1/14/2008 1:42 & 8/14/2008 1:42 & 2.242 & 26.6 \\
\hline 4798 & $1 / 14 / 20081: 44$ & $8 / 14 / 20081: 44$ & 2.233 & 26.6 \\
\hline 4799 & 1/14/2008 1:46 & $8 / 14 / 20081: 46$ & 2.23 & 26.6 \\
\hline 4800 & 1/14/2008 1:48 & $8 / 14 / 20081: 48$ & 2.227 & 26.6 \\
\hline 4801 & 1/14/2008 1:50 & $8 / 14 / 2008$ 1:50 & 2.224 & 26.6 \\
\hline 4802 & $1 / 14 / 20081: 52$ & $8 / 14 / 2008$ 1:52 & 2.22 & 26.6 \\
\hline 4803 & $1 / 14 / 20081: 54$ & $8 / 14 / 20081: 54$ & 2.218 & 26.6 \\
\hline 4804 & $1 / 14 / 2008$ 1:56 & $8 / 14 / 20081: 56$ & 2.216 & 26.6 \\
\hline 4805 & $1 / 14 / 20081: 58$ & $8 / 14 / 20081: 58$ & 2.214 & 26.6 \\
\hline 4806 & 1/14/2008 2:00 & $8 / 14 / 20082: 00$ & 2.21 & 26.6 \\
\hline 4807 & 1/14/2008 2:02 & $8 / 14 / 20082: 02$ & 2.208 & 26.6 \\
\hline 4808 & $1 / 14 / 20082: 04$ & $8 / 14 / 20082: 04$ & 2.206 & 26.6 \\
\hline 4809 & 1/14/2008 2:06 & $8 / 14 / 20082: 06$ & 2.204 & 26.6 \\
\hline 4810 & $1 / 14 / 20082: 08$ & $8 / 14 / 20082: 08$ & 2.201 & 26.6 \\
\hline 4811 & 1/14/2008 2:10 & $8 / 14 / 20082: 10$ & 2.2 & 26.6 \\
\hline 4812 & $1 / 14 / 20082: 12$ & $8 / 14 / 20082: 12$ & 2.197 & 26.5 \\
\hline 4813 & $1 / 14 / 20082: 14$ & $8 / 14 / 20082: 14$ & 2.195 & 26.5 \\
\hline 4814 & 1/14/2008 2;16 & $8 / 14 / 20082: 16$ & 2.192 & 26.5 \\
\hline 4815 & $1 / 14 / 20082: 18$ & $8 / 14 / 20082: 18$ & 2.187 & 26.5 \\
\hline 4816 & $1 / 14 / 20082: 20$ & $8 / 14 / 20082: 20$ & 2.183 & 26.6 \\
\hline 4817 & $1 / 14 / 20082: 22$ & $8 / 14 / 20082: 22$ & 2.184 & 26.6 \\
\hline 4818 & $1 / 14 / 20082: 24$ & $8 / 14 / 20082: 24$ & 2.182 & 26.5 \\
\hline 4819 & $1 / 14 / 20082: 26$ & $8 / 14 / 20082: 26$ & 2.177 & 26.5 \\
\hline 4820 & $1 / 14 / 20082: 28$ & $8 / 14 / 20082 ; 28$ & 2.175 & 26.4 \\
\hline 4821 & $1 / 14 / 20082: 30$ & $8 / 14 / 20082: 30$ & 1.601 & 26.6 \\
\hline 4822 & $1 / 14 / 20082: 32$ & $8 / 14 / 20082: 32$ & 2.924 & 26.8 \\
\hline 4823 & $1 / 14 / 20082: 34$ & $8 / 14 / 20082: 34$ & 3.711 & 25.9 \\
\hline 4824 & 1/14/2008 2:36 & $8 / 14 / 20082: 36$ & 2.886 & 25.6 \\
\hline 4825 & 1/14/2008 2:38 & $8 / 14 / 20082: 38$ & 2.577 & 25.8 \\
\hline 4826 & $1 / 14 / 20082: 40$ & $8 / 14 / 20082: 40$ & 2.416 & 25.9 \\
\hline 4827 & 1/14/2008 2:42 & $8 / 14 / 20082: 42$ & 2.325 & 26 \\
\hline 4828 & 1/14/2008 2:44 & $8 / 14 / 20082: 44$ & 2.269 & 26 \\
\hline 4829 & $1 / 14 / 20082: 46$ & $8 / 14 / 20082: 46$ & 2.228 & 26 \\
\hline 4830 & $1 / 14 / 20082: 48$ & $8 / 14 / 20082: 48$ & 2.198 & 26 \\
\hline 4831 & $1 / 14 / 20082: 50$ & $8 / 14 / 20082550$ & 2.179 & 26 \\
\hline 4832 & 1/14/2008 2:52 & $8 / 14 / 20082: 52$ & 2.165 & 26 \\
\hline 4833 & $1 / 14 / 20082: 54$ & $8 / 14 / 20082: 54$ & 2.153 & 25.9 \\
\hline 4834 & $1 / 14 / 20082: 56$ & $8 / 14 / 20082: 56$ & 2.143 & 25.9 \\
\hline 4835 & $1 / 14 / 20082: 58$ & $8 / 14 / 20082: 58$ & 2.137 & 25.9 \\
\hline 4836 & $1 / 14 / 20083: 00$ & $8 / 14 / 20083: 00$ & 2.131 & 25.9 \\
\hline 4837 & 1/14/2008 3:02 & $8 / 14 / 20083: 02$ & 2.126 & 25.8 \\
\hline 4838 & 1/14/2008 3:04 & $8 / 14 / 20083: 04$ & 2.122 & 25.8 \\
\hline 4839 & $1 / 14 / 20083: 06$ & $8 / 14 / 20083: 06$ & 2.118 & 25.7 \\
\hline 4840 & 1/14/2008 3:08 & $8 / 14 / 20083: 08$ & 2.114 & 25.7 \\
\hline 4841 & 1/14/2008 3:10 & $8 / 14 / 20083: 10$ & 2.111 & 25.7 \\
\hline 4842 & $1 / 14 / 20083: 12$ & $8 / 14 / 20083: 12$ & 2.109 & 25.8 \\
\hline 4843 & 1/14/2008 3:14 & $8 / 14 / 2008$ 3:14 & 2.106 & 25.8 \\
\hline 4844 & $1 / 14 / 20083: 16$ & 8/14/2008 3:16 & 2.102 & 25.8 \\
\hline 4845 & $1 / 14 / 20083: 18$ & $8 / 14 / 20083: 18$ & 2.1 & 25.8 \\
\hline 4846 & $1 / 14 / 20083: 20$ & $8 / 14 / 20083: 20$ & 2.1 & 25.8 \\
\hline 4847 & $1 / 14 / 20083: 22$ & $8 / 14 / 2008$ 3:22 & 2.098 & 25.8 \\
\hline 4848 & $1 / 14 / 20083: 24$ & $8 / 14 / 20083: 24$ & 2.098 & 25.9 \\
\hline 4849 & $1 / 14 / 20083: 26$ & $8 / 14 / 20083: 26$ & 2.095 & 25.9 \\
\hline 4850 & $1 / 14 / 20083: 28$ & $8 / 14 / 20083: 28$ & 2.093 & 25.9 \\
\hline 4851 & 1/14/2008 3:30 & $8 / 14 / 20083: 30$ & 2.095 & 25.9 \\
\hline 4852 & $1 / 14 / 20083: 32$ & $8 / 14 / 20083: 32$ & 2.093 & \\
\hline 4853 & 1/14/2008 3:34 & $8 / 14 / 20083: 34$ & 2.09 & 25.9 \\
\hline 4854 & $1 / 14 / 20083: 36$ & $8 / 14 / 20083: 36$ & 2.089 & 25.9 \\
\hline 4855 & $1 / 14 / 20083: 38$ & $8 / 14 / 20083: 38$ & 2.09 & \\
\hline 4856 & $1 / 14 / 20083: 40$ & $8 / 14 / 20083: 40$ & 2.09 & 25.9 \\
\hline 4857 & $1 / 14 / 20083: 42$ & $8 / 14 / 20083: 42$ & 2.09 & \\
\hline
\end{tabular}

\begin{tabular}{|c|c|c|c|c|}
\hline \multicolumn{5}{|c|}{ D4-93p } \\
\hline $\operatorname{Rec}$ & & Adjusted & Pressure & Temp \\
\hline$\#$ & DaterTime & Date/Time & psi & ${ }^{\circ} \mathrm{C}$ \\
\hline 4858 & $1 / 14 / 20083: 44$ & $8 / 14 / 20083: 44$ & 2.089 & 25.9 \\
\hline 4859 & 1/14/20083:46 & $8 / 14 / 20083: 46$ & 2.09 & 26 \\
\hline 4860 & 1/14/20083:48 & $8 / 14 / 20083: 48$ & 2.089 & 25.9 \\
\hline 4861 & $1 / 14 / 20083: 50$ & $8 / 14 / 20083: 50$ & 2.089 & 25.9 \\
\hline 4862 & 1/14/2008 3:52 & $8 / 14 / 20083: 52$ & 2.089 & 25.9 \\
\hline 4863 & 1/14/20083:54 & $8 / 14 / 20083: 54$ & 2.09 & 26 \\
\hline 4864 & $1 / 14 / 20083: 56$ & $8 / 14 / 20083: 56$ & 2.09 & 25.9 \\
\hline 4865 & $1 / 14 / 20083: 58$ & $8 / 14 / 20083: 58$ & 2.09 & 25.9 \\
\hline 4866 & 1/14/20084:00 & $8 / 14 / 20084: 00$ & 2.089 & 25.9 \\
\hline 4867 & $1 / 14 / 20084: 02$ & $8 / 14 / 20084: 02$ & 2.088 & 25.9 \\
\hline 4868 & $1 / 14 / 20084: 04$ & 8/14/2008 4:04 & 2.087 & 25.9 \\
\hline 4869 & $1 / 14 / 20084: 06$ & $8 / 14 / 20084: 06$ & 2.087 & 25.9 \\
\hline 4870 & $1 / 14 / 20084: 08$ & $8 / 14 / 20084: 08$ & 2.086 & 25.9 \\
\hline 4871 & 1/14/2008 4:10 & $8 / 14 / 20084: 10$ & 2.086 & 25.9 \\
\hline 4872 & 1/14/20084:12 & $8 / 14 / 20084: 12$ & 2.085 & 25.9 \\
\hline 4873 & 1/14/2008 4:14 & $8 / 14 / 20084: 14$ & 2.085 & 25.9 \\
\hline 4874 & 1/14/20084:16 & $8 / 14 / 20084: 16$ & 2.084 & 25.9 \\
\hline 4875 & 1/14/2008 4:18 & $8 / 14 / 20084: 18$ & 2.083 & 25.9 \\
\hline 4876 & 1/14/2008 4:20 & $8 / 14 / 20084: 20$ & 2.083 & 25.9 \\
\hline 4877 & $1 / 14 / 20084: 22$ & $8 / 14 / 20084: 22$ & 2.082 & 25.9 \\
\hline 4878 & 1/14/2008 4:24 & $8 / 14 / 20084: 24$ & 2.082 & 25.9 \\
\hline 4879 & 1/14/20084:26 & $8 / 14 / 20084: 26$ & 2.081 & 25.9 \\
\hline 4880 & $1 / 14 / 20084: 28$ & $8 / 14 / 20084: 28$ & 2.08 & 25.9 \\
\hline 4881 & 1/14/2008 4:30 & $8 / 14 / 20084: 30$ & 2.08 & 25.9 \\
\hline 4882 & 1/14/2008 4:32 & $8 / 14 / 20084: 32$ & 2.08 & 25.9 \\
\hline 4883 & $1 / 14 / 20084: 34$ & $8 / 14 / 20084: 34$ & 2.079 & 25.9 \\
\hline 4884 & $1 / 14 / 20084: 36$ & $8 / 14 / 20084: 36$ & 2.079 & 25.9 \\
\hline 4885 & $1 / 14 / 20084: 38$ & $8 / 14 / 20084: 38$ & 2.078 & 25.9 \\
\hline 4886 & $1 / 14 / 20084: 40$ & $8 / 14 / 20084: 40$ & 2.077 & 25.9 \\
\hline 4887 & $1 / 14 / 20084: 42$ & $8 / 14 / 20084: 42$ & 2.078 & 25.9 \\
\hline 4888 & $1 / 14 / 20084: 44$ & $8 / 14 / 20084: 44$ & 2.077 & 25.9 \\
\hline 4889 & $1 / 14 / 20084: 46$ & $8 / 14 / 20084: 46$ & 2.076 & 25.9 \\
\hline 4890 & $1 / 14 / 20084: 48$ & $8 / 14 / 20084: 48$ & 2.076 & 25.9 \\
\hline 4891 & $t / 14 / 20084: 50$ & $8 / 14 / 20084: 50$ & 2.075 & 25.9 \\
\hline 4892 & $1 / 14 / 20084: 52$ & $8 / 14 / 20084: 52$ & 2.075 & 25.9 \\
\hline 4893 & $1 / 14 / 20084: 54$ & $8 / 14 / 20084: 54$ & 2.074 & 25.9 \\
\hline 4894 & $1 / 14 / 20084: 56$ & $8 / 14 / 20084: 56$ & 2.073 & 25.9 \\
\hline 4895 & $1 / 14 / 20084: 58$ & $8 / 14 / 20084: 58$ & 2.073 & 25.9 \\
\hline 4896 & $1 / 14 / 20085: 00$ & $8 / 14 / 20085: 00$ & 2.072 & 25.9 \\
\hline 4897 & $1 / 14 / 20085: 02$ & $8 / 14 / 20085: 02$ & 2.071 & 25.9 \\
\hline 4898 & 1/14/20085:04 & $8 / 14 / 20085: 04$ & 2.071 & 25.9 \\
\hline 4899 & 1/14/20085:06 & $8 / 14 / 20085: 06$ & 2.07 & 25.9 \\
\hline 4900 & 1/14/20085:08 & $8 / 14 / 20085: 08$ & 2.069 & 25.9 \\
\hline 4901 & 1/14/2008 5:10 & $8 / 14 / 20085: 10$ & 2.068 & 25.9 \\
\hline 4902 & 1/14/20085:12 & $8 / 14 / 20085: 12$ & 2.068 & 26 \\
\hline 4903 & $1 / 14 / 20085: 14$ & $8 / 14 / 20085: 14$ & 2.067 & 25.9 \\
\hline 4904 & 1/14/20085:16 & $8 / 14 / 20085: 16$ & 2.069 & 26 \\
\hline 4905 & 1/14/20085:18 & $8 / 14 / 20085: 18$ & 2.069 & 26 \\
\hline 4906 & 1/14/20085:20 & $8 / 14 / 20085: 20$ & 2.069 & 26.1 \\
\hline 4907 & $1 / 14 / 20085: 22$ & $8 / 14 / 20085: 22$ & 2.069 & 26.1 \\
\hline 4908 & $1 / 14 / 20085: 24$ & $8 / 14 / 20085: 24$ & 2.068 & 26.1 \\
\hline 4909 & $1 / 14 / 20085: 26$ & $8 / 14 / 20085: 26$ & 2.067 & 26.1 \\
\hline 4910 & 1/14/20085:28 & $8 / 14 / 20085: 28$ & 2.066 & 26.1 \\
\hline 4911 & $1 / 14 / 20085: 30$ & $8 / 14 / 20085: 30$ & 2.065 & 26.1 \\
\hline 4912 & $1 / 14 / 20085: 32$ & $8 / 14 / 20085: 32$ & 2.064 & 26.1 \\
\hline 4913 & $1 / 14 / 20085: 34$ & $8 / 14 / 20085: 34$ & 2.064 & 26.1 \\
\hline 4914 & $1 / 14 / 20085: 36$ & $8 / 14 / 20085: 36$ & 2.063 & 26.1 \\
\hline 4915 & $1 / 14 / 20085: 38$ & $8 / 14 / 20085: 38$ & 2.063 & 26 \\
\hline 4916 & $1 / 14 / 20085: 40$ & $8 / 14 / 20085: 40$ & 2.062 & 26 \\
\hline 4917 & $1 / 14 / 20085: 42$ & $8 / 14 / 20085: 42$ & 2.061 & 26.1 \\
\hline 4918 & $1 / 14 / 20085: 44$ & $8 / 14 / 20085: 44$ & 2.061 & 26.1 \\
\hline 4919 & $1 / 14 / 20085: 46$ & $8 / 14 / 20085: 46$ & 2.06 & 26.1 \\
\hline 4920 & $1 / 14 / 20085: 48$ & $8 / 14 / 20085: 48$ & 2.059 & 26 \\
\hline 4921 & $1 / 14 / 20085: 50$ & $8 / 14 / 20085: 50$ & 2.059 & 26 \\
\hline 4922 & $1 / 14 / 20085: 52$ & $8 / 14 / 20085: 52$ & 2.058 & 26 \\
\hline 4923 & $1 / 14 / 20085: 54$ & $8 / 14 / 20085: 54$ & 2.058 & 26 \\
\hline 4924 & $1 / 14 / 20085: 56$ & $8 / 14 / 20085: 56$ & 2.057 & 26 \\
\hline 4925 & $1 / 14 / 20085: 58$ & $8 / 14 / 20085: 58$ & 2.056 & 26 \\
\hline 4926 & $1 / 14 / 20086: 00$ & $8 / 14 / 20086: 00$ & 2.056 & 26 \\
\hline
\end{tabular}


DOE/RL-2009-35, REV. 0

\begin{tabular}{|c|c|c|c|c|}
\hline \multicolumn{5}{|c|}{ D493p } \\
\hline Rec & & Adjusted & Pressure & Temp \\
\hline$\#$ & Date/Time & Dater/Time & $\mathrm{psi}$ & ${ }^{\circ} \mathrm{C}$ \\
\hline 4927 & 1/14/20086:02 & $8 / 14 / 20086: 02$ & 2.056 & 26.1 \\
\hline 4928 & $1 / 14 / 20086: 04$ & $8 / 14 / 20086: 04$ & 2.056 & 26.1 \\
\hline 4929 & 1/14/20086:06 & $8 / 14 / 20086: 06$ & 2.055 & 26.1 \\
\hline 4930 & $1 / 14 / 20086: 08$ & $8 / 14 / 20086: 08$ & 2.054 & 26.1 \\
\hline 4931 & 1/14/20086:10 & 8/14/20086:10 & 2.053 & 26 \\
\hline 4932 & 1/14/20086:12 & 8/14/20086:12 & 2.052 & 26 \\
\hline 4933 & $1 / 14 / 20086: 14$ & $8 / 14 / 20086: 14$ & 2.051 & 25.9 \\
\hline 4934 & $1 / 14 / 20086: 16$ & $8 / 14 / 20086: 16$ & 2.051 & 25.9 \\
\hline 4935 & $1 / 14 / 20086: 18$ & $8 / 14 / 20086: 18$ & 2.05 & 25.9 \\
\hline 4936 & $1 / 14 / 20086: 20$ & $8 / 14 / 20086: 20$ & 2.051 & 25.9 \\
\hline 4937 & $1 / 14 / 20086: 22$ & $8 / 14 / 20086: 22$ & 2.051 & 25.8 \\
\hline 4938 & $1 / 14 / 20086: 24$ & $8 / 14 / 20086: 24$ & 2.05 & 25.9 \\
\hline 4939 & $1 / 14 / 20086: 26$ & $8 / 14 / 20086: 26$ & 2.051 & 25.9 \\
\hline 4940 & $1 / 14 / 20086: 28$ & $8 / 14 / 20086: 28$ & 2.048 & 25.9 \\
\hline 4941 & $1 / 14 / 20086: 30$ & $8 / 14 / 20086: 30$ & 2.048 & 25.9 \\
\hline 4942 & $1 / 14 / 20086: 32$ & $8 / 14 / 20086: 32$ & 2.049 & 26 \\
\hline 4943 & $1 / 14 / 20086: 34$ & $8 / 14 / 20086: 34$ & 1.845 & 260 \\
\hline 4944 & 1/14/20086:36 & $8 / 14 / 20086: 36$ & 0.022 & 26.3 \\
\hline 4945 & $1 / 14 / 20086: 38$ & $8 / 14 / 20086: 38$ & 0.922 & 261 \\
\hline 4946 & $1 / 14 / 20086: 40$ & $8 / 14 / 20086: 40$ & 1.198 & 26.1 \\
\hline 4947 & $1 / 14 / 20086: 42$ & $8 / 14 / 20086: 42$ & 1.388 & 26 \\
\hline 4948 & $1 / 14 / 20086: 44$ & $8 / 14 / 20086: 44$ & 1.507 & 25.9 \\
\hline 4949 & $1 / 14 / 20086: 46$ & $8 / 14 / 20086: 46$ & 1.579 & 25.9 \\
\hline 4950 & $1 / 14 / 20086: 48$ & $8 / 14 / 20086: 48$ & 1.628 & 25.9 \\
\hline 4951 & $1 / 14 / 20086: 50$ & $8 / 14 / 20086: 50$ & 1.66 & 25.8 \\
\hline 4952 & $1 / 14 / 20086: 52$ & $8 / 14 / 20086: 52$ & 1.685 & 25.8 \\
\hline 4953 & $1 / 14 / 20086: 54$ & $8 / 14 / 20086: 54$ & 1.706 & 25.8 \\
\hline 4954 & $1 / 14 / 20086: 56$ & $8 / 14 / 20086: 56$ & 1.724 & 25.8 \\
\hline 4955 & $1 / 14 / 20086: 58$ & $8 / 14 / 20086: 58$ & 1.738 & 25.7 \\
\hline 4956 & $1 / 14 / 20087: 00$ & $8 / 14 / 20087: 00$ & 1.75 & 25.7 \\
\hline 4957 & $1 / 14 / 20087: 02$ & $8 / 14 / 20087: 02$ & 1.761 & 25.7 \\
\hline 4958 & 1/14/20087:04 & $8 / 14 / 20087: 04$ & 1.771 & 25.6 \\
\hline 4959 & $1 / 14 / 20087: 06$ & $8 / 14 / 20087: 06$ & 1.78 & 26 \\
\hline 4960 & 1/14/2008 7:08 & \begin{tabular}{|c|}
$8 / 14 / 20087: 08$ \\
\end{tabular} & 1.789 & 26.2 \\
\hline 4961 & \begin{tabular}{|l|}
$1 / 14 / 20087: 10$ \\
\end{tabular} & $8 / 14 / 20087: 10$ & 1.796 & 26 \\
\hline 4962 & 1/14/2008 7:12 & $8 / 14 / 20087: 12$ & 1.803 & 25.8 \\
\hline 4963 & 1/14/2008 7:14 & 8/14/2008 7:14 & 1.809 & 25.6 \\
\hline 4964 & 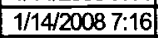 & $8 / 14 / 20087: 16$ & 1.814 & 25.6 \\
\hline 4965 & $1 / 14 / 20087: 18$ & $8 / 14 / 20087: 18$ & 1.819 & 25.5 \\
\hline 4966 & $1 / 14 / 20087: 20$ & $8 / 14 / 20087: 20$ & 1.824 & 25.5 \\
\hline 4967 & $1 / 14 / 20087: 22$ & $8 / 14 / 20087: 22$ & 1.828 & 25.4 \\
\hline 4968 & $1 / 14 / 20087: 24$ & $8 / 14 / 20087: 24$ & 1.832 & 25.4 \\
\hline 4969 & $1 / 14 / 20087: 26$ & $8 / 14 / 20087: 26$ & 1.835 & 25.4 \\
\hline 4970 & $1 / 14 / 20087: 28$ & $8 / 14 / 20087: 28$ & 1.838 & 25.9 \\
\hline 4971 & $1 / 14 / 20087: 30$ & $8 / 14 / 20087: 30$ & 1.84 & 25.5 \\
\hline 4972 & $1 / 14 / 20087: 32$ & $8 / 14 / 20087: 32$ & 1.843 & 25.4 \\
\hline 4973 & $1 / 14 / 20087: 34$ & $8 / 14 / 20087: 34$ & 1.845 & 25.4 \\
\hline 4974 & $1 / 14 / 20087: 36$ & $8 / 14 / 20087: 36$ & 1.847 & 25.4 \\
\hline 4975 & \begin{tabular}{|l}
$1 / 14 / 20087: 38$ \\
\end{tabular} & $8 / 14 / 20087: 38$ & 1.849 & 25.4 \\
\hline 4976 & $1 / 14 / 20087: 40$ & $8 / 14 / 20087: 40$ & 1.851 & 25.4 \\
\hline 4977 & 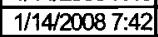 & $8 / 14 / 20087: 42$ & 1.852 & 25.4 \\
\hline 4978 & $1 / 14 / 20087: 44$ & $8 / 14 / 20087: 44$ & 1.854 & 25.4 \\
\hline 4979 & $1 / 14 / 20087: 46$ & $8 / 14 / 20087: 46$ & 1.856 & 25.4 \\
\hline 4980 & $1 / 14 / 20087: 48$ & $8 / 14 / 20087: 48$ & 1.857 & 25.3 \\
\hline 4981 & 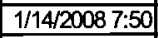 & $8 / 14 / 20087: 50$ & 1.857 & 25.3 \\
\hline 4982 & $1 / 14 / 20087: 52$ & $8 / 14 / 20087: 52$ & 1.859 & 25.3 \\
\hline 4983 & $1 / 14 / 20087: 54$ & $8 / 14 / 20087: 54$ & 1.86 & 25.3 \\
\hline 4984 & $1 / 14 / 20087: 56$ & $8 / 14 / 20087: 56$ & 1.86 & 25.3 \\
\hline 4985 & $1 / 14 / 20087: 58$ & $8 / 14 / 20087: 58$ & 1.861 & 25.3 \\
\hline 4986 & $1 / 14 / 20088: 00$ & \begin{tabular}{|l|}
$8 / 14 / 20088: 00$ \\
\end{tabular} & 1.862 & 25.3 \\
\hline 4987 & $1 / 14 / 20088: 02$ & $8 / 14 / 20088: 02$ & 1.863 & 25.3 \\
\hline 4988 & $1 / 14 / 20088: 04$ & \begin{tabular}{|l}
$8 / 14 / 20088: 04$ \\
\end{tabular} & 1.863 & 25.3 \\
\hline 4989 & $1 / 14 / 20088: 06$ & $8 / 14 / 20088: 06$ & 1.864 & 25.3 \\
\hline 4990 & $1 / 14 / 20088: 08$ & $8 / 14 / 20088: 08$ & 1.864 & 25.3 \\
\hline 4991 & $1 / 14 / 20088: 10$ & $8 / 14 / 20088: 10$ & 1.865 & 25.3 \\
\hline 4992 & 1/14/20088:12 & 8/14/2008 8:12 & 1.867 & 25.4 \\
\hline 4993 & $1 / 14 / 20088: 14$ & $8 / 14 / 20088: 14$ & 1.867 & 25.4 \\
\hline 4994 & $1 / 14 / 20088: 16$ & $8 / 14 / 20088: 16$ & 1.868 & 25.4 \\
\hline 4995 & $1 / 14 / 20088: 18$ & $8 / 14 / 20088: 18$ & 1.869 & 25.4 \\
\hline
\end{tabular}

\begin{tabular}{|c|c|c|c|c|}
\hline \multicolumn{5}{|c|}{ D493p } \\
\hline$\overline{R e C}$ & & Adusted & Pressure & Temp \\
\hline$\#$ & Date-/Time & DaterTime & psi & ${ }^{\circ} \mathrm{C}$ \\
\hline 4996 & 1/14/20088:20 & 8/14/2008 8:20 & 1.87 & 25.4 \\
\hline 4997 & $1 / 14 / 20088: 22$ & 8/14/2008 8:22 & 1.871 & $\overline{25.4}$ \\
\hline 4998 & $1 / 14 / 20088: 24$ & $8 / 14 / 20088: 24$ & 1.872 & 25.4 \\
\hline 4999 & $1 / 14 / 20088: 26$ & $8 / 14 / 20088: 26$ & 1.874 & 25.5 \\
\hline 5000 & $1 / 14 / 20088: 28$ & $8 / 14 / 20088: 28$ & 1.874 & 25.5 \\
\hline 5001 & $1 / 14 / 20088: 30$ & $8 / 14 / 20088: 30$ & 1.875 & 25.5 \\
\hline 5002 & $1 / 14 / 20088: 32$ & $8 / 14 / 20088: 32$ & 1.876 & 25.5 \\
\hline 5003 & 1/14/20088:34 & $8 / 14 / 20088: 34$ & 1.876 & 25.5 \\
\hline 5004 & 1/14/2008 8:36 & $8 / 14 / 20088: 36$ & 1.878 & 25.6 \\
\hline 5005 & 1/14/2008 8:38 & $8 / 14 / 20088: 38$ & 1.879 & 25.5 \\
\hline 5006 & $1 / 14 / 20088: 40$ & $8 / 14 / 20088: 40$ & 1.88 & 25.5 \\
\hline 5007 & $1 / 14 / 20088: 42$ & $8 / 14 / 20088: 42$ & 1.88 & 25.6 \\
\hline 5008 & $1 / 14 / 20088: 44$ & $8 / 14 / 20088: 44$ & 1.881 & 25.6 \\
\hline 5009 & 1/14/20088:46 & $8 / 14 / 20088: 46$ & 1.881 & 25.6 \\
\hline 5010 & $1 / 14 / 20088: 48$ & $8 / 14 / 20088: 48$ & 1.882 & 25.6 \\
\hline 5011 & $1 / 14 / 20088: 50$ & $8 / 14 / 20088: 50$ & 1.883 & 25.5 \\
\hline 5012 & 1/14/2008 8:52 & $8 / 14 / 20088: 52$ & 1.884 & 25.6 \\
\hline$\overline{5013}$ & 1/14/20088:54 & $8 / 14 / 20088: 54$ & 1.884 & 25.5 \\
\hline 5014 & $1 / 14 / 20088: 56$ & $8 / 14 / 20088: 56$ & 1.885 & 25.5 \\
\hline 5015 & 1/14/2008 8:58 & $8 / 14 / 20088: 58$ & 1.885 & 25.5 \\
\hline 5016 & 1/14/20089:00 & $8 / 14 / 20089: 00$ & 1.886 & 25.6 \\
\hline 5017 & $1 / 14 / 20089: 02$ & $8 / 14 / 20089: 02$ & 1.886 & 25.6 \\
\hline 5018 & 1/14/20089:04 & $8 / 14 / 20089: 04$ & 1.887 & 25.6 \\
\hline 5019 & $1 / 14 / 20089: 06$ & $8 / 14 / 20089: 06$ & 1.887 & 25.6 \\
\hline 5020 & $1 / 14 / 20089: 08$ & $8 / 14 / 20089: 08$ & 1.888 & 25.6 \\
\hline 5021 & $1 / 14 / 20089: 10$ & $8 / 14 / 20089: 10$ & 1.888 & 25.6 \\
\hline 5022 & $1 / 14 / 20089: 12$ & $8 / 14 / 20089: 12$ & 1.889 & 25.5 \\
\hline 5023 & $1 / 14 / 20089: 14$ & $8 / 14 / 20089: 14$ & 1.889 & 25.6 \\
\hline 5024 & 1/14/20089:16 & 8/14/20089:16 & 1.889 & 25.6 \\
\hline 5025 & 1/14/20089:18 & $8 / 14 / 20089: 18$ & 1.89 & 25.6 \\
\hline 5026 & 1/14/20089:20 & $8 / 14 / 20089: 20$ & 1.89 & 25.6 \\
\hline 5027 & 1/14/20089:22 & $8 / 14 / 20089: 22$ & 1.891 & 25.6 \\
\hline 5028 & 1/14/20089:24 & $8 / 14 / 20089: 24$ & 1.891 & 25.5 \\
\hline 5029 & 1/14/20089:26 & $8 / 14 / 20089: 26$ & 1.891 & 25.6 \\
\hline 5030 & $1 / 14 / 20089: 28$ & $8 / 14 / 20089: 28$ & 1.892 & 25.6 \\
\hline 5031 & $1 / 14 / 20089: 30$ & $8 / 14 / 20089: 30$ & 1.893 & 25.6 \\
\hline 5032 & 1/14/20089:32 & $8 / 14 / 20089: 32$ & 1.893 & 25.6 \\
\hline 5033 & 1/14/20089:34 & $8 / 14 / 20089: 34$ & 1.893 & 25.6 \\
\hline 5034 & $1 / 14 / 20089: 36$ & $8 / 14 / 20089: 36$ & 1.894 & 25.6 \\
\hline 5035 & 1/14/20089:38 & $8 / 14 / 20089: 38$ & 1.895 & 25.6 \\
\hline 5036 & $1 / 14 / 20089: 40$ & $8 / 14 / 20089: 40$ & 1.896 & 25.6 \\
\hline 5037 & 1/14/20089:42 & 8/14/20089:42 & 1.896 & 25.6 \\
\hline 5038 & $1 / 14 / 20089: 44$ & 8/14/2008 9:44 & 1.896 & $\overline{25.6}$ \\
\hline 5039 & 1/14/20089:46 & $8 / 14 / 20089: 46$ & 1.896 & 25.6 \\
\hline 5040 & 1/14/2008 9:48 & 8/14/20089:48 & 1.897 & 25.6 \\
\hline 5041 & 1/14/20089:50 & 8/14/20089:50 & 1.897 & 25.7 \\
\hline 5042 & $1 / 14 / 200$ & 8/14/20089:52 & 1.897 & 25.7 \\
\hline 5043 & $1 / 14 / 20089: 54$ & 8/14/2008 9:54 & 1.898 & 25.6 \\
\hline 5044 & $1 / 14 / 20089: 56$ & $8 / 14 / 20089: 56$ & 1.898 & 25.7 \\
\hline 5045 & 1/14/20089:58 & $8 / 14 / 20089: 58$ & 1.898 & 25.6 \\
\hline 5046 & 1/14/2008 10:00 & $8 / 14 / 2008$ 10:00 & 1.898 & 25.6 \\
\hline 5047 & 1/14/2008 10:02 & \begin{tabular}{|l|}
$8 / 14 / 2008$ 10:02 \\
\end{tabular} & 1.899 & 25.6 \\
\hline 5048 & 1/144/2008 10:04 & 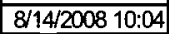 & 1.899 & 25.6 \\
\hline 5049 & 1/14/2008 10:06 & \begin{tabular}{|l|}
$8 / 14 / 200810: 06$ \\
\end{tabular} & 1.432 & 25.8 \\
\hline 5050 & 1/14/2008 10:08 & \begin{tabular}{|l|}
$8 / 14 / 2008$ 10:08 \\
\end{tabular} & 0.419 & 26.1 \\
\hline 5051 & $0810: 10$ & $8 / 14 / 200810: 10$ & 0.001 & 26.1 \\
\hline 5052 & 1/14/2008 10:12 & \begin{tabular}{|l|}
$8 / 14 / 2008 \quad 10: 12$ \\
\end{tabular} & 0.805 & 25.9 \\
\hline 5053 & 1/14/2008 10:14 & 8/14/2008 10:14 & 1.028 & 25.6 \\
\hline 5054 & 1/14/2008 10:16 & \begin{tabular}{|l|}
$8 / 14 / 2008$ 10:16 \\
\end{tabular} & 1.199 & 25.6 \\
\hline 5055 & 1/14/2008 10:18 & \begin{tabular}{|l|}
$8 / 14 / 2008$ 10:18 \\
\end{tabular} & 1.338 & $25 . \overline{6}$ \\
\hline 5056 & 1/14/2008 10:20 & $8 / 14 / 2008$ 10:20 & 1.441 & 25.5 \\
\hline 5057 & $1 / 14 / 2008$ 10:22 & \begin{tabular}{|l|}
$8 / 14 / 2008$ 10:22 \\
\end{tabular} & 1.511 & 25.5 \\
\hline 5058 & 1/14/2008 10:24 & \begin{tabular}{|l|}
$8 / 14 / 2008$ 10:24 \\
\end{tabular} & 1.559 & 25.5 \\
\hline 5059 & 1/14/2008 10:26 & \begin{tabular}{|l|} 
8/14/2008 10:26 \\
\end{tabular} & 1.596 & 25.5 \\
\hline 5060 & $1 / 14 / 200810: 28$ & \begin{tabular}{|l|}
$8 / 14 / 2008$ 10:28 \\
\end{tabular} & 1.624 & 25.4 \\
\hline 5061 & 1/14/2008 10:30 & 8/14/2008 10:30 & 1.644 & 25.4 \\
\hline 5062 & 1/14/2008 10:32 & 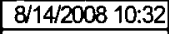 & 1.663 & 25.4 \\
\hline 5063 & 1/14/2008 10:34 & $8 / 14 / 2008 \quad 10: 34$ & 1.679 & 25.4 \\
\hline 5064 & $1 / 14 / 2008$ 10:36 & $8 / 14 / 2008$ 10:36 & 1.694 & 25.4 \\
\hline
\end{tabular}

\begin{tabular}{|c|c|c|c|c|}
\hline \multicolumn{5}{|c|}{ D4-93p } \\
\hline $\operatorname{Rec}$ & & Adjusted & Pressure & Temp \\
\hline \# & Date/Time & Date/Time & psi & ${ }^{\circ} \mathrm{C}$ \\
\hline 5065 & 1/14/2008 10:38 & \begin{tabular}{|l|}
$8 / 14 / 2008$ 10:38 \\
\end{tabular} & 1.706 & 25.3 \\
\hline 5066 & 1/14/2008 10:40 & \begin{tabular}{|l|}
$8 / 14 / 2008$ 10:40 \\
\end{tabular} & 1.717 & 25.3 \\
\hline 5067 & 1/14/2008 10:42 & \begin{tabular}{|l|}
$8 / 14 / 200810: 42$ \\
\end{tabular} & 1.728 & 25.3 \\
\hline 5068 & 1/14/2008 10:44 & \begin{tabular}{|l|}
$8 / 14 / 200810: 44$ \\
\end{tabular} & 1.738 & 25.3 \\
\hline 5069 & 1/14/2008 10:46 & \begin{tabular}{|l|}
$8 / 14 / 200810: 46$ \\
\end{tabular} & 1.746 & $\overline{25.3}$ \\
\hline 5070 & 1/14/2008 10:48 & \begin{tabular}{|l|}
$8 / 14 / 200810: 48$ \\
\end{tabular} & 1.754 & 25.3 \\
\hline 5071 & $1 / 14 / 200810: 50$ & 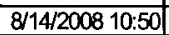 & 1.761 & 25.3 \\
\hline 5072 & 1/14/2008 10:52 & \begin{tabular}{|l|}
$8 / 14 / 200810: 52$ \\
\end{tabular} & 1.768 & 25.3 \\
\hline 5073 & 1/14/2008 10:54 & \begin{tabular}{|l|}
$8 / 14 / 200810: 54$ \\
\end{tabular} & 1.774 & 25.2 \\
\hline 5074 & 1/14/2008 10:56 & \begin{tabular}{|l|}
$8 / 14 / 200810: 56$ \\
\end{tabular} & 1.78 & 25.2 \\
\hline 5075 & 1/14/2008 10:58 & \begin{tabular}{|l|}
$8 / 14 / 200810: 58$ \\
\end{tabular} & 1.785 & 25.2 \\
\hline 5076 & 1/14/2008 11:00 & 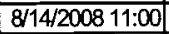 & 1.789 & 25.2 \\
\hline 5077 & $1 / 14 / 2008+1: 02$ & $8 / 14 / 200811: 02$ & 1.794 & 25.2 \\
\hline 5078 & $1 / 14 / 2008$ 11:04 & \begin{tabular}{|l|}
$8 / 14 / 2008$ 11:04 \\
\end{tabular} & 1.798 & 25.1 \\
\hline 5079 & 1/14/2008 11:06 & \begin{tabular}{|l|}
$8 / 14 / 200811: 06$ \\
\end{tabular} & 1.802 & 25.1 \\
\hline 5080 & 1/14/2008 11:08 & \begin{tabular}{|l|}
$8 / 14 / 200811: 08$ \\
\end{tabular} & 1.806 & 25.1 \\
\hline 5081 & 1/14/2008 11:10 & \begin{tabular}{|l|}
$8 / 14 / 200811: 10$ \\
\end{tabular} & 1.809 & 25.1 \\
\hline 5082 & 1/14/2008 11:12 & $8 / 14 / 20$ & 1.812 & 25.1 \\
\hline 5083 & 1/14/2008 11:14 & 8/14/2008 11:14 & 1.815 & 25.1 \\
\hline 5084 & 1/14/2008 11:16 & \begin{tabular}{|l|}
$8 / 14 / 200811: 16$ \\
\end{tabular} & 1.817 & 25 \\
\hline 5085 & 1/14/2008 11:18 & \begin{tabular}{|l|}
$8 / 14 / 200811: 18$ \\
\end{tabular} & 1.819 & 25 \\
\hline 5086 & 1/14/2008 11:20 & \begin{tabular}{|l|}
$8 / 14 / 200811: 20$ \\
\end{tabular} & 1.822 & 25 \\
\hline 5087 & $1 / 14 / 200811: 22$ & 8/14/2008 11:22 & 1.825 & 25 \\
\hline 5088 & $1 / 14 / 200$ & $8 / 14 / 200811: 24$ & 1,826 & 24.9 \\
\hline 5089 & $1 / 14 / 200811: 26$ & $8 / 14 / 2008$ 11:26 & 1.828 & 24.9 \\
\hline 5090 & 1/14/2008 11:28 & $8811: 28$ & 1.831 & 24.9 \\
\hline 5091 & $1 / 14 / 200$ & $8 / 14 / 2$ & 1.833 & 24.9 \\
\hline 5092 & 1/14/2008 11:32 & $8 / 14 / 2008$ 11:32 & 1.835 & 24.9 \\
\hline 5093 & 1/14/2008 11:34 & $8 / 14 / 200811: 34$ & 1.836 & 24.9 \\
\hline 5094 & 1/144/2008 11:36 & $8 / 14 / 20$ & 1.838 & 24.9 \\
\hline 5095 & $1 / 14 / 20$ & $8 / 14 / 20$ & 1.84 & 24.9 \\
\hline 5096 & 1/14/2008 11:40 & \begin{tabular}{|l|}
$8 / 14 / 2008$ 11:40 \\
\end{tabular} & 1.842 & 24.9 \\
\hline 5097 & 1/14/2008 11:42 & \begin{tabular}{|l|}
$8 / 14 / 2008$ 11:42 \\
\end{tabular} & 1.844 & 25 \\
\hline 5098 & 1/14/2008 11:44 & \begin{tabular}{|l|}
$8 / 14 / 200811: 44$ \\
\end{tabular} & 1.846 & 25 \\
\hline 5099 & $1 / 14 / 20$ & $8 / 14 / 2$ & 1.851 & 25.1 \\
\hline 5100 & 1/14/2008 11:48 & $8 / 14 / 200811: 48$ & 1.857 & 25.1 \\
\hline 5101 & 1/14/2008 11:50 & $8 / 14 / 200811: 50$ & 1.899 & 25.1 \\
\hline 5102 & $1 / 14 / 20$ & \begin{tabular}{|l|}
$8 / 14 / 200811: 52$ \\
\end{tabular} & 1.943 & 25.1 \\
\hline 5103 & $1 / 14 / 20$ & $8111: 54$ & 1.977 & 25.1 \\
\hline 5104 & $1 / 14 / 200811: 56$ & $8 / 14 / 200811: 56$ & 1.991 & 25 \\
\hline 5105 & 1/14/2008 11:58 & \begin{tabular}{|l|}
$8 / 14 / 2008$ 11:58 \\
\end{tabular} & 1.997 & 25 \\
\hline 5106 & $1 / 14 / 200812: 00$ & \begin{tabular}{|l|}
$8 / 14 / 200812: 00$ \\
\end{tabular} & 1.999 & 25 \\
\hline 5107 & 1/14/20 & $8 / 14 / 2$ & 2001 & 25 \\
\hline 5108 & 1/14/2008 12:04 & 8/14/2008 12:04 & 2.002 & 25 \\
\hline 5109 & 1/14/2008 12:06 & $8 / 14 / 200812: 06$ & 2.005 & 25.1 \\
\hline 5110 & $1 / 14 / 20$ & $8 / 14 / 2$ & 2.006 & 25.1 \\
\hline 5111 & $1 / 14 / 20$ & $312: 10$ & 2008 & 25.1 \\
\hline 5112 & 1/14/2008 12:12 & 8/14/2008 12:12 & 2.009 & 25.1 \\
\hline 5113 & 1/14/2008 12:14 & 8/14/2008 12:14 & 2.01 & 25.1 \\
\hline 5114 & $1 / 14 / 20$ & \begin{tabular}{|l|}
$8 / 14 / 2008 ~ 12: 16$ \\
\end{tabular} & 2015 & 25.1 \\
\hline 5115 & 1/14/2008 12:18 & 8/14/2008 १2:18 & 2.017 & 25.1 \\
\hline 5116 & 1/14/2008 12:20 & 8/14/2008 12:20 & 2018 & 25.1 \\
\hline 5117 & $1 / 14 / 200812-22$ & $8 / 14 / 200812: 22$ & 2026 & 25.1 \\
\hline 5118 & 1/14/2008 12:24 & $8 / 14 / 2008$ & 2.062 & 25.1 \\
\hline 5119 & 1/14/2008 12:26 & $8 / 14 / 2008$ & 2069 & 25 \\
\hline 5120 & $1 / 14 / 200812: 28$ & 8/14/2008 12:28 & 2.082 & 25 \\
\hline 5121 & $1 / 14 / 200812: 30$ & 8/14/2008 12:30 & 2083 & 25 \\
\hline 5122 & $1 / 14 / 200812: 32$ & \begin{tabular}{|l|}
$8 / 14 / 2008$ 12:32 \\
\end{tabular} & 2.09 & 2 \\
\hline 5123 & 1/14/2008 12:34 & $8 / 14 / 200812: 34$ & 2092 & 25 \\
\hline 5124 & $1 / 14 / 200812-36$ & 8/14/2008 12:36 & 2.092 & 25 \\
\hline 5125 & $1 / 14 / 200812: 38$ & \begin{tabular}{|l|l|}
$8 / 2008 ~ 12: 38$ \\
\end{tabular} & 2.093 & \\
\hline 5126 & \begin{tabular}{|l|l|}
$1 / 14 / 200812: 40$ \\
\end{tabular} & $8 / 14 / 2008$ 12:40 & 2094 & 25 \\
\hline 5127 & 1/14/2008 12:42 & \begin{tabular}{|l|}
$8 / 14 / 200812: 42$ \\
\end{tabular} & 2096 & \\
\hline 5128 & $1 / 14 / 2008$ 12:44 & 8/14/2008 12:44 & 2096 & \\
\hline 5129 & 1/14/2008 12:46 & $8 / 14 / 200812: 46$ & 2097 & 25 \\
\hline 5130 & \begin{tabular}{|l|}
$1 / 14 / 200812: 48$ \\
\end{tabular} & 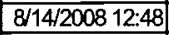 & 2.098 & 25 \\
\hline 5131 & 1/14/2008 12:50 & $8 / 14 / 2008$ 12:50 & 2.099 & 25 \\
\hline 5132 & 1/14/2008 12:52 & $8 / 14 / 2008$ 12:52 & 2.1 & 25 \\
\hline 5133 & $1 / 14 / 200812: 54$ & $8 / 14 / 200812: 54$ & 2.1 & 25 \\
\hline
\end{tabular}


DOE/RL-2009-35, REV. 0

\begin{tabular}{|c|c|c|c|c|}
\hline \multicolumn{5}{|c|}{ D4-93p } \\
\hline $\operatorname{Rec}$ & & Adjusted & Pressure & Temp \\
\hline \# & Date/Time & Date/Time & psi & ${ }^{\circ} \mathrm{C}$ \\
\hline 5134 & $1 / 14 / 200812: 56$ & $8 / 14 / 200812: 56$ & 2.101 & 25 \\
\hline 5135 & $1 / 14 / 200812: 58$ & $8 / 14 / 200812: 58$ & 2.101 & 24.9 \\
\hline 5136 & $1 / 14 / 200813: 00$ & $8 / 14 / 200813: 00$ & 2.102 & 25 \\
\hline 5137 & $1 / 14 / 2008$ 13:02 & $8 / 14 / 200813: 02$ & 2.102 & 25 \\
\hline 5138 & 1/14/2008 13:04 & $8 / 14 / 200813: 04$ & 2.103 & 24.9 \\
\hline 5139 & $1 / 14 / 200813: 06$ & $8 / 14 / 200813: 06$ & 2.104 & 25 \\
\hline 5140 & $1 / 14 / 200813: 08$ & $8 / 14 / 200813: 08$ & 2.104 & 24.9 \\
\hline 5141 & $1 / 14 / 200813: 10$ & $8 / 14 / 200813: 10$ & 2.104 & 25 \\
\hline 5142 & $1 / 14 / 200813: 12$ & $8 / 14 / 200813: 12$ & 2.105 & 25 \\
\hline 5143 & $1 / 14 / 200813: 14$ & $8 / 14 / 200813: 14$ & 2.105 & 25 \\
\hline 5144 & $1 / 14 / 200813: 16$ & $8 / 14 / 200813: 16$ & 2.106 & 25 \\
\hline 5145 & $1 / 14 / 200813: 18$ & $8 / 14 / 200813: 18$ & 2.107 & 24.9 \\
\hline 5146 & $1 / 14 / 200813: 20$ & $8 / 14 / 200813: 20$ & 2.107 & 25.1 \\
\hline 5147 & $1 / 14 / 200813: 22$ & $8 / 14 / 200813: 22$ & 2.107 & 25.5 \\
\hline 5148 & $1 / 14 / 200813: 24$ & $8 / 14 / 200813: 24$ & 2.108 & 25.6 \\
\hline 5149 & $1 / 14 / 2008$ 13:26 & $8 / 14 / 200813: 26$ & 2.109 & 25.2 \\
\hline 5150 & $1 / 14 / 2008$ 13:28 & $8 / 14 / 200813: 28$ & 2.109 & 25.1 \\
\hline 5151 & $1 / 14 / 200813: 30$ & $8 / 14 / 200813: 30$ & 2.109 & 25.1 \\
\hline 5152 & $1 / 14 / 200813: 32$ & $8 / 14 / 200813: 32$ & 211 & 25 \\
\hline 5153 & $1 / 14 / 200$ & $8 / 14 / 200813: 34$ & 211 & 25 \\
\hline 5154 & $1 / 14 / 200813: 36$ & $8 / 14 / 200813: 36$ & 211 & 25.1 \\
\hline 5155 & $1 / 14 / 200813: 38$ & $8 / 14 / 2008$ 13:38 & 2.111 & 25.1 \\
\hline 5156 & $1 / 14 / 200813: 40$ & $8 / 14 / 200813: 40$ & 2.111 & 25.1 \\
\hline 5157 & $1 / 14 / 200813: 42$ & $8 / 14 / 200813: 42$ & 2.111 & 25.1 \\
\hline 5158 & $1 / 14 / 200813: 44$ & $8 / 14 / 200813: 44$ & 2.112 & 25 \\
\hline 5159 & $1 / 14 / 200$ & $8 / 14 / 200813: 46$ & 2.112 & 25 \\
\hline 5160 & $1 / 14 / 200813: 48$ & $8 / 14 / 200813: 48$ & 2.112 & 25 \\
\hline 5161 & $1 / 14 / 200813: 50$ & $8 / 14 / 200813: 50$ & 2.113 & 25 \\
\hline 5162 & $1 / 14 / 200813: 52$ & $8 / 14 / 200813: 52$ & 2.114 & 24.9 \\
\hline 5163 & $1 / 14 / 200813: 54$ & $8 / 14 / 200813: 54$ & & 24.9 \\
\hline 5164 & $1 / 14 / 200813: 56$ & $8 / 14 / 200813: 56$ & 2.114 & 24.9 \\
\hline 5165 & $1 / 14 / 200813: 58$ & $8 / 14 / 200813: 58$ & 2.115 & 24.9 \\
\hline 5166 & $1 / 14 / 200814: 00$ & $8 / 14 / 2008$ 14:00 & 2.116 & 24.9 \\
\hline 5167 & $1 / 14 / 200814: 02$ & $8 / 14 / 200814: 02$ & 2.116 & 25 \\
\hline 5168 & $1 / 14 / 200814: 04$ & $8 / 14 / 200814: 04$ & 2.116 & 24.9 \\
\hline 5169 & $1 / 14 / 200814: 06$ & $8 / 14 / 200814: 06$ & 2.116 & 24.9 \\
\hline 5170 & $1 / 14 / 200814: 08$ & $8 / 14 / 200814: 08$ & 2.116 & 24.9 \\
\hline 5171 & $1 / 14 / 200814: 10$ & $8 / 14 / 200814: 10$ & 2.117 & 24.9 \\
\hline 5172 & $1 / 14 / 200814: 12$ & $8 / 14 / 200814: 12$ & 2.122 & 24.9 \\
\hline 5173 & $1 / 14$ & $814: 14$ & & 25 \\
\hline 5174 & $1 / 14 / 200814: 16$ & $8 / 14 / 200814: 16$ & 2.126 & 25 \\
\hline 5175 & $1 / 14 / 200814: 18$ & $8 / 14 / 200814: 18$ & 2.126 & 25.1 \\
\hline 5176 & $1 / 14 / 2008$ & $8 / 14 / 200814: 20$ & 2.126 & 25.4 \\
\hline 5177 & $1 / 14 / 200814: 22$ & $8 / 14 / 200814: 22$ & 1.439 & 25.8 \\
\hline 5178 & $1 / 14 / 200814: 24$ & $8 / 14 / 200814: 24$ & 1.81 & 26.2 \\
\hline 5179 & $1 / 14 / 200814: 26$ & $8 / 14 / 200814: 26$ & 1.844 & 26 \\
\hline 5180 & $1 / 14$ & $30814: 28$ & & 25.8 \\
\hline $5 \uparrow 81$ & $1 / 14 / 200814: 30$ & $8 / 14 / 200814: 30$ & 1.884 & 25.7 \\
\hline 5182 & $1 / 14 / 200814: 32$ & $8 / 14 / 200814: 32$ & 1.898 & 25.6 \\
\hline 5183 & $1 / 14 / 200814: 34$ & $8 / 14 / 200814: 34$ & 1.912 & 25.6 \\
\hline 5184 & $1 / 14 / 200814: 36$ & $8 / 14 / 200814: 36$ & 1.924 & 25.4 \\
\hline 5185 & $1 / 14 / 200814: 38$ & $8 / 14 / 200814: 38$ & 1.936 & 25.4 \\
\hline 5186 & $1 / 14 / 200814: 40$ & $8 / 14 / 200814: 40$ & 1.946 & 25.3 \\
\hline 5187 & $1 / 14 / 200814: 42$ & $8 / 14 / 200814: 42$ & 1.956 & 25.3 \\
\hline 5188 & $1 / 14 / 200814: 44$ & $8 / 14 / 200814: 44$ & 1.964 & 25.3 \\
\hline 5189 & $1 / 14 / 200814: 46$ & $8 / 14 / 200814: 46$ & 1.972 & 25.3 \\
\hline 5190 & $1 / 14 / 200814: 48$ & $8 / 14 / 200814: 48$ & 1.979 & 25.2 \\
\hline 5191 & $1 / 14 / 200814: 50$ & $8 / 14 / 200814: 50$ & 1.986 & 25.2 \\
\hline 5192 & $1 / 14 / 200814: 52$ & $8 / 14 / 200814: 52$ & 1.993 & 25.1 \\
\hline 5193 & $1 / 14 / 200814: 54$ & $8 / 14 / 200814: 54$ & 1.999 & 25.1 \\
\hline 5194 & $1 / 14 / 200814: 56$ & $8 / 14 / 200814: 56$ & 2.005 & 25.1 \\
\hline 5195 & $1 / 14 / 200814: 58$ & $8 / 14 / 200814: 58$ & 2.01 & 25 \\
\hline 5196 & $1 / 14 / 200815: 00$ & 8/14/2008 15:00 & 2.015 & 25 \\
\hline 5197 & $1 / 14 / 200815: 02$ & $8 / 14 / 2008$ 15:02 & 2.02 & 25 \\
\hline 5198 & $1 / 14 / 200815: 04$ & 8/14/2008 15:04 & 2.025 & 25 \\
\hline 5199 & $1 / 14 / 200815: 06$ & $8 / 14 / 200815: 06$ & 203 & 25 \\
\hline 5200 & $1 / 14 / 200815: 08$ & $8 / 14 / 200815: 08$ & 2.035 & 25 \\
\hline 5201 & $1 / 14 / 200815: 10$ & $8 / 14 / 2008$ 15:10 & 2.039 & 25 \\
\hline 5202 & $1 / 14 / 200815: 12$ & $8 / 14 / 2008$ 15:12 & 2.043 & 25 \\
\hline
\end{tabular}

\begin{tabular}{|c|c|c|c|c|}
\hline \multicolumn{5}{|c|}{ D493p } \\
\hline $\operatorname{Rec}$ & & Adjusted & Pressure & Temp \\
\hline \# & Date/Time & Date/Time & psi & ${ }^{\circ} \mathrm{C}$ \\
\hline 5203 & 1/14/2008 15:14 & $8 / 14 / 2008$ 15:14 & 2047 & 25 \\
\hline 5204 & 1/14/2008 15:16 & $8 / 14 / 200815: 16$ & 2051 & 25 \\
\hline 5205 & 1/14/2008 15:18 & $8 / 14 / 200815: 18$ & 2054 & 25 \\
\hline 5206 & 1/14/2008 15:20 & $8 / 14 / 200815: 20$ & 2057 & 25 \\
\hline 5207 & $1 / 14 / 200815: 22$ & 8/14/2008 15:22 & 2059 & 25 \\
\hline 5208 & $1 / 14 / 200815: 24$ & $8 / 14 / 200815: 24$ & 2062 & 25 \\
\hline 5209 & 1/14/2008 15:26 & $8 / 14 / 200815: 26$ & 2065 & 25 \\
\hline 5210 & $1 / 14 / 2008$ 15:28 & \begin{tabular}{|l|}
$8 / 14 / 200815: 28$ \\
\end{tabular} & 2068 & 25 \\
\hline 5211 & 1/14/2008 15:30 & \begin{tabular}{|l|}
$8 / 14 / 2008$ 15:30 \\
\end{tabular} & 2071 & 25 \\
\hline 5212 & 1/14/2008 15:32 & 8/14/2008 15:32 & 2.073 & 25 \\
\hline 5213 & $1 / 14 / 2008$ 15:34 & $8 / 14 / 200815: 34$ & 2075 & 25 \\
\hline 5214 & 1/14/2008 15:36 & $8 / 14 / 200815: 36$ & 2078 & 25 \\
\hline 5215 & 1/14/2008 15:38 & 8/14/2008 15:38 & 2079 & 25 \\
\hline 5216 & 1/14/2008 15:40 & \begin{tabular}{|l|}
$8 / 14 / 200815: 40$ \\
\end{tabular} & 2081 & 25 \\
\hline 5217 & 1/14/2008 15:42 & \begin{tabular}{|l|}
$8 / 14 / 200815: 42$ \\
\end{tabular} & 2083 & 25 \\
\hline 5218 & 1/14/2008 15:44 & \begin{tabular}{|l|}
$8 / 14 / 200815: 44$ \\
\end{tabular} & 2085 & 25 \\
\hline 5219 & 1/14/2008 15:46 & \begin{tabular}{|l|}
$8 / 14 / 200815: 46$ \\
\end{tabular} & 2087 & 25.1 \\
\hline 5220 & 1/14/2008 15:48 & \begin{tabular}{|l|}
$8 / 14 / 200815: 48$ \\
\end{tabular} & 2088 & 25 \\
\hline 5221 & 1/14/2008 15:50 & 8/14/2008 15:50 & 2091 & 25 \\
\hline 5222 & 1/14/2008 15:52 & $8 / 14 / 200815: 52$ & 2091 & 25 \\
\hline 5223 & $1 / 14 / 200815: 54$ & \begin{tabular}{|l|l|}
$8 / 14 / 200815: 54$ \\
\end{tabular} & 2094 & 25 \\
\hline 5224 & $1 / 14 / 200815: 56$ & $8 / 14 / 200815: 56$ & 2097 & 25 \\
\hline 5225 & 1/14/2008 15:58 & 8/14/2008 15:58 & 2.098 & 25 \\
\hline 5226 & $1 / 14 / 200816: 00$ & $8 / 14 / 200816: 00$ & 2099 & 25 \\
\hline 5227 & 1/14/2008 16:02 & 8/14/2008 16:02 & 2.101 & 25 \\
\hline 5228 & 1/14/2008 16:04 & 8/14/2008 16:04 & 2.103 & 25 \\
\hline 5229 & 1/14/2008 16:06 & $8 / 14 / 200816: 06$ & 2104 & 25 \\
\hline 5230 & 1/14/2008 16:08 & \begin{tabular}{|l|}
$8 / 14 / 200816: 08$ \\
\end{tabular} & 2105 & 25 \\
\hline 5231 & 1/14/2008 16:10 & \begin{tabular}{|l|}
$8 / 14 / 2008$ 16:10 \\
\end{tabular} & 2.105 & 25.1 \\
\hline 5232 & 1/14/2008 16:12 & \begin{tabular}{|l|}
$8 / 14 / 200816: 12$ \\
\end{tabular} & 2.106 & 25 \\
\hline 5233 & 1/14/2008 16:14 & \begin{tabular}{|l|}
$8 / 14 / 2008$ 16:14 \\
\end{tabular} & 2.108 & 25 \\
\hline 5234 & 1/14/2008 16:16 & \begin{tabular}{|l|}
$8 / 14 / 2008$ 16:16 \\
\end{tabular} & 2108 & 25 \\
\hline 5235 & 1/14/2008 16:18 & 8/14/2008 16:18 & 2.11 & 25.1 \\
\hline 5236 & $1 / 14 / 200816: 20$ & \begin{tabular}{|l|}
$8 / 14 / 200816: 20$ \\
\end{tabular} & 2111 & 25.1 \\
\hline 5237 & 1/14/2008 16:22 & \begin{tabular}{|l|}
$8 / 14 / 200816: 22$ \\
\end{tabular} & 2112 & 25.1 \\
\hline 5238 & $1 / 14 / 200816: 24$ & $0816: 24$ & 2112 & 25.1 \\
\hline 5239 & $1 / 14 / 200816: 26$ & $8 / 14 / 200816: 26$ & 2.113 & 25.1 \\
\hline 5240 & $1 / 14 / 200816: 28$ & $8816: 28$ & 2114 & 25 \\
\hline 5241 & $1 / 14 / 200816: 30$ & 8/14/2008 16:30 & 2115 & 25 \\
\hline 5242 & $1 / 14 / 200816: 32$ & \begin{tabular}{|l|}
$8 / 14 / 200816: 32$ \\
\end{tabular} & 2115 & 25.1 \\
\hline 5243 & 1/14/2008 16:34 & $8816: 34$ & 2.117 & 25.1 \\
\hline 5244 & $1 / 14 / 200816: 36$ & 8/14/2008 16:36 & 2117 & 25.1 \\
\hline 5245 & $1 / 14 / 200$ & $8816: 38$ & 2.118 & 25.1 \\
\hline 5246 & 1/14/2008 16:40 & $816: 40$ & 2119 & 25.1 \\
\hline 5247 & 1/14/2008 16:42 & \begin{tabular}{|l|}
$8 / 14 / 2008$ 16:42 \\
\end{tabular} & 2.12 & 25.1 \\
\hline 5248 & $1 / 14 / 200816: 44$ & \begin{tabular}{|l|}
$8 / 14 / 200816: 44$ \\
\end{tabular} & 2.12 & 25 \\
\hline 5249 & 1/14/2008 16:46 & \begin{tabular}{|l|}
$8 / 14 / 200816: 46$ \\
\end{tabular} & 2121 & 25.1 \\
\hline 5250 & $1 / 14 / 200816: 48$ & $8 / 14 / 200816: 48$ & 2.12 & 25.1 \\
\hline 5251 & $1 / 14 / 200816: 50$ & $16: 50$ & 2.122 & 25 \\
\hline 5252 & $1 / 14 / 200816: 52$ & \begin{tabular}{|l|}
$8 / 14 / 2008 \quad 16: 52$ \\
\end{tabular} & 2.122 & 25.1 \\
\hline 5253 & $1 / 14 / 200816: 54$ & \begin{tabular}{|l|}
$8 / 14 / 200816: 54$ \\
\end{tabular} & 2123 & 25.1 \\
\hline 5254 & $1 / 14 / 200816: 56$ & \begin{tabular}{|c|}
$8 / 14 / 200816: 56$ \\
\end{tabular} & 2.123 & 25.1 \\
\hline 5255 & $1 / 14 / 200816: 58$ & $8 / 14 / 200816: 58$ & 2.123 & 25.1 \\
\hline 5256 & 1/14/2008 17:00 & 8/14/2008 17:00 & 2123 & 25.1 \\
\hline 5257 & $1 / 14 / 2008$ 17:02 & $8 / 14 / 2008$ 17:02 & 2124 & 25.1 \\
\hline 5258 & $1 / 14 / 200817: 04$ & $8 / 14 / 2008 \quad 17: 04$ & 2.124 & 25.1 \\
\hline 5259 & 1/14/2008 17:06 & $8 / 14 / 200817: 06$ & 2.125 & 25.1 \\
\hline 5260 & $1 / 14 / 200817: 08$ & \begin{tabular}{|l|}
$8 / 14 / 200817: 08$ \\
\end{tabular} & 2.125 & 25.1 \\
\hline 5261 & 1/14/2008 17:10 & $8 / 14 / 2008$ 17:10 & 2.125 & 25.1 \\
\hline 5262 & $1 / 14 / 200817: 12$ & \begin{tabular}{|l|}
$8 / 14 / 2008$ 17:12 \\
\end{tabular} & 2.126 & 25.1 \\
\hline 5263 & $1 / 14 / 2008$ 17:14 & \begin{tabular}{|l|}
$8 / 14 / 2008$ \\
\end{tabular} & 2.126 & 25.1 \\
\hline 5264 & 1/14/2008 17:16 & $8 / 14 / 2008$ 17:16 & 2.127 & 25.1 \\
\hline 5265 & 1/14/2008 17:18 & \begin{tabular}{|l|}
$8 / 14 / 2008$ \\
$17: 18$ \\
\end{tabular} & 2.127 & 25.1 \\
\hline 5266 & 1/14/2008 17:20 & $8 / 14 / 200817: 20$ & 2.127 & 25.1 \\
\hline 5267 & 1/14/2008 17:22 & $8 / 14 / 2008 \quad 17: 22$ & 2127 & 25.1 \\
\hline 5268 & $1 / 14 / 2008$ 17:24 & \begin{tabular}{|l|}
$8 / 14 / 2008$ 17:24 \\
\end{tabular} & 2128 & 25.1 \\
\hline 5269 & 1/14/2008 17:26 & \begin{tabular}{|l|}
$8 / 14 / 200817: 26$ \\
\end{tabular} & 2.129 & 25.2 \\
\hline 5270 & $1 / 14 / 200817: 28$ & $8 / 14 / 2008$ 17:28 & 2.127 & 25.3 \\
\hline 5271 & $1 / 14 / 200817: 30$ & \begin{tabular}{|l|l|}
$8 / 14 / 2008$ & $17: 30$ \\
\end{tabular} & 2.127 & 25.3 \\
\hline
\end{tabular}

\begin{tabular}{|c|c|c|c|c|}
\hline \multicolumn{5}{|c|}{ D4-93p } \\
\hline $\operatorname{Rec}$ & & Adjusted & Pressure & Temp \\
\hline$\#$ & Date/Time & Date/Time & psi & ${ }^{\circ} \mathrm{C}$ \\
\hline 5272 & 1/14/2008 17:32 & \begin{tabular}{|l|l|l}
$8 / 14 / 2008$ & $17: 32$ \\
\end{tabular} & 2127 & 25.3 \\
\hline 5273 & $1 / 14 / 200817: 34$ & $8 / 14 / 2008$ 17:34 & 2126 & 25.4 \\
\hline 5274 & $1 / 14 / 200817: 36$ & \begin{tabular}{|l|}
$8 / 14 / 2008$ 17:36 \\
\end{tabular} & 2129 & 25.4 \\
\hline 5275 & $1 / 14 / 200817: 38$ & $8 / 14 / 200817: 38$ & 2129 & 25.3 \\
\hline 5276 & $1 / 14 / 200817: 40$ & $8 / 14 / 200817: 40$ & 2129 & 25.3 \\
\hline 5277 & $1 / 14 / 2008$ 17:42 & $8 / 14 / 2008$ 17:42 & 2.13 & 25.3 \\
\hline 5278 & $1 / 14 / 2008$ 17:44 & \begin{tabular}{|l|}
$8 / 14 / 2008$ 17:44 \\
\end{tabular} & 2129 & 25.3 \\
\hline 5279 & $1 / 14 / 200817: 46$ & 8/14/2008 17:46 & 2129 & 25.3 \\
\hline 5280 & $1 / 14 / 2008$ 17:48 & 8/14/2008 17:48 & 2.13 & 25.3 \\
\hline 5281 & $1 / 14 / 2008$ 17:50 & $8 / 14 / 200817: 50$ & 2.13 & 25.3 \\
\hline 5282 & 1/14/2008 17:52 & $8 / 14 / 200817: 52$ & 2131 & 25.3 \\
\hline 5283 & $1 / 14 / 200817: 54$ & 8/14/2008 17:54 & 2132 & 25.2 \\
\hline 5284 & $1 / 14 / 200817: 56$ & $8 / 14 / 200817: 56$ & 2.131 & 25.3 \\
\hline 5285 & $1 / 14 / 200817: 58$ & $8 / 14 / 2008 \quad 17: 58$ & 2.13 & 25.3 \\
\hline 5286 & 1/14/2008 18:00 & 8/14/2008 18:00 & 1.867 & 25.3 \\
\hline 5287 & 1/14/2008 18:02 & $8 / 14 / 200818: 02$ & 1.999 & 25.5 \\
\hline 5288 & 1/14/2008 18:04 & 8/14/2008 18:04 & 2007 & 25.4 \\
\hline 5289 & 1/14/2008 18:06 & 8/14/2008 18:06 & 2013 & 25.4 \\
\hline 5290 & 1/14/2008 18:08 & $8 / 14 / 200818: 08$ & 2018 & 25.4 \\
\hline 5291 & 1/14/2008 18:10 & \begin{tabular}{|l|}
$8 / 14 / 2008$ 18:10 \\
\end{tabular} & 2023 & 25.4 \\
\hline 5292 & 1/14/2008 18:12 & $8 / 14 / 200818: 12$ & 2028 & 25.4 \\
\hline 5293 & $1 / 14 / 200818: 14$ & $8 / 14 / 200818: 14$ & 2056 & 25.3 \\
\hline 5294 & $1 / 14 / 200818: 16$ & $8 / 14 / 200818: 16$ & 2061 & 25.3 \\
\hline 5295 & $1 / 14 / 200818: 18$ & 8/14/2008 18:18 & 2065 & 25.3 \\
\hline 5296 & $1 / 14 / 200$ & $8 / 14 / 200818: 20$ & 2068 & 25.3 \\
\hline 5297 & $1 / 14 / 200818: 22$ & 8/14/2008 18:22 & 2072 & 25.2 \\
\hline 5298 & 1/14/2008 18:24 & 8/14/2008 18:24 & 2075 & 25.1 \\
\hline 5299 & $1 / 14 / 200818: 26$ & $8 / 14 / 200818: 26$ & 2077 & 25.1 \\
\hline 5300 & $1 / 14 / 200$ & 8/14/2008 18:28 & 2081 & 25.1 \\
\hline 5301 & 1/14/2008 18:30 & \begin{tabular}{|l|}
$8 / 14 / 2008$ 18:30 \\
\end{tabular} & 2083 & 25.1 \\
\hline 5302 & 1/14/2008 18:32 & $8 / 14 / 200818: 32$ & 2087 & 25.1 \\
\hline 5303 & 1/14/2008 18:34 & 8/14/2008 18:34 & 2088 & 25.1 \\
\hline 5304 & 1/14/2008 18:36 & \begin{tabular}{|l|}
$8 / 14 / 200818: 36$ \\
\end{tabular} & 2091 & 25.1 \\
\hline 5305 & $1 / 14 / 200818: 38$ & $8 / 14 / 200818: 38$ & 2.094 & 25.1 \\
\hline 5306 & $1 / 14 / 200818: 40$ & $8 / 14 / 2008$ 18:40 & 2096 & 25.1 \\
\hline 5307 & $1 / 14 / 200818: 42$ & $8 / 14 / 2008$ 18:42 & 2098 & 25 \\
\hline 5308 & $1 / 14 / 200818: 44$ & $8 / 14 / 2008$ 18:44 & 2.1 & 25 \\
\hline 5309 & $1 / 14 / 200818: 46$ & $8 / 14 / 2008$ 18:46 & 2101 & 25 \\
\hline 5310 & $1 / 14 / 200818: 48$ & 8/14/2008 18:48 & 2103 & 25 \\
\hline 5311 & $1 / 14 / 200818: 50$ & 8/14/2008 18:50 & 2105 & 25 \\
\hline 5312 & 1/14/2008 18:52 & $8 / 14 / 2008$ 18:52 & 2.107 & 24.9 \\
\hline 5313 & 1/14/2008 18:54 & 8/14/2008 18:54 & 2.108 & 24.9 \\
\hline 5314 & 1/14/2008 18:56 & $8 / 14 / 2008$ 18:56 & 2.11 & 24.9 \\
\hline 5315 & $1 / 14 / 200818: 58$ & $8 / 14 / 2008$ 18:58 & 2.111 & 24.9 \\
\hline 5316 & $1 / 14 / 200$ & $8 / 14 / 200819: 00$ & 2.113 & 24.9 \\
\hline 5317 & $1 / 14 / 200819: 02$ & $8 / 14 / 2008$ 19:02 & 2.114 & 24.9 \\
\hline 5318 & $1 / 14 / 20$ & 8/14/2008 19:04 & 2115 & 24.9 \\
\hline 5319 & $1 / 14 / 20081$ & $8 / 14 / 2008$ 19:06 & 2117 & 24.9 \\
\hline 5320 & 1/14/2008 19:08 & 8/14/2008 19:08 & 2118 & 24.9 \\
\hline 5321 & $1 / 14 / 2008$ 19:10 & \begin{tabular}{|l|}
$8 / 14 / 2008$ 19:10 \\
\end{tabular} & 2.12 & 24.9 \\
\hline 5322 & $1 / 14 / 200819: 12$ & \begin{tabular}{|l|}
$8 / 14 / 2008$ 19:12 \\
\end{tabular} & 2.121 & 24.9 \\
\hline 5323 & 1/14/2008 19:14 & 8/14/2008 19:14 & 2122 & 25 \\
\hline 5324 & 1/14/2008 19:16 & 8/14/2008 19:16 & 2.124 & 24.9 \\
\hline 5325 & $1 / 14 / 2008+9: 18$ & $8 / 14 / 2008$ 19:18 & 2.125 & 24.9 \\
\hline 5326 & $1 / 14 / 200819: 20$ & $8 / 14 / 2008$ 19:20 & 2125 & 24.9 \\
\hline 5327 & $1 / 14 / 200819: 22$ & $8 / 14 / 2008$ 19:22 & 2.127 & 25 \\
\hline 5328 & 1/14/2008 19:24 & $8 / 14 / 2008$ 19:24 & 2.128 & 25 \\
\hline 5329 & $1 / 14 / 2008$ 19:26 & $8 / 14 / 2008$ 19:26 & 2.13 & 25 \\
\hline 5330 & $1 / 14 / 200819: 28$ & $8 / 14 / 2008$ 19:28 & 2.13 & 25.1 \\
\hline 5331 & $1 / 14 / 200819: 30$ & $8 / 14 / 2008$ 19:30 & 2.131 & 25.1 \\
\hline 5332 & $1 / 14 / 2008$ 19:32 & 8/14/2008 19:32 & 2.132 & 25.1 \\
\hline 5333 & t/14/2008 19:34 & $8 / 14 / 2008$ 19:34 & 2133 & 25.1 \\
\hline 5334 & 1/14/2008 19:36 & $8 / 14 / 2008$ 19:36 & 2.134 & 25.1 \\
\hline 5335 & 1/14/2008 19:38 & $8 / 14 / 2008$ 19:38 & 2.135 & 25.1 \\
\hline 5336 & $1 / 14 / 200819: 40$ & $8 / 14 / 2008$ 19:40 & 2.135 & 25.3 \\
\hline 5337 & $1 / 14 / 200819: 42$ & $8 / 14 / 200819: 42$ & 2.135 & 25.3 \\
\hline 5338 & 1/14/2008 19:44 & $8 / 14 / 200819: 44$ & 2.136 & 25.2 \\
\hline 5339 & $1 / 14 / 200819: 46$ & $8 / 14 / 2008 \quad 19: 46$ & 2136 & 25.2 \\
\hline 5340 & $1 / 14 / 2008+9: 48$ & $8 / 14 / 200819: 48$ & 2.137 & 25.1 \\
\hline
\end{tabular}


DOE/RL-2009-35, REV. 0

\begin{tabular}{|c|c|c|c|c|}
\hline \multicolumn{5}{|c|}{ D4-93p } \\
\hline $\operatorname{Rec}$ & & Adjusted & Pressure & Termp \\
\hline$\#$ & Date/Time & Date/Time & $p s i$ & ${ }^{\infty} \mathrm{C}$ \\
\hline 5341 & $1 / 14 / 200819: 50$ & $8 / 14 / 200819: 50$ & 2.137 & 25.1 \\
\hline 5342 & $1 / 14 / 200819: 52$ & $8 / 14 / 200819: 52$ & 2.137 & 25.1 \\
\hline 5343 & $1 / 14 / 200819: 54$ & $8 / 14 / 200819: 54$ & 2.138 & 25.1 \\
\hline 5344 & $1 / 14 / 2008$ 19:56 & $8 / 14 / 200819: 56$ & 2.138 & 25.1 \\
\hline 5345 & $1 / 14 / 200819: 58$ & $8 / 14 / 200819: 58$ & 2.139 & 25.1 \\
\hline 5346 & $1 / 14 / 200820: 00$ & $8 / 14 / 200820: 00$ & 2.14 & 25.1 \\
\hline 5347 & $1 / 14 / 200820: 02$ & $8 / 14 / 200820: 02$ & 2.14 & 25.1 \\
\hline 5348 & 1/14/2008 20:04 & $8 / 14 / 200820: 04$ & 2.141 & 25.1 \\
\hline 5349 & $1 / 14 / 200820: 06$ & $8 / 14 / 200820: 06$ & 2.141 & 25.1 \\
\hline 5350 & 1/14/2008 20:08 & $8 / 14 / 200820: 08$ & 2.142 & 25.1 \\
\hline 5351 & $1 / 14 / 200820: 10$ & $8 / 14 / 200820: 10$ & 2.142 & 25.1 \\
\hline 5352 & $1 / 14 / 200820: 12$ & $8 / 14 / 200820: 12$ & 2.142 & 25.1 \\
\hline 5353 & $820: 14$ & $8 / 14 / 200820: 14$ & 2.142 & 25.1 \\
\hline 5354 & 1/14/200820:16 & $8 / 14 / 200820: 16$ & 2.143 & 25.1 \\
\hline 5355 & 1/14/200820:18 & $8 / 14 / 200820: 18$ & 2.143 & 25.1 \\
\hline 5356 & $1 / 14 / 200820: 20$ & $8 / 14 / 200820: 20$ & 2.143 & 25.1 \\
\hline 5357 & $820: 22$ & $8 / 14 / 200820: 22$ & 2.143 & 25.1 \\
\hline 5358 & $1 / 14 / 2$ & $8 / 14 / 200820: 24$ & 2.144 & 25.1 \\
\hline 5359 & $1 / 14 / 200820: 26$ & $8 / 14 / 200820: 26$ & 2.144 & 25.1 \\
\hline 5360 & $320: 28$ & $8 / 14 / 200820: 28$ & 2.144 & 25.1 \\
\hline 5361 & $1 / 14 / 2$ & $8 / 14 / 200820: 30$ & 2.144 & 25.1 \\
\hline 5362 & $1 / 14 / 2$ & $8 / 14 / 200$ & 2.143 & 25.1 \\
\hline 5363 & 1/14/2008 20:34 & $8 / 14 / 200820: 34$ & 2.144 & 25.1 \\
\hline 5364 & $1 / 14 / 20$ & $8 / 14 / 200820: 36$ & 2.144 & 25.1 \\
\hline 5365 & $1 / 14 / 20$ & $8 / 14 / 200820: 38$ & 2.145 & 25.1 \\
\hline 5366 & $1 / 14 / 2$ & $8 / 14 / 200$ & 2.144 & 25.1 \\
\hline 5367 & $1 / 14 / 20$ & $8 / 14 / 200820: 42$ & 2.145 & 25.1 \\
\hline 5368 & $1 / 14 / 2008$ & $8 / 14 / 200820: 44$ & 2.145 & 25.1 \\
\hline 5369 & $1 / 14 / 2$ & $8 / 14 / 200$ & 2.145 & 25.1 \\
\hline 5370 & $1 / 14 / 2$ & $8 / 14 / 200820: 48$ & 2.146 & 25.1 \\
\hline 5371 & $1 / 14 / 2$ & $8 / 14 / 200820: 50$ & 2.145 & 25.2 \\
\hline 5372 & $1 / 14 / 2$ & $8 / 14 / 200820: 52$ & 2.146 & 25.3 \\
\hline 5373 & $1 / 14 / 2$ & $8 / 14 / 200820: 54$ & 2.146 & 25.3 \\
\hline 5374 & $1 / 14 / 2$ & $8 / 14 / 200$ & 2.145 & 25.2 \\
\hline 5375 & $1 / 14 / 2$ & $8 / 14 / 200820: 58$ & 2.146 & 25.3 \\
\hline 5376 & $1 / 14 / 2$ & $8 / 14 / 200821: 00$ & 2.144 & 25.2 \\
\hline 5377 & $1 / 14 / 2$ & $8 / 14 / 200821: 02$ & 2.144 & 25.2 \\
\hline 5378 & $1 / 14 / 2$ & $8 / 14 / 200$ & 2.144 & 25.2 \\
\hline 5379 & $1 / 14 / 2$ & $8 / 14 / 200821: 06$ & 2.145 & 25.3 \\
\hline 5380 & $1 / 14 / 2$ & $8 / 14 / 200821: 08$ & 2.144 & 25.2 \\
\hline 5381 & $1 / 14 / 2$ & $8 / 14 / 200$ & 2.145 & 25.2 \\
\hline 5382 & $1 / 14$ & $8 / 14 / 2$ & 2.145 & 25.2 \\
\hline 5383 & $1 / 14 / 200$ & $8 / 14 / 200$ & 2.145 & 25.2 \\
\hline 5384 & $1 / 14 / 200$ & $8 / 14 / 200821: 16$ & 2.146 & 25.2 \\
\hline 5385 & $1 / 14 / 2$ & $8 / 14 / 200821: 18$ & 2.145 & 25.2 \\
\hline 5386 & $1 / 14 / 2$ & $8 / 14 / 200$ & 2,147 & 25.3 \\
\hline 5387 & $1 / 14 / 2$ & $8 / 14 / 200821: 22$ & 2.146 & 25.2 \\
\hline 5388 & $1 / 14 / 2$ & $8 / 14 / 200821: 24$ & 2.146 & 25.3 \\
\hline 5389 & $1 / 14 / 200$ & $8 / 14 / 200821: 26$ & 2.147 & 25.3 \\
\hline 5390 & $1 / 14 / 200$ & $8 / 14 / 200$ & 2.146 & 25.2 \\
\hline 5391 & & $8 / 14 / 200$ & 2.147 & 25.2 \\
\hline 5392 & $1 / 14 / 200$ & $8 / 14 / 200$ & 2.146 & 25.2 \\
\hline 5393 & $1 / 14 / 200$ & $8 / 14 / 200821: 34$ & 2.146 & 25.2 \\
\hline 5394 & $1 / 14 / 200$ & $8 / 14 / 200$ & 2.147 & 25.3 \\
\hline 5395 & $1 / 14 / 2$ & $8 / 14 / 200$ & 2.146 & 25.3 \\
\hline 5396 & $1 / 14 / 2$ & $8 / 14 / 200$ & 2.147 & 25.3 \\
\hline 5397 & $1 / 14 / 200821: 42$ & $8 / 14 / 200821: 42$ & 2.146 & 25.3 \\
\hline 5398 & $1 / 14 / 200821: 44$ & $8 / 14 / 200821: 44$ & 2.147 & 25.3 \\
\hline 5399 & $1 / 14 / 200$ & $8 / 14 / 200821: 46$ & 2.147 & 25.3 \\
\hline 5400 & $1 / 14 / 2$ & $8 / 14 / 200821: 48$ & 2.147 & 25.3 \\
\hline 5401 & $1 / 14 / 200821: 50$ & $8 / 14 / 200821: 50$ & 2.146 & 25.2 \\
\hline 5402 & $1 / 14 / 200821: 52$ & $8 / 14 / 200821: 52$ & 2.147 & 25.2 \\
\hline 5403 & $1 / 14 / 200821: 54$ & $8 / 14 / 200821: 54$ & 2.147 & 25.2 \\
\hline 5404 & $1 / 14 / 200821: 56$ & $8 / 14 / 200821: 56$ & 2.147 & 25.3 \\
\hline 5405 & $1 / 14 / 200821: 58$ & $8 / 14 / 200821: 58$ & 2.146 & 25.2 \\
\hline 5406 & 1/14/2008 22:00 & $8 / 14 / 200822: 00$ & 2.147 & 25.3 \\
\hline 5407 & 1/14/2008 22:02 & $8 / 14 / 200822: 02$ & 2.147 & 25.3 \\
\hline 5408 & $1 / 14 / 200822: 04$ & $8 / 14 / 200822: 04$ & 2.147 & 25.2 \\
\hline 5409 & $1 / 14 / 200822: 06$ & $8 / 14 / 200822: 06$ & 2.146 & 25.2 \\
\hline
\end{tabular}

\begin{tabular}{|c|c|c|c|c|}
\hline \multicolumn{5}{|c|}{ D4-93p } \\
\hline $\operatorname{Rec}$ & & Adjusted & Pressure & Temp \\
\hline \# & Date/Time & Date/Time & psi & ${ }^{\circ} \mathrm{C}$ \\
\hline 5410 & $1 / 14 / 200822: 08$ & $8 / 14 / 200822: 08$ & 2.146 & 25.2 \\
\hline 5411 & $1 / 14 / 200822: 10$ & $8 / 14 / 200822: 10$ & 2.147 & 25.3 \\
\hline 5412 & 1/14/2008 22:12 & $8 / 14 / 200822: 12$ & 2.146 & 25.2 \\
\hline 5413 & $1 / 14 / 200822: 14$ & $8 / 14 / 2008$ 22:14 & 2.147 & 25.3 \\
\hline 5414 & $1 / 14 / 200822: 16$ & $8 / 14 / 200822: 16$ & 2.147 & 25.3 \\
\hline 5415 & 1/14/2008 22:18 & $8 / 14 / 200822: 18$ & 2.146 & 25.2 \\
\hline$\overline{5416}$ & 1/14/2008 22:20 & $8 / 14 / 200822: 20$ & 2.147 & 25.2 \\
\hline 5417 & $1 / 14 / 200822: 22$ & $8 / 14 / 200822: 22$ & 2.147 & 25.3 \\
\hline 5418 & $1 / 14 / 200822: 24$ & $8 / 14 / 200822: 24$ & 2.146 & 25.2 \\
\hline 5419 & $1 / 14 / 200822: 26$ & $8 / 14 / 200822: 26$ & 2.146 & 25.2 \\
\hline 5420 & 1/14/2008 22:28 & $8 / 14 / 200822: 28$ & 2.147 & 25.2 \\
\hline 5421 & $1 / 14 / 200822: 30$ & $8 / 14 / 200822: 30$ & 2146 & 25.2 \\
\hline 5422 & $1 / 14 / 200$ & $8 / 14 / 200822: 32$ & 2.145 & 25.2 \\
\hline 5423 & $1 / 14 / 200822: 34$ & $8 / 14 / 200822: 34$ & 2.144 & 25.2 \\
\hline 5424 & $1 / 14 / 200822: 36$ & $200822: 36$ & 2.144 & 25.1 \\
\hline 5425 & $1 / 14 / 200822: 38$ & $822: 38$ & 2.144 & 25.2 \\
\hline 5426 & $0822: 40$ & $8 / 14 / 200822: 40$ & 2.145 & 25.2 \\
\hline 5427 & $1 / 14 / 200822: 42$ & $8 / 14 / 200822: 42$ & 2.144 & 25.2 \\
\hline 5428 & $1 / 14 / 200822: 44$ & $8 / 14 / 200822: 44$ & 2.145 & 25.2 \\
\hline 5429 & $22: 46$ & $8222: 46$ & 2.145 & 25.2 \\
\hline 5430 & $22: 48$ & $200822: 48$ & 2.144 & 25.2 \\
\hline$\overline{5431}$ & $1 / 14 / 200822: 50$ & $8 / 14 / 200822: 50$ & 2.145 & 25.2 \\
\hline 5432 & $1 / 14 / 200822: 52$ & $8 / 14 / 200822: 52$ & 2.145 & 25.2 \\
\hline 5433 & $322: 54$ & $3822: 54$ & 2.145 & 25.2 \\
\hline 5434 & $22: 56$ & $3822: 56$ & 2.146 & 25.2 \\
\hline 5435 & $822: 58$ & $8 / 14 / 200822: 58$ & 2.146 & 25.1 \\
\hline 5436 & 1/14/2008 23:00 & $200823: 00$ & 2.146 & 25.1 \\
\hline$\overline{5437}$ & $1 / 14 / 2$ & $23: 02$ & 2.146 & 25.2 \\
\hline 5438 & $1 / 14$ & $23: 04$ & 2.146 & 25.2 \\
\hline 5439 & $23: 06$ & $0823: 06$ & 2.146 & 25.2 \\
\hline$\overline{5440}$ & $323: 08$ & 8/14/2008 23:08 & 2.146 & 25.2 \\
\hline$\overline{5441}$ & $1 / 14 /$ & $23: 10$ & 2.148 & 25.3 \\
\hline 5442 & $1 / 14$ & $23: 12$ & 2.149 & 25.3 \\
\hline$\overline{5443}$ & $\overline{1 / 14 /}$ & $8823: 14$ & 1.052 & 25.3 \\
\hline 5444 & $23: 16$ & $2823: 16$ & 1.424 & 25.2 \\
\hline 5445 & $23: 18$ & $823: 18$ & 1.478 & 25.1 \\
\hline 5446 & $1 / 14$ & $23: 20$ & 1.453 & 25.1 \\
\hline$\overline{5447}$ & $1 / 14 / 2$ & $30823: 22$ & 1.551 & 25.2 \\
\hline$\overline{5448}$ & $1 / 14 / 200823: 24$ & $\overline{00823: 24}$ & 1.632 & 25.1 \\
\hline 5449 & $1 / 14 / 200823: 26$ & $823: 26$ & 1.696 & 25.1 \\
\hline 5450 & $1 / 14 /$ & $23: 28$ & 1.745 & 25.1 \\
\hline 5451 & $1 / 14 / 2$ & $23: 30$ & 1.784 & 25.1 \\
\hline 5452 & $23: 32$ & $23: 32$ & 1.814 & 25 \\
\hline$\overline{5453}$ & $23: 34$ & $23: 34$ & 1.839 & 25 \\
\hline$\overline{5454}$ & $1 / 14$ & $23: 36$ & 1.859 & 25 \\
\hline 5455 & $1 / 14 / 2$ & $323: 38$ & 1.876 & 24.9 \\
\hline 5456 & $23: 40$ & $8 / 14 / 200823: 40$ & 1.89 & 24.9 \\
\hline 5457 & $23: 42$ & $823: 42$ & 1.904 & 24.9 \\
\hline$\overline{5458}$ & $1 / 14$ & $23: 44$ & 1.915 & 24.9 \\
\hline 5459 & $1 / 14 / 2$ & $23: 46$ & 1.926 & 24.9 \\
\hline$\overline{5460}$ & $1 / 14 / 2$ & $823: 48$ & 1.935 & 24.9 \\
\hline 5461 & $1 / 14 / 200823: 50$ & $823: 50$ & 1.944 & 24.9 \\
\hline 5462 & $823: 52$ & $823: 52$ & 1.952 & 24.8 \\
\hline 5463 & $1 / 14 / 20$ & $0823: 54$ & 1.96 & 24.8 \\
\hline$\overline{5464}$ & $1 / 14 / 200$ & $8 / 14 / 200$ & 1.968 & 24.8 \\
\hline 5465 & $1 / 14 / 200823: 58$ & $8 / 14 / 200823: 58$ & 1.975 & 24.8 \\
\hline$\overline{5466}$ & $1 / 15 / 20080: 00$ & $8 / 15 / 20080: 00$ & 1.982 & 24.7 \\
\hline 5467 & $1 / 15$ & $080: 02$ & 1.989 & 24.7 \\
\hline 5468 & $1 / 15$ & $880: 04$ & 1.994 & 24.7 \\
\hline 5469 & $1 / 15 / 20080: 06$ & $8 / 15 / 20080: 06$ & 2 & 24.6 \\
\hline 5470 & $1 / 15 / 20080: 08$ & $0080: 08$ & 2.004 & $\overline{24.6}$ \\
\hline 5471 & $1 / 15 / 20080: 10$ & $8 / 15 / 20080: 10$ & 2.009 & 24,6 \\
\hline 5472 & $1 / 15 / 20080: 12$ & $8 / 15 / 20080: 12$ & 2.014 & 24.6 \\
\hline$\overline{5473}$ & $1 / 15 / 20080: 14$ & $8 / 15 / 20080: 14$ & 2.018 & 24.7 \\
\hline 5474 & $1 / 15 / 20080: 16$ & $8 / 15 / 20080: 16$ & 2.023 & 24.7 \\
\hline 5475 & $1 / 15 / 20080: 18$ & $8 / 15 / 20080: 18$ & 2.026 & 24.7 \\
\hline 5476 & $1 / 15 / 20080: 20$ & $8 / 15 / 20080: 20$ & 2.031 & 24.7 \\
\hline 5477 & $1 / 15 / 20080: 22$ & $8 / 15 / 20080: 22$ & 2.035 & 24.7 \\
\hline 5478 & $1 / 15 / 20080: 24$ & $8 / 15 / 20080: 24$ & 2.039 & 24.8 \\
\hline
\end{tabular}

\begin{tabular}{|c|c|c|c|c|}
\hline \multicolumn{5}{|c|}{ D493 } \\
\hline $\operatorname{Rec}$ & & Adjusted & Pressure & Temp \\
\hline$\#$ & Date/Time & Date//ime & psi & \\
\hline & 1/15/2008:26 & $8 / 15 / 20080: 26$ & 2.042 & \\
\hline & & $8 / 15 / 20080: 28$ & 2.047 & \\
\hline 5481 & & & 2.05 & \\
\hline 5482 & $1 / 15 / 20080: 32$ & $8 / 15 / 20080: 32$ & 2.05 & \\
\hline 4833 & $1 / 15 / 20080: 34$ & $8 / 15 / 20080: 34$ & 2.056 & 24 \\
\hline 5484 & $1 / 15 / 20080: 36$ & $8 / 15 / 20080: 36$ & 2.05 & 24. \\
\hline 5485 & & $8 / 15 / 20080: 38$ & 2.06 & \\
\hline & $1 / 15 / 20080: 40$ & $8 / 15 / 20080: 40$ & 2.066 & \\
\hline 5487 & $5 / 20080: 42$ & $8 / 15 / 20080: 42$ & 2.067 & \\
\hline & & $8 / 15 / 20080: 44$ & & \\
\hline 5489 & $1 / 15 / 20080: 46$ & $8 / 15 / 20080: 46$ & 2.072 & \\
\hline & $1 / 15 / 20080: 48$ & $8 / 15 / 20080: 48$ & 2.075 & \\
\hline 5491 & $1 / 15 / 20080: 50$ & $8 / 15 / 20080: 50$ & 2.07 & \\
\hline & 1/15/2008 0:52 & $8 / 15 / 20080: 52$ & 2.079 & \\
\hline & $5 / 20080$ & $15 / 20080: 54$ & 2.08 & \\
\hline & $5 / 20080:$ & $8 / 15 / 20080: 56$ & 2.08 & \\
\hline & 5/2008 0:58 & $8 / 15 / 20080: 58$ & & \\
\hline & $1 / 15 / 20081: 00$ & $8 / 15 / 20081: 00$ & 2.087 & \\
\hline & $1 / 15 / 2008$ 1:02 & $8 / 15 / 20081: 02$ & & \\
\hline 498 & 1/15/2008 1:04 & $8 / 15 / 20081: 04$ & 2.09 & \\
\hline 199 & 5/2008 1:06 & $8 / 15 / 2008$ 1:06 & 2.092 & \\
\hline & $1 / 15 / 20081: 08$ & $8 / 15 / 20081: 08$ & 2.093 & \\
\hline & $1 / 15 / 20081: 10$ & $8 / 15 / 2008$ 1:10 & & \\
\hline & $1 / 1$ & $8 / 15 / 20081$ & 2.096 & \\
\hline & & & 2.097 & \\
\hline 504 & 20081 & $8 / 15 / 2008$ 1:1 & 2.099 & \\
\hline & 1/15/2008 1: & $8 / 15 / 20081: 18$ & 2.099 & \\
\hline & 1/115/2008 1:2 & $8 / 15 / 20081: 20$ & 2.101 & \\
\hline & $1 / 15 / 20081: 22$ & $8 / 15 / 20081: 22$ & 2.103 & 24 \\
\hline & $1 / 15 / 2008$ 1:24 & $8 / 15 / 20081: 24$ & 2.103 & \\
\hline & $1 / 15 / 20081$ & $8 / 15 / 20081: 26$ & 2.104 & \\
\hline & 1/15/2008 & $8 / 15 / 20081: 28$ & 2.106 & 24. \\
\hline & & 8715 & 2.107 & \\
\hline & & & 2.107 & \\
\hline & & & $2.10 \mathrm{~s}$ & \\
\hline 5514 & we & $8 / 15 / 20081: 3$ & 2.109 & 24 \\
\hline 5515 & 1/15/2008 & $8 / 15 / 20081: 38$ & 2.11 & \\
\hline & $15 / 2008$ & $8 / 15 / 20081$ & & \\
\hline & & & 2.112 & \\
\hline & & $8 / 15 / 2008$ & 2.113 & \\
\hline & & & 2.114 & \\
\hline & & & 2.115 & \\
\hline 552 & & & 2.115 & \\
\hline & & & & \\
\hline & & & 2.1 & \\
\hline & & & & \\
\hline & & $15 / 200$ & 2.119 & 24. \\
\hline 5526 & & & 2.12 & \\
\hline & & & & \\
\hline & & $8 / 15 / 2$ & 2.12 & \\
\hline & $1 / 15 / 2$ & $8 / 15 / 2$ & 2.121 & \\
\hline & & $8 / 15 / 2$ & & \\
\hline 553 & & $8 / 15 / 20$ & 2.122 & 24 \\
\hline & & & 2.123 & \\
\hline & & & & \\
\hline & & & & \\
\hline & & & $\overline{2.1}$ & \\
\hline & & & & \\
\hline & & $8 / 15 / 2$ & 2.125 & \\
\hline & & $8 / 15 / 2$ & 2.126 & \\
\hline & $1 / 15 / 2$ & $8 / 11 / 2008$ & 2.126 & 24 \\
\hline & & & .126 & \\
\hline & & & .127 & \\
\hline & & & & \\
\hline & & & & \\
\hline & & & & \\
\hline & & & & \\
\hline & $1 / 1 / 5 / 200$ & & 2.128 & \\
\hline & $1 / 15 / 2008$ & $8 / 15 / 2008$ & 2.129 & \\
\hline
\end{tabular}




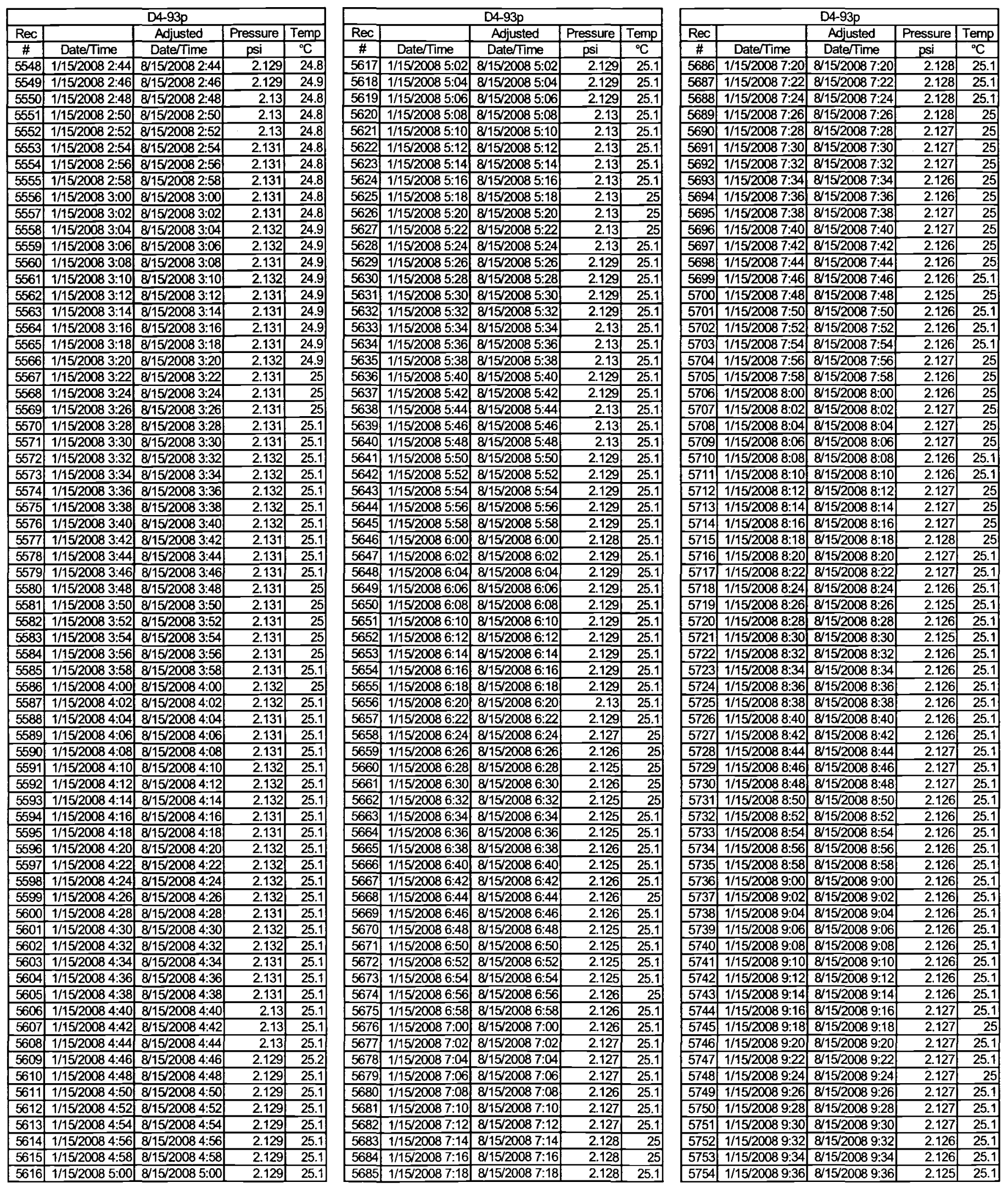




\begin{tabular}{|c|c|c|c|c|}
\hline \multicolumn{5}{|c|}{ D4-93p } \\
\hline $\operatorname{Rec}$ & & Adjusted & Pressure & Temp \\
\hline$\#$ & Date $\int$ ime & Date/Time & psi & ${ }^{\circ} \mathrm{C}$ \\
\hline 5755 & $1 / 15 / 20089: 38$ & $8 / 15 / 20089: 38$ & 2.125 & 25.1 \\
\hline 556 & $1 / 15 / 20089: 40$ & $8 / 15 / 20089: 40$ & 2.125 & 24.9 \\
\hline 5757 & $1 / 15 / 20089: 42$ & $8 / 15 / 20089: 42$ & 2.124 & 24.9 \\
\hline 5758 & $1 / 15 / 20089: 44$ & $8 / 15 / 20089: 44$ & 2.124 & 24,9 \\
\hline 5759 & $1 / 15 / 20089: 46$ & $8 / 15 / 20089: 46$ & 2.159 & 24.9 \\
\hline 5760 & $1 / 15 / 20089: 48$ & $8 / 15 / 20089: 48$ & 2.159 & 24.9 \\
\hline 5761 & $1 / 75 / 20089: 50$ & $8 / 15 / 20089: 50$ & 2.16 & 24.9 \\
\hline 5762 & $1 / 15 / 20089: 52$ & $8 / 15 / 20089: 52$ & 2.16 & 24.9 \\
\hline 5763 & $1 / 15 / 20089: 54$ & $8 / 15 / 20089: 54$ & 2.16 & 24.9 \\
\hline 5764 & $1 / 15 / 20089: 56$ & $8 / 15 / 20089: 56$ & 2.161 & 24.9 \\
\hline 5765 & $1 / 15 / 20089: 58$ & $8 / 15 / 20089: 58$ & 2.161 & 24.9 \\
\hline 5766 & $1 / 15 / 200810: 00$ & $8 / 15 / 200810: 00$ & 2.161 & 24.9 \\
\hline 5767 & $1 / 15 / 2008 \quad 10: 02$ & $8 / 15 / 2008 \quad 10: 02$ & 2.161 & 25 \\
\hline 5768 & $1 / 15 / 200810: 04$ & $8 / 15 / 2008 \quad 10: 04$ & 2.162 & 25 \\
\hline 5769 & $1 / 15 / 200810: 06$ & $8 / 15 / 200810: 06$ & 2.161 & 25 \\
\hline 5770 & $1 / 15 / 200810: 08$ & $8 / 15 / 200810008$ & 2.161 & 25 \\
\hline 5771 & $1 / 15 / 200810: 10$ & $8 / 15 / 200810: 10$ & 2.161 & 25 \\
\hline 5772 & $310: 12$ & $8 / 15$ & 2.162 & 25 \\
\hline 5773 & $1 / 15 / 20$ & $8 / 15 / 20$ & 161 & 25 \\
\hline 5774 & $1 / 15 / 2$ & $8 / 15 / 2$ & 2.162 & 25 \\
\hline 5775 & $1 / 15$ & $8 / 1$ & .162 & 25 \\
\hline 5776 & $1 / 15 / 2$ & $8 / 1$ & 2.162 & 25 \\
\hline 5777 & $810: 22$ & $8 / 15$ & 2.161 & 25 \\
\hline 5778 & $1 / 15 / 2008 \quad 10: 24$ & $8 / 15 /$ & 2.161 & 25 \\
\hline 5779 & $1 / 15 / 2008 \quad 10: 26$ & $8 / 15 / 2008 \quad 10: 26$ & 2.161 & 25 \\
\hline 5780 & $1 / 15 / 200810: 28$ & $8 / 15 / 2008 \quad 10: 28$ & 2.163 & 25.1 \\
\hline 5781 & $1 / 15 / 200810: 30$ & $8 / 15 / 2008 \quad 10: 30$ & 2.16 & 24.9 \\
\hline 5782 & $1 / 15 / 2008 \quad 10: 32$ & $8 / 15 / 2008 \quad 10: 32$ & 2.161 & 24.9 \\
\hline 5783 & $1 / 15 / 200810: 34$ & $0810: 34$ & 2.16 & 24.9 \\
\hline 5784 & $0: 36$ & & 2.161 & 24.9 \\
\hline 5785 & $10: 38$ & $8 / 1$ & 2.161 & 24.8 \\
\hline 5786 & $10: 40$ & $8 / 1$ & .157 & 24.9 \\
\hline 5787 & $0: 42$ & & 158 & 24.8 \\
\hline 5788 & $810: 44$ & & & \\
\hline 5789 & $810: 46$ & & & \\
\hline 5790 & $1 / 15 / 200810: 48$ & $8 / 15 / 2008 \quad 10: 48$ & 2.159 & 24.8 \\
\hline 5791 & $1 / 15 / 200810: 50$ & $8 / 15 / 2008 \quad 10: 50$ & 2.159 & 24.9 \\
\hline 5792 & $1 / 15 / 200810: 52$ & $8 / 15 / 2008 \quad 10: 52$ & 2.16 & 24.9 \\
\hline 5793 & $10: 54$ & $0: 54$ & 2.161 & 24.9 \\
\hline 5794 & $1 / 15 / 200810: 56$ & $8 / 15 / 2008 \quad 10: 56$ & 2.161 & 24.9 \\
\hline 5795 & & & .16 & 24.9 \\
\hline 5796 & $1 / 15$ & & 16 & 24.9 \\
\hline 5797 & $1 / 15 /$ & $8 / 1$ & 2.16 & 24.9 \\
\hline 5798 & $1 / 15$ & & 2.16 & 24.9 \\
\hline 5799 & $811: 06$ & $8 / 15 /$ & 2.16 & 24.9 \\
\hline 5800 & $1 / 15 / 200811: 08$ & $8 / 15$ & 2.16 & 24.9 \\
\hline 5801 & $1 / 15 / 2008+11: 10$ & & 2.16 & 24.9 \\
\hline 5802 & $1 / 5 / 2008+1: 12$ & $8 / 15 / 200811: 12$ & 2.16 & 24.9 \\
\hline 5803 & & & 2.17 & 24.9 \\
\hline 5804 & $\sqrt{115}$ & $8 / 1$ & 2.157 & 24.9 \\
\hline 5805 & $1 / 15 / 2$ & $811: 18$ & 2.156 & 24.9 \\
\hline 5806 & $1 / 15 / 2$ & $1: 20$ & 2.156 & 24.9 \\
\hline 5807 & $1 / 15 / 2$ & & 2.156 & 24.9 \\
\hline 5808 & $: 24$ & & 2.155 & 24.9 \\
\hline 5809 & & & & 24.9 \\
\hline 5810 & $V / 15 / 200811: 28$ & $8 / 15 / 200811: 28$ & 2.157 & 24.9 \\
\hline 5811 & $1 / 15 / 200811: 30$ & $8 / 15 / 200811: 30$ & 2.157 & 24.9 \\
\hline 5812 & $1 / 15 / 20$ & & & 24.9 \\
\hline 5813 & $1 / 15 / 2008 \quad 11: 34$ & $8 / 15 / 200811: 34$ & 2.157 & 24.9 \\
\hline 5814 & 1/15/2008 11:36 & $8 / 15 / 2008$ 11:36 & 2.155 & 24.9 \\
\hline 5815 & & & & 24.9 \\
\hline 5816 & $1 / 15 / 200811: 40$ & $8 / 15 / 200811: 40$ & 2.156 & 24.9 \\
\hline 5817 & $1 / 15 / 200811: 42$ & $8 / 15 / 200811: 42$ & 2.156 & 24.9 \\
\hline 5818 & $11: 44$ & & 1.822 & \\
\hline 5819 & $1 / 15 / 200811: 46$ & $8 / 15 / 200811: 46$ & 1.31 & 25.1 \\
\hline 5820 & $1 / 15 / 200811: 48$ & $8 / 15 / 200811: 48$ & 1.077 & 25.1 \\
\hline 5821 & $1 / 15 / 200811: 50$ & $8 / 15 / 200811: 50$ & 1.506 & 25 \\
\hline 5822 & 1/15/2008 11:52 & $8 / 15 / 200811: 52$ & 0.927 & 24.9 \\
\hline 5823 & $1 / 15 / 200811: 54$ & $8 / 15 / 200811: 54$ & 1.457 & 25 \\
\hline 5824 & $1 / 15 / 2008+1: 56$ & $8 / 15 / 200811: 56$ & 1.539 & 25 \\
\hline 5825 & $1 / 15 / 200811: 58$ & $8 / 15 / 200811: 58$ & 1.616 & 25 \\
\hline 5826 & $1 / 15 / 200812: 00$ & $8 / 15 / 200812: 00$ & 1.681 & 24.9 \\
\hline
\end{tabular}
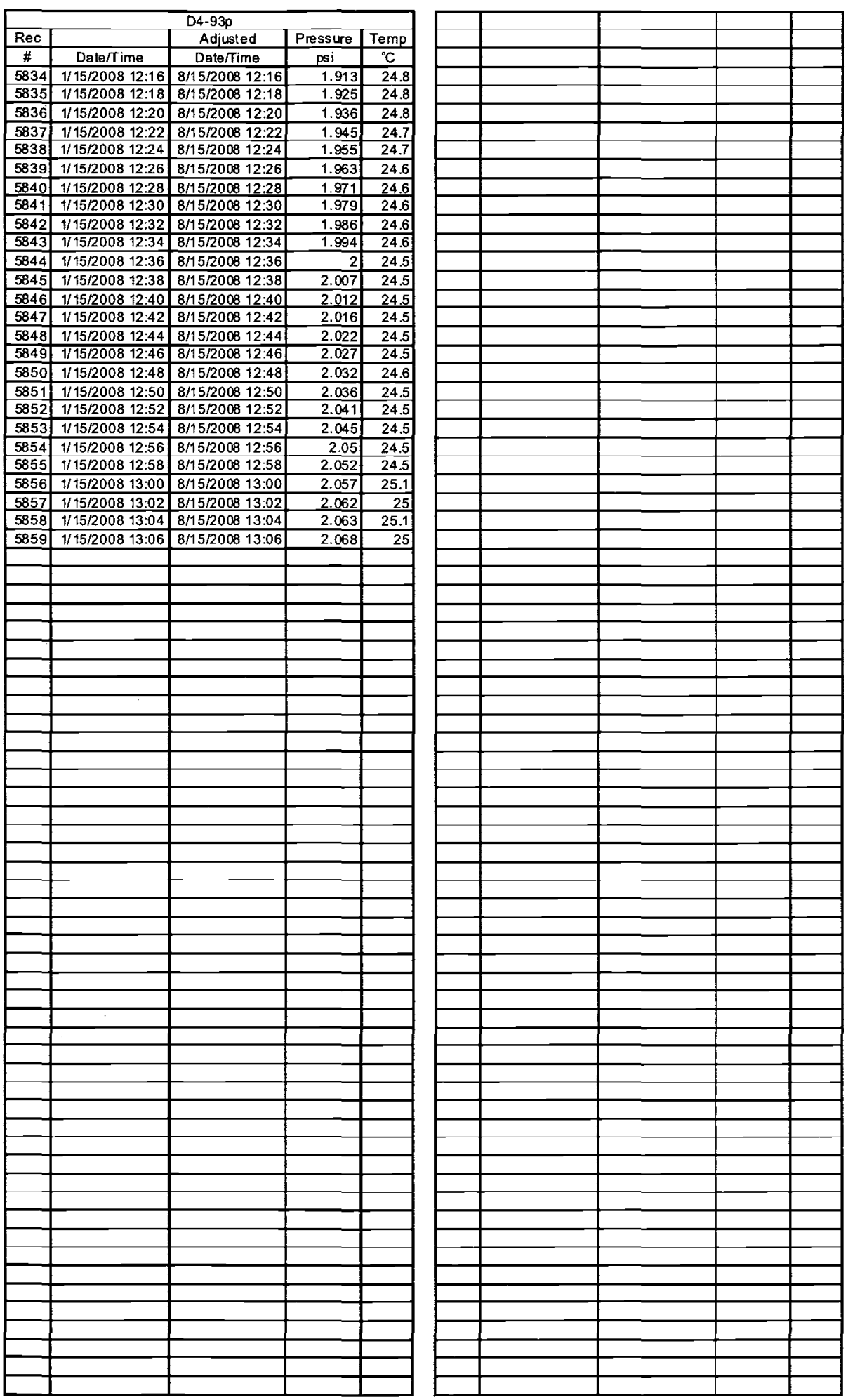


\section{D2 Geophysical Methods and Data Acquisition**}

Geophysical monitoring of the ZVI injection included electrical resistivity, frequency domain induced polarization (IP), complex resistivity, mise a la masse electric potential field mapping, time-domain electromagnetics (TEM), borehole electromagnetic (EM) induction, and total field and gradient magnetometry. A brief description of each method is provided in this section.

Geophysical data were first acquired prior to the ZVI injection to determine pre-injection baseline conditions. A static geophysical image can provide useful information about a site; however, the target of interest (in this case, the injected ZVI) may be difficult to image without sufficient knowledge of the baseline conditions. By acquiring two nearly identical surveys (one before and one after the injection), it was possible to analyze the differences in the data. These observed differences were primarily due to subsurface changes induced by the ZVI injection. Of course, there was some random noise associated with each survey, so some of the data difference was noise itself. Consequently, careful survey procedures and efforts to attenuate random noise are important aspects of the time-lapse imaging. In this study, all survey locations were staked so that the same locations could be occupied pre- and post-injection in an effort to make the data acquisition arrangements as identical as possible. Exceptions and necessary compromises are noted in this report where relevant. The survey stakes were left in place after completion of this study to facilitate possible future studies.

\section{D2.1 Location Surveying}

Locations for the geophysical measurements and electrodes were surveyed using a TopCon GTS-2B electronic distance meter (EDM) Theodolite. Survey ties were established by recording the locations of several of the wells on site and a nearby benchmark. Two survey control points were established on the site, although the second control point was needed only to locate one of the remote electrodes (Figure 2-3).

\section{D2.2 Electrical Methods}

A geoelectrical survey, in its basic form, involves injecting current into the earth and measuring the resulting electrical potential field. This is usually done using a four-electrode arrangement comprising two grounded, horizontal electrical dipoles. Current is injected using one dipole and a voltage is measured using the other dipole. Lateral and vertical resolution of an electrical survey depend on the geometry of the current injection and potential electrodes. Depth of investigation is varied by changing the electrode spacing. Lateral profiling at a constant depth is accomplished via lateral movement of the entire array for a given electrode spacing. In general, the resolution of electrical methods decreases with depth.

Typically, geoelectrical surveys are sourced with low-frequency (e.g. less than $10 \mathrm{~Hz}$ ) alternating current (ac). The use of alternating current minimizes polarization of the potential electrodes and facilitates data stacking. Data stacking refers to the procedure in which several repeated measurements of a single datum are acquired, thus allowing an estimate of data repeatability and enhancing desirable signal in the data.

\section{D2.2.1 Electrical Resistivity}

In an electrical resistivity survey, low-frequency ac is injected into the ground via a grounded dipole; the resulting electrical potential field is then measured at several locations using grounded dipoles. The measured data are normalized by the magnitude of the source current, providing a measure of subsurface electrical impedance. The impedances may be further normalized using a geometric factor (based on relative locations of the injection and measurement electrodes) to calculate a volume averaged apparent resistivity (Equation 1). Historically, the apparent resistivities were interpreted directly but modern computing facilitates more rigorous 2D and 3D numerical modeling of the data, from which reconstruction of property distributions (resistivity/conductivity) may be accomplished. Electrical resistivity data are sensitive to the electrical properties of the subsurface and are useful in imaging properties and processes associated with groundwater and unsaturated zone systems (Slater et al., 1997; Zhou et al., 2001; Binley et al., 2002; Oldenborger et al., 2007). 


$$
\rho_{A P P}=2 \pi n(n+1) a\left(\frac{\Delta V}{I}\right)
$$

Equation 1. Apparent resistivity equation for a pole-dipole (3-electrode) measurement where a is the distance between the $P 1$ and $P 2$ electrodes, na is the distance between the $C 1$ and $P 1$ electrodes, $\triangle \mathrm{V}$ is the potential difference measured between electrodes $P 1$ and $P 2$, and $\mathrm{I}$ is the magnitude of the injected current (see Figure 2-1 for a diagram of the electrode arrangement).

\section{D2.2.2 Induced Polarization}

In the frequency domain induced polarization (IP) method, as in the electrical resistivity method, low frequency alternating current is injected into the ground via an electric dipole. The measured electrical potential will oscillate at the same frequency as the injected current, but may be phase-shifted in relation to the injected current. The magnitude of the phase shift depends upon the chargeability (similar to capacitance) of the subsurface materials, which in turn depends upon the surface area, pore throat size, etc. of the investigated materials. Induced polarization data are sensitive to interfaces between regions of contrasting resistivity, such as the interface between fluid and host rock. IP data are especially sensitive to interfaces where there is a shift from ionic conduction to electronic conduction or vice-versa. Thus, induced polarization is considered a very good method for the detection of disseminated metals. Slater et al. (2005) favor IP versus other low-frequency electrical methods for in situ verification of permeable reactive barrier installations.

\section{D2.2.3 Complex Resistivity}

Complex resistivity $(\mathrm{CR})$ is an electrical method wherein the impedance and phase shift are measured for each of several source current frequencies and is also known as spectral IP. The multi-frequency nature of the data is useful in discriminating between various IP sources, allowing for more complete subsurface characterization. Another advantage to CR data versus single frequency data is that it allows for the removal of inductive coupling in the data, if such coupling is determined to be problematic. Recent research also suggests that CR is useful for determining permeability structure in the subsurface (e.g. Slater, 2007).

\section{D2.2.4 Mise a la Masse}

In the mise a la masse, or "excitation of the mass" method, one current electrode is placed down a borehole (in this case into the region of the ZVI injection) or otherwise directly grounded to a conductive body of interest, and the second current electrode is placed at "infinity" (at least five times the expected extent of the conductive body). A potential electrode is then moved to several locations surrounding the current electrode, thus mapping the lateral extent of the conductor. Quantitative interpretation of this type of data is difficult (especially if the borehole material is more conductive than the formation); however, data collection is simple and rapid compared with the other electrical methods. To normalize the data, thus eliminating the effects of distance from the injection pole, Equation 2 may be used to compute the apparent resistivity for a pole-pole measurement.

$$
\rho_{a p p}=2 \pi a \frac{\Delta V}{I}
$$

Equation 2. Apparent resistivity equation for a pole-pole (2-electrode) measurement where a is the distance between the current injection point and the potential measurement point, $\Delta \mathrm{V}$ is the measured potential, and I is the magnitude of the injected current (see Figure 2-1 for a diagram of the electrode arrangement).

\section{D2.3 Geoelectrical Data Acquisition}

The electrical resistivity, induced polarization (IP), and Complex Resistivity (CR) data were acquired using a pole-dipole electrode configuration (Figure 2-1). This configuration has the advantages of high signal strength and low EM coupling. The pole-dipole configuration requires that a remote current electrode be placed far from the survey area (in this case, greater than 1,200 ft away). To reduce directional bias in the data and to improve 
lateral coverage of the measurements, MSE acquired the measurements in both a forward and a reverse direction, thus requiring a second remote current electrode (Figure 2-1 and Figure 2-2). Depth of investigation and lateral coverage for the pole-dipole survey are adjusted by changing the location of the roving current electrode (C1) and the potential dipole (P1-P2) and also by adjusting the spacing between $\mathrm{P} 1$ and $\mathrm{P} 2$ (referred to as the a-spacing).
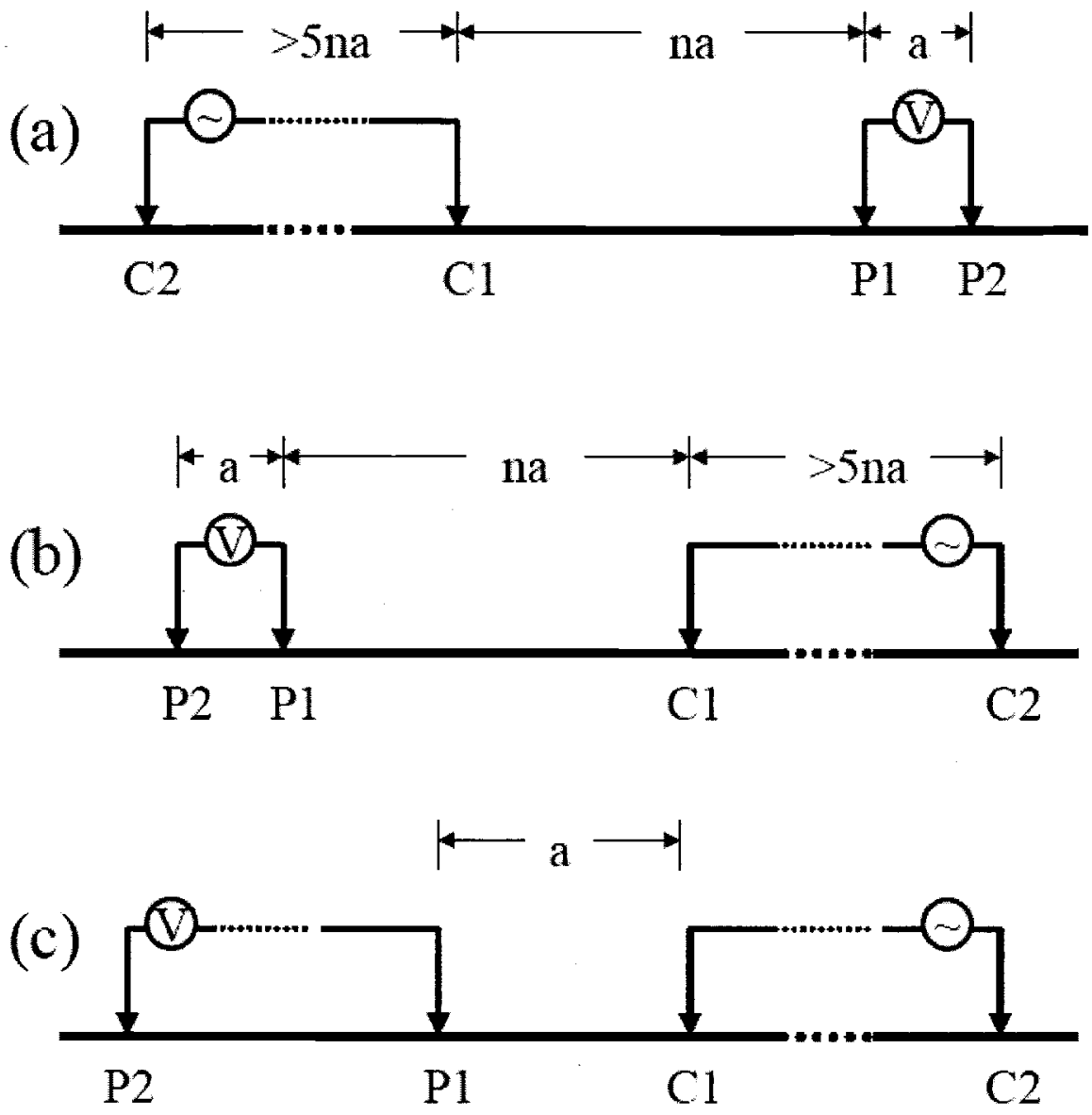

Figure 2-1 Electrode configurations used in geoelectrical monitoring: (a) forward pole-dipole, (b) reverse pole-dipole, (c) pole-pole. Electrodes $P 1$ and $P 2$ are the potential electrodes, $\mathrm{C} 1$ is the roving current electrode, and $\mathrm{C} 2$ is the remote (stationary) current electrode.

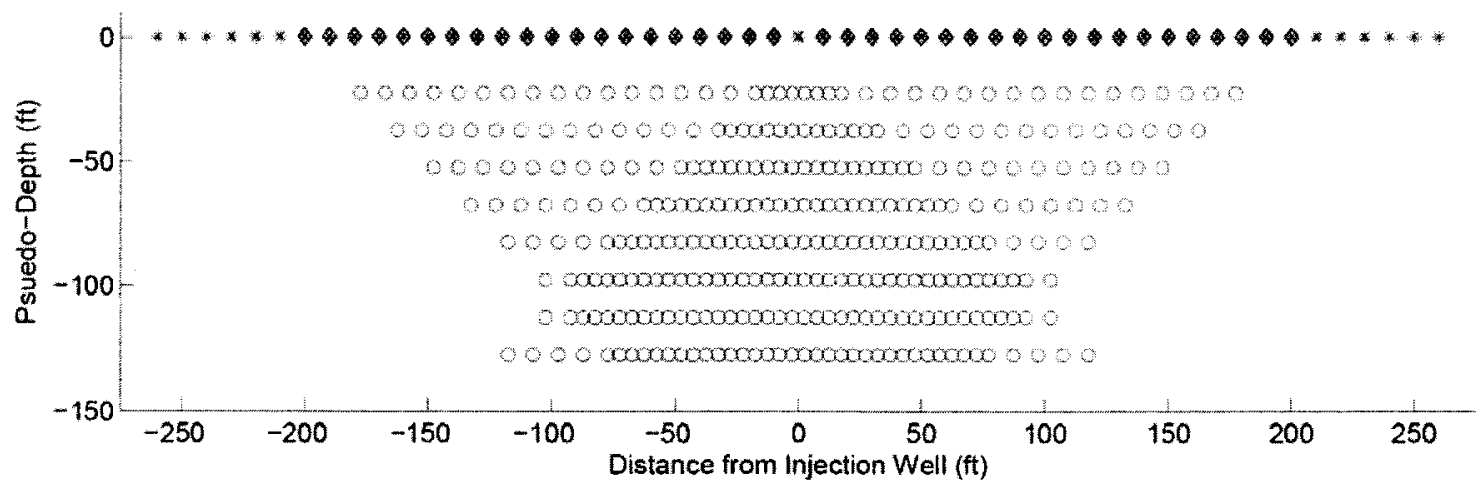

Figure 2-2 Data coverage for pole-dipole electrical surveys. The pseudo-depth plotted on the vertical axis is based on a projected data measurement point in the subsurface and generally exceeds the actual depth of investigation. This acquisition included 256 individual source receiver pairs. Diamonds indicate roving current electrode locations, asterisks indicate potential electrode locations, and circles indicate projected subsurface data measurement points. Note that the remote current electrodes are located several hundred feet to the left and the right of the region plotted here (see Figure 2-3). 
The roving current electrodes were constructed of three rebar stakes driven into the ground in a triangular pattern. Spacing between stakes and depth of stakes was approximately 10-12 inches. The current electrodes were laid out in a straight line oriented oblique to the ISRM barrier with the injection well near the center of the profile, current electrode spacing was $10 \mathrm{ft}$, with 20 electrodes on each side of the injection well and a central electrode, for a total of 41 electrodes. The remote current electrodes were constructed of two concentric rings of rebar stakes, for a total of 20-25 stakes at a depth of 8-10 inches. The remote current electrodes were established on each end of the profile at a distance of approximately $1,200 \mathrm{ft}$ from the end of the profile. The ground contact resistance for all electrodes was lowered by saturating the ground in the vicinity of the electrodes with salt water. The mean and standard deviation of the contact resistances for the potential measurement electrodes were $4037 \Omega$ and $2958 \Omega$ respectively.

The electrical resistivity, IP, and CR data were acquired along a single two-dimensional (2-D) profile centered near the injection well (D4-26) (Figure 2-3). The surveys employed an a-spacing (distance between the potential electrodes P1 and P2) of $30 \mathrm{ft}$, with n-spacings (distance between electrodes $\mathrm{C} 1$ and P1) from 1 to 8 times the aspacing. The theoretical depth and lateral coverage for the electrical resistivity survey is shown in Figure 2-2. The total distance between the two remote current electrode locations is approximately $2,800 \mathrm{ft}$. The main region of data acquisition spans a distance of $400 \mathrm{ft}$. At each roving current electrode location, the acquisition procedure was identical. Current was injected via the transmitter dipole at eight separate frequencies $(0.125$, $0.25,0.5,1,2,4,8$, and $16 \mathrm{~Hz}$ ), and the resulting electrical potential and relative phase angle of the received signal were recorded for each frequency at each of eight different $n$-spacings $(n=1$ to 8$)$. This resulted in a total of 5,760 (28,800 if including harmonic amplitude and phase observations) individual data observations being recorded both pre- and post-injection.
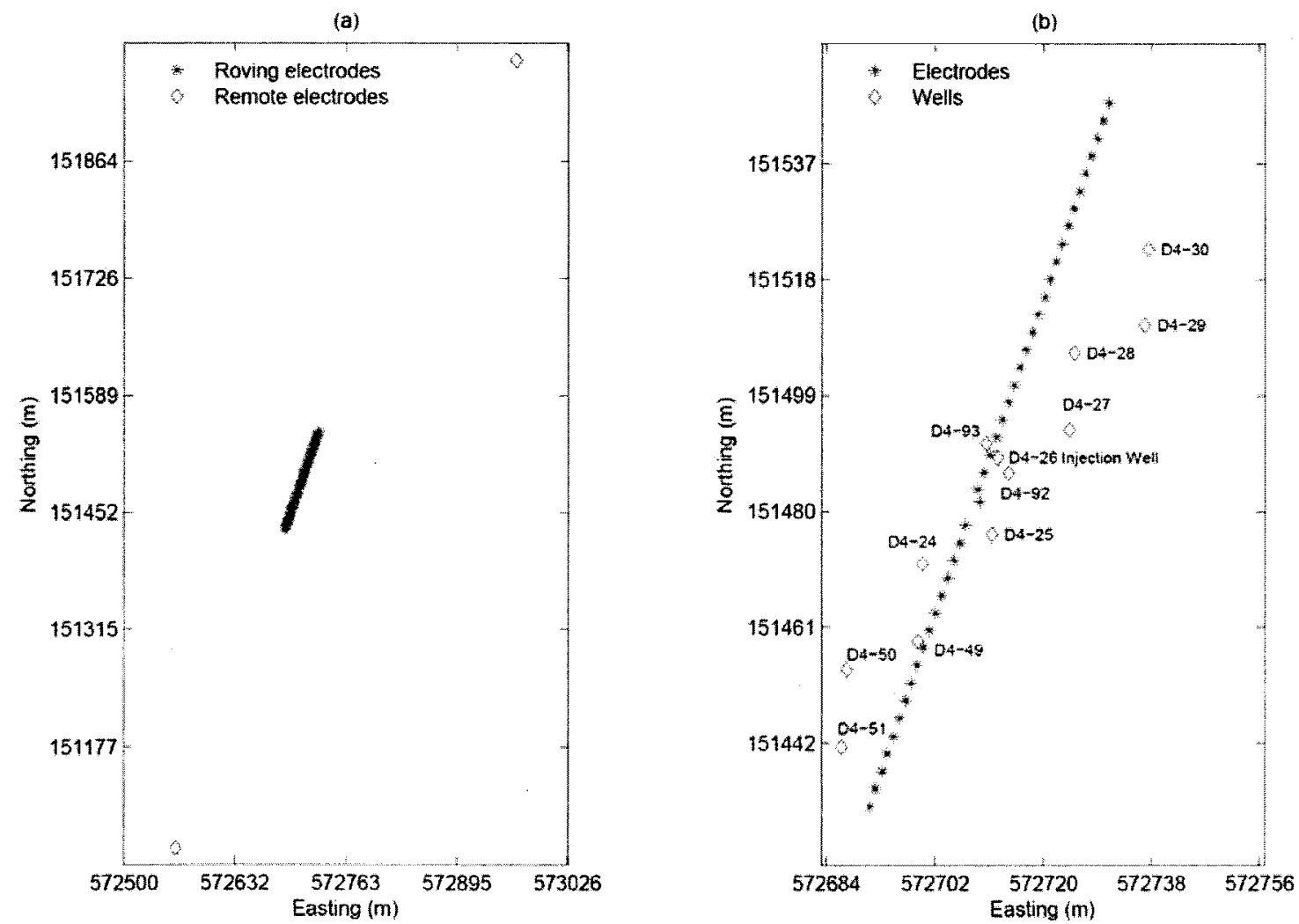

Figure 2-3 Plan view of electrical resistivity survey locations. (a) The entire survey line including the two remote electrodes. (b) A closeup of the survey area showing the orientation of the survey with respect to the well locations.

The acquisition of the mise a la masse data was somewhat simpler due to the use of a pole-pole electrode arrangement. In the pole-pole configuration, both the transmitter dipole and the receiver dipole require a remote 
electrode (Figure 2-1). The source and receiver equipment used was similar to that used for the other electrical surveys. The transmitter dipole used one of the remote current electrodes while the other end of the dipole was submerged in the PVC cased borehole located near the injection well. Electrical potential and relative phase shift measurements were acquired for a single frequency (i.e., $1 \mathrm{~Hz}$ ). Measurements were made on a radial grid of 96 stations surrounding the injection well (Figure 2-4).

As mentioned previously, the conversion of the mise a la masse potentials to apparent resistivities (Equation 2) removes the effect of the distance from the current injection pole, normalizing the amplitudes of the data. This conversion is not entirely valid due to the actual current injection being via a line-source (i.e., along the entire length of the well casing) rather than at a single point. Further complicating the situation is the fact that the current injection is not evenly distributed along this line-source but is likely stronger in the saturated zone (due to a higher electrical conductivity) and weaker in the vadose zone (due to a lower electrical conductivity). Consequently, these data cannot be modeled using conventional resistivity inversion software such as that used to invert the electrical resistivity data in an earlier section of this report. Hatanaka et al. (2005) show how current injection via a steel-cased borehole can be modeled as a line-source of current, enabling threedimensional (3-D) inversion of the mise a la masse data; however, time restrictions prevented MSE from attempting 3-D modeling of these data using such an approach.

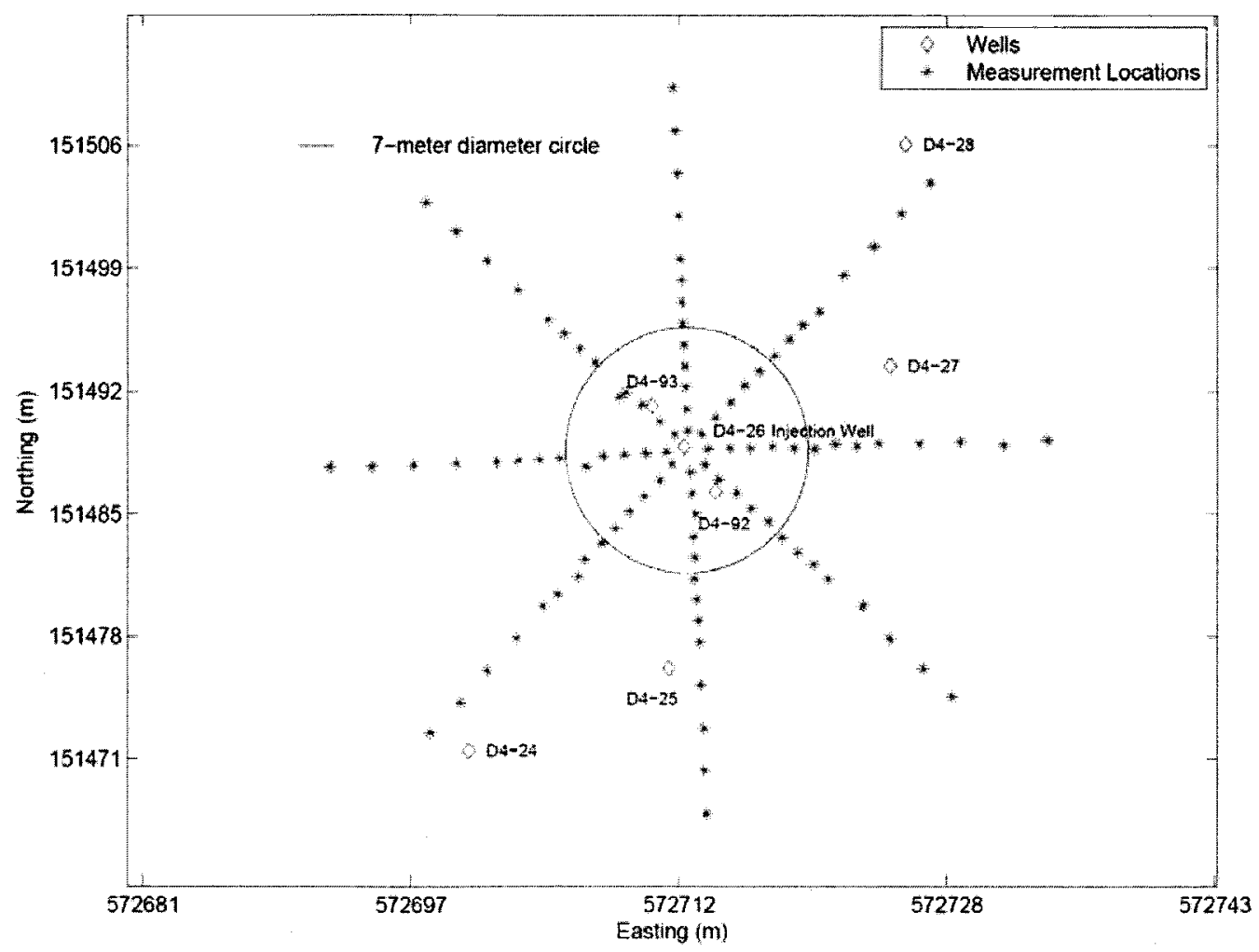

Figure 2-4 Measurement points for the magnetic and mise a la masse surveys. Not shown on this plot are the magnetic base station (located approximately $300 \mathrm{ft}$ northeast of the survey area) and the remote current electrodes (located several hundred feet NNE and SSW from the survey area).

\section{D2.4 ELECTROMAGNETIC METHODS}

\section{D2.4.1 Time-Domain Electromagnetics Survey}

In a time-domain electromagnetics (TEM) survey, the source and receiver are wire loops that do not require grounding. Current is passed through the transmitter loop and then abruptly terminated. This induces eddy currents that diffuse through the subsurface. A receiver loop is used to measure the response due to interaction 
of the induced currents with the subsurface materials. The received signal is sensitive to the electrical property distribution of the subsurface region beneath the transmitter and receiver loops. An advantage of this method versus electrical methods is that large investigation depths can be achieved with a much smaller survey "footprint." A disadvantage is that it is time consuming to collect these data over large spatial extents and the data are more susceptible to noise contamination.

\section{D2.4.2 Borehole Electromagnetic Induction}

Borehole EM induction surveying consists of lowering a tool containing a transmitter and receiver coil down into a borehole. As the tool is lowered, the conductivity of the formation surrounding the borehole is measured by the tool. The support volume of the conductivity measurement will vary depending on the size and spacing of the coils. In most cases, this support volume is on the order of a few cubic meters or less; consequently, the measurement is localized and of a relatively high resolution. The EM induction tool can only be used to $\log$ a borehole with a nonconductive casing material such as polyvinyl chloride (PVC).

\section{D2.4.3 Electromagnetic Data Acquisition}

The TEM data acquisition used a square transmitter loop, $20 \mathrm{~m}$ on each side, consisting of a single turn of wire. The receiver loop was also a square loop, $5 \mathrm{~m}$ on each side, with a single turn of wire. The in-loop configuration was used where the receiver loop was always completely contained within the transmitter loop. Electromagnetic soundings were acquired in six locations, all located north and/or east of the injection well (Figure 2-5). The transmitter loop location remained unchanged for each of the different soundings. The location of the transmitter loop was chosen so that no wells were contained within the loop, thus minimizing the effects of the steel well casings. Data were stacked 1,024 times for each sounding to quantify standard deviations, and each sounding was repeated at least 2 times to examine repeatability of the results. The excitation current was 3.00 Amperes at a frequency of $32 \mathrm{~Hz}$ and the decay voltage was sampled in 31 separate time windows during each off cycle.

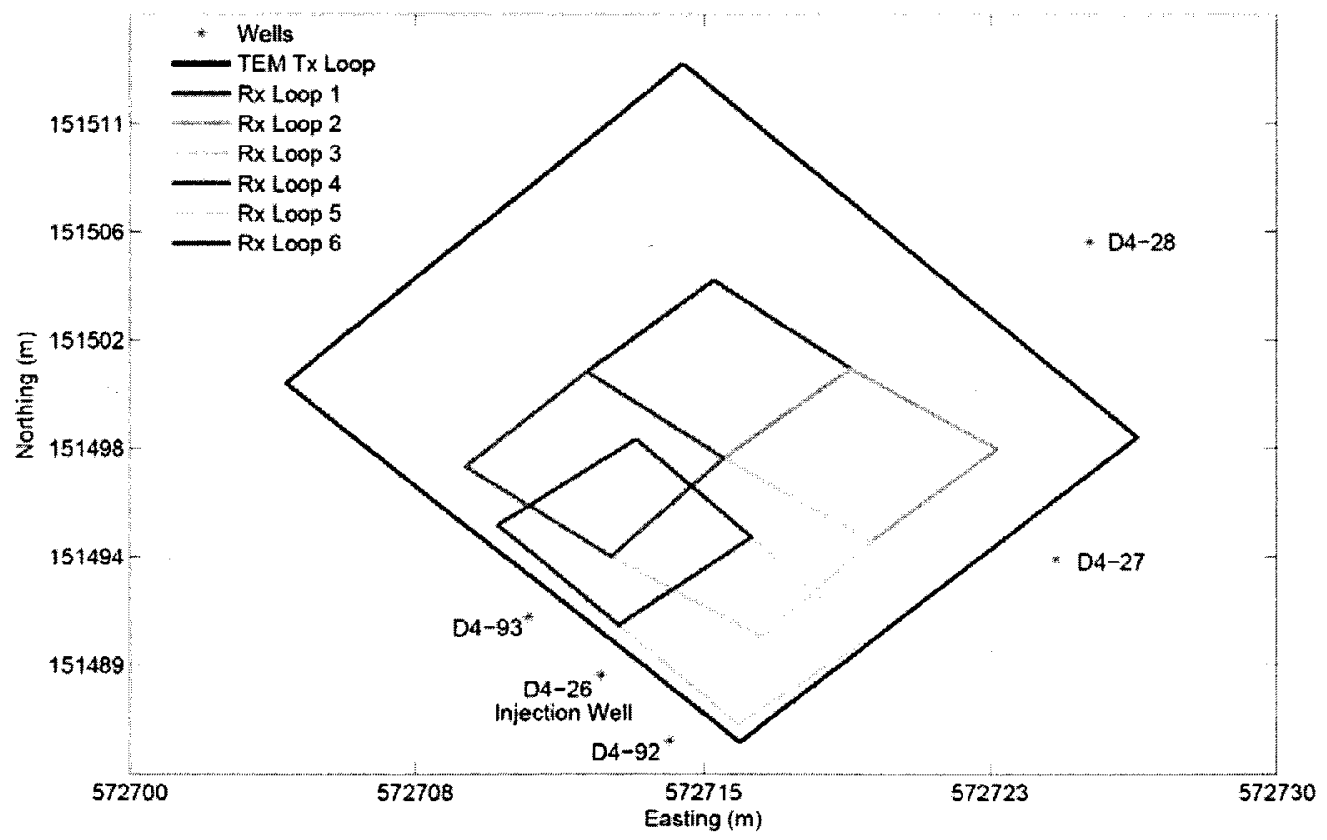

Figure 2-5 Location of TEM transmitter and receiver loops. The measurement point for each receiver loop is the center of the loop.

The borehole EM data acquisition consisted of lowering and raising the EM39C tool in the PVC cased borehole located near the injection well. Logging of the well was performed in each direction, although depth control is typically better while logging in the upward direction because there is no slack in the cabling. Calibration of the 
instrument was completed prior to and following each logging run so that temperature drift could be assessed and accounted for in the logging results.

\section{D2.5 MAGNETIC METHODS}

Magnetometers are sensitive instruments, typically capable of measuring magnetic field variations on the order of $0.01 \%$ (or less) of the Earth's total magnetic field. Magnetometer data acquired on the ground surface are sensitive to the subsurface magnetic susceptibility structure. Acquiring data at two different heights facilitates discrimination between very shallow objects and deeper objects. It also allows for determination of the vertical magnetic gradient, which is useful for discrimination between neighboring anomalies (Telford et al., 1990) for edge detection.

\section{D2.5.1 Magnetometry Data Acquisition}

Total field magnetic data acquisition was completed using the Geometrics G-858/G portable cesium magnetometer/gradiometer. A magnetic base station was established approximately 100 -meters northeast of the injection site in an area relatively free of metallic objects. First, an initial reading was taken at the base station. The data were then acquired on the radial grid (the same grid used for mise a la masse data acquisition, Figure 2-4) surrounding the injection well. A final reading was then taken at the base station so that measurement drift could be assessed and accounted for in the data. This was done for each of two sensor heights, one being located right at the ground surface, and the second being located 1-meter above the ground surface. All readings were acquired with the magnetometer oriented to the north. 
DOE/RL-2009-35, REV. 0

\begin{tabular}{|c|c|c|c|c|c|c|c|c|c|}
\hline \multicolumn{10}{|c|}{ Mag and MALM Survey Locations } \\
\hline Line & Station & Easting & Northing & Elev & Line & Station & Easting & Northing & Elev \\
\hline 1 & 1 & 572713.30 & 151489.60 & 144.11 & 5 & 2 & 572710.88 & 151486.92 & 144.00 \\
\hline 1 & 2 & 572714.10 & 151490.50 & 144.01 & 5 & 3 & 572709.99 & 151486.00 & 143.95 \\
\hline 1 & 3 & 572714.99 & 151491.38 & 144.02 & 5 & 4 & 572709.14 & 151485.15 & 143.91 \\
\hline 1 & 4 & 572715.79 & 151492.33 & 144.05 & 5 & 5 & 572708.33 & 151484.18 & 143.90 \\
\hline 1 & 5 & 572716.63 & 151493.15 & 144.08 & 5 & 6 & 572707.54 & 151483.34 & 143.91 \\
\hline$\overline{1}$ & $\overline{6}$ & 572717.51 & 151494.04 & 144.04 & 5 & 7 & 572706.58 & 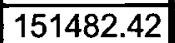 & 143.90 \\
\hline 1 & 7 & 572718.35 & 151494.96 & 144.09 & 5 & 8 & 572706.23 & 151481.43 & 143.88 \\
\hline 1 & 8 & 572719.10 & 151495.78 & 144.06 & 5 & 9 & 572705.03 & 151480.42 & 143.86 \\
\hline 1 & 9 & 572720.10 & 151496.57 & 144.16 & 5 & 10 & 572704.22 & \begin{tabular}{|l|}
151479.74 \\
\end{tabular} & 143.82 \\
\hline 1 & 10 & 572721.54 & 151498.62 & 144.13 & 5 & 11 & 572702.64 & 151477.90 & 143.71 \\
\hline 1 & 11 & 572723.26 & 151500.22 & 144.08 & 5 & 12 & 572700.93 & 151476.08 & 143.70 \\
\hline 1 & 12 & 572724.85 & 151502.12 & 144.09 & 5 & 13 & 572699.40 & 151474.25 & 143.66 \\
\hline 1 & 13 & 572726.54 & 151503.85 & 144.10 & 5 & 14 & 572697.62 & 151472.50 & 143.70 \\
\hline 2 & 1 & 572713.72 & 151488.73 & 144.10 & 6 & 1 & 572711.29 & 151488.56 & 144.03 \\
\hline 2 & 2 & 572714.94 & 151488.77 & 144.09 & 6 & 2 & 572710.07 & 151488.48 & 143.94 \\
\hline 2 & 3 & 572716.14 & 151488.75 & 144.13 & 6 & 3 & 572708.83 & 151488.41 & 143.87 \\
\hline 2 & 4 & 572717.38 & 151488.85 & 144.14 & 6 & 4 & 572707.62 & 151488.32 & 143.84 \\
\hline 2 & 5 & 572718.63 & 151488.77 & \begin{tabular}{|l|}
144.17 \\
\end{tabular} & 6 & 5 & 572706.67 & \begin{tabular}{|l|}
151487.74 \\
\end{tabular} & 143.81 \\
\hline 2 & 6 & \begin{tabular}{|l|}
572719.79 \\
\end{tabular} & 151488.73 & 144.19 & 6 & 6 & 572705.17 & 151488.20 & 143.78 \\
\hline 2 & 7 & 572721.03 & 151489.00 & 144.22 & 6 & 7 & 572703.95 & 151488.10 & 143.75 \\
\hline 2 & 8 & 572722.28 & 151488.90 & 144.25 & 6 & 8 & 572702.73 & 151488.08 & 143.71 \\
\hline 2 & 9 & 572723.56 & 151489.05 & 144.29 & 6 & 9 & 572701.49 & 151487.99 & 143.68 \\
\hline 2 & 10 & 572725.89 & 151489.05 & 144.29 & 6 & 10 & 572699.18 & 151487.88 & 143.64 \\
\hline 2 & 11 & 572728.30 & 1514 & 144.25 & 6 & 11 & 572696.65 & 151487.81 & 143.63 \\
\hline 2 & 12 & 572730.79 & 151488.96 & 144.27 & 6 & 12 & 572694.21 & 151487.71 & 143.67 \\
\hline 2 & 13 & 572733.28 & 151489.26 & 144.25 & 6 & 13 & 572691.78 & 151487.66 & 143.60 \\
\hline 3 & 1 & 572713.49 & $1514 \varepsilon$ & 144.10 & 7 & 1 & 572711.75 & 151489.55 & 144.04 \\
\hline 3 & 2 & 572714.29 & 1514 & 144.10 & 7 & 2 & 572710.88 & 0.27 & 143.92 \\
\hline 3 & 3 & 572715.32 & 151486.22 & 144.12 & 7 & 3 & 09.81 & 151491.24 & 143.87 \\
\hline 3 & 4 & 572716.17 & 151485.33 & 144.12 & 7 & 4 & 572708.94 & 151491.95 & 143.83 \\
\hline 3 & 5 & 572717.14 & 151484.59 & 144.16 & 7 & 5 & 572708.56 & 151491.69 & 143.81 \\
\hline 3 & 6 & 572717.92 & 151483.68 & 144.15 & 7 & 6 & 572707.19 & 151493.65 & 143.76 \\
\hline 3 & 7 & 572718.84 & 151482.83 & 144.20 & 7 & 7 & 572706.31 & 151494.45 & 143.74 \\
\hline 3 & 8 & 572719.73 & 151482.11 & 144.23 & 7 & 8 & 572705.39 & 151495.29 & 143.71 \\
\hline 3 & 9 & 572720.63 & 151481.26 & 144.23 & 7 & 9 & 572704.51 & 151496.08 & \begin{tabular}{|l|}
143.67 \\
\end{tabular} \\
\hline 3 & 10 & 572722.65 & 151479.77 & 144.30 & 7 & 10 & 572702.74 & 151497.77 & 143.66 \\
\hline 3 & 11 & 572724.21 & 151477.88 & 144.28 & 7 & 11 & 572700.93 & 151499.41 & 143.64 \\
\hline 3 & 12 & 572726.11 & 151476.19 & 144.27 & 7 & 12 & 572699.15 & 151501.09 & 143.64 \\
\hline 3 & 13 & 572727.77 & 151474.57 & 144.30 & 7 & 13 & 572697.37 & 151502.72 & 143.63 \\
\hline 4 & 1 & 572712.68 & 151487.39 & 144.11 & 8 & 1 & 572712.53 & 151489.78 & 144.06 \\
\hline 4 & 2 & 572712.74 & 151486.17 & 144.03 & 8 & 2 & 572712.44 & 151491.02 & 143.94 \\
\hline 4 & 3 & 572712.95 & 151485.00 & 144.07 & 8 & 3 & 572712.39 & 151492.27 & 143.94 \\
\hline 4 & 4 & 572712.83 & 151483.71 & 144.04 & 8 & 4 & 572712.34 & 151493.43 & 143.94 \\
\hline 4 & 5 & 572712.91 & 151482.52 & 144.04 & 8 & 5 & 572712.29 & 151494.64 & 143.89 \\
\hline 4 & 6 & 572712.90 & 151481.30 & 144.04 & 8 & 6 & 572712.23 & 151495.89 & 143.88 \\
\hline 4 & 7 & 572713.00 & 151480.11 & 144.06 & 8 & 7 & 572712.16 & 151497.08 & 143.90 \\
\hline 4 & 8 & 572713.14 & 151478.90 & 144.06 & 8 & 8 & 572712.15 & 151498.31 & 143.86 \\
\hline 4 & 9 & 572713.17 & 151477.67 & 144.09 & 8 & 9 & 572712.08 & 151499.52 & 143.86 \\
\hline 4 & 10 & 572713.25 & 151475.23 & 144.09 & 8 & 10 & 572711.98 & 151501.95 & 143.84 \\
\hline 4 & 11 & 572713.45 & 151472.76 & 144.05 & 8 & 11 & 572711.93 & 151504.38 & 143.86 \\
\hline 4 & 12 & 572713.47 & 151470.33 & 144.04 & 8 & 12 & 572711.78 & 151506.82 & 143.85 \\
\hline 4 & 13 & 572713.62 & 151467.87 & 144.01 & 8 & 13 & 572711.64 & 151509.27 & 143.84 \\
\hline & 1 & 3 & & & & & & & \\
\hline
\end{tabular}


DOE/RL-2009-35, REV. 0

\begin{tabular}{|c|c|c|c|c|c|c|c|}
\hline \multicolumn{8}{|c|}{ Mag Data } \\
\hline \multicolumn{4}{|c|}{ Pre Injection Raw Data } & \multicolumn{4}{|c|}{ Post Injection Raw Data } \\
\hline Line & Station & Lower Sensor & Upper Sensor & Line & Station & Lower Sensor & Upper Sensor \\
\hline 1 & 1 & 32670.93 & 0 & 0 & Base & 54659.093 & 54677.352 \\
\hline 1 & 2 & 49821.71 & 51564.77 & 0 & Base & 54659.53007 & 54679.98207 \\
\hline 1 & 3 & 53246.39 & 53327.07 & 1 & 1 & 0 & 32580.13841 \\
\hline 1 & 4 & 53992.33 & 53987.45 & 1 & 2 & 51764.748 & 49870.96575 \\
\hline 1 & 5 & 54281.76 & 54213.84 & 1 & 3 & 53388.667 & 53213.17044 \\
\hline 1 & 6 & 54381.38 & 54301.84 & 1 & 4 & 54019.67119 & 54143.86925 \\
\hline 1 & 7 & 54456.87 & 54314.11 & 1 & 5 & 54254.592 & 54302.05 \\
\hline 1 & 8 & $54335 . \overline{42}$ & 54315.05 & 1 & 6 & 54320.47178 & 54346.76656 \\
\hline 1 & 9 & 54280.99 & 54327.17 & 1 & 7 & $54 \overline{334.03771}$ & 54430.38214 \\
\hline 1 & 10 & 54304.92 & 54374.63 & $\overline{1}$ & 8 & 54336.0195 & 54339.20613 \\
\hline$\overline{1}$ & 11 & 54132.91 & 54295.22 & 1 & 9 & 54348.35857 & 54313.27 \\
\hline 1 & 12 & 52565.45 & 53990.78 & 1 & 10 & 54393.76514 & 54347.71329 \\
\hline 1 & 13 & 48610.56 & 53700.47 & 1 & 11 & 54307.946 & 54154.95314 \\
\hline 2 & 1 & 32774 & 0 & 1 & 12 & 54028.17186 & 52583.01971 \\
\hline 2 & 2 & 47524.29 & 52293.97 & 1 & 13 & 53684.81289 & 48389.99622 \\
\hline 2 & 3 & 52779.68 & 53338.71 & 2 & 1 & 0 & 14486.25911 \\
\hline 2 & 4 & 53831.7 & 53973.73 & 2 & 2 & 52326.36925 & 47869.46925 \\
\hline 2 & 5 & 54092.31 & 54235.7 & 2 & 3 & 53391.18971 & 52816.881 \\
\hline 2 & 6 & 54330.23 & 54349.48 & 2 & 4 & 53981.74043 & 53867.74314 \\
\hline 2 & 7 & 54590.98 & 54413.31 & 2 & 5 & 54239.11329 & 54130.46429 \\
\hline 2 & 8 & 54555.48 & 54443.57 & 2 & 6 & 54356.4825 & 54362.56167 \\
\hline 2 & 9 & 54584.2 & 54434.34 & 2 & 7 & 54421.05671 & 54490.24514 \\
\hline 2 & 10 & 54484.15 & 54451.7 & 2 & 8 & 54449.23757 & 54561.77343 \\
\hline 2 & 11 & 54376.03 & 54454.77 & 2 & 9 & 54439.94071 & 54591.157 \\
\hline 2 & 12 & 54296.38 & 54476.88 & 2 & 10 & 54462.39456 & 54478.365 \\
\hline 2 & 13 & 54426.6 & 54511.56 & 2 & 11 & 54468.01886 & 54421.03986 \\
\hline 3 & 1 & 30093.69 & 0 & 2 & 12 & 54487.631 & 54322.17783 \\
\hline 3 & 2 & 44272.09 & 56085 & 2 & 13 & 54518.33544 & 54447.34989 \\
\hline 3 & 3 & 51801.94 & 53789.25 & 3 & 1 & 0 & 31594.74067 \\
\hline 3 & 4 & 53273.03 & 54037.2 & 3 & 2 & 57987.3575 & 44622.22663 \\
\hline 3 & 5 & 54061.76 & 54221.25 & 3 & 3 & 53663.77775 & 51954.59725 \\
\hline 3 & 6 & 54271.96 & 54352.15 & 3 & 4 & 54035.23843 & 53329.06586 \\
\hline 3 & 7 & 54437.72 & 54457.05 & 3 & 5 & 54210.36971 & 54024.761 \\
\hline 3 & 8 & 54539.09 & 54526.95 & 3 & 6 & 54326.198 & 54280.44457 \\
\hline 3 & 9 & 54439.76 & 54498.67 & 3 & 7 & 54408.533 & 54345.50386 \\
\hline 3 & 10 & 54248.83 & 54428.75 & 3 & 8 & 54428.888 & 54425.98657 \\
\hline 3 & 11 & 54605.23 & 54532.76 & 3 & 9 & 54331.31429 & 53906.81514 \\
\hline 3 & 12 & 54493.76 & 54524.75 & 3 & 10 & 54571.64333 & 52953.77333 \\
\hline 3 & 13 & 54480.69 & 54538.48 & 3 & 11 & 54527.404 & 54412.95543 \\
\hline 4 & 1 & 22541.23 & 0 & 3 & 12 & 54521.27529 & 54462.939 \\
\hline 4 & 2 & 0 & 0 & 3 & 13 & 54543.20967 & 54493.0135 \\
\hline 4 & 3 & 51024.8 & 55883.81 & 4 & 1 & 12112.03643 & 24371.64843 \\
\hline 4 & 4 & 53447.82 & 54346.06 & 4 & 2 & 54239.30038 & 0 \\
\hline 4 & 5 & 54021.72 & 54317.33 & 4 & 3 & 55966.66033 & 51157.82083 \\
\hline 4 & 6 & 54380.42 & 54389.41 & 4 & 4 & 54368.32983 & 53422.06783 \\
\hline 4 & 7 & 54617.11 & 54513.02 & 4 & 5 & 54326.93143 & 54048.52 \\
\hline 4 & 8 & 54975.72 & 54729.83 & 4 & 6 & 54404.466 & 54404.99657 \\
\hline$\overline{4}$ & 9 & 56303.59 & 54910.1 & 4 & 7 & 54521.66517 & 54600.34817 \\
\hline 4 & 10 & 61311.08 & 0 & 4 & 8 & 54723.892 & 54995.27157 \\
\hline 4 & 11 & 54508.32 & 54452.51 & 4 & 9 & 54931.56371 & 56189.43471 \\
\hline 4 & 12 & 54506.7 & 54504.15 & 4 & 10 & 50814.24238 & 0 \\
\hline 4 & 13 & 54334.56 & 54526.49 & 4 & 11 & 54462.35117 & 54550.9935 \\
\hline 5 & 1 & 44366.91 & 55787.09 & 4 & 12 & $5 \overline{4512.91888}$ & 54516.96438 \\
\hline 5 & 2 & 51371.67 & 54081.45 & $\overline{4}$ & 13 & 54536.30533 & 54399.07533 \\
\hline 5 & 3 & 53995.18 & 54296.04 & 5 & 1 & 47262.84829 & 43590.66957 \\
\hline 5 & 4 & 54201.36 & 54361.76 & 5 & 2 & 54273.6505 & 51104.51033 \\
\hline 5 & 5 & 54039.53 & 54426.82 & 5 & 3 & 54304.09717 & 54085.8975 \\
\hline 5 & 6 & 54363.57 & 54431.3 & 5 & 4 & 54370.08929 & 54176.045 \\
\hline 5 & 7 & 54513.99 & 54398.84 & 5 & 5 & 54431.5032 & 54216.7984 \\
\hline 5 & 8 & 53972.14 & 54308.21 & 5 & 6 & $54440 . \overline{17143}$ & 54384.70471 \\
\hline 5 & 9 & 53935.79 & 54335.87 & 5 & 7 & 54410.56533 & 54425.04217 \\
\hline 5 & 10 & 54482.58 & 54484.74 & 5 & 8 & 54325.045 & 54099.98033 \\
\hline 5 & 11 & 54432.18 & 54472.31 & 5 & 9 & 54318.70867 & 53926.24333 \\
\hline 5 & 12 & 54113.79 & 54270.18 & 5 & 10 & 54462.41533 & 54408.22983 \\
\hline 5 & 13 & 53880.42 & 53825.24 & 5 & 11 & 54479.40343 & 54432.09643 \\
\hline 5 & 14 & 54106.4 & 54697.4 & 5 & 12 & 54319.83814 & 54147.94743 \\
\hline
\end{tabular}


DOE/RL-2009-35, REV. 0

\begin{tabular}{|c|c|c|c|c|c|c|c|}
\hline \multicolumn{8}{|c|}{ Mag Data } \\
\hline \multicolumn{4}{|c|}{ Pre Injection Raw Data } & \multicolumn{4}{|c|}{ Post Injection Raw Data } \\
\hline Line & Station & Lower Sensor & Upper Sensor & Line & Station & Lower Sensor & Upper Sensor \\
\hline 6 & \begin{tabular}{|l|}
1 \\
\end{tabular} & 0 & $\begin{array}{c}0 \\
0\end{array}$ & 5 & 13 & 53878.22071 & 53360.70429 \\
\hline 6 & 2 & 82889.59 & 53702.76 & 5 & 14 & 54693.40186 & 54109.333 \\
\hline 6 & 3 & 54426.39 & 54248.99 & 6 & 1 & 6577.0845 & 0 \\
\hline 6 & 4 & 54612.61 & 54373.69 & 6 & 2 & 53484.97433 & 55467.921 \\
\hline 6 & 5 & 54443.75 & 54433.13 & 6 & 3 & 54261.98233 & 54468.84683 \\
\hline 6 & 6 & 54564.29 & 54436.47 & 6 & 4 & 54383.04986 & 54647.46371 \\
\hline 6 & 7 & 54412.56 & 54421.53 & 6 & 5 & 54447.044 & 54529.66786 \\
\hline 6 & 8 & 54352.24 & 54411.58 & 6 & $\overline{6}$ & 54450.15771 & 54743.53157 \\
\hline 6 & 9 & 54361.02 & 54416.1 & 6 & 7 & 54433.28867 & 54398.139 \\
\hline 6 & 10 & 54435.27 & 54437.74 & 6 & 8 & 54427.70167 & 54369.8205 \\
\hline 6 & 11 & 54510.28 & 54461.91 & 6 & 9 & 54432.82357 & 54393.92171 \\
\hline 6 & 12 & 54523.97 & 54460.2 & 6 & 10 & 54447.87771 & 54431.337 \\
\hline$\overline{6}$ & 13 & 54508.09 & 54470.04 & 6 & 11 & 54473.37629 & 54507.03543 \\
\hline 7 & 1 & 0 & 57948.75 & 6 & 12 & 54471.84517 & 54516.57917 \\
\hline 7 & 2 & 53114.56 & 54201.72 & 6 & 13 & 54479.79075 & 54430.17725 \\
\hline 7 & 3 & 0 & 49418.8 & 7 & 1 & 58374.29686 & 55169.91657 \\
\hline 7 & 4 & 60102.5 & 53242.94 & 7 & 2 & 54181.48225 & 53159.86863 \\
\hline 7 & 5 & 54932.6 & 54484.33 & 7 & 3 & 49701.67543 & 0 \\
\hline 7 & 6 & 54439.83 & 54460.35 & 7 & 4 & 53201.28843 & 60249.05729 \\
\hline 7 & 7 & 54304.87 & 54420.92 & 7 & 5 & 54502.6405 & 55002.97917 \\
\hline 7 & 8 & 54198.7 & 54405.33 & 7 & 6 & 54492.86214 & 54503.41414 \\
\hline 7 & 9 & 54264.86 & 54399.53 & 7 & 7 & 54452.999 & 54378.53525 \\
\hline 7 & 10 & 54383.01 & 54391.9 & 7 & 8 & 54438.4195 & 54379.79383 \\
\hline 7 & 11 & 54456.84 & 54397.9 & 7 & 9 & 54437.02571 & 54345.16629 \\
\hline 7 & 12 & 54402.24 & 54413.76 & 7 & 10 & 54434.74767 & 54356.07867 \\
\hline 7 & 13 & 54349.19 & 54413.02 & 7 & 11 & 54458.47914 & 54458.81457 \\
\hline 8 & 1 & 20015 & 0 & 7 & 12 & 54491.21311 & 54572.45833 \\
\hline 8 & 2 & 50286.01 & 51548.94 & 7 & 13 & 54506.48143 & 54479.28629 \\
\hline 8 & 3 & 53101.37 & 53576.23 & 8 & 1 & 21864.6478 & 20021.255 \\
\hline 8 & 4 & 54113.75 & 54085.06 & 8 & 2 & 51578.72983 & 49960.19183 \\
\hline 8 & 5 & 54134.63 & 54338.12 & 8 & 3 & 53607.89267 & 53155.886 \\
\hline 8 & 6 & 54374.88 & 54412.48 & 8 & 4 & 54112.12829 & 54097.17743 \\
\hline 8 & 7 & 54489.89 & 54434.17 & 8 & 5 & 54367.45483 & 54236.601 \\
\hline 8 & 8 & 54433.35 & 54429.71 & 8 & 6 & 54436.287 & 54444.82833 \\
\hline 8 & 9 & 54401.22 & 54419.71 & 8 & 7 & 54459.57386 & 54490.43943 \\
\hline 8 & 10 & 54379.76 & 54418.9 & 8 & 8 & 54460.62786 & 54470.70343 \\
\hline 8 & 11 & 54450.55 & 54425.62 & 8 & 9 & 54458.00667 & 54427.32467 \\
\hline 8 & 12 & 54393.35 & 54466 & 8 & 10 & 54465.40686 & 54427.26986 \\
\hline 8 & 13 & 54502.38 & 54505.83 & 8 & 11 & 54481.27886 & 54523.416 \\
\hline Base & 1 & 54669.97 & 54652.04 & 8 & 12 & 54531.01743 & 54497.53971 \\
\hline Base & 1 & & 54652.34 & 8 & 13 & 54578.292 & 54526.30086 \\
\hline Base & 1 & & 54652.59 & 9 & Base & 54661.36725 & 54674.25425 \\
\hline Base & 2 & 54633.06 & 54652.47 & 9 & Base & 54661.87196 & 54660.04373 \\
\hline Base & 2 & 54627.61 & 54652.98 & & & & \\
\hline Base & 2 & 54662.32 & & & & & \\
\hline Base & 2 & 54661.99 & & & & & \\
\hline Base & 2 & 54624.87 & & & & & \\
\hline Base & 2 & 54632.04 & & & & & \\
\hline Base & 2 & 54662.25 & & & & & \\
\hline Base & 2 & 54662.04 & & & & & \\
\hline
\end{tabular}


DOE/RL-2009-35, REV. 0

\begin{tabular}{|c|c|c|c|c|c|c|c|c|c|c|c|c|c|c|c|c|c|c|c|}
\hline \multicolumn{20}{|c|}{ Pre Injection MALM Raw Data } \\
\hline $\begin{array}{c}\text { data block } \\
\text { number }\end{array}$ & current & line & station & $\mathbf{v}$ & $\begin{array}{c}\text { normalized } \\
\mathrm{V}\end{array}$ & phi & \begin{tabular}{c|} 
contact \\
resistance
\end{tabular} & \begin{tabular}{|l|} 
data \% \\
error
\end{tabular} & $\begin{array}{c}\text { 3pt } \\
\text { phase }\end{array}$ & v1 & p1 & v3 & p3 & v5 & p5 & v7 & p7 & v9 & p9 \\
\hline 544 & 1.5 & & & 6.45 & 4.30 & \begin{tabular}{|l|l|}
1516.6 \\
\end{tabular} & 10610 & 0.05 & 47.23 & 6.45 & 1332.9 & 2.04 & 961.7 & 1.16 & 585.4 & 0.77 & 210.8 & 0.55 & -160.6 \\
\hline 544 & 1.5 & 1 & 2 & 4.55 & 3.04 & 3090.1 & 5994 & 0.06 & 16.47 & 4.55 & 3083.4 & 4.41 & 3066.3 & 4.35 & 3044.2 & 4.30 & 3022.0 & 4.27 & 3000.2 \\
\hline 544 & 1.5 & 1 & 3 & 3.93 & 2.62 & 3091.5 & 3877 & 0.06 & 1.15 & 3.93 & 3085.0 & 3.81 & 3068.4 & 3.76 & 3047.2 & 3.72 & 3026.2 & 3.68 & 3005.5 \\
\hline 544 & 1.5 & 1 & 4 & 3.92 & 2.61 & 3091.4 & 2581 & 0.05 & -5.76 & 3.92 & 3094.9 & 3.81 & 3097.9 & 3.77 & 3095.4 & 3.75 & 3092.3 & 3.74 & 3088.7 \\
\hline 544 & 1.5 & 1 & 5 & 3.57 & 2.38 & 3092.1 & 1176 & 0.05 & -6.95 & 3.57 & 3091.4 & 3.47 & 3086.5 & \begin{tabular}{|l|}
3.43 \\
\end{tabular} & 3076.8 & 3.41 & 3066.0 & 3.39 & 3055.8 \\
\hline 545 & 1.5 & 1 & 6 & 2.52 & 1.68 & \begin{tabular}{|l|l|}
1526.3 \\
\end{tabular} & 4138 & 0.06 & 47.23 & 2.52 & 1342.8 & 0.80 & 974.1 & 0.46 & 603.0 & 0.30 & 233.0 & 0.22 & -135.3 \\
\hline 545 & 1.5 & 1 & 7 & 1.81 & 1.21 & 3098.8 & 2380 & 0.15 & 16.47 & 1.81 & 3089.2 & 1.76 & 3068.0 & 1.73 & 3044.1 & \begin{tabular}{|l|l}
1.71 \\
\end{tabular} & 3020.1 & 1.69 & 2996.2 \\
\hline 545 & 1.5 & 1 & 8 & 1.91 & 1.28 & 3101.5 & 1888 & 0.06 & 1.15 & 1.91 & 3095.3 & 1.87 & 3080.8 & 1.84 & 3063.7 & 1.83 & 3045.9 & \begin{tabular}{|l|}
1.82 \\
\end{tabular} & 3028.0 \\
\hline 545 & 1.5 & 1 & 9 & 1.91 & 1.27 & 3096.7 & 1256 & 0.08 & -5.76 & 1.91 & 3098.1 & 1.86 & 3098.5 & 1,84 & 3095.6 & 1.83 & 3092.0 & 1.82 & 3087.4 \\
\hline 545 & 1.5 & 1 & 10 & 1.48 & 0.99 & 3098.5 & 488 & 0.06 & -6.95 & 1.48 & 3099.8 & 1.45 & 3100.0 & \begin{tabular}{|l|l|}
1.43 \\
\end{tabular} & 3097.4 & 1.42 & 3094.4 & 1.42 & 3090.5 \\
\hline 546 & 1.5 & 1 & 11 & $\begin{array}{l}1.18 \\
\end{array}$ & 0.79 & 3098.7 & 388 & 0.07 & -6.95 & 1.18 & 3102.0 & 1.15 & 3106.2 & \begin{tabular}{|l|l|} 
\\
\end{tabular} & 3107.3 & $\begin{array}{l}1.13 \\
\end{array}$ & 3107.3 & 1.13 & 3105.8 \\
\hline 546 & 1.5 & 1 & 12 & 0.92 & 0.61 & 3100.5 & 605 & 0.07 & -5.76 & 0.92 & 3103.3 & 0.90 & 3106.8 & 0.89 & 3107.3 & 30.89 & 3107.0 & \begin{tabular}{|l|}
0.88 \\
\end{tabular} & 3105.7 \\
\hline 546 & 1.5 & 1 & 13 & 0.76 & 0.50 & 3100.8 & 747 & 0.08 & $\begin{array}{c}1.15 \\
\end{array}$ & 0.76 & 3105.6 & 0.74 & 3112.9 & 0.73 & 3117.1 & 0.73 & 3121.4 & 0.73 & 3124.1 \\
\hline 546 & 1.5 & & & 8.55 & 5.70 & \begin{tabular}{|l|l|}
3085.5 \\
\end{tabular} & 11250 & 0.06 & 16.47 & 8.55 & 3088.9 & 8.25 & 3093.6 & \begin{tabular}{|l|l|}
8.17 \\
\end{tabular} & 3095.6 & 8.15 & 3093.5 & 8.14 & 3087.8 \\
\hline 546 & 1.5 & 2 & 2 & 2.88 & 1.92 & 1521.6 & 4731 & 0.49 & 47.23 & 2.88 & 1334.0 & 0.91 & 958.2 & 0.51 & 581.9 & 0.34 & 206.5 & 0.24 & -167.1 \\
\hline 547 & 1.5 & 4 & 3 & 3.23 & 2.15 & \begin{tabular}{|l|l|}
1524.3 \\
\end{tabular} & 5314 & 0.09 & 47.23 & 3.23 & 1338.3 & 1.02 & $\begin{array}{c}965.2 \\
\end{array}$ & 0.58 & 590.8 & 0.39 & 217.3 & \begin{tabular}{|l|}
0.28 \\
\end{tabular} & -154.4 \\
\hline 547 & 1.5 & 2 & 4 & 3.68 & 2.45 & 3091.5 & 4841 & 0.09 & 16.47 & 3.68 & 3091.9 & 3.57 & 3090.5 & 3.53 & 3086.1 & 3.51 & 3080.1 & 3.50 & 3072.1 \\
\hline 547 & 1.5 & 2 & 5 & 3.29 & 2.20 & 3091.3 & 3251 & 0.09 & 1.15 & 3.29 & 3093.2 & 3.19 & 3094.9 & \begin{tabular}{|l|}
3.16 \\
\end{tabular} & 3093.5 & 3.15 & 3090.1 & \begin{tabular}{|l|}
3.14 \\
\end{tabular} & 3085.1 \\
\hline 547 & 1.5 & 2 & 6 & 2.87 & 1.91 & 3090.7 & 1886 & 0.09 & -5.76 & 2.87 & 3092.9 & 2.78 & 3095.0 & 2.75 & 3093.8 & 2.73 & 3090.7 & 2.73 & 3086.0 \\
\hline 547 & 1.5 & 2 & 7 & 2.28 & 1.52 & 3091.2 & 751 & 0.12 & -6.95 & 2.28 & 3082.6 & 2.21 & 3064.0 & 2.17 & 3043.6 & 2.15 & 3021.5 & 2.12 & 3000.3 \\
\hline 548 & 1.5 & 2 & 8 & 2.02 & 1.35 & 3090.4 & 664 & 0.08 & -6.95 & 2.02 & 3087.4 & 1.96 & 3078.6 & 1.93 & 3066.0 & 1.92 & 3051.7 & \begin{tabular}{|l|} 
\\
\end{tabular} & 3037.3 \\
\hline 548 & 1.5 & 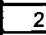 & 9 & 1.96 & 1.31 & 3088.7 & 1292 & 0.09 & -5.76 & 1.96 & 3091.8 & 1.90 & 3095.1 & \begin{tabular}{|l|l|} 
\\
\end{tabular} & 3094.6 & $\begin{array}{l}1.87 \\
\end{array}$ & 3092.7 & \begin{tabular}{|l|}
1.87 \\
\end{tabular} & 3088.7 \\
\hline 548 & 1.5 & 2 & 10 & 1.48 & 0.99 & 3088.1 & 1462 & 0.08 & 1.15 & 1.48 & 3091.2 & \begin{tabular}{|l|}
1.44 \\
\end{tabular} & 3094.0 & 1.42 & 3092.2 & 1.41 & 3090.0 & \begin{tabular}{|l|}
1.41 \\
\end{tabular} & 3084.7 \\
\hline 548 & 1.5 & 2 & 11 & 1.17 & 0.78 & 3088.5 & 1541 & 0.10 & 16.47 & 1.17 & 3091.5 & \begin{tabular}{|l|l|} 
\\
\end{tabular} & 3094.2 & \begin{tabular}{|l|l|} 
\\
\end{tabular} & 3092.3 & $\begin{array}{l}1.12 \\
\end{array}$ & 3089.0 & 1.11 & 3084.7 \\
\hline 548 & 1.5 & 2 & 12 & 0.91 & 0.61 & 1519.7 & 1501 & 0.18 & 47.23 & 0.91 & 1344.6 & 0.29 & 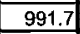 & \begin{tabular}{|l|l|}
0.17 \\
\end{tabular} & 635.3 & 0.11 & 279.4 & 0.08 & -76.8 \\
\hline 549 & 1.5 & 2 & 13 & 0.79 & 0.52 & 1520.0 & 1291 & 0.10 & 47.23 & 0.79 & 1345.4 & $\begin{array}{l}0.25 \\
\end{array}$ & 993.6 & \begin{tabular}{|l|l|}
0.14 \\
\end{tabular} & 638.1 & 0.09 & 284.8 & 0.07 & -66.5 \\
\hline 549 & 1.5 & 3 & & 7.64 & 5.09 & 3090.4 & 10050 & 0.10 & 16.47 & 7.64 & 3084.6 & 7.39 & 3071.4 & 7.29 & 3056.1 & 7.24 & 3039.7 & 7.20 & 3021.8 \\
\hline 549 & 1.5 & 3 & $\underline{2}$ & 6.01 & 4.00 & 3091.4 & 5928 & 0.09 & 1.15 & 6.01 & 3093.4 & \begin{tabular}{|l|}
5.83 \\
\end{tabular} & 3095.1 & 5.77 & 3093.7 & 5.74 & 3090.6 & \begin{tabular}{|l|l}
5.73 \\
\end{tabular} & 3086.3 \\
\hline 549 & 1.5 & & 3 & 4.68 & 3.12 & 3091,6 & 3080 & 0.10 & -5.76 & 4.68 & 3094.7 & 44.54 & 3098.3 & 4.49 & 3098.5 & $\begin{array}{l}5.47 \\
4.47\end{array}$ & 3097.4 & \begin{tabular}{|l|}
4.47 \\
\end{tabular} & 3095.1 \\
\hline 549 & 1.5 & 3 & 4 & 3.43 & 2.28 & 3086.3 & 1127 & 0.10 & -6.95 & 3.43 & 3087.4 & 3.31 & 3086.8 & 3.27 & 3082.0 & 3.25 & 3075.7 & 3.25 & 3068.6 \\
\hline 550 & 1.5 & & 5 & 2.89 & 1.93 & 3081.7 & 951 & 0.10 & -6.95 & 2.89 & 3084.2 & 2.79 & 3086.2 & 2.76 & 3084.0 & 2.74 & 3077.6 & 2.73 & 3069.9 \\
\hline 550 & 1.5 & 3 & 6 & 2.24 & 1.50 & 3073.7 & 1476 & 0.09 & -5.76 & 2.24 & 3078.9 & 2.15 & 3086.0 & 2.13 & 3088.4 & 2.11 & 3086.1 & 2.11 & 3082.5 \\
\hline 550 & 7.5 & 3 & 7 & 1.73 & 1.15 & 3064.6 & 1706 & 0.09 & 1.15 & 1.73 & 3070.2 & 1.65 & 3077.5 & 1.62 & 3079.5 & $\begin{array}{ll}1.61 \\
\end{array}$ & 3076.1 & \begin{tabular}{|l|}
1.61 \\
\end{tabular} & 3072.2 \\
\hline 550 & 1.5 & 3 & 8 & 1.42 & 0.95 & 3057.4 & 1874 & 0.13 & 16.47 & 1.42 & 3062.8 & 1.35 & 3069.7 & 1.33 & \begin{tabular}{|l|}
3071.2 \\
\end{tabular} & 1.32 & 3067.2 & \begin{tabular}{|l|l|} 
\\
\end{tabular} & 3061.9 \\
\hline 550 & 1.5 & 3 & 9 & 1.02 & 0.68 & 1465.0 & 1675 & 0.09 & 47.23 & 1.02 & \begin{tabular}{|l|l}
1293.8 \\
\end{tabular} & 0.31 & 948.3 & \begin{tabular}{|l|} 
\\
\end{tabular} & 599.0 & 0.12 & 244.7 & 0.08 & -108.3 \\
\hline 551 & 1.5 & 3 & 10 & 0.71 & 0.48 & 1466.4 & 1174 & 0.14 & 47.23 & 0.71 & 1298.1 & 0.22 & 957.4 & \begin{tabular}{|l|l|}
0.12 \\
\end{tabular} & 611.3 & 0.08 & 261.2 & 0.06 & -86.8 \\
\hline 551 & 1.5 & & 11 & 0.7 & 0.53 & 3052.0 & 1038 & 0.11 & 16.47 & & 3065.5 & 0.75 & 3085.7 & 0.74 & 3096.7 & 0.73 & 3102.4 & 0.73 & 3106.2 \\
\hline 551 & 1.5 & 3 & 12 & 0.64 & 0.42 & 3054.5 & 627 & $\begin{array}{l}0.12 \\
\end{array}$ & $\begin{array}{c}1.15 \\
\end{array}$ & 0.64 & 3062.5 & 0.60 & 3072.0 & 0.59 & \begin{tabular}{|l|l}
3072.9 \\
\end{tabular} & 0.59 & 3068.8 & \begin{tabular}{|l|}
0.58 \\
\end{tabular} & \\
\hline 551 & 1.5 & 3 & 13 & 0.92 & 0.62 & 2281.9 & 608 & 0.10 & -5.76 & 0 & 3105.9 & 0.90 & -3114.2 & 0.92 & -3069.8 & 0.94 & -3042.6 & 0.97 & -3025.2 \\
\hline 551 & 1.5 & 4 & & 8.99 & 5.99 & 3079.3 & 2957 & 0.12 & -6.95 & 8.99 & 3082.8 & 8.66 & 3084.4 & 8.60 & 3079.0 & 8.57 & 3066.0 & 8.54 & 3053.1 \\
\hline 552 & 1.5 & 4 & $\underline{2}$ & 6.48 & 32 & 3088.7 & $\begin{array}{l}2131 \\
\end{array}$ & 0.08 & -6.95 & & 3092.0 & \begin{tabular}{|l|}
6.27 \\
\end{tabular} & 3097.0 & 6.21 & 3100.0 & 6.19 & 3098.4 & \begin{tabular}{|l|l|}
6.18 \\
\end{tabular} & 3094.1 \\
\hline 552 & 1.5 & & 3 & 3.60 & 2.40 & 3087.7 & 2369 & 0.15 & \begin{tabular}{|c|}
-5.76 \\
\end{tabular} & 3.60 & 3074.9 & 3.47 & 3048.5 & 3.40 & 3021.0 & 3.35 & 2990.7 & 3.30 & 2963.0 \\
\hline 552 & 1.5 & 4 & 4 & 3.76 & 2.50 & 3082.6 & 3708 & 0.07 & 1.15 & & 3087.1 & 3.63 & 3093.2 & 3.59 & 3095.4 & 3.57 & 3093.7 & 3.57 & 3090.2 \\
\hline 552 & 1.5 & 4 & 5 & 2.79 & 1.86 & 3071.8 & 3675 & 0.08 & 16.47 & 2.79 & 3078.4 & 2.68 & 3087.1 & 2.65 & \begin{tabular}{|l|l|}
3089.7 \\
\end{tabular} & 2.63 & 3088.6 & 2.63 & 3084.8 \\
\hline 552 & 1.5 & & 6 & $\begin{array}{l}1.89 \\
\end{array}$ & 1.26 & \begin{tabular}{|l|l}
1480.1 \\
\end{tabular} & 3115 & 0.09 & 47.23 & 1.89 & 1311.3 & 0.59 & \begin{tabular}{|l}
967.6 \\
\end{tabular} & 0.33 & 615.6 & 0.22 & 262.0 & 0.16 & -91.8 \\
\hline 553 & 1.5 & 4 & 7 & 0.98 & 0.65 & 1465.0 & 1613 & 0.12 & 47.23 & 0.98 & 1301.5 & 0.30 & 963.0 & 0.17 & 609.4 & 0.12 & 250.7 & 0.08 & -108.4 \\
\hline 553 & 1.5 & & 8 & 1.09 & 0.72 & 3039.0 & 1430 & 0.11 & 16.47 & 1.09 & 3051.4 & \begin{tabular}{|l|} 
\\
\end{tabular} & 3066.6 & \begin{tabular}{|l|}
1.01 \\
\end{tabular} & 3069.0 & 1.00 & 3067.7 & 0.99 & 3062.9 \\
\hline 553 & 1.5 & 4 & 9 & 1.04 & 0.69 & 3052.3 & 1026 & 0.12 & 1.15 & 1.04 & 3062.2 & 0.99 & 3074.1 & 0.97 & 3075.5 & 0.97 & 3073.3 & 0.96 & 3069.1 \\
\hline 553 & 1.5 & 4 & 10 & 0.92 & & 3073.2 & 604 & 0.11 & -5.76 & 0.92 & 3080.0 & 0.88 & 3087.6 & 0.87 & 3087.5 & 0.87 & 3085.0 & 0.86 & \\
\hline 553 & 7.5 & 4 & 11 & 0.84 & 0.56 & 3080.7 & 278 & 0.15 & \begin{tabular}{l|l|}
-6.95 \\
\end{tabular} & 0.84 & 3085.8 & \begin{tabular}{|l|} 
\\
\end{tabular} .82 & 3091.5 & 0.81 & 3091.0 & 0.80 & 3088.0 & 0.80 & 3085.8 \\
\hline 554 & 1.5 & & & 0.81 & & 3084.0 & 267 & 0.15 & -6.95 & 0.81 & 3090.9 & 0.78 & 3100.7 & 0.77 & & $\begin{array}{l}0.77 \\
\end{array}$ & 3108.4 & 0.77 & \\
\hline 554 & 1.5 & 4 & 13 & \begin{tabular}{|l|}
0.67 \\
\end{tabular} & 0.44 & 3087.8 & 438 & 0.10 & -5.76 & $\begin{array}{l}0.67 \\
\end{array}$ & 3091.6 & $\mid 0.65$ & \begin{tabular}{|l|}
3095.7 \\
\end{tabular} & \begin{tabular}{|l|l|} 
\\
\end{tabular} & 3095.4 & 0.63 & 3093.9 & 0.63 & 3090.6 \\
\hline
\end{tabular}


DOE/RL-2009-35, REV. 0

\begin{tabular}{|c|c|c|c|c|c|c|c|c|c|c|c|c|c|c|c|c|c|c|c|}
\hline \multicolumn{20}{|c|}{ Pre Injection MALM Raw Data } \\
\hline $\begin{array}{c}\text { data block } \\
\text { number }\end{array}$ & current & line & station & $\mathbf{v}$ & $\begin{array}{c}\text { normalized } \\
\mathbf{V}\end{array}$ & phi & $\begin{array}{c}\text { contact } \\
\text { resistance }\end{array}$ & \begin{tabular}{|c|} 
data $\%$ \\
error
\end{tabular} & $\begin{array}{c}3 \mathrm{pt} \\
\text { phase }\end{array}$ & $\mathbf{v 1}$ & p1 & v3 & p3 & v5 & p5 & $v 7$ & p7 & v9 & p9 \\
\hline 554 & 1.5 & $\overline{5}$ & 1 & 10.26 & \begin{tabular}{|l|}
6.84 \\
\end{tabular} & 3083.5 & 10130 & 0.08 & 1.15 & 10.26 & 3086.1 & 9.88 & 3090.7 & 9.77 & 3094.5 & 9.76 & 3092.4 & 9.76 & 3086.1 \\
\hline 554 & 1.5 & 5 & 2 & 7.50 & 5.00 & 3087.4 & 9870 & 0.07 & 16.47 & 7.50 & 3089.8 & 7.25 & 3093.2 & 7.17 & 3094.9 & 7.16 & 3092.2 & 7.15 & 3085.8 \\
\hline 554 & 1.5 & 5 & 3 & 5.75 & 3.84 & 1518.8 & 9464 & 0.08 & 47.23 & 5.75 & 1343.3 & 1.82 & 991.7 & 1.04 & 639.1 & 0.70 & 285.2 & 0.50 & -69.2 \\
\hline 555 & 1.5 & 5 & 4 & 4.32 & 2.88 & 1519.3 & 7099 & 0.08 & 47.23 & 4.32 & 1343.8 & 1.37 & 991.5 & 0.78 & 637.2 & 0.52 & 282.5 & 0.37 & -72.3 \\
\hline 555 & 1.5 & 5 & 5 & 3.53 & \begin{tabular}{|l|}
2.35 \\
\end{tabular} & 3089.4 & 4645 & 0.08 & 16.47 & 3.53 & 3092.8 & 3.42 & 3097.0 & 3.39 & 3097.5 & 3.37 & 3096.2 & 3.36 & 3092.0 \\
\hline 555 & 1.5 & 5 & 6 & 2.88 & 1.92 & 3087.6 & 2843 & 0.08 & 1.15 & 2.88 & 3091.5 & 2.79 & 3095.9 & 2.76 & 3096.1 & 2.75 & 3094.7 & 2.74 & 3090.7 \\
\hline 555 & 1.5 & 5 & 9 & 1.06 & 0.70 & 3059.6 & 694 & 0.09 & -5.76 & 1.06 & 3069.3 & 1.01 & 3081.1 & 1.00 & 3082.9 & 0.99 & 3083.2 & 0.98 & 3082.2 \\
\hline 555 & 1.5 & 5 & 10 & 0.82 & 0.55 & 3061.5 & 270 & 0.12 & -6.95 & 0.82 & 3071.2 & 0.79 & 3082.5 & 0.78 & 3083.3 & 0.77 & 3083.7 & 0.77 & 3078.9 \\
\hline 556 & 1.5 & 5 & 11 & 0.84 & 0.56 & 3082.3 & 277 & 0.16 & -6.95 & 0.84 & 3088.7 & 0.82 & 3096.1 & 0.81 & 3096.2 & 0.80 & 3094.8 & 0.80 & 3093.4 \\
\hline 556 & 1.5 & 5 & 12 & 0.76 & \begin{tabular}{l|}
0.51 \\
\end{tabular} & 3088.6 & 502 & 0.11 & -5.76 & 0.76 & 3093.3 & 0.74 & 3098.4 & 0.73 & 3097.8 & 0.73 & 3096.6 & 0.73 & 3095.3 \\
\hline 556 & 1.5 & 5 & 13 & 0.68 & 0.45 & 3091.5 & 671 & 0.19 & 1.15 & 0.68 & 3095.7 & 0.66 & 3100.1 & 0.65 & 3098.9 & 0.65 & 3097.4 & 0.65 & 3093.7 \\
\hline 556 & 1.5 & 5 & 14 & 1.22 & 0.82 & 3081.3 & 1609 & 0.49 & 16.47 & 1.22 & 3086.5 & 1.18 & 3088.7 & 1.17 & 3079.7 & 1.17 & 3066.5 & 1.16 & 3053.9 \\
\hline 556 & 1.5 & 6 & 1 & 8.65 & 5.77 & 1506.5 & 14230 & 0.07 & 47.23 & 8.65 & 1333.6 & 2.72 & 981.9 & 1.56 & 622.5 & 1.04 & 260.2 & 0.75 & -100.3 \\
\hline 557 & 1.5 & 6 & 2 & 6.96 & 4.64 & 1513.9 & 11450 & 0.08 & 47.23 & 6.96 & 1338.8 & 2.19 & 988.1 & $1: 25$ & 636.7 & 0.84 & 283.4 & 0.60 & -70.1 \\
\hline 557 & 1.5 & 6 & 3 & 5.26 & 3.51 & 3086.2 & 6928 & 0.08 & 16.47 & 5.26 & 3089.2 & 5.08 & 3093.6 & 5.02 & 3095.7 & 5.00 & \begin{tabular}{|c|}
3095.1 \\
\end{tabular} & 4.99 & 3092.5 \\
\hline 557 & 1.5 & 6 & 4 & 4.03 & 2.69 & 3089.0 & 3979 & 0.08 & 1.15 & 4.03 & 3091.5 & 3.90 & 3094.6 & 3.85 & 3095.4 & 3.83 & 3094.5 & 3.83 & 3091.6 \\
\hline 557 & 1.5 & 6 & 5 & 3.22 & 2.15 & 3091.3 & 2122 & 0.07 & -5.76 & 3.22 & 3093.3 & 3.12 & 3095.5 & 3.09 & 3095.4 & 3.07 & 3094.5 & 3.06 & 3091.9 \\
\hline 557 & 1.5 & 6 & 6 & 2.90 & 1.93 & 3092.5 & 953 & 0.08 & -6.95 & 2.90 & 3093.9 & 2.81 & 3095.2 & 2.77 & 3094.4 & 2.76 & 3092.7 & 2.75 & 3089.8 \\
\hline 558 & 1.5 & 6 & 7 & 2.77 & $\begin{array}{l}1.85 \\
\end{array}$ & 3092.0 & 911 & 0.10 & -6.95 & 2.77 & 3093.9 & 2.68 & 3095.0 & 2.65 & 3092.5 & 2.64 & 3090.6 & 2.63 & 3087.0 \\
\hline 558 & 1.5 & 6 & 9 & 2.05 & \begin{tabular}{l|}
1.37 \\
\end{tabular} & 3093.0 & 1350 & 0.09 & -5.76 & 2.05 & 3094.6 & 1.99 & 3095.4 & 1.97 & 3092.8 & 1.95 & 3090.9 & 1.95 & 3088.1 \\
\hline 558 & 1.5 & 6 & 10 & 1.68 & 1.12 & 3093.3 & 1659 & 0.10 & 1.15 & 1.68 & 3094.9 & 1.63 & 3095.3 & 1.61 & 3092.0 & 1.60 & 3089.7 & 1.60 & 3086.6 \\
\hline 558 & 1.5 & 6 & 11 & 1.40 & 0.93 & 3094.0 & 1838 & 0.09 & 16.47 & 1.40 & 3095.4 & 1.36 & 3095.7 & 1.34 & 3092.7 & 1.33 & 3091.0 & 1.33 & 3087.6 \\
\hline 558 & 1.5 & 6 & 12 & 1.14 & 0.76 & 1523.0 & 1867 & 0.11 & 47.23 & 7.14 & 1348.3 & 0.36 & 996.6 & 0.21 & 641.8 & 0.14 & 289.8 & 0.10 & -61.1 \\
\hline 559 & 1.5 & 6 & 13 & 0.97 & $\begin{array}{ll}0.65 \\
\end{array}$ & 1522.2 & 1595 & 0.09 & 47.23 & 0.97 & 1345.4 & 0.31 & 990.3 & 0.18 & 633.0 & 0.12 & 277.2 & 0.08 & -74.9 \\
\hline 559 & 1.5 & 7 & 1 & 9.16 & \begin{tabular}{l|l|}
6.11 \\
\end{tabular} & 3075.3 & 12050 & 0.07 & 16.47 & 9.16 & 3082.3 & 8.79 & 3092.5 & 8.70 & 3097.5 & 8.67 & 3095.8 & 8.65 & 3093.3 \\
\hline 559 & 1.5 & 7 & 2 & 5.21 & 3.48 & 3056.9 & 5147 & 0.07 & 1.15 & 5.21 & 3064.7 & 4.96 & 3075.3 & 4.87 & 3079.1 & 4.83 & 3080.0 & 4.80 & 3080.3 \\
\hline 559 & 1.5 & 7 & 3 & 3.41 & 2.28 & 3040.8 & 2246 & 0.06 & -5.76 & 3.41 & 3047.9 & 3.21 & 3056.8 & 3.13 & 3058.7 & 3.08 & 3061.8 & 3.06 & 3064.7 \\
\hline 559 & 1.5 & 7 & 4 & 3.46 & 2.31 & 3069.1 & 1140 & 0.08 & -6.95 & 3.46 & 3073.2 & 3.31 & 3077.9 & 3.25 & 3078.2 & 3.22 & 3078.7 & 3.20 & 3078.7 \\
\hline 560 & 1.5 & 7 & 5 & 3.15 & 2.10 & 3082.1 & 1037 & 0.10 & -6.95 & 3.15 & 3083.9 & 3.03 & 3085.6 & 2.98 & 3084.6 & 2.96 & 3083.8 & 2.95 & 3082.6 \\
\hline 560 & 1.5 & 7 & 6 & 2.91 & 1.94 & 3087.0 & 1915 & 0.09 & -5.76 & 2.91 & 3088.3 & 2.81 & 3089.1 & 2.77 & 3087.5 & 2.75 & 3086.5 & 2.74 & 3084.6 \\
\hline 560 & 1.5 & 7 & 7 & 2.72 & 1.81 & 3089.1 & 2686 & 0.09 & 1.15 & 2.72 & 3090.0 & 2.63 & 3090.3 & 2.59 & 3088.8 & 2.57 & 3087.3 & 2.56 & 3085.5 \\
\hline 560 & 1.5 & 7 & 8 & 2.50 & 1.67 & 3090.8 & 3290 & 0.09 & 16.47 & 2.50 & 3091.5 & 2.42 & 3091.4 & 2.38 & 3089.3 & 2.37 & 3088.5 & 2.36 & 3086.1 \\
\hline 560 & 1.5 & 7 & 9 & 2.26 & 1.51 & 1521.6 & 3725 & 0.09 & 47.23 & 2.26 & 1343.3 & 0.72 & 986.3 & 0.41 & 628.6 & 0.27 & 274.3 & 0.19 & $\begin{array}{r}-79.1 \\
\end{array}$ \\
\hline 561 & 1.5 & 7 & 10 & 1.85 & $\begin{array}{l}1.23 \\
\end{array}$ & 1523.8 & 3047 & 0.07 & 47.23 & 1.85 & 1345.3 & 0.59 & 988.0 & 0.33 & 630.2 & 0.22 & 275.9 & 0.16 & -76.7 \\
\hline 561 & 1.5 & 7 & 11 & 1.60 & 1.07 & 3096.0 & 2104 & 0.06 & 16.47 & 1.60 & 3095.9 & 1.55 & 3094.7 & 1.53 & 3092.1 & 1.52 & 3090.5 & 1.52 & 3088.4 \\
\hline 561 & 1.5 & 7 & 12 & 1.35 & 0.90 & 3096.8 & 1328 & 0.09 & 1.15 & 1.35 & 3097.6 & 1.31 & 3097.8 & 1.29 & 3096.4 & 1.28 & \begin{tabular}{|l|}
3096.2 \\
\end{tabular} & 1.28 & 3094.1 \\
\hline 561 & 1.5 & 7 & 13 & 1.17 & 0.78 & 3098.1 & 769 & 0.07 & -5.76 & 1.17 & 3098.5 & 1.14 & 3098.2 & 1.12 & 3096.5 & 1.11 & 3096.4 & 1.11 & 3095.1 \\
\hline 561 & 1.5 & 8 & 1 & 5.29 & 3.52 & 3084.2 & 1739 & 0.26 & -6.95 & 5.29 & 3062.6 & 5.05 & 3020.4 & 4.93 & 2979.4 & 4.82 & 2936.1 & 4.71 & 2893.7 \\
\hline 562 & 1.5 & 8 & 2 & 5.06 & 3.37 & 3082.2 & 1664 & 0.07 & -6.95 & 5.06 & 3083.3 & 4.87 & 3084.4 & 4.80 & 3083.8 & 4.77 & 3081.3 & 4.76 & 3076.2 \\
\hline 562 & 1.5 & 8 & 3 & 4.11 & \begin{tabular}{|l|}
2.74 \\
\end{tabular} & 3081.5 & 2705 & 0.07 & -5.76 & 4.11 & 3084.2 & 3.96 & 3088.0 & 3.90 & 3089.9 & 3.87 & 3091.1 & 3.86 & 3089.8 \\
\hline 562 & 1.5 & $\overline{8}$ & 4 & 3.55 & \begin{tabular}{|l|}
2.37 \\
\end{tabular} & 3085.8 & 3503 & 0.07 & 1.15 & 3.55 & 3085.2 & 3.42 & 3082.7 & 3.37 & 3078.4 & 3.35 & 3073.9 & 3.34 & 3067.1 \\
\hline 562 & 1.5 & 8 & 5 & 3.50 & 2.33 & 3086.6 & 4600 & 0.08 & 16.47 & 3.50 & 3088.0 & 3.37 & 3089.6 & 3.33 & 3089.4 & 3.30 & 3089.0 & 3.30 & 3086.0 \\
\hline 562 & 1.5 & 8 & 6 & 3.22 & 2.15 & 1517.0 & 5293 & 0.07 & 47.23 & 3.22 & 1339.5 & 1.02 & 984.2 & 0.58 & 628.7 & 0.39 & \begin{tabular}{|l|}
274.7 \\
\end{tabular} & 0.28 & -78.4 \\
\hline 563 & 1.5 & 8 & 7 & 3.04 & 2.03 & 1516.9 & 4999 & 0.07 & 47.23 & 3.04 & 1340.2 & 0.96 & 986.1 & 0.55 & 630.6 & 0.36 & 276.0 & 0.26 & -76.2 \\
\hline 564 & 1.5 & 8 & 7 & 3.04 & \begin{tabular}{|l|}
2.03 \\
\end{tabular} & 1516.6 & 5001 & 0.07 & 47.23 & 3.04 & 1340.0 & 0.96 & \begin{tabular}{|c|}
985.3 \\
\end{tabular} & 0.55 & 628.6 & 0.36 & 274.6 & 0.26 & -78.8 \\
\hline 563 & 1.5 & 8 & 8 & 2.69 & 1.79 & 3089.3 & 3533 & 0.07 & 16.47 & 2.69 & 3089.7 & 2.60 & 3088.7 & 2.56 & 3085.3 & 2.54 & 3081.4 & 2.54 & 3076.5 \\
\hline 564 & 1.5 & 8 & 8 & 2.70 & 1.80 & 3088.9 & 3557 & 0.07 & 16.47 & 2.70 & 3089.6 & 2.61 & 3088.8 & 2.58 & 3084.8 & 2.56 & 3081.7 & 2.55 & 3076.4 \\
\hline 563 & 1.5 & 8 & 9 & 2.29 & 1.53 & 3091.6 & 2259 & 0.07 & 1.15 & 2.29 & 3091.6 & 2.22 & 3090.1 & 2.19 & 3086.3 & 2.17 & 3082.4 & 2.17 & 3077.0 \\
\hline 564 & 1.5 & 8 & 9 & 2.32 & 1.54 & 3091.1 & 2286 & 0.07 & 1.15 & 2.32 & 3091.5 & 2.24 & 3090.1 & 2.21 & 3085.6 & 2.20 & 3082.2 & 2.19 & 3077.1 \\
\hline 563 & 1.5 & 8 & 10 & 1.83 & 1.22 & 3094.5 & 1204 & 0.08 & -5.76 & 1.83 & 3095.2 & 1.77 & 3095.2 & 1.75 & 3093.7 & 1.74 & 3091.9 & 1.74 & 3089.6 \\
\hline 563 & 1.5 & 8 & 11 & 1.53 & 1.02 & 3096.4 & 504 & 0.07 & -6.95 & 1.53 & 3097.2 & \begin{tabular}{|l|}
1.49 \\
\end{tabular} & 3097.7 & 1.47 & 3096.6 & 1.46 & \begin{tabular}{|l|}
3096.2 \\
\end{tabular} & 1.45 & 3095.2 \\
\hline 564 & 1.5 & 8 & 12 & 1.26 & 0.84 & 3098.0 & 414 & 0.09 & -6.95 & 1.26 & 3099.2 & 1.22 & 3100.7 & 1.21 & 3101.1 & 1.20 & 3101.3 & 1.20 & 3100.5 \\
\hline 564 & 1.5 & 8 & 13 & 1.03 & 0.69 & 3099.0 & 677 & 0.08 & $\begin{array}{l}-5.76 \\
\end{array}$ & 1.03 & 3099.6 & 1.00 & 3099.5 & 0.99 & 3097.6 & 0.98 & 3097.0 & 0.98 & 3095.1 \\
\hline
\end{tabular}


DOE/RL-2009-35, REV. 0

\begin{tabular}{|c|c|c|c|c|c|c|c|c|c|c|c|c|c|c|c|c|c|c|c|}
\hline \multicolumn{20}{|c|}{ Post Injection MALM Raw Data } \\
\hline $\begin{array}{c}\text { data block } \\
\text { number }\end{array}$ & current & Line & Station & v & $\begin{array}{c}\text { Normalized } \\
\mathrm{V}\end{array}$ & phi & $\begin{array}{c}\text { contact } \\
\text { resistance }\end{array}$ & $\begin{array}{c}\text { data } \% \\
\text { error }\end{array}$ & $\begin{array}{c}\text { 3pt } \\
\text { phase }\end{array}$ & v1 & p1 & $\mathbf{v 3}$ & p3 & v5 & p5 & v7 & p7 & v9 & p9 \\
\hline & 2 & 1 & 1 & 10.80 & 5.40 & 3078.3 & 666 & 0.09 & $\mid-193.4$ & 10.80 & -3094.5 & 10.58 & -3111.5 & 10.48 & -3108.0 & 10.46 & -3105.7 & 10.44 & -3103.9 \\
\hline 4 & 2 & 1 & 2 & 6.55 & 3.28 & 3088.4 & 808 & 0.09 & .217 .8 & 6.55 & -3099.7 & 6.42 & -3141.5 & 6.37 & -3108.7 & 6.36 & -3106.1 & 6.35 & -3103.6 \\
\hline 4 & 2 & 1 & 3 & 5.37 & 2.69 & 3092.1 & 994 & 0.09 & -194 & 5.37 & -3101.9 & 5.27 & -3112.1 & 5.23 & $\mid-3109.7$ & 5.22 & -3107.0 & 5.21 & -3104.7 \\
\hline 4 & 2 & 1 & 4 & 4.71 & 2.36 & 3094.4 & 1163 & 0.09 & -175.7 & 4.71 & -3103.4 & 4.63 & -3112.8 & 4.59 & -3110.6 & 4.58 & -3108.4 & 4.58 & -3105.7 \\
\hline 4 & 2 & 1 & 5 & $\begin{array}{ll}4.36 \\
\end{array}$ & 2.18 & 3095.3 & 1343 & 0.08 & \begin{tabular}{|l}
-171.3 \\
\end{tabular} & 4.36 & -3104.0 & 4.28 & $-31+3.0$ & 4.25 & -3110.9 & 4.24 & -3108.3 & 4.23 & -3105.8 \\
\hline 5 & 2 & 1 & 6 & 3.94 & 1.97 & 3100.8 & 1216 & 0.07 & -171.3 & 3.94 & -3106.1 & 3.88 & -3111.7 & 3.85 & -3110.5 & 3.85 & -3107.3 & 3.84 & -3103.9 \\
\hline 5 & 2 & 1 & 7 & 3.31 & 1.66 & 3102.4 & 817 & 0.07 & -175.7 & \begin{tabular}{|l|}
3.31 \\
\end{tabular} & -3107.2 & 3.26 & -3112.2 & 3.24 & -3110.9 & 3.23 & -3108.0 & 3.23 & -3104.0 \\
\hline 5 & 2 & 1 & 8 & 2.80 & 1.40 & 3103.4 & 518 & 0.07 & \begin{tabular}{|l|}
-194 \\
\end{tabular} & 2.80 & -3108.1 & 2.76 & .3112 .7 & 2.74 & -3111.0 & 2.73 & -3107.7 & 2.73 & -3104.1 \\
\hline 5 & 2 & 1 & 9 & 2.37 & 1.18 & 3105.0 & 292 & 0.08 & -217.8 & 2.37 & -3109.2 & 2.33 & -3113.3 & 2.32 & -3111.6 & 2.31 & -3108.0 & 2.31 & -3104.5 \\
\hline 5 & 2 & 1 & 10 & 1.84 & 0.92 & 3106.4 & 113 & 0.09 & -193.4 & 1.84 & -3110.2 & 1.81 & -3113.6 & 1.80 & -3111.5 & 1.80 & -3108.2 & 1.80 & -3105.1 \\
\hline 6 & 2 & 1 & 11 & 1.44 & 0.72 & 3106.5 & 89 & 0.11 & -193.4 & 1.44 & -3110.6 & 1.42 & -3114.1 & 1.41 & -3111.2 & 1.40 & -3108.1 & 1.40 & -3106.1 \\
\hline 6. & 2 & 1 & 12 & 1.12 & 0.56 & 3108.3 & 138 & 0.09 & -217.8 & 1.12 & $-31 \uparrow 2.1$ & 1.10 & \begin{tabular}{|l|}
-3115.3 \\
\end{tabular} & 1.10 & \begin{tabular}{|l|}
-3112.7 \\
\end{tabular} & 1.09 & -3111.0 & 1.09 & -3107.6 \\
\hline 6 & 2 & 1 & 13 & 0.89 & 0.44 & 3108.7 & 164 & 0.11 & \begin{tabular}{|l|}
-194 \\
\end{tabular} & 0.89 & -3112.6 & 0.87 & \begin{tabular}{|l|}
-3115.9 \\
\end{tabular} & 0.87 & -3113.6 & 0.87 & -3111.2 & 0.87 & -3109.0 \\
\hline 6 & 2 & 2 & 1 & 11.06 & 5.53 & 3083.2 & 2729 & 0.08 & -175.7 & 11.06 & -3096.8 & 10.84 & -3111.1 & \begin{tabular}{|l|}
10.75 \\
\end{tabular} & -3108.2 & 10.72 & -3106.2 & 10.70 & -3103.4 \\
\hline 6 & 2 & 2 & 2 & \begin{tabular}{|l|} 
\\
\end{tabular} & 3.58 & 3090.4 & 2210 & 0.08 & -171.3 & \begin{tabular}{|l|}
7.17 \\
\end{tabular} & \begin{tabular}{|l|} 
\\
\end{tabular} & \begin{tabular}{|l|}
7.03 \\
\end{tabular} & \begin{tabular}{|l|}
-3110.8 \\
\end{tabular} & \begin{tabular}{|l|}
6.97 \\
\end{tabular} & -3108.2 & \begin{tabular}{|l|}
6.95 \\
\end{tabular} & \begin{tabular}{|l|}
-3105.8 \\
\end{tabular} & \begin{tabular}{|l|}
6.94 \\
\end{tabular} & -3102.8 \\
\hline 7 & 2 & 2 & 3 & 5.49 & 2.75 & 3095.9 & 1694 & 0.07 & -171.3 & 5.49 & -3102.9 & 5.40 & -3110.2 & 5.35 & -3108.7 & 5.34 & -3105.7 & 5.33 & -3102.3 \\
\hline 7 & 2 & 2 & 4) & 4.65 & 2.33 & 3096.9 & 1149 & 0.07 & \begin{tabular}{|l|l|} 
\\
\end{tabular} & 4.65 & \begin{tabular}{|l|}
-3103.4 \\
\end{tabular} & 4.57 & \begin{tabular}{|l|}
-3110.3 \\
\end{tabular} & 4.54 & -3108.8 & 4.53 & -3106.0 & 4.52 & -3102.4 \\
\hline 7 & 2 & 2 & 5 & 4.00 & 2.00 & \begin{tabular}{|l|}
3097.1 \\
\end{tabular} & 741 & 0.07 & \begin{tabular}{|l|}
-194 \\
\end{tabular} & 4.00 & -3103.4 & 3.93 & $\mid-3110.1$ & 3.90 & -3108.7 & 3.89 & -3105.8 & 3.88 & -3102.1 \\
\hline 7 & 2 & 2 & 6 & 3.57 & 1.78 & 3097.1 & 440 & 0.07 & -217.8 & 3.57 & -3103.2 & 3.50 & -3109.6 & 3.47 & -3108.2 & 3.46 & -3105.4 & 3.46 & -3101.8 \\
\hline 7 & 2 & 2 & 7 & 3.17 & 1.59 & 3097.1 & 196 & 0.07 & .193 .4 & 3.17 & -3103.0 & 3.11 & -3109.3 & 3.09 & -3107.9 & 3.08 & -3104.9 & 3.07 & -3101.3 \\
\hline 8 & 2 & 2 & 8 & 2.82 & 1.41 & 3094.2 & 174 & 0.06 & -193.4 & 2.82 & -3101.6 & 2.76 & -3109.0 & 2.74 & -3106.3 & 2.73 & -3104.0 & 2.72 & -3099.8 \\
\hline 8 & 2 & 2 & 9 & 2.45 & 1.22 & \begin{tabular}{|l|l}
3093.8 \\
\end{tabular} & 302 & 0.07 & \begin{tabular}{|l|}
-217.8 \\
\end{tabular} & 2.45 & -3101.4 & 2.39 & -3108.8 & 2.38 & -3106.2 & 2.37 & -3103.7 & 2.37 & -3100.3 \\
\hline 8 & 2 & 2 & 10 & 1.84 & 0.92 & 3094.1 & 340 & 0.07 & \begin{tabular}{|l|}
-194 \\
\end{tabular} & 9.84 & -3100.8 & 1.80 & -3107.6 & 1.78 & -3105.5 & 1.78 & -3103.3 & 1.77 & -3098.9 \\
\hline 8 & 2 & 2 & 11 & 1.45 & 0.73 & 3094.7 & 359 & 0.06 & \begin{tabular}{|l|l}
-175.7 \\
\end{tabular} & 7.45 & -3100.9 & 1.42 & -3107.1 & 1.41 & -3104.9 & 1.40 & -3102.1 & 1.40 & -3098.7 \\
\hline 8 & 2 & 2 & 12 & 1.17 & 0.59 & 3095.6 & 362 & 0.07 & -171.3 & 1.17 & -3101.4 & 1.15 & $-3 \neq 07.3$ & 1.14 & -3105.2 & 1.14 & -3102.9 & 1.13 & -3099.1 \\
\hline 9 & 2 & 2 & 13 & 0.96 & 0.48 & 3099.7 & 297 & 0.07 & -171.3 & 0.96 & -3103.8 & 0.94 & -3108.2 & 0.94 & -3107.4 & 0.93 & -3104.8 & 0.93 & -3101.5 \\
\hline 9 & 2 & 3 & 1 & 14.70 & 5.85 & 3091.5 & 2887 & 0.08 & 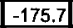 & 11.70 & -3099.8 & 11.54 & -3109.4 & 11.44 & -3110.0 & 11.41 & -3107.4 & 11.40 & -3104.3 \\
\hline 9 & 2 & 3 & 2 & 7.28 & 3.64 & 3097.3 & 1347 & 0.08 & -194 & 7.28 & -3103.2 & \begin{tabular}{|l|}
7.17 \\
\end{tabular} & $\mid-3109.6$ & 7.11 & -3109.1 & 7.09 & \begin{tabular}{|l|}
-3106.3 \\
\end{tabular} & \begin{tabular}{|l|}
7.08 \\
\end{tabular} & -3102.7 \\
\hline 9 & 2 & 3 & 3 & 5.83 & 2.92 & 3098.5 & 720 & 0.07 & -217.8 & 5.83 & -3103.8 & 5.74 & -3109.5 & 5.69 & -3108.6 & 5.68 & -3105.5 & 5.67 & -3101.9 \\
\hline 9 & 2 & 3 & 4 & 4.38 & 2.19 & \begin{tabular}{|l|}
3093.7 \\
\end{tabular} & 270 & 0.08 & -193.4 & 4.38 & -3099.6 & 4.30 & \begin{tabular}{|l|}
-3106.0 \\
\end{tabular} & 4.26 & -3105.6 & 4.24 & \begin{tabular}{|l|l|} 
\\
\end{tabular} & 4.24 & -3099.4 \\
\hline 10 & 2 & 3 & 5 & 3.58 & 1.79 & 3087.4 & 221 & 0.07 & \begin{tabular}{|l|}
-193.4 \\
\end{tabular} & 3.58 & -3095.0 & 3.50 & \begin{tabular}{|c|}
-3103.4 \\
\end{tabular} & 3.46 & -3102.7 & 3.45 & -3100.5 & 3.44 & -3097.5 \\
\hline 10 & 2 & 3 & 6 & 2.82 & 1.41 & 3081.4 & 348 & 0.06 & \begin{tabular}{|l}
-217.8 \\
\end{tabular} & 2.82 & -3089.6 & 2.74 & -3098.9 & 2.71 & -3098.9 & 2.70 & -3097.1 & 2.69 & -3094.5 \\
\hline 10 & 2 & 3 & 7 & 2.19 & 1.09 & 3072.1 & 404 & 0.08 & -194 & 2.19 & -3080.9 & 2.11 & -3091.6 & 2.08 & -3092.9 & 2.07 & -3091.3 & 2.06 & -3088.4 \\
\hline 10 & 2 & 3 & 8 & 1.80 & 0.90 & 3064.0 & 443 & 0.08 & -175.7 & 1.80 & -3073.0 & 1.72 & -3084.3 & 1.70 & -3086.7 & 1.69 & -3085.6 & 1.68 & -3083.6 \\
\hline 10 & 2 & 3 & 9 & 1.29 & 0.65 & 3045.0 & 399 & 0.08 & -171.3 & 1.29 & -3054.8 & 1.22 & -3067.8 & 1.20 & -3072.1 & 1.19 & -3072.4 & 1.18 & -3071.0 \\
\hline 11 & 2 & 3 & 10 & 0.85 & 0.43 & 3041.3 & 263 & 0.22 & -171.3 & 0.85 & -3056.5 & 0.80 & -3081.7 & 0.79 & -3099.9 & 0.78 & -3112.9 & 0.77 & -3123.7 \\
\hline 11 & 2 & 3 & 11 & 0.83 & 0.42 & 3051.6 & 205 & 0.09 & -175.7 & 0.83 & -3060.5 & 0.79 & \begin{tabular}{|r|} 
\\
\end{tabular} & 0.78 & -3073.4 & 0.77 & -3071.8 & 0.76 & -3069.9 \\
\hline 11 & 2 & 3 & 12 & 0.80 & 0.40 & 3063.5 & 148 & 0.10 & -194 & 0.80 & -3072.3 & 0.77 & $\mid-3082.6$ & 0.75 & -3083.0 & 0.75 & \begin{tabular}{|l|}
-3081.6 \\
\end{tabular} & 0.74 & -3078.5 \\
\hline 11 & 2 & 3 & 13 & 0.74 & 0.37 & \begin{tabular}{|l|}
3071.4 \\
\end{tabular} & 91 & 0.10 & -217.8 & 0.74 & -3079.8 & 0.71 & -3089.6 & 0.70 & -3090.0 & 0.70 & -3089.9 & 0.70 & -3088.2 \\
\hline 11 & 2 & 4 & 1 & 12.14 & 6.07 & 3085.2 & 749 & 0.08 & 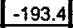 & 12.14 & -3097.5 & 11.94 & $\mid-3111.0$ & \begin{tabular}{|l|}
11.82 \\
\end{tabular} & -3109.5 & 11.79 & -3106.8 & 11.78 & -3104.4 \\
\hline 12 & 2 & 4 & 2 & \begin{tabular}{|l|} 
\\
\end{tabular} & 3.85 & \begin{tabular}{|l|}
3088.9 \\
\end{tabular} & 475 & 0.08 & 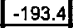 & 7.70 & -3100.0 & 7.55 & \begin{tabular}{|c|}
-3111.1 \\
\end{tabular} & 7.49 & \begin{tabular}{|l|}
-3107.8 \\
\end{tabular} & 7.47 & \begin{tabular}{|l|}
-3105.3 \\
\end{tabular} & 7.46 & -3102.0 \\
\hline 12 & 2 & 4 & 3 & 6.03 & 3.02 & 3089.5 & 744 & 0.08 & -217.8 & 6.03 & -3099.5 & 5.91 & \begin{tabular}{|l|}
-3109.6 \\
\end{tabular} & 5.86 & -3106.7 & 5.84 & -3104.2 & 5.83 & -3100.8 \\
\hline 12 & 2 & 4 & 4 & 4.70 & 2.35 & 3085.6 & 869 & 0.08 & -194 & 4.70 & -3096.0 & 4.59 & -3106.9 & 4.55 & -3104.6 & 4.53 & -3102.3 & 4.52 & -3099.2 \\
\hline 12 & 2 & 4 & 5 & 3.49 & 1.74 & 3075.9 & 860 & 0.08 & \begin{tabular}{|l|l}
-175.7 \\
\end{tabular} & 3.49 & \begin{tabular}{|l|}
-3087.7 \\
\end{tabular} & 3.39 & -3100.6 & 3.35 & \begin{tabular}{|l|}
-3099.3 \\
\end{tabular} & 3.34 & -3097.7 & 3.33 & -3094.6 \\
\hline 12 & 2 & 4 & 6 & 2.45 & 1.23 & 3057.5 & 756 & 0.08 & -171.3 & 2.45 & -3072.5 & 2.36 & -3089.8 & 2.33 & -3090.2 & 2.31 & -3089.0 & 2.30 & -3086.5 \\
\hline 13 & 2 & 4 & 7 & 1.63 & 0.81 & 3037.8 & 502 & 0.12 & -171.3 & 1.63 & -3055.9 & 1.55 & -3077.2 & 1.53 & -3078.6 & 1.51 & -3078.7 & 1.50 & -3076.4 \\
\hline 13 & 2 & 4 & 8 & 1.37 & 0.68 & 3047.7 & 337 & 0.09 & -175.7 & 1.37 & -3063.0 & 1.31 & -3081.0 & 1.29 & -3082.0 & 1.28 & -3081.5 & 1.27 & -3079.1 \\
\hline 13 & 2 & 4 & 9 & 1.31 & 0.65 & 3060.3 & 242 & 0.10 & -194 & 1.31 & -3072.8 & 1.26 & -3087.2 & 1.24 & -3087.9 & 1.23 & \begin{tabular}{|l|}
-3086.3 \\
\end{tabular} & 1.23 & -3082.9 \\
\hline 13 & 2 & 4 & 10 & 1.16 & 0.58 & 3082.5 & 143 & 0.08 & -217.8 & 1.16 & -3090.4 & 1.13 & \begin{tabular}{|l|} 
\\
\end{tabular} & 1.12 & -3098.1 & 1.11 & -3095.4 & 1.11 & -3092.4 \\
\hline 13 & 2 & 4 & 11 & 1.07 & 0.53 & 3088.4 & 66 & 0.11 & $\mid-193.4$ & 1.07 & -3095.0 & 1.04 & -3102.0 & 1.03 & -3100.4 & 1.03 & -3098.6 & 1.02 & -3094.2 \\
\hline 14. & 2 & 4 & 12 & 0.97 & 0.48 & 3092.6 & 60 & 0.25 & -193.4 & 0.97 & -3097.6 & 0.94 & $|-3102.7|$ & 0.94 & $\mid-3101.1$ & 0.93 & -3098.0 & 0.93 & -3093.9 \\
\hline 14 & 2 & 4 & 13 & 0.84 & 0.42 & 3094.2 & 104 & 0.16 & -217.8 & 0.84 & -3099.8 & 0.82 & $\mid-3105.0$ & 0.81 & $\mid-3102.4$ & 0.81 & -3099.4 & 0.81 & -3095.8 \\
\hline
\end{tabular}


DOE/RL-2009-35, REV. 0

\begin{tabular}{|c|c|c|c|c|c|c|c|c|c|c|c|c|c|c|c|c|c|c|c|}
\hline \multicolumn{20}{|c|}{ Post Injection MALM Raw Data } \\
\hline $\begin{array}{c}\text { data block } \\
\text { number }\end{array}$ & current & Line & Station & $\mathbf{v}$ & $\begin{array}{c}\text { Normalized } \\
\mathbf{V}\end{array}$ & phi & $\begin{array}{c}\text { contact } \\
\text { resistance }\end{array}$ & $\begin{array}{c}\text { data } \% \\
\text { error }\end{array}$ & $\begin{array}{c}\text { 3pt } \\
\text { phase }\end{array}$ & v1 & p1 & v3 & p3 3 & v5 & p5 5 & v7 & p7 & v9 & p9 \\
\hline 14 & & 5 & & 12.94 & 6.47 & 3076.5 & 2394 & 0.05 & -194 & 12.94 & -3093.8 & 12.64 & -3111.3 & 12.55 & -3106.1 & 12.50 & -3104.6 & 12.49 & -3101.1 \\
\hline 14 & & 5 & & 9.14 & 4.57 & 3084.5 & 2255 & 0.05 & -175.7 & 9.14 & -3098.0 & 8.94 & -3111.4 & 8.88 & -3106.7 & 8.86 & -3104.6 & 8.85 & -3100.6 \\
\hline 14 & & 5 & & $\overline{7.12}$ & 3.56 & 3088.8 & 2195 & 0.05 & -171.3 & 7.12 & -3100.4 & 6.97 & -3111.9 & 6.93 & \begin{tabular}{|c|c|c|}
-3107.8 \\
\end{tabular} & 6.90 & -3105.6 & 6.90 & -3101.8 \\
\hline 15 & & 5 & 4 & 5.36 & 2.68 & 3092.0 & 1652 & 0.06 & -171.3 & 5.36 & -3102.0 & 5.25 & -3112.2 & 5.22 & -3109.1 & 5.20 & -3107.5 & 5.19 & -3104.2 \\
\hline 15 & & 5 & 5 & 4.37 & 2.18 & 3092.8 & 1078 & 0.06 & -175.7 & 4.37 & -3102.2 & 4.28 & -3111.7 & 4.25 & -3108.8 & 4.24 & -3107.3 & 4.23 & -3104.0 \\
\hline 15 & & 5 & 6 & 3.46 & 1.73 & 3092.1 & $\frac{641}{6}$ & 0.06 & -194 & 3.46 & -3101.4 & 3.39 & -3110.9 & 3.37 & \begin{tabular}{|l|}
-3108.5 \\
\end{tabular} & 3.36 & -3106.6 & 3.35 & -3103.4 \\
\hline 15 & & 5 & 8 & 1.35 & 0.67 & $\mid 3072.0$ & 166 & 0.08 & -217.8 & 1.35 & -3084.4 & 1.31 & -3098.8 & 1.30 & -3099.3 & 1.29 & -3098.7 & 1.29 & -3096.9 \\
\hline 15 & & 5 & 9 & 1.11 & 0.55 & 3067.3 & 68 & 0.22 & -193.4 & 1.11 & -3080.1 & 1.07 & -3095.4 & 1.06 & -3097.1 & 1.06 & -3095.6 & 1.05 & -3094.4 \\
\hline 16 & & 5 & 10 & 1.03 & 0.52 & 3073.7 & 64 & 0.09 & -193.4 & 1.03 & -3085.0 & 1.00 & -3097.9 & 0.99 & -3098.0 & 0.99 & -3096.7 & 0.99 & -3095.0 \\
\hline 16 & & 5 & 11 & 1.03 & 0.51 & 3091.0 & 127 & 0.08 & $\begin{array}{l}-217.8 \\
\end{array}$ & 1.03 & -3098.3 & 1.00 & -3106.2 & 1.00 & \begin{tabular}{|c|}
-3105.2 \\
\end{tabular} & 0.99 & $\begin{array}{l}-3103.2 \\
\end{array}$ & 0.99 & -3099.4 \\
\hline 16 & & 5 & 12 & 0.95 & 0.47 & 3096.8 & 175 & 0.07 & $\begin{array}{l}-194 \\
\end{array}$ & 0.95 & -3102.8 & 0.93 & -3109.5 & 0.92 & -3109.3 & 0.92 & -3105.9 & 0.92 & -3104.2 \\
\hline 16 & & 5 & 13 & 0.84 & 0.42 & 3099.9 & 207 & 0.07 & -175.7 & 0.84 & -3104.5 & 0.82 & -3108.9 & 0.82 & -3106.8 & 0.81 & -3103.1 & 0.81 & -3099.0 \\
\hline 16 & & 5 & 14 & 0.74 & 0.37 & 3102.4 & 227 & 0.09 & -171.3 & 0.74 & -3106.0 & 0.72 & -3109.0 & 0.72 & -3106.4 & 0.72 & -3103.2 & 0.71 & -3100.7 \\
\hline 17 & & 6 & & \begin{tabular}{|l|}
12.41 \\
\end{tabular} & 6.21 & \begin{tabular}{|l|}
3093.0 \\
\end{tabular} & 3828 & 0.07 & -171.3 & \begin{tabular}{|l|l|}
12.41 \\
\end{tabular} & -3099.6 & \begin{tabular}{|l}
12.24 \\
\end{tabular} & -3107.4 & \begin{tabular}{|l|}
12.16 \\
\end{tabular} & $\begin{array}{r}-3108.2 \\
\end{array}$ & \begin{tabular}{|l|}
12.11 \\
\end{tabular} & -3106.4 & \begin{tabular}{|l|}
12.09 \\
\end{tabular} & -3102.8 \\
\hline 17 & & 6 & 2 & \begin{tabular}{|l|}
8.64 \\
\end{tabular} & 4.32 & 3094.3 & 2132 & 0.07 & -175.7 & \begin{tabular}{|l|}
8.64 \\
\end{tabular} & -3100.7 & \begin{tabular}{|l|}
8.51 \\
\end{tabular} & -3108.2 & \begin{tabular}{|l|}
8.45 \\
\end{tabular} & -3108.5 & \begin{tabular}{|l|}
8.42 \\
\end{tabular} & -3106.5 & \begin{tabular}{|l|}
8.41 \\
\end{tabular} & -3103.0 \\
\hline 17 & & 6 & 3 & 6.47 & 3.24 & 3096.1 & 1198 & 0.06 & -194 & 6.47 & -3102.2 & 6.37 & -3109.2 & 6.33 & -3109.1 & 6.31 & -3106.8 & 6.30 & -3103.3 \\
\hline 17 & & 6 & 4 & 5.06 & 2.53 & 3099.0 & 624 & 0.06 & -217.8 & 5.06 & -3104.5 & 4.97 & -3110.6 & 4.94 & -3109.8 & 4.93 & -3107.5 & 4.92 & -3103.8 \\
\hline 17 & & 6 & 5 & 4.06 & 2.03 & 3101.3 & 251 & 0.07 & -193.4 & 4.06 & -3106.3 & 4.00 & $-3 \nmid 11.4$ & 3.97 & -3110.2 & 3.96 & -3107.6 & 3.96 & -3103.8 \\
\hline 18 & & 6 & 6 & 3.56 & 1.78 & 3100.0 & 220 & 0.06 & -193.4 & 3.56 & -3106.5 & 3.50 & -3113.3 & 3.48 & -3111.9 & 3.47 & -3109.2 & 3.47 & -3106.2 \\
\hline 18 & & 6 & 7 & 3.36 & 1.68 & 3100.8 & 415 & 0.07 & \begin{tabular}{|c|}
-217.8 \\
\end{tabular} & 3.36 & \begin{tabular}{|r|}
-3107.0 \\
\end{tabular} & 3.30 & -3113.5 & 3.28 & -3112.1 & 3.28 & -3109.4 & 3.27 & -3106.5 \\
\hline 18 & & 6 & 9 & 2.51 & 1.26 & 3102.2 & 465 & 0.06 & -194 & 2.51 & -3107.8 & 2.47 & -3113.6 & 2.46 & -3112.2 & 2.45 & -3109.3 & 2.45 & $\begin{array}{l}-3106.8 \\
\end{array}$ \\
\hline 18 & & $\frac{0}{6}$ & 10 & 2.08 & 1.04 & \begin{tabular}{|l|}
3102.6 \\
\end{tabular} & 512 & 0.07 & -175.7 & 2.08 & -3108.1 & 2.04 & -3113.7 & 2.03 & -3111.7 & 2.02 & -3109.7 & 2.02 & -3106.3 \\
\hline 18 & & $\frac{6}{6}$ & 11 & 1.72 & 0.86 & 3103.3 & 531 & 0.07 & -171.3 & 1.72 & -3108.5 & 1.69 & -3113.8 & 1.68 & -3112.2 & 1.68 & -3109.5 & 1.68 & -3106.6 \\
\hline 19 & & 6 & 12 & 1.45 & 0.73 & 3104.5 & 448 & 0.10 & -171.3 & 1.45 & -3108.6 & 1.43 & -3112.7 & 1.42 & -3111.7 & 1.42 & -3108.3 & 1.41 & -3104.9 \\
\hline 19 & & & 13 & 1.22 & 0.61 & 3103.4 & 300 & 0.10 & -175.7 & 1.22 & -3108.2 & 1.20 & -3113.6 & \begin{tabular}{|l}
1.19 \\
\end{tabular} & -3113.2 & \begin{tabular}{|l|}
1.19 \\
\end{tabular} & -3110.7 & 1.18 & -3107.4 \\
\hline$\frac{19}{19}$ & & & & \begin{tabular}{|l}
11.22 \\
\end{tabular} & 5.76 & 3091.9 & 2130 & 0.11 & $\mid-194$ & \begin{tabular}{|l|l|}
11.52 \\
\end{tabular} & -3098.6 & 11.36 & -3107.4 & \begin{tabular}{|l|}
11.28 \\
\end{tabular} & -3108.8 & $\frac{11.25}{11.25}$ & -3106.8 & 11.23 & -3103.7 \\
\hline 19 & & & 2 & 4.83 & 2.41 & 3040.1 & 595 & 0.13 & -217.8 & 4.83 & $\mid-3060.7$ & 4.65 & -3086.7 & 4.60 & -3092.6 & 4.58 & -3092.6 & 4.57 & -3091.1 \\
\hline 19 & & 7 & 3 & 3.88 & 1.94 & 3051.1 & 239 & 0.09 & -193.4 & 3.88 & -3069.2 & 3.75 & -3091.8 & 3.71 & -3096.3 & 3.69 & -3095.8 & 3.68 & -3093.9 \\
\hline 20 & & & 4 & 4.07 & 2.03 & 3079.1 & 251 & 0.08 & -193.4 & 4.07 & -3090.7 & 3.97 & -3104.4 & 3.94 & -3105.1 & 3.92 & -3103.3 & 3.92 & -3100.2 \\
\hline 20 & & & 5 & 3.80 & 1.90 & 3091.5 & 469 & 0.08 & -217.8 & 3.80 & -3099.7 & 3.72 & -3109.0 & 3.70 & -3108.8 & 3.69 & -3106.3 & 3.68 & -3103.3 \\
\hline 20 & & 7 & 6 & 3.53 & 1.76 & 3096.8 & 652 & 0.08 & -194 & 3.53 & -3103.7 & 3.46 & -3111.2 & 3.44 & -3110.5 & $\begin{array}{l}3.43 \\
\end{array}$ & -3107.5 & 3.43 & -3104.2 \\
\hline & & & & 3.32 & 1.66 & 3098.8 & 819 & 0.08 & -175.7 & 3.32 & -3105.1 & 3.26 & -3111.8 & 3.24 & -3110.8 & 3.23 & -3107.8 & 3.23 & -3104.2 \\
\hline 20 & & & 8 & 3.04 & 1.52 & 3100.9 & 938 & 0.07 & -171.3 & 3.04 & -3106.6 & 2.99 & -3112.6 & 2.97 & -3111.5 & 2.96 & -3108.2 & 2.96 & -3104.6 \\
\hline 21 & & 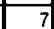 & 9 & 2.80 & 1.40 & 3101.0 & 864 & 0.09 & -171.3 & 2.80 & -3107.2 & 2.75 & -3113.4 & 2.73 & -3111.3 & 2.73 & -3108.4 & 2.73 & -3105.1 \\
\hline 21 & & & 10 & 2.31 & 1.15 & 3103.6 & 570 & 0.09 & -175.7 & 2.31 & -3109.0 & 2.27 & -3114.3 & 2.26 & -3112.3 & 2.25 & -3109.8 & 2.25 & -3106.2 \\
\hline 21 & & & 11 & 1.96 & 0.98 & 3105.4 & 363 & 0.12 & \begin{tabular}{|l|}
-194 \\
\end{tabular} & 1.96 & -3110.1 & 1.93 & -3114.7 & 1.92 & -3112.9 & 1.92 & -3109.8 & 1.92 & -3105.8 \\
\hline 21 & & & 12 & 1.66 & 0.83 & 3106.3 & 204 & 0.12 & -217.8 & 1.66 & -3111.5 & 1.63 & -3116.8 & 1.62 & -3115.1 & 1.62 & -3112.8 & 1.62 & -3110.3 \\
\hline 21 & & & 13 & 1.45 & 0.73 & 3107.1 & 90 & 0.18 & -193.4 & 1.45 & -3111.7 & 1.43 & -3116.2 & 1.42 & -3114.8 & \begin{tabular}{ll|}
1.42 \\
\end{tabular} & -3112.4 & 1.42 & -3109.3 \\
\hline 22 & & & 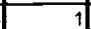 & 11.98 & 5.99 & 3087.2 & 739 & 0.06 & -193.4 & 11.98 & -3096.0 & 11.80 & -3106.4 & 11.69 & -3107.2 & 11.65 & & 11.63 & -3101.5 \\
\hline 22 & & & a & 6.27 & 3.13 & 3089.1 & 774 & 06 & -217.8 & 6.27 & -3097.5 & 6.16 & -310 & 6.11 & 77.6 & 6.09 & -3105.4 & 6.08 & -3102.2 \\
\hline 22 & & & 3 & 4.97 & 2.48 & 3090.1 & 919 & 0.06 & -194 & 4.97 & -3098.5 & 4.87 & -3108.2 & 4.83 & -3108.4 & 4.82 & -3106.2 & 4.81 & -3103.1 \\
\hline 22 & & & 4 & 4.59 & 2.30 & 3093.2 & 1133 & 0.06 & -175.7 & 4.59 & -3100.5 & 4.51 & -3108.8 & 4.48 & -3108.6 & 4.46 & -3106.3 & 4.46 & -3102.8 \\
\hline 22 & & 至 & $\frac{7}{5}$ & 4.25 & 2.13 & 3095.6 & 1311 & 0.06 & -171.3 & 4.25 & -3102.5 & 4.17 & -3110.1 & 4.45 & -3109.7 & $\begin{array}{l}4.46 \\
4.13 \\
\end{array}$ & $\begin{array}{l}-3107.2 \\
\end{array}$ & 4. & -3103.9 \\
\hline 23 & & 8 & 6 & 3.98 & 1.99 & 3096.0 & 1228 & 0.08 & -171.3 & 3.98 & -3102.9 & 3.91 & -3110.4 & 3.88 & -3109.7 & 3.87 & -3106.4 & 3.87 & -31036 \\
\hline 24 & & & 6 & 3.98 & 1.99 & 3094.0 & 1228 & 0.08 & -171.3 & 3.98 & -3102.2 & 3.91 & -3110.9 & 3.88 & -3109.0 & 3.87 & -3106.4 & 3.86 & -3103.1 \\
\hline 23 & & & 7 & 3.75 & 1.87 & 3097.2 & 925 & 0.08 & -175.7 & 3.75 & -31037 & 3.68 & -31107 & 3.66 & -3109.9 & 365 & -3106.6 & 364 & -3103.7 \\
\hline 24 & & 8 & 7 & 3.75 & 1.87 & 3095.4 & 925 & 0.07 & \begin{tabular}{|l|}
-175.7 \\
\end{tabular} & 3.75 & -3103.1 & 3.68 & -3111.1 & 3.65 & -3109.3 & 3.64 & -3106.6 & 3.64 & -3103.2 \\
\hline 23 & & 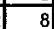 & 8 & 3.37 & 1.68 & 3098.7 & 623 & 0.08 & -194 & 3.37 & -3104.9 & 3.31 & -3111.6 & 3.29 & -3110.8 & 3.28 & -3107.5 & 3.28 & -3104.3 \\
\hline 23 & & & 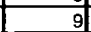 & 2.94 & 1.47 & 3101.3 & 363 & 0.09 & -217.8 & 2.94 & -3106.7 & 2.89 & -3112.6 & 2.87 & -3111.9 & 2.87 & -3108.5 & 2.87 & -3105.5 \\
\hline 23 & & & 10 & 2.30 & 1.15 & 3104.1 & 142 & 0.08 & -193.4 & 2.30 & -3108.8 & 2.26 & -3113.5 & 2.25 & -3112. & 2.25 & $-3108,3$ & 2.24 & -3105.3 \\
\hline 24 & & 8 & 11 & 1.88 & 0.94 & 3105.1 & 116 & 0.09 & -193.4 & 9.88 & $-3+09.8$ & 1.85 & -3114.2 & 1.83 & -3112.2 & 1.83 & -3109.1 & 1.83 & -3106.0 \\
\hline 24 & & 8 & 12 & 1.54 & 0.77 & 3106.8 & 190 & 0.09 & -217.8 & 1.54 & -3111.2 & 1.52 & -3115.6 & 1.51 & -3113.9 & 1.51 & -3111.7 & 1.51 & 410 \\
\hline & & $\frac{0}{8}$ & $\frac{12}{13}$ & $\frac{1.54}{1.28}$ & 0.64 & \begin{tabular}{|l|}
31007.9 \\
\end{tabular} & $\frac{190}{236}$ & $\frac{0.09}{0.10}$ & $\frac{-211.0}{-194}$ & $\frac{1.28}{1.28}$ & -3111.8 & $\frac{1.52}{1.26}$ & -3115.7 & $\frac{1.01}{1.25}$ & $\begin{array}{c}-3114.0 \\
-314\end{array}$ & $\frac{1.51}{1.25}$ & -3110.7 & $\frac{1.31}{1.25}$ & -3107 \\
\hline
\end{tabular}


DOE/RL-2009-35, REV. 0

\begin{tabular}{|c|c|c|c|c|c|c|}
\hline \multicolumn{7}{|c|}{ Rebar Locations } \\
\hline \multicolumn{4}{|c|}{ Resistivity and IP Locations } & \multicolumn{3}{|c|}{ TEM Locations } \\
\hline Electrode \# & Easting & Northing & Elev & Loop \# & Easting & Northing \\
\hline 1 & 572691.20 & 151431.73 & 143.51 & Rx Loop 1 & 572715.27 & 151504.52 \\
\hline 2 & 572692.14 & 151434.61 & 143.52 & $\mathrm{Rx}$ Loop 1 & 572718.85 & 151501.02 \\
\hline 3 & 572693.17 & 151437.49 & 143.55 & Rx Loop 1 & 572715.53 & 151497.47 \\
\hline 4 & 572694.06 & 151440.35 & 143.59 & Rx Loop 1 & 572711.95 & 151500.88 \\
\hline 5 & 572695.10 & 151443.21 & 143.63 & Rx Loop 2 & 572718.85 & 151501.02 \\
\hline 6 & 572696.07 & 151446.11 & 143.66 & Rx Loop 2 & 572722.70 & 151497.83 \\
\hline 7 & 572697.07 & 151449.00 & 143.69 & Rx Loop 2 & 572719.42 & 151494.19 \\
\hline 8 & 572698.00 & 151451.89 & 143.75 & Rx Loop 2 & 572715.53 & 151497.47 \\
\hline 9 & 572698.99 & 151454.79 & 143.73 & Rx Loop 3 & 572715.53 & 151497.47 \\
\hline 10 & 572699.99 & 151457.70 & 143.77 & Rx Loop 3 & 572719.42 & 151494.19 \\
\hline 11 & 572701.05 & 151460.55 & 143.73 & Rx Loop 3 & 572716.55 & 151490.38 \\
\hline 12 & 572702.00 & 151463.42 & 143.78 & Rx Loop 3 & 572712.58 & 151493.56 \\
\hline 13 & 572703.02 & 151466.26 & 143.81 & Rx Loop 4 & 572715.53 & 151497.47 \\
\hline 14 & 572704.05 & 151469.09 & 143.75 & Rx Loop 4 & 572712.58 & 151493.56 \\
\hline 15 & 572705.06 & 151472.02 & 143.78 & Rx Loop 4 & 572708.80 & 151497.12 \\
\hline 16 & 572706.08 & 151474.81 & 143.77 & Rx Loop 4 & 572711.95 & 151500.88 \\
\hline 17 & 572707.00 & 151477.79 & 143.85 & Rx Loop 5 & 572716.26 & 151494.34 \\
\hline 18 & 572709.37 & 151481.58 & 143.88 & Rx Loop 5 & 572719.28 & 151490.33 \\
\hline 19 & 572709.05 & 151483.58 & 143.91 & Rx Loop 5 & 572715.94 & 151486.94 \\
\hline 20 & 572710.12 & 151486.38 & 143.92 & Rx Loop 5 & 572712.78 & 151490.85 \\
\hline 21 & 572711.10 & 151489.31 & 143.97 & Rx Loop 6 & 572713.23 & 151498.21 \\
\hline 22 & 572712.17 & 151492.20 & 143.85 & Rx Loop 6 & 572716.26 & 151494.34 \\
\hline 23 & 572713.11 & 151495.08 & 143.85 & Rx Loop 6 & 572712.78 & 151490.85 \\
\hline 24 & 572714.12 & 151497.97 & 143.91 & Rx Loop 6 & 572709.64 & 151494.80 \\
\hline 25 & 572715.08 & 151500.76 & 143.93 & Tx Loop & 572714.46 & 151513.08 \\
\hline 26 & 572716.08 & 151503.69 & $\overline{143.92}$ & Tx Loop & 572726.35 & 151498.29 \\
\hline 27 & 572717.02 & 151506.63 & 143.95 & Tx Loop & 572715.95 & 151486.24 \\
\hline 28 & 572718.06 & 151509.45 & 143.94 & Tx Loop & 572704.10 & 151500.43 \\
\hline 29 & 572719.05 & 151512.37 & 143.93 & & & \\
\hline 30 & 572720.14 & 151515.24 & 143.89 & & & \\
\hline 31 & 572721.02 & 151518.18 & 143.85 & & & \\
\hline 32 & 572722.06 & 151521.03 & 143.80 & & & \\
\hline 33 & 572723.05 & 151523.93 & 143.80 & & & \\
\hline 34 & 572724.08 & 151526.84 & 143.84 & & & \\
\hline 35 & 572724.99 & 151529.66 & 143.90 & & & \\
\hline 36 & 572725.99 & 151532.50 & 143.97 & & & \\
\hline 37 & 572726.99 & 151535.40 & 143.98 & & & \\
\hline 38 & 572728.02 & 151538.31 & 143.98 & & & \\
\hline 39 & 572729.01 & 151541.14 & 143.95 & & & \\
\hline 40 & 572729.97 & 151544.05 & 143.93 & & & \\
\hline 41 & 572730.97 & 151546.95 & 143.91 & & & \\
\hline Remote 1 & 572562.04 & 151059.80 & 144.08 & & & \\
\hline Remote 2 & 572963.99 & 151981.14 & 121.25 & & & \\
\hline
\end{tabular}


DOE/RL-2009-35, REV. 0

\begin{tabular}{|c|c|c|c|c|c|c|c|c|c|c|c|c|c|}
\hline \multicolumn{14}{|c|}{ TDEM Data } \\
\hline \multicolumn{7}{|c|}{ pre-injection } & \multicolumn{7}{|c|}{ post-injection } \\
\hline Time & $1 \mathrm{avg}$ & 2 avg & 3 avg & 4 avg & 5 avg & 6 avg & Time & $1 \mathrm{avg}$ & 2 avg & 3 avg & 4 avg & 5 avg & 6 avg \\
\hline 1.22E-06 & $-1.12 E+00$ & $-1.18 E+00$ & $-1.02 E+00$ & $-1.24 \mathrm{E}+00$ & $-2.79 E-02$ & $1.10 \mathrm{E}-01$ & $1.22 \mathrm{E}-06$ & $-1.53 \mathrm{E}-01$ & $-1.72 E-01$ & $-3.17 E-01$ & $-1.97 \mathrm{E}-01$ & $-2.37 \mathrm{E}-01$ & $-2.45 \mathrm{E}-01$ \\
\hline $3.13 \mathrm{E}-06$ & $-9.06 \mathrm{E}-02$ & $-9.40 E-02$ & \begin{tabular}{|c|}
$-2.49 \mathrm{E}-01$ \\
\end{tabular} & $-1.18 \mathrm{E}-01$ & $-7.14 \mathrm{E}-01$ & $-5.09 \mathrm{E}-01$ & $3.13 E-06$ & $\begin{array}{l}-6.92 E-02 \\
\end{array}$ & $-8.38 \mathrm{E}-02$ & $-3.90 \mathrm{E}-02$ & $-9.56 \mathrm{E}-02$ & $-1.70 \mathrm{E}-01$ & $-1.23 \mathrm{E}-01$ \\
\hline $5.04 E-06$ & & $2.24 \mathrm{E}-02$ & $2.03 \mathrm{E}-02$ & & $-4.33 E-02$ & $-3.29 \mathrm{E}-02$ & 5.04E-06 & $9.29 E-04$ & 3.37E-04 & $7.95 E-03$ & $8.52 E-04$ & & $5.33 \mathrm{E}-03$ \\
\hline $6.94 \mathrm{E}-06$ & $5.87 \mathrm{E}-03$ & $6.36 \mathrm{E}-03$ & $9.89 \mathrm{E}-03$ & $7.70 \mathrm{E}-03$ & $1.71 \mathrm{E}-02$ & $1.19 \mathrm{E}-02$ & $6.94 \mathrm{E}-06$ & $2.32 E-03$ & $2.77 \mathrm{E}-03$ & $2.36 \mathrm{E}-03$ & $3.04 \mathrm{E}-03$ & & $4.35 \mathrm{E}-03$ \\
\hline $8.85 E-06$ & $4.11 \mathrm{E}-03$ & $4.51 E-03$ & $13 \mathrm{E}-03$ & 4.79E-03 & $9.30 \bar{E}-03$ & $6.82 E-03$ & $8.85 E-06$ & $1.10 \mathrm{E}-03$ & $1.28 \mathrm{E}-03$ & $1.43 E-03$ & $1.35 E-03$ & & $1.78 \mathrm{E}-03$ \\
\hline $1.08 \mathrm{E}-05$ & 3.46 & $3.82 \mathrm{E}-03$ & $35 E-03$ & $4.36 \mathrm{E}-03$ & $6.51 \mathrm{E}-03$ & $4.82 \mathrm{E}-03$ & $1.08 \mathrm{E}-05$ & $8.36 \mathrm{E}-04$ & $9.56 \mathrm{E}-04$ & $1.20 \mathrm{E}-03$ & $9.86 \mathrm{E}-04$ & & 1.37E-03 \\
\hline $1.36 \mathrm{E}-05$ & $2.64 \mathrm{E}-03$ & $2.91 \mathrm{E}-03$ & $3.28 \mathrm{E}-03$ & $3.12 \mathrm{E}-03$ & $5.04 E-03$ & $3.79 \mathrm{E}-03$ & $1.36 \mathrm{E}-05$ & $6.57 \mathrm{E}-04$ & $7.48 \mathrm{E}-04$ & $9.16 \mathrm{E}-04$ & $7.65 \mathrm{E}-04$ & & $1.07 \mathrm{E}-03$ \\
\hline $1.74 \mathrm{E}-05$ & $1.93 \mathrm{E}-03$ & $2.13 \mathrm{E}-03$ & $2.39 \mathrm{E}-03$ & $2.22 \mathrm{E}-03$ & $3.74 E-03$ & $2.81 \mathrm{E}-03$ & $1.74 \mathrm{E}-05$ & $4.82 \mathrm{E}-04$ & $5.52 \mathrm{E}-04$ & $6.64 \mathrm{E}-04$ & $5.52 \mathrm{E}-04$ & $1.11 \mathrm{E}-03$ & $7.89 \mathrm{E}-04$ \\
\hline $2.12 \mathrm{E}-05$ & $1.46 \mathrm{E}-03$ & $1.60 \mathrm{E}-03$ & $1.78 \mathrm{E}-03$ & & $2.89 \mathrm{E}-03$ & $2.19 \mathrm{E}-03$ & $2.12 \mathrm{E}-05$ & $3.70 \mathrm{E}-04$ & $4.18 \mathrm{E}-04$ & $5.02 \mathrm{E}-04$ & $4.14 \mathrm{E}-04$ & $8.60 \mathrm{E}-04$ & $6.10 \mathrm{E}-04$ \\
\hline $2.59 \mathrm{E}-05$ & & & $\bar{E}-03$ & & & & -05 & & & & & & $3 E-04$ \\
\hline $3.17 \mathrm{E}-05$ & & & 04 & & & -03 & -05 & 2.08 & -04 & & & & $3.57 \mathrm{E}-04$ \\
\hline $3.92 \mathrm{E}-05$ & & & -04 & & & $E-04$ & $3.92 \mathrm{E}-05$ & -04 & $E-04$ & -04 & & & $E-04$ \\
\hline $4.96 \mathrm{E}-05$ & & & & & & & & & & & & & \\
\hline $6.20 \mathrm{E}-05$ & $2.54 \mathrm{E}-04$ & & $30 \mathrm{E}-04$ & & $6.74 \mathrm{E}-04$ & $5.11 \mathrm{E}-04$ & $6.20 \mathrm{E}-05$ & 6.87E-05 & $7.58 \mathrm{E}-05$ & $6 \mathrm{E}-05$ & E-05 & $2.22 \mathrm{E}-04$ & $1.47 \mathrm{E}-04$ \\
\hline $7.71 \mathrm{E}-05$ & $1.67 \mathrm{E}-04$ & $1.94 \mathrm{E}-04$ & $2.24 \mathrm{E}-04$ & $1.96 \mathrm{E}-04$ & $5.09 \mathrm{E}-04$ & $3.85 \mathrm{E}-04$ & 7.71E-05 & $4.60 \mathrm{E}-05$ & $5.27 \mathrm{E}-05$ & $6.76 E-05$ & $5.03 \mathrm{E}-05$ & $1.73 E-04$ & 1.12E-04 \\
\hline $9.61 \mathrm{E}-05$ & $1.14 \mathrm{E}-04$ & $1.30 \mathrm{E}-04$ & $1.61 \mathrm{E}-04$ & $1.32 \mathrm{E}-04$ & $3.82 \mathrm{E}-04$ & $2.91 \mathrm{E}-04$ & $9.61 E-05$ & $2.90 \mathrm{E}-05$ & $3.51 \mathrm{E}-05$ & 4.89E-05 & $3.39 \mathrm{E}-05$ & $1.37 \mathrm{E}-04$ & $8.51 \mathrm{E}-05$ \\
\hline $1.21 \mathrm{E}-04$ & $7.47 \mathrm{E}-05$ & $9.46 \mathrm{E}-05$ & $1.05 \mathrm{E}-04$ & & $2.95 \mathrm{E}-04$ & $2.19 \mathrm{E}-04$ & $1.21 \mathrm{E}-04$ & & $2.34 \mathrm{E}-05$ & $3.40 \mathrm{E}-05$ & $2,33 \mathrm{E}-05$ & & $6.47 \mathrm{E}-05$ \\
\hline $1.53 \mathrm{E}-04$ & & & & & & & & & & & & & \\
\hline $1.93 \mathrm{E}$ & & & -05 & & -04 & -04 & -04 & $E-06$ & -05 & -05 & & & $4.00 \mathrm{E}-05$ \\
\hline $2.42 \mathrm{E}-04$ & & -05 & E-05 & & 04 & -04 & -04 & -06 & -06 & -05 & -05 & & $3.46 \mathrm{E}-05$ \\
\hline $3.04 \mathrm{E}-04$ & & & $6 \mathrm{E}-05$ & & $1.26 \mathrm{E}-04$ & $8.22 \mathrm{E}-05$ & $\overline{4 E-04}$ & $4.98 \mathrm{E}-06$ & $7.03 \mathrm{E}-06$ & $E-05$ & $E-06$ & & $2.64 \mathrm{E}-05$ \\
\hline $3.82 \mathrm{E}-04$ & & $6 \mathrm{E}-05$ & $2.67 \mathrm{E}-05$ & $1.72 \mathrm{E}-05$ & $1.02 \mathrm{E}-04$ & $6.88 \mathrm{E}-05$ & $3.82 \mathrm{E}-04$ & $3.44 \mathrm{E}-06$ & $5.35 \mathrm{E}-06$ & $8 E-06$ & $5.81 \mathrm{E}-06$ & $3.77 \mathrm{E}-05$ & $2.22 \mathrm{E}-05$ \\
\hline $4.82 \mathrm{E}-04$ & $8.60 E-06$ & $1.48 \mathrm{E}-05$ & $1.98 \mathrm{E}-05$ & $1.41 \mathrm{E}-05$ & $7.63 \mathrm{E}-05$ & $6.01 E-05$ & $4.82 \mathrm{E}-04$ & $3.03 \mathrm{E}-06$ & $4.34 \mathrm{E}-06$ & $7.50 \mathrm{E}-06$ & $4.70 \mathrm{E}-06$ & $3.18 \mathrm{E}-05$ & $1.92 \mathrm{E}-05$ \\
\hline $6.05 \mathrm{E}-04$ & & & $1.76 \mathrm{E}-05$ & $1.22 \mathrm{E}-05$ & $6.31 \mathrm{E}-05$ & $4.45 \mathrm{E}-05$ & $6.05 \mathrm{E}-04$ & $2.35 E-06$ & $3.48 \mathrm{E}-06$ & $5.75 \mathrm{E}-06$ & $3.83 \mathrm{E}-06$ & $2.77 \mathrm{E}-05$ & $1.42 \mathrm{E}-05$ \\
\hline $7.60 \mathrm{E}-04$ & & & & & & & & & & & & & $1.30 \mathrm{E}-05$ \\
\hline $9.57 \mathrm{E}-04$ & & & & & & & & & -06 & & & & $1.00 E-05$ \\
\hline $1.21 \mathrm{E}-03$ & & & $E-06$ & & & 2.48 & $1.21 E-03$ & & $\bar{E}-06$ & -06 & $\mathrm{E}-06$ & $4 E-05$ & $8.47 E-06$ \\
\hline $1.52 \mathrm{E}-03$ & & & EE-06 & & $\mathrm{E}-05$ & E-05 & $1.52 E-03$ & $E-06$ & $E-06$ & & & & $6.85 E-06$ \\
\hline $1.91 \mathrm{E}-03$ & $2.41 \mathrm{E}-06$ & & $5.54 \mathrm{E}-06$ & $4.25 E-06$ & $2.40 \mathrm{E}-05$ & $1.72 \mathrm{E}-05$ & & $7.48 \mathrm{E}-07$ & $1.14 \mathrm{E}-06$ & & & & 5.37E-06 \\
\hline $2.40 \mathrm{E}-03$ & $1.89 \mathrm{E}-06$ & $3.50 \mathrm{E}-06$ & $4,30 \mathrm{E}-06$ & $3.02 \mathrm{E}-06$ & $1.82 \mathrm{E}-05$ & $1.34 \mathrm{E}-05$ & $2.40 \mathrm{E}-03$ & $6.30 \mathrm{E}-07$ & $1.01 \mathrm{E}-06$ & $1.64 \mathrm{E}-06$ & $1.01 \mathrm{E}-06$ & $7.59 \mathrm{E}-06$ & $4.48 \mathrm{E}-06$ \\
\hline $3.03 \mathrm{E}-03$ & $2.15 \mathrm{E}-06$ & $2.46 \mathrm{E}-06$ & $3.88 \mathrm{E}-06$ & $2.59 \mathrm{E}-06$ & $1.50 \mathrm{E}-05$ & $1.09 \mathrm{E}-05$ & $3.03 \mathrm{E}-03$ & $5.50 \mathrm{E}-07$ & $7.76 \mathrm{E}-07$ & $1.48 \mathrm{E}-06$ & $8.86 \mathrm{E}-07$ & $5.87 \mathrm{E}-06$ & 3.63E-06 \\
\hline
\end{tabular}


DOE/RL-2009-35, REV. 0

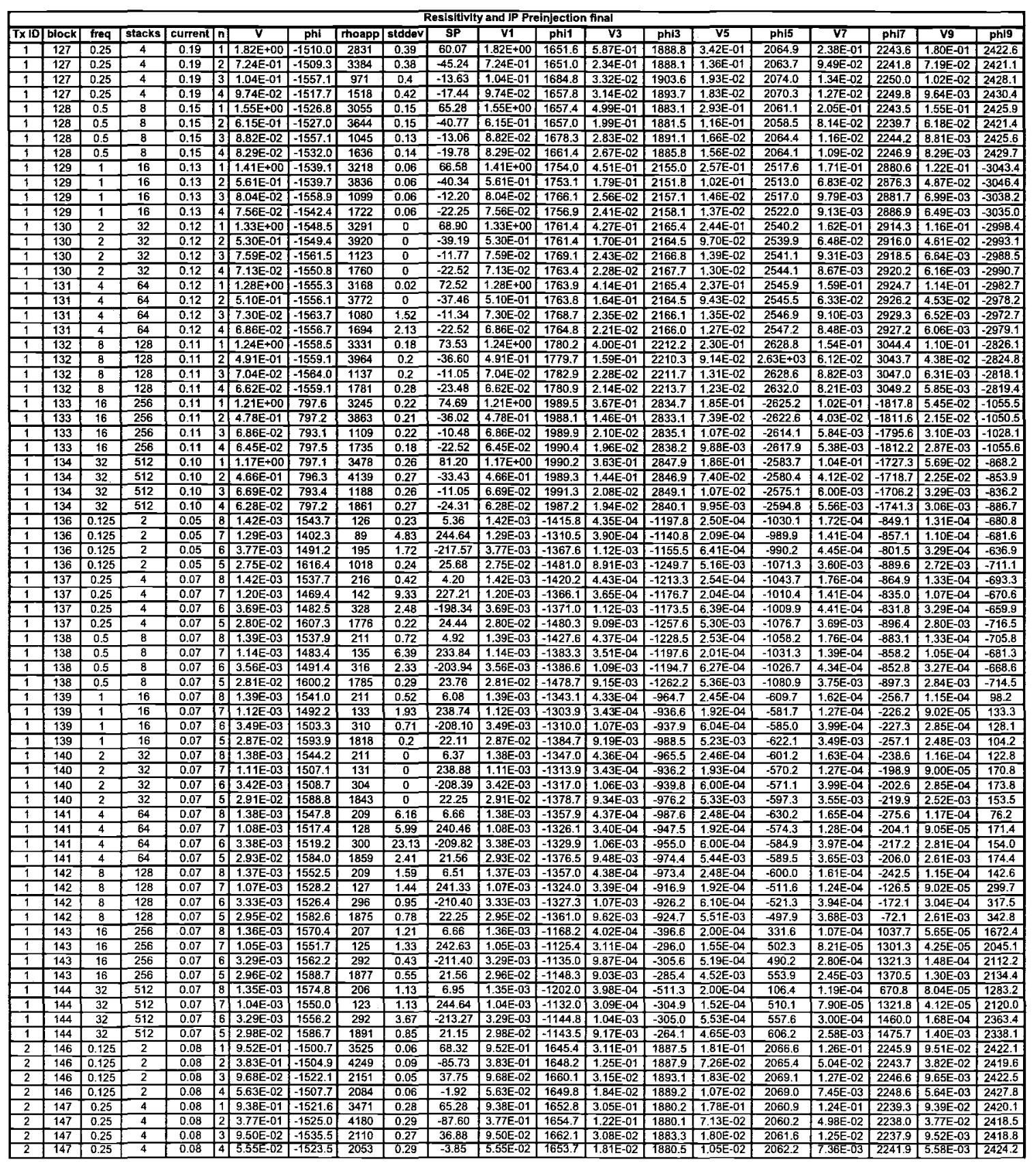


DOE/RL-2009-35, REV. 0

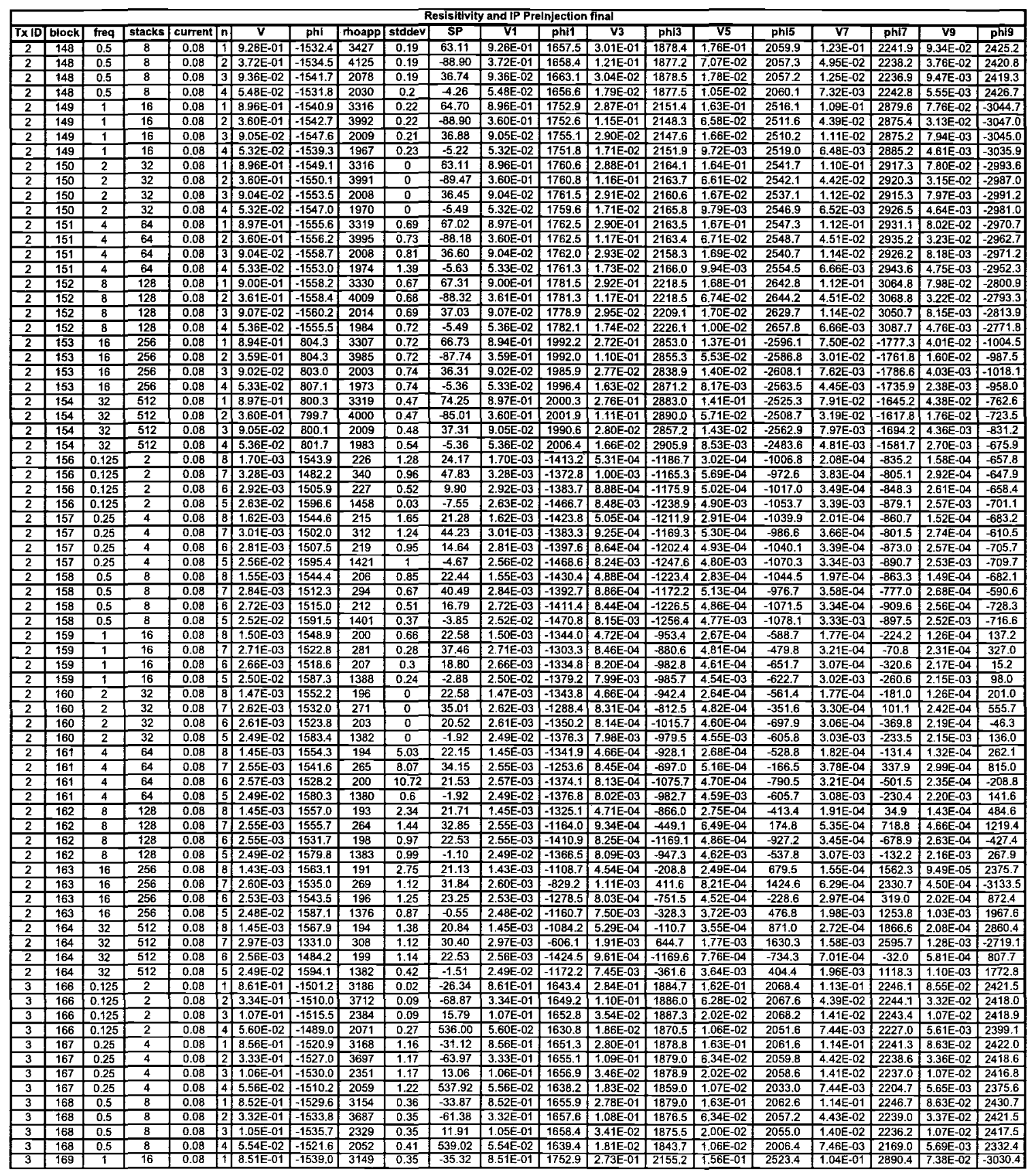


DOE/RL-2009-35, REV. 0

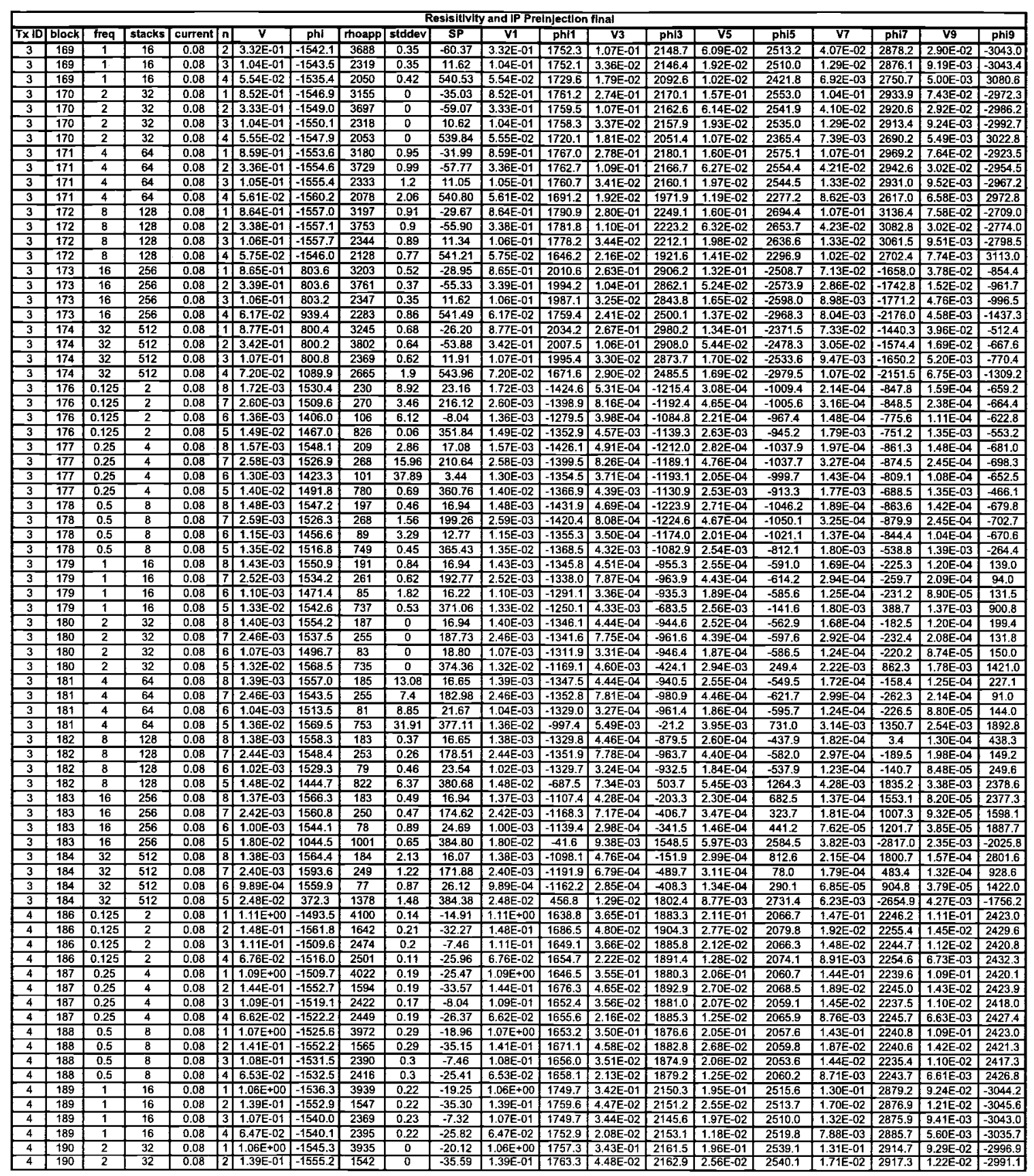


DOE/RL-2009-35, REV. 0

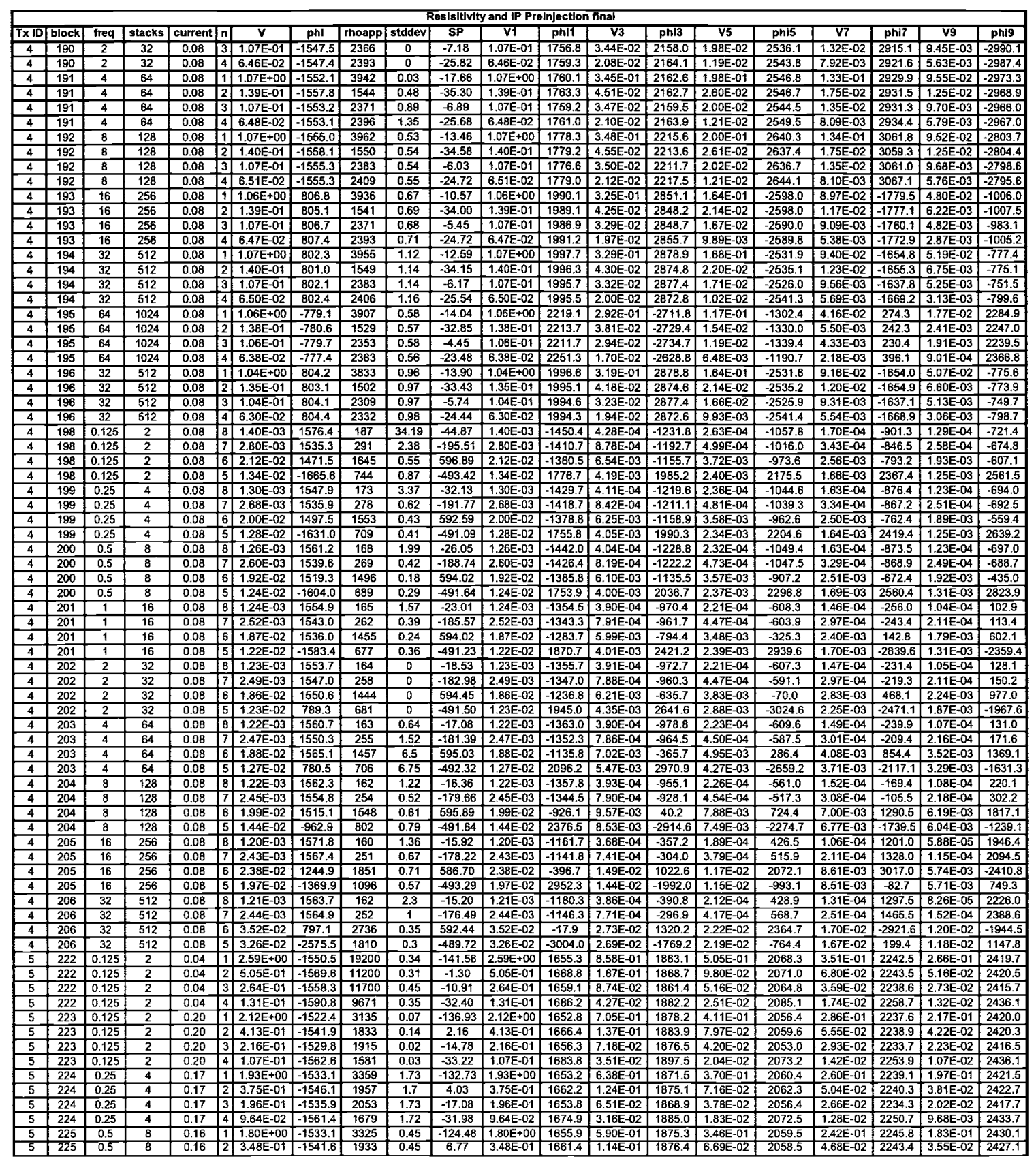


DOE/RL-2009-35, REV. 0

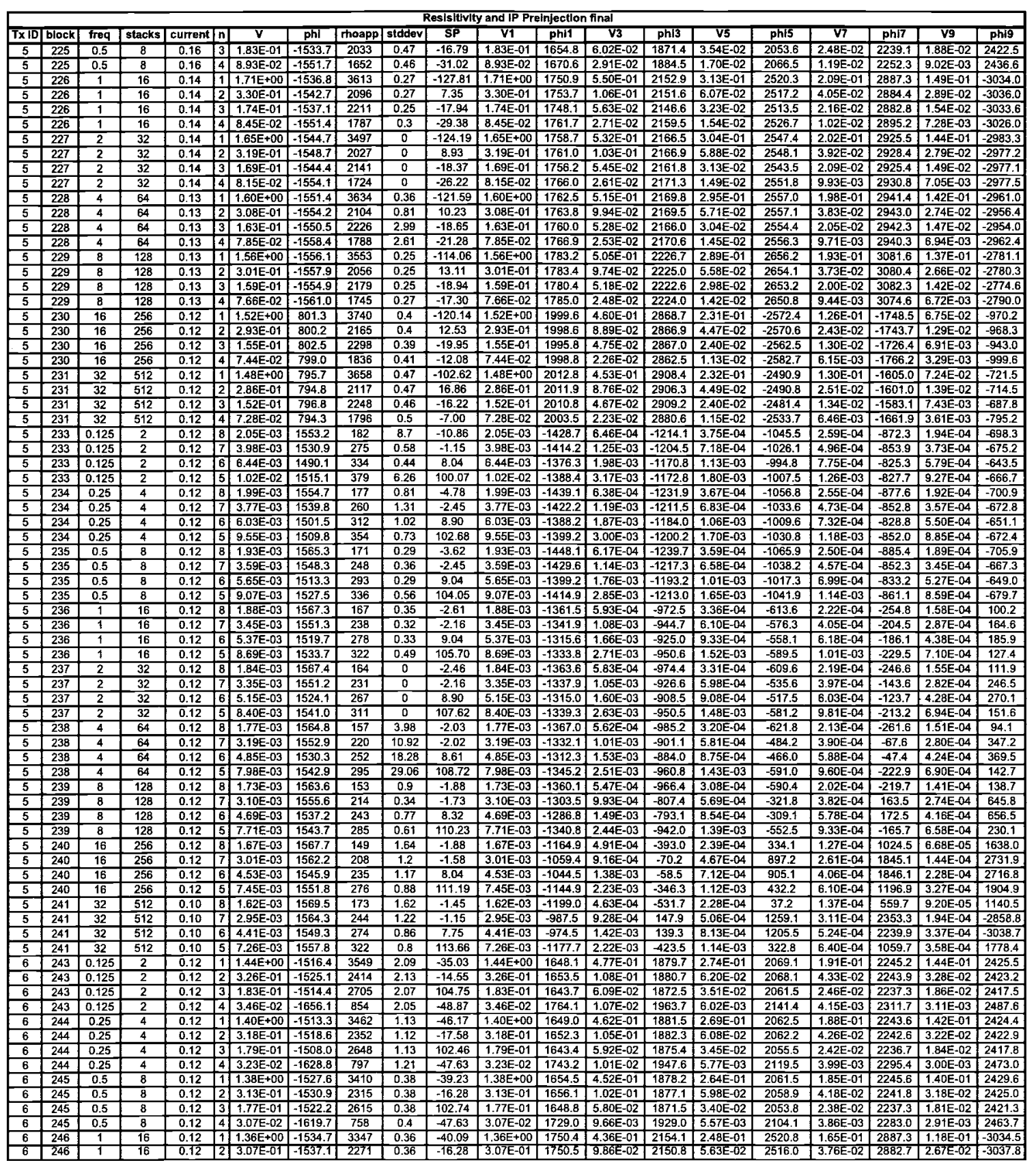


DOE/RL-2009-35, REV. 0

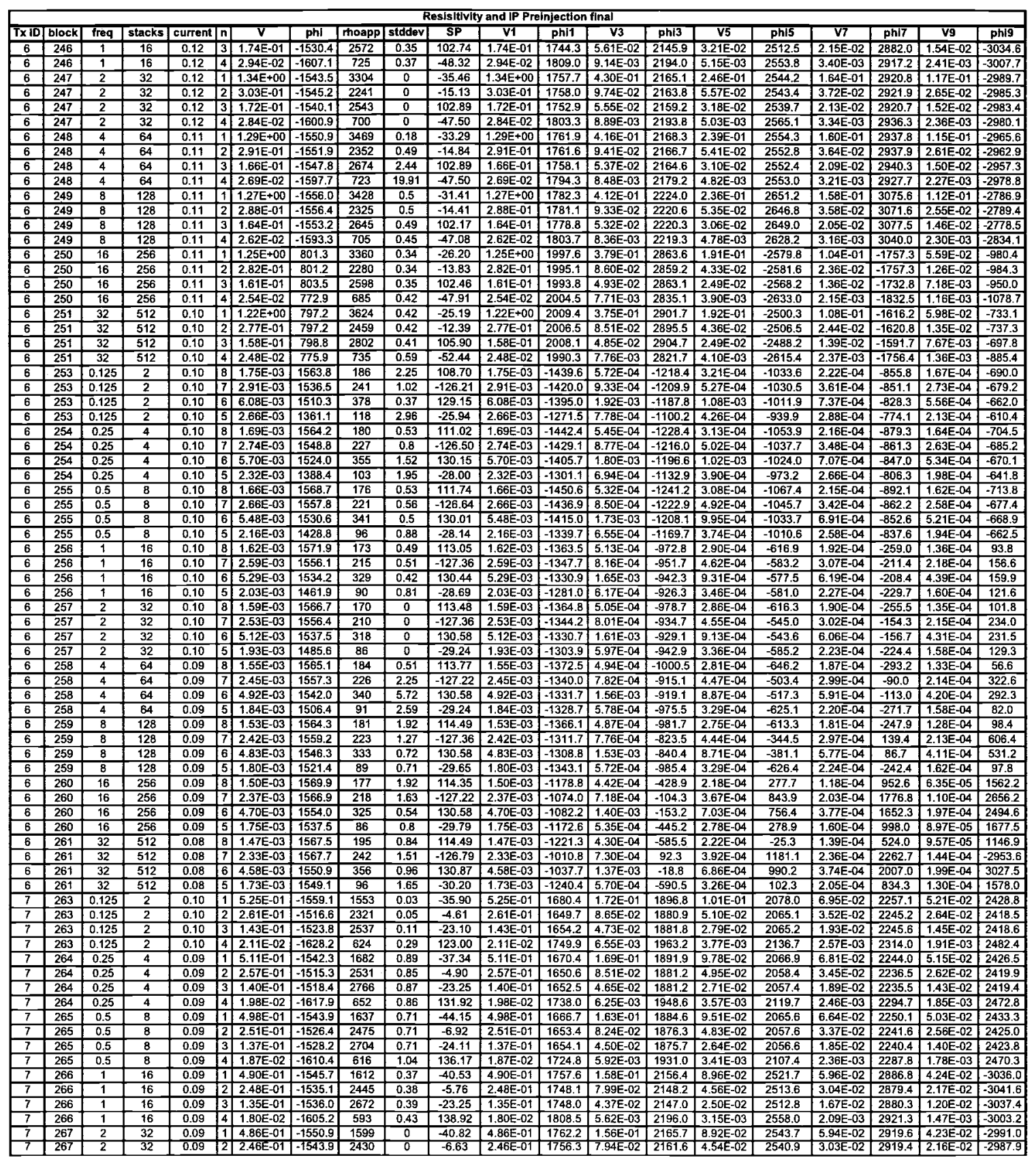


DOE/RL-2009-35, REV. 0

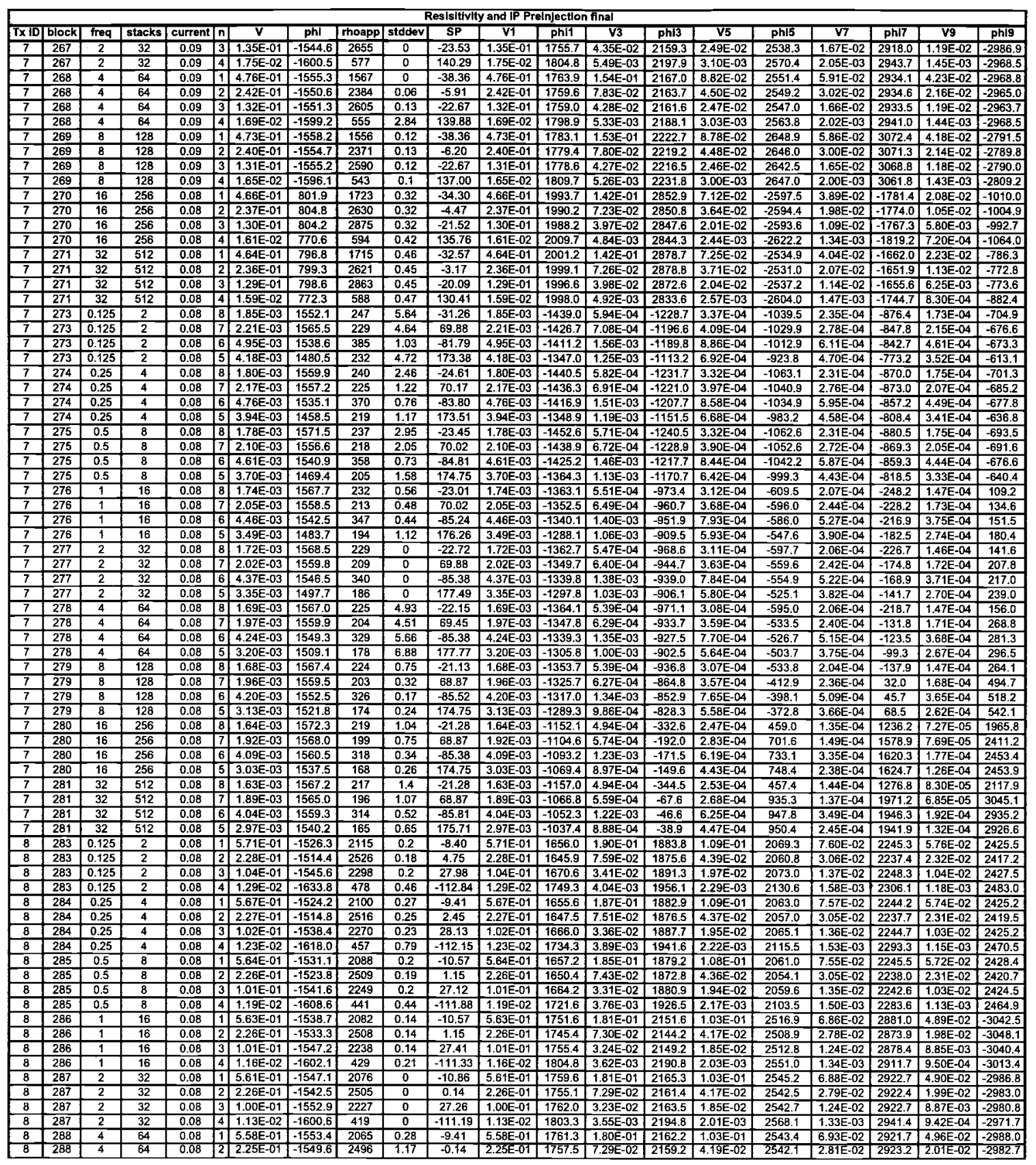


DOE/RL-2009-35, REV. 0

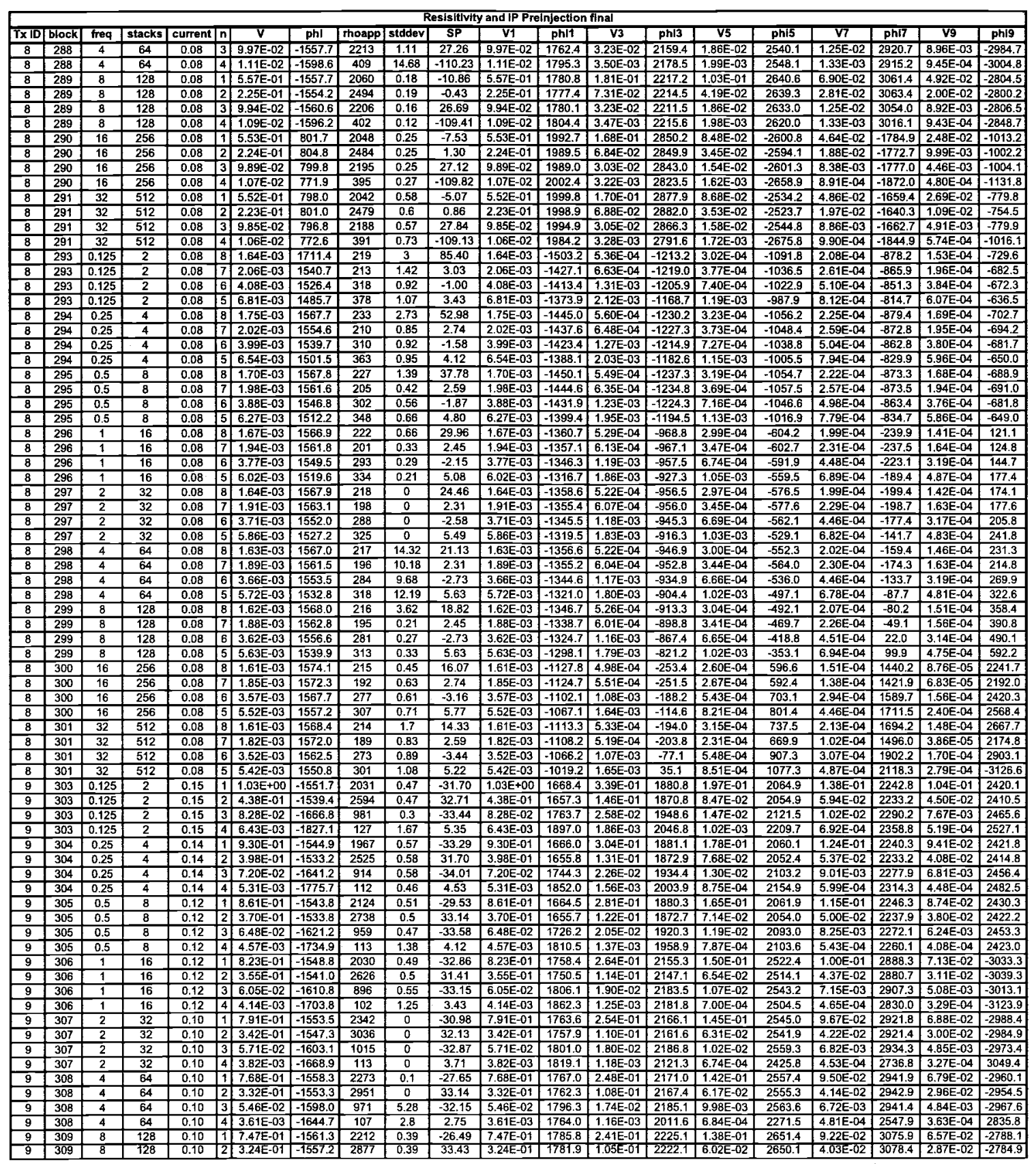


DOE/RL-2009-35, REV. 0

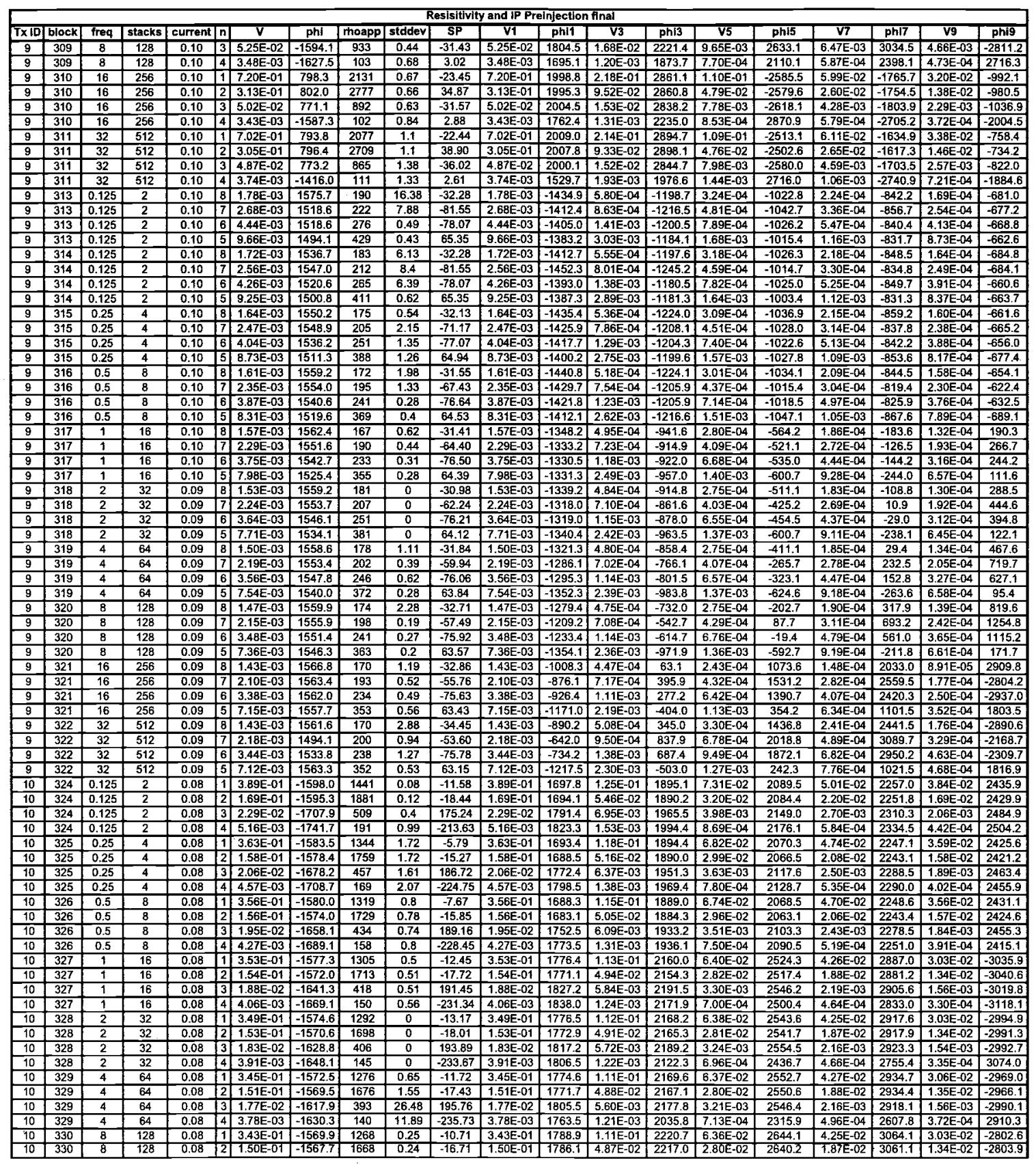


DOE/RL-2009-35, REV. 0

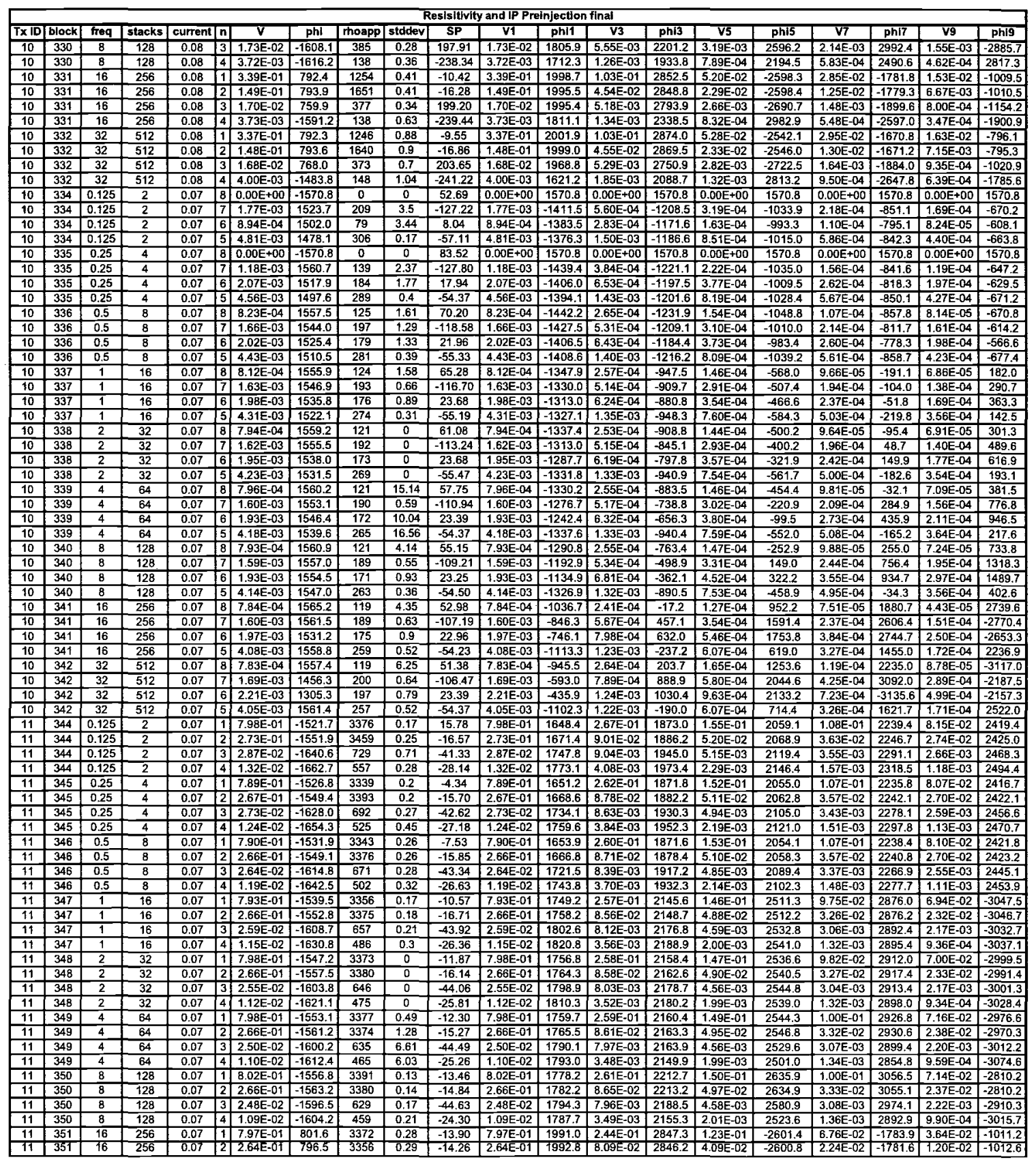


DOE/RL-2009-35, REV. 0

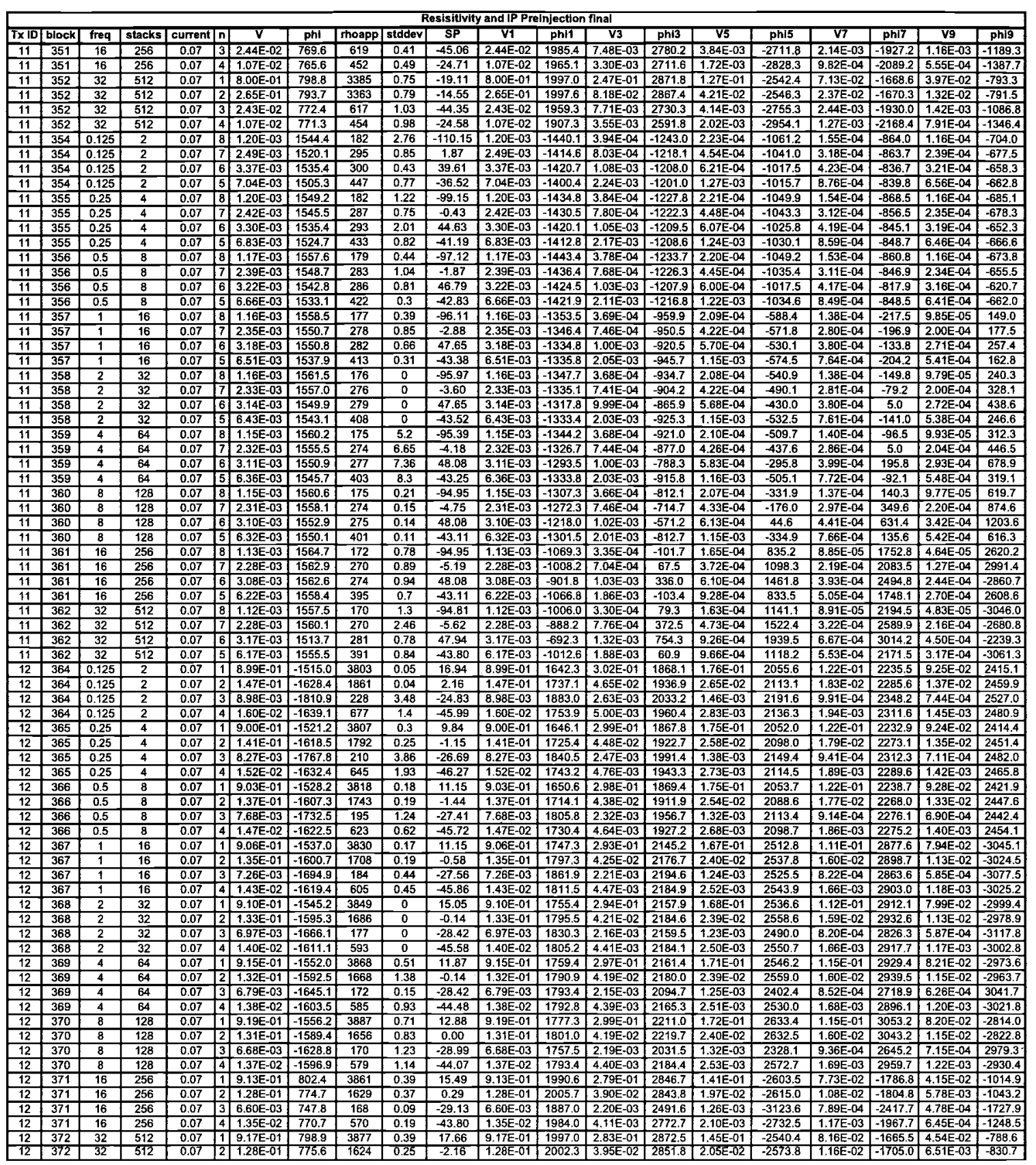


DOE/RL-2009-35, REV. 0

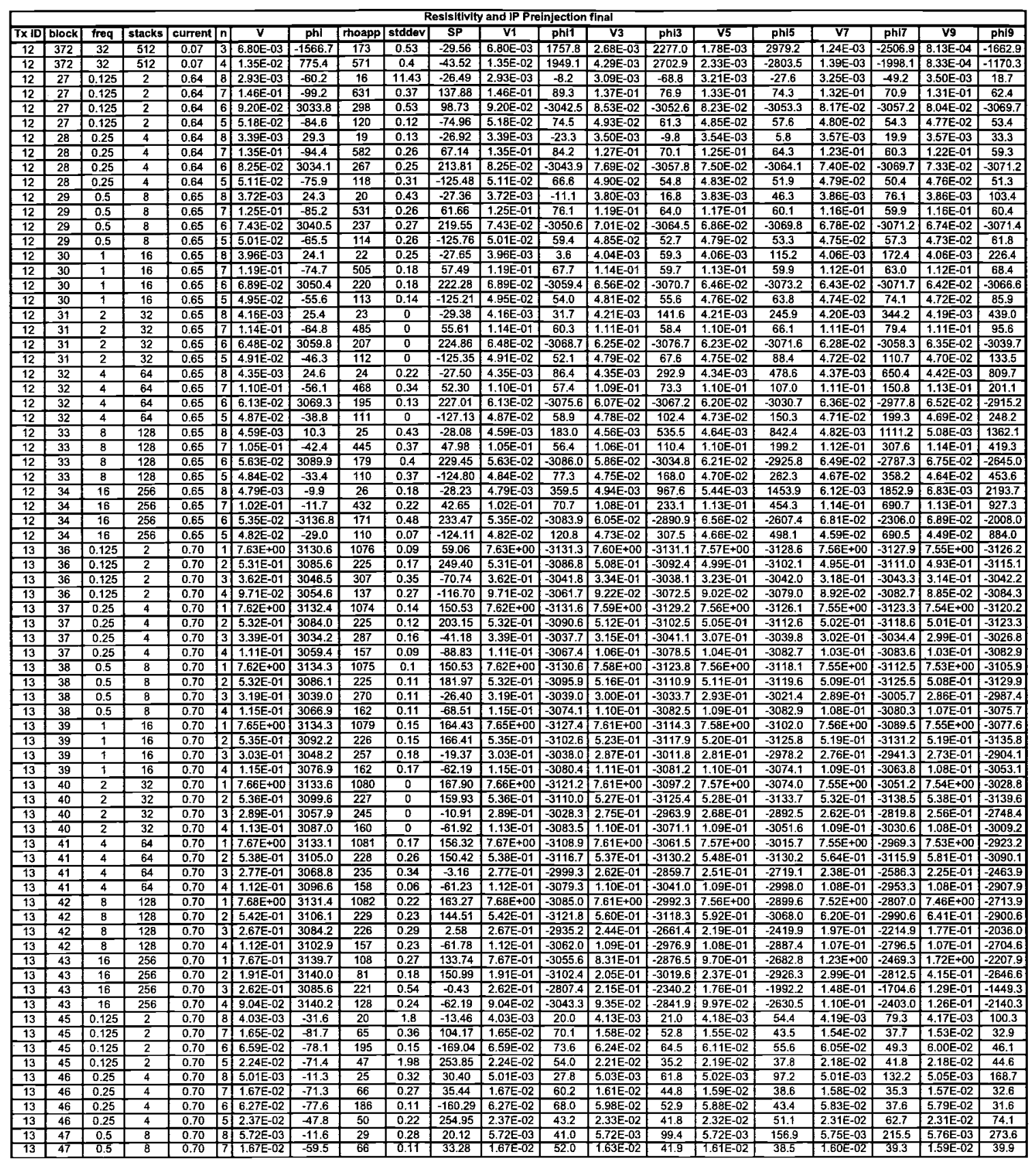




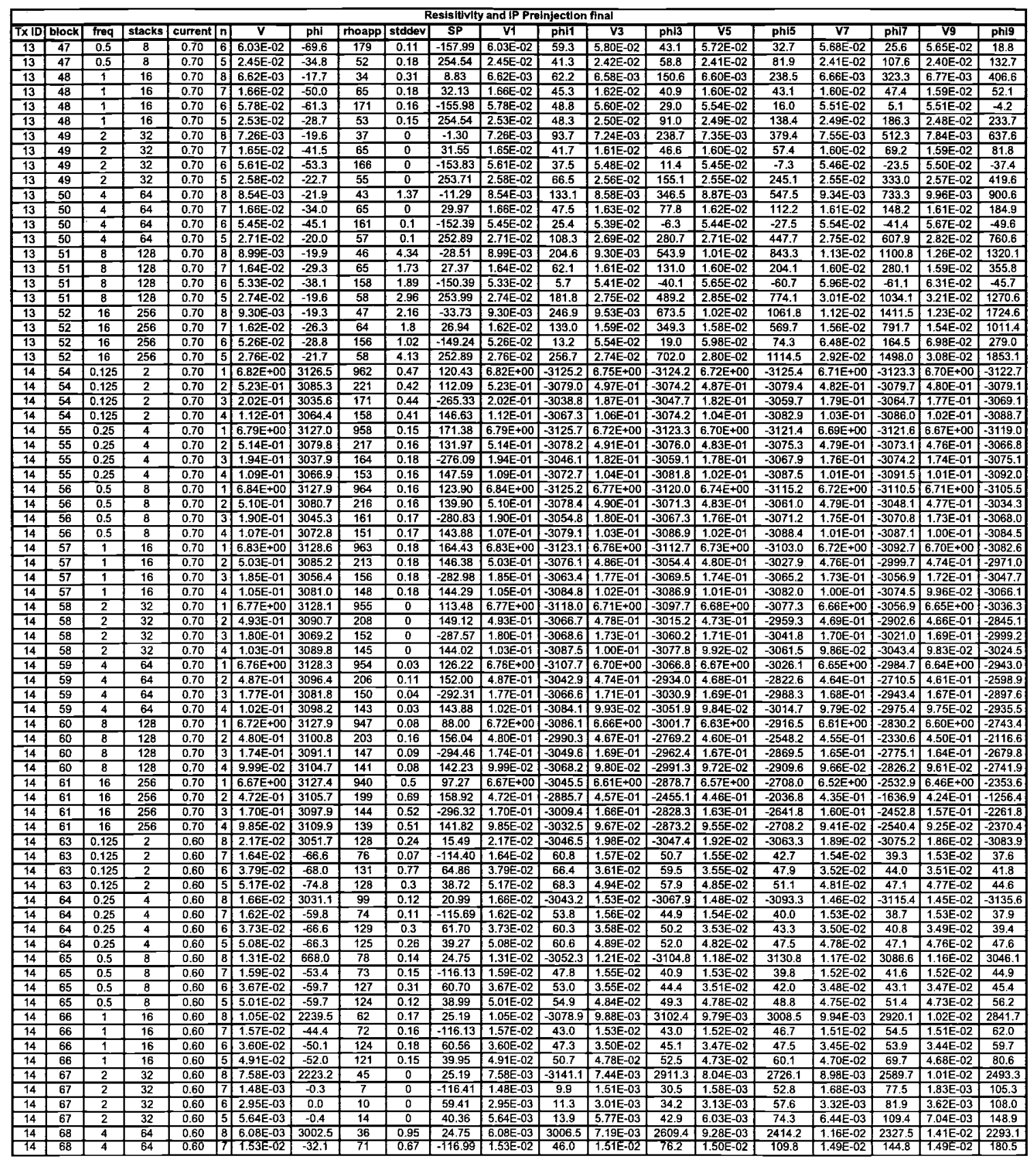


DOE/RL-2009-35, REV. 0

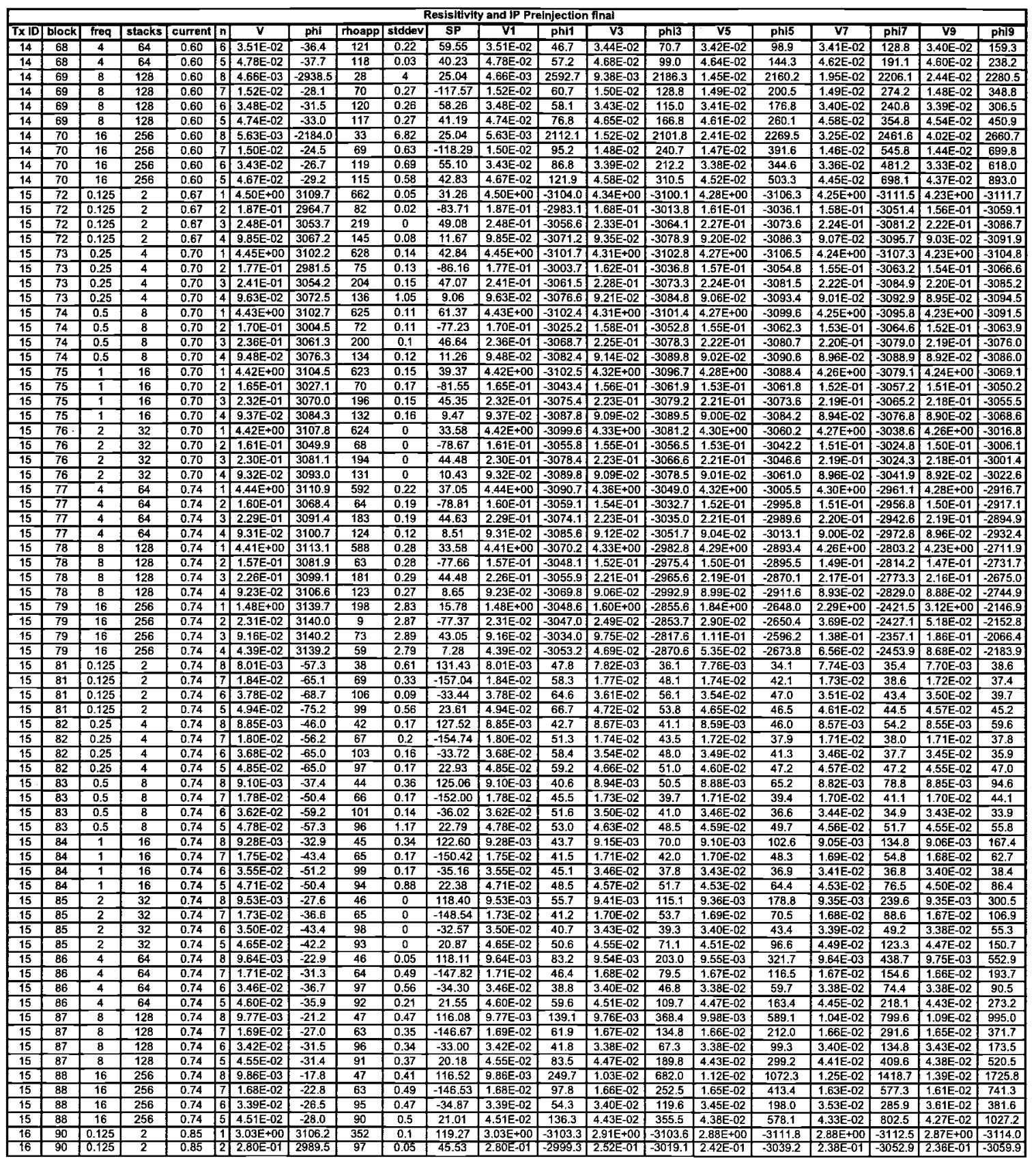


DOE/RL-2009-35, REV. 0

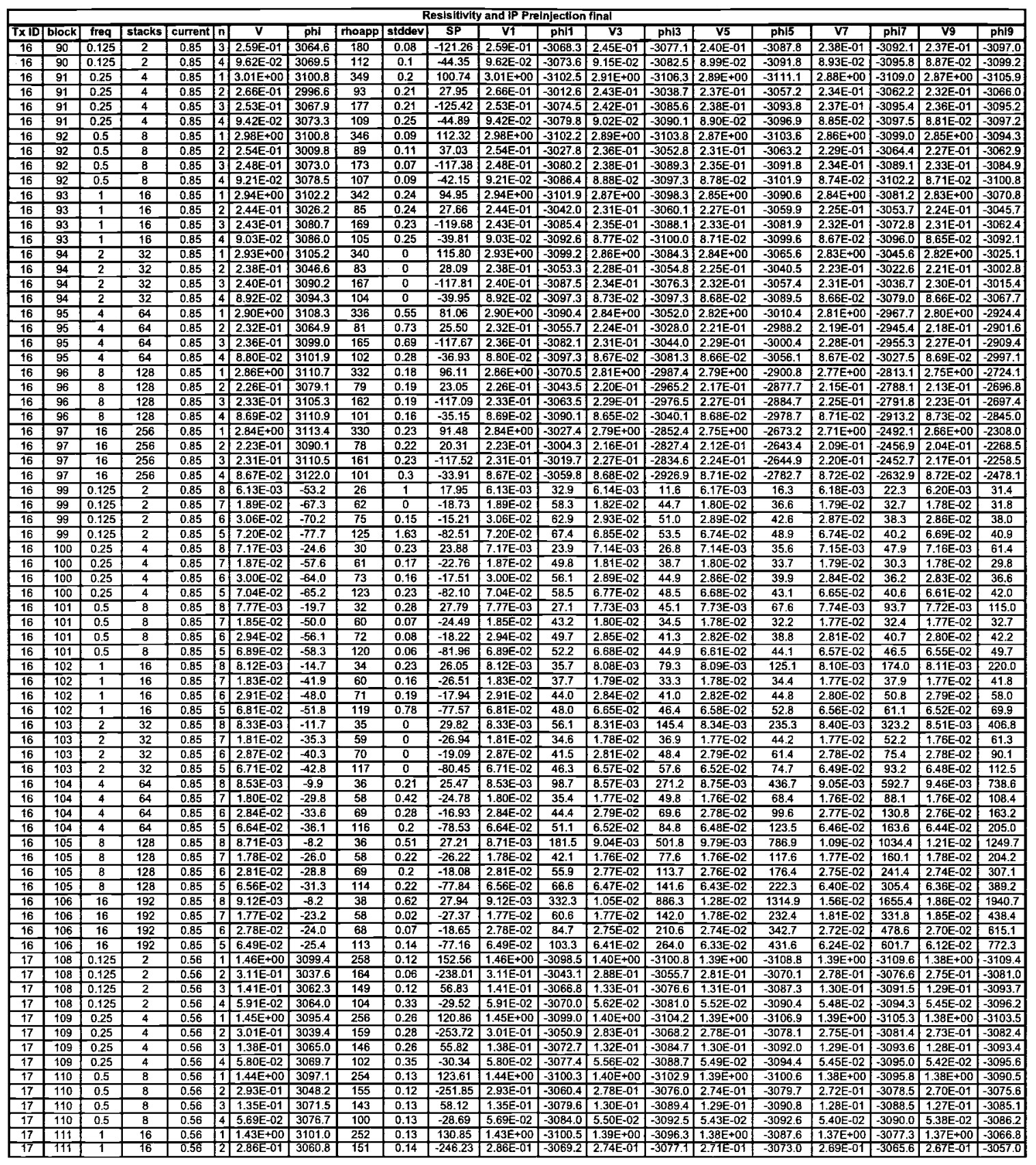


DOE/RL-2009-35, REV. 0

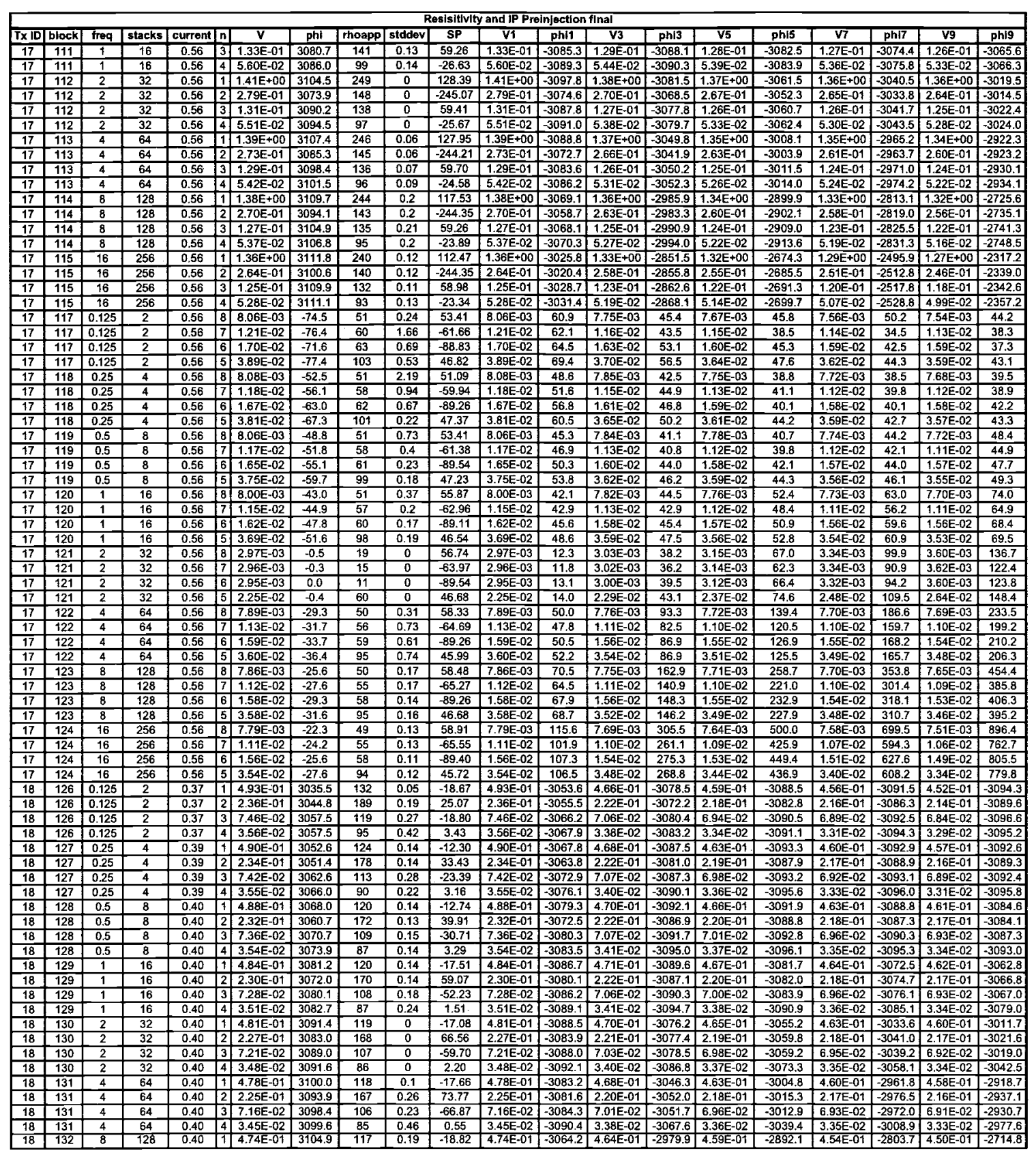


DOE/RL-2009-35, REV. 0

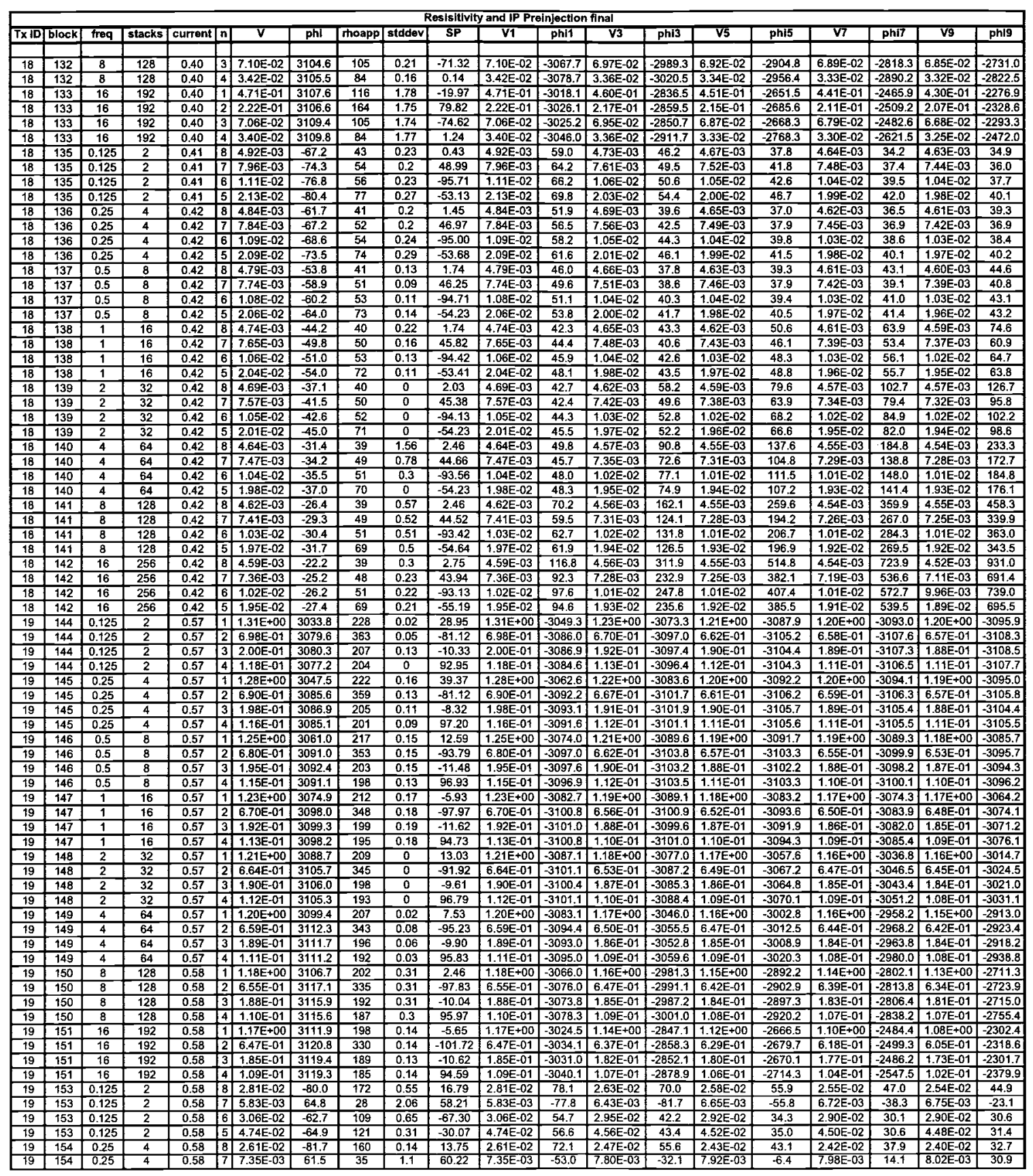


DOE/RL-2009-35, REV. 0

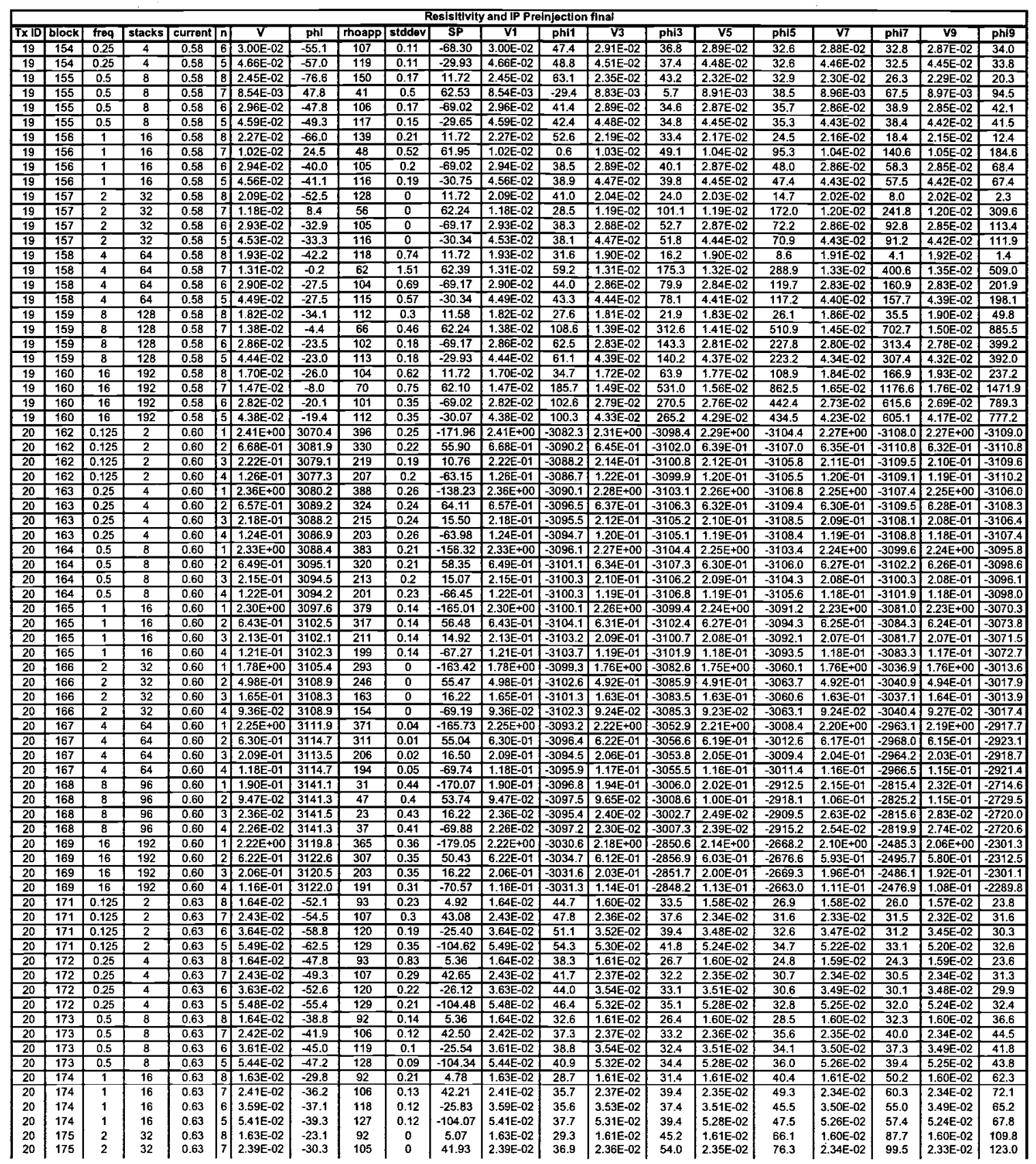


DOE/RL-2009-35, REV. 0

This page intentionally left blank. 
DOE/RL-2009-35, REV. 0

\section{Appendix E}

Iron Injection Verification Well 
DOE/RL-2009-35, REV. 0

This page intentionally left blank.

E-ii 


\section{E1. Iron Injection Verification Well Sampling Instructions}

This appendix contains the sampling instructions and analytical results for the iron injection verification well.

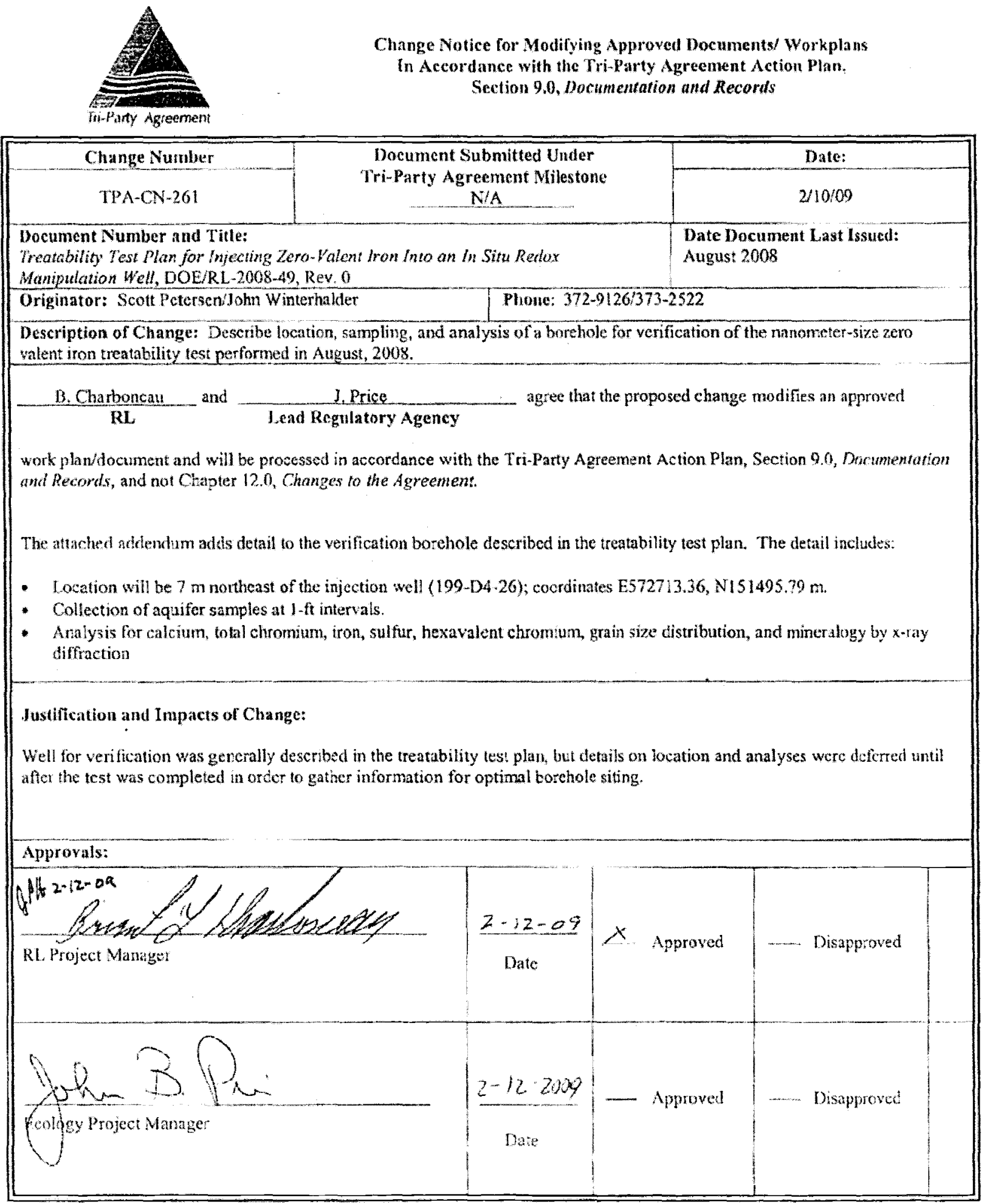


This Addendum describes sampling activities in support of verification of the nanometer-size zero valent iron (nZVI) treatability test performed in August 2008. In this test, nZVI was injected into the Ringold Formation as a slurry in well 199-D4-26, with the goal of augmenting the reductive capacity in the aquifer. One objective of the test was to communicate the iron slurry at least $7 \mathrm{~m}$ from the injection well at a concentration of $0.10 \mathrm{wt}$ percent (DOE/RL-2008-49, Section 3.2, Treatability Test Plan for Injecting Zero-Valent Iron Into an In Situ Redox Manipulation Well). This plan describes the effort to test the radius of influence of the injection.

Four nearby wells (Figure E-1) were monitored before, during, and after the test to determine the extent of injection. Figure E-1 shows the locations of the injection and monitoring wells. The monitoring consisted of measuring fluid levels and water-quality parameters, as well as extracting samples for analysis of metals and anions in the laboratory.

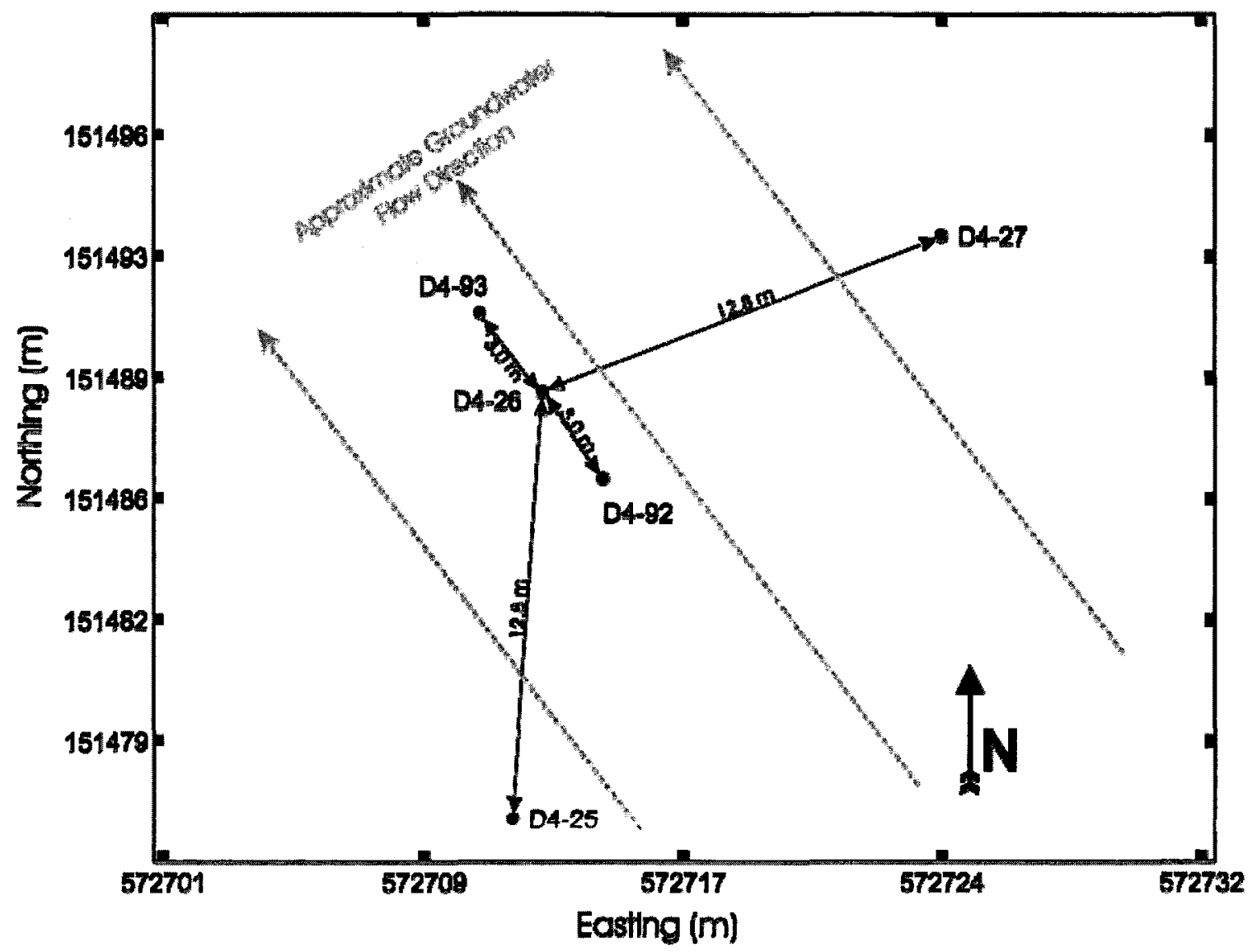

Figure E-1. Injection Well and Surrounding Monitoring Well Location Map

Visual observation of samples from the monitoring wells during and after injection indicated the following.

- The presence of nZVI was first indicated in monitoring well 199-D4-93 on August 9, 2008, at 08:45, which was 16 hours into the nZVI injection.

- nZVI was noted in monitoring well 199-D4-92 34 hours after start of injection. 
- A slight color change and the presence of bubbles (indicating the presence of the polymer) was noted in monitoring well 199-D4-25 approximately 24 hours after start of injection. nZVI has not been observed in this well.

- Monitoring well 199-D4-27 did not visually indicate influence of the injection for the duration of the testing.

These observations led to the conclusion that the nZVI front was quickly emplaced beyond a radial distance of $3 \mathrm{~m}$, but did not reach as far as $12.8 \mathrm{~m}$ from the injection well. The field parameter data corroborate visual observations, showing sharp decreases in dissolved oxygen less than a day after injection began (Figure E-2) and an increase in specific conductance after two days (Figure E-3) in the monitoring wells $3 \mathrm{~m}$ from 199-D4-26.

\section{E1.1 Location of the Well}

As described in the Sampling and Analysis Plan, one boring will be installed for the purpose of collecting soil samples. The location of this boring was discussed in a meeting held on November 6, 2008, in the Richland offices of the Washington State Department of Ecology. The factors and observations leading to deciding the location for the well included visual and chemical observations discussed above as well as geophysical measurements collected before and after the injection tests. Interpretation of the geophysical data suggests that the iron solution reached over $7 \mathrm{~m}$ laterally from the injection well. Of the several geophysical methods deployed (electrical resistivity (ER), multi-frequency induced polarization (IP), time domain electromagnetics, surface magnetics, and mise a la masse electrical potential mapping), only the IP data were useful in constraining the lateral extent of the injected ZVI. A conservative estimate from the IP modeling results is that the radial extent of the ZVI injection exceeded the target minimum of $7 \mathrm{~m}$. This distance is significant, because in order to form overlapping cylinders of nZVI between ISRM injection wells, and thus form an effective permeable reactive barrier, the radius of the cylinders must be over half the distance between the wells. With the in situ redox manipulation (ISRM) wells positioned $12.8 \mathrm{~m}$ apart, the radius of injection should be greater than $6.4 \mathrm{~m}$. If no or little $\mathrm{nZVI}$ is present at $7 \mathrm{~m}$, one of the primary objectives of the iron injection test would not be met.

Based on these considerations, it was decided at this meeting the boring would be located $7 \mathrm{~m}$ from 199-D4-26. It was also decided to locate the well along the line used for the ER survey, so any future data ER surveys could use the borehole to help calibrate the geophysical model and refine interpretation of the data. Figure E-4 shows the location of the new boring to sample and analyze the aquifer materials. The Washington State Plane coordinates for this well are Easting: 572713.36 m, Northing: 151495.79 m. 


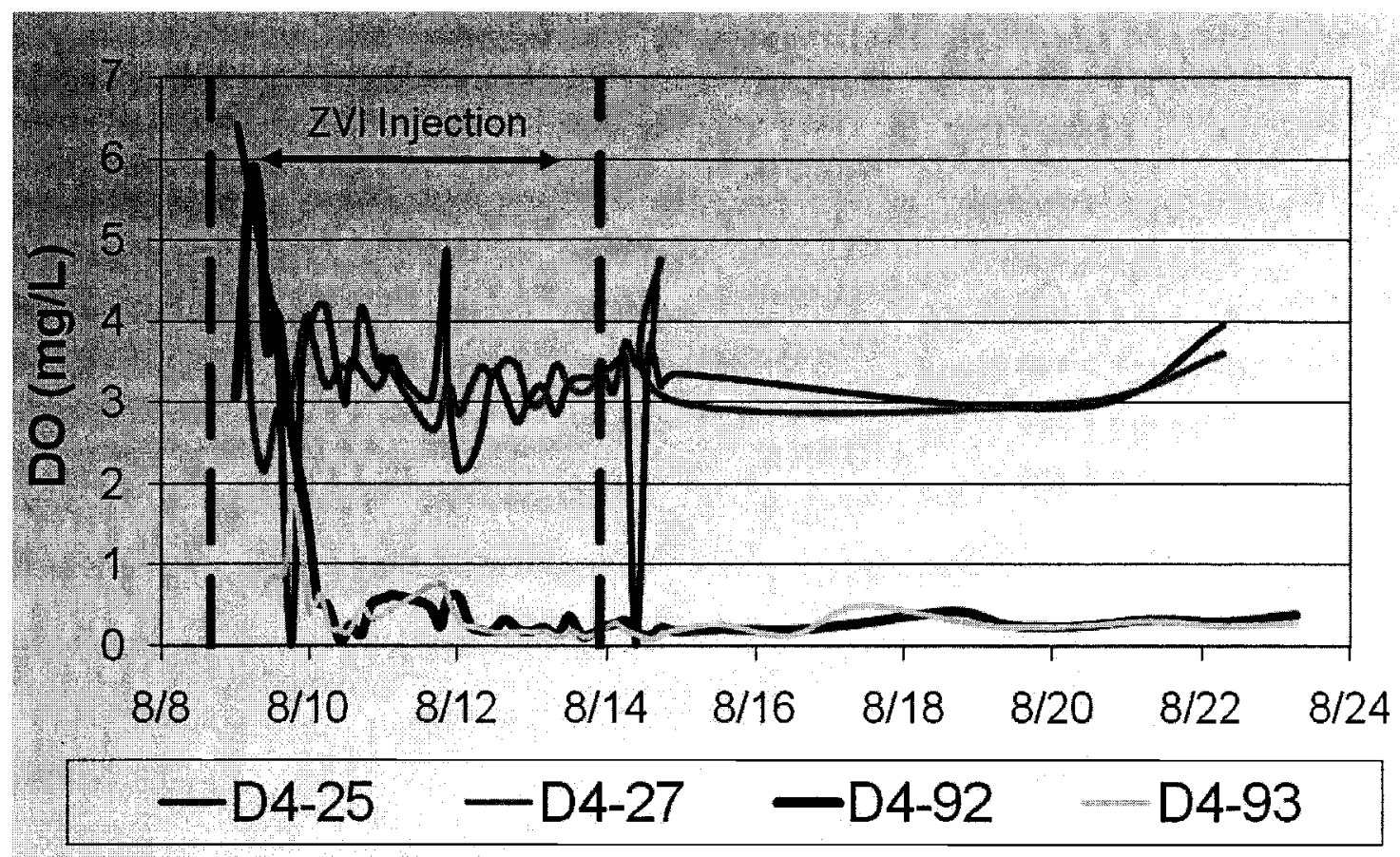

Figure E-2. Dissolved Oxygen Concentrations in Monitoring Wells

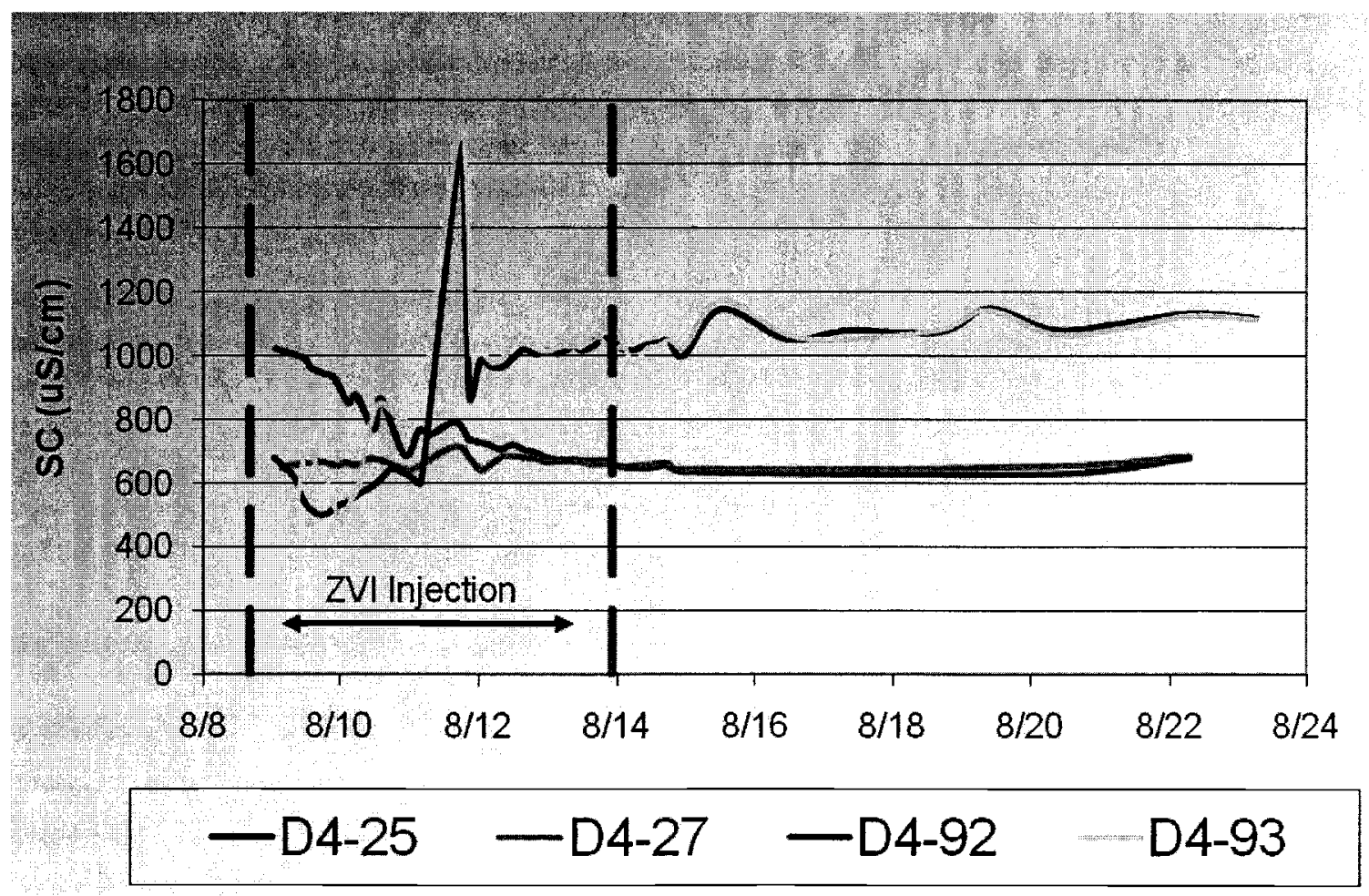

Figure E-3. Specific Conductance in Monitoring Wells 


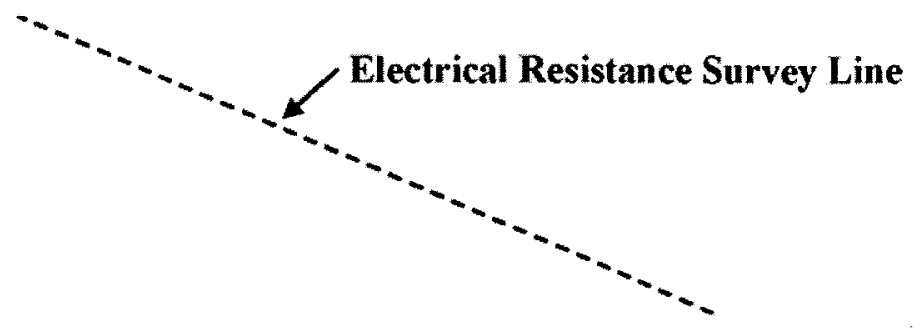

199-D4-25

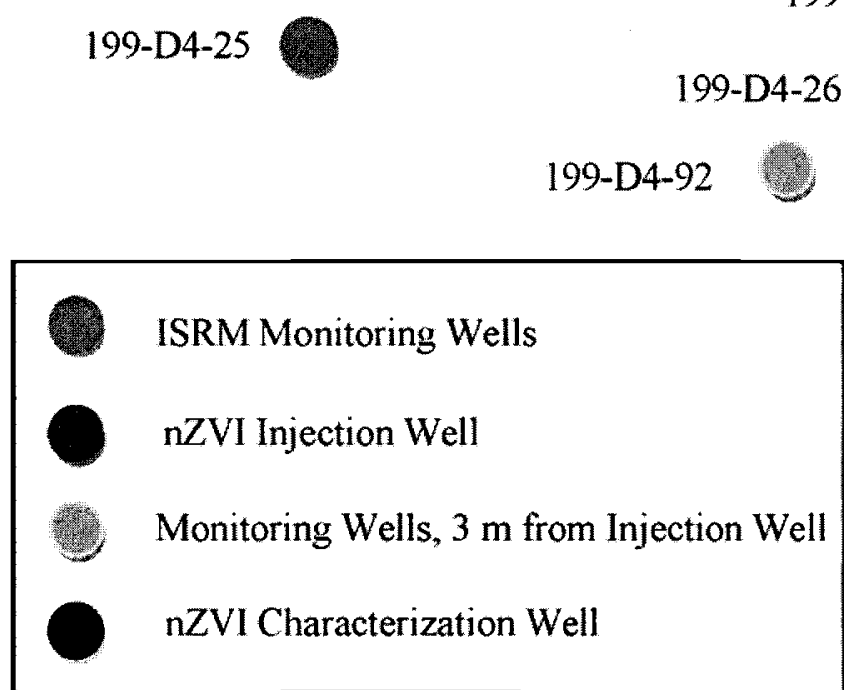

199-D4-92

199-D4-93

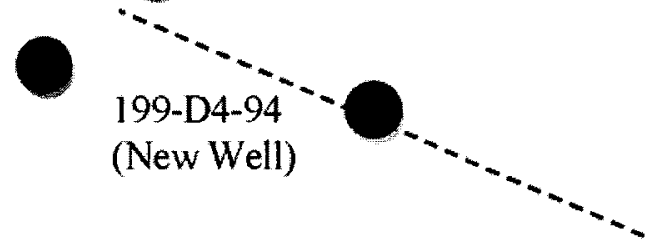

199-D4-27

Figure E-4. Location of New Well and Surrounding Existing Wells

\section{E1.2 Sample Collection and Handling}

The borehole will be drilled with cable-tool technology, and aquifer material will be collected by continuous split-spoon sampling from approximately $1 \mathrm{ft}$ above the groundwater table to $3 \mathrm{ft}$ into the Ringold Upper Mud. The diameter of the split-spoon will be 4 in with a length of 24 in. Prior to injection in August 2008, the static water level in well 199-D4-26 was $80 \mathrm{ft}$ below ground surface. The Ringold Upper Mud, which defines the bottom of the unconfined aquifer, is $101 \mathrm{ft}$ below ground surface in well 199-D4-26. Given these values, continuous split-spoon samples will be collected from $78 \mathrm{ft}$ to $104 \mathrm{ft}$. Twelve split-spoon samples will be needed to cover this interval. The sampler will be lined with 6 in Lexan liners to assist in maintaining sample integrity. Each liner will be capped, taped on the ends, and labeled with a unique Hanford Environmental Information System (HEIS) number. On receipt at the laboratory, the samples retrieved from the aquifer will be homogenized on $0.3-\mathrm{m}(1-\mathrm{ft})$ intervals, which is based upon analysis of previous sampling intervals (as reported in PNNL-15499, Effect of Geochemical and Physical Heterogeneity on the Hanford 100 D Area In Situ Redox Manipulation Barrier Longevity). The sample collected $3 \mathrm{ft}$ into the Ringold Upper Mud will be submitted to a laboratory for determination of permeability.

\section{E1.3 Sample Analysis}

All of the samples will be analyzed for selected total metals and hexavalent chromium.

Every sample will also be analyzed for grain size distribution by sieving. Sampling, labeling, shipping, and custody of the samples is described in Section A3.4 of the Sampling and Analysis Plan. 
The samples to be analyzed will use material that passes through a 200 mesh (less than $0.074 \mathrm{~mm}$ ) sieve. This is the fraction of greatest interest because the RNIP and any precipitates that form from chemical changes resulting from the injection would be far smaller than this. Thus, analyzing this size fraction should yield more accurate and precise analyses of the iron deposited, as well as constituents from any precipitates, than typical analyses performed on the less than $2 \mathrm{~mm}$ size fraction.

Table E-1 references the specific analytical methods to be performed.

\section{E1.4 Metals}

Each sample will be analyzed for selected or total metals. The samples will be individually digested using the SW-846 method $3050 \mathrm{~B}$ acid extraction procedure. This is a strong acid preparation and should dissolve the majority of RNIP-M2 present in the samples. This was verified during testing of various iron compounds prior to injections.

All of the samples will be analyzed for calcium, chromium, iron, and sulfur. These elements are of prime interest in this study for the following reasons:

- Calcium has the potential to complex with carbonate and sulfur to precipitate as gypsum, calcium, and other minerals. As pointed out by Ecology staff, this mechanism could lead to aquifer plugging in the long term.

- Chromium is the contaminant of interest.

- Iron will give a measure of the amount of RNIP deposited in this location, which is the primary reason for collecting these samples.

- Sulfur has the potential to complex with calcium, which may form a precipitate and reduce hydraulic conductivity in the aquifer.

In addition to these four metals, every fifth sample will be analyzed for all inductively coupled plasma (ICP) metals, primarily as a quality assurance check.

The 3050B extraction method will probably not dissolve any of the iron in the sample that is present as magnetite or bound in the sample in a silicate matrix. To determine if any less soluble forms of iron are present in the samples (i.e., magnetite, other spinels) a lithium tetraborate fusion will be performed on every fifth analytical sample, resulting in approximately five fusion samples. The samples will be analyzed for all ICP metals according to Environmental Protection Agency method 6010.

\section{E1.5 Hexavalent Chromium}

Samples for hexavalent chromium analysis will be prepared and analyzed using standard Environmental Protection Agency methods (See Table E-1).

\section{E1.6 X-Ray Diffraction}

Samples for X-ray diffraction analyses will be ground into a powder and analyzed with an X-ray diffractometer to produce a diffraction pattern. This pattern will be evaluated for the mineral constituents in the powder and a qualitative estimate of their abundances. Particular attention shall be given to detection of trace amounts of iron minerals in the sample and potential precipitates such as gypsum, calcite, and aragonite. 


\section{E1.7 Sieve Analysis}

Sieve analysis will be performed on each of the samples to help establish geologic correlations with nearby wells. All aquifer material not used for laboratory analysis will be archived and appropriately stored for at least one year after collection.

\section{E1.8 Discussion}

This boring will be converted into a groundwater monitoring well as described in Section A4.5 in the Sampling and Analysis Plan and in accordance with Washington Administrative Code (WAC) 173-160, "Minimum Standards for the Construction and Maintenance of Wells." A well size of 10.2-cm (4-in) inner diameter is required. Well completion materials will be polyvinyl chloride, which will facilitate any future geophysical investigations in the area.

The chemical data will be reported as a percentage of the weight of the sample analyzed, which is the fraction of the field sample that is less than 200 mesh (less than $0.074 \mathrm{~mm}$ ). This value will also be converted to a bulk sample value by multiplying it by the ratio of the weights of the different size fractions of the field sample (i.e., [weight of less than 200 sample]/[weight of greater than 200 sample]) obtained from the sieve data. The data will be tabulated and included electronically in the treatability test report for the iron injection project. Although the data will be tied to specific HEIS sample numbers for chain of custody control, these data will not be included in HEIS. Data associated with treatability tests where chemicals have been added to soil or groundwater (e.g., calcium polysulfide treatability test in 100-K Area) are typically misinterpreted by casual users of HEIS.

The chemical and mineralogical data obtained from the aquifer materials will be evaluated against background values. The background samples will be from the Ringold Unit $\mathrm{E}$ aquifer collected from well 199-D5-121 in 2008 and/or well 199-D5-34, drilled in 2003. Samples from these wells were analyzed for selected metals and also archived. Splits from the archived samples will be analyzed in the same manner as those from well 199-D4-94. Iron values will also be compared to those obtained in a previous study evaluating heterogeneity in the ISRM barrier (PNNL-15499).

As stated in the Sampling and Analysis Plan (Table A2-1), iron in concentrations at or near $0.10 \mathrm{wt}$ percent above background in the aquifer soil samples $7 \mathrm{~m}$ from the injection well would indicate that this technology is valid for mending portions of the ISRM barrier. Documentation of this sampling and analysis activity and the interpretation of results will be included in the final report for the iron injection project.

A summary of the analyses to be performed on the aquifer materials is presented in Table E-1.

Table E-1. Summary of Analyses For Soil Samples

\begin{tabular}{|c|c|c|c|}
\hline $\begin{array}{l}\text { Frequency } \\
\text { Fre }\end{array}$ & $\begin{array}{l}\text { Type of } \\
\text { Analysis }\end{array}$ & $\begin{array}{l}\text { Minimum } \\
\text { Amount of } \\
\text { Material }\end{array}$ & Extraction and Analytical Method Details \\
\hline \multirow{4}{*}{$\begin{array}{l}\text { Continuous through the } \\
\text { aquifer from the groundwater } \\
\text { table to the Ringold Lower } \\
\text { Mud. Samples will be } \\
\text { homogenized on } 0.3-\mathrm{m} \text { (1-ft) } \\
\text { centers }\end{array}$} & $\begin{array}{l}\text { Selected } \\
\text { Metals }\end{array}$ & $200 \mathrm{~g}$ & $\begin{array}{l}\text { Extraction: EPA } 3050 B \\
\text { Analysis: EPA } 6010\end{array}$ \\
\hline & $\begin{array}{l}\text { Hexavalent } \\
\text { Chromium }\end{array}$ & $50 \mathrm{~g}$ & $\begin{array}{l}\text { Extraction: EPA } 3060 \mathrm{~A} \\
\text { Analysis: EPA } 7196\end{array}$ \\
\hline & $\begin{array}{l}\text { X-ray } \\
\text { Diffraction }\end{array}$ & $50 \mathrm{~g}$ & Standard laboratory procedures and interpretation \\
\hline & Seive & $1000 \mathrm{~g}$ & ASTM \#D422 or comparable method \\
\hline
\end{tabular}


DOE/RL-2009-35, REV. 0

This page intentionally left blank. 


\section{E2 Report of Results Obtained from the Zero-Valent Iron Injection Verification Well}

\section{E2.1 Introduction}

Nano-sized zero-valent iron (nZVI) slurry was injected into well 199-D4-26 in August 2008 as part of treatability testing aimed at augmenting the reductive capacity of the hexavalent chromium contaminated aquifer located at the Hanford Site in Richland, Washington. A new borehole was drilled in March 2009 to verify the emplacement of the nZVI in the aquifer. Continuous soil samples were taken from the borehole beginning at the top of the unconfined aquifer and continuing into the underlying impermeable layer that defined the bottom of the aquifer. One objective of the nZVI injection (treatability test) was to distribute the iron slurry at least $7 \mathrm{~m}$ from the injection well at a concentration of $0.10 \mathrm{wt} \%$ (approximately 1,000 mg iron/kg) (DOE/RL-2008-49, Treatability Test for Injecting Zero-Valent Iron Into an In Situ Redox Manipulation Well, Section 3.2). Wells close to the injection site were monitored before, during, and after the injection to determine the extent of the nZVI migration. Observations and field parameter data collected during injection lead to the conclusion that the nZVI front was quickly emplaced beyond a radial distance of $3 \mathrm{~m}$, but did not reach as far as $12.8 \mathrm{~m}$ from the injection well.

\section{E2.2 nZVI Characterization Well Location}

To evaluate the amount of nZVI that was emplaced $7 \mathrm{~m}$ from the injection well, a borehole was drilled and aquifer material was collected for laboratory analysis. The well was installed $7 \mathrm{~m}$ northeast of well 199-D4-26, and was situated along the traverse line used for the electrical resistance survey. Therefore, data gathered from the borehole could be used to help calibrate the model and refine interpretation of the data.

Figure E-1 shows the location of the new well (199-D4-94) where samples were taken for analysis of the aquifer materials. The Washington State Plane coordinates for this well are Easting: $572713.36 \mathrm{~m}$, Northing: $151495.79 \mathrm{~m}$. More details about drilling and completing the well can be found in SGW-40999, Borehole Summary Report for the Installation of one Groundwater Well for the 100-D Zero-Valent Iron Project CY2009.

\section{E2.3 Sample Collection and Handling}

The borehole was drilled with cable-tool technology, and aquifer material was collected by continuous split-spoon sampling to the Ringold Upper Mud. The diameter of the split-spoon used resulted in borehole samples approximately $3 \mathrm{in}$. wide and $24 \mathrm{in}$. long. The split spoon contained four 6-in. Lexan sleeves. The first borehole sample was collected at $79.5 \mathrm{ft}$, near the top of the aquifer, since the static water level in nearby wells was $80 \mathrm{ft}$ below ground surface. The Ringold Upper Mud, which defines the bottom of the unconfined aquifer, was encountered at $99.8 \mathrm{ft}$ below ground surface in the nZVI characterization well (199-D4-94). Continuous split-spoon samples were collected from $79.5 \mathrm{ft}$ to $101.8 \mathrm{ft}$. Eleven split-spoon samples were taken to cover this interval; each of the Lexan liners was capped and taped and assigned a Hanford Environmental Information System number. After the samples were received at the laboratory, they were logged and photographed before being measured for geophysical properties and processed for analysis. 


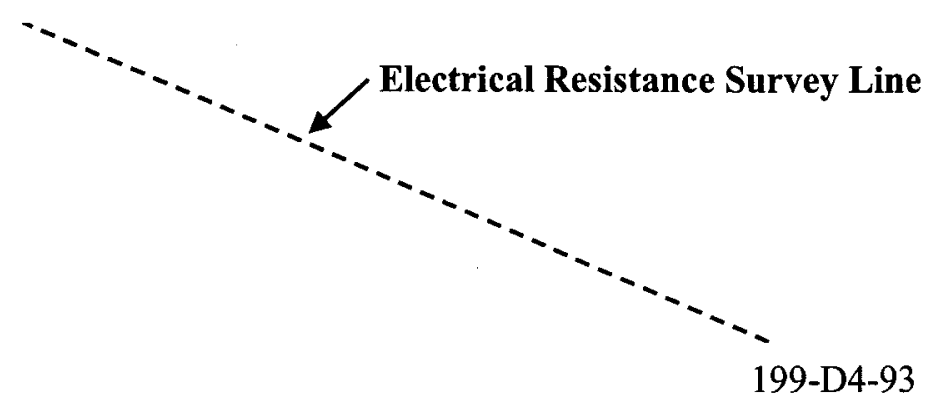

199-D4-25

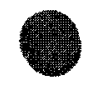

199-D4-26

199-D4-92

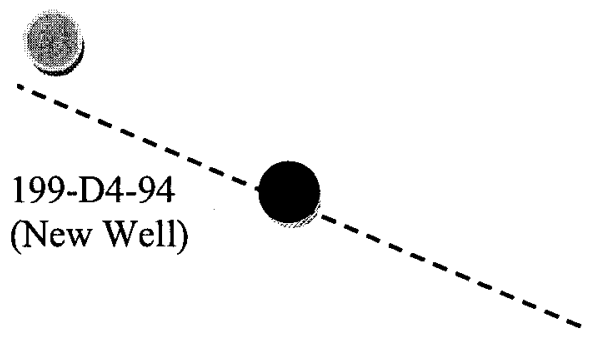

ISRM Monitoring Wells

nZVI Injection Well

Monitoring Wells, $3 \mathrm{~m}$ from Injection Well

nZVI Characterization Well

199-D4-27

Figure E-1. Location of New Well, 199-D4-99 and Surrounding Existing Wells (from DOE/RL-2008-49)

\section{E2.4 Geophysical Measurements}

Once logged and photographed, geophysical testing was performed on the cores containing the in situ samples. Based on the results of field geophysics performed at the in situ redox manipulation barrier (Section 6.2.4), it was decided to perform resistivity, IP, and magnetics on the cores.

\section{E2.4.1 Resistivity and IP Acquisition Procedure}

Electrical resistivity and induced polarization (IP) data were acquired using a dipole-dipole electrode configuration. To construct the current electrodes, an approximately 6-in.-long piece of copper grounding rod was taped using electrical tape so that only the last $1 / 3$ in. of each end of the electrode was bare. One end of the electrode was pushed into the sample and the other end was used to connect with the resistivity measurement system. For the potential electrodes, silver silver-chloride devices, similar to those used for electrocardiogram applications, were employed. Figure E-2 shows an example of these electrodes. They consist of a silver-plated tab with an adhesive, low chloride hydro-gel covering. These electrodes are very low impedance, and adhere directly to each end of the sample. Because of the consistency of the sample material, good electrode contact was maintained by holding the electrodes in place by hand. Contact resistance for the electrodes ranged from 1 to $2 \mathrm{~K}$-ohm. 


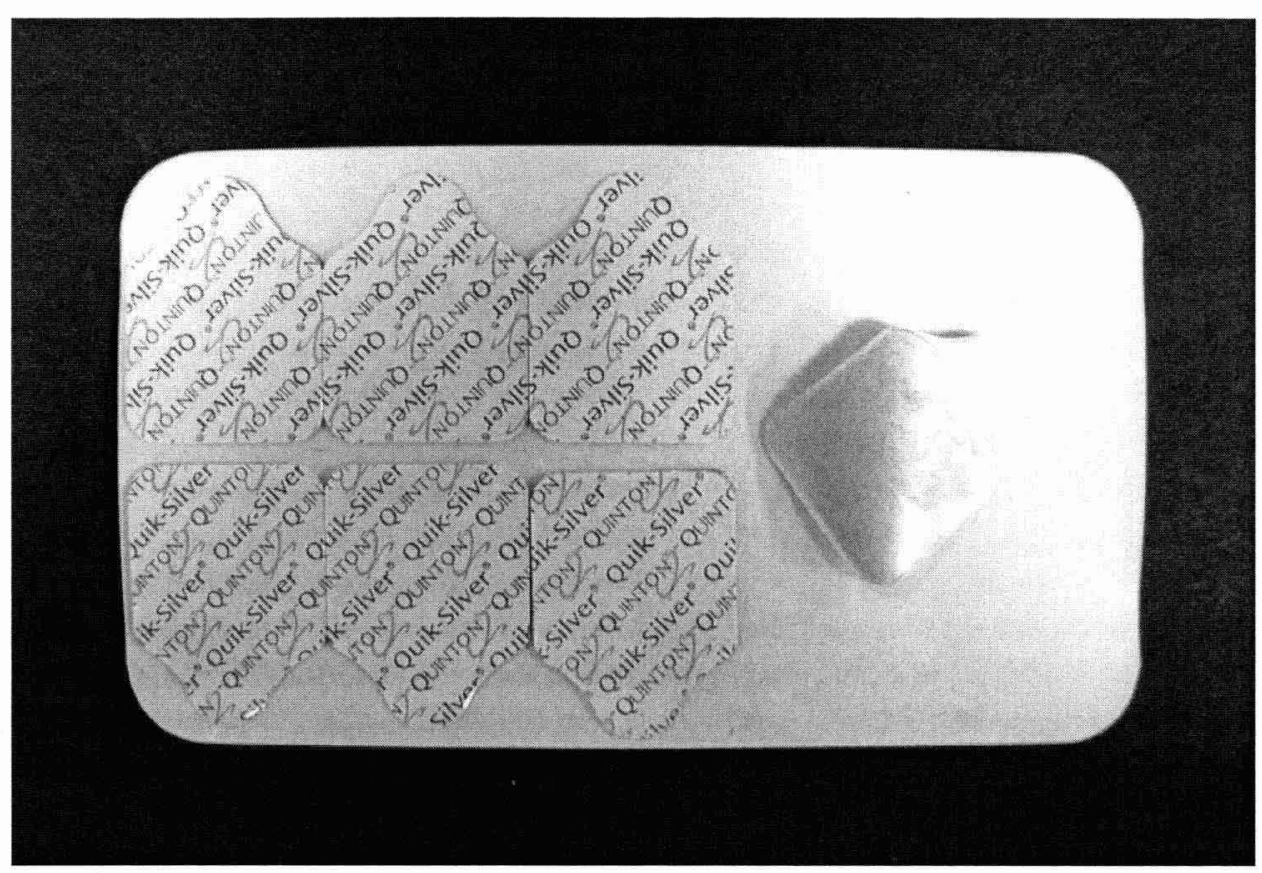

Figure E-2. Photograph of the Quinton Quik-Silver Brand Resting Electrocardiogram Electrodes used to Measure Electrical Potentials During the Experiment

A Syscal R2 resistivity/IP meter was used to acquire the data. Geometry of the measurements was variable (but accounted for during data analysis) due to differences in sample length. In some cases, measurements were not possible; e.g., overvoltage on the potential electrodes or samples consisting primarily of large cobbles. The source current frequency was $0.5 \mathrm{~Hz}$ (period $=2$ seconds) and the data were averaged for a minimum of six measurements. Chargeability was measured in the time-domain by measuring the voltage decay in four separate time windows. Two measurements were made for the majority of the samples to ensure repeatability of the results. Figure E-3 shows one of the samples instrumented for the resistivity and IP measurements.

\section{E2.4.2 Magnetic Susceptibility Procedure}

Magnetic susceptibility measurements were made with a Geoinstruments Model JH- 8 hand-held volume susceptibility meter. Measurements were taken at each end and in the center of the sample, through the sample container but with the end caps removed. If the sample length was less than the length of the sample container, the end position for the meter was adjusted to align with the end of the sample.

\section{E2.5 Sample Preparation}

Following the geophysical testing, the samples were homogenized in approximately $0.3 \mathrm{~m}(1-\mathrm{ft})$ intervals, photographed, and then sieved. Based on a preliminary total iron analysis on the various sieve fractions of samples ZIM-13-96.2-97.2' / PF, which was determined to contain a significant amount of nZVI through visual and olfactory observation, it was concluded that the majority of the iron was accumulating on the minus 60-mesh fraction. Therefore the minus 60 material was used for further analytical and hydrometer analyses. The following sections summarize the testing procedures that were used, and the results that were obtained. 


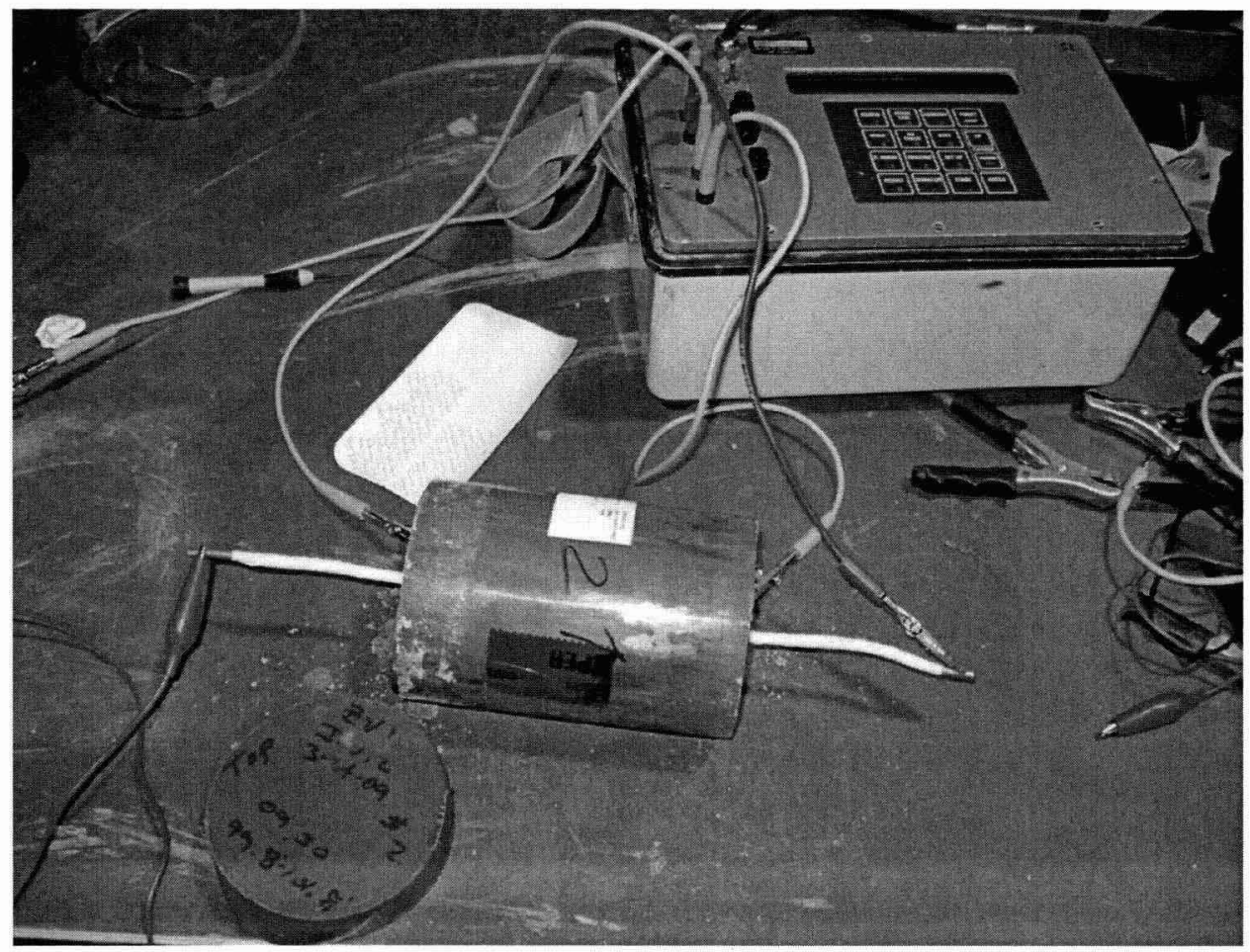

Figure E-3. Photograph of the Resistivity and IP Data Acquisition

The individual 7.5 by $15 \mathrm{~cm}$ (3- by 6 -in.) samples cores were homogenized in approximately $0.3 \mathrm{~m}$ (1-ft) intervals in an attempt to correlate with previous sampling intervals (PNNL-15499, Effect of Geochemical and Physical Heterogeneity on the Hanford 100-D Area In Situ Redox Manipulation Barrier Longevity). Because of difficulties in obtaining complete recovery from each split-spoon sample, some of the intervals were forced to deviate from the 1-ft interval. Table E-1 shows the exact intervals used in compositing the sample sleeves to generate the samples used for analyses. Based on visual observation, samples ZIM-12-95.4-95.9', ZIM-13-96.2-97.2' / PF, ZIM-14-97.2-98.2' / PF, and ZIM-15-97.7-98.7', which were collected from approximately 95 to $99 \mathrm{ft}$, have some degree of iron emplaced, as evidenced by the notable black color.

Table E-1. Analytical Sample Compositing Scheme

\begin{tabular}{|c|c|c|c|c|c|}
\hline $\begin{array}{l}\text { Split Spoon } \\
\text { ID }\end{array}$ & $\begin{array}{c}\text { Sleeve } \\
\text { No. }\end{array}$ & $\begin{array}{c}\text { Sleeve Sample } \\
\text { ID }\end{array}$ & $\begin{array}{l}\text { Analytical Sample } \\
\text { Interval }\end{array}$ & Lab Sample ID & $\begin{array}{l}\text { Pore Fluid Sample } \\
\text { (Y/N) }\end{array}$ \\
\hline \multirow{4}{*}{$1-002$} & 4 & B1YYK2 & \multirow{2}{*}{$79.5-80.5$} & \multirow{2}{*}{ ZIM-1-79.5-80.5' } & \multirow{2}{*}{$\mathrm{N}$} \\
\hline & 3 & B1YYK1 & & & \\
\hline & 2 & B1YYK0 & \multirow{2}{*}{$80.5-81.5$} & \multirow{2}{*}{ ZIM-2-80.5-81.5' } & \multirow{2}{*}{ N } \\
\hline & 1 & B1YYJ9 & & & \\
\hline \multirow{2}{*}{$1-003$} & 2 & B1YYK4 & \multirow{2}{*}{$81.7-83.7$} & \multirow{2}{*}{ ZIM-3-81.7-83.7' } & \multirow{2}{*}{$\mathrm{N}$} \\
\hline & 1 & B1YYK3 & & & \\
\hline
\end{tabular}


DOE/RL-2009-35, REV. 0

Table E-1. Analytical Sample Compositing Scheme

\begin{tabular}{|c|c|c|c|c|c|}
\hline $\begin{array}{l}\text { Split Spoon } \\
\text { ID }\end{array}$ & $\begin{array}{l}\text { Sleeve } \\
\text { No. }\end{array}$ & $\begin{array}{l}\text { Sleeve Sample } \\
\text { ID }\end{array}$ & $\begin{array}{l}\text { Analytical Sample } \\
\text { Interval }\end{array}$ & Lab Sample ID & $\begin{array}{l}\text { Pore Fluid Sample } \\
\text { (Y/N) }\end{array}$ \\
\hline \multirow{3}{*}{ I-004 } & 3 & B1YYK9 & \multirow{2}{*}{$84.1-85.6$} & \multirow{2}{*}{ ZIM-4-84.1-85.6' } & \multirow{2}{*}{$N$} \\
\hline & 2 & B1YYK8 & & & \\
\hline & 1 & B1YYK7 & \multirow{3}{*}{$85.6-86.7$} & \multirow{3}{*}{ ZIM-5-85.6-86.7' } & \multirow{3}{*}{$N$} \\
\hline \multirow{4}{*}{ I-005 } & 4 & B1YYL2 & & & \\
\hline & 3 & B1YYL1 & & & \\
\hline & 2 & B1YYL4 & \multirow{2}{*}{$86.7-87.7$} & \multirow{2}{*}{ ZIM-6-86.7-87.6' / PF } & \multirow{2}{*}{$\mathbf{Y}$} \\
\hline & 1 & B1YYL3 & & & \\
\hline \multirow{2}{*}{ 1-006 } & 2 & B1YYL6 & \multirow{2}{*}{$87.6-88.6$} & \multirow{2}{*}{ ZIM-7-87.6-88.6' } & \multirow{2}{*}{$N$} \\
\hline & 1 & B1YYL5 & & & \\
\hline \multirow{4}{*}{$1-007$} & 4 & B1YYM2 & \multirow{2}{*}{$89.5-90.5$} & \multirow{2}{*}{ ZIM-8-89.5-90.5' / PF } & \multirow{2}{*}{$\mathbf{Y}$} \\
\hline & 3 & B1YYM1 & & & \\
\hline & 2 & B1YYM0 & \multirow{2}{*}{$90.5-91.5$} & \multirow{2}{*}{ ZIM-9-90.5-91.5' } & \multirow{2}{*}{$N$} \\
\hline & 1 & B1YYL9 & & & \\
\hline I-008 & 1 & B1YYM3 & \multirow{2}{*}{$92.3-94.4$} & \multirow{2}{*}{$\begin{array}{c}\text { ZIM-10-92.3-94.4' / } \\
\text { PF }\end{array}$} & \multirow{2}{*}{$\mathbf{Y}$} \\
\hline \multirow{4}{*}{$1-009$} & 4 & B1YYNO & & & \\
\hline & 3 & B1YYM9 & \multirow{2}{*}{$94.4-95.4$} & \multirow{2}{*}{ ZIM-11-94.4-95.4' } & \multirow{2}{*}{$\mathrm{N}$} \\
\hline & 2 & B1YYM8 & & & \\
\hline & 1 & B1YYM7 & $95.4-95.9$ & ZIM-12-95.4-95.9' & $N$ \\
\hline \multirow{4}{*}{$1-010$} & 4 & B1YYN4 & \multirow{2}{*}{$96.2-97.2$} & ZIM-13-96.2-97.2' / & $\mathbf{y}$ \\
\hline & 3 & B1YYN3 & & $\mathrm{PF}$ & $r$ \\
\hline & 2 & B1YYN2 & $972-982$ & ZIM-14-97.2-98.2' / & $Y$ \\
\hline & 1 & B1YYN1 & $91.2-90.2$ & & $r$ \\
\hline & 4 & B1YYN8 & 077007 & 71490770971 & $N$ \\
\hline & 3 & B1YYN7 & $01.1-80.1$ & 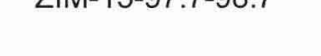 & N \\
\hline 年 & 2 & B1YYN6 & 7 & 79416007007 & A \\
\hline & 1 & B1YYN5 & $90.1-99.1$ & $21 \mathrm{VI}-10-90.1-99.8$ & N \\
\hline & 4 & B1YYP0 & 0001000 & 71401700010001 & \\
\hline & 3 & B1YYP1 & $0.0-100.0$ & 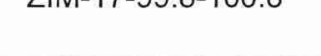 & T \\
\hline 10 & 2 & B1YYP2 & & & \\
\hline & 1 & B1YYN9 & (60.0-101.0 & $219 v 1-10-100.0-101.0$ & $\mathrm{~N}$ \\
\hline
\end{tabular}


Table E-1. Analytical Sample Compositing Scheme

\begin{tabular}{cccccc}
\hline $\begin{array}{c}\text { Split Spoon } \\
\text { ID }\end{array}$ & $\begin{array}{c}\text { Sleeve } \\
\text { No. }\end{array}$ & $\begin{array}{c}\text { Sleeve Sample } \\
\text { ID }\end{array}$ & $\begin{array}{c}\text { Analytical Sample } \\
\text { Interval }\end{array}$ & Lab Sample ID & $\begin{array}{c}\text { Pore Fluid Sample } \\
\text { (YIN) }\end{array}$ \\
\hline \multirow{3}{*}{ BKG } & - & C5935-90 & 90 & ZIM-19-90-BKG & -- \\
\cline { 2 - 6 } & -- & C5935-100 & 100 & ZIM-20-100-BKG & -- \\
\cline { 2 - 6 } & -- & C5935-105 & 105 & Archive & - \\
\hline
\end{tabular}

$I D=$ identification

\section{E2.5.1 Particle Size Analysis Procedure}

After compositing, the samples were homogenized in approximately $0.3 \mathrm{~m}(1-\mathrm{ft})$ intervals, photographed, and dried at $45^{\circ} \mathrm{C}$ in a convection oven before performing further testing. Some 6-in. Lexan sleeves had sufficient material to make an entire sample interval alone and some samples had to be mixed from three 6 -in. Lexan sleeves due to lack of sample. However, most sample intervals contained a composite from two 6-in. Lexan sleeves.

After drying, the samples were mechanically sieved in their entirety to determine if there was an adequate amount for laboratory analysis. The sieves ranged from $1.25 \mathrm{in}$. to 200 -mesh and the silt/clay/colloid particle fractions were determined from hydrometer analysis using an ASTM 151-H hydrometer. Particle size analyses were performed in accordance with ASTM D422, Standard Test Methods for Particle-Size Analysis of Soils.

\section{E2.5.2 Sample Preparation and Analysis}

As previously stated, all analysis were performed on the minus 60-mesh fraction. The samples were prepared for metals analysis by the methods presented below.

\section{E2.5.3 Acid-Extractable Analysis Procedure}

Method 3050B in SW-846, Test Methods for Evaluating Solid Waste: Physical/Chemical Methods, Third Edition; Final Update $I V$-B, uses strong acids to dissolve the constituents into an aqueous matrix for subsequent analysis by inductively coupled plasma atomic emission spectroscopy (ICP-AES). Consequently, only the more labile constituents are quantified by this method, even though it is routinely referred to as a total digestion. Insoluble sulfides and metals "locked" in the crystalline matrix are under-reported by this analysis. Because there are no developed methods that are capable of discriminating nZVI iron from "natural" iron, this method serves as a reasonable procedure to estimate the $\mathrm{nZVI}$ in soil. Previous work has shown that the iron content by Method 3050B ranged from 60 to 70 percent $(\mathrm{w} / \mathrm{w})$ for the RNIP-M2 nZVI. Theoretically, if the iron concentration of an untreated (background) soil is subtracted from the results of an $\mathrm{nZVI}$ injected soil, the iron concentration difference should provide a reasonable estimate of the nZVI injected into the soil. However, formation anisotropy, soil particle size distribution, sampling error, and analytical error will increase the uncertainty of any estimates. Chromium, calcium, and sulfur also were analyzed from the Method 3050B acid extracts.

\section{E2.5.4 Fusion Analysis}

Five samples and one background sample were prepared by lithium tetraborate fusion. Typically, the fusion recovers more of the total elemental concentration of the soil constituents regardless of the mineralogical form. Therefore, the metals results from analysis of the fusion should be greater than the results of the acid extracts from the Method 3050B preparation. The acid extracts and fusion digestates 
were both analyzed by ICP-AES for metals. All of the Method 3050B acid extracts were analyzed for iron, chromium, calcium, and sulfur.

\section{E2.5.5 Hexavalent Chromium Analysis}

All of the soil samples were analyzed for hexavalent chromium after being prepared using SW-846 Method 3060A, which is an alkaline digestion used for determining soluble and adsorbed forms of hexavalent chromium from soils, sludges, and other waste material. The digestates were analyzed by ICP-AES.

\section{E2.5.6 Pore Water Analysis}

Five pore water samples were collected from the soils as they were removed from the Lexan sleeves. The pore water was immediately filtered through a $0.45 \mu \mathrm{m}$ syringe filter, typically yielding a sample of a few milliliters, which was analyzed by ICP-AES for dissolved chromium. The sample taken from the nZVI enriched layer ( 96.2 to $97.2 \mathrm{ft}$ ) sample was analyzed for the additional analytes iron, calcium, and sulfur.

\section{E2.5.7 X-Ray Diffraction Analysis Procedure}

An X-ray diffraction (XRD) analysis was performed on five of the soil samples and one background sample. The samples were sieved to pass a 325-mesh screen and analyzed by XRD. Analysis was performed using a Philips X-ray diffractometer scanning 5 to 85 theta at 2-theta intervals. Scan time was approximately one-half hour per sample.

\section{E2.6 Results and Discussion}

\section{E2.6.1 Resistivity and IP Results}

Resistivity measurements were not interpreted, as they correlated directly with sample moisture content and did not significantly discriminate between soil types.

Based on IP measurements N8 (ZVI-15), N3 (ZVI-13), N6 (ZVI-16), N5 (ZVI-16), M7 (ZVI-12), M3 (ZVI-10), and M8 (ZVI-11) likely contain higher than background levels of iron. These samples all had a chargeability of $6 \mathrm{mV} / \mathrm{V}$ or greater. Several samples, especially the shallower samples, had no or negligible chargeability.

Figure E-4 shows a comparison of the IP data with the iron concentrations obtained via laboratory analysis. The IP data indicate a much broader region of higher iron concentrations than does the laboratory data although the peak of the iron concentration correlates reasonably well with the peak in chargeability.

\section{E2.6.2 Magnetic Susceptibility Results}

Based on the magnetic susceptibility averages, M1 (ZVI-8), L9 (ZVI-4), M3 (ZVI-10), M7 (ZVI-12), N4 (ZVI-13), N3 (ZVI-13), N8 (ZVI-15), N7 (ZVI-15) and possibly J9 (ZVI-2) and N6 (ZVI-16) likely contain higher than background levels of iron. M7 (ZVI-12) had the highest susceptibility measurement average. The five deepest samples had no measurable susceptibility.

Figure E-4 shows a comparison of the magnetic susceptibility data with the iron concentrations obtained via laboratory analysis. The magnetic susceptibility shows a relatively good correlation to the iron concentration, at least qualitatively. There are some significant differences in the two curves, especially for depths greater than $96 \mathrm{ft}$. 

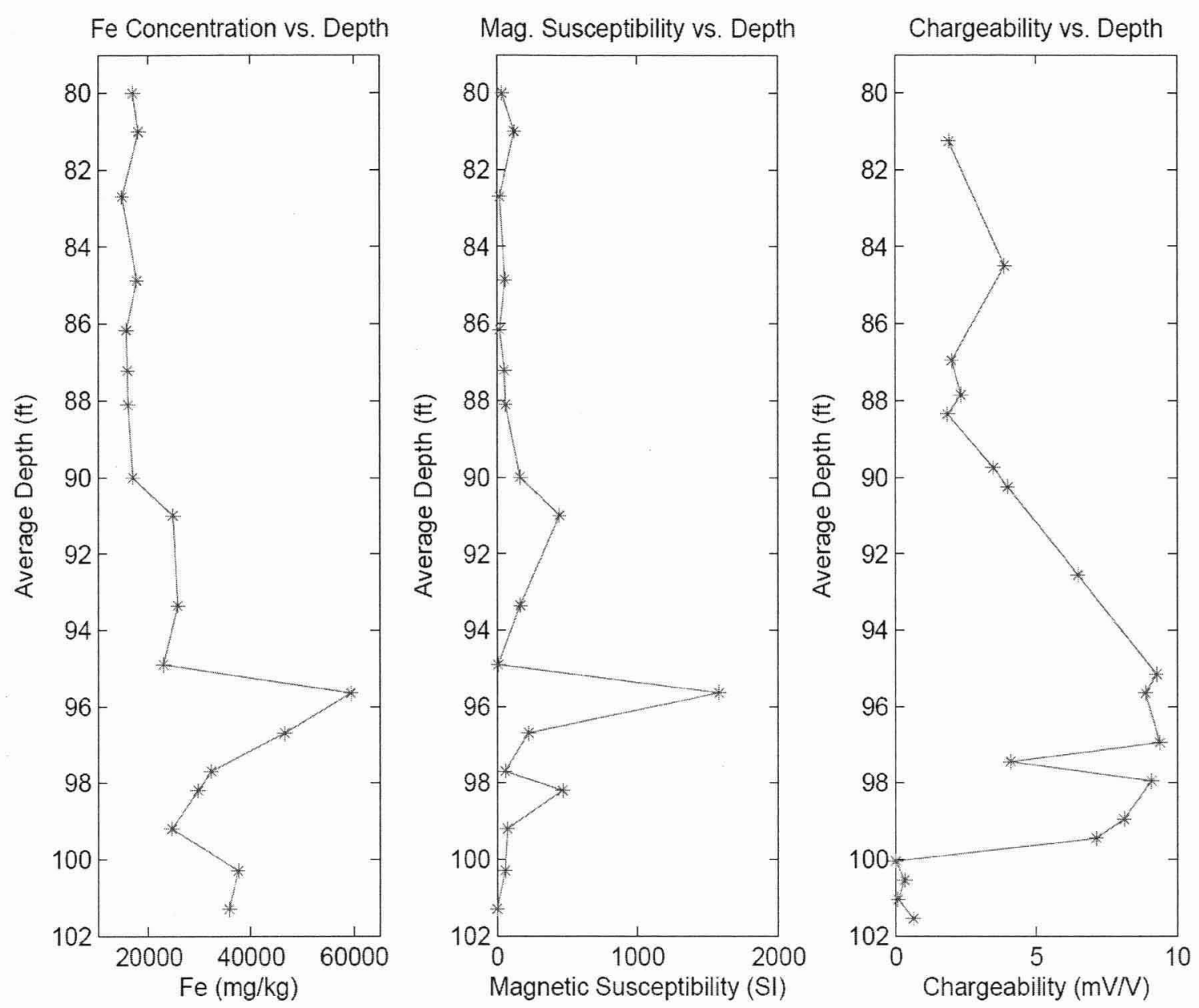

Figure E-4. Comparison of the Laboratory Data with the Geophysical Data

(The left plot shows the iron concentrations determined from laboratory analysis. The center plot shows the averaged magnetic susceptibility measurements for the same sample intervals. Not all of the samples were suitable for acquiring IP measurements. The right plot shows the averaged IP data for those sample intervals in which IP data were available.)

\section{E2.6.3 Particle Size Analysis Results}

Before performing a mechanical sieve analysis, all the samples intervals were homogenized from individual 6 -in. Lexan sleeves and dried in the oven at $45^{\circ} \mathrm{C}$. During mechanical sieving, it became apparent from visual observation that oven-drying had an adverse effect on the soil, causing agglomeration of the emplaced nZVI which resulted in much of the nZVI being retained on the larger sieve fractions. The agglomeration was especially noticeable in the samples that contained visible amounts of nZVI before sieving. This initiated a reexamination of the proper size fraction to analyze, because clumping could bias the analysis to low values if only the minus 200 -mesh soil fraction was used (as stipulated in DOE/RL-2008-49). To quantify the size fraction distribution of nZVI in the borehole soils, total iron analyses were performed on each sieve fraction of sample ZIM-13-96.2-97.2' / PF, taken from the 96.2- to 97.2-ft interval, which contained visually obvious amounts of nZVI. A background sample was used as a control. This sample was collected from the 90 to $90.5 \mathrm{ft}$ interval from borehole 199-D5-121, which is approximately $720 \mathrm{~m}$ east of 199-D4-94 and free of ZVI.

As shown in Figure E-5, the iron in sample ZIM-13-96.2-97.2' / PF deviated greatly from the background sample in the 60 -mesh and smaller sieves. Over 90 percent of the total acid-extractable iron was 
contained in the sieve fractions less than 10-mesh and about 40 percent of the sample's overall iron content was present in the minus 60-mesh fraction. Based on the above analysis, it was decided that all samples would be split on the 60 -mesh sieve, with the minus 60 -mesh being used for analytical and hydrometer analyses. Analysis on the minus 60 -mesh fraction was believed to be more likely to include the majority of emplaced nZVI and would prevent the total iron results from being excessively diluted by including too much of the bulk sample. Table E-2 shows iron concentrations as a function of sieve size fraction for the two samples tested.

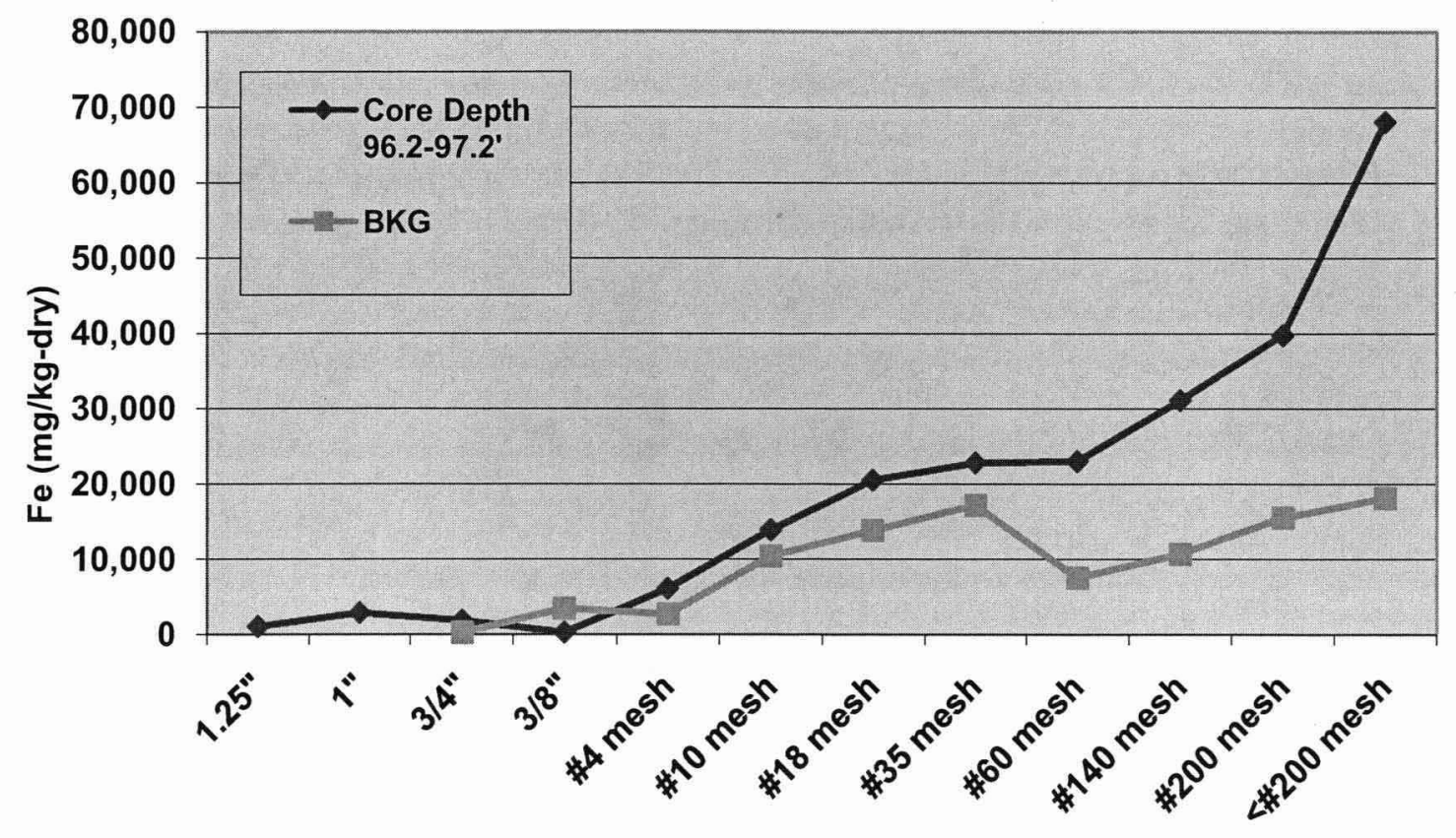

Sieve Size (retained)

Figure E-5. Iron Concentration as a Function of Sieve Fractions for Characterization Well Sample Depth 96.2 to 97.2 and Background (BKG) Sample

Table E-2. Iron Concentration as a Function of Sieve Fraction for Soil from Borehole 199-D4-94 at 96.2 to 97.2 Feet and the Background Borehole at 90 Feet

\begin{tabular}{|c|c|c|c|c|}
\hline Sample & Sieve Fraction & $\begin{array}{c}\text { Soil in Sieve Fraction } \\
(\%)\end{array}$ & $\begin{array}{l}\text { Iron in Sieve } \\
\text { Fraction (\%) }\end{array}$ & $\begin{array}{l}\text { ron Conc. in } \\
\text { Sieve } \\
\text { Fraction } \\
(\mathrm{mg} / \mathrm{kg})\end{array}$ \\
\hline \multirow{5}{*}{ 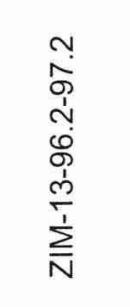 } & $1.25^{\prime \prime}$ & 2.0 & 0.1 & 1,040 \\
\hline & $1^{\prime \prime}$ & 5.2 & 1.0 & 2,870 \\
\hline & 3/4" & 5.4 & 0.6 & 1,850 \\
\hline & $3 / 8 "$ & 13.7 & 0.2 & 256 \\
\hline & \#4 mesh & 15.0 & 5.8 & 6,100 \\
\hline
\end{tabular}


Table E-2. Iron Concentration as a Function of Sieve Fraction for Soil from Borehole 199-D4-94 at 96.2 to 97.2 Feet and the Background Borehole at 90 Feet

\begin{tabular}{|c|c|c|c|c|}
\hline Sample & Sieve Fraction & $\begin{array}{c}\text { Soil in Sieve Fraction } \\
(\%)\end{array}$ & $\begin{array}{l}\text { Iron in Sieve } \\
\text { Fraction (\%) }\end{array}$ & $\begin{array}{c}\text { Iron Conc. in } \\
\text { Sieve } \\
\text { Fraction } \\
\text { (mg/kg) }\end{array}$ \\
\hline & \#10 mesh & 18.2 & 16.0 & 13,900 \\
\hline & \#18 mesh & 12.5 & 16.3 & 20,500 \\
\hline & \#35 mesh & 7.2 & 10.4 & 22,800 \\
\hline & \#60 mesh & 7.4 & 10.8 & 23,000 \\
\hline & \#140 mesh & 6.2 & 12.2 & 31,100 \\
\hline & \#200 mesh & 2.3 & 5.8 & 39,800 \\
\hline & $<\# 200$ mesh & 4.8 & 20.7 & 68,100 \\
\hline \multirow{12}{*}{ 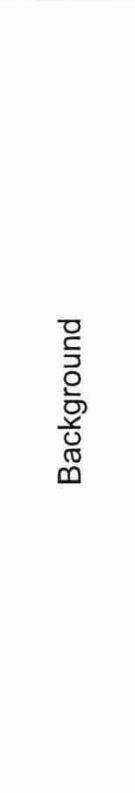 } & $1.25 "$ & 0.0 & 0.0 & - \\
\hline & $1 "$ & 0.0 & 0.0 & - \\
\hline & $3 / 4 "$ & 4.2 & 0.1 & 218 \\
\hline & $3 / 8 "$ & 16.4 & 7.2 & 3,470 \\
\hline & \#4 mesh & 19.1 & 6.5 & 2,680 \\
\hline & \#10 mesh & 17.4 & 22.9 & 10,400 \\
\hline & \#18 mesh & 8.3 & 14.5 & 13,800 \\
\hline & \#35 mesh & 3.8 & 8.2 & 17,200 \\
\hline & \#60 mesh & 13.8 & 13.2 & 7,530 \\
\hline & \#140 mesh & 12.0 & 16.3 & 10,700 \\
\hline & \#200 mesh & 1.4 & 2.7 & 15,500 \\
\hline & $<\# 200$ mesh & 3.6 & 8.2 & 18,100 \\
\hline
\end{tabular}

Following mechanical sieving, hydrometer analyses of each sample were performed in accordance with ASTM D422 on the minus 60-mesh material. Figure E- 6 shows the hydrometer laboratory setup. 


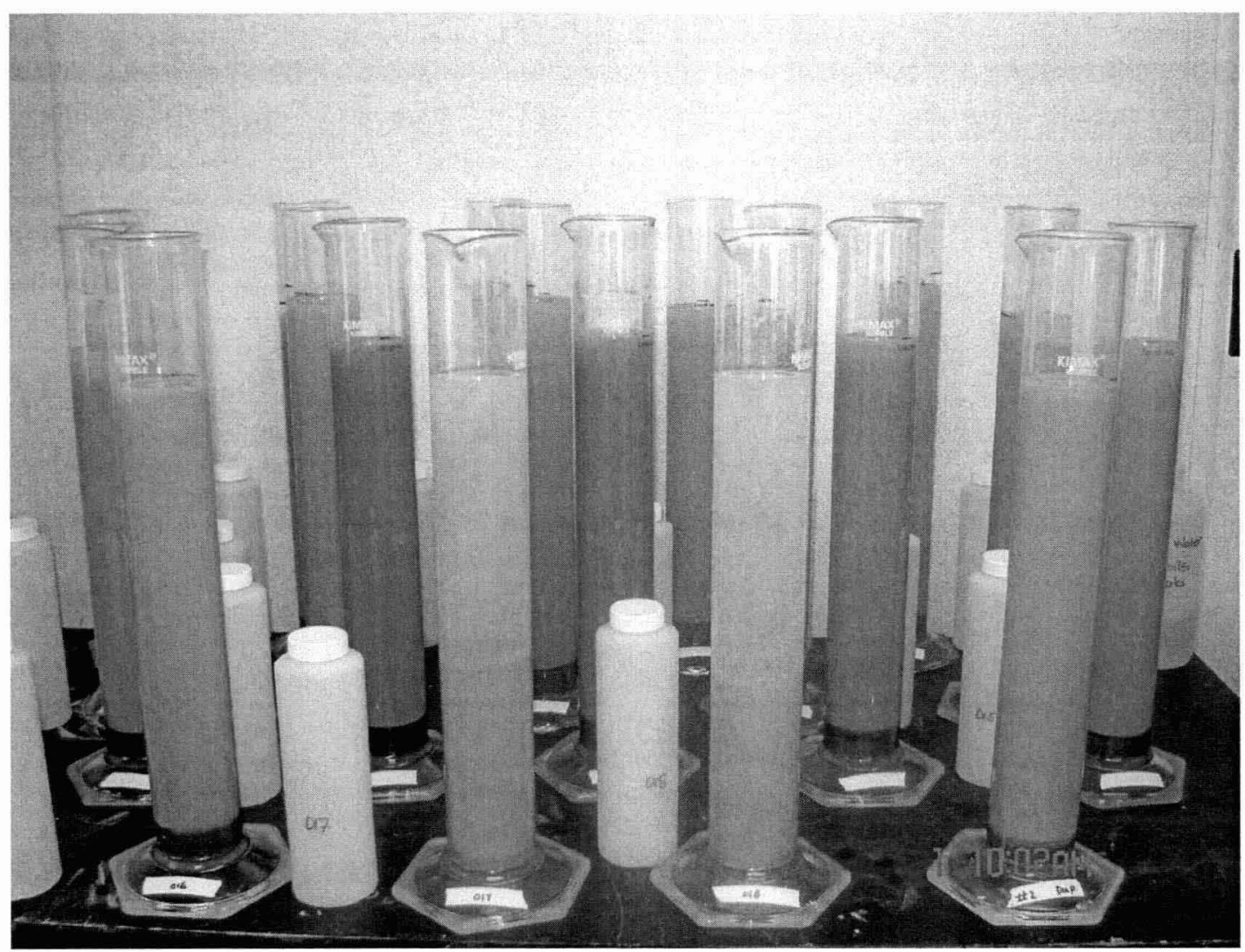

Figure E-6. Photograph of the Hydrometer Test Tubes After Testing

(The four orange-colored sample tubes in the second row are samples $12,13,14$, and 15 from left to right.)

Samples 12,13,14, and 15, shown in the second row of Figure E-6, were dark brown to black at the beginning of the hydrometer test and became orange in color as the particles began to settle, likely due to oxidation of the nZVI. Results of the particle size analyses are presented in Chapter E3.

Based on the results reported in PNNL-15499 and discussions with its author, it was determined that the modified Hazen's formula was the most suitable and straightforward formula available to approximate saturated hydraulic conductivity from the sieve analyses. As discussed in Section 3.6 of PNNL-15499, the modified Hazen's formula was empirically derived from the relationship between grain size distributions and measured saturated hydraulic conductivity measurements of various Hanford Site sediments and is written as:

$$
K_{s a t}(\mathrm{~cm} / \mathrm{s})=0.0961\left(d_{25}\right)^{1.6624}
$$

where $d_{25}$ ( 25 percent passing grain size) represents some of the grain size mixture in Hanford Site sediments. Figure E-7 shows two plots of calculated saturated hydraulic conductivities for the 18 sieve/hydrometer analyses compared to laboratory-obtained iron concentrations versus depth. 

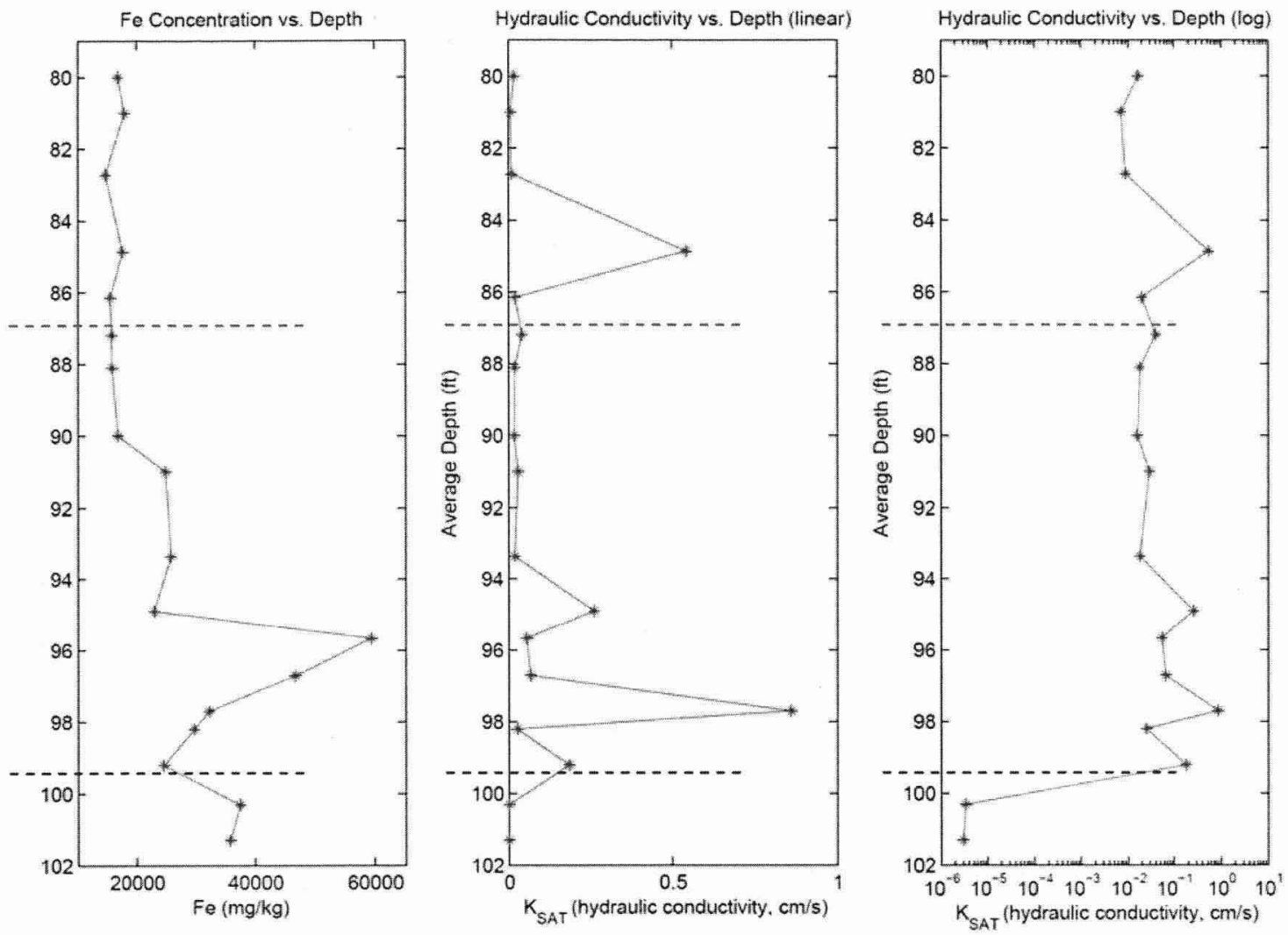

Figure E-7. Comparison of the Laboratory Iron Results and the Calculated Saturated Hydraulic Conductivity (using Modified Hazen's Method) Versus Depth

(The left plot shows the iron concentrations determined from laboratory analysis. The center plot shows the saturated hydraulic conductivity on a linear $\mathrm{x}$-scale. The right plot shows the saturated hydraulic conductivity on a $\log x$-scale. The dashed blue line at the top of the profile represents the approximate groundwater level at the time of drilling. The dashed brown line at the bottom of the profile represents the approximate top of the Ringold Upper Mud Formation.)

The saturated hydraulic conductivity plots shown above indicate a relatively permeable profile from $80 \mathrm{ft}$ to approximately $94 \mathrm{ft}$. A subtle, but visible transition occurs below approximately $94 \mathrm{ft}$, where the saturated hydraulic conductivity increases by 1 to 2 orders of magnitude. A larger and more obvious transition occurs at approximately $99.8 \mathrm{ft}$ where the hydraulic conductivity decreases by approximately 4 to 6 orders of magnitude at the interface between the sandy gravelly alluvium (Ringold Unit E) and the underlying silty layer (Ringold Upper Mud). The region of relatively higher hydraulic conductivity between approximately 94 and $99.8 \mathrm{ft}$ correlates well with increased iron concentration in that region shown in Figure E-7.

The notable increase in hydraulic conductivity observed around $85 \mathrm{ft}$ can be attributed to a piece of coarse gravel that was retained on the 1.25 in. sieve and which accounted for around 32 percent of the total weight of the sample. Saturated hydraulic conductivity calculations are presented in Table E-3. A visual determination of the upper limit of iron emplacement can be made by comparing sample ZIM-11-94.4-95.4' (Figure E-8), which does not appear to have visible iron, and ZIM-12-95.4-95.9' (Figure E-9), which contains a significant amount of emplaced iron. 
DOE/RL-2009-35, REV. 0

Table E-3. Calculated Saturated Hydraulic Conductivity

\begin{tabular}{|c|c|c|c|c|c|}
\hline Sample \# & $\begin{array}{l}\text { Average } \\
\text { Depth (ft) }\end{array}$ & $\mathrm{mm}$ range & $\%$ range & Estimated D25 & Ksat $(\mathrm{cm} / \mathrm{s})$ \\
\hline \multirow[t]{2}{*}{1} & 80 & 0.5 & 34.85 & 0.3479331 & $1.66 \mathrm{E}-02$ \\
\hline & & 0.25 & 18.66 & & \\
\hline \multirow[t]{2}{*}{2} & 81 & 0.25 & 33.63 & 0.2090102 & $7.12 \mathrm{E}-03$ \\
\hline & & 0.149 & 12.37 & & \\
\hline \multirow[t]{2}{*}{3} & 82.7 & 0.25 & 26.80 & 0.2390418 & $8.90 \mathrm{E}-03$ \\
\hline & & 0.149 & 10.19 & & \\
\hline \multirow[t]{2}{*}{4} & 84.85 & 4.76 & 29.24 & 2.8334166 & $5.43 \mathrm{E}-01$ \\
\hline & & 2 & 23.17 & & \\
\hline \multirow[t]{2}{*}{5} & 86.15 & 0.5 & 32.89 & 0.3887836 & $2.00 \mathrm{E}-02$ \\
\hline & & 0.25 & 15.15 & & \\
\hline \multirow[t]{2}{*}{6} & 87.2 & 1 & 28.56 & 0.5930615 & $4.03 E-02$ \\
\hline & & 0.5 & 24.19 & & \\
\hline \multirow[t]{2}{*}{7} & 88.1 & 0.5 & 36.32 & 0.3669822 & $1.82 \mathrm{E}-02$ \\
\hline & & 0.25 & 15.04 & & \\
\hline \multirow[t]{2}{*}{8} & 90 & 0.5 & 40.62 & 0.3416287 & $1.61 \mathrm{E}-02$ \\
\hline & & 0.25 & 15.96 & & \\
\hline \multirow[t]{2}{*}{9} & 91 & 0.5 & 25.84 & 0.4863813 & $2.90 \mathrm{E}-02$ \\
\hline & & 0.25 & 10.44 & & \\
\hline \multirow[t]{2}{*}{10} & 93.35 & 0.5 & 34.47 & 0.367593 & $1.82 \mathrm{E}-02$ \\
\hline & & 0.25 & 16.59 & & \\
\hline \multirow[t]{2}{*}{11} & 94.9 & 2 & 26.14 & 1.8219331 & 2.61E-01 \\
\hline & & 1 & 19.72 & & \\
\hline \multirow[t]{2}{*}{12} & 95.65 & 1 & 28.79 & 0.71555 & $5.51 \mathrm{E}-02$ \\
\hline & & 0.5 & 22.13 & & \\
\hline \multirow[t]{2}{*}{13} & 96.7 & 1 & 27.86 & 0.8022987 & $6.66 \mathrm{E}-02$ \\
\hline & & 0.5 & 20.63 & & \\
\hline \multirow[t]{2}{*}{14} & 97.7 & 4.76 & 26.78 & 3.7432077 & $8.62 E-01$ \\
\hline & & 2 & 21.96 & & \\
\hline \multirow[t]{2}{*}{15} & 98.2 & 0.5 & 28.65 & 0.4474696 & $2.52 \mathrm{E}-02$ \\
\hline & & 0.25 & 11.29 & & \\
\hline
\end{tabular}


Table E-3. Calculated Saturated Hydraulic Conductivity

\begin{tabular}{|c|c|c|c|c|c|}
\hline Sample \# & $\begin{array}{l}\text { Average } \\
\text { Depth (ft) }\end{array}$ & $\mathrm{mm}$ range & $\%$ range & Estimated D25 & Ksat $(\mathrm{cm} / \mathrm{s})$ \\
\hline \multirow[t]{2}{*}{16} & 99.2 & 2 & 28.21 & 1.4749244 & $1.83 \mathrm{E}-01$ \\
\hline & & 1 & 22.10 & & \\
\hline \multirow[t]{2}{*}{17} & 100.3 & 0.0028 & 49.40 & 0.0020775 & 3.34E-06 \\
\hline & & 0.0014 & 2.47 & & \\
\hline \multirow[t]{2}{*}{18} & 101.3 & 0.0028 & 57.94 & 0.0019609 & 3.03E-06 \\
\hline & & 0.0014 & 2.07 & & \\
\hline \multicolumn{6}{|c|}{ Background Samples } \\
\hline \multirow[t]{2}{*}{19} & 90 & 0.5 & 30.75 & 0.3958823 & $2.06 \mathrm{E}-02$ \\
\hline & & 0.25 & 16.94 & & \\
\hline \multirow[t]{2}{*}{20} & 100 & 0.5 & 26.36 & 0.4766108 & $2.80 \mathrm{E}-02$ \\
\hline & & 0.25 & 11.86 & & \\
\hline
\end{tabular}

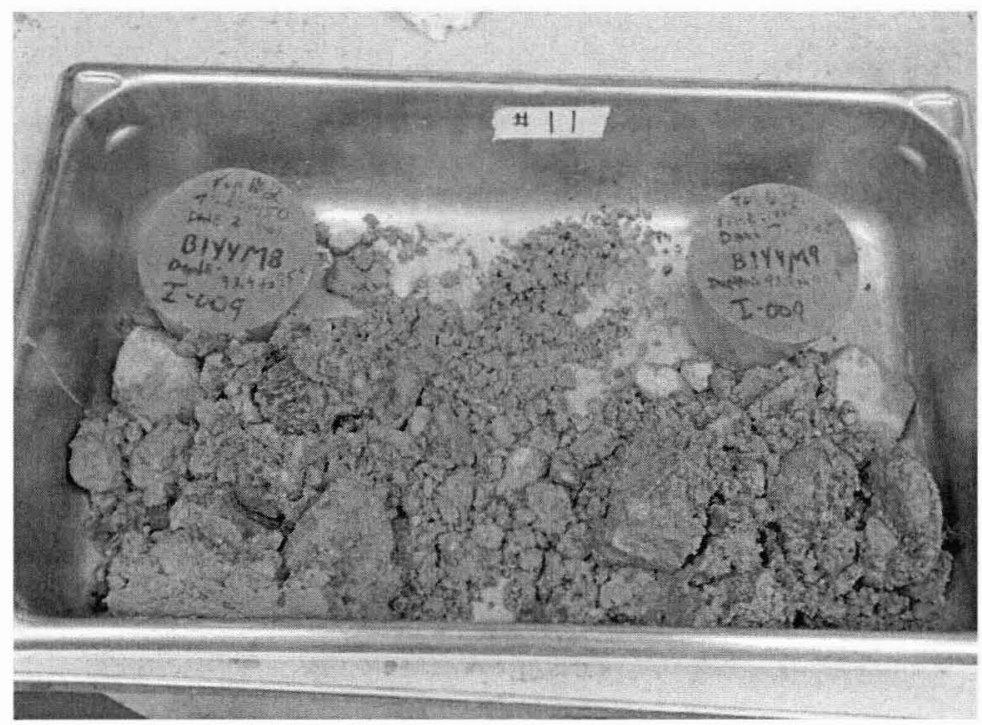

Figure E-8. Photograph of Sample 11, Indicating no Visible Iron 


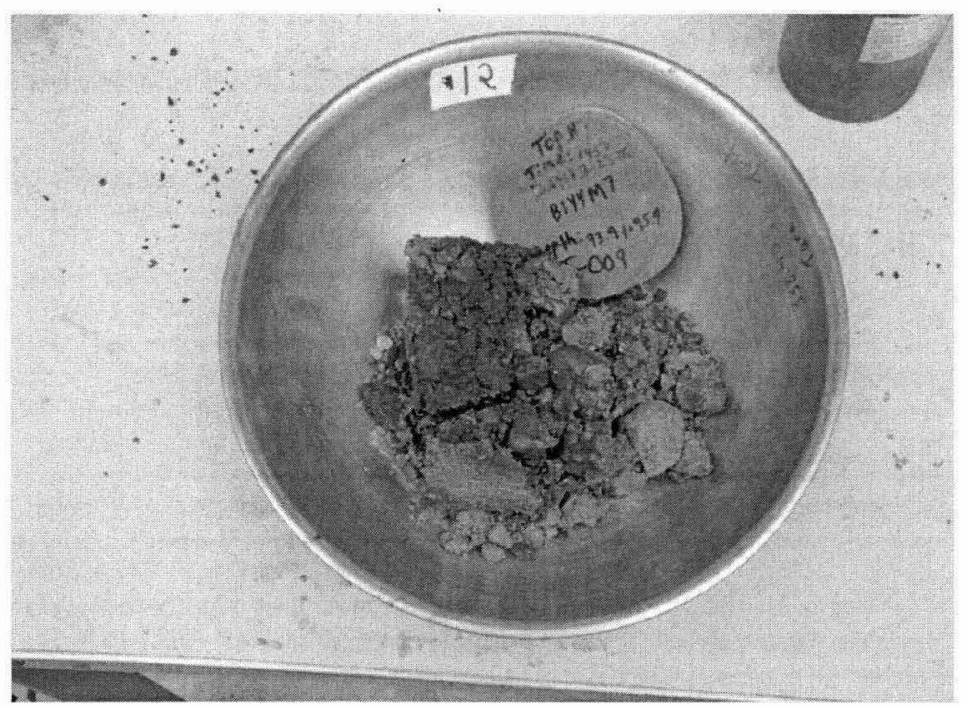

Figure E-9. Photograph of Sample 12, Indicating an Obvious Presence of Iron,

Evidenced by the Black Color

\section{E2.6.4 Acid-Extractable Analysis Results}

\section{E2.6.4.1 Iron}

The iron concentration as a function of soil depth is shown graphically in Figure E-10. The background iron concentrations shown in light blue are from two samples collected from approximately the same stratigraphic horizon in borehole 199-D5-121. The iron content increases with depth with a very large increase beginning at $95.4 \mathrm{ft}$. The soils from 95.4 to $97.2 \mathrm{ft}$ were very dark in color, indicating the presence of nZVI. This is confirmed by the data, presented in Table E-4.

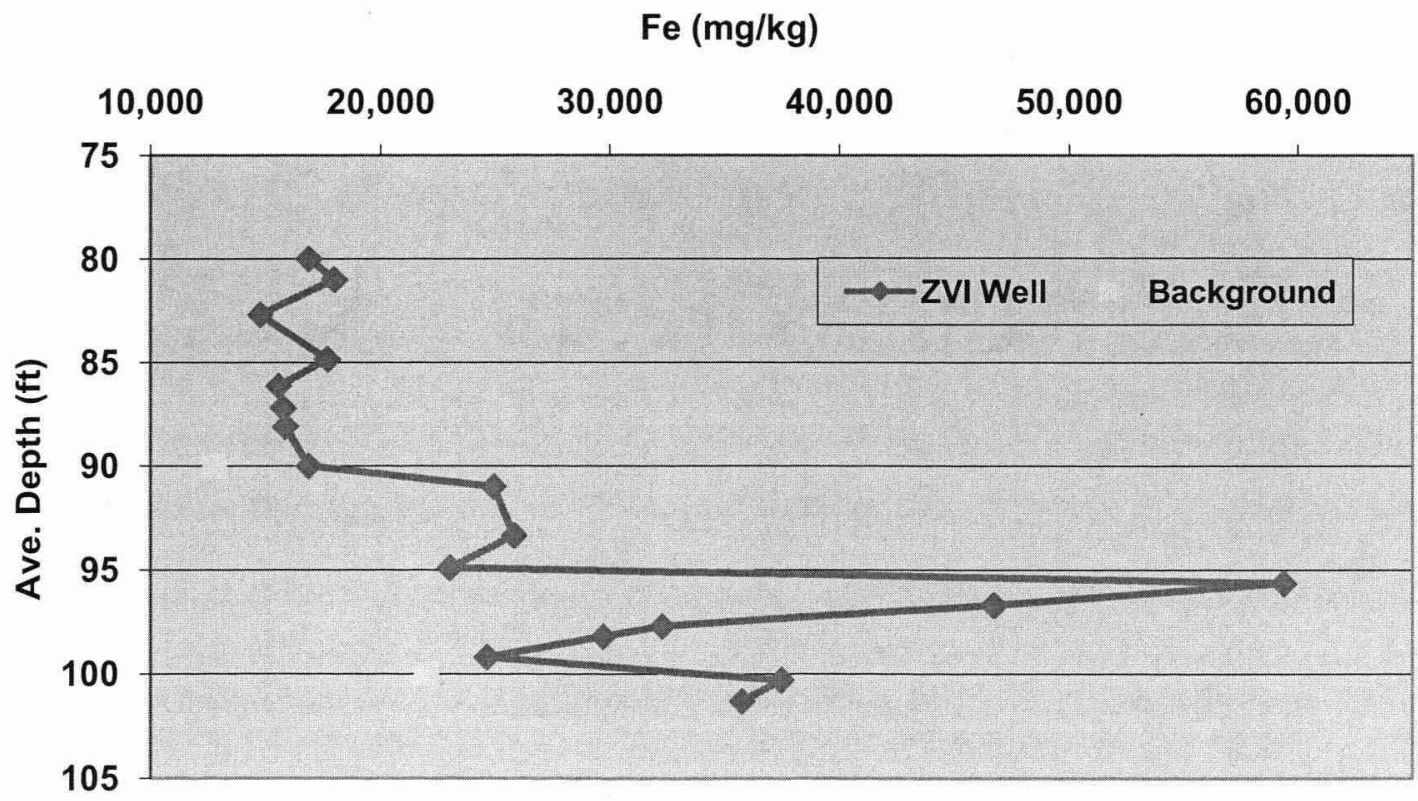

Figure E-10. Iron Concentration Profile 
Table E-4. Iron Concentration Profile

\begin{tabular}{|c|c|c|c|c|}
\hline $\begin{array}{l}\text { Depth, top of interval } \\
\text { (ft) }\end{array}$ & $\begin{array}{l}\text { Depth, bottom of } \\
\text { interval (ft) }\end{array}$ & $\begin{array}{l}\text { Mean Interval Depth } \\
\text { (ft) }\end{array}$ & $\begin{array}{l}\text { Interval Length } \\
\text { (ft) }\end{array}$ & $\begin{array}{l}\text { Iron } \\
\text { (mg/kg) }\end{array}$ \\
\hline 79.5 & 80.5 & 80.0 & 1.0 & 16,900 \\
\hline 80.5 & 81.5 & 81.0 & 1.0 & 18,000 \\
\hline 81.7 & 83.7 & 82.7 & 2.0 & 14,800 \\
\hline 84.1 & 85.6 & 84.9 & 1.5 & 17,700 \\
\hline 85.6 & 86.7 & 86.2 & 1.1 & 15,600 \\
\hline 86.7 & 87.7 & 87.2 & 1.0 & 15,800 \\
\hline 87.6 & 88.6 & 88.1 & 1.0 & 15,900 \\
\hline 89.5 & 90.5 & 90.0 & 1.0 & 16,900 \\
\hline 90.5 & 91.5 & 91.0 & 1.0 & 24,900 \\
\hline 92.3 & 94.4 & 93.4 & 2.1 & 25,800 \\
\hline 94.4 & 95.4 & 94.9 & 1.0 & 23,000 \\
\hline 95.4 & 95.9 & 95.7 & 0.5 & 59,400 \\
\hline 96.2 & 97.2 & 96.7 & 1.0 & 46,700 \\
\hline 97.2 & 98.2 & 97.7 & 1.0 & 32,300 \\
\hline 97.7 & 98.7 & 98.2 & 1.0 & 29,700 \\
\hline 98.7 & 99.7 & 99.2 & 1.0 & 24,600 \\
\hline 99.8 & 100.8 & 100.3 & 1.0 & 37,500 \\
\hline 100.8 & 101.8 & 101.3 & 1.0 & 35,800 \\
\hline BKG 90 & 90 & 90.0 & $\mathrm{~N} / \mathrm{A}$ & 12,800 \\
\hline BKG 100 & 100 & 100.0 & N/A & 22,000 \\
\hline
\end{tabular}

\section{E2.6.4.2 Total Chromium}

The acid extractable total chromium concentration profile (Figure E-11) shows most of the chromium concentrations ranging between 25 and $75 \mathrm{mg} / \mathrm{kg}$, with the background samples being similar or slightly less. There are elevated levels of chromium in the samples around 95 and $98 \mathrm{ft}$. This increased chromium could be due to reduction/immobilization of hexavalent chromium as an effect of both the in situ redox manipulation barrier and the nZVI. 


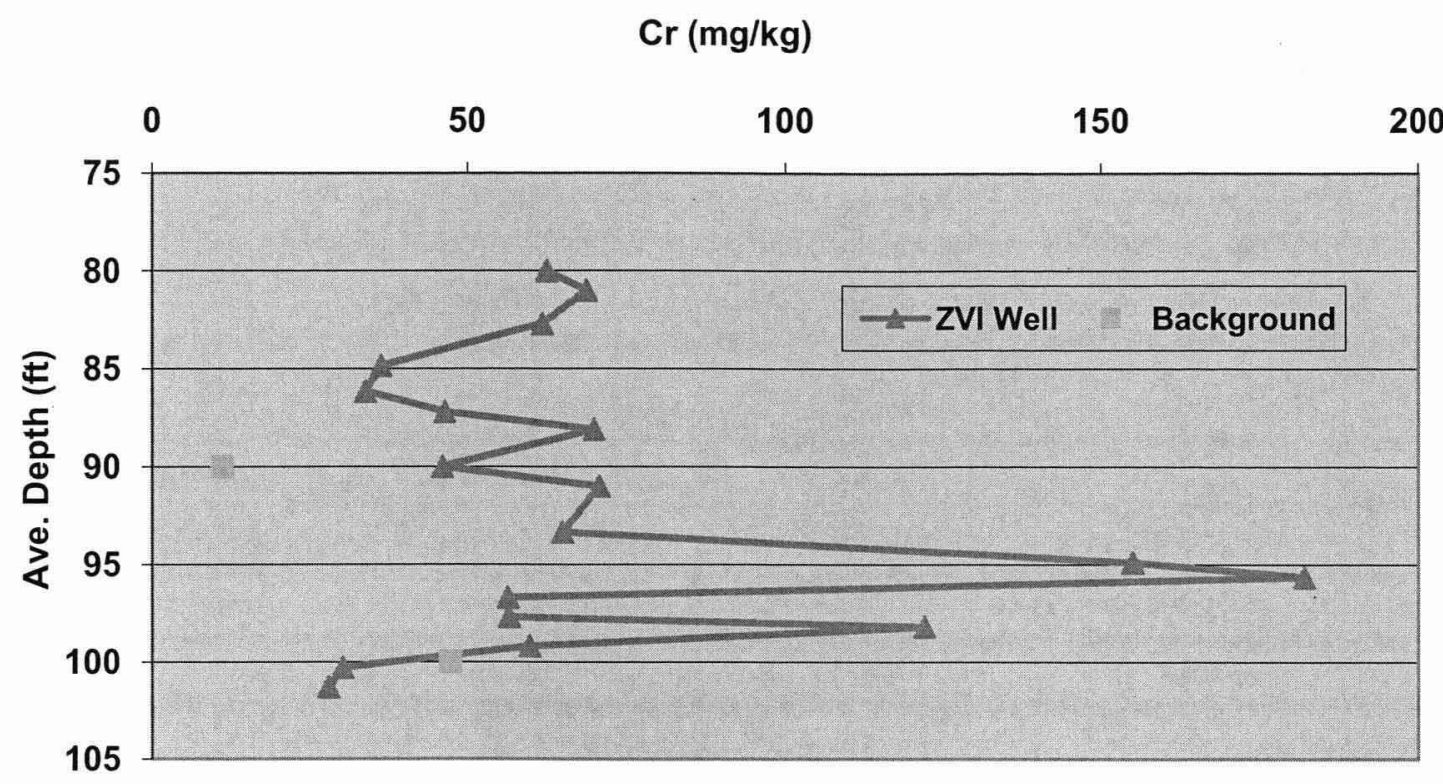

Figure E-11. Chromium Concentration Profile

\section{E2.6.4.3 Calcium}

Calcium as determined by the acid extraction is shown in Figure E-12. At $90 \mathrm{ft}$ and shallower, the calcium concentration was relatively constant near $5,000 \mathrm{mg} / \mathrm{kg}$. The concentration increased sharply below $90 \mathrm{ft}$, probably owing to a change in lithology, although no indication of such was noted on the borehole log (SGW-40999). All but one of these values are below the $90^{\text {th }}$ percentile for the sitewide background data (DOE/RL-92-24, Hanford Site Background: Part 1, Soil Background for Nonradioactive Analytes), and within the range of background value $(4,000$ to $87,000 \mathrm{mg} / \mathrm{kg})$.

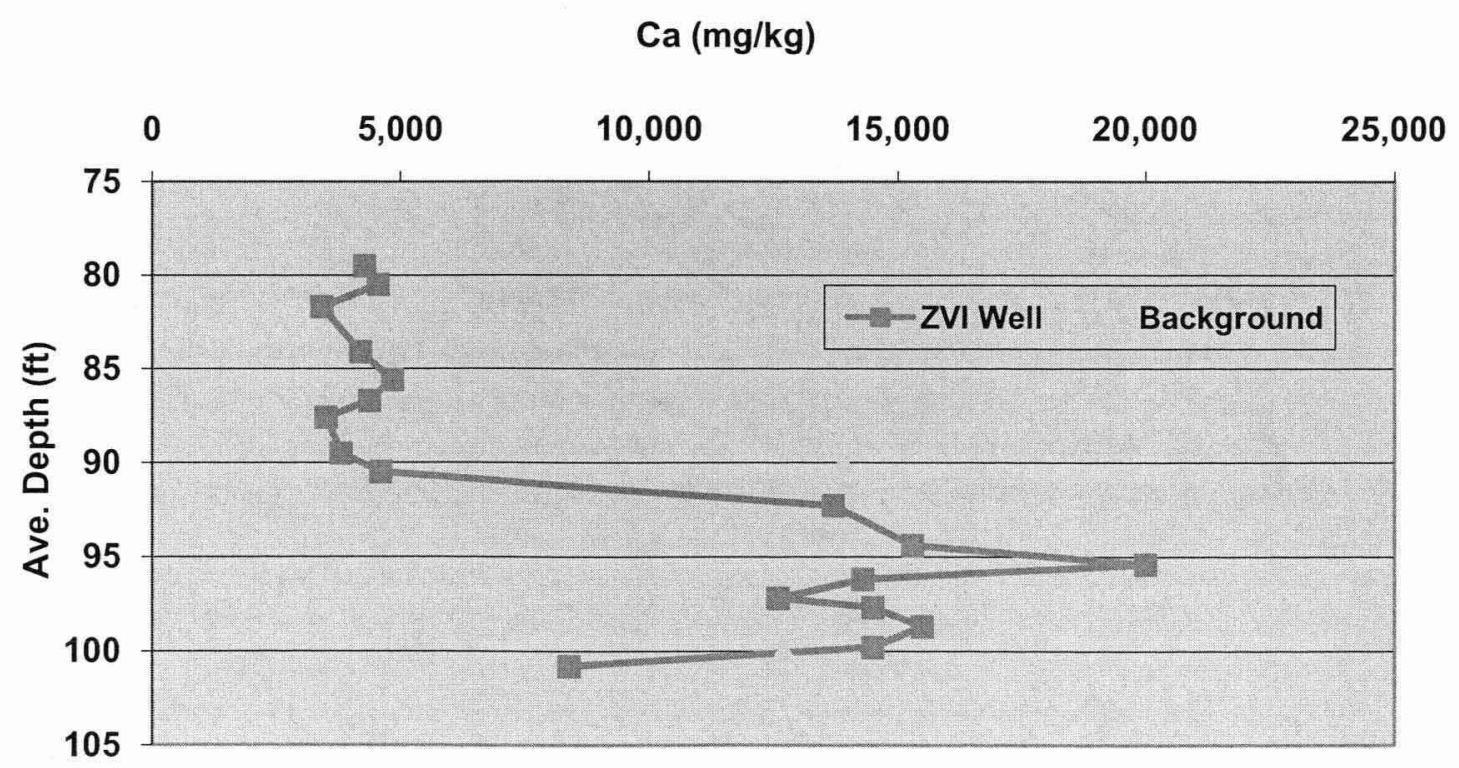

Figure E-12. Calcium Concentration Profile 


\section{E2.6.4.4 Sulfur}

Sulfur concentrations are shown in Figure E-13. There is a consistent increase in sulfur with increasing depth. Concentrations in the verification well samples are all below that of the background soils. The sulfur trend is not at all affected by increased nZVI at around $95 \mathrm{ft}$ as the elements iron, calcium, and chromium.

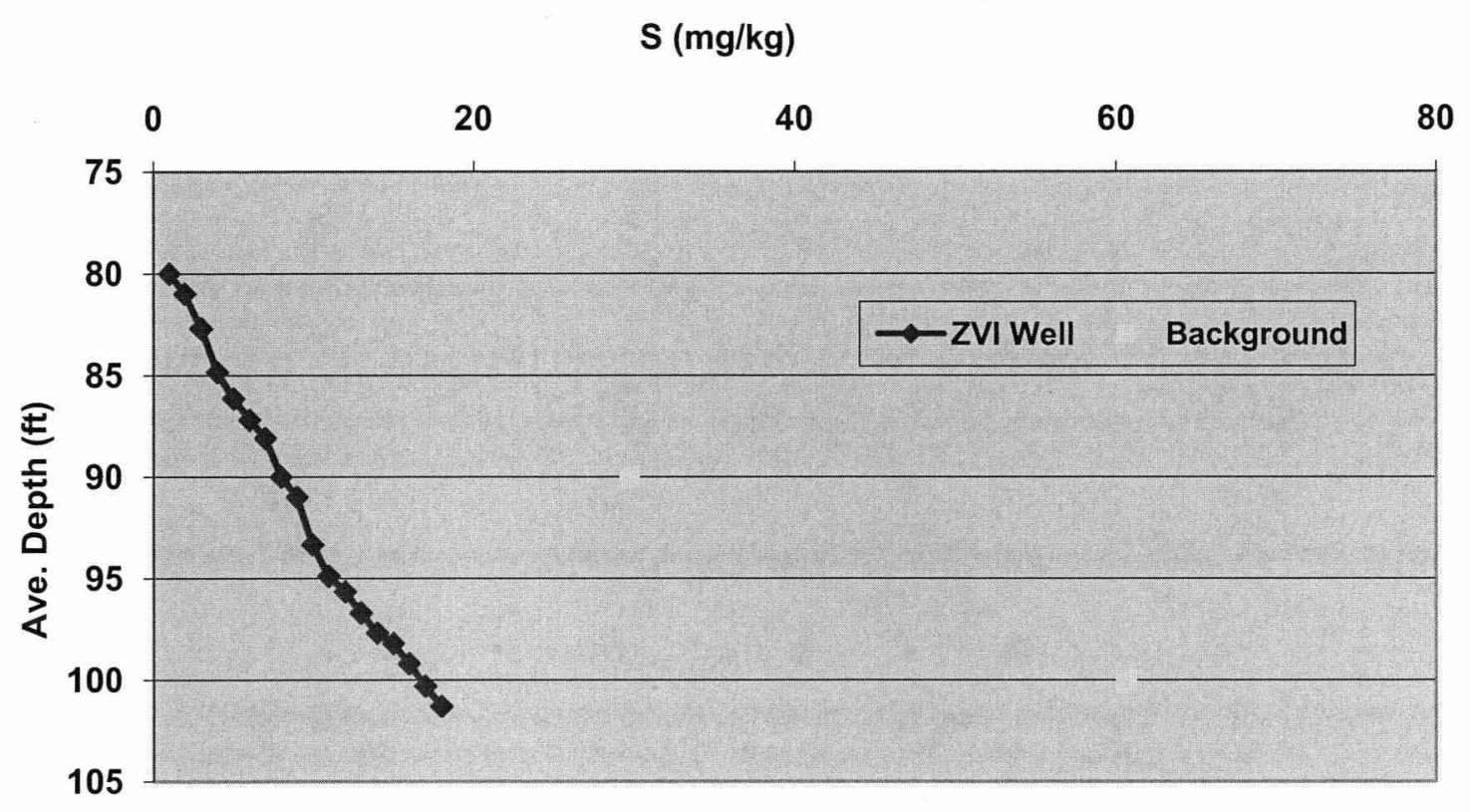

Figure E-13. Sulfur Concentration Profile

\section{E2.6.4.5 Fusion Results}

Table E-5 presents a comparison of the major metal concentrations between preparations by fusion and Method 3050B. This shows that fusion provides a more realistic total analysis, and values are approximately 50 percent greater than the corresponding Method 3050B results. In the sample with the highest nZVI (96.2 to $97.2 \mathrm{ft}$, shown as red in Figure E-14), proportionally more iron was extracted by the Method 3050B acid preparation than those with little or no nZVI. 


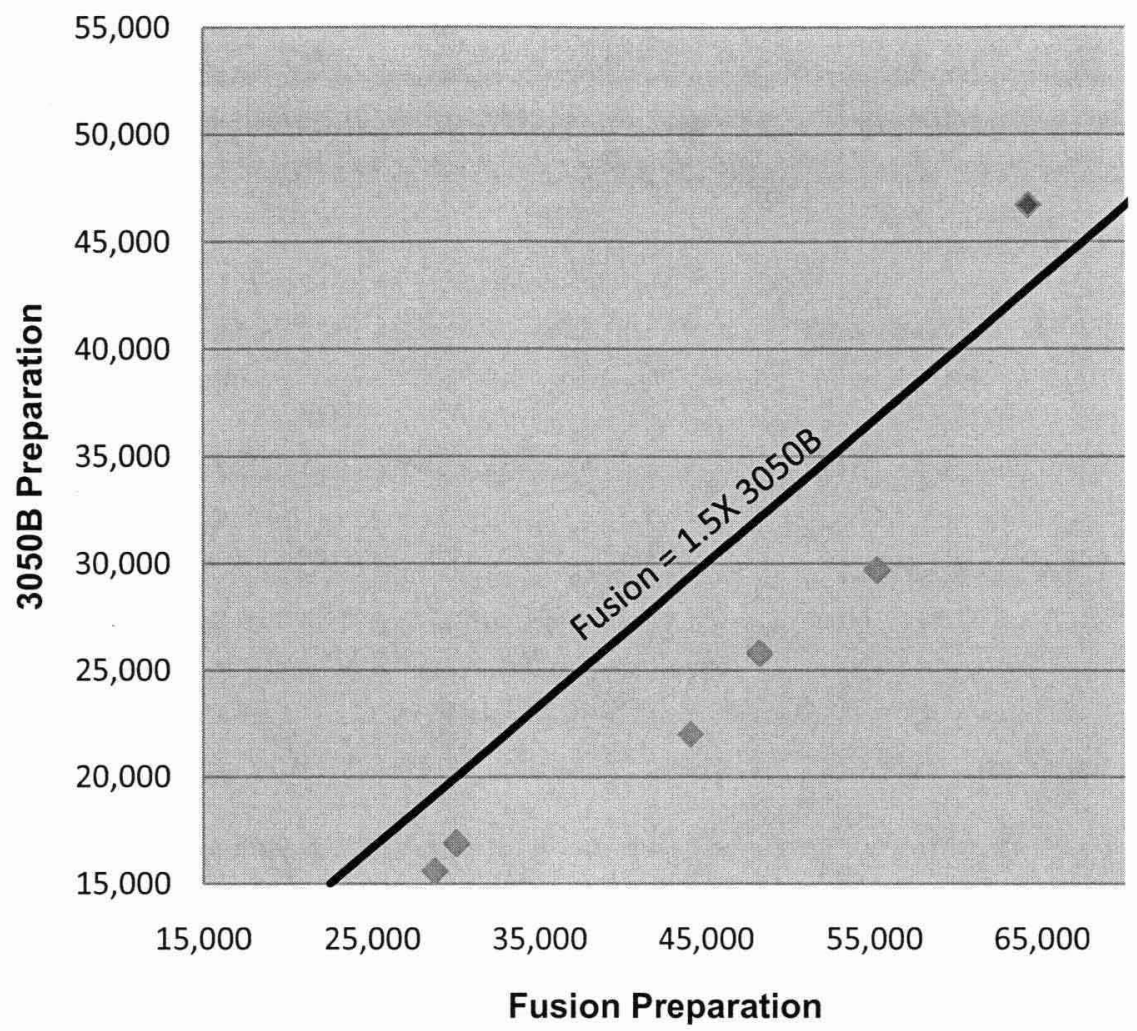

Figure E-14. Plot of Total Iron Determined from Fusion and Method 2050B Preparation Techniques (Straight line represents fusion values 1.5 times higher than Method 3050B values.)

Table E-5. Comparison of Metals Analysis by Lithium Tetraborate Fusion and Acid-Extracts (all values in $\mathrm{mg} / \mathrm{kg}$ )

\begin{tabular}{|c|c|c|c|c|c|c|c|c|c|c|c|c|}
\hline \multirow{2}{*}{$\frac{\text { Soil Interval (ft) }}{\text { Method }}$} & \multicolumn{2}{|c|}{79.5 to 80.5} & \multicolumn{2}{|c|}{85.6 to 86.7} & \multicolumn{2}{|c|}{92.3 to 94.4} & \multicolumn{2}{|c|}{96.2 to 97.2} & \multicolumn{2}{|c|}{97.7 to 98.7} & \multicolumn{2}{|c|}{100 (BKG) } \\
\hline & Fusion & $3050 \mathrm{~B}$ & Fusion & $3050 \mathrm{~B}$ & Fusion & $3050 \mathrm{~B}$ & Fusion & $3050 \mathrm{~B}$ & Fusion & $3050 \mathrm{~B}$ & Fusion & $3050 \mathrm{~B}$ \\
\hline Aluminum & 55,900 & 7,620 & 52,000 & 6,330 & 51,800 & 6,910 & 53,500 & 8,470 & 55,500 & 7,390 & 52,600 & 6,610 \\
\hline Calcium & 22,700 & 4,270 & 21,600 & 4,840 & 34,700 & 13,700 & 33,500 & 14,300 & 38,500 & 14,500 & 35,200 & 12,700 \\
\hline Chromium & 92 & 62.5 & 87.2 & 33.7 & 196 & 65 & 87.9 & 56.4 & 161 & 122 & 221 & 47.3 \\
\hline Iron & 30,000 & 16,900 & 28,700 & 15,600 & 48,200 & 25,800 & 64,200 & 46,700 & 55,200 & 29,700 & 44,100 & 22,000 \\
\hline Magnesium & 9,390 & 3,930 & 8,460 & 3,630 & 12,400 & 3,600 & 11,100 & 4,230 & 13,400 & 4,260 & 12,400 & 3,740 \\
\hline Manganese & 676 & 289 & 672 & 267 & 946 & 420 & 936 & 551 & 1090 & 436 & 904 & 353 \\
\hline Potassium & 15,300 & 1,240 & 15,800 & 1,210 & 13,200 & 750 & 14,300 & 1,630 & 13,500 & 1,470 & 13,400 & 730 \\
\hline Silicon & 314,000 & 254 & 321,000 & 182 & 297,000 & 183 & 279,000 & 378 & 276,000 & 328 & 298,000 & 251 \\
\hline Sodium & 20,700 & 589 & 19,200 & 241 & 17,900 & 379 & 19,000 & 586 & 20,100 & 467 & 19,800 & 472 \\
\hline Strontium & 355 & 29.7 & 335 & 26 & 301 & 33.1 & 327 & 42 & 344 & 42.5 & 332 & 37.7 \\
\hline Sulfur & 255 & 57.4 & 651 & 58.3 & 295 & 75.2 & 316 & 184 & 364 & 99.1 & 484 & 60.6 \\
\hline
\end{tabular}




\section{E2.6.4.6 Hexavalent Chromium Results}

The results of the hexavalent chromium analyses are presented in Table E-6. As can be seen from observation of the data, there are no hexavalent chromium anomalies.

Table E-6. Hexavalent Chromium by SW-846 Method 3060A, Alkaline Digestion

\begin{tabular}{|c|c|c|c|}
\hline $\begin{array}{l}\text { Depth, top of interval } \\
\text { (ft) }\end{array}$ & $\begin{array}{l}\text { Depth, bottom of interval } \\
\text { (ft) }\end{array}$ & $\begin{array}{l}\text { Mean Interval Depth } \\
\text { (ft) }\end{array}$ & $\begin{array}{l}\text { Hexavalent Chromium } \\
\text { (mg/kg) }\end{array}$ \\
\hline 79.5 & 80.5 & 80.0 & $<0.2$ \\
\hline 80.5 & 81.5 & 81.0 & $<0.2$ \\
\hline 81.7 & 83.7 & 82.7 & 1.0 \\
\hline 84.1 & 85.6 & 84.9 & 0.4 \\
\hline 85.6 & 86.7 & 86.2 & $<0.2$ \\
\hline 86.7 & 87.7 & 87.2 & $<0.2$ \\
\hline 87.6 & 88.6 & 88.1 & $<0.2$ \\
\hline 89.5 & 90.5 & 90.0 & $<0.2$ \\
\hline 90.5 & 91.5 & 91.0 & $<0.2$ \\
\hline 92.3 & 94.4 & 93.4 & $<0.2$ \\
\hline 94.4 & 95.4 & 94.9 & 0.4 \\
\hline 95.4 & 95.9 & 95.7 & 0.4 \\
\hline 96.2 & 97.2 & 96.7 & 1.1 \\
\hline 97.2 & 98.2 & 97.7 & 0.6 \\
\hline 97.7 & 98.7 & 98.2 & 0.3 \\
\hline 98.7 & 99.7 & 99.2 & 0.5 \\
\hline 99.8 & 100.8 & 100.3 & 1.2 \\
\hline 100.8 & 101.8 & 101.3 & 0.9 \\
\hline BKG 90 & 90 & 90.0 & 0.4 \\
\hline BKG 100 & 100 & 100.0 & $<0.2$ \\
\hline
\end{tabular}

\section{E2.6.4.7 Pore Water Results}

Table E-7 shows the results of the pore water analysis. Dissolved chromium was not detected in any of the pore water samples. Water extracted from the nZVI-enriched layer did not have any detectable iron present, indicating that if iron was being dissolved it was either being oxidized quickly and filtered out or if any was dissolved, it was less than the detection limit. 
Table E-7. Chromium and Other Metals in Pore Water

\begin{tabular}{ccccccc}
\hline $\begin{array}{c}\text { Depth, Top of } \\
\text { Interval (ft) }\end{array}$ & $\begin{array}{c}\text { Depth, Bottom } \\
\text { of Interval (ft) }\end{array}$ & $\begin{array}{c}\text { Mean Interval } \\
\text { Depth }(\mathrm{ft})\end{array}$ & $\begin{array}{c}\text { Diss. Cr } \\
(\boldsymbol{\mu g} / \mathbf{L})\end{array}$ & $\begin{array}{c}\text { Diss. Iron } \\
(\boldsymbol{\mu g} / \mathbf{L})\end{array}$ & $\begin{array}{c}\text { Diss. Ca } \\
(\mathbf{m g} / \mathbf{L})\end{array}$ & $\begin{array}{c}\text { Diss. S } \\
(\mathbf{m g} / \mathbf{L})\end{array}$ \\
\hline 86.7 & 87.7 & 87.2 & $<42.8$ & - & - & - \\
\hline 89.5 & 90.5 & 90.0 & $<42.8$ & - & - & - \\
\hline 92.3 & 94.4 & 93.4 & $<42.8$ & - & - & - \\
\hline 96.2 & 97.2 & 96.7 & $<42.8$ & $<18.6$ & 39.0 & 26.4 \\
\hline 97.2 & 98.2 & 97.7 & $<42.8$ & - & - & - \\
\hline
\end{tabular}

There were concerns that there may be gypsum formation in the aquifer, which could cause a reduction the formation permeability. From the pore water chemical analysis for the sample taken at the 96.2- to 97.2-ft interval, the ion activity product of calcium and sulfate in the pore water were well below the solubility product for gypsum $\left(\mathrm{K}_{\mathrm{sp}}\right)$ (Table E-8). This means that the pore water was undersaturated with respect to gypsum; therefore, its formation is unlikely to occur.

Table E-8. Comparison of the Calcium and Sulfate lon Activity Product to the Gypsum Solubility Product

\begin{tabular}{cccc}
\hline Calcium (M) & Sulfur as Sulfate (M) & Ion Activity Product & Gypsum Ksp \\
\hline $9.73 \mathrm{E}-04$ & $8.24 \mathrm{E}-04$ & $8.02 \mathrm{E}-07$ & $2.51 \mathrm{E}-05$ \\
\hline
\end{tabular}

\section{E2.6.4.8 XRD Results}

All soil samples contained quartz, iron, and albite (a sodium feldspar) as the primary minerals. The quartz peak produced the highest intensity in all the samples. The scan data were checked specifically for the iron-containing minerals hematite, magnetite, and goethite; if present in the sample, these minerals were not in great enough abundance to produce a diffraction peak. The XRD scans are reproduced in Chapter E4.

\section{E2.7 Conclusions}

The general conclusion from this work is that nZVI was communicated at least $7 \mathrm{~m}$ from the injection well, meeting the project goal. Specific conclusions are:

Geophysics

- Resistivity was not useful in discerning the amount of iron within the samples. If all of the samples were saturated to the same degree, it might be possible to discriminate different levels of iron using only the electrical resistivity.

- The magnetic susceptibility appears to correlate reasonably well with the iron concentrations measured in the laboratory analyses, with the exception of the deepest 3 or 4 data points.

- The IP data exhibit a weak correlation with the laboratory analyses. The highest chargeability measurements are centered on the peak of highest iron concentration, but there is no distinct peak in the chargeability measurements themselves. 
The following conclusions can be made from chemical analysis of the borehole soils:

- $\mathrm{nZVI}$ was successfully deposited at least $7 \mathrm{~m}$ from the point of injection, as evidenced by the above-background iron concentrations in the characterization well soils from the 95.5- to 97.7-ft interval.

- Hexavalent chromium is being reduced/immobilized in the aquifer, as shown by the increase in total chromium at the intervals that contain the most nZVI.

- Gypsum formation is unlikely since the ion activity product for calcium and sulfate in the pore water was well below the gypsum solubility limit 


\section{E3 Results of Sieve Analyses for Verification Well Samples}

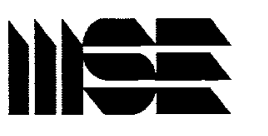

\section{PARTICLE SIZE ANALYSIS}

MSE TECHNOLOGY APPLICATIONS, INC. CLIENT: CH2MHILL

DATE: $4 / 8 / 2009$

LAB ID \#: 001A

ANALYST(S): Betty O./Nick J.

METHOD: ASTM D422

WORK ORDER \#: 0904044

Reviewed By: 2,20

Date: $5 / 6 / 2009$

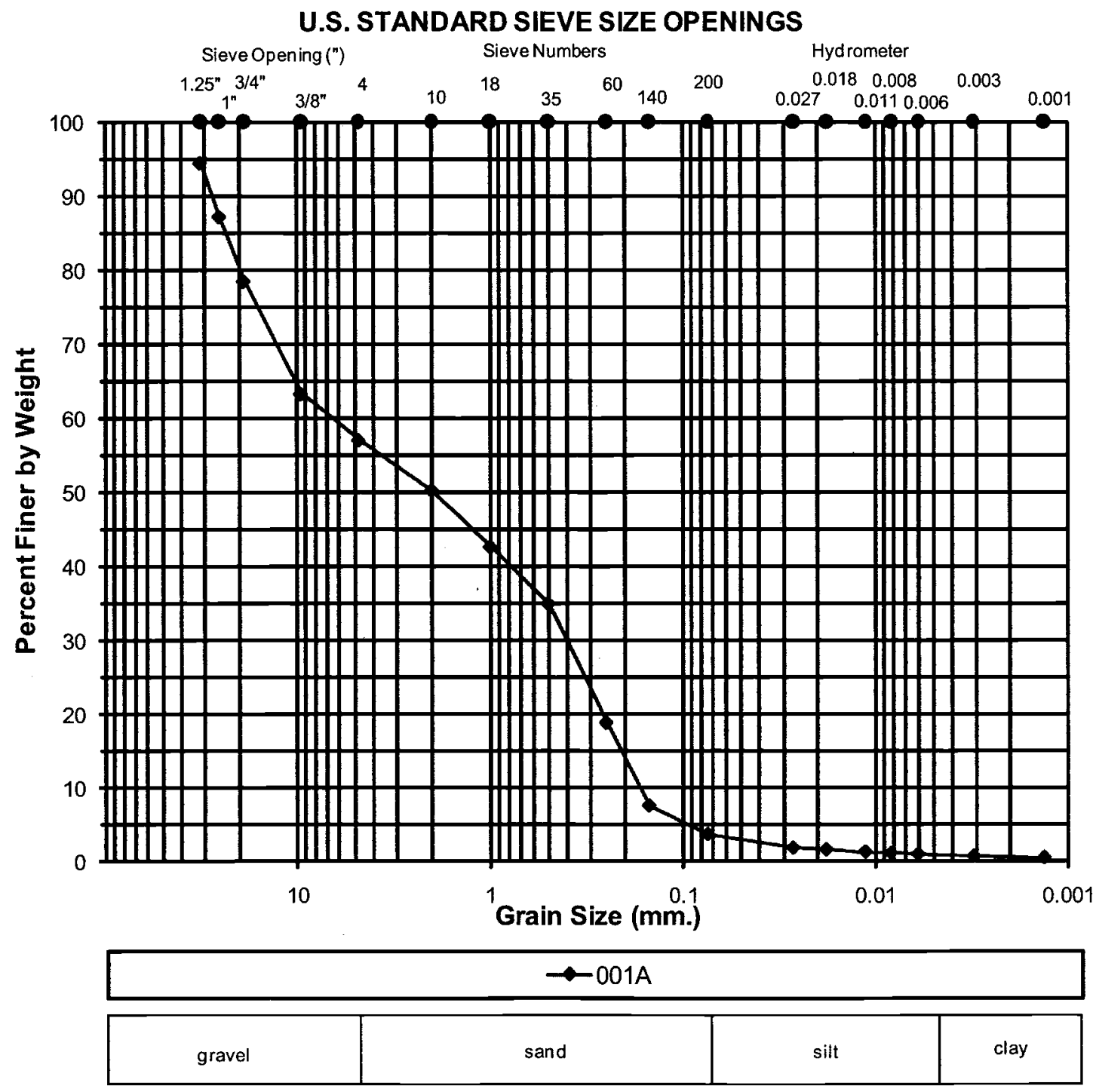

\begin{tabular}{|c|c|c|c|c|c|}
\hline \multicolumn{6}{|c|}{ Unified Soil Classification System(ASTM D2487) } \\
\hline Sample Name & Gravel & Sand & Silt & Clay & Colloids \\
\hline Size Range (mm) & $75-4.76$ & $4.76-0.074$ & $0.074-0.005$ & $<0.005$ & $<0.001$ \\
\hline $001 \mathrm{~A}$ & $43.06 \%$ & $53.42 \%$ & $2.8 \%$ & $0.70 \%$ & $0.31 \%$ \\
\hline
\end{tabular}

Figure E3-1. Sieve Analysis of Sample 001 

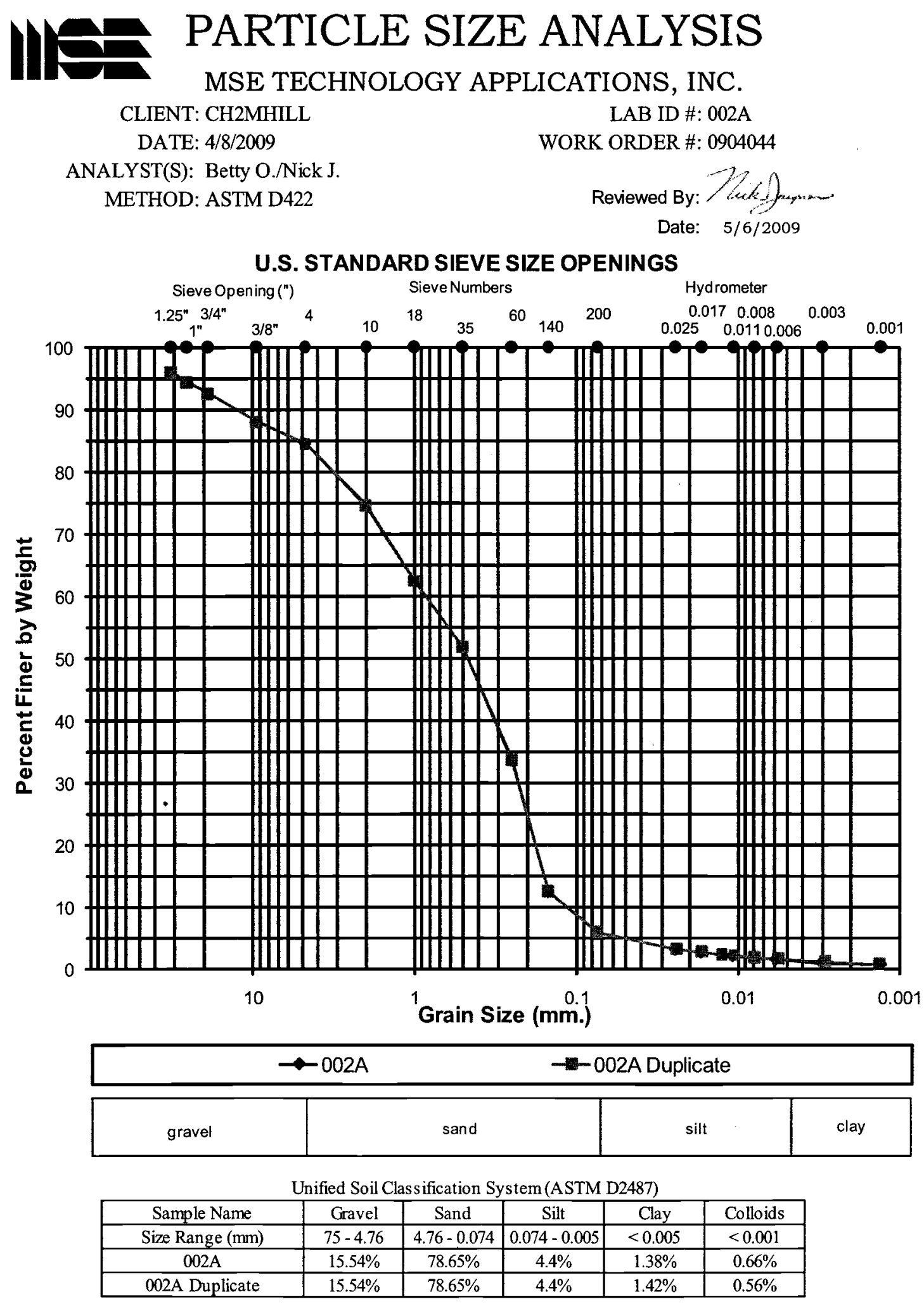

Figure E3-2. Sieve Analysis of Sample 002 


\section{PARTICLE SIZE ANALYSIS}

MSE TECHNOLOGY APPLICATIONS, INC.

CLIENT: CH2MHILL

DATE: $4 / 8 / 2009$

ANALYST(S): Betty O./Nick J.

METHOD: ASTM D422
LAB ID \#: 003A

WORK ORDER \#: 0904044

Reviewed By: $7 / 2$ ) pupian.

Date: $\quad 5 / 6 / 2009$

\section{U.S. STANDARD SIEVE SIZE OPENINGS}
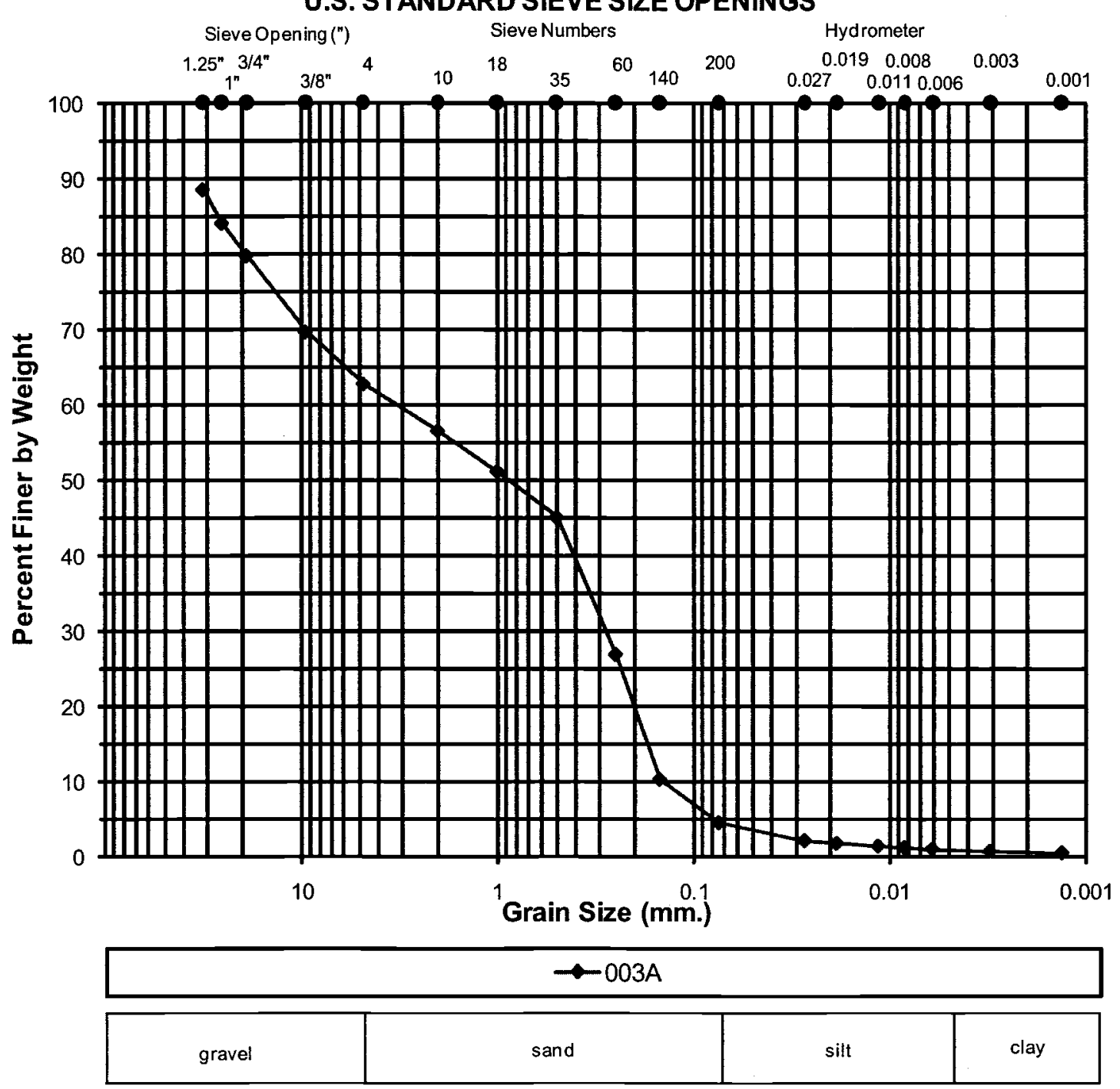

\begin{tabular}{|c|c|c|c|c|c|}
\hline Unified Soil Clas sification System(ASTM D2487) \\
\hline Sample Name & Gravel & Sand & Silt & Clay & Colloids \\
\hline Size Range (mm) & $75-4.76$ & $4.76-0.074$ & $0.074-0.005$ & $<0.005$ & $<0.001$ \\
\hline 003A & $37.34 \%$ & $58.27 \%$ & $3.6 \%$ & $0.83 \%$ & $0.39 \%$ \\
\hline & & & & & \\
\hline
\end{tabular}

Figure E3-3. Sieve Analysis of Sample 003 


\section{PARTICLE SIZE ANALYSIS}

\section{MSE TECHNOLOGY APPLICATIONS, INC.}

CLIENT: CH2MHILL

DATE: $4 / 8 / 2009$

ANALYST(S): Betty O./Nick J.

METHOD: ASTM D422
LAB ID \#: 004A

WORK ORDER \#: 0904044

Reviewed By: 72,4 ,

Date: $5 / 6 / 2009$

\section{U.S. STANDARD SIEVE SIZE OPENINGS}
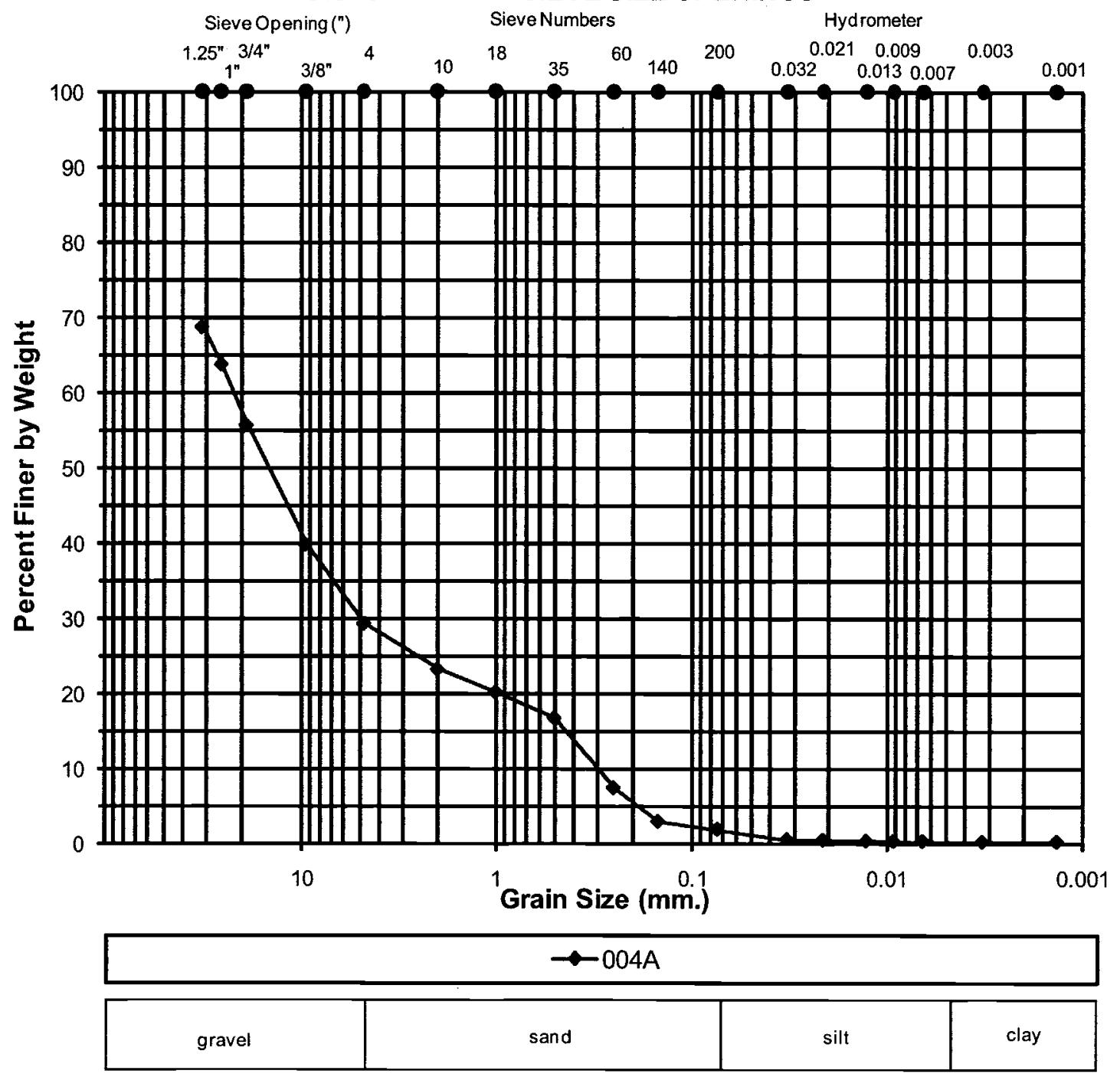

Unified Soil Classification System (ASTM D2487)

\begin{tabular}{|c|c|c|c|c|c|}
\hline Sample Name & Gravel & Sand & Silt & Clay & Colloids \\
\hline Size Range (mm) & $75-4.76$ & $4.76-0.074$ & $0.074-0.005$ & $<0.005$ & $<0.001$ \\
\hline 004A & $70.76 \%$ & $27.46 \%$ & $1.6 \%$ & $0.14 \%$ & $0.09 \%$ \\
\hline & & & & & \\
\hline
\end{tabular}

Figure E3-4. Sieve Analysis of Sample 004 


\section{PARTICLE SIZE ANALYSIS}

\section{MSE TECHNOLOGY APPLICATIONS, INC.}

CLIENT: CH2MHILL

DATE: $4 / 8 / 2009$

ANALYST(S): Betty O./Nick J.

METHOD: ASTM D422
LAB ID \#: 005A

WORK ORDER \#: 0904044

Reviewed By: $7 / 2$, funen

Date: $5 / 6 / 2009$
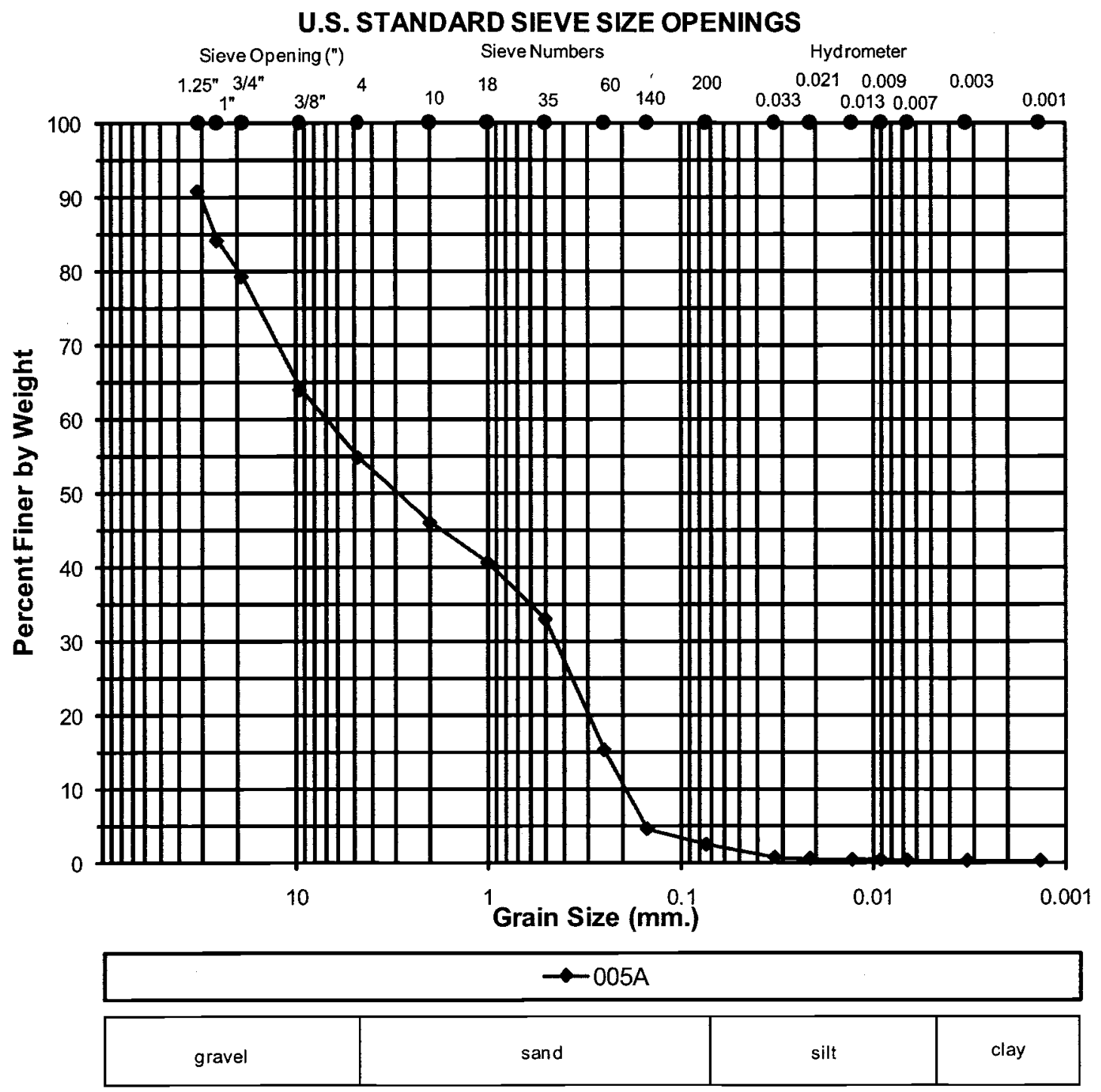

Unified Soil Classification System(ASTM D2487)

\begin{tabular}{|c|c|c|c|c|c|}
\hline Sample Name & Gravel & Sand & Silt & Clay & Colloids \\
\hline Size Range $(\mathrm{mm})$ & $75-4.76$ & $4.76-0.074$ & $0.074-0.005$ & $<0.005$ & $<0.001$ \\
\hline 005A & $45.28 \%$ & $52.44 \%$ & $2.1 \%$ & $0.14 \%$ & $0.09 \%$ \\
\hline & & & & & \\
\hline
\end{tabular}

Figure E3-5. Sieve Analysis of Sample 005 


\section{PARTICLE SIZE ANALYSIS}

\section{MSE TECHNOLOGY APPLICATIONS, INC.}

CLIENT: CH2MHILL

DATE: $4 / 8 / 2009$

ANALYST(S): Betty O./Nick J.

METHOD: ASTM D422
LAB ID \#: 006A

WORK ORDER \#: 0904044

Reviewed By: 72,6 )

Date: $5 / 6 / 2009$

\section{U.S. STANDARD SIEVE SIZE OPENINGS}
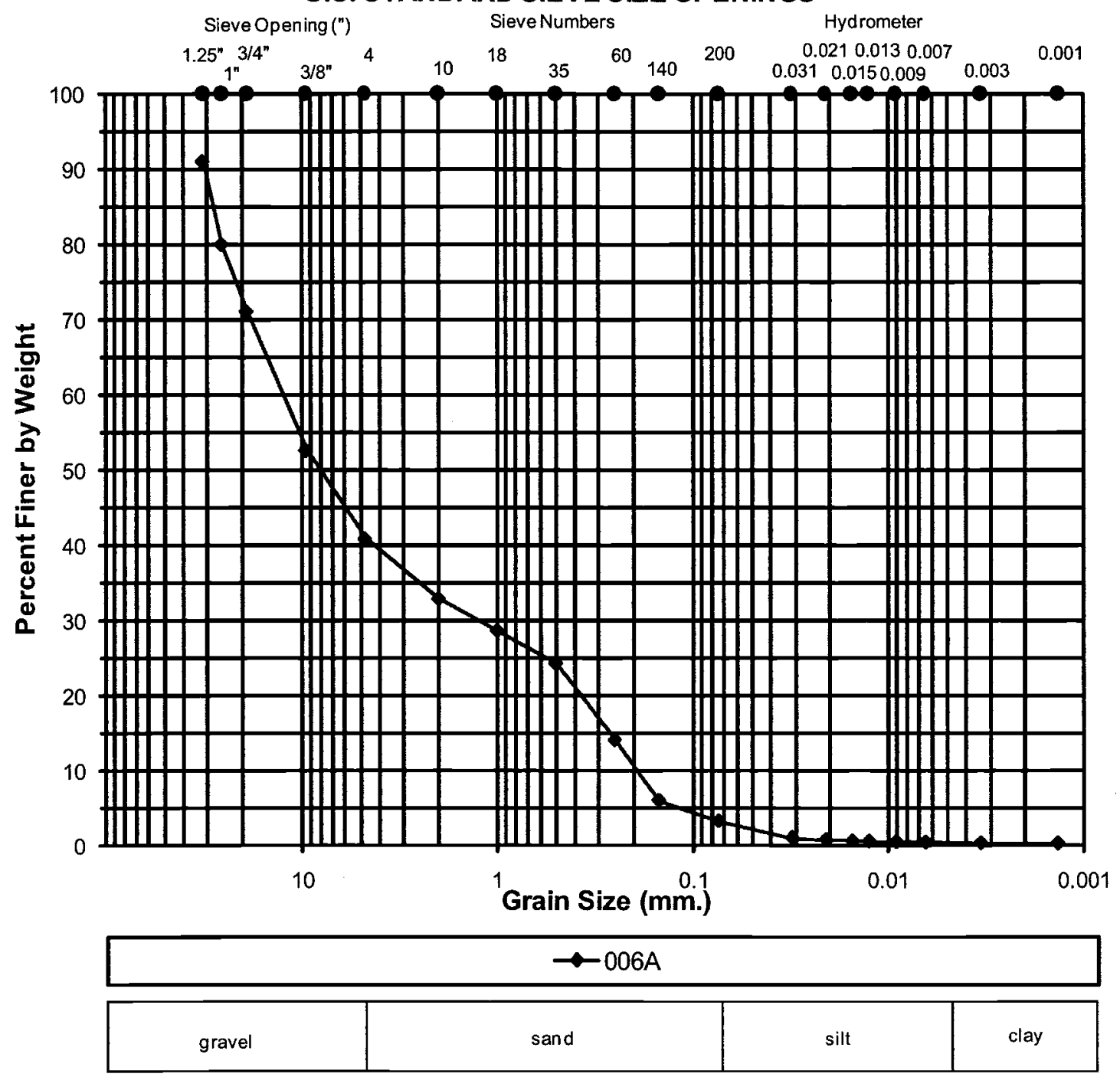

Unified Soil Classification System(ASTM D2487)

\begin{tabular}{|c|c|c|c|c|c|}
\hline Sample Name & Gravel & Sand & Silt & Clay & Colloids \\
\hline Size Range $(\mathrm{mm})$ & $75-4.76$ & $4.76-0.074$ & $0.074-0.005$ & $<0.005$ & $<0.001$ \\
\hline 006A & $59.30 \%$ & $37.55 \%$ & $2.9 \%$ & $0.24 \%$ & $0.13 \%$ \\
\hline & & & & & \\
\hline
\end{tabular}

Figure E3-6. Sieve Analysis of Sample 006 


\section{M- PARTICLE SIZE ANALYSIS \\ MSE TECHNOLOGY APPLICATIONS, INC. \\ CLIENT: CH2MHILL \\ DATE: $4 / 8 / 2009$ \\ ANALYST(S): Betty O./Nick J. \\ METHOD: ASTM D422 \\ LAB ID \#: 007A \\ WORK ORDER \#: 0904044 \\ Reviewed By: $1,2,0$, \\ Date: $5 / 6 / 2009$}

U.S. STANDARD SIEVE SIZE OPENINGS

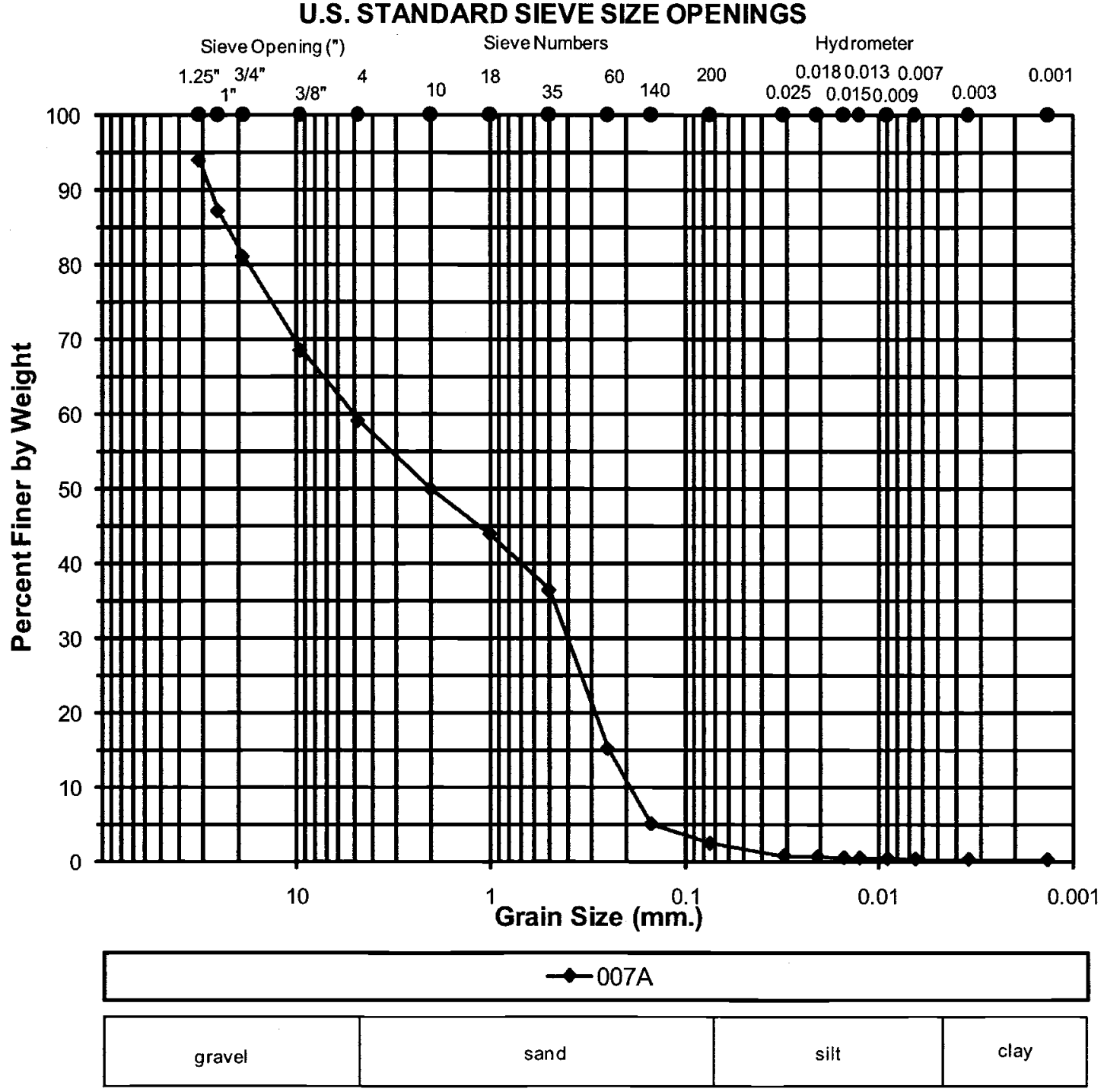

\begin{tabular}{|c|c|c|c|c|c|}
\hline Sample Name & Gravel & Sand & Silt & Clay & Colloids \\
\hline Size Range (mm) & $75-4.76$ & $4.76-0.074$ & $0.074-0.005$ & $<0.005$ & $<0.001$ \\
\hline $007 \mathrm{~A}$ & $41.02 \%$ & $56.71 \%$ & $2.1 \%$ & $0.18 \%$ & $0.09 \%$ \\
\hline
\end{tabular}

Figure E3-7. Sieve Analysis of Sample 007 


\section{M-2 PARTICLE SIZE ANALYSIS \\ MSE TECHNOLOGY APPLICATIONS, INC. \\ CLIENT: CH2MHILL \\ DATE: $4 / 8 / 2009$ \\ ANALYST(S): Betty O./Nick J. \\ METHOD: ASTM D422 \\ LAB ID \#: 008A \\ WORK ORDER \#: 0904044

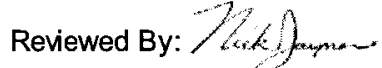 \\ Date: $5 / 6 / 2009$}

\section{U.S. STANDARD SIEVE SIZE OPENINGS}

Sieve Opening (")

Sieve Numbers

Hydrometer
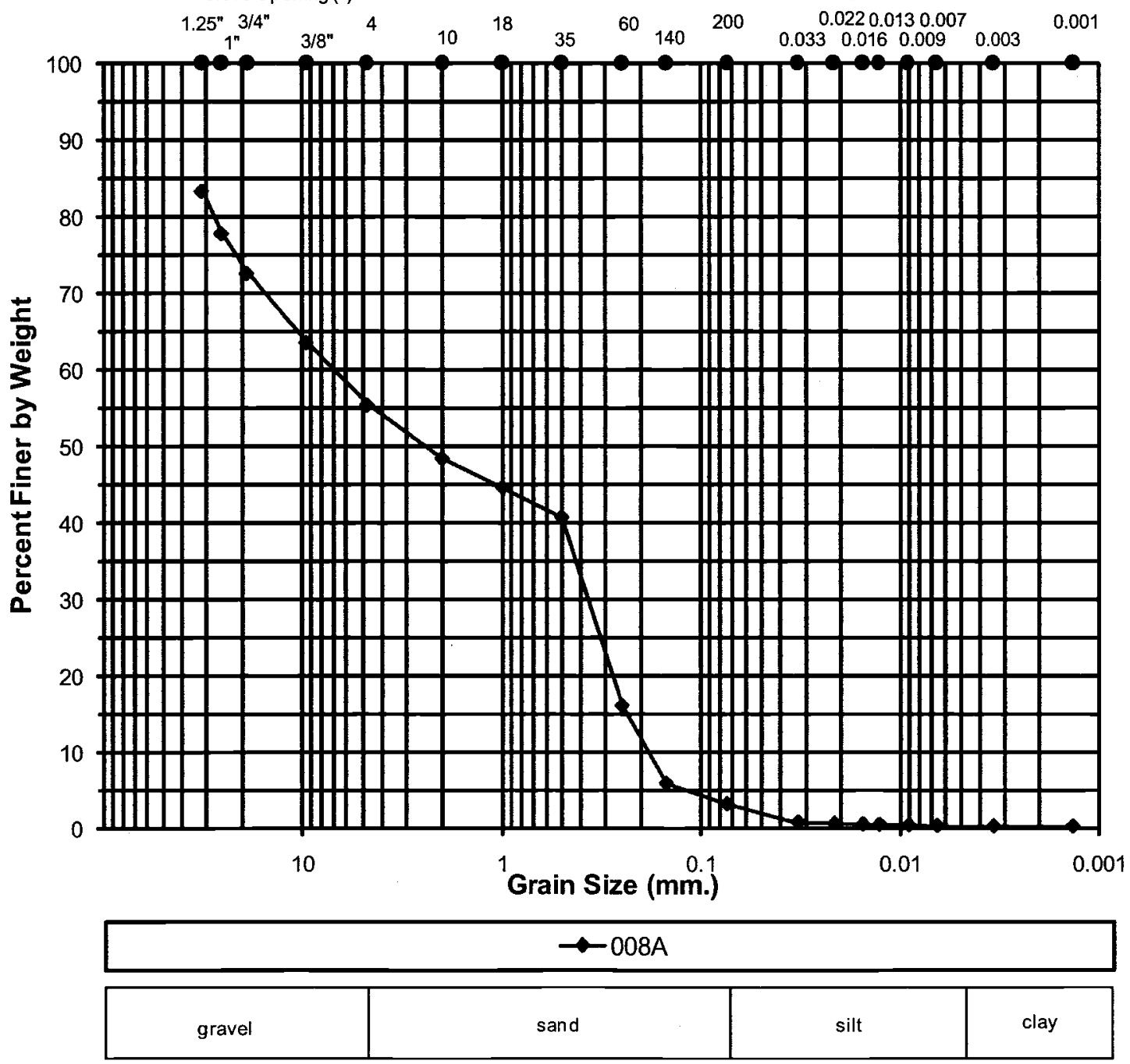

Unified Soil Classification System(ASTM D2487)

\begin{tabular}{|c|c|c|c|c|c|}
\hline Sample Name & Gravel & Sand & Silt & Clay & Colloids \\
\hline Size Range (mm) & $75-4.76$ & $4.76-0.074$ & $0.074-0.005$ & $<0.005$ & $<0.001$ \\
\hline 008A & $44.75 \%$ & $52.22 \%$ & $2.9 \%$ & $0.17 \%$ & $0.08 \%$ \\
\hline & & & & & \\
\hline
\end{tabular}

Figure E3-8. Sieve Analysis of Sample 008 


\section{PARTICLE SIZE ANALYSIS}

MSE TECHNOLOGY APPLICATIONS, INC.

CLIENT: CH2MHILL

DATE: $4 / 8 / 2009$

ANALYST(S): Betty O./Nick J.

METHOD: ASTM D422
LAB ID \#: 009A

WORK ORDER \#: 0904044

Reviewed By: $\cdots 2 / 6$, purmen.

Date: $5 / 6 / 2009$

\section{U.S. STANDARD SIEVE SIZE OPENINGS}

Sieve Opening $\left(^{n}\right)$

Sieve Numbers

Hydrometer
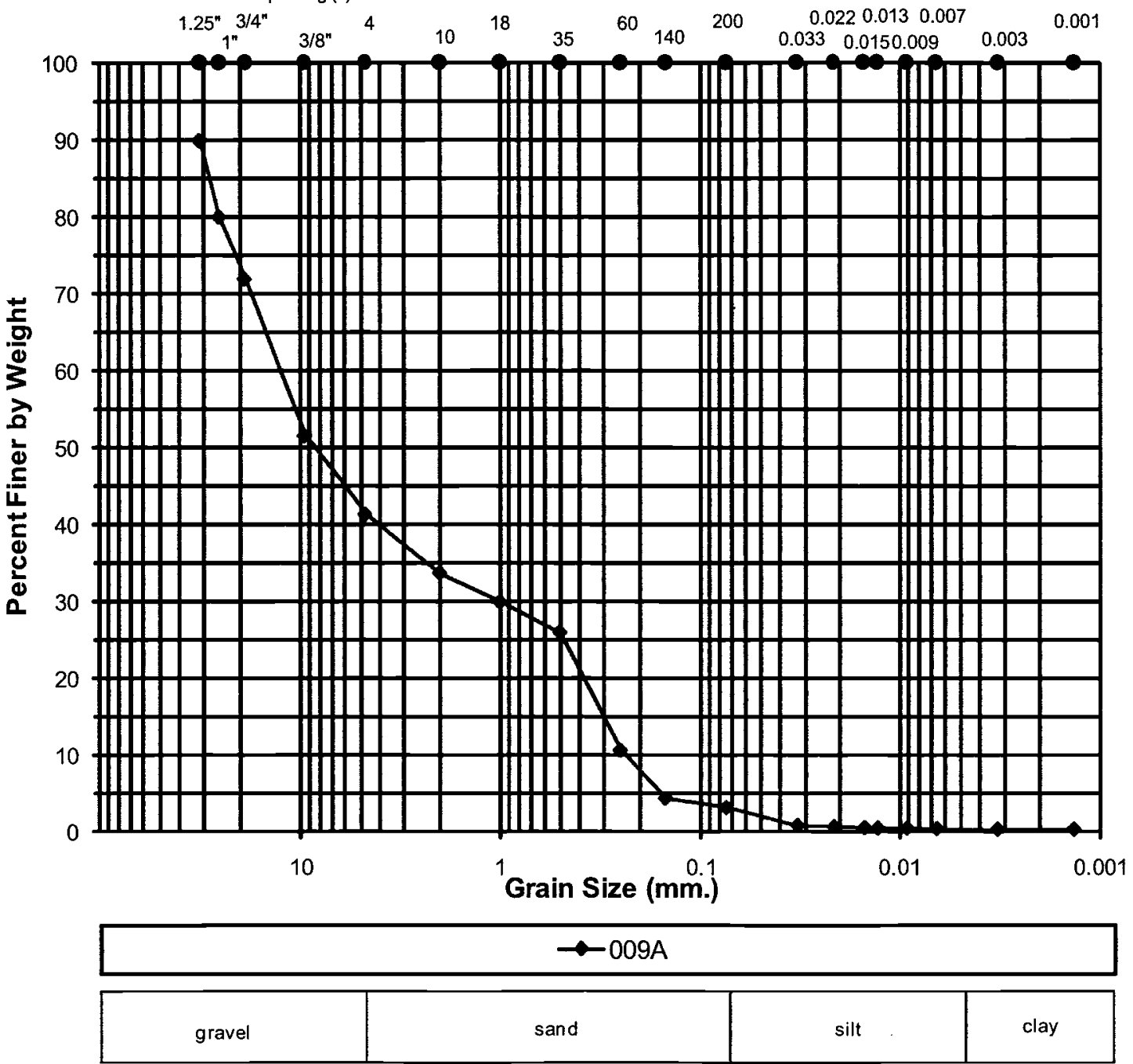

Unified Soil Classification System (ASTM D2487)

\begin{tabular}{|c|c|c|c|c|c|}
\hline Sample Name & Gravel & Sand & Silt & Clay & Colloids \\
\hline Size Range (mm) & $75-4.76$ & $4.76-0.074$ & $0.074-0.005$ & $<0.005$ & $<0.001$ \\
\hline 009A & $58.86 \%$ & $38.19 \%$ & $2.8 \%$ & $0.17 \%$ & $0.11 \%$ \\
\hline & & & & & \\
\hline
\end{tabular}

Figure E3-9. Sieve Analysis of Sample 009 


\section{PARTICLE SIZE ANALYSIS}

\section{MSE TECHNOLOGY APPLICATIONS, INC.}

CLIENT: CH2MHILL

DATE: $4 / 8 / 2009$

ANALYST(S): Betty O./Nick J.

METHOD: ASTM D422
LAB ID \#: 010A

WORK ORDER \#: 0904044

Reviewed By: 72,6 ,

Date: $5 / 6 / 2009$

\section{U.S. STANDARD SIEVE SIZE OPENINGS}
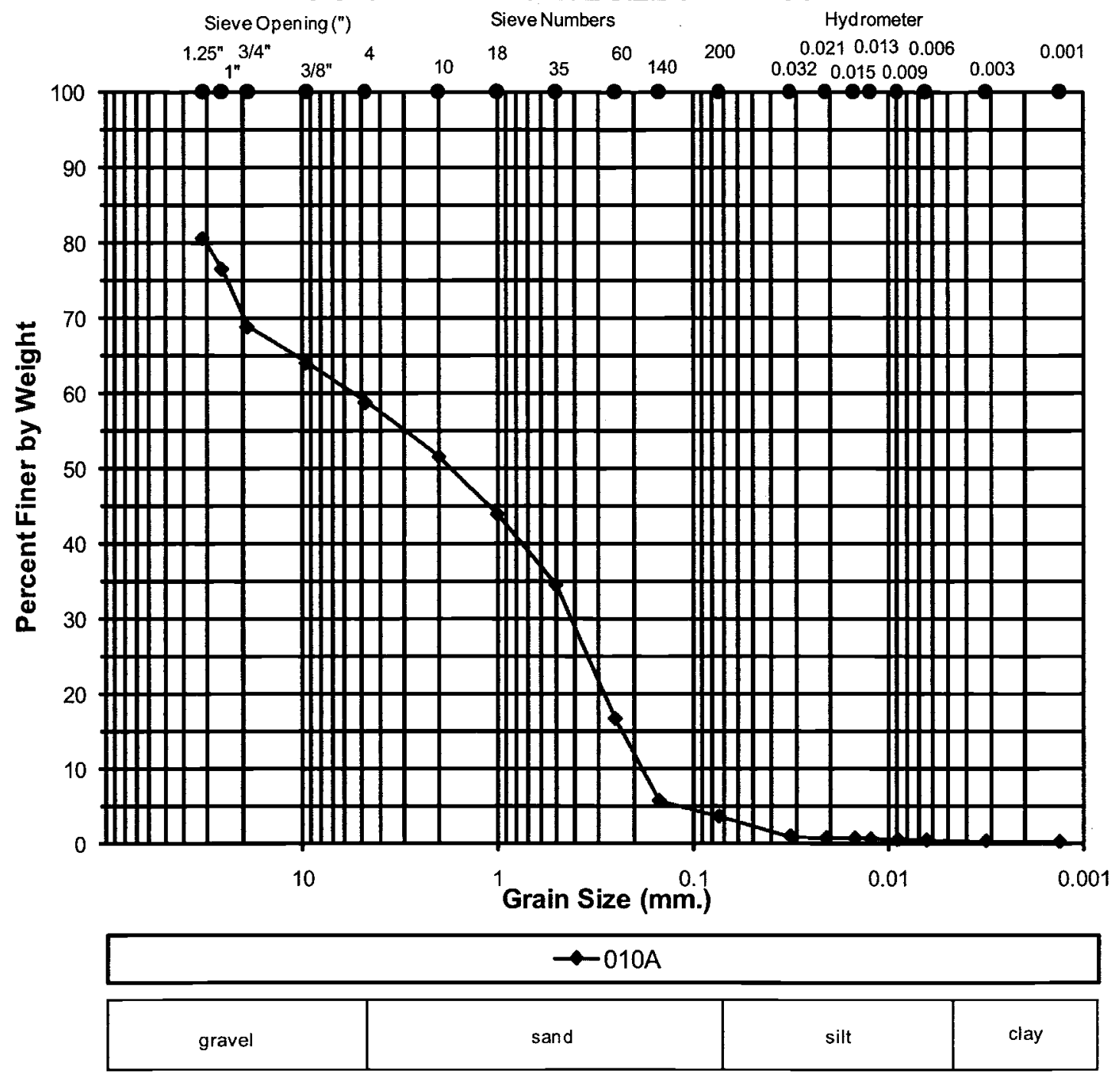

Unified Soil Classification System(ASTM D2487)

\begin{tabular}{|c|c|c|c|c|c|}
\hline Sample Name & Gravel & Sand & Silt & Clay & Colloids \\
\hline Size Range (mm) & $75-4.76$ & $4.76-0.074$ & $0.074-0.005$ & $<0.005$ & $<0.001$ \\
\hline 010A & $41.32 \%$ & $55.13 \%$ & $3.2 \%$ & $0.33 \%$ & $0.17 \%$ \\
\hline & & & & & \\
\hline
\end{tabular}

Figure E3-10. Sieve Analysis of Sample 010 


\section{PARTICLE SIZE ANALYSIS}

MSE TECHNOLOGY APPLICATIONS, INC. CLIENT: CH2MHILL

DATE: 4/8/2009

LAB ID \#: 011A

ANALYST(S): Betty O./Nick J.

METHOD: ASTM D422

WORK ORDER \#: 0904044

Reviewed By: $/ 2,4$ ham

Date: $5 / 6 / 2009$

\section{U.S. STANDARD SIEVE SIZE OPENINGS}
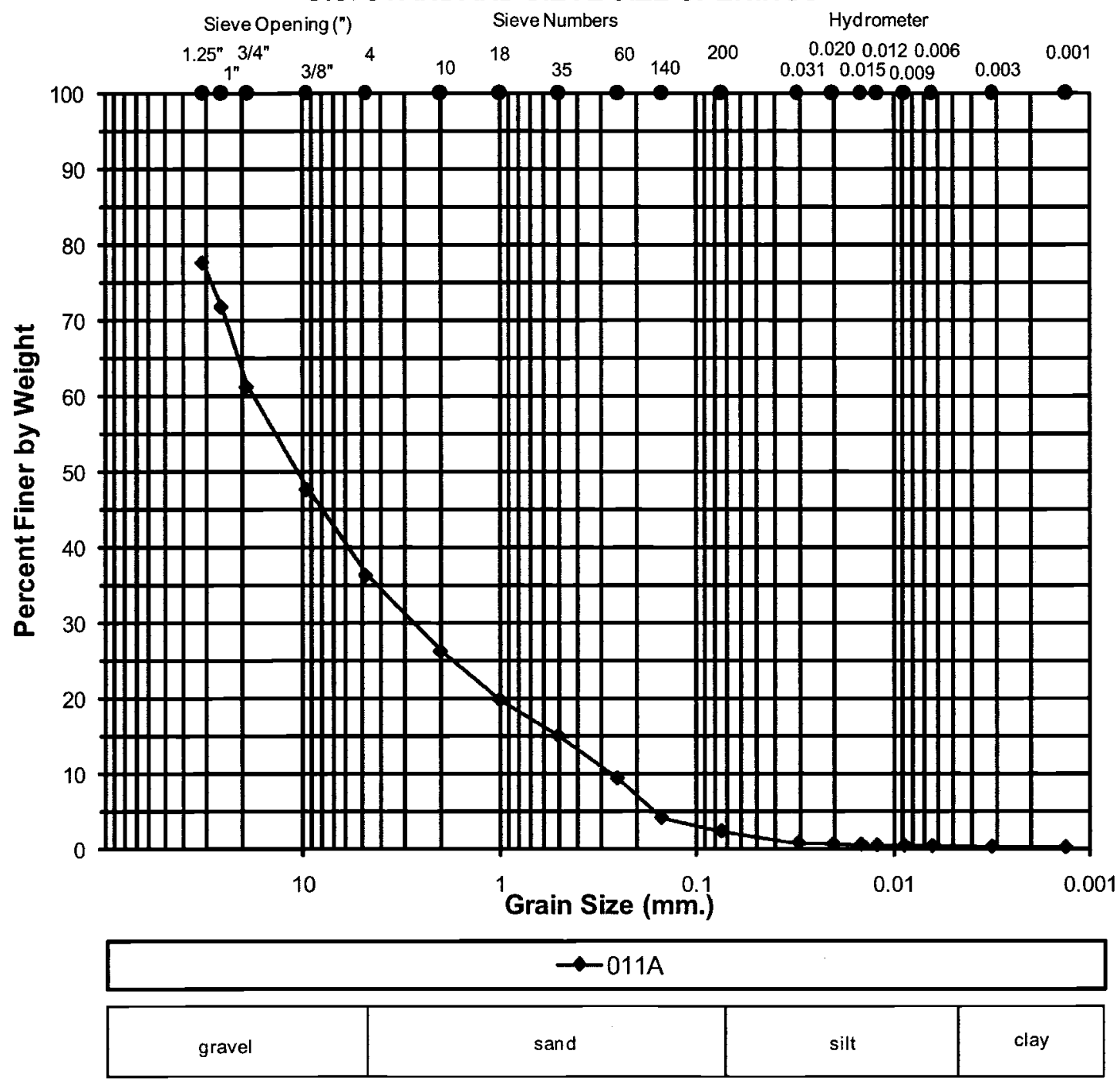

\begin{tabular}{|c|c|c|c|c|c|}
\hline Sample Name & Gravel & Sand & Silt & Clay & Colloids \\
\hline Size Range (mm) & $75-4.76$ & $4.76-0.074$ & $0.074-0.005$ & $<0.005$ & $<0.001$ \\
\hline $011 \mathrm{~A}$ & $63.80 \%$ & $33.96 \%$ & $2.0 \%$ & $0.25 \%$ & $0.13 \%$ \\
\hline
\end{tabular}

Figure E3-11. Sieve Analysis of Sample 011 


\section{PARTICLE SIZE ANALYSIS}

MSE TECHNOLOGY APPLICATIONS, INC.

CLIENT: CH2MHILL

DATE: $4 / 8 / 2009$

ANALYST(S): Betty O./Nick J.

METHOD: ASTM D422
LAB ID \#: 012A

WORK ORDER \#: 0904044

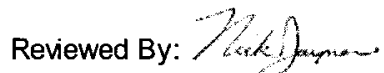

Date: $5 / 6 / 2009$

\section{U.S. STANDARD SIEVE SIZE OPENINGS}
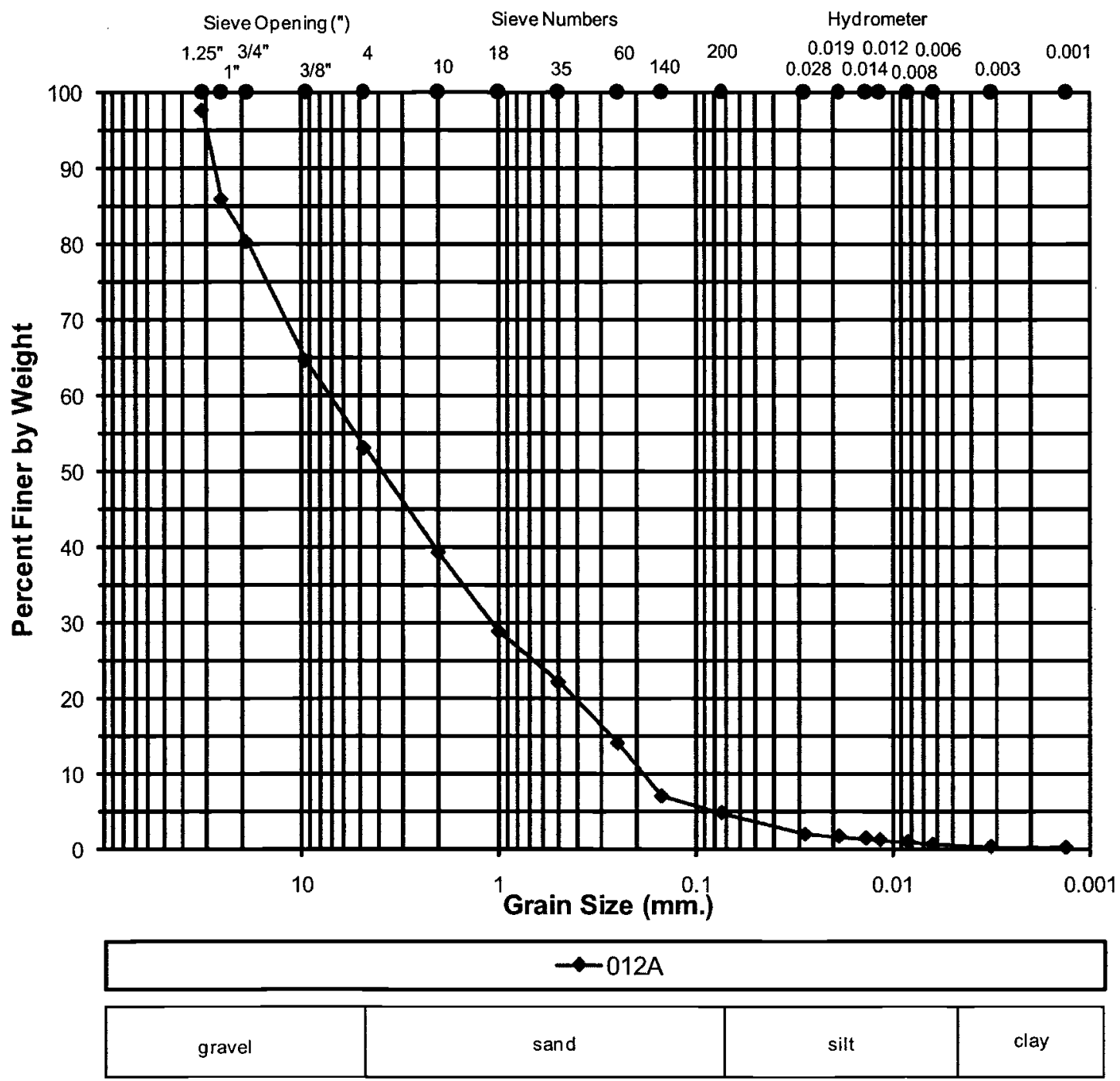

\begin{tabular}{|c|c|c|c|c|c|}
\hline Sample Name & Gravel & Sand & Silt & Clay & Colloids \\
\hline Size Range (mm) & $75-4.76$ & $4.76-0.074$ & $0.074-0.005$ & $<0.005$ & $<0.001$ \\
\hline $012 \mathrm{~A}$ & $47.04 \%$ & $48.19 \%$ & $4.3 \%$ & $0.48 \%$ & $0.19 \%$ \\
\hline
\end{tabular}

Figure E3-12. Sieve Analysis of Sample 012 


\section{PARTICLE SIZE ANALYSIS}

MSE TECHNOLOGY APPLICATIONS, INC.

CLIENT: CH2MHILL

DATE: $4 / 8 / 2009$

ANALYST(S): Betty O./Nick J.

METHOD: ASTM D422
LAB ID \#: 013A

WORK ORDER \#: 0904044

Reviewed By: $/ 2, d$ hepum

Date: $5 / 6 / 2009$

U.S. STANDARD SIEVE SIZE OPENINGS

Sieve Opening (") $1.25^{n} 3 / 4^{n}$

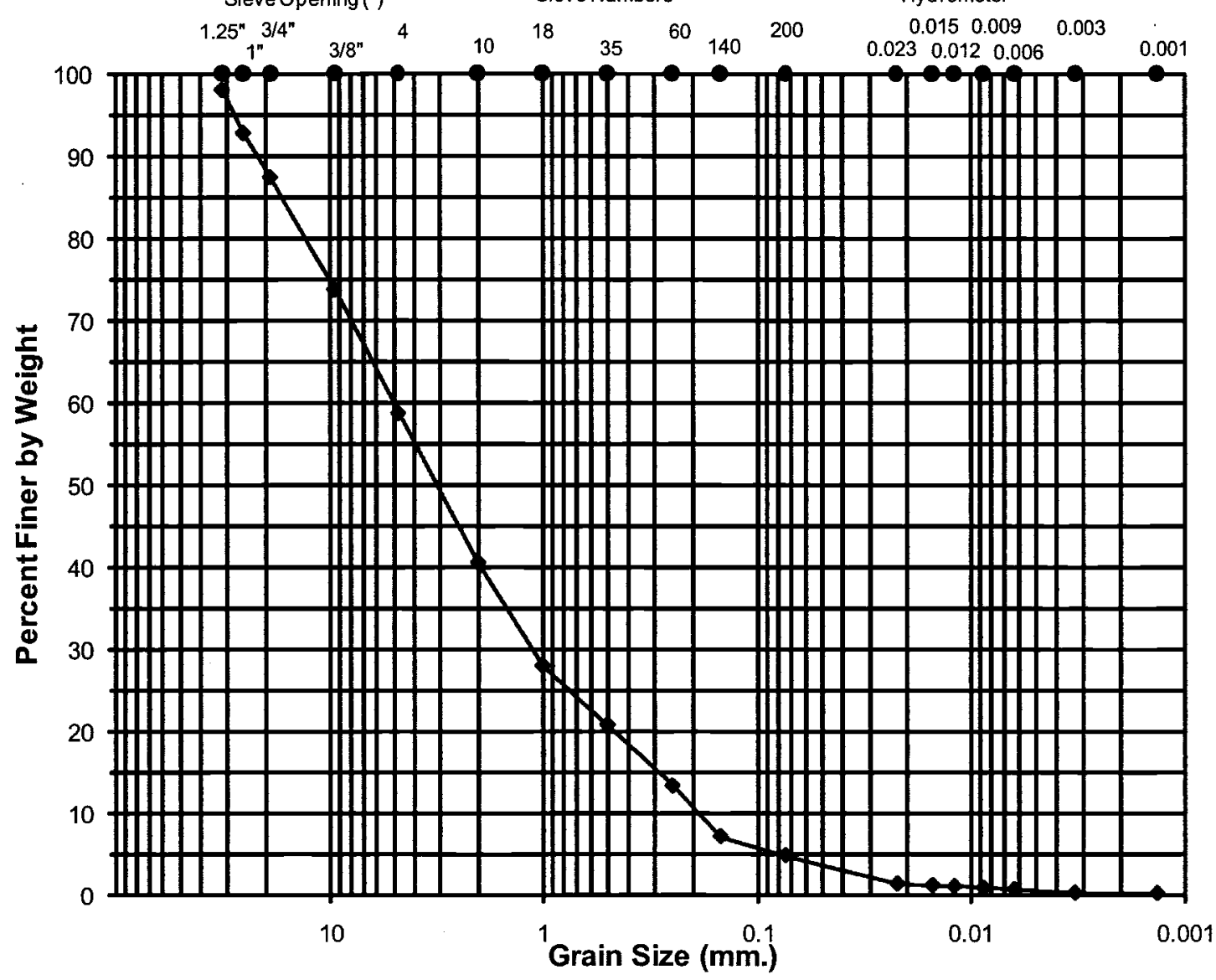

Sieve Numbers

Hydrometer

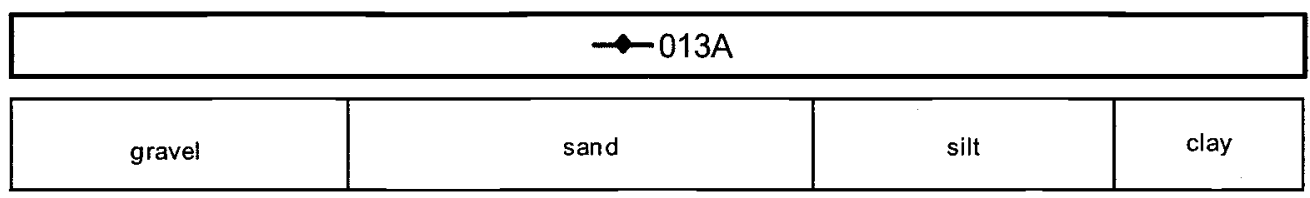

Unified Soil Classification System(ASTM D2487)

\begin{tabular}{|c|c|c|c|c|c|}
\hline Sample Name & Gravel & Sand & Silt & Clay & Colloids \\
\hline Size Range (mm) & $75-4.76$ & $4.76-0.074$ & $0.074-0.005$ & $<0.005$ & $<0.001$ \\
\hline 013A & $41.44 \%$ & $53.85 \%$ & $4.3 \%$ & $0.43 \%$ & $0.10 \%$ \\
\hline & & & & & \\
\hline
\end{tabular}

Figure E3-13. Sieve Analysis of Sample 013 


\section{PARTICLE SIZE ANALYSIS}

\section{MSE TECHNOLOGY APPLICATIONS, INC.}

CLIENT: CH2MHILL

DATE: $4 / 8 / 2009$

ANALYST(S): Betty O./Nick J.

METHOD: ASTM D422
LAB ID \#: 014A

WORK ORDER \#: 0904044

Reviewed By: $7</$ fumen

Date: $5 / 6 / 2009$

\section{U.S. STANDARD SIEVE SIZE OPENINGS}
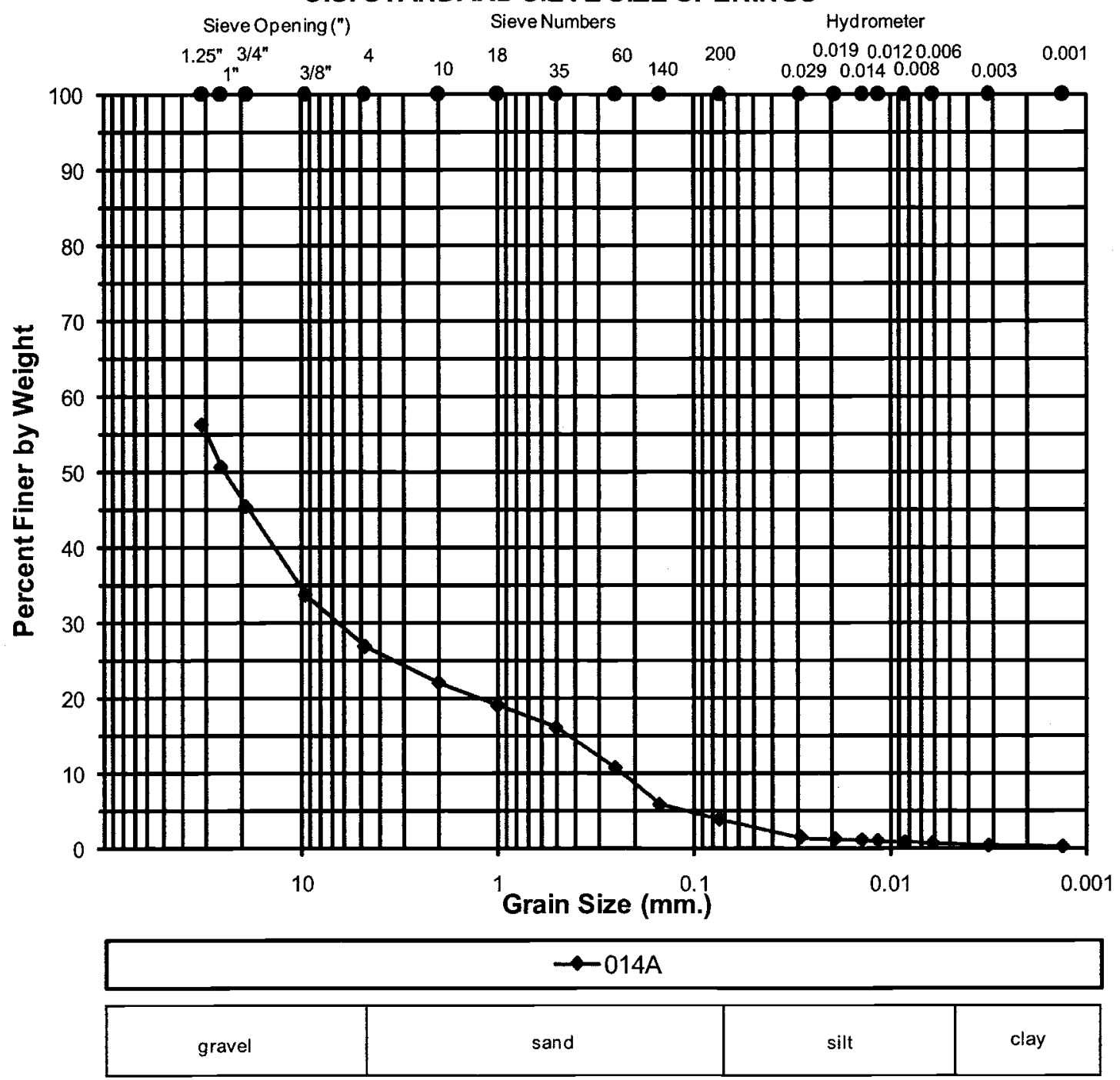

\begin{tabular}{|c|c|c|c|c|c|}
\hline Unified Soil Classification System (ASTM D2487) \\
\hline Sample Name & Gravel & Sand & Silt & Clay & Colloids \\
\hline Size Range (mm) & $75-4.76$ & $4.76-0.074$ & $0.074-0.005$ & $<0.005$ & $<0.001$ \\
\hline $014 \mathrm{~A}$ & $73.22 \%$ & $22.98 \%$ & $3.3 \%$ & $0.54 \%$ & $0.20 \%$ \\
\hline & & & & & \\
\hline
\end{tabular}

Figure E3-14. Sieve Analysis of Sample 014 


\section{PARTICLE SIZE ANALYSIS}

\section{MSE TECHNOLOGY APPLICATIONS, INC.}

CLIENT: CH2MHILL

DATE: $4 / 8 / 2009$

ANALYST(S): Betty O./Nick J.

METHOD: ASTM D422
LAB ID \#: 015A

WORK ORDER \#: 0904044

Reviewed By: /2ukf pamen.

Date: $5 / 6 / 2009$

\section{U.S. STANDARD SIEVE SIZE OPENINGS}
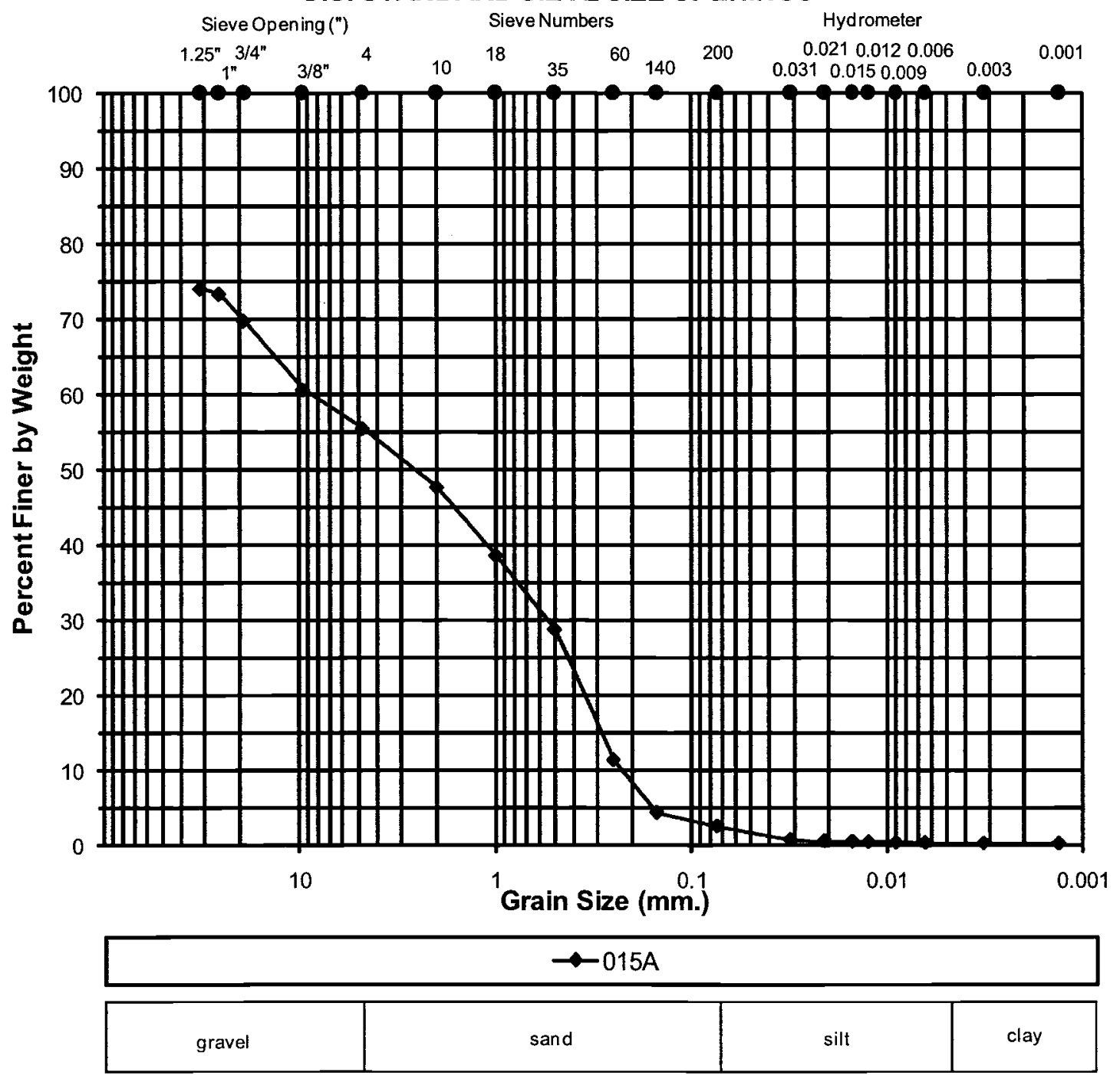

Unified Soil Classification System(ASTM D2487)

\begin{tabular}{|c|c|c|c|c|c|}
\hline Sample Name & Gravel & Sand & Silt & Clay & Colloids \\
\hline Size Range (mm) & $75-4.76$ & $4.76-0.074$ & $0.074-0.005$ & $<0.005$ & $<0.001$ \\
\hline 015A & $44.62 \%$ & $52.97 \%$ & $2.2 \%$ & $0.21 \%$ & $0.13 \%$ \\
\hline & & & & & \\
\hline
\end{tabular}

Figure E3-15. Sieve Analysis of Sample 015 


\section{PARTICLE SIZE ANALYSIS}

MSE TECHNOLOGY APPLICATIONS, INC.

CLIENT: CH2MHILL

DATE: $4 / 8 / 2009$

ANALYST(S): Betty O./Nick J.

METHOD: ASTM D422
LAB ID \#: 016A

WORK ORDER \#: 0904044

Reviewed By: 24,6 2umen

Date: $5 / 6 / 2009$

\section{U.S. STANDARD SIEVE SIZE OPENINGS}
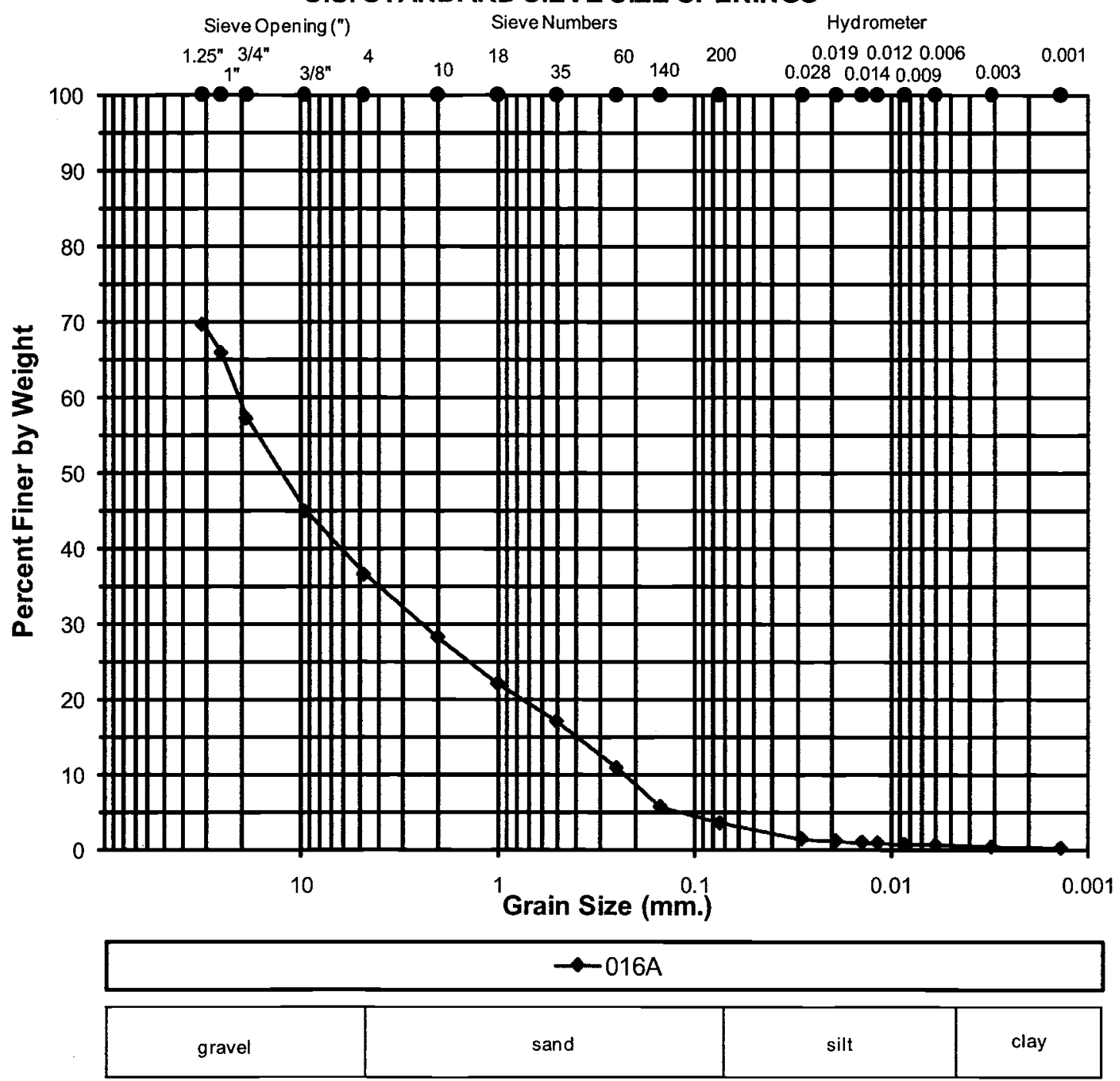

\begin{tabular}{|c|c|c|c|c|c|}
\hline \\
\hline Sample Name & Gravel & Sand & Silt & Clay & Colloids \\
\hline Size Range (mm) & $75-4.76$ & $4.76-0.074$ & $0.074-0.005$ & $<0.005$ & $<0.001$ \\
\hline $016 \mathrm{~A}$ & $63.49 \%$ & $32.96 \%$ & $3.0 \%$ & $0.58 \%$ & $0.22 \%$ \\
\hline
\end{tabular}

Figure E3-16. Sieve Analysis of Sample 016 

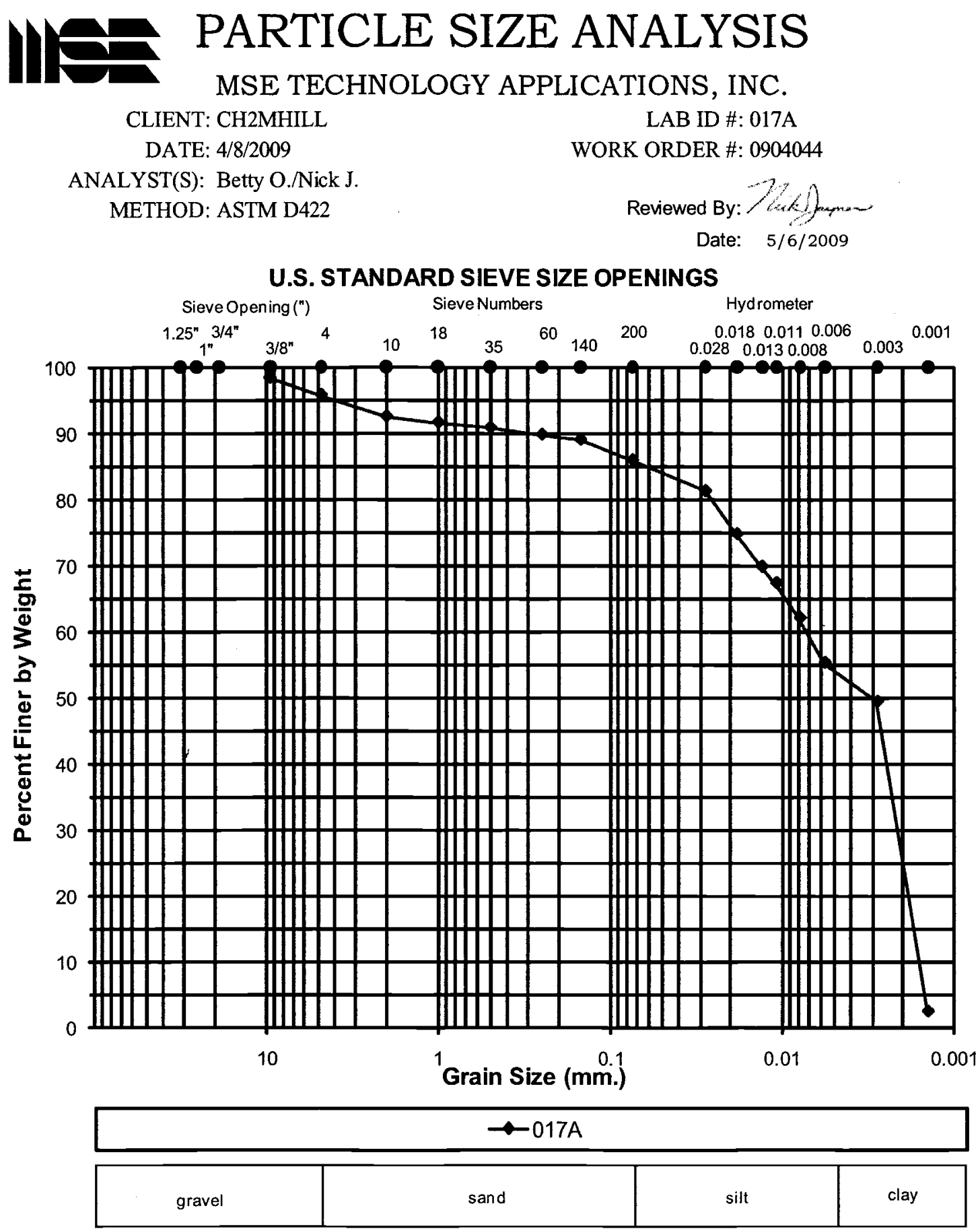

\begin{tabular}{|c|c|c|c|c|c|}
\hline Sample Name & Gravel & Sand & Silt & Clay & Colloids \\
\hline Size Range (mm) & $75-4.76$ & $4.76-0.074$ & $0.074-0.005$ & $<0.005$ & $<0.001$ \\
\hline $017 \mathrm{~A}$ & $4.32 \%$ & $9.80 \%$ & $32.6 \%$ & $53.31 \%$ & $2.47 \%$ \\
\hline
\end{tabular}

Figure E3-17. Sieve Analysis of Sample 017 


\section{PARTICLE SIZE ANALYSIS}

MSE TECHNOLOGY APPLICATIONS, INC.

CLIENT: CH2MHILL

DATE: $4 / 8 / 2009$

ANALYST(S): Betty O./Nick J.

METHOD: ASTM D422
LAB ID \#: 018A

WORK ORDER \#: 0904044

Reviewed By: $2 / 6$, purpew

Date: $5 / 6 / 2009$

\section{U.S. STANDARD SIEVE SIZE OPENINGS}

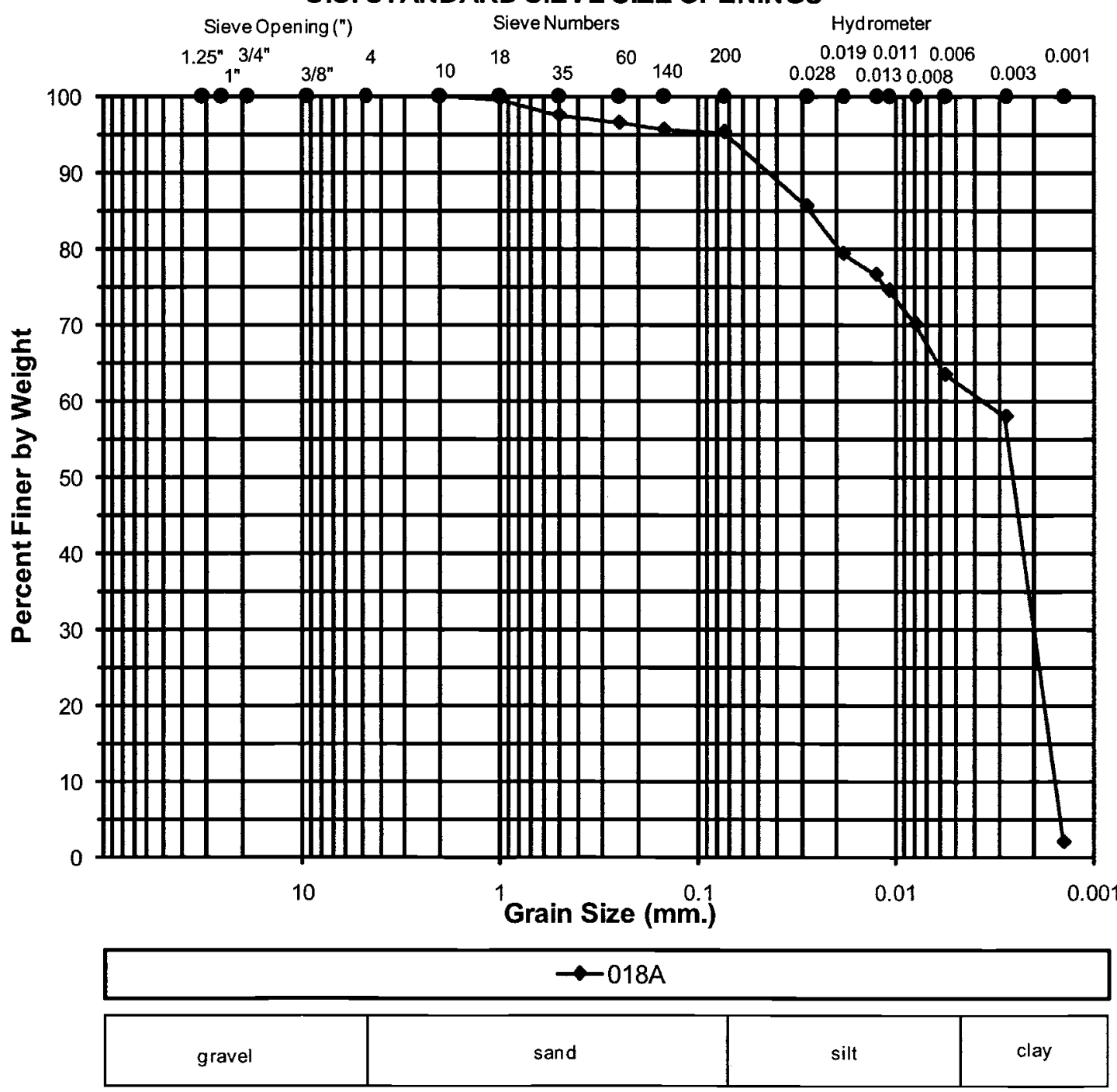

Unified Soil Classification System(ASTM D2487)
\begin{tabular}{|c|c|c|c|c|c|}
\hline Sample Name & Gravel & Sand & Silt & Clay & Colloids \\
\hline Size Range (mm) & $75-4.76$ & $4.76-0.074$ & $0.074-0.005$ & $<0.005$ & $<0.001$ \\
\hline $018 \mathrm{~A}$ & & $4.73 \%$ & $33.7 \%$ & $61.62 \%$ & $2.07 \%$ \\
\hline & & & & & \\
\hline
\end{tabular}

Figure E3-18. Sieve Analysis of Sample 018 

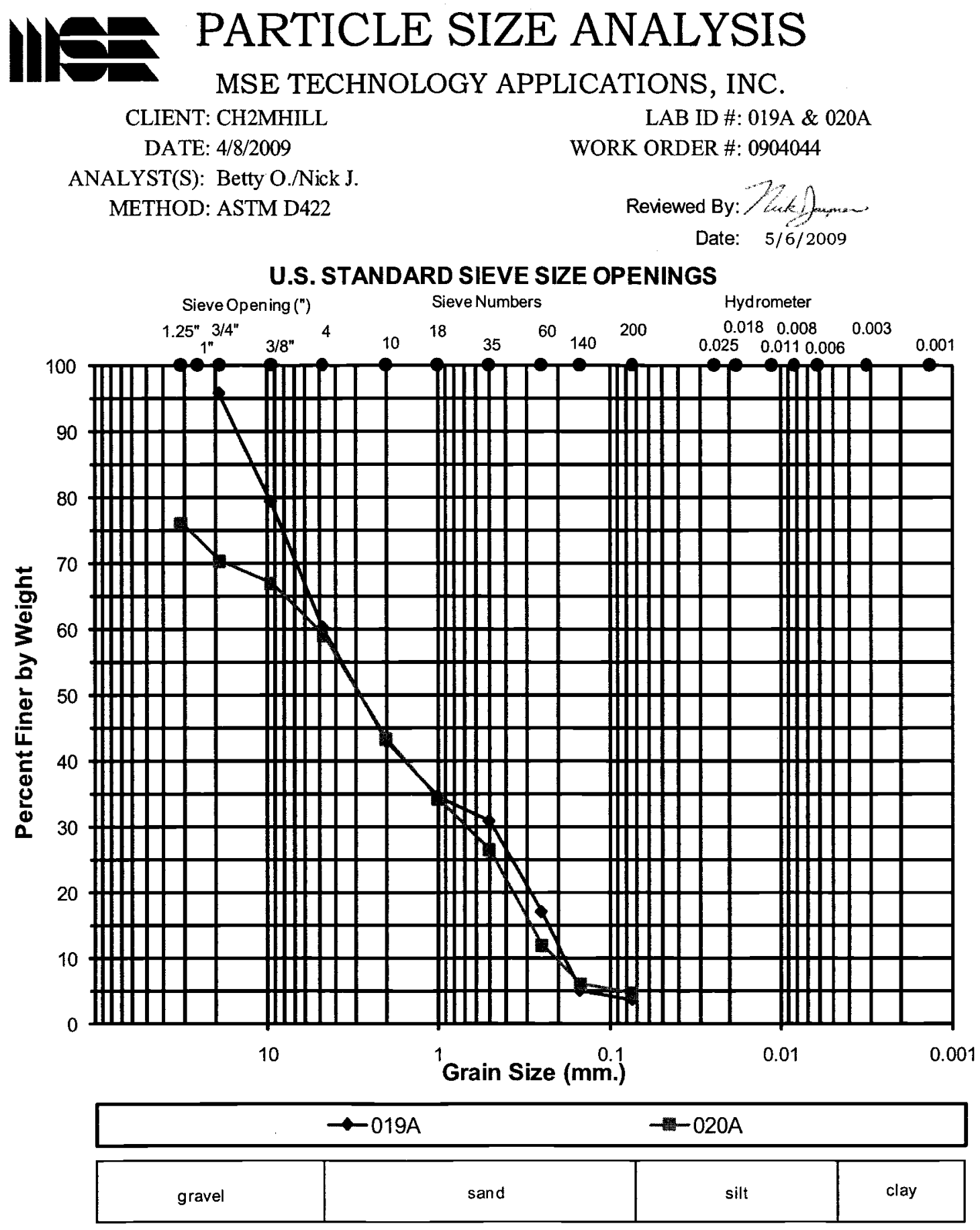

\begin{tabular}{|c|c|c|c|}
\multicolumn{4}{c}{ Unified Soil Classification System (ASTM D2 } \\
\begin{tabular}{|c|c|c|c|}
\hline Sample Name & Gravel & Sand & Silt \& Clay \\
\hline Size Range $(\mathrm{mm})$ & $75-4.76$ & $4.76-0.074$ & $<0.074$ \\
\hline 019A & $39.77 \%$ & $56.70 \%$ & $3.53 \%$ \\
\hline 020A & $41.20 \%$ & $54.22 \%$ & $4.58 \%$ \\
\hline
\end{tabular}
\end{tabular}

Figure E3-19. Sieve Analysis of Sample 019 
E4 X-Ray Diffraction Plots

[MSE001A.MDI] MSE $0904044001 \mathrm{~A}<2 \mathrm{~T}(0)=0.12>$

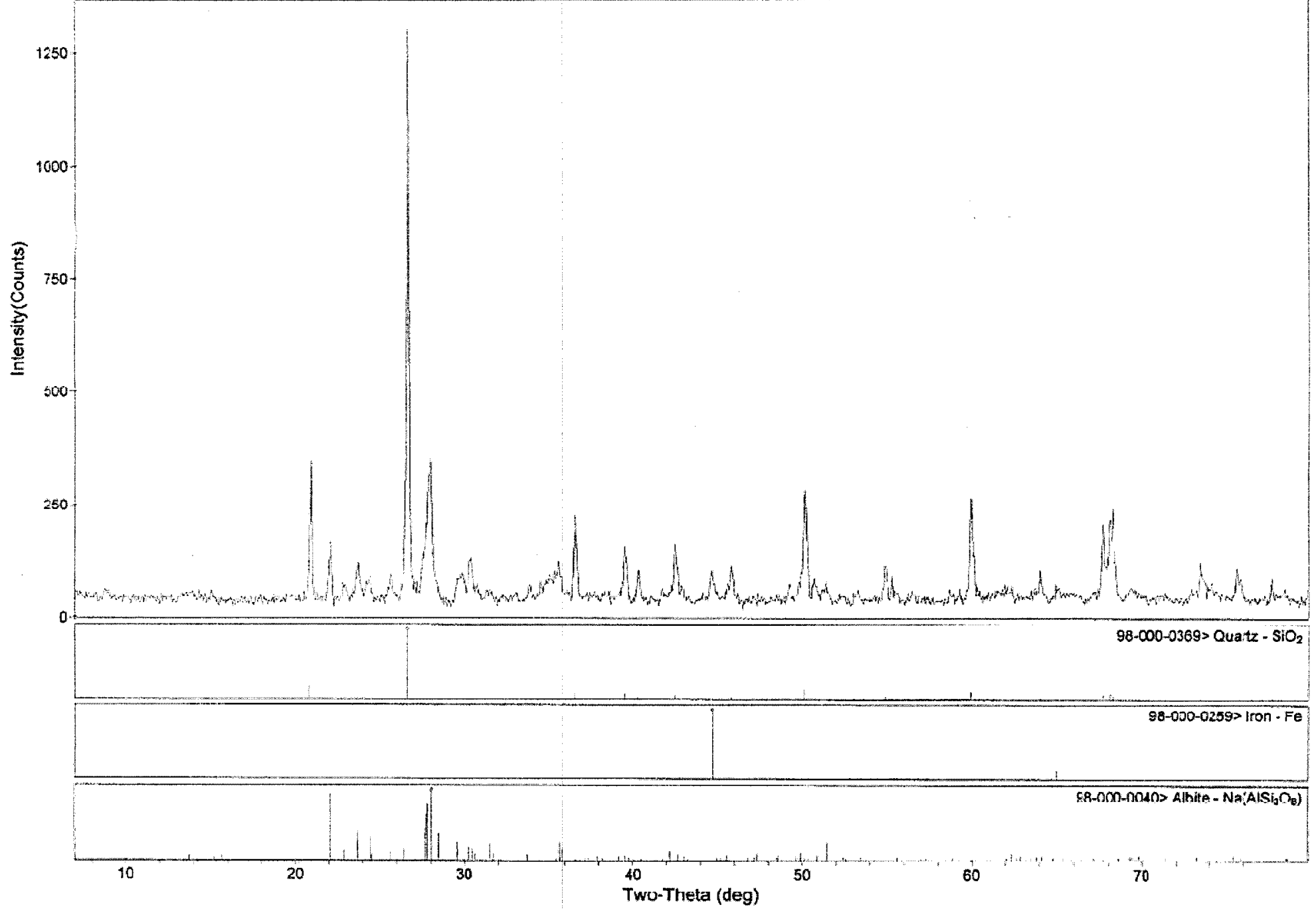

Figure E4-1. X-Ray Diffraction Plot for Sample 1 


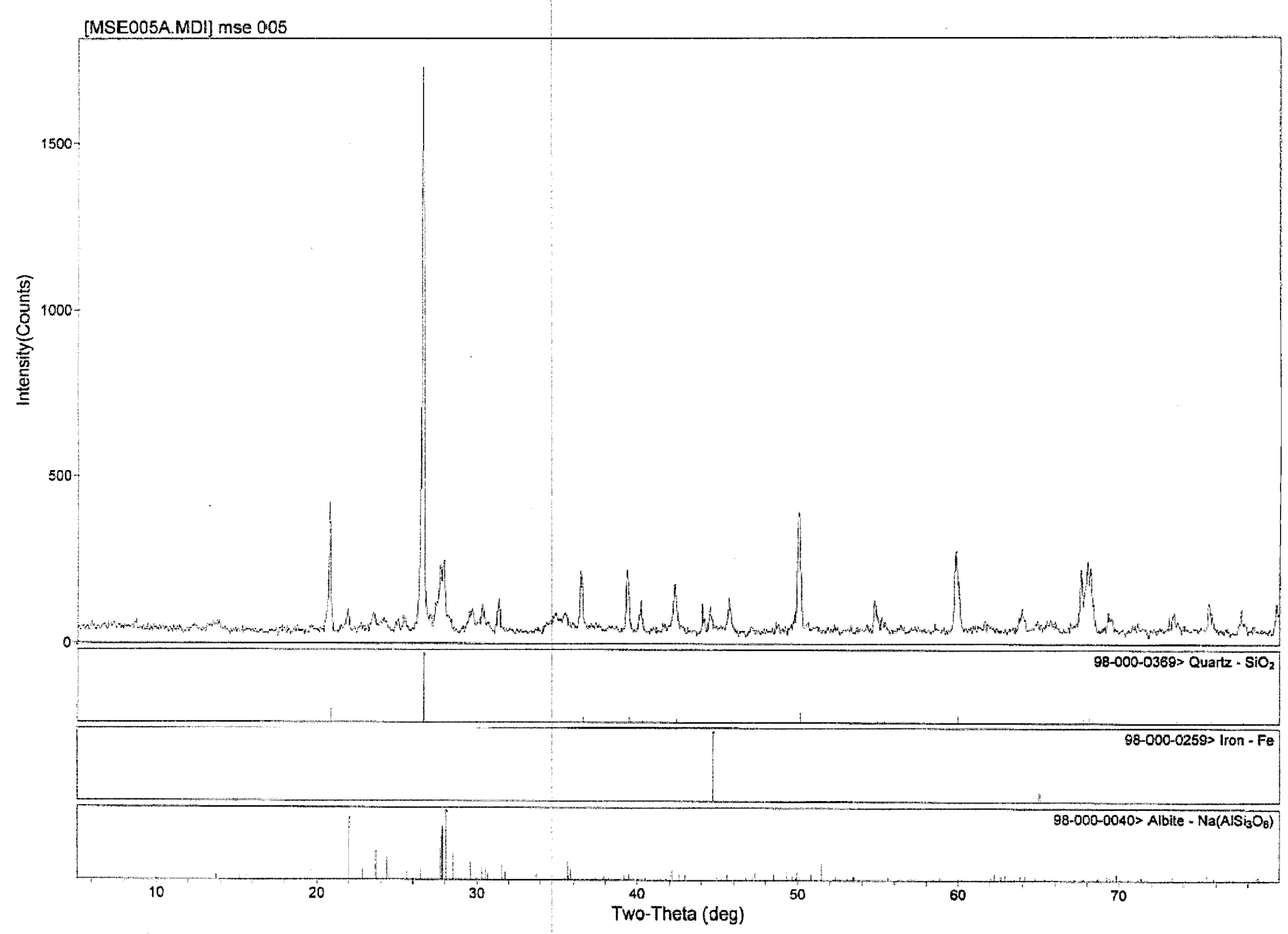

Figure E4-2. X-Ray Diffraction Plot for Sample 5 
[MSE010A.MDI] $m s e 010 A<2 T(0)=0.155>$

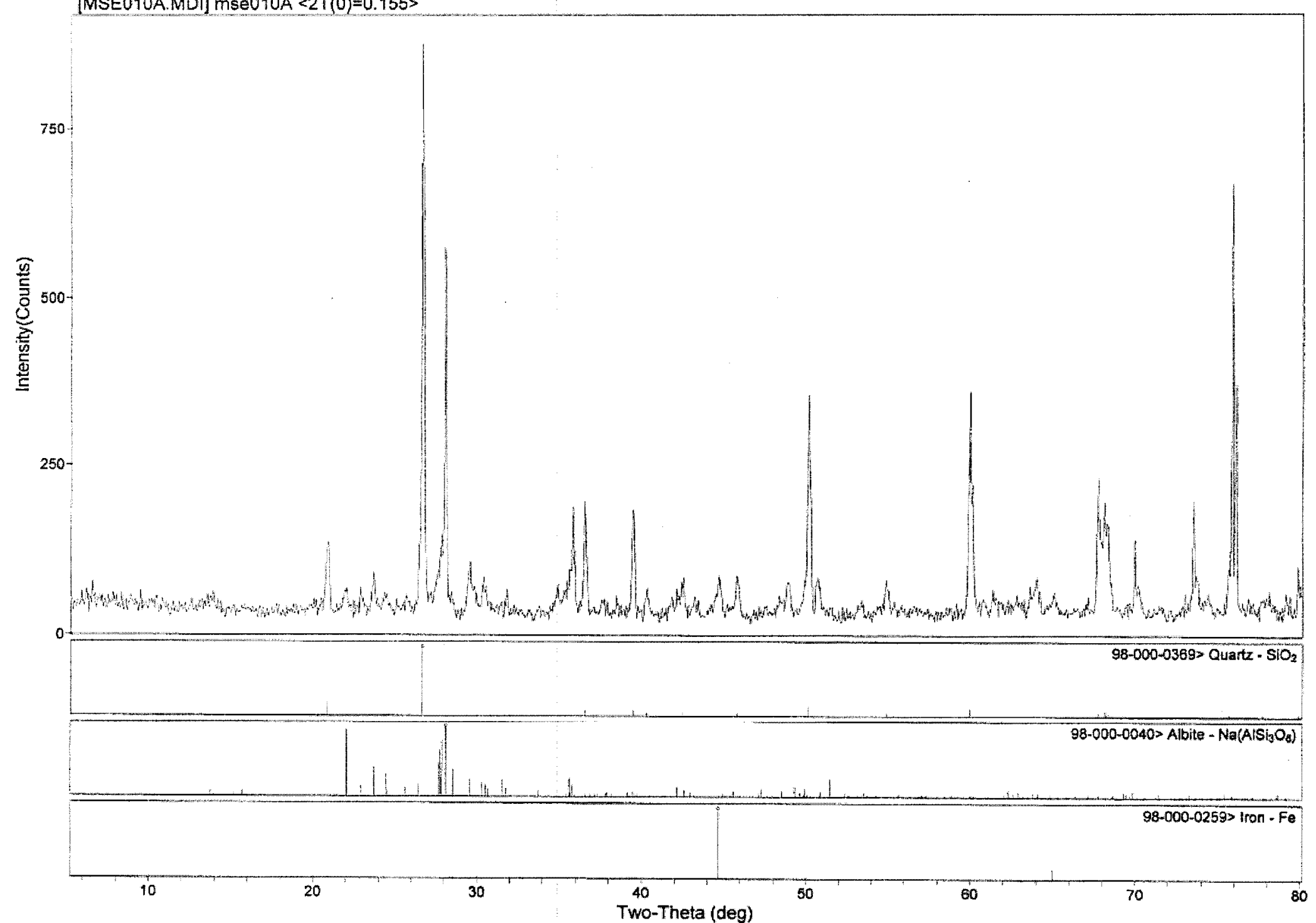

Figure E4-3. X-Ray Diffraction Plot for Sample 10 
䍐

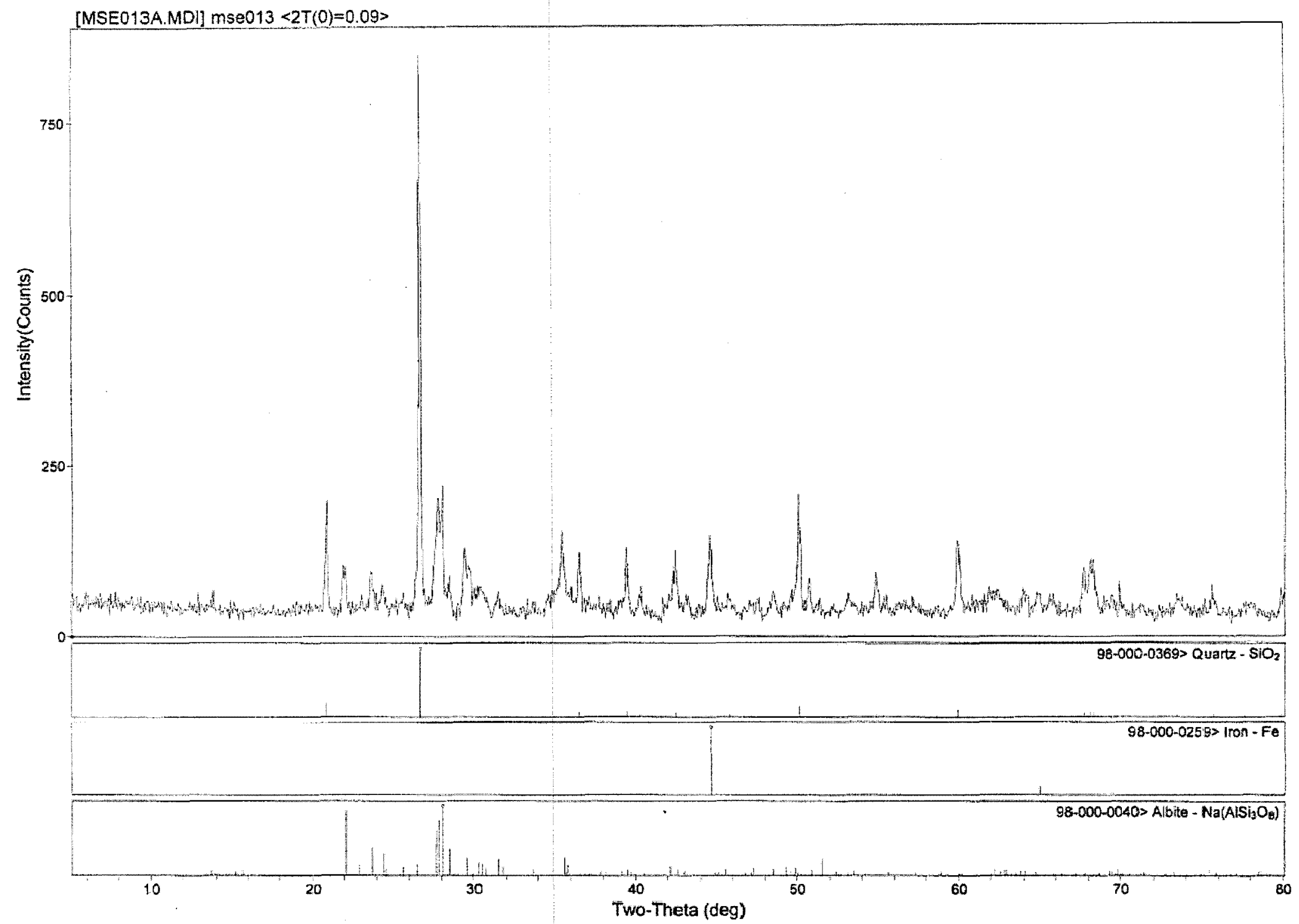

Figure E4-4. X-Ray Diffraction Plot for Sample 13 


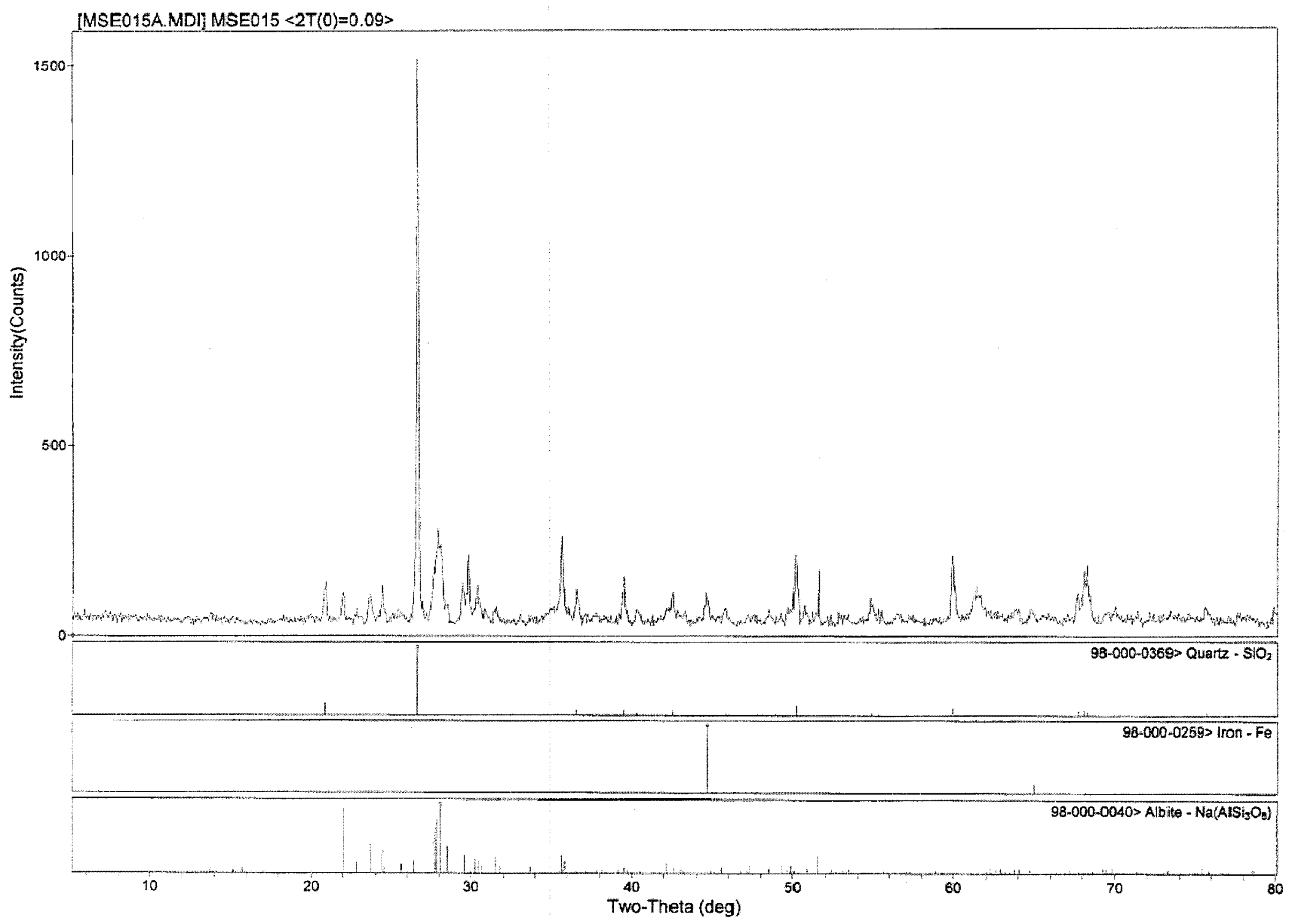

Figure E4-5. X-Ray Diffraction Plot for Sample 15 


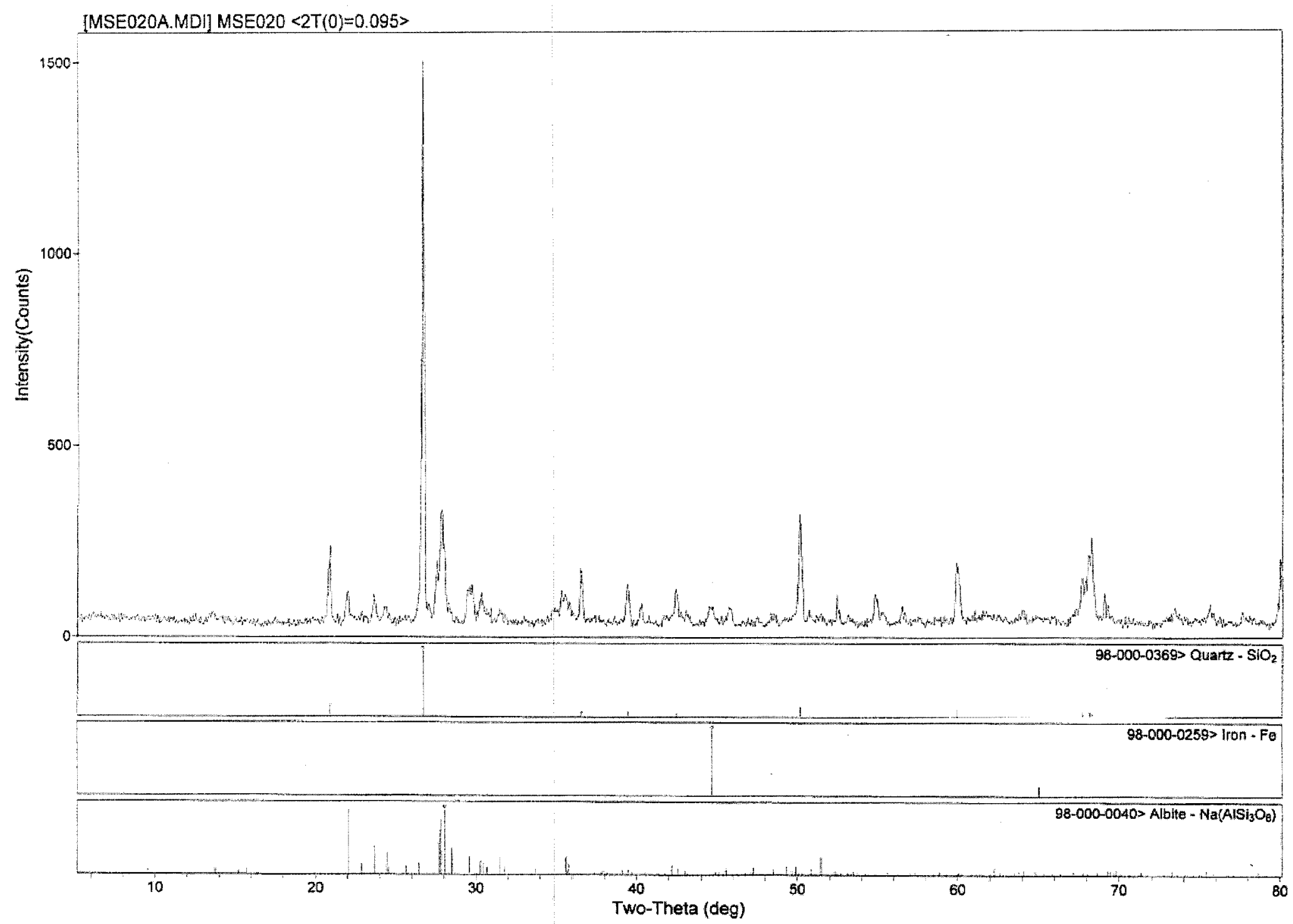

Figure E4-6. X-Ray Diffraction Plot for Sample 20 
DOE/RL-2009-35, REV. 0

This page intentionally left blank. 


\section{E5 References}

ASTM D422-63, Standard Test Methods for Particle-Size Analysis of Soils, American Society for Testing and Materials, West Conshohocken, Pennsylvania. Available at:

http://www.astm.org/Standards/D422.htm

DOE/RL-1992-24, 2001, Hanford Site Background: Part 1, Soil Background for Nonradioactive Analytes, Rev. 4, U.S. Department of Energy, Richland Operations Office, Richland, Washington. Available at:

http:/Www2.hanford.gov/arpir/?content=findpage\&AKey $=0096062$

DOE-RL, 2008-49, Sampling and Analysis Plan for Injecting Zero-Valent Iron Into an In Situ Redox Manipulation Well: DOE/RL-2008-49, Rev. 0, Appendix A.

PNNL-15499, 2005, Effect of Geochemical and Physical Heterogeneity on the Hanford 100-D Area In Situ Redox Manipulation Barrier Longevity, Rev. 1, Pacific Northwest National Laboratory, Richland, Washington. Available at:

http://www.pnl.gov/main/publications/external/technical_reports/PNNL-15499Revl.pdf

SGW-40999, 2009, Borehole Summary Report for the Installation of one Groundwater Well for the 100-D Zero-Valent Iron Project, Rev. 0, CH2M HILL Plateau Remediation Company, Richland, Washington.

SW-846, 2007, Test Methods for Evaluating Solid Waste: Physical/Chemical Methods, Third Edition; Final Update $I V-B$, as amended, Office of Solid Waste and Emergency Response, U.S. Environmental Protection Agency, Washington, D.C. Available at: http:/www.epa.gov/epawaste/hazard/testmethods/index.htm 
DOE/RL-2009-35, REV. 0

This page intentionally left blank. 


\section{Distribution}

\section{Onsite}

4

U.S. Department of Energy, Richland Operations Office

DOE Public Reading Room

$\mathrm{H} 2-53$

J. P. Hanson

A5-11

J. G. Morse

A6-38

K. M. Thompson

A6-38

11 CH2M Hill Plateau Remediation Company

J. G. Blount

H3-21

S. W. Petersen

(4)

R3-50

A. J. Rossi

R3-60

D. J. Shrimpton

R3-60

J. L. Smoot

R3-50

W. R. Thackaberry

R3-60

B. H. Von Bargen

R3-60

J. A. Winterhalder

R3-60

1

$\underline{\text { Pacific Northwest National Laboratory }}$

Hanford Technical Library

P8-55

2

Lockheed Martin Enterprise

Solutions \& Services

Administrative Record

H6-08

Document Clearance

H6-08 
DOE/RL-2009-35, REV. 0

This page intentionally left blank.

Distr-2 